Martin Hummel et Anna Gazdik

Dictionnaire historique de l'adjectif-adverbe 

Martin Hummel et Anna Gazdik

Dictionnaire

historique de

l'adjectif-adverbe

Volume 1

DE GRUYTER 
Veröffentlicht mit Unterstützung des Austrian Science Fund (FWF): PUB 689-Z

\section{FШF}

Der Wissenschaftsfonds.

ISBN 978-3-11-062958-3

e-ISBN [PDF] 978-3-11-062967-5

DOI https://doi.org/10.1515/9783110629675

\section{(cc) BY}

This work is licensed under a Creative Commons Attribution 4.0 International License.

For details go to: https://creativecommons.org/licenses/by/4.0

\section{Library of Congress Control Number: 2021940487}

\section{Bibliographic information published by the Deutsche Nationalbibliothek} The Deutsche Nationalbibliothek lists this publication in the Deutsche Nationalbibliografie; detailed bibliographic data are available on the Internet at http://dnb.dnb.de.

(C) 2021 Martin Hummel and Anna Gazdik, published by Walter de Gruyter GmbH, Berlin/Boston Typesetting: Dörlemann Satz, Lemförde Printing and binding: $\mathrm{CPI}$ books $\mathrm{GmbH}$, Leck

www.degruyter.com 


\title{
Table des matières
}

\author{
Avant-propos — IX
}

I Présentation du dictionnaire -1

Objectif -1

Historique - 1

Comment utiliser le dictionnaire ? - 5

La macrostructure du dictionnaire -7

La microstructure des articles -9

Le dictionnaire en chiffres -16

II Introduction linguistique à l'adjectif-adverbe - 19

1 Tradition, innovation et norme -19

\section{Première partie : La perspective fonctionnelle -22}

Adjectif ou adverbe ? La question de la classe des mots -22

Le point de vue typologique -24

$2.3 \quad$ La linguistique descriptive dogmatique -25

Structure de base et constructions émergentes - 27

$4 \quad$ L'accord dans les fonctions adverbiales

(" accord adverbial ») $\mathbf{2 8}$

4.1 Fonction et norme -28

4.2 L'accord purement graphique -29

4.3 L'accord littéraire - $\mathbf{3 0}$

4.4 L'accord phonétique - 31

4.5 L'accord par rapport à une scène évoquée par l'événement verbal — 31

4.6 Un schéma secondaire : l'accord fantôme du type se la couler douce - 32

4.7 Accord « illogique » ou " accord cohésif »? - 33

4.8 Remarque finale -35

5 L'absence de l'accord dans les fonctions adjectivales - 36

5.1 La modification d'un objet direct explicite - $\mathbf{3 7}$

5.2 L'absence de l'accord avec l'objet direct implicite

(« objet interne ») 38

5.3 L'absence de l'accord avec le sujet implicite (« sujet interne ») 39

5.4 Argument « interne » et lexicalisation — 39

5.5 La pertinence des contextes à portée générique - $\mathbf{4 0}$

6 La cohésion interne du groupe syntaxique - $\mathbf{4 1}$

6.1 Productivité, lexicalisation et schéma prosodique — 41 
6.2 La flexibilité combinatoire interne - $\mathbf{4 1}$

6.3 L'adjectif-adverbe comme complément du verbe ? - 43

6.4 La modification de l'adjectif-adverbe - $\mathbf{4 4}$

$7 \quad$ L'adjectif-adverbe est-il un adverbe en -ment tronqué ? — 46

8 L'appartenance des adjectifs-adverbes au lexique fondamental du français -49

8.1 La satisfaction des besoins de la communication quotidienne - $\mathbf{4 9}$

8.2 La structuration paradigmatique du lexique fondamental : l'approche structuraliste $\longrightarrow \mathbf{5 0}$

8.3 La structuration paradigmatique du lexique fondamental : l'approche événementielle - 53

L'affinité avec le langage familier et populaire - $\mathbf{5 6}$

9.1 Emploi concret -56

9.2 Emploi inférentiel (« circonstances internes ») - $\mathbf{5 7}$

9.3 Réduction de la valence syntaxique - $\mathbf{5 8}$

9.4 Marques de registre $-\mathbf{5 8}$

9.5 L’informel dans les langages de spécialité — 58

Seconde partie : La perspective diachronique -60

La tradition indo-européenne -60

La tradition grammaticographique et normative gréco-latine - 60

L'adverbe en -ment(e) dans la tradition écrite - 61

L'emploi panroman de l'adjectif-adverbe - $\mathbf{6 2}$

La tradition latine - 63

$$
\text { Les règles canoniques du latin }-64
$$

$$
\text { L'adjectif-adverbe du latin - } 64
$$

Origine et tradition de l'adverbe en -ment - 65

La périphrase latine avec mente - 65

Le renouveau de mente dans le discours chrétien - 65

La datation des origines du suffixe -mente _ 66

La transmission de l'adjectif-adverbe du latin aux langues romanes -68

La transmission d'une règle pour l'adjectif-adverbe - 68

La tradition orale et les besoins de la communication quotidienne -69

Le rôle des adjectifs-adverbes dans l'histoire de la langue française - 70

Traditions orale et écrite : effets généraux -70

La langue ancienne - 73

La normalisation du français (écrit) $\longrightarrow 75$

Le français au Canada et en Louisiane - $\mathbf{8 0}$

La reconstruction diachronique de la tradition orale $-\mathbf{8 2}$ 
17.6 L'adjectif-adverbe comme adverbe de phrase : copie analogique de l'adverbe long et / ou dynamique propre ? - $\mathbf{8 2}$

17.7 L'irruption de la tradition orale informelle dans la littérature et sur Internet -85

$18 \quad$ Conclusion $-\mathbf{8 6}$

19 Perspectives de recherche : l'adverbe du Type C $-\mathbf{8 8}$

Références et sélection bibliographique — 94

III Le dictionnaire -105

(A - L, Volume 1) 106

$(\mathrm{M}-\mathrm{V}$, Volume 2$)-813$

IV Bibliographie des sources citées — 1573

V Index alphabétique des adjectifs-adverbes —1673

VI Index des adjectifs-adverbes selon leur fréquence-type — 1687

VII Index des verbes selon leur fréquence-type — 1691 



\section{Avant-propos}

Tout dictionnaire a son histoire humaine et personnelle. Les dictionnaires historiques n’y font pas exception. L'idée du projet est née lors de mon arrivée à l'Université de Graz, en 2001. Karin Stiegler, qui venait de terminer ses études de français, s'est alors mise à rédiger le projet, qui a ensuite reçu un accueil favorable de la part du Fonds Autrichien de la Recherche (FWF). Constituée à partir de 2002, l'équipe composée de Steffen Heidinger, Elke Lackner, Ingrid Lefebvre et Carole Bourgadel, autour de Karin Stiegler, a réussi à constituer et à nourrir la banque de données de ce qu'on commençait à appeler avec attachement, dans l'argot de l'équipe, Dicoadverbe.

Cela n'aurait cependant pas été possible sans l'appui logistique du Laboratoire Informatique de la Faculté de Lettres de Graz (GewiLab), qui allait devenir un centre phare de l'université, le Austrian Centre for Digital Humanities (ACDH), qui accompagnera le projet jusqu'à son terme, en 2018. Son premier directeur, Johannes Stigler, nous a soutenus sans faille, ce qui a notamment permis la mise en ligne de la banque de données et, surtout, sa gestion et mise à jour permanentes - élément clé pour ce type d'entreprise qui doit faire face aux innovations techniques et à l'introduction de nouveaux standards. La première phase du projet s'est ainsi terminée par la publication en ligne de la banque de données (https://gams.uni-graz.at/context:aaif).

Mais on était encore loin du dictionnaire. Le financement du projet par le FWF s'étant achevé en 2005, c'est avec les ressources de ma chaire de linguistique romane et l'appui de la Fondation Hugo Schuchardt, qu'une petite équipe francophone autour de Céline Gasrel et Martine Bosson a commencé à définir la macrostructure du dictionnaire et à sélectionner les entrées du dictionnaire, et notamment à en rédiger les définitions. La microstructure des articles a été développée dans le cadre d'un séminaire avec les étudiants de l'Institut de romanistique à Graz. Cette phase a également profité de l'appui inconditionnel et bénévole de Elke Lackner.

Il convient de mentionner également que le dictionnaire s'insère dans un ensemble de recherches linguistiques qui dépassent le cadre lexicographique et le domaine du français. En effet, le groupe de recherche « The Adjective Adverb Interfaces in Romance » (https://adjective-adverb.uni-graz.at/) se voue à l'étude de relations étroites qui se produisent entre ces classes de mots dans l'ensemble des langues romanes, en synchronie et en diachronie. Le groupe a publié plus de soixante-dix articles et livres qui reflètent la portée scientifique des efforts entrepris, le projet du dictionnaire étant une des principales sources de données. S’est opérée ainsi, possiblement de façon unique, une synthèse entre lexicographie, d'une part, et recherches morphologiques, syntaxiques et sémantiques, de l'autre, dans un cadre romanistique.

En 2013, le FWF nous a accordé un second projet destiné à réaliser le dictionnaire sous forme d'un livre. Nous avons évidemment songé à une publication en ligne, ce qui aurait permis une mise à jour permanente, mais notre expérience nous avait montré que la durabilité d'une édition numérique courait de graves risques à long terme, notamment dans le domaine de la compatibilité avec les standards numériques 
à venir. Et qui s'occuperait du dictionnaire dans une perspective à très long terme ? Nous avons donc décidé de publier un livre imprimé accompagné d'une version numérique identique. L'édition numérique augmente considérablement les possibilités de recherche dans le dictionnaire, alors que la version imprimée ajoute le charme d'un livre à la durabilité.

Cette troisième phase du projet de dictionnaire a été conduite par Anna Gazdik qui pouvait compter sur l'appui de Carole Kirschbaum, Greta Korper et Helena Telsnik. Du côté de l'ACDH, Johannes Stigler et Elisabeth Steiner ont réalisé une mise à jour de la banque de données (Text Encoding Initiative (TEI) sur la base de eXist). Raimund Wilhelm, de l'Université de Klagenfurt, nous a gracieusement fait profiter de ses conseils pour la sélection des éditions de textes anciens. Frankwalt Möhren a révisé la version finale de la bibliographie datant d'avant 1500. C'est ainsi que le projet du dictionnaire disposait, au terme de cette seconde phase du projet en 2016, d'une banque de données en ligne mise à jour, ainsi que d'une première version de dictionnaire : les équipes avaient mis à ma disposition ce dont j'avais besoin pour passer à la rédaction définitive.

Dans une sorte d'épilogue, nous avons eu la chance d'obtenir un troisième projet du FWF, qui n'était pas directement lié au dictionnaire, mais destiné à publier les corpus réunis par le groupe de recherche The Adjective Adverbe Interfaces in Romance selon les nouveaux standards internationaux et en libre accès. En effet, les standards qui avaient cours en 2013, au moment où démarrait la troisième phase du projet, n’avaient plus cours en 2018. Il était grand temps qu'un effort européen soit fait pour pallier les effets pervers des innovations. Une nouvelle équipe, composé par Gerlinde Schneider et Christopher Pollin du ACDH, a donc implanté les standards du European Research Infrastructure Consortium for Language Resources CLARIN ERIC2 (http://clarin.eu/). Katharina Gerhalter a donné son appui du point de vue linguistique. La communauté scientifique dispose donc maintenant d'une banque de données qui regroupe plusieurs corpus et qui permet la recherche simultanée d'un grand nombre de traits linguistiques de l'adverbe dans une combinaison de corpus librement définie.

Il ne me reste plus qu'à remercier toutes les équipes et collaborateurs sans lesquels la publication du dictionnaire n’aurait pas été possible. Je voudrais remercier également Steffen Heidinger, « auxiliaire » du projet de première heure, en 2002, qui a passé son habilitation en 2017, et qui m’a aidé à diriger ce projet du début à la fin. Notre bibliothécaire, Klaus Schachner, nous a aidés pour toutes les questions et problèmes concernant la bibliographie. Finalement, je remercie Marie-José Brochard qui a infatigablement corrigé le manuscrit final et apporté bon nombre d'exemples supplémentaires, sans parler de sa grande expérience de lexicographe. 


\section{Présentation du dictionnaire}

\section{Objectif}

L'objectif du dictionnaire est la documentation diachronique de l'emploi des adjectifs-adverbes français dans les groupes « verbe + adjectif-adverbe » (ex. couper court) du XI ${ }^{\mathrm{e}}$ siècle à nos jours (v. Hummel / Gazdik 2014). Le dictionnaire fait ainsi la lumière sur une des richesses de la langue française qui n'est que trop souvent mise à l'écart. En effet, le souci de correction linguistique restreint l'usage de groupes du type faire facile, aller direct, mettre dur, etc., du moins dans les textes écrits. Or, la communication informelle, peu soucieuse de correction, est sous-représentée dans les corpus disponibles. Du point de vue diachronique, la restriction d'usage par le code s'associe au processus de normalisation et de standardisation de la langue qui a favorisé l'emploi des adverbes marqués en tant que tels par le suffixe -ment, donc aller directement plutôt que aller direct. Le fait que les textes dont nous disposons pour les recherches diachroniques sont écrits crée donc un biais qui risque de peser lourd sur les résultats. Ce dictionnaire essaie de pallier ces effets pervers par la documentation même de ce type de construction et par l'inclusion de données informelles de la langue actuelle (notre Corpus Web), ce qui permet au moins de mieux connaître ce type d'usage, ainsi que de les prendre comme point de départ de réflexions visant à reconstruire le passé. Ajoutons que le dictionnaire, étant historique, n'a tout de même pas une vocation étymologique. En fait, l'origine indo-européenne de l'adjectif-adverbe rend vaine toute tentative de recherche des origines d'une construction dont l'usage augmentait déjà considérablement en latin tardif (v. Introduction 16.1). On perçoit bien d'ailleurs, dans les entrées, que les emplois figurés précèdent souvent l'emploi concret censé être plus ancien (v., par exemple, choir bas).

\section{Historique}

Situé dans le cadre plus vaste de l'étude des adjectifs à fonction adverbiale dans les langues romanes à l'Université de Graz, l'idée du Dictionnaire historique des adjectifs-adverbes du français est née en 2001. Je croyais alors avoir affaire à des groupes lexicalisés du type couper court, rire jaune, manger sain, etc. En fait, il s'agit d'une vision des choses largement répandue (Grundt 1972: 6). J'ai constaté par la suite que la réalité linguistique était tout autre. S’il est vrai que le français standard tend à réduire le groupe des soi-disant adverbes courts à une liste plutôt fermée, acceptée dans l'expression standard, il n'en reste pas moins que leur emploi s'avère largement productif au fil de l'histoire, dans les registres sous-standards, dans les variétés non-hexago- 
nales, dans la communication orale informelle, et notamment aussi dans les argots de métier, c'est-à-dire le quotidien des langues de spécialité, mais aussi dans la littérature, toujours extrêmement riche. On dira alors contrôlé positif par rapport au dopage dans l'argot journalistique du Tour de France, chercher grand dans celui de l'immobilier, jouer serré dans le sport et, dans celui des étudiants, j'ai moyen avancé. On ne s'étonnera donc pas que le dictionnaire ait fini par se convertir en trésor de l'adjectif-adverbe, au double sens du terme.

La recherche se situant dans un cadre romanistique plus général (Hummel / Valera 2017), le choix du français est dû à une coïncidence heureuse qui nous a permis de contourner un écueil qui rendait difficile l'accès aux données pertinentes : le fait que l'adjectif-adverbe est morphologiquement identique à l'adjectif pose des problèmes de taille pour l'extraction des groupes dans les corpus numériques. Même si la recherche par classe de mots avait été possible en 2002, la recherche « verbe + adverbe » donnait rarement des adjectifs-adverbes, et la recherche " verbe + adjectif » les submergeait dans une pléthore de prédicats seconds (elles moururent jeunes), de verbes copules (elles sont jeunes) et d'adjectifs détachés (elle sourit, heureuse d'avoir vécu ce moment). J'ai donc décidé d'explorer les deux grands corpus d'adjectifs-adverbes qui existaient alors, et uniquement pour le français, le premier compilé par l'Allemand Wilhelm Heise (Zur historischen Syntax des adverbial gebrauchten Adjektivs im Französischen, publié en 1912), le second par le Norvégien Lars-Otto Grundt (Études sur l'adjectif invarié en français, de 1972). Ces auteurs ont réalisé un travail de recherche empirique approfondi, tout à fait remarquable. Grundt a sans doute profité de ses longues heures de bibliothécaire pour extraire les adjectifs-adverbes d'un corpus composé de presque 200 livres contemporains, sans parler de la lecture attentive d'une longue série de périodiques. Il complétait ainsi l'effort de Heise qui avait passé au peigne fin un corpus de quelque 140 ouvrages, notamment d'ancien et de moyen français. Les deux collections d'exemples nous ont permis d'identifier les groupes du type « verbe + adjectif-adverbe », ou « adjectif-adverbe + verbe », pour les rechercher ensuite dans les corpus numériques disponibles pour la langue française.

Les données mises à notre disposition par Heise et Grundt nous ont permis d'élaborer le dictionnaire en suivant deux options méthodologiques : l'étude en aval du sort des adjectifs-adverbes employés en ancien et moyen français (données de Heise) dans les corpus numériques disponibles, surtout Frantext, et la documentation en amont, en s'approchant des origines, des expressions usuelles au $\mathrm{XX}^{\mathrm{e}}$ siècle dans le même type de corpus (données de Grundt). Cette méthode souffre sans doute des limitations imposées par l'emploi des listes préétablies de Heise et de Grundt, mais la taille considérable de leurs corpus et le nombre assez limité des adjectifs-adverbes usuels dans la langue française - 427 dans ce dictionnaire, pour une quarantaine seulement selon Krenn (1995 : 84), chiffre sans doute plus proche de l'idée qu'on se fait de ce type d'adverbe - en ont sans doute minimisé l'effet. Notons qu'au moment où la base de données a été réalisée, de 2002 à 2005, le Dictionnaire du moyen français (DMF) n'était pas encore aussi avancé qu'il ne l'est aujourd'hui ; ce n'était pas davan- 
tage le cas pour l'ancien français. La nouvelle version de Frantext, de l'année 2018, a résolu dans une large mesure les difficultés techniques qu'avaient posées jusqu'alors les recherches combinées de lemmes, de formes et de catégories grammaticales, sans parler de la nouvelle rapidité qui nous fait oublier la capacité limitée de recherche à laquelle il fallait faire face avant, et qui a dû coûter des mois. Pour l'ancien français, la Base du Français Médiéval (BFM 2019) met à la disposition de nombreux textes médiévaux. On pourrait donc faire mieux, aujourd'hui, grâce aux progrès réalisés, mais mieux vaut accepter l'histoire du dictionnaire que la refaire.

Partant de la liste de combinaisons "verbe + adjectif-adverbe " provenant des ouvrages de Heise et de Grundt, la première équipe du dictionnaire s'est mise à en rechercher les emplois tels qu'ils apparaissaient dans Frantext au cours de l'histoire. La recherche comprenait aussi ce qui était alors accessible, dans ce corpus entre 2002 et 2005, de textes d'ancien et de moyen français, mais la documentation la plus systématique restait celle de Heise. Le fruit de ces efforts a été une base de données, avec environ 13500 citations (286 adjectifs-adverbes différents ; 610000 mots), catégorisées selon les critères les plus pertinents pour le dictionnaire, tout comme pour les analyses scientifiques prévues. La base de données permettait, par exemple, de connaître le nombre de syllabes des adjectifs-adverbes (pour savoir si le terme d'adverbe court est justifié), la proportion des exemples contenant un adjectif-adverbe accordé (pour discuter le dogme de l'invariabilité de l'adverbe), la position de l'adjectif-adverbe avant ou après le verbe (pour voir si la position change au cours de l'histoire), etc. C'est ainsi qu'on peut savoir en quelques fractions de secondes que la grande majorité des adjectifs-adverbes sont effectivement « courts », c'est-à-dire monosyllabiques (v. $\S$ 6.1). Fait innovateur à l'époque, cette base de données a été mise en ligne en libre accès dès 2005 (Hummel / Stiegler 2005). Dans la systématique de l'ensemble des corpus publiés sous http://www-gewi.uni-graz.at/adjadvdb/, la banque de données du dictionnaire s'appelle Fr_A_DHAA, directement accessible sous http://gams.unigraz.at/o:aaif.fradhaa. Le moteur de recherche permet les recherches dans un seul corpus ou dans plusieurs corpus à la fois.

Dans une deuxième phase, nous avons sélectionné dans la banque de données le nombre de groupes « verbe + adjectif-adverbes » à retenir dans le dictionnaire. Nous avons choisi tous les groupes où les exemples comptaient au minimum un emploi à fonction adverbiale. Le dictionnaire est donc assez complet de ce point de vue. Par contre, le dictionnaire ne pouvait pas comprendre toutes les 13500 citations de la banque de données. Nous avons donc fait un tri pour choisir les citations qui devraient figurer dans les articles du dictionnaire. L'objectif était celui de citer, pour chaque siècle, toutes les variantes d'emploi concernant la position syntaxique (vendu chercher vendu), l'accord (vendus cher[s]), la modification interne (vendre assez [bien, fort, moins, plus, si, très, trop] cher), ainsi que les emplois stylistiquement intéressants (réduplication, contrastes, proverbes, phraséologismes, registres, argots).

$\mathrm{Au}$ début de la troisième et dernière phase du projet, de 2013 à 2016, nous avons décidé d'ajouter des exemples du français informel qu'on pouvait trouver dans des 
sources internet accessibles par le moteur de recherche Google, avec comme point de départ les groupes déjà lemmatisés dans le dictionnaire. La recherche des groupes « verbe + adjectif-adverbe » en soi n'impliquait aucune restriction de registre, chose techniquement impossible, mais les expressions du dictionnaire nous ont naturellement guidé vers un langage informel, proche de l'oral, spontané et peu soucieux de correction. Le dépouillement des textes disponibles sur Internet a ainsi fourni un corpus complémentaire de quelque 5000 citations, qui est librement accessible sous le nom de Fr_A_Web dans notre banque de données (389 adjectifs-adverbes différents ; près de 140000 mots) (http://gams.uni-graz.at/o:aaif.fraweb). Ces citations sont réunies dans les entrées du dictionnaire sous une rubrique à part, le «Corpus Web (CW) ». Le dictionnaire pallie ainsi les tendances " bon usage » et " français correct » de Frantext. De plus, sans être directement orales, les données du Corpus Web rapprochent le dictionnaire du langage de tous les jours, informel et proche de l'oral. La division des articles en deux blocs d'exemples, opposant grosso modo le bon usage, à dominante littéraire, aux registres sous-standards, rend compte d'un contraste qui existe dans la pratique réelle du français. Ceci étant, les données ne sont pas sans poser problème, notamment en ce qui concerne la vérification des sources internet, mais il s'agit d'un français réel et très répandu aujourd'hui. La recherche sur Internet nous a permis aussi de retrouver des usages de l'ancienne langue qui, selon les données de Frantext, auraient disparu mais qui semblent avoir perduré dans les registres moins formels, s'ils n'ont pas été tout simplement redécouverts.

Dans la phase qui précédait la conclusion du manuscrit, nous avons essayé de combler les lacunes qui se présentaient dans certaines entrées au fil de l'ordre diachronique des exemples. En fait, les lacunes s'observaient surtout entre la seconde moitié du XVI ${ }^{\mathrm{e}}$ siècle et la seconde moitié du XVIII ${ }^{\mathrm{e}}$ siècle, selon les données que nous avons puisées dans Frantext. Google.book, Gallica et d'autres sources nous ont permis de les combler, du moins partiellement, permettant ainsi de rectifier le mirage d'un sommeil temporaire de certaines expressions. En même temps, le dictionnaire a pris une dynamique propre qui l'éloignait de la banque de données, soit par l'ajout de nouveaux exemples, soit par la mise à jour des exemples de l'ancienne langue selon les éditions de référence. Si le dictionnaire reste donc largement tributaire de la banque de données, il s'en est tout de même émancipé. L’ajout de l'emploi récent des adjectifs-adverbes, qui ne tombait pas dans la visée initiale du projet, y a joué sa part. Nous avons essayé de tenir compte, du moins dans une large mesure, des exemples attestés dans la bibliographie linguistique (v. à la fin de cette introduction). La productivité des adjectifs-adverbes nous a tout de même parfois obligé à nous limiter à des renvois, notamment pour des séries ouvertes comme, par exemple, celle des slogans : circulez tout doux, acheter intelligent, jeter intelligent, piqueniquez malin, roulez malin, dépenser malin, consommer malin, acheter malin, rouler propre, voyager propre, acheter responsable, jeter utile, roulez facile - roulez tranquille, etc.

La recherche de données pour le Corpus Web et la phase de comblement de lacunes apparentes ont mis en évidence ce qui constitue aussi bien une des grandes richesses 
de l'adjectif-adverbe qu'un problème fâcheux pour la méthode lexicographique : l'adjectif-adverbe est souvent combiné avec un autre, voire mis en série avec plusieurs, pour tout type d'effet stylistique : complémentarité, renforcement, contraste, contradiction, surprise, plaisir ludique, etc. Ce qui fait un des intérêts stylistiques de l'adjectif-adverbe, nous faisait cadeau, au jour le jour, de nouvelles expressions, des groupes non encore recensés par Grundt et Heise. Il se présentait à nous un scénario de recherche lexicographique sans horizon à vue. Notons à ce propos que le nombre de 286 adjectifs-adverbes différents dans le corpus principal passe à 389 dans le Corpus Web, malgré le fait que la recherche était limitée aux 286 unités du corpus principal, et ceci étant donné que le Corpus Web ne fait que le quart de la taille du corpus principal. L'effet de levier de la combinatoire des adjectifs-adverbes est donc considérable. Si on avait essayé de rechercher ces nouveaux groupes pour leur donner une entrée complète, on en aurait trouvé d'autres. Nous avons alors décidé de nous contenter, pour les groupes nouvellement détectés, d'une simple entrée avec définition et renvoi à l'entrée où se trouve la citation. En quelque sorte, nous nous sommes ainsi rendus à ce qui caractérise l'adjectif-adverbe : sa productivité. Telle une grammaire qui, proposant un système de règles, finit par faire la lumière sur les exceptions, notre entreprise lexicographique a fini par révéler au grand jour la productivité grammaticale qui, en nourrissant ce dictionnaire, l'allait minant. On peut capter la productivité dans son principe, dans son jeu, mais non pas embrasser complètement ses résultats. En ce sens, ce dictionnaire est inachevé, et il ne saurait en être autrement. Notons, en l'occurrence, que, dans certains cas, les groupes deviennent à la mode, tels kiffer grave qui connote, de plus, les sentiments d'une génération jeune. Dans d'autres cas, c'est tout un débat d'idées qui se cristallise autour d'une expression, comme dans celui de parler moche.

Ajoutons que nous regrettons de ne pas avoir pu intégrer de façon systématique et explicitement contrastive des données provenant des variétés francophones dans le monde. Nous avons montré l'intérêt de ces données dans notre étude sur la diachronie variationnelle de vite et vitement (Hummel / Kröll 2015), qui a mis en évidence la continuité de la vieille tradition d'employer vitement dans le ou les français pratiqués au Canada, alors que cet adverbe s'est presque perdu en France. On peut trouver un recueil systématique de données orales dans Neumann-Holzschuh / Mitko (2019 : 246-253). Pour une liste commentée des adjectifs-adverbes les plus notables en français d'Acadie et de Louisiane v. Neumann-Holzschuh / Mitko (2018 : 758-765). V. aussi les données de Wiesmath sous 17.4 .

\section{Comment utiliser le dictionnaire?}

Même si le dictionnaire se situe dans un contexte de recherche assez poussée, il est fait pour être lu. Le lecteur n'aura donc pas besoin d'aller chercher la clé des abréviations, 
symboles ou sigles dans d'autres parties du livre. Nous croyons en effet que feuilleter ce livre, le lisant au hasard de ses entrées, offrira un plaisir particulier. Il nous fait connaître la richesse, l'élégance, le charme, voire le côté coquet de ces expressions que Lucien Tesnière (1966 : 469) a qualifiées, à juste titre, de « fort savoureuses ». Citons quelques mises en bouche :

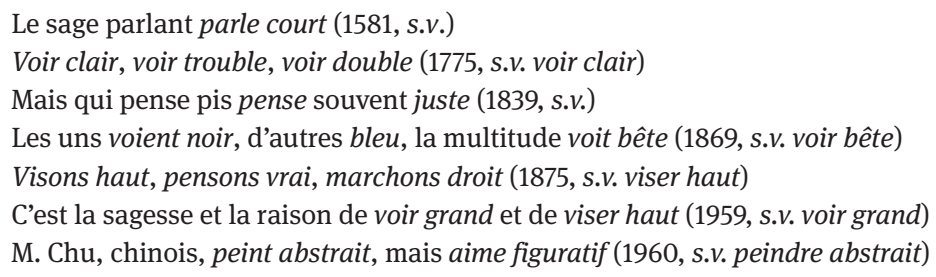

À ces exemples du style soigné, on peut en ajouter d'autres qui appartiennent à des locutions populaires rimées :

\author{
Manger froid, boire chaud, dormir couché, debout \\ Un garçon com moi s'accommode de tout (1710, s.v. manger froid) \\ Chiez dur ou chiez mou, mais chiez dans le trou (s.v. chier dur)
}

Notons aussi la transposition ludique de ce dernier exemple au monde des véhicules :

Conduis dur, conduis mou, mais conduis jusqu’au bout ! (2014, s.v. conduire dur)

Les slogans publicitaires du $\mathrm{xx}^{\mathrm{e}}$ siècle s'en nourrissent également (v. notamment les exemples réunis par Noailly 1994, 1997a et Stephan-Gabinel 2001) :

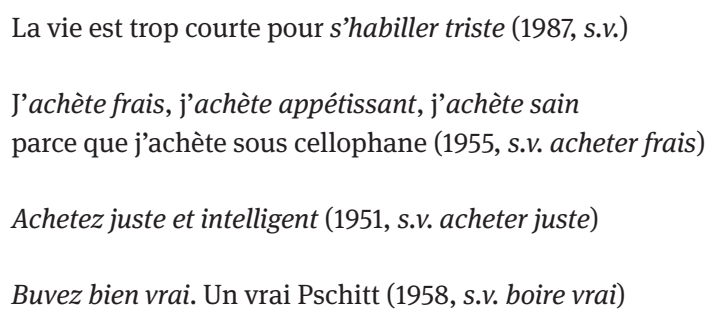

Parfois, c'est la source qui fait rire. C'est ainsi que nous sommes en mesure d'affirmer, sur une base empirique, la survie future des adjectifs-adverbes, ainsi que de la langue française en général, sur plus de 3 millénaires :

D’un homme logé haut, on dit : «Il entend les anges péter » (Bibliotheca scatologica ou Catalogue raisonné des livres traitant des vertus, faits et gestes de très noble et très ingénieux Messire Luc [à rebours], écrit à Scatopolis en l'année 5850 [1849]) 
Mais le dictionnaire n'en reste pas là. Le Corpus Web y ajoute des exemples de nature fondamentalement différente et proches de l'immédiat communicatif. Pour donner une idée, il suffit de citer un exemple de l'entrée rouler petit, la graphie originale étant conservée, comme dans tous les exemples :

Bonjour Denis,

ces voiles je les aient tes té avec du vent a plus de $60 \mathrm{~km} / \mathrm{h}$ en les laissant genre drapeau c' est te dire que ca les secouent, pour le moment ça fait deux an que je m'en sert et en transport je ne les menagent pas ca fait partie du test ! je les roulent mais jamais pliée ! [...]

Re Denis,

je te met une photo pour que tu te rende compte que je les roulent petit fait pas attention au bazard !!!!! (2015, s.v.)

On peut être choqué par la grammaire et l'orthographe de cet exemple, mais il reflète sans doute une façon de s'exprimer en français langue maternelle dans un certain type de communication : réseaux sociaux, forums, textos.

\section{La macrostructure du dictionnaire}

Le dictionnaire contient uniquement les adjectifs à fonction adverbiale qui apparaissent dans la structure « verbe + adjectif » ou « adjectif + verbe ». Ont donc été exclus les adjectifs-adverbes qui fonctionnent comme modifieurs d'adjectifs ou adverbes (grave belle, afr. grief malade, fort bien, cf. Gamillscheg 1957 : 45 et Deutschmann 1959), du groupe de déterminants nominaux (toutes contentes, seul(es) les femmes) et de la phrase (Normal, il t'a pas dit).

Nous avons cependant admis quelques cas où un participe verbal se comporte comme un adjectif, notamment par l'antéposition du modifieur. C'est ainsi qu'il faut rapprocher grand ouvert, où le participe crée un rapport avec le verbe ouvrir, du type grave belle, fin(e) bonne, fin droit, etc. Donnons en un exemple :

Cette fontaine est froide, et son eau doux-coulante (Philippe Desportes, 1596, s.v.)

On peut y ajouter une série de composés plus ou moins lexicalisés : court-vêtu, ras tondu, frais levé, fraîche cueillie, clair(-)voyant, menu serré, large baillant, étroit cousu, nouveau venu, clair(-)semé, raide mort (cf. Grevisse / Goosse 2016 : § 963c, 993e, Hummel $2014 a$ : 41). La motivation du participe par le verbe sous-jacent dépend évidemment du degré de lexicalisation du participe comme adjectif. Dans certains cas, le groupe verbal existe en dehors du participe (ex. coudre étroit), dans d'autres cas, on le cherche en vain (ex. * mourir raide). L’affinité de la série mentionnée ci-dessus avec la modification verbale dépend donc du cas, et aussi du contexte. Nous avons admis ces cas quand, parmi les citations, figuraient des emplois clairement verbaux. Grand ouvert a donc été accepté parce que ouvrir grand existait aussi. 
À partir de ce choix, le dictionnaire suit l'ordre alphabétique des verbes qui fonctionnent comme noyau du groupe. Il va donc d'abaisser bas à voyager propre. Cette macrostructure concerne soit des entrées principales avec une microstructure complète soit de simples renvois à d'autres entrées qui offrent seulement une définition, l'attestation se trouvant ailleurs. Ceci a permis de limiter l'effet de la productivité de l'adjectif-adverbe sur le nombre de pages du dictionnaire. Le dictionnaire comprend ainsi 2115 entrées principales et 544 entrées qui renvoient à une entrée principale.

Nous aurions pu sans doute choisir également une lemmatisation par adjectifadverbe, mais la logique syntaxique veut que le verbe soit le nœud du groupe, et qu'on lise et comprenne donc l'adjectif-adverbe à partir du verbe. En fait, le nombre d'adjectifs-adverbes qu'il faudrait présenter indépendamment du verbe est assez réduit : bas, fort, haut, vite, et, éventuellement, dur, gros et ferme. Et déjà pour bas et haut, plus polysémiques, on trouve des significations liées au verbes (ex. chanter haut 'la voix', tirer haut 'direction', voler haut 'lieu'). De plus, le fait qu'on trouve souvent deux adjectifs-adverbes ou plus combinés avec le même verbe aurait gonflé le nombre des exemples ou le nombre de références croisées. Finalement, pour productif qu'il soit, l'adjectif-adverbe est souvent soumis à la lexicalisation. Or, celle-ci se produit, dans la grande majorité des cas, pour l'ensemble du groupe « verbe + adjectif-adverbe ». En tout cas, les dictionnaires de langue courants offrent de bonnes descriptions des adjectifs-adverbes qui se combinent librement avec des verbes. Mentionnons, en l'occurrence, la bonne documentation de l'adjectif à fonction adverbiale dans le dictionnaire de l'ancien français de Tobler-Lommatzsch (1925-2002), où les exemples sont correctement classés comme fonction adverbiale de l'adjectif.

La macrostructure ne permettant donc pas d'accéder directement aux groupes qui contiennent le même adjectif-adverbe (ex. dire vrai, parler vrai), nous avons ajouté un index des adjectifs-adverbes à la fin du volume. Ajoutons que la publication numérique permet de rechercher sans problème les occurrences d'une unité.

Les entrées adoptent généralement la graphie moderne, sauf quand le mot n'est plus en usage (ex. acostumer 'habiller') ou si l'ensemble des citations concerne l'ancienne langue (ex. abattre soef). Dans certains cas, nous avons réuni dans une même entrée des adjectifs-adverbes qui se succèdent en diachronie sans être directement liés par leur étymologie (ex. grave / grief, voir / vrai, seri / serein).

Les critères formels de sélection des entrées, tels la structure syntaxique « verbe + adjectif » ou l'invariabilité morphologique de l'adjectif, se sont avérés peu opérationnels. La structure « verbe + adjectif » produit des constructions qui incluent des fonctions clairement adjectivales de modification nominale. On aurait pu essayer de les éliminer en se basant sur l'accord, mais ce critère est trompeur, non seulement pour le masculin. L'accord en genre et en nombre existe aussi dans les fonctions adverbiales (calmer nette l'adolescente 2014, s.v.), sans parler de l'ambiguïté du masculin quand le sujet est au masculin singulier (il parle heureux. Il parle haut). C'est la raison pour laquelle nous avons décidé de trancher selon des critères fonctionnels et sémantiques. Notons que Grundt (1972 : 38-39) est arrivé aux mêmes conclusions 
(cf. aussi Guimier 1989 : 111). Ont été retenus les groupes qui, dans au moins un des exemples, réalisent une fonction adverbiale ou " plutôt adverbiale » par rapport au verbe, qui modifient donc (aussi) le verbe. Dans ces cas-là, on a généralement ajouté un ou plusieurs exemples de prédication seconde pour ne pas présenter de façon trop arbitraire le groupe en question. Les adjectifs-adverbes qui gravitent autour du verbe vivre constituent à cet égard un cas extrême puisqu'il s'agit, dans la grande majorité des cas, de prédications secondes.

Finalement, la syntaxe peut s'avérer ambiguë. Dans les exemples suivants, la structure syntaxique permettrait une lecture comme adjectifs-adverbes : fin noué, organisé précis et parler bizarre. Seule l'expérience communicative nous dit qu'il s'agit plutôt d'adjectifs adnominaux : un fil fin / noué, un cercle organisé / très précis et, la lexicalisation de la construction une façon de parler aidant, une façon de parler / bizarre. Voici les exemples, exclus du dictionnaire :

cependant que les pêcheurs d'éponges dans ces îles lointaines (où était-ce ? Il y a été autrefois), qui plongent longuement, et qu'un mince fil relie à peine à la barque, fil très fin noué au poignet, non pour retenir le nageur du profond, mais pour qu'il puisse faire signe au batelier, s'il en avait besoin. Il rêve qu'il rêve (Claude Roy, 1979, La Traversée du Pont des Arts)

Puis un groupe de dauphins forme un cercle organisé très précis autour du banc de poissons pour en faire une boule dense

http://unefenetresurlemonde.over-blog.com/2014/09/quelques-dauphins-peu-ordinaires.html (15.8.2015)

elle a une façon de parler bizarre mais je l'aime bien http://kanato_.ask.fm/elisbz (16.8.2015)

Bibliographie. La bibliographie complète des ouvrages cités se trouve à la fin du dictionnaire. Une sélection de la bibliographie linguistique sur les adjectifs-adverbes (qui n'est pas restreinte aux ouvrages cités) conclut l'Introduction linguistique au dictionnaire.

\section{La microstructure des articles}

L'entrée figure sous le groupe « verbe + adjectif-adverbe », donc Casquer dur, Couper court, etc. Les verbes exclusivement pronominaux sont lemmatisés sans pronom, la diathèse étant spécifiée par la suite, donc Dérouler impeccable [...] « pronominal ». La documentation des exemples est divisée en trois blocs. Le premier bloc comprend les exemples de la base de données (surtout Frantext). S'ensuit un second bloc, le «Corpus Web », avec les exemples provenant de sources internet. Larticle se termine par une section « Remarques » qui propose une analyse des données et des renvois (« voir aussi »). Dans un nombre assez réduit d'entrées, nous avons renoncé aux remarques pour ne pas dépasser le cadre éditiorial prévu pour ce dictionnaire. La microstructure adopte ainsi le schéma suivant : 
[premier bloc :]

Groupe « verbe + adjectif »

I. Définition de la signification I

Transitif

Année Exemple Source

Année Exemple Source

Intransitif

Année Exemple Source

II. Définition de la signification II

III., IV., etc.

[deuxième bloc :]

Corpus Web :

Exemples provenant de sources internet, présentés dans l'ordre suivant :

- exemples sans accord morphologique ('invariés')

- variantes morphologiques

[troisième bloc :]

Remarques :

Analyse des exemples

VOIR AUSSI :

\section{Premier bloc}

Le premier bloc commence par une définition ou, le cas échéant, par plusieurs définitions précédées de chiffres latins (I., II., III., etc.). Sous chacune de ces définitions, les exemples sont classés d'abord syntaxiquement (i) et chronologiquement (ii).

(i) Le classement syntaxique réfère à la syntaxe du verbe. Il suit le schéma traditionnel « transitif, intransitif, emploi pronominal (y compris l'emploi réciproque), emploi absolu ». La transitivité et l'intransitivité sont définies par l'emploi explicite d'un complément d'objet direct, dans le premier cas, et indirect, dans le second. La notion d'emploi absolu renvoie à une réduction des arguments du verbe, par exemple l'emploi sans objet direct d'un verbe «normalement » transitif (ex. Pourquoi faire facile quand on peut faire compliqué ?). Sont inclus également les cas où seulement un des arguments «normalement » explicités manque, comme dans les exemples suivants avec objet indirect, où l'objet direct n'est pas explicitement réalisé : Il lui promet gros. Il lui propose bas (un prix bas).

Le jugement de «normalité » repose évidemment sur une décision parfois subjective et contestable. La classification des exemples ne va donc pas sans arbitraire. En effet, les catégorisations opérées dans les articles sont de nature lexicographique, c'est-à-dire que leur objectif est de faciliter l'accès à l'information disponible. Il ne faut 
donc pas confondre les catégorisations lexicographiques avec une analyse linguistique rigoureuse. C'est ainsi qu'on trouvera parmi les « modifieurs » d'un adjectif-adverbe non seulement la série des intensifieurs ou quantifieurs (si, très, assez, etc.), qui s'intercalent entre les deux membres du groupe (parler assez haut), mais aussi des unités comme pourtant, des adverbes de temps comme toujours (il parle pourtant / toujours vrai), des adverbes de lieu tels ici, voire des combinaisons du type envoyer ici tout droit, répondre alors tout net, voir vite clair.

(ii) L'ordre des définitions et des exemples est strictement diachronique. La microstructure des entrées reflète ainsi la datation des exemples. Celle-ci apparaît à gauche, dans une colonne à part, pour saisir d'emblée l'ordre diachronique :

-1200 Ou cors li mit la lance, qui qu'an plort ne qui rie Tant soué l'abait mor qu'i ne brait ne ne crie (Floovant [fin XII ])

Ce principe conduit à ce que dans certaines entrées l'emploi au figuré, équivalant à la définition I, peut précéder l'emploi au propre, classé sous II ou III, s'il est postérieur à l'emploi au figuré (par exemple, s.v. casser net). Dans ces cas-là, on pourrait supposer que l'emploi concret a précédé le figuré dans la diachronie réelle de la langue, mais le dictionnaire s'en tient, malgré tout, aux faits documentés. Or, s’il y a lieu de penser qu'un mot, disons un adjectif, qui apparaît pour la première fois dans une langue, le fait en général avec son sens propre, ceci ne vaut pas forcément pour les catégories ou constructions qui en dérivent, comme les fonctions adverbiales, celles-ci exigeant parfois un sens plus abstrait ou métaphorique, même si, bien souvent, les deux types d'emploi coexistent : couper sec un morceau de bois (au propre) / un discours (au figuré). Sous chacune des définitions, l'ordre est de nouveau chronologique.

L'ordre chronologique ne pose pas de problème, en principe, sauf pour la datation des textes anciens ou des collections de textes. Nous suivons alors, par ordre de priorité, la datation du DEAFBibl, du DMF et de Frantext en donnant un maximum de précisions. La datation de l'exemple figure dans la colonne de gauche. Les symboles employés ont été sélectionnés en fonction de leur compréhension facile : environ, + après, - avant. Si comme dans l'exemple cité l'économie de la présentation des datations crée des imprécisions (-1200), une information complémentaire est ajoutée à la référence bibliographique, ici : [fin $\left.\mathrm{XII}^{\mathrm{e}}\right]$; dans d'autres exemples du même type on lira, par exemple pour +1166 : [ $3^{\mathrm{e}}$ tiers $\left.\mathrm{XII}^{\mathrm{e}}\right]$. Dans certains cas, nous mentionnons la date de la mort de l'auteur, par exemple s'il est difficile de dater le texte, notamment quand il s'agit de poèmes, ou quand la première édition est postérieure à la mort de l'auteur.

La définition du sens n’obéit pas aux mêmes critères que celles d'un dictionnaire de mots. C'est ainsi que trotter dur a les définitions (I) 'avoir le trot dur' et (II) 'trotter durement', ce qui peut paraître redondant ou circulaire du point de vue lexical. Dans ce dictionnaire, il est cependant plus important de spécifier le type de modification que de donner une paraphrase excluant obligatoirement la même racine lexicale. 
C'est ainsi que (II) explicite un changement diachronique : si la définition (I) est encore proche d'une modification du nom, la langue moderne tend à employer dur comme alternative économique pour l'adverbe de manière durement. Évidemment, dans beaucoup de cas la paraphrase qui renonce à employer la même base lexicale peut être préférée. Mais l'objectif principal reste celui de cerner le type de modification réalisée par la construction, non celui de servir de dictionnaire de mots.

Dans la base de données, le nombre d'exemples a été limité à 50 par siècle, pour éviter une pléthore d'exemples dans des cas comme parler fort / haut. Dans le dictionnaire, nous avons retenu, pour chaque siècle, tous les exemples contenant des variantes. C'est ainsi que parler très fort ne figure qu'une fois par siècle, mais il peut figurer sept fois sur sept siècles. Cette procédure assure la documentation de toutes les variantes morphologiques et syntaxiques par siècle. Ceci concerne, par exemple, les modifieurs de l'adjectif (parler bien [très / fort] haut) ainsi que son antéposition ou postposition syntaxiques. L'antéposition est assez fréquente en ancien français (ex. voir dit), mais on la trouve aussi dans les exemples contemporains, comme celui de J'ai moyen avancé, relevé dans le discours des élèves.

Sauf indication contraire dans la Bibliographie des sources citées (V) à la fin du volume 2, les exemples cités datant d'avant 1500 ont été vérifiés et le cas échéant remplacés - le corpus de Heise étant de 1912 - d'après les éditions de référence figurant dans DEAFBibl, même s'ils se trouvent également dans Frantext ou dans la Base du Français Médiéval, BFM 2019. Les éditions imprimées offraient non seulement plus de certitude, mais aussi un accès plus facile à l'inventaire des variantes pertinentes de l'adjectif-adverbe en question, ainsi que la possibilité d'indiquer le numéro du vers (absent dans Frantext) ou la page. Les chiffres romains renvoient au volume, l'indication de la page est signalée par « p. », et les chiffres arabes réfèrent au vers (exemple : Rutebeuf, Poèmes, I, p. 507, 299). Dans les exemples de l'ancienne langue, l'usage des guillemets pour signaler le discours direct a été limité au strict nécessaire, étant donné que ce discours est souvent introduit explicitement. Quant aux éditions utilisées, nous avons pris une décision qui risque de susciter des critiques, mais qui nous semble bien-fondée. Nous avons certes essayé de recourir aux meilleures éditions, mais quand il n'en existait qu'une seule, nous ne l'avons pas exclue, pour critiquée qu'elle soit. C'est le cas, par exemple, de l'édition Constans du Roman de Thèbes. Un dictionnaire doit permettre l'accès à l'information. Or, ne pas citer un exemple d'une édition critiquée ne permettra plus de se servir de cette information dans le futur. Si dans le futur on dispose d'une édition de meilleure qualité, on pourra y chercher et vérifier l'exemple. De toute façon, toute étude linguistique a l'obligation d'utiliser les éditions les plus fiables. Ceci concerne aussi les éditions jugées acceptables ou bonnes à présent, si dans le futur on en fait de meilleures. Ce dictionnaire ne se veut pas d'entraver mais de permettre ce type de recherche. Dans certains cas, nous avons eu recours à une édition acceptée, mais nous avons tout de même ajouté les variantes mentionnées dans d'autres éditions, même critiquées (v. par exemple sous Queste de saint Graal). Ajoutons aussi que le fait d'avoir pris comme point de départ les 
données recueillies par Heise (1912), nous a souvent obligé à comparer les éditions de l'époque reconstructionniste avec des éditions plus récentes. Ce faisant, nous avons pu constater que les divergences touchent beaucoup moins les adjectifs-adverbes et leurs constructions.

En considérant que les exemples datant d'après 1500, généralement cités selon la bibliographie de Frantext, sont facilement consultables, ils ne sont plus suivis de l'indication du vers ou de la page. Par contre, nous avons essayé d'éliminer les failles de la transcription semi-automatique. Nous avons renoncé à signaler par « [...] » les omissions de texte au début et à la fin des citations. Dans la mesure du possible, les exemples provenant de Grundt et Heise ont été vérifiés d'après la source primaire. Si cela n'était pas possible, comme pour les « exemples entendus », donc oraux, de Grundt, nous indiquons la source secondaire (« exemple entendu / Grundt : page »). Les exemples provenant de textes traduits en français n’ont pas été exclus.

Puisque que l'emploi de l'adjectif à fonction adverbiale se situe dans un continuum sans frontière clairement établie avec la prédication seconde, celle-ci apparaît parfois parmi les exemples, à titre d'illustration. C'est ainsi que « vivre + adjectif-adverbe » tend à la prédication seconde. D'autre part, l'emploi non-accordé est également possible. Si on avait tranché trop nettement en faveur de l'adjectif-adverbe, l'article aurait quelque peu faussé la représentation de l'usage réel. De plus, il n'est pas toujours possible de décider. On l'a brûlé vif peut être analysé comme prédication seconde non-accordée, désignant l'état vivant d'un homme au moment de le brûler, mais on peut le lire également comme adjectif à fonction adverbiale désignant une façon de brûler les gens, également par rapport au sacrifice d'une femme. Les locuteurs en tiennent compte puisqu'ils perçoivent l'accord comme option (ex. La femme a été brûlée vif / vive). Dans certains cas, la fonction du verbe peut devenir copulative, comme dans tenir serré. Nous avons retenu ce type si, parmi les exemples, il y en avait qui n'étaient pas accordés (ex. Il la tient serré). Citons les exemples suivants, accordés et non-accordés :

les heures coulaient douces au palazzo Mérone ! (1910, s.v.)

l'existence avait coulé tout doux pour lui (1946, s.v.)

Nous avons donc décidé de ne pas trancher trop arbitrairement dans ce qui se présente, dans la réalité de l'usage, comme continuum de constructions qui disposent, certes, de noyaux morphologiquement et fonctionnellement bien distincts, mais qui n’offrent pas pour autant des frontières claires (v. l'étude de Hummel 2018b).

Les mêmes principes ont été appliqués à l'emploi détaché de l'adjectif-adverbe :

Il va balayer, rapide, un quart de l'horizon, et s'agripper sur le nord verdâtre, d'une pureté hivernale. Alors, le golfe creux ronflera tout entier comme un coquillage (Colette, 1928, La Naissance du jour) 
Cet exemple n'a pas été retenu parce qu'il s'agissait du seul exemple pour balayer rapide. Nous l'aurions peut-être intégré comme variante syntaxique si nous avions trouvé un exemple sans détachement. Si on n'avait pas appliqué ce critère, on aurait rempli ce dictionnaire de tours littéraires avec détachement de l'adjectif, comme dans l'exemple. L'exemple cité montre cependant que l'emploi de la virgule pour séparer le verbe de l'adjectif-adverbe pourrait s'expliquer par simple correction linguistique (cf. Wilmet 1997 : 418). On peut en effet préférer le détachement avec virgule pour éviter un « emploi de l'adjectif comme adverbe », contraire au principe rationaliste de clarté grammaticale.

De prime abord, l'inclusion de cas limites et de cas voisins peut paraître peu rigoureux dans un dictionnaire censé documenter l'adjectif à fonction adverbiale. Or, le fait de ne pas tenir compte des phénomènes intermédiaires, ambigus ou transitoires constitue un problème méthodologique de taille dans la presque totalité des études linguistiques sur l'adjectif-adverbe. C'est ainsi que les travaux sur l'adjectif à fonction adverbiale excluent a priori l'adjectif accordé. En sens inverse, les travaux sur la prédication seconde excluent l'adjectif non-accordé. Or, les $\S \S 4$ à 6 de l'Introduction linguistique montreront que l'adjectif à fonction adverbiale connaît des variantes accordées, et que la prédication seconde présente des variantes purement sémantiques. Déjà l'objet interne du type manger chaud est, en principe, une prédication seconde implicite. Sans objet direct explicite, le groupe est évidemment invariable. Avec objet direct explicite, l'usage hésite entre accord et invariabilité. Toute tentative d'imposer une frontière catégorielle claire est arbitraire. Nous prenons donc le contrepied des travaux qui suggèrent des frontières nettes pour mettre en évidence que la fonction adverbiale de l'adjectif est un phénomène émergent lié au fait que la classe de mots sousjacente est l'adjectif tout court (v. § 2 de l'Introduction linguistique). Celui-ci admet l'accord. Il ne surprend donc guère que son emploi soit plus spontané et varié qu'on ne croirait.

Les adverbes fort et vite posent problème parce qu'ils se combinent avec pratiquement tous les verbes. Ils sont donc trop productifs et trop librement combinés pour être retenu dans tous les cas. L’adverbe fort a cependant été enregistré pour les verbes qui se combinaient aussi avec d'autres adjectifs-adverbes. On trouve donc une entrée parler fort parce qu'il existe aussi parler haut, bas, clair, etc. Par contre, vite ne figure pas parmi les entrées du dictionnaire. Dans la langue moderne, vite est pratiquement toujours adverbe, à l'exception de cas comme une piste vite, une voiture vite dans le technolecte du sport. L'usage de l'ancien français, où viste cumulait les fonctions d'adjectif et d'adverbe, n'existe donc plus. Sa diachronie a été l'objet d'une étude détaillée qui a mis en évidence la marginalisation progressive de vite adjectif pendant le processus de standardisation alors qu'il survit dans les variétés du français parlé au Canada (Hummel / Kröll 2015).

À l'intérieur des exemples cités, tous les groupes « verbe + adjectif-adverbe » sont mis en italiques, même ceux qui ne correspondent pas au lemme. Nous avons marqué de la même façon les modifieurs de l'adjectif-adverbe (ex. dormir assez profond), le 
pronom impersonnel familier ça, qui est fréquemment employé dans la communication informelle, et les locutions (ex. péter plus haut que son cul).

La source des exemples est mentionnée de façon abrégée à la suite du texte. L’indication de la source renvoie à la bibliographie complète des sources qui se trouve à la fin du dictionnaire (v. V). Quand la source est secondaire, celle-ci est indiquée après « / ». Ainsi « (Canard enchaîné, 2 novembre 1960 / Grundt : 244) » veut dire « dans Grundt : page $244 »$.

\section{Deuxième bloc}

Le premier bloc est suivi d'un second appelé «Corpus Web (CW) ». Ce bloc réunit des exemples qui ont été ajoutés, dans la troisième phase du projet. Pour ce faire, les groupes du premier bloc ont été recherchés avec le moteur de recherche Google. Notons que la thèse de Coiffet (2018) a également combiné des données provenant de Frantext et de Google, avec, comme résultat, 97 exemples de Frantext et 372 exemples de Google. Ce type de recherche nous a généralement conduit à des textes écrits plutôt spontanément, sans correction ultérieure, dans un registre informel. Nous avons réuni les citations dans un bloc à part pour mettre en évidence l'écart qui se creuse entre le premier bloc, à tendance «bon usage » ou « standard », et le second. Les exemples cités dans le second bloc reflètent fidèlement la graphie originale, pour « fausse » qu'elle puisse paraître. Les exemples de ce bloc n’ont pas été classés chronologiquement, étant donné qu'ils datent tous de 2015-2020 (date de la recherche). Nous y citons d'abord les exemples avec un adjectif-adverbe invarié (v. 4.8 pour la terminologie) et ensuite les emplois accordés à fonction adverbiale, et, de façon optionnelle, un exemple de l'emploi comme prédicat second pour mettre en évidence les contours flous du groupe des adjectifs-adverbes (de même que de celui des prédicats seconds). Il s'agit souvent d'une question d'interprétation. S'agit-il, dans l'exemple suivant, d'une prédication seconde ou d'un accord par hypercorrection : « Les deux équipes défendent dures (2015, s.v.) » ? L’exemple appartenant au Corpus Web, on peut préférer la seconde lecture. Dans un texte littéraire, par contre, on voit mal un usage sans effet de sens voulu.

\section{Troisième bloc}

Nous avons pensé qu'un texte argumenté présenterait des avantages par rapport à une simple liste de catégories d'analyse. Les exemples font donc l'objet d'une analyse dans un petit texte appelé « Remarques » qui se trouve à la fin des entrées. Ces Remarques sont aussi une invitation aux lectrices et lecteurs à nous faire part de leur avis. En effet, il n'a pas toujours été facile d'interpréter avec certitude les exemples trouvés dans des technolectes qui ne nous étaient pas familiers, voire de toujours bien cerner 
et définir l'adjectif-adverbe dans les exemples de l'ancienne langue. De petits sondages faits sur des cas comme deviser bas 'faire un devis à bas prix' ont mis en évidence que nous ne sommes pas seuls à avoir du mal à comprendre l'usage hautement inférentiel des adjectifs-adverbes dans les argots de métier qui présupposent un savoir et une expérience communicative de spécialistes ou d'initiés.

Les Remarques permettent également de tenir compte du cumul d'adjectifsadverbes dans une même citation. En effet, la tendance au cumul est frappante. On observe, en premier lieu, des collocations du type haut et fort ou clair et net. Nous les indiquons dans les Remarques. En second lieu, on trouve assez souvent des syntagmes du type « verbe + adjectif-adverbe » qui ne font pas l'objet de l'entrée. Nous les mentionnons également dans les Remarques, avec l'infinitif du verbe. Ceci est utile pour les recherches dans l'édition numérique puisque la recherche de couper court conduit automatiquement à toutes les entrées où se trouvent des attestations.

Les références croisées du type «VoIR AUSSI : couper court » se trouvent à la fin de la section des Remarques. Ces renvois ne sont cependant pas mentionnés pour le verbe qui figure en tête de l'entrée puisque toutes les collocations du verbe manger, telles manger gros, manger gras, etc. se trouvent au même endroit, dans l'ordre alphabétique.

\section{Le dictionnaire en chiffres}

Le présent dictionnaire comprend 427 adjectifs-adverbes différents qui se combinent avec 768 verbes différents (v. les listes complètes dans les annexes VI et VII). Ce rapport de, grosso modo, 1 à 2 met en évidence une certaine productivité sur le plan combinatoire. De plus, la décision que nous avons prise de tenir compte, dans une certaine mesure, des cas limites reposant sur la même structure superficielle, implique que ces chiffres sont sans doute trop élevés si l'on veut s'en servir pour cerner le groupe des adjectifs-adverbes. Le chiffre de 768 verbes différents devrait correspondre assez bien au nombre de verbes qui se combinent avec un adjectif-adverbe, hormis quelques cas où la documentation des séries qui se forment autour d'un verbe-pivot nous a induits à inclure quelques cas de prédication seconde. Ce chiffre dépasse, en tout cas, le nombre de 700. Par contre, la tendance très manifeste de combiner, dans la même citation, un verbe avec deux ou plusieurs adjectifs-adverbes est souvent ouverte à la prédication seconde. Si l'on effectue un calcul plutôt restrictif, le nombre des adjectifs-adverbes qui se combinent avec au moins trois verbes différents est de 127, et, si l'on se rapporte aux adjectifs-adverbes employés avec au moins deux verbes différents, il est de 182. Du point de vue de la fréquence-type, c'est-à-dire de la fréquence d'unités différentes, le groupe des adjectif-adverbes devrait donc tourner autour de 200, sur toute la diachronie. Même si les fréquences ne sont pas les mêmes en diachronie, le nombre des adjectifs-adverbes qui ne sont employés que dans l'ancienne langue est assez réduit. Il 
s'agit d'environ 10 unités, si on en exclut les cas de continuité par calque du type voir / vrai. Cela veut dire que le groupe des adjectifs-adverbes constitue un fond lexical qui change peu au fil de l'histoire. On a essentiellement affaire à un groupe d'environ 200 adjectifs-adverbes qui se combinent avec 700 verbes différents.

La combinatoire de ces verbes avec les adjectifs-adverbes produit les 2659 entrées du présent dictionnaire, dont 2115 entrées principales et 544 entrées qui renvoient à une entrée principale. Le nombre des citations disponibles dans ce dictionnaire demanderait un calcul manuel. L'extrapolation d'un calcul effectué sur un échantillon de pages donne un chiffre d'environ 12000 citations. 



\section{Introduction linguistique à l'adjectif- adverbe}

\section{Tradition, innovation et norme}

Ce dictionnaire montre de nouveau qu'une langue renaît à chaque fois que nous produisons un énoncé. Par conséquent, ce qui est fonctionnellement possible peut faire surface à tout moment, même si les normes en vigueur agissent de façon restrictive. Or, l'usage et les normes en vigueur n'acceptent pas toujours ces produits de la même façon, selon l'époque en question, selon le registre, selon le locuteur / l'auteur, etc. On peut distinguer grosso modo trois types de normes : les normes d'usage (le locuteur sait ou croit savoir ce qui est usuel), les normes prescriptives (par exemple, l'enseignement d'une langue standard) et les normes idéales (la préférence pour un style, la culture d'un style).

Ce qui vaut pour la langue en général s’applique également à l'étude de constructions réalisées avec la même structure sous-jacente et qui offre ipso facto une série de possibilités. Ce dictionnaire s'occupe des variantes produites à partir de la structure « verbe + adjectif ». Pour donner un exemple, l'adjectif étant une unité flexionnelle, l'accord avec un argument du verbe peut surgir à tout moment, y compris dans des cas où le standard moderne voudrait que l'adjectif soit invariable parce que sa fonction serait celle d'un adverbe. Pour comprendre les phénomènes observables et les tendances diachroniques, il faut donc en connaître les bases fonctionnelles. En exagérant un peu, on pourrait dire que celles-ci se situent en dehors du temps. Elles expliquent ce qui peut se produire, à tout moment. Nous fondons donc notre analyse diachronique (Seconde partie) sur une analyse fonctionnelle préliminaire (Première partie).

À partir d'une réalité fonctionnelle, la langue peut développer, dans sa diachronie et dans ses synchronies variationnelles, des tendances qui favorisent ou défavorisent certaines variantes, soit par des processus qu'on a expliqués par l'action d'une main invisible (v. discussion et bibliographie dans Keller 2014 : 95-109), soit par l'intervention des trois types de norme. On reviendra sur ce dernier point sous 17.3. La main invisible, elle, vise essentiellement le développement de tendances par imitation. Plus on imite une option, plus elle se fera remarquer dans l'histoire d'une langue. Parfois les deux effets se combinent. C'est ainsi que l'expansion des adverbes en -ment aux $\mathrm{XVI}^{\mathrm{e}}$ et $\mathrm{XVII}^{\mathrm{e}}$ siècles a été animée par le prestige dont ils bénéficiaient à l'époque. De même, dans la seconde moitié du $\mathrm{xx}^{\mathrm{e}}$ siècle, des attitudes de plus en plus libérales ont favorisé des choix plutôt informels, dont bon nombre d'adjectifs-adverbes. L'accord de l'adjectif a été encouragé par les latinisants du $\mathrm{XVI}^{\mathrm{e}}$ siècle (on aime écrire fleurs fraîches écloses), alors que Malherbe le refusait, et l'école d'aujourd'hui tend à créer une certaine peur 'de ne pas faire l'accord'. Ceci se traduit dans les données 
du dictionnaire. L'accord adverbial par hypercorrection est largement attesté dans le Corpus Web. On peut y ajouter des effets de prototypicalité. En effet, l'emploi d'adverbes accordés est une réalité incontestable (v. §4), mais la tendance à l'emploi invariable prédomine tout de même parce que la modification du verbe lui-même ne peut justifier l'accord. D’une certaine façon, la norme linguistique qui veut que l'adverbe soit invariable généralise et impose cette tendance naturelle.

Cependant, même dans les cas où une tendance naturelle se voit renforcée par une norme, les variantes ne cessent de surgir, notamment dans les registres sousstandards mais aussi dans les textes littéraires, plus attirés par les charmes des variantes d'expression. Une variante bien établie au Moyen Âge peut ainsi disparaître pendant des siècles pour réapparaître dans la communication orale informelle d'aujourd'hui. On sait également que le nombre de variantes se multiplie quand une construction est très fréquente (Thompson / Mulac 1991), voire en vogue, ce qui peut se produire à plusieurs moments de la diachronie. Glatigny (1982 : 86), qui dresse le bilan des adverbes du $\mathrm{XVI}^{\mathrm{e}}$ siècle hors usage au $\mathrm{XX}^{\mathrm{e}}$ siècle, observe en effet :

Sous l'influence du raisonnement analogique, si fréquent à cette période, l'adverbe en -ment voit s'étendre son champ d'application. De proche en proche, il s'écarte de sa fonction normale : il ne qualifie plus le déroulement du procès mais exprime, dans des conditions difficilement prédictibles, les circonstances qui entourent celui-ci. Il en vient même à qualifier parfois un adjectif

Limité, dans un premier temps, à des sociolectes (poésie lyrique, traducteurs, lexicographes ; ibid.), cette dynamique a dû s'emparer aussi de l'usage général, pour des adverbes en -ment qui nous sont effectivement parvenus. C'est ainsi qu'on peut considérer la naissance et l'expansion des fonctions « de phrase » chez les adverbes en -ment en français moderne comme une conséquence de leur fréquence d'emploi aux XVI $^{\mathrm{e}}$ et XVII ${ }^{\mathrm{e}}$ siècles (v. Hummel 2018c).

S’y ajoute un effet méthodologique : l'étude de la diachronie s'occupe forcément de documents écrits. Or, ceux-ci sont particulièrement sensibles aux normes, et notamment au développement d'un standard d'écriture, du moins comme tendance générale. Ce processus affecte très clairement les données de Frantext. Il est probable, par exemple, que la vogue des adverbes en -ment aux alentours du XvI ${ }^{\mathrm{e}}$ siècle a été confinée à la tradition écrite (v. Glatigny 1982 : 86 ; cf. sur l'espagnol Company Company 2014, 2017), tandis qu'au même moment l'adjectif-adverbe dominait dans la langue parlée, du moins dans les parlers ruraux, ce qui expliquerait, par exemple, l'emploi quasi exclusif de l'adjectif-adverbe en français de Louisiane (v. § 17.4 ; détails dans Hummel 2018a : 27-28).

Étant donnée la sous-représentation, voire l'absence de l'oral dans les textes dépouillés en diachronie, le fait de (re)trouver dans la communication informelle de nos jours, en l'occurrence dans les données que nous avons réunies dans nos entrées sous la rubrique "Corpus Web », des variantes censées avoir été perdues depuis le Moyen Âge, peut signifier deux choses. Soit il s'agit effectivement d'une innovation 
qui reproduit, par simple coïncidence, un fait qui avait existé à un moment donné de l'histoire (polygenèse), soit ce fait a toujours accompagné l'usage oral informel (monogenèse), sans avoir été admis par l'usage écrit. Le dictionnaire essaie de documenter cette tension permanente de la langue, entre oralité et écriture, en complémentant la documentation diachronique traditionnelle avec un Corpus Web qui fait la lumière sur la communication informelle d'aujourd'hui. 


\section{Première partie : La perspective fonctionnelle}

\section{Adjectif ou adverbe ? La question de la classe des mots}

\subsection{La coexistence des systèmes monocatégoriel et bicatégoriel}

Du point de vue de la classe des mots, le système adverbial des langues romanes s'explique fondamentalement par la coexistence, en concurrence, d'un système monocatégoriel (Type A) de tradition orale avec un système bicatégoriel (Type B) qui s’impose progressivement comme standard d'écriture (Hummel 2013a) :

système monocatégoriel

système bicatégoriel adjectif

tradition orale

Dans le système monocatégoriel, l'adjectif s'adapte à toutes les fonctions de modification selon la position syntaxique : une femme dure (fonction adjectivale); elle travaille dur (fonction adverbiale). Dans le premier cas, la fonction de modifieur d'un nom entraîne l'accord morphologique avec ce nom, tandis que dans le second cas, le modifieur tend à l'emploi invariable de la forme non-marquée (masculine). Cependant, la position de l'adjectif-adverbe à l'intérieur du syntagme verbal admet plusieurs fonctions. Les marques morphologiques peuvent orienter l'attribution vers le sujet : Elle marche droite ('debout, le corps droit'), où droit se trouve en prédication seconde. Il modifie donc le sujet, sauf que la portée de la modification est limitée à l'événement : la position droite de la femme ne vaut que pour la marche. En l'occurrence, la construction en prédication seconde coexiste avec une lecture adverbiale du même adjectif : Elle marche droit au but ('directement'), où droit au but modifie le verbe (cf. Guimier 1989 : 113). Le fait que la même structure admette les interprétations adjectivale et adverbiale constitue un argument de taille en faveur du système monocatégoriel où une seule classe de mots, l'adjectif, réalise des fonctions syntaxiques adjectivales ou adverbiales. Nous avons suggéré de parler de modifieur du Type A.

Pour tenir compte des propriétés du système monocatégoriel nous employons le terme adjectif à fonction adverbiale qui distingue la classe des mots, l'adjectif, de 
la fonction syntaxique, qui peut être adverbiale. En fait, adjectif est le terme le plus approprié pour nommer la classe des mots, même pour les fonctions adverbiales. Pour éviter les malentendus que peut causer l'emploi du terme adjectif, fortement associé à la modification d'un nom, nous employons le terme d'adjectif-adverbe qui désigne une seule classe de mots, ambivalente par rapport aux fonctions adjectivales et adverbiales. ${ }^{1}$ Par contre, il n'est pas conforme au fonctionnement du système monocatégoriel de parler d'adjectifs adverbialisés, d'adjectifs employés comme adverbes et de conversion de l'adjectif en adverbe puisqu'on ne change pas la classe des mots mais on emploie la même classe de mots dans une série de fonctions syntaxiques appelées « adjectivales » ou " adverbiales ». Certains auteurs parlent tout de même de " sous-spécification catégorielle » pour ce qu'ils analysent comme conversion, donc le passage d'une classe de mots à une autre, sans ajouter ou enlever de marques morphologiques (par exemple, Marzo 2017). Mais le terme de sous-spécification n'est pas vraiment neutre puisqu'il implique un niveau «normal » de spécification. Or, choisir à cet effet la liste des classes de mots canonique, qui n'est qu'une liste parmi d'autres, c'est adopter un point de vue dogmatique pour définir un niveau normal de spécification.

Dans le système bicatégoriel, les fonctions de modification sont assumées par deux classes de mots : les fonctions adjectivales sont réalisées par l'adjectif au sens strict du terme, limité à la modification d'un substantif qui transmet ses marques de genre et de nombre à l'adjectif : des hommes durs (adjectif). Il y a donc chevauchement fonctionnel avec le système monocatégoriel dans ce domaine. Par contre, les fonctions adverbiales sont prises en charge par un adverbe morphologiquement marqué en tant que tel par le suffixe -ment : ils travaillent durement. Nous avons suggéré le terme de modifieur du Type $B$.

La définition des fonctions adverbiales est essentiellement négative : ce sont les fonctions où le modifieur ne modifie pas un nom avec lequel il s'accorde en genre et en nombre. Cette définition négative explique l'hétérogénéité de la catégorie de l'adverbe, ainsi que le critère de l'invariabilité morphologique. L'invariabilité est donc également un critère négatif qu'on obtient par l'exclusion des variantes accordées. Les variantes accordées sont considérées adjectivales. Les variantes de modification où l'accord n'est pas justifié par la modification d'un nom sont critiquées par la norme. Autrement dit, l'adverbe accordé n'est pas toléré (v. cependant § 4), ou est considéré comme appartenant à une structure attributive (prédication seconde, construction copulative).

L'hétérogénéité de la fonction adverbiale est mise en évidence par les fonctions adverbiales que peuvent assumer les adjectifs-adverbes :

1 Brunot / Bruneau (1949 : 416) emploient le terme d'adjectif-adverbe, mais sans trait d'union. Dans notre cas, le trait d'union insiste sur l'ambiguïté catégorielle. 
Elle travaille dur

Elle est sérieux malade / grave belle

Elle parle fort bien

Normal, elle ne le savait pas (réponse)

Elle vient sûr modification du verbe modification d'un adjectif modification d'un adverbe modification de la phrase modification de la phrase

On notera l'affinité de ces exemples avec l'expression (orale) informelle, sauf dans le cas de fort bien, où, au contraire, on a affaire à un emploi très soigné. On comprendra également qu'il n'est pas facile de les attester dans des textes écrits. Ce dictionnaire ne s'occupe que du premier type, la modification du verbe, mais il faut voir que l'adjectif peut réaliser toutes ces fonctions adverbiales. En roumain, qui ne connaît pas l'adverbe en -mente comme procédé productif, l'adjectif les assume systématiquement (standard), comme dans ces exemples français.

\subsection{Le point de vue typologique}

L'approche typologique appuie également une analyse des « adverbes courts » comme adjectifs à fonction adverbiale, donc comme adjectifs au niveau de la classe des mots qui exercent une série de fonctions syntaxiques regroupées sous le terme de fonction adverbiale. C'est ainsi que les langues du monde ont été situées à un niveau plus ou moins différencié par rapport à une hiérarchie des parties du discours : verbe $>$ nom $>$ adjectif > adverbe (Hengeveld 1992 : 62-72 ; cf. Hengeveld et al. 2004, 2010). Si une langue ne dispose pas d'une classe de mots spécialisée pour les fonctions adverbiales, celles-ci sont assumées par une classe située à un niveau supérieur de la hiérarchie. D’après cet auteur, les langues "flexibles » utilisent la même classe des mots pour une femme dure et la femme travaille dur (système monocatégoriel de Type A), tandis que les langues "différenciées » connaissent deux classes de mots pour ces fonctions, l'adjectif dans une femme dure et l'adverbe dans la femme travaille durement (système bicatégoriel de Type B). Les langues « rigides » ont recours à des solutions du type boire nature 'boire sans additifs', où un substantif (ou une autre classe située à un niveau supérieur de la hiérarchie) assume une fonction adverbiale (modifieurs de Type C ; v. § 19). L'allemand serait donc une langue flexible (all. Sie ist hart 'elle est dure'. Sie arbeitet hart 'elle travaille dur'), tandis que l'anglais est analysé comme langue différenciée à cause de l'usage du suffixe adverbial -ly.

Or, comme le français, l'anglais connaît également l'emploi adverbial de l'adjectif (angl. she works hard). C'est pourquoi Salazar García (2007) fait remarquer, à juste titre, que l'approche typologique, qui tend à classer les langues du monde selon les catégories « flexible », " différencié » et « rigide », ne tient pas compte du fait que les langues peuvent disposer de plusieurs techniques de modification à la fois, comme c'est effectivement le cas dans les langues romanes (cf. fr. rapide (adj. / adv.), rapidement, boire nature). La réalité linguistique se présente donc plutôt de façon variée et sous la forme de préférences ou de tendances par rapport à des techniques qui corres- 
pondent aux types rigide, flexible et différencié selon la terminologie suggérée par Hengeveld.

Cela ressort d'autant plus clairement si l'on se détache du corset analytique des classes des mots. Car les périphrases jouent un rôle important dans la réalisation des fonctions adverbiales : avec rapidité, d'un pas lent, à la dure, à chaud, au juste, etc. (v. Hummel 2019a,b). Nous parlons alors d'adverbiaux ou d'adverbes du Type C (v. ici § 19). Les approches typologiques, qui se limitent aux classes de mots (considérées comme fait de langue primordial), ne tiennent pas compte de ces variantes " périphrastiques » (considérées comme fait de langue secondaire), sans justification convaincante (nous avons donc affaire à une attitude dogmatique). Dans les langues romanes, c'est la façon préférée pour employer les noms dans une fonction adverbiale (à genoux), donc une alternative à la « rigidité » tout court. En effet, ce sont les périphrases qui (re)donnent de la souplesse au système de la modification : si naturellement tend à la lexicalisation au figuré dans sa fonction d'adverbe de phrase (ex. Il le dit, naturellement 'évidemment, il fallait s'y attendre'), la périphrase de façon naturelle permet un retour au sens primitif (ex. Il le dit de façon naturelle). Parfois, des nuances sémantiques s'introduisent dans la série variationnelle : Elle court léger. Elle court légère. Elle court légèrement. Elle prend les choses à la légère. Elle court avec légèreté.

\subsection{La linguistique descriptive dogmatique}

Dans le système monocatégoriel, la seule classe de l'adjectif assume toutes les fonctions de modification. Il faut donc voir, en premier lieu, que l'adjectif-adverbe ne cesse jamais d'être un adjectif du point de vue de la classe des mots (cf. Togeby 1982 : 227, Van Raemdonck 2017), ce qui augmente de beaucoup ses possibilités d'interprétation en comparaison avec l'adverbe en -ment et les périphrases adverbiales. Si l'analyse ne part pas de ce fait fondamental, elle s’imbrique nécessairement dans une argumentation incohérente et souvent contradictoire. L'appartenance à la classe des adjectifs nous dit que nous avons affaire à un modifieur dont la portée inclut les fonctions adjectivales et adverbiales, selon le cas de figure concerné. Si l'unité modifiée est le verbe, celui-ci offre aux modifieurs toute la complexité de l'événement verbal. Celui-ci comprend les participants de l'événement qu'on peut désigner par un substantif. C'est pourquoi l'appartenance syntaxique au verbe n'exclut pas la modification nominale, que le nom en question soit explicite ou sous-entendu. C'est aussi la raison pour laquelle la question de savoir «si on doit rapporter une caractéristique à l'être ou à l'action (Brunot 1922 : 602) », au verbe ou à un de ses arguments, est mal posée, dans la mesure où c'est une affaire d'interprétation qui n'exclut pas l'ambiguïté.

Ceci n'a cependant pas empêché la linguistique du $\mathrm{xx}^{\mathrm{e}}$ siècle de se poser sans cesse cette question, notamment dans les discussions sur la prédication seconde et l'adjectif-adverbe. Désireux de séparer la prédication seconde de l'adjectif-adverbe 
à fonction adverbiale (cf. Cadiot / Furukawa (éds.) 2000)², la linguistique « descriptive » du $\mathrm{XX}^{\mathrm{e}}$ siècle a en fait continué l'action normative du $\mathrm{XVII}^{\mathrm{e}}$ siècle (v. $\left.\S 17.2\right)$, en admettant les principes de l'accord systématique pour la prédication seconde orientée vers un argument du verbe, et celui de l'invariabilité pour l'adjectif-adverbe à fonction adverbiale (v., par exemple, Noailly 1994). Même Brunot, qui était pourtant un esprit ouvert et l'auteur de la première analyse approfondie de la prédication seconde et de l'adjectif-adverbe (1969: 359-363), se déclare en faveur de ce principe de la doctrine grammaticale : « L'adverbe et l'adjectif, quoique très voisins, doivent être distingués. L'un qualifie l'état, la manière d'être d'une personne ou d'une chose, l'autre qualifie l'action marquée par le verbe (1969 : 361)». On y lit bien la notion de « devoir », de tâche. Ceci n'a pas toujours été le cas : " Au XvI ${ }^{\mathrm{e}}$ siècle, les grammairiens ne s'en

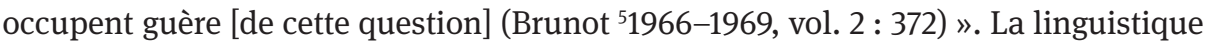
« descriptive » du $\mathrm{xx}^{\mathrm{e}}$ siècle s'est alors consacrée à cette tâche. La distinction catégorielle est à faire. Citons, à titre d'exemple (Greidanus 1990 : 23) :

\footnotetext{
Nous considérons les adjectifs dans les phrases suivantes comme des adverbes, étant donné que les formes sont invariables :

la soupe sent bon $/{ }^{*}$ la soupe sent bonne

ses paroles sonnent faux $/{ }^{*}$ ses paroles sonnent fausses

Certaines phrases sont ambiguës. Dans il mange la soupe froide, le mot froide fait-il partie du SN la soupe froide ou est-il complément du verbe à lui seul ? Seul le contexte permet de déterminer à quel cas nous avons affaire
}

Les astérisques marquent-ils vraiment des emplois qui ne font pas partie de l'usage ou du fonctionnellement possible ? - Les paroles sonnent fausses est attesté, en tout cas. - Le contexte, permettra-t-il effectivement de trancher ? S'agit-il d'une classe de mots ou d'une fonction syntaxique si la catégorisation dépend du contexte ? Même dans des travaux par ailleurs excellents, on lit (Guimier 1989 : 109) : «Les formations incriminées sont adjectifs ou elles sont adverbes mais elles ne peuvent être les deux à la fois ». On lit bien la notion de « ne pas pouvoir ». L'impossible existerait donc, même en français. Mais pourquoi ne pourraient-elles pas l'être ? En fait, seule / seul (? !) la doctrine permet de l'affirmer ; le titre de l'article le met d'ailleurs en évidence : Guimier y réfère à "l'adjectif invarié », alors même qu'il se voit obligé de constater la possibilité de l'accord (la pluie tombe dru / e), mais il se tourne alors vers la recherche de différences sémantiques. Les données de notre dictionnaire montrent que c'est fermer les yeux sur l'histoire ainsi que sur l'usage actuel de l'accord adverbial. Si l'usage littéraire moderne tend à se limiter à l'accord adverbial qui permet

2 Cette discussion a été précédée et accompagnée d'une autre, sur l'apposition, où l'on aborde aussi les adjectifs détachés, souvent proches des prédicats seconds (v. les multiples contributions dans Le Français moderne de 1957 à 1966, reprises par les études de Forsgren (e.g. 1991) et le numéro spécial de Langue française édité par Neveu en 2000). 
d'exprimer une nuance «stylistique », ce n'est pas toujours le cas, loin s'en faut, dans la communication informelle.

\section{Structure de base et constructions émergentes}

Si nous nous limitons aux codes oral et écrit, on peut dire que celui qui écoute un message perçoit des structures, audibles ou visibles. Or, on ne peut pas savoir d'emblée si la structure « verbe + adjectif » correspond à une construction appelée prédication seconde, à un verbe copule avec complément adjectival ou à un adjectif à fonction adverbiale. La structure « verbe + adjectif » est donc le point de départ d'un effort d'interprétation. Les interprétations usuelles sont généralement appelées des constructions. Une structure peut donc produire plusieurs constructions (v. Hummel 2018b).

La structure « verbe + adjectif » sous-tend ainsi une série de constructions consacrées ainsi qu'un certain nombre de variantes plutôt spontanées (cf. Abeillé et al. 2017). Le Tableau 1 en retient les variantes consacrées :

Tableau 1. Constructions consacrées de la structure « verbe + adjectif-adverbe »

$\begin{array}{cl}\begin{array}{c}\text { Prédication seconde } \\ \text { orientée vers le sujet } \\ \text { orientée vers l'objet }\end{array} & \begin{array}{l}\text { Elle vit heureuse } \\ \text { Elle l'a trouvée / vue morte }\end{array} \\ \begin{array}{c}\text { Adjectif à fonction adverbiale } \\ \text { J'y vais direct } \\ \text { Elle va droit au but }\end{array} \\ \begin{array}{c}\text { orientée vers le sujet } \\ \text { orientée vers l'objet }\end{array} & \begin{array}{l}\text { Elle est grande } \\ \text { Elle la trouve / voit plutôt malheureuse } \\ \text { Adjectifs détachés }\end{array} \\ \end{array}$

Le fait que des verbes comme trouver et voir se prêtent aussi bien à la prédication seconde qu'à une fonction de copule (v. Tableau 1) met en évidence que ces structures sont effectivement interconnectées et que leur distinction présuppose un effort d'interprétation. De même, dans la langue parlée, les frontières entre détachement par pause et contiguïté prosodique ne sont pas nettes. De plus, l'accord n'est souvent pas audible dans le code oral (v. Söll 1985 : 92-104). La réalité brouille donc quelque peu la systématique des exemples écrits du Tableau 1.

Si l'on tient compte du fait qu'il s'agit de variantes d'un système monocatégoriel qui repose sur une classe de mots unique, l'adjectif, on ne se surprendra pas de voir émerger aussi des variantes non consacrées plus spontanées, souvent « incorrectes » 
$\mathrm{du}$ point de vue normatif, telles elle va droite au but et les gars jouent forts, où la fonction adverbiale ne semble pas réussir à imposer l'invariabilité. En sens inverse, la prédication seconde n'entraîne pas toujours l'accord : cf. La soupe, je la mange chaud / chaude (v. § 4 ; cf. Olsson 1976, Balibar-Mrabti 1999, Muller 2000). La séparation claire des constructions dépend donc d'une conscience aiguë de la langue et d'un contrôle qui n'est typique que de la langue écrite, et encore - la langue écrite imprimée ou dûment corrigée, comme c'est généralement le cas des textes dépouillés pour la recherche diachronique. La séparation nette des constructions suppose ainsi une éducation linguistique assez poussée. Par contre, le langage spontané, écrit ou parlé, rend de nouveau caduque la distinction 'grammairienne' des constructions, ce qui se comprend cependant si l'on part de la structure de base.

L'approche linguistique qui distingue une structure, d'une part, des constructions qui en émergent d'autre part, favorise également l'analyse de l'adverbe court comme adjectif employé dans des fonctions dites adverbiales. Dans cette structure, la fonction adverbiale est un fait d'interprétation parmi d'autres.

\section{L'accord dans les fonctions adverbiales (" accord adverbial ")}

\subsection{Fonction et norme}

L'invariabilité de l'adverbe est un dogme grammatical qui s'est imposé à partir du $\mathrm{XVII}^{\mathrm{e}}$ siècle, notamment par le purisme linguistique (v. § 17 ; cf. l'analyse critique de ce critère par Van Raemdonck 2005). En fait, l'accord est tout à fait fonctionnel dans une fenêtre grande ouverte puisque le modifieur grand s'accorde avec le modifié ouvert. C’est sans doute la raison pour laquelle cette « erreur » est si fortement enracinée dans les langues romanes, au point de constituer la règle dans certains dialectes, notamment ceux de l'Italie centre-méridionale (Rohlfs 1969, Cruschina 2010, Ledgeway 2011, 2017, Silvestri 2017). Elle prédomine également jusqu'au XVI ${ }^{\mathrm{e}}$ siècle en français (v. § 17.2). C’est le dogme de l'invariabilité qui transforme ce qui est fonctionnel en « erreur grammaticale ». Heureusement, un autre dogme, celui de l'usage, permet de contrebalancer les effets pervers de cette règle là où l'accord ne fait pas de doute dans la pratique parlée de la langue (ex. toute contente, où tout, censé être un adverbe, devrait refuser l'accord). Dans ce dictionnaire, l'accord adverbial est attesté pour pratiquement toutes les entrées, du moins dans le Corpus Web. Contrairement à la modification de l'adjectif que nous venons d'analyser (toute contente, grande ouverte), l'accord adverbial au sein du syntagme verbal ne saurait se justifier par l'unité modifiée (parler haut), si celle-ci est le verbe lui-même. Considérons donc de plus près les faits (v. aussi Hummel 2017a). 


\subsection{L’accord purement graphique}

La langue française possède la particularité que les désinences n’y sont souvent exprimées que dans le code écrit, alors qu'elles sont inaudibles à l'oral. C'est ainsi que l'accord est de rigueur dans elles s'endorment fatiguées, qui est une prédication seconde, alors qu'à l'oral l'accord n'est audible dans aucun des membres de la phrase, sauf pour la personne du verbe. Suite à l'éducation linguistique, la peur de ne pas faire l'accord entraîne souvent un comportement hypercorrect des locuteurs (surtout à l'écrit) qui se manifeste aussi dans les fonctions adverbiales. Citons quelques exemples de notre Corpus Web :



Le dernier exemple est particulièrement intéressant parce que l'accord n'est fait que pour le pluriel alors que le sujet larme est féminin. Ce comportement schizophrène s'explique sans doute par le fait que les auteurs ne prononceraient jamais un - $e$ final dans ces phrases. On évite donc pleine(s). Par contre, l'emploi du -s pour marquer le pluriel du masculin ne se heurte pas à l'usage oral : il est inaudible. Il s'agit donc fort probablement d'une hypercorrection. Ceci est encore confirmé par la comparaison du groupe ennuyer ferme avec son synonyme ennuyer sec. L'accord purement graphique dans s'ennuient fermes se produit assez facilement tandis que l'on cherche en vain un accord graphique et phonétique du type *'ennuie(nt) sèche(s), si le sens est clairement adverbial ('s'ennuyer beaucoup'). La remotivation en tant que prédicats seconds, qui pourrait justifier l'accord, ne fonctionne pas. Sémantiquement, ni ferme ni sec n'admettent une interprétation comme prédicats seconds : on ne saurait adopter une attitude ferme ou décidée pour s'ennuyer ou se trouver dans un état « sec » au moment de s'ennuyer.

Parfois, les grammairiens en font de même, ne citant que des exemples au masculin là où la marque du féminin serait audible :

une autre sorte d'Analogie, qui est celle de certains mots ou de certaines phrases, qui se disent adverbialement, et par consequent indeclinablement, comme Ils se font fort de faire cela, et non pas ils se font forts ; Ils demeurerent court, et non pas, ils demeurerent courts (Vaugelas, Remarques, vol. 1, 22)

L'immortel avait sans doute de bonnes raisons pour y insister, mais le problème, lui aussi, s'avère immortel. Un arrêté ministériel de 1901 allait jusqu'à autoriser l'accord, même pour le féminin : Elle se fait forte de (Le Bidois / Le Bidois 1967 : 151). Brunot (1922 : 624) avait bien perçu que le problème se pose surtout au féminin : 
Une difficulté s'est présentée jadis, causée non plus par la copule, mais par l'attribut lui-même. Une femme devait-elle dire : je suis demeurée court ou courte ? Tous les théoriciens du XVII ${ }^{\mathrm{e}}$ s. ont disserté là-dessus, pour conclure finalement que court était là une sorte d'adverbe, immuable [...]. Même décision avec se faire fort de. Il faut dire : J'en suis certaine et je m'en fais fort

\subsection{L’accord littéraire}

On peut évidemment chercher une motivation aux exemples précités du type elles défendent dures : elles sont dures au moment de défendre (prédication seconde). Sauf que ceci n'est guère probable dans un texte écrit spontanément, sur Internet, comme c'est effectivement le cas des exemples cités. Dans les textes littéraires, par contre, ce type d'accord constitue un recours stylistique très apprécié pour nuancer la modification en y ajoutant une orientation vers un argument du verbe :

Ces parolles clamées hautes et profondes comme un creux son de tonnerre furent de tous entendues (1560, s.v.)

Et il lut les mots suivants qui étincelaient et tournaient rapides (1831, s.v.)

mes vers couleront plus doux et plus faciles $(1779$, s.v.)

L’accord peut ainsi ajouter une nuance résultative à la modification de manière :

la coupe de cèdre que le bûcheron a creusée assez profonde (1833, s.v.)

D'après une nouvelle lettre de vous, je me déterminerai. Ne craignez pas de me l'écrire longue (1837, s.v.)

Ces effets « expressifs » sont particulièrement appréciés dans la poésie :

Je vois tomber la pluie

Dont les flaques font luire

Notre grave planète,

La pluie qui tombe nette (1938, s.v.)

Mais l'emploi intentionnel de cet effet n'est pas nécessairement limité au style littéraire. Dans les exemples suivants du Corpus Web, l'usage invarié va de pair avec une interprétation qui penche du côté « manière » tandis que l'emploi accordé y ajoute une nuance résultative :

Elle est donc en quelques sortes illisibles [= on peut s'attendre à tout de sa part !] d'un coup d'œil rapide, mais il n'y a rien de prévu, du moment qu'elle est éclairée blanc...pas rose, pas rouge, pas bleu, pas turquoise ni jaune.... blanc! (2015, s.v. éclairer blanc)

Par la méthode additive, trois sources de lumière monochromatique R, J et B éclairant une même surface blanche (un écran) donne une plage commune éclairée blanche (2015, s.v. éclairer blanc) 
Même si l'effet de style n'est pas intentionnel au même degré que dans un texte littéraire, on ne saurait nier que la conscience des locuteurs peut capter la nuance et s'en servir, même si ces quelques exemples, qui se veulent illustratifs de cette possibilité, ne sauraient quand même pas la démontrer.

\subsection{L’accord phonétique}

Dans certains exemples tirés de sources internet, l'accord non-orthographique peut refléter la prononciation :

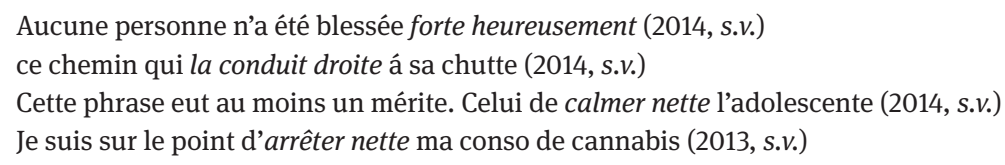

Dans les deux premiers exemples, le - $t$ final devient audible par la liaison, ou peut le devenir. L'accord graphique reflète la fausse interprétation de la liaison comme accord au féminin. Dans les exemples suivants, le fait que le -t final de net est prononcé de toute façon au masculin provoque l'accord graphique. Dans un cas comme dans l'autre, on ne peut retenir ce type d'exemples pour en tirer des conclusions sur le comportement plus ou moins adjectival ou adverbial des mots concernés.

\subsection{L’accord par rapport à une scène évoquée par l'événement verbal}

La complexité sémantique des groupes « verbe + adjectif-adverbe » crée un univers d'interprétation (cf. voir grand, rire jaune, baiser utile, baiser étroit, contrôlé positif (dopage), voyager intelligent, etc.). Ceci constitue leur intérêt pour la poésie, la publicité et les tours familiers ou vulgaires. La portée de la modification dépasse alors les limites de la valence sémantique du verbe. Autrement dit, la modification ne porte, logiquement, sur aucun argument du verbe, qu'il soit explicite ou implicite (v. §5). Les exemples qui suivent mettent en évidence que l'accord peut également être motivé par des éléments non argumentaux qui se trouvent quelque part dans la scène évoquée par le verbe :

Lorsqu'on calcule la quantitée de céréales, on calcule sèche ou prête à manger ? (2014, s.v.) je connais exactement la pointure dont j'ai besoin suivant les marques ainsi que les marques qui chaussent étroits ou larges (2014, s.v.)

Parce quelles chaussent « fins » moi les 37 me serrent alors que c'est ma pointure ! (2014, s.v.) 
Le monsieur m'a expliqué que certains modele chaussaient plus large que d'autres et que Valetta chaussait étroit. J'ai également commandé le modele Talamore qui a priori chausse plus large (2014, s.v. chausser large)

Surtout quand t'es comme moi que tu chausses du 37 et que tu n'aimes que les hommes qui chaussent larges (2014, s.v.)

Cuisinez transparent (1972, s.v.)

Dans l'emploi quotidien, donc hormis la poésie et la publicité, la modification à portée scénique s’associe étroitement aux argots quotidiens ou de spécialité. Calculer sec est une opération usuelle dans les analyses alimentaires où l'on calcule par rapport au poids sec d'un produit. De même que contrôlé positif dans l'argot journalistique du Tour de France, calculer sec se présente comme solution économique dans un univers de communication où tout le monde sait de quoi il s'agit. Le souci d'économie favorise donc la création de verbes complexes à sémantique inférentielle. L'accord n'est pas la solution la plus fréquente, mais dans le premier exemple la présence d'un substantif, on ne sait s'il s'agit de quantité ou céréales, motive l'accord. Le singulier favorise le choix de quantité, mais ceci n'est pas sûr dans l'écriture spontanée. Les trois autres exemples constituent une belle série où l'accord de large ou fin est motivé par des éléments très différents situés dans l'imaginaire de la scène : les marques, les chaussures, les hommes, l'emploi invarié n'étant pas exclu. Mais c'est surtout la publicité qui aime jouer avec les inférences suggestives, parfois surprenantes, pour susciter l'interêt des consommateurs (cf. Galliot 1955 : 431-433, déjà pour les années 1930). En l’occurrence, cuisiner transparent s'emploie par rapport à des plats de cuisson transparents qu'on essaie de vendre.

\subsection{Un schéma secondaire : l'accord fantôme du type se la couler douce}

Il existe des tours populaires, dans toutes les langues romanes, où l'accord se fait par rapport à un argument syntaxiquement explicite mais sémantiquement postiche :

il se l'était coulée douce, comme on disait dans sa famille (1884, s.v.)

L'autre a essayé de la jouer fine (1985, s.v.)

On peut évidemment s'imaginer le pronom la comme représentant d'un objet plus ou moins concrétisable ( « fantôme »), disons « la vie », « l'affaire » etc., mais la finalité est clairement adverbiale : la construction réfère à une façon d'agir. En tout cas, l'accord se fait par rapport à l'argument fantôme au féminin.

$\mathrm{Du}$ point de vue structurel et fonctionnel, on peut rapprocher ce type d'accord de celui du participe passé des temps composés : fr. je l'ai trouvée. C’est ainsi que Ledgeway (2011) a recours à it. l'ho trovata pour expliquer l'usage systématique de ce type d'accord dans les variétés méridionales de l'Italie : 
It. Anna miscava bone’i carte (dialecte de Cosenza) 'Anna mélangeait bien (lit. bonnes) les cartes’

Autrement dit, après un verbe précédé d'un objet direct (mais aussi quand celui-ci suit ; v. exemple), l'adjectif se comporte comme le participe. Ce type d'accord est systématique dans ces variétés.

Il est intéressant d'observer que ce type d'accord est assez fréquent dans les citations françaises appartenant au registre familier représenté dans ce dictionnaire. On peut donc penser que ce schéma, qui est dominant dans ces variétés de l'Italie, constitue un schéma secondaire du français familier, et également de certains technolectes ou argots de métier (ex. de 2011). Citons en quelques exemples :

\footnotetext{
c'est une très belle chanson et il est impossible de la chanter fausse !! (CW, s.v.)

jme défonce a force de la chanter forte (CW, s.v.)

Oui, mais ces quatre phrases, il faut les chanter justes (CW, s.v.)

L'inconvénient est qu'il faut majorer la pression d'entrée au moteur d'environ 10 bars, mais nous avions pris soin de la choisir basse au départ (CW, s.v.)

Tant qu'à citer des chiffres, autant les citer justes (CW, s.v.)

On comprend aisément pourquoi des icônes du sprint moderne, toutes médaillées aux championnats du monde ou aux jeux Olympiques, ont été contrôlées positives aux psychostimulants (2011, s.v.)
}

L'exemple suivant montre qu'accord et invariabilité coexistent dans le même contexte, l'accord se produisant uniquement dans la structure syntaxique « pronom objet direct + verbe + adjectif-adverbe » :

Le pouce empêche à la boule d'êtrre de rouler droit, c'est à dire qu'il donne un effet, or pour un contrôle optimum il faut pouvoir l'envoyer droite (CW, s.v. rouler droit)

Les données de ce dictionnaire montrent une prédilection du langage des sports pour l'emploi accordé, notamment quand il s'agit de bien décrire une action opérée sur une balle, un ballon, une boule, etc.

\subsection{Accord « illogique » ou « accord cohésif »?}

Selon la tradition grammaticographique, l'accord serait « illogique » dans toutes les fonctions adverbiales citées ci-dessus. Or, il est rare de trouver des cas où l'accord ne soit pas motivé. En effet, l'accord se fait toujours par rapport à un élément explicite, mis à part quelques phénomènes d'accord ad sensum (ex. On parlait contents), qui sont également motivés. Il est pratiquement exclu de trouver un accord du type *l'homme parle heureuse, quand celui-ci serait audible à l'oral. On peut en tirer deux conséquences :

(i) Le classement de l'accord adverbial comme illogique réfère au dogme de l'invariabilité, l'accord ne pouvant se justifier que par rapport à la modification d'un 
substantif. L’accord est jugé « illogique » s'il se produit dans des fonctions adverbiales (qui ne modifient pas un substantif)

(ii) Par contre, la communication spontanée reflétée par nos exemples relevés sur Internet se sert de l'accord comme instrument linguistique de cohésion thématique. C’est ainsi que l'accord dans les hommes qui chaussent larges crée une cohésion forte du sujet avec le verbe et l'objet impliqué : les chaussures. Pourquoi ce type d'accord serait-il donc « illogique », s’il est clairement motivé ? Le seul problème est que la motivation ne suit pas les principes de la norme scolaire.

La type de motivation (ii) n'est illogique que par rapport à cette règle rationaliste qui veut que l'accord se fasse entre modifiant et modifié, et ceci systématiquement, et non pas comme simple option, comme dans les exemples qu'on peut trouver sur Internet. Or, il semble que la communication informelle cherche avant tout à créer des réseaux de cohérence en s'appuyant sur l'accord. La norme scolaire impose un type de cohérence particulièrement fort : celui de modifiant et modifié (sans toutefois l'appliquer dans des cas du type des oreilles pures françaises, v. § 17.2). C’est une intervention rationaliste, arbitraire du point de vue fonctionnel. En tout cas, la communication informelle spontanée traite l'accord plutôt comme phénomène optionnel pour assurer tout type de cohérence autour d'un thème. L'accord littéraire met en évidence que les écrivains apprécient également cette liberté, dans les limites du stylistiquement explicable. Notons que la norme elle-même hésite dans certains cas : Seul / Seules les femmes peuvent le faire. L'application rigoureuse des principes voudrait que seule la variante accordée suivante soit acceptable : Seules, les femmes peuvent le faire 'étant seules, non-accompagnées' ; or, ce n'est pas le sens de l'énoncé (qui signifie 'seulement les femmes peuvent le faire, à l'exclusion des hommes'). On voit donc que même le style soigné se heurte aux principes rationalistes de la logique grammaticale.

Si l'on peut avoir l'impression, en France, d'avoir affaire à des unités « invariées », ce qui semble confirmer le titre de l'ouvrage de Grundt : Études sur l'adjectif invarié en français (malgré certains des exemples accordés cités par l'auteur), l'étude de Drapeau (1982 : 21) met en évidence la pratique systématique de l'accord dans le français populaire de Montréal :

On ne retrouve pas cette tendance [= emploi de l'adjectif invarié] en français populaire de Montréal où, bien au contraire, certains adverbes sont réanalysés comme adjectifs accordés au féminin là où le standard utilise un adverbe invariable comme dans [...] Les hirondelles volent basses

L’auteure cite également elle sent bonne. Cette variante est très marginale dans les données de Frantext, mais elle apparaît avec force dans le Corpus Web. Force est de constater que la tendance à l'accord est une propriété très répandue, voire parfois systématique, dans les dialectes de toutes les langues romanes (dans une perspective romanistique : Ledgeway 2017, Hummel 2017c ; pour l'espagnol : Feliú Arquiola / Pato 
2020, Hummel 2015 ; pour le français : Hummel 2017a ; pour les variétés d'Italie : Cruschina 2010, Ledgeway 2011, Silvestri 2017; pour le portugais : Hummel 2017b ; pour le roumain : Hummel 2017c : 36). À en juger par le Corpus Web, cette tendance est également manifeste dans la communication informelle non proprement dialectale de l'Hexagone. En fait, variétés canadiennes, langage informel sur Internet et tradition populaire hexagonale, en l'occurrence, ne font qu'une :

Et d'autre part, dans la bouche des personnes du vulgaire : Tu vois, ces branches-là, ça gêne, elles tombent trop basses. [...] De temps en temps, il a l'haleine qui sent très forte (Damourette / Pichon 1932-1951 : § 984)

Il ne faut pas oublier non plus que même l'adverbe en -ment n'échappe pas à l'accord spontané. Citons au hasard quelques exemples rapidement identifiés dans Frantext : des adverbes proprements dits, deux développements absoluments identiques, les champs largements étalés (v. aussi professionnellements s.v. travailler sérieux). On se demande même si la liaison phonétique est toujours exclue dans les deux derniers exemples. Le même phénomène se produit en espagnol où l'accord est audible dans le code oral. Il ne s'agit donc pas de hapax purement graphiques. Gerhalter (2020 : 197) cite des exemples pour esp. exactamentes, meramentes, precisamentes (cf. Felíu Arquiola 2019). Il semble que la modification d'un adjectif soit particulièrement propice à ce type d'accord, ainsi que celle des adverbes de focalisation cités par Gerhalter. Mentionnons aussi deux occurrences du type des unités qui tirent loins (s.v. tirer loin).

\subsection{Remarque finale}

Nous employons l'adjectif « invarié » pour signaler un phénomène qui se produit dans un contexte donné, donc dans le ou les exemples cités. Le terme « invariable », plus courant, implique l'idée d'absence de l'accord dans tous les contextes (invariabilité), ce qui n'est guère le cas chez les adjectifs-adverbes même si les grammaires essaient de les présenter comme un petit groupe d'adjectifs adverbialisés (ou « adverbes courts ») invariables. Certains auteurs emploient la notion d'adjectif invarié par rapport à la seule position de l'adjectif au sein du syntagme verbal, pour laquelle l'invariabilité générale est assumée (Grundt 1972, Noailly 1994 : 104, Coiffet 2018, GGHF 2020 : 913). Or, nous venons de voir que les choses ne sont pas si simples, même pour les modifieurs du verbe. Grevisse / Goosse (2016 : § 954) observent laconiquement : « Certains adjectifs employés adverbialement varient ». Goes (1999 : 215) refuse le terme alternatif d'adjectif invariable, contradictoire au vu des propriétés fondamentales de l'adjectif (on le trouve pourtant chez Le Goffic 1993 : § 236, pour le type boire chaud, acheter français, rapporter gros). C'est sans doute la raison pour laquelle les linguistes lui préfèrent celui d'adjectif invarié, inusuel dans la grammaticographie du français. On 
pourrait simplement parler d'adjectif non-accordé, mais ceci présuppose qu'il existe un argument dans un contexte qui le permettrait, ce qui n'est pas le cas dans l'emploi absolu. Il faut donc traiter l'accord comme phénomène contextuel, ce qui n'exclut pas le développement de tendances dans la pratique de l'accord, voire la lexicalisation (ex. couper court 'interrompre', parler haut 'à haute voix', invariables, ou presque).

En tout cas, le fait de ne plus parler, dans la plupart des travaux récents, d'adverbe mais d'adjectif, constitue sans doute un progrès. Il est clair alors que son emploi invarié, qui existe évidemment, se produit par rapport à une fonction (sémantique et syntaxique) et un contexte. Il est clair aussi que les données de la langue parlée captées au vol nous font découvrir un usage beaucoup plus invarié, si l'on peut dire, que ce n'est le cas pour l'écriture. Mais il existe d'autres contextes, et, admettons-le, d'autres décisions du locuteur, qui produisent l'accord morphologique, aussi dans exactement les mêmes conditions. C'est que l'usage d'un adjectif comprend naturellement l'option de l'accord. On peut en discuter les motifs ou les causes, on peut le critiquer, mais l'accord de l'adjectif-adverbe en tant que phénomène existe. Il faut considérer aussi que l'idée de l'accord obligatoire est un dada de la grammaticographie et de l'enseignement. Dans la langue parlée, la flexion morphologique retrouve son caractère optionnel, spontané, immédiat, un accord qui est fait sans contrôle postérieur (sans relecture). On trouve donc plutôt des tendances que des véritables règles uniformes. Que la grammaire scolaire en fasse des règles, c'est très bien. La standardisation a ses mérites mais aussi son prix.

\section{L'absence de l'accord dans les fonctions adjectivales}

Si l'accord dans les fonctions dites adverbiales existe (v. § 4), le phénomène complémentaire de l'absence de l'accord dans des fonctions adjectivales de modification nominale existe également. Dans la structure « verbe + adjectif-adverbe », l'accord avec un argument du verbe est justifié autant du point de vue fonctionnel que sémantique quand l'adjectif-adverbe modifie un argument nominal du verbe. C'est le cas des constructions qui figurent au Tableau 1 (prédication seconde et construction copulative, orientées vers le sujet ou l'objet direct du verbe). Elles sont donc pleinement acceptées par la norme linguistique. Or, il existe des contextes syntaxiques qui favorisent l'invariabilité de l'adjectif-adverbe dans ce type de construction. Cela fait indirectement - ou si l'on veut, improprement - grossir le groupe des adjectifs à fonction adverbiale. Notons en passant que l'hypothèse d'invariabilité défendue par Coiffet (2018 : 9-10 ; cf. également Riegel et al. 2018 : 658) repose sur la présomption d'absence systématique de l'argument dans les cas où l'adjectif-adverbe se dirige logiquement vers celui-ci. Ceci ne correspond pas aux faits, les arguments pouvant être explicites. Certes, on peut être tenté d'exclure ce cas de figure du groupe des « adverbes 
courts ", donc accepter manger chaud tout court, et exclure la manger chaude. Mais ceci est assez arbitraire, d'autant plus que la présence de l'argument dans la syntaxe n'exclut pas toujours l'emploi invarié, comme nous le verrons dans ce qui suit.

\subsection{La modification d'un objet direct explicite}

Dans couper court (les cheveux), l'adjectif ne modifie pas l'action désignée par le verbe. Car court réfère à une qualité des cheveux, celle de leur longueur. Selon toute logique, il devrait fonctionner comme un prédicat second et être systématiquement accordé. Or, il n'en est rien. On trouve les deux variantes, couper court / courts les cheveux, déjà mentionnées par Blinkenberg (1950 : 114) :

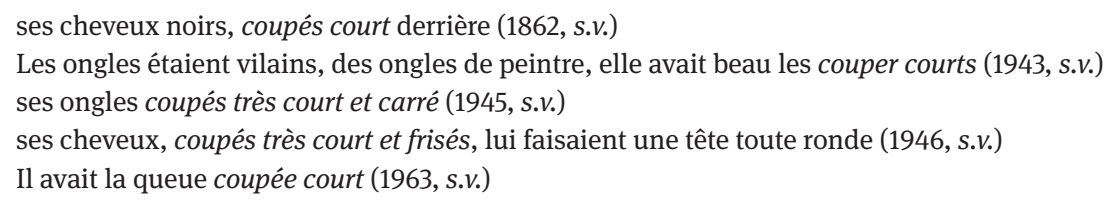

La pratique de l'accord n'est pas influencée par le registre, comme dans les cas de figure analysés au $\S 4$. On trouve ces variantes dans tout type de texte. C’est surtout ce type d'exemples qui rend finalement assez arbitraire la réduction d'un corpus au cas de figure où l'argument du verbe est absent (Coiffet 2018). Car si l'absence de l'accord découle naturellement de ce contexte, on la trouve aussi, nous venons de le voir, quand l'argument est présent.

On est tenté d'expliquer l'absence de l'accord par la lexicalisation de couper court comme verbe complexe. Dans la conscience des locuteurs, couper court serait moins une combinaison libre et productive, donc une construction à prédicat second, qu'un verbe tout fait et invariable qui peut être accompagné ou non d'un objet explicite. Plus un tel groupe serait lexicalisé, plus il tendrait à l'invariabilité même si un objet direct explicite se présente dans la syntaxe. Dans le cas de couper court, l'invariabilité s'observe de façon générale du côté de l'emploi métaphorique : couper court 'interrompre'. Ici, on peut considérer comme fait assumé l'existence d'un verbe complexe signifiant 'interrompre'. C'est la lexicalisation du groupe avec un sens nouveau qui en fait un verbe complexe. On chercherait en vain un objet, implicite ou explicite, même s'il a pu jouer un rôle à l'origine de l'expression (couper court au / ?le discours de quelqu'un). Mais il existe aussi le cas contraire, où l'emploi invarié est plus fréquent dans l'interprétation concrète (acheter cher) alors que l'accord est mieux accepté au figuré (une victoire achetée chère). Ceci joue en faveur du rôle de la simple fréquence du groupe en emploi absolu comme facteur décisif expliquant la tendance à l'emploi invarié : plus on emploie manger chaud tout court, plus on aurait tendance à conserver son invariabilité indépendamment de la présence d'un objet direct. S'y ajoute un facteur diachronique : dans le cas de acheter cher, l'emploi invarié progresse au fil de 
l'histoire (reculant tout de même sous l'influence latinisante). Autrement dit, l'invariabilité de acheter cher caractérise notamment l'emploi actuel.

La syntaxe peut également jouer un rôle, sans qu'elle permette de formuler une règle clairement établie dans l'usage. Sechehaye $(1950,163)$ se montre prudent quand il réfère à une telle règle qui a ou avait cours dans l'enseignement :

On nous enseigne à distinguer par la construction et par l'orthographe : hacher la viande menue, et hacher menu la viande. Ce sont deux systèmes de rapports entre les mêmes termes

La position syntaxique de l'objet direct, avant ou après le groupe « verbe + adjectifadverbe ", influe sur l'accord, qui est plus probable quand l'objet direct le précède. Les exemples que nous venons de citer pour couper court ne permettent pourtant pas de parler d'une règle établie par l'usage. Il s'agit plutôt d'une tendance qui demanderait une analyse empirique plus profonde.

\subsection{L'absence de l'accord avec l'objet direct implicite (" objet interne »)}

On parle d'objet interne quand celui-ci appartient à la valence sémantique du verbe sans toutefois apparaître ouvertement dans la syntaxe (ou valence syntaxique) comme objet direct (cf. Regula 1957, Moignet 1963, Hummel 2018b). L'accord devient alors impossible, et l'invariabilité s'impose. Considérons à ce sujet l'emploi de boire frais et manger chaud dans l'exemple qui suit :

Mes amis; buvez frais, mangez chaud, faites l'amour comme vous pourrez (1825, s.v. boire frais)

Logiquement parlant, les modifieurs frais et chaud y réfèrent à une qualité de la boisson ou de la nourriture, mais ces arguments du verbe restent implicites. N'ayant pas à leur disposition un complément explicite qui leur offre les marques flexionnelles pour s'accorder, les modifieurs restent invariés.

Cependant, l'interprétation sémantique n'en reste pas au niveau « logique » de la modification d'un objet interne. Libérés d'un objet direct explicite, les groupes « absolus » finissent par ne plus désigner une action concrète mais un type de comportement. C'est ainsi que boire frais, manger chaud, acheter cher, brûler vif peuvent être perçus comme des verbes complexes désignant un comportement plus ou moins typé (cf. Le Goffic 1993 : § 168). À ce niveau de généralisation ou abstraction, les groupes peuvent être lus comme une manière de faire quelque chose, s'éloignant du même coup de la prédication seconde. Manger chaud et brûler vif deviennent ainsi une façon de manger quelque chose ou de brûler quelqu'un, s'excluant de la modification simple d'un argument du verbe. Autrement dit, les modifieurs y rejoignent la modification de manière et par là-même le groupe des soi-disant adverbes courts : Les Français mangent chaud le soir. Les Norvégiens mangent salé. Mon coiffeur coupe court. 
Ce sont autant de réponses à la question « Comment ? ». On voit donc de nouveau se confondre l'interprétation adjectivale comme prédicat second, d'un côté, et l'interprétation adverbiale de manière, de l'autre.

\subsection{L'absence de l'accord avec le sujet implicite (" sujet interne »)}

On ne parle généralement pas de sujet interne puisque la phrase française moderne impose un sujet explicite. Ceci n'empêche pas l'emploi de groupes orientés vers le sujet comme formules du type acheter malin / intelligent / responsable ou bronzer idiot, aussi à l'impératif : Achetez malin!

Tant qu’à citer, citer juste (2014, s.v.)

Et même si le sujet est sémantiquement explicité dans le contexte, il n’a souvent pas de relation syntaxique directe avec le groupe « verbe + adjectif » :

Courir lent t’aidera a courir vite (2015, s.v. courir lent)

Si la formule est consacrée, une femme peut parfaitement dire j'achète malin. On s'imagine mal l'emploi du féminin maligne. Il n'est même pas besoin de l'analyser comme un verbe complexe lexicalisé. En fait, l'emploi absolu sans sujet ou objet explicites suffit à lui seul pour créer un syntagme qui désigne un type d'action ou de comportement. On peut y voir la base syntaxique de possibles processus de lexicalisation comme verbes complexes.

Selon les données du dictionnaire, le sujet interne est nettement moins fréquent que l'objet interne, les proportions relatives étant de 42 exemples, dans le premier cas, et de 330, dans le second, sur un échantillon de 3232 citations (v. Hummel 2018b).

\subsection{Argument « interne » et lexicalisation}

Le fait de pouvoir intégrer sémantiquement dans le groupe « verbe + adjectif-adverbe » aussi bien le sujet que l'objet de l'événement désigné par le verbe est à la base de nombreuses expressions lexicalisées ou de slogans fabriqués pour la publicité, de conseils de vie, ou des dictons populaires :

Chiez dur ou chiez mou, mais chiez dans le trou (s.v. chier dur)

Buvez bien vrai Un vrai Pschitt (1958, s.v.)

Ces expressions impliquent souvent une métaphore comme dans voir grand 'être ambitieux, avoir de grands projets', voir rouge 'se mettre très en colère' ou jouer sale 
'sans respecter les règles'. Il est possible de les transformer en prédication seconde en leur redonnant le sens original :

Mes enfants, je les vois plutôt grands déjà

La tour illuminée, ce soir je l'ai vue rouge

Les enfants jouent sales 'ils sont sales pendant le jeu' serait également possible dans un contexte donné, mais sans doute peu usuel. En tout cas, il suffit de choisir un autre verbe pour activer la prédication seconde : Les enfants sont rentrés sales. La lexicalisation de jouer sale et d'autres expressions peut poser problème au moment de vouloir redonner un sens concret au groupe. Mais il s'agit d'un effet de la lexicalisation, non d'un principe fonctionnel.

L' « emploi absolu » de la structure « verbe + adjectif », documenté dans la rubrique de la microstructure des entrées qui porte ce nom, met en évidence que cette tendance existe même chez les verbes fortement transitifs tels faire, dire et voir :

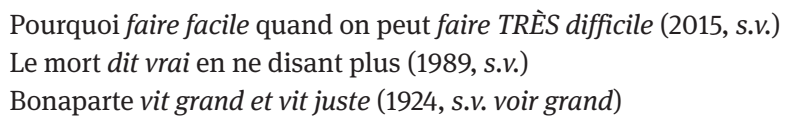

\subsection{La pertinence des contextes à portée générique}

On trouve un nombre tout à fait exceptionnel de contextes où la forme du groupe verbal, souvent à l'infinitif ou avec sujet impersonnel (ça, cela, on), produit un effet de généralisation qui convertit l'événement verbal en comportement typé. Ce type d'emploi est particulièrement pertinent dans la communication informelle, où l'on observe une nette préférence pour le sujet impersonnel ça, qui est remplacé par cela ou on dans le style plus soigné (cf. Drapeau 1982 : 24) :

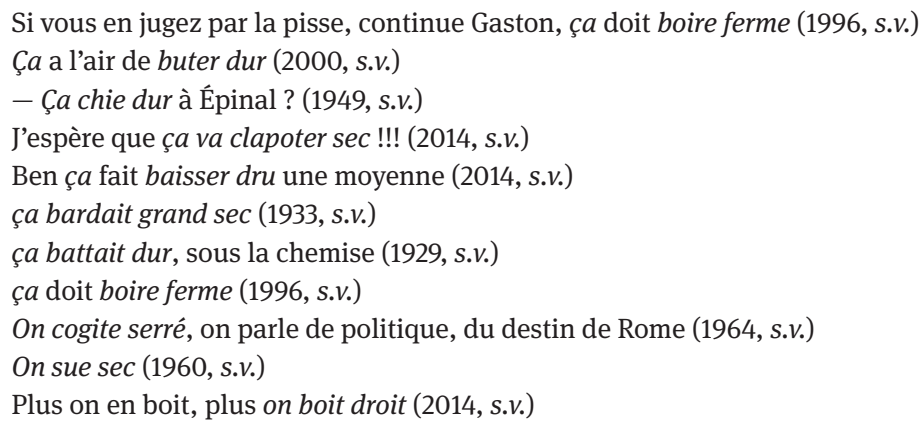

Notons en conclusion que le groupe « verbe + adjectif » peut sémantiquement inclure un argument modifié par l'adjectif, qu'il s'agisse du sujet ou de l'objet, effacés des 
relations syntaxiques directes du groupe. Cela s’insère dans une tendance manifeste à créer des énoncés qui transportent un message générique (ça, verbe à l'infinitif). L'argument interne et l'emploi générique entraînent tous les deux l'emploi invarié puisqu'ils évitent l'emploi d'un substantif qui porte les marques de genre et nombre et qui puisse servir de support à l'accord. La pertinence d'un argument interne souligne de nouveau le bien-fondé de l'analyse du modifieur comme unité appartenant à la classe de l'adjectif. L'accord reste donc possible. Il peut faire surface si un argument explicite du verbe le permet.

\section{La cohésion interne du groupe syntaxique}

\subsection{Productivité, lexicalisation et schéma prosodique}

L'emploi des groupes « verbe + adjectif-adverbe » se réalise sous la tension de deux forces contraires, la productivité et la lexicalisation. Du côté de la lexicalisation, on peut discerner une tendance à percevoir et à traiter ces groupes comme des verbes complexes. La lexicalisation de groupes du type voir grand, jouer sale, rire jaune, etc. est un fait qui trouve son reflet dans les dictionnaires. À part ces lexicalisations fortes, où l'expression acquiert un sens figuré figé, on peut mentionner les lexicalisations par simple effet de fréquence comme bosser dur, parler haut, etc. Finalement, ce dictionnaire atteste de nombreux groupes qui apparaissent au hasard de la productivité de cette construction.

On observe un schéma rythmique assez systématique qui fait que le verbe, souvent bisyllabique, est suivi d'un adjectif qui, lui, est presque toujours monosyllabique (cf. Le Goffic 1993 : § 266). La banque de données du Dictionnaire historique de l'adjectif-adverbe met en évidence une tendance à employer des adjectifs courts : 11636 adjectifs sont monosyllabiques, 1674 bisyllabiques, 214 comptent trois syllabes et 34 se composent de quatre syllabes. Ces chiffres réfèrent à la fréquence des " tokens » (ou attestations) sur 286 «types » (ou unités différentes). Ceci reflète l'usage et ce qui est donc retenu le plus souvent par « l'oreille ». Au niveau de la lexicalisation, ce fait devient un schéma. Ce schéma n'est pas limité au groupes lexicalisés, mais il pourrait favoriser leur lexcialisation.

\subsection{La flexibilité combinatoire interne}

Selon le degré de lexicalisation, le groupe « verbe + adjectif-adverbe » peut admettre ou non l'intercalation d'un modifieur ou d'un adverbe. Le fait qu'un composé comme maison de campagne ne se laisse pas transformer en *maison de campagne profonde trouve son pendant chez les groupes « verbe + adjectif » lexicalisés. Dans le cas de 
l'adjectif-adverbe, l'analyse s'avère compliquée. De prime abord, on dirait peut-être que l'on peut couper très courts les cheveux mais on ne peut pas *couper très court au discours de quelqu'un, et changer la construction est assez rare (je le coupe court 'je l'interromps'). De même, malgré la transitivité du verbe dire, on emploie dire vrai mais non pas ?dire vrai quelque chose (sauf comme copule dans une construction attributive telle que Il le dit vrai 'il dit que ceci est vrai'). Il en va de même pour battre froid, rire jaune, voir rouge. Les tests d'acceptation mettent en évidence ces faits ou tendances (cf. Guimier / Oueslati 2006). C'est aussi le cas des données de Frantext où l'emploi transitif de couper court 'interrompre' n'est pas attesté. On peut en conclure que la langue standard et le bon usage évitent cette construction. Or, on peut la trouver dans d'autres sources :

Après l'avoir tous humblement remercié, $M$. de Montelon s'aproche avec nous et lui parle de notre restablissement. Le Roi le coupe court, déclare qu'il veut que ceux de Semeur entrent devant nous en signe de leurs services (Gabriel Breunot, 1595, Journal, s.v.)

$\mathrm{Ah}$ ! je veux pas l'entendre ! Je le coupe court ! je pousse des cris de paon !... Il me regarde... Allez hop grand-père! Faut pas lambiner ! Faut que je fasse des progrès terribles !... Je vous admire ! je vous adule ! faut pas qu'on perde une seconde » (Louis-Ferdinand Céline, 1944, Guignol's band II, s.v.)

Et quel travail faisiez-vous ? Un travail comme un autre, je le coupe court. Quelque chose dans mon ton, ou peut-être dans mon aspect, l'intimide. Il hasarde un mot d'excuse, se plonge dans le fromage, lance une calotte à un garnement (Giancarlo de Cataldo, 2012, Les Traîtres [trad.], s.v.)

On pourrait encore penser que la citation de Céline est un hapax créé dans le style innovateur de cet auteur, mais l'ensemble des citations montre bien que l'emploi existe. Dans le cas de voir rouge, des variantes semblent possibles, du moins en plaisantant : Il a vu rouge, très rouge même. On trouve également couper tout court :

Là il le coupe tout court : mais la naïfve conclusion, que j'en fais naistre, et qu'il a suffoquée, est, Qu'il faut pareillement rapporter à l'Eglise de Dieu, et à ses Docteurs legitimes et Theologiens approuvez l'intelligence, et jugement des parolles de Dieu

(Jean de Bordes, 1598, Les Vrais Abus des pretendus abus de messe, s.v.)

On peut se demander si * couper très court (v. supra) est vraiment exclu.

Force est donc de constater qu'aussi bien les tests d'acceptation que le recours à un corpus comme Frantext risquent de donner une image de la langue influée par la connaissance du standard ou du bon usage. Autrement dit, les groupes sont moins figés que l'on ne croirait.

La coordination des adjectifs est également possible, dans la très grande majorité des cas. Elle est même très appréciée :

Il y a une difference entre chanter bas et grave et chanter juste et bien (2014, s.v. chanter bas)

C'est alors qu'on trouva pour sortir d'embarras, l'art de mentir tout haut en disant vrai tout bas (1701, s.v. mentir haut) 
Cette flexibilité se voit cependant limitée dans les tours fortement lexicalisés : ?voir rouge et noir. En tout cas, les groupes lexicalisés avec adjectif-adverbe sont nettement plus fréquents que chez les groupes qui combinent un verbe avec un adverbe en -ment, toujours libres.

L'exemple suivant montre que la cohésion lexicale du verbe complexe peut se traduire par la nominalisation, sur le plan fonctionnel, et par l'emploi d'un trait d'union, sur le plan graphique (cf. Stephan-Gabinel 2001 sur les nominalisations parler cru / dru /vrai) :

Le parler-vrai de Justin Trudeau détonne, peut dérouter (2016, s.v.)

Les nominalisations sans trait d'union sont également attestées :

Quand estonné j'entr'oy un doux coulant parler (Philippe Desportes, 1596, s.v.)

le dormir suave au bord d'une fontaine (André Chénier, 1794, s.v.)

des penseurs au dire clair et franc (Corpus Web, 2015, s.v.)

Notons que l'adverbe en -ment ne pourrait pas suivre le même modèle de nominalisation (un parler facile vs. *un parler facilement). Ajoutons que la motivation génétique peut également jouer en sens inverse. Dans le cas de rire frais, la fréquence dans Frantext du groupe verbal face au groupe nominal un rire frais est de 1 à 34 . C'est donc plutôt le groupe nominal un rire frais qui motive ou favorise l'emploi du groupe verbal elle rit frais.

Selon Wilmet (2010 : §339), « les censeurs tirent à boulets rouges contre les nominalisations du type un blessé léger, une blessée grave, des sourds profonds ». On ne saurait les interpréter sans en chercher soit une modification verbale sousjacente (blesser grave / léger / légèrement), soit une modification adjectivale (sourd profond, profondément sourd).

\subsection{L’adjectif-adverbe comme complément du verbe?}

Une riche bibliographie a essayé d'analyser l'adjectif-adverbe lui-même comme complément du verbe (v. Heise 1912 : 873-878 et 874-877 sur les origines de cette discussion, et Grundt 1972 : 3-5, pour la suite). Même avant Port-Royal, on trouve chez Henri Estienne (1853 [1565]) : 67) l'explication (à partir du grec) de parler gresle / gros / gras, etc. comme ellipse d'un infinitif substantivé il parle (un parler) gresle / gros / gras (v. aussi Gougenheim 1964 sur l'emploi de verbes intransitifs avec objet interne). Moignet cite l'enseignement oral de Gustave Guillaume où il analyse l'adjectif à fonction adverbiale face à l'adverbe en -ment : 
Dans chanter fort, c'est le chant, nominalement évoqué, qui est déclaré fort. Dans penser fortement, c'est l'activité pensante, verbalement évoquée, qui est déclarée forte, puissante (1961: 20 n. 2 ; cf. $1963: 178)$

Chanter faux, c'est produire un chant qui est faux ; sentir bon, c'est dégager une odeur bonne (l'adverbe bien est ici inadéquat), etc. (Moignet 1981 : 52)

Ce type d'analyse va même plus loin, allant jusqu'à considérer l'adjectif-adverbe luimême comme complément d'objet, du moins dans certains cas (Togeby 1982 : 239-240, Le Goffic 1993 : §168). La discussion a été reprise récemment, suite à la publication de Noailly (1994), suivie de Noailly (1997a,b), Abeillé / Godard (2004) et Abeillé / Mouret (2010), où l'on suggère la notion de « complément léger » pour l'adjectif-adverbe.

Or, si l'on peut, en forçant un peu, établir une correspondance entre parler fort et ce que l'on parle est fort, voire attribuer une certaine nature de complément du verbe à l'adjectif dans parler clair, ceci n'est guère concevable pour courir rapide (v. aussi les critiques de Guimier 1989 : 110-112). En tout cas, notre sentiment linguistique ne cesse de ressentir le caractère forcé de ces transformations supposées « équivalentes » et « explicatives », même quand le modifieur est ou pourrait être un substantif (boire nature, bronzer idiot). Ajoutons des exemples du français populaire parlé à Montréal : il marche tapette, il mange cochon, etc. (Drapeau 1982 : 29-30). Le modifieur dans bronzer idiot réfère, tout au plus, au sujet, et non pas à un complément implicite. Mais on y verra avant tout une modification de manière. S'il est vrai que l'adjectifadverbe occupe la même position syntaxique qu'un complément, ce qui peut en principe donner lieu à une telle interprétation, cette possibilité reste très marginale sur l'ensemble des cas. Elle ne concerne d'ailleurs que les verbes transitifs. Ceci étant, la force de la position syntaxique est sans doute présente dans les cas où l'on peut analyser le groupe comme modifieur d'un objet interne : dire vrai 'ce qui est dit est vrai' ou, plutôt, 'dire ce qui est vrai'. Mais la structure syntaxique permet également une lecture « de manière ». La conclusion est simple : la position syntaxique occupée par l'adjectif-adverbe est ambiguë. Car nous avons un adjectif en prédication seconde (orienté vers le sujet ou l'objet), un adverbe modifieur du verbe et un complément d'objet. Ceci entraîne une marge d'interprétation considérable, ce qui fait justement l'intérêt de ce groupe syntaxique. Les détails de l'hypothèse du modifieur-complément ont été analysés sur la base des données de ce dictionnaire dans Hummel (2018d).

\subsection{La modification de l'adjectif-adverbe}

Dans l'analyse linguistique des locutions, l'introduction d'un élément supplémentaire est un test pour mesurer le degré de lexicalisation. De ce point de vue, le fait qu'on trouve des modifieurs d'adjectifs-adverbes dans la plupart des entrées du dictionnaire reflète, sur l'ensemble, un faible degré de lexicalisation (cf. aussi Guimier / Oueslati 
2006). C'est ainsi que parler haut est très fréquent, au point qu'on peut le considérer lexicalisé, mais le groupe n'est pas figé puisqu'on trouve facilement des variantes comme parler très / si / assez / fort haut. Même si nous écartons les particules de négation et les compléments d'objet, la liste des unités qui se glissent entre le verbe et l'adjectif-adverbe est toujours assez longue. Voici une synopse des unités qui s'intercalent entre verbe et adjectif selon les données de notre banque de données (Fr_A_DHAA), donc hors Corpus Web et hors recherches supplémentaires pour ce dictionnaire :

Tableau 2. Unités qui s’intercalent entre verbe et adjectif-adverbe

\begin{tabular}{|c|c|c|c|c|c|c|c|}
\hline tout & 1944 & tellement & 4 & ensuite & 1 & miraculeusement & 1 \\
\hline plus & 942 & trestout & 4 & également & 1 & mystérieusement & 1 \\
\hline si & 733 & un peu trop & 4 & étrangement & 1 & naturellement & 1 \\
\hline très & 323 & beaucoup trop & 3 & excessivement & 1 & nullement & 1 \\
\hline bien & 289 & complètement & 3 & extrêmement & 1 & ore & 1 \\
\hline trop & 227 & plus longtemps & 2 & furieusement & 1 & particulièrement & 1 \\
\hline moult & 176 & plutôt & 2 & généralement & 1 & partout & 1 \\
\hline aussi & 131 & pourtant & 2 & hardiment & 1 & plus guère & 1 \\
\hline assez & 116 & terriblement & 2 & impeccablement & 1 & presqu'aussi & 1 \\
\hline fort & 72 & à peu près & 1 & indéniablement & 1 & presque à coup sûr & 1 \\
\hline toujours & 53 & absolument & 1 & infiniment & 1 & profondément & 1 \\
\hline moins & 50 & adorablement & 1 & jus & 1 & quelquefois & 1 \\
\hline tant & 34 & autant & 1 & justement & 1 & réellement & 1 \\
\hline un peu & 34 & bien aussi & 1 & lamentablement & 1 & réellement très & 1 \\
\hline encore plus & 23 & bien moins & 1 & légèrement & 1 & résolument & 1 \\
\hline encore & 19 & bougrement & 1 & lumineusement & 1 & rigoureusement & 1 \\
\hline bien plus & 12 & comme ça & 1 & maintenant & 1 & rudement & 1 \\
\hline beaucoup plus & 10 & d'abord & 1 & mal & 1 & si terriblement & 1 \\
\hline presque & 10 & diablement & 1 & même & 1 & super & 1 \\
\hline donc & 9 & divinement & 1 & même assez & 1 & tantôt & 1 \\
\hline ainsi & 6 & dosiere & 1 & même aussi & 1 & tout à fait & 1 \\
\hline parfaitement & 6 & doucement & 1 & même si & 1 & tout court & 1 \\
\hline un peu plus & 6 & effroyablement & 1 & même trop & 1 & tout ensemble & 1 \\
\hline$i c i$ & 6 & en particulier & 1 & menuement & 1 & tout royd & 1 \\
\hline encore tout & 5 & encore bien plus & 1 & méthodiquement & 1 & vachement & 1 \\
\hline \multirow[t]{2}{*}{ étroitement } & 5 & encore un peu plus & 1 & $\operatorname{mieux}$ & 1 & volontiers & 1 \\
\hline & & & & & & Total & 5367 \\
\hline
\end{tabular}

Les fréquences absolues indiquées dans le tableau renvoient au corpus de base de ce dictionnaire (Fr_A_DHAA). Nous avons observé en passant, dans les autres citations de ce dictionnaire, l'insertion des unités suivantes : au plus, avant, d'ordinaire, de grâce, en souplesse, hyper-, ja, là, le moins, ou...ou, outre, presque autant, relativement, ultra-, un jour d'avance.

La plupart de ces « modifieurs » sont des adverbes de degré, d'intensité ou d'atténuation, mais on trouve aussi des adverbes de temps ou de lieu, ainsi que des connec- 
teurs logiques comme, par exemple, dans il dit pourtant vrai. On trouve aussi des combinaisons de deux adverbes de manière :

À nuit close, l'abbé voyait mal clair, juste assez pour se diriger le long des maisons

(Georges Duhamel, 1938, Cécile parmi nous)

Il est intéressant d'observer que l'usage tend à renoncer aux modifieurs quand la modification principale est réalisée par une combinaison d'adjectifs : conter haut et fort vs. ?conter très / si haut et fort.

Quelques modifications sont assez longues :

À l'âge de votre papa, il en tombe [= du poids] juste autant qu'il en arrive, et voilà pourquoi sa taille demeure toujours la même, bien qu'il avale dans son année trois fois plus lourd que lui (Jean Macé, 1866, Histoire d'une bouchée de pain)

La modification interne du groupe verbal met en évidence une certaine liberté combinatoire des adjectifs-adverbes. Il faut se garder cependant de conclure trop vite quant à leur productivité. La question demanderait une étude approfondie. Car la modification interne du groupe verbal ne s'observe pas dans toutes les entrées. De même, il semble que la productivité de ce type de modification soit plus libre dans les zones où l'adjectif-adverbe entre en contact avec la prédication seconde, d'une part, et avec les constructions à verbe copule, de l'autre. Mentionnons, pour la prédication seconde, des cas tels répondre divinement doux, il vit maintenant misérable, vivre en paix heureux ; pour les constructions copulatives : rester complètement coi, se tenir absolument coi. Quant à la combinatoire « verbe + adjectif-adverbe » proprement dite, il faudrait cerner le groupe des combinaisons qui sont uniques, et qui ne s'insèrent donc pas dans une série. Et même dans les séries, il faudrait voir de plus près si on n'a pas affaire à des schémas ou paradigmes plus ou moins lexicalisés, c'est-à-dire ouverts à une liste sémantiquement cohérente de verbes ou d'adjectifs. Ceci étant, le nombre des groupes recensés dans ce dictionnaire et leur modification mise en évidence dans le tableau ci-dessus prouvent tout de même que la perception traditionnelle comme petite liste de groupes lexicalisés ne correspond pas aux faits. Ils admettent assez facilement du moins les adverbes de degré, d'intensité et d'atténuation.

\section{L’adjectif-adverbe est-il un adverbe en -ment tronqué ?}

L'opinion selon laquelle les « adverbes courts " résulteraient de la troncation des « adverbes longs » en -ment est très répandue parmi les locuteurs. Même des linguistes partagent cet avis. Citons à ce propos Moignet (1981 : 52 ; cf. Grevisse / Goosse 2016 : § 963e) : 
L'adverbe court, en dehors de la locution verbale, s'entend aisément aujourd'hui dans la langue parlée de niveau assez bas. Il s'agit, semble-t-il, d'un phénomène d'abréviation. Quelques phrases saisies récemment au vol : ça chauffe terrible; il en tirera facile deux cents francs ; c'est mieux de faire de l'exercice que de bronzer idiot sur la plage

La variante courte est ainsi considérée comme une déformation abusivement employée, notamment par les jeunes.

La confusion de la norme linguistique, c'est-à-dire l'emploi canonique des adverbes en -ment, avec la tradition authentique de la langue est un phénomène connu : ce qui est correct est considéré plus authentique, plus ancien. En l'occurrence, il est clair que l' « adverbe court », que nous nommons adjectif à fonction adverbiale, est beaucoup plus ancien que l'adverbe en -ment, au point de constituer la principale tradition indo-européenne, la seule que le latin a léguée aux langues romanes. C'est donc plutôt l'adverbe en -ment qui s'est mis à la place d'autres adverbes. Nous y reviendrons (v. § 16). La monographie de Grundt (1972: 1) commence tout de même comme suit :

Ce travail tente l'étude des emplois tels que parler haut, mignonne tout plein, fort innocemment, où un adjectif réduit à son expression la plus simple s'est apparemment substitué à l'adjectif adverbialisé : parler fortement, etc.

Noailly (1994) défend également l'hypothèse d'une troncation. Coiffet (2018 : 41, 43) présuppose aussi un processus de troncation puisqu'il emploie le critère de l'apocope pour éliminer l'adjectif-adverbe de manière de son étude qui porte sur les cas de figure où l'adjectif-adverbe modifie « logiquement » un argument absent :

le corpus sur lequel nous travaillons est exclusivement constitué de paires [V + Adj. Inv.] dans lesquelles l'adjectif n'est pas un adverbe en -ment auquel on a supprimé le suffixe, contrairement à ce qui semble se produire dans l'exemple suivant :

Les mobylettes, ça se pique facile [...]

On ne trouve dans notre corpus que des énoncés dans lesquels l'adjectif invarié n'est pas le résultat de la troncation d'un adverbe en -ment

À part ce groupe-ci, l'auteur en mentionne un autre, apparemment différent, celui des « adjectifs convertis en adverbe (p. 267, cf. pp. 106-107) " : fort, terrible, ferme, dur, léger. Il y aurait donc trois groupes : l'adverbe court par apocope, l'adverbe court à argument implicite, l'adverbe court par conversion. Zribi-Hertz (2015 ; cf. Bedijs 2012 : 251), qui compare l'hypothèse de troncation avec celle d'une recatégorisation (conversion) « adjectif > adverbe » dans le cas de grave / gravement - et surtout dans le langage des jeunes -, tranche en faveur de la seconde hypothèse.

On n'a pas besoin de recourir à l'histoire pour réfuter l'hypothèse de troncation. L'apocope du suffixe dans hautement donnerait haute et non pas haut. On devrait donc dire *il / elle parle haute, ce qui n'est pas le cas. Quand l'adjectif-adverbe modifie un objet interne, les adverbes 'longs' ne peuvent pas non plus se trouver à l'origine 
de l'adverbe court parce que les fonctions adjectivales se trouvent en dehors de leur portée (d’où la technique employée par Coiffet) : Elles mangent gras / *grassement. Je cherche grand / *grandement. Il coupa court / ${ }^{*}$ courtement ses cheveux. Dans les cas où il semble possible de construire un adverbe en -ment avec la même base, la troncation est plutôt contre-intuitive : bronzer idiot < bronzer idiotement, parler vrai < parler vraiment. Dans l'exemple cité par Noailly (1994 : 105), il efface génial, mon effaceur !, la troncation de génialement est possible, mais finalement peu probable. Par contre, l'apocope de facilement est intuitivement acceptable dans l'exemple de Moignet cité ci-dessus (il en tirera facile deux cents francs), ce qui ne veut pas dire que c'est le cas. On peut même penser que la validité de cette hypothèse risque de varier selon le locuteur. C'est ainsi que les pratiques de l'enseignement peuvent créer une impression de « déformation » de l'adverbe en -ment, supposé plus correct, donc primaire. Par contre, pour celui qui a l'habitude d'employer directement l'adjectif pour les fonctions adverbiales, sans se préoccuper de la correction linguistique, ceci sera moins pertinent cognitivement.

Citons aussi un exemple entendu qui semble dériver de complètement : " Je les [= les poissons] ai désarêtés complet » (v. s.v.). L'emploi de complet dans une fonction adverbiale est plutôt rare. Il est donc probable que locuteur a copié l'emploi usuel de complètement en l'adaptant aux usages d'un argot de métier, qui tend à l'emploi économique de l'adjectif-adverbe, en l'occurrence celui d'un chef de cuisine. Le verbe désarêter, qui ne figure pas dans les dictionnaires papier, prouve qu'il s'agit d'un technolecte. Or, l'apocope morphologique donnerait le féminin complète, qui n'est pas employé. Il s'agit donc tout au plus d'une formation par analogie sémantique et fonctionnelle.

Citons aussi le cas de y aller mou / y aller mollo, qui ont le même sens 'y aller doucement'. Le premier groupe ne saurait s'expliquer par une réduction de l'adverbe mollement, mais c'est sans doute le cas pour aller mollo.

Nous reviendrons à cette question au § 17.6. Du point de vue diachronique, il existe des cas où l'adverbe en -ment précède l'adverbe court. Ceci ne favorise pas nécessairement l'hypothèse de troncation - nous venons de le voir dans le cas de complet - mais on ne saurait pas toujours exclure une fonction de modèle de l'adverbe en -ment. L'emploi de l'adjectif-adverbe s'avère complexe. On peut renvoyer à la distinction de sept classes d'adjectifs-adverbes déjà proposée par Gamillscheg (1957 : 526-530). 


\section{L'appartenance des adjectifs-adverbes au lexique fondamental du français}

\subsection{La satisfaction des besoins de la communication quotidienne}

Goes (1999 : 221) constate l'appartenance des adjectifs-adverbes au fond des « adjectifs primaires ». Nous avons déjà observé que la grande majorité des adjectifs-adverbes sont monosyllabiques ou bisyllabiques. Il en va de même pour l'anglais, où les adjectifs-adverbes appartiennent généralement au fond lexical germanique primitif. Dans le cas de l'anglais, ce fond germanique est clairement discernable par rapport à la grande quantité de mots empruntés plus tard au français ou au latin, et qui forment l'adverbe avec -ly (Hummel 2014a). On peut donc y distinguer un fond germanique vernaculaire du Type A d'un « superstrat » néolatin du Type B d'origine savante. Même si les deux systèmes se nourissent mutuellement, il s'agit tout de même de traditions clairement discernables.

Lappartenance des adjectifs-adverbes, donc des adjectifs ambivalents par rapport aux fonctions adjectivales et adverbiales, au lexique primaire ou fondamental va de pair avec le nombre réduit d'unités qui composent leur inventaire (v. Présentation : le dictionnaire en chiffres). Même dans ce dictionnaire, qui dispose d'un fonds d'exemples largement enrichi par sa perspective panchronique, sa prise en compte de la créativité littéraire et l'inclusion de cas limites, leur nombre monte à 427 unités au maximum, tandis que la liste des adverbes en -ment établie par Molinier / Levrier (2000 : 29) comprend 2780 unités différentes (cf. aussi Nøjgaard 1992/1995, vol. 1 : 104). Cela s'explique par le fait que la plupart des adverbes en -ment ont été créés, avant tout, pour les besoins des textes écrits. Par rapport aux exigences considérables de l'expression écrite, la communication orale, qui satisfait les besoins quotidiens, recourt à un nombre assez limité d'unités descriptives. Ceci tient aussi à la nature même du type de communication opéré dans les codes oral ou écrit. La communication orale dispose du contexte situationnel, alors que les textes écrits se voient obligés de le décrire. L'écriture a donc besoin d'un plus grand nombre d'unités descriptives pour compenser l'absence d'une situation communicative partagée et pour satisfaire l'impératif normatif des phrases 'complètes' et pleinement explicites (Chafe 1982 : 41-42, Biber 1988 : 50-51, 104-105, 139-141, Biber et al. 1999 : 504-507, Maas 2010 : 27, 106). À la restriction du nombre des adjectifs-adverbes par les sujets habituellement thématisés dans la communication orale de tous les jours s'ajoute donc un effet situationnel qui en réduit le degré d'explicitation, sans parler du savoir partagé qui caractérise le quotidien, y compris celui des argots de spécialité, mais alors pour un nombre plus réduit de locuteurs. 


\subsection{La structuration paradigmatique du lexique fondamental : l'approche structuraliste}

Selon Grundt (1972), les adjectifs-adverbes tendent à former des paradigmes lexico-sémantiques. Il situe ainsi son analyse sémantique dans la tradition structuraliste des champs lexicaux, sauf qu'il se limite à décrire des séries paradigmatiques qui ne forment pas des champs complets. Citons-en quelques exemples :

$\begin{array}{lll}\text { clair }: \text { dru }(\text { ex. semer clair } / \text { dru }) & \text { serré : lâche } & \text { long : court : bref } \\ \text { juste : vrai : faux : droit } & \text { haut : bas } & \text { net : sec } \\ \text { grand : gros : petit : menu : fin } & \text { plein : creux } & \text { bon : dur :fort : mou : doux }\end{array}$

Si l'on peut dire, en effet, que la plupart des adjectifs-adverbes courants appartiennent au noyau dur des adjectifs les plus usuels, notamment dans la langue parlée, on peut, au vu des exemples ci-dessus, dire également qu'ils forment des paradigmes lexicaux fondamentaux. En effet, les champs lexicaux relevés reflètent d'assez près la classification sémantique des domaines sémantiques de base que toutes les langues du monde sont censées exprimer avec la catégorie de l'adjectif (Dixon 1977, Dixon / Aikhenvald 2004, Gasrel 2012).

Certains adjectifs-adverbes forment ainsi de longues séries qui s'opposent à celles établies par d'autres adjectifs-adverbes du même paradigme ou de paradigmes voisins :

serré : écrire serré, boxer serré, marcher serré, jouer serré, surveiller serré

lâche : cravater lâche, les cheveux noués lâche

large : cravater large, marcher large, chausser ni trop étroitement ni trop large, tailler large, voir large, bailler large, écrire large

étroit : tourner étroit dans le cercle, mener ou conduire un cheval étroit

long : ils tirent long (un tir long), en dire long de quelque chose, amarrer long

court : tirer trop court, la crise tourne court, demeurer court sur cette demande, couper court

bref : il parle haut et bref

grand : ouvrir grand la bouche, ouvrir grand les bras, chanter grand, voir grand, construire grand

petit : écrire petit, penser petit, jouer petit, construire petit

gros : écrire gros, parler gros, jouer gros, perdre / gagner / rapporter gros

menu : écrire menu, griller mепu-menu, trotter vite et menu, hacher menu, coudre menu

fin : écrire fin, jouer fin, voir fin, chausser fin, manger fin

On pourrait songer à mesurer le développement des relations paradigmatiques en calculant le nombre de verbes différents qui se combinent avec le même adjectif-adverbe sans que celui-ci change de signification. Cela donnerait une bonne mesure de la pénétration d'un adjectif-adverbe ou d'une structure paradigmatique dans la langue.

Partant de ces observations, on peut proposer des structures paradigmatiques comme celle qui est illustrée au Tableau 3 pour haut et bas (à comparer Grundt 1972 : 266-287) : 
Tableau 3. La structure paradigmatique des relations « haut : bas »

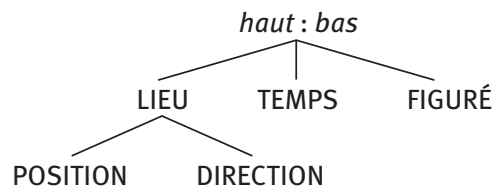

LIEU / POSITION : $\quad$ Les hirondelles volent haut

LIEU / DIRECTION : $\quad$ pousser haut comme des platanes

Les feux brûlaient si haut dans le ciel mort

TEMPS : $\quad$ Ça remonte haut, cette histoire-là

FIGURÉ : Il l'estima très haut

Haut se trouve en opposition paradigmatique avec bas qui développe une série analogue

LIEU / POSITION : On mange bas à cette table

LIEU / DIRECTION : $\quad$ La lune monte bas, à cette époque-ci

TEMPS: $\quad$ Descendez plus bas dans l'histoire

FIGURÉ : Que de cardinaux nés plus bas que moi

Les catégories TEMPS et FIGURÉ sont des extensions ou transpositions de la catégorie de base LIEU (sur l'universalité cognitive de cette transposition v. Lakoff / Johnson 1980). Au vu des exemples, on est tenté de donner raison à l'approche structurale. Les adjectifs-adverbes appartiendraient donc au lexique fondamental non seulement à titre individuel mais aussi en tant que membres de structures paradigmatiques toutes faites.

Si les relations paradigmatiques dans les exemples confirment la relation étroite des adjectifs-adverbes avec les besoins de communication quotidiens, il n'en reste pas moins que ce type d'analyse souffre du même type de problèmes que la théorie des champs lexicaux en général. C'est ainsi que la série bon, dur, fort, mou, doux contient des adjectifs polysémiques qui font que leur appartenance au paradigme ne vaut que pour une des multiples acceptions. Selon Grundt (1972 : 240), cette série forme un paradigme de quantité. Or, si ceci est valable pour coûter bon 'beaucoup' et, si l'on veut, pour travailler mou, il faut en exclure des exemples tels sentir bon ou chausser mou 'porter des chaussures molles' (1972 : 247). De même, il faudrait considérer séparément couper court les cheveux et couper court 'interrompre'. Autrement dit, les réseaux polysémiques constitués par des emplois métaphoriques, métonymiques et polyréférentiels compliquent l'analyse puisque la théorie des champs lexicaux les ignore.

Dans son étude sur le paradigme de quantité formé par grand, petit, menu, fin, gros dans des groupes comme voir grand, Gasrel (2012; cf. Grundt 1972 : 389-410) met en évidence la complexité sémantique de tels paradigmes apparemment simples. La complexité des relations paradigmatique s'avèrent inextricables, rappelant le résultat des travaux empiriques sur les champs lexicaux (ex. Geckeler 1971). Force est donc de 
constater que les adjectifs-adverbes peuvent former des oppositions paradigmatiques, mais on ne saurait réduire leur sémantisme à un simple corset paradigmatique. Les exemples montrent que les paradigmes disposent d'un certain degré de pénétration par la combinatoire de la même signification avec une série de verbes. Ces verbes sont souvent les mêmes pour les membres proches d'un même paradigme (écrire petit / gros, etc.). Par contre, s'il est facile - selon la (mauvaise) tradition structuraliste - de fonder l'analyse sur des exemples « bien » choisis, comme celui présenté au Tableau 3, il est impossible d'en faire de même pour l'ensemble des relations paradigmatiques.

Certes, on peut dire que l'emploi des adjectifs-adverbes pour créer un contraste est très apprécié du point de vue de la construction du discours :

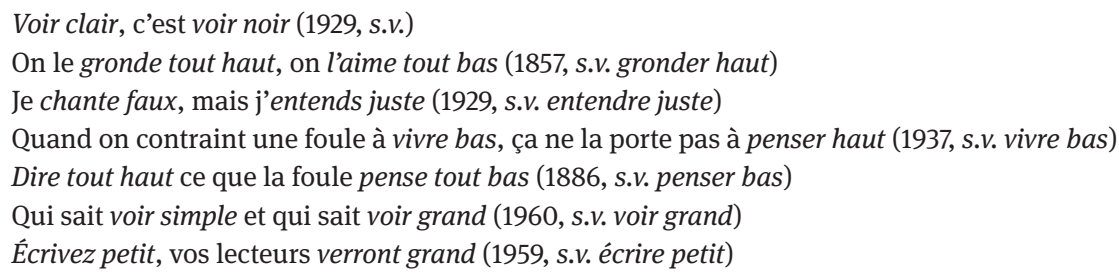

On trouve souvent des collocations du type menu et souvent, haut et clair, haut et fort, qui, tout en créant des contrastes, renforcent l'expressivité du groupe, de même que les nombreuses réduplications :

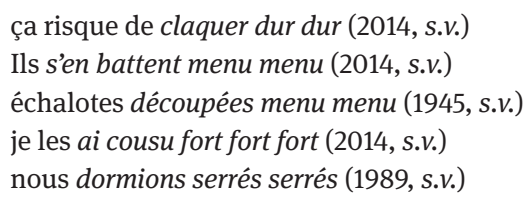

Ces réduplications sont encore un trait qui réunit les registres populaires de l'Hexagone avec certaines variétés d'outre-mer (cf. Neumann-Holzschuh / Mitko 2018 : 752).

Or, les contrastes créés dans un discours ne se laissent guère représenter par des champs lexicaux traditionnels qui reposent sur des critères logiques abstraits, établis sans contexte. On aurait peut-être encore admis dans un champ lexical, à la rigueur, le contraste clair : noir, mais on ne saurait accepter simple : grand. Autrement dit, les contrastes sont très appréciés dans les exemples, mais on ne peut pas les expliquer par la manifestation, dans un discours donné, de structures paradigmatiques préfabriquées relevant du type " champ lexical ». Les contrastes s'établissent, pour la plupart, dans les énoncés mêmes. C’est le locuteur qui les construit dans le discours. C'est la raison pour laquelle nous avons renoncé à notre intention initiale d'insérer des tableaux présentant des structures paradigmatiques dans ce dictionnaire. On les repérera dans les exemples. Qu'on y retrouve certaines oppositions fondamentales découle du fait même d'être fondamentales, du point de vue cognitif. 


\subsection{La structuration paradigmatique du lexique fondamental : l'approche événementielle}

Nous venons de voir que l'approche qui part des paradigmes lexicaux directement formés par les adjectifs-adverbes implique un biais méthodologique qui nous oblige à réduire abusivement la complexité des relations sémantiques polysémiques. Curieusement, le problème ne se pose pas, ou beaucoup moins, si l'on part du verbe plutôt que de l'adjectif. Il est, en effet, frappant d'observer la constitution de longues séries paradigmatiques qui tournent autour du même verbe-pivot. Considérons le cas du verbe jouer :

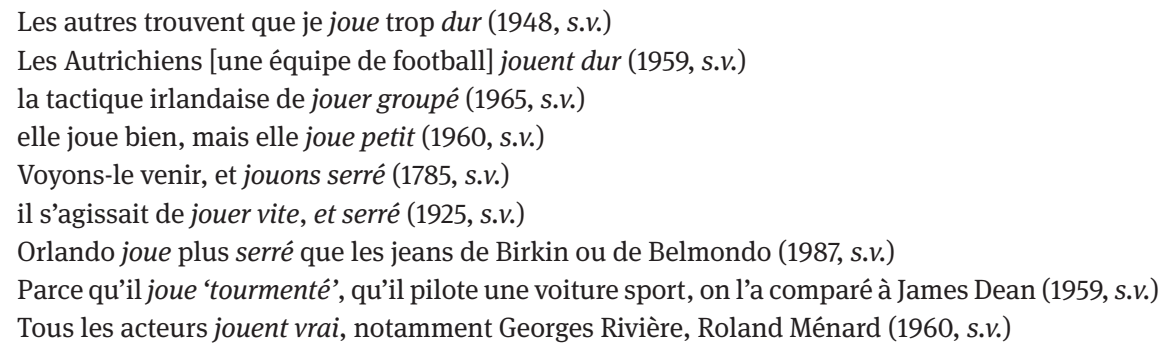

On observe aussi le développement d'emplois figurés qui peuvent déborder du domaine d'origine pour s'ancrer dans la langue commune familière :

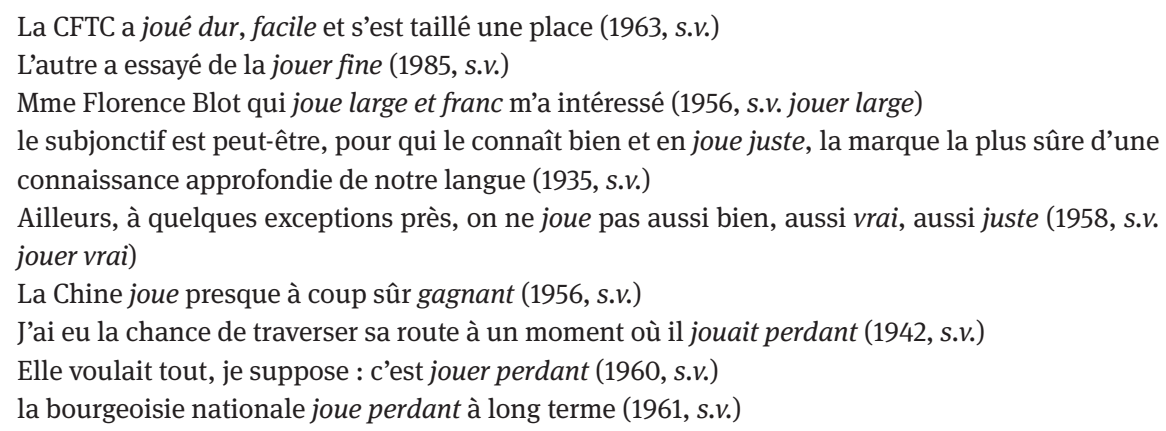

On peut ajouter d'autres adjectifs-adverbes qui se combinent avec le verbe jouer. Voici la liste complète des adjectifs combinés avec jouer dans les entrées de ce dictionnaire : ambigu, classique, coco, concentré, contenu, décontracté, dur, facile, faux, fin, fort, franc, gagnant, gai, gros, groupé, juste, large, lourd, monotone, net, nonchalant, perdant, petit, placé, planqué, rentré, safe, sec, serré, sobre, sublime, tourmenté, vrai.

Le point de vue du verbe-pivot nous fait découvrir d'emblée la productivité de l'adjectif-adverbe en tant que membre syntaxiquement subordonné du groupe verbal. Celle-ci se manifeste aussi bien sur le plan de la transposition métaphorique du domaine (sport, jeux de hasard, lutte politique, sociale, etc.) que sur celui de l'exten- 
sion du nombre d'adjectifs-adverbes. Un nombre important de séries désigne des styles (de vie, de danse, de chant, du dire, du penser, de faire l'amour, etc.). Elles se développent à partir de verbes comme aimer, baiser, composer, construire, courir, cuisiner, écrire, habiller, jouer, manger, marcher, parler, pédaler, peindre, penser, vivre etc. Les mêmes adjectifs-adverbes peuvent apparaître avec plusieurs verbes (ex. léger, simple, vrai) mais chaque série tend à être singulière. Ajoutons à celle de jouer (v. ci-dessus) la série qui gravite autour du verbe écrire : affranchi, appuyé, attractif, beau, bref, clair, classique, compliqué, concis, concret, court, démodé, dense, désespérant, direct, droit, dru, dur, efficace, économique, engagé, étincelant, étriqué, fanfaron, faux, ferme, fin, fort, froid, gras, gros, habillé, hardi, inutile, juste, large, leste, long, léger, mélodieux, moche, mesquin, mince, musclé, nerveux, net, neutre, noir, ordonné, osé, ouvert, pauvre, petit, précis, précieux, propre, rapide, sage, serré, simple, soigné, sonore, souple, structuré, succinct, tintant, tranchant, utile, vif, vigoureux, visuel, vrai. Dans ces séries, l'obligation de l'emploi de l'adverbe « court » cesse de s'imposer : les séries sont ouvertes à l'adverbe polysyllabique. Le verbe-pivot est donc un moteur de productivité, pour ne pas dire : «de profusion ». La différence se fait plutôt en termes de fréquence, les adverbes longs étant souvent moins usuels.

La productivité des séries s'observe souvent dans le même cotexte. Dans la citation suivante, l'auteur développe une séquence, non pas à partir du même verbe mais autour de l'adjectif-adverbe niais :

C'était une face de paysan bête, qui riait niais, parlait niais, marchait niais, pensait de même et qui avait eu l'esprit d'appliquer tous ces mérites aux jeux de théâtre (1876, s.v.)

Sur sa lancée, l'auteur va jusqu'à créer marcher niais. On peut certes s'imager un comportement à partir de groupe, mais il n'a guère de sens en dehors de cette série. Marcher niais ne justifie donc pas une entrée à part. L'exemple montre peut-être qu'il est difficile d'arrêter la «production en série », une fois que celle-ci est engagée. Donnons en un autre exemple :

Et Fabienne a glissé le revolver dans le tiroir de ma table de nuit et elle a répété Simplement parce que c'est utile. Comment expliquer à une personne qui marche utile danse utile baise utile pense utile et fait les choses comme il se doit quand on a l'utilité d'un cerveau qui voit midi à midi, et quatorze heures à quatorze heures que tout n'est pas aussi simple (Odile Barski, 2013, Quartier libre)

L'emploi de l'adjectif-adverbe est réputé pour être particulièrement riche et innovateur dans le domaine de la publicité. Cependant, reconnaître l'esprit ludique ou commercial qui ne cesse d'enrichir ces listes en créant de nouvelles variantes, parfois surprenantes, ne devrait pas cacher qu'il s'agit, dans la plupart des cas, de variantes prévisibles. Si l'on a acheter malin, une marque de pneus créera rouler malin. On trouve ainsi les verbes emblématiques de la société de consommation : 
acheter, boire, bricoler, bronzer, chauffer (dans le contexe de l'achat d'un chauffage), chausser, conduire, consommer, construire, cuisiner, dormir (pour vendre des matelas, etc.), économiser (synonyme de dépenser), emprunter, habiller, grignoter, jardiner, louer, maigrir, manger, maquiller, pédaler, prendre ('acheter'), randonner, raser, rénover, rouler, soigner, surfer, tricoter, vivre, voler (avion), voyager, etc.

Ces verbes se trouvent toujours associés aux mêmes adjectifs-adverbes :

artisanal, bio, chic, diététique, différent, durable, écolo(gique), élégant, facile, français, idiot (avec négation), intelligent, léger, local, malin, naturel, pratique, responsable, sain, solidaire, utile, vert, vrai, etc.

Le corpus de Coiffet (2018 : 285-328) offre la documentation la plus complète de la productivité actuelle de ces séries. Il aurait été impossible de tout documenter ici sans dépasser le cadre éditorial de ce dictionnaire - outre le fait que bon nombre des citations se réduisent au syntagme pur : Achetez malin ! Ceci confère à ces groupes une force suggestive due à leur ambivalence adjectivale et adverbiale, d'une part, et à l'absence de cotexte, de l'autre. Le lecteur a besoin et peut-être envie d'en savoir plus, donc de lire ce qu'en révèle le reste du texte. Autrement dit, l'emploi du syntagme pur sert à vendre les produits ou les idées qu'il appelle.

Une fois établie, une telle série intègre facilement, dans une situation donnée, des adjectifs plutôt moins usuels et plutôt longs. C'est ainsi qu'on voit apparaître dans les exemples le participe adjectivé tourmenté mis entre guillemets, sans doute pour marquer que cette option est innovatrice, non-usuelle (v. exemple dans 8.4). De même, l'intégration de boire nature ou boire cochon ne pose aucun problème puisque ce verbe se combine fréquemment avec des adjectifs-adverbes. Il est important de noter, cependant, que la structure « verbe + adjectif-adverbe » constitue la base et le point de départ de ces prolongations nominales. Autrement dit, il faut que la série avec adjectif-adverbe soit bien ancrée dans l'usage pour qu'on puisse remplacer le modifieur par un substantif. Cependant, dans le domaine de la publicité, le schéma « verbe + modifieur nominal » a été établi tel quel et forme une série productive : vivez santé !, habiller old school, etc. Étiemble (1964 : 190) cite : pensez conserves, pensez fermeture-éclair, pensez qualité.

Pour revenir à nos réflexiones théoriques, on peut se demander pourquoi ce type d'analyse en termes de manifestation en séries est plus approprié que celui des paradigmes lexicaux formés par des adjectifs-adverbes. Il semble que ceci soit dû au fait que le verbe nous ouvre une fenêtre sur un événement et sur les expériences auxquelles chacun peut l'associer. Si la théorie des champs lexicaux tend à nous éloigner des expériences vécues, en faisant abstraction du contexte d'emploi, la théorie cognitiviste des scenes and frames (v. Fillmore 1977), qui se réfère à des ensembles lexicaux associés à une expérience, nous en rapproche. Si le verbe-pivot revêt une si grande importance, c'est parce qu'il représente une expérience, une portion de notre vie. 
Étant donné que l'acquisition du lexique repose sans doute sur une abstraction faite à partir d'expériences communicatives, on comprend l'importance théorique et méthodologique de l'idée de situer l'adjectif-adverbe par rapport à l'événement verbal. Ceci n’exclut évidemment pas le développement de séries paradigmatiques plus abstraites, mais sans leur donner la force que leur prêtait la sémantique structurale. Les exemples cités sous 8.2 font plutôt penser à des paradigmes qui émergent des combinaisons. C’est pourquoi nous avons suggéré de mesurer le degré de paradigmatisation par une analyse quantitative de la combinatoire « adjectif-verbe », au lieu de simplement postuler de telles relations.

Ce dictionnaire tient compte du rôle des verbes puisque la macrostructure suit l'ordre alphabétique des verbes. On découvrira donc naturellement les paradigmes qui se cristallisent autour d'un verbe-pivot. Chaque série permet alors l'étude de la productivité lexicale, la transposition à d'autres domaines, le degré de lexicalisation (proportion des syntagmes lexicalisés), le développement de syntagmes ou de domaines prototypiques, les emplois métaphoriques ou métonymiques (polysémie).

\section{L'affinité avec le langage familier et populaire}

Les adjectifs-adverbes s'emploient volontiers dans les registres informels. En effet, la simple recherche de la combinaison « verbe + adjectif-adverbe » sur Google a directement conduit notre recherche vers ce type de langage, au point que les collaborateurs du dictionnaire ont dû se débattre avec bon nombre de pages érotico-pornographiques. La syntaxe, le lexique et les caractéristiques phonético-graphiques des exemples qui figurent dans le Corpus Web soulignent la prédilection de la communication spontanée familière ou populaire pour les adjectifs-adverbes. À ces faits assez évidents, on peut ajouter quelques observations de détail.

\subsection{Emploi concret}

Dans le premier bloc de la microstructure des entrées, qui reflète la tendance littéraire et 'bon usage' de Frantext, l'emploi au figuré est très présent. Il apparaît même assez souvent en premier dans la suite diachronique. Par rapport à ce premier bloc, le Corpus Web, qui ne tient compte que de la langue actuelle, se présente souvent comme un « retour à l'emploi concret ». L'impression de « retour » est toutefois simplement subjective. Les premiers documents du français montrent un état déjà avancé de la diachronie. Il est peu probable que l'emploi figuré précède si fréquemment l'emploi concret du point de vue diachronique. Il convient de penser aussi à la source des exemples pour expliquer ce phénomène. Or, il se trouve que la source est littéraire dans la plupart des cas. De ce point de vue, on admettra plutôt que la tendance à l'em- 
ploi concret marque la communication orale informelle depuis toujours, alors que les textes écrits en général, et notamment les textes littéraires, reflètent un langage plus élaboré, voire un langage qui rejette la banalité du quotidien. Autrement dit, c'est un langage qui apprécie le figuré, comme dans l'exemple suivant :

tu m'as battu froid dans le commencement (1637, s.v.) 'traiter avec froideur, rejeter'

Battre froid au figuré est très fréquent dans Frantext. Notre dictionnaire ne contient qu'un seul emploi non-figuré, celui-ci se trouvant dans le Corpus Web :

$350 \mathrm{ml}$ de crème à battre froide (2014, s.v.)

Il s'agit d'une prédication seconde qui marque un retour au concret par rapport à la tendance d'emploi au figuré dans les textes littéraires.

\subsection{Emploi inférentiel (" circonstances internes »)}

La communication informelle spontanée est peu cartésienne du point de vue du principe de clarté, qui demande plus d'explicitation. Des emplois du type les hommes qui chaussent larges (2014, s.v.), trois athlètes sont contrôlés positifs (1997, s.v.), il adore baiser étroit (2014, s.v.), etc. demandent une interprétation par rapport à une réalité, qu'on peut nommer "scène », et qu'il faut d'abord s’imaginer pour donner un sens à la relation de modification (v. § 4.5). Cette suggestivité constitue indéniablement un des attraits stylistiques et communicatifs des adjectifs-adverbes.

Les exemples cités sous « emploi absolu » prennent souvent le contre-pied de l'explicitation pleine. C'est ainsi qu'on trouve Pourquoi faire simple si l'on peut faire compliqué, ou, plus populaire, mettre profond :

Uber va bien leur mettre profond à ces taxis de merde !! Danny Plesnik avec mes potes uberistes on va te chopper sur le vieux port et bien te calmer comme le vieux porc que tu es et tes potes le méritez ! (2015, s.v.)

Le fait que la portée de la modification s'avère variable et complexe, pouvant toucher l'ensemble de l'événement verbal (la « scène » dénotée ou évoquée), y compris ses participants et ses circonstances, voire la perspective subjective du locuteur, a été analysé du point de vue cognitif dans Hummel (2018b), avec les exemples de ce dictionnaire. Notons que Guimier (1989 : 117) a parlé de « circonstant implicite » pour caractériser la portée inférentielle de la modification. On peut observer une flexibilité similaire du côté des adverbes en -ment, sans doute parce que le verbe leur offre des scénarios événementiels similaires qu'ils peuvent sonder à partir de leurs possibilités catégorielles (cf. Molinier 1985, Chanay 1998). Leur potentiel inférentiel est cependant limité par le fait qu'il s'agit d'adverbes et non pas d'adjectifs-adverbes. 


\subsection{Réduction de la valence syntaxique}

L'emploi des adjectifs-adverbes est souvent accompagné de tous les types possibles de réduction de la valence syntaxique (explicite) du verbe. Considérons, à titre d'exemple, l'emploi du verbe supposé trivalent donner :

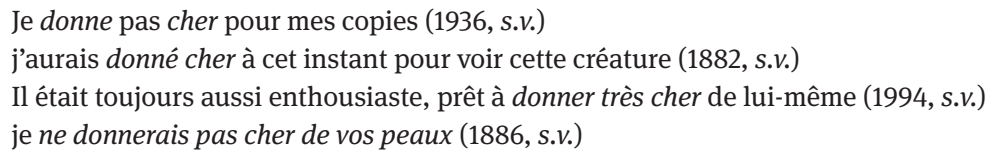

Damourette / Pichon (1932-1951 : §109) ont formé le terme de coalescence pour dénommer une « union intime entre le régime et son régent » où « la valence du régime est presque étouffée ». Ce n'est qu'une autre façon d'aborder le phénomène des arguments internes (v. §§ 5.2-5.4), sauf que l'hypothèse de la réduction de la valence n’assume pas la pertinence communicative de tels éléments implicites. Or, la valence sémantique reste active.

\subsection{Marques de registre}

Les auteurs des citations sont souvent conscients du fait que l'emploi de l'adjectifadverbe appartient à un registre non-standard, familier ou populaire, voire peu correct. Pour marquer qu'ils reproduisent à l'écrit une façon plutôt orale de s'exprimer, les auteurs ont souvent recours à des guillemets, comme dans l'exemple avec « tourmenté » cité ci-dessus (v. 8.3), s’ils ne sont pas plus explicites (« comme on disait dans sa famille » (v. § 4.6), « en bon français ») :



\subsection{L’informel dans les langages de spécialité}

Nous avons dit que la plupart des adjectifs-adverbes et des paradigmes lexicaux dont ils font partie appartiennent au vocabulaire fondamental dont nous nous servons pour répondre aux besoins élémentaires de la communication de tous les jours, surtout 
dans le code oral. Or, jouer serré appartient, tout d'abord, à l'argot des jeux et du sport. On peut même dire qu'une bonne partie des exemples cités dans ce dictionnaire proviennent à la base d'un technolecte. Giraud (1964) classe tout naturellement les adverbes courts mentionnés selon le technolecte qui les emploie. Considérons, à titre d'exemple, celui de l'hippisme, avec quelques transpositions à d'autres domaines :

Et ici, ils en profitent pour la mener dur (1962b, s.v.)

Les collines, ça se mène comme les chevaux, dur (1929, s.v.)

Ils disent que, chez lui, les apprentis sont menés dur (1962, s.v.)

Peu de temps après les chiens semblent mener dur, il y a des sangliers mais apparemment la trace est perdue (2015, s.v.)

Faciliter la vie des usagers, mais la mener dure aux fraudeurs (2015, s.v.)

Couvient aler et mener gent $(+1265$, s.v.)

Dans les tribunes, on voyait que cheval et jockey « allaient facile » et que sans incident (2016, s.v.) pas moyen de la faire marcher droit, j'aime balader à mon aise rènes longues mais c'est quasi impossible avec elle, et même en tenant les rènes plus courtes pour essayer de l'encadrer, c'est difficile. Ce n'est rien de grave, mais c'est agaçant car c'est une attention de tout instant pour la garder « droit » (2015, s.v. garder droit)

Lorsque la jument ne faisait pas d'épaule en dedans, quelle marchait droit, elle demandait quand même que le cheval ait le bout du nez à l'intérieur...lorsqu'il marchait large... (2015, s.v. marcher large)

Mais qu'est-ce qu'un argot professionnel ou, plus neutre, un technolecte ? C'est le registre oral informel créé par la pratique quotidienne du langage dans un domaine de spécialité, voire d'une langue de spécialité, si un domaine est suffisamment professionnalisé. L'emploi des adjectifs-adverbes n'est donc pas une simple affaire de la langue commune, mais une pratique orale informelle qui peut se manifester dans toutes les niches de la langue identifiables par rapport à une communauté qui se (re) connaît. Ces niches ne sont d'ailleurs pas sans se communiquer entre elles. Il est en effet difficile d'attribuer jouer serré au seul domaine du sport ou chercher grand 'un appartement grand' au technolecte de l'immobilier. Ces deux syntagmes ont largement pénétré l'argot du quotidien en général. Les exemples cités ci-dessus montrent aussi la pénétration mutuelle des argots de métier. Si porter beau sa tête a des chances d'être originaire de l'argot hippique, mener dur pourrait-être une manifestation soit du parler rural (mener dur les chiens) soit simplement du langage quotidien (la mener dure, la vie). De même, dans les citations les guillemets marquent aller facile et marcher droit comme des tournures employées par rapport à des chevaux, mais elles s’appliquent aussi bien à la vie quotidienne (Ça va facile. Marche droit !). Dans les citations, l'appartenance à un argot de spécialité est souvent marquée par des guillemets. 


\section{Seconde partie : La perspective diachronique}

Bien que séparables, en principe, l'analyse synchronique et l'analyse diachronique se présupposent mutuellement à partir du moment où l'on veut expliquer les faits de langue. Du point de vue du développement historique, la diachronie semble devoir former la première partie de l'exposé. Nous pensons tout de même que l'analyse fonctionnelle doit précéder l'analyse diachronique. Car, sans analyse fonctionnelle, on ne connaît pas les ressorts qui expliquent ce qui peut se produire. De plus, l'analyse diachronique se fait mieux quand on sait les résultats qu'elle a donnés, donc la synchronie variationnelle d'aujourd'hui. Toutefois, la langue parlée n'est accessible qu'à partir du $\mathrm{xx}^{\mathrm{e}}$ siècle, et encore ; la documentation reste très lacunaire. Cependant, quand on sait ce que l'on cherche, à savoir ce que la diachronie a produit, on peut plus facilement trouver les traces de l'oral dans l'écrit. En effet, qui attacherait de l'importance à la seule occurrence d'un adverbe en -ment dans les Gloses de Reichenau au VIII ${ }^{\mathrm{e}}$ siècle, si l'on ne connaissait pas l'ampleur que prendrait ce type de formation de l'adverbe ? Qui plus est, on peut penser que la critique faite par les gloseurs à l'encontre de solamente, écrit en un seul mot et employé au sens moderne, déjà grammaticalisé (les gloseurs recommandent de le remplacer par lat. singulariter), concernait un nombre plus considérable d'adverbes en -ment qui devaient être usuels dans la langue parlée mais qu'on évitait à l'écrit (v. § 15.2).

\section{La tradition indo-européenne}

L'adjectif à fonction adverbiale est le seul mécanisme de formation de l'adverbe que le latin a hérité de son histoire indo-européenne. Ce type d'adverbe remonte au sanscrit, où il prédominait (Fortson IV 2011 : 211). C'est ainsi que les langues germaniques et l'anglais médiéval emploient la forme non marquée ou neutre de l'adjectif comme adverbe (Hummel 2014a). Cela explique pourquoi l'adjectif-adverbe est toujours si présent dans tous les registres et variétés marqués par la tradition orale, tradition qui repose sur l'adjectif-adverbe.

\section{La tradition grammaticographique et normative gréco-latine}

Pour comprendre le rôle de l'adverbe long, pourvu d'un suffixe (Type B), il faut remonter au grec classique. Car celui-ci servait de modèle au latin classique qui cherchait à imiter sa richesse morphologique. Du même coup, ce contact fit naître une tradition 
grammaticographique et normative qui marquera les langues occidentales jusqu'à nos jours. L'adverbe, quant à lui, ne fait pas exception. On peut faire remonter la tradition de l'adverbe à suffixe jusqu'au grec ancien. Or, s'il est vrai que le grec classique préférait le suffixe - $\omega$ s pour marquer l'adverbe, l'adjectif-adverbe (Type A) est également attesté dans cette langue. Le grec moderne ne connaît plus que l'adjectif-adverbe (le neutre pluriel de l'adjectif ; Dietrich 1995 : 112 ; 2012 : 34-35), l'ancien suffixe se retrouvant uniquement chez les adverbes savants se terminant en $-\eta \varsigma$ (Ruge 1997 : 50). On peut en conclure que la tradition orale du grec n'a fait que peu de cas du suffixe au long de l'histoire. C'était une affaire de culture écrite. De même, le latin classique a imposé ses règles canoniques de formation de l'adverbe qui prescrivaient l'usage de marques morphologiques pour cette fonction (-ēet -iter, v. §14). Le latin tardif a simplifié ce système en donnant priorité au seul suffixe -iter. Plus tard, les langues romanes standardisées sélectionneront l'adverbe en -ment. Cependant, pendant la période de transition et de crise, sans écriture canonique, l'adjectif-adverbe refait surface (v. §§ 13 et 16.1). Curieusement, le passage de l'anglais médiéval à l'anglais moderne est également caractérisé par le remplacement de l'adjectif-adverbe d'origine germanique par l'adverbe suffixé en -ly. On peut y ajouter le roumain et les tentatives de lui imposer -mente pendant sa standardisation au XIX ${ }^{\mathrm{e}}$ siècle (v. § 17.6), de même que pratiquement toutes les variétés romanes qui dans un passé plus récent se sont pourvues d'une écriture standardisée (v. l'exemple du frioulan : Finco 2010-2011, Hummel 2013a). On assiste donc, dans l'histoire, et ceci très systématiquement, à une montée du Type B à chaque fois qu'un effort de standardisation passant par l'écriture est entrepris, et, par coup de ricochet, à une baisse du Type A pendant ces phases, du moins dans les textes standardisés. Le rapport de force s'inverse quand et où la pression normative diminue ou disparaît.

Ceci fait apparaître le latin classique comme phase passagère où l'écriture a imposé des règles en partie artificielles, dont l'emploi de l'adverbe suffixé. Une fois effacé le latin classique, la tradition orale refait surface. Mais la tradition grammaticographique et normative continuera son travail, avec l'essor des langues modernes écrites. Regardons les faits un par un.

\section{L’adverbe en -ment(e) dans la tradition écrite}

Contrairement à ce que l'on lit et entend généralement, l'adverbe en -ment(e) n'est pas l'adverbe par excellence des langues romanes. En réalité, son usage est pratiquement limité aux soi-disant grandes langues romanes, et plus particulièrement à celles qui ont été les premières à se doter d'une écriture romane, différente de celle du latin (v. détails dans Hummel 2013a) :
Fr. Les hommes travaillent durement
Cat. Els homes treballen durament
It. Gli uomini lavorano duramente 
Esp. Los hombres trabajan duramente

Port. Os homens trabalham duramente

Ce qui unit cet univers d'emploi de l'adverbe en -ment(e) en tant que tradition panromane, c'est la tradition de l'écriture, influencée par Rome et les textes chrétiens pendant la transition latino-romane (Queirazza 1970). Le cas du catalan est particulièrement pertinent. Durament est certes attesté dans les textes d'ancien catalan, mais les Catalans d'aujourd'hui préfèrent l'adjectif-adverbe, l'adverbe suffixé étant très peu usuel, voire hors d'usage, d'après ce que nous disent les locuteurs. Suite à ce que nous avons vu au paragraphe précédent, on peut penser que l'impact plus précaire de la tradition écrite dans la diachronie du catalan a accéléré le retour à la tradition orale de Type A, tandis que l'action permanente et durable de la langue écrite et de la standardisation a joué plus fortement en faveur de l'emploi de -ment en français, italien, espagnol et portugais. La tendance est en principe la même dans les autres langues romanes citées, où l'on emploie couramment l'adjectif-adverbe (fr. dur), surtout à l'oral, mais la variante à suffixe n'est pas hors usage et sans doute préférée à l'écrit.

\section{L'emploi panroman de l'adjectif-adverbe}

Si l'on inclut les langues et variétés qui n'ont pas joint le premier mouvement de création d'une écriture romane (grosso modo avant 1500), ou qui l'ont fait plus tard (et parfois trop tard pour introduire -mente, comme le roumain), on voit (ré)apparaître très clairement la tradition indo-européenne de l'adjectif-adverbe, qui est évidemment une tradition orale. Celle-ci est effectivement partagée par toutes les langues et variétés romanes. C'est ainsi que le roumain, le sarde et les dialectes du centre et du sud de l'Italie n'emploient pas l'adverbe en -mente, si l'on met à part une poignée d'unités empruntées à d'autres langues :

\footnotetext{
Fr. Les hommes travaillent dur

Cat. Els homes treballen fort / dur

It. Gli uomini lavorano duro / sodo

Esp. Los hombres trabajan duro

Port. Os homens trabalham duro

Roum. Oamenii lucrează greu

Sard. Sos omine trabagliana folte
}

\author{
$<$ lat. durus, dura, durum \\ sodo : à étymologie incertaine \\ < lat. gravis, gravis, gravĕ \\ (logoudourien) < lat. fortis, fortis, fortĕ
}

Le cas du roumain revêt un intérêt particulier. Séparée de Rome au $\mathrm{III}^{\mathrm{e}}$ siècle de notre ère, à un moment où l'adverbe en (-)mente n'était pas encore établi dans l'usage, l'ancienne province romaine de la Dacie, où se développera le futur roumain, ne pouvait pas participer au mouvement qui diffuserait ce suffixe et qui allait engager le catalan, l'espagnol, le français, l'italien et le portugais dans la création d'une écriture romane. De plus, le roumain n'a pas participé aux efforts de purification et de standardisation 
des XVII ${ }^{\mathrm{e}}$ et XVIII ${ }^{\mathrm{e}}$ siècles. C'est pourquoi ce qu'on appelle « l'ancien » roumain s'étend jusqu'au XVIII ${ }^{\mathrm{e}}$ siècle compris. En raison de l'absence de contact avec les autres langues romanes, la tradition orale consistant à employer l'adjectif dans les fonctions adverbiales s'est fortement enracinée. La standardisation du roumain au XIX siècle a eu beau faire un effort pour implanter l'adverbe en -mente, à l'instar du français, langue modèle, il était trop tard. Le standard moderne a donc accepté l'adjectif-adverbe. Les dialectes centre-méridionaux de l'Italie partagent cette situation : l'absence de contact avec les grands mouvements d'écriture et de normalisation ont favorisé la généralisation de l'adjectif-adverbe. La tradition orale indo-européenne s'est donc imposée. Les quelques adverbes en -mente qu'on peut trouver ici et là sont des emprunts à l'italien standard.

La comparaison de la diachronie de l'adverbe en -ment(e) (v. § 12) avec celle de l'adjectif-adverbe est très intéressante du point de vue méthodologique. Selon l'un des principes de la linguistique historique comparative, le fait qu'un même phénomène s'observe dans toutes les langues et variétés romanes indique clairement qu'il appartient à une tradition orale commune qui remonte au latin parlé. La méthode a donc l'ambition de reconstruire, au moins partiellement, le latin parlé. Or, en l'occurrence, la méthodologie de la reconstruction diachronique à partir de la réalité synchronique variationnelle des langues romanes d'aujourd'hui a mis en évidence le rôle capital que l'adjectif-adverbe a dû jouer dans l'histoire orale des langues romanes. Par contre, cette même méthodologie s'avère risquée si elle se contente d'exemples tirés des soidisant grandes langues romanes (espagnol, français, italien, portugais), et surtout de leurs registres les plus châtiés. Si l'on ne se réfère qu'à celles-ci, comme c'est souvent le cas, on risque d'attribuer l'appartenance de l'adverbe en -ment(e) à une tradition orale commune dont l'origine se trouve en latin. C'est ce que l'on lit dans tous les manuels. Or, si tradition commune il y a, celle-ci est confinée, dans le cas de -ment(e), à la culture écrite partagée de la Romania occidentale, l'italien standard ayant suivi ce modèle dans ce cas-là. La véritable tradition orale, il faut la chercher du côté de l'adjectif-adverbe. Évidemment, les traditions orale et écrite ne forment pas des systèmes étanches. Il faudra donc voir de plus près les faits. Mais du point de vue des tendances majeures, l'adverbe en -ment(e) s'associe clairement au développement des langues standard (aussi pour l'anglais -ly), tandis que l'emploi de l'adjectif-adverbe dans les registres informels, proches de l'oral, marque les langues romanes jusqu'à nos jours. D’où l'intérêt notamment de la rubrique « Corpus Web » du dictionnaire.

\section{La tradition latine}

Les langues romanes sont des langues néolatines, donc des langues issues du latin. Il faut les situer en filiation directe avec le latin. La perspective reconstructionniste développée dans les §§ 12 et 13 nous dote d'une vision de l'histoire, c'est-à-dire d'une hypothèse de recherche, qui nous permet de regarder le latin sous un nouveau jour. 


\subsection{Les règles canoniques du latin}

Selon les règles canoniques du latin classique, l'adverbe est créé sur une base lexicale adjectivale à laquelle s'ajoute un morphème qui marque la fonction de l'adverbe selon la classe de déclinaison :

$\begin{array}{llll}1^{\text {re }} \text { et } 2^{\text {e }} \text { déclinaison } & \text { longus, longa, longum (adj.) } & \rightarrow & \text { longē (adv.) } \\ 3^{\text {e déclinaison }} & \text { fortis, fortis, fortě (adj.) } & \rightarrow & \text { fortiter (adv.) }\end{array}$

Le morphème $-\bar{e}$ marquant la fonction adverbiale est une voyelle longue. Ces règles n'ont pas été transmises aux langues romanes, qui n'ont d'ailleurs pas maintenu l'opposition entre voyelles brèves et longues du latin classique. On peut donc douter que les-dites règles aient été fortement enracinées en latin parlé.

\subsection{L'adjectif-adverbe du latin}

Les manuels de grammaire latine traitent les adjectifs-adverbes comme des exceptions, voire comme des unités lexicalisées. Ceci est le cas de facilě, enseigné comme exception dans le latin classique où la règle canonique aurait donné *faciliter, forme qui ne deviendra usuelle qu'en latin postclassique écrit. Or, en y regardant de plus près, on s'aperçoit que l'usage des adjectifs comme adverbes était systématique, suivant des règles clairement établies (cf. Müller 1908 : 55-89) :

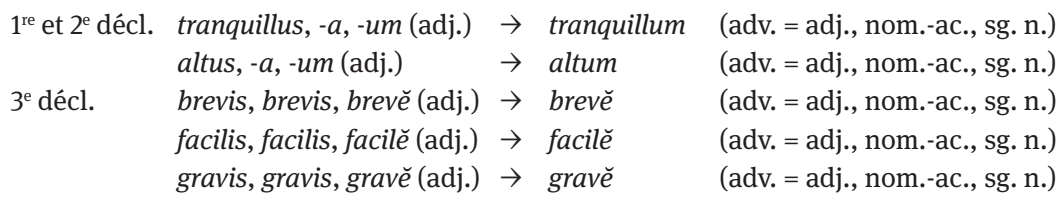

L'emploi de l'adjectif dans des fonctions adverbiales reposait sur une règle simple : il fallait tout simplement choisir la forme neutre du singulier et la placer dans un contexte déterminant sa fonction adverbiale. On trouve donc deux terminaisons : la

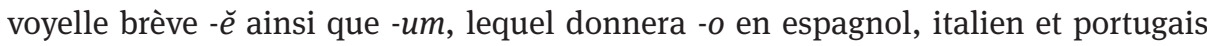
(hablar alto, parlare alto, falar alto). Fait important, l'emploi de l'adjectif dans les fonctions adverbiales était canonique au comparatif, même en latin classique : iustius, pulchrius, miserius, acrius, etc. (adj.=adv.).

Le traitement des adverbes du Type A en latin classique considérés comme des exceptions n'est pas sans rappeler les «petites listes » d'adverbes courts dans les grammaires des (« grandes ») langues romanes modernes. Citons, à titre d'exemple, la courte liste dressée par Brunot (1922 : 603) :

Il est à remarquer que ce sont seulement certains adjectifs, brefs et anciens, qui se prêtent à cet emploi : juste, bon, ferme, net, dur, raide, creux 
Dans le même esprit, Krenn (1995 : 84-85) a pu suggérer une liste « complète » des adjectifs-adverbes français, de même que Nøjgaard (1992/1995, vol. 1 : 134-137), qui distingue pourtant deux ensembles : une liste fermée d'adjectifs-adverbes monosyllabiques "de quantité-manière », et une liste ouverte d'adjectifs polysyllabiques. Seuls les seconds opéreraient sur la valence du verbe, à savoir sur un des arguments de celui-ci. En réalité, la perception des adjectifs-adverbes comme classe fermée est biaisée par les conceptions métalinguistiques canoniques et rationalistes qui se traduisent notamment dans l'écriture « correcte » de la langue. Une analyse plus objective met en évidence le rôle capital joué par l'adjectif-adverbe dans l'histoire de ces langues. Ceci étant, leur diachronie est tout de même marquée par le jeu dialectique avec les adverbes de Type B.

\section{Origine et tradition de l'adverbe en -ment}

\subsection{La périphrase latine avec mente}

Quant à l'histoire de ce type d'adverbe, il faut bien distinguer deux éléments : l'origine et l'expansion. Le latin classique employait mente comme substantif, plus précisément comme ablatif instrumental du substantif mens 'esprit, attitude, intention' pour former des périphrases adverbiales du type bona (mala) mente facere 'faire quelque chose avec de bonnes (mauvaises) intentions' (" ut si dicam : 'bona mente factum, ideo palam', 'mala, ideo ex insidiis, nocte, in solitudine' », Quintilien, Institutio oratoria 5.10.52). Le genre féminin de mens explique qu'on prenne encore aujourd'hui l'adjectif au féminin comme base de l'adverbe (ex. bonnement, curieusement), sauf cas particuliers, notamment en français (cf. évidemment et non pas *évidentement). Selon l'étude exhaustive de Karlsson (1981 : 44), mente n'a jamais remplacé de façon significative les suffixes adverbiaux du latin, pas même chez un seul auteur ou à une époque déterminée. Selon les études de Bauer (2001, 2003, 2010), dans la diachronie du latin l'emploi de la périphrase aurait même débuté dans la poésie qui suivait le modèle grec. Selon cette auteure, il s'agirait donc d'une innovation « par le haut », par l'écriture.

\subsection{Le renouveau de mente dans le discours chrétien}

La tradition de la périphrase connaît un renouveau dans l'ère chrétienne. Les textes chrétiens écrits en latin découvrent les avantages des périphrases du type devota mente facere 'faire avec dévotion, avec beaucoup de foi' pour le discours chrétien, où l'antagonisme « esprit vs. corps » a occupé une place de choix. C'est ainsi que le nouveau modèle s'implante dans l'écriture du latin tardif, y compris la langue du droit. Les langues néolatines les imitent. À la longue, le suffixe -mente remplace ainsi 
le suffixe -iter, qui est devenu canonique en latin tardif, dans l'écriture (Löfstedt 1967, Queirazza 1970, Dardel 1998, 2009).

Quant à la langue parlée, ou ce qui nous en rapproche, c'est dans les Gloses de Reichenau, écrites vers la fin du viII ${ }^{\mathrm{e}}$ siècle au Nord-Ouest du domaine galloroman, qu'on trouve la première attestation du suffixe -ment dans solamente, écrit en un seul mot (Klein 1968 : 193). La glose recommande d'employer l'équivalent classique singulariter, ce qui nous apprend deux choses. La périphrase du type bona mente facere étant appréciée et acceptée dans le discours chrétien de l'époque, la critique se dirigeait tout à la fois contre l'emploi comme suffixe agglutiné et contre l'emploi grammaticalisé (solamente signifie 'seulement, uniquement' et non sola mente 'l'esprit seul, seul, sans compagnie'). Le cas est très intéressant du point de vue méthodologique. Sachant que les textes écrits ne reflètent que très insuffisamment la réalité orale, on peut penser que solamente ne constituait que la partie visible de l'iceberg. Comme c'est souvent le cas, les critiques du langage s'en prennent à des représentants prototypiques pour viser l'ensemble. On peut penser que cette critique concernait non seulement solamente mais bien un petit nombre d'adverbes en -ment employés à l'oral mais bannis de l'écriture. La transformation en suffixe était, semble-t-il, engagée. De plus, les processus de grammaticalisation demandent du temps. Il est donc certain que l'usage de solamente est plus ancien que sa première attestation. Ceci veut dire aussi que la formation primitive du suffixe -mente était bel et bien orale et populaire. On verra dans ce qui suit qu'il faut en effet distinguer la création du suffixe -ment, d'origine orale populaire, mais probablement limitée à un nombre très réduit d'unités, d'une part, de son expansion, de l'autre, qui, elle, était liée au développement des écritures romanes. Il faudra donc probablement nuancer l'hypothèse de Bauer, mentionnée sous 15.1. En effet, la dynamique érudite du modèle savant de la poésie n'exclut pas une dynamique populaire.

\subsection{La datation des origines du suffixe -mente}

Le roumain moderne emploie l'adjectif-adverbe dans son standard d'écriture. L'ancien roumain avait cependant conservé un adverbe du latin, aimintre (< lat. alia mente) 'autrement' (Chircu 2008 : 103-104). La diachronie du roumain étant largement dominée par la tradition orale, qui continuait son chemin loin de l'essor de -mente dans l'espace de l'Empire romain occidental, on peut considérer roum. aimintre comme confirmation de l'existence d'une tradition orale populaire de l'emploi de -mente. Étant donné que le territoire de ce qui allait devenir le roumain, la Dacie, a été coupé de Rome au $\mathrm{III}^{\mathrm{e}}$ siècle de notre ère, on peut penser que les premiers emplois d'adverbes en -ment datent du $\mathrm{III}^{\mathrm{e}}$ siècle au moins, sans vouloir exclure les cas de polygenèse qui ont pu créer des dynamiques à de différents moments de l'histoire sur l'ensemble du territoire de langue latino-romane, comprenant aussi bien la création de nouvelles techniques que leur expansion ou, au contraire, leur arrêt. 
Quant au français, Hummel / Kröll (2015) ont examiné le cas doublement exceptionnel de vite et vitement. La racine de vite n'étant pas attestée en latin écrit, il est clair que le développement de vite(ment) a été populaire-oral. Dès les premiers textes en ancien français, l'adverbe vitement est plus fréquent que vite. Il était alors bien enraciné. On ne saurait donc nier l'emploi oral d'un petit groupe d'adverbes en -ment dans la langue parlée, même si ce processus était plus marginal que l'emploi de l'adjectif-adverbe. La diachronie est exceptionnelle aussi par le fait que l'adjectif-adverbe vite s'imposera en français moderne dans le registre standard aux dépens de vitement, dont l'emploi est marginal.

Selon Banniard (1992 : 34-36), l'effort de divulgation de la foi chrétienne a profondément marqué le développement de langues romanes (occidentales), écrites et parlées, suite à la nécessité de trouver une langue qui se situe à cheval entre textes écrits, fondamentaux du point de vue de la doctrine, et la capacité du commun des mortels de comprendre le discours chrétien. La périphrase avec mente et, à sa suite, le suffixe -ment permettaient justement de relier la tradition chrétienne écrite avec la langue parlée commune. Une fois établi dans l'écriture comme successeur de -iter, le suffixe -ment prend l'essor qu'on connaît et ce, comme nous l'avons dit plus haut, dans toutes les langues romanes qu'on se proposait d'écrire, ce qui explique la limitation du suffixe -ment à ces langues romanes. Il est donc capital de reconnaître l'usage très limité du suffixe -mente en latin populaire, d'un côté, et son expansion dans la tradition écrite qui s'inspire des textes chrétiens. Une fois profondément enraciné dans la tradition écrite, l'adverbe long pénétrera progressivement la pratique orale de la langue, de laquelle il n’a jamais été totalement absent, il est vrai.

Il semble donc qu'on puisse considérer la transformation, dans un premier temps, du substantif mente en suffixe -ment(e) comme caractéristique de la langue orale-populaire, tandis que, dans une seconde étape, son énorme expansion dans les langues romanes est impulsée par la tradition écrite, qui confinera l'adjectif-adverbe aux marges de l'usage. La tradition écrite s'engage donc sur une tradition double et complémentaire, celle de favoriser l'adverbe en -ment(e) et celle de défavoriser en même temps l'adjectif-adverbe. Cela crée la « tension oralité-écriture » dont a parlé Concepción Company dans ses travaux sur la diachronie de -mente en espagnol (Company Company 2012a). 


\section{La transmission de l'adjectif-adverbe du latin aux langues romanes}

\subsection{La transmission d'une règle pour l'adjectif-adverbe}

Les règles canoniques du latin classique s'affaiblissent au cours de l'histoire. Le latin tardif écrit avait déjà largement marginalisé les règles classiques en remplaçant l'adverbe classique du type humanē par humaniter. Le latin tardif écrit a ainsi généralisé le suffixe -iter. Insistons sur le fait que nous parlons ici du code écrit, car ce suffixe n’ayant pas laissé de trace morphologique dans les langues romanes, il est peu probable qu'il ait été conservé longtemps dans la langue parlée.

Mentionnons cependant quelques indices de l'usage populaire («vulgaire ») de ce suffixe. Tout d'abord, on a proposé -iter comme étant à l'origine du « $\mathrm{r}$ » qui se trouve dans les allomorphes -mientre (espagnol médiéval) ou -mentri (frioulan), entre autres (Hummel 2013a). Ensuite, les graffitis de Pompei suggèrent que -iter était usuel dans la langue courante au $\mathrm{I}^{\mathrm{er}}$ siècle de notre ère, ce qui explique sans doute les remplacements fréquents du type humanē par humaniter. Mais les traces de ce suffixe se perdent progressivement, sans doute parce que la langue parlée ne le soutenait plus.

En tout cas, les spécialistes du latin tardif (Löfstedt 1967) et de la reconstruction du latin parlé dit « vulgaire » (Dardel 1998, 2009) sont unanimes à constater l'essor parallèle des adjectifs à fonction adverbiale en latin tardif. C'est la seule règle de formation de l'adverbe déjà présente en latin classique qui survivra dans l'ensemble des langues romanes. C'est la tradition la plus forte.

L'emploi de l'emprunt germanique isnel 'vite' comme adverbe de l'ancien français (à côté de isnelement) met en évidence la productivité de la règle qui permet d'employer directement l'adjectif tel quel dans des fonctions adverbiales. Par conséquent, l'emploi de l'adverbe du Type A ne reste pas confinée au fonds lexical latin (Hummel / Kröll 2015). Heise (1912 : 998, 1027) observe aussi l'apparition de nouveaux adjectifsadverbes dans le contexte latinisant de la Renaissance : bref, incontinent, net, subit, soudain, etc. Le latin n'a donc pas seulement transmis des adverbes lexicalisés, mais une règle productive : celle d'employer l'adjectif dans les fonctions adverbiales. La diachronie est dynamique aussi du point de vue de la disparition d'adjectifs-adverbes. Selon Heise (ibid.), les unités suivantes auraient disparu avec l'ancienne langue : aise, destroit, gent, grief, isnel, lent, parfont, petit, plain, preu, seri, soef, tel, voir, etc. La diachronie s'avère donc dynamique en terme de pertes et profits. Il faut cependant nuancer le constat de perte fait par Heise, puisque étroit, lent, profond et plein, ainsi que vrai, le substitut de voir, s'emploient toujours dans des fonctions adverbiales. De même, la langue informelle connaît encore l'emploi adverbial de petit, et gent s'est conservé dans le technolecte de l'hippisme. Petit et gent font partie des unités qui ont été victimes de la standardisation du français, sans disparaître complément de l'ensemble de la langue. Bien souvent, le Corpus Web met en évidence la survie de tours 
anciens qui auraient disparu à en juger par la documentation de Frantext. C'est ainsi que le quantifieur de l'ancien français petit 'peu' (cf. bon 'très' dans bon creux), qu'on pourrait croire hors d'usage dans une optique «standard » (Capin 2007, 2010), ne l'est pas selon les sources informelles :

M’enfin pour moi qui n’sait pas boire «petit », ça m’est totalement impossible (2014, s.v.)

Les guillemets indiquent que l'auteur est conscient du fait qu'il emploie un registre non-standard.

\subsection{La tradition orale et les besoins de la communication quotidienne}

La tradition orale explique pourquoi les adjectifs-adverbes appartiennent dans leur très grande majorité au vocabulaire fondamental employé pour la communication quotidienne. Celui-ci se compose d'adjectifs généralement très courts, pour la plupart monosyllabiques en français moderne, et dont les cognats s'emploient dans plusieurs langues romanes. Donnons-en quelques exemples qui mettent en évidence la continuité latino-romane dans le domaine du lexique (le français étant la langue qui s'en éloigne le plus, avec le roumain, qui, pour sa part, a été exposé à de multiples contacts linguistiques) :

Tableau 4. La continuité lexicale des adjectifs-adverbes dans la tradition latino-romane

\begin{tabular}{llllll}
\hline Latin & Français & Espagnol & Italien & Portugais & Roumain \\
\hline multum & afr. moult & mucho & molto & muito & mult \\
altum & haut $^{3}$ & alto & alto & alto & (în)alt \\
*assum $_{\text {bassum }}$ & bas & bajo & basso & baixo & --- \\
firmum & ferme & firme & fermo & firme & ferm (néologisme) \\
tranquillum & tranquille & tranquilo & tranquillo & tranquilo & - -. $^{4}$ \\
falsum & faux & falso & falso & falso & fals (néologisme) \\
clarum & clair & claro & chiaro & claro & chiar (hérité) / clar (néologisme) \\
paucum & peu & poco & poco & pouco & puţin (<lat. paucinus) \\
\hline
\end{tabular}

3 Je laisse de côté la possible contamination avec le superstrat germanique (cf. all. hoch). L'attestation de altum clamo 'crier haut' dans les Gloses de Reichenau (Klein 1968 : I, 2629) confirme en tout cas la filière latine.

4 Roum. tranchil est un néologisme plutôt rare dont la fonction adverbiale n'est pas attestée. Le roumain compte bon nombre de néologismes introduits au cours du processus de romanisation engagé au XIX ${ }^{e}$ siècle. 
À ces adjectifs-adverbes provenant des $1^{\text {re }}$ et $2^{\mathrm{e}}$ déclinaisons latines, on pourra ajouter une liste correspondant à ceux de la troisième : fr. fort, soef (ancien fr.), bref, facile, grave / grief (ancien fr.) et leurs équivalents dans les langues romanes (cf. MeyerLübke 1895 : § 619 ; Rohlfs 1969 : 243-244).

\section{Le rôle des adjectifs-adverbes dans l'histoire de la langue française}

\subsection{Traditions orale et écrite : effets généraux}

L'emploi de l'adverbe avec suffixe, nous l'avons vu, est lié à une tradition occidentale d'origine gréco-latine (v. $§ 11)$. La tradition grammaticale occidentale a créé un discours métalinguistique qui veut que l'adjectif soit séparé de l'adverbe dans les grammaires. On veut qu'ils forment, dans la mesure du possible, deux classes de mots, les marques morphologiques servant à les séparer. S’y enchaîne un discours normatif qui considère que l'adverbe suffixé est plus correct que l'adjectif-adverbe. Cette tradition, qui a affecté aussi la culture des langues germaniques, n’apprécie guère l'adjectifadverbe.

$\mathrm{Au}$ cours de l'histoire, la priorité donnée à l'adverbe en -ment a engendré des phases où ce type d'adverbe est employé de façon excessive ( $\mathrm{XVI}^{\mathrm{e}}$ et $\mathrm{XVII}^{\mathrm{e}}$ siècles), suivies d'autres phases « puristes » où l'on essayait d'en corriger les excès (Bally 1965 : 246-248, cf. Nilsson-Ehle 1941 : 21-24, Hummel 2018a). On sait l'usage massif que faisaient les auteurs du XVI ${ }^{\mathrm{e}}$ siècle de l'adverbe long. Glatigny $(1982,2005)$ a mis en évidence que ce siècle se caractérise surtout par la création de néologismes qui n’ont pas fait long feu. L'expansion se situe donc de nouveau du côté de la culture de l'écriture, et même de la plus soignée. On peut également mentionner le mouvement des Précieuses qui préconisaient les intensifieurs en -ment dont il nous reste le tour faire cruellement défaut (Hummel 2012 : 311). Il s'agissait d'unités de haut prestige linguistique. Cependant, la productivité tous azimuts décrite par Glatigny explique aussi pourquoi l'adverbe en -ment est devenu à la fois l'adverbe modèle du standard mais aussi une unité que les locuteurs emploient avec prudence dans le style soigné : on se borne aux unités « qui sont dans le dictionnaire ».

À part la création de néologismes, la priorité donnée aux adverbes en -ment se traduit surtout par la création (hyper)correcte de pendants morphologiques pour l'adverbe "sans » suffixe - et ce, bien avant le $\mathrm{XvI}^{\mathrm{e}}$ siècle. On connaît la diachronie de comment, où le suffixe a été ajouté sans nécessité (du moins à en juger par les autres langues romanes où l'on se contente de it. come, esp. cómo, etc.). Nous avons déjà fait allusion à l'emploi hypercorrect de parler hautement pour remplacer le syntagme usuel parler haut dans l'ancienne langue (cf. Lewicka 1960 : 260-261). On trouve aussi 
des variantes hypercorrectes du type souvemment. De même, on a essayé de remplacer acheter cher par acheter chèrement. D’autre paires sont devenues courantes : fort / fortement.

Suite à ce mouvement, bon nombre d'adverbes en -ment appartiennent au style soutenu et recherché, et ceci dans plusieurs langues occidentales, peut-être toutes. On discute ainsi l'hypercorrection de l'anglais firstly au lieu de first. De même, on a créé l'allemand erstlich, qui n'a pas fait long feu, à la place de erstens. Comme le suffixe anglais -ly, l'allemand -lich, de même origine germanique, était un suffixe qui servait à former un adjectif à partir d'un nom : angl. friend > friendly, all. Freund > freundlich (-lich n'est donc pas un suffixe adverbial mais adjectival ; la fonction adverbiale se produit de façon secondaire selon le contexte ; cf. par contre Buridant 2019 : 754). Alors que l'anglais moderne a réussi à imposer -ly surtout comme suffixe adverbial (Hummel 2014a), les tentatives de l'allemand ont vite avorté, à quelques exceptions près, tels sicherlich et hoffentlich comme adverbes de phrase. En tout état de cause, la langue parlée préfère sicher à sicherlich dans cette fonction, et, pour ne pas oublier le second suffixe adverbial -weise, logisch est préféré dans la langue parlée à logischerweise, erstaunlich à erstaunlicherweise, etc. (Hummel 2018c). On assiste donc à une expansion parallèle de l'adverbe suffixé dans plusieurs langues occidentales, mais aussi au refus de la langue parlée de suivre la prolifération de l'adverbe suffixé dans tous les domaines. Le français accepte mieux ces adverbes longs que les autres langues romanes, du moins certains de ces adverbes (v. Hummel 2018c).

Curieusement, l'hypercorrection et l'attrait des variantes de prestige a fini par affecter la communication " populaire », créant une certaine dichotomie. S’il est vrai que la tendance à employer l'adjectif-adverbe est forte dans les registres informels, il n'en est pas moins que certains adverbes, bannis par la correction normative, se retrouvent justement dans les registres ruraux et populaires. On peut citer des cas devenus clairement ruraux ou « de banlieue » comme mêmement, malement, petitement, vitement. Mêmement et mal(l)ement ont été bannis du " bon usage » au XVII ${ }^{\mathrm{e}}$ siècle. Brunot ( ${ }^{51966-1969}$, vol. 3, première partie : 362) établit toute une liste d' " adverbes proscrits ». Présentement fait partie de cette liste. On voit bien d'ailleurs que présentement a été pratiquement éliminé du standard hexagonal, alors qu'il est toujours usité ailleurs dans l'espace francophone (Bergeron-Maguire 2015). Ceci montre que l'impact de cette phase de correction normative s'est limité, dans une large mesure, au standard hexagonal.

En Espagne, on a vu, plus récemment, que l'adverbe en -mente était associé au « discours politique », élégant mais peu crédible (Fuentes Rodríguez 2009 : 66 ; cf. Hummel 2018c). En effet, en français le cumul d'adverbes de phrases du type évidemment, certainement, absolument, effectivement peut également créer un effet de discours qui pèche par excès de politesse, ressemblant au discours courtois d'un vendeur, où le locuteur se compromet très peu avec ce qu'il dit : il parle beau mais faux. Le comédien italien Antonio Albanese en a fait tout un symbole. Dans son rôle comme homme politique calabrais Cetto La Qualunque, il ajoute le suffixe -mente à 
tout ce qu'il peut. C'est ainsi qu'un de ses films s'appelle Qualunquemente (2011). Le discours politique rejoint ainsi la tradition populaire. Celle-ci pourrait s'expliquer par l'imitation analogique des adverbes en -ment(e), dont on a dû percevoir le prestige dans toutes les couches sociales.

Le contraste entre la tradition orale qui consiste à employer un petit inventaire d'adjectifs-adverbes et l'expansion énorme des adverbes en -ment explique l'écart considérable qui se creuse en termes quantitatifs entre adjectifs à fonction adverbiale et adverbes en -ment. L'inventaire des premiers ne dépasse pas les 427 unités (corpus de ce dictionnaire ; 90 unités, selon Heise 1912 : 999), emplois littéraires compris, tandis que le nombre des adverbes en -ment tourne autour de 3000 unités (v. § 8.1). En effet, la communication quotidienne a besoin d'un nombre très réduit d'unités descriptives par rapport au besoin énorme qui se fait jour dans la communication écrite entre personnes qui ne se connaissent pas, qui ne partagent pas la même situation, qui sont séparées dans l'espace et dans le temps (Biber 1988, Biber et al. 1999, Bilger 2004).

Ceci étant, du point de vue diachronique, la productivité des adverbes en -ment n'est pas forcément supérieure à celle des adjectifs à fonction adverbiale si l'on met la productivité en rapport avec le registre où la règle productive est employée. À l'oral, les besoins sont vite satisfaits, tandis qu'à l'écrit cela ne se produit qu'à un niveau supérieur. Le premier cas de figure concerne surtout l'adjectif-adverbe, le second les adverbes en -ment. C'est ainsi que Bally (1965 : 246) a pu attirer l'attention sur la productivité pratiquement nulle de l'adverbe en -ment dans la langue moderne, situation que l'on observe également en espagnol (Company Company 2012b). À cet effet de saturation - qui ne vaut d'ailleurs pas au même degré pour les langues de spécialité - s'ajoute un effet normatif : à la différence de l'espagnol, le français moderne évite d'employer, voire de créer un mot qui n'est pas dans le dictionnaire (cf. Helfrich 1993 : 245-246 ; Pichon 1939 : 8 fait allusion à l'impact du « préjugé antinéologique »). C'est ainsi que l'anglais forme nanotechnically sur nanotechnical, tandis qu'on cherche en vain nanotechniquement sur Internet (Hummel 2018a ; cf. Guimier 1996 : 2, n.2). Malgré l'essor considérable de cet adjectif, nous n’avons trouvé qu'un seul exemple pour l'adverbe, mis entre guillemets. Étant donné que l'adjectif lui-même est une innovation, on pourrait en conclure que la restriction est particulièrement forte pour l'adverbe en -ment. On peut cependant trouver des occurrences de nanotechnologiquement. La GGHF (2020 : 935) cite en effet quelques exemples néologiques récents : macroniquement (< le président Macron), insoumisement. Sur l'ensemble de la diachronie, la GGHF arrive à la conclusion suivante :

Le suffixe -ment fait donc partie des suffixes très bien implantés dans la langue ; il n’a pas subi d'éclipse de productivité, bien au contraire

Il faut se demander cependant si le critère employé pour analyser la productivité - le nombre d'adverbes en -ment par siècle dans le corpus - permet d'évaluer la productivité. Il conviendrait de considérer aussi le nombre d'adverbes nouveaux par siècle, de 
distinguer les fréquences «type / token » ainsi que de séparer les créations ludiques et passagères de celles qui passent dans l'usage. On ne saurait mettre en doute la fréquence élevée des adverbes en -ment sur l'ensemble de la diachronie, mais ceci ne veut pas dire que la productivité reste élevée. La question reste donc ouverte.

On a insisté également sur la lourdeur stylistique de l'adverbe en -ment (Lombard 1930 : 49-50, Nilsson-Ehle 1941 : 7). Glatigny (1982 : 65) mentionne que déjà Ronsard éliminait « beaucoup des longs adverbes en -ment qu'il chérissait au début de sa carrière, à l'imitation des Italiens et dans le désir d'illustrer la langue française ». Mais la lourdeur est beaucoup moins ressentie en français actuel, à la différence de l'espagnol qui n'aime pas le cumul d'adverbes en -mente dans un texte, le suffixe étant bisyllabique. Cependant, dans le domaine de la publicité, la lourdeur des adverbes en -ment est ressentie : «Voyagez confortablement [face à voyager confortable] est lourd et lent (J. Giraud $1964:$ 32)».

L'appartenance de l'adverbe du Type A au vocabulaire fondamental explique aussi pourquoi et comment un nombre limité d'adjectifs-adverbes a résisté à la pléthore d'adverbes en -ment, favorisés d'abord par la mode $\left(\mathrm{XVI}^{\mathrm{e}}\right.$ et $\mathrm{XVII}^{\mathrm{e}}$ siècles) et ensuite par les normes du standard (fin du XVII ${ }^{\mathrm{e}}$ siècle et siècles suivants). On a eu beau créer parler hautement, celui-ci ne s'est pas imposé à long terme en face de parler haut, trop fortement ancré dans l'usage oral.

\subsection{La langue ancienne 5}

L'emploi de l'adjectif à fonction adverbiale en ancien français a été documenté par Heise (1912), ainsi que par Tobler-Lommatzsch (1925-2002) qui sépare les fonctions adverbiales dans les entrées concernant les adjectifs. L'ancien français employait couramment des adjectifs à fonction adverbiale comme soef 'suave', ou le quantifieur petit (parler petit 'peu' ; Capin 2007, 2010), aujourd'hui hors d'usage ou du moins exclus du registre standard, voire bien souvent réduits à quelques expressions lexicalisées telles petit à petit, un petit peu, ou tout simplement beaucoup moins fréquents (parler bref / court / long / menu).

Banni du français moderne, l'accord de l'adverbe était moins marginalisé qu'aujourd'hui dans l'ancienne langue, voire assez systématique. Brunot (51966-1969, vol. 2 : 409) caractérise comme suit l'accord des modifieurs d'adjectifs au XVI ${ }^{\mathrm{e}}$ siècle :

Deux adjectifs réunis, dont l'un qualifie adverbialement l'autre, s'accordent encore en général, suivant la syntaxe ordinaire : bourgeois...tous roides morts de faim [...], apres estre las et tous enrouez de force de crier [...], deux wallons ... tous parsemez de croix [...], les oreilles qui sont pures françaises [...] cf. il en avoit passé une toute entière [...], ses naseaux hauts ouverts

5 Nous employons ce terme pour réunir l'ancien et le moyen français ainsi que leur prolongation éventuelle dans la langue préclassique. 
Le $\mathrm{XVI}^{\mathrm{e}}$ siècle continue encore la tradition, l'invariabilité était même « rare » (ibid.), la rupture se produisant au XVII ${ }^{\mathrm{e}}$ siècle (Brunot 1887 : 267-269 ; cf. Buridant 2019 : 302). De même, Radouant (1922 : 145) a pu écrire :

Dans les adjectifs composés, chaque terme était traité par l'ancienne langue comme un adjectif.
De là les formes : Portes grandes ouvertes, fleurs fraîches écloses. Les oreilles pures françaises
(Montaigne). Le français moderne au contraire tend à considérer le premier terme comme un
adverbe et à le laisser invariable : Une petite fille nouveau-née, court-vêtue, demi-morte (cf. pur
optimiste, pure livresque, pures humaines dans Damourette / Pichon 1932-1951 : §556)

Notons cependant qu'il faudrait mieux situer l'époque latinisante, qui favorisait l'accord, aussi bien par rapport à l'ancienne langue que par rapport à la langue moderne. Brunot et Radouant renvoient à l'époque latinisante, ce qui met en doute la projection faite par Radouant sur l'ancienne langue dans son ensemble. On verra sous 17.3 que le discours normatif accompagne l'abandon de la tradition de faire l'accord : l'invariabilité est de rigueur en français moderne, du moins la norme le voudrait ainsi.

Quant à l'emploi de l'adjectif comme modifieur d'un verbe, la langue ancienne ne séparait pas clairement la prédication seconde, censée impliquer l'accord en français moderne, de l'adjectif-adverbe, censé s'employer comme unité invariable en français moderne (Hummel 2018a). Notons que l'accord avec un substantif au cas sujet en ancien français est un phénomène qui mériterait plus d'attention puisqu'il implique l'adjectif dans la fonction syntaxique du sujet (cf. Buridant 2019 : 300 ; Hummel / Kröll 2015).

Les détails de la diachronie de l'adjectif-adverbe dans la langue ancienne n’ont pas encore été analysés. Ceci vaut aussi pour le rôle des groupes résultatifs qui tendent parfois à former des verbes complexes. Contrairement à une opinion largement répandue qui voudrait que les tours résultatifs soient typiques de l'anglais (to cut short, to shoot down), à la différence du français, ces groupes sont très fréquents dans l'ancienne langue, voire après. Citons au hasard : abattre bas / mort / menu / plat ; broyer fin ; caler bas ; choir coi ; clouer court ; coiffer court / long ; couper court / droit / épais ; dépouiller nu, croître beau, cuire dur, etc. On est donc tenté de donner raison à Burnett / Troberg (2014 ; cf. Buchard 2006 : 79-82) qui observent une forte marginalisation des tours résultatifs, très usuels jusque-là, en français classique et moderne. Ils montrent en effet que l'adjectif résultatif était fort usuel en ancien français (Troberg / Burnett 2014). Or, il faudrait peut-être différencier cette analyse en séparant bien le standard moderne des registres informels. De même, les argots de métier peuvent faire bande à part, tel le langage des recettes de cuisine où l'on trouve les verbes hacher et couper combinés avec fin, menu, gros (Hödl 2004). Les données de ce dictionnaire devraient permettre de trancher cette question (v. quelques détails dans Hummel 2018b). En tout cas, il est clair que la marginalisation générale de l'adjectif à fonction adverbiale en français moderne standard a dû entraîner aussi les tours résultatifs. Or, l'adverbe en -ment, préféré en standard, ne permet pas l'expression de la résultativité. 
Finalement, la pratique de l'accord adverbial au sein du groupe verbal n'a pas disparu dans les variétés non-standards du français (v. la citation de Drapeau dans 4.7). L'accord adverbial n’est donc pas un simple phénomène littéraire « expressif » (v. §4.3: des paroles clamées hautes et profondes), sinon une technique qui a une longue tradition orale-populaire et dont les charmes ne sont pas passés inaperçus dans la littérature. En fait, ce ne sont pas les variétés qui se sont écartées d'un principe d'invariabilité de l'adverbe, dogmatiquement assumé, hypostasié et virtuellement projeté vers le passé, mais c'est le standard du français (et ceux de l'espagnol, de l'italien et du portugais) qui s'est éloigné de la tradition orale. Nous ne le disons pas pour critiquer le standard. Le standard est un acquis culturel. Il a une fonction et des avantages « économiques » dont il faut payer le prix : la perte de richesse. Mais cette richesse n’est pas nécessairement perdue en dehors du standard, même si l'éducation s'est longtemps acharnée à l'éliminer.

\subsection{La normalisation du français (écrit)}

Aujourd'hui, l'emploi de l'adjectif à fonction adverbiale est souvent critiqué comme faute de français ou décrit comme usage sous-standard (J'y vais direct. Ça prend trois mois facile). Autrement dit, les adjectifs-adverbes se voient marginalisés par rapport au registre standard, notamment à l'écrit La diachronie du discours normatif reflète ce processus de mise à l'écart par rapport à l'adverbe en -ment (Hummel 2018a).

Si l'ancienne langue s'avère plutôt libérale dans le domaine de l'adverbe (Zauner 1926 : 43), y compris des syntagmes adverbiaux se présentant sous la forme de groupes prépositionnels (v. par exemple $a$ (bien) petit, de petit, par un petit, pour un petit, à la vite, al isnel, en brave, etc. ; Hummel 2019a,b ; v. ici au §19), les tendances latinisantes des $\mathrm{XV}^{\mathrm{e}}$ et XVI ${ }^{\mathrm{e}}$ siècles favorisent dans un premier temps l'adjectif-adverbe (Heise 1912: 1026). Nous assistons donc à une première tentative d'intervention normative, certes moins au sens d'une standardisation, mais plutôt pour définir un idéal stylistique, donc une norme pour le style soutenu, pour l'enrichir surtout :

Uses donc hardiment [...]. Des noms pour les adverbes, comme ilz combattent obstinez, pour obstinéement, il vole leger, pour legerement, et mil' autres manieres de parler [...] (Joachim du Bellay 1948 [1549] : 160-161s.).

Malherbe, figure emblématique du purisme à la fin du XVI ${ }^{\mathrm{e}}$ et au début du XVII ${ }^{\mathrm{e}}$ siècle, accepte encore l'adjectif à fonction adverbiale, mais plutôt parce qu'il respectait la langue parlée, et non pas pour la latiniser :

Quand on lui demandoit son avis de quelque mot françois, dit Racan, il [Malherbe] renvoyoit ordinairement aux crocheteurs du port au Foin, et disoit que c'étoient ses maîtres pour le langage (Brunot 1969: 222-223) 
Mais il voulait que l'adjectif employé comme adverbe soit toujours invariable, se départant ainsi de l'accord latinisant :

Certains adjectifs français s'emploient depuis des siècles en qualité d'adverbes, ainsi clair, droit, ferme, fort. Ex. : chanter clair, marcher droit, parler ferme, crier fort.

Malherbe adopte ces locutions. Non seulement il les emploie, mais il les impose. Il n'admet pas que Desportes écrive : qui m’a coûté si chèrement ; il faut dire cela me coûte bien cher, et non, bien chèrement.

Seulement il voudrait que l'adjectif ainsi employé fût considéré comme véritable adverbe, et qu'il devînt invariable dans tous les cas. De même qu'on dit elle parle haut, elle achète cher, on devrait dire aussi : cette victoire a été achetée cher et non chère (Brunot 1969 : 359-360)

Le dogme de l'invariabilité s'impose alors définitivement dans le discours métalinguistique et dans les grammaires. La discussion de ce principe conduit notamment aussi à la perte du fameux -s adverbial dans avecques, donques, mesmes, etc. au cours du XVII ${ }^{\mathrm{e}}$ siècle. À présent, il semble que l'invariabilité n'ait même pas besoin de justification : " Parce qu'il est invariable, l'adverbe est à rapprocher des prépositions et de conjonctions (François et al. 2002 : 94) ». L'école en fait un cheval de bataille. Wilmet (1998 : 29) constate : « La fortune de l'adverbe à l'école française résulte de sa prétendue invariabilité ». Dans la première moitié du XVII ${ }^{\mathrm{e}}$ siècle, Vaugelas accepte le dogme de l'invariabilité de l'adverbe (v. la citation de Vaugelas dans § 4.2), mais il se prononce aussi contre l'adjectif à fonction adverbiale et en faveur de l'adverbe en -ment, qui devient ainsi le seul adverbe considéré « de bon usage » :

Monsieur de Malherbe dit, Allez tout beau. Cette façon de parler ne vaut rien pour dire tout doucement, tout bellement (Vaugelas 1880 [=1647], vol. 2 : 417)

Selon l'analyse diachronique des données par Heise (1912 : 1024), c'est en effet aux $\mathrm{XVII}^{\mathrm{e}}$ et XVIII ${ }^{\mathrm{e}}$ siècles qu'on observe l'emploi le plus restreint des adjectifs-adverbes. Il ajoute que la plupart des grammaires modernes se réfèrent à cette époque, ce qui aurait eu des répercussions sur la représentation des adjectifs-adverbes dans les grammaires.

Avec ces traditions grammaticographiques et dogmatiques, l'adjectif-adverbe se retrouve entre le marteau et l'éclume. D'une part, le dogme de l'invariabilité de l'adverbe voudrait qu'il soit invariable dans les fonctions adverbiales (Malherbe), d'autre part, le fait de convertir directement un adjectif en adverbe, selon le dogme de la classe des mots, n'est pas accepté non plus (Vaugelas). On comprend que le langage se voulant correct ou soutenu prît ses cautions à l'égard de l'emploi de l'adjectif-adverbe, et notamment par rapport à l'accord.

Cependant, au XIX $\mathrm{X}^{\mathrm{e}}$ siècle, les entrées du présent dictionnaire montrent une tendance générale à l'accord, du moins dans les textes littéraires, quand l'adjectif est employé après le verbe. Ceci favorise, en premier lieu, et notamment dans le genre romanesque, le développement massif de la prédication seconde, acceptée parce qu'elle opère une modification sémantique du sujet ou de l'objet direct. Mais 
on perçoit la même tendance - ou préférence - dans les emplois plutôt adverbiaux (v., par exemple, s.v. passer rapide), ce qui crée un effet stylistique de prédication seconde plutôt expressive que logique. La seconde moitié $\mathrm{du} \mathrm{xx}^{\mathrm{e}}$ siècle, qui tend à différencier la norme selon le code (oral ou écrit) et le registre, acceptera de nouveau plus facilement l'emploi invarié, tout en évitant l'emploi fréquent des adjectifs-adverbes dans l'expression écrite « correcte ».

Le rayonnement culturel de la France absolutiste contribue à ce que le principe de l'invariabilité et la préférence pour l'adverbe en -ment se répande dans les langues romanes, et pas seulement, puisque l'anglais, qui observe de près la discussion métalinguistique en France, finira aussi par préférer l'adverbe en -ly à l'adjectif à fonction adverbiale, qui était pourtant canonique en anglais médiéval (Hummel 2014a,b).

Le rationalisme des Lumières accepte ces principes, mais il critique l'emploi métaphorique «illogique » et donc abusif d'adverbes de phrase comme naturellement 'évidemment' ou curieusement 'étrangement', leur préférant les tours périphrastiques, plus concrets et logiques : de manière naturelle, avec curiosité. Dans une perspective déjà nettement scientifique, la Grammaire générale et raisonnée d'Arnauld / Lancelot (1676 : 76-77 ; cf. aussi Damourette / Pichon 1932-1951 : § 982) suggère une explication génétique :

Le desir que les hommes ont d'abreger le discours, est ce qui a donné lieu aux Adverbes. Car la pluspart de ces particules ne sont que pour signifier en un seul mot, ce qu'on ne pourroit marquer que par une preposition et un nom : comme sapienter, sagement ; pour cum sapientia, avec sagesse : hodie, pour in hoc die, aujourd'huy.

Et c'est pourquoy dans les Langues vulgaires, la plupart de ces Adverbes s'expliquent d'ordinaire plus élegamment par le nom avec la preposition : ainsi on dira plûtost avec sagesse, avec prudence, avec orgueil, avec moderation, que sagement, prudemment, orgueilleusement, moderement, quoy qu'en Latin au contraire il soit d'ordinaire plus élegant de se servir des Adverbes

Dans L’Art de bien parler françois (1696), Pierre de La Touche oppose au primat («joug ») de l'usage celui de la raison qui, lui, favoriserait la périphrase (préface). L'usage se serait déclaré pour armés à la légére au détriment de légérement armés (vol. 2, p. 30). Avarement « ne vaut rien. On dit par avarice, avec avarice » (vol. 2, p. 35). Certains de ces tours périphrastiques sont devenus caractéristiques des textes argumentatifs (de façon naturelle, avec curiosité), tandis que d'autres leurs seront préférés dans le style littéraire soigné (d'un œil / d'un ton / d'un air sévère ; sur un ton sévère ; d'un pas lent, le pas lent ; les yeux fermés, etc.) (cf. Furukawa 2006 et Oueslati 2018).

L'usage moderne finit en effet par adopter une attitude réservée par rapport au développement productif des adverbes en -ment. Ceci a engendré la quasi-improductivité des adverbes en -ment dans le registre standard, phénomène déjà observé par Bally (v. § 17.1).

La préférence des normes linguistiques pour l'adverbe en -ment ou une périphrase adverbiale a eu comme contrepartie la marginalisation de l'adjectif à fonction adver- 
biale. Sa productivité se limite aux registres sous-standards. C'est ainsi que les besoins d'économie de l'argot de la facturation incitent à la création d'un adjectif-adverbe nouveau à partir de la locution faire un devis :

En gros, j'me dis qu'il est tout à fait possible que la réalisation de tout ceci pour 3000 euros soit rentable, à condition de faire simple et de bosser vite... en conséquence de quoi tu ne chercheras pas à construire une vrai putain d'identité visuelle pour le dit évènement, mais tu te contenteras de faire du propre et pas cher. On peut très bien bosser comme ça (et du coup deviser bas) mais il faut en avoir conscience... (2015, s.v. deviser bas)

Le registre standard n'en admet qu'un petit nombre (haut, bas, vite, fort), ainsi que quelques expressions lexicalisées.

La méthode de la comparaison traductologique (Hummel 1998) et la comparaison de textes écrits dans les registres argotique, standard et élaboré-soutenu (Kofler 2007) confirment l'effet de la discussion normative sur le comportement linguistique. L'adverbe en -ment est nettement préféré par le registre standard, alors que le registre argotique - littéraire il est vrai - le refuse, lui préférant l'adjectif-adverbe. Le style littéraire élaboré-soutenu réduit également, mais dans une moindre mesure, l'usage des adverbes en -ment, pour profiter de la richesse expressive des adjectifs-adverbes et des périphrases. La préférence du standard pour l'emploi des adverbes en -mente a été constaté aussi pour l'italien (Bischoff 1970 : 45). Des attitudes rebelles peuvent se manifester dans les registres sous-standards, tel celui de la littérature argotique, mais l'usage standard se révèle assez sensible et docile par rapport au discours métalinguistique des grammairiens. Dans les journaux, on trouve, surtout, l'adverbe en -ment et les périphrases adverbiales, aussi bien en français qu'en italien (ou l'adjectif-adverbe est pourtant très présent dans les dialectes).

La tradition de l'accord adverbial, qui s'oppose aux normes du standard, est bien reflétée dans la discussion sur l'accord de tout, considéré adverbe par la tradition grammaticale (v. aussi le débat sur fenêtres grandes ouvertes, etc. ; v. § 17.2). Selon le juste sentiment de Gougenheim (1938 : 129-130), l'incohérence de l'usage actuel, qui veut que tout devant adjectif soit invariable au masculin et devant un adjectif féminin à initiale vocalique mais variable devant tout autre adjectif féminin, a résulté « d'un conflit entre le désir des grammairiens d'imposer l'invariabilité et l'usage linguistique qui maintenait l'accord ». "C'est toujours le même compromis. La 'logique' n’a pas triomphé entièrement, mais elle n'est point battue non plus » (Brunot 1922 : 680). En fait, la prononciation permet de conserver le dogme de l'invariabilité au masculin, invariable par définition, et avant voyelle, où la prononciation du - $t$ final s'expliquerait par liaison (tout ouverte / toute ouverte), alors que l'astuce grammairienne échoue dans toute grande. Il suffit de regarder les exemples cités par Brunot

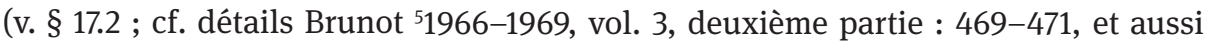
l'étude récente de Bouard / Glikman 2018) pour voir que cette norme du français est à situer dans la suite des efforts entrepris à partir des XVI ${ }^{\mathrm{e}}$ et XVII ${ }^{\mathrm{e}}$ siècles pour imposer le principe de l'invariabilité, alors que la tradition - certes renforcée au temps de la 
Renaissance - préférait l'accord, si elle n'était pas tout simplement libérale à cet égard si l'on pense à l'ancien et au moyen français : l'accord était une option qui permettait de créer une cohésion thématique (v. § 4.7), voire d'obtenir des effets stylistiques très appréciés en littérature. Un regard jeté du côté des autres langues romanes, où l'astuce est bloquée par la prononciation systématique de la fin du mot, aurait suffi pour montrer que l'accord adverbial est une tradition romane : it. tutta bella, pt. toda contente. On observe quelques répercussions du discours normatif français sur l'espagnol, où l'on peut hésiter entre toda contenta / todo contenta, mais le premier est clairement préféré. Les données de ce dictionnaire mettent en évidence que la tradition de l'accord adverbial n'est pas morte (v. § 4 et le dépouillement des données dans Hummel 2017a, ainsi que Hummel 2015 sur l'espagnol). Ajoutons que l'emploi accordé ou invarié dans nouveau $(x)$ mariés, inaudible, mais audible dans nouvelles venues n'a pas non plus disparu (Van Goethem 2010 ; cf. Tobler 1902 : 82 et Buridant 2019 : 302 sur l'ancien français). On peut regretter que la plupart de ces études analysent la diachronie interne de la langue, sans tenir compte des idées (normatives, dogmatiques, visionnaires) qu'on se fait de la langue à une époque donnée. Or, il est clair qu'on n'a pas affaire à de simples processus de grammaticalisation ou de changement impulsés de façon interne par la langue elle-même. La langue n’est pas une machine.

Finalement, le libéralisme - non seulement linguistique mais aussi culturel - se frayant de nouveau son chemin après la Seconde Guerre mondiale, les adjectifs-adverbes regagnent du terrain, au grand dam des « remarqueurs " modernes qui associent ce libéralisme à l' " américanisation de la société française », ciblant en premier lieu l'influence pernicieuse de la publicité :

On sait que le français contemporain, notamment dans le style publicitaire, tend à développer l'usage de l'adverbe court. Le goût de la brièveté se conjugue en l'espèce avec l'anglomanie (Moignet $1963: 178$ )

Étiemble (1964 : 189) en fait un cheval de bataille dans sa lutte contre le « franglais ».

Langue jeune, langue nouvelle vague, langue new look, le sabir atlantyck se devait de rénover la forme et la syntaxe de l'adverbe [...]. [...] ainsi le sabir emploie en fonction adverbiale l'adjectif du français. Ce faisant, il s'affirme courageusement atlantyck : en anglais et en américain, l'adjectif s'emploie souvent tel quel en fonction adverbiale. Exemples : poudrez-vous transparent; habillez-vous pratique ; traité irrétrécissable ; il écrit économique

Plus prudent, Giraud (1964) est prêt à accepter un certain nombre d'adjectifs-adverbes consacrés par l'usage et fonctionnellement justifiés, mais il en critique l'emploi abusif. Citons un passage de son article publié dans la rubrique «Pour la défense de la langue française » de la revue Le français dans le monde : 
Mais il est des limites à ne pas franchir. Nous tenons chauffer terrible, gesticuler terrible, rouler petit, écrire utile, voyager confortable, danser anglais, agir blanc, pour des expressions laides, prétentieuses, choquantes et sans originalité, que n'excusent ni l'audace publicitaire, ni la recherche de brièveté frappante. En vérité, ce qui commande ici, c'est moins l'usage que la loi du moindre effort (1964 : 32).

Or, si l'on peut concevoir l'anglais comme modèle de certains textes publicitaires, on ne saurait étendre cette analyse à l'ensemble des adjectifs-adverbes qui profitent tout simplement du libéralisme de l'époque. Celui-ci est souvent associé au « langage jeune », mais il ne s'agit que d'une autre variante de la recherche d'un bouc-émissaire : influence de l'anglais, décadence « jeune ». Cependant, l'appréciation du langage jeune est ambivalente : il est aussi attrayant que critiqué, à une époque où tout le monde veut être jeune. En fait, le libéralisme se saisit de la communication informelle en général, donnant tout simplement un nouveau souffle à ce qui a toujours marqué la langue parlée : l'emploi de l'adjectif-adverbe dans les fonctions adverbiales, accordé ou non.

L'idée d'une influence, voire d'un emprunt à l'anglais, se maintient jusqu'à nos jours. Curieusement, les équivalents anglais ne sont jamais mentionnés :

Adjectif devenant adverbe. Empruntés à l'anglais : il est vite, il joue utile, il voit large, il pense profond. Nous pourrions aussi en rester à : il est rapide, il joue utilement, il voit grand ou il voit loin (ce qui n'est pas pareil), il pense avec profondeur (Berchoud 2011)

Notons que l'emploi adjectival de vite remonte plutôt à l'ancien français qu'à l'anglais moderne (Hummel / Kröll 2005).

\subsection{Le français au Canada et en Louisiane}

Les dialectes de France étant réduits à peu de chose (v. cependant l'étude des traditions dialectales de l'adjectif-adverbe employé comme modifieur d'un adjectif par Deutschmann 1959), il convient de porter le regard sur les variétés du français d'outremer - variétés secondaires du français exportés de l'Hexagone - pour retrouver la tradition orale. En l'occurrence, le français de Louisiane présente un cas idéal, dans la mesure où cette variété a évolué dans l'isolement complet, après la guerre de Sécession, sauf peut-être pour les élites, et, surtout, en dehors de l'enseignement scolaire du français. Dans leur grammaire du français de Louisiane, Conwell / Juilland (1963 : 180) constatent :

Many LaF [Louisiana French] adjectives may function adverbially, e.g. [...] ça halait lourd [...,] les autres les fait différent [..., il guettait content [...] 
Les adverbes en -ment ne sont pas mentionnés.

Nous pouvons également tourner notre regard vers le Canada. Citons au hasard quelques exemples du corpus acadien inédit de Wiesmath, aimablement mis à notre disposition (Hummel 2000 : 430 ; cf. Wiesmath 2006) :

une fois que vous la vendez légal

c'était engraissée naturel là

l'étoèle pis les choses qui brillent euh positif à l'intérieur de nous-autres

on pourra en parler un petit peu plus profond

ton animau grandissait naturel

Ces exemples mettent en lumière une productivité pleinement développée. Nous avons affaire à une règle grammaticale en pleine vigueur. Les adjectifs employés dans ces exemples ont été empruntés au latin par voie savante. Ils ont été repris par la suite par la langue parlée. Ce processus est sensiblement analogue à celui des adverbes en -ment correspondants qu'on trouve dans l'usage hexagonal : légalement, naturellement, positivement, profondément. Il ne s'agit pas non plus d'adjectifs très courts. Ils s'écartent donc de la tendance hexagonale à employer surtout des adjectifs monosyllabiques pour les fonctions adverbiales. En fait, ces exemples fonctionnent exactement comme l'adverbe roumain, qui utilise les adjectifs à fonction adverbiale comme adverbe canonique, ou comme l'adverbe allemand : tout adjectif peut être adverbe, pour long qu'il soit, si leur sémantique le permet. Rappelons aussi le discours oral d'un soldat français des années 1950 :

il savait exécuter l'ordre pour l'avoir fait antérieur (Yvon, exemple oral de 1950, v. Hummel 2009)

Il paraît donc que l'emploi d'adjectifs d'origine savante dans une fonction adverbiale est un trait qui unit les parlers régionaux de France avec ceux de l'Acadie (cf. Neumann-Holzschuh / Mitko 2019 : 264).

Si l'on regarde l'envers de la médaille, il s'avère que la fréquence des adverbes en -ment modifieurs de verbes progresse dans le corpus de Wiesmath avec le degré de distance communicative du texte, tout en restant inférieure à celle des adjectifs-adverbes (Hummel 2000 : 431).

Plus récemment, Neumann-Holzschuh / Mitko (2019) ont examinél'hypothèse de la préférence pour l'adjectif-adverbe au détriment de l'adverbe en -ment dans le Nouveau Monde avec des données orales provenant de variétés nord-américaines, notamment du Canada et de Louisiane. Les auteures ont largement confirmé cette hypothèse en y ajoutant deux facteurs qui vont dans le même sens. D'une part, il faut attirer l'attention aussi sur les différences entre les variétés. De ce point de vue, c'est encore la variété la plus exposée aux efforts de standardisation, celle du Québec, qui montre une plus forte pénétration de l'adverbe en -ment. D’autre part, les jeunes, plus scolarisés, sont plus enclin à employer l'adverbe suffixé que leurs aînés. Pour une fois, ce n'est donc pas la faute du langage des jeunes si l'adjectif-adverbe devient plus fréquent. 


\subsection{La reconstruction diachronique de la tradition orale}

Ces observations revêtent un grand intérêt pour la reconstruction diachronique de la tradition orale du français de France. Il est généralement accepté que les variétés citées ci-dessus continuent les traditions orales de la France du $\mathrm{XVII}^{\mathrm{e}}$ siècle - voire d'avant, si l'on admet que ces traditions orales étaient encore assez proches de l'ancienne langue -, notamment celles du Centre-Ouest, de la Normandie / Perche et de l'île de France (cf. Mougeon / Beniak 1994). Cette observation générale a été confirmée par notre micro-analyse diachronique de vite / vitement (Hummel / Kröll 2015). Or, le $\mathrm{XVII}^{\mathrm{e}}$ siècle est surtout connu comme celui de l'apogée des adverbes en -ment, à tout le moins dans les sources écrites. Par conséquent, il semblerait qu'au XVII ${ }^{\mathrm{e}}$ siècle un écart énorme se soit creusé entre les traditions orale et écrite dans le domaine de l'adverbe de manière.

On pourrait donc avancer l'hypothèse selon laquelle l'adjectif à fonction adverbiale prédominait au $\mathrm{XVII}^{\mathrm{e}}$ siècle dans la langue parlée. Cela est moins surprenant qu'il n'y paraît de prime abord, puisqu'un Acadien lettré d'aujourd'hui, qui parle comme dans les exemples cités ci-dessus, privilégierait sans doute les adverbes en -ment à l'écrit. On observe une situation similaire dans les dialectes britanniques (Tagliamonte / Ito 2002) et aussi dans l'espagnol et le portugais d'Amérique où les adjectifs à fonction adverbiale sont l'option par défaut dans la communication orale informelle, même chez les locuteurs ayant accompli des études supérieures, alors que les mêmes personnes les éviteront largement dans l'écriture " correcte » (Hummel 2002, 2013c). Ajoutons que le fait de préférer aller directement à aller direct dans un texte du standard écrit est une pratique quotidienne en France.

\subsection{L'adjectif-adverbe comme adverbe de phrase : copie analogique de l'adverbe long et / ou dynamique propre?}

S’il est vrai que parler hautement, employé couramment dans l'ancienne langue, du moins dans les textes écrits, est formé à partir de la variante plus ancienne, parler haut, il existe d'autres adverbes de Type B qui sont nés à un moment où le substrat populaire des adjectifs-adverbes n'avait plus la force d'impulser les changements diachroniques. C'est notamment le cas de nombreux adverbes de présentation subjective du discours (adverbes de phrase, d'intensité, de cadre, etc.) qui surgissent en français moderne, et notamment à partir des XVIII ${ }^{\mathrm{e}}$ et XIX ${ }^{\mathrm{e}}$ siècles (Hummel 2013b, 2018c). Il s'agit d'adverbes du type évidemment, absolument, curieusement, naturellement, etc. Même si l'adverbe lui-même est plus ancien, les nouvelles fonctions " de phrase » ou « énonciatives / d'énonciation » ne s'établissent généralement qu'en français moderne. De plus, il s'agit d'unités préférées à l'oral. On ne s'étonnera donc pas de les retrouver à un moment donné aussi sous la forme d'un adjectif-adverbe (cf. aussi Grundt 1972 : 44-46, 375) : 
Normal, il pouvait pas savoir.

Curieux, il m’a pas appelé.

Sérieux, elle t’a dit ça?

On les trouve notamment dans le même registre informel où prolifèrent également les adjectifs-adverbes modifieurs de verbes :

La blancheur au carré. Une formule qui semble tout droit sortie d'une publicité pour la lessive. Normal, c'est le cas. Dès 1953, c'est Persil qui ouvre le bal. Persil lave plus blanc... donc plus propre ! Et qui récidive en 1959 en lançant Voici Super Persil qui lave encore plus blanc que Persil (Delphine Gaston, Nos 500 expressions populaires préférées, 1953, s.v. laver propre)

Ils s'bouffent des yeux tout leur temps, sans rien dire... Ils en auraient trop long, probable !

(Francis Carco, 1914, Jésus-la-Caille, s.v. avoir long)

ça vient clair de l'utilisation des VST (CW, s.v. venir clair)

Bedijs (2012 : 251) cite « j'aime moyen coucher avec les garçons », où l'on pourrait voir un rapport génétique qui part de l'adverbe long, moyennement (cf. «L'Élysée apprécie moyen », Libération (7.7.1989), cité d’après Noailly 2010 : 190). Citons aussi le cas, récemment très discuté, de sérieusement et sérieux (Sérieusement / sérieux, elle a dit ça ?) (Âlvarez-Prendes 2014). Le transfert analogique de la fonction de l'adverbe en -ment à un adjectif-adverbe s'observe toujours quand le mot passe au registre oral-informel.

Il est donc important de noter que chez ce type d'adverbe de phrase, la forme longue précède historiquement l'adverbe court. Ceci ne veut cependant pas dire que l'adjectif-adverbe soit une forme tronquée de l'adverbe en -ment (v. § 7) : la troncation de sérieusement donne sérieuse, pas sérieux. Mais on ne saurait nier que le système monocatégoriel peut copier par analogie des modèles offerts par le système bicatégoriel.

Le Corpus Web fournit des exemples pour ces adverbes de phrase :

Et là, trop bizarre, elle regarde si sa supérieure hiérarchique la regarde et me conseille tout bas d'acheter un billet de bus (2014, s.v. conseiller bas)

Sérieux t'en a pas marre? Qu'est ce que tu viens me citer encore alors que je suis un des seuls ici à défendre forte? (2015, s.v. défendre fort)

Vrai, beaucoup se détournent tout court de la location avec les impayés notamment (2015, s.v.)

Bref, tout ça pour dire que la vie est belle ici...même si on se gèle dru ! (2015, s.v. geler dru)

Je prie pour que ce ne soit que l'embrayage qui est peut-être mal règlé (il mord haut sur la pédale d'ailleurs... normal ?) mais le problème est qu'il va s'user prématurément en patinant de la sorte... (2015, s.v. mordre haut)

Les exemples avec bref et vrai, qui ne sont pas de création récente, montrent cependant que du point de vue fonctionnel l'adjectif-adverbe n'a pas besoin d'un modèle en -ment et qu'on peut l'associer également à des variantes du type c'est vrai. Dans le dernier exemple, on peut remplacer normal ? par c'est normal ? mais pas par norma- 
lement. Ceci n'empêche que le modèle en -ment joue un rôle dans un nombre considérable de cas.

Notons que le roumain, qui emploie l'adjectif à fonction adverbiale dans le registre standard, a introduit au XIX ${ }^{\mathrm{e}}$ siècle les adverbes de phrase normal, curios, logic, inadmisibil, evident, probabil, etc. à partir notamment de modèles français en -ment (Chircu 2008 : 123-126). Le résultat est le même qu’en français parlé informel :

Normal, că e fiică-mea. 'Normal, c'est ma fille'

Probabil vine dintr-o familie bună. 'Il est probablement de bonne famille'

Citons aussi au hasard quelques exemples captés de l'espagnol parlé qui mettent en évidence que le phénomène se trouve dans les langues romanes en général :

Fácil vienen diez personas 'dix personnes viennent facile(s)'

Lo digo general 'Je le dis (Je veux dire) en général'

Nos llevamos perfecto 'On s'entend parfait(ement)'

Un exemple paradigmatique, du point de vue historique, est l'angl. real good 'vraiment bon' qui apparaît d'abord dans le discours savant comme calque du latin (angl. really formé sur lat. realiter), avant d'adopter aussi la forme de l'adverbe court au fur et à mesure qu'il a passé de la langue soutenue au registre oral-informel des dialectes britanniques, et notamment, par la suite, à l'anglais américain (Hummel 2014a, 2013b).

L'étude de Zribi-Hertz (2015) de l'adjectif grave, déjà mentionnée au § 7, montre qu'il peut y avoir d'autres cas de copie analogique. L'irruption de l'emploi adverbial de grave dans le passé récent se traduit clairement dans les données de ce dictionnaire où les exemples proviennent surtout du Corpus Web. Elle est donc postérieure à l'emploi de gravement. Il ne faut pas oublier, cependant, les nombreuses attestations de grief adverbial en ancien français (cf. aussi greu en roumain, v. §13). On est tenté de comparer la diachronie de grave avec celle de rapide, analysée dans Hummel / Kröll (2015). Il s'agit d'emprunts du temps de la Renaissance. Les adjectifs empruntés ont donc suivi la mode de l'époque en formant d'abord un adverbe en -ment. L'emploi de l'adjectif-adverbe est un corrélat postérieur qui accompagne leur popularisation. Or, si copie il y a eu, la riche polyfonctionalité mise en évidence par Zribi-Hertz montre que le système monocatégoriel développe une dynamique propre. L’adjectif-adverbe grave est loin de se limiter aux contextes où gravement est employé. On peut donc également penser que les fonctions adverbiales prolongent tout simplement l'emploi de l'adjectif grave lui-même, sans imiter celui de gravement. En effet, grave remplit toutes les conditions nécessaires : il est court et il appartient au lexique fondamental.

La « contamination » analogique des Types A et B constitue, en tout cas, un phénomène secondaire qui est le fruit de la coexistence et concurrence des systèmes monocatégoriel et bicatégoriel dès les origines de la langue française. On observe aussi bien le développement d'adverbes plus corrects (type parler haut > hautement) 
que l'assimilation de modèles offerts par des adverbes en -ment au système monocatégoriel (sérieusement > sérieux [adv.]). À partir de possibles effets analogiques qui peuvent se trouver à l'origine de tels processus, les systèmes suivent leurs logiques propres. Hautement / bassement acquièrent ainsi des acceptions spécifiques, figurées - mais seulement à partir du XVIII ${ }^{\mathrm{e}}$ siècle (Gamillscheg 1957 : 527) -, et l'usage de grave et sérieux dépasse largement le cadre du calque des adverbes longs. Tout ceci s'insère dans les tendances générales qui peuvent changer au cours de l'histoire (affinité flexive pendant la Renaissance, invariabilité puriste et rationaliste, découverte des registres populaires au $\mathrm{XIX}^{\mathrm{e}}$ siècle, libéralisme du $\mathrm{XX}^{\mathrm{e}}$ siècle), sans parler des préférences individuelles ou situationnelles des locuteurs.

\subsection{L'irruption de la tradition orale informelle dans la littérature et sur Internet}

L'analyse différenciée de ce qui est correctement appelé « adjectifs employés adverbialement » dans Le bon usage distingue un groupe - en principe commutable avec l'adverbe en -ment formé à partir du même adjectif - du reste des adjectifs-adverbes (Grevisse / Goosse 2016 : § 963). Mis à part l'emploi familier général de direct et pareil, cet usage serait plutôt propre au « français populaire de Paris » (§ 963e). Mais il s'agit d'une propriété du français informel tout court. L'attribution à ce registre est sans doute due à la littérature argotique citée par Grevisse / Goosse qui reflète cette pratique, souvent de façon exagérée (cf. Kofler 2007, Rainer 1985). L'exagération est inévitable dans ce genre littéraire. La comparaison avec n'importe quelle transcription d'une conversation informelle met en évidence que la littérature argotique, écrite par nature, présuppose un effort considérable d'élaboration. Or, cette élaboration crée des nécessités surtout descriptives qui ne sont pas habituelles dans les conversations naturelles. Il faut donc créer des adverbes de manière. Recourir trop souvent aux adverbes en -ment constituerait une rupture de style. C'est tout le défi des romans de Céline. D’où de nombreux adjectifs-adverbes calqués sur des adverbes en -ment, que l'on veut éviter. Ceci donne évidemment l'impression d'avoir affaire à des adverbes en -ment " réduits ». Dans ce contexte, il convient de mentionner l'effort du roman naturaliste au XIX ${ }^{\mathrm{e}}$ siècle pour dénicher le langage du peuple, mais sans l'élan d'élaboration innovatrice de la littérature argotique. Nous devons à Robert (1886 : 109-124) un beau témoignage. Comme il prend comme point de départ le français classique (« la langue de notre siècle est bien différente de celle de l'âge classique »), on ne s'étonne guère que l'auteur constate « l'invasion croissante des termes populaires, grâce au roman moderne »; « la langue moderne, plus vive dans ses allures, préfère, à ce qu'il semble, l'adjectif là où, à l'ordinaire, on serait tenté d'employer l'adverbe ». Pour critique qu'il soit, Robert perçoit bien que ces termes populaires ne font que donner une nouvelle vie à de vieilles traditions réprimées par la langue classique (cf. Hunnius 1975). 
Quant à l'accord de l'adjectif-adverbe, celui-ci semble céder du terrain au $\mathrm{xx}^{\mathrm{e}}$ siècle, mais seulement dans les styles standard et littéraire (hors argot), et uniquement quand la fonction adverbiale est clairement perçue ou voulue. Autrement dit, le $\mathrm{xx}^{\mathrm{e}}$ siècle tend à faire le départ entre la prédication secondaire, adjectivale et accordée, d'une part, et l'« adverbe court », considéré « adjectif adverbialisé », de l'autre. C'est, en fait, l'analyse préférée par l'enseignement. On peut donc penser que le développement normatif commence à se faire sentir dans le standard et le bon usage. Les analyses de la linguistique dite " descriptive ", qui s'avère en fait dogmatique à chaque fois qu'il s'agit de séparer l'adjectif de l'adverbe, jouent ici en faveur de la norme. Il faudrait sans doute procéder à une analyse plus systématique des données, mais un petit sondage confirme l'impression causée par la rédaction des articles (v. remarques s.v. couper court). Par contre, le registre familier se montre assez libéral au $\mathrm{xx}^{\mathrm{e}}$ siècle, admettant aussi bien l'emploi invarié que l'accord. On observe notamment l'usage d'un schéma, minoritaire mais assez systématique, du type la chanter fausse, forte, juste (une chanson), donc une construction transitive où l'accord se fait selon le genre et le nombre de l'objet direct, comme dans les dialectes méridionaux de l’Italie (v. § 4.6).

L'inclusion dans ce dictionnaire de données provenant de recherches (Google) sur Internet pour documenter l'emploi informel des adjectifs à fonction adverbiale est un des défis de cet ouvrage. En effet, la recherche de ces adjectifs nous conduit très souvent directement vers des forums où les messages sont écrits dans un langage spontané, peu contrôlé mais souvent proche de la langue parlée informelle. Ce type d'approche offre des données utiles pour compenser le biais « écriture, littérature, standard, correction » des études traditionnelles (Taylor 2012 : 17 et suiv.). L'accord adverbial du type les gars jouent forts, éliminé au XVII ${ }^{\mathrm{e}}$ siècle, réapparaît avec vigueur dans ce type de données, sans souci littéraire.

\section{Conclusion}

Cette introduction linguistique a présenté une synthèse des travaux du Groupe de recherche sur l'interface de l'adjectif et de l'adverbe dans les langues romanes. Nous avons mis en évidence que l'adjectif-adverbe appartient à la classe de mots de l'adjectif. Cet adjectif peut, selon sa position syntaxique, assumer aussi des fonctions syntaxiques adverbiales. Il serait d'ailleurs beaucoup plus facile si, dans l'élaboration de corpus catégorisés, l'on classait l'adjectif-adverbe simplement comme adjectif, même dans des cas à forte tendance adverbialisante tels fort et vite, au lieu de vouloir trancher, dans chaque occurrence, s'il s'agit d'un adverbe ou d'un adjectif. La position syntaxique permettrait de distinguer et de trouver dans les documents numériques les fonctions possiblement adjectivale (une piste vite) et adverbiale (elle court vite) ; on pourra les passer ensuite au peigne fin pour discerner, par exemple, prédicat second et adjectif-adverbe. On aurait ainsi syntonisé théorie et empirie. 
La tradition d'employer l'adjectif dans des fonctions adverbiales est la plus ancienne et commune tradition orale des langues indo-européennes. Cette tradition repose sur un système monocatégoriel où l'adjectif sert aussi bien à la modification des substantifs qu'à celle d'autres unités (Type A). Or, depuis le grec ancien, la culture occidentale a créé une tradition de systèmes d'écriture qui essaient d'imposer la séparation de l'adjectif et de l'adverbe en termes de classes de mots, soit en ajoutant un suffixe à l'adjectif pour former l'adverbe (système bicatégoriel de Type B), soit - plus tard dans la diachronie - en ajoutant le dogme de l'invariabilité de l'adverbe dans les cas où il est identique à l'adjectif. Cette différence fondamentale des traditions orale et écrite, de l'informel et du standard, crée un jeu de va-et-vient par lequel la tradition orale se voit réprimée à chaque fois qu'un système d'écriture lui est superposé - $a$ fortiori si celui-ci est standardisé - pour prendre un nouveau souffle quand ce système écrit disparaît ou quand ses normes font place aux idéaux de richesse expressive, de la beauté du langage populaire au goût de l'autochtone ou du libéralisme. De même, le système monocatégoriel a persisté dans les variétés où la tradition orale est restée forte : dialectes, argots de métiers, langage parlé informel. Pour le roumain, la standardisation est venue trop tard, au XIX ${ }^{\mathrm{e}}$ siècle, pour éradiquer le système monocatégoriel. On l'a essayé, certes, mais la tradition orale était trop forte. On a donc canonisé l'adjectif-adverbe. Le système monocatégoriel est également presque exclusif dans les variétés de l'Italie centre-méridionale et en Sardaigne. C'est ainsi qu'on perçoit que, suite à la création précoce d'une écriture néolatine, l'emploi du suffixe adverbial -ment(e) est une tradition qui est confinée aux langues romanes occidentales (l'italien standard les suit dans ce domaine), ce qui montre que l'évolution du latin ne s'explique pas simplement par la diachronie interne des langues néolatines mais aussi par leur contexte culturel. Notons également que les langues germaniques sont restées fidèles, du moins pour l'essentiel, au système monocatégoriel. La grande exception est l'anglais. Le système monocatégoriel, qui était canonique en anglais médiéval, a été remplacé par le système bicatégorial avec le suffixe adverbial -ly. Toutefois, les dialectes britanniques conservent très clairement le système monocatégoriel. De plus, dans l'anglais du Nouveau Monde, et notamment aux États-Unis, où la tradition orale s'avère plus forte, on emploie également l'adjectif-adverbe plus fréquemment que dans le standard britannique, de même que le français dans le Nouveau Monde par rapport à la France. La même situation se reproduit encore pour l'espagnol et le portugais en Amérique.

Si l'on veut comprendre l'histoire de l'adjectif-adverbe français, il faut la situer dans ce contexte. On se rend compte alors que l'analyse des efforts d'enrichissement, de purification et de standardisation qui ont marqué notamment le français de l'Hexagone est indispensable pour comprendre aussi bien l'essor de l'adverbe en -ment que les avatars de l'adjectif-adverbe qui en reçoit les contrecoups. Ce contexte général est également important pour prendre conscience de l'insuffisance des corpus écrits. En effet, nous avons vite observé que les données de Frantext nous confrontaient à un problème de lacunes situées grosso modo entre 1550 et 1750, confirmant ainsi une 
observation déjà faite par Heise (v. § 17.3). On peut y voir le contrecoup des tendances latinisantes de la Renaissance qui favorisaient l'adjectif-adverbe (accordé), critiquées par le purisme, ainsi que celui de l'apogée de l'adverbe en -ment. Malherbe s'y oppose, dès la fin du XVI ${ }^{\text {e }}$ siècle, mais il n'imposera pas son point de vue, sauf pour l'attitude de prudence puriste par rapport à l'usage du français en général qui rattrapera aussi l'adverbe en -ment dont on critiquera les excès. Bally finira, au xx ${ }^{\mathrm{e}}$ siècle, par constater la prudence qui tend à restreindre l'emploi de l'adverbe en -ment aux unités qui «sont dans le dictionnaire ». L'intérêt porté, à partir de la seconde moitié du XIX siècle, à la langue du peuple, notamment par le genre textuel du roman, contribue à la renaissance de l'adjectif-adverbe, mieux dit, à sa visibilité dans un corpus comme Frantext où la plupart des occurrences sont attestées à partir de ce moment. S’y ajoutera le libéralisme de la seconde moitié du $\mathrm{xx}^{\mathrm{e}}$ siècle, souvent considéré " américanisant », qui favorisera l'adjectif-adverbe, dont l'usage est parfois attribué au langage publicitaire ou au langage jeune. L'avènement de la communication par Internet a permis à ce dictionnaire d'attester l'importance de l'adjectif-adverbe dans le discours informel et spontané, et souvent exempt de contrôle postérieur, comme c'est le cas dans les textes disponibles pour les études diachroniques.

Que fait ce dictionnaire dans tout cela ? Il se limite, avant tout, à l'attestation d'occurrences, à la documentation de la richesse d'usage de l'adjectif-adverbe. Il ne reflète cependant pas l'histoire ni en termes quantitatifs ni en termes de variétés ou de registres. Le fait même d'avoir comblé des lacunes va à l'encontre de toute interprétation critique objective de ce que représente, par exemple, un corpus comme Frantext par rapport à la diachronie de la langue française dans son ensemble, sans parler du fait que les données offertes par Frantext ont, elles aussi, évolué depuis 2002, moment où nous avons commencé ce dictionnaire. D’autre part, le dictionnaire aurait échoué, du moins en partie, s'il s'était limité aux données de Frantext. Le dictionnaire est plus une œuvre d'art, si j'ose dire, qu'une étude scientifique. Force est donc de constater que le dictionnaire ne saurait remplacer l'étude rigoureuse de corpus bien définis. Mais ceci doit se faire ailleurs.

\section{Perspectives de recherche : l'adverbe du Type C}

Je ne reviendrai pas sur ce qui s'ensuit des limitations mises en évidence dans la section précédente. J'insisterai plutôt sur un fait assez négligé qui constitue désormais le centre des intérêts de notre groupe de recherche : l'adverbe du Type $C$ (v. § 2.2), donc les adverbiaux avec préposition. Si l'on ne peut pas faire l'histoire des adjectifs-adverbes (Type A) sans celle des adverbes en -ment (Type B), on ne peut pas non plus analyser ces deux types sans tenir compte de ce que nous appelons la « troisième voie ", c'est-à-dire le rôle des groupes prépositionnels à fonction adverbiale (Type C), tels à la douce, pour sûr, avec élégance. 
Les adverbiaux du Type $C$ ont été assez négligés par la recherche grammaticale, surtout dans une perspective historique (avec l'exception récente de la GGHF 220 : 878-885). C'est que pour le grammairien il s'agit soit de paraphrases, donc d'unités secondaires par rapport aux classes de mots, soit de locutions figées, donc une affaire de lexicologue. Or, la priorité donnée aux classes de mots n’est qu'un dogme grammatical qui entrave la recherche objective. Dans les langues créoles, par exemple, il est complètement inopérationnel, suite aux processus de restructuration (NeumannHolzschuh / Mitko 2019 : 263, Ludwig 1996 : 141-192). Le passage du latin aux langues néolatines implique également des restructurations. Il faut donc observer tout d'abord comment la langue réalise les fonctions avant de procéder à un classement catégoriel en termes de classes de mots. Du point de vue fonctionnel, à la douce n'est pas « moins fonctionnel » que doucement, et surtout pas « inférieur » aux classes de mots. Il faut sans doute discuter les différences sémantiques, syntaxiques et de registre, de doucement, à la douce, en douceur, etc., mais il s'agit là d'un second pas. Y a-t-il synonymie avec l'adjectif-adverbe, du moins au départ ? Les prépositions servent-ils à donner une orientation spécifique, et possiblement systématique, au type de modification? Quant au classement comme locutions (figées), on verra qu'il s'agit d'un point de vue largement dominé par la perspective du présent. À l'instar de l'adjectif-adverbe, que nous avons pris l'habitude de voir comme adverbe court plutôt lexicalisé, le Type $\mathrm{C}$ a également été marginalisé au cours de l'histoire. Suite à la perte d'une bonne part de sa productivité traditionnelle, très libérale, le Type $\mathrm{C}$ a été réduit à un fonds de "locutions figées » du type à la douce. C'est du moins ainsi qu'il est perçu à présent.

Bien que l'inventaire des structures que l'on peut attribuer au Type C soit plus vaste, comprenant notamment aussi, et surtout, les structures du type « préposition + substantif » (avec élégance), nous nous intéressons aux seules structures comportant un adjectif, donc à " préposition + adjectif » (PA). Selon certains auteurs, les structures PA auraient été complètement absents du latin (classique) (v. l'état de la recherche dans Hummel et al. 2019). Même si les recherches plus poussées nous obligent à modifier ce constat rigoureux (Porcel Bueno, à paraître, Solari Jarque, en préparation), il faudra attendre le développement des langues néolatines pour voir surgir les PA, mais alors massivement, dès les premiers siècles de documentation des langues romanes. Selon Codita (2016 : 13-17), il s'est agi du principal recours productif employé dans le processus de l'élaboration-enrichissement de la langue espagnole (écrite). L'analyse des textes dépouillés par Hummel (2014b) pour la Sintaxis histórica de Company Company (2014), va dans le même sens. Nous avons pu constater que pratiquement tous les adjectifs-adverbes (Type A) avaient des pendants prépositionnels (Type C), équivalents (ex. fr. couper ras / couper à ras) ou sémantiquement différents (cf. fr. léger / à la légère / de léger). N'ayant pratiquement pas existé en latin, il était normal de penser que ces PA avaient surgi dans le cadre du fameux processus analytique qui a marqué la transition du latin, langue synthétique, aux langues romanes, plus analytiques (pour une analyse plus différenciée de ce processus « analytique » v. Ledgeway 
2012). Il était normal aussi de penser que ce processus a pu se greffer sur l'adjectifadverbe qui se trouvait en plein essor en latin tardif. En effet, si pour chaque adjectifadverbe nous avons trouvé une ou plusieurs variantes du type PA, ceci ne s'observait pas du côté de l'adverbe en -mente.

Quant au français, on ne trouve que quelques observations dans les grammaires et les travaux linguistiques (Hummel et al.2019). Cependant, une étude plus détaillée sur les variantes de vrai a mis en évidence l'emploi de nombreuses variantes prépositionnelles (Hummel 2018a,b). À l'instar de l'adjectif-adverbe, ces PA se montrent plus résistants dans le français parlé au Canada : pour vrai, pour de vrai, pour le vrai, à vrai. On ne saurait donc confirmer l'appartenance de pour de vrai / pour de faux au seul langage enfantin (Noailly 2010 : 191). À défaut d'une documentation suffisante dans les grammaires, nous avons dépouillé le toujours très riche dictionnaire de l'ancien français de Tobler / Lommatzsch (1925-2002) (v. Hummel et al. 2019) :

$\begin{array}{ll}\text { bon } & \text { en bon, de mon bon } \\ \text { chier } & \text { a chier, a chier ou a vil } \\ \text { droit } & \text { à droit, au droit (de), de droit, en droit } \\ \text { cort } & \text { de cort } \\ \text { grant } & \text { en grant, en grande, en grant de } \\ \text { large } & \text { au large, a large } \\ \text { lonc (lieu) } & \text { le lonc de, del lonc de, de lonc en lonc, de lonc et de lez, de lonc et de travers, } \\ & \text { au lonc de, tout au lonc, en lonc, par lonc } \\ \text { lonc (temps) } & \text { a lonc, au lonc de, a la longue, de lonc } \\ \text { petit } & \text { un petit, a (bien) petit, a petit de, de petit, par un petit, petit a / et petit } \\ \text { parfont } & \text { de parfont, en parfont } \\ \text { seri } & \text { a seri, au seri, en seri } \\ \text { soef } & \text { a soef } \\ \text { vil } & \text { a vil, por vil } \\ \text { voir } & \text { a voir, de voir, en voir, par voir }\end{array}$

La richesse productive du Type $\mathrm{C}$ ressort clairement de ces données. Citons aussi la GGHF (2020 : 917) : «(de legier au 15e s. 'facilement', en apert 'clairement', par exprés, au fort, etc.), sont fréquemment employés également ». Or, on constate d'emblée que le français moderne ne dispose plus de la même richesse de variation. On a donc encore affaire à un processus de sélection diachronique, plutôt que d'évolution. C'est ainsi que l'édition de Genève (1478) de Mélusine remplace « leurent la lettre tout en hault » (s.v. lire haut), qui se trouve dans le manuscrit de l'Arsenal $\left(1^{\mathrm{er}}\right.$ quart Xv $)$, par « leurent la lettre tout hault ». En effet, l'emploi de en haut au sens de 'à haute voix' s'est perdu au cours de l'histoire. L'exemple montre cependant que cet emploi existait. Le français s'insère ainsi dans une dynamique tout à fait panromane (v. Hummel et al. 2019). La dynamique panromane du Type $C$ exclut pratiquement l'hypothèse d'une influence spécifiquement germanique sur le français, hormis de possibles cas particuliers (cf. cependant Buridant 2019: 802). C'est l'ensemble des langues romanes qui s'est engagé dans ce type de formation d'adverbiaux durant la transition latino-romane. 
Si sélection négative il y a eu, ceci ne veut pas dire qu’on n'apprécierait pas, le cas échéant, l'usage du tour prépositionnel. C'est ainsi que présentement a été banni du bon usage du français de France ; on lui préfère plutôt à présent. Les rationalistes de Port-Royal, nous l'avons vu (v. § 17.3), préconisaient l'emploi des adverbiaux avec préposition pour combattre l'emploi abusif au figuré des adverbes en -ment : avec curiosité pour curieusement (cf. Nyrop 1979: §109). De même, le style littéraire soigné apprécie les adverbiaux " périphrastiques » tels d'un œil sévère. La réalité est donc complexe. Cependant, il est clair que les langues romanes naissent avec dans leur bagage une pléthore d'adverbiaux avec préposition. Cette richesse incontrôlée a disparu, du moins de l'usage écrit, sauf pour le roumain, moins influencé par standardisation de bonne heure (v. infra).

Il faut considérer l'essor des structures « préposition + adjectif » dans la transition du latin aux langues romanes comme étant un phénomène plutôt marginal face aux structures "préposition + substantif » et " préposition + préposition / adverbe ». Cette dernière, du type dedans, est plutôt populaire. Ses variantes prolifèrent dans toutes langues et variétés romanes (cf., pour l'ancien français, Buridant 2019 : 807, et Fagard 2012, pour la diachronie et la différenciation sémantique), et tout particulièrement dans celles qui reposent sur une tradition orale plus prépondérante, telle le roumain, qui aime ces combinaisons (e.g. de-a lungul - ' de-à-long + article déterminé postiche', dedesubt 'de-de-sous', pe de-a-ntregul 'sur-de-à-intégral-article déterminé postiche = complètement' ; v. l'analyse détaillée de Chircu-Buftea 2011 : 110-118). Ledgeway (2009 : 710-715 et 729-733) a réuni une documentation très riche pour le napolitain. Citons aussi deux exemples français avec combinaison de prépositions :

J'avois déjà receu quelques coups, qui me mettoient tout en sang, lorsque je me jettay bas de dessus elle, et je passay quelque temps à voir leur combat (Gabriel de Foigny, 1676, La Terre australe connue)

Et là, celuy qui mieux sa lévre poseroit

Dessus la lévre aimée, et plus fort baiseroit,

Ou soit d'un baiser sec, ou d'un baiser humide,

D'un baiser court ou long, ou d'un baiser qui guide

L'ame desur la bouche, et laisse trespasser

Le baiseur qui ne vit sinon que du penser (Pierre de Ronsard, 1578, Le Second Livre des amours)

Les structures avec adjectif ont été entraînées par cette dynamique. On voit d'ailleurs bien, dans les exemples de Tobler / Lommatzsch cités ci-dessus, que ce sont les adjectifs-adverbes de temps et de lieu qui ont créé le plus grand nombre de variantes (cf. GGHF 2020 : 879).

Selon les données de la GGHF (2020 : 884-885), le Type C est devenu de plus en plus fréquent au cours de l'histoire, et notamment en français moderne. Or, cette grammaire considère surtout les types « préposition + nom » (ex. en raison de) et « préposition + préposition / adverbe de lieu (PP / PAdv)» (ex. en dedans de). Il est donc possible que les structures " préposition + adjectif $(\mathrm{PA})$ » constituent une exception par rapport à d'autres structures appartenant au Type C. En effet, on ne saurait oublier 
que seule la structure PA a subi la concurrence des adverbes en -ment (Type B) et des adjectifs-adverbes (Type $A$ ), tandis que cette concurrence est très limitée pour les autres structures (cf. Type $\mathrm{B}$ à base nominale : vachement ; Type A à base nominale : boire nature). On ne s'étonnera donc pas de voir la fréquence diachronique des PA décroître alors que celle des PN va augmentant.

Citons, pour terminer, quelques exemples illustratifs que nous avons trouvés, plutôt au hasard, au fil des recherches pour ce dictionnaire :

De fuians est mout grans la perte.

Trop grant angoisse i ont soferte.

Seré se tienent et estroit [manuscrit W : Serré se tienent a estroit, 503]

Entrués qu'il vienent al destroit,

U li cris de la tere ert leur (Gautier d'Arras, 1175a, Ille et Galeron)

Or si vos dirai la androit,

Ou Meleaganz est venuz,

Que oiant toz, gros et menuz,

Dist a son pere molt en haut :

Pere, fet il, se Deus me saut

(Chrestien de Troyes, 1177, Lancelot ou Le Chevalier de la charrete, 6277)

Sachiez de voir qu'amours si fort me lie

En vostre amour que n’ay chose tant chiere (Christine de Pizan, +1400, Euvres poétiques)

SAINT PIERRE. Si grant courroux en moy se boute

Que boire ne mengier ne puis.

Pour Dieu, mon maistre, se je suis

Celuy qui vostre mort procure,

Dictes le au plain [variantes : dictes le cler, dictes a plain, l'a plain], car je n'ay cure Que me cellez ung tel meffait,

Affin, se j'ay vers vous meffait

Tous mes compaignons me destruisent

(Arnoul Gréban, 1450, Le Mystère de la Passion, 18132, cf. s.v. dire clair)

après avoir bien au long entendu ses justes raisons, en lieu de la reprendre et tuer, comme souvent par la parolle il la menassoit, la print entre ses braz et, en pleurant tresfort, luy dist : Ma fille, vous estes plus juste que moy (Marguerite d'Angoulême, 1559, Heptaméron)

Souvent evitant un danger,

En autre on tombe de leger

(Philippe d'Alcripe, 1579, La Nouvelle Fabrique des excellents traicts de verité, cf. s.v. tomber léger)

C'est donc pourquoy si jeune, abandonnant la France,

J'allay, vif de courage et tout chaud d'espérance,

En la cour d'un prélat, qu'avecq'mille dangers

J'ay suivy, courtisan, aux païs estrangers.

J'ay changé mon humeur, alteré ma nature ;

J'ay beu chaud, mangé froid, j'ay couché sur la dure

(Mathurin Régnier, 1609, Les Satires 1 à 13, cf. s.v. coucher dur) 
que nous allions à Louvres, chez un de nos parents qui pouvait nous donner quelques secours, et que nous nous sommes perdus dans les champs en voulant couper au court. Nous demanderons à passer la nuit à la ferme, dans un coin de l'étable (Eugène Sue, 1843, Les Mystères de Paris, cf. s.v. couper court)

Et là-dessus M. de Péréfixe ayant entamé quelques mots de discussion pour la provoquer, elle répondit ferme à son ordinaire, para les coups et se garda bien de prendre le change sur la grâce suffisante, qu'on essayait de substituer à l'efficace (Charles Sainte-Beuve, 1856, Port-Royal)

Cette tête, si reconnaissable à sa chevelure courte coupée à la malcontent, et à la fraise espagnole qui l'encadrait, à ses lignes arrêtées et d'une délicatesse anguleuse, enfin à la forme particulière de la barbe et de la moustache, c'était celle de d'Alvimar, penchée en arrière dans la roideur de la mort (George Sand, 1858, Les Beaux Messieurs de Bois-Doré)

Mais la langue moderne, plus vive dans ses allures, préfère, à ce qu'il semble, l'adjectif là où, à l'ordinaire, on serait tenté d'employer l'adverbe

(C.-M. Robert, 1886, Questions de grammaire et de langue française)

Ah, ce faux Néron ce magnat de pacotille il a tout d'un souteneur... Et Léo, impassible, se disait il a de l'allure celui-là, habillé triste ça doit être chic, moi ce chic-là je n'en ai pas besoin mais j’aime bien ça chez les autres et ce genre de gars je l'ai à la bonne, beau voûté hargneux, ce genre de gars fin de race je l'inquiète et ça me plaît (Christine de Rivoyre, 1964, Les Sultans)

Je m'en fous, en vrai, Sophie (Une fille facile, 2019, film, France)

Et c'est cela qui vous lie plus fort, plus fort qu'à la normale. Vous le connaissez par cœur, en long, en large, en travers (30.6.2020, www.facebook.com)

Les PA figurent parfois directement comme variantes d'un adjectif-adverbe, comme dans les exemples de $\sim 1175$ et $\sim 1450$. Quant aux exemples de 1856 et 1886, on peut les placer dans le contexte de l'effort des grammairiens rationalistes pour remplacer l'adverbe en -ment par une périphrase "plus logique ». Si les structures PA se sont donc, dans un premier temps, greffées sur l'adjectif-adverbe, il y aurait eu une seconde phase, prescriptive, qui aurait affecté les adverbes en -ment (ordinairement, efficacement), du moins temporairement et chez certains auteurs.

La rareté des PA en latin classique et tardif, dans des textes forcément écrits, nous fait évidemment penser à la tradition orale comme source des PA dans les langues romanes. Au vu de recherches plus détaillées, il semble plutôt qu'il existe deux traditions parallèles (Porcel Bueno, sous presse). On aurait, d'une part, une tradition écrite allant de pair avec une tradition orale châtiée, donc une série d'adverbiaux créée dans et pour le style soigné, notamment avec des substantifs, et une tradition populaire, de l'autre. Ceci n'est pas sans rappeler la diachronie clivée des périphrases en mente en latin (v. 15.1). 


\section{Références et sélection bibliographique}

Les collections de données sur l'adjectif-adverbe qui se trouvent dans quelques ouvrages sont indiquées à la fin de l'entrée bibliographique en question.

Abeillé, Anne / Danièle Godard (2004), « Les adjectifs invariables comme compléments légers en français ». Dans : Jacques François (éd.), L'adjectif en français et à travers les langues, Caen (Presses Universitaires) : 209-224.

Abeillé, Anne / François Mouret (2010), « Les compléments adjectivaux des verbes transitifs en français ». Dans : Les Tables. La grammaire par le menu, Cahiers du CENTAL 6 : 1-10.

Abeillé, Anne / Olivier Bonami / Danièle Godard / Michèle Noailly (2017), « Adjectives and adverbs in the Grande Grammaire du français ». Dans : Hummel / Valera (éds.) : 113-139. https://doi.org/10.1075/la.242.

Albanese, Antonio (2011), Qualunquemente. https://en.wikipedia.org/wiki/Qualunquemente (29.6.2016).

Álvarez Huerta, Olga (2008), « La formation des adverbes en latin tardif : le témoignage d’Égérie ». Dans : Fruyt / Van Laer (éds.) : 167-180.

Álvarez-Prendes, Emma (2014), «L'adverbe sérieusement : propriétés syntaxiques et sémantiques de ses emplois ", SHS Web of Conferences. https://doi 10.1051/shsconf/20140801355.

Arjoca-leremia, Eugenia (2010), « Les métamorphoses linguistiques des adjectifs court, bref vs. long et de leurs correspondants roumains ». Dans : Goes / Moline (éds.) : 327-347.

Arnauld, Antoine / Claude Lancelot (1973 [= 1676]), Grammaire générale et raisonnée, réimpression de l'édition de Bruxelles, Hildesheim / NewYork (Georg Olms).

Balibar-Mrabti, Antoinette (1999), « Les adjectifs chaud et froid comme attributs de l'objet ", Langages 133 : 81-97.

Bally, Charles (1965), Linguistique générale et linguistique française, 4 e édition revue et corrigée, Berne (Francke).

Banniard, Michel (1992), Viva voce. Communication écrite et communication orale du IVe au IXe siècle en Occident latin, Paris (Institut des Études Agustiniennes).

Bastian, Sabine / Françoise Hammer (2005), «Bref et en somme comme marqueurs de glose ». Dans : Agnès Steuckhardt / Aïno Niklas-Salminen, Les marqueurs de glose, Aix-en-Provence (Université de Provence) : 171-188 + 239-243.

Bauche, Henri (1951 [= 1920]), Le langage populaire, Genève (Payot).

Bauer, Brigitte L. M. (2001), " Syntactic innovation in Latin poetry ? The origins of the Romance adverbial formation in -ment(e) ». Dans : A.P. Orbán / M.G.M. van der Poel (éds.), Ad litteras. Latin studies in honour ofJ. H. Brouwers, Nijmegen (Nijmegen University Press) : 29-43.

Bauer, Brigitte L. M. (2003), « The adverbial formation in mente in vulgar and late Latin. A problem in grammaticalization ». Dans : Heikki Solin / Martti Leiwo / Hilla Halla-aho (éds.), Latin vulgaire latin tardif VI, Hildesheim (Olms-Weidmann) : 439-457.

Bauer, Brigitte L. M. (2010), « Forerunners of Romance -mente adverbs in Latin prose and poetry ». Dans : Eleanor Dickey / Anna Chahoud (éds.), Colloquial and literary Latin, Cambridge (CUP) : 339-353.

Bedijs, Kristina (2012), Die inszenierte Jugendsprache, Meidenbauer (München) [contient un inventaire d'adjectifs-adverbes employés dans le film français : 250-251].

Bergeron-Maguire, Myriam (2015), "L'éclairage des banques textuelles pour le traitement lexicographique de présentement». Dans : Gaétane Dostie / Pascale Hadermann (éds.), La dia-variation en français actuel, Berne, etc. (Peter Lang) : 275-295.

Berchoud, Marie (2011), Le Vocabulaire et ses pièges, Montréal (Archipoche). 
BFM 2019 = Base de Français Médiéval 2019, Lyon (ENS de Lyon, Laboratoire IHRIM). http://bfm. ens-lyon.fr.

Biber, Douglas (1988), Variation across speech and writing, Cambridge, etc. (Cambridge University Press).

Biber, Douglas et al. (1999), Longman grammar of spoken and written English, Harlow (Longman).

Bilger, Mireille (2004), « Quelques données sur les adverbes en ment dans le corpus de référence de [sic] français parlé », Recherches sur le français parlé $18: 63-81$.

Bischoff, Heinrich (1970), Setzung und Transposition des -mente-Adverbs als Ausdruck der Art und Weise im Französischen und Italienischen mit besonderer Berücksichtigung der Transposition der Adjektive, Zürich (Juris Druck).

Blinkenberg, Andreas (1950), Le problème de l'accord en français moderne, Copenhague (Munksgaard).

Bonnard, Henri (1960), « L'attribut se rapporte-t-il au nom ? », Le Français moderne, 28,4 : 241-248.

Bos, Gijsbertha (1967), «L'adverbe en latin. Tentative de classification structurale », Bulletin de la Société de Linguistique de Paris 62 : 106-122.

Bouard, Bérengère / Julie Glikman (2018), « Histoire de tout devant adjectif : variation linguistique et élaboration d'une règle (xvl ${ }^{\mathrm{e}} \mathrm{xIx}{ }^{\mathrm{e}}$ siècles) ». Dans : Bernard Colombat et al., Histoire des langues et histoire des représentations linguistiques, Paris (Champion) : 293-331.

Brunot, Ferdinand (1887), Précis de grammaire historique de la langue française, Paris (Masson).

Brunot, Ferdinand (1922), La pensée et la langue, Paris (Masson).

Brunot, Ferdinand (51966-1969), Histoire de la langue française des origines à 1900, Paris (Armand Colin).

Brunot, Ferdinand (1969 [= 1891]), La doctrine de Malherbe d'après son Commentaire sur Desportes, Paris (Armand Colin).

Brunot, Ferdinand / Charles Bruneau (31949), Précis de grammaire historique de la langue française, Paris (Masson).

Buchard, Anne (2006), « Pour une analyse unitaire de l'attribut du sujet et de l'attribut de l'objet », Travaux de linguistique 53 : 67-89.

Buridant, Claude (2019), Grammaire du français médiéval (XI - -XIVe siècles), Strasbourg (Société de linguistique romane / Éditions de linguistique et de philologie).

Burnett, Heather / Michelle Troberg, (2014), « On the diachronic semantics of resultative constructions in French ». Dans : Christopher Piñón (éd.), Empirical issues in syntax and semantics $10: 37-54$. http://www.cssp.cnrs.fr/eiss10.

Cadiot, Pierre / Naoyo Furukawa (éds.) (2000), La prédication seconde, Langue française 127.

Capin, Daniéla (2007), « Petit et peu en ancien et moyen français », Verbum 29, 3-4: 287-303.

Capin, Daniéla (2010), «Évolution d'un quantifieur-intensifieur : petit depuis l'ancien français jusqu'au français classique ». Dans : Bernard Combettes et al. (éds.), Le changement en français, Berne, etc. (Peter Lang) : 93-109.

Carvalho, Paulo de (2008), « Morphologie adverbiale, morphologie nominale : -ter vs $-\bar{e}(\breve{e}) »$. Dans : Fruyt / Van Laer (éds.) : 149-164.

Chafe, Wallace L. (1982), Integration and involvement in speaking, writing, and oral literature. Dans : Deborah Tannen (éd.), Spoken and written language : exploring orality and literacy, Norwood (Ablex) : 35-53.

Chanay, Hugues Constantin de (1998), «L'adverbe de manière : circonstant scénique à incidences contextuelles ». Dans : S. Rémi-Giraud / A. Roman (éds.), Autour du circonstant, Lyon (Presses Universitaires de Lyon) : 307-337.

Chircu, Adrian (2008), L'adverbe dans les langues romanes. Études étymologique, lexicale et morphologique (français, roumain, italien, espagnol, portugais, catalan, provençal), Cluj-Napoca (Casa Cărţii de Ştiinţă). 
Chircu, Adrian (2014), « Remarques sur l'emploi des adjectifs adverbialisés en français et en roumain », Studii şi cercetări lingvistice 65, 2 : 177-187.

Chircu-Buftea, Adrian (2011), Dinamica adverbului românesc. Ieri şi azi, Cluj-Napoca (Casa Cărţii de Ştiinţă).

Codita, Viorica (2016), La conformación y el uso de las locuciones prepositivas en castellano medieval, Frankfurt, etc. (Peter Lang).

Coiffet, Benoît (2018), Étude des emplois de l'adjectif invarié en français, thèse de doctorat (Université de Toulouse). http://www.theses.fr/2018TOU20057 [contient un corpus d'adjectifs-adverbes : 285-328].

Company Company, Concepción (2012a), « Condicionamientos textuales en la evolución de los adverbios en -mente », Revista de Filología Española 92, 1 : 9-42.

Company Company, Concepción (2012b), « La 'engañosa' productividad de los adverbios en -mente de la lengua española ». Dans : Victoria Béguelin-Argimón et al. (éds.), En pos de la palabra viva : huellas de la oralidad en textos antiguos, Berne, etc. (Peter Lang) : 119-136.

Company Company, Concepción (2014), «Adverbios en -mente ». Dans : Company Company (éd.) (2014) : 457-611.

Company Company, Concepción (2017), « Adverbial adjectives and -mente adverbs face to face. Diachronic evidence from Spanish ». Dans : Hummel / Valera (éds.) : 257-286. https://doi. org/10.1075/la.242.

Company Company, Concepción (éd.) (2014), Sintaxis histórica de la lengua española. Tercera parte : Adverbios, preposiciones y conjunciones. Relaciones interoracionales, vol. 1, México (Universidad Nacional Autónoma de México-Fondo de Cultura Económica).

Conwell, Marilyn J. / Alphonse Juilland (1963), Louisiana French grammar, vol. 1 : Phonology, morphology, and syntax, La Haye (Mouton).

Corte, W. (1863), «Von der Ellipse des Subjekts im Französischen », Archiv der neueren Sprachen und Literaturen 19, $34: 79-104$.

Cruschina, Silvio (2010), « Aspetti morfologici e sintattici degli avverbi in siciliano », Quaderni di lavoro ASIt. 11 : 21-42.

Dal, Georgette (2007), « Les adverbes de manière en -ment du français : dérivation ou flexion ? ». Dans : Nabil Hathout / Fabio Montermini (éds.), Morphologie à Toulouse, Munique (Lincom) : 121-147.

Dal, Georgette (2018), « Les adverbes en -ment du français : lexèmes ou formes d'adjectifs ? ». Dans : Olivier Bonami et al. (éds.), The lexeme in descriptive and theoretical morphology, Berlin (Language science press) : 87-118.

Damourette, Jacques / Édouard Pichon (1932-1951), Des mots à la pensée. Essai de grammaire de la langue française, 6 vols., Paris (d'Artrey) [contient un corpus d'adjectifs-adverbes : § 979-986].

Dardel, Robert de (1998), « Le protoroman comme héritier de l'indo-européen (à propos de la construction clamare altum) ». Dans : Louis Callebat (éd.), Latin vulgaire - latin tardifIV, Hildesheim, etc. (Olms-Weidmann) : 21-28.

Dardel, Robert de (2009), « La morphosyntaxe de l'adjectif-adverbe en protoroman », Vox Romanica $68: 1-22$.

De Cesare, Anna-Maria / Ana Albom / Doriana Cimmino / Marta Lupica Spagnolo (2020), « Domain adverbials in the news. A corpus-based contrastive study of English, German, French, Italian, and Spanish », Languages in contrast 20-1 : 31-57. https://doi.org/10.1075/lic.17005.dec.

$\mathrm{DEAFBiblEl}=$ Dictionnaire étymologique de l'ancien français. Complément bibliographique rédigé par Frankwalt Möhren. http://www.deaf-page.de/fr/bibl_neu.php.

Deutschmann, Olaf (1959), Zum Adverb im Romanischen. Anläßlich französisch Il est terriblement riche - Il a terriblement d'argent, Tübingen (Niemeyer). 
Dietrich, Wolf (1995), Griechisch und Romanisch. Parallelen und Divergenzen in Entwicklung, Variation und Strukturen, Münster (Nodus).

Dietrich, Wolf (2012), « Historische Sprachschichten von Süditalien bis zum Balkan. Areale Gemeinsamkeiten und ihre historische Deutung ». Dans : Wolfgang Dahmen et al. (éds.), Südosteuropäische Romania. Siedlungs-/Migrationsgeschichte und Sprachtypologie, Tübingen (Narr) : 29-45.

Dixon, Robert M.W. (1977), «Where have all the adjectives gone ? », Studies in language 1, 1 : $19-80$.

Dixon, Robert M. W. / Aleksandra Aikhenvald (2004), Adjective classes : a cross-linguistic typological study, Oxford (Oxford University Press).

DMF = Dictionnaire du Moyen Français, DMF 2015, ATILF-CNRS et Université de Lorraine. http://www. atilf.fr/dmf.

Drapeau, Lynn (1982), «L'utilisation adverbiale des adjectifs en français populaire ». Dans : Claire Lefebvre (éd.), La syntaxe comparée du français standard et populaire : approches formelles et fonctionnelles, vol. 2, Montréal (Office de la langue française) : 17-48.

Du Bellay, Joachim (1948 [= 1549]), La deffence et illustration de la langue francoyse, édition critique par Henri Chamard, Paris (Didier).

Estienne, Henri (1853 [= 1565]), Traicté de la conformité du langage français avec le grec, édition critique par L. Feugère, Paris (Delalain).

Étiemble (1964), Parlez-vous franglais ?, Paris (Gallimard).

Fagard, Benjamin (2012), « De ante à devant et avant : différenciation sémantique dans l'évolution des langues romanes ", Langages $188: 111-131$.

Fagard, Benjamin / Dejan Stosic / José Pinto de Lima, «Complex adpositions in Romance : emergence and variation ». Dans : Benjamin Fagard et al., Complex adpositions in European languages, Berlin / Boston (De Gruyter Mouton) 2020 : 33-64.

Falk, Paul, L'échapper belle. Histoire d'une greffe, Studia neophilologica 11 : 1-38.

Faye, Paul-Louis (1935), On certain adverbial and semi-adverbial uses of bel beau in Old French, University of Colorado studies 22,4, Colorado (Boulder) : 313-326.

Felíu Arquiola, Elena (2019), «¿Realmentes existen ?: la 'pluralización’ de los adverbios en -mente en español actual », Onomázein 44 : 166-190.

Felíu Arquiola, Elena / Enrique Pato, En torno a la denominada « concordancia adverbial » en español : tres casos de variación, Madrid (CSIC) 2020.

Fillmore, Charles J. (1977), « Scenes-and-frames semantics ». Dans : Antonio Zampolli (éd.), Linguistic structures processing, Amsterdam, etc. (North-Holland) : 55-81.

Finco, Franco (2010-2011), « Gli avverbi in -mentri negli antichi testi friulani », Archivio per l'Alto Adige 104-105 : 213-239.

Forsgren, Mats (1991), "Éléments pour une typologie de l'apposition en linguistique française ». Dans : Dieter Kremer (éd.), Actes du $18^{e}$ Congrès international de linguistique et de philologie romanes, vol. 2, Tübingen (Niemeyer) : 597-612.

Fortson IV, Benjamin W. (2011), « The historical background to Latin within the Indo-European language family ». Dans : James Clackson (éd.), A companion to the Latin language, Oxford (Wiley-Blackwell) : 199-219.

Fr_A_DHAA, corpus de base du présent dictionnaire, accessible sous http://gams.uni-graz.at/o:aaif. fradhaa.

Fr_A_Web, corpus web du présent dictionnaire, accessible sous http://gams.uni-graz.at/o:aaif. fraweb.

François, Jacques / Mathilde Salles / Véronique Lenepveu (2002), « La catégorisation adjectivale et adverbiale ». Dans : Françoise Cordier / Jacques François (éds.), Catégorisation et langage, Paris (Lavoisier) : 83-105. 
Frantext, https://www.frantext.fr.

Fruyt, Michèle / Sophie van Laer (2008) (éds.), Adverbes et évolution linguistique en latin, Paris (L'Harmattan).

Fuentes Rodríguez, Catalina (2009), Diccionario de conectores y operadores del español, Madrid (Arco Libros).

Furukawa, Naoyo (2006), «Construction absolue, possession inaliénable et cohésion intraphrastique ». Dans : Henning Nølke et al. (éds.), Grammatica, Berne, etc. (Peter Lang) : 85-100.

Galliot, Marcel (1955), Essai sur la langue de la réclame contemporaine, Toulouse (Édouard Privat). Gamillscheg, Ernst (1957), Historische französische Syntax, Tübingen (Niemeyer).

Gasrel, Céline (2012), Les structures sémantiques du paradigme de la quantité dans les syntagmes du type fr. voir grand, thèse de master, Karl-Franzens-Universität Graz. https://unipub.uni-graz. at/download/pdf/222825.

Geckeler, Horst (1971), Zur Wortfelddiskussion. Untersuchungen zur Gliederung des Wortfeldes « alt - jung - neu » im heutigen Französisch, München (Fink).

Gerhalter, Katharina (2020), Paradigmas y polifuncionalidad. Estudio diacrónico de preciso / precisamente, justo / justamente, exacto / exactamente $y$ cabal / cabalmente, Berlin / Boston (De Gruyter).

GGHF (2020) = Marchello-Nizia, Christiane, Bernard Combettes, Sophie Prévost, Tobias Scheer (éds.), Grande grammaire historique du français, 2 vols., Berlin / Boston (De Gruyter).

Giegerich, Heinz (2012), "The morphology of -ly and the categorial status of 'adverbs' in English ", English language and linguistics 16, $3:$ 341-359.

Giraud, J. (1964), «Vrais et faux adjectifs adverbialisés », Le Français dans le monde 29 : 31-32.

Glatigny, Michel (1982), « Remarques sur la formation des adverbes en -ment au seizième siècle ». Dans : Nelly Danjou-Flaux / Marie-Noelle Gary-Prieur (éds.), Adverbes en -ment, manière, discours, Lille (Presses Universitaires de Lille) : 65-90.

Glatigny, Michel (2005), «L'éternel retour des adverbes en -ment $x v \mathrm{l}^{\mathrm{e}}-\mathrm{xx}{ }^{\mathrm{e}}$ siècle ». Dans : Goes (éd.) : 43-67.

Goes, Jan (1999), L'adjectif. Entre nom et verbe, Bruxelles (Duculot).

Goes, Jan (2005) (éd.), L'adverbe : un pervers polymorphe, Arras (Artois Presses Université).

Goes, Jan / Estelle Moline (2010) (éds.), L'adjectif hors de sa catégorie, Arras (Artois Presses Université).

Google Books, https://books.google.fr/ (consulté : v. dans les citations).

Gougenheim, Georges (1938), Système grammatical de la langue française, Paris (D’Artrey).

Gougenheim, Georges (1964), "L'objet interne et les catégories sémantiques des verbes intransitifs ». Dans: Mélanges de linguistique romane et de philologie médiévale, offerts à Maurice Delbouille, vol. 1 : Linguistique romane, Gembloux (Duculot) : 271-285.

Greidanus, Tide (1990), Les constructions verbales du français parlé, Tübingen (Niemeyer). Grevisse, Maurice / André Goosse ( $\left.{ }^{16} 2016\right)$, Le bon usage, Louvain-la-Neuve (De boeck).

Grübl, Klaus (2018), « La storia degli avverbi italiani in -mente : nuove prospettive sull'origine di un paradigma morfologico ». Dans : Martin Becker / Ludwig Fesenmeier (éds.), Configurazioni della serialità linguistica. Prospettive italoromanze, Berlin (Frank et Timme) : 31-48.

Grundt, Lars-Otto (1972), Études sur l'adjectif invarié en français, Bergen, etc. (Universitetsforlaget). Guimier, Claude (1989), "Sur l'adjectif invarié en français », Revue des Langues Romanes 93, 109-120.

Guimier, Claude (1996), Les adverbes du français : le cas des adverbes en -ment, Paris (Ophrys).

Guimier, Claude / Lassâad Oueslati (2006), "Le degré de figement des constructions verbe + adjectif invarié ». Dans : Jacques François / Salih Mejri (éds.), Composition syntaxique et figement lexical, Caen (Université de Caen) :17-37. 
Haas, Joseph (1922), Abriss der französischen Syntax, Halle (Niemeyer) [contient un corpus d'adjectifs-adverbes : 159-163].

Hagège, Claude (1987), Le français et les siècles, Paris (Odile Jacob) 1987.

Håkanson, Lennart (1986), « Adverbs in Latin poetry », Eranos 84 : 23-56.

Heise, Wilhelm (1912), Zur historischen Syntax des adverbial gebrauchten Adjektivs im Französischen, Romanische Forschungen $31:$ 873-1038.

Helfrich, Uta (1993), Neologismen auf dem Prüfstand, Wilhelmsfeld (Gottfried Egert).

Hengeveld, Kees (1992), Non-verbal predication. Theory, typology, diachrony, Berlin / New York (Mouton de Gruyter).

Hengeveld, Kees / Eva van Lier (2010), «An implicational map of parts of speech », Linguistic Discovery 8-1:129-156.

Hengeveld, Kees / Jan Rijkhoff / Anna Siewierska (2004), « Parts-of-speech systems and word order ", Journal of Linguistics $40: 527-570$.

Hödl, Nicola (2004), « fein schneiden - hacher finement - picar finamente. Das deutsche Verbkompositum mit resultativem Adjektiv und seine französischen und spanischen Entsprechungen im Kochrezept », Vox Romanica 63 : 169-189.

Hummel, Martin (1998), «Zur Übersetzung adverbaler Adjektive aus dem Spanischen ins Französische. Mit einem kurzen Blick auf das Italienische und Portugiesische ». Dans : Udo L. Figge / Franz-Josef Klein / Annette Martinez [sic] Moreno (éds.), Grammatische Strukturen und grammatischer Wandel, Bonn (Romanistischer Verlag) : 209-233.

Hummel, Martin (2000), Adverbale und adverbialisierte Adjektive im Spanischen. Konstruktionen des Typs Los niños duermen tranquilos und María corre rápido, Tübingen (Narr).

Hummel, Martin (2002), « Considerações sobre os tipos Ela fala esquisito e Ela chega cansada no português coloquial e literário do Brasil e de Portugal », Confluência 24 : 43-70. http://llp. bibliopolis.info/confluencia/pdf/1345.pdf.

Hummel, Martin (2009), « La expansión de las unidades atributivas a las circunstancias de lugar y de tiempo ». Dans : Montserrat Veyrat Rigat / Enrique Serra Alegre (éds.), La lingüística como reto epistemológico y como acción social, vol. 1, Madrid (Arco Libros) : 463-480.

Hummel, Martin (2012), Polifuncionalidad, polisemia y estrategia retórica. Los signos discursivos con base atributiva entre oralidad y escritura. Acerca de esp. bueno, claro, total, realmente, etc., Berlin / Boston (De Gruyter).

Hummel, Martin (2013a), «Attribution in Romance : reconstructing the oral and written tradition ", Folia linguistica historica 34 : 1-42.

Hummel, Martin (2013b), « La dimensión intercultural de la expansión diacrónica de los adverbios en -mente ». Dans : María Pilar Garcés Gómez (éd.), Los adverbios con función discursiva.

Procesos de formación y evolución, Madrid / Frankfurt (Iberoamericana / Vervuert) : $15-41$.

Hummel, Martin (2013c), « Sincronía y diacronía de los llamados adjetivos adverbializados y de los adverbios en -mente ». Dans : Anuario de letras. Lingüística y filología (Universidad Nacional Autónoma de México) I, $2:$ 215-281.

Hummel, Martin (2014a), "The adjective-adverb interface in Romance and English ». Dans : Petra Sleeman / Freek Van de Velden / Harry Perridon (éds.), Adjectives in Germanic and Romance, Amsterdam / Philadelphia (Benjamins) : 35-71.

Hummel, Martin (2014b), « Adjetivos adverbiales ». Dans : Company Company (éd.) : 615-733.

Hummel, Martin (2015), « Los adverbios flexionados ». Dans : Carmen Galán Rodríguez / María Luisa Montero Curiel / José Carlos Martín Camacho / María Isabel Rodríguez Ponce (éds.), El discurso de la gramática. Estudios ofrecidos a José Manuel González Calvo, Cáceres (Universidad de Extremadura) : 205-233. 
Hummel, Martin (2017a), «L'accord adverbial en français ». Dans : Gaétane Dostie / Federica Diémoz / Pascale Hadermann (éds.), Cadrage sur la variation, le changement lexical et le changement grammatical en français actuel, Revue de sémantique et pragmatique 41-42: 181-205. https://doi.org/10.4000/rsp.484.

Hummel, Martin (2017b), « Existe a concordância adverbial no português brasileiro ? Considerações acerca de vamos diretos, todas contentes, bastantes grandes, muitas boas ». Dans : Mariangela Rios de Oliveira / Maria Maura Cezario (éds.), Funcionalismo linguístico. Diálogos e vertentes, Niterói (Eduff) : 113-140.

Hummel, Martin (2017c), « Adjectives with adverbial functions in Romance ». Dans : Hummel / Valera (éds.) : 13-46. https://doi.org/10.1075/la.242.

Hummel, Martin (2018a), «Éléments d'une diachronie grammaticographique et normative de l'adverbe français accompagnés de trois méthodes pour mesurer l'effet du discours normatif sur l'usage », Romanische Forschungen 130 : 3-35. https://doi. org/10.3196/003581218822496984.

Hummel, Martin (2018b), «Baseline elaboration at the adjective adverb interface », Cognitive Linguistics 29-3 : 407-452. https://doi.org/10.1515/cog-2016-0033.

Hummel, Martin (2018c), « Romance sentence adverbs in -mente : epistemic mitigation in synchrony and diachrony ». Dans : Anna-Maria de Cesare / Ana Albom / Doriana Cimmino / Marta Lupica Spagnolo (éds.), Formal and functional perspectives on sentence adverbials in the Romance languages and beyond, Linguistik online 92, 5 : 111-144. https://doi.org/10.13092/lo.92.4507. Hummel, Martin (2018d), « La structure 'verbe + adjectif'. Parler vrai, dire juste, faire simple et compagnie », Revue Romane : 261-296. https://doi.org/10.1075/rro.16021.hum.

Hummel, Martin (2019a), " The third way : prepositional adverbials in the diachrony of Romance. Part one », Romanische Forschungen 131, 2 : 145-185. https://doi. org/10.3196/003581219826376199.

Hummel, Martin (2019b), «The third way : prepositional adverbials in the diachrony of Romance. Second and last part », Romanische Forschungen 131, 3 : 295-327. https://doi. org/10.3196/003581219827190716.

Hummel, Martin / Adrian Chircu / Jairo Javier García Sánchez / Benjamín García-Hernández / Stefan Koch / David Porcel Bueno / Inka Wissner (2019), «Prepositional adverbials in the diachrony of Romance : a state of the art ॥, Zeitschrift für Romanische Philologie 135, 4 : 1080-1137. https:// doi.org/10.1515/zrp-2019-0062.

Hummel, Martin / Anna Gazdik (2014), «Le Dictionnaire historique de l'adjectif-adverbe : de aimer haut à baiser utile ». Dans : Actes du $4^{e}$ Congrès mondial de linguistique française, Berlin, 19-23 juillet 2014. http://dx.doi.org/10.1051/shsconf/20140801132.

Hummel, Martin / Karin Stiegler (2005), Dictionnaire historique de l'adjectif-adverbe, Banque de données, Graz. https://gams.uni-graz.at/context:aaif.

Hummel, Martin / Kröll, Andrea (2015) : «Vite et vitement. Étude diachronique variationnelle d'une exception », Revue de Linguistique Romane 79 : 39-91.

Hummel, Martin / Salvador Valera (2017) (éds.), Adjective adverb interfaces in Romance, Amsterdam / Philadelphia (John Benjamins). https://doi.org/10.1075/la.242.

Hunnius, Klaus (1975), « Archaische Züge des Langage populaire », Zeitschrift für französische Sprache und Literatur 8, 2, 145-161.

Karlsson, Keith E. (1981), Syntax and affixation. The evolution of MENTE in Latin and Romance, Tübingen (Niemeyer).

Keller, Rudi ( ${ }^{42014), ~ S p r a c h w a n d e l . ~ V o n ~ d e r ~ u n s i c h t b a r e n ~ H a n d ~ i n ~ d e r ~ S p r a c h e, ~ T u ̈ b i n g e n ~(F r a n c k e) . ~}$ Klein, Hans-Wilhelm (éd.) (1968), Die Reichenauer Glossen, Teil 1, München (Hueber).

Kofler, Michaela (2007), Der Gebrauch der Modaladverbien in drei französischsprachigen Romanen von Andreï Makine, Philippe Djian und Alphonse Boudard, mémoire de maîtrise, 
Karl-Franzens-Universität Graz. https://sites.google.com/site/rsgadjadv/resources/work-ofresearch-group.

Krenn, Herwig (1995), Französische Syntax, Berlin (Erich Schmidt).

Küffner, Georg (1906), Das unveränderliche Eigenschaftswort im Französischen, Ludwigshafen

(Baur) [contient un corpus constituté par des lectures contemporaines (littérature, presse) ainsi que des exemples entendus].

La Touche, Pierre de (1973 [= 1696]), L'Art de bien parler françois, 2 vols., Genève (Slatkine reprints).

Lakoff, George / Mark Johnson (1980), Metaphors we live by, Chicago (Chicago University Press).

Le Bidois, Georges / Robert Le Bidois (21967), Syntaxe du français moderne, vol. 2, Paris (Picard).

Le Goffic, Pierre (1993), Grammaire de la phrase française, Paris (Hachette).

Ledgeway, Adam (2009), Grammatica diacronica del napoletano, Tübingen (Niemeyer).

Ledgeway, Adam (2011), "Adverb agreement and split intransitivity : evidence from Southern Italy », Archivio glottologico italiano 96, 31-66.

Ledgeway, Adam (2012), From Latin to Romance. Morphosyntactic typology and change, Oxford (Oxford University Press).

Ledgeway, Adam (2017), « Parameters in Romance adverb agreement ». Dans : Hummel / Valera (éds.) : 47-80. https://doi.org/10.1075/la.242.

Lerch, Eugen (1940), L'échapper belle, Romanische Forschungen 54, 2 : 202-226.

Lewicka, Halina (1960), La langue et le style du théâtre comique français des $x V^{e}$ et $\mathrm{xVI} I^{e}$ siècles. La dérivation, Paris (Klincksieck).

Löfstedt, Bengt (1967), «Bemerkungen zum Adverb im Lateinischen », Indogermanische Forschungen $72:$ :79-109.

Lombard, Alf (1930), Les constructions nominales dans le français moderne, Uppsala / Stockholm (Almqvist et Wiksells).

Ludwig, Ralph (1996), Kreolsprachen zwischen Mündlichkeit und Schriftlichkeit, Tübingen (Narr).

Maas, Utz (2010), « Literat und orat. Grundbegriffe der Analyse geschriebener und gesprochener Sprache ». Dans : idem (éd.), Orat und literat, Grazer Linguistische Studien 73 : 21-150.

Marzo, Daniela (2017), «Quelques observations sur l'hypothèse de la sous-spécification catégorielle : le cas de la conversion dans le langues romanes ». Dans : Alain Lemaréchal et al., Actes du $27^{\circ}$ Congrès international de linguistique et de philologie romanes, Section $1: 71-81$. http://www.atilf.fr/cilpr2013/actes/section-1.html.

McCartney, Eugene (1920), « Forerunners of the Romance adverbial suffix », Classical Philology 15, $3: 213-229$.

Meier, Harri (1948), Adjectivo e advérbio. Dans : idem, Ensaios de filologia românica, Lisboa (Revista de Portugal) : 55-114.

Meyer-Lübke, Wilhelm (1895), Grammaire des langues romanes, vol. 2 : Morphologie, Paris (Welter).

Moignet, Gérard (1961), L'adverbe dans la locution verbale, Québec (Presses de l’Université Laval). Moignet, Gérard (1963), "L'incidence de l'adverbe et l'adverbialisation des adjectifs », Travaux de linguistique et de littérature 1 : 175-194.

Moignet, Gérard (1981), Systématique de la langue française, 2 vols., Paris (Klincksieck).

Moline, Estelle (2010), « Les emplois dits adverbiaux de bon ». Dans : Goes / Moline (éds.) : 203-222.

Molinier, Christian (1985), « Remarques sur une sous-classe d'adverbes en -ment orientés vers le sujet et leurs adjectifs sources », Linguisticæ Investigationes 9 : 321-341.

Molinier, Christian / Françoise Levrier (2000), Grammaire des adverbes. Description des formes en -ment, Genève (Droz).

Mougeon, Raymond / Édouart Beniak (éds.) (1994), Les origines du français québécois, Sainte-Foy (Les Presses de l'Université Laval). 
Moussy, Claude (1998), « Les emplois de iugis et de iugiter dans la latinité tardive ». Dans : Louis Callebat (éd.), Latin vulgaire - latin tardifIV, Hildesheim, etc. (Olms-Weidmann) : 237-249.

Müller, Carl Friedrich Wilhelm (1908), Syntax des Nominativs und Akkusativs im Lateinischen, Leipzig / Berlin (Teubner).

Muller, Claude (2000), « Les constructions à adjectif attribut de l'objet, entre prédication seconde et complémentation verbale », Langue française $127: 21-35$.

Neumann-Holzschuh, Ingrid / Julia Mitko (2018), Grammaire comparée des français d'Acadie et de Louisiane (GraCoFAL), Berlin / Boston (De Gruyter) [contient un corpus d'adjectifs-adverbes : 758-765].

Neumann-Holzschuh, Ingrid / Julia Mitko (2019), "Tout le monde parle différent mais on se comprend pareil : le rôle de l'adjectif-adverbe dans le français nord-américain ». Dans : Andreas Dufter / Klaus Grübl / Thomas Scharinger (éds.), Des parlers d'oïl à la francophonie, Berlin / Boston (De Gruyter) : 231-270 [contient un corpus d'adjectifs-adverbes : 245-253].

Neveu, Franck (éd.) (2000), Nouvelles recherches sur l'apposition, Langue française 125.

Nilsson-Ehle, Hans (1941), Les adverbes en -ment compléments d'un verbe en français moderne, Lund / Copenhague (Gleerup / Munksgaard).

Noailly, Michèle (1994), «Adjectif adverbal et transitivité », Cahiers de Grammaire 19 : 103-114 [contient un corpus d'adjectifs-adverbes].

Noailly, Michèle (1997a), « Les nouveaux adjectifs adverbaux du français ». Dans : Olli Välikangas / Juhani Härmä (éds.), Où va le français ?, Amsterdam (de Werelt) : 91-98 [contient un corpus d'adjectifs-adverbes].

Noailly, Michèle (1997b), " Les traces de l'actant objet dans l'emploi absolu », Travaux de linguistique 34 : 39-47.

Noailly, Michèle (1999), L'adjectif en français, Paris (Ophrys) [contient un corpus d'adjectifsadverbes : 148-150].

Noailly, Michèle (2010), «L'adjectif, quand il est invariable, sort-il pour autant de sa catégorie ? ». Dans : Goes / Moline (éds.) : 189-202.

Nøjgaard, Morten (1992/1995), Les adverbes français, 3 vols., Copenhague (Munksgaard).

Nyrop, Christopher (41979 [= 1914-1960]), Grammaire historique de la langue française, vol. 5 : Syntaxe. Noms et pronoms, Genève (Slatkine reprints) [contient un corpus d'adjectifs-adverbes : $142-151]$.

Olsson, Kerstin (1976), La construction verbe + objet direct + complément prédicatif en français, thèse de doctorat, Stockholm (Université de Stockholm).

Oueslati, Lassâad (2018), "L'interprétation des unités phraséologiques entre combinatoire interne et emploi co-textuel : le cas des unités polylexicales ", Lublin studies in modern languages and literature 42-4:60-80.

Pautex, B., Errata du Dictionnaire de l'Académie française, Paris (Hachette, etc.) 1862.

Pichon, Édouard (1939), « La vitalité de la suffixation », Le français moderne $7: 7-14$.

Pinkster, Harm (1972), On Latin adverbs, Amsterdam / London (North-Holland).

Plattner, Philipp (1905), Das Nomen und der Gebrauch des Artikels in der französischen Sprache, Karlsruhe (Bielefelds).

Plattner, Philipp (1907), Präpositionen und Adverbien, Freiburg (Bielefelds) [contient un corpus d'adjectifs-adverbes : 90-95].

Poccetti, Paolo (2008), « Convergences et divergences entre les langues de l'Italie ancienne dans l'expression des adverbes ». Dans : Fruyt / Van Laer (éds.) : 27-46.

Porcel Bueno, David (à paraître), «El latín tardío y la formación de adverbios preposicionales $(P+X)$ en los orígenes de las lenguas ibero-románicas». 
Queirazza, Gasca G. (1970), « Note storiche sulla formazione del tipo avverbiale latino-volgare AGG. + -mente ». Dans : Actes du xII ${ }^{e}$ Congrès International de Linguistique et de Philologie Romanes, vol. 1, Bucarest (Editura Academiei Republicii Socialiste România) : 109-113.

Radouant, René (1922), Grammaire française, Paris (Hachette).

Rainer, Franz (1985), «Adjektiv-Adverbien im français populaire ». Dans : Wilfried Kürschner / Rüdiger Vogt (éds.), Sprachtheorie, Pragmatik, Interdisziplinäres, Tübingen (Niemeyer) : 83-94.

Ramat, Paolo (2008), « Les adverbes latins du point de vue de l'indo-européen ». Dans : Fruyt / Van Laer (éds.) : 13-24.

Regula, Moritz (1957), « Das Adjektivneutrum als Prädikatsbestimmung », Zeitschrift für französische Sprache und Literatur 67 : 221-232.

Ricca, Davide (1998), « La morfologia avverbiale tra flessione e derivazione ». Dans : Giuliano Bernini / Pierluigi Cuzzolin / Piera Molinelli (éds.), Ars linguistica. Studi offerti da colleghi ed allievi a Paolo Ramat in occasione del suo $60^{\circ}$ compleanno, Roma (Bulzoni) : 447-466.

Ricca, Davide (2010), «Adverbs ». Dans : Philip Baldi / Pierluigi Cuzzolin (éds.), New perspectives on historical Latin syntax, vol. 2 : Constituent syntax : adverbial phrases, adverbs, mood, tense, Berlin / New York (De Gruyter) : 109-191.

Riegel, Martin / Jean-Christophe Pellat / René Rioul (72018), Grammaire méthodique du français, Paris (Presses Universitaires de France).

Robert, C.-M. (1886), Questions de grammaire et de langue françaises, Amsterdam (Brinkman) [contient un corpus d'adjectifs-adverbes : 113-120].

Rohlfs, Gerhard (1969), Grammatica storica della lingua italiana e dei suoi dialetti, vol. 3 : Sintassi e formazione delle parole, Torino (Enaudi).

Ruge, Hans (21997), Grammatik des Neugriechischen, Köln (Romiosini).

Salazar García, Ventura (2007), « Flexibilidad categorial y adverbios de manera en español : un enfoque funcional ». Dans : Pedro Barros García / Gonzalo Águila Escobar / Esteban Tomás Montoro del Arco (éds.), Estudios lingüísticos, literarios e históricos. Homenaje a Juan Martínez Marín, Granada (Universidad de Granada) : 309-326.

Sandmann, Manfred (1942), « Remarques sur la genèse d'adjectifs en fonction d'adverbes ", Revue de linguistique romane $14: 257-278$.

Sandmann, Manfred (1946), « On neuter adjectives determining verbs with special reference to French and Spanish ", The Modern language review $41: 24-34$.

Satorre Grau, Franciso Javier (2005), «El adjetivo adjunto del adverbio ». Dans : Filología y lingüística. Estudios ofrecidos a Antonio Quilis, vol. 1, Madrid (CSIC / UNED / Universidad de Valladolid) : 629-638.

Sechehaye, Albert (1950 [= 1926]), Essai sur la structure logique de la phrase, Paris (Champion). Shorey, Paul (1910), "A Greek analogue of the Romance adverb », Classical philology 5 : 83-96.

Silvestri, Giuseppina (2017), «Adverb agreement in the dialects of the Lausberg Area ». Dans : Hummel / Valera (éds.) : 173-204. https://doi.org/10.1075/la.242.

Solari Jarque, Enrique Nicolás (en préparation), Las formaciones adverbiales con preposición y adjetivo (tipos de pleno, in serium) en Latín, thèse de doctorat, Universidad de Alcalá de Henares.

Söll, Ludwig ( ${ }^{31985), ~ G e s p r o c h e n e s ~ u n d ~ g e s c h r i e b e n e s ~ F r a n z o ̈ s i s c h, ~ B e r l i n ~(E r i c h ~ S c h m i d t) . ~}$

Spitzer, Leo (1930), « Frz. voter socialiste », Neuphilologische Mitteilungen 39 : 73-81.

Stephan-Gabinel, Nicole (2001), «Bronzer catho », Lebende Sprachen 3 : 121-122.

Swiggers, Pierre / Alfons Wouters (2002), «De adverbio : statut et significations de l'adverbe chez les grammairiens latins ». Dans : idem (éds.), Grammatical theory and philosophy of language in Antiquity, Leuven, etc. (Peeters) : 287-323.

Tagliamonte, Sali / Rika Ito (2002), «Think really different : Continuity and specialization in the English dual form adverbs », Journal of sociolinguistics 6, 2: 236-266. 
Taylor, John R. (2012), The mental corpus, Oxford (Oxford University Press).

Tesnière, Lucien (1988 [=21966]), Éléments de syntaxe structurale, Paris (Klincksieck).

Thompson, Sandra A. / Anthony Mulac (1991), « A quantitative perspective on the grammaticization of epistemic parentheticals in English ». Dans : Elizabeth C. Traugott / Bernd Heine (éds.), Approaches to grammaticalization, vol. 2 : Focus on types of grammatical markers, Amsterdam / Philadelphia (Benjamins) : 313-329.

Tobler, Adolf (21902), «Adjectiva kongruierend in Verbindung mit Participien oder Adjektiven ». Dans : idem, Vermischte Beiträge zur französischen Grammatik, erste Reihe, Leipzig (Hirzel) : 75-88 [contient un corpus d'adjectifs-adverbes].

Tobler, Adolf (21912), Vermischte Beiträge zur französischen Grammatik, vol. 5, Leipzig (Hirzel) 1912.

Tobler, Adolf / Erhard Lommatzsch (1925-2002), Altfranzösisches Wörterbuch, 11 vols., plusieurs lieux et éditeurs.

Togeby, Knud (1982), Grammaire française, vol. 1 : Le nom, Copenhague (Akademisk Forlag) [contient un corpus d'adjectifs-adverbes : 235-260].

Troberg, Michelle / Heather Burnett (2014), « Le prédicat résultatif adjectival en français médiéval », Lingvisticae Investigationes 37, $1: 152-176$.

Van Goethem, Kristel (2010), «The French construction nouveau + past participle revisited : arguments in favour of a prefixoid analysis of nouveau », Folia linguistica 44, 1: 163-178.

Van Peteghem, Marleen (2010), "Quand l'adjectif seul se comporte comme un adverbe ». Dans : Goes / Moline (éds.) : 245-263.

Van Raemdonck, Dan (2005), « L'adverbe, adjectif ou verbe ? Ré-partition des rôles ». Dans : Goes (éd.) : 23-42.

Van Raemdonck, Dan (2017), «Are intrapredicative adjectives adverbs ? ». Dans : Hummel / Valera (éds.) : 141-170. https://doi.org/10.1075/la.242.

Vaugelas, Claude Favre de (1880 [= 1647]), Remarques sur la langue françoise, édition critique par A. Chassang, 2 vols., Versailles / Paris (Cerf / Baudry).

Wiesmath, Raphaële (2006), Le français acadien. Analyse syntaxique d'un corpus oral recueilli au Nouveau-Brunswick / Canada, Paris (L'Harmattan).

Wilmet, Marc (1997), «L'apposition : une fonction à réestimer ». Dans : Georges Kleiber / Martin Riegel (éds.), Les formes du sens, Bruxelles (Duculot) : 413-422.

Wilmet, Marc (1998), « Exposé final : adverbes, adverbiaux et circonstanciels », Cahiers de l'Institut de linguistique de Louvain $24: 29-38$.

Wilmet, Marc (52010), Grammaire critique du français, Louvain-la-Neuve (De boeck).

Zauner, Adolf (1926), Romanische Sprachwissenschaft, vol. 2 : Wortlehre II und Syntax, Berlin / Leipzig (De Gruyter).

Zribi-Hertz, Anne (2015), « De l'évolution des propriétés du mot grave en français européen moderne ». Dans: Gaétane Dostie / Pascale Hadermann (éds.), La dia-variation en français actuel, Berne, etc. (Peter Lang) : 63-98. 
III Le dictionnaire 


\section{Abaisser bas}

I. Abaisser à une faible hauteur, en direction du sol

Pronominal

1455 Et veritablement, je cuiday de prime face que ce fussent gouttes de cire et y mis la main pour les touchier et puis me abaissay bas pour veoir contre le jour et me sembla que c'estoient gouttes d'eaue engelées. C'est une chose que plusieurs gens ont vue (Bertrandon de la Broquière, Le Voyage d'outremer)

1949 Les yeux s'ouvrent sous la mousse Et les pieds écrasent parfois les paupières Alors les rideaux s'abaissent encore plus bas

La tête tourne et se cache dans le creux des bras

Et les souvenirs s'émeuvent

La nuit qui s'en va

(Pierre Reverdy, Main-d'œuvre)

Transitif

1848 Il en coûterait d'abaisser les regards si bas après les avoir élevés si haut (François de Chateaubriand, Mémoires d'outre-tombe)

II. Dévaloriser, humilier profondément, mettre dans une position très inférieure Pronominal

1637 Daphnis est fort aimable, et si Florame l'aime

Est-ce à dire pourtant qu'il soit aimé de même?

Florame avec raison adore tant d'appas, Et Daphnis sans raison s'abaisserait trop bas,

Ce feu, si juste en l'un, en l'autre inexcusable,

Rendrait l'un glorieux et l'autre méprisable.

Simple, l'amour peut-il écouter la raison ? (Pierre Corneille, La Suivante)

1849 S'il faut que mes yeux soient tentés, que mes pieds trébuchent, que ma croyance défaille, ah ! que je sois plutôt comme les aveugles qui tâtonnent les murs, comme les paralytiques qui se traînent sur le ventre, et comme les pauvres idiots qui n'ont pas le sens de manger. Je m'humilierai de toutes mes forces, je mabaisserai plus bas que la boue, plus bas que les fourmis et que les vers de terre. Toi seul es haut ! Je ne cherche pas à te trouver, mais à t’aimer ! (Gustave Flaubert, La Tentation de saint Antoine)

Transitif

1766 Si le corps humain est, comme on l'enseigne au peuple, d'une nature au-dessus de celle des brutes, parce qu'il est la coque ou l'enveloppe qui renferme une âme immortelle, laquelle abandonne le corps à la mort, ce corps abandonné n’a donc plus rien en soi qui nous porte à le respecter davantage que celui d'un bœuf, d'un mouton, d'un cochon, dont nous mangeons tous les jours : au contraire, si l'homme est en tout semblable aux brutes, pourquoi avoir d'autres sentiments, d'autres égards pour son cadavre que pour celui de ces dernières ? Nous sommes bien orgueilleux de nous élever si haut, ou bien injustes de les abaisser si bas. Le respect que l'on a pour un corps mort, et qui empêche de le manger, est donc ridicule et mal fondé (Henri-Joseph Dulaurens, Le Compère Mathieu)

\section{CORPUS WEB :}

Je mabaisse bas vers le sol, inclinant ma tête en révérence [https://www.fanfiction.net/s/ 1289699/3/Szajha] (24.4.2016)

Non sérieusement arrête tu fais pitié tu t'abaisse bas la sérieux [https://fr-fr.facebook. com/pages/Chez-Micha\%C3\%ABl/134272629 983326] (24.4.2016)

Une table articulée, qui monte et descend, position fauteuil etc. Une vraie révolution qui permettra à bon nombre de personnes en situation de handicap de pouvoir enfin être auscultées chez leur médecin ; de pouvoir s'installer comme il faut vu que la table s'abaisse bas et minimisant les manipulations grâce aux diverses articulations [http://dd44.blogs.apf. asso.fr/archive/2014/10/23/billet-d-humeur-demmanuelle-betty.html] (24.4.2016)

REMARQues : Bas est un adjectif-adverbe de lieu qui peut indiquer la direction, partant d'un ni- 
veau supérieur vers un niveau inférieur, au sens concret ainsi qu'au sens figuré. En tant que circonstant de lieu, il souligne l'action de faire descendre une chose à un niveau inférieur, plus bas (I). Du point de vue moral ou social (II), il s'emploie pour désigner l'état de soumission d'une personne, le fait de se plier aux exigences ou à la volonté d'une tierce personne, s'avilir. Dans le contexte amoureux, il souligne le fait de se dévouer entièrement à l'autre, l'idée de sacrifice. Outre le fait de désigner le sens d'un mouvement, bas a très souvent une connotation négative et traduit l'idée de médiocrité, d'infériorité et peut aussi souligner un sentiment de gêne ou de honte. Il reste invariable (ex. de 1637 et le troisième exemple du $\mathrm{CW}$ ) et est modifié par si, trop, plus. Il s'oppose à élever haut (ex. de 1848). VoIR AUSSI : descendre bas, élever haut

\section{Abandonner net \\ Abandonner ou cesser brusquement et complètement \\ Transitif \\ 1758 vous vous croyez en droit d'abandonner net un pauvre Suisse (Voltaire, [Lettre] / Pièces inédites)}

1876 Quoique ce ne fût qu'un vieux numéro, fort endommagé par de laborieux services, Jane y prit subitement intérêt. Elle abandonna net ses derniers apprêts et se mit à chercher dans la feuille froissée... quoi donc? (Claire de Chandeneux, Les Deux Femmes du major)

1982 En règle générale, lorsque le sportif de haute compétition se " reconvertit ", comme l'on dit, il abandonne net son activité physique antérieure (Le Débat)

\section{Abattre menu}

Anéantir, réduire, écraser en petits morceaux Transitif

1552 Les Andouilles soudain apperceurent ce nouveau renfort, et se mirent en fuite le grand gallot, comme s'elles eussent veu tous les diables. Frere Jean à coups de bedaines les abbatoit menu comme mousches : ses soubdars ne se y espargnoient mie (François Rabelais, Le Quart Livre)
REMARQUES : Suite au préfixe $a$-, abattre crée une sémantique résultative où menu désigne l'état final de l'objet de l'action. Abattre menu se dit ainsi d'une action violente, voire cruelle, où le sujet fait tomber à l'aide d'une arme un être animé. Menu reste invariable. Abattre menu est devenu un archaïsme. VoIR AUSSI : hacher menu

\section{Abattre mort}

Tuer, mettre à mort

Transitif

1100 L'escut li freint e l'osberc li desclot, Trenchet le piz, si li briset les os, Tute l'eschine li desevret del dos, Od sun espiet l'anme li getet fors, Enpeint le ben, fait li brandir le cors, Pleine sa hanste del cheval l'abat mort, En dous meitiez li ad briset le col (Chanson de Roland, 1204)

-1200 Ou cors li mit la lance, qui qu'an plort ne qui rie ;

Tant soué l'abait mor qu'i ne brait ne ne crie (Floovant [fin XII ${ }^{\mathrm{e}}$, 286)

$\sim 1460 \mathrm{ilz}$ se mirent a une fenestre. Sy n'y eurent guieres esté, quant Patroclus le bon archier descocha sa saiette sus la dame si droit qu'il lui en percha la gorge et morte l'abaty au prez de Jason, et puis il s'en issy de son embuche moult joyeux. Trop fu troublé Jason quant il vey sa dame ainsy trebuchier morte. Il la cuida relever, mais l'ame lui party du cors (Raoul Lefèvre, L'Histoire de Jason, p. 238, 15)

1515 Toutesfois à quelque peine le bouterent sur une charette pour l'emmener au Wassieulx, et quant se vint au descendre à la vallée du Wassieulx, de peure que ledit cheval ne tomba, le corche cheval mist la main darier affin qu'il ne versaist, mais par coup de fortune la corde, qui ne valloit guiere, de quoy estoient liez les piedz dudit cheval rompit, et ad cause qu'il estoit enflez, comme dit est, ses jambes ce estandirent et se remisrent en leur propre lieu, aussi ad cause du hochement de la charette, et tellement regecta ledit cheval qu'il donna proprement ung sy grant coup du fer du pied de darier contre la tente de 
la teste du corche cheval qu'i l'abatist tout royd mort. Et cecy fut vray, car plus de cent personne le veirent; et ainsi donques le cheval mort tua ung homme, dont chascun en estoit esbahis (Philippe de Vigneulles, Les Cent Nouvelles nouvelles, p. 233, 112)

1824 Le sire de Rieux, maréchal de Bretagne, arriva à la tête de sept cents lances. Les Anglais furent vivement assaillis, et le sire Tanneguy-Duchâtel abattit mort, d'un coup de sa puissante hache d'armes, le comte de Beaumont, leur capitaine. Cet avantage ne servit en rien à l'entreprise du comte de la Marche (Prosper de Barante, Histoire des ducs de Bourgogne de la maison de Valois)

1923 Merville et Phénor retrouvent enfin Néala, juste au moment où un brutal l'abat morte à ses pieds. Phénor expire ; l'affreux trépas de Néala a été pour lui le coup de grâce, et pour nous un soulagement (Servais Étienne, Les Sources de «Bug-Jargal»)

1966 Le lendemain, pendant la cérémonie, Helyanor trouve devant l'église quatre chevaliers qui, par jeu, joutent et le provoquent ; il abat morts les deux premiers, les autres se retirent ; il part ensuite s'embusquer dans les bois (Roger Lathuillère, Guiron le courtois)

Pronominal

2000 Justiciable,

pour

pesanteur

d'

offense,

elle

s'abat morte

et

vive

contre

terre (Jacqueline Frédéric Frié, Transparences)

\section{CORPus WeB :}

Tandis que l'on célèbre le Jubilé de la Reine Victoria à coups de feu d'artifices dans les rues de Toronto, Amos Robinson, boxeur ayant refusé au cours d'un match décisif, est abattu mort par balle dans sa chambre d'hôtel [http://theavengers.fr/index.php/hors-serie/ annees-2000/les-enquetes-de-murdoch-2008/ les-enquetes-de-murdoch-saison-1] (24.2.2016)

Et lorsqu'il la retira, le monstre s'abattit, mort, tel la Tour de garde Impératrice que les Vartallensis détruisirent lors de la Bataille des Chemins de givre [https://www.fictionpress. com/s/2303950/9/Darven] (24.2.2016)

Le premier réflexe du jeune homme fut de tirer une salve de trois rayons sur sa cible qui s'abattit mort sur le sol [http://board.fr.ogame. gameforge.com/board98-les-archives-du-forum/ board423-les-archives-la-vie-des-univers/ board404-archives-hall-of-fame/901134-martymacfly-elites-vs-booba74-k-o-cdr-78m] (24.2.2016)

Sans réponses tu m'as laissée abattue morte dans mon être [http://creapoemes.com/ index.php?threads/ma-pri\%C3\%A8re.97024] (24.2.2016)

REMARques : Avec le verbe abattre, mort devient un adjectif-adverbe résultatif. L'accord est la règle. On pourrait donc classer les exemples comme prédication seconde, mais dans le troisième exemple du CW il reste invarié malgré le sujet grammatical féminin. Il semble qu'abattre mort ait acquis, du moins partiellement, un statut de verbe complexe qui intègre l'adjectifadverbe. Dans l'exemple de 1515, mort est modifié par tout raide. Raide mort est devenu une collocation lexicalisée toujours en usage. Raide y occupe une fonction de modifieur de l'adjectif mort. On observe donc la combinaison de trois adjectifs où les premiers modifient les suivants. Dans l'exemple de -1200, l'adjectif-adverbe soué (soef) est antéposé à la construction résultative abattre mort, ce qui confirme la lexicalisation de celui-ci comme verbe complexe. Notons l'emploi de décocher droit et trébucher mort (ex. de -1460).

\section{Abattre plat}

Étaler quelqu'un, le faire tomber à terre de tout son long

Transitif

+1250 Quant Ysengrin vit l'uis overt, Et li vilein felun cuvert

A cuinnies et a macues Vienent corant parmi les rues, Entre la porte et le vilein 
Fet Ysengrin nn [sic] saut a plein.

Si fort le horte qu'il l'abat

En une fange trestot plat (Le Roman de

Renart [ $2^{\mathrm{e}}$ moitié XIII $\left.{ }^{\mathrm{e}}\right]$, Ib, 2588)

1403 C'est d'aventure, se monter

On les voit hault, car pou on prise

Sagece et grant science apprise,

Et verité, qui nul ne flate,

Que tricherie abat jus plate.

Toutefoiz, pouons nous veoir

De ceulx, que Dieu souffri seoir

Hault en ce siecle, qu'ilz estoient

Gouvernez par ceulx qui savoient

Et ou sapience manoit (Christine de Pisan,

Le Livre de la mutacion de fortune, II, 5088)

REMARQUES : Avec le verbe abattre, plat devient un adjectif-adverbe résultatif qui désigne ici l'état final de la cible. Dans l'exemple de 1403, l'adjectif-adverbe est accordé avec l'objet direct féminin antéposé (vérité). Plat est modifié par trestot, dans l'exemple de +1250 .

\section{Abattre seri}

Faire tomber sans faire de bruit

$\pi$ abattre soef

\section{Abattre soef}

Faire tomber en douceur, délicatement, avec soin Transitif

+1150 Puis m'en eistrai en sus demie liue large,

Si me verrez lancier, se vos en prenez guarde,

Tres qu'al piet de la tor, et l'un denier abatre

Si soëf et serit, ja nes movrat li altre

(Pèlerinage ou Voyage de Charlemagne à

Jérusalem et à Constantinople [2 $2^{\mathrm{e}}$ moitié $\left.\left.\mathrm{XII}{ }^{\mathrm{e}}\right], 611\right)$

REMARQues : Soef est un adjectif-adverbe de manière qui caractérise ici l'action de provoquer la chute d'un être animé ou inanimé, tout en montrant un certain égard envers l'objet qui subit l'action. Il est coordonné avec l'adjectif-adverbe seri 'sans faire de bruit' qui vient compléter et renforcer le sémantisme de soef.

\author{
Aboyer aigu \\ Émettre un cri de haute fréquence (en parlant \\ du chien) \\ $\pi$ aboyer grave
}

\author{
Aboyer enroué \\ Aboyer en émettant un son rauque (en parlant \\ du chien) \\ $\lambda$ aboyer grave
}

\section{Aboyer grave}

Émettre un cri de basse fréquence (en parlant du chien)

Intransitif

1946 c'était bibi tenant en laisse une cinquantaine de chiens de toutes races, de tous poils, de toutes tailles, et qui sautaient, et qui jappaient autour de moi et aboyaient à qui mieux mieux, en majeur et en mineur, grave, enroué et aigu (Blaise Cendrars, L'Homme foudroyé. La Main coupée)

CORPus Web :

Voyou se mit à aboyer grave, un aboiement de joie [http://alzheimer-maman-et-moi.overblog.com/article-18665348.html] (24.4.2016)

En revanche, ma chienne de 2 ans devient complètement hystérique, saute sur la boite aux lettres et aboie grave et agressivement quand la voiture arrive [http://nosamisleschiens.fr/lefacteur-et-le-chien] (24.4.2016)

Tous les caniches ke j'ai connus aboyaient grave !!! [http://bebes.aufeminin.com/forum/ les-bibous-de-mai-2001-sont-pas-au-top-de-leurforme-fd133569-p5] (24.4.2016)

REMARQUES : Aboyer s'insère ainsi dans le groupe des verbes du type parler, chanter, etc. qui admettent une série ouverte de modifieurs indiquant une propriété de la voix. Grave est un adjectif-adverbe de manière qui se dit d'un glapissement, hurlement, dont les tons sont bas et graves. Dans l'exemple de 1946, grave apparaît coordonné avec deux autres adjectif-adverbes : enroué, et aigu, qui intensifient ou précisent l'action. Les trois adjectifs-adverbes restent invariables (ex. de 1946 et le troisième exemple du $\mathrm{CW}$ ). Dans le $\mathrm{CW}$, grave est employé comme intensifieur au sens de 'fortement', comme dans l'emploi en vogue grave belle. Notons la coordination avec agressivement dans le second exemple du CW. 


\section{Absorber entier}

Absorber complètement

入 absorber net

\section{Absorber net}

Faire disparaître d'une manière brutale, tout d'un coup

Transitif

1853 GEORGE. Alors, la loi française, Qui souffre un mauvais acte, est une loi mauvaise. (Il se lève)

LE NOTAIRE. Vous pouvez accepter, monsieur ; mais l'héritier

Se charge, en acceptant, du passif tout entier ;

Et six cent mille francs, payés pour votre père,

Absorberont, tout net, la dot de votre mère. Vous serez, d'un seul coup, un homme ruiné. - Cela vaut examen

(François Ponsard, L'Honneur et l'argent)

CORPUS WEB :

Le champ protecteur éclata et absorba net, pile au bon moment, le sortilège de désarmement [https://www.fanfiction.net/s/9644889/17/ Sigma] (24.4.2016)

Je ne lui laissai pas le temps de protester ; mon anus dilaté absorba net son érection renaissante [http://www.gai-eros.org/w/index.php/ La_mante_religieuse] (24.4.2016)

Elle nu pas le temps de penser à autre chose car une lumière aveuglante l'absorba net et elle se sentit dans une extase puis plus rien [http:// hakanahane.skyrock.com/2445782293-Chapitre-1Tome-1.html] (24.4.2016)

Ses jambes la propulsent dans la première salle de l'exposition. Très vite le choc est là : face à elle chaque écran l'absorbe nette et entière, chaque vitrine aspire son œil, par quoi commencer? Ses pieds l'emportent dans un dédale de pas ryhtmés par les battements de cils de ses yeux dilatés [http://www.clothetome.com/Variationssur-le-fil-de-la-mode_a136.html] (13.11.2013)

REMARQues : Dans l'exemple de 1853, absorber net désigne l'action de dévorer, engloutir, épuiser une certaine somme d'argent. L'action se fait de façon brutale et sans détour, de manière crue. Tout net apparaît détaché du verbe, sans doute par souci stylistique, voire de correction linguistique, la langue parlée n'employant pas de pauses, normalement. Les trois premiers exemples du CW mettent en évidence la grande variété de ce qui peut être absorbé. L'adjectif-adverbe net a une valeur intensive qui peut être renforcée par le modifieur tout, et lorsqu'il est renforcé par tout, prenant le sens de catégoriquement. Il est invariable dans la plupart des cas, mais le dernier exemple du CW montre une variante d'interprétation comme prédicat second accordé. Celui-ci est coordonné avec entière, où le féminin est marqué phonétiquement. On ne saurait donc attribuer l'écriture absorber nette à un simple effet phonétique sur la graphie qui serait dû à la prononciation audible du - $t$ au masculin net.

\section{Accélérer fort}

Appuyer à fond sur l'accélérateur

$\pi$ emmener droit

\section{Accélérer lent}

Accélérer lentement

入 tirer fort

\section{Accepter ferme}

Accepter quelque chose d'une manière définitive, en s'en tenant aux conditions fixées $\lambda$ acheter / prendre / vendre ferme

\section{Accoler étroit}

Serrer (quelqu'un) étroitement dans ses bras Transitif

1160 Li enfant doucement dormoient, estroit acolé se tenoient ; [variante : estroit entracole s estoient, p. 114] bouce à bouce ert cascuns dormans (Flore et Blancheflor, 2626)

-1200 Mont fut granz li eschac que Frans ont conquesté.

Floovanz s’an repaire à Loon la cité. Sa mere vai ancontre, estroit l'ai escolé, Doucemant lou baisai, puis aprés lou barné (Floovant [fin XII ${ }^{\mathrm{e}}$, 2520)

+1200 Il se descharge de la somme,

Si la presente a la bourjoise ;

Et cele, a cui gaires n'en poise, 
L'acole et baise mout estroit

(Le Sacristain [XIII $], 240)$

1275 Lors le deit estreit acoler

Et baisier, pour meauz afoler (Jehan de

Meun, Roman de la rose [1269-1278], 13693)

1285 Mout volontiers le gant baisast, Ce sachiez, se baisier l'osast ; Mais bien savoit c'on li torroit, Se devant la gent le baisoit. Souz sa chemise l'ot bouté, Estroit le tenoit acolé ; Perdre nel vorroit a nul fuer, Pour ce l'ot mis contre son cuer (Adenet le Roi, Cleomadés, 6048)

Pronominal

-1300 Helissanz de Coloigne tint Berart par le doit,

Sor le jon et sor l'erbe s'assïent por le froit, Doucement s'antrebaisent et acolent estroit (Jehan Bodel, La Chanson des Saisnes [fin $\left.\mathrm{XIII}^{\mathrm{e}}\right]$, 2618)

1450 Et souvent s'entre respondoient et s'entre disoient de telles gracieuses parolles. Et tousjours s'entre acolloient estroit de plus fort en plus fort (Roman de Troilus et Cressida, p. 182)

REMARques : Accoler étroit désigne l'action de prendre quelqu'un dans ses bras en posant les mains autour du cou ou sur les épaules et en appuyant les joues l'une contre l'autre. L'adjectif étroit, employé ici adverbialement, renforce l'idée d'intimité et peut avoir un caractère érotique. Étroit reste invariable (ex. de -1200) et peut être librement antéposé ou postposé au verbe. Il est modifié avec moult. Dans l'exemple de 1450, accoler étroit est intensifié par de plus en plus fort. Vieilli aujourd'hui. Notons l'emploi de baiser étroit et s'entrebaiser étroit.

\section{Accompagner épais}

Protéger une personne d'une manière dense et rapprochée

Transitif

1573 HIPPOLYTE. Il ne se couvre point le chef ambicieux

D'un bastiment doré qui menace les cieux Il n'a mille valets, qui d'une pompe fiere
L'accompagnent espois et devant et derriere (Robert Garnier, Hippolyte)

REMARQUES : L'adjectif-adverbe de manière espois désigne ici l'action de protéger une personne de façon dense et compacte, ici pour montrer la richesse et la magnificence du maître. Vieilli aujourd'hui, il traduit la densité, le nombre élevé de personnes entourant un être animé, souligne aussi un aspect massif, voire étouffant. Espois traduit également la proximité entre le maître et les valets et met ainsi en valeur l'intention, la démarche protectrice de l'accompagnateur. Les deux adverbes de lieu qui accompagnent épais viennent souligner et renforcer l'aspect de densité et insistent sur le rapprochement entre les êtres, le côté serré et fermé.

\section{Accourir droit}

Venir en hâte, directement vers quelqu'un/

quelque chose

Intransitif

1160 Tarcons, uns Troïens,

Les voit, cele part vet poignant tot droit.

[variante : acorant droit, II, p. 186]

Il lor comança a huchier :

Ou fuiez vos, malvés guerrier?

(Eneas, 7062)

+1350 Quant a la porte vint, s’a veü .iij. serjans, Qui estoient monté sur .iij. chevaus courans ;

Quant li uns des .iij. fu le cheval percevans, Qui tout droit au chastel s'en estoit acourans,

Au devant est venus comme foudre volans (Brun de la Montaigne [2 moitié $\mathrm{XIV}^{\mathrm{e}}$, 3343)

1532 Ainsi, dist Panurge [...] : Ha pauvres pulces, ha, pauvres souris, vous aurez mauvais hyver, le feu est vostre paillier, sortirent plus de six, voire plus de treize cens et unze chiens, gros et menus tous ensemble, de la ville, fuyant le feu. De premiere venue accoururent droit à moy, sentant l'odeur de ma paillarde chair demy routie, et m'eussent devoré à l'heure, si mon bon ange ne m'eust bien inspiré, me enseignant un remede bien oportun contre le mal des dens (François Rabelais, Pantagruel) 
1863 Enfin accourut droit à moi un ancien aide de camp du duc d'Orléans qui se trouvait alors tout naturellement aide de camp du roi sans le moindre effort (Alfred de Vigny, Mémoires inédits)

1895 Ma Myrto, représente-toi ce qu'eût été ta vie si, au lieu de poser sur tous les hommes d'Arles, puis sur les deux cœurs qui te trompèrent également, elle était accourue droit à lui depuis son matin! Il parlait et Myrto l'entendait merveilleusement (Charles Maurras, Le Chemin de Paradis)

1925 Ah ! Je te connaissais bien ! Que l'on te dise : «va-t'en », c'était assez pour que tu reviennes; et que ce soit ta femme qui te le dise, assez pour que tu accoures, tout droit, sans rien voir, fou perdu. Et te voilà, et moi aussi... ah ! Bon dieu, ça y est tout de même ! Il était à présent à deux pas de Raboliot (Maurice Genevoix, Raboliot)

CORpus Web :

S'exclama bruyamment une serveuse afro-américaine avant de sauter par-dessus le bar et accourut droit vers Damon [https://www. fanfiction.net/s/11178136/11/Monster-in-theDark] (24.4.2016)

Clarke reprit rapidement ses esprits et $a c$ courut droit sur moi en attrapant mes mains pour m'inspecter sous toutes les coutures [https:// www.fanfiction.net/s/11275739/2/Love-is-weak ness] (24.4.2016)

Mais Sakura n'eut pas vraiment le temps d’y réfléchir, car un kunaï allé s’abattre sur elle, celle-ci eu juste le temps de l'esquiver, pour s'accourir droit vers Sakira, qui à son tours était visée par la lame meurtrière [https://www.fanfic-fr. net/fanfics/imprimer/animes-mangas//Naruto/ Une-mission-sans-retour/20588/102015.html] (24.4.2016)

REMARQues : Accourir droit désigne l'action de venir le plus directement, en courant, à toute hâte vers un lieu exerçant une attirance sur le sujet. Droit est un adjectif-adverbe de manière-direction qui traduit ici la précision de l'action et renforce l'idée de finalité. Il reste invariable (ex. de 1895 et le dernier exemple du CW) et est modifié par tout. Jusqu'au $\mathrm{xx}^{\mathrm{e}}$ siècle, accourir droit est ré- gulièrement complété par la préposition à , suivie d'une destination ou d'une personne. Cette tendance de s'associer à une préposition directionnelle devient encore plus pertinente à partir du $\mathrm{xx}^{\mathrm{e}}$ siècle, notamment avec sur et vers, au point de faire partie du groupe prépositionnel comme modifieur de la préposition (droit à, droit sur, droit vers). Notons l'emploi de fou perdu 'follement perdu' dans l'exemple de 1925.

\section{Accroître haut}

Rendre beaucoup plus grand, plus important Transitif

+1400 Qui trop se fie es grans biens de Fortune, En verité, il en est deceü ;

Car inconstant elle est plus que la lune. Maint des plus grans s'en sont aperceü, De ceulz meismes qu'elle a hault acreü, Trebusche tost, et ce voit on souvent Que ses joyes ne sont fors que droit vent (Christine de Pisan, Cent balades / Euvres poétiques [début $\mathrm{XV}^{\mathrm{e}}$ ], I, p. 13, 5)

CORPUS WEB :

Les plans de ZPower incluent un puits prouvé, accroissent haut l'itinéraire pour l'déploiement rapide de la technologie dans le monde entier [http://www.zpower.com/fr/ aboutus_company.htm] (25.4.2016)

le montant du paiement divisé augmenté à un rythme croissant, ce qui montre qu'il ya eu une augmentation de la rentabilité de l'entreprise et cela est dû à des efforts accrus haut externaliser le travail pas cher dans d'autres parties $\mathrm{du}$ monde [http://freefrencharticles. com/education/limpact-de-lexternalisation-surhoneywell-performance-de-lentreprise] (7.5.2014)

Le phare 190PS Land Rover Freelander SD4 accélère de repos à 60 mph en 8,7 secondes avec une vitesse accrue haut de $118 \mathrm{mph}$ [http://landrover-france.blogspot.co.at/2011/03/2011-landrover-freelander-2.html] (7.5.2014)

REMARQUES : Haut (hault) est un adjectif-adverbe de lieu qui a un sens spatial et désigne un point élevé. Au sens figuré, il réfère à l'action de rendre beaucoup plus grand, plus important, plus fort, ou d'élever le statut d'une personne. Haut reste invariable. 


\section{Accueillir bel}

Recevoir (une personne) de manière agréable, plaisante

Transitif

1175 Or li cuide cil bien merir

La mort son frere dont se deut

Et qu'en sa cort si bel l'aqeut

(Gautier d'Arras, Ille et Galeron, 961)

1275 Quant Bel Acueil fet vous avra

Si beau semblant come il savra,

Car mout set bel [variante : bien] genz acuillir,

Lors devez la rose cuillir (Jehan de Meun, Roman de la rose [1269-1278], 7677)

REMARQUES : L'adjectif-adverbe de manière adopte ici la forme neutre bel, marque de la fonction adverbiale. Accueillir bel désigne l'action de réserver à une personne un bel accueil, la recevoir agréablement se comporter devant elle d'une manière plaisante et, éventuellement, lui offrir l'hospitalité. Bel est modifié par si.

\section{Accuser bas}

accuser tout bas : porter un jugement, reprocher en secret, intérieurement

Transitif

1654 Et bien qu'à chaque membre on égale sa playe,

On épargne son Ame autant comme on l'effraye,

Lartifice cruel de ces Courages bas

Fait languir son supplice, et vivre son trépas ;

Sa Langue est arrachée, et parmy la poussiere

Acheve en palpitant une plainte grossiere, Elle accuse tout bas ces cruels traittemens, Qui deffendent les cris à de si grands tourmens,

L'oreille suit la langue, et le nez suit l'oreille,

Ses mains souffrent en suite une rigueur pareille,

Et ses Yeux tout remplis de ces coups inhumains

Ont la mesme disgrace et vont chercher ses mains

(Georges de Brébeuf, La Pharsale de Lucain)
1788 MME DE ROSELLE. Je voudrois pourtant lui ressembler.

$$
\text { (à part) }
$$

Allons, nous voilà seuls. Il est temps de parler.

(Haut)

Vous accusez tout bas Madame de Mirbelle, Monsieur: votre bonheur est retardé par elle (Collin d'Harleville, L'Optimiste)

1833 Viens ! Le jour va s'éteindre... il s'efface, et je pleure.

N'as-tu pas entendu ma voix ? écoute l'heure ;

C'est ma voix qui te nomme et t'accuse tout bas ;

C'est l'amour qui t'appelle, et tu ne l'entends pas! (Marceline Desbordes-Valmore, Euvres poétiques)

1876 Les uns prétendaient savoir que les Mouradzyys l'avaient commandé, les autres accusaient tout bas le vieil Osman d'être le meurtrier et d'avoir payé l'assassinat magique à un docteur juif (Arthur de Gobineau, Nouvelles asiatiques)

1968 Ses panégyristes vantaient sa piété, son savoir, la chasteté qui lui avait fait préférer aux secondes noces les mélancoliques austérités du veuvage ; ses détracteurs l'accusaient tout bas d'aimer les femmes, tout en convenant que ce goût est moins scandaleux chez une noble dame que pour les hommes le penchant contraire, car il est plus beau, déclaraient-ils, pour la femme d'assumer la condition virile que pour un homme d'imiter la femme (Marguerite Yourcenar, L'Euvre au noir)

\section{CORPuS WeB :}

Il aurait ainsi permis de découvrir si le commanditaire est celui qu'on accuse tout bas [http:// news.acotonou.com/h/13814.html] (28.4.2016)

A saint-Robin, petite ville de province, tous les notables reçoivent des lettres anonymes calomnieuses signées « Le Corbeau ». La plus insoutenable suspicion se propage partout, chacun s'accusant tout bas d'être le corbeau [http://www. classiquesducinema.com/page/8] (28.4.2016) 
Cette fédération est accusée tout bas d'être « voleuse de talent » chez Canada Alpin [http:// vivezvancouver.radio-canada.ca/vivezvancouver /Ski_alpin/2010/01/29/002-guay-vendredi.shtml] (28.4.2016)

REMARQUES : Bas est un adjectif-adverbe de lieu qui, avec une interprétation de manière, relève au figuré du caractère discret de l'action, du fait de ne pas le dire publiquement, à haute voix. Le verbe accuser référant à l'idée de reproche, l'objet est alors présenté comme coupable (d'une faute, d'un défaut, d'une action blâmable et répréhensible), sans pour autant que le sujet l'en informe, par peur ou manque de courage. Bas reste invariable (ex. de 1788) et est toujours modifié par l'adverbe tout qui lui donne une valeur intensive signifiant 'très bas'.

\section{Accuser faux}

Dénoncer à tort, charger sans justification

Emploi absolu

1863 Par rapport aux « faits » dont l'anonyme charge les Pères du concile d'Embrun, $\mathrm{M}$. de Sisteron montre qu'il accuse faux dans les démarches qu'il leur impute (Encyclopédie théologique)

1707 afin, (s'ils accusent faux) qu'ils soient punis comme des traitres et des espions (La Clef du cabinet des princes de l'Europe)

2014 - Non... non... j'ai tout mon esprit, et je rétracte ma première déposition... je l'annule... Je me suis trompé... j'ai accusé faux (Léon Sazie, Zigomar. Livre premier : Le Maître invisible)

\section{Accuser juste}

Signaler à juste titre

Emploi absolu

1660 MASCARILLE. Ah ! Je m'inscris en faux contre vos paroles. La renommée accuse juste en contant ce que vous valez; et vous allez faire pic, repic et capot tout ce qu'il y a de galant dans Paris (Molière, Les Précieuses ridicules)

1740 Ma petite cousine avoit accusé juste, en disant qu'elle ne nous tiendroit pas longtemps compagnie (Jacques de Varenne, Mémoires du chevalier de Ravanne)
Transitif

1822 D'après le trouble qui accompagne les discours des amants, il ne serait pas sage de tirer des conséquences trop pressées d'un détail isolé de la conversation. Ils n'accusent juste leurs sentiments que dans les mots imprévus ; alors c'est le cri du cœur (Stendhal, De l'amour)

\section{Acesmer beau (bel)}

I. Être orné, paré d'une belle manière

Transitif

+1225 Quant la pucele fu montee

Si bien et si biel acesmee,

S'est la plus biele creature

$\mathrm{U}$ ains jor se penast nature,

Ke son sens n'i ot celé (Le Chevalier as deus

espees [ $2^{\mathrm{e}}$ quart XIII'] ${ }^{\mathrm{e}}$, 1152)

II. Avoir un bon équipement pour la guerre, pour un tournoi

Transitif

1276 Armé se sont, lors est chascuns montés, N'i ot nul d'aus qui ne fust arreés Bien et a droit et tres bel acesmés (Adenet le Roi, Les Enfances Ogier, 3728)

1325 Mais quant il est biaus acesmez

Et avec ce hardiz esmez

Pour .i. fort fait d'armes outrer,

Adont se fait à droit moustrer ;

Veschi bel et bonté ensemble

Qui tournoi commence et assemble ;

Diex, comme il fait terre trembler !

(Watriquet de Couvin, Dits, p. 121, 101)

REMARQUES : Dans le premier exemple, acesmer bel se dit d'une femme portant de beaux ornements (coiffe, guimpe, atours, chaînes, anneaux, etc.). Dans le contexte de la guerre, il désigne un équipement de soldat très complet, comprenant les armes, les armures, les blasons, etc. L'adjectif-adverbe de manière tend à adopter la forme neutre bel, mais son emploi comme prédicat second accordé au cas sujet s'observe dans le dernier exemple. L'accord renforce la perspective résultative (beau comme état acquis). L'adjectif-adverbe est modifié par si. Le verbe acesmer figure dans sa forme du participe passé semi-adjectivisé et désigne le résultat du verbe transitif. 


\section{Acheminer droit}

I. Se rendre de manière directe en un lieu Pronominal

1190 Li dus Richart s'en part quant les voit ainz meslés,

A Deu a nos barons em plorant conmandés,

Parmi l'ost des paiens s'est droit acheminés.

Or le conduie Dex par ses seintes bontés (Fierabras (L), 4174)

-1200 Et quant il furent la, si l'ont tout aor[n]é, Quant ont fait lor offrande, si sont tout retorné,

Tout droit vers douche Franche se sont acheminé (Elie de Saint Gille [fin $\mathrm{XII}^{\mathrm{e}}$ ], 2739)

1275 Atant depart de la roïnne, Droit vers la porte s'achemine, Tot à pié, l'espee el poing destre Et l'escu tient à la senestre (Floriant et Florete, 1436)

1276 Quant Carahués fu de ses gens sevrés Et chascuns d'aus fu arrier retornés, Fors que li quatre qui o lui sont remés, Aprés ce n'est gaires la arrestés, Droit devers Sustre s'en est acheminés (Adenet le Roi, Les Enfances Ogier, 4430)

1610 Mais pour revenir à notre discours, apres qu'Attila eut pris Aquilée, et ruiné le pais d'alentour, il s'achemina droit à Rome, et ne faut point douter qu'il ne l'eust prise et saccagée, si Valentinian perdu de courage, ne se fust rendu son tributaire, et ne luy eust accordé sa sœur Honorique pour femme (Honoré d'Urfé, L’Astrée)

1629 Mais parce que cela n’appartient point à mon discours, je le passeray sous silence, pour vous dire seulement en continuant le cours de mon Histoire, que de Bider nous nous acheminasmes droit à Visapore, où nous estions asseurez de trouver la Cour du Roy de Decan ; et comme nous arrivions dans cette grande Cité, nous ouïmes plusieurs trompettes qui sonnerent des fanfares à trois diverses reprises dans la grande place où est assis le Palais du Roy, et vismes en suitte un grand homme vestu d'une riche cotte d'armes, accompagné de quatre Herauts (François de Boisrobert, Histoire indienne d'Alexandre et d'Orazie)

1787 Du gros de la troupe se détacha tout à coup un grand diable de palefrenier qui, s'acheminant tout droit vers la remise, commença par poser sa chandelle sur le marchepied du carrosse, où je restais dans une horrible transe (Jean-Baptiste Louvet de Couvray, Une année dans la vie du chevalier de Faublas)

1942 Enfin il se leva, les renvoya avec douceur, l'oiseau vers les arbres sombres et le chien vers la maison. Puis il s'achemina droit vers nous, à pas tranquilles, en balançant un peu les bras. Aucune hésitation, aucune gêne. Lui aussi, je le pense, avait compté les jours et les heures : il savait que c'était le dernier soir de notre séjour près de lui (Maurice Genevoix, Le Lac fou)

II. Envoyer, diriger directement vers un lieu déterminé

Transitif

-1200 Li quens Guillames a sa voie hastee, Droit vers Orenge a s'ost acheminee (Aliscans [fin XII $]$, 3969)

1532 Auquel tous furent obeissans, excepté ceux qui estoient dedans Larigno, lesquelz soy confians en la force naturelle du lieu refuserent à la contribution. Pour les chastier de ce refus, l'empereur fit droit au lieu acheminer son armée (François Rabelais, Pantagruel)

CORPUS WEB :

L’affaire des enseignants contractuels, entrés en grève de la faim depuis le 14 juillet dernier, s'achemine-t-elle droit vers une fin tragique ? [http://chlef.centerblog.net/197.html] (30.4.2016)

Chaque jour, les fruits et légumes arrivent de Rungis et sont acheminés tout droit vers le centre de stockage de La belle vie situé dans le 1er arrondissement de la Capitale [http://vivre. paris/10e-offerts-sur-votre-premiere-commandela-belle-vie-6290] (30.4.2016)

quand on est arrivé en chantant « la patrouille de la panthère, s'achemine droite et fière, la truffe en avant, la queue dans le vent, elle 
avance agilement (bis) etc..... » tout le monde se marrait on a eu notre petit effet !! [http://www. fraternite.net/forum/voirtopic.php?topic $=1506 \&$ forum=3\&start=137] (12.11.2013)

Mabrouk, Epau 2003, c'est un récit magnifique et impeccable, veut dire sans incidents, voilà une bonne préparation nous achemine droite vers la réussite de notre entrevue, on aura un répit, du début de l'année, et après ça sera le relancement dans la fin du mois,,donc,,il faut profiter du temps qui nous est donné pour intensifier notre préparation,, bonne matinée pour tous,, [http://www.forum.immigrer.com/ topic/91532-vous-attendez-lentretien/page-1643] (12.11.2013)

REMARques : Droit est un adjectif-adverbe de manière-direction qui caractérise le trajet parcouru par un objet ou une personne. Acheminer droit, sous sa forme pronominale, s'utilise en général dans le contexte de la guerre, désignant une armée qui avance vers un but sans faire de détours. Dans un contexte plus neutre, il désigne simplement l'action de s'avancer en direction d'un lieu ou d'une personne. Dans son emploi transitif, il signifie le fait d'envoyer une armée en la faisant avancer vers un lieu déterminé. Droit reste invariable (v. aussi les deux premiers exemples du CW) et est modifié par tout. Acheminer droit est généralement suivi (ou précédé) d'une préposition de lieu indiquant la direction (à, vers). Droit a ainsi tendance à s'associer avec ces prépositions au point de faire partie du groupe prépositionnel comme modifieur de la préposition. Le troisième exemple du CW montre l'emploi de droit comme prédicat second fléchi qui désigne une qualité du sujet, mais il pourrait s'agir également d'un reflet de la prononciation québécoise du - $t$ final. À la différence de cet emploi pleinement accepté, dans le dernier exemple l'accord est réalisé pour la fonction adverbiale de manière-direction. Il s'agit donc d'un adverbe accordé qui se heurte au dogme de l'invariabilité de l'adverbe. On ne saurait pas attribuer l'accord à un effet de phonétique, à l'instar de droit à, puisque l'accord n'est pas audible dans droit vers. La syntaxe met en évidence que le dernier exemple est écrit très spontanément.

\section{Acheter appétissant}

Acheter des choses appétissantes

$\pi$ acheter frais

\section{Acheter beau}

Acheter de belles choses

Emploi absolu

1952 Quand elle achetait, elle achetait beau (Exemple entendu, 27 mai 1952 / Grundt : 236)

1989 Achetez beau. Achetez réfléchi. Achetez Braun (Publicité / Noailly 1997a)

\section{CORPuS WeB :}

A trois enfants, on ne se pose même plus la question et on profite de toutes les combines possibles pour acheter beau et pas cher [http://www. lepetitmondedelvira.com/article-la-cavernede-lala-acheter-malin-et-d-occasion-pour-vosenfants-122171857.html] (30.4.2016)

savez vous ou je peux acheter $B E A U$ :-) un carnet de plongee ? car les standards je ne les trouve pas tres jolis :-) [http://www.plongeur.com/ forums/showthread.php?t=11351] (30.4.2016)

Ils voulaient juste dire, me semble t-il, qu'une plante comme celle là est achetée belle, mais qu'elle ne le reste pas longtemps parce qu'on peut difficilement leur donner les conditions adéquates pour un développement harmonieux [https://www.cactuspro.com/forum/read. php?1,271994,272056,quote=1] (30.4.2016)

REMARques : Beau est un adjectif-adverbe de manière qui appartient au langage familier $\mathrm{du}$ commerce et du marketing. Acheter beau caractérise l'acquisition d'objets dont l'achat fait naître un sentiment d'admiration, souvent mêlé de plaisir, assurant un effet d'appréciation esthétique positive. Beau reste invariable et peut complémenter un verbe transitif dans son emploi absolu. Dans ce cas-là, il modifie un objet sous-entendu, non-spécifié. Le troisième exemple du CW illustre son emploi en tant que prédicat second accordé. Notons la collocation acheter beau et pas cher ainsi que l'emploi de acheter réfléchi. 


\section{Acheter bon}

Se procurer un objet de bonne qualité Transitif

1562 JOSSE. Et voyla pourquoy davantage

Je me suis mis en mon devoir

De chercher moyen de l'avoir,

N'ayant grand esgard au doire,

Affin de plustost me complaire :

Voyla pourquoy, quoyque ce soit.

MARION. "Qui bon l'achette, bon le boit» (Jacques Grévin, Les Esbahis)

1793 BON. On dit familièrement en parlant de vin, Tirer du bon, donner du bon : Et proverbialement, Qui bon l'achète, bon le boit. Et cela ne se dit pas seulement du vin, mais figurément de toute autre marchandise, pour dire, qu'il n'y faut pas plaindre l'argent : Et que Quand on l'achète bonne, on s'en trouve bien (Nouveau dictionnaire françois)

\section{CORPUS WEB :}

Bruno achète bon et cher pour satisfaire la clientèle prête à payer le prix quand elle est bien au-dessus de son assiette [http://www.sudouest. fr/2010/05/15/du-bon-a-pessac-92431-2780.php] (30.4.2016)

et la pignorerie en plastoc me fait peur, trop de mauvais souvenir sur des machines du bricogasin du coin ou aux bout de qlq semaines le disque a meuler ne tourne plus rond. j'suis plutôt du genre, j'achète «bon » et je m'en sert de suite [http://www.metabricoleur.com/t3601-j-aime-laferraille] (30.4.2016)

La choucroute est achetée bonne et cuite, par fainéantise et parce qu'en Alsace, elle est bonne même déjà cuite [http://aumenuamidi.blogspot. co.at/2016/03/aie-confiance.html] (30.4.2016)

REMARQUES : Acheter bon caractérise l'acquisition d'objets de bonne qualité. Le proverbe Qui bon achète, bon le boit réfère, en parlant d'une boisson et par extension de denrées qu'on achète, au fait qu'en dépensant la somme nécessaire, on peut espérer une marchandise de bonne qualité, transmettant ainsi une morale selon laquelle il vaut mieux acheter une bonne marchandise chèrement qu'une mauvaise à bon marché. Notons la collocation bon et cher. L'objet interne qui est modifié par boire bon en emploi absolu peut devenir un complément d'objet explicite accordé en prédication seconde (dernier exemple du CW). Mentionnons l'emploi de boire bon.

\section{Acheter cher}

I. Acheter à un prix élevé

Transitif

1160 Voz armes sont chier achatees, Se doivent bien estre gardees ; Se vostre escuz estoit perciez, Vos serïez trop domagiez ; Tant com l'avroiz sain et antier, Ne donroiz an altre denier (Eneas, 6729)

-1200 Mais se vous port i volez prandre, L'an lou vouz voudra molt chier vandre, Molt l'estovra achater chier, Qu'an la nef vandra reverchier Premiers li sire et puis la dame (Guillaume d'Angleterre [fin $\mathrm{XII}^{\mathrm{e}}$ ], 2345)

1403 Helas ! Si est il plain de joye Qui la peine de ce degré Peut un peu de temps prendre en gré. On n'a pas grant bien pour neant, Et, cil, qui se va pourvoyant Sagement, doit chier acheter Ce dont peut en grant pris monter (Christine de Pisan, Le Livre de la mutacion de fortune, I, 3295)

+1489 De chiens, en envoyoit querir partout : en Espaigne des allans, en Bretaigne des petites levrètes, levriers, espaigneulx, et les achaptoit chier; en Valence, de petiz chiens veluz qu'il faisoit achapter plus cher que les gens ne les vouloyent vendre (Philippe de Commynes, Mémoires [1489-1498], VI)

1615 Nous aurions, des nostres mesmes, ce que nous achetons si cher des estrangers : soyes, cottons, baumes, liqueurs, gommes, bois médicinaux et aromatiques, gaïac, salsepareille, sassafras (nommé à la Floride " Pavagne », et en Virginie « Winank »), costus doux, costus amer, sandal blanc, sandal citrin, sandal jaune, bois d'esquine, casse fistule, cassia ligna, poivre long, et plusieurs espiceries (Antoine de Montchrestien, Traicté de l'économie politique) 
1668 Le pauvre Carpillon lui fit en sa manière : Que ferez-vous de moi ? je ne saurais fournir

Au plus qu'une demi-bouchée.

Laissez-moi Carpe devenir :

Je serai par vous repêchée.

Quelque gros Partisan m'achètera bien cher (Jean de La Fontaine, Le Petit Poisson et le pêcheur / Fables)

1735 LA BARONNE. Autre méprise, monsieur. Je l'ai acheté, assez cher même, d'une revendeuse à la toilette.

LE MARQUIS. Cela vient de lui, madame. Il a des revendeuses à sa disposition et, à ce qu'on dit même, dans sa famille

(Alain-René Lesage, Turcaret)

1756 Cette loi seule doit rendre sa mémoire chére à tous les peuples ; ainsi que ses efforts pour soutenir la liberté de l'Italie doivent rendre son nom précieux aux Italiens. C'est en vertu de cette loi que longtems après, le roi Louis Hutin dans ses chartes déclara que tous les serfs qui restaient encor en France, devaient être affranchis, parce que c'est, dit-il, le royaume des francs. Il faisait à la vérité payer cette liberté ; mais pouvait-on l'acheter trop cher ? Cependant les hommes ne rentrèrent que par degrés et très-difficilement dans leur droit naturel (Voltaire, Essay sur l'histoire générale et sur les mours et sur l'esprit des nations)

1830 C'est d'Angleterre que nous est venue la chimère politique de représenter le peuple par des hommes qui se rient de ses misères, et dont les intentions secrètes sont bien exprimées dans ces deux phrases ; l'une du ministre Walpole, disant : «J'ai dans mon portefeuille le tarif de toutes les probités du parlement ; » l'autre d'un député anglais, disant à ses commettans : « Je vous ai achetés cher, il faut que je vous vende cher. » Sans doute il y a des exceptions à cette perversité ; on voit des représentans [sic] très intègres ; mais qu'importe? (Charles Fourier, Le Nouveau monde industriel ou l'Agriculture combinée)
1842 Tenez, monsieur, ajouta-t-elle avec colère et en jetant trois pièces de cent sous sur la table du greffe, payez-vous. Aussi bien n'est-ce pas acheter trop cher le plaisir de ne plus vous voir. Le greffier ne répondit rien, retint sa somme, et rendit le reste : probablement il était habitué à de pareilles scènes (Louis Reybaud, Jérôme Paturot à la recherche d'une position sociale)

1873 Ceci étonna un peu Passepartout, qui savait tout ce que son maître devait au dévouement du guide. Le parsi avait, en effet, risqué volontairement sa vie dans l'affaire de Pillaji, et si, plus tard, les indous l'apprenaient, il échapperait difficilement à leur vengeance. Restait aussi la question de Kiouni. Que ferait-on d'un éléphant acheté si cher? Mais Phileas Fogg avait déjà pris une résolution à cet égard (Jules Verne, Le Tour du monde en quatrevingts jours)

1935 Les Allemands avaient besoin de peaux de lapins. Les poils filés leur servaient de textile. Ils achetaient donc très cher les fourrures de lapin, et délivraient, à ceux qui voulaient faire pour eux la récolte par les rues, des cartes qui servaient de laissez-passer (Maxence Van der Meersch, Invasion 14)

1959 MADAME. De plus en plus ! Des glaïeuls horribles, d'un rose débilitant, et du mimosa ! Ces folles doivent courir les halles avant le jour pour les acheter moins cher. Tant de sollicitude, ma chère Solange, pour une maitresse indigne, et tant de roses pour elle quand Monsieur est traité comme un criminel ! (Jean Genet, Les Bonnes)

1994 Nous espérions seulement qu'elle s’améliorerait avec le temps... Depuis, les situations se sont modifiées, mais, hélas, les règles qui président aux échanges internationaux restent les mêmes dans leurs grandes lignes : acheter le moins cher possible les matières premières, et revendre le plus cher possible les produits manufacturés (Amadou Hampâté Bâ, Oui Mon Commandant!) 
Emploi absolu

1580 POLYNICE. C'est tousjours bon marché, quelque prix qu'on y mette.

Nul n'achette trop cher qui un Royaume achette (Robert Garnier, Antigone)

1669 LA FLÈCHE. Je vous vois, Monsieur, ne vous en déplaise, dans le grand chemin justement que tenoit Panurge pour se ruiner, prenant argent d'avance, achetant cher, vendant à bon marché, et mangeant son blé en herbe.

CLÉANTE. Que veux-tu que j'y fasse ? Voilà où les jeunes gens sont réduits par la maudite avarice des pères ; et on s'étonne après cela que les fils souhaitent qu'ils meurent (Molière, L'Avare)

1770 LE MARQUIS. On peut le savoir, le calculer. On ne le peut ni ne le doit. Qui est-ce qui peut calculer et savoir quel déchet, quelle perte je puis avoir fait. Je puis avoir acheté cher. C'est à moi, si j'ai été dupé, à m'en tirer le mieux que je pourrai ; mais personne n'a droit de s'en mêler (Ferdinando Galiani, Dialogues sur le commerce des bleds)

1947 Ajoutez à ça mes frais généraux, mes frais d'encadrement, mon bénéfice et calculez. $\mathrm{Si}$ je vous achète trop cher, je suis obligé de faire un prix exorbitant, parfaitement prohibitif (Marcel Aymé, Le Vin de Paris)

1987 La nouvelle répartition de la garde-robe témoigne tout autant de l'envolée des valeurs hédonistes et psy propres à nos sociétés. Pour un nombre croissant de personnes, on préfère acheter souvent qu'acheter cher, on préfère acheter des petites pièces que des " gros vêtements ", c'est là une expression vestimentaire typique du nouvel âge de l'individualisme (Gilles Lipovetsky, L’Empire de l'éphémère)

Pronominal

1691 On a ici un grand nombre d'esclaves qui s'achètent et se vendent fort cher. Ce sont des maures et des turcs. Il y en a qui valent jusqu'à quatre et cinq cents écus (Marie-Catherine d'Aulnoy, Relation $d u$ voyage d'Espagne)
II. Subir les conséquences fâcheuses de

quelque chose

Transitif

+1265 Car se tu bois sur ma deffense

Chier accateras la despense

(Richars li Biaus [3 $3^{\mathrm{e}}$ tiers XIII ${ }^{\mathrm{e}}$, 956)

1275 Mains en noia le jour dedens cele riviere

Et mains en gist sanglens parmi la sablonniere

Qui par santé n'aront ja mais autre litiere ; La jouste Limbanor ont achetee chiere (Adenet le Roi, Buevon de Conmarchis, 2903)

1623 Mais helas il n'est point de plaisir sans tristesse,

Tousjours apres le bien, le mal se fait sentir,

Nous eusmes bon marché de ces douces carresses,

Mais nous en achetons bien cher le repentir. Nous en avons porté la robbe de Mercure, À peine en nostre bouche est resté une dent,

Si tost n'eusmes passé le destroit de nature Que nous vismes Suri Baviere et

Claquedent

(Jean Auvray, Le Banquet des muses ou Les Divers Satires)

1794 Je trouve tant de folie au voyage d'Amérique, qu'il me semble que c'est acheter même trop cher le plaisir certain de me décider à ce dernier acte si désirable dans ma situation. Avant tout, il faut que j'aille en Angleterre (Germaine de Staël, Lettres inédites à Louis de Narbonne)

1848 Annibal. Certes, je ne suis pas pour te le disputer.

Ton hymen a de quoi tous deux nous contenter,

Car à toi, s'il assure une belle retraite

Et le droit de jouer à la Madame... honnête, Il me met à l'abri, moi qui veux mourir gras,

Des caprices du sort à l'heure des repas ; Mais je l'achète cher, car jusqu'ici mon rôle Est fatigant ! (Émile Augier, L’Aventurière) 
1968 Mais le crime de bigamie n'était pas de ceux qu'on commet d'un cœur léger. « Si vous m'en croyez, fit-il, vous laisserez en paix votre serviteur et n'achèterez pas si cher deux sous de repentir... Vous plaît-il tant que cela de voir l'argent de Martin passer à des réfections d'église ?» (Marguerite Yourcenar, L'Euvre au noir)

III. Obtenir quelque chose au prix de grands sacrifices, de grands efforts

Transitif

1276 Merci requier, ne sai s'ele iert trouvee, Mais, par celui qui fist ciel et rousee, Se je ne l'ai, chier ara achetee Charles ma terre, ainz qu'il l'ait conquestee (Adenet le Roi, Les Enfances Ogier, 167)

+1400 Ayez pitié de moy, ma dame chiere : Chiere vous ay plus que dame du monde, Monde d'orgueil, ne me faites vo chiere Chiere achater par reffus, blanche et blonde ;

L'onde de plour m'ostez si que revoye Voye d'avoir soulas qui me ravoye (Christine de Pisan, Le Livre du duc des vrais amans / Euvres poétiques [début $\left.\mathrm{XV}^{\mathrm{e}}\right]$, III, p. 131, 2312)

+1415 L'AMANT. Se je vous dy bonne nouvelle, Mon cueur, que voulez vous donner? LE CUEUR. Elle pourroit bien estre telle Que moult chier la vueil acheter (Charles d'Orléans, Poésies [ 1415-1440], I, Ballade XXXIII, p. 52)

1541 Qui me contrainct

Qu'autant de temps qu'en amour juste et sainct

Je l'ay porté dedans mon cueur empraint Par amour forte, Autant de temps pour meschant je le porte. Impossible est que jamais il en sorte.

Sa lascheté

Donnera foeille à ma grant fermeté. Ô que l'honneur sera cher acheté De ne partir hors de l'amour dont le voy departir!

Où est l'esprit comme le mien martyr ?

Il n'en est point

(Marguerite d'Angoulême, La Coche)
1596 Ou comme un jeune lys, de la pluye aggravé, Laisse pendre son chef, qui fut si relevé. Victoire Cadmeane, et trop chere achetée, D’un ny d'autre party tu n'as esté chantée ! (Philippe Desportes, Euvres)

1634 DORImant. Pourriez-vous approuver que je prisse avantage

Pour immoler ce traître à mon peu de courage?

J'achèterois trop cher la mort du suborneur,

Si pour avoir sa vie il m'en coûtoit l'honneur,

Et montrerois une âme et trop basse et trop noire

De ménager mon sang aux dépens de ma gloire

(Pierre Corneille, La Galerie du Palais)

1668 Il y mourut en traînant son lien.

Sage s’il eût remis une légère offense.

Quel que soit le plaisir que cause

la vengeance,

C'est l'acheter trop cher, que l'acheter d'un bien

Sans qui les autres ne sont rien

(Jean de La Fontaine, Le Cheval s'étant voulu venger du cerf / Fables)

1836a ô hommes libres! Quand alors vous remercierez Dieu d'être nés pour cette récolte, pensez à nous qui n'y serons plus ; ditesvous que nous avons acheté bien cher le repos dont vous jouirez; plaignez-nous plus que tous vos pères! (Alfred de Musset, Confessions d'un enfant du siècle)

1836b Je n’ai reçu qu'indirectement des nouvelles de Denys Benoist depuis son départ pour Alais. Je désire que son entreprise réussisse. Les bénéfices qu'elle peut donner me paraissent achetés bien cher par les soins, la fatigue, et l'ennui d'une manutention de ce genre (Félicité de Lamennais, Lettres inédites ... à la baronne Cottu)

1863 Madeleine, je n'ai plus besoin de vous, je ne veux plus de secours, je ne veux plus rien... Je ne veux pas d'une assistance achetée si cher et d'une amitié que j'ai 
rendue trop lourde et qui vous tuerait. Que je souffre ou non, cela me regarde (Eugène Fromentin, Dominique)

1890 La plus grande des religions a vu son berceau signalé par les faits du plus pur enthousiasme et par des farces de convulsionnaires telles qu'on en voit à peine chez les sectaires les plus exaltés. Il faut donc s'y résigner : les belles choses naissent dans les larmes ; ce n'est pas acheter trop cher la beauté que de l'acheter au prix de la douleur (Ernest Renan, L'Avenir de la science)

1921 Règne rose, bonds légers, tirer des herbes parfumées de ce qui m'entoure, règne rose plaine rose règne. J'achète très cher l'invisible richesse. La lumière s'est levée avec le rideau (Paul Éluard, Les Nécessités de la vie)

1927 Je voudrais que la leçon, du moins, vous servît. Il ne vous en aura coûté qu'une petite course inutile. Ce n'est pas acheter trop cher le conseil d'être désormais moins bavard, moins empressé de prendre, et plus poli... Êtes-vous vraiment si essoufflé ? (Georges Bernanos, L'Imposture)

Pronominal

1853 Ce à quoi je me heurte, c'est à des situations communes et un dialogue trivial. Bien écrire le médiocre et faire qu'il garde en même temps son aspect, sa coupe, ses mots même, cela est vraiment diabolique, et je vois se défiler maintenant devant moi de ces gentillesses en perspective pendant trente pages au moins. Ça s'achète cher, le style ! Je recommence ce que j'ai fait l'autre semaine (Gustave Flaubert, Correspondance)

1884 Il lui avait pris les mains, il les serra paternellement, avec une émotion triste.

- Oui, si vous êtes heureuse... allez, le malheur s'achète aussi bien cher quelquefois.

Naturellement, dans l'ardeur de cette bataille qu'il livrait à la mer, Lazare avait abandonné la musique (Émile Zola, La Joie de vivre)
1893 l'action est cette méthode de précision, cette épreuve de laboratoire, où, sans jamais comprendre le détail des opérations, je reçois la réponse certaine à laquelle aucun artifice de dialectique ne supplée. Là est la compétence : peu importe si elle s'achète cher. Mais encore n’y a-t-il pas équivoque et inconséquence dans ce règlement de vie ? S'il faut toujours opter entre plusieurs partis, pourquoi sacrifier ceci à cela (Maurice Blondel, L'Action : essai d'une critique de la vie et d'une science de la pratique)

1897 L'erreur de ma vie fut dès lors de ne continuer longtemps aucune étude, pour n'avoir su prendre mon parti de renoncer à beaucoup d'autres. N'importe quoi s'achetait trop cher à ce prix-là, et les raisonnements ne pouvaient venir à bout de ma détresse (André Gide, Les Nourritures terrestres)

\section{Acheter à un prix élevé (par extension)}

Transitif

1748 - En vérité, lui répliqua la seconde, il faut avoir de bonnes raisons de ménager les gens, pour acheter si cher leur discrétion.

- Je n'en ai pas de meilleures qu'une autre, repartit Céphise ; cependant je ne m'en dédis pas (Denis Diderot, Les Bijoux indiscrets)

1800 LA DUCHESSE. (à part) Que devenir ? À quelle honte mes périls et mon ambition me condamnent !

LOPEz. Cessez d'être inexorable, et je vous paie mon bonheur d'un service que vous n'achèterez jamais trop cher. La destinée de votre époux est dans mes mains. LA DUCHESSE. Au nom du ciel... parlez (Népomucène Lemercier, Pinto ou La Journée d'une conspiration)

1822 GERVAL. Eh bien je t'en donne, deux mille... trois mille !

MARGUERITE. Ah diable... J'achèterais les vignes à Claudin.

GERVAL. Répondras-tu ? Est-ce acheter assez cher la mort ? Parlez donc !... 
MARGUERITE. Les vignes à Claudin !... Qu'est-ce que cela peut faire, il n'est pas du pays.

GERVAL. Eh bien...

(Honoré de Balzac, Le Nègre)

1848 Clorinde. Tous les jours ce sont des coups nouveaux...

Hélas! vous m'achetez plus cher que je ne vaux !

Croyez-moi, mon ami, cédez devant l'orage Et quittez un amour qui veut trop de courage (Émile Augier, L’Aventurière)

Pronominal

1942 Mais, de cette promenade d'aujourd'hui, je ne devais pas revenir non plus. Elle me donne un peu plus le droit de m'asseoir à leur table, et de me taire avec eux. Ce droit-là s'achète très cher. Mais il vaut très cher : c'est le droit d'être. C'est pourquoi, ce bouquin, je l'ai signé sans gêne... il ne gâchait rien (Antoine de Saint-Exupéry, Pilote de guerre)

V. Obtenir la complicité de quelqu'un, le corrompre contre une grosse somme d'argent Transitif

1902 Je l'apprends ; je le devance chez le gouverneur russe de la place, à qui je montre les documents de nos loges : et le comte d'Artois ne peut entrer dans la ville que sans cortège, à la condition de s'enfermer en son hôtel, sous un nom d'emprunt, de n'y recevoir âme du monde, et de n'en bouger pas... Il fallut que l'abbé de Montesquiou achetât très cher Talleyrand et les sénateurs de l'empire, pour qu'Alexandre se laissât tromper et consentît au retour des bourbons (Paul Adam, L'Enfant d'Austerlitz)

1995 Quel stratège n’a pas intérêt à connaître les plans de l'ennemi ? La Baronne avait les moyens d'acheter cher les juges ; la Comtesse n'avait les moyens que d'acheter bien les témoins. Il fallait profiter de l'aubaine (Françoise Chandernagor, L'Enfant des Lumières)

CORPUS WEB :

Dernière difficulté: dans une louable démarche vertueuse, les pouvoirs publics de- mandent aux méthaniseurs d'optimiser la consommation de la chaleur produite dans les cogénérateurs (lire ci-contre) : plus la chaleur est utilisée, plus l'électricité est achetée cher [http://www.lanouvellerepublique.fr/Vienne/ Actualite/Economie-social/n/Contenus/ Articles/2015/03/15/Pres-de-vingt-projets-dansla-Vienne-2257435] (30.4.2016)

Alors, je me demandais... je sais que c'est la première guitare américaine du groupe et que Harrison en était très fier, et qu'il l'a achetée d'occasion. Alors voilà : est-ce qu'il l'a achetée chère ? [http://www.yellow-sub.fr/forum/viewtopic. php?f=8\&t=2842] (30.4.2016)

REMARQUES : Cher peut être analysé comme un adverbe de manière, qui est l'interprétation dominante, ou comme adjectif en prédication seconde indiquant le prix élevé de ce qui est vendu (I). Dans le second cas, il peut être accordé, mais l'emploi invarié est plus usuel, surtout en français moderne. L’idée d'un coût élevé est pris au figuré pour renvoyer aux conséquences d'un comportement (II), pour mesurer un effort entrepris (III), pour décrire le prix moral de quelque chose (IV) ou dans le domaine de la corruption pour payer les faveurs de quelqu'un (V). L'emploi familier documenté dans le CW s'avère plus libéral par rapport à l'accord, qui est fonctionnellement justifié, mais moins accepté dans l'usage établi, à la différence des autres langues romanes (par exemple en espagnol Comprar cara la casa 'acheter chère la maison'). Cher est modifié par assez, bien, fort, jamais, même, (le) moins, plus, si, très, trop. Notons l'emploi de mourir gras, valoir cher, vendre cher. VOIR AUSSI : vendre cher

\section{Acheter ferme}

Acheter quelque chose sans sursis et d'une manière définitive, en s'en tenant au prix et aux conditions fixées

Emploi absolu

1853 En achetant ferme payable fin courant, l'on devenait porteur des inscriptions de rente, sans avoir déboursé autre chose que la commission due à l'agent de change (Nicolas Boyard, La Bourse et ses spéculations) 
1856 PEPONET. Je...

OCTAVE. Vous achetez ferme?...

PEPONET. Permettez...

OCTAVE. Non ?... à prime alors

(Théodore Barrière et Ernest Capendu, Les

Faux Bonshommes)

Transitif

1909 Mr. W. N. Balcombe représentait à Londres la marque Hartmann. Il achetait ferme chaque année trois cent mille bouteilles et les revendait par l'intermédiaire de sousagents dans toutes les parties du monde (Pierre Hamp, Vin de Champagne)

1935 Tout cela risquait de pourrir. A Anvers, quatre péniches de mille tonnes de blés américains, achetées "ferme », s'échauffaient et germaient. Un bateau avait pris feu. Quelques jours encore, et tout serait à jeter à la mer (Maxence Van der Meersch, Invasion 14)

1939a Office et dépôt. Les livres nouveaux ne sauraient, dans la plupart des cas, être achetés ferme par le libraire car les risques seraient trop grands (La Civilisation écrite)

1939b Les camelots. Pour les journaux de midi et du soir, les camelots sont approvisionnés par des voitures à des points fixes dans Paris ou au service central de vente des journaux du soir, rue du Croissant. Ils paient comptant et achètent ferme sans reprise d'invendus le nombre d'exemplaires qu'ils croient pouvoir vendre ( $\mathrm{La}$ Civilisation écrite)

\section{CORPUS WEB :}

En aéroport, les maisons de luxe délèguent souvent l'exploitation à un partenaire spécialisé, qui emploie ses propres vendeurs et lui achète ferme la marchandise [http://www.lefigaro.fr/ societes/2013/04/11/20005-20130411ARTFIG 00380-les-boutiques-d-aeroports-nouveleldorado-des-griffes-de-luxe.php] (4.5.2016)

Le Distributeur achète ferme les Produits au Fournisseur en vue de leur revente dans le Territoire [http://www.droit.co/mod\%C3\%A8le-decontrat-de-distribution.html] (4.5.2016)
Vous levez vos titres. C'est à dire, vous achetez ferme vos actions comme dans une opération au comptant.

Vous reportez vos titres. C'est à dire, vous ne voulez ou ne pouvez acheter ferme vos titres. Cela arrive quand le montant de vos engagements est supérieur au montant de vos liquidités [http://www.abcbourse.com/apprendre/1_le_ fonctionnement_du_srd2.html] (4.5.2016)

Pour avoir des avocats toujours mûrs, je les achète fermes et les conserve 2 ou 3 jours dans une feuille de papier journal à température ambiente [http://www.trucmania.com/Cuisine/Desavocats-a-point.html] (25.10.2013)

REMARQUES : Acheter ferme désigne le caractère définitif et conclu de l'acquisition d'un objet par l'achat. Achetant ferme, on ne revient pas dessus, les prix et les conditions étant définis par le vendeur et/ou l'acquéreur. Dans cet emploi, il reste invariable (ex. de 1909) et peut soit figurer comme modifieur d'un verbe transitif, soit comme seul complément du verbe dans son emploi absolu. Acheter ferme appartient au langage du marketing et du commerce (exemple de 1935). Le dernier exemple du CW montre l'emploi accordé en fonction de prédicat second ; ferme a ici le sens de 'consistant, assez dur, qui a la chair ferme'. Nous citons acheter ferme comme représentant d'une série de verbes : accepter / parier / ponter / prendre / vendre ferme. Notons l'emploi de payer comptant.

\section{Acheter frais}

Acheter des produits de date récente

Transitif

1911 Il avait déjà fallu changer quatre fois le bouquet du vase. Levé tôt le matin, il courait l'acheter tout frais. Chaque fois, il prenait la botte plus grosse, et le surplus mis de côté, un jour qu'elle en respirait le parfum, il fut bien forcé de le lui donner (Charles-Ferdinand Ramuz, Aimé Pache, peintre vaudois)

Emploi absolu

1955 J'achète frais, j'achète appétissant, j'achète sain parce que j'achète sous cellophane (Paris Match [publicité] / Grundt : 258) 


\section{CORPUS WEB :}

Cueillir le cassis bien mûrs au mois de juillet ou l'acheter frais sur son marché [http:// cuisinedelali.canalblog.com/archives/2005/08/ 15/725986.html] (4.5.2016)

Tout au long du week-end, le hareng sera roi et le public pourra l'acheter frais ou grillé le long des quais [http://www.paris-normandie.fr/ detail_article/articles/PN-1103242/poisson-fraispoisson-grille-1103242\#.Vynqe01f2Uk] (4.5.2016)

Le mieux pour qu'un café reste frais c'est déjà... de l'acheter frais ! [https://javry.com/ posts/comment-conserver-son-cafe-en-grains] (4.5.2016)

j'adore la choucroute, et je l'achète fraîche, c'est bien meilleurs que toutes ses boîtes à la noix [http://lechaudrondetaka.canalblog.com/ archives/2011/09/13/22024180.html] (25.10.2013)

REMARQUES : Frais peut être analysé, d'une part, comme un adverbe de manière qui s'emploie dans le domaine de l'alimentaire ou de la botanique et réfère à l'acquisition de produits nouvellement récoltés, qui n'ont subi aucune altération et destinés à être consommés ou servis en l'état. Frais est alors le modifieur d'un objet interne ('ce que l'on achète est frais') ou, sur un plan plus abstrait, un type de comportement, qui se rapproche d'une lecture comme façon d'acheter. Dans cet emploi, frais reste invariable et peut complémenter un verbe transitif (ex. de 1955). D'autre part, il se prête également à une analyse en tant que prédicat second orienté vers l'objet (exemple de 1911). Dans cet emploi, il s'accorde en genre et nombre avec l'objet (v. aussi les exemples du CW). Il est modifié par tout. Notons que l'exemple de 1955 contient aussi les groupes acheter appétissant ('acheter des produits appétissants, qui donnent envie de manger') et acheter sain.

\section{Acheter intelligent}

Acheter (des produits) judicieusement, bien mesurer leur utilité réelle en faisant preuve d'une conscience écologique $\lambda$ acheter juste, bronzer idiot

\section{Acheter juste}

Acheter de manière fondée et pertinente Emploi absolu

1951 Achetez juste et intelligent [c'est-à-dire des melons dans la saison des melons] (Elle, 30 septembre 1951 / Grundt : 362)

\section{CORPUS WEB :}

Commerce équitable : juste acheter ou acheter juste ? [http://www.ac-grenoble.fr/armorin. crest/beespip3/spip.php?article193] (4.5.2016)

Acheter juste et en toute sécurité [http:// www.lemoniteur.fr/articles/acheter-juste-et-entoute-securite-28145743] (4.5.2016)

Je suis maudite des ballerines en ce moment je crois ! J'ai pris la fâcheuse habitude de les acheter juste juste à ma taille car je déteste les perdre quand le cuir se détend... sauf que le cuir ne se détend pas toujours [http://fashion. world.free.fr/archives/tag/repetto/index-7.html] (5.5.2016)

chaussures en plastique pour rivière ou plage neuves t23 (ne chaussent pas grand), marque tribord, jamais servi car achetées justes, petit crans en dessous pour éviter de glisser, semelle assez épaisse en plastique à l'intérieur qui peut s'enlever [https://www.leboncoin.fr/ chaussures/809930100.htm] (5.5.2016)

Remarques : Dans l'exemple de 1951, acheter juste réfère à l'acquisition judicieuse de produits corrects. Il s'agit d'un slogan publicitaire qui contient également acheter intelligent. Plus récemment (premier exemple du $\mathrm{CW}$ ), il inclut un certain intérêt pour l'écologie ou le commerce équitable. Cet exemple joue avec la polysémie de juste, qui signifie 'seulement, ne faire autre que' en antéposition (juste acheter). Il reste invariable et peut modifier un verbe dans son emploi absolu. Dans le troisième et le quatrième exemple $\mathrm{du} \mathrm{CW}$, juste réfère à des chaussures trop serrées et fonctionne ainsi en tant que prédicat second orienté vers l'objet. Juste est alors accordé avec l'objet au pluriel (dernier exemple). Notons aussi l'emploi de chausser grand dans le domaine de l'habillement. 


\section{Acheter malin}

Faire un achat réfléchi, en comparant les prix et en tenant compte des promotions

入 bronzer idiot

\section{Acheter prudent}

Acheter avec précaution, avec prudence

Emploi absolu

2020 Offres de sécurité : achetez prudent. Dans le contexte de menaces actuel, il est plus important que jamais d'investir dans les bons outils et technologies de sécurité (Le Monde informatique, consulté en ligne le 20.10.2020)

REMARQUES : Achetez prudent est ici une traduction de l'anglais buy smart (généralement plutôt traduit par acheter malin)

\section{Acheter réfléchi}

Acheter après réflexion, en connaissance de cause

$\lambda$ acheter beau

\section{Acheter responsable}

Acheter des produits qui respectent

l'environnement

入 bronzer idiot

\section{Acheter sain}

Acheter des produits sains, bons pour la santé Emploi absolu

\section{Corpus Web :}

J'ai une vie saine et équilibrée, je cuisine beaucoup et surtout des légumes, j'achète sains et rien d'industriel [http://bebe.doctissimo.fr/ blog/4361-Ca-se-passe-tres-bien-chez-McDonalds.html] (25.10.2013)

REMARQUES : Accord curieux de sain, peut-être motivé par « légumes ». Voir également une occurrence d'acheter sain sous acheter frais.

\section{Acheter sérieux}

Acheter quelque chose de sérieux, de valable Emploi absolu

1981 Achetez sérieux. Flaine. La vraie propriété (Le Figaro magazine)

\section{Acheter solidaire}

Acheter en pensant au bénéfice des autres, notamment des défavorisés

Emploi absolu

2013 Achetez solidaire ! Achetons solidaire! En cette fin d'année, choisissez Frère des Hommes pour acheter vos cartes postales (http://fdh.org/Achetez-solidaire.html / Corpus Coiffet 2018 : s.v.)

\section{Acheter utile}

Acheter le strict nécessaire

Emploi absolu

2013 Non, non ! Tu achètes utile, et c'est tout ! Avec le budget qu'on a, pas de gadgets qui servent à rien et tout ! C'est toujours le même problème chez IKEA ! (Exemple entendu / Corpus Coiffet 2018 : s.v.)

\section{Acheter vil}

Acheter quelque chose à bon marché, à bas prix Emploi absolu

+1249 Dou bleif ameiz la grant vendue, Et chier vendre de ci au tans Seur lettre ou seur plege ou seur nans, Vil acheteir et vendre chier Et uzereir et gent trichier Et faire d'un deable deus Por ce que enfers est trop seux (Rutebeuf, Poèmes [pièces datables de 1249 à 1272], I, p. 507, 299)

REMARQUES : Dans l'ancienne langue, acheter vil caractérise l'acquisition d'objets à bon marché (v. l'expression à vil prix). Notons l'emploi de vendre cher. VOIR AUSSI : vendre petit

\section{Achever seul}

Achever, compléter une chose sans assistance externe

Emploi absolu

1634 Après achève seul, je ne puis sans supplice Forcer ici mes bras à te faire service, Et mon reste d'amour en cet enlèvement Ne peut contribuer que mon consentement (Pierre Corneille, La Place royale)

1663 ARNOLPHE. Vous achèverez seule; et, pas à pas, tantôt Je vous expliquerai ces choses comme il faut. 
Je me suis souvenu d'une petite affaire : Je n'ai qu'un mot à dire, et ne tarderai guère (Molière, L'École des femmes)

1664 LA PRINCESSE. Achevez seules, si vous voulez. Je ne saurois demeurer en repos ; et quelque douceur qu'aient vos chants, ils ne font que redoubler mon inquiétude (Molière, La Princesse d'Élide)

1836 Tous les beaux discours qu'ils me pourraient débiter n'y feraient rien. Je sais d'avance ce qu'ils vont dire, et j'achèverais toute seule. Je les ai vus étudier leurs rôles et les repasser avant d'entrer en scène ; je connais leurs principales tirades à effet et les endroits sur lesquels ils comptent (Théophile Gautier, Mademoiselle de Maupin)

Transitif

1704a Bien plus, après avoir commencé les choses que nous savons par cœur, nous voyons que notre langue les achève toute seule longtemps après que la réflexion que nous y faisions est éteinte tout à fait ; au contraire la réflexion, quand elle revient, ne fait que nous interrompre et nous ne récitons plus si sûrement (Jacques-Bénigne Bossuet, De la connaissance de Dieu et de soi-même)

1842a La vie me pesait; je regrettais parfois que la maladie m'eût épargné. Malvina cherchait bien à me distraire, mais la mélancolie était la plus forte. Notre jeune docteur devait seul achever ma guérison. Il faut vous dire que nous nous étions étroitement liés (Louis Reybaud, Jérôme Paturot à la recherche d'une position sociale)

1842b Puisque la seule enfant qui pouvait sur la terre

Étreindre ma pensée et toutes ses splendeurs

A refusé sa lèvre au fruit qui désaltère

Et comme un vieux haillon rejeté mes grandeurs,

J'achèverai tout seul ma course solitaire,

Et nul ne connaîtra mes sourdes profondeurs

(Théodore de Banville, Les Cariatides)
1843 Après avoir parlé ainsi avec une remarquable volubilité, le docteur remit son masque, salua profondément Consuelo, et se retira, la laissant achever son souper toute seule si bon lui semblait : elle n'était guère disposée à le faire (George Sand, $L a$ Comtesse de Rudolstadt)

1845 - Vous le voyez, reprit Rodin d'une voix si épuisée qu'elle devint bientôt presque inintelligible, la punition commence déjà... un... des Rennepont est mort... et... songez-y bien... cet acte de décès... ajouta le jésuite en montrant le papier que le père d'Aigrigny tenait à la main, vaudra un jour quarante millions à la compagnie de Jésus... et cela... parce que... je vous... ai... Les lèvres de Rodin achevèrent seules sa phrase (Eugène Sue, Le Juif errant)

1848 16. Bataille de Waterloo. Le 18 juin 1815, vers midi, je sortis de Gand par la porte de Bruxelles ; j’allai seul achever ma promenade sur la grande route. J'avais emporté les commentaires de César et je cheminais lentement, plongé dans ma lecture (François de Chateaubriand, Mémoires d'outre-tombe)

1851 - Ils sont tous amoureux de ma maîtresse, et je crois bien que le vicomte en est fou. Amaury tourna le dos brusquement, et laissa Julie achever seule ses commentaires (George Sand, Le Compagnon $d u$ Tour de France)

1872 M. Michelin achevait tout seul, à l'autre bout de la pièce, une terrine de foie gras dont il avait réussi à s'emparer (Émile Zola, La Curée)

1885 Mais quelle mort ! La chair, misérable martyre,

Retourne par son poids où la cendre

l'attire,

Vos corps sont revenus demander des linceuls :

Vous les avez jetés, dernier lest, à la terre, Et, laissant retomber le voile du mystère, Vous avez achevé l'ascension tout seuls ! (Jules Lemaître, Les Contemporains) 
1921 Avec Mme de Stermaria, cette après-midi, que j'allais achever seul, me paraissait bien vide et bien mélancolique (Marcel Proust, Du côté de Guermantes 2)

1929 LE JAPONAIS. Seigneur Rodrigue, vos paroles m'empêchent de dessiner. J'ai compris ce que vous vouliez. J'ai établi vos repères. La chose ne vous appartient plus et si vous permettez, je l'achèverai tout seul.

DON RODRIGUE. Tâche du moins de ne pas me rater ça, comme tu avais fait du saint Georges. Tu n'y avais rien compris, mon pauvre vieux

(Paul Claudel, Le Soulier de satin)

Pronominal

1704b Et il en arriveroit à peu près de même que dans la respiration, que nous pouvons suspendre par la volonté quand nous veillons ; mais qui s'achève pour ainsi dire toute seule par la simple disposition du corps, quand l'ame le laisse agir naturellement, par exemple dans le sommeil (Jacques-Bénigne Bossuet, De la connaissance de Dieu et de soi-même)

\section{CORPuS WeB :}

Concrètement, je pense qu'il ne sert à rien que quelqu'un se désigne comme responsable d'un projet qui ne lui tient pas à cœur, ou dont il sait pertinemment bien au départ qu'il ne pourrait pas techniquement l'achever seul (« seul » voulant dire ici sans qu'il n'ait lui-même la garantie que quelqu'un d'autre qui lui est proche l'aidera) [http://linux-bruxelles.bxlug.narkive.com/ TqG49TRE/postes-a-responsabilite] (5.5.2016)

Par exemple en laissant filer Jonathan Duhail, pour profiter d'une poursuite menée à trois. Et achevée seul dans la grande montée menant à Saint-Sernin-du-Bois. «J'ai recollé au ravitaillement, vers le 12e kilomètre » [http:// www.lejsl.com/sport-local/2015/03/09/un-bou quet-a-la-verrerie] (5.5.2016)

À seize ans, elle se fait modèle puis danseuse espagnole pour échapper à la monotonie de la maison meublée tenue par sa mère et elle achève seule son instruction par la lecture [http:// www.secondemain.ca/acatalog/Secondemain Nin_Ana_s_7460.html] (5.5.2016)
REMARQUES : Seul peut être analysé comme un adjectif-adverbe de manière qui désigne le fait de mener à terme une entreprise, une action, un plan, ou un repas, le sujet pouvant être un objet ou une personne qui, sans aide quelconque, sans compagnie, parvient à venir à bout du processus en cours. Dans son emploi pronominal, il désigne la manière spontanée, presque naturelle dans l'action. Il se prête également à une analyse en tant que prédicat second orienté vers le sujet. Il ne s'agit néanmoins pas d'un simple prédicat second, puisqu'il exprime plutôt une manière d'effectuer une action 'sans aide' ou, si l'on veut, une circonstance. L'accord avec le sujet du verbe est systématique. C'est un des cas où l'usage et la correction linguistique admettent l'accord. L'accord aide à différencier « Les lèvres de Rodin achevèrent seules sa phrase " de "Les lèvres de Rodin achevèrent seule sa phrase ». Seul est souvent renforcé par tout.

\section{Aconter petit}

Accorder peu d'importance à quelque chose Transitif

1365 Pas ne doit avoir honte créature vivant De faire son pourfit, en loyauté régnant Et j'aconte petit aussi, au remanant, S'on me moque de chou que requier le marquant (Li Romans de Bauduin de Sebourc, Chant II, 836)

REMARQUES : L'ancien français emploie petit comme quantifieur, remplacé par peu dans l'usage moderne, exprimant une petite quantité. Au figuré, il désigne le fait d'accorder peu d'importance ou de valeur à quelque chose ou à quelqu'un, le sujet montrant peu d'estime ou affichant peu de considération.

\section{Acostumer bel}

Habiller d'une manière raffinée, élégante Transitif

-1100 Tant i plurat e le pedra e la medra E la pulcela que tuz s'en alasserent. En tant dementres le saint cors conreierent Tuit cil seinur e bel l'acustumerent : Com felix cels ki par feit l'enorerent ! (Vie de saint Alexis [fin $\mathrm{xI}^{\mathrm{e}}$ ], BFM, 499) 
REMARQUES : En ancien français, acostumer bel est l'équivalent du tour moderne habiller beau. L'adjectif-adverbe de manière adopte la forme neutre bel. Sa fonction adverbiale ne fait donc pas de doute.

Acoudre fort

入 coudre fort

\section{Adestrer ferme}

Conduire, accompagner quelqu'un contre son gré, avec force

Transitif

1250 LI PREECIERES. Puis prisent et l'image et lui,

Mout ferm l'adestrerent et tinrent, Tant que il devant le roy vinrent, Qui mout fu liés de le victoire (Jehan Bodel, Jeu de saint Nicolas, 25 [prologue])

REMARQUES : Dans l'ancienne langue, adestrer ferme caractérise l'action de marcher fermement à côté d'une personne, et par extension, de la guider, l'amener vers un lieu ou une personne, avec fermeté. Il est invariable et est modifié par moult.

\section{Adorer fort}

Vénérer, aimer profondément

$\lambda$ adorer haut

\section{Adorer haut}

Vénérer, aimer profondément, d'un amour

supérieur, pur

Pronominal (réciproque)

1868 Je veux que nous nous adorions plus loin et plus haut, au-dessus des amours vulgaires et convenues de la foule, dans une tendresse absolue qui n'ait point le souci des misères et des hontes d'ici-bas (Émile Zola, Madeleine Férat)

Transitif

1891 L'argent, l'argent roi, l'argent dieu, au-dessus du sang, au-dessus des larmes, adoré plus haut que les vains scrupules humains, dans l'infini de sa puissance ! (Émile Zola, L’Argent)

\section{CORPUS WEB :}

Il n'y a pas d'aussi grand amour que celui que l'on donne. S'aimer oui, mais s'adorer haut et fermement ; ca tue la beauté de l'amour ; ca tue l'amour de la beauté [http://pasc-a-parle. blogspot.co.at] (5.5.2016)

Donc la saison commence. Bonheur incomparable pour la multitude, même les marioles de la politique qui détestent ça, ne peuvent pas faire autrement que d'adorer haut et fort et partout où ils peuvent le proclamer [http://www.richard3. com/2007/08] (5.5.2016)

Grosse surprise avec The Streets que j'avais découvert sur Skyrock quand j'avais 13 ans. Autant dire que je ne savais pas à quoi m'attendre. Je peux aujourd'hui les adorer haut et fort après le set tout simplement énorme qu'ils nous ont offert [http://www.aparté.com/2011/10/festivalfestival-internacional-de-benicassim-2011] (5.5.2016)

Tout mimi ses cupcakes, Emilie les adore hauts en couleurs, et vous les personnalise selon vos désirs ! Mais attention uniquement sur commande [http://boopsleblog.wordpress.com/ 2012/11/12/les-cupcakes-et-nous] (12.11.2013)

REMARQUES : Haut est un adjectif-adverbe de lieu qui a un sens spatial et désigne un point élevé. Avec une interprétation de degré, il réfère au fait d'aimer une personne d'une manière supérieure et pure, voire divine ou au fait de vénérer, de vouer un culte à une chose, telle l'argent dans l'exemple de 1891. Il reste invariable (ex. de 1868) et est modifié par plus. La collocation plus loin et plus haut met en évidence la vitalité métaphorique des concepts locaux associés à loin et haut. Notons également la collocation haut et fort. L'accord est possible quand haut devient un prédicat second orienté vers l'objet direct (dernier exemple du CW). VoIR AUSSI : adorer bas, aimer profond

\section{Adresser droit}

I. Se diriger directement, en ligne droite (vers quelque chose / quelqu'un)

Intransitif

1175 D'iloec les voient assanler, La tere bondir et tranler Öent d'iluec benignement, Et voient tot apertement 
Ces chevaliers droit adrecier,

Et ces escus fraindre et percier,

Ces haubers rompre et desconfire

Chevaliers navrer et ochire

(Gautier d'Arras, Ille et Galeron, 5805)

II. Se dresser, s'élever

Pronominal

1285 Moult doucement au commencier

Se conmença a adrecier

Tout droit encoste la grant tour

(Adenet le Roi, Cleomadés, 5181)

1628 MESSAGER. Droit à luy s'adressa la route que tenoit

Un royal Galion, qui de Sidon venoit, Dans lequel un Seigneur, qu'ils appellent Balorte,

Est chargé d'ambassade et de preuve tres-forte

Pour du fait de Leonte esclaircir nostre Roy (Jean de Schélandre, Tyr et Sidon)

III. Diriger son regard exactement, précisément Transitif

1526 Ung grant courcier sur lequel proprement Estoit ung Roy, armé triumphamment, Lequel avoit

La main en l'aer, dont le peuple disoit Que celluy Roy Venise menassoit

Et qu'ainsi soit, son regard adressoit

Droit comme picque

Vers les climatz de mer Adriatique,

En demonstrant que celle main bellique

Corrigeroit l'arrogance publique

Venitienne

(Jean Marot, Le Voyage de Venise)

IV. Expédier une chose directement

Transitif

1675a Il y a trois semaines que je vous écrivis et vous envoyai trois ou quatre lettres de recommandation pour l'affaire de M. Levasseur. J'adressai le paquet droit chez vous, et comme je n'en ai point eu de réponse, j'en suis en peine et meurs de peur qu'il n’ait été perdu (Mme de Sévigné, Correspondance)

1675b Il m'a fait mille compliments par Bandol ; je lui en ai rendu par la même voie et j'ai adressé la lettre droit à Aix. En voilà une de votre évêque, vous y verrez toujours les mêmes précautions ; il ne veut pas être pris par le bec. Nous verrons un peu sa manière de peindre (Mme de Sévigné, Correspondance)

V. Se tourner vers quelqu'un directement, pour lui parler et obtenir de lui quelque chose

Pronominal

1845 Dans cette perplexité, l'idée m'est venue de m'adresser tout droit à votre Grandeur, parce qu'on m’a dit que sa bonté égalait sa puissance, qu'elle avait l'esprit élevé et le cœur vraiment apostolique. J'ai eu foi en elle et j'ai osé (George Sand, Correspondance)

CORPUS WEB :

Halte aux magouilleurs, gameleurs, enfumeurs, frondeurs... Il faut s'adresser droit dans les yeux au peuple et non aux socialistes pas très à l'aise, en ce moment, dans leurs fauteuils de sénateurs et de députés [http://www.pcf.fr/58320] (7.5.2016)

Les thèmes et les rythmiques réussissent systématiquement à trouver une accroche efficace pour s'adresser droit au corps et au cour, quand bien même on ne saurait trop conseiller à ceux qui n'ont jamais écouté Zita Swoon d'entamer ailleurs leur pèlerinage [https:// www.playlistsociety.fr/2011/05/zita-swoongroup-dancing-with-the-sound-hobbyist/14979] (7.5.2016)

Elle dit toujours ce qu'elle pense en regardant la personne a qui elle s'adresse droit dans les yeux [http://blog.tvmag.lefigaro.fr/secretstory/2009/09/-et-cest-parti-pour.html] (7.5.2016)

Remarques : Droit est un adjectif-adverbe de manière-direction. Il est modifié par tout. Droit a tendance à s'associer avec des prépositions qu'il précède (à, dans, encoste, vers) au point de faire partie du groupe prépositionnel comme modifieur de la préposition, notamment dans la locution droit dans les yeux. Droit reste invariable (ex. de 1845, où le sujet correspond à l'auteure, George Sand).

\section{Affirmer clair}

Affirmer clairement

$\lambda$ affirmer haut 
Affirmer fort

Affirmer fortement

$\lambda$ affirmer haut

Affirmer haut

I. Affirmer sans ambages

Transitif

1912 Ils affirment bien haut qu'ils ne veulent admettre dans la pensée que des idées claires et distinctes ; - c'est en fait une règle insuffisante pour l'action, car nous n'exécutons rien de grand sans l'intervention d'images colorées et nettement dessinées, qui absorbent toute notre attention ; - or peut-on trouver quelque chose de plus satisfaisant que la grève générale à leur point de vue ? (Georges Sorel, Réflexions sur la violence)

1989 Je l'affirme haut et fort : qui ne s'est jamais retrouvé à poil devant son éditeur, sous l'œil de feu Vittorio de Sica, pendant qu'un ex-ministre de l'Intérieur pousse des petits cris autour de lui, ignore tout de la honte (Daniel Pennac, La Petite Marchande en prose)

1996 Néanmoins, ses yeux de myope nous scrutaient. Plus que ceux de Lupin, au lycée. Qui, un jour, malgré tout, en pleine classe : «Vous, Schreiber, vous seul ici, auriez une chance d'intégrer à Normale Supérieure. » Il l'affirmait haut et clair ; pourtant Boris et moi l'irritions maintes fois. Boris et moi, prince régnant. Au visage d'ange, selon Parrault (Boris Schreiber, Un silence d'environ une demi-heure)

II. Affirmer à voix haute, de manière distincte Transitif

1921 Infirmité plus morale peut-être qu'intellectuelle : au fond, et comme nous l'avons déjà montré plusieurs fois, il a peur de la lumière. Quand l'incertitude le prend, il affirme un peu plus haut, comme d'autres chantent pour se donner du courage (Henri Bremond, Histoire littéraire du sentiment religieux en France)

1935 Un mieux ! Voir un peu, sortir du néant ! Il en éprouvait un choc dans la poitrine, de penser à ces choses. Il s'arrêta, affirma tout haut, dans son abstraction :

- Il me faut ces douze séances... Une espèce d'écho nasillard lui avait répondu (Maxence Van der Meersch, Invasion 14)

1956 Le 20, le colonel de Chevigné le répétait à Maccloy. Le 23, Philip et Tixier l'affirmaient très haut à Roosevelt. Le 16 novembre, j'avais été voir MM. Churchill et Eden, qui m'avaient prié à un entretien dès qu'était parvenue à Londres la proclamation de Darlan annonçant qu'il gardait le pouvoir au nom du maréchal et avec l'accord des alliés (Charles de Gaulle, Mémoires de guerre)

\section{CORPUS WEB :}

Face à la \#rumeur : "L'affirmer haut et fort va-t-il suffire à convaincre et surtout à rassurer les patients ? » [https://twitter.com/paulinerichoux/ status/705502887296765954] (7.5.2016)

" Offrir une parole et un espace pour affirmer haut et fort la présence légitime des Juifs en France » [http://www.crif.org/fr/actualites/ $\% \mathrm{C} 2 \% \mathrm{AB}$-offrir-une-parole-et-un-espace-pouraffirmer-haut-et-fort-la-pr\%C3\%A9sence-1\%C3\% A9gitime-des-juifs-en-france- $\%$ C2\%BB/55321] (7.5.2016)

L'auteur, qui emmène le lecteur au cœur des débats politico-culturels ayant façonné l'identité irlandaise depuis l'indépendance, explore la voie culturelle irlandaise unique qui se dégage des traditions intellectuelles européennes qui ont été imposées à ce pays mais ne l'ont pas éloigné d'un certain culturalisme exclusif consistant à affirmer haut et fort la spécificité de sa culture à l'heure d'une mondialisation uniformisante [https://www.unicaen.fr/puc/html/articlea639. html?id_article=800] (7.5.2016)

»Il allait ainsi, inverser la tendance et $a f$ firmer haute et fort l'émancipation de la femme [http://www.babnet.net/festivaldetail-9772.asp] (7.5.2016)

REMARQUES : Haut est un adjectif-adverbe de lieu qui a un sens spatial et désigne un point élevé. $\mathrm{Au}$ figuré, avec une interprétation de manière, il désigne l'affirmation précise d'une conviction, manifestée à voix haute, voire, d'une voix forte, de manière distincte et perceptible, voire 
de parler sans ambages. Il reste généralement invariable (ex. de 1936, et les deuxième et troisième exemples du CW, mais il porte l'accord avec l'objet dans le dernier exemple du CW) et est modifié par bien, tout, très, un peu plus. Affirmer haut peut prendre un complément nominal (exemple de 1936) ou un complément phrastique introduit par que (exemple de 1978). Notons l'occurrence des collocations haut et clair, ainsi que de haut et fort.

\section{Affonder bas}

Sombrer profondément Intransitif

+1400 Peine esmonder, Joye abonder, Tout marchander, Et dueil seder, Bas affonder, Et reffonder, Bel regarder, Voir recorder, Sanz point bourder, Pais accorder, Non descorder, Droit recorder Pour amender, En sens fonder Et perfonder (Christine de Pisan, Lays / Euvres poétiques [début Xve], I, p. 128, 80)

Remarques : Bas s'emploie comme un adjectif-adverbe de lieu qui indique la direction, partant d'un niveau supérieur vers un niveau inférieur, au sens concret et aussi au sens figuré. Il réfère ici à l'effondrement physique ou moral du sujet, celui-ci, par dépit, en raison d'une tristesse profonde, perdant toute énergie de lutter, cessant de lutter. La citation contient une série de constructions parallèles : bel regarder, voir 'vrai' recorder, droit 'correctement' recorder.

\section{Agir global}

Agir au niveau de la planète $\lambda$ penser global

\section{Agir local}

Agir au niveau local

$\lambda$ penser global

\section{Agir net}

Agir sans hésitation

Intransitif

1933 Cela vint comme un tourbillon et passa aussi vite, parce qu'Augustin vit un urgent devoir d'en arracher sa pensée. Il fallait voir clair, agir net, dans toute la partie du traitement où il était possible d'agir. Toutes ces réflexions n'avaient pas grand sens (Joseph Malègue, Augustin ou Le Maître est là)

REMARques : Net est un adjectif-adverbe de manière qui s'emploie dans une situation où le sujet passe à l'action ou prend une mesure, une décision d'une manière claire et catégorique. Il traduit une certaine détermination dans la prise de décision ou dans l'action. Notons l'emploi en série avec voir clair.

\section{Agir vrai}

Agir avec sincérité

入 penservrai

\section{Agiter bas}

I. Tourmenter, troubler, inquiéter en secret Transitif

1560 Voilà désja la foy opprimée et esteinte. Car vaguer, varier, estre agité haut et bas, douter, vaciller, estre tenu en suspens, finalement désespérer, n'est pas avoir fiance (Jean Calvin, Institution de la religion chrestienne)

1794 Écoute, jeune ami de ma première enfance, Je te connais. Malgré ton aimable silence, Je connais la beauté qui t'a contraint d'aimer,

Qui t'agite tout bas, que tu n'oses nommer (André Chénier, Élégies)

1900 Nos sens, nos sens divins sont de beaux enfants nus

Jouant aux vagues d'or des vieilles mers païennes,

Innocents, radieux, ivres, les deux mains pleines

Des fruits juteux cueillis aux jardins ingénus.

Pensive et poursuivant ses antiques chimères 
Lâme assise non loin surveille leurs ébats ; Parfois son doigt se lève et commande et, tout bas,

Elle agite en son cœur l'espérance des mères (Albert Samain, Le Chariot d'or)

\section{Remuer dans tous les sens}

Transitif

1653 Mais comme il vous souvient, cette heureuse bonace,

Changée en un moment aux tempestes fit place.

Aprez le premier choc qui la flotte écarta, Les vaisseaux que le vent vers Damiette porta,

Haut et bas agitez, souffrirent sans naufrage,

Tout ce que peut l'esprit qui regne dans l'orage (Pierre Le Moyne, Saint-Louys)

III. Être débattu, discuté

Pronominal

1850 Non, le drame ici n'est pas restreint à la vie privée, il s'agite ou plus haut ou plus bas. Ne vous attendez pas à de la passion, le vrai ne sera que trop dramatique (Honoré de Balzac, Les Paysans)

REMARQUES : Bas est un adjectif-adverbe de lieu qui exprime la direction, partant d'un niveau supérieur vers un niveau inférieur. Au sens figuré, il peut aussi être interprété comme un adjectif-adverbe de manière qui réfère à l'état secret, non-communiqué d'un fait ou d'un sentiment. Ici, il s'utilise dans les contextes suivants : En (I), il se dit d'un sentiment qui trouble, excite le sujet mais qui est dissimulé, non communiqué. En (II), dans la collocation haut et bas, il désigne le fait de branler, secouer dans tous les sens (ici : un navire). Dans son emploi pronominal (III), il réfère à une chose (ici : un drame) mise en discussion dans un groupe et qui, parfois, peut faire sujet de débat, voire de dispute. Bas est souvent coordonné avec l'adjectif-adverbe haut avec lequel il constitue une opposition sémantique désignant les points extrêmes d'un mouvement. Haut et bas sont invariables (ex. de 1653, 1900) et ils peuvent être modifiés par plus, tout.

\section{Agiter haut}

Bouleverser

$\pi$ agiter bas

\section{Aimer bas}

I. Aimer quelqu'un qui se trouve dans une situation sociale ou hiérarchique inférieure Emploi absolu

1275 Adonc li respon Blanchandine : Dame, si comme Amors destine Covient amer, soit haut ou bas Ele ne s'i regarde pas

(Floriant et Florete, 3823)

1560 Ou quand on aime bas, jamais on n'est épris (Pour estre seule à seul) de crainte d'estre pris ;

Ou bien s'on est surpris, ce n'est que moquerie Qui n'apporte jamais querelle ny furie (Pierre de Ronsard, Élégies, p. 282)

1596 Et à l'autre un beau teint donne mortelle atteinte ;

L'un transira de froid, l'autre mourra de chaud ;

L'un compare aux rochers celle qui le tourmente,

Lautre fait de sa dame une lune inconstante ;

L'un se plaint d'aimer bas, l'autre d'aimer trop haut (Philippe Desportes, Euvres)

1913 « Ne sais-tu pas qu’un poète français a dit que, pour avoir ses ébats, on devait aimer bas ? » Et voilà comme je respecte et protège celle que j'aime. Ah ! Seule, une réparation publique, éclatante ! (Valéry Larbaud, A.O. Barnabooth)

II. Aimer discrètement, secrètement Transitif

1857 Les moralistes indigènes se plaignent de tous les excès commis dans la campagne, comme un père déplore les fredaines de son fils. On le gronde tout haut, on l'aime tout bas ; on serait bien fâché qu'il ressemblât au fils du voisin, qui n'a jamais fait parler de lui (Edmond About, Le Roi des montagnes) 


\section{CORpus Web :}

En fait je prefere optique que laser puisque la sensibilité je l'aime basse, et parce que j'ai tendance à soulever ma souris (d'après le topic apprivoiser une souris, c'est important de faire gaffe) [http://www.jeuxvideo.com/forums/1-611155919-2-0-1-0-sc2-steelseries-kana-ou-razerimperator.htm] (11.11.2013)

c'est une modification qui peut se faire dans le sens inverse en + donc pour ma part celui qui l'aime basse et bien c'est son affaire et si un jour il la vend, le prochian pourra la réhausser sans rien abimer [http://e12e28.forumperso.com/ t250p120-ma-mesrine-mobil] (11.11.2013)

REMARQUES : Bas est un adjectif-adverbe de lieu qui exprime la direction, partant d'un niveau supérieur vers un niveau inférieur. En tant que modifieur d'aimer, il se prête à une interprétation de manière au sens figuré qui réfère aux sentiments qu'une personne éprouve pour quelqu'un d'autre, et à la façon de les exprimer. En (I), il désigne la situation sociale inférieure de la personne aimée. En (II), il traduit une certaine réserve dans la façon de montrer ses sentiments ou de les transmettre, c'est-à-dire de façon discrète, sans trop les dévoiler, voire les garder secrets.

Il reste invariable et est modifié par tout. Aimer bas apparaît combiné avec haut, ce qui souligne l'intensité ou le degré de la démonstration des sentiments. L'emploi comme prédicat second est possible (v. les exemples du CW dans lesquels le sens est 'de faible intensité'), et dans cet emploi, il s'accorde avec l'objet antéposé au verbe. En fait, les groupes lexicalisés aimer bas et aimer haut appartenaient à la langue ancienne où ils désignaient un comportement culturellement typé. Aujourd'hui, il ne reste plus que l'emploi en tant que prédicat second ou, éventuellement, le fait d'aimer secrètement (aimer tout bas). Notons l'emploi de gronder haut.

\section{Aimer bref}

Aimer sur une courte durée Transitif

+1400 Se vous me donnez congié

Par conseil de mesdisans,

Dame que servie j'é

Par l'espace de dix ans,
$\mathrm{Au}$ lit me mettrez gisans ;

N'oncques ne m'amastes brief,

Se vous me faites tel grief

(Christine de Pisan, Cent balades / Euvres

poétiques [début XVe], I, p. 84, 6)

CORPUS Web :

Je n'ai rien contre les scènes hot, mais je les aime brèves et suggestives [http://lesromantiques. yuku.com/topic/6652/201209-Nous-nousaimerons-demain\#.UoEFoPPkSUk] (11.11.2013)

REMARques : Bref est un adjectif-adverbe de temps qui traduit l'expression de sentiments sur une courte durée, surtout dans la langue ancienne. Bref s'utilise également en tant que prédicat second, et dans cet emploi, il s'accorde avec le sujet antéposé au verbe (CW).

\section{Aimer cher}

I. Aimer mieux

Transitif

+1200 Or me dites foit deuez

La riens q[ue] uos pl[us] ch[ier] amez

Et q[ue] die[us] ioie uos ameint

Ou la pl[us] bele dame meint

De soissons, la pl[us] bele oire

(Le Foteor, manuscrit D, 30)

1450 SIMON CRENËUS. Ha ! messeigneurs, pardonnez moy :

Pour riens jamais ne le feroye,

Car tant reprouchié en seroye

Que jamais jour n'aroye honneur.

Vous sçavez le grant deshonneur

Que c'est huy de la croix porter :

Certes, j'aymeroye plus chier

Mourir que faire tel office (Arnoul Gréban,

Le Mystère de la Passion, 24369)

1544 Mon œil feit ternir,

Mon ame finir,

Mon corps trebucher.

Mais mon maistre cher

N'a permis secher

Mon los, bruit et fame,

Car jadis plus cher

M'ayma chevaucher

Que fille ne femme

(Clément Marot, Épitaphes) 
1580 CREON. Les voici, les serpens, Les pestes, que j'aimois plus cher que mes enfans.

Avez-vous consenti à cette sepulture ?

ISMENE. Ce fut moy qui en eut la principale cure (Robert Garnier, Antigone)

II. Éprouver, par affinité naturelle ou élective, une forte attirance pour quelqu'un ou quelque chose ; accorder beaucoup d'importance, préférer de loin

Transitif

1344 LA Royne. Mon chier seigneur, s'a fait celui

Jehan que vous si chier amez, Qui vous et moy a diffamez

Si laidement.

LE Roy. Je m'en vengeray bien briément, Par Dieu qui fist et ciel et terre (Miracle de saint Jehan Crisothomes, 566)

1547 Car sache que, s'on ayme bien, On craint courroucer sa partie Aussi cher qu'on ayme sa vie (Le Conseil au nouveau marié / Ancien Théâtre françois)

CORPUS WEB :

- 14 ans : Plomb (on fait passer le message de ne pas aller voir ailleurs) -15 ans : Cristal (les goûts de merde continuent) - 16 ans : Saphir (on commence à s'aimer cher) Ah... la bourgeoisie !: 20 ans : Porcelaine (avec les goûts, les couleurs aussi sont à chier) [http://journal.gayattitude. com/2012/08/21] (14.5.2016)

ba nan avan ct pas bein komen el fezé mé mnt el a son pelo et ils s'aiment cher dc moi jrespecte ! [http://ced69lasseu.skyrock.com/profil/ wall] (14.5.2016)

Moi, mes dentifrices, je les aime chers et dégueulasses. Ouais bébé [https://twitter.com/ chamoi/status/66919385478070272] (11.11.2013)

ReMARques : Cher est un adjectif-adverbe de manière qui caractérise la valeur accordée à une personne ou une chose. Il est parfois affaibli sémantiquement (I), se rapprochant de préférer de loin. Il reste invariable, dans la plupart des cas. Il est modifié par aussi, si, plus. D’après les données de Frantext, il s'agirait d'un archaïsme de l'ancienne langue, mais le CW montre qu'aimer cher est toujours en usage. Il s'emploie également en tant que prédicat second. Dans cet emploi, il peut s’accorder avec l'objet antéposé au verbe (dernier exemple en CW)

\section{Aimer double}

Aimer deux fois plus

Transitif

1863 - Oui, cher frère, répondit Isabelle, vous la possédez, et ce m'est un bien grand bonheur que de pouvoir vous le dire. Vous avez en moi une sœur dévouée qui vous aimera double pour le temps perdu, surtout si, comme vous l'avez promis, vous modérez ces fougues dont s'alarme notre père, et ne laissez paraître que ce qu'il y a d'excellent en vous (Théophile Gautier, $L e$ Capitaine Fracasse)

1954 Quand un enfant est anormal il faut justement l'aimer double (Exemple entendu, 23 novembre 1954 / Grundt : 389)

REMARQues : Double est un adjectif-adverbe de degré qui réfère à la quantité, l'accent étant mis sur la quantité d'amour apportée à une personne, 'multipliée par deux'.

\section{Aimer ferme}

Aimer beaucoup et avec constance

Transitif

1450 JHESUS. Or te dy que jadis estoient Deux debteurs qui foison devoient De finance a ung usurier.

Les debtes de l'un qui restoient, Bien a cinq cens deniers montoient ; L'autre a cinquante en nombre entier. Or n'ont de quoy paier tous deulx Si leur quicte que riens n'y clame. Si te demande lequel de eulx Plus ferme son crediteur ame (Arnoul Gréban, Le Mystère de la Passion, 13940)

CORPuS Web :

Faire cuire les pâtes (pour ça je pense que tout le monde sait faire - personnellement je les aime ferme " al denté ») [http://www.savaou. com/pates-a-la-carbonara-pour-6-personnes] (11.11.2013)

pour les meringues

-blancs d'œufs montés en neige... pas besoin qu'ils soient super fermes, 
-50 à $60 \mathrm{~g}$ de sucre par blanc d'œuf et remélanger au batteur.

-fariner la plaque sinon ça colle et impossible à enlever

-faire des petits tas à la cuillère

four thermostat 2 ou $150^{\circ}$ pendant minimum $1 \mathrm{~h}$ si on les aime collantes ou $2 \mathrm{~h}$ si on les aime fermes [http://www.maximomes.org/forum/ printview.php?t=33994\&start $=0 \&$ sid $=61 \mathrm{fe} 45153 \mathrm{a}$ b35a419cca2717e7229166] (11.11.2013)

REMARQUES : Aimer ferme réfère à la quantité et à l'intensité dans la démonstration de sentiments, d'amour envers quelqu'un, sujet et objet étant animés. Il désigne le caractère constant de l'action. Il peut également référer à la consistance de quelque chose (ici de la nourriture). Dans ce cas-là il adopte une fonction de prédicat second, qui devrait être accordé avec l'objet direct, selon la norme, mais le premier exemple du CW reste invarié.

\section{Aimer figuratif}

Aimer, dans l'art, le genre figuratif

Emploi absolu

1960 M. Chu, chinois, peint abstrait mais aime figuratif (France-Soir, 9 avril 1960 / Grundt : 230)

REMARQUES : Figuratif réfère au goût prononcé pour un art qui s'attache à reproduire exactement l'apparence des objets représentés. L'interprétation est inférentielle puisque l'adjectif réfère à l'objet de l'amour et non pas à la façon d'aimer. Notons l'emploi de peindre abstrait.

\section{Aimer gavé}

Aimer beaucoup

Transitif

CORPus Web :

el franchemen je l'aime gavé sé ma sœur el tro belle je te fai dé gro bisous ma cheri [https: //marseillaisdu33320bogoss.skyrock.com] (4.1.2019)

elle é TJR la pr mwa elle voit dir'ect ke jvé pa bien ou si jvé bien !!! et moi je seré tjr la pr elle pask je l'aime gavé et el é belle gentil... laché dé... [https://miniprincess13.skyrock.com/2. $\mathrm{html}]$ (4.1.2019)

hoooo ma chiri calors ste mef je l'aime gavé elle me tro delire est elle est toujours la kan ta besoin d'elle de toute façon je ne vais po ecrire un roman je l'aime tout simplement [https://mllelolita.skyrock.com] (4.1.2019)

REMARQUeS : Gavé est un quantifieur en usage régional, ici du Sud-Ouest. VoIR AUSSI : gagner gavé

\section{Aimer haut}

I. Manifester un sentiment élevé et pur, différent de l'amour bas, éventuellement au sens d'un amour très fort

Emploi absolu

$\sim 1280$ En fame de tel vice esprise Ne soit ja ton entente mise : Nul ne doit tenir en chierté Fame esprise de tel fierté. D'amer haut ne t'esbahiz mie, Quer Ovide nous certefie (Vivien de Nogent, La Clef d'amour, 273)

1578 Las ! pour avoir aymé trop haut, Et n'avoir servi comme il faut, Amour ce tourment nous accorde De nous battre le sein de coups, Et vous crier à deux genoux Mercy, pardon, misericorde (Pierre de Ronsard, Mascarades, p. 190)

1629 CARDENIO. Pardon, chaste deesse, à mes voux innocens :

Si vous estes divine, il vous faut des encens,

Et si j'aime trop haut, accusez la nature Du pouvoir de vos yeux et du mal que j'endure.

Je ne pouvois, ma sainte, ensemble à vostre aspect Avoir l'ame sensible et garder le respect (Pichou, Les Folies de Cardenio)

1648 Aussi bien de vostre œil vous pourrez captiver

Les dieux les plus puissants et plus remplis de gloire,

Mais sans aimer trop haut, je desire trouver Mes lauriers asseurez en petite victoire (Nicolas Vauquelin des Yveteaux, Euvres poétiques)

1724 Pour moi, depuis que je ne sais plus aimer, il me semble que mon âme n'est plus qu'un 
faible reste de ce qu'elle était autrefois. Cependant je ne me plains point de l'amour, car, s'il m'avait laissé un cœur sensible, il m'aurait peut-être fait aimer si haut, qu'il m'aurait fallu mourir plutôt que d'avouer mon secret (Montesquieu, Correspondance)

II. aimer tout haut : aimer publiquement, ouvertement, au grand jour

Transitif

1879 Quel bonheur que j'aie été blessé et que je sois couché dans ce lit ! Je n’aurais jamais su qu'il m'aimait. Ah ! je crois qu'on eût mieux fait de m'aimer tout haut ! Il me semble qu'il me restera toujours, de ma vie d'enfant, des trous de mélancolie et des plaies sensibles dans le cœur! (Jules Vallès, Jacques Vingtras : L'Enfant)

\section{CORPUS WEB :}

Nous avions envie de sortir et de nous promener main dans la main, de flâner en amoureux dans les endroits publics, de nous aimer haut et fort à toute heure du jour [http://www.ellequebec. com/societe/psycho/j-etais-amoureuse-dun-homme-de-20-ans-mon-aine/a/25369/2 (15.5.2016)

je tends mon verre pour une goutte champagne.. le temps de trinquer pour tous ceux qui s'aiment haut et fort !!! [https://nelhia777. wordpress.com/2010/12/30/poesie-pour-lesamoureux] (15.5.2016)

Le romantique n'a t-il pas la trique quand il aime la femme par les mots ? Mais est ce qu'il l'aime haut comme ses mots ? [http://answers. yahoo.com/question/index?qid=20111221055419 AAnXMGO] (11.11.2013)

Certains l'aime haute, d'autres basse, les classique blanche et bleu, et les plus fun en rose, menthe à l'eau ou léopard, la converse est une institution, à la base destiné aux collégiens mais vite adopté par les fashionnistas la trentaine bien rempli ! [http://bigdollsboudoir.blogspot. co.at/2013/06/du-cas-de-la-converse.html] (11.11.2013)

REMARQUES : Haut est un adjectif-adverbe de lieu qui exprime la direction, partant d'un niveau inférieur vers un niveau supérieur. En tant que modifieur d'aimer, il se prête à une interpréta- tion de manière au sens figuré qui réfère (I) à des sentiments d'amour supérieurs, souvent secrets, opposés au désir de les exprimer, voire de les réaliser charnellement (amour bas). L'amour haut cristallise ainsi un idéal culturel lié à une époque. Dans l'exemple sous (II), cet idéal est réduit au fait de manifester ouvertement son amour. Cette acception est marquée par la collocation tout haut. En tant qu'adverbe, il reste invariable et est modifié par si, tout, trop. Les deux premiers exemples du CW expriment l'intensité de l'amour, notamment par la collocation haut et fort et l'emploi pronominal du verbe. Aimer haut apparaît parfois combiné avec bas (v. aimer bas). Le troisième exemple du $\mathrm{CW}$ renoue avec la valeur morale qu'avait aimer haut au Moyen Âge, mais l'emploi de trique 'pénis en érection' crée tout de même un contexte ambigu. L'emploi comme prédicat second fléchi est possible, comme dans le quatrième exemple du CW, où il réfère à une marque de chaussure en vogue (la Converse).

\section{Aimer moyen}

Aimer moyennement, plus ou moins

Transitif

2000 Les sous-chefs se mettent à prendre la parole à tour de rôle pour donner leurs commentaires : « j'aime moyen », «j'adhère plutôt », «je suis pas hyper-convaincu même si je saisis bien l'idée ", "c'est une piste à investiguer » (Frédéric Beigbeder, 99 francs)

2012 J'aime moyen coucher avec les garçons (corpus de films français / Bedijs 2012 : 251)

VOIR AUSSI : apprécier moyen

\section{Aimer petit}

Aimer peu

Transitif

-1200 Voit le li cuens, si le contrala : Par dieu, vasal, molt petit vos ama, Ki a Guillame joster vos envoia, Celui d'Orenge, ki ja repos n'avra (Aliscans [fin $\mathrm{XII}^{\mathrm{e}}$ ], 2188)

+1200 Quant li rois ot oi toute sa naissance et son estre, il dist a Merlin : «Merlins, tu amas 
moult mon pere et moult li fus loiaus, et il ne t'amoit mie petit. Tu sés de mon afaire plus que tout cil dou monde" (Merlin [1 $1^{\text {er }}$ quart XIII'], p. 162)

+1216 Par Mahomet qui tot fist et forma, Saces de voir que moult petit t'ama Qui ce vert elme en ton cief te laça ; S'adont te vit ja mais ne te verra, Et s'il te voit grans pités l'en prendra (Huon de Bordeaux, 5537)

\section{CoRpus Web :}

On a un pâton pas beau qu'on aplatit avec les mains, plus ou moins selon qu'on l'aime petit ou qu'on l'aime gros [http://fasgianu.eklablog. com/mco-236-le-fly-et-autres-bonnes-petiteschoses-a119389192] (15.5.2016)

Perso, la courgette je l'aime petite et crue, avec son croquant, ses vitamines, sa légère âpreté... cuite, je la trouve sans grand intérêt gustatif... [http://paladar-lepet.blogspot. co.at/2011_08_01_archive.html] (15.5.2016)

REMARQUeS : L'ancien français employait petit comme quantifieur au sens de 'peu'. Aimer petit réfère donc à un amour de faible intensité. Petit est modifié par moult ou la négation mie. Historiquement, moult (< lat. multum / multō) est aussi un adjectif-adverbe. Aujourd'hui, seul l'emploi comme prédicat second semble possible ; petit adopte alors son sens concret 'contraire de grand' et s'accorde avec l'objet antéposé au verbe (CW).

\section{Aimer plein}

aimer tout plein : aimer beaucoup, énormément Transitif

1546 Cor Dieu je le croy. Ce sera d'un beau petit enfantelet qu'elle sera grosse. Je l'ayme desja tout plein, et ja en suis tout assoty (François Rabelais, Tiers Livre)

1594 Ce sont bons Princes et bons Catholiques, et qui vous ayment tout plein (Satyre Ménippée)

1863 - Oh ! Je l'aime déjà tout plein. J'en suis féru ; il me la faut et je l'aurai, dussé-je pour y parvenir user des inventions les plus subtiles, vider mes coffres et pourfendre cent rivaux (Théophile Gautier, Le Capitaine Fracasse)
1882 - Vingt francs, vous savez bien ce que c'est que vingt francs, ne faites pas la bête, reprit Berthe. Donnez-nous vingt francs, et nous vous aimerons, oh! Nous vous aimerons tout plein ! (Émile Zola, Pot-Bouille)

1906 J'attends pour bientôt une lettre de vous, mon cher Monsieur l'Abbé, une lettre de réconciliation, et je vous promets d'y répondre dans les six jours. Ergo... croyez que je vous aime tout plein. Georges (Georges Bernanos, Lettres inédites)

\section{Corpus Web :}

hé, il est sympa ce Psyclon! très yelworC, mais la petite dimension cybergremlin ultravénèr ridicule décomplexé par-dessus est assez sympax, un petit côté happy hardcore d'épouvante, je commence à l'aimer tout plein, je sais pas si ça va durer... [http://www.gutsofdarkness. com $/$ god $/$ forum.php? page $=5 \&$ sujet $=14035$ ] (15.5.2016)

Virtuellement on peut aimer tout plein tout plein. Aucun risque de contamination vénérienne de rienne [http://www.auberge-espagnole. org/sources/voir_debat.php?no_debat=7464] (15.5.2016)

J'espère qu'elles vont vite trouver une bonne famille pour les aimer tout plein [http://www. clicanimaux.com/collecte-3100-sos-transport5-chiennes-a-sauver-avant-vendredi-soir-] (15.5.2016)

\section{Son envie m'électrise}

Mes bas frottent le haut de mes cuisses

Il les aime pleines

Et, à chaque marche, son désir, je le devine [http://www.lespoemes.com/forum/poeme-ero tique-f20/les-escaliers-t37325.html] (11.11.2013)

Remarques : Plein est un adjectif-adverbe de manière qui caractérise un sentiment qu'on éprouve pour une autre personne de manière entière et profonde. Plein exprime ainsi une intensité forte. Notons l'emploi absolu dans le deuxième exemple du CW. Toujours modifié par l'adverbe d'intensité tout, il reste invariable. Plein s'utilise également en tant que prédicat second accordé avec le sens 'rondes, charnues' (dernier exemple du CW). 


\section{Aimer profond}

Aimer profondément, beaucoup

Transitif

1285 Maintenant, se Dieus me consaut, Ai nonmee une qui mout vaut ; Dont me couvient l'autre nonmer. A ! Dieus, tant par font a amer ! (Adenet le Roi, Cleomadés, 18566)

1976 Par exemple, l'idée que nous communiquons essentiellement par les mots : les femmes que j'ai aimées profond ou désirées vif, les sculptures, tableaux, objets, musique qui m’ont touché, les chats qui ont daigné vivre près de moi, m'ont persuadé du contraire. Qui peut traduire en clair, déchiffrer dans toutes ses significations le message d'une koré du $\mathrm{VI}^{\mathrm{e}}$ siècle ? (Claude Roy, Somme toute)

\section{CORPUS WEB :}

Et elle n'a pas compris pourquoi je n'avais pas fait de gâteau au chocolat à son frère alors même qu'elle m'avait dit qu'elle m'aimait profond du cœur [http://la-tribu-de-juju.net/2016/01/ tablette-clempad-5-0-chat] (15.5.2016)

Toujours aussi créatifs ses « délires » et son « Deep » ne déroge pas à la règle, alors je l'aime profond !!! son nouveau titre « obsessionnel » [http://www.zikpot.fr/artiste-G.ENJOY] (15.5.2016)

moi j'ai un ptit de 4ans qui m'a dit qu'il m'aimait profond ds son cœur jusqu'au ciel ! [http:// www.notrefamille.com/forum/Thematiques/ Papotages-(autres-sujets])/J-en-ai-de-lachance-t1010626.aspx (15.5.2016)

Et le Kréol dit « Amen », je l'aime profonde et sans vaseline [http://www.zinfos974.com/ Carburant-Les-arretes-interministeriels-signespar-trois-ministres_a67805.html] (15.5.2016)

Pour les canards c'est juste que je les aime profonds et n'ayant que des planches à faible volume, j'ai peur d'être dérangé, même dans $1 \mathrm{~m}$ ça peu parfois bien secouer sur un canard planté sans suffisamment de conviction :D et pas trop fan de reculer de 2 mètres à chaque mousse $: P$ [http://www.shaperoom.net/forum/viewtopic. php?f=10\&t=6739\&hilit=demandais\&start=30] (11.11.2013)
REMARQues : Métaphore à base conceptuelle locale, profond (parfont) est un adjectif-adverbe de manière qui caractérise un sentiment éprouvé par son intensité et sa durée. Profond s'utilise également au sens concret en tant que prédicat second accordé (deux derniers exemples du CW). Notons l'emploi de désirer vif.

\section{Aimer vrai (voir) \\ Aimer sincèrement \\ Transitif \\ 1200 B[ie]n sai me fe[m]me n'est pas fole \\ Mais voist souuent a la carole \\ A tout iours mais voir l'amerai \\ A nul iour mais nel mesq[ue]rrai \\ (Auberee, 739)}

\section{CORPUS WEB :}

Aimer vrai, aimer sans vouloir " posséder ». Aimer sans attacher mais au contraire en laissant l'autre libre d'exister en dehors de soi [https:// fr-fr.facebook.com/retouralasourcelnd/photos/a. 275583005933542.1073741830.275254235966419/5 84715301686976/?type=3\&theater] (16.5.2016)

Alors je crois que j'ai pas fini de vous aimer les copines et les amies et que je vais commencer à bien vous aimer, à vous aimer vrai [http://forum. psychologies.com/psychologiescom/rencontreset-seduction/aimer-vrai-sujet_4425_1.htm] (16.5.2016)

C'est d'ailleurs, le plus bel héritage que nous pouvons léguer à nos enfants, de les aimer "vrai » tel qu'ils sont, tel que nous sommes [http://coachingpnlfamilial.ca/article-disp. asp?i=7] (16.5.2016)

ohh ! j'adore..la 1 et la 3 c'est la simplicité de la vie que j'aime vraie sans sophistication.. s'asseoir et contempler en cessant les idées.à deux bien sûr c'est mieux [http://c-est-pas-lui.overblog.com/article-divagations-109550265.html] (11.11.2013)

REMARQues : Vrai est un adjectif-adverbe de manière qui caractérise la façon dont quelqu'un montre ou exprime ses sentiments : de façon conforme à la réalité, sans rien dissimuler, sans chercher à mentir et d'une manière incontestable, authentique. Vrai s'utilise également en tant que prédicat second (deux derniers exemples du CW). Dans l'avant-dernier exemple du CW, il réfère à 
l'authenticité du sentiment, au fait d'aimer quelqu'un tel qu'il est. Aimer vrai y est employé comme verbe complexe invarié, comme une sorte de formule. Par contre, l'accord est fait dans le dernier exemple du CW.

\section{Ajourner clair}

Assigner quelqu'un en justice, le citer officiellement, publiquement à comparaître à un jour déterminé devant un juge, un tribunal Transitif

+1100 Ainz que seit jurz mult lur est tart ;

A grant greine, a voiz truble,

Dïent que avrat peine duble.

Respunt l'abés : « Ne avrat turment

Plus que ad oüd par jugement. »

Et puis qu'il fud cler ajurnét,

Od tut Judas s'en sunt turnt

(Benedeit, Voyage de saint Brendan

[1 ${ }^{\mathrm{er}}$ quart XII $\left.\left.{ }^{\mathrm{e}}\right], 1491\right)$

\section{Ajouter bas}

Ajouter à voix basse

Transitif

1656 Et il [= le père Filiutius] y donne encore [...] un autre moyen plus sûr d'éviter le mensonge. C'est qu'après avoir dit tout haut, « Je jure que je n'ai pas fait cela », on ajoute tout bas : « aujourd'hui », ou qu'après avoir dit tout haut, "Je jure », on dise tout bas, " que je dis »; et que l'on continue ensuite tout haut, " que je n'ai point fait cela ». Vous voyez bien que c'est dire la vérité (Blaise Pascal, Les Provinciales)

1743 L'envie de plaire est l'aurore qui annonce l'arrivée de l'amour dans le cour d'une jeune personne ; aussi se faisoit-il déja sentir dans celui de cette aimable demoiselle. La premiere parole qu'elle dit au fils d'Effendi, fut qu'elle étoit charmée de le voir. Elle ajouta tout bas, que c'étoit son absence qui l'avoit mise dans l'état où il la voyoit (Claude Godard d'Aucour, Mémoires turcs)

1784 Et en-effet, nous avons-su par-après que c'était deux hommes de $\mathrm{V}$ qui passaient, dont l'un avait-demandé à l'autre, si son fils reviendrait bientôt de l'armée ? Ce- lui-ci avait-répondu avec force (car il avait-appris la mort de son fils la veille) Jamais ! ajoutant plus bas : Il est mort (Nicolas Rétif de la Bretonne, La Paysanne pervertie ou Les dangers de la ville)

1805 - Hélas ! répliqua-t-il, hier encore, j’aurois envié de si vifs témoignages d'affection, mais aujourd'hui, je n'ai de place dans mon ame que pour un seul désir : voir Mathilde un moment, lui dire un mot...

- Dites-le-moi, interrompit la reine, je vous assure qu'il ne sera pas perdu pour elle.

- Non, madame, répondit Malek Adhel, elle seule doit l'entendre.

Bérengère ayant regardé si son époux ne l'observoit pas, fit un geste de la main, pour désigner le rideau qui les séparoit de l'alcôve de l'oratoire, en ajoutant très-bas et très-vite :

- Eh bien ! Je vais me reculer, et elle seule vous entendra (Sophie Cottin, Mathilde)

1848 - Quoi?

- Mon piano, qui joue tout seul, ut, la mi ré do, la si sol ré. Gredin de ré, va ! Il sera toujours faux.

- Mais ce n'est pas chez vous, sans doute, lui dit Rodolphe, qui ajouta bas à l'oreille de Colline sur qui il appuya lourdement, il est gris

(Henri Murger, Scènes de la vie de bohème)

1877 L’abbé s'élança au-devant de Lucie en lui disant à voix basse :

- Au nom du ciel, ne faites pas ce scandale...

Et il ajouta encore plus bas :

- Si les malédictions que votre mariage attire sur ma tête excitent en vous quelque compassion...

(George Sand, Mademoiselle La Quintinie)

1884 Voici comment j'en ai parlé, le 30 avril 1877, devant l'Académie des sciences : « Dans un mémoire remarquable, le docteur Koch a constaté que les petits corps filiformes découverts par M. Davaine peuvent passer à l'état de corpuscules brillants après s'être reproduits par scission, puis se ré- 
sorber... » et plus bas, j'ajoutais : "On doit penser que ces corpuscules peuvent survivre d'une année à l'autre sans périr, prêts à propager le mal » (Louis Pasteur, Correspondance)

1904 - Qu'est-ce que tu apportes là ?

- Du lait, Rose.

Elle ajoutait tout bas : «Quatre sous de lait pour eux cinq, il n'y en aura pas assez pour les faire dormir ; quatre sous d'absinthe, y en aura assez... Dodo, l'enfant do... » (Léon Frapié, La Maternelle)

1924 - Une femme, vois-tu, doit recommencer de séduire son mari tous les jours. Il faut supporter d'être la maîtresse ou qu'il y ait une maîtresse à côté de soi.

Maman Lecœur ajoute presque bas :

- Pincengrain est un homme supérieur. Il avait sans doute droit à autre plaisir. Mais la Gerboise est vraiment moins que rien (Marcel Jouhandeau, Les Pincengrain)

1926 Pour la première fois je prends la main que j'aime, je l'embrasse. Voyez comme mon geste est sûr, comme ma main est forte, comme elle vous tient pour toujours...

Tout bas elle ajoutait :

- Vous me briseriez, si vous vouliez!

Puis, tout haut :

- Je ne sais pourquoi les autres vous aiment. Je ne sais pourquoi l'on aime (Jean Giraudoux, Simon le Pathétique)

1936 Elle songeait à la fin solitaire de Jérôme. Ses yeux s'emplirent de larmes. Elle fit une courte pause et ajouta, bas, comme pour elle-même : "Seule, avec l'Esprit » (Roger Martin du Gard, Les Thibault. L'Été 1914)

1948 Sylvaine s'écroula dans les bras de son amie en disant :

- Ma pauvre chérie! Toujours si bonne, si dévouée. Et plus bas elle ajouta :

- Tiens-toi, hein ? Je t'en supplie!

Lulu faisait attention à ne pas mettre les pieds dans les flaques d'eau (Maurice Druon, Les Grandes Familles)

1962 Il regarda de nouveau vers la femme qui s'était mise à marcher lentement sans sortir de la clarté du lampadaire ; il soupira et, très bas, il ajouta :

- Les putains ne sont pas toujours sur les trottoirs. Et puis, une putain, est-ce qu'on sait jamais pourquoi elle est putain ? (Bernard Clavel, La Maison des autres)

1997 - Y s'croit invulnérable, mon capitaine, dit le cuirassier Brunel en sautant à cheval. - Assez de sornettes ! grogna SaintDidier, qui ajouta plus bas à l'intention de Lejeune : Je ne peux pas leur en vouloir, la mort de notre général les a secoués...

Fayolle ferma sa cuirasse et Lejeune le regardait (Patrick Rambaud, La Bataille)

\section{CORPuS Web :}

On ne peut donc que se réjouir d'entendre notre Premier ministre nous promettre haut et fort « la réforme fiscale ». Et se désoler qu'il doive ajouter tout bas qu'elle prendrait dix ans [http://www.lettreducadre.fr/7738/vive-limpot] (16.5.2016)

Ce qui fait dire à nos économistes en vue : " nous avons été naïfs... », et d'ajouter tout bas : « ... et nous le resterons ! » [http://huma niterouge.alloforum.com/message.php?cate gorie $=625 \& \mathrm{msg}=3828](16.5 .2016)$

Ces derniers mots furent ajoutés tout bas, comme s'il craignait que sa remarque ne fût entendue par son meilleur ami [https://www. fanfiction.net/s/4830734/4/Lemon-Incest] (16.5.2016)

REMARQues : Bas est un adjectif-adverbe de lieu qui, dans l'emploi figuré, devient un adverbe de manière qui désigne le volume d'une voix faible. Ajouter bas se dit de l'ajout de paroles caractérisé par un abaissement de la voix par pudeur ou pour ne pas être entendu de personnes non concernées. Il reste invariable et est modifié par encore plus bas, plus, presque, tout, très. Il s'oppose à dire tout haut / dire tout bas (exemple de 1656) et à promettre haut et fort (premier exemple $\mathrm{du}$ CW). VoIR AUSSI : dire / parler haut

\section{Ajouter haut}

Ajouter à voix haute

Transitif

1667 Lorsqu'il y fut arrivé, il lui dit en présence de toute la cour : 
- Pourquoi pensez-vous que je vous ai envoyé querir?

- Je n’ai garde, Sire, de le savoir, lui répondit-il.

- Ce n'est, dit le Roi, que pour vous entretenir ; et ajouta tout haut : Je veux bien que tout le monde sache que voilà l'un des hommes de mon royaume que j'estime le plus (Robert Arnauld d'Andilly, Mémoires)

1751 Je parierois ma vie, a-t-elle ajouté assez haut pour me le faire entendre, qu'il est entré autant d'humeur que de mal de tête dans le refus qu'on a fait de voir un homme si respectable. Mon dieu! Que de gens qui se plaignent d'autrui, dont le bonheur dépend d'eux-mêmes ! (abbé Prévost, Lettres angloises [trad.])

1832 - Ma foi, je ne sais pas. Ce que j’ai de mieux à faire, continua-t-il à demi-voix et se parlant à lui-même, c'est, je crois, d'aller au fond de la rivière ou de me faire sauter la cervelle.

- Vous êtes d'heureux coquins, vous autres, ajouta-t-il haut, vous êtes à l'abri de ce qui me tue aujourd'hui

(Alphonse Karr, Sous les tilleuls)

1859 La somnambule hésita longtemps.

- Oui... oui... dit-elle tout à coup... je vois un homme grand... brun.

- Armand, pensa Baccarat. - Et elle ajouta tout haut :

- Pense-t-il à moi ?

- Non

(Pierre-Alexis Ponson du Terrail, Rocambole)

1876 Il ajouta plus haut :

- Enfin, on a besoin de tout le monde, venez vite. M. de Lamberthon s'était précipité vers la salle des séances (Émile Zola, Son Excellence Eugène Rougon)

$1881-$ Tu es donc devenu fou ? me dit tout bas Alexandrine, qui vient de rentrer et me tire par les basques de ma redingote, - et tout haut elle ajoute : " Tenez, monsieur Vingtras, voilà ce qu'on en fait, de ceux qui veulent délivrer leurs frères! » (Jules Vallès, Jacques Vingtras : Le Bachelier)
1885 - N'empêche, ajouta très haut Chaval d'un air de défi, que si ce cochon de Dansært me parle sur le ton de l'autre jour, je lui colle une brique dans le ventre... je ne l'empêche pas, moi, de se payer les blondes qui ont la peau fine (Émile Zola, Germinal)

1928 Geneviève lutte contre une seule idée : il ne sait pas... et le regarde avec étonnement. Elle ajoute tout haut :

- Je suis venue...

et passe sa main sur son front. Les vitres blanchissent, versent dans la pièce une lumière d'aquarium. « La lampe se fane », pense Geneviève

(Antoine de Saint-Exupéry, Courrier Sud)

1947 Et les petits vautours, au réfectoire, après avoir envoyé au pain sec contre le mur une cloche qui faisait du bruit avec ses sabots, ajoutaient très haut :

- Ça se laisse taper dans la lune, et ça fait du boucan. Cette outrecuidance magnifique empêchait sourires et révoltes (Jean Genet, Miracle de la rose)

1950 - Oui, reprit-il avec gaucherie, tu as raison : nous croyons les mêmes choses. Je te remercie d'avoir dit cela.

- Bonsoir, Joseph, fit David.

Il ajouta un peu plus haut, comme Joseph traversait la rue :

- Pense à la réponse que tu dois me donner (Julien Green, Mö̈ra)

1951 - On n'en parlera plus : je m'arrangerai ! conclut enfin le fermier qui ajoute, très haut : « Allons, ouste ! Rentrons. Le serein va tomber.»

Simon se penche, démonte la petite fourche qui calait sa gaule, arrache vivement sa ligne (Hervé Bazin, Le Bureau des mariages)

1958 - Non, ajouta-t-il un peu penaud, il n’y avait pas de papiers.

- Et le chargement?

- Des livrets matricules, ça doit être, mon yeutenant, fit-il d'un air gêné. Des pleines caisses de livrets matricules.

Il ajouta entre haut et bas :

- Il y en a sûrement pour toute une division (Julien Gracq, Un balcon en forêt) 
CORPUS WEB :

$\mathrm{Vu}$ comment elle était habillée, elle n'était même pas apte à se rendre à la réserve toute seule. "Franchement... une robe blanche..." J'ajoute, tout haut, parce que je trouve ça... dingue ! Dans dix minutes, elle allait être marron clair sa robe ! [http://givingforafrica.forumactif. org/t442-la-boite-a-rps-lily-euphemia-can-youhelp-me] (16.5.2016)

- Elle « Je vais voir»

- Moi, dans ma tête " ben ouais ce serait cool de ta part, vu qu'on s'apprête à cramer la $\mathrm{CB}$ » et j'ajoute tout haut « et des bas pour essayer sivouplé » trop tard, elle est déjà repartie [http://blogs. lexpress.fr/styles/paris-by-light/2012/03/17/ louboutin-comme-des-chiens] (16.5.2016)

Tu comptes sur tes doigts dix fois puis tu dis tout haut " dix ». Et tu continues une nouvelle dizaine. Tu ajoutes tout haut « vingt» ! Etc. [http:// pouvoirdespierres.forumpro.fr/t9813p325-la-loide-l-attraction-2eme-partie] (16.5.2016)

REMARQUeS : Haut est un adjectif-adverbe de lieu qui a un sens spatial et désigne un point élevé. Dans l'emploi figuré, il devient un adverbe de manière qui désigne le volume d'une voix. Ajouter haut se dit de l'ajout de paroles caractérisé par un haussement de la voix de manière à être entendu. Haut reste invariable et est modifié par assez, plus, tout, très, un peu plus. Notons la collocation ajouter entre haut et bas.

\section{Alever droit}

Lever, élever selon une ligne droite, verticale Transitif

1365 Se ie ne sentoie de mi humblement. mais ai mon arme outre que droit alleueit ; Ensicom cilz qui est de sa meire seureiz. ensi soit li retribution et li paiement de mon arme (Psautier lorrain, p. 134)

REMARQUES : Droit est un adjectif-adverbe de direction-manière qui indique la façon d'avancer, de pointer dans une direction.

\section{Aller aigu \\ Monter dans les aigus (la voix) \\ $\pi$ aller bas}

\section{Aller aise}

Se déplacer facilement, avec agilité, aisance Intransitif

1170 Qui mellor quiert, ne set qu'il viaut. Qui le chevauche, ne se diaut, Ainz va plus eise et plus soef Que s'il estoit an une nef (Chrestien de Troyes, Erec et Enide, 1401)

REMARQues : Aise est un adjectif-adverbe de manière qui caractérise le mouvement d'une personne se déplaçant sans difficultés, comme un navire glissant sur l'eau. L'adjectif-adverbe soef ajoute l'idée de tranquillité à l'action. L'emploi adverbial de aise et soef appartient à l'ancien français.

\section{Aller bas}

I. Tomber, au sens figuré, jusqu'au point de non-retour

Intransitif

1403 Encor y a un autre point, Qui trop vient a ceulx mal a point, Car tout ce qu'ilz auront cuidé, Qui au monter leur ait aidié, Cherra sur eulx au devaler, Qui si bas les fera aler Que jamais n'en releveront (Christine de Pisan, Le Livre de la mutacion de fortune, I, 3094)

1624 Mais Dieu veut qu'Angoulesme soit la fatale retraicte des affligez, et tout bien consideré, ce n'est pas aller fort bas que de tomber sur une montagne. Aussi certes, s'il y a quelque chose à redire en l'administration des Finances, on ne peut pas le blasmer d'avoir fait le mal (Jean-Louis Guez de Balzac, Les Premières Lettres)

1937 On est bien, au fond de l'abîme. Il est doux de penser qu'on ne peut aller plus bas. Quel repos dans la profondeur! Quelle paix dans le parfait désespoir ! (Georges Duhamel, Le Désert de Bièvres)

1995 Depuis deux ans il avait dégringolé par paliers : une suite de marches, puis chaque fois une plate-forme qui lui donnait l'illusion qu'il n'irait pas plus bas ; mais la plate-forme était trop courte, l'élan trop 
grand - la chute continuait. Le nouveau ministre ne fit plate-forme qu'un mois (Françoise Chandernagor, L'Enfant des Lumières)

II. la bannière va bas en cent ans : la destinée peut basculer irréversiblement à tout moment Intransitif

-1465 Chacun dira Mal

Contre luy, jurera, mesdira, Maulgrera Dieu qui luy contredira ; Parjuremens, blasphemes redira ;

C'est la maniere

Comme va bas en cent ans la baniere Et le paisant tenant vertu planiere Boit o les roys d'Anjou et de Trosniere Et aultres vins (Jean Meschinot, Lunettes des princes, p. 83, 1759)

III. s'en aller bas : disparaître, tomber dans l'oubli

Pronominal

1550 Qu'ainsi soit, je vous prie, s'il ne plaist aux hommes de croire à Dieu, fauldra-il que sa verité s'en aille bas? Mais plustost, comme dit sainct Paul, que l'homme demeure menteur tel qu'il est, et que ceux ausquels il plaist à Dieu se reveler le tienent pour veritable (Jean Calvin, Des scandales)

1953 Le lièvre court pour mettre un point Au regard fixe de la chouette L'araignée ne fait qu'une toile Utile ou inutile un grenier une ruine Je me sens m'en aller très bas Très haut très près très loin très flou Et net immense et plus petit Que le ciel amassé pour moi J'imite le plus machinal Des gestes d'un lieu dit la terre (Paul Éluard, Poésie ininterrompue)

IV. Tomber, se placer à un niveau inférieur, dans une échelle hiérarchique

Intransitif

1610 C'est pourquoy il ne faut pas aller trop haut par des parolles enflees, superbes et distraictes de la facilité : car cela est trop obscur, fardé, broüillé et pedant : comme aussi il ne faut point affecter la simple façon du langage plus commun, de peur qu'en le recherchant on ne se treuve d'aller trop bas, et de ramper sur la terre comme les animaux plus infirmes (Pierre de Deimier, L'Académie de l'art poétique)

1636 Dernier precepte de la conversation des esgaux.

À ces trois maximes j’ajouste pour dernier et general precepte, que jamais il n'entreprenne d'entretenir personne pour luy plaire, qu'il n'ait premierement bien consideré son humeur, ses inclinations, et de quelle trempe il a l'esprit : afin de n'aller point plus bas, ny plus haut qu'il ne faut, mais de l'accompagner de si près, que tous ses discours s'ajustent à sa portée (Nicolas Faret, L'Honneste Homme)

1891 Par chacun de ces mots on m'évoque, on m'adjure,

Et tantôt c'est louange, et tantôt c'est injure.

Je suis l'esprit Milieu ; l'être neutre qui $v a$ Bas sans trouver Iblis, haut sans voir Jéhovah ;

Dans le nombre, je suis Multitude ; dans l'être,

Borne. Je m'oppose, homme, à l'excès de connaître (Victor Hugo, Dieu)

1926 Toutes ces circonstances extérieures qui nous empêchent de nous rencontrer sont bien étranges. D'ailleurs avec le diable on peut aller très bas, mais jamais très loin (Paul Claudel et André Gide, Correspondance)

1943 L'énergie libérée par la disparition d'objets qui constituaient des mobiles tend toujours à aller plus bas. Les sentiments bas (envie, ressentiment) sont de l'énergie dégradée. Toute forme de récompense constitue une dégradation d'énergie (Simone Weil, La Pesanteur et la grâce)

V. Considérer des choses inférieures du point de vue social, moral, intellectuel, spirituel Intransitif

1844 Un garçon intelligent et sobre, qui aurait commencé l'escompte avec un très petit capital, comme Mlle Thuillier, achète alors un quart de charge d'agent de change. 
Allons plus bas ! Un petit clerc est notaire, un chiffonnier a mille écus de rentes, les plus malheureux ouvriers ont pu devenir fabricants (Honoré de Balzac, Les Employés)

CORPuS Web :

Marché : On peut aller plus haut avant d'aller plus bas.... [https://leblogalupus.com/2015/08/27/ marche-on-peut-aller-plus-haut-avant-dallerplus-bas] (18.5.2016)

Elle allait bas, très bas et les deux autres concurrents avaient renoncé à sa poursuite [https://www.wattpad.com/158718389-harrypotter-nouvelle-g\%C3\%A9n\%C3\%A9ration-4james-sirius/page/3] (18.5.2016)

Elle a une grande tessiture, elle va bas ET haut, je maintiens qu'elle va bien aigu [= la voix] [http://www.beaute-test.com/forums/index. php?topic=259525\&start=165] (18.5.2016)

Avoir la capacité de tracer des points élevés et à la fin d'acquérir des informations sur la tendance du marché, si elle va basse ou haute [http://www.investplus.org/strategies-debu tants-a03626677.htm] (11.11.2013)

REMARQUES : Bas est un adjectif-adverbe de lieu qui indique la direction, partant d'un niveau supérieur vers un niveau inférieur. Au sens figuré, il peut aussi être interprété comme un adjectifadverbe de manière qui réfère à l'état d'âme ou à la situation sociale d'une personne. (I), généralement utilisé dans une négation, décrit la chute du sujet, au sens figuré, caractérisée par un point de non-retour (au plus bas). (II), expression imagée certainement inspirée du proverbe Cent ans bannière, cent ans civière dans lequel bannière représenterait la destinée qui, comme dans une guerre, peut s'écrouler rapidement et inexorablement. (III) exprime métaphoriquement le fait de partir au-delà, donc ne plus exister sur Terre, de disparaître. (IV) s'emploie pour décrire un déclin, une chute vers le bas, dans une échelle hiérarchique, dont le résultat est généralement négatif. (V), dans une suite d'énonciations, exprime une descente pour le sujet qui les considère comme inférieures. Bas reste invariable et est modifié par fort, plus, si, très, trop. Le troisième exemple du $\mathrm{CW}$, qui réfère à la voix humaine, contient aussi les adjectifs-adverbes aigu et haut, ce dernier constituant le contraire de bas, ce qui en renforce le sémantisme par l'opposition. Dans le dernier exemple du CW, le verbe aller s'emploie comme copule; bas et haut s'accordent alors avec le sujet.

\section{Aller beau (bel)}

I. Se déplacer, avancer avec distinction, avec élégance

Intransitif

$\sim 1209 \mathrm{Si}$ lor prie et mande par nons Que, se Dex les deffent d'anui, Qu'il soient tuit encontre lui A Sainteron sanz nule faille Et que chascuns plus bel i aille Et miex acesmez qu'il porra (Jean Renart, Roman de Guillaume de Dole, 1948)

+1250 Puis conmande que l'en atort Bel e cortoisement la cort. Quant il out tot ce conmande, Si est tot meintenant monte Et avocques li de sa gent Tant qu'il s'en va et bel e gent (Le Roman de Renart [2 $2^{\mathrm{e}}$ moitié XIII $]$, XIII, 672)

II. Aller bien, seoir, convenir parfaitement Intransitif

-1377 Et pour ce que n'estoie mie Toudis en un point, m'estudie Mis en faire chansons et lais, Balades, rondiaus, virelais Et chans, selonc mon sentement, Amoureus et non autrement ; Car qui de sentement ne fait, Son ouevre et son chant contrefait. Ne moustrer aussi ne pooie Les maus d'amours que je sentoie A ma dame qui en chantant Me va si bel comme enchantant (Guillaume de Machaut, Remède de Fortune, 412)

III. Aller, courir avec agilité Intransitif

1389 Et aussi les chienz n'en peuent mie si bien assentir comme font par mi les fortz ne ne se peuent si bien tenir es routes, quar, quant les chienz chascent par mi les fortz, ilz vont touz jours la menee par ou le cerf va. Et, quant ilz sont ou cler pays, ilz se balancent sa et la, pour ce qu'ilz ont bel 
aler, et aucune foiz acuillent le change ou aucune foiz par le cler pays et par leur resdour trespassent routes (Gaston Phébus, Livre de chasse, p. 203, 152)

\section{IV. bien et beau s'en va carême : jouir à} nouveau des plaisirs défendus au temps de carême Intransitif

+1415 Et puis, pour jouer a tintin, Avecques moy tost se leva ; A ce jour de saint Valentin, Bien et beau Karesme s'en va (Charles d'Orléans, Poésies [ 1415-1440], II, Rondel CCXLVII, p. 432)

1552 Gens de bien, dieu vous salue et guard. Je ne vous peulx veoir. Attendez que je chausse mes lunettes. Ha, ha. Bien et beau s'en va quaresme, je vous voy (François Rabelais, Le Quart Livre, prologue)

1650 Ils n'avoient soucy d'autre affaire Que de dormir, faire grand chere, Rire, danser les mattassins, Et de joüer des mannequins, Se veautrans, allans sur l'herbette A quatre pattes, à courbette, A petits sauts, à petits bonds, Comme gentils petits Moutons, Joüans à la mouche, à la bresme, A bien et beau s'en va Caresme, A croquignolle, à coquimber, A je n'y tiens ny bois ny fer, A pille-nade, joque fore, Et mille autres beaux jeux encore (Charles d'Assoucy, L'Ovide en belle humeur)

V. aller tout beau : aller doucement, prudemment

Intransitif

1573 FLEURIE. Vaille que vaille, Je rompray l'huis.

PAQUETE. Vous n'estes sage. Ne croyez pas vostre courage ; Dissimulez, allez tout beau (Jean-Antoine de Baïf, Le Brave)
VI. s'en aller tout beau : partir, quitter un lieu doucement, sans faire de bruit, sans plus Pronominal

1610 Bien-Venu. Vos histoires m'ont fait souvenir de trois dames qui devisoient de leurs marys, et de tout ce qui estoit en eux. L'une d'entr'elles dit : "Je ne sçay que vous trouvez tant à redire en vos marys ; quant à moy, je me contente fort du mien. Il est vray qu'il y a je ne sçay quoy de petit, c'est qu'il a la c... noire » Le mary les oyoit conferer, et tout beau s'en alla en la maison (Béroalde de Verville, Le Moyen de parvenir)

\section{CORPUS WEB :}

Quel genre de chemin veut-on emprunter ou créer ? Dans quel sorte de paysage ? Seul ou en compagnie? Aller loin, ou aller vite, ou aller profond, ou aller haut, ou aller beau, etc ... ? Définir précisément ce qui, à chaque carrefour de vie, nous fera choisir telle voie plutôt que telle autre [http://www.noetique.eu/ articles/philosophies/lart-de-vivre-sa-vie/view] (18.5.2016)

dj jean jean ils vont beau les sièges du tsd 6 cet automne ils vont passer du noir au gris [http:// www.remontees-mecaniques.net/forums/index. php?showtopic=1365] (18.5.2016)

Merci pour vos réponses, elles vont belles, mais je veux du concret (); [http://www.raphaelharoche.net/forum/index.php?action=profile;ar ea=showposts; $\mathrm{u}=12178]$ (11.11.2013)

les essaies robes de mes filles, faut imaginier qu'elles ont les couronnes de fleurs, bien coiffés, elles vont belles mes poupettes [http:// www.i-services.com/membres/forum/messages. php? page $=25 \&$ uid $=6778 \&$ sid $=1809 \&$ idsujet $]$ $=976660 \& p g i=106(11.11 .2013)$

Un « jeune » en scooter... oui, oui, on voit parfaitement! toujours les même !! et même pas capable de se battre, ça va chercher un flingue. ils vont beaux les caïds! [http://m.leparisien.fr/ plus/commentaires/ajax/3103833] (11.11.2013)

Remarques : Beau est un adjectif-adverbe de manière qui caractérise la façon qu'a une personne de se déplacer, ou, au sens figuré, le fait que quelque chose convienne à quelqu'un. Jusqu'au XIV ${ }^{e}$ siècle, cet adjectif-adverbe de 
manière adopte la forme neutre bel. (I) décrit le déplacement de quelqu'un habillé avec élégance et raffinement. (II), seoir, convenir à quelqu'un. (III), ici, en parlant de chiens, décrit leur course agile et fluide. Dans l'exemple de 1389, bel aler peut être lu comme nominalisation. (IV) réfère à la fin du carême, où les excès sont à nouveaux permis, décrit la volupté, le plaisir de la chair. (V), se déplacer ou agir prudemment. Beau est modifié par plus, si, tout. La coordination syntaxique avec bien dans les exemples sous (V) souligne sa nature adverbiale. Dans cet emploi, il reste invariable (v. les deux premiers exemples $\mathrm{du}$ CW). Dans les trois derniers exemples du CW, le verbe aller se rapproche de sa fonction comme copule, vont se rapprochant de sont, suivie d'un adjectif prédicatif, mais beau permet également parfois une lecture plus adverbiale 'bien' (dernier exemple). Dans ce dernier exemple, beau adopte le sens ironique de 'ça va bien pour eux'. La langue standard n'accepte d'ailleurs guère les exemples 3 e $4 \mathrm{du}$ CW, au point qu'on peut y voir une faute de frappe (vont belles pour sont belles), mais le fait que nous pouvons citer trois emplois d'aller comme verbe copule allié au fait que la construction est usuelle dans les autres langues romanes suggère tout de même que les exemples reflètent un usage sous-standard. La continuité de l'usage ancien documenté dans le CW est plus forte qu'il n'apparaît dans les exemples de Frantext. Notons les groupes aller gent, aller profond et aller haut.

\section{Aller digne}

Marcher, se déplacer dignement, fièrement Intransitif

1385 Pour ce mendre, petite et grande Doit garder son ranc a l'offrande Et ailleurs, selon ce qu'elle est ; Et se a aucune en desplest Qui d'aler digne n'est devant (Laquel chose advient bien souvant), N'en doit chaloir a la plus digne : Tousjours soit rebouté l'indigne Contre cellui qui mieulx vaudra (Eustache Deschamps, Le Miroir de mariage, 9287)

1862 Alors, repassèrent en foule dans ses souvenirs les aimées d'autrefois, avec leurs attitudes préférées, leurs regards doux ou fiers : blondes, brunes, elles allaient lentes ou rapides, dignes ou cyniques. Mais pas une n'obtint un sourire. Elles ne parlaient plus ni à son imagination ni à son cœur. Anna était devenue tout son horizon (Paul Reider, Mademoiselle Vallantin)

\section{Corpus Web :}

Trop tard Nik c'est irratrapable, inutile de me donner l'illusion d'une quelconque convivialité ou entente dans ce forum, je préfére m'en aller digne! [http://www.lamainverte.org/ forums/viewtopic.php?f=30\&t=14035\&start=45] (22.5.2016)

Kriss écoute cet infirmier touareg raconter comment il $v a$, digne et déterminé, sans médicament, à pied, à dos d'âne ou de chameau, soigner ses frères nomades dans des régions aussi démunies qu'isolées [http://www.lemonde. $\mathrm{fr} /$ voyage/article/2009/11/20/bon-voyage-lakriss_1339735_3546.html] (22.5.2016)

Eh bien figurez-vous qu'ils y allèrent, dignes, fiers, et... seuls [https://www.justfocus.fr/ musique/critique-musique/pierre-et-georges-auconcert-des-chk-chk-chk.html] (22.5.2016)

REMARQues : Digne désigne l'attitude empreinte d'une certaine fierté, d'un respect de soi-même que montre quelqu'un. Il a donc sémantiquement une grande affinité avec la prédication seconde. Dans l'exemple de 1862, la flexion marque tous les attributs comme étant des prédicats seconds, même si leurs significations sont plus (lentes ou rapides) ou moins (dignes ou cyniques) affines à la modification du verbe. L'exemple met en évidence la force qu'acquiert la prédication seconde dans les romans du XIx ${ }^{\text {e }}$ siècle, créant un contraste avec l'ancien et le moyen français où l'emploi invariable passe plus facilement. S'y ajoute la tendance moderne du style littéraire à préférer l'emploi détaché du prédicat second (CW).

\section{Aller direct}

Aller directement

Intransitif

1972 Si vous êtes un paumé, un cradingue, un total orphelin, de préférence avec les flics au cul, alors laissez-vous faire, pas besoin de plan Taride, même en rasant les murs 
vous y allez direct. Vous trouverez facilement, c'est au bout du chemin, quand vous en avez marre, quand vous en pouvez plus (Bertrand Blier, Les Valseuses)

1987 Julius le Chien, lui, va direct inspecter sa gamelle (Pennac, La Fée Carabine)

1990 Après des paroles aussi encourageantes j'ai pas voulu tâter le terrain plus longtemps. Je suis allée direct au vif du sujet (Fanny Seguin, L'Arme à gauche)

\section{CORPUS WEB :}

Oui bien sûr et ces courriers iront directs à la poubelle. Les Députés et Sénateurs ne demanderont jamais une telle chose[twitter.com/upr asselineau/satus] (22.10.2020)

Certes le cadre pourrait être un peu plus bucolique mais c'est encore cela l'Espagne : des égouts qui vont directs à la mer et des poissons enivrés par le liquide[gobages.com/news-peche/ poissons] (11.08.2014)

Inutile de louer un local commercial au faubourg, rue de la democratie, c'est vos economies qui vont directes a ces vereux de proprietaires [https://www.tripadvisor.fr/ShowTopic-g187152i1725-k5126051-Local_commercial_collioureCollioure_Pyrenees_Orientales_Occitanie.html] (22.10.2020)

REMARQUES : Aller direct tend à remplacer aller droit dans le français plus récent. On peut le considérer comme variante économique remplaçant aller directement dans des registres familiers, surtout oraux. En effet, l'ensemble des exemples dans Frantext mettent en évidence son usage récent dans ce type de registre. L'adjectif-adverbe direct y est très apprécié. Bedijs (2012: 250-251) cite « tu prends les reflexes direct », « tu lui as dit stop direct », " tu uses direct la violence ».Direct, dont l'accord ne serait pas audible à l'oral, reste invarié dans les exemples littéraires cités, mais le CW y ajoute trois exemples qui ont été sélectionnés parmi un grand nombre de cas disponibles sur Internet. L'accord ne change ni le sens ni la fonction par rapport à l'emploi invarié. Ajoutons que l'accord de son homologue espagnol directo est très fréquent et audible à l'oral (Hummel 2015).

\section{Aller doux}

I. Se déplacer doucement, tranquillement Intransitif

1573 TAILLEBRAS. J’y vas.

SANNOM. Et tant vous allez doux !

Il s'est jetté dans les filets

Tant des maistres que des valets

Qui luy avoyent dressé l'enceinte.

Le vieillard l'attend à l'atteinte

Pour surprendre cet adultere

(Jean-Antoine de Baïf, Le Brave)

1606 une taverne que nous passasmes au village de La Ferriere sans oser boire de peur de la pleuresie toute certaine, desjà que trop en danger de prendre mal sans cela, car il est impossible de mediocrement s'echauffer ny d'aller doux parce que le corps esbranlé contrebas emporte de son poids les jambes et les pieds qui vont plus qu'ils ne voudroient et se peuvent à peine retenir (Voyage d'Italie)

1619 Saint François voyant une brebis toute seule emmi un troupeau de boucz : « Regardes, » dit il a son compaignon, « comme cette pauvre petite brebis est douce parmi ces chevres ; Nostre Seigneur alloit ainsy doux et humble entre les Pharisiens. »Et voyant une autre fois un petit aignelet mangé par un porceau : Hé, petit aignelet, dit il tout en pleurant, que tu representes vivement la mort de mon Sauveur (Saint François de Sales, Introduction à la vie dévote)

II. Fonctionner doucement, gentiment Intransitif

1601 Mais voyci la difference; le sage se reigle et se range à ce qui est selon nature et raison, regarde au debvoir, tient pour apocryphe et suspect ce qui est de l'opinion, condamne tout à faict ce qui est de la passion, et pour ce vit-il en paix, chemine tout doucement en toutes choses, n'est poinct subject à se repentir, se desdire, changer ; car quoy qu'il advienne, il ne pouvoit mieux faire ny choisir ; et puis il ne s'eschauffe poinct, car la raison va tout doux (Pierre Charron, De la sagesse) 
III. Agir tranquillement, calmement, sans faire de bruit

Intransitif

1653 Dieux ! Comme ils gagnent la guerite Et tournent le dos à vos coups : Mais c'est assez, allez tout doux, Ils pourroient rentrer en courroux, Et puis casser teste et maschoire, Suffit de les avoir soûmis, On a perdu mainte victoire Pour trop presser ses ennemis (Charles d'Assoucy, Le Ravissement de Proserpine)

1665 Réglez votre temps sur le nôtre ; Aujourd'hui l'une, et demain l'autre : Tout avec ordre ; et, croyez-nous, On en va mieux quand on va doux (Jean de La Fontaine, Les Cordeliers de Catalogne)

IV. s'en aller doux : partir doucement, lentement, tranquillement

Pronominal

1848 La mâture criait, l'air sifflait dans les poulies. À la proue, le nez dans la brise, un mousse chantait ; nous n'entendions pas les paroles, mais c'était un air lent, tranquille et monotone qui se répétait toujours, ni plus haut, ni plus bas, et qui se prolongeait en mourant, avec des modulations traînantes. Cela s'en allait doux et triste sur la mer, comme dans une âme un souvenir confus qui passe. Le cheval se tenait debout, du mieux qu'il pouvait, sur ses quatre pieds et mordillait sa botte de foin (Gustave Flaubert, Par les champs et par les grèves)

1928 ANDOCHE. « Son pouls, i' n'va guère vite ", disait el' médecin à la bientôt veuve. « Ah », dit-elle, « si seul'ment eç' pouls-là, il était monté sur un' bounn' bête ! mais s'en va tout doux, tout doux, pa'ç' qu'il est sur un bourri ! Ah, ah, ah... » (Roger Martin du Gard, La Gonfle)

1945 Des bombes à retardement sur la voie, vous ferez quelques kilomètres à pied, et vous reprendrez le train de l'autre côté du danger. Le train s'en va tout doux, tout doucement, tâtant le terrain avec les roues. Le crépuscule descend ses voiles sur le paysage : c'est une ville ou ce qui reste d'une ville (Elsa Triolet, Le Premier Accroc coûte deux cents francs)

\section{CORPUS WEB :}

Je vais m'atteler à tout ça de manière pacifique ! on pose les truelles et le plâtre, ici on y $v a$ tout doux ! On caresse notre peau dans le sens du poil et on lui dit qu'on l'aime ! [https://oakmoon. fr/astuces-anti-boutons] (22.5.2016)

Arrivée tardive pour la livraison de la semaine... petite semaine de vacances oblige, on y va tout doux ;) Cela n'enlève rien à l'utilité du contenu je l'espère, bonne pioche ! [http://alternatives.blog.lemonde.fr/2014/10/25/ la-selection-alternatives-de-la-semaine-8] (22.5.2016)

Non c’est ma maman de cœur qui est tombée gravement malade durant les fêtes d'où ma pause de presque un mois, elle va tout doux et s'affaiblit beaucoup [http://crisitane.canalblog.com/ archives/2016/01/29/33287764.html] (22.5.2016)

Dans un soyeux bruissement d'ailes, un ange blanc s'est envolé, vers ce pays plein de soleil où vont les chiens martyrisés. Va, toute douce, toi si petite, et si fragile qu'une caresse t'aurait brisee, sans te connaitre, on t’a aimée [http://www. levriersansfrontiere.com/article-petite-fanny-ma-fait-un-signe-elle-s-est-envolee-123571758.html] (22.5.2016)

RemARques : Doux est un adjectif-adverbe de manière qui caractérise la façon dont quelqu'un se déplace, ou dans un sens figuré, la façon dont quelqu'un exécute une action. Aller doux est particulièrement ouvert au jeu des interprétations métaphoriques qu'offrent l'adjectif doux et le verbe aller, qui se rapproche aussi parfois de sa fonction de copule. Doux est modifié par ainsi, tout. Il reste invariable dans la majorité des exemples ci-dessus (mais voir le dernier exemple du CW où il s'accorde avec le sujet féminin). La tendance à l'invariabilité distingue aller doux d'autres combinaisons avec le verbe aller où l'attribut en prédication seconde est systématiquement fléchi : (s'en) aller content, humble, triste, cynique, digne, etc. 


\section{Aller droit}

I. Aller en suivant une ligne droite

Intransitif

1119 E cancer signefie,

Ne larrai nel vus die,

Ki ne pot dreit aler

Par terre ne par mer (Philippe de Thaon,

Comput [1119 ou 1113], 1609)

1285 Dist Crompars : Sire, n'en doutés

Que ja mais ne se verseroit

Cis chevaus, ains va tous jors droit.

Teus est li chevaus, sans mentir

(Adenet le Roi, Cleomadés, 2442)

1544 PROU. Ouy mieux les aulx, que l'encens. PEU. Qu'il contrefait bien le gentil !

MOINS. Tournons delà.

PEU. Non, allons droit. S’il vient à nous, laissons le courre.

PROU. Il fault sçavoir par quel endroit

Se tire gresse de la bourre (Marguerite

d’Angoulême, Trop, prou, peu, moins)

1693a Mère Écrevisse un jour à sa Fille disait :

Comme tu vas, bon Dieu ! ne peux-tu marcher droit?

Et comme vous allez vous-même ! dit la Fille.

Puis-je autrement marcher que ne fait ma famille?

Veut-on que j'aille droit quand on y $v a$ tortu? (Jean de La Fontaine, L'Écrevisse et sa fille / Fables)

1719 La philosophe essuya les murmures

Du sot peuple, et les têtes dures

Firent gloire d'aller toûjours à reculon.

Pour les vieilles erreurs point de respect bizare ;

Examinons aussi la nouveauté.

Par les deux excès on s'égare ;

Mais la raison va droit ; marchons de son côté (Antoine Houdar de La Motte, Fables)

1824 Les Français sont les hommes du monde les plus propres à devenir fous, sans perdre la tête. Ils ne se trompent guère que méthodiquement, tant ils sont peu faits pour la méthode. Leur raison va toujours plus droit et plus vite que leur raisonnement (Joseph Joubert, Pensées, essais, maximes et correspondance)
1835 Il ne tournait plus en cercle autour de sa proie avec des regards fins et une marche cauteleuse ; mais il allait droit et ferme, en long et en large, brusquement, frappant du pied et faisant sonner ses talons éperonnés. La chambre tressaillit (Alfred de Vigny, Servitude et grandeur militaires)

1914 Les étoiles, une à une, se lèvent vers l'horizon oriental, tandis qu'à l'autre bord, la lune s'enveloppe dans les brumes du couchant. Ils vont tout droit, dans le vent froid, dont le frissonnement s'est levé en même temps que les ténèbres totales descendaient sur la terre (Ernest Psichari, Le Voyage du centurion)

1919 Il ne connaissait pas ces boyaux sinueux taillés dans la boue. Mais de loin en loin, des agents de liaison, ou des brancardiers lui disaient : "Suis tout droit » et il allait tout droit sans vouloir se reposer.

Il aperçut enfin une planchette : " poste de secours » et descendit dans le gourbi (Roland Dorgelès, Les Croix de bois)

II. Aller directement (+ préposition), en ligne droite, sans détour Intransitif

1170 Por tel forfet haïr te doi ;

Car trop feïs grant mesprison.

Fiancier t'an estuet prison,

Et sanz nul respit or androit

Iras a ma dame tot droit ;

Car sanz faille la troveras

A Caradigan, se la vas

(Chrestien de Troyes, Erec et Enide, 1030)

1175 Il parole a le fille au roi,

Mais mout li quiert mains de desroi,

Que la pucele ne vaudroit.

Andoi en vont au roi tot droit,

Mais Ganors prise mout petit

Tot canqu'il ont parlé et dit

(Gautier d'Arras, Ille et Galeron, 3389)

+1200 Kant chele entent k'ensi le mainterroit, $A u$ cordoan l'en veut aler tot droit

(Vie de saint Alexis [XIII'], p. 292, 439)

+1365 S’un petit alons detriant,

Tant nous est le deduit plus lons, Mès je sçai bien que nous alons 
Droit au buisson sans nul fourvoi (Jean Froissart, Poésies [3 $3^{\mathrm{e}}$ tiers XIVe])

+1415 Va tost, mon amoureux desir, Sur quanque me veulx obeir, Tout droit vers le manoir de Joye ; Et pour plus abregier ta voye, Prens ta guide Doulx Souvenir (Charles d'Orléans, Poésies [ 1415-1440], I, Chanson XLV, p. 231)

+1489 Ledit conte alla droit aux ennemys (Philippe de Commynes, Mémoires [14891498], VIII)

1601 Tout ce jour se passa en partie à l'oraison, car à ce mal il n’y avoit aucun remède humein ; nous estions logés à confort près l'église des Jacobins, nous alasmes droit à Dieu, le vray consolateur des désolés (René de Lucinge, Les Occurrences de la paix de Lyon)

1654 Le grand docteur qu'estoit cét homme en la science de gouverner ! Jamais la face des affaires ne le trompa. Jamais il ne fut politique à faux, ni ne s'esgara, pour paroistre beau parleur, dans les vastes espaces de la vray-semblance : il alloit tousjours tout droit à la verité ; et voyoit si nettement la suite des choses en leur premiere disposition, que les succez les plus irreguliers ne démentoient gueres les conjectures qu'il en avoit faites (Jean-Louis Guez de Balzac, Dissertations politiques)

1675 Ce discours est donc ce qui s'appelle des paroles vaines, qui n'ont autre but que de vous faire voir, ma bonne, que l'état où je suis sur votre sujet serait parfaitement heureux si Dieu ne permettait point qu'il fût traversé par le déplaisir de ne vous avoir plus, et pour vous persuader aussi que tout ce qui me vient de vous ou par vous, me va droit et uniquement au cœur (Mme de Sévigné, Correspondance)

1745 Que de douceurs contenues dans ce que je vous dis là, madame ! L'amour peut en avoir de plus folles ; peut-être n'en a-t-il point de plus touchantes, ni qui aillent si droit et si nettement au cœur, ni dont ce cœur jouisse avec moins de distraction, avec tant de connaissance et de lumières (Pierre de Marivaux, La Vie de Marianne)

1836 La preuve irréfragable se trouve chez les animaux, même chez ceux qui ont le moins de raisonnement. Ils vont tout droit aux corps qui donnent les sensations de l'odorat, du bruit, de la vue, sans faire aucune espèce de raisonnement ; parce qu'ils sont guidés vers ces corps par la vue ou le tact, et l'habitude établit bientôt l'association des corps avec l'impression produite par la lumière, par les vibrations sonores, par les émanations odorantes (François-JosephVictor Broussais, Cours de phrénologie)

1840 Mais alors leur consommation ne sera plus égale à leur production, le salaire ne payera pas le service productif, le travailleur ne pourra pas racheter son produit, et nous retomberons dans toutes les misères de la propriété. Je ne parle pas de l'injustice faite au travailleur dépouillé, des rivalités, des ambitions excitées, des haines allumées : toutes ces considérations peuvent avoir leur importance, mais ne vont pas droit au fait (Pierre-Joseph Proudhon, Qu'est-ce que la propriété ?)

1845 Le lendemain Sauviat partit pour Paris et fut absent pendant une semaine environ. Pierre Graslin était, vous l'imaginez, peu causeur, il allait droit et promptement au fait. Chose résolue, chose exécutée. En février 1822, éclata comme un coup de foudre dans Limoges une singulière nouvelle (Honoré de Balzac, Le Curé de village)

1867 On le prend pour éviter un détour, pour gagner quelques minutes. Il est traversé par un public de gens affairés dont l'unique souci est d'aller vite et droit devant eux. On y voit des apprentis en tablier de travail, des ouvrières reportant leur ouvrage, des hommes et des femmes tenant des paquets sous leur bras (Émile Zola, Thérèse Raquin)

1879 Est-ce que tu sais leurs noms, berger?

- Mais oui, maîtresse... Tenez ! juste au-dessus de nous, voilà le Chemin de saint 
Jacques (la voie lactée). Il $v a$ de France droit sur l'Espagne. C'est saint Jacques de Galice qui l'a tracé pour montrer sa route au brave Charlemagne lorsqu'il faisait la guerre aux Sarrasins (Alphonse Daudet, Lettres de mon moulin)

1902a - Satan est votre hôte, madame la marquise ! Il rampe et s'agite immodérément de l'autre côté de cette cloison !...

Ninon le croit devenu fou : elle va tout droit à la porte de la salle d'étude, veut l'ouvrir, l'ébranle, mais en vain : un verrou, de l'intérieur, a été poussé ; mais une autre porte communique avec l'antichambre ; elle y court : même obstacle !... (René Boylesve, La Leçon d'amour dans un parc)

1903 Notre cerveau français, s’il est fatigué, encombré, perd ses qualités de finesse. Notre vue va moins droit au centre de son objet. Nous cessons d'être des faiseurs de clarté. Notre génialité, je veux dire notre logique inventive, s'émousse (Maurice Barrès, Mes cahiers)

1905 Elle s'excusa humblement. Elle ne pouvait se faire illusion sur l'insuccès de ses innocentes avances : elles allaient droit contre leur but, elles éloignaient Christophe. Il ne prenait plus la peine de cacher sa mauvaise humeur ; il n'écoutait même plus quand elle parlait (Romain Rolland, Jean-Christophe. L’Adolescent)

1922a Parmi tous ces feux, bien distribués maintenant, aucun ne bouge. Je me mets à enjamber les voies. Je suis la seule direction que je connaisse. Je prends garde surtout aux fils de signaux, qui luisent moins que les rails et qui, tendus plus haut, trompent davantage le pas. Je vais droit sur ce grand lampadaire, auquel je me suis accrochée, le soir où j'ai fait ma première traversée de la ligne (Jules Romains, Lucienne)

1948 Cette «pratique de deux mille ans » qui n’a guère changé depuis Quintilien, nul doute qu'elle ne lui parût bavarde, ratiocinante et rabâcheuse. Lui, il était allé tout droit et tout seul au grain des choses et avait laissé la paille des mots (Jean Guéhenno, JeanJacques : En marge des Confessions)
1967 Avant de prendre l'autobus du retour, la jeune fille acheta des boucles d'oreilles bon marché, mais clinquantes, des lunettes de soleil en forme de cœur, des chaussures, des corsages, des jupes, des soutiens-gorge, un bustier, un maillot deux pièces, elle allait vite et droit à l'objet désiré, car elle l'avait choisi, après réflexion, sur les catalogues les plus récents (Jean-Pierre Chabrol, Je t'aimerai sans vergogne)

III. s'en aller droit : se rendre directement

(en un lieu, vers quelqu'un)

Intransitif

+1313 Son messaige li dist et conte, Cieus s'apareille et si monte

S'ot le messaige a compaingnon

Et s'en uont droit viers le doignon

De celi qui mande l'auoit

(Jean de Condé, Poèmes [1313-1337], 1456)

+1370 mais sitos que li contes Henris de Lancastre fu venus, qui grandement honnoura messire Jehan de Hainnau et les Hainnuiers dou grant et biau service que il faisoient à la roine d'Engleterre et à son fil et au pais, il eurent avis et consel que il s'en iroient tout droit viers Bristo, là ou li rois d'Engleterre et chils Hues li Espensiers et ses pères et li contes d'Arondiel se tenoient (Jean Froissart, Chroniques (A))

1389 Donc di je que, puis que veneur n'est oyseus, il ne peut avoir males ymaginations, et, s'il n'a males ymaginations, il ne peut fere males euvres, quar l'imagination va devant, et, s'il ne fet males euvres, il faut qu'il s'en aille tout droit en paradis (Gaston Phébus, Livre de chasse, p. 54, 34)

1538 Finablement, de ma chambre s'en $v a$ Droict à l'estable, où deux chevaulx trouva ;

Laisse le pire, et sur le meilleur monte, Pique et s'en va. Pour abréger le compte (Clément Marot, Épitres)

1584 Dès ledit jour, il fist couper sa barbe, qu'il avoit toujours nourrie longue depuis qu'il estoit prisonnier, paia les sept cents ecus pour les deux amandes, et le lendemain s'en alla droit à Fontainebleau, où la Cour 
estoit, pour tascher à obtenir son rappel de ban ; mais il n'y trouva point d'amis, et lui fut tout à plat denié (Pierre de L’Estoile, Registre-journal du regne de Henri III)

1610 Mais elle luy portoit tant de haine, qu'elle ne le peust croire mort avant que l'avoir veu. Elle sort donc de son logis, s'en va droit au pallais, et voyant le corps sans teste, se lave les mains de son sang, et receut un si grand contentement de sa mort (Honoré d’Urfé, L’Astrée)

1623 je voy que les hommes apostoliques heritiers de leur esprit, s'en vont tout droit aux princes estrangers, au roy du grand Mogo et à celuy de la Chine, qu'ils disputent contre les philosophes, et les plus apparens de la gentilité, d'autant qu'ils se fient en la bonté de leur cause, pour laquelle ils sont prests d'espancher leur sang et endurer la mort, et au contraire je voy que tous les heretiques, craintifs et desfians de leur cause, ont tasché de se couvrir et cacher dans les tenebres, d'autant que l'oracle de verité qui ne mentit jamais, dit nommément, que tout homme qui fait mal, hayt la lumiere, et ne s'advance point en public, afin que ses œuvres ne soient point descouvertes (François Garasse, La Doctrine curieuse des beaux-esprits de ce temps)

1755 Déja du jour la belle avant-courière de l'orient entrouvrait la barriére. Or vous savez que cet instant préfix changeait Madame en Monsieur Conculix. Alors brulant d'une flamme nouvelle il s'en $v a$ droit au lit de la pucelle, les rideaux tire, et lui fourant au sein les doigts velus d'une gluante main, il a déjà l'héroïne empestée d'un gros baiser de sa bouche infectée : plus il s'agite, et plus il devient laid (Voltaire, La Pucelle d'Orléans)

1810 Mon dessein est d'y rester, tant que l'eau coulera et que les arbres verdiront,

c'est-à-dire jusqu'aux grandes chaleurs, car alors tout sera sec, verdure et ruisseaux, et alors je partirai, et m'en irai droit à Paris si je ne m’arrête en Suisse, comme je fis l'an passé pour fuir la rage de la canicule ; ainsi faites état de me voir arriver au départ des hirondelles (Paul-Louis Courier, Lettres écrites de France et d'Italie)

1859 Il était assez proprement vêtu, et comme il avait rasé ses favoris et sa barbe et coupé ses cheveux, il espérait que Rocambole, si le hasard le jetait sur sa route, ne le reconnaîtrait pas au premier coup d'œil. Venture s'en alla tout droit rue de la pépinière, à l'hôtel Artoff (Pierre-Alexis Ponson du Terrail, Rocambole)

1874 Mlle Aurélie était d'une jolie force ; elle poussait un cri d'hirondelle à chaque coup de raquette, riant comme une folle quand le volant s'en allait droit sur le nez du jeune abbé ; puis, elle se ramassait dans ses jupes pour l'attendre ou reculait par petits sauts, avec un bruit terrible d'étoffe froissée

(Émile Zola, La Conquête de Plassans)

1882 La nuit, mon cœur se serre un peu dans cet isolement de Robinson. - Quand le vent siffle au dehors, quand la mer fait entendre dans l'obscurité sa grande voix sinistre, alors j'éprouve comme une sorte d'angoisse de la solitude, là, à la pointe la plus australe et la plus perdue de cette île lointaine, - devant cette immensité du Pacifique, - immensité des immensités de la terre, qui s'en va tout droit jusqu'aux rives mystérieuses du continent polaire (Pierre Loti, Le Mariage de Loti)

1896 Grâce à toi je me vois de dos Et bien plus vraisemblable : Dans ton croquis, à pas lourdauds, Je m'en vais droit au diable. Moi qui, pour la postérité. Sur une aile céleste Croyais m'envoler, révolté, Fatal et tout le reste ! (Paul Verlaine, Euvres poétiques complètes)

1922b Ses mains bouffies se croisent d'une façon rapide, coutumière : tous ses gestes ont ici quelque chose d'aisé, de secret, de so- 
litaire. Il lève sa face inerte ; son regard, filtrant sous les cils, s'en $v a$ droit vers le crucifix. Il offre à Dieu sa déception, cette épreuve nouvelle (Roger Martin du Gard, Les Thibault. Le Cahier gris)

1950 «Encore un peu de gniôle, voulez-vous ? J'ai besoin d'un coup de fouet. » J'avale une longue gorgée d'eau-de-vie rude, et je m'en vais, tout droit vers les 75 qui donnent de la gueule, avec ensemble, dans le bois. J'arrive au milieu d'artilleurs littéralement soulevés de joie (Maurice Genevoix, de 14)

IV. Aller directement (+ infinitif)

Intransitif

1559 Et, entrant en la chambre, veid sa femme lisant le livre, qu'il faignit ne veoir poinct, mais alla tout droict parler aux dames qui estoient d'un autre cousté (Marguerite d'Angoulême, Heptaméron, p. 148, 138)

1693b La rareté du fait donnait prix à la chose.

L'Oiseau, par le Chasseur humblement présenté,

Si ce conte n'est apocryphe,

Va tout droit imprimer sa griffe

Sur le nez de Sa Majesté.

Quoi ! sur le nez du Roi ? Du Roi même en personne.

Il n'avait donc alors ni sceptre ni couronne? (Jean de La Fontaine, Le Milan, le roi et le chasseur / Fables)

1805 Le long péronier péronéo-tarsien s'engage sous l'os cuboïde, et traverse la plante du pied pour s'insérer à l'os métatarsien du pouce, et au premier cunéiforme. Le court péronéi-sus-métatarsien $v a$ droit s'insérer à la base externe de l'os métatarsien du petit doigt (Georges Cuvier, Leçons d'anatomie comparée)

\section{Se comporter convenablement}

Intransitif

1567 L'un va tout droit, l'autre va de travers, Et toutesfois l'advis d'un homme sage Tout seul par art conduit tout ce mesnage (Pierre de Ronsard, Le Bocage Royal, p. 363)

1608 L'AMIRAL. Il faut servir le Roy, fust-ce contre raison.
BALORTE. Quand l'ennemy fait perte, usons de la poursuite.

LES ARCHERS. On ne peut aller droit sous meschante conduite.

THAMYs. Sauver un innocent ce n'est point trahison (Jean de Schélandre, Tyr et Sidon)

1734 Pour ce qui est de moi, je n'y entends point finesse ; je ne saurais gagner ma vie à gouverner les filles, je ne suis pas si aisé, et je la gagne à faire le tracas des maisons ; que chacun dans son métier aille aussi droit que moi. Il m'est avis que le vôtre est encore plus casuel que le mien, et je ne suis pas aussi friand de ma condition que vous l'êtes de la vôtre (Pierre de Marivaux, Le Paysan parvenu)

1785 Figaro. Et si je vaux mieux qu'elle ? Y a-t-il beaucoup de Seigneurs qui puissent en dire Autant?

LE Comte. Cent fois je t’ai vu marcher à la fortune, et jamais aller droit

(Pierre-Augustin de Beaumarchais, Le Mariage de Figaro)

1848 On est étonné tout d'abord de voir un homme aussi habituellement doux, soumis et, ce semble, timide, que l'était M. de Tillemont, - ce même homme qui se tenait toujours à genoux devant le père Lami, comme lui disait Bossuet, - parler si franc et si ferme quand il a affaire au rude abbé. Mais il n'est rien tel que ces doux et ces humbles pour aller droit et haut, quand ils sont une fois émus dans la défense de ce qu'ils jugent l'équité et la vérité (Charles Sainte-Beuve, Port-Royal)

VI. aller droit son chemin : agir selon sa propre volonté

Transitif

1844 Ma peine pour le consoler de ce qu'il s'est fait souffrir à propos de moi, ne sera-t-elle pas perdue ? Je n'en irais pas moins droit mon chemin, advienne que pourra ! Il n'est bruit ici que des libelles de Pyat à Janin, et de Janin à Pyat (George Sand, Correspondance)

1923 - Mademoiselle, prenez garde. Vos yeux voient trop clair. Ce n'est pas l'affaire des jeunes filles. 
- Oh ! les jeunes filles, aujourd'hui, vont droit leur chemin, même si ce n'est pas le droit chemin

(Henry Bordeaux, La Vie est un sport)

VII. aller droit devant soi : progresser en ligne droite, sans se détourner de sa route

Intransitif

1846 Nos enfants de France surtout, qui sont si vifs et si parleurs, avec un bon sens très-précoce, nous ramènent sans cesse aux réalités. Ces innocents critiques ne laissent pas d'être embarrassants pour le sage. Leurs naïves questions lui présentent trop souvent l'insoluble nœud des choses. Ils n'ont pas appris, comme nous, à tourner les difficultés, à éviter tels problèmes, qu'il semble convenu, entre sages, de n'approfondir jamais. Leur hardie petite logique va toujours droit devant elle (Jules Michelet, Le Peuple)

VIII. s'en aller droit : partir en se tenant droit Pronominal

1883 Elle, serrée dans un corset qu'elle ne laçait qu'une fois par semaine, s'en allait droite, la taille étranglée, les épaules larges, les hanches saillantes, en se dandinant un peu (Guy de Maupassant, Contes et nouvelles)

1893 Je ne veux pas que des ennemis restent près de moi ! Je ne veux pas qu'on reste près de moi, à me rendre fou ! Elle s’était levée, très pâle. Elle s'en alla toute droite, sans se retourner, en emportant son ouvrage. Pendant le mois qui suivit, Pascal essaya de se réfugier dans un travail acharné de toutes les heures (Émile Zola, Le Docteur Pascal)

IX. s'en aller droit (en parlant d'un chemin) : s'étendre en longueur de manière linéaire Pronominal

1886 De grand cœur, je vous assure, comme on se venge ! Ils se turent un instant. La route large de Saint-Ouen s'en allait toute droite, à l'infini ; et, au milieu de la campagne rase, le petit convoi filait, pitoyable, perdu, le long de cette chaussée, où coulait un fleuve de boue (Émile Zola, L'Euvre)
1912 Après l'étouffement des voûtes d'arbres, après la forêt pleine d'embûches, on a déjà une impression de sécurité et de « chez soi » à rentrer dans l'immense enclos du temple où les broussailles n'ont guère plus que la taille humaine et où l'avenue dallée s'en va droite et sûre vers un semblant de village (Pierre Loti, Un pèlerin d'Angkor)

$X$. Marcher en se tenant dans une position droite, verticale (prédication seconde)

Intransitif

1897 Paillot reconnut dans la foule M. le premier président Cassignol. Le vieillard faisait sa promenade quotidienne. La foule agitée, qui l'avait surpris dans son itinéraire, inquiétait sa marche petite et sa vue affaiblie. Il allait, encore droit et ferme, portant haut sa tête desséchée et blanche (Anatole France, L'Orme du mail)

1927 Une sonnette tinte trois petits coups et se baissent toutes les têtes. Alors on ne verra point cette femme qui va droite entre les rangs des chaises, et dont nul ne pourrait d'ailleurs empêcher l'ascension, car la force qui la mène déjà n'est plus de terre. Elle étend les bras (René Crevel, Babylone)

XI. s'en aller droit : partir sans faire de détours Pronominal

1902b Il se rappelait les vieux à barbe blanche, avec de gros sacs qui les tirent en arrière, qui montent pourtant la rue et s'en vont tout droit. Il se rappelait les grands gaillards qui font de grands pas et auraient bien la force de travailler et qui, bien entendu, s'arrêtent boire la goutte "Au Petit Salé » (Charles-Louis Philippe, Le Père Perdrix)

1916 - Il est venu un peu d'eau sur la glace, dit-il, et la neige a fondu ; mais nous devons être bons pour traverser pareil. Marche, Charles-Eugène !

Le cheval flaira la nappe blanche avant de s'y aventurer, puis s'en alla tout droit (Louis Hémon, Maria Chapdelaine)

XII. Bien aller, convenir parfaitement Intransitif

1915 Quand il n’y a pas de rime, il faut, ma foi, s'en passer. 
Si mon vers ne va pas tout droit, ce n'est pas qu'il y manque des pieds,

Précédant de peu ma pensée, comme l'aveugle qui tâte avec son bâton

(Paul Claudel, Corona benignitatis anni Dei)

1925 - Je suis Bonnenfant, si tu veux savoir. C'est mon nom de naissance, mais il m'allait si dret qu'on ne m'a point donné d'autre sornette (Maurice Genevoix, Raboliot)

\section{CORpus Web :}

Arudy : un passage piéton qui va... droit dans le mur ! [http://www.larepubliquedespyrenees. fr/2016/03/03/arudy-un-passage-pieton-qui-vadroit-dans-le-mur,2007268.php] (25.5.2016)

Quand la musique va droit au cœur [http:// www.lalsace.fr/haut-rhin/2016/01/11/quand-lamusique-va-droit-au-coeur] (25.5.2016)

Voila une photo que je qualifie de parfaite : quelle netteté, aucun flou, une petite merveille, merci elle s'en va droit dans mes favori [http:// www.fond-ecran-image.com/galerie-membre, riviere,courant-continujpg.php] (25.5.2016)

Les deux petites gamines attirent leur père vers la chambre mortuaire, et la Marianne, elle s'en va, droite et digne [http://alainlecomte.blog. lemonde.fr/2007/12/15] (25.5.2016)

REMARques : Droit est un adjectif-adverbe de manière-direction. Au sens figuré, il devient un adverbe de manière qui indique une action qui s'adresse directement à quelqu'un/quelque chose, ou à un comportement droit. Dans ces cas-là, droit est invariable. Droit peut s'analyser comme un prédicat second, quand il indique une position verticale ou une attitude droite, et dans cet emploi il s'accorde avec le sujet (v. aussi le dernier exemple du CW). Il s'emploie dans les contextes suivants : (I), non suivi d'une préposition, décrit le fait de se déplacer en suivant une ligne droite, sans s'arrêter ni faire de détours. (II), se rendre de manière directe en un lieu (ou vers une personne) ; il est généralement précédé d'une préposition (à, contre, jusqu'à, dans, vers). Aller droit s'emploie au sens propre ou au figuré (aller à la vérité). (III), idem que (II), y ajoutant l'idée d'un éloignement. (IV), décrit l'immédiateté de l'action, l'infinitif exprimant le but. (V), se dit d'une personne adoptant un comporte- ment convenable et invitant à l'exemple. (VI), contrairement à (VII), cette expression traduit une sécurité, une volonté d'agir chez le sujet. (VII), expression dont le sens est proche de la définition (I) mais qui, dans certains contextes, peut signifier que le sujet avance sans réfléchir, sans but précis. Peut également traduire l'idée de volonté chez le sujet. (VIII), idem que (X) avec une nuance d'éloignement de la personne. (IX), généralement accordé avec le sujet, s'en aller droit réfère ici à une route, une avenue qui s'étend de toute sa longueur à perte de vue. (X), relatif à une personne qui se déplace en tenant son dos et ses épaules bien droites (prédicat second). (XI), proche de la définition (I), mais exprimant en plus une nuance d'éloignement. (XII), se dit de quelque chose qui convient parfaitement au locuteur. Droit est modifié par aussi, moins, plus, si, tout. Notons la collocation aller droit et ferme. Mentionnons également l'emploi de marcher droit, nourrir long, parler franc, parler ferme, priser petit, voir clair. VOIR AUSSI : acheminer droit

\section{Aller dru}

Aller vivement, rapidement, avec vigueur ; de façon compacte (quand il s'agit d'un groupe) Intransitif

1594 Allons tous, dru et espais, Pour luy demander la paix : Nous irons jusqu’à sa table, Tant il est Prince accostable ! (Satyre Ménippée)

1609 Mais retournons à table, où l'esclanche en cervelle

Des dents et du chalan separoit la querelle, Et sur la nappe allant de quartier en quartier,

Plus dru qu'une navette au travers d'un mestier,

Glissoit de main en main, où sans perdre avantage,

ebrechant le cousteau, tesmoignoit son courage (Mathurin Régnier, Les Satires)

1624 Il pleure quand il faut faire de la depense ; S'il mange, c'est du pain, encore bien petit, 
Et n'est selon son goust sausse que d'appetit ;

Mais ses dens vont bien dru quand quelcun le convie ;

Ses valeureuses mains imitent la furie

D’Achilles combattant, lors qu'elles vont au plat,

Ou d'un diable affamé qui déjeune au Sabat ;

Un autre prez de luy ne fait pas ses affaires,

C'est la peur et l'effroy des tables estrangeres

(Jacques Du Lorens, Premières satires)

1734 DORIMÈNE. Votre belle : voilà une épithète bien placée!

FRONTIN. Je défie qu'on la place mieux ; si vous entendiez là-bas comme il se démene, comme les déclarations vont dru, comme il entasse les soupirs, j'en ai déjà compté plus de trente de la dernière conséquence, sans parler des génuflexions, des exclamations (Pierre de Marivaux, Le Petit-Maître corrigé)

1739 FRONTIN. Eh ! mais, mais ... mon oncle un peu de patience ; comme vous allez dru sur les questions! Vous m'essoufflez

(Antoine de Fériol, comte de Pont de Vesle, Le Somnambule)

1930 Une note douloureuse (le sapin est sonore) retentit et se prolonge sous bois. N'importe, le bûcheron y va dru ; son souffle haletant scande les coups (Marie Dutoit, Mon Jura ... et le monde)

CORPUS WEB :

Cette association de jeunes entrepreneurs qui entend « se mobiliser sur le made in France » et « faire travailler plus d'ateliers, d'usines et de salariés français ", voulait y aller dru. Avec leur enquête qui autopsie les boutiques de huit partis politiques, et celle aussi de l'Assemblée nationale, ils tentent en effet de les inciter autant que possible à s'approvisionner en matériel tricolore [http://www.marianne.net/leurs-gadgetsles-partis-politiques-aiment-peu-made-infrance-100235483.html] (25.5.2016)
Pour répondre au désormais célèbre " l'important c'est que ça glisse », je dirais qu'en escalade faut y aller dru dans le pentu ... À part ça, si vous êtes cons et arrogants ne venez pas, sinon vous pouvez venir c'est sympa (surtout si vous êtes jeunes et belles...) [http:// associationsportive.insa-toulouse.fr/fr/shn international/shn2/interviews_shn/pierre_eric_ goudal_martin_bonnet.html] (25.5.2016)

Pour s'en convaincre, il faut prendre le dur jusqu'à Lisieux puis se perdre dans ce pays d'Auge peuplé de vergers de pommiers haute tige, appelés ainsi parce que leurs troncs vont dru et droit sous les couronnes des branches [http:// next.liberation.fr/food/2016/01/01/calvados-dedrouin-divin_1423863] (25.5.2016)

Le fiacre des pauvres s'est offert cette nuit une audience de prose

Fréquences lapidées aux engeances gémellaires

Elles vont drues, les promesses aux serments oubliés

Glisser d'une vague excuse les fragments dévoués

Et c'est fête en mon âme aux flagrances des rosiers [http://laqutedekakan.blogspot. co.at/2012/03/elles-sont-venues.html] (11.11.2013)

REMARQUES : Aller dru caractérise la force d'un déplacement, d'une action, souvent par rapport à l'action compacte d'un ensemble (v. la collocation avec épais dans l'exemple de 1594) : ainsi que l'herbe drue dont les pousses sont serrées et touffues, aller dru et épais réfère à des personnes se déplaçant de manière groupée, voire serrée. À la différence d'autres collocations avec le verbe aller, où le modifieur est systématiquement fléchi (v. (s'en) aller content, triste, cynique, digne, etc.), dru reste invariable dans la plupart des cas. Ceci souligne son affinité adverbiale. L'emploi poétique peut chercher la force expressive de la flexion (v. le dernier exemple du CW). Dru est modifié par bien, plus. Notons la collocation $d r u$ et droit dans le CW.

\section{Aller épais}

Se déplacer de manière groupé, en serrant les rangs

入 aller dru 


\section{Aller facile}

Évoluer sans difficulté, sans problème, sans

effort

Intransitif

1909 Il pouvait tout : appréhender les gens, les interroger, les déshabiller, après la question réglementaire :

- Vous n'avez rien à déclarer ?

Le travail allait bien, facile; les caisses de champagne, toutes pareilles, se posent sans recherche

(Pierre Hamp, Vin de Champagne)

1960 Ça cuit vite - ça va facile

(Radiodiffusion-Télévision Française, 18 janvier 1960 / Grundt : 219)

\section{CORPUS WEB :}

Mais où s'arrêtera t'il ? Petite déception pour moi avec Voltigeur de Myrt. Il semblait aller facile dans le dernier tournant et, tout à coup à mi ligne droite, il s'est arrêté [http://www.equidia.fr/ live/796006-2] (29.5.2016)

Dans les tribunes, on voyait que cheval et jockey " allaient facile » et que sans incident, ils iraient jusqu'au bout..... et après la dernière haie BOURGUEIL a mis un bon coup de rein pour gagner de 2 longueurs [http://www. etienneleenders.fr/entraineur-chevaux-decourses-galop-plat.html?annee=2016] (29.5.2016)

" Les préparations vont facile », explique Luc Missante, de AutoTechnica [http://fr.after salesmagazine.be/nl/blog/item/Autotechnica pour_75_pour_cent_lou/109] (29.5.2016)

car moi je dis « il n'y a pas de chevaux tarés ou vraiment unmontables ou autres », il y a des gens qui pensent savoir et qui font tout de travers, qui bousillent le cheval. bizarre tout de même j'en ai débourrer des centaines (oui çà défilait à un moment de ma vie et j'ai fait çà 30a) et bizarrement tous allaient faciles après... alors coup de chance ? non savoir attendre le bon moment, SENTIR quand il faut faire quoi surtout [http:// www.chevalannonce.com/forums-9738935-votreavis-sur-ce-cheval-achat-hongre-4-ans? $p=9$ ] (29.5.2016)

REMARques : Facile est un adjectif-adverbe de manière qui se dit de quelque chose qui fonctionne facilement et donc, qui présente des avantages dans son utilisation, indépendam- ment de la volonté du sujet. Il reste invariable, mais la flexion apparaît dans l'écriture spontanée du dernier exemple dans le CW. Il s'agit d'un des adjectifs-adverbes qui, contrairement à la tendance générale, pourraient avoir succédé à l'adverbe long facilement, non pas forcément par apocope, mais par remplacement, à partir du $\mathrm{xx}^{\mathrm{e}}$ siècle. Notons son emploi usuel dans le monde des courses hippiques.

\section{Aller ferme}

I. Aller, agir avec assurance, volonté, détermination

Intransitif

1727 Lisidor. Nous allons emmener et ma nièce et ma sœur, Pour vous laisser tous deux.

LÉANDRE. (à part) Allons ferme, mon cœur.

Notre ennemi paroît ; tâchons de nous défendre (Philippe Destouches, Les Philosophes amoureux)

1835 Il ne tournait plus en cercle autour de sa proie avec des regards fins et une marche cauteleuse ; mais il allait droit et ferme, en long et en large, brusquement, frappant du pied et faisant sonner ses talons éperonnés. La chambre tressaillit (Alfred de Vigny, Servitude et grandeur militaires)

1842 Le dernier tableau est atroce : la passion augmente ; la mort, épaules courbées, contractée, attire, accroche et griffe, devant et derrière, un évêque qui le sent bien et qui va... il va, ferme et mélancolique; sous la griffe même, il ne craint que Dieu. Partis de Strasbourg à quatre heures. La flèche nous suit presque jusqu'à Offenbourg. Temps gris et bas (Jules Michelet, Journal).

1844 Mais, avec une rage que vous devez concevoir, je me mis à travailler les cadavres qui me séparaient de la couche de terre sans doute jetée sur nous, je dis nous, comme s'il y eût eu des vivants! J'y allais ferme, monsieur, car me voici! Mais je ne sais pas aujourd'hui comment j'ai pu parvenir à percer la couverture de chair qui mettait une barrière entre la vie et moi (Honoré de Balzac, Le Colonel Chabert) 
1897 Paillot reconnut dans la foule M. le premier président Cassignol. Le vieillard faisait sa promenade quotidienne. La foule agitée, qui l'avait surpris dans son itinéraire, inquiétait sa marche petite et sa vue affaiblie. Il allait, encore droit et ferme, portant haut sa tête desséchée et blanche (Anatole France, L'Orme du mail)

1900 Oh ! Ce rêve tragique en moi toujours vivace,

Que l'amour et la mort, vieux couple fraternel,

Sur mon corps disputé, quelque soir solennel,

Comme deux carnassiers, s'abordent face à face !...

Qu'importe j'irai ferme au destin qui m'attend.

Sous les lustres en feu, dans la salle écarlate,

Que mon parfum s'allume, et que mon rire éclate,

Et que mes yeux tout nus s'offrent !... des soirs, pourtant

(Albert Samain, Le Chariot d'or)

II. aller ferme devant soi : agir, poursuivre son but avec assurance, détermination Intransitif

1767 Je la perdis. Je ne me le pardonnerai jamais. Celui qui fait dépendre sa conduite de l'opinion, n'est jamais sûr de lui-même. Et où en serions-nous, si, pour être honnêtes gens, il falloit attendre un siécle impartial et un prince infaillible ? Allez donc ferme devant vous (Jean-François Marmontel, Bélisaire)

III. s'en aller ferme : partir avec assurance, volonté, détermination, fermeté

Pronominal

1908 Ce moment de faiblesse ne dura qu'un instant. D'un air posé, il reconnut :

- Eh bien ! Oui, c'est moi. Et puis après ? Une négresse : c'est pas une affaire!

Il s'en alla, toujours ferme et digne, rempart vivant de l'ordre et de la morale (Pierre Mille, Barnavaux et quelques femmes)

\section{CORPUS WEB :}

Une fois positionnée, l'arme doit s'enfoncer dans la chair et il faut y aller ferme pour la ressortir et la re rentrer [http://www.zombiesworld. com/la-scie-le-crash-test] (29.5.2016)

Le premier spectacle découvert à la rentrée, la première représentation annonciatrice des joyeusetés théâtrales de l'automne, sera donc cette formidable performance d'acteurs, cette truculente galerie d'Irlandais paumés et autres cyniques créatures hollywoodiennes incarnés avec gourmandise par Christian Pereira et Eric Métayer. Ils y vont ferme ! [http://www. ddo.fr/labruyere/dcplp/presse_telerama.htm] (29.5.2016)

Néanmoins et tout d'abord, saluons l'exploit. Du moins si l'on s'en tient à ce qu'on nous dit, à ce que nous...racontent les medias habituels, aux ordres ou pas, et qui, pour une fois ou plutôt une fois de plus, y vont ferme dans le mélo et la quasi sanctification d'une malheureuse qui n'en demandait pas tant et surtout pas d'être passée par le calvaire qui lui vaut, aujourd'hui, une notoriété planétaire [http://journal-info. blogspirit.com/archives/category/actualites/ index-10.html] (29.5.2016)

REMARQues : Aller ferme traduit l'idée d'assurance, éventuellement de courage du sujet, au moment d'agir (I, II), au sens propre (se déplacer) comme au figuré (agir), aussi avec s'en aller (III). Même si les exemples avec le sujet au singulier ne le mettent pas en évidence, ferme admet souvent une interprétation comme prédicat second. Il partage son ambiguïté avec droit. Ainsi la collocation droit et ferme donne lieu à deux interprétations 'directement et fermement' et 'debout et avec fermeté'. Le CW met en évidence la tendance à l'emploi adverbial invariable dans le langage informel de nos jours. Notons l'emploi de porter haut.

\section{Aller fort}

I. Aller avec force, entrain Intransitif

1543 Les fiers chevaulx piquer donne toy garde, Ains par la resne à force les retarde. De leur gré vont, voyre si roide et fort, 
Qu'à les tenir fault merveilleux effort (Clément Marot, Livre second de la métamorphose)

1627 Il passa pardevant une fosse d'où Cyane sortit à demie nuë, et avec de longs cheveux espars comme si elle fust venu de se baigner, mais la charrette alla si fort qu'elle ne put faire à Pluton la reprimende qu'elle avoit premeditee (Charles Sorel, $L e$ Berger extravagant)

1783 la bête est à bas ; mais je reste en selle ; je la presse à coups redoublés... va, mon ami... va... foutre !... ah !... ah !... va fort... ah !... bougre !... ah !... que tu fais bien ça ! (Honoré de Mirabeau, Le Libertin de qualité)

1857 Je me levai, décidé à l'expulser de vive force. Un mouchoir était mon arme, mais je m'en servais sans doute assez maladroitement ; je l'étourdis, je l'effrayai ; il tourbillonnait de vertige, et de moins en moins songeait à sortir. Mon impatience croissait ; j'y allai plus fort, et trop fort sans doute... il tomba sur l'appui de la fenêtre, et ne se releva plus (Jules Michelet, L'Insecte)

1993 Vous pouvez être à Rome dans trois jours ? - Naturellement.

- Disons mercredi soir pour jeudi matin très tôt. Vous voyez ?

- Je vois.

Je vois surtout qu'il faut aller vite et fort. Après tout, je me suis peut-être trompé, et le message indirect de Gleb pouvait comporter un désir de négociation inédite ? Sur l'Affaire elle-même? (Philippe Sollers, Le Secret)

II. Aller vite

Intransitif

1573 MAXIME. N'attendez point là que Cinthien retourne, car il est entré secrettement par l'huis de derriere en la maison. Et qui voudra entendre du Negromant, s'y courre apres, mais qu'il se despeche, car il va si fort qu'il semble que le diable l'emporte (Jean de La Taille, Le Négromant)
1627 Faites nous donc conduire bien dextrement, repartit Amarylle, car à ce que dit Claudian en parlant du char de Triptoleme, les routes de l'air ne sont pas moins dangereuses que celles des eaux. Le carrosse alloit bien fort tandis qu'ils parloient de la sorte, et ils furent en peu de temps au chasteau du magicien. Amarylle eut de la peine à se persuader qu'elle fust encore Lysis (Charles Sorel, Le Berger extravagant)

1882 Il semblait rouler depuis des heures sur un pont, lorsque Trublot, sortant le premier de sa rêverie, risqua cette remarque judicieuse :

- Cette voiture ne va pas fort. Mais rien ne put hâter le trot du cheval, il était onze heures, lorsqu'on arriva rue d'Assas (Émile Zola, Pot-Bouille)

1883 Pépé, toujours pendu à sa main, allongeait ses courtes jambes pour la suivre. Elle l'oubliait. Il finit par dire :

- Tu vas trop fort, petite mère. Alors, elle s'assit sur un banc : et, comme il était las, l'enfant s'endormit en travers de ses genoux (Émile Zola, Au bonheur des dames)

1995 Comme si les chiens d'ici étaient contrebandiers! Ailleurs, oui, je ne dis pas... Mais ici ils ne pourraient pas passer la rivière, le courant va trop fort. Allez, Maman, il faut décaniller, prendre l'escampette... Tirer nos chausses, quoi ! Vite ! (Françoise Chandernagor, L'Enfant des Lumières)

III. Exagérer, aller souvent

Intransitif

1675 Je vous cache, et au monde, et à moimême, la moitié de la tendresse et de la naturelle inclination que j'ai pour vous. On $v a$ fort à l'opéra ; on trouve pourtant que l'autre était plus agréable. Baptiste croyait l'avoir surpassé ; le plus juste s'abuse (Mme de Sévigné, Correspondance)

1839 Cependant une invincible curiosité me poussait à le chercher, comme si mon sort eût dépendu de cette découverte. Je me mis à l'œuvre. Oh ! Que de grimoire passa sous mes yeux! Quelle ardeur à l'étude ! 
Si mon oncle m'eût vu, ou seulement mon professeur ! - studieux jeune homme, ménagez-vous, m'eût-il dit ; vous y allez trop fort (Rodolphe Toepffer, Nouvelles genevoises)

1945 et quand, allant à la fontaine, elle rencontre une femme, elle s'arrête et hurle : "putain! » de temps en temps, elle s'administre elle-même une douche, peut-être trouve-t-elle qu'elle va trop fort ? Avanthier, je l'ai vue toute trempée, avec l'eau qui commençait à geler sur elle, et elle n’a même pas attrapé un rhume (Elsa Triolet, Le Premier Accroc coûte deux cents francs)

1947 Personne n’y croyait plus beaucoup à leurs histoires de front élastique et de replis stratégiques. Et les Anglais y allaient un peu fort avec leurs bombes et leurs messages personnels incompréhensibles. Lorsqu'on entendait : « Les bulles de savon mourront au petit jour ", il se trouvait toujours un rigolo pour souligner la présence de Pierre Dac à Londres (René Fallet, Banlieue sudest)

1986 La mort en ce tabac. Chaque jour apporte son petit nécrologe. Il verse un petit rhum dans son café :

- C'était le plus grand, c'est sûr.

- Tu crois pas que tu vas fort? Un grand acteur, je veux bien. J'ai vu tous ses films, c'est pour dire. Mais le plus grand, là, t'es sûr de sec tu dis ?

(François Caradec, La Compagnie des zincs)

IV. Se répandre rapidement

Intransitif

1740 « Songe seulement, s'il n'y auroit pas moyen d'y remédier. Tu sais que j'ai le malheur de ne pouvoir tenir contre l'ennui. » « Je le sais, Monseigneur, » répondit l'Abbé ; « mais ce malheur vous arrive si souvent, et le mal $v a$ si fort en augmentant, que faute de remèdes je crains à la fin d'être obligé de vous laisser mourir » (Jacques de Varenne, Mémoires du chevalier de Ravanne)
1936 C'était son évêque à Libourne qui réclamait l'internement...

Y avait la foule, sous nos arcades... Ils se régalaient, ils perdaient rien de la belle séance... Et les commentaires allaient fort... Ça ruminait énormément... Ils apercevaient les fafiots qu'étaient répandus dans la case... Mais moi aussi j'avais bien biglé... (Louis-Ferdinand Céline, Mort à crédit)

\section{Convenir, bien fonctionner}

Intransitif

1842 Hier, j’ai lancé une épigramme qui a dû atteindre maître Hénarez au vif, il n’a rien répondu, il avait fini sa leçon, il a pris son chapeau, et m'a saluée en me jetant un regard qui me fait croire qu'il ne reviendra plus. Cela me va très fort : il y aurait quelque chose de sinistre à recommencer La Nouvelle Héloïse de Jean-Jacques Rousseau, que je viens de lire, et qui m’a fait prendre l'amour en haine (Honoré de Balzac, Mémoires de deux jeunes mariées)

1850 Si je n'avais en France ma mère dont l'affection me rappelle, je vous assure que j'irais bien jusqu'en Chine par terre ; la vie à cheval me va fort. Nous couchons sous les arbres. Nous buvons aux fontaines. Il est vrai que la nuit les puces m'empêchent de dormir. Je regarde la lune, ça m'occupe (Gustave Flaubert, Correspondance. Supplément)

1872 Et il y avait, à côté, le trou d'un poêle, où se trouvait un bout de tuyau. L'émotion prenait l'ancien ouvrier. - J'y ai passé cinq ans, murmura-t-il. Ça n'allait pas fort dans ce temps-là, mais, c'est égal, j'étais jeune... vous voyez bien l'armoire ; c'est là que j'ai économisé trois cents francs, sou à sou (Émile Zola, La Curée)

1933 Depuis que tu es là, on a des frais, c'est forcé.

- Je vous paie largement...

- Il n'est pas question de payer. Mais on a des frais. Le travail va moins fort, les habitudes sont changées, on est obligé de manger autrement : tout coûte. Il faut 
regarder aussi qu'on t’a élevée... sans que ça paraisse, les choses vont vite (Marcel Aymé, La Jument verte)

1976 Chaque fois que je suis un peu malade : la purée. Jamais de surprise. Ce soir, quand Franck est arrivé, Maman est partie. Ça prouve quand même bien que ça ne va pas fort fort entre eux. Je lui ai raconté pour Jeanine, mais il savait déjà et on a pas mal ri, à la fin, il m’a regardé (Patrick Cauvin, Monsieur Papa)

\section{CORPUS WEB :}

Elle griffe son pere et mon fils de 13 ans. Elle y va tres fort, et plus c'est fort plus elle est contente. Ils saignent mais c'est mieux le lendemain elle griffe au meme endroit pour enlever la croute et est tres fiere de sa reussite. j'ai beau dire que ca doit s'arreter elle n'y prete pas attention. Et recommence de plus belle. Ca laisse des cicatrice tellement elle $v a$ fort [http://forum. doctissimo.fr/psychologie/parents/sos-griffesang-sujet_146252_1.htm] (30.5.2016)

Elle dérange, Juliette Bouchet, dans ses partis pris, dans les enchaînements, dans le dénouement, dans le regard qu'elle pose sur cette jeune femme paumée et violente. Elle va loin, elle $v a$ fort, elle y va tout droit ! [https://avherter. com/2015/05/27/le-double-des-corps-de-juliettebouchet-editions-robert-laffont] (30.5.2016)

Elle alla, forte de cette conclusion, à son ancien palais [https://www.fanfiction.net/s/ 11863548/1/Le-Besoin] (30.5.2016)

Elle alla, forte de sa science des étoiles lointaines, déjoua la menace d'un chemineau nocturne, réprimanda une meute de loups qui s'en voulaient faire festin ; elle se fia à sa bonne étoile qui brillait pour elle seule dans son firmament et balisait son chemin vers le « pont » [http://atelier plume901.blogspot.co.at/2013/03/ecrire-unconte-mardi-8-janvier-2012-en.html] (30.5.2016)

REMARQUES : Fort est un adjectif-adverbe d'intensité. Aller fort réfère donc à l'intensité d'une action. L'exemple de 1543 implique encore une qualité appartenant au sujet animé, qui est fort, mais la plupart des exemples n'impliquent plus la force comme qualité d'un être animé. Notons la tendance à l'emploi impersonnel dans cela / ça va fort. Fort reste invariable dans son emploi adverbial et est modifié par bien, si, très, trop, un peu. Aller fort (I) désigne le fait d'aller, par extension de faire quelque chose, avec force, vigueur, aussi combiné avec vite. Par extension, (II) désigne le fait de se déplacer à grande vitesse, fréquemment utilisé pour qualifier la vitesse des chevaux. (III) désigne le fait d'exagérer que ce soit par des paroles ou par des faits. (IV) associe la force d'un processus à celui de la rapidité de son expansion. Généralement employé à la forme négative, $(\mathrm{V})$ désigne l'état mental ou de santé de quelqu'un ou le bon fonctionnement d'une affaire ou d'une relation. Les deux derniers exemples du CW illustrent un emploi usuel où l'adjectif détaché fort retrouve son emploi par rapport à une qualité humaine : fort de est suivi de ce qui a donné une force supplémentaire au sujet. Notons l'emploi de aller raide, aller droit et la réduplication fort fort.

\section{Aller gai}

I. Aller gaiement, joyeusement, sans se préoccuper

Intransitif

1698 LE CHEVALIER. (à Valère) Fussiez-vous descendu du lugubre Héraclite

De père en fils, parbleu, vous rirez de ce trait.

Vous faites le Caton ; riez donc tout-à-fait, Mon oncle ; allons gai, gai ; vous avez l'air sauvage

(Jean-François Regnard, Le Distrait)

1709 SAINT-GERMAIN. Et montrez-vous

joyeuse,

Famille amoureuse :

De la perte d'un amant

On se console aisément ;

Et dans ce siècle nôtre

Un clou chasse l'autre.

Allons gai, monsieur le procureur, Contre fortune bon cœur (Marc-Antoine Legrand, La Famille extravagante)

1867 Tantôt, il s'asseyait sur les montagnes qui bordent le lac, où l'air est si pur et l'horizon si lumineux. La troupe fidèle allait ainsi, gaie et vagabonde, recueillant les inspirations du maître dans leur première fleur. Un doute naïf s'élevait parfois, une 
question doucement septique (Ernest Renan, Vie de Jésus)

1870 Il allait, il marchait, la tête relevée de dessus cette épaule, où elle penche fatiguée. Il allait gai, avec toutes sortes d'aimables enfantillages, qui me disaient tendrement : « Voyons, es-tu content ? Je vais mieux, je suis en train, je ne suis pas encore si bête ! » (Edmond et Jules de Goncourt, Journal)

1896 N'est-ce pas ? En dépit des sots et des méchants

Qui ne manqueront pas d'envier notre joie, Nous serons fiers parfois et toujours indulgents.

N'est-ce pas ? Nous irons, gais et lents, dans la voie

Modeste que nous montre en souriant l'Espoir,

Peu soucieux qu'on nous ignore ou qu'on nous voie

(Paul Verlaine, Euvres poétiques com plètes)

II. s'en aller gai : partir gaiement, joyeusement Pronominal

1760 [ils] reçoivent cent coups d'étrivières, se relèvent, remettent leurs culottes, remercient le bon Père, le saluent très-humblement en baisant le bout de sa manche, et s'en vont contents et gais, s’ils le peuvent. Mais voilà un orage terrible, mêlé de pluie, de grêle et de neige ; et, au milieu de cet orage, une colonie qui nous vient de Sussy (Denis Diderot, Lettres à Sophie Volland)

1843 - Je revenais plus triste que je n'étais partie... et je renfonçais mes larmes pour ne pas être battue ! Tenez... au marché... ce qui me faisait envie, oh ! bien envie, c'était de voir des petites ouvrières bien proprettes, qui s'en allaient toutes gaies, avec un beau pot de fleurs dans leurs bras. - Je suis sûr que si vous aviez eu seulement quelques fleurs sur votre fenêtre, cela vous aurait tenu compagnie? (Eugène Sue, Les Mystères de Paris)

\section{CORpus Web :}

Alors très talentueux, le sympathique Barthelemy s'en allait gai en chantant et en dansant « à gauche quand YAYI BONI dit à gauche, à droite quand YAYI BONI dit à droite ", son tamtam dont le son produisait de l'électricité et de l'eau en abondance partout dans le pays, en bandoulière... [http://24haubenin.info/?MILLIARDSHOLLANDAIS-EVAPORES] (30.5.2016)

Sharon lui saute dans les bras et lui donne un gros baiser et s'en $v a$, gaie comme un pinson [http://www.lesfeuxdelamour.org/article18453304.html] (30.5.2016)

Mais déjà, malgré le temps maussade, il faut constituer les groupes, se munir du matériel adéquat, gilet fluo, gants, sans oublier la panoplie de sacs de toutes les couleurs. Et chaque petite troupe s'en va, gaie et motivée, qui vers la Semois, le Brugeland, la Saboterie, qui vers la Haute Rive, le Bochet, la Rochette, le Charmois, les inévitables Routheux, sans oublier, au retour, les Croisettes, les Marronniers, les Paquis, la Culée, tous ces noms si familiers à notre quotidien [http://www.moyen.be/?p=280] (30.5.2016)

REMARQUES : Aller gai est un groupe figé où gai s'emploie comme interjection, donc sans flexion, notamment dans les deux premiers exemples. À partir de la fin du XVII ${ }^{\mathrm{e}}$ siècle, l'emploi comme prédicat second accordé avec le sujet du verbe commence à prédominer. Avec s'en aller, gai est toujours un prédicat second. Notons que le sens du verbe aller est plus concret dans s'en aller gai 'partir' que dans aller gai, qui peut référer à un comportement ou une attitude parfois proches de la copule soyons gais. Allons gai, notamment avec réduplication (aller gai gai), semble plus oral et informel que la prédication seconde.

\section{Aller gent}

Partir doucement, gracieusement Pronominal

+1250 Puis conmande que l'en atort Bel e cortoisement la cort. Quant il out tot ce conmande, Si est tot meintenant monte Et avocques li de sa gent Tant qu'il s'en va et bel e gent (Le Roman de Renart [2 $2^{\mathrm{e}}$ moitié XIII ${ }^{\mathrm{e}}$, XIII, 672) 
REMARQues : Gent est un adjectif-adverbe de manière vieux qui réfère aux qualités physiques et/ou morales, ou la manière douce de la personne qui se déplace ; il souligne la grâce dans l'action. La coordination de gent avec le neutre bel souligne sa fonction adverbiale. Malgré ces caractéristiques formelles, la signification de gent le relie avec le sujet du verbe.

\section{Aller haut}

S'élever, atteindre un niveau supérieur Intransitif

1119 Que il unkes ne fait, Ainz est dit par figure E par divine cure ; Quant halt ne pot aler, Ne plus bas avaler Que en capricornum, Dunc est solsticium (Philippe de Thaon, Comput [1119 ou 1113], 3267)

+1250 Et dist Renars « ce fu bien fet. Mielz chantez que ne solieez. Encore se vos voliees, Irieez plus haut une jointe» (Le Roman de Renart [2 moitié XIII'], II, 933)

1637 LYZANTE. Mes vrais supplices sont ma constance, et ma foy,

Qui me forcent, rendant mes peines eternelles,

De mourir en moy mesme, et de revivre en elles :

Quelques traits que Clytie employe à ma langueur,

J'ay plus de fermeté qu'elle n'a de rigueur, Le desir de souffrir s'augmente par ma peine,

Ma gloire va plus haut, plus elle est inhumaine (André Mareschal, Le Railleur)

1680 Car, il faut dire le vrai, cela est fort commode, mais aussi c'est bien tout ce que nous pourrons faire que d'aller par ce chemin-là jusqu'en paradis ; assurément nous n'irons pas plus haut (Mme de Sévigné, Correspondance)

1774 Enfin, mon ami, j'en suis si contente, que je voudrois que vous l'eussiez fait ; et ce- pendant je suis certaine que vous feriez mieux encore : vous iriez plus haut, et vous n'auriez pas ses défauts. Mais prononcez vite : ai-je trop d'enthousiasme? (Julie de Lespinasse, Lettres à M. de Guibert)

1805 Peu à peu le prince s'est placé si près d'elle, que, même en ne le regardant pas, elle ne perd aucun de ses mouvemens, aucune de ses émotions : cette vue a quelque chose de contagieux qui augmente son trouble ; distraite, préoccupée, penchant sa tête sur sa poitrine oppressée, hélas ! Ce n'est plus à son Dieu qu'elle pense, son imagination ne va ni si haut, ni si loin. Sans doute le prince l'a devinée, car il ose prendre sa main entre les siennes et la presser contre ses lèvres (Sophie Cottin, Mathilde)

1823 On a le droit de croire que les offres de ce plénipotentiaire envers le souverain revenu allèrent bien plus haut et bien plus loin encore ; mais que Napoléon indigné les repoussa pour ne pas trop dégrader sa politique, a-t-il dit (Emmanuel de Las Cases, Le Mémorial de Sainte-Hélène)

1839 Ainsi, quelle que soit sa condamnation, elle ne sera jamais assez forte. D'ailleurs la question va plus haut. Évidemment, en ceci les classes lettrées n'ont jamais obtenu la protection accordée aux modeleurs de pendules et aux fabricants d'indiennes qui inventent un dessin (Honoré de Balzac, Correspondance)

1848a On est étonné tout d'abord de voir un homme aussi habituellement doux, soumis et, ce semble, timide, que l'était M. de Tillemont, - ce même homme qui se tenait toujours à genoux devant le père Lami, comme lui disait Bossuet, - parler si franc et si ferme quand il a affaire au rude abbé. Mais il n'est rien tel que ces doux et ces humbles pour aller droit et haut, quand ils sont une fois émus dans la défense de ce qu'ils jugent l'équité et la vérité (Charles Sainte-Beuve, Port-Royal)

$1848 \mathrm{~b}$ Votre fin et votre principe ne diffèrent pas : c'est Dieu qui est votre père, et c'est lui qui est votre but. Il est l'alpha et l'oméga de 
votre destinée ; vous ne pouvez regarder plus bas sans vous perdre, aller moins haut sans périr. En vain, si vous êtes ingrats, en appellerez-vous à la bonté contre la justice (Henri-Dominique Lacordaire, Conférences de Notre-Dame)

1849 Je ne connaissais pas la Ciguë. C'est charmant, mais quel progrès depuis ! Allez toujours, et vous irez bien haut. Voulez-vous remercier pour moi M. Arsène Houssaye de m’avoir envoyé une loge (George Sand, Correspondance)

1859 Mon ramier, sois béni ! Sauve-toi sans retour!

Va demander pardon pour les faiseurs de chaînes ;

En fuyant les bourreaux, laisse tomber les haines.

Va plus haut que la mort, emporté dans l'amour ;

Sois clément comme lui... sauve-toi sans retour !

(Marceline Desbordes-Valmore, Élégies)

1901 Mais si nous nous en contentions, si nous ne regardions plus rien par de là, si nous en induisions que toute pensée qui va trop loin ou trop haut a nécessairement tort et que la vérité se trouve toujours dans le détail matériel, si nous ne cherchions pas, n'importe où, dans des incertitudes souvent plus étendues que celles que la petite explication nous a forcé d'abandonner, par exemple dans l'étrange mystère de la fécondation croisée, dans la perpétuité de l'espèce et de la vie, dans le plan de la nature, si nous n'y cherchions pas une suite à cette explication, un prolongement de beauté et de grandeur dans l'inconnu, j'ose presque assurer que nous passerions notre existence à une plus grande distance de la vérité que ceux-là mêmes qui s'obstinent aveuglément dans l'interprétation poétique et tout imaginaire de ces noces merveilleuses (Maurice Maeterlinck, La Vie des abeilles)

1909 le combat gigantesque de la science contre la nature ; - plus bas, troupe silencieuse, les hommes et les femmes de bonne volonté, les cœurs braves et humbles, qui, au prix de mille peines, ont atteint à micôte, et ne peuvent aller plus haut, rivés à une vie médiocre, se brûlant en secret dans d'obscurs dévouements (Romain Rolland, Jean-Christophe. Dans la maison)

1912 Aucun d'entre les Polynésiens, dans tous les cas, n'est allé aussi haut. S'il y a, entre tous les Océaniens et les vieux habitants de l'île de Pâques une filiation préhistorique, c'est chez les Maoris qu'il faut voir leurs héritiers les plus légitimes (Élie Faure, Histoire de l'art : l'art médiéval)

1953 L'air de Didon : Chers tyriens, tant de nobles travaux..., au premier acte, est solennel comme il convient, mais quelque peu froid, conventionnel ; au contraire, l'expression du désespoir de la reine, au dernier acte, atteint le sublime, et jamais l'art de Berlioz n'est allé plus haut (René Dumesnil, Histoire illustrée du théâtre lyrique)

1960 Le niveau des connaissances acquises au cours de la première étape ne $v a$ pas très haut : à la fin de cette scolarité, l'enfant bien doué sait lire et écrire une phrase simple, a retenu quelques passages poétiques, appris les chiffres et les nombres bien plus que les opérations élémentaires, a été initié aux poids et mesures (Encyclopédie pratique de l'éducation en France)

\section{CORPUS WEB :}

Quel genre de chemin veut-on emprunter ou créer ? Dans quel sorte de paysage ? Seul ou en compagnie? Aller loin, ou aller vite, ou aller profond, ou aller haut, ou aller beau, etc ... ? Définir précisément ce qui, à chaque carrefour de vie, nous fera choisir telle voie plutôt que telle autre [http://www.noetique.eu/articles/philo sophies/lart-de-vivre-sa-vie/view] (18.5.2016)

Marché: On peut aller plus haut avant d'aller plus bas.... [https://leblogalupus.com/2015/08/27/ marche-on-peut-aller-plus-haut-avant-dallerplus-bas] (18.5.2016)

Lorsque vous négociez avec la moyenne mobile, l'opérateur peut regarder la courbe de 
moyenne mobile (qui est tiré a coïncidé avec la courbe de prix en monnaie principale) et voir si elle va haute ou basse pour déterminer la tendance [http://pistecapitaine.blogspot. co.at/2012/08/forex-trading-indicateurstechniques.html] (8.11.2013)

Bonjour j'ai un mustang 95 avec un 3.8L manuel et j'ai un gros probleme au decollage l'acceleration est tres lente jusqu'a $2500 \mathrm{tr} / \mathrm{min}$ passer sa il va numero 1 et au ralenti il vire mal mais si je lui donne un coups de gaz il le prend parfaitement et la temperature du moteur monte tres vite elle va haute [http://www.montrealmustang. org/forum/index.php?/topic/20806-problememoteur] (8.11.2013)

REMARQUES : Haut est un adjectif-adverbe de lieu qui a un sens spatial et désigne un point élevé, au sens concret et aussi au sens figuré. Aller haut se dit de quelqu'un ou quelque chose atteignant un degré élevé d'intelligence, de noblesse, de talent, de spiritualité, de dévotion, de félicité, d'audace, aller devant être compris comme "atteindre ". Dans l'exemple de 1119, haut aller s'oppose à bas avaler. Haut reste invariable et est modifié par aussi, bien, bien plus, moins, plus, si, trop. Notons la collocation avec l'adjectif-adverbe droit, insistant sur le caractère droit, convenable et propre à l'élévation, ainsi qu'avec l'adverbe loin. Dans l'écriture spontanée du CW, la flexion semble possible. L'accord insiste sur la qualité d'une courbe située haut(e) ou bas(se), ou de celle de la température qui est haute. Mentionnons l'emploi de parler franc, parler ferme, aller profond, aller beau.

\section{Aller impec}

Seoir, convenir parfaitement

Intransitif

1987 Avec l'argent de Gisèle, je peux enfin m'acheter le nouveau jean de toile estampillé, couleur sable foncé, que je guignais depuis un bail à la SGGG. Il me $v a$ impec, et Gisèle de mes rêves de viol me le fait savoir gentiment au cours de dessin (Bruno Bayon, Le Lycéen)

REMARQUES : Aller impec signifie 'convenir parfaitement'. Impec est une réduction familière de l'adjectif-adverbe impeccable ou de l'adverbe im- peccablement. La combinaison « verbe + impec(cable) » constitue une série ouverte dont nous ne citons que quelques variantes.

\section{Aller isnel}

I. s'en aller isnel: partir rapidement, aussitôt

Pronominal

+1100 Quant je vi le pastorel

Qui se partoit de celi

Vers li m'en vois mout isnel,

De mon cheval descendi

(Romances et pastourelles françaises des XII ${ }^{e}$ et XIII ${ }^{e}$ siècles, p. 283)

-1300 Or s'an va li messages isnel com une aronde,

Et Murgafiers remaint sor Rune la

parfonde ;

La gent de France voit de qoi li prez abonde,

Bien li samble q'anqi soient tuit cil do monde (Jehan Bodel, La Chanson des Saisnes [fin XIII'], 4466)

1375 Dieu veult que t'en voises isnel,

La derriéres, en un prael

Ouquel il a une fontaine,

Tout seul, ame avec toy ne maine

(Miracle de Robert le Dyable, 1647)

II. Aller rapidement

Intransitif

+1350 Si apela celui que trenchoit du coutel

Et li a dit : «Amis, ales tost et isnel

A la porte savoir qu'il i a de nouvel. »

Li varles, qui tenoit un hanap a clavel,

Dist : «Sire, voulentiers, puis qu'il vos

vient a bel » (Brun de la Montaigne

[2e moitié XIV $], 1884)$

1381 CLOTILDE. Non, sire ? Donques me tairay

Pour maintenant, vaille que vaille.

Han! certes, il fault que m'en aille

De ci en ma chambre, chier sire.

Par les reins sanz tant de martire

Que trop. Faites tost, Ysabel ;

Or en alons ensemble isnel :

Ne puis plus ci (Miracle de Clovis, 1298)

REMARQues : En ancien français, isnel est un adjectif-adverbe de manière qui caractérise un déplacement rapide ; employé aussi au sens tem- 
porel de 'aussitôt', notamment en combinaison avec tost (tôt). D'origine germanique, isnel était courant jusqu'en moyen français avec la même signification que schnell 'rapide', son correspondant en allemand moderne. Le fait qu'on ait utilisé ce mot emprunté comme adjectif-adverbe montre que l'emploi adverbial de l'adjectif était un procédé productif. Isnel reste invariable et est modifié par ensemble, moult. VoIR AUSSI : venir isnel

\section{Aller juste}

Bien fonctionner, fonctionner avec précision Intransitif

1724 CLARINE. Il ne trouvoit pas plus de honte pour un honnête homme à avoir une femme infidelle qu'une montre qui n'iroit pas juste (Marc-Antoine Legrand, Le Philanthrope)

1919 Or, précisément parce que M. Baslèvre contemplait à ce moment la pendule du père Gros, il s'avisa d'y lire l'heure.

- Quoi ! dit-il, n'avance-t-elle pas ?

Et se levant d'un bond, il boutonna son pardessus. Le hasard semblait avoir décidé.

- Non, dit Gustave, elle va juste. Tu es pressé?

- Ma signature...

- Je comprends... raison de plus pour apprécier ta visite inespérée

(Édouard Estaunié, L’Ascension de $M$. Baslèvre)

\section{CoRpus WeB :}

J'ai reçu les petites chaussons de mer... Ils vont justes, peut-être s'étirent-t-ils un peu en les mettant !!! [https://fr-fr.facebook.com/Brindilles. fr/posts/122882391081070] (08.11.2013)

Remarques : Aller juste s'emploie dans le domaine de l'horlogerie, référant à tout appareil ou dispositif qui permet de mesurer le temps et d'indiquer l'heure, fonctionnant avec exactitude. Juste s'emploie aussi quand des chaussures ou vêtements sont trop étroits ou serrés (CW). L'exemple du CW montre que l'accord adverbial n’a pas disparu de l'écriture spontanée.

\section{Aller léger}

I. Aller avec légèreté, aisance, agilité et/ou insouciance

Intransitif

1894 Elle avait deux lettres ce jour-là. La première qu'elle lut exhalait une gaie odeur d'amour ; Jacques ne s'était jamais montré plus riant, plus simple, plus heureux, plus charmant. Depuis qu'il l'aimait, disait-il, il allait si léger et soulevé d'une telle allégresse que ses pieds ne touchaient plus la terre (Anatole France, Le Lys rouge)

1947 Une voix du cœur prononça : « L'intérieur se désole. » Enfin la peur se levant en eux, comme un léger vent sur la mer, la peur les gonfla. Ils allèrent plus loin, plus légers, entre des roches, des falaises vertigineuses, parfois très rapprochées, où ne volait aucun aigle. Ces parois se resserrèrent encore (Jean Genet, Miracle de la rose)

II. Partir, disparaître avec légèreté, agilité Intransitif

1922 Tandis qu'ils se glissaient à travers l'ombre des longs corridors, la jeune femme, en guise d'adieu à leurs plaisirs qu'elle sacrifiait à l'amour, lui récita les vers du poète : « La tulipe fleurit promptement et s'en va légère et rapide, mais le rubis qui se forme avec lenteur ne craint rien du vent ni de la pluie et traverse toutes les saisons " (Maurice Barrès, Un jardin sur l'Oronte)

1959 Quand un buisson lui semble propice, elle $\mathrm{y}$ entre franchement, froisse les branches, se couche pesamment, imprime sur les feuilles mortes la rondeur de ses flancs, de sa croupe, et puis s'en va, légère, ombre roussâtre qui se confond avec les palmes rousses des fougères, les feuilles sèches des chênes de taillis (Maurice Genevoix, Routes de l'aventure)

\section{CORPus Web :}

C'est bien pour ça qu'ils vont léger sur les corrections, s'ils peuvent éviter, ils le font ! [http:// www.jeuxvideo.com/forums/1-50-38086150-2-01-0-mettre-des-lunettes-conseil.htm] (8.11.2013) 
Elle allait léger, et même cette poitrine à peine suggérée (bien que malicieusement soulignée par le procédé ingénieux de la ceinture haute, il en convenait) se fondait dans la silhouette gracile [http://theordanworld.forumgra tuit.org/t221-la-ou-le-soleil-brille] (8.11.2013)

REMARQUES : Dans le premier exemple, aller léger caractérise la façon dont quelqu'un se déplace, tout en reflétant son état d'âme insouciant, libre. Aller se rapproche donc de sa fonction de copule. Les autres exemples (sauf CW) appartiennent au domaine de la prédication seconde, léger s'accordant avec le sujet du verbe aller. Léger est modifié par plus, si. Il s'emploie surtout dans un registre soutenu, littéraire. Dans l'écriture spontanée du CW, la signification adverbiale 'à la légère' (premier exemple) n’a pas disparu. Léger tend alors à l'invariabilité.

\section{Aller lent}

Aller lentement, avec lenteur

Intransitif

$\sim 1177$ Li chevaus qui ne va pas lant S'efforce, quant an l'esperone (Chrestien de Troyes, Yvain ou Le Chevalier au lion)

1275 La ou Sarrazin poignent contre la nostre gent,

Gerars et Guielins vinrent premierement ; Chascuns ot bon destrier qui ne va mie lent (Adenet le Roi, Buevon de Conmarchis, 259)

$\sim 1275$ Lors ont des esperons feruz Leurs chevaux qui pas ne vont lent Ainz courent plus isnelement Qu'arondele ne puet voler (Floriant et Florete, 1015)

1365 Quant il oï le noise et le demainement, Sus son cheval monta, qui ne va mie lent (Li Romans de Bauduin de Sebourc, Chant VII, 788)

1535 Ces flots jumeaus de lait bien époissi Vont et revont par leur blanche valée, Comme à son bord la marine salée, Qui lente va, lente revient aussi (Pierre de Ronsard, Les Amours)
1862 Alors, repassèrent en foule dans ses souvenirs les aimées d'autrefois, avec leurs attitudes préférées, leurs regards doux ou fiers : blondes, brunes, elles allaient lentes ou rapides, dignes ou cyniques (Paul Reider, Mademoiselle Vallantin)

1934 Laure avait, de nouveau, pris l'habitude de cette calme existence où le temps semble aller plus lent (Daniel-Rops, Mort, où est ta victoire?)

Pronominal (s'en aller lent)

1833 la femme qu'on appelait Lélia et qui s'en allait lente et blême, enveloppée dans son manteau de velours noir, traînant à sa suite un cortège à qui elle ne daignait pas jeter un regard... (George Sand, Lélia)

CORPUS Web :

Ouais, on avait joué à SOM et comme ma connection n'est pas fait pour les jeux en réseau sa allait lent [www.jeuxvideo.com/forums] (9.8.2020)

Le cortège allait lent...sous la pluie de septembre[m.facebook.com/permalink/Le cercueil flambant] (9.8.2020)

REMARques : Aller lent renvoie au fait de se déplacer avec lenteur. L'ancienne langue l'emploie surtout à la forme négative comme équivalent de viste(ment) et isnel(ement), sans doute quand la rime le demande. Dans la langue moderne, c'est la fonction de prédicat second accordé qui domine, et qui souligne la lenteur du sujet. Il peut être modifié par plus.

\section{Aller long}

I. Aller loin

Intransitif

1280 Pour si dous iex doit on bien lonc aler Et mout $i$ a pressïeus saintuaire, Mais on n'i laist baisier ni adeser Ne on ne doit penser si haut salaire (Adam de la Halle, Chansons, VIII, 33)

$\sim 1300$ Mais tuit si home sont mort a grant hascie ; Ains que euisent lonc ale une arcie, Tout piece a piece lor car fu dehecie (Aliscans [R], 482) 
II. Produire des selles importantes, qui 'vont loin'

Intransitif

1534 Lesdictz bergiers les requirent courtoisement leur en bailler pour leur argent, au prix du marché. Car notez que c'est viande celeste, manger à desjuner raisins avec fouace fraiche, mesmement des pineaulx, des fiers, des muscadeaulx, de la bicane, et des foyrars pour ceulx qui sont constipez du ventre, car ilz les font aller long comme un vouge, et souvent, cuidans peter ilz se conchient, dont sont nommez les cuideurs de vendanges

(François Rabelais, Gargantua)

\section{CORPUS WEB :}

Ben avec des colosses qui ont disparus, elle va longue... très longue cette quête :/

Quelqu'un a vu un colosse quelque part ? [http://forum.eredan.com/viewtopic. php?pid=747227] (7.11.2013)

Qu'est ce qu'elle va longue cette fin de saison ! Longue, mais longue... On n'éprouve plus aucune émotion avec cette équipe, c'est quand même le comble pour le PSG [http:// onlyoneparis.blogs.francefootball.com/ archive/2010/03/20/kombouare-a-l-image-de-lasaison.html] (8.11.2013)

On m'a dit que si on utilise le baby born dans le bain, elle va long à sécher et il paraît qu'il ne faut pas lui donner la bouille parce que le nettoyage pas terrible [http://m.bebe.ch/drupal/ node/83221?device=mobile] $(8.11 .2013)$

REMARQUES : Long est un adjectif-adverbe de quantité qui désigne une extension, une distance ou une durée parcourue. Usité en ancien français, (I) signifie parcourir une longue distance. Dans (II), Rabelais décrit la capacité laxative des raisins (cuides, foyrars), qui permet au sujet d'expulser des selles longues " comme un vouge ». Long reste invariable. Dans l'écriture spontanée du CW, l'accord non orthographique « qui ont disparus » prouve les difficultés orthographiques de l'auteur du premier exemple, mais la terminaison au féminin de longue est audible dans la langue parlée, donc probablement authentique. Si l'on regarde aussi le second exemple du CW, la flexion se confirme comme variante de la langue parlée informelle. Dans les trois exemples du CW, la lecture figurée temporelle prédomine. Aller se rapproche alors d'une fonction de copule.

\section{Aller menu}

I. Voler, tomber rapidement, en grande quantité Intransitif

1190 Dont oïssiez buissinez, cors et grailles sonner,

Et Turs et camelleuz et glattir et usler.

Plus menu vont saietes que noif qu'on voit gresler ;

Dont veïssiez perrieres ces grans pieres geter,

Et ces aspis d'achier et ferir et hoer

(Fierabras (L), 3928)

1598 Et apres, fut le Docteur Fauste remis à l'air et en l'instant y eut force coups de fouldre et esclairs - tellement que cela alloit si menu que le Docteur Fauste se tint coy sans sonner mot, ayant grande frayeur et tout tremblant (Pierre-Victor Cayet, L'Histoire prodigieuse du Docteur Fauste)

II. aller menu et souvent : aller avec fréquence, continuellement

Intransitif

1370 Aprés ces paroles il vendirent leur nef, et puis se mistrent a voye et errerent tant qu'il vindrent a Romme et prindrent hostel dehors les murs de la cité de Romme. Or vous dy que Silirans n'avoit mie mis en oubly le carrel par ou il entroit en la tour l'empereur, ains y ala menu et souvent, tant qu'il sceut que bon fu, et prist tant $\mathrm{du}$ tresor et apporta par pluseurs foiz a Berinus et aux autres tant qu'il en eurent a grant plenté et firent un riche manoir au dehors de Romme (Roman de Berinus, I, p. 228)

REMARques : Menu est un adjectif-adverbe de manière dont les significations se dégagent à partir de son sens de base 'petite quantité', notamment dans le domaine temporel : fréquemment, souvent en peu de temps. Par extension, il signifie 'rapide'. Usité au Moyen Âge, (II) désigne un animé allant à un endroit avec fréquence et rapidité. Aller menu (I) réfère à des flèches ou à des éclairs tombant plus rapidement et en plus 
grand nombre que des flocons de neige. Menu reste invariable et est modifié par plus, si. Notons la collocation usuelle menu et souvent et l'emploi de tenir coi.

\section{Aller moche}

Se porter mal

Intransitif

1959 - Comment ça va?

- Ça va moche

(Exemple entendu / Grundt : 219)

\section{CORPUS WEB :}

AMEL, tu as bien de la chance d'avoir du soleil. Chez moi, il va moche !!! déprimant. mais bon [http://www.yabiladi.com/forum/etes-vousessayettes-67-3575697-page=16.html] (7.11.2013)

REMARQUES : Moche est un adjectif-adverbe qualificatif qui rentre dans une réponse familière équivalente à Ça va mal. Opposé à l'adjectif standard laid, l'emploi de moche met en évidence le caractère informel de l'exemple. Dans l'exemple du CW, il va moche réfère au temps ; il équivaut donc à il fait mauvais du registre standard.

\section{Aller modeste}

y aller modeste : ne pas dépenser beaucoup d'argent, avoir un train de vie modeste Intransitif

1947 Depuis trois ans, je ne m’occupe plus de rien. Les affaires en or, je les regarde passer et je vis sur mon capital. Mes économies, elles ne sont pas lourdes, mais j’y vais modeste.

Médé se moquait de moi. Je voyais son unique petit œil briller de malice pendant qu'il me racontait ces foutaises (Marcel Aymé, Le Vin de Paris)

\section{CORPUS WEB :}

La féria mélée à la fête foraine est plutôt craignos, grand défilé de piches, beauf', cagoles, gitans et niktameres : la bagarre n'est jamais loin et le pickpocket vous frôle de près. Ceux qui ont la gueule de la terreur y font leur défilé de frime, les autres y vont modestes pour eviter les embrouilles. Un endroit plus fréquentable en hiver qu'en été.Feu d'artifice du 14 juillet de bonne qualité [http://www.faitbonvivre.com/ avis-riverains.php?idville=13774] (9.01.2014)
Tu as raison : mais les objectifs de base pour la Bravo étaient très modestes et, de fait, fait pour être dépassés. Ils y vont modestes. ça c’est bien ! [http://www.forum-auto.com/marques/fiat/ sujet6850-13720.htm] (9.012014)

REMARQUES : Dans la collocation y aller modeste, le modifieur se comporte comme un adjectifadverbe de manière équivalent à modestement, même si son affinité sémantique avec la prédication seconde est sans doute également présente. Dans le contexte financier, elle réfère à une retenue du sujet concernant ses dépenses, signifiant par extension qu'il est de condition modeste, humble. Sur l'ensemble des occurrences de modeste, la prédication seconde orientée vers le sujet du verbe prédomine clairement. Nous avons donc affaire à une locution figée dont l'interprétation oscille entre lecture adverbiale et lecture prédicative. Dans le premier exemple du $\mathrm{CW}$, seule la lecture comme prédication seconde est possible.

\section{Aller mollo}

Ralentir le rythme

Intransitif

1951 Il me prête sa canadienne et je m'embarque au volant sur des routes à peine catholiques. Il m'a recommandé d'aller mollo jusqu'au fond de la vallée, mais j'y vais encore plus mollo que ça : les virages au nord sont comme des patinoires (Jean Giono, Les Grands Chemins)

2012 - Bah, tu devrais lui expliquer d'y aller mollo sur la dope. Putain, je te jure, il fait peur à voir. L'autre jour, avec Farid, on a dû le calmer. Il voulait nous en acheter pour un régiment (Stéphane Osmont, Éléments incontrôlés)

REMARQUES : Aller mollo porte le même sens que aller mou, 'y aller doucement', mais il s'agit d'une troncation suffixée de l'adverbe mollement. C'est donc un des rares cas où l'on peut morphologiquement prouver que l'adverbe court est dérivé de l'adverbe en-ment. En sens inverse, aller mou ne saurait être expliqué comme troncation de l'adverbe en -ment. 


\section{Aller mou \\ y aller mou : agir doucement, délicatement, sans violence \\ Intransitif}

1946 Pézenas, qui s'en foutait tout autant que lui, mais qui avait du moins la prudence de s'en cacher, lui disait qu'il travaillait à la mords-moi-le-nœud. Vas-y mou, lui glissait-il, quand Monsieur Hermès bousculait un peu trop brutalement la vaisselle sous le nez d'un client. C'est plus de la carte, c'est du pancrace ! (Raymond Guérin, L'Apprenti)

1951 J'ai cru moi-même à la fracture du crâne.. - C'est très gentil, mais pourquoi avezvous choisi ma porte pour jouer au bélier? Entre parenthèses, vous n'y êtes pas allé mou, elle est toute gondolée !

- Parce que j'allais chez vous, pardi !

- Je comprends... C'est Léon qui vous envoie... (René Fallet, Le Triporteur)

1969 J'ai pris un second bifton et je l'ai traité moins rudement. Cette fois, je n'ai pas percé le papier. Alors, à la plume fine, j’ai fait un 8 d'un 2 et un 7 d'un 1. J'y allais mou. Ça m’a demandé une bonne heure, mais quand j'ai tendu le billet ainsi retouché à bout de bras, pour juger de l'effet, je n’ai pas regretté ma peine (Léo Malet, Sueur aux tripes)

\section{CORPUS WEB :}

Enfin, il dit que vous devriez toujours remplacer vos têtes de brosse au moins une fois tous les 3 mois. C'est parce qu'ils vont mou et ne peut plus maintenir la force nécessaire pour pousser le lâche plaque et les débris attaché à vos dents [http://www.neosante.org/traitementparodontale-a05085945.htm] (7.11.2013)

REMARQUes : Mou est un adjectif-adverbe de manière qui exprime l'atténuation de la façon dont quelqu'un exécute une action. Y aller mou est une locution familière qui se dit de quelqu'un adoptant un comportement plus doux, adapté à la situation, voire trop réticent, pour d'éviter un embarras, un accident, etc. Dans les exemples cités ci-dessus, mou reste invariable. Dans l'exemple du $\mathrm{CW}$, aller mou réfère à un processus par lequel la tête des brosses à dents devient molle. Il s'agit donc d'un emploi prédicatif avec aller en fonction de copule dynamique et télique.

\section{Aller net}

I. s'en aller net : partir, disparaître

immédiatement, complètement

Pronominal

1671 Mais je vous veux premièrement, Prouver par bon raisonnement,

Que ce mal dont la peur vous mine et vous consume,

N'est mal qu'en votre idée, et non point dans l'effet.

En mettez-vous votre bonnet

Moins aisément que de coutume?

Cela s'en va-t-il pas tout net?

Voyez-vous qu'il en reste une seule apparence :

Une tache qui nuise à vos plaisirs secrets ?

(Jean de La Fontaine, La Coupe enchantée)

II. cela va net : le travail se fait sans entrave Intransitif

1757 Maintenant, à chaque article, nous verrons revenir ce refrain des lois constitutives. Cela va net à l'assemblée des États généraux du royaume, et même cette réunion des parlements avec la jonction des princes et des pairs, où ceci les mène, a plus de poids et d'effet encore que les États généraux : voilà un gouvernement national tout formé, avec un avantage de plus, savoir que le clergé ne s'y trouve pas (René-Louis d'Argenson, Journal et Mémoires)

REMARQUES : Aller net (I) se dit de quelque chose qui disparaît d'un coup et totalement. (II) renvoie au fait de procéder sans faire de détours. Net est modifié par tout. VoIR AUSSI : absorber net

\section{Aller petit}

I. s'en aller petit : partir, quitter un lieu craintivement, sans gloire

Pronominal

+1150 Del moustier saint Denis le maistre confanon

Et la senescaudie de tout uostre roion, 
Et petit s'en ira que par mi ne parton

(Aiol et Mirabel [ $2^{\mathrm{e}}$ moitié XII $]$, 8095)

II. Parcourir peu de distance ; prendre peu de temps

Intransitif

1170 Isnelemant passent le pont, Mes mout orent alé petit

Quant de la tor amont les vit

Cil qui de la tor estoit sire

(Chrestien de Troyes, Erec et Enide, 3675)

+1225 Petit eurent alé en tel manière quant il virent terre. Et il demandèrent as maronniers quele terre chou estoit. Et li maronnier respondirent que che estoit terre de Sarrazins (La Comtesse de Ponthieu [2 $2^{\mathrm{e}}$ quart XIII ${ }^{\mathrm{e}}$, p. 198)

1250 Des mors et des navrez devant li tant versa Petit i peut aler qui sus mort ne monta (Doon de Mayence, p. 263)

RemARQUes : En ancien français, aller petit exprime le fait d'avancer peu. Dans l'exemple (I), la personne à laquelle réfère le sujet s'éloigne en évitant de se faire remarquer. Petit reste invariable et est modifié par plus, tout.

\section{Aller plein}

s'en aller plein : sans ralentir son allure

Pronominal

+1250 Brichemer n’i entent nul mal.

Vers la vile par mi un val

S'en vont le droit chemin tot plein.

Atant estes vos un vilein

Qui avoit avoc lui trois chens

(Le Roman de Renart [2 $2^{\mathrm{e}}$ moitié XIII'], X, 1079)

1857 Les Scythes vagabonds aux flèches meurtrières

Les Gélons demi-nus, les Sarmates lointains...

C'était plaisir alors! Des légions entières

Franchissaient le Danube, au pays des Germains!»

Et tandis que sa voix s'en allait large et pleine,

Melaenis le brûlait du feu de son haleine (Louis Bouilhet, Melænis)
CORPUS Web :

Au moins ils vont quitter le camp et à onze heures deux cars " Pous ", de Decazeville, qui étaient venus les chercher s'en vont pleins, vers la liberté [http://espana36.voila.net/r_arto/pll15. html] (13.11.2013)

Remarques : Plein est un adjectif-adverbe de manière qui caractérise la poursuite d'un chemin, indiquant sa pleine possession. Dans l'exemple de l'ancien français, il est modifié par l'adverbe d'intensité (tout) qui le précède. L'exemple rappelle la locution toute sa pleine voie 'sans ralentir son allure'. Plein s'utilise aussi comme prédicat second (avec large) accordé avec le sens 'sa voix était large et pleine' (1857) et '(les cars) étaient pleins' (CW).

\section{Aller profond}

I. Aller profondément

Intransitif

1275 Combien que dou fleuve s'aproochent ;

Un petitet, senz plus, en beivent,

$\mathrm{E}$, quant la douceur aperceivent,

Volentiers si parfont iraient

Que tuit dedenz se plongeraient (Jehan de Meun, Roman de la rose [1269-1278], 6013)

1839 Soudain apparaît

La seconde armée

De lances semée,

Comme une forêt.

Elle va profonde,

Et mugit et gronde

D'un souffle infernal

(Ernest Buschmann, Rameaux)

1937 Elle est allée seulement plus profond, si profond que la chair elle-même y répond par une souffrance inconnue, qui rayonne du centre de la vie dans le pauvre petit corps douloureux (Georges Bernanos, Nouvelle Histoire de Mouchette)

1972 Pour la voûte crevée, ils aggravèrent le trou jusqu'à ce qu'ils rencontrent de la maçonnerie saine. À vrai dire, ils n'allèrent pas bien profond, car le travail avait été bien fait, dans les siècles d'obscurantisme (Henri Vincenot, Le Pape des escargots) 
II. Aller en profondeur, pénétrer

(intellectuellement, sentimentalement, historiquement)

Intransitif

1910 Par son impotence même de mal, de cruauté Corneille va plus profond que Racine. Car la cruauté n'est point, tant s'en faut, ce qu'il y a de plus profond. Elle n'est point le profond du cœur, elle n'est point le profond de l'homme (Charles Péguy, Victor-Marie, comte Hugo)

1936 Et s'il y en a qui plus tard, en se souvenant de leur capitaine, disent : « quand même, c'était 'un bon bougre', j’aurai été bien payé. » Ayant lu cela, Costals avait relevé la tête ; cela allait très profond en lui, et il songeait : « je suis un type dans le genre d'Hurluret. Naturellement, il y a en moi autre chose. Mais je suis aussi Hurluret » (Henry de Montherlant, Pitié pour les femmes)

1938 - Tu m'aimeras plus quand je serai plus là, elle gueulait. Oh ma nine, oh ma belle quique ! elle faisait Madeleine Dietrich en pleurant aque des yeux qu'ils allaient profond dans le cœur. Tandis que toi, elle disait, tu seras toujours beau petit et $\mathrm{tu}$ viendras jamais vieux (Albert Cohen, Mangeclous)

1974 Pons Sabatier, Randon de Chateauneuf, Joachim Amargier ; d'autres portaient les noms des villages et des hameaux du canton précédés d'une particule.

- Nos racines vont profond, Olivier ! (Robert Sabatier, Les Noisettes sauvages)

1991 Passe le récit, aveuglement compris, quand la philosophie répète et piétine. Mais elle seule peut aller assez profond pour démontrer que la littérature va encore plus profondément qu'elle

(Michel Serres, Le Tiers-Instruit)

\section{CORPus Web :}

Quel genre de chemin veut-on emprunter ou créer ? Dans quel sorte de paysage ? Seul ou en compagnie? Aller loin, ou aller vite, ou aller profond, ou aller haut, ou aller beau, etc ... ? Définir précisément ce qui, à chaque carrefour de vie, nous fera choisir telle voie plutôt que telle autre [http://www.noetique.eu/ articles/philosophies/lart-de-vivre-sa-vie/view] (18.5.2016)

la largable, ascenseur, hippopotame, bouteille de périer et tout le tointoin ne sont pas la pour aller plus profond... mais pour descendre profond avec plus de sécurité..... [http://www. chasse-sous-marine.com/forums/topic/51338recherche-chasseur-ou-apneiste-pour-allezprofond] (30.1.2015)

REmarques : Profond est un adjectif-adverbe de degré qui caractérise, au sens figuré, l'intensification de pensées ou de sentiments. Aller profond (I) se dit de quelqu'un ou quelque chose (ici : les yeux) qui perce, ou rentre profondément dans quelque chose/quelqu'un. Au sens figuré (II), il se dit de pensées, paroles, sentiments qui, pour ne pas rester superficiels, s'approfondissent, s'intensifient, vont plus en détail, afin d'élargir un champ de vision ou arriver à un résultat attendu. Profond reste invariable et est modifié par assez, bien, plus, seulement, si, très. En poésie, l'accord de profond renforce l'implication du sujet dans un mouvement qui va en profondeur, mais sans lui enlever sa valeur de modifieur du verbe. Dans ce cas-là, profond peut s'accorder avec le sujet (1839). Notons l'emploi de descendre profond.

\section{Aller raide}

I. Aller impétueusement, de façon résolue Intransitif

1543 Les fiers chevaulx piquer donne toy garde, Ains par la resne à force les retarde. De leur gré vont, voyre si roide et fort, Qu'à les tenir fault merveilleux effort (Clément Marot, Livre second de la métamorphose)

1610 Il y avoit le baron de Sault avec ses fesses, dont le proverbe en est venu, qui tendoit beau cul, sans y penser. La fin du coup va roide à son cul, d'autant qu'il estoit ainsi tourné parlant à d'autres ; et partant il eut le cul coupé. «Ha ! ce dit-il, monsieur, qu'avez-vous fait ? Vous avez gasté mon haut-de-chausse » (Béroalde de Verville, Le Moyen de parvenir) 
1833 Mais telle est la nature des révolutions qu'elles ne savent pas s'arrêter ; les hommes qui leur appartiennent sont sans ménagements; ils vont raide et droit devant eux, sans s'inquiéter s'ils ne creusent pas un tombeau aux idées libérales par leur inconcevable obstination (Baptiste Capefigue, Histoire de la Restauration)

1880 Mais, comme elle prenait le bouquet, il lui sauta sur les mains, avec la gloutonnerie de son bel âge. Elle dut le battre pour qu'il lâchât prise. En voilà un morveux qui allait raide ! Tout en le grondant, elle était devenue rose, elle souriait. Et elle le renvoya, en lui permettant de revenir. Il chancelait, il ne trouvait plus les portes (Émile Zola, Nana)

II. S'en aller en adoptant une posture verticale, tendue ; avancer raide comme un piquet

Pronominal

1840 Ainsi affûtés, apprêtés, bichonnés, ces gens d'un âge indicible, d'un sexe même problématique, tant ils se sont épilés dès leur première gelée blanche, s'en vont raides comme bâtons, poupées à ressorts, momies galvanisées, colportant çà et là un éternel sourire stéréotypé sur un double râtelier de Pernet (Francis Wey, L’Ami des artistes)

1870 VICTOIRE DE SARREBRUCK

gravure belge brillamment coloriée, se vend à Charleroi, 35 centimes

$\mathrm{Au}$ milieu, l'empereur, dans une apothéose

Bleue et jaune, s'en va, raide, sur son dada Flamboyant ; très heureux, - car il voit tout en rose,

Féroce comme Zeus et doux comme un papa (Arthur Rimbaud, Poésies)

1894 Et je dis à Dieu : « Puisque, dans votre colère, vous lui avez donné la richesse et la beauté, regardez-la, seigneur, avec mansuétude, et traitez-la selon votre grande miséricorde. » Et il s'en alla, raide et trâ̂nant la jambe, par l'avenue populeuse (Anatole France, Le Lys rouge)
Intransitif

1963 La glycine s'étire et le mur en éveil

Rougit. Une journée s'accroche aux lourdes branches ;

Les paysannes vont raides sous leur palanche ;

Les maires de parade ouvrent le grand conseil (Jean-François Hocedez, La Soif)

III. Aller rapidement, avec détermination et

force

Intransitif

1853 Le tout terminé par quelques considérations sur ce que peut être la littérature de l'avenir. La Bovary ne $v a$ pas raide : en une semaine deux pages !!! Il y a de quoi, quelquefois, se casser la gueule de découragement! (Gustave Flaubert, Correspondance)

1929 Une main d'usurier, ça chasse tout seul. Où ce qu'y a de l'or et de l'argent, ça y va raide tout droit. Ça irait vous chercher la bourse dans la poche. S'y a queq'chose au fond de la mer, la main à Lévy vous le trouvera pour sûr (Paul Claudel, Le Soulier de satin)

IV. ne pas aller raide : se porter mal

Intransitif

1880 La vertu seule m’a ramené vers l'article cerveau du Dictionnaire des sciences médicales. J'imagine que la Peinture ne $v a$ pas roide en ce moment, et que mon Loulou a un moment de découragement? Est-ce vrai ? Ma lettre est bien bête, et bien décousue, tâche de m'en écrire une longue (Gustave Flaubert, Correspondance. Supplément)

CORPUS WEB :

Et ils font reculer leurs deux barques de vingt pieds

Ils sont en place et puis ils s'observent de nouveau,

Et leurs barques vont raides comme des oiseaux,

Les lances se croisent et se touchent toutes deux,

La lance se brise dans la main de Thonnérieux! [http://www.histoire-genealogie.com/spip. php?article836] (14.11.2013) 
ciao tout le monde, comme le titre peut laisser deviner, je trouve mes cheveux (je suis asiatique) beaucoup trop

raides. Ils veulent pas suivre la courbe du crâne et s'en vont raides comme des curedents !!! [http://forum.doctissimo.fr/forme-beaute/peaucheveux/cheveux-raides-help-sujet_158667_1. $\mathrm{htm}]$ (14.11.2013)

Ils reçoivent moins de 400 millions/année et ils demandent 225 millions de plus. Ils y vont raide! [http://www.radio-canada.ca/regions/que bec/2013/10/24/008-maniestation-organisationscommunautaires.shtml] (14.11.2013)

REMARQUES : Raide est un adjectif-adverbe de manière qui réfère à la vitesse ou la brutalité d'un procédé effectué résolument et sans détour. Les exemples de 1543 et 1833 indiquent un emploi invariable. Raide est modifié par si. Notons la collocation avec les adjectifs-adverbes fort et droit. Utilisé à la forme négative (IV), raide se dit de quelque chose qui se porte mal, qui n'a pas de succès. Dans ces emplois, le mot est vieilli. Raide est également employé comme prédicat second orienté vers le sujet indiquant que celui-ci se déplace tenant le dos droit et rigide (II). Dans ce sens, il s'accorde avec le sujet, du moins dans un langage soigné (ex. de 1840, 1963 et CW). Dans les exemples provenant d'Internet et représentant une écriture spontanée (dernier et avant-dernier exemple du CW), la prédication seconde se situe dans un continuum sémantique avec l'emploi adverbial au sens de 'directement, résolument'. L'emploi invariable ou fléchi de raide reflète cette situation. Le dernier exemple pourrait documenter la continuité au Canada de l'usage ancien. Mentionnons l'emploi de ça chasse tout seul (à comparer avec ça va tout seul sous aller seul).

\section{Aller rapide}

I. s'en aller rapide : partir, mourir, disparaître rapidement

Pronominal

1845 Tout en irritant sa sensibilité par son imagination, il tâchait que son esprit en annulât les effets, et que le sérieux de la sensation s'en allât rapide comme elle. Dès que quelque chose était entré en lui, il l'en chassait sans pitié, maître inhospitalier qui veut que son palais soit vide pour y marcher plus à l'aise (Gustave Flaubert, La Première Éducation sentimentale)

1893 À travers la mer des Indes, la Circé s'en allait rapide et doucement balancée, toute blanche de toiles sous une incandescente lumière, entre deux infinis très bleus, laissant derrière elle, comme une longue queue, son éternelle traînée bruissante, qui étincelait de soleil (Pierre Loti, Matelot)

1922 Tandis qu'ils se glissaient à travers l'ombre des longs corridors, la jeune femme, en guise d'adieu à leurs plaisirs qu'elle sacrifiait à l'amour, lui récita les vers du poète : « La tulipe fleurit promptement et s'en va légère et rapide, mais le rubis qui se forme avec lenteur ne craint rien du vent ni de la pluie et traverse toutes les saisons " (Maurice Barrès, Un jardin sur l'Oronte)

II. Aller rapidement, vivement

Intransitif

1862 Alors, repassèrent en foule dans ses souvenirs les aimées d'autrefois, avec leurs attitudes préférées, leurs regards doux ou fiers : blondes, brunes, elles allaient lentes ou rapides, dignes ou cyniques. Mais pas une n'obtint un sourire. Elles ne parlaient plus ni à son imagination ni à son cœur. Anna était devenue tout son horizon (Paul Reider, Mademoiselle Vallantin)

1960 pensant à la peau, à la saveur des prunes des reines-claudes mûres bleuâtres se fendant et leur jus sucré, je la lâchai retombai sur le lit tâtant ma pommette pouvant l'entendre de nouveau aller et venir rapide avec ces mouvements rapides précis qu'ont les femmes pour ranger, se baissant ramassant quelque chose je me demandai comment elle pouvait faire (Claude Simon, La Route des Flandres)

CoRpus Web :

hier, je t'ai dit:

je t'appelle dans le vide !

je t’appelle au milieu de ma nuit !

mes mots s'en vont rapide 
mais iront-ils jusqu'a toi aujourdh'ui ? [http://forum.mejliss.com/ya-moulete-fi-galbianasi-passe] (14.9.2013)

en occident les presidents viennent et s'en vont rapide (Sarko aussi n'echappera pas à la regle) contrairement aux notres, tellement ils restent trop longtemps au poste on fini par oublier le nom du pays [http://blog.lefigaro.fr/ algerie/2011/03/libye-la-doctrine-algerienneface-aux-frappes-militaires.html] (14.9.2013)

Tenten se leva et entra dans les bras de Neji, je ne sais pas pourquoi mais je la trouve entreprenante ! Elle chuchota un truc dans l'oreil a Neji et celui-la souria. Vraiment ! Les gens vont rapide ! [Regarde Sasuke] Et moi, je suis plus lente qu'une limace [http://shippuden-fanfic-x.skyrock. com/2555983559-Chapitre-08.html] (14.9.2013)

REMARQUES : Rapide est un adjectif-adverbe de manière qui caractérise la vitesse de l'exécution d'une action ou du déroulement d'un événement. S'en aller rapide réfère à une disparition rapide (I). Aller rapide (II) désigne le fait de se déplacer, de marcher rapidement. La collocation aller et venir rapide laisse sous-entendre des allées et venues du sujet. L'accord des adjectifs avec lesquels rapide se combine indique un emploi appartenant à un registre soutenu qui préfère rapide à vite. Le premier exemple du CW est une prédication seconde, même si la sémantique de rapide tend à inclure le verbe. Par contre, les exemples suivants provenant de l'écriture spontanée du français actuel confirment que rapide peut fonctionner comme modifieur du verbe aller (ou s'en aller) tout en restant invariable. Historiquement, rapide est d'abord emprunté comme adjectif et, par la suite, de l'adverbe canonique rapidement. L'emploi adverbial de rapide apparait plus tard, au gré de son passage de la langue soignée à l'usage familier. Les exemples littéraires cités ici reflètent l'essor tardif de la fonction adverbiale, ainsi que l'emploi préférentiel comme prédicat second accordé. Les exemples du CW mettent en évidence que l'emploi adverbial invariable est entré dans l'usage familier.

\section{Aller serré}

y aller serré : entreprendre résolument, intensément quelque chose, sans lâcher prise Intransitif

1942 Même la bête a manqué de cœur. Penses-y, mon vieux, ça en vaut la peine. Ne crains pas d'installer un peu. Beau comme tu es, avec ces yeux-là, cet air royal que tu peux avoir... Pense au public, pense au boss. Vas-y serré, du drame dans la prunelle... Compris ? (Maurice Genevoix, Le Nid du condor)

\section{Aller seul}

I. aller (tout) seul : évoluer, fonctionner sans intervention externe

Intransitif

1592 Il prise comme il doit la volupté corporelle, mais il prefere celle de l'esprit, comme ayant plus de force, de constance, de facilité, de varieté, de dignité. Cette cy $v a$ nullement seule selon luy (il n'est pas si fantastique), mais seulement premiere. Pour luy, la temperance est moderatrice, non adversaire des voluptez (Michel de Montaigne, Essais)

1681 Que les hommes ne pensent plus que le monde va tout seul, et que ce qui a esté sera toûjours comme de luy-mesme. Dieu qui a tout fait, et par qui tout subsiste, va noyer tous les animaux avec tous les hommes, c'est à dire qu'il va détruire la plus belle partie de son ouvrage (Jacques-Bénigne Bossuet, Discours sur l'histoire universelle)

1710 Personne ne sauroit croire avec quelle admiration tout le monde nous regardoit. On ne pouvoit comprendre comment il étoit possible que cette machine allât seule, et sonnât toutes les heures du jour (Simon Tyssot de Patot, Voyages et avantures de Jaques Massé)

1800 La France révolutionnaire n’a pas été exempte de ces atroces et ridicules inconséquences, et elles nous ramènent involontairement aux usages de ces républiques anciennes où l'homme respectant son égal, et opprimant son semblable, autorisoit par ses lois le meurtre de l'enfant, 
du gladiateur, de l'esclave, punissoit d'un supplice affreux la foiblesse d'une vestale, lors même que pour de grands crimes, il n'infligeoit qu'à regret, une légère peine au citoyen. Le pouvoir fixé ou constitué, $v a$ tout seul, dit M. Bossuet, et avec la nature (Louis de Bonald, Essai analytique sur les lois naturelles de l'ordre social)

1883 Ce n'est pas comme à Saint-Nicolas, par exemple, où on ne laissait jamais la machine aller seule ; le mécanicien était toujours là, volant à droite, à gauche, mettant partout le doigt, essoufflé, empressé, parce qu'on ne songeait pas que la machine la mieux montée est celle qui exige le moins d'action de la part du moteur (Ernest Renan, Souvenirs d'enfance et de jeunesse)

1904 Il y a des voitures que des chevaux traînent par les rues. Elles sont terribles. Il y a des voitures qui vont toutes seules en soufflant très fort. Celles-là aussi sont pleines d'inimitié (Anatole France, Crainquebille, Putois, Riquet)

1911 Pour ne pas aimer son prochain, mon enfant, il faudrait se boucher les yeux et les oreilles. À tant de cris de détresse. Mais l'espérance ne va pas de soi. L'espérance ne va pas toute seule. Pour espérer, mon enfant, il faut être bien heureux, il faut avoir obtenu, reçu une grande grâce (Charles Péguy, Le Porche du mystère de la deuxième vertu)

Pronominal

1844 - Mais tu ne réponds pas à ce que nous te demandons ? reprit Marie en essayant de la retenir.

- Voyez, voyez, Mam'selle ? dit Jeanne ; mes vaches s'en vont toutes seules. Elles sauteraient dans le jardin ! Ne me détemsez pas, ma mignonne!

Et Jeanne, se dégageant, s'enfuit à travers la prairie (George Sand, Jeanne)

II. aller tout seul : aller de soi, être clair Intransitif

1723 SILVIA. Je ne l'en empêche pas, il est le maître : mais faut-il que je l'aime, moi ?
Non, et il ne le faut pas, parce que je ne le puis pas, cela va tout seul : un enfant le verrait, et vous ne le voyez pas.

TRIVELIN. Songez que c'est sur vous qu'il fait tomber le choix qu'il doit faire d'une épouse entre ses sujettes (Pierre de Marivaux, La Double inconstance)

III. aller tout seul : évoluer, fonctionner, se faire sans difficulté, sans problème, sans effort Intransitif

1736 Après cela, on dîne sans se parler, on se couche sans mot dire, et l'on se reléve en grondant; au lieu que quand un mari est toûjours gai avec sa femme, et quand il badine avec elle, dame, cela fait qu'elle a toûjours de l'amitié pour lui de reste, le ménage va tout seul : mon poulet, que veux-tu manger, vous viendra-t-elle dire? Ma poule, ce qu'il vous plaira, repondrez-vous (Pierre de Marivaux, Le Télémaque travesti)

1854 Par bonheur, mon inclination se trouve tout à fait du même côté que la sagesse. Les choses iront donc tout seul. J'ai du reste trouvé M. de Tallenay fort accueillant et très aimable. M. Cintrat lui avait écrit une lettre fort bienveillante pour moi (Arthur de Gobineau, Correspondance avec Alexis de Tocqueville)

1856 EDGARD. (à Bassecourt) Vous aimez donc bien Anatole?

BAsseCourt. Parbleu ! Un si charmant garçon!

(à Anatole) Soyez tranquille, je reparlerai encore à Péponet, et votre mariage ira tout seul

(Théodore Barrière et Ernest Capendu, Les Faux Bonshommes)

1924 L'affaire n'allait pas toute seule. Hugues trouva heureusement un allié. Adalbéron, arche-vêque de Reims, avait eu de graves difficultés avec Lothaire qui l'avait accusé de trahison (Jacques Bainville, Histoire de France)

1962 Quand elle lui tendit un petit couteau pointu, il avança pour le prendre une main qui tremblait. 
- Vous verrez, dit-elle, c'est facile. Quand on a pris le coup, ça va tout seul.

Elle commença, penchée sur la table et Julien regardait ses mains fortes aux doigts ronds et lisses, un peu rouges. Elle portait une blouse à manches courtes (Bernard Clavel, La Maison des autres)

IV. aller seul : en solitaire

Intransitif

1844 « mais on dit qu'il y joue tous les soirs aux dominos avec son ami M. Gobseck. Je ne veux pas aller là toute seule, mon oncle me conduit et me ramène » (Honoré de Balzac, Les Employés)

\section{CORPUS WEB :}

Les gens qui vont seul au cinéma, c'est quoi votre délire ? [https://twitter.com/abdouwahab/ status/319921567394058240] (14.11.2013)

Eh bien figurez-vous qu'ils y allèrent, dignes, fiers, et... seuls [https://www.justfocus.fr/ musique/critique-musique/pierre-et-georges-auconcert-des-chk-chk-chk.html] (22.5.2016)

REMARques : Seul est un adjectif-adverbe de manière qui réfère à une action exécutée de façon interne, sans intervention extérieure. La référence au mode d'exécution produit donc un rapport métonymique avec les circonstances du déroulement. Dans les deux cas de figure, le sémantisme est plutôt adverbial-circonstanciel, ce qui n'empêche pas que l'attribut soit fréquemment accordé, suivant ainsi la même tendance que d'autres langues romanes (ex. espagnol Las puertas se abren solas 'Les portes s'ouvrent seules'). Aller seul s'utilise dans les contextes suivants : (I) se dit d'une chose (machine, monde) qui fonctionne sans cause extérieure. Sous la forme négative (exemples de 1592 et 1911), se dit d'une chose abstraite qui, pour le locuteur, va accompagnée ou suivie d'une autre. (II) se dit d'une chose qui est claire, qui n'a pas besoin d'explication. (III), expression figée dont le sujet est inanimé et souvent imprécis (ça), renvoie à quelque chose qui fonctionne sans demander d'efforts ou l'intervention d'une tierce personne. Sous (IV) nous avons ajouté deux emplois comme prédicat second. Seul est modifié par donc, là, nullement, tout. Notons que tout est également fléchi, dans la plupart des cas, même si sa fonc- tion est considérée adverbiale (ex. toute seule). L'emploi invarié est exceptionnel (exemple de 1854 et premier exemple du CW, ce dernier pouvant relever d'une simple faute d'orthographe). Mentionnons l'emploi de ça va tout seul et de souffler fort.

\section{Aller soef}

I. s'en aller soef: aller, couler doucement, lentement

Pronominal

+1100 Amunt un duit s'en vunt süef, [variante : mult suef]

E od cordes traient lur nef.

$\mathrm{Al}$ chef del duit out une arbre

Itant blanche cume marbre,

$E$ les fuiles mult sunt ledes,

De ruge blanc taceledes (Benedeit, Voyage de saint Brendan [ $1^{\mathrm{er}}$ quart XII $]$, 489)

1370 Si te convendra ouvrer par sens en telle maniere que, tantost que tu seraz entrez en la chambre, tu te mettes serré du mur, et t'en va tout soef [variante : souavet] jusques au lit du roy et te quatis tous coiement dessoubz le lit, car moult bien t'i pourras repondre, et la te tien tous cois jusques a tant que tu aies oÿ comment ti adversaires conteront leur raison (Roman de Berinus, I, p. 70)

II. Aller doucement, tranquillement Intransitif

1170 Qui mellor quiert, ne set qu'il viaut.

Qui le chevauche, ne se diaut,

Ainz va plus eise et plus soef

Que s'il estoit an une nef

(Chrestien de Troyes, Erec et Enide, 1401)

+1225a Andoi sunt a pié descendu

Et vont avant tout souavet (Le Chevalier as deus espees [ $2^{\mathrm{e}}$ quart $\left.\left.\mathrm{XIII}{ }^{\mathrm{e}}\right], 10603\right)$

+1225b Et Gaus tint l'esrer a deduit, Cair il ne se doloit de rien. Se li plot mout et li fist bien, Et li autre souef aloient Por lui. Et devisé avoient Que Gaus a la cort en iroit (Le Chevalier as deus espees [2 $2^{\mathrm{e}}$ quart $\left.\left.\mathrm{XIII}{ }^{\mathrm{e}}\right], 10885\right)$ 
+1266 Compaignète, ne vous anuit, Quar en tel lieu serons anuit Où li vilains n'aura poissance. Alons souef, n’aiez doutance, Je chanterai, s'il vous agrée (La Chastelaine de Saint Gille [3 $3^{\mathrm{e}}$ tiers XIII $\left.{ }^{\mathrm{e}}\right]$ )

REMARQUES : En ancien français, soef est un adjectif-adverbe de manière modifié surtout par l'adverbe d'intensité tout, mais aussi : avant, plus. Aller soef se dit de quelqu'un qui se déplace comme s'il glissait sur l'eau, d'une manière douce et lente voire prudente. Notons la collocation aise et soef. VoIR AUSSI : ambler soef

\section{Aller sûr}

I. s'en aller sûr : partir en sécurité Pronominal

1176 Et d'autre part li dus enrage, Qui jure et afiche et propose Que seul a seul, se Cligés ose, Iert antr'aus .ii. bataille prise, Si la fera par tel devise Que se Cligés vaint la bataille L'empereres seürs s'an aille Et la pucele quite an maint (Chrestien de Troyes, Cligés, 3930)

II. Aller sans souci, sans inquiétude, avec un sentiment de sécurité, de confiance Intransitif

+1200 « Et se vos lor mandez sorfet, La honte, se l'en la me fet, En sera vostre et li maus miens. » «Va toz seürs, ne dote riens! Por quoi je puisse chevauchier, Se tu trueves le chevalier, Retorne a moi tot erraument » (Raoul de Houdenc, Meraugis de Portlesguez [début XIII'], 2022)

1209 Tant larrons avoit essorbez, Tant robeors fet essillier, Si seür com par un moustier Aloit chascuns par mi son regne (Jean Renart, Roman de Guillaume de Dole, 617)

1275 Meauz pourrait uns ribauz de Grieve Seürs e seus par tout aller, E devant les larrons baler, Senz douter aus ne leur affaire (Jehan de Meun, Roman de la rose [1269-1278], 5281)
1905 La route était déserte, la campagne vide d'êtres, ils ne voyaient point à dix pas devant eux ; ils allaient sereins et sûrs, dans la nuit bien-aimée. Jamais ils ne butaient contre les cailloux du chemin. Comme ils étaient en retard, ils prirent un raccourci (Romain Rolland, JeanChristophe. L'Adolescent)

REMARQues : Sûr est un adjectif-adverbe de manière caractérisant les circonstances d'un déplacement effectué en se sentant rassuré, confiant soit de par le fait de porter des armes, d'être sous la protection de quelqu'un ou de marcher dans un lieu sûr, complété par la notion d'éloignement du sujet (II). (I) renvoie à un départ en sécurité. Notons l'accord au cas sujet dans les exemples de l'ancien français. Dans l'exemple de 1905, l'interprétation penche du côté d'un prédicat second : les personnes se sentent sûres et se déplacent sans trébucher. Sûr est modifié par toz (tout), partout.

\section{Aller tortu}

Aller en zigzag

Intransitif

1670 Quand cette image doit estre portée par les ruës, on la met sur un cheval de bois, qui se tient en posture comme un cheval qui regarde ou s'esleve vers l'air : ce cheval-cy est sur un theatre de planches, et est porté sur les espaules ; et quand ils marchent ils ne vont pas le droit chemin, mais ils vont tortu, comme un cheval, qui se cabre (Thomas la Grue, La Porte ouverte [trad.])

1693 Mère Écrevisse un jour à sa Fille disait :

Comme tu vas, bon Dieu ! ne peux-tu marcher droit?

Et comme vous allez vous-même ! dit la Fille.

Puis-je autrement marcher que ne fait ma famille?

Veut-on que j'aille droit quand on y $v a$ tortu? (Jean de La Fontaine, L'Écrevisse et sa fille / Fables)

1764 Mère écrevisse qui reproche à sa fille de ne pas aller droit, et la fille lui répond que sa mère va tortu, n'a point paru une fable 
agréable (Voltaire, Dictionnaire philosophique)

1906 LE BERGER. (seul) (Il rentre)

Ceux-ci ne cachent pas leur jeu ! C'est la vertu

Des jeunes d'aller droit où les vieux vont tortu ;

Ils s'aiment comme la faunesse et le satyre, Gaîment, et c'est autant de pris sur le martyre !

(Émile Bergerat, La Fontaine de Jouvence)

REMARQues : Tortu est un adjectif-adverbe de manière qui caractérise la ligne parcourue lors d'un déplacement, par opposition à aller droit. Il reste invarié. Notons l'emploi des antonymes marcher droit et aller droit.

\section{Allier ferme}

Lier, unir d'une manière forte, solide, stable Transitif

1584 Afin que ta vertu d'un tel Prince appuyée, Et au sang des Lorrains d'un nœud ferme alliée,

Luise un nouveau Soleil, privant de sa clarté

Ceux qui seront jaloux de ta felicité

(Pierre de Ronsard, Élégies, p. 213)

REMARQUES : Ferme est un adjectif-adverbe de manière 'fortement' modifiant le participe passé alliée qui s'accorde avec le sujet.

\section{Allonger droit}

S'étendre de façon rectiligne, sans dévier, selon une ligne droite

Pronominal

1848 La ville est ceinte de murailles dont à marée haute la vague vient battre la base, les mâchicoulis sont encore intacts comme au temps de la reine Anne, et la ligne des pierres dentelées s'allonge sur les remparts droite et basse, en se découpant dans la brume (Gustave Flaubert, Par les champs et par les grèves)

1860 Ils allaient, et le fleuve changeait, et la rive. Ils côtoyaient de petites falaises, de petites rampes à pic, veinées de beau sable jaune, qui s'allongeaient toutes droites, et d'où pendaient, mortes, blanchies et desséchées, des herbes chevelues qui faisaient penser à la barbe limoneuse des vieux fleuves (Edmond et Jules de Goncourt, Charles Demailly)

1872 A ce moment, la calèche sortit du bois. L'avenue de l'impératrice s'allongeait toute droite dans le crépuscule, avec les deux lignes vertes de ses barrières de bois peint, qui allaient se toucher à l'horizon (Émile Zola, La Curée)

1884 La route s'allongeait droit devant elle (Hector Malot, Marichette)

1891 L'escarpement à pic montre en bandes étroites

Ses couches s'allongeant fermes, égales, droites,

Rides profondes, plis de ce front de la nuit. Contre ce mur se heurte et flotte et roule, et fuit

Ce que chaque saison pêle-mêle charrie (Victor Hugo, Dieu)

1934 Brusquement, il mit sa bête au pas. Le sable était profond. La grande avenue aux feuilles neuves s'allongeait, très droite, devant nous, jusqu'au pied de la montagne émeraude (Roger Vercel, Capitaine Conan)

1950 Nous entrons dans les bois, tournons à gauche, vers le nord, sur une route large qui s'allonge, toute droite entre les futaies. Beaucoup l'ont déjà reconnue :

- Dis, c'est-i' pas la Calonne?

- Ça m'en a l'air.

- Mais c'est pas les Boches, là où qu'on va c'soir ? (Maurice Genevoix, Ceux de 14)

1978 Maintenant qu'on savait que Marko était mort, on s'était tous tournés vers l'entrée, pour voir le vieux qui s'en allait. Dehors, la route, comme tu sais, s'allonge tout droit entre deux collines, tantôt montant, puis descendant, puis montant encore. Il était déjà loin (Marguerite Yourcenar, Nouvelles orientales)

2011 Au sortir de la dernière forêt, au bout de la piste qui s'allongeait droit devant nous, 
nous vîmes apparaître un cavalier qui s'avançait vers nous bride abattue et qui s'arrêta à notre hauteur (Adrien Caraguel, Les Noyaux d'abricots)

Transitif

1894 Dehors, dans la nuit moite et taciturne, Une lune d'octobre allongeait droit, Comme pour défendre et protéger le toit, L'ombre grande des peupliers nocturnes (Émile Verhaeren, Poèmes)

\section{CORPUS WEB :}

Elle allongea droit devant elle le bras recouvrant sa poitrine et fit tourner son indice en cercle vers le sol lui indiquant d'en faire autant, le tirant de sa rêverie. Puis elle rétracta rapidement le membre à son emplacement d'origine : l'avantcœur [http://orquesetelfes.asiafreeforum.com/ t167p25-eamane-enialis-valkhyria] (15.11.2013)

Il suffit de s'allonger droit sur le sol, les mains le long du corps et lever les deux jambes en même temps. Jambes légèrement pliées pour les débutants et allongées pour plus de difficulté [http://www.sportregimepourmaigrir. com/2016/02/exercices-pour-perdre-des-cuisseset-du.html\#] (22.6.2016)

On m'a dit de m'allonger droite sur mon lit, les yeux ouverts, et de chanter des prières et des versets de textes saints hindous pendant l'éclipse », explique Sonya Chadha, comptable à New Delhi, enceinte de sept mois, qui a prévu de prendre aujour-d'hui un jour de congé [http:// www.lavoixdunord.fr/France_Monde/actualite/ Secteur_France_Monde/2009/07/21/article_laplus-longue-eclipse-solaire-du-siecle.shtml] (22.06.2016)

REMARQUes : Dans la plupart des cas, droit se comporte comme un prédicat second qui reflète les marques du genre et du nombre du sujet. Il ne réfère pourtant pas à une posture droite, debout, mais à une avenue, muraille, rampe, route ou rue s'étendant de façon rectiligne. L'emploi invariable apparaît dans l'emploi directionnel des exemples de 1884, 1894, 1978, 2011. Dans l'exemple de 2011, l'invariabilité pourrait être la conséquence d'une réanalyse comme modifieur de devant (droit devant ; à comparer : droit à, vers, sur, etc.). Le premier exemple du CW confirme la tendance à utiliser droit comme modifieur de la préposition devant. Dans l'exemple de 1894, où le verbe est employé transitivement, la rime impose l'emploi non-fléchi. Droit est modifié par l'adverbe d'intensité tout. Notons l'emploi en tant que prédicat second orienté vers le sujet 'sans se tordre' dans le troisième exemple du CW.

\section{Allonger net}

Faire tomber quelqu'un brutalement, tout d'un coup

Transitif

1912 Un traître croc-en-jambe de Migue la Lune l'allongea net, le nez dans une taupière, les bras en avant, la gueule ouverte (Louis Pergaud, La Guerre des boutons)

2007 Le frère aîné de Foussèni est sorti à son tour et s'est dirigé vers Tièba pour le frapper, mais ce dernier lui a flanqué un grand coup de poing dans la tête qui l'a allongé net par terre (Gérard Dumestre et Seydou Touré, Maléfices et manigances)

\section{CORPUS WEB :}

Cet apres midi je suis allé promener mon chien Chow-Chow de 2 ans en foret et au bout de $3 \mathrm{~km}$ il s'est allongé net [http://www.jeuxvideo. com/forums/1-50-134484413-1-0-1-0-meurtre-j-aitue-mon-chien-peur.htm] (18.11.2013)

Mais l'animation est vraiment bien faite et les personnages réagissent en véritables corps humain. Il ne faut pas 50 balles pour coucher un mec et au fusil à pompe en 1 coup le type s'allonge net [http://chezkjel.over-blog.net/article-test-dela-beta-multi-medal-of-honor-2010-58970091. html] (18.11.2013)

Le combat n'avait pas commencé que Rocky m’a allongé net [http://beckskulte21.skyrock.com/ 1875778261-Disney-27-au-29-juin-2008.html] (18.11.2013)

Une villageoise qui ne comprenait pas s'est allongée net, une balle au milieu du front. Tout le monde pleurait [http://groomjazzlucifer. wordpress.com/2012/04/08/la-fete-de-la-fumee] (18.11.2013)

REMARQUES : Allonger net réfère au fait de faire tomber quelqu'un, de façon brutale, sans la moindre résistance. Même si les exemples de 1912 et de 2007 ne le démontrent pas directement, on peut supposer que net tend à l'emploi 
invariable. En effet, tout comme fort ou droit, l'adjectif-adverbe net se combine productivement avec bon nombre de verbes. Si lexicalisation il y a, elle touche directement l'adjectif-adverbe, et moins le groupe qui l'unit à un verbe particulier. La fréquence élevée de net dans l'écriture spontanée du CW, surtout dans l'emploi pronominal, souligne son usage dans la langue quotidienne. Le dernier exemple met en évidence son invariabilité.

\section{Allumer haut}

Brûler en faisant de hautes flammes; produire un grand éclairage

Intransitif

-1209 Et une nuit a mie nuit mistrent le feu es nés, et laissent les voilles aler al vent, et li feu allumer mult halt, si que il sembloit que tote la terre arsist. Et ensi s'en vienent vers la navie des pelerins ; et li criz lieve en l'ost ; et saillent as armes de totes parz (Geoffroi de Villehardouin, Conquête de Constantinople, § 217)

\section{CORPus Web :}

J'allume haut les cierges

Et les yeux dans l'effroi

Les doigts transis de froid

Le souffle à bout de berge

Je coule

[http://www.univers-rr.com/RPar tage $/$ index.php? page $=$ rp\&id $=5495 \&$ start $=1]$ (18.11.2013)

Tu saisis ainsi la main, chose douce solitaire,

Et cela comme le poison - tout en haut sur ta peau,

ça allume haut mon jour - et ça aussi c'est vrai,

Ensemble on est un - séparé on est deux [http://www.pardon-my-french.fr/songs/ Glafouk\%20-\%20Fille\%20tu\%20sais $\% 20$ c'est $\% 20$ vrai $\% 20$ (Tres\%20Petit\%20Vanille]).txt (18.11.2013)

Porte de la poésie qui s'allume haut dans le ciel

Oser

Etoile filante

Sort de magie

Illuminer
Enchanter les étoiles [http://jeunes.poetes. free.fr/ecrits_stmarcel_cecm07.htm] (18.11.2013)

Pour ton voyant si tu pouvais prendre une photo du voyant !!!

Car je pense bien au shift light (qui s'allume haut dans les tours pour te dire de passer un rapport !!!) [http://www.cbr-world.com/t14464probleme-electrique-je-pense-600-cbr-fs-2001] (18.11.2013)

REMARQUES : Haut est un adjectif-adverbe de lieu qui a un sens spatial et désigne un point élevé d'un point de vue statique ou résultatif. Avec une interprétation de manière, il caractérise la démarche de brûler en parlant d'un feu. Il reste invariable et est modifié par moult. Les exemples plus récents du CW mettent en évidence que le tour est apprécié en poésie, mais on le trouve aussi dans la communication quotidienne (dernier exemple). Notons également l'emploi pronominal ou transitif du verbe dans le CW.

\section{Allumer subit}

Allumer rapidement, brusquement

Transitif

1538 A Vulcan donc son dueil elle declaire, Qui tout subit (pour à Venus complaire) De son chault feu (bien autre qu'amoureux)

Vint allumer, par un soir malheureux D’Anne le lict chaste et immaculé, Et en dormant son beau corps a bruslé, Duquel adonc l'ame noble s'osta, Et toute gaye au ciel luysant saulta, Sans se sentir du feu de Vulcanus, Encores moins de celluy de Venus (Clément Marot, Élégies)

CORPuS WeB :

Comme on peut r'allumer subit une chandelle,

Quand la mesche ard encor d'un petit souffle : ainsi

De l'Amour presque estaint on voit le doux souci

Desrechef s'embrasser de la moindre estincelle [http://emblems.let.uu.nl/catsretorica/ html/va1618039.html] (18.11.2013) 
REMARQUES : Subit est un adjectif-adverbe de temps à base adjectivale. Il reste invariable et est modifié par tout. L'exemple du CW (réallumer subit) souligne l'appartenance de subit à un style recherché et plutôt archaïque.

\section{Amarrer long}

Attacher (un bateau) avec une longue amarre, en laissant une plus grande marge entre lui et le quai

Transitif

1964 J'ai amarré le bateau aussi long que cela m'a paru possible sans risquer de contact fâcheux avec le bateau voisin. Personnellement j'aimerais mieux donner un peu plus de champ au bateau, c'est-à-dire un amarrage plus long, car je crains toujours pour les taquets et galoches quand les vagues des péniches soulèvent les bateaux (Correspondance privée de Grundt, 31 juillet 1964 / Grundt : 321)

CoRpus Web :

Si j'amarre long, je ne sais pas comment tiknot va se comporter avec les vagues [http:// www.bateaubois.com/fora/viewtopic.php?f= 25\&t=1075] (18.11.2013)

La nous amarrons au quai celui-ci est assez élevé à marée basse, alors il faut s'amarrer long et ensuite attraper l'échelle pour monter sur le quai [http://adrick.baup.fr/voguer/vacances-2008/delile-doleron-a-lile-de-re] (18.11.2013)

$\mathrm{Au}$ ponton de Port Tudy, j’amarre long mon bateau pour laisser de la place aux autres et je laisse mon moteur baissé car mon hélice peut percer les pneumatiques [http://ploemeur-touri sme.fr/wa_files/carnet_20finalise_CC_81_20ver sion_20alle_CC_81ge_CC_81e.pdf] (18.11.2013)

REMARQUES : Amarrer long caractérise la distance par laquelle le cordage sépare le bateau du quai ou d'un autre bateau. L'emploi absolu dans le premier exemple et l'emploi pronominal dans le second attestent sa lexicalisation dans le vocabulaire des marins. Il est modifié par aussi.

\section{Ambler soef}

Aller doucement, paisiblement

Intransitif

1170 Ja ne cuide veoir cele ore Enide, qu'il soient monté.
Un palefroi de grant bonté,

Soef anblant, jant et bien fet,

$\mathrm{Li}$ a l'an fors au perron tret

(Chrestien de Troyes, Erec et Enide, 5317)

+1200 Et quant fu nuis les dras vestit :

Il chanja trestout son abit ;

Desus le palefroi monta

Au moine, qui souef ambla

(Le Chevalier qui fist sa fame confesse, 82)

REMARQues : Ambler se dit généralement d'un cheval qui se déplace entre le trot et le pas, en levant alternativement les deux jambes du même côté, produisant un effet esthétique chez le spectateur. En ancien français, ambler soef désigne pour un cheval le fait d'ambler doucement, d'une manière agréable pour le cavalier. Il est antéposé au verbe.

\section{Amener droit}

Amener directement

Transitif

$\sim 1225$ Et au cinquieme [= iors], aprés hore de vespres, li avint que sa voie l'amena [variante : droit] $a$ une blanche abeie (Queste del saint Graal, § 37, 34)

1460 Et incontinent ce fait, vindrent tuer plusieurs princes et autres grans seigneurs de son sang qui estoient autour de lui. Et ces choses faictes, ledit conte de Warwyk print ledit Henry et l'amena tout droit en la ville de Londres, et portoit l'espée nue devant ledit Henry comme son connestable (Jean de Roye, Chronique scandaleuse)

1667 Cette insolence que je commis, fit eslever un grand murmure ; trois ou quatre officiers me saisirent pour me retenir prisonnier, mais un lieutenant du regiment qui me connoissoit, me retira d'entre leurs mains, disant qu'il me tiendroit en sa garde, et que je n'estois pas un gentilhomme à mal traiter : et m'amena droit en son logis (Tristan l'Hermite, Le Page disgracié)

1751 Cependant son impatience est extrême d'embrasser sa nièce. Il veut emporter cette consolation en mourant ; et je lui en ai donné l'espérance, parce que si cette chère personne consent à mon bonheur, 
mon dessein est de l'amener droit ici en sortant de l'église (abbé Prévost, Lettres angloises [trad.])

1893 Mais elle était trop bas, elle sentit que la pointe s'enfonçait ensuite dans la planche. Une seconde percée l'amena droit sur le fer du crochet. Cette fois, c'était trop direct (Émile Zola, Le Docteur Pascal)

1913 Cantique du Rhône :

LÆTA. Qu'il est beau, le navire noir que le vent et cette brise même sur mon visage

Amène tout droit en quelques instants $d u$ fond de la mer,

Quand il laisse tomber son antenne, et tourne, et se couche sur le côté !

(Paul Claudel, La Cantate à trois voix)

1939 La transition l'amenait droit au récit de sa course au Matterhorn avec Rudi, mais vue par elle, cette fois. Un garçon dangereux, ce Rudi, et dont Kate aurait à se méfier (Joseph Peyré, Matterhorn)

1985 C'est une fille qui m’a aperçu et montré du doigt... Et aussitôt, la meute fait un arc de cercle et prend une bretelle qui va l'amener droit sur moi ! Rassemblant mes dernières forces, je pique un sprint vers... vers... Vers le Néant Total (Philippe Manœuvre, L'Enfant du rock)

CORPUS WEB :

Alors qu'Emma est plutôt introvertie, Hélène est du genre dévergondée et très vite entre les deux jeunes filles naît une relation ambiguë qui effraie Emma et la rend malade. Quant à Hélène, son comportement excessif va l'amener droit vers la clinique psychiatrique [http:// www.babelio.com/livres/Tasma-Desolation-etdestruction/391713] (22.6.2016)

Belle composition d'un paysage d'hiver, j'aime bien les traces dans la neige qui nous amène droits vers les maisons ou chalets [http:// www.treklens.com/gallery/photo497403.htm] (19.11.2013)

J'ai un tournevis magnétique mais trop court, de plus la vis n'adhère pas bien, je n'arrive pas à l'amener droite sur le trou qui est étroit et me demande de forcer $=>$ la vis tombe sans arrêt [http://forum.hardware.fr/hfr/Hardware/2D-3D/ unique-nvidia-maxwell-sujet_962857_336.htm] (22.6.2016)

REMARQues : Droit est un adjectif-adverbe de manière qui caractérise le trajet parcouru par un objet ou une personne. Amener droit se dit de quelqu'un ou quelque chose qui amène, entraîne quelqu'un/quelque chose directement vers un lieu ou une personne. Droit reste invariable (ex. de 1751) et est modifié par tout. Amener droit est généralement suivi d'un adverbe de lieu (ici, là) ou d'une préposition de lieu indiquant la direction (à, vers, sur, de). Droit a tendance à s'associer avec ces prépositions au point de faire partie $\mathrm{du}$ groupe prépositionnel comme modifieur de la préposition. À la différence de l'écriture contrôlée, l'écriture spontanée du CW présente l'accord adverbial. Droite au dernier exemple du CW permet également une analyse en tant que prédicat second orienté vers le sujet : on essaie d'introduire la vis dans une position droite. VoIR AUSSI : acheminer droit

\section{Amuser ferme}

S'amuser beaucoup, à fond

Pronominal

1896 - Delestang, ce militaire épris de batailles?

Madeleine répondit, rieuse :

- Il place des engrais.

- Servet?

- À Paris encore, ne faisant rien, s'amusant ferme...

(Édouard Estaunié, L’Empreinte)

1956 Juju et L'Artisse s'amusaient ferme. Les flics les dévisageaient de leurs yeux de brochet (René Fallet, La Grande Ceinture)

CORPUS WEB :

Malgré la chaleur, les gens s'amusaient fermes au tournoi international de volleyball de plage de Québec samedi [https://www. journaldequebec.com/2011/07/23/ambiance-deplage-au-quebec-open-jeep] (23.7.2011)

\section{Amuser plein}

Amuser beaucoup, autant qu'il est possible Transitif

1883 Voilà qui m'amuse tout plein (Victorien Sardou et Émile de Najac, Divorçons) 
CoRpus Web :

Mais c'est ça qui rend les choses plus amusantes! (surtout pour moi, vu que je m'amuse plein en écrivant ça) [https://www.fanfiction. net/s/1173474/9/When-it-s-time-to-cry] (19.11.2013)

Ça les amuse plein, les Blancs, de savoîr qu'on vit à dix dans des shotgun houses, qu'on a pas de chars pour voyager, que ce monde ça pus de manger dans le frige à la fin du mois [http:// www.lilimaxime.com/documents/blues_du_ bayou_extrait.pdf] (19.11.2013)

Remarques : Plein est un adjectif-adverbe de quantité. Amuser plein se dit de quelqu'un/ quelque chose qui divertit, égaie beaucoup et occupe très agréablement, complètement. Plein est modifié par l'adverbe d'intensité tout. Les exemples montrent son appartenance au langage informel. Le second exemple du CW est canadien.

\section{Annoncer clair}

Annoncer clairement

$\lambda$ annoncer haut

\section{Annoncer haut}

Annoncer, affirmer, dire à voix haute, d'une voix forte, ouvertement, publiquement

Transitif

1450 JHESUS. Une question vueil avoir, Puisqu'a demandant procedez, Et se bien vous me repondez A celle que je vous feray, A la vostre responderay Sans differer, soyés en sceurs. Je vous demande, messeigneurs, Se le baptesme que prescha Saint Jehan et si hault asnonça, Estoit don de Dieu supernel, C'est a dire venant du ciel Ou d'umainne institucion (Arnoul Gréban, Le Mystère de la Passion, 16907)

1604 ANDROMACHE. Aussi n'est-il pas seul, d'autres mauvais augures

Annoncent haut et clair nos tristes aventures

(Antoine de Montchrestien, Hector)

1782 On le voit aux trois spectacles. S'il paroît dans une promenade, tout le monde le salue ; il parle à l'un, sourit à l'autre, aborde un troisieme, annonce tout haut la distribution de sa journée, et parle de son oisiveté avec le sérieux que pourroit prendre l'homme sensé qui annonceroit une occupation utile (Louis-Sébastien Mercier, Tableau de Paris)

1830 Voilà cet instinct qui l'annonce Plus haut que l'aurore et la nuit. Voilà l'éternelle réponse Au doute qui se reproduit !

(Alphonse de Lamartine, Harmonies poétiques et religieuses)

1889 Rattier me racontait que le chirurgien Trélat avait fait une opération à son frère, en annonçant presque tout haut que cette opération devait être nécessairement suivie d'une embolie, qui emporterait l'opéré, mais l'opération était de 6000 francs (Edmond et Jules de Goncourt, Journal)

1932 Quand le nègre domestique entra pour servir le thé nous fîmes silence.

L'une de ces visiteuses devait posséder cependant plus de discernement que les autres car elle annonça très haut que je tremblais de fièvre et que je devais souffrir aussi d'une soif pas ordinaire. Ce qu'on servit en fait de collation me plut tout à fait malgré ma tremblote (Louis-Ferdinand Céline, Voyage au bout de la nuit)

1978 Bien que privés du droit de séjourner dans les hôtels, les Tatars sont de plus en plus nombreux à Moscou : 400 à l'été 1967, qui annoncent bien haut qu'ils vont tenir une réunion sur la Place Rouge pour être enfin entendus. Le moment est choisi. Moscou s'est ouvert au tourisme et la saison bat son plein (Hélène Carrère d'Encausse, L'Empire éclaté)

\section{Corpus Web :}

Cette carte de visite allait annoncer haut et fort sa présence, se vendant à plus de 100000 exemplaires [http://www.domaineforget.com/41/ calendrier/patrick-watson] (22.6.2016)

Ce sont donc de bonnes nouvelles d'Afrique que nous devons annoncer haut et fort [http://fr. 
bab.la/dictionnaire/francais-allemand/anno ncer] (22.6.2016)

Une pièce in progress dans laquelle les indications scéniques s'annoncent haut et fort, les scènes se succèdent à un rythme effréné et où l'on ne craint pas les dérapages [http:// theatrenational.be/fr/program/266] (19.11.2013)

Avec le Khimki Moscou comme ultime adversaire, la marche vers la phase de poules de l'Euroligue s'annonçait haute pour Le Mans [http:// www.lefigaro.fr/autres-sports/2010/10/04/0202120101004ARTSPO00519-le-mans-defie-lekhimki.php] (19.11.2013)

Déjà, la crétinerie de l'épisode s'annonçait haute vu que Rayman poursuivait des lapins habillés en disco-man sur le dos d'une araignée géante [http://www.nintendomaine.com/ site-apercu-wii-rayman_raving_rabbids.html] (19.11.2013)

ReMARQUeS : Haut est un adjectif-adverbe de lieu que s'emploie ici au sens figuré de 'à haute voix', ou, au sens abstrait de 'ouvertement'. Il reste invariable et est modifié par bien, presque tout (haut), tout, très, plus. Le schéma " annoncer (+ quantifieur) + haut " semble figé. Dans les exemples du CW, sans quantifieur, l'emploi pronominal 'se présenter par anticipation' prédomine. L'accord adverbial semble possible, du moins à en juger par les derniers exemples ; dans l'avant-dernier exemple du CW, l'emploi métaphorique renvoie au sens concret de haut. Notons les collocations clair et fort et haut et fort dans le CW. Le tour renonce alors à l'insertion de quantifieurs selon le schéma mentionné ci-dessus ; autrement dit, elles les remplacent dans la fonction d'intensification.

\section{Apercevoir clair}

Constater, se rendre compte clairement, avec certitude

Transitif

1450 SAINT BERTHELEMY. Ce n'est pas icy fantasie

N'esperit qui nous puist decevoir ;

Tout cler pouons apparcevoir

Qu'il est vray homme naturel

(Arnoul Gréban, Le Mystère de la Passion, 31265)
1857 Il aperçut clairs et distincts les feux, puis les bandits, qui entouraient les feux du côté de la savane au-dessus du vent pour éviter la fumée (Émile Carrey, L’Amazone)

Pronominal

+1450 Par vieil venin et envie moderne, En quoy chascun qui entend et discerne Et du sentier du vrai droit ne desvoie, S'aperçoit clair de vostre oblique voie (Georges Chastellain, Euvres [3 $3^{\mathrm{e}}$ quart $\mathrm{XV}^{\mathrm{e}}$ ], VI, p. 223)

1870 Il est cependant facile d'éviter ces inconvénients : il suffit, une fois le grain séparé, de tenir la cuite légère, de rester exclusivement à la preuve au filet, et d'achever la séparation du grain et du sirop par des entrées fréquentes ; de la sorte le grain s'aperçoit clair et net dans la preuve (É[douard] Mérijot, Traité complet de fabrication et raffinage du sucre de betteraves [trad.])

1951 J'ai vu les gens, les rues, les maisons. Et j'ai reçu un choc. C'était comme quelqu'un qu'on revoit au bout de quelques années et dont on s'aperçoit, aussi clair qu'il fait jour, qu'il a la mort sur le visage. Les gens autour rient, s'affairent, vont et viennent comme si de rien n'était. Mais on voit, et on sait. Tout seul (Julien Gracq, Le Rivage des Syrtes)

REMARques : Clair est un adjectif-adverbe de manière employé au sens figuré de 'clairement'. Dans son emploi transitif ou pronominal, se dit $\mathrm{du}$ fait de prendre conscience de quelque chose avec certitude, après un effort d'attention ou de recherche. Clair peut être antéposé (exemple de 1450) ou postposé (exemple de 1951) au verbe. Il est modifié par aussi, tout. L'exemple de 1857 semble relever de la prédication seconde, mais du point de vue logique, l'interprétation adverbiale est plus probable, malgré la coordination avec distinct, qui, accordé, joue en faveur de la prédication seconde. Notons la collocation clair et net. 


\section{Appareiller bel}

Parer d'une façon élégante, raffinée, belle

Transitif

+1200 En chelui jour que je vous di peussiés veoir ou palais le roi maint boin chevalier viestu et apparilliet biel et richement et mainte biele damoisiele et mainte biele dame prisie de biauté ; mais sor toutes celes qui le jour i furent emporta le pris et l'ounour de biauté Morgue la fille Igerne (Merlin [ $1^{\text {er }}$ quart XIII] , p. 166)

Remarques : Beau est un adjectif-adverbe de manière qui adopte ici la forme neutre bel. Employé ici au passif, appareiller bel se dit du fait d'apprêter, de parer d'une belle façon, le sujet arborant des bijoux, parures ou habits de bon goût et précieux. Bel modifie ici deux verbes coordonnés, vêtir et appareiller. Notons la coordination avec l'adverbe richement. VoIR AUSSI : vêtir beau

\section{Appeler}

[Nous avons exclu du dictionnaire les collocations du verbe appeler au sens de 'nommer' du type II l'appelle belle]

\section{Appeler bas}

Appeler à voix basse

$\lambda$ appeler haut

\section{Appeler bel}

Appeler aimablement, agréablement, accueillir aimablement, souhaiter la bienvenue

Transitif

+1150 Teris le regarda, si tient le cief enclin, Bel et cortoisement a apeler l'en prist (Aiol et Mirabel [2 moitié XII $]$, 10364)

1176 Bien est Alixandres venuz, Car a rien qu'il vuelle ne faut, N'an la cort n'a baron si haut Qui bel [variante : bien] ne l'apialt et acuelle (Chrestien de Troyes, Cligés, 391)

+1200a Entre en le paleis li curteis forester, par le poine tint Gui le dancel, le pessoner l'altre, Miles li ignel ; $\mathrm{Bov}[\mathrm{es}]$ les vist si les apele bel (Bueve de Hanstone [début XIII'] ${ }^{\mathrm{e}}$, 3017) +1200b Et, quant le prior le choisi,

En contre lui mout biau sailli ;

Bel l'apela, sel fist descendre.

Puis si a fet son cheval prendre

(Le Chevalier qui fist sa fame confesse, 54)

1250 Puis les enprist mout bel a apeler :

Seignor, fet il, .i. don vos veil rouver,

Et par amor le vos veil demender,

Que tuit soiez avec moi au souper

(Aymeri de Narbonne [milieu XIII] ], 2084)

Remarques : Beau est un adjectif-adverbe de manière qui adopte ici la forme neutre bel. Appeler bel se disait en ancien français du fait de s'adresser à quelqu'un d'une manière douce, agréable, de façon à obtenir de lui une information relative à sa présence, ou pour lui faire comprendre gentiment qu'on lui demande de venir près de soi, le sujet comme l'objet étant toujours animés. La coordination de bel avec cortoisement (ex. de +1150) et son remplacement par la variante bien (ex. de 1176) confirment sa fonction adverbiale. Bel est modifié par moult. Notons l'emploi de accueillir bel et saillir beau 'sauter, s'élancer'.

\section{Appeler fort}

Appeler intensément

$\lambda$ appeler juste

\section{Appeler haut}

I. Appeler à voix haute, d'une voix forte Transitif

1177 Deus, com or ai le cuer riant Et lié et sain ! fet la pucele. Lors saut avant et si l'apele, [variante : haut escrie]

Si haut que toz li pueples l'ot, A mout haute voiz : Lancelot ! Trestorne toi et si esgarde Qui est qui de toi se prant garde ! (Chrestien de Troyes, Lancelot ou Le Chevalier de la charrete, 3681)

1250 A tant es dant Picons venu A sa porte, qui fermee iere ; Puis apela sa chamberiere Si haut que tuit l'ont entendu (Le Prestre teint, 339) 
1365 Il ait lou ciel delassus hault appelleit et huchieit. et la terre pour discerneir et iugieir sou pueple (Psautier lorrain, p. 52)

1572 Haut appelloit les ames, qui venoient, Et sur l'obsèque espaisses se tenoient, Faisant tel bruit que font en la nichée Les arondeaux attendans la bechée (Pierre de Ronsard, La Franciade, p. 109)

1559a Ce temps pendant, frappoit le mary à la porte, appellant le plus hault qu'il pouvoit sa femme. Mais elle faignoit de ne le congnoistre poinct, et disoit tout hault aux varletz de leans : "Que ne vous levez vous et allez faire taire ceulx qui font ce bruict à la porte ? » (Marguerite d'Angoulême, Heptaméron, p. 47, 24)

1559b La contesse, qui en partye le croyoit et en partye doubtoit, s'en alla à sa fille et luy dist : « Pourquoy m'avez vous appellée si hault ? "(Marguerite d'Angoulême, Heptaméron, p. 99, 1028)

1594 Aprés que l'Assemblée fut entrée bien avant dedans la Grande Sale, approchant des degrez où le daiz estoit eslevé et les chaires preparées, la place fut assignée à chacun par un heraut d'armes intitulé Courte-joye sainct-Denys, qui les appella tout haut, par trois fois, ainsi : «Monsieur le Lieutenant ! monsieur le Lieutenant ! monsieur le Lieutenant de l'Estat de Couronne de France ! » (Satyre Ménippée)

1612 Car il eut peur que ces nymphes fouillant ses habits ne l'eussent treuvé. En ce doute il appella fort haut le petit Meril, car pour le servir il estoit couché à une garderobe fort proche (Honoré d'Urfé, L'Astrée)

1713a Il acceptoit leurs offres, et ne délibéroit plus que du choix d'une des places qui lui étoient offertes, lorsque l'un de ces messieurs, vêtu d'une robe de Palais, l'appella plus haut que les autres (Robert Challe, Les Illustres Françoises)

1713b Je vais dans notre chambre, je vous y attendrai. Elle vint où nous nous promenions, et prit le tems que nous marchions devant elle. Elle m'appella tout haut, je me tournai et la vis : voilà monsieur, me dit-elle d'un air enjoüé, un billet qui vient de tomber de votre basque (Robert Challe, Les Illustres Françoises)

1848 Hélas! La génération qui rendit l'indépendance aux Teutons est évanouie ; il n'est demeuré en Germanie que de vieux cabinets usés. Ils appellent le plus haut qu'ils peuvent Napoléon un grand homme, pour faire servir leur présente admiration d'excuse à leur bassesse passée (François de Chateaubriand, Mémoires d'outre-tombe)

1876 Je serais bien aise d'avoir de vos nouvelles, princesse, ou plutôt chère princesse (car pourquoi ne pas vous appeler tout haut comme je vous nomme tout bas). Il doit faire beau à Saint-Gratien et je vous suppose sinon heureuse du moins tranquille (Gustave Flaubert, Correspondance)

1913 Nous devinâmes que c'était Ganache, le bohémien, qui n’osait pas ou ne savait comment traverser la cour. D'une voix pressante, anxieuse, il appelait tantôt très haut, tantôt presque bas :

- Hou-ou ! Hou-ou !

- Dites ! Dites vite ! cria Meaulnes au jeune bohémien qui avait tressailli et qui rajustait ses habits pour partir (Alain-Fournier, Le Grand Meaulnes)

1921 Point de participes à accorder, mais l'orthographe des mots les plus communs me devenait bizarre. Je voulus les appeler tout haut : mais jamais pavillon rouvert après des siècles ne rendit des portraits et des meubles plus vermoulus que ne le fit ma mémoire après deux ans de silence (Jean Giraudoux, Suzanne et le Pacifique)

1950 Alors, j'ai délibérément posé ma tête au bord de la table. Enfin, m'man Tine me secoue l'épaule en m'appelant tout haut pour chasser mon sommeil. Tenant la lumière d'une main, elle m'entraîne dans la chambre. Je suis imprégné de sommeil, et plus rien ne frappe mes sens (Joseph Zobel, La Rue Cases-Nègres) 
II. Inviter à une destinée privilégiée, supérieure dans l'ordre spirituel

Transitif

1704 L'entreprise est grande ; mais le secours est égal au travail : Dieu qui vous appelle si haut, vous tend la main ; son fils, qui lui est égal, descend à vous pour vous porter. Dites donc avec saint Paul : courage, mon ame : je puis tout avec celui qui me fortifie (Jacques-Bénigne Bossuet, Méditations sur l'Évangile)

1786 Vainement, à genoux devant la déesse, j'ai osé lui parler de mes craintes, et rappeller le vœu de ta mere. Je n'ai point accepté ce vœu, m’a répondu la fille de Jupiter ; Numa ne sera point mon prêtre, ses destins l'appellent plus haut. Numa me servira mieux sur un trône, qu'à l'ombre de mes autels : qu'il marche à Rome, et que ta tendresse pour lui ne s'oppose plus aux décrets du ciel (Jean-Pierre Florian, Numa Pompilius)

\section{CORPUS WEB :}

Pour gagner, il appartient à l'Intersyndicale d'appeler haut et clair à la grève générale jusqu'au retrait. Cet appel serait un signe fort ! [http:// www.gsiqi.org/wp-content/uploads/2016/06/ LC_GSI_23-06-2016-OK.pdf] (22.6.2016)

Pour exprimer notre horreur et notre condamnation sans faille du racisme, de l'antisémitisme, de l'islamophobie et du terrorisme sous toutes ses formes, y compris celui qui assassine et brûle des enfants avec des bombes au phosphore blanc,

Pour appeler haut et fort à la vie, à la liberté et à la fraternité [http://www.uoif-online.com/ communiques/appel-participer-aux-manifesta tions-ce-week-end] (22.6.2016)

REMARQUES : Haut est un adjectif-adverbe de lieu qui a un sens spatial et désigne un point élevé, au sens concret, et au sens figuré. Avec appeler, il caractérise le niveau supérieur de la voix. (I) se dit du fait d'appeler quelqu'un/quelque chose en haussant fortement la voix, afin d'en être entendu ou pour attirer son attention. (II) se dit du fait d'appeler, d'inviter quelqu'un à suivre une destinée particulière, privilégiée afin de s'élever dans un ordre spirituel, voire divin. Il reste invariable et est modifié par fort, le plus, plus, si, tantôt, tout, très. L'exemple de 1913 contient également l'adjectif-adverbe bas qui est en opposition sémantique (appeler à voix basse) avec haut, constituant une collocation avec lui : appeler tantôt très haut, tantôt presque bas. Notons les collocations haut et clair et haut et fort dans le CW, en emploi absolu. Mentionnons également l'emploi de dire haut, écrier haut, nommer bas.

\section{Appeler juste}

Appeler quelqu'un de manière correcte, comme il convient

Emploi absolu

1893 Il faut attendre affreusement longtemps les réponses ; et c'est pourquoi je comprends bien ceux qui préfèrent appeler fort qu'appeler juste. On ne sort de sa solitude qu'à l'aide d'une illusion ; mais il faut consentir ; il y en a dont l'orgueil répugne à consentir à être la dupe (André Gide et Paul Valéry, Correspondance)

REMARQUES : Appeler juste se dit du fait de s'adresser à quelqu'un sur un ton adéquat en utilisant des mots justes, pesés et adaptés à la situation. Notons l'opposition contextuelle à appeler fort.

\section{Appeler soef}

Appeler à voix basse, avec douceur Transitif

-1100 Li boens serganz kil serveit volentiers, il le nunçat sum pedre Eufemïen, suëf l'apelet, si li ad conseilét : "Sire, dist il, morz est tes provenders, e ço sai dire qu'il fut bons cristïens » (Vie de saint Alexis [fin $\mathrm{XI}^{\mathrm{e}}$ ], BFM, 338)

$\sim 1160$ El cors li ert li feus, qui l'art ; El se tornot de l'autre part, Relevot soi, puis s'aseoit, Et donc se recolchot a droit Et apelot celui de Troie Tot soavet, que l'en ne l'oie. Antre ses danz dit belement : Amors me moine malement, e jor ai mal et la nuit pis (Eneas, 8424)

1176 Et cele mainne grant dangier Et se desfant come pucele : Et cil la prie et si l'apele Molt dolcemant [variantes : soavet, 
bonement] sa dolce amie

(Chrestien de Troyes, Cligés, 3335)

-1200 Quant Godefrois l'entent, s’a de pitiet ploré, Les maroniers apele belement et soef : Signor, dist Godefrois, .i. petit m'entendés (Elie de Saint Gille [fin $\mathrm{XII}$ ], 2478)

REMARQUES : Usuel en ancien français, soef est un adjectif-adverbe de manière qui peut être antéposé (ex. de -1100) ou postposé (ex. de 1160) au verbe. Appeler soef se dit du fait de s'adresser à quelqu'un en baissant légèrement la voix, afin d'émettre un son agréable à l'oreille de l'interlocuteur. Il reste invariable et est modifié par moult, tout. Son usage relève d'un registre soutenu, littéraire. Notons la coordination avec l'adverbe belement (ex. de -1200) et son remplacement par les variantes dolcemant et bonement dans l'exemple de $\sim 1176$, ce qui confirme sa fonction adverbiale.

\section{Applaudir bas}

I. Se vanter, se glorifier en secret

Pronominal

1745 Vous m'objecterez que c'est encore là une saillie de l'amour-propre, qu'on s'applaudit tout bas, et qu'on ne manque point de se mettre au-dessus des autres, lorsqu'on s'imagine avoir plus la faculté de penser : j’y consens, je veux bien que vous me supposiez de l'orgueil, pourvu que vous m'invitiez vous-même à l'entretenir (François de Baculard d'Arnaud, Les Époux malheureux)

II. Applaudir quelqu'un en secret, sans le lui faire savoir

Transitif

1830 Il offre en souriant sa vie en sacrifice, Il se confie au dieu que son œil ne voit pas ; Coupable, a le remords qui venge la justice, Vertueux, une voix qui l'applaudit tout bas ! (Alphonse de Lamartine, Harmonies poétiques et religieuses)

1867 Elle parle argot, elle nage dans la Seine (en costume de bain) avec un prétendant qu'elle voit pour la première fois, elle le met en fuite à coups d'inconvenances, elle fait le rapin et le gamin, elle tire les pétards les plus saugrenus au milieu des conversations graves, se lâche et se livre, et son père, qui la gronde tout haut, l'applaudit tout bas (Hippolyte Taine, Notes sur Paris)

REMARQUES : Bas est un adjectif-adverbe de lieu qui désigne un niveau inférieur. En tant qu'attribut d'applaudir, il se prête à une interprétation de manière au sens figuré qui réfère au caractère discret de l'action (ici un applaudissement). Il reste invariable (ex. de 1867) et est généralement modifié par l'adverbe d'intensité tout. Notons gronder tout haut, applaudir tout bas. VoIR AUSSI : gronder haut

\section{Applaudir jaune}

Applaudir de façon contrainte en dissimulant sa gêne, son dépit

Emploi absolu

1884 M. Ferry s'est mis à faire du zèle, à la grande joie de la gauche, au grand scandale du centre qui, par nécessité de situation, applaudissait, mais qui applaudissait... jaune, si l'expression est permise (L'Illustration)

1957 Après qu'ils eurent applaudi jaune [= l'envoi du spoutnik], les savants américains rentrèrent dans leurs laboratoires (Paris Match, 19 août 1957 / Grundt : 249)

\section{CORPUS WEB :}

À la fin, on a applaudi. Je ne peux pas parler pour les autres, mais je suis pas mal certain que nous étions plusieurs à applaudir jaune [http:// sharedsite.com/hlm-de-renaud/journaux/index. php5/articles/ledevoir_25-01-01.htm] (25.11.2013)

Les Sarkozystes qui ont applaudi jaune à Périgueux, aussi, çà les ronge quelque part, d'entendre dans les commentaires que Sarko a fait du gaullisme-gauchisme, tout comme la fée Ségo est plus à droite que Chirac... [http://www. les4verites.com/politique/segolene-royal-latentation-du-gauchisme] (25.11.2013)

REMARQUES : Calqué sur le modèle de rire jaune, applaudir jaune se dit du fait d'applaudir de manière forcée, avec gêne, à contrecœur, sans approuver complètement les actes du sujet ap- 
plaudi. Les attestations dans l'écriture spontanée du CW traduisent l'emploi familier. Jaune reste invariable. VoIR AUSSI : rire jaune

\section{Apporter droit}

Apporter directement

Transitif

1285 Lors y a tantost envoiié.

Et cil furent apareillié

Qui le cheval de fust garderent ;

Droit en la chambre l'aporterent

La ou Meniadus estoit

(Adenet le Roi, Cleomadés, 13112)

\section{CORPUS WEB :}

Les publications religieuses peuvent apporter droit instruction religieuse dans la maison avec une vente en douceur qui convient le confort du lecteur et de commodité [http://www.expertstourisme.fr/christianisme-incitation-b974143. htm] (25.11.2013)

Malheureusement, le portail les a apportés droits devant Sidorak, roi des hordes de visorak, équi ont projeté les employer comme amorce en rassemblant Zivon, afin d'essayer d'apporter une extrémité au Toa Hordika [http://www.gamekult com/blog/igni-tion/54049/combo-visorak.html] (25.11.2013)

Explorer le pays avec un guide ou faire cavalier seul en utilisant une carte et une boussole. Si vous utilisez un guide, il va connaître l'emplacement du buffle et vous apporter droite pour le troupeau. Si non, vous aurez à suivre le troupeau de loin [http://www.cardplayerr.com/ VKNQRKEP] (22.6.2016)

REMARQUES : Apporter droit caractérise le fait de conduire quelqu'un, de porter quelque chose directement en un lieu ou vers quelqu'un. Droit est normalement suivi d'une préposition de lieu indiquant la direction (en) qui traduit la précision de l'action et renforce l'idée de finalité. Il est également possible d'analyser droit comme modifieur de la préposition. Les deux derniers exemples du CW montrent la possibilité de fléchir l'adjectif-adverbe dans des registres non contrôlés par la norme.

\section{Apprécier moyen}

Approuver sans enthousiasme, ne pas trop apprécier

Emploi absolu

1989 L'Élysée apprécie moyen

(Libération, 7.7.1989 / Noailly 2010)

VOIR AUSSI : aimer moyen

\section{Apprendre dur}

Recevoir une éducation dure, sévère, sans indulgence

Transitif

+1365 En jonece me vint cils flueves ;

Car s'en viellece m'euïst pris, J'euïsse esté trop dur apris (Jean Froissart, Poésies [3 tiers XIVe])

\section{CORPUS WEB :}

Si vous avez un esprit créatif, vous trouverez d'autres méthodes qui peuvent être meilleurs que ceux. Mais peu importe la façon dont vous pouvez choisir, vous devez apprendre dur avec vos objectifs [http://www.edukeo.net/apprendreetrangere-a05309257.htm] (25.11.2013)

en tant que débutant ça me choque pas d'apprendre dur une électronique, ce que je sais faire actuellement $\mathrm{c}$ en l'apprenant seul sur ma Roland TD9... [http://www.ladrummerie.com/ viewtopic.php?p=412529] (25.11.2013)

La phrase correct est " Horses are animals ». On peut mettre " The horses are animals " si on parle des chevaux du dernier film qu'on a vu, par exemple. Or la phrase « Les chevaux sont des animaux » est une vérité général donc « the » à bannir

Anna4493 6 : J'ai du mal avec « some »

augustine.legay1 7 : moi aussi tes comme moi ???

sibydou 10 : Moi aussi are some c'est trop complex mais bon faut apprendre dure dure l'anglais !!!!! [https://de.duolingo.com/ comment/2840940] (21.6.2016)

REMARQUeS : Dans l'exemple du XIV siècle, $a p$ prendre dur désigne le fait d'éduquer, d'instruire quelqu'un (généralement une jeune personne) de manière dure, sévère, inflexible. Dans la langue moderne du CW, apprendre dur est un synonyme d'apprendre durement, donc en faisant un effort. 
Notons l'accord dans le dernier exemple du CW, avec la réduplication usuelle dur dur.

\section{Apprendre long}

en apprendre long : apprendre beaucoup, bien

(s')instruire sur quelque chose/quelqu'un Intransitif

1782 Il lui fit chanter souvent les couplets qu'elle savoit, regrettant qu'elle n'en eût pas appris plus long (Robert-Martin Lesuire, L’Aventurier françois ou Mémoires de Grégoire Merveil)

1855 J'ai souvent entendu ma mère soulever devant moi ce problème : « Mon enfant sera-t-elle plus heureuse ici qu'avec moi ? Je ne sais rien, c'est vrai, et je n'aurai pas le moyen de lui en faire apprendre bien long. L'héritage de son père peut être amoindri si sa grand'mère se désaffectionne en ne la voyant pas sans cesse, mais l'argent et les talents font-ils le bonheur? " (George Sand, Histoire de ma vie)

1876 Enfin, tout cela devait mal tourner... dès mon arrivée à Coulonges, au Lion d'Or, où nous avons pris une chambre, j’ai questionné les gens, j'en ai appris encore plus long (Émile Zola, Son Excellence Eugène Rougon)

1928 - Mais si je réussis, c'est pour moi la direction des ateliers d'ameublement moderne aux quatre quartiers...

- Tu ne m'en as jamais appris aussi long là-dessus (Colette, La Naissance du jour)

1959 - C'est ta nièce... ta putain de nièce...

- Ah ! attention, s'écrie Gabriel en retirant sa main pour la lever au ciel, ma nièce c'est ma nièce. Modère ton langage ou tu vas en apprendre long sur ta grand-mère (Raymond Queneau, Zazie dans le métro)

1978 Pourquoi n’ai-je jamais exigé que tu te livres un peu à l'écrivain, à supposer que la décence eût interdit au fils d'en $a p$ prendre trop long sur tes premiers émois? (Alain Bosquet, Une mère russe)

1981 J'en apprenais long sur les goûts, les dégoûts, les manies et les espoirs de chacun (Françoise Chandernagor, L’Allée du roi)

\section{CORPuS WEB :}

Regardez les vêtements et les cheveux de la personne. En plus du langage corporel, des expressions faciales et autres indicateurs physiques, vous pourrez en apprendre long sur quelqu'un en regardant simplement la façon dont quelqu'un se présente au monde. Les vêtements, les accessoires, la coiffure et le maquillage de quelqu'un peuvent être très révélateurs [http:// fr.wikihow.com/observer-les-gens] (21.6.2016)

Certains ont bien sûr rédigé des lettres qui ont survécu ; d'autres ont laissé derrière eux leur journal personnel ; le témoignage de leur existence figure dans les recensements et les actes de naissances, de mariages et de décès. Ils survivent aussi dans leurs chansons et les récits qu'ils nous ont légués. Tout cet héritage peut nous en apprendre long sur nos ancêtres. Mais les témoignages les plus importants que ces êtres ordinaires nous ont légués sont les objets qu'ils ont fabriqués et utilisés au quotidien [http:// allaboutshoes.ca/fr/chronicles/activity02 teaching_yourself.php] (21.6.2016)

REMARQUeS : Long est un adjectif-adverbe de dimension. Dans la collocation en apprendre long, il est employé au sens figuré comme quantifieur et signifie 'beaucoup, en profondeur'. En apprendre long est régulièrement modifié par aussi, bien, encore plus. À partir du $\mathrm{xx}^{\mathrm{e}}$ siècle, la locution prend un complément indirect introduit par la préposition sur (exemples de 1928, 1959, 1978, 1981 et CW).

\section{Approcher fort}

(S')approcher beaucoup, venir très près

$\lambda$ chevaucher fort

\section{Approcher petit}

S'approcher un peu

Pronominal

1364 Moult coiettement la huchai

Et petit de li m'approchai,

En sa grant biauté regardant,

S'onneur et son estat gardant,

Qu'autrement faire ne l'osoie

Pour son courrous que je doubtoie 
(Guillaume de Machaut, Le Livre du voir dit, 3911)

CORPuS WeB :

L'Approche. On va commencer par apprendre aux oiseaux à ne plus paniquer à notre approche. Pour cela il suffit de passer beaucoup de temps autour de la cage, à siffler, les observer de temps à autre mais faire comme s'ils n'étaient pas là. Faire ses activités les plus diverses autour d'eux, comme lire un livre, boire un verre d'eau, tout en fait ! Au début, il vont paniquer, il faut alors être un peu plus éloigner et s'approcher petit à petit. Ne pas les fixer mais leur parler, les appeler par leur nom ect... [http://infosperroquet.e-monsite. com/pages/apprivoiser-son-oiseau.html] (21.6.2016)

REMARQUeS : L'ancien français employait petit comme quantifieur équivalent à peu en français moderne. Notons l'expression figée petit à petit 'lentement, prudemment', usuelle dans l'usage moderne, dans le CW.

\section{Ardre bel}

ardre au plus bel : brûler de la manière la plus satisfaisante, avec intensité

Transitif

1300 Si trairont mi arcier environ de tous lés De mes dars en ardrai au plus bel les costés. [a cel bel, Fierabras (L), 2051]

- Sire, ce dist Brulans, ce n'est mie bontés: Ja est ja li solaus ens ou ciel esconsés ; S'or commenciés justice, vous en seriés blamés (Fierabras (K), 1948)

Intransitif

1386 Ces vaisseaux ardoient bel et clair, et le faisoient les Anglois à cette entente (intention) que ils se prensissent (attachassent) aux grands et gros vaisseaux qui là étoient d'Espagne et d'autres pays, ils n'avoient cure de qui (Jean Froissart, Chroniques (B), X, p. 329)

REMARQUES : Le neutre bel fait partie du groupe adverbial au plus bel qui réfère à la perfection dans l'action ou au sentiment de vouloir mener à bien son projet, se rapprochant d'un rôle d'intensifieur signifiant 'fort'. Notons la collocation avec l'adjectif-adverbe clair.

\section{Ardre clair}

Brûler en éclairant beaucoup, vivement Intransitif

$\sim 1000$ Il liuol faire mult amet. beuure liroua a porter. garda si uid grand claritet. decel uindre fud depardeu et sicum roors in cel esgranz et sicum flammes clar ardaz (Vie de saint Léger, 204)

$\sim 1170$ Li feus mout cler devant aus art. $\mathrm{Li}$ vavasors serjant n'avoit, Fors un tot seul qui le servoit, Ne chanberiere ne meschine (Chrestien de Troyes, Erec et Enide, 484)

$\sim 1180$ Et sachiez que de grant maniere Li sist au flanc et miex el poing, Et sambla bien que al besoing S'en deüst aidier comme ber. Derriers lui vit vallés ester Entor le fu qui cler ardoit (Chrestien de Troyes, Perceval ou Le Conte du Graal, 3181)

+1225 Si vi un image desus

De ma dame sainte Marie ;

S'avoit devant par seignourie Une lampe ki cler ardoit ; Hons ne feme ne le gardoit (Le Chevalier as deus espees [ $2^{\mathrm{e}}$ quart $\left.\mathrm{XIII}^{\mathrm{e}}\right]$, 475)

+1250 Ce dist Poncez « molt volonters ». Atant se metent es senters : En sa mein porte une candoille Qui si art cler con une estoille (Le Roman de Renart [2 moitié XIII'], Ib, 2946)

+1300 Adont li bailla par le main : Li chevaliers joians le prent. $\mathrm{Au}$ fu, qui cler art et esprent, Li escuiers tantost retourne, Si le recouvre, n’i sejourne, Puis entra errant en son lit (Le Prestre et le chevalier [ $1^{\mathrm{re}}$ moitié XIII'] $]$, 645)

REMARQUES : Clair est un adjectif-adverbe qualificatif qui forme une collocation usuelle avec le verbe ardre. Il reste invariable et est modifié par moult. L'antéposition de cler au verbe prédomine en ancien français. VoIR AUSSI : brûler clair 
Areer bel

Parer joliment

$\lambda$ arroyer bel

\section{Arer profond}

Labourer

Intransitif

1275 Asprement les esperonez

E les plus granz cos leur donez

Que vous onques doner pourreiz,

Quant plus parfont arer [variante : aler] vourreiz (Jehan de Meun, Roman de la rose [1269-1278], 19720)

REMARQues : Profond est un adjectif-adverbe de dimension. Il est modifié par plus.

\section{Armer beau (bel)}

Munir de belles armes imposantes, bien armer

Transitif

1170 La nueme bataille fu grant

E defensable e redotee :

Onc gent ne fu si bel armee [variante : bien] (Benoit de Sainte Maure, Le Roman de Troie, 7984)

$\sim 1177$ Deus an i ot, qui li estoient Ne sai ou cosin ou neveu, Por voir bien anseignié et preu : Cil l'arment si bel et si bien Qu'il n'i a soz le monde rien Don nus hon reprandre les puisse Por mesprison nule qu'il truisse An chofe qu'il i aient fet (Chrestien de Troyes, Lancelot ou Le Chevalier de la charrete, 6793)

1190a Garim, quer me di ore, garde ne soit chelés,

Por coi n’i est venus Rollant li alosés, Ou li quens Olivier qui tant est biax armés, Berart de Montdidier et Ogier l'alosés (Fierabras (L), 468)

1190b Un chevalier de Franche ai piecha aamé : Gui a nom, de Borgoigne, mout i a bel armé ;

Parens est Karlemaine et Rollant l'aduré (Fierabras (L), 2340)

1230 Sarasins et Persans le keurent esgarder, Et dist li uns à l'autre : "Véés com bel armé!»
De ci que en la place ne se sont aresté

(Gui de Bourgogne, p. 69)

+1265 Diex ! donnés que li puisse rendre

Sa courtoisie et sa vaillanche ;

Et se li doinst Dieus tel poissanche

Que ses cors n'i soit entamé,

C’ainques ne vi si biel armé

(Richars li Biaus [3e tiers XIII $]$, 1428)

-1334 Li Beaus Chevaliers chevaucha,

Qui sa route bien ordena,

Bien estoit parmi apparant ;

Car haus estoit et si iert blanc,

Escu ot noir de blanc lermé,

Molt par estoit tres bel ermé (Le Romans de la dame a la lycorne [1 ${ }^{\mathrm{er}}$ tiers XIV] $\mathrm{X}^{\mathrm{e}}$, 2677)

+1350 Quant Brun de la Montaigne fu en la court entré,

Onques nus hons ne vit de lui plus bel armé.

Doy chevalier si l'ont maintenant desarmé, Si tost que du cheval le virent desmonté (Brun de la Montaigne [ $2^{\mathrm{e}}$ moitié XIV $]$, 3576)

Pronominal

+1175 Del chastel issent maint et comunalment ; Li cuens Guillaumes s'en ist premierement,

Et fu armez bel et cortoisement

Sor un destrier arrabi et corrant

(Garin le Loherain [ $4^{e}$ quart XII $]$, 4674)

+1225 Et on si fait, et il se lieve

Et s'atorne, ke ne li grieve.

Et viest une cote a armer

En son dos d'un drap d'outre mer.

Puis s'arme, si biel comme il pot,

De quan c'a chevalier estot

Por assalir et por deffendre (Le Chevalier as deus espees [ $2^{\mathrm{e}}$ quart $\left.\mathrm{XIII} \mathrm{e}^{\mathrm{e}}\right]$, 1589)

1393 Atant vindrent au pié de la montaigne. Et descend Gieffroy et s'arma bien et bel, et remonte a cheval, et met l'escu au col et la lance ou poing (Jean d'Arras, Mélusine, p. 710 [manuscrit Arsenal])

1515 Ne demeura guiere aprés cela fait que celluy verlet vint pour soy armer et se arma bien et beau; puis mect la sallade en sa teste et monte à cheval et s'en va avec son 
maistre et avec les aultres gens d'armes, mais quant il vint avec eulx aux champs, il puoit comme le deable (Philippe de Vigneulles, Les Cent Nouvelles nouvelles, p. 125, 25)

REMARQUES : Le neutre bel s'emploie ici comme adverbe de manière, l'emploi de la forme adjectivale étant occasionnel, impliquant davantage le sujet. Armer bel se disait du fait de munir quelqu'un de belles armes imposantes et donnant de l'allure. Dans son emploi intransitif, désigne le fait d'être paré, d'arborer de belles armes puissantes. L'emploi pronominal accentue le sens de se parer soi-même de ces armes, impliquant davantage le sujet dans l'action. L'emploi du neutre bel est une caractéristique de l'ancien français. L'exemple de 1515 reprend la collocation ancienne, tout en remplaçant le neutre par le masculin beau. Notons que le verbe apparaît souvent dans sa forme de participe passé armé qui s'accorde avec le sujet. Bel / beau est modifié par plus, si, très. Notons la coordination de bel/ beau avec les adverbes bien et courtoisement.

\section{Armer dru}

Se munir d'une grande quantité d'armes, connotant la force

Emploi absolu

-1300 Par tote l'ost des Saisnes furent levé li hu ; Lors se corent armer espessement et dru (Jehan Bodel, La Chanson des Saisnes [fin XIII'], 6348)

REMARQUES : Armer dru réfère à un armement puissant, dans lequel on met tous les moyens. L'adverbe espessement, précédant l'adjectifadverbe, renforce l'idée de quantité et de force.

\section{Arraisonner bel}

Adresser à quelqu'un des paroles

convaincantes, raisonnables

Transitif

1230 Dus Sanses de Borgoigne fist forment à prisier,

Et sachiés tot sans faille qu'il ot Guion molt chier,

Qu'il l'avoit engendré de sa france moillier.

Bel et cortoisement le prist à araisnier

(Gui de Bourgogne, p. 94)
1275 De Malatrie fu Gerars bel araisniés:

Amis, dist la pucele, envers moi vous traiés,

Bien sai que a moi estes en message envoiiés (Adenet le Roi, Buevon de Conmarchis, 3670)

-1334 Au Beau Chevalier tout remue Li coers, quant ou manoir entra. Privés Dangiers tost l'avisa, Molt bel le va araisonner Et molt tres bel samblant moustrer (Le Romans de la dame a la lycorne $\left[1^{\mathrm{er}}\right.$ tiers XIV $\left.\left.{ }^{\mathrm{e}}\right], 7298\right)$

REMARQUES : En ancien français, arraisonner bel désigne le fait d'interpeller, d'adresser la parole à quelqu'un en cherchant à le persuader, à justifier son propos par des preuves ou des raisons. Le neutre bel est modifié par l'adverbe d'intensité moult. Notons que dans l'exemple de 1275, le verbe apparaît dans sa forme de participe passé qui s'accorde avec le sujet. Mentionnons aussi la coordination de bel avec l'adverbe cortoisement dans l'exemple de $\sim 1230$.

\section{Arrêter coi}

S'arrêter ou faire arrêter de façon à ne plus faire de bruit (hommes), voire à ne plus bouger (animaux) ; interrompre brusquement Intransitif

+1313 Tout cil qui la nouuielle sorent S'esmierueillent de la prouecce De celui qui tant ot perece D'ariester quoi en son ostel, Or a cel iour conquis los tel Que iamais ne sera blasmes Ne plus n'iert sauuages clames (Jean de Condé, Poèmes [1313-1337], 793)

1346 LE PAPE. Ho! seigneurs, coiz nous arrestons,

Puis que nous sommes en l'eglise

La dame plaine de franchise, Et me laissiez m'offrande faire, [Ave], royne debonnaire, Du treshault Dieu souverain temple Et aussi de tout bien exemple, Souverain mont de forteresse, Souveraine humble et en hautesse, Souveraine beneurté 
Des sains après la trinité !

(Miracle de un Pape qui vendi le basme, 1213)

1373 THIBERT. Seigneurs, arrestons ycy coy Touz ensemble, ce vous conmans. En la forest sommes du Mans (Miracle de notre dame Berthe, 700)

Pronominal

+1365 Je pri dou papier et de l'encre Et tous quois m'arestai à l'ancre Jusques à tant que j'ai escript Ensi com vous vés en escript (Jean Froissart, Poésies [3e tiers XIV $\left.{ }^{\mathrm{e}}\right]$ )

1370 Et quant il furent assez pres approuchié li uns de l'autre, li chevaliers qui gardoit le pas s'en vint vers Aigre, esperonnant sanz mot dire ; et li bers s'arresta tous cois et attendi tant que cilz fu prez de lui (Roman de Berinus, I, p. 280)

1558 Et à fin que l'Empereur fust plus esclaircy au vray de la verité de cela, il pensa à part soy : «Maintenant j'ay ouy dire souventesfois qu'il avoit une grosse verrue sur la nuque du col "; et s'approcha pour $\mathrm{y}$ voir si elle estoit ainsi en cete figure et s'il l'y trouveroit ; et il y trouva ainsi la verrue, - car il s'arresta coy comme un baston picqué et incontinent apres il se disparut, apres que l'Empereur en eut accomply son desir (Pierre-Victor Cayet, L'Histoire prodigieuse du Docteur Fauste)

1563 Les argentées suivent de mesme : et plus n'estoit qu'une ligne, qu'une d'elles ne fust royne nouvelle créée : mais en cestuy endroit le custode auré la guettoit : pourtant elle s'arresta coy (François Rabelais, Cinquième Livre)

1596 Car le fleuve d'oubly contre Amour n’a puissance.

L'esprit à cette fois tout coy s'est arresté, Adorant le saint lieu, tombeau de loyauté (Philippe Desportes, Euvres)

1838 On apprend aux chiens courants à décrire ces cercles en avant et en arrière, pour que plus tard cette manœuvre leur serve à lever un défaut. L'animal que l'on chasse a marché ou s'est arrêté coi dans un lieu que vous ignorez (Elzéar Blaze, Le Chasseur au chien courant)

2006 - M'ma Songo que désirez-vous ? questionna Wendkonta interloquée.

La jeune fille s'arrêta coite et attendit imprudemment l'arrivée de la dame (Adama Salle, Un mariage oblique)

Transitif

+1370 Adont les fist-on arester tout quoy pour avoir aultre consseil et fist-on aucuns compaignons monter sour courssiers pour escarmuchier as Escos et pour aviser le passage del rivière et pour veoir leur convenant de plus priès (Jean Froissart, Chroniques (A))

1550 Que Pallas, la sage guerriere, Luy happant les cheveux derriere, Tout gromelant l'arresta coy? (Pierre de Ronsard, Les Odes, p. 279)

1666a Un villageois, ayant perdu son veau, L'alla chercher dans la forêt prochaine. Il se plaça sur l'arbre le plus beau, Pour mieux entendre, et pour voir dans la plaine.

Vient une dame avec un jouvenceau.

Le lieu leur plaît, l'eau leur vient à la bouche,

Et le galant, qui sur l'herbe la couche, Crie, en voyant je ne sais quels appas :

« $\mathrm{O}$ dieux ! que vois-je ! et que ne vois-je pas!»

Sans dire quoi : car c'étaient lettres closes. Lors le manant les arrêtant tout coi :

«Homme de bien, qui voyez tant de choses, Voyez-vous point mon veau ? dites-le moi » (Jean de La Fontaine, Le Villageois qui cherche son veau)

1666b Sur ce propos l'autre l'arresta coy. Je vous entends, dit-elle, c'estoit moy (Jean de La Fontaine, La Servante justifiée)

1868 Quand je vois un archéologue se lancer dans cette voie, j'ai toujours envie de l'arrêter coi, et de lui dire, comme le bon fabuliste : 
Homme de bien qui voyez tant de choses Voyez-vous pas mon veau! Dites-le moi ? (F. Parenteau, La Découverte du Jardin des Plantes de Nantes)

REMARQUES : ( $S$ ')arrêter coi 's'arrêter et ne plus bouger' est vieux. Notons la dynamique résultative dans l'emploi transitif. Au figuré, il peut renvoyer à une pensée qui reste en suspens, ou à l'esprit qui cesse de cogiter. Le verbe prend alors le sens de 'demeurer', traduisant l'idée de se taire, de ne pas bouger, de ne pas intervenir. Le groupe s'est maintenu dans le vocabulaire archaïsant de la chasse. Il est modifié par tout. On trouve même un exemple fléchi (ex. de 2006). La flexion y est informelle ou 'modernisée' par rapport au féminin coie. Notons l'emploie de nouvelle créée (créer nouveau).

\section{Arrêter court}

I. Arrêter instantanément, brusquement Transitif

1544 O doncques, Roy, son cousin, frere et pere, Arreste court l'entreprise impropere ; Et toy, sa sœur, en qui tant elle espere, Mets y la main (Clément Marot, Chants divers)

1577 Mais ainsi que les deux armees n'attendoient sinon que le signe du combat, il arresta tout court ses gens à un ject d'arc des autres, et du haut d'une petite motte de terre, qui de fortune se rencontra là tout à propos, leur escria à haute voix en cette sorte (Blaise de Vigenère, L'Histoire de la décadence de l'Empire grec [trad.])

1610 Je voy bien qu'ils me respondent que si ceste beauté a esté produite pour estre aimée, c'est pour sa propre gloire et pour le dommage de ceux qui l'aimeront comme moy. Ceste pensée l'arresta si court, qu'en cessant de marcher, apres l'avoir long temps roulée dans son esprit, il profera telles paroles (Honoré d’Urfé, L’Astrée)

1638 SOSIE. La lune, pour me voir, arrêta court ses pas :

De vrai, cette première était plus longue encore,

Et je désespérais du retour de l'aurore (Jean de Rotrou, Les Sosies)
1702 Si vous avez de la broderie, bientôt les valets de chambre en porteront. Le seul moyen d'arrêter tout court le luxe est de donner vous-même l'exemple que Saint Louis donnait d'une grande simplicité. L'avez-vous donné en tout, cet exemple si nécessaire? (Francois de Fénelon, Examen de conscience)

1735 sans le consentement que j’avois donné à la rupture de mon mariage, qui avoit occasionné une lettre de la Cour, par laquelle on lui faisoit entendre que s'il poussoit les choses plus loin, il ne me reverroit jamais ; menace qui l'avoit arrêté tout court, par la tendresse qu'il avoit pour moi (Charles de Mouhy, La Paysanne parvenue)

1822 Si l'un des deux amants est trop supérieur dans les avantages qu'ils estiment tous les deux, il faut que l'amour de l'autre meure, car la crainte du mépris viendra tôt ou tard arrêter tout court la cristallisation. Rien n'est odieux aux gens médiocres comme la supériorité de l'esprit : c'est là, dans le monde de nos jours, la source de la haine (Stendhal, De l'amour)

1916 Il était grand et massif, moustachu de gris, et sa figure épaisse avait toujours une expression un peu gênée de bonne humeur arrêtée court par l'annonce d'un chagrin d'autrui, auquel il devait faire semblant de compatir (Louis Hémon, Maria Chapdelaine)

1925 Au pied d'un chêne isolé dans une lande, la petite chienne huma le vent ; un geste de son maître l'arrêta court, comme déjà elle s'élançait. Raboliot lui cingla le museau, tandis qu'un gros oiseau filait bas sur leurs têtes (Maurice Genevoix, Raboliot)

Pronominal

1579 Il y eut un homme en nostre forest qui avoit en son logis un gros chien mastin de poil noir, et laid comme un beau diable, lequel faisoit peur aux petits enfants. Il advint un jour, ainsi qu'il suivoit son maistre allant à ses affaires, vint rencontrer dedans les bois en un estroit chemin un grand regnard, lequel voyant le chien s'arresta 
sur le cul, tremblant comme la fueille. Le chien mesme s'arresta tout court. Or estant ainsi tous deux aculez l'un devant l'autre, commencerent à eux entreregarder sans rire si tres-ententivement et sans ciller ne parler (Philippe d'Alcripe, La Nouvelle Fabrique des excellents traicts de vérité)

1596 Je feray desormais ta puissance plus grande,

Et rendray par mes traits ton bras victorieux.

La mort s'arresta court, oyant cette promesse :

Et le cruel Amour du depuis n'a eu cesse, Faisant mourir tous ceux qui regardent vos yeux (Philippe Desportes, Euvres)

1624 Moy qui voyois que son regard estoit tout égaré, et qu'il sembloit à son geste qu'elle fust transportée de quelque fureur, et comme animée d'un esprit plus fort que le sien ; ne pouvant assez m'estonner de ceste nouveauté ; je m'arrestay tout court, sans me mettre en devoir, ny de m'advancer vers elle, ny de luy respondre (Jean de Gombauld, L'Endimion)

1835 Nous avançâmes sur les Arabes, ils s'arrêtèrent court; je me détachai de la caravane, en lui ordonnant de rester sous les armes ; je m’avançai avec mes deux compagnons et mon drogman ; nous parlementâmes ; et le scheik avec ses principaux cavaliers nous escortèrent eux-mêmes jusqu'à la brèche, en donnant ordre aux Arabes de l'intérieur de nous respecter, et de nous laisser examiner les monuments

(Alphonse de Lamartine, Souvenirs, impressions, pensées et paysages pendant un voyage en Orient)

1846 Quelque rapide que fût son élan, quelque glissant que fût un bloc de granit, elle $s^{\prime} y$ arrêtait tout court, au mot de «Mignonne » (Honoré de Balzac, Une passion dans le désert)

1902 Je travaille depuis une heure, quand un très léger frôlement derrière moi, du côté des petits couloirs d'entrée, me donne le sentiment de quelque discrète et gentille présence, et je me retourne : un chat, qui s'arrête court, une patte en l'air, hésitant, et me regarde bien dans les yeux, avec un air de dire : « Qui es-tu toi ? » (Pierre Loti, Les Derniers Jours de Pékin)

1940 - Oui, je vous demande si votre mari vous écrit quelquefois?

Ma question fit grand effet sur Rosita, qui traversait la chambre. Elle s'arrêta court, comme attendant la réponse de sa sœur.

- Non, dit enfin Délia. Il ne m'écrit pas, et il fait aussi bien. Nous n’avons rien à nous dire (Colette, La Lune de pluie)

1950 Je le précède, élevant la bougie. Et soudain, tous les deux ensemble, nous nous arrêtons court :

- Bigre!

- Ça, alors!

Sans transition, le parquet brut de la salle devient brillant et uni comme une glace ; la flamme du lumignon y plonge son reflet vacillant (Maurice Genevoix, Ceux de 14)

1972 Sous les halliers sortaient les premiers perce-neige. Il se mettait presque à courir, mais arrivé au gros foyard il s'arrêtait court puis retournait à la Rouéchotte en disant: - Lundi de Pâques! Pas avant ! Et il se remettait à l'établi (Henri Vincenot, Le Pape des escargots)

Intransitif

1679 Enfin l'on s'amusa tant que la petite pointe du jour (c'étoit dans les plus grands jours de l'été) commençoit à paroître quand l'on fut au bas de la descente des bonshommes. Justement au pied, le carrosse arrêta tout court (Jean-François de Gondi (Cardinal de Retz), Mémoires)

II. S'interrompre ou interrompre quelqu'un dans son discours, couper la parole Transitif

1630 Pour ton argument, s'il estoit ainsi, Judas, les Juifs et les bourreaux seroient les precurseurs de nos Prestres : mais je l'arrestai tout court, par un sophisme bien mieux troussé. Croyez-vous, lui dis-je, que le Pape est l'Antechrist ? Oüy, dict il, il n'est pas Chrestien qui ne le croit 
(Théodore Agrippa d'Aubigné, Confession catholique du sieur de Sancy)

1834 Il me semblait lâche et cruel d'avoir pris cette noble colère au dépourvu, de l'avoir fait rentrer en elle sans pitié, et de n'avoir pas respecté un fonds d'inviolable douleur jusque dans cette divagation violente. $\mathrm{M}$. de Couaën m'arrêta court avant que j'eusse fini : «Amaury, me dit-il, combattez-moi, réfutez-moi à extinction, pourvu que vous nous aimiez ! » (Charles Sainte-Beuve, Volupté)

1914 GABRIELLE. (même jeu) Ah ! Général... ! LE GÉNÉRAL. (l'arrêtant court) Mais ceci, bien entendu, à la condition que votre mari confirme vos excuses en y ajoutant les siennes ! Il passe numéro 1 devant Gabrielle.

GABRIELLE. Oh ! Si ce n'est que ça, il vous les fera.

LE GÉNÉRAL. Vous comprenez, moi... j’ai giflé votre mari !

(Georges Feydeau, La Dame de chez Maxim)

Pronominal

1744 En arrivant à la maison de Madame de Marignan, nous entrâmes d'abord chez D. Clara ; elle parloit avec agitation à un jeune homme qui embrassoit ses genoux, et dont le discours paroissoit aussi trèsanimé : mon ami s'arrêta tout court de surprise ; mais D. Clara n'eût pas sitôt apperçu son amant qu'elle vola vers lui pour l'embrasser ; ah ! lui dit-elle, en se jettant à son col, cher S. Julien, ne me condamnez pas au moins sans savoir si je suis coupable (Jean-Baptiste Jourdan, Le Guerrier philosophe)

1748 - On n'est point toujours une bête pour l'avoir été quelquefois ; et Votre Hautesse.. Mirzoza craignant d'offenser le sultan, s'arrêta là tout court.

- Achevez, madame, lui dit Mangogul, je vous entends ; et Ma Hautesse n'a-telle jamais fait la bête, voulez-vous dire, n'est-ce pas ? (Denis Diderot, Les Bijoux indiscrets)
1825 En cherchant la gloire, nous trouvons la mort. Je m'arrête tout court sur cette phrase, car je sens qu'un pareil style m'emporterait haut et loin (Paul-Louis Courier, Lettres écrites de France et d'Italie)

1886 Il lui arrivait d'entonner les Fillettes de Paimpol ; ou bien, en balançant la tête et battant la mesure avec son pied, elle prenait :

Pour la pêche d'Islande, mon mari vient de partir,

Il m’a laissée sans le sou,

Mais... trala, trala la lou..

J'en gagne!

J'en gagne !...

Chaque fois, cela s'arrêtait tout court, en même temps que ses yeux s'ouvraient bien grands dans le vague en perdant toute expression de vie, - comme ces flammes déjà mourantes qui s'agrandissent subitement pour s'éteindre (Pierre Loti, Pêcheur d'Islande)

III. Limiter quelqu'un dans son champ d'action, avoir une influence sur quelque chose Transitif

1830 Il avait osé lui faire des questions sur une foule de petites choses, dont l'ignorance arrête tout court l'intelligence d'un jeune homme né hors de la société (Stendhal, $L e$ Rouge et le noir)

1922 Je n’en étais pas arrivé à ce point pour Albertine. Ses mensonges, ses aveux, me laissaient à achever la tâche d'éclaircir la vérité : ses mensonges si nombreux, parce qu'elle ne se contentait pas de mentir comme tout être qui se croit aimé, mais parce que par nature elle était, en dehors de cela, menteuse (et si changeante d'ailleurs que, même en me disant chaque fois la vérité sur ce que, par exemple, elle pensait des gens, elle eût dit chaque fois des choses différentes ; ses aveux, parce que si rares, arrêtés si court, ils laissaient entre eux, en tant qu'ils concernaient le passé, de grands intervalles tout en blanc et sur toute la longueur desquels il me fallait retracer, et pour cela d'abord apprendre, sa vie (Marcel Proust, La Prisonnière) 
1929 Qu'on ne s'y laisse pas tromper ; c'est ici le nœud gordien de l'œuvre, celui que les débutants doivent s'évertuer à dénouer s'ils ne veulent être arrêtés court au commencement de la pratique (Fulcanelli, Les Demeures philosophales et le symbolisme hermétique)

1937 Ils avaient mis leurs bras au service de haines implacables, inexpiables, impuissantes, des haines de vieux. Si la France de 1918, arrêtée court en plein essor de production industrielle de guerre, s'est trouvée encombrée d'un matériel désormais inutilisable, elle disposait de plus vastes réserves de haine

(Georges Bernanos, Les Grands Cimetières sous la lune)

1938 Il a emmené captive la captivité, cela veut dire que, comme Samson, chargeant sur ses épaules les portes de Gaza et laissant là-bas ces autres portes démantibulées qui n’ont pas prévalu contre lui, il emporte avec lui jusqu'au ciel ces obstacles mêmes de la matière et de la chair qui nous tenaient prisonniers et qui arrêtaient court notre vue et notre mouvement et notre action (Paul Claudel, Un poète regarde la croix)

\section{CORPuS Web :}

Ainsi, arriver avec une assiette positive et ne rien changer jusqu'à l'impact avec le sol peut au moins faire toucher des roues plus tôt. Ensuite il ne s'agit plus que d'une question d'efficacité du freinage pour s'arrêter court. Toutefois, le pilote doit faire attention afin de ne pas toucher trois points sous prétexte de ne pas arrondir. L'assiette doit impérativement être positive pour que ce soit le train principal d'atterrissage qui percute en premier le sol. Si ce n'est pas le cas, il doit faire un arrondi, quoiqu'il arrive [http://home.nordnet.fr/ dmorieux/perfect0009.htm] (21.6.2016)

« Continue, mon frère, et achève ce que j’ai commencé. » Et celui qui se moquait reprit l'histoire, mais comme il n'avait ni le ton ni la manière il finit par s'arrêter court, et les pèlerins qui étaient là à souper l'abreuvèrent d'injures et de coups la moitié de la nuit [http://kiplinginfrench. free.fr/LH00.html] (21.6.2016)
Thomas Lélu, page 45. Je manque de m'endormir, fatigue passagère. Les flammes ont crépité tout ce temps. La danse s'est arrêtée courte, empêchement soudain. J'ai essayé d'être crédible à ses yeux, essayé d'être sérieuse et moimême [http://autourdejulien.canalblog.com/ archives/2007/11/01/6737797.html] (5.12.2013)

L'accouplement sert à interrompre la transmission de l'entraînement du moteur à la transmission, sur le demi-tour ou d'arrêter courte [http://www.beevar.com/renault-lagunacouplage-vous-detectez-des-defauts-de-sorte] (21.6.2016)

REMARques : Court est un adjectif-adverbe de manière qui reste invariable. Il est modifié par là, si, tout. (S')arrêter court forme un verbe complexe lexicalisé avec les significations de 'stopper', 'interrompre la parole' et 'empêcher quelqu'un de faire quelque chose'. Dans le langage actuel du CW, on trouve l'accord de l'adverbe dans les deux derniers exemples. Notons l'emploi de filer bas ; emporter haut et loin.

\section{Arrêter droit}

I. s'arrêter (tout) droit : s'arrêter brusquement, soudainement, brutalement

Pronominal

-1200 Et quant les voit Elies, s'en a gete .i. ris ; De che fist il que faus, quant ne daigna fuir.

A estal s'aresta droit en mi le chemin (Elie de Saint Gille [fin XII $]$, 1210)

1276 De Gloriande fu Ogiers adestrés, Devant le roi s'est tout droit arrestés (Adenet le Roi, Les Enfances Ogier, 3327)

-1334 Tost erranment, sans plus y atarder, Vient li secons, bel fet a regarder, Au bout du pré tout droit il s'aresta, A haut vois a celui s'escria : « Or cha! vas la! encor vus faut jouster! » Celui l'atent tout prest a retourner, Sans plus atendre viennent lance levee (Le Romans de la dame a la lycorne [1 ${ }^{\mathrm{er}}$ tiers $\left.\left.\mathrm{XIV}^{\mathrm{e}}\right], 320\right)$ 
II. s'arrêter (tout) droit devant quelqu'un/ quelque chose : s'arrêter juste, précisément devant quelqu'un ou devant un lieu Pronominal

1629 Il me suffira de vous dire, qu'apres que sous l'estendart d'Araxe, j'eus bien fait mon devoir avec Piroxene au premier combat des Zagayes, qu'ils firent à la façon des Mores, et des Perses, et où je m'estois desja fort exercé dans la Cour du Roy mon pere, je fus tout estonné, le Bal s'estant recommencé comme le soir precedent, que la Princesse Orixe suivie de six belles Dames, et accompagnee des Juges et des Herauts, se vint arrester tout droit devant la place de l'eschaffaut où j'estois assis, et le Roy d'armes qui la devançoit prenant aussi tost la parole me fit ce compliment à haute voix devant tous (François Le Métel de Boisrobert, Histoire indienne d'Alexandre et d'Orazie)

1832 Un soir, assis sur le pont qui est au bas de la terrasse de Richmond, je lisais les mémoires de Mme Hutchinson ; c'est l'une de mes passions.

- Mister Bell ! Dit un homme en s'arrêtant droit devant moi.

C'était M B - que j'avais vu en Italie, chez Milady Jersey à Milan (Stendhal, Souvenirs d'égotisme)

1942 Il se tailla une nouvelle tranche dans son quignon. Soudain Pompelune s'élança... Il trotta, comme d'une petite course entravée de gugusse, et, s'arrêtant droit devant Tonin Bagot, il fit, avec sa canne, un superbe moulinet, qui rasa la casquette de Tonin (Louis Guilloux, Le Pain des rêves)

III. arrêter droit : stopper quelque chose exactement, en un lieu ou sur quelqu'un de précis

Transitif

1837 Le regard de ses yeux vairons doublés d'une feuille d'argent était fuyant, mais terrible quand il l'arrêtait droit sur sa victime. Sa voix semblait éteinte comme celle d'un homme qui a longtemps parlé. Ses lèvres minces ne manquaient pas de grâce (Honoré de Balzac, Histoire de la grandeur et de la décadence de César Birotteau)
1931 Se sentant fatiguée elle avait seulement voulu s'étendre.

- Que tu m'as fait peur!

Pauline s’inquiétait de la voir si pâle, avec cette figure tendue, ces yeux arrêtés droit devant elle. Elle voulut aller chercher de l'eau d'arquebuse à la maison. Anne-Marie la retint par la jupe (Henri Pourrat, $L a$ Tour du Levant ou Quand Gaspard mit fin à l'histoire)

Pronominal

1849 ANTOINE. Les lèvres frémissent, les narines semblent s'ouvrir au mouvement du sein gonflé.

(Un coup de vent subit arrache l'image et la fait voltiger aux yeux d'Antoine)

LA VOIX. (mielleusement susurrante)

La voilà, elle te suit, elle saute.

(L’image s'arrête droit en l'air) (Gustave

Flaubert, La Tentation de saint Antoine)

\section{CORPUS WEB :}

Bonjour, j’ai un problème assez énervant pour ma discipline, mon cheval refuse catégoriquement de s'arrêter droit. Je l'ai longé, fait marché en main etc.... Il refuse de s'arrêter droit [http://equideo.actifforum.com/t4016-chevalrefusant-de-sarreter-droit] (20.6.2016)

Les freins ne se distinguent pas d'un autre scooter. Performant et précis, ils ne vous déstabiliseront pas. Pour vous arrêter droit, le frein arrière vous sera très utile pour atteindre la vitesse qui autorise le blocage [http://acidscooter. ch/cms/content/essai/2010/05/17/piaggio-mp3hybride-125] (20.6.2016)

REMARQues : Droit est un adjectif-adverbe de position spatiale. Il reste invariable (ex. de 1849 et 1931) et il est modifié par tout. Droit a tendance à s'associer avec des prépositions qu'il précède (devant, en, sur) au point de faire partie du groupe prépositionnel comme modifieur de la préposition.

\section{Arrêter ferme}

I. (s')arrêter d'une manière résolue, déterminée, inébranlable

Emploi absolu

-1469 Et pour ce, Monseigneur, quant on va en guerre, on doit chevaucher deliberé d'arrester et tenir ferme, quelque chose qu'il 
adviengne, sinon on ressemble à aucuns larrons de guerre, qui vont pour embler ung homme en sa maison, ou pour guetter ung chemin, ou pour prendre ung cheval à l'abrevoir, ou pour courre et racourre (Jean de Bueil, Le Jouvencel [1461]-1468, I, p. 201)

Pronominal

1816 On le [= le chamois] voit souvent sauter, en descendant, de vingt à trente pieds, et s'arrêter ferme pour peu qu'il trouve une pointe de roc pour le recevoir ; aussi sa chasse est-elle très-pénible et souvent dangereuse, lorsque, ne trouvant plus de moyen d'échapper, il se jette sur les chasseurs et les fait tomber dans les précipices sur les bords desquels ils sont obligés de le suivre (Frédéric Cuvier, Dictionnaire des sciences naturelles, s.v. Le Chamois)

II. arrêter ferme en quelque chose : au concret : fixer, être fortement ancré ; au figuré : s'en tenir à quelque chose d'une manière résolue, déterminée, inébranlable

Transitif

1566 Que plusieurs s'asseurans de leur Sauveur promis,

Me sont en ceste foy obstinez ennemis.

Le mesme premier homme, arresté ferme en elle,

A tenu le chemin de la vie eternelle

(Louis Des Masures, David fugitif)

1688 Posez dedans ce trou le gros bout de l'arbre coupé, élevez-le et l'arrêtez tout droit aiant lié auparavant à deux ou trois pieds proche du bout $\mathrm{F}$ [= renvoi au dessin]. Plusieurs liens de bois attachez bout à bout les uns des autres, comme vous le voiez par les lettres a, b, c, d, e, f, g, h, i, k, afin de les arrêter fermes avec des crochets de bois fichez en terre tout autour (Francois Fortin, Les Ruses innocentes)

III. s'arrêter ferme à quelque chose : s'attarder, fixer son attention sur quelque chose

Pronominal

1596 Qui veut au ciel d'amour voir ses ailes haussées,

Et de tous vieux ennuis la mémoire bannir,
Vienne au jour de vos yeux s'il les peut soustenir,

Beaux yeux, les doux meurtriers de mes paines passées.

Quiconque ainsi que moy s'y peut ferme arrester,

D’autres biens ne sçauroit son esprit contenter (Philippe Desportes, Euvres)

1683 Les vérités métaphysiques sont sublimes et délicates, et il est difficile à des hommes pétris de chair et de sang de s'arrêter fermes à la contemplation de ces vérités (Nicolas Malebranche, Méditations chrétiennes)

\section{CORPUS WEB :}

Les premiers soins d'Anne me permirent d'affermir mon intention d'arrêter et cela sans que j'eusse à faire un effort insurmontable, comme si le terrain avait été préparé à l'avance. Et rapidement j'arrêtais du jour au lendemain sans éprouver, à ma grande surprise, un manque énorme comme lors des précédents arrêts. Et surtout je sentais mon intention d'arrêter ferme et sans appel, ce qui pour moi était une première [http:// www.votreguerison.com/T\%E9moignages $\% 20$ de\%20clients.html] (20.6.2016)

Les vérités métaphysiques sont sublimes et délicates, et il est difficile à des hommes pétris de chair et de sang de s'arrêter ferme à la contemplation de ces vérités : leur imagination les séduit, et, prenant pour des principes incontestables des sentiments qui flattent quelqu'une de leurs passions, imprudents, téméraires, impies, ils se font des systèmes qui renversent les fondements de la foi [http://www.biblisem.net/meditat/malebpri. $\mathrm{htm}](20.6 .2016)$

REMARQUES : (S')arrêter ferme réfère à un arrêt brusque et décidé. L'accord peut renforcer l'implication du sujet dans l'action de s'arrêter (ex. de 1683). Notons l'emploi de arrêter droit et de tenir ferme.

\section{Arrêter net}

\section{I. s'arrêter net : cesser d'agir}

Pronominal

1823 Quelle audace! A la vue des grenadiers de la garde, les Russes s'arrêtèrent net. " Il était plus que temps disait Bertrand ; 
l'Empereur n’avait pas bougé ; tout ce qui l'entourait avait frémi » (Emmanuel de Las Cases, Le Mémorial de Sainte-Hélène)

1866 Jamais je ne lutte contre la mauvaise volonté, et je préfère extirper en moi le désir. Inépuisable de patience avec les enfants, avec les êtres faibles et humbles, je m’arrête tout net avec mes égaux, dès que j'entrevois l'ombre du mauvais vouloir pour ma personne (Henri-Frédéric Amiel, Journal intime de l'année 1866)

1875 LU MUSARDIÈRE. Oui, Mariette, et je cours...

(il fait un mouvement pour sortir)

MARIETTE. Edouard !

(La Musardière s'arrête net)

MADAME PICHARD. (à part) Hein !... comme c'est dressé !...

(Henri Meilhac et Ludovic Halévy, La Boule)

1913 soudain, la jument ralentit son allure, comme si son pied avait buté dans l'ombre ; Meaulnes vit sa tête plonger et se relever par deux fois ; puis elle s'arrêta net, les naseaux bas, semblant humer quelque chose. Autour des pieds de la bête, on entendait comme un clapotis d'eau. Un ruisseau coupait le chemin (Alain-Fournier, $L e$ Grand Meaulnes)

1915 L'effet était admirable, et Gaspard s'abandonna à l'idée que l'ennemi s'en arrêterait net. Il riait, riait, tapant la table, avec des glouglous dans la gorge.

- Non, non... mais l'est pilant c'mec-là !... dis donc, vieux?

(René Benjamin, Gaspard)

1925 Une branche craqua, un peu plus fort. Il s'arrêta tout net, se retourna, se frotta les yeux : décidément il avait la berlue ! Rien ni personne ne remuait plus à la place où il avait cru voir... mais qu'est-ce qu'il avait cru voir ? (Maurice Genevoix, Raboliot)

1932 La délivrance devient possible dans un sens tout nouveau ; la poussée mystique, si elle s'exerce quelque part avec assez de force, ne s'arrêtera plus net devant des impossibilités d'agir ; elle ne sera plus refoulée sur des doctrines de renoncement ou des pratiques d'extase ; au lieu de s'absorber en elle-même, l'âme s'ouvrira toute grande à un universel amour (Henri Bergson, Les Deux Sources de la morale et de la religion)

1948 Elle s'arrêta net et pâlit.

- Je ne peux pas plaisanter là-dessus, ditelle simplement.

- Je ne plaisante pas ; si j'ai l'air de tourner en rond, c'est parce que l'histoire est comme ça

(Boris Vian, Le Grand Sommeil [trad.])

1950 - C'est un phonographe, dit Suzanne. Joseph s'arrêta net de manger. Sous ses paupières à demi levées, ses yeux apparurent, éclatants. Chacun le regardait, même M. Jo.

- On en a déjà un, dit Joseph, de phono (Marguerite Duras, Un barrage contre le Pacifique)

1962 Le mercredi, ne voulant pas être en reste, Peinture apporta une fléchette qu'on empoisonna soigneusement en l'enduisant d'une décoction de cloportes pilés dans l'adhésine. Quand la flèche l'atteignit en plein dos, le retraité s'arrêta tout net et se redressa presque. On s'attendait à le voir faire face comme un vieux sanglier, mais il ne dit rien et au bout d'un instant il se courba plus bas (Boris Vian, Les Lurettes fourrées)

1988 Chapeau, j’ai pensé. Je n'avais plus du tout envie de pleurer. Tout s'était arrêté net. Chapeau. Je n'ai même plus le réflexe de dire képi. Ce képi que j’avais toujours sur la tête, vissé à jamais (Jean-Bernard Pouy, La Clef des mensonges)

II. Arrêter quelque chose/quelqu'un de façon brusque, soudaine

Transitif

1837 Constance, vêtue en matin, sortit de la chambre à coucher de Césarine où elle s'était habillée ; son premier coup d'œil arrêta net la verve de son mari, qui cherchait à formuler une phrase normale pour 
apprendre avec modestie ses grandeurs au prochain (Honoré de Balzac, Histoire de la grandeur et de la décadence de César Birotteau)

1854 Jadis, ceux qui avaient goûté aux fruits $\mathrm{du}$ Lotos oubliaient leur patrie et ne pouvaient plus quitter le pays des lotophages ; ceux qui ont trempé leurs lèvres dans l'eau du Nil l'aimeront, le regretteront et y penseront toujours. Depuis trois jours à peine j’avais quitté le Kaire, lorsque s'éleva un vent violent de khamsin qui nous arrêta net ; nous cherchâmes un abri à la pointe d'un îlot et nous attendîmes que la bourrasque fût passée (Maxime Du Camp, Le Nil. Égypte et Nubie)

1864 C'est bien parler pour un mathématicien et même pour un physicien ; mais il n'en est pas moins vrai que la nature réintégrée en son tout et divisée en ses parties concrètes, non plus dépouillée de certains attributs essentiels qui embarrasseraient sans profit la science, ou plutôt qui l'arrêteraient net, la nature exige qu'on lui rende les causes finales (Charles Renouvier, Essais de critique générale)

1876 Londres, sous l'oligarchie, existe, et Paris, sous la démocratie, n'existerait pas ! La cité de Londres a de tels droits qu'elle arrête tout net devant sa porte le roi d'Angleterre. À Temple-Bar le roi finit et le peuple commence. La porte se ferme, et le roi n'entre qu'en payant l'amende (Victor Hugo, Actes et paroles)

1881 Cela paralyse un homme dans la politique, les affaires ou sous l'Odéon! Il y a eu un moment même où j’ai été incapable de rien apprendre, mais rien ! Mon éducation moderne arrêtée net ! - les bords de mon chapeau avaient fait leur temps... ils se coupaient près du tuyau, et c'eût été folie de continuer à le porter par là (Jules Vallès, Jacques Vingtras : Le Bachelier)

1886 ... et $d z i n n$ encore, et $d z i n n !$ il en pleut maintenant, des balles. Tout près des marins, arrêtés net, elles s'enfoncent dans le sol inondé de la rizière, chacune avec un petit flac de grêle, sec et rapide, et un léger éclaboussement d'eau (Pierre Loti, Pêcheur d'Islande)

1899 Souvent, tandis qu'il parle, Guitry flûte. On ne l'interrompt pas aisément. Il a un « permettez! » qui vous arrête, net et sec. - Nous autres, dit-il, les quinze ou vingt connaisseurs de Paris... Il ne peut pas manger un fruit sans en dire l'espèce et sans la comparer aux autres (Jules Renard, Journal)

1928 Je pris mon parti rapidement : relevant mon col de pardessus, je me disposais à quitter ce couple décidé, à les laisser à leurs petites affaires. Un roulement de tambour et la curiosité m'arrêtèrent net. C'était un roulement sourd, presque étouffé, comme si le musicien avait eu peur de faire trop de bruit (Philippe Soupault, Les Dernières Nuits de Paris)

1939 Devant les flammes menaçantes, les malheureux furent bien obligés de sortir en foule dans les rues; ils y trouvèrent Bohémond qui, l'épée au poing, les poussait vers les créneaux. Plusieurs quartiers étaient incendiés, mais l'assaut des turcs fut arrêté net. Néanmoins, pour relever le moral de l'armée, il fallait un miracle. Le miracle se produisit. Ce fut la découverte de la Sainte lance (René Grousset, L'Épopée des croisades)

1975 Un camion freina devant « Le Roi du survêtement ». Le livreur descendit en courant chercher Charlie pour qu'il l'aide à décharger, mais en voyant L'Équipe il arrêta net de se presser, alluma fébrilement une gitane et se plongea dans la lecture (Florence Delay, Le Aïe aïe de la corne de brume)

1981 Monsieur Racine se jeta dans un buisson en déchirant son habit et disparut. Je regagnai l'allée. Le Roi, qui conduisait luimême sa calèche, l'arrêta tout net à ma vue et me tendit la main pour que je prisse place à son côté pour la suite de la promenade (Françoise Chandernagor, L'Allée $d u$ roi) 
Emploi absolu

1945 Sam s'était levé et marchait de long en large dans la partie la plus éclairée de la boutique.

- Oui, mais oublie pas qu'ils vont arrêter ça. Il y en aura plus de secours. Ça va arrêter net.

Il noua solidement ses grosses mains derrière son dos (Gabrielle Roy, Bonheur d'occasion)

III. s'arrêter tout net à quelque chose : fixer son attention sur quelque chose

Pronominal

1936 Je constate que le cinématographe plaît au peuple. Ce sont des suppositions. Un homme me parle ; je ne connais pas sa pensée, je la suppose. Si l'on s'arrêtait tout net à l'apparence, en s'appliquant à bien fixer le son, comme font les musiciens, quand ils s'accordent, on serait mieux placé ensuite pour deviner (Alain, Propos)

CORpus Web :

Un site pour arrêter net la fumette [http:// next.liberation.fr/vous/2008/05/22/un-site-pourarreter-net-la-fumette_72303] (20.6.2016)

Je voudrais vous donner un truc extrêmement simple pour arrêter net le hoquet. Je ne l'ai jamais vu mentionné nulle part. Vous remplissez à ras bord un verre d'eau et vous buvez une ou deux gorgées en posant vos lèvres sur le bord opposé à celui sur lequel vous buvez normalement [http://www.rebelle-sante.com/ rebelle-sant $\% \mathrm{C} 3 \% \mathrm{~A} 9-\mathrm{n} \% \mathrm{C} 2 \% \mathrm{~B} 0-178 /$ trucs/pourarr\%C3\%AAter-net-le-hoquet] (20.6.2016)

Je crois que je cherchais à lui faire comprendre qu'il ne devait pas me prendre pour une idiote qui était accrochée à lui... Sauf que j’ai perdu l'effet du SR je pense, ça a du le renvoyer à son angoisse que je ne croyais pas en notre couple... Il a arrêté de me répondre net... Je m'en veux car il n'est même plus question de sortie cette semaine alors qu'on en parlait la semaine dernière... [http://www.jerecuperemonex.com/ forum/reconquete/mon-recontactee-que-fairemaintenant-t39811.html] (23.11.2015)

Je passerai les détails sur les critiques virulentes et destructives que vous allez vous adresser, à la suite de cette apparition, les flagellations que vous allez vous infliger, les auto-censures que vous vous prescrivez ; c'est la descente aux enfers avec un impact cuisant sur votre progression, qui va s'arrêter nette [http://egeria.overblog. com/faites-taire-votre-gremlin] (6.12.2013)

Je suis sur le point d'arrêter nette ma conso de cannabis, dans l'attente de vos réflexion, vos interrogation, vos exeperiences, attention ce qui ne tue pas ne t'épargne pas pour autant alors bannissons le mot douce après drogue c'est ma conviction il n'y a que des drogues nuisible pour notre santé moral et physique [http:// sante-medecine.commentcamarche.net/forum/ affich-1259701-drogue-douce-et-dur-dependance] (6.12.2013)

Remarques : $\left(S^{\prime}\right)$ arrêter net désigne un arrêt brusque, sans freiner. Le groupe est lexicalisé au point de permettre l'emploi absolu. Il reste invariable, soit pour le sujet (ex. de 1823, 1913, 1932, 1948 et les trois premiers exemples du CW), soit pour le complément d'objet (ex. de 1854, 1864, 1881, 1886, 1981) et est modifié par tout. Ceci étant, l'écriture spontanée du CW admet l'accord de net avec le complément d'objet ou le sujet d'un verbe pronominal (deux derniers exemples $\mathrm{du} \mathrm{CW}$ ). Notons qu'à l'oral le - $t$ final est toujours prononcé, même au masculin. Dans le troisième exemple du CW, on perçoit à première vue le groupe répondre net, qui est attesté dans ce dictionnaire, mais il s'agit en réalité de la combinaison arrêter net (Il a arrêté net de me répondre) où net se voit déplacé après le second verbe, ce qui est assez exceptionnel pour un adjectif-adverbe. Mentionnons également la collocation net et sec.

\section{Arrêter petit}

s'arrêter petit : s'arrêter brièvement

Pronominal

1276 De Gloriande estoit moult honnorés, Au partir fu de ses bras acolés. Quant l'ot conduite Carahués en ses tres, Moult petitet s'est illuec arrestés ; A Ogier est erranment retoornés, Par son commant fu ses lis aportés Iluec, et est la nuit la demorés (Adenet le Roi, Les Enfances Ogier, 3717)

1370 Quant les mariniers seurent et entendirent la volenté de leur seigneur, si prindrent 
port et getterent leur ancre, et moult petit orent arresté quant les autres nefz vindrent au port, et ot chascun grant joye quant ilz se virent prez de terre, car moult orent eü a souffrir (Roman de Berinus, I, p. 38)

+1370 Le roy, qui avoit encoires l'annoy ou cœur, les receut en passant, petit s'arresta, ne fist contenance sus eulx, et passa oultre, et le plus, sus le chemin, à qui il parla, ce fut à l'evesque de Londres (Jean Froissart, Chroniques $(\mathrm{A})$ )

Intransitif

1364 Car petit au lire arresta

Pour ce qu'en un feu les getta (Guillaume de Machaut, Le Livre du voir dit, 5798)

\section{CORpus WeB :}

Sinon, pour répondre sur la mise à l'envol, je ne m'inquiéterai pas et essaerai de lui montrer le plus de gibier possible. S'il a arrêté petit, même pas longtemps, il arrêtera de nveau mais faut lui laisser le temps et SURTOUT le mettre le + possible en présence [http://www.epagneul-breton. org/viewtopic.php?t=2038] (6.12.2013)

Bref, ça me faisait plaisir et ça faisait plaisir à mon fils, alors tant que nous en éprouvions le besoin tous les 2, j'ai continué. Pourquoi veux-tu arrêter ? Est-ce que cela te pèse à toi ? Parce que là, ce serait différent - tu dois alors lui expliquer (mais si il comprendra !) et puis arrêter petit à petit - un soir tu lui dis que maintenant il est grand et que tu ne vas + l'allaiter que qques jours [http:// forum.infobebes.com/Mon-bebe/Allaitementbiberon-nutrition/arreter-allaitement-impossiblesujet_27462_1.htm] (20.6.2016)

REMARQUES : En ancien français, arrêter petit signifiait 'arrêter peu'. Le sujet désignait une personne qui interrompt son mouvement, cesse d'avancer ou fait halte en un lieu, le processus étant de courte durée. Petit est modifié par moult, illuec. Le groupe antonymique s'arrêter long n'est pas attesté. Rappelons tout de même l'emploi de long temps. Le premier exemple du CW pourrait être une prédication seconde qui a la même structure mais interprétée au concret comme 'arrêter quand il était petit', mais le contexte suggère plutôt une lecture temporelle. Le dernier exemple du CW met en lumière la continuité de petit comme adjectif-adverbe de temps dans la collocation petit à petit.

\section{Arrêter sec}

Arrêter brutalement, rudement, brusquement

Transitif

1899 Souvent, tandis qu'il parle, Guitry flûte. On ne l'interrompt pas aisément. Il a un « permettez! » qui vous arrête, net et sec. - Nous autres, dit-il, les quinze ou vingt connaisseurs de Paris... Il ne peut pas manger un fruit sans en dire l'espèce et sans la comparer aux autres (Jules Renard, Journal)

Pronominal

1920 Gédéon qui tapait avec sa serpe sur un aubépin, s'arrêta sec :

- Ça, c'est une menterie

(Ernest Perochon, Nêne)

1985 - Voyez-vous, monsieur Malaussène, j'en ai par-dessus la tête de me faire engueuler à ma place !

Suit un long rire suraigu qui semble une fuite de quelque chose, incontrôlable. Et ça s'arrête aussi sec (Daniel Pennac, $A u$ bonheur des ogres)

2002 Hypnotisées par nos haut-parleurs ! Le sol tremblait sous les sabots. La frousse qu'on a eue ! On a coupé le son, elles se sont arrêtées aussi sec : comme si on les avait débranchées. D’un seul coup, toutes à brouter, peinardes, l'air de rien. Apparemment il y avait quelque chose dans nos braillements, une longueur d'onde, ou une fréquence, qui les attirait prodigieusement (Olivier Rolin, Tigre en papier)

2006 c'est le beep-beep beep des engins de road construction (puisque là-bas on construit non seulement les bâtiments, mais aussi les routes et les rues, et souvent du même béton) sur Mercer, qui commençait aux petites heures du matin (petites du moins selon mon horloge interne) pour s'arrêter aussi sec, assez tôt dans l'après-midi : l'ouvrier américain regagne sa banlieue à temps pour la douche à l'étage, le dîner en famille et le feuilleton d'access primetime (Gérard Genette, Bardadrac) 
Intransitif

1989 Le Tigré, Qu'une-Oreille, la Blanche sourde, la Grincheuse-même-en-dormant, tous, ils ont arrêté aussi sec de me miauler, de me barrer la route, de me donner des coups de cul et de patte (Remo Forlani, Gouttière)

CoRpus Web :

j'ai fumer toute ma vie quasiment , j'ai commencer a 14 ans et j'ai arrêter sec a 26ans, je peut te dire que je recouvres la vrai vie, je dort mieux , je rêve en full HD, j'ai la pêche le matin :ok: par contre il faut bannir le bedo de ta bouche, l'es petite lattes occasionnelles te fon vote retomber :ok: [http://www.jeuxvideo.com/forums/1-5165509998-1-0-1-0-quel-effet-ca-fait-d-arreter-lebedo.htm] (20.6.2016)

Merci à toi qui à arrêter sec en auto tantôt quand je suis passé devant toi sans t’avoir vu. Tu m'as sauvé la vie. Merci encore [https://www. facebook.com/permalink.php?id=5786056621 60539\&story_fbid=1017595488261552] (20.6.2016)

J'étais encore une fille de rue et de méthadone... J'étais pas encore prête à arrêter sec comme ça [http://www.amecq.ca/dossier_du mois/2013/11/26] (6.12.2013)

Ta bagnole dérape en un crissement terrifiant, se marque au sol par deux larges traits sombres. La blonde pousse un hurlement de terreur et ta caisse finit par s'arrêter, sèche et brusque [http://xwritetolive.skyrock. com/3107256061-First-one-shot.html] (6.12.2013)

REMARQUES : Arrêter sec et arrêter net expriment le même concept de stopper brusquement, avec parfois une connotation de brutalité, froideur et immédiateté qui est plus forte dans le premier cas. La collocation net et sec renforce ce concept. Sec reste invariable (ex. de 2002). Dans le dernier exemple du CW, sec est employé au féminin et détaché syntaxiquement, mais sans abandonner la fonction adverbiale. Le style écrit de l'exemple l'identifie comme variante recherchée et non pas comme phénomène d'écriture spontanée.

\section{Arriver doux}

I. Arriver (concret) sans brusquer, sans à-coups, doucement

Intransitif

1908 Alors ils mouraient avec une résignation de chameaux mahométans ; on demandait de l'argent pour en acheter d'autres, et les nouveaux chameaux arrivaient tout doux, tout doux, trotti-trotta, cahin-caha, balançant la tête, bavant, rognant, et flairant sur le sable les squelettes de leurs frères et amis, morts à la peine (Pierre Mille, Barnavaux et quelques femmes)

II. Survenir sans se faire remarquer, doucement Intransitif

1963 Travaillerais. Travaillerais. Voilà quelque chose de nouveau, qui arrive, comme ça, tout doux, au conditionnel (Christiane Rochefort, Les Stances à Sophie)

\section{CORPUS WEB :}

Vous pouvez partager l'expérience de manger du pain fait maison et montrer à vos amis et proches que vous aimez en leur envoyant une miche. Bien que le pain d'envoi peut sembler compliqué, avec la bonne planification et à l'emballage, vous pouvez être sûr que votre pain va arriver, doux et frais [http://www.inspectian. com/jz6axeBGR] (20.6.2016)

REMARques : Doux est un adjectif-adverbe de manière équivalent à doucement (I, II). Il est modifié par tout. Notons que tout intensifie l'idée de calme, de modération dans le déplacement. L'emploi de doux comme modifieur du verbe penche facilement du côté de la prédication seconde : le pain est doux et frais au moment d'arriver (CW). Mentionnons la réduplication tout doux, tout doux.

\section{Arriver droit}

I. arriver droit (à, chez, devers, en, là, sur) : (sujet animé) parvenir directement, sans détours, en un lieu, à destination Intransitif

-1100a Danz Alexis entrat en une nef, ourent lur vent, laisent curre par mer, andreit Tarson espeiret ariver, mais ne puet estra, ailurs l'estot aler, 
andreit a Rome les portet li orez

(Vie de saint Alexis [fin $\mathrm{XI}^{\mathrm{e}}$ ], BFM, 193)

+1150 Vienent a Tornebrie, la sont droit ariue (Aiol et Mirabel [2 $2^{\mathrm{e}}$ moitié XII ${ }^{\mathrm{e}}$, 9815)

$\sim 1160$ Uit jors tos plains par mer erra Que nule terre ne trova. Au nueme jor sont arivé Tot droit a Baudas la cité Qui sist sor une roce bise, Desor le port en haut assise (Flore et Blancheflor, 1391)

$\sim 1235$ En la mer ne fu c'une nuit. L'endemain matin a deduit Sans avoir tormente n'ahan Est tout droit arrivés au Dam. Ses cevax des nes ou rivage Fist mettre, qu'il n'i eut damage (Philippe de Remi, sire de Beaumanoir, $L a$ Manekine, 2618)

1275 Atant se regardent, si voient Une galie qui venoit Par mi la mer a grant esploit. $A u$ port est tot droit arrivee, Fors en issent sanz demoree Jusqu'à .iiij.c. chevalier, Fors et hardi, preus et legier (Floriant et Florete, 8015)

1398 Nous partismes de Corfo le mardy ensuivant, .vije. jour de septembre et vigille de Nostre Dame ; et errasmes par mer, tant a voille comme a rames, jusques au sabmedy ensuivant que nous arrivasmes en une isle qu'on appelle Chifornia. Et arrivasmes droit $a$ une belle fonteine d'eaue doulce ou il ot jadis une ville que l'en appeloit Alexandria (Le Saint Voyage de Jherusalem, p. 7)

1680 J'ai été à Versailles ; je ne sais si je ne vous l'ai point mandé. J'allai avec d'Hacqueville tête à tête. Nous partîmes à trois heures. Nous arrivâmes droit chez M. de Louvois, que nous trouvâmes; ce bonheur me parut comme de donner droit dans le treize d'un trou-madame (Mme de Sévigné, Correspondance)
1755 Le nombre pair étant formé de quatre on vit bientôt les deux fléches abattre le pont mobile ; et les quatre coursiers font en marchant gémir les madriers. Le gros Bonneau tout essouflé chemine en arrivant droit devers la cuisine, songe au souper. Le moine au même lieu, dévotement en rendit grace à Dieu (Voltaire, La Pucelle d'Orléans)

1857 Comme j'ai été attendri, chère Madame, de votre bonne lettre! Les questions que vous m'y faites sur l'auteur et sur le livre sont arrivées droit à leur adresse, n'en doutez pas : voici donc toute l'histoire (Gustave Flaubert, Correspondance)

1859 Le marquis va dans le monde ; cent personnes de vos connaissances pourront vous présenter à lui. « Avec une lettre du marquis Gontran, vous arriverez tout droit en Bretagne chez le chevalier. Pourvu que vous aimiez passionnément la chasse, rien ne vous empêchera de passer un an au manoir » (Pierre-Alexis Ponson du Terrail, Rocambole)

1966 Des corps le frôlaient continuellement, touchant ses vêtements et déplaçant des souffles d'air. Des figures pâles, aux yeux enfoncés, arrivaient droit sur lui, et, au dernier moment, faisaient un détour. Il y avait des hommes debout devant les magasins, qui regardaient avec insistance (Jean-Marie Gustave Le Clézio, Le Déluge)

II. arriver droit (à quelqu'un) : (sujet inanimé) arriver à destination, qui va à son destinataire sans détour

Intransitif

-1100b Dreit a Lalice, ço fut citét mult bele, Iloec arivet sainement la nacele, Dunc an eisit danz Alexis acertes, Ço ne sai jo cum longes i converset, Ou que il seit de Deu servir ne cesset (Vie de saint Alexis [fin $\mathrm{XI}^{\mathrm{e}}$ ], BFM, 81)

1840 Heureuses et bénies ces vocations modestes et fermes, obéissantes et sûres, ces natures auxquelles il est donné d'arriver tout droit, en reconnaissant un guide illustre, en le suivant à côté et dans l'ombre, 
en se souvenant jusqu'au bout de lui ! Littérairement parlant, Lancelot est pour M. de Saint-Cyran, dans des teintes plus sombres, ce que Racine fils en ses mémoires est pour son père

(Charles Sainte-Beuve, Port-Royal)

1893 Et il ne pouvait pas plus le lui demander qu'elle-même n'avait pu montrer la lettre infâme à cette mère qui disait souvent : « J'élève ma fille d'après les principes anglais, dans la plus complète indépendance... » Elle avait d'heureux résultats, cette indépendance qui permettait à un billet de cet ordre d'arriver droit à la pauvre petite! (Paul Bourget, Cosmopolis)

III. Accoster

Pronominal

1371 LE PREVOST. Hyer, chier sire, m'estoie mis,

Avec de mes gens trois ou quatre, Jusques sur le port pour esbatre ;

Ainsi que je fu la, avint

Q'une nasselle par mer vint

Sanz gouvernement par mer nul, Sanz trait de cheval ne de mul, Sanz mast, sanz aviron, sanz voille, Quel qu'il fust, de soie ou de toille ;

Et si s'arriva droit au port.

Et je, qui estoie en desport,

M'en alay la sanz attendue,

Quant a rive la vy venue

(Miracle de la fille du roy de Hongrie, 635)

IV. Se diriger directement vers quelqu'un/ quelque chose (abstrait)

Intransitif

1833 Ses yeux, dépourvus de cils, n’avaient plus cette lenteur voilée qui sied si bien à la jeunesse. Son regard vous arrivait droit au visage, brusque, fixe et presque arrogant (George Sand, Lélia)

1932 Sa rousse et perverse chevelure (la peau allant avec) était parcourue pendant ce temps-là d'ondes étonnantes qui m'arrivaient droit par vibrations jusqu'au périnée. Comme elle m’interrogeait cette divine sur mes actions de guerre, je lui donnai tant de détails et des si excités et des si poignants, qu'elle ne me quitta désormais plus des yeux (Louis-Ferdinand Céline, Voyage au bout de la nuit)

V. arriver droit (sur, dessus) : arriver vers

quelqu'un à grande vitesse

Intransitif

1839 Voilà mes deux poltrons qui se mettent à vociférer, le guide qui jure, la demoiselle qui crie au secours. Je les envoie à tous les diables, et, n'apercevant ni père, ni chiens, je me lance dans l'avalanche, j'arrive droit sur leur demoiselle, et, aidé du guide, je la ramène saine et sauve sur la chaussée (Rodolphe Toepffer, Nouvelles genevoises)

1926 alors, voyant Romain être tranquillement assis devant une chopine et un verre, la joie l'a faite changer de couleur ; parce que la joie a tiré d'abord tout son sang au cœur, puis l'a refoulé, lui faisant les oreilles devenir toutes chaudes, lui gonflant les veines du cou. Elle arriva droit sur Romain :

- Mon dieu ! Romain qu'est-ce qui se passe?

(Charles-Ferdinand Ramuz, La Grande Peur dans la montagne)

1948 on voit des voiles fantomatiques à bâbord et à tribord, les feux d'un cargo qui vous arrive droit dessus, un paquebot tout illuminé qui passe à contrebord, à vous frôler (Blaise Cendrars, Bourlinguer)

VI. Arriver directement (un son) à quelque chose

Intransitif

1857 Mais l'anéantissement de ma vigueur physique ne diminuait en rien la netteté de mes perceptions. J'aurais été incapable de soulever mes paupières, et cependant le plus léger bruit arrivait droit à mes oreilles. Je ne perdis pas un mot de ce qui se disait autour de moi (Edmond About, Le Roi des montagnes)

VII. arriver tout droit de : venir directement de quelque part

Intransitif

1886 C'était $d u$ couvent qu'elle arrivait tout droit, la supérieure ayant fini par lui trouver 
cette place de lectrice, chez sa vieille amie, Mme Vanzade, devenue presque aveugle (Émile Zola, L'Évure)

1939 On nous servit des cocktails étranges et des sandwichs qui tenaient du bibelot, et qui arrivaient tout droit de la rue de Rivoli. La dernière Parisienne, qui s'appelait, je crois, Sarah, circulait entre les pétales et les porcelaines de son petit musée d'hôtel (Léon-Paul Fargue, Le Piéton de Paris)

1985 «Il t’a vu tout nu dans la cave, avec une fille !... Et tu vas me dire qui c'est, ta femelle !... » Elle avait hurlé sur les derniers mots. Il n'y avait plus ni douceur ni sourire, il n'y avait plus qu'une voix gorgée de haine arrivant droit des entrailles (Yann Queffélec, Les Noces barbares)

\section{Corpus Web :}

J'avais vu la voiture arriver droit sur nous [http://www.leprogres.fr/actualite/2015/04/25/javais-vu-la-voiture-arriver-droit-sur-nous] (20.6.2016)

dans tous les cas il doit changer le ballon de main et vu que le mec ne se baisse pas il doit raffuter voire tenter un cadrage débordement meme si l'espace est super limité mais forcément quand les deux arrivent droits ben ils s'ouvrent comme un livre, c'est impressionnant mais ce sont des gestes que tu es censé maitriser en senior [http:// www.ultras-sapiac.com/forum/viewtopic. php?f=2\&t=13\&start=60] (7.12.2013)

À travers les immenses verrières, les rayons du soleil nous arrivent droits dans les yeux, on se croirait en plein été! [http://lebaiserdelamouche. wordpress.com/2011/12/13/mon-1er-salonma-mouche-et-le-petit-peuple-de-decembre] (7.12.2013)

Qui peux m'expliquer pourquoi les ogives de la munition F5 de chez IMI que nous (militaires) utilisons dans les FAMAS arrivent droites dans les cibles à $25 \mathrm{~m}$ (et bien sûr plus loin) [http://94.23.243.216/ tirmaill/mildot/viewtopic. php?t=35826\&view=next\&sid $=46811570 \mathrm{cc} 847311$ a0575175829074c5] (7.12.2013)

Sur la cible, y'en a pas une meilleure que l'autre je trouve. Il faut prendre en compte, pour la précision en cible, que le tireur n'est pas expérimenté. Pour ce qui est d'arriver droites ou de travers, les photos parlent d'elle-mêmes. J'en conclus que si je dois en racheter, je chercherais la meilleure offre car je ne vois pas de différence à l'usage [http://corsicarms.activebb.net/ t34294p390-club-fabarm] (20.6.2016)

Et la première épreuve fait déjà des dégâts. $2,5 \mathrm{~km}$ autour du lac, il y a plus facile pour commencer. Le record à battre est de 13 minutes, la première équipe féminine (il y en a quatre en tout) s'en rapproche avec cinq petites minutes supplémentaires. Et certaines ont quelques difficultés. «Si vous pouviez arriver droites... non, c'est pour plaisanter, leur lance l'homme au micro » [http:// www.ladepeche.fr/article/2001/10/15/301812-lesforcats-du-bonheur.html] (20.6.2016)

REMARQues : Droit est un adjectif-adverbe de manière-direction qui est modifié par tout. Droit est souvent suivi d'une préposition de lieu indiquant la direction finale (à, chez, devers, en, sur, dessus) ou la provenance (de). Dans cet emploi, droit a tendance à s'associer avec les prépositions qui le suivent, au point de faire partie du groupe prépositionnel comme modifieur de la préposition. L'accord adverbial es fréquent dans l'écriture spontanée du CW, notamment dans le cercle des tireurs. L'ensemble des citations du CW met en évidence la tendance à faire l'accord dans des fonctions plutôt adverbiales au sens de 'directement'. Seul le dernier exemple actualise une prédication seconde au sens concret de 'debout en position verticale', où l'accord est pleinement justifié.

\section{Arriver haut}

I. Réussir, avoir du succès, atteindre une haute position sociale

Intransitif

1647 DON BERNARD. Je sais que, par un heur qui ne se conçoit pas,

Pour arriver si haut je n'ai pas fait un pas, Et que tout mon crédit et toute ma puissance

Ne sont qu'un simple effet de mon obéissance, Que je méritais moins que vous ne méritez, Et qu'on m'a tout donné ce que vous achetez

(Jean de Rotrou, Don Bernard de Cabrère) 
1845 - J'approuve cette idée, dit le cardinal après un moment de réflexion ; avec son mérite, avec sa puissance d'action sur les hommes, l'abbé Gabriel peut arriver très haut... s'il est docile ; et s'il ne l'est pas... il vaut mieux pour le salut de l'Église qu'il soit à Rome qu'ici... (Eugène Sue, Le Juif errant)

1854 Ils se firent les interprètes, les secrétaires, les conseillers des sultans ; et, cachés modestement dans des positions secondaires, ils eurent le talent de mener leurs maîtres. Plus d'un s'éleva jusqu'au rang d'hospodar, c'est-à-dire de gouverneur de province ; ceux qui n'arrivèrent pas si haut s'en consolèrent en s'enrichissant (Edmond About, La Grèce contemporaine)

1939 Entouré de banques, de bureaux, de compagnies de navigation, de magasins parfaitement parisiens, le Scribe est avant tout l'hôtel d'un certain nombre d'hommes d'affaires pour qui l'économie du taxi, le sauvetage d'une épingle, l'arrivée à pied bien visible au rendez-vous décisif, sont des moyens d'arriver vite et haut, à l'américaine, et fournit l'occasion de sourire à ce que les provinciaux appelleront toujours le trottin (Léon-Paul Fargue, Le Piéton de Paris)

\section{Sens spatial concret \\ Intransitif}

1812 Nos marins suspendent leur course : ils attendent une vague qui puisse les porter au but ; elle arrive haute et fière, couronnée d'écume, nous saisit, nous entraîne, se déroule en grondant, et dans son retour subit nous laisse à trente pas sur le rivage (Jean-Florimond Boudon de Saint-Amans, Voyage agricole, botanique et pittoresque)

2007a Évolutions : bonifications si le point fait suite à une réception en passe haute ou à une réception qui arrive haute dans une zone déterminée (ex. : les 3 mètres) ou encore à une attaque à l'aile en seconde main ; bonification pour l'équipe au service si l'équipe en réception ne peut renvoyer le ballon en attaquant (Gilles Bortoli, Manuel de volley-ball) 2007b La passe doit arriver haute et précise sur le passeur. Le passeur renvoie la balle parallèle au filet en hauteur. L'attaquant smatche, le ballon doit tomber dans le terrain adverse (Gilles Bortoli, Manuel de volley-ball)

III. Atteindre une valeur élevée

Intransitif

1945 Les trois commissions ne se cumulent jamais, et très souvent elles ne font renchérir le coût du crédit que de $1 \%$ par an, ou d'un montant de cet ordre de grandeur. Il y a néanmoins des cas où l'on arrive sensiblement plus haut, surtout dans des périodes de désordre monétaire et de crises de crédit (Fernand Baudhuin, Crédit et banque)

\section{Corpus Web :}

Voici toutefois ce que défend l'école Républicaine : à force de travail et d'abnégation, tout le monde peut y arriver. Mais pour arriver haut, très haut, il faut faire preuve d'autre chose. Il faut avoir un don/talent. Et c'est cette chose qui fera la différence [http://leplus.nouvelobs.com/ contribution/1214602-du-bac-a-l-ena-le-meriten-existe-pas-c-est-une-invention-qui-sert-bienla-republique.html] (20.6.2016)

C'est une vraie star : 97\% des Français la reconnaîtraient au premier coup d'œil, selon une étude. Cette icône, drapée de rouge et sourire aux lèvres, est l'une des plus belles réussites de l'histoire des marques françaises. Il faut dire que La vache qui rit est partie de loin pour arriver haut, très haut même... [http://www.francesoir.fr/ lifestyle-gastronomie/la-vache-qui-rit-toujoursle-sourire] (20.6.2016)

REMARQUES : Haut est un adjectif-adverbe de lieu qui a un sens spatial concret ou figuré, désignant un point élevé dans une perspective résultative. Dans l'emploi spatial concret (II), la flexion optionnelle de haut pousse son interprétation du côté de la prédication seconde. L'adjectif-adverbe insiste alors sur la position d'un objet, sans dynamique résultative. L'accord de haut, bas et droit par rapport à la position d'un ballon, d'une balle, d'un projectile, etc. est courant dans le domaine du sport. Employé au figuré (I, III), haut reste invariable et est modifié par si, plus, très. Notons la collocation 
avec vite qui suggère une ascension sociale ou professionnelle fulgurante. Notons l'emploi de renvoyer parallèle (le ballon); arriver précis.

\section{Arriver juste}

Arriver au bon moment, quand il faut, de manière opportune

Intransitif

1679 Le courrier dépêché à la cour, pour savoir les intentions de la reine, arriva juste, et il sembloit que le ciel étoit sur le point de bénir ce grand ouvrage, quand toutes les espérances s'évanouirent (Jean-François de Gondi (Cardinal de Retz), Mémoires)

+1847 Manicamp arrivait souvent trop tard par paresse. Cette fois, ils arrivèrent juste. Cinq chevaux étaient préparés (Alexandre Dumas père, Le Vicomte de Bragelonne [1847-1850])

1877 On lui donnait vingt minutes pour aller de la Rue de la Goutte-d'Or à la Rue du Caire, ce qui était suffisant, car ces tortillons de filles ont des jambes de cerf. Des fois, elle arrivait juste, mais si rouge, si essoufflée, qu'elle venait bien sûr de dégringoler de la barrière en dix minutes, après avoir musé en chemin (Émile Zola, L’Assommoir)

1934 Après avoir embrassé son fils, elle reprend sa besogne, sans cesser de parler :

- Comme ça, t'arrives d'à présent ?

- D’à présent, de la gare, j’arrive.

- T'arrives juste ! Je dis juste, à propos qu'on voulait t'écrire. On a bien fait de pas s'y décider, puisque voilà que t'arrives. C'est à propos qu'on y avait pensé, que je dis : t'arrives juste.

- À propos de quoi, vous vouliez m'écrire? - Des choses, des histoires qui traînent dans le bourg... T’as causé à personne, en venant ? (Gabriel Chevallier, Clochemerle)

1963 J'entrave tout d'un seul coup ! Si je me propulse vers la sortie! Malsain au possible de rester en contemplation. J'arrive aux marches juste quand le maton donne l'ordre de couper la flotte. « Tout le monde dehors! Pressons ! Pressons ! » Pas besoin de me le dire... le feu au derche littéralement (Alphonse Boudard, La Cerise)
CORPUS Web :

Cela nous assure que tout point libre sera nécessairement accroché à la grille du plan cartésien. Autrement dit, les coordonnées « arrivent justes » [http://www.gilles-jobin.org/ maths/monpremierscenario/etape2details.htm] (9.12.2013)

REMARQUES : Employé avec le verbe arriver, juste adopte la signification de 'exact' appliqué à un contexte temporel, 'au moment juste', les connotations 'presque trop tard' ou 'risquer d'arriver tard' étant possibles (Fais attention, tu vas arriver juste). Juste reste invariable (ex. de +1847). L'adjectif-adverbe juste peut également modifier une conjonction temporelle qui le suit. Ainsi, dans l'exemple de 1963, cité au hasard, il appartient à la subordonnée introduite par quand. Notons l'emploi accordé dans le CW, mis entre guillemets, et signifiant 'au moment juste, à propos'.

\section{Arriver précis}

Arriver à l'heure exacte

$\lambda$ arriver haut

\section{Arroyer (areer) bel}

Arranger, équiper, parer joliment, avec éclat et élégance

Pronominal

1275 Congié prent, si s'en torne que plus n’i arresta.

Venus est à son tre, moult bel s'apareilla, D'armes et de cheval bien et bel s'arrea (Adenet le Roi, Buevon de Conmarchis)

Transitif

1276 Lors prent congié Carahués com senés. Ou cheval monte ; quant fu issus des tres, A grant merveille fu de tous esgardés, Car richement et bel ert arreés (Adenet le Roi, Les Enfances Ogier, 2345)

1285 Et cil le firent sans dangier Noblement et bel arreer (Adenet le Roi, Cleomadés, 10261)

+1365 Trois jours dura la feste; mès Il y eut danses et carolles, Pour quoi j'ai empris les parolles, Car bien .VI ${ }^{\mathrm{xx}}$. jones et belles, Toutes dames et damoiselles, Filles de chevaliers ou fames, 
Dou pays les plus frices dames, Moult ricement et bel arrées, Très noblement et bien parées En draps de canjans et de soie (Jean Froissart, Poésies [3 $3^{\mathrm{e}}$ tiers XIV $]$ ])

REMARQUES : En ancien français, arroyer bel caractérise l'éclat, le faste dans l'équipage (vêtements, armes, cheval), qui contribue à la bonne apparence, au prestige de quelqu'un. La collocation du neutre bel avec les adverbes bien, richement et noblement accentue l'idée de magnificence et de faste. Notons l'emploi de s'appareiller bel. VOIR AUSSI : acesmer beau / bel

\section{Articuler mou}

Articuler mollement, sans énergie, indistinctement

Intransitif

1959 Mlle Arlette a tort d'articuler mou (Le Monde, 13 septembre 1959 / Grundt : 227)

Remarques : Articuler mou désigne ici le fait de prononcer les syllabes, un son, un mot, une phrase, de façon peu claire et peu distincte, l'adjectif-adverbe mou soulignant un manque d'exactitude, une sonorité faible, difficilement perceptible. Il reste invarié.

\section{Aspirer haut}

I. Avoir de grandes, nobles aspirations, ambitions ; viser haut

Intransitif

1589 LE DUC DE GUISE. Puis que Christ ne planta sa foy par la pistole, Qu'il dissimule bien le sac, l'impieté, Qu'il deteste la guerre, et toute hostilité, Que nourri en l'erreur qu'on luy a fait apprendre,

Si fausse on la cognoit, est contraint de se rendre,

N'est-ce un signe assez seur qu'il aspire plus haut,

Et qu'il veut reculer pour faire un plus grand saut?

(Pierre Matthieu, La Guisiade)

1596a Tourne, mon cœur, ailleurs ton esperance,

Laissant le bien vainement desiré ;

Pour un mortel c'est trop haut aspiré,
Il faut couper l'aile à notre arrogance

(Philippe Desportes, Euvres)

1596b Angelique beauté, je sacre à la memoire Ces vers, avantureux courriers de vostre gloire,

Qui n'atteindront pourtant au ciel de vostre honneur :

Pour aspirer si haut ma force est trop petite,

Je sçay mon impuissance et vostre heureux merite,

Et sçay qu'il vous faudroit un plus divin sonneur (Philippe Desportes, Euvres)

1628 Qui de vous posseder ne s'estimast heureuse?

Réveillez vostre force : une ame genereuse Jamais sur ses desseins ne demeure en deffaut ;

Le Ciel ayde au mortel aspirant tousjours haut (Jean de Schélandre, Tyr et Sidon)

1651 Il a son but à part, Grimoald, prends-y garde :

Quelque dessein qu'il ait, c'est toi seul qu'il regarde.

Examine ce cœur, juges-en comme il faut. Qui m'aime et me trahit aspire encor plus haut (Pierre Corneille, Pertharite)

1656 J'aspire un peu trop haut, il faut que je l'avouë,

Mais un grand cœur prétend qu'on l'aime, et qu'on le louë, Autant qu'on doit traitter de haine, et de mépris,

Les timides esprits

(Guillaume Colletet, Poésies diverses)

1833 J'ai aspiré trop haut, je t'ai revêtu d'une gloire qui ne fut sans doute jamais la tienne et que j'ai voulu égaler (George Sand, Lélia)

1838 Le peuple, qui a l'avenir et qui n'a pas le présent ; le peuple, orphelin, pauvre, intelligent et fort ; placé très bas, et aspirant très haut ; ayant sur le dos les marques de la servitude et dans le cœur les préméditations du génie ; le peuple, valet des grands seigneurs, et amoureux, dans sa misère et 
dans son abjection, de la seule figure qui, au milieu de cette société écroulée, représente pour lui, dans un divin rayonnement, l'autorité, la charité et la fécondité (Victor Hugo, Ruy Blas)

1839 Du désespoir si haut élevé au-delà de l'espérance, il aspire encore plus haut : insatiable de poursuivre une vaine guerre contre les cieux, et non instruit par son succès, il déploya de la sorte ses imaginations orgueilleuses (François de Chateaubriand, Le Paradis perdu)

II. aspirer tout haut : souhaiter ouvertement, afficher clairement ses ambitions

Intransitif

1799 Au milieu de ces excitateurs qu'il vient de signaler, qui, encore une fois, sont en petit nombre, mais semblent se multiplier par le bruit, il ne perd pas de vue ces autres royalistes d'une incurable frénésie, qui aspirent tout haut après un maître, qui le rappellent de tous leurs vœux, de toutes leurs actions (Emmanuel Sieyès, Euvres)

\section{CoRpus Web :}

Il faut faire exactement tout le contraire, pense-t-il, le théâtre est un lieu d'enchantement où chacun doit être transporté au-dessus de la vie courante. Et il n'est pas seul à penser ça. En 1927 Jouvet, Baty, Dullin et Pitoëff se regroupent pour former le fameux Cartel des Quatre, une manière pour eux d'aspirer haut et fort à un renouveau [http://www.lebandeau.net/t2552-giraudoux-oul-ironie-souriante] (20.6.2016)

Pour voir grand, il faut aspirer haut, et donc transcender l'horizon du présent. Ce qui ne suggère pas, que l'on doive faire fi du passé. Mais si le passé décrit une trajectoire d'expérience donnée, rien n'indique qu'il doive automatiquement se prolonger dans l'avenir suivant une courbe d'évolution fixe [https://www.linkedin. $\mathrm{com} /$ pulse/voir-grand-marcel-jb-tardif-mba] (20.6.2016)

Quelques fois par année, vous pouvez également battre les tapis de sortir la poussière profondément réglé. Vous pouvez accrocher ces puis utiliser un aspirateur vertical au réglage élevé. Ce va secouer toute la saleté et la crasse lâche, et puis vous pouvez aspirer haut en bas, puis côté à l'autre [http://www.davistile.com/lainecarpettes-do-it-yourself_5169926] (20.6.2016)

REMARQUES : Haut (I) est un adjectif-adverbe qui indique le lieu d'arrivée, partant d'un niveau inférieur vers un niveau supérieur, aussi au sens figuré de 'viser haut, d'avoir des visées ambitieuses' Haut (II) peut également signifier 'ouvertement, publiquement, à haute voix' (premier exemple du CW). Haut reste invariable et est modifié par plus, si, haut, tout, trop, encore plus qui soulignent le caractère ambitieux, voire irréalisable, du projet. Le sens concret directionnel 'passer l'aspirateur de haut en bas' est illustré par le dernier exemple du CW qui appartient au langage quotidien. Notons la collocation haut et fort ainsi que l'emploi de placer bas ; élever haut ; voir grand.

\section{Assaillir bel}

Assaillir, attaquer avec bravoure, avec courage

Emploi absolu

1176 Qant remese fu la parole,

Li rois Alixandre aparole,

Si l'apele son ami chier.

Amis, dist il, molt vos vi hier

Bel assaillir et bel desfandre [variantes :

bien ... bien ; biel ... bien]

(Chrestien de Troyes, Cligés, 1447)

REMARQUES : L'adjectif-adverbe de manière adopte ici la forme neutre bel qui indique la fonction adverbiale. Les variantes le remplacent donc par bien. Dans un combat, mené avec courage, il souligne la qualité d'attaque ou, plus généralement, les exploits ou prouesses du chevalier ou du combattant face à son adversaire. Notons l'emploi de défendre bel.

\section{Assaillir dur}

Assaillir, attaquer avec force, avec violence Transitif

1276 Avoec lui erent Açopart et Luti, Moult le tenoient a preu et a hardi. De no gent fist le jor maint malbailli, Car souvent orent esté dur assailli De lui ce jour, et entour et enmi (Adenet le Roi, Les Enfances Ogier, 5897) 


\section{CORPUS WEB :}

Il a cessé ; et Satan est resté pour ne pas répondre, mais, heureux que maintenant sa mer devrait trouver un rivage, avec l'alacrité fraîche et la force remplacée jaillit ascendant, comme une pyramide du feu, dans l'étendue sauvage, et par le choc des éléments de combat, sur tout l'entouré rond de côtés, gagne sa manière ; plus dur assailli et plus mis en danger que quand Argo a traversé Bosporus intermédiaire les roches justling, ou quand Ulysse sur le bâbord a évité Charybdis, et par le Th l"autre tourbillon a orienté [http:// bryantmcgill.com/wiki/poetry/john_milton/para dise_lost_book_02\#.UqXqFPPkSUk] (9.12.2013)

Remarques : Dur est un adjectif-adverbe de manière qui réfère ici à la façon dont le sujet attaque, dans une lutte ou un combat, son adversaire avec violence, force et sans ménagement. VOIR AUSSI : défendre dur

\section{Assaillir raide}

Attaquer quelqu'un avec vigueur, avec violence Emploi absolu

1365 Si alons assalir et si fort et si roit Qu'à terre l'abatons ; et s'abatus estoit, Sé li .i. de vous .iiii. li lanchoit d'un espoit, Je vous ai en couvent mes corpz li pardonroit (Li Romans de Bauduin de Sebourc, Chant III, 825)

REMARQUeS : Raide est un adjectif-adverbe de manière qui désigne la façon dont, dans une lutte ou un combat, le sujet, qui désigne une personne, attaque brusquement, vivement son adversaire. La collocation avec fort suggère l'idée de force et de rapidité dans l'action. VoIR AUSSI : défendre raide

\section{Assener droit}

I. Frapper, assener, donner (un coup) directement, exactement, avec précision Transitif

1176 Or la fera Amors dolante, Et molt se cuide bien vangier Del grant orguel et del dangier Qu'ele li a toz jorz mené.

Bien a Amors droit assené, [variante : droit a Amors]

Qu'el cuer l'a de son dart ferue.
Sovant palist, sovant tressue, Et maugré suen amer l'estuet (Chrestien de Troyes, Cligés, 460)

1177 Et cil an la gorge l'assanne Trestot droit par desoz la panne De l'escu, si le giete anvers Dessus les pierres an travers (Chrestien de Troyes, Lancelot ou Le Chevalier de la charrete, 2238)

+1225 Cil, tant con chevaus puet aller, De force haut et droit l'assene, Et le fiert en mont en la pene De l'escu, et si fort l'empaint Que li chevaus pas ne remaint En piés. La ciele a cil vuidie, Si ke par poi il n'a brisie L'espaule. Il est outre passés De son poindre, et s'est apensés K'a lui ne se combatra plus (Le Chevalier as deus espees [ $2^{\mathrm{e}}$ quart $\mathrm{XIII}{ }^{\mathrm{e}}$ ], 8765)

1250 U hauberc sous le bras l'a si droit assené Que l'espée trenchant l'a derout et faussé; U bras l'a .i. petit en la moure navré Que le cheval en a devant ensanglenté (Doon de Mayence, p. 133)

1276 Puis que dou Toivre passa les rades gués Quant combatirent dedenz l'isle ens es prés,

Il et Charlos ainsi com vous savés. $\mathrm{Au}$ tre Charlon est tout droit assenés Rois Carahués et Ogiers li senés (Adenet le Roi, Les Enfances Ogier, 4473)

Intransitif

+1313 Des lances si droit assenerent

K'en .iij. troncons les tronconnerent, Mais li artisiens tel cop ot K'ou ceual tenir ne se pot (Jean de Condé, Poèmes [1313-1337], 681)

II. Diriger, mener, conduire directement quelqu'un

Transitif

1200 Tant ont cerchié contreval la cité, Si com Deu plot, le Roi de majesté, Qu'a cel ostel sont tout droit assené, $\mathrm{Ou}$ ja estoient pluisor gent assamblé (Jourdain de Blaye, 3431) 
III. Donner, attribuer directement quelque chose à quelqu'un

Transitif

1325 Car à lui tout droit assena

La couronne et en couronna

Son chief ou plus haut, tout enson ;

Sans noise faire et sanz tençon

(Watriquet de Couvin, Dits, p. 89, 197)

CoRpus Web :

Que veut dire par là Luc Carvounas? Que le fait d'avoir fait arrêter le bus sur un parking durant la sortie scolaire, d'avoir fait amener la jeune fille dans une salle plutôt que d'avoir pris d'assaut le bus avec une escouade pour braquer des enfants est un bienfait dont il faudrait se targuer ? Partant de là oui, le solférinien Carvounas peut assener droit dans les yeux : « En cela, cette gauche qui est au pouvoir est vraiment une gauche humaniste " [https://cocq.wordpress. com/2013/10/17/carvounas-procureur-anti-romavocat-du-diable] (17.6.2016)

REMARQues : Droit est un adjectif-adverbe de manière-direction invariable qui est modifié par $s i$, tout. Assener droit appartient à l'ancien français, mais le CW atteste aussi l'emploi actuel où assener réfère au fait d'imposer avec force par la parole. Droit est modifié par si, tout, trestot. Notons la collocation haut et droit. Mentionnons également l'emploi de empeindre fort 'pousser fort'.

\section{Assener haut}

Atteindre, frapper fortement, gravement Transitif

+1365 Or est ainsi que bon Amour A mon cuer si hault assené En bien, en paix et en honneur Qu'il n'est homme de mere né Qui puist ymaginer comment Amours le m'a mis fermement Et assis en si hault endroit Que mon petit cuer vraiement Ameroit mieulx grace que droit (Jean Froissart, Poésies [3e tiers XIV]]

\section{CORPUS WEB :}

Cet homme, au cuir épais (des années de triathlon...ça fortifie !) reconnait et regrette, il est vrai, son entrée tardive dans la bataille. Mais comme il aime l'assener haut et fort, « mon combat et mon investissement pour la ville d'Anglet ne date pas d'hier » [https://fr-fr. facebook.com/permalink.php?story_fbid $=6092$ 91142449324\&id=543269369051502] (12.12.2013)

Alors moi, je soupçonne sérieusement les mamies un peu ginder de faire exprès d'asséner haut et fort à mes garçons « oh, les jolies petites filles... ». Rien que parce que ça la gène les cheveux long sur des garçons... [http://www. jumeaux-et-plus.fr/component/option,com_smf/ Itemid,88/topic,8029.255/wap2,wap2] (12.12.2013)

Jaime Ortega, tout sourire, a dit tout ce qu'il avait à dire : que l'absence de moyens de diffusion n'empêche pas les églises de se remplir, que la santeria (religion africaniste, pratiquée par $85 \%$ de la population) n'est qu'une « superstition », et qu’au fond Cuba n’a jamais été réellement évangélisée, que les Cubains doivent « abandonner le mensonge et l'hypocrisie qui les caractérisent aujourd'hui ». Autant de vérités que seul son habit de cardinal lui permet d'asséner haut et fort [http://www.liberation.fr/monde/1995/02/20/ jaime-ortega-l-eglise-cubaine-consacree_122595] (12.12.2013)

Encore une fois, des gros mensonges assénés hauts et forts pour faire vrai !! Sans nucléaire, plus de radiothérapie et autre radiographie, renseignez vous [http://www.francebleu.fr/ infos/centrale-nucleaire/evacuation-la-centralede-cruas-914926] (12.12.2013)

REMARques : Haut est un adjectif-adverbe de lieu employé au sens figuré désignant l'impact très fort que peut avoir quelque chose, un sentiment tel l'amour, sur l'être ou sur le corps. Le CW montre que la collocation assener haut et fort s'est lexicalisée, même sous sa forme fléchie (v. dernier exemple du CW), toujours employé par rapport au fait de frapper, d'imposer avec force par la parole.

\section{Asseoir bas}

I. Être placé / placer quelqu'un dans une position inférieure

Transitif

$\sim 1209$ Ne se contint pas come sires, Car ses granz senz et sa proece, Sa bonté et sa grant largece L'assist mout plus bas que ne die (Jean Renart, Roman de Guillaume de Dole, 352) 
1617 je diray que j'en donnay à prendre à deux gentils-hommes, l'un desquels estant un jour à mon logis, tomba en foiblesse, il fallut l'asseoir bas, luy donner du vin, luy frotter les temples de vin-aigre, je le fus voir quand il fust revenu à soy (Louise Bourgeois, Observations diverses sur la sterilite)

1883 Cet aviron étant plus facile à manier, le thalamite n'a pas besoin d'être dans des conditions aussi favorables et on peut l'asseoir bas, ce qui le forcera à lever plus haut les bras pour nager, mais le mettra hors d'atteinte de l'aviron zygite (Raoul Lemaître, De la disposition des rameurs sur la trière antique)

Intransitif

1403 Et aucuns princes de l'accort Se voulsissent bien entremettre, Mais, a peine y pourra on fin mettre, Se Dieu, de grace, n'y pourvoit, Car le plus sage a peine y voit ! De leurs gens, assis hault et bas En plusieurs degrez, ne sçay pas Qu'oncques veisse plus faulses gens Qu'aulcuns y a ; de tieulx sergens Fait on pastours, qui sont droit loups Et de char devourer jaloux (Christine de Pisan, Le Livre de la mutacion de fortune, II, 4353)

II. S'asseoir en-dessous de quelqu'un

Pronominal

1235 Lors le fait asseoir delés ly a destre et monseigneur Gauvain a senestre. Et le chevalier se vouloit asseoir plus bas que la damoiselle n'estoit, maiz elle ne le seuffre mie, ains li dit : " Ne vous remués, beau sire. Aussi hault vous devriés vous seoir ou plus que je ne devroye, car vostre dignité l'aporte : c'est la haultesse de chevalerie qui le commande » (La Suite du Roman de Merlin, § 467, 33)

Intransitif

1398 et pour luy faire grant honte lui firent porter plus que pour aidier a Nostre Seigneur ; et illec ou Nostre Seigneur reprint la croix a une pierre quarrée d'environ pié et demy de tous lez, assise plus bas que les autres pierres d'entour, sur laquelle estoit le pié de la croix quant Nostre Seigneur la reprint pour porter sur le monlt du Calvaire (Le Saint Voyage de Jherusalem, p. 14)

REMARques : Pris au sens propre (local) ou au sens figuré, asseoir bas réfère à l'idée d'une position inférieure ou de mouvement vers une telle position ou un état inférieur. Notons le contraste avec l'adjectif haut dans la collocation hault et bas. Il reste invariable et est modifié parfois par plus et moult plus. Notons l'emploi de seoir haut ; lever haut.

\section{Asseoir dur}

Poser sur un siège dur

$\pi$ coucher dur

\section{Asseoir haut}

I. Donner une place importante, une place d'honneur ; estimer beaucoup

Transitif

+1400 Humilité en riche homme bien siet : Plus se tient bas et plus hault on l'assiet (Christine de Pisan, Proverbes moraulx / Euvres poétiques [début Xve], III, p. 52)

+1415 S'il est ainsi mort par vostre peresse, Je vous requier, au moins, tant que je puis, Chascun de vous donnez lui une messe, Et j'ai espoir que brief ou paradis Des amoureux sera moult hault assis, Comme martir et treshonnoré saint, Qui a tenu de Loyauté le cours : Grant tourment a, puis que si fort se plaint ; Je l'oy crier piteusement secours (Charles d'Orléans, Poésies [ 1415-1440], I, Ballade XXVI, p. 45)

1450 JASPAR. Si fault dire qu'elle demonstre Quelque signifficacion. Ne quant a situacion Aux autres point ne s'appareille, Car ceste est moult bas a merveille Et les autres sont hault assises. Par quoy, aprés toutes devises, Il fault dire qu'elle nous signe Quelque hault et mirable signe Qui est de nouvel avenu (Arnoul Gréban, Le Mystère de la Passion, 5242) 
II. Asseoir, mettre dans une position supérieure Intransitif

1826 Son amour-propre et un reste de respect pour les choses de l'Église le faisaient souffrir à l'idée de voir le misérable agent couvert du même chapeau qui était une couronne pour lui, et assis aussi haut que lui-même, à cela près de l'emploi passager de ministre (Alfred de Vigny, Cinq-Mars)

1858 La mer montait rapidement, mais nous avions près de nous un escalier naturel. Elle mit la main devant ses yeux pour se garder de l'éblouissement des flots soleillés. Elle était assise très haut, sur un rocher, moi très bas, à ses pieds (Jules Michelet, Journal)

1866 Vous m'en direz des nouvelles dans huit jours, si vous avez des étouffements nerveux, d'après ce que m'a dit Lefébure. Pas trop d'exercice, au contraire, d'abord ! Laissez pendre vos pieds, en vous asseyant haut, quand le sang se porte à la poitrine, 5 minutes ! Et ne travaillez pas de suite après vos repas, mais une heure et demie après (Auguste de Villiers de L'Isle-Adam, Correspondance générale)

REMARQUES : Asseoir haut s'emploie ici au sens concret ou figuré : établir quelqu'un dans une position supérieure, dans une situation digne et propre à lui faire honneur. Il souligne également l'idée d'estimer quelque chose ou quelqu'un, de le considérer comme étant supérieur. Haut reste invariable et est modifié par aussi, moult, plus, très. Notons l'emploi de tenir bas. VoIR AUSSI : seoir haut

\section{Asseoir mou}

Poser sur un siège souple

入 coucher dur

\section{Assommer net}

Porter un coup violent

Transitif

1859 Nous avons vu un soir une jeune fille assommer net d'un coup de sa cruche de terre, un renard enragé qui se glissait autour d'une maison (Frédéric de Tschudi, Les Alpes: description pittoresque de la nature et de la faune alpestres [trad.])
1976 Le Colt .45 automatique pèse près de trois livres. J'ai assommé net ce mec. Il est tombé dans l'allée (Jean-Patrick Manchette, Que d'os!)

\section{Atourner bel}

Orner, parer, arranger d'une belle manière, de façon élégante

Transitif

1170a As osteus vienent, si s'aeisent, Si se deshuesent et atornent ; De lor beles robes s'aornent. Quant bien et bel atorné furent, Por aler a la cort s'esmurent (Chrestien de Troyes, Erec et Enide, 6457)

+1225a Puis li a sa grieve drecie,

Et li met un chief .i. capel.

Et quant fu atornés si bel,

Si fu si biaus comme il disoient

K'il onques mais veü n'avoient

Si bel, ains mais onques ne le vit (Le Chevalier as deus espees [ $2^{\mathrm{e}}$ quart $\left.\mathrm{XIII}{ }^{\mathrm{e}}\right], 4816$ )

+1225b Quant li dui

Chevalier ont le pastourel

Veü, si tres bien et si bel

Et si noblement atorné,

Tantost sunt cele part torné

Tout contreval le praërie.

Et li pastourials les escrie

K'il voisent fors de sa pasture (Le Chevalier as deus espees [2 $2^{\mathrm{e}}$ quart $\left.\left.\mathrm{XIII}^{\mathrm{e}}\right], 10514\right)$

1250a Il atourna son vis es sa plaie al plus biel k'il pot, et vint à la fieste, ki fu toute jour molt grans de boire et de mangier et de baus et de karolles (Le Roi Flore et la belle Jehanne [milieu XIII'], p.108)

1250b «Feites les vos aussi, et les barbes fremer ; Grant mestier nous ara, je cuit, ains retourner. »

Lors a fet Valebron, son bon mestre, mander.

Chil les atourna bel, que bien s'en sot aidier (Doon de Mayence, p. 247)

-1300 Tel mireoir covient au cors, Por bel atorner ce defors (La Vie de sainte Paule [fin $\left.\mathrm{XIII}^{\mathrm{e}}\right], 1221$ ) 
Pronominal

1170b Tant s'est la dame demantee Que bien et bel s'est atornee De la mellor robe qu'ele ot (Chrestien de Troyes, Erec et Enide, 2612)

1372 Atant la parole laissieren, Si dormirent et reposerent. Au matinet qu'il ajourna, Li roy bien et bel s'atourna Et trestuit li autre ensement (Guillaume de Machaut, La Prise d'Alexandrie [(1370-)1372], 2084)

1403 Si ont, en la fin, roy esleu Alixandre, si com j'ay leu, Car preux le virent et vaillant. Ainssy acrut ja son vaillant Alixandres, qui s'en retourne Vers son pere, et moult bel s'atourne, Mais, quant approcha du palays, D’assez loings il a oÿ les Instrumens sonner et la feste, Que li roys Phelippes appreste, Pour nouvelle femme espouser ; La mere Alixandre poser Vouloit jus, et une aultre prendre (Christine de Pisan, Le Livre de la mutacion de fortune, IV, 22196)

REMARQUES : En ancien français, atourner bel réfère à la façon de se vêtir, avec élégance et soin. Si le sujet désigne une personne, il souligne le fait de se préparer, de s'arranger de manière soignée, souvent dans le but de plaire à autrui. Notons la coordination fréquente du neutre bel avec l'adverbe bien, et aussi avec noblement. Dans le premier exemple pronominal ( 1170b), le sujet désigne une femme, sans que bel soit accordé. Il est modifié par al plus, moult, si. VoIR AUSSI : arroyer bel, atourner gent

\section{Atourner droit}

Aller, se diriger directement à

入 tourner droit

\section{Atourner gent}

Préparer, présenter, arranger avec goût Transitif

1250 Do de Maience aval u grant palès deschent ;
En la cuisine vint, si trouva largement

Char et fresche et salée atournée moult gent,

Venesons et oisiaux quanque au jour apent (Doon de Mayence, p. 109)

REMARQUES : Usuel en ancien français, gent est un adjectif-adverbe de manière qui, employé avec le verbe atourner, désigne le fait d'accommoder, de préparer, d'arranger des mets avec goût, d'une belle façon. Il est modifié par moult. VOIR AUSSI : arroyer bel

\section{Attacher court}

I. Attacher quelqu'un ou un animal avec un lien court, petit

Transitif

1496 BOURREAU. Il montent tous de[ux] au hault de l'eschelle, puis le bourreau lui mect a point son cas en disant ce qui s'ensuit : Mon amy, au temps advenir Ne pencez plus, mais du passé Veillez vous present souvenir, S’en bien vous l'avez compassé. Tantost vous serez trespassé Et ataché cy hault et court. Si de parler n'estes lassé, Despeschez vous, faictes le court (Andrieu de la Vigne, Le Mystère de saint Martin, 4276)

-1500 LE GENDARME. Je demande avoir du conseil

Et metz ad octo probandum.

LA FILLE. Mais une corde ou ung landon Pour vous attacher hault et court

(Le procès d'un jeune moyne et d'un viel gendarme devant Cupido, 404)

1891 Deux pauvres bœufs étiolés, amaigris, pitoyables, la peau déjà usée sur les saillies des os par les frottements du roulis. Depuis bien des jours ils naviguaient ainsi misérablement, tournant le dos à leur pâturage de là-bas où personne ne les ramènerait plus jamais, attachés court, par les cornes, à côté l'un de l'autre et baissant la tête avec résignation chaque fois qu'une lame venait inonder leur corps d'une nouvelle douche si froide (Pierre Loti, Le Livre de la pitié et de la mort) 
1914 une grosse Italienne noire et flasque, puis beaucoup d'enfants bouchaient les portes étroites des voitures - et, attaché court sous la première, un vieil ours pelé faisait trois petits pas, puis levait une patte de derrière, puis revenait et refaisait trois petits pas et ainsi de suite, indéfiniment, à donner le vertige (Alain-Fournier, Correspondance avec Jacques Rivière)

1928 Cachons sous la dernière lettre l'image que je ne veux pas voir : une tête à demi vaincue qui tournait de côté et d'autre, sur l'oreiller, son col sec et son impatience de pauvre chèvre attachée court... La dernière lettre, ma mère en l'écrivant voulut sans doute m'assurer qu'elle avait déjà quitté l'obligation d'employer notre langage (Colette, La Naissance du jour)

1934 Déjà, déroulant les cordes, le bonhomme Herbelot improvisait un attelage.

- Ne l'attachez pas trop court, dit mon père, qu'il ait du jeu.

Les cordes nouées, Herbelot prit le cheval par la bride et commença de lui parler (Georges Duhamel, Vue de la terre promise)

II. Attacher, maintenir quelque chose

(à / sur quelque chose)

Transitif

1798 Le plus sûr est de leur donner leur avoine dans un sac, et de les attacher court et haut à un anneau de chaque côté (J.-F. Bastien, La Nouvelle Maison rustique)

1851 Peut-être n’avait-il que vingt-huit ans ; on pouvait, sans l'offenser, lui en donner hardiment trente-cinq, grâce sans doute aux nobles ennuis qui avaient pâli son front. Il était mis avec recherche. Le ruban d'un ordre étranger brillait à sa boutonnière. Attaché court au gilet, un bouquet de breloques pendait sur sa poitrine (Jules Sandeau, Sacs et parchemins)

1902 Chose bizarre, une perche pointue, liée au bras de l'homme, oscillait avec ses mouvements. Plus près, il laissa voir son mufle barbu et tout encadré de longs cheveux gras. A cause des étriers, attachés court par des cordes, ses genoux relevaient la longue crinière du cheval (Paul Adam, L'Enfant d'Austerlitz)

2011 Elle était banale et revêche, toute vêtue de gris, avec des cheveux noirs attachés courts sur la nuque (Anthony Horowitz, $\mathrm{La}$ Maison de soie [trad.])

REMARQUeS : Attacher court désigne le fait de fixer, maintenir ou retenir une personne ou un animal à l'aide d'un objet, d'une attache (une chaîne, un crochet, une corde, un lien quelconque) qui lie et qui a peu de longueur. Court est invariable dans la plupart des cas, mais l'exemple de 2011 montre que la flexion n'est pas exclue. Notons le groupe figé haut et court (à comparer : pendre haut et court) qui a un sens spatial et désigne un point élevé. Court est modifié par trop. Attacher court est surtout employé dans le langage rural par rapport aux animaux domestiqués.

\section{Attacher serré}

I. Attacher quelqu'un ou quelque chose en serrant, avec un lien étroit, serré

Transitif

1691 Je lui dis qu'elle était la maîtresse de me bander les yeux, et même de me les crever, si elle y trouvait quelque plaisir. Elle m'attacha un mouchoir autour de la tête, si serré, qu'elle me fit d'abord une douleur effroyable (Marie-Catherine d'Aulnoy, $R e$ lation du voyage d'Espagne)

1946 Je me suis lavé avec un peu de whisky ; mon bras ne saignait plus ; j'ai réussi à le retirer de ma manche et à l'attacher serré autour de mon torse avec mon foulard et de la corde. J'ai failli chialer, tellement j'avais mal, car il fallait que je le replie (Boris Vian, J'irai cracher sur vos tombes)

1964 En me servant de sa laisse je l'ai attachée [= la chienne] à la poignée de la porte arrière droite - la plus éloignée de moi. Pas trop serré pour qu'elle pût s'étendre si l'envie lui en prenait. Assez serré pour qu'il lui fût impossible de m'atteindre (Colette Audry, La Chienne et nous)

1977 En attendant, je passe le commandement au chef du premier groupe. Je vais livrer 
personnellement mes prisonniers. En tas, derrière. Quelques grognements. Ils sont attachés serrés. Je peux y aller tout seul. Trois kilomètres de route, un peu plus de chemin... (Jean-Pierre Chabrol, La Folie des miens)

1992 Les archers avaient eu du mal à mater les filles déchaînées dont la force était décuplée. Elles les mordirent, il fallut les attacher serré, les embarquer ainsi dans une charrette jusqu'à l'hôpital des fous, à Saujon (Hortense Dufour, La Fille du saulnier)

2008a La marchandise dans du papier de soie, rangée bien à l'abri de boîtes en carton, emballées elles-mêmes par deux ou trois épaisseurs de papier kraft, maintenues à leur tour par une ficelle attachée serrée en croix. Rien de visible, il faut demander. Trente ans plus tard rien n'a changé dans la boutique quand, au dernier jour de mes longues vacances, on achète là ma blouse pour la rentrée (Martine Sonnet, Atelier 62)

2011 Eurydice vint changer son pansement, elle apporta sur un plateau métallique des bandages, du désinfectant, du coton et des épingles de sûreté toutes neuves, toute une boîte écrite en anglais. Elle attachait ses cheveux très serré et boutonnait sa blouse jusqu'en haut, mais il suffisait à Victorien un battement de ses cils, un frémissement de ses lèvres pour la deviner tout entière, son corps nu et toutes ses courbes, sa peau vivante (Alexis Jenni, L’Art français de la guerre)

Pronominal

1890 Et toute notre ville se démonte de la même manière, se plie, s'attache serré dans des quantités de ficelles; puis se charge sur des mules qui ruent, sur des chameaux qui grognent ; en route, notre camp est levé ! (Pierre Loti, Au Maroc)
II. s'attacher à quelque chose : être très lié à quelqu'un ou quelque chose, tenir beaucoup, fermement à quelqu'un ou quelque chose Pronominal

1901 Souviens-toi de ce que je t’ai enseigné : l'homme, faisant de lui-même sa fin, moins il se peut satisfaire, plus serré il s'attachera à ses causes, à la cause par laquelle il existe en tant qu'homme, et celui-ci entre les autres (Paul Claudel, Le Repos du septième jour)

Transitif

2008bEn juin 1962, c’était grâce aux nommés Sauvet, Lebail et Schwartz, qu'avec 15 points ceux des forges avaient gardé la coupe. Le rempart contre l'ennui à la ville, et ce qui m'y attache serrée, c'est la Bibliothèque juste derrière chez nous. D'abord un drôle de chantier sous nos fenêtres, côté cuisine, salle de bains, chambre des parents (Martine Sonnet, Atelier 62)

\section{CORPUS WEB :}

J'ai enfin trouvé quelques réponses au pourquoi je n'arrive jamais à avoir les cheveux longs. En voici les causes...

J'ai appris qu'il ne fallait pas les attacher serré, car ça casse les cheveux. Ensuite, il ne faut pas les déméler en tirant de dessus. Il faut arrêter le sèche cheveux. Il faut faire attention à bien les placer quand on dort [http://journaldepousse. canalblog.com] (17.6.2016)

si tu veux un carré plongeant, cheveux longs devant et courts derrière, il faudra les attacher serrés dans la nuque et couper : si tu visualises, les cheveux au niveau de la nuque seront coupés à ras, tandis que ceux de devant garderont de la longueur [http://forum.doctissimo.fr/forme-beaute/ Coiffure-et-coloration/possible-degradescheveux-sujet_11653_1.htm] (13.12.2013)

L'autre chose à noter est que certains des modèles plus anciens laisser un espace entre le matelas et le bedrail afin que votre bébé pourrait tomber entre le rail et le matelas. Regardez donc pour les modèles plus récents ou ceux qui s'attachent serrés pour le matelas et vous évitera cette issue [http://www.experts-tourisme.fr/ securite-ferroviaire-s365878.htm] (13.12.2013) 
REMARQues : Serré est un adjectif-adverbe de manière, issu du verbe serrer. Dans cet emploi, serré est invariable (ex. de 1890, de 1964, de 1992 et de 2011), mais dans les exemples de 1977, de 2008a/b, et dans le deuxième exemple du CW, il s'accorde en genre et en nombre avec l'objet, ce qui peut relever d'une interprétation de prédicat second orienté vers l'objet. Dans l'emploi pronominal du verbe, il peut s'accorder avec le sujet (v. le troisième exemple du CW). Dans l'exemple de 1977, la flexion pourrait référer au fait de former un groupe serré, compact, mais le contexte induit la même interprétation que dans les autres exemples : celui qui livre les prisonniers peut le faire tout seul parce que ceux-ci sont bien attachés, sans marges de manœuvre. Serré est modifié par assez, pas trop, plus, très.

\section{Attacher solide}

Attacher sans risque de se détacher

Transitif

1937 Mais ta jument tu as dû l'attacher solide. Le cul du tilbury flotte mais elle est toujours attachée en bas au fond (Jean Giono, Batailles dans la montagne)

1979 Loret le mataf qui pique sa crise [...], faut qu'on le maîtrise, qu'on l'attache solide (François Cavanna, Les Russkoffs)

REMARQUes : Attacher solide se dit du fait de fixer fermement un être animé ou un objet qui risquent de se détacher.

\section{Atteindre haut}

I. Parvenir à un niveau élevé, supérieur, ou obtenir de bons résultats, accomplir un travail considérable qui est le résultat, l'aboutissement d'un effort

Emploi absolu

$\sim 1275$ E pour ce que nule richece A valeur d'ami ne s'adrece, Qu'el ne pourrait si haut ataindre Que valeur d'ami ne seit graindre, Qu'adès vaut meauz amis en veie Que ne font denier en courreie (Jehan de Meun, Roman de la rose [1269-1278], 4945)

1538 Au temps passé Apelles, painctre sage, Feit seulement de Venus le visage, Par fiction ; mais pour plus hault attaindre,
Ton pere a faict de Venus, sans rien faindre,

Entierement la face et le corsage

(Clément Marot, Rondeaux)

1592 Nostre ame ne sçauroit de son siege atteindre si haut. Il faut qu'elle le quitte et s'esleve, et, prenant le frein aux dents, qu'elle emporte et ravisse son homme si loing qu'apres il s'estonne luy-mesme de son faict (Michel de Montaigne, Essais)

1625 En cela outre la gloire qui vous demeurera d'avoir avancé vostre Cadet, je croy que vous suivrez le dessein du Ciel et de la Terre : Le party est de telle sorte, qu'estant trop peu pour vous, qui pouvez atteindre plus haut et esperer davantage, il est trop riche pour moy, qui comme Cadet n'ay que la cappe et l'espee : car les loix de la Catalogne nous rangent tout à fait à la mercy et discretion de nos aisnez (Jean-Pierre Camus, Palombe ou La Femme honnorable)

1637 Je lui serai bon père, et puisque ce parti À sa condition se rencontre assorti, Bien qu'elle pût encore un peu plus haut atteindre,

Je la veux enhardir à ne se plus contraindre (Pierre Corneille, La Suivante)

1715 Je suis charmé d'un auteur qui s'efforce de vaincre les anciens [...]. Le public doit louer ses efforts, l'encourager, espérer qu'il pourra atteindre encore plus haut dans la suite et admirer ce qu'il a déjà d'approchant des anciens modèles :... etc. Je voudrois que tout le Parnasse le comblât d'éloges :... etc. (François de Fénelon, Lettre à l'Académie)

1783 MAURICE. Il ne faudrait aussi plus de bœufs pour labourer la terre : on tirerait la charrue soi-même ; et en dix pas on serait au bout du champ. Tenez, encore, je vis l'autre jour plus de cinquante hommes qui enfonçaient des pilotis pour faire une chaussée. Comme ils travaillaient! Eh bien! Avec un grand marteau, comme on pourrait alors en porter, un homme seul aurait fait toute leur besogne en un jour. N'est-il pas vrai, mon papa? 
M. DE LEYRIS. Voilà qui est fort bon à dire ; mais avec tous ces beaux souhaits, vous n'êtes que des fous?

MAURICE. Comment des fous ?

M. DE LEYRIS. Oui, de croire que vous seriez alors plus heureux que vous ne l'êtes.

MAURICE. Mais si nous devenions capables de faire plus de choses que nous n'en faisons à présent ?

FRÉDÉRIC. Par exemple, ne serait-ce pas fort commode de pouvoir atteindre bien haut, et de faire d'un seul pas bien du chemin ? (Arnaud Berquin, L'Ami des enfans)

1890 L'école philosophique a sa patrie sous le ciel de la Grèce et de l'Inde ; le temple et la science sacerdotale, s'expliquant en énigmes et en symboles, voilant la vérité sous le mystère, atteignant souvent plus haut, parce qu'elle est moins inquiète de regarder en arrière et de s'assurer de sa marche, tel est le caractère de la race religieuse et théocratique des Sémites (Ernest Renan, L’Avenir de la science)

1923 Poésie anglaise, plus riche, plus abondante que la française ; mais celle-ci, me semble-t-il, atteint parfois plus haut. Je ne puis aimer toutes les facilités que le poète anglais s'accorde, et cette absence de rigueur ; les cordes de sa lyre, presque toujours, me paraissent insuffisamment tendues (André Gide, Journal)

1956 afin de couper court aux effusions et leur garder ainsi une juste résonance, baiser la main d'une pauvre femme et briser là, croyez-moi cher monsieur, c'est atteindre plus haut que l'ambitieux vulgaire et se hisser à ce point culminant où la vertu ne se nourrit plus que d'elle-même. Arrêtons-nous sur ces cimes (Albert Camus, $\mathrm{La}$ Chute)

II. Concerner, toucher quelqu'un fortement Transitif

1823 Dans la situation extraordinaire où le sort m’avait élevé, mes trésors étaient les siens ; je m'étais identifié sans réserve avec ses destinées. Quel autre calcul eût pu m'atteindre si haut? M'a-t-on jamais vu m'occuper de moi ? Je ne me suis jamais connu d'autres jouissances, d'autres richesses que celles du public

(Emmanuel de Las Cases, Le Mémorial de Sainte-Hélène)

\section{CORPUS WEB :}

Mettez la cocotte sur le poêle à feu moyenélevé et attendre la jauge d'atteindre haute. Selon la taille de l'autocuiseur, cela peut prendre entre 2 et 5 minutes [http://nourriture.fooddrink.info/ cooking-baking/cooking-techniques/1007009021 .html] (16.6.2016)

REMARQUES : Atteindre haut confère une interprétation directionnelle à l'adjectif haut qui désigne un point élevé. Il s'emploie également au sens figuré. Haut reste invariable dans la majorité des cas, mais dans l'exemples du CW il est mis au féminin. Il est modifié de façon très varié par bien, plus, encore plus, encore un peu plus, parfois plus, si, souvent plus.

\section{Atterrir court}

Atterrir sur une courte distance

Intransitif

1961 Les Boeing 707320 B atterrissent et décolleront plus court (Le Monde, 6 octobre 1961 / Grundt : 317)

2011 Il calcule ses chances : atterrir trop court reviendra à se fracasser sur les rochers, et atterrir trop long à dépasser la zone de pose pour dégringoler de six mille mètres le long de la montagne (Patrick de Gmeline, Baron rouge et cigogne blanche)

\section{CORPUS WeB :}

Le problème, avec le DA40, c'est qu'il est un peu difficile sur ces vitesses d'atterrissage : si on est trop rapide, il ne se pose pas. Personnellement, j'ai un peu de mal à l'atterrir court [http:// petite.pilote.legere.over-blog.com/categorie439375.html] (13.12.2013)

Les spécifications techniques étaient sévères, car cet avion doit atterrir court, sur tout type de terrain, lancé, à pleine charge, à plus de 270 km/h [http://www.linguee.fr/francais-anglais/ traduction/atterrir+court.html] (13.12.2013) 
La vitesse de croisière est voisine de 150 $\mathrm{km} / \mathrm{h}$ et la vitesse d'atterrissage est de $45 \mathrm{~km} / \mathrm{h}$ ( $58 \%$ de la demande). Il est capable de poser et d'atterrir court (STOL), sur des pistes de fortune (tout-terrain) [http://www.ulmag.fr/mag/ dossiers/sondage_131101_8.php] (13.12.2013)

Remarques : Dans le domaine de l'aviation, atterrir court désigne le fait de prendre contact avec le sol pour arrêter le vol, court se rapportant à la distance réduite dont l'avion a besoin pour atterrir. Notons l'emploi transitif dans le premier exemple du CW. Court reste invariable et est modifié par plus, trop. Il s'oppose à atterrir long (ex. de 2011). Notons l'emploi de décoller court.

\section{Atterrir long}

Atterrir sur une longue distance

$\lambda$ atterrir court

\section{Avaler bas}

Descendre beaucoup, fortement

$\pi$ aller haut, exemple de 1119

\section{Avaler doux}

I. avaler doux comme lait : avaler un liquide facilement, sans peine

Transitif

+1480 LE SOT. Pour Dieu, qu'elle me soit aprise. Ventre bieu, la me celés vous ?

MAISTRE PIERRE. Recipe pour gens qui sont coux :

Quelque bon bruvaige doulcet,

C'est a dire ung bruvaige doux

Et l'avaler doux comme lait

(Sottie de Maître Pierre Doribus, 91)

II. avaler doux comme lait, confiture, eau, miel, sirop, vin : accepter quelque chose sans critique, sans rancune, ou avec plaisir ; être crédule, croire facilement

Transitif

1579 Je me doubte bien que ce belistre de Ruffin me l'aura desbauchée ; toutesfois, il faut que j'avalle cela doux comme laict, ne luy en osant parler, crainte que, mouvant trop ceste ordure, l'odeur ne se respande d'avantage parmy le peuple, et que ce qui n'est sçeu que d'un ou de deux devienne la fable du commun (Pierre de Larivey, Les Esprits)
1646 Son valet mesme a sceu nous en-seigner, En l'estrillant au lieu de le peigner, Qu'aucun ne doit le souffrir à sa table ; Dés qu'il paroist, on le chasse à l'estable, On siffle, on hue, en le poussant abas $\mathrm{Au}$ son des pots, des chaudrons, et des plats ;

Sans s'estonner, aussi-tost il remonte ;

Doux comme vin il avale la honte ;

Et le premier nous le voyons placé, Dés que son nez luy dit qu'on a dressé (François de Boisrobert, Épistres en vers)

1713 Il n'y a point de chat qui craigne tant l'eau. Comment ! Jamais ne se laver pour soimême, et ne décrasser que ce qu'il faut nécessairement que l'on montre, c'està-dire la gorge et les mains ! La Temple avalait cela plus doux que les confitures ; et l'officieuse Hobart, pour ne pas perdre de temps, la déshabillait en attendant sa femme de chambre (Antoine Hamilton, Mémoires de la vie du comte de Gramont)

1732 C'est une dame nouvellement mariée, et si belle, que... mais, ajouta-t-elle en s'interrompant elle-même, je ne vous en dirai pas davantage ; il faut vous laisser le plaisir de la surprise que sa vue doit vous causer. J'avalai tout cela doux comme lait, et je ne me possédais pas, tant j'étais enivré de mon mérite (Alain-René Lesage, Histoire de Guzman d'Alfarache)

1807 - Grace, voisin. - Non, point de grace ;

Pan ! pan! à la fin, je me lasse

D'avaler doux comme sirop

Tous les affronts qu'elle me brasse !

- On se met bien à votre place

Mais... Mais on ne s'y met que trop ! (Philippe-Laurent Pons de Verdun, Le Pourquoi)

1843 - Et qu'elle boira avec la petite blonde.

- C'est crânement arrangé, bourgeois.

- Et surtout que la vieille ne se doute de rien!

- Calmez-vous, bourgeois, elle avalera ça doux comme miel.

- Allons, bonne chance, mon garçon! Si je suis content, peut-être je vous emploierai encore (Eugène Sue, Les Mystères de Paris) 
1931 Anne-Marie ne paraissait pas. Du tournant, cela le surprit singulièrement d'entendre sa voix, qui s'élevait comme pour une semonce. À qui en avait-elle?

- Hé ! Madame Anne-Marie, vous voulez rire ! C'était au bossu. Il avalait doux comme l'eau ce qu'elle lui disait, se contentant de répéter : "Hé ! Vous voulez rire, Madame Anne-Marie ! »

(Henri Pourrat, La Tour du Levant ou Quand Gaspard mit fin à l'histoire)

REMARQUES : Au sens propre, avaler doux désigne le fait de boire un liquide, soit en raison de son goût agréable au palais, soit en raison de sa composition, de sa matière, le liquide descendant facilement. Au sens figuré, il souligne la façon plutôt positive dont une personne prend les choses. L'exemple de 1480 inclut la douceur du liquide (prédicat second), mais l'ensemble des citations montre bien que l'interprétation adverbiale est primordiale, l'inclusion de la douceur de quelque chose ayant un statut inférentiel. Avaler doux a développé un schéma phraséologique dans lequel le liquide apparaît comme variable : avaler doux comme + LIQUIDE.

\section{Avaler droit}

s'en avaler droit : descendre rapidement et directement, dévaler

Pronominal

+1200 Que puet chaloir ? Sains et hetiez Issi chascuns de la nef fors.

Li cuens Gladoains qui fu lors

A Handitou s'en avala

Droit a la mer (Raoul de Houdenc,

Meraugis de Portlesguez [début XIII'], 3432)

CORPus WeB :

C'est pas de la faute à Hollande si les truffes coutent si cher, la droite lump critique encore la gauche caviar, pour un article de fond, il y est bien! Ca reste quand même bien moins cher que le morceau de rillette à 600 mille euros que sarko vient se fourrer dans le museau devant 2 ou 3 cents journalistes avec 2 ou 3 mille policiers pour veiller à ce qu'on ne l'empeche pas d'avaler droit [http://www.agoravox.fr/commentaire3207056] (6.16.2016) j'ai voulu mixer une petite carotte préalablement coupée en petits dés pour la cuisson, et le résultat me laisse perplexe : cela ne ressemble pas du tout à une purée ! le mixage est grossier, la petite n'a pas réussi à avaler « droit » et du coup elle s'est ruée sur le sein embarrassé (oops) [http:// www.forums.supertoinette.com/recettes_53443. mixage_baby_c_k.html] (6.16.2016)

REMARQUES : En ancien français, avaler droit désigne un mouvement de descente vers le bas, en aval. En français moderne (CW), avaler droit réfère surtout au fait d'ingérer directement, correctement, sans complications.

\section{Avaler ferme}

Manger beaucoup

Emploi absolu

1877 - Ah ! Si vous croyez que c'est toujours amusant? On voit bien que vous n'avez pas été en ménage... non, Monsieur Coupeau, il faut que je pense aux choses sérieuses. La rigolade, ça ne mène à rien, entendez-vous ! J'ai deux bouches à la maison, et qui avalent ferme, allez ! Comment voulez-vous que j'arrive à élever mon petit monde, si je m'amuse à la bagatelle ?... et puis, écoutez, mon malheur a été une fameuse leçon (Émile Zola, L’Assommoir)

REMARQUES : Avaler ferme désigne le fait de se nourrir abondamment, d'avaler de la nourriture en grande quantité. L'emploi absolu invarié souligne l'usage comme tour figé dans le langage quotidien.

\section{Avaler gros}

avaler gros comme ça (de quelque chose):

avaler, manger en abondance

Transitif

1878 - Ne te tourmente pas, ce ne sera rien, bien vrai... maintenant que tu as fini, tu vas me recoucher... je voulais te voir à table, parce que je te connais, tu n'aurais pas avalé gros comme ça de pain (Émile Zola, Une page d'amour)

1884 Ce n'est pas parce que votre mari est parti, que vous devez vous crever de désespoir. Bien sûr, quand j'ai perdu Gabin, j'étais pareille à vous, je suis restée trois jours sans 
pouvoir avaler gros comme ça de nourriture (Émile Zola, La Mort d’Olivier Bécaille)

\section{CORPus WEB :}

L'un de mes mâles combattant passait sa journée à chasser à l'affut les alevins de gouramis. Dès qu'un combattant aura compris qu'une crevette, ça se mange, quelque soit les cachettes, il les aura à terme. Et ça a une bien grande bouche, ça peut avaler gros (ou déchiqueter comme l'écrivait Pecky) [http://www.aquariophilie.org/ forum/viewtopic.php?f=15\&t=78087\&start=40] (14.12.2013)

REMARQues : Avaler gros désigne le fait d'ingurgiter, de faire descendre de la nourriture dans le gosier en grande quantité ou en gros morceaux, le sujet désignant une personne. Émile Zola documente ainsi cet emploi dans le registre populaire, que l'on reconnaît aussi à l'emploi du sujet générique ça en emploi absolu (CW).

\section{Avaler lourd}

Manger autant que son propre poids

Emploi absolu

1866 À l'âge de votre papa, il en tombe [= du poids] juste autant qu'il en arrive, et voilà pourquoi sa taille demeure toujours la même, bien qu'il avale dans son année trois fois plus lourd que lui (Jean Macé, Histoire d'une bouchée de pain)

\section{CORPUS WEB :}

Et puis, « réformateur » est bien une lettre du PRL ; c'est là une menue consolation pour les libéraux qui avalent lourd et mal le sacrifice du L de « libéral » [https://www.lalibre.be/belgique/ 24-mars-2002-51b8da9fe4b0de6db9c341e9] (24.9.2011)

REMARQUES : La citation du CW met en évidence l'emploi au figuré 'accepter avec difficulté'.

\section{Avaler net}

avaler (tout) net : avaler d'un seul coup Transitif

1532 Voyant Pantagruel qu'il s'amusoit à tirer sa dite masse, qui tenoit en terre entre le roc, luy courut sus, et luy vouloit avaller la teste tout net ; mais son mast, de male fortune, toucha un peu au fust de la masse de
Loupgarou, qui estoit pheée, comme avons dit devant (François Rabelais, Pantagruel)

\section{CORPUS WEB :}

Portant au col un anneau qui l'empêche D'avaler net le produit de sa péthe [= pêche]. Tout cormoran bien dressé doit savoir Plonger, happer truite, carpe ou lamproie, Puis, au signal donné, rendre sa proie, Comme un Tantale'du devoir [http://gallica.bnf.fr/ark:/12148/bpt6k2739559/ f3.textePage] (14.12.2013)

Sachez que votre personnage aura sans doute une durée de vie très courte, dans un monde où un tyrannosaure peut l'avaler net ou un géant peut l'écraser sans même s'en rendre compte [http://hotel.muxxu.com/tid/forum\#! view/11|thread/25301329] (14.12.2013)

Il fallait dire que cette tarte là était de la largeur du creux de la main. On pouvait donc l'avaler net [http://dream-nightmare.forumactif. com/t146-petit-creux-pv-reechart] (14.12.2013)

C'est à cet instant que Dino Cavallone pénétra dans l'immense salle à manger de la Varia, son instinct de survie s'étant fait la malle. Ledit Cavallone claqua violemment les portes de la pièce, en interrompant de même le petit déjeuner mouvementé. Bel lâcha la mâchoire de Tsuna, geste qui avait pour but de lui faire avaler nette sa petite cuillère [https://www.fanfiction. net/s/5863949/7/Boss-Amn\%C3\%A9siqueEmmerde] (16.6.2016)

Harry s'assit au comptoir et commanda un verre de whisky un petit remontant ne lui ferait pas de mal après les évènements passés. Il l'avala cul-sec et en commanda un autre. Il repensa à sa portion sensée lui guérir sa blessure au dos et la déboucha avant de l'avaler nette elle aussi [https://www.fanfiction.net/s/4199261/6/Il-y-ades-choses-qu-on-oublie-pas] (16.6.2016)

REMARQUES : Avaler net désigne le fait d'ingurgiter, de manger quelque chose entier, en un seul morceau et d'un seul coup. Net est modifié par l'adverbe d'intensité tout. Dans l'écriture spontanée du CW, l'adjectif-adverbe peut s'accorder avec l'objet féminin (v. les deux derniers exemples du CW), tout en conservant son interprétation de manière. Notons que le masculin net et le féminin nette sont prononcés de la même façon, ce qui peut favoriser la graphie nette. 


\section{Avancer ferme}

Progresser dans une démarche ou une action avec volonté et de manière décidée

Intransitif

1839 Elles avancent fermes sans se rompre : ni haute colline, ni vallée rétrécie, ni bois, ni ruisseau, ne divisent leurs rangs parfaits, car elles marchent élevées au-dessus du sol et l'air obéissant soutient leur pas agile : comme l'espèce entière des oiseaux rangés en ordre sur leur aile, furent appelés dans Éden pour recevoir leur nom de toi, ô ADAM (François de Chateaubriand, Le Paradis perdu)

1891 Ma cantate continue à avancer ferme. Elle sera bien, très bien orchestrée, mais un point c'est tout (Guillaume Lekeu, Corres pondance)

Transitif

1853 Il en va être ainsi pendant trois semaines. Je suis curieux de voir la mine que je vais faire. J'éprouverai si l'homme décidément est un animal sociable. J'espère d'ici à ton arrivée avancer ferme la Bovary. Si ma scène d'amour n'est pas faite, elle le sera aux trois quarts (Gustave Flaubert, Correspondance)

Pronominal

1879 Mais, quand on les [= les martyrs] sommait de renier Jésus-Christ, ils s'avançaient fermes et invincibles (François Moigno, Les Splendeurs de la foi)

1882 Le maître de forges, pris à partie, s’avança ferme et presque menaçant. Claire pâlit. Les deux hommes allaient-ils se trouver lancés l'un contre l'autre par l'implacable haine de la duchesse ? (Georges Ohnet, Le Maître de forges)

CORPUS WEB :

Touba, le Magal et les fidèles. La foule, la poussière aux abords de la mosquée est partout dans la ville. La visibilité n'est pas des meilleures, la lumière du jour mêlée à la poussière rend fou. Comme hypnotisés par ces minarets si proches et si loin à la fois, ils avancent les pèlerins massifs. Ils respirent l'air crasseux, toussent, mais avancent fermes [http://www.enqueteplus. com/content/magal-touba-2013-bamba-draineencore-sa-foule] (16.6.2016)

Mais les enfants de Dieu tiennent à prévoir, pour rester purs. Ils se souviennent du chant très suave qui est celui de la Cité chaste : «Bienheureux ceux qui sont immaculés dans leurs voies, et qui s'avancent fermes dans les sentiers de la loi divine »[http://gallica.bnf.fr/ark:/12148/ bpt6k65607207/texteBrut] (16.6.2016)

REMARQUES : Avancer ferme désigne la résolution ferme du sujet, sa ténacité, se situant parfois aux confins de la prédication seconde, mais pouvant également se rapprocher de la fonction adverbiale 'fermement, sans ralentir' (ex. de 1853, 1891). L'accord de ferme est particulièrement apprécié dans les textes religieux pour inclure davantage l'attitude du sujet (ex. de 1879 et CW).

\section{Avoir cher}

I. Aimer, avoir de l'affection pour quelqu'un, chérir ; tenir beaucoup à quelque chose Transitif

1100a Ço dist Rollant : « Mis cumpainz est irez ! Encuntre mei fait asez a preiser. Pur itels colps nos ad Charles plus cher. » A voiz escriet : «Ferez i, chevale ! » (Chanson de Roland, 1560)

1100b Ja devers els bataille n'ert lessee. Suz cel n'ad gent que Carles ait plus chere, Fors cels de France, ki les regnes cunquerent (Chanson de Roland, 3031)

1100c U est Otes e li quens Berengers? Ive e Ivorie, que jo aveie tant chers? Qu'est devenuz li Guascuinz Engeler? Sansun li dux e Anseïs li bers?

(Chanson de Roland, 2406)

+1125 Noé, ses treiz fiz, Quant vint li periz, Volt deus retenir, Lor quatre moilliers ; Cez out deus si ciers, Nes laissat perir (Un sermon en vers [ [2 $2^{\mathrm{e}}$ quart $\mathrm{XII}{ }^{\mathrm{e}}$ ], 24)

+1150a Bien pert as beles armes et al destrier, As riches garnimens que il a chier, Qu'il n'a en nule tere tel cheualier (Aiol et Mirabel [2 $2^{\mathrm{e}}$ moitié XII ${ }^{\mathrm{e}}$, 1971) 
+1150b Vous ne cremies nient le pooir l'auersier ; Vos amis en getastes, que tant auies chier (Aiol et Mirabel [2 moitié XII $\left.{ }^{\mathrm{e}}\right], 6211$ )

1165 Ensemble od sa femme premiere Mist sa femme que tant ot chiere. El la receut cum sa serur E mult li porta grant honur ; De deu servir l'amonesta E sun ordre li enseigna (Marie de France, Lais, 1166)

1176 Li cuens Angrés est molt marriz, Por i tant que traïner voit Ces devant lui que chiers avoit (Chrestien de Troyes, Cligés, 1500)

$\sim 1177$ a Car a lor plaies ressener Ont mestier de mire et d'antret. Devant lui mener les an fet Li rois, qui mout chiers les avoit. Un cirurgiien, qui savoit De cirurgie plus que nus, Lor fet mander li rois Artus (Chrestien de Troyes, Yvain ou Le Chevalier au lion, 6503)

$\sim 1177$ b Li vavasors avoit a fame Une bien afeitiee dame Et cinc fiz qu'il avoit mout chiers, Trois vaslez et deus chevaliers, Et deus filles jantes et beles, Qui ancore estoient puceles (Chrestien de Troyes, Lancelot ou Le Chevalier de la charrete, 2059)

1177c Et quant il vindrent del recet Pres a sis liues ou a set, Ou li rois Bademaguz iere, Novele que il ot mout chiere Li fu de Lancelot contee, Si l'a volantiers escoutee, Qu'il vit et vient sains et heitiez (Chrestien de Troyes, Lancelot ou Le Chevalier de la charrete, 4428)

$\sim 1200$ Procas fu rois prouz et vailanz, De sa mulier out dous enfanz, Communement les out mult chiers ; Amulius fu li premiers, Numitor out l'altres a nom (Brut, 3819)
+1200 Ensi vint la dame a court o tout ses enfans qu'elle avoit moult chiers. Et elle estoit de si grant biauté plainne que a paines peust on veir ne trouver sa pareille de biauté (Merlin [ $1^{\mathrm{er}}$ quart XIII ${ }^{\mathrm{e}}$, p. 146)

1209 Tote nuit i sont sorvenant Chevalier, baron d'autre terre, Qui lor conpegnons vienent querre Por raiembre ou por ostagier. Sachiez li prodoms a plus chier De ceuz qu'il a a sa main pris, Que s'onor i soit et son pris, Ce sachiez, qu'il les raensist (Jean Renart, Roman de Guillaume de Dole, 2922)

+1225 Je sui Sarrazine et renoie, car autrement ne peusse je jà durer, ains fusse piecha morte. Mais or vous pri jou et casti si chier comme vous avés vos vies, et honneurs à avoir gregneurs ke vos n'eustes onques, que por chose que vos aiiés oïe ne veue nul plus biel semblant n'en faites, mais simplement vos maintenés (La Comtesse de Ponthieu [2 $2^{\mathrm{e}}$ quart XIII'], p. 213)

-1234 Dit Otinel : Issi doit on changier Cop por colée, maille por denier. Ja Alfanie ne vos aura mestier, La vostre amie, que vous aviés tant chier (Otinel [ $1^{\mathrm{er}}$ tiers XIII $\left.\left.{ }^{\mathrm{e}}\right], 1494\right)$

1235 Mais, pour chou que ne sont pas beles, Le vous avons nous tant celé ; Mais or vous sera revelé. Mesires nous a fait savoir, Si chier que nous volons avoir Nos vies sans recevoir mort, Que nous, ou a droit ou a tort, Vous metons ardoir en un fu Et chou que de vous est issu (Philippe de Remi, sire de Beaumanoir, $\mathrm{La}$ Manekine, 3668)

1250 Vers Kallez le bon roi, qu'en sot tant henourer, Et comme il prist Flandrine la courtoise à moullier, La fille l'Aubigant que onques Dieu n'ot chier ; 
Sire estoit de Vauclere et tint tout l'eritier (Doon de Mayence, p. 182)

1275 Margiste nostre serve avoec vous laisserai Et Aliste sa fille, plus belle riens ne sai Pour ce que vous ressamble, assés plus chiere l'ai,

Et Tibert leur cousin avoec envoierai (Adenet le Roi, Berte aus grans piés, 187)

1280 Aprés cen, se tu me veuz crere, Tu doiz tant laborer et fere Que cognoisses la chamberiere Que ta dame a segree et chiere (Vivien de Nogent, La Clef d'amour, 588)

1325a Luxure, c'on avoit tant chier, Y est jetée en telle ordure Que nuls n'a jà mais de li cure, Et ont chacié à grant effort Hors de la court Mesdit le fort, Pour ce qu'en li a trop de vice (Watriquet de Couvin, Dits, p. 343, 64)

$\sim 1325$ b Lors fis en repentance i. saut, A Souffiance à lie chière Alai, car moult la dame oi chiere, Qui me reçut mont chierement Et me conta tout l'errement De la dame à la grant biauté, Que Haute Honneur et Loiauté Orent de par Nature en garde ; Moult en faisoient bonne garde (Watriquet de Couvin, Dits, p. 18, 542)

1364a Si vous pri si chier que vous m’avés que vous le veilliez savoir, se vous poés (Guillaume de Machaut, Le Livre du voir dit, p. 572)

1364b Hé las, je l'avoie si chier Et tant l'amoie sans trichier Qu'en verité je ne savoie Se je l'ooie ou vëoie (Guillaume de Machaut, Le Livre du voir dit, 8271)

+1365a Car je sçai bien combien l'ai chiere. Mès elle fait trop millour ciere A pluisours gens Qu'à moi, qui ai mis tout mon temps (Jean Froissart, Poésies [3 $3^{\mathrm{e}}$ tiers XIV $\mathrm{XV}^{\mathrm{e}}$ ) +1365b Car Aurora ne l'a pas chier, Ançois le tint en grant debat (Jean Froissart, Poésies [3 ${ }^{\mathrm{e}}$ tiers XIV $\left.{ }^{\mathrm{e}}\right]$ )

+1400a Telz chevaliers doit on avoir moult chiers ; Dieu et les sains et le monde les prise. Or suive donc toudis si fais sentiers, Qui maintenir veult l'ordre a droite guise (Christine de Pisan, Cent balades / Euvres poétiques [début $\mathrm{XV}$ ] , I, p. 66, 25)

+1400 b A vous, vaillant seigneur de haute emprise,

Et si vous viens donner d'amour esprise La riens qui soit que doy plus chier avoir Et soubzmettre du tout a vo franchise, Si le vueilliez, noble duc, recevoir (Christine de Pisan, Autres balades / Euvres poétiques [début $\mathrm{Xv}^{\mathrm{e}}$ ], I, p. 232, 8)

+1540 L'Homme. Or bien, Alyson, qu(e j)'ay tant chère,

Baise moy (un peu) au departement (Farce nouvelle d'un amoureux / Ancien Théâtre françois)

1544 Tant plus je veulx d'elle me souvenir, Plus à mon mal, maulgré moy, je consens. Que j'aurois cher (s'il debvoit advenir) Que la douleur m'osta plus tost le sens Que la memoire, ou reposer je sens Le nom de celle, Amour, ou tu regnois Lors qu'au besoing tu me circonvenois, Tant qu'à la perdre à present je souhaicte Car si en rien je ne m'en souvenois, Je ne pourrois sentir douleur parfaicte (Maurice Scève, Délie, object de plus haulte vertu)

1556 Au mien propos ha si bien respondu Celle que j'ay plus chere que mon ame, Et mon vouloir sagement entendu, Que je consens qu'il me soit donne blame Si je l'oublie : car elle m'a rendu Le sens, l'esprit, l'honneur, le cœur et l'ame

Estant navré

(Louise Labé, Double rondeau, à elle)

1558 Nature ne nous peut donner qu'un pere, et qu'une mere : mais le mariage en represente plusieurs en noz enfans, lesquels 
nous reverent et honorent, et ont plus chers que leurs propres entrailles (Pierre Boaistuau, Le Théâtre du monde)

1610 Il m’a sacrifiée, à ce qu'il dit, pour la santé de Calidon, monstrant en cela qu'il l'avoit plus cher que moy. Et bien, à la bonne heure! Mais ne se contente-t'il que son sacrifice ait esté receu, et que son cher Calidon ait esté rappellé du tombeau ? (Honoré d'Urfé, L’Astrée)

1636 HERCULE. Alcide a vaincu tout, et cede à ce poison ;

Ce feu ne cesse point, la toille qu'il allume, Attachée à ce corps, avec luy se consume ; En vain tout mon effort s'employe à l'arracher ;

Voila le sort du fils que vous eustes si cher (Jean de Rotrou, Hercule mourant)

Pronominal

+1150 Or sont li fil Aiol andoi si escuier,

Meruelles s'entramoient, durement s'orent chier (Aiol et Mirabel [ $2^{\mathrm{e}}$ moitié XII $], 10235$ )

II. Avoir, obtenir contre beaucoup d'argent Transitif

1945 «Pas étonnant, songeait Rose-Anna, qu'on l'a eue pas cher. Si près des tracks, c'est quasiment pas habitable. Ce bruit-là, je m’y habituerai jamais. » Et cependant, elle ne perdait pas pied (Gabrielle Roy, Bonheur d'occasion)

1965 - Faut savoir acheter, disait-il. C'est pas l'tout d'bien travailler, faut savoir acheter. - Et les fers, lui dis-je, vous pouvez pas les avoir moins cher à Paris ?

Il me regarda avec étonnement ; il n'y avait pas pensé. Mais comment s'y prendre ? Pour les clous, un représentant était passé chez lui, mais les fers? (Jacques Perry, Vie d'un païen)

\section{CORPus Web :}

j'ose mm pas imaginer le son de cette vieille boite de conserve... t'as pas du l'avoir chère [http:// www.latavernedesbatteurs.com/viewtopic. php?f=22\&t=988] (14.12.2013)

Si tu veux du bon son sans avoir cher un 2voies, vmais pas besoin d'amplifier le kit
Sauf si tu veux te péter les tympans, j'ai jamais écouter oxygène mais je crois que c'est une bonne marque à confirmer, les 13,5 sont un peu moin puissant (généralement fait pour les portières arrière) que des 16,5 [http://www.meganefrance.net/xoops/modules/newbb/viewtopic. php?viewmode=compact\&topic_id=] 15627\&fo rum $=7$ (15.12.2013)

dans un immeuble tout blanc où il ne devait pas y avoir cher d'économiquement faibles 1963 [http://www.languefrancaise.net/bob/detail. php?id=1300] (14.12.2013)

Encore bravo ! Revenez vite en Belgique les pélos, y'a cher de la gâche pour le hip hop ici ;-) [https://www.facebook.com/Lanimalerie] (15.12.2013)

Remarques : D'une part, cher est un adjectifadverbe qui peut référer à une qualité de cœur du participant désigné par le complément d'objet direct (I). Ceci explique l'accord morphologique qui s'observe dans la plupart des cas, surtout quand cher désigne une qualité humaine. Cet emploi est privilégié dans la langue ancienne. D'autre part, avoir cher se comporte aussi comme un verbe complexe qui a intégré la forme masculine neutre. Ceci vaut notamment pour l'emploi moderne au sens de 'acheter cher' (II et deux premiers exemples du CW). Il est modifié par assez plus, moins, moult, plus, si, tant. Les exemples du CW illustrent l'usage dans l'écriture spontanée. Dans les deux premiers exemples, l'adjectifadverbe réfère au prix de quelque chose, l'accord étant facultatif. Dans le restant des exemples $\mathrm{du}$ CW, (ne pas) avoir cher de quelque chose est employé dans l'acception '(ne pas) avoir beaucoup de quelque chose'.

\section{Avoir gras}

I. Avoir beaucoup de réserves, de provisions Intransitif

1333 Ne ne cuide pas orgueileus

Ne userier ne convoiteus,

Luxurieus ne bobencier,

Pour ce s'il ont gras leur pail[ier],

Assez a boire et a mengier

(Le « Bestiaire marial » tiré du « Rosarius ») 
II. il y a gras : il y a beaucoup de

Emploi absolu

1843 - Que ça d'honnêteté ?... merci !... dis donc, Malicorne, reprit l'homme en se retournant vers son camarade, il n'y a pas gras... ici... c'est pas comme chez le vicomte de Saint-Remy?

(Eugène Sue, Les Mystères de Paris)

III. il y a gras : il y a beaucoup à gagner

Emploi absolu

1844 Fougères regarda la pratique sans rire, car M. Vervelle présentait un diamant de mille écus à sa chemise. Fougères regarda Magus et dit : « Il y a gras ! » en employant un mot d'argot, alors à la mode dans les ateliers (Honoré de Balzac, Pierre Grassou)

1951 «Continua la commedia, se dit Angelo. Et personne ne songe à jouer des coudes ou la fille de l'air. Si je prends mon temps, il y aura gras » (Jean Giono, Le Hussard sur le toit)

REMARQUES : Gras est un quantifieur signifiant 'beaucoup' (II) ou, plus spécifiquement, 'beaucoup à gagner' (III) ; il a son origine dans le domaine de la nourriture (I). Comme dans le cas de gros, son emploi avec le verbe avoir peut motiver des emplois où gras se rapproche d'une fonction de manière (s.v. échapper gras).

\section{Avoir gros}

I. (en) avoir gros comme : avoir une quantité égale à

Intransitif

1532 Adonc que Galemelle fut descendue : il luy demanda quelle chausse elle avoit là. Adonc luy respond en eslargissant ses cuysses qu'elle avoit celle playe de nature : Grant Gosier regardant la playe large et rouge comme le feu Sainct Antoine : le membre lui dressa : lequel il avoit gros comme le ventre d'une cacque de hareng : et long à l'advenant : il dist à Galemelle que il estoit barbier, et que de son membre feroit esprouvette pour sçavoir si la playe estoit parfonde : à laquelle playe il ne trouva nul fons (Les Grandes et Inestimables Chroniques)
1852 Mon Dieu, qu'est-ce donc que ce chagrin? N'en avons-nous pas assez, en dehors de nous-mêmes ? Dites, et si j'y puis quelque chose, je suis entièrement à vous. Moi, j'en ai gros comme une montagne, aussi ! Ce ménage que vous savez est un enfer, et chacun vient à son tour me faire sa plainte et son récit (George Sand, Correspondance)

1862 Demoiselle Jeannette lui rit au nez et parla plus clairement ; il éclata de rire à son tour et dit avec la plus aimable confiance :

- Ch'est de l'argent qu'il faut pour cha? Vous auriez dû le dire tout de chuite. J'en ai gros comme moi, de l'argent! (Edmond About, Le Nez d'un notaire)

1942 Au partage, on commence par tirer l'eau du pot, et chacun fait oraison pour qu'on retrouve la viande : la joie éclate quand on la retrouve, et finalement, quand on l'a découpée, chacun en a gros comme un dé. La table demeure nette, on peut le croire : les chiens se plaignent de n'avoir pas un reste d'os à ronger. C'est là une pasquinade (Edmond Faral, La Vie quotidienne au temps de saint Louis)

II. il y a gros que, gros à parier que : il y a de bonnes raisons de penser que

Intransitif

1790 Ah, messieux, les bons apôtres, vous faisiez la patte de velours pour nous mieux écorcher, et monter vous-mêmes sur des échasses ; mais je savons aujourd'hui le fin mot de votre pensée, et les États généraux rabattront votre caquet de plus d'un cran. Vous en avez la foire, mes enfans, et $y$ a gros que vous en serez les dindons. Quand on ne pisse pas clair, le médecin fait peur

(Cahier des plaintes et doléances des Dames de la halle et des marchés de Paris / Les Femmes dans la Révolution française)

1938 Il y a, en quelque sorte, fort peu de chances pour l'appel de ce mot dans notre activité intérieure, et il y a gros à parier que l'on peut vivre et réfléchir, agir et méditer toute une année, sans que la nécessité de l'articuler ou de le penser soit une seule fois ressentie (Paul Valéry, Variété IV) 
III. (en / y) avoir gros : (y) avoir beaucoup (de)

Intransitif

1833 - Voyez, ma mère, le beau travail.

- Oh ! il y a gros d'or, dit Nanon en apportant le café.

- Qu'est-ce que c'est que cela, demanda Charles en riant

(Honoré de Balzac, Eugénie Grandet)

1884 Mais, enfin, il faut au moins avoir l'air de quelque chose... ah ! Voilà M. Lazare qui la soulève, pour qu'elle ne mouille pas ses bottines. Il n'en a pas gros dans les bras, allez ! C'est vrai qu'il y a des hommes qui aiment les os... Véronique s'interrompait net, en sentant près d'elle le tressaillement de Pauline (Émile Zola, La Joie de vivre)

1922 MME GRAYOTTE. Il sera dans les bras de qui qu'y voudra, nous le ferons-ben lever ! D'abord il nous attend. Ah ! c'est que j'en ai gros à lui raconter... Elle-le-dé-mo-li-ra son-mur, la Philomène !... Elle nous en a fait voir, allez ! (George Chepfer, Saynètes, paysanneries 1 )

IV. (en) avoir gros sur le cœur, sur la patate, sur la pomme : avoir beaucoup de chagrin, de dépit, de rancune Intransitif

1865 Brulette, qui avait eu gros sur le cœur le mauvais comportement envers elle des muletiers dans le bois de la Roche, fut si sensible à l'estime et aux compliments du Grand-Bûcheux, qu'elle en eut des larmes prêtes à couler, et que, se jetant à son cou, elle ne sut lui répondre qu'en le baisant comme si ce fût son propre père (George Sand, Les Maîtres sonneurs)

1890 Mais je sais à quel point tu es tenu, je n'osais pas te demander de venir. Enfin, te voilà, et j'en ai si gros, si gros sur le cœur ! Elle s'interrompit, pour jeter craintivement un regard par la fenêtre (Émile Zola, La Bête humaine)

1936 C'était pas un moment commode pour entreprendre des promenades !... Il faisait tout de même un peu frais! Je peux dire qu'elle était en rage... Elle en avait gros sur la pomme... Elle arrêtait plus de glapir.
- Il m’a fait ça le pourceau ! le satyre ! la finie canaille ! À moi, Ferdinand !... À moi !...

(Louis-Ferdinand Céline, Mort à crédit)

1944 - Je viens de passer six mois dans la forêt vierge à filmer des borgeiros, indiens particulièrement sauvages comme vous ne l'ignorez pas.

- Faut avoir tué père et mère pour faire des trucs comme ça.

- Exactement. Faut en avoir gros sur la patate.

- À cause d'une femme.

- Exactement

(Raymond Queneau, Loin de Rueil)

1969 Il écumait et sa voix, quoique faiblarde, portait loin, dans l'air calme de cet aprèsmidi printanier. Je n'ai pas perdu un mot de sa diatribe. Il en avait gros sur la patate, il se débondait. J'ai compris que Jeanne, en somme, était l'attraction de ce bistrot. Elle faisait fonction d'allumeuse (Léo Malet, Sueur aux tripes)

V. en avoir gros : en avoir assez

Intransitif

1932 Comme l'averse finissait on a trouvé un taxi. On se précipite et nous voilà casés les uns contre les autres. D'abord, on ne se dit rien. On en avait gros entre nous et puis j'avais comme ça assez gaffé pour ma part. Je pouvais attendre un petit peu avant de m'y remettre (Louis-Ferdinand Céline, Voyage au bout de la nuit)

\section{CORPuS WeB :}

Que faire lorsqu'on en a gros sur la conscience et que l'on a déjà tué sept hommes ? [http://calmann-levy.fr/livres/magdalenapecheresse] (15.12.2013)

Remarques : Gros est un adjectif-adverbe de quantité invariable qui a développé une série de locutions qui reflètent un usage oral informel plutôt populaire ou familier. En avoir gros comme (I) compare l'ampleur de quelque chose avec un objet dont les dimensions sont supposées connues. Il y a gros à parier (II) représente un effort rhétorique qui met en relief ce qui est affirmé par la suite. (III) est une expression fami- 
lière pour 'avoir beaucoup de'. (En) avoir gros sur le cœur, la patate, la pomme (IV) transpose métaphoriquement la pesanteur associée à gros sur le plan des préoccupations humaines. Finalement, (V) exprime le fait d'en avoir assez. Les locutions sont rarement modifiées, mais on trouve si pour l'acception (IV), ex. de 1890. Notons l'emploi de interrompre net. VOIR AUSSI : avoir cher de (CW)

\section{Avoir long}

I. avoir long comme le doigt de quelque chose : en avoir peu

Intransitif

1623 Vous voudriez avoir de l'authorité dessus nos autres aussi long que le bras, apres en avoir eu long comme le doigt : mais à qui vendez vous vos coquilles (Charles Sorel, Les Nouvelles françaises)

II. (en) avoir long: en avoir beaucoup, aussi au sens temporel

Intransitif

1771 On vous mandera les détails de ce qui s'est passé aujourd'hui : il y en a bien long et je ne saurais par où m'y prendre pour vous en informer (Julie de Lespinasse, Lettres à Condorcet)

$1813 \mathrm{Si}$ vous me demandez, après avoir lu l'intrigante, comment il se fait qu'une comédie en cinq actes, en vers, dont le caractère est bien aperçu et fortement tracé, dont les mœurs sont vraies, dont le style est de la meilleure école, n’ait pas fourni sur la scène une plus longue carrière, je vous répondrai... j'en aurais trop long à vous répondre (Étienne de Jouy, L'Hermite de la Chaussée-d'Antin)

1832 Par mercredi le paquet, tu en auras plus long : ceci est pour répondre seulement à ta lettre, adieu ma bonne mère, je t'embrasse de tout mon cœur (Honoré de Balzac, Correspondance)

1880 Je ne t'en ai pas parlé, de celle-là, lorsque tu pleurais par terre ; j'aurais trop long à en dire (Émile Zola, Nana)

1914 Ils s'bouffent des yeux tout leur temps, sans rien dire... Ils en auraient trop long, probable ! (Francis Carco, Jésus-la-Caille)
1925 C'est un carnet que j'ai trouvé par hasard ; un journal intime de papa ; je ne comprends pas comment il l'a laissé traîner. N'importe qui pouvait le lire. Je l'ai pris pour ne pas qu'Armand le voie. Ne lui en parlez pas. Il n'y en a pas très long. Vous pouvez le lire en dix minutes et me le rendre avant de partir (André Gide, Les Faux-Monnayeurs)

1943 Oh ! Il y en avait long dans sa tête ce soir (Simone de Beauvoir, L'Invitée)

1962 Elle doit en avoir long comme un peloton de ficelle à nous raconter. M'est avis qu'elle est dans les papelards du chef poulet, elle (San-Antonio, Ménage tes méninges)

2002 Pour que les apprenants acquièrent cette éducation, il faut que les enseignants l'aient eux-même acquise. On dit que " pour donner long comme la main, il faut avoir long comme le bras"

(Félicité Muhimpundu, Éducation et citoyenneté au Rwanda)

\section{CORPuS Web :}

si on lui en donne long comme le doigt, il veut en avoir long comme le bras [http://www. languefrancaise.net/bob/detail.php?id=49392] (15.12.2013)

C'est une satire qui croule littéralement sous le nombre de ses cibles (et sous un casting qui est l'équivalent franco-québécois de celui du peu mémorable Voyage des damnés) et s'enferre dans le piège du contenu : croire qu'en avoir long à dire revient à en avoir long à narrer, sans réel souci d'entraîner le spectateur à sa suite, un peu comme d'autres tombent dans le piège de la forme [http:// dvdtoile.com/Thread.php?94652] (15.12.2013)

REMARQUES : Long est un adjectif-adverbe de dimension ou de temps qui s'emploie ici également au sens figuré de 'beaucoup' et de 'beaucoup de temps'. Il reste toujours invariable. Le premier exemple de 1623 montre bien le rapport qui s'établit entre le sens dimensionnel (la longueur d'un bras, d'un doigt) et l'emploi comme quantifieur. La construction en avoir long $\grave{a}+$ verbe est un schéma lexicalisé. Le premier exemple du CW illustre la locution figée long comme le bras qui désigne les exigences exagérées de quelqu'un. 
Avouer haut

avouer tout haut : avouer à voix haute, franchement, ouvertement, publiquement Transitif

1667 CLITANDRE. Pour moi, je ne sais pas, mais j'avouerai tout haut

Que j’ai cru jusqu'ici Madame sans défaut. ACASTE. De grâces et d'attraits je vois qu'elle est pourvue ;

Mais les défauts qu'elle a ne frappent point ma vue (Molière, Le Misanthrope)

1833 Christine. (à Falkenskield)

Il vous trompe, il vous abuse.

ÉrIC. Non, mademoiselle ; ce que je dis, je dois le dire ; je suis trop heureux de l'avouer tout haut, (avec intention et la regardant) et de donner au parti que je sers ce dernier gage de dévouement (Eugène Scribe, Bertrand et Raton)

1848 il devina que le monarque prendrait cette route, et ne se mêlerait pas de la guerre de l'Occident. En n'avouant pas tout haut son projet d'invasion, Bonaparte ne pouvait néanmoins le cacher ; avec les diplomates il mettait en avant trois griefs (François de Chateaubriand, Mémoires d'outre-tombe)

1872 Elle avait aussi de grandes affaires, des affaires qu'elle pouvait avouer tout haut, et dont elle rebattait les oreilles des gens qui l'approchaient : un long procès qu'une famille noble ruinée l'avait chargée de suivre, et une dette contractée par l'Angleterre vis-à-vis de la France, du temps des Stuarts, et dont le chiffre, avec les intérêts composés, montait à près de trois milliards (Émile Zola, La Curée)

1884 De Falloux, plus hautain et plus cauteleux, appartenait à cette secte libérale dans laquelle étaient déjà réunis et de Montalembert et Cochin, et Lacordaire et de Broglie ; il appartenait, tout entier, aux idées du Correspondant, une revue qui s'efforçait de couvrir d'un vernis de tolérance les théories impérieuses de l'Église ; Veuillot, plus débraillé, plus franc, rejetait ces masques, attestait sans hésiter la tyrannie des volontés ultramontaines, avouait et ré- clamait tout haut l'impitoyable joug de ses dogmes (Joris-Karl Huysmans, À rebours)

1916 On en est incommodé. Nous nous regardons en hochant la tête et n'osant pas avouer tout haut que ça sent mauvais. On ne s'éloigne pourtant que lentement. Voici poindre dans la brume des dos courbés d'hommes qui sont joints par quelque chose qu'ils portent (Henri Barbusse, Le $\mathrm{Feu}$ )

1949 - Mais il se contente d'éliminer Arthur de notre vie, d'envelopper de silence cette affection malade. Abcès mal pansé : le pus coule en dedans. »

Brusquement, Roberte avoue, tout haut :

- Tu sais, papa, il y a une chose que je ne m'explique pas. J'écris toutes les semaines à Arthur : il ne m’a jamais répondu (Hervé Bazin, La Tête contre les murs)

Emploi absolu

1780 M. B. aura mardi toutes vos lettres, dont je veux tirer du moins les brouillons que je n'ai pas. Pour les miennes, faites-en ce qu'il vous plaira. J'écris toujours ce que j'ai dans l'ame ; j'avoue tout haut mes amis, et je me moque des caquets (Honoré de Mirabeau, Lettres originales écrites $d u$ donjon de Vincennes)

1846 - Et ce père, c'est...

- Eh bien! Caderousse, c'est le comte de Monte-Cristo.

- Bah!

- Oui ; tu comprends, alors tout s'explique. Il ne peut pas m'avouer tout haut, à ce qu'il paraît, mais il me fait reconnaître par M. Cavalcanti, à qui il donne cinquante mille francs pour ça (Alexandre Dumas père, Le Comte de Monte-Christo)

Pronominal

1948 Or, elle, elle était à la fois gênée et émue. Il lui aurait donné rendez-vous pour le lendemain qu'elle eût, avec la moindre résistance, accepté. Sans se l'avouer trop haut, elle désirait renouer (Maurice Druon, Les Grandes Familles) 


\section{CoRpus WeB :}

Aujourd'hui, on peut l'avouer haut et fort, que le gouvernement veut étouffer les populations réputées proches de l'opposition au su et au vu de la communauté internationale qui demeure silencieuse face à ces violences ethniques [http:// www.lejourguinee.com/index.php/fr/nouvelles/ societe/1473-violences-a-conakry-l-inquietanteattitude-du-gouvernement] (15.12.2013)

De toutes manières on le sait les déchets venus d'autres pays et non triés sont brulés chez nous, il n'y a vraiment plus besoin d'en faire un fromage surtout quand on sait qu'une personne âgée et son passé compte désormais pour beurre chez certains socialistes qui n'ont aucune crainte à l'avouer haut et clair [http://guinchard.blog.tdg. ch/archive/2013/03/31/dechets-plastiques-et-si-1exemple-venait-d-asie.html] (15.12.2013)

Je le savais, je connaissais mes sentiments à son égard, mais les avouer haut et fort ne ferait que rendre la chose plus réelle encore, pour ensuite quoi ? [http://www.berkeley-u.com/ t34348-quelques-explications-s-imposent-pvemy] (15.12.2013)

Ils semblent se rapprocher tous les deux, peut être pas s'avouer haut et fort qu'ils s'aiment [https://www.fanfiction.net/r/3556066/0/2] (15.07.2016)
Les signes de la crispation toute proche ont beau être tenus en respect, voire refoulés, ils ne s'accumulent pas moins avec une cruelle cohérence. Vient le moment où il faut s'avouer haut et net que «ça ne sera décidément pas possible ». Et passer son chemin sans crainte d'avoir péché par impatience : après tout, à chacun de fixer le point au-delà duquel une divine surprise paraît chimérique [http://www.juanasensio. com/archive/2013/10/12/alice-ferney-passesous-silence-olivier-rolin-tigre-papier.html] (15.07.2016)

Naoki. Ce connard. Comme s'il n'avait pas assez de problèmes. On lui rajoutait celui-là. Réellement, le jeune homme ne regrettait pas d'être venu aujourd'hui... Son collègue aurait fait ça derrière son dos, sans jamais lui avouer haute. Et, il ignorait ce qui l'énervait en réalité... [http:// inappropriate-city.forumactif.org/t489-heybrother-there-s-an-endless-road-to-rediscover-o] (15.07.2016)

REMARQUES : Haut est un adjectif-adverbe de lieu dimensionnel qui s'emploie ici au sens métaphorique de 'à haute voix' et 'publiquement' ou 'ouvertement'. Haut reste invariable dans la majorité des cas, mais dans le dernier exemple du CW, il est mis au féminin. Il est modifié par trop et, bien souvent, tout. Il apparaît en collocation avec les adjectifs-adverbes fort, clair et net. Notons l'emploi de réclamer haut. 


\section{Baer haut}

Aspirer haut

$\lambda$ descendre bas

\section{Baiser étroit}

Embrasser (sur la joue, la bouche) avec ferveur, étreindre étroitement

Transitif

-1200 Mauderanz et ses freres li sont venuz a piez,

Le souler et la chauce li a estroit baisié.

L’amiraux lor demande : «Qui estes,

chevalier?"

- Sire, dit Mauderanz, ne lou vos quier noier (Floovant [fin XII ${ }^{\mathrm{e}}$, 705)

+1200 a Mais li frans hon en ses bras le rechoit, Et si l'en baise ansdos les ieus estroit (Vie de saint Alexis [XIII'], p. 292, 441)

+1200 b Il se descharge de la somme,

Si la presente a la bourjoise ;

Et cele, a cui gaires n'en poise,

L'acole et baise mout estroit

(Le Sacristain $\left.\left[\mathrm{XIII}^{\mathrm{e}}\right], 240\right)$

-1250 Je quid Dix le veut avoir

Por la lumiere de soir

$[\ldots]$

Que que fust du recaoir,

Que fuisse lassus o toi :

Ja te baiseroie estroit.

Se j'estoie fix a roi,

suer douce amie

(Aucassin et Nicolette [ $1^{\mathrm{re}}$ moitié $\left.\mathrm{XIII}^{\mathrm{e}}\right]$, $\mathrm{XXV}$ )

\section{CORPUS WEB :}

L'acteur est un type assez baraqué avec un sexe énorme déjà bandé, il regarde la gosse en me regardant en même temps de coté. Je l'ai déjà fais tourner avec des adolescentes et il adore baiser étroit comme il dit [http://www. asstr.org/ Histoires_Fr/txt2012/fantasman_le_ casting_chapitre_2.8.html] (30.1.2014)

REMARques : Dans l'ancienne langue, baiser étroit réfère à un enlacement, en maintenant une forte pression avec la personne, le sujet ressentant un fort sentiment ou respect pour l'objet embrassé, entrant dans son intimité. Notons la collocation accoler étroit dans l'exemple de +1200b qui renforce l'idée d'étreinte. Estroit reste invariable et est modifié par moult. Dans l'usage actuel, le verbe baiser renvoie à l'acte sexuel humain dans un registre familier ou vulgaire. L'exemple du CW illustre ce sens dans un emploi absolu où étroit renvoie, par inférence, au vagin. VOIR AUSSI : accoler / embrasser étroit

\section{Baiser fort}

I. Embrasser sur la joue, la bouche, donner un baiser

Pronominal (réciproque)

1200 Vers lui se torne quant il l'ot ravisé, Par tel vertu se sont entr'acole, Tant fort se baisent et estraingnent soef, A poi ne sont estaint et definé (Ami et Amile, 180)

Transitif

1553 EUGENE. Elle s’appaise, Elle accourt, et plus fort me baise : Puis, s'arrestant, elle se mire Dedans mes yeux MESSIRE. Ô doux martyre ! (Étienne Jodelle, L'Eugène)

1832 Mais la mère la baisa plus fort et s'en alla ravie de la bonne aventure que les devineresses avaient dite à son Agnès (Victor Hugo, Notre-Dame de Paris)

1840 Le 12. Nous avons perdu une de nos pauvres, Annette la boiteuse, celle qui m'avait si fort baisée pour un raisin que je lui donnais. La pauvre fille ! J'espère qu'à présent elle prie pour nous dans le ciel (Eugénie de Guérin, Journal)

1896 On dirait, ta querelle, un enfant qu'on fait taire

Et qu'on baise bien fort au front, du moment qu'il s'est tu

Pour le récompenser du bon pli salutaire Pris d'obéir, conformément à la vertu (Paul Verlaine, Euvres poétiques complètes)

\section{Intransitif}

1578 Et là, celuy qui mieux sa lévre poseroit Dessus la lévre aimée, et plus fort baiseroit, Ou soit d'un baiser sec, ou d'un baiser humide, 
D'un baiser court ou long, ou d'un baiser qui guide

L'ame desur la bouche, et laisse trespasser Le baiseur qui ne vit sinon que du penser (Pierre de Ronsard, Le Second Livre des amours)

\section{Exécuter l'acte sexuel}

Transitif

2019 Wade le baisa fort alors, les coudes plantés de chaque côté de la tête de Russ, et ses hanches doublant leur rythme, alors qu'il regardait Russ dans les yeux (Blake Moreno, Si différent)

\section{CORPus WeB :}

Quand à lui faire l'amour les amis, sachez qu'en la pénétrant, on a l'impression de s'enfoncer dans la soie, le velours, mmmmmm tout chaud et trempé ! ça rentre tout seul après quelques coups de reins vous pouvez la secouer grave et la baiser fort et à fond! [http://www. journal-sexuel.com/salope/blonde-faite-pourbaiser-3] (30.1. 2014)

REMARQUES : Baiser fort (I) se disait du fait de poser ses lèvres sur quelqu'un, le sujet éprouvant généralement une grande tendresse ou des sentiments amoureux pour la personne embrassée. Baiser fort n'a aujourd'hui plus la même signification, étant donné que baiser ne s'emploie que rarement dans cette acception, mais réfère à un acte sexuel (II et CW). Fort reste invariable et est modifié par bien, plus, si, tant. Notons l'emploi de estraindre soef (ex. de 1200 ), ainsi que de secouer grave 'secouer fortement', dans le dernier exemple du CW.

\section{Baiser menu}

baiser souvent et menu : embrasser (sur la joue) très fréquemment

Transitif

$\sim 1170 \mathrm{Li}$ pere et la mere autressi La beisent sovant et menu. De plorer ne se sont tenu : Au departir plore la mere, Plore la pucele et li pere (Chrestien de Troyes, Erec et Enide, 1459)

-1200a Ernaus le baise et sovent et menu Les iex, la face et le col et le bu (Aliscans [fin $\mathrm{XII}^{\mathrm{e}}$ ], 2216) 1200b Li peres baise son fil menu souvant (Ami et Amile, 3422)

1235 Li senescax s'en vint au roy, Qui s’amie avoit delés soi, Et entre ses bras son enfant, Qu'il baisse menu et souvent (Philippe de Remi, sire de Beaumanoir, $\mathrm{La}$ Manekine, 6614)

\section{CORPuS Web :}

Qui n’a jamais eu l'impression de se faire baiser menu par le propriétaire du cinéma qui vend aux marchands le fait établit qu'on ne peut pas ne pas prêter attention à leurs produits à la con lorsqu'ils s'affichent grossis 346 fois à l'écran, comme si on nous les collait à la gueule ? [http:// scandi-cafe.toile-libre.org/?p=205] (30.1.2014)

REMARQUES : Usité en ancien français et généralement accompagné de l'adverbe souvent, baiser menu désigne le fait d'embrasser quelqu'un continuellement. Le sujet est fréquemment un parent donnant à un enfant de nombreux petits baisers. On peut se demander si dans l'exemple de 1200b menu souvent n'est pas devenu un adverbe composé. Menu reste invariable malgré le pronom objet antéposé au verbe (ex. de 1170). L'exemple du CW contient le verbe baiser employé au sens métaphorique moderne de 'tromper, rouler', dans un langage peu soutenu.

\section{Baiser plein}

baiser tout plein : embrasser en posant les lèvres un grand nombre de fois, beaucoup, partout

Transitif

1936 Je serrais le petit Marcel sur mon sein, sur mon visage, entre mes jambes, je le baisais tout plein, il barbotait en moi, il était notre fils, j'étais saoule d'enfant (Henry de Montherlant, Les Jeunes filles)

REMARQues : Plein est un adjectif-adverbe de quantité qui se dit, dans ce contexte, du fait d'embrasser quelqu'un avec profusion, le sujet posant ses lèvres le plus souvent possible sur l'objet dans le but de couvrir de baisers une grande superficie du corps de l'objet (ici : d'un enfant). Plein reste invariable, étant modifié par l'adverbe d'intensité tout qui vient en renforcer le sémantisme. 


\section{Baiser soef}

Embrasser sur la joue, la bouche, délicatement, avec douceur

Transitif

1200 Agaie jut par desor l'erbe a dans, Elle la baisse soef et bellement.

Deus, dist Agaie, qui formas mer et vent, Guairis Guibert par ton conmendement (La Prise de Cordres et de Sebille, 2815)

1300 O le Guillaumes, s a Guiborc regardee ; $\mathrm{L}$ eve dou cuer li est as ious montee ; Souavet l a baisie et acolee. Dist li quens : Dame, nen estre trespensee ! (Aliscans [R], 1879, manuscrit L)

1555 Si de mes bras le tenant acollé, Comme du Lierre est l'arbre encercelé, La mort venoit, de mon aise enuieuse : Lors que souef plus il me baiseroit, Et mon esprit sur ses levres fuiroit, Bien je mourrois, plus que vivante, heureuse (Louise Labé, Sonnets, élégies, débat de folie et d'amour)

Pronominal (réciproque)

$\sim 1230$ Et quant il s'entrelaissent, si se sont regardé ;

Lors se corurent sore, si se baisent souef (Gui de Bourgogne, p.120)

REMARQUES : Usuel dans l'ancienne langue, soef réfère au fait de poser ses lèvres sur quelqu'un avec douceur et délicatesse, procurant une sensation agréable aux acteurs ; le geste est généralement accompagnée d'un enlacement. Notons la collocation avec le verbe accoler, renforçant l'idée d'étreinte au baiser, et la coordination de soef avec bellement.

\section{Baiser utile}

Avoir des relations sexuelles dans le but d'obtenir un avantage

Emploi absolu

1982 Je pense même que c'est elle qui a inventé l'expression le jour où sa meilleure amie, Dotty, vous savez, Dorothée, les papeteries, lui a demandé si ça ne la gênait pas, ces centimètres surajoutés de sexes d'hommes qu'elle actionnait et aspirait à longueur de journée, et Doudouce lui a répondu : « Mais non, voyons, je baise utile!»

(Philippe Labro, Des bateaux dans la nuit)

2013 Et Fabienne a glissé le revolver dans le tiroir de ma table de nuit et elle a répété Simplement parce que c'est utile. Comment expliquer à une personne qui marche utile danse utile baise utile pense utile et fait les choses comme il se doit quand on a l'utilité d'un cerveau qui voit midi à midi, et quatorze heures à quatorze heures que tout n'est pas aussi simple (Odile Barski, Quartier libre)

CoRpus Web :

On apprendra qu'elle est parvenue où elle se trouve grâce notamment à une vigilance sans faille à « baiser utile » (les mots figurent en toutes lettres dans la biographie de Jacqueline Rémy, même si aucun nom d'amant " utile " n'est mentionné) [http://www.liberation.fr/medias/2009/05/04/ cendrillon-dati_556007] (3.2.2014)

Baiser utile, baiser futile... les « D » sont jetés ! [http://www.conseilmunicipal.org/ article-baiser-utile-baiser-futile-les-d-sontjetes-104924135.html] (3.2.2014)

$\mathrm{K}$ baisons utile, baisons futile, mais baisons à fond ! Ca rend moins cons ! [http://fr.rec.sport. vtt.narkive.com/AXN66e4i/video-jeu-a-la-con.2] (3.2.2014)

REMARQUES : Baiser utile se dit du fait d'avoir des relations sexuelles en obtenant un autre bienfait que le plaisir charnel, le sujet voulant bénéficier d'un avantage pouvant être d'ordre financier, social ou autre. Utile reste invariable. Notons l'expression rimée baiser utile, baiser futile. Mentionnons également l'emploi de danser utile, marcher utile, penser utile. La citation met en évidence la tendance à la productivité de cette matrice.

\section{Baisser dru}

Baisser vivement, vigoureusement, rapidement Transitif

1651 Le seul Ragotin n'avait pas envie de rire et sa colère s'était tournée contre l'Olive qui, s'en sentant injurié, le porta tout brandi, comme l'on dit à Paris, sur le lit que faisait la servante et là, d'une force d'Hercule, il acheva de faire tomber ses chausses, dont 
la ceinture étoit déjà rompue, et haussant et baissant les mains dru et menu sur ses cuisses, et sur les lieux voisins, en moins de rien les rendit rouges comme de l'écarlate (Scarron, Le Roman comique)

\section{CORPUS WEB :}

Que nenni ! du galop actif un petit bout vite, pas mal de trot normal mais aussi du pas (la demi heure legale du Gros au depart) et pour partir, et pour rentrer un dylou poilu sec. Ben ça fait baisser dru une moyenne. :D [http:// www.1cheval.com/membre/forum/ethologues/ sujet-8495-22-trombinoscope] (3.2.2014)

En fait, je vais un peu vite : dés que ca baisse $d r u$, je lis 3 et quand ca rebaisse (dru ou pas), je lis 5. Et quand ca remonte, je lis 1 , puis 3 si ca remonte très vite... etc.... et entre les deux, ben ca corrige, comme ca peut :-))... [http://www.dailybourse.fr/forum-CAC-40-Les-vagues-d-Elliotten-geometrie-fractale-vtptc-3991-start-816.php] (3.2.2014)

REMARQUES : Baisser dru réfère à la force et, le cas échéant, à la densité d'un mouvement multiple. Dans l'exemple de 1651, baisser se trouve en opposition avec le verbe hausser et est accompagné d'un autre adjectif-adverbe de manière : menu ('par des petits mouvements répétés et rapides'). Dru reste invariable. Notons l'emploi de hausser dru et menu.

\section{Baisser fort}

I. Se pencher fortement, se courber vers l'avant Pronominal

1559 Et, en parlant à elle, se baissa fort pour la regarder, et apperceut la bouche si rouge et si plaisante qu'il ne se peut tenir luy haulser le voyle pour veoir si les yeulz acompaignoient le demourant, ce qu'il trouva (Marguerite d'Angoulême, Heptaméron, p. 219, 42)

1631 Dit le druide, que c'est un grand abuseur, et que si vous sçaviez en quoy Polemas s'en est voulu servir, vous jugeriez bien que l'un et l'autre est bien digne de chastiment, mais le discours en seroit trop long pour ceste heure que je vois le soleil se baisser si fort, que vous n'avez pas du temps à perdre pour vous en retourner de jour (Honoré d'Urfé, L'Astrée)
1686 Il me dit en me prenant par les épaules, et en se baissant fort, (car j'étois fort baissé :) Levez-vous, Bussy ; et comme je ne le fis pas d'abord, il me redit encore d'un ton plus gracieux : Hé, levez-vous, Bussy (Roger de Bussy-Rabutin, Les Lettres de messire Roger de Rabutin)

1696 Le roi d'Angleterre se baissa fort, comme s'il eût voulu embrasser ses genoux ; le roi l'en empêcha, et l'embrassa à trois ou quatre reprises fort cordialement (Mme de Sévigné, Correspondance)

II. Diminuer fortement de hauteur Intransitif

1662 ÉRASTE. Mes Fâcheux à la fin se sont-ils écartés?

Je pense qu'il en pleut ici de tous côtés. Je les fuis, et les trouve ; et pour second martyre,

Je ne saurois trouver celle que je desire.

Le tonnerre et la pluie ont promptement passé,

Et n'ont point de ces lieux le beau monde chassé.

Plût au Ciel, dans les dons que ses soins y prodiguent,

Qu'ils en eussent chassé tous les gens qui fatiguent !

Le soleil baisse fort, et je suis étonné Que mon valet encor ne soit point retourné (Molière, Les Fâcheux)

1859 Lorsque nous arrivâmes à Harlingen, toute la population du dimanche nous attendait sur la double jetée du port, où nous entrions au moment où la marée baissait si fort que nous faillîmes ne plus trouver assez d'eau (Maxime Du Camp, En Hollande)

1903 Que ne puis-je légitimement espérer d'une application plus assidue dans une époque où le niveau intellectuel a si fort baissé (Maurice Barrès, Mes cahiers)

1967 La mode des jeux de perspective a fort baissé au XIX ${ }^{\mathrm{e}}$ siècle ; mais elle a été remise en honneur, curieusement, par le surréalisme (Jeux et sports) 
1991 Lors de notre déplacement, la température baissa si fort, paraît-il, que je faillis mourir (Amadou Hampâté Bâ, Amkoullel, L'Enfant peul)

III. Mettre à un niveau moins haut, descendre fortement quelque chose

Transitif

1770 Peu-à-peu on baissa si fort le prix de leurs denrées, on haussa si fort le prix de celles du monarque, qu'ils perdoient considérablement (abbé Raynal, Histoire philosophique et politique des établissements et du commerce des Européens dans les Deux Indes)

1967 une foule qui gagnait ses loisirs à la sueur de son front, marchait, s'attablait au café et baissait très fort les paupières quand, dans ses eaux territoriales, se glissaient d'inquiétantes espèces mal nourries (Claire Etcherelli, Élise ou La Vraie Vie)

1981 Le proviseur lui remet un petit billet rose, comme un diplôme, et lui caresse la joue « tu diras à ton père que je suis fier de toi ». Yves baisse si fort la tête que le proviseur le prend par le menton et lui dit « tu n'es pas heureux ? " Mademoiselle Triboulet explique « il est timide vous savez et... » Elle regarde la classe. Hésite. Le proviseur attend. MademoiselleTriboulet ajoute « ... mais très consciencieux » (Yves Navarre, Biographie)

REMARQUES : Baisser fort est employé dans des contextes syntaxiques et sémantiques variés qui sont à la base des nuances sémantiques adoptées. (I) renvoie à un mouvement du corps, (II) à la diminution du prix, de la température, de la mode, du niveau intellectuel, (III) au fait de baisser activement le corps ou le niveau de quelque chose. Notons l'emploi peu usuel de la forme pronominale dans l'exemple de 1631. Fort reste invariable et est modifié par si, très. Notons l'emploi de hausser fort.

\section{Barboter menu}

Parler rapidement et de manière indistincte, incompréhensible

Intransitif

1365 Juliens va devant, par les plains de Surie; Et Esmeret le sieut, sour .i. coul d'Orcanie ; Li prestrez est derrière, toudis demi archie, Barbetant plus menut que singes c'on tarie (Li Romans de Bauduin de Sebourc, Chant V, 521)

-1475 La singe commença lors a barbeter menu et souvent sus moy. Et quant elle eut fait son personnaige, elle couru sus a ceulx qui grever me vouloient, menant ung tel bruit qu'elle sambloit mieulx foursenee que autrement, et tant fist que tous les singes se retrairent en la forest (Le Roman de Perceforest, 1955)

REMARQUES : Barboter menu caractérise ici le fait de parler dans sa barbe, de grommeler en débitant rapidement une grande quantité de mots, incompréhensibles pour l'interlocuteur. La collocation menu et souvent, qui signifie 'très fréquemment', est figée dans la langue ancienne.

\section{Barder sec}

Devenir très dangereux, prendre une tournure très violente, se gâter

Emploi absolu

1933 - Il y a eu beau tapage une minute passée.

- Vous arrivez trop tard de rien.

- Ils se sont causé du pays un bon coup.

- Pour dire tout juste, ça bardait grand sec (Marcel Aymé, La Jument verte)

2008 - Ça va barder sec pour tous ceux qu'ont pas déniché l'poison, dit celui qui avait la responsabilité du tabouret (Michel Folco, Même le mal se fait bien)

2012 Au Nord, ça devait barder sec, enfin, on peut le penser, car c'était le black-out, pas une nouvelle ne filtrait en provenance de la Zone Inquiète, juste des bruits, des rumeurs, des odeurs, de poudre, de gaz, de sang (Arthur Bernard, Paris en 2040)

\section{CORPUS WEB :}

C'est vous le boucher et ça va barder sec ! [http://2point0.20minutes-blogs.fr/archive/2010/ 
04/16/c-est-vous-le-boucher-et-ca-va-barder-sec. html] (4.2.2014)

REMARQUES : Barder sec s'emploie dans une situation qui devient dangereuse, pénible. Le sujet étant impersonnel, sec reste invariable et est modifié par grand, produisant la locution lexicalisée Ça barde (grand) sec. Notons l'emploi adverbial de grand comme intensifieur de sec.

\section{Barrer sec}

I. Partir, s'en aller brusquement, fuser Pronominal

1956 Que voulez-vous qu'elle fasse d'autre ?... qu'elle travaille [...] ? Comme ménagère éprouvée quand les trois ou quatre premiers gigolos l'ont engrossée pour se barrer aussi sec, leur coup fait (Jean-Paul Clébert, Clôtures)

Intransitif

1977 Question débagoule c'était le contraire de Grenouillard... le quolibet barrait sec (Alphonse Boudard, Les Combattants du petit bonheur)

II. Tenir la barre d'une embarcation Emploi absolu

2012 Notre petite embarcation passait souvent inaperçue mais nous devions quand même nous méfier des grands navires : à plusieurs reprises nous dûmes barrer sec pour éviter de se faire éventrer par l'un d'eux, qui ne prêtant pas attention au bateau d'un simple pêcheur, ne voyait d'aucune manière un souci à l'envoyer par le fond (Léonard Dacier, Liondacier)

CORPus WeB :

Quant à moi, jen'ai qu'une hâte, me barrer sec de ce trou à rats et aller siroter un scotch au Lapin Agile ! [http://www.pion.ch/colles/newquiz.ph $\mathrm{p}$ ? nocolle $=2661 \&$ PHPSESSID $=42 \mathrm{le} 7 \mathrm{~g} 69 \mathrm{st} 2 \mathrm{uta}$ cgtqd478efp5] (5.2.2014)

T'as intérêt à te barrer sec quand ton visa expirera sinon tu sais ce qui t’attend !! Ça donne pas envie de débarquer au pays des kangourous cette histoire... [http://alsacedownunder.centerblog. net/4389179-Advance-Australia-Fair-] (5.2.2014)

REMARques : Propre au langage familier, (se) barrer sec (I) désigne le fait de partir, voire s'en- fuir, brusquement, en témoignant d'une intention blessante. Dans le langage maritime, il réfère à la barre, donc au fait de gouverner fermement un bateau. $S e c$ reste invariable.

\section{Bâtir éternel}

Construire pour l'éternité

Emploi absolu

1910 Ces barbares, écartant le bois, et la brique et la terre, bâtissent dans le roc afin de bâtir éternel! (Victor Segalen, Aux dix mille années / Stelae

\section{Bâtir haut}

Construire des bâtiments hauts

$\lambda$ creuser profond

\section{Battre bas}

Battre discrètement, à peine, en silence Intransitif

1920a Ton cœur d'oiseau battait tout bas : La chambre était très sombre... L'immortelle, et l'œillet de mer Qui pousse dans le sable, La pervenche trop périssable, Ou ce fenouil amer Qui craquait sous la dent des chèvres, Ne vous en souvient-il, Ni de la brise au sel subtil Qui nous brûlait aux lèvres? (Paul-Jean Toulet, Les Contrerimes)

1920b Toutes ensemble avaient glissé au silence on eût dit par un agenouillement, et elles se penchaient sur leur silence, ... ni ces mains qui battent tout bas la mesure, ni ces têtes qui battent tout bas le silence (Henry de Montherlant, La Relève du matin)

CORPUS WEB :

Il y a des pluies qui lavent, qui rincent, qui essorent, qui épuisent le ménage, polissent jusqu'à la douceur de la peau neuve.

Il y a à la pluie, son tempérament, ses humeurs.

Celle d'hier était belle, sans doute parce que le rythme intérieur battait bas et lourd, parce que tout se faisait hymne et écho par le lourd pas du cœur. Amplifié par les graves et la 
lenteur [http://chroniquesdunelibrairenomade. weebly.com/2/post/2013/06/double-je.html] (5.2.2014)

Dans mon village il y a : des fermes, des maisons par milliers, une mairie, une pharmacie, des vieilles personnes et puis des chats, des chats qui se battent tout bas [http://ecole.cote.free.fr/ JOURNAL/poesie-2.htm] (5.2.2014)

Les fléaux battent bas les vigueurs de mon corps comme un bœuf bâte au bât du sillon qu'il ignore, et que genou plié sur nos champs d'inculture, on vienne supplier de briser nos mâtures ! [http://annaondu.blogspot.co.at/2010/03/ abattage.html] (5.2.2014)

REMARQues : Pris au sens figuré, battre bas exprime l'atténuement et se dit du fait de produire un son léger, doux sous l'impulsion d'un mouvement, notamment dans la collocation tout bas. En parlant du cœur, il réfère au fait qu'il est animé de battements faibles, à peine perceptibles. Bas reste invariable et est modifié par tout. Notons la coordination avec l'adjectif-adverbe lourd dans le premier exemple du CW, et l'usage pronominal réciproque au sens de 'lutter' dans le deuxième exemple. Dans le dernier exemple $\mathrm{du}$ CW, battre bas, en construction transitive, est synonyme d'abattre ; l'auteur l'emploie peut-être, dans le style soutenu, pour éviter le tour pléonastique critiqué d'abbattre bas.

\section{Battre chaud}

À chaud, avec fureur

$\pi$ battre froid

\section{Battre dur}

I. Battre avec force, avec vigueur (également en parlant du cœur)

Intransitif

1874 VULCAIN. (essuyant avec une éponge ses membres en sueur)

Le monde se refroidit. Il faut chauffer les sources, les volcans et les fleuves qui roulent des métaux sous la terre !

- Battez plus dur ! à pleins bras ! de toutes vos forces!

Les Cabires se blessent avec leurs marteaux, s'aveuglent avec les étincelles, et, marchant à tâtons, s'égarent dans l'ombre
(Gustave Flaubert, La Tentation de saint Antoine)

1896 La mer est dure et mon cœur dur Comme la vengeance et la haine, La mer moins que mon cœur bat dur. La mer est calme, et mon cœur, donc ! Tout est passé, trombe et bonace - mon cœur est calme, mais tant, donc !

La mer est immobile, et moi Je suis impassible au possible (Paul Verlaine, Euvres poétiques complètes)

1914 Prince du dernier jour

Garde sa foudre

De nous réduire en poudre

Au noir séjour.

Bélier des lourds Arvernes

Qui battais dur

Comme un ours des cavernes

L’angle du mur (Charles Péguy, Quatrains)

1929 Puis, ça a grandi, et ça s'est trouvé, subito, en face de moi, à dix mètres de l'autre côté de la fontaine. Je suis resté un moment, tu sais, ça battait dur, sous la chemise... Cette chose droite regardait Gagou. Petit à petit, je me suis dit : « Mais, César, c'est pas Ulalie, ça ? » Ça semblait bien, en tout cas (Jean Giono, Colline)

II. Lutter, se battre de toutes ses forces Pronominal

1931 Il attira Gaspard, le poussa contre la muraille. «Qu'est-ce que c'est que ce pâtissier? Me le donnes-tu comme bon? » - Vous verrez, on se battra dur.

Rouvet, après l'avoir soupesé de son petit œil vert, donnait des conseils à son client (Henri Pourrat, La Tour du Levant ou Quand Gaspard mit fin à l'histoire)

1933 Toutes les craintes d'avant n'étaient rien. C'est maintenant qu'elles commencent. Il va falloir voir juste, se battre dur. Des puissances d'action désespérées se lèvent au cœur de Christine, quelque chose d'une gravité, d'un sérieux écrasants (Joseph Malègue, Augustin ou Le Maître est là) 
1947 - Pis, j'ai entendu qu'ils avaient débarqué en Normandie... Qu'ça se battait dur... Qu'i f'saient tout pour pas être rejetés... Qu'y avait des parachutistes plein le ciel... Enfin ça y est, quoi (René Fallet, Banlieue sud-est)

1953 CAUCHON. (demande soudain sourdement) Et tu as à te défendre de cette façon-là depuis le début du procès?

JEANNE. Depuis que je suis prise, Messire - toutes les nuits. Dès que vous me renvoyez là-bas, le soir, cela recommence. Je me suis habituée à ne pas dormir, c'est pour cela que quelquefois, le lendemain, quand on me ramène devant vous, je réponds un peu de travers. Mais c'est long toutes les nuits et ils sont forts et rusés. Il faut que je me batte dur. Seulement, si j'ai une jupe... (Jean Anouilh, L'Alouette)

1961 Et parce qu'il se battait si dur, et pour une affaire qui tenait tant au cœur de tout homme du pays, on finissait presque par n'avoir plus d'autres pensées que les siennes (Zoé Oldenbourg, Les Cités charnelles)

\section{CORPUS WEB :}

L'entraîneur des Black Stars du Ghana, Kwesi Appiah, exhorte les joueurs de l'équipe nationale à ne pas se contenter de leur large victoire 6-1 en match aller contre l'Egypte mais à continuer par se battre durs pour le match retour en vue de se qualifier pour le mondial 2014 [http:// www.livefoot.fr/afrique/egypte.php?p=5] (10.2. 2014)

REMARQUes : Battre dur réfère au battement du cœur (I) ou au fait de lutter (II). Dur reste invariable et est modifié par si. Battre dur appartient à la langue commune, l'emploi impersonnel constituant une variante orale informelle : ça bat dur. Dans l'exemple du CW, dur s'accorde avec le sujet au pluriel, ce qui donne lieu à une interprétation de prédicat second, mais on peut également le considérer comme une hypercorrection. Notons l'emploi de voir juste.

\section{Battre frais}

frais battu 'venant d'être battu'

$\lambda$ battre fort, ex. de 1653

\section{Battre fort}

I. Frapper fort, porter des coups puissants

Transitif

+1250 Renars ne muet ne pie ne main, Bien fait semblant qu'il n'est pas sain. Ysengrin l'a batu si fort, Enz ou champ l'a laissie pour mort : Li baron sont de lui parti (Le Roman de Renart [2 ${ }^{\mathrm{e}}$ moitié XIII $]$ ], VI, 1341)

1558 Mais pour cela personne n’y alloit, sinon que s'il sortoit du monde, c'estoit pour aller voir maistre Jehan du Pontalais, qui faisoit tousjours battre plus fort son tabourin. Quand le prescheur veid qu'il ne se taisoit point et que personne ne luy en venoit rendre response : Vrayement dit-il, j'iray moy-mesmes (Bonaventure Des Périers, Les Nouvelles Récréations et joyeux devis)

1653 JAPHET. Ha! Messieurs, suspendez la sentence mortelle!

Je ne suis point voleur, je ne suis seulement Qu'homme à bonne fortune, ou bien fidel Amant ;

De plus, l'on m'a battu bien fort depuis une heure :

Si frais battu, Messieurs, est-il juste qu'on meure?

(Paul Scarron, Don Japhet d'Arménie)

1721 Hier, j’avois mille affaires dans la maison ; je sortis, et je demeurai tout le jour dehors. Je crus, à mon retour, qu'il me battroit bien fort ; mais il ne me dit pas un seul mot. Ma sœur est bien autrement traitée : son mari la bat tous les jours ; elle ne peut pas regarder un homme, qu'il ne l'assomme soudain (Montesquieu, Lettres persanes)

1843 Hélas ! mon Dieu ! ce que j'avais tant redouté était arrivé. Oui, je l'avais dit à mon frère, un jour mon mari me battra si fort... si fort... que je serai obligée d'aller à l'hospice. Alors... mes enfants... qu'est-ce qu'ils deviendront ? (Eugène Sue, Les Mystères de Paris) 
1907 Et pour persuader sa femme, il la bat très fort. Après quoi il sort et s'en va dans la forêt. Mais, en chemin, il rencontre le vali qui va à la chasse (Claude Farrère, L'Homme qui assassina)

Pronominal

1325 Et com plus, ce te fais fermaille, Se batent fort et aigrement, Tant ont plus d'amonnestement De l'un faire à l'autre moleste Du monde, qui leur amonneste De quanqu'il puet le mal à faire (Watriquet de Couvin, Dits, p. 241, 321)

1866 Donc, nous nous tiendrons au milieu, en empêchant qu'on ne se batte trop fort. Mais l'Autriche perdra quelques plumes de son aile, et La Chaussée ne sera pas maréchal de France. Tu sais bien que j'ai fait beaucoup de démarches pour lui (Gustave Flaubert, Correspondance)

1868 - Voilà six grands mois que nous avons quitté l'Europe, répondit Paganel, je ne puis donc savoir ce qui s'est passé depuis notre départ, sauf quelques faits, toutefois, que j'ai lus dans les journaux de Maryboroug et de Seymour, pendant notre traversée de l'Australie. Mais, à cette époque, on se battait fort dans l'île d'Ikana-Maoui (Jules Verne, Les Enfants du Capitaine Grant)

II. Battre avec force (le cœur, le sang, la mer) Intransitif

1592 Quand la vertu mesme seroit incarnée, je croy que le poux lui battroit plus fort, allant à l'assaut, qu'allant disner : voire il est necessaire qu'elle s'eschauffe et s'esmeuve (Michel de Montaigne, Essais)

1778 En m'élançant sur le cheval de Mlle de Graffenried je tremblais de joie, et quand il fallut l'embrasser pour me tenir, le cœur me battait si fort qu'elle s'en aperçut ; elle me dit que le sien lui battait aussi par la frayeur de tomber ; c'était presque, dans ma posture, une invitation de vérifier la chose (Jean-Jacques Rousseau, Les Confessions)
1839 Sur la jetée, l'on attendait le paquebot de Brighton, que le mauvais temps retenait... la mer battait fort, les bateaux rentraient, hommes et femmes tiraient la corde. La lune, les feux rouges et blancs des fanaux donnaient à cette soirée un assez bel effet (Jules Michelet, Journal)

1842 Le peintre garda la main d'Adélaïde dans les siennes, une même chaleur et un même mouvement leur apprirent alors que leurs cœurs battaient aussi fort l'un que l'autre (Honoré de Balzac, La Bourse)

1864 Enfin il se décida, monta, traversa un long vestibule, entendant son sang battre si fort dans ses tempes, qu'il couvrait pour lui le bruit de ses pas (George Sand, Le Marquis de Villemer)

1910 le sang de l'espoir bat plus fort aux veines de la bête et son désir grandit de la pâture prochaine (Louis Pergaud, De Goupil à Margot : histoire de bêtes)

1925 Leurs cœurs, ensemble, avaient battu plus fort au jaillissement de la lumière, à l'éveil sonore du grelot (Maurice Genevoix, Raboliot)

1936 Élisabeth s'assit sur une marche de l'escalier et prit sa tête dans ses mains pour mieux réfléchir, mais son cœur battait trop fort et tous ses efforts pour se recueillir demeuraient stériles (Julien Green, Minuit)

1939 BERTHA. Si tu veux être franc avec toimême, avoue que ce qui faisait battre le plus fort ton cœur, dans les forêts hantées, c'était d'apercevoir quelque hutte abandonnée de bûcheron, d'y entrer en courbant la tête, d'y trouver, avec l'odeur de meubles moisis, quelque charbon mal éteint où rôtir une grive et allumer ta pipe... (Jean Giraudoux, Ondine)

1945 Son cœur battait si fort qu'elle en perdait le souffle, épiant le jeune homme et craignant malgré tout qu'il l'aperçût... il leva la tête, replia son journal et s'engagea dans la rue (Gabrielle Roy, Bonheur d'occasion) 
CORPUS WEB :

Je l'ai vue envoyer des Mangemorts à travers le hall d'un coup de baguette. Je l'ai vue se battre, forte, rapide... [http://www.hpfanfiction.org/fr/ viewstory.php?action $=$ printable\&textsize $=0 \&$ sid $=23765 \&$ chapter $=$ all $](10.2 .2014)$

Remarques : Fort est un adjectif-adverbe de degré qui se combine librement avec les verbes, avec quelques collocations usuelles, dont battre fort. Il reste invariable et est modifié par, bien, le plus, plus, si, très, trop. Dans l'exemple du CW, cependant, fort s'emploie en tant que prédicat second syntaxiquement détaché s'accordant avec l'objet direct au féminin antéposé au verbe (style littéraire). Notons l'emploi de battre frais.

\section{Battre froid}

I. Être d'un tempérament froid, distant; traiter avec froideur (opposé à battre chaud 'avec ardeur')

Emploi absolu

1604 Après que mondict sieur mareschal de Biron fut parti de Guyenne, fut en sa place subrogé le mareschal de Matignon, un très-fin et trinquat Normand, et qui battoit froid, d'autant que l'aultre battoit chaud ; et c'est ce qu'on disoit à la Cour, que le Roy et la Royne disoient qu'il falloit und tel homme au roy de Navarre et au pays de Guyenne, car cervelles chaudes les unes avec les autres ne font jamais bonne soupe (Pierre de Bourdeille, Euvres complètes)

1734 Comme je ne répondais qu'à ses expressions, et non pas à ses pensées, qu'il ne pouvait pourtant pas cacher au point qu'on ne le démêlât dans ce qu'il disait, je me contentai de battre froid, de supprimer l'accueil et les remerciements que je lui avais faits (Pierre de Marivaux, Le Cabinet du philosophe)

\section{Battre en procurant une sensation de froideur \\ Intransitif}

1626 Mais quand le peu de sang qui restoit aux veines, regorgeant demy figé soubs l'estreincte de ses embrassemens, vint à luy battre froid au visage, il se réveilla en sursaut (Marie Le Jars de Gournay, Le Proumenoir de Monsieur de Montaigne)
III. battre froid (à) quelqu'un : lui manifester de la froideur

Transitif

1637 SILINDE. Que tu fais bien la fine?

Quand tu veux déguiser que tu fais bonne mine,

Que tu m'as battu froid dans le commencement (L. C. Discret, Alizon)

1780 Alors toute relation a fini entre nous ; il m'a battu très-froid, et m'a traité même assez lestement. Cependant, il y a environ un mois, qu'il me dit de ne pas manquer de lui parler au moment où je sortirais d'ici, et que cela m'était important. J'avoue que dans la terrible inquiétude où je suis depuis quatre-vingt-dix ou cent jours sur le compte de mon amie, ce mot me remua jusqu' au fond de l'âme

(Honoré de Mirabeau, Lettres originales écrites du donjon de Vincennes)

1784 Le lendemain, mon amant, qui m'avait toujours battu-froid depuis son entretien avec le bourgeonné, me parla d'un air plus-ouvert ; il me proposa la promenade, et me fit-descendre chés la-G. Il ne me fut pas difficile de comprendre son dessein

(Nicolas Rétif de la Bretonne, La Paysanne pervertie ou Les Dangers de la ville)

1835 Si je devenais un imbécile, si je fermais mon salon, si je n'allais plus à l'opéra, il pourrait peut-être songer à s'arranger avec une autre maison, encore je ne le crois pas de cette force de tête-là. Il va te battre froid cinq ou six jours, après quoi il y aura explosion de confiance. C'est le moment que je crains (Stendhal, Lucien Leuwen)

1890 - Alors, avoue-le, ce sont les Lachesnaye qui t'ont battu froid.

Sans doute, depuis son mariage avec M. de Lachesnaye, Berthe avait cessé d'être pour elle ce qu'elle était autrefois (Émile Zola, La Bête humaine)

1922 C'est curieux, les gens à qui je parle pour la première fois sont toujours très gentils, puis la seconde ils le sont moins, la troisième fois ils me battent froid ; la quatrième fois n’a pas lieu : ils ont fait ceux 
qui ne me reconnaissaient pas (Henry de Montherlant, Le Songe)

2007 Pour la petite histoire, elle aurait également eu la peau d'Armand Déüs qui ne manquait pas une occasion de la battre froid (Didier Laurens, Monaco)

Intransitif

1722 COLOMBINE. (à part les premiers mots)

Battons-lui toujours froid. Tous les diamants y sont, rien n'y manque, hors le portrait que monsieur Lélio a gardé. C’est un grand bonheur que vous ayez trouvé cela, je vous rends la boîte (Pierre de Marivaux, La Surprise de l'amour)

1936 Pourtant je rassurai ma mère et la suppliai de ne plus me faire retourner au lycée. Continuer à voir Sara et lui battre froid, alors que tout mon être s'élançait vers elle, c'était vraiment au-dessus de mes forces (André Gide, Geneviève ou La Confidence inachevée)

Pronominal (réciproque)

1904 Ils ne touchèrent plus à ce sujet, de toute l'après-midi ; mais ils se battaient froid, en affectant une politesse exagérée, inaccoutumée entre eux, surtout de la part de Christophe. Les mots lui restaient dans la gorge (Romain Rolland, Jean-Christophe. Le Matin)

1922 Les choses en sont là... La semaine suivante, nous sûmes que les Gougier et les Bonnarjaud «se battaient froid " (Colette, La Maison de Claudine)

1990 J'avais retrouvé Anna par hasard dans le hall de l'Hôtel Imperial à Tokyo, où Albert lui avait fixé rendez-vous. Nous nous battions froid. L'aventurière sortait, passablement sonnée, d'un voyage de trois semaines en Transsibérien où, à travers la Russie et la Chine, elle n'avait fait que piller le caviar d'un apparatchik de Vladivostok (Hervé Guibert, À l'ami qui ne m'a pas sauvé la vie)
CORPUS WEB :

$350 \mathrm{ml}$ de crème à battre froide (de la 20\% MG minimum) [http://blogdaude.canalblog.com/ archives/2007/04/11/4591009.html] (10.02. 2014)

REMARQUES : Battre froid se dit du fait de traiter quelqu'un avec froideur en lui adressant des paroles sèches, froides, glaciales. Notons la collocation battre chaud, sémantiquement opposée à battre froid, dans l'exemple de 1604. Froid reste invariable et est modifié par toujours, très. L'emploi assez limité de modifieurs souligne la forte lexicalisation de ce tour. Dans l'exemple du CW, froid fonctionne comme prédicat second qui s'accorde en genre avec la crème.

\section{Battre laid}

Battre avec méchanceté

Transitif

1250 La dame est o palès, ainsi com jen vous di, Où lez mains ot liées par forche et de tel bri Que le sanc tout vermeil dez onglez li sailli.

Et bret et cria durement à haut cri.

Herchembaut i sourvint, qui moult lait la bati (Doon de Mayence, p. 24)

REMARQUES : Battre laid réfère ici au fait de porter des coups à quelqu'un avec méchanceté, en éprouvant de la haine pour l'objet. L'emploi adverbial de laid au sens de 'méchamment' était usuel en ancien français.

\section{Battre lourd}

Battre avec lourdeur (le cœur)

入 battre bas

\section{Battre menu}

I. battre souvent et menu : battre, donner des coups répétés avec fréquence et rapidité, continuellement

Transitif

1275 Une marrastre avoie, Damedies la cravant ! Qui tous jours me batoit molt dolereusement

Et de poins et de piez et menu et souvent (Adenet le Roi, Berte aus grans piés, 1200) 
II. Battre (du cœur)

Intransitif

1987 J'écoute, sous l'épaisseur du papier, son cœur battre, menu et lointain, un pouls d'oiseau (Jean-Pierre Otte, Le Ravissement)

CORPuS WeB :

Alors, l'avenir du denturo, du protho, et du dentisto... Ils s'en battent menu тепu !!! [http:// www.reseauetudiant.com/forum/read/f298/ i8321t8321/zoub-denturologie.htm?page=2] (10.2.2014)

REMARQUES : Dans la collocation lexicalisée avec souvent, battre menu se dit du fait de porter des coups sur quelqu'un/quelque chose de manière vive et répétée. Menu reste invariable. Notons dans le CW le sens de 's'en moquer, s'en ficher' et la réduplication de l'adjectif-adverbe qui renforce son sémantisme. Notons également la longue série d'adverbiaux dans l'exemple de $\sim 1275$ : batoit molt dolereusement et de poins et de piez et menu et souvent.

\section{Bavarder ferme}

Discuter avec intensité, avec conviction

Intransitif

1892 Car on bavardait ferme, ces soirs-là ; on discutait, on soutenait des théories ( $L^{\prime} A r$ tiste)

1937 Lorsque nous arrivâmes, on bavardait ferme autour d'apéritifs bien servis (Raymond Queneau, Odile)

\section{Bêcher ferme}

I. Retourner la terre résolument, creuser Intransitif

1857 David, qui bêchait ferme [= une fosse], n'entendit pas un mot de cette question (Charles Dickens, Le Magasin d'antiquités [trad.])

1957 Carrés de terre rouge, vite retournés quand on est dix côte à côte pour bêcher ferme. On sarcle à la houe, on sulfate avec des balais de romarin (Jacques Chardonne, L'Amour c'est beaucoup plus que l'amour)
1970 HUGONIN. Allons, Messieurs, Mesdames, l'agriculture a besoin de bras, et l'État de soldats... Alors, je vous dis comme ça, bonsoir, et bêchez ferme! (Aimé Césaire, La Tragédie du roi Christophe)

II. Critiquer sévèrement

Transitif

1886 Lecomte m'a dit à propos de Cézanne qu'il s'était mis à me bêcher ferme auprès de Geffroy, dont il fait le portrait, en ce moment, comme c'est gentil ; moi, qui depuis trente ans le défend [sic] avec tant d'énergie et conviction d'ailleurs (Camille Pissarro, Correspondance)

1889 C'était à New-York. Une troupe française était de passage, et naturellement les artistes, entourant la Grande Comète, la bêchaient ferme : " Elle nous oblige à jouer l'adoration des Mages et c'est toujours Elle qui fait le petit Jésus !... » (Yvette Guilbert, Prologue / Ferdinand Bac, Femmes de théâtre)

\section{Bêcher profond}

Retourner ou creuser profondément (au propre et au figuré)

Intransitif

1867 Trois ans après la plantation, on peut travailler et niveler la terre, mais il ne faut pas bêcher profond, afin de ménager les racines (Revue des jardins et des champs)

2014 Bon courage à celui qui a mission de faire 50 milliards d'économies sur la dépense publique nationale ! Il faut bêcher profond pour arracher les racines de la routine (Christian Sautter, Lettres à nos amis)

\section{Bedonner ferme}

Prendre du ventre

Emploi absolu

1881 Et son regard allait avec une expression de regret comique, du grillage serré des arcades au large gilet blanc où ses quarante ans sonnés bedonnaient ferme (Alphonse Daudet, Numa Roumestan) 


\section{Besogner dur}

Travailler durement, avec intensité

Intransitif

1859 Si c'est un rat, il besogne dur ! mais un rat ne mène pas semblable vacarme avec ses fosses nasales ; évidemment, ça doit être un autre animal (Henry-Émile Chevalier, La Huronne de Lorette)

1882 Les deux paysans besognaient dur sur la terre féconde pour élever tous leurs petits (Guy de Maupassant, Contes et nouvelles)

1949 Il [= Sartre] besogne dur sur le quatrième tome de son interminable roman (Simone de Beauvoir, Lettres à Nelson Algren)

\section{Bifurquer droit}

bifurquer droit sur quelque chose : changer de direction et se diriger directement vers quelque chose

Intransitif

1942 Le capitaine Pénicot m’a raconté son vol de ce matin : « quand une des armes automatiques me paraissait tirer trop juste, je bifurquais droit sur elle, à pleine vitesse, au ras du sol, et je lâchais une giclée de mitrailleuse qui éteignait net cette lumière rougeâtre, comme un coup de vent une bougie » (Antoine de Saint-Exupéry, Pilote de guerre)

\section{CORPUS WEB :}

Je savais qu'on allait bifurquer droit sur la soupe au chou, surtout avec Zelly, c'était impossible de l'éviter [http://lescouleursdemyriam.cen terblog.net/843-philosophie-moderne-logiquescientifique] (10.2.2014)

En appliquant un peu de créativité, vous pouvez commencer à bifurquer droit de revendre ces produits et de créer peu de produits backend [http://www.experts-tourisme.fr/scorpionimmediats-b930744.htm] (10.2.2014)

Elle remit sa capuche et dans l'ombre, se dirigeât vers la lumière de la porte d'entrée avant de bifurquer droit vers l'est [http://forum. navigatorcraft.net/t440-la-taverne-est-un-bonendroit-pour-oublier-avant-je-faisait-du-rp-maisca-c-etait-avant] (10.2.2014)
ReMARQues : Bifurquer droit 'changer de direction, se détourner' appartient au français familier moderne. Droit est suivi par un groupe prépositionnel et peut également être analysé comme modifieur de la préposition (vers, sur). Notons l'emploi de éteindre net.

\section{Blesser fort}

Causer, infliger une blessure physique ou morale grave

Transitif

1177 A anviz passe a la fenestre, $S$ 'i antra il mout volantiers. N'avoit mie les doiz antiers, Que mout fort i estoit bleciez (Chrestien de Troyes, Lancelot ou Le Chevalier de la charrete, 4727)

+1415 Combien que parler envieux Souventesfoiz moult fort me blesse, Mais ne vous chaille, ma maistresse, Je n'en feray pourtant que mieulx, Par Dieu, mon plaisant bien joyeux (Charles d'Orléans, Poésies [ 1415-1440], I, Chanson VII, p. 208)

1559a Mais, pource que le nombre des bandouliers estoit le plus grant, et aussy qu'ilz estoient fort blessez, conmençoient à se retirer, ayans desja perdu desja grant partye de leurs serviteurs (Marguerite d'Angoulême, Heptaméron, p. 3, 77)

1559b Parquoy, la doulceur de ceste parolle penetra ses oreilles jusques au cueur, et la beaulté et grace de son visaige passa par les yeulz et blessa sy fort son esprit de la dame, qu'elle fut comme une personne ravye (Marguerite d'Angoulême, Heptaméron, p. 311, 19)

1584 Par espreuve je sens que les amoureux traits

Blessent plus fort de loing qu'à l'heure qu'ils sont prés,

Et que l'absence engendre au double le servage.

Je suis content de vivre en l'estat où je suis. De passer plus avant je ne dois ny ne puis : Je deviendrois tout fol, où je veux estre sage (Pierre de Ronsard, Sonnets pour Hélène) 
1627 Bien donc, repartit Anselme, je vous acorde que c'est un satyre, vous l'avez mieux senty que moy. Voyons seulement si vous estes si fort blessé (Charles Sorel, Le Berger extravagant)

1631 À ce mot, mettant tous deux la main aux espées, nous nous mismes à ses costez; et quoy que mon maistre fust fort blessé, si est-ce que son courage qui n'a jamais deffailly, luy donna assez de force pour retenir la furie des soldats (Honoré d'Urfé, L’Astrée)

1681 De six personnes qui étoient sous un noyer, il en tua trois, et il blessa fort les trois autres, comme vous pourriez dire, de rendre un homme digne d'entrer dans le Serrail, et de bruler sa femme en pareil endroit qu'il avoit été blessé (Roger de Bussy-Rabutin, Les Lettres de messire Roger de Rabutin)

1732 Eh, bon Dieu ! ma mère, vous êtes donc bien changée, si ma métamorphose vous blesse si fort la vue. Au lieu de vous révolter contre mon turban, regardez-moi plutôt comme un acteur qui représente sur la scène un rôle turc (Alain-René Lesage, Histoire de Gil Blas de Santillane)

1867 Dès le vivant de Jésus, plusieurs, sans être ses disciples, chassaient les démons en son nom. Les vrais disciples en étaient fort blessés et cherchaient à les empêcher. Jésus, qui voyait en cela un hommage à sa renommée, ne se montrait pas pour eux bien sévère (Ernest Renan, Vie de Jésus)

1929 Nous ne nous connaissons pas nousmêmes : cependant je ne crois pas que mon amour-propre ait été fort blessé par l'événement (Charles Du Bos, Byron et le besoin de la fatalité)

1952 Toutefois, quand il traversait le village, lorsqu'il rencontrait sur les chemins, dans les champs, des cultivateurs, hommes et femmes, ou d'anciens camarades, on lui rappelait férocement sa condition, avec des sourires narquois qui le blessaient fort. - Salut, le militaire ! Bientôt la classe ?
- Tiens, v'là l'soldat à Bourbaki !

(Yves Gibeau, Allons z'enfants)

Pronominal

1285 Cleomadés point n’arrestoit, Mais tout adés les assailloit ; Roi Agambart ot abatu A la terre tout estendu ; Au cheoir si fort se bleça K'ains puis ce jour coup ne donna, Mais sa gent l'orent relevé Et sor son cheval remonté (Adenet le Roi, Cleomadés, 893)

1559 Car le roy, pour quelque affaire d'importance, manda incontinant Amadour ; dont sa femme eut si grant regret que, en oyant ces nouvelles, elle s'esvannoyt et tumba d'un degré où elle estoit, dont elle se blessa sy fort que oncques puis n'en relleva (Marguerite d'Angoulême, Heptaméron, p. 87,648$)$

1686 - On sut aussi que madame la comtesse de Soissons, allant dans un corps de carrosse sur un traîneau, comme cela se pratique à Amsterdam où elle est, avoit été emportée par le cheval qui la menoit, qu'elle s'étoit cassé le bras, et s'étoit fort blessée à la tête (Philippe de Dangeau, Journal)

\section{Corpus Web :}

Aucune personne n'a été blessée forte heureusement [http://www.fnaut-paysdelaloire.org/ article-a-caen-le-tvr-va-marcher-moins-bien107977380.html] (10.2.2014)

REMARQUES : Blesser fort se dit du fait de causer, involontairement ou avec l'intention de nuire, une forte blessure. Au passif, réfère à l'état de quelqu'un ayant reçu une ou plusieurs blessures graves. Au figuré, il signifie le fait d'importuner, de déplaire fortement à quelqu'un (par exemple : blesser la vue de quelqu'un). Sous sa forme pronominale, il désigne le fait de se faire une forte blessure, généralement à la suite d'une chute. Fort reste invariable et est modifié par moult, plus, si. Dans l'exemple du CW, l'adjectif-adverbe s'accorde avec le sujet féminin : un cas d'hypercorrection due à la liaison phonétique de fort heureusement, fort appartenant plutôt à heureusement. 


\section{Boire anglais}

Boire une boisson typiquement anglaise

Emploi absolu

1926 La rumeur des causeries se mêlait au bruit des instruments, piano, violons et cuivres. Tout ce monde - deux cents personnes peut-être - parlait anglais, buvait anglais, dansait anglais (Paul Bourget, Le Danseur mondain)

1968 Mon cher Fromageot, vos Byrrh, St-Raphaël, Cinzano, Porto, Frontignan, Dubonnet, Suze, Martini, Fernet-Branca et compagnie je vais vous dire : c'est aussi marrant que les maisons à clochetons. Il faut, Mon cher Fromageot, boire anglais ou russe. L'hygiène c'est ça. Souvenez-vous en : anglais ou russe (François Nourissier, Le Maître de maison)

\section{CORPUS WEB :}

Les « English sparkling wines » constituent vraiment un marché de niche, dont le produit est relativement cher d'ailleurs, même pour un portefeuille anglais. Ce type de produit pourra servir utilement à certains événements ou soirées de prestige où il sera de bon ton de «boire anglais » tout en montrant que la qualité n’a rien à envier à ce qui se produit sur le continent [http://www. atlantico.fr/decryptage/britanniques-se-mettentproduire-vin-massivement-mais-allons-mettreboire-fabrizio-bucella-811079.html] (10.2.2014)

A la Bibliothèque Anglophone, 60 rue Boisnet à Angers, on parle, on lit, on boit anglais ! [http://www.uni.asso.fr/spip.php?article7837] (10.2.2014)

REMARQUES : En général, l'adjectif anglais réfère à une nationalité (adverbe relationnel) mais il admet aussi une interprétation comme adjectif de qualité. Il renvoie ici à l'acte de boire comme un Anglais, et par extension, de boire une boisson typiquement anglaise, en général de nature alcoolisée telle que le gin. Notons les collocations danser anglais, boire russe. Anglais reste invariable. Dans le premier exemple du $\mathrm{CW}$, boire anglais réfère à une boisson produite en Angleterre. Mentionnons également les collocations analogues parler anglais et lire anglais. VOIR AUSSI : danser anglais

\section{Boire bon}

Boire quelque chose de bon

$\pi$ acheter bon

\section{Boire chaud}

Boire une boisson chaude

Emploi absolu

1654 Juste Lipse en a fait un Chapitre dans ses Electes : Et vous pouvez sçavoir qu'encore à present, ceux du Japon boivent le plus chaud qu'il leur est possible, au cœur mesme de l'Esté. Ils sont si curieux de ce breuvage qui brusle la langue, que les Princes l'apprestent eux-mesmes, avec autant de soin et d'attention, que je compose cette sorte de potage que Monsieur Voiture prefere au Panegyrique de Pline (Jean-Louis Guez de Balzac, Dissertations critiques)

1710 CRISPIN. Tu vois ; quoi qu'il m’arrive, Je conserve toujours un embonpoint égal : Chasser le jour, la nuit, à pied comme à cheval,

Le fusil sur l'épaule, en carrosse, en litiere, Forcer chevreuil, cerf, daim, sanglier, sangliere,

Manger froid, boire chaud, dormir couché, debout ;

Un garçon comme moi s'accommode de tout (Philippe Destouches, Le Curieux impertinent)

1732 Nous laissions l'un demander inutilement à boire pendant tout un repas ; il avait beau nous faire des signes, nous feignions de ne les pas entendre : nous versions à l'autre de petits coups, encore était-ce dans des verres faits de façon que la moitié de la liqueur qu'il y avait dedans y restait ; ce qui ne faisait qu'irriter sa soif : nous faisions boire chaud à un autre, ou bien nous ne lui présentions que de l'eau rougie

(Alain-René Lesage, Histoire de Guzman d'Alfarache)

1735 Comme ils n’ont point de cheminées, rien ne leur est plus commode : toute la famille y travaille sans ressentir le moindre froid, et sans qu'il soit nécessaire de prendre des habits fourrez de peaux : c'est à l'ouverture 
$\mathrm{du}$ fourneau que le menu peuple fait cuire sa viande ; et comme les Chinois boivent toûjours chaud, il y fait chauffer son vin, et il y prépare son thé (Jean-Baptiste Du Halde, Description géographique)

1899 Allons ! Cavaignac, allons ! Brisson, chefs d'une démocratie révoltée, passez la coupe pleine au prêtre qui a soif et demande à boire chaud et rouge (Georges Clemenceau, Vers la réparation)

1908 Content du chemin libre, il passa, indifférent. On n'est pas poli aux halles. Les porteurs du pavillon de marée patientaient et buvaient chaud (Pierre Hamp, Marée fraîche)

1938 - Quelle horreur ! Verse-moi vite une tasse. C'est affreux ce que j'ai envie de boire chaud ce matin.

- Moi aussi, dit M. Deume, soudain guilleret, en versant le café puis le lait

(Albert Cohen, Mangeclous)

Transitif

1936 Heureusement, il restait un peu de vin au fond de la bouteille. Je l'ai bu très chaud et très sucré (Georges Bernanos, Journal d'un curé de campagne)

\section{Corpus Web :}

Bien d'autres populations à travers le monde ont l'obligation de faire bouillir leur eau sans pour autant la boire chaude [http://www. legastronomeparisien.fr/hong-kong/hong-kongfood-culture-1-pourquoi-servir-de-leau-chaude/] (19.02.2014)

REMARQUeS : Chaud caractérise une boisson chaude telle que thé ou café, voire le vin, bue dans le but de se réchauffer. Notons la collocation boire chaud et rouge. Chaud reste invariable et est modifié par plus. Le CW montre l'emploi de boire chaud en tant que prédicat second (de même, l'exemple de 1936). Dans ce cas-là, boire s'accorde avec l'objet au féminin.

\section{Boire droit}

Boire d'un seul coup, d'un trait

Emploi absolu

1532 Lors y perdit rables et cropions

Maistre levrault, quand chascun si efforce :

Sel et vinaigre, ainsi que scorpions,

Le poursuivoient, dont en eurent l'estorce.

Car l'inventoire

D'un defensoire

En la chaleur,

Ce n'est que à boire

Droict et net, voire

Et du meilleur

(François Rabelais, Pantagruel)

1538 Bacchus alors chappeau de treille avoit, Et arrivoit pour benistre la vigne ;

Avec flascons Silenus le suyvoit,

Lequel beuvoit aussi droict qu'une ligne ;

Puis il trepigne, et se faict une bigne (Clément Marot, Chansons)

\section{CORPUS WEB :}

Née du celte « ar » et « bos » signifiant « terre fertile ", l'histoire parle pour elle. C'est à Arbois que Pasteur réalisa en 1878 ses remarquables expériences sur les fermentations. "Plus on en boit, plus on boit droit » (dicton local) [http:// www.nicolas.com/page.php/fr/18_17_10024. htm?p_imp=1] (19.2.2014)

Il encourage également les digestions appropriées qui explique pourquoi la plupart des amateurs de thé boivent droit de thé après chaque repas pour qu'ils se sentent plus légers et dynamiser [http://freefrencharticles.com/aliments-etboissons/comment-perdre-du-poids-avec-tisaneminceur] (19.2.2014)

REMARQues : Droit réfère ici, au sens figuré, à l'action de vider son verre d'un trait, cul-sec. L'exemple de 1538 explicite la base directionnelle de l'emploi figuré : boire aussi droit qu'une ligne. Notons la collocation boire net, en rapport synonymique, ainsi que la comparaison aussi droit qu'une ligne renforçant l'idée de descente verticale de la boisson. Droit reste invariable et est modifié par aussi. Dans le dicton cité dans le premier exemple du CW, droit pourrait avoir le sens ancien de 'comme il faut'. 


\section{Boire dur}

Boire beaucoup

Emploi absolu

1808 Il n'aura pas la pépie. Se dit en plaisantant d'un bon buveur, d'un homme qui boit dur et sec (Dictionnaire du bas-langage)

1860 Ils buvaient dur les loups de mer ! Ils avaient toujours soif (Charles de Ribelle, Les Fastes de la marine française)

1947 Nous sommes retournés dans les dancings à matelots : comme ces types boivent ! Ça, ils boivent dur (Simone de Beauvoir, Lettres à Nelson Algren)

1982 Jan buvait dur et ressassait de bonnes histoires, souvent sales, qui le faisaient s'esclaffer (Marguerite Yourcenar, Un homme obscur)

\section{CoRpus Web :}

Très tôt, sa mère (dont il confie qu' ' elle était dure et buvait dure ») l'encourage à s'aventurer au-dehors et à faire l'apprentissage de la nature [https://www.gala.fr/l_actu/news_de_stars/ sean_penn_a_cannes_118067] (13.5.2008)

Les gens buvaient durs mais il n'y avait pas de voitures [https://www.cinemathequebretagne.bzh/Base-documentaire-Communede-Fay-de-Bretagne-7-426-27698-0-960.html?] (9.10.2020)

Tout le monde mangeait, les grands $b u$ vaient durs [http://philippeseguin.fr/Pictures/ Hedera\%20helix.120204.pdf] (9.10.2020)

\section{Boire épais}

I. Boire de l'alcool fort et de basse qualité Emploi absolu

1873 D'abord, ces banquets sont toujours lourds ; on y mange mal et l'on boit épais (Arthur Buies, Chroniques [Québec])

II. Boire un liquide épais, pâteux

Transitif

2008 On le [= le chocolat] boit épais, à l'espagnole, ou plus léger selon la mode française (Réponses cuisine)

REMARQUES : Boire épais (I) réfère au fait de boire des boissons fortes. Il s'oppose partiellement à boire léger. Selon Giraud (1964) il boit épais signi- fie plus concrètement 'boire du gros vin'. En (II), épais est employé au propre 'qui a la consistance d'une pâte'.

\section{Boire ferme}

Boire beaucoup (surtout des boissons

alcoolisées)

Emploi absolu

1885 Elles s'étaient d'abord beaucoup amusées à cuisiner elles-mêmes ce dîner ; puis elles l'avaient mangé avec gaieté en buvant ferme pour calmer la soif qu'avait éveillée dans leur gorge la chaleur des fourneaux (Guy de Maupassant, Contes et nouvelles)

1907 Ils ont des coiffeurs - pas tous -, des chemises, des habits, des hôtels, des châteaux et des femmes. Ils boivent ferme et mangent bien. Mais leurs concessions s'arrêtent là ! Halte-là ! Vanité ! Ils ne montent pas à cheval. Mais ils ont des automobiles (Georges Bernanos, Premiers Écrits)

1913 Le temps s'annonçait bien. On nous a dit tant mieux. On nous a fait goûter de quelque bœuf en daube, puisqu'il est entendu que le bon pèlerin est celui qui boit ferme et tient sa place à table, et qu'il n'a pas besoin de faire le comptable, et que c'est bien assez de se lever matin (Charles Péguy, La Tapisserie de NotreDame)

1922 On devait boire ferme à la table du colonel Kurthausen (Marcel Dupont, Fragilité).

1996 Tout ce que dit Gaston lui paraît entaché d'intentions douteuses et secrètes.

- Si vous en jugez par la pisse, continue Gaston, ça doit boire ferme.

- Ça pisse, donc ça boit, dit Mme Dodin (Marguerite Duras, Cahiers de la guerre et autres textes)

2006 Un bon feu brûlait dans la vaste cheminée. On buvait ferme. Les hommes fumaient. C'était très « intérieur flamand » de Breughel (Jeanne Pouquet, Journal sous l'Occupation en Périgord (1942-1945))

REMARQUES : Boire ferme se dit du fait de consommer des boissons alcoolisées en grande quantité, 
avec abondance et en général dans la bonne humeur, lors d'une fête. Ferme reste invariable.

\section{Boire fin}

Boire avec finesse, raffinement

Emploi absolu

1867 Du temps du Titien, elle aurait été simplement énergique et stupide ; aujourd'hui salie, avilie, effrontée, habituée aux affronts et à l'insolence, elle a dix ans de bains, de poudre de riz, de veilles, de pâtés de foies gras. Ce qu'elle a appris, c'est à bien manger et finement, à boire fin et $s e c$; c'est une femme à soupers (Hippolyte Taine, Notes sur Paris)

\section{CORPuS Web :}

Cadeau de choix pour tous ceux qui s'intéressent de près aux vins. Des schémas synthétiques permettent de repérer les données essentielles qu'il convient de connaître pour fixer une stratégie de sélection, pour faire de bon choix, pour déguster " juste ", pour apprendre à boire fin [http://www.educvin.com/pages/presse.htm] (19.2.2014)

Dans les vinothèques, le plaisir de boire fin a remplacé celui de boire trop [http://www.hebdo. ch/les_suisses_se_mettent_au_verre_12191_. html] (19.2.2014)

REMARQUeS : Boire fin se dit du fait de boire de l'alcool avec finesse, en suivant les règles de bienséance. La collocation avec boire sec souligne l'opposition entre la délicatesse de l'action et l'abondance de boisson ingurgitée. Notons que fin pourrait également référer à la qualité de la boisson, dénotant une boisson de bonne qualité, recherchée. Fin reste invariable. L'appartenance au langage de la dégustation et de la consommation se traduit par toute une série analogique, dont déguster juste, stigmatisé par des guillemets.

\section{Boire fort}

Boire beaucoup (surtout de l'alcool)

Emploi absolu

1450 SAFFRET. Qu'esse cy ? Vous ne buvez point!

Ilz sont simples comme pucelles.

Et buvez fort. Vignes sont belles
Et pensez de vous aplicquer (Arnoul Gréban, Le Mystère de la Passion, 13825)

1461 Viel je seray ; vous laide, sans couleur. Or buvez fort, tant que ru peult courir ; Ne donnez pas a tous ceste douleur : Sans empirer, ung povre secourir (François Villon, Le Testament, 963)

1696 Comme nous avions impatience de manger de la viande, nous voulusmes faire media noche. Ce repas là ne fut pas si sobre que les autres; nous busmes fort, et sur les trois heures aprés minuit nous nous allasmes coucher (Roger de Bussy-Rabutin, Les Mémoires de messire Roger de Rabutin)

1755 C'est un vieux reproche du temps où les gens de ville étoient carillonneurs, brelandiers et tires-soie. Je ne nierai cependant pas que l'on ne boive fort dans les provinces où il y a encore de la noblesse à la campagne, et qu'on n'y chasse beaucoup ; mais qu'on n'y fasse que cela, c'est ce que je nie (Victor de Mirabeau, L’Ami des hommes ou Traité de la population)

1829 Ah ! Mon dieu ! Je suis mort peut-être ; C'est ce qu'il est urgent de voir. Je me tâte comme sosie ; Je ris, je mange, et je bois fort (Pierre-Jean de Béranger, Chansons)

1893 Et celui-ci, c'est mon cousin Qui fut curé et but si fort du vin Que le soleil en devint rouge ; J'ai su qu'il habitait un bouge, Avec des morts, dans ses armoires. Car nous avons pour génitoires Deux cailloux Et pour monnaie un sac de poux (Émile Verhaeren, Les Campagnes hallucinées)

\section{CoRpus WeB :}

Moi qui avait peur qu'elle préfère le bib : - ( Ma tactique, c'est quand je sens un RE, je lui retire le sein et je re-donne. Dès que je l'entends boire fort ou que je sens le picottement, je retire sa bouche.

On dirait que ça marche, ça l’aide à boire moins vite [http://forum.aufeminin.com/forum/ 
allaitement/_f27937_allaitement--trise-ref-finallaitement-triste.html] (19.2.2014)

Oui merci je vais boire fort mais pas trop fort (:) [http://www.jeuxvideo.com/forums/1-50124724482-2-0-1-0-conseils-nouvel-an.htm] (19.2. 2014)

REMARQueS : Boire fort se dit du fait de consommer surtout des boissons alcoolisées en grande quantité, avec abondance. Fort reste invariable et est modifié par si. Le premier exemple du CW réfère à l'allaitement d'un bébé. Dans le dernier exemple du CW, boire fort pourrait avoir le sens de 'boire un alcool fort'.

\section{Boire frais}

Boire une boisson fraîche, froide

Emploi absolu

1534 Nous, dirent ilz, avons jà donné ordre à tout. Par la mer Siriace, vous avez neuf mille quatorze grandes naufz, chargées des meilleurs vins du monde ; elles arriverent à Japhes. Là se sont trouvez vingt et deux cens mille chameaux, et seize cens elephans, lesquelz avez pris à une chasse environ Sigeilmes, lorsque entrastes en Libye, et d'abondant eustes toute la caravane de Lamecha. Ne vous fournirent ilz de vin à suffisance ? Voire, mais, dist il, nous ne beusmes point frais. Par la vertu, dirent ilz, non pas d'un petit poisson, un preux, un conquerent, un pretendant et aspirant à l'empire univers ne peut tousjours avoir ses aizes. Dieu soit loué que estes venu vous et voz gens, saufz et entiers, jusques au fleuve du Tigre (François Rabelais, Gargantua)

1674 J'en vais donner pour preuve une personne Dont la beauté fit trébucher Rustic.

Il en avint un fort plaisant trafic :

Plaisant fut-il, au péché près, sans faute ; Car, pour ce point, je l'excepte, et je l'ôte : Et ne suis pas du goût de celle-là

Qui, buvant frais (ce fut, je pense, à Rome), Disoit : «Que n'est-ce un péché que cela !» Je la condamne, et veux prouver en somme Qu'il fait bon craindre, encor que l'on soit saint (Jean de La Fontaine, Le Diable en enfer)
1683 Que m'importe qu'Arnauld me condamne ou m'approuve?

J'abbats ce qui me nuit par tout où je le trouve.

C'est là mon sentiment. A quoy bon tant d'apprests?

Du reste, déjeûnons, Messieurs, et beuvons frai (Nicolas Boileau, Le Lutrin)

1691 On nous donna des eaux très-bien faites. L'on peut dire qu'il n'y a point de lieux où l'on boive plus frais. Ils ne se servent que de la neige, et tiennent qu'elle rafraîchit bien mieux que la glace (Marie-Catherine d'Aulnoy, Relation du voyage d'Espagne)

1762 Ce même homme qui veut que les enfans se baignent l'été dans l'eau glacée ne veut pas quand ils sont échauffés qu'ils boivent frais ni qu'ils se couchent par terre dans des endroits humides (Jean-Jacques Rousseau, Émile ou De l'éducation)

1778 L'avenir quelque jour, en lisant cet ouvrage, puisqu'il est fait pour vous, en chérira les traits : cet auteur, dira-t-on, qui peignit tant d'attraits, n'eut jamais d'eux pour son partage que de petits soupers où l'on buvait très-frais ; mais il mérita davantage (Voltaire, Épitres)

1825 Adieu ! Major ; adieu, Hasard, et tous mes camarades connus et inconnus ; adieu ! Mes amis ; buvez frais, mangez chaud, faites l'amour comme vous pourrez. Adieu! (Paul-Louis Courier, Lettres écrites de France et d'Italie)

1843 Après tant de factions montées en vain rue du Sentier, il trouvait le Journal attablé, buvant frais, joyeux, bon garçon (Honoré de Balzac, Les Illusions perdues)

1933 Honoré faillit donner dans la querelle que l’Adélaïde lui cherchait par manière de distraction, mais il s'avisa que rien ne valait de boire frais (Marcel Aymé, La Jument verte)

1934 Alors on a trinqué, et puis on s'est mis à rester là sans rien dire, à tourner nos chapeaux sur nos têtes, sauf que j'avais mon képi comme d'habitude, mais bien 
contents de boire frais, et du bon, et de voir tant de soleil plein la porte, en se tenant bien à l'ombre, ce qui m'ôtait l'envie de sortir (Gabriel Chevallier, Clochemerle)

\section{CORPUS WEB :}

mais consulte tous les documents, archives, récits de voyages, traités philosophiques ou médicaux, romans, cartes maritimes, susceptibles de montrer comment est née, comment s'est diffusée, comment a été techniquement rendue possible, comment a été refusée (dans les îles Britanniques, l'extrême Orient sino-japonais), comment à été discutée, louée, condamnée, l'habitude de boire frais [http://www.liberation. fr/livres/1995/07/13/comment-s-est-propagee-1habitude-de-boire-frais_137859] (20.2.2014)

Et pour cela, la meilleure boisson, c'est tout simplement de l'eau, à température ambiante, c'est-à-dire à une température proche de celle de notre température corporelle. Pour l'effet « rafraîchissant ", vous pouvez la boire fraîche en la conservant au frigo, mais par contre, évitez d'y mettre des glaçons [http://sante.journaldes femmes.com/nutrition-digestion/garder-ligneet-manger-equilibre-ete/on-evite-l-eau-glacee. shtml] (20.2.2014)

L'avis de Anaïs Moisan sur la recette Margarita. Cocktail du délice Bien décrite et facile à faire, cette recette est donc délicieuse. Ma suggestion : La boire frais [http://cuisine.journaldesfemmes. com/recette/avis/307470/1175652682/margarita. shtml] (20.2.2014)

REMARQUES : Boire frais réfère à la température d'une boisson refroidie ou rafraîchie jusqu'à une température agréable, bue afin de se rafraîchir. Frais reste invariable et est modifié par plus, très. Dans le deuxième et le troisième exemple du CW, frais fonctionne en tant que prédicat second orienté vers l'objet, mais il présente l'accord avec le complément d'objet uniquement dans le deuxième exemple. Notons l'emploi de manger chaud.

\section{Boire froid}

Boire un liquide froid

Emploi absolu

1592 Ils ne le sçauroient souffrir revenir suant et poudreux de son exercice, boire chaud, boire froid, ny le voir sur un cheval rebours, ny contre un rude tireur, le floret au poing, ny la premiere harquebouse (Michel de Montaigne, Essais)

1654 Mais pour vous faire voir la diversité des appetits, et la bizarrerie du goust des hommes, il n'y auroit point de mal de remarquer que ces mesmes Romains, qui prenoient tant de plaisir à boire froid, avoient aussi essayé, s'il n'y en auroit point à boire chaud, et y en avoient trouvé en effet (Jean-Louis Guez de Balzac, Dissertations critiques)

1761 Il faut d'abord mettre le malade au régime, et avoir soin qu'il ne boive jamais trop froid (Samuel Auguste Tissot, Avis au peuple)

1762 Que si par quelque autre exercice il se met en sueur et qu'il ait soif, qu'il boive froid même en ce tems-là. Faites seulement en sorte de le mener au loin et à petits pas chercher son eau (Jean-Jacques Rousseau, Émile ou De l'éducation)

1946 LECAPITAINE. Si je n'étais pas bon, péronnelle de mes rotules ! Je ne serais pas là ! Si je n'étais pas là, le bonheur de boire chaud n'existerait pour personne, à bord, de boire chaud, ou de boire froid, ou de manger du homard, ou de se retourner dans sa couchette, le soir, avant le sommeil, sur un côté, sur l'autre, ha... (Jacques Audiberti, Quoat-Quoat / Théâtre)

Transitif

1982 je me souviens de mon premier plaisir gustatif : tous les soirs, avant de m'endormir, je laissais un peu de tilleul au lait sucré dans la tasse pour avoir l'agrément de le boire froid au réveil ; je le trouvais ainsi bien plus succulent (Émile Ollivier, L'Orphelin de mer)

\section{CORPUS WeB :}

Certains vous conseilleront de ne jamais boire froid, pour préserver notamment le foie et les organes digestifs, qui ont besoin de chaleur pour bien fonctionner. Ainsi le matin à jeun, boire très froid affaiblira le foie qui aura du mal à s'activer [http://www.santeonaturel.com/actualiteboire-chaud-ou-froid-,21.html] (20.2.2014) 
Cracher dans la soupe et la boire froide... [http://twicsy.com/i/y4VXmd] (20.2.2014)

Et il faut la boire chaud ou froid cette eau ? [http://forum.aufeminin.com/forum/matern2/ f270526_matern2-Gastro-eau-de-cuisson-du-riz. html] (20.2.2014)

REMARQUES : Boire froid désigne l'action de boire une boisson froide, inférieure à la température ambiante ou de laisser une boisson chaude refroidir, afin de la boire froide. Notons les collocations boire chaud, boire froid. Froid reste invariable et est modifié par jamais, trop. L'exemple de 1982, cité au hasard, montre que l'objet interne de boire froid peut apparaître de façon explicite comme complément d'objet direct modifié par le prédicat second froid. Dans les deux derniers exemples du CW, froid remplit la fonction de prédicat second orienté vers l'objet, même si l'adjectif ne s'accorde avec l'objet que dans le premier cas.

\section{Boire glacé}

Boire une boisson très froide (plus

spécifiquement : avec des glaçons)

Transitif

1879 On le lui fait boire glacé comme le lait (Gazette obstétricale)

Emploi absolu

1886 De plus, quand on boit glacé alors que l'estomac est vide, on s'expose, par le fait de la brusque contraction des vaisseaux qui peut s'ensuivre, à la répercussion soudaine de la sueur et à des congestions dangereuses (Lyon scientifique et industriel)

1964 Ici, donc, on mange glacé, on boit glacé, on suce et croque de la glace. Dès qu'un enfant est né, les parents lui donneraient à boire du lait glacé pour lui faire acquérir de bonne heure le sang froid américain (Bernard Binlin Dadié, Patron de New York)

Pronominal

2016 Agua de panela. [...] Se boit glacé ou chaud selon la région et le climat (Dominique Auzias et Jean-Paul Labourdette, Colombie)

REMARQUES : Notons l'emploi de manger glacé ; boire chaud.

\section{Boire net}

Boire d'un seul coup, d'un trait, sans laisser une goutte dans son verre

Emploi absolu

1534 Grandgousier estoit bon raillard en son temps, aymant à boire net, autant que homme qui pour lors fust au monde, et mangeoit voluntiers salé

(François Rabelais, Gargantua)

1547 La dance finie, recommençoyent de plus belle à dringuer et boire hault et net sans se blesser, puis, apres se estre chauffez, si bon leur sembloit alloyent voir quelque pré, ou champ bien accoustré, et là d'ordinaire se asseoyent pesle mesle, jeunes et vieux (Noël Du Fail, Les Propos rustiques)

1624 L'un crie : « Donne moy, apporte, » l'autre boute :

«Veux tu qu'à mon honneur je face banqueroute?

Et viste, mon amy, produis moy du clairet. »

C'est, à le faire court, à qui boira plus net Et à qui fera voir qu'en ce brave exercice Il est un vieux routier, et non pas un novice (Jacques Du Lorens, Premières satires)

\section{CORPUS WEB :}

Qu'ils soient de la Nouvelle-Zélande (Clos Henri en sauvignon blanc ou en pinot noir du côté de Marlborough) ou de la Loire (Sancerre, Pouilly-Fumé, Menetou Salon, Quincy, Châteaumeillant et autres Coteaux du Giennois), il y a rapidement cette invitation à boire pur et à boire net [http://www.ledevoir.com/art-de-vivre/ vin/298050/la-qualite-bourgeois] (20.2.2014)

Mdr je blague même pas avec l'eau je la boit net puis je la recrache salement ah weee [https:// fr-fr.facebook.com/MemoiresDeMaGrossesseA VotrePireCauchemard/posts/549657838432028] (20.2.2014)

REMARQUES : Boire net réfère à l'action de vider son verre d'un trait, de boire cul-sec. Notons la collocation boire hault et net. Net reste invariable. Notons l'emploi de boire pur dans le premier exemple du CW. Dans le deuxième exemple du CW, net s'emploie en tant que prédicat second, mais il ne s'accorde pas avec l'objet pronominal 
antéposé au verbe. Notons l'emploi du connecteur à le faire court.

\section{Boire petit}

Boire peu, en petite quantité

Emploi absolu

+1150 Aiols manga asses, mais de uin but petit, Car durement se gaite li cheualiers gentis (Aiol et Mirabel [ $2^{\mathrm{e}}$ moitié XII $]$, 6048)

$\sim 1170$ Erec manja come malades Et but petit, que il n'osa Mes a grant eise reposa Et dormi trestote la nuit ; Qu'an ne li fist noise ne bruit (Chrestien de Troyes, Erec et Enide, 5169)

1280 Mengier et boire dois petit, Non pas croire ton apetit, Et toi biau contenir a table : Mont en seras plus deletable (Vivien de Nogent, La Clef d'amour, 3245)

1364 Quant elle se partoit ainsi En tel haste et en tel soussi, Je bus petit et mains menjai ; Et a la table adés sonjai Comment ma dame estoit venue Pour faire si courte venue Qu'assez mieulz vaulsist sa demeure Que venir et raler en l'eure (Guillaume de Machaut, Le Livre du voir dit, 2861)

1558 - Je n’ay que faire de boire, disoit-elle ; cest yvrongne icy ! verras-tu ?

- Eh ! Jannette, tu ne bevras que tant petit que tu vourras

(Bonaventure Des Périers, Les Nouvelles Récréations et joyeux devis)

\section{Corpus WeB :}

J'pense que la plupart des gens ici, (mais peut-être me trompe-je 8)) aimerait bien boire un p'tit quelque chose, à l'occasion, juste pour un plaisir occasionnel.. Je sais pas.. M'enfin pour moi qui n'sait pas boire "petit ", ça m'est totalement impossible.. [http://www.stop-alcool.ch/ blog/index.php/lire-le-forum?func=view\&catid= 2\&id=3219] (23.02.2014)

REMARQUeS : Dans l'ancienne langue, petit était un adjectif-adverbe de dimension qu'on employait aussi comme quantifieur. La langue moderne le remplace par peu, du moins dans l'expression standard. Boire petit se disait ainsi du fait de boire de petites quantités, en général de l'alcool. Notons la collocation manger et boire petit. Petit reste invariable et est modifié par tant. Le CW met en évidence que l'emploi adverbial de petit 'peu' n'a pas complètement disparu, tel qu'on pourrait le croire à la lumière des données de Frantext, mais les guillemets signalent que l'auteur est conscient du fait que petit n'appartient pas à la langue commune. Mentionnons également l'emploi de manger petit ; contenir beau.

\section{Boire pur}

Boire une boisson pure

$\pi$ boire net

\section{Boire raide}

Boire énergiquement, rapidement

Transitif

+1267 A p[re]miers orent pois au lart

[Et] puis, .ii. [et] .ii., .i. marlart

Si orent hastes [et] lardez

[Et] si orent $\mathrm{m}[\mathrm{ou}] \mathrm{lt}$ bons pastez

Bon vin burent [et] fort [et] roit

Ce m'est auis d'auçoirre estoit

Plaine vne bout de .iii. sistiers

(Le Sot Chevalier, manuscrit A, 195)

Emploi absolu

1894 N'empèche [sic] que l'on a bu raide et $r i$ large, à midi, autour des assiettes à fleurs (Petites Annales de Provence)

1991 On buvait raide le soir. Le seul plaisir du tenancier était d'avoir des vitres à ses lucarnes. Notre seul plaisir, c'était de les briser en jetant un verre à la volée quand l'homme regardait ailleurs. Un sport comme un autre (Louis Delluc, L'Homme des bars)

\section{CoRpus Web :}

Et oui, parce que la Dordogne de Sanders a cela de particulier : elle n'est jamais xénophobe. Un obstacle y est traité comme un obstacle, quelque soit la langue qu'il parle, les manières qu'il a ou sa capacité à boire raide [http://boxnine. net/html/page-2-Documentaires_Sanders_sur_ Dordogne-8.htm] (23.2.2014) 
Un sucre dans son café. Depuis deux semaines, elle n'arrive pas à le boire raide et fort [http://lesheuresdecoton.canalblog.com/archi ves/2010/08/13/18802336.html] (23.2.2014)

REMARQUES : Boire raide réfère à l'action d'absorber une boisson rapidement, d'un geste énergique et généralement d'un seul trait. Notons la collocation fort et raide. Dans le deuxième exemple du CW, raide réfère au goût du café, métaphoriquement perçu comme étant corsé, puissant. Mentionnons également l'emploi de rire large. VOIR AUSSI : manger raide

\section{Boire rouge}

Boire une boisson idéologiquement associée au communisme

Emploi absolu

1986 A partir de 1972, Pepsi a commencé à produire en Russie, tandis que son concurrent se réservait le «monde libre ». Depuis la chute du mur de Berlin, l'image s'est inversée. Coca-Cola, incarnation de l'impérialisme américain devenu symbole de liberté, a poussé ses pions en Europe de l'Est. Boire Pepsi, c'était boire rouge (Le Monde, 28.4.1996 / Noailly 1997a)

\section{Boire sec}

Boire beaucoup, boire de l'alcool fort, boire de l'alcool sans le mélanger avec des boissons sans alcool

Emploi absolu

1588 RENOMMEE. Leur armé ne parut, au prix de la traversse,

Qu'une Cohorte Grecque, au front du Camp de Xerxe,

Ou Gedeon suivy de ceux qui burent sec :

De mesmes ilz en ont les enseignes dontées,

Comm’ Aristide fist les Persses à Platées, Et ce vailhant Hebrieu, les foules d'Amalec (Loys Papon, Pastorelle)

1623 Car vivre tousjours sans soucy, Avoir le ventre bien farcy De salmigondis, de salades, De Jambons, et de Carbonnades, Et boire sec comme un Sapin Sont les Amours de Turlupin
(Jean Auvray, Le Banquet des muses ou Les Divers Satires)

1646 Bacchus n'est point aux champs, la ville est son sejour,

C'est où les bons buveurs font de la nuit le jour,

Tantost dans leurs maisons, tantost dans la taverne,

Que les Predicateurs nomment un autre averne,

Mot significatif des choses qui s'y font ;

Mais ils ne disent pas que les Prétres y vont,

Et qu'ils y boivent sec pour celebrer l'orgie, $\mathrm{Au}$ lieu de s'amuser à la theologie (Jacques Du Lorens, Satires)

1732 LISIMON. Parbleu ! nous boirons bien. Vous buvez sec, dit-on ; moi, je n’y laisse rien.

Je suis impatient de vous verser rasade, Et ce sera bientôt. Mais êtes-vous malade ? (Philippe Destouches, Le Glorieux)

1755 en un mot, mon curé le dit, et ce n'est pas à moi à le contredire, quoique ce soit assez la mode aujourd'hui (mode entre nous qui ne vaut rien, et qui n'étoit pas du temps de nos ivrognes ;) mais boire un peu sec, et seulement jusqu'à chanter, rire, et s'embrasser, épanouit la rate, bannit les inimitiés, et lie la société (Victor de Mirabeau, L’Ami des hommes ou Traité de la population)

1764 HENRI. La soif d'un Chasseur ; c'est tout dire.

MICHAU. Tant mieux, morgué ! V'm'avais l'air d'un bon vivant. Buvez-vous sec? (Charles Collé, La Partie de chasse de Henri IV)

1828 Au royaume d'Utopie, situé devers Chinon, régnait, durant la première moitié du $\mathrm{Xv}^{\mathrm{e}}$ siècle, le bonhomme Grandgousier, prince de dynastie antique, bon raillard en son temps, aimant à boire sec et à manger salé (Charles Sainte-Beuve, Tableau historique et critique de la poésie française et $d u$ théâtre français au XVI siècle) 
1835 LORD TALBOT. (consterné)

Ah ! Si

tu veux jouer encore du pistolet, comme tu voudras ! Mais je croyais t'avoir fait plaisir, moi. Est-ce que je t’ai affligé ? Ma foi, nous avons bu un peu sec ce matin (Alfred de Vigny, Chatterton)

1867 Du temps du Titien, elle aurait été simplement énergique et stupide ; aujourd'hui salie, avilie, effrontée, habituée aux affronts et à l'insolence, elle a dix ans de bains, de poudre de riz, de veilles, de pâtés de foies gras. Ce qu'elle a appris, c'est à bien manger et finement, à boire fin et sec ; c'est une femme à soupers (Hippolyte Taine, Notes sur Paris)

1872 Tout en sirotant le vin rosé de Crescia, il écouta patiemment Tartarin lui parler de sa Mauresque et même il se fit fort, connaissant toutes ces dames, de la retrouver promptement. On but sec et longtemps. On trinqua « Aux dames d'Alger ! $\mathrm{Au}$ Monténégro libre !...» (Alphonse Daudet, Aventures prodigieuses de Tartarin de Tarascon)

1967 Sa famille invitait tous ses amis, qui honoraient d'autant plus celui qui les avait quittés qu'ils dansaient plus longtemps et buvaient plus sec à sa santé. Il s'agit de la mort d'un autre, mais en de tels cas, la mort de l'autre est toujours l'image de la propre mort (Jacques Derrida, L'Écriture et la Différence)

1976 De ce séjour chez mes grands-parents, hormis les scènes de violence et la folie de grand-mère, je garde un souvenir assez flou. Les images sont décousues et ne se suivent pas forcément dans le temps. D’abord le hameau. Une dizaine de fermes où l'on travaillait dur et buvait sec. On y trouvait du bon lait, du bon beurre, du fromage blanc, c'était du cousu main, rien que des choses vraiment naturelles (Jacques Lanzmann, Le Têtard)

1979 Il se replie sur Audincourt où je suis revenu également. Je l'y retrouve assez semblable à toi, je veux dire polissonnant aussi gaiement et buvant aussi sec que ses mains et les temps le permettent. Il ne rêve qu'à la nouba que nous ferons quand l'Alsace sera libre (Jean Egen, Les Tilleuls de Lautenbach)

2007 Dans le jardin joliment envahi de mauvaises herbes, je bois sec et, bien que nous ayons toi et moi arrêté de fumer depuis un an, je tape des cigarettes que j'allume à la chaîne en oubliant de manger (Emmanuel Carrère, Un roman russe)

Transitif

1856 Tu courtisais ta belle esclave quelquefois, Myrtale aux blonds cheveux, qui s'irrite et se cabre

Comme la mer creusant les golfes de Calabre,

Ou bien tu t'accoudais à table, buvant sec Ton vin que tu mettais toi-même en un pot grec (Victor Hugo, Les Contemplations)

\section{CORPUS WEB :}

Bon pour résister à ce froid, moi, je propose de boire une PETITE vodka... Tu veux la boire sec ou avec un peu d'orange ? [http://gitanne. blogspot.co.at/2007/12/dpche.html] (23.02.2014)

J'ai testé une fois une «bonne " vodka et c'était un plaisir de pouvoir la boire sèche comparé aux daubes comme l'Eristoff qui te fait gerber direct si tu la coupe pas avec 3/4 de jus de fruit [http://www.jeuxvideo.com/forums/1-5125241483-1-0-1-0-qui-a-deja-goute-la-vodka-greygoose.htm] (23.02.2014)

REMARQUES : Pris au sens traditionnel, boire $s e c$ réfère au fait d'absorber de grandes quantités d'alcool ou des boissons à haute teneur en alcool, conduisant généralement le sujet à l'état d'ivresse. Boire sec est souvent employé dans un contexte où il est question de nourriture, voire de gloutonnerie. $\mathrm{Sec}$ reste alors invariable et est modifié par aussi, plus, un peu. L'usage moderne dans le CW met en évidence une tendance à remplacer le sens traditionnel lexicalisé boire sec par un emploi remotivé qui désigne une qualité d'une boisson bue sans ajouter de l'eau ou d'autres liquides (aussi dans l'exemple de 2007). Sec apparaît alors comme un prédicat second orienté vers l'objet pronominal antéposé au verbe. Toutefois, sec s'accorde avec l'objet féminin uniquement 
dans le deuxième exemple du CW, tandis qu'il reste invariable dans le premier. Notons les collocations manger salé, manger saignant, boire fin et sec, travailler dur et gerber direct qui mettent en évidence une certaine prédilection pour l'adjectif-adverbe dans le domaine de la boisson et de la nourriture. VOIR AUSSI : manger ferme

\section{Boire sucré}

Boire une boisson additionnée de sucre Emploi absolu

2005 En cas d'exercice prolongé, supérieur à 1 heure 30, il faut associer les deux méthodes : manger des " sucres lents » au repas précédent et boire sucré pendant! (Stéphane Cascua, Le Sport pour maigrir)

CORpus Web :

De plus ces boissons vous habituent à boire sucré et à toutes les douceurs en général... ce qui peut expliquer pourquoi vous prenez votre café avec du sucre ! [http://www.menshealth.fr/ Rlechissez-avant-de-boire_26.html?artpage=3-3] (23.2.2014)

Bien qu'on puisse la boire sucré (sucre ou miel), on préfèrera peut-être la boire nature. L'infusion se mariera cependant parfaitement avec une petite goutte de lait [http://ileauxepices.com/ thes-verts/179-chocolat-truffe.html] (23.2.2014)

L'infusion très amer est bue chaude ou froide avec une paille en acier appelé « Bombilla ». Pour nous européens, c'est trop amer, il peut être bon de la boire sucrée ou alcoolisée avec un peu de cointreau par exemple pour adoucir [http://www. voyage2sensations.com/pages/La_Gastronomie_ dArgentine-8693365.html] (23.2.2014)

REMARQues : Boire sucré se dit du fait de boire une boisson qu'on a préalablement adoucie avec du sucre, par exemple du café, du lait, du vin, de l'eau, etc. Dans cet emploi, sucré reste invariable. Toutefois, quand un complément d'objet direct est présent, il se prête à une analyse de prédicat second qui peut s'accorder avec l'objet, mais l'accord n'est pas systématique (v. les exemples du CW). Notons l'emploi adverbial du nom nature dans la boire nature, qui relève du langage publicitaire.

\section{Boire utile}

Boire ce qui donne le plus de résultat

Emploi absolu

1952 Quand le Vin des Rochers couvre Paris de ses poèmes, et séduit les journaux de France à imprimer ses ritournelles, quand les eaux minérales rivalisent avec lui de rimes venderesses : Fidèle à Vittel, Boire Contrexéville C'est boire utile (Étiemble, Hygiène des lettres : poètes ou faiseurs ?)

\section{Boire vrai}

Boire une boisson authentique

Emploi absolu

1958 Buvez bien vrai. Un vrai Pschitt

([Publicité] / Grundt : 374)

2006 Armance a envie de manger et de boire vrai, de bon cœur, avec les autres sans avoir la peur au ventre d'avaler des aliments trafiqués, des inventions transgéniques dont on dit qu'elles sont l'avenir de l'agroalimentaire (Christophe Maris, Je hais les dimanches)

CORPUS WEB :

En prime, la carte des vins regorge de vins bio, natures, certifiés Demeter et issus de la culture raisonnée ou de la biodynamie. On traverse la rue au Cercle (228, rue Saint-Joseph Est, Québec, le-cercle.ca) pour le même esprit vinicole, avec une sélection différente. Boire vrai, diront certains ! [http://voir.ca/voir-la-vie/ gastronomie/2013/10/17/courir-le-bio-dans-saintroch] (24.2.2014)

Chez oenopole, on aime boire vrai, on aime les vins qui sont le reflet d'histoires uniques, on aime partager les vins qui sont faciles à boire, propres et naturellement bien faits par des artisans vignerons qui travaillent fort dans leurs vignes et non dans les labos. Buvez Vrai ! [http:// sat.qc.ca/fr/mauditsouper] (24.2.2014)

Remarques : Dans l'exemple de 1958, boire vrai réfère à une publicité pour une boisson gazeuse aromatisée à l'orange ou au citron. Il s'agit d'un appel à l'authenticité qui incite le consommateur à boire la boisson connue de marque « Pschitt », et non pas un quelconque substitut. Dans l'exemple de 2006, vrai réfère à la nourriture naturelle, chimiquement non traitée et génétique- 
ment non modifiée. Vrai reste invariable et est modifié par bien. Notons l'emploi de manger vrai.

\section{Boiter bas}

Boiter beaucoup, fortement

Intransitif

1668 Ce qui étonne à ces sortes de maux, est que le Cheval en boite souvent tout bas, en sorte qu'on ne peut se persuader que ce mal les puisse faire boiter de la sorte (Jacques de Solleysel, Le Parfait Maréchal)

1680 Cependant monsieur boite tout bas, monsieur crie, monsieur se vante d'un rhumatisme quand il n'est pas devant moi, car ma présence l'embarrasse (Mme de Sévigné, Correspondance)

1879 Docile, en veine d'indulgence, il se montra débonnaire, mais, en s'exécutant, il plaqua sur le faux infirme un tel regard de mépris que cet odieux acteur, ivre de rage, pensa se vendre plus de vingt fois avant de parvenir à la dernière marche de l'escalier monumental, sur laquelle, après avoir traversé la lice en boitant très bas, il s'assit à portée de l'urne métallique où rayonnaient, tendre objet de ses vœux, les cinq cents louis d'or promis au vainqueur, dans la peau duquel il n'était pas (Léon Cladel, Ompdrailles, le Tombeau des-Lutteurs)

1951 Non, surtout pas de sang !... Faire mijoter durant une heure... Mijoti, mijota, mijotons pour l'éternité ! Enfin, il abandonna la cuillère, régla le tirage et, boitant plus bas que d'habitude, se dirigea vers son fauteuil où il s'écroula. Son rhume, quinze nuits d'insomnie et, surtout, ce petit geste - une, deux, trois - l'avaient exténué (Hervé Bazin, Le Bureau des mariages)

1994 Assez de forces pour entamer d'un bon pas cette montagne pelée derrière laquelle s'étendait une vaste plaine que l'on traversa en son nord-est durant trois longs jours. On souffrit de la soif et des brûlures du soleil. Les pieds gonflèrent dans les bottes de cuir mal tanné. Les talons de Nathan éclatèrent comme une grenade trop mûre. Boitant bas, le juif ne fit pas entendre une seule plainte (Jacques Lanzmann, La Horde d'or)

1996 Me voyant apparaître, il se laisse glisser de sa chaise pour courir vers moi. Non! pas pour courir! Pour claudiquer, boiter, bas, très bas. Mon fils, mon petit prince, est bancroche (Janine Boissard, Une femme en blanc)

2000 Mme Levin se levait rarement et se déplaçait à l'aide d'une canne ; elle boitait bas ; elle usait d'un russe ou d'un allemand également autoritaires et traitait son monde avec une courtoisie impérieuse de reine en exil (François Nourissier, À défaut de génie)

2006 Maintenant seul, Michel Terrier réfléchissait. Comme il s'y attendait, Feltin n'avait rien cédé. Il était aux abois, dans un état de désarroi pitoyable. Boitait plus bas que d'ordinaire (Anne-Marie Garat, Dans la main du diable)

Remarques : Boiter bas désigne le fait de marcher en inclinant très fortement le corps d'un côté. Bas reste invariable et est modifié par plus, souvent, tout, très.

\section{Bouillir vif}

Ébouillanter vivant (un animal, une personne)

$\lambda$ écorcher vif

\section{Bouler droit}

Rouler selon une ligne droite

Intransitif

1558 Il y avoit en Avignon une bande d'escolliers qui s'esbattoyent à la longue boulle hors les murailles de la ville, l'un desquelz, en faisant son coup, faillit à bouller droict et envoya sa boulle dedans un jardin (Bonaventure Des Périers, Les Nouvelles Récréations et joyeux devis)

\section{Corpus Web :}

Se traitant d'imbécile, car elle n'était pas sûre d'avoir raison, elle chassa le tendre volatile et l'envoya bouler droit sur la lune où de lourdes gouttes commencèrent à gémir, laissant passage à une multitude d'hirondelles curieuses qui se rassemblèrent en un éclair dans la cour de la 
prison dans laquelle un malheureux prisonnier rêvait en vain de son futur bébé [https:// plumesdelaisne.wordpress.com/category/textes/ mots-emmeles] (24.2.2014)

Puis Uriel sentit son estomac lui remonter dans la gorge et comprit que la tête du monstre était en chute libre. Il se cramponna de toutes ses forces à une dent jusqu'à ressentir un choc qui se répercuta dans tous ses os et le fit rebondir comme une quille dans la bouche de la créature, manquant l'envoyer bouler droit dans l'œsophage [http://entre-monde.forumactif.com/t2341p20suite-psylle-pour-nahash] (24.2.2014)

Elle jetait un dernier regard à la ronde, repoussant d'un vigoureux coup de pied, une masse de deux, non trois, individus essayant de s'étouffer mutuellement. Ils allèrent bouler droit sur l'un des videurs qui les prit pour cible, assénant de vigoureux coups de gourdin dans le tas [http://les4royaumes.forumperso.com/t1860quetel-anneau-de-longevite] (24.2.2014)

REMARQues : Bouler droit se dit d'une chose, généralement ronde, qui roule à terre en suivant une ligne bien droite. Droit tend à quitter l'appartenance au verbe pour s'intégrer dans un groupe prépositionnel (dans, sur) en tant que modifieur de la préposition. Dans les deux premiers exemples du CW, envoyer bouler droit adopte le sens de 'se débarrasser de quelque chose'.

\section{Boulotter dur}

Travailler beaucoup

Intransitif

2008 Il boulotta dur une semaine. Mais hélas... Le chantier ferma pour détournement de crédit par l'entrepreneur (André Lam, Ebolo ou Le Refus d'un jeune de mourir)

CORPUS WEB :

Ça boulotte dur [https://www.facebook.com/ Sainte-Anne-Wanferc\%C3\%A9e-Baulet-17261 37707633072/videos/\%C3\%A7a-boulotte-dur/ 392824504942906] (20.9.2019) [Belgique]

Le mystère de la mue enfin résolu ! Les poils ne tombent pas, non, non... Ce sont les corneilles qui boulottent dur ! [https://www.facebook.com/ eric.bertrand.cheval.convaincu/videos/vrai ment-dur-/342300649731479] (5.4.2019)
REMARQUES : Employé dans le langage familier, boulotter dur signifie 'bosser, travailler durement'. Selon Plattner (1907 : 92), boulotter dur peut également signifier 'bouffer énormément', ce qui correspond à la deuxième acception de boulotter, mais il ne donne pas de source. En tout cas, on peut penser que l'usage actuel tend à associer boulotter avec le substantif boulot. Dans les citations, boulotter dur est synonyme de bosser dur.

\section{Bousculer dur}

Bousculer brutalement, violemment

Pronominal

1960 La mort d'un vieux bonhomme de Paris pour qui la servitude était trop dure et la solitude trop grande... de la mer, les confiseries pleines de miroirs, le Tir photographique et les petites autos électriques, mal élevées, qui se bousculent dur (Claude Roy, Le Journal des voyages)

\section{CORPUS WEB :}

Le problème, comme c'est la seule rivière Bretonne ou la pêche est encore autorisée, au premier coup d'eau cela risque de bousculer dur sur les rives de l'Elorn! [https://fr.groups.yahoo. com/neo/groups/mouchefr/conversations/ topics/13175] (24.2.2014)

Nous avons tordus les avants Rochellais, ce qui n'est pas rien quand on a vu la séance infligée au Montois la semaine derrière, mais il faudra compter sur cette équipe au final. N'enterrons pas Agen! Bref, ça va bousculer dur derrière le RCT, et rien ne sera fait avant l'ultime journée ! [http://forums.rugbyrama.fr/archive/index.php/ t-9466.html] (24.2.2014)

à 7 semaines du denouement final, çà doit se bousculer dur dans la caboche... [http://www. onlinetri.com/phpBB2/viewtopic.php? $\mathrm{p}=881383$ ] (24.2.2014)

Chez Franciline, c'est la fête, 7 bébés berger allemand sont nés !!! quelle nurserie !!! la maman va avoir fort à faire avec tout ce petit monde.. ça va se bousculer dur pour aller têter !! [http:// www.weightwatchers.fr/community/mbd/post. aspx?page_size $=25 \&$ rownum $=3 \&$ threadpage_no $=1 \&$ sincedate $=25 \% 2 \mathrm{~F} 06 \% 2 \mathrm{~F} 2010+00 \% 3 \mathrm{~A} 00$ $\% 3$ A00\&thread_id $=9838468 \&$ board_id $=230$ \&forum_id=1\&thread_name=hello!!!+les+ 
Sybelles\%2C+c'est+dimanche+26!!!!+dodo\& mod_no $=\&$ daterange $=2$ days $\&$ ] viewchange $=$ LASTPOSTDESC (24.2.2014)

REMARQUes : (Se) bousculer dur se dit de choses ou de personnes qui se poussent, se heurtent brutalement entre elles. L'adjectif-adverbe $d u r$ souligne la dureté et la brutalité du choc. Dur reste invariable. Notons l'emploi impersonnel dans les exemples du CW.

\section{Bouter bon}

Bouter selon ce qui convient

$\lambda$ bouter fort

\section{Bouter droit}

Jeter, pousser directement

Transitif

+1370 Chils vens contraires lor dura deus jours, et costyèrent Frise, et ne savoient bonnement a dire li maronnier ou il estoient. Au tierch jour, vens lor revint à droit souhet, et qui les mena et bouta droit contre Engleterre, et tant que li maronnier en orent la congnissance (Jean Froissart, Chroniques (A))

Pronominal

1460 Congnoit bien toutesvoies l'acteur qu'il ne luy appartenoit soy bouter droit cy, ne de prendre une correction si aigre sur une si haulte et glorieuse nacion comme est celle de Frans, là où vertus et bonnes meurs sont comme en rivière poisson (Georges Chastellain, Exposition sur vérité mal prise, p. 582)

CORPUS WeB :

N'empêche que si ils pouvaient "bouter » droit, ça éviterait les trous sur nos jolis single que nous mettons tant d'amour à confectionner à la sueur de notre front... :D [http://forum.velovert. com/topic/32920-le-forum-de-bleau-77/page st_2396] (24.2.2014)

REMARQUes : Bouter droit désigne le fait d'exercer une poussée ou de jeter quelqu'un/quelque chose directement vers un lieu. L'exemple du CW atteste bouter droit comme terme de vénerie qui a ici le sens de 'fouiller (la terre) avec le boutoir [= le groin] en ligne droite', en parlant des sangliers. Droit reste invariable. Notons l'emploi de mener droit.

\section{Bouter fort}

Frapper, pousser fortement

Transitif

+1300 Et Garins lui alla si droittement viser Que le fer lui a fait au heaume couller. En sourlevant la lanche l'alla si fort bouter Que le fer lui a fait au heaume raser Et a fait le cheval a le destre cliner, Le maistre et le cheval a terre versser (Les Enfances Garin de Monglane [XIV ${ }^{\mathrm{e}}$ )

1389 La maniere de l'estouper [= le renard] si est que on preigne des fouchieres et menu boys, et les boute l'en dedanz les fousses et puis mettre de terre dessus et bouter bien fort, affin qu'il n'y puisse entrer en nulle maniere. Et, si vous voulez qu'il n'aproiche ja les pertuis, prenez deux bastons pelez blans et les metez en croiz sus chascun pertuis (Gaston Phébus, Livre de chasse, p. 243,10$)$

\section{INCORRECTION}

Pluto vint d'enfer, pour tant que Tiffon, le geant, avoit moult fort bouté, la montaingne de Ethna soubz laquelle il estoit ensevelis ; et en la boutant il rompi la terre, tellement que par une crevace la lumiere $\mathrm{du}$ soleil ala jusques en enfer, dont Pluto et ses gens furent moult courrouciéz (Jacques Legrand, Archiloge Sophie, p. 170, 1)

1403 Ja ot affolé et occis Et mahaigné ou .V. ou .VI., Par sa tres hardie proece, Quant vers une roche s'adrece Grant et pesant, si la bouta Si fort que tous acravanta Les traïcteurs, qui soubz estoient (Christine de Pisan, Le Livre de la mutacion de fortune, II, 12761)

+1415 Je ne vueil plus riens que la mort, Pour ce que voy que Reconfort Ne peut mon cueur eslyesser. Au Dieu d'Amour je m'en rapport Qu'en peine suis bouté si fort 
Que povair n'ay plus d'endurer ;

S'en ce point me fault demourer

(Charles d'Orléans, Poésies [ 1415-1440], I, Chanson XVII, p. 214)

Pronominal

1460 Et ce ceste manière de faire savoit bien l'occasion le derrenier venu, mais il n'en faisoit nul semblant ; et aussi a la vérité il ne luy en challoit gueres, si non que ung pou luy desplaisoit la folie du premier venu, qui trop fort a son gré se boutoit en chose de petite value. Et de fait se pensa qu'il l'en advertiroit tout du long, ce qu'il fist (Les Cent Nouvelles nouvelles, p. 229, 58)

1824 Les Anglais, qui par cesdites divisions se sont enhardis au point de se bouter fort avant, ont conquis, occupent et usurpent une grande partie de cette seigneurie, et pourraient faire plus si les choses restaient dans la même disposition (Prosper de Barante, Histoire des ducs de Bourgogne de la maison de Valois)

\section{CORpus Web :}

Pas plus facile s'ils tiennent leurs promesses càd de nous faire un jeu digne de ce nom et de meilleure qualité. Car pour nous faire un bon graphisme, faut bouter fort mais bon... [http://www. teampremiereinfanterie.org/t1860p400-call-ofduty-black-ops-wii] (28.3.2014)

REMARQUES : Bouter fort se dit du fait de frapper, heurter avec force. Au sens figuré, lorsque le sujet subit l'action, il réfère à un mal (ex. de 1415 : la peine) causant une souffrance psychologique. Fort reste invariable et est modifié par bien, moult, si, trop. Notons l'usage de bouter bon 'selon ce qui convient' dans le CW.

\section{Bouter raide}

Frapper fortement, fermement

Transitif

+1366 Les tableaux de son livre ouvri ;

Sa plume y bouta roide et dure :

Un po cria, mais elle endure (Eustache Deschamps, Euvres complètes [3 $3^{\mathrm{e}}$ tiers $\mathrm{XIV}$ ])
1532 J'en aimerois mieux (dist Panurge) une mouillée de quelque bon vin d'Anjou. Boutez donc, boutez bas et roide (François Rabelais, Pantagruel)

Remarques : Pour l'exemple de 1532, un commentaire dans l'édition citée ajoute : « expression prise, suivant Le Duchat, du jeu de paume, pour dire : Expédiez donc vite votre messe basse ». Raide sert ici à intensifier. Il reste invariable. L'exemple 1366 illustre l'emploi des adjectifs-adverbes raide et dur en tant que prédicats seconds qui s'accordent avec le sujet féminin.

\section{Boutonner droit}

Attacher au moyen de boutons disposés en ligne droite, verticalement

Transitif

1831 Il porte ordinairement un habit bleu, à boutons d'or ; il a coutume de le boutonner droit jusqu'au cou ; son pantalon est bleu clair (Petit courrier des dames)

1857 Ses cheveux grisonnants, coupés avec une régularité sévère, ses moustaches rudes, ses favoris courts et taillés carrément, son col haut et inflexible, sa redingote boutonnée droite, et la rosette des grades élevés de la Légion-d'Honneur qui s'épanouissait à sa boutonnière, composait cet ensemble d'une distinction un peu vulgaire, qui forme le type très-connu de l'officier supérieur retraité (Xavier de Montépin, Les Chevaliers du Lansquenet)

1868 pour les gens d'un certain rang, le langouti est en soie ; on y ajoute souvent une petite veste boutonnée droit sur la poitrine, à manches très étroites et une autre pièce d'étoffe également en soie (Francis Garnier, Voyage d'exploration de l'Indo-Chine)

1964 Tailleurs boutonnés droit assez bas (MarieClaire, juillet 1964 / Grundt : 385)

Intransitif

1859 L'ancien sous-officier n'était point, comme à l'ordinaire, vêtu d'une redingote boutonnant droit sur un pantalon à la hussarde. Il portait une blouse bleue, de celles qui descendent à peine sur les hanches et qu'on 
appelle bourgeron (Pierre-Alexis Ponson du Terrail, Rocambole)

1907 Ainsi, par exemple, l'habit d'uniforme, au lieu de boutonner droit, recevait des revers coupés en pointe, comme ceux du frac vert de l'empereur ; quelques officiers hasardèrent même le revers bleu clair comme le collet (Bulletin de la Société des sciences et arts de Bayonne)

Pronominal

1902 Ces blouses peuvent se boutonner droit au milieu de devant ou croiser légèrement à gauche de 4 ou 5 centimètres au plus, cette fermeture croisée est beaucoup plus solide et moins grossissante que le bouton au milieu (Tissus et nouveautés, janvier 1902)

REMARQUES : L'objet du verbe transitif boutonner, tout comme le sujet du verbe intransitif et pronominal, désigne un vêtement qui se ferme à l'aide de boutons disposés verticalement. Droit peut rester invariable (ex. de 1868, 1964), mais il peut également s'accorder avec l'objet (ex. de 1857), tout en conservant son interprétation adverbiale. Boutonner droit est lexicalisé dans le domaine de la mode.

\section{Boutonner étroit}

I. étroit boutonné : doté d'une pointe aiguë en forme de bouton (par analogie avec le bouton du fleuret)

Transitif

1825 Un porte-aiguille, des pinces à anneau et un bistouri étroit boutonné sont les autres instrumens dont il [= le chirurgien] se sert (Bulletin des sciences médicales)

II. étroit boutonné : fermé par des boutons séparés par peu d'espace (d'un vêtement) Transitif

2007 Un homme vêtu d'un habit très étroit boutonné jusqu'à la taille est illustré tirant le saint par la main et indiquant la direction du chemin à suivre avec sa main droite (Une icône historiée de Saint Georges du XIII siècle)

REMARques : La structure syntaxique de l'exemple de 2007 est ambiguë. On préférera sans doute la lecture un habit très étroit // boutonné jusqu'à la taille.

\section{Boxer serré}

Boxer en maintenant peu d'écart avec son adversaire, sans lâcher prise

Intransitif

1959 La garde haute et boxant serré, Gonzalès prit l'initiative du premier round (FrancTireur, 29 novembre 1959 / Grundt : 297)

REMARQUES : Boxer serré réfère à l'action de livrer un combat de boxe en se tenant très proche de son adversaire, sans céder du terrain, privilégiant les crochets et uppercuts, dans le but de lui mettre la pression, de le fatiguer et de l'empêcher de porter des coups longs et précis. L'expression appartient au vocabulaire de la boxe.

\section{Braire haut}

Hurler, se lamenter d'une voix forte, pleurer Intransitif

+1100 La flamme est grant, escalfed fort, Pur quei icil crement la mort. Sanz mesure grant ad le cors, Plus halt braiet que quinze tors ; Peril n'i oust fors sul de denz Sil fuireient mil e cinc cenz (Benedeit, Voyage de saint Brendan [1 ${ }^{\text {er }}$ quart XII $]$, 916)

1285 Qu'il se donerent tex corgies Que vos lez eüssiéz oïez Des montaignes et do chastel. Bruiant, Garniers et Wauterel Oïssiéz braire haut et cler : "Baisi au gentil bacheler ! " (Jacques Bretel, Le Tournoi de Chauvency, 1227)

+1365 Si les ferés tout quoi taire, Ou plus hault cryer et braire Qu'il ne font presentement (Jean Froissart, Poésies [3 $3^{\mathrm{e}}$ tiers XIV $]$ ])

1450 GRIFFON. Ta charoigne est a mort livree ; $\mathrm{Tu}$ pers temps de braire si hault (Arnoul Gréban, Le Mystère de la Passion, 26264)

1910 En français moderne, ce verbe [= braire] ne désigne que le cri de l'âne. Dans notre patois, il se dit aussi bien de l'homme que de maître Aliboron, conservant du reste 
le sens général qu'il avait anciennement. « Cet enfant brait haut » (pleure bruyamment) (Charles Lecomte, Le Parler dolois)

\section{CORPuS Web :}

Ca m'a fait marrer. Parce que tout le monde dit ça ! c'est comme l'anti-américanisme, $90 \%$ des gens braient haut et fort leur « refus d'obtempérer », y'a un forumer qu'a cité très justement l'expression « mutins de Panurge » [http:// forum.judgehype.com/judgehype/LaTaverne/ philosophie-balles-bonheur-sujet_198356_2. $\mathrm{htm}]$ (4.4.2014)

Entre le négligent qui s'en balance (et là, c'est une question de politesse) et celui qui fait des efforts mais ne peut pas et souffre réellement de sa mauvaise orthographe, il y a bien des nuances, et c'est facile pour les ânes qui braient haut et fort qu'ils sont experts en cette science de se sentir supérieurs à peu de frais [http://lestroisgrobills.blogspot.co.at/2009/06/ la-disortografy.html] (4.4.2014)

Remarques : Braire haut désigne le fait de pousser des cris forts, des hurlements, et, par extension, de se lamenter, de pleurer en faisant beaucoup de bruit. Disparu des textes écrits dépouillés par Frantext, ce mot est resté comme régionalisme (ex. de 1910) au moins jusqu'au début du $\mathrm{xx}^{\mathrm{e}}$ siècle. Le CW montre cependant qu'on le trouve aussi dans la langue commune informelle comme référent de l'obstination, de l'entêtement de l'âne. Haut reste invariable et est modifié par plus, si. Notons la collocation haut et clair (exemple de 1285) et haut et fort dans le CW.

\section{Brasser carré}

Orienter la vergue d'un navire à l'angle droit avec la quille

Transitif

1850 Wilder fit quelques tours sur le gaillard d'arrière, promena ses yeux sur le ciel, sur les vergues, sur son équipage dans l'attente ; puis il s'écria :

- Brassez carré les vergues d'arrière !

Les vergues craquèrent en prenant la position indiquée (Fenimore Cooper, Le Corsaire rouge [trad.])

\section{Briller clair}

Répandre une lumière vive et claire Intransitif

1623 Son œil armé de maint esclair Brilla plus luisant et plus clair Que le soleil après l'orage, Quand sa reluisante beauté D'un clair rayon a surmonté Le noir amas de maint nuage (François Maynard, Le Philandre)

1852 Il y fait froid quelquefois, n'est-ce pas ? Mais qu'importe ! On voit les étoiles briller clair et l'on n'entend plus les dindons. Adieu, voilà deux heures du matin. Comme je voudrais être dans un an d'ici (Gustave Flaubert, Correspondance)

1883 Alors, pendant que l'ardent soleil séchait très vite toutes ces choses qu'ils avaient mouillées, eux commençaient à fourbir ; les cuivres, les ferrures, même les simples boucles, devaient briller clair comme des miroirs (Pierre Loti, Mon frère Yves)

1893 Non ce n'est pas Ellis la blonde ; je me suis trompé tristement ; je me souviens maintenant que ses cheveux étaient noirs et que ses yeux brillaient aussi clairs que son âme. Son âme était vivace et violente, et sa voix très calme pourtant ; car elle était contemplative (André Gide, Le Voyage d'Urien)

1944 Ce fut une fête extraordinaire. Les hommes bâtirent des fours de sable qu'ils emplirent de bouse sèche, laquelle brillait clair comme du foin. Et la graisse des corbeaux parfuma l'air (Antoine de Saint-Exupéry, Citadelle)

1970 Il se mit à marcher le long de la route. La lune s'était dégagée des brumes et brillait plus claire, la bande de ciel jaune du couchant n'éclairait plus les arbres, mais elle ne ternissait pas encore (Julien Gracq, $L a$ Presqu'île)

1979 Et les femmes ? Tiens, c'est vrai, il n'a pas parlé des femmes. Il n’y aura pas pensé... Le soleil brille haut et clair. Il fait même chaud, soudain, vraiment chaud pour un 
début d'avril. Les merles sifflent dans les haies, habitués maintenant au roulement de la canonnade (François Cavanna, Les Russkoffs)

\section{CoRpus Web :}

Le matin de l'esprit brille clair dans ce beau livre [http://www.franceculture.fr/oeuvremanquant-tomber-de-alain-leveque.html] (4.4.2014)

Imaginez à quel point sur une froide journée d'hiver lorsque le soleil brille clair, une personne ressent la chaleur des soleils sur leur visage, même si il fait froid dehors [http://www.improhome. org/electriques-infrarouges-a03383100.htm] (4.4.2014)

REMARQUES : Briller clair se dit d'un astre (soleil, lune, étoiles) qui répand directement une lumière vive, ou d'une chose (œil, bouse) sur laquelle la lumière se reflète fortement. Notons la comparaison brilla plus luisant et plus clair que le soleil et la collocation haut et clair. L'emploi invariable étant la règle, clair peut tout de même s'accorder avec le sujet, ce qui le rapproche des prédicats seconds, notamment à partir du XIX ${ }^{\mathrm{e}}$ siècle, où la prédication seconde est en vogue. Clair est modifié par aussi, plus.

\section{Briller doux}

Répandre ou refléter une lumière douce Intransitif

1845 Les émotions dont était agité le cœur d'Adrienne devenaient si vives, que son beau visage se colora d'un rose vif, son sein battit violemment, et ses grands yeux noirs, jusqu'alors tristement voilés, brillèrent doux et radieux à la fois ; elle attendait avec une impatience inexprimable (Eugène Sue, Le Juif errant)

1882 «C'est un garçon manqué. " Ses traits s'étaient fondus et adoucis, ses yeux brillaient plus doux. Elle s'était féminisée, et n'ayant plus le même port de tête superbe et altier, elle semblait plus petite (Georges Ohnet, Le Maître de forges)

1916 Ton sourire brilla doux et harmonieux Comme un lys pur et blanc, une aile diaphane,
Ou la molle lueur d'une étoile qui plane $\mathrm{Au}$ fond du firmament pâle et mystérieux (Philippe Tristani, Fleur d'espérance)

2013 Cet homme-là était ermite depuis soixantedix années. Et quand ses rares visiteurs se risquaient à lui demander d'où lui venait cette lumière qui brillait doux dans son regard, il ne savait que répondre et partait d'un rire enfantin (Henri Gougaud, Petits Contes de sagesse pour temps turbulents)

\section{CORPUS WEB :}

Champagne.. petit péché mignon, parure de cristal comme des yeux qui brillent doux comme un oisillon, un nectar ambré à savourer comme un trésor, une poignée d'aiguilles, mille paillettes d'or des bulles irisées sans souci de leur sort, montent gaies et vives dans la coupe où elles pétillent, savoureux à souhait juste glacé comme il faut avec toi je viens partager la coupe de l'amitié.. [http://misterlover-00.skyrock.com/profil/wall/ ?last_item_id=c:42893507\&comments_page = 1\&last_comment_id=42893507\&id_filter $=1$ ] (7.4.2014)

Seul son regard étincelant, réveillait son visage endormi. Son regard brillait, doux et tendre, admirant la beauté sauvage qui daignait rester à ses côtés [http://www.hp-hogwarts.com/ t4763-mission-d-un-ete-pour-une-nouvelle-viesurprenante] (7.4.2014)

Remarques : Briller doux se dit de quelque chose (surtout : les yeux) qui répand ou reflète une lumière agréable à regarder, sans éblouir ni agresser. Le fait que doux s'emploie souvent avec des sujets au masculin tels les yeux, le sourire, rend difficile, voire impossible, de séparer l'adjectif-adverbe du prédicat second. Dans l'exemple de 2013 cependant, doux reste invariable malgré le sujet au féminin (la lumière). Doux est modifié par plus. Notons la coordination avec les adjectifs radieux, harmonieux et tendre.

\section{Briser menu}

I. Casser, (s')écraser en petits morceaux Emploi absolu

1765 Ainsi l'Oriental dit Pharphar, pour briser fort menu, moudre, et le latin dit aussi pour bled moulu, far, furfur, farina. Je ne multiplie pas les exemples, de peur d'en- 
nuyer le lecteur, qui de lui-même en trouve assez (Charles de Brosses, Formation méchanique des langues)

Transitif

1880 tandis que, dans l'air moite, dans la fadeur exhalée des cuvettes, traînait par instants une odeur plus aiguë, quelques brins de patchouli sec, brisés menu au fond d'une coupe (Émile Zola, Nana)

1972 Le pèlerinage de Pâques continue de s'y faire mais c'est une honte : la chapelle croule et la croix est par terre, brisée menu dans les ronces... (Henri Vincenot, Le Pape des escargots)

II. les briser menu à quelqu'un : exaspérer, agacer quelqu'un

Transitif

1987 Pour tout dire, il commence à me les briser menu, ce tueur mondain, avec ses « belles dames " susurrées dans l'oreille sans défense de ma Julia (Daniel Pennac, $L a$ Fée Carabine)

2004 À chacun ses chimères... Mais il y en avait un, là-bas, tout au bout du couloir sur la gauche, qui commençait à les lui briser menu. Grand ponte ou pas, ce mec-là était un goret et ça commençait à bien faire. En plus d'être crade, son bureau puait le mépris (Anna Gavalda, Ensemble, c'est tout)

2005 En gros, notre Shérif savait se faire respecter. Il n'aimait pas que l'on les lui brise menues (Jean-Claude Estampe, Nosfératus)

2007 Je veux du sen- sa-tionnel ! Du paparazzien! Du Lynx ! Tu te crois à la Nuit blanche pour me les briser menues avec ton happening ? Capté ? (Jean-Pierre Mocky, Les Vacances du pouvoir)

\section{Corpus Web :}

Un casse-noix qui les brise menues 12 janvier 2015 Naomi c'est le nom de ce petit objet malin et ludique. On va enfin pouvoir prendre notre vengeance sur les noix et les noisettes ! [https:// pepscreation.com/blog/un-casse-noix-qui-lesbrise-menues] (12.1.2019)
A propos, il me vient en tête une réplique de Lino Ventura dans les Tontons flingueurs, assez faciles à adapter aux Bleus : " L'homme de la Pampa, parfois rude, reste toujours courtois. Mais la vérité m'oblige à vous le dire : votre Domenech commence à me les briser menu ! » [https://www.ouest-france.fr/sport/football/ brise-menu-496151] (12.1.2019)

À la Audiard : Ma donzelle et moi, c'est fini. Elle me les brisait menu, la Valoche, alors je lui ai dit: « Tu ramasses tes cliques et tes claques et tu vas aller voir ailleurs si j'y suis pas » [https:// www.lejdd.fr/Chroniques/Anne-Roumanoff/Lesmots-pour-rompre-651335] (12.1.2019)

En deuxième position et vraiment juste après : l'heure qui suit le réveil en fanfare ou l'on explique un bon milliard de fois à Nouknouk qu'il ne mangera pas de bonbons toussuite et même pas pendant la matinée parcequ'il nous les a brisé menu-menu une fois de trop [http:// barbiturik.over-blog.com/article-7225620.html] (12.1.2019)

Révolution française, ni Front populaire, ni Mai 68, ni rien, pas de congés payés, pas de semaine des quarante ou des trente cinq heures... Rien ! L' " usager en colère » nous les brise menues [https://yetiblog.org/20071114216-1-usager-encolere] (12.1.2019)

Raaaah elle me les a brisé menu celle là ! Pfff elle pouvait pas se taire une bonne fois pour toutes [http://forums.madmoizelle.com/sujets/ le-debat-du-2-mai.9110/page-2] (12.1.2019)

REMARQUES : Briser menu (I), au concret, réfère à un objet que l'on casse ou qui tombe seul, finissant en petits morceaux (v. aussi le premier exemple du CW). L'expression familière les briser menu à quelqu'un (II) renvoie au fait d'agacer ou d'exaspérer quelqu'un ; équivalent moins vulgaire que casser les bonbons, les couilles, ce dernier mot étant sous-entendu et exprimé par les. Sous (I), menu peut être modifié par fort. Plutôt invariable en diachronie, l'orthographe moderne tend à introduire l'accord de menu, que l'on peut effectivement interpréter comme prédicat second résultatif (v. surtout le premier exemple du CW), s'il ne s'agit pas d'une simple hypercorrection. Notons la réduplication menu-menu dans l'avant-dernier exemple du CW. 


\section{Briser net}

I. Briser, casser précisément, sectionner ; interrompre brutalement

Pronominal

1726 Qui l'auroit cru, qu'un Dieu de pierre, Appuyé d'un ferme soutien Iroit donner du nez en terre,

Et se briser net comme un verre !

II ne faut répondre de rien

(Jean-Antoine du Cerceau, Poësies diverses)

1863 Arrivé à sa chambre, il jeta son feutre à terre si rudement que la forme en resta tout aplatie et que la plume ébouriffée se brisa net (Théophile Gautier, Le Capitaine Fracasse)

1932 Il semblait, lorsque les plaintes naissaient et se propageaient comme une fusée, que le navire était tordu par une main de fer. Elles étaient de nature et comme de formes diverses. Les unes étaient brèves et aiguës, les autres duraient plusieurs secondes. Là, un panneau se brisait net, plus loin une latte de bois sautait sur toute la longueur d'une cabine. Puis, c'étaient de petits bruits ; une table qui se renversait, un fauteuil qui pivotait (Édouard Peisson, Parti de Liverpool)

1954 C'est une voix qui a été un peu trop près de l'indicible, qui a dit : "Plus de mots », qui s'est brisée net (France observateur, 2 février 1954 / Grundt : 352)

2009 Au plus fort de la mêlée, l’on voit un Karayan acharné, frappant aveuglément ici et là. Et, tout à coup, sa matraque se brise net sur le crâne de l'un de ses adversaires. L'instant d'après, André éclate en sanglots (Dominique Perrut, Patria o muerte)

Transitif

1845 Naturellement notre capitaine s'y refuse ; mais le colonel fait signe à sa première batterie d'avancer, et malgré le soin que le conducteur mit à se jeter sur le bois la roue du premier canon prit la jambe droite de notre capitaine, et la lui brisa net en le renversant de l'autre côté de son cheval. Tout cela fut l'affaire d'un moment (Honoré de Balzac, Autre étude de femme)

1910 Un second coup de cordon arracha le ressort à la muraille, brisa net le fil de fer, laissant la sonnette berliquotante à son clou. Phine atteignit la porte (Louis Delattre, Carnets d'un médecin de village)

1923 Il avait réussi à entrer à la Chambre. Il était même devenu sous-secrétaire d'État. Marie Vialis se trompait-elle en rattachant le désastre de cette carrière politique, brisée net en 1898, au crime commis par lui vingt ans auparavant (Paul Bourget, La Geôle)

1931 Le carabe est blessé : il se traîne de guingois sur le sable, une gouttelette d'ambre perle à son corselet. C'est trop facile maintenant de briser net sa fuite : Rroû a été brutal comme un chaton, brutal et maladroit comme il le fut naguère, au temps de ses premiers jeux (Maurice Genevoix, Rroû)

1982 Apparut le Kislar Aga dans tout l'apparat de ses soieries rouges, de ses zibelines, de sa suite d'eunuques : il venait me chercher. Son irruption, l'ordre qu'il lança, brisèrent net cette agitation. Instantanément, gestes désordonnés et gémissements cessèrent (Michel, prince de Grèce, La Nuit du sérail)

2009 rendue au milieu de cette escouade à un anonymat bienheureux qui me délivrait de la sollicitude de mes deux mères, je goûtais deux mois durant un enchantement sauvage que la guerre brisa net (Mona Ozouf, Composition française : retour sur une enfance bretonne)

II. Cesser immédiatement ses relations avec quelqu'un

Emploi absolu

1846 Quelle belle vie dans la vie nous fait ainsi la pensée ! Je songe à inventer des tendresses qui ne seront qu'à moi, dont le secret ne sera deviné par aucune femme. Il me prend des sueurs froides qu'il n'arrive un empêchement. Oh ! Je briserais net avec lui, s'il le fallait ; mais ce n'est pas d'ici que jamais viendra l'empêchement, c'est de toi, tu pourras vouloir aller dans le monde, 
chez une autre femme peut-être (Honoré de Balzac, Un prince de la Bohème)

\section{CORpus WeB :}

Le rêve olympique de Lokman Kaplanbaba vient de se briser net puisque la fédération française de lutte a décidé de ne plus lui faire confiance [http://www.lejsl.com/sport-local/2012/03/09/ pas-de-j-o-pour-kaplanbaba] (9.4.2014)

Les grévistes ont même eu écho que la direction avait cherché à faire passer plusieurs personnes en comparution immédiate. La direction voulait ainsi briser net la grève, mais les grévistes ne sont pas tombés dans le piège et ont su sortir au bon moment [http://npa-secteurpostal. org/?p=1064] (9.4.2014)

REMARQUES : Au sens propre, briser net (I) se dit du fait de casser, mettre en pièces une chose inanimée, la cassure apparaissant nettement, précisément. Si l'objet est un animé, la cassure est d'ordre psychique. Au sens figuré, l'objet est une chose abstraite (fuite, phrase) qui est interrompue de manière brutale, soudaine. S'y ajoute l'acception (II) de rompre franchement avec une personne, sans revenir sur sa décision. Net reste invariable.

\section{Broder menu}

Broder à petits points, finement Transitif

1170 La ot dreciee mainte lance, E despleié maint confanon E mainte enseigne e maint penon Vert e vermeil, de seie ovré E de fil d'or menu brosdé [variante : moult bien broude] (Benoit de Sainte Maure, Le Roman de Troie, 9686)

\section{CORPUS WEB :}

Un peu plus instruit désormais, je vais tâcher de présenter un tableau moins incomplet, et donc forcément plus compliqué : qu'il s'agisse de cricket, de la confection du thé, du système métrique ou de la Chambre des Lords, rien de ce qui vient d'Angleterre n'est vraiment simple, de toutes façons. Aussi ne saurais-je trop recommander au lecteur de se munir à l'instant d'un scaphandre et de quelques bouteilles d'oxygène. À tout le moins, de se préparer une bonne théière ou de bourrer une pipe. J'ai l'intention de broder menu [http://lescalier.wordpress.com/ 2009/11/16/langlicanisme-aujourdhui-crises-etralliements-i] (9.4.2014)

À la fontaine, l'eau glousse en lavant sa beauté des mirages sanglants où se complaît Hécate. Quelle insolite atmosphère se brode menu dans les hautes dentelles rousses des chênes [http://xavier.bordes.over-blog.com/articletransparences-10-a-19-117119718.html] (9.4.2014)

je trotte menu, je pense menu, et je brode menu, tu vois je commence l'année comme je finis l'autre, en plaisantant [http://poussine1. canalblog.com/archives/2018/01/06/36022925. html] (9.1.2018)

REMARQUES : Broder menu se dit du fait d'orner une étoffe de broderies fines, en exécutant de petits points (ici : avec un fil d'or). Dans le premier exemple du CW, broder menu signifie 's'étendre longuement ; raconter ou expliquer avec force détails'. Dans le dernier exemple du CW, le sens est plutôt celui de 'conter par le menu, détailler, expliquer avec force de détails' ou 's'occuper à de menus ouvrages'. Notons que broder menu n'a pas disparu du langage tel qu'on pourrait le croire à en juger par les données de Frantext. Mentionnons également l'emploi des groupes trotter menu, penser menu.

\section{Bronzer idiot}

Bronzer stupidement, bêtement, sans profiter des richesses culturelles

Intransitif

1973 Ne pas bronzer idiot. Objet : promouvoir des rencontres culturelles enrichissantes (Journal officiel de la République française)

1989 On vadrouille dans le Wurtemberg. Ça vaut mieux que bronzer idiot. Je fais du cheval (Georges Perec, L'Infra-ordinaire)

2001 Je bronze parfaitement idiote, comme en 63, en Italie, quand j'attendais une lettre de Philippe (Annie Ernaux, Se perdre)

REMARQUES : Bronzer idiot 'bronzer stupidement' est largement cité et discuté dans la bibliographie linguistique et dans d'autres commentaires sur les adjectifs-adverbes. On l'associe aux vacances au soleil et à l'influence de l'anglais sur le langage publicitaire. Or, personne ne cite l'original 
anglais. On constate, au contraire, que les sources anglaises le considèrent comme une expression typiquement française difficile à traduire : « The 'anti-Club Med' trend of those years [= les années 60] also took the shape of the travel agency Nouvelles frontières (New Frontiers), founded in 1967, whose motto On ne veut pas bronzer idiot (We don't want to just stupidly get a sun tan) reflected its antiestablishment, antibourgeois take on travel to other countries (Roger Célestin et Eliane DalMolin (2007), France from 1851 to the present : universalism in crisis, New York (Palgrave Macmillan), p. 329) ». Stephan-Gabinel (2001) ajoute les variantes bronzer épanoui et bronzer catho et les insère dans une longue liste de slogans et conseils : acheter intelligent, jeter intelligent, piqueniquez malin, roulez malin, dépenser malin, consommer malin, acheter malin, rouler propre, voyager propre, jeter utile, conduire citoyen, roulez facile - roulez tranquille. Cette série se prolonge au jour le jour : acheter responsable, manger confortable, voyager confortable. L'accord de idiot dans l'exemple de 2001, qui en augmente l'emphase en impliquant davantage le sujet, le rapproche du substantif, comme dans conduire citoyen.

\section{Broyer fin}

Broyer en petites particules fines

Transitif

1638 Pour faire, en outre, que de l'eau jaillisse de la tête on fera cheminer un autre homme sous le plancher de la scène et sous la tête, juste, du dauphin, lequel tiendra en main un cornet de carton grand un peu plus d'un demi-pied qui soit ouvert en son fond et en quoi il faudra mettre bonne quantité de menues parcelles d'argent battu ou de talc broyé fin (Nicola Sabbatini, Pratique pour fabriquer scènes et machines de théâtre)

17968 livres de potasse broyée très-fin, sur 100 livres d'eau.

10 de sel marin ordinaire, bien sec, et broyé fin sur 100 livres d'eau.

10 liv. de couperose séchée, et broyée fin sur 100 livres d'eau

(Le Febvre de Villebrune, Mémoire relatif à de nouveaux procédés pour éteindre les incendies)
1829 Le charbon de sarment est encore très-recherché ; il est difficile à broyer fin (Jacques-Nicolas Paillot de Montabert, Traité complet de la peinture)

1832 Ce noir est bon et beau, et on fait un trèsgrand usage, surtout pour les grands tableaux, où l'on emploie beaucoup de couleur. Il est assez bleuâtre, et il va bien partout : en un mot, on aurait peu de chose à lui reprocher, s'il n'était pas très-difficile à broyer fin (Pierre Louis Bouvier, Manuel des jeunes artistes et amateurs en peinture)

1958 Le grès cérame est fait d'une argile vitrifiable, séchée et broyée aussi fin que la poudre (Fémina pratique / Grundt : 409)

\section{CORpus Web :}

Avec le fouet électrique, travailler le beurre et le sucre glace en une masse claire. Dans un mortier, broyer fin les graines de pavot et les incorporer [http://www.saison.ch/fr/recettes/ etoiles-au-massepain-fourrees-labricot/detail] (9.4.2014)

Je possède un broyeur à moteur thermique sur roues, diamètre de broyage maxi $40 \mathrm{~mm}$, 2 grilles permettant de broyer fin ou gros pour compostage ou BRF ? [http://troc-legumes.fr/articles/ atla-atla-atla-les-haricots-les-haricots-atla-atlaatla-les-haricots-sont-la-99.html] (9.4.2014)

REMARQUES : Broyer fin est résultatif. Il se dit du fait de réduire en une poudre ou une pâte très fine, l'objet étant dur (pierre, os, graines, bois). Notons la comparaison broyée aussi fin que la poudre, et l'opposition sémantique entre fin et gros dans le CW. Fin reste invariable et est modifié par aussi. Les exemples du CW illustrent l'usage actuel dans le domaine culinaire et jardinier.

\section{Bruire dru}

Faire beaucoup de bruit

Intransitif

-1400 Gensdarmes près vous verrez bruire Plus dru que mousches à milliers (Le Testament de Monseigneur des Barres [fin XIVe], p. 109) 


\section{Bruire fort}

Faire beaucoup de bruit

Intransitif

+1250 Li bois comance fort a bruire

Et les lieures proignent a fuire.

Sus un estant sont arestees

De paour toutes esgarees

(Ysopet de Lyon [2e moitié XIII $], 1383$ )

1600 Celuy qui sort du Levant brumal, est nómé en grec Euros, et en latin Vulturnus, pource qu'il bruict fort, et vole hault, comme le vautour. Les mariniers l'appellent Sudest (Nicolas Abraham de La Framboisière, Le Gouvernement nécessaire à chacun pour vivre longuement en santé)

1992 Cette rivière bruissait fort et son courant était rapide. Les bouleaux des petits bois qui prolongeaient le parc avaient donné son nom au domaine avant que le père de mon arrière-grand-père ne l'achetât (Francine Mallet, D'un amour l'autre)

2009 Le sang bruissait fort dans son cerveau, l'étourdissant. La douleur irradiait dans sa main blessée (Theresa Révay, Tous les rêves du monde)

2011 Je pensais que c'était la faute de la chaleur et du vent du sud qui bruissait fort dans les arbres (Brigitte Giraud, Pas d'inquiétude)

\section{CORPUS WEB :}

Soudain il bruit fort et Benkei se sentit projeter à l'autre boue de la chambre. Il leva la tête et vit sa chambre en ruine et il cria : [http://narutonindo-v2.forum-actif.net/t123-benkai-nasu] (9.4.2014)

Mon pas sur les feuilles d'herbe raidies par la gelée fait des froissements qui bruissent fort à mon oreille [http://www.thomasbouvier.ch/ index.php?option=com_content\&view=article\&i $\mathrm{d}=11 \&$ Itemid=31] (9.4.2014)

les abeilles bruissent fort

nous avons des acouphènes

faites cérémonie [http://www.jeuxvideo. com/forums/1-50-95778372-1-0-1-0-haiku-original. $\mathrm{htm}](9.4 .2014)$

REMARQUES : Bruire fort se dit du fait d'émettre un son d'une forte intensité, le sujet étant générale- ment inanimé (ici : le bois, le sang, une rivière, ou le vent), sauf dans le cas du bruit, confus, causé par un essaim d'abeilles dans le CW. Notons l'emploi impersonnel il bruit fort. Notons l'emploi de voler haut.

\section{Bruire frais}

Produire un bruit léger en provoquant une sensation de fraîcheur

Intransitif

1905 Une cascade, un peu loin, bruissait frais comme le vent dans les feuilles (Jean Nesmy, L'Tvraie)

1925 Au même moment, des égouttis claquaient dans l'eau, bruissaient frais contre la berge du canal (Maurice Genevoix, Raboliot)

REMARQUES : Bruire frais réfère ici au fait de s'agiter, remuer en produisant un bruit donnant une sensation de fraîcheur, de légèreté agréable. Son emploi est littéraire. Frais reste invariable.

\section{Brûler clair}

I. Brûler en éclairant beaucoup

Intransitif

1888 Angélique avait pris le cierge allumé, et d'une main ferme, elle le tenait droit. La vie était revenue, la flamme brûlait très claire, chassant les esprits de la nuit. Un grand cri traversa la chambre, Félicien était debout, comme soulevé par le vent du miracle (Émile Zola, Le Rêve)

1908 C'était aussi l'heure où la Marie-Rose, son fanal brûlant clair et bien, sa coque sombre invisible dans la nuit noire, passait en pleine mer, draguant dans l'eau froide son lourd chalut où mouraient les soles des dîners de demain (Pierre Hamp, Marée fraîche)

1934 Je sais que le feu s'étendra. C'est comme un feu de forêt qui s'éteint ici, reprend là. C'est chez nous qu'il y a cent ans il brûlait le plus clair. Mais qu'il s'allume en France ou en Russie, c'est toujours le même feu (Jean Guéhenno, Journal d'un homme de quarante ans)

1967 Sur cette grande plaine nue des polders de Flandre, à cette heure-là on marchait un 
peu comme sur la mer. Sortis du bois, le pays autour de nous ressemblait beaucoup moins à un champ de bataille que plutôt à une nuit de la Saint-Jean. Des fermes et des meules brûlaient clair çà et là dans l'étendue, autour des feux on entendait de loin monter des chœurs allemands avinés (Julien Gracq, Lettrines)

2006 Pour contenter cette femme qu'il vénérait, il courait, il volait, jamais lassé de la servir, portait un à un les fagotins de sarments qui allaient brûler haut et clair, sans fumée, pour parachever la netteté des chairs plumées (Yvette Frontenac, $L a$ Soupe des autres)

II. Être animé de sentiments très forts Intransitif

1953 Montesquieu attend toujours, comme Titien, les amours de retour, et qu'on en ait fini de jeter feu et flamme, pour enfin brûler clair (Claude Roy, Le Commerce des classiques)

CORPuS Web :

Ces entreprises peuvent également effectuer le nettoyage de la pile de sorte qu'il n'y a pas une énorme accumulation de débris de suie ou de lâche. Ceci est très important si les feux doivent être tenus brûler clair et lumineux dans les mois d'hiver [http://www.improhome.org/entretienmaconnerie-a04597029.htm] (9.4.2014)

Tu n'avais rien, mais tu as voulu donner ce qui te semblait une grande richesse, cette belle bûche de bois capable de brûler clair et de réchauffer les malheureux transis [http://www. biblisem.net/narratio/vailbuch.htm] (9.4.2014)

REMARQUES : Dans son emploi intransitif, brûler clair désigne une chose étant en état de combustion pour être détruit ou pour produire chaleur et lumière. Au figuré, le sujet réfère à une personne ou, par métonymie, à une âme, qui éprouve des sentiments très vifs. Clair peut s'accorder avec le sujet (ex. de 1888), ce qui le rapproche des prédicats seconds, mais il peut également refuser l'accord (exemples de 1967, 2006). Il peut être coordonné avec un adverbe (bien) et avec un autre adjectif-adverbe (haut). Notons aussi la coordination avec lumineux. Il est modifié par bien, le plus. Mentionnons également l'emploi de tenir droit. VoIR AUSSI : brûler haut

\section{Brûler dru}

I. Être en feu ; brûler la peau

Transitif

1779 Il était brûlé dru

Chez le gnome Lustucru ;

Quand sortant de son derriere,

J’ai rafraîchi sa taniere (Nicolas Rétif de la

Bretonne, Le Nouvel Abeilard)

Intransitif

1906 Le feu avait pris cette fois sur Planeyse encore, vers le pont du chemin de fer de Bôle. L'herbe brûlait dru et le feu menaçait de se propager au petit bois situé près de la poudrière, au risque de faire sauter celle-ci, qui contient une grande quantité de schrapnels et de cartouches (L'Impartial, 28.8.1906)

II. Se manifester avec force, vigueur Intransitif

1920 Toute la vie était là. Sur une échelle réduite. Oui, seulement brûlant plus dru (Henry de Montherlant, La Relève du matin)

\section{CORPus Web :}

Le soleil sec brûle dru.

L'enfant sage est nu [https://fr.groups.yahoo. $\mathrm{com} /$ neo/groups/poesieuniverselle/conver sations/topics/24175] (09.04.2014)

REMARQues : Au sens propre et au figuré, dru souligne l'intensité du fait de brûler. Il reste invarié (exemple de 1920) et est modifié par plus.

\section{Brûler dur}

I. Brûler très fort (feu, soleil)

Pronominal

1881 Quand l'eau fut chaude, on la descendit du feu, et la chèvre dit :

- Saute, compère le loup.

- Non, saute, toi, commère la chèvre.

La chèvre sauta et ne tomba pas dans l'eau. Quand ce fut le tour du loup, il prit mal son élan et tomba au milieu de l'eau, et il disait : 
- Ah! que je me brûle dur !

- Tourne-toi, répondit la chèvre, cela te brûlera moins.

- Ah ! je me brûle encore plus, dit le loup qui s'était retourné

(Paul Sébillot, Littérature orale de la Haute-Bretagne)

Intransitif

1917 Dame, c'est la fortune du pays qui brûle, et qui brûle dur et fort, comme si la flamme des étés se vengeait d'un coup d'avoir été emprisonnée aux troncs des pins sous l'espèce et avec le titre de résine. Le feu !

(Charles Derennes, Cassinou va-t-en guerre)

1933 Le soleil brûlait dur depuis cinq jours et ce pays resté désertique malgré ses bourgades fortifiées et quelques cimetières isolés dans le bled avec leurs tertres recouverts de pierres plates, ne semblait réserver aucune surprise joyeuse (Georges Le Fèvre, Expédition Citroën Centre-Asie)

1948 « Ça brûle dur... » annonce un guetteur (Julien Guillemard, L'Enfer du Havre, 1940-1944)

II. Brûler de façon à rendre dur

Transitif

1931 Le four était construit en carborundum (deux parties de gros morceaux, une partie de fins, mélangés à 50/0 d'argile, damé et brûlé dur) ; il fallait une heure pour fondre $18 \mathrm{~kg}$ de rognures de tubes très volumineuses (Revue de métallurgie)

\section{CoRpus Web :}

En parlant de remèdes de l'époque, je me souviens avoir été soigné à l'aide de ventouses [...] Il y avait aussi les fameux buvards " Rigolot». - ma parôôôle, ou ce qu'ils ont trouvé un nom pareil - Pas si marrant que çà les séances, ces buvards ayant de la moutarde dans leur composition parait-il, çà brulait dure dure. Dos rouge et decongestion assurés [http://esmma.free.fr/ mde4/livror2006/LO06-P13.htm] (26.1.2006)

REMARQUES : Brûler dur (I) renvoie à un feu et, au figuré, au soleil, à la peau, qui brûlent fortement. (II) est une prédication seconde résultative orientée vers l'objet du verbe (ici : l'argile). Dans l'exemple du CW, il ne s'agit probablement pas d'un accord au féminin avec « la composition ». La graphie « dure » est très fréquente, même au masculin, dans beaucoup de groupes verbaux avec dur que l'on trouve sur Internet. Il s'agit donc plutôt d'un reflet graphique de la prononciation renforcée du -r final. Notons la collocation dur et fort et la réduplication dur dur.

\section{Brûler fort}

I. Chauffer, éclairer fortement ; consumer

Transitif

1554 La fievre plus fort me brûle

Que la chemise d'Hercule :

Et le mont Sicilien

N'eut onq' feu pareil au mien

(Jean de La Péruse, Poésies complètes)

1559 Car, quant Floride venoit parler à luy priveement, comme celle qui ne y pensoit en nul mal, le feu caché en son cueur le brusloit si fort qu'il ne pouvoit empescher que la coulleur ne luy montast au visaige et que les estincelles ne saillissent par ses yeulz (Marguerite d'Angoulême, Heptaméron, p. 74, 258)

1894 L'âme noble mérite de plus hautes occupations. Je sais qu'il est des âmes très nobles que l'amour de Dieu a brûlées plus fort que tout autre désir ; il semble que cette ardeur angélique ait comme absorbé l'autre flamme (André Gide, Journal)

Intransitif

1633 Et puis l'air le plus espais qui descend au lieu du plus subtil par la chaleur, ne peut descendre en un instant, et neantmoins au mesme instant que je presente un miroir bruslant au soleil, il brusle aussi fort que s'il demeure plus long-tems exposé (Marin Mersenne, Correspondance)

1849 LA FOI. [...] Rien n'est vrai que l'éternité de l'éternel, et la grâce seule a l'intelligence de lui. Espère-la pour l'acquérir, garde-la pour qu'elle s'augmente, n'en désespère pas afin qu'elle revienne. Si tu l'obtiens, tu posséderas alors cette compréhension incompréhensible, et, toujours brûlant plus fort pour monter plus haut, ton âme 
aspirée sortira d'elle-même, comme fait au-dessus du feu la flamme qui s'en élève (Gustave Flaubert, La Tentation de saint Antoine)

1914 Durant ces vingt années où Lamartine s'enfonce dans une solitude qui semble au premier regard un désert de prosaïsme, de violentes lueurs font voir que le génie brûle toujours aussi fort (Maurice Barrès, Mes cahiers)

1963a Et de ce feu, l'écorce de la terre prenait la puissance entière, au point qu'il paraissait que ces rochers, que ces mers, ces arbres et ces airs brûlaient encore plus fort, étaient les flammes d'une nature pétrifiée (Jean-Marie Gustave Le Clézio, Le Procèsverbal)

1963b - Ceux de San Bastian demandent de l'aide, dit Néca. Il paraît que ça brûle si fort qu'on ne peut pas tenir à vingt mètres des flammes, ceux de Coggio y sont montés. Est-ce qu'on voit le feu de l'église?

(Pierre Moinot, Le Sable vif)

2008 Il n'avait pour Camille qu'une pensée aiguë, la pointe d'un tison lancé dans la nuit, elle rejoignait bizarrement celle de son frère qui pouvait lécher un trottoir à quatre pattes et réfléchir à la question, lumineuse, dans toute cette obscurité. Surtout écarter cette pensée incandescente, elle brûle trop fort, carbone pur (Anne-Marie Garat, L’Enfant des ténèbres)

II. Subir violemment les effets du feu

Pronominal

1627 Je mis un de mes doigts dans le feu pour voir s'il estoit bien chaud, et Carmelin en voulut faire aussi de mesme, mais nous nous bruslasmes si fort, que nous nous retirasmes soudain (Charles Sorel, Le Berger extravagant)

\section{CORPUS WeB :}

mais tu es quand même cruel, elle a dû se brûler fort la fille [http://www.forum-olympusfrance.com/forum/topic/3115-capture] (15.4.2014)

En voyant le serpent de feu se dresser, pour le coup, elle se sentit un brin insignifiante. Elle empêcha de justesse le feu de la bruler trop fort en créant une sorte de boule d'eau entre elle et le feu bien qu'il fallait le renouveler sans cesse [http://ested.forumactif.org/t1613-dangermortel] (15.4.2014)

REMARques : Sous (I), le sujet peut désigner une source de chaleur comme le feu ou le soleil, mais très souvent, au figuré, le sujet désigne un être vivant ou par métonymie l'âme humaine qui éprouve de vifs sentiments, une passion forte. Dans son emploi pronominal, brûler fort (II) désigne une personne qui subit volontairement ou accidentellement les effets du feu ou d'une trop forte chaleur. Il reste invariable et est modifié par aussi, encore plus, plus, si, toujours aussi, trop.

\section{Brûler haut}

Brûler en faisant de grandes flammes Intransitif

1661 elles font gloire de le faire enrager, et de le laisser brûler haut et bas avant qu'elles se reconnoissent : mais souvent ces Déitez mortelles usans de refus d'un côté, font des acceptions d'un autre qui donnent assez de marques de leur foiblesse (Chapelle, Voyage de messieurs de Bachaumont et de La Chapelle)

1878a Dans le petit salon, les bougies qui brûlaient très hautes, avaient mis l'odeur chaude d'une fin de soirée. Par moments, on entendait au dehors le ruissellement d'une averse, un roulement sourd dans le grand silence (Émile Zola, Une page d'amour)

1878b La lampe brûlait très haute, avec sa flamme blanche, éclairant le désordre de la chambre, où les meubles étaient culbutés (Émile Zola, Une page d'amour)

1884a Quand il cria enfin, d'un faible cri plaintif, elle tomba assise devant le fauteuil, remuée jusqu'au ventre. Le grand feu brûlait très haut, emplissant la chambre d'une clarté vive. Pauline restait par terre devant l'enfant, qu'elle n'avait pas encore regardé (Émile Zola, La Joie de vivre) 
1884b Dans la cuisine, elle trouva Véronique qui l'attendait, endormie sur un coin de la table ; et la chandelle qui brûlait très haute, fit battre ses yeux, d'un noir profond, comme emplis des ténèbres de la route, où ils étaient restés grands ouverts, depuis Arromanches (Émile Zola, La Joie de vivre)

1885 Il fit environ deux cents pas. Brusquement, à un coude du chemin, les feux reparurent près de lui, sans qu'il comprît davantage comment ils brûlaient si haut dans le ciel mort, pareils à des lunes fumeuses (Émile Zola, Germinal)

1892 Les feux, sur les deux rives, brûlaient plus haut, et leur clarté en ce moment devenait si vive, que la scène, dans son effroi, s'évoquait avec une netteté d'apparition. Sous le poids de la cavalerie et de l'artillerie défilant depuis le matin, les bacs qui supportaient les madriers, avaient fini par s'enfoncer, de sorte que le tablier se trouvait dans l'eau, à quelques centimètres (Émile Zola, La Débâcle)

1967 Quelques débris d'aluminium commencèrent en tournoyant leur descente. Puis nous avons aperçu le parachute fatal. Nul n'a brûlé si haut que moi. Un réacteur arraché plongea vers la mer, sa chute encore accélérée par la traînée de feu de cent millions de chevaux fous (Michel Bataille, L’Arbre de Noël)

1981 Ils étaient vivants, vivants au point que leur force fascinait ceux qui ne savaient pas brûler haut et droit et qui se contentaient de les regarder à la dérobée. Ils étaient nus et personne avant eux n'avait été nu comme ils l'étaient (Nicole Avril, La Disgrâce)

2001 Sa haine des gardiens remonta comme un flux, une nausée ; une flamme qui trouve un combustible, une mèche pour brûler haut et visiblement... (Samuel Mourier, Vers les rivages de l'Amer)

\section{CORPUS WEB :}

Alors que, depuis Soul Society, les voix de ses compagnons s'éteignent les unes après les autres, les flammes d'un homme se mettent à brûler haut... [http://www.comicstore.fr/manga/ 21377-bleach-t57-9782723498203.html] (15.4.2014)

Consciente que les gardes n'en resteraient pas là Hayalee entreprit d'élargir ses murs crépitants, puisant sans retenue au fond d'elle afin qu'ils brûlent haut, aussi haut et large que possible pour que personne ne puisse les franchir d'une enjambée [http://www.fanfic-fr.net/fanfics/ imprimer/fics-originales/F/Fantasy/Derri\% C3\%A8re-les-Portes---Premier-Mouvement/ 19928/220844.html] (15.4.014)

REMARQues : Haut est un adjectif-adverbe de position, référant à l'intensité de la combustion. Le sujet désigne une source de chaleur ou de lumière (lampe, bougie, chandelle, feu) qui se caractérise par de grandes flammes et qui provoque une chaleur puissante ou éclaire de manière forte. Généralement invariable, haut peut tout de même s'accorder avec le sujet, ce qui le rapproche des prédicats seconds. Les exemples cités d'Émile Zola font penser que l'accord est préféré quand la lecture est plutôt statique, indiquant la hauteur de la flamme, tandis qu'il est absent quand la lecture est directionnelle (ex. de 1885 et 1892). La phonétique pourrait également jouer un rôle, l'accord ne se produisant qu'au féminin (haute, hautes), mais jamais au masculin-pluriel (hauts). Le degré d'abstraction semble également favoriser l'emploi invarié (ex. de 1981, 2001). Haut est modifié par aussi, plus, si, très. Notons les structures coordonnées haut et bas, haut et large, haut et droit, haut et visiblement.

\section{Brûler jaune}

Brûler avec une flamme jaune

Intransitif

1887 Le tambour les [= chandelles] alluma, ils brûlèrent jaune, d'une belle flamme jaune, couleur d'or, qui monta comme un soleil dans sa gloire (Émile Zola, La Terre)

1956 Le catafalque se dresse sous la croisée des voûtes, recouvert d'un grand drap tricolore ; des cierges innombrables brûlent jaune, et des torchères tordent dans le fond leur flamme verte (Fernand Gregh, L’Âge de fer) 
REMARQUES : Brûler jaune réfère à une flamme jaune qui brûle. Il reste invarié. Nous le citons comme représentant de bon nombre de couleurs qui peuvent apparaître avec ce verbe.

\section{Brûler vif}

I. Brûler une personne vivante, en vie Transitif

1461 Bien eureux est qui riens n’y a ! Mais que ce jeune bachelier Laissast ces jeunes bachelectes? Non, et le deust on vif bruler Comme ung chevaucheur d'escouvettes ! (François Villon, Le Testament, 667)

1521 - Sire roy, dirent tous les habitans du lieu, soit le trahistre bruslé tout vif, et que tous ses biens soyent confisquez au prouffit de vostre fille (Le Violier des histoires rommaines moralisées)

1623 La troisiesme chose que je remarque en ce livre, c'est que jadis lors qu'il y avoit encores un peu de sentiment et de pieté dans les ames des bons vieux François, au seul nom de sodomie, on ne parloit que de brusler tout vif celuy qui en eust esté seulement soupçonné, et aujourd'huy on verra un livre qui se vend publiquement dans les galeries du palais, qui porte en front un sonnet execrable, par lequel l'autheur, qui se dit le Sieur Theophile se repentant, à ce qu'il dit, d'avoir eu et contracté une maladie infame avec une prostituée, fait vœu à Dieu d'estre sodomite tout le reste de ces jours (François Garasse, La Doctrine curieuse des beaux-esprits de ce temps)

1719a Et que vous avoit-elle fait, lui dit-elle d'un ton sévère, que vous avoit-elle fait, cette Fleur d'Épine, pour la brûler toute vive? L'assemblée frémit d'étonnement ou de joie à ces paroles (Antoine Hamilton, Histoire de Fleur d'Épine)

1719b Mais il s'obstina à vouloir qu'avant toutes choses on lui livrât les decemvirs, et il menaçoit hautement de les faire bruler tous vifs. Valerius et Horatius n'étoient gueres plus favorables à ces magistrats que le peuple même (René de Vertot, Histoire des révolutions arrivées dans le gouvernement de la République romaine)

1800 VASCONCELLOS. (seul) Demeurez ! arrêtez ! Quoi donc ? elle me fuit... Ma fortune est tombée, plus d'amis. Quel bruit entends-je ? Où fuir ?... Et ces papiers ?... Où les cacher ?... Il y a de quoi te faire brûler vif... D’où les as-tu sauvés?

(Népomucène Lemercier, Pinto ou La Journée d'une conspiration)

1902 le long de ses galeries sont représentés les supplices de l'enfer bouddhique : quelques centaines de personnages de grandeur naturelle, en bois tout rongé de vermoulure, se débattent contre des diables qui s'empressent à leur étirer les entrailles ou à les brûler vifs (Pierre Loti, Les Derniers Jours de Pékin)

1906 Il fit crier sous les remparts que dorénavant chacun qui sortirait de Barbastro serait brûlé vif. Et ce n'était pas une vaine menace (Maurice Barrès, Mes cahiers)

1919 Je me suis surprise moi-même méconnaissable avec un visage que les hommes ne pourraient me voir sans me brûler vive, la folie de l'heure nocturne. Un halo, une cernure entourait l'âme : le spectre d'enfance (Mireille Havet, Journal)

2001 Il paraît qu'on se bat dans les faubourgs de Lyon. On raconte que les Allemands ont fait brûler vives 150 personnes à Saint-Genis-Laval (Denise Domenach-Lallich, Demain il fera beau)

Pronominal

1601 puis elle [= la colère] remplist tout de feu, fumée, tenebres, bruict, semblable à celuy qui mist le maistre hors la maison, puis y mist le feu, et se brusla vif dedans, et comme un navire qui n'a ny gouvernail, ny patron, ny voiles, ny aviron, qui court fortune à la mercy des vagues, vents et tempestes, au milieu de la mer courroucée (Pierre Charron, De la sagesse) 
II. Brûler vivement, fortement

Intransitif

1845 C'est-à-dire que le feu allait brûler doucement sur la peau du patient, au lieu de brûler vif (Eugène Sue, Le Juif errant)

\section{CORPUS WeB :}

Le visage rouge par la chaleur, l'odeur de la fumée, Dream n'est pas très belle à voir dans cet état. Voilà 10 minutes que des créatures essayent de la brûler vif [http://kingdom.muxxu.com/tid/ forum\#!view/11|thread/11840542] (15.4.2014)

C'est un geste que le père voulait faire pour tuer sa pauvre fille la brûler vif [http://www.rtl.fr/ actualites/info/article/un-pere-soupconne-davoir-tente-de-bruler-sa-fille-7744353901] (15.4.2014)

REMARQUES : Brûler vif(I) revoie au fait de brûler une personne vivante. Le groupe est lexicalisé, ce qui renforce l'idée d'un objet interne, mais il s'adapte aussi bien à la prédication seconde explicite qui peut entraîner l'accord (1719a,b, 1902, 1919, 2001). Malgré sa fonction de prédicat second, vif ne s'accorde pas avec l'objet au féminin dans les exemples du CW. Étant donné que l'accord serait audible, on peut penser que la langue parlée tend à l'emploi invariable, tandis que la langue littéraire marque la relation logique (la personne vit au moment de mourir) par l'accord morphologique. Brûler vif (II) désigne une source de chaleur (le feu) qui produit une chaleur intense. Dans l'exemple de 1845, il est adverbialisé comme équivalent de vivement, ce qui est mis en évidence par le contraste avec doucement.

\section{Bûcher ferme}

Travailler avec acharnement, beaucoup ; apprendre dur Intransitif

1877 L'ouvrage débordait ; on avait calculé qu'il faudrait veiller jusqu' à onze heures, en se dépêchant. Tout l'atelier, maintenant, n'ayant plus de distraction, bûchait ferme, tapait dur. Les bras nus allaient, venaient, éclairaient de leurs taches roses la blancheur des linges (Émile Zola, L’Assommoir)

1894 POIL DE CAROTTE. Compte sur moi, papa. Je t'accorde que je me suis un peu laissé aller l'année dernière. Cette fois, je me sens la bonne volonté de bûcher ferme. Je ne te promets pas d'être le premier de ma classe en tout (Jules Renard, Poil de carotte)

1954 Oui, c'était urgent : il fallait qu'il s'établisse un programme et qu'il se mette à bûcher ferme. Il aurait dû le faire depuis longtemps. Son excuse, c'est que les événements l'avaient pris de court, il avait paré au plus pressé (Simone de Beauvoir, Les Mandarins)

1977 Dès ce moment, je la détestai cordialement. Imaginant apporter quelque adoucissement au chagrin de mes parents par une scolarité plus brillante, je m'étais mis à bûcher ferme, progressant chaque mois de quelques places (Albert Simonin, Confessions d'un enfant de La Chapelle)

2011 Des cinq enfants de ce dernier, l'aîné, dixneuf ans, bûchait ferme pour réussir sa première candi en sciences économiques, tandis que la benjamine achevait sa cinquième première (André Hanssens, Ce soir, dans le jardin d'Eden...)

Transitif

1936 Notre instituteur - un Parisien pourtant - fait bien des conférences sur les assolements et les engrais. Je m'en vais bûcher ferme toutes ces questions. Il faudra aussi que je réussisse à fonder une société sportive, à l'exemple de la plupart de mes confrères (Georges Bernanos, Journal d'un curé de campagne)

\section{CORPUS WEB :}

Même lorsque le pays ripaille ou s'apprête à réveillonner, au Transport et à l'Équipement, on continue à bûcher ferme [http://www.bakchich. info/france/2007/03/07/en-architecture-perbenassure-50257] (15.4.2014)

Un gros os, taillé sur la longueur, ce qui expose la délicieuse et bien grasse moelle que la chaleur intense du four, un filet d'huile et d'ail ont rendu encore plus gras. Il faut bûcher ferme pour retirer toute la moelle qui se cache dans les cavités [http://www.lapresse.ca/le-droit/weekend/restos/201402/28/01-4743451-pourquoi-lecarafe-passe-inapercu.php] (15.4.2014) 
REMARQUES : Le sujet de bûcher ferme désigne une personne volontaire qui travaille de manière acharnée, sans répit, pour arriver à son but. L'objet interne peut référer à une activité intellectuelle ou à un travail physique (emploi avec taper dur dans l'exemple de 1877). Bûcher ferme s'emploie dans un registre familier. Ferme tend à l'emploi invariable, même si les exemples n'en fournissent pas la preuve (sauf peut-être le premier exemple du CW avec on 'nous'). En tout cas, l'accord étant inaudible, l'invariabilité est un fait acquis dans la langue parlée. Notons l'emploi de taper dur.

\section{Buquer bas}

Frapper à une porte doucement Intransitif

+1540 LA FEMME. Que bucquez-vous ?

qu'esse-là ?

Bucquez bas ; ce n'est point bordeau

(Farce nouvelle d'un amoureux / Ancien Théâtre françois)

REMARQUES : Buquer bas réfère au fait de frapper doucement à une porte en donnant quelques coups légers, afin de demander à y entrer. L'expression est vieille.

\section{Buquer haut}

Tonner fort

Intransitif

1518 Lequel admirai, à l'aprochier, salua la seigneurie de trois coups de canon, qui bucquèrent si hault que le Roy s'en esveilla (Laurent Vital, Premier Voyage de Charles Quint en Espagne, de 1517 à 1518)

REMARQUES : Contraire de buquer bas, dans l'ancienne langue.

\section{Buter dur}

Buter, se heurter rudement, violemment

Intransitif

1936 Le pantalon en fins volants, il était plus que des loques... c'était tout mouillé autour... Antoine il venait buter dur en plein dans les miches... Chaque fois, ça claquait... Ils s'agitaient comme des sauvages... Il pouvait sûrement la crever de la manière qu'il s'élançait... Son falzar, il lui traînait le long des mollets jusque par terre... (Louis-Ferdinand Céline, Mort à crédit)

2000 Et ça y va et ça ronronne [= le moteur]. Ça a l'air de buter dur. Pourtant, la terre làhaut, sans être des meilleures, n'est pas si mauvaise (Claude Kerlaz, La Fin des paysans)

Transitif

2004 CARLA. C'est pas si simple.

EGON. Tu l'as buté dur, dis donc, Denis ! (Luc Dumont, Trente-deux / dix)

\section{CORPUS WeB :}

mon train croiseur lui passe sur la déviation à gauche mais ne dèclanche pas le vert et là je bute dur dur comment il faut que je fasse pour avoir le vert à nouveau sur le train joueur àprés le train croiseur ? [http://forum.activitysimulatorworld. net/viewtopic.php?f=114\&t=21653] (15.4.2014)

@LeChatBeautey au moins tu avoue lol par contre certaines se butent dur yen a qui ont déja finit le jeu il vient juste de sortir [https://twitter. com/SoLlgalsene/status/380437007559708672] (15.4.2014)

REMARQUeS : Buter dur réfère au fait de cogner fortement contre quelque chose $\mathrm{Au}$ sens figuré (CW), buter dur réfère à une difficulté à laquelle l'être animé désigné par le sujet doit faire front. Notons la réduplication de dur dans le premier, et l'emploi pronominal dans le deuxième exemple. Dur reste toujours invariable. 


\section{Cabrioler net}

Faire brusquement une culbute, tomber en faisant un roulé-boulé

Intransitif

1883 À peine en marche, il me part un lièvre dans les culottes. Le gaillard ne se pressait pas, je lui envoie mon premier coup, il fléchit, je redouble. Il cabriole net. J'étais tout fier (Gaston d'Hailly et al., Les Livres en 1883)

\section{Cacher serré}

I. Se cacher adroitement, astucieusement Pronominal

1925 Et elle parla encore, contre ceux qui l'avaient envoyée, contre Volat surtout, avec une rancune forcenée :

- Ah ! Pour sûr que j'en sais ! Il se cache ben serré, il est rudement subtil, mais moi j'ai tout appris quand même !

(Maurice Genevoix, Raboliot)

II. Se cacher en se blottissant étroitement contre quelque chose

Pronominal

1942 Elle approche, les manches troussées sur ses bras forts. Elle essuie ses mains mouillées à la corne de son tablier. La petite fille se jette contre Nazaire, se cache serré, le front blotti dans le pli de son cou. Et elle dit : « À pus, Eva ! Je veux rester avec son père » (Maurice Genevoix, Laframboise et Bellehumeur)

\section{Corpus WeB :}

Puis, alors qu'il allait commencer à déboutonner le chemisier d'Hermione, des bruits de pas se firent entendre et les jeunes gens se stoppèrent instantanément, se regardèrent et coururent tout les deux vers l'armoire la plus proche pour s'y cacher serré l'un contre l'autre [http://www.hpfanfiction.org/fr/viewstory. php?sid=1532\&chapter=5] (16.4.2014)

la fille nue marchant avec un arrosoir $d \& n s$ une main et la main de son partenaire dans l'autre le garçon nu marchant fiermenet à ceci près que son sexe était caché serré entre ses cuisses (faites preuve d'imagination) on ne voyait rien [http://www.bladi.net/forum/threads/lactricemarocaine-latifa-ahrar-deshabille-art-corporelstreaptease.246966/page-3] (16.4.2014)
$\mathrm{Tu}$ peux la " cacher » serrée contre des pots ou des plantes plus hauts... Voici la mienne, elle est dans la serre, mais toujours à l'ombre... [http://www.kuentz.com/forum/read. php?1,140547,140557,quote=1] (16.4.2014)

REMARQUES : En parlant d'une personne, cacher serré (I) désigne le fait de se dérober à la vue de quelqu'un, de se mettre dans un endroit secret, le mouvement du corps étant caractérisé par une certaine souplesse qui souligne l'adresse et la ruse du sujet. (II) réfère au fait de se soustraire aux regards d'autrui, le sujet cherchant un refuge, un abri, le côté étroit évoquant quelque chose de rassurant, qui lui donne un sentiment de sécurité. Serré, qui admettrait l'interprétation comme prédicat second, reste pourtant invariable dans l'exemple de 1942 et dans le premier exemple du CW. Ceci souligne un début de lexicalisation comme adjectif-adverbe, plutôt rare pour un participe, mais serré est particulièrement présent dans les entrées de ce dictionnaire, souvent sans être accordé. Serré est modifié par bien.

\section{Calculer juste}

I. Calculer avec précision, avec exactitude Intransitif

1696 Il est vrai que je me suis toujours trompée, mais en disant dimanche $20^{\mathrm{e}}$, cela était visible, et je ne vois pas que, quand j'aurais su calculer plus juste, vous eussiez pu faire autrement que ce que vous faites (Mme de Sévigné, Correspondance)

1755 Tout germe se desséche et meurt, si les sucs alimentaires qui lui sont propres, n'entourent et n'échauffent les organes de sa croissance, et ne fournissent à sa subsistance. C'est de ce principe simple et vrai qu'il faut partir pour calculer juste sur la population, sur les moyens de l'étendre, sur les vices qui la restreignent et la font languir (Victor de Mirabeau, L'Ami des hommes ou Traité de la population)

1771 Qu'elle attendît une autre récompense de m'avoir sacrifié un amant aimable, et de qui elle étoit adorée, cela est assez probable ; mais si elle eût calculé plus juste, ce n'auroit pas été sur le prix qu'elle exige de son manque de foi ; mais sur le prix qu'elle 
en reçoit, qu'elle auroit compté (Alexandre Dumas fils, Lettres athéniennes)

1836 Voici Frame et ses acolytes. J'en suis bien aise. Tu as calculé juste. J'ai fait le gros de l'ouvrage, avec soixante hommes qui me sont arrivés de Milly en l'attendant (Alphonse de Lamartine, Correspondance générale)

1939 J'ai pensé d'abord qu'en me demandant de remplir cet office, elle avait cru me donner une dernière preuve d'amour, et la plus définitive de toutes. J'ai compris depuis qu'elle n'avait voulu que se venger, et me léguer des remords. Elle avait calculé juste : j'en ai quelquefois. On est toujours pris au piège avec ces femmes (Marguerite Yourcenar, Le Coup de grâce)

Transitif

1950 - Pourvu qu'il n’y ait pas de pépin, dit Wolf. Après tout, ça peut ne pas tenir. C'est calculé juste.

- Si on a un seul pépin avec une machine pareille, grogna Saphir, j’apprends le brenouillou et je ne parle plus que ça tout le reste de ma vie (Boris Vian, L'Herbe rouge)

II. Calculer en ne laissant pas suffisamment de quelque chose (temps, argent)

Transitif

2009a Ils me font rigoler, ceux qui disent qu'un plan de surendettement c'est trop facile, on vous efface vos dettes et basta, mais c'est une vie d'enfer, on ne fait plus que payer, payer pendant dix ans, il n'y a pas d'épargne possible, pas de crédit possible, pas de consommation de confort, et c'est calculé tellement juste qu'on n'a pas droit à l'erreur, la moindre dépense imprévue devient un désastre (Emmanuel Carrère, D’autres vies que la mienne)

Intransitif

2009b Alors l'enfant se trouve seule à attendre, anxieuse à l'idée d'avoir peut-être raté le bon passage, celui de sept heures trente : le prochain, elle le sait, arrivera trop tard pour qu'elle soit à l'heure. C'est de sa faute : elle calcule toujours trop juste, ne part pas assez tôt. Le temps, elle s’y perd (Marie Sizun, Éclats d'enfance)

\section{CORpus WeB :}

Pour la rapidité , jusque là , je n'ai rien fait de significatif, de la peinture, c'est après que je vais coincer, les lardons du trainard $\odot$, je ne sais pas comment m'y prendre pour les calculer juste et ensuite les faire usiner (;) [https://www. usinages.com/tours/conseils-lexique-t37751-120. html] (16.4.2014)

Notons que cette matrice reste constant pendant tout le calcul et il est donc nécessaire de la calculer juste la première fois [http://hal. archives-ouvertes.fr/docs/00/59/28/89/PDF/ar ZL3Q7B70.pdf] (16.4.2014)

Je teste actuellement l'écriture d'un secteur. En lecture je ne vérifie pas les deux octets de CRC, par contre en écriture il faut les calculer justes, sinon la commande CMD24 renvoie un code d'erreur [http://forum.system-cfg.com/viewtopic. php?f=18\&t=3710\&start=90] (16.4.2014)

REMARQues : Dans son emploi concret (I), calculer juste se rapporte au fait d'additionner, de comptabiliser quelque chose, d'évaluer la somme de quelque chose. Dans son emploi figuré, il désigne toujours le fait d'évaluer quelque chose avec précision et exactitude, de bien voir, sentir ou percevoir les choses : l'âge d'une personne, une date, les conditions d'existence, de fonctionnement ou de réalisation d'une chose concrète ou abstraite. Selon le contexte, il peut adopter le sens de 'trop juste, sans marge suffisante' (II), en analogie avec des chaussures trop justes. Juste reste invariable, dans la grande majorité des cas, mais dans le dernier exemple du CW il s'accorde avec l'objet pronominal au pluriel antéposé au verbe, même s'il garde son interprétation d'adverbe de manière. Juste est modifié, par plus, tellement, toujours trop. VoIR AUSSI : compter juste

\section{Calculer sec}

I. Calculer quelque chose à l'état sec Transitif

1893 Ce volume gazeux et les suivants sont $\mathrm{cal}$ culés secs, à $0^{\circ}$ et sous la pression de $760^{\mathrm{am}}$ (Comptes rendus hebdomadaires des séances de l'Académie des sciences)

1910 Ses expériences lui montrèrent que 100 litres d'air de la capitale, calculés sec à 0 et à 760 millimètres, donnent en moyenne : Carbone combustible total milligr. 12,29 
Hydrogène 4,32 (Eugène Macé et Edouard Imbeaux, Hygiène générale de villes)

1941 Le volume et la composition des fumées fournies par la combustion de $100 \mathrm{~g}$ de bois calculé sec deviennent, dans ces conditions avec l'excès d'air signalé (Georges-Honoré Dupont, Le Bois carburant)

\section{Calculer précisément}

Transitif

1960 Cette si heureuse conjoncture arrivera - on calcule sec les éphémérides - au moment du débat onusien sur l'Algérie (Canard enchaîné, 28 septembre 1960 / Grundt : 358)

\section{CORPUS Web :}

Et empêcher les concurrents directs du nord du pays de calculer sec pour se retrouver entre eux. Farciennes, lui, compte sur son déplacement tongrois pour asseoir définitivement sa huitième position [http://www.oxyjeunesfarciennes. be/Presse/va_bs-140127.pdf] (16.4.2014)

Les machines se mirent à calculer sec. Il y eut assez vite des problèmes méthodologiques pour dessiner la cartographie de la zone touchée par le zombisme car la définition des symptômes comprenait un facteur d'aléas important, lié à la réception du phénomène par l'épouse des hommes atteints [http://www.demailly-chantraine.fr/ index.php/litterature/ecrits-de-lise-demailly/44petites-aventures-de-delta?017a994831800a811a a206e7270d3da4=ddaf34d31a4fb0a82ce5c9ba9f1 36f45] (16.4.2014)

Je me pose une question depuis que ma fille a commencé à manger. Lorsqu'on calcule la quantitée de céréales, on calcule sèche ou prête à manger ? Disons que c'est pas tout à fait la même chose [http://www.mamanpourlavie.com/ forum/sujet/quantita-ca-ra-ales-1] (16.4.2014)

Remarques : Calculer sec (I) est employé au sens propre pour désigner l'état sec d'un produit. L'accord est alors possible (interprétation comme prédicat second), sans être systématique, tandis que son emploi au figuré (II) tend à l'invariabilité ; il désigne le fait d'évaluer avec une précision, de manière rigoureuse les conditions d'existence, de fonctionnement, de paiement ou de réalisation d'une chose concrète ou abstraite.
Dans le dernier exemple du CW, sec et prêt sont mis au féminin pour faire l'accord avec l'objet absent mais récupérable dans le contexte (la quantité). À strictement parler, dans cet exemple il ne s'agit ni d'un adverbe de manière fléchi ni d'un prédicat second, mais d'une relation attributive inférentielle qu'on peut gloser par 'calculer la quantité sur la base des céréales sèches'. Ce type d'économie est typique des argots de métier et du langage informel de la vie quotidienne (à comparer, par exemple, contrôlé positif dans le domaine du sport). Les tendances à l'économie linguistique, qui sont caractéristiques des langages de métier, peuvent entraîner l'absence de flexion, comme dans les exemples de 1910 et 1941. Notons aussi l'emploi absolu, qui est systématique dans le registre informel du CW, alors que les autres exemples réalisent une structure transitive.

\section{Caler bas}

Immobiliser quelque chose à un niveau bas, à faible hauteur

Transitif

1578 Amour, voyant du ciel un pescheur sur la mer,

Calla son aile bas sur le bord du navire, Puis il dit au pescheur : Je te pri'que je tire Ton reth, qu'au fond de l'eau le plomb fait absymer

(Pierre de Ronsard, Le Second Livre des amours)

Emploi absolu

1625 une vague pouvait tout abismer : il y avoit assez de d'un escueil pour les faire eschoüer; d'une mesme bouffee de vẽt leur proüe d'or, leur rame d'argẽt, leur voile de soye aux cordages cramoisis, leurs Cupidons emperlez pouvoient caller bas ; car la mer ne pardonne pas mesme aux Dieux qui sont peincts à leurs proües (Jean de la Pierre, Le Grand Empire de l'un et l'autre monde divisé en trois royaumes)

\section{CORPUS WEB :}

Si la pêche est bonne, le negre ou maigre s'engage dans les mailles, qui sont assez larges et y reste pris : le bas du filet qu'il faut regarder comme un ret dérivant, est chargé de plomb qui 
le cale bas ; les pêcheurs le relevent aussitôt qu'il a coulé à fond. [http://portail.atilf.fr/cgi-bin/ getobject_?a.80:322:4./var/artfla/encyclopedie/ textdata/IMAGE] (22.4.2014)

Cotre au mouillage par bonne brise et mer formée un matelot cale bas le mât de hune, le mouillage dans le chenal ne devait pas etre toujours confortable [http://www. histoiremaritimebretagnenord.fr/\%C3\%AEle-debatz/histoire-de-1-\%C3\%AEle-de-batz-page-3] (22.4.2014)

Chaque entreprise a besoin de crier sur leurs marques, produits et services de temps en temps pour rappeler aux consommateurs à quel point ils sont ainsi que leur existence si elle a été calé bas pendant un certain temps [http://www. proreferencement.fr/page/5] (22.4.2014)

Je travaille l'aile, j'essaie de la caler bas mais c'est un peu galère [http://tubelesskite.trodlabal. com/t4889-samedi-15-09-2012-furax-dechire-agruissan] (22.4.2014)

REMARQUES : Bas, un adjectif-adverbe de position, peut admettre une interprétation résultative selon le verbe, comme dans caler bas. Provenant du langage maritime, caler bas désigne le fait de fixer quelque chose, de l'installer dans une position à la fois fixe et commode, bas référant à l'espace et soulignant la faible hauteur du lieu où se fixe l'objet. Bas reste invariable.

\section{Calmer net}

Calmer tout d'un coup, d'une manière brutale Transitif

1872 Cette douche jetée sur mon ardeur suffit pour la calmer net. Je rentrai chez moi et je mis au feu les trente-cinq pages que j'avais déjà écrites sur ce sujet fécond (Pierre Véron, Le Roman de la femme à barbe)

1888 - Âne, bête, cochon, salaud, mouchard, va-de-la-gueule et menteur !

L'autre dit :

- Tais-toi donc, eh ! farceur, y a du bon.

Du coup, Croquebol se tut. Calmé net, il dégringola de son «plumard»

(Georges Courteline, Le Train de 8 h 47)

1894 Qui sert même en cas de difficulté.

Comme les humains, les bœufs ont leurs têtes,
Plus d'un l'a souvent très près du bonnet, Et ce mot suffit pour les calmer net (Paul Déroulède, Chants du paysan)

1912 - Vous n'avez pas vu mon frère? demanda la Marie qui passa aux joueurs de billes disputant avec acharnement un coup douteux.

Son interrogation les calma net (Louis Pergaud, La Guerre des boutons)

2009a Parfois, quand son père allait trop loin à son gré, elle lui passait un savon devant tout le monde, dans un mélange de chinois et de créole, ce qui avait le don de calmer net M. Chine (Raphaël Confiant, L'Hôtel du bon plaisir)

Pronominal

1884 L'ami, bourgeois pauvre, eut une inspiration : « Faites-le payer par votre assurance. Les compagnies paient les objets brûlés, pourvu que le dégât ait eu lieu dans votre domicile. " À ce conseil, la petite femme se calma net (Guy de Maupassant, Contes et nouvelles)

1992 J'eus l'unique phrase susceptible de le neutraliser à travers sa furie : Bec-d'argent va régler ton compte si tu me touches... Il se calma net. Je ne l'entendis plus durant de longues minutes, puis la guitare frissonna dans sa chambre (Patrick Chamoiseau, Texaco)

2009b Ce qu'il lut dans les yeux injectés de sang de Charlie l'incita à se calmer net (Laurent Scalese, La Cicatrice du diable)

\section{CORPUS WEB :}

A l'adolescence par contre, j'ai été une connasse mais les gifles me calmaient net (sur le coup, pas sur la durée grâce à mon caractère têtue... --')! lol [http://paris.weemove.com/ Interdire_la_gifle_a_ses_enfants_qu_en_pensez _vous-Vie_quotidienne-forum_messages-296630-0-26.aspx] (22.4.2014)

J'ai toujours été ban déf, si jamais c'est tempo, je me calmerais net (); [http://www. jeuxvideo.com/forums/1-50-85832352-1-0-1-0-jene-comprend-pas-les-gens-qui.htm] (22.4.2014)

Cette phrase eut au moins un mérite. Celui de calmer nette l'adolescente [http://xmenrpg. 
superforum.fr/t1297-je-bois-tu-bois-il-boit-euhnon-je-partage-pas-pv-eric-von-hoenheim] (06.6.2014)

REMARQues : Calmer net désigne le fait d'apaiser d'un coup l'agitation physique ou la nervosité d'une personne, l'élément déclencheur pouvant être une parole, un ordre, une gifle, une question qui agit sur la personne de manière radicale et subite. Net reste invariable, mais dans le dernier exemple du CW, net s'accorde avec l'objet féminin, même s'il garde son interprétation d'adverbe de manière. Notons que la différence entre les formes masculine et féminine est inaudible.

\section{Caqueter clair}

Bavarder d'une voix claire

$\pi$ caqueter $d r u$

\section{Caqueter dru}

Bavarder beaucoup, à tort et à travers

Intransitif

1668 C'est une vieille connaissance.

Notre Magot prit pour ce coup

Le nom d'un port pour un nom d'homme.

De telles gens il est beaucoup,

Qui prendraient Vaugirard pour Rome,

Et qui, caquetants au plus dru,

Parlent de tout et n'ont rien vu (Jean de La

Fontaine, Le Singe et le dauphin / Fables)

1854 Jamais les servantes de Landernau ne sauront caqueter aussi dru que ces honorables en faisant leur marché (Edmond About, La Grèce contemporaine)

1907 Sa mobilité d'esprit et de geste le rend apte aux fonctions embrouillées. À son caractère affairé, cérémonieux, il joint la qualité de « caqueter dru » : « Venez Singe, parlez le premier » (Mathias Tresch, La Fontaine, naturaliste, dans ses fables)

\section{CORPUS WEB :}

Cinq minutes avant le miam, quand ça commence à caqueter dru dans la salle à manger, il s'agit de dégager paupiettes et légumes à l'écumoire [http://jeromeestebe.blog.tdg.ch/archive/ 2007/03/18/les-chouettes-paupiettes-de-bibi. html] (29.4.2014)
Rangés en file, selon leur sexe ou le genre de leurs occupations, les serviteurs attendent, en caquetant dru, en riant et en fredonnant, qu'on vienne marchander leur travail, mettre à prix leur intelligence présumée et leur force, acheter pour un temps leur liberté [http://www.roynel.com/ hl/le/bocage.htm] (29.4.2014)

Le Dru parlait rude et rare. Le Tiac prisait, chiquait et crachait sur le brasier de la forge. Le Caquésiau caquetait clair et dru [http://www. gilblog.fr/la_borne_mon_village/savez-vousrouler-les-r-html] (30.4.2014)

REMARQUES : Appartenant au registre familier, caqueter dru désigne le fait de parler abondamment, parfois pour le seul plaisir de parler, de tenir des propos futiles, verbeux, sans ordre ni suite. Dru reste invariable et est modifié par $a u$ plus, aussi. Notons la collocation clair et dru et l'emploi de parler rude, parler rare.

\section{Caracoler clair}

Sauter, cabrioler en produisant un effet de clarté $\lambda$ piaffer clair

\section{Carapater droit}

S'enfuir en prenant le chemin le plus court

$\lambda$ fuir droit

\section{Carguer court}

Trop retrousser (d'un vêtement)

$\lambda$ marcher franc

\section{Casquer dur}

Payer cher

Intransitif

1913 - Oui ! oui ! car le premier résultat de cette guerre est de remplir mon escarcelle ; ils casquent dur à mon bénéfice, ceux qui profitent des soi-disants abus, qui ne sont tels que parce que nous n'y avons point part

(Robert Randau, Celui qui s'endurcit)

1960 Jenner ne laissant qu'une fortune insignifiante, les six compagnies ont dû casquer dur pour dédommager Krieg et Larsen... (Paul Gerrard, Catch-catch party) 
1986 Ou bien casquer dur pour convaincre un pilote canadien qui serait assez fou pour le tenter (Claude Rank, L'autre no man's land)

\section{Casser net}

I. Dégrader, priver de son titre ou de son emploi sans autre forme de procès

Transitif

1680 Mon fils est demeuré pour des adieux ; il viendra me voir ensuite. Il faut qu'il aille à l'armée, les eaux viendront après. On a cassé encore tout net un M. D. pour des absences. Je sais bien la réponse, mais cela fait voir la sévérité. Adieu, ma très chère. Consolez-vous du petit ; il n'y a de la faute de personne. (Mme de Sévigné, Correspondance)

1750 PERSINET. Messieurs, permettez l'importunité, je viens à vous, monsieur Sorbin, les affaires d'État me coupent la gorge, je suis abîmé, vous croyez que vous aurez un gendre, et c'est ce qui vous trompe ; madame Sorbin m'a cassé tout net jusqu'à la paix ; on vous casse aussi, on ne veut plus des personnes de notre étoffe, toute face d'homme est bannie ; on va nous retrancher à son de trompe, et je vous demande votre protection contre un tumulte (Pierre de Marivaux, La Colonie)

II. Casser d'une manière précise et brutale Transitif

1814 Quoi qu'il en soit, on découvre facilement les trachées des plantes en cassant net des tendrons de vigne ou de jeunes branches de rosier, de tilleul, etc. : elles paraissent en forme de spirales de couleur argentée (Bernardin de Saint-Pierre, Harmonies de la nature)

1845 La forme des racines indique au moins trois cents ans d'existence. Au-dessous la roche est cassée net. La commotion, dont les traces sont écrites en caractères ineffaçables sur cette côte, a emporté les morceaux de granit je ne sais où (Honoré de Balzac, Béatrix)

1850a On les [= les nègres] revoit, ils arrivent à nous et montent à bord ; l'eau ruisselle sur leurs corps lisses comme sur les statues de bronze des fontaines. La description de la manière dont on passe les cataractes est trop longue. Sache qu'un coup de gouvernail à faux casserait le bateau net sur les rochers (Gustave Flaubert, Correspondance)

1850b Socquard, alcide de naissance, pouvait porter onze cents pesant ; son coup de poing, appliqué dans le dos d'un homme, lui cassait net la colonne vertébrale ; il tordait une barre de fer, il arrêtait une voiture attelée d'un cheval (Honoré de Balzac, Les Paysans)

1872 Sacrant tous les bandits royaux dans leurs repaires,

Punissant les enfants pour la faute des pères,

Arrêtant le soleil à l'heure où le soir naît, $\mathrm{Au}$ risque de casser le grand ressort tout net,

Dieu mauvais géographe et mauvais astronome,

Contrefaçon immense et petite de l'homme, En colère, et faisant la moue au genre humain (Victor Hugo, L’Année terrible)

1926 Parfois on entendait contre la barrière le claquement sec d'une ruade, incroyable de vivacité et de souplesse, une de ces ruades qui vous cassent la jambe net (Henry de Montherlant, Les Bestiaires)

1979 Il entendit une branche cassée net sous un pas avant que parvinssent les voix et guetta à la jumelle le groupe des bûcherons qui devaient changer de coupe et marchaient lourdement sous le poids des outils et des cordes (Pierre Moinot, Le Guetteur d'ombre)

2009 Il n'est plus guère concevable que l'avion puisse encore résister à cette succession de chocs, de torsions. Forcément, ça va finir ainsi, fuselage cassé net, en deux parties. Eux, tous les passagers, aspirés par le trou béant dans le noir glacé, les yeux exorbités (Dominique Perrut, Patria o muerte) 
2011 Tantôt Elle murmure des mots d'amour qui me remuent le cœur. Tantôt Elle m'envoie carrément son poing dans la figure, une fois elle m'a cassé net un appareil auditif tout neuf en me fracassant l'oreille gauche (Serge Doubrovsky, Un homme de passage)

Pronominal

1835 il se rendait au bois de Boulogne dans son cabriolet restauré, lorsqu'en descendant la rue de Bourgogne, à l'endroit où se trouve l'égout, en face la Chambre des députés, l'essieu se cassa net par le milieu, et le baron allait si rapidement que cette cassure eut pour effet de faire tendre les deux roues à se rejoindre assez violemment pour lui fracasser la tête (Honoré de Balzac, Histoire des Treize)

1986 Je suis devant lui, les lumières éteintes, le noir au ras de l'informe. La clé n'est pas celle de la porte. Il n'y a plus de porte. La clé peut bien sêtre cassée net dans la serrure... Il n'y a plus rien. Tout s'est ouvert et perdu (Gisèle Bienne, Le Silence de la ferme)

Intransitif

1868 Leur manœuvre eut pour résultat de les rapprocher de la rive gauche. Ils n'en étaient plus qu'à cinquante toises, quand l'aviron de Wilson cassa net. Le radeau, non soutenu, fut entraîné (Jules Verne, Les Enfants du Capitaine Grant)

1932 ... à divers signes, les marins comprenaient que l'Étoile-des-mers n'allait pas tarder à sombrer ; le navire était plus lourd, il avait perdu sa rigidité. Les haubans et les galhaubans cassaient net, et les craquements entendus par Haynes dans les fonds étaient, maintenant, perceptibles de tout endroit à bord (Édouard Peisson, Parti de Liverpool)

1945 Les bêtes étonnées grognèrent de colère et je les entendis courir aussitôt en tous sens. Pour me mettre à l'abri je me lançai à travers un fourré où une branche craqua en cassant net (Henri Bosco, Le Mas Théotime)
1962 Patrick grattait désespérément l'allumette sur le mur dont la peinture un peu éraillée fournissait un frottoir de choix. Au sixième aller et retour, elle cassa net et il s'arrêta, car il ne connaissait pas encore l'art de se brûler les doigts en allumant le petit bout trop court (Boris Vian, Les Lurettes fourrées)

2008 - Moi quoi ? répondit-il sans lever la tête. - Vous ne voulez pas que je vous coupe les cheveux à vous aussi ?

Sujet sensible. Sa mine [= de son Rotring] cassa net (Anna Gavalda, La Consolante)

III. Interrompre brutalement, brusquement Intransitif

1913 BAROIS. (Il s'arrête, passe rapidement en revue les visages rayonnants, et sourit)

Voilà.

(Une seconde de vie intense... Et brusquement, sans raison apparente, comme un fil trop tendu, son enthousiasme casse net. Il s'assied, souriant, gêné, très las) (Roger Martin du Gard, Jean Barois)

Pronominal

1938 Je suis sur le bord du trottoir de la rue Paradis, à côté du dernier réverbère. Le ruban de bitume se casse net. De l'autre côté de la rue, c'est le noir et la boue (JeanPaul Sartre, La Nausée)

1948 Jamais. Pas une fois. Maintenant, il suffit que j'entreprenne une rêverie, ma gorge sèche, le désespoir brûle mes yeux, la honte me fait baisser la tête, ma rêverie se casse net (Jean Genet, Notre-Dame-desfleurs)

1954 on a besoin d'instants de fête où le présent ramasse en soi tout le passé et triomphe de l'avenir... Les ruminations d'Henri se cassèrent net; on frappait les trois coups (Simone de Beauvoir, Les Mandarins)

Transitif

1950 Des détonations rares éclatent par-ci par-là, étonnamment sèches dans l'air engourdi et glacé. L'oreille les perçoit une à une ; mais entre elles, autour d'elles, semblant les menacer, les cassant net, 
le silence. Silence morne, qui soudain s'abat comme une chape immense dont je sens la matière froide et lourde (Maurice Genevoix, Ceux de 14)

Emploi absolu

1954 Elle s'est mise à criailler. Aussi j’ai cassé net :

- Mets la table, j’ai faim

(Jean Hougron, Les Portes de l'aventure)

IV. casser net le morceau : avouer un secret, donner l'ultime explication d'une manière directe, franche, brutale

Transitif

1936 Le plus loin que je peux... Ça a pas beaucoup fait de bruit... J'ai fait ça automatique... Le lendemain matin Courtial, je lui ai cassé net le morceau... J'ai pas attendu... J'ai pas pris trente-six tournures... Il a rien eu à répondre... Elle non plus d'ailleurs la chérie, qu'était aussi dans le magasin... (Louis-Ferdinand Céline, Mort à crédit)

V. casser net la baraque : faire grande impression très rapidement

Transitif

1960 Chargée de godets, sa petite frangine, arpète de l'année, suivait, double surprenant par la ressemblance. Rien que des méritantes avait voulu Mâ'me Communal. Elle en était à se demander si la première, stylée, les aurait pas par hasard, ces trésors, filés à poil sous leurs blouses immaculées ? Armand, inscrivant sa silhouette, qui en paraissait plus haute, dans la porte basse, vint casser net la baraque. Ratée l'intimité polissonne ! Fini le temps des bluettes! Il s'avançait Armand, et chacun de ses pas augmentait la déroute de la bignole (Albert Simonin, Du mouron pour les petits oiseaux)

VI. Tomber brutalement, brusquement Intransitif

1987 Voilà que ma maîtresse s’affaisse. Non, elle ne s'affaisse pas : elle casse net, sur ses belles jambes fermes, si galbées, que je surveillais : vlam (Bruno Bayon, Le Lycéen)

\section{CORPUS WEB :}

Les deux favoris, sur « Gedimat », ont vu un hauban casser net dans la nuit. Ils sont sains et saufs [http://www.liberation.fr/sports/2014/04/ 19/transat-ag2r-chabagny-et-tabarly-dematent _1000801] (30.4.2014)

Tandis qu'il était en train d'enfiler sa chemise, il ressentit tout à coup une forte douleur au bras, suivi d'un bruit sec. Il réalisa, terrifié, que son bras gauche venait de se casser net... [http:// lenouvelliste.com/lenouvelliste/article/116432/ Le-maestro-Joel-Constantin-donne-une-bellelecon-de-courage.html] (30.4.2014)

Lothar et Martin commençaient à peine à se faire oublier qu'une tempête d'un nouveau genre a secoué nos établissements en ce printemps 2008. Le vent de la réforme, baptisé RGPP (révision générale des politiques publiques), a en effet bien failli les casser net [http://crpfpaysdelaloire.fr/content/la-tempete-souffle-surles-crpf] (30.4.2014)

d'abord, je regarde la taille des feuilles, si les feuilles deviennent toute petite, j'en enlève ou alors, je regarde combien de branche a mon géranium, si il en a plus de une, j'enlève les branches supperflues délicatement en veillent bien de ne pas les casser nettes [http://www.aujardin.org/ viewtopic.php?f=1\&t=1986\&start\&view=print] (30.4.2014)

Remarques : Casser net s'utilise dans les contextes suivants : I. Dégrader, démettre quelqu'un de ses fonctions et ce, de manière immédiate, voire brutale. II. Diviser d'une manière soudaine, précise, par choc, coup, pression une chose inanimée, fréquemment une partie du corps humain. Sous la forme pronominale, se rompre, se briser d'une manière nette et brutale. III. Interrompre soudainement, brusquement le cours d'une action, d'un état ou d'une chose s'étendant dans l'espace. IV. Dans un contexte familier, il s'agit de dire ses vérités à quelqu'un, lui avouer un secret de manière directe et franche. V. Familièrement, il est utilisé dans un contexte de victoire, emporter un succès fracassant, déchaîner un grand enthousiasme. VI. Le sujet est une personne qui subitement s'affaisse sur soimême, ne tient plus sur ses jambes. Net reste invariable, normalement, et est modifié par encore, 
tout. Dans le dernier exemple du CW, cependant, net s'accorde avec l'objet féminin pronominal antéposé au verbe, tout en gardant son interprétation d'adverbe de manière. Notons que la différence entre les formes masculine et féminine n'est pas audible. Mentionnons l'emploi de faire automatique. VoIR AUSSI : briser net

\section{Cataloguer impec}

Classer impeccablement

Emploi absolu

1953 mais pour moi, je cataloguais impec, même sans matricule. Ce portrait, on me l'avait tiré à Fontevrault, lors de mon dernier sapement, mes dix-huit marqués (Albert Simonin, Touchez pas au grisbi!)

RemaRques : Cataloguer impec signifie 'classer parfaitement, sans erreur'. Impec est une réduction familière de l'adjectif-adverbe impeccable ou de l'adverbe impeccablement. La combinaison « verbe + impec (cable) » constitue une série ouverte dont nous ne citons que quelques variantes.

\section{Causer bas}

Parler à voix basse, d'une voix faible

Intransitif

1578 CALISTE. Que vas tu groumelant entre les dents, yvrongne ? envieux ? que vas tu causant si bas, qu'on ne te peut entendre? Chemine où je te commande, et que je ne le die plus. Pourquoy me romps tu la teste? (Jacques de Lavardin, La Celestine [adapt.])

1761 On se mit à causer tout bas, et reprenant sans y penser un ton de familiarité peu décente, on chuchetoit on sourioit en me regardant, tandis que la dame de la maison me questionnoit sur l'état de mon cœur d'un certain ton résolu qui n'étoit guère propre à le gagner (Jean-Jacques Rousseau, La Nouvelle Héloïse)

1832 La messe de mariage commence. Et la voix des prêtres monte au ciel avec l'encens qui parfume l'église. Et tout bas causent les femmes et les hommes.

- Un beau couple !

(Alphonse Karr, Sous les tilleuls)
1848 - Et l'as est l'ennemi de ma famille, acheva le banquier, qui retourna encore un roi. Vive le roi ! s'écria-t-il. Ma mie Sidonia, envoyez-moi deux louis.

- Mets-les dans ta mémoire, fit Sidonie, furieuse d'avoir perdu.

- Ça fait cinq cents francs que vous me devez, petite, dit le banquier. Vous irez à mille. Je passe la main. Sidonie et Musette causaient tout bas. La partie continua (Henri Murger, Scènes de la vie de bohème)

1849 Il est fort aimable ; gras, la tête dans les épaules, avec un collier de barbe blonde ; il boite et il a déjà des flatteurs qui disent : C'est une grâce. Il cause peu, bas et bien (Victor Hugo, Choses vues)

1890 Et, comme nous ne nous voyions jamais, jamais qu'en classe, obligés de causer mystérieusement bas, sous la férule des maîtres, nos relations étaient, par cela seul, maintenues dans une courtoisie inaltérable et ne ressemblaient pas aux relations ordinaires des enfants entre eux (Pierre Loti, Le Roman d'un enfant)

1891 Mais lui-même, en parlant, ne quittait pas des yeux la table voisine, où Mazaud et Amadieu continuaient, dans le bruit, à causer très bas. Peu à peu, la salle entière s'inquiétait de ces longues confidences. Qu'avaient-ils à se dire, pour chuchoter ainsi ? (Émile Zola, L’Argent)

1907 Tout était silencieux : la maison et la rue dormaient. Christophe se retourna, il vit le vieil homme, qui pleurait : il se leva et alla l'embrasser. Ils causèrent tout bas, dans le calme de la nuit. Le tic tac de l'horloge, amorti, battait dans une chambre voisine (Romain Rolland, Jean-Christophe. La Révolte)

1938 Tous les invités se composaient des figures de maison mortuaire; de petits groupes de personnages causaient bas dans les coins ; des députés serraient des mains avec une mine et un dos rond pleins de familiarité écrasée (Paul Nizan, La Conspiration) 
1961 L'assistance formait un grand carré de plusieurs rangs d'épaisseur, les femmes occupant deux des côtés et les hommes les deux autres. L'assistance causait tout bas, et cela faisait un grand murmure, semblable à la voix du vent. Soudain, le murmure décrut. Un des côtés du carré s'ouvrit et la Grande Royale pénétra dans l'arène (Cheikh Hamidou Kane, L'Aventure ambiguë)

CORPuS WeB :

Mais Delhomme s'était mis à causer bas avec son voisin, Clou, le maréchal-ferrant, un grand, sec et noir. Comme on les écoutait, ils se turent [http://www.sculfort.fr/articles/grammaire/ approfondissement/participe.html] (30.4.2014)

De toute facon causer droite gauche en France, ne sert plus rien, autant causer bas ou haut dans l'espace. C'est juste une bipolaristion voulue par la sphére politico médiatique pour brouiller les cartes et continuer leurs politiques dégeulasses [http://forum-plus.forumactif.org/ t 4029p15-message-pour-les-frontistes] (30.4.2014)

REMARQUES : Causer bas réfère au fait de s'entretenir familièrement à voix basse, en prenant son temps. Bas reste invariable et est modifié par si, tout, très, voire mystérieusement. Notons d'une part la collocation «peu, bas et bien » (ex. 1849) où l'adjectif-adverbe bas apparaît coordonné avec deux adverbes et d'autre part l'opposition sémantique entre bas et haut (dernier exemple du CW). VoIR AUSSI : parler bas / fort

\section{Causer fort}

I. Parler, bavarder beaucoup

Intransitif

1675 On dit que la brune a repris le fil de son discours avec le chevalier de Lorraine, et qu'ils causèrent fort à cette fête que donna monsieur le duc, où ils attendirent si scrupuleusement que minuit fût sonné le dimanche de la passion pour manger de la viande (Mme de Sévigné, Correspondance)

1825 J'ai vu Lamberti à Milan. Nous causâmes fort de vous, il avait reçu vos lettres, et il voulait que je lui montrasse votre perspec- tive (Paul-Louis Courier, Lettres écrites de France et d'Italie)

1954 Nadine rit d'un air sournois : «Une femme qui parle de ses amours à une autre femme, ça cause fort " (Simone de Beauvoir, Les Mandarins)

II. Parler avec une intensité de voix élevée Intransitif

1878 C'était l'heure où Pauline triomphait. On causait plus fort, des rires et des bruits cristallins d'argenterie sonnaient, l'odeur de musc se chauffait encore des parfums pénétrants du thé (Émile Zola, Une page d'amour)

1924 Elles causaient très fort de façon que tous les bourgeois d'alentour qui parlaient bas derrière leurs persiennes fermées, suivaient le verbiage et en étaient incommodés

(Marcel Jouhandeau, Les Pincengrain)

CORPuS WeB :

On en entend causer fort dans le monde du SEO depuis quelques jours... après panda, voici penguin !!! [https://www.facebook.com/ orthozen.referencement/posts/367072629996369 ?comment_id=4208392\&offset=1\&total_com ments=4] (30.4.2014)

Moi j’ai eu un brave papy qui a ânonné presque tout mon $\mathrm{CV}$ à haute voix, ça se passait dans une pièce très vide et haute de plafond, et le monsieur avait dû passer sa vie sur un chantier, là où il faut causer fort pour se faire entendre [http://www.actuchomage.org/forum/ index.php?f=3\&t=11841\&hilit=livr\%C3\%A9\&rb_ $\mathrm{v}=$ viewtopic\&start $=285](30.4 .2014)$

REMARQUES : Causer fort (I) désigne le fait de s'entretenir familièrement avec quelqu'un de manière spontanée et en prenant son temps, le sujet bavardant avec animation, longuement et vivement. Fort peut également référer à l'intensité de la voix (II). Lorsque le sujet est impersonnel, l'accent est mis sur la vivacité des propos ou des médisances. Fort reste invariable. VoIR AUSsI : parler fort 


\section{Causer franc}

Causer avec franchise, sans cacher quoi que ce soit

$\lambda$ penser net

\section{Causer haut}

Parler à haute voix

$\pi$ causer bas

\section{Causer juste}

Parler avec raison, avec justesse, avec exactitude Intransitif

1829 Je trouve dans cet ouvrage [= Stendhal, Promenades dans Rome] instruction et divertissement : c'est bonheur par le temps qui court, d'entendre causer d'art si leste et si juste (Charles Sainte-Beuve, Lettre du 8 octobre 1829)

2013 Pour causer juste, il sait qu'il faut parler moins et entendre plus. Dans les affaires, le pro sait écouter et découvrir le client, trouver sa logique et convaincre avec le bon argument (Lionel Bellenger, Les 7 secrets des vrais pros)

\section{CORPus Web :}

Moi aussi j'aime bien les gens qui savent causer juste, surtout parce que du coup les autres se disent " oula si je veux pas passer pour un naze, va falloir que je fasse un effort »

À la fac, Antho (guitare) avait un sac sur lequel il avait écrit Beatles, ça a attiré mon attention. Flavien (basse) causait juste et fort, voilà en gros pourquoi je me suis rapproché d'eux [http:// www.lorrainedarts.fr/musique-concerts/1271rencontre-avec-sang-d-encre] (30.4.2014)

Remarques : Causer juste désigne le fait de s'entretenir de quelque chose plus ou moins longuement avec quelqu'un, le sujet affichant une parfaite connaissance du thème abordé en insérant dans la conversation des remarques justes et fondées. Notons la collocation de juste avec leste, qui ajoute à l'idée de justesse dans le propos celle d'aisance de la part du locuteur. Juste reste invariable et est modifié par si. VoIR AUSSI : parler juste

\section{Causer léger}

Communiquer dans un registre informel, peu soutenu, sans insister, sans s'appesantir ; tenir des propos fins et subtils Intransitif

\section{CORPuS WeB :}

Maintenant, tout ce que tu énumères sujet, cadrage, prise - reste le b-a-b-a de la photo et encore, en causant légér. Perso je suis sur Virus-photo [www.virus.photo.com/discussions/ sur] la retouche photo (10.6.2020)

Bon j'aurais pu peaufiner le complimentage en causant léger et délicat, mais y aurait eu comme qui dirait soupçon! Et quand t'as un soupçon au cul... çon au cul... ça fait... [www. metabricoleur.com/projets] et réalisations/créations en bois (10.6.2020)

Après, parler toujours d'une façon soutenue comme ça, je trouve que ça fait vraiment pompeux alors j'espère aussi que tu sais causer léger (pour que les autres puissent se dire « ouf ça y est il redescend, je vais pouvoir ranger mon larousse ») [http://alth.meilleurforum.com/ t2402-thorin-d-erebor] (30.4.2014)

REMARQUES : Causer léger renvoie au fait de communiquer informellement, sans profondeur, superficiellement.

\section{Causer leste}

Parler avec aisance, habileté sans souci de quoi que ce soit

Intransitif

1829 Je trouve dans cet ouvrage [= Stendhal, Promenades dans Rome] instruction et divertissement : c'est bonheur par le temps qui court, d'entendre causer d'art si leste et si juste (Charles Sainte-Beuve, Correspondance générale, lettre du 8 octobre 1829)

\section{CORPuS Web :}

-Elle est crue (on la croit).

-Elle est crue (ce n'est pas Jeanne d'Arc).

-Elle est crue (elle cause leste et elle t'emmerde !) [http://www.neoprofs.org/t50130p20croitre-et-alii] (30.04.2014)

REMARQUES : Causer leste réfère au fait de parler avec aisance, voire avec désinvolture ou en risquant de choquer le public (CW). 


\section{Causer moche}

Parler en mauvais français (ou dans une autre langue)

入 parler moche

\section{Ceindre étroit}

Ceindre, attacher en serrant fortement, étroitement

Transitif

1209 Sanz delai et sanz contredit, Ou bien li poist ou mal li sache, Uns chevaliers li tret et sache La robe amont et la chemise, Que chascuns vit qu'il l'avoit mise Et çainte estroit a sa char nue (Jean Renart, Roman de Guillaume de Dole, 4865)

REMARQues : Ceindre étroit se disait du fait d'attacher étroitement avec une ceinture.

\section{Cesser net}

S’interrompre, (s')arrêter brusquement, brutalement

Intransitif

1838 Mondini a vu aussi que quand l'épiderme se détache par l'effet de la macération, cette membrane cesse net à l'ombilic, et qu'il n'y a que la peau qui se prolonge dans la gaîne (Antoine Jacques Louis Jourdan, Traité de physiologie considérée comme science d'observation [trad.])

1883 - Il me semble que ce n'est pas à vous de rire. Nous n'en serions pas là si vous n'aviez gaspillé votre fortune et mangé votre avoir. À qui la faute si vous êtes ruinés ? Toute la gaieté fut glacée, cessa net. Et personne ne dit un mot. Jeanne, prête à pleurer maintenant, monta sans bruit près de sa mère (Guy de Maupassant, Une vie)

1915 J'ai eu peur, quand j'ai vu en face la nécessité de cette opération sur Dufour, de n'être plus moi-même, et, dans un cas pareil, ne pas agir, pour un Ortègue, c'est déserter... Alors, je me suis donné ma parole de ne plus me piquer, et j'ai cessé net (Paul Bourget, Le Sens de la mort)

1924 Au bronzage des genoux qui cesse net on voit que ça n’a jamais mis de pantalon.
Ça croque - on se donne des forces ! - six sucres pendant la mi-temps (Henry de Montherlant, Les Olympiques)

1938 Mais, au même moment, il surprit mon regard. Il cessa tout net de parler et pinça les lèvres d'un air irrité. Découragé, je détournai rapidement les yeux et repris mon journal, par contenance (Jean-Paul Sartre, La Nausée)

1959 L'amélioration de la balance des paiements est due surtout à des rapatriements de devises. Ceux-ci risquent de cesser net lorsque l'argent sera devenu abondant et bon marché en France (Express, 12 mars 1959 / Grundt : 351)

1996 Le bref traçage lumineux des balles dans la nuit. L'injonction du chef : - Suffit. Je vais l'achever.

Des claquements. Les râles qui cessent net - Maintenant, on file. Tous chantent, dans la voiture

(Boris Schreiber, Un silence d'environ une demi-heure)

2006 J'ai 40 ans depuis le mois de Janvier, un âge que, dans l'adolescence, j’ai décidé de ne pas dépasser. La joie de conduire à nouveau cesse tout net la nuit dans les rues de Gênes (Pierre Guyotat, Coma)

2007 Pourquoi, vers la fin des vacances, nous quitte-t-elle une journée pour, avec mon père - qui cesse tout net de fumer -, aller faire une course à Lyon? (Pierre Guyotat, Formation)

2011 Le bruit d'une gifle retentit, faisant cesser net le bourdonnement des conversations qui agitait la salle. C'est Olivier le testostérhomme qui vient de s'en manger une, de la part d'une participante un peu plus prude que les autres (Agnès Abécassis, Le Théorème de Cupidon)

\section{CORPUS WEB :}

Ce phénomène, est général, dans tout le territoire national...ces agissements irresponsables de certains enseignants doivent cesser net... [https://fr-fr.facebook.com/Mafia.Tunisienne/ posts/717587108255592] (30.4.2014) 
Mais une telle assurance dans la voix du jeune homme fitcessernet la conversation, comme un coup de frein d'urgence [http://masahiko 666jv.blog.jeuxvideo.com/1884459/Du-coeur-7 ieme-partie] (30.4.2014)

Vous ne trouvez pas qu'il y aurai des injustices à régler dans notre pays... au lieu d'essayer de faire croire que l'on est un pays influent à tel point de faire cesser nette la guerre dans les autres pays ? [https://www.facebook.com/francetvinfo/ posts/439002272811196] (30.4.2014)

REMARques : Cesser net désigne le fait qu'une personne arrête de faire quelque chose, qui met fin à une action soudainement, brusquement. Le sujet peut également être une attitude, une action, une manière d'être, un état et aussi un bruit (brouhaha, râle) qui prend fin subitement, tout d'un coup. Net reste invariable, dans la grande majorité des cas, mais dans le dernier exemple du CW il s'accorde avec l'objet féminin pronominal antéposé au verbe, même s'il garde son interprétation d'adverbe de manière. Notons que la différence entre les formes masculine et féminine est inaudible. VoIR AUSSI : arrêter net

\section{Chaloir petit \\ Importer peu \\ Impersonnel \\ +1125 S'il torment en at, Petit en chaldrat. \\ Tels at son aveir, \\ Ne durrat denier \\ Por chanter mestier, \\ Ne li ' $n$ puet chaleir \\ (Un sermon en vers [ $2^{\mathrm{e}}$ quart $\left.\mathrm{XII}{ }^{\mathrm{e}}\right], 61$ )}

REMARQUeS : Petit est un adjectif-adverbe de dimension qui adopte le sens figuré 'peu', usuel en ancien français. Dans chaloir petit, il traduit l'absence d'intérêt que porte le sujet à quelque chose ou à l'égard d'autrui, et souligne une certaine indifférence, un détachement à l'égard d'une chose, d'un événement. Ajoutons l'expression archaïsante mais encore fréquente aujourd'hui en style soutenu de peu m'en chaut.

\section{Changer direct}

Changer directement, immédiatement

$\lambda$ revenir court

\section{Changer gros}

Changer beaucoup

Intransitif

1945 Enfin le paysage lui livra la maison paternelle. Le toit à pignons se précisa entre les érables. Puis se dessina nettement la galerie à balustrade avec ce qui restait de concombres grimpants, ratatinés par l'hiver. Rose-Anna, projetée vers Azarius, murmura avec un tressaillement de douleur physique aussi bien que d'émoi : - Eh ben, nous v'là !... quand même ç’a pas gros changé!

(Gabrielle Roy, Bonheur d'occasion)

\section{CORPUS WEB :}

Pour elle tu veux changer gros pour elle tu veux te ranger

Et nous tu nous calcule plus on est devenu des etranger [http://rapgenius.com/Mclij-elle-tatue-lyrics] (30.4.2014)

Un petit geste qui peut changer gros! [http:// momentsdemaman.blogspot.co.at/2010/10/unpetit-geste-qui-peut-changer-gros.html] (30.4.2014)

REMARQUeS : Gros est un adjectif-adverbe de dimension transposé à une fonction de quantifieur. Changer gros réfère à une évolution, une transformation ou modification importante (ici : d'un lieu), le sujet étant inanimé. Le changement, qui est fortement marqué, peut aussi affecter une personne et donc référer à l'aspect physique ou moral. Il reste invariable. L'antéposition des adjectifs-adverbes est généralement peu fréquente, mais elle correspond bien à la fonction de quantifieur, comme dans peu important, très important, incroyablement grand, etc. Dans l'optique des oppositions lexicales entre adjectifs-adverbes qui remontent à la langue ancienne, gros s'oppose à menu comme petit à grand. La langue standard a fini par marginaliser ces oppositions qui, selon toute probabilité, appartenaient au cœur de la langue parlée ancienne. Dans deux des exemples (1945, premier exemple du CW) il s'agit de québécismes. Notons l'emploi absolu dans le CW. 


\section{Chanter aigu}

Chanter d'une voix aiguë

$\lambda$ chanter haut

\section{Chanter aimable}

Chanter agréablement, avec plaisir

Transitif

1959 C'est mon cœur qui chante aimable

La chanson de l'air et de l'eau

Et puis et puis sur les quais

La pluie n’a pas compliqué

La vie qui rigole

Et qui se mire dans les mares des rigoles

(Charles Trenet, Chansons, 1946-1959)

\section{CORPUS WEB :}

je chante aimable. laissez des commentaires et abonnez vous [http://videos.animationkaraoke.com/video/jV2MosAOXZO/chantaimable.html] (1.5.2014)

REMARQUES : Chanter aimable réfère au soin, à l'attention apportés par le sujet et au plaisir qu'il aime à transmettre à son auditoire lorsqu'il prononce, récite ou chante de belles paroles (ici : une chanson). En l'occurrence, chanter aimable prolonge de façon productive la série d'adjectifs-adverbes qui pivote autour du verbe chanter.

\section{Chanter bas}

I. Chanter à voix basse

Intransitif

+1100 Si cum la lei est asise,

Chantout mult halt, a voiz clere. [variante : mult alt]

Dunc li dient tuit li frere :

«Beal pere chers, chante plus bas,

U si ço nun, perir nus fras »

(Benedeit, Voyage de saint Brendan

[1 ${ }^{\mathrm{er}}$ quart XII $], 1043$ )

+1200 « Or dou chanter totes et tuit!

C'est li refrez ; s'il ne s'en fuit,

La joste avra certainement. »

Lors chantent destraveement

Et gros et gresle et bas et haut

De joie qui pas ne lor faut

(Raoul de Houdenc, Meraugis de

Portlesguez [début XIII ${ }^{\mathrm{e}}$, 2979)
1578 Marie, tout ainsi que vous m'avez tourné Ma raison, qui de libre est maintenant servile,

Ainsi m’avez tourné mon grave premier stile,

Qui pour chanter si bas n'estoit point ordonné (Pierre de Ronsard, Le Second Livre des amours)

1627 Ce qui estoit de plaisant estoit que pour feindre une deffaillance, il fondoit petit à petit, et enfin il chanta si bas que l'on ne l'entendit presque plus (Charles Sorel, Le Berger extravagant)

1779 Si cela est beau, mordieu ! Si cela est beau ! Comment peut on porter a sa tete une paire d'oreilles et faire une pareille question. Il commençoit a entrer en passion, et a chanter tout bas. Il elevoit le ton, a mesure qu'il se passionnoit davantage ; vinrent ensuite, les gestes, les grimaces du visage et les contorsions du corps (Denis Diderot, Le Neveu de Rameau)

1867 Une flamme qui tremble et qui va faiblissant

Fait courir sur les murs les ombres plus fébriles ;

Et la vieille Mâhall chante encore tout bas : «À travers un cadre il tendait la bouche. J'ai frotté la fleur. Que nul ne le touche !» (Léon Dierx, Les Lèvres closes)

1876 Pozzo continuait à gratter sa guitare en chantant très bas, l'air ravi, perdu dans une contemplation. Mme Correur roula un fauteuil près de la jeune femme. $M$. Kahn et M. Béjuin finirent par trouver des chaises libres (Émile Zola, Son Excellence Eugène Rougon)

1884 Merveilleusement appareillés, dans une conformité d’âge, de goût, de lourdes tournures, c'était touchant d'entendre ces amoureux à fin de jeunesse chanter en duo tout bas, en s'appuyant à la balustrade, de vieilles romances sentimentales... (Alphonse Daudet, Sapho)

1930 Je cherche une Amérique ardente et plus ombreuse 
Avec un océan la touchant de plus près, Plus vive en son écume, et de son corps peureuse.

Ses oiseaux chantent bas, vous prennent à parti,

Vous tirent à l'écart dans un coin de forêt, Vous disent leur secret, vous laissent interdit

(Jules Supervielle, Le Forçat innocent)

1941 Tout un orchestre de drapeaux, Et la barque parée en reine ! Des fleurs, des flûtes, des flambeaux, Et de rubans flottante chaîne ! Vins et liesse : à pleine haleine Le rire danse en vos ébats, Mais apaisez cette lumière, Joyeux rameurs, chantez plus bas, $\mathrm{Au}$ fil de l'an fuit la rivière !

Qu'as-tu fait des jours les plus beaux, Mouton, qu'as-tu fait de ta laine ! (Vincent Muselli, Euvre poétique)

2006 «Elles [= les moniales] ne sortent jamais, chantent bas ou même ne chantent pas du tout, mais, comme en lisant, elles célèbrent les heures du jour ... » (Bernadette Barrière, Limousin médiéval)

Transitif

1732 Je portais un jour dans mon cabas un quartier de mouton que venait d'acheter un honnête cordonnier qui marchait devant moi ; j’aperçus à mes pieds, dans la rue, un papier que je ramassai ; c'étaient de vieux couplets de chansons : je me mis à les lire et à les chanter tout bas (Alain-René Lesage, Histoire de Guzman d'Alfarache)

1833 Dites-lui, de notre part, s'il est tout petit enfant, que nos tours sont bien hautes, mais que nous le porterons à notre cime ; que nos portes sont bien lourdes, mais qu'il les fera crier seulement en les touchant ; que nos chariots sont rapides, mais qu'il tiendra tout seul, pour s'amuser, les brides de nos cavales indomptées ; que nos couronnes de rois sont pesantes sur la tête des hommes, mais que nous l'en coifferons dans son berceau, pour jouer ; que nos voix sont de grandes voix d'empires qui retentissent, mais que nous lui chanterons bas de doux cantiques de jeunes filles, pour dormir (Edgar Quinet, Ahasvérus)

1853 Je me trouvai ensuite, toujours au jardin des Plantes, dans la galerie intérieure des cellules où sont nourris les animaux vivants. Il y avait beaucoup de curieux et aussi l'Auvergnat qui jouait toujours le même air dont je continuais de chanter tout bas les paroles (Maxime Du Camp, Mémoires d'un suicidé)

1905 Ma vieille bonne me dorlotait, ne savait rien refuser à mes caprices. Elle me portait dans la rue, chantait le soir près de mon lit pour m'endormir. Je me rappelle encore sa voix, sa voix tremblante et modérée, j'entends encore ce qu'elle chantait. Que de fois, même, je me le chante tout bas, comme un grand enfant! (Paul Léautaud, In memoriam)

1942 Et comme un grand ave de grâce sur nos pas chante tout bas le chant très pur de notre race. Et il y a un si long temps que veille en moi cette affre de douceur... dame de haut parage fut votre âme muette à l'ombre de vos croix (Saint-John Perse, Exil)

Pronominal

1886 On marchait à toute vitesse toujours ; cette mer plus chaude avait à sa surface des marbrures rouges et quelquefois l'écume battue du sillage avait la couleur du sang. Il vivait presque tout le temps dans sa hune, se chantant tout bas à lui-même Jean-François de Nantes, pour se rappeler son frère Yann, l'Islande, le bon temps passé (Pierre Loti, Pêcheur d'Islande)

II. Produire un son faible Intransitif

1864 Ce sont là des nouveautés insupportables. Et puis, la flûte chante trop haut, et le tétracorde chante trop bas, et qu'a-t-on fait de la vieille division sacrée des tragédies en monodies, stasimes et exodes? (Victor Hugo, William Shakespeare) 
1931 Le roucoulement du fauve chantait bas sur sa tête, son haleine chaude l'enveloppait toute. Elle fut de nouveau une petite vie furieuse, révoltée sous l'attaque et cabrée devant la mort (Maurice Genevoix, Rroû)

\section{CORPUS WEB :}

Seulement, il lui arrivait parfois, sans doute par suite d'un peu de fatigue, - car elle donnait beaucoup de leçons, - de chanter bas pendant tout un morceau [http://reynaldo-hahn.net/ Textes/RH/duchant4.htm] (1.5.2014)

Il y a une difference entre chanter bas et grave et chanter juste et bien. Ce type de voix est hyper limité et pour le moment a besoin de beaucoup de travail pour atteindre la justesse et un beau timbre de voix [https://fr-fr.facebook.com/ lavoixtva/photos/a.327556664006515.73909. 272493026179546/591397357622443/] ?type=1 (1.5.2014)

Et pour ceux qui se demandent si un jour je vais les chanter bas je ne pense pas je chante pas vraiment bien et ces textes que je trouve pas tellement super sont inconnu pour la plupart de ceux que je connais... [http://xxcyrilxx25xx.skyrock. com/5.html] (1.5.2014)

Il commença donc à se dandiner (cf. mon icons de la signature) tout en marmonnant une chanson que seul lui pouvait entendre tant il la chantait basse [http://anotherside.forumactif. org/t23-cross-academy-nom-peu-familier-pvside-le-paresseux] (11.6.2014)

REMARQUES : Chanter bas s'utilise dans les contextes suivants : I. En parlant d'une personne, il désigne le fait d'exécuter un morceau de musique vocale (un air, un cantique, une chansonnette, des paroles) à voix basse, sans élever le ton, d'une voix douce et sereine souvent pour endormir ou apaiser l'autre. II. En parlant d'une émission sonore, d'un son ou d'un bruit, caractérisé par de basses fréquences, il réfère au registre de la voix ou d'un instrument qui est grave. Notons les collocations avec d'autres adjectifs-adverbes : chanter grave, chanter grêle, chanter gros, chanter haut, chanter juste. Bas reste invariable et est modifié par encore tout, plus, si, tout, très, trop. Dans le dernier exemple du CW, bas se met au féminin pour faire l'accord avec l'objet pronominal féminin antéposé au verbe. Il se prête à une analyse en tant que prédicat second orienté vers l'objet, mais en même temps, il garde son interprétation d'adverbe de manière caractérisant le processus de chanter.

\section{Chanter beau (bel)}

Chanter bien, mélodieusement, d'une belle voix Transitif

1209 Uns vallés qui fu fils son oste, Qui li baille quanqu'il demande, Vet aprés por doner offrande ; Et quant il ont oï la messe, Q'uns chapelains d'une abeesse Lor a mout bel chantee et dite En l'onor de Saint-Esperite, Lors s'en revindrent as ostex (Jean Renart, Roman de Guillaume de Dole, 2443)

Intransitif

+1225 Et li fous estoit tous couvers

De tantes manieres d'oisaus

Que c'estoit deduis et aniaus

D’oïr la joie k'il faisoient,

Car en lor langage cantoient, Chascuns endroit soi, si tres bel, Ke por l'amor du tans nouvel Et por la douce matinee, Ke nule rien de mere nee Onques mais tel joie ne fist (Le Chevalier as deus espees [2 $2^{\mathrm{e}}$ quart $\left.\left.\mathrm{XIII}^{\mathrm{e}}\right], 2725\right)$

1348 L'HERMITE. Et la doulce vierge Marie, Quant on ot matines chanté Si bel com vous m’avez compté, Ne parla elle point a vous Ne ne fist semblant, sire doulx? (Miracle de l'evesque a qui nostre Dame s'apparut, 769)

1352 NOSTRE DAME. Ceste voie tant qu'elle fine Et en alant vous chanterez

Tout au plus bel que vous sarez Pour nous esbatre (Miracle de un prevost que Nostre Dame delivra, 821)

1364 La pooit on assés apprendre, Car chascuns faisoit son effort De chanter bien et bel et fort (Guillaume de Machaut, Le Livre du voir dit, 3810)

+1415 Comme j'oy que chascun devise : On n'est pas tousjours a sa guise ; 
Beau chanter si ennuye bien ;

Jeu qui trop dure ne vault rien;

Tant va le pot a l'eaue qui brise

(Charles d'Orléans, Poésies [ 1415-1440],

II, Rondel LVIII, p. 322)

1983 - Mais je ne devais pas chanter ce soir-là !

- Tu as bel et bien chanté devant lui, oui ou non?

- Oui, c'est vrai, mais...

(Laura Benjamin, L’Opéra du fond des mers)

1986 L'interprète se trouve ainsi amené, s'il veut chanter juste, s'il veut chanter beau, à faire en quelque sorte le deuil de l'intelligibilité (Michel Poizat, L’Opéra)

1987 Comme un chanteur, qui sait manier la cithare, tend aisément la corde neuve sur la clef et fixe à chaque bout le boyau bien tendu, Ulysse alors tendit, sans effort, le grand arc, puis sa main droite prit et fit vibrer la corde, qui chanta bel et clair, comme un cri d'hirondelle... (Philippe Sollers, Le Cour absolu)

2013 Ils chantent bien. Cela ne veut pas dire qu'ils chantent " beau ». Jacques arrache de sa poitrine concave des sons incroyables venus d'une caverne où un rêveur tenterait d'élever des marguerites et des jonquilles (Nathalie Solence, Mes années Serize)

\section{CORPUS WeB :}

«Il ne faut pas chanter beau, il faut chanter vrai» [http://fr.canoe.ca/divertissement/musi que/dossiers/2009/03/19/8811701-jdm.html] (1.5.2014)

Chanter noble, ce n'est pas seulement chanter beau et chanter bien. Chanter noble, c'est exprimer par la ligne de chant plus que par l'effet, c'est intégrer l'accent et le caractère dans un legato tenu, maîtrisé [http://www.lucapisaroni. com/press/pressitem.php?id=38] (1.5.2014)

Et il avait tellement pris l'habitude d'entendre dans sa tête cette musique qu'il ne faillit pas la remarquer. Mais quelqu'un la chantait bel et bien, de manière plus distincte que jamais [http://www.harrypotter2005.net/t5819p570balade-au-clair-de-lune] (11.6. 2014)
La vie est belle et je la chante belle, belle

J'aime les saisons, la pluie et aussi le temps

C'est pourquoi je chante cette belle rebelle

Et je chanterai la vie encore longtemps [http://dragueverbe.wordpress.com/2011/03/17] la-vie-est-belle] (11.6.2014)

REMARques : L'emploi de beau comme adjectif-adverbe a une diachronie remarquable. Le neutre bel, dont l'emploi productif finit avec l'ancien français, caractérise la manière de chanter. Il se conserve jusqu'à nos jours dans la locution bel et bien 'effectivement (et qu'on ne dise pas le contraire)' (ex. de 1983, avant-dernier exemple du CW). L'exemple de 1987 est un archaïsme voulu. En moyen français, le masculin commence à inclure les fonctions du neutre, comme dans chanter haut, etc., où le masculin n’a jamais été différent du neutre. Par conséquent, chanter beau réfère également à la façon de chanter. En français moderne, l'affaiblissement de la fonction purement adverbiale entraîne une remotivation du chanter beau par rapport à la beauté de ce qui est chanté. Le sujet désigne alors un être animé qui exécute un morceau de musique vocale (un air, une chanson, la messe) généralement dans un souci esthétique. Le sujet peut aussi désigner un objet (ex. de 1987 : la corde d'un arc) où le verbe exprime de façon imagée l'effet sonore qui résulte du mouvement de la corde, mélodieux, agréable à l'oreille. La sémantique de chanter beau ne sort cependant pas du cadre de l'objet interne caractérisé par beau pour devenir une prédication seconde. Celle-ci impliquerait la possibilité de dire La chanson, je la chante belle (dernier exemple du $\mathrm{CW}$ ), qui est cependant très marginale. Notons l'emploi d'autres adjectifs-adverbes (chanter clair, chanter fort, chanter juste, chanter noble, chanter vrai), et la locution figée bel et bien, où bel reste invariable malgré l'objet pronominal féminin antéposé au verbe (avant-dernier exemple du CW). Bel est modifié par moult, si, si très, tout au plus.

\section{Chanter clair}

I. Chanter d'une voix claire, pure Intransitif +1100 « Uncore ore ne vus vint cist. Clamez culpe ! » Brandans lur dist Chantat plus halt et forment cler [variante : plus alt] 
(Benedeit, Voyage de saint Brendan [1 ${ }^{\mathrm{er}}$ quart $\mathrm{XII}^{\mathrm{e}}$ ], 1061)

1250 Qex est ses chanz? Gel vos dirai, Que ja certes n'en mentirai,

Car g'en sui molt bien recordant. Cortoisie venoit chantant

Cler et seri, a longue aleine, Comme cele qui molt se peine De parsivre toz jorz Biauté, E dit, bien en sui apensez

(Tibaut, Le Roman de la poire, 886)

1285 La damoisele oï chanter

Tres plaisanment et haut et cler ;

Cele part au plus tost qu'il pot

S'en vint ou chanter oÿ l'ot

(Adenet le Roi, Cleomadés, 5554)

+1400 Adonc des foys plus de six

Me pria que je chantasse

Hault et cler, riens ne doubtasse,

Mais longuement m'excusay

De chanter, car je n'osay

(Christine de Pisan, Le Dit de la pastoure

/ Euvres poétiques [début Xve], II, p. 242, 604)

1544 LE SECOND. Bien venu, par saincte Penotte !

Sois, mignon, le bien arrivé.

LE PREMIER. Luy siet il est bien d'estre privé ?

Chantez vous clair ? (Clément Marot, Dialogue de deux amoureux)

1560 Parquoy s’approcha avec salut et humaine parolle, et à force de mains, de coups de caillou sur les maschoires du loup, et avec un costeau qu'il avoit, luy desserra les dens et en delivra le bras d'Alector ; lequel voyant sa victoire au premier combat d'espée qu'il eut jamais faict, de grande joye se print à chanter hault et clair en langage Scythic, Cokalestis, qui est à dire Victorieux (Barthélemy Aneau, Alector ou Le $\operatorname{Coq}$ )

1783 - Est-ce que tu t'aviserais de faire le second tome d'Abélard?

- Je n'en sais rien... mais dussé-je chanter clair, je foutrai ma charmante abbesse, ou nous verrons pourquoi... les compliments furent ce qu'ils devaient être, joliment tournés de la part de la nonne et galamment de la mienne

(Honoré de Mirabeau, Le Libertin de qualité)

2006 Cela tient à ce qu'ils chantent « clair » alors que presque tous les Français «sombrent les sons aigus du passage de la voix ", cela d'après les indications de la méthode la plus suivie en France, celle du baryton Faure. Non, les Italiens je veux seulement parler des bons, les seuls qui nous intéressent, n'ouvrent pas la bouche, ils chantent « clair » et « rond» (Jacqueline et Bertrand Ott, La Pédagogie du chant classique)

2008 Skis aux pieds, c’est évident, les écoliers de douze ou treize ans n'apprendront jamais à compter. Le coq Pathé Journal chante haut et clair (Gérald Tenenbaum, L'Ordre des jours)

Transitif

1671 Je vous le chante clair, comme un chardonneret

(Molière, La Comtesse d'Escarbagnas)

1979 Martin Luther debout dit pasteur au pasteur :

«Mon frère, n’oublie pas de louer le Christ dans sa résurrection, et que son nom soit clair chanté !» (Léopold Sédar Senghor, Élégies majeures)

II. Produire des sons harmonieux et clairs Intransitif

1200 Ce fu a Pasques que on dist en avril, Que li oisel chantent cler et seri (Ami et Amile, 538)

1879 vous savez qu'à l'heure où nous dormons, un monde mystérieux s'éveille dans la solitude et le silence. Alors les sources chantent bien plus clair, les étangs allument des petites flammes. Tous les esprits de la montagne vont et viennent librement ; et il y a dans l'air des frôlements, des bruits imperceptibles (Alphonse Daudet, Lettres de mon moulin) 
1883 Tant qu'ils étaient au fond de l'ombre, la fanfare,

Comme un aigle agitant ses bruyants ailerons,

Chantait claire et joyeuse au fond des escadrons,

Trompettes et tambours sonnaient, et des centaures

Frappaient des ronds de cuivre entre leurs mains sonores,

Mais, dès qu'ils arrivaient devant le

flamboiement,

Les clairons effarés se taisaient

brusquement,

Tout ce bruit s'éteignait

(Victor Hugo, La Légende des siècles)

1974 Le marteau de Victor chantait plus clair sur l'enclume après chaque série de coups puissants. On entendit le tambour (Robert Sabatier, Les Noisettes sauvages)

1987 Comme un chanteur, qui sait manier la cithare, tend aisément la corde neuve sur la clef et fixe à chaque bout le boyau bien tendu, Ulysse alors tendit, sans effort, le grand arc, puis sa main droite prit et fit vibrer la corde, qui chanta bel et clair, comme un cri d'hirondelle... (Philippe Sollers, Le Cœur absolu)

Transitif

1896 Sur cet arbre, été comme hiver, Un oiseau vient qui chante clair Sa chanson tristement fidèle.

Cet arbre et cet oiseau c'est nous (Paul Verlaine, Euvres poétiques complètes)

III. Proclamer clairement, franchement Transitif

1560 Au contraire nous voyons comment l'Escriture nous chante haut et clair que celuy qui doit naistre de la vierge Marie sera nommé Fils de Dieu (Luc 1, 32), et qu'icelle vierge est mère de nostre Seigneur

(Jean Calvin, Institution de la religion chrestienne)

\section{Corpus Web :}

Ne tentez pas de retenir en cage l'oiseau, contentez-vous de son ramage au coteau. Ainsi des femmes, quand elles sont libres elles chantent clair. Avec elles, en équilibre, envolez-vous dans l'air qui vibre [http:// maljuna.kris.voila.net/poemoj/elleschantent clair.html] (1.5.2014)

Nous cherchons un chanteur capable de chanter clair et death. qui soit polyvalent et techniquement en place. Merci de faire passer le mot !; [https://www.facebook.com/Doxaworld/posts/ 287092228059640?stream_ref=10] (1.5.2014)

REMARques : Chanter clair s'utilise dans les contextes suivants : (I) se dit du fait de prononcer, dire un texte ou un chant de manière claire et distincte. Dans cet emploi, l'adjectif-adverbe clair est souvent coordonné avec l'adjectif-adverbe haut qui vient accentuer l'idée de clarté dans la voix. En (II), le sujet peut également désigner un animé (un oiseau) ou un inanimé (une corde, un marteau) dont le chant ou la vibration se caractérisent par des sons harmonieux et doux. $\mathrm{Au}$ figuré, (III) souligne le fait de proclamer ou dicter quelque chose très nettement. Clair reste invariable, à l'exception de l'exemple de 1883 où la flexion renforce la diction poétique. Clair est modifié par bien plus, forment [fortement], plus, si, tout, très, trop. Notons les collocations chanter haut et clair, chanter clair et seri [serein 'mélodieusement, harmonieusement'], chanter clair et joyeux [accordés], chanter « rond », ainsi que l'antéposition dans l'exemple de 1979. Notons aussi la coordination clair et death qui montre bien la productivité dans le domaine de la musique. Dans l'exemple de 1783, chanter clair pourrait vouloir dire 'chanter d'une voix de castrat'.

\section{Chanter cointe}

Chanter d'une voix agréable, plaisante, gracieuse, d'une jolie voix

Intransitif

+1250 Encore se vos voliees, Irieez plus haut une jointe.

Cil qui se fet de chanter cointe, Comence de rechef a brere (Le Roman de Renart [2 $2^{\mathrm{e}}$ moitié $\mathrm{XIII}{ }^{\mathrm{e}}$, II, 934)

REMARQUES : Le sujet de chanter cointe désigne un être animé qui exécute un morceau de musique vocale (un air, une chanson) dans un souci esthétique, d'une voix agréable et plaisante, avec grâce et élégance. Chanter cointe est vieux. 


\section{Chanter cru}

Chanter sans atténuer, sans soigner la voix $\lambda$ chanter doux

\section{Chanter doux}

I. Produire des sons doux, harmonieux Intransitif

1554 Là ton Luth qui si doux chante, Là ta Flute, là ta voix Sur le bord de la Charante M'endormiront mainte-fois (Jean de La Péruse, Poésies complètes)

1850 Roseaux qui de la terre exprimez tout le miel,

Où passent en chantant si doux les vents du ciel ! (Alphonse de Lamartine, Toussaint Louverture)

1872 Et puis, je ne sais pas pourquoi, mais le ciel me semblait plus clair que d'ordinaire, les arbres avaient plus de feuilles, les ortolans chantaient plus doux, et j'étais bien... alors le médecin est entré, et il a dit en me regardant : «Il est guéri ! » (Alphonse Daudet, L’Arlésienne)

Transitif

1961 Or voici aujourd'hui ma sœur la Brise, qui me visitait à Joal. À l'heure où des oiseaux étranges, vieux messages d'ancêtres, chantaient doux la rosée du soir (Léopold Sédar Senghor, Nocturnes)

II. le mot chante doux : est agréable, doux à l'oreille

Intransitif

1934a Derborence, le mot chante doux ; il vous chante doux et un peu triste dans la tête. Il commence assez dur et marqué, puis hésite (Charles-Ferdinand Ramuz, Derborence)

1934b Et, à droite et à gauche, elles augmentent de hauteur, ces arêtes ; à mesure qu'on s'élève, elles s'élèvent elles-mêmes ; et le mot continue à vous chanter doux dans la tête pendant qu'on passe près des beaux chalets d'ici, qui sont longs, bien crépis de blanc, avec un toit fait de bardeaux semblables à des écailles de poisson (Charles-Ferdinand Ramuz, Derborence)
2005 Avec cet argent, il s’installerait maître charpentier à Angers et tirerait un trait sur son passé à Villevêque - mais que ce nom chantait doux à son cœur (Isabel Nail, Bleu horizon)

\section{CORPUS WEB :}

Pour Jason, Jean-MarcetSophie, par exemple, il semble que chanter doux ne soit pas un exercice facile. Par contre, le pédagogue rappelle à ces candidats que ce n'est pas un défaut [http://www. staracademie.ca/nouvelle/le-doux] (1.5.2014)

Car le dénominateur commun reste sa sensibilité artistique, celle-là même qui permet au clown blanc de porter un nez rouge, au vrai dur de chanter doux, au mec à moitié cuit de chanter cru, d'être noir ou d'être blanc, petit ou grand, soigné ou grunge, les pieds sur terre ou en orbite, bossa ou reggae... [http://jerometatin.free.fr/ index.php?option=com_content\&view=article\&i $\mathrm{d}=44$ \&Itemid=92] (1.5.2014)

Thierry, Thierry ! Pourquoi tu nous fais Johnny quand tu chantes ?;) Cette chanson là, faut la chanter douce. La puissance dans cette chanson doit faire une place à la nostalgie [http:// www.youtube.com/watch?v=kj0MKqUlrAA] (1.5.2014)

REMARQues : Doux est un adjectif-adverbe qualificatif qui caractérise la manière de chanter ou la façon de percevoir le chant 'qui sonne doux'. Chanter doux s'utilise dans les contextes suivants : I. Le sujet désigne un instrument à cordes (le luth), mais aussi un animal (un oiseau) ou un phénomène naturel (le vent) qui produit un son léger, caressant et harmonieux. II. Emploi métaphorique où le sujet désigne un mot, dont l'ensemble des sons, son contenu sonore mais aussi thématique est harmonieux, peu sonore et agréable à l'ouïe. Doux reste invariable, sauf dans le dernier exemple du CW où il se rapproche des prédicats seconds orientés vers l'objet dans une perspective résultative, même s'il garde son interprétation d'adverbe de manière. Il est modifié par plus, si. L'antéposition de doux est poétique dans l'exemple de 1554 . Le premier exemple du CW crée des contrastes : un homme dur qui chante doux, un homme cuit qui chante cru. 


\section{Chanter faux}

I. Chanter sur un ton qui n'est pas juste, à

l'encontre des règles de l'harmonie

Intransitif

1668 Si un Grammairien commet des fautes contre la diction, si un Musicien chante faux, cela leur est honteux ; mais il l'est encore plus à un Philosophe, qui doit estre vertueux et sçavant, s'il ne vit pas bien (Gilles de Launay, Dissertation de la philosophie en général)

1733 Ces inconveniens n'arrivoient point lorsque la declamation étoit notée, ou du moins ils ne pouvoient arriver que comme ils arrivent à l'Opera quand un Acteur chante faux. C'est-à-dire que la faute venoit de l'artisan et non point de l'art qui avoit pourvû suffisamment à empêcher qu'on ne la fist (Jean-Baptiste Dubos, Réflexions critiques sur la poésie et la peinture)

1760 Or, imaginez qu'une nation fût tout à coup saisie d'un goût général pour la musique : il est sûr qu'on n'y auroit jamais tant fait de mauvais airs, tant chanté faux, tant mal joué des instruments (Denis Diderot, Lettres à Sophie Volland)

1825 Quant à ceux pour qui la musique n'est qu'un amas de sons confus, il est bon de remarquer que presque tous chantent faux ; et il faut croire, ou que chez eux l'appareil auditif est fait de manière à ne recevoir que des vibrations courtes et sans ondulations, ou plutôt que les deux oreilles n'étant pas au même diapason, la différence en longueur et en sensibilité de leurs parties constituantes fait qu'elles ne transmettent au cerveau qu'une sensation obscure et indéterminée, comme deux instruments qui ne joueraient ni dans le même ton ni dans la même mesure, et ne feraient entendre aucune mélodie suivie

(Jean-Anthelme Brillat-Savarin, Physiologie $d u$ goût)

1839 On lui a fait ici un très maigre service funèbre l'évêque rechignant. Je ne sais pas si les chantres l'ont fait exprès, mais je n'ai jamais entendu chanter plus faux (George Sand, Correspondance)

1843 Notre conscience nous force de dire qu'il était plein, et cependant on jouait La Dame Blanche qui est loin d'être une nouveauté ; la salle est presque de la même dimension que celle de l'Opéra de Paris, mais beaucoup moins ornée. Les acteurs chantaient aussi faux qu'au véritable Opéra-Comique (Théophile Gautier, Voyage en Espagne)

1854 Si le peuple n'est pas poëte, il est encore moins artiste. Tous les Grecs sans exception chantent faux et du nez; ils n'ont ni le sentiment de la couleur, ni le sentiment de la forme ; ils ne sont ni peintres, ni architectes, ni statuaires (Edmond About, La Grèce contemporaine)

1900 Mademoiselle nous menace tout bas de châtiments effroyables si nous chantons faux, et allons-y de l'hymne à la nature : déjà l'horizon se colore des plus éclatantes lueurs ; allons, debout ; voici l'aurore ! (Colette, Claudine à l'école)

1929 Elles sont vraiment jeunes, la plupart n'ont aucune voix, plusieurs sont touchantes de médiocrité. C'est surtout quand elles se mettent à chanter faux que j'ai envie de les embrasser. J'aime voir, en rose, sur leurs jambes nues, la marque laissée par leurs jarretières (Henry de Montherlant, La Petite Infante de Castille)

1934 - N'est-ce pas une petite dinde rougissante, assez dodue, ma foi ! qui chante moins faux que les autres bécasses de la confrérie?

(Gabriel Chevallier, Clochemerle)

1945 Il ne nous appartient pas de dire jusqu' où on peut aller dans la recherche des accords qualifiés dissonants ou des notes dites « étrangères », et du reste, c'est une affaire de « main »; mais on a vu d'excellents compositeurs chanter lamentablement faux lorsqu'ils se sont risqués à faire partie d'un chœur ; la leçon devrait servir (Henri Potiron, La Musique d'église. Esquisse d'un traité de composition) 
1953 moi aussi je chante faux, atrocement faux, si j'en crois ceux qui chantent juste (Jacques Perret, Bâtons dans les roues)

1977 Ces talents supplémentaires ajoutaient à mon accablement, n'ayant moi-même jamais rien entravé au solfège, et chantant résolument faux (Albert Simonin, Confessions d'un enfant de La Chapelle)

1991 Il portait un béret basque, chantait horriblement faux, des larmes coulaient le long de ses joues (Antoine Blondin, Un malin plaisir)

2000 Nous lui avions mitonné une Marche lorraine imprévue qui devait, dans notre esprit, l'accabler de honte. Au lieu de quoi - je passe sur le fait que nous chantions si faux - il nous l'avait jouée au patriotisme, écoutant nos miaulements - «fiers zenfants de la Lorraineu... » (François Nourissier, À défaut de génie)

2006 Tous les dimanches matin, mes parents se chamaillaient pour savoir lequel d'entre eux « détonnait » et lequel « chantait faux » ; la nuance m'échappait, mais mon père mettait fin à la compétition en s'attribuant (il l'avait) « une belle voix pour écrire » (Gérard Genette, Bardadrac)

Transitif

1829 Plus haut, la prostitution est parée, nue, en cheveux, avec des refrains chantés faux, une voix enrouée, du musc et de l'ambre, la prostitution que M. Debelleyme a délivrée de tout impôt ; puis la prostitution de jeune homme, un cachemire, trente-six ans, un fiacre, une pièce au gymnase et un étudiant ruiné pour tout un trimestre ; puis enfin la prostitution de grand seigneur : une femme jeune et belle, séduisante et parée, de beaux cheveux ; que vous dirai-je ? (Jules Janin, L’Âne mort et la femme guillotinée)

II. Écrire dans un mauvais style, raboteux, maladroit

Intransitif

1824 Le goût est la conscience littéraire de l'âme. Le goût sert plus souvent de mesure au plaisir que de discernement de ce qui est bien. Que de gens, en littérature, ont l'oreille juste, et chantent faux ! (Joseph Joubert, Pensées, essais, maximes et correspondance)

III. Donner une impression de fausseté, d'insincérité

Intransitif

1963 Comme les girafes sont muettes, La chanson reste enfermée dans leur tête. C'est en regardant très attentivement les girafes

Dans les yeux qu'on peut voir si elles chantent faux

Ou si elles chantent vrai

(Jacques Prévert, Histoires)

1973 Le Bon Dieu déconnait. J’ai décroché Jésus De sa croix : n’avait plus rien à faire dessus. Les lendemains chantaient. Hourra l'Oural ! bravo !

Il m’a semblé soudain qu'ils chantaient un peu faux

(Georges Brassens, « Les Illusions perdues » / Poèmes et chansons)

\section{CORPUS WEB :}

est ce que les personnes qui chantent faux entendent juste et chantent faux, ou bien est ce qu'elles chantent faux parce qu'elles entendent faux? Une deuxième question découle de la première : est ce que les personnes qui chantent faux se rendent compte qu'elles chantent faux ou bien est ce qu'elles le savent uniquement parce qu'on le leur a fait remarquer ? [http://www.partoch. com/forum/post_687818,qu+est+ce+que+chant er+faux.html] (6.5.2014)

Alors il parait que le fait de chanter faux, vient du fait d'avoir mal écouté, et donc mal enregistré la mélodie, l'air, avec toutes les fausses Notes que cela comporte !!! Et donc on reproduit ces fausses notes avec sa voix, d'où le terme « avoir l'oreille musicale »!!! Donc en fait à la base ces personnes qui chantent faux, en fait devraient tout simplement d'abord savoir et apprendre à « écouter juste ", avant de pouvoir et savoir " chanter juste »[http://fr.audiofanzine.com/techniquesde-chant/forums/t.141410,comment-faire-chan ter-juste-quelqu-un-qui-chante-faux,p.2.html] (6.5.2014) 
Dans ma mémoire joue une chanson que j’aime. Elle y est telle que je l'ai entendue.

Si je la siffle, je la sifflerai juste.

Si je la chante, je pourrais la chanter faux alors qu'elle m'est clairement en tête [http://forums.jeuxonline.info/showthread. php?t=885411] (6.5.2014)

Pourqui ce cacher !! c'est unse très belle chanson et il est impossible de la chanter fausse !! [https://www.facebook.com/permalink. php?id=209734399050612\&story_fbid=3353224 19877054] (6.5.2014)

REMARQUES : Faux est un adjectif-adverbe qualificatif qui caractérise le chant, mais, avec une interprétation de manière, également le processus de chanter. Chanter faux s'utilise dans les contextes suivants : Dans son emploi intransitif comme transitif (I), le sujet désigne le plus souvent une personne qui produit un son disharmonieux, mais il peut aussi, dans un sens métaphorique, désigner un animal. Dans son emploi transitif comme participe, moins usité, l'objet désigne un morceau de musique vocale (ex. de 1829 : un refrain) qui est chanté sans harmonie, avec des intonations qui ne sont pas justes, pas dans le ton. Dans le domaine de l'écriture (II), il réfère à un travail, une composition dont le résultat révèle la médiocrité littéraire, le style plat ou incohérent de son auteur. En (III), on trouve un emploi métaphorique où le sujet inanimé proclame ou promet quelque chose qui semble faux, qui ne correspond pas à la réalité. Dans l'exemple de 1963, Prévert crée un contraste avec chanter vrai ; ainsi, faux adopte le sens de 'qui n'est pas vrai'. Faux reste invariable, sauf dans le dernier exemple du CW, où il s'accorde avec l'objet pronominal féminin antéposé au verbe (à comparer : les dialectes méridionaux de l'Italie ; v. Introduction $\S 4.6)$. Le fait que l'adjectif-adverbe est accordé le rapproche des prédicats seconds orientés vers l'objet, même s'il garde son interprétation d'adverbe de manière. Faux s'associe à une série de modifieurs particulièrement riche : aussi, moins, plus, si, tant, un peu, atrocement, horriblement, lamentablement, résolument. Les exemples du CW font apparaître une série analogique : chanter juste, chanter vrai, entendre faux, entendre juste, écouter juste, siffler juste. Notons l'emploi de menacer bas. VOIR AUSSI : jouer / peindre faux

\section{Chanter fort}

I. Chanter d'une voix forte Intransitif

1364 La pooit on assés apprendre, Car chascuns faisoit son effort De chanter bien et bel et fort (Guillaume de Machaut, Le Livre du voir dit, 3810)

1578 MELIBEE. Chante plus fort, Lucrece, tandis que mon amy viendra : je sens un plaisir nompareil en t'escoutant parmy ces herbes verdissantes : nous ne serons ouyes de ceux qui passent là dehors (Jacques de Lavardin, La Celestine [adapt.])

1782 Je n'avois gueres envie de chanter ; mais j'étois sans argent, le besoin rend souple ; je renforce ma voix, et je chante aussi fort qu'auroit pu faire le grenadier lui-même : le mari m'embrasse avec transport (Robert-Martin Lesuire, L'Aventurier françois ou Mémoires de Grégoire Merveil)

1840 Le curé chantait fort, et riait sous son livre D'entendre sur le plat sonner argent et cuivre (Auguste Brizeux, Marie)

1845 Marcelle se pencha alors en dehors de la patache pour appeler le passant ; mais il chantait trop fort pour l'entendre (George Sand, Le Meunier d'Angibault)

1859 Dans vos luttes d'amour sans larmes, Musiciens toujours d'accord, Vous rendez seulement les armes A qui chantera le plus fort. Peuple d'en haut, joyeux mystère, Donnez votre exemple à la terre, Vous qui suivez la même loi ! (Marceline Desbordes-Valmore, Élégies)

1869 Ces grands talents, sur tout sujet, ont besoin de chanter haut et fort ; le vrai s'en accommode comme il peut (Charles SainteBeuve, Pensées et maximes)

1881 Il était parti comme d'autres enfants de son village, - en chantant très fort pour ne pas fondre en larmes (Pierre Loti, Le Roman d'un spahi) 
1904 Christophe le regardait avec inquiétude et craignait de voir sa tête se changer en une forme fantastique. Il chantait plus fort pour le réveiller, ou il se laissait dégringoler à grand fracas de son talus de pierres (Romain Rolland, Jean-Christophe. L'Aube)

1927 Les oiseaux chantent pour eux seuls.

Mais il arrive que certains oiseaux semblent rechercher, pour chanter le plus fort, le voisinage de l'homme

(Pierre Reverdy, Le Gant de crin)

1944 Personne ne comprenait goutte au détail de l'hymne latin - est-ce que cela comptait ? Chacun essayait de chanter le plus fort possible. Il fallait que le chant devînt un effort, une fatigue - -au bruit des voix Dieu mesurerait la sincérité des cœurs (Henri Queffélec, Un recteur de l'île de Sein)

1946 C'est de lui que je tiens l'art de préparer un feu dans un trou de terre, et je n'oublierai plus que si le pivert chante très fort et très souvent, c'est qu'il demande ou salue la pluie (Francis Ambrière, Les Grandes Vacances)

1985 Un oiseau s'est mis à chanter à la fenêtre, à chanter très fort, pendant que la vieille me balançait un pied de chaise à travers la banane (Frédéric Lasaygues, Vache noire, hannetons et autres insectes)

Transitif

1904 c'était une source intarissable de chansons : l'une succédait à l'autre. Christophe les trouvait superbes. Il y en eut une surtout qui lui parut si belle qu'il voulut attirer l'attention de grand-père. Il la chanta plus fort (Romain Rolland, Jean-Christophe. L'Aube)

II. Produire un bruit fort et harmonieux Intransitif

1908 Ce nom qui me surprend chante si fort qu'il m’oblige à m'arrêter. Je parcours le cimetière. Sur le côté du village, un triste enclos de quatre murs, où les morts sont pressés, avec bien peu d'arbres (Maurice Barrès, Mes cahiers)
1968 Le père se leva pour remettre une bûche dans la cuisinière dont la bouillotte chantait moins fort. Il le fit lentement. Ce n'était pas qu'il voulût se donner le temps de réfléchir. Il avait déjà pris sa décision (Bernard Clavel, Les Fruits de l'hiver)

CORpus WeB :

Par contre, s'il est un peu basané, alors là il a intérêt à la chanter la Marseillaise. Et plus il sera basané, plus il aura intérêt à la chanter fort. Ben oui, faut bien compenser la couleur de peau pour montrer qu'il représente bien la France [http://www.leparisien.fr/sports/abidal-lamarseillaise-on-n-est-pas-oblige-de-la-chanter12-12-2010-1187696.php] (20.5.2014)

HAAAAAAjm tro la toune la c fou je lécoute pi jme défonce a force de la chanter forte [http:// luvnnicc.skyrock.com] (20.5.2014)

REMARQues : Fort est un adverbe d'intensité. Le fait qu'il est souvent modifié souligne qu'il se combine assez librement avec le verbe, sans lexicalisation du groupe (aussi, le plus, le plus fort possible, moins, plus, si, très, trop. Il reste invariable, mais dans le deuxième exemple du CW, il s'accorde avec l'objet pronominal féminin antéposé au verbe, ce qui le rapproche des prédicats seconds résultatifs orientés vers l'objet (à comparer : les dialectes méridionaux de l'Italie ; v. Introduction § 4.6), même s’il garde son interprétation d'adverbe de manière. Notons les collocations bien et bel et fort, haut et fort.

\section{Chanter grand}

Chanter avec intensité

Intransitif

1957 [Jean Nohain et Mireille ont écrit le Petit Chemin] Quelques jours après Maurice Chevalier venait voir Mireille. Je l'entends encore :

- Pourquoi le Petit Chemin ? Vous écrivez beaucoup trop mince, beaucoup trop étriqué. Pour réussir dans la chanson, il faut faire large ! il faut chanter grand ! Du souffle, mes amis, du souffle!

(Marie-Claire, mars 1957 / Grundt : 311)

CORPUS WEB :

Milo n'aime pas Julie, elle chante trop fort à son goût et « chanter fort ce n'est pas chanter 
grand » dit il puis « les chanteurs qui n'utilisent que la voix vont dans une impasse mais ils ne le savant pas » [http://forum.aufeminin.com/fo rum/loisirs11/_f49410_loisirs11-resume-partieldu-debrief.html] (12.5.2014)

REMARQUES : Dans le domaine du chant, chanter grand réfère à l'intensité de la voix, à la puissance vocale de l'artiste, connotant de la grandeur. Au sens métaphorique, il réfère à un texte puissant, riche, de haute qualité, digne d'être reconnu, apprécié d'un grand nombre de personnes. L'exemple tient du langage des artistes. Dans le CW, grand s'oppose à fort pour désigner une qualité qui ne tient pas uniquement au volume mais aussi à la grandeur. Il est intéressant d'observer que grand, qui servait dans l'ancienne langue comme quantifieur au même titre que beaucoup, se conserve dans la langue moderne dans des emplois qui métaphoriquement reposent sur l'adjectif, ce qui donne 'avec grandeur' au lieu de simplement 'beaucoup'. L'adjectif-adverbe grand a donc en quelque sorte été remotivé. Notons aussi la série écrire mince, écrire étriqué et faire large qui met en évidence des contrastes conceptuels.

\section{Chanter gras}

Grasseyer ; chanter avec une voix de gorge Intransitif

1757 Chanter gras, défaut qui vient plus souvent de l'éducation que de l'organe. Voyez la grammaire de Restaut, sur la lettre R. Il est rare que les enfans ne parlent pas gras, il est rare aussi qu'avec des soins on ne vienne pas à-bout de les guérir d'un défaut de prononciation aussi désagréable (Denis Diderot, Encyclopédie ou Dictionnaire raisonné des sciences, des arts et des métiers)

1984 « C'est souvent des fois, on s'assisait, et moi, j'essayais de chanter. Elle me disait, « Pouie-aie, tu connais pas chanter. Ta langue est trop lourde. " Mam chantait gras. Mais moi, je peux pas » (Barry Jean Ancelet, Les Musiciens cadiens et créoles)
1987 Elle aussi replongeait sa voix dans ses racines. Cela chantait gras (Pierre Alain Talhian, Chemin de traverse)

\section{Chanter grave}

Chanter d'une voix grave

$\lambda$ chanter bas

\section{Chanter grêle}

Chanter d'une voix aiguë et faible

Intransitif

+1200 « Or dou chanter totes et tuit!

C'est li refrez ; s'il ne s'en fuit,

La joste avra certainement. »

Lors chantent destraveement

Et gros et gresle et bas et haut

De joie qui pas ne lor faut

(Raoul de Houdenc, Meraugis de

Portlesguez [début XIII'], 2979)

1564 Et pourtant cõme on ne peut restraindre les plus gros, pour leur faire prendre un tel ton, et les faire chanter gresle et clair cõme les menus, ainsi on ne peut eslargir les petits pour les faire sonner gros et bas, comme les plus grans (Pierre Viret, Exposition de la doctrine de la foy chrestienne)

1576 Et de fait, quelle impieté est ceste-là, de ne reconoistre en Dieu ce qui est bien et iustement attribué aux Musiciens en leur art, lesquels encores que l'un monte, l'autre descende, l'un chante gresle, et l'autre gros, ce neantmoins ne trouvent leur harmonie qu'en ceste repugnance attrempee par certains tons et mesures (Simon Goulart, $M e$ moires de l'estat de France sous Charles IX)

\section{CORPuS WeB :}

Devant l'âtre

apaisé

rêve le

ménestrel,

tandis que la

braisée

poudroie et chante

grêle [http://sos.best-seller.over-blog.com/

20-categorie-492020.html] (12.5. 2014) 
REMARQUES : Grêle est un adjectif-adverbe de manière qui s'oppose à gros dans l'ancienne langue. Le sujet de chanter grêle désigne une personne qui exécute un morceau de musique vocale d'une voix aiguë et d'une faible intensité. L'exemple du CW montre la possible récupération de grêle dans l'emploi archaïsant actuel, du moins en poésie. Notons la collocation grêle et clair. Notons l'emploi de sonner bas, sonner gros.

\section{Chanter gros}

Chanter sans retenue, sans réserve, d'une voix forte

Intransitif

1605 Qu'on fasse veni ce moine, c'estoint des moines de poterie dont Il se jouoit et disoit cecy en raillant : Il chantoit gros, quelcun dict que le Savoiard de Mr. de Vernueil estoit bon bassecontre (Jean Héroard, Histoire particulière de Louis XIII)

\section{CoRpus Web :}

Mais à l'Opéra, on n'en veut pas, la scène est trop vaste ; il faut chanter gros pour qu'on nous entende, il faut parler lentement pour qu'on nous comprenne ; et ce n'est que sur des sons soutenus dans le mouvement moderato et mezzo-forte qu'on y peut dire : « Portez... armes ! » [http:// www.hberlioz.com/feuilletons/debats570703. $\mathrm{htm}]$ (12.5.2014)

gros bisous a vous 2 vous nous donnez du bonheur a chaque fois que nous allons vous voir chanter gros [http://lucasmenuge.skyrock. com/3001191347-duo-avec-jcl.html] (12.5.2014)

REMARQues : Gros est un adjectif-adverbe de manière qui s'oppose à grêle dans l'ancienne langue (v. chanter grêle). En parlant d'une personne, chanter gros désigne le fait d'exécuter un morceau de musique vocale à voix haute, gros soulignant aussi le manque de retenue, voire l'exagération, la démesure dans l'action. Les données de Frantext pourraient faire croire que chanter gros a disparu, mais les exemples du CW prouvent le contraire. Dans les domaines de spécialité, ce type d'emploi tend à être conservé plus longtemps que dans la langue standard.

\section{Chanter haut}

I. Chanter d'une voix forte Intransitif

+1100 a « Uncore ore ne vus vint cist.

Clamez culpe! » Brandans lur dist

Chantat plus halt et forment cler [variante : plus alt] (Benedeit, Voyage de saint Brendan [1 $1^{\mathrm{er}}$ quart XII $\left.\left.{ }^{\mathrm{e}}\right], 1061\right)$

+1100 b Si cum la lei est asise,

Chantout mult halt, a voiz clere. [variante : mult alt]

Dunc li dient tuit li frere :

«Beal pere chers, chante plus bas,

U si ço nun, perir nus fras »

(Benedeit, Voyage de saint Brendan

[1 ${ }^{\mathrm{er}}$ quart XII $], 1043$ )

+1200 « Or dou chanter totes et tuit !

C'est li refrez ; s'il ne s'en fuit,

La joste avra certainement. »

Lors chantent destraveement

Et gros et gresle et bas et haut

De joie qui pas ne lor faut

(Raoul de Houdenc, Meraugis de

Portlesguez [début XIII' ${ }^{\mathrm{e}}$, 2979)

1209 Hé ! Hé ! amors d’autre païs,

Mon cuer avez et lié et souspris.

Quant el ot chanté haut et bien :

«Or ne me demandez plus rien.

- Non ferai ge, ma bele suer,

Se la franchise de vo cuer

Ne vos en fet dire par grace. » (Jean Renart, Roman de Guillaume de Dole, 1193)

1250 Puis montent as querniax contre l'avesprement ;

Et Robastre canta haut et si fierement

Que trestous cheus dehors s'en effréent forment,

Et moult s'en esbahissent du grant estonnement (Doon de Mayence, p. 300)

1276 Si haut chantoient vesque, moine et abé Et li clergiez dont y avoit plenté, Qu'il n'ert nus cuers, tant eüst de durté, Qui ne l'eüst voulentiers escouté Et n'en deüst avoir joie et pité (Adenet le Roi, Les Enfances Ogier, 7341) 
1285 La damoisele oï chanter

Tres plaisanment et haut et cler ;

Cele part au plus tost qu'il pot

S'en vint ou chanter oÿ l'ot

(Adenet le Roi, Cleomadés, 5554)

1325a Je m’i voudrai de chanter aatir

Si haut que touz diront que je songoie ;

Quant le douz mal de mort ne puis sentir, Or voi je bien, je pert soulas et joie

(Watriquet de Couvin, Dits, p. 298, 88)

$\sim 1325$ b Li rai du oler solei luisant

S'espandoient par les buissons,

Et cil oiselet à douz sons

S'esforçoient de haut chanter

(Watriquet de Couvin, Dits, p. 3, 47)

$+1365 \mathrm{Li}$ airs clers et quois et seris !

Et cil rosegnol hault chantoient,

Qui forment nous resjoïssoient ;

La matinée ert clere et nette

(Jean Froissart, Poésies [3 $3^{\mathrm{e}}$ tiers XIV $\mathrm{XI}^{\mathrm{e}}$ )

+1389 Lesquelx, afin que les voisins ne les oyssent ou apperceussent, ouvrirent ledit huys aus pointes des dagues qu'il portoient ; et, ce fait, lui et ledit Jehannin Favas, demourant en la rue au devant dudit huys, et par maniere d'esbatement, se prindrent à chanter haut et cler de leur povoir, afin que les voisins ne peussent pas si aisiement oïr aucune noise, se lesdiz compaignons le faisoient, à l'entrée de la chambre dudit Cloz (Registre criminel $d u$ Châtelet de Paris [1389-1392])

+1400 Adonc des foys plus de six

Me pria que je chantasse

Hault et cler, riens ne doubtasse,

Mais longuement m'excusay

De chanter, car je n'osay

(Christine de Pisan, Le Dit de la pastoure / Euvres poétiques [début $\mathrm{xV}^{\mathrm{e}}$ ], II, p. 242, 604)

1538a Les prebstres lors bien hault chantent et crient,

Et les amans tout bas leurs dames prient, Et puis entre eulx comptent de leurs fortunes, En mauldisant les langues importunes,
Ou en disant choses qui mieulx leur plaisent (Clément Marot, Élégies)

1538b Musiciens à la voix argentine, Doresnavant comme un homme esperdu Je chanteray plus hault qu'une buccine : Hélas ! si j’ay mon joly temps perdu (Clément Marot, Ballades)

1566 Les vierges lors de la saincte Cité Chantoyent tout haut aux cantons de la ville,

Deux hommes seuls beaucoup en ont dompté,

Mille Säul, et David bien dix mille :

Que David soit sur tous autres vanté (André de Rivaudeau, Aman)

1610 ALGESILAUS. Quel est l'oyseau qui chante plus haut que le cocu?

ALCIBIADE. C'est l'hirondelle, qui est en la cheminée, tandis que les cocus sont dessous, lesquels elle couvre

(Béroalde de Verville, Le Moyen de parvenir)

1627 Et lors, parce qu'il estoit assez pres, et qu'il chantoit fort haut, ils ouyrent tels vers (Honoré d'Urfé, L’Astrée)

1733 On entend, par exemple, distinctement le passage où Suetone dit que Caligula aimoit avec tant de passion l'art du chant et l'art de la danse, que même dans les spectacles publics il ne s'abstenoit pas de chanter tout haut avec l'Acteur qui parloit, ni de faire le même geste que l'Acteur qui étoit chargé de la partie de la gesticulation, soit pour approuver ce geste, soit pour y changer quelque chose (Jean-Baptiste Dubos, Réflexions critiques sur la poésie et la peinture)

1817 La longueur absolue de la trachée-artère, et par conséquent son ton fondamental, dépend principalement de la longueur du cou de chaque oiseau ; et nous voyons que l'expérience, à l'égard du ton, est conforme à ce principe : les petits oiseaux chantant le plus haut, et ceux qui ont le cou long ayant en général la voix la plus basse (Georges Cuvier, Le Règne animal) 
1829 D'abord elle fredonna son air tout bas ; elle chanta plus haut ensuite ; elle y mit enfin toute sa voix : c'était un air insignifiant, un air de bravoure, une bonne fortune de chanteur de carrefour aux sons ambigus de l'orgue; mais elle lui donnait une expression indéfinissable ; et moi, couché sur mon banc, je recevais ces chants tout tremblant : c'était le sourire d'un jeune homme blessé à mort, et qui tombe comme s'il devait se relever et se venger l'instant d'après (Jules Janin, L’Âne mort et la femme guillotinée)

1839 Je chantais bien haut dans les airs, et je voyais arriver des campagnes hommes, femmes, vieillards et enfants, accourant, accourant vite et se pressant sous mon portail (Gustave Flaubert, Smarh)

1851 La preuve, c'est que moi, qui ne faisais que siffler en travaillant dans mon chantier, je remontai aux Huttes qu'il était déjà quasi nuit, et en chantant si haut que ma voix faisait sauver les oiseaux déjà couchés dans les buissons et sur les arbres (Alphonse de Lamartine, Le Tailleur de pierre de Saint-Point)

1907 Les vingt bûcherons, lancés à la chasse de Cloquet, avaient dû prendre des précautions et chanter moins haut, à mesure qu'ils approchaient des réserves du château, car le bruit des voix devenait pareil à celui d'une troupe de chanteurs troublés par le vin, et qui n'achèvent pas tous la chanson commencée (René Bazin, Le Blé qui lève)

1942 Beauté créée pour les heureux Beauté tu cours un grand danger Ces mains croisées sur tes genoux Sont les outils d'un assassin Cette bouche chantant très haut Sert de sébile au mendiant Et cette coupe de lait pur Devient le sein d'une putain (Paul Éluard, La Dernière Nuit)

1947 Il se mit à chanter tout haut pour accompagner sa marche, et s'arrêta, car les échos lui renvoyaient des mots hachés et mena- çants et chantaient un air opposé au sien (Boris Vian, L'Écume des jours)

1957 Prends garde, mon maître, ce sont gens de poids et ils se trouvent sur leur terrain. C'est dans son poulailler que le coq chante le plus haut (Albert Camus, Le Chevalier d'Olmedo)

2001 Tu as chanté trop haut par-delà le miroir. Tu as chanté si haut que la phalange garrotte. Il sera désormais calypso quotidien l'air des bijoux carbone (Chloé Delaume, Le Cri du sablier)

Transitif

1950 Je l'ai relue dans les feuilles de la ville, avec ses mots gesticulants:ilm'asembléquej'entendais une cabotine chanter trop haut la Marseillaise ; et j'ai eu honte, à cause de vous et de moi (Maurice Genevoix, Ceux de 14)

II. Proclamer vivement, avec enthousiasme Transitif

1560 Au contraire nous voyons comment l'Escriture nous chante haut et clair que celuy qui doit naistre de la vierge Marie sera nommé Fils de Dieu (Luc 1, 32), et qu'icelle vierge est mère de nostre Seigneur (Jean Calvin, Institution de la religion chrestienne)

1609 Aussi leur bien ne sert qu'à monstrer le deffaut,

Et semblent se baigner quand on chante tout haut

Qu'ils ont si bon cerveau qu'il n'est point de sottise

Dont par raison d'estat leur esprit ne s’advise (Mathurin Régnier, Les Satires)

III. Louer, célébrer avec beaucoup

d'enthousiasme, de ferveur

Transitif

1578 Mais en lieu d'un sacré poëte, Qui si haut chantoit ton honneur, Tu as nouvelle amitié faite Avecques un nouveau seigneur, Qui maintenant tout seul te tient, Et plus de moy ne te souvient (Pierre de Ronsard, Le Second Livre des amours) 
1660 Je chanteray si haut ses grandeurs immortelles,

Que les échos du temple et les cœurs des fidelles

Y répondront tout à la fois,

Eet les marbres courbez dans ces voûtes antiques

Par le resonnement que feront mes cantiques

Prendront l'usage de la voix (Honorat de Bueil, chevalier de Racan, Les Psaumes)

Intransitif

1913 C'est vous Pie X et toi

Que les fenêtres observent la honte te retient

D'entrer dans une église et de t'y confesser ce matin

$\mathrm{Tu}$ lis les prospectus les catalogues les affiches qui chantent tout haut

(Guillaume Apollinaire, Alcools)

IV. Produire des sons harmonieux et d'une grande intensité

Intransitif

1840 Et, comme l'océan n'apporte que sa vague, Il n'apporta que l'art du mystère et du vague!

La lyre qui tout bas pleure en chantant bien haut!

Qui verse à tous un son où chacun trouve un mot!

Le luth où se traduit, plus ineffable encore, Le rêve inexprimé qui s'efface à l'aurore ! (Victor Hugo, Les Rayons et les ombres)

1849 Alors Landry fit comme s'il l'apercevait, et lui dit sans beaucoup crier, car la rivière ne chantait pas assez haut pour empêcher de s'entendre :

- Hé, mon Sylvinet, tu es donc là ?

(George Sand, La Petite Fadette)

1858 - L'édifice est plus bas que la mer, qui y chante parfois plus haut que ses prêtres (Jules Barbey d'Aurevilly, Quatrième Memorandum)

1860 Tout à coup, une mélodie énergique et suave, capricieuse et une à la fois, enveloppe, étouffe, éteint, dissimule le tapage criard [= du violon]. La guitare chante si haut, que le violon ne s'entend plus. Et cependant c'est bien l'air, l'air aviné qu'avait entamé le marbrier (Charles Baudelaire, Les Paradis artificiels)

1864 Ce sont là des nouveautés insupportables. Et puis, la flûte chante trop haut, et le tétracorde chante trop bas, et qu'a-t-on fait de la vieille division sacrée des tragédies en monodies, stasimes et exodes?

(Victor Hugo, William Shakespeare)

CORPUS WEB :

Voila, J'ai une voix assez grave enfin je ne sais pa vraiment plutot medium enfin barython je crois plutot $;$ et j'aimerais avoir des conseils et des petits exercice a faire pour pouvoir chanter plus haut, plus aigue [http://fr.audiofanzine.com/ techniques-de-chant/forums/t.191244,chanterplus-haut.html] (12.5.2014)

Olympe va continuer à chanter haut et fort ! [http://www.melty.fr/the-voice-2-olympe-dejadeux-albums-en-preparation-galerie-514249-150 3300.html] (12.5.2014)

REMARQUes : Chanter haut s'utilise dans les contextes suivants : En (I), le sujet désigne une personne ou un animal (oiseau) qui exécute un morceau de musique vocale à haute voix. Au figuré, (II) souligne le fait de proclamer ou de dicter quelque chose en montrant beaucoup d'enthousiasme et d'énergie. (III) désigne le fait de célébrer, chanter l'éloge de quelqu'un, son honneur ou une victoire ; d'exprimer des louanges à l'égard de quelqu'un ou de quelque chose. Emploi poétique ou lyrique (IV) dans lequel le sujet désigne souvent un instrument de musique (lyre, guitare, flûte), mais aussi un élément de la nature dont le son ou le bruit se caractérise par des sonorités harmonieuses et douces. Dans le premier exemple du CW, haut réfère à la hauteur $\mathrm{du}$ son. Notons les adjectifs-adverbes aiguë et fort, ainsi que les collocations bas et haut, haut et clair, haut et bien, plus haut et forment clair, haut et si fierement. Haut reste invariable et est modifié par assez, bien, fort, le plus, moins, moult, parfois, plus, si, tout, très, trop. Mentionnons également l'emploi de fredonner bas. 


\section{Chanter joyeux}

Produire des sons harmonieux et gais

Intransitif

1883 Tant qu'ils étaient au fond de l'ombre, la fanfare,

Comme un aigle agitant ses bruyants ailerons,

Chantait claire et joyeuse au fond des escadrons,

Trompettes et tambours sonnaient, et des centaures

Frappaient des ronds de cuivre entre leurs mains sonores,

Mais, dès qu'ils arrivaient devant le

flamboiement,

Les clairons effarés se taisaient

brusquement,

Tout ce bruit s'éteignait

(Victor Hugo, La Légende des siècles)

1994 Le résultat appassionato, con fuoco - à chanter très joyeux au départ - déborde d'invention accumulée, d'élan mélodique, de vie harmonique ; si le poème est plutôt convenu, la musique, qui exige des interprètes impeccables, est animée d'un souffle peu commun (Guide de la mélodie et du lied)

\section{CORPUS WEB :}

En groupes à l'aspect plus ou moins symétrique,

Rutilant sous des flots de lumière électrique.

Partout rire et gaîté : le givre éblouissant

Semblait chanter joyeux sous le pied du passant ;

Tout paraissait noyé dans des lueurs d'opale [http://laurentiana.blogspot.co.at/2010/12/lapoupee-conte-de-noel.html] (12.5.2014)

Ainsi, sab71 mangeait voracement des grenouilles gluantes qu'il lui refila avec la grippe mexicaine mais heureusement pour Leroy Merlin qui vendait illégalement poudres, berlingots et saucisses-merguez roulantes, il chanta joyeux et pimpant [http://kdos-vpc.fr/p410362.htm] (12.5.2014)

De ma cuisine-salon où j'écris porte fermée, j'entends chanter joyeuse ta voix de l'autre côté, dans ma chambre [http://humushumanus.word press.com/2009/07/27/je-tentends-chanter] (11.6. 2014)

REMARQuES : Chanter joyeux revêt un emploi métaphorique où l'objet désigne l'air vif et rythmé produit par une fanfare, un ensemble de bruits et de sons éclatants, qui se distinguent par leur résonance gaie et harmonieuse. L'accord avec le sujet renforce l'expression poétique (ex. de 1883 et dernier exemple du CW). Dans les deux premiers exemples du CW, l'ambiguïté du masculin joyeux admet une lecture à la fois adverbiale de manière et adjectivale de prédication seconde, qui est actualisée de façon univoque dans le dernier exemple. Notons la coordination avec clair, pimpant.

\section{Chanter juste}

I. Chanter avec justesse, selon les règles de l'harmonie

Intransitif

1671 On ne disoit pas aussi au temps de Coeffeteau, et de Malherbe, raisonner juste, parler juste, chanter juste, un esprit juste, un discours juste (Le père Dominique Bouhours, Les Entretiens d'Ariste et d'Eugène)

1694 AMILARÉ. Allons, monsieur, tout de bon : $\mathrm{Cu}, \mathrm{cu}, \mathrm{cu} .$. Chantez donc juste, si vous voulez.

TROTENVILLE. (lui jetant le papier au nez) Oh ! chantez juste vous-même ; je sais bien ce que je dis. Est-ce que je ne vois pas bien qu'il faut marquer là une dissonance, et que l'octave s'entrechoquant avec l'unisson, vient à former un dièse bémol. Mais, voyez cet ignorant !

(Jean-François Regnard, Le Divorce)

1762a Sophie a des talens naturels ; elle les sent et ne les a pas négligés ; mais n’ayant pas été à portée de mettre beaucoup d'art à leur culture elle s'est contentée d'exercer sa jolie voix à chanter juste et avec gout, ses petits pieds à marcher légérement, facilement, avec grace, à faire la révérence en toutes sortes de situations sans gêne et sans maladresse (Jean-Jacques Rousseau, Émile ou De l'éducation) 
1762b La finale soit toujours ut ou la selon le mode. De cette maniére il vous concevra toujours, les raports essenciels du mode pour chanter et joüer juste seront toujours présens à son esprit, son éxecution sera plus nette et son progrès plus rapide (JeanJacques Rousseau, Émile ou De l'éducation)

1813 Si je prenais un livre, elle lisait ; si j’approchais du piano, elle me priait de l'accompagner ; et, comme elle avait l'habitude de ne point chanter juste, toute grande musicienne qu'elle était, elle me faisait un véritable supplice de ma passion pour la musique (Étienne de Jouy, L'Hermite de la Chaussée-d'Antin)

1837 Survient un tiers, qui réplique à tous deux : « les deux articles sont aussi absurdes l'un que l'autre ; Chollet ne chante ni faux ni juste, il chante du nez; la Madeleine n'est ni belle ni hideuse, elle est médiocre, bête et ennuyeuse. » Ceci commence à devenir brutal (Alfred de Musset, Lettres de Dupuis et Cotonet)

1844 Ne faut-il pas attendrir les uns, et réchauffer les autres ? Toutes les voix chantent juste dans ce grand hymne qui invoque l'avenir, la voix de l'enfant et celle de la femme, comme celle de l'homme mûr et de l'austère vieillard (George Sand, Correspondance)

1922 En quinze jours, elle a su bostonner ; elle est légère comme un duvet. À part ça, elle n'est pas sotte. Elle chante juste, une voix chaude, un rien canaille : j'adore ça (Roger Martin du Gard, Les Thibault. Le Pénitencier)

1923 Il [= l'artiste] doit donc s'y soumettre, comme le penseur pour penser juste, pour chanter juste le chanteur (Henri Massis, Jugements)

1946 C'est peut-être une musique trop difficile à chanter parfaitement juste. Seules la voix et les intonations de Yonnel m'ont paru rendre le son qu'il fallait (Julien Green, Journal)
1953 moi aussi je chante faux, atrocement faux, si j'en crois ceux qui chantent juste (Jacques Perret, Bâtons dans les roues)

2000 Toujours la vieille histoire du feu sous la glace - pas même : une connivence, deux corps qui chantent juste. Quand le destin vous offre cette aubaine, posez votre sac, jetez l'ancre (François Nourissier, À défaut de génie)

2010 Elle est gaie, observatrice, espiègle, jamais méchante. Elle écrit bien, chante juste, sait des dizaines de poèmes de Baudelaire, Nerval, Apollinaire, n'a que des gestes gracieux et bienveillants (Claude Arnaud, Qu'as-tu fait de tes frères?)

Transitif

1713 Non monsieur, dit-elle en riant, mes sentimens ne paroissent point dans l'air que je viens de chanter. Il est nouveau, il est beau, on m'a dit que je le chante assez juste, et c'est la seule raison qui me l'a mis à la bouche, sans aucun rapport à ce que je pense (Robert Challe, Les Illustres Françoises)

1965 Un jour viendra où père aura à s'accommoder d'un agneau de Dieu à la sauce amère. Non que je le lui souhaite, mais après tant de violations, il m'étonnerait qu'il réussisse à passer au travers des mailles du filet, chantât-il juste les cantiques à saint Jean de la Croix (René-Victor Pilhes, La Rhubarbe)

II. Ecrire dans un style harmonieux, selon les règles de la versification

Intransitif

1824 Les vers de J.-B. Rousseau sont trop pensés. Leur harmonie est plus exacte qu'agréable. Il chante juste, mais non pas divinement (Joseph Joubert, Pensées, essais, maximes et correspondance)

III. Parler, penser avec raison et justesse Intransitif

1833 Je sais que le public, c'est moi, c'est-à-dire une raison qui souvent s'égare, une voix qui chante tantôt juste tantôt faux, une opinion souvent équitable, souvent injuste (George Sand, Correspondance) 
IV. S’intégrer de manière harmonieuse, cohérente

Transitif

1961 C’est par là que le papyrus perd quelque peu de son prestige : il est isolé, perdu, si l'historien ne le replace pas dans l'ensemble, dans ce chœur où il chante, très juste, mais trop discrètement parfois, sa partie (L'Histoire et ses méthodes)

CORPus Web :

Si tout le monde peut chanter sous sa douche, juste ou faux peu importe, tout le monde ne chante pas instinctivement juste, tout le monde ne développe pas, n'utilise pas sa voix au mieux de ses capacités [http://cours-gratuits. toutapprendre.com/?cours=apprendre-a-chan ter-juste] (13.5.2014)

Alors il parait que le fait de chanter faux, vient du fait d'avoir mal écouté, et donc mal enregistré la mélodie, l'air, avec toutes les fausses Notes que cela comporte !!! Et donc on reproduit ces fausses notes avec sa voix, d'où le terme « avoir l'oreille musicale »!!! Donc en fait à la base ces personnes qui chantent faux, en fait devraient tout simplement d'abord savoir et apprendre à " écouter juste ", avant de pouvoir et savoir « chanter juste »[http://fr.audiofanzine.com/ techniques-de-chant/forums/t.141410,commentfaire-chanter-juste-quelqu-un-qui-chantefaux,p.2.html] (6.5.2014)

il faut favoriser un travail plus intense de l'oreille en jouant la note ou quelques notes à la suite et tenter jour après jour de les chanter juste [http://www.guitariste.com/forums/chantet-autres-instruments, apprendre-a-chanterjuste,205652,70.html] (11.6.2014)

Oui, mais ces quatre phrases, il faut les chanter justes. C'est quand même une responsabilité ! [http://www.entretiens.ch/5085/pro priete_partage_solidarite_individualisme/ article_education.php] (11.6.2014)

REMARQUes : I. Dans son emploi intransitif, le sujet de chanter juste désigne le plus souvent une personne ou un ensemble de personnes (une voix, un chœur), produisant un son harmonieux, agréable à l'oreille, mais il peut aussi désigner un animal, un élément naturel, un morceau de musique vocale (un chant). Dans son emploi transitif, moins usité, l’objet désigne un morceau de musique vocale, une composition lyrique (ici : un air, un cantique) qui sont chantés conformément aux règles de l'harmonie, avec des intonations justes. II. En référence à l'écriture, le sujet désigne un écrivain, un homme de lettres dont le travail d'écriture est comparé à une composition lyrique, montrant le soin de composer selon les règles de la versification. III. Le sujet désigne une personne ou, par analogie, une voix, une opinion, une pensée ou un message qui soulignent la justesse et la cohérence du propos. IV. Par analogie, le sujet désigne un objet qui s'intègre parfaitement à un autre environnement naturel. Notons les nombreuses collocations qui soit renforcent la connotation positive de juste : juste et avec goût, chanter et jouer juste ou qui, au contraire, mettent en évidence un contraste conceptuel : $n i$ faux ni juste, juste ou faux, tantôt juste tantôt faux. Juste reste normalement invariable et est modifié par assez, donc, parfaitement, très. Notons aussi l'emploi de groupes proches : écouter juste, jouer juste, parler juste, penser juste, raisonner juste. Dans les trois premiers exemples du CW, l'interprétation adverbiale prédomine, ce qui se manifeste, dans le troisième exemple, par le fait que juste ne s'accorde pas avec l'objet pluriel pronominal. Par contre, l'accord est réalisé avec l'objet pluriel pronominal antéposé au verbe dans le dernier exemple, où une interprétation de prédicat second orienté vers l'objet semble donc plus motivée (à comparer : les dialectes méridionaux de l’Italie ; v. Introduction § 4.6).

\section{Chanter lent}

Chanter lentement

入 chanter triste

\section{Chanter lourd}

Avoir une sonorité lourde (en parlant d'un accent)

Intransitif

1940 L'avocate parlait épais, elle était alsacienne et savait assez mal le français, ça chantait lourd dans sa bouche (Jean-Paul Sartre, Lettres au Castor et à quelques autres)

REMARQUES : Chanter lourd renvoie à l'impression acoustique de lourdeur du discours de quelqu'un, ici à un accent germanique. Il s'asso- 
cie dans l'élocution à parler épais qui désigne un manque de fluidité et de finesse.

\section{Chanter menu}

I. chanter menu et souvent : chanter très fréquemment Intransitif

1325 Ainssi se deduit et envoise ; Et puis i refont si grant noise Cil autres oiselés menus, Qu'uil n'est hons jœnes ne chanus Grant deduit n'i poïst avoir, Et bien i paie son devoir Li chardonnereuls, bien s'i vent De chanter menu et souvent, Le col tendu, le bec as nues (Watriquet de Couvin, Dits, p. 233, 760)

II. Chanter un peu, à voix faible Intransitif

1894 Une moite odeur de bois émanait des feuilles tombées, et de temps à autre un rouge-gorge chantait menu dans les ramures (André Theuriet, Tentation)

III. Rappeler de petits souvenirs agréables Intransitif

1942 S'ouvrent des mains et des oiseaux S'ouvrent les jours s'ouvrent les nuits Et les étoiles de l'enfance Aux quatre coins du ciel immense Par grand besoin chantent menu Lorsque nous nous regardons La peur disparaît le poison (Paul Éluard, Le Livre ouvert 2)

\section{Corpus Web :}

À ouïr ses rythmes tout en détails, à l'entendre chanter menu avec un filet de voix légèrement trafiqué, on croirait entendre un authentique coléoptère humanoïde, grignotant puis s'envolant d'une pièce à l'autre en promenant sa rondeur rouge et tachetée [http://voir.ca/ musique/2003/07/16/emilie-simon-un-amour-decoccinelle] (13.5.2014)

Joëlle triche, bel oiseau-lyre

On ne lui en veut pas, ses nus

Elle les brode avec le sourire

L'amante est ingénue

L'amour et ses soupirs
Elle le chante menu тепu... [http://ludique poesie.blog.fr/2007/11/18/adieu 3317414] (13.5.2014)

REMARques : Menu est un adjectif-adverbe de quantité, exprimant, par extension, la fréquence (I) ou une faible quantité (II). Il est plus typique de l'ancienne langue, mais encore présent dans des textes littéraires. Il reste invariable. Notons la réduplication de menu dans le deuxième exemple $\mathrm{du}$ CW, ainsi que la collocation lexicalisée menu et souvent qu'on retrouve avec les verbes aller, baiser, baisser, barboter, battre, clamer, férir, gracier, heurter, jeter, pleurer, rire, tornoïr, voir, etc.

\section{Chanter noble}

Chanter d'une voix pure

$\lambda$ une définition plus précise s.v. chanter beau

\section{Chanter pimpant}

Chanter avec élégance, grâce et fraîcheur

$\lambda$ chanter joyeux

\section{Chanter rond}

Chanter la bouche et les lèvres arrondies

$\pi$ chanter clair

\section{Chanter seri}

Chanter doucement, paisiblement, sereinement Intransitif

+1100 Chantes seri, Marot, Vos amis revient, S'aporte un novel mot De vous, car il covient Ke je de cou chant et not Dont plus sovent me sovient (Romances et pastourelles françaises des XII ${ }^{e}$ et XIII ${ }^{e}$ siècles, p. 218)

+1150 Celes imagenes cornent, l'une a l'altre sorrist,

Que ço vos fust viaire que il fussent tuit vif, L'uns halt, li altre cler ; molt fait bel a oïr. Ço'st avis, qui l'escoltet, qu'il seit en paraïs, La ou li angele chantent et soëf et serit (Pèlerinage ou Voyage de Charlemagne à Jérusalem et à Constantinople [ $2^{\mathrm{e}}$ moitié $\mathrm{XII}]$, 377) 
$\sim 1200$ Ce fu a Pasques que on dist en avril, Que li oisel chantent cler et seri (Ami et Amile, 538)

1250 Qex est ses chanz ? Gel vos dirai, Que ja certes n'en mentirai, Car g'en sui molt bien recordant. Cortoisie venoit chantant Cler et seri, a longue aleine, Comme cele qui molt se peine De parsivre toz jorz Biauté, E dit, bien en sui apensez

(Tibaut, Le Roman de la poire, 886)

REMARQUeS : Seri est un adjectif-adverbe de manière de l'ancien français. Le sujet de chanter seri désigne une personne, un être spirituel (ange) ou un animal qui, en chantant, produisent un son doux, paisible et harmonieux. Il s'emploie aussi métaphoriquement et le sujet peut renvoyer à une attitude physique et morale (la courtoisie). Notons la collocation de seri avec soef et clair qui renforcent le sémantisme du groupe.

\section{Chanter suave (soef)}

Chanter d'une manière douce, agréable Emploi absolu

1275 De son lit ert levez droit à cel ajornant, Pour oÿr les oisiaus qui soëf vont chantant, Une fenestre ouvri droit devers Oriant, De France li remenbre, si en va souzpirant, Ce fu un petitet devant soleil levant (Adenet le Roi, Buevon de Conmarchis, 2431)

2011 C'est là qu'elle chantait, suave, là qu'elle était assise,

Là que ses yeux charmants transpercèrent mon cœur...

Mon âme en deuil ne pense plus qu'à elle, Mes oreilles sourdes n'entendent plus qu'elle,

Depuis que sa fouce voix n'est plus de ce monde (Sarah Dunant, Un cœur insoumis)

\section{CoRpus Web :}

Reste que ça ne vaut pas le premier album, et que Broadrick, plus il essaie de chanter suave, plus il me fait tiquer... [http://www.gutsofdark ness.com/god/commentaires.php?objet=8240] (13.05.2014) mais aussi quelques chansons qui rappellent Laetitia Sheriff (ma petite chouchoute que j'ai vu en concert y a longtemps et qui est très jolie), notamment dans la façon de chanter, suave et délicate [http://the.great.mustache.overblog.com/article-4717354.html] (13.05.2014)

REMARQUES : Le sujet de chanter suave désigne une personne, un être spirituel (ange) ou un animal qui, en chantant, produit un son léger, caressant et harmonieux, agréable à l'ouïe. Dans l'exemple de 2011, suave se prête également à une analyse en tant que prédicat second orienté vers le sujet, tout en gardant son interprétation d'adverbe de manière. Suave (soef) reste invariable, du moins en apparence, puisqu'il est coordonné avec le féminin délicate dans le dernier exemple du CW, où il modifie la façon de chanter, d'où l'accord avec le nom féminin. Ladjectif-adverbe suave est surtout usité dans l'ancienne langue, mais il s'est conservé dans le domaine de la musique auquel appartiennent tous les exemples modernes. Ceci souligne la conservation de la tradition orale des adjectifs-adverbes dans certains milieux dans lesquels on se fait tenter par la création de nouvelles combinaisons (à comparer : chanter death [= death metal] sous chanter clair).

\section{Chanter tranquille}

Chanter avec calme, nonchalance

Transitif

1786 J'admire des traits glorieux ; Et tantôt je chante tranquille

Mes amis, les belles, les Dieux (Étienne de Lafargue, Euvres mêlées de littérature)

Intransitif

1963 Il continue de chanter tranquille (Express, 18 juillet 1963 / J. Giraud)

\section{Corpus Web :}

Je deteste quand la chanson se trompe alors que je suis en train de chanter !

On peut meme plus chanter tranquille! [https://www.facebook.com/permalink.php? story_fbid $=135675733142597 \& i d=10258396645$ 1774] (13.5.2014)

Je chante tranquille dans ma chambre et je reçois un message de mon papa "Tais toi ! " [https://twitter.com/OceonD/status/4402204293 03939072] (13.5.2014) 
REMARQUES : Tranquille est un adjectif-adverbe qui admet les interprétations de manière et de prédicat second. En parlant d'un être animé, il fait référence au comportement adopté par le sujet (ex. : un chanteur) qui fait preuve de calme, qui ne s'agite pas, dans un contexte de surexcitation et de climat survolté. Dans le premier exemple du CW, tranquille adopte le sens circonstanciel de 'sans être dérangé'. Dans le second, tranquille réfère à la disposition de la personne, mais il connote également l'idée de 'sans vouloir déranger personne'.

\section{Chanter triste}

Chanter avec tristesse, mélancolie ; résonner tristement

Transitif

1920 Celui qui les écrivit [= les mélodies] n’a pas dit comment

Il fallait les chanter.

Moi, je les chante triste et lent

Je les chante lent et tristement tendre ;

Un peu au hasard et sans grande étude

Comme celle que j'aimais me les fit ap-

prendre ;

Et comme j'en ai l'habitude

(Henry Bataille, La Quadrature de l'amour)

Intransitif

1957 Quand je vais chez la fleuriste, Je n'achèt' que des lilas...

Si ma chanson chante triste

C'est que l'amour n'est plus là

(Georges Brassens, « Les Lilas » / Poèmes et chansons)

$2010 \mathrm{Au}$ vrai, je me lamentais beaucoup, mon public m'attendait il me voulait divine et moi, j'étais ô combien perturbée que ma voix chanta triste (Jeanne R., Les Noces d'éternité)

CORPUS WEB :

Comment l'interpréter ? Surtout, " ne pas s'impliquer dedans, éviter de chanter triste " conseille Brice [http://www.chansoncontemporaine.net/Voyage-en-chansons-sur-laroute-de-Dijon_a350.html] (13.5.2014)

C'est un genre de noyau post-dur musique. . est 80 est son plus lent et mélodique emo vient de noyau dur émotionnelle <- ou plutôt d'expliquer, c'est comme crier ou chanter triste exprimer vos émotions, que la société ignorante pense maintenant que c'est une forme de robe ou la coiffure [http://icommentfaire.com/forum/arts-et-vie/ ask107743-Dou_vient_le_mot_EMO_ou_sens. html] (13.5.2014)

Les One Direction ont un don pour changer mes humeurs. Ils sont bien, j'suis bien. Ils chantent tristes, j'suis triste [https://fr-fr. facebook.com/permalink.php?story_fbid $=71438$ 7925245234\&id=555510974466264] (11.6.2014)

Remarques : Triste fonctionne plutôt comme prédicat second renvoyant à un état émotionnel du sujet, mais il développe également une interprétation de manière (ex. de 1957), notamment comme verbe complexe (premier exemple $\mathrm{du} \mathrm{CW}$, avec sujet intérieur). Chanter triste revêt ainsi un emploi métaphorique où le sujet désigne une chanson ou un mot, dont l'ensemble des sons, son contenu sonore mais aussi thématique est perçu par l'oreille comme sombre, triste et mélancolique. Dans le dernier exemple du CW, triste s'accorde avec le sujet, tout en gardant son interprétation d'adverbe de manière : la façon de chanter des One Direction se traduit immédiatement dans l'humeur de la personne qui écoute. Notons la collocation triste et lent où l'adjectif lent favorise une lecture de manière qui entraîne triste, d'autant plus que dans le domaine du chant, le groupe chanter triste renvoie à une pratique apprise et étudiée qui ne reflète pas nécessairement l'état d'âme du sujet.

\section{Chanter vrai}

Chanter en étant authentique, sans artifice

$\lambda$ chanter beau, chanter faux

\section{Chantonner bas}

Chantonner à voix basse, d'une voix faible Intransitif

1848 Comme il arrivait toujours le repas commencé, il se faisait remonter les plats, les renvoyait, puis éternuait fort, crachait loin, se dandinait sur sa chaise, chantonnait tout bas, se couchait sur la table et faisait claquer son cure-dents (Gustave Flaubert, Par les champs et par les grèves) 
1902 Céline, la brodeuse, chantonnait tout bas : je voudrais que la rose fût encore au rosier, que mon amant fidèle fût encore à mes pieds... lala, lala, lalaire, lala, lala, tralala ! (Paul Adam, L'Enfant d'Austerlitz)

1904 Il chantonne tout bas, puis moins bas, puis tout haut, puis très haut, jusqu'à ce que de nouveau la voix exaspérée du père crie : « Cet âne-là ne se taira donc jamais ! » (Romain Rolland, Jean-Christophe. L’Aube)

1947 Ils chantonnaient tout bas, en tirant de petites bouffées de fumée grise, car Bernard, supplié, avait sorti ses " gauloise »... Les boueux soufflaient fort sur les doigts avant d'empoigner les poubelles gelées (René Fallet, Banlieue sud-est)

1992 On ne sait trop sur le moment d'où ils s'en viennent ainsi, de quel lac, de quel fleuve ou quel marais, de quel recoin de la mémoire. Ils chantonnent tout bas d'une voix argentine, - écho mélancolique de voix qui se sont tues (Sylvie Germain, La Pleurante des rues de Prague)

2002 L'eau noire clapote sur la plage. Ils ne disent rien ou plutôt si, ils murmurent, certains chantonnent très bas. De vieux chants de guerre et d'espoir, la liberté guide nos pas, dans les rangs des yeux clairs fixent notre drapeau (Olivier Rolin, Tigre en papier)

Transitif

1851 La jeune fille garda le silence. Le bonhomme Jadis regarda les deux jeunes gens ; un sourire courut sur ses lèvres, et il chantonna tout bas le refrain de son vieil ami : tra deri, dera, dera (Henri Murger, Scènes de la vie de jeunesse)

1979 Il avait envie d'écrire le nom de sa fille à côté, Claire, avec des ornements en crête sur le dos de la majuscule comme ceux des initiales des manuscrits gothiques, il le chantonna tout bas gaiement (Pierre Moinot, Le Guetteur d'ombre)

\section{CORPUS WEB :}

L'air qu'on avait composé avec Nick et Kevin, « Please Be Mine »... Je commençai à chantonner bas le refrain... Lorsque j'entendis frapper à ma porte, je fis une fausse note à la guitare et m'arrêta de chanter, surpris [http://ps-just-friend-but. skyrock.com/2724344790-Chapitre-24-Forget-MeI-Forget-You.html] (21.5.2014)

Il dort bien. Je me sens bien qu'il soit si bien. Je chantonne bas, à bouche fermée, la mélodie " The Lord's my Shepherd, I'll not want » qu'il avait rapportée d'Angleterre... [http://ephrem. skynetblogs.be/archive/2008/12/10/a-daywithout-gay.html] (21.5.2014)

REMARques : Chantonner bas désigne le fait de chanter, de fredonner quelque chose (des paroles, une chanson) à demi-voix, bas traduisant la faible intensité de la voix. Bas reste invariable et est généralement modifié par l'adverbe d'intensité tout (aussi : très, moins) qui renforce et accentue le contenu sémantique de bas. Notons l'adjectif adverbe haut dans l'exemple de 1904, qui est en contraste avec bas. Notons aussi la modification secondaire du groupe dans chanter tout bas gaiement (ex. de 1979) qui souligne la forte cohérence syntaxique de chanter (tout) bas, voire sa lexicalisation comme verbe complexe.

\section{Chantonner doux}

Chantonner d'une voix faible, douce et mélodieuse

Intransitif

1925 Tournefier avançait sans méfiance ; il chantonnait tout doux, entre ses dents (Maurice Genevoix, Raboliot)

CORPUS WEB :

A celle ci, passant à portée d'oreilles délicates il fredonne :

Chantonnez doux la farandole

Poussez les bancs, secouez les pieds.

Nous voici, chère Mirandole,

Vos épées, vos colères, vos cavaliers ! [http://www.univers-rr.com/RPartage/index. php? page $=$ rp\&id=12210\&start=4] (21.5.2014)

Pour ensoleiller ce dimanche, danser comme on joue, chantonner tout doux... en laissant faire notre spontanéité [http://m2.facebook.com/ parentsaparents? refsrc $=$ http $\% 3 \mathrm{~A} \% 2 \mathrm{~F} \% 2 \mathrm{Fm} 2$. facebook.com $\% 2 \mathrm{Fa} \% 2$ Flanguage.php] (21.5.2014)

Sur le dos d'un fauteuil, une petite fille nage vers vous en riant aux éclats. On déambule 
de surprise en clin d'œil ; en fond sonore, une voix féminine chantonne, douce et entêtante [http://web-archive-net.com/net/p/peripheries. net/2013-02-17_1425600_24/P\%C3\%A9riph\%C3 \%A9ries_R\%C3\%A9gression] (16.6. 2014)

ReMARQues : Chantonner doux désigne le fait de chanter, de fredonner quelque chose (des paroles, une chanson) à mi-voix, caractérisé par une sonorité douce et agréable à l'oreille, doux soulignant la faible intensité de la voix. Doux reste invariable dans le premier exemple du CW (malgré l'objet au féminin), mais il s'accorde avec le sujet dans le troisième, où il se prête à une analyse en tant que prédicat second orienté vers le sujet ; cependant l'interprétation d'adverbe de manière n'est pas exclue non plus. Notons la coordination avec l'adjectif-adverbe entêtant et le détachement syntaxique par une virgule. Doux est modifié par tout.

\section{Charrier droit}

Bien se comporter, marcher droit Intransitif

$\sim 1280$ Or te garde donc de cen fere, Se d'amors veus a bon chief trere :

Il couvient trop droit cariër Qui vers amours se veut liër (Vivien de Nogent, La Clef d'amour, 671)

+1489 Nous faisions peu d'expedition en actendant la fin de ceste maladie, car il estoit maistre avecques lequel il failloit charrier droict (Philippe de Commynes, Mémoires [1489-1498], VI)

1548 ilz estoient merveilleusement provoquez à mal, pour double raison : le butin et proye les y invitoit, et la mort prochaine s'ilz failloient à charrier droit : dont imprimoient desespoir de leur salut, s'estans lourdement et sans advis esquartez hors leur charge, au moyen dequoy faisoient mille maux (Noël Du Fail, Les Baliverneries d'Eutrapel)

1680 Cette Puisieux était bien épineuse ; Dieu veuille avoir son âme ! Il fallait, comme vous dites, charrier bien droit avec elle (Mme de Sévigné, Correspondance) 1736a À l'égard du reste de la dépense, ayez soin de vous informer de ce que valent les choses, et faites-vous rendre compte jusqu'au dernier liard ; quand les domestiques vous remarquent un si grand soin, ils charient droit. Si on vous casse, ou plats, ou verres, ou assiettes de fayence, ayez un memoire, sur lequel vous écrirez tout cela, et rabatez-les sur les gages des étourdis ; qui casse les verres les rompt, c'est le proverbe (Pierre de Marivaux, Le Télémaque travesti)

1736b Dans une autre occasion, je n'eusse pas été si scrupuleux ; mais en fait de ce voyage, la peste, je veux charier droit. J'ai mon chemin tracé ; il faut que je mette le pied où Télemaque a mis le sien (Pierre de Marivaux, Le Télémaque travesti)

1792 On doit en dire autant de la conduite du conseil exécutif provisoire, dont les différents membres, excepté le patriote Danton, paraissent tous des malveillants, pour ne pas dire des machinateurs uniquement occupés à paralyser les mesures prises pour sauver la chose publique. Dans la vue de les faire charrier droit, il n'y a pas de jour que Danton ne rompe quelque lance avec eux. Encore n'en peut-il venir à bout (Jean-Paul Marat, Les Pamphlets)

\section{CORPUS WEB :}

La charia pour charrier droit ? Le congrès général national libyen a déclaré que la charia, la loi islamique devait être la source de la législation en Libye. Cette annonce peut faire peur vue de l'étranger mais n'inquiète pas les Libyens [http://www.africanouvelles.com/religion/72monde/7511-libye-le-pays-veut-appliquer-lacharia-.html] (21.5.2014)

Sous des cierges consumés, les visages des autres enfants semblent tailler au burin dans la brume quand ils passent les portes de ce cloaque empli d'ignares et s'engouffrent dans le domaine des douleurs, pour environ vingt berges. Presqu'une éternité. C'est long. Pendant ce temps, ils apprendront à ne plus écouter leur voix, à accepter de charrier droit sur leur dos une croix qui n'leur appartient pas [http://laplumeduchakal. wordpress.com/2014/04/10/20-deux-cent-vingtsept-ans-statiques] (21.5.2014) 
Le problème est que probablement, le patron a votre chéri dans le colimateur. La réponse au RAR prouverait votre bonne foi si les choses se gataient et qu'il faille aller aux prud'hommes par exemple. En attendant faites profil bas, achetez un portable à votre moitié, et qu'il essaie de « charrier droit » pour garder sa place [https:// fr.answers.yahoo.com/question/index?qid=2007 1105174429AAjpe99] (21.5.2014)

REMARQUES : Charrier droit réfère au comportement ou à la manière d'agir, de vivre ou de penser, c'est-à-dire à un comportement conforme à la raison, juste, sain, sensé, où le sujet fait preuve de sincérité et d'honnêteté. Le second exemple du CW n'a plus rien à voir avec ce sens lexicalisé, archaïque dans les exemples récents, mais il montre bien le développement de droit qui fonctionne comme modifieur au sein du groupe prépositionnel droit sur leur dos, ce qui donne charrier droit 'porter quelque chose droit sur son dos'. Droit reste généralement invariable (mais il peut également faire l'accord avec le sujet, comme dans l'exemple de 1841). Il est modifié par bien, trop.

\section{Chasser fort}

Pousser fortement (à faire quelque chose) Transitif

1426 Tant plus pres suis, et plus desir Pour l'ardeur qui ainsi m'enflame. La douleur me fera gesir, Se je n'accompliz mon plaisir, Tant fort me chasse l'ardant flame (Narcissus, 330)

1450 Et ainsi Troylus trop plus sent qu'il n'a acoustumé son pouvre cueur affebly et lassé, pour ce que desir le chasse plus fort que jamais. Dont ses grefz martyrs et souppirs lui retournent de plus belle (Roman de Troilus et Cressida, p. 157)

CORPuS WeB :

Le coté positif pour moi et l'ensemble du groupe je pense ou je confirme n'ai pas venu pour faire des sacs d'oiseaux, pendant six jours de chasse. il a fallu chasser fort pour trouver des oiseaux,ce qui à certainement fait grandir certain chien [http://forums.bluebelton. com/chasser-ailleurs-f81/chasser-laponie-lesphotos-t17320-56.html] (23.5.2014)
C'est pas le chien d'Aka Mountain (sur un autre forum) ????? En tout cas la lignée au niveau travail est excellente... ça risque de chasser fort... A suivre donc.... [http://becasse-desbois.forumactif.org/t391-ma-complice-au-bois] (23.5.2014)

Oui enfin, celle la, j’attends de voir le contrat signé parce que ca me parait loin d'etre fait. Surtout qu'Airbus est en train de chasser fort pour convaincre GE de motoriser l'A350 [http:// forum.hardware.fr/hfr/Discussions/Actualite/ aviation-campaign-progress-sujet_26595_1141. $\mathrm{htm}]$ (23.5.2014)

Prends une chambrière, et au moindre signe agressif envers toi, chasses la. (et n'hésite pas à la chasser fort, quitte à la toucher avec la chambrière si elle abuse trop, penses à bien garder tes distances) [http://www.chevalannonce.com/ forums-3861219-travail-en-liberte] (23.5.2014)

REMARQUES : Dans l'ancienne langue, chasser fort renvoie à un désir fort, violent qui excite, aiguillonne, pousse quelqu'un à faire quelque chose, à agir d'une certaine façon. Dans les exemples modernes du CW, chasser prend le sens de 'faire la chasse', également au sens figuré de 'conquérir des parts de marché' (avant-dernier exemple) ou au sens de 'éloigner', dans le dernier exemple. Notons l'emploi absolu dans les trois premiers exemples du CW. Les emplois modernes sont une création contemporaine où l'adverbe fort se combine librement avec chasser. Il est donc peu probable qu'ils s'expliquent par continuité avec les exemples anciens cités ci-dessus.

\section{Chasser noir}

Faire de la chasse au sanglier

Emploi absolu

1665 Chapitre II. De la taille qu'il faut que soient les Chiens-courans pour chasser Noir (Robert de Salnove, La Venerie royale)

1721 tous les chiens aiment naturellement à chasser noir, ce qui fait qu'on en trouve aisément [...] On peut se servir de lévriers pour chasser noir ; mais il faut qu'ils soient de grande taille (Louis Liger, La Nouvelle Maison rustique)

1887 J'accepte de grand cœur, M. le comte, reprit Santa-Fiore, car je vous avoue que 
j'aime beaucoup à chasser noir, et nous n'avons pas une vraie compagnie sur mes terres (Paul Féval, Euvres)

\section{Chauffer dur}

I. Être tendue (situation); prendre une mauvaise tournure (événements) Intransitif

1830 (Ils se jettent sur les canonniers et les forcent d'abandonner la pièce qu'ils emportent aux cris de vive la liberté)

MARTIN. Sacredieu ! capitaine, ça chauffe dur, tout d'même !..... V'là une compagnie d'Suisses qui nous a jeté plus de vingt hommes par terre (Les Barricades de 1830)

1845 «Ma foi ! madame, je ne vous aurais jamais reconnue, ni vous monsieur. Il paraît que ça chauffe dur en Afrique ?... » (Honoré de Balzac, Un début dans la vie)

1976 Mon père m'emmenait souvent au stade de football, où se jouaient alors des parties épiques, entre Français, ou entre Français et Arabes. Et cela chauffait dur. C'est là que j'entendis tirer le premier coup de feu de ma vie. Il y eut une panique

(Louis Althusser, Les Faits)

2007 Quelle histoire ! « Va le retrouver, ton Jules! » gueulait mon papa... Mais elle lui lançait en furie ses liaisons multiples, à lui, au village, son côté d'aimer les femmes en sournois. Ça chauffait dur. Moi et la Rita on n'en menait pas large, des fois qu'ils allaient se cogner pour de bon... (Claude Duneton, La Chienne de ma vie)

II. Faire une chaleur très forte

Intransitif

1875 Vers les dix heures, le soleil commence à chauffer dur (Pierre Jakez Hélias, Le Cheval d'orgueil)

\section{Corpus Web :}

Et dans la descente, les freins chauffaient durs [http://www.rendezvousnationale7.fr/site/ etape05/rendez_vous_nationale_7_etape_05b. $\mathrm{htm}](10.9 .2020)$

RemARques : L'exemple du CW atteste le sens 'devenir très / trop chaud'.

\section{Chauffer égal}

Chauffer à une température constante Intransitif

1911 - Mieux que la dernière fois, oui, mais mon four ne chauffe pas égal (Louis Mercier, Hélène Sorbiers)

REMARQUES : Chauffer égal est ici employé par un boulanger villageois et signifie que la température du four n'est pas la même suivant l'endroit où l'on met le pain à cuire.

\section{Chauffer terrible}

Devenir très animé, surexcité, survolté Intransitif

1979 Dans l'appartement d'à côté, Gerry Rafferty se démène en stéréo. Ça chauffe terrible. La batterie s'affole. France se relève en étouffant un rire : dans ses jambes, Bloody-Mary a vachement envie de danser sur Baker Street (Jean Vautrin, Bloody Mary)

1981 Berthe tiens ta bougie droite nous voilà dans la piaule du jeune homme. On s'enlace on s'embrasse on se fait des gouzi-gouzi, ça commence à chauffer terrible (Evane Hanska, J'arrête pas de t'aimer)

\section{CORPUS WEB :}

Ca va chauffer terrible sur le gazon, à mon avis, parce que sur les 16 tops, il y en a bien 9 qui peuvent se retrouver, dans 15 jours, sur le podium à recevoir la bise de la Duchesse de Kent. Evidemment, y’a d'abord Steffi qui après Roland Garros va surtout pas vouloir lâcher un seul point [https://groups.google.com/forum/\#!topic/ microsoft.public.fr.start.sports/eqq_cao_BCo] (23.5.2014)

j'ai acheté une batterie pas chere pour mon Xpro1, apres une dizaine de chatges dans un chargeur fuji, elle s'est mise à chauffer terrible dans le boitier. j'ai racheté une batterie d'origine! [http://www.chassimages.com/forum/index. php?topic=193865.55;wap2] (23.5.2014)

Moi j ai un $6900 \mathrm{kv}$ dans mon b44 qui est 1 equivalent a un $6.5 \mathrm{t}$ pis faut je check mais temp beaucoup car ya envie de chauffer rapidement... Un 3.5 equivaut a $10500 \mathrm{kv}$ sa doit marcher terrible mais sa doit chauffer terrible aussi!!!! [http:// www.lemordudurc.com/forum/viewtopic.php?f $=428 \mathrm{t}=2069]$ (23.5.2014) 
sinon sur pc j'attends avec impatience crysis, un fps révolutionnaire niveau graphisme et immersion, jetez un peu un coup d'œil aux vidéos, même si vous n'êtes pas forcément fan, car ça vaut vraiment le détour seul bémol les cartes graphiques vont chauffer terribles !! [http://www.clubxtrem. net/modules/newbb/viewtopic.php?topic _id=13369\&forum=9\&start=260] (16.6.2014)

REMARQUES : Dans le registre familier, chauffer terrible renvoie à un événement, une action, une situation ou une atmosphère, par exemple une ambiance dans une salle de concert, créée par une musique bien rythmée et excitante ou par le jeu de l'artiste ; il peut aussi référer à une étreinte amoureuse, des enlacements, qui prennent une tournure très vive, animée, traduisant une certaine excitation sexuelle. Le premier exemple $\mathrm{du}$ CW réfère aussi à l'ambiance, mais les autres exemples renouent avec la signification de base de 'chauffer beaucoup = produire de la chaleur'. Terrible s'accorde avec le sujet dans le quatrième exemple, même s'il garde son interprétation d'adverbe de manière, l'interprétation comme prédicat second ne faisant aucun sens. Notons l'emploi de tenir droit, marcher terrible.

\section{Chausser chic}

Chausser avec élégance, avec classe $\lambda$ coiffer chic

\section{Chausser classique}

Porter des chaussures dans la tradition

Emploi absolu

2011 Louboutin chausse classique (Corpus Coiffet 2018 : s.v.)

Corpus Web :

On note un important changement de mentalité entre les pères et les fils qui se chaussent classique. La nouvelle génération recherche du confort, de la qualité, mais aussi un style madame.lefigaro.fr_mode (20.10.2012)

\section{Chausser étroit}

Mettre, porter des chaussures étroites, justes, petites

Transitif

1300 Si vus estes cointement chaucé

E avez bons soudlers al pié,
Si serra ascun par delee

Que vus avera al dey mostree,

E à soun compaignoun est torné :

«Ce n'est mie tot, pur Dé,

De estre si estroit chaucé.»

Dirra l'autre : «A noun Dé,

C'est pur orgoil e fierté

Que li est al cuer entree»

(Le Roi d'Angleterre et le jongleur d'Ely)

Pronominal

1884 Il eut de longues conférences avec Pomadère, son tailleur français, acheta pour quatre cents louis de parfumerie et de cravates, se fit tirer du sang à deux reprises, afin d'entretenir sa pâleur, qu'il jugeait intéressante et singulière, et prié d'une fête au Palais-Royal, inventa de se tenir les pieds, toute l'après-midi, dans l'eau froide, à l'effet de se chausser plus étroit (Élémir Bourges, Le Crépuscule des dieux)

1925 M. Robert marchait raide comme une personne mécontente. Ses belles bottes à la hongroise luisaient - on disait que pour se chausser plus étroit, il se tenait les pieds dans l'eau... (Henri Pourrat, L'Auberge de la Belle Bergère ou Quand Gaspard de guerre revint)

\section{CORPUS WEB :}

C'est quand même étrange car Salomon a la réputation de chausser étroit et mes boots c'est du 38.5 pas du 42 [http://www.skipass.com/forums/ sports/snowboard/sujet-114094.html] (23.5.2014)

En trois groupes ou genres. Ceux qui se chaussent trop étroit, ceux qui se chaussent trop large, et ceux - et n'allez pas croire qu'ils représentent la majorité ! - ceux, donc, qui se chaussent juste [http://remue.net/spip.php?article3229] (23.05.2014)

Si les mags look vraiment bien, moi ce que je ferais je les garderais propre et j'irais me chercher des rim ou mag aftermarket, pi je revendrai les mags OEM parce qu'il gardent leur valeur. Anyway l'hiver il faut le plus possible chausser étroit, mais sans que ca nuise trop à la stabilité du char, et juste assez pour pas que ca fasse un effet traîneau sur la neige [http:// www.elantraquebec.com/forums/showthread. php?p=69909] (23.5.2014) 
Perso j'achète les miennes par internet, golfonline dernièrement, sans problème car d'expérience je connais exactement la pointure dont j'ai besoin suivant les marques ainsi que les marques qui chaussent étroits ou larges [http://www.golftechnic.com/forum/viewtopic. php?f=68\&t=9752\&p=130605] (16.6.2014)

REMARQUES : Dans chausser étroit, étroit désigne le fait que la pointure n'est pas adaptée, ajustée, étant inférieure à la taille du pied ; ceci peut avoir un but esthétique, celui de donner l'impression d'avoir des pieds plus petits, plus fins. Étroit est modifié par plus, si, trop. En général, étroit reste invariable. Toutefois, il s'accorde avec le sujet dans le dernier exemple du CW, ce qui le rapproche des prédicats seconds orientés vers le sujet. Notons les adjectifs-adverbes large "porter des chaussures larges, qui ne serrent pas le pied' et juste 'chausser comme il faut, étroit mais confortable', avec lesquels étroit constitue une opposition conceptuelle. Le troisième exemple, du Québec, réfère aux pneus de voiture censés être plus efficaces dans la neige s'ils ne sont pas larges. Mentionnons également l'emploi de marcher raide.

\section{Chausser fin}

Mettre des chaussures adaptées à un pied fin, ou qui rendent le pied fin

Emploi absolu

1959 Vous croyez encore aux dieux morts, aux bottiers qui, pour chausser fin, suppliciaient les pieds (Le Figaro littéraire, 16 mai 1959 / Grundt : 410)

\section{CoRpus Web :}

J'ai aussi noté des remarques sur les forums sur les SIDI, qui semblent chausser fin également [http://www.onlinetri.com/phpBB2/viewtopic. php? $\mathrm{p}=507521]$ (23.5.2014)

Tu as essayé les Dynafit ? Elles ont tendance à chausser fin pour la plupart [http://www.ski tour.fr/forum/read_88570.html] (23.5.2014)

Ah non elles te seront beaucoup trop petites je pense ! Parce quelles chaussent " fins " moi les 37 me serrent alors que c'est ma pointure ! Et les 38 me vont [https://www.facebook.com/ sezaneparis/posts/782097305134513?stream $\mathrm{ref}=5$ ] (16.6.2014)
REMARques : Chausser fin désigne ici le fait de porter des chaussures qui se distinguent par leur finesse, enveloppant étroitement le pied, pouvant parfois le serrer fortement. Dans les deux premiers exemples du CW, fin reste invariable, tandis qu'il se met au masculin pluriel dans le troisième (même s'il s'agit d'un sujet féminin). L'exemple donne l'impression que la locutrice connaît l'emploi oral de chausser fin. L'écriture lui pose problème parce qu'elle perçoit fin comme adjectif, ce qui l'induit à le mettre au pluriel. Elle ne fait tout de même pas l'accord complet, chaussent "fines ", sans doute parce que l'accord serait alors audible dans la langue parlée, ce qui ne correspond pas à l'intuition.

\section{Chausser grand}

Avoir une grande pointure de chaussures (personne); avoir une dimension légèrement supérieure à la pointure donnée (chaussure) Emploi absolu

1952 ESTRAGON. Je les [= les chaussures] laisse là. (Un temps.) Un autre viendra, aussi... aussi... que moi, mais chaussant moins grand, et elles feront son bonheur (Samuel Beckett, En attendant Godot)

2009 Le type s'est penché et a ramassé une paire de vieux rollers qu'il nous a tendus : du 43, alors qu'on avait demandé du 44, mais ils chaussent grand, il y avait une chance qu'ils lui aillent (Catherine Cusset, New York, journal d'un cycle)

CORPUS WeB :

Bonjour, est-il possible d'avoir des indications sur les pointures? Si elles chaussent grands ou petits ? Ou directement un guide des taille. Merci [https://www.amazon.fr/ask/questions/ Tx16NGQF07WJPZV/ref=ask_ql_ql_al_hza] (10.4.2018)

IMPORTANT : Nos pointures chaussent grands, merci de bien vous référez à notre tableau de correspondance des pointures [http://www. altan-bottier.com/fr/guide-des-tailles] (20.10.2020)

Salut, les Supra chaussent grandes ou petites ou normales ? Car je voudrais m'en commander sur internet. Merci [https://www.jeuxvideo. 
com/forums/1-50-79043053-1-0-1-0-les-suprachaussent-comment.htm] (22.8.2011)

REMARQues : Chausser grand renvoie au fait de porter des chaussures d'une grande pointure. Dans la communication spécialisée du domaine de la vente des chaussures (CW), l'accord est très fréquent ; nous n'en citons que quelques exemples. Curieusement, l'accord se fait fréquemment au pluriel mais non pas selon le genre (deux premiers exemples du CW). Comme dans d'autres cas similaires, la pression normative semble inciter certains locuteurs à faire l'accord, mais si l'accord n'est pas audible dans la pratique communicative, on ne réalise que l'accord qui est également inaudible. Autrement dit, on évite l'accord audible, en l'occurrence celui du genre dans grandes. Ceci étant, on trouve tout de même aussi l'accord complet (dernier exemple du CW). Grand est modifié par moins. Notons l'emploi de chausser petit / normal.

\section{Chausser isnel}

Revêtir rapidement un équipement

Transitif

-1234 Au col li pendent .i. fort escu novel, Blanc comme noif, à [.i.] vert lioncel, Entre ses piez portoit .i. dragonnel. Uns esperons li a chaucé isnel La damoisele Rossete de Ruissel (Otinel [ $1^{\text {er }}$ tiers XIII $\left.{ }^{\mathrm{e}}\right], 369$ )

REMARQUES : Isnel est un adjectif-adverbe de manière vieilli qui s'employait au sens de 'vite'.

\section{Chausser juste}

I. Chausser comme il faut, étroit mais confortable

Transitif

1712 Qui ne sçait que Paul Emile ayant répudié sa femme, qui estoit en considération pour sa vertu, et par là s'estant exposé aux reproches de ses amis, se contenta de leur répondre en leur montrant le pied ; vous voyez, dit-il, ce soulier, il est bien fait et me chausse juste, vous ne sçavez pas où il me blesse (Augustin Nadal, Du luxe des dames romaines)
Pronominal

1841 Deux jours de son application suffisent pour se chausser juste sans être incommodé, et on le débite indifféremment chez les bottiers et chez les pharmaciens (Émile de La Bédollière, Le Pharmacien)

II. Chausser trop étroit

Pronominal

1845 L'autre a été actrice sur un petit théâtre, ou cuisinière, elle s'est estropiée à force de se chausser juste (Alphonse Karr, Fort en thème)

\section{Chausser large}

Porter des chaussures larges, qui ne serrent pas le pied

Pronominal

1960 Ne vous chaussez ni trop étroitement, ni trop large (Arts ménagers, mars 1960 / Grundt : 308)

\section{CORPUS WEB :}

En trois groupes ou genres. Ceux qui se chaussent trop étroit, ceux qui se chaussent trop large, et ceux - et n'allez pas croire qu'ils représentent la majorité ! - ceux, donc, qui se chaussent juste [http://remue.net/spip.php? article3229] (23.5.2014)

Le monsieur m'a expliqué que certains modele chaussaient plus large que d'autres et que Valetta chaussait étroit. J'ai également commandé le modele Talamore qui a priori chausse plus large [http://www.vivelesrondes.com/ forum/viewtopic_187115_30.htm] (23.5.2014)

mais bon en gros lorsqu'un virage tourne vraiment, une voiture de $1600 \mathrm{~kg}$ il faut commencer à la chausser large pour qu'elle tienne autant qu'une simple compacte toute nulle qui pèse $500 \mathrm{~kg}$ de moins mais que l'on traitera de oldschool (je pense à la 306 par ex.) [http:// www.forum-auto.com/automobile-pratique/ discussions-libres/sujet13101-35.htm] (23.5.2014)

Surtout quand t'es comme moi que tu chausses du 37 et que tu n'aimes que les hommes qui chaussent larges [https://fr.answers.yahoo. com/question/index?qid=20100927094259AAhz 89X] (16.6.2014) 
REMARQUES : Chausser large désigne le fait de mettre des chaussures dont la pointure n'est pas adaptée, pas assez ajustée puisqu'elle est légèrement supérieure à la taille du pied. Large tend à l'emploi invariable, mais il est fléchi dans le dernier exemple du CW, où l'accord avec hommes n'est pas justifié du point de vue logique. Dans le troisième exemple du CW, chausser large s'emploie par rapport à des pneus de voiture. Large est modifié par plus, trop. Observons aussi l'emploi de large avec étroitement qui souligne sa fonction adverbiale.

\section{Chausser normal}

Porter des chaussures de pointure moyenne $\pi$ chausser grand

\section{Chausser petit}

Avoir une petite pointure de chaussures ; avoir une pointure légèrement plus petite que celle donnée Emploi absolu

2015 Trois cents paires seulement avaient été distribuées dans le monde entier, mais il devait sûrement rester un 38 qui n'avait pas été réclamé - à Mexico peut-être, ou à Hong Kong, où les femmes avaient tendance à chausser petit (Cecily von Ziegesar, Gossip girl)

2018 «Parce que les chaussures, 43, d'accord, mais quand elles chaussent petit, il me faut un 44 ; quand ça chausse grand, parfois du $42 »$ (Dominique Pasquier, L'Internet des familles modestes : enquête dans la France rurale)

\section{CORPUS WEB :}

Je les adore : modèle, matière, confortables et coquettes, elles sont parfaites ! MAIS ATTENTION, choisissais une pointure au dessus car elles chaussent petits !!! [https://www.amazon. fr/pcr/Mieux\%20not\%C3\%A9s-Chaussureshopitaux-et-chaussures-de-cuisine-pourhomme-Commentaires/9684360031] (25.11.2016)

Je fais une publication seule pr que ce soit + clair. Comme elles chaussent petites, j'ai adapté automatiquement les pointures [www. facebook.com $\% 2$ Flesfoliesdesissi $\% 2$ Fposts $\%$ 2Fje-fais-une-publication-seule-pr-que-ce-soit- clair-comme-elles-chaussent-petites \%2F29197 26831449472\%2F] (20.10.2020)

REMARQUES : voir S.v. chausser grand

\section{Cheminer droit}

I. Avancer directement, en ligne droite (généralement suivi d'une préposition) Intransitif

-1334 Molt fu lonc temps, que onques ne la vit, Maint jour passa et mainte laide nuit ; Mes or li semble temps est du reperer, Droit a sa dame se prent a cheminner (Le Romans de la dame a la lycorne [ $1^{\mathrm{er}}$ tiers $\mathrm{XIV}^{\mathrm{e}}$, 355)

1370 « Mauldit est chelui qui va seul car, s’il chiet, il n'a qui le relieve ", selonc le dit de l'Apostre aux Hebrieus ou .xii ${ }^{\mathrm{e}}$. chapitre : «Drechiés les mains basces et les genous desliés l'un a l'autre, et de vos piés cheminés droit, affin qu'en clochant auchun ne boute en erreur mais soit en aprés sané » (Jean Daudin, De la erudition [manuscrit : $1^{\text {re }}$ moitié $\left.X V^{\mathrm{e}}\right]$ )

1502 Et, lorsqu'il fut sur l'eschaffault, ledit Petit-Jehan lui lya les mains d'un ruben de soye ; ce qu'il souffrit bien benignement. Et portoit on la croix devant luy en cheminant droit à l'eschaffault où il fina son derain jour (Jean Le Clerc, Interpolations et variantes de la Chronique scandaleuse)

1631 A ces nouvelles Harald fait faire montre à des troupes dans la ville de Londres, et les trouve fort diminuées par la bataille donnée contre Toston et les Norwegiens, et apres avoir levé quelques recrevës (encor que sa mere bien affligée, et pour la perte de son aisné, et pour le peril tout apparent dont le reste de ses enfans estoit menacé, voulut apporter du retardement à ses resolutions) il chemina droit en la Comté de Suthsex, et ferma son camp dans une grande plaine, esloignée tout au plus de sept mil pas de celuy des Normands (Gabriel Du Moulin, Histoire générale de Normandie)

1832 Tout y était clair, expéditif, explicite. On y cheminait droit au but, et l'on apercevait 
tout de suite au bout de chaque sentier, sans broussailles et sans détour, la roue, le gibet ou le pilori. On savait du moins où l'on allait (Victor Hugo, Notre-Dame de Paris)

1879 - Volontiers, mon ami... Tenez, chaussez vite ces sandales, car les chemins ne sont pas beaux de reste... Voilà qui est bien... Maintenant, cheminez droit devant vous. Voyez-vous là-bas, au fond, en tournant? (Alphonse Daudet, Lettres de mon moulin)

1923 Il repartit, sans s'en apercevoir, cheminant droit devant lui (Roger Martin du Gard, Les Thibault. La Belle Saison)

2011 Yann indiquait le nord au hasard, comme il aurait choisi le sud ou l'est. La puissance cachée qui tirait les ficelles dans leur dos se fit la réflexion que ce hasard lui octroyait bien des facilités. Il lui éviterait de devoir faire venir ses " invités » jusqu’á elle par des moyens détournés. Le trio cheminait droit sur l'une de ses stations de surface (Régis Lavaud, Convergences macrocosmiques)

II. S'en tenir à ses décisions, à ses convictions, rester fidèle à ses principes

Intransitif

1919 Gustave renonçait donc au ministère et prétendait vivre de sa « littérature ». Après ceci, aucun terme ne manquait plus à l'équation : il n'y avait qu'à cheminer droit, l'inconnue se dégageait d'elle-même (Édouard Estaunié, L’Ascension de M. Baslèvre)

1954 Depuis l'époque très lointaine où le projet s'était levé en lui d'en faire sa femme et de l'emmener un jour, il avait cheminé tout droit, ancré dans cette volonté (Maurice Genevoix, Fatou Cissé)

\section{CORpus Web :}

Va vers ce qui te procure le plus grand bien et fais ce qu'il te plait. Pour ce faire, commence déjà par cheminer droit vers ton but, sans t'en détourner, ni porter de regard inquiet, car tu vas y arriver [http://1coup2pousseparjour.over-blog. com/va-vers-ce-qui-te-procure-le-plus-grandbien-et-fais-ce-qui-te-plait] (23.5.2014)
Entre-temps, Askell et Hyara arrivèrent pour constater les premiers dégâts ; restants d'hommes à moitié grignotés et un autre, dont le bassin et les membres inférieurs manqueront au restant du corps qui gisait un peu plus loin. Un carreau sifflait d'ores et déjà près de la tête de Skalldir pour cheminer droit jusqu'à la gorge d'un autre assaillant à la peau blême [http://uotemrael.com/ forum/viewtopic.php?f=35\&t=6684] (23.5.2014)

Remarques : Droit est un adjectif-adverbe directionnel. Cheminer droit s'emploie dans les contextes suivants : En (I), le sujet désigne une personne qui se dirige vers un lieu ou vers une personne, le plus souvent à pied, en suivant une ligne droite, directement, sans détour. En (II), il désigne le fait de progresser, d'avancer dans un projet, le sujet, pour atteindre son but, cherchant à ne pas dévier, en restant fidèle à ses principes, ses décisions ou choix stratégiques. Droit reste invariable et est modifié par tout. Il a tendance à s'associer avec une préposition (à, devant, en, jusque, sur, vers) qui le suit, du moins dans la langue moderne (à comparer : ex. de -1334), au point de faire partie du groupe prépositionnel comme modifieur de la préposition. VoIR AUSSI : aller droit

\section{Cheminer fort}

Cheminer, marcher beaucoup, longtemps Intransitif

+1350 « Il n'a autre que nous dedens ce bois ramé. » "Seigneur, " dit li varlès, " j’ai si fort cheminé

Que mes chevax est mors en mon chemin ferré,

Mais je ai mon mesage acompli et porté

Por ce que mon seigneur n'i ait honte et vieuté.

En l'ame de mon corps je vos ai voir conté » (Brun de la Montaigne [2 $2^{\mathrm{e}}$ moitié XIV"e], 160)

-1400 Et Marc dist : «Allons, de par Dieu, qui nous puist aidier. » Lors commencherent a cheminer fort, sy desjunerent a une villette qu'il trouverent (Ysä̈e le triste [fin $\mathrm{XIV}^{\mathrm{e}}$, p. 431)

1435 Et sembloit a ladicte devote creature que lesdictes dames ainsy acompaignees che- 
minoient tant fort que s'estoit merveilles (Jean Juvénal des Ursins, Audite celi, p. 150, 3)

1515 Aprés ces devises et qu'ilz eurent disnés, Mannis leur dit qu'il s'en yroit devant. « Car, dit il, je cheminerez plus fort que vous » (Philippe de Vigneulles, Les Cent Nouvelles nouvelles, p. 110, 131)

1534 touteffois ilz n'en osèrent monstrer le semblant de la grant paour qu'ilz avoyent dudict Gargantua, et pour autant que ledict Gargantua avoyt fort cheminé ce jour-là il avoit grant soif, car il pria les Normans de luy donner à boire, lesquelz luy apportèrent de la bière (Les Chroniques admirables)

CORPuS WEB :

Vraiment je suis très émue, merci à tous. Vous me faites vraiment cheminer fort. Je sens vraiment que je vais me retirer, car c'est vrai Lise, je m'expose trop et tellement trop que ce fut une tentative d'activer le monde [http:// www.revelationlumiere.org/forum/viewtopic. php?pid=48492] (26.5.2014)

REMARQUES : L'ancienne langue emploie cheminer fort pour référer aussi bien à la quantité du chemin parcouru qu'à la vigueur et à la rapidité de celui qui chemine. Fort reste invariable et est modifié par si, plus, tant. Cheminer fort refait sporadiquement surface sur Internet au sens figuré de 'faire avancer, progresser'. Notons l'emploi de conter voir.

\section{Chercher grand}

Chercher un grand logement

Emploi absolu

1956 Avant la mort de Fanny j'avais trouvé un appartement nous convenant, depuis mon retour, j'avais trouvé à remettre le mien, mais à présent, il me faut chercher plus grand ou y renoncer pour le moment (Paul Léautaud, Lettres à ma mère)

1968 Mais jamais un mot sur leur vie ou leurs occupations. Tenez un jour, je vous le raconte parce que ça m’a frappé, voyant qu'ils cherchaient grand j'ai demandé discrètement Madame pense sans doute aux enfants ? Vous savez ce qu'il m'a répondu, lui, pas elle, d'une voix glacée ? (François Nourissier, Le Maître de maison)

CORPUS Web :

Pour l'instant c'est pas immense chez moi mais je suis en train de chercher grand pour pouvoir accueillir [http://caddykulture.fr/view topic.php?f=13\&t=5682\&start=990] (26.05.2014)

Une couche d'acier

Ce fer dessus

Une couche d'acier

Ce fer dessus

Acier trempé.

Ecrire avec une plume

En plume

Chercher grand comme une formule

A faire fondre son armure [http://cribas.fr/ post/2009/08/29/Auto\%C3\%A9dition] (26.5.2014)

REMARQUes : Grand est un adjectif-adverbe de dimension qui réfère ici à la surface, aux dimensions d'un logement. Sémantiquement, il modifie donc l'objet absent du verbe. L'ellipse est caractéristique du langage du marché immobilier. Grand reste invariable et est modifié par plus. Dans le premier exemple du $\mathrm{CW}$, grand réfère toujours à un logement, tandis qu'il ouvre son éventail d'interprétation dans l'expression poétique du second exemple.

\section{Chercher gros}

ça va chercher gros : coûter beaucoup d'argent, atteindre une grosse somme d'argent; chercher un défi

Emploi absolu

1925 Raboliot avait été condamné ; il avait deux cents francs d'amende. Avec les frais, ça allait chercher gros (Maurice Genevoix, Raboliot)

CORPUS WEB :

Encore plus glamour, elle habite actuellement le manoir de son compatriote Paul McCartney à Los Angeles, qu'elle loue 55.000 euros par mois. Une bouchée de pain pour cette artiste expatriée venue chercher gros à Hollywood [http:// www.gala.fr/1_actu/news_de_stars/adele_roule_ sur_1_or_282812] (26.5.2014) 
Cette femme s'est mise dans une merde parce qu'elle cherchait gros pour venir investir dans sa Guineé natale [http://lebanco.net/ banconet/bco7075.htm] (26.5.2014)

[Planche à voile] Dimanche on se met à l'eau steir, la houle est microscopique, $1 \mathrm{~m}$ à tout casser, c'est la mega deception surtout que Nico me chauffe pour aller tater du gros.. Lundi tout le monde travaille, je suis seul.. heureusment que Pierre est dispo, on hesite à aller chercher gros puis notre choix s'oriente de nouveau vers un spot de repli, le steir qui devrait mieux marcher que la veille [http://ben.perdu.en.bretagne. over-blog.com/article-tempete-120845477.html] (26.5.2014)

REMARQUES : Ça va chercher gros est une locution signifiant 'coûter beaucoup d'argent'. Chercher gros s'emploie aussi dans le langage familier pour souligner l'importance que peut atteindre une chose concrète ou abstraite, une entreprise, voire une vague, comme pour la planche à voile dans le dernier exemple du CW.

\section{Chercher profond}

I. Chercher sous la superficie, à une profondeur plus importante

Transitif

1580 Il faut donc conclure que la marne ne se peut apprendre à trouver par theorique non plus que les eaux cachées sans source, et que tout ainsi que les terres argileuses se trouvent quelquesfois pres la superficie, et quelquesfois les faut chercher profond, semblablement la terre de marne se trouve, comme je t'ay dit cy dessus (Bernard Palissy, Euvres complètes)

1936 Elle, criant : « Non ! Non ! » la bouche grande ouverte, roulant sa tête à droite et à gauche, et il sentait son souffle, qui n'avait pas l'odeur qu'il lui connaissait, mais une odeur qui venait de plus profond, une odeur que ses cris allaient chercher plus profond. Il ne put lui immobiliser la tête qu'en lui saisissant la langue entre ses dents, et en la serrant quand elle tentait de bouger (Henry de Montherlant, Pitié pour les femmes)
II. chercher plus profond : chercher davantage, de manière plus approfondie

Transitif

1914a Barrès est sincère. Et sa continuité, il faut la chercher plus profond que dans ses soucis d'esthétique. Rodenbach : un jeune homme qui cherchait à dire de bien jolies choses sur tel et tel sujet (Alain-Fournier, Correspondance avec Jacques Rivière)

2006 Et ne t'étonne pas si la nuit je geins plus lourdement

Ou si mes mains étranglent plus sourdement

C'est le troupeau des vieilles peines qui vers mon odeur

Noir et rouge

En scolopendre allonge la tête et d'une insistance du museau

Encore molle et maladroite

Cherche plus profond mon cœur

Alors rien ne me sert de serrer mon cœur contre le tien (Aimé Césaire, La Poésie)

Emploi absolu

1914b Cela est bien superficiel et bien « moderne » d'être déçu parce qu'on y trouve comme un code en images pour un peuple primitif. Il faut chercher plus profond. J'ai lu le Lévitique et pour presque toutes les fautes, il dit immundus erit usque ad vesperum (Alain-Fournier, Correspondance avec Jacques Rivière)

\section{CORPUS WEB :}

Comme prévu, il va falloir chercher profond pour retrouver la Boule Noire. On l'a fait totalement exploser. Elle est carbonisée [https://www. facebook.com/permalink.php?id=153046211 401782\&story_fbid=479863278720072] (27.5.2014)

Parfois il faut chercher profond en soi l'énergie d'entretenir la petite flamme qui nous fait avancer dans la vie [https://plus.google.com/ 103339521062416874659/posts/estea1xA3vZ] (27.5.2014)

galadriel allez motivation motivation moi je vais la chercher profonde parfois c'est super dur mais à fond il le faut !! [http://www.weight watchers.fr/community/mbd/post.aspx?page size $=25 \&$ rownum $=36 \&$ threadpage_no $=2 \& \operatorname{sinc}$ edate $=22 \% 2 \mathrm{~F} 05 \% 2 \mathrm{~F} 2011+00 \% 3 \mathrm{A00} \% 3 \mathrm{A00} \&$ 
thread_id=10542528\&board_id=480\&forum id $=1 \&$ thread_name $=\% \mathrm{E} 2 \% 99 \% \mathrm{~A} 3 \% \mathrm{E} 2 \% 99 \% \mathrm{~A}$ 3\%E2\%99\%A3+Les+\%2B+25+du+23+\%E2\%99 \%A3\%E2\%99\%A3\%E2\%99\%A3\&m]od_no=\& daterange $=2$ days $\&$ viewchange $=$ OPENDATE DESC (27.5.2014)

Remarques : Profond est un adjectif-adverbe de dimension qui peut être pris au sens concret (I). Dans l'exemple de 1936, les cris font sortir l'odeur à une profondeur qui dépasse celle d'où provient le simple souffle. Au figuré (II), il désigne le fait d'aller au fond des choses, de façon insistante, de chercher plus loin, ce qui implique de la part du sujet une réflexion plus profonde, un investissement plus grand, une grande acuité d'esprit. Profond reste invariable et est modifié par plus, notamment sous (II). Profond s'accorde cependant avec l'objet pronominal au féminin antéposé au verbe dans le dernier exemple du $\mathrm{CW}$; il réfère en premier lieu au fait de chercher la motivation dans les profondeurs de soi, donc au lieu où l'on espère trouver quelque chose, mais l'interprétation résultative n'est pas exclue.

\section{Chevaucher bas}

Monter un petit cheval

Intransitif

+1150 Se seoit as fenestres sor un brun paille Et uit l'enfant Aiol qui bas cheuauche, - Ch'estoit fiex sa seror de son linage Mout grans pities l'en prist en son corage (Aiol et Mirabel [ $2^{\mathrm{e}}$ moitié XII $\left.{ }^{e}\right], 1987$ )

REMARQUeS : En ancien français, bas dans chevaucher bas référait à la position, le sujet désignant ici une personne (un enfant) qui se trouve sur une monture de petite taille.

\section{Chevaucher bel}

Aller à cheval de façon élégante, adroite Transitif

+1250a Et Tybert qui bien veü l'a, Ne fet pas semblant qu'il le voie, Ainz chevace molt bel sa voie. Einsi s'en vait molt cointement, Ses piez regarde molt sovent Et puis son cors de chef en chef (Le Roman de Renart [ $2^{\mathrm{e}}$ moitié $\left.\left.\mathrm{XIII}{ }^{\mathrm{e}}\right], \mathrm{XII}, 492\right)$
Intransitif

+1250 b Lor batailles ont conmenciees

A renger. Si les ont rengiees,

Dis escheles font de lor gent.

Molt chevaucent et bel et gent (Le Roman

de Renart [2 $2^{\mathrm{e}}$ moitié XIII'], XI, 2032)

1285 De deffendre leur herités

Sambloit chascuns entalentés ;

Sagement et bel chevauchoient,

Com gent qui d'armes duit estoient,

Les batailles l'une aprés l'autre,

Le petit pas, lance sor fautre,

Escus as couls, hiaumes laciez

(Adenet le Roi, Cleomadés, 613)

REMARques : Beau est un adjectif-adverbe de manière employé en ancien français sous sa forme neutre bel pour les fonctions adverbiales. Chevaucher bel désigne l'allure d'une personne lorsqu'elle se déplace à cheval ; celle-ci se caractérise par une certaine élégance et de beaux mouvements, soulignant aussi la dextérité et l'assurance dans la chevauchée. Le contexte est souvent celui d'une bataille. Notons les collocations sagement et bel et bel et gent, cette dernière renforçant l'idée de grâce dans le mouvement. Bel est modifié par moult.

\section{Chevaucher court}

Porter les étriers courts

Intransitif

1690 Les Orientaux chevauchent court, pour dire, n'allongent pas leurs étriers tant que nous (Antoine Furetière, Dictionaire universel)

1856 Le Numide chevauche court ; sa selle est pleine et fort retirée en arrière (Guide de l'ami du cheval)

REMARQUES : Contraire de chevaucher long.

\section{Chevaucher droit}

I. Aller à cheval en ligne droite, sans détour, se diriger tout droit (vers un lieu)

Intransitif

+1133 Quar il m'estuet errer et chevauchier Tot droit a Rome, por saint Pere proier ; Bien a .xv. anz, a celer ne vos quier, Que m'i promis, mes ne poi esploitier (Le Couronnement de Louis [ $2^{\mathrm{e}}$ tiers XII $], 234$ ) 
1160 Molt se conrea bien de dras

Et monta an un palefroi ;

Set vinz an fist monter o soi,

Et chevalcha droit vers Cartage,

Si com lo moinent li mesage

Qui devant i orent esté (Eneas, 703)

1190 - Sire, dist Sortimbrans, tuit soient

desmembrez!

Aprés porrons par forche cevauchier et errer

Tout droit a Morimonde, ou Karles est ostelez.

Si le prendez par forche, le malvois rasotez (Fierabras (L), 2814)

1230 Or chevauce li rois, et il et ses barnez, Droit vers la tor, [el chief] les vers hiaumes gemez (Gui de Bourgogne, p. 54)

1235 « Sire, fait elle, a vo volentet en soit. Toute serai aprestee demain au jour. " Et il dist que ensi le couvient il. A l'endemain se parti li rois de Carduel atout tel gent comme il avoit et chevaucha tout droit vers le roiame de Norgales, car cele part savoit il bien qu'il trouveroit ses anemis (La Suite du Roman de Merlin, § 343, 9)

+1313 Li ceualiers des rens se part

Et ceuauce droit celle part

$\mathrm{V}$ sa tente tendue auoient

Ses maisnies qui le sieruoient

(Jean de Condé, Poèmes [1313-1337], 486)

-1469 Et, ainsi qu'ilz chevauchoient droit à Crathor, rencontrerent le Jouvencel, qui, tantost qu'il les advisa, donna des esperons, lui et les siens, au travers d'eux, tellement que, par la voullenté de Dieu, il les desconfit (Jean de Bueil, Le Jouvencel [1461]1468, I, p. 147)

1843 Celui-ci, que le diable aidait, dit Jean d'Outremeuse, et qui n'allait plus par la cité qu'escorté d'un grand nombre d'hommes des métiers, prêts à mourir pour sa défense, chevaucha droit à Huy, où il fut reçu avec pompe et honneur (Matthieu Lambert Polain, Henri de Dinant)

1948 AMFORTAS. Tu as beaucoup d'esprit quand tu ne réfléchis pas. Et à chevau- cher droit devant soi, on ne réfléchit guère (Julien Gracq, Le Roi pêcheur)

1981 Il va, il va, il chevauche droit vers le mur bordé de haies. Pas un regard en arrière (Christiane Lesparre, L'Impossible Monsieur Bierce)

II. Aller debout

Transitif

2008 PHILIPPE. Ah s'encombrer d'un vélomoteur rien que pour avoir le plaisir de le pousser, sur toutes distances, tous dénivelés ! Celui qui n’a jamais connu ce bonheur ne sait pas ce qu'est le bonheur ! Au bout de six ans de classique cycliste Ligney-Waremme-Ligney j'en connaissais déjà chaque mètre, mais à présent j'en peux détailler chaque centimètre et rivaliser en connaissance de terrain avec n'importe quel facteur du parcours.

[...]

PHILIPPE. Et quand par extraordinaire la capricieuse machine daigne accomplir l'intégralité du parcours, en pétant d'importance, je me trouve de toute manière passablement grotesque à la chevaucher droit comme un " $i$ ", comme un vieux (André Streel, Des sectes à l'avatar)

\section{CORPUS WEB :}

Chers fans du football, je mesure votre soif de victoire, votre ardente passion de voir les Etalons chevaucher droit au but et triompher de leurs adversaires [http://www.sidwaya.bf/ quotidien/spip.php?page=imprimer\&id_article= 9866] (27.5.2014)

D’après Marco Polo, elle avait l'habitude de chevaucher droit sur l'ennemi, puis de saisir un homme comme un aigle agrippant sa proie, avant de ramener le malheureux à son père [http:// www.aaarg.fr/?p=2873] (27.5.2014)

REMARQues : Chevaucher droit (I) réfère à une personne, un cavalier qui se déplace à cheval pour atteindre un lieu, l'adjectif-adverbe soulignant le but, la destination. L'emploi moderne le transpose au motocycliste (ex. de 2008) ou à d'autres domaines. Droit reste invariable et est modifié par tout. Il a tendance à s'associer avec la préposition qui le suit, au point de faire partie 
du groupe prépositionnel comme modifieur de la préposition (à, au but, devant soi, sur, vers). Par contre, en (II) il devient un prédicat second désignant la position droite du cycliste, dans la locution droit comme un « $i$ ».

\section{Chevaucher étroit}

Chevaucher en se serrant les uns les autres, en restant rapprochés

Intransitif

1100 Laissent les muls e tuz les palefreiz, Es destrers muntent, si chevalchent estreiz (Chanson de Roland, 1001)

REMARQUES : Chevaucher étroit réfère à la distance minime qui sépare les cavaliers groupés en rangs serrés lors de leur déplacement à cheval.

\section{Chevaucher fort}

Chevaucher très vite, avec force, vigueur et entrain

Intransitif

+1350a Il chevaucha si fort et par telle vertu Que nus oisiaus volans, tant l'ait vent esmeü,

Ne l'atainsist ja mais, qu'il ne l'eüst perdu Si eüst aresté a .j. petit festu,

Tant avoit du varlet les esperons sentu (Brun de la Montaigne [2 moitié XIV ${ }^{\mathrm{e}}$, 253)

+1350 b « Il chevauche plus fort que ne font soudoier

Si tost c'om crie a l'arme ! et on doit chaploier. »

Ainsi s'en aloit Bruns a guisse d'aversier. Or commança moult fort le bois a aprochier. Quant il vint a l'entrée, ens s'ala embuchier (Brun de la Montaigne [2 moitié XIV ${ }^{\mathrm{e}}$ ], 3076)

+1370 Celle nuit, enssi c’à soleil esconssant, se parti li jovènes messires Guillaumes de Douglas et li jovènes contes de Moret et messires Robers de Versi et messires Simons Fresel à bien CCCC armures de fer bien montés et bien abillyés, et chevauchièrent fort par voies couvertes et landes nient antées et vinrent environ mienuit assés priès de Bervich, en ung biel pret environ une petite lieuwe engelsce de l'ost (Jean Froissart, Chroniques (A))
+1400 Lors au chemin par ou croissent herbetes Nous sommes mis et de flours nouveletes Eusmes chapiaulx, et parlant d'amoretes Chevauchions fort

Par la forest, pleine de grant deport (Christine de Pisan, Le Livre du dit de Poissy / Euvres poétiques [début XV'], II, p. 186, 900)

1495a Le roy anglois ce partit iceluy jour d'Estempes et chevauchoit moult fort ; si luy dirent ses gens que devant eulx avoit une compaignie de gens moult bien acoustrez, « il seroit bon envoyer veoir que c'est » (Roman de Jehan de Paris, p. 27)

1495b « Certes », dit Jehan de Paris, « il ne vous en fault ja soucier, car j'en ay bien plus ailleurs. Or chevauchons plus fort, car il nous fault aller anuyt coucher près d'Orleans » (Roman de Jehan de Paris, p. 32)

1502 Et, du lieu de Fontaine, ledit conte envoya Jehan de Harmes devant jusquez à SaintMorise et luy dist qu'il chevauchast fort, car ceulx dudit lieu congnoistroient son cheval ; parquoy incontinant sans difficulté le mettroient dedans pour l'amitié (Jean Le Clerc, Interpolations et variantes de la Chronique scandaleuse)

1745 et on appella il qui parle, disant que Monsieur le Dauphin le demandoit ; et lors il qui parle chevaucha devers mondit sieur ; et quand il fut avec lui, il chevaucha fort par les prez, et prit il qui parle par le col, et lui dit, venez-çà (Charles Duclos, Histoire de Louis XI)

CORPUS WEB :

Une brunette qu'on aimerait chevaucher fort !!! [http://bobvideosx.com/feed/atom] (28.5.2014)

Il m'a plutôt pris pour un cheval, tellement il m'a chevauché fort. Mes lèvres touchaient les siennes, y'avait pas que ça qui se touchait, mesz mains étaient baladeuses [http://forums. mangas-fr.com/index.php?topic=16150.5; wap2] (28.5.2014)

REMARQUES : Fort est un adjectif-adverbe de manière qui réfère à la vitesse avec laquelle le ca- 
valier se dirige vers un lieu, qui inclut aussi une certaine détermination de la part du sujet pour l'atteindre. La langue moderne le transpose aussi au domaine sexuel où il renvoie à l'intensité de l'acte où l'un des deux chevauche l'autre. Fort reste invariable et est modifié par moult, plus, si. Notons l'emploi de approcher fort.

\section{Chevaucher gent}

Chevaucher gentiment, doucement

$\lambda$ chevaucher bel

\section{Chevaucher isnel}

Chevaucher rapidement, avec vivacité Intransitif

+1350 Einsi que parlement tenoient ou chastel De Brun de la Montaigne, i. courtois damoisel, A la porte s'en vint sur .i. cheval moult bel Une dame plaisans qui chevauchoit isnel ; Avecques li venoit .i. courtois jouvencel Qui bien estoit montés sus un cheval grisel (Brun de la Montaigne $\left[2^{\mathrm{e}}\right.$ moitié XIV $]$, 1876)

REMARQUES : Isnel désigne la vitesse à laquelle le cavalier se déplace à cheval, soulignant la rapidité dans le mouvement, mais aussi l'agilité, le caractère vif de celui qui dirige l'animal.

\section{Chevaucher long}

Porter les étriers longs

Intransitif

1387 Et doit tout veneur chevauchier court anssois que long, quar il en est plus aisié et moins en grieve son cheval, quar, s'il monte une coste, il se puet soustenir sus les estrieux et ne grievera mie tant son cheval. Et aussi se puet tourner et virer sa et la et baissier, et, s'il chevauchoit long, il ne le pourroit fere (Gaston Phébus, Livre de chasse, p. 233, 54)

1955 Sachez encore que ces gens chevauchent long comme les Français (Marco Polo, La Description du monde [trad.])

REMARQUES : Contraire de chevaucher court.

\section{Chevaucher rangé}

Chevaucher en rangs, en ordre

Intransitif

1276 François chevauchent et rengié et serré, Un petitet se furent arresté, Chevaus escoutent hennir à grant plenté (Adenet le Roi, Les Enfances Ogier, 1613)

1300 Entr'aus communaument se sont Franc adobé,

Moult bielement cevaucent et rengié et seré (Fierabras (K), 5120)

+1370 Tout ainsi que les batailles furent ordonnées, on chevaucha tout rangé après les Écossois, à l'assent (senteur) des fumières, jusques à basses vespres (Jean Froissart, Chroniques (B), I, p. 80)

REMARQUeS : Dans l'ancienne langue, chevaucher rangé désignait une façon de chevaucher en groupe dans un ordre préétabli. Il ne désigne pas un objet interne du verbe au sens strict, mais un élément de la scène évoquée par le verbe, à savoir un ordre bien rangé. Notons la collocation bielement, rengié et seré, le dernier adjectif-adverbe renforçant l'idée d'ordre, de structure. Rangé est modifié par tout.

\section{Chevaucher serré}

Chevaucher en rangs serrés, les uns près des autres

Intransitif

1170 Serré ensemble chevauchierent, De la bataille s'aprochierent (Benoit de Sainte Maure, Le Roman de Troie, 9545)

1235 Or portent e argent en cofres a sumer Pur duner, si par el ne poent espleiter. Ne finent a jurnees tut serré chevaucher, Si unt le clerc truvé par querre e demander, Prechant e baptizant, ke ço fu sun mester (La Vie de seint Auban, 1291)

1250 Vont s'en li més qui ne se targent mie, Droit vers Nerbone ont lor voie acoillie. .X. escuiers ont en lor conpangnie, Q'an destre moinent les destriers de Hongrie.

Chascuns ot armes et espee forbie, Qui grant mestier lor orent ainz conplie. 
Serré chevauchent l'enbleüre serie

(Aymeri de Narbonne [milieu XIII ${ }^{\mathrm{e}}$, 2707)

-1334 Tant alerent qu'apartement

Choisirent l'ost de l'emperere ;

De chascun virent la baniere.

Lors se sont apoint ordené

Et chevauchierent tuit serré (Le Romans de

la dame a la lycorne [1 ${ }^{\mathrm{er}}$ tiers XIV $]$, 7845)

\section{CORpus Web :}

Etaler la pâte dans un moule beurré, allumer le four, thermostat $5 / 6$. Eplucher les pommes en fines lamelles et faire chevaucher serré [http:// pierre.aubril.pagesperso-orange.fr/page8.htm] (29.5.2014)

REMARQUES : Serré est un adjectif-adverbe de manière-dimension. Au niveau spatial, il réfère à la distance minime qui sépare les cavaliers lors de leur déplacement à cheval, au fait qu'ils se déplacent en groupe, en colonnes, en rangs serrés, de façon rapprochée. Notons la collocation rengié et serré qui vient renforcer et confirmer le sémantisme. Serré reste invariable et est modifié par tout (= tut, tuit). Notons aussi la collocation serré ensemble, sans accord au pluriel. Dans cette interprétation, chevaucher serré est vieilli. L'exemple du CW illustre l'usage actuel dans le domaine de la cuisine où se chevaucher a le sens de 'se recouvrir en partie'. Serré reste toujours invariable, ce qui est plutôt rare pour un participe passé.

\section{Chevaucher soef}

Chevaucher doucement, lentement, sans hâte Intransitif

-1200 D'Orliens issi, a esperons s'en va Demie liue ses conpagnons pasa, Guillaume ataint, ki soef cevaucha (Aliscans [fin XII ], 2174)

1300 Puis a seignié son cief, s’a le ciel encliné. Or cevauce tous liés, bielement et soué ; [Lors chevauche li rois, belement et serré, Fierabras (L), 5304]

Damediex le conduie, li rois de maïsté ! (Fierabras (K), 5128)

+1370 Adont rechenglèrent-il leurs chevaux et restraindirent leurs armures et chevauchièrent tout souef et vinrent droit à l'ajournée si à point devant le fort castiel de Mortaingne que il trouvèrent le guichet d'une des portes ouvert (Jean Froissart, Chroniques (A))

REMARQUES : Souvent employé dans un contexte de bataille, chevaucher soef désigne l'allure, le mouvement tranquille et sans brusquerie du chevalier lorsqu'il se déplace à cheval, soulignant aussi la souplesse et la douceur dans le mouvement. Notons la collocation bielement et soué, qui ajoute à l'idée de douceur celle de beauté et de grâce. Soef reste invariable et est modifié par tout.

\section{Cheviller creux}

Avoir une résistance vitale ancrée profondément Transitif

1925 Cruellement empêtré, le fugitif avait cherché les éclaircies. Il devait perdre pas mal de sang ; des gouttes rouges, encore fraîches, tachaient les feuilles mortes. Cent mètres, cent cinquante mètres, Raboliot fit le pied. Une admiration lui venait pour l'énergie de l'animal, peu à peu une pitié obscure. Un renard, bien sûr, un adulte. Fallait-il qu'il voulût vivre, qu'il eût la vie chevillée creux ! La trace s'alourdissait, les gouttes rouges se faisaient plus serrées, disparaissaient dans un fossé, sous les ronces (Maurice Genevoix, Raboliot)

REMARques : Cheviller creux renvoie à la vie d'une personne qui résiste à de grandes maladies, à des blessures dangereuses, des dangers de mort. Creux reste invariable.

\section{Chier dur}

I. chiez dur, chiez mou (mais chiez dans le trou) : évacuer ses selles de consistance dure ou molle

Intransitif

1946 Chiez dur, chiez mou. Cré nom de Dieu ! Chiez donc dans le trou. Ce couplet bien tourné le fit rire. Il s'entendit rire, gêné. Il frissonna. Il eut peur d'avoir été entendu (Raymond Guérin, L’Apprenti)

1977 Un graffiti d'époque, répété dans presque toutes les tartisses des bâtisses pauvres, intimait alors sans euphémiser : « Chiez 
dur..., chiez mou..., mais chiez dans le trou... » Les goguenots élémentaires étant dépourvus de chasse d'eau, il y stagnait une puanteur abominable d'urée et de caca (Albert Simonin, Confessions d'un enfant de La Chapelle)

II. en chier dur : être dans une situation très pénible, souffrir

Intransitif

1949a Vous prenez vos types entre quat'zyeux et vous leur dites : « Le cureton, tu as vu? Il a dit qu'on allait en chier dur. » Le typo demande avec effort : "Parce que toi, tu penses qu'on en a pour longtemps?» (Jean-Paul Sartre, La Mort dans l'âme)

III. ça chie dur: les choses se gâtent beaucoup, ça barde, ça devient très dangereux Intransitif

1949b Le soldat rit à son tour et montra quatre types assis sur le trottoir.

- La voilà, la division, dit-il.

Les yeux de Pinette étincelèrent :

- Ça chie dur à Épinal ?

- Ça chiait. À présent ça doit être très calme (Jean-Paul Sartre, La Mort dans l'âme)

1978 La radio continue de causer comme quoi une tempête de j'sais pas combien de millibars souffle au large du Cotentin et que ça risque de chier dur pour les bateaux croisant dans cette région (San-Antonio, Si ma tante en avait)

\section{CORPUS WEB :}

Si toi aussi tu préferes chier dur, que chier liquide [https://fr-fr.facebook.com/pages/Si-toiaussi-tu-pr\%C3\%A9feres-chier-dur-que-chierliquide/195506213854429] (29.5. 2014)

Nan mais chier mou, ba après la merde reste collé au poils de cul faut pas se voilé la face, puis c'est dégueulasse [http://www.jeuxvideo.com/ forums/1-50-100920656-1-0-1-0-vous-preferezchier-mou-ou-dur.htm] (29.5.2014)

moi j'arrête pas de chier mou... mais ça gosse, ça beurre toute... presque obliger de prendre une douche après... [http://www.physiquextreme. com/showthread.php?6212-Selle-dure-ou-molle] (29.5.2014)
Je vais a nouveau farmer le poils de torren alors planquez vous les H2 car ca va chier dur !!! [http://mg-atlantinus.forumgratuit.org/t655-lesgardiens-le-retour] (29.5.2014)

REMARQUES : Dans l'emploi familier voire vulgaire de chier dur, l'adjectif-adverbe caractérise l'objet direct sous-entendu du verbe et s'utilise dans les contextes suivants : I. Proverbe employé pour faire remarquer à une personne qu'elle est maladroite aux toilettes et lui faire prendre conscience de l'endroit où elle évacue ses excréments, quelle que soit leur consistance, c'est-à-dire dans le trou et non pas à côté. Dans cet emploi, notons la collocation chiez dur, chiez mou qui est indissociable. II. Le sujet désigne une personne qui se trouve dans une situation difficile, qui est astreinte à un effort pénible et qui sue ou va suer sang et eau. III. Le sujet réfère à une situation, souvent conflictuelle, à un événement ou à une affaire qui prend une tournure défavorable. Les exemples du CW complètent la série avec chier liquide.

\section{Chier liquide}

Évacuer ses selles de consistance liquide

入 chier dur

\section{Chier mou}

Évacuer ses selles de consistance moue $\lambda$ chier dur

\section{Chiqueter menu}

Découper en petits morceaux

Transitif

1582 Racines en laict buré cuits et peaux menu chiquetés, estoit viande ordinaire à plusieurs (Théophile D. L., Histoire des troubles et guerres civiles du Pays-Bas)

VOIR AUSSI : découper menu

\section{Choir bas}

I. Perdre sa dignité, son statut social, son bien, devenir vil, méprisable, tomber socialement Intransitif

1275 Mais ses orgueauz, sa felonie

Si forment l'orent envaï

Que de si haut si bas chaï,

Con tu m'as oï raconter (Jehan de Meun, Roman de la rose [1269-1278], 6484) 
+1370 Enssi chei li dis messires Hues de si hault si bas et tous ses linaiges ossi (Jean Froissart, Chroniques (A))

1427 Car a ceulx que fortune la variable a plus haultement eslevez ne reste plus si non cheoir de si hault si bas, pour ce qu'elle ne leur doibt plus rien, si non ruyne (Alain Chartier, Le Curial)

-1465 Or m'est il donc tresgrandement mescheu Qui me vy hault et me sens si bas cheu Que je n'ay plus aulcun qui bien me vueille : Mes maistres mors, mon honneur est descheu,

Et tout malheur m'est en partaige escheu (Jean Meschinot, Lunettes des princes, p. 14, XXXVII, 2)

1899 Et, maintenant qu'ils ont pris la place des autres, ils nous font justement choir un peu plus bas. Brisson et ses amis sont en train de tuer ce qui restait de foi dans les idées républicaines (Georges Clemenceau, Vers la réparation)

II. Diminuer beaucoup, prendre une valeur très inférieure, tomber (sens figuré)

Intransitif

1325 Com plus est hons puissans veüs, Tant est ses pris plus bas cheüs, Se il à mal faire s'acline (Watriquet de Couvin, Dits, p. 143, 167)

1580 Qui de soy cherra bas quand le fruit sera meur.

Or, le chretien qui droisse au grand Ciel sa demeure

Ne s’arreste à cela qui se perd en peu d'heure

(André de Rivaudeau, Euvres poétiques)

REMARQues : Choir bas appartient à l'ancienne langue, souvent dans la collocation de si haut si bas, qui désigne le point de départ. La langue moderne le remplace par tomber bas. Au figuré (I), il souligne la déchéance d'une personne, d'un groupe. Au sens propre (II), il renvoie à l'idée de chute, de mouvement vers le sol. Bas est invariable. Il est modifié par si, un peu plus.

\section{Choir coi}

Demeurer, rester brusquement tranquille, silencieux, sans bouger Intransitif

1250 Li bouriois li a creanté

Cele le prist a esforcier

Plus de boiure que de me[n]gier ;

[Et] cil s'en est si porueuz

Qu'il est iluec touz coi cheuz

(Les Trois Dames qui troverent l'anel, 84)

REMARQUES : Coi est un adjectif-adverbe de manière aujourd'hui vieilli. Il souligne l'aboutissement d'une action ou d'un geste qui se traduit par le silence du sujet, une certaine inactivité. Il est invariable et modifié par tout.

\section{Choir droit}

I. choir tout droit : tomber directement Intransitif

1468 C'est du demourant d'Ancenys, Par ma foy, ou de Champ Toursé. Helas, que je me vis coursé De la mort d'ung de mes nepveux ! J'euz d'ung canon par les cheveux, Qui me vint cheoir tout droit en barbe (Le Franc Archier de Baignollet, 45)

1498 Mais la puissance des faulcons, bombardes, canons, serpentines et bombardelles y firent si horrible deluge que tout alloit par terre en pieces et en lopins ; parquoy ceulx de dedens voyant estre si de pres chassez, chargerent ung mortier, puis mirent le feu dedens, et vint choir tout droit sur la nef de l'eglise des freres mineurs, Cordeliers de l'Observance, et rompit la dicte nef sans faire mal a homme ne a femme du monde qui fust en la dicte eglise : et si en avoit largement de tous costez (Andrieu de la Vigne, Le Voyage de Naples, p. 252)

II. choir droit : tomber selon une ligne droite Intransitif

1729 GRÉGOIRE. Ne nous accusé pas, vous dis-je de l'esclandre.

Ce n'est qu'au feu du ciel, Monsieu, qu'i faut s'en prendre Ste nuit, que je dormion, par le mitan du toit, 
Patatrâs! su la grange, al est chu tout fin droit (Alexis Piron, L'École des pères)

1937 ÉLECTRE. Elle peut encore être une courbe, une conque, une pente maternelle, un berceau. Mais elle est restée figée, dressée, et il a chu tout droit, du plus haut de sa mère! (Jean Giraudoux, Électre)

2012 Le sol se dérobe sous le rocher qui choit droit dans les ténèbres de l'En-Dessous. Il défonce un immeuble souterrain, étage après étage, puis un autre, encore un autre (Jérôme Noirez, Féerie pour les ténèbres)

2013 Sans déduire que j'allais être châtiée de la sorte, je me suis insurgée contre ce régime qui ne me plaisait plus. Auprès de ma mère attendant d'atterrir, lieu prévisible que j'avais sélectionné et le seul qui devrait me contenir, mon parachute, mal manœuvré, fut ouvert, je chus droit dans un autre, imprévisible (Karima Alawî As-Sulaïmani, Écrire ou se laisser mourir)

CORPuS WeB :

Pour clore le débat, il me gratifia d'une grande tape dans le dos qui me fit choir droit devant, tout près du poêle [http://www.prologue. qc.ca/jj/03janvier.htm] (30.5.2014)

Ou alors une jeune Terriene rencontrée lorsqu'ils retourneront sur Terre. Peut-etre, grace a un vaisseau amoureusement conçu par Bombastus, nos héros se veront-ils retourner sur Terre et choir droit sur... Maracaibo [http://www.decape. askell.com/forum/viewtopic.php?f=7\&t=385] (30.5.2014)

REMARQUES : Choir droit (I) souligne l'aboutissement d'un déplacement, le sujet arrivant directement à un lieu précis. Sous l'acception (II), il réfère au fait de tomber, de chuter de façon verticale, également au figuré (ex. de 2013). Droit a tendance à s'associer avec la préposition qui le suit (de, devant, en, sur), au point de faire partie du groupe prépositionnel comme modifieur de la préposition. Il est régulièrement modifié par tout. Notons l'adjectif-adverbe de degré fin dans tout fin droit en patois. La collocation choir droit semble avoir survécu, du moins dans le registre littéraire auquel prétendent les exemples du CW.

\section{Choisir bas}

I. Choisir secrètement, intérieurement Transitif

1834 Et si ces amis louables et bons, ces vivants de notre connaissance que j'aime ainsi à choisir tout bas un à un, pour les voir confirmer de leurs défauts mêmes la parole de l'apôtre, nous choquaient trop à la longue par ces taches que nous distinguons en eux, qu'est-ce, mon ami, sinon que nous serions à notre tour moins chrétiens qu'il ne faudrait ? (Charles SainteBeuve, Volupté)

II. Faire un choix inférieur, indigne Transitif

1956 En vain. J'avais enfin compris qu'il cherchait à introduire entre nous, comme une lourde complicité, l'érotisme. Il cherchait quelque chose qui nous liât, il s'accrochait aux branches et, pour une fois, la choisissait un peu basse (Françoise Sagan, Un certain sourire)

Emploi absolu

1988 Les confidences du comte Spada avaient appris à Egon que la brutalité sensuelle, le goût bien défini du vol et du mensonge n'étaient pas chez Franz qu'un phénomène récent. À un dégoût physique comme une nausée, s'ajoutait l'horreur d'avoir choisi si bas. Mais où commençait le choix ? Et si sa présente répulsion, qui parfois confinait à la haine, n'était pas aussi une forme d'hypocrisie ? (Marguerite Yourcenar, Le Labyrinthe du monde)

\section{CORPUS WEB :}

En bonne adepte du chignon, Eva Mendes le choisit bas et décoré d'une mèche libre pour une allure glamour [http://www.puretrend. com/media/en-bonne-adepte-du-chignon-evamendes_m593017] (30.5.2014)

L'esprit serait le voile maya, et l'âme en s'incarnant choisirait le niveau qu'elle veut lui donner. Plus on choisit bas, plus on peut évoluer comme c'est l'âme qui nous guide, donc ainsi on peut mieux avancer, ou éprouver de la facilité (les « dons ») à redécouvrir des choses qu'on maitrisait bien dans les incarnations précédentes [http://www.psitk.com/v3/forums/viewtopic.ph 
$\mathrm{p} ? \mathrm{p}=4955 \& \mathrm{sid}=8 \mathrm{~d} 4 \mathrm{fefcc} 1 \mathrm{a} 212 \mathrm{fd} 74805 \mathrm{~b} 5549 \mathrm{~b} 9 \mathrm{~d} 8$ 5dc] (30.5.2014)

L'inconvénient est qu'il faut majorer la pression d'entrée au moteur d'environ 10 bars, mais nous avions pris soin de la choisir basse au départ [http://joho.p.free.fr/EC/THEMES/MOTEURS/ Dimensionnement\%20d'un\%20moteur\%20hyd. (chaine])1.htm (16.6.2014)

REMARQUes : Bas est un adjectif-adverbe de position qui désigne dans le groupe choisir bas une action qu'on passe sous silence, sans le dire ou confesser (I). (II) renvoie également à un niveau bas, soit au sens concret (ex. : la pression), soit au sens figuré, à une moralité inférieure, notamment dans le domaine sexuel, donc à des sentiments dits 'bas'. Bas réfère donc à un niveau inférieur où quelque chose est situé (le chignon, la pression, l'exigence morale). Dans le dernier exemple, bas est un prédicat second qui est accordé avec le complément d'objet de choisir : la pression (à comparer : les dialectes méridionaux de l'Italie ; v. Introduction § 4.6).

\section{Chuchoter bas}

Parler, dire indistinctement, à voix basse, d'une voix très faible

Intransitif

1792 L'un louoit ta figure, un autre ton maintien ;

Celui-ci ta blancheur, cet autre ton corsage Et les femmes en proie à la jalouse rage, Regardant en-dessous et chuchotant tout bas,

Te cherchoient des défauts et ne t'en trouvoient pas

(Nicolas-Thierry Jacquemart, Contes et Poésies du c. [citoyen] Collier)

1842 Beautiful view ! Very fine, Very pretty waterfall! etc., etc. - Les jeunes filles, d'abord intimidées et surprises de ma rencontre, se mirent à chuchoter tout bas avec un petit rire étouffé. Elles étaient charmantes ainsi, mais il est évident qu'elles se moquaient de moi (Victor Hugo, Le Rhin)

1855 Il ne fallait plus se rouler par terre, rire bruyamment, parler berrichon. Il fallait se tenir droite, porter des gants, faire silence ou chuchoter bien bas dans un coin avec
Ursulette. À chaque élan de mon organisation on opposait une petite répression bien douce, mais assidue (George Sand, Histoire de ma vie)

1856 Crois à l'amour, toujours entier, Toujours brillant sous tous les voiles !

À l'amour, tison du foyer !

À l'amour, rayon des étoiles !

Dans ton âme où parfois je passe, Où mes vers chuchotent tout bas, Laisse chaque chose à sa place (Victor Hugo, Les Contemplations)

1886 Déjà, l'envie était à l'œuvre : le monsieur qui fait de l'esprit avec les dames ; celui qui, sans un mot, regarde, hausse terriblement les épaules, puis s'en va ; les deux qui restent un quart d'heure, coude à coude, appuyés à la planchette de la cimaise, le nez sur une petite toile, chuchotant très bas, avec des regards torves de conspirateurs (Émile Zola, L'Euvre)

1890 Elle répondit en le serrant entre ses bras, d'une étreinte passionnée, et en lui couvrant le visage de baisers muets. Cela l'égayait, de jouer au mystère, de ne plus chuchoter que très bas.

- Oui, oui, tu vas voir : on ne nous entendra pas plus que deux petites souris (Émile Zola, La Bête humaine)

1900 - Les âmes n'ont pas de sexe, mon cher Maurice... elles ont...

- Du poil... aux pattes... chuchota Victor Charrigaud, très bas, de façon à n'être entendu que du romancier psychologue à qui il offrait, en ce moment, un cigare... et l'entraînant dans le fumoir (Octave Mirbeau, Le Journal d'une femme de chambre)

1904 Mercredi, 18 avril. Éveillé avant le jour, par des voix d'hommes et de femmes, qui chuchotent tout près et tout bas; avec mon interprète, ils parlementent discrètement pour demander la permission d'ouvrir le portail et de sortir (Pierre Loti, Vers Ispahan) 
1940 D'autres, magnanimes, jettent en souriant des paquets de chocolat (des chocolats pillés dans nos boutiques) aux gamins stupéfaits. La foule chuchote, mais tout bas, car devant cette force déchaînée qui s'étale dans la rue, on éprouve déjà la contrainte du vaincu (Berthe Auroy, Jours de guerre)

1995 Ou, le cas échéant, entrer dans cette pharmacie à l'angle du boulevard et m'asseoir sur une chaise en cuir, ne pas bouger, me taire et quand les gens viendront s'attrouper autour de moi, chuchoter tout bas : «Laissez-moi tranquille, une minute, dans cette lumière et cette chaleur » (Andreï Makine, Le Testament français)

Transitif

1881 Leur vice était public, officiel, patent. On en parlait comme d'une chose naturelle, qui les rendait presque sympathiques, et l'on chuchotait tout bas des histoires étranges, des drames nés de furieuses jalousies féminines, et des visites secrètes de femmes connues, d'actrices, à la petite maison du bord de l'eau

(Guy de Maupassant, La Femme de Paul / Maison Tellier, Une partie de campagne et autres nouvelles)

1890 Et, comme pendant la nuit des aveux, à Paris, dans la chambre de la mère Victoire, lui l'écoutait, silencieux, tandis qu'elle, la bouche collée à son oreille, chuchotait très bas des paroles sans fin. Peut-être, ce soirlà, avait-elle senti la mort passer sur sa nuque, avant d'éteindre la lampe (Émile Zola, La Bête humaine)

1952 Une suite d'essais défile avec rapidité devant ses yeux, muets pour la plupart, ou chuchotés si bas qu'on en perd complètement les mots - ce qui accuse encore leur caractère mimé, caricatural, voire grotesque (Alain Robbe-Grillet, Les Gommes)

Pronominal (réciproque)

1958 En tout cas l'accent outragé de mon père, le visage scandalisé de ma mère, me confirmèrent qu'il ne faut pas se hâter de formuler à voix haute toutes les paroles inquiètes qu'on se chuchote tout bas
(Simone de Beauvoir, Mémoires d'une jeune fille rangée)

CORPuS WeB :

Elle me regarde, perdue, et chuchote bas, d'une voix affreusement suppliante [http:// serie-fanfic-aide.skyrock.com/3188038323-Seraccrocher-l-un-a-l-autre.html] (30.5.2014)

Elle se tourne alors vers l'homme, riant, mais lui chuchote bas sa première phrase, de manière à ce que les Barbouillés ne l'entendent pas [http://www.univers-rr.com/RPartage/index. php?page $=r p \& i d=12592](30.5 .2014)$

- Ma princesse ... Où elle est ma petite princesse qui va être gentille avec son papa?

La voix chuchotait, basse, insistante [http:// ahvousecrivez.blogspot.co.at/2010/01/un-crimequelconque.html] (16.6.2014)

REMARQUes : Bas est un adjectif-adverbe de position, référant ici à l'intensité de la voix. Dans son emploi transitif, il désigne le fait de dire quelque chose (une parole), de raconter quelque chose à voix basse à son interlocuteur ou de le murmurer à l'oreille de façon qu'une tierce personne ne saisisse pas le sens de la conversation. Le sujet désigne le plus souvent une personne, mais dans un emploi métaphorique, il peut aussi désigner l'écriture, la poésie et donc son contenu (les vers). Dans son emploi intransitif, le sémantisme est plus centré sur l'échange d'informations à voix basse entre deux personnes. En général, bas reste invariable et est modifié par bien, si, très, et notamment par tout. Dans le troisième exemple du CW, il s'accorde avec le sujet, ce qui le rapproche des prédicats seconds détachés du verbe par une virgule. VoIR AUSSI : parler bas

\section{Circuler doux}

Circuler prudemment, en douceur, à petite vitesse

Intransitif

1995 Automobilistes, circulez tout doux (panneau route nationale / StephanGabinel 2001] 


\section{Ciseler fin}

Ciseler, tailler d'une manière précise et fine, avec une grande perfection

Transitif

1838 Commandé aussi des boutons d'acier fin ciselé pour un gilet de velours noir, sublime invention qui doit me faire plus d'honneur que n'importe quelle découverte scientifique (Jules Barbey d’Aurevilly, Premier Memorandum)

1896 Avenues de mille mètres de long, bordées d'innombrables échoppes où miroitent les choses orientales : les armes, les faïences, les meubles peinturlurés ou incrustés de nacre ; les cuivres, ciselés fin comme des dentelles ; les costumes de nuances rares (Pierre Loti, La Galilée)

\section{CORPUS WEB :}

Ciseler très fin les échalotes et les faires suer avec de l'huile d'olive, ajouter la pulpe de tomate, le lait de coco le gingembre et la citronnelle, couper en morceau [http://www.francepizza.fr/recette257-Crevettes--curry-d-agneau--citronnelle--coco-pulpe-de-tomate-Mutti.php] (30.5.2014)

Craquant : juste avant de servir, ciseler fin la menthe et mélanger avec les pistaches et le sucre [http://www.lemenu.ch/fr/recettes/ LM201306_51/bavarois-au-yogourt-et-aux-fraises. html?pdf=1\&type=.pdf] (30.5.2014)

Ciseler fine l'autre oignon [http://chinoischez moi.blogspot.co.at/2013_07_01_archive.html] (30.5.2014)

Ajouter la coriandre ciselée fine. Mettre en poche et réserver au froid [http://www.tv5.org/ cms/chaine-francophone/Revoir-nos-emissions/ Epicerie-fine/Episodes/p-28113-Les-crabes-deBretagne.htm] (30.5.2014)

REMARQUES : Ciseler fin réfère à une personne qui travaille, taille avec précision un objet de métal ou plus rarement de toute autre matière dure, à l'aide du ciseau ou du ciselet ; le résultat traduit alors l'aptitude du sujet à exécuter son travail dans le moindre détail, à la perfection. Fin reste invariable dans cet emploi. Dans les exemples du CW, ciseler fin est confiné au langage des recettes de cuisine. L'accord s'observe dans deux cas sur quatre, mais dans le troisième exemple il n'est pas justifié par le genre masculin du substantif oignon. Notons l'antéposition de fin au participe dans l'exemple de 1838, ce qui peut vouloir dire que fin modifie acier ; la structure syntaxique étant donc ambiguë.

\section{Citer juste}

Citer conformément à l'original

Transitif

1678 Comme on n'a pas le Rituel de Cambray en main, on ne sçait si ce Père le cite juste (Remarques sur un écrit dicté à Douay par le père Fr. Jacops)

1888 Et milles louanges délicates, deux ou trois vers cités juste, avec l'assurance que mon maître Astier était ravi ; il l'avait chargée de me le dire, dans le cas où il ne pourrait quitter ses archives (Alphonse Daudet, L'Immortel)

Emploi absolu

1736 L'orateur le plus consommé a tous les jours le texte à la main, et sa fidélité à citer juste lui fait autant d'honneur que son éloquence. L’observance du catéchisme est de même décision pour le salut que la coutume d'un païs pour une question débatuë (Charles-François-Nicolas Le Maître de Claville, Traité du vrai mérite de l'homme)

1785 Si les graves messieurs qui l’ont tant répété me font l'honneur de lire cette préface, ils y verront au moins que j'ai cité bien juste ; et la bourgeoise intégrité que je mets à mes citations n'en fera que mieux ressortir la noble infidélité des leurs (Pierre-Augustin de Beaumarchais, Le Mariage de Figaro, Préface)

1838 Elle ne confondait mon moi avec celui de personne. M'a dit m'avoir rencontré là et là (elle a cité juste) et brief m'a engagé à aller la voir. M'a dit son nom et son adresse. - N'est-ce pas singulier ? (Jules Barbey d'Aurevilly, Premier Memorandum)

2000 J'imagine la stupéfaction de mon père s'il eût entendu un Premier ministre réhabiliter les mutins de 1917, ou, citons juste, les " réintégrer dans la communauté nationale ». Les hommes qui s'étaient soustraits 
à l'héroïsme absurde de la Grande Guerre étaient des embusqués

(François Nourissier, À défaut de génie)

CORPUS WeB :

Pour bien comprendre et citer juste : fermer les yeux, respirer calmement, serrer les poings et se laisser pénétrer par le sens profond de la citation [http://www.teleologie.org/OT/ deboard/1617.html] (2.6.2014)

Correction à 00.15 le 12 mai : " Tout le monde le dit qu'il y a eu de la gégène. » Tant qu'à citer, citer juste. Mea culpa. Mais à mon sens, les propos du général Bigeard restent très clairs [http://lignesdedefense.blogs.ouest-france. fr/archive/2012/05/11/29-juin-a-carcassonneinauguration-d-une-stele-en-hommage-au.html] (2.6.2014)

Quand on cite les grands auteurs, la moindre des politesses est de les citer juste [http://wrath. typepad.com/wrath/2011/02/prix-des-lecteursde-lexpress-moins-de-50-ans-sabstenir.html] (16.6.2014)

C'est bien vôtre droit d'y croire... Juste un détail : ce n'est pas $71 \%$ des français qui soutiennent « les syndicats », mais 70,985\%. Tant qu'à citer des chiffres, autant les citer justes [http://plus.lefigaro.fr/comments_reply/4104536] (16.6.2014)

REMARQUES : Citer juste réfère à une personne qui reprend mot à mot, oralement ou par écrit, des paroles ou un texte empruntés à un auteur, pour éclairer, illustrer ou prouver ce qu'elle dit ou écrit. L'action est caractérisée par une indication précise des sources ou de l'auteur original. Juste reste généralement invariable et est modifié par bien. Dans le dernier exemple, cependant, juste s'accorde avec l'objet pronominal préverbal, sans doute pour insister sur le fait que les chiffres sont corrects, ou par la même tendance à l'accord de l'adverbe que l'on observe de façon systématique pour la même structure syntaxique dans les dialectes méridionaux de l'Italie (v. Introduction § 4.6). Juste est modifié par bien.

\section{Clamer fort}

Crier fort, hurler

Transitif

1885 Il était temps, les Grégoire disparaissaient, lorsque la grêle des pierres recommença. Revenue de son étonnement, la foule clamait plus fort :

- À mort les bourgeois ! Vive la sociale ! (Émile Zola, Germinal)

1904 alors, d'autres groupes frôlés se joignirent, des grands entraînèrent leurs petits frères, des causeurs tranquilles sautèrent, brusquement emballés, plus éperdus, plus frénétiques, clamant plus fort que les premiers, et ce fut une ruée d'élément, un haro unanime, un emportement destructeur et oppresseur : panique, assaut, joie brute (Léon Frapié, La Maternelle)

1922 Un homme gémit, le bras cassé ; un autre se plia en deux, frappé à l'aine. Des cris montèrent. Ceux qui n'étaient pas touchés clamaient plus fort que les autres :

- Assassins ! - Bandits ! - Que le Seigneur vous écrase !

(Joseph Kessel, La Steppe rouge)

1985 Hilare, tout seul au milieu de l'échauffourée générale, j'essuie le sang qui ruisselle de mon nez et explose de rire. À deux mètres de là, Christian Vander, le batteur de Magma, clame haut et fort qu'il a tout vu et qu'il est de mon côté. Un type lui ouvre la lèvre d'un uppercut. Vander fonce sur l'impudent et le satonne d'importance (Philippe Manœuvre, L'Enfant du rock)

2003 Il prêtait tant d'attention à la voix intérieure qui lui racontait les bienfaits de ses sentiments régénérés qu'il croyait entendre le zéphyr tumultueux clamer fort à son entendement le nom de Lasselle, puis comme il cassa les branches des amandiers qui protégeaient la demeure de leur ombre bienfaisante, il croyait entendre la fameuse expression « Lasselle au yeux doux » (Ernst Delma, Lasselle)

2007 Mais il ne suffit pas de clamer haut et fort sa motivation, encore faut-il la prouver ! Lorsque vous répondez à une annonce 
ou envoyez une candidature spontanée, testez votre motivation en listant les points qui vous intéressent dans le poste et l'entreprise (Christine Aubrée, Bien préparer ses entretiens avec les recruteurs)

\section{Corpus Web :}

De comparaison en comparaison, j'arrive à saisir la Lybie, qui dans le fond, n'était pas citée comme exemple de pays mal géré, en tout cas socialement parlant ; le peuple a eu faim jour après jour de plus d'équités morale et juridique, au point de la clamer fort cette faim-là, le grand jour venu [http://www.lefaso.net/spip. php?article41748] (2.6.2014)

Nous nous targuons tous d'être des démocrates, des chrétiens, dans ce cas seule la vérité, la nôtre peut nous affranchir. Encore, nous faut-il la reconnaître, l'appréhender et nous l'approprier. Commençons donc par la clamer haut et fort à ceux-là qui ne le sauraient pas, en ce qui a trait à notre situation vis-à-vis de la constitution de mil neuf cent quatre-vingt sept [http://www. potomitan.info/ayiti/moise/constitution.php] (2.6.2014)

\section{Alors il faut clamer fort et haut}

Nos couleurs de peau nos différences

Partout en faire écho

Et que nos cœur résonnent

De nos défauts être fière et beau

En faire un cadeau en faire une chance

Personnen'est jamais personne [http://www. youtube.com/watch?v=IvPyDj1gsBE] (2.6.2014)

Les hommes et les femmes publiques de notre pays côtoient les journalistes d'une façon démesurées et lorsque des éléments ne conviennent plus à ces personnages publics, l'atteinte à vie privée est clamée haute et forte pour en interdire l'usage [http://mathieudufain.hautetfort.com/ archive/2008/01/12/vie-publique-vie-priveequand-la-machine-s-emballe.html] (17.6.2014)

Elle pouvait bien se clamer forte ou même l'être véritablement mais, elle restait tout de même une fille et portait un garçon avec une corpulence supérieur à la sienne n'était vraiment pas aisée... bien au contraire même ! [http://forum. khdestiny.fr/topic/2298-under-a-new-day-und/ page-3] (16.6.2014)
REMARQUES : Souvent employé dans un contexte de crise ou de révolte, clamer fort renvoie à une personne ou à un groupe de personnes qui crie, voire hurle son désarroi ou son mécontentement. Notons la collocation usuelle haut et fort qui renforce le sémantisme, le sujet annonçant hautement quelque chose en cherchant à atteindre un vaste public. Fort reste généralement invariable (ex. de 2007 et les trois premiers exemples du CW, mais v. l'avant-dernier ex. du CW) et est modifié par plus. Dans le dernier exemple du CW, fort s'accorde avec le sujet du verbe suivant le modèle de se croire / se déclarer / se vouloir fort où fort est un adjectif prédicatif : elle clame être forte. Il ne s'agit donc pas d'un adverbe de manière comme dans clamer fort 'crier fort', qui ne permettrait pas cette paraphrase. VoIR AUSSI : crier fort

\section{Clamer haut}

\section{Clamer d'une voix forte}

Transitif

1560 Ces parolles clamées hautes et profondes comme un creux son de tonnerre furent de tous entendues, et tous y accoururent pour veoir que c'estoit, mais rien n'apparoissoit, car le serpent estoit bien du tout mort et celle voix n'estoit point de la beste (Barthélemy Aneau, Alector ou Le Coq)

1923 Cela parut la rassurer, sans qu'elle cessât pour cela son monologue conjugal, haut clamé comme des fenêtres en Orient (Paul Morand, Fermé la nuit)

1982 Un jour, Pierre Guyot et moi avions proposé une partie de pêche à la grenouille dans un étang voisin, en clamant bien haut qu'en France c'était un mets de choix (Paul Thorez, Les Enfants modèles)

1988 Enfin Massu paraît. Il n’aime pas ce « bordel », il le clame haut et fort, il rétablira l'ordre. Une ovation immense salue le baroudeur bien-aimé (Gisèle Halimi, Le Lait de l'oranger)

2009 Éric, dans le Nord, était et resterait le fils d'un déchet, d'un violent dévoré d'alcool, incapable de tenir une place plus de quinze jours, perdu de réputation, un individu que les employés des services sociaux, à bout 
de ressources, se renvoyaient de bureau en bureau, clamant haut et fort, exaspérés, vaincus, que le cas relevait de la police ou de la psychiatrie, voire de l'une et de l'autre (Marie-Hélène Lafon, L'Annonce)

Intransitif

1837 Un autre se prend à clamer haut et fort ; ses compagnons acclament et progressent, concert en tout semblable à celui que nous donnent certains oiseaux domestiques (Anthelme Richerand, De la population dans ses rapports avec la nature des gouvernemens)

REMARQUES : Haut réfère à l'intensité de la voix, et, au figuré, au fait de dire ouvertement. Le sujet du verbe clamer désigne une personne ou un groupe de personnes qui annonce d'une voix forte et parfois hardiment quelque chose (des paroles, un texte) en cherchant à atteindre un vaste public. Notons la collocation usuelle haut et fort qui renforce le sémantisme. Remarquons l'expressivité littéraire de l'accord dans l'exemple de 1560 qui insiste davantage sur une qualité des paroles elles-mêmes (v. aussi les occurrences de clamer haut et fort sous clamer fort).

\section{Clamer menu et souvent}

Déclarer souvent avec insistance

Transitif

1100 Pur ço l'ad fait que il voelt veirement

Que Carles diet e trestute sa gent,

Li gentilz quens, qu'il fut mort cunquerant. Cleimet sa culpe e menut e suvent, Pur ses pecchez Deu en puroffrid lo guant (Chanson de Roland, 2364)

REMARQUeS : Menu est un adjectif-adverbe de manière-fréquence. La collocation menu et souvent est usuelle en ancien français.

\section{Clamer profond}

Clamer, déclarer d'une voix profonde, grave $\pi$ clamer haut

\section{Clapoter sec}

Produire des petits bruits répétés, rapides et

sans résonance

Intransitif

1963 Il fait soleil mais le vent souffle, les glissières [= d'un camion] clapotent $\mathrm{sec}$, beaucoup plus sec, tiens! (Le Figaro littéraire, 21 septembre 1963 / Grundt : 355)

2003 La camionnette, avec ses 4 flics, elle déplaçait donc 120 verres qui devaient clapoter sec dans les estomacs, ce qui, même compte tenu du volume et de la cylindrée de la camionnette en cause, dépassait largement le taux d'alcoolémie autorisé (Roger Lemineur, Les Propos des classe du p’tit Gégé)

\section{CORPUS WEB :}

L'entrée de la baie se trouve à l'abri de la barrière extérieure qui bien qu'immergée à cet endroit casse quand même la houle du large. L'entrée elle même est très encombrée de récifs qui protègent l'intérieur de la houle résiduelle. Mais elle n'est pas bien large et on doit la prendre bien dans l'alignement des deux pylônes qui se trouvent sur la rive nord et dont on ne voit le plus bas qu'en arrivant dans la passe !!! Alors on s'approche sur le cap indiqué (283 vrais) de celui du haut qu'on voit de loin. Ça clapote sec des deux cotés de la passe et ça incite à rester au milieu... [http://www.getaway-arb.fr/index. php?page $=$ mouillages $/$ nouvelle] caledonie sud noumea.html (2.6.2014)

\section{Lily}

Comme vous l'aurez compris, le thème de ce tu veux ma photo n'est autre que le site de rencontres. Un personnage de TVD de votre choix décide de s'inscrire sur un site de rencontre ou bien quelqu'un l'y inscrit. A vous d'imaginer un profil, de raconter ce qui s'y passe, peut-être même de créer un premier échange de mails voire un premier rendez-vous ! A vos claviers gentes damoiselles ! (ou vieilles sorcières selon votre âge) Vous avez jusqu'à mardi prochain pour ME faire parvenir vos textes !

JustD.

Alors merci pour la vieille sorcière hein... :o heureusement, le profil de klaus te pardonne presque tout... ! J'espère que ça va clapoter sec !!! 
[http://www.vampire-diaries.fr/forum/view topic.php?f=25\&t=2965\&view=next] (2.6.2014)

REMARQUES : Clapoter sec réfère au bruit provoqué par le mouvement brusque et répété de deux choses qui s'entrechoquent. Dans le deuxième exemple du CW, il renvoie au bruit du clavier sur lequel on frappe (pour rédiger des textes). Sec reste invariable et est modifié par plus. Dans les deux cas du CW, clapoter sec apparaît dans une construction impersonnelle.

\section{Claquer dur}

Claquer fortement, violemment

Intransitif

1866 - J'ai claqué dur, j'en ai les mains qui me cuisent.

- Je parie vingt francs pour un succès (Le Journal amusant)

1918 En avant ! et vivement, car la fusillade claque dur ! (François Parnet, En suivant la flamme)

1919 Le premier round a lieu en belle forme. Les coups claquent durs (La Revue hebdomadaire)

1938 Dans L'Argent n'a pas d'odeur, le fouet claque dur, les dents son longues, la main, évidemment, celle d'un maître [= Bernard Shaw] (Nouvelle Revue française)

1949 Il n'avait pas peur de mourir, il avait peur de la haine. Ça y est ! Ça claquait dur dans ses oreilles, il rouvrit les yeux : la rue était déserte et silencieuse ; il essaya de croire qu'il avait rêvé. Personne n'a tiré, personne... (Jean-Paul Sartre, La Mort dans l'âme)

\section{CoRpus Web :}

Joli cadrage, le rendu de la coque extérieure est bon. Dommage que la lumière soit un peu plate. La même avec un ciel bleu pétant devrait claquer dur [http://www.pentaxone.fr/compo nent/option,com_smf/Itemid,28/topic,12065. msg1576133] (2.6.2014)

ouch la page de BD ! avec un bon choix de couleures ca risque de claquer dur dur ! les angles de vue sont très bien choisis [http://www. catsuka.com/interf/forum/viewtopic.php?t=4714 \&postdays $=0$ \&postorder $=$ asc $\&$ start $=90 \&$ sid $=6$ be 7d61ff3418b47ffc794f5517932df] (2.6.2014)

REMARQues : Claquer dur réfère à un bruit sec et éclatant qui se manifeste par des vibrations sonores fortes pour l'oreille (applaudissements, coups de boxe, coups de fouet, fusillade, etc.). Dans les exemples du CW, claquer dur renvoie au figuré à l'effet saisissant provoqué par la lumière ou les couleurs. Notons la réduplication $d u r d u r$ pour intensifier. Dans l'exemple de 1919, l'accord rapproche claquer dur d'une prédication seconde pour souligner la dureté de coups.

\section{Claquer fort}

Claquer fortement

$\lambda$ gronder bas

\section{Claquer franc}

Produire un bruit sec

Intransitif

1845 Mais son haut grade et ses victoires ne rendirent pas Lazare plus fier qu'auparavant, et tous les soirs le baiser filial accoutumé n'en claquait pas moins franc sur les joues de la fruitière (Hégésippe Moreau, Le Neveu de la fruitière)

Corpus Web :

Pour Frédéric et Patrice, son frère, c'est le coup de foudre pour les deux vielles dames [= 2 CV Citroën] qui offraient un bruit de moteur inimitable, des clignotants qui claquaient franc et sec, des demi-vitres qui retombaient parfois avec fracas sur les coudes sans crier gare. Il y avait du travail en perspective pour remettre les « bolides » bicylindres sur la route [https:// www.saintpoldeleon.fr/IMG/pdf/070813.pdf] (15.08.2013)

\section{Claquer net}

I. Claquer d'une manière précise, brutale Intransitif

1916 Les coups de fusil crépitent de tous les côtés. Tout à coup, une balle claque net dans la terre du talus où je m'appuie. Je mets la face au créneau (Henri Barbusse, Le Feu) 
II. Mourir

Intransitif

1940 L'adjudant y raconte pour la dixième fois ses histoires, il veut à présent « couper les moustaches du petit père Staline » et rêve qu'on nous envoie en corps expéditionnaire en Finlande. Il y claquerait net, d'ailleurs, étant frileux comme une vieille (Jean-Paul Sartre, Lettres au Castor et à quelques autres)

III. Frapper, éclater (les paroles, les pensées) Intransitif

1997 Ses ordres claquent nets et précis (Vincent Goudis, Cap'tain Vagabond)

2004 Les premières connaissances empiriques de l'homme de par la religion lui inspirèrent et lui confortèrent ses craintes $d u$ mal ; car s'il y avait dieu qui était l'immensité infinie du bien, il y avait alors selon eux, un diable à l'inverse dont le mal était sans fin !... Ce dernier raisonnement fit claquer net le retentissement des conclusions des hommes : Il y avait une terrifiante et implacable menace venue d'un monde pervers, dépravé qui était leur ennemie jurée (Gilbert Cauvin, Psychanalyse de la peur)

2013 - Je n'ai pas de père !

La réponse claqua nette et précise.

- Vous voulez dire... articula le clone (Claude Michel, Psy... en liberté)

IV. Se rompre

Intransitif

2007 Les barques sont toujours immobiles, mais déjà, tendant davantage les mailles dont le chanvre depuis longtemps au repos se prête, perdant son eau comme une lessive tordue, déjà les chevaux commencent d'avancer. Les cordages vibrent comme s'ils allaient claquer net, et le convoi s'ébranle, labourant un peu plus profond le corps musculeux du Rhône (René Descombes, Chevaux et gens de l'eau)

\section{CORPUS WEB :}

Puis il déchira la paperasse, vidant son godet d'un trait avant de le claquer net sur le bar puis se dirigea vers la sortie, poussant tous ces biturins sur son passage afin de ressentir l'air extérieur.... [http://www.univers-rr.com/RPartage/ index.php? page $=$ rp\&id=3270\&start=1] (4.6.2014)

Tom ouvrit la porte et la claqua net, en prenant bien soin de fermer à double tour... [http://x-fan-fic-x3.skyrock.com/984223194Chapitre-N-8.html] (4.6.2014)

Puis tu peux laisser ta voiture tourner pour voir si ça recharge ta batterie, mais vu les symptômes la batterie a pu claquer net (oui ça arrive) et elle est bonne à jeter [http://m.jeuxvideo.com/ forums/27-1000019-764373-1-0-764478-0-petitprobleme-clio-1-9d.htm] (4.6.2014)

REMARQUES : Claquer net (I) réfère au bruit sec et éclatant provoqué par le contact d'un objet, par exemple une balle, avec le sol ou avec quelque chose de dur, l'action se produisant soudainement et de manière rapide. Il s'emploie également au sens figuré de 'mourir' (II) et de 'rompre' (IV). Le sens (I) se transpose par métaphore aux paroles et aux pensées (III). Net reste invariable dans la plupart des cas, mais dans les exemples de 1997 et 2013, il s'accorde avec le sujet, tout comme précis, l'autre adjectif-adverbe. Dans cet emploi, les adjectifs-adverbes se rapprochent des prédicats seconds : les ordres sont nets et précis, la réponse est nette et précise. Dans le CW, on retrouve les significations de 'faire un bruit sec' et 'être mort (de la batterie)', y compris dans la collocation usuelle claquer une porte 'fermer brusquement une porte, action qui cause un bruit violent et sec'. Autrement dit, l'emploi de net accompagne la riche polysémie du verbe claquer. Notons l'emploi de labourer profond.

\section{Claquer raide}

Claquer avec force et rapidité

Intransitif

1925 j'ai mon fusil à percussion centrale, et des cartouches à pleine charge dont la poudre blanche claque raide, autrement sec et gai que la poudre noire des anciens et son gros tonnerre enfumé ! Il regardait le cadran du réveil, sur la tablette de la cheminée (Maurice Genevoix, Raboliot)

2011 Il était un peu ivre. Pourtant, elle ne l'avait jamais vu dans cet état, froid et sec. Acide. Ses réponses claquaient, raides comme 
des coups de fouet (Véronique Drouin, $L a$ Chatière)

\section{CORpus WeB :}

j'arrive donc facon urgences dans la salle de bain, ouvre les placards en grand comme si j'etais sur le point de claquer raide, et prends tout ce qui me tombe sous te pouce-la main.... magigi se sentant pousser des ailes d'infirmier (bin oui... il regarde dr house...) attrappe au vol betadine [http://lilicouette.canalblog.com/ archives/2008/03/17/8360631.html] (17.6.2014)

Ben voilà. Ca fait un baille que je me la jouais avec mon paquet de tunes à faire claquer raide un Somalien et mes comptes offshore aux Bahamas [http://www.econsultantpointcom. com/index.php?Humeurs/2006/09] (17.6.2014)

REMARQUES : Claquer raide désigne un bruit sec et brutal. L'exemple de 2011 contient une prédication seconde détaché où raide réfère à l'effet brutal 'de fouet' que causent les réponses. Notons la collocation de raide avec les adjectifs-adverbes sec et gai qui entrent en opposition avec raide.

\section{Claquer sec}

Claquer, péter d'une manière nette, vive, rapide (au propre et au figuré)

Intransitif

1887 Comme elle apportait les haricots, elle faillit casser le plat, en se pâmant. Jésus-Christ, avant de s'asseoir, en lâchait trois, réguliers et claquant sec (Émile Zola, La Terre)

1919 C'est trop tranquille aussi, pas un obus ; on dirait que les boches sont partis. Tac ! Un coup de feu claque sec, venant des lignes boches. Puis un autre, aussitôt... Les hommes qui rêvassaient à leur créneau se sont brusquement redressés (Roland Dorgelès, Les Croix de bois)

1947 Il s'allongea près de moi, sur le bat-flanc. Il picorait sur mon visage mille rapides baisers qui claquaient sec. J'ouvris les yeux (Jean Genet, Miracle de la rose)

1960 Il y eut encore un bruit de crochet remué, la targette qui fermait la porte du plateau grillagé claqua plus sec et ce fut soudain comme un grand réveil de toute cette ombre, de tout ce silence qui pesait sur eux (Bernard Clavel, Malataverne)

1961 Dans la lutte, Judat, qui se roulait comme une chatte, me fit mal. Je lâchai ses poignets, et de toutes mes forces je fauchai l'air du bras droit et du bras gauche. Je rencontrai au bout de mon gauche une petite tête dure. Cela claqua sec. Il me sembla que je venais de chasser une balle d'un coup de raquette (Pierre Mac Orlan, Sous la lumière froide)

1964 Au moment d'écrire, Morand injecte du vifargent dans la syntaxe, les images claquent sec, détonnent sans fumée (Express, 19 mars 1964 / Grundt : 355)

1972 L'orchestre jouait quelque chose de terrible. Pas mauvais du tout les péquenots. Ça claquait sec les guitares électriques. Entre les deux murailles de la sono, y avait pas place pour un murmure, pour un soupir (Bertrand Blier, Les Valseuses)

2008 Ô Dieu, ô Dieu, qu'épuisant et vicié, insipide, stérile, me semble le cours du monde. Chaque adjectif, gorgé de la plus noire mélancolie - excès néanmoins sans boursouflure -, claque sec comme une voilure réduite dans le grand vent, et soumet la nuit à son souffle (Denis Podalydès, Voix off)

Transitif

1953 sans parler des édifices qu'on a vu s'écrouler d'un seul coup pour une seule porte claquée un peu sec (Jacques Perret, Bâtons dans les roues)

\section{CORPus WEB :}

Ouille ouille ouille, ça va claquer sec dans les portefeuilles ce weekend [https://www. facebook.com/permalink.php?id=143498229 076789\&story_fbid=280549732046655] (17.6.2014)

Je n'y croyais plus trop, mais, merci Fauré, il nous claque 1 but super classe..on s'en sort pas trop mal contre les Auvergnats ; va falloir claquer sec les Bretons de Nantes, et les Aubois de TROYES..APRES ? [http://www.reimsvdt.com/ forums/index.php?s=e1f67562308f5fac5b49325f6 fdf8a1e\&act $=$ ST\&f=3\&t=18369\&st=60] (17.6.2014) 
J'entendis une ultime rafale claquer, seche, bruyante, je vis les flammes sortir du canon du fusil d'un des VOPOs, a peu de distance [http:// forum.doctissimo.fr/doctissimo/recits-erotiques/ cousin-cousine-sujet_13034_5.htm] (17.6.014)

REMARQUeS : Claquer sec désigne le plus souvent une chose (une porte, un coup de feu, une targette) qui, par son mouvement rapide et vif, produit un bruit sec et éclatant. Le sujet peut aussi désigner un mouvement entre deux corps, le bruit d'un instrument ou encore une parole, une décision. Notons l'emploi métaphorique dans l'exemple de 1964, où le sujet réfère aux images employées par l'écrivain, soulignant la force ou l'impact des mots (v. aussi l'exemple de 2008). Dans le deuxième exemple du CW, claquer sec prend le sens de 'donner une correction, imposer une défaite cuisante'. Sec reste généralement invariable, mais il s'accorde avec le sujet dans le troisième exemple du CW. Il est modifié par plus, un peu.

\section{Clouer court}

Fixer, immobiliser

Transitif

1578 Mais le point de l'epicycle auquel ceste planette est clouee court en tournoyant sa petite rondeur tousjours cinquante sept minutes, sept secondes et quarãte quatre tierces, achevant le cercle entier en un an treize jours et quelques heures (Guillaume de Saluste Du Bartas, La Sepmaine ou Creation du monde)

REMARQUES : Clouer court désigne le fait d'être fixé serré quelque part. Il n'est plus documenté en français moderne. VoIR AUSSI : couper court

\section{Cogiter serré}

Réfléchir avec précision et rigueur

Intransitif

1964 Alec Guiness pense à haute voix (forcément puisqu'il joue Marc-Aurèle) et James Mason, philosophe grec, prêche et moralise. On cogite serré, on parle de politique, du destin de Rome : une intarissable logorrhée (Express, 7 mai 1964 / Grundt : 300)

\section{CORPus WEB :}

Je pense, et ça me parait légitime, que Mme Gicquel préfère rencontrer les adoptants. Peux-je avoir confirmation ? Parce que ça cogite serré de l'autre côté de la frontière... [http://chiensapaa.activebb.net/t4p15-patch-croise-labradoradopte] (19.6.2014)

REMARQUES : Cogiter serré réfère à une situation ou un contexte propice à la réflexion, qui amène le sujet à penser ou réfléchir de façon laborieuse. Il souligne la rigueur et l'exigence du sujet, bien que pouvant être employé avec ironie, peut-être par le simple effet du registre familier auquel il appartient.

\section{Cogner abominable}

Dégager une très mauvaise odeur

Intransitif

1949 Le margis est revenu vers moi, il m’a reniflé d'encore plus près.

- Mais il pue, cet ours, ma parole !

C'était trouvé, il exultait !

- Mais il cogne abominable

(Louis-Ferdinand Céline, Casse-pipe)

REMARQUES : Abominable est un adjectif-adverbe qualificatif qui, dans cet emploi familier, réfère à l'odeur nauséabonde que dégage une personne.

\section{Cogner dur}

I. Heurter, frapper avec force, violemment Intransitif

1845 Nous autres, nous ne connaissons pas la théorie, nous n'avons que la pratique. Vous êtes plus adroit que moi, probablement ; moi, je cognerai un peu plus dur que vous ; ça égalisera la partie. Allons derrière le vieux rempart si vous voulez, ou bien au café du père Robichon (George Sand, Le Meunier d'Angibault)

1915 - Un vol, fit Gaspard, tiens, ça m’étonne pus que tu soyes gradé. $Y$ a qu'un gradé pour vous servir d'ces boniments à la graisse d'oie!

Et avec sa baïonnette il cognait dur sur le tonneau pour le débonder

(René Benjamin, Gaspard) 
1923 J'ai souvent revu sa tête, à lui ! Sa face blême! Et la balafre, qui devenait de plus en plus foncée ! Ah ! Il aimait cogner, lui aussi : même qu'il cognait dur ! Pourtant, cette fois, ah ! ah ! C'est lui qui l'avait reçu, le coup de cravache (Roger Martin du Gard, Les Thibault. La Belle Saison)

1945 C'était lui qui se battait à la place du Survenant.Ses muscles durcissaient sous l'effort. L'écume à la bouche et la tête au guet, les jambes écartées et les bras en ciseaux, il affrontait l'adversaire. V'lan dans le coffre! Ses poings, deux masses de fer, cognaient dur, fouillaient les flancs de l'autre (Germaine Guèvremont, Le Survenant)

1946 Alors un concert de hurlements s'élevait, et une nuée d'ukrainiens, bâton haut, se précipitait pour rétablir l'ordre. Ils $\mathrm{Co}^{-}$ gnaient dur et longtemps, sans choisir, au hasard du tas (Francis Ambrière, Les Grandes Vacances)

1948 S'accotant au mur d'une maison, Divine lançait des petits coups de pied et tapait dans le vide avec ses poings, de haut en bas. Mimosa la plus forte cognait dur. Divine réussit à se dégager et courir, mais, au moment d'atteindre la porte entre-bâillée d'une maison, déjà Mimosa l'attrapait (Jean Genet, Notre-Dame-des-fleurs)

1953 JEANNE. Ils cognent dur, ils boivent sec, oui, mais pour ce qui est d'entendre des voix (Jean Anouilh, L'Alouette)

1961 AHMED. (se levant d'un bond) La haine des étrangers, elle est là ?

MALIKA. (surprise mais fixant Ahmed) Sous ma ceinture? Le feu qui vous y brûle quand vous entrez, il vient d'elle.

AHMED. Elle est là ?

BRAHIM. (une main sur son cœur, mais sans cesser de fixer Warda) Cent ans après ma mort, elle y sera encore.

AHMED. Elle est là ?

MUSTAPHA. (sans cesser de fixer Warda). Dans mon caleçon ? Elle y cogne plus dur que dans le cœur de Brahim. Elle y brûle plus que sous la ceinture de Malika (Jean Genet, Les Paravents)
1979 Mais la guerre n'est-elle pas justement faite pour que tournent les usines à faire des bombes? Ah, oui, tiens, c'est vrai. Quand t'expliques, tout devient clair. Ça cogne dur. Ouh la la... Terriblement dur. Tiens, la sirène se décide (François Cavanna, Les Russkoffs)

1987 L'Espagnol cogne plus dur, normal, je grandis, je deviens plus coriace et à l'école rue Asseline je cogne aussi, j'attrape les mômes par le col et je demande : «Qu'est-ce que t’as dit, sale con? " (Denis Belloc, Néons)

1992 Ainsi, quelques jours avant le procès, il y a eu une manifestation place de l'Opéra, à l'initiative du M.L.F. et de Choisir. M. Marcellin avait donné des ordres précis : la police a cogné particulièrement dur. Une voiture pie a même tenté de renverser des femmes, qui refusaient de circuler (Gisèle Halimi, La Cause des femmes)

II. Se heurter violemment par maladresse, inadvertance

Transitif

1951 Sa voix traversa ses lèvres en même temps qu'un petit bout de langue :

- Je m’ai cogné dur.

- On dit : je me suis, rectifia Gamichel d'un ton qui redevenait acide.

- Petite affaire ! soupira Torain rassuré, mais curieusement déçu

(Hervé Bazin, Le Bureau des mariages)

III. Avoir des relations sexuelles violentes Intransitif

1987 Toi, mon petit bonhomme, jouer les coquettes à ton âge... N'empêche que les cinquante, il ne les fait pas, sinon les traits ravinés de ces gauchos qui, dos droit comme la conscience de Lincoln, les genoux heurtant les panses des bestiaux, de temps à autre, ostensiblement, présentent à la caméra le paquet de Marlboro. Hâlé profond - pas du bronzage à la lampe, un rien dilué dans le gin, juste ce qu'il faut pour faire ressortir le bleu de l'œil ; pantalon serré, velours beige clair. 
Force et souplesse ! Prudence, Catherine ! doit cogner dur, indistinctement homme... femme (Maurice Rheims, Les Greniers de Sienne)

\section{CORPus WeB :}

Ça va cogner dur samedi dans Soyons sport [http://france3-regions.francetvinfo.fr/pays-dela-loire/2014/05/23/ca-va-cogner-dure-samdidans-soyons-sport-483415.html] (19.6.2014)

« Oui, il y a des fois où j'ai envie de cogner dur» [http://www.arretsurimages.net/emissions/ 2008-08-08/Oui-il-y-a-des-fois-ou-j-ai-envie-decogner-dur-id879] (19.6.2014)

C'est une provocation au Peuple tout entier, tous les dignes fils du Senegal doivent les cogner dur car c'est des malfratset ils savent qu'ils passeront devant la barre tous [http:// www.seneweb.com/news/commentaire/audioen-comite-directeur-les-liberaux-appellenta_n_93380_c_2539104.html] (19.6.2014)

Apres l'extreme gauche a d'autres moyens d'action dehors des elections. et de toute facon avec SArko casera pire.. (les CRS vont cogner durs pendant 5 ans) [https://answers.yahoo.com/ question/index?qid=20070419141131AAFi0cl] (19.6.2014)

REMARQUES : Souvent employé dans le cadre d'une bagarre, d'une altercation entre deux personnes ou d'une manifestation, cogner dur (I) réfère au fait de frapper violemment quelqu'un, de donner des coups à une autre personne. Le sujet désigne le plus souvent un être animé mais peut aussi désigner une chose qui donne ou fait entendre des chocs, des coups répétés et brusques, l'objet battant contre quelque chose. Dans son emploi transitif (II), le sujet désigne une personne qui s'est heurtée violemment contre quelque chose par maladresse ou inadvertance. Cogner dur peut occasionnellement référer à l'acte sexuel (III). Notons la collocation cogner dur et longtemps. Il appartient au langage familier ou vulgaire. Dur reste généralement invariable, mais il s'accorde avec le sujet pluriel dans le dernier exemple du CW, peut-être par hypercorrection. Il est modifié par (un peu) plus, particulièrement. Notons aussi l'emploi de hâlé profond 'très bronzé' et de boire sec.

\section{Cogner fort}

I. Frapper, heurter avec force (au propre)

Pronominal

1813 Nous sortons au plus vite sur le perron, et nous le voyons de loin qui, tenant sa tête à deux mains, commençait à la balancer et à se la cogner fort et ferme contre le siége et les parois de son banc (Armand Marc Jacques Chastenet de Puységur, Appel aux savans observateurs du XIX ${ }^{e}$ siècle)

1981 Quand Macaire décida d'explorer, sinon le fond, du moins quelques mètres dans cette direction-là, il se cogna très fort la tête contre le plafond qui s'abaissait brusquement. Il eut le sentiment que quelqu'un l'avait saisi par la nuque et projeté contre la pierre, et accusa un démon (François Weyergans, Macaire le copte)

1986 Son choix m'écœurait. Abattu par tant de désillusions, je me perdis dans les ruelles obscures de Rome et, presque hagard, je me cognai si fort la tête en heurtant de plein fouet un panneau de sens interdit que j'en tombai à la renverse. Une prostituée qui tapinait dans le coin rit aux éclats

(Alexandre Jardin, Bille en tête)

1993 Ils meurent aussi quand il fait froid, quand il fait chaud, quand ils se cognent un peu fort, quand ils ont faim ou soif, quand quelque chose ne va pas, quand le chagrin les submerge ou quand le moment est venu de l'usure, de la déglingue et de l'avachissement (Jean d'Ormesson, La Douane de mer)

Intransitif

1874 La cuisinière branla terriblement la tête. - Pourquoi n’avez-vous pas ouvert ? demanda-t-elle ; nous avons cogné assez fort. - Je vous assure, ce n'est pas moi, dit-il de nouveau avec plus de douceur encore. Je ne savais pas ce qu'elle avait (Émile Zola, La Conquête de Plassans)

1879 Personne ne répondant à cet appel, l'indiscret frappa deux ou trois légers coups sur les vantaux et, respirant à peine, attendit. On avait marché, lui semblait-il, à l'inté- 
rieur du réduit et l'on y marchait encore. « Hep ! Hep ! » Pas de réplique. Il cogna plus fort, avec ses poings d'abord, avec ses pieds ensuite ; et, comme nul bruit de pas, de voix, ne se produisait, il s'ingéra d'écouter et de regarder par le trou de la serrure (Léon Cladel, Ompdrailles, le Tombeau-des-Lutteurs)

1887 Mais la femme et l'homme ne l'écoutaient pas, la femme s'était ruée, cognait plus fort que l'homme (Émile Zola, La Terre)

1919 Attendre quoi ? Tous assis sur le bord de nos litières, nous regardions la terre, comme un désespéré regarde couler l'eau sombre, avant le saut. Il nous semblait que la pioche cognait plus fort à présent, aussi fort que nos cœurs battants. Malgré soi, on s'étendait pour l'écouter encore (Roland Dorgelès, Les Croix de bois)

1936a Ils s'accoudent à leur vitrine... Maman va dérouiller c'est sûr. De mon côté je préfère personne. Pour les gueulements et la connerie, je les trouve pareils... Elle cogne moins fort, mais plus souvent. Lequel que j'aimerais mieux qu'on tue ? Je crois que c'est encore mon papa (Louis-Ferdinand Céline, Mort à crédit)

1936b Elle renonçait, complètement battue !... Elle se laissait aller au chagrin... Elle sanglotait si violemment contre son buffet, elle cognait si fort de la tête... que la vaisselle se débinait, cascadant par terre... Lui, s'arrêtait pas pour si peu ! (Louis-Ferdinand Céline, Mort à crédit)

1954 Mais qu'est-ce qu'on y gagnera ? Un scandale, des échos dans tous les journaux, un nouvel article, pire que celui-ci...

- Cogne assez fort, et il taira sa gueule, dit Nadine

(Simone de Beauvoir, Les Mandarins)

1972 - Pardon, madame, Mado n'est pas là ?

- Qui Mado ? Ah ! mademoiselle Madeleine. Elle a déménagé. Elle vit à Nice maintenant.

- Excusez-moi.

- Y’a pas de mal.
Il redescendit, cogna plus fort à la porte de ses cousins et la porte du voisin s'ouvrit (Robert Sabatier, Trois Sucettes à la menthe)

1976 Il y avait soixante camions et je ne sais combien de bagnoles à gazogène pleins à ras bord de gars et de matériel. Les camions étaient poussifs, mais les poitrines cognaient si fort et les gorges sous les drapeaux chantaient tellement que les moteurs semblaient marcher à l'enthousiasme (Jacques Lanzmann, Le Têtard)

Transitif

2001 Il a l'air vraiment heureux. Une voiture tout à coup cogne son corps très fort, mais lui, il tient toujours la tête levée vers nous, je vois son corps s'en aller sous la voiture. Pierrot et moi, on se regarde, abasourdis (Colette Fellous, Avenue de France)

II. Frapper, heurter avec force (au figuré)

Intransitif

2006 Beau joueur il faisait référence à des mots que j'utilisais, des phrases qui venaient de lui, et tentait de rétablir sa version une dernière fois. « Tu as bien réglé mon compte. $\mathrm{Tu}$ as raison de t'en prendre aux bourgeois qui sont en effet ridicules depuis Molière, et à moi qui en suis un (bien qu'un bourgeois qui te fait lire Rose poussière n'est pas que cela). Tu aurais pu cogner encore un peu plus fort sur ce thème "

(Christine Angot, Rendez-vous)

CORPUS Web :

L'OM est prêt à cogner fort après la bagarre avec les supporters de l'OL [http://www.foot01. com/equipe/marseille/l-om-est-pret-a-cognerfort-apres-la-bagarre-avec-les-supporters-de1-ol,114273] (19.6.2014)

J'aimerais savoir quelles sont les conséquances si on se cogne très fort la tête [http:// www.tasante.com/forum/posts/66_1436976/Secogner-fort-la-tete.html] (19.6.2014)

REMARQUES : Fort est un adjectif-adverbe de degré. Cogner fort (I) renvoie le plus souvent à une personne qui frappe (sur) quelqu'un ou quelque chose (la porte) avec force, à coups répétés et violents. Par extension, le sujet peut 
désigner une partie du corps comme le cœur qui bat plus fort, cogner fort soulignant l'accélération du rythme cardiaque. Le sujet peut aussi désigner une chose, un objet (pioche) dont le coup est porté avec force. Dans son emploi pronominal, le sujet désigne une personne qui s'est heurtée violemment contre quelque chose par maladresse ou inadvertance. En (II), le groupe peut également référer au figuré à l'écriture ou à l'expression verbale, ou plus exactement à son impact sur le lecteur, le sujet s'exprimant de manière virulente et osée dans le but de provoquer. Fort reste invariable et est modifié par assez, (encore) un peu, moins, si, très, plus. Notons la collocation fort et ferme.

\section{Cogner juste}

Cogner, frapper avec exactitude, précision Intransitif

1887 Il en éprouva une jalousie brusque, il les regarda comme s'il les surprenait ensemble, accouplés dans cette besogne chaude, d'accord pour cogner juste, au bon endroit, tous les deux en sueur, si échauffés, si défaits, qu'on les aurait dits en train plutôt de planter un enfant que de battre du blé (Émile Zola, La Terre)

1984 Le guitariste mettait de la pédale fuzz partout, raclait le riff à toute vitesse, oubliant l'émotion moisie de la chanson. La rythmique par contre cognait juste. Surtout l'énigmatique Rebel derrière la batterie. Malheureusement, le crâne d'œuf ne chantait pas : il beuglait (Michel Embareck, Sur la ligne blanche)

2011 - Ce que je te demande, c'est pas de cogner dur, c'est de cogner juste. Donc regarde-moi, et tu peux compter avec moi si tu veux, si ça t’aide de compter (Ollivier Pourriol, Vertiges du désir)

\section{CORPUS WEB :}

Mais il ne s'agit pas ici de voir un document-vérité, il s'agit bel et bien d'un pamphlet, d'un cinéma engagé qui veut cogner fort, quitte à ne pas toujours cogner juste [http:// unpointcpastout.over-blog.com/2014/02/ critique-cin\%C3\%A9ma-sicko.html] (19.6.2014)
Car de ce premier Raincoats, il n'y a rien à jeter. Disque sœur du Cut des Slits, il n'a en fait que peu de points communs avec celui-ci, étant aussi Do It Yourself que l'album des Slits est calibré pour cogner juste. Du reste, les Raincoats ne cherchent ni à cogner, ni à séduire [http://www.gutsofdarkness.com/god/objet. php?objet=16098] (19.6.2014)

Cherches pas Dirk, c'est des anglais. On peut pas raisoner ces gens. Faut les cogner juste [http://www.pirates-caraibes.com/fr/index. php? u_i_page $=5 \&$ theme $=6 \&$ sujet $=27154 \& u_{-} i_{-}$ page_theme $=2](23.6 .2014)$

Je comprends très bien Dan et ses trolls. Ils cognent justes et sont assez marrant. (sauf quand c'est moi la victime, là ça m'énerve (autodérision=0)) [http://forums.jeuxonline.info/ showthread.php?t=582758\&page=14] (23.6.2014)

Remarques : Cogner juste désigne le fait de frapper sur quelque chose à coups répétés, cogner marquant la force physique nécessaire pour accomplir l'action (1887 : battre le blé) à l'aide d'un instrument dont le sujet doit savoir se servir en visant juste. Dans le domaine musical, il réfère à l'importance de l'élément rythmique qui est rendu avec précision, ce qui souligne une certaine harmonie entre les différents instruments. Juste reste invariable, sauf dans le quatrième exemple du CW, où il s'accorde avec le sujet pluriel du verbe intransitif tout en gardant son interprétation d'adverbe de manière. L'accord de juste est probablement un cas d'hypercorrection. Notons aussi le fait que l'adjectif modifiant le même sujet (marrant) n'est pas accordé. Lavant-dernier exemple du CW pourrait aussi s'entendre comme il faut juste les cogner 'seulement'. Dans le premier exemple du CW et celui de 2011, cogner juste s'oppose à cogner fort ou cogner $d u r$, sans doute parce que le fait de cogner fort ou dur risque d'affecter la précision.

\section{Cogner sec}

I. Frapper d'une manière brutale, sans façon Intransitif

1912 mais peu à peu, la réflexion aidant, il abandonna chacun de ces projets, car il convenait d'agir avec prudence, Lebrac, Camus et les autres n'étant point des gaillards à se laisser faire sans frapper dur et 
cogner sec (Louis Pergaud, La Guerre des boutons)

1950 J'ai tourné à gauche, vers les Trois-Jurés. La Calonne monte vers le ciel pâle entre les taillis clairsemés. Je suis tout seul ; mon gourdin cogne sec contre l'empierrement (Maurice Genevoix, Ceux de 14)

1962 - Tu as encore manqué des occasions, ragea Maurice. Tu vas faire le con jusqu'à ce qu'il te touche. Fais gaffe ; il cogne plus sec que toi (Bernard Clavel, La Maison des autres)

1976 Albert s'en était pris à Marcel et les deux frères s'étaient cassé la figure. Après ça, le Sessel avait dérouillé sa femme une bonne partie de la nuit. Ça cognait sec et moi, de mon étable, j'entendais papa traîner ma mère par les cheveux (Jacques Lanzmann, Le Têtard)

1981 Le souvenir d'Alain cognait sec au carreau de ma mémoire. Qu'est-ce qu'on se dirait ? Alors le pur et dur comment va ta belle âme (Evane Hanska, J'arrête pas de t'aimer)

II. Agresser, attaquer d'une manière virulente (dans un texte, un discours) Intransitif

1977 - J'ai vu votre tribune libre dans la Dépêche de Bléville, dit Aimée.

- J'ai cogné sec, hein ? (Sinistrat bomba le torse.)

- Sinistrat, dit Lindquist, vous êtes un galopin et je tiens à vous dire...

(Jean-Patrick Manchette, Fatale)

\section{CORPUS WEB :}

L'un des jeux les plus jouissifs de l'ère 16 bits (v. le test ici) risque enfin d'avoir une suite digne de ce nom. Les Bitmap Brothers sont de retour et ça va cogner sec [http://gamopat.com/article6782091.html] (23.6.2014)

Mais c'est des psychopathes ici... 'Faut absolument qu'on se barre. En plus, y a cette peste de Nana, je crois que je pourrais pas supporter de rester ici sans la cogner sec [http://ladyoscarandre.forumactif.fr/t1885-amours-malsaines] (23.6.2014)
Car Gelb et Convertino ne lésinent pas, la guitare se fait cheval fou, volontier s'échappant dans des bouillonnements dissonants et abrasifs, alors que la batterie cogne sèche et brutale, tout en tirant à droite à gauche des ruptures de rythmes et des coups de semonces irréguliers mais sans pitié [http://www.gutsofdarkness. com/god/objet.php?objet=15852] (23.6.2014)

REMARQues : Dans un emploi familier (I), cogner sec se dit du fait de se battre, de frapper quelqu'un violemment, avec des coups durs et sourds. Il s'emploie aussi au sens figuré (II) et ce, par rapport au langage. Dans le premier et le troisième exemple du CW, cogner sec réfère à une musique violente, et particulièrement à la percussion. Le second exemple renvoie au fait de frapper la personne. Sec reste généralement invariable, mais il s'accorde avec le sujet dans le troisième exemple du CW, où, coordonné à l'adjectif brutal, il se rapproche des prédicats seconds descriptifs, tout en gardant son interprétation d'adverbe de manière. Sec est modifié par plus. Notons l'emploi du synonyme frapper dur. VoIR AUSSI : frapper dur / ferme / fort / raide / sec

\section{Coiffer chic}

Coiffer élégamment, avec élégance et classe Emploi absolu (et transitif)

+1933 "Monic coiffe chic. » (Nom d'un magasin de modes, Bd. de Clichy)

"Rolls habille chic sur mesures. » (ParisSoir, 25.4.34)

"Chaussez-vous chic, sans vous chausser cher, chez André. " (Nancy-Étudiant, janvier 1934)

« Aux Louves, Arras, habille chic et pas cher. » (Courrier Pas-de-Calais, 8/9.1.33)

(Marcel Galliot, Essai sur la langue de la réclame contemporaine, p. 432)

REMARQUeS : Coiffer chic 'coiffer avec élégance' est cité comme un exemple d'une série plus large de combinaisons dont habiller chic et chausser chic figurent dans la citation. Notons l'emploi de habiller pas cher. 


\section{Coiffer court}

Porter les cheveux courts

Transitif

1908 les cheveux, relevés sur la tête et coiffés courts, sont poudrés (Henri Courteault, Mademoiselle Aissé, le chevalier d'Aydie et leur fille)

1955 Ongles vernis rouge vif, plusieurs en bigoudis ; les jeunes sont coiffées court, à la Jeanne d'Arc (Jean Malaurie, Les Derniers Rois de Thulé)

1992 Charlotte avait une légère malformation de l'oreille gauche : un lobe en forme de chou-fleur. C'était une bizarrerie qui la prédisposait aux cheveux longs. Seulement ma mère, qui a toujours eu l'esprit de contradiction, la coiffait très court. Elle disait que la boule à zéro lui allait bien (Franz-Olivier Giesbert, L’Affreux)

2001 Pardessus ses cheveux blonds coiffés courts, elle avait ajusté une perruque aux longs cheveux bruns (Charles Cieter, La Seconde Enquête)

Pronominal

1961 Mais demander à une femme qui se coiffe court depuis dix ans de se laisser repousser les cheveux : impossible (Express, 14 septembre 1961 / Grundt : 320)

\section{CORPUS Web :}

Bientôt 50 ans : comment me coiffer, court ou long, pour avoir « la tête de mon âge » ? [https:// fr.answers.yahoo.com/question/index?qid=2007 0401060740AAIKISz] (23.6.2014)

ah moi j'adore ça être une fille ! tu fais des frout frout avec tes cheveux, tu peux te les coiffer, court, long, mi long, rasé [http://www.forumalgerie.com/entre-femmes/91061-quest-ce-quivous-plait-dans-le-fait-detre-une-femme-3.html] (23.6.2014)

Coucou, je dois bientot aller couper mes cheveux et je voudrais bien les coiffer courts à la garçonne, je cherche des idées, photos, pour des coiffures meme un peu bizarres !!!! [http:// forum.doctissimo.fr/forme-beaute/Coiffure-etcoloration/cheveux-courts-coupe-sujet_16267_1. htm] (23.6.2014)
REMARQUES : Court réfère à la coupe de cheveux, adoptée ou privilégiée par le sujet, soit une coupe courte. Même si court désigne une propriété des cheveux, donc un objet interne du verbe coiffer, l'interprétation de manière 'façon de coiffer' est également possible (mais non pas le remplacement de court par ${ }^{*}$ courtement). Accord et emploi invarié varient librement. Notons les collocations coiffer long, mi-long, rasé. Court peut être modifié par très.

\section{Coiffer droit}

Couvrir la tête de quelqu'un avec un chapeau bien droit Transitif

1858 La tenue était celle de l'ancien régime : [...] chapeau à trois cornes coiffé droit, cheveux coupés en brosse avec une queue sans poudre (Raymond de Montesquiou, Souvenirs militaires de 1804 à 1814)

Emploi absolu

1956 Ce qui est nouveau [= dans la mode]: Chapeaux coiffant profond et droit (Marie-Claire, mars 1956 / Grundt : 385)

CORPUS WEB :

Car, c'est un fait acquis, aussitôt qu'une livraison de czapskas est faite par un magasin de l'Etat à un régiment, il s'empresse de démonter toutes les visières pour les mettre tellement en contrebas que l'homme ne peut plus se coiffer droit sans être entièrement aveuglé, ce qui fait qu'il cache toujours un œil [http:// www.laguerrede1870enimages.fr/page19.html (24.6.2014)

après on est pas obligé de la coiffer droit sur la tête, c'est l'avantage de cette coupe. on peut les lisser, les attacher en arrière etc.... [http:// www.vivelesrondes.com/FlowriianeShouk mam/82308] (24.6.2014)

Faisant gentiment courir l'ustensile de plastique dans ses cheveux sombres, le vampire sépara et démêla adroitement les mèches, les coiffant droites de sorte qu'elles pendent comme des rideaux autour de son visage en forme de cœur [http://series-passion.superforum.fr/ t304p15-une-crise-de-foi-c-a-b-r] (24.6.2014)

REMARQues : Le sujet de coiffer droit désigne le plus souvent un chapeau (ou la coupe, p. ex. les 
mèches), qui a pour but de couvrir la tête d'une personne et dont la forme ou la position suivent une ligne droite et verticale. Notons l'adjectifadverbe profond dans la collocation profond et droit où profond souligne plus précisément l'aspect du chapeau qui couvre une grande partie de la tête et du front et aussi l'allure qu'il donne au sujet. Droit et profond restent généralement invariables, mais droit s'accorde avec l'objet antéposé au verbe dans le quatrième exemple du $\mathrm{CW}$, ce qui le rapproche des prédicats seconds. Notons l'emploi pronominal du verbe dans le CW.

\section{Coiffer long}

Porter les cheveux longs

$\lambda$ coiffer court

\section{Coiffer mi-long}

Porter les cheveux mi-longs

$\lambda$ coiffer court

\section{Coiffer profond}

Mettre un chapeau qui descend bas

$\lambda$ coiffer droit

\section{Coiffer rasé}

Se raser totalement ou en partie les cheveux $\lambda$ coiffer court

\section{Coller étroit}

S'imposer de manière importune, envahissante, insupportable

Pronominal

1573 PHEDRE. Las ! Nourrice, il est vray : mais je n'y puis que faire.

Je me travaille assez pour me cuider distraire

De ce gluant Amour, mais tousjours l'obstiné

Se colle plus estroit à mon cœur butiné (Robert Garnier, Hippolyte)

\section{Corpus Web :}

Les photos montrent Parc Hyung Shik et Lim Si Wan coller étroit les uns avec les autres, comme s'ils étaient sur le baiser les uns avec les autres [http://fr.hikpop.com/post/read_p.html?p=9427] (24.6.2014)

Vous recoupez les jantes pour les coller étroit ou vous laissez les jantes des $4 \times 2$ comme elles sont d'origine pour les coller ? [http://www. petitrc.com/_forumphp/archive/index.php/t49107.html] (24.6.2014)

REMARques : Étroit est un adjectif-adverbe de manière caractérisant une grande proximité. $\mathrm{Au}$ figuré, il réfère à une personne qui, par amour, cherche à imposer sa présence à l'être aimé, et à se rapprocher de plus en plus de celui-ci, son comportement devenant gênant, voire insupportable pour l'autre. Dans l'emploi plus concret documenté dans le CW, il désigne la proximité physique de personnes ou d'objets. Notons l'emploi absolu dans le premier exemple du CW et l'emploi transitif, dans le second. Étroit reste invariable et est modifié par plus.

\section{Colloquer haut}

I. Placer en hauteur

Transitif

1560 Aux deux costez d'iceliuy Tribunal, estoient colloquées assez hault deux statues (Barthélemy Aneau, Alector ou Le Coq)

1634 Il vous souvient de ce qu'il a dit de la collocation de la jambe, là où il a enseigné que le pied fust colloqué haut, tellement qu'elle ne fust tenue du tout droicte (Guido Guidi, Les Anciens et Renommés Autheurs de la médecine et chirurgie)

II. Porter une estime démesurée

Transitif

1606 Car la Vertu marche devant luy comme un estandart de gloire et d'asseurance : tellement que nature n'a rien colloqué si haut à quoy elle ne puisse parvenir. C'est elle qui fa fait les Princes, qui esleve les hommes aux dignités (R. Bonnefons, Le Cabinet $d u$ vray thresor)

1841 Quand, par exemple, il tombe sur des gens colloqués si haut en leur propre estime, il sait fort bien les comparer au paon qui, quand il fait sa roue pour se voir en levant ses belles plumes, se hérisse tout le reste, et découvre de part et d'autre ce qu'il a de honteux (Onésime Leroy, Corneille et Gerson dans l'Imitation de Jésus-Christ) 
Pronominal

1619 Aucuns jugent temerairement non point par aigreur mais par orgueil, leur estant advis qu'a mesure qu'ilz depriment l'honneur d'autruy, ilz relevent le leur propre : espritz arrogans et presomptueux, qui s'admirent eux mesmes et se colloquent si haut en leur propre estime qu'ilz voyent tout le reste comme chose petite et basse : Je ne suis pas comme le reste des hommes, disoit ce sot Pharisien (Saint François de Sales, Introduction à la vie dévote)

REMARQUES : Haut est un adjectif-adverbe de lieu qui désigne un point élevé. Au sens propre (I), colloquer haut renvoie au fait de placer quelque chose en haut, c'est-à-dire à un endroit situé en hauteur. Au sens figuré (II), il réfère au comportement qu'adopte une personne présomptueuse et arrogante, à l'image qu'elle donne d'ellemême à autrui en se plaçant toujours au-dessus des autres (" en sa propre estime »), en affichant orgueil et mépris vis-à-vis des autres. Haut reste invariable et est modifié par assez, si, fort.

\section{Coloïer bas}

$\lambda$ coloïer haut

\section{Coloïer haut et bas}

coloïer haut et bas : secouer la tête de haut en bas

Intransitif

+1250 Atant s'en entre en un plassie.

Tot belement le col bessie

Vet por savoir et por prover

Se viande porroit trover.

Belement s'en vait et le pas,

Sovent coloie haut et bas

(Le Roman de Renart [ $2^{\mathrm{e}}$ moitié $\left.\mathrm{XIII}{ }^{\mathrm{e}}\right], \mathrm{XI}$, 44)

REMARQUES : Dans l'exemple, haut apparaît en collocation avec l'adjectif-adverbe bas et se dit d'un animal agitant le cou de haut en bas pour trouver ou atteindre quelque chose. Le verbe coloïer/coloyer a disparu du français moderne.

\section{Colorer blond}

Donner une couleur blonde, dorée, jaune

Transitif

1815a Lorsqu'ils sont colorés blonds et refroidis, vous masquez la moitié de la largeur du croissant de blanc d'œuf, ensuite de gros sucre (Marie Antonin Carême, Le Pâtissier royal parisien)

1815b Les abaisses de pâte d'amandes sont colorées blondes au four doux (Marie Antonin Carême, Le Pâtissier royal parisien)

1847 a et ajoutez les perches, les carpes, ainsi qu'une forte assiettee de petits oignons que vous avez colorés blonds dans le beurre (Marie-Antonin Carême, L'Art de la cuisine française au XIX siècle)

1847b Lorsque l'anguille est colorée blond, vous la renversez sur un grand couvercle (Marie-Antonin Carême, L'Art de la cuisine française au XIX siècle)

1952 Servez dès que les croissants sont colorés blond (Modes et travaux, janvier 1952 / Grundt : 253)

\section{CoRpus Web :}

Elle a la cinquantaine, s'habille sportwear, se fait colorer blond vénitien, et parle un français tout mignon en roulant les $\mathrm{R}$ [http://camcamaupay sdurubikcube.blogspot.co.at/2007/08/mercredi22-aout.html] (24.6.2014)

Passer les filets mignons farcis au maroilles dans l'anglaise puis dans la chapelure et mettre à cuire à feu doux dans l'huile d'olive. Les faire colorer blond des deux côtés et laisser cuire au four à $120^{\circ} \mathrm{C}$ pendant 10 à 15 min [http:// www.france3.fr/emissions/midi-en-france/ chroniques/orchies-la-recette-de-mercredi 158430] (24.6.2014)

Ben moi depuis le début de ma grossesse $\mathrm{g}$ arrête de me colorer blonde, maintenant je suis rousse avec coloration sans ammoniaque car suivant la couleur il y a de l'ammoniac, et pareil il faut éviter les vernis à ongles qui pénètrent par les tégument donc plutôt gel ou rien... [http:// www.babycenter.fr/thread/63693/que-pensezvous-des-colorations--cheveux--pendant-lagrossesse--] (24.6.2014) 
REMARQUES : Blond désigne une caractéristique des cheveux qui résulte ici de l'action de les teindre ; il peut s'agir aussi de la couleur dorée d'un gâteau (croissant, filet mignon). Par conséquent, blond peut être entendu comme prédicat second qui entraîne l'accord. Il semble que cette lecture soit plus typique du XIX ${ }^{\mathrm{e}}$ siècle, le français actuel tendant plutôt à l'emploi invarié. Dans le cadre de la dynamique résultative du groupe, les variantes accordées mettent l'accent davantage sur l'état acquis à la fin.

\section{Combattre ferme}

Combattre avec fermeté et assurance Intransitif

1686 Zisca distribua les chevaux à ceux qu'il avoit resolu de monter et leur servit luimême d'Ecuier, il leur montra si parfaitement la maniere d'être bien et de combattre ferme à cheval que de simples païsans qu'ils étoient, ils devinrent sous lui la meilleure et la mieux disciplinée cavalerie de l'Europe (Antoine Varillas, Histoire des révolutions arrivées dans l'Europe en matière de religion)

CORPUS WEB :

Ils n'ont pas atteint leur objectif et devront encore combattre ferme durant les jours qui suivent pour libérer tout le Vexin. Les Allemands restent fortement retranchés autour de Vétheuil [http://www.leparisien.fr/ val-d-oise/les-cinq-jours-les-plus-longs-duvexin-27-08-2004-2005242059.php] (24.6.2014)

Point de contact : qu'est-ce qui me fait du bien, là, maintenant ? Et il me faut parfois combattre ferme avec la raisonnabilité de ce qu'on pense qui est le mieux pour moi [http:// lavienface.wordpress.com/2012/12/02/il-neige] (24.6.2014)

il préconisa que les cadres et les travailleurs se préparent soigneusement sur le plan idéologique, combattent ferme la passivité et le conservatisme, le retard et la stagnation et redoublent particulièrement d'effort [http://www. gamadilavoce.it/marco01.pdf] (24.6.2014)

Les démocrates devront combattre fermes sur le terrain politique afin de répondre à la démagogie pirate des républicains et à celle de leur furie hallucinée Sarah Palin [http:// soulagement11.rssing.com/chan-7426269/all_ p2.html] (24.6.2014)

REMARQUES : Combattre ferme désigne le fait de lutter contre un adversaire, le sujet montrant une certaine assurance dans sa façon de procéder, sûr de ses décisions et mouvements dans l'attaque. Il peut aussi référer au fait de mener un combat personnel ou idéologique, de lutter pour obtenir quelque chose ou s'opposer à quelque chose, le sujet montrant une certaine rigueur dans la manière de penser, de s'exprimer ou d'agir. Même si ferme reste généralement invariable, il s'accorde avec le sujet dans le dernier exemple $\mathrm{du} \mathrm{CW}$, ce qui reflète une interprétation en tant que prédicat second.

\section{Combattre fort}

Lutter avec force et énergie

Pronominal

-1234 Un colp li veit donner de mantenant ;

Meis li paen jette l'escu devant,

Trestut li trenche quanke l'espée enprent, Fort se conbat, mès ne li valt nient :

«Seigneurs [fait-il], ma vie vos demant ; Pernez mei vif, eschec avez fait grant. Quels est li sires ? par m'espée me rent » (Otinel $\left[1^{\mathrm{er}}\right.$ tiers XIII $\left.{ }^{\mathrm{e}}\right], 877$ )

Intransitif

+1366 Princes, tous ceuls qui sont les mieulz parez Quant a l'oneur soient les premiers mis ; Avisez bien que fort vous combatez : Vous n'estes pas sur Grant pont a Paris (Eustache Deschamps, Euvres complètes [3 $3^{\mathrm{e}}$ tiers XIV $]$ )

+1415a Tresfort vous avez combatu,

Et j'ay mon billart bien tenu ;

C'est beau debat que de deux bons :

Bien assailly, bien deffendu

(Charles d’Orléans, Poésies [ 1415-1440], II, Rondel XIV, p. 298)

+1415b Il a convenu fort combatre, Mais, s'il vous plaist, parfait le tien :

Le fer est chault, il le fault batre, Vostre fait que savez va bien (Charles d'Orléans, Poésies [ 1415-1440], II, Rondel CI, p, 348) 
1550 Combien de fois pensons-nous qu'estant assailli d'injures et outrages, il ait combatu fort et ferme pour la justice de Dieu ? (Jean Calvin, Des scandales)

1587 C'est mal mettre l'argent du Roy. Le bonhommeau est demi Roy Des Ligueurs, qui lui font promesse Que, s'il combat fort pour la Messe, Avant que soit un an passé On verra quelque trespassé, Et lui vouent la Saincte Ampoulle (Pierre de L'Estoile, Registre-journal du regne de Henri III)

1615 Le Diable a ses martyrs aussi bien que Dieu, les Philistins combattent aussi fort pour Dagon qu'Israël pour l'Arche (Jean-Pierre Camus, Homélies des États généraux)

1639 CHARIS. Madame, avec sujet tout le monde aprehende

Que dans les mouvemens d'une douleur si grande,

Et qui combat si fort contre vostre raison, Vous tombiez sans secours dans quelque pamoison (Tristan l'Hermite, Panthée)

1713 La duchesse, prévoyant les conséquences d'un tel engagement, combattit fort et ferme contre le penchant qui l'entraînait ; mais mademoiselle Hobart s'étant mise du côté de ce penchant, la combattit ellemême et la vainquit (Antoine Hamilton, Mémoires de la vie du comte de Gramont)

Transitif

1393 « Beaulx seigneurs, quelle noise est ce?» «Par foy, sire, ce dit un chevalier, ce sont gens d'armes qui se sont despourveuement feruz en vostre ost et crient « Lusegnen ! » et vous ont ja fait grant dommage et, se le guet de nuit ne feust, ilz le vous eussent fait greigneur, car ilz leur sont venus au devant et les combatent fort et ferme au dehors des logeiz ou ilz les ont reboutéz par force » (Jean d’Arras, Mélusine, p. 470 [manuscrit Ars])

1829 Une tempête empêcha cette dernière de rallier le pavillon de Tourville, qui luimême retenu par les vents contraires dans la rade de Brest, y reçut ordre de chercher l'armée anglaise, dont on venait d'apprendre la sortie, et de la combattre forte ou faible (Charles-Théodore Beauvais de Préau et Antoine-Alexandre Barbier, Biographie universelle classique)

\section{CORPUS WEB :}

oui, mon fils est autiste, et on a du combattre fort pour qu'il intègre l'école avec ses comportements inapropriés... [https://fr.answers.yahoo. com/question/index?qid=20071019073909AAeN ldw] (25.6.2014)

« Moi je n'ai pas la culture de l'excuse, la délinquance on doit la combattre fort. Mais derrière ça, si on ne traite pas les maux du malaise, on ne s'en sortira pas », s'explique Karim Zéribi [http:// www.rtl.fr/actu/marseille-la-ville-a-besoin-dun-vrai-plan-d-action-estime-un-conseillermunicipal-7764363365] (25.6.2014)

REMARQues : Combattre fort désigne le fait de lutter contre un adversaire et souligne la vigueur de l'effort physique quand le verbe traduit l'action du corps. Il peut aussi référer au fait de mener un combat personnel ou idéologique, de lutter pour obtenir quelque chose ou s'opposer à quelque chose, de façon puissante, énergique et efficace. Notons la collocation fort et ferme, où ferme ajoute à l'idée de vigueur une certaine rigueur dans la manière de penser, de s'exprimer ou d'agir et une certaine assurance dans la façon de procéder, sûr de ses décisions et mouvements dans l'attaque. Fort reste invariable dans la plupart des cas, et est modifié par aussi, si, très. Dans l'exemple de 1829, il s'accorde avec l'objet au féminin antéposé au verbe. Il sort alors de son cadre fonctionnel pour désigner par ellipse l'état de l'armée anglaise : il faut la combattre, qu'elle soit forte ou faible. Notons l'emploi de tenir parfait (ex. de +1415b).

\section{Commencer bas}

Commencer à parler à voix basse

$\lambda$ continuer haut 


\section{Commencer clair}

I. Commencer à dire, à parler clairement, distinctement

Transitif

1209a «Biau filz, mout m’avez conjuree, Ja ceste foiz n'iert parjuree Tant com ge le puisse amender. » Lors conmença seri et cler : Fille et la mere se sieent a l'orfrois, A un fil d'or i font orieuls croiz (Jean Renart, Roman de Guillaume de Dole, 1158)

Intransitif

1209b Ainz que ceste fust bien fenie, Une dame sanz vilonie, Qui ert suer au duc de Maience, Haut et seri et cler commence (Jean Renart, Roman de Guillaume de Dole, 309)

II. Commencer sous un ciel limpide Intransitif

1967 J'avais vraiment peur. Le trajet n'en finissait pas. Nous avions pris l'autobus porte de la Chapelle et nous descendîmes porte de Choisy. La journée commençait claire et pure. Une allégresse communicative fusait de chacun des arbres du boulevard Masséna où les oiseaux se réveillaient (Claire Etcherelli, Élise ou La Vraie Vie)

\section{CORPUS WEB :}

Alors on va commencer clair avec tout ce que j'ai vu comme poste sur cette partie du forum avec les gens cherchant à profiter un max [http:// eu.battle.net/wow/fr/forum/topic/5036304108] (1.7.2014)

La décharge pourrait commencer claire et puis tourner à vert foncé. Vous verrez les chiots commencent à sortir, parfois la tête la première et parfois l'extrémité arrière arrive en premier [http://fr.jsxys.com/dogs/breedingdogs/1007022170.html\#.U7KxyPM_-70] (1.7.2014)

REMARQues : Commencer clair (I) réfère à la prise de parole, le sujet débutant son discours de façon claire et distincte. Notons les collocations avec les adjectifs-adverbes haut et seri ‘serein' qui soulignent et complètent la manière de s'exprimer du sujet. En (II), le sujet désigne un espace de temps (la journée), commencer clair renvoyant aux conditions météorologiques et soulignant un début de journée agréable, beau et ensoleillé. L'adjectif se trouve alors en prédication seconde. Notons la collocation avec l'adjectif pur qui ajoute à l'idée de lumière et de clarté, celle de clarté que rien ne ternit. Clair reste invariable, sauf quand il adopte la fonction de prédicat second (ex. de 1967 et dernier exemple du CW).

\section{Commencer doux}

I. Commencer agréablement, en douceur, doucement

Intransitif

1840 Le 9. La journée a commencé douce et belle, point de pluie ni de vent. Mon oiseau chantait toute la matinée, et moi aussi, car j'étais contente et je pressentais quelque bonheur pour aujourd'hui (Eugénie de Guérin, Journal)

II. Commencer doucement, lentement Intransitif

1984 Parce que les malheureuses portent toutes un badge avec leur matricule inscrit dessus. Elles sont classées par spécialités. Ça commence tout doux, par celles qui exécutent de simples massages (Evane Hanska, Les Amants foudroyés)

CORPUS WEB :

Car elle n'a pas la main très douce encore et avec un mors a levier c'est dur de jauger la longueur de reines idéal quand on commence. Je lui avait pourtant dit que c'était mieux de commencer doux, avec de gros mors, a aiguilles [http:// poneyxpress.com/forum.php?cat $=7 \& d v=36277]$ (1.7.2014)

Seul truc : je ne sais pas par où commencer ! Mieux manger ? Mais quoi et comment ? Faire du sport à bloc ou commencer doux ? [http:// lucilewoodward.com/reprise-en-main-par-oucommencer] (1.7.2014)

Une révolution peut commencer douce et finir violente [http://gabonreview.com/blog/benmoubamba-nouveau-jeune-theologico-politiquepour-la-revolution] (1.7.2014)

REMARques : Le sujet de commencer doux (I) désigne un moment (le jour) ; doux est alors un prédicat second qui réfère aux conditions météorologiques et souligne un début de journée avec un temps tiède, modéré, produisant une 
sensation de bien-être. Notons la collocation avec l'adjectif-adverbe beau qui ajoute à l'idée de bien-être et de calme celle de luminosité, de ciel sans nuages. L'emploi comme prédicat second entraîne l'accord. Dans l'emploi proprement adverbial (II), commencer (tout) doux désigne une action dont le processus débute tout doucement, lentement, sans précipitation. Doux reste alors invariable. Doux est modifié par tout. Dans les deux premiers exemples du CW, doux équivaut à doucement et modifie le verbe, doux restant invariable, tandis que dans le troisième il réfère au sujet au féminin (une révolution), avec lequel il s'accorde en genre, tout comme l'autre adjectif (finir violent : « violente »). En même temps, le registre passe de familier à littéraire.

\section{Commencer faux}

Commencer par un raisonnement incorrect, faux Emploi absolu

1957 Le problème de géométrie était difficile et j'avais commencé faux (Exemple entendu, 4 mai 1957 / Grundt : 377)

2018 Dans nos îles on a ce principe : [...] Ce qui commence faux finit faux

(David Fauqemberg, Bluff)

\section{Corpus Web :}

Il y a une grosse différence entre commencer simple et commencer faux. Je ne vois pas en quoi c'est plus simple de faire un fichier par page plutot qu'un fichier qui appelle les pages en fonction de l'url [http://fr.openclassrooms.com/ forum/sujet/structure-de-mon-projet-de-site] (2.7.2014)

Merci d'avance tous pour vos échanges et expériences. Cela m’aidera surement beaucoup à débuter dans les meilleures conditions et éviter de perdre du temps à commencer faux [http:// www.musculaction.com/forum/comment-biendebuter-correction-programme-t115418.html] (2.7.2014)

Je pense que c'est en attaquant la corde que la 'courbe' de la note commence fausse pour terminer juste [http://www.guitariste.com/forums/ accessoires-et-lutherie,regler-sa-guitare,14290, 150.html] (2.7.2014)

REMARQUES : Commencer faux réfère à une personne qui accomplit la première phase d'un pro- cessus comme par exemple la résolution d'un problème mathématique, en raisonnant de façon inexacte ou illogique. Dans le dernier exemple du CW, faux s'accorde avec le sujet du verbe dans son emploi intransitif. L'accord relève d'une interprétation de prédicat second qui modifie le sujet, la note, et non pas le verbe. Notons le contraste conceptuel avec finir faux, terminer juste ainsi que l'emploi de commencer simple.

\section{Commencer haut}

I. Commencer plus haut, au sens figuré, à un niveau intellectuel, spirituel, social ou artistique élevé

Intransitif

1429 FOY. La declaration entendras par ceste proposition : qui veult discerner les estatz des creatures par le Createur, il commence trop hault (Alain Chartier, Le Livre de l'espérance)

1821 Non-seulement donc les hommes ont commencé par la science, mais par une science différente de la nôtre et supérieure à la nôtre, parce qu'elle commençoit plus haut, ce qui la rendoit même très-dangereuse ; et ceci vous explique pourquoi la science dans son principe fut toujours mystérieuse et renfermée dans dans les temples, où elle s'éteignit enfin, lorsque cette flamme ne pouvoit plus servir qu'à brûler (Joseph de Maistre, Les Soirées de Saint-Pétersbourg)

1862 Quant aux Bacchiochi, c'est une fortune assez difforme qui commence haut et finit bas ; une princesse sous Napoléon Ier, un chambellan sous Napoléon III (Victor Hugo, Choses vues)

II. Commencer à dire, à parler à voix haute, d'une voix forte

Intransitif

1628 Alors ayant commencé tout haut à dire : Celadon, j'ay dit apres elle, Celadon, et ayant adjousté, je vous commande, j'ay dit aussi, je vous commande, de vous presenter à moy, a repris Leonide, et moy j'ay dit, de vous presenter à moy (Balthazar Baro, La Conclusion et dernière partie d'Astrée) 
Transitif

1855 Aussitôt on court fermer au verrou les portes de la classe, et de l'avant-classe ; on se hâte de ranger tout, on repêche les tabourets et les flambeaux, on rajuste et on rallume les chandelles; puis, quand tout est en ordre, tout le monde se met à genoux et on commence tout haut la prière $\mathrm{du}$ soir, tandis qu'une de nous rouvre les portes au moment où la supérieure s'y présente, après quelque hésitation (George Sand, Histoire de ma vie)

III. Commencer plus haut sur une page, plus tard dans un discours; commencer à une position plus haute en général Intransitif

1839 La branche n'était qu'un accident sans conséquence ; une fois coupée, elle ne nuisait plus à l'arbre, et même il serait plus élancé, sa membrure commençant plus haut (Stendhal, La Chartreuse de Parme)

1931 Mais adossée au montant de la petite porte, elle regardait le bois noir qui montait vers Virennes : ces étages et ces étages de sapins, derrière quoi elle savait les creux de mousse ou de plantes pendantes et les retraites bouchées de fougères. Plus haut commençait le pays qu'elle avait devant soi, de la fenêtre de Balance. Et ce pays se confondait ce soir, dans son idée, avec ses années mêmes, avec son histoire à elle

(Henri Pourrat, La Tour du Levant ou Quand Gaspard mit fin à l'histoire)

Transitif

1849 Je prenais quatre feuilles du plus grand et du plus mince papier de Hollande que Julie m'avait envoyé de Paris pour cet usage, et dont chaque page commencée très haut, finissant très bas, écrite sur les marges, surécrite encore en travers des lignes, contenait des milliers de mots

(Alphonse de Lamartine, Raphaël)

1949 Quelques expériences privilégiées conduisent la réflexion au voisinage de ce rapport ; au premier rang se place le sentiment de responsabilité dont nous avons commencé plus haut l'analyse ; en lui se nouent le sentiment de pouvoir et celui de valoir (Paul Ricœur, Philosophie de la volonté)

CORPUS WEB :

Les ouvriers ne sont augmentés que si le patron le veut... un peu réaliste non ? Bon, après on peut dire que le prix devrait commencer haut et descendre... mais là, c'est tout le code qu'il faut réécrire ! [http://www.simuland.net/forum/ viewtopic.php? $\mathrm{p}=4456 \& \mathrm{sid}=9 \mathrm{f} 43 \mathrm{c} 04 \mathrm{dcd} 30 \mathrm{f} 5 \mathrm{~cd} 2$ 47ff4bd64dd7bd3] (7.7.2014)

Oui là aussi faut se méfier ! il est préférable de commencer haut dans le taux de nicotine pour réduire ensuite. Avec les vdlv, c'est toi qui conditionne ce taux [http://www.forum-ecigarette. com/coin-nouveaux-f92/parfois-ca-gratteparfois-ca-gratte-pas-t124703-10.html] (7.7.2014)

Je n'ai pas compris, j'ai une pince banane, mais on la commence haut ? et on t dis qu'on la remonte avec la pince en bas, donc on la descend............ ? La vidéo n'est pas visible, il y a une croix........... Et si on fait un french braid, ça ne marche pas ? [http://milleetunecoiffure. blogspot.co.at/2013/06/chignon-partir-dunedutch-braid-et-dune.html] (7.7.2014)

MINIMUM : $\mathrm{CDR}=20 \mathrm{M}$

Comme c'est un ${ }^{\star} 200$.. on peut commencer haute la barre :D [http://forum.spaccon. net/index.php?page=Thread\&threadID=11646] (7.7.2014)

REMARQUES : Commencer haut peut renvoyer à une position objective (III) ou à un niveau intellectuel supérieur (I). Au sens figuré, il réfère à l'intensité de la voix (II). Haut reste généralement invariable, mais dans le dernier exemple du CW il s'accorde avec l'objet et se prête ainsi à une analyse d'adjectif en fonction de prédicat second. Il est modifié par plus, tout, très, trop. Commencer haut s'oppose à finir bas.

\section{Commencer petit}

I. Former (quelqu'un) dès le jeune âge Transitif

1869 Pour que l'homme hochet réussisse, il faut le prendre de bonne heure. Le nain doit être commencé petit. On jouait de l'enfance. Mais un enfant droit, ce n'est pas bien amusant. Un bossu, c'est plus gai. 
De là un art. Il y avait des éleveurs (Victor Hugo, L'Homme qui rit)

II. Commencer modestement, médiocrement, pauvrement

Intransitif

1953 - Si j'ai rien d'autre... j'essaierai.

- T'en fais pas, tu commenceras petit, on te mettra à l'épreuve

(Albert Paraz, L’Adorable Métisse)

1972 - Nous avons commencé petit...

Elle ajouta avec humour : « Nous sommes des riches nouveaux », et lui narra une ascension qui partait, pour elle, de Saugues, fille d'artisans ruraux éclairés lui ayant permis de solides études, pour l'oncle Henri, de bonne famille mais déclassée, d'obscurs apprentissages à de petits métiers (Robert Sabatier, Trois Sucettes à la menthe)

1996 Poser une question à Loubet, c'était comme un boomerang, ça vous revenait toujours dans la gueule.

- Tu n'avais pas fini sur Fabre.

- Bof... De famille bourgeoise. Il a commencé petit. Il est aujourd'hui un des architectes les plus en vue à Marseille, mais aussi sur toute la Côte. Surtout dans le Var. Un gros cabinet (Jean-Claude Izzo, Chourmo)

\section{CORPus Web :}

Issad Rebrab, voir grand, commencer petit, aller vite retrace l'itinéraire d'un vrai « capitaine d'industrie » [http://www.dziri-dz.com/?p=550] (7.7.2014)

Il peut être décourageant de nous mesurer à celles et ceux qui font office de référence dans notre secteur : un artiste célèbre, un blog à succès ou une entreprise star. Pour autant, nous ne devrions jamais avoir honte de " commencer petit " [http://www.thibaudclement.com/commencerpetit] (7.7.2014)

Fred DeLuca fondateur de Subway ou l'art de commencer petit et finir gros [http://blogs. lentreprise.com/esprits_business/2011/06/17/ fred-deluca-fondateur-de-subway-ou-lart-decommencer-petit-et-finir-gros] (7.7.2014)
17 ans 1metre 7276 kilo j'ai commencer petit la muscu je metait fait une lombalgie sa mavait bloquer la croissance fait gaffe a ton dos [http://www.jeuxvideo.com/forums/1-5040841054-4455-0-1-0-discutons-musculation. $\mathrm{htm}]$ (7.7.2014)

si oui, il faut un maximum de 12 bosses (13, ca porte malheur!) tu les commence petites ( $30 \mathrm{~cm}$ pour la première), hauteur $30 \mathrm{~cm}$, ensuite, tu augmentes à chaque fois la hauteur et la distance suvant la formule suivante : [http://www. mx2k.com/forum-motocross/82541/terrain-desupercross.html] (7.7.2014)

REMARQues : Commencer petit (I) désigne le fait de commencer à former, modeler, exploiter quelque chose ou quelqu'un alors que ceux-ci sont encore petits, jeunes (avant-dernier ex. du CW), en croissance, afin de pouvoir encore les modifier. Commencer petit s'utilise au sens figuré (II) pour décrire l'ascension sociale d'une personne, il désigne le fait de débuter dans la vie professionnelle, le sujet démarrant son projet avec peu de moyens, en partant de rien. Petit réfère aussi à la quantité et peut souligner un degré de difficulté mesurable. Notons les oppositions sémantiques voir grand - commencer petit et commencer petit - finir gros. Dans le dernier exemple du CW il s'accorde avec l'objet antéposé au verbe, ce qui relève d'un emploi en tant que prédicat second orienté vers l'objet direct.

\section{Commencer serein (seri)}

I. Commencer à dire, à parler doucement, sereinement, paisiblement Intransitif

1209 « Biau filz, mout m’avez conjuree, Ja ceste foiz n'iert parjuree Tant com ge le puisse amender. » Lors conmença seri et cler : Fille et la mere se sieent a l'orfrois, A un fil d'or i font orieuls croiz (Jean Renart, Roman de Guillaume de Dole, 1158)

\section{Commencer pur et calme}

Intransitif

1635 c'est le monde, l'un descend et l'autre monte, le bon-heur suit le mal-heur, chaque chose suit son contraire, et cherche son semblable, apres la guerre, 
la paix que nous pouvons avoir sans coup ferir, le jour qui commance beau et serain, nous pronostique qu'apres la pluie vient le beau temps

(Adrien de Montluc, La Comédie de proverbes)

\section{CORPUS WEB :}

planche bien large et stable, parfait pour commencer serein et aussi pour continuer [https://www.standup-guide.fr/test/ari-i-nuiblower-10.6?824] (7.7.2014)

Les modelistes font souvent l'analogie avec la voiture. $\mathrm{Tu}$ apprendrais a conduire sur une F1 ? Une voiture de Rally ? si tu veux commencer serein, tu passes par une citadine [http://www. modelisme.com/forum/1858803-post9.html] (7.7.2014)

3 points à saisir absolument pour commencer serein la série de match difficiles [http://fcbarcelone.com/forum/viewtopic.php?f=28\&t=57 04\&st=0\&sk=t\&sd=a\&start=0] (7.7.2014)

et puis tu sais la fiv c'est pas si terrible que ca. en tt cas il faut la commencer sereine, c'est important pour eviter un petage de cable en cours de route sous la pression [http://www. enceinte.com/forum/sterilite-fiv/fiv-et-tec-on-ycroit-t21763-1850.html] (7.7.2014)

REMARQUES : Commencer seri / serein réfère à l'état d'une personne, d'une journée, etc., calmes et purs au point de justifier l'optimisme. Le verbe favorise l'interprétation comme prédicat second, qui tend cependant vers une lecture comme adverbe de manière dans l'exemple de 1209 ; coordonné avec clair, il souligne une expression claire et distincte. Le CW met en évidence une tendance à l'emploi absolu qui implique l'invariabilité, mais le dernier exemple montre que l'accord est récupérable.

\section{Commencer simple}

Débuter sans prétention, modestement

入 commencer faux

\section{Commenter fort}

Commenter avec insistance, en élevant la voix (haut et fort : publiquement)

入 commenter haut

\section{Commenter haut}

I. Commenter à voix haute Intransitif

1772 Dès la première Scène on commente tout haut, on plaisante indécemment sur ces deux vers, qui expriment très-noblement une idée simple (Mercure de France [éd. de 1780])

2016 Paysans et villageois, venus en foule, ne se privaient pas de commenter haut et fort. Certains le plaignaient déjà, en lui prédisant une courte participation au tournoi (Jean-Luc Bizien, Katana)

Transitif

1805 J'avais derrière moi, à l'orchestre, M. Pétiet et son fils ; à côté, Antonelli le célèbre dans la Révolution, à Arles, je crois, superbe vieillard, âme passionnée, qui commentait tout haut Corneille, et qui vient souvent lier conversation avec lui (Stendhal, Journal)

1896 Francis Poictevin vient me mendier des compliments sur son livre de Tout Bas, dont il m'a envoyé un exemplaire aux épithètes et aux expressions quintessenciées soulignées au crayon bleu par Rodenbach ; et prenant le volume en main, il me le commente tout haut en phrases semblables à celles-ci : « Rodenbach a trouvé ce passage étonnant » (Edmond et Jules de Goncourt, Journal)

2009 Lorsque j'avais publié quelques souvenirs de ma vie dans l'organisation, je m'étais bien gardé de ne citer aucun nom, par respect pour les personnes. Et elles se permettaient de commenter haut et fort des détails sur la vie de mes enfants, avec noms et prénoms à l'appui. Mes enfants mineurs ! (Bruno Devos, La Face cachée de l'Opus Dei)

II. Commenter plus haut dans un texte Transitif

1779 Dans son commentaire IV [...], Galien transcrit un aphorisme [...] et observe qu'il l'a commenté plus haut, où il est rapporté en mêmes termes (Journal de médecine, chirurgie, pharmacie) 
1949 La partie négative de ce programme avait été réalisée par l'élimination des institutions de Vichy que l'on a commentée plus haut à propos du rétablissement de la légalité républicaine (Georges Vedel, Manuel élémentaire de droit constitutionnel)

CORPuS Web :

Depuis un bon bout, plusieurs hommes de hockey que ce soit Groulx, Beausoleil etc sur l'arrivée de Grigorenko ou maintenant des hommes comme Patrick King etc qui commence à commenter haut et fort à quel point els Remparts sont les chou-chou de la ligue et que tout leur es permit à eux, enfin le monde ce réveille [http://blogues.lapresse.ca/plante/2014/02/03/ de-retour] (7.7.2014)

En effet, y avait une bande de ptits cons qui sont venus entre potes pour commenter haut et fort durant tout le long du film, limite en se marrant à chaque scène qui fout la frousse... (:) [http://m.jeuxvideo.com/forums/27-52-147124519-0-1539401-0-0.htm] (7.7.2014)

Sur scène, face à face, ils s'invectivent en breton, déclenchant les rires tonitruants d'un public qui en redemande et n'hésite pas à commenter haut et fort la qualité du spectacle [http:// www.kabyle.com/forum/comme-les-kabylesles-bretons-pavoisent-leur-langue-gagne-enrichesse-1009887] (7.7.2014)

REMARQUES : Commenter haut (I) réfère à l'intensité de la voix. Il désigne le fait d'interpréter, d'expliquer le texte ou l'œuvre d'un auteur, le sujet animé apportant des remarques ou procédant à un jugement critique à voix haute. Notons les collocations tout haut 'ouvertement, publiquement' et haut et fort 'communiquer à haute voix et publiquement une information'. Dans l'acception (II), haut renvoie à un passage précédent d'un texte. Haut reste invariable (ex. de 2009) et est modifié par plus, tout.

\section{Comparer cher}

I. Acheter, payer à un prix élevé ; obtenir au prix de grands sacrifices

Transitif

+1100 A ! Lowis, bon emperere, cum as oi France bien aquitee, e Gorm[un]d l'ad chier cumparee ! (Gormont et Isembart [1 $1^{\text {re }}$ moitié XII $]$, 486)
-1234 Dame, dist il, je irai Dieu vengier, Paiene gient honir et vergondier ; La vostre amor comperront il mult chier, Se Dex me gart sain et sauf et entier. Amis, dist elle, Dex vos gart d'encombrier ! (Otinel [1 ${ }^{\mathrm{er}}$ tiers XIII $\left.{ }^{\mathrm{e}}\right], 1423$ )

+1313 N'est pas a auoir si legiere Qu'elle seroit d'unne bergiere $\mathrm{V}$ d'unne autre femme esgaree, Cier l'estuet iestre comparee (Jean de Condé, Poèmes [1313-1337], 420)

1325 Biaus filz, se tu d'onneur te peres, Tu seras richement parez Mais ains t'iert moult chier comparez Li nons d'onneur que en la terre Viengnes, pour pris et los conquerre, Où Honneurs à ses soudoiers Paie les gracieus loiers (Watriquet de Couvin, Dits, p. 118, 22)

+1400a Car trop amer si empetre ce don Au pouvre amant, qui de son cuer fist don ; Si lui semble que trop perderoit don S'un autre avoit Le bien que si chier comparer se voit (Christine de Pisan, Le Débat de deux amans / Euvres poétiques [début XVe], II, p. 67,601$)$

+1400b Et liement lui dist : « Ma dame chiere, Que j'aim et craing et ay plus que riens chiere,

Dire ne doy qu'aye comparé chiere

Si doulce amour »

(Christine de Pisan, Le Livre des trois jugemens / Euvres poétiques [début Xve], II, p. 116, 155)

+1400c Trés doulz cousin, vous savez, Se souvenance en avez, Comment vous et moy alames Pieça en lieu ou trouvames Assez près de cy venue Tel dame dont la venue Ay depuis chier comparée, Car trés lors fut separée De moy ma trés simple enfance (Christine de Pisan, Le Livre du duc des vrais amans / Euvres poétiques [début $\mathrm{XV}^{\mathrm{e}}$ ], III, p. 112, 1759) 
II. Subir les conséquences fâcheuses d'une action

Transitif

+1150 Se Franceis le me diënt, donc l'otreierai bien.

Se vos m’avez mentit, vos le comparrez chier:

Trencherai vos la teste od m'espee d'acier (Pèlerinage ou Voyage de Charlemagne à Jérusalem et à Constantinople [2 moitié $\mathrm{XII}]$, 24)

1170 Mien esciant tant ne valez Que vers li doiiez aprochier. Vos conparroiz ancui mout chier Vostre folie, par ma teste ! (Chrestien de Troyes, Erec et Enide, 5912)

1175 Ains que li jeus remagne mes, Ert li plus liés tous irascus ; Qu'il s'entrefierent es ecus Et s'entreportent a la terre Tel qui cier conperront la guerre (Gautier d'Arras, Ille et Galeron, 501)

+1200 Si durement plure le enfant, a poi ke il chauncele.

Hai, mere, fet il, mar fustes si bele !

Bien resemblez puteine, ke deit tener bordele ;

mes, par ceoly ke nasquit de la virgine pucele!

si jeo puse taunt vivre ke mounté sci en la sele

e puise porter armes e la targe novele, vus comprez mou cher, dame, ceste novele (Bueve de Hanstone [début XIII'], 219)

REMARQues : Comparer cher 'acheter cher' appartient à l'ancienne langue. En (I), il souligne le coût élevé, matériel ou moral, dans l'acquisition d'un bien obtenu en déployant une certaine énergie. En (II), le sujet désigne une personne qui, en raison d'une action ou parole prononcée et considérée comme contraire au bien ou à la morale, doit payer lourdement pour cette faute. Cher reste invariable et est modifié par moult, si. VOIR AUSSI : coûter bon / cher / gros

\section{Composer léger}

Écrire (ici : jouer) une pièce de musique gaie, allègre, légère

Emploi absolu

2013 Et maintenant, après cette improvisation dans le style sombre et profond de Duruflé, je compose léger, pour détendre vos oreilles (Exemple entendu lors d'un concert d'orgue / Corpus Coiffet 2018: s.v.)

\section{Comprendre faux}

Percevoir contrairement à la réalité

$\lambda$ voir faux

\section{Comprendre juste}

Comprendre à peine

Transitif

1932 L'homme avait l'air soucieux, mais point trop abattu.

- Je vous ai mené ici, hein ? Parce qu'on est tranquille. Ce sont des youpins, ils comprennent tout juste le français. En tout cas, pas de risque, au moins, ici, de rencontrer une mouche... dès l'entrée, on la remarquerait du premier coup d'œil... (Jules Romains, Les Hommes de bonne volonté)

2002 L'oncle pianotait nerveusement des doigts sur le volant de plastique crème. Malraux, le colonel Berger, ça ne te disait rien, tu comprenais juste que c'était un type important, bien que mauvais chasseur de lapins. Trop secoué de tics pour viser juste, selon elle (Olivier Rolin, Tigre en papier)

\section{CORPuS WeB :}

Mais bon honnêtement te prends pas le chou avec ça, dis-toi juste que ça existe, et là ce que tu dois comprendre juste c'est qu'une pression négative sera donc inférieure à une pression positive, et de là il en découle les transferts de liquide, le liquide passera du compartiment avec la plus haute pression vers le compartiment à basse pression [http://www.tutoweb.org/forum/ topic/2165-pression-hydrostatique-interstitielle] (8.7.2014)

Et il faut comprendre juste pour être intelligent. C'est aussi simple que ça [http:// inspirationdesurvie.net/blog/2012/07] (8.7.2014) 
Comme je l'ai dit, j'ai lu tout ce que j'ai trouvé dans ce forum sur ce sujet, et j'ai pu constaté beaucoup d'émotionnel et peu de rationnel... C'est pourquoi je peux comprendre les réactions ci dessus, les comprendre juste [http://www.sshf.com/forums/viewtopic. php?f=99\&t=3237\&p=103740] (8.7.2014)

Simplement car le rendu final n'est pas un cour mais un vrai champ de mine : des trous partout (des oublis qui peuvent être vraiment importants), des pièges (des choses que l'on a copié, que l'on a cru comprendre justes mais qui en réalité sont fausses)... [http://progdupeu. $\mathrm{pl} /$ forums/sujet/342/prendre-des-notes-pourapprendre-a-programmer] (8.7.2014)

Remarques : Comme dans le cas de droit (ex. aller droit au but), juste commence à se séparer $\mathrm{du}$ verbe pour faire partie du complément qu'il envisage comme focalisateur : comprendre tout juste le français 'comprendre à peine / seulement le français', mais la structure reste ambiguë. Ceci est mis en évidence par les trois derniers exemples du CW, où comprendre juste signifie 'comprendre conformément à la réalité, comme il convient, sans erreur'. Juste reste généralement invariable ; il s'accorde cependant avec l'objet pluriel féminin dans le quatrième exemple $d u$ CW. Notons l'emploi absolu du verbe dans le deuxième exemple du CW. Notons aussi l'emploi de viser juste. VoIR AUSSI : voir faux

\section{Compter double}

Compter deux fois autant

Pronominal

1691 Les Travées des Planchers à bois apparent, se comptent doubles, à cause des enfonçures de leurs Entrevoux (Augustin Charles d'Aviler, Architecture de Vignole)

1774 Cette dénomination de foule, pour désigner la hauteur totale d'une Maille, n'est pas universellement adoptée dans les Villes des Manufactures ; il en est où les pouces de foule se comptent doubles (Jean Paulet, L'Art du fabriquant d'étoffes de soie)

Intransitif

1827 THÉODORE. Oui, et malgré tout ça, vos campagnes vous comptent doubles, n'est-ce pas ? (Ferdinand de Villeneuve, $L e$ Hussard de Felsheim)

1840 - Est-ce que vous avez été à Waterloo ? Vous êtes bien jeune.

- Pardon, mon colonel ; c'est ma seule campagne.

- Elle compte double, dit le colonel.

Le jeune corse se mordit les lèvres (Prosper Mérimée, Colomba)

1844 M. de Maufrigneuse avait trente-huit ans quand je l'épousai, mais ces années étaient comme celles des campagnes des militaires, elles devaient compter double. Ah ! il avait bien plus de soixante-seize ans. À quarante ans, ma mère avait encore des prétentions, et je me suis trouvée entre deux jalousies (Honoré de Balzac, Les Secrets de la princesse de Cadignan)

1847 Dans la fortune du vieux garçon moribond, âgé d'ailleurs de cinquante-six années, qui devaient compter doubles à cause de ses campagnes amoureuses, il se trouvait une magnifique maison sise rue Richelieu, valant alors deux cent cinquante mille francs (Honoré de Balzac, Le Cousin Pons)

1890 Et je la sais d'avance, la réponse du légionnaire. Les campagnes de la galanterie comptent double, celles de la passion quadruple. L'homme a trente ans d'âge, mais son cœur, lui, touche à la cinquantaine (Paul Bourget, Physiologie de l'amour moderne)

1907 Je voterai blanc, et, la voix d'Hennique comptant double... Il m'affirme qu'il a eu le cœur déchiré de voter contre moi, mais il est lié à son frère (Jules Renard, Journal)

1949 Quinze jours de perdus. Les minutes comptaient double, triple, elles étaient des ans, il ne fallait pas laisser échapper l'occasion. Elle me prendrait pour un imbécile et ce serait la fin de tout (Léo Malet, Le Soleil n'est pas pour nous)

1963 Cinq piges ça paraît pas lerche en regardant derrière soi, on se demande comment ils ont pu passer si vite... Devant c'est plus 
du même... les années au trou comptent double ou triple (Alphonse Boudard, La Cerise)

1990 Il est vrai encore que je me couche très tard, ou tôt le matin, pour être exact et, comme dirait mon père, "le sommeil avant minuit compte double ». Maux de crâne aussi, mais dus au rhume (Jean-Luc Lagarce, Journal)

2000 j'appris à une heure et quelques secondes, par le brusque démarrage des voitures multicolores des grandes radios stationnées devant chez moi, que le roman baptisé chez Julius n'avait pas obtenu le prix Goncourt. Cinq voix contre cinq, « la voix du président comptant double $» . .$. (François Nourissier, À défaut de génie)

\section{CORPUS WEB :}

Un but de Gignac devrait toujours compter double [https://fr-fr.facebook.com/so.foot/ posts/227234460733358?comment_id=760355\& offset=12\&total_comments=40] (8.7.2014)

Une multitude de listes ont été déposées, l'abstention est le pire ennemi de la démocratie. Chaque voix compte, et va même compter double [http://europe-ecologie.eu/votre-voix-comptedouble-la-procuration] (8.7.2014)

Il faut juste vous organiser entre vous pour éviter d'oublier les messages ou de les compter double (vu que vous êtes beaucoup à avoir accès à cette messagerie, il est fort probable que ça puisse arriver) [http://twinoid.com/tid/forum\#!v iew/66514|thread/18168306] (8.7.2014)

Beuh la bière ça s'compte en cannettes, pas en litres :D:D:D !!! Et au-delà d'un certain nombre j'ai tendance à les compter doubles ! [http:// aquasquale.com/V3/modules/newbb/viewpost. php?start $=72 \&$ forum $=30$ \&viewmode $=$ compact $\&$ type $=\&$ uid $=0$ \&order $=$ DESC\&mode $=0](8.7 .2014)$

REMARQUES : Le sujet de compter double réfère en général au temps ou à un espace de temps (les années, les heures, les minutes) que l'on peut mesurer et qui, en raison de leur contenu, de leur intensité ou de leur poids historique ont une importance double pour le sujet. Le sujet peut aussi renvoyer à un objet mesurable (une quantité) ou non mesurable qui, en raison de son intérêt ou de sa valeur, compte deux fois plus pour le sujet. Notons l'emploi analogue de triple et quadruple. L'accord, assez courant jusqu'au XIX ${ }^{\mathrm{e}}$ siècle, tend à être remplacé par l'emploi invarié dans l'emploi plus récent. Parmi les 26 exemples de Frantext, qui commencent en 1844, un seul est accordé (ex. de 1847). Notons l'emploi de voter blanc.

\section{Compter droit}

à droit compter : pour dire la vérité

Intransitif

1385 L'amour aux peres ne remonte

Des enfans. Avecques moi compte,

Et se tu scés a droit compter,

Clerement te pourray moustrer

Que bonneurez est entre mille

Cilz qui n'a eu ne fil ne fille,

Car Dieux paix et repos li donne (Eustache

Deschamps, Le Miroir de mariage, 2149)

+1415 Je l’ay congneu pieça au cler,

Il ne fault ja que je le nye,

Par quoy dis et puis advouer,

Ce n'est fors que plaisant folie.

A droit compter, sans decevance,

Quant un amant vient demander

Confort de sa dure grevance,

Que vouldroit il faire ou trouver?

(Charles d'Orléans, Poésies [ 1415-1440],

I, Ballade XCII, p. 146)

1426 Pour quoy notez que cest escript

Fut fait en l'an de Jhésu Crist

Mil quatre cens, à droit compter,

Et vignt et cinq, sans plus monter,

Ou quel temps, faulx et douloureux,

Néant plaisant ne amoureux (Olivier de La

Haye, Poëme sur la grande peste de 1348)

\section{Corpus Web :}

Non 10 fans, ouh là là nous n'arrivons plus à compter droit tellement les fans nous rejoignent à vitesse grand V ! [https://m.facebook.com/ story.php?story_fbid=10151103237360927\&id= 342404190926\&_ft_=fbid.10151103237360927] (9.7.2014)

Réjouissez-vous de Saint Joseph, c'est un homme très responsable, il a accompli son devoir, de sorte que vous pouvez compter droit avec lui [http://viens-seigneur-jesus.forumactif. com/t13279-preparez-vous-vos-souffrances-vont- 
commencer-tres-bientot-dieu-met-en-garde-lemonde] (9.7.2014)

REMARQUES : Au sens figuré, la locution à droit compter (conter en français moderne) s'employait jusqu'en moyen français pour affirmer la véracité, l'exactitude d'un récit. Notons que droit est antéposé au verbe. Il reste invariable. Suite à un processus déjà engagé en ancien français, compter 'raconter' est définitivement remplacé par compter 'calculer' à partir du $\mathrm{XV}^{\mathrm{e}}$ siècle. Dans le premier exemple du CW, droit adopte le sens de 'calculer correctement', tandis qu'il se rapproche de 'sûrement' dans le second, ajoutant une connotation de droiture morale, probablement sous l'influence de l'expression pouvoir compter sur quelqu'un 'pouvoir être sûr de l'appui de la personne'. On observe donc un regain de productivité qui va de pair avec la postposition de droit. VoIR AUSSI : les collocations s.v. conter

\section{Compter faux}

Compter en se trompant

入 compter juste

\section{Compter juste}

I. Compter avec justesse, avec exactitude, avec précision

Intransitif

1680 Sa femme n'est point encore accouchée ; ces créatures-là ne comptent point juste. Vous me priez, ma très chère, de vous laisser dans la capucine, pendant que je me promènerai. Je ne le veux point ; je ferais ma promenade trop courte (Mme de Sévigné, Correspondance)

1736a enfin, des chagrins réels prennent la place de vos esperances chimeriques, et vous souffrez d'autant plus vivement, que vous vous êtes plus lourdement trompé dans votre calcul. Vous souffririez moins, si l'on vous avoit accoutumé à compter juste

(Charles-François-Nicolas Le Maître de Claville, Traité du vrai mérite de l'homme)

1868 - Me tromperai-je beaucoup, ajouta Ayrton, en affirmant que le Duncan file aisément ses quinze nœuds à toute vapeur? - Mettez-en dix-sept, répliqua John Mangles, et vous compterez juste.
- Dix-sept ! S'écria le quartier-maître, mais alors pas un navire de guerre, j'entends des meilleurs qui soient, n'est capable de lui donner la chasse?

- Pas un! (Jules Verne, Les Enfants du Capitaine Grant)

1916 Lamuse veut se faire une raison là-dessus, et, plaçant ses deux mains près du lumignon pour compter plus juste, il énumère sur ses gros doigts de brique poussiéreuse : deux poches dans la capote derrière qui pendent, la poche à paquet à pansement qui sert pour le tabac, deux à l'intérieur de la capote, devant (Henri Barbusse, Le Feu)

1989 l'insistance du brigadier aux prises non seulement avec son laborieux travail de couture mais encore avec la conscience du vide de non pas à vrai dire ses vingtsix années, puisqu'il fallait en soustraire celles de sa petite enfance et celles qu'il avait passées dans l'institution religieuse au sévère uniforme déjà militaire mais, en comptant juste, dix bonnes années, ou, autrement comptabilisé, cent vingt mois d'oisiveté (Claude Simon, L'Acacia)

1995 On avait vite compris à Malval, Fresselines, et Chéniers, qu'on devrait compter avec elle, et compter juste... Les paysans de la région avaient " la charrue longue » - quelque chose qui les empêchait de tourner exactement au bout de leur champ, qui les forçait à empiéter un peu sur celui du voisin (Françoise Chandernagor, L'Enfant des Lumières)

Transitif

1736b Si l'on compte bien juste les peines et les plaisirs que produit l'amour même le plus délicat, c'est ensemble sagesse et volupté de s'en garantir ; cependant, l'amour trouve des victimes dans tous les âges. Pourquoi cela ? (Charles-François-Nicolas Le Maître de Claville, Traité du vrai mérite de l'homme)

2000 Mes alexandrins sont tordus de toutes les manières du côté de la césure.

Là, c'est exprès. 
Il faut souvent se battre pour les compter juste.

Là, c’est exprès (Jacques Roubaud, Poésie)

II. Au figuré : compter trop exactement (sur

quelqu'un)

Intransitif

1696a Adieu, mon très cher. Je vous embrasse. Aimez-moi toujours, je le veux, c'est ma folie, et de vous aimer plus que vous ne m'aimez, mais vous êtes trop aimable ; il ne faut pas compter juste avec vous (Mme de Sévigné, Correspondance)

1696b Il y a des gens qu'il faut aimer à leur mode, et superficiellement ; quand on veut compter plus juste avec eux, on tombe dans l'aversion, dans l'embarras, et enfin dans la disgrâce (Mme de Sévigné, Correspondance)

III. Compter en quantité juste suffisante Intransitif

1956 Si la Société a compté trop juste, elle devra, pour combler le déficit, amputer son capital au détriment des actionnaires. Si au contraire, elle a compté trop large, rien ne s'oppose à ce que le surplus vienne augmenter le capital au profit des actionnaires (Le Figaro économique et financier, 5-6 mai 1956 / Grundt : 308)

\section{CORPuS WEB :}

Normes comptables internationales : pour « compter juste ", nous devons retrouver l'horizon delong terme [http://www.lemonde.fr/economie/ article/2013/04/22/normes-comptablesinternationales - pour-compter-justenous-devons-retrouver-1-horizon-de-longterme_3163967_3234.html] (9.7.2014)

Dans ce cas là, Gilson ne fera jamais l'item « Les résultats de cette expérience suggèrent que blablabla... » en le comptant faux. Premièrement, il évitera de faire un item comme ça parce que c'est ambigu et pas dans ses habitudes. Deuxièmement, il me semble que ça lui est quand même déjà arrivé de formuler ce genre d'items et de les compter justes. Dans tous les cas, si ça arrive au concours, ce n'est pas un piège et c'est à compter juste [http://www.carabinsnicois.fr/phpbb/ viewtopic.php?f=335\&t=27029] (9.7.2014)
Il y a ceux qui disent « Je compte sur vous ». David Lisnard, lui, veut compter pour les Cannois. Et compter juste [http://www.lisnard2014.fr/ david-lisnard-veut-compter-les-cannois] (9.7.2014)

REMARQUES : Compter juste réfère à un calcul mathématique juste (I), voire trop juste (III), ou, au figuré, sur le fait de se confier à quelqu'un (II). En (I), il s'oppose à compter faux (CW), en (III), à compter large. Juste reste invariable, mais le second exemple du CW est fléchi. Le dernier exemple du CW joue avec les acceptions (I) et (II) de compter juste. Juste est modifié par bien, plus, trop. VoIR AUSSI : calculer juste

\section{Compter large}

Compter d'une manière peu rigoureuse, avec une marge confortable

Intransitif

1888 Les dépenses d'exploitation, pour l'exercice 1887 , se décomposent comme suit : [...] ; sur cette quantité il faut compter large. Ces dépenses seront moindres à l'avenir (Revue générale des chemins de fer)

1934 - Il est parti quand?

- À la lune de juillet.

- Il en avait pour combien?

- Deux mois en comptant large

(Jean Giono, Le Chant du monde)

1985 Mario est venu voir ce qui se passait mais il était trop crevé pour rester, il a simplement embrassé les deux filles et il s'est tiré. J'avais compté large pour cinq, ce qui fait qu'on s'est retrouvés avec quatre verres bien remplis, un truc que je venais d'inventer dans la seconde écoulée, un truc un peu raide (Philippe Djian, $37^{\circ} 2$ le matin)

1986 Une vingtaine, disons, comptons large. Du solide. Pas trop lourd, pas trop compliqué (Jean Echenoz, L'Équipée malaise)

1993 Le calcul est simple, pourtant, irréfutable. Une moyenne de vingt pages chaque jour ; vingt lignes par page ; dix-sept centimètres par ligne (je compte large pour les marges). Six jours sur sept (Éric Orsenna, Grand Amour) 
2000 Devant de tels prodiges, je me sens tout petit. En comptant large, je ne peux pas me considérer responsable de beaucoup plus de quatre cents exemples de la forme (Jacques Roubaud, Poésie)

2008 Entre Vaux, Fougilet et Les Chaumots, j'avais eu en comptant large quatre ou cinq copines ou copains et, chaque fois, de façon provisoire. Depuis mon adoption, rien (Yvette Szczupak-Thomas, Un diamant brut)

\section{CORPuS WeB :}

J'en ai pris douze metres. Trois pour chacun. Il vaut mieux compter large que de se retrouver bien embeté parce que c'est trop court [http:// forum.wordreference.com/showthread.php?t= 2539690\&langid=6] (9.7.2014)

Oui enfin normalement c'est de $7 \mathrm{~h}$ à $9 \mathrm{~h}$ mais bon. On va dire 10h pour compter large, comme d'hab' quoi :p' [http://forum.dofus.com/ $\mathrm{fr} /$ dccbe1223f30-utilisateur-metttalhardcore?sct= posts\&id=43378254] (9.7.2014)

Ravie d'apprendre que je vais encore patienter une bonne semaine, vu qu'avec les jours fériés les 10 jours je peux les compter large... [http:// www.materielceleste.com/t41560p60-le-murdes-lamentations-3] (9.7.2014)

Je n’ai ressenti aucune douleur prémenstruelle et mes reds sont venues avec 2 jours de retard! Logiquement elles ne durent que 4 jours en comptant larges mais cette fois ca fait déjà 6 jours et ce sont les chutes du niagara! [http://forum.aufeminin.com/forum/matern1/ f54989_matern1-mais-keski-m-arrive.html] (9.7.2014)

REMARQues : Compter (trop) large s'oppose à compter (trop) juste, le dernier évitant les marges de précision qui caractérisent le premier. Large tend à l'invariabilité et est modifié par trop. Dans le troisième exemple du CW, large reste invariable malgré l'objet pluriel antéposé au verbe, tandis que dans le quatrième, il s'accorde avec le sujet pluriel féminin de la phrase (qui est également l'objet sous-entendu du verbe), tout en gardant son interprétation d'adverbe de manière. VoIR AUSSI : juger / voir large

\section{Compter lourd}

Avoir une grande importance

Intransitif

1887 Dire que la famille l'habitait depuis trois cents ans, qu'on avait fini par l'aimer et par l'honorer comme une vraie relique, si bien qu'elle comptait lourd dans les héritages ! (Émile Zola, La Terre)

1973 S'il y attentait, son prestige militaire tout neuf ne pouvait pas compter lourd, d'autant que ses victoires avaient masqué plus qu'effacé les haines que sa traîtrise avait fait naître à Babylone (Pierre Briant, Antigone le Borgne)

2006 Il [= Henri Stuart, cardinal-duc d'York] est influent au sein de la curie pontificale, dont il deviendra, en 1801, le doyen. Sa voix compte lourd dans les conclaves (Michel Duchein, Les Derniers Stuarts)

2012 Ce fut une raison importante qui compta lourd dans sa décision, mais ce ne fut pas la seule (Claude Devallan, Le Défi d'un Breton)

\section{CORPUS WEB :}

Comme si cela allait compter lourd dans la quantité de pilotes français volant en Gelbique !!! [http://www.parapentebelge.be/parapentebelge/ forum/list.php?id=affili\%E9s $\% 20$ FFVL $\% 20$ en\%20belgique\&nx_first=24] (9.7.2014)

Promesse tenue donc à l'égard de la gent féminine. Un élément qui peut compter lourd dans la suite des débats, en cas de volonté de Boni Yayi d'aller au-delà de 2016 [http://www. lanouvelletribune.info/index.php?option=com content\&view=article\&id=8176:nou] (9.7.2014)

« Organisons-nous pour compter lourd dans la société civile dont nous sommes, avec les salariés, la force montante ", a lancé le baron Seillière [http://www.humanite.fr/node/214990] (9.7.2014)

REMARQUES : Dans l'échelle des valeurs, compter lourd réfère à l'impact d'une action sur quelqu'un ou quelque chose, à quelque chose qui a une grande importance. Lourd reste invariable.

\section{Compter quadruple}

Compter quatre fois autant

入 compter double 


\section{Compter triple}

Compter trois fois autant

त compter double

\section{Conclure juste}

Tirer les bonnes conclusions

Intransitif

1751 Il n'est cependant pas aussi dur à lui-même qu'on le suppose ; il calcule très-finement, conclut assez juste d'après un faux principe, et trouve bien des jouissances dans ses privations (Charles Duclos, Considérations sur les mœurs de ce siècle)

1872 Mais, à la différence du public, l'artiste a le sentiment qui le guide et qui l'éclaire ; ses prémisses peuvent être fausses, mais peu importe, puisque d'intuition, il conclut juste (Rodolphe Toepffer, Réflexions et menus propos d'un peintre genevois)

1957 - L'Ecclésiaste est un grand bonhomme !... Il voit juste, il conclut juste ... Donc j'ai lu, relu, réfléchi, jusqu'au jour où je me suis dit : « Tant que tu ne seras pas baptisé, tu restes loin du Grand Patron » (Benjamin Vallotton, Jardiniers du paradis)

REMARQUES : Notons l'emploi de voir juste.

\section{Condamner tout bas}

condamner tout bas : condamner

intérieurement, en secret, à part soi

Transitif

1668 PYRRHUS. Vous ne m'attendiez pas, Madame ; et je vois bien

Que mon abord ici trouble votre entretien.

Je ne viens point armé d'un indigne artifice

D'un voile d'équité couvrir mon injustice :

Il suffit que mon cœur me condamne tout bas ;

Et je soutiendrois mal ce que je ne crois pas.

J'épouse une Troyenne. Oui, Madame, et j'avoue

Que je vous ai promis la foy que je lui voue (Jean Racine, Andromaque)

1725 L'on voit assez de ces devots commodes qui [...] retenus par un vil interêt ou par une lâche timidité, étouffent leurs soûpirs, dissimulent leurs murmures, applaudissent peut-être tout haut à ce qu'ils condamnent tout bas, et partagez entre leur fortune et leur conscience, bornent leur vertu à leur salut particulier (Jean-Baptiste-Louis de La Roche, Sermons pour le carême)

1752 Enfin pour tout dire en un mot, bien différent de ces maris qui, jouant le bonheur, approuvent hautement ce qu'ils condamnent tout bas (Mercure de France)

1776 Je ne pus lui montrer ces égards politiques, au milieu desquels le protégé, par complaisance, fait semblant d'approuver le protecteur, en le condamnant tout bas (Louis-Sébastien Mercier, Jezennemours)

1853 Nous avons beau corrompre notre conscience, elle nous absout tout haut et nous condamne tout bas (Adolphe d'Houdetot, Dix Épines pour une fleur)

REMARQUES : Au sens figuré, condamner tout bas désigne le fait de critiquer quelqu'un, de désapprouver un comportement sans l'exprimer à voix haute, intérieurement ; le sujet est une personne ou un inanimé abstrait ou concret (le cœur) qui fait apparaître le tort de quelqu'un, l'accable. Bas apparaît toujours dans la collocation tout bas. Dans les exemples, condamner tout haut s'oppose à absoudre haut, applaudir haut et à la variante emphatique approuver hautement.

\section{Conduire brutal}

Conduire avec brutalité

$\pi$ conduire dur

\section{Conduire droit}

I. Conduire directement

Transitif

+1150 Apres uous iurerai desor ma loiaute, Que se uous droit en Franche conduire me poes,

Ie uos donrai tresor tout a uo uolente (Aiol et Mirabel [2 $2^{\mathrm{e}}$ moitié XII ${ }^{\mathrm{e}}$, 9760)

1275 Car ainçois qu'il repairent aront chier achetee

L'amor que Malatrie a a Gerart donnee. 
Les un tertre chevauchent pres d'une grant valee,

Malaquins les conduist, qui bien sot la contree,

Droit vers le tre as dames (Adenet le Roi, Buevon de Conmarchis, 3525)

1325 Cil au lieu droit te conduira

Où Prouesce est, et t'estruira

Comment hons se doit maintenir

Qui la voie aus preus veult tenir

(Watriquet de Couvin, Dits, p. 193, 209)

1450 JUDAS. Sus, sus, seigneurs, plus ne targiez,

Suivez moy tous en ordonnance !

Ne homme si hardy ne s'advance

Fors ainsi que je luy diray ;

Tous droit au lieu vous conduiray

Ou nous chargerons nostre prise,

Mais a le prendre est la maistrise (Arnoul

Gréban, Le Mystère de la Passion, 18588)

1559 Car amour loyalle et ferme,

Qui n'a jamais fin ne terme

Droict au ciel nous conduira (Marguerite d’Angoulême, Heptaméron, p. 183, 223)

1680 Quelle raison vous a-t-il donnée pour ne point faire un voyage si naturel et si bien placé ? Il me semble que l'amitié qui est entre vous les devait conduire tout droit à Époisses. Pour moi, monsieur, je suis dans cette forêt solitaire et triste comme vous savez (Mme de Sévigné, Correspondance)

1696 J'ai voulu tâter des préjugés, que je trouve admirables, et ce qui donne le prix à tout cela, ma très aimable, c'est que toutes ces choses me conduisent droit à vous (Mme de Sévigné, Correspondance)

1731 Vous pourriez, continua-t-il, la venir prendre la nuit dans votre carosse, et la conduire droit à Rouen (abbé Prévost, Le Philosophe anglois)

1840 « Ainsi, continuai-je, en abordant à terre, Tina, je vous conduis tout droit chez votre mère,

De là chez le curé. Jeune fille, irons-nous ?» Et Tina répondit : «Je ferai comme vous » (Auguste Brizeux, Marie)
1885 Du coup, toutes deux retombèrent sur la Pierronne. Oh ! ça ne manquait jamais, dès que la compagnie faisait visiter le coron à des gens, on les conduisait droit chez celle-là, parce que c'était propre. Sans doute qu'on ne leur racontait pas les histoires avec le maître-porion (Émile Zola, Germinal)

1887 Je ne la trouve pas. Nous la cherchons partout avec Mariette et Jean, jusqu'à ce que ce dernier a eu l'idée de lâcher le chien, qui nous a conduits droit au bûcher. Nous la voyons là, tombée de son long à terre (Paul Bourget, André Cornélis)

1924 Le régent et Dubois s'abandonnèrent aux Anglais qui les conduisirent droit à la guerre. Et la guerre avec qui ? (Jacques Bainville, Histoire de France)

1927 Donc, plutôt que la mère prenons la sœur pour guide : l'espagnole. Elle nous conduira tout droit par la route royale des équivalences phonétiques et orthographiques (Valéry Larbaud, Jaune bleu blanc)

1955 Les gens n’ont pas tant de mémoire ; il leur fabriquerait des enfances qui les conduiraient tout droit à l'achat d'un chronomètre (Alain Robbe-Grillet, Le Voyeur)

2011 soixante-trois années de rab, miracle, échappé de justesse à la chambre à gaz, au four crématoire, mais il n'y a pas qu'une seule mort dans mon passé, toutes mes maladies mortelles de l'après-guerre, toute la série de bactéries, de bacilles, de virus me conduisaient droit à ma tombe, leur ai aussi échappé, un deuxième miracle (Serge Doubrovsky, Un homme de passage)

Intransitif

1629 Comme nous estions à deux lieuës de cette grande cité de Bisnagar, où nous avions apris que le Roy faisoit son semestre, passans par une forest de Palmiers, au milieu de la route qui conduit droit à la ville, nous vismes un chasseur de fort bonne mine, et fort magnifiquement habillé, qui monté sur un cheval aussi 
viste que la beste qu'il suivoit, avoit laissé bien loing derriere luy la compagnie des veneurs (François de Boisrobert, Histoire indienne d'Alexandre et d'Orazie)

1865 Elles [= les doctrines du socialisme humanitaire] conduisent tout droit aux révolutions, dont à coup sûr je ne m’inquiète pas à un point de vue personnel, moi qui désormais n'ai rien à perdre et qui aurais peut-être tout à gagner dans un milieu agité et dans une éclosion d'aventures politiques (George Sand, Monsieur Sylvestre)

1922 Sans doute il faut alors lutter contre une amitié qui conduira tout droit à la trahison (Marcel Proust, La Fugitive)

1959 Ces mots, anodins en apparence - mais seuls les non-initiés pouvaient s'y tromper - ces mots, comme ceux qui autrefois révélaient l'hérésie et conduisaient droit au bûcher, ont montré que le mal était toujours là, aussi vivace et fort... (Nathalie Sarraute, Le Planétarium)

2004 Car si les enfants raffolent tant de cette histoire, c'est qu'ils en comprennent tous les sens à la fois, et aucun, n’attendant dès son début que sa résolution annoncée, jubilant de sa dynamique à effet retard, qui conduit tout droit, au fond de leur lit, $\grave{a}$ maman se jetant sur eux pour rire en disant les derniers mots : «Et, en disant ces mots, ce méchant loup se jeta sur le Petit Chaperon rouge, et la mangea » (Anne-Marie Garat, Une faim de loup)

II. Bien conduire, bien mener

Transitif

1385 Le temps s'en va sanz revenir, Et vieil te faurra devenir Et espargnier en ta juenesse Pour conduire droit ta vieillesse Jusqu'a la fin de l'eage humain (Eustache Deschamps, Le Miroir de mariage, 96)

\section{CORPus Web :}

Mon avis sur « la bonne » position sur route : Je pense qu'il faut majoritairement essayer de conduire droit. Ca a pour avantage de donner une assez bonne visibilité, et peu de fatigue (ce qui ne veut pas dire qu'il ne faut être vigilent) [http:// moto-securite.fr/position] (17.7.2014)

Etre derrière un jeune couple à moto peut s'avérer dangereux : difficile de se parler les yeux dans les yeux et de conduire droit en même temps.... [http://annemad.over-blog.com/article13189305.html] (17.7.2014)

Armée de son nouvel album « Droit dans la gueule du Loup », la délicieuse meliSsmelL arpente un territoire mélancolique et sombre, couronnée d'une poésie délicate qui devraient la conduire droit dans nos cœurs [http://www. infoconcert.com/artiste/melissmell-41016/news7993.html] (17.7.2014)

Le mansonge á toujours ete leur fer de lance. Enfin l'Amerique devait cette fois savoir sortir grande de cette election et non rester sur ce chemin qui la conduit droite á sa chutte [http:// www.lexpress.fr/actualite/monde/amerique/ obama-et-le-rouge-a-levres-qui-fache_563872. html] (17.7.2014)

REMARQUES : Au sens directionnel (I), conduire droit souligne l'accompagnement d'une personne d'un lieu vers un autre sans détour, directement, s'associant à des prépositions comme à, chez, dans, en, par, vers. Dans son emploi intransitif, le sujet désigne une chose qui mène à un endroit. Lobjet peut aussi référer à une conséquence. $\mathrm{Au}$ sens figuré (II), conduire droit souligne le fait de gérer, maitriser, dominer quelque chose, une action, le sujet ayant la volonté de la mener à bien. Le CW fait apparaître le sens de 'conduire une voiture'. Le premier exemple du CW renvoie à la position du conducteur (prédicat second), le second au fait de conduire en ligne droite avec une moto (fonction adverbiale de manière). Droit reste invariable et est modifié par tout. Dans le dernier exemple du CW, droit s'accorde tout de même avec le complément d'objet, probablement comme simple reflet de la liaison dans droit à. Notons l'emploi de acheter cher. VoIR AUSSI : mener droit

\section{Conduire dur}

Conduire vite et sans égard pour les autres Intransitif

1948 Le chauffeur noir conduit dur. Il écrase, en trois heures, deux cochons et un chevreau qu'un geste lui eût fait éviter (Emmanuel Mounier, L'Éveil de l'Afrique noire) 


\section{CORPUS WEB :}

Niveau ennuis pour moi c'était le vanos qui arretait pas de poser probleme (chronique sur ce modèle) et egalement quelques fuites d'huile. Bilan pas super niveau fiabilité je trouve. Je conduisais dur mais pas brutal comme la Porsche [http://www.forum-auto.com/automobilepratique/discussions-libres/sujet343603.htm] (17.7.2014)

"Conduis dur, conduis mou, mais conduis jusqu'au bout ! » la maxime de base. :D [http:// forum.hardware.fr/hfr/Discussions/Sports/bierbratwurst-hockenheimring-sujet_11172_4507. $\mathrm{htm}]$ (17.7.2014)

REMARQUeS : Conduire dur réfère au comportement brutal et égoïste d'un conducteur d'automobile ; il est le contraire de conduire mou. Le deuxième exemple du CW est un calque de Chier dur, chiez mou, mais chiez dans le trou. Notons l'emploi de conduire brutal qui vient renforcer le concept de conduire dur. VoIR AUSSI : chier dur

\section{Conduire mou}

Conduire mollement, sans mouvement brusque du volant

$\lambda$ conduire dur

\section{Conduire soef}

Conduire délicatement, avec douceur Transitif

+1100 Cument i vinc ? En nef entrai

Tute preste cum la truvai;

Deus me cunduist tost e süef ;

Quant arivai, ralat la nef (Benedeit, Voyage de saint Brendan [ $1^{\mathrm{er}}$ quart XII $]$, 1557)

REMARQUES : En ancien français, conduire soef désigne le fait d'accompagner, de mener quelqu'un vers un lieu avec délicatesse, en douceur. Notons la collocation tost e suef, qui fait apparaître deux adjectifs-adverbes opposés, l'un soulignant la vitesse dans l'action, l'autre la tranquillité, l'absence d'agitation.

\section{Confesser clair}

Confesser sans détour

$\lambda$ confesser haut

\section{Confesser fort}

Dans la collocation haut et fort : à haute voix et en public

$\lambda$ confesser haut

\section{Confesser haut}

Confesser, avouer à voix haute, d'une voix forte ; reconnaître franchement, ouvertement

Transitif

1583 enfin s'il faut toucher ceste chorde que voulez que pincetions, il ne sçait sur quel pied danser et confesse haut et clair qu'il ignore que c'est qu'amour (Bénigne Poissenot, L'Esté)

1596 Je baillonne mes maux, je contrains mon vouloir,

Et tasche à le couvrir d'une façon subtile ; Mais mon vague penser, et mon œil qui distile,

Confessent haut et clair ce qui me fait douloir (Philippe Desportes, Euvres)

1624 mais nous ne sommes pas sur ce poinct, et suffit maintenant que vous apperceviez la meschanceté de vostre poëte, qui vouloit persuader au monde, que nous accusons la bonté divine d'une eternelle malice, ou au contraire nous l'adorons en toute humilité, et confessons haut, et clair que sa bonté ne paroist pas moins en la punition des meschans, qu'en la recompense des bons, mais seulement en diverse maniere, car l'un, et l'autre, comme j'ay desja dit, est un œuvre signalé, et eternel de la justice divine (Marin Mersenne, L'Impiété des déistes, athées et libertins de ce temps)

$1660 \mathrm{Au}$ lieu que les esprits, mesme les plus celebres,

Se sentent convaincus de leurs propres tenebres,

Et confessent tout haut que la terre et les Cieux

Se cachent à l'esprit en se montrant aux yeux,

Que le plus vil insecte, ou le moindre reptile,

Ne rencontrent en nous qu'une raison sterile, 
Lorsqu'elle ose entreprendre avecque ses clartez

D'en définir l'essence ou voir les qualitez (Georges de Brébeuf, Entretiens solitaires)

1835 - Oh ! Pour cela, lui dis-je, c'est une autre question. - Nul plus que moi ne souffre et ne gémit du gémissement universel de la nature, des hommes et des sociétés. - Nul ne confesse plus haut les énormes abus sociaux, politiques et religieux. - Nul ne désire et n'espère davantage un réparateur à ces maux intolérables de l'humanité. - Nul n'est plus convaincu que ce réparateur ne peut être que divin ! (Alphonse de Lamartine, Souvenirs, impressions, pensées et paysages pendant un voyage en Orient)

1933 Autant confesser tout haut les mouvements de son cœur. Il emprunta cependant à l'école pour plus de commodité, la Dogmengeschichte de Harnack (Joseph Malègue, Augustin ou Le Maître est là)

1950 CLÉRAMBARD. Dieu merci, je suis conscient de la noirceur de mon crime. Je n'entends d'ailleurs pas le tenir secret. Dussé-je en crever de honte, je le confesserai bien haut à ma femme, à ma belle-mère et, bien entendu, à mon fils (Marcel Aymé, Clérambard)

1968 Depuis plus de vingt ans la certitude de sa damnation ne l'avait pas quittée ; c'était tout ce qu'elle retenait de cette doctrine qu'elle n'avait pas osé confesser tout haut (Marguerite Yourcenar, L'Euvre au noir)

Intransitif

1848 De sorte que Pascal, abandonnant la tactique de ses dix-septième et dix-huitième provinciales et se rendant compte enfin de la situation, l'envisageant avec toute la lucidité et la franchise de son intelligence, l'exprimant avec toute la concision et la véhémence de sa parole, Pascal n'hésitait pas à confesser bien haut combien la chrétienté catholique, presque tout entière, était engagée par son chef dans des voies selon lui parjures, c'est-à-dire qu'il soutenait contre Arnauld sur ce point et à l'égard de Rome un coin précisément de la même thèse (sauf conclusion) que le calviniste Melchior Leydecker devait soutenir plus tard contre Quesnel (Charles SainteBeuve, Port-Royal)

\section{Pronominal}

1886 Un jour, seul avec Claude, dans une île, étendus côte à côte, les yeux perdus au ciel, il lui conta sa vaste ambition, il se confessa tout haut (Émile Zola, L'Euvre)

CORPuS WeB :

Si tu ne trouves pas de passage allant ce sens, je te propose de le confesser haut et clair et de t'infliger pénitence : lire en entier le fil miroir HFR où tes amis se sont littéralement fait massacrer - parfois au sein même du fil de discussion [http://forum.reopen911.info/t15483attaque-sur-l-afghanistan-le-fond-des-choses. html] (17.7.2014)

Empruntage plein de déférence à Boris Vian et Henri Salvador... Bon , je n'ai rien demandé à la SACEM , je le confesse haut et clair, j'espère qu'on ne m'en voudra pas trop.... [http:// foofind.com/en/download/y9hp6UimwfZ1YnN3/ Chanson\%20surr\%C3\%A9aliste.html] (17.7.2014)

Peut-être pas de la façon qu'elle se déroule actuellement dans l'église catholique, mais au début de l'église il y avait les confessions publiques. Ce que nous faisons dans l'église Orthodoxe. C'est permis de se confesser haut et fort devant l'assemblée [http://eschatologie.free.fr/ forum/mai2006/unite2.htm] (17.7.2014)

L'humain glorifie encore le Seigneur, confessant haut et clair sa dépendance et jouissant de son privilège, en rapportant l'hommage de la terre dans la non-œuvre reconnaissante du culte - le septième jour... [http://www.servir.caef.net/wpcontent/uploads/2008/pdf2008/2008_03_06_ face-au-mandat-de-gestion-de-la-planete.pdf] (17.7.2014)

S'il y a des jours où il faut nous souvenir de notre position de justifiés et confesser haut et fort notre appartenance à la famille de Dieu, il y en a d'autres où nous devons simplement crier [http://www.bible-ouverte.ch/meditations/ le-point-de-vue-biblique/1299-aie-pitie-de-nous. html] (17.7.2014) 
REMARQUES : Au sens figuré, confesser haut désigne le fait de proclamer ou d'avouer publiquement ou à la personne concernée quelque chose (un secret, un péché) jusqu'alors non révélé. Notons qu'il est souvent employé dans la collocation confesser haut et clair - et occasionnellement aussi avec fort -, qui ajoute à l'idée de déclaration rendue publique, officielle, celle de clarté dans le propos. Haut, clair et fort restent invariables et peuvent être modifiés par bien, plus, tout.

\section{Confier bas}

Confier à voix basse, en murmurant Transitif

1840 Nous voici en mesure peut-être de nous bien expliquer, dans leur vraie acception et leur juste portée, ses jugements sur Rome et sur les désordres de l'Église, que nous lui avons entendu confier tout bas à la mère Angélique (Charles Sainte-Beuve, Port-Royal)

1904 « illustres juges, savez-vous pourquoi l'ami coupable est là sur cette sellette ? » chacun des assesseurs doit alors se lever et venir confier tout bas à l'oreille de l'accusateur quel est le reproche qu'il a à faire à l'ami coupable (Henry-René d'Allemagne, Récréations et passe-temps)

1933 Incapable de retenir ses conclusions, il les confia tout bas à son poing arrondi en microphone, à portée de l'oreille d'Augustin. - Doit avoir de la galette, ce type-là. Me demande ce qu'il fout ici (Joseph Malègue, Augustin ou Le Maître est là)

1961 L'eau et les accessoires de l'eau, je vomis dessus. De cette façon, je vomis également sur la poésie et sur la... Il approcha ses lèvres de mon oreille et tout bas me confia le mot de l'énigme : « la peur » (Pierre Mac Orlan, Sous la lumière froide)

2009 Marcel, le p'tit Marcel comme on disait alors, vint me confier bas à l'oreille : t'as vu leurs mains... Des mains de gratte-papier ! (Alain Garot, L'Eau d'épine)

\section{CORPUS WEB :}

eh si ta envie de te confié bas tu peus te confié a moi stuve je serais la meme si je te conné pas [http://www.diariste.fr/journal/28858,d-e-pr-e-s-s-i-o-n-partie-1.html] (17.7.2014)

Puis, fixant ses interlocuteurs, confiant bas cette réflexion, plissant encore ses yeux, il révèle d'une voix lente et méthodique : "Tu sais, cette histoire, elle parle un peu de moi... » [http://eas tenwest.free.fr/?type=articles\&ID=250] (17.7.2014)

REMARQUES : Au sens figuré, confier bas désigne le fait de faire part d'informations confidentielles, de communiquer quelque chose de personnel sous le sceau du secret, en le murmurant à l'oreille, de façon très discrète. Bas est invariable et est modifié par tout.

\section{Confondre facile}

I. Rendre confus

Emploi absolu

1828 Un triste événement semble accuser ma foi,

En un mot tout ici dépose contre moi.

L'apparence est toujours à confondre facile. $\mathrm{Si}$, pour me disculper, tout devient inutile, $\mathrm{Si}$ je ne puis combattre un injuste courroux, Que pourrai-je répondre à mon cruel époux?

(Darrodes de Lillebonne, La Clovisiade)

II. Se tromper, prendre (une personne) pour quelqu'un/quelque chose d'autre Transitif

1977 Seulement les péripatéticiennes de la place ... rue Geoffroy, on les confond facile avec les concierges sur le pas de leur porte (Alphonse Boudard, Les Combattants du petit bonheur)

\section{Corpus Web :}

Après y'a le cuistot qui demande si c'est de la pomme qu'y boit, mais en fait c'est de la chartreuse. C'est vrai que c'est proche, on peut confondre facile [http://www.tripadvisor.fr/Show UserReviews-g187265-d1323094-r136748477-La Luna-Lyon_Rhone_Rhone_Alpes.html] (17.7.2014) prenez ézoprémazole 40 et amlodipine 10 : deux gélules quasi identiques ; avec la vue basse ou mal réveillé on peut confondre facile : j'en suis 
sûr, c'est mon traitement et j'ai failli prendre 2 amlor 10....... [http://www.pratistv.com/modules/ services/bilan.php?comment $=1076 \&$ add ] (17.7.2014)

C'était l'époque ou je commençais a muer et ou ma voix se confondait facile a celle d'une fille (heureusement ça a pas duré longtemps :o) [http://forum.hardware.fr/hfr/Discussions/ Viepratique/topic-sales-coups-sujet_90962_177. htm] (17.7.2014)

mais en belgique si tu veux vendre des oiseaux à un prix correct (20-25€ pièce) alors que ton voisin les vend à $15 €$ il faut que la taille soit bonne.... « forse vogels » comme diraient les neerlandophones car j'ai dejà vu des cath crème ino que tu confondais facile avec un gros touis céleste hein..... et ça c'est dommage.... [http:// perruche.catherine.free.fr/forum/viewtopic.ph $\mathrm{p} ? \mathrm{p}=11512 \&$ sid $=\mathrm{a} 0391 \mathrm{c}$ - ba2c14fa0332f9dd92716 69e4] (17.7.2014)

Remarques : Confondre facile réfère au fait de se tromper facilement en mélangeant les choses. Il est employé en tant qu'adverbe de phrase au même titre que il est facile de confondre, il arrive facilement de confondre. Facile reste invariable.

\section{Conforter beau}

Se consoler de manière satisfaisante, bien Pronominal

1250 Graer covint le mariage

A l'ancien, voisist ou non,

Et li veix au fronci grenon

S'en conforta plus biau qu'il pot

(Huon le Roi, Du Vair Palefroi)

REMARQUES : En rapport avec une situation désagréable ou peu plaisante, conforter beau souligne en ancien français un comportement à travers lequel le sujet cherche à se consoler, se rassurer du mieux qu'il le peut. L'adjectif-adverbe est modifié par plus.

\section{Conjecturer juste}

Conjecturer, supposer comme il convient, sans erreur

Intransitif

1775 Il semble que le Maréchal de Catinat ait montré pendant cette guerre la véritable science du Général ; celle de conjecturer juste sur des apparences données ; de prendre promptement une résolution qui puisse parer aux évènemens, ou les prévenir (Charles-Marie de Créquy, Mémoires pour servir à la vie de Nicolas de Catinat)

1866 Ce trapèze était creusé au centre comme une cuvette. Travail des pluies. Gilliatt, du reste, avait conjecturé juste. On voyait à l'angle méridional du trapèze une superposition de rochers, décombres probables de l'écroulement du sommet (Victor Hugo, Les Travailleurs de la mer)

1927 Après une hésitation de quelques secondes, M. Laporte reprit, pesant ses mots : - Vous aviez conjecturé juste : les pièces d'or volées ont trahi l'assassin (Maxime Audouin, Sous le couperet)

CORPUS Web :

En étudiant ces manuscrits, le savant liturgiste se convainquit qu'il avait conjecturé juste en disant que Benoît XIV avait peut-être renoncé à son projet de réforme du bréviaire, parce que les principes qui avaient présidé à ce travail n'étaient pas de nature à l'amener à une fin heureuse et convenable [http://assum.over-blog.org/articleinstitutions-liturgiques-xxii-1-103663972.html] (18.7.2014)

donc tu conjecturais juste. mais je me demande quand même comment t'as pu conclure ça à partir de ça [http://www.bladi.net/forum/ threads/amoureuse-meilleur-ami.305391/page-9] (18.7.2014)

REMARQUeS : Conjecturer juste réfère au fait de formuler des hypothèses plutôt vagues, de faire des prévisions ou des pronostics, qui finalement s'avèrent exactes.

\section{Conjouir petit}

Se réjouir peu, un peu

Pronominal

1250 Mès de ce ont trop grant souffrète

Qu'il ne se pueent solacier,

Ne li uns vers l'autre touchier.

Petit se pueent conjoïr

Fors que de parler et d'oïr

(Huon le Roi, Du Vair Palefroi) 
REMARques : En ancien français, l'adjectifadverbe petit est encore employé au sens de 'peu', disparu en français moderne (standard). En collocation avec conjouir, il se rapporte à une situation dans laquelle le sujet éprouve peu de joie, de plaisir et qui lui procure peu de satisfaction.

\section{Connaître clair}

Reconnaître clairement, distinctement, de manière certaine

Transitif

+1415 Vous taschez a croistre mon dueil Et gens engigner par vostre art ; A ! a ! maistre sebelin regnart, On vous congnoist tout cler a l'ueil : Passez oultre, Decevant Vueil! (Charles d’Orléans, Poésies [ 1415-1440], II, Rondel CCCXXIII, p. 477)

1841 La guerre des Albigeois, par exemple, demande encore de nombreuses investigations avant que nous puissions espérer de la connaître claire et vraie dans tous ses détails (Claude-Charles Pierquin, Histoire littéraire, philologique et bibliographique des patois)

1970 La réponse que j’aimerais avoir en ce domaine conditionne la santé du marché viticole français. Nous attacherons donc le plus grand prix à la connaître, claire et nette, comme il se doit en ces heures cruciales (Journal officiel de la République française, 17 octobre 1970)

2013 Plus spécifiquement, on reprochait au SAPSCQ son attitude à la négociation alors qu'un certain nombre de membres avait fait irruption lors des discussions pour faire connaître, clair et net, leur mécontentement face à l'attitude du Gouvernement (L’Horizon)

REMARQUES : En ancien français, connaître clair désigne le fait de distinguer ou reconnaître une personne de manière claire, sans difficultés. En français moderne, la collocation clair et net est devenue usuelle ; elle peut tendre à l'emploi comme prédicat second accordé (ex. de 1841, 1970), mais l'emploi de manière prédomine sans doute dans l'usage récent (ex. de 2013), surtout dans le registre familier.

\section{Connaître droit}

Connaître bien

Transitif

1160 Bien l'en conois droit a m'amie Que el s'an soit un po marrie, Car grant desmesurance fis Que demenois ne la requis, Quant la bataille fu finee ; Male amistié li ai mostree, Bien lo conois que tort an oi (Eneas, 9999)

1950 Mille détails, que vous ne perceviez plus pour vous être habitués à eux, me donnaient, à moi, un choc au cœur : le dos voûté d'un homme que j'avais connu droit et fort ; le regard que je surprenais, vers mes vêtements neufs, d'un pauvre diable qui grelottait dans sa capote élimée par l'usure... (Maurice Genevoix, Ceux de 14)

REMARQUES : En ancien français, connaître droit se disait du fait d'avoir des connaissances fiables et véritables sur quelque chose ou quelqu'un. En français moderne (ex. de 1950), droit perd ce sens et prend celui de 'intègre'. Il s'emploie alors comme prédicat second orienté vers le complément d'objet du verbe : je l'ai connu en homme droit et fort.

\section{Connaître fort}

I. Connaître à fond

Transitif

+1400 Dont regreter en plourant maintes fois Me fault cellui, dont je n'ay nul secours ; Et les griefs maulx d'amours plus fort cognois,

Les pointures, les assaulx et les tours (Christine de Pisan, Cent balades / Euvres poétiques [début XVe], I, p. 35, 19)

$1648 \mathrm{Au}$ reste, vous parlez des vents comme feroit Christofle Colomb ; vous avez bien la mine d'avoir pris tout cela mot à mot dans un livre ; car je jurerois que vous n'avez jamais sceu qu'à cette heure ce que c'est qu'un rhomb de vent, et pour ce qui est du destroit de Vegas, je ne voudrois pas as- 
seurer que vous le connussiez fort (Vincent Voiture, Lettres)

1722 une coquetterie si folâtre, si bruyante, que je ne pus m'empêcher de sourire en jetant mes yeux sur elle, et de dire : Voici une dame qui doit être de bonne compagnie ! Je la connais fort, me répondit d'un ton nonchalant mon camarade (effectivement ils s'étaient salués) (Pierre de Marivaux, Le Spectateur français)

1823 Durant ce temps est arrivé le gouverneur de Java (Raffles) avec son état-major, retournant en Europe. Il connaissait fort tous les Hollandais que j'avais vus en 1810, lors de ma mission à Amsterdam (Emmanuel de Las Cases, Le Mémorial de Sainte-Hélène)

1835 Elle votait pour que l'épicier fût menacé indirectement de destitution par le tambour de la compagnie de grenadiers, qu'elle connaissait fort (Stendhal, Lucien Leuwen)

2008 Il nomma aussi M. de Saint-Gilles et sa famille, témoignant là encore la connaître fort et être du même pays (Antoine de Baudry de Saint-Gilles d'Asson, Journal d'un solitaire de Port-Royal (1655-1656))

Pronominal

1624 Monseigneur,

Si je ne me connoissois fort moy-mesme, je pourrois prendre de la vanité de la lettre que vous m'avez faict l'honneur de m'escrire, et m'estimer quelque chose de plus que je n'estois le jour auparavant que je la receusse (Jean-Louis Guez de Balzac, Les Premières Lettres)

II. Faire connaître à haute voix

Transitif

2003 Et quand il dut se résoudre à accepter le scrutin, il n'hésita pas à faire connaître haut et fort son intention de ne pas aller voter pour « une bande de tricheurs » $(L e$ Bélarus, l'État de l'exception)

\section{CORPuS WeB :}

La question est : est ce que ce genre de truc c'est bien ? Est ce qu'il faut s'y connaitre fort en programmation ? [http://forums.d2jsp.org/topic. php?t=37747633\&f=150] (19.7.2014) voila je prefere que tu me reponde comme ca que d'un coups sec, oui tu as surement raison j ai jamais eu trop d explication sur l elevage de mes pogo, $\mathrm{j}$ ai du me debrouiller seul sans renseignement a part mon veto qu y doit pas si connaitre fort alors, je v ecouter des conseils [http://forum.reptiles-passion.com/index. php?showtopic=18645] (19.7.2014)

Ben vla pauline une fille ke je conné pa spécialement mé ki est en 2A au CNDK !! lol. Sans la connaître fort, jla trouve kan meme, par msn,kel est super sympa, super cool, super délirante, super jolie, super.... [http://valentin9.skyrock. com/72337074-Pauline.html] (19.7.2014)

Si on pardonne plus facilement à Danny, c'est tout simplement parce qu'on a eu le temps de la connaître forte et déterminée avant de la découvrir brisée [http://www.babelio.com/livres/ Saintcrow-Une-aventure-de-Jill-Kismet-Tome-1-Mission-noctu/295276/critiques] (19.7.2014)

REMARQUES : Connaître fort réfère au fait de posséder des connaissances profondes sur quelque chose ou quelqu'un. Fort reste invariable (ex. de 1722, de 1823 et de 2003 ; l'accord changerait la construction en prédication seconde dans les exemples de 1722 et 1823 ; v. ci-dessous) et est modifié par plus. Dans l'exemple de 2003, faire connaître est pris comme verbe de communication : on le dit haut et fort. Les deux premiers exemples du CW ajoutent la variante s'y connaître fort 'connaître fort bien'. Dans l'exemple suivant fort pourrait être un régionalisme de fréquence usité dans le Nord et en Belgique. Dans le dernier exemple, fort est un prédicat second accordé, orienté vers l'objet - usage fréquent que nous citons à titre d'exemple ('la connaître comme étant forte est déterminée'). Notons la collocation haut et fort.

\section{Connaître haut}

I. S'y connaître très bien en quelque chose, être très compétent, avoir des connaissances approfondies dans un domaine Pronominal

1485 PATHELIN. Il n'y a nul qui se congnoisse Si hault en advocation (Maistre Pierre Pathelin, 53) 
II. faire connaître haut : annoncer publiquement, diffuser largement

$\lambda$ ex de 2003 sous connaître fort

CORPUS WEB :

Miss de la Mayenne : "C’est un beau département. Je veux le faire connaître haut et fort » [http://www.ouest-france.fr/miss-de-lamayenne-cest-un-beau-departement-je-veux-lefaire-connaitre-haut-et-fort-420226] (18.7.2014)

Ce jeudi, à la gare de Libramont, les ou vriers du rail bloqueront les voies de chemin de fer entre $10 \mathrm{~h} 30$ et $11 \mathrm{~h} 30$, environ. Cela afin de faire connaitre haut et fort leurs revendications [http://www.lameuse.be/755619/article/regions/ luxembourg/actualite/2013-06-26/les-ouvriersdu-rail-vont-manifester-ce-jeudi-a-libramontvoies-bloquees-] (18.7.2014)

Stéphanie : On l'a connue haute comme une pomme Quelques rayures multicolores lui tricotaient une robe de poupée... [http://www. millemercismariage.com/steph_yannick/livred-or.html?page=1] (18.7.2014)

REMARQUES : Dans l'ancienne langue, haut s'emploie par rapport à une connaissance profonde (I). La langue moderne interprète connaître comme verbe du dire dans faire connaître, qui se combine avec la collocation haut et fort. De plus, elle admet haut comme prédicat second orienté vers le complément d’objet s’accordant avec celui-ci (dernier exemple du CW).

\section{Connaître net}

Connaître bien, précisément

入 connaître clair

\section{Conreer gent}

Traiter, s'occuper de quelqu'un avec gentillesse Transitif

+1150 Li covertors fut bons, que Maseüz ovrat, Une fee molt gente qui le rei le dunat ; Mielz en valt li conreiz del tresor l'amiral. Bien deit li reis amer qui li abandonat Et tant bien le servit et gent le conreat (Pèlerinage ou Voyage de Charlemagne à Jérusalem et à Constantinople [2 $2^{\mathrm{e}}$ moitié $\left.\mathrm{XII}^{\mathrm{e}}\right]$, 434)

REMARQUES : En ancien français, conreer gent se dit du fait de traiter, de considérer quelqu'un avec respect gentiment, aimablement, de manière plaisante, agréable.

\section{Conseiller bas}

Conseiller à voix basse, en murmurant

Transitif

+1200 Et il li demandent : " Merlins, comment le cuides tu faire parler ?» Lors se torna Merlins de l'autre part deviers le chief le roi et li consilla moult bas en l'oreille (Merlin [1 ${ }^{\mathrm{er}}$ quart XIII $\left.{ }^{\mathrm{e}}\right]$, p. 131)

+1365 Et elles qui mettent grant cure A savoir de quoi elle est plainne, Se c'estoit de soie ou de lainne, Ou d'un frion ou d'une aloe, Consillent si bas que ne l'oe (Jean Froissart, Poésies [3 $3^{\mathrm{e}}$ tiers $\left.\mathrm{XIV}^{\mathrm{e}}\right]$ )

1756 Lélio demande où est sa valise, et sçachant qu'elle est à l'Hôtellerie, il ordonne a Arlequin de l'apporter, et sur le refus qu'il fait d'y aller seul, par la peur qu'il a des Corsaires, Trivelin conseille tout bas à Lélio de l'y mener, de lui faire bien donner à boire et à manger, et pendant ce temps-là, de prendre dans la valise ce qui peut achever de prouver le nom et la qualité qu'il se donne (François et Claude Parfaict, Dictionnaire des théatres de Paris)

1864 Il pensait laisser son présent, que Justine conseillait tout bas d'accepter, afin qu'il ne s'étonnât de rien. Caroline trouverait toujours le temps de le lui renvoyer (George Sand, Le Marquis de Villemer)

1925 Parle et dis-moi ces mots que le monde ne comprend pas.

C'est Jésus-Christ que j'entends et qui me conseille tout bas.

Et je crois que demain je serai avec toi dans le paradis,

Tenant le pan de ta robe sacerdotale dans ma main, simplement parce que tu me l'as promis (Paul Claudel, Feuilles de saints)

\section{CORPUS WEB :}

Et là, trop bizarre, elle regarde si sa supérieure hiérarchique la regarde et me conseille tout bas d'acheter un billet de bus 150BATH= 3.33€ [http://milouinwonderland.blogspot.co.at/ 
2014/03/bien-arrivee-en-thailande.html] (18.7.2014)

- Moins fort, Jérôme.. On pourrait nous entendre ! conseille tout bas une jeune femme à la peau métissée, postée juste à côté de lui [http:// claire-sa-vie.blog.jeuxvideo.com/1444920/445] (18.7.2014)

Remarques : Conseiller bas désigne le fait de recommander quelque chose à voix basse à quelqu'un, de proposer une solution ou des règles qui peuvent guider quelqu'un dans ses choix, ses décisions ou dans l'action qu'il doit mener. Bas reste invariable et est modifié par moult, si, tout. En français moderne, la collocation tout bas est figée. Notons aussi l'emploi détaché de bizarre dans le premier exemple du $\mathrm{CW}$, ce qui lui confère une fonction d'adverbe de phrase : c'est bizarre (je trouve).

\section{Conseiller soef (suave)}

Conseiller d'une voix douce et agréable

Transitif

1200 Enz en l'oreille li conseilla souef : Amis biaux frere, ou est Gombaus reméz ? (Ami et Amile, 345)

2006 À la fin de l'opération (un peu plus de deux litres, tout de même), il me demanda si j'avais souffert, d'un ton léger qui suggérait fortement la réponse. Je l'assurai donc courtoisement du contraire ; de fait, et à part la légère douleur due à l'introduction du trocart entre deux côtes, la sensation interne de vacuum cleaning avait été plutôt plaisante. Après avoir nettoyé aussi et remballé son matériel, le docteur conseilla, toujours suave, un séjour de quelques mois en sanatorium, à fins de consolidation (Gérard Genette, Bardadrac)

REMARQUES : En ancien français, conseiller soef réfère au ton doux sur lequel le sujet recommande ou propose une solution ou des règles qui peuvent guider quelqu'un dans ses choix, ses décisions ou dans l'action qu'il doit mener, de manière affectueuse, aimable, d'une voix très douce. L'exemple de 2006 récupère cette fonction, mais l'adaptant au style littéraire moderne qui préfère l'emploi détaché. L'exemple montre aussi que l'emploi adverbial de suave est inusuel mais récupérable, dans un registre très soutenu, et non exempt d'ironie, de fausseté, de manipulation.

\section{Consommer malin}

Consommer sans tomber dans les pièges, dans

le respect du travail et de l'environnement

$\pi$ bronzer idiot

\section{Construire basique}

Construire l'essentiel faute de moyens

Emploi absolu

2012 On n'avait pas les moyens de leur donner plus, alors ils ont fait construire basique. Je suis pas sûr qu'ils regrettent pas, mais il fallait bien se lancer... Il ne faut pas rester locataire trop longtemps (Exemple entendu / Corpus Coiffet 2018: s.v.)

\section{Construire durable}

Construire pour durer

入 construire léger

\section{Construire léger}

Construire en évitant du poids superflu ; construire avec des matériaux légers

Emploi absolu

1886 Mais, pour cela, il faut que nos ingénieurs, qui ne savent plus construire léger, qui ont la main gâtée par les cuirassés, qui donnent à nos croiseurs des vitesses si déplorablement réduites, changent complètement d'habitudes (Gabriel Charmes, $L a$ Réforme de la marine)

1987 Pour que la puissance massique soit suffisante il faut construire léger ce qui ne manquera pas de réduire le prix et donc d'augmenter les quantités de Chars pour un même tonnage d'acier et un même montant de crédit (Alain Gougaud, L’Aube de la gloire)

2018 Construire léger et durable, c'est possible (Corpus Coiffet 2018 : s.v., sans date)

\section{Transitif}

1998 Et comme la plupart des appartements sont construits légers, ils n'emmagasinent pas la chaleur (François Gault, Le Japon au jour le jour) 
2003 En 1970, ces bâtiments sont très fatigués, construits "légers » et pas toujours dans les meilleures conditions, ils ont souffert des intempéries et demandent des réparations de plus en plus coûteuses : réfection des parties basses des murs (Abderahmen Moumen, Les Français musulmans en Vaucluse)

REMARQues : Construire avec des matériaux légers. Contraire de construire solide. Les exemples transitifs sont accordés. Notons l'emploi de construire durable. VoIR AUSSI : faire léger

\section{Construire petit}

Construire de petits logements, de petits bâtiments

Emploi absolu

1924 Mais, alors que les autres pionniers avaient prudemment vu petit, fait petit, construit petit, limité leurs ambitions, lui, qui a souffert des plans hâtifs, des constructions provisoires, des villes minuscules étouffant dans leurs enceintes de pierre (José Germain et Stéphane Faye, Le Nouveau Monde français : Maroc, Algérie, Tunisie)

1953 Tout en construisant petit, chacun doit voir grand et loin, il faut ouvrir les fenêtres (Économie et humanisme)

1960 On construit petit en URSS (France observateur, 10 mars 1960 / Grundt : 402)

CORPus WeB :

Mais, finalement, les difficultés ont décuplé l'imagination des architectes permettant ainsi de réaliser un bâtiment unique, original et vraiment intéressant pour ceux qui voudraient construire petit [http://www.archimeo.org/une-maisonannexe-au-japon] (21.07.2014)

Contrairement aux idées reçues, construire de façon compacte ne signifie pas construire petit [http://particuliers.myenergy.lu/files/ Construction $\% 20$ passive $\% 20$ Demarche $\% 20$ active_FR_V3_2013.pdf] (21.07.2014)

REMARQUes : Dans le domaine de la construction, construire petit désigne le fait de réaliser un bâtiment, une construction, petit soulignant les dimensions de l'édifice. Il peut connoter une construction "sans ambition ». Dans l'emploi absolu, petit caractérise l'objet interne du verbe construire, mais, à un niveau plus abstrait, il permet aussi une lecture en tant qu'adverbe de manière à interpréter comme un type de comportement : « la façon de construire ». Notons dans l'exemple de 1924 l'emploi en série avec voir petit, faire petit, ainsi que l'opposition avec voir grand et loin dans celui de 1953.

\section{Construire solide}

Construire en employant du matériel censé tenir longtemps. Contraire de construire léger

$\lambda$ faire léger

\section{Contenir bel (beau)}

Se comporter correctement, bien se comporter Pronominal

1175 Mais se largece est si tres grans Que ses pooirs est mains parans.

Mout par se set bel contenir [manuscrit W : bien contenir, 39]

(Gautier d’Arras, Ille et Galeron, 111)

1200 Tuit li vallant me sont emblei :

Molt voi lou siecle nice et fol.

Qui refu li quiens de Saint Pol !

Qui furent sil de Trianeil ! -

Molt se tiendrent et riche et beil [manuscrit

A : molt se contindrent bien et bel]

(Guiot de Provins, Euvres, 452)

+1249 Onques home de sa jonesse

Ne vit nuns contenir si bel,

En guait, en estour, en cembel

(Rutebeuf, Poèmes [pièces datables de 1249 à 1272], I, p. 483, 79)

1280 Mengier et boire dois petit, Non pas croire ton apetit, Et toi biau contenir a table : Mont en seras plus deletable (Vivien de Nogent, La Clef d'amour, 3245)

+1300 Le roy monte au pallais, a ung prince s’appoye.

En sa chambre est entré, et noblent s’aroye. Aussy bel se contient et paire et se contoye Que s'il eust concquiz la terre de Savoye (Les Enfances Garin de Monglane [XIV $\left.{ }^{\mathrm{e}}\right]$ ) 
+1313 Si ruistes cols donnes se uont Que troncons de lor lances font ; Li ceualier ferme se tiennent Es ceuaus et biel se contiennent (Jean de Condé, Poèmes [1313-1337], 668)

-1334 Lau elle vient il n'est nus qui ne die : «Ves chi la fleur des dames souverainne!» En li siervir nus ne peut perdre painne, Que par tous lieus la nouvele si vient, Si doucement et si bel se contient, Que par ce qu'est de tous biens affinee Jhesu Crist volt, que li fust destinee Unne mervelle, que chi vus conterai (Le Romans de la dame a la lycorne [ $1^{\mathrm{er}}$ tiers $\left.\left.\mathrm{XIV}^{\mathrm{e}}\right], 182\right)$

1404 en ses jeunes fais est toutes choses tres advenant, bel est de corps et a tres doulce et bonne finozomie, gracieux en ses esbatemens, ses riches et jens abillemens bien li sieent ; bel se contient à cheval, à feste plaisamment se scet avoir et tres bien dance, jeue par courtoise maniere, rit et soulace entre dames advenanment (Christine de Pisan, Le Livre des fais et bonnes meurs du sage roy Charles $V, \mathrm{I}, \mathrm{p}$. 172)

\section{CORPUS WEB :}

L'obus contenait bel et bien du sarin [http:// www.ledevoir.com/international/actualitesinternationales/55371/1-obus-contenait-bel-etbien-du-sarin] (21.7.2014)

Mais jusqu'à présent, les responsables du Pentagone n'avaient pas tranché sur le fait de savoir si le livre contenait bel et bien des informations classées top secret [http://www.20minutes. fr/monde/pakistan/996935-etats-unis-livre-benladen-contient-informations-classifiees] (21.7.2014)

REMARQUeS : Dans l'ancienne langue, contenir bel réfère à la manière d'être extérieure d'une personne (démarche, gestes, expressions) qui se caractérise par une certaine réserve, le sujet s'efforçant de garder quelque retenue dans son attitude en montrant les bonnes manières ou l'attitude à adopter dans tel ou tel cas. L'ancien français préfère le neutre bel pour les fonctions d'adverbe. Il est intéressant, à cet égard, que le manuscrit W, également picard, emploie bien à la place de bel. Notons la collocation bien et bel (bel et bien) où les deux adjectifs-adverbes se complètent au niveau sémantique. Dans l'exemple de -1334, bel est coordonné avec doucement. La collocation bel et bien s'est conservée en français moderne avec le sens de 'réellement', 'contrairement à ce que l'on pourrait croire'. Il s'agit donc d'un adverbe de phrase. La lexicalisation de cette collocation permet son emploi occasionnel avec contenir au sens moderne de 'renfermer' que nous documentons dans le CW. Bel est modifié par aussi, si. Mentionnons l'emploi de se tenir riche, se tenir bel, manger petit, boire petit.

\section{Conter bas}

Raconter à voix basse

Transitif

1559 Et que les voix d'un million d'oiseaux, Comme à l'envy du murmure des eaux, L'un haut, l'un bas, contoient leurs amourettes

A la rousée, aux vents et aux fleurettes (Pierre de Ronsard, Éclogues, p. 72)

1626 Tout leur contentement est d'oüir conter bas leurs loüanges à l'oreille d'un tiers ; la Cour, à leur dire, leur est toujours un poison, bien qu'on ne cesse de les y voir ; et si iamais l'on y fait chose qui vaille, pour ce que les charges et elles ont juré divorce (Philippe d'Angoumois, La Florence convertie a la vie devote)

1762 D'Albersac ravi de voir Chevraye chez Madame de St. Ange, après l'avoir embrassé et dit de lui à la Comtesse des choses très-flateuses, lui conta bas ce qui s'étoit passé, et la ridicule fatuité de Tameré, qui faisoit tous les efforts pour qu'on lui attribuât l'honneur d'avoir donné la fête

(Marie Françoise Abeille de Kéralio, Les Succés d'un fat)

1835 Ce matin, quand le jour a frappé ta paupière,

Quel séraphin pensif, courbé sur ton chevet,

Secouait des lilas dans sa robe légère,

Et te contait tout bas les amours qu'il rêvait? (Alfred de Musset, La Nuit de mai) 
1881 M'éblouit-elle autant que le soleil ? Ce prêtre

Me voit-il le dimanche à sa messe apparaître?

Ai-je même jamais fait semblant de vouloir Lui conter mes péchés tout bas dans son parloir ? (Victor Hugo, Les Quatre Vents de l'esprit)

REMARQUES : Au sens figuré, conter bas désigne l'intensité de la voix et réfère au fait de faire le récit détaillé d'un événement, de raconter quelque chose à quelqu'un avec calme, à voix basse, le sujet cherchant à ne pas en révéler publiquement le contenu si celui-ci est d'ordre privé. Notons le contraste bas-haut dans l'exemple de 1559 où les deux adjectifs-adverbes soulignent et précisent la hiérarchie dans les intensités de la voix. Bas reste invariable (ex. de 1626, 1881) et est modifié par tout. Dû au verbe conter, conter haut reflète un usage vieux ou archaïsant. La langue moderne le remplace par raconter y ajoutant tout bas.

\section{Conter bouillant}

Raconter immédiatement, sur le vif $\lambda$ conter chaud

\section{Conter chaud}

Raconter immédiatement, sur le vif Transitif

1785 Et M. Chamberrj descendit, et j'm'en alis quant et quant lui, en-lli contant toutchaud m'n avanture, qui lli fit plaisir, vu ma sagesse d'Honnête-fiye (Nicolas Rétif de La Bretonne, Les Contemporaines communes)

1843 - Ne suis-je pas chez moi, Marion ? fit le bonhomme honteux.

- Ah ! çà, devenez-vous voleur sur vos vieux jours... Vous êtes à jeun, cependant... Je vas conter cela tout chaud à madame.

- Tais-toi, Marion, dit le vieillard en tirant de sa poche deux écus de six francs. Tiens...

(Honoré de Balzac, Les Illusions perdues)

1855 Puisque les extrêmes se cherchent, j'aime à babiller avec toi, et je veux te conter tout chaud, tout bouillant mes plaisirs de ce soir (George Sand, Histoire de ma vie)

1951 Mes lecteurs, que j’ai lâchement abandonnés à Reggan, ceci pour leur conter tout chaud (c'est le cas ou jamais de le dire, par 50 degrés !...) la petite aventure qui nous est survenue entre Bidon 5 et Tabankort, voudront bien m'excuser d'avoir anticipé (René Gouzy, À travers le Sahara)

\section{CoRpus Web :}

Dans les quinze année que constituaient sa vie, Harry n'avait jamais été aimé, ou en tout cas, n'avait gardé aucun souvenir de ce sentiment qu'on lui contait chaud et réconfortant [https:// www.fanfiction.net/s/7330908/4/Magie-es-tu1\%C3\%A0] (24.07.2014)

REMARQUES : Archaïque ou archaïsant dans l'emploi actuel, conter tout chaud désigne le fait de faire le récit détaillé d'un événement récent, de raconter quelque chose à quelqu'un, souvent d'ordre privé ou intime, chaud soulignant l'impatience du sujet, une certaine agitation et l'envie de tout dévoiler à l'autre. Notons la collocation tout chaud, tout bouillant, qui souligne une gradation de l'intensité. Chaud et bouillant restent invariables. Dans le CW, chaud figure en emploi comme prédicat second elliptique au sens de 'ce sentiment qu'on disait être chaud et réconfortant'.

\section{Conter droit}

Raconter avec exactitude et justesse

Transitif

+1475 Mes, par ce que a l'eure de l'offrande il $\mathrm{y}$ cheoit mistere pour faire aller offrir les chevaliers par ordre deu, il convient conter droit cy ung especial point qui autre part en nul service qui ait esté ne s'est trouvé semblable : c'est touchant le duc d'Alenchon, frere de l'ordre, qui en l'eglise avoit un tableau de ses armes comme les autres (Georges Chastellain, Chronique [ $4^{\mathrm{e}}$ quart $\left.\mathrm{XV}^{\mathrm{e}}\right]$, p. 280)

\section{Intransitif}

1673 CHARLOTTE. C'est donc le coup de vent da matin qui les avoit renvarsés dans la mar? 
PIERROT. Aga, guien, Charlotte, je m'en vas te conter tout fin drait comme cela est venu ; car, comme dit l'autre, je les ai le premier avisés, avisés le premier je les ai (Molière, Dom Juan)

\section{CORPUS WEB :}

Cette romancière a écrit des pièces étranges et surprenantes par leur cheminement indirect. Ici, pas de route tortueuse, le soliloque est celui d'une comédienne contant tout droit l'échec d'une salle de théâtre (un commerce consacré aux images nouvelles va occuper le bâtiment, la clef est déjà sur la porte) et vendant aux enchères les objets fétiches de la troupe mise à la rue [http:// www.lesechos.fr/13/06/2000/LesEchos/18171-147ECH_la-clef-sur-la-porte.htm] (24.7.2014)

REMARQUes : Dans les exemples plus anciens, conter droit désigne le fait de faire le récit détaillé d'un événement, raconter quelque chose à quelqu'un, le sujet prenant soin de relater l'objet avec exactitude, justesse et authenticité. Notons l'emploi intensif de tout fin droit. Le CW montre un emploi moderne où droit adopte le sens de 'directement, sans détour'.

\section{Conter fort}

Conter à haute voix, en insistant

$\lambda$ conter haut

\section{Conter haut}

Raconter à voix haute

Transitif

1607 Fuyez celuy qui sans honte ne crainte Conte tout haut son vice hors d'usance (Clément Marot, Euvres)

1678 Il conta tout haut son avanture, et ne pouvoit se lasser de donner des louanges à cette personne qu'il avoit veue, qu'il ne connoissoit point (Madame de La Fayette, La Princesse de Clèves)

1782 Une femme de la cour, également distinguée par sa conduite et par sa beauté, dînoit chez le comte de ${ }^{\star \star \star}$ avec cinquante personnes ; son mari arrive au moment où l'on alloit se mettre à table, et conte tout haut que le baron de $\mathrm{L}$ vient de se casser la jambe en tombant de cheval : comme il achevoit ce récit, il jette les yeux sur sa femme, il la voit pâlir, changer de visage, et enfin s'évanouir (Stéphanie-Félicité Du Crest, comtesse de Genlis, Adèle et Théodore)

1875 Bientôt elle pourrait le prendre par le petit doigt, le mener à cette couche d'herbe, dont son silence contait si haut la douceur. Ce jour-là, elle ne parla pas encore, elle se contenta de l'attirer à ses pieds, assis sur un coussin (Émile Zola, La Faute de l'abbé Mouret)

1890 Ses yeux s'hallucinaient à la regarder, les choses autour du lit reprenaient des voix, contaient l'histoire tout haut. Elle sentait les mots lui en monter aux lèvres, avec l'onde nerveuse qui soulevait sa chair (Émile Zola, La Bête humaine)

2007 une arme à la main, du sang sur l'autre, et combien il était apprécié des vieux voyous marseillais - non pas de ceux qui contaient haut et fort des exploits qui n'en n'étaient pas, mais de ceux qui avaient passé toute leur vie à ne jamais s'en vanter (Thierry Colombié, Beaux Voyous)

CORpus Web :

Enfin il pourrait conter haut et fort le récit qu'il avait construit de toutes pièces [http:// forum.dofus.com/fr/1178-comptoir-tavernerp/1414630-recit-mois-animation-tavernerecit-communautaire-2-souvenirs-ile-wabbits] (1.8.2014)

Ce que vous dites est bien vrai, mais il n'est peut-être pas sain de le conter haut et fort [http://www.univers-rr.com/RPartage/index. php?page $=$ rp\&id=6924\&start=20] $(1.8 .2014)$

Il fallait dire aussi qu'il n'avait pas été malin de la part de Jyrkain de conter haut et fort dans la taverne du coin ses aventures avec ses amis Laguz dans la forêt de Gallia, pas à l'approche d'un probable conflit entre les deux races, et surtout pas devant une assemblée plus ou moins raciste [http://fire-emblem.frenchboard.com/ t254-y-a-t-il-un-heros-pour-sauver-un-bardesnow-jyrkain] (1.8.2014)

REMARQUES : Conter (tout) haut réfère au fait de faire le récit détaillé d'un événement, de raconter 
quelque chose à quelqu'un avec bruit, de façon parfaitement perceptible, le sujet cherchant à rendre public son récit. Notons la collocation usuelle haut et fort, les deux adjectifs-adverbes soulignant et précisant la hiérarchie dans les intensités de la voix. Haut reste invariable (ex. de 1678 , de $1875,1890,2007)$. Le CW indique le figement de la collocation conter haut et fort. Haut tend à apparaître dans la combinaison tout haut, en analogie avec tout bas (aussi : si haut).

\section{Conter isnel}

Raconter rapidement, brièvement, de manière concise

Intransitif

1250 « Ne le savés ? " « Par mon chief, non. » «Comment va dont, pour saint Thumas?» Chele li conte isnel le pas

Com il l'avoit u bois trouvee ;

L'aventure li a contee, Onques ne l'en deigna mentir (L’Atre périlleux, appendice, 226)

+1265 Li rois est levés dou mangier ; Rose se vait appareillier, 0 .vii. contez isniel et tost Vient en la maison au prevost (Richars li Biaus [3e tiers XIII] ], 4979)

REMARQUES : En ancien français, conter isnel désigne l'action de raconter quelque chose à quelqu'un, sans perdre de temps, de manière brève et rapide. Notons la collocation isnel et tost, où l'adjectif-adverbe tost vient renforcer l'idée de rapidité dans l'action, et isnel le pas 'sur le champ'.

\section{Conter net}

Raconter clairement, directement, sans

ambiguïté

Intransitif

1755 Monrose tuë l'aumônier. Charles retrouve Agnès qui se consolait avec Monrose dans le chateau de Cutendre. J'avais juré de laisser la morale, de conter net, de fuir les longs discours (Voltaire, La Pucelle d'Orléans)

1829 [Pline :] L'homme qui nous apprend le plus de choses sur l'antiquité, parce qu'au lieu de faire des phrases comme Cicéron, il conte net (Stendhal, Promenades dans Rome)

1839 Il y avait sans doute, dans l'histoire de cette catastrophe, des choses qui pouvaient profondément offenser quelque personnage encore puissant en 1750, époque où l'on croit que le moine écrivit, car il se garde bien de conter net (Stendhal, Suora Scolastica)

Transitif

1817 Contez-moi net ce que vous en a dit Maisonnette, excellent juge à mes yeux (Stendhal, Correspondance)

REMARQUES : Net réfère à la façon dont le sujet s'exprime lorsqu'il fait le récit détaillé d'un événement. Evitant les longs discours et les phrases compliquées, le sujet privilégie un discours précis et sans ambiguïté, qui traite directement du sujet en question et qui est clair pour le destinataire, même si le propos est gênant.

\section{Conter sec}

Conter sans détour, sans égard

$\pi$ conter vrai

\section{Conter vrai (voir)}

Raconter, dire la vérité

Emploi absolu

+1234 Ainz Yfame ne vout entendre

Lor parole ne lor reson,

Ainz a tout conté son baron

L'afere, tout si com il va.

Jehans li respondi : Di va,

Bele suer, me contes tu voir ?

(Huon Paucele, Estormi [2 $2^{\mathrm{e}}$ tiers XIII $]$, 41)

CORPus WeB :

Conter vrai, est-ce parler vrai ? Oui, bien sûr, parl'intention qui sous-tend votre conte, par le but qu'il poursuit. Un conte, un vrai bon conte est toujours généreux, utile [http://toutpetits.wordpress. com/2009/07/06/conter-vrai] (11.9.2014)

Homme des îles, Lim Chul-woo est confronté à la rude verticalité des monts et à l'à-plat de la mer : ici, on parle patois ou argot, pour conter vrai, vite, sec; là où dominent les émotions - hiers enfuis, demains trop prévisibles - et les moments teintés de poésie [http:// 
www.k-vox-festival.com/scenes-coreennes.ws] (11.9.2014)

Boris valentin et max ces les pote qure qui je pzux conter vrai [http://ask.fm/Corentin Dufresne/best] (11.9.2014)

REMARQUES : Voir, que la langue moderne remplace par vrai, est un adjectif-adverbe qualificatif désignant la véracité du contenu raconté. Le second exemple du CW caractérise le langage rude d'une personne qui conte vrai, vite et sec 'authentique, rapide, sans artifice'. Notons l'emploi de parler vrai.

\section{Continuer bas}

Continuer (par dire) à voix basse, en murmurant Emploi absolu

1637 CLARIMAND (continuant bas)

S’il parle de son cœur, tu l'auras dérobé ;

Laisse luy dire au moins « je meurs, je vous proteste ",

Et tous ces autres mots qui luy seront de reste :

Ah ! ce masque fâcheux a troublé sa leçon (André Mareschal, Le Railleur)

1874 M. de Condamin, voyant entrer deux dames, continua tout bas à l'oreille de Guillaume, qui faisait des signes affirmatifs, en pouffant de rire. Celui-ci, pour ajouter sans doute quelques détails, se pencha à son tour (Émile Zola, La Conquête de Plassans)

1885 Devant les flammes qui s'effaraient, le vieux continuait plus bas, remâchant des souvenirs. Ah ! Bien sûr, ce n'était pas d'hier que lui et les siens tapaient à la veine ! (Émile Zola, Germinal)

1960 ELLE. Elle revient quand?

LUI. Ces jours-ci.

(Elle continue, bas, comme dans un aparté)

ELLE. Comment elle est, ta femme?

(Marguerite Duras, Hiroshima mon amour)

Transitif

1863 Sous l'éclair d'un regard sa force fut brisée ; Et, dès qu'il vit ployer son aile maîtrisée, L'ennemi séducteur continua tout bas : « Je suis celui qu'on aime et qu'on ne connaît pas » (Alfred de Vigny, Poèmes antiques et modernes)
1876 - Si Rougon saute, murmura M. La Rouquette, je ne donne pas deux sous du procès des Charbonnel... c'est comme Mme Correur... il se pencha à l'oreille de M. Kahn, et continua très bas :

- En somme, vous qui connaissez Rougon, dites-moi au juste ce que c'est que Mme Correur

(Émile Zola, Son Excellence Eugène Rougon)

1945 Elle chercha machinalement la date du journal. C'était celle de la veille, le vingtdeux mai.

- Je sais pas si le tour d'Eugène viendra betôt, dit-elle.

Et elle continua tout bas sa pensée : «Eugène... Florentine... qui s'en ira après? On achève-t-y d'être ensemble ? Déjà ! » (Gabrielle Roy, Bonheur d'occasion)

Intransitif

1869 Il s'arrêta. On se taisait. Les rires continuaient, mais bas. Il put croire à une certaine reprise d'attention (Victor Hugo, L'Homme qui rit)

REMARques : Au sens figuré, continuer bas désigne l'intensité de la voix et souligne le fait de poursuivre son récit, de continuer par dire quelque chose à voix basse, en le murmurant, le sujet désignant une personne et le complément d'objet étant un propos rapporté au discours direct. Bas reste invariable et est modifié par plus, très, tout. L'absence d'exemples dans le CW reflète le caractère plutôt littéraire de continuer bas, employé notamment dans les didascalies.

\section{Continuer droit}

I. Poursuivre son chemin en ligne droite, devant soi

Emploi absolu

1690 CROMORNE. s. m. Terme de Musique. C'est un jeu de l'orgue accordé à l'unisson de la trompette. Il a quatre pieds depuis son noyau jusqu'au sommet, dont le premier demi-pied va en élargissant jusqu'à cinq pouces, et puis il continue tout droit, ayant un pouce et demi de diamètre (Antoine Furetière, Dictionaire universel) 
1846 En ce moment nous étions à une vingtaine de pas de ce récif dans lequel se jouait la mer ; notre guide prit le chemin qui entourait les rochers ; nous continuâmes droit devant nous ; mais Pauline me prit le bras (Honoré de Balzac, Un drame au bord de la mer)

1869 Le quai de la gare se trouvant inondé, sans doute, on continua tout droit, et la campagne recommença. Au loin, de hautes cheminées d'usines fumaient. Puis on tourna dans Ivry (Gustave Flaubert, L'Éducation sentimentale)

1907 Lorchen ne pouvait guère venir avant deux ou trois heures. En attendant l'arrivée des trains, il faisait les cent pas sur le quai de la petite gare. Il continua tout droit au milieu des prairies (Romain Rolland, Jean-Christophe. La Révolte)

1911 Puis Jules Dufey vint et lui tendit aussi la main, et Milliquet lui tendit la main. Il continua tout droit vers la porte. Et alors la cousine Laure se mit à sangloter et vint, lui tendant les deux mains ; mais Marianne s'était détournée (Charles-Ferdinand Ramuz, Aimé Pache, peintre vaudois)

1927 Il marchait vite. Elle le suivit un instant d'un œil distrait. Il traversa la rue du Président Carnot et continua tout droit, le long du mur du pavillon. Puis elle le vit s'arrêter à une porte qu'il ouvrit (Julien Green, Adrienne Mesurat)

1963 Il vaudrait mieux arriver par la route de Salamanque, d'où l'on découvre toute la cité. En venant comme nous de Madrid, on continuera droit devant soi, sans entrer dans la ville, en longeant la muraille jusqu'au pont du rio Adaja, que l'on traversera (Albert T'Serstevens, L'Itinéraire espagnol)

1991 Parvenu là, continuer tout droit ou revenir sur soi s'équivalent-ils ? (Michel Serres, Le Tiers-Instruit)

2002 À Roag, vous avez le choix. Vous tournez à gauche, ou vous continuez tout droit. Vous tournez à gauche (c'est votre choix, pas le nôtre) et vous descendez jusqu'au niveau zéro, passant dans le bout ambigu de terre (île ou presqu'île) (Jacques Roubaud, $L a$ Bibliothèque de Warburg)

Transitif

1761 car il n’y a guéres d'apparence que le sang, au lieu de continuer tout droit son chemin dans la veinecave, se détourne pour aller passer dans la veine du poumon par le trou ovale (François Planque, Bibliothèque choisie de médecine)

1849 LE DIABLE. Ah ! comme l'aérolithe flamboyant qui passait tout à l'heure, si dans un effort suprême, elle se dégageait de ce qui la retient, qu'elle pût sortir aussi de l'attraction qui la retient et continuer droit son mouvement, s'enflammant de plus en plus au courant de sa course, elle deviendrait peut-être le principe d'un ordre nouveau, le noyau d'un monde (Gustave Flaubert, La Tentation de saint Antoine)

1921 L'Évangile nous montre le Christ traversant la meute de ses calomniateurs, et continuant droit son chemin, comme s'il n'avait rien entendu (Henri Bremond, His toire littéraire du sentiment religieux en France)

1948 Ses yeux, habitués à l'obscurité, trouvaient aisément le passage à travers les jeunes sapins clairsemés : en continuant tout droit sa descente, elle [= Simone] devait nécessairement rejoindre la route de Dombasles, presque parallèle à celle qu'elle venait de quitter (Georges Bernanos, Un mauvais rêve)

Pronominal

1851 La nuque est herculéenne, se continuant droit au col. Front bas, charnu, gras, ridé ; sourcils épais, yeux enfoncés, ensemble brutal (Gustave Flaubert, Notes de voyages)

Intransitif

1887 Puis, l'œil rond et satisfait, l'un des jars continua tout droit, l'autre jars prit à gauche ; tandis que chaque troupe filait derrière le sien, allant à ses affaires, d'un 
déhanchement uniforme (Émile Zola, $L a$ Terre)

1932 Sur une des lignes où elle avait réussi à aller le plus loin, on aurait pu croire que cette énergie vitale entraînerait ce qu'elle avait de meilleur et continuerait droit devant elle ; mais elle s'infléchit, et tout se recourba (Henri Bergson, Les Deux Sources de la morale et de la religion)

II. Continuer directement

Transitif

1905 Front très peu haut, mais assez large ; visage sans nuances, comme taillé au couteau ; cou de taureau continué tout droit par la tête, où l'on sent que la passion monte congestionner aussitôt le cerveau. Oui, je crois que c'est là l'impression qui domine : la tête fait corps avec le tronc (André Gide, Journal)

III. Se poursuivre tout droit (d'une chose)

Pronominal

1907 On pouvait, naturellement, passer de l'une de ces pièces dans l'autre sans qu'il fût nécessaire de passer par la galerie. Le salon et l'antichambre étaient les seules pièces de l'appartement qui eussent une porte sur la galerie. La galerie se continuait, toute droite, jusqu'à l'extrémité est du bâtiment où elle avait jour sur l'extérieur par une haute fenêtre (Gaston Leroux, Le Mystère de la chambre jaune)

\section{CORPus WeB :}

En continuant droit sur la rue de Castiglione, on s'offre le plaisir d'arriver aux Tuileries pour une flânerie bien parisienne entre les fontaines et une chaise au soleil [http://www.thechesshotel. com/blog/parfum-ete-paris-142561] (11.9.2014)

Environ $500 \mathrm{~m}$ plus loin, on quitte alors la route en continuant droit dans le chemin menant beaucoup plus loin aux serres des Bichons, après avoir remarqué la diversité des séchoirs à tabac [http://www.lerepublicain.net/entre-meilhanet-saint-sauveur-la-terrasse-de-garonne-et-lavallee-du-lisos_172] (11.9.2014)

Il reste les $18 \mathrm{~m}$ du milieu, les continuer droit pour la patte d'épaule, pendant $9 \mathrm{~cm}$; rabattre alors du côté droit pour l'encolure : 1fs 4m ; 1fs
$3 \mathrm{~m}$; $1 \mathrm{fs} 2 \mathrm{~m}$; et $3 \mathrm{fs} 1 \mathrm{~m}{ }^{\star \star \star} \mathrm{Il}$ reste $6 \mathrm{~m}$ que l'on rabat à $13 \mathrm{~cm} 5$ de hauteur totale de patte d'épaule $\star \star \star$ Exécuter la manche gauche en sens inverse [http://1fleurette.free.fr/tricot4/index.htm] (11.9.2014)

REMARQUeS : Continuer droit s'applique le plus souvent à une personne qui poursuit son chemin, sa route vers une direction précise, droit marquant l'orientation du sujet (I). Le sujet peut aussi désigner un inanimé ayant un développement spatial, le verbe soulignant une suite, une prolongation dans une direction (II). Droit reste invariable dans la majorité des cas, sauf quand il est employé comme prédicat second et qu'il désigne une position droite, verticale (ex. de 1907). Il est modifié par tout. Il a tendance à s'associer avec les prépositions qu'il précède (à, au milieu, dans, devant, le long, sur, tout, vers) au point de faire partie du groupe prépositionnel comme modifieur de la préposition.

\section{Continuer ferme}

I. Continuer d'une manière décidée, énergique, inébranlable

Intransitif

1596a L'an desjà quatre fois a fourny sa carriere, Depuis que le beau jour de vos yeux m'esclaira ;

Mais qu'il se renouvelle autant qu'il luy plaira,

Je continueray ferme en ma course premiere (Philippe Desportes, Euvres)

1573 Aussi ay je receu une infinité de fascheries causees sur l'arrogante bestise de ceux de nostre canton. Ce qui m'a fort degousté de continuer ferme, et posposer l'honneste proffit, et plaisir que, malgré leur envie, j'eusse peu tirer, à l'incommodité que m’apportoit leur langue debordee (Jean Duret, Traicté des peines et amendes)

Transitif

1877 Et, redressant sa taille, le plastron élargi, il continua sa route, plus ferme et résolu qu'avant.

M. de Monpavon marche à la mort

(Alphonse Daudet, Le Nabab) 
II. Continuer, se poursuivre d'une manière stable, durable

Intransitif

1596b A quel bien desormais faut-il plus aspirer, Puisque rien icy bas ferme ne continuë. Tout n'est que vent, que songe et peinture en la nuë,

Qui se passe aussi-tost qu'on s'en pense asseurer (Philippe Desportes, Euvres)

\section{CORPUS WEB :}

Catherine Lapilule prit son embauche à la ferme, tandis que son mari continuait ferme sa débauche [http://www.cistes.net/newsletter. php?idnews=92] (11.9.2014)

Je vous demande de continuer fermes dans le chemin de la prière. Quand vous sentirez le poids des difficultés recourez à Jésus [http://crisduciel. free.fr/septembre_2011.htm] (11.9.2014)

REMARQUeS : Continuer ferme (I) renvoie à une personne qui poursuit son but, persévère dans un choix, une conduite ou une décision, une personne qui continue avec obstination à être dans telle disposition, à vouloir accomplir tel projet ou à penser de telle façon. En (II), le sujet désigne un inanimé dont le processus se déroule lentement, de façon inefficace, de façon inconstante. L'exemple de 1877 reflète la tendance de la langue moderne à renforcer la fonction prédicative de modifieur du sujet en détachant ferme. L'accord s'observe dans le dernier exemple du CW, où il permet au discours religieux d'insister davantage sur l'attitude ferme des destinataires.

\section{Continuer fort}

Continuer à haute voix, en insistant

$\lambda$ continuer haut

\section{Continuer haut}

Continuer (par dire) à voix haute

Emploi absolu

1627 mais quant à ce que vous me demandez, que veut dire que je ne suis point chez Dorinde, sçachez que vous en estes doublement la cause, car, continua-t'il tout haut, Florice ayant sceu que vous vous trouviez un peu mal, m’a commandé de venir sçavoir de vos nouvelles (Honoré d’Urfé, L’Astrée)
1934 Il faisait trop froid : cela pouvait aggraver son mal.

- Calme-toi. Que vas-tu chercher ?...

- Quand je pense aussi que, si souvent...

Il n'osa pas continuer tout haut. Il pensait à ces conversations où ils avaient repris, Xave et lui, leur débat essentiel, celui où tout s'engageait (Daniel-Rops, Mort, où est ta victoire?)

Transitif

1758 CÉCILE. (après avoir parlé bas à mademoiselle Clairet, continue haut, et d'un ton chagrin)

Conduisez-la

(Denis Diderot, Le Père de famille)

1877 Les Romains seuls pouvaient produire cette extermination. Des plaintes s'échappaient :

- Assez ! Assez ! Qu’il finisse !

Il continua, plus haut :

- Auprès du cadavre de leurs mères, les petits enfants se traîneront sur les cendres (Gustave Flaubert, Trois Contes)

1895 Il se tournait vers moi ; je me tournai vers Ildevert et Isidore et leur dis :

- Hein ! Qu'est-ce que je vous disais ? Valentin continua, très haut, me regardant :

- Dans Virgile, elle s'appelle Tityre ; c'est celle qui ne meurt pas avec nous, et vit à l'aide de chacun (André Gide, Paludes)

1907 Je veux être enterré dans la terre bénite, comme mes défuntes. L’abbé, qui crut dire merci, ne s’aperçut pas, tant il était troublé, qu'il continuait seulement tout haut la prière commencée tout bas : Sancta Maria, mater dei... Le journalier n'y prit pas garde non plus (René Bazin, Le Blé qui lève)

1949 Tout à fait à gauche, une voix miaula soudain :

- Alors, Elzéar, vous nous éreintez tous?

Chambrelle protesta d'une main molle et continua tout haut :

- Vous venez d'entendre Gallufet, directeur des mines de Bécon.

- Spécialiste en mineures, filles de mineurs, nul ne l'ignore ! lança l'autre (Hervé Bazin, La Tête contre les murs) 


\section{CORPUS WEB :}

Chez les juniors filles, Cloé Capdordy (Solo Escalade) entre bien dans sa finale en en négociant facilement un démarrage plutôt bloc, pour continuer haut dans la voie. Elle prend également une jolie troisième place [http://crmpffme.fr/competition/competition-escalade/55actualites/actualites-escalade/actualitescompetitions-escalade/383-2e-etape-de-lacoupe-de-france-de-difficulte.html] (11.9.2014)

ué ben je commence bas jespere continuer haut lool [http://forum.france.boinc-af.org/ index.php?topic=1095.75] (11.9.2014)

Notre réseau se resserre dans cette épreuve et trouve dans la colère et l'état des lieux de ce pays toutes les raisons de continuer haut et fort son combat pour la dignité de tous. Joe Sacco était venu à Rennes pour des raisons militantes [http://fr.squat.net/2008/04/16/rennescommemoration-pour-joe-sacco] (11.9.2014)

REMARQUES : Au sens figuré, continuer haut réfère à la parole et souligne le fait de poursuivre son récit ou une prière, de continuer de dire quelque chose à voix haute, le sujet désignant une personne et le complément d'objet étant un propos rapporté au discours direct. Haut reste invariable (ex. de 1907) et est modifié par tout, plus, très. Dans les deux premiers exemple du CW, haut ne réfère pas à la voix humaine mais au niveau d'exécution d'une action, opposé à bas. Notons la collocation haut et fort 'ouvertement, publiquement, au grand jour' dans le dernier exemple du CW. Mentionnons également l'emploi de parler bas.

\section{Contrôler impec}

Contrôler parfaitement

Emploi absolu

1976 Cruyft file le long de la touche, feinte un adversaire, shoote dans la foulée sur l'avant-centre qui contrôle impec de la tête, reprend du pied gauche et marque. Bon sang, ça c'est du foot. Ah la vache, ça c'est du foot, c'est du sacré foot (Patrick Cauvin, Monsieur Papa)

REMARQUES : Contrôler impec signifie 'contrôler parfaitement'. Impec est une réduction familière de l'adjectif-adverbe impeccable ou de l'adverbe impeccablement. La combinaison « verbe + impec(cable) " constitue une série ouverte dont nous ne citons que quelques variantes.

\section{Contrôler positif}

Afficher un résultat positif lors d'un contrôle de substances non autorisées ou dont la présence est inattendue

Transitif

1997 Trois athlètes sont contrôlés positifs pour dopage (Revue politique et parlementaire)

2006 L'établissement continue notamment à recevoir et à utiliser du lait contrôlé positif à la présence de résidus d'antibiotiques (Journal officiel de l'Union européenne, 14.10.2006)

2007 Parce que sont amalgamées, dans ces jugements, les grandes, les musclées, les costaudes, les contrôlées positives aux androgènes, ainsi que les homosexuelles déclarées (Corps dominés, corps en rupture)

2011 On comprend aisément pourquoi des icônes du sprint moderne, toutes médaillées aux championnats du monde ou aux jeux Olympiques, ont été contrôlées positives aux psychostimulants à un moment ou à un autre de leur carrière (Toutes les questions que vous vous posez sur votre cerveau)

\section{CORPuS WEB :}

Pour tout lévrier contrôlé « positif », les frais de contrôle antidopage sont à la charge du détenteur du lévrier incriminé [https://www.igwr. ch/de/category/aktuelles-news] (20.10.2020)

L'américain Floyd Landis est contrôlé positif à la testostérone, suite à sa victoire au Tour de France [https://www.linguee.de] (20.10.2020)

REMARQUES : Toujours à la voix passive, contrôlé positif s'emploie récemment dans le cadre des tests destinés à détecter des substances généralement nocives ou interdites. Dès les années 1930, on trouve déjà des publications statistiques ayant trait à la vaccination (v., par exemple : Bulletin mensuel, Office international d'hygiène publique, vols. 34-35, 1942) où une colonne intitulée « (personnes) contrôlées » côtoie la colonne portant « positives »; dans d'autres publications, 
il y a trois colonnes : contrôlées/positives/négatives (v., par exemple : Archives de l'Institut Pasteur à Alger, vol. 14, 1936). Ceci a pu favoriser le développement du groupe dans le domaine des sciences et des sports.

\section{Copier juste}

Copier conformément à l'original

Transitif

1674 C'est encore un bon moyen pour copier juste un Tableau en huile (Claude Boutet, Traité de mignature)

1717 II n'y a qu'à savoir lire et écrire pour copier les Lettres, et le principal est de les copier juste, sans rien changer de ce qui est écrit dans les Lettres que l'on copie (Samuel Ricard, L'Art de bien tenir les livres de comptes en parties doubles à l'italienne)

1755 Un autre moyen pour copier juste un tableau à l'huile, c'est de donner un coup de pinceau sur tous les principaux traits avec de la laque broyée à l'huile, et d'appliquer sur le tout un papier de même grandeur (Charles-Antoine Jombert, Méthode pour apprendre le dessein)

Emploi absolu

1835 Lorsqu'on voudra copier un dessin composé de lignes horizontales et de perpendiculaires seulement, je suppose que ce soit une façade de maison [...], on commencera d'abord par les lignes horizontales, dont on prendra tous les intervalles compris entre elles, avec le compas ; mais pour parvenir à copier juste, il faudra d'abord commencer par les masses, c'est le seul moyen d'opérer sûrement

(Alexandre Baudrimont, Dictionnaire de l'industrie manufacturière, commerciale et agricole)

\section{CORPUS WEB :}

En tout cas les équations sont copiées justes je crois [Forums.futura-sciences.com/physique/ 27041-constante-de-planck-2] (20.6.2020)

REMARQues : Copier juste désigne le fait de reproduire un écrit en respectant la version originale, juste soulignant le souci d'exactitude dans l'acte. Il tend à l'emploi invariable, mais le désir de souligner l'exactitude d'un calcul peut créer des conditions favorables à l'accord (CW).

\section{Copier vrai}

Copier fidèlement l'original

Emploi absolu

1958 Copiez vrai. Même les couleurs "viennent» bien sur la copie au Develop, car Develop voit comme l'œil et copie tout le visible, ce en quelques secondes; sur le coin de votre bureau (Le Figaro, 23 septembre 1958)

REMARQues : Copier vrai désigne le fait de reproduire un écrit en respectant la version originale, vrai soulignant le souci d'exactitude dans l'acte. Par rapport à copier juste, copier vrai est hyperbolique, pour mieux transmettre le message publicitaire. Juste reste invariable.

\section{Corner clair}

Produire des sons clairs, aigus avec un instrument à vent

Intransitif

+1250 Li chevaliers tint une croce Dont il va les boissons batant.

$\mathrm{E}$ li veneres va cornant Si hautement et issi cler, Tot le bois en fait retinter Del cler son que li cor rendi (Le Roman de Renart [2 $2^{\mathrm{e}}$ moitié XIII $\left.{ }^{\mathrm{e}}\right]$, XIII, 399)

REMARQUES : En ancien français, corner clair renvoie au fait de produire des sons au moyen d'un instrument à vent comme la corne ou la trompe, qui produisent à l'oreille un effet comparable à celui que produit sur les yeux une lumière vive. Notons la collocation avec l'adverbe hautement qui souligne l'énergie déployée par le sujet pour produire ce son net. Ce sens de hautement a disparu dans la langue moderne, qui préfère l'adjectif-adverbe haut. Clair est modifié par issi.

\section{Corner fort}

Produire des sons forts, d'une grande intensité, en particulier avec un instrument à vent Intransitif

1341 PREMIER CHANOINE. Non fait, non ; mais il chace proye Que il prendra par son effort. Oez conme il a corné fort 
De grant testée (Miracle de l'evesque que l'arcediacre murtrit, 748)

1374 LE PREMIER CHEVALIER. Toute la teste me tournoye

De corner fort a longue alaine,

Et si m'est avis que ma paine

Pers : je n'oy ame

(Miracle du roy Thierry, 1224)

$1941 \mathrm{Au}$ bout de quelques minutes, la mule corna très fort, s'agenouilla, s'abattit et commença de râler. Je répugnais à lui tirer une balle dans la tête pour abréger ses souffrances (Georges Duhamel, Suzanne et les jeunes hommes)

\section{CORPUS WEB :}

j'en ai connu un [= cheval] que je montais qui cornaitfort (assez impressionnant) Etj'ai une amie qui en a un qui corne en DP. Elle fait des concours [http://www.chevalannonce.com/forums-640 6258-acheter-un-cheval-qui-corne] (14.10. 2014)

Le tour était plusieurs milles long et j'ai apprécié des voitures cornant fort à chaque tour [http://www.m.fruitymag.com/les-joies-s30550. $\mathrm{htm}]$ (14.10.2014)

Des landes sur des lieues, de maigres arbustes, d'impressionnants rocs, des chemins cahotants et mal entretenus, des courants d'air froid traversant des vallées profondes et un vent cornant fort quand on débouchait sur des plateaux déserts [http://www.unesourissurdeslivres. com/gitana-22.php] (14.10.2014)

Aux dépends des uns - le poète Peuchmaurd se prêtant aussi au jeu -, des autres, de l'Univers en ses composantes, et mine de rien, des pensées cornent haut et fort : mines d'or à propos de tout. Et le rire tantôt frais et franc, tantôt jaune, tantôt triste, tantôt neutre, joue un peu partout [http://isabelledalbe.blogspot. co.at/2009_03_01_archive.html] (14.10.2014)

Non pas d accord ! C est aussi au vrai supporter de montrer 1 exemple et de corner haut et fort ses ambitions pour son club ! Cela est a quelque chose justement! Tu crois que les révolution se font comment ? Ça commence toujours par la base ! [http://dijonfoot1998.com/forum/ index.php?topic=858.45] (14.10.2014)

c'est la nouveauté de la rentrée (tadaaaam, roulements de tambours, hérauts embouchant leurs trompettes pour corner haut et fort) les toiles peintes Jardin Secret ! [http://secretjardin. canalblog.com/archives/2008/09/17/10612883. html] (14.10.2014)

REMARQUES : Dans l'ordre de la perception et sur l'échelle musicale, corner fort réfère aux sons produits par un instrument à vent comme la corne ou la trompe, le sujet faisant retentir fortement son instrument, fort soulignant à la fois l'intensité du son émis par l'instrument et l'énergie déployée par le sujet. Par extension et comme terme d'hippiatrie, le sujet peut aussi désigner le bruit anormalement fort de la respiration émise par un animal (une mule, un cheval), comparable au son émis par un instrument à vent comme la corne. Fort reste invariable et est modifié par très. Le CW montre que corner fort peut s'appliquer au cheval, à la voiture, au vent, à la pensée, à l'ambition, parfois dans la collocation usuelle haut et fort. Fort est modifié par très.

\section{Corner haut}

Produire des sons forts, d'une grande intensité avec un instrument à vent

Intransitif

+1150 Celes imagenes cornent, l'une a l'altre sorrist

Que ço vos fust viaire que il fussent tuit vif, L'uns halt, li altre cler; molt fait bel a oïr (Pèlerinage ou Voyage de Charlemagne à Jérusalem et à Constantinople [2e moitié $\mathrm{XII}]$, 373)

+1250 Renart qui tot ot cel afere

Veü de pres et espie,

Un lonc cor qu'il avoit lie

A son col, a mis a sa boce :

Si fort et si tres bien le toce

Et conmenche a corner si haut,

Que retentir en fait le gaut (Le Roman de

Renart [2 $2^{\mathrm{e}}$ moitié XIII $\left.{ }^{\mathrm{e}}\right]$, IX, 785)

-1334 Lors est l'estour tel devenu,

Que si cruel nus hons ne vit ;

Car du matin dusqu'a la nuit

Sans ciesser l'estour si dura.

Qui hardement et avis a,

Conment secourus il seroit,

Dou Chevalier Faét avoit 
Un cor, dont molt haut il corna (Le Romans de la dame a la lycorne $\left[1^{1 \mathrm{r}}\right.$ tiers XIV $]$, 2394)

Transitif

1583 Pour tesmoigner le sort, et la disgrace, Qui noz Françoys amorçent en leur hain : Il me faudroit une trompe d'airain, Cornant plus haut les chantz qu'icy je traçe (Jean de La Gessée, Les Jeunesses)

2008 Il atteignit la route en lacets qui descendait du col, et quand l'autobus de la poste corna plus haut son air d'opérette, il posa son sac par terre, s'assit dessus et attendit ; comme un qui rentre fourbu d'une longue randonnée (Anne-Marie Garat, L'Enfant des ténèbres)

CORPus WeB :

v. exemples s.v. corner fort

REMARQUES : Au sens figuré, dans l'ordre de la perception et sur l'échelle musicale, corner haut réfère aux sons puissants produits par un instrument à vent comme la corne ou la trompe, le sujet faisant retentir fortement son instrument, haut soulignant aussi l'énergie déployée par le sujet. Notons que corner haut a aussi un emploi transitif qui souligne davantage le fait de mettre des paroles (chants) en musique, de les révéler au public grâce à l'instrument. Notons la construction parallèle : L'uns halt, li altre cler (ex. de +1150). Haut reste invariable (ex. de 1583) et est modifié par moult, plus, si.

\section{Correspondre juste}

se correspondre juste : se correspondre exactement, se trouver dans la bonne configuration, se positionner exactement $\lambda$ touner rond

\section{Corseter serré}

Revêtir d'un corset noué serré

Transitif

1895 Pimpantes et alertes, gentiment chapeautées, gantées de frais, chaussées de neuf, corsetées serré, elles avaient, presque toutes, la même tournure (La Revue de Paris)

1900 Des murailles le [= le jardin] corsètent serré; nulle branche ne bouffe. Ainsi qu'un col bien blanc, le perron le surmonte et la maison sourit au-dessus, claire, rose, gaie (La Nouvelle Revue)

1912 Hardi, on se mit à pousser l'auto ; Mme Charmot corsetée serrée comme toujours, la croupe exagérée (Mercure de France)

1956 Nous prêtons une oreille nostalgique à ce bruit de robes traînantes qui nous arrive de la belle époque, celle de la femme cariatide, galbée comme un meuble Louis XV et corsetée serré (Elle, 27 février 1956 / Grundt : 303)

2007 Sur un autre cliché, la femme corsetée serré, à la coiffure compliquée avec sa double rangée de boucles sous le chignon, qui prend la pose avec le garçon de six ans, c'est sa mère ; la ressemblance est frappante et, et l'équilibre n'est pas forcé (Guylaine Massoutre, Renaissances)

Pronominal

2012 Ils sortaient et se levaient tard, le soir, Isolde, en volute de dentelles, se corsetait serré et ajustait ses manches gigot pour aller écouter Yvette Guilbert (Axel III, Hercule)

\section{CORPus Web :}

Carte de visite : Ronde, j'aime être corseter serré porter talon haut, bas couture, être attacher, sucer, être prise en photos et beaucoup plus si un bon felling [http://www2.clubfetich.com/annu/ detail.php?an_key=22954\&] (14.10.2014)

...une grande femme sèche, peu aimable, habillée comme en 1900 - je n'aurais jamais imaginé que cela put exister encore ! - le cou serré dans un col montant jusqu'au menton, en dentelle noire, la taille corsetée serré, avec une « tournure » sur les reins, un chignon haut perché sur un visage anguleux... [http://meregrand. blogspace.fr/41] (14.10.2014)

J'adore être en grande robe corsetée serrée et talons hauts à dispo [http://blog.aufeminin. com/blog/seeone_514803_9112535/Poupee/sissi] (14.10.2014)

REMARQUES : Généralement invariable, corseté serré réfère à l'habillement, l'objet désignant une personne revêtue d'une gaine baleinée et lacée 
qui a la particularité de serrer la taille et le ventre des femmes. L'exemple de 1900 le transpose par métaphore aux murailles encerclant un jardin. Dans le deuxième exemple du CW, serré reste invariable malgré le sujet (l'objet du verbe passif) au féminin, tandis que, dans le dernier, il fait l'accord avec le sujet au féminin, tout en gardant son interprétation d'adverbe de manière.

\section{Cosser dur}

Se heurter violemment (des cornes ou des bois d'animaux en rut)

$\lambda$ résonner dur

\section{Coter cher}

Avoir un cours élevé ; être apprécié, prisé Transitif

1853 C'est ce qui inspire à l'auteur du manuel du commerce les réflexions suivantes : [...] il y aurait une infinité d'acheteurs de moins, et que conséquemment les inscriptions de rente étant moins demandées, seraient cotées moins cher, partant, plus de hausse fabuleuse, etc. (Nicolas Boyard, $L a$ Bourse et ses spéculations)

1857 Ces messieurs de grand chemin ne sauraient me coter bien cher. J'ai envie, tandis que tu es encore là, de leur demander ce que je vaux, au plus juste prix (Edmond About, Le Roi des montagnes)

1869 Que les animaux et les plantes destinés à orner les parcs et les jardins soient côtés chers, très-cher même, rien de mieux (Journal de viticulture pratique)

1873 Son cœur a pris du ventre et dit bonjour en prose.

Il est coté fort cher... ce Dieu c'est quelque chose

(Tristan Corbière, Les Amours jaunes)

1907 Dans ce catalogue les seuls autographes des frères de Napoléon, Joseph et Lucien, sont cotés plus cher que les miens ! (Léon Bloy, Journal 2: L'Invendable)

\section{Coucher aise}

I. Se coucher confortablement

Intransitif

1350 L'OSTE. Sire, oil, vous me semblez gent

Nobles ; bien serez hebergiez.

Entrez ens et aise couchiez

Et sans riote.

GRIMAUT. Sa, mon seigneur, vezci nostre hoste

Qui nous fera aise, se dit,

Et s'arons blans draps et mol lit

Sur toute rien

(Miracle de la marquise de la Gaudine, 934)

II. Coucher facilement, placer facilement dans

la position horizontale

Transitif

1456 Et a ce malostru changon,

Moutonnier, qui le tient en procés,

Laisse troys coups d'un escourgon

Et coucher paix et aise es ceps

(François Villon, Le Lais, 144)

REMARques : Aise est un adjectif-adverbe de manière de l'ancienne langue. Dans son emploi intransitif (I), il réfère à la position dans laquelle le sujet se couche ou s'allonge, lui laissant une liberté et souplesse totale des mouvements du corps et lui conférant un certain confort. Dans son emploi transitif (II), coucher aise désigne le fait de placer quelque chose dans une position horizontale et avec commodité. La coordination avec paix dans l'exemple de 1456 met en évidence son ambiguïté de substantif-adjectif-adverbe.

\section{Coucher dur}

S'allonger, dormir sur une couche dure Intransitif

1592 Platon veut plus de mal à l'excés du dormir qu'à l'excés du boire. J'ayme à coucher dur et seul, voire sans femme, à la royalle, un peu bien couvert ; on ne bassine jamais mon lict ; mais, depuis la vieillesse, on me donne quand j'en ay besoing des draps à eschauffer (Michel de Montaigne, Essais)

1601 La nourrisse, si elle est à choisir, soit jeune, de temperament le moins froid et humide qu'il se pourra, nourrie à la peine, à coucher dur, manger peu, endurcie au froid et au chaud (Pierre Charron, De la sagesse) 
1955 Les Norvégiens couchent dur (Exemple entendu, 1 août 1955 / Grundt : 238)

1987 Tu sais ce qu'on disait des voyageurs à l'époque, garçon ? Vivent dur, couchent dur, dorment dur, et mangent des chiens! Ha ! (Ronald Lavallée, Tchipayuk ou Le Chemin du loup)

CORPUS WeB :

28. Mets préféré : les pommes frites

29. Préférez-vous coucher dur ou tendre? dur

30. Peuple étranger le plus sympathique : les Peaux-Rouges [https://groups.google.com/ forum/\#!msg/fr.rec.arts.litterature/1ejvp5QTl MM/E6ODdBHOG3IJ] (22.10.2014)

Transports intérieurs : Trains : nombreuses lignes de chemins de fer. Quatre classes : Coucher mou (très cher), et coucher dur (hard sleeper, tres bien), et assis mou et assis dur (pour la journée) [http://tourdumondesansavion.uniterre.com/ 21192/Infos+Chine+et+Asie+du+sud+est.html] (22.10.2014)

Il faisait le jardin de l'autre. En d'autre termes oui ça couchait dur [http://forum.canardpc. com/threads/82299-LDJ-le-topic-des-bisous-(quipiquent-un-peu])/page71 (22.10.2014)

REMARQues : Coucher dur renvoie au manque de souplesse et de moelleux au contact d'une chose référant à la literie, le sujet désignant un corps. Dur reste invariable. Notons l'opposition sémantique avec l'adjectif-adverbe tendre dans le deuxième exemple du CW, avec l'adjectifadverbe mou dans le troisième exemple, et l'emploi impersonnel dans le dernier dans lequel ça couchait dur signifie que les personnes entretenaient des relations sexuelles fréquentes. Notons également l'emploi de asseoir dur, asseoir mou, vivre dur, dormir dur.

\section{Coucher gros}

I. Faire l'amour / risquer

Emploi absolu

1584 Despesche-toy de descendre et de m'ouvrir la porte si tu veux sauver ta vie et l'honneur de ta maistresse ! Car je te puis asseurer que Dame Louyse ne fait que de partir d'icy, et a veu par le trou de la serrure mon maistre qui jouoit beau jeu avec Geneviefve, car il couchoit gros (Turnèbe, Les Contens)
II. Jouer gros jeu ; risquer

Emploi absolu

1613 Au cas qui s'offre, vous avez le dé en la main, livrez la chance ; que si on vous couche plus gros que vous ne desirez, vous pouvez quitter la main (Estienne Pasquier, Lettres familières)

\section{Coucher mou}

Coucher sur un matelas souple

入 coucher dur

\section{Coucher soef}

Coucher délicatement, doucement, confortablement

Transitif

1100 Cuntre sun piz puis si l'ad enbracet, Sur l'erbe verte puis l'at suef culchet. Mult dulcement li ad Rollant preiet : «E ! gentilz hom, car me dunez cunget : Noz cumpaignuns, que oümes tanz chers, Or sunt il morz, nes i devuns laiser » (Chanson de Roland, 2175)

1177a An son escu li fet litiere De la mosse et de la fouchiere. Quant il li a feite sa couche, Au plus soëf qu'il puet le couche, Si l'an porte tot estandu Dedanz l'anvers de son escu (Chrestien de Troyes, Yvain ou Le Chevalier au lion, 4658)

$\sim 1177 b$ Et si tost com il fu venuz, Quant il fu de sa robe nuz, An une haute bele couche La pucele soef le couche, Puis le baingne, puis le conroie Si tres bien que je n'an porroie La meitié deviser ne dire (Chrestien de Troyes, Lancelot ou Le Chevalier de la charrete, 6682)

1190 Kant Olivier l'entent, mout enn a grant pité ;

S’espee mist el floure, s’a le roi acolé ; Desus l'erbe le couche belement et soué (Fierabras (L), 1592)

1312 En la burse v[us] me q[ue]rez E p[ur] veir la me troverez, Mut ferm lié. 
Les un[s] me q[ue]rent en la bouch[e] Ke q[ue]re me dusse[n]t en la huche, Mut suef coché (Plainte d'Amour, 144)

+1350 Tout li .iiij. serjant ont Bruiant en porté Et l'ont moult doucement de la table levé ; Si l'ont couchiet souef dedens .i. lit paré, Et si l'ont bien couvert d'un couvertour fourré,

Et moult tres doucement si li ont demandé S'il vouloit chose avoir qui fust por sa senté (Brun de la Montaigne [2 moitié XIV] $]$, 2311)

Intransitif

1200 Anuit de nuit quant il fu enseré

Et je me fui couchiéz en lit souef, Me vint uns angres qui gieta grant clarté Que m'envoia Jhesus de majesté (Ami et Amile, 2893)

1230 Quant vos estes soef en vostre lit couchiez, Et mangiez les gastiaus, les poons, les ploviers, Lors menaciez Espaigne la terre à essillier (Gui de Bourgogne, p. 2)

REMARQUES : En ancien français, coucher soef désigne le fait de placer, de mettre quelqu'un dans une position horizontale qui procure repos et confort. Soef reste invariable et est modifié par au plus, moult. Notons la coordination avec bellement et l'ambiguïté nominale-adverbiale de couchiéz en lit soef dans l'avant-dernier exemple. Mentionnons également l'emploi de lier ferme ; avoir cher.

\section{Coucher tendre}

Coucher sur un matelas moelleux

$\lambda$ coucher dur

\section{Coudre étroit}

Coudre étroitement, en serrant

Transitif

1190 De som bliaut li ont un des panz derompu, Les eulz li ont bendés et mout estroit coussu.

Inselement le lievent sor un ceval quernu. Olivier s'escria : Karlemaine, ou es tu ? (Fierabras (L), 1785) $\sim 1275 \mathrm{Li}$ a, por meauz estre vestues, Ses deus manches estreit cousues [variantes : trés bien cousues / Chascune manche estroit cousue]

(Jehan de Meun, Roman de la rose [12691278], 21002)

\section{CORPUS WEB :}

L'autre objet long et rond me fait penser à un triboulet, outil de bijoutier pour mesurer le diamètre des bagues et éventuellement les élargir. Pour une couturière, cela pourrait servir à tourner un tissus cousu étroit, une ceinture par exemple..., afin que l'ourlet se trouve ensuite à l'intérieur. ?? [http://www.leblogantiquites. com/2010/04/beaux-objets-en-bois.html] (22.10.2014)

Je peux pas te dire, j'ai jamais refais de Récaro. Mais les sièges avant c'est toujours un peu plus galère, parce qu'il y a les cotés enveloppants et au niveau du bas, pour que çà tende bien, c'est cousu étroit. Attention à la déchirure [http:// golfoo.net/forum/viewtopic.php? $\mathrm{p}=711490 \&$ sid $=$ eda24ff010781365a21514a6602086eb] (22.10.2014)

Anneau de sangle cousue étroit, léger et très résistant [http://www.sports2nature.com/P51, beal-anneau.dyneema.6mm.html] (22.10.2014)

Remarques : Coudre étroit renvoie au fait de faire tenir (un tissu, une étoffe) au moyen de petits points serrés, étroit soulignant la précision, l'exactitude dans le geste. Étroit reste invariable et est modifié par bien. L'ancien français tend à l'antéposition d'étroit (aussi pour la rime, il est vrai), tandis que l'emploi actuel, dans le CW, au sens de "coudre sur une bande étroite de tissu, sur une petite largeur' le postpose.

\section{Coudre (acoudre) fort}

Coudre fortement, solidement

Transitif

+1225 Li Soudans les departit et les envoia en pluisours lius en ses prisons. Li cuens de Pontiu et ses fils et me sire Thiebaus estoient si fort acousu ensamble c'on ne les pooit departir (La Comtesse de Ponthieu [ $2^{\mathrm{e}}$ quart XIII'], p. 199)

CORPUS Web :

Ma collègue Cathy va hurler mais j'ai cousu deux boutons boules pour les yeux, je 
trouvais que ça lui donnait un air marrant !!! (mais je les ai cousu fort fort fort, hein !) [http:// latelierdemisstinguette.over-blog.com/articleooo-le-chat-qui-avait-perdu-ses-bras-ooo-109320 836.html] (23.10.2014)

Deux bandes fluo de chaque côté des flans, sangles polypro 50mm cousues fort supportant 4 poignées dorsales, deux sangles ventrales et une sangle poitrail de maitien $50 \mathrm{~mm}$ montées sur mousse doublée $8.5 \mathrm{~cm}$ pour plus de confort. Fermetures rapides extra robustes, poignée arrière. Longueur $60 \mathrm{~cm}$ [http://www.lescanailloux.com/ component/hikashop/produit/188393-harnaisspecial-terre-neuve.html?Itemid=122] (23.10.2014)

Et dire que j'ai le livre et que je n'ai jamais songéà coudre cemodèle! Tout me plaît, le style, la couleur, les tissus, tu as encore cousu fort Maïta... Douce soirée dominicale à toi [http://maitalcrea. canalblog.com/archives/2014/05/04/29799591. html] (23.10.2014)

REMARQUes : Pris au sens de base, coudre fort réfère en couture au fait de serrer bien fort le fils (CW). Dans l'exemple de l'ancien français, il désigne les liens très forts qui unissent des membres d'une famille ou plusieurs personnes entre elles, qui sont inséparables et qui apparaissent toujours ensemble, étroit soulignant l'attachement, les liens serrés. Fort reste invariable et est modifié par si. Dans le premier exemple $\mathrm{du}$ CW, fort signifie 'solidement', ou, en analogie avec faire fort, 'avoir très bien réussi, avoir fait un exploit' Notons également la réduplication emphatique de fort dans le premier exemple du CW.

\section{Coudre menu}

Coudre à petits points, coudre souvent

Transitif

+1175 Estoit la dame, estroit vestue

E d'un fil d'or menu cosue

(Béroul, Tristan $\left[4^{\mathrm{e}}\right.$ quart XII $\left.\mathrm{e}\right], 1147$ )

Emploi absolu

1886 Oh ! Ces veillées d'hiver, quand les branchages manquaient pour faire du feu ! Travailler ayant froid, travailler pour gagner sa vie, coudre menu, achever avant de dormir les ouvrages rapportés chaque soir de Paimpol. La grand'mère Yvonne, assise dans la cheminée, restait tranquille, les pieds contre les dernières braises, les mains ramassées sous son tablier. Mais, au commencement de la soirée, il fallait toujours tenir des conversations avec elle (Pierre Loti, Pêcheur d'Islande)

\section{CORPus Web :}

Pour traduire, moi j'aurais bien lu un chapitre $41 / 2$ entre le $4 \mathrm{e}$ et le $5 \mathrm{e}$. Il manque un petit bout d'histoire, non ? Ça me fait cette impression... Un tout petit bout. Il faut dire - ou redire - que je quitte plus de 1000 pages d'une intrigue ficelée, cousue menu, au fil d'or, du même auteur [http://maman-baobab.blogspot.co.at/2013/01/ oups-un-peu-bof.html] (23.10.2014)

REMARQuES : Coudre menu désigne le fait de faire retenir (un tissu, une étoffe) au moyen de petits points, menu soulignant la finesse, mais aussi la précision, l'exactitude dans le geste. Dans langage de la couture, on parle de " couture menue " qui désigne une suite de points par lesquels on assemble avec du fil deux pièces d'étoffe, du cuir, etc. On parle aussi de " couture fine ou plate ». Menu reste invariable, même si le participe passé de coudre s'accorde avec l'objet du verbe (ex. +1175 et $\mathrm{CW}$ ). Le dernier exemple est un emploi au figuré, renvoyant à la structure complexe d'un texte. Notons l'emploi de vêtir étroit.

\section{Coudre serré}

Coudre à points serrés

$\pi$ faire solide

\section{Couler abondant}

Couler en grande quantité

$\lambda$ couler facile

\section{Couler bas}

I. (S')abattre, faire s'effondrer, faire s'écrouler Transitif

1615 C'est ceste seule appréhension qui fait que le Roy d'Espagne commande et encharge expressément qu'en quelque part que l'on puisse prendre les François, soit endeçà, soit au-delà de lignes, on les pende et coule bas. Que, surtout, on empesche la communication des habitans du pays avec eux (Antoine de Montchrestien, Traicté de l'économie politique) 
1780 Voilà, chère enfant, ma confession, ma vraie confession ; je suis capable et coupable de tous ces péchés, mais seulement pour toi. Au reste, tu l'as coulé bas, le pauvre Dupont, et ton sermon sur les purgations est charmant : je t'en remercie, tendre et charmante amie (Honoré de Mirabeau, Lettres originales écrites $d u$ donjon de Vincennes)

1863 Mais on entend au loin le canon des Corsaires ;

Le Négrier va fuir s'il peut prendre le vent. Alerte ! et coulez bas ces sombres adversaires!

(Alfred de Vigny, Les Destinées)

Intransitif

1962 Sur le lit, il s'étonna de se relâcher encore, de couler plus bas, de ne plus sentir que deux écailles posées de chaque côté d'une sphère molle : ses mains recroquevillées posées sur les ongles de part et d'autre de ce qui lui restait de pensée : cette présence creuse et contractée, tapissée de muqueuses d'une douceur de naissance (Daniel Boulanger, Le Téméraire)

II. Être englouti au fond de l'eau, sombrer ; provoquer un naufrage

Intransitif

1623 Pensez-vous bastir desormais Vos fortunes sur mes ruynes?

Non, non, vous n'enterez jamais

Des roses dessus mes espines.

Si mon navire coule bas

En quel port vous irez-vous rendre?

Sy je brusle, serez-vous pas

Ensevelis dessous ma cendre?

(Jean Auvray, Le Banquet des muses ou Les Divers Satires)

1770 De l'aveu du sage administrateur qui nous sert principalement de guide, on doit la regarder comme un corps épuisé, qui ne se soutient que par des cordiaux. C'est, suivant son expression, un vaisseau qui coule bas, et dont la submersion est retardée par la pompe (abbé Raynal, Histoire philosophique et politique des établisse- ments et du commerce des Européens dans les Deux Indes)

1801 Pourquoi, las de la vie, ne sait-on pas la quitter, comme on sort d'une maison prête à tomber, comme on abandonne un vaisseau prêt à couler bas ? Enfin je me soumis, et ne pouvant mourir, je fis profession d'ignorance et de superstition pour le reste de mes jours (J. Hector St John de Crèvecœur, Voyage dans la Haute Pensylvanie et dans l'État de New-York)

1862 Le premier objet qui frappa nos yeux fut notre barque. Elle gisait environ à deux cents toises de l'endroit où elle avait coulé bas (Théophile Gautier fils, Aventures du baron de Münchhausen)

1863 Cet anneau rompu semblait arracher du sable son ancre de miséricorde et quelques jours après celui-là, il ne fit que dériver et, enfin, couler bas en trois heures (Alfred de Vigny, Mémoires inédits)

1869 Ils se prirent à bras-le-corps, deux par deux, trois par trois ; c'était le moyen de ne pas sauver leur vie ; car leurs mouvements devenaient embarrassés, et ils coulaient bas comme des cruches percées... Quelle est cette armée de monstres marins qui fend les flots avec vitesse ? (Lautréamont, Les Chants de Maldoror)

1909 Beaucoup sont chargées à couler bas de ces jarres en terre, invariables depuis trois mille ans, que les fellahines savent poser sur leur tête avec tant de grâce, et on voit ces entassements de poteries fragiles prendre la course au-dessus de l'eau, comme soulevés par des ailes gigantesques de mouette (Pierre Loti, La Mort de Philæ)

1930 Les premiers armateurs de New-York réussissent assez mal ; leurs capitaux et leurs bateaux coulent bas ; mais ils voient grand; ce sont les premiers qui, en introduisant le confort, le luxe, les gros tonnages, forcent les Anglais à comprendre que la mer n'est pas réservée exclusivement aux marins (Paul Morand, New-York) 
Transitif

1797 Ce qui paraîtra, sans doute, inconcevable, c'est que pendant ce temps, cinq ou six pirogues partirent de la côte, et vinrent avec des cochons, des pigeons et des cocos, nous proposer des échanges : j'étais, à chaque instant, obligé de retenir ma colère, pour ne pas ordonner de les couler bas (Louis-Antoine Destouff Milet-Mureau, Voyage de La Pérouse autour du monde)

1842 - Lui ? s'écria le capitaine. Ah ! il ne s'appelle pas l'Othello sans raison. Il a dernièrement coulé bas une frégate espagnole, et n'a cependant pas plus de trente canons ! Je n'avais peur que de lui, car je n'ignorais pas qu'il croisait dans les Antilles... (Honoré de Balzac, La Femme de trente ans)

\section{Disparaître}

Intransitif

1734 Monsieur, dis-je à ce geôlier en lui mettant dans la main quelques-unes de ces pièces d'or que m'avait donné Mlle Habert, qu'il ne refusa point, qui l'engagèrent à m'écouter, et que j'avais conservées, quoiqu'on m'eût fait quitter tout ce que j'avais, parce que de ma poche qui se trouva percée, elles avaient, en bon français, coulé plus bas ; il ne m'était resté que mon billet, que j'avais mis dans mon sein après l'avoir tenu longtemps chiffonné dans ma main (Pierre de Marivaux, Le Paysan parvenu)

1963 La mare en forme de roue était bue lentement par le sol de graviers, et tous, on est le cœur serré par un passage étrange ; le corps de l'homme mort, maintenant, se dépouillait tranquillement de son souvenir risible. Il coulait bas au fond des esprits, qui n'essayaient même plus de le retenir, de l'imaginer ballotté dans les morgues et les fosses communes (JeanMarie Gustave Le Clézio, Le Procès-verbal)

IV. S'échapper, s'éloigner furtivement Pronominal

1839 Dernièrement, lorsque le fier Ennemi pendait sur notre arrière-garde rompue, nous insultant, et qu'il nous poursuivait à travers le gouffre, qui n’a senti avec quelle contrainte, et quel vol laborieux nous nous coulions bas ainsi ! (François de Chateaubriand, Le Paradis perdu)

V. Glisser (dire) à voix basse, en chuchotant Transitif

1899 C'est un chef qui reçoit une consigne. Pour les autres, le cas est différent. On ne peut pas rencontrer un député sans qu'il vous coule tout bas dans l'oreille cette confidence : «Vous savez, je suis avec vous. Mais la politique, mon cher ! On ne peut se mettre tout le monde à dos, comme ça. Il faut louvoyer. Attendez, vous verrez » (Georges Clemenceau, L'Iniquité)

\section{CORPUS Web :}

le tir à couler bas, en dessous de la ligne de flottaison du navire, est d'une efficacité toute relative. Le boulet peut traverser la muraille en bois, mais les fibres de bois ont tendance à se redresser après son passage et le charpentier et ses aides peuvent appliquer un calfatage de fortune avec des tampons suiffés pour colmater les voies d'eau [http://marine-imperiale.pagespersoorange.fr/vie_bord/artillerie.htm] (28.10.2014)

Lorsqu'un bâtiment est coulé ou menace de couler bas ou qu'il est amarré d'une façon insuffisante et placé de façon à présenter du danger pour les accostages, les ouvrages d'art ou les installations portuaires, les commissaires maritimes et en général les agents du Service des voies navigables sont autorisés à prescrire aux capitaines ou aux propriétaires toutes mesures qu'ils jugent nécessaires [http://www.leganet. cd/Legislation/Droit\%20economique/transport/ 0.64.560.22.12.1958.htm] (28.10.2014)

Terribles, ces vierges druidesses le sont par leur puissance. Elles savent comment calmer les vents furieux ou les lancer sur votre barque pour vous couler bas [http://eden-saga.com/ $\mathrm{fr} /$ histoire-gaule-religion-croyances-des-druid esses.html] (28.10.2014)

Le combat s'engage entre la sultane qui se défend âprement et les deux vaisseaux maltais. Ses mâts sont abattus par les boulets ennemis mais quoique complètement désemparée, elle refuse de se rendre, et cela malgré les menaces réitérées de de Chambray de la couler bas [http://fr.wiki 
pedia.org/wiki/Bataille_au_large_de_Damiette] (28.10.2014)

Bon, démerdez vous, moi, la dernière fois que j'ai essayé d'être sympa et de pointer les choses telles qu'elles sont, on m'a dit de fermer ma gueule, donc je ferais pas la connerie de l'ouvrir plus que ça aujourd'hui. Et en plus j'ai été obligé de me la couler basse etc... Moui, je suis peut-être un peu rancunier [http://forums. euw.leagueoflegends.com/board/showthread. php?t=400052] (28.10.2014)

REMARQues : Dans un contexte de guerre ou de combat (I), couler bas désigne le fait de faire tomber son adversaire, de l'abattre. Lorsque l'objet désigne une personne, un aspect de son activité intellectuelle ou de sa conduite morale, couler bas réfère aussi au fait de discréditer quelqu'un. Dans son emploi intransitif, il désigne un mouvement vers le bas, le sujet s'écroulant ou s'effondrant de fatigue. En (II), le sujet du verbe intransitif désigne une embarcation qui ne se maintient plus à la surface de l'eau, qui s'engloutit et sombre ; celui du verbe transitif provoque le naufrage d'une embarcation. En (III), le sujet désigne un être animé ou inanimé dont le souvenir disparaît dans l'esprit d'autrui. En (IV), en référence au mouvement, il renvoie au fait de s'échapper, de s'éloigner doucement d'un endroit. En (V), il réfère au fait de dire quelque chose à voix basse à quelqu'un. Bas reste invariable et est modifié par tout, plus. Le dernier exemple du CW montre un emploi fléchi dans le tour populaire se la couler basse 'se taire' qui entraîne le féminin sans affecter la fonction adverbiale (à comparer avec se la couler douce). Notons l'emploi de voir grand.

\section{Couler brut}

Couler une substance comme, par exemple, du béton ou de la chape, et laisser durcir sans soins additionnels

Emploi absolu

2012 Tu te souviens du coulage de la dalle ? C'était affreux : on n'avait pas le matériel, et c'était épuisant. Les gars ont coulé brut, et pour le lissage, on n'avait qu'une pauvre règle de maçon... Plus jamais tu m'embarques dans tes plans ! (Exemple entendu / Corpus Coiffet 2018 : s.v.)

\section{Couler clair}

I. (au propre) Couler sans être trouble (d'un liquide)

1869 Lorsque les jus ont été saturés au point voulu, on les laisse tomber dans un décanteur où le carbonate de chaux se dépose, ou bien, ce que nous croyons préférable, dans un monte-jus d'où ils sont envoyés dans l'appareil appelé Presse filtre d'où ils coulent clair à la première filtration

(Bulletin de la Société des anciens élèves de l'École spéciale de commerce, d'industrie et des mines)

1906 Les ruisseaux du trottoir coulent clair ([journal] / Küffner s.v.)

1955 Il mourut dans le fossé, Guerif pleurait, les larmes coulaient clair sur ses joues noircies (Claude Roy, À tort ou à raison)

1967 Les eaux de l'oued Tindja coulent clair, même en hiver : la garâa sert de bassin de décantation des oueds et protège le lac de l'envasement (Jean Despois et René Raynal, Géographie de l'Afrique du NordOuest)

\section{II. (au figuré) Parler avec clarté}

2019 Il avait parlé avec des mots qui coulaient clair et disaient vrai (Patrick Breuze, La Lumière des cimes)

\section{CORPUS WEB :}

Il m'a dit que je ne devais pas m'inquiéter temps que les chats avaient de l'appétit et que leurs yeux et nez coulaient clair [https://www. chatsdumonde.com/forum/f47/fievre-apres5jours-le-vaccin-du-coryza-est-ce-possiblet319630/] (10.10.2010)

REMARQUES : Couler clair renvoie au propre (I) à un liquide qui coule clair et transparent, sans résidus visibles et, au figuré (II), à la clarté d'un propos. Nous ne citons que des exemples où clair n'est pas accordé. Dans Frantext, on ne trouve que des emplois accordés qui reflètent probablement une tendance de bon usage (v. Remarques s.v. couler doux). Notons la collocation couler clair et dire vrai. 


\section{Couler doux}

I. Être très agréable, bon, plaisant (à entendre, à lire, à voir, etc.)

Intransitif

1538 Venus, venuste et celeste deesse, Ne sentit onc au cueur si grand' liesse En recevant par Paris, juge esleu. La pomme d'or, comme moy quand j'ay leu Ta lettre doulce et d'amour toute pleine, Tant coule doulx, tant nayfve a la veine, Tant touche bien noz jeunesses muées (Clément Marot, Épitres)

1596c Le desespoir tiroit ces plaintes de ma bouche,

En mes larmes desjà à nage estoit ma couche,

Quand estonné j'entr'oy un doux coulant parler,

Mon oreille flattant, qui me vient consoler (Philippe Desportes, Euvres)

1652 Ineffable et pleine douceur, Daigne, ô mon Dieu, pour moi changer en amertume

Tout ce que le monde présume Couler de plus doux dans mon cœur (Pierre Corneille, L'Imitation de JésusChrist)

\section{SUR DES CRUCHES DE CALVADOS}

Ami, bois ce jus de pomme

$\mathrm{Tu}$ te sentiras un homme.

Je fais le vœu que ma liqueur

Vous coule douce jusqu'au cœur.

Je tiens secret ce que pense

L'homme qui vida ma panse

(Stéphane Mallarmé, Vers de circonstance)

1910 Et voilà qu'un rire étrange résonnait soudain si loin, si loin et si près de moi ! Un rire d'adolescente chère à mon adolescence, un rire d'autrefois et d'avenir, un rire de sauvagesse coulant et fleurant doux tel du baume tranquille... les yeux clos, la vie suspendue toute à cette mélodie de la jeunesse, je me reportais, Monsieur le chevalier, à mon sombre passé de rocher perdu au milieu de la solitude des mers (Oscar Milosz, L’Amoureuse Initiation)
II. S'écouler, couler doucement, lentement

Intransitif

1596a Un petit ruisseau doux coulant

A dos rompu se va roulant, Qui t'invite de son murmure (Philippe Desportes, Euvres)

1596b Cette fontaine est froide, et son eau doux-coulante,

A la couleur d'argent, semble parler d'Amour (Philippe Desportes, Euvres)

1656 Ce foudre, par son vol, ebranslera la Flandre :

Thionville par luy verra son mur en cendre. Et le superbe Rhein, estonné de ses coups, Respectera les lys, et coulera plus doux (Jean Chapelain, La Pucelle)

1943 La source coulant douce et nue

La nuit partout épanouie

La nuit où nous nous unissons

Dans une lutte faible et folle

Et la nuit qui nous fait injure

La nuit où se creuse le lit

Vide de la solitude

L'avenir d'une agonie (Paul Éluard, Les Sept Poèmes d'amour en guerre)

III. Passer, s'écouler d'une manière douce, agréable, délicieuse

Intransitif

1620 Car le mortel ennuy dont elle estoit pressee D'esloigner pour jamais le bien de sa pensee,

Joint au juste regret de voir finir ses ans Alors qu'ils luy couloient si doux et si plaisans,

Ternissoit les rayons de sa grace premiere, Desanimoit ses yeux de leur vive lumiere, Et cruel violoit de son secret effort Ce qu'avoit respecté l'œil mesme de la mort (Jean Bertaut, Les Euvres poétiques)

1910 et ma douce mie me baisait tendrement.. d'amour singulier, enfantin, pervers, profond et mélancolique ; de l'amour le plus rare, ma mie adorée ! Venez, venez, que je vous rende la pareille ! Ah ! Chevalier, que les heures coulaient douces au palazzo Mérone! (Oscar Milosz, L’Amoureuse Initiation) 
1946 Inhérent à la condition humaine ? Ou une leçon bien apprise ? Et dont personne n'osait ni ne semblait vouloir s'affranchir? Parbleu, jusqu'à son départ pour Paris, l'existence avait coulé tout doux pour lui. $\mathrm{Au}$ jour le jour. Des angoisses, certes. Mais mesurées (Raymond Guérin, L’Apprenti)

2005 Il y fait chaud, la vie semble couler douce, loin de la guerre dont il ne parle pas, pour un groupe de jeunes gens insouciants, partageant leurs loisirs entre pique-niques et balades à vélo (Marie Chaix, L'Été du sureau)

\section{Venir à l'esprit avec légèreté \\ Intransitif}

1779 D'un long et doux sommeil j'y goûterai l'ivresse ;

Et lorsque m’arrachant à sa molle paresse, Je voudrai des saisons célébrer les bienfaits,

Ou chanter des héros l'audace et les hauts-faits,

Je n'y trouverai point les muses indociles, Et mes vers couleront plus doux et plus faciles (Jean-Antoine Roucher, Les Mois)

V. se la couler douce : mener une vie agréable Pronominal

1877 Pourvu que son mari et son amant fussent contents, que la maison marchât son petit train-train régulier, qu'on rigolât du matin au soir, tous gras, tous satisfaits de la vie et se la coulant douce, il n'y avait vraiment pas de quoi se plaindre (Émile Zola, L'Assommoir)

1884 Fils d'un marchand de nouveautés de Caen, il se l'était coulée douce, comme on disait dans sa famille, jusqu'à l'âge de vingt-cinq ans (Guy de Maupassant, Contes et nouvelles)

1911 Il n'était pas à plaindre, il avait sa retraite du chemin de fer, et pas de charges. Il allait pouvoir se la couler douce. Voilà ce que c'est ! (Jules Romains, Mort de quelqu'un)

1952 D’abord, vous savez pas ce que vous perdriez. Être officier, ou même sous-off, c'est pas à la portée d'n'importe qui... Et puis comment qu'on s'la coule douce... Aux colonies, par exemple, y a rien à branler (Yves Gibeau, Allons z'enfants)

1985 Quant aux autres, ils s'agitent beaucoup, ils font du bruit, ils fument, ils vont au cinéma, ils s'occupent des filles... pour passer le temps. Et puis il y a ceux « qui se la coulent douce ", qui ne s'ennuient pas du tout et qui, dans la vie, se laisseront, parasites, porter par les autres (Françoise Dolto, La Cause des enfants)

2007 L'argument selon lequel Sérioja se barre en Tchétchénie pour se la couler douce et échapper à la corvée de bois est tellement saugrenu que tout le monde, lui le premier, éclate de rire, et elle, sentant qu'elle tient son public, qu'elle amuse et capte l'attention, ne peut plus s'arrêter, en rajoute, il n'en faudrait pas beaucoup plus pour qu'elle monte sur la table et se mette à danser (Emmanuel Carrère, Un roman russe)

CORPus WeB :

Séverin, il nous a fait couler doux l'été avec son album L'Amour Triangulaire, sorti en digital, en juin dernier [http://www.arkult.fr/2011/09] (28.10.2014)

Oui : j'ai vu (et tu as intérêt à couler doux car je n'ai pas vocation à devenir le laquais de pépé) [http://www.insecte.org/forum/viewtopic. php?f $=2 \& t=100755]$ (28.10.2014)

OUI, Monsieur SARKOSY est dangereux pour les faignasses et les profiteurs. A bon entendeur... se remettre à bosser... non mais... quel scandale, quand on pouvait (sous les socialistes) se la couler doux aux frais de la Princesse [http:// forum.doctissimo.fr/viepratique/politique/ monsieur-sarkozy-dangeureux-sujet_3826_5. $\mathrm{htm}]$ (28.10.2014)

Et si août était le mois rêvé pour vous la couler douce? Voici trois conseils pour apprendre l'art subtil de la glande estivale au bureau [http:// www.terrafemina.com/emploi-a-carrieres/vietravail/articles/47261--astuces-pour-se-la-coulerdouce-au-bureau-en-aout.html] (28.10.2014)

REMARques : Couler doux (I) désigne une atmosphère ou un moment agréable. Il peut aussi 
référer à une action qui se passe sans problèmes, qui est perçue par le sujet de manière positive ou qui a un impact positif sur celui-ci. En (II), le sujet désigne un liquide (l'eau d'un ruisseau, d'un fleuve) qui se déplace d'un mouvement continu et naturel, de façon agréable et harmonieuse. Le liquide peut aussi correspondre aux larmes ou au sang d'une personne dont l'écoulement se caractérise par une certaine fluidité. En (III), le sujet se rapporte au temps (la vie, les années ou des heures) qui s'écoule de manière agréable, sans peine. En référence à l'écriture, couler doux (IV) désigne une certaine aisance du poète ou de l'écrivain dans la rédaction de son texte, les mots ou les idées lui venant à l'esprit de façon spontanée, avec fluidité. La locution se la couler douce (V) reflète un emploi familier. Dans la langue moderne, la tendance générale (acceptions I à V) est à l'emploi prédicatif postposé et fléchi. C'est ainsi que doux s'accorde souvent avec le sujet. Cette tendance est propre au verbe couler. Nous avons exclu du dictionnaire quelques groupes usuels parce que l'accord avec le sujet est systématique, du moins à en juger par Frantext (ex. couler chaud, immobile, limpide, $n u$, onctueux, pur). Par contre, couler doux peut ressortir à une lecture adverbiale de manière et rester invariable (1946) (v. aussi s.v. couler clair). La collocation doux et facile lui confère une interprétation plutôt adverbiale, même si facile est fléchi (ex. de 1779). Doux-coulant est un groupe figé (1596a,b,c). L'exemple de 1652 diffère par la fonction partitive, mais il s'inspire sans doute de l'expression couler doux. On le retient donc comme variante. Doux est modifié par plus, si, tant, tout. L'expression du type se la couler douce, qui a son pendant dans d'autres langues romanes, est populaire. Notons que dans le troisième exemple du CW, doux ne s'accorde pas bien qu'il fasse partie de l'expression figée se la couler douce. Ajoutons l'emploi impersonnel de vous la couler douce en référence au monde du travail (vous généralisant). Les variantes syntaxiques dans le CW soulignent la vitalité et la productivité de l'expression. Mentionnons aussi l'emploi de fleurer doux.

\section{Couler dru}

Couler avec force, couler dense et épais

(boisson, larmes, discours)

Intransitif

1574 Si je la voy d'un glissant pied couler $D r u, d r u$, fuyant en ronde verdugade (Jacques Tahureau, Poésies)

1609 C'est pourquoy dans Homere ceste façon de parler esmeuë et sans intermission, qui coule dru comme neige, est donnee à l'orateur : Mais le langage gracieux, et doux comme miel coule de la bouche d'un vieillard (Mathieu de Chalvet, Les Euvres de L. Annæus Seneca [trad.])

1887 Hélas et encore hélas ! pour les larmes qui ont coulé dru et vite des yeux de femmes et pour les pleurs qui sont restés dans les yeux d'hommes forts, bons ou mauvais, et les ont brûlés! (Francis Marion Crawford, La Marchesa Carantoni)

1913 Non qu'il se révèle comme un caractère très varié : la gaieté est toute sa philosophie, une gaieté qui coule drue et intarissable, et qui prend une pénétrante saveur au contact de la réalité la plus vulgaire (L'Art dramatique à Valencia)

1944 Combien d'années m'arrêtai-je, une fois par an, à Aix-en-Provence, sur le trajet de Paris à Saint-Tropez, parce qu'une eau millénaire coule dru d'une fontaine? (Colette, Gigi)

1974 Bientôt, le vin aidant, et il coulait dru ! des plaisanteries fusèrent, grasses à souhait, en patois le plus souvent qu'Olivier ne comprenait pas toujours (Robert Sabatier, Les Noisettes sauvages)

2013 Dans l'horizon tuméfié, les femmes râlent, elles râlent le destin, elles râlent l'horizon, et la bière coule drue, sur leurs haillons (Elie Bady, La Nébuleuse des idiots)

2020 Les larmes coulent drues sur mes joues (Georges Bitton, Phimosis ou Les Errances d'Henry Golan) 


\section{Couler épais}

Se répandre largement, avec une consistance épaisse

Intransitif

1662 cela fait, ils la [= la semence] mettent à la meulle, où l'huile en coule époisse à guise de moustarde (Blaise de Vigenère, Les Illustrations sur l'histoire [trad.])

1668 Ils attaquent d'abord ses deux enfans aimables ;

Couvrent ces petits corps de leurs plis effroyables,

S'entortillent autour, mordent ces tendres chairs,

Dont le sang coule épais dans leurs gosiers ouverts

(Jean-Regnault de Segrais, Eneïde [trad.])

1819 La méthode pratiquée par la plupart des peintres sur verre, est de dessiner les contours avec de l'encre de la Chine ou avec une couleur brune broyée à l'essence et à l'huile de térébenthine, et de laisser ensuite couler épais la couleur préalablement broyée à l'eau (Bulletin de la Société d'encouragement pour l'industrie nationale)

1931 Jusque par delà des villages et des collines, la route, toute noire, roule le flot des soldats. Ça coule lentement dans tous les plis de la terre ; ça emplit les vals ; ça déborde les combes ; ça suinte des bois ; près du village, un gros lac de soldats dort à la pleine herbe d'un verger creux. La route coule épaisse entre les arbres (Jean Giono, Le Grand Troupeau)

1990 Ici, dans le vide, non loin d'une maison blanchâtre, un couteau démesuré, horizontal, je dis horizontal, et d'où perlait un sang très sombre sur fond de ciel encore bleu, noircissant : rien d'autre - couteau sans nul support, fiché à même un horizon inexistant, à l'angle d'une rue - et d'où coulait, épais, un peu de sang. C'est cet « un peu » qui m’a frappée (Dominique Arban, Je me retournerai souvent)

2010 La chaleur de la journée continuait de couler, épaisse comme un limon, engluée dans les premières ombres du soir (Gérard Georges, Les Chemins d'améthyste)

2011 Hors d'atteinte ? Une autre goutte. Partout le mur se boursoufle, bouillonne. Bouches, partout, qui s'ouvrent. Leur bave lentement me cerne, visqueuse. Je la sens couler entre mes seins. Je suis bouche moimême. Liqueur. Elle monte du fond de moi, déborde. Au coin de mes lèvres, elle coule, épaisse. Orgeat tiède, avec un relent acide. Ma paume, à plat sur le mur, pour conjurer le flux (Pascaline Mourier-Casile, La Fente d'eau)

\section{CORPUS WEB :}

je mets du Cortanmycétine crème (gel avec antibio) lorsque les yeux commencent à couler " épais », signe de début d'infection [http:// forum-acheval.net/post.asp? method=Reply Quote\&REPLY_ID=552623\&TOPIC_ID=35006\& FORUM_ID=9] (28.10.2014)

Elle m'a fait 10 otites en 6 mois et des angines et son nez n'a JAMAIS cessé de couler épais depuis Decembre dernier [http://forum.aufeminin.com/ forum/enfants3/_f5754_enfants3-inquietude-dune-maman.html] (28.10.2014)

Ce n'est pas le point fort du texte. Les longueurs, les lourdeurs, les précisions inutiles, les formules en forme de coquilles vides (v. rubrique style), plombent l'ensemble. Le texte coule épais et le suspense, difficile à agacer compte tenu de l'intrigue, est quasi inexistant [http://www. atramenta.net/lire/oeuvre42949-chapitre327657. html] (28.10.2014)

D'une main tremblante j'essaie de déblayer le terrain pour mettre en lumière les dégâts, je nettoie à l'eau, doucement. Ça fait mal, ça commence à coller, le sang part difficilement, il continue de couler, épais et tenace [https://fr-fr. facebook.com/permalink.php?story_fbid $=4290$ 52130505606\&id=387141568029996] (28.10.2014)

J'imagine comment ta creme devait couler epaisse vers ton anus [http://pt.m.xhamster. com/story/fr/196437.html?openc] (28.10.2014)

REMARQUES : Comme les autres adjectifs qui se combinent avec le verbe couler, épais tend à s'accorder avec le sujet du verbe, dénotant ainsi l'épaisseur d'un liquide, son manque de fluidité. L'interprétation comme adverbe de manière est 
cependant possible dans le sang coule épais, pouvant entraîner l'absence de flexion, notamment dans le langage de la peinture (ex. de 1819). Au figuré, il est transposé à des sujets tels la chaleur, le cours d'une route, la lourdeur d'un style d'écriture (troisième exemple du CW). Les deux premiers exemples du CW font apparaître l'emploi de couler épais dans le domaine du traitement des maladies : le nez, les yeux coule(nt) épais témoignent de couler au sens de 'laisser échapper un liquide (ici : physiologique)’.

\section{Couler facile}

I. Évoluer, se passer sans difficultés, sans peine Intransitif

1779 D'un long et doux sommeil j’y goûterai l'ivresse;

Et lorsque m'arrachant à sa molle paresse, Je voudrai des saisons célébrer les bienfaits,

Ou chanter des héros l'audace et les hauts-faits,

Je n'y trouverai point les muses indociles, Et mes vers couleront plus doux et plus faciles (Jean-Antoine Roucher, Les Mois)

1782 Ainsi d'un long effort moi-même rebuté, Quand j'ai d'un froid détail maudit l'aridité, Soudain un trait heureux jaillit d'un fond stérile,

Et mon vers ranimé coule enfin plus facile.

Il est des soins plus doux, un art plus enchanteur.

C'est peu de charmer l'œil, il faut parler au cœur (Jacques Delille, Les Jardins)

1794 Toi, qui la [= Hippocrène] vis couler plus lente et plus facile,

Quand ta bouche animait la flûte de Sicile ; Toi, quand l'amour trahi te fit verser des pleurs,

Qui l'entendis gémir et pleurer tes douleurs (André Chénier, Élégies)

1943 Dieu ! Que ces larmes sont douces! Oui, que la chaude honte en est douce, libératrice ! Elles coulent plus abondantes et plus faciles encore que les mots, il [= Ouine] les laisse ruisseler sur ses joues, elles inondent sa bouche de leur sel tiède (Georges Bernanos, Monsieur Ouine)
1964 Léo était parti, entraînant ses fidèles. Alors les petites heures de la nuit se mirent à couler, faciles, et Laurent recommença à boire (Christine de Rivoyre, Les Sultans)

1976 Je m'étais mis à marcher le long de la rivière avec les chaussons rouges toujours sous le bras et l'odeur du bouc sous le nez. Je marchais et je parlais. La conversation coulait facile (Jacques Lanzmann, Le Têtard)

II. Couler facilement

Intransitif

1839 Les larmes étaient venues à ses yeux, et les caresses de Henriette les faisaient couler douces et faciles. Le géomètre, conservant seul toute sa fermeté, s'était rapproché de sa femme, et soutenait son courage par des paroles raisonnables et affectueuses (Rodolphe Toepffer, Nouvelles genevoises)

\section{CORPUS WEB :}

Il est des pays qui semblent arrosés et fertiles comme un jardin de l'Éternel, et qui sont maudits, comme cette terre de Sodome, que Lot (Gen. XIII.) se félicitait d'avoir choisie pour résidence, parce que la vie semblait devoir y couler facile, douce et prospère [http://www.regard. eu.org/Livres.11/Fermes_dans_la_tourmente/05. php] (30.10.2014)

je crois que c'est là que ça peut être dangereux, l'OM est tellement fragile en ce moment qu'on peut le couler facile [http://www.opiom. net/forums/archive/index.php?thread-8182-42. $\mathrm{html}]$ (30.10.2014)

attention à ce que tu dis très cher pour les body...bon, je préfère les surfeurs, mais ils sont pas si génant que ca... si ? m’en fous, je suis windsurfille et catatiste... alors les body et les surfeurs, je peux les couler facile.... [http://forum.ucpa. com/showthread.php? $\mathrm{p}=335412](30.10 .2014)$

J'ai testé NineSky et franchement, c'est.... assez bluffant! Rein à redire, tout semble couler facile. Tout est bien placé, bien pensé [http:// forum.frandroid.com/topic/73-navigateur-autreque-chrome/page-2] (30.10.2014)

Un bon rythme et des mots qui coulent faciles et bondissants.

Un message clair. 
J'ai bien aimé la musique des vers [http:// www.oniris.be/poesie/gorgonzola-il-faut-yretourner-1911.html] (30.10.2014)

REMARQUES : Très fréquent dans le langage familier, facile s'accorde comme les prédicats seconds avec lesquels il se coordonne parfois, mais sémantiquement il désigne la façon dont se déroule un événement. En (I), le complément d'objet désigne un liquide (les larmes) dont le verbe décrit le mouvement léger et sans peine. En (II), le sujet peut désigner une durée qui s'écoule sans peine, voire rapidement, mais peut aussi référer à la parole et souligne une certaine fluidité dans l'échange de propos entre deux personnes ou dans la façon d'exprimer quelque chose. Notons la collocation couler doux et facile et les adjectifs-adverbes doux, lent, abondant, prospère et bondissant. Facile est modifié par (enfin) plus. Le second exemple du CW actualise la signification de 'noyer, détruire' (une équipe de football) qui revient également dans le troisième exemple. Dans le second exemple du CW, facile devient un adverbe de phrase qui ne désigne plus une manière de réaliser un événement, mais un jugement 'il est facile de le couler'.

\section{Couler fluide}

Couler rapidement, en un flot continu (les mots d'un discours)

入 filer raide

\section{Couler frais}

Couler fraîchement, en donnant une sensation agréable de fraîcheur

Intransitif

1835 le sang de l'alliance éternelle coule frais et vivant des plaies du Rédempteur (JeanHenri Grandpierre, Discours évangéliques)

1839 Mes yeux il ferma, mais laissa ouverte la cellule de mon imagination, ma vue intérieure, par laquelle, ravi comme en extase, je vis, à ce qu'il me sembla, quoique dormant où j'étais, je vis la Forme toujours glorieuse devant qui je m'étais tenu éveillé, laquelle se baissant, m'ouvrit le côté gauche, y prit une côte toute chaude des esprits du cœur, et le sang de la vie coulant frais : large était la blessure, mais soudain remplie de chair et guérie (François de Chateaubriand, Le Paradis perdu)

1925 Et il criait, de belle humeur pour trois :

- Allons, Norine, fais-nous frire des beignets ! Et va qu'ri une bouteille de vin ! Raboliot finissait par céder. Le vin coulait frais dans la gorge, vous laissait au palais une rustique et bonne âpreté (Maurice Genevoix, Raboliot)

1934 Les odeurs coulaient toutes fraîches. Ça sentait le sucre, la prairie, la résine, la montagne, l'eau, la sève, le sirop de bouleau, la confiture de myrtilles, la gelée de framboise où l'on a laissé des feuilles, l'infusion de tilleul, la menuiserie neuve, la poix de cordonnier, le drap neuf (Jean Giono, Que ma joie demeure)

1976 L'eau coulait fraîche et pure et tous autant qu'on était, on pensait à nos copains engagés depuis la matinée dans la bataille du mont Mouchet (Jacques Lanzmann, Le Têtard)

Transitif

1866 Un mur de quai en béton, coulé frais dans des caisses sans fond et panneaux d'entredeux (Jacques-Eugène Armengaud, Publication industrielle des machines, outils et appareils)

CORPUS WEB :

J'aime bien l'image de la source, c'est bien $\mathrm{vu}$; ça doit donc jaillir, couler frais, ruisseler. Sauf que par ces temps de raz de marée... [http:// gponthieu.blog.lemonde.fr/2005/01/04/2005_ 01_blog_cest_quoi] (30.10.2014)

Dès 1930, la voix de Maurice Fombeure1 a commencé de couler frais sur les pentes surchauffées de la poésie française [http://www.devoir-dephilosophie.com/dissertation-maurice-fomb eure-173793.html] (30.10.2014)

Un parfum de mots à couler frais sur mon cœur chiffonné. Merci de cette attention [http:// www.jepoeme.com/forum/poeme-triste/Sale_ nuit/94417/1.html] (30.10.2014)

Le Festival de Pessac est aussi une volonté d'ouverture et de débat où la parole peut couler fraîche et libre faisant de cette manifestation un lieu de rencontres et de dialogues autour 
des projections [http://www.cinema-histoirepessac.com/archives/historique-du-festival-2] (30.10.2014)

Remarques : Frais désigne la propriété d'un liquide qui coule dans la gorge en donnant une sensation de fraîcheur agréable, mais il se prête aussi à l'emploi figuré où il désigne l'apport d'idées nouvelles. Par rapport au sang, tiède par nature, il réfère plutôt au sang qui vient de s'écouler, pas encore altéré (ex. de 1839). L'exemple de 1976 montre un emploi figuré en prédication seconde.

\section{Couler gros}

I. Être plein, bien rempli de quelque chose Transitif

1838 mais on sait combien est lente la marche des améliorations, et bientôt le temps vint à couler gros de politique et d'orages, et plusieurs années successives retrouvèrent encore des jeunes prisonniers régis par les usages que nous venons d'exposer (Société de patronage pour les jeunes libérés du Département du Rhône, Assemblée générale, procès verbal des séances)

II. Couler en abondance, en grande quantité Intransitif

1979 Sur la pluie qui les a chassés des égouts. Leurs vêtures fument. Ils sentent l'ail et le méthane. Ils ont les poings fermés sur des verres de gnôle.

- Là-d'ssous, ça doit couler gros comme un torrent, dit l'un d'eux. Il secoue son ciré. Il demande qu'on lui remette un calva. Victoire s'avance

(Jean Vautrin, Bloody Mary)

1996 -Va pour le bras d'Emma ! Voilà pourquoi si tu vas un jour dans ce village, tu verras l'eau de la belle fontaine couler gros comme ton bras dans les bidons des gens heureux (Jean-Olivier Héron, Arrête de faire des miracles!)

Corpus Web :

scaphismeNAKK laisse couler gros ils ont oublier c'était quoi le vrai rap [http://www.jeux video.com/forums/1-51-18245875-4-0-1-0-je-met-1ambiance-dans-le-tess-le-soir.htm] (30.10.2014)
Mascun avec de l'eau s'est descendu ce WE. Gorgas pas fait, aucune info pour savoir si des groupes l'ont fait ce WE, mais ca doit couler gros. Balces coule bien, doit être sympa. On a pas fait les Oscuros, que les Estrechos. Aucun soucis [http://www.descente-canyon.com/forums/ viewtopic.php?id=12424] (30.10.2014)

Remarques : Gros est un adjectif-adverbe de dimension qui, au sens métaphorique, réfère à l'abondance en quelque chose. En (I), il désigne ce qui remplit une période temporelle. En (II), le sujet désigne un liquide (la pluie) considérée dans son mouvement, gros renvoyant à une quantité mesurable et soulignant l'écoulement abondant du liquide. Notons la comparaison avec le «torrent » qui souligne le débit permanent du cours d'eau, à crues subites et violentes (ex. de 1979), image que l'on retrouve dans le dernier exemple du CW. Gros reste invariable. VOIR AUSSI : pisser gros

\section{Couler intact}

I. Se manifester de la même manière, comme avant Intransitif

1918 Swann refit la révérence et la princesse eut pour nous tous un divin sourire qu'elle sembla amener du passé, des grâces de sa jeunesse, des soirées de Compiègne et qui coula intact et doux sur le visage tout à l'heure grognon, puis elle s'éloigna suivie des deux dames d'honneur qui n'avaient fait, à la façon d'interprètes, de bonnes d'enfants, ou de gardes-malades, que ponctuer notre conversation de phrases insignifiantes (Marcel Proust, À l'ombre des jeunes filles en fleurs)

II. S'enfoncer dans l'eau sans avoir été endommagé

Intransitif

1948 Souvent la mer se fait la complice de l'ennemi et les navires sont poignardés. Sauf la blessure dans les œuvres vives que fait l'arme cachée, ils coulent intacts. Ils coulent sans avoir eu à lutter, et le marin se confie aux embarcations (Édouard Peisson, La Mer est un pays secret) 


\section{CoRpus Web :}

Sans compter ceux, assez nombreux, qui ne sont pas capables de le dire. Mais il se trouve que plusieurs officiers étaient au nombre de ceux qui affirmaient l'avoir vu couler intact. C'est cela, à mon avis, qui a été déterminant dans la conclusion tenue par l'enquête [http://titanic. superforum.fr/t2790p165-la-cassure-une-theseprouvee] (4.11.2014)

Le témoignage de Seaman Buley est tout à fait exact, mais d'autres témoignages, dont beaucoup furent racontés dans le livre de Walter Lord, décrivirent le paquebot perpendiculaire à l'eau et couler intact [http://x-titanic-1912-x.skyrock. com/3211485673-Le-Titanic-se-brisa-en-deux. html] (4.11.2014)

Est-ce qu'un amerrisage contrôlé par un pilote expérimenté aurait pu permettre l'avion d'amerrir doucement puis couler intact en seul morceau ce qui pourrait expliquer l'absence de débris ? [http://www.madeinnews.com/infos/ redirect.php?actu=1795454] (04.11.2014)

N'oublie pas que c'est avec ma semence que tes maîtres ont procréé... n'oublie pas que c'est avec mon âme, noircie et désolée, que l'on a ouvert les portes. N'oublie pas que les gènes diminués qui te rendent délectable le sang dilué de tes idoles coulent, intacts, dans mes veines [http:// www.gutsofdarkness.com/god/objet.php?objet= 8841] (4.11.2014)

Remarques : Dans le premier exemple (I), intact réfère à l'apparence et à l'expression discrètement rieuse du visage qui reste inchangée. Notons la coordination avec l'adjectif-adverbe doux qui ajoute l'idée de luminosité, d'harmonie. Les autres exemples (II et CW) prennent couler au sens de 'disparaître dans l'eau' ou, dans le dernier exemple du CW, de 'circuler (du sang dans les veines)'. Intact se prête à une analyse en tant que prédicat second orienté vers le sujet, ce qui explique la flexion (ex. de 1948 et le quatrième exemple du $\mathrm{CW}$ ).

\section{Couler lent}

Couler à une cadence modérée

$\lambda$ couler facile

\section{Couler plein}

I. Mouler, fondre plein ; opposé à creux

Transitif

1758 Les premiers canons coulés pleins qui furent rebutés, le furent pour avoir l'ame ondée ; ce n'étoit qu'avec la lumiere du soleil réflechie, et dirigée dans l'ame d'un canon par le moyen d'un miroir, qu'on pouvoit s'apercevoir de ce défaut (Mémoire historique sur la fonte des canons en fer)

1788 Dès lors tous nos canons coulés plein ont été fondus de cette matière douce, c'està-dire d'une assez mauvaise fonte, et qui n’a pas, à beaucoup près, la pureté, la densité, la résistance qu'elle devroit avoir (Georges-Louis Leclerc de Buffon, Euvres complètes)

II. Passer, s'écouler de manière intense, dense (concret et figuré)

Intransitif

1835 D’abord paisible et fortunée,

De ses enfans environnée,

Ses jours coulaient pleins et joyeux ;

Ainsi qu'une blanche colombe

Moi, la première, de la tombe,

J'ai pris mon essor vers les cieux

(Edouard Gout-Desmartres, L’Ange gardien)

1844 Les deux autres ajutages avaient 16 centimètres de côté, le diamètre extérieur de l'un était à peu près moyen entre ceux des deux premiers, le diamètre extérieur de l'autre était à peu près moyen entre ce dernier et celui de 28 millimètres. Les deux ajutages les moins ouverts coulent pleins, sans qu'il soit nécessaire de les faire déboucher sous l'eau, mais il faut que la charge d'eau soit suffisante (A. de Caligny, Expérience sur les ajutages coniques)

1859 J'appris d'elle, Seigneur, d'où vient votre lumière,

Quand j'amusais mes yeux à voir briller ses yeux,

Qui ne quittaient mon front que pour parler aux cieux.

À l'heure du travail qui coulait pleine et pure, 
Je croyais que ses mains régissaient la nature,

Instruite par le Christ, à sa voix incliné, Qu'elle écoutait priante et le front prosterné (Marceline Desbordes-Valmore, Élégies)

1892 Les tuyaux des canalisations ont été calculés de manière à couler demi-pleins avec le débit normal. Le volume des eaux salies (ménagères et fécales) n'étant qu'une fraction du débit normal, il en résulte que ces eaux pourront doubler à certaines heures de la journée sans que les conduites coulent pleines (Paul Pignant, Principes d'assainissement des habitations des villes et de la banlieue)

1985 C'est lui que j'aurais dû épouser, songe-telle vaguement. Avec lui la vie aurait coulé pleine et riche (Roger Ikor, Les Fleurs du soir)

2003 Près d'elle le monde ne faisait pas défaut, le ciel était atteint, les heures coulaient pleines ou le temps s'arrêtait (Pierre Grouix, Laboureur de larmes)

III. Sonner avec intensité, avec plénitude (sens figuré)

Intransitif

1914 Je vais tâcher de lire les notes de Claudel. Charles Guérin a quelque chose dans le ventre. Parmi tous les jeunes en connais-tu un, dont le vers coule aussi plein?

(Alain-Fournier, Correspondance avec Jacques Rivière)

IV. couler plein : remplir quelque chose, être rempli

Intransitif

1921 La perle trouble envahit tout, pénètre l'air, la peau nue. Elle environne sa luxure. Il ne frôle les beaux bras des femmes, les bras coulant pleins comme une colonne vivante, gonflés de sucs et de sang (Élie Faure, Histoire de l'art : l'art moderne)

Transitif

1930 Eau boueuse et foule décolorée coulent plein les rues. Cependant, parmi les fourrures pelées, les jaquettes luisantes, les pardessus corrodés, quelques paysannes bariolées, arlequines à la fois et pierrettes, se hâtent vers la Calea Victoriei... (Roger Vercel, Notre père Trajan)

1987 Ce que bouche doit taire Les yeux le font glisser. Avant qu'un mot ne soit prononcé Les larmes coulent plein les paupières. Misère...

(Anthologie de la littérature vietnamienne : deuxième moitié du XIX ${ }^{e}$ siècle à 1945 [trad.])

\section{CORPUS WEB :}

Après un refroidissement de plusieurs jours, la réplique du canon a été démoulée et ébarbée. Comme cela se pratiquait au XVIIIe siècle, le canon a été coulé plein et l'âme forée ensuite. Puisqu'il s'agissait d'une réplique, le forage n'a été réalisé que sur une vingtaine de centimètres afin de simuler l'âme [http://www.lanildut.fr/ histoire/JYB-Canon.html] (10.12.2014)

C'est un squelette. Il a eu peur d'un fantôme. Il est sur un pont. Il a peur parce que l'eau a débordé, elle a coulé plein partout dans la ville. Le squelette a eu peur de couler. Il y a du soleil en vagues dans le ciel. Aussi peut-être qu'il a peur des sorcières, des araignées [http://sv2. pragmacom.be/ arcadesr/ia/1257541fff1b787cde/ index.html] (10.12.2014)

mets ton robinet d'essence sur PRI (prime, amorce en anglich), et devisse le vis de purge sur le bas de la cuve du carbu. Quand l'essence coule plein tes mains, le tournevis, le moteur, par terre... c'est que l'essence arrive bien au carbu donc referme le vis et demarre, n'oubliant pas de remettre le robinet sur ON une fois demarrer [http://www.lerepairedesmotards.com/forum/ read.php?2,587772] (10.12.2014)

Or, certaines mesures (ASCE/WEF, 1982) indiquent que le $\mathrm{n}$ varie en fonction de la hauteur d'eau et qu'il peut être jusqu'à 29 \% supérieur a la valeur lorsque la conduite coule pleine [http:// www.mddelcc.gouv.qc.ca/Eau/pluviales/chap7. pdf] (10.12.2014)

C'est avec le cœur qui fait mal et les larmes qui coulent pleins mon visage que je vous annonce que Flèche est morte tôt ce matin.... [http:// lililoli64.skyrock.com/2120370905-Fleche-estpartie.html] (15.12.2014) 
...à partir du bord du talus pour les cours d'eau aménagés ou travaillés compte tenu que leur profilage est fait de façon A ce qu'ils coulent pleins lors des crues printanières [http:// www.bape.gouv.qc.ca/sections/mandats/prodporcine/documents/BIO144.PDF] (15.12.2014)

REMARQUES : Couler plein (I) renvoie à un procédé métallurgique dans lequel le canon moulé n'est perforé qu'après avoir été fondu (v. aussi le premier exemple du CW). En parlant d'une durée, couler plein (II) caractérise une période intense en travail, bien chargée, durant laquelle le sujet est très occupé ; il s'applique également à un liquide. En référence à la sonorité des mots (III), il en souligne l'intensité, leur sonorité nette, forte, bien marquée. (IV) réfère à l'aspect physique, le sujet désignant une partie du corps qui se caractérise par ses formes pleines. La flexion de plein souligne son interprétation comme prédicat second orienté vers le sujet. Il est modifié par aussi. L'exemple de 1788 et le CW montrent cependant que plein peut rester invarié. Il semble que le langage soutenu actuel préfère l'emploi fléchi, tandis que le langage plus spontané admet également son invariabilité. Dans (V), plein se détache syntaxiquement du verbe couler pour former un nouveau groupe du type plein quelque chose qui entraîne son invariabilité.

\section{Couler vif}

I. Couler, s'écouler vivement, rapidement Intransitif

1885 leurs relations avaient commencé d'une façon si étrange. Puis, la tête s'était échauffée, les nerfs avaient vibré, le sang avait coulé plus vif, et le cœur battait maintenant. Il battait d'autant plus fort, il s'éveillait d'autant plus ardent, qu'il avait sommeillé, que sa somnolence, son inaction, avaient été plus longues (Adolphe Belot, Une affolée d'amour)

1886 L'herbe jeune, brillante, l'herbe du printemps poussait sur la berge en pente jusqu'à l'eau, et l'eau coulait vive et claire, dans ce lit vert et luisant, une eau joyeuse qui semblait courir comme une bête en gaieté dans une prairie (Guy de Maupassant, Contes et nouvelles)
II. Se fondre, se mouler dans quelque chose

avec vigueur, avec vitalité

Pronominal

1949 Comment fait-on pour se mettre en un vers Lorsque bourdonne en nous tout l'univers, Pour isoler une rose entre toutes Lorsque notre âme est sur toutes les routes, Pour se couler tout vif dans un objet, Chasser le reste en un même rejet, Lorsque l'on est plus dispersé au monde Qu'une comète à la queue vagabonde, Comment fait-on pour être de ce temps (Jules Supervielle, Oublieuse Mémoire)

1963 Seules les cimes des arbres étaient éclairées. Partout, cependant, la lumière se coulait, vive ou atténuée, presque semblable à cette brume qui pénètre même les vêtements (Bernard Clavel, Celui qui voulait voir la mer)

\section{III. se la couler vive : mener une vie active}

Pronominal

2008 Canot, kayak, surf de rivière, kitesurf, rabaska et descente de rapides se pratiquent dans les eaux tout autour de l'île même de Montréal. Voici quelques destinations pour se la couler vive (Catherine Eve Groleau et al., Montréal au fil de l'eau)

\section{Corpus Web :}

Tu sais, t'aurais dû le laisser couler vif, si c'est pour l'upper pour rien du tout [http://www.jeux video.com/forums/1-36-10175919-3-0-1-0-chaudjak-qui-critique-windows.htm] (6.11.2014)

Demain, lorque Tshisekedi ne sera pas candidat, la faute est a IUNAFEC. Arretez d'intimider, de calomnier, desclavagiser, de lyncher, de couler vif le bateau katangais [https://groups. yahoo.com/neo/groups/mediascongolais/ conversations/messages/69815] (6.11.2014)

D'avoir une opinion dessus ? Bah moi je prefere prendre des contre-pieds, fussent-ils provocateurs, que de me laisser couler vif dans le beton du tout est pareil au même niveau [http:// forums.jeuxonline.info/showthread.php?t= 495721\&page $=8]$ (6.11.2014)

REMARques : Vif est un adjectif-adverbe de manière qui fonctionne essentiellement en tant que prédicat second et s'accorde avec le sujet. 
En (I), il caractérise le mouvement d'un liquide. En (II), il désigne le fait de passer d'un lieu à un autre, de se glisser dans un autre modèle, entrer dans une forme prédéterminée de manière forte, avec un certain dynamisme, le sujet désignant une personne (ici : l'âme). (III) intègre le groupe dans une locution de type populaire où l'accord est systématique même si l'interprétation est adverbiale. Vif est modifié par tout. Le CW ajoute trois exemples pour couler vif au sens de '(se) noyer'.

\section{Couper court}

I. Couper de manière à rendre court Transitif

1551a Mais à la pepinniere ou l'on garde les chevelues, on peult laisser troys ou quattre ans lesdictes marquottes couppées courtes : car ce lieu la n'est ordonné pour en avoir vendange. Quand la plante ja posée à trente moys passez, c'est à dire au troiziesme autumne, il luy fauldra bailler plus forts pesseaux (Claude Cotereau, Les Douze Livres de Lucius Junius Moderatus Columella des choses rusticques [trad.])

1551b quand ils commenceront à croistre il fauldra les tailler avec la serpe, et de leurs rameaulx et branches en faire comme des estages, les laboureurs appellent ainsi les branches qui sortent, lesquelles ilz couppent court avec leur ferrement, ou les laissent croistre longs pour laisser la dessus brancher les vignes, cecy sera bon en terre grasse (Claude Cotereau, Les Douze Livres de Lucius Junius Moderatus Columella des choses rusticques [trad.])

1564 toutesfois s'il advient que la vigne soit gastee de la gelee et qu'il apparoisse que le fruit soit perdu, la faudra coupper fort court, afin que sa vertu luy demeure : car l'annee suivante elle apportera du fruit au double (Charles Estienne, L'Agriculture et maison rustique)

1651 Mes cheveux, que j'avais fait couper fort courts, me rendirent méconnaissable à ceux qui m'avaient vu souvent auprès de mademoiselle Angélique (Paul Scarron, Le Roman comique)
1839 les cheveux d'un roux charmant, sans aucune boucle et coupés très courts comme ceux d'un garçon (Jules Barbey d'Aurevilly, Deuxième Memorandum)

1843 Un poêle de faïence blanche était placé dans la cheminée, où l'on avait symétriquement rangé une petite provision de bois coupé si court, si menu, que sans hyperbole on pouvait comparer chaque morceau à une énorme allumette (Eugène Sue, Les Mystères de Paris)

1862 Elle le voyait ainsi de profil avec sa fine moustache, en pointe aux coins des lèvres, son cou dont la blancheur était éblouissante, et ses cheveux noirs, coupés court derrière, relevés aux tempes. L'oreille restait à découvert, petite et rosée comme les narines mobiles de son nez aquilin (Paul Reider, Mademoiselle Vallantin)

1869 Deux [= femmes habillés] en blanc rosâtre se signalent de loin au milieu de cette population morne. D'autres en bleu foncé, riches colliers, cheveux coupés courts et collés sur le front par des graisses (Eugène Fromentin, Voyage en Égypte)

1888a La barbe, à peine grisonnante, est coupée assez court : les cheveux sont taillés en brosse (Paul Belon et Georges Price, Paris qui passe)

1888b Les cheveux taillés en brosse sont tout blancs, comme les favoris coupés très courts (Paul Belon et Georges Price, Paris qui passe)

1893 Mais on voyait nettement le profil de sa petite tête ronde, aux cheveux blonds et coupés court (Émile Zola, Le Docteur Pascal)

1907 - C'est bien le même homme : les cheveux en brosse, des yeux noirs sans reproche et sans peur, un nez à la serpe, et la moustache coupée court... (René Bazin, Le Blé qui lève)

1911 Une assiette tomba et se cassa drôlement, non en mille morceaux, mais simplement en deux, ce qui les amusa longtemps, 
et plus encore le garçon baissé avec sa veste noire, coupée court aux reins, et son tablier blanc serrant les hanches (CharlesFerdinand Ramuz, Aimé Pache, peintre vaudois)

1923 Les prunelles ardentes, le nez coupé court et sensuel, la bouche joliment ourlée, la vigueur du menton frappé d'une fossette, tout en elle disait l'énergie nerveuse, comme aussi l'affirmation habituelle de son allure, la cambrure souple de sa taille et la netteté avec laquelle ses pieds minces frappaient leur pas en marchant (Paul Bourget, La Geôle)

1943 Les ongles étaient vilains, des ongles de peintre, elle avait beau les couper courts, il y restait toujours accroché un peu de bleu (Simone de Beauvoir, L'Invitée)

1945 Il posa son panama sur le bout de la table. De ses ongles coupés très court et carré, comme des ongles de pied, Morize pianotait sur le tapis vert.

- Le curé attaque...

- Qu’a-t-il déniché ? questionna

Tattignies.

- Le bal, répondit Morize (Jean-Louis Bory, Mon village à l'heure allemande)

1958 coupez assez court $(10 \mathrm{~cm})$ les branchettes (Écho de la mode 5 / Grundt : 322)

1963 Il [= le chien] avait la queue coupée court et le pelage jaunâtre avec de larges plaques de poil terne et se tenait assis en éveil, la gueule à demi ouverte, haletante et retroussée comme s'il eût été prêt à quelque jeu sans pitié (Pierre Moinot, Le Sable vif)

2000 Des photos de Nina aussi, beaucoup plus jeune, avec les cheveux coupés court, en cotte de peintre, tenant fièrement un rouleau dégoulinant ou en maillot de bain, en train de lire un gros pavé, l'air absorbé et le front plissé (Anna Gavalda, Ceux qui savent comprendront)

2005 Mes cousins et moi avions toujours les cheveux coupés très courts, ce qui n'empêchait d'ailleurs pas les « totos » d'y faire camping (Alice Prin, Souvenirs retrouvés (de Kiki de Montparnasse))

II. Exprimer de manière concise, brève

(équivalent de pour être bref)

Transitif

1577 Que si d'aventure les affaires icy touchez paroissent aucunement steriles, ou partrop couppez-court, et comme tronçonnez et entrerompus, le subject veult et porte cela. Car les Turcs ainsi lourds, barbares, et grossiers, ne s'amusent pas à mener et conduire leurs guerres par certaines petites practiques, negotiations, et intelligences (Blaise de Vigenère, L'Histoire de la décadence de l'Empire grec [trad.])

1580 Je sçay bien toutesfois qu'ayant si beau sujet je n'ay pas traité les diverses matieres que j'ay touchées, d'un tel style ni d'une façon si grave qu'il falloit : mesme entre autres choses confessant encores en ceste seconde edition avoir quelquesfois trop amplifié un propos qui devoit estre coupé court, et au contraire, tombant en l'autre extremité, j'en ay touché trop briefvement, qui devoyent estre deduits plus au long (Jean de Léry, Histoire d'un voyage faict en la terre du Brésil)

1601 Coupons le court : le voyage du Bêly ne proufita à autre chose sinon de nous tenir suspendus en nos irrésolutions sans nous préparer ou à cecy ou à cela (René de Lucinge, Les Occurrences de la paix de Lyon)

1722 PIERRE. Oui, Monsieur, voilà tout fin dret ce que c'est, et Jacquelaine a itou queuque doutance que vous vourez bian de votre grâce, et pour l'amour de son sarvice, et de stila de son père et de sa mère, qui vous ont tant sarvi quand ils n'étient pas encore défunts, tant y a, Monsieur, excusez l'importunance, c'est que je sommes pauvres, et tout franchement, pour vous le couper court... (Pierre de Marivaux, La Surprise de l'amour)

1728 J'avais deux de mes camarades avec moi, qu'on laissait boire et manger en paix sans leur dire mot, ils ne me servaient que de 
frères lais. Bref, enfin, pour vous le couper court, nous donnâmes notre seconde représentation, qui fit autant de plaisir que la première, et puis nous partîmes, parce qu'on nous attendait dans une autre ville (Pierre de Marivaux, L'Indigent Philosophe)

Emploi absolu

1603 Pour couper court, nous devons considerer en la ressemblance individuale, le traict, la couleur, et la proportion (Jourdain Guibelet, Trois Discours philosophiques)

1658 Sa gouvernante n'eut pas la force de cette jeune fille, et resistant plus foiblement à une si rude atteinte, donnoit plus de liberté à sa forte douleur. Mais enfin, pour couper court, le consolateur mesme se trouva surprit d'un assaut si bien soutenu et d'une marque de force d'esprit si extraordinaire (Michel de Pure, La Prétieuse)

1751 Il n'y a, sans doute, personne qui ne sente à quel point un journal bien circonstancié du voyage de ce Prince, seroit intéressant, sur-tout si l'on y joignoit des réflexions ; mais les mêmes Historiens de qui j'ai tiré tant de minuties, coupent si court en cet endroit, tout important qu'il est, que j'avoue qu'ils ne nous en ont dit que ce qu'ils ne pouvoient se dispenser de nous dire (Alexandre Dumas fils, Ah quel conte !)

1836 Pour couper court, après que nous eûmes atteint Pampelune, il continua à neiger avec tant de violence et si longtemps, qu'on disait que l'hiver était venu avant son temps (Daniel Defoe, Vie et aventures de Robinson Crusoé [trad.])

1980 Pour couper court, un militant enchaîne sur une autre question (Dorothée Letessier, Le Voyage à Paimpol)

III. couper court (à quelque chose): interrompre, arrêter quelque chose, mettre un terme à quelque chose brusquement Transitif

1595 Après l'avoir tous humblement remercié, M. de Montelon s'aproche avec nous et lui parle de notre restablissement. Le Roi le coupe court, déclare qu'il veut que ceux de Semeur entrent devant nous en signe de leurs services (Gabriel Breunot, Journal)

1598 Là il le coupe tout court : mais la naïfve conclusion, que j'en fais naistre, et qu'il a suffoquée, est, Qu'il faut pareillement rapporter à l'Eglise de Dieu, et à ses Docteurs legitimes et Theologiens approuvez l'intelligence, et jugement des parolles de Dieu (Jean de Bordes, Les Vrais Abus des pretendus abus de messe)

1657 Il se faut neanmoins toûjours souvenir, Que les discours pathétiques ne doivent pas finir comme ils commencent, lors que d'abord on fait éclater la passion en surprenant l'Acteur, afin que les Spectateurs en soient aussi surpris ; car en ces occasions il ne faut pas que la fin en soit dure et couppée court (François Hédelin, abbé d'Aubignac, La Pratique du théâtre)

1944 Ah ! je veux pas l'entendre ! Je le coupe court ! je pousse des cris de paon !... Il me regarde... « Allez hop grand-père! Faut pas lambiner ! Faut que je fasse des progrès terribles !... Je vous admire ! je vous adule ! faut pas qu'on perde une seconde » (Louis-Ferdinand Céline, Guignol's band II)

2012 Et quel travail faisiez-vous ? Un travail comme un autre, je le coupe court. Quelque chose dans mon ton, ou peut-être dans mon aspect, l'intimide. Il hasarde un mot d'excuse, se plonge dans le fromage, lance une calotte à un garnement (Giancarlo de Cataldo, Les Traîtres [trad.])

Emploi absolu

1637 SILINDE. La vertu toutesfois merite quelque chose.

CLARISTE. C'est un grand argument que ton esprit propose,

Dont l'explication trop longue à mon advis,

Me fera couper court pour changer de devis (L. C. Discret, Alizon)

1715 LE C. BESSARION. J'avoue que je n'ai pas encore oublié votre injustice, quand vous 
me prîtes par la barbe, dès le commencement de ma harangue.

LOUIS XI. Cette barbe grecque me surprit, et je voulois couper court pour la harangue, qui eût été longue et superflue (François de Fénelon, Dialogues des morts)

1823 Cette condescendance inusitée de sa part devenait pour moi un guide assuré ; aussi ai-je tenu ferme et coupé court, en lui disant que le soir même il recevrait de moi ma détermination irrévocable, et mes motifs aussi bien que mes observations aux diverses pièces qu'il m'avait adressées (Emmanuel de Las Cases, Le Mémorial de Sainte-Hélène)

1830 Remarquez, ajouta le marquis, d'un air fort sérieux, et coupant court aux actions de grâces, que je ne veux point vous sortir de votre état. C'est toujours une faute et un malheur pour le protecteur comme pour le protégé (Stendhal, Le Rouge et le noir)

1840 ils voulurent, par un remède absolu, couper court et net à tout ce qui tendait à la mitigation sur ce dogme du Christ-sauveur (Charles Sainte-Beuve, Port-Royal)

1855 Mais cette concession faite, elle conservait son droit de ne pas admettre chez elle une personne dont la présence lui était désagréable. Son explication adroite et nette coupait court à toute récrimination, ma mère le sentit et son courroux tomba. « À la bonne heure, maman, » dit-elle, et elles parlèrent à dessein d'autre chose (George Sand, Histoire de ma vie)

1908 Enfin, Antoinette, qui avait complètement perdu pied dans son morceau, et qui s'apercevait avec terreur qu'à un certain passage, au lieu de continuer, elle avait repris au commencement, et qu'il n'y avait pas de raison pour qu'elle en sortît jamais, coupa court, et termina par deux accords qui n'étaient pas justes, et un troisième qui était faux (Romain Rolland, JeanChristophe. Antoinette)

1943 Le maire essaya de maintenir la conversation pendant quelque temps sur ce sujet commode, puis à un signe de Leuilly il coupa court, et sortit une clef de sa poche : - Charles Jeannin offre de vous louer une maison. Le prix sera sans importance, bien entendu

(André Dhôtel, Le Village pathétique)

2001 Oui, dit-il encore plus froidement, et je ne trouve pas ça bon. Puis, comme j'essaie d'en savoir un peu plus, il coupe court à l'échange en me représentant que cette conversation me coûterait trop cher en téléphone (Jean Echenoz, Jérôme Lindon)

IV. Se dit d'un chemin de traverse qui raccourcit le trajet

Emploi absolu

1788 on trouve ici un chemin pratiqué par où les gens du pays coupent court pour aller du Mont-d'Or à la Tour (Journal de physique, de chimie, d'histoire naturelle et des arts)

1890 Un instant, au coin des ateliers de réparation, ils le perdirent de vue ; puis, comme ils coupaient court en traversant une voie de garage, ils le retrouvèrent, à vingt pas au plus (Émile Zola, La Bête humaine)

1925 Dès la Patte d'Oie, il quitta la gamine, prit l'allée de Malvaux qui coupait plus court vers la route : il allait rentrer chez lui (Maurice Genevoix, Raboliot)

\section{CORPUS WEB :}

Je voudrais d'abord couper court aux remarques négatives émises au sujet de cet hôtel [http://www.tripadvisor.fr/ShowUserReviewsg293731-d677579-r145977377-Royal_Atlas-Agadir_ Souss_Massa_Draa_Region.html] (13.11.2014)

INFO : Pour couper court à toute rumeur alarmiste... [http://www.ville-labenne.fr/ actualites/2014/10/info-pour-couper-court-atoute-rumeur-alarmiste] (13.11.2014)

Déséquilibre fiscal: Ottawa veut couper court au débat [http://www.lapresse.ca/actualites/ politique/politique-canadienne/201409/10/014798739-desequilibre-fiscal-ottawa-veut-coupercourt-au-debat.php] (13.11.2014)

Couper court les cheveux pour les rendre plus raides [http://fr.hairfinder.com/cheveuxquestions/cheveuxraides.htm] (13.11.2014) 
« Ça fait longtemps que j’y pense... » entend-on souvent de la part de femmes qui hésitent à couper courts leurs cheveux [http://www. tetue.net/?article82\&lang=fr] (13.11.2014)

REMARQUeS : Court est un adjectif-adverbe de dimension qui s'oppose à long. (I) désigne le fait de tailler, de couper à une certaine longueur. En parlant du visage et de ses traits, il souligne la forme d'une des parties du visage (le nez). En parlant des vêtements, il réfère à ceux qui ont été taillés en vue d'une forme déterminée, qui ont une certaine coupe. Au sens concret, en parlant d'une partie du corps qui se renouvelle (ongles, cheveux, barbe). (II) souligne le fait d'abréger ce qui est dit, de réduire à l'essentiel, le sujet s'efforçant d'exprimer son propos en peu de mots. En référence au discours, (III) désigne le fait de terminer cette discussion au plus vite, de l'abréger hâtivement, voire d'y mettre fin. Dans un déplacement, (IV) souligne le choix du sujet d'aller plus vite en prenant un raccourci. Notons les collocations : couper court, menu; couper court et sensuel; couper court et frisé ; couper court et carré, couper court et net; tenir ferme et couper court, ainsi que l'expression du concept opposé de croitre long (avec accord). En (II), le verbe tend à prendre un complément indirect introduit par la préposition à. Dans son emploi figuré (II, III, IV), court est invariable. Par contre, en ce qui concerne son emploi concret (I), il peut également s'accorder avec l'objet, ce qui le rapproche des prédicats seconds orientés vers l'objet. Parfois, c'est le même auteur qui hésite. Dans deux exemples du même auteur (1551a/b), court est accordé dans le premier, mais invarié dans le second, où l'on trouve tout de même croistre longs (v. également 1888a/b). La fréquence élevée de couper court dans Frantext (778 exemples ; 25.7.2020) se prête à une analyse des tendances en diachronie. Sur le plan sémantique, la signification (III) est assimilée par (II). C'est ainsi que la locution pour couper court passe du sens de 'abréger, être succinct' à celui de 'interrompre'. Dans l'acception concrète (I), la seconde moitié $\mathrm{du} \mathrm{xx}^{\mathrm{e}}$ siècle prête une importance particulière à la coupe des cheveux. En même temps, on observe une préférence pour l'emploi invarié. La fréquence élevée dans ce domaine d'emploi ainsi que le modèle des emplois au figuré, tou- jours invariés, se trouvent peut-être à l'origine de cette tendance. On pourrait également considérer une hypothèse complémentaire, selon laquelle le XIX ${ }^{e}$ siècle manifesterait une tendance générale plus favorable à l'accord sur l'ensemble des adjectifs-adverbes que le $\mathrm{xx}^{\mathrm{e}}$ siècle. Court est modifié par assez, bien, fort, plus, si, tout, très. Notons que dans l'acception (IV) la variante avec préposition, couper au court 'raccourcir ', est plus fréquente dans Frantext que couper court. Notons l'emploi de tenir ferme.

\section{Couper droit}

I. Couper exactement selon une ligne droite Transitif

1575 là où se fait le Cap des Agulhas, y a un port, ou goulphe si estroit, que plustost on le doibt apeller four, veu son entree en terre, laquelle il coupe droit au long du promonitoire (Françoys de Belle-Forest, La Cosmographie universelle de tout le monde)

1610 la forme de l'escu estoit telle : il avait le haut large, duquel l'estomac et les espaulles estoient couvertes, coupé droit descendant en pointe, pour le manier plus aisément (Claude Fauchet, Euvres)

1691 Ils veulent que l'on marche légèrement, que l'on ait la jambe grosse et le pied petit, que l'on soit chaussé sans talon, que l'on ne mette point de poudre, qu'on se sépare les cheveux sur le côté de la tête et qu'ils soient coupés tout droits et passés derrière les oreilles, avec un grand chapeau doublé de taffetas noir, une golille plus laide et plus incommode qu'une fraise, un habit toujours noir ; au lieu de chemise des manches de taffetas ou de tabis noir, une épée étrangement longue, un manteau de frise noire par là-dessus, des chausses très-étroites, des manches pendantes et un poignard (Marie-Catherine d'Aulnoy, Relation du voyage d'Espagne)

1857 Il avait les cheveux coupés droit sur le front, comme un chantre de village, l'air raisonnable et fort embarrassé (Gustave Flaubert, Madame Bovary) 
1926a Alors de l'observer de loin : il avait le poil gris ; le visage blanc paraissait pâle, évoquant à la fois celui poudré d'une vieille marquise et celui illuminé d'un saint avec de grands chiens noirs éminemment raides, coupés droits sur le front ; les yeux sous la paupière clignaient obliques, à la chinoise (Marcel Jouhandeau, Monsieur Godeau intime)

1926b Le duc de la Cuesta était un homme de cinquante-huit ans, au teint sombre, aux cheveux ras coupés droit sur le front à la romaine (Henry de Montherlant, Les Bestiaires)

1950 Les yeux ouverts dans l'ombre, j'évoque avec ferveur le visage vivant de mon ami. Je le retrouve, avec son front volontaire, ses veux clairs au loyal regard, et sa bouche un peu dédaigneuse sous la moustache coupée droit (Maurice Genevoix, Ceux de 14)

II. Aller par la voie la plus courte, en ligne droite Intransitif

1696 Dans ce temps-là, m'appercevant qu'un regiment d'infanterie des ennemis taschoit à regagner le pont qu'ils avoient sur le canal de Furnes, je coupay droit à ce pont où je fus plûtost que luy, et je pris ce regiment tout entier : c'estoit celuy que le prince de Condé avoit fait descendre de la dune pour l'opposer au regiment de Bretagne (Roger de Bussy-Rabutin, Les Mémoires de messire Roger de Rabutin)

1865 Mais quand je vis qu'elle mettait tout son bras sous celui de Joseph, pour s'en aller, la jalousie me galopant encore une fois, je les laissai partir par le chemin, et, coupant droit par le côté de la chènevière, je traversai le petit pré et me postai sous la haie pour les voir passer ensemble (George Sand, Les Maîtres sonneurs)

1874 J'ai cru remarquer que le plus souvent nous coupions droit devant nous en pleine montagne, et je n'ai pas vu d'ailleurs que cette voie escarpée, où nous entraînait notre chef de file, fût autrement tracée que par le passage des bergers ou par l'écoulement naturel des eaux de pluie (Eugène Fromentin, Un été dans le Sahara)

1885 Dans la plaine rase, sous la nuit sans étoiles, d'une obscurité et d'une épaisseur d'encre, un homme suivait seul la grande route de Marchiennes à Montsou, dix kilomètres de pavé coupant tout droit, à travers les champs de betteraves (Émile Zola, Germinal)

1936 On va toujours battre ce versant, couper droit pendant une quinzaine de kilomètres, après on verra. Il y a du gibier en masse, je peux tenir longtemps (Jacques Perret, Roucou)

1938 Les bêtes couraient sans galoper, les biches en tête, la Bréhaigne les devançant toutes. Elle coupait droit vers la première allée, sous le vent, couchant parfois ses grandes oreilles pour écouter les hommes derrière elle (Maurice Genevoix, La Dernière Harde)

1945 Je ne savais pas trop ce que j'allais faire, ni pourquoi j’avançais si vite, par ce chemin, qui est le plus court pour aller au village, car « la carraire » coupe tout droit (Henri Bosco, Le Mas Théotime)

1979 Déjà le ciel blanc révélait tout ce qui l'entourait, sans que pourtant les choses eussent retrouvé leur couleur. Il coupa droit dans les herbes craquantes de gel et s'assit enfin pesamment au pied des rochers de la crête (Pierre Moinot, Le Guetteur d'ombre)

1994 À Barkoul, sur l'autre versant des Tian Shan, on abandonna les chevaux pour des chameaux et l'on coupa droit sur l'Altaï. On laissa à l'ouest le désert de Dzoungarie pour rejoindre la rivière Narun et franchir les hauts monts de l'Altaï par le col de Dabiscan (Jacques Lanzmann, La Horde d'or)

III. coupé droit : qui a une forme régulière, droite Transitif

1966 Agathe avait une peau indécente de blancheur, et la main, le pied, le front coupés court et droit. Les dents se retenaient si 
fort aux mâchoires que, sept ans plus tard, elles allaient se refuser à tomber, il fallut les arracher (Irène Monési, Nature morte devant la fenêtre)

\section{CORPuS WeB :}

Ne vous moquez pas, je ne sais pas couper droit, ça ne date pas d'hier, vous me donnez une feuille c'est la même chose.... [http://www. threadandneedles.fr/groupes/le-collectif-desgrandes-debutantes/forum/topic/couper-droit] (30.11.2014)

J'ai acheté par la suite un guide de $80 \mathrm{~cm}$. Travailler avec le guide c'est avoir l'assurance de couper droit [http://www.copaindescopeaux. $\mathrm{fr} /$ forum/viewtopic.php?f=29\&t=355\&start=30] (30.11.2014)

Lorsque vous coupez l'ongle, suivez sa forme, et veillez à couper droit. Des ciseaux spéciaux pour bébé, aux bouts arrondis / aplatis, éviteront toute blessure et sont faciles à utiliser [http://www.bebe-jou.fr/landing/fr/couper-lesongles-de-bebe.php] (30.11.2014)

Veillez à bien couper droit la sangle (schéma I) et à bien fixer l'auto-agrippant. Une fois celui-ci positionné, testez la bonne tenue du bout de sangle en tirant dessus (schéma II) [http://www2. thuasne.fr/thuasne/front/site/france/cache/ bypass/pid/8677;jsessionid=B80182231B6DE7117 279CDAFAA078D32?print=true] (30.11.2014)

Pour couper une frange en dégradé, on peut aussi la couper droite en dessous des sourcils avec un ciseaux plus ou moins épais et ensuite avec un ciseaux beaucoup plus fin prendre quelques mèches les mettrent en laire et couper en dégradé ;) [http://www.elle.fr/Beaute/Cheveux/ Astuces/Pour-couper-sa-frange-toute-seule71710] (30.11.2014)

REMARQUES : Droit est un adjectif-adverbe de manière-direction qui peut aussi revêtir une interprétation résultative et se rapprocher des prédicats seconds orientés vers l'objet. Couper court (I) désigne le fait de tailler une production du corps qui se renouvelle (les cheveux, la moustache), ou des objets tels un papier, etc. en suivant une ligne droite, avec exactitude. En (II), le complément désigne une chose considérée du point de vue de son étendue que le sujet traverse ou franchit en ligne droite, en prenant la voie la plus courte ou la plus rapide. En parlant du visage et de ses traits, (III) souligne la forme régulière et droite d'une des parties du visage (le front). Notons la collocation couper court et droit. Au sens concret (I), droit peut s'accorder avec le sujet. Il est modifié par tout, bien. Le langage quotidien documenté dans le CW ne contient que la signification (I), où, dans le dernier exemple, droit s'accorde. Il est modifié par tout. Notons aussi l'emploi absolu de couper court (I) dans les trois premiers exemples $\mathrm{du}$ CW. Mentionnons également l'emploi de se retenir fort.

\section{Couper épais}

Couper en grosses tranches, tondre ras (le gazon)

Transitif

+1761 C'est avec ce pitoyable instrument qu'on coupe le gazon d'environ d'un pouce d'épaisseur plus ou moins suivant la quantité des racines des herbes ; car plus elles sont nombreuses, plus le gazon doit être coupé épais (Jean-Baptiste DupuyDemportes, Le Gentilhomme cultivateur [1761-1764])

1887 On ne le bourrait plus de nourriture ainsi qu'aux premiers jours, chaque tartine coupée trop épaisse lui attirait des paroles dures : quel trou ! Moins on travaillait, plus on bâfrait, alors ! (Émile Zola, La Terre)

Emploi absolu

1923 Antoine, en pyjama, debout devant la cheminée, attaquait avec un criss malais un pavé de plum-cake. Rachel bâilla.

- Coupe épais, mon minou, fit-elle d'une voix paresseuse. Elle était sur le lit, les mains sous la tête, et nue (Roger Martin du Gard, Les Thibault. La Belle Saison)

2009 Son mari était à la guerre, un éclat d'obus lui avait fracassé le crâne. Depuis, elle tenait de main de maître son auberge, elle était connue et reconnue à des kilomètres à la ronde et on venait de loin pour déjeuner ou dîner chez elle. Sa devise : " servir plein et couper épais » (Gyula Kis, Le Sorcier numérique) 


\section{CORPus WeB :}

Epluchez quelques pommes mais pas trop et les couper épaisse pour les temper ensuite dans la pate avant de les jeter dans l'huile chaude [http:// blog.aujourdhui.com/Lunesoleil23/2584970/ apres-l-effort-le-reconfort.html] (16.12.2014)

Rouelles de tomates (tranches de tomate coupée épais) garnies de fromage à la crème et d'olives tranchées ou de demi cerises. Servir avec mayonnaise sur des feuilles d'épinards tendres [http://chez.manon.free.fr/chezmanon5/ 272/95.htm] (16.12.2014)

REMARques : Épais réfère à la densité ou à l'épaisseur de quelque chose. Il se prête également à une analyse comme adverbe de manière ou comme prédicat second orienté vers l'objet ; dans ce dernier cas, il adopte une interprétation résultative. Il désigne le fait de couper un objet consommable (pain, gâteau) à l'aide d'un instrument tranchant en faisant de grosses tranches. L'accord étant la règle, le $\mathrm{CW}$ montre tout de même qu'il peut rester invarié. Notons l'emploi familier de servir plein 'servir des assiettes ou des plats pleins' dans l'exemple de 2009.

\section{Couper menu}

I. Couper en petits morceaux

Transitif

1466 UNE VINESGRETE DE MENUZ HASTEZ DE PORC. C'est assavoir foyez, ratez et frasez ; et lez fault couper menu et a lopins quarrés. Et fault cuire l'ongnon en bon saing de lart ou en saing doulx et mectre frire tout ensemble dedans ung chauderon. Et puis fere broyer lez espicez : giroffle, graine, et nois muscade, et ung poy de poivre long, et du saffran ; et destremper de vin aigre. Et s'il est tropt fort, il y fault mectre du vin et du boullon de beuf ensemble (Le Recueil de Riom, p. 71)

1603a Ajouster à ce vin-rappé, la vingtiesme partie de ses raisins, du bois vert de fousteau, c'est à dire sur vingt corbeillées de raisins une de fousteau, couppé menu par retailleures, avec un rabot de charpentier, lui donne force et odeur agréable, ainsi que le pratiquent assés souvent les taverniers de Paris (Olivier de Serres,
Le Théâtre d'agriculture et mesnage des champs)

$1603 \mathrm{~b}$ Sur quoi on ad-jouste quelque peu de fines estouppes de chanvre, couppées menu, et un peu davantage de graisse de bouc ou de chèvre, crue, hachée subtilement, qu'on incorpore tout ensemble fort proprement (Olivier de Serres, Le Théâtre d'agriculture et mesnage des champs)

1704 Par le moyen de ces eaux et à la faveur de la chaleur du foie, les viandes se cuisent dans l'estomac, à peu près comme elles feroient dans une marmite mise sur le feu ; ce qui se fait d'autant plus facilement, que ces eaux de l'estomac sont de la nature des eaux fortes : car elles ont la vertu d'inciser les viandes, et les coupent si menues qu'il n'y a plus rien de l'ancienne forme (Jacques-Bénigne Bossuet, De la connaissance de Dieu et de soi-même)

1735a Pour donner un prompt soulagement aux infirmes, on jette sur eux des joncs secs, ou de la paille coupée un peu menue, surquoi l'on seme des feüilles de mûriers : ils montent pour manger, et par là ils sortent du milieu des crottes qui les échauffent (Jean-Baptiste Du Halde, Description géographique)

1735b Entrons dans un plus grand détail : ces vers mangent également le jour et la nuit : dès qu'ils sont éclos, il leur faut quarante-huit repas par jour, deux par heure. Le second jour on leur donne trente fois des feüilles, mais qui sont coupées moins menues. On leur en distribue encore moins le troisiéme jour (Jean-Baptiste Du Halde, Description géographique)

1842 Dix et même vingt fois plus de feuille, qui ne serait pas coupée menue, ne pourrait pas suffire à la quantité de vers sus indiquée, parce qu'ils ont besoin à cette époque, de trouver, dans un petit espace et dans le même temps, de quoi manger commodément (Théodore Magouet, Le Bon Agriculteur suisse) 
1854 Cette ration d'aliments se composait, pour Mars, de : 50 gr. bouilli maigre coupé menu, 20 [= gr.] pain blanc de deuxième qualité coupé menu, 100 [= gr.] bouillon (Archives de physiologie, de thérapeutique et d'hygiène)

1904 Nous distribuons - sur les genoux, dans le creux du tablier, - des tuyaux de paille coupés menu, de la dimension d'un grain de blé, et des bouts de fil ; nous montrons à faire des bagues, des chaînes de montre, des bracelets (Léon Frapié, La Maternelle)

1966 Il versa la farine de maïs chaude sur la viande coupée menu, répartie dans les assiettes, passa ses cigarettes à Agathe, $\mathrm{du}$ feu, un dictionnaire qu'elle lui demandait (Irène Monési, Nature morte devant la fenêtre)

1985 Olivier étala sur le sol le contenu de son havresac : quatre pommes de terre, une fourchette ébréchée, le bois coupé menu d'un cageot de légumes, trois tartines de gelée de groseille, deux tablettes de chocolat « des Gourmets », du papier journal, une boîte d'allumettes Tisons (Robert Sabatier, David et Olivier)

2008 Il avait décidé de les surprendre en leur préparant un bon dîner. Cogita le menu dans la queue chez le boucher, acheta des fleurs et passa chez le caviste. Mit de la musique, remonta ses manches, chercha un torchon propre et coupa tout тепи : l'ail, l'échalote, sa faiblesse et ses errances. Ce soir, trêve, il les écouterait (Anna Gavalda, La Consolante)

Pronominal

1850 Les champignons se coupent menu, sont frits dans l'huile avec quelques ingrédients dont le nom m'échappe. On y met une pointe d'ail, je crois... (Honoré de Balzac, Petites Misères de la vie conjugale)

Emploi absolu

1933 Mais, patience, et ne t'énerve point, si l'on te sert de l'informe alors que tu voudrais $\mathrm{du}$ lapidaire. Tu aimes la précision. Tout le monde aime la précision. Mais, à force de couper menu, on en vient au hachis, au gâchis. Après les fibres, la poudre (René Crevel, Les Pieds dans le plat)

II. Diviser, partager en petites parties Transitif

1869 Il est minutieux, il a de petites affaires bien réglées ; son temps est coupé теnu ; il cligne de l'œil et branle gentiment la tête d'un air résolu en vous parlant de ses petits arrangements, de ses principes politiques (Charles Sainte-Beuve, Pensées et maximes)

1873 Et elle aurait continué pendant des journées, enfilant les phrases vides, s'amusant extraordinairement à des faits coupés menus, sans aucun intérêt (Émile Zola, $L e$ Ventre de Paris)

1902 Cela ne mène à rien de bon. Je n'ai pas achevé la correspondance de Tourgueneff ; je n'ai pas achevé les Mémoires de Retz... Mon temps est coupé trop menu. J'ai hâte de gagner Cuverville. J'ai hâte d'être moins dérangé (André Gide, Journal)

III. Enlever peu à peu

Transitif

1932 J'aurais été curieux de savoir comment il pouvait la retrouver lui sa sœur dans une nuit pareille.

Le tam-tam du village tout proche, vous faisait sauter, coupé menu, des petits morceaux de patience (Louis-Ferdinand Céline, Voyage au bout de la nuit)

\section{CoRpus Web :}

Durant plus de deux heures, ils épluchent et coupent menu. Une mosaïque de couleur prend forme sur les tables où se mêlent ustensiles de cuisine et une multitude de légumes [http://amoureusement-soupe.com/actualites/ actus-2013/51-clap-de-fin-sur-la-3eme-edition] (16.12.2014)

Laver soigneusement la choucroute, la couper menu et faire cuire. Ajouter laurier, genévrier. Couper le chou et cuire séparement [http:// asso-aasf.fr/index 2 .php?option=com_content\&t ask $=$ view\&id $=226 \&$ pop $=1$ \&page $=0$ \&Itemid $=233$ ] (16.12.2014) 
Laver soigneusement la laitue, la couper menue et réservez. Laver les herbes puis hacher le persil, la coriandre et les feuilles de menthe [http://ith-yaala.discutforum.com/t1140omelette-au-poivron-et-tomate] (16.12.2014)

RemaRques : Couper menu (I) désigne le fait de diviser un corps solide (objet consommable ou non) à l'aide d'un instrument tranchant, l'objet désignant une partie du tout. En (II), le complément d'objet réfère au temps ou à un fait fractionné en petites parties, l'adjectif-adverbe menu soulignant un emploi du temps serré, le manque de temps. Меnu peut s'accorder avec l'objet, notamment dans la langue moderne, tandis que l'orthographe ancienne préfère l'invariabilité. Menu est modifié par moins, si, trop, tout, un peu. Le CW met en évidence un emploi préférentiel dans le langage de la cuisine.

\section{Couper net}

I. Couper, trancher d'une manière précise, brutale

Transitif

1579 mais à l'unziesme coup de sa faulx, rencontra (de fortune) une pierre bise, grosse comme une boule de rapeau, laquelle coupa en deux pieces aussi net qu'un naveau (Philippe d'Alcripe, La Nouvelle fabrique des excellents traicts de vérité)

1610 GUILLAUME. Il aymoit une femme qui luy donna assignation, et faisant semblant de le recevoir courtoisement, l'empoigna ; et comme maistre Antitus de braguette sentoit ceste main douillette, il s'exaltoit. Adonc ceste femme avec l'autre main avança un cousteau dont elle le coupa tout net (Béroalde de Verville, Le Moyen de parvenir)

1735 Les jeunes arbrisseaux qu'on a trop effeüillez avant qu'ils eussent trois ans, se ressentent dans la suite de cet épuisement : ils deviennent foibles et tardifs. Il en arrive de même à ceux dont on ne coupe pas bien net les feüilles et les branches, qu'on emporte tout effeüillées (Jean-Baptiste Du Halde, Description géographique)
1769 L'autre extrémité se termine quelquefois en pointe mousse ; d'autres fois elle semble coupée net : on croit même y appercevoir une ouverture, comme seroit celle d'un Tube capillaire (Charles Bonnet, La Palingénésie philosophique)

1839 Elle rencontre l'épée de Satan; et, descendant pour frapper avec une force précipitée, la coupe net par la moitié : elle ne s'arrête pas, mais d'un rapide revers, entrant profondément, elle fend tout le côté droit de l'Archange (François de Chateaubriand, Le Paradis perdu)

1874 OANNÈS. (d'une voix plaintive)

Sur l'ensemble de ces êtres, Omorôca, pliée comme un cerceau, étendait son corps de femme. Mais Bélus la coupa net en deux moitiés, fit la terre avec l'une, le ciel avec l'autre ; et les deux mondes pareils se contemplent mutuellement (Gustave Flaubert, La Tentation de saint Antoine)

1891 Oui, si bien qu'il y en a un dernièrement, à Notre-Dame, je crois, qui n’a pas retiré sa jambe à temps ; la cloche est revenue à toute volée dessus et l'a coupée nette, comme un rasoir (Joris-Karl Huysmans, Là-bas)

1950a Rive a le tympan crevé. Je lui ai dit : « Descends, mon vieux. " Secousse a perdu la jambe : une plaque d'acier blindé qui est retombée de très haut et qui la lui a coupée net, s'enfonçant creux en terre après la lui avoir coupée ; il a murmuré : « Oh ! ma jambe "; je lui ai dit : « Descends, mon vieux » (Maurice Genevoix, Ceux de 14)

1950b « Allez ! Allez ! Par-dessus !» Quelque chose de lourd a cogné dans mes jambes, et j'ai fléchi, les jarrets coupés nets. « Par-dessus ! En avant! » C'est la tête de Grondin qui a cogné dans mes jambes (Maurice Genevoix, Ceux de 14)

1961 Moi je fais attention, madame, je me fais toute petite. Ce n'est pas comme ce bonhomme qui, tout à l'heure, a failli me renverser, moi et mes pots. Et même une des 
fleurs, une belle grosse jaune, a été coupée net au passage, c'est bien regrettable... (Claude Mauriac, La Marquise sortit à cinq heures)

1997 Brunel se redressa sur les coudes ; il respirait mal. Un cuirassier découpa des lanières dans son tapis de selle pour lui bander la main dont deux doigts étaient coupés net (Patrick Rambaud, La Bataille)

II. Interrompre brusquement, brutalement (un mouvement physique ou intellectuel)

Emploi absolu

1835 Tout à coup, il rencontra trois domestiques de son père qui le cherchaient partout pour lui remettre un billet de deux lignes : - Courez à la bourse, entrez-y vous-même, arrêtez toute l'opération, coupez net (Stendhal, Lucien Leuwen)

1945 Je me suis armé de courage et j'ai commencé mon discours : « Joseph, ta femme est chez nous depuis deux jours et j'ai pensé que le mieux... » Il n'écoutait même pas. Il a coupé tout net : «Quelle heure est-il ? Deux heures... seulement deux heures ! (Georges Duhamel, La Passion de Joseph Pasquier)

1987 - Alors, où en es-tu ? Pour certaines, un simple dépoussiérage suffira, d'autres exigeront un surcroît d'attention. J'ai fait un vague devis, environ trois cents heures.

Philippe coupa net :

- Catherine, tu remets tout ça en état, quand tout sera fini, tu me diras ce que je dois garder et ce que je peux me permettre d'offrir

(Maurice Rheims, Les Greniers de Sienne)

Intransitif

1840 Le lendemain du seizième siècle, et cent ans avant les débuts de Montesquieu et de Voltaire, ils devinèrent toute l'audace de l'avenir ; ils voulurent, par un remède absolu, couper court et net à tout ce qui tendait à la mitigation sur ce dogme du Christ-sauveur (Charles Sainte-Beuve, Port-Royal)

1877 Elle n’en était pas encore réduite à se nourrir de choses où les autres avaient pataugé. Et, dès lors, Gervaise coupa net à tous les cadeaux : plus de litres de vin, plus de tasses de bouillon, plus d'oranges, plus de parts de gâteau, plus rien. Il fallait voir le nez des Boche! (Émile Zola, L’Assommoir)

Transitif

1842 « Ma chère petite, tu l'as traité comme Tullia traite ton frère. - Quelle école que le couvent de ma sœur !! » s'est écrié mon père. Je jetai sur mon père un regard qui lui coupa net la parole ; puis je me suis etournée vers la duchesse, et lui ai dit : « Madame, j’aime mon prétendu, Felipe de Soria, de toutes les puissances de mon âme » (Honoré de Balzac, Mémoires de deux jeunes mariées)

1865 Mais voilà que, tout d'un coup, il se fit, non loin de là, comme une sonnerie de clochette, pareille à celle que j'avais ouïe sur la fougeraie, et la flûterie de Joset s'arrêta comme coupée net au beau mitant (George Sand, Les Maîtres sonneurs)

1874 - Mais ils dormaient donc comme les Sept Dormants, les parents de cette Alberte ? fis-je railleusement, en coupant net les réflexions de l'ancien dandy par une plaisanterie, et pour ne pas paraître trop pris par son histoire, qui me prenait, car, avec les dandys, on n'a guère que la plaisanterie pour se faire un peu respecter (Jules Barbey d'Aurevilly, Les Diaboliques)

1922 Ainsi, je me laissais quelquefois envahir sournoisement par de mauvaises pensées, je favorisais leur développement dans mon imagination, je prenais plaisir à m'y exciter, puis, avec une sorte de passion, je coupais net ces mauvais rameaux (Jacques de Lacretelle, Silbermann)

1928 - Et Borodine?

- Je l'ai vu en passant. Malade. Chacun son tour. Je me demande si l'on n'a pas tenté de l'empoisonner. Ses boys sont sûrs, et, de plus...

La phrase est coupée net. Descendant très vite derrière moi, il a manqué une marche 
et a pu, juste à temps, saisir les barreaux de la rampe (André Malraux, Les Conquérants)

1963 Rien de plus composite ou biscornu que la cathédrale ou Seo. Cela commence en façade gothique, coupée net au-dessus de la rosace, sans pignon ni toiture, tourne ensuite au baroque le plus extravagant, et s'achève par une série d'arcades, comme une plaza de toros (Albert T'Serstevens, L'Itinéraire espagnol)

1985 Le beur opine du chef. Je bredouille :

- C'est pas un peu tôt, non ? Berlan, ça fait que quat'jours qu'il a le job... J'sais pas moi, mais...

Mandrax me coupe tout net :

- Si dèfois tu veux prendre les commandes et passer colonel des Rebelles, Cooloss, te gêne pas!

Brutal dans le ton. Glacial dans la prunelle. Le look vivagel!

(Frédéric Lasaygues, Vache noire, hannetons et autres insectes)

1996 - Borinka, je te l'avoue. Il y a des moments où ce Hitler m'effraie. Boris et moi n'aimions pas ce genre de confidences. Elles coupaient net l'idyllique tableau de notre plus tard. Les courbettes, les rayonnements, les exotismes, de quel droit dissoudre ces chatoiements par des craintes ridicules ? (Boris Schreiber, Un silence d'environ une demi-heure)

2001 La madeleine toujours la pâte était mal cuite la rengaine colle toujours je cours dans ce palais car je sais parfaitement à dessein qui je hais. J'ai coupé net, papa, le mal à la racine (Chloé Delaume, Le Cri du sablier)

2008 Mais rien, je ne me souviens de rien. Une chose est certaine : mes velléités de rébellion ont été coupées net. J'ai dû confusément sentir que ce n'était pas le moment. J'ai recommencé à avoir de bonnes notes en classe (Virginie Linhart, Le Jour où mon père s'est tu)
Pronominal

1960 Fissa il la chasse cette idée démoralisante. Se remouiller dans un turbin, il n'en sera plus jamais question ! L'appétit qu'il avait pas féroce, s'est coupé net à cette pensée (Albert Simonin, Du mouron pour les petits oiseaux)

1995 L'officier, riant aux éclats, proféra : « Vas-y, cours. Sauve-toi, petit vaurien ! " Et ils continuaient à rire en chargeant les fusils. Soudain, leurs voix se coupèrent net. L'enfant réapparut et se mettant près du mur, à côté des adultes, lança : « Me voilà ! » (Andreï Makine, Le Testament français)

III. coupé net : qui a une forme nette, régulière Transitif

1880 Les cheveux courts se redressaient sur le front très développé. Un nez droit s'arrêtait, coupé net, comme par un coup de ciseau trop brusque, au-dessus de la lèvre supérieure, qu'ombrageait une moustache assez épaisse (Guy de Maupassant, Contes et nouvelles)

CoRpus Web :

je suis une femme, la 40 taine, je ne sais pas depuis quand je suis comme ça mais j'ai une tendance à couper net avec les choses ou certaines personnes. J'ai eu à couper les ponts du jour au lendemain avec 2 amies, pas au même moment mais le scénario était toujours le même [http://forum.psychologies.com/ psychologiescom/Mieux-se-connaitre/tendancecoupersujet_4613_1.htm] (17.12.2014)

Bonjour, hier en allant chercher ma copine au lycée, j’ai eux un soucie chimique : ma yamaha dt 50 sm a couper net donc arrêté d'urgence.... jais remis un coup de kike et la elle redémarre... [http://forum.mobcustom.com/problemespannes-(50-a-boites])/moteur-qui-a-couper-netune-seul-fois-et-qui-roule-encore (17.12.2014)

La scie à métaux n'est pas conseillée ai-je lu ici.... Mon coupe tube pour cuivre écrase l'aluminium au lieu de couper net Je ne vois pas bien les caractéristiques des outils proposés par Facq (livre rouge) [http://www. bricozone.be/fr/plomberie/t-avec-quoi-couperle-multicouche-8580.html] (17.12.2014) 
Les hommes avec une barbe plus fine pourront se servir de lames plus émoussées, même si celles-ci peuvent tirer sur la barbe au lieu de la couper net [http://fr.wikihow.com/se-raseravec-un-rasoir-de-s\%C3\%A9curit\%C3\%A9] (17.12.2014)

On met alors le morceau de capillaire dans la cleaveuse qui va la couper nette, en plaçant la partie propre [...] au niveau du diamant de la cleaveuse [http://physique.unice.fr/sem6/20082009/PagesWeb/Gouttes/4_capillaires.html] (17.12.2014)

REMARques : Net est un adjectif-adverbe de manière. (I) se dit du fait de diviser en parties un corps solide (consommable ou non) à l'aide d'un instrument tranchant, l'objet désignant une partie du tout et pouvant représenter une partie du corps (bras, jambe, main, doigts). En (II), le sujet peut renvoyer à une personne qui interrompt brusquement, soudainement, sans prévenir, son flot de paroles ou qui est interrompu dans la conversation par quelqu'un. Le sujet peut aussi désigner une parole qui fait cesser subitement la conversation. Couper net peut également désigner une activité déjà mise en place, dont le processus ou l'essor est soudainement interrompu ou stoppé. (III) réfère à la forme d'une partie ou d'un élément du visage (ici : le nez), dont les contours sont nets, réguliers, comme taillés au ciseau. Notons la collocation couper court et net. Net tend à l'emploi invariable, mais il peut occasionnellement s'accorder avec l'objet. Il est modifié par aussi, tout. Dans le CW, net reste invariable (comme dans le troisième exemple, où l'objet est au féminin), mais il s'accorde avec l'objet pronominal féminin antéposé au verbe dans le dernier exemple. L'accord est sans doute influencé par le fait que les différentes formes morphologiques de l'adjectif net sont prononcées de la même manière, avec le - $t$ final. Notons l'emploi de s'enfoncer creux dans l'exemple de 1950a.

\section{Couper ras}

Couper à la base, à la racine, au plus près du sol, de la surface de quelque chose

Transitif

1690 Le Baume étant une fois planté n’a besoin d'autre culture particuliere que d'être coupé ras tous les ans à la fin de l'Automne
(Jean de La Quintinye, Instruction pour les jardins)

1701 il suffit que cette herbe [= le baume] soit en bonne terre pour qu'elle y réussisse, ne demandant point d'autre culture particuliere que d'être coupée rase tous les ans

(Louis Liger, Economie generale de la campagne ou Nouvelle Maison rustique

1785a RAS. On dit bien, un poil ras, mais non pas, couper ras, pour raser. [...] Couper un arbre rez-pied, rez-terre, ou à rase-terre (Pierre-Augustin Boissier de Sauvages, Dictionnaire languedocien-françois)

1785b Il y a deux points noirs sur l'extrémité postérieure du corps [= du vers], qui est comme coupée rase. Le corps est composé de dix anneaux, sans pieds (Le Journal des sçavans)

1843 Comme elle ne peut rien supporter sur sa tête, ses cheveux blancs, coupés très ras, dessinent la forme de son crâne, au front aplati ; ses épais sourcils gris ombragent ses orbites profondes où luit un regard d'un éclat sauvage (Eugène Sue, Les Mystères de Paris)

1859 C'est plus étrange que joli, car cette coiffure a le tort impardonnable de cacher absolument les cheveux, qu'un lieu-commun bien souvent répété a appelé, avec raison, le plus bel ornement de la femme. Ici, en effet, la chevelure n'apparaît point, et presque toujours elle est coupée ras, à la Titus, comme disaient nos grand'mères (Maxime Du Camp, En Hollande)

1882 Elle s'est retirée pour le moment dans une case isolée, bâtie auprès du tombeau de sa petite-fille, et ne veut plus voir âme qui vive. « Rarahu observa dans cette circonstance la même coutume que les suivantes de la cour ; en signe de deuil, elle fit couper tout ras ses admirables cheveux noirs » (Pierre Loti, Le Mariage de Loti)

1914 À quarante-six ans, Anthime Armand-Dubois n'avait plus à songer à plaire ; il coupa ras ses cheveux et adopta cette forme de faux cols demi-hauts dans lesquels une 
sorte d'alvéole réservée cachait la loupe et la révélait à la fois (André Gide, Les Caves du Vatican)

1921 Les masses liquides, les murs découpés du feuillage font des voûtes, des berceaux, des murs, des couronnes, des avenues, l'hymne solennel s'élève et plane avec un grand murmure froid, du gravier bien peigné et de l'herbe coupée ras aux longues façades austères qui alignent sur trois rangs leurs fenêtres superposées (Élie Faure, Histoire de l'art : l'art moderne)

1928 au fond donc de ce verbalisme toxique, il y a le spasme flottant d'un corps libre et qui regagne ses origines, la muraille de mort étant claire, étant coupée rase et renversée. Car c'est ainsi que la mort procède, par le fil d'une angoisse que le corps ne peut manquer de traverser (Antonin Artaud, L'Osselet toxique)

1936 Solitude du cœur, avoir compris la limite de nos sentiments, mesuré le cerne d'égoïsme qui emprisonne nécessairement chaque individu - et prendre son parti de son propre cerne, enfin couper les cheveux ras à l'illusion (Pierre Reverdy, Le Livre de mon bord)

1977 Je manque rarement quand je descends dans le Midi de m'arrêter à Barbizon pour lui faire visite. C'est un gnome minuscule au cheveu gris coupé ras, appuyé sur deux cannes qui m'apostrophe aussitôt d'une voix éraillée et goguenarde, sans lâcher sa bouffarde (Michel Tournier, Le Vent Paraclet)

2006 - Vos conclusions, donc ? demanda von Bittenfeld, l'aide de camp de Köstring. Weintrop gratta ses cheveux blancs, coupés presque ras :

- Quant à l'origine, difficile à dire : les informations sont contradictoires (Jonathan Littell, Les Bienveillantes)

2007 Maladroitement, elle glisse l'élastique derrière sa tête, il se coince dans ses cheveux gris fer, coupés ras, elle rabat le masque blanc sur son visage, et tout à coup, l'al- cool qui n'a cessé de couler aidant, c'est une vision de cauchemar, cette petite femme soûle, submergée de désespoir, qui s'agite au milieu de son studio sinistre avec son masque blanc d'hôpital, et qui crie, et qui se met à pleurer

(Emmanuel Carrère, Un roman russe)

\section{Corpus Web :}

Quand on patiente pour voir ses ongles pousser et qu'un petit accro vient tout gâcher, c'est la tuile. Avant de couper ras et vous lamenter, vous pouvez colmater la fissure [http:// www.mariefrance.fr/beaute/la-question-quitue/comment-reparer-ongle-casse-sans-lecouper-139557.html] (17.12.2014)

Pour moi la seule chose a faire pour avoir une belle brosse bien droite, bien belle, couper ras la peau au début, et entretenir souvent (la mienne est délécé et du coup horrible ${ }^{\wedge} \wedge$ ] [http:// www.1cheval.com/membre/forum/general/sujet2588991-1-couper-criniere-en-brosse-1ere-fois] (17.12.2014)

C'est vrai que les agneaux garder pour la reproduction sont mieux evec la queue coupés, cela permet de gagner du temps lors de la tonte, d'éviter les parasites, de mieux surveiller les agnelages.... Attention cepandant à ne pas trop la couper rase, il faut laisser la vulve cacher (donc $4 \mathrm{~cm}$ envion) [http://www.catalogue-fr.com/ phpBB2/viewtopic.php?t=8834\&sid=25e7df67ad a80a4a5c45a1190233089e] (17.12.2014)

REMARQUES : Couper ras désigne le fait de tailler très court une production du corps qui se renouvelle tels que les cheveux ou les ongles. L'objet peut aussi référer à un élément de la végétation (chaume, herbe, blé) qui, coupé, ne s'élève pas très haut au-dessus du sol. L'attestation de 1701 copie en paraphrasant celle de 1690, où l'on parle également du baume, dans un livre publié par le même éditeur, passant tout de même de l'adjectif-adverbe invarié à sa variante accordée. On trouve deux exemples accordés au XviII ${ }^{\mathrm{e}}$ siècle. Par la suite, les exemples en diachronie tendent à l'invariabilité. Un seul des 123 exemples dans Frantext - celui de 1928 - est accordé. L'accord ne pouvant se produire qu'au féminin, il devient par là même peu fréquent, ce qui peut favoriser l'invariabilité générale, même au féminin. Le dernier 
exemple du CW contient cependant un emploi fléchi de ras, ce qui le rapproche d'une fonction de prédicat second orienté vers l'objet. La qualité orthographique du français dans cet exemple est douteuse, mais la flexion présuppose le fait qu'elle est réalisée ou puisse l'être à l'oral. La citation de 1785a ( « on ne dit pas couper ras ») n'est pas descriptive, mais normative : on conseille de ne pas utiliser couper ras. En effet, les éditions ultérieures du dictionnaire remplacent couper ras tout court par couper ras de terre. Ras est modifié par presque, tout, très.

\section{Couper sec}

I. Couper quelque chose de la façon la plus nette, la plus directe (ici : tailler un arbre) Emploi absolu

1690 mais aussi il faut sentir jusqu'où pourra aller l'effort qu'il faudra donner pour emporter tout d'un coup la partie qui est à ôter, sans qu'en chemin faisant la serpette nuise à aucun de ses voisins ; et voilà ce qu'on appelle couper sec comme il faut pour bien tailler, c'est-à-dire, couper net, de manière que si c'est une branche, la coupure soit en quelque façon ronde, platte, tout au moins qu'elle ne soit nullement longue, comme les gens mal-adroits les font ; et s'il arrive qu'on l'ait fait longue, il faut encore donner quelques coups de serpette (Jean de La Quintinye, Instruction pour les jardins)

II. Couper, interrompre brusquement, brutalement

Emploi absolu

1961 Les rares effets optiques qui subsistent dans mon film ne servent jamais à établir les transitions entre le présent et les flashbacks. J'aime couper sec d'une image à l'autre (France observateur, 26 janvier 1961 / Grundt : 357)

1977 Je coupe aussi sec :

- J'préfère le faire moi-même !... des fois que tu trouves pas les mots justes !... que tu brodes !... (Albert Simonin, Confessions d'un enfant de La Chapelle)

1990 Pas du tout : Rosalind-Ruth avait décidé de couper vite et sec, c'était le seul moyen d'éviter l'enlisement, les arrangements pratiques viendraient progressivement (Julia Kristeva, Les Samouraïs)

Transitif

1982a - Monsieur Léon nous avait dit que vous étiez...

Il n'a pas le temps de s'expliquer plus avant, il se fait couper sec.

- Léon est un pédérrraste, un malheurrreux qui voudrrrait que je le sodomise...

(Alphonse Boudard, Les Enfants de chœur)

1982b Il avait coupé sec le flot aigre dont le volume sonore augmentait à chaque seconde, et déguisé sa voix avec ce ton que l'on prend quand on téléphone de loin et qui, même si la communication est parfaitement claire, permet tous les mensonges et toutes les échappées :

- Bon, ben j'te laisse, à tout à l'heure

(Philippe Labro, Des bateaux dans la nuit)

\section{CORPUS Web :}

Il peut arriver que vous ayez à ce moment-là une autre couleur où vous ne possédez qu'une seule carte. Préférez le défausser sur ce deuxième tour, pour pouvoir couper sec la couleur défaussée ensuite [http://www.beloteenligne. com/couper-le-second-tour-dune-couleur.php] (17.12.2014)

C'est censé aider en quoi de couper sec la console ?? [http://www.jeuxvideo.com/forums/160-2761773-1-0-1-0-0.htm] (17.12.2014)

pour ce qui est de la [= la poupée] couper seche oui c'est possible, mais dejà c'est difficile et ensuite c'est pas tres esthétique, j'ai essayé de la poncer et là c'est juste l'horreur, c'est quasi impossible et le rendu est tres moche [http:// www.materielceleste.com/t2022p510-creer-unepoupee-en-resine-une-bjd-conseils] (17.12.2014)

REMARQUES : Couper sec (I) réfère au fait de tailler un arbre le plus directement possible. (II) désigne le fait d'arrêter de façon brusque, nette et rapide, voire inattendue, une parole, une conversation, une action. Notons la collocation couper vite et sec. Dans le CW, le dernier exemple montre l'emploi comme prédicat second fléchi où sec s'oppose à liquide en tant que qualité de la résine 
non encore séchée. Le premier exemple du CW renvoie au jeu de cartes où l'on « coupe » avec l'atout une couleur jouée. Sec reste généralement invariable et est modifié par aussi.

\section{Courir doux}

I. Couler doucement, tranquillement Intransitif

1596 Priant tous palladins qui passeront icy, S'ils ont jamais senty le doux-poignant soucy

Du grand vainqueur des dieux, qu'aux fidelles aubrages,

Aux autres tenebreux, aux prez et aux rivages,

Aux bois delicieux, aux doux courans ruisseaux,

Espressement bordez d'amoureux arbrisseaux (Philippe Desportes, Euvres)

II. Aller doucement, avec prudence et modestie Intransitif

2001 Il a bien fallu faire contre mauvaise fortune bon cœur et courir doux avec le salaire d'appoint (Dominique Méda, Le Temps des femmes)

\section{CORPuS Web :}

Si vous ne possédez pas le temps d'exercer seul, ne vous inquiétez pas. Prenez votre bébé pour une promenade dans le parc ou investir dans une poussette de jogging et aller courir doux [http://www.ordenan.com/comment-perdre-duventre-poids-apres-une-cesarienne] (17.12.2014)

un fantome avec un epee, il courait doux il vient apres le mur se ferme. Il regarda la piéce, il voit un coffre, il vas voir une epée contre l'Epée qui va gagner [http://www.jeuxvideo.com/ forums/1-4550-4693196-2-0-1-0-0.htm] (17.12.2014)

J'ai fait un montage du capteur à partir d'un morceau d'aluminium, $j$ ai obtenu une position correcte en utilisant le boulons de fixation moteur. Fired le moteur et il courut doux comme un écrou [http://www.france-helico.com/ topic/9918-transformation-glow-vers-gaz-peutetre-possible] (17.12.2014)

Un génie nous traverse, nous rend éblouissant !

Nos doigts courent, doux mais fermes, sur le clavier bouillant
Nous concevons le post pour la postérité [http://atouts.site.pagesperso-orange.fr/potao. html] (17.12.2014)

REMARQUeS : Courir doux (I) se dit d'une rivière ou d'un liquide (dans l'exemple de 1596 : un ruisseau) qui coule ou s'écoule légèrement, d'une manière agréable, le son de l'eau produisant un sentiment de calme dans la nature environnante. Séparée par un écart de quatre siècles, l'acception (II) renvoie à un train de vie modeste, au fait d'avancer doucement dans sa vie, en l'occurrence suite à des problèmes économiques. Dans le CW, courir doux est documenté au sens de 'se déplacer rapidement' (concret) ; le groupe s'applique également à la course d'un moteur. Doux apparaît dans la fonction de prédicat second orienté vers le sujet dans le dernier exemple du CW où l'accord au pluriel se manifeste sur l'adjectif ferme coordonné avec doux. Notons l'emploi antéposé au participe verbal dans l'exemple de 1596 : doux-poignant (poindre doux).

\section{Courir droit}

I. Courir directement

Intransitif

1250 Mais mult par firent grant murmure

Tuit cil qui el chastel estoient

Des chevals qu'iluec laissiez voient.

Uns serjanz cort tost et isnel

Tot droit au seignor del chastel,

Que il trova en son dojon,

Si l'a mult tost mis a reison

(Joufroi de Poitiers, 1314)

1604 HECUBE. Vous deviez refrener sa nuisible vaillance.

CHEUR. Il parut si terrible en cet accoustrement,

Que nul à l'arrester ne songea seulement.

Il court droit à l'estable où sa main ne dédagne

D'equiper son cheval, puis sort à la campagne

(Antoine de Montchrestien, Hector)

1628 CASSANDRE. Desja les roussins noirs qui trainent la charrette

De l'ennuyeuse nuit esperoient leur retraitte, 
En sentant de leur train les trois quarts mesurez,

Couroient à chef baissé droit aux flots desirez (Jean de Schélandre, Tyr et Sidon)

1637 HERODE. Ce qu'escrit le Destin ne peut estre effacé.

Il faut bon-gré, mal-gré, que l'ame resoluë Suive ce qu'a marqué sa puissance absoluë: De ses pieges secrets on ne peut s'afranchir, Nous y courons plus droit en pensant les gauchir (Tristan l'Hermite, La Mariane)

1830 HERNANI. Je n'ai plus un ami qui de moi se souvienne,

Tout me quitte, il est temps qu'à la fin ton tour vienne,

Car je dois être seul. Fuis ma contagion.

Ne te fais pas d'aimer une religion !

Oh ! par pitié pour toi, fuis ! - Tu me crois peut-être

Un homme comme sont tous les autres, un être

Intelligent, qui court droit au but qu'il rêva.

Détrompe-toi. Je suis une force qui va ! (Victor Hugo, Hernani)

1858 Il se confirma dans cette ingénieuse idée quand son maître lui défendit de parler de sa course à travers les prés. Au lieu de s'arrêter à Ars, le marquis fit courir droit sur Briantes. Il était surpris, et un peu honteux déjà, du moment d'effroi qui l'avait entraîné à quitter Brilbault sans rien éclaircir

(George Sand, Les Beaux Messieurs de Bois-Doré)

1863 Hannon, par désir d'humilier son rival, ne balança pas. Il cria de sonner les trompettes, et toute son armée se précipita sur les barbares. Ils se retournèrent et coururent droit aux Carthaginois (Gustave Flaubert, Salammbô)

\section{II. courir droit à sa perte, au naufrage Intransitif}

1596 A toute heure, en tous lieux, de tout je me déplais, La nuict est mon soleil, le discord est ma pais,
Je cours droit au naufrage et fuys ce qu'il faut suivre ;

Je me fache en fachant les hommes et les dieux

Je suis las de moy-mesme et me suis odieux ;

Bref, je ne puis mourir, et si je ne puis vivre (Philippe Desportes, Euvres)

III. Courir en suivant une ligne droite

Intransitif

1933a - Pour l'intelligence contemporaine, bardée de positivisme, continuait Augustin, c'est le chemin direct, la route nationale où le trafic actuel roule tout seul, tant elle court droite, descendante et tentatrice. À la descente, tous les diables aident (Joseph Malègue, Augustin ou Le Maître est là)

1933b Qui savait ? Qu'importait ? Chaque moment est créateur. Son amour courait fort et droit comme un grand vent. Il était plénitude, simplicité, renouvellement de tout (Joseph Malègue, Augustin ou Le Maître est là)

1979 Nous y courons tout droit lorsque la Providence - ou le diable gardien, allez savoir - intervient. Le moteur ralentit, émet des toussotements de plus en plus poussifs et finit par s'étrangler tout à fait (Jean Egen, Les Tilleuls de Lautenbach)

CORpus Web :

En l'absence de telles subventions, bon nombre des producteurs affectés par des périodes de gel intense courent droit à la faillite [http:// www.linguee.de/deutsch-franzoesisch/search?s ource=auto\&query $=$ courent $<+$ droit] $(7.1 .2015)$

Les jeunes courent droit vers l'enfer [https:// twitter.com/FababyOfficiel/status/32785837613 6605696] (7.1.2015)

Et ce lieu alors où j'aimais me rendre n'était pas la croix faite par latitude rencontrant cousine verticale. C'était frontière et c'était limite. C'était la ligne qui courait, droite et blanche comme l'interdit, entre le monde du normal et celui du bien moins [http://troudair.free.fr/ceslieux.php] (8.1.2015) 
REMARQues : Courir droit (I) réfère au fait de se déplacer rapidement en direction d'un lieu, sans détour. En (II), le sujet est une personne qui tombe, de manière inéluctable, dans une situation extrême, dangereuse ou source d'ennuis. (III) désigne le fait d'aller, de se déplacer rapidement en un lieu, vers un lieu ou une personne, en suivant une ligne droite, le sujet pouvant être une personne ou, dans son emploi métaphorique, une chose abstraite, un sentiment (l'amour) ; le verbe souligne alors la plénitude de l'amour qui comble l'être. Au niveau spatial, le sujet peut aussi désigner une route qui s'étend dans une certaine direction. Notons la collocation courir fort et droit (III). Droit peut s'accorder avec le sujet (ex. de 1933a). Le style littéraire élaboré préfère dans cet exemple la prédication seconde orientée vers le sujet pour mettre en avant le rôle du sujet, mais l'invariabilité est la règle. En (I) et en (II), droit est suivi d'une préposition de lieu indiquant la direction (à, sur, vers). Dans cet emploi, droit a tendance à s'associer avec les prépositions qui le suivent, au point de faire partie $\mathrm{du}$ groupe prépositionnel comme modifieur de la préposition. Ceci est particulièrement bien mis en évidence dans l'exemple de 1250 où tout droit à est une seconde modification adverbiale orientée vers le but du déplacement : « cort tost et isnel tot droit au seignor del chastel ». Droit est modifié par tout, plus. Dans le dernier exemple du CW, droit est employé en fonction de prédicat second détaché orienté vers le sujet, avec lequel il s'accorde en genre, tout comme l'adjectif blanc.

\section{Courir fort}

I. Courir avec force

Intransitif

+1250 Quar l'autre qu'est por ses cheas grigne, Tant fort cort sus a ceste chine, Qu'ele li fait uudier la place, Tout fuer de son porpris la chace? (Ysopet de Lyon [2 moitié XIII] $]$, 544)

+1400 Si m’affondent et plungent en asprece ; Car parmi moy cuerent plus fort que Saine Source de plour, riviere de tristece. (Christine de Pisan, Rondeaux / Euvres poétiques [début Xve], I, p. 182, 6)
+1489 Ilz me dirent que la rivière estoit trop large et couroit fort, par quoy ilz ne s'entenderoient point à parler ; et ne sceüz tant faire qu'ilz vousissent venir plus loing ; et me dirent que je feïsse quelque ouverture (Philippe de Commynes, Mémoires [14891498], VIII)

\section{Courir rapidement}

Intransitif

1460 Et est assavoir que, le jeudi XXIII jour de juillet, oudit an LXI, qui fut le lendemain de ladicte mort, environ IX heures de nuit, fut veue ou ciel courir bien fort une très longue comete, qui gectoit en l'air grant resplendisseur et grande clarté, tellement qu'il sembloit que tout Paris feust en feu et en flambe (Jean de Roye, Chronique scandaleuse)

1627 Au moins menez moy sans scandale, dit le berger, ne me tenez plus, j'iray de bon gré, pourveu que vous m’apreniez en quel lieu vous voulez que j'aille au giste, puis que vous me faites courir si fort. Ne voyez vous pas que je suis un messier? (Charles Sorel, Le Berger extravagant)

1645 ERGASTE. Je vais trouver Anselmme et commencer mon rôle,

Où, si de mes efforts le succès n'est frivole, Il sera bien adroit s'il nous peut échapper, Et, s'il ne court bien fort, je saurai l'attraper (Jean de Rotrou, La Soeur)

1883 Mon moutard avait beau tirer la langue comme un chien de chasse et courir si fort que ses genoux heurtaient son front, nous l'avons bien vite laissé derrière nous (Paul Claudel, L'Endormie)

1885 Et Chaval fut emporté avec les camarades. Il bouscula Catherine, il l'accusa de ne pas courir assez fort. Elle voulait donc qu'ils restassent seuls dans la fosse, à crever de faim ? (Émile Zola, Germinal)

1887 Cette fois, son chapeau noir avait roulé parmi les cailloux. Il le suivit, le ramassa, courut plus fort. Derrière lui, les coups de feu continuaient, pan! pan! pan! sans un arrêt, une vraie fusillade, au milieu de 
grands rires, qui achevaient de le rendre imbécile (Émile Zola, La Terre)

\section{CORPUS WEB :}

Beaucoup de coureurs qui visent un temps plus rapide au marathon supposent que courir fort tous les jours va les rendre plus rapides [http://www.jogging-course.com/Marathon/ plus-rapide.html] (7.1.2015)

Ça va courir fort au Défi des Collines. Sébastien Roulier a confirmé qu'il serait de retour pour défendre son titre au $30 \mathrm{~km}$ [https://www. facebook.com/CourirEnEstrie/posts/3446211856 24190] (8.1.2015)

(renseignement pris, c'était pas un marathon, c'était un semi... reste que même pour un semi les gars couraient fort !) [http://www.rolle renligne.com/phpBB2/viewtopic.php?t= $11944 \& \mathrm{p}=223524]$ (8.1.2015)

Pour un il y a quelques semaines la rumeur courait forte sur Twitter que les Arctic Monkeys pourrait revenir dans le pays aztèque, dans le cadre de la tournée promotionnelle pour son dernier Suck It and See [http://www.wikinoticia. com/fr/Divertissement/Musique/106330-arcticmonkeys-en-mexico] (8.1.2015)

REMARQUES : Courir fort (I) réfère à la force avec laquelle une personne se déplace, le verbe traduisant une action du corps et fort soulignant la vigueur d'un effort physique. En parlant d'un liquide (la rivière), il exprime la force avec laquelle il coule. En (II), il désigne le fait d'aller vite, le sujet désignant une personne et fort soulignant la rapidité dans le mouvement. Fort reste invariable et est modifié par assez, bien, plus, si, tant. Dans le CW, fort reste invariable dans le troisième exemple malgré le sujet au pluriel, tandis qu'il s'accorde avec le sujet féminin dans le dernier exemple, tout en gardant son interprétation de manière. Dans le troisième exemple $\mathrm{du} \mathrm{CW}$, les gars couraient fort est aux limites d'un emploi comme adverbe d'opinion, dans la mesure où l'on peut proposer la paraphrase ils ont fait fort 'je trouve fort ce qu'ils ont fait'.

\section{Courir isnel}

Se déplacer rapidement (vers un lieu ou en direction d'une personne)

Intransitif

1170 Ja i avra estor plenier, Quar al bosoing i vint Paris

0 plus de dis mile Persis

Sor les destriers isneaus coranz

[variante : Sor le destrier isnel corrant]

(Benoit de Sainte Maure, Le Roman de Troie, 12267)

1177 La dameisele cort isnel

A sa chambre et revint mout tost, S'aporta un chapon an rost

Et un gastel et une nape

Et vin, qui fu de buene grape, Plain pot d'un blanc henap covert, Si li a a mangier ofert (Chrestien de Troyes, Yvain ou Le Chevalier au lion, 1046)

1250 Mais mult par firent grant murmure Tuit cil qui el chastel estoient Des chevals qu'iluec laissiez voient. Uns serjanz cort tost et isnel Tot droit au seignor del chastel, Que il trova en son dojon, Si l'a mult tost mis a reison (Joufroi de Poitiers, 1314)

REMARQUES : Emprunt d'origine germanique, isnel était employé jusqu'en moyen français avec la même signification de 'rapide' que son équivalent en allemand moderne (schnell). Le fait qu'on ait utilisé ce mot emprunté comme adjectifadverbe montre que l'emploi adverbial de l'adjectif était un procédé productif. Isnel est accordé dans l'exemple de $\sim 1170$. Notons la collocation tost et isnel où tost suggère l'idée de rapidité ('en peu de temps') dans le mouvement et vient renforcer le sémantisme d'isnel.

\section{Courir léger}

Courir avec la légèreté de l'air

$\pi$ courir rapide 


\section{Courir lent}

Courir lentement, avec lenteur

Intransitif

-1300 Charles sist ou cheval qi ne cort mie lant, Antre Saisnes et Rune une angarde porprant (Jehan Bodel, La Chanson des Saisnes [fin XIII ], 4792)

\section{CORPuS Web :}

j sais kil faut une alimentation equilibrer mais $j$ voudrais savoir si courir lent durant une heure, trois par semaine ca maiderait et $\mathrm{k}$ en pensez vous des ceinture de sudation ou des jogging de sudation, est ce aue cela serre ou pas [http://www.courseapied.net/forum/msg/1149. $\mathrm{htm}]$ (8.1.2015)

Oui, commence par de l'endurance pendant 1 mois mini. Tu dois etre tres à l'aise et ne pas entendre ta ventilation, en cas de doute il ne faut pas hésiter a ralentir. Oui, je sais, c'est dur mais important pour pouvoir progresser ; Courir lent t’aidera a courir vite [http://www.conseilscourseapied.com/forum/9-entrainement-demifond-800m-1500m-3000m-5000m/107580debutant-3000m.html] (8.1.2015)

Une fois installé sur les ordinateurs, il modifie immédiatement sur des fichiers système et injecte un code sur les processus du système légitimes. Ainsi, les ordinateurs affectés commencent à courir lent et vous empêchent de terminer normale, activités quotidiennes [http:// www.removalvideos.com/fr/how-to-completelyget-rid-of-win32adware-multiplug-ck] (8.1.2015)

Bien plus, tout ce qui est à sa surface est doué de mouvement : les eaux descendent des montagnes et courent, lentes ou rapides, formant les rivières et les fleuves, qui s'en vont vers la mer [http://www.salve-regina.com/ salve/Manuel_d'apologétique_1re_partie:Les_ préambules_rationnels_de_la_Foi] (8.1.2015)

REMARQues : Courir lent désigne le fait d'aller à pied, ou de se déplacer à cheval, le déplacement s'effectuant de manière lente et se caractérisant par un manque de rapidité dans le mouvement. Dans le CW, lent reste invariable dans le troisième exemple, tandis qu'il s'accorde avec le sujet féminin pluriel dans le dernier exemple, tout comme l'adjectif rapide. Dans ce dernier exemple, les adjectifs se prêtent à une analyse en tant que prédicats seconds détachés orientés vers le sujet. Courir lent s'oppose à courir vite.

\section{Courir rade}

Jaillir avec force

$\lambda$ courir vif

\section{Courir raide}

Courir rapidement, très vite

Intransitif

1530a Lors il mist le sac à terre et dist au serviteur : « Je n'oserois porter cest ort pain à monsieur mon maistre. Courez royde à l'hostel et y en allez querir ung aultre ! Je vous attendray icy! » (Ulenspiegel)

1530b Ainsi elle s'en alla avec la meschine et rencontra son mary qui luy demanda pourquoy elle couroit si roide. Elle dist : " Ulespiegle est à nostre maison qui dit que on vous avoit donné ung esturgeon, lequel nous vous ayderions à porter ». L'homme se courrouça et dist : « Ne sçavez vous demourer à l'hostel ? Ce n'est que une finesse ! » Et quant elles furent dehors la maison, si ferma Ulespiegle la maison partout (Ulenspiegel)

1896 Ensuite, toute secouée d'une fureur grandissante, elle courut raide comme balle au cabaret du Père Sauvage, qui fait, vous le savez, face à ma maison (Louise Bugnon Renard, Contes de Bretagne)

CoRpus Web :

Ces pros courent raide, L'entremetteur millionnaire autoproclamé de Houston est important [https://webreiting.ru/fr/matchmaking-softwarefor-a-profitable-matchmaking-business] (9.10.2020)

[ $=$ des joueurs $]$ qui courent raide comme avec des balais [...] a la limite du comique [https:// www.jeuxvideo.com/forums/1-13395-108129-1-0-10-0.htm] (22.10.2007)

\section{Courir rapide}

Aller rapidement Intransitif

1801 on croit voir ceux [= les chevaux] de Pluton enlevant Proserpine, leur haleine enflammée semble lancer des étincelles ; narines 
poudreuses, bouche écumante, œil enflammé, ils courent rapides comme le vent, orageux comme la tempête (Pierre-JeanBaptiste Chaussard, Fêtes et courtisanes de la Grèce)

1833 Il y a des rêves plus pénibles encore. C'est de se croire condamné à accomplir quelque tâche extravagante, quelque travail impossible, comme de compter les feuilles dans une forêt ou de courir rapide et léger comme l'air (George Sand, Lélia)

1840 Sous chaque étincelle Grossit et ruisselle Le feu souverain. Vermeil et limpide, Il court plus rapide Qu'un cheval sans frein ; Et l'idole infâme, Croulant dans la flamme, Tord ses bras d'airain! (Victor Hugo, Les Orientales)

1861 Le soleil à peine disparu, le vent fraîchissait, les vagues couraient rapides, vertes et sombres (Jules Michelet, La Mer)

1868 Et la nef courait, ferme et rapide, et l'épervier, le plus rapide des oiseaux, n'aurait pu la suivre (Charles-Marie Leconte de Lisle, Odyssée [trad.])

\section{CORPUS WeB :}

Marcher ou courir... Rapide ou lent... Ce qui compte plus, c'est la destination... [https://www. facebook.com/sabretravelnetwork.ci] (8.1.2015)

Oh la la, même sans trop le connaitre celui-là, je sens que je vais courir rapide pour me le procurer [http://www.dvdclassik.com/forum/ viewtopic.php?t=20632\&view=next] (8.1.2015)

Il manque juste une chose : la pluie. Pour calmer les esprits, calmer les nerfs, arreter les pensées qui courent rapides et sans cesse s'entassent dans les journées trop ensoleillées [http:// commeunphenix.blogspot.co.at/2013/08/lapluie.html] (8.1.2015)

REMARQUES : Courir rapide réfère au fait d'aller, de se déplacer, d'avancer rapidement, de filer sur l'eau. Par extension, le sujet peut désigner un élément ou un phénomène comme le feu qui se propage très rapidement ou s'étend progressivement dans l'espace. Notons la collocation détachée ferme et rapide, où ferme ajoute à l'idée de rapidité la notion de force dans l'action ou le mouvement. Dans l'exemple de 1868, les adjectifs se prêtent également à une analyse en tant que prédicats seconds orientés vers le sujet. Rapide est modifié par plus. Le fait que rapide est un emprunt savant du XvII ${ }^{\mathrm{e}}$ siècle (du lat. rapidus ; la forme héritée est rade; à comparer : courir rade), préféré à la Cour à vite (adjectif), jugé rural, explique que son adverbialisation ne se produit que relativement tard ; ceci peut surprendre étant donné que sa signification favorise une interprétation de manière, comme dans le cas de vite employé en ancien français comme adjectif et adverbe. L'adverbialisation tardive de rapide reflète le processus de popularisation du mot emprunté qui, dans un premier temps, n'adopte que la forme adverbiale canonique, $r a$ pidement. Les données reflètent ce processus, les exemples hors CW appartenant au style littéraire élaboré, tandis que les deux premiers exemples du CW appartiennent au registre familier. Le dernier exemple du CW met en évidence l'effet de l'accord littéraire qui attribue la rapidité aux pensées. Notons les collocations ferme et rapide, rapide et léger, rapide ou lent.

\section{Courir subit}

Courir rapidement, hâtivement Intransitif

1534 S'il y a rien caché dessoubz l'habit, Meilleur le pense : elle court plus subit Que vent leger, et ne prend pied la belle Aux dictz de cil qui en ce poinct l'appelle (Clément Marot, Livre premier de la métamorphose)

Remarques : Dans l'ancienne langue, subit réfère au fait d'aller, de se déplacer, d'avancer rapidement, précipitamment, le sujet désignant une personne ; le mouvement traduit une certaine précipitation, l'empressement du sujet. Subit reste invariable et est modifié par plus. 


\section{Courir vif}

Courir, couler rapidement, avec vivacité

Intransitif

+1365 Et droitement en un vert pré, En l'ombre d'un vert arbrissiel, Tout joindant un joli ruissiel Où l'aigue couroit rade et vive Qui d'une fontainne y arrive, Fu li esbanois ordenés (Jean Froissart, Poésies [3e tiers XIV] ])

1373 En venant a une fontainne Qui pas ne leur estoit lontainne, Car dedens le vregier sourdoit, Belle et clere ; riens ne l'ordoit, Ains couroit moult rade et moult vive, Sans buse ne tuiel ne tive (Jean Froissart, La Prison amoureuse, 1360)

1836 Pensez, combien je fus heureuse, puisqu'il me prit un baiser sans que je lui fisse défense. Je jouai avec son doux présent ; je le caressai ; j’avais peur de le ternir ; je le faisais courir vif et clair sur mon front, sur ma robe et partout, lorsqu'un lutin passant tout-à-l'heure, a pris mon trésor et l'a brisé (Camille Delevoy, Une veillée)

1876 Un malaise indéfinissable chassa, pour lui, jusqu'à l'apparence de la lassitude. Son sang courait vif dans ses veines et bouillait. Il sentait un danger (Arthur de Gobineau, Nouvelles asiatiques)

\section{CORPuS WeB :}

Dans Crysis 2, il est possible d'approcher de différentes manières les ennemis. Par exemple, grâce à un pouvoir de la combinaison, il est possible de courir vif comme l'éclair et tuer tous les adversaires avec célérité et classe [http://www. gamergen.com/actualites/crysis-2-defouraillevideo-alien-new-york-fps-crytek-cry-engine-3invisible-force-nano-combinaison-suit-5686-1] (8.1.2015)

Claudio, il n'a pas arreté de courir, vif comme l'eclair, il a pas mal tenté sans reussite malheureusement. Certainement l'un des plus offensif ce soir, son envie et sa hargne n'auront pas suffit ce soir pour sauver l'equipe [http://claudiobeauvue.skyrock.com/2692683684-Estac-Frejus- 1-2-premiere-defaite-domicile-mais-ce-n-est-pasci-grave.html] (8.1.2015)

J'y vis souvent le petit Klepfisz, garçonnet blond aux yeux bleus, courir, vif et espiègle, à travers l'appartement... [http://www.editionszones.fr/spip.php?page=lyberplayer\&id article $=81](8.1 .2015)$

D'autres femmes préféraient se rendre au lavoir du bas de Villers, ou encore au ruisseau des Vernes au coin d'Amont où l'eau courait vive et claire [http://canardsurlaloue.com/frame_jour_ de_lessive.htm] (8.1.2015)

Remarques : Courir vif se dit d'une rivière ou d'un liquide (ici : l'eau [l'aigue], le sang) qui coule rapidement, avec une grande force. Notons la collocation rade et vif, rade [la forme héritée de lat. rapidus] venant renforcer le sémantisme de vif. Dans les exemples de +1365 et de 1373 , l'accord au féminin se manifeste uniquement sur l'adjectif vif qui est coordonné à rade. Les adjectifs se prêtent également à une analyse en tant que prédicats seconds orientés vers le sujet. Dans les deux premiers exemples du CW, vif relève d'une interprétation de manière, tandis que dans les deux derniers vif est ambigu, étant situé entre les fonctions d'adverbe de manière et celle de prédicat second orienté vers le sujet. Dans le dernier exemple, il s'accorde avec le sujet féminin, tout comme l'adjectif clair avec lequel il est coordonné.

\section{Couronner blanc}

Tonsurer en laissant une couronne de cheveux blancs

Transitif

1250 A Poitiers dedenz un donjon

Lo tient li cuens longuement pris,

Quant li bon home del païs,

Li evesque et li abé

Et li moine blanc coroné,

En firent pais. Savez coment

Firent d'eus dos l'acordement?

(Joufroi de Poitiers, 4592)

REMARQUES : Blanc réfère à la tonsure conférée aux ecclésiastiques - un petit cercle rasé au sommet de la tête - les cheveux blancs restants formant une couronne. 


\section{Couronner vert}

Munir d'une couronne de verdure Transitif

1836 Tous les ans, pour leur récompense, on les fouettait publiquement au pied de l'autel de Diane, mais je dis fouetter d'importance, et celui qui criait le moins, on le couronnait vert comme pré. Que les parents devaient être aises ! A eux, d'ailleurs, permis de voler ; c'était aux fruitières à garder leurs boutiques (Alfred de Musset, Lettres de Dupuis et Cotonet)

CORpus Web :

collier Absinthe style Art Nouveau avec representation de la fee Verte fiole couronnée verte et breloque cuillere

longueur de la chaine principale $50 \mathrm{~cm}$ [http://fr.dawanda.com/product/12012354Collier-fiole-Absinthe-la-fee-verte] (12.1.2015)

REMARques : Couronner vert désigne le fait de ceindre la tête de quelqu'un d'une couronne garnie d'éléments de couleur verte de la végétation, comme par exemple des fleurs, des feuillages ou des herbes. Dans le CW, vert réfère au bouchon vert de la fiole et s'accorde avec fiole.

\section{Courroucer fort}

Entrer dans une violente colère Pronominal

+1400 Elle contre terre le getta tellement qu'elle le tua. Son mary principalment de ce s'esmerveilla et trés fort se courrouça et luy voulut courir sus (Nouvelles françaises $d u$ $X V^{e}$, p. 25)

1550 Phœbus, qui suit les pastoureaux, Luy dérobant et arc et trousse, Lors que plus fort il se courrousse D’avoir perdu ses beaus toreaux (Pierre de Ronsard, Odes retranchées, p. 422)

1559a L'affaire ne sceut estre mené sy secretement que quelque varlet ne le vist entrer là dedans au jour de jeusne, et le redist en lieu où il ne fut cellé à la royne, qui s'en courrouça sy fort qu'oncques puis n'ousa aller le bastard en la chambre des damoiselles (Marguerite d’Angoulême, Heptaméron, p. 199, 116) 1559b Le jeune prince, qui ne vouloit point user d'autres moyens que de ceulx que l'honnesteté commande, craingnant aussi que, s'il en estoit quelque bruit et que sa mere le sceust, elle auroit occasion de s'en courroucer bien fort, ne osoit rien entreprandre, jusques à ce que son gentilhomme luy bailla ung moyen si aisé qu'il pensoit desjà la tenir (Marguerite d’Angoulême, Heptaméron, p. 355, 243)

1623 Si tu trouves (amy) ta besongne parfaicte Tu ne dois t'en fascher n'y courroucer si fort, La ville se prend mieux lors que la bréche est faicte,

Le bourg demantelé resiste à moindre effort (Jean Auvray, Le Banquet des muses ou Les Divers Satires)

1770 Et de quoi se courrouce-t-il si fort, ce Dieu? Et ne dirait-on pas que je puisse quelque chose pour ou contre sa gloire, pour ou contre son repos, pour ou contre son bonheur ? (Denis Diderot, Addition aux pensées philosophiques)

REMARQUES : Dans l'ancienne langue, courroucer fort réfère à une personne qu'une situation ou un fait irrite ou énerve, la mettant dans un état de grande agitation. Fort reste invariable et est modifié par bien, plus, si, très.

\section{Coûter bon}

I. Causer, attirer des ennuis, avoir des conséquences fâcheuses

Intransitif

1546 Ceste parolle, dist Epistemon, jadis cousta bon, et fut cherement vendue es enfans de Jacob (François Rabelais, Le Tiers Livre)

1552 La moindre desquelles est le mal Saint Eutrope de Xaintes, dont Dieu nous saulve et guard. Que pensez vous, nostre voisin, mon amy ? Aussi me coustent ilz bon (François Rabelais, Le Quart Livre)

II. Coûter beaucoup d'argent Intransitif

1867 Des Russes voulurent une fois dîner dans le rond-point. Il leur en coûta bon (Auguste Luchet, Les Grandes Cuisines et les grandes caves) 
1957 Dans les milieux modestes, c'est très apprécié, le marron glacé. Ça coûte bon, hein (Félicien Marceau, L’Euf)

REMARQUeS : Emploi vieilli, coûter bon (I) réfère aux conséquences désagréables, à la perte matérielle ou financière que peut entraîner une action ou une décision quelconque. En (II), au sens propre, coûter bon souligne le coût élevé d'un produit (ici : le marron glacé). Il reste invariable. Cet emploi adverbial de bon n'est plus documenté de nos jours, ce qui n'exclut pas sa conservation dans les parlers locaux. En tout cas, on dit encore ça coûte bonbon (avec réduplication de bon). VOIR AUSSI : valoir cher / petit

\section{Coûter chaud}

I. Coûter beaucoup d'argent Intransitif

1857 Cela viendra : mais jusqu'alors on est jaloux, on sourit dans sa barbe, on désapprouve, on critique par derrière, on lâche le grand argument : ça coûte chaud à Monsieur. Cependant Monsieur prouve que ça n'est pas cher (F. Jeannin, Rapport [oral])

1914 J'ai perdu beaucoup de choses dans mon bombardement, aussi ai-je dû me ravitailler, cela m'a coûté chaud, mais j'ai encore 60 francs, cela me suffit (Le Correspondant)

1939 Je suis sèche avec elle ; elle fait de discrètes tentatives de tendresse mais je ne peux prendre sur moi d'y répondre. Elle me coûte chaud. Je ne mets rien de côté pour $M$. Védrine ce mois-ci. Il faut compter : 1 $000 \mathrm{f}$.... Cette dame $1000 \mathrm{f}$. Poupette 1500 f. Kos. 500 f.... Vêtements $500 \mathrm{f}$. (Simone de Beauvoir, Journal de guerre)

1954 - Oui. Mais...

- Avec des mais on n'arrive à rien. Je vous dis que la petite est ravissante. Le jour où vous viendrez chez moi, je vous la présenterai. Vous séchez toujours mes jeudis, mais je vais vous demander un service que vous ne pourrez pas me refuser, dit Claudie avec pétulance ; je m'occupe d'un home pour enfants de déportés, et ça coûte chaud, trop chaud pour moi toute seule. Alors j'organise une série de conférences avec des conférenciers bénévoles (Simone de Beauvoir, Les Mandarins)

2013 Le garçon était venu dans son dos, illico. Une pensée lui traversa douloureusement l'esprit : cette journée de menus plaisirs allait lui coûter chaud. À ce tarif ! (Pierre d'Ovidio, Le Paradis pour demeure)

II. Causer, attirer des ennuis, avoir des conséquences fâcheuses Intransitif

1868 - Allez demander de ses nouvelles à Paris ! Elle est jeune, mais elle est déjà connue... Ça a coûté chaud à Léonard avant! (Marie Lètizia Rattazzi, Les Vieilles Amours)

1922 - Que je tombe sur place si je le sais. On ne nous dit rien. J'étais dans le couloir quand l'homme m'a demandé de venir te parler. Il faut même que je retourne vite ou il m'en coûterait chaud (Joseph Kessel, La Steppe rouge)

1933 - Tout policeman de service, dit l'inspecteur, peut se munir d'un revolver, mais ce n'est pas l'usage ; nos hommes mettent leur point d'honneur à ne pas être armés. Les malfaiteurs ne le sont pas davantage. Pas un sur mille. Il en coûte chaud, chez nous, d'être trouvé porteur d'un pistolet : ce sont les travaux forcés (Paul Morand, Londres)

1973 - Laisse-le, il m’a planqué quand même pendant longtemps et ça pouvait lui coûter chaud de cacher un Juif (Joseph Joffo, Un sac de billes)

CORPUS WEB :

C'est superbe, bravo, mais fais attention car quand ton père et moi nous allons passer ça risque de te coûter chaud... je vous embrasse tout les deux [https://www.facebook.com/ardoawinebar/ posts/689883767709774] (15.1.2015)

merci de nous expliquer ce phénoménes (vous allez me dire que si c est une entreprise qui a réalisée le travaux, les differents frais lui incomberont, ce qui peut lui couter chaud... [http://www.maisons-et-bois.com/discussions/ viewtopic.php?pid=139450] (15.1.2015) 
J'ai déjà eu des colis de 3 DVD non taxés (parce que DVD pas chers) alors que certains paquets de 2 DVD m'ont coûtés chauds (parce que Saving Private Ryan coute plus cher que... le futur Papillon (-)) [http://www.homecinema-fr.com/ forum/oe-7eme-art/achat-de-dvd-z1-2-internetrisques-t24101000.html] (15.1.2015)

REMARQUES : Au sens propre (II), coûter chaud souligne le coût élevé d'un service ou les frais élevés relatifs au bon déroulement d'une activité. Au figuré, coûter chaud (I) réfère aux conséquences désagréables que peut entraîner une action ou une décision quelconque. Chaud reste invariable (ex. de 1939) et est modifié par trop. Dans le troisième exemple du CW, chaud s'accorde avec le sujet au pluriel, tout comme le participe passé, dont l'accord est fautif. Il s'agit probablement d'une hypercorrection. L'ensemble des citations met en évidence l'usage familier parlé de coûter chaud. VoIR AUSSI : valoir cher / gros / petit

\section{Coûter cher}

I. Causer de grands sacrifices, de grands malheurs, avoir des conséquences fâcheuses Intransitif

$\sim 1170$ Tuit cil qui ceste joste virent A mervoilles s'an esbaïrent, Et dient que trop chier li coste, Qui a si buen chevalier joste (Chrestien de Troyes, Erec et Enide, 2214)

1325 Ce me perça poumon et fie Et le cuer, quant je l'oi leü Et le faus monde apercüe Qui moult chier couste et petit vaut (Watriquet de Couvin, Dits, p. 18, 539)

1393 « Et comment, diable ! dist Gieffroy, mes deux freres et moy avons tant fait que nous avons treu du soudant de Damas et de ses complices, et ce mastin puant, qui est tout seul, tendroit le paÿs de mon pere en patiz ? Par mon chief, mal le pensa, car il lui coustera moult chier, car ja n’y lerra autre gaige que la vie » (Jean d'Arras, Mélusine, p. 654 [manuscrit Ars])

+1489 Tout ce jour demoura encores monsr de Charroloys sur le champ fort joyeux, es- timant la gloire sienne, qui depuis luy a cousté bien cher : car oncques puis ne usa de conseil d'homme, mais du sien propre (Philippe de Commynes, Mémoires [14891498], I)

1534 Mais un ribaud canonnier, qui estoit au machicoulis, luy tyra un coup de canon, et le attainct par la temple dextre furieusement : toutesfois ne luy feist, pour ce, mal en plus que s'il luy eust jetté une prune. Qu'est cela? dist Gargantua, nous jettez vous icy des grains de raisins ? La vendange vous coustera cher !; pensant de vray que le boullet fust un grain de raisin (François Rabelais, Gargantua)

1541 Laisser ainsi mon bien, mon heur, ma vie ! Helas, amy, à la mort te convie Lors qu'on t'ira cest adieu annuncer. Que diras tu, amy, de ton amye? Ou que l'amour luy a trop cher cousté ? Ou tu pourras juger d'autre costé Qu'elle te hayt, la nommant ennemye ? (Marguerite d'Angoulême, La Coche)

1589 LA NOURRICE. Pour avoir part au lict d'une nopciere foy,

Pour jouir d'une Dame, on cherit quelquefoy

Un chagrineux espoux, et de maintes caresses

On voile l'appetit des secrettes destresses, Et par l'injuste fer, il vous plait de chercher La mort de celuy là qui vous couste si cher (Pierre Matthieu, Clytemnestre)

1645 LÉLIE. Ah ! si d'amour tu ressentais l'atteinte,

Tu plaindrais moins ces mots qui te coûtent si cher,

Et qu'avec tant de peine il te faut arracher, Et cette avare Écho, qui répond par ta bouche,

Serait plus indulgente à l'ennui qui me touche (Jean de Rotrou, La Sœur)

1697 CEPHISE. De quoi ? de votre foy? ANDROMAQUE. Hélas ! pour la promettre est-elle encore à moi ?

Ô cendres d'un époux ! ô Troyens ! ô mon père! 
Ô mon fils, que tes jours coûtent cher à ta mère !

Allons (Jean Racine, Andromaque)

1734 ADELAÏDE. Est-il bien vrai ? Nemours serait-il dans l'armée?

O discorde fatale ! amour plus dangereux ! Que vous coûterez cher à ce cœur malheureux !

(Voltaire, Adélaïde du Guesclin)

1884 Mais si j’avais épousé quelqu'un, n’importe qui, entends-tu, j'en aurais eu des enfants. Ah ! Je te conseille de parler ! Cela me coûte cher d'avoir épousé une chiffe comme toi! (Guy de Maupassant, Contes et nouvelles)

1928 Nul auteur ne fit moins pour se faire pardonner son génie. Tant de malignité dans le triomphe risque de coûter cher à ceux qui n'ont pas une vie toute pure (François Mauriac, La Vie de Jean Racine)

2008a Thomas est l'un de ces enfants dont les parents se sont brûlé les ailes en 1968. Une adhésion totale à l'air du temps qui leur a coûté cher... (Virginie Linhart, Le Jour où mon père s'est tu)

II. Coûter beaucoup d'argent

Intransitif

$\sim 1250$ Et li mire aront ja leur louier avenant

De chen qu'Erchambaut oignent et le vont soulegant.

Bien sai que moult chier couste li oignement traiant

(Doon de Mayence, p. 177)

1400 Ainxin se font les besongnes du bon homme son mary. Or a la dame sa robe que son mary ne li avoit voulu donner, qui lui a cousté et coustera bien chier (Quinze Joies de mariage, p. 30)

1460 Lors le dit Jehan Stotton, oyant ce, en fut moult esbahy, soy donnant grand merveille et en soy signant, dist que tout le semblable luy estoit advenu en la propre nuyt, ainsi que cy devant est declaré ; et que il tenoit fermement avoir laissé cheoir son dyamant ou le dit Thomas l'avoit trouvé, et qu'il luy devoit faire plus mal de l'avoir perdu qu'il ne faisoit audit Thomas, lequel n'y perdoit rien, car il luy avoit cher cousté (Les Cent Nouvelles nouvelles, p. 395, 312)

1461 Si ne crains avoir despendu

Par friander ne par lescher;

Par trop amer n'ay riens vendu

Qu'amis me peussent reprouchier,

Au moins qui leur couste moult cher ;

Je le dy et ne croys mesdire

(François Villon, Le Testament, 189)

1553 MESSIRE JEAN. Mesmes il pourroit estre ainsi,

Que, si ce bon Creancier-ci

Avoit enfans, il la voudroit,

Mieux qu'une terre elle vaudroit :

Et ne luy cousteroit si cher

(Étienne Jodelle, L’Eugène)

1654 Autrefois on vendoit et on achetoit les personnes qui n'estoient pas libres : le travail des mercenaires coustoit cher : la volupté n'estoit point à bon marché, et les arts faisoient riches ceux qui les sçavoient (Jean-Louis Guez de Balzac, Dissertations politiques)

1740 Il me dit ensuite, qu'il donneroit cent louis pour savoir autant de flamand que j'en savois. Je lui répartis que peu de chose à ce prix-là lui coûteroit bien cher. Je le parlois effectivement très-mal ; mais je l'entendois beaucoup mieux (Jacques de Varenne, Mémoires du chevalier de Ravanne)

1755 Les services de l'intérêt coûtent trop cher à l'État, ceux de la vanité et de l'honneur se paient en monnoie qui ne manque jamais à un gouvernement éclairé, et économe de distinctions (Victor de Mirabeau, L'Ami des hommes ou Traité de la population)

1835 OLIVIER. Vous lui demanderez tout naturellement pourquoi ces pêches, aussi grosses, aussi belles, aussi mûres, aussi appétissantes, coûtent moins cher que les autres? (Alexandre Dumas fils, Le Demimonde)

1848 Vous avez spirituellement tranché la difficulté, en baissant et en relevant tour à 
tour de dix pas en dix pas, ce merveilleux tissu, tramé sans doute dans ces contrées d'arachnides qu'on appelle les Flandres, et qui, à lui tout seul, a coûté plus cher que toute votre ancienne garde-robe... ah ! (Henri Murger, Scènes de la vie de bohème)

1853 Canivet, à force de rêver, trouva un moyen économique de remplacer les petits canons de cuivre, qui coûtaient cher et qui ne produisaient qu'une décharge médiocre : ce fut de serrer un peu de poudre dans une première enveloppe de parchemin ficelé avec soin, puis d'entourer de papiers cette première enveloppe, de la reficeler, et de recommencer jusqu'à ce qu'il eût obtenu une bombe épaisse dans laquelle il pratiqua une lumière avec un poinçon (Champfleury, Les Souffrances $d u$ professeur Delteil)

1854 Malheureusement les Grecs n'ont point de caves ; à peine ont-ils des futailles. Les bouteilles, qui viennent d'Europe, coûtent fort cher dans les ports. Il ne faut pas songer à les transporter dans l'intérieur du pays : elles arriveraient en miettes (Edmond About, La Grèce contemporaine)

1862 Henri Dermal a pour maîtresse la première ingénue du théâtre royal du parc. La voulant sans partage, elle lui coûte très cher (Paul Reider, Mademoiselle Vallantin)

1867 L'administrateur aura tué l'apôtre. Le murmure qui lui échappe à Béthanie semble supposer que parfois il trouvait que le maître coûtait trop cher à sa famille spirituelle. Sans doute cette mesquine économie avait causé dans la petite société bien d'autres froissements (Ernest Renan, Vie de Jésus)

1937 On ne refera pas la France par les élites, on la refera par la base. Cela coûtera plus cher, tant pis! Cela coûtera ce qu'il faudra. Cela coûtera moins cher que la guerre civile (Georges Bernanos, Les Grands Cimetières sous la lune)
1967 La construction d'un grand navire demandant plus d'un an et les formes à écluse coûtant très cher à construire, il eut été d'un mauvais rendement d'attendre que le navire fût entièrement construit pour libérer la cale et pour mettre un autre navire en chantier (Aimé Perpillou, L'Industrie des constructions navales)

1968 MORCOL. Alors va falloir que je recommence mon enquête à zéro ?

HUBERT. Évidemment, si vous cherchiez un Nick.

MORCOL. Eh bien, eh bien, voilà une erreur qui va vous coûter cher, monsieur Lubert. Il me faudrait un nouvel acompte de vingt louis (Raymond Queneau, Le Vol d'Icare)

1978 Je bouge beaucoup, je m'invente des besognes de pur camouflage, je ne peux m'empêcher d'aligner quelques calculs sommaires : ta mort brutale, sans maladie majeure et sans hospitalisation, m'aura coûté moins cher qu'une longue agonie (Alain Bosquet, Une mère russe)

2008b - Beau papier, belles photos... -, pas du tout un petit journal sur papier recyclé comme tant de revues féministes de l'époque.

- Justement, il coûtait cher à fabriquer et les publicitaires, qui s'étaient un peu laissé forcer la main et nous avaient accordé de gros budgets, retrouvaient leurs réflexes misogynes (Benoîte Groult, Mon évasion)

\section{CORpus Web :}

TGV : les gares qui coûtent cher [http://www. bfmtv.com/mediaplayer/video/tgv-les-gares-quicoutent-cher-337759.html] (15.1.2015)

Opérations extérieures : l'Afghanistan et la Libye coûtent cher à la France [http://www.bfmtv. com/mediaplayer/video/operations-exterieures1-afghanistan-et-la-libye-coutent-cher-a-lafrance-10693.html] (15.1.2015)

Salariés, attention aux accidents : ils vous coûtent cher [http://www.humanite.fr/politique/ salaries-attention-aux-accidents-ils-vous-cou tent-cher-509768] (15.1.2015) 
L'Union syndicale Solidaires a décidé, après consultation de ses instances décisionnelles, de lancer pour fin mars 2014 une campagne intitulée « Les capitalistes nous coûtent chers » [http:// www.solidaires.org/rubrique435.html] (15.1.2015)

REMARQUES : Les exemples en (I) illustrent l'emploi figuré du prix à payer pour quelque chose. Coûter cher peut aussi désigner une action concrète, ou abstraite, dont le processus pose des problèmes ou crée des ennuis à quelqu'un. Il souligne également les efforts que doit déployer le sujet ou son investissement pour acquérir quelque chose. Il peut référer à la douleur provoquée par quelque chose (la mort) ou à quelque chose qui est dit (des mots ou paroles). Dans son emploi concret (II), il renvoie au prix élevé d'une chose (un aliment, un plat, etc.). Il peut aussi souligner les dépenses élevées liées à la construction d'un édifice imposant ou les moyens financiers importants déployés. Le sujet peut être une personne (par métonymie : son activité), dont l'emploi représente beaucoup d'argent. Dans l'exemple de 1325 , coûter cher s'oppose à valoir petit. Cher reste invariable et est modifié par bien, fort, moins, moult, plus, si, très, trop. Notons cependant qu'il s'accorde avec le sujet dans le dernier exemple du CW.

\section{Coûter gros}

Coûter beaucoup d'argent

Intransitif

1757 Les voici : depuis qu'il est question de guerre et de préparatifs, le Roi a pris de l'humeur contre la marquise de Pompadour qui, à la vérité, est bien chère et coûte gros à l'État, tant pour elle que pour les arts inutiles et pour les prodigalités qu'elle protége (René-Louis d'Argenson, Journal et mémoires)

1832 - Hélas ! maître Claude, toute cette maçonnerie me coûte gros. À mesure que la maison s'édifie, je me ruine (Victor Hugo, Notre-Dame de Paris)

1879 Ah ! elle me coûte gros, la fête de mon père! (Jules Vallès, Jacques Vingtras : L'Enfant)
$1932 \mathrm{Au}$ fond, en ai-je jamais eu envie ? Il aurait fallu représenter, recevoir. Ce sont des honneurs qui coûtent gros; le jeu n'en vaut pas la chandelle (François Mauriac, Le Noeud de vipères)

1936 Vous avez laissé la chrétienté inachevée, elle était trop lente à se faire, elle coûtait gros, rapportait peu. D'ailleurs, n'aviezvous pas jadis construit vos basiliques avec les pierres des temples ? (Georges Bernanos, Journal d'un curé de campagne)

1948 Et quant à me racheter de la servitude sociale, comme jadis du service militaire, tu l'avoues toi-même, ça coûterait gros, et je n'ai pas le sou. Je sais bien qu'à la rigueur, je serais peut-être capable de me libérer d'un seul coup, par le suicide ou par un crime (Georges Bernanos, Un mauvais rêve)

1961 - Hélas ! maître Claude, toute cette maçonnerie me coûte gros. À mesure que ma maison s'édifie, je me ruine (Claude Mauriac, La Marquise sortit à cinq heures)

CORPus Web :

Etats-Unis - Une petite gâterie dans l'avion qui peut leur coûter gros [http://www.routard. com/actus-voyageur/cid131383-une-petitegaterie-dans-l-avion-qui-peut-leur-couter-gros. html] (15.1.2015)

Quand miser sur les matières premières peut coûter gros [https://www.easybourse.com/ bourse/financieres/article/19045/quand-misersur-les-matieres-premieres-peut-couter-gros. html] (15.1.2015)

ça y est : statoil a un prix inférieur. Pour Statoil vois mon message réponse du 22-10 dans «Intéressant fiscalement ». Parce que ça risque fort de nous couter gros en IRPP [http://www. boursorama.com/forum-norsk-hydro-ca-y-est-statoil-a-un-prix-inferieur-365844341-1] (15.1.2015)

REMARques : Coûter gros se dit d'une chose, d'un événement ou d'une entreprise dont l'achat ou l'acquisition représente beaucoup d'argent (un voyage, une fête, du matériel, des travaux de rénovation). Au sens figuré, le sujet désigne les dépenses inconsidérées ou le train de vie luxueux d'une personne. Notons l'emploi métaphorique 
dans l'exemple de 1932 avec le sujet « les hon neurs » qui représentent un bien moral qui doit se mériter et qui n'est pas acquis d'avance. Dans le premier exemple $\mathrm{du} \mathrm{CW}$, le sens est plus abstrait : 'valoir de gros soucis'. Observons aussi le contraste dans coûter gros, rapporter peu. Gros reste toujours invariable. Ceci est à noter, étant donné que l'accord graphique peut se produire dans coûter cher, où il n'est pas audible à l'oral, mais non pas dans coûter gros, où il le serait.

\section{Coûter lourd}

Coûter beaucoup (au propre : de l'argent, au figuré : de la peine)

Intransitif

1852 Tu as là de bien beaux pistolets, mais ils doivent t’avoir coûté lourd (Jean Humbert, Nouveau Glossaire genevois)

1877 Ils s'aiment, ils sont jeunes, bien-portants et honnêtes, voilà de belles dots constituées et qui ne coûteront pas lourd d'enregistrement chez le notaire (Alphonse Daudet, Le Nabab)

1954 Quand j'ai vu ce tas de pierres je me suis dit qu'il ne devait pas coûter lourd (Michel Sernoz, Il n'y a pas de mal)

2019 lui-même [= l'écrivain] ne cessant d'ailleurs de mentionner ces aspirations, comme s'il lui en avait coûté lourd de vivre dans cette solitude (Adrien Blouët, L'Absence de ciel)

\section{Coûter petit}

I. Coûter peu d'argent

Intransitif

1230 Chapel de flors, qui petit coste,

Ou de roses a Pentecoste, Ice puet bien chascuns avoir, Qu'il n'i covient pas grant avoir (Guillaume de Lorris, Roman de la rose, 2161)

\section{Coûter, nécessiter peu d'efforts} Intransitif

+1265 Va, fait il, di ce chevalier, Que je ai mout a chevauchier, S'il me relaira de la jouste, Car chilz relais mout petit couste (Richars li Biaus [3e tiers XIII $\left.{ }^{\mathrm{e}}\right], 1128$ )
+1313 Mais que cascun an d'un baisier Voellies ma dolour apaisier, Car mout petit uous coustera Et asses me confortera (Jean de Condé, Poèmes [1313-1337], 491)

REMARQUeS : En ancien français, petit s'employait comme quantifieur au même titre que peu en français moderne. Coûter petit se dit d'une chose dont l'achat ou l'acquisition représente une petite somme d'argent (I). Au figuré (II), il souligne le peu d'efforts qu'exige ou nécessite la réalisation de quelque chose et suggère le peu d'investissement du sujet. Petit reste invariable et est modifié par moult.

\section{Couver bas}

I. Être entretenu sourdement, être prêt à se déclarer (du feu)

Intransitif

1892 Aux profondeurs touffues, l'incendie couvait, bas, lent et lourd sous d'âpres flocons de fumée humide, puis criait, éclatait, s'élançait, mordait les branches minces et les feuilles racornies, flambait sur les herbes séchées, frôlait longtemps les gros arbres, et brusque, se dispersait en gerbes détonantes où ses forces semblaient mortes (J.-H. Rosny, Vamireh)

\section{Nourrir en secret}

Transitif

1968 À d'autres les bruits de cloches ou de bombardes, les chevaux fringants, les femmes nues ou drapées de brocart, à eux la matière honteuse et sublime, honnie tout haut, adorée ou couvée tout bas ; pareille aux parties secrètes en ce qu'on en parle peu et qu'on y pense sans cesse, la jaune substance sans laquelle Madame Impéria ne desserrerait pas les jambes (Marguerite Yourcenar, L'Euvre au noir)

\section{CORPus Web :}

Ce sont donc les habitants, de la dernière région ralliée à la France, qui se sont « révoltés » à juste titre, tout ça couvait tout bas depuis longtemps en attendant l'étincelle [http:// www.francois-ihuel-05.com/article-revolte-ouinsurection-120499770.html] (17.1.2015) 
Cela arrive tard... mais cela arrive !: Cela fait près de trois ans maintenant que nous disons tout haut ce qui couvait tout bas depuis longtemps déjà ! [https://www.youtube.com/ watch?v=r8eGJuVZ3oM] (17.1.2015)

REMARQUES : Au sens concret (I), couver bas réfère à un feu caché. Le $\mathrm{CW}$ révèle des cas où ce sens est transposé métaphoriquement à des situations qui portent le germe d'un danger. $\mathrm{Au}$ figuré (II), le groupe désigne la convoitise ou l'intérêt que l'objet suscite et que le sujet dissimule ou ne dévoile pas. Notons la collocation avec honnir tout haut qui souligne le contraste entre ce que l'on dit publiquement et ce que l'on n'avoue pas. Bas reste invariable et est modifié par tout.

\section{Cracher blanc}

I. cracher blanc comme coton (de Malte) : avoir soif

Emploi absolu

1461 Je congnois approucher ma seuf, Je crache blanc comme coton Jacoppins groz comme ung estuef (François Villon, Le Testament, 730)

1532 De quoy le monde ne se advisa que la nuyct ensuyvant, car un chascun se sentit tant alteré de avoir beu de ces vins poulsez qu'ilz ne faisoient que cracher aussi blanc comme cotton de Malthe, disans : « Nous avons du Pantagruel, et avons les gorges sallées » (François Rabelais, Pantagruel)

1624 Il enfle nos poumons de sottes vanitez, Il pourrit nostre foye en ces cupiditez Qui s'advancent tousjours, et ne peuvent faire alte, Qui nous font cracher blanc comme cotton de Malthe (Jacques Du Lorens, Premières Satires)

II. Cracher de la salive blanche Emploi absolu

1654 Quoy qu'il en soit, j'infere delà que leur Mahomet estoit rousseau, comme je conclus que vostre Jupiter estoit alteré, et qu'il avoit la bouche seche, quand il crachoit si blanc sur les Alpes (Jean-Louis Guez de Balzac, Dissertations critiques)
1916 Nous avons l'air d'être à la fois nousmêmes et d'étranges vieillards.

- Quand on s'ra vioques, c'est comme ça qu'on sera laids, dit Tirette.

- Tu craches blanc, constate Biquet

(Henri Barbusse, Le Feu)

1933 L'Adélaïde trouva le père et la fille assis sur un tas de gerbes, les mains pendantes entre les genoux.

- Je crache tout blanc, tellement que je l'ai sec, disait Honoré. Non, mais regarde un peu comme je crache, hein?

(Marcel Aymé, La Jument verte)

2013 Autour des tailleries où on le [= le marbre] débite à la scie en dalles, en lames, en cubes, en plaques de toutes dimensions, les routes, les arbres en sont enfarinés. Les scieurs se mouchent et crachent blanc, comme les meuniers (Jean Anglade, Le Sculpteur de nuages)

\section{CoRpus Web :}

un lama pouvoir cracher jusqu'à $2 \mathrm{~m} 50$, cracher blanc sauf quand avoir bronches infectées, dans ce cas cracher vert ! ok ça être dégueu mais ça être comme ça :o [https://fr.answers. yahoo.com/question/index?qid=2009091302325 1AAaoHyg] (16.1.2015)

« Je fais des va et vient dans ta bouche, je mesure environ $15 \mathrm{~cm}$ et je te fais cracher blanc. Qui suis-je ? La brosse à dents ! LMAO ! ». Si vous avez pensé à autre chose, vous avez l'esprit mal placé [http://www.programme-tv.net/news/ people/34000-twitter-nabilla-ayem-distingueesblague-mcdoo] (16.1.2015)

REMARQUeS : Cracher blanc comme coton (I) est une locution qui exprime que le sujet est assoiffé et qu'il a le palais sec et échauffé. (II) réfère à la couleur de la salive (ou métaphoriquement à celle de la neige), désignant le fait de rejeter quelque chose hors de la bouche, souvent en rapport avec le fait d'avoir la bouche sèche. Blanc, qui porte sur l'objet omis du verbe, reste invariable et est modifié par aussi, si, tout. Notons l'emploi de cracher vert dans le premier exemple du CW. VoIR AUSSI : moucher, tousser, vomir 


\section{Cracher doux}

on ne peut mâcher amer et cracher doux

(proverbe) : on ne peut produire quelque chose

de bon si l'on n'en a pas les moyens

Emploi absolu

1889 L'idée de l'auteur est que les pauvres taffetatiers étant mal nourris, ne peuvent livrer à l'exportation autre chose que ce qu'ils reçoivent à l'importation. C'est, plus crùment, l'application du vieux proverbe: On ne peut mâcher amer et cracher doux (La Revue du siècle)

\section{Cracher dur}

I. Crépiter fort, débiter énormément Emploi absolu

1860 L'homme, en effet, ayant vu le lion qui avançait au pas, marchait à lui, et, arrivé à portée, il épaula son fusil et tira. « Le fils de l'homme crache dur ", dit le lion gravement en secouant la tête, où la balle avait porté en plein front, et il s'avança encore (Guillaume Lejean, Voyage de M. Guillaume Lejean dans l'Afrique orientale)

1918 - La nuit, on allait barboter dans les boules de pain et on fourguait ça aux affamés. Ils crachaient dur... Tu penses ! Ils la crèvent... (Camille Rouvière, Journal de guerre d'un combattant pacifiste)

1919 Les pignons des villas, les monticules de sable nous procurent des abris provisoires que nous utilisons de notre mieux, car l'artillerie boche crache dur et fait des barrages au pont Joffre sur tout la ligne de l'Yser (Charles Le Goffic, Saint-Georges et Nieuport : les derniers chapitres de l'histoire des fusiliers marins)

2004 Ils sont partis tous les deux et ils se sont fait tuer bêtement par les Allemands. Toute la compagnie a entendu les mitrailleuses qui crachaient dur ! Et après, les canons ont tiré aussi. Les Français et les Allemands. L'horreur, quoi ! (Bernard Clavel, Les Grands Malheurs)
II. Lancer brutalement, rudement, de manière dure, violente

Transitif

1960 La dissuasion faut pas sfrapper on va la cracher dur (Canard enchaîné, 2 novembre 1960 / Grundt : 244)

III. Laisser s'échapper, débourser beaucoup d'argent

Emploi absolu

1992 - On s'demande d'où viennent les sous, mais y en a. Tout l'monde en trouve. Doit y avoir des bas de laine qui crachent dur. Des ouvriers sont au travail sur toutes les toitures (Bernard Clavel, La Révolte à deux sous)

\section{CORPUS WEB :}

Il inventait tout ce que sa parole ne lui permettait pas de faire, des bêtises, et il disait absolument tout ce à quoi il n'arrivait pas : grimper jusqu'au ciel, pisser en l'air et cracher dur, ce qui était encore des sottises [http://www.acaciia.fr/ index.php?option=com_content\&view=article\&i d=94\&catid=14\&Itemid=40] (16.1.2015)

Les tirailleurs envoient une fusée demandant le barrage. Aussitôt le lieutenant en envoie une autre, et comme hier, la réponse ne se fait pas attendre ! Bing ! Zing ! Bing !... Bing ! Zing ! Bing ! Nos 75 crachent dur et ferme [http://www.muad.com/andre/andrelire. php?partie=4\&chap=2\&page=7] (17.1.2015)

J'ai malgré tout passé un bon moment, car à travers donc toutes ces portes qui s'ouvraient, il y avait en fond des photos de concerts qui crachaient durs ; des arrêts sur l'image étaient bien aussi [http://forum-johnnypassion.forumpro. fr/t1749p40-sur-france-2-samedi-13-decembre] (17.1.2015)

REMARQues : Cracher dur (I) réfère à l'éjection violente et continue de projectiles. (II) le transpose sur le plan abstrait de la dissuasion, tandis que (III) renvoie à des bas de laine qui rejettent de la monnaie. Dur reste invariable dans la majorité des cas, mais il s'accorde avec le sujet pluriel dans le quatrième exemple du CW (hypercorrection dans un style qui cherche à être soigné). Notons la collocation dur et ferme. 


\section{Cracher épais}

Cracher une substance liquide épaisse

$\pi$ cracher vert

\section{Cracher ferme}

Cracher avec de la persévérance

$\lambda$ cracher dur

\section{Cracher juste}

I. Dire juste

Intransitif

1937 LE GROGNARD. C'est malheureux, tout de même, de traiter comme ça des bêtes !

GUIRAUD. Qui trop aime les bêtes, il aime moins le monde. Chique ce que je te dis et crache juste.

LE GROGNARD. Oui, c'est malheureux ! (Jacques Audiberti, L’Ampélour / Théâtre)

II. Cracher (au propre) avec précision, exactitude Intransitif

1947 Il s'approcha de moi et m'écarta les mâchoires avec ses poignes d'acier. Je restai ainsi. Il revint à quinze mètres, se pencha un peu sur le côté droit, visa, et me cracha dans la bouche. Un mouvement de déglutition presque inconscient me fit avaler le glaviaud. Les sept hurlèrent de joie. Il avait craché juste, mais il les fit taire afin de ne pas attirer l'attention du chef de famille (Jean Genet, Miracle de la rose)

\section{Corpus Web :}

faut pas confondre, le syndicat c'est pas ceux qui sont avec les popolitiques, mais bien ceux qui bossent et qui crèvent sous le poids du sacrosaint profit, c'est bien de cracher faut-il cracher juste... [https://fr-fr.facebook.com/Leviflexpress/ posts/10151958996014817] (17.1.2015)

Cette popularité n'aurait rien d'offusquant, si Rudy n'était pas un bourgeois pur sucre qui n'a pas digéré son licenciement de la haute administration et qui crache dans la soupe. Encore faut-il cracher juste et à bon escient [http://www. richard3.com/2008/09/un_nationaliste_dun_ nouveau_ge.html] (17.1.2015)

Il faut dire que la formation ne cache pas ses influences mais, au contraire, les travaille suffisamment pour rendre un disque étudié. L'énergie rock est bien présente, les guitares crachent juste
(« Origin of illness », « No heroes »), la voix de Tom est à la fois active et mesurée [http://www. musicactu.com/actualite-musique/51363/killthe-young-kill-the-young] (17.1.2015)

REMARQUES : Au figuré (I), cracher réfère à ce que l'on débite (voix, musique). Ce sens prédomine. Cracher juste (II) désigne le fait de rejeter des crachats, le sujet ayant pour cible quelque chose ou quelqu'un et faisant preuve de précision dans le geste ou l'action. Juste reste toujours invariable.

\section{Cracher menu}

Pleuvoir sous forme de crachin, bruiner Emploi absolu

1951 Novembre crachait menu sur l'asphalte où fleurissaient les ombelles noires des parapluies (Hervé Bazin, Le Bureau des mariages)

\section{Cracher noir}

Cracher une substance de couleur noire

Intransitif

1694 LE PAYSAN. ne pourri[o]ns-nous point trouver moyan de te faire cracher noir, afin que tu ayes un garcon? Ah, dit-elle, ce sera bian difficile (Arlequin comédien aux Champs Elysées)

1801 Rendre dans la pleurésie des crachats bilieux, purulens ou mêlés de sang et de pus, qui n'en finissent pas avec le temps, sont dans un état mortel; ceux qui crachent noir, brun, ou coleur de vin rouge, meurent (Traduction des oeuvres médicales d'Hippocrates)

1838 aux Tuileries va le beau monde, c'est donc aux Tuileries qu'il faut aller. Le sable grince sous les pieds, une poussière subtile pénètre les habits et happe les poumons ; le visage est piqué, les yeux en rougissent, on tousse et l'on crache noir, mais on se pavane en beaux habits (Lectures $d u$ soir)

1885 Jamais je ne toussais, à présent je ne peux plus me débarrasser... et le drôle, c'est que je crache, c'est que je crache... un raclement monta de sa gorge, il cracha noir (Émile Zola, Germinal) 
1906 Le sourire puéril des dents blanches et des yeux blancs, mais il sait des ordures et carotterait la dame la plus sensible. Il crache noir comme s'il chiquait. Tout irait bien, sans la suie qui lui entre dans les yeux (Jules Renard, Journal)

1932 Robinson se mit à nous raconter une fois de plus que les acides lui brûlaient l'estomac et les poumons, l'étouffaient et le faisaient cracher tout noir (Louis-Ferdinand Céline, Voyage au bout de la nuit)

1933 Du compartiment postes, un employé, en manches de chemise, tend, par la fenêtre, un sac cadenassé. Joigneau lui passe le sien :

- Adieu, Bergeon ! Tu es au frais, toi !

L'homme, un vieux, d'aspect rachitique, accoudé à la portière, vide sa pipe dans sa paume, crache noir, et ne répond pas (Roger Martin du Gard, Vieille France)

1980 Un homme aux cheveux courts, à la moustache cirée, mâchait une chique et se levait pour aller cracher noir dans la ruelle (Robert Sabatier, Les Fillettes chantantes)

\section{CORPUS WEB :}

ça c'est parce que tu fumes du mauvais shit, du vrai hash, ou de la weed ne te fera jamais cracher noir.

Le pire, c'est couler des douilles au mauvais shit, tu finis par cracher du sang très rapidos, c'est nofake [http://www.jeuxvideo.com/forums/1-50106246230-1-0-1-0-toxico-cracher-des-glairesnoirs.htm] (17.1.2015)

pareille j'ai coller des douilles pendants des années jusqu'a cracher noir, au debut ça me faisait flipper puis j'ai quand meme continuer. j'ai arreter y'a 5 ans a peu prés, j'ai pas d'ennuies de santé (a ma connaissance du moins) par contre je crache toujours noir [http://forum. doctissimo.fr/sante/alcool-tabac-drogues/ crachat-noir-douilles-sujet_182208_1.htm] (17.1.2015)

Vous etes tous d'accord pour dire que c'est pas dangereu de cracher noir ? Ah mon avis ya quelque chose de dangereux : moi qui fume relativement beaucoup et de tout depuis quelques années, j’ai jamais craché noir... [http://forum.
ados.fr/forum-sante/Drogue/crachat-noirsujet_1037_1.htm] (17.1.2015)

Ns avons récupérer notre voiture $48 \mathrm{~h}+$ tard et celle ci crachait noire !!! Retour chez Mercédes pour leur soumettre le probléme [forum-auto. caradisiac.com/mercedes/classe E] (20.6.2020)

C'était une vague plus haute que la plage arrière du bâtiment avec une cheminée qui crachait noire ! C'était le feu dans les calorifugeages (amiante !). [www.anciens-cols-bleus.net/les] croiseurs (20.6.2020)

REMARQUES : Le sujet de cracher noir désigne une personne, le plus souvent âgée, qui rejette hors de la bouche une matière (des crachats) dont la coloration noire est liée au liquide ou à la substance que le sujet a dans la bouche ou mâche (une chique), au fait qu'il fume ou soit en contact avec une matière noirâtre comme la suie ou le charbon ; ces expectorations noires soulignent le fait qu'il est malade. Dans les deux derniers exemples du CW, cracher noir est transposé au domaine technique (voiture, cheminée). Noir, qui porte sur l'objet omis du verbe, reste généralement invarié (langage soutenu), mais l'accord apparaît dans les deux derniers exemples $\mathrm{du}$ CW, dans le registre familier. Noir peut être modifié par toujours, tout. Notons l'emploi de cracher rapidos dans le premier exemple du CW où rapidos signifie 'peu de temps après'.

\section{Cracher rapidos}

Cracher très bientôt

入 cracher noir

\section{Cracher rouge}

Cracher du sang

Emploi absolu

1885 Le monstre crache rouge, et, malgré sa jactance,

Il s’arrête. Les Grecs poussent un cri joyeux (Philibert Le Duc, Les Idylles de Théocrite [trad.])

1950 Plusieurs spasmes convulsifs ébranlent sa poitrine puis, soudain, elle vomit en gémissant... elle crache rouge et je vois qu'elle va encore perdre connaissance (André Favières, Le Manchot obsédé) 
1962 Au milieu de la deuxième reprise $[=$ de la boxe], Pilon se mit à saigner du nez. Un garçon sortit et revint avec une casserole pleine d'eau. Lorsque celui qui tenait la montre ordonna l'arrêt, Pilon se trempa le visage dans la casserole, renifla, cracha rouge et s'essuya sur son gant avant de recommencer (Bernard Clavel, La Maison des autres)

\section{Cracher vert}

Cracher une substance verte

Emploi absolu

2013a Quand je crache vert et que je me mouche blanc, je suis bon pour une bonne angine carabinée ! (Exemple entendu / Corpus Coiffet 2018: s.v.)

2013b J'ai craché vert tout à l'heure : je me suis demandé si j'étais pas un peu malade, mais tout va bien ! (Exemple entendu / Corpus Coiffet 2018: s.v.)

2018 Je crache vert et épais... (Corpus Coiffet 2018: s.v., sans date)

\section{Craindre grave}

Être dangereux, faire peur

Emploi absolu

\section{CORPUS WEB :}

Ça craint grave. Charcuterie sous cellophane surgelés mal réchauffés apéritif planque sous un glaçon la totale pour 80 euros pour deux [https:// www.tripadvisor.fr/ShowUserReviews-g187111d1326888-r321395073-Le_chamois-Dijon_] (24.10.2015)

Découvrez et achetez le livre Vampire, ça craint (grave) écrit par Naïma Zimmermann [https://www.lalibrairie.com/livres/vampire_ca_ craint_grave.html] (7.4.2016)

\section{Crêper clair}

Gonfler légèrement la chevelure

Transitif

1831 - Vraiment?

- Mais oui, madame, les cheveux crêpés clair ne vont bien qu'aux blondes

(Honoré de Balzac, La Peau de chagrin)
1996 Entre les épaules inégales, le visage de Lolo, très blanc sous les cheveux clairs crêpés, yeux très bleus, nez très courbe. Lolo, joyeux, zozotait, tandis que l'oncle Émile plaisantait avec lui (Boris Schreiber, Un silence d'environ une demi-heure)

2019 Elle avait des cheveux clairs crêpés en chignon (Sol Elias, Tête de tambour)

REMARQUES : Dans le langage de la coiffure, crêpé clair souligne le fait de gonfler la chevelure en la rebroussant mèche par mèche avec un peigne ou une brosse. Clair tend à l'emploi non-fléchi dans cet ordre de collocation, mais l'accord est fait dans les exemples de 1996 et de 2019, où l'on analysera clairs plutôt comme modifieur de cheveux.

\section{Creuser profond}

I. Creuser en profondeur

Transitif

1581 Les Sepulcres, qu'on faisoit aux extrémités des champs, devoyent estre eslongnés de la piece voisine, d'autant qu'il estoit creusé profond en terre (Claude Guichard, Funerailles et diverses manieres d'ensevelir des Romains, Grecs, et autres nations)

1655 Or, la terre est creusée aussy profonde que l'édifice est eslevé, et le tout est construit de cette sorte, affin qu'aussi tost que les gelées commencent à morfondre le ciel, ilz descendent leurs maisons en les tournant au fonds de cette fosse, et que, par le moyen de certaines grandes peaux dont ilz couvrent et cette tour et son creusé circuict, ilz se tiennent à l'abry des intempéries de l'air (Savinien Cyrano de Bergerac, Les Estats et empires de la lune)

1833 NATHAN. Que veux-tu donc, Ahasvérus ? Quand tu étais petit comme tes frères, je te donnais une tunique neuve ou une coupe de cèdre, et tu chantais tout un jour sur mon banc. A présent, où est la coupe de cèdre que le bûcheron a creusée assez profonde dans le bois pour contenir tous tes désirs ? (Edgar Quinet, Ahasvérus) 
1963 Derrière l'abside, au milieu du parterre de plantes médicinales on a creusé profond la tombe du poète (France-Soir, 15 octobre 1963 / Grundt : 288)

1965 Mon petit mari chéri, Cette fois, ta place est creusée profond, profond... mais oui, nous parlerons beaucoup, lorsque tu reviendras l'occuper (Albertine Sarrazin, Lettres de la vie littéraire)

2009 Chaque groupe de trente s'appelait le chapelet. Mode d'emploi : D'abord, on aligne et on adosse le chapelet à une fosse creusée profond. Ensuite, on fusille. Pan ! Pan! Pan! Les grains de chapelet tombent (Patrick Chevalier, J'avais rêvé d'une république)

Intransitif

1643 le mot duquel il se sert est métaphorique, pris de ceux qui cerchent l'or et l'argent aux mines, ils creusent profond, et rompent chaque motte de terre en pieces pour trouver les pailles d'or (David Le Clerc, L'Armure complette de Dieu [trad.])

1860 Pierre tâtait les paysans ; il disait devant eux :

- Ah ! Si on pouvait inventer une charrue qui fît le travail toute seule, bien légère et creusant profond! (Louis Duranty, Le Malheur d'Henriette Gérard)

1916 Ce cri se répercute et court tout le long de la rangée de terrassiers.

- Y a d'la flotte. Rien à faire !

- L'équipe où est Mélusson a creusé plus profond, et c'est de l'eau. On arrive à une mare.

- Rien à faire (Henri Barbusse, Le Feu)

1929 C'était une bonne colline. Elle savait de belles chansons. Elle bourdonnait comme une grosse guêpe. Elle se laissait faire ; on creusait jamais bien profond : un coup de bêche ou deux, qu'est-ce que ça peut faire? (Jean Giono, Colline)

1979 Nous nous aplatissons dare-dare au fond du fossé. Ceux qui n’ont pas creusé assez profond se donnent des gifles. Mais déjà les premières gamelles descendent

(François Cavanna, Les Russkoffs)

Pronominal

1872 Pendant ce temps, au même moment, des sociétés s'écroulaient sous lui, de nouveaux trous se creusaient plus profonds, par-dessus lesquels il sautait, ne pouvant les combler (Émile Zola, La Curée)

1911 Et alors plus on va, plus les talus s'élèvent, plus la Viorne se creuse et s'enfonce profond, entre des parois de mollasse (Charles-Ferdinand Ramuz, Aimé Pache, peintre vaudois)

II. S'ancrer profondément, de manière intense, s'attacher fortement à quelque chose

Pronominal

1919 Un copain de moins, c'était vite oublié, et l'on riait quand même ; mais leur souvenir, avec le temps, s'est creusé plus profond, comme un acide qui mord... (Roland Dorgelès, Les Croix de bois)

III. Rechercher quelque chose de manière approfondie

Intransitif

1948 La paix est-elle en danger ? On a beau essayer de n'y point trop songer, l'âme est tout occupée de ce grand problème et c'est dans des journées comme celles-ci que la religion personnelle est mise à l'épreuve. Il s'agit de savoir, en effet, jusqu'à quel point elle fait partie de nous et si elle n'est pas seulement quelque chose d'ajouté à nos habitudes de vie. Peut-on creuser très profond et la trouver encore? Si la grande épreuve arrive, puissions-nous ne pas être trouvés légers ! La peur est un manque d'amour (Julien Green, Journal)

1999 Il suffit que le malheur frappe - même une seule fois, même modérément - et l'être-humain ne va plus de soi ; le questionnement dont il devient l'objet creuse profond en dessous des coups subis (Lytta Basset, Guérir du malheur) 


\section{CORPus WeB :}

Pour bâtir haut, il faut creuser profond [http://www.dicocitations.com/citations/ citation-58526.php] (14.1.2015)

Moi je dis que c'est Niamor que creusé une Très Grosse ZliCitrouille et il a tellement voulu la creuser profond qu'il é tombé dedans [http:// zliton.com/viewtopic.php?p=109824] (14.1.2015)

Comment faire, en effet, croire que vous détenez tout ce précieux métal si l'on vous Stress la tasse Surtout que si tout le monde voulait retirer comme ça, d'un seul coup tout son or, en métal ou équivalent en devises, HSBC n'en ayant que le 10ième tomberait en faillite et dans la tombe qu'elle se creuse profond [http://necronomie. blogsmarketing.adetem.org/archive/2009/05/08/ la-reprise-de-mes-chaussettes.html] (15.01.2015)

Le rocher sur lequel nous sommes, c'est le sommet de la plus haute montagne qu'il y avait dans l'île. Mais, des fois, quand les flots se creusent profond, on aperçoit le faîte d'une tour, le donjon du palais du roi ; et, parmi les nuages, on voit passer une livide chevauchée de hérauts tirant de leurs olifants une sonnerie qui se perd dans les rires de la tempête [http:// www.phareland.com/Lettres/N36/Dossier.htm] (15.01.2015)

Remarques : En (I), le sujet désigne le plus souvent une personne ou l'instrument (la charrue) dont elle a besoin pour faire une cavité dans le sol en enlevant de la matière comme la terre. Lorsque le sujet désigne une personne, l'instrument nécessaire à l'action est souvent mentionné, comme par exemple la bêche. Dans son emploi pronominal à sens passif, l'action du sujet ou de l'instrument rend quelque chose plus profond, lui donne plus de profondeur. En (II), il se rapporte à un souvenir fort et intense qui est ancré dans l'esprit d'une personne. En (III), il désigne le désir d'approfondir une idée, d'examiner avec attention et intérêt en allant plus loin dans la réflexion. Profond reste invariable dans la plupart des cas, mais il peut également s'accorder avec le sujet de la voix passive (ex. de 1655) et qui correspond à l'objet direct dans la voix active (1833, 1872). On peut interpréter ces exemples aussi comme prédication seconde orientée vers l'objet. La flexion renforce le caractère résultatif de l'événement (creuser profonde) au détriment de l'aspect final (directionnel) dans creuser profond. L'adjectif-adverbe est modifié par assez, aussi, bien, plus, très. Le premier exemple du CW, où creuser profond est complémentaire à bâtir haut, inscrit cette phrase parmi les proverbes. Notons la réduplication dans l'exemple de 1965. Mentionnons également l'emploi de s'enfoncer profond ; bâtir haut.

\section{Crever net}

I. Fatiguer jusqu'à la mort, éreinter Intransitif

1776 À tire-d'aile, en l'air, bride avalée, De val à mont, du mont à la vallée, Je portois vers et prose à gros paquet, De l'or, du plomb, marchandise mêlée, Charge pesante, à faire crever net Tout bon Mallier, qui n'eût pas été Fée (Alexis Piron, Épitres, odes, poëmes)

\section{Crever brusquement}

Intransitif

1920 J'ai jeté mon fusil par terre en disant : "J'aime mieux crever net » et je me suis couché dans la neige, attendant la mort (Émile Fabre, La Rabouilleuse)

1971 Je veux crever net, tomber comme un arbre calciné que l'on abat parce qu'il rend le paysage lugubre (Yves Navarre, Lady Black)

\section{Crever tranquille}

Mourir en paix, dans la quiétude, sans être dérangé

Intransitif

1887 - Faut la rendre, faut la rendre... enfin, nous avons assez travaillé, nous voulons crever tranquilles... n'est-ce pas, Rose? - C'est ça même, comme le bon Dieu nous voit ! dit la vieille. Un nouveau silence régna, très long (Émile Zola, La Terre)

1894 On ne peut même pas crever tranquilles. Ils [= les médecins] viennent arroser nos bicoques de phénol, nous empester. Ils ne s'occupent de nous qu'à ces moments-là, parce qu'ils ont peur que nos cadavres ne les empoisonnent (Léon Daudet, Les Morticoles) 
1927 - Qu'est-ce que vous voulez que je vous dise! Je ne sais rien. Je suis un honnête homme, entendez-vous ! J'étais paré, j'étais tranquille. Oui, mossieur ! j'aurais crevé tranquille! Vous raconter quoi ? J'ai le droit pour moi. J'ai le droit d'être ce que je veux, et mon polichinelle, et tout, c'est la loi (Georges Bernanos, L'Imposture)

1968a - À présent, je voudrais qu'on me foute la paix... tu comprends ! Qu'on pense ce qu'on voudra, mais qu'on me foute la paix... Qu'on me laisse travailler tranquille, et crever tranquille... C'est tout ce que je demande! (Bernard Clavel, Les Fruits de l'hiver)

1968b Et le père continua sa journée : travail, repas, sieste, travail, avec ces mots qu'il se répétait sans cesse : "Crever tranquille... Crever tranquille... » Il alla ainsi jusqu'à la fin de l'après-midi, au moment où arriva un garçon d'une quinzaine d'années que Paul employait comme aide-livreur (Bernard Clavel, Les Fruits de l'hiver)

1989 Je la ferai tard, la nuit, sur un trottoir, pour pas être emmerdé, pour crever tranquille, mais pas trop loin quand même : je veux voir la tour Montparnasse et imaginer que derrière la tour vit Jérôme (Denis Belloc, Képas)

2007 Je ne viendrai pas mourir dans vos bras comme vous l'espérez en disant : « Papa Maman - je vous aime. » Je vous aime certainement, mais vous m'énervez. Je veux crever tranquille, sans votre hystérie et sans la mienne, celle que vous déclenchez en moi. Vous apprendrez ma mort dans un journal (Hervé Guibert, Le Protocole compassionnel)

2010 Il est mort. Je soupire. Il s'est caché pour crever tranquille (Caroline Guézille, Préhi-story)

CORPus Web :

"Laissons la gauche crever tranquille» [http://www.franceinter.fr/emission-la-chro nique-de-daniel-morin-laissons-la-gauchecrever-tranquille] (14.1.2015)
« Va crever ! » (« crève ! ») ou « Disparais !» (toujours dans le même sens) dans toutes les langues ? Et en un peu plus " complexe ", « Tu peux crever tranquille, ça ne me concerne plus "? [http://forum.lokanova.net/viewtopic. php?f=23\&t=10864\&start=0] (14.1.2015)

Vous qui avez eu la malchance de naître dans le dernier pays stalinien de la planète, vous pouvez crever tranquilles... » [http://www. bibliomonde.com/livre/famine-coree-nord-1212. $\mathrm{html}]$ (14.1.2015)

$\mathrm{n}$ allez pas au match, c est dangereux , mais vous pouvez crever tranquilles dans la région , y a pas de danger... [http://s462318061. onlinehome.fr/supp-rouen/viewtopic. php?f=47\&t=12741\&start=850] (14.1.2015)

REMARQUES : Crever tranquille est l'équivalent populaire de mourir tranquille. Il réfère au désir de mourir en paix, paisiblement, sans agitation, le sujet désignant une personne ou une entité abstraite personnifiée (la gauche, dans le CW). Tranquille désigne donc moins une façon de mourir mais les circonstances de la mort. Tranquille s'accorde avec le sujet (ex. de 1887, deux derniers exemples du CW), même ad sensum (« on » dans l'exemple de 1894), ce qui le rapproche des prédicats seconds orientés vers le sujet. Notons l'emploi de travailler tranquille dans l'exemple de 1968a.

\section{Crier clair}

I. Se manifester avec force, être criant, très clair, évident, flagrant

Intransitif

1560 Que ces chiens icy abbayent tant qu'ils voudront que le sainct Esprit n'est point descendu sur les Apostres, qu'ils tiennent une histoire si patente pour fable, toutesfois la chose crie haut et clair (Jean Calvin, Institution de la religion chrestienne)

II. Crier d'une voix claire, pure

Intransitif

1778 M. Simon se fâche, et n'en crie que plus clair (Jean-Jacques Rousseau, Les Confessions)

1936 Où sont-ils ? Où peut-on trouver les socialistes?

Des hommes l'entouraient maintenant, qui l'interrogeaient. Au dehors, des enfants 
jouaient, cela riait et criait clair. Le soir tombait (Louis Aragon, Les Beaux Quartiers)

REMARQUES : En parlant d'un son ou d'un bruit, crier clair (II) réfère au cri net et bien perceptible produit par la voix. Au figuré (I), le sujet désigne une chose abstraite qui se manifeste avec force, dont l'importance est évidente et visible pour l'autre. Notons que l'adjectif-adverbe clair est employé en collocation avec haut, qui renforce le sémantisme du groupe et accentue l'idée de clarté de la voix ou du son produit par le sujet qui est une personne (v. crier haut). Observons également l'emploi de rire clair. Clair reste invariable et est modifié par plus.

\section{Crier fort}

Prononcer des paroles d'une voix très forte

Transitif

1176 Atant une poire destele, Si chiet Fenice lez l'oroille. Ele tressaut et si s'esvoille Et voit Bertran, si crie fort : Amis, amis, nos somes mort ! (Chrestien de Troyes, Cligés, 6447)

+1250 « Qu'est ce la ? » a haute uoiz crie Si fort que l'oist sa mesnie. Le cer sent qui se terpissoit, Qui tout de paour fremissoit (Ysopet de Lyon [2 $2^{\mathrm{e}}$ moitié XIII ${ }^{\mathrm{e}}$ siècle], 3146)

1285 Lors commença fort a crier: Ha ! ma fille, ou veus tu aller? Lasse ! que nous est avenu? (Adenet le Roi, Cleomadés, 5231)

1330 Vien aprez moy où me verras Aler et crie fort : halas! (Guillaume de Digulleville, Le Pèlerinage de vie humaine)

1465 Laquelle [= la fille toute nue] subitement se va esveiller et commença a crier moult fort ses pucelles et les barons (Jehan Bagnyon, L'Histoire de Charlemagne, p. 102)

1660 MASCARILLE. Ne trouvez-vous pas la pensée bien exprimée dans le chant? Au voleur !... Et puis, comme si l'on crioit bien fort : au, au, au, au, au, au voleur ! (Molière, Les Précieuses ridicules)
1771 M. GÉRONTE. (tâche de se débarrasser et crie fort) Paix, paix, paix ! (Carlo Goldoni, Le Bourru bienfaisant)

1879 Tu entreras sans frapper, - la porte est toujours ouverte ; - et, en entrant, tu crieras bien fort : «Bonjour, braves gens ! Je suis l'ami de Maurice... » (Alphonse Daudet, Lettres de mon moulin)

2003 Les situations de l'existence exposent l'homme aux pires veuleries s'il n'a pas l'opiniâtreté de crier forts ses choix. Aurais-je aimé un homme qui se cache, qui déguise, se dérobe ? (Corinne Javelaud, $\AA$ fleur de vie)

Intransitif

1374 Certainement, ains que soit soir

G'iray tant qu'en saray le voir.

Escoute conme ilz crient fort !

Pour certain j'ay a ce mon sort

(Miracle du roy Thierry, 291)

+1415 Ce jour aussi, pour partir leur butin Des biens d'Amours, faisoient assemblee Tous les oyseaulx, qui parlans leur latin, Crioyent fort, demandans la livree Que Nature leur avoit ordonnee (Charles d'Orléans, Poésies [ 1415-1440], I, Ballade LXVI, p. 92)

1558 mais il n'y trouva plus rien que le pendant [= de la gibecière], dont il se print à crier plus fort que de sa jambe (Bonaventure des Périers, Les Nouvelles Récréations et joyeux devis)

1559 «Qu'esse que vous voulez ? Resvez vous? » Mais, pour cella, il ne laissoit de la poursuivre d'aussy près que sy ce eust esté la plus belle fille du monde. Et, n'eust esté qu'elle crya si fort que ses varletz et chambrieres vindrent à son secours, elle eust passé le chemyn qu'elle craignoit que sa fille marchast (Marguerite d'Angoulême, Heptaméron, p. 50, 33)

1627 AGLANTE. Je vay querir de l'eau, Criez luy cependant, Mais criez fort, qu'elle est encore en vie (Honoré d'Urfé, La Sylvanire) 
1769 PICARD. Et dit qu'on l'a trompée, et que sa fille est prise ;

Et qu'il faudra bien que quelqu'un l'indemnise

Et puis elle s'apaise, et convient qu'elle a tort,

Puis dit qu'elle a raison, crie encor plus fort

(Voltaire, Le Dépositaire)

1838 Je m'en importunerai peu, je me laisserai aller au courant du cœur et de l'imagination, et si l'on crie trop fort je me retournerai peut-être comme Phocion, pour dire : quel est ce bruit de corneilles !

(Gustave Flaubert, Correspondance)

1949 - Ça va, crie pas si fort, dit Mathieu dépité (Jean-Paul Sartre, La Mort dans l'âme)

CORPUS WEB :

sa fait déja quelque semaines que j'ai envi de crier fort comme une chose qui est sur moi qui veut crier mais fort mais jarive à le retenir.il veut dire quoi ce symptomes de vouloir crier fort [http:// maher.fr/questions-diverses-autres-roqya/4151une-envie-de-crier-fort.html] (14.1.2015)

J ai envie de crier fort tres fort [http://forum. aufeminin.com/forum/psycho6/__f38492_ psycho6-J-ai-envie-de-crier-fort-tres-fort.html] (14.1.2015)

Pardon «mes chers compatriotes " mais je n'ai pas honte de crier clair et fort que MES AMIS FIDELES SONT TUNISIENS.... !!!!! Et comme vous, mon cher Victor, je me sens plus djerbienne que tout autre chose.... [http://m2.facebook. com/story.php?story_fbid $=10151772170058532$ \&id=113319798531] (14.1.2015)

J'ai l'impression que j'ai écris dans le front que j'ai pas réussi a m'être mon Laurent au monde sain et sauve, la mort dans mon âme un parti de moi et éteint la lumière veut sortir mais rien ne réussi a sortir de bon. Je veux tellement crier forte ma peine a tout moment que mon corps fait mal physiquement et que j'ai peur de me retrouver sans force pour continuer mon chemin [http:// www.nospetitsangesauparadis.com/t2717-monpetit-laurent] (14.1.2015)

Elle a déclaré : « Kim c'est comme les petits chiens. Ils vont aboyer alors que finalement, ils ne sont pas méchants. Ils vont se protéger du coup ils vont crier forts, vont en faire des tonnes pour cacher peut-être quelque chose » [http:// www.purebreak.com/news/kim-les-ch-tis-vs-lesmarseillais-comparee-a-un-chien-par-gaelle/ 75202\#lt_source=external,manual] (14.1.2015)

Le trouble magnétique de l'atmosphère à cet endroit - au moment où la bouche tordue de Mr. Evans s'écrasait contre la bouche tordue de Cordelia - était agitation pour le vieil arbre dans la haie (...) \{et les deux arbres\} pouvaient élever l'un vers l'autre leurs voix infra-humaines, et crier, claire et forte, leur plainte végétale ancienne [http://www.powys-lannion.net/Powys/ LettrePowysienne/FSBAf.pdf] (14.1.2015)

REMARQues : Crier fort réfère à l'intensité de la voix, le sujet forçant sa voix pour donner implicitement plus d'importance à ce qu'il veut exprimer ou pour que son contenu soit entendu et compris de son auditoire. Fort reste invariable dans la plupart des cas, mais il est accordé avec l'objet au pluriel dans l'exemple de 2003, tout en gardant son interprétation adverbiale. Dans le dernier exemple du CW, l'accord est également réalisé par rapport à l'objet direct, « leur plainte végétale », mais on l'analysera plutôt comme prédication seconde. ZDans l'avant-dernier exemple du CW, fort s'accorde avec le sujet. Il est modifié par bien, encore plus, moult, plus, si, très, trop. Notons la collocation clair et fort et la réduplication fort, très fort.

\section{Crier haut}

I. Crier, proclamer, déclarer avec force, d'une voix forte

Intransitif

+1100 b Quant vint le jurn al declinant, Vers le vespre dunc funt un cant ; Od dulces voiz mult halt crïent, E enz el cant Deu mercient (Benedeit, Voyage de saint Brendan [ $1^{\mathrm{er}}$ quart XII $]$, 559)

+1313a Quant vit ses cambrelens widies. Crie haut con sauuaige bieste Et fait ciere amere et rubieste, Apries aighe caude se dierue, Mais il ne troeue qui le sierue (Jean de Condé, Poèmes [1313-1337], 121)

+1313b Al matin, quant l'aube se crieue, S'esuelle adies et si se lieue Et crie si haut et si cler 
Que chierf et chieueroel et saingler

Et toutes biestes s'ebahissent

Et hors de lor repaires issent

(Jean de Condé, Poèmes [1313-1337], 1175)

+1365 Si les ferés tout quoi taire,

Ou plus hault cryer et braire

Qu'il ne font presentement

(Jean Froissart, Poésies [3e tiers XIV $]$ ])

+1415 Quant a moy, j’ay ja deffié

Celle qui le tient en tourment,

Et aprés son trespassement,

Par moy sera bien hault cryé,

Comme parent et alyé !

(Charles d'Orléans, Poésies [ 1415-1440],

II, Rondel CCCLVIII, p. 497)

1567 Au marché porter il me faut

(Ma mère Jeanne m'y envoye)

Nostre grand cochon et nostre oye,

Qui le matin crioit si haut (Pierre de

Ronsard, Odes retranchées, p. 485)

1577 ayant desja rompu et mis en fuitte toutes les armees de l'Asie, et tenant de fort court ceux qui restoient de l'Europe, ou Caratz le plus estimé personnage qu'ils eussent, avoit esté mis à mort, se prirent à crier tout haut (Blaise de Vigenère, L'Histoire de la décadence de l'Empire grec [trad.])

1627 Cependant Hircan lisant dans son livre, fit quelques figures en terre avec une baguette qu'il tenoit, et en fin il se mit à crier haut et clair (Charles Sorel, Le Berger extravagant)

1727 FINETTE. (à part. haut) Toujours lire ! Monsieur, madame votre femme...

ARISTE. (crie encore plus haut) Finette. Très-volontiers. Madame Votre...

(Philippe Destouches, Le Philosophe marié)

1843 - Pour l'amour du ciel, M. de Lucenay, ne criez pas si haut et tenez-vous tranquille, ou vous allez nous faire quitter la place, dit Mme d'Harville avec humeur (Eugène Sue, Les Mystères de Paris)

1912 Il y crie plus haut, mais c'est toujours pour demander des réformes dans les cadres de la société actuelle (Georges Sorel, Réflexions sur la violence)
1913 WOLDSMUTH. Il faut qu'une parole accréditée se fasse entendre... Qu'un homme, dont la droiture est reconnue de tous, soit averti, soit convaincu, et que sa conscience crie tout haut, pour nous tous ! (Roger Martin du Gard, Jean Barois)

1918 Trois heures et demie. La terre gronde sourdement et se balance avec rudesse. Une grosse mine.

- Aux armes!

J'ai tâché de crier haut, mais avec lenteur. C'est très bien, les poilus ne s'affolent pas et répètent de proche en proche dans la galerie :

- Aux armes !... aux armes!

(André Pézard, Nous autres à Vauquois)

1967 Pourtant nul n’a crié plus haut que moi. Mais ce fut en silence. J'ouvrais la bouche grande, comme font les animaux qui hurlent à la mort (Michel Bataille, L'Arbre de Noël)

1999 Les accusations de « stupide », de « trompeur » peuvent néanmoins s'estomper si, par exemple, Celui-qui-crie-haut-et-fort peut se permettre de "crier haut et fort " sans que cela ne prête à conséquence. $\mathrm{Si}$ cela ne déclenche pas l'hostilité... (Josiane Massard-Vincent et Simonne Pauwels, D’un nom à l'autre en Asie du Sud-Est)

Transitif

+1150a Al matin par som l'albe, quant li jorz lor apert,

Li mul et li somier sont guarnit et trosset ; Et montent li baron, el chemin sont entret, Vienent en Jerico, palmes prenent assez, «Oltree, Deus aïe! » crïent et halt et cler (Pèlerinage ou Voyage de Charlemagne à Jérusalem et à Constantinople $\left[2^{\mathrm{e}}\right.$ moitié $\mathrm{XII}$ ], 243)

+1200 Fe[m]me ! dist Josian, a tere est palmé ; a peyne est ele a vie redrescé, e haut cria : Mar fu jeo unkes né ! $\mathrm{K}[\mathrm{a}] \mathrm{nt}$ ai $\mathrm{B}[\mathrm{oun}] \mathrm{p}[\mathrm{er}] \mathrm{du}$, a las, quele destiné !

(Bueve de Hanstone [début XIII'], 1421) 
+1389 et quant ilz furent entrez et alez bien avant esdiz bois, les aucuns d'iceulx xii compaignons, n'est record lesquelz, pour ce qu'il estoit nuit et faisoit moult obscur, prindrent icellui chevalier et escuïer, le aterrerent à terre de coups qu'il ouy que l'en lui donnoit ; et lequel, en ce faisant, disoit, en criant moult haut, ces paroles en substance : « Pour Dieu, beaus seigneurs, que me demandez-vous? » (Registre criminel du Châtelet de Paris [1389-1392])

1559 Mais ung Turcq, par derriere, luy couppa les deux cuysses, et, en cryant bien haut : «Allons, cappitaine, allons en paradis veoir Celluy pour qui nous mourons!» (Marguerite d'Angoulême, Heptaméron, p. 132, 379)

1560 Car il n'y a vraye foy, tesmoin sainct Paul, sinon celle qui nous suggère ce nom tant doux et amiable de Père, pour invoquer Dieu franchement, et mesme qui nous ouvre la bouche pour oser crier haut et clair : Abba, Père (Jean Calvin, Institution de la religion chrestienne)

1589 Ce qui donna tel applaudissement au peuple, que lors que le Roy, avec les Princes se partit de l'assemblee pour aller rendre graces à Dieu, en l'Eglise S. Sauveur, où fut chanté un Te Deum laudamus, il cria haut et clair, Vive le Roy, Vive le Roy : mais ceste extreme joye fut bien tost convertie en deuil (Pierre Matthieu, La Guisiade)

1627 Le peuple qui void cecy commence à siffler les comediens, et chacun s'imaginant que Lysis est de leur bande, l'on crie tout haut qu'il n'a rien fait qui vaille (Charles Sorel, Le Berger extravagant)

1755 Le Richemont crioit tout haut, par Dieu Dans Orléans il faut mettre le feu, Et que l'Anglois qui pense ici nous prendre N'ait rien de nous que fumée et que cendre (Voltaire, La Pucelle d'Orléans)

1782 D'autres font de mauvaise prose, pour nous faire détester notre idiôme, et pouvoir crier plus haut encore : Vivent les grecs! (Louis-Sébastien Mercier, Tableau de Paris)
1851 Mais pour éviter des rencontres que l'on qualifie de fâcheuses en Égypte, mais qu'en France on regarderait comme heureuses, les hommes qui montent l'escalier ne discontinuent point de crier bien haut : « Destour ! (permission) ya siti ! (ô dame !) » ou de faire d'autres exclamations, afin que les femmes qui pourraient se trouver sur cet escalier puissent se retirer, ou tout au moins se voiler (Gérard de Nerval, Voyage en Orient)

1871 Ils savent bien que ce rêve est irréalisable, et c'est ce qui leur fait crier très haut qu'ils sont libres penseurs, des libres penseurs tout de paroles, fort amis de l'autorité, se jetant dans les bras du premier sauveur venu, au moindre grondement du peuple (Émile Zola, La Fortune des Rougon)

1921 J'avais beau cligner des yeux, cligner de l'âme, rien qui me redonnât ce monde dont le mouvement était l'allure Gaumont des cinémas médiocres et où j'eusse retrouvé mes amis... parfois j'avais l'impression qu'il me suffirait de trouver un mot et de le crier tout haut pour sortir de cet enchantement (Jean Giraudoux, Suzanne et le Pacifique)

1985 Règle numéro UN de la vente : faire savoir qu'on existe. Règle numéro DEUX : le crier haut et fort. Je me suis approché de la vitrine, j’ai écrit en dessous DU JAMAIS VU !!!. Ça avait l'air d'amuser Betty (Philippe Djian, $37^{\circ} 2$ le matin)

II. Faire beaucoup de bruit

Intransitif

1885 Mais ces vengeances ne donnaient pas à manger. Les ventres criaient plus haut. Et la grande lamentation domina encore :

- Du pain! Du pain! Du pain!

(Émile Zola, Germinal)

\section{Corpus Web :}

Le saviez-vous? La municipalité qui crie haut et fort que les caisses sont vides, vient de valider une délibération pour le rachat du terrain Maréchal, sis à côté de la place Jeanne d'Arc, en vue de la réhabilitation de la place.... [http://www. nieppe-la-douce.com/2014/08/le-saviez-vous- 
la-municipalite-qui-crie-haut-et-fort-que-lescaisses-sont.html] (13.1.2015)

Ce n'est pas une question de plogue ou léchage de raie mais je dois partager ma passion, la crier haute et forte, que tous les Dieux des Cieux... et ceux des abysses aussi, l'entendent ! [http:// klimbo.bangbangblog.com/2007] (13.1.2015)

REMARQUes : Haut s'emploie ici au sens figuré par rapport à l'intensité de la voix. En (I), le sujet force sa voix pour donner implicitement plus d'importance à ce qu'il veut exprimer ou pour que son contenu soit entendu et compris de son auditoire. En (II), le sujet désigne un inanimé qui émet un bruit soulignant la sensation de faim de la personne qui crie famine. Notons les collocations crier haut et clair, haut et fort, chanter et crier haut. Haut reste invariable et est modifié par bien, encore plus, moult, plus, si, tout, très. Le CW contient tout de même un emploi fléchi, orienté vers l'objet direct, dans un contexte d'emphase.

\section{Crier plat}

crier tout fin plat mercy : demander grâce, pardon à genoux ou allongé, d'une manière soumise, suppliante

Transitif

1505 FrÉRE GUILLEBERT. Mon Dieu, je demande pardon;

Tout fin plat je te cry mercy

(Frère Guillebert / Ancien Théâtre françois)

REMARques : Plat réfère à la position de soumission dans laquelle le sujet, qui désigne une personne, se trouve pour demander grâce à Dieu. Plat reste invariable. Il est modifié par tout fin.

\section{Crocher dur}

S'agripper fortement à quelque chose

$\lambda$ marcher dur

\section{Crocher serré}

Accrocher, attraper solidement

Emploi absolu

1938 Il crochera un peu plus serré. Quand il tient, le diable ne le ferait pas lâcher (Maurice Genevoix, Bernard)

REMARQUES : Crocher serré réfère au fait d'agripper, de saisir quelqu'un ou quelque chose fort et étroitement, en serrant, avec le bras, la main, les doigts courbés en forme de crocher, de manière à l'immobiliser.

\section{Croire dur}

I. croire dur comme fer (et variantes) : croire

fermement, sans en démordre

Transitif

1729 Mais, quelle absurdité [,] ne peut-on pas persuader à des gens qui paroissent croire dur comme fer, qu'une statue de marbre a eu la peste, qu'elle en a encore une partie du visage enflée (Jaques Serces, Traité sur les miracles)

1750 Pour faire accroire au pauvre Monde Que le Pape étoit à la ronde Maitre de la Tarre et la Mar : Falloit croire dur comme far Qu'au Bonhomme il étoit loisible (Comme il est écrit dans sa Bible) Des Empereurs, comme des Rois, D'en faire de simples Bourgeois (Nicolas Jouin, Troisième Harangue des habitans de la paroisse de Sarcelles à Monseigneur l'archevêque de Paris)

1917 Ils croient, dur comme roc, que les rois et les ministres se sont entendus pour leur fournir tout mâchés les éléments d'une thèse à soutenir ou d'un livre à faire couronner (Revue des études napoléoniennes)

1927 Ainsi ce naïf compliqué croit dur comme fer qu'un homme de lettres, un journaliste, un député, même de l'espèce bien pensante, bénéficie d'une sorte d'alibi moral, a droit à un traitement de faveur, ne peut être tenu, avec le commun des êtres raisonnables, d'observer les règles élémentaires de la simple honnêteté (Georges Bernanos, L’Imposture)

1934 Et ceux-ci, qui ne sont pas tous en Gâtinais, croient dur comme un cœur de garde mobile que le ministère Daladier a fait « tout son devoir républicain » (Henri Béraud, Pavés rouges)

Intransitif

1954 et puis j'avais appris dans l'Évangile que tous les hommes sont tous égaux, tous frères, et ça je continuais à y croire dur 
comme fer (Simone de Beauvoir, Les Mandarins)

2003 La Lorraine vivra. Le spectacle était en plein air, toute la ville tournée vers sa mémoire ouvrière, vers son passé minier, sidérurgique, son passé d'acier. Croire dur comme fer au fer qui va durer. Une représentation qui se donne au cœur d'une ancienne mine à ciel ouvert, avec un chevalement authentique côté jardin (Aurélie Filippetti, Les Derniers Jours de la classe ouvrière)

2012 On s'engueulait pendant des heures au sujet de l'élection présidentielle. Mais lui, continuait à croire dur comme fer en la victoire. Il sillonnait le Quartier latin dans tous les sens avec ses tracts et ses affiches (Stéphane Osmont, Éléments incontrôlés)

II. croire dur (à quelque chose/quelqu'un) : croire vraiment, fermement

Transitif

1939 Frère Dominique. Tous ces grands hommes qui t'ont condamnée, ces docteurs et ces savants, Malvenu, Jean Midi, Coupequesne et Toutmouillé,

Ils croient dur au Diable, mais ils ne veulent pas croire à Dieu

(Paul Claudel, Jeanne d’Arc au bûcher)

1946 On me croyait étudiant, sans plus, et même étudiant en lettres, parce que je ne me contentais pas de citer Marx, mais Saint Just et Péguy (je crois avoir lu presque tout ce qui a été écrit en propre sur Saint-Just) et même Rimbaud : « qu'est-ce que ça peut faire à la putain Paris ?... » c'était bien vrai, et j'y croyais dur, alors, à ce dévouement que j'appelais kilométrique, et qui faisait de moi un pèlerin sans besace et sans bâton (Raymond Abellio, Heureux les pacifiques)

1961 On parlait de ses droits et de ses titres, et de la façon d'assurer son héritage, et le père n'était pas encore marié ni fiancé. Puis fiancé et non marié. Mais comme les gens privés de leur droit croient dur à la justice et au bon sens ! à coup sûr, s'ils étaient écoutés, la terre serait un paradis (Zoé Oldenbourg, Les Cités charnelles)
2012 Ils y croient, dur dur, à mes scandales, à mes remaniements, à mes faux complots masquant des vrais (Pierre Jourde, Le Maréchal absolu)

CORPUS WEB :

Croire dur comme fer à l'avenir de la sidérurgie [http://www.lalibre.be/economie/actualite/ croire-dur-comme-fer-a-l-avenir-de-la-siderurgie51b8ea0de4b0de6db9c66c95] (13.01.2015)

Alors que les mauvaises nouvelles s'accumulent concernant l'état de santé du champion de formule 1, les proches de Michael Schumacher tentent d'être optimistes et de croire dur comme fer à sa guérison [http://www.public.fr/ News/Michael-Schumacher-sa-famille-continuede-croire-tres-fortement-qu-il-va-guerir-501457] (13.1.2015)

REMARQUES : Croire dur à désigne le fait de croire à quelque chose de manière très forte, le sujet étant persuadé de quelque chose, de l'existence réelle de quelque chose ou de quelqu'un (le diable). En (I), la locution croire dur comme fer accentue l'idée de force et d'assurance, le sujet s'obstinant dans son opinion et n'y renonçant pas. Dur reste invariable. Notons la réduplication dur dur.

\section{Croire faux}

Croire en se trompant, contraire de croire juste $\pi$ croire juste

\section{Croire ferme}

Croire fermement, résolument

Emploi absolu

1839 « Il obéit ponctuellement; il ne connaît point la terre où il va, cependant il croit ferme » (François-René de Chateaubriand, Le Paradis perdu)

Transitif

1848 Réal, de la narration duquel je vous ai déjà entretenu, finit son exposition par ces niaiseries que croient ferme les Parisiens (François-René de Chateaubriand, Mémoires d'outre-tombe)

1936 Avec cela je crois pourtant ferme que chaque individu naît, vit et meurt selon sa nature propre, comme le crocodile est crocodile, et qu'il ne change guère (Alain, Propos) 
Intransitif

2008 Confier qu'on croyait ferme à l'arrivée de la gauche risquait de porter malheur (Annie Ernaux, Les Années)

\section{Corpus Web :}

Quelques grands personnages croyaient fermes à la lune et ses pouvoirs et réglaient leur vie autour [http://sommeteo.free.fr/observer_la nature.htm] (9.10.2020)

\section{Croire juste}

I. Penser qu'il est normal, convenable, juste (de / que)

Emploi absolu

1643 PTOLOMÉE. Allez donc, Achillas, allez avec Septime

Nous immortaliser par cet illustre crime.

Qu'il plaise au ciel ou non, laissez-m'en le souci.

Je crois qu'il veut sa mort, puisqu'il l'amène ici.

ACHILLAS. Seigneur, je crois tout juste alors qu'un roi l'ordonne

(Pierre Corneille, Pompée)

Pronominal

1662 À quoi sert cela pour consoler les justes et sauver le désespoir? Non, car personne ne peut être en état de se croire juste (Blaise Pascal, Pensées)

Transitif

1766 Vous ne leur proposez cependant que six meurtres au lieu de quatre mille, et vous leur présentez une récompense très forte. Pourquoi vous refusent-ils ? C'est qu'ils croient juste de tuer quatre mille ennemis, et que le meurtre de leur souverain, auquel ils ont fait serment, leur paraît abominable (Voltaire, Le Philosophe ignorant)

1775 J'en suis bien fâchée ; mais, mon ami, pourquoi me demandez-vous l'impossible ? Donnez-moi l'occasion de vous être utile dans ce que vous croirez juste, je vous réponds que cela se fera, et sans que je m'en mêle : vous n'aurez qu'à parler (Julie de Lespinasse, Lettres à M. de Guibert)

1832 Ayez la complaisance de me répondre sur tous ces points et d'après votre réponse, nous concluerons vraisemblablement parce que je crois juste de vous donner cette édition. Le second dixain des contes (drolatiques) est tellement avancé que ma mère en aura le manuscrit complet en novembre (Honoré de Balzac, Correspondance)

1927 Nous lisons alors, Sir... (grognements et cris de : « oh ! »). Si les honorables membres croient juste de m'interrompre, je me soumettrai. (fou rire). Tout ce que je peux dire c'est que je ne me conduirais ainsi envers personne. (rires) (André Maurois, La Vie de Disraëli)

1929 Quand j'étais plus jeune, je m'étonnais qu'il fût si bon, car il ne va jamais à la messe, et je ne crois pas très juste ce qu'il dit : que " la religion ne rend pas les gens meilleurs » (André Gide, L'École des femmes)

1936 car nous ne sommes point fiers de faire si peu et de risquer si peu pour ce que nous croyons juste ou vrai. Certes je découvre ici des vertus rares, qui veulent respect, et une partie au moins de la volonté. Mais c'est à la pensée qu'il faut regarder (Alain, Propos)

II. Avoir une opinion, des croyances, des idées, conformes à la réalité, à la vérité.

Emploi absolu

1740 «Pour moi, » dit Ferdinande, « je laisse croire tout ce qu'on veut, et je fais tout ce que je puis pour qu'on croie juste. » " On seroit donc bien niais de s'y méprendre, » dis-je à mon tour (Jacques de Varenne, Mémoires du chevalier de Ravanne)

1911 Oui, c'est entendu ; on croit toujours qu'on a toutes les maladies qu'on lit. Mais quelquefois on croit juste... (Julien Benda, L'Ordination)

\section{CORPUS WEB :}

Il ne suffit pas de croire en n'importe quoi pour s'acquitter ou prétendre être croyant, il faut croire juste, c'est-à-dire en l'existence du salut expiatoire de DIEU et aussi en sa grâce imméritée qu'il nous offre par le sacrifice de son Fils Unique [https://sites.google.com/site/labible parolededieu/Home/faut-il-croire] (13.1.2015) 
parce qu'il est tout de même mieux de croire juste que de croire faux. Pour ma part en croyant que Yeshoua et le fils de Dieu et le messie je c'est que je croie juste (-) [http://messianique. forumpro.fr/t4087-croire-au-nom-du-fils-dedieu.] (13.1.2015)

M. Duplessis paraît croire juste et légitime d'affamer l'opposition : qu'il s'agisse de situation ou de routes, d'écoles ou de ponts, seuls ses favoris sont servis. Il vient d'appliquer ce principe aux journaux : un adversaire à son gré n'est pas digne de l'entendre [http://www.vigile.net/ Maurice-Duplessis-a-l-Assemblee] (13.1.2015)

Remarques : Croire juste (I) renvoie au jugement ou à la façon d'estimer ou de juger quelque chose, soulignant l'appréciation personnelle ou suggérant une part de subjectivité. On pourrait l'expliquer par élision (croire juste quelque chose = croire que quelque chose est juste), mais rien ne prouve que la construction plus explicite est primaire. La construction s'explique aussi bien comme effet de sens où le locuteur cherche la relation attributive dans la valence sémantique $\mathrm{du}$ verbe (v. aussi dernier exemple du CW). Croire juste (II) réfère à la perception des choses, à l'image ou à l'idée qu'une personne se fait de quelque chose qui correspond à la réalité ou qui lui correspond. Croire juste s'oppose ainsi à croire faux (second exemple du CW). Notons la collocation croire juste ou vrai (croire vrai). Juste reste invariable et est modifié par tout, très.

\section{Croire noir}

Croire le contraire

Transitif

1951 Pour parer à ses caprices, celui-ci ne dispose que de la foi, telle du moins qu'elle est définie dans les exercices spirituels de saint Ignace : «nous devons toujours pour ne jamais nous égarer être prêts à croire noir ce que, moi, je vois blanc, si l'Église hiérarchique le définit ainsi »(Albert Camus, L'Homme révolté)

Emploi absolu

1987 Quand je me mets à penser, c'est toujours dans le désordre, en vrac, et je ne suis jamais assuré, si je pense blanc au début de mon propos, que je ne finirais pas par croire noir à la fin. Je suis dans le gris au sens chromatique, dans le blues au sens moral (Dominique Lemaire, Le Trèfle à quat' feuilles)

REMARQUES : Le langage littéraire emploie noir s'appliquant à une vision pessimiste des choses, il suggère une image sombre de la réalité ou de la vie. Notons le contraste avec voir blanc et penser blanc qui soulignent un regard plutôt optimiste, sans nuages.

\section{Croire vrai}

I. Considérer quelque chose comme vraie, réelle

Emploi absolu

1697 GÉRONTE. Comme le voilà fait !

Débraillé, mal peigné, l'œil hagard ! à sa mine

On croiroit qu'il viendroit, dans la forêt voisine

De faire un mauvais coup.

HECTOR. (à part) On croiroit vrai de lui : Il a fait trente fois coupe-gorge aujourd'hui (Jean-François Regnard, Le Joueur)

2006 Évidemment, comme l'écrit quelque part John Searle, croire consiste à croire vrai, c'est-à-dire en somme croire savoir : je crois, c'est-à-dire je crois savoir, que la Terre tourne autour du Soleil (Gérard Genette, Bardadrac)

Transitif

1730 Il ne m'appartient pas d'apprecier les agrémens ni les difficultés des autres : or en convenant que le goût des vers est naturel à tous les peuples ; ce que je crois vrai, puisque les vers sont nés du chant et que l'on a chanté par tout (Antoine Houdar de La Motte, Discours sur la tragédie)

1734 Dans de telles circonstances j'espère que le public aussi-bien que vous, mon Reverend Pere, aprouverez que je ne garde point le secret qu'on me demande et je ferai plus, puisque je déposerai cette seconde lettre dans le même dépôt, où je mettrai toutes celles que j’ai reçües ; car je me fais justice et pour la croire vrai, il faut l'avoir luë (Lettre de Madame M... au R. P. Lenet) 
1758 GERMEUIL. Ensuite, monsieur le commandeur ; de quoi s'agit-il ?

Le Commandeur. D’abord de me croire vrai, comme je le suis.

Germeuil. Cela se peut.

LE CommandeUr. Et de me montrer que tu n'es pas indifférent à mon retour et à ma bienveillance

(Denis Diderot, De la poésie dramatique)

1771 Un esprit éclairé sait que la violence fait les hypocrites et la persuasion les chrétiens ; qu'un hérétique est un frere qui ne pense pas comme lui sur certains dogmes métaphysiques ; que ce frere privé du don de la foi est à plaindre, non à punir, et que si nul ne peut croire vrai ce qu'il voit faux, nul pouvoir humain ne peut commander à la croyance (Claude-Adrien Helvétius, De l'homme)

1847 Il changera d'avis quant au mariage. Il a encore du temps devant lui, mais je crois assez vrai que nous serons toujours tout l'un pour l'autre. Les garçons aiment mieux leur mère que les filles. Je crois que c'est dans l'ordre éternel des choses (George Sand, Correspondance)

1909 Il disait :

- Vous êtes trop humbles. Le grand ennemi, c'est le doute neurasthénique. On peut, on doit être tolérant et humain. Mais il est interdit de douter de ce qu'on croit bon et vrai. Ce qu'on croit, on doit le défendre. Quelles que soient nos forces, il nous est interdit d'abdiquer. Le plus petit, en ce monde, a un devoir, à l'égal du plus grand (Romain Rolland, Jean-Christophe. Dans la maison)

1913 Je n'étais curieux, je n'étais avide de connaître que ce que je croyais plus vrai que moi-même, ce qui avait pour moi le prix de me montrer un peu de la pensée d'un grand génie, ou de la force ou de la grâce de la nature telle qu'elle se manifeste livrée à ellemême, sans l'intervention des hommes (Marcel Proust, Du côté de chez Swann)

1922 Celle-ci était causée non pas par le mensonge lui-même et par l'anéantissement de tout ce que j'avais tellement cru vrai que je me sentais comme dans une ville rasée, où pas une maison ne subsiste, où le sol nu est seulement bossué de décombres (Marcel Proust, La Prisonnière)

1936 car nous ne sommes point fiers de faire si peu et de risquer si peu pour ce que nous croyons juste ou vrai. Certes je découvre ici des vertus rares, qui veulent respect, et une partie au moins de la volonté. Mais c'est à la pensée qu'il faut regarder (Alain, Propos)

1943 Bientôt à un croisement de routes, la voiture les abandonna. Elle m'entraînait loin de ce que je croyais seul vrai, de ce qui m'eût rendu vraiment heureux, elle ressemblait à ma vie (Georges Bataille, L'Expérience intérieure)

1983 Comme ils s'en allaient, j'ai entendu une grossièreté par la bouche d'un masque qui disait : " L'abbé s'en va au bras de sa catin "; ce que je ne crois pas vrai. Car on ne dit rien de ce genre obscène de la Foscarini, qui est très secrète, sinon de Don Giovani, qui passe pour se débaucher avec des filles du peuple (Claude-Michel Cluny, Un jeune homme de Venise)

1976 - Demandez-lui, avec précision, ceci : croit-il vrai, lui, Grain-de-Café (enfin, je veux dire...) qu'un homme viendra, qui donnera aux Sedangs la puissance et les rendra maîtres des autres Moïs ?

(André Malraux, Le Règne du malin)

Pronominal

1926 Ne parlez pas d'une société capitaliste chez vous. Parlez d'une société de conquérants. Chez nous, Latins, le cas est autre, et un Dréard peut se croire vrai avec lui-même, en dressant une cloison étanche entre ses débauches et son existence avouée (Paul Bourget, Nos actes nous suivent)

II. Croire véritablement

Emploi absolu

1859 La fleur n'a pas le temps de naître et de se détacher devant ces réalités trop actuelles et trop sérieuses pour ne pas être redoutables ; trop croire, croire trop vrai n'est pas 
une condition heureuse pour que l'imagination se joue (Charles Sainte-Beuve, PortRoyal)

\section{CORPUS WEB :}

«Une opinion scientifique est une opinion qu'il y a une raison de croire vraie ; une opinion non scientifique est une opinion qui est défendue pour une raison autre que sa vérité probable » [http://www.opuscules.fr/la-religion-la-verite-etles-raisons-de-croire] (7.1.2015)

Enfin, rien n'empêche que des explosifs soient placés dans l'avion ou encore dans le pentagone, prêt à se déclencher au moment de l'impact. Mais que cette possibilité s'avère vraie ou non (et j'aurais tendance à la croire vrai, en raison de certains témoignages qui concordent), cela ne change en rien le raisonnement quant a présence du véritable vol 77 [http://forum.reopen911.info/ p119174-20-02-2008-17-05-44.html] (7.1. 2015)

REMARQUeS : Le sujet de croire vrai (I) désigne une personne qui admet la certitude de ce qui va suivre (d'une chose, d'un fait) ou ce qu'une personne peut ou est capable de faire. L'emploi absolu est sémantiquement ambigu, permettant l'interprétation (I) (ex. de 1697, 2006) aussi bien que celle de 'croire véritablement' (II) (ex. de 1859). Notons les collocations croire bon et vrai, croire juste ou vrai, qui jouent avec les contrastes sémantiques. Vrai reste invariable, comme dans l'exemple de 1734, où il pourrait s'agir d'une simple faute typographique, mais on trouve, sur la même page, "la regarde comme vrai ». $\mathrm{Cu}$ rieusement, seul ce deuxième cas figure dans les errata, où l'on veut le remplacer par le féminin vraie. La seule conclusion qu'on peut tirer de cette situation confuse, c'est que toutes les formes grammaticales de vrai sont invariables sur le plan phonétique, ce qui rend plus facile l'absence de l'accord à l'écrit, qu'il s'agisse d'une erreur (interprétation adjectivale) ou pas (interprétation adverbiale). Vrai est modifié par assez, plus, trop. $\mathrm{Si}$ les exemples cités ci-dessus contiennent des réflexions générales qui ne placent pas l'adjectif vrai dans des contextes qui permettraient de faire l'accord, les exemples du CW l'insèrent dans des discours plus concrets. L'accord devient alors la règle, sauf pour le dernier exemple. S'il ne s'agit pas d'un lapsus, il semblerait que la forte lexicali- sation de croire vrai joue en faveur de son emploi invarié, d'autant plus que la flexion dans s'avérer vrai le précède immédiatement. Dans l'exemple de 1976, on peut penser que vrai fonctionne comme adverbe de phrase, au même titre que le serait vraiment : croit-il vraiment 'réellement'. Notons l'emploi de voir faux (ex. de 1771). Dans l'exemple de 1943, on observe une double relation prédicative : ce que je croyais seul vrai 'ce que je croyais être le seul qui est vrai'. On peut évidemment exclure l'emploi prédicatif (I) du domaine des fonctions adverbiales.

\section{Croître beau}

Pousser, bien grandir, de façon harmonieuse Intransitif

1564 Il [= le meurte] se peut aussi semer à la façon du laurier : mais il vient tardivement. Il croistra fort beau et haut eslevé, si tu le nettoye et escure souvent à l'entour (Charles Estienne, L'Agriculture et maison rustique)

1589 Quand à mon advis, dés le commencement du monde la vigne a pris sa naissance avec les autres arbres fruictiers, encor que nos premiers peres ayent ignoré l'usage du vin, jusques au temps de Noé : Et qu'ainsi soit, il est certain qu'en l'Amerique, et en la Floride, mesme presqu'en toutes les autres provinces du Perou, n'agueres descouvertes, les vignes croissent fort belles, sans l'industrie de l'homme, et portent fort bons raisins, combien que l'usage du vin jusques à ce siecle soit demeuré incogneu aux habitans (Julien le Paulmier, Traité $d u$ vin et du sidre [trad.])

1660 LA SUIVANTE. Le précepteur qui fait répéter la leçon

À votre jeune frère $\mathrm{a}$ fort bonne raison Lorsque, nous discourant des choses de la terre,

Il dit que la femelle est ainsi que le lierre, Qui croît beau tant qu'à l'arbre il se tient bien serré,

Et ne profite point s'il en est séparé (Molière, Sganarelle ou Le Cocu imaginaire)

1723 Le chanvre et le lin qui y croissent beaux et en abondance, passent dans les élec- 
tions voisines qui en savent mieux profiter (Jacques Savary Des Bruslons, Dictionnaire universel de commerce)

1836 En peu de temps les ennemis abandonnèrent donc la place, et ma moisson crût belle et bien, et commença bientôt à mûrir. Mais si les bêtes avaient ravagé mon blé en herbe, les oiseaux me menacèrent d'une nouvelle ruine quand il fut monté en épis

(Daniel Defoe, Vie et aventures de Robinson Crusoé [trad.])

1864 Bref, elle guérit, et se mit à croître bel et bien. La petite Théonice, nous devons le dire, eût très-probablement échoué dans cette cure, n'eussent été l'aide et les bons avis d'un jeune paysan du voisinage (L'Illustration)

2008 Les arbres de la forêt sociale (qu'il s'agisse de la société civile des individus ou de la société internationale des peuples-Etats) ne croissent beaux et droits que si, tout en rivalisant entre eux dans leur quête de lumière et d'espace, ils croissent tous dans le même sens et à un rythme comparable (Jean-Marie Pelt, La Compétition, mère de toutes choses ?)

\section{CORPuS Web :}

Suivre les règles générales sur les meilleures pratiques pour fournir assez d'eau, la préparation d'un lit de fleurs bien, en choisissant les bons engrais et de faire des nutriments du sol riche, et vous devriez être en mesure de croitre beau, accrocheur fleurs année après année [http:// vie.0685.com/famille/Gardening/201305/198666. $\mathrm{html}]$ (5.1.2015)

- Je vais voir Dieu, pour lui demander pourquoi il me couvre de malheurs depuis ma naissance.

- Si vous le voyez, demandez lui aussi s'il vous plaît, pourquoi je ne puis croître beau et droit comme mes frères pommiers, pourquoi je ne porte aucun fruit, et pourquoi je reste petit et chétif.

- Je lui demanderai, répondit l'homme [http://the-inn-at-lambton.cultureforum.net/ t974p25-me-and-mr-darcy-a-lire-absolument] (5.1.2015)
REMARques : Le sujet de croitre beau désigne normalement un végétal (le lierre, la vigne), mais aussi une personne, ou, au sens figuré, les individus et les peuples comparés à des arbres qui poussent à une vitesse satisfaisante, tout en prenant un bel aspect. Notons les collocations croître bel/belle et bien et beau et droit. La collocation bel et bien, figée dans la langue actuelle, conserve encore son sens primitif. L'accord est préféré. Il s'agit donc plutôt d'un prédicat second, mais l'interprétation de manière est également présente (ex. de 1864), de même que la lecture résultative (ex. de 1564). Beau est modifié par fort. Notons l'emploi de tenir serré.

\section{Croître fort}

Grandir beaucoup

Intransitif

1370 Mais ces ondes feroient si durement contre la nef que elles la faisoient drecier contremont, et cuidoient tous vrayement que leur nef deüst depecier. Et les és croissoient moult fort, si qu'il n'avoient nulle entente d'eschapper de ce peril ; ains cuidoient tousjours mourir de heure en heure, se Dieux ne leur aidoit

(Roman de Berinus, I, p. 213)

1538 N'est ce pas toy qui du Roy fut esprinse Sans l'avoir veu, mesmes après sa prinse, Où tellement aux armes laboura Que, le corps pris, l'honneur luy demoura. N'est ce pas toy qui sentis plus fort croistre L'amour en toy, quand tu vins à congnoistre Et veoir son port, forme, sens et beauté, Qui ne sent rien que toute royauté ? (Clément Marot, Épitres)

1671 Il y a quantité de bois, parce que les arbres $\mathrm{y}$ croissent fort, et entr'autres ceux qu'ils appellent Zcyba, qui grossissent de telle sorte que quinze hommes se tenant par la main à peine les peuvent-ils embrasser (Nicolas de La Coste, Histoire générale des voyages et conquestes)

1880 Qu'il croisse fort et puissant comme notre République (François Noël Le Roy de Sainte-Croix, L'Alsace en fête) 
1907 Le père travaillait avec ses fils, deux grands gaillards, aux membres robustes, un peu déformés par le travail. Leurs yeux s'ouvraient très blancs, dans leurs bonnes faces de moricauds. Ils appartenaient à une autre race, plus solide encore et plus résistante, celle des plateaux lorrains, où la plante humaine croît plus forte, nourrie seulement d'eau-de-vie et de pommes de terre (Émile Moselly, Terres lorraines)

CORPUS WEB :

Grâce à Dieu et à sa providence, la santé du dauphin Louis n'offre aucune alarme et, à 3 ans, il semble croitre fort comme un tronc et beau comme un lys. Toutefois, il y a déjà deux ans, la princesse Anne-Elisabeth avait également passé après quelques jours seulement [http://www. parismatch.com/Royal-Blog/Monde/La-reineMarie-Therese-accouche-d-un-bebe-noir-577781] (5.1.2015)

les algériens a l'époque venaient au maroc en masse acheter des bananes par ex et autres produits qu'on trouvait pas en algérie. depuis, on s'est ouvert et il y a de tout maintenant. mais on dépend encore du tout état, mais le secteur privé va croitre fort a l'avenir et on manque pas d'argent pour l'aider [http://www.algerie-dz.com/forums/ archive/index.php/t-192793.html] (5.1.2015)

...le druide dit : « ce chêne était déjà vieux lors de ma naissance. A présent je suis vieux et je vais bientôt mourir, et cet arbre continuera à croître, fort et vigoureux. Nous sommes de petites créatures, nos vies ne sont pas longues, mais suffisamment longues pour apprendre ce qui nous est demandé »[http://paulocoelhoblog. com/2006/08/16/edition-n\%C2\%BA-127-leguerrier-de-la-lumiere-et-la-strategie] (5.1.2015)

REMARQUeS : Le sujet de croître fort désigne un animé ou un inanimé, par exemple un sentiment qui grandit ou devient plus fort. Fort tend à l'invariabilité, mais dans l'exemple de 1907 l'accord entraîne une nuance résultative. Le dernier exemple du CW montre l'effet de la pause marquée par une virgule dans le code écrit : fort devient une propriété de l'arbre. Il est modifié par moult, plus.

\section{Croître long}

Pousser en longueur (des cheveux)

$\lambda$ couper court

\section{Croître serré}

Pousser d'une manière dense, compacte Intransitif

1784 Le Frêne épineux. [...] C'est un arbrisseau qui s'éleve quelquefois de dix à quinze pieds ; et il doit son épithète à une multitude de petites épines dont ses branches sont couvertes, et qui le rendent fort incommode au voyageur qui est obligé de traverser les lieux où il croit serré (Jonathan Carver, Voyage dans les parties intérieures de l'Amérique septentrionale [trad.])

1792 Il en est du pin comme du chêne : pour que sa tige s'élance il faut qu'il croisse un peu serré ; et comment pourroit-il croître serré dans un terrain détestable tel que celui de la longue et triste montagne de Tarar? (Philibert Charles Varenne-Fenille, Mémoires sur l'administration forestière)

1827 Ce nom indique assez qu'elles sont destinées à défendre les propriétés rurales ; on doit choisir, pour les former, les arbres ou arbustes indigènes les plus communs, qui croissent vite et n'ont besoin d'être tondus qu'une fois chaque hiver ; ils doivent croître serrés, de manière à ne laisser aucun vide, ou bien être garnis d'épines assez fortes et assez nombreuses pour repousser les animaux ou les maraudeurs (André Thoüin, Cours de culture et de naturalisation des végétaux)

1844 L'herbe croissait haute et serrée dans cette cour battue jadis comme le sol d'une aire par les pas des hommes d'armes (George Sand, Jeanne)

1872 Un épais tapis de mousses y amortit le bruit des pas ; les feuilles aciculaires tombées ne permettent qu'à bien peu de plantes de se développer et les arbres croissant serré empêchent tout arbrisseau de végéter (L. Piré, La Forêt)

1913 On conseille, en effet, parfois de se servir de jeunes semis naturels arrachés dans les 
bois. C'est souvent un mauvais conseil ; ces plants ont presque toujours un mauvais enracinement ; ils ont crû serré, à l'ombre : leur tige est alors effilée et mince (Bulletin de la Société centrale forestière de Belgique)

1950 En effet, il semble que le peuplement idéal, pour le gui, soit cette futaie régulière, surtout si elle est composée de gros bois bien élagués parce qu'ils ont $c r u ̂$ serrés. Dans ce cas, le parasite arrive à s'implanter jusque sur les troncs

(F[rançois] Plagnat, Le Gui du sapin)

\section{Corpus Web :}

Bois qui doivent croitre serrés [http://www. lausanne.ch/thematiques/culture-et-patri moine/histoire-et-patrimoine/archives-commu nales/open-archives/Le-traite-des-bois-benja min-secretan/mainArea/00/links/0/linkBinary/ Le-traite-version-pdf.pdf] (28.12.2014)

REMARQUES : En parlant d'un végétal, croître serré se dit du fait de pousser étant planté très proche d'autres végétaux, de façon à donner à la plantation un aspect serré, épais, compact. Notons la collocation croître haut et serré. Serré peut s'accorder avec le sujet, mais il peut également rester invarié (ex. de 1872 et de 1913).

\section{Cuire dur}

I. Cuire jusqu'à être dur (d'un œuf)

Transitif

1564 comme seroit la paste de laquelle nous ferons mention cy-apres : ou au lieu d'icelle paste, prenez un œuf tout fraiz (car autrement il pourrait causer quelque maladie et faire mourir l'oiseau) Faites-le cuire dur, donnez luy à manger le moyeu (Charles Estienne, L’Agriculture et maison rustique)

1603 Outre les eaux, sont ici employées diverses onctions, comme huiles, linimens, pommades, telles que celles-ci : fendés par moitié des œufs cuits durs, ostés-en les moyeux, remplissés-en le vuide avec poudre de tartre bruslé (Olivier de Serres, Le Théâtre d'agriculture et mesnage des champs)
1740 Prenés un ou plusieurs œufs frais pondus le même jour d'une poule noire, ou au défaut d'une poule noire d'autres poules ; faites-les cuire dur entre les cendres chaudes, puis coupés les en quartiers égaux, et ôtés leur le jaune, au lieu duquel vous mettrés autant de sucre candis pulvérisé (Noël Chomel, Dictionnaire œeconomique)

1777 Dans les Indes occidentales, chez les Malaies, on a le secret de saler les œufs sans casser les coquilles, en les faisant cuire dur, ce qui les rend fort délicats, les conserve long-temps, et les rend commodes pour être transportés en voyage (Pierre-Joseph Buc'hoz, Traité économique et physique des oiseaux de basse-cour)

1894 On les faisait alors cuire dur pour les conserver, puis on les teignait soit en jaune, soit en rouge ; de là l'origine des œufs de Pâques et des œufs rouges que l'on consomme en tous temps aujourd'hui (Encyclopédie chimique)

1930 Mais, lorsqu'il veut casser les œufs, le voilà camus : ils étaient cuits durs (Henri Pourrat, Le Pavillon des amourettes ou Gaspard et les bourgeois d'Ambert)

2012 Les jumeaux babillent à demi allongés dans leurs sièges posés sur la table de cuisine. Ils observent maman découpant tomates, concombres, poivrons, œufs cuits dur (Jean Molinié, La Jeune Femme indigne)

II. Cuire jusqu'à être dur (une terre argileuse)

Transitif

$1836 \mathrm{Au}$ bout de quelque temps il arriva que, ayant fait un assez grand feu pour rôtir de la viande, au moment où je la retirais étant cuite, je trouvai dans le foyer un tesson d'un de mes pots de terre cuit dur comme une pierre et rouge comme une tuile (Daniel Defoe, Vie et aventures de Robinson Crusoé [trad.])

1933 On emploie généralement des briques ordinaires cuites dur, mais on peut employer tous les genres de briques; on les pose 
avec du mortier de ciment (La Technique moderne)

III. Emploi hyperbolique

Transitif

2010 Il fait chaud à cuire dur la cervelle de Yul Brynner. Dans ces régions, le littoral n'adoucit pas l'implacable température. La fin du jour non plus. On coule dans des incandescences (San-Antonio, Appelez-moi chérie!)

CORpus Web :

Disposer les œufs dans une casserole d'eau frémissante puis les cuire dur pendant $9 \mathrm{~min}$. Les rafraîchir ensuite dans de l'eau froide, puis les écaler et les couper en dés [http://www. atelierdeschefs.fr/fr/recette/8186-lasagnes-a-lanapolitaine.php] (28.12.2014)

Il mange 32 œufs cuits dur en 60 secondes ! Le Japonais Takeru Kobayashi (34 ans, 1m73 pour $58 \mathrm{~kg}$ !) est considéré comme un des plus gros mangeurs du monde. Début octobre, il a avalé 32 œufs cuits dur lors d'une démonstration de son appétit dans les locaux d'un magazine américain [http://www.20min.ch/ro/ videotv/?vid=222759\&cid=120] (28.12.2014)

Merci pour ce « truc ». J'essaierai mais d'habitude, les œufs que je fais cuire durs sont les moins frais que j'ai. Alors peut-être, sinon pour le reste je fais pareil [http://cuisiner.journaldes femmes.com/forum/affich-43984-commentecaler-facilement-les-oeufs-durs] (28.12.2014)

REMARques : Cuire dur réfère à l'état final de l'objet après la cuisson. En (I), il réfère à la consistance solide de l'œuf après cuisson dans sa coquille à l'eau bouillante et souligne la transformation d'un aliment après avoir cuit. En (II), il désigne le fait de soumettre un matériau à l'action d'une source de chaleur qui le modifie dans sa substance pour le rendre propre à un usage spécifique, le complément d'objet désignant certains matériaux. (III) transpose l'effet de la chaleur sur l'homme. Dur tend à l'emploi invariable, mais il peut s'accorder avec le sujet, ce qui renforce l'interprétation résultative.

\section{Cuire mollet}

Ramollir en faisant cuire

Transitif

$1603 \mathrm{Au}$ contraire des autres fièvres, ceste-ci est froide, pour laquelle cause, le fébricitant de la quarte, boira du vin avec peu ou poinct d'eau, afin de l'eschauffer ; et pour la mesme cause, prendra tous les matins un œuf frès, cuit mollet, avec cinq ou six grains de poivre (Olivier de Serres, Le Théâtre d'agriculture et mesnage des champs)

1903 Coiffer les œufs cuits mollets avec les morilles, et dresser en croûtes de tartelettes cannelées, garnies d'une purée de foie gras légère (Auguste Escoffier, Le Guide culinaire)

1967 Il [= Vendredi] trait les chèvres, fait cailler le lait, ramasse les œufs de tortue, les fait cuire mollet, creuse des rus d'irrigation, entretient les viviers, piège les bêtes puantes, calfate la pirogue, ravaude les vêtements de son maître, cire ses bottes (Michel Tournier, Vendredi ou Les Limbes du Pacifique)

REMARQUES : Dans le domaine de la cuisine, cuire mollet réfère au fait de faire cuire un œuf dans de l'eau de façon à ce que le jaune soit encore un peu coulant. Mollet tend à l'invariabilité, mais l'accord peut favoriser une lecture plutôt résultative (v. ex. de 1903).

\section{Cuisiner cher}

Acheter des ingrédients chers

$\pi$ cuisiner sain

\section{Cuisiner fin}

Faire une cuisine raffinée

Emploi absolu

\section{CORPUS WeB}

Ces deux là cuisinent fin et malin, méditerranéen et savant, finaud et séducteur à la fois, à quatre mains. Cela donne, par exemple une joli et fine tarte croustillante de sardines, une bien belle soupe de poissons, une dorade avec sa polenta aux agrumes, un filet de rascasse à la plancha avec sa semoule de céleri et carottes à l'huile d'argan, 
des seiches à la plancha sur leur lit de polenta ou encore des chipirons farcis aux légumes citronnés et riz vénéré, vifs, bien vus et bien frais [http://www.gillespudlowski.com/34695/ restaurants/marseille-peron-tendance-etgourmand] (18.12.2014)

Je voulais devenir cuisinier en souvenir de mon grand-père, boulanger-pâtissier et de mes parents qui m'ont appris à bien manger, à cuisiner fin et à boire bon. Comme la greffe avait bien pris en Suisse, au moment de choisir une destinée professionnelle, je me suis presque naturellement tourné vers la vigne et le vin en m'inscrivant à l'Ecole d'Ingénieurs de Changins [http://www. commerce-qualite.com/pdf/gazette/La_Gazette automne-11.pdf] (18.12.2014)

Question épices, le chef a la main très lourde. Trop d'épices tue l'épice, c'est bien connu ! Je confirme ! Comment peut-on cuisiner fin en dosant comme un bûcheron moldave ? En plus, des traits de balsamique machin, de la poudre de truc orange pour faire joli, et même, des bouts de pruneau dans le mesclun ! Et du pain de mie à la place du pain normal ! Et la confiture d'oignons, c'est un défoliant ! [http://www.le-bouche-aoreille.com/restos/R2277/page.html] (18.12.2014)

Ca y est, j'ai franchi le pas, j’ai testé ma première recette tirée d'un La Mode Illustrée, de 1877. J'ai pas pris au hasard dans mes magazines, quand même. Parce que la tarte aux nouilles, il n'y a guère que mon geek domestique dire que c'est testable. Il n'a quand même aps dit " à tester ». Autrement dit, un humain normal a toutes les raisons de prendre ses jambes à son cou. Ca, c'était si quelqu'un dans l'assitance croyait encore que nos ancêtres cuisinaient fin et léger [http://accouphene.livejournal.com] (18.12.2014)

REMARQUES : Cuisiner fin s'insère dans toute une série d'attributs tels cuisiner sain, malin, léger, gourmand (v. cuisiner sain). Il se prête aussi bien à une interprétation de manière qu'à une lecture d'attribut d'un objet interne : ce qui est fin, c'est ce que l'on cuisine. Fin reste invariable. Dans cuisiner fin et malin la coordination syntaxique réunit un attribut orienté vers l'objet interne du verbe (fin) avec un attribut orienté vers le sujet (malin). Ceci est un effet de la signification des adjectifs qui n'admettent qu'une seule cible d'at- tribution, malin étant un attribut humain, fin un attribut du repas. Notons l'usage de boire bon, qui réfère également à la qualité de ce que l'on boit. On trouvera une liste plus complète des adjectifs-adverbes combinés avec cuisiner dans le Corpus Coiffet (2018 : s.v.). Mis à part les adjectifs ethniques tels japonais, la liste comprend notamment bio, bon, casher, chic, cru, durable, écolo, facile, frais, pratique, végétarien, vert, solidaire.

\section{Cuisiner gourmand}

Cuisiner de manière à provoquer et attiser la gourmandise, à faire envie

$\pi$ cuisiner sain

\section{Cuisiner léger}

Préparer un repas frugal ou peu calorique

त cuisiner fin

\section{Cuisiner malin}

Cuisiner d'une manière astucieuse, économique $\lambda$ cuisiner fin, sain

\section{Cuisiner sain}

Cuisiner des plats bons pour la santé Intransitif

1957 Cuisinez fin. Cuisinez sain. Cuisinez « pain » avec Symphonie (Paris Match [publicité], avril 1957 / Grundt : 236)

2012 Cuisiner sain ne veut pas dire cuisiner cher. Un planning hebdomadaire et une liste de courses vous aideront par exemple à acheter moins d'aliments (superflus). Vous pouvez en outre appliquer les conseils (Weight Watchers, Cuisine saine et facile)

\section{Corpus Web}

Cuisinez sain et gourmand ! [http://www. darty.com/dossier/petit_electromenager/les astuces_pour_cuisiner_sain_et_gourmand_les_ fruits_et_legumes.html] (17.12.2014)

4 conseils pour cuisiner sain [http://www. iterroir.fr/cuisine/recettes/astuces/4-conseilspour-cuisiner-sain/145] (17.12.2014)

Matin : fruits à volonté + fruits secs non salés + thé vert sans sucre

Midi : belle assiette de crudités variées +1 trait d'huile et jus de citron +1 bol de légu- 
mineuses selon les goûts et cuisinées sain avec épices +1 ou 2 fruits selon la faim

Soir : bouillon de légumes de saison maison (on boi le jus et on mange les légumes avec un trait d'huile) + 1 ou 2 fruits selon la faim [http:// blog.aufeminin.com/blog/see_149218_1/Bullede-Plume-1-mois-de-Detox-avant-de-decider-unregime-ou-pas] (17.12.2014)

Pour cuisiner sain et malin, mieux vaut choisir des légumes de saison. Découvrez ici les légumes à privilégier au moment de vos achats et équilibrez ainsi vos différents plats de pâtes [http://barilla.cuisineaz.com/mois_calendrier_ legumes] (17.12.2014)
REMARQues : Cuisiner sain désigne le fait de préparer un plat avec des produits ou des aliments bons pour la santé et de bonne qualité. Notons la collocation avec l'adjectif-adverbe fin qui renforce le sémantisme et ajoute la notion de raffinement dans la préparation culinaire. Sain reste toujours invariable, même dans le troisième exemple du CW, où le participe passé du verbe transitif manifeste l'accord au passif avec l'objet du verbe actif.

\section{Cuisiner transparent}

Cuisiner dans des plats de cuisson transparents Emploi absolu

1972 Cuisinez transparent (Maison de MarieClaire / Noailly 1997a) 


\section{Danser anglais}

Danser selon la mode, la coutume anglaise Intransitif

1926 La rumeur des causeries se mêlait au bruit des instruments, piano, violons et cuivres. Tout ce monde, - deux cents personnes peut-être, - parlait anglais, buvait anglais, dansait anglais (Paul Bourget, Le Danseur mondain)

\section{CORPUS WEB :}

Parler anglais, manger anglais, danser anglais, boire anglais ; viens vivre l'Angleterre ce samedi à La Cartonnerie de Reims avec The Mouse Outfit et Lady Leshurr Support Page !!! [https://www.facebook.com/cartonnerie.reims. fanpage/posts/584840864936233?stream_ref=10] (19.1.2015)

La montagne écossaise dansant (également appelé l'épée d'Scottish dansant) est aussi différente du pays écossais dansant que danser de Morris est de danser anglais de pays [http:// wikipedia.qwika.com/en2fr/Talk:Folk_dance] (19.1.2015)

Si l'envie vous prenait de danser anglais pendant une semaine, ou bien autre chose ou ne rien faire dans les Cévennes. C'est tellement beau. et sympa ! [https://larondedherblay. wordpress.com/2013/03/20/divers-stages-autresgroupes-manifestations] (19.1.2015)

REMARques : Danser anglais désigne le fait de danser comme un Anglais, et, par extension, de danser selon la mode anglaise. L'exemple met en évidence l'effet analogique à partir du modèle parler anglais. Le CW confirme ce phénomène. Notons l'emploi de boire anglais.

\section{Danser classique}

Pratiquer la danse classique

Intransitif

1982 « Il est évident que je ne pourrais plus danser classique » (Antenne 2, 19.12.1982 / Hagège 1987 : 45)

\section{Danser contemporain}

Pratiquer la danse contemporaine (opposé à

'pratiquer la danse classique')

Intransitif

2003 Paul fait danser contemporain (Paris Match)

\section{Danser utile}

Danser dans le but d'obtenir un avantage

$\lambda$ baiser utile

\section{Dater faux}

Donner une date erronnée

Emploi absolu

1833 L'Hercule des Persans est le fameux Roustan antérieur à Arsace $\mathrm{I}^{\mathrm{er}}$, qui fonda en 256 avant J. C. l'empire de Parthie. Ceux qui prétendent en savoir davantage, datent faux (Louis Capello, comte de Sanfranco, Mythologie de tous les peuples)

\section{Décapiter net}

Couper la tête d'un seul coup

Transitif

1857 Le chef de dépôts, le malheureux Miau (d'Auch), à été décapité net, et son corps tellement maltraité que les restes ont pu tenir dans un sac d'une médiocre grandeur (La Presse)

1913 «Porfire doit nous y attendre avec l'automobile... voici ma « vorace » d'été, pour aller et venir entre Moscou et Pétrovskoïé. Les deux grands sabres à l'avant ? C'est pour couper les fils de fer que nos révolutionnaires tendent en travers des routes, depuis quelque temps. Le chauffeur de mon cousin Constantin a été décapité net, le mois dernier, sur la route d'Oranienbaum » (Valery Larbaud, Journal intime / A.O. Barnabooth)

2009 Les loups connaissent les coutelas, pas les sabres. Il ne s'est pas méfié. Tu l'as décapité net (Hubert de Maximy, La Rebouteuse de Champvieille)

\section{Déchaumer droit}

Enlever le chaume du sol, comme il faut

त labourer droit 


\section{Déchevaucher dur}

Faire tomber violemment de cheval

Transitif

1275 Se ne fust une estache, Limbanors fust noiiés,

Dont Sarrazin avoient mains poissons engingniés.

Ahi ! Mahonmet sire, fait il, et car m'aidiés!

Malement est sor moi retornés li meschiés, Quant par un François sui si dur deschevauchiés

(Adenet le Roi, Buevon de Conmarchis, 2618)

REMARQUES : En ancien français, déchevaucher dur désigne le fait de faire tomber quelqu'un de cheval avec force.

\section{Déchirer menu}

Déchirer en petits morceaux

Transitif

1874 Il était tellement absorbé dans ses méditations que, certainement, il ne s'apercevait pas du travail de ses doigts. Ce travail consistait à déchirer si menu, si menu, les confidences de sa belle cousine, que ce monument de la papeterie moderne s'en alla joncher la terre en atomes (Arthur de Gobineau, Les Pléiades)

1932 Le colonel ne bronchait toujours pas, je le regardais recevoir, sur le talus, des petites lettres du général qu'il déchirait ensuite menu, les ayant lues sans hâte, entre les balles (Louis-Ferdinand Céline, Voyage au bout de la nuit)

1947 Comment pouvait-elle être assez vulgaire, assez basse... Elle qui avait le besoin de la voix de cet homme, comme d'une chanson. Elle écrivait son nom sur des petits bouts de papier, qu'elle déchirait ensuite, patiemment, тепи, тепи, comme une souris, avec ses ongles (Louis Aragon, Les Voyageurs de l'impériale)

1960 Lucie déchire menu la feuille de carnet, en flambe les fragments comme par jeu dans le cendrier, en allumant une cigarette. Quatre cent sept mille ! c'est pas des pous- sières ! (Albert Simonin, Du mouron pour les petits oiseaux)

1969 Le morceau de journal contenait encore autre chose : déchirés menu, vingt billets de banque irrémédiablement gâchés par mes retouches maladroites. Les grands seigneurs jettent l'argent par les fenêtres (Léo Malet, Sueur aux tripes)

\section{CORPUS WEB :}

Apprennez à déchirer menu menu vos papiers ;). L'opération recollage sera plus fastidueuse et à force il n'aura peut être plus assez de temps !! [http://forum-juridique.net-iris.fr/ travail/83504-pdg-eboueur.html] (19.1.2015)

pour le reste un super concert samedi soir (grace au « Stephanois ») avec Classic and trouble comme groupe, de la caillette aussi du sauss a en pleuvoir, du tres bon picodon, certainement la crique ou la bombine ! je suis parré pour vous réjouir le gosier en fin de soirée. ça va dechirer тепи, тепи...... [http://www.voxanclubdefrance. com/forum/viewtopic.php?t=12561] (19.1.2015)

après avoir trouvé l'origine du mal, le patient doit l'écrire (ah, les vertus cathartiques de l'écriture !), puis déchirer menu la feuille chargée désormais de toutes les misères (autrefois c'était un bouc qui portait tous les maux) et enterrer les morceaux (le bouc, lui, était chassé dans le désert) [http://www.pseudo-sciences.org/spip. php?article680] (19.1.2015)

REMARQUES : Déchirer menu réfère au fait de mettre quelque chose (souvent du papier) en pièces, en petits morceaux sans se servir d'un instrument tranchant. Menu reste invariable et est modifié par si, ensuite, patiemment. Notons la réduplication menu, menu. Le second exemple du CW, en emploi absolu, renvoie par métaphore à un impact de la musique qui va « déchirer » le public, en jouant sur le sens argotique de déchirer « être génial».

\section{Décider juste}

Juger, prendre une décision juste Intransitif

1694 Mais où sont ceux qui décident juste en leur propre affaire, qui prononcent contre eux-mesmes, et qui veulent bien preferer une condamnation équitable à un gain de 
cause sans appel ? (Recueil de quelques sermons prononcez par monsieur l'abbé de Pezenne)

1736 Si vous le prenez mal, il vous conduira à deux défauts que vous ne sçauriez trop éviter dans vos jugemens, l'entêtement et la prévention. Quand vous avez décidé juste, à la rigueur, vous êtes quitte (Charles-François-Nicolas Le Maître de Claville, Traité du vrai mérite de l'homme)

1784 j'ai vu admirer les défauts de l'acteur, et honnir ses qualités, la sagesse, la finesse, la raison de son jeu senti. Mais, me direz-vous, ce publiq décide juste cependant ! Oui : deux ou trois têtes au-plûs, quelquefois une, qui donnent le branle à cette grosse bête qu'on appelle le publiq (Nicolas Rétif de la Bretonne, La Paysanne pervertie ou Les Dangers de la ville)

1911 Il en sera toujours ainsi quand le commandement supérieur, manquant à lui-même, par insuffisance de vue ou de volonté, voudra se substituer à ses subordonnés, penser et décider pour eux ; il faudrait, pour qu'il pensât droit et décidât juste, qu'il vît par leurs yeux, du point où ils sont, qu'il pût être à la fois partout

(Ferdinand Foch, Des principes de la guerre)

1997 Il contient deux dimensions qui s'entre-détruisent : le savoir pour décider juste et l'ignorance pour permettre aux équipes de travailler en équipe (Bruno Jarrosson, Le savoir, le pouvoir et la formation)

CORpus WeB :

Des Repères pour décider « juste » Dans la désolation, je ne change pas de cap... [http:// www.dioceseauxarmees.catholique.fr/statutaumonier/2-uncategorised/458-des-reperes-pourdecider-juste.html] (19.1.2015)

Bien se connaître pour décider juste - comprendre ses modes de fonctionnement et ses mécanismes de pensée - identifier ses freins et ses croyances [http://maison-equilibres.ch/wpcontent/uploads/2014/12/Decider-vite-et-juste. pdf] (18.5.2016)
Comprendre pour décider juste

En raison de la diversité des origines, des cultures et des croyances des communautés composant la population réunionnaise, celle-ci n'est comparable à aucune autre [http://www. lequotidien.re/opinion/le-courrier-des-lecteurs/ 134772-comprendre-pour-decider-juste.html] (18.5.2016)

REMARques : Décider juste réfère au fait de prendre une décision moralement correcte, le sujet prenant soin de le faire comme il convient, sans erreur. Décider est un verbe transitif/intransitif qui tend à l'emploi intransitif ou absolu dans décider juste. Notons l'emploi de penser droit.

\section{Déclarer bas}

Déclarer à voix basse

Transitif

1635 Ce grand Prince entretient ses langoureuses plaintes,

Promene son esprit dans ses passions saintes,

Et reschauffe tantost ses timides froideurs De l'espoir du retour de ses Ambassadeurs ; Lors qu'un prompt Messager s'en vient à grosse haleine

Luy declarer tout bas le sujet qui le meine (Pierre Le Hayer Du Perron, Les Palmes du juste)

1735 Huascar, prêt d'éclater, se modere pour remplir ses fonctions à la Fête du Soleil. Il declare bas ses intentions à un des complices de sa fureur (Mercure de France)

1787 Quand cette précaution a été prise, nous ordonnons aux curieux de nous déclarer tout bas quel est le mort dont ils veulent que les mânes se presentent aux regards de la personne isolée (Les Historiettes du jour ou Paris tel qu'il est)

1863 Lui que jamais ici l'on ne vit en défaut,

A déclaré tout bas que ces marques récentes

Annonçaient la démarche et les griffes puissantes

De deux grands loups-cerviers et de deux louveteaux (Alfred de Vigny, Les Destinées) 
2011 Ensommeillée, Hermine se redressa. Elle eut un regard rêveur avant de déclarer tout bas :

- En effet, je reste au sanatorium, ce matin, je prendrai un autre train, mais pour rentrer à Chambord (Marie-Bernadette Dupuy, Le Rossignol de Val-Jabert)

CoRpus Web :

Problématique car la laïcité sert ici de prétexte à Marine Le Pen pour ne pas dire tout haut ce que les français déclarent tout bas lorsqu'ils sont interrogés dans le cadre de sondages [http:// www.dreuz.info/2014/04/dans-les-villes-fnmarine-le-pen-supprime-les-menus-halal-descantines] (19.1.2015)

N'oublies pas le frais de douane $(-)+<150$ euros :o ils déclarent bas. J'en ai eu pour $60 €$ pour le captain (-) [http://www.marvelscustoms. net/t19079p90-premium-collectibles-hawkeye-14-scale-statue-comics-wip] (19.1.2015)

REMARQUES : Presque toujours modifié par tout, déclarer (tout) bas se dit du fait de formuler un jugement ou d'énoncer ses idées, ses pensées, ses opinions ou ses sentiments à voix basse, en cachette, ne voulant pas être entendu de tous, par timidité, pudeur, honte ou peur. Bas reste invariable. Notons dans le CW l'emploi de dire haut, l'antonyme de déclarer bas. Le dernier exemple met évidence la productivité de l'emploi adverbial : en emploi absolu, déclarer bas réfère à la déclaration d'un montant inférieur pour, en l'occurrence, économiser sur les frais de douane.

\section{Déclarer court}

Déclarer brièvement, sans rien ajouter, sans plus, sans différencier

Transitif

1858 Enfin, Pline déclare tout court que l'idée d'une existence après le trépas, est une chimère de la simplicité enfantine ou de l'insatiable désir de vivre qui tourmente les mortels (Johann Joseph Ignaz von Döllinger, Paganisme et judaïsme [trad.])

1901 Et je dis que lorsque les radicaux déclarent tout court qu'ils veulent maintenir la propriété individuelle, ou cela ne signifie rien, ou cela signifie qu'ils veulent maintenir la propriété capitaliste (Jean Jaurès, Études socialistes)

1937 Si faute de mots, vous appelez poésie la langue des trois écrivains ci-dessus (Chateaubriand, Bossuet, Claudel), vous tombez instantanément d'accord avec tous les Anglo-Saxo-Germains qui déclarent haut et court... que la poésie française n'existe pas (Goéland, 1 février 1937 / Grundt : 317)

\section{CORPUS Web :}

J'essaye de remplir le formulaire d'aide juridictionnelle, et je ne sais pas si déclarer les revenus de mon copain et voire même si je dois le déclarer tout court ? [http://droit-finances. commentcamarche.net/forum/affich-4016415aide-juridictionnelle] (19.1.2015)

Lors d'un dossier de surendettement de ma part, est-ce que ses ressources sont prises en compte lors du montage du dossier. dois-je déclarer son emploi récent dois-je la déclarer tout court sur le dossier de surendettement [http:// droit-finances.commentcamarche.net/forum/ affich-6281820-ressources-prises-en-comptedossier-de-surendettement] (19.1.2015)

« Vous n’avez pas déposé ces sommes dans le circuit ? On vous déclare court même si vous avez la taille requise, ou alors ils décident que votre tension est haute, donc ne venez pas mourir ici " avis recueilli auprès de quelques candidats au recrutement à Bafoussam [http:// www.cameroun24.net/?pg=actu\&ppg=1\&pp=1 \&id=6196] (19.1.2015)

REMARQues : Déclarer (tout) court se dit du fait de formuler un jugement ou d'énoncer ses idées, ses pensées, ses opinions ou ses sentiments de façon brève, en peu de mots, sans différenciation (ce qui serait cependant nécessaire selon l'auteur). Notons la collocation déclarer haut et court. Court reste invariable et est modifié par tout. La collocation usuelle tout court fonctionne comme adverbe de phrase au sens de 'sans plus' en français moderne. Dans le dernier exemple du CW, court est employé comme prédicat second orienté vers l'objet, en l'occurrence une recrue dont on estime que la taille est trop petite pour le service militaire, en français d'Afrique. 


\section{Déclarer haut}

I. Énoncer (un fait) de manière claire, évidente, avec conviction ; déclarer ouvertement

Transitif

1582 ce Pontife lors caloit ou appelloit le Peuple des champs au Capitole, pour declarer tout haut, combien de jours restoient des $\mathrm{Ca}$ lendes jusques au Nones (Henri LancelotVoisin de La Popelinière, L'Histoire des histoires)

1699 On couroit en foule le signer. Déjà même plusieurs prélats de l'assemblée déclaroient tout haut qu'ils n'avoient jamais prétendu exiger d'autre signature (Jean Racine, Abrégé de l'histoire de Port-Royal)

1713 Si tôt que nous y fûmes je me retirai avec elle dans la chambre qui nous avoit été préparée ; et là les habits qu'elle avoit sur le corps, ne m'empêchérent point d'en faire ma femme. Je le déclarai tout haut ensuite, afin que qui que ce fût n'en pût douter ; et je le fis, parce que j'aprehendois encore quelque accident (Robert Challe, Les Illustres Françoises)

1734 Chaque société forme un public à part : Mais il en est un autre, et c'est le véritable, Le moins nombreux de tous, et le plus redoutable,

Qui sçait ce qui lui plaît, qui sçait ce qu'il lui faut,

Qui, tous les jours ici, le déclare assez haut (Pierre Claude La Chaussée, La Fausse Antipathie)

1823 Aussi, quand la lutte fut finie, et que le directoire triomphant se plut à déclarer tout haut qu'il devait toute son existence à Napoléon, il conserva néanmoins dans le cœur quelques sentiments vagues que Napoléon n'avait embrassé son parti que dans l'espoir de le voir culbuté, et de se mettre à sa place (Emmanuel de Las Cases, Le Mémorial de Sainte-Hélène)

1881 Ce soir, Labiche, après avoir déclaré bien haut qu'il n'avait jamais lu une ligne de Manuel, pas plus que de Sully Prudhomme, a annoncé qu'il voterait pour Manuel (Edmond et Jules de Goncourt, Journal)
1883 Le bourgeois, en les parcourant d'un cerveau brouillé par les affaires, écarquille les yeux, vous traite, tout bas, de « poète », sourit in petto et se désabonne, - en déclarant, tout haut, que vous avez beaucoup de talent ! (Auguste de Villiers de L'Isle-Adam, Contes cruels)

1921 Vincent estimant nécessaire de couper court à cette illusion, déclara bien haut " que celui-là serait fou qui s'imaginerait que la compagnie était celle dont a prophétisé saint Vincent Ferrier » (Henri Bremond, Histoire littéraire du sentiment religieux en France)

1937 Si faute de mots, vous appelez poésie la langue des trois écrivains ci-dessus (Chateaubriand, Bossuet, Claudel), vous tombez instantanément d'accord avec tous les Anglo-Saxo-Germains qui déclarent haut et court... que la poésie française n'existe pas (Goéland, 1 février 1937 / Grundt : 317)

II. se déclarer tout haut contre quelque chose : faire savoir ouvertement qu'on prend parti contre quelque chose

Pronominal

1914 Dès les premières séances, il apparut avec évidence qu'un certain nombre des commissaires, n'osant se déclarer tout haut contre l'opinion générale, utiliseraient tous les moyens obliques pour faire échouer le projet (Maurice Barrès, Mes cahiers)

\section{CORPus Web :}

Après nous avoir récemment donné quelques bonnes infos sur l'histoire de ce Uncharted 4, les développeurs sont revenus sur des problématiques techniques, et déclarent tout haut que la priorité, c'est l'expérience de jeu [http://www. journaldugamer.com/2015/01/15/uncharted-4images-seconde-framerate] (19.1.2015)

Ce n'est pas rare de rencontrer des personnes qui disent : " Moi, j’aime tel musicien ou rien ». Certains en politique, le déclarent tout haut : " c'est lui ou personne " d'autres encore, sans gêne, crient en public : " c'est mon rappeur préféré, je l'adore » et les exemples sont légions [http://notrevoix.mondoblog. org/2014/06/30/119] (19.1.2015) 
Nous retrouvons les mêmes ingrédients, entre drogue et expériences à vivre. Ces jeunes filles déclarent tout haut leur rupture avec un monde qui semble privatiser les populations, une société chère et mensongère [http:// cinematoman.blogspot.co.at/2013_05_01_ archive.html] (19.1.2015)

REMARQUES : Déclarer (tout) haut se dit du fait de formuler un jugement ou d'énoncer ses idées, ses pensées, ses opinions ou ses sentiments à voix haute, ouvertement ou en public (I). Dans son emploi pronominal (II), il désigne le fait de donner son avis, s'expliquer, se prononcer contre quelque chose (ou quelqu'un). Notons la collocation déclarer haut et court. Haut reste invariable, étant presque toujours modifié par assez, bien, tout. Mentionnons également l'emploi de couper court.

\section{Déclarer net}

I. Annoncer clairement et franchement un fait Transitif

1667 ALCESTE. Mais après ce qu'en vous je viens de voir paroître, Je vous déclare net que je ne le suis plus, Et ne veux nulle place en des cœurs corrompus (Molière, Le Misanthrope)

1732 Je le déclarai tout net à ma mère, qui, se sentant elle-même très mortifiée de l'accueil dont le peuple m'avait régalé, ne s'opposa point à un si prompt départ (Alain-René Lesage, Histoire de Gil Blas de Santillane)

1768 Que ne restiez-vous où vous étiez ? Vous étiez si bien! Pourquoi vous charger de payer pour les sottises d'autrui ? Que ne déclariez-vous net à votre père que ce rôle ne vous convenait pas ?... Cet ange est tout à fait goguenard, et le Christ paraît assez convaincu de la justesse de sa remontrance (Denis Diderot, Salon de 1767)

1833 Un médecin lui conseilla l'usage du safran, qui n'eut aucun résultat; alors il la déclara tout net en grossesse. A cette nouvelle, Apolline tomba dans la consternation et le désespoir (Pétrus Borel, Champavert)
1839 Après s'être jeté à ses genoux en amant jaloux et passionné, il lui déclara fort net que son honneur était intéressé à ce qu'elle ne fût pas la dupe du jeune prince (Stendhal, La Chartreuse de Parme)

1882 J'aime mieux décidément avoir une explication avec cette jeune fille et lui déclarer net que son mariage n'est pas remis, mais qu'il est rompu (Henry Becque, Les Corbeaux)

1894 C'était accepté par Injalbert ; mais ce sculpteur, qui a de la conscience, dans ses études sur les faunes, ayant acquis la conviction qu'ils étaient une race poilue, barbue, déclara un jour tout net au glabre cabotin « qu'il n'était pas du tout son affaire comme faune » (Edmond et Jules de Goncourt, Journal)

1936 Eh bien, l'ukase du tsar a été signé avanthier jeudi, dans l'après-midi ; - et cela, malgré le terrible avertissement qu'avait donné l'Allemagne, en déclarant d'avance et tout net que la mobilisation russe signifierait la guerre (Roger Martin du Gard, Les Thibault. L'Été 1914)

1995 Afin que vous mesuriez l'injustice d'une telle accusation, voici quelques exemples de ce que ma femme considère chez moi comme des preuves irréfutables de ma méchanceté :

[...]

- avoir perdu ses illusions et le déclarer net (méchanceté entre toutes impardonnable) (Lydie Salvayre, La Puissance des mouches)

2009 C'est plus que n'en pouvaient supporter naguère ces catéchistes du Nord-Cameroun déclarant tout net que cette page de l'Évangile apportait avec elle la « mort du village » (René Luneau, Jésus, l'homme qui évangélisa Dieu)

2011 Je mentionne au téléphone à ma sœur que je viens de raconter le jour où elle est venue me chercher à Normale sup, après mon absorption excessive de barbituriques. Elle me déclare aussi net qu'elle 
n'est jamais venue me chercher à Normale (Serge Doubrovsky, Un homme de passage)

II. se déclarer tout net pour (ou contre) quelque chose/quelqu'un : faire savoir qu'on prend parti pour (ou contre) quelque chose/quelqu'un Pronominal

$1864 \mathrm{Au}$ reste, vous voyez que dans mon livre je me déclare tout net pour l'admiration en bloc (Victor Hugo, Correspondance)

\section{CoRpus Web :}

Je suis en ce moment, chez mes parents, sur les terres de Mgr d'Ornellas et l'on vient de me mettre sous les yeux le texte étonnant que le prélat a jugé bon de publier sur le site du Diocèse de Rennes, faisant l'apologie de la pièce de Castellucci Sur le concept de visage du Christ et déclarant tout net, sous l'inter-titre : Le débat est ouvert, « ceci n'est pas de la christianophobie » [http:// ab2t.blogspot.co.at/2011/11/leveque-le-ministrele-journaliste-et.html] (19.1.2015)

Qu'elle coure donc porter plainte contre ceux-là - seulement - et qu'elle nous dispense de la légende propagée par un film, déclarant tout net que toute la Creuse ou peu s'en faut a été, pour de jeunes Réunionnais, une sorte de territoire nazi sur lequel tout le monde a su fermer les yeux et que le premier des nazis... est Michel Debré, à l'origine de la prétendue déportation [http:// www.courriers-reunion.fr/Stele-Gillot.html] (19.1.2015)

Ainsi, le représentant des ouvriers comme celui de la paysannerie déclarent tout net leur opinion au nom de l'immense majorité du peuple, mais le gouvernement Kérensky fait le contraire, pour servir les capitalistes! [https://www.mar xists.org/francais/lenin/works/1917/09/ vil19170910i.htm] (19.1.2015)

REMARQues : Déclarer (tout) net (I) réfère au fait de faire connaître un sentiment, une volonté ou une vérité d'une façon manifeste. Dans son emploi pronominal (II), il désigne le fait de donner son avis, s'expliquer, se prononcer pour ou contre quelque chose ou quelqu'un. Net reste invariable et est modifié par aussi, d'avance, fort, tout, un jour.

\section{Décocher droit}

Lancer (un projectile) tout droit avec une arme de trait

Transitif

$\sim 1460$ ilz se mirent a une fenestre. Sy n'y eurent guieres esté, quant Patroclus le bon archier descocha sa saiette sus la dame si droit qu'il lui en percha la gorge et morte l'abaty au prez de Jason, et puis il s'en issy de son embuche moult joyeux. Trop fu troublé Jason quant il vey sa dame ainsy trebuchier morte. Il la cuida relever, mais l'ame lui party du cors (Raoul Lefèvre, L'Histoire de Jason, p. 238, 15)

1596 Mais c'est peu que d'un cœur pour offrir à vos yeux,

Rois de tous les esprits de ceux qui s'en approchent ;

J'en voudroy mille et mille, afin de pouvoir mieux

Recevoir tous les traits que si droit ils décochent (Philippe Desportes, Euvres)

\section{CORPuS WeB :}

quand je suis sur place à l'heure, ma procédure est la suivante :

greffe

buvette (sandwich du matin)

échauffement (court, juste parvenir à l'allonge et à décocher droit)

peloton

arbitre

GO !!! [http://www.webarcherie.com/index. $\mathrm{php} /$ topic/19396-vous-prenez-combien-detemps-le-midi-a-la-pause/page-4] (19.1.2015)

Un des loups s'attaqua alors à ses confrères et, après avoir repris ses esprits, l'archer encocha vite une nouvelle flèche qu'il s'empressa de décocher droit dans un des loups, qui dans sa chute emporta un autre loup à côté du lac gelé [http:// www.skyrim-universe.com/forum/index.php?/ topic/2338-presentez-votre-personnage/page_ st_580] (19.1.2015)

Soudain, sous le regard médusé des dizaines de personnes présentes dans le bar, il prend une flèche, la décoche droit sur moi et s'en va en courant [http://www.wattpad.com/41948739until-i-die-arrow-fan-fiction-arr\%C3\%AAt $\%$ C3\%A9-black-feather/page/2] (22.1.2015) 
REMARQues : Décocher droit désigne l'action de lancer un projectile, de tirer à l'arc en suivant une ligne droite. Droit reste invariable et est modifié par si. Droit tend à former un groupe syntaxique avec la préposition qui le suit : dans, sur. Notons l'emploi absolu dans les deux premiers exemples $\mathrm{du}$ CW. Mentionnons également l'emploi de abattre mort ; trébucher mort.

\section{Décoincer direct}

Décoincer immédiatement, sans hésiter

$\lambda$ redescendre doux

\section{Décoller court}

Décoller sur une courte distance

$\lambda$ atterrir court

\section{Décolleter profond}

Laisser le cou et une grande partie de la gorge ou du dos nu

Transitif

1958 Une robe décolletée profond (Exemple entendu, 18 février 1958 / Grundt : 292)

CORPuS WEB :

Très bien pensée, cette robe ultra sexy possède un lien entre la poitrine permettant de la sublimer et en même temps évitera que la robe s'ouvre malencontreusement. Très courte et décolletée profond, cette robe Dreamgirl présentée peut se fronçer... [http://www.loucaline.fr/Mode-Femi nine/Les-Robes/Robes-Courtes-Sexy/Robe-liber tine-decollete-profond,1,84999.html] (22.1.2015)

Vintage : Robe longue rouge. Décolletée profond dans le dos. Devant perlé et plissé [https:// fr.pinterest.com/urap/robes-longues] (22.1.2015)

Robe de mariée élégante décolletée profonde dos nu en satin et dentelle description détaillée [http://www.chouchourouge.com/robe-demariee-elegante-decolletee-profonde-dos-nu-ensatin-et-dentelle.html] (22.1.2015)

REMARQues : En parlant d'un vêtement, décolleté profond se dit d'une robe ou d'un corsage qui dégage le cou, parfois les épaules ou le dos, dont l'échancrure est plus ou moins profonde, large. Profond tend à l'emploi invariable, mais il s'accorde dans le dernier exemple du CW avec le nom féminin (la robe) sur lequel porte le participe passé du verbe.

\section{Décorer baroque}

Décorer dans le style baroque, parer de

décorations baroques

Transitif

1967 Un grenier décoré très baroque (Robert Siegfried, Sabine ou La Décision)

CORPus WeB :

Une jolie nappe baroque, associée à ces chaises modernes, mais aux formes rétro, voilà une jolie façon de décorer baroque sans l'esprit rococo [http://www.idee-deco-by-helline.fr/ decoration-baroque-conseils-deco-interieure] (22.1.2015)

Cadre en bois médium à décorer baroque avec de la mosaïque [http://www.choozen.fr/tsmosaiques-a-poser mosaiques,3090814.html] (22.1.2015)

Remarques : Décorer baroque désigne le fait d'orner, parer ou agrémenter une pièce d'ameublement, de décors, d'accessoires ou de meubles de style baroque de façon à les embellir. Notons l'emploi absolu dans le CW.

\section{Découper menu}

Découper en petits morceaux

Transitif

1557 La première [= espèce] a les fueilles [sic] fort menu decoupées, estendues sur la terre (Rembert Dodoens, Histoire des plantes)

1584 Racines en laict buré cuits, et peaux decoupé menus, estoit viande à plusieurs (Pedro Cornejo, Histoire des troubles et guerres civiles du Pays-Bas)

1603 Poussière de pièces de marbre ou de cailloux de rivière trés-blancs, et de verre blanc, le tout subtilement sassé, est destrempé dans huile de noix, où sont ad-joustées des fines estoupes de chanvre, découppées menu, et de la graisse crue de bouc ou de chèvre, hachée à petits morcillons (Olivier de Serres, Le Théâtre d'agriculture et mesnage des champs)

1624 Quant à sa preparation, il faut premierement decouper menu et concasser les racines de souchet, de sarrazine, de gentiane, et de cappres, puis les faire infuser dans l'huyle, les exposer au soleil 
(Jean de Renou, Le Grand Dispensaire medicinal)

1811 Elles se préparent en mêlant les substances qui les composent, dans des proportions déterminées. Il faut avoir soin de découper menu sur-tout celles qui sont les plus denses ou les plus actives, afin de les bien disséminer dans le mélange (Julien-Joseph Virey, Traité de pharmacie théorique et pratique)

1945 Quel effondrement quand, par exemple, le vendredi elle reçoit inopinément un contre-ordre de madame Bassinet, la veuve du marbrier, la privant du blanc fromage hebdomadaire, arrosé de crème presque rosée, saupoudré de gros sel, de poivre fin, de ciboulettes et d'échalotes découpées menu menu! (George Chepfer, Portraits, sketches, divers)

1952 Elle avait découpé menu des pages du Larousse, " pour faire des livres de lecture à ses animaux » (Béatrix Beck, Léon Morin, prêtre)

2011 Même si en cadeau, dans Monrovia en ruine, on a offert à ces gamins, des mitraillettes et des machettes pour découper menu ceux qui se présentaient à eux (Ahmed Kalouaz, Je préfère qu’ils me croient mort)

\section{CORPUS WEB :}

Bien élevés on répond alors que nous avons une seule envie que cela se finisse, trouver une excuse n'importe quoi une gastro fulgurante, notre hamster cardiaque qui doit prendre ses médocs sinon il va croiser la grande faucheuse et vu sa taille elle va le découper menu menu en quelques secondes [https://misspivoibulle. wordpress.com/2014/09/page/2] (22.1.2015)

Tout découper menu тепи (oignons, poivrons, œufs, olives...) [http://www.unomafu.fr/ article-argentinaaaaaa-80460117.html] (22.1.2015)

Tout ça pour dire... j’ai acheté un beau filet de saumon, des pétoncles, et des miliards de légumes (si si au moins !). Et surtout : j’aurai le courage de découper menu menu ces ptites bestioles crues! [http://missbonbon95.canalblog. com/archives/2007/10/26/6666170.html] (22.1.2015)

Père Dodudaboum sonne plus comme une marque de petits plats surgelés pour la famille qu'un projet électro skizophrene, et pourtant. Sa recette secrète, jouer nu sous son tablier derrière sa console, à découper menus des beats de violons et de jeux vidéos, puis mixant le tout au robot électrique [http://www.lesinrocks. com/lesinrockslab/news/2011/08/decouvrez-laselection-daout] (22.1.2015)

Remarques : Découper menu est souvent employé dans le contexte culinaire, se disant du fait de réduire, de couper en menus morceaux des ingrédients (aromates ou légumes) avec un instrument tranchant. L'objet peut aussi désigner un morceau de papier. Notons la réduplication mепи тепи qui suggère ou met l'accent sur une découpe particulièrement fine. Dans cet emploi, menu se rapproche sémantiquement de l'adjectif-adverbe fin. Il souligne plutôt le résultat de l'action de trancher ou couper l'aliment que la précision ou la minutie dans le geste. Menu tend à l'invariabilité, mais les exemples de 1582 (s.v. chiqueter) et 1584, extraits de deux éditions de la même œuvre, montrent qu'il ne s'agit pas d'une règle fixe. Ces exemples - avec deux verbes différents mais sémantiquement proches (découper et chiqueter) - semblent cependant confirmer que l'accord se produit plus facilement quand menu vient après le verbe, ce qui renforce la dynamique résultative du verbe. Dans le $\mathrm{CW}$, menu reste invariable dans la plupart des cas, s'accordant toutefois avec l'objet pluriel dans le dernier exemple, ce qui le rapproche des prédicats seconds orientés vers l'objet. VoIR AUSSI : couper fin / menu / petit ; hacher menu

\section{Décrire juste}

Représenter avec justesse et précision

Transitif

1707 Comme il est difficile de déterminer les differentes combinaisons de ces causes, il est pareillement difficile de décrire juste toutes les cataractes mixtes (Antoine Maître-Jan, Traité des maladies de l'œil)

1761 ainsi il faut corriger cet endroit dans la description, où ces derniers vaisseaux ne 
sont pas décrits justes (Joseph-Guichard Duverney, Euvres anatomiques de M. Duverney)

1834 En vous préparant tous les matins par la lecture de vingt pages de Marianne de Marivaux, vous comprendrez les avantages qu'il y a à décrire juste les mouvements du cœur humain (Stendhal, Correspondance)

1989 Tous ces messieurs de la finance que décrivent les romans de J.L.B. se posent la même question : qui est-il ? qui donc les connaît si bien pour les décrire si juste? Cette émulation par la curiosité se répercute jusqu'aux couches du tout petit commerce et n'est pas pour rien dans notre chiffre de vente, croyez-moi ! (Daniel Pennac, La Petite Marchande de prose)

Emploi absolu

1836 Que de choses à dire pour qui aurait la patience de décrire juste! (Stendhal, Vie de Henri Brulard)

1996 Par quel miracle leurs yeux étaient-ils tous bleus, délavés, reptiliens ? Maman décrivait juste : des yeux de fonctionnaires antisémites, faits pour le mépris et l'aplatissement (Boris Schreiber, Un silence d'environ une demi-heure)

\section{CORPuS WeB :}

Je ne mens pas, je décris, je parle en décrivant juste, ne vous inquiétez dans ma description la chose s'invite à avoir une part de chaleur [http://www.penrose.fr/m/article-122075160. html] (22.1.2015)

En disant que tu étais un Batard, je ne t'insultait pas, mais je te décrivait juste donc viens pas me saouler maintenant... [http://astrid-ethaming way.skyrock.com/3178940563-posted-on-201308-09.html] (22.1.2015)

Jésus accorde plus de place à ceux qui reconnaissent leurs erreurs et se tournent vers Dieu, qu'à ceux qui ont tout fait pour être dans les « petits souliers » de Dieu se décrivant justes et purs, par pur orgueil ! [https://fr.answers.yahoo. com/question/index?qid=20110316121022AAM ATG7] (22.1.2015)
REMARQues : Décrire juste désigne le fait de dépeindre, représenter en détails quelqu'un ou quelque chose par écrit ou oralement. Juste reste invariable, sauf dans l'exemple de 1761. Il est modifié par si. Dans le second exemple du CW, juste est pris au sens de 'seulement'. Le dernier exemple du CW représente une lecture orientée vers le complément d'objet : ils se décrivent comme étant justes et purs. Si juste peut être remplacé par justement dans les autres exemples, ou par avec justesse, pour éviter l'ambiguïté, cela n'est pas possible dans ce dernier exemple, où le verbe n'est pas la cible d'attribution.

\section{Déduire bel}

se déduire bel : s'amuser beaucoup

Pronominal

+1200 La pucele bel se deduist Et messire Gavains et tuit Rient et juent sor le table. Mais ço n'est pas de cuer estable Que messire Gavains s'envoise (Raoul de Houdenc, La Vengeance Raguidel [début XIII'], 2447)

1349 Mais la dame premierement Me vit, eins que nuls me veïst, Ne que nuls semblant en feïst, C'est assavoir d'icelle gent Qui conduisoient son corps gent. Lors un escuier appella Et li dist : Vois tu celui la Qui bel se deduit et deporte? (Guillaume de Machaut, Le Jugement dou roy de Navarre, 561

-1400 « Sy me deduiray volentiers avoecq ces dames que tu peus oïr que sy bel se deduisent, mes que tu ne t'en voelles chourouchier » (Ysaÿe le triste [fin XIV ${ }^{\mathrm{e}}$, p. 389)

REMARQUES : Dans l'ancienne langue, se déduire bel désigne le fait de se divertir, de se distraire, le sujet animé passant un moment fort agréable en compagnie d'une ou plusieurs personnes. Beau adopte toujours sa forme neutre bel et est modifié par si. VoIR AUSSI : déporter beau 


\section{Défendre bel}

Défendre bien, avec vigueur, énergie

$\lambda$ assaillir bel

\section{Défendre dur}

Défendre de toutes ses forces, âprement

Pronominal

1925 On l'attaquait ? On le volait ? Et bien, il allait se défendre! et raide, et dur, sans pitié pour le bandit (Maurice Genevoix, Raboliot)

\section{Corpus Web :}

La priorité était de défendre dur face à une équipe très offensive nous n'avons encaissé que 66 points donc c'est une bonne chose ! [http:// www.insidebasketeurope.com/actu/pascaldonnadieu-la-priorite-etait-de-defendre-dur. html] (26.1.2015)

Antoine Mendy défend dur, Tony Dobbins est partout en défense, Mykal Riley est malin. Toute l'équipe défend dur et c'est ce qui nous permet d'être là dans les matches [http://www.lnb.fr/fr/ Accueil/100003/Article/19639/Ferdinand-Pre nom-Dijon-On-ne-va-pas-commencer-a-se-voirtout-beaux] (27.1.2015)

C'est possible. On a d'abord un match à Bourg à gagner. Je crois que nous sommes prêts à défendre durs lors de cette rencontre décisive [http://www.pb86.fr/actualite/basket/2304/ gomez-le-maestro-donne-le-la] (26.1.2015)

Les deux équipes défendent dures : 5 à 4 pour Donetsk, il reste 6'38 dans le premier quart temps [https://www.facebook.com/BCMbasket/ posts/10150386149215787] (26.1.2015)

Pour moi, l'équipe qui nous a causé le plus de soucis est Neuville en Ferrain. Elles sont combattants et défendent dures [http://www. femina-wasquehal-basket.asso.fr/ope/menuprincipal-equipes/menu-seniors/menu-senior2/a-la-decouverte-de/443-a-la-decouverte-de-lanf3-lauriane-zwolinski] (26.1.2015)

REMARQues : Le sujet de défendre dur désigne un animé qui montre la volonté de résister à une attaque physique ou du moins tente de la repousser en y mettant toute son énergie. Notons la collocation se défendre raide et dur. Dans le cas de raide, le sujet fait preuve de vigueur et de rigidité face à son adversaire. Dans le CW, dur reste inva- riable dans le deuxième exemple malgré le sujet féminin, tandis que, dans le troisième, le quatrième et le cinquième exemple, il s'accorde avec le sujet au pluriel ou au féminin, sujets qui réfèrent aux joueurs d'une équipe. Dans ces cas-là, il garde son interprétation d'adverbe de manière, en se rapprochant par nuance stylistique des prédicats seconds orientés vers le sujet. Notons l'emploi absolu dans le CW.

\section{Défendre ferme}

Défendre en opposant une forte résistance $\lambda$ défendre fort

\section{Défendre fort}

I. Défendre violemment, énergiquement Pronominal

1160 La bretesche fist asaillir, Et cil dedenz fort se deffandent Et merveillos estor lor randent (Eneas, 5403)

+1227 Mais cil de toutes pars l'assalent, Mout durement si le travaillent, De grans haces fierent au bort ; Mais cil se desfendent si fort K'il ne pueent dedans entrer (Roman de Wistasce le Moine [ $2^{\mathrm{e}}$ tiers XIII ${ }^{\mathrm{e}}$, après 1227], 2290)

1372 Tantost monta sus son courcier Et s'en ala devers le roy, Et li dist : « Monsigneur, je voy Vostre gent qui se sont retrait Pour la deffense et pour le trait Des Sarrasins qui se deffendent Moult fort, et a bien traire entendent » (Guillaume de Machaut, La Prise d'Alexandrie [(1370-)1372], 2847)

1389 Ilz [= les blaireaux] font une foiz l'an leurs cheaus comme renarz et portent autant comme renarz, et les font dedanz les fosses comme renarz. Quant on les chasce, ilz se deffendent fort et ont leur morsure venimeuse comme renart. Encore se deffendent ilz plus fort que ne fet le renart [variante : encore plus fort se deffendent il] (Gaston Phébus, Livre de chasse, p. 102, 8 et 9) 
1403 Toute la terre conquesta; Grans batailles ot, et gasta La contree et puis s'en ala En Gaule, et tant fu par dela Qu'il l'ot aux Rommains toute acquise ; Et sur les Bretons, par tel guise, Ala, mais fort se deffendirent ; En bataille les desconfirent (Christine de Pisan, Le Livre de la mutacion de fortune, IV, 21979)

1580 Suivant donc cette délibération, l’Amiral avec son armée, ayant passé la Loire à Baugency le 30 décembre, arriva le 2 janvier 1563 devant la ville de Selles en Berry, où s'était retiré grand nombre de moines et de prêtres du pays qui commencèrent, avec les habitants à se défendre fort et ferme contre les soldats gascons et provençaux restés de la bataille, qui les environnèrent de toutes parts (Théodore de Bèze, Histoire ecclésiastique des Églises réformées au royaume de France)

1598 Puis apres il se presenta au Docteur Fauste, dans son poisle un lyon et un dragon qui combattoyent ensemble : et combien que le lyon se defendist fort et ferme, si fust-il toutesfois englouty par le dragon (Pierre-Victor Cayet, L'Histoire prodigieuse du Docteur Fauste)

1627 M. de Suilly nous l'avoit voulu retrancher, mais nous nous deffendismes fort et ferme (Nicolas de Peiresc, Lettres aux frères Dupuy)

Transitif

+1400 Requestes du Palaiz, fust oudit lieu de Marle, et combien que ledit monseigneur le Chancellier eust moult fort defendu la cause de la Court et dudit esleu, toutevoie le Roy lui avoit commendé qu'il sellast la lettre du don par lui fait, et combien que il eust fait tout son effort (Nicolas de Baye, Journal [1400-1417])

1612 Cependant Galathée lisoit les lettres de Celadon, car il estoit fort vray, qu'elle les avoit ostées à Meril, suivant la curiosité ordinaire de ceux qui aiment ; mais elle luy avoit fort deffendu de n'en rien dire, parce qu'elle avoit intention de les rendre, sans qu'il sceust qu'elle les eust veues (Honoré d'Urfé, L’Astrée)

II. se défendre de quelque chose : nier, refuser d'admettre

Pronominal

1824 Pendant que l'on m’interrogeait à la préfecture de police sur mes nom, prénoms, qualités, comme vous avez pu voir dans les gazettes du temps, un homme, se trouvant là sans fonctions apparentes, m’aborda familièrement, me demanda confidemment si je n'étais point l'auteur de certaines brochures ; je m'en défendis fort. Ah ! Monsieur, me dit-il, vous êtes un grand génie, vous êtes inimitable (Paul-Louis Courier, Pamphlets politiques)

\section{CORPUS WEB :}

SIG : il faudra défendre fort à Dijon [http:// www.lalsace.fr/sport/2013/04/20/sig-il-faudradefendre-fort-a-dijon] (27.1.2015)

Coach Todorov n'envisage pas autre chose que la victoire. "Si on arrive à défendre fort sur de longues séquences, on doit passer. On connaît cette équipe, ses points faibles et ses points forts » [http://www.lamontagne.fr/limousin/sports/ actualite/basket/2014/10/11/lus-tulle-correze-ale-couteau-sous-la-gorge_11177850.html] (27.1.2015)

Sérieux t'en a pas marre? Qu'est ce que tu viens me citer encore alors que je suis un des seuls ici à défendre forte ? [http://www.www.csplive. net/viewtopic.php?pid=337099] (27.1.2015)

Sitôt un tir ou une passe ratée, une balle perdue, ils sont déjà dans l'action suivante, prêts à défendre forts et à repartir à l'assaut intelligemment et en équipe, en partageant la balle, pendant que nous, on se lamente encore sur l'action d'avant, et on finit par sortir du match en usant d'actions individuelles trop rapides (une passe - un tir), et surtout en relâchant nos efforts défensifs [http://www.mondial-tour-basket.com/ actualites/bilan_du_sejour_a_porec.html] (27.1.2015)

REMARQues : Le sujet de défendre fort désigne un animé qui montre la volonté de résister à une attaque physique ou de la repousser en y mettant toute sa force, de façon énergique. Notons la col- 
location fort et ferme, qui renforce la fonction d'intensification de fort. Du point de vue sémantique, la motivation par l'idée de force (fort 'avec force') est souvent présente, mais la fonction d'intensification est exclusive dans les exemples de 1612 et 1824. Fort reste généralement invariable. Dans le CW, fort s'accorde avec le sujet dans le troisième et le quatrième exemple, introduisant ainsi une nuance de prédication seconde, mais tout en gardant son interprétation d'adverbe de manière. Notons aussi l'emploi de sérieux comme adverbe de phrase dans le troisième exemple du CW. Fort est modifié par encore plus, moult, si. Notons aussi l'emploi absolu dans les exemples du CW.

\section{Défendre net}

Défendre, interdire formellement, catégoriquement

Transitif

1669 ORGON. Taisez-vous, vous ; parlez à votre écot :

Je vous défends tout net d'oser dire un seul mot (Molière, Le Tartuffe)

1730 POLÉMON. C’est que jamais je ne puis y répondre,

Et que vous vous donnez les airs de me confondre.

Mais, lorsque nous aurons tous deux un entretien,

Je vous défens tout net de raisonner si bien.

Comme pere, je veux paroître le plus sage ;

Et vous l'étes toujours plus que moi, dont

j'enrage (Philippe Destouches, Les Philosophes amoureux)

1738 FRANCALEU. (à Lisette, qu'il ne voit que par derrière)

Lucile, redoublez de fierté pour Dorante, Vous n'êtes pas encore assez indifférente.

Vous souffrez qu'il vous parle; et je défends cela

Tout net ! entendez-vous, ma fille !

(Alexis Piron, La Métromanie)

1889 Lors donc que son frère lui parla de la nécessité du recours en cassation, il répondit en défendant tout net ce recours, suivant lui aussi inutile que fâcheux (Louis de Loménie, Les Mirabeau)
2005 Primitivement, l'aérostat devait être monté par le chevalier de Chevelu, qui était le moteur et le chef naturel de l'entreprise, et le public, dont il est fort aimé, aurait bien désiré le voir suivre son projet ; mais, la tendresse paternelle s'opposa au vœu général et l'amour de la physique n'empêcha point un père alarmé de défendre net à M. son fils de monter cette voiture d'un nouveau genre (Philippe Barthelet, Joseph de Maistre)

Pronominal

2005 Je me défendis tout net de le suivre du regard, bien qu'une atroce curiosité me brûlât le cœur : Qui donc voulait-il ainsi, à toutes forces rencontrer? (Isabelle et MarieHélène Morot-Sir, De lettres en lettres...)

CORPUS WEB :

Et croyez-moi, le Fouta peut décider son retrait et le défendre net. Comme en Ethiopie et au Soudan ou dans d'autres pays, il y aura des morts de tous les côtés et non plus du côté peul seulement mais on finira bien par consacrer le partage de la Guinée [http://www.guineepresse. info/index.php?id=10,12180,0,0,1,0] (26.1.2015)

Hâte de voir, peut être un jour, défiler notre fils sur les champs élysée ! Avec la Marine Nationale ! Hommage à nos militaires qui défendent net représentent notre pays et drapeau français [http://m2.facebook.com/127027683999474/ photos/a.270174389684802.57852.1270276839 $99474 / 701974769838093 /$ ?type=1\&_tn__=E] (26.1.2015)

REMARQues : Défendre net se dit du fait d'empêcher, d'interdire à quelqu'un de faire quelque chose. Net reste invariable et est modifié par tout.

\section{Défendre raide}

Défendre en résistant aux attaques

Pronominal

1925 On l'attaquait ? On le volait ? Et bien, il allait se défendre ! et raide, et dur, sans pitié pour le bandit (Maurice Genevoix, Raboliot)

CORPUS WEB :

Il se peut que j'en oublie ou que je me trompes, mais toujours est-il que, l'infrastructure 
se développe considérablement, on voit quand même les résultats, et Lulu ne laisse jamais attaquer sa guadeloupe gratuitement ni ses guadeloupéens et les défends raide [http://www. volcreole.com/forum/sujet-8387.html] (27.1.2015)

Remarques : Défendre raide désigne le fait de vouloir résister à une attaque physique (ou morale) ou de la repousser, le sujet faisant preuve de vigueur et de fermeté face à son adversaire.

\section{Déguster juste}

Déguster correctement, comme il faut

$\lambda$ boire fin

\section{Demander bas}

I. Demander à voix basse

Transitif

+1365 Mais Courtoisie m’appella,

Disant : «Ta chambre, où tu jerras,

Est là dessus, tu la verras ;

Demande ceens, bas et hault,

Tout plainement ce qu'il te fault »

(Jean Froissart, Poésies [3e tiers XIV']

1559 Et, à l'heure, le plus bas qu'il luy fut possible, luy demanda sy elle estoit aussy contante de luy que luy d'elle (Marguerite d’Angoulême, Heptaméron, p. 139, 118)

1594 Aprés que ledit sieur Archevesque eut fini son epiphoneme en grande emotion de corps et de voix, il demanda permission tout bas à Madame de Montpensier de se retirer pour changer de chemise, parce qu'il s'étoit eschauffé en son harnois (Satyre Ménippée)

1627 Aussi tost le dieu de riviere commença de ronfler comme un pourceau, et Lysis s'en estonnant tira Synope par la manche, et luy demanda tout bas en quel langage c'estoit que parloit ce dieu (Charles Sorel, Le Berger extravagant)

1631 Mais en fin pour ne se point méprendre, elle s'addressa à Thamire, et luy demanda assez bas, si ce berger qui parloit n'estoit pas Hylas, et luy ayant respondu qu'ouy, elle revint vers Daphnide, et s'approchant à son oreille, luy dit : " Madame, vous parlez à Hylas sans le cognoistre »
(Honoré d'Urfé, L’Astrée)

1761 Délia ne se fit point prier. Roxelane parut charmée. Elle demanda tout bas un mouchoir à Soliman : il lui en donna un, sans se douter de son dessein (Jean-François Marmontel, Contes moraux)

1832 Prenant pour fiancée un rêve, une ombre vaine, et fouillant dans le cœur d'une hécatombe humaine, prêtre désespéré, pour y chercher ton dieu. Et que voulais-tu donc? Voilà ce que le monde au bout de trois cents ans demande encor tout bas. Le sphinx aux yeux perçants attend qu'on lui réponde (Alfred de Musset, Namouna)

1869 Et, sans attendre sa réponse, il demanda bas à Hussonnet :

- Comment l'appelez-vous, votre ami ? (Gustave Flaubert, L'Éducation sentimentale)

1928 Comme je savais que M. d'Hennezel jouait du violon, je le tirai par sa jaquette, en lui demandant, très bas :

- Qu'est-ce qu'on joue, dites, monsieur ? (Gyp, Souvenirs d'une petite fille)

1960 Armand, il feinte :

- Vous êtes certaine qu'elle est morte ? il demande bas.

La mère Communal pose la pogne sur le mince avant-bras de la petite vieille.

- Elle est glacée... tenez, rendez-vous compte! (Albert Simonin, Du mouron pour les petits oiseaux)

2011 Mes deux compagnons sont en train de draguer les gonzesses. Elles semblent se prêter de bonne grâce au jeu. Je demande bas à Walter, qui sont-elles. Répond, des étudiantes de droit à la Faculté (Serge Doubrovsky, Un homme de passage)

II. Se demander en silence, en son for intérieur ; hésiter

Pronominal

+1532 GEORGE LE VEAU. Je vous prye, sans longue pose, Vous me conseillez sur ce cas. Tousjours me demande hault et bas Qui je suis et d'où suis venu 
(Farce de George le Veau / Ancien théatre françois [entre 1532 et 1550])

1719 Tandis que notre homme marchande, Hésite sur le choix et tout bas se demande, Lequel vaudra le mieux? (Antoine Houdar de La Motte, Fables)

1794 Sur la foi de mes vers mes amis transportés Cherchaient partout vos pas, vos attraits si vantés,

Vous voyaient, et soudain, dans leur surprise extrême,

Se demandaient tout bas si c'était bien vous-même,

Et, de mes yeux séduits plaignant la trahison,

M'indiquaient l'hellébore, ami de la raison (André Chénier, Élégies)

1851 Il y avait des instants où il voyait Gaspard blanc comme neige, et il voulait aller le chercher ; il y en avait d'autres où ses yeux se dessillaient à demi, et il osait se demander tout bas si sa fille n'avait pas raison (Jules Sandeau, Sacs et parchemins)

1867 Plus d'une fois, quand j'étais dans ma chambre, seul et les portes fermées à double verrou, je me suis demandé tout bas si la femme n'était pas naturellement supérieure à l'homme (René Lefebvre, Paris en Amérique)

1910 Et tandis qu'elles écrivaient, écrivaient, sans que leur regard curieux cessât de détailler furtivement la figure et les gestes de l'idole, Jacqueline et Simone se demandaient tout bas :

- Crois-tu qu'il serait bien, avec une cravate à pois bleus ? (Romain Rolland, Jean-Christophe. Les Amies)

\section{CORPUS WEB :}

Les parents de Juliette ne sont pas à la maison? Mais cet homme, il n'est pas le père de Juliette ? Alors, c'est qui ??? Luc demande bas à Juliette qui est l'homme. « C'est Serge, notre domestique. Tu as vraiment pensé qu'il est mon père? » [http://www.avwernsing.de/contes.html] (27.1.2015)
Je me demande s'ils sont à deux,

Où s’ils ont baissé les bras,

Même si quand on veut on peut,

Je me demande tout bas,

je me demande tout bas,

Comment garder l'amour,

comment faire que ce jour ne ressemble pas aux autres.

Comment tenir l'amour... [http://www. letrasmania.com/letras/letras_de_canciones_ john_mamann_64103_letras_fais_pas_la_ gueule_john_178386_letras_comment_garder_ lamour_1611552.html] (27.1.2015)

Ensuite je me suis demandé tout bas, quel est mon trait particulier? La reponse que je me donnai fut longue oreille...mais pour rien au monde je n'accepterai que cela soit mentionné dans mon passeport... [http://www.affection. org/trait-particulier_102271_HISTOIRE_poemetype] (27.1.2015)

Remarques : Demander bas (I) désigne le fait de faire connaître à quelqu'un, ce qu'on désire obtenir de lui, exprimer un désir, un souhait de manière à en provoquer la réalisation, sans toutefois l'exprimer à haute voix, le sujet ressentant de la pudeur, de la honte ou de la peur. (II) réfère au fait de se poser une question à soi-même, en la gardant pour soi, ou à d'autres personnes, mais en l'exprimant à voix très basse, généralement par manque de certitude ou par peur. Bas reste invariable et est modifié par assez, encore, plus, tout, très. Notons la collocation très usitée tout bas, ainsi que haut et bas / bas et haut.

\section{Demander bel}

Demander gentiment

Transitif

1365 AMIS. Diex vous gart de pesance, sire ! Vous estes, je croy, traveilliez. S'il vous plaist, dire me vueilliez Ou vous alez.

AMILLE. Sire, si bel le demandez Que je respons, ne vous ennuit, Que je pense ains demain la nuit A Paris estre (Miracle de Amis et Amille, 106) 
REMARQUES : En ancien français, demander bel désigne le fait de faire connaitre à quelqu'un ce qu'on désire obtenir de lui, le fait également d'exprimer un désir, un souhait de manière à en provoquer la réalisation, la requête étant formulée avec gentillesse, bonté, galanterie.

\section{Demander cher}

I. Demander, exiger un prix élevé (pour quelque chose)

Emploi absolu

1824 Tout le monde me dit que j'ai tort de chercher de ce côté. D’ailleurs je n'ai rien vu qui pût nous convenir qu'un seul appartement $\mathrm{n}^{\circ} 53$ avant la place Beauveau, dont on demande trop cher (George Sand, Correspondance)

1843 - Au fait, quand il bavarde, vous vous tenez tranquilles... Au moins on n'a pas besoin d'être sur votre dos.

- Oui, reprit le Squelette, mais PiqueVinaigre demande cher pour conter... il veut vingt sous.

- Oui, la bagatelle de vingt sous... et c'est pour rien, s'écria Pique-Vinaigre

(Eugène Sue, Les Mystères de Paris)

1890 et la voilà à me conter les canailleries de Derenbourg, qui avait voulu faire racheter à Porel un congé de Dumény, après lui avoir écrit une lettre, où il le poussait à demander très cher en lui insinuant qu'ils partageraient, - canaillerie qui lui avait valu d'être traité de filou par Porel et par Sardou (Edmond et Jules de Goncourt, Journal)

1932 Parions que le musicien avait demandé moins cher que notre confrère. Nous avons dit que les femmes avaient recours, pour la grande toilette, aux faux cheveux (Stéphane, L'Art de la coiffure féminine)

1955 Il fera ça pour vous rendre service.

- Oui, je vous remercie. Mais j'ai mon billet de retour qui est encore valable, ça m'ennuie de le perdre. - Ceux-ci ne vous demanderont pas bien cher, soyez tranquille, et peut-être que la compagnie vous remboursera (Alain Robbe-Grillet, Le Voyeur)
1995 au début de l'hiver, un pastelliste ambulant, qui allait avec sa boîte de château en château, s'était arrêté à La Commanderie pour offrir ses services. Il ne demandait pas cher : le quart d'un " toîton » de meule. Bien qu'à court d'argent, Madame de Breyves n’avait pu résister au plaisir d'immortaliser son fils avant qu'il grandît (Françoise Chandernagor, L'Enfant des Lumières)

2004 Ce qui me fait hésiter, pour le cheval de Fernand, c'est plutôt le prix. Gilles Chapeyroux risque d'en demander cher (Bernadette Puijalon, Un parfum de gentiane)

II. ne pas demander cher: se contenter de peu Emploi absolu

1975 Il était assis devant sa tasse de café, il avait posé sa main sur le livre de Victor Hugo et il paraissait heureux parce que c'était un homme qui ne demandait pas cher.

- Mon petit Mohammed, je ne pourrais pas épouser une Juive, même si j'étais encore capable de faire une chose pareille (Romain Gary, La Vie devant soi)

\section{CORPUS Web :}

Les hôpitaux sont inaccessibles, les médicaments coutent cher, les analyses médicales coutent cher, les radios et scanners coutent cher, les médecins et spécialistes demandent cher. Qu'est ce qui reste ? les plantes qui ne coutent pas cher, et on est trop nombreux à les utiliser [http://www.seneweb.com/news/commentaire/ de-nombreuses-plantes-medicinales-risquentde-disp_n_104607_c_2803845.html] (27.1.2015)

on parle de trou a la secu mais la sante bucco dentaire et sa prevention eviterais bien $d$ autres pathologies donc d autres soins qui a la base sont causer par ses problemes les dentistes sont de moins en moins competents demandent cher et il fournissent des matieres appareils dont on ne connait pas l origine DANGER [http://jesigne. fr/non-aux-soins-dentaires-trop-chers] (27.1.2015)

J'ai pas mal d'amis qui ont fait le trajet Bangkok - Siem Reap en mini van/bus, trajet arrangé et proposé par des logements à Bangkok, malheureusement ceux ci étaient des plus pénibles car ils ont changé plusieurs fois de véhi- 
cules, attendus que ceux ci se remplissent de touristes, entassés dans e mini van et pour terminer ces compagnies de mini vans vous déposent à Siem Reap dans un coin perdu près de l'aéroport de Siem Reap, où il n'y a rien du tout mis à part des chauffeurs de tuktuks qui vous demandent chers ! pour rejoindre le centre [http://www.routard. com/forum_message/3052873/2/aux_habitues_ du_passage_poipet_siem_reap.htm] (27.1.2015)

Moi j'habite Bailleul je sais pas si tu connais (à 10km d'Armentières) et je me marie le 26 août 2006. Le problème où j'habite c'est que la ville ne veut pas louer les salles communales aux particuliers avant le mois de décembre (les associations passent avant) et les particuliers demandent chers. Essayes les salles communales des petites villes autour sinon si tu veux je peux me renseigner aurpès de mon beau père, il habite marcq en baroeul ????? [http://forum.aufeminin. com/forum/mariage1/_f151118_mariage1-Lesfilles-du-nord.html] (27.1.2015)

Remarques : Demander cher (I) se dit du fait d'indiquer la somme que l'on veut obtenir contre un objet ou un service, celle-ci étant trop haute, démesurée pour le client. En (II), à la forme négative, il réfère à quelqu'un de modeste, se contentant de peu sur le plan financier. Cher tend à être invariable et est modifié par bien, moins, très, trop, mais il s'accorde dans les derniers exemples $\mathrm{du}$ CW, tout en gardant sa fonction de modifieur du verbe.

\section{Demander fort}

\section{Réclamer avec véhémence}

Transitif

+1389 a Item, confessa que, un an avoit ou environ, il mal print et embla, ès estables dudit evesque, trois paires d'esperons neufs qui estoient penduz en ycelle estable, et yceulx vendi aus esperonniers de Paris, ne scet à qui, vii s. par. ; et dit que lors on les demanderoit fort (Registre criminel du Châtelet de Paris [1389-1392])

+1400 Jacques fut quis en maint païs ; tant que messire Enguerran a Rodes arriva et fort le demanda, mais on ne savoit qui estoit Jacques de Voisines (Nouvelles françaises du $X V^{e}$ siècle, p. 7)

\section{Désirer, exiger fortement}

Transitif

+1389b Perrin Houssaut, prisonnier cy-dessus escript, juré et examiné l'an et jour dessus diz, par serement, de dire verité sur les accusacions dessus dites, dit et afferme par serement qu'il est demourant en icelle ville de Rungy, en l'ostel Jehan du Pressouir, et que au temps et heure du lundi de Penthecouste, que l'en dit que iceulx compaignons prisonniers dessus nommez furent en icelle ville de Rungy, il estoit present quant ilz vindrent en icelle ville de Rungy, environ heure de vespres, et vit et oy que iceulx compaignons demandoient moult fort à avoir icelle fillete (Registre criminel du Châtelet de Paris [1389-1392])

1559 Au demourant, Monseigneur, me semble qu'il eust esté bon que les Gentilshommes qui sont de la retenue de ceste ville, y fussent venus servir ; la Justice et les habitans le demandent fort (Hyacinthe Morice, Mémoires pour servir de preuves à l'histoire ecclésiastique et civile de Bretagne, [lettre de 1559])

1564 Ne demandent aussi grand solage : parquoy, sera bon les semer soubs les treilles : sur tout le persil demande fort estre arrousé, qu'ainsi ne soit quand il est semé ou planté pres de quelque fontaine ou ruisseau, il croist fort beau et en grande quantité (Charles Estienne, L’Agriculture et maison rustique)

1672 On dit qu'il demande fort à revenir à Paris, mais qu'il est si foible et si abattu, que l'on ne sait comment l'y ramener. Peu de gens le voient ; il n'y a guère que le roi, et peu de ses officiers ; le prince de Condé ne le voit point (Gui Patin, Lettres)

\section{Demander à voix haute}

Transitif

1393 Les mariez firent aprez leurs rapports, l'un aprez l'autre. Le premier dit qu'il fist avant couchier, secretement, le commandement a sa femme, qui lui demanda moult fort a quoy c'estoit bon et que ce vouldroit ( $L e$ Menagier de Paris, p. 85, 21) 
1961 Je me réveillai en entendant la maîtresse qui demandait, plus fort, en nous regardant d'un air sévère :

- Qu'est-ce que Dieu ? (Christiane Rochefort, Les Petits Enfants du siècle)

2005 En tout cas, j'ai pas dû le demander fort. Si j'avais su... (soupir) Les gens sont tellement ingrats avec nous. Dans le temps, on nous craignait un peu, on n'osait pas nous vexer. C'est fini ça. Ils n’ont plus foi en rien. Vous leur demandez s'ils croient en Dieu, bon bah, s'ils ont un peu de jugeote, ils vous répondront non, hein, comme tout le monde (Thomas C. Durand, Mont de Dieux)

IV. S'enquérir avec grand intérêt ou avec insistance

Transitif

1675 Monsieur le duc me demanda fort de vos nouvelles l'autre jour, et me pria de vous faire beaucoup d'amitiés, M. et Mme de Noailles, Mmes de Leuville et d'Effiat, les Ravay, les Beuvron, qui vous diraije encore ? (Mme de Sévigné, Correspondance)

1676 Pour cette cause, Monsieur, ce Roy et autres Seigneurs ses Ministres me demandent fort, s'il est vray que l'accord de l'Empereur soit fait avec le Turc (Lettres et memoires d'Estat)

V. Demander quelque chose de fort

Transitif

1746 Dose : maladies qui la demandent forte, celles qui la demandent plus foible

(François Alexandre Pierre de Garsault, Le Nouveau Parfait Maréchal)

CORpus Web :

Oui mais je fait plutot des fetes pour les jeunes, et ils demandent fort même si cela couvre déjà suffisament la piste de danse. $=\backslash[$ http://fr. audiofanzine.com/sono/forums/t.392425, changement-d-enceintes,p.2.html] (27.1.2015)

REMARQues : Demander fort (I) se dit du fait de prier quelqu'un de venir, de le faire chercher, le sujet éprouvant un grand besoin de voir la personne réclamée. En (II), suivi de la préposition à, il réfère à un fort désir, à un souhait impatient. En (III), il désigne le fait de poser une question en élevant fortement la voix ; moult, plus est intercalé entre le verbe et l'adjectif-adverbe, qualifiant le degré d'intensité de la voix. En (IV), il renvoie au fait de s'informer auprès de quelqu'un, de lui poser beaucoup de questions au sujet de quelque chose ou de quelqu'un. (V) est une prédication seconde où fort, fléchi, réfère au complément d'objet : requérir une forte ou faible dose de médicament. Fort reste invariable. Notons l'emploi de croître beau.

\section{Demander gros}

Demander une grosse somme

Emploi absolu

1709 On dit que le traité de M. de Savoie avec l'empereur est à renouveler, comme les gazettes l'ont imprimé, mais qu'il demande gros (Journal du marquis de Dangeau)

1865 En même temps, plus lui arrive des commandes plus il élève le prix de ses ouvrages ; et plus il demande gros plus on lui demande de tableaux (L’Artiste)

1913 C'est vraiment demander gros à une Compagnie qui, ainsi que ses congénères, a eu, pendant bien longtemps, les plus sérieuses difficultés à payer de médiocres dividendes (Revue politique et parlementaire)

1998 La vue des billets alignés dans le coffre attire l'appétit et on n'hésite pas à demander gros (Guédouma Samaké, Le Chemin de l'honneur)

\section{Demander haut}

I. Demander à haute voix

Transitif

+1365 Mais Courtoisie m’appella, Disant : « Ta chambre, où tu jerras, Est là dessus, tu la verras ; Demande ceens, bas et hault, Tout plainement ce qu'il te fault » (Jean Froissart, Poésies [3 $3^{\mathrm{e}}$ tiers XIV ${ }^{\mathrm{e}}$ )

+1532 GEORGE LE VEAU. Je vous prye, sans longue pose, Vous me conseillez sur ce cas. 
Tousjours me demande hault et bas

Qui je suis et d'où suis venu

(Farce de George le Veau / Ancien théatre françois [entre 1532 et 1550])

1610 L'AUTRE. Sur l'aprés-disnée, on le pria de fiancer une belle fille ; ainsi qu'il estoit aprés, et que desjà il tenoit sa main, il se souvint de son valet et de son advertissement ; parquoy, de peur de faillir, il demanda tout haut : " Luy en a-t-on rien fait ? » (Béroalde de Verville, Le Moyen de parvenir)

1627 Il se delibera de l'interroger pour se divertir, et luy demanda fort haut par trois ou quatre fois si elle estoit là, et comment elle se portoit, mais elle n'avoit garde de parler, car Anselme n'y estoit pas pour respondre au lieu d'elle (Charles Sorel, $L e$ Berger extravagant)

1713 Laprès-dînée il alla courre le cerf avec ses chiens. Au retour de la chasse, M. Voisin, qui étoit demeuré hier à Versailles, vint dans le temps qu'il se débottoit ; le roi lui demanda tout haut s'il n'avoit point de nouvelles de Landau, il dit au roi qu'il n'en avoit que du 20, qui étoient venues par l'ordinaire (Philippe de Dangeau, Journal)

1778 Il vit tous ses péchés lavés d'un petit mot de pénitence, et reçut ce que vous savez avec beaucoup de bienséance. Il fit même un très-beau sermon, qui satisfit tout l'auditoire. Tout haut il demanda pardon d'avoir eu trop de vaine gloire (Voltaire, Épîtres)

1832 Ces pauvres hommes! S'écrie au surplus en terminant la mère Susanne, qu'ils cessent donc de se montrer si récalcitrans, et se hâtent de nous octroyer notre affranchissement définitif ; autrement nous allons le leur demander si haut et d'une voix si étourdissante, nous allons tant crier, si nous ne faisons mieux, qu'ils seront bien contraints de nous l'accorder (Alfred de Musset / Revue des deux mondes)

1845 - Veux-tu être à Châteaubrun demain soir?
- Oui, Monsieur. Prenez des précautions pour ne pas vous faire suivre, et ne me demandez pas trop haut à la porte. Allons, grâce à vous, j'ai encore les étoiles sur la tête, et je n'en suis pas mécontent.

Il partit comme un trait (George Sand, Le Péché de Monsieur Antoine)

1862 C'était un bourdonnement confus de voix qui chuchotaient. Quelqu'un demanda assez haut :

- A-t-on fait chercher un médecin?

- Il vient.

- Et le prêtre?

- Il faudrait de la lumière!

On entendit courir dans la rue

(Paul Reider, Mademoiselle Vallantin)

1869 Et la nuit s'avançant, la douleur désespérée de ses supplications, le cri de cette grâce qu'elle demandait toujours plus haut, finissaient par réveiller Honorine qui crut un moment quelqu'un entré chez sa maîtresse (Edmond et Jules de Goncourt, Madame Gervaisais)

1886 Mais déjà l'entrepreneur s'était planté sur ses courtes jambes, écarquillant les yeux, lui demandant très haut, de sa grosse voix rauque :

- Dites donc, quel est le sabot qui a fichu ça ? (Émile Zola, L’Euvre)

1900 La rousse, décidément devenue son esclave, n'y tient plus et va la trouver en demandant très haut : "Mademoiselle Lanthenay, vous n'avez pas chez vous le registre des présences? » Ça y est, elle est partie ; elles jacassent tout bas (Colette, Claudine à l'école)

1929 - Que vous êtes drôle ! fit-elle avec un rire qu'elle étouffa. J'aurais cru que ça vous faisait plaisir de me voir.

Le bruit de l'eau couvrait presque ces paroles prononcées à mi-voix. Elle demanda plus haut :

- Vous n'avez rien à me dire?

(Julien Green, Léviathan)

1968 Monseigneur trouva cette vue excessive. Le visage apoplectique du docteur s'en- 
flamma, et il demanda fort haut pourquoi on l'avait dérangé pour donner son avis sur des erreurs en matière de mœurs et de doctrine qui n'eussent pas fait hésiter un instant un juge de village (Marguerite Yourcenar, L'Euvre au noir)

1986 On fit sortir les enfants, qui avaient tout compris. Du haut de ses dix ou douze ans, Jessica, les yeux brillants, demandait très haut si elle pouvait venir avec nous et me murmurait à l'oreille qu'elle savait des tas de choses (Jean d'Ormesson, Tous les hommes sont fous)

II. Se demander à voix haute, ouvertement Pronominal

1848 Bref, de détours en détours, pied à pied, pas à pas, il en arriva tout doucement à ses fins, c'est-à-dire à se demander tout haut, sous forme de réflexion, si, par ces mauvais jours, une alliance avec les Stamply n'offrirait pas aux La Seiglière plus d'avantage et de sécurité qu'une alliance avec les Vaubert (Jules Sandeau, Mademoiselle de la Seiglière)

1919 Le vieux ne répondait pas. Il avait une barbe blanche, et les copains qui le dévisageaient se demandaient tout haut ce qu'il venait faire là.

- Ce qu'il vient faire ? nous expliquait Lambert, il vient prendre ma place, tout bonnement

(Roland Dorgelès, Les Croix de bois)

1993 Et une bleue, le soir, quand il commence à pleurnicher, à se rencogner dans son fauteuil, à errer sans but, les bras ballants dans l'appartement, à se demander tout haut si la vie a un sens en oubliant de s'occuper des biberons. Une pilule rose, on atténue ! Une pilule bleue, on remonte ! Très bon dosage suédois : Homo reconciliatus... (Philippe Sollers, Le Secret)

2008 Yacine se demandait tout haut si l'on disait baleinon ou baleineau, Nedra contemplait la flamme d'une bougie et Charles contemplait Nedra (Anna Gavalda, La Consolante)

\section{CORPuS WeB :}

A nous de demander haut et fort ce changement, car il est à la fois réaliste (v. le site de negawatt.org), responsable et apaisant. C'est un changement profond à entreprendre vite et en protégeant les plus démunis [http://www. alternatives-economiques.fr/il-faut-changer-demodele-_fr_art_1083_53730.html] (27.1.2015)

Il est là, toujours prêt à convoquer la presse pour demander haut et fort que justice soit faite. Le tueur a l'air d'un notable de province [http:// forum.aufeminin.com/forum/enfants6/_f 3595 enfants6-Erreur-medicale-qui-a-eu-le-cas-etcomment-faire.html] (27.1.2015)

Pour maintenir l'intégrité des professions d'ingénieurs et par respect pour la Science ellemême, les ingénieurs et les scientifiques du monde entier doivent s'exprimer et demander haut et fort une nouvelle étude validée par un comité de lecture, qui soit transparente et ouverte, portant sur l'effondrement des Tours Jumelles du WTC, et qui utilise l'ensemble des éléments factuels à disposition [http://www.reopen911. info/News/2014/10/22/les-trucages-du-nist-danslaffaire-du-11-septembre-etales-publiquement] (27.1.2015)

REMARQues : Demander haut (I) réfère au fait d'exprimer un désir, un souhait à voix haute et forte de manière à en provoquer la réalisation. (II) exprime le fait de se poser une question à soimême, d'exprimer un doute à haute voix, ouvertement. Notons les collocations haut et bas, haut et fort. Dans le CW, demander est employé au sens de 'exiger'. On constate donc un contraste assez fort avec l'emploi comme verbum dicendi dans les textes littéraires. Haut reste invariable et est modifié par assez, fort, plus, tout, très, trop, si. Notons l'emploi de jacasser tout bas.

\section{Demander long}

en demander long (à quelqu'un)

\section{Exiger, réclamer beaucoup \\ Intransitif}

1849 Mais ceux qui n'ont rien à eux n'en demandent pas si long au bon Dieu, et ils s'accommodent de la première pierre venue pour poser leur tête (George Sand, La Petite Fadette) 
II. Poser une question qui demande une longue explication ou à laquelle on ne peut pas répondre

Intransitif

1850 - C'est la faute aux riches.

- La faute aux riches ! comment donc ça ?

- Tu m'en demandes bien long aujourd'hui ; je te dirai ça plus tard (George Sand, François le Champi)

1874 - Alors... vous m'aimez ?

- Vous m'en demandez trop long, répondit-elle avec un air de tête qui me rendit fou

(Arthur de Gobineau, Les Pléiades)

1934 - Une chose m'étonne, monsieur Beausoleil, dans votre récit. Comment se fait-il que les soldats aient eu des cartouches? - Vous m'en demandez trop long, mon bon monsieur (Gabriel Chevallier, Clochemerle)

\section{Demander net}

Demander quelque chose sans détours, sans ambages, sans gêne

Transitif

1641 L'amour qu'il portoit à la saincte Vierge le poussa à de grands desirs de la voir durant cét exil : il fut bien si assidu et pressant en ce sien desir, demandant tout net a la saincte Vierge cette faveur de la voir en sa beauté (Paul de Barry, L’Année saincte)

1828 L'une des douairières alla jusqu'à demander tout net à la moderne Cléopâtre, dans quelle ville de France ou d'Italie avait été conclu son mariage avec le général Moreau, leur compatriote (Charles Louis de Sevelinges, La Contemporaine en miniature)

1882 Les bras de la marquise se tendirent vers le ciel, la baronne se laissa tomber avec abattement dans un fauteuil, et resta dix minutes sans parler. Octave demanda tout net à sa sœur si elle devenait folle Philippe ne fit pas connaître sa manière de voir (Georges Ohnet, Le Maître de forges)

1906 Puis sur une réponse favorable, se tournant vers la Cordouane, il lui demanda tout net qu'ils mourussent ensemble, car il ne pouvait vivre sans elle (Maurice Barrès, Mes cahiers)

1938 Il a dit aussi : « Vous savez, Sartre n'est pas un type à vous prendre les mains et à vous embrasser : il vous demandera tout net de coucher avec lui. Est-il amoureux de vous ? " (Jean-Paul Sartre, Lettres au Castor et à quelques autres)

CORPUS WeB :

Yop, j'ai 15 ans, et y'a 2 mois, j'avais jamais eu de copine (comme 99\% du 15-18) et une fille m'a demander net mon num en septembre (j'avais fais un topic sur elle) là après avoir fais mes premieres baisés sur elle (elle en à 14 ans) elle veut $\mathrm{Z}+<\mathrm{V}$ [= zizi et vagin] elle me la clairement dit et demain elle vient chez moi ;) je fais comment pour aborder ça ? [http://www.jeuxvideo.com/ forums/1-50-151794568-1-0-1-0-j-ai-changer-net. $\mathrm{htm}](28.1 .2015)$

Je vais garder un bébé au domicile des parents, 40h semaine ! lundi, mardi, jeudi, vendredi de $8 \mathrm{~h}$ a $18 \mathrm{~h}$ combien puis-je demander net par mois ? [http://droit-finances.comment camarche.net/forum/affich-5721402-combiendemander-pour-garder-un-bebe] (28.1.2015)

J'aimerais savoir combien je pourrais $d e$ mander net de l'heure pour un contrat de 40 à 45 heures par semaine sur 37 semaines ? [http:// www.forums.assistante-maternelle.org/topic/ 74438-tarif] (28.1.2015)

REMARques : Demander net désigne le fait de faire connaître à quelqu'un ce qu'on désire obtenir de lui ; il renvoie au fait d'exprimer un désir, un souhait de manière à en provoquer la réalisation, la requête étant formulée d'une manière claire, sans ambiguïté, ni équivoque. Net reste invariable et est généralement modifié par l'adverbe d'intensité tout qui vient en renforcer le sémantisme. Les deux derniers exemples du CW y ajoutent l'emploi au sens de net d'impôts et de charges où net s'oppose à brut.

\section{Demander sec}

Demander sèchement, froidement

Transitif

1958 Ce jour-là le dénommé Maurice Schumann se pointe au Quai d'Orsay, tenant L'Express sous le bras et avisant l'huissier, lui demande aussi sec : 
- Est-ce que le roi des cons est là ? (Canard enchaîné, 7 mai 1958 / Grundt : 359)

2008 Cette fois j'étais allé demander aussi sec à tout mon voisinage s'il n'y avait pas un problème de connection [sic] aujourd'hui (Jean Pierre Ceton, Le Pont d'Algeciras)

Corpus Web :

En couenne, sortir une voie signifie partir du bas, et clipper le relais sans demander sec. Ca veut dire quoi sortir une grande voie ? Est ce qu'il faut sortir chaque segment sans demander sec ? (ca me parait impossible) [http://www.camptocamp. org/forums/viewtopic.php?id=245363] (28.1.2015)

bf42 > C'est le moment de te jeter à l'eau et de lui demander sec. (-) [http://www.jeuxvideo. com/forums/1-50-71984907-4-0-1-0-all-je-reglevos-problemes-d-amour.htm] (28.1.2015)

Inhabitués à faire fonctionner leur raison, ils préfèrent esquiver toute joute ruinant leurs folles superstitions. Et évidemment, ils demandent aussi sec le recours à la censure! [http:// www.forumfr.com/sujet77391-post490-peut-onencore-critiquer-l-islam.html] (28.1.2015)

$\mathrm{Si}$ je prends ta question au pied de la lettre, ce que tu veux capter c'est comment on fait pour se pointer fine fleur avec sa teub et sa cravate devant son boss et lui demander sec une augment' [http://econsultantpointcom.com/ index.php?2006/07/19/146-salaire] (28.1.2015)

REMARques : Demander sec désigne le fait de faire connaître à quelqu'un ce qu'on désire obtenir de lui, sans ambages ; il renvoie au fait d'exprimer un désir, un souhait de manière à en provoquer la réalisation, le sujet s'exprimant rapidement, froidement, avec dureté, sans amabilité. Dans le premier exemple du CW, sec est une interjection employée, dans le langage de l'alpinisme par un grimpeur, demandant à celui qui l'assure, de réduire la longueur de la corde (s'oppose à mou). Dans les deux derniers exemples du CW, demander actualise le sens de 'exiger'. Sec reste invariable et est modifié par aussi.

\section{Demander soef (suave)}

Demander d'une manière douce, tranquillement

Transitif

1100 A icel colp l'ad Rollant reguardet,
Si li demandet dulcement e suef : «Sire cumpain, faites le vos de gred? Ja est ço Rollant, ki tant vos soelt amer ! Par nule guise ne m'avez desfiet ! » (Chanson de Roland, 1999)

1988 Le président R..., connu au Palais pour les tours sadiques qu'il se plaisait à jouer aux avocats, se cale dans son fauteuil : « Vous avez terminé, Maître B... ? » demande-t-il, suave. L'avocat se rassoit, satisfait : " J'ai terminé, monsieur le Président » (Gisèle Halimi, Le Lait de l'oranger)

2011 Les blonds ne doivent pas rougir : on croit qu'ils ont attrapé un coup de soleil. Elle avança de quelques pas puis demanda, suave :

- Pourquoi entreprends-tu ça ? (EricEmmanuel Schmitt, La Femme au miroir)

\section{CORPuS WeB :}

La même garce demandait suave à une autre des nouvelles de son mari alors qu'elle savait que le mari en question s'était fait la malle avec une autre... [http://forum.orange.fr/messages/indexpage-2/100207/ecrivez-en-ligne-l-homme-quivoulait-se-faire-hair.html] (28.1.2015)

J'y mis pourtant fin, demandant, suave :«Quelle surprise? Tu fais bien des mystères pour attiser la curiosité, c'est mal de me faire languir ainsi ! » [http://miradelphia.forumpro.fr/t14069quelques-mots-echanges-avant-de-partir-roxane] (28.1.2015)

REMARQues : Dans l'ancienne langue, demander soef désignait le fait de faire connaître à quelqu'un ce qu'on désire obtenir de lui calmement, doucement, voire avec précaution et renvoie au fait d'exprimer un désir, un souhait de manière à en provoquer la réalisation. L'adjectif-adverbe réapparaît dans cette même interprétation au $\mathrm{xx}^{\mathrm{e}}$ siècle, mais avec une connotation plutôt ironique, permettant également une analyse de prédicat second orienté vers le sujet, éventuellement détaché par une virgule. 


\section{Démarrer sec}

Démarrer, mettre brusquement en mouvement Intransitif

1963 Démarrant sec, dans un tintamarre d'aluminium, le camion attaqua les lacets, vira onze fois au plus court et ne fit qu'une bouchée du dernier raidillon (Hervé Bazin, Bouc émissaire)

1983 Il mit la main sur son cœur. La bande recula. Il éclata de rire, mit le contact et la bagnole démarra sec, crissant de tous ses pneus (Mehdi Charef, Le Thé au harem d'Archi Ahmed)

1984 - Gabin est drôlement plus baraqué, dit-il. Celui-là a l'air d'un sale youpin, comme dit Polo.

- D’un quoi ? dit Victoire.

- Au plaisir quand même ! dit Raymond en démarrant sec, debout sur les pédales, le mollet déjà noueux, comme un livreur chevronné (Bertrand Poirot-Delpech, L'Été 36)

2008 La baleinière est une embarcation longue et fine qui ressemble à une pirogue. «On y voyait des choses extraordinaires. Les bœufs étaient débarqués attachés par une patte. Si une voiture était livrée, on couplait deux baleinières. À l'approche de la plage, le conducteur devait enclencher la première et attendre un creux de vague pour démarrer sec... » (Eddy Przybylski, Brel, la valse à mille rêves)

Transitif

1984 C'est plein de monde qui veulent lyncher le brigadier Poilala, biscotte cézigue, en voyant débouler l'ancien échineur de bidets coursé par Lurette, a eu la belle géniale idée de démarrer sec son fourgon et de catapulter le fuyard (San-Antonio, Les Deux Oreilles et la queue)

\section{CORPus WeB :}

En fait, le mazout, c'est bien en côte en 5 ème, et à la caisse de la station service, mais si tu veux démarrer sec et pousser tes rapports, laisse tombé.... ça vaut pas une essence [http://www. yaronet.com/posts.php?s=78561\&p=3] (28.1.2015)
Accrochez vos ceintures car ça va démarrer sec avec Fast \& Furious : Showdown ! Pilotez de bons gros bolides ou mettez vous du côté passager pour tirer sur vos ennemis, en solo ou en coopération ! [http://www.gamoniac.fr/jeu-fastfurious-showdown-ps3-gid-1646.html] (28.1.2015)

Perso je vais tenter Trintignant sur arte et ça a intérêt à démarrer sec je vous le dis ! [http:// forum.psychologies.com/psychologiescom/ rencontres-et-seduction/demande-olivesujet_4094_4134.htm] (28.1.2015)

REMARques : Démarrer sec réfère au fait de démarrer une mécanique (moteur d'un véhicule, pédale d'un vélo) ou une action directement, sans préliminaire, de manière brusque (deux derniers exemples du CW). Sec reste invariable. VoIR AUSSI : filer / relayer sec

\section{Demeurer coi}

I. Rester silencieux sans bouger, rester tranquille

Intransitif

+1200 D’Abevile vint a Paris ; Ilueques demora tout qoi, Et si fist hommage le roi Et fu ses hom et ses borgois (La Housse partie [XIII $]$, 35)

+1313 Or me couuient demourer coi En cest lieu, si ne sai de quoi Ie puisse .ij. mois entiers viure, Ensi sui menes pour la wiure, Et le sierpent qui m'a trahi, Bien croi qu'elle ait .j. autre ami, Qu'elle a le cuer felon et fier (Jean de Condé, Poèmes [1313-1337], 805)

-1334 Mes maintenant, quant il sara

Que tués est li emperere, Du tournoy se retrest arrere Et s'en va con tous adolés. Le tournoy est quois demorés (Le Romans de la dame a la lycorne [1 ${ }^{\mathrm{er}}$ tiers XIV $]$, 3605)

1580 Quoy voyans et n'ayant lors pas un seul de nous harquebuzes ni pistoles, ains seulement nos espées, et à la maniere des sauvages chacun l'arc et les flesches en la main (armes qui ne nous pouvoyent pas beaucoup servir contre ce furieux animal 
si bien armé), craignans neantmoins si nous nous enfuiyons qu'il ne courust plus fort que nous, et que nous ayant attrappez il ne nous engloutist et devorast : fort estonnez que nous fusmes en nous regardans l'un l'autre, nous demeurasmes ainsi tous cois en une place (Jean de Léry, Histoire d'un voyage faict en la terre du Brésil)

1841 Je demeurai aussi coi et penaud qu'un président à qui son greffier aurait pris une puce chevauchant sur le nez (Aloysius Bertrand, Gaspard de la nuit)

1879 Quand Céline eut terminé une série d'exclamations qui ne voulaient rien dire, ils demeurèrent cois, les uns devant les autres (Joris-Karl Huysmans, Les Soeurs Vatard)

1904 ACHILLE. Achille, disent-ils, est-ce Eurus ou Borée

Qui s'apprête à souffler par le détroit d'Eubée?

Attendrons-nous toujours ces butins, ces lauriers,

Qui nous ont fait te suivre et quitter nos foyers?

De nous tirer d'Aulis en vain tu t'évertues : Puisqu'il te faut encore ici demeurer coi, Que ne retournons-nous plutôt à nos charrues,

En laissant ceux d'Argos aux lenteurs de leur roi ? (Jean Moréas, Iphigénie)

1914 La comtesse s'obstinant à demeurer coite, le chanoine lâcha son bras, reprit sur un ton plus posé :

- Je ne chercherai pas, madame, à vous apitoyer sur les souffrances d'un captif (André Gide, Les Caves du Vatican)

1924 Mais M. Vedel était bon : il répéta sa définition avec la patience des vrais maîtres, proposa de nouveau le même exemple ; mais quand il me demanda de nouveau de redire après lui le mot synonyme de « coudrier », de nouveau je demeurai coi (André Gide, Si le grain ne meurt)

1933 Un moment, il demeura immobile et coi, comme se dérobant à un péril, puis l'obscurité lui rendit l'inspiration ; j'entendis le souffle rauque du vieillard et le halètement complaisant de la servante (Marcel Aymé, La Jument verte)

2000 Mais je trahissais la Marquise. "Court» est un mot féroce et drôle. Moi je disais : « coi » (et son dada demeura coi, à Lérida), ce qui était charmant, mais un doute, quand même, me venait, je tâtonnais (François Nourissier, À défaut de génie)

2009 Bref, filles de la laïque nous sommes, et devons le rester. Et c'est pourquoi nous nous gardons bien de poser des questions et demeurons immobiles et coites sur les bancs du fond avec notre lot de perplexités (Mona Ozouf, Composition française : retour sur une enfance bretonne)

II. Rester muet, être stupéfait

Intransitif

1610 Nous demeurasmes tous cois, et plus estonnez qu'un evesque sans mitre. Elle nous ferma la bouche, puis nous dit : il luy faudroit dire : C... sans cul, que fais-tu là ? (Béroalde de Verville, Le Moyen de parvenir)

1899 Les autres demeuraient cois, le pape, trop politique, n'ayant point bougé (Georges Clemenceau, Vers la réparation)

1918 J’y demeurai coi, et j'entendis ma mère accabler de reproches l'inerte Gomboust (Anatole France, Le Petit Pierre)

1956 Et ça, ça m'épate plus que si je voyais JésusChrist se radiner drapé dans ses rideaux pour me commander un Byrrh-cassis. Milou et Pinel demeurèrent cois. Juju n'avait pas même fini son verre (René Fallet, $L a$ Grande Ceinture)

CORpus Web :

Ce restaurant a fait de la pasta, de la pâte fraîche, sa spécialité. Et avec quelle maestria ; à demeurer coi devant la nouille [http://www. tripadvisor.fr/Restaurant_Review-g580326d3361086-Reviews-Celeste-Cadaques_Costa Brava_Province_of_Girona_Catalonia.html] (28.1.2015)

Entendre M. Prudhomme tenir des propos à la Danton : «De l'audace, encore de l'audace, 
toujours de l'audace! » et demeurer coi devant les agences de notation, l'hyper-libéralisme en cours à Bruxelles driblé depuis Washington et Berlin, on hésite comme Jean Ferrat [http://blogs. mediapart.fr/blog/max-angel/050115/hollandeou-la-grande-consternation] (28.1.2015)

Dans La littérature à l'estomac, Julien Gracq se moque d'un certain esprit français qui adore parler de littérature, quitte à répéter les propos des autres plutôt que de demeurer coi [http:// www.troisiemebureau.com/regards-croises-14e/ edito-cest-quoi-le-probleme] (28.1.2015)

A ce moment-là, j'ai eu droit à un énorme foutage de deux ados illares postées juste derrière moi à la caisse. Etrangement, moi qui suis de nature à l'ouvrir, ce jour-là je suis demeurée coi [http://maboiteallumette.canalblog.com/ archives/2013/04/18/26953358.html] (28.1.2015)

A juste titre, il a souligné que la communauté internationale n'eût su demeurer coite, tandis que la violence faisait plus que jamais rage entre les deux parties [http://www.ism-france. org/analyses/Quels-naifs-ces-Europeens--article5820] (28.1.2015)

REMARQues : Demeurer coi (I) réfère au fait de ne pas se mouvoir et se taire ou simplement se tenir tranquille et silencieux, les circonstances le prescrivant. Le sujet étant normalement animé, on trouve néanmoins un exemple de sujet inanimé : «Le tournoy est quois demorés ». Dans l'acception (II), il désigne le fait d'arrêter de se mouvoir, le sujet étant stupéfait, bouche bée. $\mathrm{Coi}$ peut s'accorder avec le sujet, et dans ce cas-là il se prête également à une analyse de prédicat second orienté vers le sujet. Coi reste invariable dans le quatrième exemple du $\mathrm{CW}$, malgré le sujet féminin, tandis qu'il s'accorde avec le sujet féminin dans le dernier exemple, adoptant une fonction de prédicat second orienté vers le sujet. Il est modifié par aussi, ainsi, tout. On peut se demander si dans l'exemple de 1580 " tous" est pronom ou - plus probable - l'équivalent de la forme adverbiale moderne tout. En français moderne, l'emploi de coi est pratiquement limité à des collocations du type demeurer / se tenir coi, en langage soutenu. Notons l'emploi de courir fort.

\section{Demeurer court}

Manquer d'idées, d'à-propos, être à court de

mots

Intransitif

1592 Mais, comme il leur a esté bien aisé de representer leurs rithmes, ils demeurent bien aussi court à imiter les riches descriptions de l'un et les delicates inventions de l'autre (Michel de Montaigne, Essais)

1596 Mais bien souvent encor, au milieu de ma plainte,

Je demeuroy tout court, palle et tremblant de crainte,

Et reprenoy mon cœur qui de vous se plaignoit,

Quand vostre cruauté plus fort le contraignoit (Philippe Desportes, Euvres)

1655 « Il en va des langues tout de mesme; qui rencontre cette vérité de lettres, de mots et de suite, ne peut jamais, en s'exprimant, tomber au dessous de sa conception : il parle toûjours égal à sa pensée ; et c'est pour n'avoir pas la connoissance de ce parfait idiome que vous demeurez court, ne connoissant pas l'ordre ny les paroles qui puissent expliquer ce que vous imaginez » (Savinien Cyrano de Bergerac, Les Estats et empires du soleil)

1675 Je ne saurais plus écrire depuis que mes lettres ne vont point à vous ; me voilà $d e$ meurée tout court. Je songe quelquefois que, pendant que je me creuse la tête, on tire peut-être le canon, on est aise, on se réjouit pour votre accouchement (Mme de Sévigné, Correspondance)

1696 Je suis en peine de la santé de monsieur le chevalier, et de l'effet du quinquina, redonné dans sa dose ordinaire ; sa chaleur contre celle du sang du chevalier me fait souvenir de ce qu'on dit quelquefois : quand brave rencontre brave, brave demeure. Nous espérons aussi que ce brave quinquina fera demeurer tout court ce brave sang. Dieu le veuille ! Il est bien difficile à dompter. Dites-moi donc ce que vous avez fait de Mme Reinié. Parle-t-elle encore ? (Mme de Sévigné, Correspondance) 
1732 Je ne demeurai pas court à des paroles si propres à m'obliger de rompre le silence : je lui découvris le fond de mon âme, et lui dis qu'il pouvait me rendre le plus heureux des hommes en m'accordant Eugénie (Alain-René Lesage, Histoire de Guzman d'Alfarache)

1821 Ayez le plaisir de voir que vous n'êtes arrêté dans la lecture que par les difficultés qui sont invincibles, où les commentateurs et les scholiastiques eux-mêmes demeurent courts, si fertiles d'ailleurs, si abondants (John Locke, De l'éducation des enfants / Euvres philosophiques de Locke [trad.])

1836 - Est-ce que je le savais ? m'écriai-je ; est-ce que je savais que cette misérable?... Desgenais pinça les lèvres comme pour signifier : vous en saviez assez.

Je demeurais court, balbutiant à tout moment une phrase ridicule (Alfred de Musset, Confessions d'un enfant du siècle)

1950 Chez lui, dans sa petite ville natale, on le trouvait plus instruit que la moyenne des garçons parce qu'il connaissait l'écriture et qu'il retrouvait sans peine les passages qu'on en citait devant lui ; de plus, il s'exprimait presque aussi bien que le pasteur, mais à l'université on entrait dans un monde très différent et il semblait à Joseph que tous les élèves étaient mieux équipés que lui : à les entendre parler entre eux, il les trouvait plus rapides de pensée, plus prompts à répondre, alors qu'il lui fallait toujours du temps pour réfléchir et que, sans cesse, il demeurait court (Julien Green, Moïra)

1981 Je le regardai bien en face en souriant et dis seulement entre haut et bas : « SaintLegier, tient-on bien les hommes par l'esprit ? » Mon Saintongeais en demeura tout court (Françoise Chandernagor, L’Allée du roi)

2000 «Et son dada demeura court, à Lérida. » " Lérida? " La citation traînait depuis si longtemps dans ma mémoire qu'elle s'y était usée (François Nourissier, $A$ défaut de génie)
2003 Marcel, qui n'a pas ces préventions, s'alarme comme tant d'autres Français de la menace croissante de guerre, de la faiblesse des alliés français et britanniques demeurés court face aux provocations hitlériennes (Michel Winock, Jeanne et les siens)

CORPUS WEB :

L'URL est très important pour le référencement. Il devrait demeurer court, contenir des mots-clés pertinents et ne pas inclure de caractères spéciaux ( ?, \%, \$, = ) [http://www.abacusreferencement.com/lexique/url.htm] (28.1.2015)

Ce temps de préparation par le massage doit demeurer court et rapide dans son exécution et généralement ne pas dépasser 20 minutes pour l'ensemble du corps [http://www.luimagazine.fr/ sports/quel-massage-pour-quel-sport] (28.1.2015)

D'une manière générale, la sieste doit demeurer courte et circonstanciée [http://www. sommeil-mg.net/spip/Sieste-Fiche-detaillee] (28.1.2015)

REMARQUES : Demeurer court désigne le fait de se retrouver dans une situation où le sujet manque subitement d'idées, d'arguments, de repartie, est à court de mots. Court tend à l'invariabilité, mais l'exemple de 1821 fait exception, ce qui montre l'incertitude du XIX ${ }^{\mathrm{e}}$ siècle à cet égard ; celle-ci est bien reflétée dans le discours normatif (v. Introduction §4.2). Court est modifié par bien aussi, tout. Dans les exemples du CW, demeurer est un verbe copule au sens de 'rester'. Court est alors pris au sens de 'bref' et est accordé.

\section{Dénoncer fort}

Dénoncer quelque chose avec une grande intensité

$\lambda$ dénoncer haut

\section{Dénoncer haut}

Dénoncer (quelque chose/quelqu'un) à voix haute, publiquement

Transitif

1560 L'Escriture dénonce par tout haut et clair que Dieu ne trouve rien en l'homme dont il soit incité à luy bien-faire, mais qu'il le prévient de sa bénignité gratuite (Jean Calvin, Institution de la religion chrestienne) 
1922 Ces deux Américains, nos voisins (je te les dénonce tout haut, car ils ne savent pas le français ; et d'ailleurs, entre membres d'une association secrète, ce qui est le plus inutile, c'est de se comprendre quand on parle), récoltent de l'or par tous les moyens défendus (Jean Giraudoux, Siegfried et le Limousin)

1951 Je lui fis faire à Rome des funérailles triomphales, réservées d'ordinaire aux seuls empereurs ; cet hommage à un bon serviteur obscurément sacrifié fut ma dernière et discrète protestation contre la politique de conquêtes : je n'avais plus à la dénoncer tout haut depuis que j'étais maître d'y couper court (Marguerite Yourcenar, Mémoires d'Hadrien)

2002 Que la torture, en ce temps-là, était une doctrine militaire et la négation de l'autre une doctrine politique. " Amère victoire », a écrit Pierre Vidal-Naquet, pour ceux qui, comme lui, ont dénoncé cela haut et fort au temps où il fallait le faire (François Maspero, Les Abeilles et la guêpe)

\section{CORPUS WEB :}

Dénoncer haut et fort ce sujet tabou peut choquer, mais le taire serait également un leurre [https://www.facebook.com/POSEMAG/posts/ 130069163836627] (28.1.2015)

Les habitants de Gaza : les langues se délient pour dénoncer haut et fort les crimes de guerre du Hamas [http://www.europe-israel.org/2014/09/ les-habitants-de-gaza-les-langues-se-delientpour-denoncer-haut-et-fort-les-crimes-de-guerredu-hamas] (28.1.2015)

Je viens dénoncer haut et fort les conditions de vie de la MA de Fleury [http://prison. eu.org/spip.php?page=imprimer_article\&id article $=4494](28.1 .2015)$

REMARques : Le sujet de dénoncer haut peut désigner un animé (plus rarement un inanimé) dont le but est de faire connaître à haute voix ou publiquement une chose de manière à la faire condamner par l'opinion. Notons les collocations dénoncer haut et clair et haut et fort. Haut reste invariable et est modifié par partout, tout. Mentionnons également l'emploi de couper court.

\section{Départir dru}

Départager, séparer, diviser

Intransitif

-1334 En eux se fiert si radement,

Que par force les faut partir.

Lors leur conmenche a despartir

De ces grans cops dru et souvent

(Le Romans de la dame a la lycorne [ $1^{\mathrm{er}}$ tiers $\mathrm{XIV}^{\mathrm{e}}$, 2564)

Remarques : Départir dru se disait du fait de porter des coups vigoureux et fréquents pour départager. La locution dru et souvent signifiant 'à plusieurs reprises' suit le modèle de menu et souvent.

\section{Dépenser malin}

Dépenser sans tomber dans les pièges, sans se

faire avoir

$\pi$ bronzer idiot

\section{Déplier grand}

Déplier complètement

Transitif

1927 Et là, insouciant, tranquille malgré le tintamarre de la vaisselle, caché de la tête aux genoux derrière La Presse toute grande dépliée, il se mit à fumer sa vingtième pipe (Robert Choquette, La Pension Leblanc)

$1945 \mathrm{Nu}$; le poète : homme nu ; le poème est nu mais avec cette rondeur antique, signe de fertilité ; les beaux fruits ne sont jamais ratatinés, les grandes idées sont toutes grandes dépliées (Jean Bouhier, La Bataille du poète)

1955 Cette garce de fille $H$. derrière un journal grand déplié (Exemple entendu, 15 août 1955 / Grundt : 392)

1976 D'un seul coup de couteau, l'Auguste avait fendu le pigeon de bas en haut, puis il avait tiré sur les ailes pour bien l'écarteler. L'oiseau tout grand déplié sur sa poitrine, l'Auguste s'était mis à insulter la maladie (Jacques Lanzmann, Le Têtard)

2017 Je me suis avancé vers lui, les bras tendus et les mains grandes dépliées (Adrien Gygax, Aux noces de nos petites vertus) 
CORPuS WeB :

Je sautai donc du haut de mon échafaudage les bras croisés, les jambes pliées et mes sabres pointant vers le bas, en direction de cette troupe de marine. Puis, à environ deux mètres du sol, je dépliai grand mes bras et tournai sur moimême dans les airs, créant une jolie tornade de coup [http://www.onepiece-requiem.net/t6710une-apres-midi-quelque-peu-mouvementee] (29.1.2015)

Le pokémon oiseau déplia grand ses ailes et se secoua rapidement [http://www.allsoluces. com/gba/forums/fans-fics/a_10-387-1-330-quandles-pokemons-revinrent-sur-terre.html?s=1] (29.1.2015)

REMARQUES : Déplier grand se dit du fait de défaire, d'étendre, d'ouvrir ce qui est plié, fermé ou intact, l'adjectif-adverbe grand soulignant la forme ou le format de l'objet complètement ouvert. Grand tend à l'emploi accordé. Dans les exemples de 1927 et 1945, l'accord est réalisé, probablement favorisé par le féminin toute, mais on trouve l'accord aussi dans l'exemple de 2017. Grand est modifié par tout. VOIR AUSSI : déployer / ouvrir grand

\section{Déployer grand}

Étendre largement, complètement une chose qui était pliée

Transitif

1834 Oh ! reviens, céleste religion, reviens planer sur nous, tes ailes blanches toutes grandes déployées! (Journal des femmes)

1843 Les conjurés avaient caché dans les plis d'un drapeau, qu'ils espéraient déployer grand, leurs arrhes d'avenir (Jérôme Delandine de Saint-Esprit, Histoire de l'Empire, 1804-1814)

1893 Des bouteilles, heurtées, croulèrent ; des journaux, sortis on ne sait d'où, s'abattirent, grand déployés, sur l'éparpillement des quintes et des quatorze (Georges Courteline, Messieurs les ronds-de cuir)

1972 et je ne m'en plains pas, m'en étant accommodé tout jeune, d'autant que les vacances étaient là pour déployer grandes les ailes de la liberté (Pierre de Brissac, En d'autres temps, 1900-1939)
$2006 \mathrm{Au}$ fond de lui-même, il ne voulait pas d'une existence sans envergure et se sentait appelé à déployer grand ses ailes pour une vie plus extraordinaire (Xavier de Brabois, L'Éclat du pendentif)

\section{Corpus Web :}

mais quand elle passa à leur niveau, leurs ailes se déployèrent grand toutes seules et ils écarquillèrent les yeux tout en étant bouche bée, laissant tomber leurs lances... [https://mlpfic tions.com/chapter/354] (29.1.2015)

Il s'agit de se libérer des limites imposées pour déployer grand ses ailes et découvrir le vaste horizon ! [http://aikidotenjinkai.centerblog. net/91-le-sabre-de-aiki-v-devoir-de-vacances] (29.1.2015)

L'absence de quatre exposants de renom aura permis à plusieurs distributeurs de prestige de déployer grandes leurs ailes de telle sorte que le Salon de janvier prochain regorgera de nouveautés [http://m2.facebook.com/notes/ association-maritime-du-qu $\% \mathrm{C} 3 \% \mathrm{~A} 9 \mathrm{bec} / \mathrm{un}$ salon-haut-en-couleur-le-salon-2011-plus-actifet-plus-diversifi\%C3\%A9-que-jamais-/488520 199490] (29.1.2015)

REMARQues : Déployer grand (ses ailes) est une expression figée, parfois pris au sens figuré. Grand reste invarié ou s'accorde avec l'objet, ce qui peut le rapprocher d'un prédicat second référant à la taille de l'objet (journal, drapeau). Dans l'exemple de 1834, la présence du féminin au pluriel toutes favorise l'accord de grand. Notons l'usage pronominal dans le premier exemple du CW. VOIR AUSSI : déplier grand

\section{Déporter beau}

Se divertir, bien s'amuser

Pronominal

$\sim 1180$ " Cist doit bien en cheval seoir Et la lance et l'escu porter, Qui si bel s'en set deporter.» Et sa suer, qui lez li seoit, Li dist que plus bel i avoit (Chrestien de Troyes, Perceval ou Le conte du Graal, 5008)

1200 Puis que la dame ot esté morte, Le bourgeis, qui bel se deporte, Par le conseil de ses amis $\mathrm{A}$ a reson le pere mis (Auberee, 64) 
1349 Mais la dame premierement

Me vit, eins que nuls me veïst,

Ne que nuls semblant en feïst,

C'est assavoir d'icelle gent

Qui conduisoient son corps gent.

Lors un escuier appella

Et li dist : Vois tu celui la

Qui bel se deduit et deporte?

(Guillaume de Machaut, Le Jugement dou

roy de Navarre, 561)

+1350 Et la dame entra ens qui moult bel se deporte,

Sur son cheval emblant qui moult souef la porte (Brun de la Montaigne [ $2^{\mathrm{e}}$ moitié XIV $], 1892)$

1560 Toutesfois il ne peut tant faire par ses crieries, que le Décret du Concile n'eust sa vigueur. Parquoy ses successeurs, voyans qu'ils n'y gagnoyent rien, se déportèrent bien et beau de ceste obstination ; car ils ordonnèrent qu'il deust estre le second Patriarche (Jean Calvin, Institution de la religion chrestienne)

REMARQues : Déporter bel est une expression aujourd'hui hors d'usage, référant au fait de s'amuser, se divertir, se réjouir ou jouer, l'adjectif-adverbe bel ayant une fonction emphatique. Calvin remplace le neutre de l'ancien français par le masculin-neutre beau, coordonné avec bien. Beau (bel) reste invariable et est modifié par moult. Notons l'emploi de porter soef.

\section{Dépouiller nu}

Dépouiller de tout, totalement, dénuder

entièrement

Transitif

1230 Puis, faites les enfans trestous nus despoiller,

C'ancor nos pueent bien lor dras avoir mestier (Gui de Bourgogne, p. 34)

+1389 Lequel prisonnier, sur ce juré et affermé par serement de dire verité, après ce qu'il ot fait et dist qu'il n'en estoit ne n'en savoit aucune chose, et qu'il eust esté despouilliez tout nu, et lié et ataché par les mains à ladite question, afin qu'il deist de ce la verité, et aussi fait plusieurs variacions en ce, requist que il feust desliez, et qu'il diroit verité de ce que dit est, et autres chosses qu'il avoit faites et commises (Registre criminel du Châtelet de Paris [1389-1392])

1559 Et, quant elle fut hors de ce villain lieu, la faillut despoiller toute nue et changer de tous habillemens avant qu'elle partist du couvent (Marguerite d'Angoulême, Heptaméron, p. 109, 42)

1782 Je devins furieux ; on sauta sur moi, on me lia les pieds et les mains ; un monstre en ma présence, apporta un grand bain d'eau chaude ; ma Julie se fit dépouiller toute nue. Hélas! (Robert-Martin Lesuire, L'Aventurier françois ou Mémoires de Grégoire Merveil)

1859 Plus de paroles, plus de repos (brebis qui bêle perd sa dentée d'herbe) ; le mûrier qui les porte est à l'instant dépouillé tout nu ! (Alphonse de Lamartine, Cours familier de littérature)

1863 Son amant est massacré par vingt drôles qui l'attachent sanglant sous ses yeux ; elle est dépouillée nue et violée. Elle survit, sa raison lui est conservée (Alfred de Vigny, Le Journal d'un poète)

Pronominal

1275 S'en ont si grant pitié les nues

Qu'eus s'en despueillent toutes nues,

Ne ne prisent lors un festu

Le neir mantel qu'eus ont vestu ;

Car a tel deul faire s'atirent

Que tout par pieces le descirent (Jehan de Meun, Roman de la rose [1269-1278], 17922)

1558 L'abbesse leur feit sa remonstrance et leur dit pourquoy elle les avoit assemblées, et leur commanda qu'elles eussent à se despouiller toutes nues (Bonaventure des Périers, Les Nouvelles Récréations et joyeux devis)

1592 Cela faict, elle descent, et, prenant par la main le plus proche des parents de son mary, ils vont ensamble à la riviere voisine, où elle se despouille toute nue et distribue ses joyaux et vestements à ses amis et se va 
plongeant dans l'eau, comme pour y laver ses pechez (Michel de Montaigne, Essais)

1673 PIERROT. O ! donc, tanquia qu'à la parfin, pour le faire court, je l'ai tant sarmonné, que je nous sommes boutés dans une barque, et pis j'avons tant fait cahin caha, que je les avons tirés de gliau, et pis je les avons menés cheux nous auprès du feu, et pis ils se sant dépouillés tous nus pour se sécher (Molière, Dom Juan)

1691 Cette petite chrétienne avait été si bien accoutumée, lorsqu'on la voulait vendre, de quitter son manteau blanc et de se dépouiller toute nue, que j'ai eu beaucoup de peine à l'empêcher de le faire (MarieCatherine d'Aulnoy, Relation du voyage d'Espagne)

1766 En finissant ces mots, le compère se dépouilla tout nu comme la main, et jeta ses habillemens dans le feu (Henri-Joseph Dulaurens, Le Compère Mathieu)

\section{CORPuS WeB :}

Ce qui fit soupçonner qu'il était muni de quelque enchantement et, pour en être éclairci, on le fit dépouiller nu comme la main et, après une exacte recherche, on ne trouva autre chose sur lui qu'un petit papier où était la figure des trois Rois, avec ces paroles sur le revers [http:// univers-paranormal.over-blog.com/2014/06/sortd-invulnerabilite-a-la-torture-selon-albert.html] (29.1.2015)

Ces manuels recommandent l'arrestation de suspects tôt le matin par surprise, leur bander les yeux, et les dépouiller nu [http://mon independancefinanciere.com/lenciclopedie/ seccion-c/cia-actions-humaines-transnationalede-lhomme.php] (29.1.2015)

Les gardiens ont ordonné à un groupe de huit détenus de la dépouiller nue à l'extérieur d'une toilette d'hommes au premier étage [http:// fr.clearharmony.net/articles/a22769-printSeptembre-2005-Encore-quarante-quatre-44autres-deces-de-pratiquants-de-Falun-Gongconfirmes-Photo.html] (29.1.2015)

REMARQues : Dépouiller nu est résultatif, l'adjectif désignant l'état de ce qui est dénudé ou de celui qui est dénudé. En parlant d'une personne, il se dit pour 'ôter tout ce que l'on porte sur soi, enlever ses vêtements ou ses bijoux'. Le sujet peut aussi désigner un végétal (ici : le mûrier) qui ne possède plus de fruits. $\mathrm{Nu}$ s'accorde normalement avec le sujet. Notons que nu reste invariable dans le deuxième exemple du CW, malgré l'objet au pluriel. Il est modifié par tout. Mentionnons l'emploi de l'incise discursive pour le faire court.

\section{Dérouler impeccable}

Se passer sans problèmes

Pronominal

1933 Avec son clair génie, l’auteur du Traité de l'Amour de Dieu, dont la logique se déroule impeccable à travers les méandres des images et des comparaisons, avait bien vu que [...] (Ernestine Lecouturier, Françoise-Madeleine de Chaugy et la tradition salésienne au XVII siècle)

1938 À ce principe mes camarades ne voulaient pas faillir ; ils m’avaient désigné comme leur délégué et, dans leur esprit, leur chef. De sorte que le travail se déroulait impeccable, sans incident, sans faute (Gaston Guiraud, P'tite gueule)

1987 Tout se déroule impeccable (Victoria Thérame, Bastienne)

REMARQUES : Se dérouler impeccable signifie que quelque chose se passe sans problème. La combinaison « verbe + impec $($ cable $)$ » constitue une série ouverte dont nous ne citons que quelques variantes.

\section{Désafeutrer dur}

Désarçonner avec force, vigueur

Transitif

1275 Cil qui a lui jousta est plains de seürté, Celui doit on tenir pour vassal esmeré : Or demandés Corsolt se je di verité, De lui le vi je ore si dur desafeutré Que ce est grans merveille se il l'a oublié (Adenet le Roi, Buevon de Conmarchis, 2964)

REMARQUES : Désafreutrer dur est une expression hors d'usage référant au fait de faire tomber vivement un adversaire de sa monture (en général, un cheval), dérivée du verbe afeutrer signifiant 'harnacher'. 


\section{Désarêter complet}

Enlever toutes les arêtes d'un poisson

Transitif

2010 Je les [= les poissons] ai désarêtés complet (Exemple entendu [par un cuisinier], février 2010)

\section{Désarmer soef}

Ôter doucement, délicatement une armure Transitif

1100 Li reis ad pris Tierri entre sa brace, Tert lui le vis od ses granz pels de martre, Celes met jus, puis li afublent altres ; Mult suavet le chevaler desarment. Munter l'unt fait en une mule d'Arabe (Chanson de Roland, 3942)

REMARQues : Désarmer soef désigne le fait d'enlever doucement, avec précaution et calme les armes ou l'armure, l'objet désignant une personne. Il est modifié par moult.

\section{Descendre aise}

Descendre facilement

Intransitif

1372 Sire, je m'en vueil entremettre,

Car de ce fait assez suiz duiz,

Et si voy assez de lieux vuiz

Pour y descendre aise et monter

Fuiez vous : je m'y vueil bouter

(Miracle de saint Jehan le Paulu, 1500)

REMARQUES : Dans l'ancienne langue, descendre aise réfère au fait de descendre avec facilité d'un cheval.

\section{Descendre bas}

I. S’avilir, devenir indigne

Intransitif

1235 S’en tele honneur estoie entree, Griés me seroit la consiurree.

Pour chou me vaut mix a bas tendre Que haut baer pour bas descendre

(Philippe de Remi, sire de Beaumanoir, $L a$ Manekine, 1974)

1639 Quand le ciel pour nos fronts a marqué des couronnes,

Ses soins dès le berceau veillent sur nos personnes,

Gouvernent notre vie, et ne permettent pas
Que, destinés si haut, nous descendions si bas (Jean de Rotrou, Laure persécutée)

1652 Quiconque me choisit pour maître, Et ne cherche qu'à me gagner, M'approche d'autant plus qu'il sait mieux s'éloigner

Des consolations que les hommes font naître :

Plus dans leur folle estime il se trouve compris,

Plus il ravale de son prix,

Et va d'autant plus haut vers ma grandeur suprême,

Qu'il descend plus bas en lui-même,

Et se tient abîmé dans le propre mépris (Pierre Corneille, L'Imitation de Jésus-Christ)

1767 ATHAMARE. Je m'abaisse, il est vrai ; mais je veux tout tenter.

Je descendrais plus bas pour la mieux mériter.

Ma honte est de la perdre ; et ma gloire éternelle

Serait de m’avilir pour m'élever vers elle (Voltaire, Les Scythes)

1812 Un peuple qui s'était élevé si haut pouvait-il descendre si bas ? (François de Chateaubriand, Itinéraire de Paris à Jérusalem)

II. Descendre jusqu'à une certaine limite Intransitif

+1354 Bien est voir car aussi comme nule foiz il ne descendoient si bas que il venissent a la multitude derreyne, (43.12) ne ne se doit nus mervillier se le nombre et l'ordre des trente et sinc ligniez doublés qui est horesendroit en la cité ne se proporcionnent pas au nombre des centuriez dessus dictes (Pierre Bersuire, Les Décades de Titus Livius [trad.] [probablement 13541358])

1377 Et la cause est pour la difference de l'aer a l'eaue en pesanteur et en legiereté, lequel aer est dedens le vaissel et resiste a ce que il ne descende plus bas (Nicole Oresme, Le Livre du ciel et du monde, p. 400, 113)

-1465 Conduy tes sens

En telle forme que Raison ne soyes sans 
Et a Folie jamais ne te consens,

Ne monte hault ne trop bas ne descends, Le moyen garde,

De toutes pars mect en toy seure garde :

L'on oyt tes dicts, tes gestes on regarde,

Bien seras dyct sy aulcun ne te larde

(Jean Meschinot, Lunettes des princes, p. $84,1813)$

1560 ROYNE CATHOLIQUE. Comme un beau Lys, est en fleur la jeunesse D’Elizabeth, et si en corps mortel Vouloit çà bas descendre une Déesse, Pour estre belle elle en prendroit un tel (Pierre de Ronsard, Mascarades, p. 196)

1776 Alors les salaires se proportionneroient toujours au prix permanent des bleds : ils ne monteroient jamais trop haut, ils ne descendroient jamais trop bas (Étienne de Condillac, Le Commerce et le gouvernement)

1911 On pourrait descendre plus bas, à 1900 et même 1800 calories (A. Gautier), soit 30 calories par kilogramme de poids corporel, dans le repos absolu et dans un but thérapeutique (arthritisme, dyspepsies) (Maxime Macaigne, Précis d'hygiène)

1919 Ceci posé, il faut savoir qu'en hiver, soit du mois d'octobre jusqu'en avril, il y a souvent des gelées nocturnes, donc la température descend souvent très bas (Hubert Tscheuschner, La Prévision du temps sans instrument)

1927 Il faut descendre bas dans la mine du rêve pour trouver les plus belles pépites (Pierre Reverdy, Le Gant de crin)

1942 La température nocturne y descendait assez bas pour transformer en glace l'eau de mon pot à eau (Antoine de SaintExupéry, Pilote de guerre)

2004 Quarante-huit kilos, ça ne fait pas bien lourd...

- Oui, acquiesça-t-elle vaincue, oui... Je suis d'accord... Il y a longtemps que je n'étais pas descendue aussi bas... Je..

- Vous?

- Non. Rien

(Anna Gavalda, Ensemble, c'est tout)
III. S’éloigner vers le bas

Intransitif

1465 Et aprés que tous deux furent rassis, Fyrebras trait Plourance, qui luy pendoit au cousté ; Olivier prinst Haulte Clere, reluysant a merveilles, et vint sur Fyrebras, et en hault de son heaulme luy donna sy grant coup que les fleurs et pierres precieuses, dont il estoit moult anobli, fist voller a terre ; et de ce coup, en descendant bas, luy entame l'espaule, mais le cuyr de Capadouce le saulva (Jehan Bagnyon, L'Histoire de Charlemagne, p. 48)

1515 Et nostre amoureux, voiant les choses mieulx aller qu'il ne pensoit, descendit bas et tout doulcement à pas de larron s'en alla en son hostel (Philippe de Vigneulles, Les Cent Nouvelles nouvelles, p. 188, 70)

1932 Il descendit encore plus bas et atteignit les salles à manger (Édouard Peisson, Parti de Liverpool)

2004 Longtemps tes yeux myopes ont cru que les étoiles descendaient très bas le soir pour aider les lucioles à éclairer les bruits de la nuit (Daniel Maximin, Tu, c'est l'enfance)

IV. Descendre jusqu'à une couche sociale moins élevée

Intransitif

1844 Plus elle a oublié la haute position où elle était placée, plus elle est bas descendue (Alexandre Dumas père, Les Trois Mousquetaires)

1845 - Plus bas on descend dans la société, dit amèrement Marie, plus on y trouve de sentiments généreux sans ostentation (Honoré de Balzac, Les Chouans ou La Bretagne en 1799)

1849 Le sentiment de la liberté politique, cette aspiration des hommes de loisir, ne descend pas si bas dans le peuple (Alphonse de Lamartine, Les Confidences)

CORPUS WEB :

La profondeur du squat est très importante et fait une grande différence dans le développement. Le fait de descendre bas est plus difficile mais il offre un entraînement plus efficace car il 
nécessite un plus grand recrutement des fibres musculaires [http://www.all-musculation.com/ exercices-entrainement/conseils-pour-squat. html] (30.1.2015)

La difficulté n'est pas de descendre bas en fréquence, mais d'avoir du niveau, de la puissance acoustique, dans le grave. Quand le contrebassiste de Georges BRASSENS par exemple tire sur les cordes de son instrument, il en sort un son qui n'est pas rikiki [http://www.petoindominique.fr/ php/caisson.php] (30.1.2015)

respire autant de fois que tu en ressens le besoin. et pour pas étouffer, visualise qq chose que tu aimes, moi c est un arbre. dans ta tete pour te sentir mieux, et imagine ton angoisse qui t étouffe, là sur la poitrine, visualise la, et fais-la descendre bas, très bas, tout en bas.. pour libérer ta poitrine [http://www.regime-jean-michelcohen.fr/forum/questions-medicales/112758/ maladie-bipolaire-ou-maniacodepressive. asp?topic_id=112758\&p=5] (30.1.2015)

La Bourse est bradée en ce moment. Je vous l'aurais dit...

Attends un peu quand même, ils vont la tuer et la faire descendre basse pour mieux repartir [http://www.bulle-immobiliere.org/forum/ viewtopic.php? $\mathrm{f}=204 \& \mathrm{t}=43596 \&$ start $=22650$ ] (30.1.2015)

REMARQUES : Descendre bas apparaît au sens propre et au sens figuré. En (I), souvent dans un sens abstrait, il se dit du fait de déchoir de son rang, de sa dignité, de s'abaisser sur le plan moral. En (II), il se dit de quelqu'un qui descend, au sens propre comme au figuré, ou de quelque chose (température, salaire, poids) qui décroît, diminue jusqu'à une certaine limite. En (III), il désigne le fait de s'éloigner en descendant les étages d'une maison, par exemple. En (IV), il réfère au fait de déchoir, de passer à un rang inférieur. Bas est modifié par assez, aussi, encore, jamais, plus, si, souvent, très, trop. Il reste invariable ; très exceptionnellement, dans le quatrième exemple du CW, bas s'accorde avec l'objet au féminin, en l'occurrence, la bourse ; il y suit un schéma répandu dans le registre informel (v. Introduction § 4.6). Notons l'emploi de tendre bas, baer 'aspirer' haut, aller haut, élever haut, monter haut.

\section{Descendre chaud}

tout chaud descendu : juste descendu,

descendu à l'instant

Intransitif

1891 Et il n'est certes pas leur parent ce Richepin, non plus que nul des siens, son père, son cousin, - un ancien médecin de marine, aujourd'hui retraité, rabattu au pays, - qui, avec ses moustaches à la chinoise, semble quelque Hun tout chaud descendu de cheval (Hugues Le Roux, Jean Richepin)

\section{Descendre doux}

Se diriger en un lieu situé plus bas avec douceur $\pi$ descendre soef

\section{Descendre droit}

I. Descendre, aller directement ou immédiatement Intransitif

$\sim 1235$ Es les vous a la court venus, Droit au perron sont descendus (Philippe de Remi, sire de Beaumanoir, $L a$ Manekine, 1246)

1371 LE SENATEUR. Dame, vous estes descendue

A Rome droit

(Miracle de la fille du roy de Hongrie, 1877)

1579 La sepmaine passée, une femme de la vallée d'Andelle lavoit sur le bord de la rivière un oreiller sur lequel un sien petit enfant avoit chié (ne vous vueille desplaire), et pour mieux le laver et nettoyer (après l'avoir longuement froté entre ses mains) ruoit et dauboit dessus à grands coups de batoir, comme dessus un linge qui vient de la buée, et si bien le coigna, frapa et dauba qu'elle le creva, et par ce moyen toute la plume en sortit, qui s'en alla, nageant aval la riviere, droit descendre à quelques moulins (Philippe d'Alcripe, La Nouvelle fabrique des excellents traicts de vérité)

1629 que de deux choses l'une, nous irions servir un de ces deux Roys pour faire parler de nous, ou que nous descendrions tout droit dans un des ports de Narsingue, 
dont le Roy est voisin, amy et allié du Roy de Zeilan (François de Boisrobert, Histoire indienne d'Alexandre et d'Orazie)

$1668 \mathrm{Au}$ partir de ce lieu, qu'elle remplit de crainte

La perfide descend tout droit

À l'endroit

Où la Laie était en gésine (Jean de La Fontaine, L'Aigle, la laie et la chatte / Fables)

1732 Je ne connoissois personne à Ganderon, ni dans le pays, qui m'y pût introduire ; je craignois de leur faire de la peine, et de passer pour un aventurier si j'osois descendre tout droit chez elles (AlainRené Lesage, Aventures du chevalier de Beauchêne)

1839 Ainsi pendant qu'à travers les ténèbres, je vais descendre aisément par votre chemin chez mes puissances associées, pour leur apprendre ces succès et me réjouir avec elles, vous deux, le long de cette route, parmi ces orbes nombreux (tous à vous), descendez droit au paradis (François de Chateaubriand, Le Paradis perdu)

1876 MISTRESS CLARKSON. Ça passera. Quand j’ai reçu votre dépêche m’annonçant votre arrivée pour ce matin, j’ai été vraiment heureuse. Je vous avais fait préparer votre appartement, comptant que vous descendriez tout droit ici (Alexandre Dumas fils, L'Étrangère)

1911 Il se leva, prit son chapeau : il descendit tout droit au cimetière (Charles-Ferdinand Ramuz, Aimé Pache, peintre vaudois)

1935 Et je me perdais en conjectures mais je «suivais » la tige qui de cette pauvre plaque rouillée devait descendre droit jusqu'au cœur de la dépouille, homme ou femme (Pierre-Jean Jouve, La Scène capitale)

1985 - C'est normal, j'ai dit, c'est un ange qui descend tout droit $d u$ ciel, vous voyez pas... ? (Philippe Djian, $37^{\circ} 2$ le matin)
II. Descendre de manière rectiligne

Intransitif

1377 Et appert par ce que dit est que tout mouvement n'est pas simple qui est selonc droite ligne mais seullement celui qui est en montant droit ou en descendant droit (Nicole Oresme, Le Livre du ciel et du monde, p. 60, 53)

2006 Il me faut donc traverser le coude du canal et descendre tout droit par la broussaille, où des oiseaux se disputent une petite charogne (Pierre Guyotat, Coma)

2008 Elle était prête à sortir, en robe du soir de Lucien Lelong, une coupe raffinée, d'extrême sophistication dans sa géométrie. Le long fourreau bleu d'eau moulait sa taille et descendait droit, fluide sur les hanches, ouvert d'un fin plissé sur le devant, une fente pleine de promesses qu'écartait le moindre mouvement du genou (AnneMarie Garat, L'Enfant des ténèbres)

\section{CORPUS Web :}

De même, pour une pente légère, vaut mieux la descendre droit avec les deux roues avants qui touchent le bas en même temps ou descendre en biais, une roue après l'autre en bas de la pente ? [http://www.patrol-gr.net/lapratique-du-4x4/26955-qts-sur-devers-et-pente. $\mathrm{html}$ (30.1.2015)

Vous pouvez aussi descendre droit vers le Grand Bornand par une super piste nouvelle et enneigée tout l'hiver [http://lapetitemya.com/ lapetitemya/Les_pistes_de_la_Floria.html] (30.1.2015)

Le plus difficile, fut de déposer la cuve droite dans le trou, car il faut la lever haut et la descendre droite [https://sites.google.com/site/ voyagegastronomieetculture/bricolage/cuve] (30.1.2015)

Impossible de descendre droit, je suis obligé quand je descends de continuer a cambre, je n'arrive pas (même sans poids) a descendre sans cambrer [http://www.jeuxvideo.com/forums/178-399233-1-0-1-0-squat-impossible-morphologie. $\mathrm{htm}]$ (30.1.2015)

REMARQues : Descendre droit (I) désigne le fait de descendre ou simplement de se rendre de 
manière directe en un lieu (ou vers une personne). (II) se dit de quelqu'un ou de quelque chose (ici : une flèche) qui, « selonc droite ligne » (ex. de 1377), se déplace de manière verticale vers le bas, sans osciller. Il reste invariable et est modifié par tout qui vient en renforcer le sémantisme. Notons que dans les exemples 1 et $3 \mathrm{du}$ CW, descendre apparaît dans son emploi transitif ; droit reste invariable dans le premier exemple malgré l'objet au féminin, tandis qu'il s'accorde avec l'objet dans le troisième exemple où il sert de prédicat second indiquant la position, comme dans le dernier exemple. Notons que dans l'avant-dernier exemple, descendre droite est syntaxiquement coordonnée avec lever haut, mais seul le premier est accordé, ce qui permet de l'interpréter comme modifieur du complément d'objet (prédicat second). Dans les deux derniers exemples du CW, droit ne réfère pas à la direction du mouvement mais à la position verticale du sujet (prédication seconde). Droit est généralement précédé ou suivi d'une préposition (à, chez, contre, dans, par, sur, vers, au-dessus). Droit a tendance à s'associer avec ces prépositions au point de faire partie du groupe prépositionnel comme modifieur de la préposition. Notons l'emploi de monter droit ; lever haut. VoIR AUSSI : aller droit

\section{Descendre dru}

I. Descendre, tomber vigoureusement, énergiquement

Intransitif

1393 Et lors senty descendre sur lui, aussi dru que pluie chiet du ciel, coups et horions d'un costé et d'autre et fu moult defroissiéz de coupz orbes, et puis fu tiréz moult vilainement hors de la forteresse et traynéz tout hors de la barriere et la fu laissiéz (Jean d’Arras, Mélusine, p. 806 [manuscrit Ars])

1934 La pluie descendait aussi drue et le vent la jetait par gerbes au visage (Roger Vercel, Capitaine Conan)

2006a Elle étouffait, alors elle entrouvrit la fenêtre, se pencha, aussitôt fascinée par la neige silencieuse, qui descendait dru, en rideau serré, ensevelissant les formes, au point que la lanterne n'était plus qu'un vague halo jaune dans toute cette blancheur (Anne-Marie Garat, Dans la main du diable)

2006b Le lendemain il neigeait encore, le vent était tombé et la neige descendait épaisse et drue, recouvrant les arbres et la terre (Jonathan Littell, Les Bienveillantes)

II. Parvenir à une destination avec vigueur, force

Intransitif

1572 - C'est le vaillant et juste Merovée, Aspre ennemy des Huns, qui descendront Plus dru que gresle, et par force prendront, Pillant, bruslant, à flames allumée

(Mars tout sanglant conduira leurs armées)

(Pierre de Ronsard, La Franciade, p. 225)

CORPUS Web :

Hier soir a partir de $22 \mathrm{~h} .30$ feu d'artifice du nord-est au sud-est qui a dure trois heures. Tres peu d'eau on etait dans une zone neutre. ça a du descendre dru vers Nantes et Rennes [http://www2.mgcontact.eu/phpBB2/viewtopic. php?p=289790] (30.1.2015)

$\mathrm{Au}$ début c'est plus ou moins plat, mais très vite ça va descendre dru, le GR est encombré des pierres comme toujours dans ces pentes, je dois veiller aux endroits où poser les pieds, rares sont ceux où le pied est à plat [http://doische-quarante.blogs.midilibre.com/ archive/2011/06/29/mercredi-29-juin-2011.html] (30.1.2015)

Le chemin descendait dru à certain endroits pour aller dans les Woods indiqués sur la carte... [http://soomfz.blogspot.co.at/2011_10_01_ archive.html] (30.1.2015)

REMARQues : Descendre dru (I) se dit de quelque chose (pluie, coups, neige) tombant avec force, pouvant même blesser sur son passage. (II) désigne quelqu'un se déplaçant, arrivant rapidement et énergiquement, en donnant une impression de force. Notons les expressions associées à des éléments météorologiques : " aussi dru que pluie » ou « plus dru que gresle ». Dru peut s'accorder avec le sujet (ex. de 1934 et de 2006b) et être modifié par aussi, plus. Le premier exemple du CW contient l'emploi quotidien du tour impersonnel ça descend dru 'il pleut très fort'. Les 
deux derniers exemples du CW montrent un glissement de sens de l'idée de concentration ou d'apparence compacte vers la signification de 'beaucoup'.

\section{Descendre isnel}

Descendre rapidement

Intransitif

1275 Lors descendi Geras moult tost et moult isnel, Car se Limbanors noie, ne li sera pas bel. Ferrant a atachié a un rain d'un aubel, A s'espee a coupé le plançon d'un saucel, Tant fist que Limbanors refu sor le prael (Adenet le Roi, Buevon de Conmarchis, 2634)

REMARQUES : L'adjectif-adverbe isnel, usité jusqu'au moyen français, signifie 'rapidement'. Il désigne le fait de descendre rapidement, avec hâte. Cette idée est renforcée par moult tost 'sans tarder, rapidement'.

\section{Descendre profond}

I. Pénétrer loin à l'intérieur de quelque chose Intransitif

1936 car le sourire descend aussi profond que le bâillement, et, de proche en proche, délie la gorge, les poumons et le cœur (Alain, Propos)

1945 Il descendait toujours plus profond dans le regard, jusqu'aux cailloux de mica et jusqu'aux sables

(Jean-Louis Bory, Mon village à l'heure allemande)

1995 Et comme chaque nuit je descendais plus profond dans la faiblesse, l'esprit avait de plus en plus de mal à redresser le corps que je voulais noble, pas dolent, portant bien haut la tête, afin de me faire respecter malgré ma saleté, me donnant une importance qui seule m'aidait encore à ne pas me sentir dépossédé de moi-même (Hector Bianciotti, Le Pas si lent de l'amour)

2010 au lieu de se briser, le miroir m'avale comme le ferait une bouche : c'est celle de ma mère, et je vais descendre profond dans son gros corps tout fiévreux : ((((il y a des milles et des milles d'intestins ; muni d'une petite pelle, je débarrasse les intestins des excréments durs comme la pierre qui les bloquent (Victor-Lévy Beaulieu, Bibi)

II. Aller chercher loin, descendre profondément Intransitif

1937 Les degrés du sépulcre, où les graves tenues des cordes qui, par le la bémol, descendent plus profond encore, jusqu'au sol, semblent prolonger sous les voûtes l'écho des plaintes, qui s'éteignent dans le silence (Romain Rolland, Beethoven)

1945 Toutefois certains docteurs vont plus loin et estiment que la musique ne descend pas encore assez profond dans l'ineffable (Julien Benda, La France byzantine)

1979 Sous les vagues du devenir qui agitent la surface de ce qui est, la courbe thermodynamique du temps s'efface et elle disparaît peu à peu au fur et à mesure qu'on descend plus profond (Claude Roy, La Traversée du Pont des Arts)

2013 Nous sommes capables d'aller dans l'espace, mais pour l'instant les vastes profondeurs océaniques nous sont interdites. Nous y envoyons des robots, nous les sondons avec des radars, mais pour descendre profond, il faudra inventer une combinaison spéciale (Yannick Bernabé, Demain sera pour aujourd'hui)

\section{CORpus Web :}

la largable, ascenseur ,hippopotame, bouteille de périer et tout le tointoin ne sont pas la pour aller plus profond... mais pour descendre profond avec plus de sécurité..... [http://www. chasse-sous-marine.com/forums/topic/51338recherche-chasseur-ou-apneiste-pour-allezprofond] (30.1.2015)

Entre ca et un vieux chisel à la con, jpense que le rapid fait un meilleur boulot, non ? pour descendre profond, c'est pas de ma faute si le chef veux descendre profond... pourquoi ca coute plus cher ? [http://www.agricool.net/forum/index.ph $\mathrm{p} ? \mathrm{~s}=\mathrm{dd} 21 \mathrm{ee} 0318058 \mathrm{fod} 2 \mathrm{~d} 91 \mathrm{ae} 6752 \mathrm{e} 5 \mathrm{e} 63 \mathrm{f} \&$ showt opic $=15586 \& \mathrm{st}=0 \&]$ (30.1.2015) 
Vous avez du temps à perdre et vous voulez découvrir les dessous d'une source géogienne, celle de Borjomi ? Et bien soyez heureux, un site promotionnel a été mit en place, et sur celui-ci, vous pouvez descendre profond, très très profond sous la terre, jusqu'à l'eau ! [http://jeromecold. fr/wordpress/2012/05/30/le-site-le-plus-profonddu-monde] (30.1.2015)

REMARQUeS : En (I), qui est un emploi souvent métaphorique, descendre profond se dit du fait de pénétrer dans quelque chose, le sujet désignant une personne ou, par métonymie, les yeux. Il peut aussi souligner le mouvement intérieur provoqué par un sourire chez une personne. Dans descendre profond (II), le sujet réfère généralement à une musique dont le ton baisse ou se définit par ses sonorités graves. Profond reste invariable et est modifié par aussi, pas encore assez, plus, toujours plus. L'emploi en prédication seconde en change le sens : dans la nuit descend profonde et silencieuse, c'est la nuit ellemême qui est profonde. Notons l'emploi de aller profond ; coûter cher.

\section{Descendre seul}

descendre tout seul : descendre facilement, par le propre mouvement, sans intervention externe Intransitif

1377 Et toutesvoies nous voions sensiblement que le bacin noera et le fonz tout seul descendroit, et pour ce il convient en ce cas et en samblables assigner et mettre autre resistence que celle par quoy l'eaue resiste a ce que elle ne soit divisee ne distraite (Nicole Oresme, Le Livre du ciel et $d u$ monde, p. 716, 87)

1864 - Allons, montez vous autres. Est-ce qu'on ne peut pas rabattre le manteau?

- Pardon, Monsieur Kobus, vous n'avez qu'à tourner le bouton, cela descend tout seul.

Ils montèrent donc, heureux comme des princes. Fritz s'assit et rabattit la capote. Il était à droite, Hâan à gauche, Schoultz au milieu (Émile Erckmann et Alexandre Chatrian, L’Ami Fritz)

1921 Heurté par une sentinelle maladroite, un boulet de l'arsenal descendait tout seul la rue à pic, ralenti aux passages à escaliers, poursuivi par la trompette. Puis la sirène de l'Amélie siffla, le dernier reflet de l'Europe me sourit (Jean Giraudoux, Suzanne et le Pacifique)

1972 On attaque. On se jette sur les douze douzaines sans perdre une seconde. On mange en silence, concentrés. Finalement 48 huîtres c'est rien du tout à liquider. Ça descend tout seul. Et c'est très bon. C'est plus que bon. C'est fascinant de la voir manger comme ça. Du coup je m'arrête pour la regarder (Bertrand Blier, Les Valseuses)

\section{CORPUS WEB :}

Volet roulant électrique descend tout seul [http://forums.futura-sciences.com/depannage/ 515300-volet-roulant-electrique-descend-seul. html] (30.1.2015)

Parfois, sur une période de quelque jours, le volume du son monte et descend tout seul, et la télécommande n'est plus opérante. Dans le pire des cas, le téléviseur s'éteint tout seul [http://www. teleservice-depannage.com/t8633-volume-LCDqui-monte-et-descend-tout-seul.htm] (30.1.2015)

le moteur de la vitre tourne toujours car je l'entent mais elle ne répond pas ! et aujourd'hui cet vitre ses mit à descendre tout seul ! [http:// www.auto-evasion.com/forum-auto/panneauto-mecanique-et-entretien/peugeot/306/ jeune-conducteur-qui-ne-connait-rien-la-vitredescend-tout-seul/228732-1050.html] (30.1.2015)

Pour testé ton système de frein, tu appuis fort sur la pédale sans laché et si elle descend tout seul çà peut etre un problème [http://www. forum-auto.com/les-clubs/peugeot-206-207/ sujet386880.htm] (30.1.2015)

J'ai un TV samsung serie 6000 UE46B6000 VWXXC, depuis peu le son monte et descend seul en ce moment [https://forums.futura-sciences. com/depannage/697580-tv-samsung-serie-6000monte-descend-seul.html] (28.1.2019)

salut, depuis quelques sorties, dans les montées bien pentues (donc quand je suis sur le pignon 1 ou 2), j'ai la chaîne qui descend tout seule du moyen au petit plateau [http://forum.velovert. com/topic/153168-chaine-qui-descend-sur-lepetit-plateau] (30.1.2015) 
Bonjour j'ai ma vitre passager qui descend seule et ne referme pas avec la télécommande skoda octavia 2010 merci de m'aider [http://forumauto.caradisiac.com/pole-technique/meca nique-electronique/sujet671300.htm] (28.1.2019)

Remarques : Descendre tout seul se dit d'un élément qui se déplace, se dirige vers le bas, sans obstacle, sans difficulté matérielle, sans être contraint à le faire. Le sujet peut aussi désigner un objet qui roule vers le bas, le mouvement s'exerçant sans problèmes. Dans son emploi familier, se dit du fait d'avaler, d'ingurgiter une boisson ou un aliment facilement, sans peine. La grande majorité des exemples contient la collocation tout seul. Les exemples 5 et $7 \mathrm{du}$ CW montrent cependant que l'emploi sans tout existe. Seul reste invariable et est généralement modifié par l'adverbe d'intensité (tout) qui vient en renforcer le sémantisme. Notons que seul reste invariable dans le troisième et dans le quatrième exemple du CW, tandis qu'il s'accorde avec le sujet féminin dans les deux derniers exemples sans se conformer au schéma usuel elle descend toute seule. Mentionnons également l'emploi de monter seul, éteindre seul.

\section{Descendre soef}

I. Déposer doucement, délicatement Transitif

+1150 Il dessendi a tere del destrier auferrant, Puis uint a la pucele al gent cors auenant, Entre ses bras le prent, tout soef le dessent, Tres enmi le maison l'asist desor .i. banc, Puis uint a ses cheuaus, si les ua atachant, As keuestres de quir les ua bient arenant (Aiol et Mirabel [ $2^{\mathrm{e}}$ moitié XII $]$ ], 5800)

+1225a Tantost le vait par les flans prendre. Si l'a mout souef descendue. Et quant il l'espee a veüe K'ele avoit chainte, si l'esgarde (Le Chevalier as deus espees [ $2^{\mathrm{e}}$ quart $\left.\mathrm{XIII}^{\mathrm{e}}\right]$, 1285)

+1225 bt li rois maintenant le prist Entre ses bras. Si le descent Mout souavet, et puis le prent Il meïsmes et l'a menee Es cambres, $\mathrm{u}$ estoit alee La roïne. Et jut en un lit (Le Chevalier as deus espees [ $2^{\mathrm{e}}$ quart $\mathrm{XIII}$ ] $]$, 5228)

\section{Descendre doucement}

Intransitif

1285 Quant ou chastel furent entré, Clarmondine, mout tres soué Jus dou palefroi descendirent (Adenet le Roi, Cleomadés, 6888)

1524 Et au fin beau mylieu, sur un tertre plaisant,

Duquel souef descend, maint ruissel arrosant

La racine fertile à tout fructueux arbre, Est un Palais, construit de dur et riche marbre,

De jaspe, de crystal, de porphyre poli, Dont l'ouvrage est tant cher, tant noble, et tant joli,

Qu'au monde ne se treuve un si bel habitacle

(Jean Lemaire de Belges, Description $d u$ rocher)

\section{CORPUS WEB :}

Cette parole, elle passa sur les lèvres des Prophètes, dans le cœur des Patriarches, sur la plume des Évangélistes ; elle retentit dans les plaines de la Palestine, tantôt faible et discrète dans la maison de Nazareth, tantôt éclatante et solennelle sur la montagne des béatitudes ; elle tomba terrible sur l'âme des Pharisiens, elle descendit suave et douce dans le cœur des malheureux ; elle promit le pardon à Madeleine, elle offrit la miséricorde à tous [http://lepaternoster. com/cariboost_files/Rayons_20Eucharistiques. pdf] (31.1.2015; texte de 1908)

REMARQueS : Descendre soef (I) réfère au fait de déposer quelqu'un/quelque chose à terre avec précaution. (II) désigne le fait de descendre, de se diriger en un lieu plus bas que le point de départ, en se déplaçant avec douceur, tranquillité, paisiblement. Soef reste invariable et est modifié par moult très, tout. L'exemple du CW montre que l'emploi de suave comme prédicat second orienté vers le sujet est possible dans l'usage moderne. VOIR AUSSI : baiser soef 


\section{Déshydrater sévère}

Perdre en grande quantité l'eau nécessaire à

l'organisme

Pronominal

1997 «Je suis en train de me déshydrater sévère » (publicité Coca-Cola, TF1 / StephanGabinel 2001)

REMARQues : Déshydrater sévère s'emploie par rapport au fait de ne pas boire assez d'eau. La combinaison "verbe + sévère " constitue une série ouverte dont nous ne citons que quelques variantes.

\section{Désirer ferme}

Désirer, convoiter quelqu'un, quelque chose intensément

Transitif

1576 Quoy advenant, encor qu'elle [= la reine Marie] fust grandement deplaisante de voir la paix rompue, come elle la desire ferme en toute la Chrestienté, elle esperoit tant au Dieu tout puissant qu'il luy donneroit force de resister à tels dangers (Louis Régnier de La Planche, Histoire de l'Estat de France, tant de la république que de la religion)

1607 Si vous peux-je assurer que nous sommes fort retenus, et qu'à la réponse qu'il a fallu faire à la proposition des États, j'en avais dressé par écrit une beaucoup plus modérée que celle que je vous envoie, que je fis après l'autre ; et que ne pouvions assez contenter les députés d'Angleterre qui la desiraient ferme, et tendant plutôt à approuver la guerre que la paix ; encore que leur but soit pour certain la paix, par ce qu'en avons pu découvrir jusqu'à présent (Pierre Jeannin, Négociations diplomatiques et politiques du président Jeannin)

1961 elle portait assez beaux le visage et le buste, ma future mère, pour qu'on la désirât ferme (René Étiemble, Blason d'un corps)
CORPUS Web :

Le nouvel affrontement entre Aliens et Predator laisse vraiment à désirer ferme [http://www. allocine.fr/membre-Z20060228114214647364117/ critiques/?sort=5] (31.1.2015)

Jean-Paul Belmondo pestait contre les 25 copies France de son dernier film, Désiré, et désirait ferme une salle sur les Champs-Elysées [http://www.lexpress.fr/informations/49emefestival-de-cannes-profession-acteur_613926. html] (31.1.2015)

D'une voix qu'elle désirait ferme et autoritaire, Elora héla le gamin tout en s'approchant, décidée [http://m.jeuxvideo.com/forums/1-27833176603-42-0-1-0-la-compagnie-de-mugill-acte-ii. $\mathrm{htm}]$ (31.1.2015)

REMARques : Désirer ferme désigne le fait de convoiter la possession de quelque chose, voire charnellement celle d'une personne, de montrer un attrait très fort envers l'autre. L'accord n'est pas visible dans le dernier exemple du CW, mais la signification est bien celle d'un prédicat second orienté vers le complément d'objet. Le premier exemple du CW contient laisser à désirer 'ne pas être parfaitement satisfaisant'.

\section{Désirer vif}

Désirer vivement

$\lambda$ aimer profond

\section{Dessiner ample}

Dessiner à grands traits, pleins d'ampleur

$\lambda$ dessiner large

\section{Dessiner confortable}

Dessiner à grands traits, larges et souples

$\lambda$ dessiner large

\section{Dessiner correct}

Dessiner scrupuleusement

$\lambda$ dessiner large

\section{Dessiner énorme}

Dessiner à très gros et grands traits

$\lambda$ dessiner fort

\section{Dessiner faible}

Dessiner avec des traits fins

$\lambda$ dessiner fort 


\section{Dessiner fort}

Dessiner des figures aux contours très marqués Emploi absolu

1943 en matière d'impressions, c'est ce qui est fort qui compte. Leçon d'esthétique : il faut écrire fort pour écrire bien et dessiner fort pour donner des impressions que le lecteur retrouve avec plaisir (Max Jacob [Lettre à François Sentein du 6 mai 1943])

Transitif

1977 Une fillette de seize ans, dont j'ai oublié le prénom, mais que grand-mère n'appelle que la « diablesse », lui paraît éminemment suspecte, pour sa passion du bain de rivière, qu'elle pratique en maillot noir une pièce, moulant ses formes déjà fort dessinées (Albert Simonin, Confessions d'un enfant de La Chapelle)

CORPUS WEB :

$\rightarrow$ Dessiner minuscule ou énormes, ou en agrandissant et diminuant.

$\rightarrow$ Dessiner fort ou léger, rapide ou lent [http://www.ac-orleans] tours.fr/fileadmin/ user_upload/eps37/conscience_corporelle/ APD_2009_2010_Fichier_Rituels.pdf (31.1.2015)

on applique une forme cercle ou carré et un angle et une taille en dessinant fort la traîne sera épaisse, et faible la trace sera fine [http:// forum.jenesaispasdessineretjemenfous.com/vostutoriels-f42/topic176.html] (31.1.2015)

Ça dessine fort à Boucherville... [http:// www.ravent.net/blog/index.php?post/2012/ 06/\%C3\%87a-dessine-fort-\%C3\%A0-Boucher ville...] (31.1.2015)

Sûrement cette flegme naturelle chez Hikari (après l'autre dessin j'ai eu envie de la dessiner forte, ronchon comme d'habitude, je n'aime pas la voir "faible »), la gentillesse naïve de Docky et... Marty toujours calme [http://goku-chan. deviantart.com/art/I-WANT-U-109883866] (19.5.2016)

REMARques : Dessiner fort désigne le fait de représenter quelque chose par le dessin en insistant fortement sur les contours, ou, par analogie, celui de rendre apparents, de faire ressortir fortement les contours, le dessin de quelque chose ou de quelqu'un (ici : les formes d'une femme). Notons la série d'adjectifs-adverbes qui se com- binent avec dessiner : minuscule, énorme, léger, rapide, lent et faible. Fort reste invariable. Le dernier exemple illustre les adjectifs fort et faible en fonction de prédicat second accordé orienté vers le sujet. Dans l'exemple de 1977 et dans l'avant-dernier exemple du CW (probablement un québécisme au sens de 'beaucoup'), fort peut signifier respectivement 'beaucoup' et 'très bien'. Le développement de toute une série d'adjectifs-adverbes s'alliant au verbe dessiner est caractéristique d'un langage de spécialité. Par contre, les adverbes en -ment ont tendance à transposer la signification sur un autre plan, plus abstrait, qui comprend l'intensification ou l'atténuation. On ne saurait remplacer large par largement, fort par fortement ou léger par légèrement sans changer le sens de l'énoncé. Notons l'emploi de écrire fort.

\section{Dessiner gros}

Dessiner de grosses formes, à gros traits

Emploi absolu

1768 Cela est savant de détails, contours bien sûrs, dessiné large, à ce que croit l'artiste ; c'est plutôt dessiné gros. Grosses formes (Denis Diderot, Le Salon de 1767).

1992 À trop faire joli, écrit-il, on oublie en route ce que l'on veut signifier. Par conséquent, il faut dessiner gros, ce qui ne veut pas dire grossièrement (Raymond Savignac, L’Affiche de A à Z)

\section{CORPuS WeB :}

Comment vous faites pour dessiner des croquis petit, jaitendancea dessinergros.... [http:// www.hyjoo.com/sujet-54281.html] (31.1.2015)

Seulement ça tombe en grande partie dans l'acte 3 avec Bart au courant, et puis surtout, le final de l'épisode commence à se dessiner gros comme une maison [http://www.simpsonspark. com/episodes/million_dollar_ma_biche.php] (31.1.2015)

Faut pas la dessiner grosse parce qu'en réalité, elle l'était pas [http://www.bulledair.com/ index.php?rubrique=album\&album $=$ commeriv $]$ (31.1.2015)

REMARques : Dessiner gros désigne le fait de représenter ou suggérer par le dessin des objets dont les formes sont grosses, voire grossières ; la 
grosseur du trait ou l'absence de contours précis souligne ainsi un manque de minutie ou de souci du détail. Gros reste invariable, sauf dans le dernier exemple du CW où il fonctionne comme prédicat second orienté vers le complément d'objet. L'emploi pronominal avec l'expression gros comme une maison désigne, au figuré, le fait de se manifester de manière évidente.

\section{Dessiner large}

I. Tracer des traits larges, souples Emploi absolu

1758 De l'étude du dessein, suivie par le maniement du pinceau, avec le secours de la couleur il résulte une maniere de dessiner large, mais incertaine, et telle que l'on la tâte dans l'empâtement des couleurs où l'on évite les contours trop décidés (Charles-Nicolas Cochin, Voyage d'Italie)

1768 Homme nu à demi-couché sur une espèce de sopha, dont le dossier est relevé. On le voit de face. Sa jambe droite est croisée sur la gauche ; et sa main droite posée sur sa jambe, il est appuyé du coude sur le sopha ; sa main embrasse son menton et soutient sa tête. Cela est savant de détails ; contours bien sûrs, dessiné large, à ce que croit l'artiste, c'est plutôt dessiné gros, grosses formes. Cela me rappelle un fait qu'on lit dans Macrobe et qui revient trèsbien ici (Denis Diderot, Salon de 1767)

1812 On remarque dans ses tableaux [= de Claude Charles], outre la fraîcheur du coloris, une grande facilité dans la composition, et une manière de dessiner large et correcte (Louis-Mayeul Chaudon, Dictionnaire universel)

II. Tracer (un chemin) large (opposé à étroit) Transitif

2006 En attendant, pour le commun des visiteurs qui s'y aventurent sur quatre roues (si possible, toutes motrices), le beltway est un parkway comme un autre, qu'on a dessiné assez large pour voguer encore à travers l'une des plus belles campagnes d'un continent qui n'en manque pas. Je n'en dirai pas autant de notre périphérique, définitivement aussi pénible à par- courir qu'à prononcer (Gérard Genette, Bardadrac)

\section{CORPUS WEB :}

Amusez-vous ! N'hésitez pas à dessiner large, ample, confortable. Ne vous inquiétez pas pour les marges, nous les supprimerons ensuite [http://www.forum-dessine.fr/index. php?id=06007] (31.1.2015)

Godet de 12 Dessinalo, couleurs assorties. Pointe ogive pour dessiner large ou fin [http://www. rueducommerce.fr/m/ps/mpid:MP-78654M8 9466\#moid:MO-78654M170262] (31.1.2015)

Les épaules architecturées. Elles se dessinent larges et rondes sur le haut des bras ou forment des plastrons, protection pour guerrières [http:// www.elle.fr/Mode/Les-defiles-de-mode/Print emps-Ete-2010/Femme/Londres/Defile-JulienMacDonald/Defile-Julien-MacDonald-968218] (31.1.2015)

REMARQUES : Dessiner large réfère soit au fait de représenter ou suggérer par le dessin des objets dont les contours sont larges, bien dessinés (I), soit aux dimensions effectives d'un objet, d'un espace (II). Dans les exemples de 1758 et 1812, la coordination avec un adjectif fléchi implique que large est également pris au féminin. En fait, il s'accorde dans les deux cas avec manière et fonctionne donc comme adjectif adnominal, mais dans un contexte toujours adverbial. Il est possible que l'auteur de la citation de 1812 ait choisi cette construction apparemment plus correcte pour éviter d'employer dessiner correct tout court. Le CW ajoute les adjectifs ample, confortable, fin et rond. Dans le deuxième exemple du CW, large pourrait avoir le sens de 'épais' (opposé à fin). L'emploi pronominal dans le dernier exemple réfère au fait de faire ressortir des formes généreuses (prédication seconde).

\section{Dessiner léger}

Dessiner avec des traits délicats

$\pi$ dessiner fort

\section{Dessiner lent}

Dessiner avec lenteur

$\lambda$ dessiner fort 


\section{Dessiner maigre}

Dessiner à traits fins, à peine visibles

Intransitif

1795 N'en déplaise à la prédiction, ces gravures seront de mauvais modeles, et n'apprendront qu'à dessiner maigre et sec (Mercure de France)

\section{Dessiner minuscule}

Tracer de tout petits dessins

$\lambda$ dessiner fort

\section{Dessiner rapide}

Dessiner avec rapidité

$\lambda$ dessiner fort

\section{Dessiner sec}

Dessiner sobrement

$\pi$ dessiner maigre

\section{Destiner haut}

I. Être destiné à un rang élevé

Transitif

1639a LE ROY. Quand le Ciel pour nos fronts a marqué des couronnes,

Ses soings dès le berceau veillent sur nos personnes,

Gouvernent nostre vie, et ne permettent pas

Que destinés si haut nous descendions si bas (Jean de Rotrou, Laure persécutée)

1648 LE ROY. Toute obscure qu'elle est, la nuit a beaucoup d'yeux,

Et n'a pas pû cacher vostre forfait aux Cieux,

(L'embrassant)

Adieu, sur l'eschaffaut portez le cœur d'un Prince,

Et faites-y douter à toute la Province, Si né pour commander, et destiné si haut, Vous mourez sur un throsne, ou sur un eschaffaut (Jean de Rotrou, Venceslas)

II. Prédestiner à quelque chose de noble Transitif

1639b LAURE. Ce jour si desiré, si cher aux yeux de tous,

Avec la mesme torche éclaireroit pour nous,
Si ma condition, à la sienne inégale,

N'armoit une puissance à nos désirs fatale, Qui destine plus haut la foy que j'ay de luy, Et nous comble tous deux de misere et d'ennuy (Jean de Rotrou, Laure persécutée)

\section{CORPUS WEB :}

Avant la création des quais, les navires mouillaient aussi à partir du Pont de Pierre et débarquaient par allèges pour ce qui était stocké à Bordeaux ou sur des bateaux de Garonne et des canaux du Midi pour ce qui était destiné «plus haut » vers Agen, Toulouse, voire Méditerranée.. [http://bordabord.org/news/variations-photosde-fluvial] (31.1.2015)

REMARQUES : Destiner haut s'emploie au figuré. Souvent dans un emploi passif, (I) réfère à quelqu'un ayant été destiné à un rang élevé, dont le destin, la destinée tend vers le haut. (II) désigne le fait de prédestiner quelque chose, de réserver à un destin noble, élevé. Haut reste invariable et est modifié par plus, si. L'exemple du CW reflète l'emploi par économie linguistique des adjectifs-adverbes dans un argot de métier, ici au sens de 'plus en amont'. Notons l'emploi de descendre bas.

\section{Détester ferme}

Détester quelqu'un, quelque chose

intensément, résolument

Pronominal (réciproque)

1874 Pour ça, ils se détestent ferme ! (Émile Zola, La Conquête de Plassans)

Transitif

1974 Elle se mit à le détester ferme (Jean Vautrin, Billy-Ze-Kick)

1975 S’agissant de toi, Polka, il n'est pas question d'exécution capitale ; je ne parle de guillotine que pour faire image. Encore qu'on nous déteste ferme, toi et moi, à l'occasion! (François Nourissier, Lettre à mon chien)

\section{Corpus WeB :}

- Ah... De toute façon il doit me détester ferme maintenant ! [http://tomber-danssesyeux. skyrock.com/3152439352-En-fuyant-la-pluie-onrencontre-la-grele.html] (31.1.2015) 
j'aime déjà pas la politique faite sous le règne de Sarko mais avec en plus cette ministre là : je la déteste ferme cette personne [http:// suppermamy76.skyrock.com/1695270626-raz-lebol.html] (31.1.2015)

Mais... il y a déjà ma Nini qui DÉTESTE ferme les autres chats... et qui a le privilège du grand âge... [http://www.beaute-test.com/forums/ index.php?topic $=154168 \&$ start $=15]$ (31.1.2015)

Moi sa me fait rire j'ai l'impression que la tecktonik c'est un peu comme dans les années 70-80 le disco qui était adoré par certains et que d'autres détestaient fermes cette mode [http:// www.xbox-gamer.net/forum/viewtopic.php?p= 174961] (31.1.2015)

Remarques : Détester ferme se dit du fait d'avoir en horreur, de condamner résolument quelque chose, d'éprouver une aversion forte pour quelque chose (un vice), d'exprimer une antipathie déclarée pour quelqu'un. Ferme reste invariable, mais dans le dernier exemple du CW l'accord est fait, peut-être par hypercorrection.

\section{Détester fort}

Abhorrer profondément ; condamner résolument Transitif

1546 Pour à la quelle chose obvier, luy faisoit tout plein de beaux contes touchant les desolations advenues par adultere ; luy lisoit souvent la legende des preudes femmes, la preschoit de pudicité, luy fit un livre des louanges de fidelité conjugale, detestant fort et ferme la meschanceté des ribauldes mariées ; et luy donna un beau carcan tout couvert de saphyrs orientaulx (François Rabelais, Tiers Livre)

1562 Bref un Peroceli aparoist entre vous Plus sage, et continent, plus modeste, et plus doux,

Qui reprend asprement les violeurs d'images,

Les larrons, les meurtriers : qui de fardés langages

N'entretient point la guerre, ains deteste bien fort

Ceux qui plains de fureur nourrissent le discord.
Il est vrai que sa faulte est chose abominable,

Toutesfois en ce fait elle est bien excusable (Pierre de Ronsard, Discours des misères de ce temps)

1657 Parlons maintenant des gens d'affaires. Vous savez que la plus grande peine qu'on ait avec eux est de les détourner de l'usure ; et c'est aussi à quoi nos pères ont pris un soin particulier ; car ils détestent si fort ce vice, qu'Escobar dit [...] que de dire que l'usure n'est pas péché ce seroit une heresie (Blaise Pascal, Les Provinciales)

1792 LE GRAND COUSIN. Par le cousin il est fort détesté,

Et vraisemblablement sera déshérité

(Collin d'Harleville, Le Vieux Célibataire)

1846 Si elle déteste si fort le mariage, pourquoi s'est-elle mariée elle-même?

(Alexandre Dumas père, Le Comte de Monte-Christo)

1874 Et comme je ne pouvais pas me délivrer de ses regards, je répétais machinalement en moi-même : Je t'aime ! Je t’aime ! Au moment où je me blâmais de la détester si fort ! (Arthur de Gobineau, Les Pléiades)

1924 Ce qui restait de ces droits était naturellement fort détesté (Jacques Bainville, Histoire de France)

1928 Car j’ai oublié de dire qu'à la suite d'une conversation avec le docteur De Schacken, on a supprimé la gymnastique que je détestais si fort, et on l'a remplacée par l'escrime et la danse (Gyp, Souvenirs d'une petite fille)

1975 - Je vois, monsieur Surin, que vous n'êtes pas encore parti et que vous apprivoisez ces miroirs que vous détestiez si fort (Michel Tournier, Les Météores)

1988 J'approchai mon visage du sien et lui murmurai à l'oreille :

- Je te déteste, maman. Je te déteste si fort! (Christine Aventin, Le Coeur en poche) 
CORPUS WEB :

On s'aimait bien, on détestait fort, mais on protégeait l'outil de production et le copain blessé sans que ce dernier puisse obtenir quoi que ce soit de l'État sinon l'avantage facilement acquis de quelques jours de taule [http://a-l-i. org/freud/Champs_specialises/Presentation/ Il_fut_un_temps] (31.1.2015)

On disait d'elle qu'elle était gentille, elle se détestait fort mais ne faisait pas de bruit qui s'entende, et sa porte était toujours fermée aux colères et aux revendications, mais derrière le bois brut [http://hazel04.skyrock.com/262279561une-vie-dans-les-tissus.html] (31.1.2015)

Mélanie ne devait rien connaître de plus sur moi, elle ne devait pas savoir que j'étais sortit avec Claire, car elles se détestaient fort à l'époque, mais je croyais que si je lui disais que Claire était morte dans une explosion, Mélanie serait peutêtre contente de joie! [http://fic-laytonxmelanie. skyrock.com/tags/gCuJFBNhYc0-Chapitre-4. html] (31.1.2015)

REMARQues : Détester fort se dit du fait d'avoir en horreur, de condamner résolument quelque chose, d'éprouver une forte aversion pour quelque chose (un vice, une activité, un sport), d'exprimer une antipathie déclarée pour quelqu'un. Notons la collocation fort et ferme, où ferme vient renforcer le sémantisme de fort. Fort reste invariable et est modifié par bien, si. Sa sémantique oscille entre l'emploi concret 'avec force' et celui de simple quantifieur, surtout en antéposition (fort détesté). Notons aussi l'emploi absolu dans le premier exemple du CW, et l'emploi pronominal dans les autres exemples du CW.

\section{Détourner court}

(Se) détourner brusquement, rapidement ; changer brusquement de direction

Pronominal

1538 «Si tu vas, amy, tu n’es pas sage;

Car tu pourrois avoir maulvais visage

De ton seigneur. » Lors, comme le nocher

Qui pour fuyr le peril d'un rocher

En pleine mer se destourne tout court, Ainsi, pour vray, m'escartey de la Court, Craignant trouver le peril le durté

Où je n'euz onc fors doulceur et seurté (Clément Marot, Épitres)
1681 Cette grande necessité lui fit perdre cœur, et ce qui mit le comble à ses ennuis, fut qu'un grand Hiroquois s'en vint'un jour droit à elle la hache sur l'épaule, alors croïant qu'il n'y avoit plus de vie pour elle, elle se disposa à la mort par la priere, mais Dieu permit que cet homme étant proche d'elle, se détourna tout court pour entrer dans le bois (Lettres de la vénérable mère Marie de l'Incarnation, première supérieure des Ursulines de la Nouvelle France)

\section{CORPus Web :}

Graham détourna les yeux, se détourna tout court [http://unseen-handled.skyrock.com/ tags/3nqJnzdC1VZ-Milice.html] (31.1.2015)

Vrai, beaucoup se détournent tout court de la location avec les impayés notamment [http:// www.forumconstruire.com/construire/topic250214.php] (31.1.2015)

Les images mentent souvent, qu'on les détourne de leur propos, de leur sens ou même aujourd'huiqu'onles détournetoutcourt[http://www. rtbf.be/info/emissions/article_la-chronique-depaul-hermant?id=5023753] (31.1.2015)

REMARQUeS : Détourner tout court désigne le fait de changer subitement de direction, de dévier brusquement dans le but de s'éloigner ou de s'écarter d'un danger. Dans le CW, la collocation usuelle tout court tend à développer le sens de 'sans plus', mais sans toujours perdre la connotation de changement ou de rupture brusques. Court reste toujours invariable. Notons l'emploi transitif du verbe, au sens de 'dénaturer', dans le troisième exemple du CW. Notons l'emploi de s'en venir droit à elle.

\section{Dévaler bas}

Descendre rapidement vers le bas

$\lambda$ tomber bas

\section{Deviner juste}

Deviner avec justesse, exactitude

Transitif

1678 Mme de Clèves rougit de ce que Mme la Dauphine devinoit si juste et de ce qu'elle disoit devant M. de Nemours ce qu'elle avoit deviné (Madame de La Fayette, $L a$ Princesse de Clèves) 
1760 Fort bien, reprit-il avec un sourire encore plus malin ; j’avois deviné assez juste, que l'amour avoit beaucoup de part à votre voyage (abbé Prévost, Le Monde moral)

1768 L'Homme Aux QuARANTE Écus. J'entends. Mais vous m'avez dit que nous sommes vingt millions d'habitants, hommes et femmes, vieillards et enfans, combien par chacun, s'il vous plaît?

LE GÉomètre. Cent vingt livres ou quarante écus.

L'Homme Aux QuARANTE Écus. Vous avez deviné tout juste mon revenu (Voltaire, L'Homme aux quarante écus)

1805 Ignorez-vous, madame, continua-t-il, poussé par cet instinct qui fait toujours deviner si juste le mot qui doit réussir, ignorez-vous tout ce que vous pouvez obtenir par l'intercession de la princesse? (Sophie Cottin, Mathilde)

1887 Si j'ai deviné juste à travers les conversations trop courtes, trop rapides qu'il m'a été donné d'avoir avec vous, votre vie, sous son apparence comblée, est déshéritée de bien des choses (Paul Bourget, Mensonges)

2008 Méfiez-vous de l'as de cœur, du valet de cœur, le cœur n'est pas pour vous. Ça, elle devinait juste. Une affaire d'argent, beaucoup d'argent voyage, le roi de carreau est éliminé, une bonne chose pour vous (Anne-Marie Garat, L'Enfant des ténèbres)

Emploi absolu

1740 MAÎTRE BLAISE. Stependant, je me baillerai bian du tourment pour avoir Angélique, et il en pourra venir que je l'aurons, ou bian que je ne l'aurons pas, faut mettre les deux pour deviner juste (Pierre de Marivaux, L'Épreuve)

1830 Ce mot tomba directement sur le cœur de Mathilde. Il est vrai, se dit-elle, ma mère a deviné juste, tel est le sentiment qui l'anime. Alors seulement cessa la joie de la scène qu'elle lui avait faite la veille. Eh bien, tout est fini, se dit-elle avec un calme apparent (Stendhal, Le Rouge et le noir)
1843 Tout cela est infâme, et convenez que j'ai eu raison d'éloigner de mes états ce $\mathrm{Ca}$ gliostro qui devine si juste, et qui donne de si bonnes nouvelles des gens morts et enterrés (George Sand, La Comtesse de Rudolstadt)

1885 «En voulez-vous une goutte ? ça vous rappellera l'pays. » Avec son instinct d'être de même race, loin de chez elle aussi peut-être, elle avait deviné et touché juste. Ils furent émus tous les deux (Guy de Maupassant, Contes et nouvelles)

1923 Et comme le jeune homme ne répondait pas, consterné d'avoir deviné trop juste, elle continua :

- Michelle est en âge de se marier (Paul Bourget, Le Geste du fils)

1963 Je comprends, je comprends, mais vous savez, quelquefois également, on croit deviner juste et on se trompe (Bernard Clavel, Celui qui voulait voir la mer)

2011 là, cette tumeur cancéreuse sous le rein droit, j’ai failli tourner de l'œil, mon cardiologue avait donc raison, il avait deviné juste, qu'est-ce qu'on va faire, opérer, bien sûr, mais où, quand, je cours chez le Dr J., il fronce les sourcils en regardant les clichés (Serge Doubrovsky, Un homme de passage)

\section{CORPUS WEB :}

Dans les grands classiques de la PB, il faut deviner le sexe de son enfant avant l'écho des 12 SA grâce à de nombreux conseils et astuces, j'ai décidé d'explorer toutes les théories que j’ai pu trouver sur plusieurs sites pour être certaine de deviner juste [https://lareinedelapma.wordpress. com/2015/01/16/pb-en-folie-deviner-le-sexe] (31.1.2015)

Si vous arrivez à deviner juste, le Cerveau vous offrira de quoi assouvir votre soif ou vous couvrir en cas d'intempéries. A gagner deux bouteilles de Tru Blood le vendredi 27 Septembre et un hoodie spécial Tru Blood le 5 Octobre prochain [http://braindamaged.fr/2012/09/27/trueblood-devinez-la-meteo-de-nt1-et-repartez-avecdes-lots] (31.1.2015) 
au passage je ne connais pas l'expression « pince sans rire » ben oui si personne ne vous explique un jour le sens des expression il est difficile de les deviner juste [http://forum.judgehype. com/judgehype/LaTaverneHardcore/vous-arriveaussi-sujet_181910_2.htm] (31.1.2015)

L'ennui avec les ordres de ce dieu-éprouvette, c'etait qu'il fallait les deviner, mais surtout qu'il valait mieux pour sa peau de les deviner justes [http://fevlia-v3.forumactif.com/t104-lapremiere-bataille] (31.1.2015)

REMARques : Deviner juste désigne le fait de parvenir à connaître quelque chose, un fait, par conjecture, supposition, intuition, avec succès, exactitude, sans se tromper. Juste reste invariable et est modifié par assez, si, tout, trop. Dans le CW, juste reste invariable dans le troisième exemple malgré l'objet au pluriel, tandis qu'il s'accorde avec l'objet pluriel dans le quatrième, tout en gardant son interprétation d'adverbe de manière. Notons l'emploi de toucher juste.

\section{Deviser bas}

Parler, discuter à voix basse

Intransitif

+1400 Si esveillay les autres, et le pas

Nous alames en devisant tout bas

Jusques au lices

De la grant court de hors, ou edifices

(Christine de Pisan, Le Livre du dit de Poissy / Euvres poétiques [début $\mathrm{XV}^{\mathrm{e}}$ ], II, p. 178, 635)

1558 Apres avoir salué toute ceste compagnie, nous commençames en troupe à deviser tout bas ; puis ce malade tira un de ses rideaux, à quoy la contesse Marguerite s’avança, me tenant par la main (Théodose Valentinian, L’Amant resuscité de la mort d'amour)

1642 (Angelique et Florestan devisent bas) CARRILLE. Je ne fus en ma vie

Surpris comme je suis, que mon ame est ravie,

Est-ce une illusion, ou quelque enchantement ? (Antoine d'Ouville, L'Esprit folet)

1749 Ravies de leur liberté, elles s’approchèrent en un tas, tout le long d'un lit de veille à pavillon et le joignant ; et comme elles étaient toutes affectées de même à l'égard de l'événement qui rassemblait là tout le monde, elles se mirent à en deviser tout bas ensemble dans ce groupe avec liberté (Saint-Simon, Mémoires complets et authentiques du duc de Saint-Simon sur le siècle de Louis XIV et la Régence [1739-1749])

1941 Sans même comprendre les raisons de ce changement de régime, les jeunes gens s'étaient mis à deviser tout bas et jetaient à l'entour des regards inquiets (Georges Duhamel, Suzanne et les jeunes hommes)

2007 Avisant deux dames de noblesse qui devisaient tout bas, il pensa que ces deux-là devaient se confier des secrets d'alcôves, certainement croustillants (Bernard Grousset, En ton nom, Révolution)

\section{CORPUS WEB :}

Distraite, nous sommes la même personne, biologiquement parlant du moins. Je sais que tu ne dors pas. » Distraite continue obstinément à deviser tout bas avec elle-même [http://plumedegivre.skyrock.com/3241801529-Distraite-etObstinee.html] (31.1.2015)

Sylphide et MKA devisaient tout bas de l'étroitesse d'esprit de Mme B., l'espionne intraitable et aveugle qui nourrissait Ursula [http:// www.weightwatchers.fr/community/mbd/ post.aspx?page_size $=25 \&$ rownum $=1$ \&page noHidden $=3 \&$ threadpage_no $=1 \&$ sincedate $=$ 25\%2F09\%2F2009+<00\%3A00\%3A00\&thr ead_id=9053008\&thread_name $=$ pause $+<$ caf $\% 26 \% 23233 \% 3 \mathrm{~B}+<$ dans $+<$ le $+<$ Nord\&forum id=1\&board_id=480\&setview=TRUE\&dateran] ge $=$ \&viewchange $=$ POSTSDESC (31.1.2015)

En gros, j'me dis qu'il est tout à fait possible que la réalisation de tout ceci pour 3000 euros soit rentable, à condition de faire simple et de bosser vite... en conséquence de quoi tu ne chercheras pas à construire une vrai putain d'identité visuelle pour le dit évènement, mais tu te contenteras de faire du propre et pas cher. On peut très bien bosser comme ça (et du coup deviser bas) mais il faut en avoir conscience... [http://forum. kob-one.com/graphistes-f7/le-juste-devis-votreavis-sur-un-devis-t29270.html] (31.1.2015) 
REMARQUES : Au figuré, deviser bas désigne le fait de s'entretenir familièrement sans trop élever la voix, afin de ne pas être entendu de tous. Bas reste invariable et est modifié par tout. Le dernier exemple du CW contient le néologisme deviser bas 'faire un devis pas cher' usuel dans le vocabulaire des artisans et architectes, tout comme faire simple et bosser vite.

\section{Deviser dru}

deviser dru et menu : parler, discuter beaucoup et souvent (de quelque chose)

Intransitif

1568 Mais la nouvelle mariée n'eut cognoissance par quelque temps de ce deffaut, sinon par communication d'autres bonnes commères qu'elle frequentoit, et lesquelles elle ouyt deviser du passe-temps dru et menu qu'elles recevoient de leurs jeunes marys (Bonaventure des Périers, Les Nouvelles Récréations et joyeux devis)

REMARQUES : Deviser dru et menu désignait le fait de s'entretenir familièrement au sujet de quelque chose avec fréquence et profusion, les adjectifs-adverbes dru et menu, en collocation, insistant sur la quantité et la répétition de paroles. Ils restent invariables.

\section{Deviser menu}

Parler beaucoup

入 deviser $d r u$

\section{Devoir gros}

Devoir beaucoup d'argent ; avoir une dette morale importante

Emploi absolu

1782 Figeac doit gros, mais pourtant par mégarde ;

Figeac s'obstine à ne jamais payer ;

Il a de plus mainte dette criarde,

Mais en revanche, il les laisse crier (Étrennes lyriques, anacréontiques, pour l'année 1782)

1862 Le Thénardier se replia en bon ordre.

- Cette signature est assez bien imitée, grommela-t-il entre ses dents. Enfin, soit ! Puis il essaya un effort désespéré.
- Monsieur, dit-il, c'est bon. Puisque vous êtes la personne. Mais il faut me payer « toutes les petites choses». On me doit gros (Victor Hugo, Les Misérables)

1884 Il n'osa pas refuser, car il devait gros dans la maison (Alphonse Daudet, Sapho)

1942 - Tu n'es pas libre ? Tu es son engagé ? - Ou tout comme, je lui dois gros d'argent. Mais c'est pas ça, pantoute, tu ne pourrais pas comprendre (Maurice Genevoix, Laframboise et Bellehumeur)

1987 Hélène ne décolérait pas. Il lui devait gros, ce trouchamand, toujours à voir le mal, à lasser le personnel, à rouméguer pour un oui pour un non! (Evelyne Sullerot, L'Enveloppe)

2004 Je ne sais pas s'ils lui seront reconnaissants. Mais ils lui doivent gros !...

Je peux le dire aujourd'hui. Il était obligé de compter sur tous. Il aidait. Il était payé en nature (Philippe Roucarie, Un passé pas si simple)

2007 Benoît était sûr à présent que Bogue n'était pas son père, mais il avait conscience de lui devoir gros. Sa lyre, déjà. Et depuis toujours cette précieuse présence masculine amicale, la seule (Georges-Olivier Châteaureynaud, L'Autre Rive)

\section{CORPUS WEB :}

Je lui souhaite un excellent courage à travers cette expérience, de garder la tête haute, car même si il a eu des erreurs de parcourt, il à jusqu'à maintenant apporter beaucoup au niveau de la justice québécoise. Je suis certain que beaucoup de gens lui doivent gros [http:// www.exruefrontenac.com/nouvelles-generales/ justice/27027-proces-lambert] (1.2.2015)

Non seulement il les accompagnait mais en plus il lui sauvait la vie. Visiblement, elle lui devait gros [http://www.gothicat-world.com/ forum/viewtopic.php?f=43\&t=11548\&start=50] (1.2.2015)

REMARQUeS : Devoir gros réfère au fait d'avoir à payer une grosse somme d'argent ou de devoir fournir à quelqu'un quelque chose de valeur, d'avoir beaucoup de dettes envers quelqu'un. Gros 
reste invariable. Dans l'exemple de 1942, l'adjectif-adverbe forme un groupe avec gros d'argent, explicitant ainsi ce qui reste implicite dans devoir gros. Dans les exemples de 2004, 2007 et dans le CW, le sens passe au figuré. Certains auteurs analysent devoir gros comme construction transitive (à complément « léger »; v. Introduction § 6.3), gros jouant le rôle du complément direct. En effet, devoir gros n'admet pas d'autre complément : on ne peut pas dire *devoir gros 3000 euros alors que devoir 3000 euros est usuel.

\section{Diagnostiquer juste}

Diagnostiquer avec justesse, poser le bon

diagnostic

Emploi absolu

1842 L'élève traitant interrogeait le malade en présence du professeur et de tous les élèves ; des questions de la part du premier, des discussions de la part des derniers, s'en suivirent toujours, et le traitant reçut des marques de bienveillance de la part de notre excellent professeur, s'il parvenait à diagnostiquer juste et à prescrire convenablement

(Constant Crommelinck, Rapport sur les hospices d'aliénés)

1893 Le coup d'œil du chirurgien avait diagnostiqué juste. La balle de Dorsenne avait frappé Gorka au-dessous du poignet. Deux centimètres de plus à droite ou à gauche, et sans doute Boleslas était tué du coup (Paul Bourget, Cosmopolis)

1952 Et s'il leur arrive de s'en apercevoir à la suite d'une consultation avec un confrère plus clairvoyant, il est généralement trop tard pour faire machine arrière : le mal irrémédiable est fait, le malade est perdu. Le confrère, qui a diagnostiqué juste, se tait : il préfère se retrancher derrière l'admirable invention du secret professionnel plutôt que de révéler au grand jour la faute impardonnable d'un collègue (Guy des Cars, La Corruptrice)

2008 À eux deux ils retournent la bicyclette, la mettent en équilibre sur sa selle et son guidon, puis entreprennent de démonter la roue arrière. Ils ont visiblement diagnos- tiqué juste, rapidement la roue est extraite, le moyeu démonté. Le réparateur m'en tend l'axe (Christophe Tanguy, Carnets d'un expatrié au cour de la Chine)

\section{CORPUS Web :}

«Diagnostiquer juste est à moitié guérir. » La France d'aujourd'hui se cherche et ne se retrouve pas, au lieu de chercher plus profondément les vrais raisons qui pourraient s'avérer complexes et compromettantes, on a préféré la facilité [http:// www.alterinfo.net/Une-crise-a-la-francaise a8567.html] (1.2.2015)

S'en tenir à cette vue négative serait pourtant négliger que l'hôpital reste le lieu de l'excellence médicale, que les urgences doivent une part de leurs problèmes à l'afflux de sollicitations que leur vaut la confiance dans leur capacité à agir vite, diagnostiquer juste ou soigner bien [http:// www.liberation.fr/evenement/2002/07/13/ myopie_410119] (1.2.2015)

Cela fait 10 ans que je vis le parcours du combattant et encore je ne suis pas arrivée à connaître des noms de médecins ou de pédopsychiatres formés en autisme pour diagnostiquer juste mon enfant, qui a aujourd'hui déjà 12 ans ! [http://forum.autisme.ch/viewtopic.php?id=432] (1.2.2015)

REMARQUES : Diagnostiquer juste désigne le fait d'identifier, de déterminer avec exactitude une maladie par ses symptômes, en faisant un diagnostic correct. Notons que diagnostiquer juste est transitif dans le dernier exemple du CW. Si l'on peut dire que juste réfère à l'objet interne du verbe diagnostiquer (son résultat, le diagnostic, est juste), cet objet interne ne correspond pas au complément d'objet direct 'mon enfant', qui est explicité dans cet exemple. Juste reste invariable.

\section{Dîner bel}

dîner bien et bel : bien dîner

Intransitif

+1365 Et cils, qui au parler s'arine, Les fist venir en un tropel Et dist : Dimence, à bonne estrine, Quant on ot disné bien et bel, De Saint Denis, ce bon hamel, Parti la dame à qui nous sons (Jean Froissart, Poésies [3 $3^{\mathrm{e}}$ tiers XIV ] $]$ ) 


\section{CORPus WeB :}

Jack : " très drôle !.... » Néanmoins, il confirme qu'il dînait bel et bien avec M Kim hier soir quand il a eu son malaise [http://www.lesfeu xdelamour.org/article-4227429.html] (1.2.2015)

Non non ne te frotte pas les yeux, tu n'es pas en train de rêver, on dîne bel et bien dans des bureaux ! [http://www.goutdfood.com/2013/10/ jpeux-pas-ce-soir-jcooknmeet.html] (1.2.2015)

Ils rentrèrent, et finalement, ils dînèrent bel et bien en amoureux [http://tamashii.skyrock. com/3.html] (1.2.2015)

REMARQUES : En ancien français, dîner bel souligne le fait de prendre un repas composé d'aliments délicieux, savoureux et de qualité, régalant et satisfaisant pleinement celui ou celle qui les mange. Notons la collocation dîner bien et bel qui confirme la fonction adverbiale du neutre bel. Le français moderne du CW ne retient plus que la collocation bel et bien au sens de 'effectivement, contre toute expectative', avec possible remotivation dans le dernier exemple. La collocation bel et bien sert donc d'adverbe de phrase à fonction évidentielle.

\section{Dire bas}

I. Dire à voix basse, en murmurant Transitif

1170 Mout par li fait Jason grant joie ; Soëf, basset, que l'om ne l'oie, [variante : bassez]

Li dist : Vassaus, ne tenez mie

A mauvaistié n’a legerie,

Se a vos me vieng acointier (Benoit de Sainte Maure, Le Roman de Troie, 1312)

1177 « Ja, ce croi, ne me leississiez

Sanz chalonge mener un pas !»

Mout le cuida avoir dit bas,

Mes li cuens Guinables l'öi, Qui au monter fu pres de li

(Chrestien de Troyes, Lancelot ou Le Chevalier de la charrete, 214)

+1250 La roïne l'anel li tent,

Et Renart volenters le prent.

Entre ses denz basset a dit

Certes qui unques ne le vit

L'anel, por voir le comparra (Le Roman de

Renart [2e moitié XIII ${ }^{\mathrm{e}}$, I, 1455)
1285 Pour ce en verité retint

Que il Cleomadés estoit,

Sa prouece li tesmoignoit.

Basset a dit : Mout sui joians,

Quant Cleomadés sui servans

(Adenet le Roi, Cleomadés, 13301)

1340 Suer Ysabel. Chiére dame, nous trois ensamble

La dirons, s'il vous plaît, tout bas.

Seez vous hault et nous en bas

Entre vos piez

(Miracle de l'abbeesse grosse, 675)

1357 L'ABBESSE. Pour estre a nous mains ennuiant,

Tout bas disons (Miracle de Theodore, 207)

+1415 Raison s'en rit, disant tout bas :

Escoutez moy ces malleureux !

(Charles d'Orléans, Poésies [ 1415-1440],

II, Rondel LXXIII, p. 331)

1515 Et encor ce qui leurs faisoit pis, c'estoit le tabourin, qui nullement ne se vouloit contenir et disoit tout bas que, par la chair bieu, il sortiroit (Philippe de Vigneulles, Les Cent Nouvelles nouvelles, p. 382, 99)

1596 Ma bouche à haute voix chante assez liberté,

Et dit que je suis franc d'Amour, mon adversaire ;

Mais mon cœur languissant tout bas dit le contraire,

Soupirant sous le joug d'une fiere beauté (Philippe Desportes, Euvres)

1627 Mais elles, feignants de ne recognoistre point son artifice, proferoient entr'elles assez haut des paroles pleines d'admiration qu'elles faisoient toutesfois semblant de vouloir dire bas (Honoré d'Urfé, L'Astrée)

1629 car quoy que je sceusse bien qu'il se devoit faire des jeux d'escrime les jours suivants, et qu'elle vouloit peut-estre parler des prix qui s'y donneroient, lesquels je me devois promettre de mon adresse, si est-ce qu'oyant une si grande Princesse, me dire bas en l'oreille une chose que le pur et simple effect de la courtoisie luy pouvoit 
faire dire tout haut, je fus contraint de prendre une civilité si grande et si extraordinaire, pour tesmoignage de sa bonne volonté, qu'elle me fit depuis assez parestre (François de Boisrobert, Histoire indienne d'Alexandre et d'Orazie)

1667 CÉLIMÈNE. C’est de la tête aux pieds un homme tout mystère,

Qui vous jette en passant un coup d'œil égaré,

Et, sans aucune affaire, est toujours affairé. Tout ce qu'il vous débite en grimaces abonde ;

À force de façons, il assomme le monde ;

Sans cesse il a, tout bas, pour rompre l'entretien,

Un secret à vous dire, et ce secret n'est rien ;

De la moindre vétille il fait une merveille,

Et jusques au bonjour, il dit tout à l'oreille (Molière, Le Misanthrope)

1833 Toujours gardée à vue, comme une criminelle d'État, je ne puis seulement te presser la main, te dire un mot bas à l'oreille (Pétrus Borel, Champavert)

1845 Avant que Gabriel se fût retourné, Rodin eut le temps de dire tout bas au révérend père :

- Il ne sait rien, et l'Indien n'est plus à craindre (Eugène Sue, Le Juif errant)

1866 Cela fut dit si bas que Gilliatt seul entendit (Victor Hugo, Les Travailleurs de la mer)

1886 Et Gaud s'excusait, comme étant chargée de sa tenue :

- C'est qu'elle sera tombée, pour être si sale, disait-elle tout bas ; sa robe n'est plus bien neuve, c'est vrai, car nous ne sommes pas riches, Monsieur Yann ; mais je l'avais encore racommodée hier, et ce matin quand je suis partie, je suis sûr qu'elle était propre et en ordre (Pierre Loti, Pêcheur d'Islande)

1907 Il dit, tout bas :

- Je ne partirai pas (Romain Rolland, Jean-Christophe. La Révolte)
1913 Cette fois, le jeune homme salua, en disant très bas :

- Voulez-vous me pardonner?

(Alain-Fournier, Le Grand Meaulnes)

1932 Une vraie scène de famille... Elle a comme réfléchi un bon coup et puis elle l'a dit plus bas, mais tu sais alors elle l'a dit et puis de tout son cœur «Assassin! Assassin! » qu'elle m’a appelé. Ça ma refroidi un peu (Louis-Ferdinand Céline, Voyage au bout de la nuit)

1979 Ce qui nous est dérobé de la nature et des hommes est incommensurable ; ce que nous en recueillons est minime tant les deux disent bas leurs secrets (René Char, Fenêtres dormantes et porte sur le toit)

1996 Même au moment où ma réputation fut telle qu'il était devenu à peu près inutile d'essayer de me faire passer pour « bonne à marier ", je ne pouvais entrer nulle part sans que ma mère me dise tout bas : "Souris, une jeune fille doit sourire », et elle-même arborait une espèce de pauvre grimace (Marguerite Duras, Cahiers de la guerre et autres textes)

1997 Le général, il était blême, il a dit tout bas : «Son apparition annonce ma mort prochaine », et il est allé dormir ailleurs (Patrick Rambaud, La Bataille)

2000 Alors Marie demande à nouveau combien et le gérant dit tout bas un prix bien plus bas que celui qu'il donnait tout à l'heure, si bien qu'il nous a mises dans sa poche, comme prévu, pour une bouchée de pain quotidien (Anne-Marie Garat, Les Mal Famées)

Pronominal

1698 ne voyant point paroître leur cadet, ils s'applaudissoient de sa négligence, et se disoient tout bas l'un à l'autre : voilà qui est bien heureux, il est mort ou malade, il ne sera point notre rival dans l'affaire importante qui va se traiter (Marie-Catherine d'Aulnoy, La Chatte blanche)

1755 Au fier aspect de cet animal pie le cordelier riant d'un ris malin se dit tout bas, cet 
homme est Jacobin (Voltaire, La Pucelle d'Orléans)

1833 Quand le flot me maudissait dans ma barque, l'orage dans mon sentier, l'épée dans son fourreau, la foudre sur ma tête, ils se disaient tout bas : prenons garde de le toucher, puisque les doigts du Christ l'ont touché avant nous (Edgar Quinet, Ahasvérus)

1886 De temps en temps, il lui montrait d'un signe sa petite sœur Marie et Sylvestre, les deux fiancés, qui dansaient ensemble. Il riait, d'un air très bon, en les voyant tous deux si jeunes, si réservés l'un près de l'autre, se faisant des révérences, prenant des figures timides pour se dire bien bas des choses sans doute très aimables (Pierre Loti, Pêcheur d'Islande)

1979 Mais dès qu'on le laissait seul, il regardait seulement couler le temps qui l'éloignait un peu plus chaque jour. Qui l'éloignait de quoi ? Il se disait tout bas : d'avant. Ce n'était pas un bonheur disparu qu'il regrettait, mais le plus jamais de l'autrefois (Claude Roy, La Traversée du Pont des Arts)

Emploi absolu

$1701 \mathrm{Du}$ soin d'aider le pauvre on dispensa l'avare ;

Et même chez les Rois le superflu fut rare.

C'est alors qu'on trouva pour sortir d'embarras,

L'art de mentir tout haut en disant vrai tout bas.

C'est alors qu'on aprit qu'avec un peu d'adresse,

Sans crime un Prêtre peut vendre trois fois sa Messe

(Nicolas Boileau, Satires [1664-1701])

II. Dire quelque chose secrètement

Pronominal

1694 Si tout votre discours n'est obscur, emphatique,

On se dira tout bas : " C'est là ce bel esprit?»

Tout comme une autre elle s'explique,

On entend tout ce qu'elle dit

(Antoinette Des Houlières, Épîtres)
1747 VALÈRE. Lise a quitté le rouge, et l'on se dit tout bas

Qu'elle ferait bien mieux de quitter Licidas (Jean-Baptiste Gresset, Le Méchant)

1830 Qu'elle m'aime huit jours, huit jours seulement, se disait tout bas Julien, et j'en mourrai de bonheur (Stendhal, Le Rouge et le noir)

1900 ces femmes me sont odieuses; je les déteste, et je me dis tout bas que je n'ai rien de commun avec elles... l'éducation, le frottement avec les gens chics, l'habitude des belles choses, la lecture des romans de Paul Bourget m'ont sauvée de ces turpitudes... ah! (Octave Mirbeau, Le Journal d'une femme de chambre)

Transitif

1898 LE BRET (après un silence, passant son bras sous le sein)

Fais tout haut l'orgueilleux et l'amer, mais, tout bas, dis-moi tout simplement qu'elle ne t'aime pas!

(Edmond Rostand, Cyrano de Bergerac)

CORPUS WEB :

je viens d'entendre la journaliste de BFM dire tout bas "putin " [http://www.jeuxvideo. com/forums/42-51-38099496-1-0-1-0-je-viens-dentendre-la-journaliste-de-bfm-dire-tout-basputin.htm] (1.2.2015)

Ce n'est pas de le dire tout bas, car crois moi j'aimerais bien avoir une discussion d'homme à homme avec Flamby ! [https://fr.answers.yahoo. $\mathrm{com} /$ question $/$ index?qid $=20141123003020 \mathrm{AAg}$ piM5] (1.2.2015)

vous savez il y a ceux qui clament tout haut que la thèse officielle ne peut tenir la ligne et ceux qui la disent tout bas entre 2 lignes comme je me suis laissée entendre par un attaché (intelligence ?) militaire Français que ce n'est pas Ben Laden et que ca se sait tres bien [http://archives. plumedepresse.net/spip.php?article1334] (1.2.2015)

REMARQUES : Dire bas (I) réfère au fait de communiquer quelque chose à quelqu'un en baissant la voix afin de ne pas être entendu de personnes non concernées. (II) désigne le fait d'exprimer par la parole un propos que l'on tient à garder 
secret. Il est souvent employé sous sa forme pronominale, le sujet voulant garder l'information exprimée pour lui-seul. Bas reste invariable et est modifié par bien, plus, presque, si, tout, très. L'exemple de 1701 combine deux adjectifs-adverbes dans dire vrai tout bas. Notons l'emploi de mentir tout haut (mentir haut), faire tout haut (faire haut 'faire semblant d'être') ; clamer haut. VoIR AUSSI : parler bas

\section{Dire beau (bel)}

Dire de façon éloquente, avec de belles paroles Transitif

-1200 Et Floovanz li dit bel et cortoisemant : «Sire, ce ne pout estre, sachez certenemant » (Floovant [fin XII ${ }^{\mathrm{e}}$, 2221)

+1250 Tybert a dit apres le vers, Renart li respont a envers. Puis dit Tybert en sa reison Moult bel Dominus vobiscum (Le Roman de Renart [2e moitié XIII ${ }^{\mathrm{e}}$, 874, XII)

1275 Quant furent pres des tentes, Malaquins s'arresta, Bel et courtoisement lor dist et devisa C'un petit l'atendissent car il revenroit ja. Hastés vous, dist Gerars, car ja ajournera (Adenet le Roi, Buevon de Conmarchis, 3643)

+1350a Tant chevaucha de jor et de nuit ensement Qu'il trouva des barons du seigneur jusqu'a cent,

Et les assembla touz a .i. avesprement, Puis leur dit en oiant bel et courtoissement : «Seigneur, entendez moy, oiez le mandement

Que mes sire vous mande a tous communaument» (Brun de la Montaigne [2 moitié XIV $]$ ], 71)

+1350b A genous se mist moult grascïeussement, Sa dame salua bien et honnestement Et li dit bien et bel : Chiere dame au cors gent,

Me [s]ire vous requiert a cel

commancement

Ceste premiere lance ; or vos veigne a talent (Brun de la Montaigne [ $2^{\mathrm{e}}$ moitié XIV ${ }^{\mathrm{e}}$, 2092)
1663 GROS-RENÉ. M’oses-tu bien encor parler, femelle inique, Crocodile trompeur, de qui le cœur félon Est pire qu'un satrape ou bien qu'un Lestrygon?

Va, va rendre réponse à ta bonne maîtresse, Et lui dis bien et beau que, malgré sa souplesse,

Nous ne sommes plus sots, ni mon maître, ni moi,

Et désormais qu'elle aille au diable avecque toi (Molière, Dépit amoureux)

Emploi absolu

+1200 Por seulement de biau parler

Puet l'en mout grant los acueillir.

Quar qui biau dit, biau veut oür,

Et qui mal dit et qui mal fait, Il ne puet estre qu'il ne l'ait (La Housse partie, 50)

REMARQUES : Dire bel réfère au fait d'énoncer un propos en choisissant bien ses mots, de façon à impressionner ou persuader son interlocuteur. La coordination de bel avec bien et courtoisement souligne sa fonction adverbiale. Le masculin-neutre beau tend à remplacer le neutre bel à partir du moyen français. Dans l'exemple de 1663, l'emploi en coordination syntaxique avec l'adverbe bien confirme que beau succède diachroniquement au neutre dans la fonction adverbiale; dans cet exemple, bien et beau a le sens moderne de 'bel et bien'. En ancien français, bel 'bien' s'opposait à beau 'joli', en ce qui concerne leur emploi au sein du groupe verbal. Ceci est mis en évidence par l'exemple de +1200 , en l'occurrence dans le dicton : qui biau dit, biau veut oïr. Biau parler dans l'exemple de +1200 pourrait être une nominalisation du groupe verbal.

\section{Dire blanc}

I. dire (prononcer, voir) blanc et dire (répondre, entendre, faire) noir : dire une chose et son contraire Emploi absolu

+1366 Garde toy de l'oisel flatant, Car il te cuide decepvoir ; S'il te dit blanc, respons lui noir (Eustache Deschamps, Euvres complètes [3 $3^{\mathrm{e}}$ tiers XIV $\left.\left.\mathrm{X}^{\mathrm{e}}\right]\right)$ 
1396 Parlons de ces traitres, et premierement de flateur mensongeur. C'est comme l'enchanteur du dyable qui fait apparoir ce qui n'est pas, dit de blanc noir et de noir blanc, et tourne en folie et frenesie ceulx et celles qui le recoivent, quer il occist Verité ; et quant Verité fault, Erreur et Fausseté s'i boute (Jean Gerson, Sermon pour la fête de l'annonciation)

1623 donques il n'y a point d'escriture saincte, depuis qu'on void un tel desordre parmy les esprits, que les uns disent blanc et les autres noir, que ceux-cy reçoivent ce livre pour canonique, et ceux-là le renvoyent comme estant apocryphe (François Garasse, La Doctrine curieuse des beauxesprits de ce temps)

1701 Souvent, j'ay beau réver du matin jusqu'au soir :

Quand je veux dire blanc, la quinteuse dit noir (Nicolas Boileau, Satires [1664-1701])

1719 C'est bien la peine d'imprimer.

C'est ainsi que chaque rencontre

Vous voit changer de mesure et de poids ; Disant blanc ou noir ; pour ou contre (Antoine Houdar de La Motte, Fables)

1764 Cela seroit contre toute raison quant au législateur ; parce qu'alors toute la solemnité des loix seroit vaine et ridicule, et que réellement l'État n'auroit point d'autre loi que la volonté du petit conseil, maître absolu de négliger, mépriser, violer, tourner à sa mode les regles qui lui seroient prescrites, et de prononcer noir où la loi diroit blanc, sans en répondre à personne

(Jean-Jacques Rousseau, Lettres écrites de la montagne)

1845 - Ceci me fait souvenir, mesdemoiselles, qu'hier vous avez chuchoté tout le long de l'étape... et quand je vous disais blanc, vous me répondiez noir (Eugène Sue, Le Juif errant)

1863 Je suis comme toi, tu vois bien, je perds la boule ; je dis alternativement blanc et noir (Gustave Flaubert, Correspondance)
1875 PATUREL. C'est non quand je dis oui, oui quand je dis non, noir quand je dis blanc, blanc quand je dis noir... une contradiction perpétuelle, une bataille de tous les instants... si nous allons au théâtre ensemble, elle trouve bête la pièce qui m’amuse, elle s'amuse à la pièce qui me paraît idiote (Henri Meilhac et Ludovic Halévy, La Boule)

1914 Non contents de différer sur des points graves, les deux ministres se contredisaient, l'un disant blanc, l'autre disant noir, et leur lutte intestine naturellement ignorée du peuple français, c'est-à-dire du maître et du souverain, était connue de toute l'Europe (Charles Maurras, Kiel et Tanger)

1918 Alors le général vit qu’ils étaient trop nombreux. Il avait nom Peyre; on en a dit blanc et noir, comme de tous les hommes qui tinrent la queue de la poêle en ce temps-là, mais il était honnête et avait des moyens. Voyant donc le nombre des brigands, il fit sonner la charge pour les effrayer et battit en retraite (Anatole France, Le Petit Pierre)

1954 On préfère l'aveu. " Vous avez dit blanc, vous ne pouvez plus dire noir » et personne ne songe que c'est précisément parce qu'on a dit blanc qu'on peut dire noir et zut (France observateur, 25 février 1954 / Grundt : 251)

1960 FRANTZ. (très sec) Sais-tu qu'il m'arrive de dire blanc quand je veux leur faire entendre noir? (Jean-Paul Sartre, Les Séquestrés d'Altona)

2012 C'était à qui crierait le plus fort. Quand les uns disaient blanc, les autres répondaient noir, un ton au-dessus (Stéphane Osmont, Éléments incontrôlés)

II. Dire sciemment le contraire de quelque chose

Emploi absolu

1863 Il n'y a pas d'art sans liberté, car l'art est une expression de la pensée ; et qu'est-ce donc que l'expression de la pensée, si vous êtes contraint à répéter ce que dit votre voisin, ou à dire blanc quand vous voyez 
noir ? (Eugène Viollet-Le-Duc, Entretiens sur l'architecture)

1896 C'est ainsi qu'aujourd'hui, comme nous nous levions

Après une nuit belle, et que nous nous devions,

Depuis trois fois que nous étions forcément sages,

Tu t’avisas, dans le plus prude des langages Mitigé d'ailleurs par ton air naïf et franc, De me blâmer de faire noir ayant dit blanc, Et dédier ma chair d'homme à la chair des femmes

En des rapprochements nombreux et polygames

(Paul Verlaine, Euvres poétiques complètes)

CORPUS WEB :

Dire blanc et faire noir : la spécialité de la FDSEA87!

Dans son journal de campagne, la liste FDSEA-JA de la Haute-Vienne fait de la défense du revenu des agriculteurs sa principale préoccupation. La CR87 et ses candidats de la liste « Changer, c'est vital » sont heureux de voir que leur opposants se réveillent enfin! [http://www. coordinationrurale.fr/comment-la-fdsea87-oseparler-de-revenu.html] (1.2.2015)

La gauche clamait sa volonté de rétablir la laïcité bafouée par la droite. Elle n’en fait rien. C'est insupportable. Elle tient des discours de droite pour acheter les voix de la droite. Dire blanc et faire noir, c'est pousser les gens à s'abstenir, ce qui n'est déjà pas bien, ou à voter Front national [http://www.sudouest.fr/2014/12/12/lalaicite-en-debat-ce-vendredi-avec-henri-penaruiz-1766508-3536.php] (1.2.2015)

En société, la Sagittaire adore caracoler, et tant pis si cela doit l'amener à être plus snob que sincère. De toute façon, cette pragmatique sera toujours capable de dire blanc et noir sans s'emmêler dans ses pinceaux [http://www.style listquebec.ca/2014/01/19/horoscope-2014-droleet-cruel-3e-partie] (1.2.2015)

Les couleurs ont un goût de bleu, sentent le jaune, sont rouge au touché, se voient en blanc et parfois elles peuvent s'entendre noir [http://www. saithbautistaart.com] (24.3.2015) oui Il est l'homme du mensonge qui nous dit blanc il faut entendre noir [http://www.bfmtv. com/politique/la-perte-du-aaa-un-obstacle-surla-route-de-nicolas-sarkozy-217779/avis $/$ ?page= 30] (24.3.2015)

Le plus dur est de confronter l'être avec le paraitre, entendre noir alors que l'on ressent blanc est parfois difficile à gérer et croyez moi il faut avoir la foi [http://niombrenilumiere.forum gratuit.org/t1184p30-un-petit-peu-bizarre] (24.3.2015)

REMARQUES : Au figuré, dire blanc s'oppose à dire noir, c'est-à-dire son contraire, formant un schéma lexicalisé qui désigne un comportement contradictoire. (I) désigne le fait d'énoncer un propos et son contraire, celui-ci pouvant être émis par la même personne ou non, les énoncés opposés étant représentés par les antonymes blanc et noir. (II) décrit la situation dans laquelle la chose dite ne coïncide pas avec l'action effectuée (dire blanc et faire noir), ou avec la perception de la réalité (voir blanc et faire noir). Le CW met en évidence la productivité du schéma qui admet aussi d'autres verba dicendi et sentiendi qui s'opposent souvent à ce qui est fait (faire noir). Dire blanc est ainsi mis en opposition avec répondre noir, prononcer noir, entendre noir, faire noir, voir noir. Ces exemples montrent que l'opposition blanc : noir se retrouve dans une série assez ouverte de verbes. Dans le quatrième exemple du CW, s'entendre noir s'emploie dans un sens concret et métaphorique à la fois, évoquant éventuellement des sentiments noirs, sans l'opposition avec blanc (ici : en blanc), dans lesquels se voit baigner celui qui perçoit cette mer de couleurs. Blanc et noir restent invariables. Dire blanc / noir ne se prêtent pas à la modification (* plus blanc / noir), mais on trouve le modifieur alternativement pour les contraster. Notons l'emploi de ressentir blanc. VoIR AUSSI : répondre noir ; d'autres exemples sous dire noir

\section{Dire bref}

Dire brièvement, de manière concise Transitif

1341 SECOND MENESTERÉ. Voirment yrons nous de cuer baut.

Mais, $d y$ nous brief, sanz delaier, Ou l'en doit ainsi festaier : 
Est ce une noce? (Miracle de l'evesque que l'arcediacre murtrit, 635)

-1342 Or te vueil dire brief et court De quoy il servent a ma court (Guillaume de Machaut, Le Dit dou vergier, 629)

+1400 A brief dire, sans jamais le ravoir, Toute m'amour je vous octroye en don (Christine de Pisan, Cent balades d'amant et de dame / Euvres poétiques [début $\mathrm{xV}^{\mathrm{e}}$ ], III, p. 235, 23)

1579 LUCIAN. Le suc de nos melliflus propos est à bref dire ce que chante l'Eclesiaste : Cum sancto sanctus eris, et cum perverso perverteris. Ideo, Cato, cum bonis ambula (Pierre de Larivey, Le Laquais)

1828 FAUST. Monsieur le magister, laissez-moi en paix ; et je vous le dis bref et bien : si la douce jeune fille ne repose pas ce soir dans mes bras, à minuit nous nous séparons (Gérard de Nerval, Faust [trad.])

1837 Il m’a donc dit ce matin à l'amphithéâtre que... que... eh bien, que le censeur des études M. C qui [a] une chemise sale, des bas sales, une âme sale, et qui enfin est un salop, il m'a dit bref qu'il avait été surpris dans un bordel et qu'il allait être traduit devant le conseil académique (Gustave Flaubert, Correspondance)

CORPUS WEB :

Tout ça pour dire bref, que contrairement à ce que tu penses, je ne suis pas une si méchante fille pour t'en vouloir jusqu'à ta mort et comme tu t'es justifié de façon correcte, je passe à mon tour l'éponge [http://forums.mangas-fr.com/index. php?topic=40797.610;wap2] (1.2.2015)

Dsl andie c que je t'ai souvent écrit et j'ai pas eu de réponse pas personnellement juste te dire bref que tu es vraiment une chanteuse ACCOMPLI continue !! [https://fr-fr.facebook.com/ andieduquette/posts/497504850371684] (1.2.2015)

Puis, une de mes amies regarde le prix et me demande, sourir en coin, d'essayer de le deviner... $167000 \$$ !!! (Je crois que l'équivalent en euro soit de +/- 115000 euro) Disons, pour dire bref, que je me sentais presque gêné d'y toucher... Ah oui ! [http://www.pianomajeur.net/forum/viewtopic. php?f=1\&t=859] (1.2.2015)

REMARQUES : Dire bref désigne le fait d'énoncer un propos en employant peu de mots, donc en peu de temps. Notons l'expression à dire bref ainsi que la collocation bref et court, renforçant le sémantisme. Bref (brief) reste invariable. L'exemple de +1400 , à brief dire 'pour tout dire', reflète le développement vers une fonction de marqueur du discours de récapitulation correspondant au français moderne bref (ex. Bref, il n'était pas content) et enfin bref (ex. Enfin bref ! au sens de 'il n'y a rien à faire, c'est comme ça, il faut l'accepter'). Bref reste invariable.

\section{Dire brut}

Dire (quelque chose) sans ménagement, brutalement

入 dire $\mathrm{cru}$

\section{Dire clair}

Dire clairement, distinctement, explicitement

Transitif

1100 Cler en riant l'ad dit a Guenelun :

« Tenez m'espee, meillur n'en ad nuls hom ;

Entre les helz ad plus de mil manguns.

Par amistiez, bel sire, la vos duins,

Que nos aidez de Rollant le barun,

Qu'en rereguarde trover le poüsum » (Chanson de Roland, 619)

+1100 Ele avoit le chief blondet,

Si faisoit un chapelet

Et disoit ceste chancon

Molt haut et seri et cler

« Robeconet, la matinee

Vien a moi joer » (Romances et pastourelles

françaises des XII et XIII ${ }^{e}$ siècles, p. 283)

1365 La Royne i entra, puis prist à apeller

Son gentil maronnier, si li dist haut et cler : Biaus maistrez, je vous pri que nous voelliez mener

Droitement à Boulongne, car g'i voel arriver (Li Romans de Bauduin de Sebourc, Chant III, 193)

1450 SAINT PIERRE. Si grant courroux en moy se boute 
Que boire ne mengier ne puis.

Pour Dieu, mon maistre, se je suis

Celuy qui vostre mort procure,

Dictes le au plain [variante : dictes le cler],

car je n'ay cure

Que me cellez ung tel meffait,

Affin, se j'ay vers vous meffait

Tous mes compaignons me destruisent

(Arnoul Gréban, Le Mystère de la Passion, 18132)

1538 Lors Renommée avec ses esles painctes Ira volant en bourgs et villes maintes, Et sonnera sa trompette d'argent,

Pour autour d'elle assembler toute gent ;

Puis hault et clair de cent langues qu'elle a

Dira ta vie ; et puis deçà et là

Ira chantant les fins tours dont tu uses,

Tes laschetez, tes meschances et ruses

(Clément Marot, Élégies)

1560 Qui plus est, que plaidons-nous du sens de ces parolles, comme s'il estoit obscur ou douteux, veu qu'on ne sauroit rien dire plus clair ne plus certain? (Jean Calvin, Institution de la religion chrestienne)

1604 Tu le dis haut et clair et d'une voix certaine, En branlant le Laurier dont ton chef est orné (Antoine de Montchrestien, Hector)

1866 J'aime cette vie saine et franche, et cet homme droit et naturel, qui raconte ses trente années de paysannerie et ses vingt et une années de régisseur rural, suivies de la période d'instituteur et d'écrivain chasseur, et raconte tout cela sans gloriole ni fausse honte, d'un parler sobre et net, qui va droit au but et dit clair ce qu'il veut dire (Henri-Frédéric Amiel, Journal intime de l'année 1866)

1920 Le meilleur repas m'est, je vous le dis tout clair, une chose odieuse, s'il me faut l'avaler, par exemple, sur l'air de la " veuve joyeuse » (Raoul Ponchon, La Muse au cabaret)

\section{CORPUS WEB :}

Pour dire clair, on aura du mal à cerner toutes ces comptines, et c'est tant mieux, car notre bonhomme n'aime rien tant que ces mots impressionnistes, comme lorsqu'on fixe de très près une tache sur le sol, et que la couleur finit par perdre ses contours [http://www.amazon.fr/ Clair-Jp-Nataf/dp/B002OFG5LC] (1.2.2015)

Ils ne font qu'exécuter un ordre qui leur est transmis par le parquet. Donc pour le dire clair et net : eux n'y sont pour rien! [http://www.ances. lu/index.php/55-radelux/166-le-placement-desenfants-et-l-intervention-des-forces-de-l-ordrela-force-de-la-loi-ou-la-loi-de-la-force] (1.2.2015)

Résolument installé dans la mouvance des penseurs au dire clair et franc, ses thèses proposent une véritable armature de compréhension du fait négrier et colonial à la base du peuplement nouveau des Caraïbes [http://www. rogertoumson.com/2.html] (1.2.2015)

Je vais te la dire clair et net, la Russie n'est pas une democratie, les droits de l'opposition n'y sont pas du tout respectés et Poutine fait ce qu'il veut dans le pays ! [http://forum. olweb.fr/showthread.php?152439-Actualit\%E9sinternationales/page27] (1.2.2015)

Certes il est plus facile de communiquer le commun et donc de prétendre à une idée claire puisquechacuns'accordera àla dire claire [https:// www.google.fr/\#q=\%22la $+<$ dire $+<$ claire $\% 22$ ] (1.2.2015)

Remarques : Dire clair désigne le fait de communiquer quelque chose, d'énoncer un propos à quelqu'un d'une manière claire, que ce soit en prononçant distinctement ou en tenant des propos sans ambiguïté. Notons la collocation haut et clair, traduisant l'idée d'élévation de la voix pour que ce soit entendu de tout le monde. L'usage actuel dans le CW tend à employer la collocation clair et net, avec la variante analogique clair et franc. Clair reste invariable et est modifié par moult, plus, tout. Il s'accorde cependant avec l'objet au féminin dans le dernier exemple du CW ; clair insiste alors sur la clarté de l'idée. Le même effet s'observe avec le masculin dans l'exemple de 1560 , où le français moderne pourrait remplacer ne saurait rien dire plus clair par ne saurait rien dire de plus clair. Ces deux exemples marquent le passage de la fonction d'adverbe de manière dans dire clair à la modification de l'objet direct, ce qui explique aussi la flexion dans le dernier exemple, qui met en avant la clarté d'une idée. Notons la nominalisation des verbes dans 
le troisième exemple du CW. Notons également l'emploi absolu dans le premier exemple du CW. Mentionnons également l'emploi de aller droit au but. VoIR AUSSI : confesser clair

\section{Dire compréhensible}

S'exprimer clairement

$\pi$ dire juste

\section{Dire court}

I. Dire rapidement, brièvement, simplement Emploi absolu

1340 Je me rens confesse et coupable A Dieu le pére esperitable, Qui pour nous en croiz mort souffri, Et a sa doulce mére aussi Et des cieulx a toute la court, Sire, et a vous, pour dire court, Conme celle qui a meffait Contre Dieu trop vilain meffait (Miracle de l'abbeesse grosse, 1121)

Transitif

-1342 Or te vueil dire brief et court De quoy il servent a ma court (Guillaume de Machaut, Le Dit dou vergier, 629)

1364 Se savoir vuelz pour quel raison Je fui bannie de sa court, Je le te dirai brief et court (Guillaume de Machaut, Le Livre du voir dit, 7816)

+1480 A le vous dire brief et court, Parleray je de gens de court $\mathrm{Ou}$ praticiens en court laye ? (Sermon nouveau d'ung fol changant divers propos [ 1480-1490], 123)

1500 La court est une estrange beste : Pour le vous dire brief et court, Il est bien fol qui la acourt Pour y trouver tous les jours feste (Antitus, Poésies)

1560 Il ne nie pas que ce ne soit un Concile légitime, mais il dit plat et court qu'il a peu errer (Jean Calvin, Institution de la religion chrestienne)

1601 et, pour le dire plus court et plus clairement, c'est que le temperament du cerveau, duquel a esté tant parlé cy-des- sus, par lequel et selon lequel l'ame agist, est divers et changeant ; et estant bon pour une fonction d'ame, est contraire à l'autre (Pierre Charron, De la sagesse)

II. dire tout court : Dire sans plus, tout simplement; nommer tel quel

Transitif

-1456 Les seigneurs françois que le roy lui avoit bailliés pour lui servir ne l'en peurent destourner, lors lesdits seigneurs poulains lui dirent tout court qu'ilz ne le serviroient plus en tel estat (Antoine de la Sale, Jehan de Saintré, p. 157, 29)

1515 Et ce fait, s'en alla au lict, auquel il ne fut pas demeye heure que le ventre petit à petit luy racommence à faire mal et tant que aprés pluseurs parolles qu'ilz eurent, luy et sa femme, il luy dit tout court qu'il estoit force qu'il allaist encor au retraict (Philippe de Vigneulles, Les Cent Nouvelles nouvelles, $\mathrm{p} .315,140$ )

1619 Mais je vous dis nettement et sans exception, ne vous courroucés point du tout, s'il est possible, et ne recevés aucun pretexte quel qu'il soit pour ouvrir la porte de vostre cour au courroux ; car saint Jacques dit tout court et sans reserve, que l'ire de l'homme n'opere point la justice de Dieu (Saint François de Sales, Introduction à la vie dévote)

1669 MONSIEUR DE SOTENVILLE. Doucement, mon gendre. Apprenez qu'il n'est pas respectueux d'appeler les gens par leur nom, et qu'à ceux qui sont au-dessus de nous il faut dire "Monsieur » tout court (Molière, George Dandin)

1704 puisque lui-même qui n'ignoroit rien et surtout, qui n'ignoroit pas cette heure dont il estoit le dispensateur, ayant trouvé un costé par où il pouvoit dire qu'il l'ignoroit, parce qu'il l'ignoroit dans son corps et qu'il estoit de son dessein que son dessein que son Église l'ignorast, il dit tout court qu'il l'ignore et nous enseigne à ne rougir pas de nostre ignorance (Jacques-Bénigne Bossuet, Méditations sur l'Évangile) 
1842 Solange est très orgueilleuse de dire Pauline tout court en parlant de vous (George Sand, Correspondance)

1956 Et, renonçant aux moyens dont seul le roman dispose, ils renoncent à ce qui fait de lui un art à part, pour ne pas dire un art tout court (Nathalie Sarraute, L'Ėre du soupçon)

1983 Il aimait apprendre (On disait apprendre tout court, comme boire ou manger) (Annie Ernaux, La Place)

CORPUS WEB :

Et pourquoi doit-on identifier quelqu'un selon sa nation ? Pourquoi pas selon sa citoyenneté et dire tout court qu'il est canadien ? [http:// fr.wikipedia.org/wiki/Discussion:Marc_Favreau] (1.2.2015)

Assumez vos responsabilités jusqu'au bout pour dire tout court, je suis charlie et je ne suis pas musulman [http://senego.com/2015/01/16/ macky-sall-je-ne-peux-pas-cautionner-lapublication-de-charlie-hebdo-dans-mon-paysmusulman-a-95_210600.html] (1.2.2015)

Du coup, Monseigneur Dagens aurait mieux fait de ne rien dire tout court ! ça dénote ces paroles hors coup médiatique.... [http://www. charentelibre.fr/2015/01/12/1-eveque-d-angou leme-scandalise-par-les-bancs-grillages, 1934660.php] (1.2.2015)

Si on n'aime pas la verite soi meme, on a du mal souvent a la dire tout court [http://jesus isthehealer.les-forums.com/topic/123/les-epouxdoivent-tout-se-dire/goto/231] (1.2.2015)

REMARques : Court est un adjectif-adverbe de dimension. Relatif au temps, dire court désignait le fait d'énoncer un propos brièvement, en employant peu de mots ou de dire quelque chose simplement, sans pédanterie, notamment dans la collocation usitée jusqu'en moyen français bref et court. À partir du XVII ${ }^{\mathrm{e}}$ siècle, tout court se lexicalise au sens de 'sans plus, tout simplement', seul présent dans le CW. Dans l'emploi moderne, il peut s'associer syntaxiquement au nom ou au verbe qui le précèdent immédiatement : Pauline tout court (1842), un art tout court (1956), dire « apprendre » tout court (1983). Court reste invariable et est modifié par plus, tout. Notons les variantes dire plat et court, et dire plus court et plus clairement. Ce dernier souligne la fonction adverbiale de court.

\section{Dire cru}

Dire directement les choses, dire directement ce qu'on pense, sans ménagement

Transitif

1781 Voici autre chose, M. le Turc, tous les mouchars, ou, si vous aimez mieux, tous les Mandrins font aux trousses d'un autre sublime Linguet, barbouilleur, qui barboüille à merveille ! qui dit tout cru ce qu'il pense (Mercure Turc)

1823 C'était pour lui un jour d'étonnement : il fut surpris de mon grec. Il me montra luimême un morceau de la Couronne qu'il avait traduit. Nous parlâmes encore de politique et de religion ; et je lui dis tout cru ce que je pensais (Jules Michelet, Écrits de jeunesse)

1831 Je te le dis net et cru, une telle neutralité est à mes yeux un crime envers soi-même, une blessure inguérissable à sa conscience (Alphonse de Lamartine, Correspondance générale)

1836 Je dis tout net et tout cru ce qui me vient (George Sand, Correspondance)

1935 Oh ! à certains moments, oui, ils se surveillent, ou plutôt ils parlent comme on leur a appris qu'il était convenable de parler. Mais à d'autres ils disent tout cru ce qu'ils pensent, ce qu'ils sentent (Jules Romains, Les Hommes de bonne volonté)

1984 Lalaire, à qui j’avais dit tout cru ma façon de penser, avait tenu à nous accompagner à Orly (Evane Hanska, Les Amants foudroyés)

1994 Mais tout cela était assez confus dans sa tête et si quelqu'un s'était avisé de le lui dire tout cru, Francis aurait répondu qu'un couple devait vivre comme cela, que c'était évident, et qu'il était inutile et inconvenant d'en parler (François Delivré, Le Pouvoir de négocier) 


\section{Corpus Web :}

Non mais c'est dur de te dire tout cru comme ça si pour toi c'est une bonne affaire ou non... [http://forum.macbidouille.com/index.php?sho wtopic $=339608 \&$ pid $=3386819 \&$ mode $=$ threaded $\&$ start=] (1.2.2015)

je ne suis pas le genre à mettre les pieds dans le plats, vous me connaissez tout en tact et délicatesse, mousse et pampre... mais là, l'honnêteté m'oblige à vous le dire tout $\mathrm{cru}$, ça sent le gars qui veut se faire sucer [http://www.planete-ducati. com/forum/index.php?topic=18927.10;wap2] (1.2.2015)

En fait, je vais vous le dire tout cru et brut de coffrage : c'est de l'animisme revêtu d'un langage chrétien! [https://actualitechretienne.wordpress. com/2014/07/18/remy-bayle-au-cameroun-il-ya-une-forme-devangile-qui-nest-pas-levangile] (1.2.2015)

le mieux c'est que tu étudies plus sérieusement toutes ces questions de "terrorisme", bien entendu pas sur tfi fr2 etc, la vérité sur le terrorisme, mon petit poulet, je vais te la dire tout cru et tanpis pour tes illusions de justicier à deux balles [https://fr.answers.yahoo.com/question/ index?qid=20070605082656AAtdhdY] (1.2.2015)

le meilleur moyen de cacher la vérité, c'est de la dire toute crue! [http://forum.macbidouille. com/lofiversion/index.php/t31534.html] (1.2.2015)

REMARQUeS : Employé presque exclusivement dans la collocation dire tout cru, le groupe désigne le fait d'énoncer un propos sans altération et sans détours, d'exprimer les choses telles qu'elles sont, sans fard, ni affectation, avec franchise et naturel. Notons les collocations dire net et cru, et cru et brut, renforçant le sémantisme. $\mathrm{Cr} u$ reste invariable dans la plupart des cas. Il s'accorde cependant avec l'objet au féminin dans le dernier exemple du CW, se rapprochant ainsi d'un prédicat second orienté vers l'objet ; l'accord y est appuyé par le féminin toute.

\section{Dire direct}

Dire directement, sans ambages

$\lambda$ aller direct

\section{Dire droit}

I. Dire le droit (substantif)

Transitif

$\sim 1160$ As ne sorent trover nul home

Qui miauz en sache dire droit

que Paris, qui el bois estoit (Eneas, 115)

+1233 Seignor, fet il, dites me droit [variantes, éd. Constans : direz me drois / dites ent dreit]

De cest mien traïtor revoit, Savoir qual justice en ferai Ferai le pendre, ou se l'ardrai (Roman de Thèbes [ $2^{\mathrm{e}}$ tiers XIII $]$ ], 7801)

Emploi absolu

1370 Semblabement en ceste vie humaine, ceulz qui font operacions de bonnes choses et de tres bonnes œuvres, il sont $a$ droit dire nobles, excellens et beneurés (Nicole Oresme, Le Livre de Ethiques d'Aristote, I, p. 126)

II. Dire directement, avec franchise, ouvertement, honnêtement

Transitif

1480 A parler de la fureur et violences de leurs bonbardes, ne s'en pourroit droit dire ce qui en est, car c'est la chose la plus impétueuse et mervilleuse qui jamaiz fust ne de quoy on oyt oncques parler a grant paine le peut l'en croyre (Pierre Barbatre, Le Voyage à Jérusalem en 1480)

1844 Pour moi, je ne sais rien inventer et je vous dis tout droit la vérité, vous laissant le choix du mensonge (George Sand, Correspondance)

1850 Pourquoi ne pas dire tout droit à ce Monsieur V. Henry, que je n'agis que par vos conseils et que vous ne me conseillez pas de me fourrer dans sa bagarre ? (George Sand, Correspondance)

1911 Comme il dit tout droit ce qu'il lui importe de dire! (Maurice Barrès, Greco ou Le Secret de Tolède)

1958 Pour soutenir l'histoire [...] on n'a point fait d'effort littéraire. Ça dit, tout droit, tout gros, ce que ça a à dire, strictement (Sélection du Monde, 2-7 mai 1958 / Grundt : 383) 
Pronominal

1701 Tierce, Sexte et None se diront en mesme ordre ; la priere, c'est à dire, le Verset, Deus in adjutorium, puis les Hymnes des mesmes Heures, les trois Pseaumes, la Leçon, le Verset, Kyrie eleison; et ainsi on finira. Si la Congregation est grande, que ces Heures là soient chantées avec Antiennes : et si elle est petite, qu'elles se disent tout droit (saint Benoît, La Regle du bienheureux pere saint Benoist)

\section{CORPUS WEB :}

Fin 2002, Ferrat disait tout droit à rfimusique.com : "Ce qui est pour moi un sujet de satisfaction, c'est d'avoir mis dans la rue des chansons issues de la grande poésie française, en particulier Aragon » [http://www.petitions24. net/forum/15254/start/30800] (2.2.2015)

Nous prenons la parole pour qu'elle sonde, pour qu'elle s'affranchisse, pour qu'elle emporte avec elle le secret des mots anciens, ceux qui pesaient comme la pierre, ceux qui ne se cachaient pas, ceux qui disaient tout droit le poids de leur sens [https://nantes.indymedia.org/ articles/23824] (2.2.2015)

c'est clair que si tu vas chez Cit avec une panne hydrau, il te disent tout droit : « faut pas insister mon bon monsieur ! qd ça commence, on ne sait pas qd ça s'arrête - voyez donc là-bas notre nouvelle C5 à $25000 \mathrm{E}$ ! » [http://www. yaronet.com/posts.php?s=80583] (2.2.2015)

@Akina, je me disait droit la même chose au niveau densité rien qu'un pied à la taille d'un lingot de $20 \mathrm{~kg}$ en plus les reflets ça fait plus feuille d'or que lingot fondu [http://lelombrik. net/12266] (2.2.2015)

REMARQUES : Dire droit (I), où droit est un substantif, ne devrait pas figurer dans ce dictionnaire, en principe, mais les trois citations mettent en évidence une possible transition au sens (II). $\mathrm{Au}$ figuré, dire droit (II) désigne le fait d'énoncer un propos sans altération et sans détours, d'exprimer les choses telles qu'elles sont, sans fard, ni affectation, avec franchise et naturel. Notons les locutions à dire droit ou à droit dire ainsi que l'emploi analogique de dire gros dans l'exemple de 1958, dans un registre populaire. Droit reste invariable. Dans l'emploi moderne, il est générale- ment modifié par l'adverbe d'intensité tout, mais le dernier exemple du CW renoue clairement avec l'usage vieilli (possible régionalisme).

\section{Dire dur}

S'exprimer avec dureté

$\lambda$ dire sec

\section{Dire faux}

I. Dire une chose non conforme à la vérité, mentir

Emploi absolu

1370 Teles vertuz selon lesquelles l'ame dit verité, ou en affirmant ou en noiant, il sont .v. en nombre et sont cestes : art, science, prudence, sapience, entendement. Car suspicion et opinion ne sont pas de cest nombre, pour ce que il avient aucune foiz que par suspicion et par opinion l'en dit faux (Nicole Oresme, Le Livre de Ethiques d'Aristote, II, p. 334)

1601 Et Charles incertain s'ils disoyent faux ou vray, les tenant en son pouvoir, estima qu'il pouvoit mettre en deliberation s'il devoit faire le voyage d'Espaigne, ayant la paix tout par tout : et qu'aussi bien il luy convenoit rompre son armée (Claude Fauchet, Fleur de la maison de Charlemaigne)

1655 Le Diable (dites-vous) est Père de mensonge. Pourquoy donc, l'autre jour, fistesvous brûler ce Magicien, qui ne fut accusé que par le Diable? Car je responds comme vous : « le Diable est Père de mensonge ». Avoüez, avoüez, mon Révérendissime, que le Diable dit vray ou faux, selon qu'il est utile à vostre malicieuse paternité (Savinien Cyrano de Bergerac, Les Lettres)

1668 Mercure, au lieu de donner celle-là, Leur en décharge un grand coup sur la tête.

Ne point mentir, être content du sien, C'est le plus sûr : cependant on s'occupe À dire faux pour attraper du bien : Que sert cela? Jupiter n'est pas dupe (Jean de La Fontaine, Le Bûcheron et Mercure / Fables) 
1684 Cependant, demesme que de deux hommes, dont il y en a un qui dit, Corisque joue, l'autre Corisque ne joue pas, ou dont il y a un qui dit, Corisque joüa hyer, l'autre Corisque ne joua pas hyer, l'un dit vray, et l'autre faux, encore que je ne puisse pas dire lequel des deux dit vray, lequel dit faux, acause que presentement je suis, ou que je fus hyer absent (François Bernier, Abrégé de la philosophie de Gassendi)

1715 - Je ne veux pas m'opiniâtrer contre vous, ajouta Danhasch ; le moyen de vous convaincre si je dis vrai ou faux, c'est d'accepter la proposition que je vous ai faite de venir voir ma princesse, et de me montrer ensuite votre prince (Antoine Galland, Les Mille et une nuits)

1762 Mais quand trompé par son jugement il va plus loin, et qu'après avoir affirmé qu'il voit un bâton brisé, il affirme encore que ce qu'il voit est en effet un bâton brisé, alors il dit faux : pourquoi cela ? (JeanJacques Rousseau, Émile ou De l'éducation)

1774 Car tant que vous ne détruirez pas les faits articulés dans mon supplément : tant que vous ne prouverez pas que j'ai dit faux sur les débats de notre confrontation, sur vos aveux forcés, sur les contradictions de vos interrogatoires ; tant que vous ne laverez pas M. Goëzman de l'infamie d'avoir suborné Lejay, d'avoir minuté la déclaration chez lui, dans sa maison, à son bureau, avant qu'il y eût de procédure entamée, et d'avoir fait et nié les faux remarqués dans ces déclarations [...] je ne suis pas tenu d'user mon temps à vous répondre (Pierre-Augustin de Beaumarchais, Mémoires contre M. Goëzmann)

1776 Allez, allez, leur dit Joseph ; vous êtes des espions. Envoyez quelqu'un de vous chercher votre petit frere ; et vous resterez en prison, jusqu'à ce que je sache si vous avez dit vrai ou faux (Voltaire, La Bible enfin expliquée par plusieurs aumoniers de S.M. L.R.D.P.)

1822 Si l'on m'a dit vrai, que toute ta trace de toi soit séparée, que toute nouvelle de toi soit ensevelie. Si l'on m'a dit faux, je ne fais rien de mal en enfouissant un coffre : ce n'est que du bois enterré (Stendhal, De l'amour)

1835 - Dis-tu vrai ? Répondit Sanréal, enchanté.

- Dans ces choses-là, mon cher, répliqua Roller d'un ton sec et piqué, tu dois savoir que je ne dis jamais faux.

- Est-ce que tu vas me faire des phrases, à moi ? Répondit Sanréal d'un air de spadassin. Nous nous connaissons (Stendhal, Lucien Leuwen)

1851 « Tu veux m’attraper ou tu veux rire, Denise ; ça n'est pas bien ; tu sais qu'il ne faut pas badiner avec les aveugles, parce qu'ils ne peuvent pas voir si on dit vrai ou faux. " Puis, se tournant de mon côté en entendant rire la jeune fille : " dis-moi, Claude, comment elle est " (Alphonse de Lamartine, Le Tailleur de pierre de SaintPoint)

1905 Tenez, voilà qui est décidé, je ne veux plus me « fouiller » l'âme ainsi, vous ne pouvez deviner comme cela me fatigue, m'énerve, m'exaspère dans le doute où je flotte, ne sachant si je dis vrai ou si je dis faux, si je me trompe moi-même en m'excitant aux mots, aux injures que je prodigue à mon esprit et qui une fois votre lettre écrite me laisseront face à face avec mon bleu défraîchi (Georges Bernanos, Lettres inédites)

1936 Occasion encore de se tromper. Ce serait trop beau si les menteurs mentaient toujours ; et il n'y a point de vraisemblance pour qu'un homme que je n'aime point dise toujours faux. Et certes cela s'explique assez déjà par les passions. Nous n'aimons point contredire quand nous aimons, ni approuver quand nous haïssons (Alain, Propos)

1987 - Ça peut aller ? y me colloque, ce vieux singe.

Je dis oui comme quand on sort de chez l'arracheur de crocs, si t'en reste... Mais lui, y se demande pas si je dis vrai ou faux. 
S'assoit à côté. Il est lourd pour un paquet de tibias. Les os morts pèsent peut-être plus que les autres. Va savoir (Jean-Louis Degaudenzi, Zone)

II. Dire avec des intonations fausses, en manquant de naturel

Emploi absolu

1426 Maiz, quant des choses composées

Et à ce propos disposées, Est le triacle, pour certain, Moult précieux et souverain, Maiz qu'il soit fait depuiz dix ans, Ou les acteurs sont faulx disans, Duquel fault prendre chascun moiz, Ou par quinzaines une foiz (Olivier de La Haye, Poëme sur la grande peste de 1348)

\section{CORpus Web :}

Le principe qui déternime le mensonge est non de dire faux, mais l'intention de tromper en disant faux. Il faut donc faire une distinction entre erreur (involontaire) et mensonge (volontaire) [http://www.etudier.com/dissertations/ Qu'Est-Ce-Que-Mentir/95593.html] (2.2.2015)

Mais... c'est bien, nous sommes forcés, ce qui prouve que nous ne pouvons pas dire faux, hein ? C'est que nous sommes forcés d'énoncer des propositions dont nous ignorons nous-même le sens... [http://www2.univ-paris8.fr/deleuze/ article.php3?id_article=266] (2.2.2015)

Quelque sinistre urluberlu pourrait s'amuser à montrer, en mentant, que dire faux et dire vrai sont la même chose ou même que dire faux par intention est préférable à dire faux par erreur [http://www.franceculture.fr/emissionle-gai-savoir-le-mensonge-la-querelle-kantconstant-2013-06-02] (2.2.2015)

REMARQUeS : Dire faux (I) désigne le fait d'énoncer un propos contraire à la vérité ou qui contredit l'existence de quelque chose, la vérité étant connue par celui qui écoute ce propos (l'autre se trompe) ou celui qui le dit (ment). En (II), il renvoie à une certaine fausseté dans le discours, à un manque d'authenticité. Il peut également connoter la fausseté de quelqu'un. Notons la collocation contrastive dire vrai et faux. Faux reste invariable. Il est modifié par jamais, toujours.

\section{Dire ferme}

I. Dire avec fermeté, dire avec certitude ; confirmer fermement

Transitif

1698 Avez-vous dit cela à Dona Juana, dit Isidore ? Je n'y ai pas manqué, répliqua Don Louis, et je lui ai trouvé quelque répugnance à les renvoyer : mais je lui ai dit si ferme qu'il le falloit, et que j'en prendrois le soin, qu'ayant peur que je ne les maltraite, elle m'a dit qu'elle veut le faire ellemême (Marie-Catherine d'Aulnoy, Finette Gendron)

1842 On pourrait bien objecter, pour le fond, que saint Thomas vient là un peu en contrebande, que Saint-Cyran ne l'y aurait pas mis, que Jansénius et lui n'auraient pas dit si ferme que c'était là leur créance ; car ils croyaient que les justes n'ont pas toujours ce pouvoir (Charles Sainte-Beuve, Port-Royal)

1952 ESTRAGON. Il devrait être là.

VLADIMIR. Il n'a pas dit ferme qu'il viendrait (Samuel Beckett, En attendant Godot)

II. Discuter vivement

Emploi absolu

1934 Tout ça, c'est des histoires de femmes, et les histoires de femmes, pour bien les comprendre, faut connaître ce qui se passe sous les jupes de celles qui en débitent. Enfin, ça disait ferme, en pleine rue. Elles en disaient à peu près comme elles tricotent, sans plus d'effort, et sans mettre plus de bon sens dans une parole que dans une maille, comme des poules après l'œuf, ça pouvait se comparer (Gabriel Chevallier, Clochemerle)

\section{Dire fort}

I. Dire en élevant fortement la voix Transitif

+1350 .I. chevalier i ot c'om apeloit Bruiant, Que Butor tenoit bien a tout le plus sachant ;

Si a dit a Butor moult fort en soupliant : " Baro[n], sire Butor, et qu'alez vous pensant? »

(Brun de la Montaigne [2e moitié XIV $]$ ], 505) 
1450 BELZEBUTH. Sathan, tu nous metz en grant doubte

Et sur le point de desconfort.

SATHAN. Encor vous diray je plus fort :

Ceste vierge a eu ung enffant,

Et si n'ay sceu comment ne quant (Arnoul

Gréban, Le Mystère de la Passion, 7325)

1882 Sa voix montait peu à peu, emplissait la pièce de cris aigus, lorsque tous deux entendirent brusquement, derrière leur dos, quelqu'un dire très fort :

- Madame ! (Émile Zola, Pot-Bouille)

1893 Quand messieurs les journalistes sont forcés de me nommer, de rompre, une minute, le silence concerté qu'ils croient si mortel, ils n'ont à dire que cela et ils le disent le plus fort qu'ils peuvent (Léon Bloy, Journal 1 : Le Mendiant ingrat)

1931a Comme ça on a monté la montée du village au plateau et tout le long, à tous ceux qu'on rencontrait on disait bien fort : «Bonjour, monsieur ! (Jean Giono, Le Grand troupeau)

1931b Et j'y ai pensé, patron, je te le dis, tant fort, que ça m’a brûlé (Jean Giono, Le Grand troupeau)

1995 De son coin, assez fort, il dit : « Bonjour !» Les gendarmes, occupés à secouer la neige de leurs bottes, n'avaient pas remarqué sa présence et cherchèrent des yeux qui avait parlé (Emmanuel Carrère, La Classe de neige)

2005 J'ai soudain une envie folle de refaire de l'équitation.

Suit le deuxième message.

Vous dites assez fort : « Moi, accessoirement, je t'aime. »

Je ris (Anne Brochet, Trajet d'une amoureuse éconduite)

2011 Et elle disait tout fort, à celles qui l'accompagnaient, que c'était un cousin ; assez fort pour que moi je l'entende, et tous ceux qui attendaient les bus de Voracieux-les-Bredins (Alexis Jenni, L’Art français de la guerre)
Emploi absolu

1963 MARIE. Ne dites pas si vite, ne dites pas $s i$ fort (Eugène Ionesco, Le Roi se meurt)

II. Insister, dire avec force, emphase

Transitif

1405 Et non obstant que de Dieu viengne la grace d'en hault, je suis celle qui la mets a œuvre ou cuer de la personne, et sans moy riens ne prouffiteroit. Et te dis plus fort que, se je n'estoie avec Foy, Esperance et Charité, point ne seroit es humains (Christine de Pisan, Le Livre de l'advision Cristine, p. 55, 41)

1584 Il seroit bon y adviser de bonne heure, Sire, car nostre trafic se pourroit bien perdre et aneantir par ceste negligence et faineantise, et fault que je vous die, puis qu'il vient à propos que vostre bien se diminue : ce que je ne vous voulois aussi plus celer, estant vostre principal serviteur, en qui vous avez le plus de fiance, et vous diray plus fort, j'ay entendu qu'il commence à s'endetter (François d'Amboise, Les Neapolitaines)

1654 Pour nouvelles chacun dit fort

Que le Duc Charles est d'accort,

Landrirette,

La neutralité fait grand bruit, Landriry (Vincent Voiture, Poésies)

1686 Le P. Rapin et vous m'avez si fort dit que j'avois de l'esprit, que je vous offenserois d'en douter (Roger de Bussy-Rabutin, Les Lettres de messire Roger de Rabutin)

1888 BOILEAU. Ce qu'on dira contre moi, je le dirais plus fort encore (Ernest Renan, Drames philosophiques)

Emploi absolu

1515 « Hé ! fait il, cecy n'est rien, et vous direz bien plus fort, car j'ay veu ung poisson qu'on appelle bachet prendre ung lievre sans aultre aide que de luy mesme et le proverés bien, et est tout vray » (Philippe de Vigneulles, Les Cent Nouvelles nouvelles, p. 231, 14)

1648 Si on m'eust laissé en ma liberté, j'eusse pris le grand chemin, avec la mesme fran- 
chise et la mesme seureté que tousjours, et je fusse allé d'icy droit au Bourg la Reine. $\mathrm{Au}$ moins j'eusse eu le plaisir de passer encore une nuict à Paris, et j'avois resolu de vous donner en passant de la ravegarde, et de la raoussette ; mais je vous dis fort fort, ma foy. Je pense qu'en me dissuadant ce dessein, et en ayant peur pour moy, on a eu peur de moy aussi, et que l'on s'est imaginé que l'on le sçauroit au bureau d'adresse, et que je me fourrerois estourdiment parmy tout le monde (Vincent Voiture, Lettres)

Pronominal

1671 Ce mot de gens tout seul est un vieux mot que nous avons renouvellé. Je me connois un peu en gens; vous n'avez gueres de charité pour les gens.

Seûr et Seûreté se disent fort. C'est un coup seûr (Le père Dominique Bouhours, Les Entretiens d'Ariste et d'Eugène)

1748 Je fais bien ici vos affaires, car j'ai parlé de vous à Mme la comtesse de Senecterre, qui se dit fort de vos amies (Montesquieu, Correspondance)

1913 Presque tout occupé de notre véhicule qui semblait lui-même effrayé des efforts qu'il fallait faire pour avancer dans la seule voie ouverte aux charrettes, aux voitures, aux troupeaux de brebis, de chèvres et de pourceaux, je me disais plus fort que jamais encore : Oh ! Non, tu n'es pas Sion (Maurice Barrès, La Colline inspirée)

\section{CoRpus WeB :}

La solution de base indispensable - Se rendre disponible pour son ado et le lui dire fort et clair [http://www.hommepage.fr/enfants.php? article=98] (4.2.2015)

Aujourd'hui, quand tu oses dire fort ce que tous pensent tout bas, tu te fais accuser étymologiquement d'autocratie [https://www.facebook. com/patback2thelight/posts/10151561459598220] (4.2.2015)

Les enfants sont installés sur deux lignes face à face et éloignées d'une dizaine de mètres. Un des groupes va s'approcher lentement de l'autre en répétant une phrase (ex. : " Holà, braves gens, venez donc boire un coup »). Ils devront la dire fort et bien articuler quand ils sont loin, puis de plus en plus faiblement en s'approchant [http://www.educ-envir.org/ euziere/ internetlivre/annexe13.html] (4.2.2015)

Catarina on a rien vu d'elle on peut pas la dire forte. Je te parle des femmes qu'on a vu en actions jusqu'à présent tu me cite des inconnu $>\mathrm{D}$ [http://www.forums-mx.com/index. php?topic=7481.810; wap2] (4.2.2015)

Cela va de paire avec la force physique. On ne peut pas se dire fort tout seul mais par rapport à d'autres ou à une échelle prédéfinie. Celui qui soulève $200 \mathrm{~kg}$ aux altères (exemple pris au hasard) ne peut se dire fort que parce que les autres font moins [http://www.atoute.org/n/ forum/showthread.php?t=176436] (4.2.2015)

REMARques : Dire fort (I) désigne le fait de communiquer quelque chose à quelqu'un en élevant la voix afin d'être entendu d'une ou de plusieurs personnes. (II) réfère au fait d'énoncer un propos en insistant, voire en exagérant, en le considérant comme vrai et digne de crédit. Sous sa forme pronominale, il peut renvoyer au fait de penser, de se dire quelque chose à soi-même avec force, de se considérer fortement comme tel ; il peut également avoir un emploi passif, référant alors à l'emploi oral d'un terme, d'une expression. En dernier lieu, l'exemple de 1671 met en évidence la fonction de fort comme quantifieur au sens de 'beaucoup', voire d'adverbe de temps signifiant 'souvent'. Notons la réduplication de fort dans l'exemple de 1648. Fort reste invariable mais l'accord est fait dans le quatrième exemple du CW (prédication seconde); fort a alors le sens de 'qui a de la force' (v. dernier exemple du CW). Fort est modifié par assez, bien, bien plus, le plus, moult, plus, si, tant, tout, très. Mentionnons également l'emploi de penser bas.

\section{Dire franc}

Dire franchement, sans détour, avec sincérité Transitif

1656 Souvent la cour, peu courtoise, La traite en dame bourgeoise, Et l'huissier du cabinet Luy dit souvent franc et net, Retournez, pauvre ingenüe, Par où vous estes venüe, Car avec gens comme nous 
Il ne fait pas bon pour vous

(Georges de Brébeuf, Lucain travesti)

1666 Le corsaire apprend d'abord

L'aventure de la belle ;

Et, la tirant à l'écart,

Il en veut avoir sa part.

Elle fit fort la rebelle.

Il ne s'en étonna pas,

N'étant novice en tel cas.

Le mieux que vous puissiez faire,

Lui dit tout franc ce corsaire,

C'est de m'avoir pour ami ;

Je suis corsaire et demi (Jean de La Fontaine, La Fiancée du roi de Garbe)

1669 MARIANE. Vous m'avez dit tout franc que je dois accepter

Celui que pour époux on me veut présenter :

Et je déclare, moi, que je prétends le faire, Puisque vous m'en donnez le conseil salutaire (Molière, Le Tartuffe)

1736 Parmi ces gens, étoient, disoit-il, le procureur du roi, une bonne partie des procureurs, le maire de ville... comment, corbleu, s'écria là-dessus Phocion, ces messieurs ne perdent pas leur bonnet quarré, plutôt que de ne pas se ranger de vôtre côté : il faut que vous ne vaillez rien, je vous le dis tout franc (Pierre de Marivaux, Le Télémaque travesti)

1944 Il fit un effort pour se maîtriser :

- Mais dis-moi franc ce que tu veux faire (Jacques Roumain, Gouverneurs de la rosée)

1970 MAGNY, duc de Plaisance. Mon cher Vastey, je suis un vieux soldat. J'ai commandé sous Toussaint et Dessalines et je vous dirai tout franc que je suis mal fait à ces manières courtisanesques dont vous avez l'air de faire vos délices! (Aimé Césaire, La Tragédie du roi Christophe)

Emploi absolu

1896 Pourtant, c'est trop beau, pour dire franc... Un pressentiment fait comme une ombre À ce tableau d'extases sans nombre, Et du noir rampe au nuage blanc! (Paul Verlaine, Euvres poétiques complètes)
1911 Devant cette merveille de goût, je suis capable de me hausser au bien-être, à l'apaisement que nous donne la beauté, bref de goûter l'art pour l'art mais à dire franc, ce n'est pas ce plaisir sensuel qui me retient ici (Maurice Barrès, Greco ou Le Secret de Tolède)

CORPUS WEB :

Résolument installé dans la mouvance des penseurs au dire clair et franc, ses thèses proposent une véritable armature de compréhension $\mathrm{du}$ fait négrier et colonial à la base du peuplement nouveau des Caraïbes [http://www.roger toumson.com/2.html] (1.2.2015)

Pour dire franc, on pensait qu'en ce vendredi 9 août, le petit garage de Longvilliers serait fermé [http://www.lavoixdunord.fr/region/lapres-inondations-ils-pataugent-dans-1incomprehension-ia0b0n1477093] (4.2.2015)

Et ce n'est qu'en entrant dans son secteur, son quartier, et en ces lieux communs où l'on retrouvait les personnes de confiance avec lesquelles on pouvait se lâcher, le naturel revenait, pour dire franc et fort, le fond de sa pensée, et ainsi donner libre cours à ses sentiments réels [http:// www.lejourdalgerie.com/Editions/Speciale/ Contribution\%20Decembre\%201960.htm] (4.2.2015)

C'est facile de se dire franc hein! Mais un peu moins de l'être vraiment [https://twitter. com/patoucathy/status/542947361614745600] (4.2.2015)

C'est bien beau de se dire franche et directe, comme 95\% des gens [http://www.genaisse.com/ forums/viewtopic-44213.html] (4.2.2015)

REMARques : Dire franc désigne le fait d'énoncer un propos de manière sincère, ouvertement et sans dissimulation. Notons l'expression $\grave{a}$ / pour dire franc, synonyme de à dire vrai / à vrai dire, s'employant pour introduire une restriction et signifiant 'franchement' ou 'en réalité' (v. dire vrai). Dans le premier exemple du CW, le groupe est nominalisé (un dire franc). Franc reste invariable et est modifié par souvent, tout. Notons les collocations franc et net, clair et franc, franc et fort. Franc (et direct) remplissent la fonction de prédicat second orienté vers le sujet dans les deux derniers exemples du CW, ce qui entraîne l'accord (elle se dit franche est synonyme de elle 
dit (prétend) qu'elle est franche). Mentionnons également l'emploi de faire fort.

\section{Dire gros}

Dire grosso modo, en gros

Transitif

1958 Pour soutenir l'histoire [...] on n'a point fait d'effort littéraire. Ça dit, tout droit, tout gros, ce que ça a à dire, strictement (Sélection du Monde, 2-7 mai 1958 / Grundt : 383)

CORPuS WEB :

J'ai actuellement ma jument dans une écurie de propriétaire qui est en fait une association. Pour dire gros, je paye $110 €$ par moi pour « simplement " bénéficier des installations [http:// www.1cheval.com/membre/forum/general/sujet2724073-1-projet-ouverture-ecurie-de-proprio-endordogne] (4.2.2015)

Dire tout gros ce que tout le monde pense tout gras [http://phippopotame.blogspot.com/ 2015/09] (4.2.2015)

Elle dit tout gros ce que les Québécois pensent tout gras [http://www.cliqueduplateau. com/2012/10/11/si-tu-veux-sauter-sur-moe-tuvas-avoir-du-fun] (4.2.2015)

REMARQUES : Au figuré, dire gros désigne le fait d'énoncer un propos sans détours, sans égards, d'exprimer les choses telles qu'elles sont, sans entrer dans les détails. Notons dans le CW l'expression en l'occurrence probablement québécoise dire tout gros ce que (tout le monde) pense tout gras, basée sur dire tout haut ce que l'on pense tout bas, a sonorité proverbiale. Gras est employé ici au sens trivial de 'vulgaire'. Dans le premier exemple du CW, dire gros prend l'acception de 'grosso modo, en gros, approximativement', avec peut-être la connotation de payer gros (d'argent). Gros reste invariable.

\section{Dire haut}

I. Dire à voix haute

Transitif

+1100 Ele avoit le chief blondet, Si faisoit un chapelet

Et disoit ceste chancon

Molt haut et seri et cler

« Robeconet, la matinee

Vien a moi joer » (Romances et pastourelles françaises des XII ${ }^{e}$ et XIII ${ }^{e}$ siècles, p. 283)
1225 Et quant il parla, si dist si haut que cil de laienz le porent bien oïr : « Gauvains Gauvains mis m'avez le grant corroz ou cuer donc jamés ne me porrai esbatre devant que je sache veraiement a quele fin ceste queste porra torner, car trop ai grant doute que mi ami charnel n'en reviegnent ja » (Queste del saint Graal, § 23, 31)

1275 Corsols entre en la tente qui estoit de sami, L'amustant salua et l'amirant aussi, Si haut dist ses nouveles que chascuns l'entendi (Adenet le Roi, Buevon de Conmarchis, 1483)

1365a Il ont panceit et dit mauuistieit et malice. et contre lou tres hault ont dit iniquiteit et blasme (Psautier lorrain, p. 73)

1365b La Royne i entra, puis prist à apeller Son gentil maronnier, si li dist haut et cler : Biaus maistrez, je vous pri que nous voelliez mener

Droitement à Boulongne, car g'i voel arriver (Li Romans de Bauduin de Sebourc, Chant III, 193)

1372 Il avoit la un amiraut Qui respondi et dist tout haut : «Sire, j'en diray mon penser : Vous devez bien considerer .v. choses qui sont a ce fait, Si les vous diray tout a fait » (Guillaume de Machaut, La Prise d'Alexandrie [(1370-)1372], 2640)

1460 Quand elle se trouva leens, elle cuida bien enrager, et dist tout haut : " Et que fays ceens? " (Les Cent Nouvelles nouvelles, p. 341, 105)

1538 Lors Renommée avec ses esles painctes Ira volant en bourgs et villes maintes, Et sonnera sa trompette d'argent, Pour autour d'elle assembler toute gent ; Puis hault et clair de cent langues qu'elle a Dira ta vie ; et puis deçà et là Ira chantant les fins tours dont tu uses, Tes laschetez, tes meschances et ruses (Clément Marot, Élégies) 
1550 Sur la roche thespienne,

Des Sœurs la plus ancienne,

Qui de tes faits a souci,

Me garde une melodie,

Afin qu'un jour je la die

Bien plus haut que celle-ci

(Pierre de Ronsard, Les Odes, p. 131)

1559 Ce temps pendant, frappoit le mary à la porte, appellant le plus hault qu'il pouvoit sa femme. Mais elle faignoit de ne le congnoistre poinct, et disoit tout hault aux varletz de leans : «Que ne vous levez vous et allez faire taire ceulx qui font ce bruict à la porte ? » (Marguerite d'Angoulême, Heptaméron, p. 47, 25)

1568 « Pource (dit-il) que je n'entrois mie en colère ; mais toutes et quantes fois, disoit-il en continuant son propos, on voudra confesser verité, on dira haut et clair que les Italiens ont plus souvent porté les marques des François colerez que les François n'ont porté les marques des Italiens desesperez »

(Bonaventure des Périers, Les Nouvelles Récréations et joyeux devis)

1575 Et mesmes le vendredi $11^{\text {e }}$ de ce mois, jour de Sainct Martin, on lui donna advis d'un capitaine de Provence qui s'estoit eslevé et faisoit comme un parti à part ; ce que le Roy aiant entendu, comme il alloit à la messe, dit assez haut ces mots. « Voilà que c'est des guerres civiles ; un Connestable, Prince du sang, jadis ne sceut faire parti en France : maintenant les valets y en font » (Pierre de L'Estoile, Registre-Journal $d u$ regne de Henri III)

1656 Et il [= le père Filiutius] y donne encore [...] un autre moyen plus sûr d'éviter le mensonge. C'est qu'après avoir dit tout haut, «Je jure que je n'ai pas fait cela », on ajoute tout bas : « aujourd'hui », ou qu'après avoir dit tout haut, "Je jure ", on dise tout bas, « que je dis »; et que l'on continue ensuite tout haut, « que je n'ai point fait cela ». Vous voyez bien que c'est dire la vérité (Blaise Pascal, Les Provinciales)
1752 Un vieux péripaticien dit tout haut avec confiance : l'ame est une entéléchie et une raison par qui elle a la puissance d'être ce qu'elle est (Voltaire, Micromégas)

1755 Ô chère Miss Grandisson! Ai-je dit assez haut pour être entendue (abbé Prévost, Nouvelles Lettres angloises [trad.])

1831 Elle se regarda dans la glace et dit tout haut, d'un air de mauvaise humeur :

- Je n'étais pas jolie ce soir !... Mon teint se fane avec une effrayante rapidité... Je devrais peut-être me coucher plus tôt, renoncer à cette vie dissipée... Mais Justine se moque-t-elle de moi ?

(Honoré de Balzac, La Peau de chagrin)

1832 LOUIS. D'un chevreuil je veux suivre la trace.

Dis bien haut que le roi va partir pour la chasse (Casimir Delavigne, Louis XI)

1907a (La porte de la salle à manger s'ouvre et Charles fait une fausse entrée ; mais on entend la voix de Courpière qui dit, très haut:) « Charles, je vous défends expressément d'aller ouvrir » (Abel Hermant, Monsieur de Courpière)

1907b - Il disait tout haut : « celui qui a fait cela est un mauvais ouvrier. » Et ni les ricanements, ni les grognements, ni les injures ne le faisaient se déjuger (René Bazin, Le Blé qui lève)

1966 Comme la caissière le regarde, interdite, il lui dit, assez haut pour que Thomas Pezner l'entende :

- Méfiez-vous de mon ami, il va essayer de vous vendre un aspirateur

(Robert Sabatier, Le Chinois d'Afrique)

1987 La plupart de ces fabricants de croûtes ont dit partout haut et fort, et très franchement, qu'ils voulaient enculer le catholicisme et foutre les églises en l'air (Philippe Sollers, Le Cour absolu)

1995 Faut pas gamberger... entrevoir la poloche et se prendre la fantaisie de le dire tout haut ou de l'écrire (Alphonse Boudard, Mourir d'enfance) 
2006 un Papa auquel je peux dire alors, l'embrassant de toute la force qui unit les enfants à leurs papas et que j'ai aussi, moi, Stéphane, baptisé « Stéphane » par Papa et Maman, un Papa auquel je peux dire haut et fort, auquel je peux crier sans plus avoir peur cette chance incroyable que j'ai eue d'échapper à la morsure à coup sûr gravement mortelle des crocodiles (Stéphane Crémer, Comme un charme)

Pronominal

1869 Si l'on se mettait à se dire tout haut les vérités, la société ne tiendrait pas un seul instant (Charles Sainte-Beuve, Mes poisons)

II. Dire publiquement

Transitif

1235 Se vous estes a cele presse,

Vous i orrés mainte confesse.

Car chascuns dit haut ses peciés,

Dont ce jor se sent entechiés ;

Puis s'est assaus de tous ses fais

Dont il se sent cel jour confès

(Philippe de Remi, sire de Beaumanoir, La Manekine, 6887)

1675 Vous pouvez croire que ma joie n’a pas été médiocre d'entendre dire tout haut cela de vous (Mme de Sévigné, Correspondance)

1829 Je chantais, lorsqu'un long rire

D'épouvante m'a glacé ;

Puis tout haut j'entends dire :

Notre règne est passé

(Pierre-Jean de Béranger, Chansons)

2007 Je continue bien sûr à imaginer des choses : un ballet de regards, des sourires discrets, un clin d'œil entre filles ; un rire étouffé, peut-être un fou rire, peut-être un acting out carabiné ou alors un scandale, pourquoi pas ? Quelqu'un qui dit haut et fort que c'est dégoûtant et qu'il n'achète pas le journal d'Hubert Beuve-Méry pour y lire des cochonneries pareilles (Emmanuel Carrère, Un roman russe)
III. Dire franchement

Transitif

+1400 Pour Dieu ne me vueilliez nuire, Trés doulce estoille de mer Par qui je me vueil conduire ; Vous seule vueil reclamer, Vueillez moy ami clamer, Ou je vous diray tout hault Que vigour et cuer me fault (Christine de Pisan, Cent balades / Euvres poétiques [début $\mathrm{XV}{ }^{\mathrm{e}}$ ], I, p. 71, 13)

\section{CORPUS WEB :}

Je ne saurai trop vous conseiller de dire haut et fort ce que vous m'avez écrit, c'est à dire que vous n'avez pas de projet de domination, et que les banquiers ne vous représentes pas [http:// www.leava.fr/questions-reponses/non-juifs-2/ je-ne-saurai-trop-vous-conseiller-de-dire-hautet-fort-ce-que-vous-mavez-ecrit-cest-a-dire-quevous-navez-pas-de-projet-de-domination-et-queles-banquiers-ne-vous-representes-pas-il-estevide.php] (4.2.2015)

Idée $\mathrm{N}^{\circ} 38$ : Dire haut et fort que le projet de société du Front National est sexiste et réactionnaire [http://laregledujeu.org/2012/03/21/9358/ idee-n\%C2\%B0-38-dire-haut-et-fort-que-leprojet-de-societe-du-front-national-est-sexisteet-reactionnaire] (4.2.2015)

François Fillon, à droite, rejoint Manuel Valls, à gauche, sur l'idée que dire la vérité, et la dire haut, est la seule façon d'enrayer le vote Front national [http://www.lesechos.fr/07/10/2013/ LesEchos/21537-006-ECH_la-politique-en-modefortissimo.htm] (4.2.2015)

REMARQues : Dire haut (I) désigne le fait de communiquer quelque chose à quelqu'un en élevant la voix afin d'être entendu d'une ou de plusieurs personnes. (II) signifie 'proclamer, déclarer quelque chose publiquement, officiellement'. (III) réfère au fait de dévoiler quelque chose, de dire ce qu'on pense, avec sincérité, franchise, droiture. Notons la collocation haut et clair (aussi : haut et seri et clair), ajoutant l'idée de limpidité du message, et la collocation, plus moderne, haut et fort, renvoyant à l'intensité de la voix ou au fait de dire quelque chose publiquement. Haut reste invariable et est modifié par assez, bien, bien plus, moult, partout, si, tout, très. Mentionnons égale- 
ment l'emploi de appeler haut ; ajouter bas. VoIR AUSSI : annoncer / parler haut

\section{Dire juste}

Dire avec raison, justesse, véridicité

Transitif

$\sim 1450$ BOSO. Cela ne puis je pas nyer.

ANSELME. Nous ne trouvons nulz qui soit par dessus tout quenques n'est pas Dieu, fors que Dieu.

BOSO. Il est vray.

ANSELME. Il s'ensuit dont que nulz ne peult faire satisfacion du pechié de l'omme se non Dieu.

BOSO. La consequence est bonne.

ANSELME. Et nulz ne doit faire ceste satisfacion fors que l'omme.

BOSO. Riens ne peulx tu dire plus juste

(Pierre Crapillet, Le «Cur deus homo » d'Anselme de Canterbury [trad.], p. 212, §125)

1876 Toutes les expressions de la sainte Écriture, celles spécialement du Cantique des Cantiques, conviennent d'une manière étonnante à cette perfection... Elles disent juste ce qui est, ce qui fut et dut être (Mgr Félix Dupanloup, Journal intime)

Pronominal

1696 Douloureux ne vient pas plus naturellement de douleur que de chaleur vient chaleureux ou chaloureux, celui-ci se passe, bien que ce fût une richesse pour la langue, et qu'il se dise fort juste où chaud ne s'emploie qu'improprement (Jean de La Bruyère, Les Caractères)

Emploi absolu

1733 LISETTE. Mais il dit qu'il n'a pas lieu d'être content, et je crois qu'il dit assez juste : qu'en pensez-vous, Madame ? (Pierre de Marivaux, L'Heureux Stratagème)

1865 Ce grand bon bêta de Nieuwerkerke nous disait, en fumant, qu'il manquait une certaine tendresse à nos œuvres, ce que donne à l'homme la fréquentation de la femme. Il disait vrai et juste. Mais il faut bien se garder de guérir de cela (Edmond et Jules de Goncourt, Journal)
1887 - Madame Moraines a eu la bonne idée de me garder une place...

- Dans votre loge... reprit Paul qui ne croyait pas dire si juste

(Paul Bourget, Mensonges)

1933 Pour dire juste, il n'y avait pas grand monde dans le paradis, et c'est peut-être ce qui m’a le plus surpris (Marcel Aymé, $L a$ Jument verte)

1936 Ah j'allais oublier : encore une ressource du magasin, celle-là une fois par an seulement, au printemps, les brassards de première communion. [...] Une fois par an, ce n'est peut-être pas dire juste : faut pas oublier la confirmation (Louis, Les Beaux Quartiers)

1976 Bien des choses qu'il avait dites, en étant certain de dire juste mais sûrement sans penser que c'était à la lettre qu'elles devaient être prises, il s'affligeait maintenant de ce qui lui montrait qu'elles avaient tout le poids de vérités d'expérience (Michel Leiris, La Règle du jeu 4 : Frêle Bruit)

2005 C'est une écriture à laquelle toutes les procédures ordinaires du travail sont interdites : le diariste ne peut ni composer, ni corriger. Il doit dire juste du premier coup (Philippe Lejeune, Signes de vie)

\section{CORPUS WEB :}

Peut-on tout dire à l'enfant ? Deux extrêmes sont à éviter, nous fait remarquer J. HARDUIN, « D'une part, la croyance fausse que l'enfant peut tout entendre. D'autre part, le rien dire qui ne peut que générer de l'angoisse. Il ne s'agit pas de tout dire ou de ne rien dire, mais de dire juste, de trouver la parole authentique et vraie que l'enfant peut entendre " [http://www.ram68.fr/index.php?option=com content\&view=article\&id=106:le-langage-chezlenfant\&catid=41:lenfant\&Itemid=64] (4.2.2015)

Cette image est forcément vraie tant l'obsession de dire et de dire juste, ne peut laisser place à la tricherie [http://www.loeilebloui.fr/wp-con tent/uploads/les-e\%CC\%81ditos.pdf] (4.2.2015)

où les mots vous échappent et vous êtes là à chercher ces mots - et la manière de les dire juste et compréhensible, pour viser le sujet que vous 
vous voulez aborder ? [https://fr.answers.yahoo. com/question/index?qid=20140323002830AAHL gsk] (4.2.2015)

«Sa fermeture n'est pas en lien avec la perte des habitants ", a insisté le maire, adressant cette remarque à l'élu absent : «Quand on dit des choses, il faut les dire justes " [http://www.lejsl. com/edition-de-chalon/2011/05/21/une-dettemaitrisee-et-des-taux-moderes-a-0-5] (4.2.2015)

REMARQues : Dire juste désigne le fait d'énoncer un propos fondé, sensé, judicieux, véridique. Sous sa forme pronominale, il réfère à l'emploi oral correct d'un terme, d'une expression. Juste reste normalement invariable et est modifié par assez, fort, plus, si. Juste s'accorde cependant avec l'objet au pluriel dans le dernier exemple $\mathrm{du} \mathrm{CW}$, où il permet également une analyse de prédicat second orienté vers l'objet. Notons l'adjectif-adverbe compréhensible dans le troisième exemple du CW, où l'absence de l'accord peut surprendre. Mentionnons également la collocation vrai et juste. VoIR AUSSI : jouer juste

\section{Dire laid}

Dire des choses désagréables, blâmer

Emploi absolu

+1150 Toutes gens set lait dire et reprouer (Aiol et Mirabel [ $2^{2}$ moitié XII $]$, 2590)

\section{CORPUS WEB :}

Le blobfish est ainsi une espèce menacée de disparition à cause de captures accidentelles dans les filets des pêcheurs : " Certains le disent laid, mais je pense que la face triste du blobfish cache un cerveau malin et gentil », a expliqué le président de l'association, Simon Watt [http:// www.20minutes.fr/planete/1222327-2013091220130912-animal-plus-laid-monde-est-blobfis] (4.2.2015)

Ceci dit, quelques sites anti-moi étaient apparus, critiquant le fait que nous ayons un enfant hors-mariage, et que je n'étais même pas célèbre, et beaucoup me disaient laide comme un poux [http://dict.leo.org/frde/index_de.html\#/ search $=$ poux\&searchLoc $=0$ \&resultOrder=basic\& multiwordShowSingle $=$ on] (4.2.2015)

REMARQues : Dans l'exemple de +1150 , dire laid désigne le fait d'énoncer un propos déplaisant, produisant un effet désagréable chez le locuteur.
Laid reste invariable. L'emploi adverbial de laid était usuel en ancien français. Cette fonction disparaît en français moderne où le CW ne documente que celui de 'dire que quelqu'un ou quelque chose n'est pas beau', d'un point de vue esthétique, ce qui entraîne l'accord (prédication seconde).

\section{Dire long}

I. en dire long sur quelque chose (sujet animé): dire, raconter beaucoup sur quelque chose Intransitif

1760 Si j'y trouvois une lettre de vous, je remplirois la demi-page qui me reste et qui ne me resteroit pas, car je l'aurois remplie tout en disant que je ne voulois pas en dire plus long, si l'on ne m'invitoit pas à descendre. Je vais voir ce qu'on veut... (Denis Diderot, Lettres à Sophie Volland)

1775 De plus, vos parents arriveront qu'il n'y aura plus ni vert ni feuille. Cette belle vue, ce joli jardin seront tristes, et leur maison serait affreuse si le vent y venait de partout, et elle serait dangereuse s'il y avait des plâtres neufs. J'en dis bien long parce que j’ai réellement fort à cœur que vous évitiez d'avoir un repentir qui troublerait votre vie (Julie de Lespinasse, Lettres à Condorcet)

1830 Je ne t'en dis pas bien long car je suis toujours éreintée et endormie en rentrant, et c'est presque le seul moment où je puisse écrire (George Sand, Correspondance)

1886 - Oh ! Nous... c'est différent ; ça nous est défendu de faire du bruit. (Il avait répondu cela avec un air de sous-entendre quelque mystère noir ; avec un sourire drôle, qui, par la suite, revint souvent en tête à ceux de la Marie et leur donna à penser beaucoup.) Et puis, comme s'il en eût dit trop long, il finit par cette plaisanterie :

- Notre corne à nous, c'est celui-là, en soufflant dedans, qui nous l'a crevée (Pierre Loti, Pêcheur d'Islande)

1892 Il ne put d'ailleurs tirer aucun détail précis de ceux qu'il s'efforça d'interroger : les uns répondaient, hébétés, qu'ils ne savaient pas ; les autres en disaient si long, dans 
une telle furie de gestes, une telle exaltation de paroles, qu'ils ressemblaient à des fous (Émile Zola, La Débâcle)

1920 Qu'il soit permis de n'en dire pas plus long sur ce difficile sujet (Alain, Système des beaux-arts)

1925 Et elle parla, et elle en dit rudement long (Maurice Genevoix, Raboliot)

1943 - Eh ! ma pauvre dame, vous nous en dites bien plus long qu'on ne vous en demande (Colette, Le Képi)

Emploi absolu

1847 Vendredi saint. Je ne dirai pas long ce soir, étant fatiguée de ma journée d'église (Eugénie de Guérin, Lettres)

II. en dire long sur quelque chose (sujet inanimé) : être révélateur, significatif Intransitif

1874 Il ne se plaignait pas, mais il avait des pincements de lèvres qui en disaient long (Émile Zola, La Conquête de Plassans)

1922 - Les mots ne nous trahissent pas tant qu'ils ne nous trahissent : l'erreur du langage en dit long sur notre pensée cachée (Louis Aragon, Les Aventures de Télémaque)

1926 Chose incroyable ! Pas un instant, Gallet ne douta qu'elle eût dit vrai. Dès les premiers mots, il l'avait crue, tant le regard en dit plus long que les lèvres (Georges Bernanos, Sous le soleil de Satan)

1963 Sous l'angle de la curiosité, un cabaret vaut bien une cathédrale, et m'en dit parfois bien long sur la cathédrale elle-même (Albert T’Serstevens, L'Itinéraire espagnol)

1993 Comme ces phrases en disent long sur les soi-disant élites du temps et leurs minables ruminations de l'ombre! (Philippe Sollers, Le Secret)

2000 Les regards, fermés, goguenards, les yeux des femmes qui estimaient le prix des plis savants de Mme Grès drapés sur Elsa, en disaient long. Je prenais goût à susciter cette réprobation. Il me plaisait de partager cette sorte d'exil intérieur où était alors maintenu Aragon (François Nourissier, À défaut de génie)

2004 Écrite avec une rigueur fantaisiste qui rappelle les romans d'un écrivain d'une génération précédente, cette fable légère et profonde en dit plus long que bien des reportages sur le désordre, mais aussi l'intensité qui souffle dans le pays (Édouard Levé, Journal)

CORPuS Web :

C'estfou commeparfois un simpleregard peut en dire long... [https://fr-fr.facebook.com/pages/ Cest-fou-comme-parfois-un-simple-regardpeut-en-dire-long/10150106008015203?sk=info] (5.2.2015)

Les pupilles peuvent en dire long lors de vos phases de séduction [http://forum.psychologies. com/psychologiescom/rencontres-et-seduction/ seduction-pupilles-peuvent-sujet_8122_1.htm] (5.2.2015)

REMARQues : En dire long (I) désigne au figuré le fait de raconter quelque chose, d'informer quelqu'un, de rapporter avec beaucoup de détails et de précision. En (II), le sujet étant inanimé, il se dit de quelque chose ayant une grande signification, étant porteur de sens, dont l'analyse peut s'avérer révélatrice. Long reste invariable et est modifié par bien, bien plus, parfois, plus, rudement, si, trop. Sémantiquement, long est un adjectif de dimension qui se transpose métaphoriquement au domaine de la quantité 'beaucoup', de l'intensité 'avec plus de détail' et du temps 'longuement', sans qu'il soit possible de les démêler clairement, mais le côté quantitatif prédomine dans les exemples.

\section{Dire net}

I. Dire directement, franchement

Transitif

1573 Puis luy dirent tout net, qu'ils voyoyent bien que de nopces il n'en failloit plus parler (Blaise de Vigenère, Les Chroniques et annales de Poloigne)

1668a CLÉANTE. Et je vous ai trouvé, Monsieur, fort à propos,

Pour vous en dire net ma pensée en deux mots (Molière, Le Tartuffe) 
1668b DOM PÈDRE. Et vous voulez du bien à tous ceux qui prennent ce soin?

ISIDORE. Assurément.

DOM PÈDRE. C'est dire fort net ses pensées (Molière, Le Sicilien)

1693 Je me rapporte aux yeux d'une Ourse mes amours.

Te déplais-je ? va-t'en, suis ta route et me laisse :

Je vis libre, content, sans nul soin qui me presse ;

Et te dis tout net et tout plat :

Je ne veux point changer d'état

(Jean de La Fontaine, Les Compagnons d'Ulysse / Fables)

1732 Ce secrétaire m'a dit tout net : Seigneur gentilhomme, ne vantez pas tant votre zèle et votre fidélité (Alain-René Lesage, Histoire de Gil Blas de Santillane)

1773 GLYCĖRE. Je ne puis te souffrir : je te l'ai dit, je pense,

Assez net, assez clairement.

Va-t'en, ou je m'en vais

(Voltaire, Les Deux Tonneaux)

1833 Mais ne le lui dites pas si net et ménagez son amour propre (George Sand, Correspondance)

1854 Si bien qu'en soulevant ma valise après votre départ, l'aubergiste inquiet a soupçonné une partie de la triste vérité, et m'est venu dire tout net que j'étais un prince de contrebande (Gérard de Nerval, Les Filles $d u f e u$ )

1907 Je dis non, très net, m'attendant toutefois au pire (Claude Farrère, L'Homme qui assassina)

1918 C'est dit trop sec et trop net, mais je vois cette opération se faire sous mes yeux (Maurice Barrès, Mes cahiers)

1962 Aussi, ma foi, La prochain' fois

Qu'on mariera Jeannett',

On s'pass'ra d'vous,

Tonton, je vous,

Je vous le dis tout net
(Georges Brassens, "Tonton Nestor »/ Poèmes et chansons)

2004 Ça me pèse... Moi aussi, j’ai ma famille, mes soucis et mes petits ennuis de santé alors, je te le dis tout net : tu dois prendre tes responsabilités maintenant... (Anna Gavalda, Ensemble, c'est tout)

Emploi absolu

1936 Ou plutôt, et pour dire net, il n'y a pas de littérature parlée, improvisée, il n'y a que de la littérature écrite (Albert Thibaudet, Réflexions sur la littérature)

\section{Dire explicitement}

Transitif

1656 Cela veut dire tout net, Adieu soutane et bonnet, Flamberge contre écritoire Emportera la victoire (Georges de Brébeuf, Lucain travesti)

\section{CORPUS WEB :}

Ils ne font qu'exécuter un ordre qui leur est transmis par le parquet. Donc pour le dire clair et net : eux n'y sont pour rien! [http://www.ances. lu/index.php/55-radelux/166-le-placement-desenfants-et-l-intervention-des-forces-de-l-ordrela-force-de-la-loi-ou-la-loi-de-la-force] (1.2.2015)

Je vais vous dire net et clair. Nous, nous sommes contre l'émigration massive des Camerounais à l'étranger, et spécialement dans les pays européens. Pour la simple raison que, vu les conditions dans lesquelles ces Camerounais vivent en Europe, c'est impensable [http://www. cameroon-info.net/stories/0,16866,@,anicetekane-president-du-manidem-nous-sommescontre-l-emigration-des-camerounai.html] (5.2.2015)

Je vais te la dire clair et net, la Russie n'est pas une democratie, les droits de l'opposition n'y sont pas du tout respectés et Poutine fait ce qu'il veut dans le pays ! [http://forum. olweb.fr/showthread.php?152439-Actualit\%E9sinternationales/page27] (1.2.2015)

REMARQUES : Dire net (I) se dit pour énoncer un propos sans altération et sans détours, pour exprimer les choses telles qu'elles sont, sans fard, ni affectation, avec franchise et naturel. Dire net (II) désigne le fait de dire quelque chose claire- 
ment, d'avoir une signification claire. Net reste invariable et est modifié par assez, fort, si, tout, très, trop. Notons la collocation tout net et tout plat, ainsi que celle de clair et net dans le CW, qui prédomine dans l'usage actuel. Notons l'emploi de dire sec.

\section{Dire noir}

faire blanc et dire noir : dire une chose et faire son contraire

Emploi absolu

1846 Votre intention est excellente, et j'en prends acte : mais j'ajoute que vous vous êtes trompé de boule, que vous avez voté blanc quand vous vouliez dire noir, que la société a été prise par vous pour l'égoïsme, et réciproquement l'égoïsme pour la société (Pierre-Joseph Proudhon, Système des contradictions économiques)

\section{Corpus Web :}

Quand a ton BF no comment. Je ne sais même pas comment ils font ces gens la. Faire blanc et dire noir a la rigueur qu'il se tait se fasse petit etc. [http://forum.doctissimo.fr/grossessebebe/grossesse-libre/marsette-complet-angessujet_210738_470.htm] (5.2.2015)

C'est ça kes femme un jour blanc un jour noir, défois elles pensent blanc et disent noir [http://www.forum-algerie.com/humour/37840delirez-ici-764.html] (5.2.2015)

il ne faut pas s'etonner aussi de voir des gens avoir un peu la rage de lire ici des questions ou des affirmations (bien que ce ne soit pas tton cas precis) de gens qui font blanc et disent noir apres pour moi, y'a plus de question a se poser, y’a juste a jouer [http://forums.jeuxonline.info/ showthread.php?t=540801\&page=4] (5.2.2015)

REMARQUeS : Dire noir s'oppose à dire blanc. Les adjectifs-adverbes noir et blanc restent toujours invariables. Notons l'emploi de faire blanc, penser blanc, voter blanc. Voir commentaire sous dire blanc.

\section{Dire plat}

Dire franchement, dire simplement

Transitif

1515 Et aprés pluseurs prepos et d'ung costez et d'autre l'ostesse leur dit tout plat qu'elle n'en laisseroit rien de chascune .v. groz de Mets à leurs faire tres bon marchez (Philippe de Vigneulles, Les Cent Nouvelles nouvelles, p. 355, 217)

1560 Il ne nie pas que ce ne soit un Concile légitime, mais il dit plat et court qu'il a peu errer (Jean Calvin, Institution de la religion chrestienne)

1693 Je me rapporte aux yeux d'une Ourse mes amours.

Te déplais-je ? va-t’en, suis ta route et me laisse :

Je vis libre, content, sans nul soin qui me presse;

Et te dis tout net et tout plat :

Je ne veux point changer d'état

(Jean de La Fontaine, Les Compagnons d'Ulysse / Fables)

\section{CORPUS WEB :}

mais un peu de cheveux sur les bords.. c'est un signe héréditaire de con sur les bords. Il faut parfois vous le dire tout plat pour que vous compreniez votre débilité cellulaire...devant un forum audacieux [http://www.agri-web.eu/2013-01-02_ tarir-sans-antibiotiques-cest-possible] (5.2.2015)

Etant un habitant des EU maintenant, si je le rencontrais je le remercierais de ne pas m'avoir fait trop de promesses en l'air et en me disant, tout plat, que c'est au peuple de se reveiller et de faire quelque chose [http://www.lapresse.ca/ debats/vos-reactions/200902/16/01-827686-sivous-rencontriez-obama.php] (5.2.2015)

J'ai moi même une série de pigeons de courant sanguin Aarden et van Wanroy.... mais ce sont des Beijers car les croisements ont été réalisés par cet amateur et c'est lui qui a réalisé des résultats avec ses pigeons... Celui qui dit aujourd'hui vendre de vrais Aarden est je le dis tout plat un arnaqueur [http://mondialpigeons.forumpro.fr/ t2013-race-jan-aarden\#31202] (5.2.2015)

REMARques : Dire plat désigne le fait d'énoncer un propos sans altération et sans détours, d'exprimer les choses telles qu'elles sont, sans fard ni affectation, avec franchise et naturel. Au vu des sites cités dans le CW, dire plat pourrait être un régionalisme (Canada, Belgique). Plat reste invariable et est modifié par l'adverbe d'intensité 
tout. Notons les collocations dire plat et court et dire tout net et tout plat. VOIR AUSSI : perdre plat et court

\section{Dire sec}

Dire sèchement, froidement

Transitif

1782 Le curé, qui se trouva là, prit la liberté d'approcher de sa voiture, pour lui demander ce qu'il vouloit ordonner à l'égard de ce petit malheureux. « Moi ! dit l'homme sec et dur, que voulez-vous que je fasse d'un estropié ? » (Robert-Martin Lesuire, L'Aventurier françois ou Mémoires de Grégoire Merveil)

1925 Le vieux Tancogne, sans avoir frappé, poussa la porte de Volat.

- Bonjour, dit-il, tout sec

(Maurice Genevoix, Raboliot)

1947 J'étais inquiet en face de tant de joie. Je sentais qu'elle était dirigée contre mon bonheur et je lui fis un mauvais accueil. Je dis encore très sec :

- T’as pas besoin de faire du théâtre, ça me touche pas. Fous le camp, les gâfes vont radiner.

Il partit, léger, sans cesser de sourire (Jean Genet, Miracle de la rose)

1985 Elle arrondit ses yeux noisette très ordinaires. Toute sa figure est butée, avec deux grandes rides de mépris de chaque côté de sa bouche tombante. Elle dit, sec :

- Je fournis pas ce genre de choses.

- Comment, ce genre de choses? Mais les roses, c'est des fleurs ! Vous êtes fleuriste ou boulangère? Manivelle sourit un peu (Victoria Thérame, Bastienne)

\section{CoRpus Web :}

jvais te le dire sec tu me plait beucoups :\$ [http://ask.fm/Jouustine7/answer/102765988916] (5.2.2015)

Incapable de lui dire sec de même que je la trouve pas belle [https://twitter.com/kefosch/ status/376525971169345536] (5.2.2015)

Je reprends le discours relevé sur le document [1], et le commente sommairement. Ces idées n'engagent que moi, et je peux me tromper, mais quand même... Je préfère le dire tout sec [https://www.facebook.com/avantimegamaths/ posts/548848721918205] (5.2.2015)

REMARQues : Dire sec désigne le fait d'énoncer un propos sèchement, crûment, d'exprimer les choses telles qu'elles sont, sans sensibilité ni tendresse, avec indifférence. Sec reste invariable et est modifié par tout, encore très. La syntaxe de l'exemple de 1782 est ambiguë, mais l'interprétation de sec et dur comme adjectifs adnominaux d'homme n'a pas de sens.

\section{Dire seri}

Dire, réciter agréablement, paisiblement

Transitif

+1100 Ele avoit le chief blondet,

Si faisoit un chapelet

Et disoit ceste chancon

Molt haut et seri et cler

« Robeconet, la matinee

Vien a moi joer »

(Romances et pastourelles françaises des $\mathrm{XII}^{e}$ et XIII ${ }^{e}$ siècles, p. 283)

REMARQUES : L'ancien français dire seri signifie ici 'dire d'une voix claire, sereine'. Notons sa collocation avec haut et clair traduisant l'idée de limpidité de l'énoncé.

\section{Dire soef}

Dire doucement, calmement

Transitif

1170 Mout par li fait Jason grant joie ; Soëf, basset, que l'om ne l'oie, [variante : bassez]

Li dist : Vassaus, ne tenez mie

A mauvaistié n'a legerie, Se a vos me vieng acointier (Benoit de Sainte Maure, Le Roman de Troie, 1312)

+1175 Venuz s'en est aeschariz. «Lasse, fait ele, mes amis Est trovez, mes sires l'a pris!» Souef le dit entre ses denz (Béroul, Tristan [ $4^{\mathrm{e}}$ quart $\mathrm{XII} \mathrm{I}^{\mathrm{e}}$ ], 3165)

-1200 Et Franchois furent coi et mu et taisant ; De lui aidier, n'i a nul ki s'en vant. Li uns a l'autre le souef disant : Quex vis deables porroient soffrir tant? (Aliscans [fin XII ${ }^{\mathrm{e}}$, 2694) 
1235 Effreez sunt paens de ço e esbaiz,.

Le poer Jesu prisent volentris u enviz ;

Li un en sunt joius e li autre mariz.

Dient entre eus suef : N'est droitz k'il seit despiz,

Li Deus Auban pur ki mortz est e escharniz (La Vie de seint Auban, 921)

REMARQUES : Dire soef désigne en ancien français le fait d'énoncer un propos doucement, agréablement, avec calme, voire précaution. Soef reste invariable.

\section{Dire vrai (voir)}

I. Dire la vérité Emploi absolu

$\sim 1100$ « Vers Carlemagne li durrai bon conseill : Cunquis l'avrat d'oi cest jur en un meis. De Sarraguce les clefs li portereiz, Pui li dites il n'en irat, s'il me creit. » Cil respundent : "Sire, vus dites veir» (Chanson de Roland, 2754)

1119 Or oez sun sermun

Cum le met a raisun, Icil Deus ki tut fist

E ki tuz jurz veir dist, Il guart l'anme de tei (Philippe de Thaon, Comput [1119 ou 1113], 16)

$\sim 1160$ Et ne fist il, il a voir dit, Car il n'i fu, n’il ne la vit ; Ne sai coment il i morust, Car ainz que la bataille fust, Li fist Nisus lo chief voler : Ce ne sot il pro deviner (Eneas, 5069)

1170 Onques mes, fet il, n’oï tel. Mainne moi dons a son ostel ; Que certainnemant vuel savoir Se tu me diz mançonge ou voir (Chrestien de Troyes, Erec et Enide, 3254)

1177 Or si vos dirai la androit, Ou Meleaganz est venuz, Que oiant toz, gros et menuz, Dist a son pere molt en haut : Pere, fet il, se Deus me saut, S'il vos plest, or me dites voir, Se cil ne doit grant joie avoir Et se mout n'est de grant vertu, Qui a la cort le roi Artu
Par ses armes se fet doter?

(Chrestien de Troyes, Lancelot ou Le Chevalier de la charrete, 6277)

+1200 a « Gauvains, ce n'est mie novele, Tuit sevent que la damoisele Perdi par toi en ton servise Son ami. Or sez qu'ele est prise Par toi ; quant tu ne la secors, Tu es honiz en totes corz. » Mes sire Gauvains sanz respit Demande se cele a voir dit (Raoul de Houdenc, Meraugis de Portlesguez [début XIII'], 5152)

+1200b « Sire, de chou que vous savés ne vous puis jou faire menchoingne a croire. Ne autre chose ne vous dirai je mie, mais pour Dieu aiiés mierchi de moi ; car je vous dirai merveilles et voir, se vous m'asseurés que vous ne me lairés mie » (Merlin [1 ${ }^{\mathrm{er}}$ quart XIII'], p. 121)

1225a Par foi, fet li rois, je sai bien que vos dites voir (Queste del saint Graal)

$+1225 \mathrm{~b}$ Je cuit bien que vous dites voir, Dist il, et mout bien avés dit. Ne demeure que mout petit K'il sont a l'ostel venu (Le Chevalier as deus espees [ $2^{\mathrm{e}}$ quart $\left.\mathrm{XIII}^{\mathrm{e}}\right]$, 5268)

1285 Et je cuit bien que nus fors il Ne se metroit en tel peril, Et pour ce ne sai que j'en die. Voir me dites, je vous en prie (Adenet le Roi, Cleomadés, 3214)

1339 LA DAME. Il dirent, si disoient voir, Que le terme demain cherroit Du respit qui donné m'estoit, Et je tant prié et requis Qu'a huit ans me ront terme mis (Miracle de l'enfant donné au diable, 598)

+1400 Tiens ta promesse et petit jure, Gard ne soies trouvé parjure, Car le menteur est mescreü Et, quant voir dit, il n'est creü. (Christine de Pisan, Les Enseignemens moraux / Euvres poétiques [début XVe], III, p. 32) 
+1415 Alors mon cueur, pour dire voir, De joye souvent soupiroit, Et, combien qu'il portast le noir, Toutesfoiz pour lors oublioit Toute la doleur qu'il avoit, Pensant de recouvrer briefment Plaisance, Confort et Liesse.

Et d'avoir en gouvernement Tresor d'amoureuse richesse (Charles d'Orléans, Poésies [ 1415-1440], I, Ballade XXXVII, p. 57)

1450 Pandaro dist : " Je congnois que vous dictes vroy ; mais souventesfoiz advient que tel ne se scet garder du venin, qui par son advis en garde bien ung aultre. Et autresfois c'est veu celui qui avoit la lumière en la main esgaré, et celui qui n'en avoit point alloit le droit chemin » (Roman de Troilus et Cressida, p. 137)

+1489 Beaucoup furent esbahiz de ceste fantaisie, qui blasmèrent ce cas, disant qu'ilz avoyent faict pour bien, et disoyent vray (Philippe de Commynes, Mémoires [14891498], VI)

1495 « Vrayement, ma fille, » dit le roy, « vous dictes vray. Si envoyray devers ses gens qui sont venus, pour les faire fornir de linge, vaixelle et tapisserie, et de tout ce que leur sera necessaire » (Roman de Jehan de Paris, p. 52)

1562 L'ADVocAT. Tu dis bien vray, Marion ; mais Magdelon est-elle contente ? (Jacques Grévin, Les Esbahis)

1696 Il ne vous dirait point plus vrai que moi sur ma jambe (Mme de Sévigné, Correspondance)

1701 Du soin d'aider le pauvre on dispensa l'avare ;

Et même chez les Rois le superflu fut rare. C'est alors qu'on trouva pour sortir d'embarras,

L'art de mentir tout haut en disant vrai tout bas.

C'est alors qu'on aprit qu'avec un peu d'adresse,
Sans crime un Prêtre peut vendre trois fois sa Messe

(Nicolas Boileau, Satires [1664-1701])

1715 - Je ne veux pas m'opiniâtrer contre vous, ajouta Danhasch ; le moyen de vous convaincre si je dis vrai ou faux, c'est d'accepter la proposition que je vous ai faite de venir voir ma princesse, et de me montrer ensuite votre prince (Antoine Galland, Les Mille et une nuits)

1722 JAQUELINE. [...] après ça, ma tante disait toujours qu'un amant, c'est comme un homme qui a faim : pû il a faim, et pû il a envie de manger, pû un homme a de peine après une fille et pû il l'aime.

PIERRE. Parsanguenne, il faut que ta tante ait dit vrai ; car je meurs de faim, je t'en avertis, Jacquelaine

(Pierre de Marivaux, La Surprise de l'amour)

1734 On dit bien vrai, lorsqu'on assure qu'en dormant nous dépendons si peu de nousmêmes, que l'objet du monde qui nous est le plus odieux, triomphe de notre répugnance (Alexandre Dumas fils, L'Écumoire)

1745 SIDNEI. Je ne dis que trop vrai : plaignez mon sort funeste (Jean-Baptiste Gresset, Sidnei)

1812 - Vous dites plus vrai que vous ne croyez, répondis-je (Étienne de Jouy, L'Hermite de la Chaussée-d'Antin)

1836 À vrai dire, je ne suis rien moins que sûr d'avoir quelque talent pour me faire lire (Stendhal, Vie de Henry Brulard)

1899 Je veux croire, jusqu'à la fin, que nous n'aurons pas le spectacle de Picquart condamné pour avoir dit vrai (Georges Clemenceau, Vers la réparation)

1978 Poussé par Ėve, Adam se décide. Il mord dans le fruit. Et il ne meurt pas. Ses yeux s'ouvrent au contraire, et il connaît le bien et le mal. Yahvé avait donc menti. C'est le serpent qui disait vrai (Michel Tournier, Le Coq de bruyère) 
1989 Le mort dit vrai en ne disant plus et si, sur lui, l'on jette tant de silence, c'est pour ne rien entendre (Christian Bobin, La Part manquante)

1997 - Essayé, vous dites vrai, mais il ne l'a pas fait ! (Patrick Rambaud, La Bataille)

II. Dire franchement, avec sincérité

(introduisant une restriction)

Emploi absolu

1450 Et en tant que sa bonne renommée appetisseroit, à vous dire vray, il m'en desplairoit ; mais, au fort, elle s'en passera comme fist Helène ; si faittes tant seulement que voustre desir soit accomply (Roman de Troilus et Cressida, p. 218)

1566 Et pour dire vrai il m'eust fasché que tant de livres indignes et pernitieux, comme les Amadis, Tristans, et autres de mesme farine, c'est à dire, ou inutiles, ou indoctes, ou deshonnestes, tant en vers qu'en prose, eussent eu plus de credit et de vogue que telle chose que mes longues veilles et mon bien grand et bien long travail eussent taillé pour servir à la chose publique (André de Rivaudeau, Aman)

1587 Si le feu n'eust pris à l'amorce, Il n'eust tiré le pistollet ;

Et, à vrai dire, un cabasset

Est fort propre pour la cervelle

(Pierre de L'Estoile, Registre-journal du regne de Henri III)

1664 FLAVIE Il lui parle à présent. Qu'en ditesvous, madame,

Et de cet entretien que souhaite votre âme? Voulez-vous qu'on l'accepte, ou qu'il n'obtienne rien?

PLAUTINE. Moi-même, à dire vrai, je ne le sais pas bien (Pierre Corneille, Othon)

1824 Vous n'avez donc nulle preuve, et n'en sauriez avoir, de ces sentiments que vous attribuez au premier ministre ; mais quand vous en auriez, quand nous serions certains (comme, à vous dire vrai, j'y vois de l'apparence) que M. Decazes au fond n'a pas pour nous beaucoup de considération, faudrait-il nous en plaindre et nous en étonner ? (Paul-Louis Courier, Pamphlets politiques)

1863 Cette nouvelle entrevue, la première, à vrai dire, qui m’ait donné entrée dans la maison des Trembles, n'eut rien non plus de bien mémorable, et je n'en parlerais pas si je n'avais à dire un mot tout de suite de la famille de $\mathrm{M}$. Dominique (Eugène Fromentin, Dominique)

1895 Vous étiez utiles alors, vous étiez nécessaires ; vous n'étiez pas invincibles. $A$ dire vrai, dans ces vieux âges, et pour longtemps encore, il vous manquait le charme (Anatole France, Le Jardin d'Épicure)

1937 À dire vrai, elle n'avait guère besoin de l'amour de son mari (et moins encore, grand Dieu ! de la corvée sexuelle, par bonheur de moins en moins fréquente) (Henry de Montherlant, Le Démon du bien)

+1963 Pour dire vrai, il n'y passait jamais personne et le vieux chat n'avait à signaler que quelque commandeau de renards (Antoine Blondin, Ma vie entre les lignes [1963-1970])

2000a Ton corps agit comme toi. Pour l'heure vous agissez séparément, vous tirez à hue et à dia, chacun de son côté, vous disputant votre héritage commun, absolument commun et unique. Les frères ennemis. Et donc ton corps te fait comme tu le fais. Pour dire vrai, il te fait mal comme tu lui fais mal. Agissez ensemble, soyez-un et tu paries que tout va changer? Un corps, un seul corps, un tout corps (Richard Morgiève, Ton corps)

2000b CATHERINE. Oui. Pardon. Ce que je disais, il s'appelle comme vous, mais, à vrai dire... ANTOINE. Je m'excuse. Ça va, là, je m'excuse, je n'ai rien dit, on dit que je n'ai rien dit, mais tu ne me regardes pas comme ça, tu ne continues pas à me regarder ainsi, franchement, franchement, qu'est-ce que j'ai dit ? (Jean-Luc Lagarce, Juste la fin du monde) 
CORPUS WeB :

Quelque sinistre urluberlu pourrait s'amuser à montrer, en mentant, que dire faux et dire vrai sont la même chose ou même que dire faux par intention est préférable à dire faux par erreur [http://www.franceculture.fr/emissionle-gai-savoir-le-mensonge-la-querelle-kantconstant-2013-06-02] (2.2.2015)

"C'est un combat difficile. Et pour dire vrai, Papa Sow m'empêche de dormir. A chaque fois que j'y pense, je me dis que ce duel est capital pour moi. C'est un combat de vie ou de mort et je vendrai chèrement ma peau ", avoue-t-il dans un entretien avec "L'As » [http://www. seneweb.com/news/Sport/lac-de-guiers-2-laquopour-dire-vrai-papa-sow-m-rsquo-empeche-dedormir-raquo_n_143081.html] (5.2.2015)

Si je dis : « Tout est faux.»

Et bien, je me contredit derechef : pourquoi ?

Parce que je considère que la phrase participe au vrai pour la dire vrai.

Donc tout n'est pas faux [http://www. sens-de-la-vie.com/forums/view topic. php?topic=1743\&forum=8] (6.2.2015)

- Le monde, la vie, c'est ma consommaction.

- Ma consommaction est une proposition apophantique : on peut la dire vraie ou fausse visà-vis du monde [http://spqrepublicaine.blogspot. co.at/2014/04/consommaction.html] (6.2.2015)

REMARQues : Dire vrai (I) désigne le fait d'énoncer un propos conforme à la réalité, à la vérité, le fait d'être honnête. Dans à dire vrai, à vrai dire et pour dire vrai (II), la préposition transforme la collocation en adverbe de phrase portant sur la vérité de la proposition, introduisant une restriction équivalant à 'en réalitế. Vrai reste invariable. Dans le CW, dire vrai s'oppose à dire faux. Dans le troisième exemple, vrai reste invariable en tant que modifieur du verbe (malgré l'objet au féminin), tandis que dans le quatrième exemple, les adjectifs-adverbes s'accordent avec l'objet féminin pronominal antéposé au verbe, en se prêtant à une analyse de prédicat second orienté vers l'objet : dire que quelque chose est vrai. Dans les exemples de $\sim 1170$ et $1200 \mathrm{~b}$, voir est employé comme adjectif substantivé au sens de 'vérité' et est coordonné avec respectivement mançonge et merveilles, tous deux substantifs. Ceci constitue un argument en faveur des linguistes qui considèrent certains adjectifs-adverbes comme étant des « compléments légers » (v. Introduction $§ 6.3$ ). En effet, ceci est possible, du moins occasionnellement, avec des verbes fortement transitifs tels dire, faire. Il est intéressant d'observer que la coordination avec des substantifs est caractéristique de l'ancien français. On peut y ajouter le fait que l'afr. voir n'est jamais modifié. Par contre, son équivalent moderne vrai se combine facilement avec des adverbes de degré (bien, plus, trop). On peut en conclure que la perception de vrai est plutôt celle d'un adverbe, tandis que l'ancien français emploie voir (aussi) comme un « complément " que l'on peut coordonner avec des substantifs. Mentionnons également l'emploi de jouer petit ; mentir haut.

\section{Diriger bas}

Diriger vers le bas

$\lambda$ diriger haut

\section{Diriger droit}

I. (Se) diriger en suivant une ligne droite Transitif

1560 Maintenant ayant plus clairement revelé la grace de la vie future par l'Evangile, il dirige noz entendemens tout droit à la meditation d'icelle (Jean Calvin, Institution de la religion chrestienne)

1684 Cela fait que les rayons du Soleil, et des autres Astres, qui viennent de cette Region Etherée tres rare et tres pure, tombant obliquement sur l'Atmosphere, se rompent vers le rayon perpendiculaire, c'est à dire vers ce rayon que le Soleil dirige droit au centre de la Terre, qui est le mesme avec celuy de l'Atmosphere (François Bernier, Abrégé de la philosophie de Gassendi)

1937 Qu'a-t-elle [= Mouchette] en effet de commun avec ce que les gens appellent l'amour, et les gestes qu'elle sait ? Elle ne peut que continuer à diriger tout droit, sans trembler, le jet de la lampe sur la main blessée.

- Ouvre la porte, commande-t-il. Je m'en vas jeter les cendres (Georges Bernanos, Nouvelle Histoire de Mouchette) 
1989 Les bustes des quatre musiciens aux têtes d'épouvantails sont absolument droits, les quatre masques absolument parallèles aussi, leurs regards endormis d'aveugles dirigés droit devant eux (Claude Simon, L'Acacia)

Pronominal

1899 Puis, entraîné par le mouvement naturel de sa pensée, songeant qu'il faut, pour se diriger droit, le point de repère d'abord : « Il est des circonstances, » a-t-il dit [= le général Derrécagaix], " où la notion du juste s'obscurcit, où les caractères bien trempés hésitent » (Georges Clemenceau, Vers la réparation)

1966 Son sac en cuir se balançait au bout de sa main ; elle avançait comme si elle avait eu un moteur caché quelque part au fond de son corps. Sa face se dirigeant droit dans la direction du trottoir, les yeux mobiles, à demi dissimulés par les paupières et les cils, la bouche ouverte pour respirer, et la gorge palpitant régulièrement (Jean-Marie Gustave Le Clézio, Le Déluge)

II. (Se) diriger directement vers quelque chose/ quelqu'un

Transitif

1745 LA FLEUR. Moi.

LE MARQUIS. Mons de la Fleur, vous n'aurez plus la bourse.

Va.

LA FLEUR. Droit au cabinet dirigeons notre course.

Et vîte et vîte, allons nous payer par nos mains (Pierre Claude La Chaussée, L'École des mères)

1945 Le Survenant cessa de percher et Didace plaça les rames dans les tolets. Il venait d'apercevoir son canot de chasse, avec un homme à l'aviron. Il dirigea droit à lui l'embarcation qu'il colla à côté (Germaine Guèvremont, Le Survenant)

1946 Lalagüe, Récayte, qui aviez de si belles voix de soprano, Etchecopar le sentencieux, avare de paroles qui ne fussent pas dirigées droit sur l'essentiel, je ne vous ai pas oubliés, mes camarades ; et ce spec- tacle d'une belle race si fidèle à ses traditions me fut un réconfort dans l'humiliation (Francis Ambrière, Les Grandes Vacances)

2002 La cause principale était un acte de malveillance, dirigé spécifiquement contre elle. Une fenêtre en effet, un haut de fenêtre repliable, dirigeait droit sur elle un courant d'air tenace, pratiquement incessant (Jacques Roubaud, La Bibliothèque de Warburg)

Pronominal

1812 Il y avait déjà une heure que nous courions par un chemin uni qui se dirigeait droit au sud-est, lorsqu'au lever de l'aurore, j'aperçus quelques débris et un long mur de construction antique : le cœur commence à me battre (François de Chateaubriand, Itinéraire de Paris à Jérusalem)

1846 En ce moment, il vit briller comme une étoile le phare de Planier. En se dirigeant droit sur ce phare, il laissait l'île de Tiboulen un peu à gauche ; en appuyant un peu à gauche, il devait donc rencontrer cette île sur son chemin (Alexandre Dumas père, Le Comte de Monte-Christo)

1859 Nous suivons donc la procession chantante par toutes les allées, en nous dirigeant tout droit à travers le jardin vers la solitude, dont nous connaissons la porte rouge : là nous tournons à droite vers les fraisiers, nous passons le pont proche du glacis pour continuer de cheminer tout le long de l'allée de l'ormois jusqu'à la porte à barreaux, par laquelle, rentrés dans le jardin, nous faisons, malgré son vilain nom, toute l'allée des crapauds (Charles Sainte-Beuve, Port-Royal)

1885 Cet homme achevait de boutonner son collet en se dirigeant droit du côté d'Hubert. Ce dernier s'avança aussi et frôla l'inconnu (Paul Bourget, Cruelle Énigme)

1909 À travers le silence des salles d'en haut, voici que nous nous dirigeons maintenant tout droit vers ceux et celles à qui j'ai demandé audience nocturne (Pierre Loti, La Mort de Philæ) 
1967 Le corps a sa voix, le cœur la sienne. Pascal sortait du Gimère-III. Il se dirigeait tout droit vers la table de son ami Vincent. Elle ne le reconnut pas sur-le-champ (Jean-Pierre Chabrol, Je t'aimerai sans vergogne)

1973 Mais le véhicule a fini par me dépasser, un peu avant Alésia et s'est arrêté près du trottoir, dix mètres devant moi, et la portière s'est entrouverte. Je me suis dirigé droit dessus. C'est comme ça qu'on se fait tuer au cinéma. J'ai ouvert la portière et personne ne m'a vidé son chargeur dans les viscères (Jean-Patrick Manchette, Morgue pleine)

2006 Mais ce dernier, après s'être assuré de son départ, au lieu d'escalader les étages, sembla se raviser, se dirigea tout droit vers la loge et y cogna du poing (Anne-Marie Garat, Dans la main du diable)

\section{CORPuS WeB :}

A Destin (Floride), deux touristes étaient en train de baigner à quelques mètres de la plage et n'ont pas vu un requin-marteau qui se dirigeait droit vers eux [http://reunion.orange.fr/ loisirs/videos-reunion/actu-et-politique/deuxbaigneurs-ne-voient-pas-un-requin-se-dirigerdroit-vers-eux.html] (6.2.2015)

L'avion peut se faire tirer par la station ellemême (VDF) dont l'opérateur au sol donne une information radiophonique des caps à prendre pour pouvoir se diriger droit vers la verticale de cette station [http://home.nordnet.fr/dmorieux/ homing.htm] (6.2.2015)

Comme tous les sauts de valse, la clé est au moment du décollage. Glissez sur longue carre arrière droite sans forcer du haut du corps. On voit souvent des gens tirer leur côté gauche vers l'arrière et balancer la jambe en rond plutôt que de la diriger droit devant et en haut [http:// fr.wikipedia.org/wiki/Saut_de_valse] (6.2.2015)

Harry a craché dehors le mot Tom comme une malédiction. Rapidement il a saisi sa baguette magique hors de sa poche, la dirigeant droite chez Voldemort. Mais Voldemort n'a pas semblé s'inquiéter, au lieu de cela ses yeux snakelike débarqués sur les amis de Harry [http://poudlardfutur.nice-board.com/t6p15fanfics-d-harry-potter] (6.2.2015)
REMARQues : (Se) diriger droit (I) désigne le fait d'orienter quelque chose ou de s'orienter vers un but déterminé, le déplacement étant effectué en ligne parfaitement droite. Dans son emploi transitif, l'objet désigne souvent un faisceau ou un rayon de lumière, dont la lueur éclaire de manière longitudinale. En (II), il réfère au fait de diriger ou de conduire, de guider ou de manœuvrer quelque chose directement vers une personne ou un lieu précis. Dans cette acception, droit est toujours suivi d'une préposition (à, vers, sur, etc.) avec laquelle il s'associe au point de faire partie du groupe prépositionnel comme modifieur de la préposition. Droit reste invariable et est modifié par l'adverbe d'intensité tout. Dans le dernier exemple du CW, droit s'accorde avec l'objet. Sans plus de contexte, on ne saurait dire s'il garde son interprétation directionnelle ou s'il désigne la position verticale de la baguette, mais, dans un tel contexte, la baguette magique est habituellement dirigée vers la cible. Droit maintiendrait donc son sens directionnel malgré l'accord. VOIR AUSSI : aller droit

\section{Diriger haut}

S'exercer à un haut niveau hiérarchique Transitif

1815 Ainsi les hommes faibles et les hommes raisonnables, les hommes vénaux et les hommes scrupuleux, se trouveront engagés par des motifs différents à ménager les dépositaires infidèles de l'autorité exécutive. La responsabilité sera nulle, parce qu'elle aura été dirigée trop haut (Benjamin Constant, Principes de politique)

\section{CORPUS WEB :}

Il conclu rapidement que plus on utilisait de cordes plus on projetait l'éclair loin, plus la note était haute plus il était dirigé haut (de bas en haut), les cordes étant de plus en plus aiguës de gauche à droite. Donc corde du milieu grattée rapidement : tir droit devant à hauteur d'homme (buste) $5 \mathrm{~m}$. corde de gauche (basse) grattée rapidement : tir vers le bas (pied) corde de droite (aigüe) grattée rapidement : tir vers le haut (tête) [http://donjonsetdragons.net/viewtopic. php?f=89\&t=844\&start=20] (6.2.2015)

une cartouche tirant 70 plombs est de la simple grenaille « pas réellement dangereuse » 
quoi que si le tube avait été dirigé haut vers la tête... ca serais une autre histoire il s'agit pas d'un tir au double zéro !!!! [http://www.leparisien.fr/ faits-divers/elle-fait-ses-courses-a-la-ferme-etrecoit-70-tirs-de-plombs-13-08-2009-605800.php] (6.2.2015)

« Avancez, » James a indiqué, obtenant à ses pieds, « nous passerons par cette porte. » Il s'est dirigé haut vers le haut de quelques escaliers. «Et laisse juste l'espoir que j'ai sélectionné le droit » [http://poudlardfutur.nice-board.com/t16p45prongs-rides-again] (6.2.2015)

J'ai toujours eu des problèmes avec mes potences. Et j'en ai eu ! 90, 95, 100, 110 j'ai du mal à me decider. Je viens d'avoir pour mes 60 ans un giant defy advanced 3 taille $\mathrm{M}$ et la potence est une 100. La façon dont elle est mise elle fait $104 \mathrm{~mm}$. Tout dépend si elle est dirigée haut ou bas [http://www.velo101.com/forum/voirsujet/ potence-95mm-14801] (6.2.2015)

REMARQUES : Au sens figuré, diriger haut désigne le fait d'assumer les responsabilités d'un pouvoir, d'un commandement à un haut niveau hiérarchique. Haut reste invariable et est modifié par trop. Dans le CW, haut y figure dans son sens concret directionnel. Il reste invariable, malgré le sujet au féminin dans le dernier exemple, tout comme l'adjectif-adverbe bas, avec lequel il est mis en opposition.

\section{Discuter ferme}

Discuter avec énergie, âpreté

Intransitif

1885 On discutait ferme, et un chef d'orchestre fameux, très ardent pour l'œuvre de Wagner (mettons qu'il soit d'Italie) prenait à partie un de nos jeunes confrères (Le Ménestrel)

1936 Cadieux, qui descendait, passa en coup de vent :

- Tu ne montes pas ? Ça discute ferme, là-haut... C'est intéressant : il y a un Autrichien, en mission, le camarade Boehm, qui arrive de Vienne... Il dit que la note autrichienne sera remise ce soir à Belgrade... aussitôt que Poincaré aura quitté Pétersbourg (Roger Martin du Gard, Les Thibault. L'Été 1914)
1958 Nous lui passâmes cette niaiserie. Mais nous n'étions pas toujours aussi accommodantes ; quand un sujet nous intéressait nous discutions ferme. Nous respections beaucoup de choses; nous pensions que les mots patrie, devoir, bien, mal, avaient un sens ; nous cherchions simplement à le définir (Simone de Beauvoir, Mémoires d'une jeune fille rangée)

1996a Essoufflés, nous nous sommes cachés derrière un porche. Des passants se retournaient. Boris et moi voyions nos parents qui discutaient ferme. Et maman, avançant dans cette rue avec ses « Boria, Boria! », tandis que notre père attendait. Nous sommes sortis de derrière notre porche (Boris Schreiber, Un silence d'environ une demi-heure)

1996b Pire encore : cet espoir ne nous alléchait plus. Peut-être fallait-il argumenter ? Le premier pas dans l'aventure, n'était-ce pas plus grisant que dans les normes? Discuter ferme. Elle aurait cédé. Alors? Andrée ouvrit son sac de plage, y prit une feuille qu'elle nous tendit :

- Mon nom et mon adresse. Je voudrais les vôtres, en retour

(Boris Schreiber, Un silence d'environ une demi-heure)

2002 Président du PINGO (Coordination des organisations non gouvernementales palestiniennes), le canon pointé vers la rue par où nous arrivions. Il a fallu discuter ferme pour que ne soit pas refoulé le médecin palestinien, spécialiste en dermatologie, qui nous accompagnait (François Maspero, Les Abeilles et la guêpe)

2005 On lit le compte rendu, on le critique pour la forme et le fond, on pose des questions au lecteur, on propose des rectifications, etc. On discute ferme des mérites du texte, des problèmes existentiels qu'il pose, on le compare à d'autres textes lus précédemment (Philippe Lejeune, Signes de vie)

Transitif

1985 Heureusement, j'avais une certaine habileté pour les soins et j'étais sérieuse dans 
mon travail. En salle de garde, on me discutait ferme, on mettait en boîte la jeune externe qui était en analyse prolongée et qui, à l'hôpital, parlait aux bébés

(Françoise Dolto, La Cause des enfants)

\section{CORPUS WEB :}

« Le douanier m’a indiqué que je n'étais pas en règle, j'ai dû discuter ferme pour qu'il consente à déplacer les plots sur la chaussée pour me faire reprendre la voie de sortie sans m'acquitter de la vignette et me rendre à la piscine par l'ancienne douane »[http://www.estrepublicain. $\mathrm{fr} /$ insolite/2014/12/17/indispensable-vignette (6.2.2015)

L'autre grand cheval de bataille de PSA est bien entendu l'annualisation du temps de travail. Il s'agirait de calculer le temps de travail sur une année entière afin d'intégrer de manière plus souple les aléas de l'activité (un peu comme les cycles agricoles autrefois). Autant prévoir que cela va discuter ferme dans les semaines à venir... [http://www.caradisiac.com/Actu-del-eco-PSA-propose-un-gel-des-salaires-a-sessalaries-89084.htm] (6.2.2015)

Faut les discuter ferme les contrats à st trop ! et c'est surtout difficile mentalement donc, apres faut se reposer ! [http://forum.elprofessor.com/ index.php?topic=9210.15;wap2] (6.2.2015)

Mais je peux vous assurer qu'ils discutent fermes pour trouver des solutions qui puissent relativement réunir tout le monde et qu'ils s'intéressent aux impressions de ceux qui se déplacent pour les shows [http://www.painthorseforum. com/t4747p45-mooslargue] (6.2.2015)

REMARQUes : Discuter ferme désigne le fait de parler avec d'autres en échangeant des idées, des arguments sur un même point, les sujets s'exprimant vivement, voire rudement les uns envers les autres. Dans son emploi transitif, il peut désigner le fait de mettre en doute avec rigueur les compétences de quelqu'un (ex. de 1985). Ferme tend à l'invariabilité. Toutefois, il s'accorde avec le sujet au pluriel dans le dernier exemple du CW, insistant ainsi sur l'attitude du sujet. VoIR AUSSI : disputer ferme

\section{Disputer ferme}

Disputer de manière décidée, résolue, tenace

Pronominal

1943 On se dispute ferme dans le grand monde et alors en avant les âneries (Robert Desnos, Le Vin est tiré...)

1976 Je l'aimais beaucoup. Je me disputais ferme avec lui. Je lui reprochais son mauvais goût en littérature, son indifférence au «style » et le côté bergerie libertaire de sa philosophie (Claude Roy, Somme toute)

2009 Mon père était d'un naturel anxieux. Il n'avait pas accueilli la nouvelle de notre voyage en France avec beaucoup d'enthousiasme. Au contraire, je l'avais entendu se disputer ferme avec maman à ce sujet. Mes parents étaient divorcés depuis deux ans et les vieilles rancœurs refaisaient vite surface lors des grandes décisions me concernant (Angélique Isselin, Ses yeux comme des miroirs)

2012 « Je ne l'ai vue qu'une fois. À la boutique avec Romain. Une présence exceptionnelle. Je ne me souviens plus s'il me l'avait présentée ou non. Je venais juste d'ouvrir le magasin et, ce jour-là, quand ils étaient passés, mes deux premiers clients (pour ainsi dire) se disputaient ferme le même bibelot, au point que j'avais dû les séparer avant qu'ils ne me rompent quelque objet dans la boutique... » (Robert Deleuse, Un dernier coup de théâtre)

\section{CORPuS Web :}

Groupe assez simple pour ManU, qui devrait se qualifier sans soucis. $\mathrm{Ca}$ devrait par contre se disputer ferme pour la deuxième place, mais je vois tout de même les Russes devant [http://www. allocine.fr/communaute/forum/voirmessage gen_refmessage $=15119853 \&$ nofil $=581228 . \mathrm{html}]$ (9.2.2015)

C'est le collectif qui distingue le Maccabi. Haïfa ne dispose pas de vedettes au talent inné, comme Vermouth ou Shechter, à l'Hapoël TelAviv, qui brille en Europa League (l'autre coupe européenne), et qui est bien décidé à disputer ferme le titre de champion d'Israël à Haïfa cette saison [http://www.metulanews.net/article. php?sid=2541] (9.2.2015) 
Les 4 équipes remaniées de la catégorie Atome se disputent ferme les honneurs du championnat terminant les matchs par des marges très serrées [http://www.ahmverdun.com/Nouvelles/ Saison\%202010-2011/2011-03-21\%20les $\% 20$ jeunes $\% 20$ hockeyeurs $\% 20$ verdunois $\% 20$ aux $\% 20$ championnats $\% 20$ maison.htm ] (9.2.2015)

«Messire Cadenwarr, en ces temps troublés où les grands disputent fermes, recevez toutes mes bénédictions quant à votre mariage et votre descendance à venir. » (Il s'inclina légèrement.) $\mathrm{Si}$ je puis m'atteler à un quelconque projet ayant rapport avec vos enfants ou votre ravissante et jeune épousée, j'ouvrerais avec diligence » [http://retrahant.forumactif.com/t3380p1mariage-royal] (9.2.2015)

RemARQues : Disputer ferme désigne le fait d'avoir une discussion vigoureuse, de débattre avec fermeté, les sujets dénotant de l'assurance et de la résolution. Dans l'emploi pronominal (le plus courant aujourd'hui), disputer ferme réfère à une querelle énergique, vive et réciproque. Pour la collocation fort et ferme, v. disputer fort. Ferme tend à l'invariabilité. Dans le $\mathrm{CW}$, ferme reste invariable dans le troisième exemple malgré le sujet au pluriel, tandis qu'il s'accorde avec le sujet dans le dernier exemple, ce qui le rapproche des prédicats seconds orientés vers le sujet. Le CW met en évidence l'emploi dans le domaine du sport où l'on (se) dispute une victoire. Disputer ferme est transitif dans le second exemple du CW. L'emploi absolu apparaît dans le dernier exemple. VoIR AUSSI : discuter ferme

\section{Disputer fort}

I. Disputer, débattre énergiquement, vivement Transitif

1602 Laffaire feust fort disputée de part et d'aultre et ne passa qu'à fleur de corde, car si bien quelques ungz estoyent retenuz de bon zeelle pour ne passer pas outre à la veriffication, ce neanmoingz plusieurs aultres n'en estoient pas d'advis pour d'aultres considerations de moingz de mise, entre lesquelz aucungz avoyent esté d'advis de la veriffication dez la derniere foys qu'on fit l'arrest des remonstrances, lesquelz maintenant estoyent d'advis contraire pour ce que les choses avoyent changé de face, et qu'il y avoit de nouveaux interestz sur le tapis (Nicolas de Peiresc, Lettres à sa famille)

Intransitif

1624 Puisque pour croire en Dieu chacun choisit sa forme,

Et que l'on trouve bon qu'en ce point la loy dorme,

Qu'on ne craint pas icy les inquisitions,

Et qu'on dispute fort sur les traditions,

Que le livre est ouvert où le salut se puise,

Et qu'on voit que chacun l'interprete à sa guise,

Estans par ce moyen de nostre sens conduits,

Je vous laisse à penser où nous sommes reduits,

S'il y a pas autant comme il y a de testes

D'opinions, d'erreurs, excitans des

tempestes,

Et des brouillars obscurs qui ostent à nos yeux,

Il y a trop long tens, le droict chemin des cieux

(Jacques Du Lorens, Premières satires)

1627 Quelques escoliers les soustiendront, et l'on disputera contre eux fort et ferme pour s'exercer l'esprit, et afin que la verité sorte de cette altercation, comme faict une estincelle de feu du heurt de deux cailloux (Charles Sorel, Le Berger extravagant)

1710 Quant à la destination des élus à la vie éternelle, les protestants aussi bien que ceux de l'Église romaine, disputent fort entre eux si l'élection est absolue, ou si elle est fondée sur la prévision de la foi vive finale (Gottfried Leibniz, Essais de théodicée sur la bonté de Dieu)

1749 Ce château ne faisoit presque que sortir de terre, lorsque le roi s'aperçut d'un défaut à une croisée qui s'achevoit de former dans la longueur du rez-de-chaussée. Louvois, qui étoit brutal, et gâté jusqu’à souffrir difficilement d'être repris par son maître, disputa fort et ferme, et soutint 
que la croisée étoit bien (Saint-Simon, Mé moires complets et authentiques du duc de Saint-Simon sur le siècle de Louis XIV et la Régence [1739-1749])

2013 Ah ! nous étions fort loin des sermons incompréhensibles en dialecte taïwanais des églises de Tamsui, mais emportés $\mathrm{au} \mathrm{IV}$ e siècle à l'époque où les pères de l'Église disputaient fort contre d'autres saints hommes - parce que je ne vois pas pourquoi on ne respecterait pas Origène ou Pélage pour leurs efforts (Amélie de La Musardière, Professeur à Tä̈wan)

II. Se quereller

Pronominal

1854 dans l'une d'elles [= chambres] des matelots bronzés et hâlés [...] jouaient avec des cartes rondes représentant des lunes, des croissants, des sabres, des soleils et des étoiles ; des coquilles blanches servaient de jetons. On criait haut et l'on se disputait fort (Maxime Du Camp, Le Nil. Égypte et Nubie)

1863 Victor qui a lu des pages çà et là est dans le ravissement, il ne pouvait ce matin s'arracher du livre, et nous nous sommes fort disputés à qui l'aurait, ma majesté l'a emporté, mais c'est un coup d'état et un acte de tyrannie (Victor Hugo, Correspondance)

2006 - Il y avait des disputes à la maison et tout ça?

- Ouais des trucs comme ça.

- Oui, j’ai connu ça aussi.

- Tapage nocturne.

- Ah, ils se disputaient fort

(Lionel Thelen, L’Exil de soi)

CoRpus Web :

Arrêtez de faire des HS, on va se faire disputer fort après [http://battlelog.battlefield.com/bf4/ fr/forum/threadview/2979150493936541431/2] (9.2.2015)

Et pourtant, par la magie du téléphone, alors que j’appelais simplement pour demander justement 'Ça va ?', et dire 'Ici... Ça va, rien de nouveau, donc ça va', je me suis fait disputer fort, même très très fort par une petite voix, à trois cent soixante-cinq kilomètres de moi, parce que je tousse et que je ne vais pas voir le docteur et que ce n'est pas bien' [http://sylvainbarraux.net/ blog/category/une-histoire] (9.2.2015)

Non, rassure toi, tu n'es pas la seule. Je viens de tomber sur ton blog parceque justement, je me demande ce que cela fait à un bébé de 7 mois de voir ou d'entendre ses parents se disputer fort. Avec un haut volume sonore. Ou avec une grosse grosse tension rentrée quand on essaye de ne pas crier [http://unblogunemaman.blogspot.co.at/ 2008/12/pas-devant-les-enfants.html] (9.2.2015)

Remarques : Disputer fort (I) désigne le fait d'avoir une discussion énergique, de débattre avec fermeté, les sujets dénotant de l'assurance et de la résolution. Dans son emploi pronominal (le plus courant aujourd'hui), il réfère à une querelle vive et réciproque (II). Notons la collocation fort et ferme et l'emploi de crier haut, soulignant l'idée de dynamisme de la discussion. Fort reste invariable. Notons que l'emploi de disputer fort s'applique surtout aux querelles entre parents, entre parents et enfants ou entre mari et femme. Les deux premiers exemples du CW contiennent la variante se faire disputer. Fort est modifié par très. Mentionnons également l'emploi de crier haut.

\section{Donner cher}

I. (au figuré) donner cher pour : donner beaucoup, désirer ardemment

Emploi absolu

1882 Avec un singulier serrement de cœur, je voyais s'envoler ces derniers moments de notre dernière soirée. - J'attendais avec une inexplicable anxiété ; j'aurais donné cher à cet instant pour voir cette créature, dont j'avais rêvé dans mon enfance, et qui était liée au lointain et poétique souvenir de Rouéri (Pierre Loti, Le Mariage de Loti)

1933 Rien qu'à penser le mot de parapluie, une salive de bonne volonté leur venait à la bouche, ils auraient donné bien cher pour l'avoir encore son parapluie (et si le vieux avait essayé de sortir de sa tombe, ils l'auraient peut-être fait rentrer à coups de soulier sur la tête) (Marcel Aymé, $L a$ Jument verte) 
1956 Néanmoins on était persuadé qu’il y avait réellement un monde d'oiseaux qui passaient avec une rapidité déconcertante à des moments où seul Timard levait le nez. - Je donnerais cher pour toucher un de ces oiseaux, disait Timard.

- Les Dassigne sont cette fois complètement ruinés, répondait Fortan.

C'était vers le début de février (André Dhôtel, Le Ciel du faubourg)

1984 On s'en est d'ailleurs vite aperçus, que c'était bruyant, parce que ce soir-là, justement (« Justement ! » jubilait Proccema), ma belle-mère a téléphoné, et... « Fantastique. Je donnerais cher pour qu'il bosse avec moi, ce Rima falot!»

- Eh bien, monsieur Rima, je vous remercie (Anne Vergne, L'Innocence du boucher)

2004 Que vous ayez un mot gentil. Lorsque vous sortez entre amis, vous discutez ensemble alors pourquoi n'est-ce pas la même chose avec moi ? Je donnerais cher pour savoir ce que vous apprenez, ce que vous faites, si vous avez passé un bon après-midi (Valérie Mréjen, Eau sauvage)

II. ne pas donner cher de : ne pas donner de garantie sur (notamment dans l'expression je ne donne pas cher de sa peau 'je pense qu'il / elle va mourir')

Emploi absolu

1886 c'est à cause d'eux que l'empereur a voulu permettre au public de réviser le procès ; ce sont eux enfin qui triomphent... ah ! J'en entends de belles, je ne donnerais pas cher de vos peaux, jeunes gens! Il riait de son grand rire, les bras ouverts, comme pour embrasser toute la jeunesse qu'il sentait monter du sol (Émile Zola, L’Euvre)

1912 Jamais !... et si tu découvres cet autre-là, comme tu m'as découvert, un autre viendra, et un autre ! Et un autre ! Jusqu'à ce que ce Trébassof paie ses crimes ! C'est tout ce que j'ai à te dire, Koupriane !... quant à vous, mon petit, ajouta-t-il en se tournant vers Rouletabille, je ne donnerais pas cher de vos os! Nous ne valons guère mieux tous les deux. Et c'est ce qui me console! (Gaston Leroux, Rouletabille chez le tsar)

1968 Il doit traîner quelque part au fond d'un tiroir une photo de moi oubliée de tous, que Bettina exhumera, agrandira, encadrera. Elle lui vouera un culte. Je ne donne pas cher, moi mort, de la peau de ses amoureux. Comparé à moi aucun ne vaudra la corde pour le pendre (François Nourissier, Le Maître de maison)

1988 Toi, tu risques soit de te faire plomber, soit de terminer en taule. Moi... s'ils estiment que tu m'as tout raconté, et ils n'auront pas tort, je donne pas cher de mes abattis... La seconde diskette, c'est toi qui l'as ? (Jean-Bernard Pouy, La Clef des mensonges)

1993 Je ne donne pas cher non plus de l'École des Beaux-Arts. Un jour, on déplacera les Matisse en herbe sur le plateau de Saclay entre Polytechnique et les Hautes Études Commerciales (Éric Orsenna, Grand Amour)

2006 Ils n'étaient pas des amis, juste des associés. J'ai mis Jean en garde : je ne donnais pas cher de son collègue, moi. Mais il était entiché de lui, vraiment. Que s'est-il passé, une fois là-bas ? (Anne-Marie Garat, Dans la main du diable)

III. Payer cher

Emploi absolu

1936 C'était au fond de la cheminée qu'elle garait la Remington qu'elle l'avait pas fini de payer... Soi-disant. Je donne pas cher pour mes copies, c'est exact, encore... soixante-cinq centimes la page, mais ça cube quand même à la fin... Surtout avec des gros volumes (Louis-Ferdinand Céline, Mort à crédit)

IV. S’investir beaucoup, faire un effort Emploi absolu

1994 En conclusion, Minvelle laissait percer son pessimisme mais n'abandonnait pas la partie. Il était toujours aussi enthousiaste, prêt à donner très cher de lui-même pour apprendre comment Arnaud de Beltram 
et son escorte avaient bien pu quitter Menzalé et se faufiler entre les lignes ennemies en ce début d'été de l'an 1226 (Jacques Lanzmann, La Horde d'or)

\section{CoRpus Web :}

On pourrait ne pas donner cher de la peau de David Ferrer en finale de Bercy [http://www. eurosport.fr/tennis/paris-bercy/2013/bercy-2013les-chiffres-a-savoir-avant-la-finale-djokovicferrer_sto3990917/story.shtml] (10.2.2015)

@Mastakilomaitre @melanie_diams j’aurai donner cher pour vivre ca en studio pendant qu'elle pause son " vous etes trop gentille gentille » [https://twitter.com/romainjeunot/status/ 519042736662773761] (10.2.2015)

Deux jeunes hommes, convaincus de la fidélité des deux sœurs qu'ils avaient fiancées, font un pari avec l'un de leurs amis, un vieux célibataire, qui ne semble pas vouloir donner cher de la fidélité féminine [http://www.corsenetinfos. fr/Ouverture-du-4eme-Festival-Lyrique-de-Calvi_ a4322.html] (10.2.2015)

Si le PSG avait fini 18e, je n'aurais pas donner chère de la peau des Grenoblois [http://www. vaenl1.com/forum/viewtopic.php?f=11\&t=15303] (10.2.2015)

REMARQUES : Au conditionnel, donner cher pour (I) renvoie au fait de souhaiter vivement quelque chose, d'être prêt à faire d'énormes concessions pour obtenir l'objet souhaité. En (II), l'expression ne pas donner cher de se dit quand le sujet n'est pas prêt à donner des garanties sur quelque chose, notamment sur la vie ("la peau ») de quelqu'un. Il renvoie alors au fait d'être persuadé que quelque chose n'a pas d'avenir, pas de chance de fonctionner et, par extension, de ne pas être prêt à y investir son argent, à parier là-dessus. Donner cher (III) désigne le fait de donner beaucoup d'argent pour quelque chose, d'accorder une grande importance à quelque chose, cher se référant à sa valeur. (IV) désigne l'engagement fort d'une personne. Cher reste invariable et est modifié par bien, très. Dans le CW, cher reste également invariable, à l'exception du dernier exemple, où il s'accorde avec le complément indirect (la peau), mais l'orthographe générale de l'exemple ne permet pas d'y voir un effort stylistique. Notons aussi que donner est un verbe dit trivalent qui s'emploie avec un objet direct et un objet indirect (donner quelque chose à quelqu'un), alors que dans les exemples le seul actant est le sujet (emploi monovalent). Il tend donc à l'emploi absolu quand un adjectif-adverbe le modifie.

\section{Donner gagné}

Donner raison, reconnaître

Emploi absolu

1560 Je respon que si le Juge signifie Dieu en ce passage, la partie adverse signifie le diable, le sergeant un Ange, la prison purgatoire, je leur donne gagné (Jean Calvin, Institution de la religion chrestienne)

1645 BEATRIS. Or si vous en tirez la moindre lachrymule, Je vous donne gagné, foy de Beatricule, Vous riez Dom Louis de ce diminutif, Dame nous en usons, et du superlatif (Paul Scarron, Le Jodelet)

1654a Ainsi il [= Victorius] intente un proces contre une possession de seize cens ans ; ne considere ni la faveur d'Auguste, ni l'amitié de Mecenas, ni les applaudissemens de tous les siecles, ni toutes les voix de la renommée, qui donnent gagné à sa partie (Jean-Louis Guez de Balzac, Dissertations chrestiennes et morales)

1654b Mais quand je dis joli, je ne donne pas gagné pour cela, à l'autre que je dis beau : je me conforme seulement à l'opinion d'Aristote, qui assignant à chaque chose les termes qui luy sont propres (Jean-Louis Guez de Balzac, Dissertations critiques)

1734 D'un autre côté, cet honneur plaidait sa cause dans mon âme embarrassée, pendant que ma cupidité y plaidait la sienne. À qui est-ce des deux que je donnerai gagné ? Disais-je ; je ne savais auquel entendre. L'honneur me disait : « tiens-toi ferme » ; déteste ces misérables avantages qu'on te propose ; ils perdront tous leurs charmes quand tu auras épousé Geneviève (Pierre de Marivaux, Le Paysan parvenu)

1824 Nous étions d'une gaîté folle, et, selon ma coutume, c'était moi qui donnais le ton. On parla des prouesses de certains 
mangeurs d'huîtres détérminés. Je fis le pari, pour ma part, d'en manger cent douzaines. Le pari fut tenu, et voilà les ouvreuses à l'œuvre. L'hôte me conseilla de boire du lait au lieu de vin ; j'y consentis, et j'entrai en besogne. J'avais déjà avalé les deux tiers de mes cent douzaines sans que rien annonçât que je serais forcé de lâcher le pied, et j'avalais encore ; mais mes camarades me donnèrent gagné, et ne voulurent absolument pas que j'allasse audelà, comme j'insistais à le faire pour l'acquit de ma forfanterie (Bernard Fonvielle, Mémoires historiques)

1850 Cette dernière bonne raison donna gagné à Madeleine (George Sand, François le Champi)

1936 Car je semble donner gagné à ceux qui disent que la guerre est dans la nature humaine et durera autant que les hommes (Alain, Propos)

Transitif

1563 Quant au premier poinct, je te le donne gagné, mais quant est de ce que tu dis, qu'il est requis un lieu montueux pour edifier jardins, je ne puis à ce accorder (Bernard Palissy, Recepte veritable)

\section{CORpus Web :}

Les Caennais ont toutes les cartes en main pour aller au bout. Ils comptent un match de moins, face à Nîmes, que la Ligue vient de leur donner gagné sur tapis vert, l'appel des Crocos au CNOSF étant probablement vain [http://www. lamontagne.fr/auvergne/sports/actualite/foot ball/2014/04/14/embouteillages-serres-a-tousles-etages_1964763-6671.html] (10.2.2015)

Une petite incompréhension demeure cependant, à savoir pourquoi le match a été reporté dans un premier temps, pour ensuite le donner gagné par forfait? [http://ascm-foot.footeo.com/ actualite/2013/01/04/c-est-reparti-mon-kiki. html?sf_culture=fr] (10.2.2015)

Inconnu dans l'Ouest, sans profondes racines dans ce parti, M. Mulcair avait hésité à se lancer dans cette course que l'on donnait gagnée d'avance à Brian Topp [http://fr.canoe. ca/cgi-bin/imprimer.cgi?id=1141901] (10.2.2015)
REMARQUES : Donner gagné se dit d'une personne qui reconnaît que son adversaire l'emporte, qu'il a gagné, ou simplement qu'il a raison. Gagné reste invariable, sauf dans le dernier exemple du CW, où il est accordé avec l'objet au féminin, ce qui le rapproche d'un prédicat second orienté vers l'objet. Le CW montre l'emploi préférentiel dans le langage du sport.

\section{Donner gros}

I. Donner beaucoup d'argent

Emploi absolu

1749 À la fin, et à force de donner gros, le marché fut conclu (Saint-Simon, Mémoires complets et authentiques du duc de SaintSimon sur le siècle de Louis XIV et la Régence [1739-1749])

1756 le Roi donne gros à la compagnie des Indes pour cette entreprise (René-Louis d'Argenson, Journal et mémoires)

1945 Tu me payeras, je suppose, la semaine des quat'jeudis. Et haut : « Moi, Emma Philibert, je suis pas assez bête pour me faire prendre, va ! Je donne pas gros comme mon petit doigt » (Gabrielle Roy, Bonheur d'occasion)

II. Donner beaucoup, payer cher (au figuré) Emploi absolu

1769 Je suis las de ce métier, et vous conviendrez que c'est le plus plat métier qu'il y ait au monde que celui de lire tous les plats ouvrages qui paroissent. On me donneroit aussi gros d'or que moi, et je ne suis pas des plus minces, que je ne voudrois pas continuer (Denis Diderot, Lettres à Sophie Volland)

1862 L'ex-horloger aurait donné gros pour reprendre ses anciennes occupations (Paul Reider, Mademoiselle Vallantin)

1877 Je donnerais gros pour être à sa place (Émile Zola, L’Assommoir)

1925 Il réfléchissait, ou plutôt il en revenait toujours à ceci, qu'il eût donné gros pour voir Anne-Marie pourvue d'un parti sortable (Henri Pourrat, L'Auberge de la Belle Bergère ou Quand Gaspard de guerre revint) 
1943 - Je te réponds qu'elles donneraient gros, ces petites bonnes femmes, pour ressembler à Harbley ou à Bouget, dit Elizabeth avec aigreur (Simone de Beauvoir, L'Invitée)

1955 De ces lacunes obsédantes - lésions qui sont cause d'inquiétude et qu'il faudrait réparer pour avoir le sentiment euphorique de se posséder en totalité - l'une, peutêtre, me fait sentir son vide de manière un peu plus gênante que les autres et je donnerais gros pour parvenir à la combler (Michel Leiris, La Règle du jeu 2 : Fourbis)

1972 Pas question de labeur honnête, notre vie fallait bien qu'on la vole. À la sueur de nos tripes ! C'est ce qui nous manquait le plus, un bon boulot peinard. On aurait donné gros pour s'établir citoyens modèles. Un petit commerce, tenez... Une rue calme dans un coin chic. Que des hôtels particuliers classés monuments historiques... (Bertrand Blier, Les Valseuses)

III. ne pas donner gros de : ne pas donner de garantie

Emploi absolu

1936 Les voisins eux s'en occupaient, ils se sur passaient en conseils... Ils donnaient pas gros de ma carrière... Même le gardien du Passage, il m'était défavorable... Il rentrait dans toutes les boutiques, au moment de son allumage. Il colportait les ragots. Il répétait à tout le monde que je finirais hareng saure (Louis-Ferdinand Céline, Mort à crédit)

IV. S'investir beaucoup, faire un effort

Emploi absolu

1946 Elle crée et donne sans compter parce qu'elle porte en elle, sinon de la ressource pour donner toujours plus gros, du moins du mouvement pour aller toujours plus loin. Mais en même temps, elle sait pourquoi elle donne, à qui elle donne, et pourquoi surabondamment (Emmanuel Mounier, Traité du caractère)

\section{CORPUS WEB :}

Perso en soft j'utilise maxxbass de chez waves tu peux au choix faire ressortir la frappe ou la basse du kick, pour le metal c'est bien de pouvoir faire les 2, mais si il faut choisir j'préfère la frappe (entre 150 et 200hz généralement) qui va donner gros d'impact à ta gc [http:// fr.audiofanzine.com/techniques-du-son/forums/ t.84760,gros-kick.html] (10.2.2015)

Quelques minutes à peine avant le premier match de Thomas Vanek avec l'équipe, hier soir en Arizona, le directeur général du Canadien a tenu à dire qu'il avait eu à donner gros afin d'aller chercher l'attaquant mécontent des Islanders de New York [http://www.lapresse.ca/sports/ hockey/201403/07/01-4745435-marc-bergevinavait-thomas-vanek-a-loeil.php] (10.2.2015)

De plus, vu leur puissance, c'est un peu normal qui faut donner gros pour les invoquer, c'est impossible de faire la 3ème mission sans s'entrainer par exemple, sauf si on utilise Shiva, et là, elle bat les monstres en deux, trois coups [http://khisland.info/forum-2-241-5-final-fantasytype-0--discussions-impressions.html?PHPS $E S S I D=88 d 5976 f 1 f 6283 b 4 b 7745 d f 4 a 6 b 34173$ ] (10.2.2015)

REMARQuES : Donner gros reprend exactement la polysémie de donner cher (v. ci-dessus). Notons la comparaison donner gros comme le petit doigt. Les collocations gros d'or, gros d'argent (s.v. devoir gros), gros d'impact montrent sa grammaticalisation comme quantifieur équivalent à beaucoup. C'est aussi la fonction qui prévaut dans les deux derniers exemples du CW, où donner gros signifie 'donner beaucoup de soi-même'. Gros est invariable. Il est modifié par aussi, toujours plus.

\section{Donner juste}

Donner peu, donner juste ce qu'il convient Emploi absolu

1963 Mais nous le faisons toutes [= gratter sur les comptes du ménage], dit-elle, comment veux-tu qu'on s'en tire autrement ? Ils [= les maris] nous donnent trop juste (Christiane Rochefort, Les Stances à Sophie)

\section{CORpus Web :}

Et si je donnais trop -> mort des « voraces » par suralimentation.

Et si je donnais trop juste -> discus, scalaires et cardinalis sous alimentés ! [http://dict.leo.org/ frde/index_de.html\#/search=unterern $\%$ C3\%A4 
hrt\&searchLoc=0\&resultOrder=basic\&multiwor dShowSingle $=$ on] $(10.2 .2015)$

Parfois même la batterie qui donne trop juste ce qu'il faut pour demarrer [http://www. auto-evasion.com/forum-auto/aide-mecaniqueet-panne-moto/triumph-bonneville-2001/159487. html] (10.2.2015)

Remarques : Donner juste désigne le fait de donner quelque chose, une somme d'argent, de la nourriture ou tout type d'effort, suffisant à peine pour réussir. Juste reste invariable et est modifié par trop.

\section{Donner mou}

Frapper faiblement ; mollir, perdre de la vigueur Emploi absolu

1933 Après une demi-heure de travail, son fléau donnait mou, perdait la cadence et, à chaque instant, elle manquait de se le cogner sur la tête (Marcel Aymé, La Jument verte)

CoRpus WeB :

Poussez la partie inférieure de l'avant de dérailleur pour donner mou à la chaîne et laisser revenir en arrière dans sa position de repos [http://www.besteartikel.com/sportif/guidepour-lachat-dune-deuxime-main-vtt] (11.2.2015)

sympa les soirées y'en a pour tous les gouts. par contre when you're gone si c'est avril lavigne ca va donner mou [http://www.makinarena.com/ index.php?topic=8657.0] (11.2.2015)

Il me semble que stefspirit a du acheter le sien dans les 400 euros.

En plus ils sont rares.

Les critiques les donnent mou à PO [http:// www.alphadxd.fr/viewtopic.php?f=1\&t=69318 \&start=0] (11.2.2015)

REMARQUES : Donner mou désigne le fait de porter un coup, de battre avec faiblesse, de ralentir la cadence, le sujet étant généralement inanimé (ici : le fléau). Mou reste invariable. Dans le premier exemple du CW, donner (du) mou signifie 'lâcher, laisser une marge de mouvement'. Il est plus difficile de spécifier la signification dans les autres exemples. Dans le dernier exemple, mou appartient au domaine de la photographie et réfère à un objectif (pleine ouverture).

\section{Dormir aise}

Dormir / s'endormir confortablement, sereinement

Pronominal

1235 « Si ferai jou, fait elle, mais moult me duel encore dou cheoir que j'ai fait. " Et il esracha de l'erbe a ses mains et le met desous son chief por chou que elle se dormist plus aise. Et il meismes oste s'espee et son hyaume et son hauberc et remaint en pur cors, et puis se prent des chevaus garde et lour oste les frains et les seles et les laist paistre (La Suite du Roman de Merlin, § 299, 17)

Intransitif

1325 Aise puet dormir et veillier

Pour qui vous voulez travaillier

(Watriquet de Couvin, Dits, p. 132, 19)

1371 LA MÈRE. Mais que nous arons beu, je vueil,

Godeffroy, que couchier le maines,

Et que de li couvrir te paines,

Si qu'il dorme aise

(Miracle de la fille du roy de Hongrie, 1429)

1379 YSABEL. Egar ! qu'il est tart ! Haro ! qu'est ce?

Je croy que j'ay dormi trop aise

(Miracle de la fille d'un roy, 2747)

REMARQUES : En ancien français, dormir aise réfère au fait de dormir dans un état de confiance, avec sérénité, confortablement, le sujet ne ressentant ni crainte, ni malaise. Aise renvoie également aux conditions extérieures. Le français moderne le remplace par tranquille dans cette fonction : dormir tranquille, laisse-moi dormir tranquille 'sans être dérangé'. Aise reste invariable et est modifié par trop.

\section{Dormir calme}

Dormir d'un sommeil calme, non agité

$\lambda$ dormir profond 


\section{Dormir couché}

Dormir dans une position couchée, dormir allongé

Intransitif

1625 Jusques à samedy dernier qu'un païsan me remis l'os de mon espaule fort heureusement, dieu mercy, et aussytost je commançay à remüer mon bras comme auparavant le mal et à pouvoir dormir couché et respirer (Nicolas de Peiresc, Lettres aux frères Dupuy)

1710 CRISPIN. Tu vois ; quoi qu'il m'arrive, Je conserve toujours un embonpoint égal : Chasser le jour, la nuit, à pied comme à cheval,

Le fusil sur l'épaule, en carrosse, en litiere, Forcer chevreuil, cerf, daim, sanglier, sangliere,

Manger froid, boire chaud, dormir couché, debout ;

Un garçon comme moi s'accommode de tout

(Philippe Destouches, Le Curieux impertinent)

1819 Dormir bien couché, vivre à ma fantaisie, travailler selon mon goût, ne rien faire quand je veux, m'endormir sur l'avenir, n'avoir pour compagnie que des gens d'esprit, le petit père compris, et les quitter quand ils me fâchent (Honoré de Balzac, Correspondance)

1840 Les vitraux éclatants ou sombres, Le caveau froid où, dans les ombres, Sous des murs que le temps abat, Les preux, sourds au vent qui murmure, Dorment couchés dans leur armure, Comme la veille d'un combat (Victor Hugo, Odes et ballades)

1908 C'est une chose triste, quand on a descendu le fleuve Rouge des jours et des jours, sur un sampan où l'on ne peut ni se tenir tout à fait debout, ni dormir tout à fait couché, c'est une chose triste de voir des maisons, de sentir l'odeur des cuisines et de ne pas oser pourtant passer une nuit sous un de ces toits (Pierre Mille, Barnavaux et quelques femmes)
1965 - Toi, Urbain et même Aubain, quand le matin, quittant la maison mère, tu agitais la main vers le perron blanc-gris sur la plus haute marche duquel se tenait, noire et droite et debout, ta grand-mère adorée humant le vent du mont, si droite et si debout qu'en ce moment tu te demandes encore si, vraiment, en haut à gauche, ta grand-mère dort couchée (René-Victor Pilhes, La Rhubarbe)

1976 Supports de ces trois femmes : un grand fauteuil Louis XIII pour la première (qui $r \hat{e}$ verait ou dormirait assise, et non couchée, au moment de mon arrivée), un divan recouvert de velours noir pour la deuxième, une couche quelconque mais très basse pour la troisième (Michel Leiris, La Règle du jeu 4 : Frêle Bruit)

2001 Une autre fois, un de mes récits imprudemment détaillé me valut une vengeance moins colérique bien que tout aussi violente : un coup de rasoir donné à l'épaule droite, alors que je dormais couchée sur le ventre, mais non sans que la lame ait été au préalable soigneusement désinfectée à la flamme de la cuisinière (Catherine Millet, La Vie sexuelle de Catherine M. précédé de Pourquoi et comment)

\section{CORPUS WEB :}

Évidemment il faut dormir couché dans un lit confortable, ce n'est pas en restant assis devant un pc que tu t'endormira dans les bras de morphee [http://www.jeuxvideo.com/forums/151-58512225-1-0-1-0-conseils-pour-bien-dormirtuto-pour-ins.htm] (11.2.2015)

Non merci, pour moi, je continuerai à manger à table et à dormir couché dans mon lit [https://fr.toluna.com/opinions/478874/Avezvous-d \%C3\%A9j\%C3\%A 0-mang \%C3\%A9couch\%C3\%A9] (11.2.2015)

D'un point de vue médical et scientifique, il est recommandé de dormir couché sur le dos ou sur le côté, en s'assurant que le cou est maintenu en ligne avec le reste de la colonne, en utilisant un oreiller de dimension appropriée [http:// pilule.telequebec.tv/occurrence.aspx?id=848] (11.2.2015) 
REMARques : Dormir couché réfère au fait de dormir dans une position horizontale. L'accord étant systématique, il se prête à une analyse de prédicat second orienté vers le sujet ; mais à un niveau plus abstrait, on peut dire aussi que dormir couché forme un verbe complexe qui désigne une façon de dormir, par opposition à dormir debout ou dormir assis / rêver assis. Couché est modifié par bien. Notons la série rimée de style populaire dans l'exemple de 1710 : manger froid, boire chaud, dormir couché, debout.

\section{Dormir dur}

I. Dormir fermement, profondément Intransitif

1275 Ne croi qu'il eüst dame de là dusqu'a Delfur

Qui de si grant afaire fust a tel meseür ;

Damedieus par sa grace li renvoit bon eür, Car de tres fin cuer l'aime, de vrai et de meür.

De paine et de travail dort si fort et si dur, Desouz un arbrisel, lez un viés petit mur, Que on ne l'esveillast pas dou son d'un tabur

(Adenet le Roi, Berte aus grans piés, 1007)

1865 Comme il était pas mal sourd et dormait dur, Brulette coucha le petit, nous servit un bout de collation, et se consulta avec nous sur le réveil qu'on lui ferait, avant qu'il eût fini son premier somme (George Sand, Les Maîtres sonneurs)

1947 Il tourna le commutateur, prit son colt d'une main, entra dans la cuisine.

- Ça dort dur dans le coin ! souffla Bernard légèrement anxieux

(René Fallet, Banlieue sud-est)

2005 - Tu parles! Il aurait fallu qu'elle dorme dur en bébite pour ne pas se réveiller avec une explosion pareille, les sirènes et tout. Les pompiers ont vérifié quand même, mais évidemment... (Marie-Danielle Croteau, Un pas dans l'éternité)

2014 Il s'enquit de Thomas qui dormait dur et de Gabrielle qui finalement s'était endormie collée sur Sam mais où était Inndia ? Le corridor baignait dans le noir et les plan- chers craquaient (Rachel Paulin, 6 petits enfants disparus...)

II. Dormir sur un matériel dur Intransitif

1987 Tu sais ce qu'on disait des voyageurs à l'époque, garçon ? Vivent dur, couchent dur, dorment dur, et mangent des chiens ! Ha! (Ronald Lavallée, Tchipayuk ou Le Chemin du loup)

CORpus Web :

Dormir dur, c'est à dire avoir une bonne quantité de sommeil profond, ne peut exister que dans certaines conditions [http://www.brigitte langevin.com/sommeil-et-reves/bulletin-infosommeil/archives/168-bulletin-mars-2011-no-38] (11.2.2015)

J'habite sur Dufferin et j'ai rien entendu. Je dois dormir dur... [http://www.lapresse.ca/latribune/faits-divers/201409/25/01-4803370centre-ville-lorigine-de-la-deflagration-demeureun-mystere.php] (11.2.2015)

Ca m'est arrivée de m'inquietier aussi qqe fois quand je trouvais qu'il était plus tranquille que d'habitude mais ca na jamais durer vraiment longtemps longtemps. des fois je me disais qu'il devait dormir dur ! [http://forum.canalvie.com/ grossesse-et-bebe/232378-mouvements-du-bebeen-fin-de-grossesse-baisse-ou-hausse.html] (11.2.2015)

Remarques : Dormir dur désigne le fait de dormir à poings fermés (I). Dur reste invariable et est modifié par si. Il peut également renvoyer à la dureté du matériel sur lequel on se couche (II). L'exemple sous (II) est en ambiguïté avec (I). Notons l'emploi de vivre dur ; coucher dur.

\section{Dormir faux}

Dormir d'un sommeil artificiel

$\lambda$ habiller faux

\section{Dormir ferme}

I. Dormir profondément Intransitif

1195 PINCEDÉS. Or tost ! fil a putain, larron !

Car li roys dort et si baron

Si ferm que s'il fussent tout mort

(Jehan Bodel, Jeu de saint Nicolas, 997) 
1879 Et, quand elle se fut assurée qu'il dormait ferme, elle souleva sans bruit une portière de velours, et bonsoir !... « où va-telle? » (Léon Cladel, Ompdrailles, le Tombeau-des-Lutteurs)

1887 Villiers de l'Isle-Adam à Marie Dantine vve Brégeras (ce 17 août 1887): ma bonne chère Marie, je suis comme ressuscité : je mange comme quatre ; j'ai dormi ferme ; cet air des bois m'a fait un bien extraordinaire ; je ne souffre plus du tout (Auguste de Villiers de L'Isle-Adam, Correspondance générale)

1936 Carlotta dormait ferme, avec le désespoir des enfants qui savent qu'on les dérangera (Louis Aragon, Les Beaux Quartiers)

1998 Mais elle dormait ferme. La veille elle avait eu des moments difficiles, la visite imprévue d'un Monsieur l'Inspecteur de l'Enseignement secondaire qui ne s'était pas gêné pour critiquer sa façon d'enseigner les sciences. Le sale macho (Annie Saumont, Embrassons-nous)

2014 La montagne respirait au ralenti, par la bouche des racines et les trous des mares qui tardaient à geler. Même si je savais qu'on dormait ferme là-dedans, parce qu'on ne rigole pas avec l'hibernation chez nous, j'imaginais la java sous les flocons (Gautier Battistella, Un jeune homme prometteur)

II. Dormir profondément sur un matelas ferme Intransitif

1997 Dormez ferme (Slogan de la marque de matelas Lattoflex / Noailly 1997a)

CORPUS WEB :

@milou Saint Amand les Eaux, si tu ne mets pas un ou plusieurs secteurs pavés sur le circuit on va dormir ferme pendant 7 heures [http://www.cyclismactu.fr/news-mondiaux2017-france-candidate-pour-l-organisation-25535. html] (11.2.2015)

Nul, en un mot, le spectateur peut dormir ferme sans avoir la moindre envie de regarder le film ! [http://www.allocine.fr/film/fichefilm138301/critiques/spectateurs/recentes] (11.2.2015)
Ils s'endorment dès la tête posée sur l'oreiller et dorment ferme jusqu'au son du réveil matin [http://www.thehozercanada.com/dealer_ inquiries-f.html] (11.2.2015)

REMARQues : Dormir ferme (I) désigne le fait de dormir à poings fermés. En (II), le slogan d'une marque de matelas joue sur l'ambiguïté de ferme qui signifie, au propre 'dormir sur un matelas ferme' et, au figuré, 'dormir profondément'. Ferme reste invariable et est modifié par si.

\section{Dormir fort}

Dormir profondément, éventuellement en ronflant

Intransitif

+1175 Governal vit le forestier

Venir des tres, sor un destrier, Qui vout Tristran livrer a mort En sa forest, ou dormoit fort (Béroul, Tristan $\left[4^{\mathrm{e}}\right.$ quart XII $\left.\mathrm{e}\right], 4048$ )

1195 PINCEDÉS. Qu'est chou ? Qui nous a esvillie?

Dieus ! con je dormoie ore fort ! (Jehan Bodel, Jeu de Saint Nicolas, 1280)

1341 PREMIER CHANOINE. Je ne sçay, par les sains de Romme ;

Mais je vois sa mesnie querre.

Or, sus, seigneurs, or sus, bonne erre!

Trop fort dormez (Miracle de l'evesque que l'arcediacre murtrit, 263)

+1389 et ainsi qu'il fu illec couchié, vit et aperceust que icellui de La Rue dormoit moult fort (Registre criminel du Châtelet de Paris [1389-1392])

1400 Je scey bien que elle vous ame bien, et pour ce que mon seigneur n'y est pas, venez vous en par nostre huis derriere encore ennuyt de nuit, et je vous mectroy en sa chembre, - elle dort bien fort quar el n'est que pas ung enfant -, et vous couchez avecques elle, car aultre remyde je n’y voy (Quinze Joies de mariage, p. 30)

1424 Disoit cellui qu'Amours tenoit En telle pensee amoureuse Que de dormir ne lui tenoit Ne de faire chiere jouyeuse : 
«Ce me semble chose honteuse

Que de dormir tant et si fort ;

Et pour ce m'est elle ennuyeuse

Car il ne sert de riens qui dort »

(Alain Chartier, Le Debat de reveille matin, p. 307, 22)

1515 Et aprés pluseurs complainctes et lamentacions que ladicte sa femme faindoit de faire s'en alla chascun coucher fors que elle et une sienne bonne voisine, et quant se vint entour mey nuict, elle donna à boire audit son mary je ne sçay quelle chose, qui le fist dormir si tres fort, avec ce qu'il estoit si tres colin, tellement que on l'eust bruslez leens, luy et son lict, qu'il n'en eust rien sceu (Philippe de Vigneulles, Les Cent Nouvelles nouvelles, p. 358, 303)

1559 Ce qu'il fist incontinant, et, en montant en hault par ung petit degré de bois, trouva la fille toute seulle dans le lict, qui dormoit bien fort (Marguerite d'Angoulême, Heptaméron, p. 374, 53)

1592 La mort de cet Empereur a beaucoup de choses pareilles à celle du grand Caton, et mesmes cecy : car Caton prest à se deffaire, cependant qu'il attendoit qu'on luy rapportast nouvelles si les senateurs qu'il faisoit retirer, s'estoient eslargis du port d'Utique, se mit si fort à dormir, qu'on l'oyoit souffler de la chambre voisine (Michel de Montaigne, Essais)

1670 PREMIER MÉDECIN. Tant pis : cette grande appétition du froid et de l'humide est une indication de la chaleur et sécheresse qui est au dedans. Dormez-vous fort? MONSIEUR DE POURCEAUGNAC. Oui, quand j'ai bien soupé (Molière, Monsieur de Pourceaugnac)

1715 Et, en disant ces paroles, il la baisa au front, aux deux joues et à la bouche, avec si peu de précaution, qu'elle se fût éveillée si elle n'eût dormi plus fort qu'à l'ordinaire, par l'enchantement de Danhasch (Antoine Galland, Les Mille et une nuits)

1844 Monsieur Léonard jeune, dit-il en secouant Cadet pour l'éveiller, vous dormez trop fort, vous réveillez toute la chambrée (George Sand, Jeanne)

1950 Polo dormait très fort, mais, par contre, il était très matinal (Joseph Zobel, La Rue Cases-Nègres)

2000 Sous la lampe, elles tenaient conciliabule à voix basse, j'avais pris du retard. La petite dormait si fort qu'elle n'a pas bronché dans les tas de chiffons quand je me suis levée (Anne-Marie Garat, Les Mal Famées)

\section{CORPUS WEB :}

Je devais vraiment dormir fort cette nuit pour ne pas avoir entendu la dameuse tasser l'accès au gîte ! Un grand merci au service des pistes ! [https://fr-fr.facebook.com/Oxysports] (12.2.2015)

Aujourd'hui je vais avoir du mal à vous donner un verdict....... je me suis endormie bien avant lui, et j'ai dormir fort toute la nuit...... jusqu'à ce qu'il parte travailler ce matin :D [http:// www.notrefamille.com/forum/Sante/Santegenerale/Douce-nuit-pour-dormir-t344789.aspx] (12.2.2015)

Hein? tu quoi ? tu ronfles?

Non non, je dors fort.

Euh.... (là je ne vois pas trop à quoi ça ressemble de dormir fort)

Ben oui, quand je dors je respire fort ! Oh tu comprends rien toi ! [http://monavis.canal blog.com/archives/2005/01/29/285758.html] (12.2.2015)

REMARQUES : Dormir fort désigne le fait de dormir à poings fermés. Fort reste invariable et est modifié par bien, moult, ore, plus, si, si très, très, trop. Notons l'emploi euphémique pour celui qui ronfle (ex. de 1592, 1844, et le dernier exemple du CW). Mentionnons également l'emploi de respirer fort.

\section{Dormir immobile}

Dormir paisiblement, sans bouger

$\lambda$ dormir profond 


\section{Dormir profond}

Dormir profondément

Intransitif

1847 Cette immense quantité de procès-verbaux des commissaires de police, de rapports, de notes, de dossiers, cet océan de renseignements dort immobile, profond et calme comme la mer. Qu'un accident éclate, que le délit ou le crime se dressent, la justice fait un appel à la police (Honoré de Balzac, Splendeurs et misères des courtisanes)

1950 Ensemble tout le temps qu'il nous fallait pour vivre

Toute une éternité

Et plus je te voyais vivre à côté de moi

Plus je te confondais avec l'aube et l'été

Dormir profond rêver plus haut

Et s'éveiller l'un bien à l'autre

Telle est la loi de l'innocence

Et vivre plus haut que nos rêves

Etre pareils par la confiance

Tel a été notre plaisir

(Paul Éluard, Une leçon de morale)

1967 Il y avait beaucoup de candeur dans ses yeux larmoyants.

- Les béquilles ? lui demanda Ouroz.

- Tu dormais si profond, dit l'homme, que

tu ne m'as pas entendu les déposer. Sur

l'ordre du grand Toursène

(Joseph Kessel, Les Cavaliers)

CoRpus Web :

Mais jvai dormir profond, ils m’ont épuisé [https://twitter.com/SissouCheriti/status/197788 267117158401] (12.2.2015)

Oui Evy !! je pense quettre enceinte moi aussi je ferais la meme chose !! moi je ne massoupie pas jai trop peur de dormir profond ! [http:// www.magarderie.com/forum/archive/index. php/t-34917.html] (12.2.2015)

Le sommeil de votre enfant n'est pas seulement contrarié par cet empêcheur de dormir profond. Il est hanté par des images terrifiantes et parfois très violentes [http://www.vosquestions deparents.fr/dossier/1404/cauchemars-com ment-laider] (12.2.2015)

REMARques : Dormir profond désigne le fait de dormir d'un profond sommeil. Profond reste in- variable et est modifié par si. Notons l'emploi de vivre haut.

\section{Dormir sage}

Dormir sagement, chastement

Intransitif

1896 Car, après tout, l'amour, n'y pensons plus, C'est chimère à notre âge.

On a fixé des vœux irrésolus, On vit calme, on dort sage.

On n'a plus de ces cœurs qu'il ne faut plus. Raison et mariage !

(Paul Verlaine, Euvres poétiques complètes)

1931 - Là, c'est fini, reste tranquille. N'est-ce pas que ça te fait moins mal ? Maintenant tu vas dormir, bien sage. Tu vois, je pousse la porte, mais sans la fermer tout à fait. Je suis tout près, je reviendrai souvent (Maurice Genevoix, Rroû)

1947 Elle s’amusa comme une folle, laissant le petit à l'hôtel, à la caissière, une femme d'âge, qui n'oublierait pas de lui donner ses fioles à l'heure dite. Le soir, il dormait bien sage ; Paulette pouvait aller au théâtre, qu'elle adorait, et elle eut une toquade pour un ténor qu'elle s'en fut écouter dans ses rôles. Admirable dans Le Trouvère (Louis Aragon, Les Voyageurs de l'impériale)

\section{CORPUS WEB :}

Je gémis, m’agitant

A..Arrête... 1..laisse moi sortir...j..je veux pas avec toi... j..je veux juste aller dormir sage.... [http://gothicat-world.com/forum/viewtopic. php?f=43\&t=11184\&start=6070] (12.2.2015)

Il pleure il hurle il est cramoisit.. il tousse a etouffer.. On lui explique il se calme nous dit qu'il va dormir sage... on le remet dans le grand lit et ca recommence... [http://forum.assistantematernelle.biz/viewtopic.php?pid=2360917] (12.2.2015)

@Apu : offre-lui rien.Si elle se plaint tu lui refoutras sa phrase dans la gueule et elle ira dormir sage comme une image. Au pire kebab, c'est bien le kebab [http://www.footmanager.net/forum/letopic-des-histoires-de-coeurs-t15268-1740.html] (12.2.2015) 
REMARques : Dormir sage désigne le fait de dormir calmement, docilement, ou, dans un autre contexte, avec chasteté. Sage inclut donc le comportement du sujet, c'est-à-dire une propriété circonstancielle, à l'instar de dormir aise, tranquille. Notons la collocation avec vivre calme, renforçant l'idée de tranquillité, docilité. Sage est modifié par bien.

\section{Dormir serré}

I. Dormir profondément

Intransitif

1642 CARISALE DOCTEUR. C'est cela, mais Seigneur, souffrez que mon discours

Exalte en vos vertus la gloire de nos jours, Permettez que j’observe avecque diligence, Et vostre extreme soin et vostre vigilence, Surtout quand le grison cet Asne mon pareil

De qui sont descendus les mulets du Soleil, Vous fut volé soubs vous à la montagne noire

D'une façon estrange et dificile à croire.

SANCHE. Je dormois bien serré.

CARISALE DOCTEUR. Plustost en ce moment

Vostre esprit grand et fort pensoit profondement

(Guyon Guérin de Bouscal, Le Gouvernement de Sanche Pansa)

1865 Enfin je dors serré, ce qui m’amuse encore plus, car je rêve beaucoup, et mes rêves sont généralement agréables (George Sand, Monsieur Sylvestre)

1906 Trois heures du matin. L'auberge de la Hourque sommeille quiètement sous le ciel étoile. Dans la pièce réservée aux touristes mâles, Florent Garaudel, étendu sur le lit de camp, dort serré, et sa bouche entr'ouverte semble fleurie par un rêve heureux (André Theuriet, Mon oncle Flo)

II. Dormir blotti l'un contre l'autre Intransitif

1886 Les balles du Barbare ont troué ces poitrines

Et rompu ces cœurs généreux.

La rage du combat gonfle encor leurs narines,
Ils dorment là serrés entre eux (CharlesMarie Leconte de Lisle, Poèmes tragiques)

1907 L'un, à demi réveillé, se grattant le côté $\mathrm{du}$ ventre, nous regarde d'un œil vide et bée d'un air de délice ; l'autre dort si serré qu'on dirait qu'il colle à la pierre (Paul Claudel, Connaissance de l'Est)

1916 Après un couloir, où dorment, serrés, les agents de liaison, une pièce boisée, avec un siège et une table, et, dans le fond, un lit de fer (Henry Bordeaux, Les Derniers Jours du fort de Vaux)

1919 Les autres étaient prêts à dormir, bien serrés pour se tenir chaud (Roland Dorgelès, Les Croix de bois)

1978 Au col sud, nous dormons serrés dans une tente montée par des Allemands. Nuit d'angoisse dans le vent. Nous dormons serrés contre les autres. Tout est hallucinant. Il faut rester assis pour que la tente ne s'envole pas. La peur nous réveille, le froid aussi (Le Point)

1989 Ou alors nous dormions serrés serrés l'un contre l'autre dans ma maison à moi qui était devenue notre maison à nous avec son bon Dieu russe qui nous faisait de larges sourires bénisseurs (Remo Forlani, Gouttière)

2012 Quand je monte à l'étage pour aller me coucher, le chat et le chien dorment serrés l'un contre l'autre dans un coin de la cuisine. Cette image hors de l'ordinaire me hantera toute la nuit (Micheline Duff, Paysages éclatés)

CORPUS WEB :

Close-up d'un koala assis dans un arbre, et dormir serré (jusqu'à 20 heures par jour) [http:// fr.123rf.com/footage_26216143_.html] (4.2.2015)

Boîte à Musique est là pour vous aider ! Oubliez les nuits sans sommeil et la folie d'un bébé qui pleure. Avec cette boîte à musique panda mignon votre bébé va dormir serré et faire de beaux rêves. Avec la berceuse de bébé parfait que vous et votre enfant ne prendrez jamais le sourire de vos visages [http://www.androidpit.fr/ application/com.BabySleepMusicBox] (4.2.2015) 
Une fois que nous sommes assez éloigné, je laisse LightFall nous choisir un endroit où dormir, et constate qu'il ne s'arrête qu'une fois Cepheus et les autres suffisamment loin derrière nous. La pluie glaciale ayant tremper nos fourrures, nous dormons serré l'un contre l'autre [http:// plume-d-orage.skyrock.com/tags/9WejKlWyuQeCepheus_3.html] (4.2.2015)

... en effet, en saison froide, par manque d'autres moyens, il est nécessaire d'améliorer la température en mettant un brasero au milieu de la case souvent exigüe. La nuit les tout-petits dorment serrés contre leur mère et dans le sommeil il arrive parfois que les bébés roulent proche du brasero et se brûlent les extrémités [http:// www.handicapsante.org/nos-actions/chirurgieplastie] (4.2.2015)

REMARQUES : Dormir serré (I) signifie dormir à poings fermés. Dans l'acception (II), serré est un prédicat second qui s'accorde avec le nom dénotant celui qui dort très proche de quelqu'un, laissant peu ou pas de vide entre les deux corps. Il est modifié par bien, là, si. L’accord fait cependant défaut dans l'avant-dernier exemple du CW. Notons la réduplication serré, serré.

\section{Dormir soef (suave)}

Dormir / s'endormir tranquillement, paisiblement Intransitif

+1100 « Chevalier, mult m'en est bel Que reverdissent prael ; Si avront assez a pestre mi aignel, Je m'irai soef dormir soz l'arbroisel » (Romances et pastourelles françaises des $X I I^{e}$ et XIII ${ }^{e}$ siècles, p. 183)

-1200 En ce que li frans dux se dormoit bien soué Li anfes Floovanz l'a formant esgardé ; .I. coutel out ou poig, qui mont trenchoit soué,

Don il se desdusoit a une pome ou pré. Dou coutel ai la barbe a son maitre copé. Li dux si s'esvoilai, qui ot dormi soué, Regardai ses grenons que cil li ai copez, Et de sa barbe a veü tout autretel ; Adonques ot tel doel a pou n'est forsannez (Floovant [fin XII ${ }^{\mathrm{e}}$, 72 / 77)
1794 Souviens-toi que Cybèle est la mère commune.

Laisse la probité que trahit la fortune Comme l'oiseau du ciel se nourrir à tes pieds

De quelques grains épars sur la terre oubliés.

Son épaule pliait sous une outre vineuse. Et le dormir suave au bord d'une fontaine (André Chénier, Les Bucoliques)

Pronominal

1250 Li enfes se dormoit douchement et souef

Et li peres en a Jhesu Crist aoré ;

Belement l'esveilla et si l'a apelé

(Doon de Mayence, p. 55)

REMARques : Dormir soef (suave) désigne le fait de dormir dans un état de confiance, avec sérénité, sans que rien ne vienne perturber le sommeil. Soef reste invariable. Dans l'exemple de 1794, le groupe verbal est nominalisé : le dormir suave. En ce sens, son emploi au XVIII ${ }^{\mathrm{e}}$ siècle est archaïsant. Notons une seconde attestation de l'emploi pronominal se dormir 's'endormir' dans l'exemple de -1200 et la collocation douchement et soef.

\section{Douter ferme}

Douter profondément

Emploi absolu

1936 Et Descartes a même su dire que bien certainement, quand il doutait ferme, Dieu était de son côté (Alain, Propos)

Transitif

2018 Par ailleurs, il doutait ferme de dénicher des survivants (Marianne Stern, Récits $d u$ monde mécanique)

\section{Douter fort}

Douter beaucoup, fortement ; craindre, redouter, se méfier

Transitif

1177 Que trop savoient d'escremie, Et lor escu n'estoient mie Tel, que rien an ostast espee, Tant fust tranchanz et aceree. Et por ce se pooit mout fort Mes sire Yvains doter de mort : Mes adés tant se contretint, 
Que li lions outre s’an vint,

Tant ot dessoz le suel graté (Chrestien de Troyes, Yvain ou Le Chevalier au lion, 5625)

+1250 Li droiz suet les consaz noter Per quoi fort cuers se puet doter : Virge cui l'on uuet faire outraige, Por corrompre son pucelaige (Ysopet de Lyon [2 moitié XIII'], 1546)

1275 Or est Florianz empereres ; Desouz lui est touz li empires Il n'est nus qui l'en face tort. Et il se fet douter si fort Que traïtour ne losengier N'osent la contree aprochier (Floriant et Florete, 8130)

1562 Que si quelcun ainsi contraint vient à croire (ce que toute fois je doute fort s'il le fait), mais s'il vient à croire, cela ne se fait pas par la contrainte (Sébastien Castellion, Conseil à la France désolée)

1578 MALICAN. Ne t'esmerveille de ma crainte, puis que c'est le commun de la condition humaine de jamais ne voir accomply son desir : et sur tout par ce qu'en ce cas je doute fort ton ennuy, et le mien (Jacques de Lavardin, La Celestine [adapt.])

1664 MORON. Ma foi, Madame, vous ne feriez pas mal : il le mériteroit bien ; mais à vous dire vrai, je doute fort que vous y puissiez réussir (Molière, La Princesse d'Élide)

1688 je doute fort que la plupart des gens entrent dans la remarque que je vais faire ; je la ferai cependant pour ceux qui se connaissent en raisonnements, et je puis me vanter que c'est avoir du courage que de s'exposer pour l'intérêt de la vérité à la critique de tous les autres, dont le nombre n'est assurément pas méprisable (Bernard de Fontenelle, Digression sur les anciens et les modernes)

1715 - Je vous le promets, répondit le sultan ; mais je doute fort que nous trouvions personne qui le puisse être (Antoine Galland, Les Mille et une nuits)
1761 Depuis il ne s'est rien passé dans cette négociation. Il a ordre seulement de ces trois Puissances de faire la compagne avec sa Majesté ; mais je doute fort comme on vient de me dire, que le Roi lui accorde la permission (Friedrich Ernst von Fabrice, Anecdotes du séjour du roi de Suède à Bender)

1764 Il faut encourager la jeunesse. Je l'ay engagé à retravailler son ouvrage, et il doit vous être remis. Je doute fort que malgré tous ses soins vous trouviez un libraire qui veuille l'imprimer (Voltaire, Correspondance)

1770 Si mes Lecteurs éprouvaient la même sensation, ce dont je doute fort, j'aurais approché du but où j’aspirais, en me proposant de réunir le pathétique du Thêâtre de Paris à la terreur du Théâtre de Londres (PierreLaurent de Belloy, Gabrielle de Vergy)

1836 Aussi, ne pouvant ni ne voulant faire couper la tête à mes amants au sortir de mon lit, et n'étant pas non plus d'humeur à supporter ce que les autres femmes supportent, il faut que j'y regarde à deux fois avant d'en prendre un ; c'est ce que je ferai plutôt trois fois que deux, si l'envie m'en prend, ce dont je doute fort, après ce que j'ai vu et entendu (Théophile Gautier, $M a-$ demoiselle de Maupin)

1938 Mais à défaut de ces millions, il n'est pas indifférent de sauver mystiquement la dignité humaine, la semence invisible de l'avenir... de cet avenir dont tu doutes si fort maintenant (Jules Romains, Les Hommes de bonne volonté)

1943 On ne peut emporter avec soi que deux mille francs et un peu de monnaie italienne. Me laisserait-on emporter également des manuscrits ? J'en doute fort et supporte mal l'idée de me les voir confisqués. Puis, là-bas, trouverais-je un gîte possible? (André Gide, Journal)

1972 Mélissa finit le brouillon de « King Cohn ». Pierre Grunstein s'accroche. Simultanément, je doute fort de la volonté de 
Vera de monter le film. La seule chance de Jean-Marie est de monter un certain nombre de choses pour forcer la main à Vera. Mais il faut qu'il agisse. Mais il faut qu'il agisse vite ou je vais le lâcher. Je ne compte pas attendre un an pour aboutir à rien (Jean-Patrick Manchette, Journal)

2006 Je connais un écureuil, si du moins c'est tous les ans le même, et si c'est connaître un écureuil qu'apercevoir furtivement de ma fenêtre son nuage roux, vers la fin de l'été, ondulant sur la pelouse et grimpant en vrille aux branches d'un prunier sauvage qui ne lui sert qu'à me narguer, car je doute fort qu'il se nourrisse de prunes. Peut-être y cache-t-il ses noisettes (Gérard Genette, Bardadrac)

Pronominal

+1370 Or se perchust li dis messires Hues le Espenssier de ceste œuvre et comment on murmuroit sur lui et sur son affaire ; si se doubta trop fort que maux ne l'en venissent : si y pourvey tantost de remède moult fellenèse (Jean Froissart, Chroniques $(\mathrm{A}))$

1588 Par ceste parole le Duc se sentant fort offensé, commença à se douter fort de ce costé là : entra en tres grand soupçon, et ne vouloir point de bien au Duc de Bourgongne : lequel estant à sainct Denis, le Duc de Berry et le Roy de Sicile, et autres y allèrent (Bertrand d'Argentré, L'Histoire de Bretaigne)

1666 quant au Cardinal du Bellay, il se doute fort que le premier venu qui le prendra bien à propos, luy tirera les vers du nez (Lettres et mémoires d'Estat)

1776 On se doute fort que M. de Voltaire n'est pas oublié dans l'énumération de nos orateurs modernes (Madame Du Hausset, Mémoires de Madame Du Hausset, femme de chambre de Madame de Pompadour)

\section{CORPus WeB :}

Les arguments présentés par nos instances de santé publique pour nous inciter à passer une mammographie affichent clairement qu'elles doutent fort que nous ayons un cerveau, et encore davantage que nous soyons capables de faire une recherche sur Internet. Dit autrement : on nous prend pour des gourdes [http://www. expertisecitoyenne.com/livres] (4.2.2015)

Gaétan Barrette promet de régler le problème. Par contre, les spécialistes doutent fort qu'il y arrive [http://tvanouvelles.ca/lcn/infos/ national/archives/2015/01/20150124-175621.html] (4.2.2015)

Même si on a eu un brin d'espoir après sa nomination comme chef de gouvernement, la plupart des Guinéens doutent forts aujourd'hui que le changement vienne de lui et de son équipe. Le mode de formation de son équipe... [http://guineeactu.info/HTML/ne-brulez-pasmon-paradis-s\%E2\%80\%99il-vous-plait.htm] (14.2.2015)

REMARQues : Douter fort désigne le fait d'être fortement dans le doute sur l'existence de quelqu'un, la valeur ou la vérité d'une affirmation. Fort reste invariable dans la majorité des cas et est modifié par moult, si, trop. Notons que fort s'accorde avec le sujet au pluriel dans le dernier exemple du CW tout en gardant son interprétation d'adverbe de degré, modifieur du verbe. Mentionnons également l'emploi de l'incise discursive à vous dire vrai.

\section{Douter petit}

Redouter, craindre peu

Transitif

+1200 et cil qui dedenz se sont mis sont si preudome qu'il douteroient petit vostre efforz (Mort Artu [1 ${ }^{\text {er }}$ quart XIII $]$, p. 135, 51)

+1233 Galeran vet avant ses guie, Si en jure le braz s'amie Que s'il ore vis s'en estort, Tendra se mes toz jors a mort. Avant les autres tient sa route, Mes Thideüs petit le doute

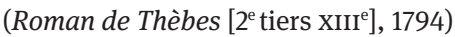

1250 Ains a mis le main a l'espee. A tant conmence la meslee ; Onques hom si dure ne vit. Moult doute l'uns l'autre petit, Au sanlant que cascuns d'ex fait (L’Atre périlleux, 1300) 
REMARQUES : En ancien français, douter petit désigne le fait d'éprouver peu de crainte ou de peur pour quelque chose ou quelqu'un. Petit assumait les mêmes fonctions de quantifieur que peu dans la langue moderne. L'opposition sémantique avec moult dans le dernier exemple souligne la fonction de quantification de petit. Les deux quantifieurs modifient le verbe douter. Petit reste invariable.

\section{Dresser fort}

Dresser avec force

Pronominal

1856 Dans nos antiques forêts de la Gaule et de l'Allemagne se dresse fort et sérieux, lentement, solidement bâti, l'orme ou le chêne, ce héros végétal aux bras noueux, au cœur d'acier, qui a vaincu huit ou dix siècles (Jules Michelet, L'Oiseau)

2010 Mais à présent, face à Moro prisonnier des Brigades Rouges, l'État italien se dresse fort et solennel. Qui ose douter de sa force, de sa solennité ? (Chiara Nannicini, Heinrich Böll et Leonardo Sciasca " ennemis de l'État »)

\section{CORPUS WEB :}

Il se dresse fort et grand, vieillit lentement, Il peuple les forêts, les bois et les marais,

C'est un cœur, un poumon, un si doux battement

Je l'entoure de mes bras, me rapproche tout près [http://www.ipernity.com/blog/192290/ 363083] (2.2.2015)

Les guérisseurs, les artistes et les visionnaires sont souvent nés sous Duir. Le chêne se dresse fort et sage dans le solstice d'été du 21 juin, la plus longue journée de l'année [http:// forums.reblochons.com/viewtopic.php? $\mathrm{f}=1 \& \mathrm{t}=$ 1258\&view=previous] (2.2.2015)

REMARQues : Dresser fort désigne le fait de se soulever, de se redresser en manifestant de la force, notamment en parlant d'un arbre comme le chêne qui symbolise la force et la durée, donc une existence qui résiste aux intempéries. Même si les exemples ne permettent pas l'accord marqué, fort y apparaît comme prédicat second. Notons les adjectifs-adverbes sérieux, solennel, grand et sage coordonnés à fort.

\section{Dresser grand}

(Se) dresser de toute sa grande taille

$\lambda$ dresser fort

\section{Dresser haut}

Élever à un niveau supérieur

Transitif

1553 PROCULEE. Si bien par tout mon devoir se fera,

Que mon Cesar de moy se vantera.

Ô ! s'il me faut ores un peu dresser

L'esprit plus haut, et seul en moy penser :

Cent et cent fois miserable est celuy

Qui en ce monde a mis aucun appuy

(Étienne Jodelle, Cleopatre captive)

1564 Après le siècle d'enfer, de néant, d'abâtardissement que l'humanité vient de vivre, les chrétiens fidèles, que Jésus Christ appelle à être le sel de la terre et la lumière du monde, sauront-ils prendre le temps, avec patience, de dresser haute et claire, la flamme de leur témoignage ? pour que revivent l'Église, les familles et la société (Pierre Viret, Instruction chrétienne)

1876 Renan, dans son histoire du peuple d'Israël, montre les juifs élargissant et dressant plus haut l'idée messianique à mesure qu'ils sont plus vaincus, plus abaissés, plus trompés dans leurs espoirs présents (Louis Ménard, Rêveries d'un païen mystique)

1945 Elle saisit le regard moqueur de M. Létourneau et continua son manège délibérément, la tête dressée haut (Gabrielle Roy, Bonheur d'occasion)

1975 Africains qui veulent une Sainte Vierge négresse, ou les Tibétains qui exigent un Petit Jésus aux yeux bridés, et je n'imagine pas Dieu autrement qu'un pénis dressé haut et dur sur la base de ses deux testicules, monument érigé à la virilité, principe de création, sainte trinité, idole à trompe accrochée au centre exact du corps humain, à mi-chemin de la tête et des pieds (Michel Tournier, Les Météores)

2000 Mais aussi, utopie oblige, dresser haut la statue de ce zombi, afin que tous ne rêvent 
que de cet Homme nouveau, et se précipitent d'eux-mêmes vers l'avenir radieux à lui promis... (Flora Montcorbier, Le Communisme de marché. De l'utopie marxiste à l'utopie mondialiste)

Pronominal

1833 Pourtant, je ne sais pourquoi la grande et féconde idéalité est refusée au génie normand. Il se dresse haut, mais tombe vide. Il tombe dans l'indigente correction de Malherbe, dans la sécheresse de Mézerai, dans les ingénieuses recherches de La Bruyère et de Fontenelle (Jules Michelet, Tableau de la France)

1835 Alors on vit la honte de la France se dresser haute et fière et prononcer sur notre sort, comme si la gloire eût parlé par l'organe de ce sénat (Duchesse d'Abrantès, Mémoires)

1983 « Non, tu ne feras pas ça »... exerçant une douce et ferme et insistante et inexorable pression, celle que j’ai perçue plus tard dans les paroles, le ton des hypnotiseurs, des dresseurs... " Non, tu ne feras pas ça... » dans ces mots un flot épais, lourd coule, ce qu'il charrie s'enfonce en moi pour écraser ce qui en moi remue, veut se dresser... et sous cette pression ça se redresse, se dresse plus fort, plus haut, ça pousse, projette violemment hors de moi les mots... « Si, je le ferai » (Nathalie Sarraute, Enfance)

\section{CORPUS WEB :}

Qu'un arbre, né pour se dresser haut, et grandir compagnon des oiseaux et des astres, se laisse aller à poser genou à terre, à ramper comme un lierre, pour complaire à un très banal et sans doute provisoire réverbère, cela n'arrive pas que dans les jardins de la ville, si l'on y réfléchit un peu [http://www.chemindesjours.com/ article-obsequiosite-98234511.html] (28.2.2015)

Les deux serpents sont de belle taille. Ils enroulent leurs queues faisant une sorte de tresse, ils s'entortillent, dressent leur tête.... C'est étonnant de voir comment ces bêtes qui rampent sont capables de se dresser haut ! [http://groupe naturefaverges.over-blog.fr/30-index.html] (28.2.2015)
Au début, je croyais à une simple force tranquille, mais j'ai vite constaté que l'homme peut être bouillonnant et se dresser haut et fort, pour ses idées, les militants, et plus que tout, pour la cause [http://quebec.huffingtonpost.ca/etienneboudou-laforce/sol-zanetti-nouveau-chef-dop tion-nationale_b_4132776.html] (28.2.2015)

Dresser haut le nom de votre club dans le sens propre du terme. Qui n'a pas un fanion digne de ce nom n'est pas un authentique supporter. Bayern Munich, Schalke 04, Borussia Mönchengladbach ou Bayer Leverkusen ne sont que quelques clubs dans lesquels nos fanions se dressent haut dans le ciel [http://www. fahnenherold.de/info/francais.html.] (28.2.2015)

Elle dresse haut les couleurs de son sport et de son pays [http://philyra-magazine.com/2014/ 03/09/elle-minspire-celine-dumerc] (28.2.2015)

Il y a la rose, et ces roulements de tambour, solennels et graves... Cette même rose dressée haut par François Mitterand il y a déjà 28 ans... L'espoir était " vainqueur » et se voulait être " la chose de France la mieux partagée » [http://archives-lepost.huffingtonpost.fr/ article/2009/05/14/1535893_les-annees-roses-etle-mal-etre-socialiste.html] (28.2.2015)

REMARQUeS : Dresser haut se dit du fait d'élever un objet, inanimé, abstrait (l'esprit, une idée) à un rang supérieur, à un degré plus élevé, devenant ainsi plus noble. Haut reste invariable dans la plupart des cas (ex. de 1945 et 2000), mais il peut également s'accorder avec le sujet (ex. de 1564 et 1835) en se rapprochant d'un prédicat second orienté vers le sujet. Au vu des exemples du CW, il semblerait que la flexion appartienne au style littéraire, soutenu. Il est modifié par plus. Notons les collocations avec dur, fier.

\section{Dresser sage}

(Se) dresser avec sagesse

$\lambda$ dresser fort

\section{Dresser sérieux}

(Se) dresser avec sérieux

$\lambda$ dresser fort

\section{Dresser solennel}

(Se) dresser avec solennité $\lambda$ dresser fort 


\section{Ébattre petit}

S'amuser, se divertir un peu

Intransitif

+1249 Aprés mengier, petit esbatre

Le lessa, bien le vous puis dire

(Rutebeuf, Poèmes [pièces datables de 1249 à 1272], II, p. 295, 62)

1383 Issir voel de ceste devise :

Je croi bien qu'il eurent assés.

Lors que li soupers fu passés

On s'ala .i. petit esbatre.

De ce ne poet on riens rabatre

(Jean Froissart, Méliador, 8683)

REMARQUeS : En ancien français, ébattre petit signifie se détendre un peu, notamment en se promenant. Petit fonctionne comme quantifieur. Il sera remplacé par (un) peu.

\section{Écarter droit}

Séparer, éloigner deux choses l'une de l'autre en ligne droite

Transitif

1857 Il en était si surchargé, que l'on apercevait seulement la pointe de ses sabots, avec le bout de ses deux bras, écartés droit. C'était Lestiboudois, le fossoyeur, qui charriait dans la multitude les chaises de l'église (Gustave Flaubert, Madame Bovary)

2006 Thomas se tenait droit, une jambe passée par-dessus l'autre, il paraissait très heureux de notre équipée ; j'étais plutôt affaissé, les jambes écartées droit devant moi dans une pose fort peu militaire ; un Oberst affairé qui passait devant nous, une serviette sous le bras, me jeta un regard de dédain (Jonathan Littell, Les Bienveillantes)

CORPUS WEB :

Pour que ça écarte "droit » j’ai soudé une glissière de l'autre coté [http://www. jeepsuperforum.com/t9830-outils-speciauxpour-dana-30] (13.2. 2015)

J'avais la tête au soleil près du vantail écarté droit. Je sentais dans mes jambes un mouvement pour partir, une pesanteur pour rester [http:// www.gai-eros.org/w/index.php/L'entref $\%$ C3\%AAte_(2]) (13.2. 2015)
L'écho 3D s'est très bien passée... bb un poil pénible car il avait bcp la main devant le visage... par contre les jambes écartées droit à l'écho... [http://mobile.beaute-test.com/forum. php?topic $=190169 \&$ start=1620] (13.2. 2015)

Elle s'assit dans l'herbe, les deux jambes écartées, droites devant elle [http://le-puits-sansfond-de-limagination.e-monsite.com/pages/ ecrits/coquelicots-sous-le-vent-du-printemps. html] (13.2. 2015)

REMARQUES : Écarter droit réfère à une partie du corps, comme par exemple les bras, ceux-ci étant séparés l'un de l'autre de façon rectiligne. Il peut être transposé dans d'autres domaines (premier exemple du CW). Dans l'exemple de 2006, droit forme un groupe avec devant. Droit reste invariable, puisqu'il ne permet pas de lecture comme prédicat second, comme dans elle marche très droite. L'accord est fait dans le dernier exemple, mais l'interprétation comme prédicat second modifiant jambes paraît très forcée puisque droit forme un groupe syntaxique avec devant : droit devant elle. Il s'agit d'un effort stylistique intentionné quelque peu artificiel.

\section{Écarter large}

Écarter beaucoup

Transitif

1954 Là-dessus je l'empoigne, la traîne à son lit, l'oblige à se mettre nue ou presque, et séance fort agréable, elle vite en train, écartant large les cuisses (La Parisienne, octobre 1954 / Grundt : 309)

1991 Des matelots pêchaient pour eux des petits poissons vite transformés en larges plaques de fiente. Ils connaissaient bien leur monde, écartant large leurs ailes naissantes pour repousser les assauts des chiens qui les avaient adoptés (Georges Fleury, Pyrrhus, Lesko et les autres)

\section{CORPUS WEB :}

Claude, il te suffira d'écarter large deux des volets présents dans les questionnaires, pour espérer entendre l'un d'eux ! :wink [http://www. campiello-venise.com/forum-venise/viewtopic. php?t=4798\&start $=0 \&$ sid $=7776780$ a8e8a988e61f 8eff59a7386d6] (13.2.2015) 
C'est très précis en dosage, super pour les tronçons (4 tronçons sur $24 \mathrm{~m}$ ). Par contre il te faut travailler avec des engrais adhoc si tu veux l'ecarter large mais en général ça va [http://www. agricool.net/forum/index.php?s=bbea8eb2edc9 1118b00245d2b9af34af\&showtopic=19590\&hl=] (13.2.2015)

pour faire un analogie tu en as un qui serait un gros rugby man bien robuste mais un peu brutal et l'autre une fragile pucelle en chaleur prête à écarter large les jambes [http://www.forum-auto. $\mathrm{com} / \mathrm{marques} / \mathrm{seat} / \mathrm{sujet} 642-17815 . \mathrm{htm}$ ] (13.2.2015)

Triangulaire $290 \mathrm{~mm}$ (oublie les dimensions inférieures), 2 ou 3 longueur de $2 \mathrm{M}$, pieds lumière à treuil qui monte haut !!! (3,5m/4m) avec des pieds qui s'écartent larges et des jambes de force, j'ai des eurolite 400 chinois à prix sympa [http://www.sonomag.com/Forum/forum_posts. asp?TID=6631] (13.2.2015)

REMARques : Écarter large se dit du fait de séparer deux membres du corps (ici : les cuisses ou les ailes) ou deux parties d'un même ensemble, l'écart obtenu étant important. Large reste invariable, mais il s'accorde au pluriel dans le dernier exemple du CW, tout en gardant son interprétation adverbiale.

\section{Échapper belle}

l'échapper belle : esquiver de justesse

(un danger)

Transitif

-1469 Or retournons au Jouvencel, qui est à Crathor et se mocque de ses compaignons et dit qu'il l'a eschappée belle et qu'il fault penser de soy revenger et faire bonne chière (Jean de Bueil, Le Jouvencel [1461]-1468, II, p. 117)

1584 DIEGHOS. Il l'a eschappee belle. GASTER. Hardiment, il a eu belle vezarde, comme il joue de l'espee à deux piez (François d'Amboise, Les Neapolitaines)

1673 TRISSOTIN. Je viens vous annoncer une grande nouvelle.

Nous l'avons en dormant, Madame, échappé belle :

Un monde près de nous a passé tout du long,
Est chu tout au travers de notre tourbillon ; Et s'il eût en chemin rencontré notre terre, Elle eût été brisée en morceaux comme verre (Molière, Les Femmes savantes)

1736 Je l'échapai belle, comme vous voyez, madame ; car ne voulant pas mentir, le méchant Pymion m'eût peut-être suposé coupable de je ne sai quoi, qui m'eut fait aller aux galeres ; et par ma foi l'avanture ne valloit rien (Pierre de Marivaux, Le Télémaque travesti)

1832 - Oh ! repartit Gringoire, ce n'est pas ma faute, mais celle du guet et du roi. Je viens de l'échapper belle ! Je manque toujours d'être pendu. C'est ma prédestination (Victor Hugo, Notre-Dame de Paris)

1977 Luce reçoit enfin une lettre de son mari, la première depuis la carte lui annonçant sa captivité. Il l'a échappé belle, ses deux officiers ont été tués, il est le seul survivant des commandants de compagnie de son bataillon (Claude Mauriac, La Terrasse de Malagar)

REMARQUES : L'échapper belle est une locution figée qui renvoie au fait d'échapper de justesse à un danger. Le Trésor de la langue française (s.v. échapper) s'étonne que certains auteurs fassent l'accord non seulement de belle mais aussi du participe passé (v. ex. de -1496 et 1584 ; v. aussi Faye 1935). Or, l'accord est parfaitement grammatical si l'on considère que le pronom objet direct est au féminin. Selon l'opinion courante, il s'agirait d'un terme du jeu de paume signifiant « laisser échapper la balle quand elle est belle, c'est-à-dire facile à prendre » (hypothèse 1 ; Falk 1938-1939 : 12). Le problème est surtout sémantique : on peut vouloir échapper à une balle provenant d'une arme, mais dans le jeu de paume on cherche à l'attraper. On peut chercher une explication par contamination (la manquer belle 'échapper de justesse', la faillir belle 'manquer une belle occasion ; échapper au dernier moment') mais, plus on réalise l'extension de ce groupe (l'avoir belle 'avoir une belle occasion ; avoir été trompé', la bailler belle 'avoir été trompé', la donner belle 'donner une occasion favorable ; avoir été trompé', la payer belle 'être 
tenu responsable de ses actes, les payant cher'), plus on se rend compte qu'il s'agit d'un principe de construction plus général qui dépasse l'hypothèse du jeu de paume. Nous estimons donc peu probable que l'expression soit originaire du jeu de paume. Les deux explications alternatives qui nous sont venues à l'esprit à la rédaction de ce dictionnaire, ont été en fait déjà avancées par Lerch (1940). Selon Lerch, on peut, d'une part, expliquer l'échapper belle comme faisant partie de la longue série populaire du type se la couler douce, où "la " représente un objet postiche « neutre » qui entraîne l'accord (hypothèse 2 ; v. déjà Tobler ${ }^{2} 1912$ [1867] : pp. 305-306 ; v. aussi Introduction, § 4.6). En effet, la famille d'expressions qui gravite autour de l'échapper belle met en évidence que le pronom objet direct est au féminin. Or, l'emploi neutre du pronom féminin la pour dénoter un objet postiche est très courant dans les langues romanes. Il ne faut pas s'étonner non plus de retrouver quelques-unes de ces expressions dans le domaine du jeu de paume. L'usage moderne connaît toujours, dans le domaine du jeu, ce schéma ; ce dictionnaire atteste, par exemple, (se) la jouer dure, fine, franche, gaie, grosse. L'autre hypothèse proposée par Lerch (hypothèse 3), qui n'est pas incompatible avec la précédente, envisage la possibilité d'une réinterprétation de l'adverbe bel 'bien', usuel en ancien français, en la forme féminine belle, ce qui a pu se produire dans la langue parlée (pour Faye 1935, c'est la seule hypothèse valable). Cette troisième hypothèse résoudrait le problème sémantique qui demeure dans la construction l'échapper belle : même si l'accord grammatical au féminin se justifie par rapport à l'article dénotant un objet postiche, on ne saurait s'imaginer un tel rapport sémantique, pourtant clair dans se la couler douce 'la vie, la chose', la jouer dure 'la balle, l'affaire', etc. Ceci joue en faveur d'une possible réinterprétation en partant de échapper bel 'bien'. Le premier problème de cette troisième hypothèse, c'est que échapper bel n'est pas attesté. Tobler / Lommatzsch (s.v. eschaper) attestent la prédication seconde " eschaper vive » et " vifs escapé », ce dernier avec accord au cas sujet, mais *eschaper bel n'y figure pas (v. aussi Faye 1935). Étant donné qu'il s'agit d'une construction courante, l'absence de documen- tation est plutôt surprenante. S'ajoute à cela le fait que l'ancien français bel est assez systématiquement remplacé par le masculin-neutre beau en moyen français, et non pas par le féminin belle (v. les entrées de ce dictionnaire). De plus, si eschaper bel 'bien' peut résoudre un problème sémantique dans ce cas précis, il n'en va pas de même pour la manquer belle où 'manquer bien' créerait un problème sémantique : on ne peut pas manquer bien. Ceci étant, il vaut mieux s'en tenir au fait que eschaper bel n'est pas attesté et qu'on peut donc exclure la troisième hypothèse. Reste donc l'hypothèse de l'appartenance à la famille productive du type « article féminin déterminé + verbe + adjectif au féminin ». Mais il faut alors tenir compte d'un troisième facteur : l'emploi ironique de beau (Faye 1935) par antiphrase. Celui-ci est en effet systématique dans les polysémies données ci-dessus, comme, par exemple, 'avoir une belle occasion ; avoir été trompé'. Mentionnons finalement que l'expression daterait du Xvi ${ }^{\mathrm{e}}$ siècle, selon la bibliographie. L'exemple de -1469, cité ci-dessus, nous permet d'antédater cette expression.

\section{Éclairer blanc}

Émettre une lumière blanche, blanchâtre

Transitif

1855 Plante moyenne, épi long un peu grêle et un peu lâche de fleurs moyennes bien ouvertes, rouge-ponceau pourpré, richement velouté et nuancé feu, éclairé blanc vers l'entrée du tube (Journal de la Société impériale et centrale d'horticulture)

2001 Cavale vers la consigne, couloir sombre, des hommes qui attendent, une queue d'hommes, ils ont tous des chapeaux, feutres noirs, ne disent rien, tant pis, je resquille, dépasse 50 clients, arrive dans une salle haute, éclairée blanche, aveuglante (Luc Lang, Les Indiens)

2009 cherchant aux murs les éventuelles aspérités qui nous permettraient d'échapper, et finalement revenant, au carrefour, à cette porte vitrée éclairée blanc, où donnait le bas d'un escalator mince, lui-même donnant dans la vaste patinoire à l'étage, cette patinoire déserte sous ses voûtes 
(François Bon, L'Incendie du Hilton)

Emploi absolu

1891 Un triste soleil d'hiver éclaire blanc dans un ciel bleu pâle plus sinistre que ne serait un ciel gris (Pierre Loti, Le Livre de la pitié et de la mort)

1954 Krypton éclaire mieux et plus blanc (Le Monde [publicité], 23 novembre 1954 / Grundt : 253)

CORPus WEB :

Si tu veux éclairer blanc tourne toi vers du $6000 \mathrm{~K}$, le 4300 c'est éclairage type halogène donc inutile. Le $8000 \mathrm{~K}$ comme moi tu vas éclairer bleu [http://www.jeuxvideo.com/forums/11000019-796660-5-0-1-0-montage-des-xenonshid.htm] (13.2.2015)

mais a toi de voir si tu as envie de bidouiller pour éclairer blanc ou si tu reste sur les ampoules d'origine (blanc/jaune) [https://www. dealabs.com/bons-plans/ampoules-auto-paschres/93738?page=3] (13.2.2015)

En dessous de l'appareil, « on aurait dit une barre néon, la lumière dépassait l'engin, l'éclairait blanc comme un tube néon, on voyait les tombes comme en plein jour, on aurait pu lire les inscriptions »[http://mistere.e-monsite. com/pages/content/les-ovnis-dans-la-regionbourgogne-3.html] (13.2.2015)

Elle est donc en quelques sortes illisibles d'un coup d'œil rapide, mais il n'y a rien de prévu, du moment qu'elle est éclairée blanc... pas rose, pas rouge, pas bleu, pas turquoise ni jaune.... blanc ! [http://www.motoclubquebec. com/forum/modifications-legales-ou-non-oucomment-savoir] (13.2.2015)

Par la méthode additive, trois sources de lumière monochromatique $\mathrm{R}$, J et $\mathrm{B}$ éclairant une même surface blanche (un écran) donne une plage commune éclairée blanche [http://fr. wikiversity.org/wiki/Donn\%C3\%A9es_de_ physique_utilis\%C3\%A9es_en_biologie/ Lumi\%C3\%A8re] (13.2.2015)

REMARQUES : Éclairer blanc désigne une source d'éclairage intérieur (ampoule ou lampe) ou extérieur (soleil) qui a la spécificité de produire une lumière blanche. Blanc peut référer aussi bien à la couleur de la lumière source (orientée vers le sujet) qu'à celle de l'objet illuminé (orientée vers l'objet), ce qui explique sa flexion, plutôt occasionnelle. Remarquons que l'accord occasionnel se fait notamment dans le second cas. En effet, l'emploi invariable dans éclairer blanc renvoie plutôt à une activité de la source, tandis que l'accord du type éclairée blanche met en avant l'effet que la lumière produit sur l'objet illuminé. Notons les adjectifs-adverbes d'autres couleurs dans le cinquième exemple du $\mathrm{CW}$ : rose, rouge, bleu, turquoise, jaune, qui restent tous invariables. Éclairer est un verbe naturellement transitif qui s'emploie également de façon absolue.

\section{Éclairer large \\ Éclairer pleinement \\ 入 éclairer loin}

\section{Éclairer loin}

Éclairer sur une longue distance

Emploi absolu

1664 comme nous voions, que de tous les feux de la nature il n'y en en a point qui éclairent plus loin, et dont l'action ait une plus large étenduë, que ceux qui luisent dans le ciel (Jean Daillé, Sermons)

1883 Ces chandeliers n'éclairent pas loin et il y a dans cette chaumière des recoins noirs ; on voit se mouvoir de grandes choses bien blanches, qui sont les coiffes à larges ailes et les collerettes (Pierre Loti, Mon frère Yves)

1974 Elle tricota des guibolles vers la achélème. La dynamo suralimentée éclairait plus loin que de coutume. Vite, elle prit l'ascenseur. Elle rentra chez elle en coup de vent (Jean Vautrin, Billy-Ze-Kick)

2001 Il y a les dames Filion aux doigts de fée, elles cousent, elles brodent, elles boulangent, elles prient, elles sont gardiennes de la tradition, des petites lampes qui éclairent loin (Jean François Casabonne, Du cour aux pieds)

Pronominal

1886 les gerbes de rayons, qui entraient par les traînées de cette voûte de temple, s'allongeaient en reflets sur l'eau immobile 
comme sur un parvis de marbre. Et puis, peu à peu, on vit s'éclairer très loin une autre chimère : une sorte de découpure rosée très haute, qui était un promontoire de la sombre Islande... les noces de Yann avec la mer ! (Pierre Loti, Pêcheur d'Islande)

\section{CoRpus Web :}

Bien sûr, c'est une petite puissance, mais il dispose d'un faisceau bien concentré qui permet d'éclairer loin dans le noir, pointer certaines parties à éclairer (très bien pour indiquer un poisson bien planqué) et farfouiller loin dans les trous [http://diveh2o.free.fr/conseils/matos/ phares1.htm] (14.2.2015)

Je mets un système lumière à 3 Led blanches hautes performances qui éclairent loin, 2 fonction clignotant ou permanent [http://www. grenoblevtt.com/forum_phpbb/viewtopic.php $? t=5032 \&$ sid $=1056898660152363230 b 3 f 15 e 058 d$ 25c] (14.2.2015)

Il est donc possible d'éclairer loin avec un angle fermé $\left(10 \sim 30^{\circ}\right)$ ou d'éclairer large mais sur une distance moins importante. Pour faire bref, ce que l'on gagne en largeur on le perd en longueur [http://www.ampoule-leds.fr/bien-choisirson-ampoule-a-led.php] (14.2.2015)

REMARQUes : Loin est un adverbe de lieu que nous intégrons dans ce dictionnaire parce qu'il fait partie du paradigme lexical qui pivote autour $\mathrm{du}$ verbe éclairer. Loin met en évidence que les adjectifs-adverbes du paradigme incluent des fonctions adjectivales et adverbiales. Le sujet du groupe éclairer loin désigne un ensemble de rayons lumineux provenant d'une même source (faisceau d'une lampe) qui donne de la clarté sur une longue distance ou diffuse une large lumière. Notons la collocation éclairer loin et large qui place large dans la même ligne fonctionnelle que l'adverbe de lieu. Loin et large réfèrent ainsi à deux dimensions d'extension spatiale, mais seul le second est un adjectif qui permettrait de faire l'accord.

\section{Éclairer net}

Projeter une lumière claire qui fait apparaître nettement un objet

Emploi absolu

1972 Le faisceau croisement doit être rabattu vers le sol et cependant il ne doit pas l'être trop pour éclairer net et assez loin (Revue $d u$ Touring club de France / Grundt : 346)

\section{CoRpus Web :}

Que je suis trop maniaque... la moto consomme pas et ne fume pas, elle prends 100 $\mathrm{km} / \mathrm{h}$ sur le plat et le tableau de bord est enfin éclairé «net » (ampoules changées) [http://www. honda125cbf.com/topic/2306/ralenti-instable] (14.2.2015)

Sur route ouverte en revanche c'est pas bon vu que les contraintes sont exactement opposées : besoin de ne pas trop projeter de lumière vers le haut, pas vraiment besoin d'éclairer les cotés, besoin d'éclairer net droit devant à moyenne distance [http://forum.velotaf.com/topic/3639leclairage/page_st_2303] (14.2.2015)

REMARQUES : Éclairer net désigne le fait d'émettre un ensemble de rayons lumineux provenant d'une même source (faisceau d'une lampe) qui donne de la clarté, illumine clairement l'espace et découpe nettement les objets. Net reste invariable. Notons éclairer net droit devant dans le dernier exemple, qui met en évidence l'appartenance de net au verbe et celle de droit au groupe prépositionnel avec devant. Notons aussi la collocation éclairer loin et net. Net est modifié par plus.

\section{Éclairer rouge}

Émettre une lumière rouge, rougeâtre, quand on la projette sur un objet

Transitif

1870 Abritée en un coin de la lande déserte Une chaumière en feu brûlait à l'abandon. Dans la fumée, un pin dressait sa cime verte

Que la flamme éclairait rouge comme un brandon

(Achille Millien, Légendes d'aujourd'hui)

Emploi absolu

1886 Cependant la nuit venait; on avait replié les cirages commencés, suspendu le 
travail. Les petits Gaos et la petite adoptée, assis sur des bancs, se serraient les uns aux autres, attristés par l'heure grise du soir, et regardaient Gaud, ayant l'air de se demander : "À présent, pourquoi ne s'en va-t-elle pas ? »Et, dans la cheminée, la flamme commençait à éclairer rouge, au milieu du crépuscule qui tombait (Pierre Loti, Pêcheur d'Islande)

1903 À l'est, au-dessus de la mer, très haut sur l'horizon, une chaîne de montagnes désertes et désolées, tout en granit sanglant, se met à éclairer rouge comme une braise : c'est le Sinaï, le Serbal et l'Horeb (Pierre Loti, L'Inde (sans les Anglais))

1912 Le soleil est déjà bas et commence d'éclairer rouge quand mon petit cortège de charrettes se met en marche, s'éloignant pour toujours d'Angkor, par l'avenue dallée, entre les broussailles aux fleurs blanches qui embaument le jasmin (Pierre Loti, Un pèlerin d'Angkor)

1948 Ils se décoiffent et s'approchent du feu qui éclaire rouge, de face, le faux Méliant resté casqué (Julien Gracq, Le Roi pêcheur)

2011 Certains même pensaient que la ville donnait à la voûte sa couleur. C'était un point de vue indéfendable quand on songeait que l'onglet éclairait rouge, bleu ou vert selon le réglage de son faisceau !

(Gilles Warembourg, L’Ellipse)

CoRpus WeB :

A bien lire ton tableau, mes veilleuses devrait éclairer rouge car ce sont des $3400 \mathrm{~K}$ il me semble bien !!! [http://www.golf5forum.fr/index. php?topic=1802.55;wap2] (13.2.2015)

Joli lever de soleil sous les stratocumulus (si je ne me trompe pas) éclairés rouge [http:// www.infoclimat.fr/photolive-photos-meteo81661-lever-de-soleil-sous-les-stratocumulus. html?auteur=1702] (13.2.2015)

Les 2 grands écrans sont rétro-éclairés rouges [http://www.amazon.fr/Balance-digitalecompteuse-carats-grains/dp/B002WTD96E] (13.2.2015)
REMARQUES : Éclairer rouge désigne le fait de répandre une lumière rouge, la source d'éclairage ou de chaleur (le soleil, le feu, voire un élément du paysage, une chaîne de montagnes) illuminant le ciel ou le paysage. Notons les adjectifs-adverbes d'autres couleurs : bleu et vert. Rouge reste invariable dans le deuxième exemple du CW, malgré le sujet pluriel avec lequel le participe passé du verbe est accordé. Toutefois, le troisième exemple montre l'accord dans la même construction passive avec le sujet, ce qui lui prête une interprétation résultative de prédicat second orienté vers le sujet, qui est en fait l'objet de l'éclairage. Comme dans le cas d'éclairer blanc, orienté vers la source et la façon d'éclairer, éclairer rouge tend à l'invariabilité (premier exemple du CW), tandis que la modification de l'objet illuminé admet plus facilement l'accord, même s'il n'est pas systématique (v. les deux derniers exemples du CW).

\section{Éclater bas}

I. éclater haut et bas : commencer, se déclencher de manière chaotique Transitif

1615 faire polir avec industrie et jugement les facultés naturelles des hommes qui y vivent, les rendre convenables par ensemble, et profitables à l'entretien et conservation du corps universel dont ils sont membres animés, y faisant éclater haut et bas l'action : comme le seul esprit vital qui luy donne un pouls vigoureux, tesmoin de sa parfaite santé (Antoine de Montchrestien, Traicté de l'économie politique)

II. Éclater au ras de quelque chose (sens spatial)

Intransitif

1919 Les coups éclataient bas, fouettant parfois le boyau d'éclats, et des cris montaient de tous ces corps blottis (Roland Dorgelès, Les Croix de bois)

III. Éclater en produisant un bruit faible, étouffé, sourd

Intransitif

1961 ... des bruits secs... des bruits d'éclats contre fer... les premiers que j'entends... ça avait éclaté plus bas jusqu'à présent... si ils cherchaient à broyer le pont ça serait déjà 
fait... leur but devait être les sous-marins, en bas... d'un bout à l'autre du canal... mer du Nord-Baltique... je vous ai dit, cent kilomètres ! (Louis-Ferdinand Céline, Rigodon)

IV. Éclater (de rire) sans faire beaucoup de bruit, en silence

Intransitif

1963 Au moment même où Valdès éteignait la lampe, leurs yeux se rencontrèrent et ils éclatèrent tout bas d'un fou rire nerveux, comme des enfants.

- À quoi jouons-nous, à présent ? Demanda Jacques en s'essuyant les yeux.

$-\mathrm{Tu}$ as sommeil ?

- Oh! Non, plus maintenant

(Pierre Moinot, Le Sable vif)

CORPuS Web :

La voie du bas à pour but de porter tes alliés à la victoire, mais attention si tu joues tireur parce que les assassins et les porteurs de pouvoir d'abilité peuvent t'éclater bas très vite [http:// www.jeuxvideo.com/forums/1-19163-8228180-20-1-0-c-est-qui-le-hero-le-plus-operationnel.htm] (14.2.2015)

c'est clair en multi faut pas cheater mais en solo si t'as fini le jeu et que tu veux t'eclater bas t’as le droit [http://www.jeuxvideo.com/ forums/1-8058-2881416-1-0-1-0-0.htm] (14.2.2015)

Euuuuh euuh ouais ouais elle s'éclate bas ouais pourquoi pas ! [https://fr-fr.facebook.com/ Hiphoppeople/posts/746389005418193] (14.2.2015)

REMARQues : Éclater bas (I) s'emploie dans la collocation éclater haut et bas 'déclencher une action'. En (II), le même sens que (I), mais employé par rapport à un niveau spatial de bas. (III) réfère à l'intensité de la voix ou du bruit produit. Bas reste invariable et est modifié par plus, tout. Les deux premiers exemples du CW relèvent du langage utilisé dans la sphère des jeux vidéo. L'anglais y distingue trois voies, top lane, middle lane, bottom lane, dont la dernière correspond à la voie du bas. Le groupe signifie donc 'abattre, tuer, faire voler en éclats sur la voie du bas'. Dans le dernier exemple du CW, s'éclater signifie 's'amuser'. Notons l'emploi pronominal ('s'amuser') et transitif ('tuer') dans les exemples du CW.

\section{Éclater fort}

Éclater en produisant un bruit retentissant

入 éclater haut

\section{Éclater haut}

I. Se manifester ouvertement, franchement, publiquement

Intransitif

1655 Il faut pour satisfaire à ma haine infinie, Qu'on éclate tout haut contre sa Tyrannie, Qu'il soit hay de tous, qu'il soit abandonné, Qu'il soit assiegé, pris, degradé, detrôné, Que sa haute valeur se treuve mesprisée, Qu'aux plus petits du Peuple il serve de risée,

Qu'il perde toute estime et toute authorité (Tristan l'Hermite, Osman)

Transitif

1657 En ces rencontres donc il faut trouver des couleurs pour obliger un homme à faire éclater tout haut sa passion, ou bien luy donner un confident avec lequel il en puisse parler comme à l'oreille ; en tout cas le mettre en lieu commode pour s'entretenir seul, et réver [sic] à son aise, ou enfin lui donner un temps propre pour se plaindre à loisir de sa mauvaise fortune (François Hédelin, abbé d'Aubignac, $L a$ Pratique du théâtre)

II. Se manifester bruyamment, avec une grande intensité sonore, avec force

Intransitif

1840 Si l'orage, à grands flots tombant, grondait dans l'air,

Les rires éclataient aussi haut que la foudre,

La flamme en tournoyant s'élançait de la poudre,

Comme pour s'unir à l'éclair !

(Victor Hugo, Odes et ballades)

1875 Puis, le soir, on lui avait montré leur lit. Chacune des paroles qu'il leur avait adressées éclatait plus haute à ses oreilles. Il disait au grand Fortuné que Dieu lui envoyait une compagne, parce qu'il n'a pas voulu que l'homme vécût solitaire (Émile Zola, La Faute de l'abbé Mouret) 
1884 La maison semblait vide, le lourd silence était retombé, et la continuelle lamentation du malade éclatait plus haute. Comme Pauline descendait la dernière marche, Lazare qui revenait de la cour, se trouva en face d'elle. Tout son corps fut pris d'un tremblement nerveux (Émile Zola, La Joie de vivre)

\section{CoRpus WeB :}

Alors laisse éclater haut et fort toutes tes belles couleurs et sois en fier, c'est comme ça qu'on t' :cœur : ! [http://forum.ucpa.com/print thread.php?t=10626\&page=4\&pp=15] (15.2.2015)

Avant d'être hors sujet, passons au Maillon faible (au fait, en passant, c'est VOUS le maillon faible, oui je sais, ça fait mal de se le voir dire en pleine tronche comme ça, mais la vérité doit éclater haute et forte et il faut vous rendre à l'évidence : vous avez une gueule de maillon) [http:// www.ciao.fr/Maillon_faible_Le__Avis_254852] (15.2.2015)

REMARQues : Éclater haut (I) désigne le fait de dire, d'exprimer quelque chose (un état d'âme, un sentiment) à voix haute, officiellement, en public. Éclater haut (II) désigne un cri, un rire, une parole pouvant traduire différents états d'âme (la joie, une plainte, etc.) qui se manifestent ou se produisent avec une certaine intensité. Haut peut exceptionnellement s'accorder avec le sujet (ex. de 1875) et être modifié par aussi, plus, tout. Notons la collocation haut et fort dans les deux derniers exemples. Les adjectifs-adverbes s'accordent avec le sujet au féminin dans le dernier exemple du CW ainsi que dans l'exemple de 1884, ce qui prête à une interprétation, quelque peu forcée, de prédicat second orienté vers le sujet, pour intensifier. Notons que l'entrée ne retient pas l'emploi comme adverbe de lieu (ex. éclater haut dans le ciel).

\section{Éclore frais}

frais éclos : né, apparu récemment, fraîchement, nouvellement

Intransitif

1612 Je vous laisse à penser s'il est croyable que nôtre Roy [...] voulût maintenant changer la croyance [...] pour aller apprandre les nouveaux Rudimans d'une secte fraîche éclose depuis tente cinq ou quarante ans en l'école d'un Moine renié (Antoine de Laval, Desseins de professions nobles et publiques)

1745 et effectivement c'était une situation qui m'exposait d'autant plus que j'étais d'une figure très aimable, et à cet âge où les grâces sont si charmantes, parce qu'elles sont ingénues et toutes fraîches écloses

(Pierre de Marivaux, La Vie de Marianne)

1854 Prends donc quelque brave garçon tout frais éclos, un homme à belles manières et à idées reçues (Gustave Flaubert, Correspondance)

1858 Proserpine nourrissait une idée toute fraîche éclose, idée hardie et bizarre, dont elle n'avait garde de faire part au lieutenant (George Sand, Les Beaux Messieurs de Bois-Doré)

1896 C'est le jour baptismal aux paupières divines

De l'enfant, la rumeur de l'aurore aux oreilles

Frais écloses, c'est l'air emplissant les poitrines

En fleur, l'air printanier rempli d'odeurs vermeilles (Paul Verlaine, Euvres poétiques complètes)

1908 Les villas de Garavan, toutes blanches et toutes roses, paraissaient fraîches écloses de cette nuit (Gaston Leroux, Le Parfum de la dame en noir)

1937 Même ce rictus hagard de l'ivresse qu'elle hait tant sur la face de son père et qu'elle retrouve, hélas ! sur celle de son ami, ne lui inspire qu'une espèce de compassion tendre, et un autre sentiment qu'elle ne connaît pas du tout - car les gosses lui font horreur - d'humilité protectrice, d'inaltérable patience, d'une patience plus forte que tous les dégoûts - l'instinct maternel frais éclos dans sa conscience, aussi fragile qu'une rose de mai (Georges Bernanos, Nouvelle Histoire de Mouchette) 
1983 Et aussi elles me semblaient pour la plupart charmantes, ces jeunes Anglaises candides, toutes fraîches écloses de leurs enfances champêtres de filles de pasteurs, d'instituteurs... des enfances qui n'avaient pu être que ce que sont les « vraies » enfances vécues dans l'insouciance (Nathalie Sarraute, Enfance)

\section{CORpus WeB :}

Reçu à la station de soins, un caneton frais éclos. (Le reste de la famille a été écrasée sur une route.) [https://fr-fr.facebook.com/177292592144/ photos/a.177340577144.121245.177292592144/ 10151688138597145] (15.2.2015)

Minuscules, désarmées, elles doivent vite se frayer un chemin vers l'océan avant d'être dévorées par les crabes, les ratons crabiers et d'autres espèces dangereuses pour ces fragiles bébés frais éclos [http://www.cityzeum.com/les-tortues-demontjoly] (15.2.2015)

Mais cela n'empêcha pas le Centre d'étude de la délinquance juvénile de disparaître sur l'autel de la communautarisation : chaque Communauté, frais éclose, édicta ses règles de subsidiation, l'une à l'activité, l'autre au projet, la troisième à l'intérêt pour la Communauté germanophone [http://www.jdj.be/jdj/documents/ docs/affaire_Tabitha_JDJB255.pdf] (15.2.2015)

À l'heure qu'il est, premier samedi de janvier, que sais-je de cette année 2015 encore fraîche éclose ? [http://histoiresdoph.blogspot. co.at/2015/01/droit-devant-2015-dans-mesphares.html] (15.2.2015)

REMARQUES : Frais éclos, avec l'adjectif-adverbe toujours antéposé au participe, réfère au processus d'épanouissement récent d'une personne, celle-ci commençant à exister, à s'ouvrir ou à se dévoiler. Le sujet peut aussi désigner un objet qui devient visible, ou une chose abstraite, une idée qui prend forme. Frais est modifié par l'adjectif tout. La tradition grammaticographique rationaliste aurait voulu que tout, considéré comme un adverbe, soit invariable dans toute fraîche, toutes fraîches (v. Introduction $\S 17.3$ ).

\section{Écorcher vif}

Dépecer vivant (un animal, un être humain) ; mettre au supplice (figuré)

Transitif

1385 Lors fut li consaulx assamblez De quelle mort cilz loups mourroit : L'un disoit qu'om l'escorcheroit Tout vif, pour souffrir plus de mal ; L'autre disoit qu'a un cheval Fust trainez et qu'om le pendist Tout vif, si qu'en pendant languist (Eustache Deschamps, Le Miroir de mariage, 957)

+1494 lesdits deux chevalliers furent escorchez tout vifz et leurs genitoires couppées et puis traynez et penduz (Simon de Phares, Recueil des plus celebres astrologues [1494-1498], p. 143)

1592 On les brule vifs, et, demy rotis, on les retire du brasier pour leur arracher le cœur et les entrailles. À d'autres, voire aux femmes, on les escorche vifves, et de leur peau ainsi sanglante en revest on et masque d'autres (Michel de Montaigne, Essais)

1732 Je ne fis pourtant que lui dire en jurant, que si je n'étois pas payé dans vingt-quatre heures, j'irois l'écorcher toute vive dans sa maison et y mettre ensuite le feu

(Alain-René Lesage, Histoire de Gil Blas de Santillane)

1959 Elle se moque de ce que pensent les gens, elle n'a pas besoin d'être aimée, elle, elle n'a pas peur de froisser leur susceptibilité. S'ils sont écorchés vifs, tant pis pour eux (Nathalie Sarraute, Le Planétarium)

Pronominal

1691 La dame regarde cette jolie scène au travers des jalousies de sa chambre, et, par quelque signe, elle l'encourage à s'écorcher tout vif, et elle lui fait comprendre le gré qu'elle lui sait de cette sotte galanterie (Marie-Catherine d'Aulnoy, Relation du voyage d'Espagne)

1886 Il ne s'était pas adressé à lui, le sachant fort gêné et capable, néanmoins, de s'écorcher vif et de se tanner sa propre peau, s'il 
eût fallu, pour lui procurer un peu d'argent (Léon Bloy, Le Désespéré)

Emploi absolu

1852 s'il n'a pas roué vif, brûlé vif, bouilli vif, écorché vif, crucifié, empalé, écartelé, ne vous en prenez pas à lui, ce n'est pas sa faute : c'est que le siècle s'y refuse obstinément (Victor Hugo, Napoléon le Petit)

CORPus WeB :

on devraitlesécorchervif ces ordures [https:// www.facebook.com/defendrelesanimaux/ photos/a.147829035119/10152813389745120/?com ment_id=10152813876060120] (7.11.2014)

Dans les deux cas, faut les ecorcher vif [https://twitter.com/Dhul_Q9/status/9170117689 83146496] (8.10.2017)

REMARQUES : Écorcher vif est une expression lexicalisée employée au propre pour renvoyer au fait d'arracher la peau à quelqu'un afin de le tuer en causant un maximum de souffrance, ou, pour le manger, dans le cas d'un animal. La langue moderne s'en sert plutôt au figuré, surtout pour exprimer l'envie de faire souffrir quelqu'un pour ce qu'elle/il a fait, sans avoir l'intention de le faire. L'accord est systématique dans le langage littéraire attesté dans Frantext. Il s'agirait donc d'une prédication seconde, mis à part l'emploi absolu (ex. de 1852). Par contre, dans le CW l'emploi invariable est fréquent. Dans les exemples plus anciens, vif est modifié par tout. Notons l'emploi des groupes analogues bouillir vif, brûler vif, pendre vif, rouer vif.

\section{Écouter fort}

Tendre l'oreille avec une grande attention

入 hurler bas

Écouter juste

Avoir l'oreille juste

入 chanter faux, entendre juste

\section{Écraser net}

Aplatir violemment, anéantir (au propre et au figuré)

Transitif

1815 Quels coups de tonnerre ! quelles effroyables clartés, mon cher Léonide ! quel indigne orage ! la voûte du ciel en est ébranlée pour vingt ans ! Et mon moulin des quatre saules, où j'avais établi Dominique et sa famille, mon moulin, le plus joli moulin de l'Europe, la foudre vient de l'écraser net! (José Marchena, L'Amour et l'érudition)

1936 au point que les grèves de Pétersbourg ont bêtement cessé, juste au moment où le soulèvement commençait à Moscou ; au point que la grève des postes et des chemins de fer était terminée en décembre, juste au moment où l'arrêt des communications aurait paralysé le gouvernement, et l'aurait empêché de lancer sur Moscou les régiments qui ont écrasé net l'insurrection (Roger Martin du Gard, Les Thibault. L'Été 1914)

2011 L'époque où les magnolias le long de la rue commencent à fleurir, leurs pétales pointus luisant d'un bleu, d'un mauve odorants, qui embaument les trottoirs. Mais cette fois, je les sentais à peine, écrasé net par la catastrophe de ma vie, la mort de ma mère en février (Serge Doubrovsky, Un Homme de passage)

Pronominal

1868 Ils seraient morts de faim, si le vent ne les avait poussés à la côte. Là, ils furent jetés avec une telle violence sur des galets, que le matelot s'y écrasa net et que Jacques y resta évanoui, les côtes à demi rompues (Émile Zola, Madeleine Férat)

\section{Écrier clair}

Crier d'une manière claire et distincte Intransitif

1100 Ki lui veïst Sarrazins desmembrer, Un mort sur altre geter, De bon vassal li poüst remembrer. L'enseigne Carle n'i volt mie ublïer : Munjoie escriet e haltement e cler ; Rollant apelet, sun ami e sun per : «Sire cumpaign, a mei car vus justez ! A grant dulor ermes hoi desevrez » (Chanson de Roland, 1974) 
REMARQues : Écrier clair désigne le fait de pousser un cri, de prononcer quelque chose en criant distinctement de manière à se faire entendre. Notons la coordination avec un adverbe en -ment qui justifie l'analyse de clair comme adjectif-adverbe.

\section{Écrier fort}

S'écrier, dire en criant d'une voix très forte, puissante

Pronominal

+1233 Cil de Thebes mout fort s'escrient

Et sus le cors jeuent et rient

Les fames forment le maudient

Et de pitié plorent et crient

(Roman de Thèbes [ $2^{\mathrm{e}}$ tiers XIII ${ }^{\mathrm{e}}$, 6739)

$\sim 1450$ et souppire et plaint pour Brisaïda, laquelle il cuide bien avoir perdue, et s'escria si tresfort qu'il n'estoit pas possible qu'il ne fust ouy de ceulx qui par la court se pourmenoient. Et tout ce jour là durèrent touz ses plains ; ne serviteur ne amy qu'il eust ne le vit (Roman de Troilus et Cressida, $\mathrm{p}$. 246)

1815 « Personne ici n'en est la dupe, et nous voyons bien que ce ne sont pas là des paysans. " Mon mari demanda à Elvire pourquoi elle s'était si fort écriée, et il ajouta : "On dirait que c'est là le chanteur mystérieux » (Jean Potocki, Manuscrit trouvé à Saragosse)

1894 Lors elle s'écria, et pleura, et tâta sa jarretière, en vain. Et elle s'écria plus fort, voyant qu'elle marchait sur la route de trois couleurs, faite de poussière jaune, d'un canal bleu, et d'un talus vert (Marcel Schwob, Le Livre de Monelle)

1967 Et que pouvais-je, moi, qui avais conduit mon mensonge et ma cupidité jusqu'à la face de mon prince, que pouvais-je sinon m'écrier encore plus fort que Roustan « Oui, Seigneur! ( Joseph Kessel, Les Cavaliers)

Transitif

1389 Chacun des varlez doit avoir deux bastons, et, quant le lou les aura passez et sera entre eulx et la haye, ilz ne le doivent pas trop fort escrier, quar il s'en retourneroit par aventure, mes li doivent gieter l'un des bastons aprés le cul (Gaston Phébus, Livre de chasse, p. 256, 91)

\section{CORPuS WeB :}

La femme continue à s'écrier fort. Alors les disciples, dérangés par ses appels, implorent le Christ de faire quelque chose pour elle, afin qu'elle arrête de crier si fort et qu'elle parte [http:// orthodoxievco.blogspot.co.at/2010_09_12_ archive.html] (16.2.2015)

Un restaurateur chinois s'est écrié fort, quand il a vu que les pratiquants persistaient dans leur activité malgré la température qui avoisinait zéro, « Vous continuez vos activités par un temps aussi froid ? Je vous souhaite le meilleur » [http://fr.clearharmony.net/articles/a17629Quelques-commentaires-des-New-Yorkaissur-les-expositions-anti-torture-a-Manhattanphotos.html] (16.2.2015)

$\mathrm{Au}$ collège, dans le bus, Maëva regarda si sa mère lui avait envoyé un sms mais rien mais quand Laura regarda si elle avait reçu un sms, elle vit un message de Wilson qu'elle ouvrit et elle lu le message en silence avant de s'écrier fort : [...] [http://monhistoireamoa.canalblog.com/ archives/2007/10/29/6723648.html] (16.2.2015)


pousser un cri sous l'effet d'une émotion, d'un état physique ou moral ressenti très intensément, de prononcer quelque chose en criant d'une voix puissante. Fort reste invariable et est modifié par encore plus, moult, plus, si, si très, trop. Notons l'emploi de crier fort.

\section{Écrier haut}

S'écrier, dire en criant d'une voix très forte, puissante

Pronominal

+1100 Li meudre rei e le plus franc Qui unques fust el munde vivant, Se il creust Deu le poant, S'est escrié haut en oant : Ces crestiens sunt nunsavant, Qui de juster me vont hastant ! (Gormont et Isembart [1 $1^{\mathrm{re}}$ moitié XII $]$, 32)

1177 Mes de duel feire estoit si fole, Qu'a po qu'ele ne s'ocioit. 
A la foiiee s'escrioit

Si haut, qu'ele ne pooit plus,

Et recheoit pasmee jus (Chrestien de Troyes, Yvain ou Le Chevalier au lion, 1153)

1355 Et le vaillant Tritran fu a la mot feru.

Lors sescria moult hault : Beaumanoir, ou est tu (Le Combat de trente Bretons contre trente Anglois)

1532 Mais elle commença à s'escrier, toutesfois non trop haut. Adonc Panurge retourna son faulx visage et luy dist : Vous ne voulez donc autrement me laisser un peu faire? (François Rabelais, Pantagruel)

1621 Tandis qu'à mon secours tous les dieux je reclame, je voy venir Phillis : quand j'apperceus ses yeux, je m'escriay tout haut : ce sont icy mes dieux, ce temple et cet autel appartient à ma dame (Théophile de Viau, (Euvres poétiques)

1627 Neantmoins quand il voyoit couper le coû à l'ame de quelque poulet, il s'escrioit aussi haut que si l'on luy eust coupé le sien (Charles Sorel, Le Berger extravagant)

1693 Quand deux Hommes, armés de fer et d'insolence

Retinrent vos chevaux avecque violence, Et, d'un ton plein d'audace et plein d'emportement,

S'écrièrent fort haut : " La Bourse, et promtement!»

(Charles de Charleval, Poésies)

1751 Il fallait absolument l'interrompre.

- Misérable ! me suis-je écrié plus haut qu'elle. Ah ! madame, vous savez que je n'ai pas mérité des noms si violens (abbé Prévost, Lettres angloises [trad.])

1766 Mon cher compère ! m'écriai-je tout haut, vous n'avez jamais connu de vrai bonheur (Henri-Joseph Dulaurens, Le Compère Mathieu)

1830 - Tu vas à Paris! S'écria assez haut, Mme de Rênal. Sa voix était presque étouffée par les larmes, et montrait tout l'excès de son trouble (Stendhal, Le Rouge et le noir)
1974 Claude traversa la petite pièce attenante qui servait de bureau aux aides de camp du général et, au moment où il allait la quitter, il entendit un des officiers, en train de lire un journal ou de terminer une conversation, s'écrier assez haut : «Ah ! mort aux cons ! » (Jean d'Ormesson, $A u$ plaisir de Dieu)

2010 L'hôtelier Hinman se leva précipitamment et, sans laisser à Joseph le temps de poursuivre sa réponse, il s'écria haut et fort :

- Ne le croyez pas, monsieur le juge !

(Micheline Duff, Les Méandres du destin)

Intransitif

+1150 Al recerqier des rens souent tornes, Monioie le Karlon haut escries Et souvent et menu grans cos feres (Aiol et Mirabel [2 $2^{\mathrm{e}}$ moitié XII $], 301$ )

Transitif

1200 Jordains l'entent, ne se volt pas celer, Vers Fromont point, cui Dex puist mal donner,

Et li escrie a sa vois haut et cler: Fromont traïtres, com osas ce panser (Jourdain de Blaye, 4049)

+1200 Si en est moult liez et li vet a l'encontre tout a pié et li escrie si haut qu'il le pot bien oïr : « Hestor, bien veingniez vos ! » (Mort Artu $\left[1^{\mathrm{er}}\right.$ quart XIII $]$, p. 95, 113)

1230 De sa mere li membre, s'a tendrement ploré.

Bertrans, li fils Naimon, li a haut escrié : «Par mon chief, sire rois, mult grant tort en avés » (Gui de Bourgogne, p. 62)

1276 Bien fu montez sor un destrier d'Espaigne, Poi ot meillor de la jusqu'en Behaigne, Enmi les Turs escrioit haut s'ensaigne (Adenet le Roi, Les Enfances Ogier, 5626)

+1341 Et quant messire Ancelin les vit ainxi barguignier, si leur va escrier plus haut qu'il pot en grejoys : «Seignor, fet il, quele marchandise faites vous la aval ? " (Livre de la conqueste de la princée de l’Amorée [(1341)1346]) 
1382 Donc il en advint ainsi ; car quand ils approchèrent pour combattre aux François, chevaliers et écuyers commencèrent à écrier haut et clair plusieurs cris et de plusieurs voix (Jean Froissart, Chroniques (B), VIII, 307)

+1400 Nostre en fut la commençaille, Adonc ouïssiez crier

Hairaulx et hault escrier

Son nom qui en Angleterre

Ert congneu et mainte terre

(Christine de Pisan, Le Livre du duc des vrais amans / Euvres poétiques [début $\left.\mathrm{XV}^{\mathrm{e}}\right]$, III, p. 89, 982)

\section{Corpus Web :}

Puis d'un ton fort de maître de ces lieux, je m'écriais haut et clair : Femme, ne serait'il pas venu, le temps des rires et des chants où que nous mangerions? [http://www.ciao.fr/Luang_poulet_ champignons_noirs_Avis_801063] (15.2.2015)

En effet Mesdames, Le 14 février est passé, et votre cher et tendre, après s'être écrier haut et fort qu'il était contre cette fête commerciale, vous a néanmoins offert une magnifique Saint-Valentin [http://www.bladi.net/forum/threads/journeemecs.92171] (15.2.2015)

En apprenant qu'Alice avait l'intention d'aller manger avec les adhérents de son club, elle s'était écriée haut et fort que c'était injuste, parce que justement, ce soir-là, elle avait prévu de faire un dîner aux chandelles avec sa chérie [http://www.lesbiennes-stories.net/TW_chap11. html] (15.2.2015)

REMARques : ( $S^{\prime}$ )écrier haut désigne le fait de pousser un cri sous l'effet d'une émotion, d'un état physique ou moral ressenti très intensément, de prononcer quelque chose en criant d'une voix puissante de manière à se faire entendre. Notons que haut apparaît en collocation avec clair, ajoutant l'idée de clarté et de netteté dans la voix, et avec l'adjectif-adverbe fort renforçant l'idée d'intensité. Haut reste invariable et est modifié par assez, aussi, fort, moult, plus, si, tout, trop.

\section{Écrire affranchi}

Écrire, libéré des traditions et des contraintes

liées à la norme

त écrire beau

\section{Écrire appuyé}

I. Écrire en appuyant fortement sur la pointe du crayon, du stylo

Emploi absolu

1972 N'écrivez pas si appuyé (Exemple entendu [conseil de maître d'école] / Grundt : 256)

II. Écrire en exagérant

Emploi absolu

1975 Il faudrait dire - ces réflexions ont place ici - que notre plume, à l'occasion, fait du zèle. Elle en remet, elle joue les indics, les auxiliaires dévouées. Elle prend sur elle d'écrire appuyé, d'écrire sonore et fanfaron avant qu'on ne le lui ait demandé (François Nourissier, Lettre à mon chien)

CORpus Web :

En début de cycle 2, c'est-à-dire du cycle des apprentissages fondamentaux, l'élève aura recours à la dictée à Même de t’avoir, là, allongée devant moi, nue comme au premier jour, endormie alors que ma plume gratte le parchemin, si proche que je pourrais écrire appuyée sur ton dos... [http://guillon.christelle.free.fr/forum/ viewtopic.php?t=2164] (16.2.2015)

l'adulte pour produire de l'écrit et progressivement il sera amener à écrire appuyé sur des matériaux pré rédigés puis il passera à l'écriture autonome [https://www2.espe.u-bourgogne.fr// doc/memoire/mem2005/05_04STA00476.pdf] (16.2.2015)

REMARQUES : Écrire appuyé (I) réfère à la manière de tenir son crayon ou son stylo, le sujet appuyant fortement sur la pointe. Par métaphore, (II) renvoie au style de l'écrivain qui cherche à exprimer ses idées avec insistance, à marquer ou souligner fortement certains aspects, en ayant recours à l'exagération. Notons les adjectifs-adverbes sonore et fanfaron qui viennent intensifier l'idée d'excès et l'intention de mettre en relief le contenu ou une partie du contenu. Appuyé reste invariable et est modifié par si. Le CW ajoute deux exemples où appuyé est un prédicat second qui se rapporte à la position que prend la personne (premier exemple) ou au fait d'écrire en s'appuyant sur des matériaux prérédigés (deuxième exemple). Ceci entraîne l'accord avec le sujet. 


\section{Écrire attractif}

Écrire dans un style propre à séduire le lecteur 入 écrire utile

\section{Écrire beau}

Écrire dans un beau style

Emploi absolu

1943 Quand j'écris beau, quelque chose en moi m'échappe et me fuit, la peur me dérobe à moi-même et, comme si j'avais tenté de fixer le soleil, mes yeux glissent, se détournent (Georges Bataille, L'Expérience intérieure)

1991 Platon drogue Socrate de ciguë pour écrire long et beau, plonge dans la torpeur la torpille même, lui administre un narcotique pour ne pas se trouver soi-même torpillé, immobilisé, obligé sans cesse à la dichotomie épuisante et aussi infinie en son genre que le discours le plus dilué (Michel Serres, Le Tiers-Instruit)

2000 Pour écrire il faudrait que je sois démoli et vaincu je veux dire pour finir ce que j'écris là il faudrait que je sois foutu pour écrire beau et vrai ? comme si rien ne pouvait coexister avec l'écriture ? rien qu'une certaine vérité qui serait la mort ? (Richard Morgiève, Ma vie folle)

2006 L'interne de garde [...] me demande de répéter après lui le vers de Mallarmé : Aboli bibelot d'inanité sonore. Croit-il que je n'ai pas été capable - et le serai-je à nouveau ? - d'écrire aussi beau, aussi tintant et mélodieux, aussi désespérant (vanité de l'âme sonore) (Pierre Guyotat, Coma)

CoRpus Web :

La ville antique de Médéa abrite depuis lundi dernier une expo calligraphique, cet art d'écrire beau [http://www.djazairess.com/fr/ lemaghreb/40015] (17.2.2015)

Pour écrire, il suffit de s'asseoir devant une feuille, un ordinateur ou, pour les plus vieux, une machine à écrire. Et se lancer. Mais écrire bien, écrire beau, est un processus bien différent [https://litteractu.wordpress.com/2014/04/03/ charles-bukowski-professeur-malgre-lui] (17.2.2015)
Je dis « bizarrement » car c'est dans ces rangs là que je découvre le plus de beauté pour la langue, le plus d'originalité et le plus de poésie. A croire qu'il est nécessaire pour écrire beau d'écrire affranchi [http://www.lecture-ecriture. com/3103-Les-intermittences-de-la-mortJos\%C3\%A9-Saramago] (17.2.2015)

je suis assez d'accord avec la phrase de Truffaut, quand la vie n'est pas assez belle à mon goût, me reste la possibilité de l'écrire belle, d'écrire une belle histoire [http://cailloutendre. fr/WordPress3/2008/03/la-beaute-et-sarepresentation] (17.2.2015)

Cette expression, il te fallait l'écrire. Celle-lá et pas une autre. Si tu l'avais révoquée, remplacée par autre chose pour sacrifier au désir de l'«écrire beau », tu te serais trahie, tu aurais fait taire en toi l'émotion, le sentiment qui voulaient prendre cette forme verbale-là pour émerger [http:// lepavillon-melancolique.over-blog.com/articleles-indignations-89074973.html] (17.2.2015)

REMARQUES : Écrire beau se dit du fait de rédiger, de composer un ouvrage ou un article en adoptant un beau style qui se caractérise par un vocabulaire soigné et choisi, l'emploi d'images et de figures de style, un certain rythme. Notons les collocations long et beau, beau et vrai, et les adjectifs-adverbes tintant, mélodieux, et désespérant, qui mettent en évidence que l'action d'écrire s'associe avec une série ouverte d'adjectifs-adverbes. Le sens est clairement dirigé vers l'objet interne du verbe : ce qui est écrit. C'est pourquoi il peut fonctionner, dans les deux derniers exemples du CW, en construction transitive comme prédicat second résultatif qui s'accorde avec l'objet direct. Notons l'adjectif-adverbe $a f$ franchi dans le troisième exemple du CW. Beau est modifié par aussi.

\section{Écrire bref}

Écrire brièvement, de manière concise Emploi absolu

1563 Je vous puis asseurer que si je voulois narrer au long la monstruosité de la chose, il me faudroit plus d'une rame de papier pour le discourir, voire sans escrire autre chose que la verité. Mais je me suis estudié d'escrire le plus bref que j'ay peu en ce petit dialogue, lequel se doit plutost appeller un 
abregé, ou epitome, que non pas dialogue (Bernard Palissy, Recepte veritable)

1913 MM. Jérôme et Jean Tharaud ont le souci d'écrire bien, d'écrire bref (Revue des deux mondes)

1963 Scènes courtes, mouvements rapides... Avez-vous écrit si bref, ou coupé, retaillé, retravaillé la pièce? (Le Figaro littéraire, 25 mai 1963 / Grundt : 324)

2001 Flaubert voyait grand et écrivait bref. Madame Bovary et Salammbô sont pourtant sortis de la même plume, issus de la même conviction que la matière d'un livre réside tout entier dans sa manière, qu'il n'y a strictement rien à dire et que les romans ne tiennent que par leur style (Michel Schneider, Prima donna)

2010 Écrire oui, mais plus de la même façon. Façon web. C'est-à-dire écrire bref (parce que nous perdons $25 \%$ en vitesse lorsque nous lisons à l'écran), de manière à ce que le texte puisse être balayé du regard, puisque les internautes "scannent " les pages (Stéphane Dangel, Storytelling. Le guide)

\section{CORPus Web :}

Le mot « style » désigne un poignard effilé ; puis un art d'écrire bref et tranchant [http:// nosdevoirs.fr/devoir/211673] (17.2.2015)

Je vous propose, durant les vacances scolaires, de participer à un stage organisé sur 2 demi-journées pour travailler à écrire une nouvelle, une histoire courte. Apprendre à écrire bref, oui mais comment? [http://duaae.sufco.fr/2013/02/ stage-ecrire-une-nouvelle] (17.2.2015)

REMARQUES : Écrire bref réfère à une écriture concise, réduite à l'essentiel. Bref est modifié par plus, si. Notons aussi l'adjectif-adverbe tranchant dans le CW. Mentionnons également l'emploi de voir grand.

\section{Écrire clair}

Écrire dans un style clair, intelligible ; exprimer des idées claires

Emploi absolu

1927 Or, pour écrire clair, il faut écrire juste, donner à tous les éléments de la langue un rôle et une valeur bien précis, classer rigoureusement les formes et les tours grammaticaux (Gaston Guillaumie, J. L. Guez de Balzac et la prose française)

1959 Il écrit très clair, et direct, s'efforçant de peindre ou plutôt dessiner avec une stricte exactitude le spectacle qu'il a sous les yeux (Le Monde, 15 avril 1959 / Grundt : 331)

2005 Mais écrire bien quand on vit mal, n'est-ce pas trahir ? Je veux dire : écrire ordonné, je veux dire : écrire sage et clair. J'ai un souvenir d'épouvante : la lecture, en 1969 des trop sages Mémoires d'André Maurois. Tellement biographe de lui-même, tiré à quatre épingles, armoire bien rangée, jardin à la française (Philippe Lejeune, Signes de vie)

2008 [Dédicace du livre]

à

[...]

et Albert Crommen (5e),

mes maîtres de l'école primaire Saint-Paul qui m'ont appris

fortiter ac suaviter

à penser et à écrire clair, simple et soigné par respect du prochain comme de soi (François-Xavier Nève, Thèses, mémoires et TFE)

\section{CORPUS WEB :}

Ecrire clair, concis et concret : phrases courtes, au présent, avec des verbes actifs le plus souvent [http://ww2.ac-poitiers.fr/clemi/IMG/ pdf/fiche_ecriture.pdf] (17.2.2015)

Ecrire clair, précis, structuré [http:// atalaformation.com/desc_stages/ecrire_01.htm] (17.2.2015)

Vous voulez sans doute dire " Vos gueulles à tous »!!!! Il faut l'écrire clair et net... Du courage !!!! [http://forums.grenouille.com/index. php?s=71936b739b70d03f26ca41c0615eb00d\&sh owtopic $=61477 \&$ st $=15]$ (17.2.2015)

C'est dur de lire les règles ? Y'en a qui s'embête a les écrire claires pour que tout le monde comprenne, la moindre des choses serait de les lire... [http://www.forum-auto.com/automobilepratique/discussions-libres/sujet266824-2730. $\mathrm{htm}](17.2 .2015)$ 
REMARQUES : Écrire clair réfère à une écriture qui traduit la volonté de l'écrivain ou du rédacteur d'exprimer des idées claires et précises, sans équivoque, de manière explicite et concise. Le verbe écrire produit toute une série d'adjectifs-adverbes dénotant le style : succin[c]t, juste, ordonné, sage, simple, soigné et la collocation clair et direct, ce dernier soulignant l'aspect d'une écriture abrupte, franche, qui traduit la volonté de l'auteur de mettre les choses à nu, d'aller droit au but. Les adverbes lexicalisés bien et mal s'insèrent dans la même série. Le CW ajoute les adjectifs-adverbes concis, concret, précis et structuré, et la collocation clair et net; dans le dernier exemple, clair fonctionne comme prédicat second résultatif orienté vers l'objet et en tant que tel, et il s'accorde avec celui-ci. Remarquons cependant que l'orthographe de l'exemple n'est pas très sûre.

\section{Écrire classique}

Écrire selon les règles traditionnelles

Emploi absolu

1917 Léon Daudet aime les choses bien composées, bien ordonnées, harmonieuses, au sens d'équilibre du mot, et non au sens musical, car les fausses notes sont nombreuses. Son goût est pour le classique, il écrit classique (Maurice Wilmotte, La Renaissance du livre)

1949 On peint impressionniste, fauve, cubiste [...] on écrit naturaliste, symboliste, existentialiste, comme jadis on sculptait gothique, peignait renaissant, écrivait classique ( $L a$ Table ronde)

1975 mon texte est en effet lisible : je suis du côté de la structure, de la phrase, du texte phrasé : je produis pour reproduire, comme si j'avais une pensée et que je la représente à l'aide de matériaux et de règles : j'écris classique (Roland Barthes par Roland Barthes)

\section{Écrire compliqué}

Écrire dans un style qui complique la

compréhension

Emploi absolu

1886 Il [= Hamilton] voit d'ordinaire juste et simple ; il écrit compliqué, si l'on peut dire
(Joseph Reinach, Préface / La Logique parlementaire de Hamilton)

2020 C'est l'une de ses marques de fabrique, d'ailleurs : ne pas faire du style pour le style, ne pas écrire compliqué, mais chanter des choses qui parlent au plus grand nombre, que le moins éduqué des auditeurs puisse comprendre et s'approprier (Lomig Guillo, Serge Lama)

REMARQUeS : Notons l'emploi de voir juste ; voir simple.

\section{Écrire concis}

Écrire succinctement, dans un style sobre

$\lambda$ écrire clair

\section{Écrire concret}

Écrire en s'exprimant concrètement

$\lambda$ écrire clair

\section{Écrire court}

Écrire en peu de mots

Intransitif

1840 Mon très-cher frère, je t'écris court et vite, pour ne pas manquer une bonne occasion (Pierre-Louis Arondineau, Les Souvenirs de l'amitié ou Vie et opuscules)

Transitif

1853 Il m'est impossible de l'écrire court. Il me ronge (Gustave Flaubert, Correspondance)

Emploi absolu

1939 elle vous aime passionnément mais il faut lutter pour obtenir qu'on vous écrive chaque jour, "écrivons court " dit-elle (Simone de Beauvoir, Lettres à Sartre)

2018 Écrire court et dense : livrer un maximum d'information en un minimum de mots (Corpus Coiffet 2018 : s.v., sans date)

\section{CORPUS WEB :}

Écrire court et dense c'est apprendre à faire des choix, et s'y tenir sans états d'âme à chaque étape de votre article [https://blog.cfpj.com/ 2017/04/07/astuces-ecrire-court-dense] (7.4.2017) 


\section{Écrire démodé}

Écrire dans un style désuet, démodé

Emploi absolu

1957 Un autre [= critique] va jusqu’à: « Giraudoux vieillit mal » et écrit "démodé ». « Le charme s'use vite... cette langue s'est affadie... » (Sélection du Monde, 28 février - 6 mars 1957 / Grundt : 256)

Remarques : Écrire démodé se dit du fait de rédiger un texte en adoptant un style qui n'est plus à la page, qui ne correspond plus aux goûts ou aux attentes du lecteur contemporain.

\section{Écrire dense}

Écrire en condensant ses idées

$\lambda$ écrire court

\section{Écrire désespérant}

Écrire dans un style inspiré par le désespoir तécrire beau

\section{Écrire direct}

Écrire sans détour, franchement, ouvertement Emploi absolu

1959 Il écrit très clair, et direct, s'efforçant de peindre ou plutôt dessiner avec une stricte exactitude le spectacle qu'il a sous les yeux (Le Monde, 15 avril 1959 / Grundt : 331)

\section{CORPuS Web :}

Ah ok. Et sinon je peux l'écrire direct sur l'ordi le nom ou il le faut en vrai ? [http://ask.fm/ ZakiNiall/answer/104807153664] (17.2.2015)

Moi j'avais pas des masses de moments que je souhaitais réécrire, et pourtant ça m'a parut insurmontable. Alors tout refaire? ! Non, autant bien écrire direct, en un temps moins strict... [http://www.ecrire-un-roman.com/forumecriture/viewtopic.php?f=39\&t=4891] (17.2.2015)

Et aussi au bout de combien de temps je peu espérer avoir une bonne oreille (reconnaitre une mélodie et pouvoir l'écrire direct par exemple) ? [http://fr.audiofanzine.com/theorie-musicale/ forums/t.250370,travail-de-l-oreille-relativecombien-de-temps.html] (17.2.2015)

Moi j'crois que j'aurais eu tendance à l'écrire direct avec un $\mathrm{H}$, le prénom (à la base) s'écrit ainsi [http://www.i-services.com/membres/ forum $/$ messages.php?uid=6778\&sid=66394\&ids ujet $=1316219 \&$ page $=83]$ (17.2.2015)
Pour les lignes de commandes tu peux me les écrire directs ? je suis en mode flemme se soir x) merci [http://www.gtaonline.net/forums/ index.php?topic=10593.0] (17.2.2015)

REMARQUES : Dans l'exemple de 1959, écrire clair et direct réfère à une écriture directe, franche, qui traduit la volonté de l'auteur de mettre les choses à nu, d'exprimer des idées claires et précises, sans équivoque, de manière explicite. Dans le langage quotidien du CW, direct est l'équivalent de directement. Il renvoie au fait d'écrire directement la version finale, sans brouillon. Dans l'avant-dernier exemple, il signifie plutôt 'simplement', 'sans se poser des questions'. Dans le dernier exemple, la flexion de direct ne change pas sa fonction adverbiale. Notons que les exemples du CW tendent à l'emploi transitif ; ceci est lié au fait que écrire direct ne renvoie pas à un style d'écriture, comme dans l'exemple de 1959.

\section{Écrire droit}

I. Tracer des lettres droites

Emploi absolu

1693 Ayez donc soin d'écrire droit, de peur que l'obliquité de vos lignes ne fatigue les Lecteurs et leur fasse faire des fautes (Lettres de Saint Basile le Grand [trad.])

1819 Lorsqu'il espace bien les lettres et qu'il écrit droit entre deux cordons, dont l'écartement est d'environ deux lignes, on en enlève un, et on l'exerce de nouveau ; on ôte ensuite une seconde ligne et successivement on les ôte toutes (Sébastien Guillié, Essai sur l'instruction des aveugles)

1975 « À la manière dont il parle, je puis savoir s'il écrit droit ou penché, gros ou fin et aux pieds de quel mont il meurt ", disait-il encore (Edmond Jabès, Le Livre des marges)

1982 Je songe à un proverbe portugais rapporté par Gracq : « Dieu écrit droit au moyen de lignes courbes » (Éric Ollivier, L'Orphelin de mer) 
II. Écrire en adoptant une position droite Intransitif

1976 Ce que je trouve le plus marrant dans tout ça, c'est quand je me couche sur la table, la tête sur le coude et l'œil au ras du papier, ça fait de grosses lettres énormes et pourtant, j'écris tout petit. Chaque fois que je fais un petit $\mathrm{O}$, on dirait un cercle grand comme la page et plat, complètement déformé.

- Bon Dieu, tu peux pas te redresser et essayer d'écrire droit !

(Patrick Cauvin, Monsieur Papa)

REMARQUES : Écrire droit (I) réfère au fait d'écrire avec des lettres tracées droites. Dans l'exemple de 1976, droit est employé comme prédicat second référant à la position droite que devrait adopter l'enfant (II). Dans l'exemple de 1982, il signifie, sur un plan plus abstrait, que le message de Dieu est clair pour qui sait le saisir derrière des apparences plus confuses. Notons les collocations droit ou penché, gros ou fin et l'emploi du modifieur tout.

\section{Écrire dru}

Écrire dans un style incisif, dense et vif Emploi absolu

1959 Revu et adapté, magistralement, par un écrivain qui parle cru, qui écrit dru, qui pense dur (France observateur, 27 août 1959 / Grundt : 326)

1994 Il écrit dru et leste : " Dans Dieu, comme dans le cochon, tout est bon ". C'est le récit d'une grande découverte et l'entrée dans une grande famille (Émile Poulat, $L a$ Galaxie Jésus)

CORpus WeB :

Quand on tente de penser librement, de parler et d'écrire dru, quand on ne désire pas s'installer dans le cortège confortable des bienséances intellectuelles et politiques, il faut s'attendre au pire, savoir qu'on va naturellement payer une rançon [http://www.philippebilger. com/blog/2008/03/la-haine-de-zem.html] (18.2.2015)

Mais on peut écrire dru en ayant peu à dire, comme tant de textes d'humeur tentent désormais de le faire en ne suscitant que défoulement [http://mobile.ledevoir.com/non-classe/78198/ hommage-a-gerard-filion-un-parcours-quiepouse-notre-liberation-collective] (18.2.2015)

Couronné par plusieurs prix littéraires, Mabanckou écrit dru. Et certainement vrai. Un petit hic : il renforce à son insu certains préjugés sur l'immigration. Mais c'est certain : il n'écrit pas pour rien [http://salon-litteraire.com/fr/ polar/review/1799753-alain-mabanckou-tais-toiet-meurs-un-roman-noir] (18.2.2015)

REMARQUES : Écrire $d r u$ réfère à une écriture directe, fraîche, qui traduit aussi la volonté de l'auteur de mettre les choses à nu, d'exprimer de manière explicite des idées claires mais concises, des idées précises, sans équivoque. Notons la collocation dru et leste et les groupes parler cru, penser dur, ainsi que parler dru et écrire vrai dans le CW.

\section{Écrire dur}

Écrire avec ténacité

入 écrire ferme

\section{Écrire économique}

Écrire de manière efficace

Emploi absolu

1964 Il écrit économique (Étiemble)

\section{Écrire efficace}

Écrire de manière pertinente, efficace

入 écrire vif

\section{Écrire engagé}

Écrire en s'investissant pleinement

$\lambda$ écrire fort

\section{Écrire étincelant}

Écrire avec finesse et vivacité, brillamment 入 écrire vif

\section{Écrire étriqué}

Écrire dans un style sec, qui ne fait preuve d'aucune imagination

Emploi absolu

1957 [Jean Nohain et Mireille ont écrit le Petit Chemin] Quelques jours après Maurice Chevalier venait voir Mireille. Je l'entends encore : 
- Pourquoi le Petit Chemin ? Vous écrivez beaucoup trop mince, beaucoup trop étriqué. Pour réussir dans la chanson, il faut faire large ! il faut chanter grand! Du souffle, mes amis, du souffle!

(Marie-Claire, mars 1957 / Grundt : 311)

Corpus Web :

La musique qui m'inspire suscite l'émotion, emporte l'imagination dans un registre grandiose ou romanesque : elle me pousse à ne pas écrire étriqué, mesquin [http://lacroiseedesmondes. hautetfort.com/archives/tag/\%C3\%A9criture/ index-7.html] (18.2.2015)

REMARQUES : Écrire étriqué réfère à la manière d'écrire ou au style de la personne qui rédige un texte, dans un style médiocre, qui manque d'idées et dont le contenu est fade et peu intéressant ; écrire étriqué souligne le caractère peu créatif du rédacteur. Notons la collocation avec mince, qui ajoute à l'idée d'un style commun, peu recherché, traduisant ainsi le manque d'originalité de l'auteur et son désir de ne pas prendre de risques, de ne pas sortir de la norme imposée. La citation de 1957 montre bien que les collocations appartiennent à un langage de spécialité qui comprend également faire large et chanter grand. Notons aussi l'adjectif-adverbe mesquin dans le CW.

\section{Écrire fanfaron}

Écrire sur le ton de la fanfaronnade, avec

exagération

Emploi absolu

1975 Il faudrait dire - ces réflexions ont place ici - que notre plume, à l'occasion, fait du zèle. Elle en remet, elle joue les indics, les auxiliaires dévouées. Elle prend sur elle d'écrire appuyé, d'écrire sonore et fanfaron avant qu'on ne le lui ait demandé (François Nourissier, Lettre à mon chien)

\section{CORPuS WeB :}

Colette lui avait été préférée alors qu'il croyait la chose pliée en sa faveur : « La diplomatie contre l'Institut de beauté ! Je vois d'ici le pleur sublime que je verserai sur le frêle squelette de la Comtesse de Noailles ", avait-il écrit, fanfaron, à un ami [http://archives.lesoir.be/lamarge_t-20110610-01FEWK.html] (18.2.2015)
REMARQUES : Écrire fanfaron se dit d'une écriture à travers laquelle l'auteur se met en avant, une écriture caractérisée aussi par une certaine exagération. Notons la collocation écrire sonore et fanfaron, l'adjectif-adverbe sonore renforçant ou explicitant cette idée d'exagération.

\section{Écrire faux}

I. Écrire sans naturel, sans réalisme ou vraisemblance

Emploi absolu

1868 Il nous lit une pièce qu'il a commise pour les Français. C'est étonnant comme tout homme faux et comédien pense et écrit faux (Edmond et Jules de Goncourt, Journal)

1961 De ce quatuor [= les acteurs et l'auteur d'un film] c'est à qui jouera, ou écrira, ou dira le plus faux (France observateur, 5 janvier 1961 / Grundt : 378)

1989 Plus que du pseudo-imprévu, des attentes controuvées, des hasards refabriqués de toutes pièces. Même en voulant dire vrai, on écrit faux. On lit faux. Folie. Une vie réelle passée se présente comme une vie fictive future (Serge Doubrovsky, Le Livre brisé)

\section{II. Écrire avec des fautes d'orthographe} Transitif

2009 Les élèves n'ont aucun moyen d'écrire correctement des mots qu'ils n'ont pas pu apprendre. Pis encore, s'ils les écrivent faux lors de la dictée en classe, ils les mémoriseront ainsi (Pierre Vianin, L'Aide stratégique aux élèves en difficulté scolaire)

\section{CORPuS Web :}

C'est d'ailleurs en réfléchissant à cette expérience de la censure que Pierre Salducci en vient à proposer trois types d'écriture : écrire faux, écrire neutre et écrire vrai. Dans le premier cas, l'auteur tend à camoufler toute trace de son homosexualité, allant même jusqu'à la nier ; dans le deuxième, il use de stratégies formelles, lesquelles créent une ambiguïté quant au genre des personnages ; finalement, dans le dernier, il écrit franchement, sans faux-semblant et subterfuge [http://www.lecrachoirdeflaubert.ulaval. ca/2014/08/en-amont-du-dire-gai] (18.2.2015) 
Merde ! il faut écrire faut si on ne veut pas écrire faux [http://www.arretsurimages.net/ forum/read.php?4,1426054,1426325] (18.2.2015)

T'es un troll pour ecrire faux la marque de la bagnole que tu prétends avoir ? [http:// www.forum-auto.com/automobile-pratique/ discussions-libres/sujet387799.htm] (18.2.2015)

Edit : tant qu'à ne pas se servir de la formule à trois termes, autant ne pas l'écrire fausse [http://www.les-mathematiques.net/phorum/ read.php?3,990697,991197,quote=1] (18.2.2015)

REMARQUES : Écrire faux réfère soit à une écriture truquée, manquant de naturel et de crédibilité (I), soit, plus concrètement, au fait d'écrire avec des fautes d'orthographe (II). D’après le CW, l'acception (II) prédomine dans la communication quotidienne. Notons l'emploi de penser faux, jouer faux, dire faux, lire faux, ainsi que d'écrire neutre et écrire faux dans le CW. Faux reste invarié dans le troisième exemple du CW, malgré l'objet au féminin, tandis que dans le dernier exemple il remplit la fonction de prédicat second résultatif orienté vers l'objet et s'accorde avec l'objet pronominal féminin. Faux est modifié par le plus.

\section{Écrire ferme}

Écrire avec détermination et énergie

Emploi absolu

1789 Vous devez y reconnaître son ame tendre, sensible, aimante; vous devez y retrouver sa manière d'écrire ferme, hardie, vigoureuse, ses tableaux rians et pittoresques, ses descriptions naturelles, ses goûts simples et champêtres (Antoine Joseph de Barruel-Beauvert, Vie de J. J. Rousseau)

1849 Il l'a fait par zèle et par bonté, mais moi je n'aime pas que Bertholdi se sache si bien protégé, je crains que cela ne le rende feignant et imprudent. Je compte lui écrire un peu ferme à cet égard, mais j'attends que ma petite ait pondu. Je crains de jeter une mercuriale dans ce moment critique et je ne veux pas troubler sa situation physique (George Sand, Correspondance)

1883 À son immense savoir M. Le Hir joignait une manière d'écrire juste et ferme (Ernest Renan, Souvenirs d'enfance et de jeunesse)
1939 C'est contre les mots qu'il en a - non contre la pensée. Naturellement, à l'opposé de ce souci, il y a la préoccupation constante de travailler, d'écrire ferme et dur (Jean-Paul Sartre, Carnets de la Drôle de Guerre)

Transitif

1940 Je vous dis, c'est une question d'un jour ou deux et ça ne m'inquiète guère. Je suis d'excellente humeur et je travaille comme un dur. J'ai écrit ferme 17 pages en 6 jours, ce qui est un record pour moi pissevinaigre (Jean-Paul Sartre, Lettres au Castor et à quelques autres)

\section{Corpus Web :}

La tablette est couverte de quatre lignes d'écriture en hébreu carré, seul l'aleph appartient à la cursive. L'écriture est celle d'une personne habituée à écrire, ferme et sans hésitation [http://judaisme.sdv.fr/perso/rweyl/tablett.htm] (18.2.2015)

L'abbé Xavier BERTRES était un prêtre de terroir, passionné de vieilles pierres. J’ai découvert au travers de ses écrits, l'autorité d'un ecclésiastique sachant écrire ferme et net [http://www. barbazandebat.fr/img/pdf/eglise.pdf] (18.2.2015)

Je veux écrire ferme des tas de jolis mots. Je veux qu'ils s'enchaînent et qu'ils trouvent leur tempo, je veux mes mots sans chaîne, des mots comme des bravos [http://collections.banq. qc.ca/ark:/52327/bs60850] (18.2.2015)

REMARQUES : Écrire ferme réfère à une écriture directe, franche, qui traduit l'assurance et la détermination de l'auteur. Notons les collocations juste et ferme, ferme et dur, ainsi que ferme et net dans le CW. Il est difficile de se prononcer sur l'accord de ferme qui ne distingue pas le féminin du masculin, mais la série d'adjectifs-adverbes dans l'exemple de 1789 montre que ferme est pris au féminin. On peut y voir un effort de correction linguistique puisque l'accord y est formellement justifié par le substantif «manière ». Ferme est modifié par un peu. 


\section{Écrire fin}

Écrire en petites lettres, en petits caractères peu épais

Emploi absolu

1780 mon bon ange donc, m’a soufflé tout bas à l'oreille que je me tuais les yeux à écrire si fin, et que je pouvais bien ne pas tant économiser le papier (Honoré de Mirabeau, Lettres originales écrites du donjon de Vincennes)

1802 Mets-toi donc un peu en train, et accoutume-toi à m'écrire une longue lettre d'une page, mais écris fin, je t'en supplie (Stendhal, Correspondance)

1897 Il avait écrit si fin que je ne pouvais pas lire... vous concevez ? (Anatole France, L'Orme du mail)

1984 Raymond s'exerçait parfois à lire les flancs de Paris-Soir, quand les clients se faisaient rares. Celui du Temps était écrit plus fin (Bertrand Poirot-Delpech, L'Été 36)

Corpus Web :

En effet, je fais un cornet de papier sulfurisé, je fais fondre le chocolat noir au bain-marie (eau frémissante), je le mets dans le cornet, j'aime que le trou soit le plus petit possible pour écrire fin, mais le chocolat durcit vite, je mets au micro-onde pour ramollir, mais ce n'est pas très pratique [http://forum.aufeminin.com/forum/ cuisine1/_f120549_cuisine1-Ecrire-au-cornet-depapier-sulfurise-sur-un-gateau.html] (19.2.2015)

La plume dite " Music » possède deux fentes, présentes uniquement sur ce modèle. Cette découpe vous permet d'écrire fin à l'horizontale et large à la verticale [http://morastylos. com/stylos/neufs/nakaya/outil-didactique.html] (19 février 2015)

Avant ils avaient une autre marque, ils étaient sympas car ils avaient deux bouts, un pour écrire fin, l'autre pour écrire gros, mais ils ne tenaient pas longtemps et ceux de Colargol fuyaient (elle avait acheté la marque d'avant, ceux à double écriture) [http://gateauxrigolos.superforum.fr/ t9781-feutre-alimentaire] (19.2.2015)

je vais voir si je me trouve une plume pour écrire fine je galère avec la plume et l'encre de chine [http://www.glenatmanga.com/forum/ touslesmessages.asp? $\mathrm{u}=1879$ \&page=3] (19.2.2015)
REMARQUES : Écrire fin désigne la grosseur de la pointe d'un crayon, d'un stylo, d'une plume, qui permet de produire des lettres fines, d'écrire en petits caractères. Ce type d'écriture a pour objectif une meilleure clarté et par conséquent une meilleure lisibilité, mais aussi une économie de papier. Fin est modifié par plus, si. Notons écrire large ou gros en opposition avec écrire fin, dans le CW. Fin s'accorde avec le substantif féminin plume dans le dernier exemple, mais la fonction est plutôt celle d'une épithète (une plume pour écrire // fine). Notons l'emploi de souffler bas.

\section{Écrire fort}

I. Écrire beaucoup

Emploi absolu

1892 « On a fort écrit sur l'argent. Les politiques, les économistes, les moralistes, les psychologues et les mystagogues s'y sont épuisés. Mais je ne remarque pas qu'aucun d'eux ait jamais exprimé la sensation de mystère que dégage ce mot étonnant » (Léon Bloy, Le Salut par les Juifs)

II. Écrire des idées fortes, écrire avec une grande intensité

Emploi absolu

1943 en matière d'impressions, c'est ce qui est fort qui compte. Leçon d'esthétique : il faut écrire fort pour écrire bien et dessiner fort pour donner des impressions que le lecteur retrouve avec plaisir (Max Jacob [Lettre à François Sentein du 6 mai 1943])

1958 BARTHOLOMÉUS III. Écrivez plus fort ! (Eugène Ionesco, L'Impromptu de l'Alma)

2010 J'aime son nom. Je le marque. Chéri amour. J'aime être bête. Je l'aime. Je l'aime. Je l'aime. Je l'aime. Je veux l'écrie [sic], l'écrire au Bic bleu, l'écrire fort. C'est MERVEILLEUX. Il pense à moi maintenant. Il me l'a dit. Nous avons dansé (Laurent Gervereau, L'Homme planétaire)

\section{CORPUS WEB :}

Ca va écrire fort ce soir, si vous avez des instrus a me balancer, hésitez pas ! [https://www.facebook.com/Clash113/ posts/10151373323870452] (19.2.2015)

C'est parfois quelconque, car écrire fort en 40 pages n'est pas évident, mais quelques-uns 
valent vraiment la lecture [http://www.babelio. com/livres/Prevot-Voleuse-/465017] (19.2.2015)

La chanteuse coréenne Youn Sun Nah, avec son vibrato tendu mais aussi sa manière d'écrire forte, engagée, qui peut faire penser à Björk, impose d'emblée un univers à la fois savamment arrangé et rythmiquement énergique [http://www.novartbordeaux.com/wp-content/ uploads/2014/10/novart-2005.pdf] (19.2.2015)

REMARQUES : Fort, en collocation avec le participe passé écrit, se comporte comme un adjectif ; il adopte une fonction de quantifieur (I). Écrire fort (II) réfère à une écriture directe, franche, qui traduit la volonté de l'auteur de mettre les choses à nu, d'exprimer des idées claires et fortes, permettant ainsi de capter l'attention du lecteur. Le dernier exemple du CW montre comment on peut échapper à l'emploi adverbial strictement dit en optant pour une paraphrase adverbiale qui emploie l'adjectif comme modifieur de substantif manière (manière d'écrire // forte). Notons l'emploi de dessiner fort.

\section{Écrire froid}

Écrire sans émotion, impartial

Emploi absolu

1991 Il faudra donc écrire froid, hiératique, implacable, taillé (Le Monde, 29.11.1991 / Noailly 1997a)

\section{Écrire gras}

I. Employer un langage vert, argotique

Emploi absolu

1881 Les bas-bleus, qui, paraît-il, sont toutes maigres comme des clous, se plaisent à écrire gras. Ah! mesdames, par charité, renoncez à l'érotisme et n'inondez plus la place de ces livres niais, malpropres, souvent immondes (Léon Chapron, Les Coins de Paris)

1940 Comme je comprends que Stendhal ait aimé ces opuscules où quatre ou cinq pages en disent plus que les pesants volumes de M. Céline, déplorable disciple d'Honoré d'Urfé, de M. Céline qui écrit gras exactement comme on écrivait précieux au $\mathrm{XVII}^{\mathrm{e}}$ siècle (Robert Desnos, Mines de rien)
II. Écrire dans un style « grand public » et complaisant

Emploi absolu

1986 Si l'euphorie stylistique oléagineuse a ses adeptes, c'est qu'il existe une jubilation à écrire gras : baratin de l'auteur grand public barbotant dans le beurre qu'il se fait. Le gras-écrire est le degré le plus élevé de l'intériorisation de la censure. Plaire au public exige d'écrire sous la dictée du gros animal, le plus simple alors est de se le mettre dans la tête (Max Genève, Le Roman [jeu de mots avec Éditions Legras])

\section{Écrire gros}

I. Écrire en gros caractères

Intransitif

1770 Mon cher ange, je suis presque aveugle, j'écris de ma main et le plus gros que je peux (Voltaire, Correspondance)

1773 Adieu, bon Condorcet, revenez vite et ne vous en allez plus. $N$. $b$. il faut, s'il vous plaît, écrire plus gros et plus noir (Julie de Lespinasse, Lettres à Condorcet)

1780 et moi qui n'entends pas les affaires, j’ai commencé une cinquième page, parce que j'ai écrit bien gros pour ne pas fatiguer les yeux de mon bon ange (Honoré de Mirabeau, Lettres originales écrites du donjon de Vincennes)

2004 Pendant que ton père recopiait l'article en écrivant gros pour toi de sa très belle écriture, tu as échangé une timide conversation avec les deux filles adoptives du maire, que tu avais déjà remarquées en jouant (Daniel Maximin, Tu, c'est l'enfance)

Transitif

2002 Le professeur de dessin apprécia, mais pas dans le bon sens : fâché, il décida que le titre était «écrit trop gros », et notre œuvre fut la seule à ne pas figurer dans l'exposition qui précédait l'envoi à Vichy (François Maspero, Les Abeilles et la guêpe)

II. Écrire beaucoup

Intransitif

1851 Vous voilà donc guéri, et je serais flattée que, sans souffrir, vous eussiez toujours 
dans les yeux la nécessité d'écrire gros comme aujourd'hui (George Sand, Correspondance)

III. Avoir une pointe épaisse, large (d'un stylo, d'une plume)

Intransitif

1968 - Je dis que je suis triste d'être moi, je lâche les amarres, je... - Oh, tu sais, Fabienne Leflec en classe elle a un bic recourbé du bout et qui écrit très gros

(Benoîte et Flora Groult, Il était deux fois)

1972 - J'ai envie de dessiner, il me dit.

- D’accord, je fais. Si ça peut te distraire... Je lui achète toute une collection de feutres, des gros qui écrivent gros, des petits qui écrivent petit, avec le maximum de couleurs. Ça me faisait plaisir de lui faire plaisir (Bertrand Blier, Les Valseuses)

IV. Avoir de l'importance, être très important, considérable, marquant

Pronominal

1990 l'Artois, la Serbie, les Dardanelles, la Marne et la Meuse, la Lorraine et l'Alsace, l'Argonne, l'Yser, comme une couronne d'effroi qui dénombre sur la trame de rameaux d'olivier le sous-ensemble des communes martyres, à l'aune du charnier, si bien que Vimy s'écrit aussi gros que Lens, Dixmude qu'Ostende, Les éparges que Nancy (Jean Rouaud, Les Champs d'honneur)

\section{Corpus Web :}

Ecrire gros dans une copie, pour faire croire que tu as écris bcp de chose [https://fr-fr. facebook.com/pages/Ecrire-gros-dans-unecopie-pour-faire-croire-que-tu-as-\%C3\%A9crisbcp-de-chose/191490757932] (19.2.2015)

Avant ils avaient une autre marque, ils étaient sympas car ils avaient deux bouts, un pour écrire fin, l'autre pour écrire gros, mais ils ne tenaient pas longtemps et ceux de Colargol fuyaient (elle avait acheté la marque d'avant, ceux à double écriture) [http://gateauxrigolos. superforum.fr/t9781-feutre-alimentaire] (19.2.2015)
C'est comme écrire gros une rédaction pour qu'elle prenne plus de place et donne l'impression d'avoir fait une rédaction garnie [https:// fr.answers.yahoo.com/question/index?qid=2012 0624112822AA1MMKN] (19.2.2015)

REMARQUES : Écrire gros (I) réfère à la taille, à la dimension des caractères typographiques. Notons que la grosseur de la lettre ou le besoin d'écrire dans un format plus grand a un lien avec la vue, la taille de la lettre visant en effet à faciliter la lecture et à ne pas fatiguer l'œil. Dans (II), gros correspond au texte, à la quantité produite, c'est-à-dire au nombre de pages produit par l'écrivain. Gros (III) renvoie à la taille, à l'épaisseur de la pointe du crayon, du stylo, du feutre et s'oppose à écrire petit. Dans l'emploi métaphorique (IV), le verbe écrire ne se rapporte pas à la façon d'écrire quelque chose, mais le groupe écrire gros symbolise l'importance de l'événement (Vimy en emploi métonymique pour la bataille de Vimy) et de dimension égale à d'autres batailles telle celle de Lens par exemple. Notons les collocations écrire gros, écrire petit, écrire plus gros et plus noir. Gros reste invariable et est modifié par aussi, bien, plus, le plus, très, trop.

\section{Écrire habillé}

Écrire en cachant, en dissimulant quelque chose Emploi absolu

1955 Poussant l'art de choisir, d'épurer, de transfigurer aussi loin qu'il le pouvait, écrivant toujours "habillé " et non pas « mis à nu », il nous a peut-être dissimulé ce qui nous semblerait le meilleur de luimême? (Robert Kemp, La Vie des livres)

\section{CORPuS WeB :}

Moi même, je ne suis pas exempt de tout reproche... il m'arrive parfois d'écrire habillé... un comble quand on pense que je me met à nu face à vous depuis une éternité [http://www.beaute-test. com/forums/index.php?topic=112242\&start=330] (19.2.2015)

REMARQUES : Écrire habillé se dit ici du fait de rédiger un texte en exprimant ses idées ou son opinion de façon détournée, l'écrivain ne voulant pas dévoiler ou dire de façon directe, sans fioritures, les choses, soit par nécessité, soit pour forcer l'imagination du lecteur. Il est mis en op- 
position avec mis à nu. Habillé est modifié par toujours. L'exemple du CW joue avec l'ambiguïté de l'adjectif au sens concret et figuré. Dans cet exemple, écrire habillé pourrait également s'opposer à écrire en déshabillé ou en pyjama.

\section{Écrire hardi}

Écrire d'une plume énergique

त écrire ferme

Écrire inutile

Écrire sans utilité publique

Emploi absolu

1963 J'écris inutile, mes sales histoires n'intéresseront pas les élites (Alphonse Boudard, La Cerise)

\section{Écrire juste}

Écrire avec justesse et précision

$\lambda$ écrire clair

\section{Écrire large}

Tracer des lettres aux traits larges

$\lambda$ écrire fin

\section{Écrire léger}

Composer une musique plaisante

Emploi absolu

2013 Là, tu me fais n'importe quoi: on dirait une marche militaire. Tu sais ce que ça veut dire, "scherzando " ? Là, il a écrit léger, donc tu joues léger ! Ce n'est pourtant pas compliqué à comprendre, non ?

(Exemple entendu [professeur de piano] / Corpus Coiffet 2018 : s.v.)

\section{Écrire leste}

Écrire dans un style ramassé et désinvolte

入 écrire dru

\section{Écrire long}

Écrire beaucoup, en entrant dans les détails

Emploi absolu

1821 C'est un beau et vrai triomphe. Adieu, revenez ou répondez-moi vite, et écrivez long (Alexandre Guiraud [lettre] / Victor Hugo, Correspondance)

1991 Platon drogue Socrate de ciguë pour écrire long et beau, plonge dans la torpeur la tor- pille même, lui administre un narcotique pour ne pas se trouver soi-même torpillé, immobilisé, obligé sans cesse à la dichotomie épuisante et aussi infinie en son genre que le discours le plus dilué (Michel Serres, Le Tiers-Instruit)

Intransitif

1822 Je suis fâché que tu n'aies pas lu ma lettre, je t'avais écrit une partie de la nuit, j'y avais mis tout mon cœur, c'est dire que je t'en avais écrit long, mais qu'importe! Tu m'aimes, je t’adore (Victor Hugo, Lettres à la fiancée)

1849 L'approche de la discussion des lois dont je suis rapporteur me force à ne pas vous en écrire plus long aujourd'hui (Alexis de Tocqueville, Correspondance avec Henry Reeve)

1878 Vous voilà un peu plus tranquille, n'est-ce pas ? Vous allez re-travailler? Je vous en écrirais long, mais je suis éreinté à force de lire et de prendre des notes (Gustave Flaubert, Correspondance)

1909 Je ne puis vous en écrire plus long aujourd'hui, occupé par les préparatifs de voyage (Paul Claudel et André Gide, Correspondance)

1968 Ah, nous sommes peu de chose quand l'amour souffle! Pas le temps de t'en écrire plus long. Il faut que je profite à plein de mes derniers jours ici (Benoîte et Flora Groult, Il était deux fois)

Transitif

1837 D'après une nouvelle lettre de vous, je me déterminerai. Ne craignez pas de me l'écrire longue, d'entrer dans le détail de vos réflexions sur votre situation présente, sur les véritables besoins de votre esprit (George Sand, Correspondance)

REMARQUES : Écrire long s'emploie surtout dans les lettres, renvoyant au fait d'écrire en exposant tout les détails, sans souci de brièveté. Dans les exemples de Frantext, la construction ne pas (pouvoir, avoir le temps de) en écrire plus long prédomine. Long est modifié par plus. Notons l'emploi résultatif accordé dans l'exemple de 
1837, à comparer avec la barbe pousse longue (Gamillscheg 1957 : 526), les cheveux poussent longs (Frantext), exclus de ce dictionnaire (prédication seconde). VOIR AUSSI : nourrir long

\section{Écrire mélodieux}

Écrire dans un style harmonieux, agréable $\pi$ écrire beau

\section{Écrire menu}

Écrire en petits caractères (concret) ; écrire timidement ou de façon détaillée (figuré)

Emploi absolu

1664 Une plume qui écrit menu (Pierre Delbrun, Le Dictionnaire du p. Pierre Delbrun)

1884 La plume des sensuels écrit gras, celle des délicats écrit menu. Les audacieux ne s'accommoderont pas d'une plume qui bronche, tandis qu'elle suffira parfaitement aux timides (Journal d'hygiène)

1886 Un soir, en parlant de l'inspiration et de la manière dont étaient conçus les beaux livres :

- Il y a des jours, disait-il, où l'on écrit avec son sang, d'une écriture fière, solide, forte ;

d'autres jours où l'on écrit menu

(Jules Claretie, La Canne de M. Michelet)

1914 M. René Boylesve écrit menu, menu. Il s'attarde dans des détails, pour lesquels il recherche mille grâces (La Renaissance contemporaine)

REMARques : Notons la réduplication menu, тепи.

\section{Écrire mesquin}

Écrire dans un style parcimonieux, fruste

त écrire étriqué

\section{Écrire mince}

Écrire dans un style commun, plat, qui manque d'audace

Emploi absolu

1957 [Jean Nohain et Mireille ont écrit le Petit Chemin] Quelques jours après Maurice Chevalier venait voir Mireille. Je l'entends encore :
- Pourquoi le Petit Chemin ? Vous écrivez beaucoup trop mince, beaucoup trop étriqué. Pour réussir dans la chanson, il faut faire large! il faut chanter grand! Du souffle, mes amis, du souffle !

(Marie-Claire, mars 1957 / Grundt : 311)

CORPUS Web :

POURQUOI ÉCRIRE SI MINCE ? MALI WEB TU COMMENCE A DÉGOUTER [http://www.mali web.net/category.php?NID=68462] (23.2.2015)

La crainte de l'image s'étend même à celle de l'adjectif que, dit aussi Cocteau, " les poètes doivent craindre comme la peste ». Le véritable écrivain doit écrire mince, musclé, grâce à quoi la poésie ne sera plus « une façon compliquée de dire des choses simples, mais une façon très simple de dire des choses compliquées " [http://www.academie-francaise.fr/discours-dereception-de-jacques-rueff] (23.2.2015)

REMARQUES : Écrire mince réfère à une écriture qui met en avant un style commun, peu recherché, traduisant ainsi le manque d'originalité de l'auteur et son désir de ne pas prendre de risques, de ne pas sortir de la norme imposée, ce dernier modérant ses affirmations, en atténuant son opinion. Le premier exemple du CW crée un contraste en recourant aux lettres majuscules. Le second exemple du CW confère une connotation positive au fait d'écrire mince par la transposition « sportive » induite par l'ajout de musclé. Notons l'emploi de faire large, chanter grand.

\section{Écrire moche}

Écrire en mauvais français (ou dans une autre langue)

$\lambda$ parler moche

\section{Écrire musclé}

Écrire dans un style incisif, concis

$\lambda$ écrire mince

\section{Écrire nerveux}

Écrire dans un style énergique

त écrire souple

\section{Écrire net}

Écrire sans fioritures

$\lambda$ écrire ferme 


\section{Écrire neutre}

Écrire en laissant planer le doute, sans prendre position

入 écrire faux

\section{Écrire noir}

I. Écrire à l'encre noire

Emploi absolu

1773 Adieu, bon Condorcet, revenez vite et ne vous en allez plus. $N$. $b$. il faut, s'il vous plaît, écrire plus gros et plus noir (Julie de Lespinasse, Lettres à Condorcet)

1979 Les caves servent d'abri, effectivement, c'est écrit dessus, noir sur jaune, avec une grosse flèche qui désigne une porte d'entrée (François Cavanna, Les Russkoffs)

II. écrire noir sur blanc : écrire de manière claire, nette et précise ; écrire de manière à éviter la moindre contestation

Transitif

1899 [Ils] reprochent à l'officier français, dans l'exercice de son devoir, d'avoir voulu porter préjudice au traître. Et ils s'imaginent que, parce qu'ils auront écrit cela, noir sur blanc, et que des juges dûment galonnés auront contresigné la chose, l'absurdité deviendra l'expression pure et simple de la vérité (Georges Clemenceau, Vers la réparation)

1950 Est-ce que dans les pages de ce livre il ne trouvait pas sa propre condamnation, écrite noir sur blanc, comme si lui seul était visé ? (Julien Green, Moïra)

1954 Les mots de traître et de vendu n'étaient pas écrits noir sur blanc, mais on les lisait entre les lignes (Simone de Beauvoir, Les Mandarins)

1987 Tenez, c'est écrit là, noir sur blanc, dans Télémust (Philippe Sollers, Le Cour absolu)

2004 Les roses, les retrouvailles, la soirée : tout était là, écrit noir sur blanc, et une multitude de détails que je connaissais de sa vie me sautaient à présent aux yeux, comme on dit, et tous semblaient faire signe à Clarissa Dalloway et lui témoigner un amour magnifique (Grégoire Bouillier, L'Invité mystère)
2005 Parfois, comme un chien sans pedigree et qui a été un peu trop livré à lui-même, j'éprouve la tentation puérile d'écrire noir sur blanc et en détail ce qu'elle m'a fait subir, à cause de sa dureté et de son inconséquence. Je me tais. Et je lui pardonne (Patrick Modiano, Un pedigree)

\section{CORPuS WeB :}

Je ne suis pas raciste->je n'hésite pas à écrire noir sur blanc mes pensées [https://fr-fr. facebook.com/pages/Je-ne-suis-pas-racisteje-nh\%C3\%A9site-pas- $\%$ C3\%A - $\%$ C3\%A9 crire-noir-sur-blanc-mes-pens \%C3\%A9es/ 255870486167] (23.2.2015)

KPMG : « La rupture transactionnelle évite d'écrire noir sur blanc tous les reproches faits à un salarié » [http://www.journaldunet. com/management/ressources-humaines/ dossier/marche-du-travail-5-drh-dressent-lebilan-des-reformes-de-2008/kpmg-la-rupturetransactionnelle-evite-d-ecrire-noir-sur-blanctous-les-reproches-faits-a-un-salarie.shtml] (23.2.2015)

Pour vous débarrasser de ces pensées, pourquoi ne pas les écrire noir sur blanc [http:// www.journaldunet.com/management/viepersonnelle/selection/10-activites-pour-decom presser-apres-une-journee-de-travail/ecrire-sonblog-pour-se-liberer.shtml] (23.2.2015)

Ca va te paraitre un peu scolaire mais je pense que ça vous ferais beaucoup de bien de vous fixer tous les deux des " objectifs", de les écrire noirs sur blanc! [http://www.beaute-test. com/forums/index.php?topic $=99572 \&$ start $=30$ ] (23.2.2015)

REMARQUES : Écrire noir (I) réfère à la couleur de l'encre utilisée pour écrire. Notons la collocation écrire (plus) gros et (plus) noir. Écrire noir sur blanc (II) est une expression idiomatique qui souligne le fait de mettre les choses par écrit, de les noter sur papier, en général par souci de clarté, de manière définitive et durable en assumant la responsabilité de ses propos. Noir reste invariable dans la majorité des cas. Dans le CW, il reste invariable malgré l'objet au pluriel dans le troisième exemple, tandis qu'il s'accorde avec l'objet dans le quatrième exemple, ce qui est peu usuel, mais parfaitement possible puisqu'il 
s'agit de la couleur des lettres. Noir est modifié par dessus, là, plus.

\section{Écrire ordonné}

Écrire méthodiquement

$\lambda$ écrire clair

\section{Écrire osé}

Écrire avec audace, d'une manière licencieuse ; écrire dans un style non-conventionnel, innovant

Emploi absolu

1898 Il dit cela avec une gravité d'émotion. Mais ne s'étend pas sur les conseils que Taine lui a donnés, sinon : " Ne vous servez que de mots connus, n'écrivez pas osé " (Maurice Barrès, Mes cahiers)

\section{CoRpus Web :}

ne pas hésitez à écrire osé plutôt qu'un banal bonjour [http://www.histoires-de-sexe.net/ confessions-v3/theme-can.php?p=38] (23.2.2015)

Ecrire très osé et sans tabous [http://www. planete-bdsm.com/annonce-homme-domina teur/2496-maitre-aise-pour-femme-uro-etobeissante] (23.2.2015)

REMARQUES : Écrire osé se dit du fait de rédiger un texte dans un style se caractérisant par une prise de risques de l'auteur, soit que celui-ci ne manifeste pas le souci des convenances et cherche à dépasser les limites de la bienséance, soit qu'il cherche à éviter un style convenu. Osé est modifié par très.

\section{Écrire ouvert}

Écrire dans un bon style ouvert à ce que l'on veut transmettre

Emploi absolu

1967 on peut distinguer " écriture close » et « écriture ouverte »: Je définirai l'écriture close : « écriture de celui qui se prend pour un styliste alors qu'il ne l'est pas ». M. Dumont n'est pas et ne se prend pas pour un styliste : il écrit ouvert ; c'est-à-dire bien pour le propos qu'il veut servir (Express, 6 décembre 1967 / Grundt : 254)

\section{CORPuS Web :}

Les blogs sont une excellente façon de garder une trace de vos objectifs et des plans tout en écrivant ouvert [http://www.besteartikel.com/ ligne-promotion/quel-est-blogging] (23.2.2015)

REMARQUES : Écrire ouvert réfère à une écriture directe, franche, qui traduit la volonté de l'auteur de mettre les choses à nu, d'exprimer des idées claires et précises, sans équivoque, de manière explicite. Les exemples du CW ajoutent à l'idée d'ouverture d'esprit celle de s'exposer à l'opinion publique, donc la disposition à accepter des modifications, des innovations, des idées neuves ou alternatives.

\section{Écrire pauvre}

Écrire juste ce qu'il faut

Emploi absolu

1952 J'ai vu vingt fois la perfection de son style déconcerter d'authentiques écrivains des maîtres, heurtés par lui dans leur conviction que l'universitaire écrit pauvre. Jamais un mot de trop (Lucien Febvre, Combats pour l'histoire)

\section{Écrire petit}

I. Écrire en petits caractères

Transitif

1710 mais, ayant essayé de la lire [= la lettre], il ne le put, parce qu'il avait la vue très mauvaise, et que cela était écrit fort petit et couramment, de sorte qu'il fallut que celui qui l'avait faite l'emportât chez lui pour, avec une meilleure plume, l'écrire bien et gros (Philipp de Dangeau, Journal)

Intransitif

1966 Il a ouvert le dossier pour Milkaby, des pages couvertes d'une écriture minuscule (je n’ai jamais compris qu'une grande brute comme lui écrive si petit), et il m'a expliqué les difficultés que je pourrais rencontrer (Sébastien Japrisot, La Dame dans l'auto)

1976 Ce que je trouve le plus marrant dans tout ça, c'est quand je me couche sur la table, la tête sur le coude et l'œil au ras du papier, ça fait de grosses lettres énormes et pourtant, j'écris tout petit (Patrick Cauvin, Monsieur Papa) 
II. Écrire en modérant ses affirmations, de manière atténuée, euphémique, implicite Emploi absolu

1959 Quand on vous interdit d'outrager la grandeur officielle "sous peine de... » prenez pour leit-motiv la petitesse [...] Écrivez petit, vos lecteurs verront grand (Canard enchaîné, 15 juillet 1959 / Grundt : 401)

III. Écrire avec un stylo à pointe fine Emploi absolu

1972 - J'ai envie de dessiner, il me dit. - D’accord, je fais. Si ça peut te distraire.. Je lui achète toute une collection de feutres, des gros qui écrivent gros, des petits qui écrivent petit, avec le maximum de couleurs. Ça me faisait plaisir de lui faire plaisir (Bertrand Blier, Les Valseuses)

\section{CORPUS WEB :}

J'utilise depuis hier notability qui est vraiment très bien et on aime particulièrement la possibilité d'écrire petit avec l'effet loupe mais en tant que prof de sciences je regrette parfois sur des graphes de ne pas avoir d'outils pour tracer des droites parfaites [http://www.tilekol. org/trois-applications-decriture-manuscrite-suripad] (23.2.2015)

Sur les blogs, on peut écrire petit [http:// forum.doctissimo.fr/sante/aide-forums/ecrirepetit-sujet_7965_1.htm] (23.2.2015)

psss, Fredo , je l'écris petit, j'ai peur de m'faire gronder... mais... dans ton profil ici, tu as un caisson Seacam ? [http://forum-photosub.fr/ forum/viewtopic.php?f=19\&t=10306] (23.2.2015)

REMARQUeS : Écrire petit (I) renvoie à la taille des caractères. Écrire petit (II) se dit au figuré par rapport au contenu, au texte produit qui se caractérise par une atténuation des propos de l'auteur, un style qui laisse libre cours à l'interprétation et qui requiert une participation active du lecteur. Écrire petit (III) désigne la grosseur de la pointe d'un crayon ou d'un stylo qui permet de reproduire des lettres fines, d'écrire en petits caractères. Petit reste invariable et est modifié par fort, si, tout. Dans les deux derniers exemples du CW, écrire petit est employé au sens (II) ; l'avantdernier exemple y ajoute la connotation de 'sans s'exposer'. Notons l'emploi de voir grand dans Écrivez petit, vos lecteurs verront grand.

\section{Écrire précieux}

Écrire dans le style des Précieuses

$\lambda$ écrire gras

\section{Écrire précis}

Écrire avec précision, exactitude

$\lambda$ écrire clair

\section{Écrire propre}

I. Écrire soigneusement, clairement, comme il faut

Emploi absolu

1784 Nous nous bornerons à un seul exemple, non-seulement pour donner une idée de l'application de l'Astronomie à la Géographie, mais encore pour faire connoître plus particulièrement combien ces Sciences ont besoin essentiellement du style didactique, dont la véritable et unique signification est la manière d'écrire propre pour enseigner, ou pour expliquer la nature des choses (J. Beauvais, L'Art de bien parler et de bien écrire en françois)

2008 Car au-delà de la nécessité de s’adapter aux lois du marché éditorial, d'obéir tant bien que mal à la mode littéraire alors en vogue s'ébauche une envie de penser et d'écrire propre, attachée au combat d'un art de vivre (Xavier Escudero, La Bohème littéraire espagnole)

II. Écrire proprement, sans faire de tache Emploi absolu

1956 J'écris propre avec la pointe Bic ([affiche publicitaire], 9 novembre 1956 / Grundt : 228)

\section{CORPUS WEB :}

Alors si je devais écrire propre, je devrais parler de " la décollation de St Jean-Baptiste » (terminus technicus, décoller = trancher le cou), comme est nommée la fabuleuse toile du Caravage (la seule qu'il ait d'ailleurs signée) [http:// www.strogspraguepics.blogspot.co.at/2009/12/ visiter-leglise-de-st-jean-baptiste.html] (24.2.2015)

J'ai eu une ex qui était prof d'anglais et prof d'espagnol et qui écrivait propre sans fautes d'orthographes, assez canon genre un peut Marilyn Monroe [http://fr.mailarchive.ca/soc. feminisme/2013-10/0321.html] (24.2.2015) 
REMARQUES : Au figuré (I), écrire propre revoie à un effort de clarté, de style approprié. En (II), il réfère à la grosseur ou à la taille de la pointe d'un stylo qui permet de reproduire ou de tracer les signes graphiques de façon soignée. Le premier exemple du CW l'emploie au sens de 'comme il convient, approprié', et le dernier exemple actualise l'acception de 'sans faute'.

\section{Écrire rapide}

Écrire dans un style impétueux, fougueux

$\lambda$ écrire vif et écrire souple

\section{Écrire sage}

Écrire dans un style conventionnel

$\lambda$ écrire clair

\section{Écrire serré}

I. Écrire de manière concise et percutante, en condensant les idées

Intransitif

1627 Tavernier a eu grand tort de ne r'apporter incontinant la piece que vous luy aviez confiée, je luy en escrivis bien serré par la derniere despeche, et tascheray d'escrire à Buon par la premiere pour luy deffendre de me rien envoyer sans vous avoir communiqué (Nicolas de Peiresc, Lettres aux frères Dupuy)

Emploi absolu

190617 mai.

Ne pas écrire trop serré. Il faut aider le public avec de petites phrases banales. Daudet savait les intercaler (Jules Renard, Journal)

II. Écrire en rapprochant les lettres ou les mots Transitif

1822 Si je puis donner des ordres, je vous prescris que vous fassiez écrire l'adresse de l'ami, mais je veux que les lettres soient écrites menu serré et sans blanc (Honoré de Balzac, Correspondance)

1890 Les lettres de mon frère, écrites serré sur leur papier très mince, continuaient d'arriver de temps à autre, sans régularité, au hasard des navires à voiles qui passaient par là-bas, dans le grand océan (Pierre Loti, Le Roman d'un enfant)
Intransitif

1938 Je suis content d'avoir retrouvé ces notes. Voilà dix ans que je ne les avais pas relues. Mon écriture a changé, il me semble : j'écrivais plus serré. Comme j’aimais $\mathrm{M}$. de Rollebon cette année-là ! (Jean-Paul Sartre, La Nausée)

CORPUS WEB :

Comment, en effet, sur un tout petit morceau de papier, un trésor de la taille d'une vignette, pourrait-on écrire le plus de choses possible pour rendre compte de sa vie, dire son amour, ou simplement parler? La contrainte du prisonnier permet d'écrire serré, si serré qu'on n'a que faire des lettres aux jambages encombrants [http:// www.detambel.com/f/index.php?sp=liv\&livre id $=11114]$ (24.2.2015)

Voici qu'Éric nous lance cette fois sur un vaste sujet, sinon infini, et il va falloir écrire serré pour ne pas déborder dans les marges et verser dans le hors-sujet [http://www.bbs-consultant. net/taxonomy/term/66] (24.2.2015)

Ces écritures étaient en effet d'autant plus compliquées que la cherté du papier contraignait autrefois nos ancêtres à écrire serré et à utiliser de nombreuses abréviations [http:// www.beaucarnot-genealogie.com/contenu/ sujets-annexes/accueil-sujets-annexes/4-lapaleographie] (24.2.2015)

REMARQUES : Écrire serré (I) se dit du fait d'exprimer ses idées en peu de mots ou en les réduisant à l'essentiel. II réfère également à la dimension spatiale et à la façon d'écrire du sujet, celui-ci laissant peu d'espace entre les lettres ou les lignes (II). Cette signification est la seule illustrée par les exemples du CW. Serré reste invariable (ex. de 1890) et est modifié par bien, menu, plus, $s i$, trop. L'invariabilité étant plutôt atypique pour un participe passé, elle met en évidence un degré élevé de lexicalisation comme adverbe. Notons la réduplication serré, si serré.

\section{Écrire simple}

Écrire dans un style dépouillé, compréhensible Emploi absolu

1936 Un grand écrivain ne pense pas simple et ne voit pas simple, mais il peut être amené à écrire simple, parce que le style est une 
interprétation libre en vue d'un effet à produire, et d'un résultat à obtenir (Albert Thibaudet, Réflexions sur la littérature)

REMARQUES : Notons l'emploi de penser simple ; voir simple.

\section{Écrire soigné}

Écrire dans un style travaillé, raffiné

入 écrire clair

\section{Écrire sonore}

Écrire de façon à se faire remarquer

Emploi absolu

1975 Il faudrait dire - ces réflexions ont place ici - que notre plume, à l'occasion, fait du zèle. Elle en remet, elle joue les indics, les auxiliaires dévouées. Elle prend sur elle d'écrire appuyé, d'écrire sonore et fanfaron avant qu'on ne le lui ait demandé (François Nourissier, Lettre à mon chien)

\section{CORPUS WEB :}

Mais il est aussi une autre façon d'écrire, sonore et visuelle, qui déchire les phrases en mots, qui déchire les mots en cris, des mots privés du sens commun, un sens qui s'obtient non par raison mais par constat, au long des pages, dans la stupeur, l'étonnement, c'est à dire frappant comme un coup de tonnerre, une autre façon d'écrire visuelle, l'ombre des mots gravés sur les pages suivantes et précédentes s'affichant sur les pages en cours de lecture [http://www. cafedelaterrasse.com/index1.html] (24.2.2015)

Moi, j'écris sonore. Je veux écrire de la musique avec les mots [http://www.spectacles. fr/traine-pas-trop-sous-la-pluie] (24.2.2015)

Étroitement, les mots y sonnent. Moi j'écris sonore. Je parle à voix haute. C'est de la tradition orale [http://www.biblioblog.fr/post/2007/ 07/27/615-interview-de-richard-bohringer] (24.2.2015)

REMARQUES : Écrire sonore se dit d'une écriture à travers laquelle l'auteur se met en avant, une écriture caractérisée aussi par une certaine exagération. Le CW y ajoute la signification de 'qui évoque des sons'. Notons la collocation écrire sonore et fanfaron, l'adjectif-adverbe fanfaron renforçant ou explicitant cette idée d'exagération, et le contraste avec écrire visuel.

\section{Écrire souple}

Manier avec souplesse, avec aisance

l'instrument qui sert à écrire

Emploi absolu

1956 Écrivez plus souple avec le nouveau Bic monté sur amortisseur. Vous aussi essayez-le, vous serez surpris d'obtenir une écriture aussi souple, aussi personnelle, avec pleins et déliés (Express [publicité], 9 novembre 1956 / Grundt : 228)

\section{CORPUS WeB :}

Remèdes stratégiques (déjà énoncés en 2008 dans un livre intitulé Ce qui ne demande rien, toujours plus d'actualité) : dormir beaucoup, traîner au lit, partir marcher, écrire souple et nerveux, rapide, arrêter de remuer, ne rien faire, sortir du lit en sautant, ralentir tout, dormir le moins possible [http://remydurand.com/pdf/ lsbdouz.pdf] (24.2.2015)

Moi c'est un Waterman il faut juste changer la plume pour écrire souple et bien, parfois le capuchon parce que c'est comme les parapluies : moi je les distribue partout, arranger pour bien enquiller la cartouche. Déboucher le petit conduit parfois : mais à part ça il gratte et vole sur le papier [http://forum.pcastuces.com/ objets_ecriture-f9s38731.htm] (24.2.2015)

REMARQUES : Écrire souple réfère au confort d'écriture que permet la forme d'un stylo et de sa pointe, celui-ci se maniant avec aisance, souplesse. Dans le premier exemple du CW, souple renvoie au style dans lequel on écrit, gracieux et aisé. Notons les adjectifs-adverbes nerveux et rapide dans le CW, qui font que souple devient plutôt une attitude de celui qui écrit. Souple est modifié par plus.

\section{Écrire structuré}

Écrire selon un plan défini

$\pi$ écrire clair

\section{Écrire succin(c)t}

Écrire dans un style concis et bref

入 écrire clair

\section{Écrire tintant}

Écrire dans un style éclatant, brillant

$\lambda$ écrire beau 
Écrire tranchant

Écrire dans un style cassant

入 écrire bref

\section{Écrire utile}

Écrire des choses utiles, dont l'usage peut être avantageux, qui satisfont un besoin ; adapter ou sacrifier l'écriture à un dessein

Emploi absolu

1963 Il faut écrire pour le peuple, aider le pays ; bref, il faut écrire utile (Express, 23 mai 1963 / J. Giraud)

1995 C’est un fantôme qui a des idées. En plus, il m’aide à écrire utile. La littérature, à quoi ça sert sinon à enrayer le chômage ? T'es pas content que la tête de ton futur beau-père ait été sauvée ? (Georges-Noël Jeandrieu, Le Fiancé de la fille du chômeur)

2000 Puisque nous en sommes là, à gérer la pénurie, disons que, pour un temps, le " prosaïque » doit l'emporter sur le "poétique », en attendant la régulation à venir... Et, d'autre part, en quoi le fait de savoir «écrire utile », convenablement et simplement, contreviendrait-il à l'exercice ultérieur, savant et esthétique de la littérature ? (Philippe Choulet et Philippe Rivière, La Bonne École)

\section{CORpus Web :}

Ecrire utile et attractif. Développer la qualité de ses écrits professionnels dans un style personnel [http://www.cfpj.com/formation/ communication/innover-dans-ses-ecritsprofessionnels.html] (26.2.2015)

Ricochet : Avez-vous envie d'écrire utile, de mettre en lumière une époque mal connue ?

Evelyne Brisou-Pellen : Absolument pas. Ecrire, c'est tout d'abord : me faire plaisir [http:// www.ricochet-jeunes.org/entretiens/entretien/ 79-evelyne-brisou-pellen] (26.2.2015)

Les femmes écrivent de la paperasse inévitable dans chaque foyer. Dans les institutions, les associations, elles font les comptes rendus, les bilans. Elles écrivent tout le temps. Mais elles écriventutile [http://theatremavie.canalblog.com/ archives/2009/12/08/16073408.html] (26.2.2015)
REMARQUES : Écrire utile réfère à une écriture dont le contenu est ou peut être profitable aux autres, à la société, au locuteur. Notons l'adjectif-adverbe attractif dans le CW. Utile reste invariable.

\section{Écrire vif}

Écrire avec vigueur, dans un style vif, énergique

Emploi absolu

1776 Mais ce secret n'est que pour le petit nombre ; le plus grand travaille, sue ; fait mille efforts, aspire à une perfection glaçante. Celui qui est né pour écrire, vif, étincellant, rapide au-dessus de regles, jette du même trait de plume et son idée et le plaisir dans l'ame du lecteur (LouisSébastien Mercier, L’An deux mille quatre cent quarante)

1949 R. Kemp écrit vif et net

(Joseph Bédier et Paul Hazard, Histoire de la littérature française illustrée)

CORPuS Web :

Écrire vif, clair, concis, efficace... Voici l'enjeu pour celui qui écrit dans le cadre professionnel. Pour l'atteindre, on s'appuie ici sur les fondamentaux de l'écriture de la presse et de la communication [http://www.aleph-ecriture.fr/ Techniques-redactionnelles] (26.2.2015)

Ecrire vif, c'est un titre de belle facture, des mots dans un article qui font du bruit ou donnent de la couleur, des images inattendues, une formule bien sentie... C'est un ensemble de détails, qui, au-delà de la qualité normale et attendue d'un article, donneront à la rédaction Sequoia sa patte, son style, sa griffe [http://www. sequoia-corporate.com/category/a-lire/page/4] (26.2.2015)

À partir des documents familiaux, notamment de très nombreuses lettres, elle a plongé dans les archives bretonnes, interviewé des témoins, analysé et réfléchi... Et gardé l'habitude d'écrire vif et concis, en phase avec la verve chaleureuse des lettres de Louis [http:// www.petitpave.fr/petit-pave-auteur-marinemargelidon-283.html] (26.2.2015)

REMARQues : Écrire vif réfère à une écriture directe, fraîche, d'un genre nouveau, à un style 
qui traduit aussi la volonté de l'auteur de mettre les choses à nu, d'exprimer des idées claires et précises, sans équivoque, de manière explicite. Notons les collocations vif et net, vif et concis, et les adjectifs-adverbes étincelant, rapide, clair, efficace. Vif reste invariable (v. dernier exemple du CW).

\section{Écrire vigoureux}

Écrire avec vigueur, dans un style vif

$\lambda$ écrire ferme

\section{Écrire visuel}

Écrire de manière à ce que le lecteur visualise les mots

$\lambda$ écrire fanfaron

\section{Écrire vrai}

Écrire avec sincérité et exactitude

入 écrire beau et écrire dru

\section{Écumer rose}

Laisser couler, sécréter de la bave mêlée à du sang

Intransitif

1962 LA FILLE. Le mors, c'est terrible. Ça fait saigner les gencives et la commissure des lèvres. Je vais baver du sang.

LE GÉNÉRAL. Écumer rose et péter du feu ! Mais quel galop ! (Jean Genet, Le Balcon)

\section{CORPUS WEB :}

J'ai eue un poney qui écumais rose [http:// www.chevalannonce.com/forums-884622liquide-blanc-entre-les-fesses-de-mon-cheval] (26.2.2015)

Aux staffs des revues on avait l'habitude si elle se souvient alors...il leur en débarquait deux ou trois par soirée qui jetaient leurs paquets de feuillets incendiaires au milieu des chroniques quotidiennes et il ne leur restait entre les paluches au bout de la nuit quand ils s'endormaient d'ivresse verte et de vomissures douceâtres qui écumaient rose leurs lèvres à mégots roussies que des cendres [http://lesdiablesbleus.com. over-blog.com/article-venice-orient-expresssuite-120818060.html] (26.2.2015)

REMARQUES : Écumer rose se dit du fait de laisser couler ou de sécréter de la bave par la bouche, le saignement donnant une couleur rosâtre à la salive. Rose reste invariable.

\section{Effacer génial}

Effacer facile et efficace

Emploi absolu

1997 Mais si ! Il efface génial, mon effaceur ! (exemple oral / Noailly 1997a)

\section{Élancer droit}

I. Lancer avec force, directement, exactement

Transitif

1588 ils ont seulement un trou, à cause dequoy ils ne peuvent uriner droict en devant, sans renverser fort le membre contre le petit ventre : ils ne peuvent aussi engendrer, parce que ceste imperfection les empesche d'elancer droit la semence dans la matrice (Jacques Dalechamps, Chirurgie françoise)

1596 Il l'élance en bruyant comme un trait de tempeste

Droit contre Mandricard, et l'atteint

tellement,

Que l'esprit estourdy perd tout le sentiment (Philippe Desportes, Euvres)

II. Élever, dresser avec une certaine force dans une direction précise, tout droit

Pronominal

1859 Le fleuve s'élance droit entre deux rives plates plantées de hêtres magnifiques noyés d'une intense clarté et qui entourent les hautes tourelles où s'évertue l'aile des moulins (Maxime Du Camp, En Hollande)

1929 Et c'était l'aube. Une alouette s'élança droite au milieu du vent ; elle y grinçait comme un couteau dans un fruit vert (Jean Giono, Un de Baumugnes)

1930 Bordée d'un côté par Central Park et de l'autre par les résidences que l'on désigne sous le nom de Chemin des millionnaires, Millionaire's row, Fifth Avenue s'élance, droit vers le nord, vers Harlem et le Bronx (Paul Morand, New-York)

1942 La pièce est construite à la façon d'une fleur. Les deux premiers actes, dépouil- 
lés, d'une ligne extrêmement simple, qui ne supporte même aucune scène d'articulation, s'élancent droit comme une tige (Henry de Montherlant, La Reine morte)

1947 Elle était là, devant, toute noire, avec ses arbres tordus d'où s'élançaient droits les sapins (Louis Aragon, Les Voyageurs de l'impériale)

1982 Et, émergeant de cette masse confuse, une multitude de coupoles roses, vestiges des anciennes églises byzantines, un semis de mosquées et de minarets qui s'élancent droit dans le ciel, semblables aux cyprès qui les ont inspirés (Michel, prince de Grèce, La Nuit du sérail)

Transitif

1869 L'une, raide, élançant tout droit

Sa tige aux longues feuilles sèches, Darde au plafond, comme des flèches, Les pointes d'un calice étroit (Armand Sully Prudhomme, Les Solitudes)

III. Bondir, se précipiter sur quelqu'un/quelque chose, se ruer, foncer directement vers

Pronominal

1888 CARMENTA. (entre tout à coup, en son costume noir, les cheveux épars. Elle s'élance droit sur Casca)

Ainsi, c'est toi, dit-on, qui es maintenant le vrai prêtre de Nemi?

(Ernest Renan, Drames philosophiques)

1967 Il sauta sur la digue, franchit d'un bond une gouttière d'irrigation et s'élança droit devant lui, la vue brouillée par le désespoir (Michel Tournier, Vendredi ou Les Limbes du Pacifique)

1989 Simon s'élança droit vers la bête (Sylvie Germain, Jours de colère)

2010 Il saisissait déjà son arc et s'apprêtait à s'élancer, droit vers l'horizon rougeoyant, quand son compagnon le retint (JeanLouis Fetjaine, Le Pas de Merlin)

2011 Les têtes se juchent sur mon corps, puis s'entrechoquent et disparaissent remplacées par des membres autonomes qui s'agitent en tous sens, s'élancent droit devant eux comme des volatiles que l'on vient d'égorger, avant d'effondrer, inertes (Michel Louyot, La Japonaise de Prague)

CORPUS Web :

A noter cette saison les Championnats du Monde de ski de vitesse organisés à Vars. Comptons sur Edouard pour s'élancer droit dans la pente ("dré dans l'pentu », comme on dit chez nous) dans le but de dépasser les $200 \mathrm{Km} / \mathrm{h}$ [http://www.lacharpenterie-vars.sport2000.fr/ fr/notre-magasin] (27.2.2015)

Oubliant les règles que nous nous fixons pour défier le hasard, il nous arrive de nous en remettre à lui. S'élancer droit dans un mur en espérant retomber sur nos pieds [https://fabwittner. wordpress.com/tag/urban-plagne] (27.2.2015)

Cette garce, loin de tenter d'éviter l'onde de choc, s'est élancée droit dessus et profite de l'impact pour rebondir en l'air jusqu'à arriver droit sur elle comme une balle, ses griffes tendues [http://daoc.19c.org/text/kronik1101387559.html] (27.2.2015)

REMARQUeS : Usité aux alentours du XVI ${ }^{\mathrm{e}}$ siècle, (I) souligne le fait de lancer, projeter quelque chose dans une direction précise. Élancer droit (II) réfère à la situation spatiale d'un inanimé, le sujet désignant très souvent un élément de la nature, un végétal (un fleuve, les troncs, les sapins). Il peut aussi souligner la croissance rapide d'un végétal dans un sens déterminé, sans déviation d'un bout à l'autre. En (II), élancer droit se rapproche de la prédication seconde, ce qui explique l'accord dans les exemples de 1929 et 1947, mais l'accord n'est pas systématique. (III) se dit du fait de se lancer en avant sur quelqu'un, de se diriger vers un lieu de façon impétueuse, le sujet désignant un animé. Notons la collocation s'élancer droit et net. Dans son emploi pronominal, droit a tendance à s'associer avec la préposition qui le suit (dans, vers, contre, devant, à, dessus) au point de faire partie du groupe prépositionnel comme modifieur de la préposition. Ceci est mis en évidence par l'emploi d'une virgule qui sépare le verbe de l'adjectif-adverbe dans l'exemple de 2010. Notons l'emploi de la variante dialectale dré dans le premier exemple du CW, ainsi que l'occurrence de renverser fort. 


\section{Élancer dru}

I. Lancer, projeter avec fréquence, densité et rapidité

Transitif

1592 On dict que la lumiere du Soleil n'est pas d'une piece continuë, mais qu'il nous élance si dru sans cesse nouveaux rayons les uns sur les autres, que nous n'en pouvons appercevoir l'entre deux (Michel de Montaigne, Essais)

II. Se dresser touffu, compact

Pronominal

1914 Cet enterrement provoque le tallage d'automne et l'émission de nouvelles racines adventives au-dessus du collet. Presque un mois après, lorsque les tiges sont bien multipliées, toutes sélançant $d r u$, on adosse le restant de la terre de la charpente et de la crête du billon (Journal d'agriculture pratique)

1969 Plus loin, un peu à l'écart dans la mer, se dresse une haute sculpture qui impressionne aussi par son caractère inusité, l'Alfil. Sa silhouette plutôt particulière s'élance dru vers le ciel depuis un petit monticule entouré d'eau. Pour cette raison on l'appelle souvent le « doigt de Neptune »! (Stéphane Guimont-Marceau, Los Cabos et La Paz)

REMARQues : Élancer dru (I) se dit du fait de lancer au loin ou en hauteur, de jeter devant soi une chose dans une direction déterminée avec rapidité et force. Au sens pronominal (II), il renvoie à un corps compact. Dru reste invariable et est modifié par si.

\section{Élancer net}

Se dresser majestueusement de manière rectiligne

Pronominal

1921 des troncs dépouillés de feuilles qui s'élancent droits et nets, découpant l'espace à intervalles réguliers (Élie Faure, Histoire de l'art : l'art moderne)

1939 J'avais au premier plan un jardin de fleurs vivaces et tout allumées de soleil, découpant son beau galbe ; puis les ver- dures claires et sombres se groupaient, s'amassaient, montaient, grandissaient, et vers le fond formaient un grand massif de feuillages mordorés, à travers lequel, dans une découpure, on voyait s'élancer, net et délicat d'arêtes, le Pavillon de Flore, flanqué de ses hautes cheminées sculptées (Albert Samain, Carnets intimes)

CORpus Web :

Il est maintenant temps de provoquer l'algarade,

Durcir les crocs de ce peuple docilisé au flanc fade.

Jeter le saupiquet face dans ces gros sédentaires

Saponifiés qui se laissent glisser dans les rails battus au fer

S'élancer net sans parachute ni peur de l'inertie

Têtes bien remplies en avant dans la lutte avant la calvitie [http://arkotonic.canalblog.com/ archives/2007/07/19/5658956.html] (27.2.2015)

REMARQUES : Le sujet de s'élancer net désigne un objet perçu visuellement : un végétal, un élément de la nature (par exemple, un tronc), ou par extension un pavillon de flore qui a une certaine hauteur et se dresse, rectiligne, se montre dans une forme haute, mince, parfaitement visible. Notons la collocation s'élancer droit et net. Net peut s'accorder avec le sujet, se rapprochant ainsi d'une fonction de prédication seconde (ex. de 1921). Dans le CW il est clairement adverbialisé au sens de 'directement, sans hésitation'.

\section{Élever droit}

I. Mettre, porter vers le haut, selon une ligne droite, verticale

Pronominal

1432 la II , il se inclina et incurva, en denotant que ung juge doit avoir compassion de son prochain, tellement que il luy face mal de donner sa sentence, et conme envis ; la III, combien que nous tenons que ung juge assis doit donner sa sentence, toutesvoye il se esleva tout droit, en denotant que ung juge ne doit point flescher par dons ou prieres (Jean Juvénal des Ursins, Audite illos, p. 33, 27) 
1560 Laquelle coronne recevant, elle s'abaissa humblement par un doux volume de queüe, puys l'ayant gracieusement receüe, s'eleva droicte et haute plus que de costume, en heroique prestance, avec un visage plein de majesté et neantmoins amiable et gracieux, outre la beauté naturelle, encore retainct d'une rougeur vereconde (Barthélemy Aneau, Alector ou Le Coq)

1655 il remplit deux grands vases qu'il luta hermétiquement, et se les attacha sous les esselles ; la fumée aussi tost qui tendoit à s'eslever droit à Dieu et qui ne pouvoit que, par miracle, pénétrer le métal, poussa les vases en hault, et, de la sorte, enlevèrent avec eux ce saint homme (Savinien Cyrano de Bergerac, Les Estats et empires de la lune)

1759 Les Canards et autres oiseaux de riviere, en sortant de l'eau, s'élèvent droit en haut pour voler vers le Ciel (François-Alexandre Aubert de La Chesnaye des Bois, Dictionnaire raisonné et universel des animaux)

1805 si on couvre les yeux composés de la guêpe, elle s'élève droit en l'air, et monte à perte de vue (Georges Cuvier, Leçons d'anatomie comparée)

1821 La plante s'élève droite ; ses fleurs forment à l'extrémité des tiges des bouquets blancs (J.-B. Kapeler et Joseph-Bienaimé Caventou, Manuel des pharmaciens et des droguistes)

$1881 \mathrm{Au}$ loin, tout au loin, de grands feux d'herbages allumés par les Maures ; des colonnes de fumée s'élevant toutes droites, à d'étonnantes hauteurs, dans l'air immobile (Pierre Loti, Le Roman d'un spahi)

1910 Alors modifiant son vol et sélevant tout droit, sans plus rien voir, dans un essor fou, l'oiseau monta, monta, Fuseline enfoncée dans son cœur comme une flèche de mort qu'il serrait de plus en plus furieusement dans les contractions frénétiques de son agonie (Louis Pergaud, De Goupil à Margot : histoire de bêtes)
1926 Notre voix s'élevait de nous tout droit, comme d'un bateau sa fumée (Jean Giraudoux, Simon le Pathétique)

1942 Dans cette vallée, large fond étalé entre deux versants qui s'élèvent droit au-dessus de la partie plate quelques accidents se rencontrent. Ce sont d'abord les grands cônes de déjection des affluents du Rhône (Jean Brunhes, La Géographie humaine)

1989 les feuilles remuaient sans arrêt, comme d'elles-mêmes, sans raison non plus puisque la fumée de la locomotive s'élevait toute droite (Claude Simon, L’Acacia)

2013 Mais, à la surprise générale, ses doigts n'eurent pas le temps de se refermer sur lui. Mue, par une incroyable énergie, la lance, pointe en avant s'éleva droit vers le ciel. Tous les spectateurs levèrent les yeux (Joel Jaud, Les Dolmens ne savent pas mourir)

Transitif

1787 le lilas de Perse, qui élève droit en l'air ses girandoles gris de lin (Bernardin de SaintPierre, Paul et Virginie)

1890 Et, tandis que je contourne à cheval ces débris de remparts, sous legrand écrasant soleil, une de ces portes m'arrête comme la chose la plus délicieusement arabe que j'aie encore jamais vue, et la plus étrangement mélancolique : au milieu de cent mètres de monotone et formidable muraille, elle ouvre son ogive isolée, qu'encadrent des dessins mystérieux ; et, à côté, un vieux dattier solitaire élève tout droit son bouquet de palmes jaunies... (Pierre Loti, $A$ u Maroc)

1938a JEANNE. Je vous supplie humblement que vous alliez en l'église prochaine et que vous m'apportiez la croix, pour la tenir élevée tout droit devant mes yeux jusques au pas de la mort, afin que la croix, où Dieu pendit, soit en ma vie continuellement devant mes yeux (Robert Brasillach, Pierre Corneille) 
1938b Rien n’arrête mon regard

Qui te trouve dans ton gîte

Plus vite que la lumière

Ne descend du haut du ciel

Et tu peux me reconnaître à la luisante pensée

Qui parmi tant d'autres hommes élève à toi toute droite

Sa perspicace fumée

(Jules Supervielle, La Fable du monde)

II. Éduquer avec droiture

Transitif

1930 Sa défunte mère l'avait élevée fort droit, et sous tout son endiablement elle cachait une peur, une aversion, des amourettes (Henri Pourrat, Le Pavillon des amourettes ou Gaspard et les bourgeois d'Ambert)

CoRpus WeB :

Monter à la Tête Pelouse. S'élever droit devant dans la pente en tirant un peu à droite à la fin jusqu'à un petit collet à l'W du sommet [http://www.skitour.fr/topos/tete-pelouse,133. $\mathrm{html}]$ (27.2.2015)

Prendre à nouveau une cheminée (5c), puis s'élever droit dans le grand dièdre de sortie (rocher médiocre). Faire relais au mieux [http:// www.camptocamp.org/routes/54669/fr/tours-duplaynet-5eme-tour-pilier-gauci] (27.2.2015)

Elle s'est élevée droit dans un ciel sans nuage. Dix minutes environ plus tard, Shenzhou (« Vaisseau divin ») X s'est séparé sans problème de son véhicule transporteur, pour entrer en orbite. Puis le module a déployé ses panneaux solaires [http:// www.ladepeche.fr/article/2013/06/11/1647570la-chine-lance-sa-plus-ambitieuse-missionspatiale-habitee.html] (27.2.2015)

Échappant à l'encerclement, la prière s'est élevée, droite, verticale et pure. Épiphanie, c'est un oiseau qui vole dans la brume. Épiphanie, c'est la route qui se redresse devant toi, inondée de soleil ! [http://www.ling.ch/lettre/lettre09. $\mathrm{htm}]$ (27.2.2015)

REMARQUeS : Dans l'emploi pronominal (I), l'adjectif-adverbe souligne la forme sous laquelle quelque chose apparait, avec la notion dominante de hauteur vers laquelle tend l'objet. Dans l'emploi transitif du verbe, il désigne le fait de mettre, de porter vers le haut, le complé- ment indiquant la direction ou le but vers lequel l'objet est élevé. Notons la collocation s'élever droit et haut. L'acception (II) réfère à une qualité morale. Droit peut s'accorder avec le sujet dans l'emploi pronominal du verbe (ex. de 1560, 1821, 1881, 1989 et le quatrième exemple en CW) ou avec l'objet dans l'emploi transitif (ex. de 1938b). Dans ces cas, il se prête à une analyse de prédicat second orienté respectivement vers le sujet ou vers l'objet. Il indique alors le fait de se trouver en position droite, debout. Toutefois, l'accord n'est pas obligatoire, droit pouvant rester invariable malgré le sujet au féminin ou au pluriel (ex. de $1655,1759,1805,1926,1942,2013)$ ou malgré l'objet au féminin (ex. de 1930 et de 1938a ainsi que le troisième exemple du CW). Dans tous ces cas - sauf l'exemple de 2013, qui appartient à (II) -, droit s'associe à une préposition pour adopter un sens directionnel. Dans ce cas de figure, on pourrait expliquer l'invariabilité de l'adjectifadverbe aussi bien par son sens directionnel que par la tendance à se rattacher syntaxiquement au groupe prépositionnel. En fait, les deux explications se superposent plutôt, ou, si l'on veut, s'additionnent. Notons les adjectifs coordonnés vertical et pur. Dans l'exemple de 1938b, l'accord est fait par emphase comme caractéristique du discours religieux. Droit est modifié par tout.

\section{Élever haut}

I. Porter, mettre à un haut rang, à un rang (social, moral) élevé, supérieur

Transitif

+1400 comme il soit de droit et raison que toute princesse et haulte dame, tout ainsi comme elle est hault eslevée en honneur et estat sur les autres que elle doye estre en bonté, sagece, meurs, condicions et manieres, excellente sur toutes a fin que elle soit l'exemplaire par lequel les autres dames, et mesmement toutes femmes, se doyent riuler en tout maintien (Christine de Pisan, Le Livre du duc des vrais amans / Euvres poétiques [début Xve], III, p. 163)

+1472 et avec tant d'adresse, de force et de vertu de chevalier, que luy, entrepreneur, garde et deffendeur d'icelluy noble pas, enluminoit et eslevoit si haut la renommée dudit pas, qu'il desiroit, sur tous les biens qu'il 
povoit jamais acquerir, donner confort à la dame de Plours (Olivier de la Marche, Mémoires [ $4^{\mathrm{e}}$ quart $\left.\mathrm{Xv}^{\mathrm{e}}\right]$ )

1560 Il n'y a sentence en tous ses escrits, là où il eslève plus haut sa primauté, que quand il dit : Je ne sache évesque lequel ne soit subjet au siège Apostolique, quand il se trouve en faute (Jean Calvin, Institution de la religion chrestienne)

1604 Ceux à qui les Destins ont mon heur octroyé,

Les eslevant si haut sur la basse commune Sont logez seurement à l'abri de fortune (Antoine de Montchrestien, Aman)

1646 Que le dieu dont le temple est si cher à la trace,

Va t'eslever bien haut par dessus tes rivaux, Et que l'heureux progrez de tes fameux travaux

Adjoustera de lustre aux honneurs de ta race! (François Maynard, Poésies)

1675 La petite personne a envoyé des chansons à sa sœur, que nous ne trouvons pas trop bonnes. Je suis aise que vous ayez approuvé les miennes ; on ne peut pas les élever plus haut que de les mettre sur le ton des dragons (Mme de Sévigné, Correspondance)

1698 Que par un coup du sort au grand jour amené,

Et des bords du Permesse à la Cour entraisné,

Je sçeûs, prenant l'essor par des routes nouvelles,

Eslever assés haut mes poétiques aîles (Nicolas Boileau, Épîtres [1670-1698])

1702 Le ciel qui les choisit les élève assez haut Pour faire voir en eux jusqu'au moindre défaut (Edme Boursault, Ésope à la cour)

1757 Tel homme élevé trop haut par de petites intrigues, a fini par n'être pas même placé dans son rang (Charles Palissot de Montenoy, Petites Lettres sur de grands philosophes)
1766 Nous sommes bien orgueilleux de nous élever si haut, ou bien injustes de les abaisser si bas (Henri-Joseph Dulaurens, Le Compère Mathieu)

1805 Il tomboit, ce redoutable ennemi de la foi, et la foi devoit se réjouir sans doute ; mais l'orgueil de l'homme pleuroit celui dont les grandes vertus avoient élevé si haut la dignité de l'homme (Sophie Cottin, Mathilde)

1843 Et puis, si vous saviez, mon père, ce que j'ai souffert, ce que je souffre encore chaque jour en me disant : « Si Dieu voulait que le passé fût connu... avec quel mépris mérité on traiterait celle qu'à cette heure on élève si haut ! " (Eugène Sue, Les Mystères de Paris)

1911 Avec de pareilles données, où aller en étudier la conduite, sinon dans la période révolutionnaire qui, dès le début, éleva si haut les visées demandées à la guerre, les moyens / nombre, enthousiasme, passion / consacrés à son service ?

(Ferdinand Foch, Des principes de la guerre)

Pronominal

1578 MALICAN. Et sans nulle doute l'extremité est pire se laisser dechoir de son grade, que de s'eslever plus haut qu'on ne doit (Jacques de Lavardin, La Celestine [adapt.])

1604 D'entre tous ces tesmoins et muets et parlans

Qui vont à qui mieux mieux ta vertu revelans,

S'esleve haute en l'air la prompte Renommée

Qui d'une bouche vraye et non jamais fermée

Publie à tous venans qu'en valeur et conseil Tu n'as point de second sous le cours du Soleil (Antoine de Montchrestien, Hector)

1688 Les gens qui ont mediocrement de l'esprit, ou l'esprit mediocrement cultivé, ont un langage qui ne roule que sur les choses particulieres qu'ils ont senties ; et les autres s'élevant plus haut, reduisent tout 
en idées generales (Bernard de Fontenelle, Discours sur la nature de l'églogue)

1767 Mais comment la religion chrétienne aurait-elle pu s'élever si haut, si elle n'avait eu pour base que le fanatisme et le mensonge ? (Voltaire, Le Dîner du comte de Boulainvilliers)

1930 J'ai soutenu il y a longtemps que la vertu n'est pas estimée, mais que mon père avait raison quand il voulait que je m'élève très haut au-dessus de ses confrères (Paul Éluard et André Breton, L'Immaculée Conception)

2005 Quand je voyais un papillon blanc voleter au-dessus des fleurs, hésitant, cherchant son chemin dans un labyrinthe d'air, se cognant à des murs invisibles et soudain s'élevant très haut dans le ciel, j'étais aussitôt guéri de toute mélancolie. La lumière vagabonde de ses ailes qui venait me délivrer m'enchantait (Christian Bobin, Prisonnier au berceau)

II. Retentir fortement, avec intensité (voix) Pronominal

1864 Le vieux lied recommençait en s'éloignant, et la même voix s'élevait toujours plus haute, plus touchante que les autres (Émile Erckmann et Alexandre Chatrian, L’Ami Fritz)

\section{CORPUS WEB :}

Pour s'élever haut, il ne suffit pas d'avoir la tête dans étoiles... Pour s'élever haut, il faut également avoir les pieds sur Terre, bien ancrés. Toute élévation se pose sur un équilibre,... Entre le Haut et le Bas... [https://fr-fr.facebook.com/imre. simon.35/posts/2696943657555] (28.2.2015)

La force de Cette Femme Guérisseuse est de pouvoir s'élever haut dans le ciel, de bénéficier des énergies célestes et d'avoir un vision élargie de ce qui se vit sur la Terre [http://femininsacre.com/ feminin-sacre-chamane-du-jour-19-decembre-lafemme-qui-vole-haut-dans-le-ciel] (28.2.2015)

Dans un message adressé au Président de la République, les signataires réitèrent leur engagement à participer d'une manière agissante à élever haut la voix de la Tunisie, à hisser sa bannière parmi les nations et à mobiliser les efforts auprès des membres de la colonie tunisienne à l'étranger et des amis de la Tunisie pour les encourager à investir en Tunisie et contribuer à consolider son processus de développement [http:// fr.allafrica.com/stories/200907210688.html] (28.2.2015)

Le Prêtre des Diables et des Démons se leva... et éleva haute la voix, mais parla dans un calme relatif [http://www.bahagon.com/forumagon/ viewtopic.php?t=2435] (28.2.2015)

REMARQues : Élever haut (I) se dit du fait de porter quelqu'un ou quelque chose (des valeurs comme l'honneur ou la vertu) à un rang supérieur, de porter plus haut dans l'ordre moral, intellectuel ou spirituel un objet qui est déjà à un certain degré de valeur ou de noblesse. Il désigne aussi le fait de prendre du grade, de monter dans l'échelle sociale. (II) réfère à l'intensité de la voix, qui progresse en puissance, de manière à être mieux perçue. Haut peut s'accorder avec le sujet du verbe pronominal (ex. de 1604, 1864) ou avec l'objet du verbe transitif (v. le quatrième exemple $\mathrm{du} \mathrm{CW}$ ) tout en se rapprochant des prédicats seconds orientés respectivement vers le sujet ou vers l'objet, essentiellement pour augmenter l'expressivité du tour (emphase), notamment dans le discours religieux. L'accord n'est pas obligatoire (v. troisième exemple du CW), mais plutôt stylistiquement marqué. Haut est modifié par assez, bien, plus, si, toujours, très, trop. Notons l'emploi de abaisser bas.

\section{Embarrer profond}

Enfoncer une arme, cabosser profondément comme avec une barre

Transitif

1276 Le bran entoise Ogiers, moult l'a hasté, Brunamon a telement refrapé Pres qu'il ne l'a a la terre versé. L'iaume li a si parfont enbarré Que il le chief en ot tout estonné (Adenet le Roi, Les Enfances Ogier, 3962)

REMARQUES : Embarrer profond se disait du fait d'enfoncer profondément une arme comme une barre dans quelque chose ou quelqu'un ou de frapper à l'aide d'une barre. 


\section{Embêter ferme}

Ennuyer beaucoup

Pronominal

1856 Le lendemain son capitaine lui ayant demandé son opinion sur le spectacle, il répondit avec la politesse de quelqu'un qui fait des concessions : " C'est des farceurs, mais on s'embête ferme » (Encylopédiana)

1892 Je crois néanmoins au succès bruyant de cette œuvre, et voici pourquoi : d'abord, on s'embête ferme. Les divertissements se clairsèment et les émotions se raréfient. On ne se gifle pas tous les jours au parlement et les bousculades ministérielles manquent de carnage, les théâtres se lézardent visiblement (Léon Bloy, Journal 1 : Le Mendiant ingrat)

2006 Elle s'embêtait ferme. C'était une de ces soirées auxquelles elle ne se rendait que par convenance (Anne-Marie Garat, Dans la main du diable)

Transitif

1894 C'est qu'elle s'ennuie. Rien ne lui va mieux que l'ennui. Depuis que nous sommes ici, nous l'embêtons ferme (Anatole France, Le Lys rouge)

1963 « Les femmes m'embêtent, se dit-il, elles m'embêtent ferme » (Pierre Moinot, Le Sable vif)

CORPUS WEB :

Les E.T qui s'embêtent fermes chez eux, ont décidé de venir coloniser la terre, pour passer le temps [http://www.gamesup.ch/tests/230/spacechannel-5.html] (9.10.2020)

\section{Emblaver mou}

Ensemencer en blé une terre détrempée Emploi absolu

1903 1er octobre.

Avec l'orage qui s’éloigne, Dieu s'en va. Les paysans sont contents : ils vont pouvoir emblaver «mou ». Le temps a mal au cœur. Les arbres, d'abord immobiles, anxieux, s'agitent bientôt de joie sous la bonne pluie désaltérante (Jules Renard, Journal)
REMARQUES : Emblaver mou se disait du fait d'ensemencer en blé ou toute autre céréale, une terre molle ou ramollie par de l'eau.

\section{Embrasser étroit}

Serrer étroitement dans ses bras

Transitif

1100 Rollant s'en turnet, le camp vait recercer, Sun cumpaignun ad truvet, Oliver. Encuntre sun piz estreit l'ad embracet ; Si cum il poet a l'arcevesque en vent, Sur un escut l'ad as altres culchet, E l'arcevesque l'ad asols e seignet (Chanson de Roland, 2202)

+1200 Qui vestus ert estroit a las, Desous le col soef li met, L'autre desus, mult souavet Sa bouce à la soie tout droit, Si le baise et embrace estroit : Mais ce n'est mie de cuer faint : De mult fin cuer souef l'estraint (Amadas et Ydoine [début XIII ${ }^{\mathrm{e}}$ ], 3294)

1275 Lors deit cele estreit enbracier, Baisier, blandir et soulacier, E crier merci dou mesfait, Puis qu'il ne sera jamais fait (Jehan de Meun, Roman de la rose [1269-1278], 9843)

1285 Pinchonnet estroit embraça, Voiant tous, souvent le baisa, Qu'ele tenir ne s'en povoit De la grant joie qu'ele avoit (Adenet le Roi, Cleomadés, 13937)

+1300 « Ains vivre chastement quant vo fis m’a lessie. "

Quant le comte l'oy, estroit l'a embrachie (Vie de saint Alexis [XIV ${ }^{\mathrm{e}}$, p. 355, 44)

REMARQUES : Embrasser étroit signifiait en ancien français 'prendre quelqu'un dans ses bras en posant les mains autour de son corps en le serrant étroitement ; l'étreindre avec force'. Notons l'emploi de baiser étroit, estraindre soef, mettre soef, vêtir étroit. 


\section{Embrasser ferme}

I. Embrasser, étreindre avec vigueur, avec force Transitif

1560a mais il l'avoit si bien bouclé et le tenoit si ferme embrassé comme s'il eust esté né et uni avec le corps et les bras (Barthélemy Aneau, Alector ou Le Coq)

1877 Fais leur trouver un emploi, que sais-je, fais comme j'aurais fait pour toi si j'avais eu le temps de sortir de tristesse et de pauvreté, - et tiens, en ce moment, de loin, si à travers les choses du passé un droit grave subsiste, par cette épée que je vais tenir tout à l'heure au nom du vieux Jehan, je t'embrasse ferme et, (ne ris pas, vieil ami, j'ai le cœur d'un roi) ; - je te fais chevalier, moi ! (Auguste de Villiers de L'Isle-Adam, Correspondance générale)

1912 Henriette vint à moi les bras tendus et m'embrassa ferme sur les deux joues ; son mari, le visage souriant et rose, le crâne rond et brillant, me prit les deux mains et me dit sans façon que j'avais bien raison de venir habiter Paris (René Boylesve, Madeleine jeune femme)

1914 Nous t'embrassons fort et ferme (AlainFournier, Correspondance avec Jacques Rivière)

Pronominal

1865 Avez-vous vu quelqu'un de ces pauvres intérieurs où l'on s'aime peut-être, mais où l'on ne sait pas se le dire, où l'on ne sait ni s'embrasser fort et ferme, ni se donner de bonnes poignées de main ? (Agénor de Gasparin, La Famille)

II. Adopter (quelque chose), s'attacher (à quelque chose) avec énergie, conviction Transitif

1560b Et d'autant nostre perversité est-elle moins excusable, si nous n'embrassons fort et ferme ce bénéfice inestimable qui nous est proprement destiné (Jean Calvin, Institution de la religion chrestienne)

CORPUS WEB :

Pour les retrouvailles, ça s'embrassait ferme et les photographes présents étaient particulière- ment sollicités [http://www.maroc-hebdo.press. ma/Site-Maroc-hebdo/archive/Archives_871/ html_871/rni.html] (02.3.2015)

Julius l'embrassa, ferme et profond, utilisant presque plus les dents que la langue [https:// www.fanfiction.net/s/10527702/1/Une-nuit-enGaule] (02.3.2015)

REMARQUES : Embrasser ferme (I) désigne le fait de prendre quelqu'un dans ses bras en posant les mains autour de son corps et en le serrant avec force. À partir du XVII ${ }^{\mathrm{e}}$ siècle, il peut référer au fait de donner un ou des baisers à quelqu'un avec effusion, vivement (ex. de 1912 et le deuxième exemple du CW). (II) renvoie au fait de s'attacher par libre choix à quelque chose, d'y adhérer, et de s'y consacrer avec conviction et vivacité, l'objet étant inanimé. Notons la collocation usuelle embrasser fort et ferme, ainsi que ferme et profond. Ferme reste invariable et est modifié par si.

\section{Embrasser fort}

Embrasser, étreindre avec vigueur, avec force

Transitif

1250 Lors s'aprocha de li mesire Raous et l'enbracha fort entre ses bras, ke il avait fors, et le traist fors dou baing toute nue et l'enporte viers son lit ; et si tos com il l'ot forstraite dou baing, si vit une noire take ke elle avoit en la diestre ainne, aukes priès de sa nature (Le roi Flore et la belle Jehanne [milieu XIII'] , p. 105)

1285 Li une saisi l'oreillier

Et le prent fort a embracier, Et l'autre le cuevrechief prent

Et le baise piteusement, La tierce aert le couvertour (Adenet le Roi, Cleomadés, 5358)

1559 Le marchant, qui d'un tel cas ne fut poinct estonné, la laissa incontinant et s'en alla audevant de la mere. Et en estendant les braz, l'embrassa le plus fort qu'il lui fut possible (Marguerite d'Angoulême, Heptaméron, p. 50, 26)

1623 Aussi les Rois porte-couronnes Devroyent balançer les personnes Qu'aux charges ils vont eslevant, 
Mais les fleurs hastives se passent, Et les grands estouffent souvent Ceux-là que plus fort ils embrassent (Jean Auvray, Le Banquet des muses ou Les Divers Satires)

1660 Heureux donc mille fois celuy que vostre grace

Arrache pour jamais à tant de changemens, Qui vous cherit si fort, qui si fort vous embrasse,

Qu'il vit et qu'il expire en ces embrassemens (Georges de Brébeuf, Entretiens solitaires)

1757 ÉRASTE. (à Clitandre) Quel transport! Il m'étouffe!

CLITANDRE. Oh ! jadis on embrassoit bien fort.

ÉRASTE. Et sur-tout son rival ?

(Jean-Baptiste Sauvé de La Noue, $\mathrm{La}$ Coquette corrigée)

1871 Tu peux lui dire que je ne la plains nullement et la gronde très fort. Après quoi tu l'embrasseras encore plus fort (Gustave Flaubert, Correspondance)

1936 Elle m'embrassait tellement fort, dans une trombe tellement violente, que j'en vacillais... La force d'un cheval en tendresse qui lui remontait dans ces cas-là du fond de sa carcasse biscornue... Ça la trempait à l'avance les séparations (Louis-Ferdinand Céline, Mort à crédit)

1972 Je termine en t'embrassant bien fort (Robert Sabatier, Trois Sucettes à la menthe)

1996 Pour finir, elle et notre père allaient souvent au restaurant russe, aimaient la rue Saint-Ferréol, et nous embrassaient très fort (Boris Schreiber, Un silence d'environ une demi-heure)

2001 On aurait dit qu'on irait se coucher très très tard. Que maman viendrait me border en m'embrassant très fort. On aurait dit qu'on aurait eu un magnifique mois de juin (Chloé Delaume, Le Cri du sablier)

2004 Mais je vois bien que cette petite Camille aime beaucoup mon jardin et c'est la raison pour laquelle j'aimerais bien le lui léguer si tu n’y vois pas d'inconvénients... Fais bien attention à toi et à elle, si tu peux. Je t'embrasse bien fort, Mémé (Anna Gavalda, Ensemble, c'est tout)

Pronominal (réciproque)

1649 Enfin ces combatans, estant tous deux lassez,

Tous deux tombez à terre et tous deux enlacez,

Ils s'embrassent plus fort et d'une telle étreinte,

Prisonniers l'un de l'autre, ils souffrent la contrainte

(Claude Malleville, Euvres poétiques)

1700 Madame d'Armagnac a été voir à Paris le maréchal et la maréchale de Villeroy sur la mort de leurs fils ; ils se sont fort embrassés, et on espère que c'est un raccommodement parfait. Il y a déjà quelque temps qu'ils ne se voyoient plus (Philippe de Dangeau, Journal)

1867a Il se mettrait debout, et, me montrant d'une patte, te montrant de l'autre, il s'écrierait : "Monsieur et madame s'embrassent très fort dans la chambre » (Émile Zola, Thérèse Raquin)

1867b Alors, nous nous sommes promenées en faisant de grands pas dans la chambre, nous nous sommes embrassées bien fort, nous nous sommes serré les poignets, nous avons fait les yeux blancs comme au théâtre, et tout est venu (Hippolyte Taine, Notes sur Paris)

1956 Imbécile affectueux, aussi, qui se lamente lorsqu'on ne s'embrasse pas assez fort sur les banquettes, et qui le dit, et qui fouille toute sa cargaison de blues jusqu'à ce qu'il ait trouvé un déchirant soupir à jeter (François-Régis Bastide, Les Adieux)

\section{CORPuS WEB :}

Je ne sais pas comment finir ce texte très creux pour être tout à fait honnête avec vous alors je vais juste vous embrasser fort et vous envoyer le peu de paillettes imaginaires qu'il me restait pour la journée [http://www.natacha-birds.fr/ leblog/arreter-de-briller] (02.3.2015) 
Dernier bisou virtuel ma Charlotte avant de t'embrasser fort demain soir !! [http:// pierredohmecole.blogspot.co.at/2010/09/ gemmage.html] (02.3.2015)

J'étais heureuse sur le trajet à l'idée de les serrer dans mes bras, de les embrasser fort mais j'appréhendais également d'être replongée dans les cris et les disputes sans parler des grognements et râles réguliers de Petit Loulou [http:// www.mamanathome.com/article-ca-y-est-ilssont-de-retour-117373763.html] (02.3.2015)

REMARQues : Embrasser fort désigne le fait de prendre quelqu'un dans ses bras en posant les mains autour de son corps et en le serrant avec force. À partir du XVII ${ }^{\mathrm{e}}$ siècle, il peut référer au fait de donner un ou des baisers à quelqu'un avec effusion, vivement. Fort reste invariable et est modifié par assez, bien, encore, le plus, plus, si, tellement, très. Notons qu'embrasser fort est souvent employé familièrement à la fin d'une lettre adressée à une personne proche (ex. de 2004).

\section{Embrasser profond}

Embrasser en enfonçant la langue dans la bouche

$\lambda$ embrasser ferme

\section{Embrasser serré}

Embrasser étroitement, en serrant fortement ; enlacer

Transitif

1553 Mais il les prie de venir de bonne heure, pour l'extresme envye qu'il a de baizer les mains de M. de Nevers, et d'embrasser bien serré le Lyon-Vulpe de l'Empereur (François de Scépeaux, sire de Vieilleville, Mémoires)

1627 en mesme instant que nos cœurs le reclament avec verité, il accourt le bon Seigneur, comme le Pere de l'enfant prodigue ; il nous embrasse bien serré et nous arrouse de ses larmes, et d'un grand excez d'amour il interine toutes nos requestes (Étienne Binet, Recueil des ceuvres spirituelles)

1678 Dieu fait des graces à qui il lui plait : mais avec le respect que je dois à sa providence, vous m'en paroissez bien digne ; et sur cela, madame, je vous embrasse si serré, que j'ai peur de vous faire crier (Roger de Bussy-Rabutin, Les Lettres de messire Roger de Rabutin)

1769 Ce qui m'a plu davantage que tout cela, c'est d'avoir été embrassé bien serré par toutes ces actrices parmi lesquelles il y en a trois ou quatre qui ne sont pas trop déchirées (Denis Diderot, Lettres à Sophie Volland)

1825 Ah, mon Dieu. Mathilde s'impatiente et vous aussi sans doute; je finis donc à la hâte en vous embrassant bien serré et en vous souhaitant santé, bonheur et félicité sur cette terre, et in sæcula sæculorum (Coraly de Gaïx, Correspondance)

1949 Pour la dernière fois, embrassez-moi comme quand j'avais froid. Embrassez-moi bien serré, bien serré, bien serré... RENÉ (Colette, La Vagabonde)

\section{CORpus Web :}

Mrs Weasley a eu un regard sur lui et le souffle coupé, " Harry! Oh mon... ce qui est arrivé ? » elle lui a inauguré à l'intérieur et l'embrassa serré [https://www.fanfiction.net/s/ 7627252/6/Meant-to-be] (02.3.2015)

REMARQUES : Embrasser serré réfère au fait de prendre quelqu'un dans ses bras en posant les mains autour de son corps en le serrant étroitement, en l'étreignant avec force ; il est aussi employé au sens figuré comme formule d'adieu. Serré est modifié par bien, si. Il reste invariable, ce qui relève de la difficulté d'attribuer la modification à une seule personne ( ?Il l'embrasse serrée), alors que le pluriel ne devrait pas poser de problème (Ils s'embrassent serrés). L'usage préfère toutefois l'invariabilité. Notons la réduplication bien serré, bien serré, bien serré.

\section{Emmener droit}

Emmener directement

Transitif

1285 Cleomadés enmainent droit En la chambre ou geü avoit La nuit que il venus ert la (Adenet le Roi, Cleomadés, 10149) 
1626 mais la passion de ceux qui portoient la guerre s'appercevans de cela, uzerent de toutes sortes de violence pour tirer le Roy de Paris, et comme à la desrobee par la porte le derriere de Louvre, le jour de Pasques Flories, comme s'ils l'eussent enlevé, l'emmenerent droit le long de la riviere jusqu'à Nantes (Le Mercure françois)

1628 Neantmoins, quoy qu'il nous sauvast la vie, si ne laissa-t'il point de nous faire ses prisonniers. Car à mesme temps il nous emmena droit au port de Sube, sans nous permettre d'entrer dans la ville (François de Gerzan, L'Histoire afriquaine de Cleomede et de Sophonisbe)

1712 Le bruit que cela fit réveilla toute la Ville, et par conséquent le Magistrat, qui voulut faire mettre la troupe en prison, sans un des plus yvres qui le prit par la main ; et comme il n'avoit pas main forte avec lui, la clique Bachique l'emmena droit à la maison où étoit l'accouchée, qui pensa mourir de frayeur de la galanterie que lui faisoit son Amant (Charles Dufresny, Mercure galant)

1966 D’abord la voiture a fait un bond en avant, parce que j'accélérais trop fort, mais elle s'est calmée aussitôt, elle m'a emmenée en souplesse droit devant moi, à une allure solennelle (Sébastien Japrisot, La Dame dans l'auto)

1991 Une chaînette d'or, un modeste médaillon, peut-être vide, glissait entre ses seins. Sûrement moins habituée de sa cuisine que du restaurant, elle nous emmena tout droit manger du coq au Madiran chez Pierre, où je remarquai que, se faisant appeler Madame, elle hélait les serveurs par leurs prénoms (Hervé Bazin, L'École des pères)

2001 C’est une vraie école de la vie, elle dit, avec un animal de cette puissance, 500 kilos de muscles, tu es obligée de composer, de ruser, d'être calme, sinon il t'emmène droit aux enfers, les musicos, en comparaison, sont de petits chats. Le cheval est une éponge, il sent ton stress, ta raideur, ton corps qui n'épouse pas le mouvement de son dos (Luc Lang, Les Indiens)
2009 De quoi faire renoncer le plus grand des explorateurs en martelant que la terre est plate et que la croire ronde peut nous emmener droit à l'échafaud (Pascal Caussimon, L’Art de se métamorphoser)

\section{CORPUS WEB :}

Le crabe, curieux de cette nouvelle technologue déposé devant son habitat, semble examiner la GoPro pendant un moment, avant de l'attraper et de l'emmener droit dans sa tanière [http://documystere.com/insolite/un-crabekidnappe-une-gopro] (03.3.2015)

Tiens ça me rappelle tous ceux qui nous annonçaient le pire avec les 2 présidents qui soi disant se tiraient toujours dans les pattes et non seulement étaient la risée du foot français mais en plus allaient nous emmener droit dans le mur [http://www.poteaux-carres.com/ forum/viewtopic.php?f=1\&t=6225\&p=1331860] (03.3.2015)

Reinette fait moins des sauts de brute, et elle se tient mieux à l'abord. Mon problème reste que j'aborde très en avant, selon ma mono c'est ma façon de trouver l'équilibre pour l'instant, mais ça me porte préjudice notamment sur le double, où du coup, j'arrive pas à l'emmener droite avec mes épaules, et je me laisse tirer vers l'extérieur, sur le double c'est pas grave en soi, mais ça aurait été un triple je pense qu'elle m'aurait sorti [http://forum.chevalmag.com/index. php?topic=31444.115;wap2] (03.3.2015)

REMARQUES : Emmener droit désigne le fait de prendre quelqu'un ou quelque chose avec soi pour le conduire directement en un lieu. Droit reste invariable dans la majorité des cas, malgré l'objet au féminin ou au pluriel, mais il s'accorde avec l'objet au féminin dans le dernier exemple du CW, où il réfère à une position droite. Il a tendance à s'associer avec la préposition qui le suit (dans, en, devant, à) au point de faire partie du groupe prépositionnel comme modifieur de la préposition. Il est modifié par en souplesse, tout. Notons l'emploi de accélérer fort. 


\section{Emmener soef}

Emmener avec douceur, délicatesse

Transitif

1200 Douz chevaliers de sa cort apella, Et cil l'en mainnent souavet et le pas (Ami et Amile, 2112)

REMARQUES : En ancien français, emmener soef désignait le fait de prendre quelqu'un avec soi délicatement, avec précaution, pour le conduire ailleurs.

\section{Émouver dru}

Pousser fortement

Intransitif

1450 SATHAN. Lucifer, horrible segoigne

$\mathrm{Au}$ nit d'orgueil sans fin couvant,

Esmouvez, derriere et devant,

Deables, plus druz que pere et mere !

(Arnoul Gréban, Le Mystère de la Passion, 23326)

REMARques : Émouver dru désigne le fait de pousser quelque chose ou quelqu'un avec violence, de façon vive, la cause en étant une personne.

\section{Émouvoir fort}

Bouleverser fortement, vivement Transitif

+1250 Au derrier dit qu'en cel menoir Vuet malgre l'oste remenoir. Per corroz sibloit la colueure, Por son uenin plus fort esmueure (Ysopet de Lyon [2 $2^{\mathrm{e}}$ moitié XIII $\left.{ }^{\mathrm{e}}\right], 588$ )

1575 Le mardi $10^{\mathrm{e}}$ jour de may, la nuit, fut derobbée la Vraie croix estant en la SainteChapelle du Palais à Paris dequoi le peuple et toute la ville furent fort esmeus et troublés, et s'esleva incontinent un bruit qu'elle avoit esté enlevée par les menées et secrettes pratiques des plus grands du Roiaume (Pierre de l'Estoile, Registrejournal du regne de Henri III)

1654 Il est certain que le plus souvent leur zele est artificiel, et lors qu'on pense qu'ils soient fort esmeus, ils n'ont que des exclamations feintes et une cholere de theatre. Mais aussi en certains lieux, comme en celuy-cy, leurs ressentimens sont naturels
(Jean-Louis Guez de Balzac, Dissertations chrestiennes et morales)

1727 Cette nouvelle émut fort le Peuple, en faisant connoitre la mauvaise intention du Roi (Henri de Boulainvilliers, Histoire de l'ancien gouvernement de la France)

1732 Inès alla donc au jardin ; et peu de temps après je la vis rentrer dans mon appartement fort émue : Madame, dit-elle, votre soupçon n'est que trop bien éclairci

(Alain-René Lesage, Histoire de Gil Blas de Santillane)

1824 Le lieutenant et Jeanneton finirent par oublier le moment d'attendrissement qui les avoit si fort émus, et la joie reparut au milieu de leur festin (Honoré de Balzac, Annette et le criminel)

1913 Devant cette porte close, ils étaient tous fort émus et l'imagination surexcitée ; mais quelques-uns faisaient les braves (Maurice Barrès, La Colline inspirée)

1931 Il m’arriva subjugué par M. Maritain et fort ému de la crise religieuse qu'il avait découverte (Jean-Richard Bloch, Destin du siècle)

2003 Depuis l'enfance Marie nourrissait dans le secret de son cœur une tendresse admirative à l'endroit de son cousin qu'elle s'était tristement résignée à ne lui jamais avouer. Pour lors la peine de Jean l'émou vait fort, elle eut tout hasardé dans l'espoir de l'apaiser (Didier Lachavanne, Que la volonté du Père)

\section{CORPUS WEB :}

C'est condensé et destiné à frapper et à émouvoir fort et rapidement ? Oui il y a l'envie de ne pas s'étaler par pudeur aussi. Il y a un moment vers la fin, important dans le spectacle, qu'on ne révélera pas, qui est surprenant quand on le découvre, mais qui est arrivé à la trentième représentation [http://www.rtbf.be/ culture/article/detail_les-enfants-de-jehovahde-fabrice-murgia-au-grand-manege-jusqu-au-2fevrier?id=7917935] (03.3.2015)

Cela semblait l'émouvoir fort de nous dire que le drapeau grec ne doit pas servir à ça 
[http://blogledessousdescartes.blogspot.co.at] (03.3.2015)

Depuis peu de temps la page par défaut quand je démarre internet explorer est MSN. com, alors qu'avant c'étais " about:blank ». Au début je me suis dit que c'étais pas grâve : j’ai fais outils/options internet...et appliquer. Mais ca n'a pas l'air de l'émouvoir fort car bien souvent elle repasse sur ce sattané msn.com [http://forum. zebulon.fr/page-par-defaut-msncom-t56157.html] (03.3.2015)

REMARQUES : Émouvoir fort réfère au fait d'agiter, de bouleverser, ébranler quelqu'un avec violence, de façon vive, la cause pouvant désigner une personne ou une chose. Fort reste invariable et est modifié par plus, si. L'antéposition dans fort ému le transforme en simple intensifieur. Notons l'emploi absolu dans le premier exemple du CW.

\section{Émouvoir seri}

Inciter tranquillement et paisiblement quelqu'un à faire quelque chose

Transitif

+1150 Et tant com l'emperere cele parole at dit, Devers les porz de mer oït un vent venir. Bruiant vint al palais, d'une part l'acoillit, Si l'at fait esmoveir et soëf et serit :

Altresil fait torner com arbre de molin (Pèlerinage ou Voyage de Charlemagne à Jérusalem et à Constantinople [2 moitié $\mathrm{XII}^{\mathrm{e}}$, 371)

REMARQUES : Émouvoir seri désignait le fait d'inciter quelqu'un à se mettre en mouvement, le sujet agissant avec calme, sans s'énerver. Notons la collocation soef et serit. Soef rajoute l'idée de douceur en veillant à ne pas brusquer autrui.

\section{Émouvoir soef}

Inciter tranquillement, avec douceur (quelqu'un à faire quelque chose)

入 émouvoir seri

\section{Emparler petit}

petit emparlé : peu bavard, peu éloquent Intransitif

+1400 Et bien est droit que soye rabatue, Pleine de plour et petit enparlée ; Je suis vesve, seulete et noir vestue
(Christine de Pisan, Rondeaux / Euvres poétiques [début $\mathrm{Xv}^{\mathrm{e}}$ ], I, p. 149, 6)

REMARQUES : Emparlé petit se disait de quelqu'un de peu loquace, qui parle, cause peu.

\section{Empoigner ferme}

I. Empoigner solidement, avec force

Transitif

1450 BRAYART. Celuy sera le plus vaillant Qui en aura plus grant poignee. ORILLART. Je l'ay ja si ferme empoignee Que la char est venue après Et le cler sang (Arnoul Gréban, Le Mystère de la Passion, 22957)

1566 Mais je fis tel effort, Qu'au menton j'empoignay le lion ferme et fort

(Louis Des Masures, David combattant)

1766 Or, il est facile d'éviter tous ces inconvéniens, si l'on a l'attention de saisir d'une main la masse du placenta, à la sortie de la vulve, et de l'autre main qui tenoit le cordon, d'empoigner ferme les membranes rassemblées, et les tirer très-doucement pour empêcher qu'elles ne se déchirent dans le col de la matrice, qui les serre quelquefois assez pour cela (André Levret, Mémoire sur la méthode de délivrer les femmes après l'accouchement)

1877 Coupeau lui cria en riant d'empoigner ferme la rampe et de ne plus la lâcher (Émile Zola, L’Assommoir)

II. Se bagarrer, se quereller

Pronominal

1837 Celui-ci, après avoir contribué à la formation de la fameuse barricade qui défendait l'entrée du faubourg, s'apercevant que le troisième régiment de la garde royale, où servait son fils, se disposait à l'attaquer, dit à ses concitoyens : "Écoutez, vous autres! on va s'empoigner ferme : les « boutonnières blanches » vont attaquer; et comme Alexis est du nombre, j'n'entends pas m'exposer à tirer sur lui, ou l'exposer lui-même à ce qu'il fasse feu sur moi. Par ainsi, vous trouv'rez que j'me r'tire » (Jean Nicolas Bouilly, La Barricade) 
1996 Un brouhaha indescriptible régnait pendant les cours. Aux récréations, on s'empoignait ferme. Babou détestait cette atmosphère de caserne rendue invivable par le fait que, les Chamar étant majoritaires, ils régnaient en maîtres sur l'établissement (Lyane Guillaume, Fière et intouchable)

2006 Et que je te fais passer de la capacité trois à la six. Et que je te mets deux fois le même dans la trois et la quatre. Et que celui-là il va au placard. Ça s'empoignait ferme les lundis matin. Seulement en face des tripatouilleurs il y avait encore une armée de distributeurs et de producteurs qui beuglaient pour qu'on maintienne leur film (Jean-Jacques Beineix, Les Chantiers de la gloire)

2008 Il s'agit de savoir si l'on renouvelle pour trois ans, à sa demande, le mandat de Jacques Fauvet, soixante-cinq ans, comme les statuts de la société le permettent. Je suis médusée : on s'empoigne ferme. Tous les caciques sont présents, des hommes bien sûr - il n'y a que deux femmes dans la hiérarchie (Josyane Savigneau, Point de côté)

\section{CORPUS WEB :}

En effet le congrès du PS se tiendra à Reims. On croyait que l'affaire était conclue, et ben non, on a dû s'empoigner ferme au Bureau National ! [http://www.saint-quentin02.fr/article-19580021. html] (04.3.2015)

3) mettre les bras autour d'elle en enfermant les bras de la « victime »; 4) la tête reposera sur notre épaule - clavicule. attention, la tête va bouger, les jambes aussi, il ne faut pas lâcher, et empoigner ferme ! [http://www.creapharma. fr/N6587/crise-d-epilepsie-mesures-a-prendre. html] (04.3.2015)

Il empoignait ferme la pierre dans sa main, et le plaça contre le dos de Malice, malgré ses résistance. Alors on voit claire une flux magique circulait dans le corps d'elle et est aspirée par Dean à travers la pierre [http://www.jeuxvideo. com/forums/1-4233-8651933-19-0-1-0-0.htm] (04.3.2015)
REMARQues : Empoigner ferme (I) désigne le fait de saisir vivement dans sa main, de tenir fermement quelqu'un ou quelque chose, l'objet pouvant être un animé ou un inanimé. Dans l'emploi pronominal (II), il réfère au fait de se colleter ou de se quereller ; tous les exemples pronominaux sont impersonnels (ça, on). Notons la collocation ferme et fort. Ferme reste invariable (ex. de 1766) et est modifié par si.

\section{Empoigner fort}

I. Empoigner solidement, avec force

Transitif

+1225 Et li vilains, ki fu hideus, Empuigna mout fort la quignie.

Si l'a, au plus k'il puet, haucie (Le Chevalier as deus espees [2 $2^{\mathrm{e}}$ quart $\mathrm{XIII}^{\mathrm{e}}$ ], 3829)

1658 la Vierge des Vierges, la Mere de la chasteté, la Reyne des Vierges, marque de l'amour qu'il avoit pour la Virginité, luy qui estoit Vierge. Son dernier moment arrivant il empoigna fort son Crucifix, ses Regles, et son chapelet et prononçant le nom de I E S V S, et de M A R I E il rendit sa belle ame à son Createur (Paul de Barry, La Mort de Paulin et d'Alexis)

1916 Dans ce coin bourbeux où, faibles encore et impotents, nous étions assaillis par des souffles de vent qui nous empoignaient si brusquement et si fort que la surface du terrain semblait osciller comme une épave, le cri de l'homme qui avait l'air de vouloir s'envoler éveilla d'autres cris pareils (Henri Barbusse, Le Feu)

1934 Celle-là, Stefanesco l'empoigna si fort que la chair du bras se gonflait en bourrelets blêmes entre ses doigts (Roger Vercel, $\mathrm{Ca}$ pitaine Conan)

2004 Le ventre et les jambes. Pour le reste, ma foi, elle verrait... Il essora le gant et le posa sur son front. Il lui fallait de l'aspirine à présent... Il empoigna si fort le tiroir de la cuisine qu'il en renversa tout le contenu sur le sol. Fichtre. De l'aspirine, de l'aspirine... (Anna Gavalda, Ensemble, c'est tout)

2014 Tyee s'approche et m'empoigne fort, trop fort. 
- Merci, Céline, d'avoir eu assez de cran pour nous permettre de connaître notre aïeul (Brune-El, La Lune cendrée)

\section{II. Émouvoir, intéresser profondément}

Transitif

1898 Je n'ai pas envie de te parler enfin de moi, c'est-à-dire de te raconter ce que je pensais hier, avant-hier. Cela m'empoignait fort, et aujourd'hui les embêtements ci-dessus et autres me paralysent (André Gide et Paul Valéry, Correspondance)

\section{CORPuS Web :}

Et si tu accusais McGonagall de t'avoir brutalisé ? dit inopinément Peter, le doigt dans les airs comme lorsqu'il demandait la parole en classe. Je l'ai vu t'empoigner fort le bras devant l'entrée de ses appartements. Tu portes sûrement encore les marques ? [http://www.hpfanfiction.org/fr/ viewstory.php?sid=26830\&chapter=2] (07.3.2015)

Après, en situation d'urgence, c'est clair que le premier réflexe est d'empoigner fort le levier de frein avant toute chose, le but étant d'éviter l'obstacle à tout prix, ensuite si tu cales, tu t'en branles [http://www.club-scootergt.com/651677post329.html] (07.3.2015)

Se posant sur le crochet de portière, il suffit simplement de prendre appui pour pouvoir monter ou descendre de la voiture, fourgon, van ...Avec une ergonomie travaillée, l'utilisateur de la poignée peut l'empoigner fort sans ressentir aucune douleur [http://www.handimobil.net/ details-poignee+de+transfert+handybar-177. html] (07.3.2015)

REMARQUES : Empoigner fort (I) désigne le fait de saisir vivement dans son poing, tenir fermement quelqu'un ou quelque chose. Si le sujet est un inanimé (par exemple, le vent), il présente un caractère abstrait signifiant 'saisir, agripper avec force'. Au sens figuré (II), il se dit du fait de saisir, d'émouvoir fortement quelqu'un. Fort reste invariable et est modifié par moult, si, trop. Notons la réduplication fort, trop fort.

\section{Emprisonner laid}

Emprisonner vilainement, dans des conditions dures, pénibles, cruelles

Transitif

1250 La hache mist u poi[n]g, et Damedieu jura Que la honte Garin son segnor vengera,
Que le roi Danemont si lait emprisonna (Doon de Mayence, p. 307)

REMARQUES : Emprisonner laid désignait le fait de mettre quelqu'un en prison et de le tenir incarcéré dans des conditions exécrables, cruelles, rendant la détention immorale.

\section{Encager bien et beau}

Mettre tout à fait, entièrement en cage

Transitif

1668 Elle empêtra si bien les serres du Corbeau Que le pauvre Animal ne put faire retraite : Le Berger vient, le prend, l'encage bien et beau,

Le donne à ses enfants pour servir d'amusette

(Jean de La Fontaine, Le Corbeau voulant imiter l'aigle / Fables)

REMARQUES : Encager beau désigne le fait de renfermer complètement dans une cage. Beau remplace ici la forme neutre de l'ancien français, $b e l$.

\section{Encaisser gros}

Recevoir, toucher beaucoup d'argent Intransitif

1954 Nous sommes en train d'organiser un comité de défense des Malgaches. Il aurait mieux valu que ce soit d'autres que nous, qui en prennent l'initiative ; mais les idéalistes petits bourgeois n'ont pas toujours la conscience chatouilleuse ; à l'occasion ils sont capables d'en encaisser gros sans broncher. Le fait est que personne ne lève le doigt (Simone de Beauvoir, Les Mandarins)

\section{CORPuS WEB :}

L'option binaire est la méthode idéale pour encaisser gros rapidement ! Le dépôt minimum sur les plateformes de trading d'option est en général de 200 euros et le trade minimum est de $5 €$ [http://www.marecette.org/faire-fructifier-lecheque-de-mamie-avec-les-options-binaires] (07.3. 2015)

Et elle permet réellement de se lâcher en vitesse. Mais alors vraiment ! Pas du tout timidement. Elle est réellement capable d'encaisser gros. Comme une une grosse berline... oui mais une grosse berline très agile ! [http://www.fluofun.fr/ 
tests/boards/furlan_ash-water/2013_8273.html] (07.3. 2015)

ils ont bon goût, c'est le plus beau pont de PARIS, mais c'est quand même inadmissible rien n'arrête ces nouveaux voleurs, qui pillent le mobilier urbain et les monuments qui appartiennent à la communauté, dans l'optique d'encaisser gros sans se fatiguer !!! [http://www.bfmtv. com/societe/paris-a-vole-plaques-bronze-pontalexandre-iii-486682/avis] (07.3. 2015)

REMARQUES : Encaisser gros réfère au fait de recevoir, toucher une grosse somme d'argent ; dans un registre plus familier, il signifie 'recevoir beaucoup de coups', au sens propre comme figuré et, par extension, 'accepter, admettre, supporter des coups, quelque chose de difficile'. Gros reste invariable. Notons l'emploi absolu dans les exemples du CW. Naturellement transitif, le fait que le verbe encaisser est toujours en emploi intransitif quand il se combine avec gros constitue un argument en faveur de l'hypothèse selon laquelle l'adjectif occuperait lui-même la place du complément direct (v. Introduction $\S$ 6.3).

\section{Encontrer dur}

Faire une rencontre hostile, se heurter avec

force

Transitif

1275 François oënt la noise, ne lor vint pas a gre, Bien sevent qu'il seront ja moult dur encontré

(Adenet le Roi, Buevon de Conmarchis, 3862)

REMARQUES : Encontrer dur se disait du fait de faire une rencontre défavorable, désagréable et, en particulier dans le combat, de rencontrer dans une intention hostile, d'attaquer durement.

\section{Endormir ferme}

Plonger dans un profond sommeil

Transitif

$\sim 1235$ La nuit estoit peisible, li tens beus e seri. En mun lit fu chuchez e ferm fu endormi (La Vie de seint Auban, 223)

\section{Corpus Web :}

Mais vous êtes avertis : il faut disposer d'une bonne compréhension du langage PureBasic pour vivre entièrement ce tutorial, au risque sinon de s'endormir ferme [http:// forums.purebasic.com/french/viewtopic. php?f=8\&t=10791\&view=previous] (07.3.2015)

perso les boulettes de papier m'ont pas perturbé ni les superbes avions lancés par les doublants sur le prof essayant pitoyablement de les immiter... enfin ça se raconte pas mais ça se vit !! même si souvent les blagues sont un peu lourdes on apprend vite à les apprécier et elles sont les bienvenue qd on commence à s'endormir ferme ! [http://forums.remede.org/ montpellier_faculte_de_medecine/sujet_11634. html] (07.3.2015)

Le problème est que le soir ils s'endorment ferme après le bain de $18 \mathrm{~h}$ et on les réveille pour 1 bib vers $21 \mathrm{~h} . .$. . [http://www.jumeaux-etplus.fr/component/option,com_smf/Itemid,88/ topic,28216.1500/wap2,wap2] (07.3.2015)

REMARQUES : Endormir ferme réfère au fait d'assoupir, d'entraîner quelqu'un dans un sommeil profond ou, dans un emploi pronominal plus usité, de tomber dans un sommeil profond. Notons l'emploi pronominal systématique du verbe dans le CW. Ferme reste invariable malgré le sujet au pluriel.

\section{Endormir fort}

I. Sombrer ou être dans un profond sommeil Transitif

1285 Lors prennent a crier : « Harou ! Mout par nous aiment li dieu pou, Quant si fort endormies fumes Que nous ne nous aperceümes De ce k'ainsi nous est ravie Dou monde la mieus ensaignie Et la meilleur et la plus bele » (Adenet le Roi, Cleomadés, 5349)

1404 Bien et bel ordenna cellui filz ces fausses lettres, et aussi la quittance plaine et bonne du dit argent. Tant espia son point que, une nuit, vid son pere fort endormi ; adonc prist le sael soubz son chevet et seella les dittes lettres et la quittance, que lepere ne s'en aperçut (Christine de Pisan, Le Livre des fais et bonnes meurs du sage roy Charles V, II, p. 71)

1698 Tant que la soirée fut longue, elles ne parlèrent que de leur dessein, elles se cou- 
chèrent sur l'herbe ; mais lorsque Finette leur parut fort endormie ; Fleur-D'Amour dit à Belle-De-Nuit, savez-vous ce qu'il faut faire, ma sœur ; levons-nous et nous habillons des riches habits que Finette a apportés (Marie-Catherine d'Aulnoy, Finette Gendron)

1710 J'étois si fort endormi, reprit-il, que je ne songeois plus que nous étions dans une barque (Simon Tyssot de Patot, Voyages et avantures de Jaques Massé)

1715 Une nuit qu'Amine me croyait fort endormi, elle se leva tout doucement, et je remarquai qu'elle s'habillait avec de grandes précautions, pour ne pas faire de bruit, de crainte de m'éveiller (Antoine Galland, Les Mille et une nuits)

1859 Ma mie, fort endormie le soir. Cependant, au coucher, très bonne (Jules Michelet, Journal)

Pronominal

1623 Elle se deshabilla donc, et sa servante en ayant fait de mesme, s'endormit si fort qu'elle tira sans crainte son billet de sa poche et leut ces paroles qui y estoient escrites (Charles Sorel, Les Nouvelles françaises)

1851 Mais, monsieur, la lassitude du corps, et encore plus la lassitude de l'esprit et du cœur par toutes les idées qui m'avaient battu le front depuis deux longues journées, trompèrent mon espérance, et je m'endormis si fort et si bien que ni le chant de l'alouette, ni le quiqui-riqui du coq, ni le mugissement de cent bœufs appelant le bouvier dans l'étable, ne m'auraient pas tant seulement réveillé (Alphonse de Lamartine, Le Tailleur de pierre de SaintPoint)

II. Faire dormir profondément

Transitif

1627 Lysis à surmonté tout cela lors qu'il s'est trouvé dans la prison, si Anaximandre ne s'est point monstré pour l'empescher de forcer ses gardes, c'est que je l'avois endormy plus fort que s'il eust esté dans le palais du sommeil, car je ne veux point nier que ce ne fust moy qui tira Lysis et Carmelin de mon carrosse pour les conduire en la prison (Charles Sorel, Le Berger extravagant)

\section{CORPuS WeB :}

Compter des moutons quand tu es zéophile, ça ne doit pas endormir fort fort [http://old.tweet tunnel.com/reverse3.php?ga $=0 \& b=\& p g n=1$ $3 \& \mathrm{tz}=-18000 \& \mathrm{bt}=574431913076781056 \& \mathrm{st}=189184$ 507969146880\&id=24123712\&pn=2] (9.3.2015)

Ah, je pensais je ne sais quoi moi. Ca a l'air de t'endormir fort ce truc [http://www.jeuxvideo. com/forums/1-50-112441118-2672-0-1-0-le-blablades-fous.htm] (9.3.2015)

- une autre a la réputation d'endormir fort les chats pour les opérations. Résultats, plusieurs ne se sont pas réveillé ! [http://www. forum-chien.com/t35942p348-hizmo-le-bergerallemand] (9.3.2015)

C'est d'ailleurs en chantant et en marchant qu'elle s'endort. Et elle s'endort fort comme Willy. Willy essaie de s'approcher et trouve des astuces pour la distraire... [http://delafontaine.unblog. fr/2010/07/27/1-er-mail] (9.3.2015)

REMARQUeS : Dans un emploi pronominal ou dans une construction résultative où le participe passé du verbe désigne l'état du sujet résultant $\mathrm{du}$ processus dénoté par le verbe, (s')endormir fort réfère au fait d'être ou de tomber dans un sommeil profond, lourd (I). Dans l'emploi transitif (II), il désigne le fait de faire dormir quelqu'un, de l'entraîner dans un sommeil profond. Fort reste invariable et est modifié par plus, si. Notons la réduplication fort fort et l'emploi de ordonner bel et bien.

\section{Endormir soef}

S'endormir doucement, paisiblement

Pronominal

1177 La rëine la matinee

Dedanz sa chanbre ancortinee

Se fu mout soef andormie

(Chrestien de Troyes, Lancelot ou Le Chevalier de la charrete, 4757)

REMARQUES : S'endormir soef désignait le fait de s'assoupir doucement, de tomber dans un sommeil paisible et agréable. 


\section{Enfler fort}

I. Enfler, gonfler fortement (en particulier à la suite d'une blessure)

Emploi absolu

+1100 Puurs i vent itant grande

Ne guart quant me quers espande ;

Ne puis vomir pur le queivre

Que cil la me firent beivre ;

Puis enfle fort, e li quirs tent ;

Anguisus sui, pur poi ne fent.

Tels calz, telz freiz e tels ulurs

Suffret Judas, e tels dolurs

(Benedeit, Voyage de saint Brendan

[1 $1^{\text {er }}$ quart XII $\left.], 1429\right)$

Transitif

1619 En me traictant comme un valet,

Vous me donnastes un soufflet,

Qui m’a si fort enflé la joüe

Que malgré moy j'en fay la moüe

(Claude d'Esternod, L'Espadon satyrique)

1680 J'ai la main droite encore fort enflée

(Mme de Sévigné, Correspondance)

1732 Il allait ajouter à cela beaucoup d'autres choses pour exhorter don Alphonse à prendre patience, lorsque nous vîmes entrer dans l'ermitage un autre ermite chargé d'une besace fort enflée (AlainRené Lesage, Histoire de Gil Blas de Santillane)

1831 Je suis arrivée ce matin accablée de chaleur et les pieds fort enflés, la tête malade, mais le cœur plein et léger (George Sand, Correspondance)

1981 La gangrène se trouva dans tout le pied, dans le genou, et la cuisse fort enflée (Françoise Chandernagor, L'Allée du roi)

\section{Enorgueillir fortement}

Transitif

1560 Mesmes les Philosophes (qui ont le plus combatu pour monstrer que la vertu est à désirer à cause d'elle-mesme) ont esté si fort enflez d'orgueil et fierté, qu'on peut appercevoir qu'ils n'ont pour autre raison appété la vertu, sinon pour avoir matière de s'enorgueillir (Jean Calvin, Institution de la religion chrestienne)
1573 MESSAGER. Jamais le froid Boree armé contre le Nort,

Et le Nort contre luy, ne l'enflerent si fort (Robert Garnier, Hippolyte)

III. Gonfler

Pronominal

1628 Car naiz avec le feu vous ressemblez aux vents,

Dont le mont de Sicile a ses esclairs mouvans,

Et ne pouvez causer qu'une flamme cuisante,

Mais au moins pouvez-vous la rendre plus luisante :

Enflez-vous donc si fort de sanglots eslancez

Qu'on cognoisse l'effort dont vous estes poussez (Jean de Schélandre, Tyr et Sidon)

Transitif

1709 Ce petit succès enfla si fort ses espérances, qu'il ne se proposa rien moins que d'enlever Elvire d'entre les mains des barbares, et de la remettre en France (Jean-François Regnard, La Provençale)

\section{CORPuS Web :}

ne cogites pas trop, si l'endroit où elle a piqué n'a pas rougit, enflé, etc... c'est pas un soucis... c'est grave si ça enfle fort, etc, dans les jours qui suivent... [http://forum.aufeminin.com/ forum/matern1/_f437583_matern1-Morsure-detique.html] (10.3.2015)

De toutes façons d'ici demain jmlasoupe vera bien dans quel état sera la plaie, il se peut que ça chauffe un peu (ce n'est pas forcément alarmant) mais si ça enfle fort, il faut aller voir le véto qui le mettra sous antibiotiques [http:// www.aujardin.org/viewtopic.php?f=21\&t=106127 \&start=225\&view=print] (10.3.2015)

M. Bartolone semble lire les réactions sur votre site entre autre et entendre le grondement qui enfle fort [http://www.bfmtv.com/politique/ un-referendum-pour-le-droit-de-vote-desetrangers-274150/avis/?page=14] (10. 3.2015)

Remarques : Au sens médical (I), enfler fort désigne le fait de provoquer l'enflure d'une partie du corps. Au sens figuré (II), il réfère au fait d'enorgueillir fortement, de gonfler la vanité de 
quelqu'un. De façon générale (III), il signifie sur un plan plus abstrait 'faire augmenter le volume (de quelque chose) ou grossir (quelque chose)'. Fort reste invariable et est modifié par si.

\section{Enfler gros}

I. Enfler, gonfler beaucoup

Intransitif

+1300 Oyl, fet Johan. Yl fist tribler un herbe, et la mist en sa bouche ; e sa face comença d'engroser e emflyr moult gros e tu devynt si descolorée qe ces compaignons demeyne à grant peyne le conurent (Fouke le Fitz Waryn [début XIV e], p. 66)

1925 Les veines du cou lui enflaient gros comme le doigt (Henri Pourrat, L'Auberge de la Belle Bergère ou Quand Gaspard de guerre revint)

Pronominal

1594 Quand vous devriez crever et vous enfler gros comme un bœuf, comme feit la mere grenouille, vous ne serez jamais si gros seigneur que luy, encore qu'on die qu'il n'a pas de graisse sur tout son corps pour paistre une alouette (Satyre Ménippée)

1652 lequel [= le Saint Homme] lui mettant la main droite sur la teste et la gauche à l'endroit du cœur : pria si long-temps, qu'il le fit suspendre en l'air. Et alors, le corps de cét enfant s'enfla gros, comme un muid d'une extreme pesanteur ; puis jettant un grand cry, il versa à même temps grande quantité d'eau par tous les conduits de son corps, apres quoy il revint en sa premiere grosseur (Simon Martin, Les Fleurs de la solitude)

1659 Une autre fois, un de ses condisciples, nommé Thethgonus, s'estant endormy sur son livre en un champ, fut mordu d'un Serpent, le venin s'écoula incontinent par tout le corps, qui s'enfla gros et devint tout noir et plombé (Albert Le Grand, La Vie, gestes, mort et miracles des saints de la Bretagne-Armorique)

Transitif

1772 mais on ne put le remonter que mort : on l'ouvrit, il avoit le cerveau sec, les me- ninges extraordinairement tendues, les poumons tachetés de marques noires, les boyaux enflés gros comme le bras, enflammés et rouges comme du sang ; tous les muscles des bras, des cuisses et des jambes, comme séparés de leurs parties (L'Esprit des Journaux)

II. Se montrer très orgueilleux, se donner beaucoup d'importance

Pronominal

1587 Il nous accorde quasi tout.

En fin, elle en aura le bout

De la paix, nostre bonne Dame,

Que depuis dix mois elle trame,

Mais elle est fascheuse à ourdir.

Il s'enfle gros pour estourdir,

Ce bon prince tant catholique,

Qui ne veut ni noise ni pique :

Dieu ne l'a fait que pour aimer

(Pierre de L'Estoile, Registre-journal du regne de Henri III)

\section{CORPUS WEB :}

personne ne veut venir à paris, si les mercenaires et les mauvais joueurs en fin de carriere, qui se disent c'est le dernier contrat ou je vais pouvoir me gaver les quataries ont de l'argent, ils se font enfler gros comme une maison !!!! [http:// rmcsport.bfmtv.com/football/thiago-silva-et-lepsg-ca-brule-265920/avis/?page=4] (10.3. 2015)

Mon genou était enfler gros comme un pamplemousse (en arrivant chez moffette) ! J'ai payer en esty mon gars xd [https://fr-fr.facebook. com/events/573482639403586/permalink/595 806703837846] (10.3. 2015)

Après la partie, peinant à sortir quelques mots de sa bouche enflée gros comme ça, il s'était excusé à mon collègue Marc Defoy et à moi en mettant court à la discussion. « Ça fait trop mal et je dois aller chez le dentiste ", avait-il prétexté... avec raison ! [http://tennisman88.unblog.fr] (10.3. 2015)

Moi hier, j'ai manqué une marche dans les escalier je me suis tordu le pied... j'ai une grosse entorse, la cheville enflée grosse comme une balle de tennis, je souffre ! [http://pierrelapointe. forumactif.com/t60p375-tristesse-de-la-journee] (10.3. 2015) 
RemARQues : Au sens médical (I), enfler gros désigne le fait de gonfler une partie du corps. $\mathrm{Au}$ sens figuré (II), il réfère au fait d'enorgueillir, de gonfler la vanité de quelqu'un. En argot, se faire enfler signifie 'se faire gruger, se faire avoir' (v. premier exemple du CW). Gros reste généralement invarié mais le dernier exemple du CW illustre son emploi résultatif avec accord. Gros tend à former un groupe syntaxique avec une comparaison introduite par comme : gros comme le doigt / un bouf / un muid / une maison / ça / une balle de tennis. Notons l'emploi de mettre court à la discussion 'y mettre fin'

\section{Enfoncer creux}

Enfoncer profondément

Transitif

1925a Des armatures de fil de fer, des bandelettes de papier collées maintenaient les ailes déployées ; des bouchons fichés au bout des becs les gardaient étroitement fermés, tandis que des becs de rapaces, tout grands ouverts pour menacer, montraient des tampons d'ouate enfoncés creux dans la gorge (Maurice Genevoix, Raboliot)

1925b Sur son crâne qu'on devinait chauve, Tancogne portait un bonnet de loutre, une fourrure peladeuse et qui montrait son cuir ; la lourde toque enfoncée creux rabattait les minces oreilles, plus cireuses encore que le visage, mais qui par transparence laissaient voir une fade nuance mauve, la même qui colorait les lèvres et les bords éraillés des paupières (Maurice Genevoix, Raboliot)

1926 Ils ont les mêmes yeux verts enfoncés creux sous des sourcils couleur de paille, les mêmes joues maigres recuites par le hâle, les mêmes bras noueux et secs (Maurice Genevoix, La Boîte à pêche)

Pronominal

1950 Secousse a perdu la jambe : une plaque d'acier blindé qui est retombée de très haut et qui la lui a coupée net, s'enfonçant creux en terre après la lui avoir coupée (Maurice Genevoix, Ceux de 14)

\section{CoRpus Web :}

Présentement la douleur du Monde est grande et ses leaders officiels sont capables de s'enfoncer creux dans le mensonge pour ne pas apercevoir sa détresse [http://perceval.over-blog. net/article-manifeste-pour-une-eglise-dans-lemonde-de-ce-temps-113585778.html] (10.3.2015)

Gentille comme tout, la dame offre de trimbaler mes skis pour me permettre de me concentrer sur la remorque. Mais je décline son offre et j'entreprends d'avancer les bâtons dans une main, les skis dans l'autre, veinard de ne pas trop enfoncer creux avec mes bottes de ski [http://www.geocities.ws/skiernouvelles/04/art/ jan/P18.html] (11.3.2015)

Plante des dunes improprement appelée chardon bleu. Elle est protégée et la cueillette donc interdite. Sa racine s'enfonce creux dans la dune (comme une carotte) pour résister à la sécheresse, au vent [http://photos.linternaute.com/ photo/1400598/2093536677/895/le-panicautmaritime-1] (11.3.2015)

REMARQUES : Souvent à la forme passive, enfoncer creux se dit de quelque chose se trouvant au fond, dans le creux d'autre chose. Lorsque le sujet est un couvre-chef, il signifie que celui-ci est abaissé sur la tête avec force afin qu'elle soit placée bien au fond. Dans un emploi pronominal, le sens est celui d'entrer profondément dans quelque chose et enfoncer creux est suivi d'une préposition de lieu. Notons que les exemples sont littéraires et probablement régionaux (Loire). Les deux premiers exemples du CW mettent en évidence la continuation des emplois régionaux dans l'usage québécois. Dans le second exemple du CW, enfoncer creux est employé de façon absolue, alors que l'auteur pourrait prendre bottes de ski comme objet direct. Creux reste invariable.

\section{Enfoncer profond}

Enfoncer, faire entrer, faire pénétrer profondément, en profondeur

Pronominal

1911 La rougeur restait marquée à son front, creusant sous la peau, s'enfonçant profond comme une brûlure (Charles-Ferdinand Ramuz, Aimé Pache, peintre vaudois) 
1945 Le feldwebel nous reçoit à la grille, ma chère. À la grille du parc, comme dans le beau monde. Je m'enfonce plus profond dans la colonne. On va camoufler des munitions. Il s'agit d'ouvrir l'œil et le bon, comme disent les détectives. C'est couillon, des Boches. Oui, ce travail-là, je suis volontaire ; ça m’amuse. Et ça m'instruit (Jean-Louis Bory, Mon village à l'heure allemande)

Transitif

1929 Alors, ils ont inventé de s'appeler avec des harmonicas qu'ils enfonçaient profond dans la bouche pour pouvoir jouer avec le bout de langue qui leur restait (Jean Giono, Un de Baumugnes)

1944 - Dis-moi comment est ce nègre ? demanda Bienaimé qui s'était réveillé.

- C'est un nègre noir, dru et membré, avec des cheveux en grains de poivre.

- Et des yeux enfoncés profond?

- Oui (Jacques Roumain, Gouverneurs de la rosée)

1985 Parfois je m'étonne de ne pas mourir : une lame glacée enfoncée profond dans la chair vivante, de nuit, de jour et on survit (Marguerite Duras, La Douleur)

1989 Il faut enfoncer l'aiguille plus profond, la pompe plus inclinée. Je fouille, je cherche cette putain de veine, sang, boule (Denis Belloc, Képas)

\section{CoRpus Web :}

tu vois les rageux comme toi j'y prete pas attention jsais sque je vaux et j'emmerde le monde, j'aimerai bien savoir qui tu es, pour t'enfoncer profond sous terre, ops juste en te regardant encore une fois dans lmiroir tellement taura honte de toi meme que tu t'y enfoncera tt seul sur cee [http://ask.fm/mehdichaoui3/best] (16.3.2015)

Mais se fourrer le doigt dans l'œil à $40 \%$ près, c'est risque de se l'enfoncer profond dans ... la narine. Original, mais ça reste une belle marge, d'autant qu'il s'agit de l'argent du contribuable et de ses enfants dont la dette à rembourser atteint maintenant des sommets stratosphériques [http://h16free.com/2009/09/29/894-woerth-auvolant-budget-gourmand] (16.3.2015)

Des tiges sculptées, assemblées, soudées, des angles aigus, des chevauchements calculés, l'apparence de brut, des proportions participant du sens et de l'humour : la hauteur des pattes les pieds sur la pointe afin d'enfoncer profond la tête, le croupion joufflu levé, les plumes hérissées [http://www.raphaelmognetti.com/texte-E012-1. html] (16.3.2015)

Et en ce qui concerne citron ? Ils vont me l'enfoncer profonde la facture ou j'ai le droit à un échantillon de vaseline? [http://forum.hardware. $\mathrm{fr} / \mathrm{hfr} /$ Discussions/Auto-Moto/mecaniquesoucis-referencement-sujet_22884_1772.htm] (16.3.2015)

REMARQUeS : Enfoncer profond désigne le fait d'enfoncer, de faire pénétrer quelque chose profondément, vers le fond ou jusqu'au fond. Dans l'emploi pronominal, lorsque le syntagme est suivi d'une préposition de lieu, il signifie 'entrer ou pénétrer profondément dans quelque chose'. $\mathrm{Au}$ sens figuré, le sujet est un être animé qui va vers le fond et, par extension, vers une situation de plus en plus grave. Profond reste invariable dans la majorité des cas, mais dans le dernier exemple du CW il est accordé avec l'objet au féminin, par simple emphase, sans qu'on puisse interpréter profond comme modifieur de facture. Ce dernier exemple relève de l'acception argotique et érotique 'se faire mettre'. L'objet est bien la facture mais l'ajout de vaseline n'est pas équivoque. Profond est modifié par plus.

\section{Enformer dur}

Donner beaucoup d'informations

Transitif

+1370a Là s'umelioit li rois de Navare grandement, et disoit au roy de France : « Ha ! monsigneur, pour Dieu merci, qui vous a si dur enfourmé sur moy? » (Jean Froissart, Chroniques (A))

+1370b Si se voult excuser par biau languaige en luy amolliant de pluseurs choses, mais il ne pot, car le duc estoit si dur informez sur luy et sur les aultres de sa secte du duc d'Irlande que excusance n'y valoit riens (Jean Froissart, Chroniques (A)) 
REMARQUES : Enformer (aussi, avec la graphie latinisante : informer) désignait le fait de mettre quelqu'un parfaitement au courant, de lui apporter beaucoup de renseignements sur quelqu'un/ quelque chose. Dur est modifié par si.

\section{Enfouir profond}

Enfouir, cacher, enterrer profondément, en profondeur

Transitif

1794 Déguise son courroux qu'il mûrit en silence

Et dans son cœur profond enfouit sa vengeance (André Chénier, L’Amérique)

1961 ... alors il n'avait pu qu'une chose, les mêler aux autres, aux travailleurs de la prairie... à décharger les wagons et creuser des fosses... ça allait... on ne parlait plus des lépreux, ni de lèpre... l'Oberartz Haupt ne demandait pas de nouvelles... pourvu que les wagons soient vides et morts soient enfouis profond ! (Louis-Ferdinand Céline, Rigodon)

1992a Et alors c'est à d'autres passants qu'elle manifeste sa présence, remuant soudain en eux des souvenirs profonds enfouis, des songes et des visions depuis longtemps en gésine mais qui n'avaient pas encore trouvé leur heure, - l'instant propice pour s'éployer (Sylvie Germain, La Pleurante des rues de Prague)

1992b Des cygnes et des canards dormaient à ses pieds, la tête enfouie profond sous l'aile comme s'ils cherchaient une seconde nuit dans la chaleur de leur corps, sous la douceur de leur plumage (Sylvie Germain, La Pleurante des rues de Prague)

Emploi absolu

1936 - Je souhaiterais que mon cadavre fût emporté directement du lit de mort à la fosse commune. Et enfoui là pas trop profond, pour que les chiens le déterrent, et le mangent (Henry de Montherlant, Pitié pour les femmes)

\section{CORPus WeB :}

Il y a des fils que tu peux enfouir sous terre, c'est du nmwu. Si tu ne veux pas l'en- fouir profond passe le dans un tuyau de carlon 100lbs [http://forum.jardinage.net/viewtopic. php?f=14\&t=92980] (17.3.2015)

Les dieux Ases, menés par Bor, vainquirent les elfes noirs (on dit " svartalfar ») et voulurent détruire l'anneau, l'éther, le truc-qui-fait-vachement-mal, mais TGCM, ils n'y parvinrent pas et décidèrent de l'enfouir profond, profond, pour que personne ne le découvre [https://lesboggans. wordpress.com/2014/03/01/thor-le-monde-destenebres-the-dark-world-dalan-taylor] (17.3.2015)

Tout le jour, elle observe les allers et venues de la rue, du bistrot, de la gare. Elle apprivoise sa mémoire à ces images paisibles, essaie d'enfouir profond la mauvaise graine, retourne les souvenirs à cette lumière si blanche [http:// www.tv5monde.com/cms/chaine-francophone/ lf/Tous-les-dossiers-et-les-publications-LF/ Prix-Jeune-Ecrivain-2012/p-19499-contributionVotez-pour-votre-nouvelle-preferee-.htm?\&id contrib=208562] (17.3.2015)

Gris au corps et au ventre. À demi dévêtu sur des lits plissés. Fissure fichée comme une lame enfouie profonde dans ma mémoire. Invite d'une cuisse épaisse et tendre [http://www. jeanpaulschmitt.com/tag/metamotphoses] (17.3.2015)

REMARQUES : Enfouir profond désigne le fait de mettre en terre profondément, et, par extension, d'enfoncer, de mettre dans un lieu couvert et caché. Au sens figuré, il se dit de quelque chose qui a trouvé refuge dans un lieu (souvenirs). Profond peut s'accorder avec le sujet (ex. de 1992a et le quatrième exemple du CW), plutôt par simple emphase que pour réellement modifier le sujet, mais on ne saurait exclure, dans certains cas, le renforcement stylistique de la position finale de l'objet enfoui. On pourrait interpréter l'exemple de 1992a aussi comme souvenirs profonds // enfouis. Ce serait un effet de style où profonds pourrait s'appliquer aussi bien aux souvenirs qu'à leur enfouissement. Profond est modifié par là pas trop. Notons la réduplication profond, profond dans le second exemple du CW.

\section{Engager net}

Débuter brusquement

入 engager sec 


\section{Engager sec}

(S')engager, commencer brusquement, rapidement, énergiquement, sans pitié

Pronominal

1957 La partie s'engageait bien, net et sec, sans bavures (Roger Vailland, La Loi)

CoRpus Web :

De quoi déclarer la guerre, ou au moins annoncer son arrivée, sans équivocité. Le combat s'engagea net [https://www.fanfiction.net/s/1002 9044/30/L-Amour-plus-fort-que-la-Mort] (17.3.2015)

Ca s'engage sec en ce moment sur bide : [Merci pour les paroles :)] [http://www.bide-etmusique.com/song/5741.html] (17.3.2015)

\section{Et ç'est vrai que ça engageait sec !}

Rassure-toi, au début, on a tous eu l'impression de faire de la figuration dans ROF, c'est cette difficultéqui donne du piment à cette simu [http:// www.checksix-forums.com/viewtopic.php?f= 400\& $\mathrm{t}=174142 \& \mathrm{p}=1246523]$ (17.3.2015)

Par contre sur les courses d'enduro, affreux. Ca engageait sec dès la première spécial, j'était paralysé avec la selle trop haute (je la mettait en position intermédiaire) [http://www.26in.fr/ forums/autres/blah-blah/sujet-9644-26in-bynight-21h-08h_83575.html] (17.3.2015)

REMARQues : Engager sec désigne le fait qu'une action commence brusquement, vivement, soudainement. Notons la collocation net et sec, où net souligne l'idée de promptitude et de clarté de l'action, ainsi que la mise en série avec l'adverbe bien. Remarquons par ailleurs l'emploi fréquent du sujet impersonnel en construction absolue ou pronominal, attesté dans le CW. Sec reste invariable.

\section{Engueuler sévère}

\section{Réprimander sévèrement}

Pronominal (réciproque)

2000 Non, ça j'ai pas vu mais, la veille, j'ai vu et surtout entendu la gamine, sur le pas de la porte d'une maison avec un gars, son chef à ce que j'ai compris, et j'te jure qu'i s'engueulaient sévère (Michel Embareck, La Mort fait mal)
Transitif

2008 Le taximan l'a engueulé sévère (Jean-Michel Basquiat, Bordel)

2019 Mon père, lui, s'est fait engueuler sévère. Tout ça sous le nez du curé, s'il vous plait ! (Pascaline Nolot, Sur l'écorchure de tes mots)

\section{Enlacer ferme}

Étreindre avec fermeté, avec vigueur, avec force Transitif

1584 Qu'une si sainte amour ne prenne jamais fin ;

Mais d'âge en âge croisse, autant ferme enlacée

Que la Vigne tient l'Orme en ses plis embrassée

(Pierre de Ronsard, Élégies, p. 213)

Remarques : Enlacer ferme désigne le fait de serrer quelqu'un dans ses bras, ou de passer un bras autour de sa taille. Si le sujet est un inanimé, il réfère au fait d'entourer quelque chose plusieurs fois étroitement. L'adjectif-adverbe vient renforcer l'idée de force et de fermeté dans l'étreinte. Ferme est modifié par autant.

\section{Ennouer fort}

Lier, enchaîner avec force Transitif

1552 L'an est passé, et l'autre commence ores, Où je me voy plus que devant encores Pris dans leurs rets; et, quand par fois la mort

Veut deslacer le lien de ma peine, Amour tousjours, pour l'ennouer plus fort, Flatte mon cœur d'une esperance vaine (Pierre de Ronsard, Le Premier Livre des amours, p. 71)

REMARQues : Ennouer fort désignait le fait de mettre dans des liens, de lier, d'enchaîner fermement quelque chose, au sens propre ou métaphorique.

\section{Ennuyer ferme}

Importuner, embêter, lasser beaucoup

Transitif

1836 Je devais l'ennuyer ferme (Stendhal, Vie de Henri Brulard) 
Pronominal

1879 La mère et la fille s'ennuyaient ferme en ce pays perdu, où les distractions n'abondent point et où elles n'avaient aucune relation agréable (André Theuriet, La Maison des deux barbeaux)

2008 De cette lecture lyrique, vociférante et répétitive, il n'apprenait rien, en particulier sur ce qu'il guettait : rien, bonne nouvelle. Il s'ennuyait ferme (Anne-Marie Garat, L'Enfant des ténèbres)

\section{CORPUS WeB :}

$\mathrm{Si}$ vos enfants s'ennuient fermes pendant les vacances, vs pouvez tjs jouer avec eux à \#offthedead [https://twitter.com/kaligram/ status/42151926313398272] (28.2.2011)

Une chose simple, certains médias s'ennuient fermes et ont besoin d'animer leurs (maigres) ventes estivales [http://lalettredejaures.overblog.com/article-contre-hollande-choisissezvotre-rumeur-109276799.html] (21.8.2012)

REMARQUES : Ennuyer ferme renvoie au fait d'embêter quelqu'un ou soi-même. La comparaison du groupe ennuyer ferme avec le synonyme ennuyer sec met en évidence que l'accord purement graphique dans s'ennuient fermes passe plus facilement que l'accord graphique et phonétique dans ${ }^{*}$ s'ennuyer sèche(s), quand le sens est clairement adverbial.

\section{Ennuyer sec}

S'embêter beaucoup

Pronominal

1957 « Même que tu as bien failli me manquer car je m'ennuyais sec et j'allais partir ", avait-il ajouté (Françoise Sagan, Dans un mois, dans un an)

CORPUS WEB :

je possède la version stand-alone de Pacific

Fighters. Comme je commence à m'ennuyer sec entre les 3 maps disponibles (Okinawa, Mer de Corail et iles du Pacifiques) J'ai vu qu'il y avait la possibilité d'installer des patchs rajoutants maps etc. [http://forums-fr.ubi.com/showthread. php/39917-Difficult\%C3\%A9es-avec-les-patchPacific-fighters-Forums] (19.3.2015)

En partant passer 15 jours à la campagne, dans la ferme du grand-père de Bastien, sans or- dinateur et sans Internet, Gaspard est persuadé qu'il va passer son temps à regarder fleurir les haricots et les courgettes, et s'ennuyer sec [http:// scrineo.fr/f/index.php?sp=liv\&livre_id=229] (19.3.2015)

La maman toujours en avance qui du coup poireaute en râlant car elle a trop froid ou trop chaud et surtout elle commence à bouffer la pain au chocolat de ses kids car elle s'ennuie sec [http://serialmother.infobebes.com/les-8-typesde-mamans-papanounou-etc-reperees-a-lasortie-de-lecole] (19.3.2015)

REMARQUES : S'ennuyer sec réfère au fait d'éprouver un vif ennui, le sujet ressentant un fort sentiment de vide, de désœuvrement, de lassitude. $S e c$ reste invariable.

\section{Enrager bas}

I. enrager haut et bas : faire rage, se déchaîner en tous sens

Intransitif

1604 Que sous un frein paisible à ton vouloir tu ranges :

Sire, on voit bien souvent que tels commencemens

Ont à la fin produit de grands évenemens : Car comme en la forest une foible estincelle,

Que quelque vieille souche en sa cendre recelle,

S'accroissant peu à peu brusle tout à la fois Du plus grand au petit tous les arbres du bois ;

Un seul, un seul à peine évite le ravage

De cest embrazement qui haut et bas enrage ;

Et si comme il naissoit quelqu'un l'eust fait mourir,

On n'eust point veu sa flame en la forest courir (Antoine de Montchrestien, Aman)

II. Enrager en silence, en secret

Intransitif

1727 ARISTE. Insensé que j’étois ! Ai-je dû présumer

Que le Ciel pour moi seul eût pris soin de former

Ce qu'on ne vit jamais, une femme accomplie?

Je l'ai cru cependant, et j’ai fait la folie. 
C'est à moi, si je puis, d'éviter tous débats ; De prendre patience, et d'enrager bien bas (Philippe Destouches, Le Philosophe marié)

1859 Mais furieux bientôt de n'être plus aimé d'elle, ce vilain homme d'esprit fit tout pour la compromettre devant le monde et la diffamer ; il poussa la vengeance de la fatuité jusqu'à faire peindre dans le grand salon du Château de Bussy des tableaux emblématiques avec devises, où il insultait à l'inconstance de celle qu'il appelait de mille noms, et qu'il enrageait tout bas d'aimer toujours (Charles Sainte-Beuve, Port-Royal)

Remarques : Employé métaphoriquement (I), enrager haut et bas se dit d'une chose inanimée (ici : le feu) qui se déchaîne, atteint la plus grande violence. La collocation haut et bas réfère à la force et à la hauteur des flammes. Enrager bas (II) désigne le fait d'éprouver un violent dépit sans toutefois l'exprimer publiquement, de garder un sentiment de colère, de rage pour soimême, secret, bas étant modifié par bien, tout.

\section{Enrager haut}

Faire rage, se déployer en tous sens

$\lambda$ enrager bas

\section{Enseigner fort}

Enseigner publiquement, en faisant entendre sa voix

$\pi$ enseigner haut

\section{Enseigner haut}

Enseigner quelque chose publiquement, ouvertement, franchement

Transitif

1624 Il n'est pas besoin de m'estendre davantage sur ce suject, car tous leurs livres crient, et enseignent haut et clair, que ce monde, et toutes ses parties, n'ont peu estre disposees comme nous les voyons, sans la providence d'un souverain seigneur (Marin Mersenne, L'Impiété des déistes, athées et libertins de ce temps)

1956 C'était la carte maîtresse du jeu de M. Lévêque : la franchise de son procédé. Il enseignait tout haut ce que les Français pensent tout bas, chaque fois qu'ils reviennent de voyage : il n'y a qu'un pays, la France (François-Régis Bastide, Les Adieux)

\section{CoRpus Web :}

Comme l'argent, la parole doit circuler dans ce sens ! Tu sais donc ce qu'il te reste à faire pour enseigner haut et fort ! [http://euroblogalainmalegarie.eu/?p=98] (19.3.2015)

M. le prof Tshibangu Kalala serait-il en train d'enseigner haut que meme en justice internationale il y aurait le fameux principe de deux poids deux mesures ? [https://groups.yahoo.com/ neo/groups/mediascongolais/conversations/ topics/140834] (19.3.2015)

Ces gens là, ce sont ceux qui se disent êtres « enfants nés de DIEU, né de l'ESPRIT », mais prêchent et enseignent haut et fort, qu'ils sont toujours des pécheurs esclaves de leurs péchés, mais quand même sauvés! [http://www.congo page.com/forums/viewtopic.php?f=22\&t=8905 \&view=next] (19.3.2015)

a mon époque ce renseignement je l'ai cherché toute seule, faut croire qu'une telle théorie enseignée haut et fort pourrait ébranler quelques croyances [http://www.algerie-dz.com/forums/ archive/index.php/t-56880.html] (19.3.2015)

REMARQUES : Enseigner haut désigne le fait de faire connaître quelque chose, de transmettre un savoir publiquement, manifestement. Notons les collocations haut et fort, et haut et clair, soulignant la clarté du message communiqué. Haut reste invariable et est modifié par tout. Notons également l'emploi de penser bas ; prêcher haut et fort.

\section{Entamer profond}

Couper, blesser, pénétrer, affecter profondément Transitif

1190 Si parfont fu vo cuers, Sire Dex, entamés, Ke jusqu'en Golgatas fu vostre sanc coulés. « Deus meus » deïs ; adonc fus deniés (Fierabras (L), 1265)

1965 Mais j'étais loin de me douter que les sangles de cuir entamaient si profond et depuis si longtemps la chair blanche de son échine délicate (René-Victor Pilhes, La Rhubarbe) 
1981 Je regarde en face de moi mon amour congédié. Je vais sans doute raquer le prix fort comme d'habitude. Pas la moindre ristourne sur les peines de cœur. C'est quoi au juste ce qui nous a entamés si profond? Le quotidien ? Le manque de blé ? Les mensonges ? Je sais seulement que je veux pas d'une rupture dans un café à deux heures de l'après-midi pendant que d'autres bouffent tranquillos leur sandwich aux rillettes (Evane Hanska, J'arrête pas de t'aimer)

\section{CORPuS WEB :}

Cette idée que ce qui ne tue pas nous rend plus fort, n'est pas si juste au fond. Certains événements dans la vie qui ne tuent pas peuvent nous entamer profond et nous rendre plus fragile [http://helenablue.hautetfort.com/tag/partge] (19.3.2015)

Tiens hier je suis alle me promener a coté de la marne, un gardon avait entamé profond un asticot, il arrivait pas a enlever l'hamecon, je lui ai proposer de l'enlever, il a pas voulu [http:// www.pechemaniac.com/forums/viewtopic_9321. $\mathrm{htm}]$ (19.3.2015)

Un médecin généraliste sinon omnipraticien, aussi habile chirurgien que l'on puisse l'être, peut-il se recoudre lui-même la plante entamée profond ? [http://comme.des.manches. free.fr/la_tete_de_pierre_ecoute_le_temps.htm] (19.3.2015)

REMARQUES : Entamer profond se dit du fait de blesser quelqu'un, au sens propre, avec un objet contondant ou tranchant ; au sens figuré, il désigne le fait de porter fortement atteinte à l'intégrité de quelqu'un, de l'affliger profondément. Profond reste invariable et est modifié par si.

\section{Entendre brouillé}

Entendre mal, de manière confuse, indistincte Emploi absolu

1964 mon oreille droite est normale, mais de l'oreille gauche j'entends brouillé (Exemple entendu, 16 juillet 1964 / Grundt : 257)

\section{CoRpus Web :}

$\mathrm{Au}$ fait, je précise que quand je dis que je suis inaudible, je ne veux pas dire qu'on me m'entend pas, au contraire, mais on m'entend brouillé [https://www.gamerezo.com/forums/ vt_t-26341_f-6.htm] (20.3.2015)

En même temps, le plus gros spoiler du jeu, il est pas là, il est dans le message qu'on entend brouillé dans la radio tout au début [http:// johannesviii.deviantart.com/art/It-s-gone-now194210958?offset=50] (20.3.2015)

Comme on entend mal dans la journée, il écoute au 300, à tout hasard comme il le fait souvent. Soudain, il entend, brouillée, une conversation en arabe [http://journalwattenne. canalblog.com/archives/2012/02/18/23551157. html] (20.3.2015)

REMARQUES : Dans le domaine de l'audition, entendre brouillé réfère au fait de percevoir des sons indistincts, troubles. Brouillé reste invariable dans la majorité des cas, mais dans le dernier exemple du CW, où il est détaché du verbe, il s'accorde avec l'objet du verbe, pour mettre en relief la conversation elle-même.

\section{Entendre clair}

I. Percevoir clairement, distinctement par l'oreille

Intransitif

+1225 Lors entent bien ke c'est besoing Gernemans, ki ot au digner Mengié. S'ert assis por juer A .i. chevalier as eschiés. Në il n'entendi onques mais Si cler, ne si tres fort l'oïe $\mathrm{Du}$ cor. Lors rist par felonnie (Le Chevalier as deus espees [2 $2^{\mathrm{e}}$ quart $\left.\mathrm{XIII} \mathrm{e}\right]$, 4617)

1626 Et bien que parmy l'ombre on entende plus clair

Aucun bruit ne parvient à l'oreille tenduë Comme dans un daedale égarée et perduë Taschons à remarquer la chambre ou retenir

Un signal au volleur funeste à l'avenir (Alexandre Hardy, La Force du sang)

Transitif

1610 - Çà, ma cousine, allons dancer.

- Je n'oserois, de peur de perdre mon honneur.

- O, ho, dit-il, n’y a-t'il que cela ? Venez, cousine ; allons icy en ceste petite 
chambre ; je vous le coudray si bien qu'il ne cherra pas.

Il luy dit tout bas; et elle l'entendoit bien clair, pource qu'elle avoit envie de dancer : par quoy elle le suivit. Il la poussa contre un coffre, et luy enseigna la dance du loup, la queuë entre les jambes, et luy recousit son honneur de la sorte qu'on attache la chose aux nouvelles mariées, et l'asseura que jamais son honneur ne tomberoit par ceste fente-là (Béroalde de Verville, Le Moyen de parvenir)

1963 PIERROT DU GARS PIERRE. Comment m'entendez-vous?

LE GARS PIERRE DE PIERROT. Je vous entends clair et fort

(Express, 7 octobre 1963 / Grundt : 330)

1977 Un geai, il y a eu un geai, quelque part, derrière lui, côté tombe, ou au-dessus, dans les feuillages, il l'a pas vu, Jeannot, le geai, mais il l'a entendu, net et clair, cinq sur cinq, son ricanement d'oiseau, son cacalaca méprisant de mec au-dessus de tout ça, son flafla d'ailes froissant les feuilles

(Jean-Pierre Chabrol, La Folie des miens)

\section{Bien comprendre}

Transitif

+1365 Des foelles lisi jusqu’à sis,

Et puis recommenchai mon tour

A la premiere page, pour

Mieuls concevoir et cler entendre

A quoi la matere poet tendre,

Qui me sambla belle et jolie,

Hors de toute merancolie

(Jean Froissart, Poésies [3e tiers XIV'])

\section{CORPuS WeB :}

Avec nous, la révolution numérique vous fait entendre clair ! [http://laflammeetassocies. com] (20.3.2015)

Tout le monde ne possède pas ces capacités d' " entendre clair », de « voir clair » ou encore de « ressentir, sentir clair ». En fait, très peu les ont. Cependant, les voyants purs sont plus réceptifs à ces dons de divination et donc ils sont enclins à les posséder [http://www.kelavenir.com/blog/ clairaudience-clairvoyance-et-clairsentiencecest-quoi] (20.3.2015)
« Helen Juren, on l'entend clair. Elle a le sens de l'impalpable et les mots visiteurs... enracinée entre terre et ciel, élégance et délicatesse pour mieux voyager...frisson unanime d'un cri saisi devenu beau, et le monde qui tourne avec ses voix d'ailleurs » [https://www.mymajorcompany. com/helenjuren] (20.3.2015)

Merci Pierre ta réponse est tout à fait claire. Je suis étonné de cet avertissement car c'est la première fois que je l'entend claire et nette [http://assiste.forum.free.fr/viewtopic. php?f=29\&t=4095\&start=10] (20.3.2015)

REMARQues : Dans le domaine de l'audition, entendre clair (I) réfère au fait de percevoir par l'oreille un son (musique, rire, voix) net, clair et distinct. Sens répandu jusqu'au XVIII ${ }^{\mathrm{e}}$ siècle, (II) se dit du fait de comprendre, de saisir de manière claire et distincte des propos. Clair reste invariable dans la majorité des cas, mais il s'accorde avec l'objet féminin dans le dernier exemple du CW. Clair est modifié par bien, plus, si. Notons les collocations clair et fort et net et clair, renforçant le sémantisme du groupe. Le premier exemple du CW met en série paradigmatique les groupes entendre clair, voir clair, ressentir clair et sentir clair. Notons aussi dans l'adresse du site de ce même exemple les substantifs clairaudience, clairsentience créés sur le modèle de clairvoyance. Dans ce contexte, on analysera la modification nominale dans voyants purs comme faisant double jeu avec la nominalisation de voir pur.

\section{Entendre double}

Entendre deux fois la même chose

Emploi absolu

1958 la jeune Sophie téléphone interminablement : comme elle a la même voix que sa mère [= qui s'entretient avec l'auteur de l'article] on croit entendre double

(Nouvelles littéraires, 30 avril 1958 / Grundt : 390)

\section{CoRpus Web :}

Aujourd'hui, vous aurez l'impression d'entendre double ! Un phénomène étonnant, qui pourrait bien vous amuser pendant quelques heures. Rendez-vous donc au sommet d'une montagne et criez le plus fort possible ! Avec un peu de chance, quelqu'un vous répondra... ou 
vous jettera des pierres [http://www.krosmoz. com/fr/almanax/2014-04-24] (20.3.2015)

Chez Isaya, le choc auditif s'accompagne d'un trouble visuel : on voit et on entend double. Le chant et son chœur à la tierce sont les signatures vocales de ces sœurs jumelles nées sous le signe des guitares jumbo [http://theatrejoliette. fr/evenement/soiree-douverturearts-de-la-scene] (20.3.2015)

Dans le cas ou ils sont entendus (type enregistrement devant un public d'un piano et traitement en direct) il y aura au mieux des effets de phase, au pire les sons seront entendus double [http://fr.audiofanzine.com/interfaceaudionumerique-firewire/tc-electronic/studiokonnekt-48/forums/t.363105,latence-pour-uneutilisation-en-live.html] (20.3.2015)

REMARQUES : Entendre double se dit d'un son qu'on entend de manière dupliquée simultanément. Double reste invariable. Notons l'emploi de voir double.

\section{Entendre dur}

Être dur d'oreille

Emploi absolu

1669 Il est constant qu'un muet, ne peut ny stipuler, ny promettre, ce qui s'entend aussi d'un sourd. Parce que celuy qui stipule, doit entendre les paroles de celuy qui s'oblige, et celuy qui s'oblige doit pareillement entendre les paroles de celuy qui stipule. D'où vient que nous ne parlons pas de celuy qui entend dur, mais de celuy qui n'entend point du tout (Les Instituts de l'empereur Justinien [trad.])

1810 Car, ne vous y trompez pas, ce bon M. Tartuffe vit plus que jamais : il est bien vieux, mais il est dru encore ; sa tête branle, ses jambes flageolent, sa voix chevrotte, son oreille entend dur, son œil voit trouble et son esprit radote ; mais l'estomac fonctionne bien ; la santé végétative est parfaite (Louis Desnoyers, La Grande Famille de ce bon Monsieur Tartuffe)

1913 car le malade a des bourdonnements d'oreilles et il «entend dur ». Il entend la montre seulement à 3 centimètres à gauche, à 6 centimètres à droite
(Bulletins et mémoires de la Société médicale des hôpitaux de Paris)

1990 Elle entendait dur. Elle pensait de parler à elle-même, puis elle criait à pleine tête (Beau sauvage et autres contes de la Mauricie)

Remarques : Peu attesté dans les textes, entendre dur 'être un peu sourd', se trouve tout de même largement enregistré dans les dictionnaires depuis le Furetière 1690. Notons l'emploi de voir trouble.

\section{Entendre faux}

Entendre un ton faux

$\lambda$ chanter faux

\section{Entendre ferme}

Croire avec conviction

$\lambda$ entendre fort

\section{Entendre fort}

I. entendre fort à : mettre tous ses soins à faire quelque chose, s'y appliquer, s'y intéresser Transitif

+1370a Si en furent touttes gens durement esbahis, et à bonne cause, car leurs ennemis estoient trop prez amassez et n'en savoient que dire ne que faire, et entendirent fort à garder leur ville (Jean Froissart, Chroniques (A))

+1370 b Et trop a point fu secourus messires Gautiers de Manni, car il le trouverent enclos entre ses ennemis, et entendoient moult fort a lui prendre, qant chil Englois, fresc et nouviel, se bouterent dedens euls et les requlerent moult avant, en sus de mesire Gautier de Manni et le remonterent (Jean Froissart, Chroniques (A))

1372 Il s'ensuit aprés en la loy des princes que il ne decline point a destre ne a senestre partie. Decliner a la destre partie est entendre trop fort et trop vehementement aus vertus et aus euvres de vertus, qui doit estre en mesure, et exceder en maniere et passer mesure (Denis Foulechat, Le Policratique de Jean de Salisbury [trad.], p. 74) 
+1389 Item, confessa que d'illec il se transporta en l'ostel d'icellui messire Phelippe, ouquel la dame et plusieurs autres damoiselles estoient, qui moult fort entendoient $\grave{a}$ faire aouster et mettre leurs biens ens (Registre criminel du Châtelet de Paris [1389-1392])

II. Être très habile dans quelque chose, bien s'y connaître

Intransitif

1452 et en ce vous devés fort entendre, car la charge en est votre. Et la chose que doit avoir ung bon juge, c'est bonne conscience, sans avarice et convoitise (Jean Juvénal des Ursins, Verba mea auribus percipe, Domine, p. 339, 5)

1713 Madame de Mailly, qui est dame d'atours, a prié madame Cantin, qui est la première femme de chambre, qui est fort entendue et qui sert madame la Dauphine à son gré, de se charger de tous ces petits détails-là (Philippe de Dangeau, Journal)

1881 À vrai dire, le fils n'a point hérité des nobles inclinations du père. M. Paul s'est adonné aux sports ; il est fort entendu en chevaux et en chiens, et je crois que, de toutes les sciences propres à assouvir ou à tromper l'inépuisable curiosité des hommes, celles de l'écurie et du chenil sont les seules qu'il possède pleinement (Anatole France, $L e$ Crime de Sylvestre Bonnard)

1921 Les sciences ne l'attiraient [= de Condren] pas moins : toutes les sciences : « il se rencontra par une providence de Dieu qu'il passa une partie de ce temps-là auprès d'un gentilhomme de ses parents, qui était fort entendu aux secrets de la nature » (Henri Bremond, Histoire littéraire du sentiment religieux en France)

Pronominal

1664 on nous a dit que c'estoit Mademoiselle de Senneterre, et qu'aprés sa mort un bon esprit de ce siecle qui s'entend fort à la narration, a pris la peine de revoir le livre (Charles Sorel, La Bibliothèque françoise de M. C. Sorel)
1913 - Vraiment, reprit le père abbé, je vous rappellerai ce que disait un jour saint François de Sales : vous vous entendez fort à la seule culture qui importe, celle des âmes ! (Maurice Barrès, La Colline inspirée)

III. Se mettre parfaitement d'accord, avoir de bons rapports avec quelqu'un

Pronominal

+1472 Le conte de Charrolois, par le moyen d'aucungs ses serviteurs, et disoit on que c'estoit Guillaume Bische, s'entendit fort avec le nouveau Roy de France (Olivier de la Marche, Mémoires [ $4^{\mathrm{e}}$ quart $\left.\mathrm{Xv}^{\mathrm{e}}\right]$ )

IV. Percevoir quelque chose (un son) d'une grande intensité Transitif

1684a ainsi à l'egard d'une Voix qu'on a coutume d'entendre forte, et distincte dans une certaine distance, on juge cette Voix bien plus eloignée lors qu'elle nous vient foible et debile, et par consequent moins distincte (François Bernier, Abrégé de la philosophie de Gassendi)

1888 Enfin, un soir qu'une obscurité plus chaude tombait du ciel sans lune, quelque chose commença. Elle craignait de se tromper, cela était si léger, presque insensible, un petit bruit, nouveau parmi les bruits qu'elle connaissait. Il tardait à se reproduire, elle retenait son haleine. Puis, il se fit entendre plus fort, toujours confus. Elle aurait dit le bruit lointain, à peine deviné, d'un pas, ce tremblement de l'air annonçant une approche, hors de la vue et des oreilles (Émile Zola, Le Rêve)

1963 PIERROT DU GARS PIERRE. Comment m'entendez-vous?

LE GARS PIERRE DE PIERROT. Je vous entends clair et fort

(Express, 7 octobre 1963 / Grundt : 330)

1979 Quand il entendait enfin lui répondre le miaulement de la petite bête, il s'agenouillait près d'elle, la prenait dans ses bras et la caressait doucement. Il collait l'oreille à sa fourrure chaude afin d'entendre plus fort dans le noir le moulin de son rouet (Claude Roy, La Traversée du Pont des Arts) 
Pronominal

1684b Il est vray que le vent contraire peut bien par ses corpuscules arrester quelques corpuscules de Son, ce qui fait que le vent estant contraire, le Son ne s'entend pas si fort (François Bernier, Abrégé de la philosophie de Gassendi)

1963 Il se regarde de nouveau une seconde dans la glace, en toussant, ouvre la fenêtre, les souffles des fauves s'entendent plus fort, il tousse de nouveau (Eugène Ionesco, Rhinocéros)

V. Prétendre, croire avec conviction, avec certitude

Transitif

1766 Imagine-toi une société de fous, qui prétendent avoir fait renaître entre eux l'égalité primitive de l'âge d'or, et de rassembler en eux toutes les vertus morales possibles, tandis qu'un gentilhomme franc-maçon entend fort et ferme, dans le fond de son âme, qu'il est à cinq mille piques au-dessus d'un autre franc-maçon, mais marchand ou artisan (Henri-Joseph Dulaurens, Le Compère Mathieu)

1829 Non pas qu'elle ait, je pense, un cœur capable, au fond, De sentir le poète et son amour profond, Qu'elle vaille bien mieux qu'Adèle ou que Fanie,

$\mathrm{Ni}$ qu'elle entende fort ce que c'est que génie (Charles Sainte-Beuve, Poésies)

VI. Ressentir avec force

Transitif

1906 Souvent, l'après-midi, avant le crépuscule, De fenêtre en fenêtre, au long du pignon droit,

Ils s'agitent et bruissent jusqu'à mon toit ; Souvent aussi, quand l'astre aux occidents recule,

J'entends si fort leur fièvre et leur émoi Que je me sens vivre, avec mon cœur, Comme au centre de leur ardeur (Émile Verhaeren, La Multiple Splendeur)

CORPuS WEB :

Le montant total maximum du présent contrat indiqué ci-dessus s'entend ferme et non révisable et inclut tous les impôts, droits, taxes, frais, assurances et dépenses de toute nature que le Prestataire pourrait éventuellement avoir à supporter ou qui pourrait lui être réclamé au titre de son activité ou au titre de la réalisation de la Prestation objet du présent contrat [http:// f3e.asso.fr/media/attached/app_appel/modele_ cps_etude_13ifc059-26-1416.pdf] (23.3.2015)

Il n'est pas important d'entendre fort mais de comprendre le mieux possible. Reprenez confiance en vous et réhabituez-vous à écouter, car une perte auditive ancienne vous a rendu moins à l'écoute de votre environnement [http:// www.entendre-angouleme.com/conseils/ reglage-intensite] (23.3.2015)

T'énerver et puis entendre fort " Moi aussi j't'aime " de son meilleur ami, ca fait plaisir [https://www.facebook.com/ permalink.php?id=430142923716822\&story_ $\mathrm{fbid}=536696846394762]$ (23.3.2015)

D'abord en date du 22 septembre 2014 le Président de la RDC fera une communication du haut de la tribune de la 69ème session ordinaire de l'Assemblée générale des Nations Unies en plénière I du sommet sur le climat, pour revenir ensuite le jeudi 25 septembre 2014 faire entendre fort la voix de la République démocratique du Congo [http://www.digitalcongo.net/ article/102757] (23.3.2015)

L'homme déglutit péniblement, sa voix tremble légèrement, mais Severin se demande si ce n'est pas une trouble excitation qui voile ainsi la voix de ce monsieur qui n'ose plus soutenir le regard de la jeune femme. Sa voix à elle se fait entendre, ferme, moqueuse [http://revebebe.free. $\mathrm{fr} /$ histoires/rvb149/reve14989.html] (23.3.2015)

Je voudrais savoir comment on fait pour mettre une musique, plus on s'approche plus on l'entend forte, plus on s'éloigne moi on l'entend, comme pour l'horloge dans TR3 [http:// www.tro-online.com/forums/diminuer-le-fondsonore-vt1996.html] (23.3.2015)

REMARQUES : Entendre fort (I) traduit une tension morale du sujet vers l'activité qui l'occupe : se consacrer à quelque chose, s'efforcer de faire quelque chose. Sous la forme participiale, fort entendu, (II) se dit de quelqu'un qui s'entend bien à quelque chose, qui est habile, capable, compétent, ingénieux. Sous la forme pronominale, 
il souligne les parfaites connaissances du sujet dans un domaine. (III) a le sens de 's'accorder, fraterniser, sympathiser avec quelqu'un'. Dans le domaine de l'audition, (IV) désigne le fait d'entendre un son avec une forte intensité, de percevoir des ondes sonores soutenues. (V) désigne le fait de considérer avec assurance, d'avoir une idée précise et inébranlable de quelque chose. (VI) signifie 'percevoir, saisir, concevoir, comprendre quelque chose avec force, limpidité', l'objet référant à des sentiments. Fort reste invariable dans la majorité des cas où il réalise une fonction clairement adverbiale. Toutefois, dans l'exemple de 1684a, et dans les deux derniers exemples du CW, il s'accorde avec l'objet au féminin, en se rapprochant d'un prédicat second orienté vers l'objet, à savoir vers ce que l'on entend acoustiquement. Ce rapprochement se produit également dans le troisième exemple du $\mathrm{CW}$, mais sans que fort soit accordé. Le premier exemple du CW représente l'emploi le plus abstrait, très courant dans l'usage récent, au sens (VII) de 'se comprendre, devoir s'interpréter comme étant'. La polysémie du groupe entendre fort est donc très dynamique sur les plans diachronique et synchronique. Il en va de même pour la polyfonctionnalité puisque l'accord fait glisser la modification du côté de la prédication seconde. Notons les collocations clair et fort, et fort et ferme, ferme renforçant l'idée de considérer quelque chose avec assurance, d'en avoir une idée précise et inébranlable. Fort est modifié par moult, plus, si, trop.

\section{Entendre grêle}

Entendre peu

$\lambda$ entendre gros

\section{Entendre gros}

entendre ni gros ni grêle : comprendre dans

l'ensemble, globalement

Emploi absolu

1485 LE BERGER. Il m'a parlé de vous, mon maistre...

Je ne sçay quelle adjournerie... Quant à moy, par saincte Marie, Je n'y entens ne gros ne gresle (Maistre Pierre Pathelin, 1030)

\section{CORPUS WEB :}

Ne fais jamais de compliments qui laissent entendre gros comme un maison que tu veux un rencard (genre «tu es charmante, magnifique, mignone...etc » mais plutôt des compliments détournés genre « toi, tu as du style », « ta manière de penser me plait », " quelle classe ! », etc etc. [http://forum-seduction.artdeseduire.com/so-s-aide-perso-posez-vos-questions/14043-jaiun-gros-probleme-une-fille-de-mon-travail-meplait.html] (23.3.2015)

Parfois, l'édition ne peut se faire qu'au beau milieu d'une forme d'onde et cela s'entend gros comme un camion... Mais ne perdez pas espoir, il nous reste encore quelques atouts dans notre manche ! [http://fr.audiofanzine.com/biendebuter/editorial/dossiers/qu-est-ce-que-lecomping.html] (23.3.2015)

REMARQUES : Entendre ni gros ni grêle se disait d'une chose qu'on ne comprend ni dans l'ensemble ou dans les grandes lignes, ni précisément ou dans les détails. Le CW montre l'emploi hyperbolique d'entendre gros comme une maison / un camion.

\section{Entendre juste}

Entendre ou comprendre avec justesse, précision, exactitude

Emploi absolu

1929 - Je chante faux, mais j'entends juste (Marcel Achard, Jean de la lune)

1959 L'Académie - ne fut jamais dans tes petits papiers - Et, déjà, tu étais injuste. Car, de tout temps, il y eut parmi les « son et lumière ", des types qui, parfois, entendaient juste et parvenaient de loin en loin, à trouver la minuterie (Canard enchaîné, 2 décembre 1959 / Grundt : 364)

1976 POUR AINSI DIRE... qui veut dire que la chose ainsi dite ne l'est pas tout à fait, qu'il y a une certaine marge entre ce qui est dit et ce qu'on voudrait dire, et que l'autre pour entendre juste - doit tenir compte de cette marge (Michel Leiris, La Règle du jeu 4 : Frêle Bruit) 


\section{CORPUS WEB :}

Entendre juste, c'est d'abord être capable de se concentrer pour écouter juste [http://www. formationvocalenantes.fr/annexe_1.2.html] (23.3.2015)

Ces questions peuvent paraître sans rapport mais il faut savoir qu'on fabrique sa note au violon ; il est donc indispensable d'entendre juste [http://www.violoneli.com/cours/ preambules_002.html] (23.3.2015)

50 à $60 \%$ des élèves ont plus ou moins de difficultés ; ce ne sont pas des gens qui ne connaissent rien, mais ils ne sont pas habitués aux structures de la langue française ou sont dans l'incapacité de prononcer certain mots, de les entendre juste ou d'en discriminer le sens [http://voixdexils.ch/2012/02/09/on-peutcomparer-lapprentissage-de-la-langue-a-celuide-la-bicyclette] (23.3.2015)

Certains cours seront completement inutile pour certains, pour d'autre indispensable pour progresser (exemples : la respiration, le pas, le battement du pied, chanter les notes pour les entendre justes [http://www.slappyto.net/ForumBasse/Topic-Basse.aspx?id=25434] (23.3.2015)

REMARQUeS : Selon le contexte, entendre juste désigne le fait d'entendre ou de comprendre une musique, un message de manière correcte, exacte ; il désigne aussi le fait d'avoir l'ouïe fine et/ou un discernement judicieux. Juste reste invariable dans la majorité des cas, mais il s'accorde dans le dernier exemple du CW avec l'objet pronominal pluriel antéposé au verbe. Notons dans le premier exemple du CW l'emploi de écouter juste comme condition préalable pour entendre juste. Mentionnons également l'emploi de chanter faux.

\section{Entendre mauvais}

Vouloir dire que quelque chose est mauvais

1944 Il y a des faits révoltants; ainsi on coupe tout le bois, petit ou gros, le mauvais comme le bon, sans distinction ; j'entends mauvais, celui qui est classé comme ayant $80 \%$ de sa valeur. Il est considéré comme inutile (La Forêt québécoise)

1960 Et pourtant, même un mauvais article doit paraître (j'entends : mauvais quant au style, bien entendu). Le devoir d'un journaliste est la ponctualité (Morvan Lebesque, Chroniques du Canard enchaîné)

1970 Ce sont les pamphlets de Paul-Louis Courrier, cet helléniste sophistiqué, ce mauvais propriétaire, j'entends mauvais pour ses employés et fermiers, si mauvais qu'il finira assassiné (M. Girard, Le Libéralisme en France de 1814 à 1848)

REMARQUES : Entendre mauvais n'est pas employé dans une fonction adverbiale, mais comme recours rhétorique elliptique 'entendre (penser) que quelque chose est mauvais d'un point de vue qui est dit dans ce qui suit', surtout dans un discours oral ou oralisant. L'exemple de 1960 marque par la ponctuation ce qui est purement implicite - ou seulement marqué à l'oral - dans l'exemple de 1970 provenant d'un cours à la Sorbonne. Une occurrence plutôt adverbiale, mais purement contextuelle, se trouve s.v. toucher mauvais.

\section{Entendre net}

Entendre clairement, distinctement, précisément (au concret et au figuré 'comprendre')

Emploi absolu

1896 D'ailleurs maints d'entre vous, troupeau trié déjà,

Valent mieux que le monde autour qui vous jugea,

Lisent clair, visent droit, entendent net en somme,

Vivent et pensent, plus que non pas un autre homme,

Que tels, mes chers lecteurs, que moi, cet écrivain,

Tant leur science est courte et tant mon art est vain!

(Paul Verlaine, Euvres poétiques complètes)

1911 Et ce pas était bien le sien, il l'entendit plus net à l'étage au-dessous, et on montait toujours : il se sentit tout à coup pâle et, difficilement à présent, il cherchait son souffle, comme quand on a reçu un coup de poing dans l'estomac : mais il s'était trompé (Charles-Ferdinand Ramuz, Aimé Pache, peintre vaudois) 
1924 Tandis qu'échappent à ma mémoire les trésors les plus gracieux, ces rengaines misérables, je les entends aussi net que le premier jour (André Gide, Si le grain ne meurt)

Pronominal

1925 D'autres coups de feu s'entendirent, plus nets, qui, cette fois, semblèrent trouer le vent, heurter la nuit entière et l'émouvoir d'une chiquenaude (Maurice Genevoix, Raboliot)

\section{Corpus Web :}

c est mon premier casque gamer et je ne peut donc donner un avis trés objectif sur la qualité auditive dont il est l'objet. néanmoins, je pense qu il se défend trés bien sur le marché. il englobe trés bien les oreilles, pas lourd, on entend net, un bon casque qui tient la route [http://battlelog.battlefield.com/bf3/fr/forum/ threadview/2832654490169363508] (24.3.2015)

Pour la voie oui. Je l'entend net si pendant l'enregistrement je tape sur mon bureau je l'entend si ma femme me parle alors qu'elle est a $2 \mathrm{~m} \mathrm{du} \mathrm{pc}$ on l'entend moyennement fort [http:// www.guitariste.com/forums/homestudio,le-sonde-ma-guitare-avec-disto-est-pas-terrible-souscubase,161225,20.html] (24.3.2015)

S'agissant de primes d'assurances, le montant inscrit au précédent bloc doit s'entendre net et non hors taxes [http://ted.europa.eu/ udl?uri=TED:NOTICE:38668-2012:TEXT: FR:HTML] (24.3.2015)

REMARQUES : Dans le domaine de l'audition, entendre net désigne le fait de percevoir par l'oreille un son (musique, rire, voix) net, clair et distinct. Dans le dernier exemple du CW, s'entendre net est pris au sens de 'tout compris / ce qu'il faut payer effectivement'. Net est accordé dans l'exemple de 1925 (prédicat second détaché). Notons l'emploi de lire clair ; viser droit.

\section{Entendre noir}

Entendre le contraire (de quelque chose qui est dit blanc)

$\pi$ dire blanc

\section{Entendre prou}

n'entendre prou : ne pas bien comprendre

Transitif

1130 Pur ço Deus les laissat

$E$ a nus repairat,

E al prince de mort

Nus tolit par sa mort ;

Laissames la viez lei

Que Judeu unt pur fei,

Que il pru n'entendirent

Quant il Dé deguerpirent ;

C'est lur lei e lur vie

Qu'ordure signefie

(Philippe de Thaon, Bestiaire [trad., proba-

blement entre 1121 et 1135], 2819)

1119 Dit est obscurement

De la païene gent ;

Bien ert ço qu'il diseient,

Mais prut ne l'entendeient ;

Kar c'est allegorie

De fil sainte Marie

(Philippe de Thaon, Comput [1119 ou 1113], 822)

REMARQUES : Employé en tournure négative, entendre prou se disait en ancien français d'une chose qu'on ne comprenait pas vraiment, pas exactement.

\section{Enterrer profond}

Enterrer à une grande profondeur

Transitif

1632 Quand les caves sont faites en sorte que les corps sy peuvent conserver sans corruption, il est bien de les laisser sur des treteaux ; mais se cela n'est, il les faut enterrer assez profond (sainte Jeanne de Chantal [Jeanne Françoise Frémiot], Vive Jesus)

1652 Le diable [...] voyant que Nostre Seigneur l'avoit renversé de son siege, et luy avoit brisé la teste avec le baston de la Croix, voulut en perdre la mémoire : et se servant $\mathrm{du}$ ministere des Juifs et des Gentils ses complices, le fit enterrer profond dans la terre sur le mont de Calvaire (Jacques Branche, La Vie des saincts et sainctes d'Auvergne et de Velay) 
1857 Aussitôt après l'arrachage, nous mîmes la même quantité de fumier que la première fois et nous labourâmes pour l'enterrer profond, en suivant les mêmes lignes des sillons (Journal d'agriculture pratique)

2018 De toutes ses forces elle secoue l'appareil [= un piège], en vain. Il est riveté à un lest enterré profond. Sa jambe lui fait très mal, elle s'évanouit (Anne-Marie Garat, Le Grand Nord-Ouest)

\section{Entreheurter fort}

(Se) heurter mutuellement avec violence $\lambda$ heurter fort

\section{Entrelacer menu}

menu entrelacé : entrelacé étroitement, de manière serrée, finement

Transitif

-1300 Les crins ot biax et blons, menuz antrelaciez,

La barbe un po rossete, ses vis fu camoissiez

(Jehan Bodel, La Chanson des Saisnes [fin XIII'], 5668)

1511 Cest accoustrement assez longuet et large, estoit cueilly et retroussé au fauts du corps, et ne luy venoit que jusques à my jambe : sa ceinture estoit dosiere menue entrelassee à nœuz damours bien gentement (Jean Lemaire de Belges, Les Illustrations de Gaule et singularitez de Troye)

REMARQUES : Toujours employé avec le participe du verbe, entrelacer menu désignait le fait d'enlacer, d'emmêler, d'enchaîner des objets les uns avec les autres, de tresser des choses entre elles de manière fine, étroite, ajustée. Мenu s'accorde avec le sujet. Ceci met en évidence l'ancienneté de la tradition d'accorder l'adjectif-adverbe qui précède un participe (type fenêtres grandes ouvertes).

\section{Entre-pousser dru}

Se succéder rapidement, de manière convulsive Pronominal

1583 LE PROPHÈTE. Luy, ayant le parler arresté de sanglots,
S'entre-poussant l'un l'autre aussi dru que les flots

D'une mer courroucee, elevoit, pitoyable, Ses yeux enflez de pleurs vers le ciel implacable (Robert Garnier, Les Juifves)

REMARQUES : Entre-pousser dru désigne le fait de se succéder rapidement, vigoureusement, l'un poussant l'autre. Dans un emploi métaphorique, il réfère à des sanglots qui se succèdent vivement, de manière convulsive, " aussi dru que les flots ». Dru reste invariable et est modifié par aussi.

\section{Entrer droit}

Entrer directement, en ligne droite Intransitif

$\sim 1170$ Erec va siuant tote voie Le chevalier qui armez fu Et le nain qui l'avoit feru Tant qu'il vindrent a un chastel Mout bien seant et fort et bel ; Parmi la porte antrent tot droit. El chastel mout grant joie avoit (Chrestien de Troyes, Erec et Enide, 347)

$\sim 1250$ Et cil qui n'en ert pas naïs, Ne nul honme n'i counissoit, Entra par la porte tout droit, Si ala vers le tor amont (L’Atre périlleux, 4058)

+1341 et s'en ala droit a son ostel, et entra droit en ses chambres, et commença a faire le plus grant dueil du monde, du grant despit que elle ot de ce que sa suer lui ot dit (Livre de la conqueste de la princée de l'Amorée [(1341)-1346])

+1350 De la joie qu'il ot couleur prist a muer, Et a dit au varlet : « Toy voudroie sauver Droit par dedens mon sain s'i povoies entrer;

Car cix est mes cousins dont je t'oy tant loer "

(Brun de la Montaigne [2 $2^{\mathrm{e}}$ moitié XIV"e], 198)

+1489 Mais ilz vindrent ung peu tard. Ilz entrèrent tout droit en la chambre dudict duc, luy faisant reverence (Philippe de Commynes, Mémoires [1489-1498], II) 
1680 Je me trouvai de l'esprit ce jour-là, car songez que je ne savais rien, et qu'au hasard j'entrai tout droit dans ce ton, que j'aurais pris si j'avais été instruite (Mme de Sévigné, Correspondance)

1696 On voit une porte de fer, et une allée, à travers les choux et les champs, d'une grande longueur, à droite une autre porte, qui entre droit dans la première allée du bois, et à gauche une autre qui va dans les champs (Mme de Sévigné, Correspondance)

1755 Nos paladins enchantés, éblouïs crurent entrer tout droit en paradis (Voltaire, La Pucelle d'Orléans)

1836 Je montai chez elle comme un éclair ; je ne parlai à aucun domestique, j'entrai tout droit, connaissant la maison, et je poussai la porte de sa chambre (Alfred de Musset, Confessions d'un enfant du siècle)

1878 Rosalie entra droit dans la chambre, comme elle en avait l'habitude familière, pour montrer les provisions du matin à sa maîtresse (Émile Zola, Une page d'amour)

1910 ce mois de décembre et dans cette canicule $\mathrm{du}$ froid, alors que toute étreinte est resserrée et raccourcie, et cette nuit même toute brillante, l'esprit de joie ne m'entre pas moins droit au corps que lorsque parole fut adressée à Jean dans le désert sous le pontificat de Caïphe et d'Anne (Paul Claudel, Cinq Grandes Odes)

1947 LE LIEUTENANT. La balle s'est écrasée sur la queue de sa perruque. Si les balles étaient pointues, de tels accidents n'arriveraient pas. Les balles entreraient tout droit (Jacques Audiberti, Le Mal court / Théâtre)

1989 Ma maison avec son bon Dieu russe, sans confort, sans l'ombre d'un coussin, était on ne peut mieux. Mais quand elle se mettait elle aussi à faire des bruits... Parce qu'ils ne me venaient pas que du dehors, ils me venaient aussi du dedans. De tout près, de si près qu'ils m'entraient droit dans une de mes oreilles ou dans les deux à la fois (Remo Forlani, Gouttière)
Pronominal

1200 Li cuens Amiles ot ses ostaiges mis, Puis s'en entra tout droit en son chemin, Celui qui va de Blaivies a Paris, Ainz ne fina, si vint en pré flori (Ami et Amile, 906)

\section{CORPUS WEB :}

IRIMI : Point fort de l'AIKIDO, c'est l'action d'entrer droit sur l'adversaire tout en esquivant, action très positive. Presque tous les mouvements d'AIKIDO utilisent le IRIMI et au paroxysme du IRIMI : TENKAN [http://www.aikido.com.fr/ Glossaire-des-principaux-termes] (24.3.2015)

Entrer en psychiatrie, c'est entrer droit dans le mur, et ce jusqu'à la fin de votre vie. La psychiatrie vous laisse cependant le choix d'abréger votre vie [http://forum-anti-psychiatrie.com/ stefan-meijer] (24.3.2015)

C'est une bonne voie pour entrer droit dans la vie active [http://www.briag.com/baip/spip. php?article68] (24.3.2015)

Son image est entrée droit dans mon cœur, pour ma part, je ne puis l'oublier [http://www. jardinierdedieu.com/article-le-saint-pere-jeanpaul-ii-68718956.html] (24.3.2015)

Alors, India est entrée droite, avec ses longs cheveux brillants sur les épaules, une légère crispation dans le sourire, et elle a réussi [http://www. lavoixdunord.fr/Locales/Roubaix/actualite/ Secteur_Roubaix/2009/11/09/article_india-19ans-roubaisienne-elue-juree-du.shtml] (24.3.2015)

REMARQUES : Entrer droit se dit de quelqu'un/ quelque chose pénétrant à l'intérieur d'autre chose ou passant par autre chose en suivant une ligne droite, sans s’arrêter ni faire de détours. Droit reste invariable dans la majorité des cas. Dans le dernier exemple du CW, il s'accorde avec le sujet au féminin, se prêtant à une analyse de prédicat second orienté vers le sujet qui 'entre debout, dans une position bien droite, raide'. Droit est modifié par moins, tout. Il a tendance à s'associer avec la préposition qui le suit assez systématiquement (sur, dans, etc.). Dans les premiers exemples du CW, droit adopte le sens plus abstrait de 'directement'. Notons l'emploi de aller droit. 


\section{Entrer isnel}

Entrer rapidement

Intransitif

1235 Quanques j'en sai vous en dirai, Que ja de mot n'en mentirai.

Nous troi estiiens hui isnel

Entré dedens nostre batel

Pour venir en l'iauwe pescier,

Car d'argent avions mestier

(Philippe de Remi, sire de Beaumanoir, La

Manekine, 5041)

REMARQUES : En ancien français, entrer isnel désigne le fait d'aller à l'intérieur, de passer, de pénétrer, de s'introduire dans un lieu rapidement.

\section{Entrer juste}

Entrer exactement

Intransitif

1669 tirés la teinture, que vous metrés dans une fiole qui ait l'orifice tres-étroit, qu'il faut boucher, s'il se peut avec un bouchon de verre qui entre juste (Nicaise Le Febvre, Traicté de la chymie)

1857 On fait ensuite une petite tringle de même épaisseur que le montant, et taillée, quant à sa longueur et à sa largeur, de manière à pouvoir entrer juste dans l'entaille (Paul Nosban, Nouveau Manuel complet de l'ébéniste)

1914 Extrayant sans trop de peine un long caillou à moitié pris dans la surface d'un bloc isolé de marbre vert, Kourmelen obtint une cavité parfaite où le précieux objet lourd entra juste, offrant dès lors le même aspect que les multiples échantillons d'or partout sertis dans l'ophite de la caverne (Raymond Roussel, Locus solus)

\section{Entrer profond (parfont)}

Entrer, (s')enfoncer profondément

Intransitif

1170 Reüsant les ont amenez

Par estoveir jusqu'a la mer :

Lors en i covint maint entrer

Plus parfont que jusqu'as aisseles (Benoit de Sainte Maure, Le Roman de Troie, 7210)

1275 Li os par les illiers li saillent $\mathrm{Ou}$ trestoutes humeurs defaillent,
N'el n'a, ce semble, point dou ventre

Fors le leu, qui si parfont entre

Que touz li piz a la meschine

Pent a la claie de l'eschine (Jehan de Meun, Roman de la rose [1269-1278], 10174)

1276 Voit le Corsubles, le bran sacha errant, Moult fierement et de hardi samblant ; Jofroi refiert seur l'iaume esplendissant. Parfont ala li coups ou hiaume entrant, Li bons haubers li fist de mort garant (Adenet le Roi, Les Enfances Ogier, 5502)

+1350 Li .iiij. sont entré bien parfont ens ou bois, Et li autre vassal estoient au hernois, Qui de la grant forest gardoient les destrois (Brun de la Montaigne [2 moitié XIV $]$, 738)

1926 Il fallut encore les [= les chemises] serrer avec force pour que la lente hémorragie cessât et, à chaque mouvement, les plis entraient plus profond (Georges Bernanos, Sous le soleil de Satan)

1936a Mais tenez ! Lorsqu'on réfléchit au succès fabuleux, ininterrompu, d'un livre comme le Don Quichotte, on est forcé de comprendre que si l'humanité n'a pas encore fini de se venger par le rire de son grand espoir déçu, c'est qu'elle l'avait porté longtemps, qu'il était entré bien profond !

(Georges Bernanos, Journal d'un curé de campagne)

Transitif

+1472 Et advint de celluy gect que le seigneur de Haulbourdin fut atteint sur le bort en dehors de sa targe ; et glissa le cop, et vint atteindre sur le cousté senestre, ung peu au dessus du faulx du corps, perça le harnois, et entra le fert très profond en la char dudit seigneur de Haulbourdin (Olivier de la Marche, Mémoires [ $4^{\mathrm{e}}$ quart $\left.\mathrm{XV}^{\mathrm{e}}\right]$ )

1936b Le gardien m'a remis sur mes pieds, il portait plus qu'un haut de tunique... Par le bas il finissait en queue de boudin... Sa longue fourche pour allumer le gaz, il nous a fait bien rire avec... Il se l'entrait profond dans le nez, et même jusqu'au bout (Louis-Ferdinand Céline, Mort à crédit) 


\section{CORPus WeB :}

dans les pubs ont jette les mecs par les fenêtres, ou ils sont des gros cons faineants, insensibles, sales et irresponsables. 20 fois par jour. même avec de l'humour, ça finit par entrer profond dans le systeme nerveux de tout le monde [https://fr-fr.facebook.com/francetvinfo/ posts/664340216942813] (24.3.2015)

Pour répondre à cette question, il faut entrer profond dans les recoins obscurs de l'âme humaine, individuelle et collective [http://www. homo-rationalis.com/texte.php?idte $=71$ ] (24.3.2015)

C'était parfaitement justifié au regard de la violence du coup (7 Blessures quand même, la lame est entrée profond) et c'était une manière narrativement assez élégante de l'armer avant le combat final contre Sophie [http:// www.terresetranges.net/forums/viewtopic. php?pid=6642] (24.3.2015)

Je ne veux pas entrer profonde et significative sur une série de $\mathrm{HBO}$ qui a pris fin presque 10 il ya des années, mais soyons réalistes ici : Big était pas un ange, et Carrie était loin d'être une pute [http://www.celebrityabout.com/fr/chrisnoth-says-sex-and-the-citys-carrie-bradshawwas-a-whore] (24.3.2015)

REMARQUES : Sous sa forme transitive, entrer profond désigne le fait de faire entrer, d'introduire, d'enfoncer quelque chose profondément. Sous sa forme intransitive, plus usuelle, il réfère au fait de pénétrer, de s'introduire, de s'engouffrer profondément dans un lieu ou dans quelque chose d'abstrait (ex. : le sommeil). Profond reste invariable dans la majorité des cas. Toutefois, dans le dernier exemple il s'accorde avec le sujet caractérisant son attitude. Profond est modifié par bien, plus, si, très.

\section{Entrer soef}

s'en entrer soef: entrer, s'introduire doucement, lentement (dans quelque chose)

Pronominal

+1250 Par la ou li regorz couroit

Du jardin quant pleü avoit :

Par la s'en est entrez dedenz

Tout souef, et jure ses denz

Que a cui que il doie nuire

$\mathrm{Y}$ fera il ses grenons bruire
Ou de chapon on de geline (Le Roman de Renart [ $2^{\mathrm{e}}$ moitié XIII $\left.{ }^{\mathrm{e}}\right]$ XVI, 160)

REMARQUES : Entrer soef désignait le fait de pénétrer, de s'introduire tranquillement, sans précipitation dans un lieu (ici : un jardin).

\section{Envoyer clair}

Dire clairement, sans ambiguïté

$\pi$ envoyer net

\section{Envoyer courant}

envoyer tout courant : envoyer spontanément, sur le champ, en grande hâte, sans hésiter Emploi absolu

1740 De la campagne où elle est, elle envoie tout courant savoir de Mme du Châtelet, si S.M. passera (Voltaire [lettre de Voltaire à Frédéric II])

REMARQUes : Envoyer courant désigne le fait de faire partir, de faire parvenir quelque chose à quelqu'un par l'intermédiaire d'une personne ou d'un service public, l'action étant décidée spontanément par le sujet, sans hésitation. Courant reste invariable et est généralement modifié par l'adverbe d'intensité tout.

\section{Envoyer droit}

I. Envoyer directement

Transitif

+1150 Son oste les enuoie droit a Poitiers, C'un anel li dona par amistiet, Le chemise et les braies dont ot mestier (Aiol et Mirabel [ $2^{\mathrm{e}}$ moitié $\left.\mathrm{XII}\right]$, 3754)

1230 - Oïl, ce dist li enfes, ja mar le mescrerez ; Tot droit à Montorgueil nos envoie li bers.

Il est à son neveu coreciez et irez

Tant que il l'a feru de son gant sor le nez (Gui de Bourgogne, p. 52)

$\sim 1275$ Et si m'i a fait chevalier

Morgain, mentir ne vous en quier, Qui suer est au bon roi Artui ;

Et si m'envoie droit a lui

Por moi apenre et enseignier

Comment je me pourrai aidier

D'armes, se mestier en avoie

(Floriant et Florete, 998) 
1285 Devant Marcadigas alerent, Tout en plorant le saluerent, Car ne s'en porent consirrer. Et lors li prirent a moustrer Que li rois Carmans les avoit Envoyez a lui trestout droit (Adenet le Roi, Cleomadés, 6098)

-1469 Puis envoya deux ou trois compaignons droit à la ville veoir s'il y avoit plus ame, et ilz lui rapporterent que non (Jean de Bueil, Le Jouvencel [1461]-1468, II, p. 19)

1669 et finalement qu'il fit un feu commun où chacun se pouvoit librement chauffer, proche lequel il avoit mis un archer d'airain avec sa fleche encochée, et une telle inscription, quiconque me frappera je tireray ma fleche, ce qui arriva lors qu'un fol frappa ledit archer, qui ne manqua tout aussi-tost de décocher sa fleche et de l'envoyer droit au feu, qui fut soudainement esteint (Gabriel Naudé, Apologie pour tous les grands hommes qui ont esté accusez de magie)

1837 Aussi n’hésitez-vous pas et vous tuez un amour sincère de peur qu'il ne mente plus tard, comme cette mère qui, dans la prévoyance que son enfant pourrait pécher un jour, le poignarda, pour l'envoyer tout droit au ciel (Maurice de Guérin, Correspondance)

1884 Vous pouviez l'envoyer droit en cour d'assises... et ça ne l'a pas corrigée, elle vous mange encore aujourd'hui, elle vous grugera jusqu'au dernier liard... vous croyez peut-être que je mens ! (Émile Zola, La Joie de vivre)

1937 Parce qu'Arsène est bien trop canaille pour t'avoir envoyée ici tout droit, dans la gueule du loup (Georges Bernanos, Nouvelle Histoire de Mouchette)

1939 C'est là qu'il fit le coup du bras et de la tête ensemble d'un émir bardé de fer qu'il envoya droit en enfer (René Grousset, L'Épopée des croisades)
II. Jeter, lancer quelque chose horizontalement Transitif

1933 - Fort bien fait. En somme, récapitule-t-il : ceci, qui vous a frappé, comme s’il avait reçu une blessure ; et aussi naturellement, les vomissements de lait. Quatre biberons bien bus, n'est-ce pas ? Et le cinquième rejeté, mais là, franchement. Envoyé net, droit, comme un beau jet (son geste dessine la parabole) (Joseph Malègue, Augustin ou Le Maître est là)

\section{CORPUS WEB :}

L'algorithme de pilotage a deux possibilités : l'écraser ou vous envoyer droit dans un mur. Autrement dit, la tuer ou vous tuer ? [http://blog.tcrouzet.com/2015/03/23/bruxellesbelgique-2145] (24.3.2015)

Après avoir fait rouler un ballon, nous apprenons à l'envoyer droit devant nous et quoi de mieux que le bowling pour que ce soit plus amusant... [http://www.em-herail.ac-aixmarseille.fr/spip/spip.php?article106] (24.3.2015)

En ayant pris un élan de 5 pas à allure de marche, frapper la balle pour l'envoyer droit devant soi [http://www.polo-velo.net/regles/ Commentinitierdesdebutantsaupolo-velo.pdf] (24.3.2015)

Le pouce empêche à la boule d'êtrre de rouler droit, c'est à dire qu'il donne un effet, or pour un contrôle optimum il faut pouvoir l'envoyer droite. Et dans certaines situations, adapter son geste pour y mettre un effet. [http://www. boulistenaute.com/modules/forum_supporters/ viewtopic.php?topic_id $=4096 \&$ viewmode $=$ co mpact \&order $=$ ASC \& type $=\&$ mode $=0 \&$ start $=24]$ (24.3.2015)

REMARQues : En (I), envoyer droit désigne le fait d'envoyer, de faire partir quelqu'un/quelque chose directement, sans détours. Envoyer droit est suivi d'une indication de lieu ou du destinataire. Notons que le lieu de destination peut être concret ou abstrait (le ciel, l'enfer). Sous (II), il réfère au fait de jeter un objet dans les airs, celuici parcourant une ligne droite, horizontale. Droit reste invariable dans la majorité des cas, mais dans le dernier exemple du CW il s'accorde avec l'objet au féminin. Droit est modifié par l'adverbe d'intensité tout qui vient renforcer l'idée de fi- 
nalité de l'action. Droit remplit souvent la fonction du modifieur de la préposition qui le suit (à, dans, devant, en). Notons l'emploi de rouler droit.

\section{Envoyer net}

I. Envoyer, dire d'une manière catégorique, sans ambiguïté, sans équivoque

Transitif

1845 Je ne sais si les jésuites s'en sont mêlés, mais on lui a envoyé clair et net sa destitution du collège (Gustave Flaubert, Correspondance)

II. Envoyer, éjecter d'une manière précise, nette Transitif

1933 - Fort bien fait. En somme, récapitule-t-il : ceci, qui vous a frappé, comme s'il avait reçu une blessure ; et aussi naturellement, les vomissements de lait. Quatre biberons bien bus, n'est-ce pas ? Et le cinquième rejeté, mais là, franchement. Envoyé net, droit, comme un beau jet (son geste dessine la parabole) (Joseph Malègue, $\mathrm{Au}$ gustin ou Le Maître est là)

\section{CORPuS Web :}

une identité unique, des musiciens qui se donnent à l'ensemble sans imposer une dissonance pour l'honneur personnel, un chanteur qui ne se réserve aucun repos et maîtrise les variations au service encore une fois d'un ensemble qui envoie net, et sans détour, mérite le respect le plus total et l'espoir d'un nouvel opus, le plus vite possible [http://archives.magicfiremusic. net/chronique.php? cat $=$ chronique\&id $=3285$ ] (24.3.2015)

Au début, t'as l'impression d'être assis sur le réservoir par rapport à la Calif, mais p’tain quel bourrin. Ca envoie net. Limite pousse au crime, t'as envie de rouler comme avec un 4 pattes japoniais qui gueule, mais là s'arrête la comparaison [http://perso.ovh.net/ webemoi/guzzi/ viewtopic.php? $\mathrm{p}=72730 \&$ sid $=03 \mathrm{c} 250 \mathrm{~b} 07 \mathrm{~b} 8 \mathrm{ec} 273$ 7b4768ad99daf871] (24.3.2015)

Je sais pas si tu 1 as envoyee net mais $j$ ai rien recu [http://www.gturismo5.net/forum/ viewtopic.php? $\mathrm{p}=595378 \&$ sid $=1$ edadfd34fe2bbc7 02e4e78ea0633afe] (24.3.2015)
REMARQUES : Envoyer net (I) réfère au fait de faire parvenir à quelqu'un une missive, dont le caractère est clair, incontestable, précis. (II) signifie 'jeter, lancer (quelque chose) d'une manière précise, nette'. Notons les collocations avec les adjectifs-adverbes droit et clair, définissant plus précisément l'action, soulignant sa netteté. Net reste invariable. Notons l'emploi absolu dans le premier et le deuxième exemple du $\mathrm{CW}$, au sens de 'être puissant, efficace'.

\section{Éplucher gros}

Écrire dans un but critique, sans ménagement, écrire grossièrement

Emploi absolu

1964 M. Philippe Dereux - auteur d'un Traité des épluchures - ne compose ses toiles qu'avec ce qu'on ne mange pas des fruits et des légumes. - Quand il écrit, il épluche très gros - et il traite sans ménagement ce beau fruit qu'est la langue française (Le Figaro littéraire, 10-16 décembre 1964 / Grundt : 396)

Corpus Web :

Ceux que j'ai conservé et que je replante régulièrement sont encore d'une troisième sorte dite " patate ", ils sont assez gros et productifs, une partie sort un peu " tourmentée », mais la taille fait qu'on est moins embêté d'éplucher gros, et la plupart sont quand même assez réguliers aussi [http://fr.rec.jardinage.narkive.com/ BUbCzeMO/contre-les-mulots] (24.3.2015)

1 tonnes de patates à éplucher gros ! [https://twitter.com/El_nympho/status/ 251613025914736641] (24.3.2015)

REMARQUES : L'exemple de 1964 illustre l'emploi métaphorique du verbe éplucher qui souligne l'examen minutieux, l'intention critique dans la production écrite. Gros suggère une expression maladroite, le fait de rédiger ou de critiquer sans ménagement, avec peu d'égards et sans doute dans le but de provoquer le lecteur. Par contre, le verbe est employé dans son sens concret dans le CW. Gros reste invariable et est modifié par un adverbe d'intensité très. 


\section{Épurger blanc}

Purifier totalement

Transitif

1130 Kaladres signefie

Jesu le fiz Marie :

Tuz est blans espurgiez

E mundes de pechiez,

Sulune ço que Deus dit

Meïsme en sun escrit

(Philippe de Thaon, Bestiaire [trad., probablement entre 1121 et 1135], 2177)

REMARQUES : Dans un contexte religieux, épurger blanc prend un sens résultatif référant au fait de rendre le cœur, l'âme ou les sentiments de quelqu'un plus purs, de les purifier en chassant les pensées ou les sentiments contraires à une religion, aux bonnes mœurs ou à l'honneur.

\section{Équiper moderne}

Munir d'un équipement moderne

Transitif

1959 On commence à nous équiper moderne (Exemple entendu, 24 avril 1959 / Grundt : 239)

\section{CORPUS WEB :}

Je pense que tu as raison je vais choisir de m'équiper " moderne " avec un produit adapté à win 8.1 [http://forum.pcastuces.com/ acquisition_images-f4s 83318 .htm?page $=1 \&$ ] (24.3.2015)

Avec la chute vertigineuse de la cote de cette marque et par rapport au prix neuf c'est une aubaine pour s'équiper moderne en MF avec une très bonne qualité d'image [http://www.galeriephoto.org/n2-f1-99790.html] (24.3.2015)

Si tu participe à un nature ou un 3D avec un arc en bois tu pars avec un handicap certain par rapport aux tireurs équipés moderne [http:// www.webarcherie.com/index.php/topic/18193les-aventures-de-brutus48/page-4] (24.3.2015)

Ce centre d'affaires parisien met à votre disposition des solutions de location de bureaux équipés modernes à l'intérieur de la Gare de Lyon, dans un immeuble classé monument historique [http://www.multiburo-gare.com/sites/ $\mathrm{fr} /$ Domino/location-bureau-paris-gare-de-lyonimmobilier.html] (24.3.2015)
REMARQUES : Équiper moderne désigne le fait d'aménager un espace, un lieu, un matériel au moyen de fournitures, d'accessoires, de meubles modernes. Moderne reste invariable dans la majorité des cas, mais dans le dernier exemple du CW il s'accorde avec l'objet du verbe, se rapprochant ainsi des prédicats seconds orientés vers l'objet, ce qui accentue la dynamique résultative. On peut également interpréter ce dernier exemple comme suite de deux adjectifs adnominaux modifiant « bureaux ».

\section{Errer droit}

Voyager, se rendre directement, en ligne droite Intransitif

+1150a Puis en uient droit esrant al cheualier, Vn escamel d'iuoire mist a ses pies, Andeus ses esperons a resachies, Puis les a bien forbis et essuies, Al renge de l'espee bien atachies (Aiol et Mirabel [2 moitié XII $\left.{ }^{\mathrm{e}}\right], 2064$ )

+1150b Droit a saint Nicolai dont uous oi aues, Celui c'on dist a Bar, sont .i. main ariue, Tout droit a Panpelune ne finent de l'esrer (Aiol et Mirabel [2 $2^{\mathrm{e}}$ moitié XII $\left.{ }^{\mathrm{e}}\right], 10602$ )

1177 Que par trois foiz mout longuemant Sona li corz mout hautemant. Et ele erra droit vers la voiz, Tant qu'ele vint a une croiz, Qui sor la chauciee iert a destre, Et la pansa que pooit estre Li corz et cil, qui l'ot soné (Chrestien de Troyes, Yvain ou Le Chevalier au lion, 4871)

$\sim 1190$ - Sire, dist Sortimbrans, tuit soient desmembrez!

Aprés porrons par forche cevauchier et errer

Tout droit a Morimonde, ou Karles est ostelez.

Si le prendez par forche, le malvois rasotez (Fierabras (L), 2814)

+1233 Li damoisiax mot n'en savoit, Par iluec vint errant tot droit [variante, éd. Constans : passant tot dreit] Et quant le vit de loing le montre, De la roche venir encontre Grant et hideus et fier et fort, 
Adont ot grant poor de mort

(Roman de Thèbes [ $2^{\mathrm{e}}$ tiers $\left.\mathrm{XIII}{ }^{\mathrm{e}}\right], 288$ )

\section{CORPus Web :}

Après avoir commandé une bière, il la but goulûment, puis laissa son regard errer droit devant lui [http://short-edition.com/oeuvre/ nouvelles/les-oiseaux-de-nuit] (24.3.2015)

Bande de fouteurs de merde!

David est parti errer droit devant lui, anéanti... [https://es.answers.yahoo.com/ question/index?qid=20100414110948AAOhvD0] (24.3.2015)

Des yeux comme je n'en avais jamais vu auparavant me firent l'honneur d'errer droit devant eux, avant de plonger vers le sol à la recherche du trésor perdu [http://ryoma-naruto.forumactif. com/t6221-tori-event-a-l-abri-des-masques] (24.3.2015)

REMARQUeS : En ancien français, errer droit désigne le fait d'aller, de marcher, de voyager directement, en ligne droite vers un lieu, ou, de manière plus abstraite, vers une chose (ici : une voix). Le verbe oirrer [errer], qui remonte au latin iterare, signifiait 'faire du chemin'. Plus tard, la contamination avec errer (du lat. errare 'commettre une erreur') donnera errer 'aller sans savoir où aller, en ayant perdu le nord'. Le CW illustre l'expression errer droit devant quelqu'un qui réfère au fait d'aller, de bouger sans but ni direction, de vagabonder. Droit reste invariable et est modifié par tant, tout. Il remplit souvent la fonction du modifieur de la préposition qui le suit (à, par, vers).

\section{Errer épais}

Se déplacer en groupes denses, compacts Intransitif

1572 Et tels qu'on voit au milieu de l'este, Sous la plus vive et brulante clarté, Errer espais d'un gros monceau qui tremble,

Les moucherons qui volent tous ensemble, Gresles, menus, tournans de lieux en lieux,

Et si petits qu'ils nous trompent les yeux (Pierre de Ronsard, La Franciade, p. 109)
REMARQUES : Errer épais se disait d'un essaim d'insectes se déplaçant, allant d'un côté et de l'autre sans but ni direction précise, l'adjectifadverbe épais référant à la densité, à la compacité de l'essaim.

\section{Errer étroit}

Avancer dans des passages étroits

$\lambda$ errer serré

\section{Errer serré}

Avancer en rangs serrés

Intransitif

1175 Par uns destrois doutés et fors

Convient passer les Poitevins,

Les Normans et les Angevins.

Tant oirrent seré et estroit

Qu'il sont venu a cel destroit

(Gautier d'Arras, Ille et Galeron, 1555)

REMARQUES : Errer serré et étroit s'insère dans la série productive qui pivote autour du verbe errer, notamment dans l'ancienne langue. Serré et étroit restent invariables.

\section{Esbanier bel}

Se divertir, s'amuser beaucoup

Pronominal

1285 Reviaus et Deduis et Baudours

Erent adont si sormonté

Qu'il estoient roi coronné.

Moult se sont bel esbaniié

(Adenet le Roi, Cleomadés, 17531)

Remarques : Traduisant l'idée de divertissement, de bon temps passé, s'esbanier bel se dit du fait de s'amuser, de se réjouir, de s'égayer considérablement. Beau adopte la forme neutre bel qui est précédé par l'adverbe d'intensité moult.

\section{Esgarder droit}

Regarder fixement devant soi, observer (quelqu'un/quelque chose) dans les yeux Transitif

$\sim 1130$ Aigle est reis des oisels, Mult mustre essamples bels.

En latine raisun

Cler-veant l'apelum,

Kar le soleil verat

Quant il plus clers serat, 
Tant dreit l'esguarderat

Ja l'oil ne cillerat

(Philippe de Thaon, Bestiaire [trad., proba-

blement entre 1121 et 1135], 2019)

1160a Por ce qu'el li avoit mentie

La foi qu'el li avoit plevie,

Ne s'osoit pas vers lui torner,

Ne ne l'osot mie esgarder, [variante : dreit

esguarder, II, p. 159]

Ne pres de lui ne s'aprismot :

Por son forfet se vergondot (Eneas, 2660)

1160b Qui un l'an amoine devant,

Se il doit vivre an avant,

Li calades lo set et voit,

Enmi lo vis l'esgarde droit ;

Et s'il morir doit de cel mal,

Il an mostre signe mortal (Eneas, 7474)

1200 O li descendent li prodome,

Li senator, li per de Rome ;

Mes a l'entrer esgardent droit

Si qu'il n'i soient trop estroit

(Li Romanz d'Athis et Prophilias, 8841)

REMARQUES : En ancien français, esgarder droit désigne le fait de regarder ou de considérer quelque chose/quelqu'un fixement, comme si le sujet était obsédé, fasciné par l'objet contemplé. Droit reste invariable et est modifié par tant. Notons l'emploi de cler-veant (clairvoyant). VoIR AUSSI : regarder droit

\section{Esgarder grand}

Regarder avec envie, avidité (avec de grands

yeux), intensément

Intransitif

1325 Autres deduis au cuer le point,

N'i esgarda ne poi ne grant,

Adès avoit le cuer engrant

De Dieu loer et gracier

(Watriquet de Couvin, Dits, p. 205, 191)

REMARQUES : En ancien français, esgarder grand désignait le fait de regarder intensément. Dans l'exemple grand s'oppose à poi 'peu'. Étant donné que le quantifieur principal de l'ancien français était petit, on peut dire que le verbe esgarder grand est le contraire d'esgarder petit.

\section{Essouffler net}

Essouffler, couper le souffle brusquement, brutalement

Transitif

1945 Une idée tout d'un coup l'essoufla net (Jean-Paul Sartre, L'Âge de raison)

CORPUS WEB :

Un parc d'attraction est dans l'obligation permanente de se renouveler, ce qui fait par exemple europa Park qui fait limite une nouvelle attraction par an (ce que je trouve un peu énorme car un jour, en panne d'idées cela va s'essouffler net et plis dur sera la chute) [http://www. disneycentralplaza.com/t44376p440-ratatouille1-aventure-totalement-toquee-de-remy] (25.3.2015)

C'est flagrant quand je te dis que le TDI s'essouffle net à 3500/3700tr/min alors que le TDS souffle encore à 4000tr/min [http://www.forumauto.com/marques/volkswagen/sujet17391.htm] (25.3.2015)

Le moulin était typé On/Off. En dessous de 2000tr/min c'était le coma, puis d'un coup elle partait comme une balle avant de s'essouffler net vers les 4000tr/min dans un énorme panache de fumée noir [http://www.forum-auto. com/automobile-pratique/discussions-libres/ sujet425088-16310.htm] (25.3.2015)

REMARQUES : Essouffler net désigne le fait de mettre presque hors d'haleine, à bout de souffle et ce, d'une manière nette, brutale, abrupte, ou, pour un moteur, de baisser brutalement en puissance. Net reste invariable (v. le dernier exemple du CW où le sujet est au féminin).

\section{Estimer fort}

Estimer beaucoup

Transitif

1713a LL. MM. [= Leurs Majestés] ont envoyé ordre à M. Guerra, autrefois grand chancelier de Milan et qui étoit ici depuis quelque temps, fort aimé et estimé de ceux qui le connoissent, de se rendre diligemment à Madrid où on lui donnera un emploi digne de ses services (Philippe de Dangeau, Journal)

1713b Le roi d'Angleterre, toujours sous le nom de chevalier de Saint-Georges, a passé quelques jours chez M. le prince de Vau- 
demont à Commercy, où étoit M. de Lorraine avec toute sa cour ; il s'est fait fort estimer et aimer en ce pays-là (Philippe de Dangeau, Journal)

\section{Corpus Web :}

Tu pourra t'estimer fort quand tu sera dans le top 10 d'un tournois (c'est beaucoup plus dur) [http://www.urban-rivals.com/community/ forum/?mode=viewsubject\&id_subject=122511\&1 anguage $=1 \&$ subject_page $=0$ ] (25.3.2015)

A la fête foraine il y a un jeu de force qui consiste à pousser un chariot sur une piste horizontale puis à le lâcher verste une piste en pente. Plus le chariot monte haut, plus le lanceur pourra s'estimer fort [http://www.ilephysique. net/forum-sujet-237817.html] (25.3.2015)

Et plus tu prouves ta valeur sur un terrain où elle s'estime fort, plus tu as de chance que tu la mettes dans ta poche [http://www.jeuxvideo. com/forums/1-51-52842610-1-0-1-0-copine-avecego-surdimensionne.htm] (25.3.2015)

Toujours est-il que sa vie est un enfer depuis des mois et queson corpsémet dessignauxd'alerte. Elle s'estime forte pour supporter tout ça [http:// www.weightwatchers.fr/community/mbd/post. aspx?page_size $=25 \&$ rownum $=4 \&$ threadpage_no $=1 \&$ sincedate $=24 \% 2 \mathrm{~F} 11 \% 2 \mathrm{~F} 2010+00 \% 3 \mathrm{~A} 00 \% 3 \mathrm{~A}$ 00\&thread_id=10132688\&board_id=490\&forum id=1\&thread_name=les+mamans+du+24+novem bre\&mod_no $=$ \&daterange $=2$ days\&viewchange $=$ OPENDATEDESC] (25.3.2015)

REMARQUeS : Accompagné du verbe aimer, généralement sous la forme passive, estimer fort se dit de quelqu'un qui est très apprécié, considéré, dont on a une très bonne opinion. Dans cette acception, fort est un intensifieur antéposé au verbe. Le CW fait apparaitre le sens, plus usuel aujourd'hui, de 'estimer être fort', qui entraîne l'accord (prédication seconde orientée vers l'objet direct du verbe). Notons l'emploi de aimer fort.

\section{Estimer haut}

I. Estimer, apprécier beaucoup ; porter un jugement très favorable, très positif sur quelque chose ou quelqu'un

Transitif

1550 Certenement celui que tes chansons Paissent, ravy du plaisir de leurs sons, Ne sera point haut estimé pour estre
Ou à l'escrime, ou à la lutte adestre,

Ni de laurier couronné ne sera, Car l'arme au poingt jamais n'abaissera L'orgueil des rois ni la fureur des princes, Portant vainqueur le feu dans leurs provinces (Pierre de Ronsard, Les Odes, p. 128)

1648 De cent princes qui te verront

Tu seras tout haut estimée ;

Et nos poetes écriront

Pour soutenir ta renommée

(Tristan l'Hermite, Les Vers héroïques)

1831 Je le veux bien, non que je sois une femme à estimer bien haut comme vous le croyez, mais parce que j'ai un cœur ardent pour chérir mes amis (George Sand, Correspondance)

1843 Il me donnera les renseignements que je désirerai. Il n'estime pas assez haut l'influence de la presse quotidienne (Jules Michelet, Journal)

1862 La particule, on le sait, n’a aucune signification. Mais les bourgeois du temps de La Minerve estimaient si haut ce pauvre de qu'on se croyait obligé de l'abdiquer (Victor Hugo, Les Misérables)

1921 «Le P. de Condren, qui avait sa confiance, l'estimait très haut » (Henri Bremond, Histoire littéraire du sentiment religieux en France)

1936 ce sont des valeurs qui ne s'achètent point, des valeurs estimées bien plus haut que l'argent (Alain, Propos)

1943 Il s'agit de Raymond Radiguet. Je l'envoyai à Cocteau qui le comprit entièrement, l'estima très haut, et comme on disait alors, le « lança » (Max Jacob [Lettre à J. F. Lefèvre-Pontalis du 14 janvier 1943])

II. Faire une estimation élevée, déterminer le prix (d'un bien, d'une valeur, d'un objet), qui est élevé

Pronominal

1791 Ensuite, on sait que le capital d'une rente territoriale s'estime beaucoup plus haut que le capital d'une rente égale sur le Trésor public (Emmanuel Sieyès, Euvres) 
1891 Peut-être, après les renseignements que publient ses journaux sur le Tonkin, était-il disposé à s'estimer trop haut, mais quand il lit les articles de Rochefort, nul doute qu'il ne s'écrie : «L'excellent penseur ! » (Maurice Barrès, Le Jardin de Bérénice)

1953 Si je ne puis dire de qui je suis le fils, je sens un tel feu et une telle âme en moi, une si haute passion enfin me transfigure que je m'estime assez haut pour mériter Julia (Albert Camus, La Dévotion à la croix)

Emploi absolu

1870 je crois qu'un tiers en sus et même la moitié, ce ne serait pas estimer trop haut (Émile Erckmann et Alexandre Chatrian, Histoire d'un paysan)

\section{CORPUS WeB :}

En fait, pour être tout à fait franc avec toi, j'ai cru comprendre en te lisant que tu cherchais à me faire passer pour un businesman qui cherche à toujours estimer haut [http://usebu. forumactif.org/t2339-les-estimations-nec-cest-la] (25.3.2015)

On estime à plus de douze mille les séances que donna Jasmin pendant trente ans, et à plus de $4300000 \mathrm{~F}$. les sommes ainsi recueillies pour les pauvres. Tant de gloire et de charité devaient faire estimer haut et loin le poète [http://www. cosmovisions.com/Jasmin.htm] (25.3.2015)

Chaque personne qui estime haut la logique ou même les lois n'en peut guère ressentir que du mépris [http://www.ahriman.com/fr/ censure_09_2010.htm] (25.3.2015)

Rien d'étonnant si on réfère au fait que plus de $90 \%$ des interviewés ne connaissent pas cette céréale. Pour autant, 31,5\% ont estimé haute la valeur nutritive du fonio [http://pdf.usaid.gov/ pdf_docs/PA00HMX8.pdf] (25.3.2015)

REMARQues : Estimer haut (I) désigne le fait d'avoir une très bonne opinion de quelqu'un, de l'apprécier beaucoup, de le juger positivement. Sous la forme pronominale, il signifie 'avoir une très bonne opinion de soi'. (II) renvoie au fait de déterminer le prix, la valeur (au sens propre ou au sens figuré) de quelque chose par une appréciation, passablement élevée, supérieure aux attentes. Haut reste invariable dans la majorité des cas, mais il s'accorde quand il adopte le sens de 'estimer être haut' dans le dernier exemple du $\mathrm{CW}$, au sens concret, pour indiquer une valeur haute. Il est modifié par assez, beaucoup plus, bien, pas assez, si, tout, très, trop.

\section{Estimer serré}

Donner l'estimation la plus juste possible

Emploi absolu

1938 Les adjudications étaient proches : le garde-ventes ne manquait point d'ouvrage. Il fallait estimer serré, très serré ; on s'attendait à une nouvelle baisse des cours (Maurice Genevoix, Bernard)

\section{CORPUS WEB :}

Auparavant, on a pu mesurer combien l'attente des résultats d'un scrutin, tout d'abord estimé serré, s'était révélée petit à petit un désaveu pour la majorité sortante, comme dans nombre de villes socialistes [http://www.lavoixdunord. $\mathrm{fr} /$ region/loos-victoire-historique-pour-annevoituriez-qui-emporte-ia21b49767n2029756] (25.3.2015)

Le CÉ [= Comité d'entreprise] émet toutefois une réserve pour le projet de Katherine concernant le budget attribué aux repas l'estimant serré [http://www.csmb.qc.ca] (25.3.2015)

Ton bet Turn représente pas mal de faiblesse, certains joueur exploitent ça à outrance avec des bluffs pourri sur scarry card River face à des joueurs qu'ils estiment serré [http://www. poker-academie.com/forum/texas-hold-em-nolimit/372824-nl25-coment-lire-lead-riviere.html] (25.3.2015)

Tes parents, s'ils s'estiment " serrés », devraient avoir encore plus à cœur que tu réussisses parce que chacun sait bien que nos parents (à plus forte raison sans épargne) devront compter sur nous financièrement pendant leurs vieux jours et notamment en cas de perte d'autonomie ou de veuvage... [http://forum.doctissimo. $\mathrm{fr} /$ grossesse-bebe/mamans-chretiennes/allefatima-sujet_4293_13.htm] (25.3.2015)

REMARQues : Estimer serré désigne le fait de déterminer le prix, la valeur de quelque chose par une appréciation, laquelle doit être la plus précise possible. Il réfère aussi comme prédicat second à l'écart serré qui sépare les résultats d'un 
scrutin (premier exemple du CW) ou à une situation financière difficile (dernier exemple du CW). Serré est aussi un terme du jeu de poker et désigne un joueur qui ne joue que peu de mains preflop, ou qui ne reste dans le coup postflop qu'avec une main décente (v. avant-dernier exemple du CW). Serré reste invariable dans la majorité des cas, sauf dans le dernier exemple. Il est modifié par très. Notons la réduplication serré, très serré.

\section{Estraindre soef}

Serrer délicatement, doucement

Transitif

+1100 L'anfes Gerairs revient de la cuitainne, S'ait chosie Gaiete sor la fontainne, Antre ses bras l'ait pris, soueif l'a strainte. Vante l'ore et li raim crollent :

Ki s’antraimment soueif dorment (Romances et pastourelles françaises des $X I I^{e}$ et XIII ${ }^{e}$ siècles, p. 8)

Pronominal (réciproque)

1200 Vers lui se torne quant il l'ot ravisé, Par tel vertu se sont entr'acole, Tant fort se baisent et estraingnent soef, A poi ne sont estaint et definé (Ami et Amile, 180)

REMARQUES : En ancien français, estraindre soef désigne le fait de serrer quelqu'un dans ses bras en signe d'affection, de l'enlacer tendrement, avec délicatesse. Soef reste invariable et est en opposition avec estraindre étreindre fort. Notons l'emploi de dormir soef ; baiser fort.

\section{Étamper gras}

Percer les trous du fer d'un cheval près de la fourchette (contraire d'étamper maigre) 入 étamper maigre

\section{Étamper maigre}

Percer les trous du fer d'un cheval près du bord extérieur (contraire d'étamper gras)

Transitif

1678 Le fer de ce Cheval, luy a fait eclater toute la corne qui estoit au dessous de Rivets parce qu'il estoit estampé trop maigre (Georges Guillet de Saint Georges, Les Arts de l'homme d'epée)
1970 - On l'a toujours paré à fond, ditelle, enfin, tant qu'on a pu. Il n'est pas commode. Même au travail il se débat comme un diable. D'ailleurs, il a toujours usé ses fers en pince.

- Ce n'est pas sa faute, vous verrez les avalures, vous m'en direz des nouvelles. Si on le dessole, si on l'étampe maigre et si on le planche, barca (Jean Giono, L'Iris de Suse)

Emploi absolu

1859 On dit étamper maigre, quand on perce ces trous près du bord extérieur ; et étamper gras, quand on les place plus près du bord qui regarde la fourchette (Nicolas Lebeaud, Nouveau Manuel complet du vétérinaire)

\section{Éteindre net}

Éteindre d'un coup (au propre) ; mettre fin brusquement

Transitif

1832 Cette petite contrariété éteint net l'imagination chez moi (Stendhal, Souvenirs d'égotisme)

1942 Le capitaine Pénicot m’a raconté son vol de ce matin : « quand une des armes automatiques me paraissait tirer trop juste, je bifurquais droit sur elle, à pleine vitesse, au ras du sol, et je lâchais une giclée de mitrailleuse qui éteignait net cette lumière rougeâtre, comme un coup de vent une bougie » (Antoine de Saint-Exupéry, Pilote de guerre)

Emploi absolu

1968 Balla insistait. Il rappelait le devoir de saluer le défunt à sa demeure. Comme le palabre se ravivait, Fama, coléreux, d'un mouvement de la main droite éteignit net. Balla ne sera pas del'escorte (Ahmadou Kourouma, Le Soleil des indépendances)

\section{Éteindre seul}

S'éteindre sans aide ou influence extérieures Pronominal

1655 Cierge allumé s'éteint tout seul pour tesmoigner la volonté de Dieu (Francisco de Santa María, Histoire generale des Carmes 
deschaussees et Carmelites deschaussees [trad.])

1685 Le feu de la fournaise s'éteignit tout seul et Denis fut tiré plus pur que l'or épuré par le feu (Pierre Jurieu, Préjugez légitimes contre le papisme)

\section{CORPUS WEB :}

Parfois, sur une période de quelque jours, le volume du son monte et descend tout seul, et la télécommande n'est plus opérante. Dans le pire des cas, le téléviseur s'éteint tout seul [http://www. teleservice-depannage.com/t8633-volume-LCDqui-monte-et-descend-tout-seul.htm] (30.1.2015)

REMARQUES : S'éteindre seul se dit d'un appareil, d'une flamme, d'une vie qui finissent par euxmêmes, sans qu'on y touche ou porte atteinte. Seul est modifié par tout.

\section{Étendre haut}

入 étendre large

\section{Étendre infini}

入 étendre long

\section{Étendre large}

Se déployer ou occuper un grand espace Pronominal

1836 Elle était assez grande, avec une taille et un port de déesse ; ses cheveux, d'un blond doux, se séparaient sur le haut de sa tête et coulaient sur ses tempes comme deux fleuves d'or ; on aurait dit une reine avec son diadème ; son front, d'une blancheur bleuâtre et transparente, s'étendait large et serein sur les arcs de deux cils presque bruns, singularité qui ajoutait encore à l'effet de prunelles vert de mer d'une vivacité et d'un éclat insoutenables (Théophile Gautier, La Morte amoureuse)

1839 D'abord l'Enfer, votre cachot, s'est étendu long et large sous mes pieds ; ensuite dernièrement, le Ciel et la Terre, un autre monde, pendent au-dessus de mon royaume, attachés par une chaîne d'or à ce côté du Ciel (François de Chateaubriand, Le Paradis perdu)

\section{CORPuS WeB :}

C'est un Globe refuge, un Globe carrefour de rêve, point de départ de vies que l'auteur rattrape d'une écriture précise. Et ça s'élève du sol, petitement mais sûrement, avant de s'étendre large [http://christinejeanney.net/spip.php?article422] (25.3.2015)

Jérusalem était très vulnérable du côté N. ; ce fut toujours par là que les ennemis d'Israël tentèrent l'assaut et ce fut par là que Titus s'empara de la ville. Comme le ravin n'était pas très profond, le mur qui le surplombait dut avoir des proportions massives et s'étendre large et haut [http://www.topchretien.com/topbible/ dictionnaire/jerusalem-ses-murs-et-ses-portes] (25.3.2015)

La montera est le chapeau de torero traditionnelle. Bien que l'apparence du chapeau varie en fonction des préférences de torero, monteras sont généralement chapeaux noirs qui s'étendent large au-dessus des oreilles [http://www.it-age. com/idees-de-costumes-de-torero] (25.3.2015)

Les allées s'étendent larges et paisibles, bordées d'arbres généreux, le cadre défile bourgeois et familiale ; écho de films américains, une sorte de banlieue aisée en plein cœur de la ville [http://lovemeless-butlonger.blogspot. co.at/2009/05/plongeons-dans-la-grandevente-de.html] (25.3.2015)

REMARQUES : Dans l'espace et en référence à un lieu, s'étendre large se dit du fait d'occuper un espace ou une superficie considérable. $\mathrm{Au}$ figuré, il souligne l'idée dominante d'une représentation statique, le sujet référant à une partie du visage (ici : le front) qui se distingue par sa largeur. Notons les collocations large et serein, long et large et large et haut, qui, dans le style littéraire, font que la longueur du groupe reflète l'extension dénotée. Large reste invariable dans la majorité des cas. Cependant, dans le dernier exemple du CW, larges et paisibles s'accorde avec le sujet pluriel, se situant entre la fonction de prédicat second orienté vers le sujet et celle de modifieur du verbe.

\section{Étendre lent}

入 étendre long 


\section{Étendre long}

I. être long étendu : couvrir une grande surface, être vaste

Intransitif

1175 Car je vos di bien que mes pere

$\mathrm{Ne}$ fu ne rois ne emperere

Ne il ne fu ne quens ne dus,

Ains fu de Bretagne Elidus

Qui soufri mainte grant besoigne.

Sa tenëure le tesmoigne,

Qui gaires lonc n'est estendue

(Gautier d'Arras, Ille et Galeron, 4709)

II. S'étendre longuement (sur quelque chose), développer longuement (un sujet)

Pronominal

1561 Je m'estendroye plus long en ce propos, et divagueroye à vous assembler en bref recit les nobles et ingenieuses femmes, n'estoit que tout ainsi que des nobles et vertueuses de l'ancien temps assez en ont escrit Hesiode et Plutarque, aussi des modernes Jehan Bocace (Charles Estienne, Paradoxes)

III. Déployer complètement, dans toute sa longueur, dans toute sa largeur

Intransitif

1893 Il avait gardé sa casquette, laquelle, couleur bleu de Prusse, était plus vaste qu'une roulette de jeu. De son bras droit, long étendu, on ne voyait que l'extrémité des doigts hors du bâti grossier de la manche (Georges Courteline, Messieurs les rondsde cuir)

IV. Durer longtemps, couvrir un long laps de temps

Pronominal

1920 Je me sentais plein de force, la vie s'étendait plus longue devant moi ; c'est que j'avais reculé jusqu'aux bonnes fatigues de mon enfance à Combray, le lendemain des jours où nous nous étions promenés du côté de Guermantes (Marcel Proust, $D u$ côté de Guermantes 1)

\section{CORPUS WEB :}

Car je voudrais avoir le design « Glacier » mais l'espage des articles est beaucoup trop petit et il y presque seulement 3 mots par lignes qui apparaisent et donc cela s'étend long sur la page pour uniquement 1 article [http://beta.forum. over-blog.com/thread-2606482.html] (25.3.2015)

Le couloir s'étend, long, lent, infini. C'est l'habitude... L'infini n'arrête pas... Oh mais l'habitude... On parvient à un carrefour, on prend un autre couloir [http://jokeromega.joueb.com/ la_farce_des_abimes.shtml] (25.3.2015)

En sortant la tête de l'eau, on découvre une île montagneuse couverte de végétation qui s'étend long devant nous [http://bibouate. blogspot.co.at/2012_12_01_archive.html] (25.3.2015)

Restent les chaises déplacées, les sachets de fruits triturés, les bonbons grignotés, les papiers scribouillés, les plannings, éparpillés. La grande table du conseil municipale s'étend longue, longue, longue [http://www.hvdz.org/blog/ archives/category/vies-de-quartiers/monche court/page/7] (25.3.2015)

REMARQues : ( $\left.S^{\prime}\right)$ étendre long (I) se dit du fait d'occuper un certain espace, une certaine superficie. Dans (II), le sujet désigne un animé qui développe longuement un propos ou parle beaucoup sur un sujet particulier. (III) souligne l'idée dominante d'une représentation statique, le sujet désignant une partie du corps (ex. : le bras) qui se distingue par sa forme allongée. (IV) réfère à l'espace de temps, à la durée, suggérant les nombreuses années que l'homme a encore devant lui. Long peut s'accorder avec le sujet (ex. de 1920 et le dernier exemple du CW), mais il peut également rester invariable (v. le troisième exemple du CW). Il est modifié par plus. Notons la collocation long, lent, infini au second exemple du CW et la réduplication multiple de "longue » dans le dernier exemple pour insister sur l'extension de la table.

\section{Étinceler menu}

Briller en grande quantité Intransitif

-1234 Oient les corns, les busines suner, Veient les healmes menu estenceler, E les enseines par amunt venteler. Rollant les veit, si comence à sifler, A ses estriers [si] s'afiche li ber (Otinel $\left[1^{\mathrm{er}}\right.$ tiers XIII $\left.{ }^{\mathrm{e}}\right]$, 893) 


\section{Étoiler menu \\ Parsemer de nombreuses petites étoiles \\ Transitif \\ 1190 Vestue fu d'um paille gallicïen safré ; La fee qui lle fist l'out menu estellé D'estoilles de fin or qui getent grant clarté (Fierabras (L), 2118)}

REMARQUES : Étoiler menu se disait du fait de parsemer un vêtement, un drap, une tenture ou une tapisserie de motifs décoratifs figurant plusieurs petites étoiles, de les orner d'un grand nombre de petites étoiles.

\section{Étouffer net}

I. Cesser brusquement, brutalement de respirer Intransitif

1841 j'ai eu la sensation d'étouffer net ; j'étais fort rouge (Stendhal, Correspondance)

Transitif

1933 Ils pouvaient mourir subitement, bâillonnés, étouffés net (Joseph Malègue, Augustin ou Le Maître est là)

II. Supprimer, anéantir brutalement Transitif

1860 J'entasserais les unes sur les autres mille sottises, qui serviraient à votre mère pour étouffer net nos pauvres espérances, tandis qu'étant un peu connu d'elle, par exemple, ce serait plus simple (Louis Duranty, Le Malheur d'Henriette Gérard)

1936 Pour lui, les grèves russes étaient une arme à double tranchant : elles pouvaient, en effet, paralyser les velléités belliqueuses de l'état-major ; mais elles pouvaient aussi offrir à un gouvernement en mauvaise posture la tentation de faire une diversion brutale : de décréter l'état de siège, sous prétexte du danger de guerre, et d'étouffer net l'insurrection populaire par une répression implacable (Roger Martin du Gard, Les Thibault. L'Été 1914)

III. Cesser d'être perceptible, se perdre Pronominal

1970 Les pins venaient frôler le toit du faux hôtel basque : dès que la porte refermée eut soufflé la lumière violente, coupé les tintements de vaisselle et le glapissement du juke-box, son pas s'étouffa net dans le sable et il s'arrêta saisi, aussi étourdi qu'un homme qui tourne la clé de sa maison et s'aperçoit brusquement qu'une énorme armée dans l'obscurité, avec ses lances, ses bannières, son odeur sauvage, a occupé la ville par surprise et campe à perte de vue dans ses rues (Julien Gracq, La Presqu'île)

CORPUS WEB :

Un peu abruti par le flot de paroles, Michel jeta un coup d'œil aux croquis esquissés sur la feuille et manqua s'étouffer net [https://www. fanfiction.net/s/9914825/1/Birds-and-Bees] (26.3.2015)

Mais en faisant une lecture synoptique de cette initiative, on se rend compte que le présent protocole d'accord vient étouffer net le mouvement dit " Abt » (Abdoulaye Bio Tchané) [http://bj.jolome.com/news/article/suite-ala-signature-de-leur-protocole-d-accord-lemouvement-abt-etouffe-le-mythe-bio-tchanetom-647?t=similaire] (26.3.2015)

La bonne quinzaine d'hommes est parvenue à étouffer net la propagation des flammes, même si, comme le confirme l'un d'eux, « le quartier aurait vraiment pu prendre feu si le propriétaire n'avait pas été réactif en vidant un extincteur sur le foyer, évitant ainsi que l'incendie ne s'attaque à un stock de textile tout proche » [http:// www.ladepeche.fr/article/2008/07/09/463348castelsarrasin-le-four-de-la-boulangerie-prendfeu.html] (26.3.2015)

Comme on pouvait s'y attendre, la marche de protestation annoncée à grand renfort de battage médiatique par les organisations de la société civile et plus précisément celles qui s'activent dans le domaine de la défense des droits de l'homme (Opdh) a été étouffée nette dans l'œuf hier [http://www. nouvellesmutations.com/2010/10/13/marche-deprotestation-des-organisations-des-droits-de1\%E2\%80\%99homme-le-mouvement-etouffedans-1\%E2\%80\%99oeuf] (26.3.2015)

REMARQUES : Etouffer net (I) désigne une personne qui est subitement gênée dans ses fonctions respiratoires ou dont la respiration est brusquement empêchée soit par une forte com- 
pression du cou, soit par l'application de quelque chose sur le nez et la bouche. Au figuré (II), il se dit du fait de supprimer d'un coup quelque chose, de l'empêcher de se développer ou de se manifester, le complément d'objet désignant une chose abstraite (par exemple : une espérance). Également au figuré (III), le sujet désigne un bruit, un son (ici : des pas) mais peut aussi désigner une voix, un soupir qui cessent d'être perceptibles, de se propager ou de se faire entendre. Net reste invariable dans la majorité des cas, sauf dans le dernier exemple du CW où il s'accorde avec le sujet du verbe au passif, sans perdre sa valeur adverbiale.

\section{Étrangler court}

Étrangler avec une corde courte

$\lambda$ étrangler net

\section{Étrangler net}

I. Étrangler tout d'un coup, sur place, à l'instant Transitif

1668 On lui donna certaine somme.

Il devait au bout de dix ans

Mettre son Âne sur les bancs ;

Sinon il consentait d'être en place publique

Guindé la hart au col, étranglé court et net, Ayant au dos sa Rhétorique,

Et les oreilles d'un Baudet

(Jean de La Fontaine, Le Charlatan / Fables)

1719 Un chat le plus gourmand qui fut,

N'ayant d'autre ami que son ventre,

Fondit sur un serein, et sans respect du chantre,

L'étrangla net et s'en reput (Antoine Houdar de La Motte, Fables)

1734 NÉRINE. Il faut que je t'étrangle. Approche, double traître.

Ton Maître est marié ; tu m'en fais un secret?

FRONTIN. Si j'en sais rien, je veux être étranglé tout net.

Mon Maître est un sournois comme on n'en trouve gueres :

Oui, je crois que le diable est son homme d'affaires

(Pierre Claude La Chaussée, La Fausse Antipathie)
1845 Le carlin, exaspéré de cette audace, oubliant sa prudence habituelle, emporté par la colère et par la méchanceté, sauta au museau de Rabat-Joie, et le mordit si cruellement, que de son côté le brave chien de Sibérie, exaspéré par la douleur, se jeta sur Monsieur, le prit à la gorge, et en deux coups de sa gueule puissante l'étrangla net... ainsi qu'il apparut à un gémissement étouffé du carlin déjà à demi suffoqué par l'embonpoint (Eugène Sue, Le Juif errant)

1874 Top se battait avec une fureur véritable, sautant à la gorge des renards et les étranglant net (Jules Verne, L'Île mystérieuse)

1953 URBAIN. Je n’y comprends rien mais le temps presse. C'est entendu

FRONTIN. Cet Urbain était sage avant que l'amour l'eût rendu fou. Maintenant, il ne sait ce qu'il fait. Si son père apprend qu'il fait la débauche, que croyez-vous qu'il décidera ? Il étranglera son fils tout net (Albert Camus, Les Esprits)

II. Rester subitement bloqué dans la gorge Pronominal

1907 Il se tait encore, longtemps. Enfin :

- Mon ami... j'ai encore tout à vous dire.... Mais sa voix s'étrangle net (Claude Farrère, L'Homme qui assassina)

1951 - Le danger de sécession des provinces du sud, si lointaines, qui devrait, si dix autres raisons ne se faisaient plus pressantes, à lui seul nous inciter à la fermeté...

De nouveau il eut son étrange rire de gorge, et de nouveau ce rire coupant et triste s'étrangla net (Julien Gracq, Le Rivage des Syrtes)

Corpus Web :

Dean crut s'étrangler net. "Ah oui » bafouilla-t-il, en tentant de chasser les images qui essayaient de se frayer un chemin dans son esprit [https://www.fanfiction.net/s/10412603/1/ Personal-Space] (26.3.2015)

Il se promit d'ailleurs de l'étrangler net quand il le trouverait [http://www.fanfic-fr.net/ fanfics/fics-originales/S/Science-Fiction/NashDailey--le-terrien/22682/117648.html] (28.3.2015) 
La Red Queen approcha son visage des barreaux et me fixa dans les yeux, j'aurais pu lui sauter au cou et l'étrangler net mais je n'avais pas assez de force [http://onceuponatime-rpg.oneforum.net/t2281-flashback-etes-vous-perduedarling-feat-regina] (26.3.2015)

REMARQues : Étrangler net (I) se dit du fait de perdre soudainement, de manière inattendue, la faculté de respirer ou de s'exprimer normalement, l'agent étant de nature émotionnelle, morale ou physique. (II) désigne le fait de serrer, d'irriter la gorge de quelqu'un au point de provoquer une sensation d'étouffement, l'action se faisant d'un coup, de manière brutale. Notons la collocation court et net (ex. de 1668), court référant au fait d'étrangler avec une corde courte (qui empêche que la nuque ne se brise lorsque le corps tombe, provoquant ainsi une mort plus lente). Net reste invariable. Il est modifié par tout.

\section{Étreindre fort}

I. Serrer, comprimer (quelqu'un) avec force, avec vigueur

Transitif

1230 Puis, faites les enfans trestous nus despoiller,

C'ancor nos pueent bien lor dras avoir mestier.

Puis, lor faites lier et les mains et les piés

Et faites à chascun une corde lacier

Par desous le menton, fort estraindre et lier,

Si les faites noer as keues des somiers

(Gui de Bourgogne, p. 34)

1372 Quant li roys se senti bleciez,

Tous nus est de son lit dreciez

Et par la gorge le hapa

A .ii. poins et si l'atrapa

Que dessous li le mist a terre,

Et si fort li estreint et serre

Que pour po qu'il ne l'estrangla

(Guillaume de Machaut, La Prise d'Alexandrie [(1370-)1372], 8708)

1610 Or jugez si vos nœuds estreignent bien fort, puis que Hylas en est si fort attaché, Hylas, dis-je, que cent beautez et unies et separées, n'ont jamais peu arrester (Honoré d'Urfé, L'Astrée)
II. Saisir, oppresser, faire une impression

soudaine et vive (sur quelqu'un)

Transitif

1596 Je ne sçaurois parler, je devien palle et blanc;

Une tremblante peur me gele tout le sang ; Le froid m'étreint si fort, que plus je ne respire (Philippe Desportes, Euvres)

1857 Ma chambre (à deux), c'était tout (la petite ville n'était pas pour moi). Et, autour de ma chambre, un petit cercle de forêt parcouru à pied, donc petit et toujours le même. Ce cercle m'étreignait fort dans les grandes chaleurs, où le soleil miroitait sur le grès (Jules Michelet, Journal)

III. Serrer (quelqu'un) fort contre soi

Transitif

1624 Les animaux souvent étouffent leurs petis, Qu'encor à peine au jour ils ne sont pas sortis,

Pour les idolatrer et trop fort les étreindre (Alexandre Hardy, Panthée)

1627 FOSSINDE. Je crains que transporté

De ceste amour trop grande,

Me tenant en tes bras,

Tu n'estreignes si fort

Ces liens amoureux,

Sans penser de le faire,

Que j'en estouffe

(Honoré d'Urfé, La Sylvanire)

1946 Et quand elle se révoltait, elle les [= les mains] lui étreignait plus fort (Raymond Guérin, L’Apprenti)

1948 D'elle-même, la main de l'assassin cherche sa verge qui bande. Il la caresse par-dessus le drap, doucement d'abord, avec cette légèreté d'oiseau qui volète, puis la serre, l'étreint fort (Jean Genet, Notre-Dame-desfleurs)

1981 Il fit un pas en arrière, comme pour s'éloigner de moi, mais, brusquement, me saisit dans ses bras, m'étreignant si fort que je faillis étouffer (Michel Del Castillo, La Nuit du décret)

1983 Sur le chemin, devant la jeune fille, un flamboyant allumait le brouillard, 
Lucille leva les yeux, étreignant bien fort son panier des deux mains (Catherine Hermary-Vieille, L'Épiphanie des dieux)

Pronominal (réciproque)

1938 Père et enfants s'étreignirent fort, tout en calculant les salaires des mercenaires, le nombre et la nature des armes à acheter (Albert Cohen, Mangeclous)

CORPuS Web :

Parfois je me dis que j'aurais dû plus souvent l'étreindre fort, fort dans mes bras. Mais, voilà, je n'osais pas... [http://moi.emois.mes-moi.overblog.com/article-ma-nounette-85428468.html] (28.3.2015)

Avant d'être interrompus par les événements que l'on sait, les deux pays avaient su s'étreindre fort, tout se pardonner et échafauder, à nouveau, des plans pour un avenir commun et radieux [http://bravepatrie.com/monde/saintvalentin-la-france-accepte,2023] (28.3.2015)

Je veux la chercher et la trouver, je veux enfin la voir, je veux courir et l'étreindre fort. Mais fort. Je veux lui dire que je l'aime et la photographier quand elle rit [http://serre-pan.blogspot. co.at/2011/02/je-veux-desir-exige-prendre-letrain.html] (28.3.2015)

Des cintres descend un parapluie bleu. Nos deux critiques y trouvent refuge, la neige tombe, l'émotion nous étreint, forte et palpable [http://www.letelegramme.fr/local/finisteresud/quimper/ville/theatre-un-bel-hommageau-masque-et-la-plume-12-03-2012-1629663.php] (28.3.2015)

REMARQUES : Dans un contexte de lutte, étreindre fort (I) désigne le fait d'entraver son adversaire, de le serrer très fort dans le but de le dominer, de le maîtriser, de l'empêcher de nuire. Sous (II), le sujet désigne un inanimé, un phénomène naturel, un élément physique (ici : le froid) qui vient surprendre l'homme. De manière générale, (III) se dit du fait de serrer quelque chose ou quelqu'un fortement. Relevant du domaine affectif, étreindre fort se dit du fait de serrer quelqu'un dans ses bras, de l'enlacer fortement en signe d'affection et de tendresse. Notons les collocations étreindre et serrer (si) fort, fort étreindre et lier. Fort reste invariable, sauf dans le dernier exemple du CW où les adjectifs-adverbes fort et palpable fonctionnent comme des prédicats seconds détachés orientés vers le sujet. Fort est modifié par bien, plus, si, trop. Mentionnons également les réduplications fort, fort et fort, mais fort et l'emploi de dépouiller nu.

\section{Étreindre}

\section{$\lambda$ aussi estraindre}

\section{Étudier ferme}

Étudier, travailler beaucoup, avec ardeur Transitif

1836 J'étudiai ferme le latin et le dessin et j'eus un premier prix, je ne sais dans lequel de ces deux cours, et un second (Stendhal, Vie de Henri Brulard)

\section{CORPUS WEB :}

je suis tombé sur un autre tuto vidéo mais visiblement il était virosé... vu la complexité de ce logiciel qui est assez puissant, je vais devoir étudier ferme... [http://www.chassimages. com/forum/index.php?topic=170509.0; wap2] (28.3.2015)

Merci Kara! Tu m'a sortit de la case 19 où il faut passer 2 tours à étudier la carte ! ${ }^{\wedge}$ T’as plus qu'à étudier ferme pendant 2 tours ! $\mathrm{mdr}$ [http://allianceforumdiscret.pro-forum.fr/t385le-plateau-de-l-oie] (28.3.2015)

à partir de demain on va étudier ferme les propositions de crédit, et une fois ça bouclé va falloir que je pense aux vacances!!!! [http://www. mamanandco.fr/forum/topic64053-555.html] (28.3.2015)

REMARQUES : Lorsque l'objet désigne une discipline d'enseignement (ici : le latin, le dessin), étudier ferme souligne le désir d'apprendre quelque chose, le fait d'acquérir des connaissances dans un domaine précis par un effort intellectuel, le sujet faisant preuve de ténacité et de constance dans l'apprentissage. Ferme reste invariable et est modifié par si. Notons l'emploi absolu dans le CW.

\section{Étudier fort}

I. Étudier beaucoup un domaine, en montrant un vif intérêt

Emploi absolu

+1480 RAOUL MACHUE. Et dictes-vous qu'il estudie 
En ce point si fort et si ferme?

C'est danger qu'il ne fasse un cherme

Pour faire venir l'ennemy

(Farce joyeuse de maistre Mimin / Ancien

Théâtre françois [1480-1490, DMF])

1612 - Je ne sçay, repliqua le berger, si je le vous sçauray bien deduire, car il a fort estudié, et entre nous, nous le tenons pour homme tres-entendu (Honoré d’Urfé, L'Astrée)

1615 Quelques-uns rapportent que Bavo, Roy de la haute Phrigie, homme très versé en la Magie et Astronomie (en quoy les Princes de cest âge là estudioyent fort, comme estans sans telle connoissance en peu d'estime) avoit préveu et prédit la ruine de ceste grande et fleurissante Cité (Antoine de Montchrestien, Traicté de l'économie politique)

1728 Je suis homme à vous tenir compagnie. Allons, voilà qui est bien ; revenons dans ma chambre, où j'étudie fort et ferme. Ma mémoire fit un coup d'essai immortel : le lendemain je sus mon rôle sur lebout du doigt (Pierre de Marivaux, L'Indigent Philosophe)

Transitif

1699 Ses cheveux se hérissoient au seul nom de Port-Royal, et il avoit toute sa vie ajouté une foi entière à tout ce que les jésuites publioient contre cette maison : très-dévot d'ailleurs, et qui avoit fort étudié les casuistes (Jean Racine, Abrégé de l'histoire de Port-Royal)

1715 M. Racine, qui avoit fort étudié les grands modelles de l'antiquité, avoit formé le plan d'une tragédie françoise d'Edippe suivant le goût de Sophocle, sans y mêler aucune intrigue postiche d'amour et suivant la simplicité grecque (François de Fénelon, Lettre à l'Académie)

1735 les premiers transports en étant à peine passez, il lui causa une grande joie en se montrant tout d'un coup à elle : et environ une heure après, il lui apprit, par des adoucissemens fort étudiez, qu'ils n'avoient plus de fils (Nicolas Lenglet du Fresnoy, L'Histoire justifiée contre les romans)
1846 et voilà un homme tué avec art et dans toutes les règles, sur lequel la justice n'a rien à apprendre, comme disait un horrible chimiste de mes amis, l'excellent abbé Adelmonte de Taormine, en Sicile, lequel avait fort étudié ces phénomènes nationaux (Alexandre Dumas père, Le Comte de Monte-Christo)

1867 Ce soir, il a de la conversation ; en belles phrases bien écrites, il cause avec un banquier, son voisin, des queues de mouton, plat remarquable, fort étudié en Autriche et en Angleterre, mal compris en France, et qui, pourtant, après diverses tentatives, a rencontré un interprète convenable dans le cuisinier de M. de Rothschild (Hippolyte Taine, Notes sur Paris)

1961 Les échinodermes ont été fort étudiés au $\mathrm{XIX}^{\mathrm{e}}$ siècle (Histoire générale des sciences : le XIX ${ }^{e}$ siècle)

1976 Picasso voyait-il en l'Homme au mouton, œuvre fort étudiée qu'il choisit pour la place de Vallauris, le Guernica de sa sculpture ? (André Malraux, La Corde et les souris)

II. S’appliquer à (quelque chose)

Pronominal

1615 Ils ont eu Jean Cabot, Vénitien, qui s'estudia fort à faire de nouvelles découvertes (Antoine de Montchrestien, Traicté de l'économie politique)

1696 Leurs souliers de satin brodez d'or, d'argent et de soye, sont d'une propreté achevée ; et quoy-que petits, elles s'étudient fort, en marchant, à les faire paroistre (Louis Le Comte, Nouveaux Mémoires sur l'état présent de la Chine)

CORPUS WEB :

Il ne faut pas seulement étudier fort : il faut étudier activement [http://www.csrdn.qc.ca/ discas/Parents/parentsApprentissage.html] (28.3.2015)

Je sais que ça doit être incroyablement difficile d'être en classe et d'étudier fort [http:// ici.radio-canada.ca/regions/saskatchewan/ 2015/01/14/009-collecte-fonds-aide-famillesinistree-ecoles-regina.shtml] (28.3.2015) 
Possible puisque le réalisateur de L'Attaque du métro 123 et de True Romance étudie fort la probabilité de mettre en scène l'ascension et la descente aux enfers de Steve Banerjee [http://toutlecine.challenges.fr/cinema/l-actucinema/0001/00012285-tony-scott-chez-leschippendales.html] (28.3.2015)

REMARQUES : Étudier fort (I) souligne le désir d'apprendre quelque chose, le fait d'acquérir des connaissances dans un domaine précis par un effort intellectuel, le sujet faisant preuve de ténacité et de constance dans l'apprentissage, en s'engageant fortement et en y mettant toute son énergie. Dans son emploi pronominal (II), s'étudier fort est employé au sens de 's'appliquer (à quelque chose)'. L'adjectif-adverbe fort peut aussi référer uniquement à l'idée d'intensité et souligner le nombre important de recherches ou d'études réalisées dans un domaine particulier. Notons la collocation étudier (si) fort et (si) ferme, où ferme désigne la ténacité et la constance du sujet dans l'apprentissage. Fort reste invariable et est modifié par si.

\section{Éveiller clair}

I. s'éveiller clair : sortir d'un état sombre, obscur et apparaître sous une forme claire, lumineuse

Pronominal

1883 Mais, tout d'un coup, le domestique entra avec deux lampes, et le charme fut rompu. Le salon s’éveilla, clair et gai (Émile Zola, Au bonheur des dames)

II. Éveiller complètement, être ouvert, épanoui Transitif

1955 L'être éveillé clair, d'une riche plasticité, tombe à nouveau en silence au service de l'être (Simone de Beauvoir, Privilèges)

Corpus Web :

l'autre du regard

ne pourra le dire

mais sera dispos

et pleine sa voix

un rai de jour filtre

qui l'éveille clair

il retrouve en lui

à peine une phrase [http://gammalphabets. org/2011/02/28/sommeil-vanite-24] (28.3.2015)
REMARQUes : Dans son emploi pronominal (I), éveiller clair souligne l'état physique dans lequel une chose (ici : un lieu) apparaît, l'adjectifadverbe renvoyant à la clarté de la pièce. En référence aux traits de caractère d'une personne (II), il souligne sa capacité d'épanouissement, d'ouverture totale au monde. Notons la collocation s'éveiller clair et gai. L'exemple du CW joue avec l'ambiguïté du sens qui peut référer aussi bien à l'état résultatif de la personne qu'au rai de jour.

\section{Examiner critique}

Analyser de façon critique

Pronominal

1978 Tout ce qui n'est pas moi est le fils qu'elle aurait préféré avoir. Pas très réchauffant, pour un môme déjà trop porté à s'examiner critique et à ne pas être tellement content $\mathrm{du}$ résultat de l'examen... (François Cavanna, Les Ritals)

REMARQUES : Examiner critique s'emploie dans le registre familier pour examiner de façon critique. Grevisse / Goosse (2016 : § 963e) le mentionnent comme exemple d'un adjectif-adverbe populaire qui ne correspond pas à un adverbe en -ment dans le registre standard, donc critiquement (que l'on trouve cependant dans Frantext, mais Le Bon Usage l'attribue à la langue littéraire, et le correcteur automatique de Word le souligne rouge).

\section{Exciter bas}

Inciter secrètement, pousser discrètement

(quelqu'un à faire quelque chose)

Transitif

1844 Chacun vantait la tenue et le courage des siens ; et tout en se prononçant tout haut contre les duels et contre les rixes, ils les excitaient tout bas à en venir aux mains, et concevaient un véritable chagrin ou une joie immodérée de la défaite ou de la victoire des leurs (Alexandre Dumas père, Les Trois Mousquetaires)

REMARQUES : Exciter bas désigne le fait d'inciter à faire quelque chose, de donner le désir ou la volonté à quelqu'un de faire quelque chose, de le pousser à une activité blâmable et ce, à voix basse, de manière secrète et furtive. Bas est modifié par tout. 


\section{Expliquer bas}

Expliquer à voix basse, en chuchotant Pronominal

1698 Leurs cœurs s'y soulageoient, et s'expliquant tout bas,

Des plus tendres douceurs goûtoient l'heureux appas

(Thomas Corneille, Les Metamorphoses d'Ovide mises en vers françois)

Transitif

1775 mais Freind ayant promis d'être intelligible, ils demeurèrent ; et moi, j'expliquais tout bas à Parouba quelques mots un peu scientifiques que des gens nés sur les montagnes bleues ne pouvaient entendre aussi commodément que des docteurs d'Oxford et de Cambridge (Voltaire, Histoire de Jenni)

1855 Ma sœur, qui était auprès d'elle, m'expliqua tout bas que le choix de cet affreux domicile était une fantaisie de malade, et non une nécessité (George Sand, Histoire de ma vie)

1900 Après s'être fait dûment expliquer mon plan, tout bas, mes deux voisines se lèvent pour se laver les mains, et le milieu du banc reste vide, Marie à un bout, moi à l'autre (Colette, Claudine à l'école)

\section{CORPUS WEB :}

La bonne fée explique tout bas à la femme ce qu'elle doit faire ! [http://www.christiane53.com/ article-mon-chemin-samedi-17-avril-2010-flaujacpoujols-lascabanes-56448486.html] (20.4.2015)

Olivia recommence à pleurer sans bruit, pendant qu'il lui explique tout bas la situation [https://www.google.fr/\#q=\%22explique +tout $+b$ as+la\%22] (20.4.2015)

Je sais pas comment ni pourquoi c'est arrivé, j’ai expliqué tout bas, mais c'est comme ça [http://culturez-vous.over-blog.com/articleclaire-lise-marguier-le-faire-ou-mourir-roman100-pages-rouergue-collection-doado-aout-20119-108742140.html] (20.4.2015)

REMARques : Expliquer bas désigne le fait de faire comprendre quelque chose à quelqu'un par un développement, une démonstration et ce, en baissant la voix, en chuchotant. Bas reste invariable. Il est presque toujours modifié par tout. Notons l'emploi absolu dans le dernier exemple du CW. 


\section{Fâcher blanc}

Se mettre vivement en colère

Pronominal

1939 Mais l'Ange Noir n'aime pas du tout qu'on le surprenne en flagrant délit de magie. Il frémit de couleur. Il se fâche tout blanc (Jules Romains, Les Hommes de bonne volonté)

\section{CORPUS WEB :}

Moi j'vais me facher tout blanc, comme ton tube plein de déconne [http://forum.doctissimo. fr/grossesse-bebe/futures-mamans/attendentmini-moules-sujet_322288_10.htm] (20.4.2015)

La belle s'est fâchée tout blanc et nous a même menacé d'appeler son ennemie jurée la pluie si on l'empêchait de participer à la fête [http://www.nrgi.ch/?p=4264] (20.4.2015)

englués dans la bienpensance islamogauchiste dictatoriale frappant injustement toute voix discordante s'élevant pour dénoncer cet odieux état de fait-voici venir le nouveau motif de se facher tout blanc, ouh la la la rance est colère et c'est normal : MISS FRANCE 2014 EST MOITIE NEGRE. Ce qui est déjà trop vous en conviendrez [http://ficusphere.over-blog.com/ article-pendant-ce-temps-en-debilie-121515610. html] (20.4.2015)

REMARQUES : Se fâcher tout blanc se dit du fait de se mettre fortement en colère, la cause ou l'objet du mouvement d'humeur ou de furie étant mentionné avant. La motivation sémantique originale de blanc est résultative : la couleur du visage pâli, vidé de son sang. Le dernier exemple $\mathrm{du} \mathrm{CW}$ cherche à donner au groupe une connotation raciste. Blanc reste invariable et est modifié par tout.

\section{Fâcher brusque}

Se fâcher brusquement

Pronominal

1978 Mon amitié avec Kristian était profonde, mais traversée d'orages. Il se fâchait brusque, revenait de même (Henri Queffélec, Un Breton bien tranquille)

REMARQUES : Se fâcher brusque s'emploie dans un registre plutôt familier pour se fâcher brusquement, ce dernier étant sans doute plus fréquent (trois occurrences dans Frantext).

\section{Fâcher fort}

Être très mécontent de quelque chose, manifester de la colère

Intransitif

1538 Ce Monsieur là (Syre) c'estoit moy mesme, Qui, sans mentir, fuz au matin bien blesme,

Quand je me vey sans honneste vesture, Et fort fasché de perdre ma monture ; Mais de l'argent que vous m’aviez donné, Je ne fuz point de le perdre estonné (Clément Marot, Épitres)

1559 Qui fut bien pesneulx, ce fut le secretaire, tant pour avoir esté trompé de celluy qu'il cuydoit tromper que pour avoir aussy trompé celle à qui il voulloit et pensoit dire verité ! Et, d'autre part, luy faschoit il fort de se contanter d'un potaige pour son soupper (Marguerite d'Angoulême, Heptaméron, p. 276, 69)

Pronominal

1770 Là-dessus, Sandomir se fâche très-fort (Journal de musique)

1867 Là c'est une femme qui se fâche très fort contre le ministre parce qu'en revenant d'une réunion son mari lui dit que le pasteur avait raconté tout ce qui se passait dans leur ménage, et l'avait personnellement indiqué du doigt (Feuille religieuse du Canton de Vaud)

1933 Je réponds que moi aussi je me fais des idées à propos de ces lettres et que je n'irai pas. Papa se fâche très fort (Adrienne Thomas, Catherine soldat)

2017 La juge des enfants se fâche très fort. Si Jérôme ne se retrouve pas le soir même dans un centre éducatif fermé (CEF), c'est peut-être parce qu'il n'y a pas de place (Bernard Ollivier, Marche et invente ta vie)

CORPUS WEB :

Pire encore, il suffit de fâcher fort notre interlocuteur pour qu'il nous abatte, nous obligeant à tout reprendre depuis le début [https:// www.indiemag.fr/articles/long-way-lappelroute] $(20.4 .2015)$ 
A six ans et demi, Pierrafeu est encore constamment dans la provocation. Il faut toujours se fâcher fort pour qu'il s'arrête [http:// sabineetassocies.hautetfort.com/archive/2013/ 04/02/mon-gamin-ce-boulet.html] (2.4.2013)

Quand elle est fâchée, et ô comme elle se fâche fort et souvent ! [https://dansmatribu. wordpress.com/tag/fierte] (20.4.2015)

REMARQUES : (Se) fâcher fort se dit de l'état d'une personne qui éprouve un certain désagrément, manifeste un mécontentement très fort vis-à-vis de quelque chose. Fort reste invariable.

\section{Fâcher net}

Se fâcher sur le champ

Pronominal

1823 Délivrance-Noire, esprit et parole, se fâcha net (Le Padma Than Yig [trad.])

1884 Sur cela, un mauvais plaisant de SaintGermain s'étant permis d'insinuer qu'aux derniers temps de l'Empire la rosière avait, en moins de quatre mois, offert à son époux un petit rosier de la plus belle venue, - nos Nanterrois se fâchèrent net (Stéphen Liégeard, Au caprice de la plume)

1929 Mais tout en leur concédant la part légitime de liberté, il se fâchait net contre toute déformation de ses personnages susceptible de nuire à la vérité cherchée ou contre toute atteinte à sa dignité d'auteur (Jules Patouillet, Les Idées de A. N. Ostrovskij sur l'art dramatique)

\section{CORPuS WeB :}

Mais, si par hasard, l'un de nous proposait un coup douteux, RIRI se fâchait net : «C'est pas franc, ça, j'marche pas ». On n'insistait pas ... [http://postale.free.fr/aeropostale/guillaumet/ guillaumet/MEMOIRES-DE-L-AMI-DE-BOUY. html] (15.11.2013)

\section{Fâcher rouge}

Se mettre vivement en colère, devenir rouge de colère

Pronominal

1780 Un instant, un seul instant... je donnerais ma vie pour un instant... je la donnerais pour qu'un de mes songes pût se réali- ser... mon cher tout ! Ne sois donc plus si poltronne ; et sur-tout plus d'esprit, ou je me fâcherai tout rouge, car ton esprit me suffoque aussi bien que tes vous (Honoré de Mirabeau, Lettres originales écrites $d u$ donjon de Vincennes)

1850 mais Gourdon le savant, dans une soirée où l'on fut sur le point de part et d'autre de se fâcher tout rouge, écrasa le parti des anti-disquaires, par cette observation : « La Lune, appelée disque par les poètes, est un globe ! (Honoré de Balzac, Les Paysans)

1880 Des cris d'indignation s'élevèrent autour de la table, et tous, légitimiste, orléaniste, républicains par nécessité, se fâchèrent tout rouge. M. Patissot, particulièrement, suffoquait et, se tournant vers M. Rade : «Alors, monsieur, vous ne croyez à rien » (Guy de Maupassant, Contes et nouvelles)

1903 Ses facéties sont, je le veux bien, innocentes, mais n'empêche que, l'autre jour, en en entendant une, le père zélateur s'est fâché tout rouge et a adressé une plainte au père Abbé qui s'est borné heureusement à sourire (Joris-Karl Huysmans, L'Oblat)

1920 Saint-Cyran ayant traité de petit garçon une de nos gloires, Rapin se fâche presque rouge :

- Je n'exposerai point, dit-il, le détail des injures ou plutôt des calomnies, dont il a voulu flétrir l'honneur de la société

(Henri Bremond, Histoire littéraire du sentiment religieux en France)

1936 Il était jamais prêt non plus. Son vice à lui c'était la pêche. Il passait souvent une semaine canal Saint-Martin, au lieu de pousser les commandes. Ma mère se fâchait tout rouge (Louis-Ferdinand Céline, Mort à crédit)

1963 Et c'est pour cela qu'il fait la gueule Et qu'il n'est pas content Et qu'il secoue en rugissant Sa grande crinière crépusculaire Sur les passants Et les passants se fâchent tout rouge 
Et clignent des yeux

(Jacques Prévert, Histoires)

1990 Grand-mère, de son côté, s'était fâchée tout rouge quand les cousins avaient évoqué pour le jour de la cérémonie de décorer la $2 \mathrm{CV}$ de voiles et de rubans et de peinturlurer à l'arrière, sur le coffre bombé, "Vive les mariés »: qu'on ne compte pas la voir participer à une telle mascarade (Jean Rouaud, Les Champs d'honneur)

Transitif

1785 FIGARO. Tant mieux : pour tirer parti des gens de ce caractère, il ne faut qu'un peu leur fouetter le sang ; c'est ce que les femmes entendent si bien ! Puis, les tient-on fâchés tout rouge ; avec un brin d'intrigue on les mène où l'on veut, par le nez, dans le Guadalquivir (Pierre-Augustin de Beaumarchais, Le Mariage de Figaro)

1913 Lorsqu'il releva la tête, presque tout le monde était là rassemblé, mais il ne vit personne. Il était fâché rouge.

- Je me demande, cria-t-il, qui a bien pu l'attacher de la sorte ! Et lui laisser sa selle sur le dos toute la journée !

(Alain-Fournier, Le Grand Meaulnes)

1922 Il avait passé sa tête derrière la mien sans que je le voye, et il en faisait une grimace ! J'étais fâchée tout rouge, vous pensez bien ; c'n'est pas pa'c'qu'on est veuv' qu'on n'tient pas à sa réputation. J'voulais le déchirer, mais c'était du fer blanc. Pour me remettre il m'a dit : « C'est une surprise et un cadeau que j'voulais vous faire, ma cousine » (George Chepfer, Saynètes, paysanneries 1)

1945a - (riant toujours) Ton nez hoche, Brigitte, t'as tout cru, tout cru que je te dis. Mais je ne t'en veux pas, va!

- (pas encore rassurée) Oh ! vous dites ça. Et moi je suis bien caponne maintenant de m'avoir fâchée tout rouge.

- (malin) Je croyais que vous faisiez semblant.

- (se reprenant peu à peu) C'est de votre faute aussi

(George Chepfer, Saynètes, paysanneries 2) 1945b Il me laisse pas le temps de réfléchir à mes oignons, et la première chose que je sais pas, le v'là fâché rouge. « Où c'est que vous avez passé vot'vie pour être si ignorant?» qu'il me dit. - « Où c'est que vous avez passé la vôtre ? Ça devait pas être au bord du canal, hein ? » que j'y demande à mon tour (Gabrielle Roy, Bonheur d'occasion)

\section{CoRpus WeB :}

Ahhhhh je viens de me facher rouge contre mon grand !! [http://forum.aufeminin.com/ forum/matern2/_f645471_matern2-Ahhhhh-jeviens-de-me-facher-rouge-contre-mon-grand. html] (4.5.2015)

Les pauses sont attendues avec impatience et longuement savourées ! A la fin du voyage le chauffeur «a les cornes, il va se fâcher rouge !!! » [http://galilee-lyc.spip.ac-rouen.fr/spip.php? article292] (4.5.2015)

La première question va nous fâcher rouge et porte sur le snacking pratiquant abondamment le fétichisme du plaisir [http://www.snacking.fr/ news-1978-Tous-au-Sirha--.php] (4.5.2015)

Alors, Ribery, c'est l'OL ou Arsenal ?

Je ne le vois pas trop à Arsenal, donc OL c'est plus probable.

Vont être fachés rouges les Marseillais [http:// www.homecinema-fr.com/forum/oe-emis sions-tele-radio/mediasat-max-hd-canalcanalsat-t29822091-1095.html] (4.5.2015)

REMARQUES : (Se) fâcher rouge se dit du fait de s'emporter violemment, de se mettre très en colère, celle-ci pouvant jusqu'à faire perdre au sujet le contrôle de ses actes. La couleur rouge réfère à la coloration du visage qui rougit sous l'effet d'une émotion intense ou d'un sentiment très vif (construction résultative). Rouge reste normalement invariable, mais il s'accorde dans le dernier exemple du CW avec le sujet, par hypercorrection. Il est assez souvent modifié par tout ; aussi par presque. Notons que tout est toujours invariable, même au féminin où la norme imposerait toute rouge (ex. de 1922, 1936, 1945a, 1990). 


\section{Façonner flou}

Fabriquer des vêtements souples

Emploi absolu

1957 moi qu'ai vu la capilotade de bien des Empires, je verrai, si je dure assez longtemps (carbi, carottes) la capilotade des « actuels »... horde de balourds bluffeurs, pochetées !... pardi !... carbi ! carottes !... condition ! façonne pas trop flou ! ...et couse à l'aiguille !... petit empiècement de souvenirs! (Louis-Ferdinand Céline, D’un château l'autre)

REMARQUES : Façonner flou (ici au figuré) fait partie de l'argot du métier de la couture. Il a trait à la technique de réalisation de vêtements souples par opposition à la technique du tailleur. Flou est modifié par trop.

\section{Faire anguleux}

Peindre, faire de manière anguleuse, découpée, discontinue, avec des lignes brisées

Emploi absolu

1958 Pour moi devant cette narration littéraire où Buffet s'est contenté de faire grand, anguleux, monotone - je commence à croire au génie de ce peintre (France observateur, 13 février 1958 / Grundt : 392)

\section{CORpus Web :}

Ouais j'arrive pas à les faire, je sais pas si je dois les faire anguleux ou arrondie, et dans le dernier cas j'ai vraiment du mal à faire l'arrondie appliqué [http://www.jeuxvideo.com/forums/4236-39218326-9-0-1-0-hs-gdcjl-s1-hiragana.htm] (4.5.2015)

Ni mot, ni onomatopée, et pourtant la lecture est limpide. Le trait est expressif et le graphisme, très particulier, peut se faire anguleux ou s'adoucir en fonction des émotions qu'il doit faire passer [http://www.bdgest.com/chronique-3544BD-Fabrica-Fabrica.html] (4.5.2015)

Reprenant le flou onirique, la ligne peut se faire anguleuse, pour des meubles déformés à l'imagination baroque [http://www.maison. com/decoration/inspiration/decoration-paysmerveilles-tim-burton-6659] (4.5.2015)

REMARQUes : Dans le domaine de la peinture, faire anguleux désigne le fait de produire un dessin aux lignes brisées, dont les angles sont aigus et saillants (emploi résultatif). Il s'oppose a arrondi. Notons l'emploi de faire grand et faire monotone. Les exemples du CW montrent que l'emploi absolu est plus rare que les variantes syntaxiques explicites, pronominale et transitive, avec une dynamique résultative. On analysera donc l'emploi absolu de faire anguleux comme réduction économique des variantes plus explicites dans le domaine de la peinture ou du style littéraire. Dans le dernier exemple du CW, anguleux s'accorde avec le sujet du verbe pronominal.

\section{Faire âpre}

Être, devenir très violent, très dur

Pronominal

+1489 La trefve ne duroit jamais guères que ung jour ou deux. Aux autres jours, se faisoit la guerre tant aspre qu'il estoit possible et continuoient les escarmouches depuis le matin jusques au soir (Philippe de Commynes, Mémoires [1489-1498], I)

\section{CORPuS WeB :}

Dans toute polémique on est obligé de se faire âpre et vif, à la limite même agressif, et Jacques Givet en avait pressenti les difficultés [http://www.crif.org/fr/tribune/Portrait-d-unpolemiste-Jacques-Givet2629] (4.5.2015)

le film ne jouant à aucun moment la carte du sensationnalisme. Peu de grands rebondissements finalement, simplement un récit qui s'étire et se dilate, puise sa force sur sa durée imposante, joue magistralement de l'ellipse et s'aère joliment avant de se faire âpre là où on ne l'attend pas [http://silencio.unblog.fr/2013/03/06/ mildred-pierce-todd-haynes-2011] (4.5.2015)

Rien qui ne sonne faux, pourtant, car sa voix veloutée sait se faire âpre quand il faut donner à ses compositions toute la profondeur qu'elles méritent [http://www.paperblog.fr/2646523/therodeo-hotel-utah] (4.5.2015)

La règle et le compas défièrent le zanahary masina et bien que les discussions se faisaient âpre, l'on entendit " zanahary tsy mety diso " [http://www.chansons-sans-frontieres.fr/www. memorial-caen.fr/fr/jules_verne/Menabe.htm] (4.5.2015)

REMARQUES : L'entrée est justifiée par l'exemple de 1400 qui permet une lecture de manière 
au sens de faire âprement la guerre. L'usage moderne du CW emploie se faire comme verbe copule 'devenir' qui admet le complément âpre, tout comme d'autres adjectifs (vif, agressif). Sous la forme pronominale, se faire âpre désigne le fait d'être violent, pénible, terrible, comme résultat de quelque chose. Âpre reste invariable dans le dernier exemple du CW. Il est modifié par tant. Notons l'emploi de sonner faux.

\section{Faire automatique}

Agir par réflexe, automatiquement

$\lambda$ casser net

\section{Faire bas}

Dire à voix basse, en chuchotant

Emploi absolu

1209 «Ce ne sont pas genz a gabois », Font il basset li uns a l'autre (Jean Renart, Roman de Guillaume de Dole, 1591)

\section{CORPUS WEB :}

oups,sorry,

je me suis trompée dans l'accordage * je t'ai donné $1 / 2$ ton plus bas, alors que tu demandais $1 / 2$... viou * ça va faire bas * [http://www.partoch. com/forum/post_924029,accorder+une+guitare+ 1+et+demi+ton+en+dessous.html] (4.5.2015)

Donner à un bâtiment la forme d'une frégate, c'est-à-dire le faire bas sur l'eau, peu chargé d'œuvres mortes et à tillac étroit [http://fr.wiktionary.org/wiki/fr\%C3\%A9gater] (4.5.2015)

Mais les queues de cheval sont toujours d'actualité ! On peut la faire basse en y ajoutant une petite tresse à l'intérieur pour une touche d'originalité discrète, ou même un Métal Ring Hair, l'accessoire mode pour avoir de l'or dans les cheveux [http://www.meltyfashion.fr/lescoiffures-pratiques-et-tendances-a-la-plage-cetete-a120376.html] (4.5.2015)

REmARques : Dans l'exemple de 1209, faire basset désigne le fait d'exprimer par la parole, de dire ou de répondre à voix basse, en chuchotant. Cet emploi, où bas reste invariable, est encore courant en français moderne. Dans le CW, bas fonctionne comme prédicat second orienté vers l'objet et s'accorde avec l'objet, référant soit au sens concret à une localisation basse (dernier et avant-dernier exemple), soit, dans le premier exemple, métaphoriquement à la hauteur d'un son en musique, dans une construction impersonnelle typiquement familière (ça va faire bas 'trop bas').

\section{Faire bel (beau)}

I. Procurer de la satisfaction, du plaisir ; faire du bien, être agréable, plaisant

Emploi absolu

+1150 Celes imagenes cornent, l'une a l'altre sorrist

Que ço vos fust viaire que il fussent tuit vif, L'uns halt, li altre cler; molt fait bel a oïr.

Ço'st avis, qui l'escoltet, qu'il seit en paraïs,

La ou li angele chantent et soëf et serit

(Pèlerinage ou Voyage de Charlemagne à Jérusalem et à Constantinople [2 $2^{\mathrm{e}}$ moitié $\mathrm{XII}$ ], 375)

II. Bien décorer, de manière à rendre beau

Transitif

+1365 Je perderoie ma saison.

J'auroie plus chier un chapiel

Fait de flouretes bien et bel

(Jean Froissart, Poésies [3e tiers XIV $]$ )

1450 Or est la terre preparee

Et de la mer bien separee :

La terre de bestes fournie,

La mer de poissons bien garnie

Et tout bel et bon et bien fait

(Arnoul Gréban, Le Mystère de la Passion, 320)

\section{CORPus Web :}

Il faut se risquer aux crissements. L'important n'est pas de faire beau, c'est de faire juste [http://www.telerama.fr/livre/l-auteur-anneherbauts-1-important-n-est-pas-de-faire-beau-cest-de-faire-juste,120083.php] (5.5.2015)

Météo : il va faire beau tout le week-end ! [http://www.metronews.fr/info/meteoi l-va - faire-be a u - t o u t - le - w e ek-end / mncC!8FHKrWcpaB6Q] (5.5.2015)

Voilà le mien après un lifting l'an passé, instal en Alsace oblige, avant il était bleu délavé « france télécom ». Bon là on la fait beau pour le mariage du petit frère airsofter [http://www.c25j5-ducato.com/t1483-un-de-plus.htm] (5.5.2015) 
La Mel, sur une proposition de Nancy Huston et de Séverine Auffret, et avec la participation des éditions Actes Sud, organise un colloque atypique autour de la coquetterie, de l'art de se faire beau ou belle aujourd'hui, et pour quelles raisons [http://www.franceculture.fr/ evenement-colloque-autour-de-la-coquetterieou-l-art-de-se-faire-beau.html] (5.5.2015)

REMARQUES : Faire beau (I) peut être suivi d'un infinitif, définissant la finalité de l'action ; il se dit du fait de procurer de la satisfaction, du plaisir, le sujet référant à quelque chose d'agréable, de plaisant. En (II), il désigne le fait de produire quelque chose de beau, d'esthétique. Le neutre bel l'identifie comme adverbe, coordonné avec bien et bon ; bon peut être l'équivalent de bien dans la fonction adverbiale (v. faire bon). Dans l'usage moderne, il se dit du fait de simuler, de se donner une apparence de beauté, le paraître contrastant avec le contenu (premier exemple du CW). Dans l'usage le plus commun, dont nous ne citons qu'un seul exemple illustratif, faire beau renvoie surtout au temps météorologique (v. le deuxième exemple du $\mathrm{CW}$ ), très proche de l'emploi du neutre bel en ancien français. En effet, le masculin-neutre tend à se substituer à bel dans la langue moderne (v. les entrées où beau se combine avec d'autres verbes). Beau reste invariable dans la plupart des cas (v. le deuxième exemple du CW), mais il s'accorde avec le sujet (ou avec l'objet) s'il fonctionne en tant que prédicat second (dernier exemple du CW). Notons l'usage de faire juste et l'emploi pronominal du verbe dans le CW. Mentionnons également l'emploi de chanter soef, chanter seri.

\section{Faire bizarre}

Procurer une impression étrange

$\pi$ faire moche

\section{Faire bon}

Faire bien

Transitif

+1150a DIABOLUS. Ço est le fruit de sapience :

De tut saveir done science.

Se le manjues, bon le $f[e]$ ras

(Le Jeu d'Adam [2 moitié $\mathrm{xII}{ }^{\mathrm{e}}$ ], 159)

1882 Il [= Paul Alexis] s'analysera lui-même, il analysera les personnes qu'il a coudoyées, avec une pénétration, une souplesse et une abondance tout à fait remarquables ; tandis qu'il hésitera et fera moins bon, s'il cherche à bâtir, en dehors de ce qu'il a vu ou éprouvé (Émile Zola, Une campagne)

\section{CORPUS WEB :}

Comme la "Règle de Saint Benoît », qui régit la vie de la communauté, les autorise à boire du vin, tant qu'à faire, autant le faire bon [http://www.fontfroide.com/venez-decouvrirnos-vignobles] (5.5.2015)

Météo en Mayenne. Il devrait encore faire bon aujourd'hui ! [http://www.ouest-france.fr/ meteo-en-mayenne-il-devrait-encore-faire-bonaujourdhui-3335283] (5.5.2015)

Pour moi, quiche rime avec lunch et, tant qu'à faire une quiche, autant la faire bonne et en faire beaucoup [https://recettesdantanpouretudiants. wordpress.com/2015/01/26/a-toute-heure-laquiche] (5.5.2015)

REMARQUES : Dans la langue ancienne, faire bon équivaut à faire bien ; comme dans les dialectes centre-méridionaux de l'Italie, l'adjectif qui provient du latin bonus y a servi d'adverbe. Dans le premier exemple du CW, faire bon est en rapport associatif avec faire du bon vin : tant qu'à faire du vin, autant qu'il soit bon. Dans la langue courante, l'emploi en rapport avec le temps météorologique prédomine (nous n'en citons qu'un exemple illustratif), et il s'oppose à faire mauvais, voire faire moche. Notons finalement l'emploi résultatif fléchi en prédication seconde dans le dernier exemple du CW.

\section{Faire clair}

I. Faire jour ; voir comme en plein jour Intransitif

+1200 La nuis fu bele, si fist cler Que li uns pot l'altre coisir (Raoul de Houdenc, La Vengeance Raguidel [début XIII ${ }^{\mathrm{e}}$, 2958)

$\sim 1460$ Et combien qu'il fust nuyt, il y faisoit cler comme a plain jour par force de feux, torses et chandeilles que le roy avoit fait alumer hastivement pour festoyer les Gregois (Raoul Lefevre, L'Histoire de Jason, p. 192) 
1587 CORNEILLE. Ô qu'il faict clair en cette chambre ! Est-il jour ? (Jacques de Lavardin, La Celestine [adapt.])

1627 Lysis ayant quité avec regret un si bon guide, marcha le long d'une allee au bout de laquelle il y avoit un grand cellier où il faisoit clair par le moyen de deux chandelles attachees à la muraille (Charles Sorel, Le Berger extravagant)

1736 j'avois mon épée au poing tout comme Télemaque ; il y [= au goufre] faisoit clair comme dans notre cuvage, et par ma foi, s'il faut vous le dire, mon oncle, j'aurois souhaité que ce lieu eut été une cave, j'aurois ma foi tourné le fausset pour boire dans mon chapeau, car le cœur me manquoit comme dans un jour de jeûne (Pierre de Marivaux, Le Télémaque travesti)

1843 Je ne pouvais me procurer de lumière, on ne m'en laissait jamais... J'attendis qu'il fit clair, tâchant de le réchauffer comme je le pouvais (Eugène Sue, Les Mystères de Paris)

1950 C'est là que nous entrons, accueillis par l'adjudant.

Les consignes. "Vite : il va faire clair » (Maurice Genevoix, Ceux de 14)

II. Avoir l'esprit clair

Intransitif

1824 Il est des esprits dont on peut dire : il y fait clair, et d'autres, seulement : il y fait chaud. Il y a beaucoup de chaleur où il y a beaucoup de mouvement, et beaucoup de lumière où il y a beaucoup de sérénité ; sans la sérénité, point de lumière (Joseph Joubert, Pensées, essais, maximes et correspondance)

III. Faire clairement, mettre les choses au clair (abstrait)

Emploi absolu

1876 Car je me suis embarqué dans une petite œuvre qui n'est pas commode, à cause des explications dont le lecteur français a besoin. Faire clair et vif avec des éléments aussi complexes offre des difficultés gigantesques (Gustave Flaubert, Correspondance)
1898 J'ai apprécié le mal que tu as dû te donner pour faire clair (André Gide et Paul Valéry, Correspondance)

2012 ANQUETIL : Le peloton est intenable, nerveux, on y sent des tensions, des alliances. Je redoute un coup fourré. Les équipiers rechignent, les adversaires se montent le bourrichon. Dès le départ je me porte en tête. Il faut faire clair. Je mets le grand braquet et j'enroule. À partir de là, je ne me retourne plus, j'accélère progressivement (Paul Fournel, Anquetil tout seul)

\section{CORpus Web :}

Il va faire clair plus tard aujourd'hui. Clind'œil et sourire à tous ceux qui souffrent de dépression saisonnière [https://twitter.com/ noemiebergeron/status/560853236526358528] (5.5.2015)

Pour faire clair, oui Sebastian est bien arrivé à Cannes et oui il n'y a pas de droit d'entrée ce soir, petite compensation du GOTHA Club pour tous les petits couacs qu'il y a pu y avoir ! ENJOY !!!! [https://www.facebook.com/ GOTHAclub/posts/229671000410641?comment id $=3389491]$ (5.5.2015)

Ok bon il veut se la faire clair et net [https:// twitter.com/michscht/status/3104876751886745 60] (5.5.2015)

je fais un solo de funk qui finis sur la fondamentale en suraigu... j'arrive à la faire clair, mais j'aimerais la faire « crier », le coup d'esbrouffe final quoi :p [http://saxovince.free.fr/forum/ viewtopic.php? $\mathrm{f}=4 \& \mathrm{t}=2166]$ (5.5.2015)

C'est la plus longue de mes vidéos, mais j'ai préféré essayer de la faire claire et longue plutôt que courte et s'embrouiller ! [http:// lespassionsdelaure.over-blog.fr/trousse-decouture-de-voyage-tuto-vidÉo-8] (5.5.2015)

REMARQUES : Faire clair (I) réfère au temps météorologique et signifie 'faire jour, avoir de la visibilité', par analogie avec faire beau, bon, chaud, froid, mauvais, moche. (II) transpose l'emploi concret au figuré : il fait clair dans l'esprit comme il fait clair dehors. En (III), il renvoie au fait d'exposer des arguments ou d'exécuter une action (ex. de 2012) de façon à ce que le message soit compris, que tout soit transparent. Clair reste invariable dans son usage adverbial, mais en tant 
que prédicat second résultatif, il s'accorde avec l'objet (v. le dernier exemple du CW), même si ce n'est pas le cas dans l'avant-dernier exemple. Le premier exemple du CW équivaut à être clair. Le troisième exemple est particulièrement intéressant parce que la collocation clair et net traduit une opinion du locuteur : C'est clair et net, il veut se la faire. Ceci revient à dire que clair et net ne forme pas un groupe syntaxique avec faire. Du point de vue fonctionnel, il s'agit d'un adjectifadverbe évidentiel, donc d'un adverbe de phrase, employé sans détachement. On peut s'imaginer une pause prosodique dans le code oral ou une virgule dans le code écrit pour marquer son détachement de la proposition, mais (c'est) clair et net est lexicalisé dans cette fonction discursive, ce qui permet de l'employer sans marque prosodique ou de ponctuation. La polysémie et polyfonctionnalité de faire + adjectif-adverbe met en évidence qu'il s'agit effectivement d'un adjectif-adverbe qui embrasse des fonctions qui vont du pôle adjectival au pôle adverbial, glissant subtilement, sans ruptures. Il serait vain de vouloir séparer l'adjectif de l'adverbe.

\section{Faire court}

I. (pour le) faire court: (s')exprimer de manière concise, brève, en peu de mots, abréger Transitif

1450 JEHAN BAPTISTE. Amis, puisque finer me fault,

Pour tenir justice et raison,

Accorde moy une oroison

A Dieu par pensee devote.

GROIGNART. Faictes le court; qu'il ne se crote ;

J'ay a faire en autres paÿs (Arnoul Gréban, Le Mystère de la Passion, 12128)

1498 S'ensuyvent les noms de plusieurs mignons, familiers et domestiques du roy. Mignons du roy ainsi que Bourdillon, Balsac, Lachaulx, Galliot, Chastillon, George, Edoville et autres familiers Comme Paris, Gabriel et Dijon, Pour assailir ung feminin donjon Trop plus propres que dix autres miliers. Je n'escriptz point ung grant tas de galiers Comme escuyers, panetiers, eschançons,
Enfans d'onneur, huissiers, paiges, garçons,

Tabourineux, harpeux, saulteurs, danceurs,

Ne ung grant tas de rustres gauldisseurs

Qu'on voit souvent suivre et hanter la court ;

La je les laisse pour le faire plus court (Andrieu de la Vigne, Le Voyage de Naples, p. 152, 839)

1568 Pour vous le faire court, voilà l'arbre par terre ; voicy venir le mary : elle lui en fait coucher des branchages au feu, qui furent incontinent apperceuz par luy

(Bonaventure des Périers, Les Nouvelles Récréations et joyeux devis)

1645 LÉLIE. Pour vous le faire court, il y manda ma mère,

Et, nous voulant à tous partager son crédit, Souhaita que ma sœur encore s'y rendit, Que ma mère élevait en sa plus tendre enfance (Jean de Rotrou, La Sœur)

$1845-\mathrm{Ah}$ ! Tu es jaloux, répondait-elle. Tant pis pour toi. Comment es-tu assez bête pour cela ? Ne vois-tu pas que je t’aime, puisque je ne t'ai jamais demandé d'argent?

Lorsqu'elle parlait ainsi, j'avais envie de l'étrangler.

- Pour le faire court, monsieur, Carmen me procura un habit bourgeois avec lequel je sortis de Séville sans être reconnu (Prosper Mérimée, Carmen)

Emploi absolu

1558 Pour faire court, elles s'apperceut qu'elle en avoit dedans le dos, dy-je dedans le ventre (Bonaventure des Périers, Les Nouvelles Récréations et joyeux devis)

1630 BELLARIS. En fin, pour faire court, que nous avons perdu

Un tresor, qui jamais ne nous sera rendu : Vous sçavez d'autre-part que l'amour feminine,

Pour ferme qu'elle soit, s'ébranle et se termine (Jean Mairet, Chryséide et Arimand)

1833 Mais, pour faire court, je te dirai que ma résignation est à peu près complète là- 
dessus comme sur bien d'autres points, et que je n'aspire à autre chose sinon à faire soupçonner par le peu que je dis ce qui me reste à exprimer (Maurice de Guérin, Correspondance)

1946 Par grand souci de faire court (toujours, et depuis mon enfance, la crainte de ne pas être écouté jusqu'au bout) je ne présente, à l'ordinaire, que des aboutissements de pensées (André Gide, Journal)

II. Faire, réaliser quelque chose de court, bref Transitif

1655 quoyque je la fisse assez courte [= la promenade], le temps que j'employai aux particularités de ces spectacles et à visiter quelques endroits de la ville, fut cause que j'y arrivé plus de deux heures après le disné préparé (Savinien Cyrano de Bergerac, Les Estats et empires de la lune)

1714 Elles sont toutes singulieres et de mesme parure que tout ce que nous avons vû :... etc. A ce compte il ne l'a pas fait encore assez court, car on ne le lit point, et ses plus grands Partisans l'abandonnent (Anne Dacier, Des causes de la corruption du goust)

1762 Contentez-vous de faire réguliérement les vôtres devant elles sans les forcer pourtant d'y assister. Faites-les courtes [= les prières] selon l'instruction de Jesus-Christ (Jean-Jacques Rousseau, Émile ou De l'éducation)

Emploi absolu

1939 Si je vous regardais de biais, moi aussi, comme vous nous regardiez en nous écrivant, et si j'avais votre stylo, je sais bien comment je vous répondrais : " lettre un peu longue »- il se peut, mais proportionnée à l'importance du débat et de votre personne. Quand j'aurai autant de temps que vous, je ferai plus court (Jean Guéhenno, Journal d'une « Révolution »)

CORPUS WEB :

Je vous réponds : " oui et non ». Nous essayons de faire court et pour le moment de structurer votre récit [http://www.commentfaireunfilm. com/comment-ecrire-un-scenario-de-courtmetrage] (5.5.2015)

Pourquoi faire court quand on peut faire long ? [http://alafortunedumot.blogs.lavoix dunord.fr/archive/2015/04/21/pourquoi-fairecourt-quand-on-peut-faire-long-13951.html] (5.5.2015)

Je vais vous la faire court : si la page vous interesse pas et que vous êtes là rien que parce qu'on vous a demandé, partez, les autres, je vous en conjure AIMEZ CE P*TIN DE STATUT !!!!!!!! [https://www.facebook.com/permalink.php?id= 321944571194636\&story_fbid=373746602681099] (5.5.2015)

« Je vais vous la faire courte : ce jeune chef antillais a de l'avenir ! » [http://www.tripadvisor. fr/ShowUserReviews-g1432141-d2535031r178811825-O_Z_Epices-Bouillante_Basse_Terre_ Island_Guadeloupe.html] (5.5.2015)

La période est délicate : vous êtes pour beaucoup d'entre vous dans des révisions de bac blanc, dans l'attente aussi des résultats imminents de l'admissibilité à Paris...nervosité...tensions...Autant la faire courte et efficace [http:// blog.letudiant.fr/concours-sciences-po-iep/ category/methodes] (5.5.2015)

REMARQUES : Faire court est très usité dans la locution pour (le) faire court. (I) réfère au fait d'abréger, de dire quelque chose en peu de mots (synonyme : pour faire bref). (II) se dit d'une chose que l'on réalise, récite, fait, etc. de manière courte. Notons sous cette acception l'accord de l'adjectif-adverbe là où il se prête à une analyse en tant que prédicat second orienté vers l'objet (de même dans le CW). Notons la locution familière du tour la faire court(e) (à comparer avec le type se la couler douce). Court est modifié par assez, encore, plus. Notons l'emploi de l'antonyme faire long. VOIR AUSSI : boire net

\section{Faire différent}

Faire différemment

Emploi absolu

1992 Ou bien Harnoncourt n’a rien compris à rien, ou bien il veut vraiment faire différent (France-Musique / Noailly 1997a) 
1993 Quand on invitera Michèle, il faudra faire différent (Exemple entendu [à propos de cuisine] / Noailly 1994)

\section{Faire difficile}

Faire de manière complexe, compliquée

$\lambda$ faire facile

\section{Faire droit}

I. Faire bien, correctement

Transitif

+1150 Nostre Sires parlad á Hieu, si li dist : « Pur çó que tu ás dréit fáit é çó que me plóut encuntre le lignage Acháb, tes fiz jesque a la quarte generatiun tendrunt le regne de Israel » (Quatre Livres des rois $\left[2^{\mathrm{e}}\right.$ moitié $\mathrm{XII}$ ], p. 196, 31)

II. Avoir raison de

Intransitif

1190 Alori, dist li rois, ch’avez vos tout meslé, Desflubez cel mantel, essi l'ai esgardé, Si faites droit Regnier, tout a sa volenté (Fierabras (L), 4675)

III. Faire directement

Transitif

-1334 Molt souspira, n’el ne dist mot.

A son cheval est arivé

Li Beaus Chevaliers molt iré.

Lors a soi dist con dolereus,

Que droit u Val Aventureus

La vorra son voiage fere (Le Romans de la dame a la lycorne [1 $1^{\mathrm{er}}$ tiers XIV $\left.\left.\mathrm{X}^{\mathrm{e}}\right], 1344\right)$

\section{CORPus Web :}

Le refus du ministre de la Défense de faire droit à une demande de modification des " conditions d'application » d'une loi [http:// www.revuegeneraledudroit.eu/blog/2013/08/13/ droit-administratif-francais-quatrieme-partiechapitre-1/\#.VUipdqM_-Uk] (5.5.2015)

Les conclusions sont les actes dans lesquels les avocats des parties exposent leurs arguments respectifs, leurs demandes et/ou leur défense et tentent de convaincre le juge d'y faire droit [http://www.cliquedroit.com/la-proceduredevant-le-tribunal-de-grande-instance-c5-f172. $\mathrm{html}]$ (5.5.2015) merci pour cette recette, je vais la faire droit ce soir, Une grand merci [https://www.google. $\mathrm{fr} / \# \mathrm{q}=\% 22 \mathrm{la}+$ faire+droit $\% 22]$ (5.5.2015)

mais cette idée de la faire droit est vraiment originale. En revanche c'est un mur porteur en effet...... [http://forums.futura-sciences.com/ bricolage-decoration/375485-soucis-escalierbeton.html] (5.5.2015)

Moi aussi j’ai été victime de ma propre folie de me couper moi-même la frange... Et à force de vouloir la faire droite et de couper, elle s'est retrouvée trop courte [http://forum.doctissimo. fr/forme-beaute/Coiffure-et-coloration/frangecourte-secours-sujet_4382_1.htm] (5.5.2015)

REMARQUes : Il est parfois difficile de séparer l'emploi adverbial faire droit (adjectif-adverbe) de l'emploi nominal faire droit (substantif) dont nous avons retenu deux exemples de l'emploi actuel, le premier et le second du CW. Il nous a semblé que droit est adjectif-adverbe dans (I) : faire quelque chose exactement, correctement, comme il se doit. Dans (II), il signifie 'avoir raison de faire quelque chose'. (III) signifie 'faire quelque chose directement, marcher directement vers un lieu'. Le troisième exemple du CW signifie 'directement', au sens temporel 'ce soir même'. Les deux derniers exemples montrent l'emploi résultatif comme prédicat second fléchi (ou comme complément, si l'on analyse faire comme verbe copule). L'adjectif-adverbe est alors fléchi, normalement, mais l'avant-dernier exemple montre que droit ne l'est pas nécessairement. Il ne s'agit probablement pas d'une faute d'orthographe mais d'un emploi réel dans le code parlé, sans flexion.

\section{Faire efficace}

Faire avec efficacité, être efficace

$\pi$ faire rapide et faire simple

\section{Faire exact}

Exécuter avec exactitude

Emploi absolu

2008 Mes plus grands dessins avaient couvert les pages doubles de mes cahiers d'école. J'y avais organisé des cimetières de mésanges et de lapins dans une jungle de feuilles de tabac ; des Cécile flottant sur les algues de la ville d'Ys ; des choses plus joyeuses 
parfois, en m'acharnant à rendre visibles les plus petits des détails, accumulés avec la volonté de faire exact, précis (Yvette Szczupak-Thomas, Un diamant brut)

REMARQUeS : Faire exact 'faire quelque chose d'exact' s'emploie habituellement comme prédicat second orienté vers l'objet direct du verbe (ex. Je les fais exact(e)s). Ceci étant, son emploi absolu le rapproche d'un adjectif-adverbe qui rappelle des cas comme couper court, manger chaud, etc.

\section{Faire facile}

Faire (quelque chose) sans difficulté, sans peine, facilement Transitif

1955 J'ai fait ça facile (Exemple entendu, 10 septembre 1955 / Grundt : 219)

\section{Corpus Web :}

Pourquoi faire facile quand on peut faire TRÈS difficile [http://www.valerieorsoni.com/fr/ pourquoi-faire-facile-quand-on-peut-faire-tresdifficile] (5.5.2015)

Bac S - Astuce maline : équation d'un plan, comment faire facile et rapide ? [http://www. intellego.fr/soutien-scolaire-terminale-s/aidescolaire-mathematiques/bac-s--astuce-malineequation-d-un-plan-comment-faire-facile-etrapide-/33467] (5.5.2015)

Perso je joue en conquête, tu joue ta classe a fond et les objectif tu va les faire facile les points [http://battlelog.battlefield.com/bf3/fr/forum/ threadview/2832654347807903622] (5.5.2015)

De nouveaux mouvements me mettent à mal : non je ne sais toujours pas faire de Push Up (pompes), c'est plutôt handicapant, et pourtant motivant de penser qu'un jour je pourrais les faire faciles (on a tous un rêve !) [https:// monjardindhiver.wordpress.com/2014/09/01/ bbg-semaine-2-il-y-a-du-mieux] (5.5.2015)

Remarques : Faire facile désigne le fait de faire quelque chose aisément, sans effort. Les premier et deuxième exemples du CW montrent l'emploi absolu. Facile reste invariable dans la majorité des cas, malgré l'objet au pluriel dans le troisième exemple du CW, mais il s'accorde avec l'objet pluriel dans le dernier exemple. Cet accord n'est pas logique en terme de modifica- tion sémantique, mais il correspond bien au schéma traditionnel de l'accord, par exemple dans les dialectes centre-méridionaux de l'Italie ou de l'italien écrit ( « le sue lagrime corsero più facili », Manzoni, I promessi sposi). Faire facile montre que la sémantique résultative du verbe faire peut faire place à une lecture de manière : 'avec facilité, de la façon la plus facile possible'. Notons l'emploi de faire difficile et faire rapide dans le CW.

\section{Faire ferme}

Agir, résister, communiquer avec fermeté, sévérité, détermination

Intransitif

+1370 Li Escot sont à trois lieuwes priès de chy logiés sus une belle montaigne et vous atendent là et $\mathrm{y}$ ont bien estet VIII jours et ne savoient nouvelles de vous non plus que vous ne saviés nouvelles d'iaux. Che vous fay-ge ferme et vrai (Jean Froissart, Chroniques (A))

Emploi absolu

1578 Là dessus, la Noblesse (comme c'est l'ordinaire), fait ferme pour son Roy, sans avoir esgard à autre chose qu'à la manutention de l'Estat et de la Couronne (Pierre de L'Estoile, Registre-journal du regne de Henri III)

1659 Il faut faire ici ferme et montrer du courage (Pierre Corneille, Edipe)

1731 Le général Stenau fit ferme un moment avec deux régiments ; le moment d'après il fut lui-même entraîné dans la fuite générale des son armée qui se dispersa avant d'être vaincue (Voltaire, Charles XII. Roi de Suède)

\section{CoRpus WeB :}

Peux tu me dire le secret du glaçage ? Je n'arrive pas à le faire ferme j'utilise les même ingrédients que toi [http://www.foodreporter.fr/dish/ index/id/147165] (5.5.2015)

Depuis le temps que je fais des yaourts je viens enfin de trouver comment les faire ferme comme dans le commerce [http://ideesrachel. unblog.fr/2012/10/26/yaourt-ferme] (5.5.2015) 
Tu peux les faire ferme, ou coulant (genre yaourt bulgare), entier, allégés [http://forum. doctissimo.fr/cuisine/conseils-astuces/yaour thiere-acheter-fait-sujet_89_1.htm] (5.5.2015)

moi j'aimerai les faire fermes mais ils sont souvent plus crémeux. mon précédent essai au citron [http://www.supertoinette.com/listerecettes/comment $\% 2$ Bfaire $\% 2$ Bdes $\% 2$ Byaou rts/68] (5.5.2015)

REMARQUES : Dans l'ancienne langue, faire ferme désigne le fait d'agir avec assurance, détermination, voire autorité ou sévérité envers quelqu'un, et, comme dans l'exemple de 1731, le fait d'attendre l'ennemi de pied ferme. Küffner (1906 : s.v. ferme) note l'emploi militaire encore dans les journaux de 1905 et 1906.Notons la collocation ferme et vrai. Ferme reste invariable dans son emploi adverbial. Dans les exemples actuels du CW, il s'emploie en tant que prédicat second résultatif orienté vers l'objet au sens de 'consistant'. Il reste invariable dans les deuxième et troisième exemples, mais est accordé avec l'objet dans le quatrième. Notons, toutefois, que l'auteur du troisième exemple n'est pas constant quant à l'accord des adjectifs : allégé est au pluriel, tandis que ferme, coulant et entier sont au singulier.

\section{Faire fort}

I. Se montrer, se faire plus fort Pronominal

$\sim 1100$ Li quens Rollant, quant il les veit venir, Tant se fait fort e fiers e maneviz! [variantes : tant se fait proç; tant se fait fier ; tant par est fiers de si]

Ne lur $<$... >rat tant cum il serat vif (Chanson de Roland, 2125)

II. se faire fort (de) : s'engager (pour quelqu'un), se porter garant; se prévaloir de quelque chose; se vanter

Pronominal

1330 Pierre de Villeneuve, demourant a Mons sur Ourge, es noms de lui et de Jehanne, sa femme, dont il se fait fort en ceste partie, confesse avoir vendu a tousjours desmaintenant, et promet garantir etc. a religieuse personne et honneste l'abbé et couvent de l'eglise Saint Magloire a Paris, pour eulx, leurs successeurs et aians cause, une maison, court, puis, jardin et lieu, si comme tout se comporte (Chartes de l'abbaye de Saint-Magloire)

1364 Je ai eu les .iiii. balades que vous m'avés envoiees ; et en ai envoiee une, ainsi comme celle qui se fait fort de vous (Guillaume de Machaut, Le Livre du voir dit, p. 460 [Lettre d'une dame])

1400 Telx gens ressemblent aus femmes des Teutoniques desqueles racompte Valere ou livre desus dit, comment elles prierent Marius qu'il leur voulsist donner congié d'aler parler aux pucelles qui servoient la deese Vesta, et elles se faisoient fortes de les encliner et faire consentir au pechié de luxure (Jacques Legrand, Livre de bonnes meurs / Archiloge Sophie, p. 327)

$-1469 \mathrm{Et}$, pour ce qu'il n'estoit pas grant argentier et qu'il avoit plus applicqué son entente à vaillance que à avarice, par quoy il n'eust pas peu payer grant somme de denyers, il se fist fort de leur baillier ung bon cheval pour sa delivrance (Jean de Bueil, Le Jouvencel [1461]-1468, I, p. 75)

1543 Or est-il vray qu'il ne l'a [= la maison] qu'à reachept, mais il se faict fort de vous la maintenir et guarantir en vendition pure et simple (Jean Calvin, Lettres à Monsieur et Madame de Falais)

1623 En cét affaire comme en toute autre verité de la religion il y a deux extremitez contraires, moins dangereuses l'une que l'autre. La premiere, de quelques esprits hypocondriaques, qui se font fort de monstrer le mystere de l'incarnation par raisons naturelles (François Garasse, La Doctrine curieuse des beaux-esprits de ce temps)

1669 Et l'on peut repondre par mesme moyen à la seconde proposition de l'argument contraire, laquelle se faisoit forte de l'authorité de ce Berose pour prouver que Cham avoit esté magicien (Gabriel Naudé, Apologie pour tous les grands hommes qui ont esté accusez de magie)

1713 Le marquis de Sénantes se fit fort de les avoir à sa maison de campagne le len- 
demain au soir, et pria la compagnie d'y souper (Antoine Hamilton, Mémoires de la vie du comte de Gramont)

1828 L'année dernière, la femme de chambre de Mme Angel avait mis la maison en révolution par ses plaintes, ses propos. Les uns me demandaient leur compte pour aller à Paris où elle se faisait fort de les placer ; les autres voulaient doubler leurs gages, etc., etc. (George Sand, Correspondance)

1891 dans sa poche, il a, toute rédigée, une lettre où il lui propose le duel assis sur deux chaises, se faisant fort de lui fournir des témoins (Edmond et Jules de Goncourt, Journal)

1909 Le bon Mooch, qui était farci d'illusions humanitaires, disait, les yeux brillants, avec une grande douceur, qu'il fallait empêcher la guerre, et que le meilleur moyen était d'exciter les soldats à la révolte : qu'ils tirent sur leurs chefs! Il se faisait fort d'y réussir (Romain Rolland, Jean-Christophe. Dans la maison)

1931 Ensuite elle se targuait de ses relations, se faisant forte de tout aplanir si jamais la justice voulait intervenir entre Gaspardet et cet homme (Henri Pourrat, $L a$ Tour $d u$ Levant ou Quand Gaspard mit fin à l'histoire)

1936 La guerre rendrait à l'Autriche sa prospérité économique ; elle lui assurerait tout ce marché des Balkans que les Slaves cherchent à accaparer... et, comme ils se font forts de pouvoir, en deux ou trois semaines, contraindre militairement la Serbie à capituler, quels risques courentils ? (Martin du Gard, Roger, Les Thibault. L'Été 1914)

2006 Et d'ailleurs, puisqu'elle n'avait pas de père, ou de mari, pas de tuteur pour conseil, lui se faisait fort de défendre ses intérêts... (Anne-Marie Garat, Dans la main du diable)
III. Exagérer, dépasser les limites, se vanter

Emploi absolu

$\sim 1370 \mathrm{Et}$ tu, pour vaincre la voix de ton Seigneur, cuides faire plus fort par hardie ou fole emprinse et contempnement detestable (Jean Daudin, De la erudition [manuscrit : $1^{\text {re }}$ moitié $\left.\mathrm{XV}^{\mathrm{e}}\right]$ )

1939 - Et toi tu t'y complaisais, répond-elle sans se troubler. Tu disais ça pour faire fort. D'ailleurs tu t'indignes comme cela dans la conversation, mais tu es bien assez traître pour te marier un jour dans la coulisse (Jean-Paul Sartre, La Nausée)

IV. Marquer le coup, impressionner ; employer la force

Emploi absolu

1984 Il voulut me claquer les paumes. Je lui tendis le second verre. La fille d'à côté fuit à la première grossièreté.

- Dans le genre boomerang, tu fais fort !

L'alcool affûtait son humour

(Michel Embareck, Sur la ligne blanche)

1989 Je veux que la Vérole me fasse un demiképa mais il refuse, alors je me dis qu'il faut faire fort, qu'il faut pleurer et j'ai tellement mal au ventre que ça va pas être difficile de pleurer (Denis Belloc, Képas)

2000 il avait fait à la Simone ce gros bébé, Robert, Robertino, qui sent le pas propre et qui va monter sur le matelas et le chevaucher, faire vite, faire fort, des deux mains empêchant l'air de passer, s'agitant pour ne pas trop sentir les convulsions

(François Nourissier, À défaut de génie)

CORPUS WeB :

Lors d'une nuit passionnée dans une auberge de la ville, elle parvient à le persuader d'accepter de devenir membre de la Garde-Royale où elle se fait fort de le faire entrer [http://www. lagardedenuit.com/wiki/index.php?title=Cersei_ Lannister] (5.5.2015)

Les applaudissements nourris ont fini par éclater à l'écoute du dernier engagement « $57 \%$ de dépense publique, ça ne va pas. Il faut réduire le poids des dépenses publiques, il faut le faire vite, il faut le faire fort » [https:// www.lepartidegauche.fr/actualites/edito/table- 
ouverte-pour-le-medef-chez-moscovici-24739] (5.5.2015)

REMARQUES : Se faire fort (I) signifie à l'origine se montrer fort. Se faire fort (de) (II) est une collocation figée dont le sens oscille entre une lecture plutôt juridique de responsabilité civile, 's'engager pour quelqu'un', et celle de 'prétendre à / se prévaloir de', voire 'se vanter', souvent à connotation négative. La seconde lecture semble plus récente. L'accord optionnel de fort dans cette collocation est usuel jusqu'au XviII ${ }^{\mathrm{e}}$ siècle, moment où il disparaît des données de Frantext, sans doute suite à la discussion des grammairiens (v. Introduction § 4.2 ; TLFi : s.v. se faire fort; v. aussi: se porter fort). L'accord réapparaît au $\mathrm{xx}^{\mathrm{e}}$ siècle. Faire fort (III) signifie 'faire trop fort', 'se gonfler', donc, se faire / se montrer plus fort qu'on ne l'est. Faire fort (IV) 'impressionner', 'employer la force', s'emploie avec une connotation positive ; le groupe peut même transmettre l'admiration (réelle ou ironique) de celui qui parle.

\section{Faire grand}

Faire en grand, dans de grandes dimensions

Emploi absolu

-1200 Ome maintent bien e confórte ;

E ki la garde chastement

Mult li fait grant seurement

(Les Lapidaires français du Moyen Âge, Premier lapidaire [fin $\mathrm{XII}]$ ], 156)

1880 Nos modernes font grand, sans se demander si la valeur du sujet permet de si ambitieuses proportions ; ils font laid, systématiquement, par opposition au beau suranné ; ils font vulgaire, par haine de l'élégant ; peintres en rupture de ban, si l'on veut, mais peintres (Gazette des Beaux-arts)

1903 Cela commence par une enceinte absolument cyclopéenne, antérieure au reste du temple et d'une antiquité mal connue : œuvre d'une génération qui avait rêvé de faire grand comme la tour de Babel et qui s'éteignit avant d'avoir pu finir (Pierre Loti, L'Inde (sans les Anglais))

1958 Pour moi devant cette narration littéraire où Buffet s'est contenté de faire grand, an- guleux, monotone - je commence à croire au génie de ce peintre (France observateur, 13 février 1958 / Grundt : 392)

\section{CORPUS WEB :}

On peut le faire petit! On peut le faire grand ! Il y a mille façons de faire plaisir à quelqu'un [http://www.grenouilledechainee.fr] (7.5.2015)

Salut c'est un bon projet, mais tant qu'a le faire autant le faire grand ! [http://www. opalecraft.com/t6875-Mus-e-de-la-pal-ontologie. $\mathrm{htm}]$ (7.5.2015)

C'est un homme qui meurt comme il a vécu, il affronte la mort de la même façon qu'il a affronté la guerre et qu'il commandait ses troupes : non parce qu'il avait le grade pour le faire mais parce qu'il en avait la compétence. Il a l'intuition qu'avec la mort, il ne doit pas se faire grand mais au contraire plus petit, pour être à égalité [http:// fr.wikipedia.org/wiki/Le_M\%C3\%A9tier_des_ armes] (7.5.2015)

Quand on prends déjà l'Avenue du Prado, d'un coup Marseille se fait grand, comode, jolie [http://www.tripadvisor.fr/Restaurant_Reviewg187253-d3707272-Reviews-Le_David-Marseille_ Bouches_du_Rhone_Provence.html] (7.5.2015)

«Un fait est là : notre institution, pour meurtrie qu'elle soit, est constituée. Nous sommes bien faibles, puisque seul un tiers de notre organisme a renoué la chaîne d'union. Il ne dépend que de nous-mêmes de la développer, de la faire grande, forte et belle et de lui faire jouer le rôle national et international que nous ambitionnons" [http://www.glff.org/la-grande-loge-femininede-france.html] (7.5.2015)

RemARques : Faire grand désigne le fait de réaliser quelque chose, de manière concrète ou abstraite, à grande échelle. Cet emploi absolu, qu'on retrouve dans les deux premiers exemples du CW, permet à la fois une lecture résultative et une lecture de manière, le premier exemple l'opposant à faire petit. Dans les autres exemples, la lecture est résultative et s'applique à un objet explicitement nommé, ce qui explique l'accord (qui manque cependant dans l'avant-dernier exemple). Notons l'emploi préférentiel dans le domaine de l'art : peinture, littérature, architecture. Faire grand réfère soit à des dimensions concrètes soit à celles d'un projet, d'une vision. 


\section{Faire gras}

I. Manger de la viande

Emploi absolu

1756 On en peut juger par une requête qu'ils lui présentèrent ; ils demandèrent que le roi ne portât point d'habits découpés à la mode de France, et qu'on fît bruler tous les citoyens qui feraient gras le vendredi. C'était presque la seule chose à quoi ils distinguaient les catholiques d'avec les luthériens (Voltaire, Essay sur l'histoire générale et sur les mours et sur l'esprit des nations)

1778 Dans les choses indifférentes elle aimait à obéir, et s'il ne lui eût pas été permis, prescrit même, de faire gras, elle aurait fait maigre entre Dieu et elle, sans que la prudence eût eu besoin d'y entrer pour rien (Jean-Jacques Rousseau, Les Confessions)

1855 Elle n’allait pourtant jamais à confesse et faisait gras le vendredi : mais elle ne manquait pas la messe le dimanche, ou, quand elle était forcée de la manquer, elle faisait double prière (George Sand, Histoire de ma vie)

1901 1er novembre.

Très troublée aujourd'hui parce que la Toussaint tombe un vendredi et qu'elle ne sait pas si elle doit faire maigre ou gras, le curé de Saint-Augustin lui-même n'ayant pu la renseigner, notre bonne dit :

- Ce n'est pas un malheur !

(Jules Renard, Journal)

1920 À côté de ces « pochetées » par contre, il est de ces athées intransigeants (oh ! c'est leur droit, assurément) qui, par système, font gras pendant tout le carême en vérité, le bel exploit ! (Raoul Ponchon, La Muse au cabaret)

1933 - Ah ! Pour cela non, rassurez-vous : il ne ruine pas ses neveux ; il paraît que la pauvre petite ne fait pas gras tous les jours... (François Mauriac, Le Mystère Frontenac)
II. Faire un temps brumeux et humide (terme de marine)

Emploi absolu

1840 - Me voilà, charmante femme... Je me suis fait un peu attendre, mais ma foi il fait gras à marcher... et puis vous avez choisi le rendez-vous un peu loin... et je ne pouvais pas trouver de feu pour allumer mon cigare... (Paul de Kock, Un jeune homme charmant)

III. il fait gras à marcher : il est difficile de marcher à cause du terrain glissant

Emploi intransitif

1857 Ces dallages ne sont pas réunis par des joints de toute hauteur, comme on le fait dans les carrelages ordinaires pour avoir des surfaces complètement unies ; nous avons reconnu que les trottoirs complétement unis, outre l'inconvénient d'être fort glissants quand il fait gras à marcher et quand il gèle, ont le défaut de présenter, lors de chaque pluie, des nappes continuelles de boues liquides peu épaisses, mais très-désagréables et qui crottent beaucoup (Description des machines et procédés)

IV. Donner une impression de grossièreté Emploi absolu

1984 J'ai pas de mobile. Ah, bien sûr, bien sûr, si on cherche la petite bête... Tenez, moi, j'aurais pu entrer chez elle. Je ne dis pas m'introduire, ça fait gras. C'est pourtant le terme officiel. Parce que moi, dans le temps, j'ai étudié la serrurerie, et je sais même fabriquer un parapluie (Anne Vergne, L'Innocence du boucher)

CORPUS WEB :

Faire maigre, faire gras... en février, les deux tu feras

Février, c'est le mois des extrêmes, de la contradiction par excellence. Ne réunit-il en effet pas les excès du carnaval et l'abstinence du carême ? [http://www.gpsromania.com/fairemaigre-faire-gras-en-fevrier-les-deux-tu-feras] (7.5.2015)

merci pour vos réponses, je pense la faire en polystiréne, la faire gras ou maigre avec de la fibre ou pas ? [http://www.cyberbricoleur.com/index. php?showtopic=300322030] (7.5.2015) 
Il faut surtout si l'on fait un régime, c'est de garder le plaisir de la table, on peut très bien assaisonner une salade correctement sans pour autant la faire grasse ou lourde [http://forsv.frbb. net/t2003p2-regime-dukan] (7.5.2015)

Quant à se lever à $7 \mathrm{~h}$, je vois Jean se lever plutôt à $10 \mathrm{~h}$ et se la faire grasse et crapuleuse :-) [http://bruxelles.blogs.liberation.fr/2008/11/12/ amende-record-p] (7.5.2015)

REMARQUES : Faire gras (I) réfère à la consommation de viande généralement pendant les jours de carême où l'Église catholique l'interdit. Il s'emploie par opposition au fait de se priver de viande (faire maigre). Dans le langage de la marine (II), faire gras réfère à un temps brumeux et humide. (III) est une locution qui renvoie à la difficulté de marcher, d'avancer sur un terrain glissant. On trouve cet emploi encore dans les journaux de 1906 (Küffner 1906 : s.v. gras). (IV) se dit du fait de donner par ses actes ou paroles une impression de grossièreté, voire d'obscénité. Gras reste invariable dans son emploi adverbial. Toutefois, dans l'emploi transitif du verbe, il peut fonctionner comme prédicat second orienté vers l'objet et s'accorder avec l'objet (v. les deux derniers exemples du CW). Néanmoins, il reste invariable dans le deuxième exemple du CW. Il faut interpréter le dernier exemple par rapport à faire la grasse matinée 'se lever tard, rester au lit sans rien faire'. Notons le proverbe Faire maigre, faire gras... en février, les deux tu feras.

\section{Faire gratuit}

Faire quelque chose gratuitement, sans

contrepartie

Pronominal (impersonnel)

1547 Pour scavoir que cest de mandement, Mandatum, en Latin dit la glose, est un office gratuit, à exhiber et faire par celuy qui lha prins et recu : ce sil ne se fait gratuit commence estre louage (Nicolas de Lescut, Institutions imperialles [trad.])

Transitif

$1686 \mathrm{Ou}$ il s'agit d'obligation et de prest fait gratuit, ou de contract de constitution de rente à prix d'argeant fait en écus d'or (Recueil de plusieurs notables arrests de la Cour de parlement)
1972 Sous la rampe de l'escalier, y avait une fille qui le regardait, avec des yeux de cocker. La salope, je parie qu'elle lui aurait fait ça gratuit, au béguin (Bertrand Blier, Les Valseuses)

Emploi absolu

1987 il convient d'être très vigilant lorsque les assureurs font gratuit (Recueil Dalloz Sirey)

2000 - Premièrement, ce n'est pas parce que je fais pas gratuit que je fais semblant. Cela n'a rien à voir (Frédéric Beigbeder, 99 francs)

2014 Les filles me demandaient : « Et le dimanche, pourquoi tu ne fais pas gratuit?». Je leur disais : « Pourquoi? Le client, tu lui fais gratuit quand il vient le dimanche? " (Sophie Bonnet, Bordel)

REMARQUES : Faire gratuit signifie 'faire quelque chose (pour quelqu'un) sans demander de l'argent ou un autre type de contrepartie'. L'emploi absolu du verbe faire, fortement transitif, reflète son passage au registre oral-familier.

\section{Faire haut}

Faire, dire à voix haute

Transitif

1878 - Maman, est-ce qu'on le mettra au pain sec ! Puis, c'étaient des exclamations, des réflexions faites tout haut. Cependant, Hélène cherchait parmi les enfants (Émile Zola, Une page d'amour)

\section{Corpus Web :}

Notre institution continue meme apres la révolution d'etre la " vache à lait " ou la " poule aux œufs d'or " des collectionneurs d'heures supplémentaires, de tueurs à gages pratiquants des liquidations «pseudo-scientifiques » derrière les portes closes car ils n'ont ni le courage, ni la virilité de la faire haut et court !!! [https://corruptionuniversit2013.wordpress. com/2013/03/14/faculte-des-lettres-de-soussehaut-lieu-de-larbitraire-et-de-la-corruptionuniversitaire-sponsorise-par-le-ministere-detutelle-et-luniversite-de-sousse] (07.05.2015)

$2 \mathrm{~m} 24$ ?? T’es sûr ??? ça commence à faire haut ça [http://basketinforum.com/viewtopic. php?t=45579] (07.05.2015) 
Mais en plus, comme avec l'effet coupé, en faisant monter la balle, on risque de la faire sortir en longeur (elle est attirée vers le haut), on évite de la faire haute [http://www.la-technique-dutennis.com/coupdroitlifteintro.htm] (07.05.2015)

REMARQUES : Faire haut signifie 'exprimer par la parole, dire, répondre à voix haute'. Notons l'emploi de faire court dans le premier exemple du CW où faire haut et court signifie 'exécuter' sur le modèle de pendre haut et court. Haut reste invariable dans son emploi adverbial. Toutefois, il peut fonctionner, au sens concret de 'hauteur', comme prédicat second orienté vers l'objet (dernier exemple du CW), et dans ce cas-là il s'accorde avec l'objet. Dans l'avant-dernier exemple, faire se rapproche d'une fonction de verbe copule 'sembler être'. Haut est modifié par tout. VoIR AUSSI : dire bas

\section{Faire isnel}

Faire rapidement

Transitif

1235 Se nous i trouvons bon poisson, J'en acaterai a fuison.

Sire, dist il, tost et isnel

Sera fait chou qui vous est bel

(Philippe de Remi, sire de Beaumanoir, $L a$ Manekine, 4999)

REMARQUES : En ancien français, faire isnel désigne le fait de faire (quelque chose) vite, rapidement, immédiatement, l'adverbe tôt 'tout de suite' renforçant l'idée de rapidité de l'action. D'origine germanique, isnel était employé jusqu'en moyen français avec la même signification que schnell 'rapide', son correspondant en allemand moderne. Le fait qu'on ait utilisé ce mot emprunté comme adjectif-adverbe montre que l'emploi adverbial de l'adjectif était un procédé productif.

\section{Faire joli}

Avoir un effet esthétique

$\lambda$ faire net

\section{Faire juste}

Écrire avec justesse

$\pi$ faire beau

\section{Faire laid}

Faire, créer des choses laides, sans harmonie, désagréables à regarder

Emploi absolu

1843 Dans cette longue file d'enfants, nous en vîmes bien peu qui eussent une jolie figure, et l'Hymen lui-même, dans toute son insouciance conjugale, aurait eu de la peine à faire plus laid que ces enfants de l'Amour (Théophile Gautier, Voyage en Espagne)

1864 J'en ai assez... mon dieu ! Peut-on s’amuser à faire laid... plus laid que nature ! Quelle drôle d'idée! (Edmond et Jules de Goncourt, Renée Mauperin)

\section{CORPUS WEB :}

J'ai trop envie de me faire tatouer mais quand je serais vieille ca va faire laid et je suis une chochotte je vais crier partout [https://twitter.com/ lucie_mty/status/334372977196011523] (7.5.2015)

- Dis, César, il va falloir te faire beau, ce soir ! Est-ce que tu as tout ce qu'il te faut?

- Pour me faire beau, oh non ! Mais pour me faire laid, je n'ai pas besoin de grand-chose ! Avec l'âge, il vaut mieux savoir se faire laid que d'essayer de se faire beau, vois-tu ! [http://www. cles.com/chronique/demandez-du-nouveau] (7.5.2015)

L'année suivante, Charlize se fait laide dans « L’affaire Josey Aimes », et très paumée, en 2012, dans « Young Adult » [http://www.parismatch. com/People/Cinema/Charlize-Theron-quand-lafiction-depasse-la-realite-741404] (12.5.2015)

J'aissaye de la faire laide mais elle reste toujours belle parce que les gens la font belle [http:// www.jeux-fille.fr/jeux-maquillage/habille-etmaquille-rihanna.html] (12.5.2015)

REMARQUES : Faire laid désigne le fait de faire, de créer, de produire quelque chose qui par sa forme, sa couleur, son aspect, son manque d'harmonie, est désagréable à regarder et heurte l'idée que l'on se fait du beau. Dans son emploi absolu, faire se rapproche du sens de 'paraître', 'donner une apparence (de laideur)', notamment dans le premier exemple du CW. Laid reste invariable dans son emploi adverbial. Dans le deuxième, troisième et quatrième exemple $\mathrm{du} \mathrm{CW}$, il fonctionne comme prédicat second. Dans le troisième 
exemple, le verbe apparaît dans son emploi pronominal ; l'adjectif s'oriente alors vers le sujet et s'accorde avec ce dernier. Dans le quatrième exemple, il s'oriente vers l'objet et s'accorde avec celui-ci. Il est modifié par plus.

\section{Faire large}

I. Déployer les troupes

Emploi absolu

1577 Or avoit-il desja practiqué les soldats Cabazitans, lesquels furent ceux qui trahirent l'empereur : Car estans commis à la garde de sa personne dans le faux-bourg de l'Acanthe, où il s'estoit allé camper avec ses chariots et machines, tout vis à vis de Jean, ils firent large ; tellement que sur la minuict les capitaines de son fils le surprirent, qu'il ne se doutoit de rien, et le mirent à mort (Blaise de Vigenère, L'Histoire de la décadence de l'Empire grec [trad.])

II. Faire les choses en grand, de façon excessive ; être généreux

Emploi absolu

1925 Si enclin que je sois à faire large, très large, la part de sublimation que comporte l'œuvre d'art, si l'on va jusque-là, c'est vraiment lui faire la part du lion (Charles Du Bos, Journal)

1936 La tête vide, Edmond suivait l'oscillation grise de l'oiseau. Avec deux cents francs par mois, le docteur Barbentane croyait faire très large pour son fils. Il y avait pourtant déjà là-dessus quarante francs qui partaient pour la chambre (Louis Aragon, Les Beaux Quartiers)

1957 [Jean Nohain et Mireille ont écrit le Petit Chemin] Quelques jours après Maurice Chevalier venait voir Mireille. Je l'entends encore :

- Pourquoi le Petit Chemin ? Vous écrivez beaucoup trop mince, beaucoup trop étriqué. Pour réussir dans la chanson, il faut faire large! il faut chanter grand! Du souffle, mes amis, du souffle! (Marie-Claire, mars 1957 / Grundt : 311)
1996 Maman insistait pour savoir. Il finit par avouer qu'il avait mis sur la table toutes leurs rations du mois. - Pour faire large, Genia. Pour faire russe !

Maman, catégorique :

- Il n'en est pas question! Vous allez me ranger tout ça ! Se réduire à la famine, pour une réception à la russe ! (Boris Schreiber, Un silence d'environ une demi-heure)

\section{CORPUS WEB :}

Pour faire large, une classe abstraite est une classe qui à des méthodes abstraites. Elles peuvent représenter des concepts comme par exemple un moyen de transport ou un repas, on a une idée de ce que l'on peut faire avec, mais on ne sait pas comment c'est concrètement [http:// autourducode.com/classes-abstraites-et-ducktyping] (12.5.2015)

D'apres certains on a l'impression que le cintre large rend aussi le vélo plus maniable en meme temps que plus stable, que ça a que des bons cotes! Apres 750 tu te rend pas comptes mais ça commence a faire large quand tu fais moins d'un metre 80 et qu'est pas forcement costaud [http://www.26in.fr/forums/matos/ peripheriques/sujet-8266-cintre-large-tout-estrelatif_1000.html] (12.5.2015)

On va donc me faire des cales sur mesures et du coup j'en profite pour les faire large [http:// www.forum-auto.com/pole-technique/prepara tion-vehicule/sujet382383.htm] (12.5.2015)

le truc c'est que j'envoie 80 pompes d'affilé mains écartées, et dés que je me met normal je peine à arriver à 50 . Mais bon à mon avis je pourrai les faire larges il y pas de raison :) [http://www. aumilitaire.com/forum/topic/10386-pompeslarges-pendant-les-classes] (12.5.2015)

REMARQUES : Faire large signifiait, au $\mathrm{XVI}^{\mathrm{e}}$ siècle, 'déployer les troupes'. Dans la langue moderne, il signifie 'être généreux', ainsi que 'dire grosso modo quelque chose' (pour faire large, premier exemple du CW). Dans l'exemple de 1996, faire large 'être généreux' s'oppose à faire russe 'faire quelque chose sans mesure ; exagérer'. Le restant des exemples du CW montre que l'emploi au sens concret spatial est fréquent dans la langue familière. Large reste invariable dans son emploi adverbial figuré, qui tend à l'emploi absolu. Au sens 
concret, comme prédicat second résultatif, il peut s'accorder avec l'objet (v. le dernier exemple du $\mathrm{CW}$ ), mais il peut également rester invariable (troisième exemple du CW). Faire large s'emploie alors en construction transitive, mais l'emploi absolu n'est pas exclu (second exemple du CW). Large est modifié par très. Notons la réduplication faire large, très large. Notons aussi écrire mince, chanter grand, faire russe, ainsi que l'emploi comme adverbe de phrase de l'adjectif-adverbe normal 'c'est normal' dans le dernier exemple du CW.

\section{Faire léger}

Faire quelque chose de manière à le rendre léger Emploi absolu

1958 - J'ai la réputation de pêcher fin, me disait-il en souriant, avant de m'emmener dans son atelier-laboratoire, où il fabrique lui-même lignes, plumes et hameçons. C'est inimaginable. Il paraît impossible de faire plus petit, plus léger (Point de vue, 20 juin 1958 / Grundt : 409)

\section{CORpus WEB :}

Faire léger avant les vacances, pour partir en forme, et revenir serein ! Faire léger consisterait à réellement se poser la question de l'utilité de boucler telle ou telle chose avant les vacances. Quelle conséquence si je le fais après ? Quel bénéfice si je laisse décanter et que j’aborde ça à mon retour, l'esprit reposé ? [http://www. troisiemevoie.com/isabelle_harle/2008/03/fairelger-pour.html] (12.5.2015)

Mais je voudrais inciter les futurs constructeurs à construire léger, à mettre un point d'honneur à faire LÉGER mais SOLIDE (c'est possible) [http://pouguide.org/construire-leger] (12.5.2015)

J'en voulait un pratique, j'aime pas quand ça coule entre les doigts, alors j'avais envie d'une texture sprayable, et puis comme mon gros bidon m'empeche de me contorsionner à souhait, c'est parfait ! Qui dit sprayable, dit léger...... j’ai donc essayé de la faire léger... voyez plus tôt [http://curiorainette.canalblog.com/ archives/2010/09/12/19020274.html] (12.5.2015)

Pareil pour moi, la crème au beurre c'est pas ma préférée mais je ne savais pas qu'on pouvait la faire "légère " [http://christaliefolie.canal blog.com/archives/2011/10/19/22354419.html] (12.5.2015)
REMARQUES : Faire léger désigne le fait de produire, de fabriquer quelque chose de léger, de peu pesant (par exemple des articles et des accessoires de pêche). Dans le premier exemple du CW, il signifie 'se comporter sans se stresser, sans se surcharger, ne faire que le strict nécessaire'. Léger reste invariable dans son emploi adverbial en construction absolue. En tant que prédicat second orienté vers un objet explicite, il peut s'accorder avec celui-ci (v. le dernier exemple du CW). Il est modifié par plus. Notons aussi les groupes pêcher fin, faire petit, construire léger, faire solide, qui appartiennent au langage du quotidien.

\section{Faire lourd}

I. n'en faire pas lourd : travailler sans faire un effort

Emploi absolu

1906 Il n'en fait pas lourd (Exemple entendu [à Limoges] / Küffner s.v.)

II. ça ne fait pas lourd: ne pas peser beaucoup dans la balance

1938 J'ai passé en revue, en venant te voir, les hommes importants auxquels je peux m'adresser. Ça ne fait pas lourd, mais j'irai les voir (Nouvelle Revue française)

2004 A propos de Sarkozy et de son dîner amical de début d'année au ministère de l'Intérieur avec 120 parlementaires, Juppé s'amuse : "Sur 577 députés et 321 sénateurs, ça ne fait pas lourd en pourcentage » (Paris Match)

REMARQUES : Nous ne citons pas l'emploi météorologique au sens de 'faire chaud et humide'.

\section{Faire maigre}

Ne manger ni viande ni aliment gras

Emploi absolu

1691 Grâces au ciel, le carême est passé, et bien que je n'aie fait maigre que la semaine sainte, ce temps-là m’a paru plus long que tout le carême n'aurait fait à Paris, parce qu'il n'y a point de beurre ici (MarieCatherine d'Aulnoy, Relation du voyage d'Espagne) 
1762 Je ne le voyois point s'inquieter si ceux qu'il aidoit alloient à vépres, s'ils se confessoient souvent, s'ils jeûnoient les jours prescrits, s'ils faisoient maigre, ni leur imposer d'autres conditions semblables sans lesquelles, dût-on mourir de misére, on n'a nulle assistance à espérer des devots (Jean-Jacques Rousseau, Émile ou De l'éducation)

1830 Ma cuisinière, avant la révolution j'avais des gens, ma cuisinière fait maigre le vendredi (Stendhal, Le Rouge et le noir)

1862 Les bernardines-bénédictines de cette obédience font maigre toute l'année, jeûnent le carême et beaucoup d'autres jours qui leur sont spéciaux, se relèvent dans leur premier sommeil depuis une heure du matin jusqu'à trois pour lire le bréviaire et chanter matines (Victor Hugo, Les Misérables)

1936 L’opinion publique se calma sur ce point, et sur le risque de péché mortel pour les députés qui s'enverraient les 250 kgs de veau et de jambon, quand Mgr Gibier, un nom prédestiné, évêque de Versailles, fit assavoir qu'il levait ce vendredi-là, pour toute la Seine-et-Oise, l'obligation de faire maigre (Louis Aragon, Les Beaux Quartiers)

1989 Du moins elle accompagnait chaque dimanche sa mère et sa sœur à la cathédrale, se confessait régulièrement - quoiqu'on pût se demander quelles vétilles elle pouvait avouer au prêtre invisible qui se tenait derrière les croisillons de bois -, faisait maigre le vendredi (ce qui ne signifiait pas grand-chose, ce jour étant celui où l'on servait de vastes poissons à la chair délicate que le mareyeur venait livrer luimême) (Claude Simon, L’Acacia)

\section{CORPUS WEB :}

Jésus est mort sur la croix un vendredi : le Vendredi Saint. En mémoire de son sacrifice et en esprit de pénitence, l'Église demande aux chrétiens de faire maigre le vendredi, c'est-à-dire de s'abstenir de viande, considérée comme aliment riche. (Attention, faire maigre est différent de jeûner) [http://www.pourquois.com/societe/ pourquoi-catholiques-mangent-pas-viandevendredi.html] (12.5.2015)

L'obligation de faire maigre pendant le Carême (sauf les dimanches) demeure en théorie. En pratique, certaines personnes essaient de manger moins riche, en supprimant par exemple la viande rouge, les confiseries, la pâtisserie [http://fr.wikipedia.org/wiki/Religion_ et_alimentation] (12.5.2015)

Pourtant, l'utilisation illicite de la drogue est courante dans le secteur agricole ou les porcs sont nourris de la drogue pour les faire maigre et charnue [http://www.steroidsone.eu/lang-fr/ clenbuterolo/305-clenbuterol-hubei-50-tabs004mg-tab.html] (12.5.2015)

La pièce, d'une forme indéfinissable, était remplie de miroirs. Sur les murs, le plafond, sur le sol. Ceux disposés sur les murs renvoyaient des reflets différemment déformés. L'un les allongeait considérablement, l'autre les grossissait, un autre les faisait maigres, d'autres petits [http://www.bestfanfictions.com/s/1983693/8/ Attaques-\%C3\%A0-Poudlard] (12.5.2015)

REMARQUES : Faire maigre se dit avant tout du fait de ne pas consommer de viande les vendredis et pendant le carême, généralement par prescription de l’Église catholique. Il s'oppose alors à faire gras. Maigre reste invariable dans son emploi absolu. Toutefois, en tant que prédicat second d'une construction transitive, avec le sens de 'amaigrir' (v. les deux derniers exemples du CW) il peut s'accorder avec l'objet (v. le dernier exemple du CW).

\section{Faire mauvais}

Enrager, être en colère

Emploi absolu

1847 Cette instabilité, l'attente de l'avenir, l'incertitude de savoir si j'aurai une maison, si je serai encore à loyer, si le Nord haussera, tout cela tue et ravage mon imagination, ma volonté n'est plus assez forte pour écarter les sujets de trouble, parce qu'ils sont dans mon cœur. Et j'ai fait mauvais (Honoré de Balzac, Lettres à Madame Hanska)

1852 C'est [= le travail] mon grand moyen contre les chagrins de la vie : non pas que je m'en- 
rage souvent. Quant je fais mauvais je suis fort triste (Lettres de Eugène Delacroix)

\section{CoRpus Web :}

Images du passage des Hommes en armes hier nuit à la base du CCDO à l'école de police. Ouais ils ont fait mauvais... [https:// resistancisrael.com/attaques-armees] (20.7.2017)

REMARQUES : Il n'y a pas lieu ici d'attester faire mauvais au sens météorologique 'faire mauvais temps', même s'il peut entrer dans le groupe des adjectifs-adverbes. Par contre, faire mauvais au sens de 'enrager' n'est pas sans intérêt. Bien que l'expérience communicative nous dit qu'il est usuel, il est difficile de l'attester dans les sources écrites. Dans l'exemple du CW, il est plus difficile d'extraire le sens mais le contexte suggère celui de 'faire du mal', à savoir, beaucoup de blessés.

\section{Faire moche}

Faire mal (quelque chose), de manière

maladroite, imparfaite

Transitif

1920 Il fait ça moche (Henri Bauche, Le Langage populaire)

CORPUS WEB :

Il va faire moche à Paris le WE prochain !! Venez vous réchauffer par ici [https://www. facebook.com/CoupDePoucePousse/posts/64851 0238564195] (12.5.2015)

Après si tu as une mousse ou un truc dans le genre met la en essayant le plus possible de mettre en forme tes cheveux de la forme que tu les veux, bon toi je pense que tu les voudras pas gonflé donc essayé de les applatir le plus possible mais pas en racine parce qu'en racine ça va te faire tout tout plat au dessus et en dessous ça va faire bizzare, ça va faire moche en gros [http:// forum.aufeminin.com/forum/cheveux/_f27795_ cheveux-Help-cheveux-tres-frises-et-touffe.html] (12.5.2015)

L'idée de faire des véhicules électriques, d'accord ! Mais est-il nécéssaire de les faire moche ? [http://www.autotitre.com/forum/Chrysler/ Le-design-selon-Chrysler...-98427p1.htm] (12.5. 2015)

J'adore vos sims moches... Perso j'arrive pas à les faire moches, pourtant j'ai essayé de toutes mes forces [http://forums.thesims.com/
fr_FR/discussion/769779/vos-sims-moches/p5] (12.5.2015)

REMARQUES : Faire moche réfère normalement au fait de produire quelque chose de peu esthétique ou de moralement critiquable, d'agir d'une manière inadéquate, qui inspire le mépris, la désapprobation. À part ceci, il fait aussi partie de la série météorologique faire beau, bon, mauvais, etc. (il fait moche). Il peut aussi renvoyer à l'effet produit par quelque chose (ça va faire moche). Dans les deux cas de figure, le groupe se trouve en construction absolue. Moche reste invariable dans son emploi adverbial, notamment en construction absolue, mais en tant que prédicat second il peut s'accorder ou non avec l'objet en construction transitive (v. les deux derniers exemples du CW).

\section{Faire monotone}

Faire de manière à produire une impression de monotonie

$\pi$ faire grand

\section{Faire net}

Faire très rapidement, brusquement, soudainement

Transitif

1836 Ce qui fit ma conquête net dans Barral la première fois que nous parlâmes ensemble, $[. .$.$] ce fut 1^{\circ}$ la beauté de son habit dont le bleu me parut enchanteur, $2^{\circ}$ sa façon de dire ces vers de Voltaire (Stendhal, Vie de Henry Brulard)

\section{CORPuS Web :}

nous passons notre temps à conseiller des reflex pour ceux qui veulent absolument plein de bokeh avec un maximum de flou derrière... pour faire net partout, c'est vraiment un compact qui convient, et comme l'a fait pertinemment remarquer Sanine, un compact à petit capteur [http:// www.lesnumeriques.com/legrandforum/avis/ Photo/portrait-arriere-plan-sujet_12635_1.htm] (12.5.2015)

la courbe est un peu à main levée mais à la base ce serait plutôt une arc-tangente (histoire de faire net et joli, lol), enfin bon, ça c'est pas grave [http://www.crystalxp.net/forum/fr/entraidegraphique-archives/Graphisme-Questions- 
Generales/deformation-etirement-demandesujet_44047_1.htm] (12.5.2015)

c'est vrai qu'il est souvent difficile de trouver la petite bête et de la faire nette dans le viseur du 5D si le grandissement dépasse 2 [http://www.chassimages.com/forum/index. php?topic=183469.30;wap2] (12.5.2015)

La 3e partie est rapide. Pour la faire "nette ", il suffira de marquer la 1ère note de chaque groupe de quatre [http://savoir-chanter.ca/pdf/ 4_Exercice_simple.pdf] (12.5.2015)

REMARques : Faire net désigne le fait de faire quelque chose d'une manière brusque, nette, incontestable. Dans les exemples du CW, faire net a le sens de 'faire avec précision'. Net reste invariable dans son emploi adverbial, qui tend à l'emploi absolu, mais en tant que prédicat second, il peut s'accorder avec l'objet (v. le troisième et le quatrième exemple du CW).

\section{Faire noir}

Faire le contraire de ce que l'on a dit $\lambda$ dire blanc

\section{Faire petit}

I. Faire peu

Emploi absolu

1170 Lors recomança sa proiiere ;

$\mathrm{Au}$ roi parole an tel meniere :

«Sire, fet il, bien sai et voi

Que petit feriiez por moi

Quant ce don m'avez refuse » (Chrestien de

Troyes [attribué], Philomena, 498)

1175 Amis, fait [e]l', or aient honte Cil qui desfirent nostre conte. Mout sevent dire et petit faire (Gautier d'Arras, Ille et Galeron, 3341)

1177 Aprés ce me pria, que gié Par son ostel m'an revenisse An guerredon, se je poïsse, Et je li dis : « Volantiers, sire ! ", Que honte fust de l'escondire. Petit por mon oste feïsse, Se cest don li escondeïsse (Chrestien de Troyes, Yvain ou Le Chevalier au lion, 267)
II. Faire quelque chose de manière à le rendre petit

Emploi absolu

1958 - J'ai la réputation de pêcher fin, me disait-il en souriant, avant de m'emmener dans son atelier-laboratoire, où il fabrique lui-même lignes, plumes et hameçons. C'est inimaginable. Il paraît impossible de faire plus petit, plus léger (Point de vue, 20 juin 1958 / Grundt : 409)

\section{Avoir l'air petit, passer inaperçu}

Emploi absolu

1977 Hanjure a oublié ses touristes néerlandais, ils font petit, petit... Cette cuisine-salle-àmanger de mineur gréviste modèle 48 , le terril pointu par-dessus les toits si bas si noirs, et le bouquet fané depuis août dernier, sur la plaque de marbre au coin de la rue (Jean-Pierre Chabrol, La Folie des miens)

\section{CORPUS WEB :}

Si Samsung inonde le marché avec ses smartphones et ne lésine pas sur la communication, le groupe sud-coréen peut aussi se faire tout petit. La preuve avec les modèles Galaxy S6 et S6 Edge qu'il écoule au pays du soleil levant [http:// www.generation-nt.com/samsung-galaxys6-edge-absence-redondance-logo-strategiemarketing-communication-actualite-1914336. html] (12.5.2015)

\section{Faire petit pour voir grand}

La firme américaine Coca-cola sait innover lorsqu'il s'agit de communiquer sur ses produits. Il y a quelques jours, le géant du soda dévoilait avec l'aide de l'agence Ogilvy \& Mather Berlin une installation de mini kiosque pour accompagner le lancement de son mini format $(0,15 \mathrm{cl})$ en Allemagne [http://www.monsieur-loyal.com/ blog/faire-petit-pour-voir-grand] (12.5.2015)

La femme de droite est accroupie et présente une écuelle. Celle de gauche tend la main avec quelque hésitation, un peu gênée. Celle qui tient l'écuelle est celle qui donne, mais elle ne donne pas avec un geste hautain. Elle se fait petit : elle ne donne pas d'en haut avec un complexe de supériorité [http://www.odn-solidarites.org/fr/lanoblesse-du-partage] (12.5.2015) 
Ma louloute est en pré/box, donc elle se promène toute la journée avec ses copains. Mais ce qui me fait hésiter c'est qu'elle est déjà très sensibles des pieds... pour partir en balade c'est pas la peine de négocier le chemin caillouteux, elle se fait petite et passe sur la mini bande d'herbe latérale [http://www.chevalannonce.com/forums9203159-cheval-pieds-nus-transition] (12.5.2015)

La pièce, d'une forme indéfinissable, était remplie de miroirs. Sur les murs, le plafond, sur le sol. Ceux disposés sur les murs renvoyaient des reflets différemment déformés. L'un les allongeait considérablement, l'autre les grossissait, un autre les faisait maigres, d'autres petits [http://www.bestfanfictions.com/s/1983693/8/ Attaques-\%C3\%A0-Poudlard] (12.5.2015)

REMARQues : En ancien français, petit est employé comme quantifieur au sens de 'peu'. Faire petit (I) signifie alors 'faire peu, de manière insuffisante ; agir sans trop s'investir'. L'emploi moderne privilégie le sens résultatif (II) de 'produire, fabriquer quelque chose de petit, de réduit (par exemple, des articles de pêche)'. Dans l'acception (III), (se) faire petit signifie 'donner l'impression d'être petit', donc d'occulter la vraie taille, la véritable importance sociale, etc. Petit reste invariable dans son emploi adverbial. En tant que prédicat second, il peut s'accorder avec l'objet (dernier exemple du CW), ou, dans l'emploi pronominal du verbe, avec le sujet (quatrième exemple du CW), mais l'accord est absent dans le troisième exemple. Le fait que l'accord est audible avec petit, nous laisse supposer que l'absence de l'accord arrive aussi dans la langue parlée. Petit est modifié par plus, tout. Notons aussi l'emploi de pêcher fin, faire léger, faire maigre, voir grand, ainsi que la réduplication petit petit. VoIR AUSSI : construire petit

\section{Faire précis}

Exécuter avec précision

$\lambda$ faire exact

\section{Faire prou}

Tirer profit d'une situation

Emploi absolu

1170 De s'avanture s'esjoïst :

Mout estoit liez de s'avanture ;

Qu'amie ot bele a desmesure,
Sage et cortoise et deboneire.

De l'esgarder ne pot preu feire :

Quant plus l'esgarde, plus li plest

(Chrestien de Troyes, Erec et Enide, 1486)

REMARQUES : En ancien français, faire prou désigne le fait de tirer profit d'une situation, ici à la forme négative.

\section{Faire rapide}

I. Faire vite, promptement, vivement

Emploi absolu

1885 L'écrivain qui se propose de peindre des actions doit faire rapide; celui qui se propose de peindre des états doit au contraire donner l'impression de la durée (Paul Bourget, Nouveaux essais de psychologie contemporaine)

II. Faire en sorte que quelque chose se fasse rapidement (résultatif)

Pronominal

1886 C'était comme une marée d'amertume qui montait en elle, et le tournoiement de ses idées se faisait si rapide que toute notion des choses ambiantes s'effaçait de sa conscience (Paul Bourget, Un crime d'amour)

1887 Il remit le pistolet dans le tiroir, s'assit dans son fauteuil, - le fauteuil de Suzanne, et il se laissa rouler dans cet abîme de la rêverie tragique où les images se dessinent avec un relief extraordinaire, où les raisonnements se font rapides comme dans la fièvre, où s'élaborent les résolutions désespérées (Paul Bourget, Mensonges)

Transitif

1962 Non sans peine, au début, d'autant que je travaillais de bonne heure comme naguère quand j'étais seul dans ma chambre et Virginie je devais la découvrir, l'enjamber, puis la recouvrir, des gestes que je n'arrivais pas à faire rapides et j'ai décidé de la fuir en fermant les yeux pour ne pas la voir, belle, nue, respirante et quelquefois soupirante (Yves Berger, Le Sud)

CORPuS Web :

Bac S - Astuce maline : équation d'un plan, comment faire facile et rapide ? [http://www. 
intellego.fr/soutien-scolaire-terminale-s/aidescolaire-mathematiques/bac-s--astuce-malineequation-d-un-plan-comment-faire-facile-etrapide-/33467] (5.5.2015)

16 trucs que vous pouvez utiliser pour faire rapide le goût des aliments Better Way

Il est facile de mettre à niveau votre expérience de la restauration rapide.

Certains amateurs de restaurant de la chaîne récemment partagé leurs hacks pour obtenir un meilleur service [http://coachesmail. com/16_trucs_que_vous_pouvez_utiliser_pour_ faire_rapide_le_gout_des_aliments_better_way_ n9PQ5g.html] (29.04.2015)

Parcouru de frissons immenses et délicieux, les révélations se font rapides et efficaces ... [https://journaldunpratiquant.wordpress. com/2012/02/06/flash] (29.04.2015)

REMARQUES : Faire rapide (I) équivaut à faire vite. Faire rapide (II) renvoie au fait de produire quelque chose de rapide ou de conférer cette qualité à quelque chose. Il est alors un prédicat second qui tend à l'emploi fléchi. L'emploi comme adverbe au sens de 'vite' (I) est moins fréquent que celui de (II) dans les textes écrits de Frantext, mais il prédomine dans la communication informelle dans le CW. Le troisième exemple du CW est ambigu, situé entre une lecture progressive 'les révélations deviennent rapides et efficaces' et une lecture de manière 'rapidement et efficacement'. Rapide est modifié par si.

\section{Faire russe}

Faire quelque chose sans mesure ; exagérer $\lambda$ faire large

\section{Faire savant}

Faire en sorte de paraître, d'être savant 入 faire vrai

\section{Faire simple}

Faire les choses simplement, sans complication Emploi absolu

1923 Nous avons pensé qu'il fallait faire plus simple encore que nos devanciers (Instructions du 20 juin 1923 relatives au nouveau plan d'études des écoles primaires élémentaires / Revue pédagogique)

\section{CORpus Web :}

Pourquoi faire simple...

Après avoir dribblé le gardien, Wilson Moreno a attendu un peu, l'a dribblé à nouveau pour la forme avant de marquer en deux temps. Pas franchement logique, l'action s'est finalement bien terminée, non sans un peu de chance... [http://www.cahiersdufootball.net/ article-pourquoi-faire-simple-5688] (29.04.2015)

D’ailleurs, Christopher Nolan ne sombre pas dans la facilité en nous affichant des grandes villes dévastées. Non, il fait simple et efficace en nous montrant de la terre aride et de la poussière. Alors que certains auraient pu tomber dans la facilité en nous offrant une débauche de spectaculaire et de catastrophes spatiale, Nolan nous offre du spectaculaire mais aussi de l'émotion [https:// captainblogbuster.wordpress.com/2014/11/03/ critique-interstellar] (29.04.2015)

D’autres cellules, appelées macrophages, restent en mouvement et sont responsables de l'affadissement du dessin au fil du temps. Pour faire simples, elles mangent l'encre [http://www. konbini.com/fr/inspiration-2/creme-enlevertatouages] (29.04.2015)

REMARQUES : Faire simple réfère au fait de ne pas compliquer les choses. Il rappelle une phrase des Shadoks (1966 1968) qui a connu un vrai succès : " pourquoi faire simple quand on peut faire compliqué » (http://www.lesshadoks.com/index2. php?page=3). La flexion dans le dernier exemple du CW est peu logique, donc fausse, si l'on veut. Simple est modifié par plus.

\section{Faire solide}

Produire, construire quelque chose de solide, faire du solide

Emploi absolu

1911 Louise, en fille raisonnable, avait cousu elle-même son trousseau. Il y avait les vieilles habitudes, à quoi Mme Suzanne tenait, qui sont de donner aux filles du linge pour jusqu'à leur mort : trois douzaines de chemises, huit douzaines de paires de bas et des draps de lit en proportion, et ainsi de suite ; car, les modes, on n'en tient pas compte, et on fait solide, et on coud serré (Charles-Ferdinand Ramuz, Aimé Pache, peintre vaudois) 
1978 Faire solide, c'est la hantise du maçon (François Cavanna, Les Ritals)

REMARQUES : Faire solide renvoie au fait de produire quelque chose de solide qui dure. Notons l'emploi de coudre serré dans le même contexte.

\section{Faire vivant}

Paraître animé

入 faire vrai

\section{Faire vrai (voir)}

I. Dire quelque chose de vrai Emploi absolu

+1365 Mès si tretos que dedans fui, Je ne cuidai trouver nullui Fors les oiseillons et Plaisance Et sa bonne amie Esperance, Mès si fis voir, pas ne m'en doeil, Car je trouvai là Bel Acueil Qui faisoit chapeaus de flourettes (Jean Froissart, Poésies [3 $3^{\mathrm{e}}$ tiers $\left.\mathrm{XIV}^{\mathrm{e}}\right]$ )

II. Faire, produire quelque chose de vrai Emploi absolu

1858 Savez-vous ce qui présentement m’occupe ! Les maladies des serpents (toujours pour Carthage). Je vais aujourd'hui même écrire à Tunis à ce sujet. Quand on veut faire vrai, il en coûte ! Tout cela est bien puéril et au fond considérablement sot ! Mais à quoi passer la vie, si ce n'est à des rêves! (Gustave Flaubert, Correspondance)

1869 Faire vrai, c'est créer. Paul Huet a fait vrai, de là sa puissance. Il a compris la nature comme il faut la comprendre, empreinte de réalité et pénétrée d'idéal. Oui, je le pleure. C'était en même temps un noble et ferme caractère (Victor Hugo, Correspondance)

1882 Seulement M. Dumas tout en gardant le thème, a fait plus vulgaire et par conséquent plus vrai (Émile Zola, Une campagne)

III. Donner une impression de vérité

Emploi absolu

1883 Tenez que la plupart n'ont reçu aucune éducation, qu'ils n'ont rien vu et rien lu, que «faire distingué », pour eux, c'est tout bonnement ne pas faire vivant et ne pas faire vrai (Joris-Karl Huysmans, L'Art moderne)
1927 Le naturalisme est un exemple de cette soumission à la réalité sensible. On passe sur le résultat. Car il ne s'agit pas de faire vrai ; le vrai d'aujourd'hui en art est le faux de demain. C'est pourquoi les poètes n'ont jamais eu aucun souci du vrai, mais toujours, en somme, du réel (Pierre Reverdy, Le Gant de crin)

1942 Plus Cézanne semblait, aux yeux de ses contemporains, s'orienter vers l'abstraction, plus il cherchait à faire ressemblant : « je ne dois chercher à compléter mon œuvre, écrivait-il, que pour le plaisir de faire plus vrai et plus savant » (André Lhote, La Peinture d'abord)

1963 Des voluptés aussi souveraines ne s'oublient pas. Elle va dire au juge Elbron tout ce que je lui ai fait demander de dire. Dates, heures... les petits détails qui font vrai... et qu'elle m'aidait, pour justifier les fameuses dépenses qu'on me reproche (Alphonse Boudard, La Cerise)

1979 Mon truc, c'est justement d'être menteur. Plus fort que moi, j'peux pas m'empêcher. Alors, j'lui ai dit que j'voyais un champignon. J'ai dit un cep. Pour faire plus vrai. Il me regarde (Jean Vautrin, Bloody Mary)

\section{CORPUS WEB :}

Vouloir «faire vrai » est une erreur colossale; l'art doit être artificiel et constamment recréer. C'est cette facilité de recréation qui était la raison d'être du cinéma et, en l'oubliant, il se perd luimême [http://www.universalis.fr/encyclopedie/ luchino-visconti/3-copier-le-vrai-c-est-peut-etreune-bonne-chose-mais-inventer-le-vrai-c-estmieux-c-est-beaucoup-mieux-verdi] (29.04.2015)

La peinture reste un de mes rêves depuis tout gosse, donc un jour ça me prendra et je m'y consacrerai, je continue un peu mais pas avec la même intensité. J'étais un peu paumé : tu fais un tube malgré toi, tu te retrouves avec ça dans les mains, qu'est-ce que tu fais ? Il faut faire mieux? Et en fait non, il faut faire vrai. Donc j'ai attendu que ce soit un vrai moment, avec un truc qui me tenait à cœur, qui m'impliquait personnellement et c'est ce qui s'est passé avec cette rencontre des Monophonics [http://www.leprog.com/26-1interview-ben-l-oncle-soul.html] (29.04.2015) 
REMARQues : Dans l'exemple de +1365 , faire est pris au sens de 'dire'. Le sens du verbe persiste dans la langue moderne, mais la collocation faire voir avec ce sens disparaît. Les acceptions (II) 'faire quelque chose de vrai' et (III) 'donner une impression de véracité, d'authenticité ou de réalité' forment un continuum difficile à séparer. La problématique du faire vrai est discutée dans le domaine de l'art, artificiel par nature. De même, l'impression qu'un individu donne ou 'fait' en société est une préoccupation quotidienne, souvent située dans le domaine de la mode. Les collocations du même type qui figurent dans les exemples sous faire ferme, faire vivant, faire savant, et faire vulgaire, montrent que les acceptions (II) et (III) font partie d'une série analogique avec prédominance de (III). Vrai reste invariable et est modifié par plus.

\section{Faire vulgaire}

I. Mettre en langue vulgaire

Transitif

1561 Mais aussi je diray ceci sans arrogance, que je suis encores à voir tragedies et comedies Françoises, excepté celles de Medée et d'Hecuba, lesquelles ont esté faictes vulgaires et prises du Grec d'Euripide (Jacques Grévin, César)

II. Produire quelque chose de vulgaire Transitif

1839 Le peintre, pour la figure principale, avait deux écueils à éviter : ou bien il la jetait dans un moule déjà connu, et alors adieu, à toute individualité, ou bien il la faisait vulgaire (Le Magasin universel)

Emploi absolu

1880 Nos modernes font grand, sans se demander si la valeur du sujet permet de si ambitieuses proportions ; ils font laid, systématiquement, par opposition au beau suranné ; ils font vulgaire, par haine de l'élégant ; peintres en rupture de ban, si l'on veut, mais peintres (Gazette des Beaux-arts)

III. Vulgariser, se mettre à la portée du plus grand nombre

Pronominal

1849 nous croyons avoir pleinement démontré que si la vérité revêt souvent l'apparence d'un paradoxe, ce n'est pas notre faute, mais celle de l'erreur, qui n'a besoin que de se faire vulgaire pour qu'à l'envie tout le monde l'accueille comme si elle était la vérité (Émile de Girardin, Questions de mon temps)

IV. Donner une impression de vulgarité Emploi absolu

1943 Et puis elle [= Édith Piaf] sait faire peuple sans faire vulgaire - alors que tant d'autres font vulgaire même sans essayer de faire peuple (Le Journal)

1975 Quand une femme emploie l'expression " se soûler la gueule », cela fait vulgaire et bas, pour un homme c'est moins vulgaire et cela sonne fort et triste. Une femme ça se grise, ça s'enivre, au pire ça boit (Marie Cardinal, Les mots pour le dire)

\section{CORPUS WEB :}

Etre sexy ... sans faire vulgaire!

Rien de pire en matière de style que d'en faire trop. Votre tenue ainsi que votre apparence générale reposent sur l'équilibre des pièces que vous choisissez, le tout devant être harmonieux, juste avec une pointe de sexy sans rajouter de superflu! [http://www.my-image-expert.com/etresexy-sans-faire-vulgaire] (29.04.2015)

Par contre, une robe moulante parce qu'elle est trop petite, option bourrelets en pagaille, non seulement c'est vulgaire, mais c'est moche. J'associe souvent la vulgarité à ce qui n'est pas clean, qui fait crade ou douteux. Une fille habillée très sexy aura peu de chances de faire vulgaire si elle est irréprochable : vêtements qui tombent bien, repassés, sans tâches ou fils qui pendouillent, cheveux propres (pas de vieilles racines de coloration), peau et épilation nickel... [http://www. carolinedaily.com/forum/comment-etre-sexysans-etre-vulgaire-t38210.html] (29.04.2015)

REMARQuES : Faire vulgaire (I) s'emploie dans le contexte de la vulgarisation d'un ouvrage dans une langue contemporaine, généralement écrit à l'origine en grec ou en latin. (II) réfère au fait de produire quelque chose de vulgaire. L'emploi pronominal (III) fait allusion aux efforts qu'on pourrait faire pour être à la portée du grand public. Faire vulgaire (IV) s'emploie pour 'donner 
une impression de vulgarité', dans la façon de se comporter, de s'habiller, de se maquiller, notamment en rapport avec l'attirance sexuelle (CW). Le sens (IV) prédomine dans l'emploi actuel, comme le soulignent aussi les exemples du CW. Notons l'emploi de faire bas, faire laid, faire peuple ; sonner fort, sonner triste.

\section{Faucher serré}

Faucher en faisant un grand effort

Intransitif

1897 Les faucheurs au loin s'inquiétaient. Ceux qui relevaient leur faux, pour passer la pierre sur la lame, interrogeaient un instant la dépression de la prairie, le fond de la vaste conque où ils peinaient si rudement, puis ils se baissaient et fauchaient plus serré, comme ceux qui comptent les minutes. Ce n'était plus le travail quotidien, mais la hâte tragique et la rage contre les éléments plus forts que l'homme. Une richesse allait périr (René Bazin, De toute son âme)

\section{Fêler net}

Se fêler, se briser d'une manière précise et brutale

Pronominal

1920 Une multitude transfigurait, sentait dans un chant gémir toute la douleur du monde, parce qu'elle-même était mal à l'aise de trop craindre que ce chant se fêlât net (Henry de Montherlant, La Relève du matin)

\section{Corpus Web :}

Je suis dans une sorte de rage - dégoût vis à vis de mon accident d'hier, On jouait de manière assez active et j'ai fait une chute, Mon tout nouvel EBBR, pourtant un Marui M4 CQBR Blowback V2 acheté il y a 2 semaines, à vue son corps se fêler net au niveau de l'entrée du tube de crosse ${ }^{\star}$ CRAC $^{\star}$ C'est même pas réparable juste changeable, mais il n'y a pas de pièces (corps) de rechange de dispo et les autre corps ne sont pas compatible !! héhééé ! [http://forum. gbb-technics.fr/viewtopic.php?f=27\&t=1337] (29.04.2015)
REMARques : Fêler net fait partie de la série analogique de casser /couper / trancher net et marque une rupture brusque et claire, qui brise d'un coup le potentiel de résistance d'un matériel, d'une personne.

\section{Férir bas}

Frapper, donner un coup dans la partie inférieure du corps

Transitif

+1175 Se par le bois vait cerf ne dains, Se il atouchë a ces rains Ou cil arc est mis et tenduz, Se haut hurte, haut est feruz, Et se il hurte a l'arc an bas, Bas est feruz eneslepas (Béroul, Tristan [ $4^{\mathrm{e}}$ quart XII $\left.\mathrm{e}\right], 1758$ )

+1200 Li keu saillent de la cuisine : Ne demanderent que ce fu, Ainz traient les tisons du fu, Si fierent sor lui a un tas ; Tant le fierent, et haut et bas, Que brisies li ont les rains (Le Provost a l'aumuche, 118)

REMARQUES : Férir haut et bas se disait du fait de porter des coups sur quelqu'un/quelque chose, à plusieurs endroits ici et là. Notons l'emploi de heurter haut, férir haut.

\section{Férir droit}

Frapper directement ou exactement, par la voie la plus courte, la plus directe

Transitif

+1200a A la dame vint corant un messag[er] ke la conte noveles de Doun li fer. Quant ele l'oy, si p[r]ent un cotel de asser, le messag[er] fert dreit p[ar] mi le qer.

A sa haut tur va la dame mo[n]ter, de son gré chet jus, q[ue] le col fet deb[r] iser (Bueve de Hanstone [début XIII'], 2371)

+1200 b Cil qui i met sa force tote Done a Meraugis sor l'escu De sa lance par tel vertu Que sa lance peçoie en .II. ; Et Meraugis li merveilleus Brandist sa lance, sel fiert haut Si droit qu'il porte en mi le gaut Le chevalier et son cheval 
Tot en .I. mont ; mes n'ot nul mal (Raoul de Houdenc, Meraugis de Portlesguez [début XIII'], 1718)

Remarques : Aujourd'hui inusité, férir droit réfère à une arme (ici : une lance, un couteau) projetée en direction de l'adversaire selon une ligne droite, la plus courte et directe. Notons que l'indication de lieu férir haut forme un premier groupe qui est modifié à son tour par droit.

\section{Férir dur}

Frapper durement

Transitif

1300 Or sui ge li plus durfeüs [variante : durs ferus]

Et li plus maiscéans del monde

(Jakemes, L'Histoire du châtelain de Coucy

et de la dame de Fayel, 4449)

REMARQUES : L'adjectif-adverbe dur est accordé au cas sujet dans la variante analytique.

Férir fort

Frapper avec force, violemment

Transitif

1177 Et li chevaliers s’adreça

Vers la meslee maintenant, S'ancontre un chevalier venant

Et joste a lui, sel fiert si fort

Parmi l'uel que il l'abat mort

(Chrestien de Troyes, Lancelot ou Le Che valier de la charrete, 2397)

-1200 Puis a pris en son poing le baston de pumier,

Si fort en feri l'autre mort l'abat a ses piés.

Et li tiers torne en fuie, en mi le bos se fiert (Elie de Saint Gille [fin $\mathrm{XII}^{\mathrm{e}}$ ], 1160)

1275 Mes cil de l'ost s'arment tous jors, Vers la bataille en vont le cors :

Fort les i veïssiez ferir,

Li autre prenent a foïr

(Floriant et Florete, 4677)

-1334 Lors maintenant se fiert dedens

Le Beau Chevalier au Lyon,

Haut se sourdi sur son archon

Et fiert si fort .i. chevalier

Que tout par mi le va coper.

Outre passa isnelement
Et feroit aussi freschement

Conme s'il fust au conmenchier (Le Romans

de la dame a la lycorne [1 $1^{\mathrm{er}}$ tiers XIV $]$, 8078)

REMARQUeS : Dans un combat ou une bataille, férir fort, aujourd'hui inusité, se disait du fait de frapper, de porter des coups à l'adversaire de manière vive et violente. Fort est modifié par si. Notons l'emploi de abattre mort.

\section{Férir haut}

Porter des coups en hauteur

入 férir bas

\section{Férir grand}

Donner de grands coups violents, blesser

beaucoup

Transitif

+1100 Et l'altre doyst d'escud cubrir Et de ss'espaa grant ferir

(Alberic de Besançon, Fragment d'un Roman d'Alexandre [1 $1^{\mathrm{er}}$ quart $\left.\mathrm{XII}^{\mathrm{e}}\right]$, 95)

REMARQUES : Dans la série analogique de férir, productive en ancien français, grand est employé comme intensifieur, virtuellement opposé à férir petit, qui n'est pas attesté.

\section{Férir menu}

férir souvent et menu : frapper continuellement, en donnant de petits coups répétés

Transitif

+1150 Al recerqier des rens souent tornes, Monioie le Karlon haut escries Et souvent et menu grans cos feres (Aiol et Mirabel [2 $2^{\mathrm{e}}$ moitié XII ${ }^{\mathrm{e}}$, 302)

+1250 L'autre escofle por ce nel dote Ne plus a envis nel requiert, Vers li en vet et puis le fiert Granz coz et menu et sovent. Molt esta Renart malement, Car cil qui estoit sanz poor, Li est sus coru par irur (Le Roman de Renart [2 $2^{\mathrm{e}}$ moitié XIII $]$, IX, 601)

REMARQUeS : Menu étant généralement suivi ou précédé de l'adverbe souvent, férir menu, aujourd'hui inusité, se disait du fait de porter des coups sur quelqu'un/quelque chose de manière vive et répétée, de distribuer une pluie de coups. 


\section{Férir seri}

Frapper doucement, tranquillement

Transitif

+1250 As plantees jeuent la nuit.

Le pie leva premierement

Ysengrins moult joieusement,

Et Tieberz li chaz i feri

Si doucement et si seri,

Que d'autre part le fist chaoir (Le Roman

de Renart [2 $2^{\mathrm{e}}$ moitié $\left.\left.\mathrm{XIII}{ }^{\mathrm{e}}\right], \mathrm{XVII}, 664\right)$

REMARQUES : Férir seri se disait du fait de donner des coups, de frapper quelqu'un/quelque chose calmement, sans agitation. Seri est modifié par si. Il est syntaxiquement coordonné avec l'adverbe doucement.

\section{Férir soef}

S'élancer doucement, lentement

Pronominal

+1200 «Quel part vet il ? Quel la ferai?

Il n'est pas loing ! » Lors vet au tref.

De plain eslés, non pas soëf

Se fiert dedenz, mes il n'i voit

Home de char ; pas n'i estoit

L'Outredotez. - Ou estoit il ?

(Raoul de Houdenc, Meraugis de

Portlesguez [début XIII'] ${ }^{\mathrm{e}}$, 4402)

REMARQUES : Ici employé à la forme négative, ne pas férir soef se disait du fait de se lancer, de s'engouffrer avec fougue dans quelque chose, suggérant le vif intérêt du sujet.

\section{Ferrer fort}

Tirer vigoureusement la canne de façon à ce que le fer de l'hameçon pénètre profondément les chairs du poisson

入 pêcher fin

\section{Figer net}

Immobiliser brusquement, paralyser

Transitif

1903a Il [= Mac-Kinley] présidait, on l'acclamait ; ses mains démocratiques indistinctement se tendaient vers le peuple immense, quand un homme « correctement vêtu de noir », d'un geste brutal, figea net sur ses lèvres son sourire présidentiel (Le Mouvement social)
2019 - Elva, embrasse-le ou ignore-le mais par tous les diables fais-le taire.

Je m'arrête net, la bouche ouverte, ma réplique prête à s'envoler est désormais en suspension, figée net par les paroles d'Adrian (Sonia Brito de Freitas, Elva)

Pronominal

1903b Thérie riait, très amusé de l'idée ; mais, son sourire se figea net, dans un tiraillement nerveux des lèvres et un froncement des sourcils (La Nouvelle Revue)

1972 Mattone s'est figé net. Dans le silence, Charley sort de sa poche une balle à bout doré, qu'il tient entre le pouce et l'index (Sébastien Japrisot, La Course du lièvre à travers les champs)

2008 Les autres fauves se figèrent nets, quand leur dominant se dirigea vers le haut de la dune (Claude Degret, Clothilde de Waterberry)

Emploi absolu

1924 Il [= le chef] parut, et notre animation figea net (André Gide, Si le grain ne meurt)

CORPUS WEB :

Ceux-ci [= les bras] restèrent ouverts sur l'espace vide, ses mains à trois centimètres des épaules de Lucifer ; figées nettes [https://www. fanfiction.net/s/12273396/34/Hell-Sweet-Hell] (10.10.2020)

\section{Figurer faux}

Se faire de fausses idées

Pronominal

1805 Je décrirais en dix pages, avec tout le soin possible, tout ce que fit M[artial] en cette matinée, que, ne l'ayant jamais vu, tu te figurerais toujours faux, tandis qu'un homme du monde de $\mathrm{P}$ [aris] m'entendrait parfaitement à demi-mot (Stendhal, Correspondance)

\section{CORPUS WEB :}

Affaire est donc finalement faux, tant sur le plan spirituel et scientifiquement. Comme dans le rêve, tous les objets semblent être réel, donc l'état éveillé, toutes choses nous voir et entendre semblent réels. Lorsque nous nous réveillons de 
rêve, les objets de rêve semblent être fausse ; $\mathrm{Si}$, après la mort ce monde visible doit figurer faux [http://www.bonyoganidra.com/le-spiritisme-etyoga] (29.04.2015)

REMARQUES : Pronominal ou intransitif, figurer faux réfère à une propriété de l'imaginaire, de l'idée fausse que l'on se fait de quelque chose ou de quelqu'un.

\section{Filer doux}

Se soumettre, obéir humblement

Emploi absolu

1557 Cependant ce n'est pas aux sujets de s'esmouvoir a l'encontre de leurs superieurs, ains avoir patience et filer doux, cõme l'on dit (Michel Cop, Le Livre de l'ecclesiaste)

1577 Ce propos courrouça le prince, lequel fit tout sur le champ mettre cette espie en prison : et depescha l'un de son conseil devers Amurat pour luy mettre en avant quelques articles d'appoinctement, à la verité trop superbes, et du tout hors de saison : Car en lieu de filer doux, il bravoit, et voulloit que le reste de l'Istme luy fust rendue, avec les terres adjacentes hors d'iceluy, qu'Amurat avoit conquises de bonne guerre (Blaise de Vigenère, L'Histoire de la décadence de l'Empire grec [trad.])

1584 BASILE. (seul)Mon Dieu ! qu'il filoit doux ! qu'il fasoit le courtois et gracieux ! (Odet de Turnèbe, Les Contens)

1625 Et faict de depuis quelque temps, soit que la course des eaux de sa bourse soit basse, soit qu'il se lasse de se voir mangé par cette canaille, comme Acteon le fut de ses propres chiens, je le voy un peu plus moderé et comme desireux de me r'accoster, il file plus doux, et semble qu'il vueille chanter sur un autre ton, et monter sa guiterre d'une autre maniere (Jean-Pierre Camus, Palombe ou La Femme honnorable)

1732 Sur de semblables discours, les bourgeois nous crurent plus timides et moins terribles que nous n'étions. Ils s'imaginèrent même que nous voyant réduits au nombre de trente-cinq François, nous jugions plus à propos de filer doux que de faire les méchants (Alain-René Lesage, Aventures $d u$ chevalier de Beauchêne)

1842 Mais filez doux avec votre chef : le bonhomme est fin, il doit avoir de l'influence sur votre oncle, et peut encore l'empêcher de léguer tout à l'Église (Honoré de Balzac, Ursule Mirouët)

1877 Dans les commencements, quand l'un criait, elle suppliait l'autre du coin de l'œil, pour en tirer une parole de bonne amitié. Seulement, ça ne réussissait guère. Elle filait doux maintenant, elle pliait ses grosses épaules, ayant compris qu'ils s'amusaient à la bousculer, tant elle était ronde, une vraie boule (Émile Zola, L'Assommoir)

1927 Le temps coule insaisissable et monotone. Elle doit s'avouer son vague à l'âme. Et le vieux positiviste de mari qui file si doux qu'elle ne trouve pas le moyen de reprendre la controverse commencée le soir du cambriolage (René Crevel, Babylone)

1935 Gare aux filles, qui vont danser chez Caubert, à Andrain. Et si un gosse a seulement manqué l'Évangile, pif ! paf ! Deux paires de claques. Même les vieux filent doux, ainsi! (Georges Bernanos, Un crime)

1955 Je subis sa loi, je file tout doux Sous son empire, Bien qu'ell' soit jalouse au-delà de tout, Et même pire...

Un' joli' pervench', qui m’avait paru Plus joli' qu'elle, Un' joli' pervenche un jour en mourut À coups d'ombrelle (Georges Brassens, « Je m'suis fait tout p'tit » / Poèmes et chansons)

CORPuS WeB :

On commence à «filer doux » ?

Conférence islamique : branle-bas de combat chez les autorités | Fabrice de Pierrebourg | Montréal

La conférence islamiste organisée à Montréal crée un branle-bas de combat chez les autorités concernées, a constaté [https://fr-fr.facebook. com/independantes/posts/462802387159936] (28.04.2015) 
Danièle Nouy, la Française devant laquelle « les banquiers filent doux »

La secrétaire générale de l'Autorité de contrôle des banques françaises devrait présider la nouvelle instance de supervision des établissements européens [http://www.alphacompta. fr/daniele-nouy-la-francaise-devant-laquelle-lesbanquiers-filent-doux] (28.04.2015)

Mais le souffle de tes mots

La chaleur de tes baisers

Me consolent aussitôt

Et les heures filent douces,

Au creux d'un lit de mousse

[http://marydan.centerblog.net/rub-heuresdouces-pensees-marydan-.html] (28.04.2015)

REMARQUES : Couramment employé dans la langue actuelle, notamment aussi dans la presse, filer doux est un emploi métaphorique du sens concret de filer 'transformer en fil'. Il désigne le fait d'être docile, de se soumettre sans opposer de résistance, l'adjectif-adverbe doux soulignant l'obéissance, voire la lâcheté du sujet. Doux reste invariable dans son emploi adverbial, sauf dans le troisième exemple du CW. Dans cet exemple, filer est pris dans l'acception de 'glisser, courir vite'. Doux adopte alors la fonction de prédicat second orienté vers le sujet avec lequel il s'accorde. Doux est modifié par plus, si, tout.

\section{Filer droit}

I. Partir tout droit, sans se retourner, sans

hésiter ; s'enfuir

Intransitif

1566 Et au reste, considerez qu'il n'a peu continuer son propos au compas, et le faire filer droict, d'autant que les choses dont il discouroit sont par trop diverses et meslees (Giovanni Battista Gelli, Les Discours fantastiques de Justin Tonnelier)

1842 Jérôme, me dit-elle au moment décisif, jette ton bonnet par-dessus les moulins ; il faut qu'Artémise réussisse. Pas de si, pas de mais, file droit ton chemin et porte-la plus haut que le dôme du panthéon. Si t'es une autorité, prouve-le pour voir. C'est le cas de donner de la grosse caisse à se démancher le bras (Louis Reybaud, Jérôme Paturot à la recherche d'une position sociale)
II. Glisser, se diriger, voler en ligne droite (sur

l'eau, sur des rails, dans les airs...)

Intransitif

1652 Dedale qui estoit adroit

Ne marqua [sic] point à filer droit

(L'Icare sicilien ou La Cheute de Mazarin)

1771 dans les plaines, elles [= les perdrix] filent droit et avec roideur ; lorsqu'elles sont suivies de près et poussées vivement, elles se réfugient dans les bois (Georges-Louis Leclerc comte de Buffon, Histoire naturelle des oiseaux)

1883 Quelquefois une frégate - grand oiseau mystérieux qui est toujours seul - traversait à une excessive hauteur les espaces de l'air, filant droit avec ses ailes minces et sa queue en ciseaux, se hâtant comme si elle avait un but (Pierre Loti, Mon frère Yves)

19037 octobre.

Les perdrix filent droit comme le long d'un fil (Jules Renard, Journal)

1915 Les maisons qu'on quittait étaient perchées sur une colline. On paraissait, cette fois, filer droit vers l'ennemi, en dégringolant le long d'un champ de blé. Le village, qui avait l'air de regarder partir le régiment, se chauffait au soleil et ne beuglait plus (René Benjamin, Gaspard)

1955 Après quoi, elle fila droit sur le village et pénétra par une fenêtre ouverte de la petite mairie pour aller fracasser le buste en plâtre de la République, posé sur une console (André Dhôtel, Le Pays où l'on n'arrive jamais)

1963 Cardoni sortit son tabac et ses feuilles, et roula une cigarette. La barque dont ils ne distinguaient plus les passagers filait droit sur le caboteur (Pierre Moinot, Le Sable vif)

1992 L'épicière, l'épicière est une sorcière Je l'ai vue, je l'ai vue quand elle volait à cheval sur un balai

Filant droit au rendez-vous

Où le Diable je vous l'avoue

L'attendait.

(Charles Trenet, Chansons, 1960-1992) 
III. Se dérouler (selon l'image du fil qui se déroule)

Intransitif

1876 Les études sont même commencées... on cherche à éviter le coude que vous faisiez, pour venir passer à Bressuire. La ligne filerait droit par Parthenay et par Thouars (Émile Zola, Son Excellence Eugène Rougon)

1960 Arrivés à une dizaine de pas de la maison, ils obliquèrent à gauche pour rester sous le couvert des pommiers dont les lignes filaient droit vers le fond du val (Bernard Clavel, Malataverne)

1963 Nous nous sommes donné rendez-vous à la foire de Mérida. La route file tout droit parmi des oliviers et des labours (Albert T'Serstevens, L'Itinéraire espagnol)

IV. Passer de manière bien droite Intransitif

1896 Les clapotis s'agitaient sur la rivière en fuyant vers les arches lointaines ; et c'était, en travers de la Seine, une succession de ponts qui, marcheurs étranges, la franchissaient. Quelques-uns filaient droit, comme d'un seul jet, en gens hâtifs. D'autres, maladroits, passaient le dos courbé (Édouard Estaunié, L'Empreinte)

V. Obéir

Intransitif

1934 - Penses-tu, disait-il, elle crâne un peu devant le monde, la Tine ! Elle fait sa mariolle. Mais je connais les bons trucs pour la faire filer droit, en douce...

Une certaine façon canaille de fermer son œil gauche le dispensait de révéler les mystérieux procédés qu'il employait sans témoins (Gabriel Chevallier, Clochemerle)

CORpus Web :

Tir à l'arc : les flèches plourinoises filent droit

Dire que la compagnie d'arc est en pleine forme, c'est peu dire. Les performances s'enchaînent, même au niveau national. Hubert Boulch, spécialiste arc à poulie, a tout simplement réalisé un nouveau record de France en tir à salle [http://www.ouest-france.fr/tir-larc- les-fleches-plourinoises-filent-droit-3140140] (28.04.2015)

Les plantes filent droit à toute heure

Sans les arceaux de noisetiers qui leur donnent de la structure, ces grandes folles de sauges n'auraient pas aussi fière allure [http:// www.laliberte.ch/news/les-plantes-filent-droita-toute-heure-253309\#.VT-uefM_-Uk] (28.04.2015)

Il est clair que l'arrivée de Bielsa a transcendé l'équipe de par son empreinte tactique et par sa main de fer. Les joueurs filent droits et tirent tous dans le même sens. On verra s'ils tiendront ce rythme effréné jusqu'à la fin de la saison, mais, en attendant, si on compare cette équipe avec Baup ou Anigo, 'y a même pas match [http:// www.hooper.fr/forums/autres-passions/football ?page=317\#comment-1128309] (28.04.2015)

Plus plat ce n'est pas possible ! Yanagawa pourrait être aux Pays-Bas ou au Bangladesh. La plaine humide est ici sillonnée par des canaux de toutes tailles. Ils filent droits, à la campagne comme en ville. Régulés par un efficace réseau d'irrigation, ils permettent toutes sortes de cultures. Les eaux sombres sont peuplées d'anguilles, qui peuplent elles-mêmes les légendes locales... [https://www.tourisme-japon.fr/recitsde-voyage/176-du-cap-soya-au-cap-sata/353-ducap-soya-au-cap-sata-5] (28.04.2015)

REMARQUES : Filer droit (I) désigne le fait d'aller droit devant soi, en ligne droite. En (II), il renvoie au fait de se déplacer, de voler vite suivant une ligne droite. Sur un plan plus abstrait (III), il s'emploie par rapport à une disposition spatiale « en ligne » d'objets inanimés. En (IV), il se rapporte à la position droite de celui qui file. Il s'agit donc, logiquement, d'un prédicat second, mais l'accord n'est pas réalisé. En (V), il signifie 'obéir', étant mis en série avec en douce, ce qui évoque la locution de filer doux. Droit reste invariable dans son emploi adverbial, mais en tant que prédicat second référant à une propriété du sujet, il peut s'accorder avec celui-ci (v. le quatrième exemple du CW). Employé en rapport avec la main de fer de l'entraîneur dans le troisième exemple en CW, filer droit semble être calqué sur filer doux 'obéir' (V) mais, à la différence de celui-ci, droit s'accorde avec le sujet. Droit est modifié par tout. 


\section{Filer égal}

Fabriquer un fil régulier, uni

Transitif

1845 - Ah ! vous regardez l'ouvrage de notre fille ? Savez-vous que c'est filé aussi égal et aussi menu que la meilleure fileuse de campagne ? (George Sand, Le Péché de Monsieur Antoine)

REMARQUES : Filer est pris au sens premier de 'produire un fil', un fil régulier. Filer égal est coordonné avec menu 'dense, fin' et modifié par l'adverbe d'intensité aussi.

\section{Filer fin}

Fabriquer un fil fin; produire une texture fine Transitif

1680 Cotton filé fin, le quintal cy-devant taxé, trente sols (Tariffe de la Doanne de Lyon)

1838 il [= Nucingen] est impénétrable, on ne le voit jamais venir, tandis que la finesse de du Tillet ressemble, comme le disait Napoléon de je ne sais qui, à du coton filé trop fin, il casse (Honoré de Balzac, La Maison Nucingen)

1843 La plaisanterie est comme le coton qui, filé trop fin, casse, a dit Bonaparte (Honoré de Balzac, Les Illusions perdues)

Pronominal

1761 Aux Andelys tout au contraire, on a reconnu par un long usage, que plus les Laines ont de façons, plus elles se filent fin (Journal œeconomique)

Emploi absolu

1842 En 1499, l'archevêque demande aux bourgeois s'ils veulent une université ou une manufacture. On transporte les machines ailleurs, mais non la race de tisserands ; ils filent fin dès leur enfance. Mais les premiers bourgeois filaient-ils fin ? C'est que l'habitude de filer fin existait déjà dans les campagnes de Reims ; de filer la laine aussi fin qu'on filait le lin ailleurs. Les femmes, dans les veillées, filaient fin, à l'envi (Jules Michelet, Journal)
18996 septembre.

Une vieille. Elle a filé au fuseau. Son rouet marche toujours. Elle ne se met jamais à table parce qu'elle est à peine aussi haute. Elle mange quand elle a faim, jamais aux heures des repas, et toujours le pain rassis le plus dur. Elle boit le vin qui tourne à l'aigre. Il n'y a pas beaucoup de vieilles femmes pour filer aussi fin qu'elle. Elle a connu les chènevottes qu'on trempait dans le soufre et qui servaient d'allumettes (Jules Renard, Journal)

\section{CORPuS WeB :}

Il est facile de filer de grosses laines irrégulières, mais seule l'expérience vous permettra de filer fin et régulier [http://femmeetmode.fr/cvmt/ filer_rouet.htm] (28.04.2015)

Pour une fileuse débutante comme moi, le fil fin revêtait une aura de mystère, et je me disais : si j'arrive à filer fin, j'aurais tout compris ! Le filage au fuseau me paraissait également très obscur [http://www.hellocoton.fr/filer-fin6718912\#fYXe1pmY6pLAWF6q.99] (28.04.2015)

samba le film à voir et à revoir

trop dense dans sa trompeuse simplicité on a des yeux de caméra ou de tarsier et les émotions filent fines comme la soie. Un bon moment une bonne ambiance drôle et tendue parfois détendue plus souvent et pourtant une plaie ouverte sur le monde actuel [https://itunes.apple. $\mathrm{com} / \mathrm{fr} /$ album/samba-la-bande-originale-du/ id927442121] (28.04.2015)

REMARQUES : Filer fin réfère à la texture fine du produit, à la fabrication du fil, fin et mince, à partir d'un produit de base brut et grossier, tel que la laine. Le groupe permet aussi bien une interprétation de manière que de résultat. Fin reste invariable, sauf dans le troisième exemple du $\mathrm{CW}$, où il s'accorde avec le sujet et se prête à une analyse de prédicat second orienté vers le sujet, modifiant donc les émotions. Il est modifié par aussi, trop. Notons l'emploi de filer régulier.

\section{Filer menu}

Fabriquer mince, petit, fin un fil ou un objet tissé Transitif

1845 - Ah ! vous regardez l'ouvrage de notre fille? Savez-vous que c'est filé aussi égal 
et aussi menu que la meilleure fileuse de campagne ? (George Sand, Le Péché de Monsieur Antoine)

1850 Elle avait été chez la bourgeoise de Presles pour lui remettre de la laine qu'on lui avait donné à filer très menu, parce qu'elle était la meilleure filandière du pays (George Sand, François le Champi)

\section{CoRpus WeB :}

Paul habite une ville où la promenade en semaine au bord du fleuve vous fait croiser autant de retraités le long des berges que de cygnes et de canards sur l'eau. L'alliance de l'aisance pécunière et de l'érosion physiologique confert aux lieux quelque chose de morne et doux, de vaguement suisse, de banlieusardement cannois sans la mer. La paix ambiante en impose aux rares jeunes, qui filent menu. Tomber ici sur une horde vociférante est une incongruité plus improbable que l'éloge du profit dans la bouche d'un homme de gauche [http://jlhuss.blog.lemonde. fr/page/20/]

REMARQUES : Filer menu désigne le fait de faire du fil, ou de tisser, de manière très fine, mince, délicate à partir d'un produit brut, tel que la laine. Notons la connotation plutôt positive contenue dans l'adjectif-adverbe menu qui traduit le travail de précision et de minutie et souligne par conséquent le savoir-faire de la fileuse. Notons l'emploi de filer régulier et filer égal, ce dernier référant au fait de faire du fil, ou de tisser, de manière régulière, lisse, uniforme. L'exemple du CW prend l'acception de 'obéir, se faire tout petit'. Menu reste invariable, avec possible modification par aussi ou très.

\section{Filer raide}

I. Aller, passer, partir de manière très rapide, abrupte, sans égards et sans se ménager Intransitif

1855 Eux, dévalaient sur le dos, aplatissaient leurs épaules, de peur de s'arracher la peau du front ; et ils filaient si raide, le long de la roche polie par tous les derrières des chantiers, qu'ils devaient, de temps à autre, se retenir aux bois, pour que leurs fesses ne prissent pas feu, disaient-ils en plaisantant (Émile Zola, Germinal) 1877a il faisait déjà grand jour, il fallait reprendre son collier de misère. Les gaillards pourtant sifflaient, tapant des pieds, filant raides, le bec tourné vers la soupe. Et Gervaise laissait couler la cohue, indifférente aux chocs, coudoyée à droite, coudoyée à gauche, roulée au milieu du flot (Émile Zola, L'Assommoir)

1877b Les hommes, au moins, sortaient dans la rue ; Lorilleux et Poisson, l'estomac dérangé, avaient filé raide jusqu'à la boutique du charcutier. Quand on a été bien élevé, ça se voit toujours

(Émile Zola, L’Assommoir)

1925 Va-t-en, Raboliot, va-t-en vite ! Il y en a lourd sur ta tête ! Si j'étais à ta place, cent bons dieux ! Je ne la lèverais pas si haut. Tournefier fit demi-tour, et fila raide par le sentier. Au bout de quelques pas, Raboliot le vit prendre sa course : pas possible ? C'était lui qui se sauvait. Il essaya de rire encore (Maurice Genevoix, Raboliot)

1930 C'est juste au moment où vous avez fait le grand saut, et, on vous a bien vu, tout allongé dans l'eau qui tombait. Alors on est venu en courant. Vous filiez tout raide sous l'eau comme un gros poisson, et l'élan vous a mis au bord. Et on vous a tiré sur l'herbe, lui et moi. Tout de suite, vous avez dégorgé de l'eau (Jean Giono, Regain)

1950 Allons-y, dépêchons-nous. Il faut que nous nous y lancions, tout de suite, au plein tumulte, parmi les balles qui filent raide et qui frappent. C'est nécessaire (Maurice Genevoix, Ceux de 14)

II. Disparaître, être consommé très rapidement Intransitif

1887 Merci ! Pour qu'il y eût une bouche encore à la maison, où le pain déjà filait si raide ! Aussi ouvrait-il l'œil, se surveillant avec sa femme, si grasse, la mâtine, qu'elle goberait la chose du coup, disait-il (Émile Zola, La Terre)

CORPUS WEB :

Et la perfection, c'est quoi selon eux ? C'est surtout une plus grande intelligence. Là où 
leur rivaux font, disent-ils, le tour de toutes les pièces pour retrouver la base de recharge, lui connaît l'appartement comme sa poche et y file raide comme balle [http://www.lesnumeriques. com/robot-aspirateur-by-samsung-n5846.html] (28.04.2015)

Tu ne t'es même pas relu. Les mots filent raides et le va-et-vient de tes boucles ne souffre d'aucunes ratures. Tu étais convaincu, ça coulait fluide en toi. C'est clair, directif, sans ambages. Les mots sont simples [http://www.fut-il. net/2013_09_01_archive.html] (27.04.2015)

REMARQUes : Filer raide (I) réfère à un être animé qui glisse rapidement ou, par extension, qui va, se déplace, part droit devant soi. Il peut également renvoyer à un sujet qui s'en va, disparaît ou qui, dans le contexte de la nourriture, est consommé très rapidement (II). Le dernier exemple du CW réfère au style d'un texte, ce qui le rapproche de l'accord poétique (v. remarques sous filer régulier). Dans l'exemple de 1877a, l'accord ne semble pas être motivé par un effet de prédication seconde employée pour désigner la raideur des personnes : la fonction est clairement adverbiale. Raide est modifié par si, tout. Notons l'emploi de couler fluide.

\section{Filer régulier}

Fabriquer une étoffe à texture régulière

\section{CORpus Web :}

Transitif

Perso je n'arrive pas vraiment à filer régulier des rolags, pas autant que depuis une nappe ou un ruban [http://www.forumtricotin.com/index. php?topic $=63300.0](28.04 .2015)$

Intransitif

Bien sur, il faut que j’apprenne à filer régulier, mais je suis bien embêtée quand mon ruban fait des bouboules à cause du hackle [http:// moutonetcoton.blogspot.co.at/2012_09_01_ archive.html] (28.04.2015)

TU M ILLUMINES PAR CES PRECIEUX MOTS QUI FILENT REGULIERS ET TELLEMENT MERVEILLEUX A BIENTOT AMITIES [http:// creapoemes.com/index.php?threads/lesmots.105059] (28.04.2015)
REMARQUES : Dans les deux premiers exemples, filer est pris au sens concret de 'fabriquer un fil, une étoffe'. Le dernier exemple réfère au flux des mots d'un poème. La flexion peu logique de régulier - ce ne sont pas les mots qui sont réguliers mais leur suite - n'est pas un problème d'orthographe mais un recours stylistique voulu qui renforce la diction poétique (v. aussi la flexion de filer raide sous cette entrée).

\section{Filer sec}

I. Filer de la laine débarrassée du suint

Emploi absolu

1690 Les Artisans appellent filer sec, quand ils filent de la laine degraissée avec du savon noir (Antoine Furetière, Dictionaire universel)

II. Partir rapidement, tout de suite Intransitif

1912 Camus était déjà un peu en retard sur les autres, il fallait filer sec s'il ne voulait pas être pincé (Louis Pergaud, La Guerre des boutons)

1984 Noëlla renifla, car l'émotion, puis fila aussi sec commander un autre lapin, par superstition (Anne Vergne, L'Innocence du boucher)

\section{CORPUS WEB :}

Par contre, je comptais m'acheter leur décapant ainsi que leur baguettes de brasure argent car ils en ont de $0,3 \mathrm{~mm} \mathrm{X} 2 \mathrm{~m}$ adapté aux petites brasures Mais, je ne sais pas si je peux faire beaucoup de brasures avec $2 \mathrm{~m}$ ? ! car je suppose qu'avec 0,3mm d'épaisseur... ça doit filer sec !! [http://mini-engins-rc.forumgratuit.org/t419micro-chalumeau] (28.04.2015)

Le serveur est d'une amabilité assez rare ; vous savez : gentil, honnête, fun sans être familier, détaché sans être obséquieux, mielleux ou désagréable d'amabilité... Les commandes filent sec et 15/20 minutes après les plats arrivent [http://critiquespopulaires.blogspot.co.at/ 2013/03/macis-muscade-resto.html] (28.04.2015)

L’œil légèrement endormi, le garda fixa l'homme qui venait de le déranger pendant sa sieste estivalo-journalière... 
«Quoiqu'il veut, lui ??? Humpffff Encore un qui passe ici sans prendre la peine d'taper la causette avec l'pauvre gueux que j'suis. Sont tous pressés, ces gens, d'nos jours. »

Dépliant lentement sa lourde carcasse, il se leva et fit face au sieur, avant de s'en aller en marmonnant vaguement:

M'en va voir si l'dernier venu... 'fin, la dernière venue... s'ra cor là pour vous r'cevoir... C'est qu'ils filent secs, les Grands, dernièrement... Doivent vouloir batt'e des r'cords, j'vous l'dis, moué... [http://curiarr.forumactif.org/t21p160accueil-pour-les-ecuries-et-venerie-royalesordres-de-chevaleries] (28.04.2015)

REMARQUES : Filer sec (I) s'emploie d'abord dans le domaine de la production de la laine quand on utilisait la laine débarrassée du suint. D’un usage familier, filer sec (II) désigne le fait de s'en aller, de se retirer rapidement, de déguerpir, de disparaître ou de se consommer de suite. Sec reste invariable et est modifié par aussi. L'orthographe - 'familière', si l'on veut - admet cependant l'accord (v. dernier exemple du CW). VoIR AUSSI : démarrer / relayer sec

\section{Finer cher}

Acheter à un prix élevé

Transitif

1325 Chier li fu ses escos finez,

Qu'à honte et à duel fu finez,

Dont mais parole n'iert finée

(Watriquet de Couvin, Dits, p. 81, 119)

REMARQUES : Finer cher désignait le fait de s'acquitter d'une grande somme d'argent, voire de terminer une affaire en payant cher.

\section{Finir aise}

finir ses jours aise : terminer sa vie de manière agréable, sans peine, dans la tranquillité, dans le bonheur

Transitif

1450 SIMËON. O saincte vierge prëeslite, Combien ce digne fruit proufite A toy et a tous les humains, Je te requiers a joinctes mains Que ta grace puisse obtenir De l'enfant en mes bras tenir ; Plus aise en fineray mes jours (Arnoul Gréban, Le Mystère de la Passion, 7002)

\section{Finir gros}

Terminer très important

$\lambda$ commencer petit

\section{Flairer bon}

I. Répandre une bonne odeur, une odeur agréable

Intransitif

1348 SECOND CLERC. Par m'ame, oil. Diex ! qu'il sent bon !

Onques mais je ne senti chose

Si bon flairant, ne lis ne rose, Ny autre espice

(Miracle de l'evesque a qui Nostre Dame s'apparut)

1589 Celuy qui flaire bon, engendre sang bon et louable, estant propre pour recreer les esprits : mais il donne fort à la teste, principalement s'il est subtil, clair et transparent, la remplissant de vapeur et de chaleur, offençant par ce moyen toutes parties nerveuses, et troublant l'entendement, peu commode à toutes personnes catharreuses (Julien le Paulmier, Traité du vin et du sidre)

II. Sentir une bonne odeur

Transitif

1381 CLOVIS. Qu'est ce que je flaire si bon, Sire, qu'entre voz mains tenez? Onques mais puis que je fu nez Je ne senti si noble odeur (Miracle de Clovis, 2348)

1887 Il en faisait le tour, se baissait et prenait de son geste accoutumé une poignée, une motte grasse qu'il aimait à écraser, à laisser couler entre ses doigts, heureux surtout s'il ne la sentait ni trop sèche ni trop humide, flairant bon le pain qui pousse (Émile Zola, La Terre)

\section{CORPUS WEB :}

Plaiderai bientôt pour l'installation de douches ds les gares : arrivée @Bxl via train de $8 \mathrm{~h}$ av l'impression de flairer bon la sardine [https:// fr-fr.facebook.com/hassanbousettafanpage/ posts/10150902443186903] (28.04.2014) 
Simba :

Humm, miam un carnet qui va flairer bon, les épices, l'océan, la finesse du sable blanc, l'art des femmes pour récolter les algues... [http://www.colorsofwildlife.net/forum/index. php?topic=7969.0;wap2] (28.04.2015)

Ensuite, pour ce qui est de quitté un emploi qui n'allait plus... en plein dedans ${ }^{\star \star}$ Pour les galères aussi, et le pain noir, la maia, elle en veut plus * cahcun sont tour, désolée * Je vise 2 choses qui sont mes objectifs, l'un ou l'autre... et dans les deux cas, ça commence sérieusement à flairer bon * Dont un où j'ai réussi à glisser un orteil, l'autre, pour un très bon retour * avec une éventualité à la clé * [http://forum.aufeminin.com/ forum/f557/_f10061_f557-Bon-je-me-lance-quiveut-que-je-lui-tire-les-tarots.html] (28.04.2015)

RemARQues : Flairer bon (I) désigne le fait de fleurer, d'exhaler une bonne odeur, le sujet pouvant être animé ou inanimé. En (II), il a le sens de 'percevoir par l'odorat, d'humer une odeur très agréable', le sujet étant animé. Bon reste invariable et est modifié par si. VoIR AUSSI : sentir bon

\section{Flairer doux}

Répandre, avoir une odeur douce, légère, délicate

Intransitif

1589 LE N.N. Que le ciel odorant les printannieres fleurs

Nous attire à l'envy à ses douces odeurs, Nos sens sont recreez, l'œil mille fois admire

Un bouquet doux flairant, l'odeur le nez attire :

Un Prince tout ainsi plein de grace et d'amour,

Invite à le servir ses Mignons à la Cour, À tourner l'œil sur luy, et seul le recognoistre (Pierre Matthieu, La Guisiade)

REMARques : Flairer doux désigne le fait de fleurer, d'exhaler une odeur agréable, délicate, suave, le sujet étant inanimé (ici : un bouquet de fleurs).

\section{Flairer juste}

Pressentir juste

Intransitif

1859 Rocambole, en homme qui flaire juste et a le pressentiment des événements, alla droit à lui et le regarda (Pierre-Alexis Ponson du Terrail, Rocambole)

2018 Anton, et quand il m'annonce que les relevés téléphoniques de Lambert Roos ont été effacés, je comprends que j'ai flairé juste (Charmaine Pauls, En eaux troubles [trad.])

\section{Flairer soef}

Répandre une odeur suave, délicieuse, agréable Intransitif

+1100 Li flur süef mult i flairent, Cum la u li piu repairent, D'arbres, de flurs delicius, De fruiz, d'udurs mult precius (Benedeit, Voyage de saint Brendan [1 $1^{\text {er }}$ quart XII $]$, 1741)

1190 La peinne estoit de seible, qui mout flarroit soué ;

Ne vaut muguellïas a lui un ail pelé

(Fierabras (L), 2137)

1209 D'escarlate noir come meure Ot robe fresche a pene hermine ; Mout soëf flerant et mout fine La vesti lués q'en ot mengié (Jean Renart, Roman de Guillaume de Dole, 1532)

+1249 Cele clartez qui se resclere Avoec tot ce si soefflere (Rutebeuf, Poèmes [pièces datables de 1249 à 1272], II, p. 229, 542)

$\sim 1280$ Et ne pour quant bien fait a pardouner, Car, quant dame est noble et de haut afaire Et biele et boine et gent set honorer, Tant desiert mix c'on l'aint par essamplaire. Et doit estre deboinaire Enviers povre home en otriant merchi, Sauve s'ounor, car jou di : Ki de boins est souëf flaire (Adam de la Halle, Chansons, VIII, 16)

+1350 Li enfes fu ou bois qui biauté enlumine, Que la couleur avoit gracieuse et sanguine. 
Quant Bruiant le vit tel, si dit : «Vierge roïne,

Ausi que ma pensee est du tout enterine, Que vos cors alaita la puissance devine,

Donnes a cel enfant ennuit si bonne estrine

Qu'en son lignage n'ait ne parant $\mathrm{n}[\mathrm{e}]$ cousine

Qui n'en soit honnorés de lui a brief termine,

Car ses viaires est tains de couleur rosine

Et flaire plus souef que ne fait fleur d'espine

(Brun de la Montaigne [ $2^{\mathrm{e}}$ moitié XIV $]$, 848)

1450 ADAM. Et, si plaist Dieu, mon crëateur,

Estre ta guide et bonne garde,

L'ange trouveras qui la garde

Atout une espee en son poing.

Requier luy qu'a mon grant besoing,

De moy envoyer se recorde

De l'uille de misericorde

Qui est doulce et souef flairant (Arnoul

Gréban, Le Mystère de la Passion, 1309)

1511 Eux arrivez au noble palais d'llion, la noble Nymphe fut descendue et menee en une chambre prochaine à celle de la Royne. Et illec par les matrones de damoiselles fut promptement baignee et estuvee en herbes souef flairans (Jean Lemaire de Belges, Les Illustrations de Gaule et singularitéz de Troye)

RemARQues : Flairer soef désignait le fait de fleurer, d'exhaler une odeur agréable, délicate, suave, le sujet pouvant être animé ou inanimé (herbes, fleurs). Notons les collocations soef et fine, doulce et soef. Soef reste invariable et est modifié par moult, plus, si.

\section{Flamber clair}

I. Flamber, brûler en éclairant beaucoup Intransitif

1579 Puis après fit mettre toutes les bourrées et coterets, buches, gloes, cordes, falourdes et coypeaux de trente deux arpents, deux perches de bois de haute fustaye, dessous iceluy estang, et allumer un feu clair flambant, lequel en peu de temps commença à si bien eschauffer cette grande marmite qu'elle se print à bouillir à haut boüillon, au moyen de quoy fut le poisson cuit en deux fils de coton (Philippe d'Alcripe, $L a$ Nouvelle fabrique des excellents traicts de vérité)

1842 Le fagot de Calvin s'allumait aussi bien et flambait aussi clair à Genève que le fagot de Torquemada à Madrid (Victor Hugo, Le Rhin)

1848 Et les amis recommencèrent à boire à plus amples rasades, pendant qu'en dehors la neige tombait toujours, et que dans l'âtre le bois flambait clair en tirant des feux d'artifice d'étincelles (Henri Murger, Scènes de la vie de bohème)

1911 Pour finir, selon la coutume, on alluma le feu de la moisson, on y mit la dernière gerbe. Elle flamba claire, tout d'un coup, - et, se donnant la main, tout le monde ronda autour (Charles-Ferdinand Ramuz, Aimé Pache, peintre vaudois)

1968 La fumée n'avait plus l'odeur du bois sec qui flambe clair dans le foyer du four, mais celle plus âcre des plantes arrachées au jardin de l'automne et brûlées sur place, en gros tas, les matins de brouillard (Bernard Clavel, Les Fruits de l'hiver)

II. Être animé d'une vive ardeur, de sentiments violents

Intransitif

1883 Or, en dehors de la feuille que vous dirigez, il y a en France des journalistes dont la probité défie l'entraînement vénal de l'époque, dont le style sonne pur, dont le verbe flambe clair et dont l'utile critique rectifie sans cesse les jugements inconsidérés de la foule (Auguste de Villiers de L'Isle-Adam, Contes cruels)

1918 Les Masques

Carnaval, tes mascarades, Tes chansons, tes sérénades, Nous rendent tout langoureux Et notre cœur amoureux Flambe clair dans la nuit pâle Comme flammes de Bengale (Guillaume Apollinaire, Casanova) 
REMARQUES : Flamber clair (I) se dit en général d'un feu qui brûle, se consume en produisant des flammes claires, illuminant fortement autour d'elles. Au sens figuré (II), il se dit de quelque chose qui est animé d'une vive ardeur (sentiments) ou qui se manifeste avec éclat, produit une forte impression. Clair peut s'accorder avec le sujet (ex. de 1911). Il est modifié par aussi. Notons l'emploi de sonner pur.

\section{Flamber dru}

Brûler de manière très vive, très intense त flamber haut

\section{Flamber haut}

I. Brûler en faisant de grandes et hautes flammes

Intransitif

1872 Dans l'air moite et odorant de la pièce, les trois bougies flambaient très haut, la flamme droite, avec l'immobilité d'une larme ardente (Émile Zola, La Curée)

1876 Alors l'esclave vint allumer un grand feu au milieu de la place la plus vaste du quartier, et, quand le bûcher flamba tout haut, Kassem parut dans la rue à son tour (Arthur de Gobineau, Nouvelles asiatiques)

1879 La femme Teston enfourna de vieilles savates dépareillées et, le mufle dans son mouchoir, la carcasse cassée, regarda le feu qui s'éjouissait bruyamment, flambant haut et sec, pétant à petites bordées (Joris-Karl Huysmans, Les Sœurs Vatard)

1892 Autour d'eux, les incendies flambaient plus haut, les fenêtres vomissaient de grandes flammes rouges, tandis qu'on entendait, à l'intérieur, l'écroulement embrasé des plafonds (Émile Zola, La Débâcle)

1950 Les voitures à vivres sont là, qui nous attendent. De grands feux s'allument, flambent clair et haut (Maurice Genevoix, Ceux de 14)

1979 Nous traversons des villages dévastés, des maisons flambant haut et dru, d'autres réduites à des moignons calcinés encore rougeoyants (François Cavanna, Les Russkoffs)
II. Se manifester avec intensité, avec force Intransitif

1892 Devant les boulangeries et les boucheries, les longues queues qui attendaient, dans la neige, s'égayaient encore parfois, à la nouvelle de grandes victoires imaginaires. Après l'abattement de chaque défaite, l'illusion tenace renaissait, flambait plus haute, parmi cette foule hallucinée de souffrance et de faim (Émile Zola, La Débâcle)

CORPUS WEB :

Autopsie d'un vote

Les scalpels sont aiguisés et les langues taillées dans le meilleur des bois, un bien sec, gorgé de nœuds, qui va flamber haut et fort sur les plateaux de télé. Tous les pontes légistes seront là à $20 \mathrm{H} 01$ précises [http://www.lagitedulocal. com/?cat=5\&paged=7] (28.04.2015)

Vive la REVOLUTION (mon correcteur automatique souligne ce mot en rouge, signe qu'il ne le connait pas - evidement) Mais ce n'est pas une utopie, elle a déjà eu lieu historiquement. Je ne parle pas de la revolution de 89 mais bien des nombreuses expériences pleybeennes, (ah, mot inconnu aussi pour windows, windows ne connait pas le peuple), de la revolution de 48, de la commune, des revolutions arabes... MERCI pour ce que vous faites. A nous tous, chacun où qu'il soit, de prendre le flambeau et de le faire flamber haut !!!! Plus haut que les nuages de pollution, plus haut que l'étendard du capitalisme avec sa logique mortifère, plus haut que les discours moribonds de ceux qui croient encore au vieux monde (ou qui se forcent a y croire, faute d'alternative) [http://www.radiogresivaudan.org/Le-monde-allant-vers-2963. $\mathrm{html}$ (28.04.2015)

Bjr messieurs mesdames voyez vous le prix flambent hauts les gouvernement ne font rien du tout je demande combien touche leur pourcentage pour eux ? Ca sent l'embrouille la tout les prix montent vite et les salaires bas pfff [http:// www.ladepeche.fr/article/2011/12/14/1239566le-prix-du-gaz-va-augmenter-de-4-4-le-1erjanvier-2012.html] (28.04.2015)

REMARQUES : Flamber haut (I) s'emploie au sens de 'brûler, se consumer avec de hautes flammes'. En (II), il est employé par métaphore pour ren- 
voyer à la force d'une idée, à l'enthousiasme qui l'accompagne. Le CW ajoute l'emploi hyperbolique en rapport avec les prix 'qui flambent', qui augmentent considérablement. Notons les collocations haut et sec, ce dernier soulignant la brutalité, la vivacité du feu, des flammes, haut et $d r u, d r u$ se référant à la densité et à la force, à la vigueur du feu, des flammes (de même : haut et fort), ainsi que clair et haut, clair référant aux flammes claires du feu, illuminant fortement autour d'elles. La fréquence élevée de ces adjectifs-adverbes employés par paires reflète l'emphase rhétorique qui est le propre du verbe flamber. Haut reste généralement invarié, mais il peut s'accorder avec le sujet (exemple de 1892 [emphase littéraire], troisième exemple du CW) pour mettre en relief une propriété du sujet, insistant sur sa localisation finale, tandis que l'emploi invariable est plus ouvert, en rapport avec une interprétation directionnelle. Haut est parfois modifié par plus, tout, très.

\section{Flamber rouge}

I. Prendre une couleur rouge vif Intransitif

1895 En route, le long de la mer, et, sitôt disparue la petite oasis charmante, le grand désert nous ressaisit. Tout ce qui, hier au soir, flambait rouge s'est éteint et s'est changé (Pierre Loti, Le Désert)

1942 Je regardais les érables jaunir, puis flamber rouge. J'écoutais appeler dans les combes la femelle de l'orignal. Des vols d'oies traversaient le ciel (Maurice Genevoix, Le Couguar de Tonquin Valley)

II. Flamber, brûler en produisant une flamme rouge

Intransitif

1904 Un village est là blotti dans un renfoncement, tout contre la base de l'abrupte montagne, un village en pierres, avec un rempart et donjon crénelé : toutes choses que l'on distinguerait à peine - tant il fait brusquement sombre sous la retombée de ces roches terribles -, si des feux de joie, qui flambent rouge, n’éclairaient les maisons, la mosquée, les murs et les créneaux (Pierre Loti, Vers Ispahan)

\section{CORPuS WeB :}

Un chanteur extraverti et son attirail cuivré (baritone saxophone et alto saxophone). L'étincelle qui fait flamber rouge. L'explosion sous l'autel rock. Café Flesh se transforme en orchestre suintant de chaleur, en bouge surchauffé mais toujours tendu, débordant de partout mais débarrassé de tout superflu [http://www.perteetfracas. org/zine/kros2012/kros_c/cafe_flesh_lions_will_ no_longer_be_kings.htm] (28.04.2015)

REMARQUES : Flamber rouge (I) s'emploie au sens figuré de 'prendre une couleur rouge ardent, éclairer rouge comme un feu', voire en référence également à un spectacle fulgurant, qui " chauffe » la salle (CW). (II) actualise le sens propre de 'brûler, se consumer avec des flammes rouge vif'. Rouge reste invariable.

\section{Flamber sec}

Flamber, brûler vivement

$\pi$ flamber haut

\section{Fleurer bon}

I. Répandre une bonne odeur, une odeur agréable

Intransitif

1578 Je veux faire un beau lict d'une verte jonchée,

De parvanche fueillue encontre-bas couchée,

De thin qui fleure bon et d'aspic porte-epy, D'odorant poliot contre terre tapy,

De neufard tousjours verd, qui la froideur incite,

Et de jonc qui les bords des rivieres habite (Pierre de Ronsard, Le Second Livre des amours)

$1863 \mathrm{Au}$ bout de quelques minutes elle la reprit, la respira longuement, et la tendit à Sigognac, après y avoir mis furtivement un baiser. Comme elle fleure bon, maintenant ! La chaleur de mon sein lui fait exhaler sa petite âme de fleur timide et modeste (Théophile Gautier, Le Capitaine Fracasse)

1922 Il y a dans mon travail une rareté et une sorte d'excellence, quelque chose de non anonyme, de difficile à suppléer, qu'il n'y 
a pas au même point dans ces semelles pourtant pimpantes et qui fleurent bon (Jules Romains, Lucienne)

1963 Avant de remonter, il coupa avec son couteau une des roses du rosier ; elle n'était pas très grande, mais elle était bien formée, assez ronde, avec des pétales jaune tendre qui fleuraient bon. Il la plaça dans une bouteille de bière vide, sur le plancher de sa chambre, à côté du tas de couvertures (Jean-Marie Gustave Le Clézio, Le Procèsverbal)

Transitif

1951 Mammouth les embrassa tous d'un coup d'œil reconnaissant. Puis, ravalant une salive fleurant bon le triple sec, il hoqueta son chagrin (René Fallet, Le Triporteur)

1966 Ils ne reviendraient que sur les huit heures, lorsque la maison brillerait de ses lumières hospitalières, les pièces autour des cuisines fleurant bon le dîner (Irène Monési, Nature morte devant la fenêtre)

1986 Ses livres sentaient l'estragon, le romarin ou le rôti de porc. Certains, les meilleurs, fleuraient bon le pâté de canard. Chaque livre avait son parfum. Chaque plat avait son livre (Alexandre Jardin, Bille en tête)

II. Évoquer à l'esprit l'idée de quelque chose d'agréable

Transitif

1949 Tout ça fleure bon la révolution (Marcel Aymé, Le Confort intellectuel)

1982 Clientèle jeune, un peu loubarde, à prédominance méditerranéenne. Des accents, des expressions qui ne trompaient pas, qui fleuraient bon le Bab-el-Oued de jadis (Alain Page, Tchao Pantin)

\section{Corpus Web :}

Astuces qui fleurent bon...

Un talc à base de bois de santal, de citronnelle et de racine d'iris sur le corps des Egyptiens ; une coiffe de cire parfumée sur la chevelure de leurs femmes [http://www.psychologies. com/Moi/Moi-et-les-autres/Relationnel/Articleset-Dossiers/J-aime-ton-odeur/7 Astuces-quifleurent-bon] (28.04.2015)
Ça fleure bon au parc de Schoppenwhir

Le ciel ombragé n'a pas fait fuir les visiteurs de la 35e Fête internationale des plantes $\mathrm{du}$ parc de Schoppenwihr. Jardiniers en herbe et collectionneurs chevronnés se sont croisés dans les allées, portés par les effluves de milliers de plantes aux parfums délicats [http://www. lalsace.fr/haut-rhin/2015/04/26/ca-fleure-bonau-parc-de-schoppenwhir] (28.04.2015)

Pont-sur-Sambre : des cours d'Ikebana, l'art japonais qui fleure bon la création

Le temps qui s'écoule, la figuration : en matière de compositions florales, Danièle Colson n'a pas son pareil pour prodiguer de bons conseils à la japonaise. L'ikebana, une passion née par hasard, mais partagée pour ses valeurs et vertus quasi-thérapeuthiques par cette $\mathrm{Ba}$ vaisienne [http://www.lavoixdunord.fr/region/ pont-sur-sambre-des-cours-d-ikebana-l-artjaponais-ia12b45214n2504248] (28.04.2015)

REMARQUES : Fleurer bon (I) s'emploie au sens de 'fleurer, exhaler une bonne odeur', le sujet pouvant être un animé ou un inanimé. Au sens figuré (II), il signifie 'donner une impression agréable, rappeler une chose agréable (à quelqu'un)'. Bon reste invariable.

\section{Fleurer doux}

I. Répandre, avoir une odeur douce, légère, délicate

Intransitif

1592 Ceux qui l'ont approchée [= la vertu], la tiennent au rebours logée dans une plaine fertile et fleurissante, d'où elle void bien souz soy toutes choses ; mais si peut on y arriver, qui en sçait l'addresse, par des routtes ombrageuses, gazonnées et doux fleurantes, plaisamment et d'une pante facile et polie, comme est celle des voutes celestes. Pour n'avoir hanté cette vertu supreme, belle, triumfante, amoureuse, délicieuse (Michel de Montaigne, Essais)

II. Évoquer à l'esprit l'idée de douceur, de tranquillité.

Intransitif

1910 Et voilà qu'un rire étrange résonnait soudain si loin, si loin et si près de moi ! Un rire d'adolescente chère à mon adoles- 
cence, un rire d'autrefois et d'avenir, un rire de sauvagesse coulant et fleurant doux tel du baume tranquille... les yeux clos, la vie suspendue toute à cette mélodie de la jeunesse, je me reportais, Monsieur le chevalier, à mon sombre passé de rocher perdu au milieu de la solitude des mers

(Oscar Milosz, L'Amoureuse Initiation)

CORpus Web :

« MOVEMBER, LET'S PARTY TOGETHER : L'IAE remet le couvert!»

Cela ne vous aura pas échappé, nous sommes en novembre. Ça commence a fleurer doux le sapin et le cuissot de sanglier mais STOP ! [https://www.facebook.com/ events/782471141825595] (28.04.2015)

Dans le pot, différentes tailles de billes baignent dans la texture épaisse et gélifiée. Humm ça fleure doux et poudré, ça doit jouer sur le côté destressant... Très agréable à utiliser, en effet, c'est doux et respectueux de la peau. Après le rinçage, la peau est fraîche et douce comme j'aime. Test réussi [http://www. dieu-crea-la-femme.com/2014/04/04/test-antiage-bio-peeling-effect-de-nature-effiscience] (28.04.2015)

REMARQUES : Fleurer doux (I) s'emploie au sens de 'fleurer, exhaler une odeur agréable, délicate, suave', le sujet étant généralement inanimé. En (II), il signifie 'donner une impression agréable, une impression de douceur et tranquillité'. Notons la comparaison tel du baume tranquille, soulignant l'idée d'apaisement, d'adoucissement des peines, de dissipation des inquiétudes. Notons aussi l'emploi de fleurer poudré ; couler doux. Doux reste invariable, notamment dans l'exemple de 1592.

\section{Fleurer fort}

Répandre une odeur intense Intransitif

1891 Il fait bon le matin monter sur nos coteaux pierreux où on trouve la lavande sauvage et l'immortelle qui fleurent fort (Eugène Le Roy, Le Moulin du Frau)

Transitif

1907 C'est un second bouquet pareil au premier... le voilà à mes pieds, et il fleure fort l'haleine sensuelle des tubéreuses.... (Claude Farrère, L'Homme qui assassina)

2014 Certains mots du dictionnaire, cependant, fleurent fort leur origine argotique (Boris Seguin et Frédéric Teillard, Les Céfrans parlent aux français)

\section{Fleurer mauvais}

Répandre une mauvaise odeur

Transitif

1968 Les quartiers achalandés, tels SaintGermain-des-Prés, les quais [...] fleurent mauvais la gargote (Le Monde, 26 juillet 1968 / Grundt : 233)

\section{CORPUS WEB :}

Alors, je dis haut et clair que le racisme n'est pas mon truc, que le mensonge n'est pas ma tasse de thé et que ces couillons qui se régalent de tout ce qui peut fleurer mauvais ne sont pas de mes amis [http://humeurs-en-billets.over-blog. com/2014/09/ce-n-est-plus-du-ras-le-bol.html] (27.04.2015)

Vous pratiquez les châtiments corporels ? - Jamais. C'est contre nos principes. " Cause toujours ! La gamine avait Nous avons traversé une zone nauséabonde : le coton cultivé au Rajasthan est tissé et teint dans des usines qui fleurent mauvais les produits chimiques [http:// francoisdailleurs.over-blog.com/article-du-forta-la-toile-de-tente-114662819.html] (28.04.2015)

Le concours, on le vomit avant même de l'avoir ingurgité. C'est une sorte de potion, de ces médicaments qui fleurent mauvais à distance, que vous approchez de votre nez dans une cuillère, que vous ne voulez pas avaler, surtout pas mais que vous avalerez quand même [http:// hypo-2007.skyrock.com/2462609969-Le-magmainforme-de-l-avant-concours.html] (28.04.2015)

disparu le soir, après retour du collège. Il avait fallu qu'elle sorte, et des raisons pour ça. Après quoi, une mauvaise rencontre ? Deux jours, ça commençait à fleurer mauvais. «Elle avait de bons résultats, à l'école ? - Moyens. " De toute façon, pas de bulletin prévu dans l'immédiat : le précédent avait un mois : « Travail convenable», « Peut mieux faire », etc. [http://narcipat.overblog.com/article-empathie-2-89646983.html] (27.04.2015) 
Sarkozy a fait de la transparence un principe de gouvernance. Pas sûr qu'il ait eu raison, car on se fait vite piéger à ce petit jeu-là. La vertu appelle le vice et la suspicion. Ces mêmes vice et suspicion qui fleurent mauvais la démagogie et le populisme. Assez ! Revenons à l'essentiel, l'action politique [http://www.pichenelwittenheim. com/archive/2009-03] (28.04.2015)

REMARQUES : Fleurer mauvais désigne le fait de propager une odeur désagréable, le sujet étant généralement un inanimé. Les deux derniers exemples du CW l'emploient au figuré en rapport avec un doute, une suspicion qui planent sur ce que l'on affiche, sur les apparences. Mauvais reste invariable. Notons l'emploi de dire haut et clair.

\section{Fleurer poudré}

Avoir un parfum, un toucher de poudre

入 fleurer doux

\section{Fleurir blanc}

Avoir des fleurs blanches

Intransitif

1619 L'Espine noire fleurit blanc, et d'une fleur momentanee, passagere, et entestante, bien qu'elle flaire doux (Jean-Pierre Camus, Premières Homélies dominicales)

1823 Il y a aussi des lauriers roses qui fleurissent blancs (Étienne Garcin, Le Nouveau Dictionnaire provençal-français)

1872 Presque partout, cette année, les consoudes fleurissent blanches (Bulletin de la Société des amis des sciences naturelles de Rouen)

1934 - Ça fleurit blanc, dit Jourdan. Le plateau est tout planté d'amandiers blancs. Ça désespère (Jean Giono, Que ma joie demeure)

REMARQUES : Fleurir blanc renvoie à la couleur des fleurs. Nous le citons comme représentant d'une série qui est ouverte à d'autres couleurs. L'accord est optionnel mais, préféré, semble-t-il, au XIX siècle.

\section{Fonctionner impeccable (impec)}

Fonctionner sans le moindre problème

Intransitif

1952 Ça fonctionne impeccable, t’sais. J’ai eu Londres facilement, mais le matin seulement et à 7 heures du soir (Claude Gobert, Bois-Trudan)

1979 Le cri quand, brusquement, le cochon comprend. Le hurlement de folie quand l'éventré voit ses tripes couler. Il y a dix secondes - dix secondes! - tu étais vivant, entier, tu fonctionnais impeccable, et voilà ton ventre troué (François Cavanna, Les Russkoffs)

1984 «Il en a deux [= des béguins, concubines] comme papa, et ça fonctionne impec. » Il s'agissait là d'une chaude recommandation, en quelque sorte d'une incitation à la débauche (Evane Hanska, Les Amants foudroyés)

REMARQUES : Fonctionner impeccable signifie 'fonctionner sans le moindre problème'. Impec est une réduction familière de l'adjectif-adverbe impeccable ou de l'adverbe impeccablement. La combinaison "verbe + impec(cable) » constitue une série ouverte dont nous ne citons que quelques variantes.

\section{Fouetter ferme}

I. Fouetter avec force (au propre et au figuré) Emploi absolu

1823 Grillon, indigné de voir dans une situation si honteuse un homme dont il était le parent, s'écria : «Frappez tout de bon, fouettez ferme, c'est un lâche qui a endossé le froc pour ne plus porter les armes » (Victoires, conquêtes, désastres, revers et guerres civiles des Français)

1879 Elle l'embrassa sans façon et lui présenta sa fille Laurence. Celle-ci, à demi aveuglée par la pluie qui fouettait ferme, lui tendit la main (André Theuriet, La Maison des deux barbeaux)

1881 Et la journée n'était complète que lorsque toute la cavalcade se trempait en route d'un de ces orages de montagne, criblé d'éclairs et de grêle, qui effrayait les 
chevaux, dramatisait le paysage, préparait un retour à sensation, la petite Bachellery, sur le siège, en paletot d'homme, sa toque ornée d'une plume de gélinotte, tenant les guides, fouettant ferme pour se réchauffer (Alphonse Daudet, Numa Roumestan)

1921 Sur le pont, deux ou trois hommes se promenaient les mains derrière le dos, la casquette rejetée en arrière. [...] - Ça [= le vent $]$ fouette ferme, dit Bordioule (Pierre Mac Orlan, La Cavalière Elsa)

1987 À longueur de journée on lui amenait les élèves récalcitrants, il les calait entre ses jambes énormes et les fouettait ferme selon « la prescription » envoyée par les maîtres qu'il exécutait fidèlement. C'était le bourreau du lycée ! (Jacqueline Turian Cardozo, On ne guérit pas de son enfance)

II. Fouetter afin de rendre ferme (quelque chose)

Transitif

1856 amalgamez alors peu à peu les blancs fouettés très-fermes (Urbain Dubois et Émile Bernard, La Cuisine classique)

1964 Ajouter en dernier lieu deux fortes cuillerées à bouche de crème fouettée bien ferme (Cécile Éluard-Valette, Les Grandes Heures de la cuisine française)

\section{Fourmiller épais}

Fourmiller, aller et venir en tous sens en formant un groupe dense et rapproché

Intransitif

1579 HECUBE. Qu'il vienne quelque Roy, qui les peuples d'Asie

Face marcher un jour dans la Grece saisie, Fourmillant plus espais pour revanger nos torts,

Que ne sont les espics aux Gargariques bords (Robert Garnier, La Troade)

1839 L'essaim des Esprits fourmille épais, à la fois sur la terre et dans l'air froissé du sifflement de leurs ailes bruyantes (François de Chateaubriand, Le Paradis perdu)

REMARQUES : Fourmiller épais désigne le fait de s'agiter en grand nombre, d'aller et venir en tous sens et continuellement, comme des fourmis, épais référant à la densité, au nombre élevé de sujets ainsi qu'à l'idée de promiscuité. Le sujet peut être un animé ou, dans un sens figuré, un inanimé (ici : les Esprits). Épais est modifié par plus.

\section{Fourmiller vert}

Être en grand nombre (d'objets de couleur verte) Intransitif

1909 Dans le pressoir large, les pelles de bois des hommes aux manches retroussées égalisaient le tas noir où les tiges de grappes fourmillaient vert (Pierre Hamp, Vin de Champagne)

\section{Fourrer gros}

Fourrer beaucoup, plein

Intransitif

1883 Le blessé le plus près de moi avait reçu un biscayen dans le ventre. C'était lui qui râlait. La vieille femme approcha du matelas avec la chandelle et nous dit tout bas en montrant son poing :

- Si vous voyiez le trou que ça a fait ! Nous lui avons fourré gros de ça de charpie dans le ventre (Victor Hugo, Histoire d'un crime)

\section{CORPuS Web :}

Donc oubliez Spacek, oubliez Gomez !!!

Sutter va demander des gars comme Subban, Gionta (Oui oui ! Le capitaine !! Sa fera pas différent des 20 dernières années que le Canadien échange leurs capitaine !!) à la limite Hamrlik, mais j'en doute fort !! C'est sûr que Eller va être demander aussi (espoir pas cher en voie de s'en aller centre du 2e trio !!), mais arrêtons de rêver en pensant que Gauthier va fourrer gros comme le bras Sutter (Désolé l'expression, mais c'est celle que je trouve la plus approprier) !!! [http://www.vestiaire.ca/forums/index. php?topic=3496.70;wap2] (27.04.2015)

Apparemment encore une loi pour nous enchaîner, nous mettre à poil et ensuite nous fourrer gros et profondément dans le postérieur. Ce qui est fort, c'est qu'on s'en rend jamais compte sur le moment mais bien après, quand c'est trop tard [https://fr.answers.yahoo.com/question/index?q $\mathrm{id}=20100120063429 \mathrm{AAnmAcl}](27.04 .2015)$ 
REMARQUes : Fourrer gros désigne le fait de glisser, de faire entrer quelque chose en grande quantité dans un endroit, sans soins ni précautions, brutalement ou sans ordre. Les exemples du CW prennent en charge le sens de 'se faire mettre, se faire avoir, se faire baiser, se faire foutre'. Notons la collocation gros et profondément qui souligne la fonction adverbiale de gros.

\section{Fraîchir dur}

Faire plus froid

Intransitif

1892 «Ça fraîchit dur, patron!» lui cria le maître de manœuvre (Paul Bonnetain, Passagère)

1936 Ça fraîchit dur, me dit Tati ! ça " refuse » aussi plein nordouest ! Je regarde le baromètre; il a descendu en catastrophe ! (Éric de Bisschop, Au-delà des horizons lointains)

\section{CORPus Web :}

Il fait un temps magnifique, mais c'est le mistral ; ça va fraîchir dur [https://www.forums. supertoinette.com/recettes-557954-culture-des involture-et-epluchures?start=17010] (26.12.2016)

REMARQUES : Fraîchir réfère au fait de se rafraîchir, devenir plus frais souvent sous l'effet du vent.

\section{Frapper droit}

I. Frapper directement (au propre et au figuré) Transitif

1538 Ha ! la meschante, escoutez sa malice : Premier occit en martial destroict Quatre meilleurs chevaliers de ma lice, Lescut, Bayard, la Tremoille et Pallice, Puis est entrée en mon conseil estroict, Et de la troupe alla frapper tout droict Le plus aymé et le plus diligent (Clément Marot, Complaintes)

1698 Non, dit le nain jaune, ce ne sera point à tes yeux que je deviendrai son époux ; un rival aimé m'est trop redoutable. En achevant ces mots, malgré les pleurs et les cris de Toute-Belle, il frappa le roi droit $a u$ cœur, et l'étendit à ses pieds (MarieCatherine d'Aulnoy, Le Nain jaune) 1833a Ainsi depuis long-temps je la considérais, quand par hasard, elle égara sur moi ses beaux yeux pers ; ses deux prunelles, comme deux balles parties d'une arquebuse, me frappèrent droit au cœur (Pétrus Borel, Champavert)

1851 Il lui sembla qu'à ce nom de Levrault, un sourire narquois partait comme une flèche de chaque cadre et venait la frapper droit au cœur. Puis, elle raconta par quel hasard elle s'était trouvée seule au milieu des campagnes et comment la curiosité l'avait poussée jusque dans la cour du château (Jules Sandeau, Sacs et parchemins)

1955 il lui arrivera tout à l'heure d'élever à l'extrême bout de ses bras comme pour le présenter - signe de reconnaissance ou d'ovation (je dirais presque : d'oblation) à l'orateur prenant appui sur la foule, et la foule sur lui, en un étonnant crescendo né du surcroît de chaleur que renvoie à celui qui parle la réaction des gens que son discours a frappés droit au cœur et qu'à son tour il leur renvoie sous la forme de mots encore plus chaleureux (Michel Leiris, $L a$ Règle du jeu 2 : Fourbis)

Intransitif

1833b Ah ! Comme les vieux airs qu'on chantait à douze ans frappent droit dans le cour aux heures de souffrance! (Alfred de Musset, Rolla)

1948a L'œil électrique frappa droit dans le regard d'Isabelle, tandis qu'un doigt de caoutchouc lui retroussait une paupière, la forçant à soutenir l'éblouissement en pleine pupille (Maurice Druon, Les Grandes Familles)

1948b L'élan les fit glisser toutes deux sur le carreau ciré chaque jour, poli comme une glace, et la main droite de Simone se posant par hasard sur un objet lourd et froid - elle sut plus tard que c'était l'un des chenets de bronze - elle frappa droit devant elle, posément, sauvagement (Georges Bernanos, Un mauvais rêve) 
II. Frapper exactement, précisément, habilement

Intransitif

1596 Vous juriez la deesse en vostre ame logée, Et la foy qui n'estoit qu'à moy seul engagée ; Vous juriez cet archer qui droit sçait frapper,

Et mille autres sermens trop forts pour me tromper (Philippe Desportes, Euvres)

1928 Antoine eut l'intuition qu'il fallait répondre tout de suite ; et frapper droit :

- Père est au plus mal. Père va mourir. Il prit un temps, et ajouta : "Je viens te chercher, mon petit »

(Roger Martin du Gard, Les Thibault. La Sorellina)

\section{CORPUS WEB :}

L'équipe Cobra R\&D a conçu l'hybride Baffler XL pour rendre le golf plus facile. Facile à frapper loin, facile à frapper droit, et le plus important, facile pour apprécier davantage votre jeu. La distance facile commence avec la tête de club peu profonde, en acier haute densité pour une vitesse de balle plus rapide et des coups plus longs [http://www.golfleader.fr/golf,fr,4,hybridecobra-14-baffler-xl-lady.cfm] (31.03.2015)

Pour les joueurs les moins expérimentés, ils peuvent se rabattre sur du mini-golf, qui ne leur demandera pas de louer une voiturette ou encore d'avoir un sac à dos rempli de clubs de golf. Les jeux de golf vont reproduire la partie d'un golfeur comme si elle se déroulait réellement. Il faudra bien choisir son club, frapper droit et fort pour que la balle atteigne le trou et évite de terminer dans le décor. Certains jeux de golf nécessitent aussi l'intervention du joueur avant de frapper la balle puisqu'il doit placer lui-même les obstacles sur la piste pour arriver à ses fins [http://www. zebest-3000.com/portail/golf.html] (31.03.2015)

REMARQUES : Frapper droit (I) se dit du fait de frapper directement, sans détours, de manière immédiate. Au sens propre (I), il renvoie au fait de donner un coup de manière précise et habile, atteindre par une frappe un point précis. Au sens figuré, il signifie 'produire une impression vive, directe' ou 'provoquer un état émotif soudain'. Notons les collocations frapper droit au cœur, très usitée, soulignant le caractère affectif de l'action, et droit et fort. Le CW ajoute un emploi dans le domaine du golf. Droit reste invariable (ex. de 1851, 1948b et de 1955) et est modifié par tout. Il a tendance à s’associer avec la préposition qui le suit (à, dans, devant), au point de faire partie du groupe prépositionnel comme modifieur de la préposition.

\section{Frapper dru}

Frapper durement

Transitif

1615 Les Cloches que les coups de marteaux frappent dru et menu, retentissent horriblement (Ludovico Ariosto, Roland le furieux [trad.])

1992 Il n'avait pas grêlé ce qui étonnait profondément le quartier et le faisait remercier la Vierge d'avoir protégé les potagers même s'ils n'avaient pas bonne mine tant la pluie avait frappé drue salades et haricots (Pierre Cros, Les Bijoutiers du roc des perles)

2010 Toute une époque semble s'évanouir, car la mort, les accidents, les overdoses, les suicides, frappent dru les milieux gauchistes et artistes en ce début des années 1970 (Antoine de Baecque, Godard)

2015 Sa tête envoûtée résonnait, des coups la frappaient drus, telle la peau de chèvre polie d'un tambour (Mohamed Saïd, Jours de liesse)

Intransitif

1845 Savez-vous qu'il y a des hommes qui frappent dru et ferme ! (Baptiste Capefigue, François Ir et la Renaissance)

1918 De nouveau, les marteaux font résonner l'air. Ils luisent au soleil et frappent dru (Albert Laberge, La Scouine)

\section{CORpus WeB :}

les canons frappent drus, les mâts tombent comme des mouches, les ponts sont jonchés de cadavres [http://shangols.canalblog.com/ archives/2007/10/08/6466919.html] (8.10.2007)

Les sabots du cheval frappaient drus, tantôt sur les pavés glissants de la citée, tantôt dans les larges flaques qui inondaient les ruelles 
[http://miradelphia.forumpro.fr/t25300-jour-dautomne-lohie] (5.11.2020)

La lumière frappe drue sur les cercados [= en tauromachie] [http://bregaorthez.blogspot. com/2009/06] (4.6.2009)

\section{Frapper dur}

Frapper durement, rudement, de manière violente, avec force

Intransitif

1770 PHILIPPE. Voyons donc. (Colin invisible lui donne un coup d'archet sur la main). Que diable est cela, peste, que cela frappe dur, vous en riez (L'Heureuse Pêche)

1859 En somme ce pauvre bonapartiste est romantique, il vous glorifie, il acclame Paul Meurice, il célèbre Victor, ce qui fait que j'ai peine à frapper dessus, et à frapper dur (Victor Hugo, Correspondance)

1898 Toute aurore même gourde À crisper un poing obscur Contre des clairons d'azur Embouchés par cette sourde A le pâtre avec la gourde Jointe au bâton frappant dur Le long de son pas futur Tant que la source ample sourde Par avance ainsi tu vis Ô solitaire Puvis De Chavannes Jamais seul De conduire le temps boire À la nymphe sans linceul Que lui découvre ta gloire (Stéphane Mallarmé, Poésies)

1912 mais peu à peu, la réflexion aidant, il abandonna chacun de ces projets, car il convenait d'agir avec prudence, Lebrac, Camus et les autres n'étant point des gaillards à se laisser faire sans frapper dur et cogner sec (Louis Pergaud, La Guerre des boutons)

1915 Sans équipement, sans sa capote, la chemise ouverte sur sa poitrine velue, remontant son pantalon qui lui tombait des hanches, avec une demi-douzaine de bidons lui pendant à l'épaule, il sautait sur le ballast, de traverse en traverse, courait aux barrières, aux maisons, secouait les portes, frappait dur, criait fort, repartait avec toute sa ferblanterie et remontait furieux, disant :

- J'marche pus!

(René Benjamin, Gaspard)

1927 Un assassin ! Elle le croyait un assassin : il avait tué une femme. "Assassin! Maudit, va crever à la rue !... » Comme elle lançait ces mots ! Ils frappaient dur - la nuit surtout (André Baillon, Délires)

\section{CORpus Web :}

« Aujourd'hui, la procédure est tellement longue que le pirate a la possibilité de faire disparaître le produit de son forfait. Donc, si on fait de la coquetterie, je crois qu'on se trompe. Il faut frapper dur et être ferme avec les pirates, il faut être dissuasif, réprimer. Quand on vole un poulet, on est passible de peine. Il faut aller dans le même sens, ça fera peur aux pirates ", dit-il. Oui, mais concrètement que faire ? [http://www. cinematunisien.com/index.php?option=com content\&task=view\&id=1560] (31.03.2015)

«Mais pour leur part, les salariés se sont vus imposer des coupures et des baisses. Stelco, profitant de la restructuration, les a frappés dur et ce n'est tout simplement pas juste. Ils ont droit à une bonne convention et, à titre de Métallos, ils auront la possibilité de l'obtenir » [http://www.usw. $\mathrm{ca} /$ presse/nouvelles/communiques?id=0490] (31.03.2015)

Dimanche était Fête des pères et le premier jour d'été et a jamais fait l'été nous a frappés durs, avec temps au-dessus de 30 degrés les jours passés à Ottawa. Je ne me plains pas ; au contraire, je rentre tout le soleil je peux aller avec heure du déjeuner promenades autour du campus à travail et sommet-en bas automobilisme sur la route du retour ! [http://french. autoao.com/thread-98228-1-1.html] (31.03.2015)

REMARQues : Frapper dur désigne le fait de donner des coups avec force, vivacité, violence, le sujet étant un animé ou un inanimé (le soleil). Au sens figuré, il signifie 'produire une impression vive, forte sur quelqu'un'. Dur reste invariable dans la majorité des cas. L'emploi transitif est attesté dans les deux derniers exemples du CW. 
Dans le deuxième exemple du CW, dur reste invariable malgré l'objet au pluriel, tandis que dans le troisième exemple il s'accorde avec l'objet au pluriel, sans justification sémantique, l'interprétation comme prédicat second ne faisant aucun sens (hypercorrection). L'exemple confirme cependant l'hypothèse selon laquelle l'accord de l'adjectif-adverbe se comporte celui du participe passé, du moins en terme de tendance sous-standard (v. Introduction § 4.6). Notons l'emploi de cogner sec, crier fort. VoIR AUSSI : cogner dur

\section{Frapper ferme}

Frapper bien et fort, porter un coup violent (au propre et au figuré)

Intransitif

1635 Je ne dis pas pour leur demander si Plutarque et Seneque sont de grands autheurs, car la reputation les dresse en ce poinct là ; mais pour sçavoir de quelle part ils le sont plus : si c'est en la faculté de juger, si c'est en celle d'inventer et de produire, et comme eux qui devisent de ces facultez les entendent ou comprennent : qui frape plus ferme que son compagnon en tel et tel endroit (Marie Le Jars de Gournay, Préface sur les Essais de Michel de Montaigne)

1834 LE DUC. Quand mon Giomo frappe, il frappe ferme

(Alfred de Musset, Lorenzaccio)

1862 Les révolutions ont le bras terrible et la main heureuse ; elles frappent ferme et choisissent bien (Victor Hugo, Les Misérables)

1912 À la vue de ces enragés qui frappent ferme et $d r u$, les Américains perdent la tête, jettent leurs armes et se sauvent dans le grenier ou dans les caves (Statistique des accidents du travail)

1927 Ils frappent ferme, chaque coup laisse sa marque, son sillon et souvent le sang coule (Louis Tauxier, La Religion Bambara)

1966 À ces mots, les deux forgerons crachent sur leurs mains, grincent les dents et frappent ferme sur le biniou (Revue des traditions populaires)

\section{Frapper fort}

I. Frapper avec force; assener des coups violents

Transitif

1250 Je sçay bien que tu m'as fait chi endroit trahir,

Pour ce que de mon arc t'alay l'aultrier ferir,

Quant je te vi ma mere folement requerir ; Pour ce qu'elle ne vault à ton gré abaïr, Tu le frapas moult fort, dont j'ay au cœur aïr,

Et je le revengié : pour ce m'as fait tenir (Les Enfances de Doon de Mayence [milieu $\mathrm{XIII}{ }^{\mathrm{e}}$ )

1543 Il fault que le laboureur des terres soit de grand corpulence et facture : car tel personnage en s'appuyant fort sur le manche de la charrue, il appesantist le soc, affin que le rayon ne se face sur la terre. Et d'avantage les coups qui viennent de hault, frappent plus fort les bœufs. Les vignerons ne fault pas qu'ilz soyent si haultz, mais qu'ilz soyent carrez

(Cassianus Bassus, Les XX Livres de Constantin Cesar [trad.])

1691 En achevant ces mots, les joueuses de tambour commencèrent à les frapper plus fort ; elles poussèrent de hauts cris, et ces belles pirates firent l'exercice de la rame en sautant et dansant avec beaucoup de disposition et de bonne grâce (MarieCatherine d'Aulnoy, Relation du voyage d'Espagne)

1938 Il posait à Salomon cette question menaçante en le frappant fort sur la poitrine (Albert Cohen, Mangeclous)

2012a Il faut vraiment être un nazi de flic pour frapper aussi fort un gosse dehuit ans (Stéphane Osmont, Éléments incontrôlés)

Intransitif

1450 LE VARLET. Par la mort, vous serés batu, Ou me paierés jusque a ung fort.

(Et le bat, et fier l'aveugle son varlet sur le cervel) 
L'AVEUGLE. Qu'es ce, dia ? tu frappe trop fort ! Tu ne te truffes bien, le voy ( $L e$ Mystère de S. Bernard de Menthon, 4154)

1559 Et, incontinant qu'il fut party, sa femme envoya querir son homme, lequel ne fut pas demye heure avecques elle que va venir le mary, qui frappa bien fort à la porte (Marguerite d'Angoulême, Heptaméron, p. 46, 17)

1603 Et de peur que du grain n’en chée par trop en terre en le transportant, comme tousjours quelque portion s'en perd, pour doucement qu'on le manie, le blé couppé et lié, sera laissé sur terre, jusques au lendemain grand matin, pour lors avant que le soleil frappe fort, les gerbes estre enlevées et accumulées en petits monceaux, chacun d'une ou de deux charretées, ou, de sept à huict charges de mulet (Olivier de Serres, Le Théâtre d'agriculture et mesnage des champs)

1788 Telle est en général la méthode des physiciens qui écrivent sur les affaires civiles ou politiques : accoutumés au calme et au bel ordre qui règne dans la nature, ils veulent introduire parmi les hommes la police qui dirige les astres. Mais M. Carra, qui frappe toujours juste, a cette fois frappé trop fort (Antoine de Rivarol, Petit Almanach des grands hommes)

1809 C'est en France qu'a été inventée cette maxime, qu'il valait mieux frapper fort que juste. Contre un pareil principe il faut des règles fixes, qui empêchent les écrivains de frapper tellement fort qu'ils ne frappent plus juste du tout (Benjamin Constant, Wallstein)

1944 Ce marchand de tableaux modernes eut la fantaisie d'éditer des livres de luxe et l'idée de demander leur collaboration à des peintres-graveurs n'ayant jamais travaillé pour l'illustration. Il ne manquait pas d'audace, il aimait à frapper fort et il n’a pas toujours frappé juste, avec Chagall, Picasso, Rouault, notamment (Émile Dacier, La Gravure française) 1994a Tandis qu'il immobilisait le chef et lui posait le cimeterre sur la gorge, Aude faisait merveille. Bondissant en tous sens, elle frappait fort et sec, et bousculait les quelques courageux qui osaient ferrailler (Jacques Lanzmann, La Horde d'or)

1994b Il avait frappé très fort et très vite, jetant la consternation dans l'assemblée (Jacques Lanzmann, La Horde d'or)

2012b C'est durant le trajet en Allemagne de l'Ouest que nous avons appris que la Fraction armée rouge avait encore frappé fort en assassinant le 30 juillet 1977 le patron d'une grande banque, Jürgen Ponto (Stéphane Osmont, Éléments incontrôlés)

2013 Ce sont des conquistadors et ils méprisent cet Indien qui n'en est pas un! Ils frappent forts et ils posent des questions! (JeanMarc Chamoulaud, Nuage bleu)

2019 Les policiers sont cruels et ils frappent forts, assura Alanna. Quand j'ai vu Hurvin traîner Katerina hors de la pièce, j'ai cru qu'il allait la tuer (Sandra Laguilliez, Katerina)

II. Impressionner, faire une vive impression Transitif

1735 cette idée me frapa si fort, que je ne pus m'empêcher d'en faire part. Elle est adorable ! (Charles Fieux de Mouhy, La Paysanne parvenue)

1836 - Je ne m'en aperçois que trop, répondit M. Daru avec une intonation riche de sentiment et qui me frappa fort chez un homme si plein de mesure et d'habitudes périphrasantes et diplomatiques (Stendhal, Vie de Henri Brulard)

\section{CORPuS Web :}

Son exécution a simplement coïncidé avec la mise à mort de notre pilote, notre héros. La Jordanie va frapper fort, l'exécution de Sajida al-Richawi, cette criminelle arrêtée à Amman, ne venge en rien la mort de Maaz al-Kassasbeh. La réponse de la Jordanie à ces terroristes va être terrible [https://www.rfi.fr/fr/moyenorient/20150204-jordanie-choc-colere-apresexecution-pilote-groupe-ei] (31.03.2015) 
Un bon entraînement au sac juste n'est rien de plus que de bonnes frappes et des bons mouvements du corps. C'est si simple et pourtant si souvent mal exécuté. La cause est la tendance naturelle à vouloir cogner le plus fort possible. Frapper fort vous donne l'air cool et ça défoule. A bon claquement du sac te récompense de chaque coup puissant. Et plus tu frappes fort, mieux tu te sens [http://www.expertboxing.fr/entrainementde-boxe/comment-taper-dans-un-sac-de-frappe] (31.03.2015)

Si j'échappe ou je frappe fort les cubes lorsqu'ils sont congelés, puis-je continuer à les utiliser?

Non, les Baby Cubes sont comme tous les objets en plastique : ils sont plus fragiles lorsque congelés et peuvent fendre s'ils sont échappés ou frappés fort [http://www.babycubes.com/ faq_fr.html] (31.03.2015)

REMARQUES : Au propre, frapper fort (I) désigne le fait de donner des coups forts et avec insistance, de même quand un État réagit très durement (premier exemple du CW). Sur le plan abstrait (II), il est employé par rapport à une idée, une personne qui impressionnent. On l'utilise aussi par rapport à une source de lumière forte (soleil, lune). En fait, fort accompagne la polysémie du verbe frapper. Notons les collocations de fort avec juste, vite, sec, ainsi que l'emploi de cogner fort. Fort tend à l'emploi invarié, mais l'accord est réalisé dans les exemples de 2013 et 2019. Il est modifié par aussi, bien, mult, plus, si, tellement, très, trop. VOIR AUSSI : cogner dur / fort.

\section{Frapper imprévu}

Frapper de manière inattendue, sans s'annoncer Transitif

1843 Se préparer à un pareil malheur... c'est en savourer peu à peu et d'avance les lentes angoisses... C'est un raffinement de douleurs inouï... Cela est mille fois plus affreux que le coup qui vous frappe imprévu... (Eugène Sue, Les Mystères de Paris)

\section{Frapper juste}

I. Frapper de manière exacte, précise Intransitif

1691 Elle s'exerçoit plusieurs fois le jour, à tirer un pistolet chargé à balles contre le por- trait de Cromwel, tant afin de s’apprendre à frapper juste, que pour s'accoûtumer à ne point s'effrayer de l'original lors qu'elle se verrait en sa présence (François Raguenet, Histoire d'Olivier Cromwel)

1704 Nous l'éprouvons en nous-mêmes dans les premiers mouvements de la colère ; et lorsque sa violence nous ôte toute réflexion, nous ne laissons pas toutefois et de nous mieux situer, et souvent même dans l'emportement de frapper plus juste que si nous y avions bien pensé

(Jacques-Bénigne Bossuet, De la connaissance de Dieu et de soi-même)

1788 Telle est en général la méthode des physiciens qui écrivent sur les affaires civiles ou politiques : accoutumés au calme et au bel ordre qui règne dans la nature, ils veulent introduire parmi les hommes la police qui dirige les astres. Mais M. Carra, qui frappe toujours juste, a cette fois frappé trop fort (Antoine de Rivarol, Petit Almanach des grands hommes)

1839 C'est dans ce triste exercice que leur œil se forme à saisir du premier coup le côté vulnérable de leur adversaire, et à y décrocher d'une main prompte et sûre un trait qui frappe juste et fort (Rodolphe Toepffer, Nouvelles genevoises)

1863 Il faut piquer d'honneur les enfants et les sociétés. C’est ce que je veux faire par mes consultations. Je frapperai juste et, dès lors, ce sera frapper fort, car la France, nation du bon sens, n'adopte pas le faux raisonnement (Alfred de Vigny, Le Journal d'un poète)

1886 Seulement, à cette heure, c’est le dédain plus que le désespoir qui gonfle mon cœur, et le fait éclater en phrases que je crois éloquentes. Dans le silence, il me paraît qu'elles frappent juste et luisent clair (Jules Vallès, Jacques Vingtras : L'Insurgé)

1925 Raboliot lui aussi travaillait à l'embauche : tout ch'ti qu'il était d'apparence, avec ses mains de femme, si menues qu'elles l'humiliaient, sa cognée frappait juste et raide au pied des arbres qu'elle besognait ; les 
éclats blancs volaient, pulpeux, frais de résine (Maurice Genevoix, Raboliot)

1945 Il hoquetait, tirant de son médiocre larynx des sonorités caverneuses, expédiant, comme au hasard, vers le piano, des coups de poing furieux qui frappaient miraculeusement juste et faisaient pousser à l'instrument des soupirs et des cris de douleur (Georges Duhamel, La Passion de Joseph Pasquier)

1959 « Oui, vous le connaissez aussi bien que moi. Vous savez comme il a besoin d'être rassuré, soutenu... » Elle sent qu'en lui tout bouge et se déplace, elle a frappé juste, il se raidit sous le coup, il y a dans ses mâchoires alourdies, dans son regard immobile, fixé droit devant lui une mâle et courageuse résignation, il fait penser à un taureau ensanglanté qui baisse la tête et fait face au matador (Nathalie Sarraute, $L e$ Planétarium)

1990 Trois contre une. Si elle n'est pas mise hors jeu, elle va les écraser. Seule une colère blanche est à la mesure de la haine qui n'explose ni n'implose, mais frappe juste. Il n'y a que la colère neutre qui sache mesurer ses coups (Julia Kristeva, Les Samouraïs)

II. Faire mouche, frapper où cela fait le plus d'effet

Intransitif

1835 Elle contait à ravir, donnait des ridicules à pleines mains et presque sans distinction de parti. Elle frappait juste en général, et l'on riait toujours dans le groupe où elle était. Volontiers Lucien en eût été amoureux (Stendhal, Lucien Leuwen)

1863 Les récits, les traits rapides frappaient juste et résonnaient longtemps ensemble dans les salons de France comme un coup de l'horloge de Versailles dont le bruit se serait conservé dans toutes les mémoires, sur la même note claire, sonore et répandue au loin à travers l'espace et les temps (Alfred de Vigny, Mémoires inédits)

1922 Et savez-vous qui mène la danse ? Des étrangers, des Juifs crochus, des circoncis.
Une vaste clameur montra au boiteux qu'il avait frappé juste en désignant le bouc émissaire traditionnel (Joseph Kessel, La Steppe rouge)

1939 « Comme tout ce qu'elle dit frappe juste !» pensait Costals (Henry de Montherlant, Les Lépreuses)

1992 C'est que, tout en elle est vrai, vise droit, frappe juste. A Bobigny, avec les mots les plus simples, elle donne à sa démonstration une densité remarquable (Gisèle Halimi, La Cause des femmes)

\section{CORPuS WEB :}

C'est une étape en trois phases : créativité / prototypage rapide / test avec utilisateurs en contexte réel. L'objectif est de donner rapidement forme aux idées pour les partager et en comprendre les conséquences en terme d'expérience vécue par les utilisateurs et de faisabilité technique. Il faut frapper juste [http://www.dschool. fr/wp-content/uploads/brochure-dschool.pdf] (31.03.2015)

† 26 mai 2014 : Un groupe de naturalistes de la société Aquabio (sous contrat avec Vinci) ont été surpris. Il leur a été vivement conseillé de partir, ce qu'ils ont fait, à pied... Leur matériel a été volé. Suite à cet évènement nous avons reçu le mail suivant de la société aquabio pour nous expliquer qu'en "s'en prenant à nos collègues et à notre matériel, les opposants au projet se trompent de cible ». Il n'empêche qu'ils avaient frappés juste : «AQUABIO décide d'annuler toute intervention liée à ce projet d'aéroport » [http:// zad.nadir.org/spip.php?article2680] (31.03.2015)

Ta tenue est réellement superbe !! Une fois encore tu frappes juste !! Ça semblait être une super soirée !! J'ai testé la marque et quand on est rondes comme moi c'est vrillent un plaisir d'avoir une marque qui sait vous sublimer ! [http://www. helloitsvalentine.fr/1124145/balsamik-et-moi-etvous] (31.03.2015)

A partir d'une maquette qu'il réalise, le peintre-verrier l'interprète en volume, en dalles de verre de $2,5 \mathrm{~cm}$ d'épaisseur, éclatées sur le tranchet, " frappées juste et net avec la marteline, travaillées à l'oreille pour sentir le son de la rupture à l'endroit voulu »(H Guérin), apportant des nuances et des passages de ton et 
finalement jointoyées à l'aide d'un joint minéral dont la formule, mise au point par $\mathrm{H}$ [http:// www.baladou.fr/uploads/vitraux_cazes.pdf] (31.03.2015)

REMARQUES : Frapper juste s'emploie au sens concret de 'frapper, donner un coup de manière précise, exacte', le sujet pouvant être un animé ou un inanimé (I). Au figuré (II), il réfère à tout type d'action, de parole ou de pensée qui touchent l'essentiel, causant ainsi un effet maximal. Notons les collocations juste et fort, juste et net, juste et raid, et l'emploi synonymique de viser droit. Juste reste invariable et peut être modifié par miraculeusement, plus, toujours. Mentionnons aussi l'emploi de luire clair, fixer droit et viser droit.

\section{Frapper lourd}

Frapper, cogner avec force, durement, lourdement

Intransitif

1953 Et puis l'injure me fut faite Je fus d'un seul coup déréglé Les monstres prenaient pied sur moi L'or sonnait mat et frappait lourd On pêchait dans l'eau d'un diamant De sales de lugubres bêtes (Paul Éluard, Poésie ininterrompue)

CORPuS Web :

Il faut savoir que souvent le travail au sac est mal fait.... En effet il doit servir

1) à trouver la distance maximum à laquelle on peut toucher une cible

2) à développer la vitesse

3) la puissance

Pour cela, rien ne sert de faire valser le sac en croyant frapper lourd. Et qui en fait ne fait que pousser le sac. Ca flatte son égo c'est tout [http://www.davidmanise.com/forum/index. php?topic=52656.0] (31.03.2015)

J'emploie toujours le plus grand anneau d'attaque avec l'anneau de poids le plus lourd que j'ai ainsi mon adversaire ne peut pas frapper mon disque de poids et m'envoyer hors de la commande. Après j'emploie une base d'attaque pour frapper lourd. Bonne chance avec ce bout [http:// beyblade.e-monsite.com/pages/strategie.html] (31.03.2015)
C'est une équipe très efficace en contre. Capable d'attaquer quand tu t'y attends le moins. Ils peuvent rentrer dans ton rythme et tout d'un coup accélérer. Ils me font penser à l'équipe d'Australie championne du monde en 99. Ils sont solidement armés dans ce domaine. Gelez est un redoutable buteur. Elhorga et Sarraméa frappent lourd et font avancer leur équipe [http:// www.rugby365.fr/top-14/la-s-r-nit-catalane-119. shtml\#ghaFOHO4eWuptOdA.99] (31.03.2015)

REMARques : Frapper lourd désigne le fait de donner des coups forts, violents, d'avoir la main lourde, de faire des dégâts (sport, guerre). Dans l'exemple de 1953, il réfère au poids de la monnaie. Notons la collocation sonner mat et frapper lourd. Lourd reste invariable.

\section{Frapper menu}

Frapper souvent, en peu de temps, mais

faiblement

Intransitif

1572 Les morions, les piques des soldars

Et les harnois fourbis de toutes pars,

Et l'emery des lames acerées,

Frappez menu de flames etherées,

Et du rebat du soleil radieux,

Une lumière envoyoient dans les cieux, Qui çà, qui là, comme à pointes menues En temblotant s'esclatoit dans les nues (Pierre de Ronsard, La Franciade, p. 73)

Remarques : Frapper menu désigne le fait de frapper, de donner de petits coups rapides, brefs. Dans l'exemple, le groupe réfère aux reflets causés par les flammes et les rayons de soleil qui se réfléchissent sur l'acier de la lame. Menu reste invariable.

\section{Frapper net}

Frapper directement, sans ambages

$\lambda$ frapper juste

\section{Frapper raide}

Frapper avec vigueur, avec force

Intransitif

1853 BENGALI. (paraissant au fond).

Tiens ! tiens ! tiens ! meeting est fini... tout le monde est parti... Oh !... Philémon !... camarade à moi... bon camarade, qui batté 
moi toujours !... Li ronfler ferme... (Vivement) Si moi rendé une bonne calotte ?... Oui !... moi frapper raide... sans réveiller li !... ça qu'est malin! (Il donne un soufflet à Philémon)

(Adolphe d Ennery et François Pinel Dumanoir, La Case de l'oncle Tom)

2008 Juste ça. Me semble que ça irait mieux. Son silence sur mon père, comme un poing fermé prêt à frapper raide sur $\mathrm{n}$ 'importe quoi. Un jour, je vais le casser en deux, son silence (Louise Desjardins, Le Fils du Che)

\section{Corpus Web :}

Ici a Clarence-Rockland a environ $3 \mathrm{kms}$ a l'est d'ici, la foudre c'est abattu sur un arbre près d'un champ de blé d'inde et ca pris un bon 15 a 20 minutes au service d'incendie pour eteindre le feu causser par la foudre. La foudre frappe raide parfois [https://www.facebook.com/meteo media/posts/123866741036441] (31.03.2015)

À 50 kilomètres/heure, un enfant qui se fait frapper, ça frappe raide. À 30 kilomètres/heure, déjà l'automobiliste a beaucoup plus de temps pour arrêter et l'enfant aussi 2360 plus de temps pour se tasser. On le voit venir de plus loin aussi [http://ocpm.qc.ca/sites/import.ocpm.aegirvps. net/files/pdf/P22/8i.pdf] (31.03.2015)

Ne pas prendre les choses au sérieux est aussi un risque... ont t'ils votés pour le génocidaire interne et ont t'ils mis la démocratie et les citoyens en danger de mort.. où n'est ce encore qu'un autre hoax psychiatrique populaire le beau jeu est d'utiliser la croyance aux hoax et de frapper raide.. Il y a des limites à bluffer et selon ce que je comprends, ce programme à fonctionner souvent dans l'histoire Aliens sera notre nouveau Dieu, mais le Plan de la vidéo là haut le montrait déjà des idées.. [http://www.forumreligions.org/t5513-baby-bleu-blood] (31.03.2015)

REMARQUES : Frapper raide réfère au fait de frapper brutalement, qu'il s'agisse de la foudre, de l'impact d'une voiture qui cause un accident ou d'une idée. Le groupe tend à l'emploi intransitif-absolu. Notons l'emploi de ronfler ferme.

\section{Frapper sec}

Frapper de manière vive, dure, sans égards (au propre ou au figuré)

Transitif

1789 En bon ordre, le groupe est là, sur la terrasse ;

Les deux musiciens s'agitent, non sans grâce ;

Chacun d'eux frappe sec le vibrant parchemin

De la main droite et fait jouer, de l'autre main (Jean Aicard, Poëmes de Provence)

Intransitif

1950a En même temps, des balles allemandes filent à travers les feuilles, plus sournoises du mystère des taillis; elles frappent sec dans les troncs des arbres, elles fracassent les grosses branches, hachent les petites, qui tombent sur nous, légères et lentes (Maurice Genevoix, Ceux de 14)

1950b Les Boches, cette fois, tiraient plus bas. A chaque instant des balles s'enfonçaient autour de nous, frappant sec (Maurice Genevoix, Ceux de 14)

1982 Un livre pareil ne peut être apprécié que par des obsédés sexuels, des vicieux, des corrompus ! Il est moins brillant jacteur que Lubary mais il fait mouche. Il frappe plus sec (Alphonse Boudard, Les Enfants de chœur)

1994 Bondissant en tous sens, elle frappait fort et sec, et bousculait les quelques courageux qui osaient ferrailler (Jacques Lanzmann, La Horde d'or)

CORPUS Web :

En Espagne la crise a frapper sec. la bulle comme ils disent la crise vient de banque juifs américaine Ok mais je te promet qu'ont a pas eu besoin d eux en Espagne un bâtiment sur deux n'a pas de permit de construire.la maire de malaga en taule elle en avait pour 2 milliards d euro juste dans sa maison [http://quenelplus.com/ revue-de-presse/une-faillite-immobilieregigantesque-menace-lespagne.html] (31.03.2015)

Je ne suis pas sûr de saisir le sens de ta question : l'enclume doit peser plus de $250 \mathrm{~kg}$, le billot à vue de nez 120/130. Le marteau a beau frapper 
sec, cela reste une petite puissance, la frappe est totalement absorbée par l'inertie de l'enclume et du billot. Pour avoir utilisé bien d'autres types de pilons, je suis sûr quec'est même sur-dimensionné. La chabotte d'un Tyro ne fait pas $300 \mathrm{klg}$ loin s'en faut et cela ne pose pas de problèmes [http:// metal-connexion.fr/forum/restauration-d-unmartinet-outil-de-forge-t963-10.html] (31.03.2015)

la gloire m'a frappée sec depuis toute ces salopes elle mouilles mais quand le buzz il tombe a l'eau mais dit moi est ce qu'il rouille hein ? * * [http://www.enjoygram.com/elvyndimeglio] (31.03.2015)

Les textes d'Adeline Picault sont d'une grande intimité et d'une intense proximité. Son style, très particulier, souvent syncopé, où les mots frappent secs pour mieux nous livrer leurs personnages, donne une force au sujet qu'elle traite et s'épanouit naturellement à la scène [http://www.theatredubalcon.org/compagnie/ bats\%20lenfance.html] (31.03.2015)

Remarques : Frapper sec désigne le fait de donner des coups vifs et brutaux, le sujet pouvant être un animé ou un inanimé (ici : des balles), employé parfois aussi comme métaphore d'un bruit. Notons la collocation fort et sec. Sec reste invariable dans la majorité des cas, mais dans le dernier exemple du $\mathrm{CW}$, où il réfère au style d'écriture, il est accordé. Il est modifié par plus. Notons l'emploi de tirer bas.

\section{Fredonner bas}

fredonner tout bas : chantonner très bas

$\pi$ chanter haut

\section{Freiner sec}

Donner un coup de frein brutal

Intransitif

1946 Il se tut un instant et freina sec pour respecter un feu rouge (Boris Vian, J'irai cracher sur vos tombes)

1982 Démarra comme il en avait le secret. Freina aussi sec à la suite d'un cri en provenance de Lola-la-dingue. Derrière, un automobiliste les traita de pédés (Alain Page, Tchao Pantin)

\section{Friser court}

Faire de petites boucles, des boucles courtes Transitif

1765 Si l'on finit la brisure sur le 4, on fait un 4 de cheveux naturels peu frisés, un 3 et un 2 , et on en tresse proportionnément pour faire les devans ; on coud sept à huit petits rangs de courts frisés ; ensuite on a une tresse faite avec de cheveux un peu longs et crêpés forts (Denis Diderot, Encyclopédie)

1922 Au milieu d'elles, pareil à un satyre, dansait en bras de chemise le petit homme à ventre rondelet, avec ses gros mollets et sa barbe court frisée, tel que vous l'eussiez imaginé derrière un comptoir, adonné à des besognes basses

(Henry de Montherlant, Le Songe)

\section{CORPUS WEB :}

Les produits concurrentiels coiffure cheveux frisés court fournis par fournisseurs coiffure cheveux frisés court et fabricants coiffure cheveux frisés court sont énumérés ci-dessous, Veuillez les parcourir et choisir le produit désiré [http://french.alibaba.com/Favorite/coiffurecheveux-fris\%C3\%A9s-court.html] (30.03.2015)

coiffure homme cheveux court frisés est une photo issue l'article : Quelle coiffure pour un homme aux cheveux bouclés ? dans lequel vous allez retrouver également pas moins de 68 photos de coiffure homme et de coupe de cheveux [http:// www.coiffurehomme.info/coupe-cheveuxboucles/coiffure-homme-cheveux-court-frises] (30.03.2015)

Bonsoir, les cheveux court frisés c'est jolie mais également un style à adopter ! Après tu n'as pas de boucles très volumineuses donc les cheveux plus court sa ne fera pas année disco ;) Pour ce qui est de savoir si cela t'ira ou non il vaut mieux aller le Jour J avec plusieurs modèles et demander au coiffeur car il est professionnel et il saurat te conseiller ! [http://www.vinted. fr/forum/conseils-et-astuces-beaute/cheveuxet-ongles/490152-coupes-de-cheveux-frisescourtes] (30.03.2015)

REMARQUES : Frisé court ou court frisé désignent le fait de mettre en boucles fines, serrées des cheveux, une barbe, des poils, etc. courts. On 
peut également lire ces tours comme un raccourcissement économique de courts et frisés. Dans l'emploi actuel, court reste invariable, mais dans l'exemple de 1765 on trouve aussi bien le tour elliptique courts frisés que celui de crêpés forts (crêper fort).

\section{Friser fin}

Friser finement

Transitif

1864 Je ferai observer que pour obtenir un très beau damas frisé fin, il faut que les baguettes, une fois tordues, soient étirées de manière à ce qu'on leur donne une longueur à peu près double de celles qu'elles ont après la torsion, plutôt moins que plus (Ronchard-Siauve, Traité de la fabrication des canons de fusils)

1877 Elle était simplement mise, drapée dans un costume noir brodé et chamarré de jais, tempérant la sévérité de sa tenue par un scintillement de reflets et l'éclat d'un ravissant petit chapeau tout en plumes de lophophores, dont ses cheveux frisés fin sur le front, divisant la nuque en larges ondes, semblaient continuer et adoucir le chatoiement (Alphonse Daudet, Le Nabab)

1982 Tantôt les cheveux frisés fin retombent sur les épaules, tantôt ils sont retenus par un bandeau qui forme coiffe ; parfois un ruban est visible au-dessus du front (Colette et Gilbert Charles-Picard, La Vie quotidienne à Carthage au temps d'Hannibal)

\section{CORPUS WEB :}

Si vous avez donc les cheveux crépus, frisés fins sachez qu'il est mieux de privilégier les laits, leave-in et sprays capillaires. Car ils ont une forte teneur en eau [https://www.nappynko.com/ blog/cheveux-fins-crepus-6-conseils-pour-lesentretenir] (25.11.2020)

\section{Friser menu}

Faire de petites boucles, friser finement Transitif

1886 Ensuite, quand il reparut, le petit-fils bien décolleté dans sa tenue de sortie, elle avait été émerveillée de le trouver si beau : sa barbe noire, qu'un coiffeur lui avait taillée, était en pointe à la mode des marins cette année-là ; les liettes de sa chemise ouverte étaient frisées menu, et son bonnet avait de longs rubans qui flottaient terminés par des ancres d'or (Pierre Loti, Pêcheur d'Islande)

REMARques : Friser menu désigne le fait de mettre en boucles fines, serrées et courtes des poils, ou tout type de fibres, rubans, etc. Menu reste invariable.

\section{Friser serré}

Faire de très petites boucles, très serrées Transitif

1886 Ses moustaches blondes étaient assez courtes, bien que jamais coupées ; elles étaient frisées très serré en deux petits rouleaux symétriques au-dessus de ses lèvres qui avaient des contours fins et exquis (Pierre Loti, Pêcheur d'Islande)

1897 Les bons spécimen de cette race sont très attrayants. Le pelage frisé serré montre avec avantage la forme du corps (CharlesMaurice de Vaux, Notre ami le chien)

1922 Il représente une Muse, le cou et les épaules nus, les cheveux frisés serrés dans un cécryphale et ceints d'une bandelette (Revue de l'art ancien et moderne)

1923 Avec les plus grandes difficultés, le coiffeur anglais de l'hôtel, Marius Calvaire, était en train de le friser si serré qu'on eût dit une calotte d'astrakan (Paul Morand, Fermé la nuit)

\section{CoRpus WeB :}

La technique de Luigi, c'est de gaufrer ou friser serré les cheveux (il y a des fers fins qui font tout ça très bien), puis de les brosser (à la brosse plate) pour faire exploser le volume [http://www.elle.fr/Beaute/Dossiers-beaute/ Cheveux/Cheveux-conseils-de-pro-pour-volumeet-texture-sexy-1467332\#] (30.03.2015)

J'ai maintenant des dreads depuis 7 mois, mais j'ai un problème, dans ma nuque, il y a des « traîtresses » qui décident de s'épanouir ailleurs, en gros, elles se défont systématiquement. J'ai beau essayé plusieurs solutions, (en autre, je les 
ai crêper plusieurs fois ; j’ai essayer la méthode roots ; j'ai essayer de les resserrés au crochet ; j'ai même fait des tresses pour voir si elles allaient s'emmêler) rien ne tient. Pour infos : j'ai des cheveux qui frisent serrés, d'une douzaine de centimètres et les racines aux alentours sont bien séparées. J'hésite toujours à aller voir un dreadeur... [http://forum.dreadfrance.fr/viewtopic. php?t=5346\&p=124023] (30.03.2015)

Les cheveux qui frisent serrés et deviennent tout crépus sont en général des cheveux très secs, qui manquent d'hydratation et de produits nourrissants [http://www.photo-coiffure.com/ articles/que-faire-avec-des-cheveux-crepus] (30.03.2015)

REMARQUES : Friser serré désigne le fait de mettre en boucles fines et très serrées des cheveux, une barbe, des poils, etc. Notons l'emploi intransitif-ergatif du type les cheveux frisent serrés (CW). Serré est modifié par si, très. Dans les deux derniers exemples du CW, tous intransitifs-ergatifs, serré s’accorde avec le sujet. Notons l'emploi de gaufrer serré.

\section{Frotter dur}

I. Frictionner vigoureusement Intransitif

1880 Elles mettent le linge à la lessive, faite d'eau et de cendre bouillie ; puis elles le portent dans un grand baquet où elles le lavent avec de l'eau et du savon; il faut frotter dur, parfois, et même se servir de la brosse et du battoir pour les grosses pièces (Anna Yon, Guide pratique pour un cours de langue française)

2006 Il se lava les cheveux en frottant dur, puis s'adossa au mur carrelé et laissa couler l'eau tiède les yeux fermés, les bras ballants (Fred Vargas, Dans les bois éternels)

Transitif

2016 La baguette devenue blanche, il ficha d'un coup son couteau dans le talus, et se mit à la frotter dur entre ses mains pour la faire briller (Marie Robert Halt, Histoire d'un petit homme)
II. Frapper durement, porter des coups (au

figuré)

Intransitif

1910 Tant qu'on porte le poids des choses, il faut être heureux ou périr ; mais dès qu'on porte, en inquiétude, le poids de soi, tout chemin est rude. Le passé et l'avenir frottent dur sur la route (Alain, Propos)

III. Passer un savon, réprimander

Transitif

1946 J'ai vu le recteur de Lillemer frotter dur un gars qui lui avait crié (Hommes et mondes)

Intransitif

1950 Les pleurs faisaient bien dans le tableau. N'empêche que je lui lavai la tête et je frottai dur. Un peu de dispute ne faisait pas mal non plus (Jean Giono, Les Âmes fortes)

\section{Fuir droit}

I. S’éloigner avec hâte en prenant une ligne droite

Intransitif

+1227 Il s'en fuit a molt grant besoing Droit chi amont, il n'est pas loing, Vous le porrés molt bien ataindre (Roman de Wistasce le Moine [2 $2^{\text {thiers XIII }}{ }^{\mathrm{e}}$, après 1227], 1358)

1389 Lievres fuient en diverses manieres, quar aucunnes fuient tout droit, tant comme pourront tirer, une ou deux lieues, puis fuient et refuient sus elles et demeurent, quant plus ne peuent, et se font prendre, que ja de tout le jour on ne l'aura veüe (Gaston Phébus, Livre de chasse, p. 79, 30)

1848 L'élégance des mâts et des cordages, la légèreté des matelots qui voltigent sur les vergues, les différents aspects dans lesquels se présente le navire, soit qu'il vogue penché par un autan contraire, soit qu'il fuie droit devant un aquilon favorable, font de cette machine savante une des merveilles du génie de l'homme (François de Chateaubriand, Mémoires d'outre-tombe)

1873 Du désert de bitume fuient droit en déroute avec les nappes de brumes échelonnées en bandes affreuses au ciel qui se recourbe, se recule et descend, formé de la 
plus sinistre fumée noire que puisse faire l'océan en deuil, les casques, les roues, les barques, les croupes (Arthur Rimbaud, Illuminations)

1926 Et tout de suite il se rendit compte que quelque chose de nouveau s'était fait. Le taureau fuyait droit devant lui, fourgonnant avec des coups de tête embrouillés, sans relever la tête. Et chaque fois qu'il tapait ainsi il grognait, ridiculement (Henry de Montherlant, Les Bestiaires)

1938 Les bêtes restaient frémissantes, elles écoutaient tourner la chasse. Cela ne durerait plus longtemps. Le mâle déhardé, parfois, prenait un grand parti désespéré, fuyait tout droit en rassemblant ses dernières forces. Mais les chiens le chassaient presque à vue, retournaient avec lui sur son contre par le chemin familier des étangs (Maurice Genevoix, La Dernière Harde)

1983 Il pensait que depuis le moment même où il était arrivé à Miragoâne, il n’attendait plus que d'en repartir. Pour où ? Il ne savait pas vraiment, il guettait quelqu'un, quelque chose qui lui dise où aller, comment laisser loin derrière lui le martèlement de la peur qui lui faisait se boucher les oreilles et fuir droit devant lui dans ses rêves, silhouette désarticulée qu'une ombre traquait (Catherine Hermary-Vieille, L'Épiphanie des dieux)

II. Paraître s'enfoncer dans le lointain par l'effet de la perspective

Intransitif

1941 Si loin et si droit fuyait la ligne du fossé que la vue se fatiguait à la suivre, mais à un endroit, une source qui semblait jaillir entre les arbres et se perdre ensuite sous le chemin que nous foulions, bousculait les eaux stagnantes et s'épandait de l'autre côté du fossé dans le foisonnement des herbes, brillant au soleil de telle sorte qu'elle paraissait devenue elle-même une nappe de lumière vivante (Julien Green, Journal)

1955 Mathias s’avançait au milieu du faisceau des parallèles grises, entre la ligne d'af- fleurement de l'eau et l'arête extérieure du parapet, vers le large - l'arête intérieure du parapet, l'angle formé par la chaussée avec la base de celui-ci, le bord de la paroi sans garde-fou - lignes horizontales et rigides, mais coupées d'embûches, qui fuyaient tout droit vers le quai (Alain RobbeGrillet, Le Voyeur)

1957 Et maintenant, râ râ feu sur la pitié, feu sur l'impuissance et sa charité, feu sur tout ce qui retarde la venue du mal, feu deux fois, et les voilà qui se renversent, tombent, et les chameaux fuient droit vers l'horizon, où un geyser d'oiseaux noirs vient de s'élever dans le ciel inaltéré (Albert Camus, L'Exil et le royaume)

\section{CORPUS WEB :}

Si tu es chargé de face tu fuis sur ton arrière ou face à la charge au choix. Si ton adversaire a bien pensé à orienter sa charge, tu es coincé, tu sors (dura lex sed lex !). A toi de faire attention à bien placer ton Lh... Si tu es chargé de flanc, tu es obligé de faire face à la charge et de fuir droit sur ton arrière. Si tu es chargé de dos, tu te carapates tout droit !!!! [http://artdelaguerre.fr/forum/ viewtopic.php?t=1806\&start=15\&sid=256896a772 e92b27d269db8861a04341] (30.03.2015)

Quand tu fuis, ne jamais fuir en face de lui... zig-zag et décale sur le coté gauche/droit quand tu vois qu'il est à portée de grab, si tu poursuis ta fuite tout droit, il est sûr de t'attraper... (et encore... c'est pas encore gagné, mais ça marche bien mieux que de fuir tout droit...) [http:// canardpc.com/forums/threads/48935-LoLBlitzcrank-grabby-l-ami-des-tout-petits] (30.03.2015)

L'ours a d'abord assommé le bélier avant de le mordre au niveau du sternum, le haut du ventre de la pauvre bête a été ouvert sur plusieurs centimètres ; une plaie béante a été constatée sur l'animal qui était toujours vivant après le passage de l'ours. Quant aux brebis, elles ont fui droit devant elles, explosant littéralement la clôture que l'on a retrouvée cinquante mètres plus loin selon le témoignage de l'éleveur [http://www.ladepeche. fr/article/2007/05/02/8351-ariege-1-ours-attaqueau-hameau-d-olbier.html] (30.03.2015) 
REMARQUES : Fuir droit (I) réfère au fait de s'éloigner en toute hâte, de partir en suivant une ligne bien droite, sans bifurquer, le sujet étant un animé. Dans le domaine de l'art (II), le sujet désigne une ligne, un plan de l'espace et signifie 's'enfoncer, s'éloigner par un effet de perspective'. Droit reste invariable et est modifié par si, tout. Notons l'usage de se carapater droit dans le CW.

\section{Fuir lent}

Fuir lentement, avec lenteur

Intransitif

+1175 Governal s'acoste a un arbre,

Enbuschiez est, celui atent

Qui trop vient tost et fuira lent.

Nus retorner ne puet fortune :

Ne se gaitoit de la rancune

Que il avoit a Tristran fait

(Béroul, Tristan [4 ${ }^{\mathrm{e}}$ quart XII $\mathrm{e}$ ], 1696)

Remarques : Fuir lent désignait le fait de s'éloigner, de prendre la fuite lentement, sans hâte.

\section{Fumer bleu}

Produire une fumée bleue

Intransitif

1888 L'encensoir pendu à la torsade du plafond fumait bleu (La Revue indépendante de littérature et d'art)

1904 une maisonnette de chaume, qui fume bleu tranquillement, et semble un gros nid de terre et de mousse, posé dans les branches au bord d'un clos (La Revue hebdomadaire).

1911 Il tenait vaguement ses yeux fixés là-bas, par-dessus le ravin, sur la ligne des toits du village, à moitié aperçue dans l'encadrement des branches pendantes, - rien qu'une ligne là, avec les cheminées qui fumaient bleu parmi le ciel, - et par derrière il n'y avait que le trou du lac plein de flammes et d'une cendre de soleil (Charles-Ferdinand Ramuz, Aimé Pache, peintre vaudois)

1962 - Vive le Négus, vive les troupes du Négus, criait-il. Quand c'est noir et que ça fume bleu, c'est que c'est cuit!
Le chef lui allongea un coup de pied au derrière.

- Tu peux te marrer, dit-il

(Bernard Clavel, La Maison des autres)

\section{CORPuS Web :}

Comment réparer cette panne après avoir fait changé la courroie de distribution par mon garagiste. Depuis j'accumule les pannes, ma voiture consomme plus de carburant, elle fume bleu, des vibrations quand elle roule, des ratés à l'accélération ? [http://auto.linternaute.com/ forum/affich-36446-pourquoi-ma-voiture-fumebleu] (25.03.2015)

Ma voiture fume bleu et sens mauvaise [http://www.forum-auto.com/marques/Peugeot/ sujet38694.htm] (25.03.2015)

j ai un sprinter 208d et depuis quelques jours il fume bleue avec une sale odeur d huile brûlée, a la sortie $d$ un cylindre le collecteur d échappement est plein d huile. Quand pensez vous ? [http://mercedes-benz.forumactif.com/t66159sprinter-208d-qui-fume-bleue] (25.03.2015)

Depuis hier apres midi elle fume bleue de maniere importante. C'est arriver soudainement quand je rentrai, je me suis apercu a un feux qu'elle fumait beaucoup [http://forum.321auto. com/topic-2680331-tourne-mal-et-fume-bleuepage-1.html] (25.03.2015)

REMARQUES : Fumer bleu désigne le fait de dégager de la fumée de couleur bleue, bleuâtre, le sujet référant à quelque chose en combustion ou de très chaud, surtout en rapport avec une voiture. Bleu reste invariable dans la majorité des cas, mais il s'accorde avec le sujet au féminin dans le dernier exemple du CW (aussi dans l'avant dernier exemple, mais il s'agit d'une simple erreur). Dans le deuxième exemple, il reste invariable malgré le sujet au féminin, tandis que l'autre adjectifadverbe (mauvais) s'accorde avec le sujet. Dans l'exemple de 1904, fumer bleu est modifié dans son ensemble par tranquillement ; fumer bleu est donc traité comme un verbe complexe.

\section{Fumer noir}

Produire une fumée noire

Intransitif

1902 mais la carburation qui est riche, alors qu'elle pourrait l'être moins, entraîne une 
dépense plus grande d'essence ; au-delà de 9 millimètres le moteur s'alourdit, fume noir et s'arrête si le niveau continue à monter (Office national de la propriété industrielle, Brevet d'invention)

1905 Ce n'est pas le même cocher que d'habitude. Je n'ai pas vu les chevaux, mais ils sentent bien mauvais et fument noir. Arrivera-t-on bientôt, ô toi qui rêves silencieuse et ne me regardes pas? (Colette, Sept dialogues de bêtes)

1911 Et c'était tout le temps une chose nouvelle, devant quoi ils étaient obligés de se taire, jusqu'aux hautes maisons parues entre les branches, et les cheminées fumant noir dans l'air (Charles-Ferdinand Ramuz, Aimé Pache, peintre vaudois)

\section{CORPuS Web :}

bonjour a tous mon $\mathrm{x} 5$ que je viens d acheté fume bien noir quand je pousse les rapport en position sport sa peu venir de quoi merci a vous tous [http://www.apreslachat.com/forum/BMW/ X5/Fumer-noir/760330/43] (25.03.2015)
Après alerte de l'ordinateure de bord qu'il fallait diminuer le volume d'huile en éxcés (presque un litre) ce qui est fait, mais depuis lors elle n'a pas cesser de fumer noire surtout quand le moteur est chaud [http://www.forum-mercedes. com/topic-1926-fumee-noire-apres-acceleration220-cdi-w203006-annee-2000.html] (25.03.2015)

La durite que vous voyez..ete couper en haut. Je pense que c'est peut etre ca mon probleme.. que la baniole fumer noire [http://www. forum307.com/viewtopic.php?t=32859\&sid=b0d d167580ab7d8d2e56282851926891] (25.03.2015)

REMARQUES : Dire que quelque chose fume noir s'emploie par métonymie pour signaler la fumée de couleur noire, noirâtre, le sujet référant au moteur ou à la voiture qui dégagent cette fumée. L'exemple de 1905 compare la fumée qui sort de la locomotive à vapeur à la vapeur, noire en l'occurrence, qui sort des naseaux des chevaux. Notons la collocation sentir mauvais et fumer noir. Noir reste invariable dans la majorité des cas, mais l'accord est fait dans le deuxième et le troisième exemple du CW, où il s'accorde avec le sujet féminin. 


\section{Gâcher clair}

Délayer (du plâtre) avec beaucoup d'eau

ત gâcher serré

\section{Gâcher lâche}

Délayer (du plâtre) avec beaucoup d'eau

入 gâcher serré

\section{Gâcher nourrissant}

Délayer (du plâtre) avec très peu d'eau

入 gâcher serré

\section{Gâcher profitant}

Délayer (du plâtre) avec très peu d'eau

入 gâcher serré

\section{Gâcher serré}

Délayer (du plâtre, du mortier) avec peu d'eau pour qu'il soit épais et consistant

Transitif

1915 Maçon, n'est-ce pas, il aimait que ce fût gâché serré, nourrissant, profitant. On pouvait l'admirer (René Benjamin, Gaspard)

1934 Le gâchage du plâtre se fait avec un volume d'eau égal au sien. Il est ainsi gâché serré et prend vite ; avec plus d'eau il est gâché clair et prend lentement (Quillet, Encyclopédie Quillet / Grundt : 333)

1935 la poudre obtenue est gâchée très serrée, à consistance de mastic (Arts et littérature dans la société contemporaine)

CORPUS WEB :

On gâche "serré" en augmentant la quantité de poudre par rapport à l'eau afin d'obtenir rapidement un plâtre consistant et thixotrope. On gâche “clair" en mettant un peu moins de poudre dans cette même quantité d'eau, ceci pour le couler ou pour faire des réparations sur un plâtre sec (bien le mouiller au préalable) [http://www. pascalrosier.com/conseil/produits/platre.htm] (15.5.2015)

Détremper du plâtre dans une auge avec de l'eau pour remployer sur le champ - On distingue la manière de gâcher, serré et lâche : Gâcher serré - Mettre du plâtre dans l'eau jusqu'à ce que toute l'eau soit bue : ce plâtre prend plus vite ; Gâcher lâche - Mettre peu de plâtre dans l'eau, en sorte qu'il soit totalement noyé [http://fr.wikipedia. org/wiki/Lexique_du_pl\%C3\%A2tre] (15.5.2015)

C'est pourquoi je conseillerai plutôt le plâtre, avec les précautions suivantes :

- ne pas gâcher trop serré, respecter un temps de repos avant la pose (ce qui oblige à gâcher une consistance genre crème dessert, ou béchamel un peu liquide, car ça épaissit à la prise) [http://www.cyberbricoleur.com/index. php?showtopic $=2100117004]$ (15.5.2015)

\section{Shakira est enceinte}

Encore?

Qui est le père?

Ce n'est pas Edika il gâche clair, il a eu les oreillons a 15 ans [https://groups.google.com/ forum/\#!topic/fr.rec.sport.football/5QmToqtd_ dc] (15.5.2015)

En plus il a pas voulu se soumettre aux prélèvements biologiques ( $\mathrm{ADN}$ et empreintes)... Bah oui, on ne sait jamais... Des fois que sur la barre, on s'était aperçu qu'il gâche clair ... Il y met pas de la bonne volonté le nanar ! [http://www. astrosurf.com/ubb/Forum11/HTML/000519-4. html] (15.5.2015)

REMARQUES : Gâcher serré se dit du fait de délayer (du plâtre, du ciment, du mortier) avec de l'eau, en faisant en sorte de ne donner au plâtre que ce qu'il faut d'eau pour en faire une pâte épaisse. Gâcher serré s'oppose ainsi à gâcher lâche ou clair qui désignent le fait de combiner une substance compacte ou en poudre (plâtre, ciment, mortier) avec peu (serré) ou beaucoup (lâche, clair) de liquide. Lâche est le contraire de serré, tandis que clair renvoie en plus à un changement de la couleur. Dans les deux derniers exemples $\mathrm{du}$ CW, le verbe figure dans le sens probable de 'être stérile'. Serré et clair restent invariables, sauf dans l'exemple de 1935, et peuvent être modifiés par très. Les collocations du verbe gâcher mettent en évidence le lien des adjectifs-adverbes avec les argots de métier.

\section{Gaffer sévère}

Fouiller du regard, être très attentif, être aux aguets

Intransitif

1995 N'empêche les valets, les femmes de chambre, les chauffeurs de maître, ils 
gaffent sévère, ils savent petit à petit tout sur leurs patrons (Alphonse Boudard, Mourir d'enfance)

REMARQUES : Gaffer sévère s'emploie par rapport au fait de scruter intensément. Sévère est donc un intensifieur qui laisse transparaître son sémantisme primitif. La combinaison "verbe + sévère " constitue une série ouverte dont nous ne citons que quelques variantes dans ce dictionnaire.

\section{Gagner dur}

Gagner beaucoup d'argent

Transitif

1957 Oui, ça, je gagne dur là-dessus (Exemple entendu, 11 juillet 1957 / Grundt : 244)

\section{CORPus WeB :}

et ben alors bouffez la merde des hypers et foutez la paix aux maraîchers qui doivent se la gagner dur pour les faire pousser les salades !!! [http://www.larepubliquedespyrenees.fr/2013/ 01/04/les-forains-reviennent-place-margueritelaborde,1112061.php] (15.5.2015)

Tot dans la matinée? C'est le parfait exemple de la france qui se lève tot pour gagner dur sa vie ! [http://www.forum-bussy.fr/viewtopic. php?f=3\&t=1009\&start=0] (15.5.2015)

Mais je te comprends quand on gagne dure sa vie ça fait toujours un peu mal au moment où il faut faire le chèque... [http://forum.doctissimo.fr/ famille/argent-budget-famille/classe-moyennesujet_1889_2.htm] (15.5.2015)

REMARQUES : Gagner dur désigne le fait de s'assurer un profit matériel considérable. Dans le CW, dur fonctionne comme adverbe de manière et réfère aux difficultés que quelqu'un doit surmonter pour gagner sa vie. Dur reste invariable dans la majorité des cas, mais il s'accorde avec l'objet au féminin dans le dernier exemple du CW, tout en conservant sa fonction adverbiale.

\section{Gagner gavé}

Gagner beaucoup d'argent

Intransitif

\section{CORPuS Web :}

de l'argent, j'en ai gagné gavé [http://www. topito.com/top-expressions-connaitre-passerinapercu-sud-ouest] [https://forum.word reference.com/threads/gav\%c3\%a9-gav\%c3

\%a9-gav\%c3\%a9.1549648] (4.1.2019).

REMARQues : Gavé est un quantifieur en usage régional, ici du Sud-Ouest. VoIR AUSSI : aimer gavé

\section{Gagner gros}

Faire de gros bénéfices

Intransitif

1678 J'ai vu dans le Palais une robe mal mise Gagner gros : les gens l'avaient prise Pour maître tel, qui traînait après soi Force écoutants ; demandez-moi pourquoi (Jean de La Fontaine, Les Devineresses / Fables)

1780 Ils assurent qu'ils prendraient à prix fait de nous nourrir à un écu, et y gagneraient gros, et que nous ne pouvons coûter 40 sols, traités comme nous sommes (Honoré de Mirabeau, Lettres originales écrites du donjon de Vincennes)

1830 Tu sais l'arithmétique mieux que moi, tu tiendras mes comptes. Je gagne gros dans mon commerce (Stendhal, Le Rouge et le noir)

1882 Je connais vos affaires, vous gagnez gros comme vous, et vous rouleriez sur l'or, si vous ne le jetiez pas par les fenêtres... moi, je ne vous demande rien (Émile Zola, PotBouille)

1912 Les gens habiles qui, comme Jean Blaise, gagnaient gros dans la misère publique, allaient chez le traiteur où ils montraient leur esprit en s'empiffrant (Anatole France, Les Dieux ont soif)

1947 Malgré le Panama, les Mercadier étaient des gens qui avaient encore, somme toute, leurs aises. Non point que l'on gagnât gros à être professeur, mais il leur restait des valeurs de portefeuille, des intérêts dans les chemins de fer, qui leur venaient de l'industrie d'un oncle Mercadier sous le Second Empire (Louis Aragon, Les Voyageurs de l'impériale)

1987 On allait gagner gros en vendant ça sur le wharf, ou rue du Commerce, genre « arti- 
sanat touristique ». Ouehh ! D’ac (Bruno Bayon, Le Lycéen)

\section{CoRpus Web :}

Parier sur un match aussi indécis que FC Barcelone-Bayern Munich n'est pas évident. Mais il y a moyen de gagner gros. Telefoot.fr a fait le choix de miser sur des buts et une victoire du Barça au Camp Nou [http://www.tf1.fr/telefoot/ news-football/fc-barcelone-bayern-munichcomment-gagner-gros-sur-ce-match-8605104. html] (15.5.2015)

Si vous jouez dans un casino en dur et que votre machine à sous vous fait gagner gros, il se peut que vous ayez besoin d'un membre du personnel pour libérer l'argent pour vous [http:// fr.casinotop10.net/conseils-de-machines-a-sous. shtml] (15.5.2015)

Benjamin accroche-toi, lâche pas l'affaire ! C'est la course de ta vie et tu vas la gagner gros ! [https://bjschots.wordpress.com/blog-officiel] (15.5.2015)

REMARQUES : Gagner gros désigne le fait de s'assurer un profit matériel considérable, d'encaisser de grosses sommes d'argent. Gros reste invariable (malgré l'objet au féminin dans le dernier exemple du CW). Notons l'emploi transitif du verbe dans le dernier exemple du CW.

\section{Gagner lourd}

Gagner beaucoup d'argent

Intransitif

1852 NOÉMIE. Je ne sais... toujours est-il, que ma pauvre mère travailla pour elle et son enfant... et dame ! on ne gagne pas lourd avec une aiguille, monsieur Morisset (Lambert Thiboust et [Alfred] Delacour, Les Souvenirs de jeunesse)

1950 Si j'en juge par ton intérieur, tu ne dois pas gagner lourd (Hervé Bazin, La Mort du petit cheval)

\section{Gagner petit}

Gagner peu

Intransitif

CoRpus WeB :

Je crois que c'est un phénomène sociétal typique à 2 versants : celui-ci et celui des « beaufs » des petits commerçants et artisans, des classes moyennes bref des gens qui gagnent petit et qui pensent creux ! [http://www.insolent. $\mathrm{fr} / 2014 / 11 /$ scandaleuses-gesticulations-autourdu-budget.html] (11.9.2015)

REMARQUES : Gagner petit signifie 'gagner peu'. La fonction de petit comme quantifieur équivalant à peu était caractéristique de l'ancien français. Il disparaît par la suite des textes écrits réunis dans Frantext. L'exemple met en évidence la survie de cette fonction dans la langue familière, grâce à l'existence en français moderne du nom gagne-petit. Contrairement à l'hypothèse d'Henri Frei sur le rôle du français populaire comme anticipation du futur standard (« français avancé »), les adjectifs-adverbes mettent souvent en évidence son rôle conservateur (ce qui n'empêche évidemment pas les innovations).

\section{Galoper ferme}

Aller très vite, rapidement

Intransitif

1882 - Est-ce que vous ne croyez pas le moment venu de nous mettre en marche? Il y a au moins une heure que ces messieurs sont partis avec leurs papiers, et s'ils ont été à une bonne allure, il va falloir galoper ferme pour les rejoindre (Georges Ohnet, Le Maître de forges)

\section{Corpus Web :}

Attention toutefois de bien surveiller l'heure car on doit penser tout seul à sortir le soir : pas de rameutage intempestif des retardataires par haut-parleur ! Et comme le parc est très grand, il faut galoper ferme si l'on s'y prend à la dernière minute !! [http://lepetitrenaudon.blogspot. co.at/2012/07/une-journee-chaumont-surloire_6.html] (15.5.2015)

Sans cette stabilité, les conséquences de cette course effrénée pourrait être terribles. Une fois qu'il a le contrôle assuré de sa monture (qui sont souvent des forces en opposition), c'est le temps de galoper ferme [http://letarotaubleulag oon.blogspot.co.at/2011_05_01_archive.html] (15.5.2015)

Il y a environ 2 ans, Rominou (le dernier chat errant recueilli) qui ne venait alors qu'irrégulièrement, se mettait sous le chauffage du hall (rezde-chaussée) et ne supportait pas que l'on touche 
à son arrière-train ; il avait probablement mal ; et maintenant, il galope ferme [http://domino.overblog.net/m/article-99652753-10.html] (15.5.2015)

REMARQUES : Galoper ferme désigne le fait d'aller au galop, et, par extension, courir rapidement, aller vite, se hâter, marcher à toute allure.

\section{Ganter juste}

Être avare

$\lambda$ ganter long

\section{Ganter large}

Être généreux

$\pi$ ganter long

\section{Ganter long}

Mettre de longs gants

Transitif

1877 Après Mme Jenkins, c'est le Nabab qui se précipite, et prenant entre ses grosses pattes les deux mains long et finement gantées de l'artiste, exprime sa reconnaissance avec une cordialité qui lui met à luimême des larmes dans les yeux (Alphonse Daudet, Le Nabab)

Remarques : Ganter long désigne le fait de couvrir ses mains ou ses bras de longs gants, d'enfiler et de porter de longs gants. Long reste invariable. Notons la coordination long et finement qui souligne la fonction adverbiale de long. Remarquons que la variante *longue et finement gantées n'est pas une option pour l'auteur, sans doute en raison de la lexicalisation de long(-) ganté. Le Dictionnaire du jargon parisien de Lucien Rigaud (1878) mentionne : «Ganter juste 'être avare', ganter large 'être généreux', dans le jargon des demoiselles entretenues ».

\section{Ganter serré}

Porter un gant (des gants) serré(s), moulant(s), trop petit(s)

Transitif

1885 Des gants de Suède le gantaient trop serré (Malot, Le Sang bleu)

REMARQUES : Ganter serré réfère au fait d'enfiler de gants qui collent à la main. Serré reste invariable.

\section{Garder destroit}

Surveiller, protéger étroitement

Transitif

1230 Male Bouche, que Deus maudie,

Ot soudeiers de Normandie :

Cil garde la porte detrois ;

E si sachiez qu'as autres trois

Vait il e vient quant il li siet,

Qu'il doit la nuit fere le guiet

(Guillaume de Lorris, Roman de la rose, 3891)

RemaRques : Garder destroit désignait le fait de protéger, de défendre, de préserver quelque chose étroitement, avec rigueur.

\section{Garder droit}

I. Regarder droit

Intransitif

$\sim 1130$ E quant li oiselet

Sunt el ni petitet,

Entre ses piez les prent,

Porte les belement

Al soleil, quant est cler,

Si lur fait esguarder.

E celui qu'il verat

Ki plus dreit guarderat,

Cel tient de sun lignage,

Guarde le, mult est sage

(Philippe de Thaon, Bestiaire [trad., probablement entre 1121 et 1135], 2034)

II. Tenir verticalement

Transitif

1903 Ceux d'en haut seuls, protégés par l'amas des granits, par l'entassement des substructions de tous les âges, ont gardé droites leurs pointes rouges ou leurs pointes d'or qui montent dans le ciel, chacune accompagnée de son tourbillon d'oiseaux noirs (Pierre Loti, L'Inde (sans les Anglais))

1936 Elle renversa un peu la tête, et appuya sa main au banc, le bras raidi pour garder le buste droit (Roger Martin du Gard, Les Thibault. L'Été 1914)

1937 Gardet aidait Mireaux à ramener sur son corps ses membres écartelés, et à se dresser sur les genoux. Lorsqu'il s'inclinait, son visage brûlait, et il tentait d'aider 
Mireaux en gardant la tête droite (André Malraux, L'Espoir)

1948 Quand ils sont passés devant moi, roulant leurs hanches et gardant bien droites leurs épaules, je voyais déjà à leurs omoplates la bosse des muscles, couvrant les racines de leurs ailes (Jean Genet, Notre-Damedes-fleurs)

CORPuS Web :

Bonjour je travail actuellement un jeune cheval et j'ai du mal à le garder droit dans les lignes. il zizgague meme en l'encadrant avec mes jambes, des conseils svp, merci [http://www. chevalannonce.com/forums-8167296-le-garderdroit] (19.5.2015)

pas moyen de la faire marcher droit, j'aime balader à mon aise rènes longues mais c'est quasi impossible avec elle, et même en tenant les rènes plus courtes pour essayer de l'encadrer, c'est difficile. Ce n'est rien de grave, mais c'est agaçant car c'est une attention de tout instant pour la garder « droit » [http://www.1cheval.com/ membre/forum/general/sujet-2326370-0-chevalqui-zigzag-sans-cesse-en-balade] (19.5.2015)

Question de jeunes padawan.... comment stocker ses clearos ? Je m'explique, j'utilise un mini Nautilus et je viens de recevoir un subtank Nano. Je pense garder le Nautilus pour la semaine et me servir du Nano en soirée... ${ }^{\star}$ Mais voilà, comment stocker le Nano ? Vaut il mieux le vider avant de le ranger, ou pour la résistance vaut il mieux garder un fond de juice et le garder droit pour éviter les fuites ?? [http://www. forum-ecigarette.com/les-clearomiseurs-f1322/ stockage-des-clearomiseurs-t172176.html] (19.5.2015)

Gardez les épaules alignées avec la planche pour la garder droite et pour qu'elle ne tourne pas. Il s'agit d'un problème familier pour les novices qui essayent d'apprendre à faire un kickflip [http://www.sk8france.fr/trick-tips/apprendrele-kickflip] (19.5.2015)

REMARQUES : En ancien français, garder droit pouvait s'employer au sens de 'regarder correctement' (I). Dans l'usage moderne, garder droit se dit généralement d'une partie du corps qu'on tient, maintient verticalement, bien droite. Droit est alors un prédicat second qui s'accorde avec le nom désignant l'objet tenu droit, et ceci notamment dans le style littéraire. Dans le domaine de l'hippisme, garder droit réfère au contrôle du cheval censé suivre une direction rectiligne, ce que l'on obtient si on arrive à tenir droit le cheval lui-même. L'emploi dans le CW est donc ambigu par rapport aux fonctions adverbiale ou adjectivale (prédication seconde). Il peut logiquement adopter les formes variée (dernier exemple du CW) et invariée (second exemple du CW). Droit est modifié par bien, plus. Notons l'emploi de marcher droit.

\section{Garnir bel}

Garnir joliment, avec de belles choses Transitif

$\sim 1235$ Leur nes au port retorner firent, Bel et richement les garnirent.

A l'apostole ont congié pris Comme courtois et bien apris (Philippe de Remi, sire de Beaumanoir, $L a$ Manekine, 7850)

REMARQUES : Garnir bel désignait le fait d'orner, de décorer joliment, précieusement, d'embellir quelque chose (ici : un navire). Beau adopte sa forme neutre bel. Il est coordonné avec richement.

\section{Gaufrer serré}

Imprimer des ondulations très rapprochés dans les cheveux, généralement avec un fer à gaufrer $\pi$ friser serré

\section{Geler blanc}

Faire un gel blanc

Intransitif

1861 une sorte de brouillard, pareil à celui qui s'élève à la première aube des prés où il a gelé blanc (Edmond et Jules de Goncourt, Soeur Philomène)

2003 L'hiver il gelait blanc au bord de la Bièvre (Marie-Hélène Lafon, Sur la photo)

\section{Geler dru}

Geler fortement

Intransitif

1987 M'auraient jeté comme un rat borgne, tu parles, les morbaques... Et jouissifs encore, de me vouer tout naze au macadam frigo des rues et des bancs publics! 
Va geler dru, cette nuit, pas pour se marrer. Et ça leur déplaît pas aux clodos de la Péniche (Jean-Louis Degaudenzi, Zone)

\section{CORPUS WEB :}

Demain je pense qu'on va rester sagement à la maison car à mon avis ça va geler dru ! La neige dans le sud c'est joli mais je vous le dis c'est la CATA !!! [http://chezmimounette.canalblog.com/ archives/2009/01/07/12003981.html] (19.5.2015)

Heureusement que c'est Brest car du coté de Camors et Baud ça gèle dru [http://www. aidecampingcar.com/forum1/viewtopic.php? $\mathrm{p}=$ 566816] (19.5.2015)

Bref, tout ça pour dire que la vie est belle ici... même si on se gèle dru ! [http:// lepetithoursoislibere.blogspot.co.at/2010/01/ phl2.html] (19.5.2015)

Je veux bien qu'on interdise la clope (et le cigare) dans les restaurants (si je ne m'abuse, cette normative interdit les " zones fumeurs »), mais les interdire egalement dans les bistrots a deux balles en contraignant les (bons) clients fumeurs a se les geler dru sur le trottoir avant de choper une broncho-pneumonie me semble aussi debile que puritain et hypocrite (comme tu l'as deja dit) [http://www.rationalisme.org/forum atheisme/viewtopic.php?f=76\&t=442] (19.5.2015)

REMARQUES : Dans un contexte météorologique, geler dru désigne le fait de geler fortement, d'atteindre des températures très basses, au-dessous de $0^{\circ}$. L'emploi impersonnel va de pair avec le style familier, d'autant plus que ça est préféré à il (v. il gèle ferme). Dru reste invariable (v. le dernier exemple du CW). Notons l'emploi pronominal et transitif du verbe dans le CW, et la locution se les geler dru.

\section{Geler dur}

Geler fortement

Intransitif

1867 - Ça gèle dur ! père Michel, ça gèle dur... et il fait joliment bon à vous apporter des soupières chaudes!

(André Bragiel, La Servante du curé)

1880 Il gelait dur, cet hiver-là, et, malgré les panerées de charbon englouties dans la grille, nous voyions, par ces veilles laborieuses indéfiniment prolongées, le givre dessiner sur la vitre un voile aux fantastiques arabesques (Alphonse Daudet, Le Petit Chose)

1965 Juste avant la neige et l'entrée de l'hiver, la saison donne brusquement quelques jours d'une limpidité extraordinaire. Ils sont précédés d'une semaine dont les nuits gèlent très dur (Jean Giono, Deux Cavaliers de l'orage)

\section{Geler ferme}

Geler fortement

Intransitif

1885 Chacun de nous garde le sien sous ses pieds pour avoir chaud. Et nous voilà partis, secoués abominablement. Il gelait, il gelait ferme. Nous étions contents. Vers cinq heures nous arrivions (Guy de Maupassant, Contes et nouvelles)

1945 - Ça serait dommage nemme donc ? de m'en aller avec tout mon savoir !

- Pour sûr ! Emballez-vous bien, père Pounatte. Je cois qu'y va geler ferme entre nous deux la nuit-ci... Brrr...!!! (George Chepfer, Saynètes, paysanneries 2)

\section{CoRpus WeB :}

Demain, il devrait geler ferme toute la journée. C'est l'attente sur le quai qui sera pénible [http://ancion.hautetfort.com/archive/2015/02/ index.html] (19.5.2015)

Il suffit juste de remplir une cruche de lait de 4 litres (1 gallon) à moitié de votre bière/vin, la laisser geler ferme dans le congélateur, puis prendre un récipent à large embouchure d'un litre (1 quart), et de placer la cruche de lait à l'envers sur cette embouchure [http://www.fairesagnole. eu/homedistiller_fr/notstill.htm] (19.5.2015)

Mme GUIGOU, les sanctions contre la Russie vont faire mal à qui ? Toujours aux mêmes, c'est à dire les européens pauvres qui vont se les geler ferme, lorsque Poutine aura décidé de ne plus envoyerson gazàl'Europe [http://www.rtl.fr/actu/ international/ukraine-les-sanctions-peuventfaire-tres-mal-a-la-russie-selon-elisabethguigou-7770217281] (19.5.2015)

Les sabords ? Tu veux parler des fenêtres sur les flancs ! En principe ils étaient fermés parce que l'équipage devait se les geler ferme 
[http://fighters.forumactif.com/t57651p45-b-24d-screamin-mimi-carpetbaggers-1-48] (19.5.2015)

REMARQUES : Dans un contexte météorologique, geler ferme désigne le fait de geler fortement, d'atteindre des températures très basses, au-dessous de $0^{\circ}$. Ferme reste invariable (v. le deuxième, le troisième et le quatrième exemple du $\mathrm{CW}$, où le verbe apparaît dans son emploi transitif, sans que l'adjectif-adverbe s'accorde avec l'objet au féminin ou pluriel). Dans le second exemple du $\mathrm{CW}$, geler ferme désigne le fait de congeler un produit. Notons la locution lexicalisée se les geler ferme.

Gémir aigu

Gémir en poussant des cris aigus

入 gémir bas

\section{Gémir bas}

Gémir à voix basse, secrètement

Intransitif

1748 La pieuse veuve se fit une postérité nombreuse ; mais lorsque le scandale dont on avait gémi tout bas eut éclaté et que le conseil des discrètes, assemblé, eut appelé le médecin de la maison, je méditai ma retraite (Denis Diderot, Les Bijoux indiscrets)

1849 Nous ne murmurions pas, de peur de nous confondre avec les partisans de l'empire ; mais nous gémissions tout bas et nous remontions ou nous descendions les siècles pour y retrouver des gouvernements dignes de l'humanité (Alphonse de Lamartine, Les Confidences)

1905 Qu'il essaie, la gorge enrouée, de gémir bas, puis aigu, que sa face disgraciée, son corps pelé, taché de travers, se disloquent en une ataxie mensongère (ils sont encore à ces vieux moyens !) (Colette, Sept dialogues de bêtes)

1931 On se roulait lentement ; on gémissait bas, comme lui, en griffant l'herbe à petits coups (Maurice Genevoix, Rroû)

1980 Sur les joues de Lalla, les gouttes roulent un peu, comme des larmes. La jeune femme se réveille et gémit tout bas. Elle n'ouvre pas encore les yeux, mais sa plainte monte, se mêle au bruit ininterrompu de la mer, qui vient à nouveau dans ses oreilles (Jean-Marie Gustave Le Clézio, Désert)

\section{CORPUS WEB :}

J'ai couché avec une autre qui faisait que gémir très bas [http://www.jeuxvideo.com/ forums/1-50-67508925-1-0-1-0-qui-a-deja-reussia-faire-crie-une-fille.htm] (19.5.2015)

Elle se mit à gémir très bas, d'un son rauque qui venait du plus profond de sa gorge. Je me sentais de plus en plus excité [http://evelyneraconte.skyrock.com/2751944372-CHAPITRE42-PAS-POUR-LES-MOINS-DE-15-ANS.html] (19.5.2015)

Puis - elle se souleva vers lui et commença à gémir très bas, tandis que ses deux mains se rabattaient définitivement sur le dos maintenant rigide d'Édouard [http://flofloshome.blogspot. co.at/2009/05/lu_08.html] (19.5.2015)

REMARQUeS : Gémir bas se dit du fait de pousser, voire murmurer des cris étouffés ou plaintifs qui peuvent être l'expression d'un malaise, d'une douleur physique, voire du plaisir sexuel. Bas reste invariable et est modifié par tout, très. Notons l'emploi de gémir aigu.

\section{Gémir fort}

I. Exprimer sa peine fortement, avec violence Intransitif

1393 Ce fait, Raimondin fiert le porc tellement qu'il le mist à terre tout mort, et puys vint au conte et le cuida soubslever ; ce fut pour neant, car il estoit jà tout mort. Adoncques quant Raimondin apperceut la plaie et le sang en saillir, il fut moult merveilleusement couroucé, et commenca à crier en plourant et gemissant moult fort et le regarder et plaindre, en faisant le plus grans lamentations que oncques vit homme jour de vie (Jean d'Arras, Melusine, p. 34 [éd. Genève])

II. Émettre un son assourdi semblable au gémissement humain

Intransitif

1882 Les jeunes filles étaient toujours là assises, avec leurs couronnes de gardénias qui répandaient leur parfum du soir ; tous 
étaient immobiles, la tête tournée vers la forêt, groupés, comme pour s'unir contre l'obscurité envahissante, contre la solitude et le voisinage des bois. Le vent gémissait plus fort, il faisait froid et il faisait nuit... (Pierre Loti, Le Mariage de Loti)

\section{CORPUS WEB :}

Mais dites moi, je me suis imaginer gemir fort avec mon copain, mais je sens que $\mathrm{j}$ aurai de la gene, parce que lui serai silencieux, a part sa respiration forte, et on entendrais que moi ! [http:// forum.doctissimo.fr/doctissimo/orgasme/ question-exprime-bruyamment-sujet_145595_1. htm] (19.5.2015)

Ouais pareil, je crie pas comme une folle, mais je peux gémir fort $\mathrm{xD}$ mais je me retiens vu que chez lui c'est suuuuper mal insonorisé (pas du tout en fait) [http://forum.cosmopolitan. $\mathrm{fr} /$ cosmo/rencontre-celibataire-mec-couple/ pendant-amour-aussi-sujet_453_1.htm] (19.5.2015)

J'entends mon amant gémir fort. Il me relève la tête et me saisit le cou de sa main, m'attire vers lui pour me rouler une pelle [http://revebebe.free. fr/histoires/rvb164/reve16498.html] (19.5.2015)

Remarques : Gémir fort (I) se dit du fait de pousser des cris étouffés et plaintifs à voix haute, de manière à être entendu, qui peuvent être l'expression d'un malaise ou d'une douleur physique, mais aussi d'une grande douleur ou d'un mécontentement fort. En (II), le sujet désigne une chose, un phénomène naturel (le vent) qui émet un son continu ou discontinu, assourdi et rappelant une plainte humaine. Le $\mathrm{CW}$ illustre son usage dans le domaine sexuel. Fort reste invariable et est modifié par moult, plus. Notons l'emploi de pleurer fort.

\section{Gémir haut}

Exprimer quelque chose de manière intense, d'une voix forte et plaintive

Intransitif

1754 FLORANCE. Oh ! J'en suis assuré ; car bien que la Comtesse

de suivre son exemple elle-même me presse,

Comptez qu'au fond du cœur sa gloire gémira,
Et peut-être si haut qu'elle me vengera.

Quel triomphe pour lors ce fera pour la mienne!

(Philippe Destouches, Le Mari confident)

1780 et je sens tout ce qu'elle souffre dans ces mêmes momens d'attente et de tourment où je gémis plus haut, mais non pas plus amèrement (Honoré de Mirabeau, Lettres originales écrites du donjon de Vincennes)

1830 Quelle ne fut pas sa joie d'y trouver il signor Geronimo, le célèbre chanteur. Établi dans un fauteuil qu'il avait fait apporter près du feu, le Napolitain gémissait tout haut et parlait plus, à lui tout seul, que les vingt paysans allemands qui l'entouraient ébahis (Stendhal, Le Rouge et le noir)

1900 La pauvre Marie Belhomme reste plantée, toute pâle, devant la méchante feuille, qu'elle considère de ses yeux brillants d'oiseau, agrandis et ronds ; puis, les coins de sa bouche se tirent et elle éclate en pleurs bruyants... Mademoiselle l'emmène, ennuyée ; nous suivons, sans songer aux passants qui se retournent, Marie gémit et sanglote tout haut (Colette, Claudine à l'école)

1935 Elle gémissait tout haut, elle invoquait son mari mort :

- Jean, Jean, pardonne-moi, pardon ! (Maxence Van der Meersch, Invasion 14)

\section{CORPuS WEB :}

Je gémis doucement et avant que Mitchy ne puisse gémir haut et fort, je couvris sa bouche de ma main [http://www.wattpad.com/110820452time-to-play-daddy-garde-tes-mains-sur-toibiebo/page/6] (19.5.2015)

Et bientôt, ce fut avec trois doigts en lui, et les mains toujours sur le torse de Kei que Yamaguchi se laissait aller à gémir haut et fort [https:// www.fanfiction.net/s/10776236/1/Cold-BodiesWarm-Hearts] (19.5.2015)

J'éclate en pensant à vous, mais je ne puis crier, je ne puis gémir haut [http://muse particuliere.tumblr.com/post/78475237974/ douce-punition] (19.5.2015) 
REMARQUES : Gémir haut se dit du fait de pousser des cris étouffés et plaintifs à voix haute, de manière à être entendu, qui peuvent être l'expression d'un malaise, d'une douleur physique, du plaisir sexuel, mais aussi d'une peine ou d'un mécontentement fort, Notons sangloter haut et la collocation haut et fort dans le CW. Haut reste invariable et est modifié par plus, si, tout.

\section{Gerber direct}

Vomir juste après avoir bu / mangé

$\lambda$ boire sec

\section{Gérer court}

Gérer ses affaires à court terme

$\lambda$ penser court

\section{Gérer long}

Gérér ses affaires à long terme

$\pi$ penser court

\section{Germer dru}

Germer, pousser avec force, avec vigueur Intransitif

1939 Maintenant, cette ignominie, il l'aimait : " c'est ma matière. " Le gorille latin, l'ouistiti parisien, la pétroleuse à teint de limande, le sans-culotte à la bouche cloaqueuse et à la voix de fille, tous ces gens gris tendus vers le mal faire - tromper, voler, b..., resquiller, se défiler, - tout ce débraillé judéo-latin (extérieur) qui horrifie et fascine le décent nordique, parce qu'il témoigne du débraillé intérieur et promet qu'ici tout est possible, - ce fumier battu de soleil (fumier de corps et d'âmes), c'était cela dont il recouvrait sa terre, et qui la faisait germer si dru (Henry de Montherlant, Les Lépreuses)

CORPuS Web :

Il reste même quelques parcelles de colza dont les petites graines noires sont en train de germer $d r u$ à terre [http://itinerrance2011. blogspot.co.at/p/approche.html] (19.5.2015)

Dans leur enclos je leur jettent aussi beaucoup de grain rond (sarrasin et avoine), plus que ce qu'elles mangent. sa finit par leur faire une méchante pelouse fraiche quand sa se mets à germer dru ! [http://coop-la-basse-cour.forumactif.com/ t12385-question-parcours] (19.5.2015)
Utitlisant la stratégie de Vin, j’ai fait des fèves en godet, mais ça va pas passer 15 jours, ça germe dru dans le tunnel sous la serre, heu faut encore surveiller un peu les d'jeuns, la Biquette voulait remettre la fève dans ce sens là en terre [http://www.forum-tomates.net/viewtopic. php?t=5579\&start=375] (19.5.2015)

Remarques : Germer dru désigne le fait de germer fortement, de produire des germes, et, par extension, d'être très fertile (ici : la terre). Dru reste invariable et est modifié par si.

\section{Gésir mat}

Gésir, être allongé, affaibli

$\lambda$ gésir mort

\section{Gésir mort}

Gésir, être allongé sans vie

Intransitif

1275 Mais la chaitive, la dolente, Ne pot foïr ne sei defendre

Puis que l'en li ot fait entendre

Que maz e morz gisait Mainfreiz,

Par chief, par piez et par mains freiz

(Jehan de Meun, Roman de la rose [12691278], 6719)

\section{CORPus Web :}

tjrs pas de CC , ça va faire hum, 3 semaines ou un mois... pas le temps, recherche de panne, silence radio depuis jeudi, le garagiste doit gésir mort écrasé sous notre CC... y'a pas d'autre explication ! [http://www.magrossesse.com/vb_ forum/bebes-janvier-2004-f133/loulou-encoremalade-t403683] (19.5.2015)

En plus si le gars aurait vu ça, il se serait chier dessus jusqu'à en mourir pour finalement gésir mort sur ses excréments [http://www. jeuxvideo.com/forums/1-50-87343093-1-0-1-0satan-dans-le-metro.htm] (19.5.2015)

148 globicéphales (un des plus grands cétacé à dent, similaire au dauphin et faisant environ 8 mètres de long) gisent mort sur le littoral, morts en suivant leur chef, leur pilote. Échoués sur la plage, ils ne peuvent ou ne veulent plus retourner vers la mer [http://www.podcastjournal. net/animal/m/Baleines-suicidaires-Un-tiersdes-cetaces-echoues-a-pu-etre-sauve_a68.html] (19.5.2015) 
Il atteignit l'endroit où il a vu la femme ascète saint. Elle gisait mort, les bras croisés sur sa poitrine, et son visage était tourné vers l'est [http:// cosaque.over-blog.net/article-fete-le-1er-avril14-venerable-sainte-marie-d-egypte-120022171. html] (19.5.2015)

Macabre découverte à Lochristi (Flandre): une femme gisait morte sur son lit depuis des mois [http://www.rtl.be/info/regions/flandre/ macabre-decouverte-a-lochristi-flandre-unefemme-gisait-morte-sur-son-lit-depuis-desmois-702147.aspx] (19.5.2015)

Remarques : Gésir mort se dit du fait d'être étendu (sur une surface) sans vie (par suite d'un malaise, d'une blessure ou d'une maladie). Notons la collocation mat et mort, l'adjectifadverbe mat soulignant l'idée d'abattement et de faiblesse. Mort reste invariable dans la majorité des cas, mais dans le dernier exemple du CW, il s'accorde avec le sujet, renforçant ainsi une analyse de prédicat second orienté vers le sujet.

\section{Gesticuler terrible}

Faire beaucoup de gestes rapides et brusques Intransitif

1963 Ça chauffe terrible [...] Sur scène, Claude François gesticule terrible [...] Il continue de chanter tranquille (L'Express, 18 juillet 1963 / J. Giraud)

1979 L'équipe des Champs-Elysées se prépare. Avec le plus grand sérieux, comme pour une finale de Coupe du monde. Tous les copains sont là. On les devine de loin. Ça parle fort, très fort, avec les mains... Ça gesticule terrible, un pied noir ! C'est sa façon à lui de se réchauffer. L'hiver parisien le surprend encore (Daniel Hechter, Le Football business)

REMARQues : Gesticuler terrible désigne le fait de faire beaucoup de gestes, généralement en parlant, ici, en chantant, terrible accentuant la rapidité, l'abondance, la brusquerie des gestes. Terrible est un intensifieur métaphorique. Notons aussi chanter tranquille, chauffer terrible, parler fort.

\section{Glisser furtif}

Glisser rapidement sans se faire voir, furtivement

$\lambda$ glisser rapide

\section{Glisser léger}

Glisser avec souplesse, délicatement, légèrement

$\lambda$ glisser rapide

\section{Glisser penaud}

Se faire mal en glissant

$\lambda$ perdre gros

\section{Glisser profond}

Glisser profondément

Intransitif

1925 Raboliot, toujours couché sur l'ados du fossé, au seuil de la plaine, avait glissé profond dans sa rêverie (Maurice Genevoix, Raboliot)

CORPUS WeB :

- desinfiltrer les tissus et évacuer les déchets mobilisés par stimulation des systèmes circulatoires grâce à des manœuvres plus douces telles que palper-rouler et glisser profond [https:// fr-fr.facebook.com/134275783382351/photos/ a.134279253382004.31021.134275783382351/ 556990467777545] (21.5.2015)

En résumé, la Kommission européenne crée un groupe de réflexion pour savoir comment nous la glisser profond et en douceur... [https://fr-fr. facebook.com/permalink.php?story_fbid $=1055$ 817967813480\&id=302002546528363] (21.5.2015)

Mais bon francois tu ne va pas lire cela, mais va te faire enculer vielle salope de communautariste ! Un ancien electeur du ps devenu fierement une Ananas! Le jour ou je te croiserait enculer je vais te la glisser profond croit moi ! [http://quenel plus.com/revue-de-presse/emmanuel-todd-le-11janvier-a-ete-une-imposture.html] (21.5.2015)

- Ça a commence avec Roosevelt qui a essayé de la glisser profonde à DeGaulle non ? [http://www.jeuxvideo.com/forums/42-5138456140-1-0-1-0-les-usa-un-controle-total-sur-1europe.htm] (21.5.2015)

REMARQUeS : Glisser profond désigne le fait de se déplacer d'un mouvement continu, sur une 
surface lisse, en s'enfonçant. Au sens figuré, il réfère au fait de se trouver entraîné dans quelque chose, de s'abandonner, de se laisser aller à, de sombrer profondément dans quelque chose (ici : une rêverie). Dans les trois derniers exemples du $\mathrm{CW}$, la glisser profonde à quelqu'un adopte le sens de 'se faire avoir', voire 'enculer' ou 'baiser' pris au sens métaphorique, suivant un schéma familier assez répandu (v. par exemple se les geler dru, se la couler douce). Notons l'emploi transitif du verbe dans le CW. Profond reste invariable dans la majorité des cas, mais dans le dernier exemple du CW il s'accorde avec l'objet au féminin tout en gardant son interprétation d'adverbe de manière.

\section{Glisser rapide}

Glisser rapidement et agilement

Intransitif

1849 APOLLONIUS. Désires-tu savoir ce qu'implorent les oiseaux quand ils crient dans les nuages? Ce que disent les moucherons bourdonnant dans la poussière ? Ce que bêlent les troupeaux qui se tassent aux épaules ? À quoi songent les bœufs tranquilles ruminant, couchés sur l'herbe ? Pourquoi glissent rapides et muets les poissons luisants, dont l'œil rond est ouvert? (Gustave Flaubert, La Tentation de saint Antoine)

1910 Goupil regagna les taillis, puis les fourrés épais au travers desquels son habileté de vieux forestier le faisait glisser rapide comme une ombre sur un mur et où il espérait bien, à la faveur des ronces et des clématites, faire perdre sa trace au limier farouche qui lui donnait la chasse (Louis Pergaud, De Goupil à Margot : histoire de bêtes)

1967 Les poissons glissent rapides sur le corps $\mathrm{du}$ rebelle, les lacets de ses espadrilles flottent à la surface de l'eau, le soldat entraîne la jeune fille sous les buis ; les sergents battent les murs et les massifs, crient des menaces (Pierre Guyotat, Tombeau pour cinq cent mille soldats)

\section{CORPus WeB :}

Elle glissait, rapide et furtive, sur les murs glacés de la vieille bâtisse. Son déplacement n'émettait pas un bruit, elle passait tel un coup de vent meurtrier prêt à embrasser de sa bise glaciale le premier malheureux qui se trouverait sur son chemin [http://impero.unlimitedboard.com/ t15-exemple-de-fiche-rp-bellatrix-black-x-ancienadmin] (21.5.2015)

Le pinceau glissait rapide sur le rectangle de papier. En peignant, il pensa que Jeanne devait se tromper [http://jdepetris.free.fr/Livres/ planet_blue/lune.html] (21.5.2015)

La toile était encore là, cachée sous un drap dans un coin de l'atelier. D'une main frémissante de curiosité il écarta le voile blanc qui glissa, rapide, à terre [https://4internazionalea.word press.com/la-nouvelle-de-nausicaa] (21.5.2015)

Ce sont les limaces, les escargots ou bien encore les patelles qui semblent glisser, rapides et légers [http://www.rtbf.be/tv/guide-tv/detail_ le-jardin-extraordinaire? uid $=729415955668]$ (21.5.2015)

REMARQues : Glisser rapide désigne le fait de se déplacer d'un mouvement continu et vif sur une surface lisse et de se faufiler, de s'infiltrer rapidement, furtivement. Notons les adjectifs-adverbes furtif et léger. Rapide peut s'accorder avec le sujet (v. ex. 1849, 1967, dernier exemple du CW), de préférence comme adjectif détaché. Ceci est caractéristique du style littéraire soutenu. Dans ces conditions, la flexion sert à augmenter l'expressivité de la phrase en soulignant le rôle du sujet.

\section{Goder fort}

Avoir une forte érection

$\lambda$ parler juste

\section{Goter menu}

Moucheter de petits points colorés

Transitif

1170a Sevelir le fait Telephus Si richement come il pot plus : En un sarqueil l'ont embasmé De vert marbre menu goté (Benoit de Sainte Maure, Le Roman de Troie, 6606)

$\sim 1170 \mathrm{~b}$ En sarqueuz riches de liois

E de fin marbre verz e blois, Jaunes e pers, menuz gotez, [variante : menu] Sont seveliz e enterrez (Benoit de Sainte Maure, Le Roman de Troie, 13049) 
REMARQUES : Emprunté au latin guttare sous la forme goter ou dérivé de goutte, goutter menu désignait le fait de laisser tomber de petites gouttes, et, par extension, de moucheter, de parsemer de petites taches de couleur. L'auteur cité semble préférer l'accord.

\section{Gouverner beau}

Gouverner, diriger correctement

Transitif

1400 - Vroiement, mon amy, je m'en esbahiz comme vous faictes. Je ne scey auxi que ce peut estre, car je le cuide mener et gouverner le plus beau que je puis et le plus doulcement (Quinze Joies de mariage, p. 38)

REMARQUES : Si l'objet est inanimé, gouverner beau désigne le fait de gérer, administrer, régir, dominer quelque chose correctement. Si l'objet est animé, gouverner réfère au fait de s'occuper de quelqu'un, d'exercer un pouvoir politique sur, commander, exercer une influence sur quelqu'un, assurer son éducation, en prendre soin, le soigner convenablement. Beau est modifié par le plus. Notons la collocation le plus beau et le plus doucement. Mentionnons également l'emploi de mener beau.

\section{Gracier menu et souvent}

Rendre grâce (à quelqu'un), remercier continuellement (quelqu'un)

Transitif

1285 Moult en fu ses cuers aaisiez, A genous en a graciié Ses dieus et menu et souvent (Adenet le Roi, Cleomadés, 4877)

REMARQUES : Gracier menu et souvent se disait $\mathrm{du}$ fait de remercier, de gratifier quelqu'un fréquemment, d'être constamment reconnaissant envers lui.

\section{Grever fort}

Tourmenter fortement

Transitif

1176 Amors celi li represante

Por cui se sant si fort grevé [variante : si fort se sent]

Que de son cuer l'a esgené

Ne nel lesse an lit reposer

(Chrestien de Troyes, Cligés, 619)
+1225 Ce me grieve certes mout fort

Ke de ce ke je sui navrés (Le Chevalier as deus espees [ $2^{\mathrm{e}}$ quart $\left.\mathrm{XIII}{ }^{\mathrm{e}}\right], 3410$ )

1275 Mais s’Amours, qui si fort me grieve, Pour mei le voulait achever, Nus maus ne me pourrait grever Qui m'avenist en son servise (Jehan de Meun, Roman de la rose [1269-1278], 4202)

+1433 Le despartir me grefve fort, Ma dame, mais c'est par contrainte, Dont j'ay au cueur tel desconfort Que ma joye en est toute estainte (Chansons du $\mathrm{XV}^{e}$ siècle [datables du $2^{\mathrm{e}}$ tiers $\mathrm{du} \mathrm{XV} \mathrm{v}^{\mathrm{e}}$ à la fin $\mathrm{du} \mathrm{XV} \mathrm{V}^{\mathrm{e}}$, p. 84,8$)$

CORPUS WEB :

Elle demande 2 volontaires par trajet pour accompagner les enfants dans le bus de la Division. Insiste pour obtenir des médicaments via les clubs. (Les médicaments grèvent fort le budget.) [http://www.kiwanis.be/sambreville-jemeppesur-sambre/files/documents/(Kiwanis-Cpterendu $\% 20$ r\%C3\%A9\%20Div\%20Namur\%20 8\%20nov\%202014]).pdf (21.5.2015)

au début j'ai compris comme vous Papymèche, mais en interprétant le style de Kharmah... je me suis dis qu'il voulait dire que la réponse lui a été expédiée ou reçue 4 jours plus tard, ce qui grevait fort les « 15 jours » [http://www.autoevasion.com/forum-auto/droit-penal-routiercode-de-la-route/commissaire-de-police-quiviole-ouvertement-l-article-529-2-du-cpp/123645. html?id=123645\&p=1] (21.5.2015)

Bon messieurs les fonctionnaires, ca va grever fort, après cette annonce (enfin je suppose, puisque ce texte permettra à terme de « licencier $\mathrm{du}$ fonctionnaire ») [http://www.bbnwn.eu/ phpbb2/viewtopic.php?p=170929\&highlight=] (21.5.2015)

REMARQUES : Dans l'ancienne langue, grever fort était fréquemment employé dans le contexte de l'amour, désignant le fait d'accabler, de tourmenter fortement quelqu'un, de le blâmer sévèrement. En français moderne, il réfère au fait d'entamer lourdement quelque chose (ici : le budget, le temps disponible, un sentiment). S'y ajoute le néologisme grever au sens de 'faire la grève' (dernier exemple du CW). Fort reste invariable et est modifié par certes, moult, si. 


\section{Grever petit}

I. Gêner faiblement

Transitif

+1249 Ainsinc jut la nuit en l'ostel, C’onques més dame ne l'ot tel, Més li gesirs petit li grieve : D'entor la mienuit se lieve

(Rutebeuf, Poèmes [pièces datables de 1249 à 1272], II, p. 133, 1071)

II. Se blesser un peu, superficiellement Pronominal

1275 Ains fu presque midis venus Qu'i laissassent cele envaïe. Molt fu lor force afebloïe, Petit se pueent mes grever De cols qu'il se sachent doner (Floriant et Florete, 5359)

REMARQUeS : Dans les domaines sentimental (I) et militaire (II), grever petit désigne le fait de recevoir un léger dommage, subir une blessure superficielle, légère. Petit est un quantifieur de l'ancien français qui reste invariable, étant modifié par mes 'plus'.

\section{Griller menu}

griller menu-menu : fumer (une cigarette) à toutes petites bouffées

Transitif

1948 Chacun allongé dans son hamac sur la véranda, Paul Prado grillait menu-menu une cigarette turque à pétale de rose et moi, je fumais voluptueusement un long cigare de Pernambouc (Blaise Cendrars, Bourlinguer)

Remarques : Griller menu désigne le fait de griller, par extension, de brûler une cigarette en la fumant, en tirant de petites bouffées et en produisant peu de fumée. Мenu reste invariable. Notons la réduplication mепи тепи.

\section{Gronder bas}

I. Gronder, grommeler à voix basse Intransitif

1656 Ayant au veau trépassé

Diligemment delacé

Ou fendu la hongreline,

Et décousu la poitrine :

Hon, dit-il grondant tout bas,
Cette beste n'estoit pas bien saine de sa personne

(Georges de Brébeuf, Lucain travesti)

1751 Jean et Joseph parloient ensemble, et sembloient gronder tout bas (abbé Prévost, Lettres angloises [trad.])

1945 Alors, il est venu près de moi et il a grondé tout bas : "Toi, Laurent, je te connais » (Georges Duhamel, La Passion de Joseph Pasquier)

II. Réprimander peu, faiblement

Transitif

1833 Quand je descendrai rapide, palpitante, L'invisible sentier qu'on ne remonte pas, Reconnaîtrai-je enfin la seule âme constante

Qui m’aimait imparfaite et me grondait si bas ? (Marceline Desbordes-Valmore, Euvres poétiques)

III. Émettre un cri sourd et menaçant

Intransitif

1925 Il s'interrompit tout à coup, se tourna vers la petite chienne. Elle se tenait raide sur ses pattes, le poil de l'échine soulevé, le mufle droit tendu vers la porte d'entrée. Ses babines, froncées, découvraient ses crocs éclatants, et elle grondait tout bas, avec des spasmes d'abois retenus (Maurice Genevoix, Raboliot)

\section{CORPUS WEB :}

Je n'ai jamais vu qu'il n'existait qu'un son de cloche en la matière. Je veux donc bien faire la cloche supplémentaire du carillon, celle qui tinte haut et clair (visiblement, tu as déjà le son des grosses cloches qui grondent bas et sourd) [http:// forum.doctissimo.fr/famille/enfants-precocessurdoues/systeme-enfants-erwan-sujet_2250_2. $\mathrm{htm}$ ] (21.5.2015)

A des milliers de mètres : la mer. Dans les rafales de vent les vagues montaient comme des cyclones et au dedans l'orage grondait, bas et terrible [http://ter-aelis.newgoo.net/t4505p15circonvolutions-rp-concerte] (21.5.2015)

Ça y est, elle l'a ! Elle gronde bas, le signal habituel pour prévenir Severus qu'il faut partir [https://www.fanfiction.net/s/9484108/23/Laccord-du-Wyrm] (27.5.2015) 
Avec la brusquerie propre à cette étrange famille, Steven m’arrache à lui, me tenant par les épaules, me maintenant à distance. Son regard vert planté au fond du mien, j'entends la fureur du volcan gronder, basse, sourde, puissante [http://forum.doctissimo.fr/doctissimo/ recits-erotiques/maintenant-sujet_4736_22.htm] (27.5.2015)

REMARQUES : Gronder bas (I) s'emploie au sens de 'murmurer, grommeler, ronchonner à voix basse', le sujet se plaignant souvent entre ses dents, sous l'effet de la colère ou autre. En (II), l'objet est généralement un enfant qui se fait réprimander à voix basse, avec peu d'intensité, voire avec indifférence de la part du sujet. En (III), gronder bas signifie 'émettre un son menaçant et sourd' mais de faible intensité, le sujet étant généralement un animal, retenant ses grondements. Notons les collocations bas et sourd, et bas et terrible, et l'adjectif-adverbe puissant dans le CW. Bas reste invariable dans la majorité des cas. Dans le dernier exemple du CW, il s'accorde avec le sujet, se rapprochant ainsi d'un prédicat second orienté vers l'objet qui augmente l'emphase. Il est modifié par si, tout. Mentionnons l'emploi complémentaire de tinter haut et clair.

\section{Gronder haut}

I. Produire un hurlement rauque et puissant, crier d'une voix forte Intransitif

1756 Il a mal harangué, et d'une voix si faible, qu'on ne l'entendait pas à l'assemblée des chambres, tandis qu'il fallait gronder haut ou point du tout (René-Louis d'Argenson, Journal et mémoires)

1873 La grande voix des halles grondait plus haut (Émile Zola, Le Ventre de Paris)

1958 - Je ne sais quelle grâce la protégeait peut-être, mais pour moi...

Le lion gronda plus haut, sa queue claqua plus fort (Joseph Kessel, Le Lion)

II. Réprimander quelqu'un ouvertement, émettre violemment son désaccord Transitif

1830 Vous convenez de si bonne grâce de tous vos torts que je ne puis vous gronder bien haut (George Sand, Correspondance)
1857 La population se voit piller par les brigands comme une femme du peuple se sent battre par son mari, en admirant comme il frappe bien. Les moralistes indigènes se plaignent de tous les excès commis dans la campagne, comme un père déplore les fredaines de son fils. On le gronde tout haut, on l'aime tout bas; on serait bien fâché qu'il ressemblât au fils du voisin, qui n'a jamais fait parler de lui (Edmond About, Le Roi des montagnes)

1867 Elle parle argot, elle nage dans la Seine (en costume de bain) avec un prétendant qu'elle voit pour la première fois, elle le met en fuite à coups d'inconvenances, elle fait le rapin et le gamin, elle tire les pétards les plus saugrenus au milieu des conversations graves, se lâche et se livre, et son père, qui la gronde tout haut, l'applaudit tout bas (Hippolyte Taine, Notes sur Paris)

III. Tonner violemment

Intransitif

1839 L'orage ne venait jamais assez vite et ne grondait jamais assez haut (George Sand, Lélia)

1859 Il ne se faisait faute de protester de son estime pour M. Arnauld en particulier, et se prévalait d'avoir tâché de le servir dans les occasions ; qu'il n'y en avait eu qu'une dans laquelle il avouait qu'il n'y avait pas eu moyen, et que le tonnerre avait grondé trop haut (Charles Sainte-Beuve, Port-Royal)

\section{CORPus WeB :}

Le cas du Bénin voisin de l'Est faisait école. Eyadema va gronder haut et fort : « Il n'y aura pas de suivisme » [http://www.diastode.org/Echos/ invit8087.html] (27.5.2015)

Je ne peux pas te regarder car le courage me manque, et je ne peux plus te gronder haut et fort car la dépression me guette [http://purshiit.skyrock.com/2916195669-Je-crois-que-lexplication-n-est-plus-a-donner-Ca-en-devientlassant.html] (27.5.2015)

Ils s'étaient tous levés en entendant les orages et les cris gronder haut dans le ciel [http://gefangnis.forumactif.org/t530-prologuechapitre-3-le-voleur-est-demasque] (27.5.2015) 
La Peta aura eu beau la gronder haut et fort, Lady Gaga a fait la sourde oreille... Pour recevoir son Moonman de la Vidéo de l'année (Bad Romance), la chanteuse avait revêtu sa robe en viande crue [http://www.grazia.fr/people/newspeople/archives-galeries-news-people/LadyGaga-triomphe-encore-aux-MTV-Video-MusicAwards-58541/(offset])/1 (27.5.2015)

REMARQUES : Gronder haut (I) s'emploie avec un sujet qui est un animal émettant un son menaçant, puissant, ou une personne s'exclamant, voire criant d'une voix forte, retentissante. Dans un emploi transitif (II), l'objet est généralement un enfant qui se fait réprimander à voix haute, ou une personne envers laquelle on exprimer son désaccord violemment, ouvertement. En (III), le sujet est un inanimé (ici : l'orage, le tonnerre) qui laisse entendre un son sourd, grave, bruyant, plutôt menaçant. Notons la collocation haut et fort et le contraste dans On le gronde tout haut, on l'aime tout bas et la gronde tout haut, l'applaudit tout bas. Haut reste invariable et est modifié par bien, jamais assez, plus, tout, trop. VoIR AUSSI : aimer bas, applaudir bas,

\section{Gronder fort}

Gronder avec virulence, ouvertement \ gronder haut

\section{Gronder sourd}

Gronder en émettant un bruit sourd

\ gronder bas

\section{Gronder terrible}

Gronder avec violence

7 gronder bas

\section{Guerroyer bel}

Guerroyer vaillamment

Intransitif

1250 Dous Jhesus, com cil bel guerroie

Et come noblement tournoie, Qui volentiers au moustier tourne, Ou l'en le saint servise atourne Et celebre le saint mistere

Du doux fils de la vierge mere !

(Du chevalier qui ooit la messe et Nostre Dame estoit pour lui au tournoiement, 1)
REMARQues : Dans le domaine militaire, guerroyer bel désignait le fait de faire la guerre valeureusement, noblement. Le neutre bel correspond à la fonction adverbiale.

\section{Guerroyer fort}

I. Guerroyer violemment Intransitif

+1370 Chils y reporta les alianches confermées et séellées des roys dessus dist, de quoy li seigneur d'Escoce et tout li pays fu tout joiaux, et commencièrent à guerryer plus fort et plus asprement que devant (Jean Froissart, Chroniques (A))

II. Tourmenter fortement, harceler Transitif

+1400 On se doibt garnir contre la mort de tout son sens et pouoir ; car qui y fault n'y peut recouvrer. A ce point de la mort, le deable nous guerroye fort et fait tout son pouoir de nous decevoir (Nouvelles françaises $d u X^{e}$ siècle, $\mathrm{p}$ 136)

+1433 Ma dame, Dieu vous doint bon jour !

Je suis venu par devers vous :

Vostre amour sy fort me guerroye !

(Chansons du $X V^{e}$ siècle [datables du $2^{e}$ tiers du $X v^{\mathrm{e}}$ à la fin du $X v^{\mathrm{e}}$ ], p. 138, 9)

\section{CORPuS WEB :}

En tout cas on voit que ça guerroyait fort pour que tu aies le temps d'oublier ton armée en chasse [http://fourmizzz.cforum.info/t3322Resume-des-bugs.htm?start=165] (27.5.2015)

Un vrai livre d'Histoire et de Préhistoire, puisque c'est dans cette région que fut découvert des peintures rupestres vieilles de 35000 ans, et les bastides et chateaux fort qui rappellent que l'on guerroyait fort dans cette région riche d'un passé encore présent comme le Pont Valentré, construit pour faciliter l'accès à la ville de Cahors il y a 700 ans vers 1320 [http://vacancearcachon. canalblog.com] (27.5.2015)

Pas peur qu'elle te tire dessus ? Et que tu sois sa première victime ? ! Et qui te dit que je ne suis pas canon moi aussi lol Alors là, incompatibilité totale entre 2 canons, ça risque de guerroyer fort [http://www.algerie-dz.com/forums/archive/ index.php/t-242769-p-7.html] 
REMARQUES : Guerroyer fort (I) s'utilise dans le domaine militaire, au sens de 'faire la guerre, lutter violemment, âprement'. En (II), il signifie 'mettre à mal quelque chose, persécuter, torturer, tourmenter fortement quelqu'un'. Fort reste invariable et est modifié par plus, si. Notons l'emploi impersonnel du verbe dans le CW, ainsi que la transposition de l'image de la guerre sur le plan de l'attirance érotique dans le dernier exemple.

\section{Guier droit}

Mener, conduire directement

Transitif

-1200 Et il si firent lors, [la] en i corent quinse, Les huis ont desfremés et les cambres ovrirent,

Elye i ont trové et sa seror Olive :

Droit de devant lor pere les menerent et guient (Elie de Saint Gille [fin XII ${ }^{e}$, 31)

REMARQUes : Suivi d'une préposition de lieu, guier droit désignait le fait de guider, conduire quelqu'un directement vers un lieu ou une personne. Droit reste invariable. Notons l'emploi de mener droit.

\section{Guier soef}

Guider avec douceur

Transitif

+1150 Et se il uieut ostel, souef l'en guie Por amor Iesu Crist, le fil Marie,
Et por l'arme del pere qui m'a norie

(Aiol et Mirabel [ $2^{\mathrm{e}}$ moitié $\left.\mathrm{XII}\right]$, 2008)

REMARQUES : Guier soef désigne le fait de guider, mener, conduire quelqu'un doucement, tranquillement.

\section{Guimpler bel}

Mettre une belle guimpe

Pronominal

+1150 A l’unzíme án Jorám, le fíz Acháb, púis que Híeu l'óut mórt é le réi Achazíe nafred á mort, Híeu entrad en Jésrael. Cume Jezabel le sout que il i vint, bien [variante : bin] se acésmád é bel se guimplad, si vít par úne fenestre, cume Híeu s'en venéit, si li dist : « Cument? Si averat cil bone páis é ferme, ki sun seignur ad mort? » (Quatre Livres des rois $\left[2^{\mathrm{e}}\right.$ moitié $\left.\mathrm{XII}\right]$, p. 193, 30)

REMARQUES : Se guimpler bel désignait le fait de mettre, de se vêtir d'une belle guimpe ; la guimpe (guimple) était une banderole fixée à la lance de joute ou, comme dans cet exemple, un ornement consistant en une pièce de tissu couvrant la tête et entourant les tempes et le cou. Beau y adopte sa forme neutre bel pour la fonction adverbiale. 


\section{Habiller beau}

Porter de beaux vêtements

Pronominal

1943 Que vous êtes gentille, dit-elle, si j'avais su que c'était un soir de gala, je me serais habillée beau (Simone de Beauvoir, L'Invitée)

1948 Pour distraire sa pensée, elle détailla l'épaisse cravate noire sur le col raide, rabattu et haut de quatre doigts, le veston noir bordé, le pardessus entr'ouvert, le pantalon à rayures grises et tout cet air cossu qui, malgré la laideur de Lulu, répandait une espèce de chaleur dans la pièce.

- Vous vous habillez toujours beau comme cela dès le matin? Demanda-t-elle.

- Non, aujourd'hui je suis habillé sérieux parce que je vais à un enterrement... (il consulta sa montre) (Maurice Druon, Les Grandes Familles)

1954a L'invitation à la noce se fait par une tournée des promis à domicile, munis du « panier des fiancés » rempli de dragées (Bourgogne). Elle dure parfois plusieurs jours en raison de l'éloignement des parents ou amis et du mode de transport ; " vous cirerez vos bottes pour tel jour », disent-ils, invitation à s'habiller « beau », en dimanche, égale pour les hommes et pour les femmes (Île-de-France) (Menon et Lecotté, Au village de France : Des moissons à la Noël)

Transitif

1954b Les femmes coquettes sont « habillées belles » et parées de leurs bijoux : anneaux d'or aux oreilles, la croix de " ma mère ", la « croix huguenotte » à huit pointes ou le «Saint-esprit », attaché à un ruban autour du cou (Berry) (Menon et Lecotté, Au village de France : De la Chandeleur à la Saint-Jean)

\section{CORPUS WEB :}

La fête du Plaix s'est tenue les 16 et 17 août 2012 autour du thème : " Hier en Berry, se vêtir, s'habiller beau... » Le costume berrichon existet-il ? [http://bernard.desjeux.free.fr/article. php3?id_article=424] (27.5.2015)
Avec Chictypes.com, les hommes ne subissent plus le douloureux passage du magasin pour s'habiller beau et bien [http://madame. lefigaro.fr/style/nouveau-type-190613-390650] (27.5.2015)

De toute facon la Norvege n'est pas le pays de la mode..... on s'habille utile avant de s'habiller beau. De toute facon le beau norvegien ne coincide pas avec le beau francais [http://www. norvege-fr.com/phpBB3/viewtopic.php?f=2\& $\mathrm{t}=4881$ \&start=30] (27.5.2015)

La rentrée est derrière nous mais l'hiver approche... Si la garde-robe de vos bouts de chou n'est pas encore complète, voici quelques adresses milanaises très utiles pour les habiller beau et pas cher [http://visiter-milan.e-monsite. com/pages/shopping-enfants.html] (27.5.2015)

J'aime faire ces belles promenades avec vous. Même la poupée s'habille belle ! [http:// celestineetcie.canalblog.com/archives/2015/02/ 16/31511853.html] (27.5.2015)

REMARQueS : $\left(S^{\prime}\right)$ habiller beau désigne le fait de porter des vêtements chics, élégants, de s'habiller avec recherche de façon à plaire, voire de mettre des vêtements de cérémonie ou une tenue de soirée. Notons l'emploi de s'habiller sérieux, s'habiller utile et s'habiller pas cher, ainsi que la collocation beau et bien, beau et pas cher. Beau peut s'accorder avec le sujet dans l'emploi pronominal du verbe, mais il reste invariable malgré l'objet au pluriel dans l'exemple de 1943 et dans le quatrième exemple du CW, où le verbe est transitif. Il est modifié par toujours.

\section{Habiller branché}

S'habiller suivant la mode actuelle

入 habiller classique

\section{Habiller cher}

Porter des vêtements chers

入 habiller beau

\section{Habiller chic}

Habiller avec élégance

入 habiller simple, coiffer chic 


\section{Habiller clair}

Porter des couleurs claires

Transitif

1922 Sans doute le type existe-t-il sous d'autres aspects et nous en connaissons de jeunes, maigres, bon teint, habillés clair par le tailleur. Mais le papier de tournesol rougit aux acides et nos nerfs se crispent au contact de cet individu (Mercure de France)

Pronominal

2018 On doit s'habiller clair quand il fait chaud (Corpus Coiffet 2018 : s.v., sans date)

\section{Habiller classe (class)}

Habiller de vêtements très chics, qui impressionnent

Transitif

1999 Un grand mec d'une quarantaine d'années, habillé class, chemise blanche, pantalon gris à pinces, gilet et chaussures vernies noires, m’a fixé longuement (Akim Malouk et Danièle Lederman, 1, 2, 3... Cités !)

2007 Pourtant cette fois Miss Francfort était habillée classe. Costume d'homme anthracite, chaussures vernis à talons on ne peut pas faire plus sobre (Michel Le Person, Belle-île en rouge)

Pronominal

2008 Il n'était pas beau selon les critères parentaux, mais avec l'âge, les types de son genre, pour peu qu'ils restent secs et s'habillent classe, ont des têtes de rockeur anglais (Marion Ruggieri, Pas ce soir, je dîne avec mon père)

\section{Habiller classique}

Porter des vêtements classiques, sobres, sans extravagance

Pronominal

1953 Elle s'habille assez classique pour pouvoir mettre longtemps la même chose sans se lasser (Elle, 23 mars 1953 / Grundt : 238)

\section{CORPUS WEB :}

S'habiller classique, c'est s'habiller vieux, démodé, couleurs ternes ou banales genre jupe bleue marine et chemisier blanc ou beige [https://fr.answers.yahoo.com/question/index?q id=20070626022158AAoKt9C] (27.5.2015)

Pour ce qui est des affaires, je pense qu'il faut s'habiller relativement classique mais il surtout se sentir bien dans ce que l'on porte : les filles, ne mettez pas des talons si vous n'en portez jamais par exemple [http://forumcapes.free.fr/ viewtopic.php? $\mathrm{p}=20067 \&$ sid $=36 \mathrm{~d} 5$ e923b324c0d7 a3275515d2e006db] (27.5.2015)

zaza on a les mêmes gouts je crois, moi j’aime bien les habiller classique mes garcons, j'aime pas trop les fringues avec des gros bonhommes disney ou autres [http://forum.doctissimo.fr/ grossesse-bebe/ramadanettes/ramadanettessujet_2_2550.htm] (27.5.2015)

et bien su tu n'as jamais mis les pieds du coté des tous petis, c'est un tors... y'en a pour tous les gouts, à petits prix... on peut les habiller " classiques ", " branchés "... [http://www.ciao. fr/H_M_Avis_304185] (27.5.2015)

REMARQUES : (S')habiller classique désigne le fait de porter des vêtements conformes à des règles établies par la tradition. Notons aussi s'habiller vieux, s'habiller démodé et s'habiller branché. Classique reste invariable dans l'emploi pronominal du verbe, mais dans l'emploi transitif $\mathrm{du}$ verbe il peut ou bien rester invariable (v. le troisième exemple du $\mathrm{CW}$ ) ou bien s'accorder avec l'objet (v. le dernier exemple du CW). Il est modifié par assez, relativement.

\section{Habiller coloré}

Habiller de vêtements colorés

入 habiller serré

Habiller court

Habiller de vêtements courts

Pronominal

1737 Tiens, Gogo, ne me parle pas de ces petits nés retroussés ; et puis, elle se pince toujours la bouche, sans cela seroit-elle si petite ? Godiche n'est pas mal faite, faut tout dire ; mais elle n'est pas si grande que moi. As-tu vu comme elle s'habille court ? (Anne-Claude de Caylus, Histoire de monsieur Guillaume)

1968 Maintenant, de quinze à soixante ans, nous puisons toutes dans le même sac à 
malices. Les pauvres putains elles-mêmes sont dépossédées : elles ne peuvent s'habiller plus court ou se maquiller plus habilement que nos honnêtes jeunes filles (Benoîte et Flora Groult, Il était deux fois)

Transitif

1884 Elle était en grand deuil, vêtue d'une robe de mérinos qui l'habillait trop court et trop serré (Hector Malot, Marichette)

1945 au lieu de la Cathie en espadrilles, un petit fichu noué sous le menton, il y avait là une jeune femme luxueuse, en noir, habillée très court, très serrée à la taille fine, savamment coiffée, les cheveux noirs, lustrés descendant en huit sur le cou (Elsa Triolet, Le Premier Accroc coûte deux cents francs)

1950 Je bois, je fume. J'écoute encore chanter le grand sergent. J'admire la cocasserie de ses gestes habillés trop court, la bosse de son nez en bec d'ara, le clignotement de son œil rond (Maurice Genevoix, Ceux de 14)

CORPuS Web :

Astuces pour s'habiller court sans faire vulgaire [http://www.onlyvahine.com/annonces/ index.php/actualites/17-actualite/149-astucespour-s-habiller-court-sans-faire-vulgaire] (27.5.2015)

Ha oui ça pour s'habiller court la bas c'est pas un problème. Mais justement je trouve ça mieux, du coup y a moins de « bon je vais pas mettre ça parce qu'on va me regarder trop chelou » [http://www.carolinedaily.com/forum/ comment-s-habiller-pour-une-boite-de-nuitlondonienne-t43548.html] (27.5.2015)

Ahah c'est vrai que ces anglaises ont tendance a s'habiller court! je l'ai remarqué lors de mes achats londoniens !;) [http://www. lapenderiedechloe.com/2011/11/la-notion-detrop-court-en-angleterre.html] (27.5.2015)

D’ailleurs, cette années on mélange beaucoup le jean avec de la dentelle anglaise par exemple. J'adore m'habiller courte et ultra féminin ! [http://forum.aufeminin.com/forum/ beaute2/_f8216_beaute2-Dentelles-volantsrubans-et-noeuds.html] (27.5.2015)
REMARQUES : ( $\left.S^{\prime}\right)$ habiller court désigne le fait de porter un vêtement, en général une jupe, une robe, généralement au-dessus du genou, considéré par la majorité comme étant trop court, peu convenable. Notons l'emploi d'habiller ultra féminin, habiller serré, ce dernier référant à des vêtements très près du corps, ajustés, faisant ressortir les formes du corps, la combinaison court et serré étant considéré comme provocation extrême. Court reste invariable dans la majorité des cas, mais dans le dernier exemple du CW il s'accorde avec le sujet au féminin. Il est modifié par plus, très, trop, ultra. Dans l'exemple de 1945, s'habiller court n'est pas accordé, à la différence de s'habiller serrée, qui pourtant renvoie au même sujet grammatical, peut-être en raison du fait que serré réfère à l'effet du vêtement sur le corps humain, donc sur la personne, tandis que court désigne une propriété exclusive des vêtements. Dans ce contexte, la coordination des adjectifs accordés dans s'habiller serrée et courte peut prêter à rire. Notons l'emploi de faire vulgaire.

\section{Habiller démodé}

Habiller de façon désuète, démodée

$\pi$ habiller classique

\section{Habiller élégant}

Porter des vêtements élégants

$\pi$ habiller joli

\section{Habiller excentrique}

Habiller de manière excentrique, extravagante, originale

Pronominal

1896 Cécile, exubérante, toujours bavardeuse à tort et à travers, toujours sa manie de s'habiller excentrique, à la je-me-fiche-dutiers-comme-du-quart, et jolie ; oh ! ( $\mathrm{La}$ Vie parisienne)

1953 Grande, 1m 68, brune aux yeux marrons, elle s'habille " net mais un peu excentrique » (Elle, 23 mars 1953 / Grundt : 350)

1961 De même l'originalité n'est pas dans une manière de s'habiller excentrique, ni dans un cri d'oiseau que l'on ajoute à 
ses phrases pour ponctuer leur cynisme (Quadrum)

2002 Il y a une quête dans la passion de s'habiller excentrique, disons excentrée. Chercher le lien magique qui fera soudain cohabiter la robe impossible avec le manteau incroyable (Christine Orban, Fringues)

Corpus Web :

Qui y va ? Allez vous vous habiller excentrique? [http://www.beaute-test.com/forums/ index.php?topic $=204694 \&$ start $=0$ ] (29.5.2015)

S'habiller excentrique, à Paris ? J'aurais l'impression d'être un clown, cette ville n'est pas faite pour les excentriques [https://petrolebleu. wordpress.com/tag/different] (29.5.2015)

mais à côté de ça, j’ai trouvé les anglais très accueillants, polis, joyeux, leur façon de s'habiller excentrique les jeunes comme les vieux (un peu année 60) c'est assez marrant [http://forum. doctissimo.fr/viepratique/Actualites/anglaissysteme-sujet_16253_1.htm] (29.5.2015)

Et puis, pour les gens qui s'habillent excentriques, c'est dans leurs droits, il n'y a pas de loi qui interdise quoi que ce soit à ce sujet [http:// www.jeuxvideo.com/forums/1-50-19512882-10-1-0-le-japon-cest-de-la-grosse-merde.htm] (29.5.2015)

REMARQUES : Habiller excentrique réfère au fait de porter des vêtements considérés comme excentriques, en opposition avec les habitudes reçues et dont la singularité attire l'attention. Excentrique reste invarié dans la majorité des cas (malgré le sujet au féminin ou pluriel), mais dans le dernier exemple du CW excentrique s'accorde avec le sujet au pluriel. Excentrique est modifié par un peu. Notons l'emploi de s'habiller net.

\section{Habiller faux}

Habiller de façon non naturelle Transitif

1951 Les acteurs veulent jouer faux, être habillés faux, être peinturluré faux, être perruqués faux. La nonne a du rouge baiser aux lèvres, le poilu qui sort des tranchées des bottes vernies, l'amoureuse est jouée par un gamin (Henry de Montherlant, La Ville dont le Prince est un enfant)
CORPUS Web :

je suis en partenariat avec des operateurs economique de l'etranger, desormais plus de chinoiseries, habillez vous ORIGINAL. je reside au ghana et je suis a present a douala pour le lancement de votre magasin. merci de partager la page pour le bien de nos freres et sœurs, evitons de nous habiller faux (CHINOIS) car notre santé en depend [https://fr-fr.facebook. com/DoualaMarket/posts/497765666962846] (29.5.2015)

Ne pas connaître son style et s'habiller faux, avec trop de bijoux... Une femme doit trouver son style, son caractère, et jouer avec [http://journal. hautehorlogerie.org/fr/article/caroline-gruosischeufele-red-carpet] (29.5.2015)

C'est malheureux, mais ca Dakar, gnodi rek et ils n'ont rien ou ne croient pas a ce kil font. Les gens a dkr, parlent faux, s'habillent faux, mangent faux, dorment faux [http://www.dakaractu.com/ Apres-avoir-offert-une-4x4-a-Doudou-NdiayeMbengue-Marie-Coulibaly-reprend-les-clefs-desa-voiture_a63653.html] (29.5.2015)

Remarques : Habiller faux désigne le fait de porter des vêtements contraires à la justesse, au naturel, à la tradition, donnant ainsi une fausse image du sujet. Il peut impliquer une forte dose d'arrogance culturelle. Notons l'emploi de jouer faux, s'habiller original, manger faux, dormir faux, parler faux, peinturlurer faux, perruquer faux. Faux reste invariable.

\section{Habiller féminin}

habiller ultra féminin : habiller avec des tenues

qui correspondent à l'image stéréotypée que

l'on se fait de la femme

$\lambda$ habiller court

\section{Habiller jeune}

(Se) vêtir de manière moderne, (s')habiller comme les jeunes

Transitif

1914 CÉLESTE. Ah ! Maintenant, je crois que je peux aller ouvrir.

(Brotonneau paraît. Il a changé d'aspect. Sa barbe est taillée plus court. Ses cheveux sont moins longs. Il est habillé plus jeune et il a l'air épanoui. Il pose un bouquet de violettes sur la cheminée) 
(Robert de Flers et Gaston Arman de Caillavet, Monsieur Brotonneau)

Pronominal

1949 elles [= les femmes de 45 ans et plus] se mettent à «s'habiller jeune », elles adoptent des mimiques enfantines (Simone de Beauvoir, Le Deuxième sexe)

\section{CORPUS WEB :}

Prés de chez moi, il y a une femme d'une cinquantaine d'années qui s'habille hyper jeune : jeans et veste en jeans super délavé, tee-shirt moulant etc... [http://forum.aufeminin.com/ forum/beaute2/_f10028_beaute2-Y-a-pas-d-agepour-s-habiller-jeune.html] (29.5.2015)

où s'habiller jeune, en grande taille et pas cher ??? [http://www.vivelesrondes.com/forum/ viewtopic_315956.htm] (29.5.2015)

Ceux qui critiquent les personnes âgés qui s'habillent "jeune ", on verra quand ça sera votre tour si vous voudrez pas faire moins vieux [https://twitter.com/RemiGozard/status/287252 725723459584] (29.5.2015)

Elles s'habillent « jeunes » et très souvent, ne veulent pas vieillir ! [http://resterzen.eklablog. com/grand-meres-d-hier-et-d-aujourd-hui-a1148 61690?noajax\&mobile=1] (29.5.2015)

REMARQUES : Habiller jeune désigne le fait de porter des vêtements réservés à des personnes jeunes, dans le but de paraître plus jeune et moderne. Jeune reste invariable dans la majorité des cas, mais, dans le dernier exemple du CW, il s'accorde avec le sujet pluriel. Il est modifié par plus, hyper. Notons aussi l'emploi de s'habiller pas cher, tailler court.

\section{Habiller joli}

Porter de jolis vêtements

Pronominal

1957 Mousseline vaporeuse pour les invitations de famille où l'on s'habille " joli », simple (Elle, 22 avril 1957 / Grundt : 239)

\section{CORPUS WEB :}

Sofia me regarde de haut en bas et d'un air coléreux me dit : "Maman, pourquoi tu t'habilles moche ? T'as dit qu'il fallait s'habiller joli pour aller à l'école ! » [http://www.jumeaux-etplus.fr/component/option,com_smf/Itemid,88/ topic,2914.3060/wap2,wap2] (29.5.2015)
L'homme a accepté l'invitation car nous étions dispo mais moi, j'ai pas envie d'y aller. J'ai pas envie de devoir m'habiller joli, j'ai pas envie de me cogner 1 heure dans la voiture pour manger toujours la même chose [http://ledragonetmoi. canalblog.com/archives/2011/07/13/21600751. html] (29.5.2015)

Cette jeune fille va à l'école le matin et me suis réveillé avec une mauvaise humeur. Aidonsla à s'habiller joli et élégant, pour le rendre plus agréable [http://re.game-game.com/64294] (29.5.2015)

Quand une fille s'habille comme un thon, on va dire « Bouh qu'elle est dégueulasse, elle doit puer de la chatte » et quand elle s'habille jolie/ sexy c'est forcément une chienne qui cherche à se faire déboiter [http://www.jeuxvideo.com/ forums/1-69-4589382-10-0-1-0-elle-filme-leharcelement-de-rue-dont-so.htm] (29.5.2015)

REMARQUES : Habiller joli désigne le fait de porter de beaux vêtements, soignés, de s'habiller avec recherche de façon à plaire, voire de mettre des vêtements de cérémonie ou une tenue de soirée. Notons l'emploi de s'habiller moche / élégant / sexy / simple. Joli reste invarié dans la majorité des cas (v. le troisième exemple du CW), mais il s'accorde avec le sujet dans le quatrième exemple.

\section{Habiller juste}

I. S'habiller comme il faut

Pronominal

1868 L'éducation seule enseigne à se meubler juste, de même qu'à s'habiller juste (Arnould Frémy, Les Gens mal élevés)

1954 Des exemples qui vous inspireront pour choisir vos distractions, pratiquer certains sports, prendre quelques soins de beauté indispensables, vous équiper et vous « habiller juste » en toutes circonstances (Paris-Match)

\section{Enserrer, serrer de trop près}

Transitif

1919 puis, fermant la colonne, le phaéton du vaguemestre, tiré par un percheron de labour que les brancards habillaient trop juste (Roland Dorgelès, Les Croix de bois) 
III. Porter des vêtements (trop) courts

Emploi absolu

2009 « Je dois faire court, car la femme monte l'escalier. Comme la jupe est courte, je vois le haut des bas donc je lui mets un collant, ma robe est faite pour habiller juste ", disait-il (Sophie Delassein, Les Dimanches de Louveciennes)

REMARQUES : Notons l'emploi de meubler juste ; faire court.

\section{Habiller large}

Revêtir un vêtement large, ample

Pronominal

1780 Sophie, habille-toi bien large, pour que ton enfant se place à son aise (Honoré de Mirabeau, Lettres originales écrites $d u$ donjon de Vincennes)

\section{CORPUS WEB :}

ah bon je savais pas qu'un certain style de fringue correspondait a un certain niveau... Heureux de l'apprendre... en même temps c'est vraiment logique.

Depuis quand il faut plaquer du cork 900 pour s'habiller large ? [http://www.skipass.com/ forums/sports/ski_freestyle/sujet-115711.html] (29.5.2015)

Alors là, pas beaucoup de solutions : on trouve un rayon grandes tailles chez Kiabi, Gémo, La Halle, mais souvent on a le sentiment de devoir s'habiller comme une grand-mère et j'ai 41 ans... Pas le choix non plus que de s'habiller large, on ne trouve rien qui soit un peu près du corps, donc on ressemble à un sac ! [http://archives-lepost. huffingtonpost.fr/article/2010/01/22/1900661_ pas-facile-de-s-habiller-quand-on-est-trop-ci-oupas-assez-ca.html] (29.5.2015)

Ceux qui s'habillent large chez moi c'est genre le jeans avec une coupe absolument pas ajuster, les victimes négligées [http://www. jeuxvideo.com/forums/1-51-72632483-1-0-1-0pourquoi-les-gens-s-habiller-large-avant.htm] (29.5.2015)

je vous souhaite a toutes une bonne journee, en rp il fait vraiment pourri, je suis deja sortie pour echanger un vetement, il y en a certains qui habillent larges alors que c est la bonne taille [http://forum.doctissimo.fr/famille/ grands-parents/generation-actives-modernessujet_264_523.htm] (29.5.2015)

REMARques : Habiller large désigne le fait de porter des vêtements larges, amples, qui ne serrent pas. Large reste invariable dans la majorité des cas (v. le troisième exemple du CW), mais dans le dernier exemple, il s'accorde avec le sujet certains du verbe dans son emploi absolu, non pronominal (ergatif). Le tour caractérise le langage de la vente où l'on trouve aussi les chaussures ou les hommes "qui chaussent large(s) ", faire large, etc. Large est modifié par bien.

\section{Habiller léger}

Porter des vêtements légers

Pronominal

2018 Peut-on s'habiller léger en hiver ? (Corpus Coiffet 2018 : s.v., sans date)

\section{Habiller moche}

Habiller de manière moche, laide ; mal habiller

入 habiller joli

\section{Habiller net}

Porter des vêtements sobres et soignés

Pronominal

1953 Grande, 1m 68, brune aux yeux marrons, elle s'habille «net mais un peu excentrique » (Elle, 23 mars 1953 / Grundt : 350)

\section{CORPUS WEB :}

A titre d'info, j'ai opté pour des chemises ouvertes, manches retroussées. Mine de rien, ça habille net et ça voile un peu le popotin... [http:// forum.doctissimo.fr/nutrition/m6-maigrir/hyper hages-regimettes-boulimiques-sujet_147339_183. htm] (30.5.2015)

Dans les vide-grenier, marrant, on ne nous a jamais boudé les vêtements mis en vente.... Et bien contents ceux qui payaient une pièce pour pouvoir s'habiller net [http://forum.doctissimo. $\mathrm{fr} /$ famille/argent-budget-famille/donnez-clo chards-mendiants-sujet_11953_2.htm] (30.5.2015)

Le premier interet etait « l'amour » qui se developpait par internet (etudes serieuses), ainsi cet ingenieur donna la possibilté aux femmes et aux hommes de s'asperger de parfum et de s'habiller net comme si on sortait en soirée [http:// board.fr.ogame.gameforge.com/board613- 
ogame-origin/board616-projet-origin/board347archives-origin/671207-sip-missile] (30.5.2015)

Remarques : Habiller net désigne le fait de porter des vêtements donnant un aspect soigné, de s'habiller proprement. Net reste invarié (ex. de 1953). Notons l'emploi ergatif dans le premier exemple du CW.

Habiller neuf

Habiller de vêtements neufs

Transitif

1540 LE PREMIER. Se on ne vous trouble Vous serez maistre Et ne s'en fauldra pas ung double. Vous vous en yrez à couple, Ainsi qu'une vache et ung beuf, Et serez habillé tout neuf, Pourpoint de vert gris d'ung escu, Chaussez à plain fons jusques au cul, Le collet de vert couvert, Et la chausse de velours vert Et les beaulx chabos deux à deux (Farce nouvelle des cris de Paris / Ancien Théâtre françois)

CORPUS WEB :

ISEE Clothing vous permet de vous habiller neuf et old school en même temps tout en s'accordant au streetwear actuel [https://www. amogado.com/concours/538-isee-4-tee-shirts isee.html] (30.5.2015)

Pour beaucoup de parents et d'enfants qui ont les moyens, Noël est la grande fête des cadeaux, jouets et bonbons où il est impératif de s'habiller neuf et de manger comme des rois [http://www.tiboo.com/contenu/vipratic/noel03. htm] (30.5.2015)

L'aid en Tunisie est une fête religieuse et une bonne habitude,

Pour que les enfants s'habillent neuf et visitent leurs parents [http://fattoumabidi.overblog.com/article-les-fillettes-et-les-garcons83175916.html] (30.5.2015)

Que ce soit une construction à rénover, ou à 'habiller' neuve, nous saurons vous aider pour tout, sols, murs, plafonds, agencement, mobiliers et décorations, et apporter une touche différente ! [https://www.pinterest.com/pin/788136 8073722863] (30.5.2015)
REMARQues : Habiller neuf désigne le fait de (faire) étrenner un vêtement, de porter un habit neuf. Dans le dernier exemple du CW, habiller neuf s'emploie transitivement dans le domaine de la construction au sens de 'recouvrir de matériaux neufs'. Notons l'emploi de l'anglicisme nominal old school comme modifieur opposé à neuf. Neuf reste invariable dans le troisième exemple du CW, mais s'accorde dans le dernier exemple avec l'objet du verbe en construction transitive, se rapprochant d'une prédication seconde. Neuf est modifié par tout.

\section{Habiller old school}

(s)'habiller 'vieille école', d'une manière traditionnelle

入 habiller neuf

\section{Habiller original}

Habiller traditionnellement, conformément à son origine

入 habiller faux

\section{Habiller pareil}

Habiller pareillement (à), de la même manière Pronominal

+1489 Le plaisir du roy avoit esté que je fusse vestu pareil de luy ce jour. Il avoit accoustumé de long temps en avoir quelcun qui s'abilloit pareil de luy souvent (Philippe de Commynes, Mémoires [1489-1498], IV)

1982 - Un costume par jour pour toute une année, souligne Boss avec une sorte de fierté. Vous pouvez vérifier. Il y a le compte. Jason s'habillait jamais deux fois pareil. Je ne peux m'empêcher de grimacer :

- Et au bout d'un an, qu'est-ce qu'il faisait? Il brûlait tout?

(Philippe Labro, Des bateaux dans la nuit)

Transitif

1877 Cette jeune personne de quinze ans, à qui son père avait légué un peu de ses facultés imaginatives, arrangeait déjà sa vie d'avance et déclarait formellement qu'elle épouserait quelqu'un de la noblesse et n'aurait jamais plus de trois enfants : un garçon pour le nom, et deux petites filles... pour les habiller pareil... (Alphonse Daudet, Le Nabab) 
1976 Ce qui m’a plu c'est qu'il [= papa] avait gardé son blouson et sa chemise en jean comme les cow-boys, il était pas habillé pareil que les autres et ça prouvait qu'il s'en faisait pas, que c'était un type décontracté et j'ai été fier (Patrick Cauvin, Monsieur Papa)

CoRpus WeB :

Cela fait trois ans que Matilda Kahl s'habille pareil tous les jours, pour aller travailler. Mais pourquoi donc ? [http://www.grazia.fr/ au-quotidien/what-the-buzz/galeries/maispourquoi-cette-jeune-femme-s-habille-t-ellepareil-tous-les-jours-depuis-3-753286] (30.5.2015)

Pour ou contre : mère et filles peuventelles s'habiller pareil ? [http://www.dressingdes modeuses.com/?p=409] (30.5.2015)

Pour éviter qu'en cas de montage, il y ait une différence dans les vêtements des jurés, la production a décidé de les habiller pareil pendant les quatre émissions consacrées aux auditions à l'aveugle [http://www.voici.fr/tv-tele-realite/ news-tv-tele-realite/the-voice-pourquoi-lejury-est-tout-le-temps-habille-pareil-443008] (30.5.2015)

j’ai 15 ans et ma mère 29 (oui elle est jeune, elle m'a eu à 14 ans) le problème c qu'elle fait tout comme moi elle s'habille pareille! [http:// www.100drine.be/amis/ma-mere-fais-toutcomme-moi] (30.5.2015)

REMARQUES : Dans le cadre d'une comparaison, habiller pareil désigne le fait de s'habiller de la même manière que quelqu'un (ou soi-même), de porter le même vêtement. Pareil reste invariable dans l'exemple de 1877. Dans les premiers exemples du CW, il ne s'accorde pas avec le sujet au féminin ou pluriel, de même que dans le troisième exemple du CW, où le verbe figure dans son emploi transitif, le modifieur restant invariable malgré l'objet pluriel. Toutefois, dans le dernier exemple du CW, il s'accorde avec le sujet au féminin. Il est modifié par jamais deux fois. Notons l'emploi de vêtir pareil.

\section{Habiller pas cher}

Porter des vêtements bon marché

$\rtimes$ habiller beau et habiller jeune

\section{Habiller pratique}

Porter des vêtements pratiques

Pronominal

1964 Habillez-vous pratique (Étiemble)

\section{Habiller sérieux}

Habiller dans un style sobre et strict

入 habiller beau

\section{Habiller serré}

Porter des vêtements moulants

Pronominal

1848 Il avait entendu dire par une des femmes de la dauphine, nommée Dubois Ménart, qu'elle mangeait trop de pommes vertes et buvait trop de vinaigre, que tantôt elle s'habillait serrée outre mesure, tantôt elle restait sans aucune ceinture (Antoine Le Roux de Lincy, Les Femmes célèbres de l'ancienne France)

1974 Il s'habille serré. Les pectoraux sont en pierre dure sous la chemise empesée par les mains de la Faroles. Son ventre est plat comme une plaine à saccager (José Luis de Vilallonga, Furia)

1990 Elle voudrait se débarrasser des femmes jalouses qui l'insultent parce qu'elle s'habille serré et court et que ça lui va bien (Impressions du Sud)

Transitif

1903 Ceux qui liront cet article devront rappeler leurs souvenirs et chercher au fond de leur mémoire la représentation d'une dame du $\mathrm{XV}^{\mathrm{e}}$ siècle, voilée de blanc, habillée serré, les mains jointes, ayant une sainte Catherine derrière elle (La Revue de l'art ancien et moderne)

1996 Seins à l'air, le bas du corps habillé serré, jupe longe, visage décidé, voire en colère, elle vocifère (Philippe Peissel, Les Natures fondamentales)

CORPUS WEB :

Un homme a t-il besoin de s'habiller serré et coloré pour se sentir beau ? [http://www. seneweb.com/news/Societe/jeans-slim-ou-serrebody-tenue-laquo-pres-du-corps-raquo-bagues- 
bracelets-et-pendentifs-le-cote-effemine-deshommes_n_48909.html] (30.5.2015)

De ton point de vue de métrosexuel, oui, car pour vous les bobos métrosexuels parisiens, la virilité c'est s'habiller serré à la mode comme des grosses tafioles [http://www.jeuxvideo. com/forums/42-51-39546951-2-0-1-0-j-ai-envie-debaiser-korra.htm] (30.5.2015)

Il lance aussi ce conseil à la gent féminine : "Ma sœur, ne crois pas que de t'habiller serré, court et de te parfumer tu vas te trouver un mari [...] Les hommes sont des loups, ils veulent juste prendre ta virginité » [http://plus. lapresse.ca/screens/49b9-7b50-52139193-9edc5a8dac1c606a\%257C_0] (30.5.2015)

(je me sous estime bcp religieusement parlant vu que je suis « nouvelle » dans l'islam) des fois j'ai des envies de me maquiller m'epiler les sourcils m'habiller serrée et sortir comme ça mais dès que j'y pense je me sens mal de suite [https://fr-fr.facebook.com/tchatcheorientale/ posts/919706898080396] (30.5.2015)

REMARQUES : (S')habiller serré réfère à des vêtements portés très près du corps, ajustés, faisant ressortir les formes du corps, la combinaison serré et court (ex. de 1990, troisième ex. du CW) étant considéré comme provocation extrême. Serré tend à l'emploi invariable. L'accord se fait plus facilement quand le groupe adjectival est complexe, comme dans l'exemple de 1848 (" serrée outre mesure »), ou quand l'adjectif-adverbe est détaché du verbe par une virgule (v. exemple sous habiller court), mais on trouve l'accord aussi dans la structure pronominale $\mathrm{du}$ dernier exemple du CW.

\section{Habiller sexy}

Porter une tenue sexy, séduisante

入 habiller joli

\section{Habiller simple}

Porter une tenue simple, souvent modeste, mais aussi « simple et chic »

Pronominal

CORPUS WEB :

Messieurs, vous ne pouvez plus dire qu'il est difficile de s'habiller simple et chic en grande taille homme [http://www.ma-grande-taille. com/shabiller-simple-et-chic-lorsque-lon-est-unhomme-fort-cest-possible-37683] (30.5.2015)
On vous avait dit de vous habiller simple, vous arrivez en jean et blouse et tout le monde s'est mis sur son 32....Aïe ! [http://www.glamourcoaching. fr/2015/04/30/j-adopt-un-look-s-habiller-pourune-c\%C3\%A9r\%C3\%A9monie] (30.5.2015)

j'm trop les mecs qui s'habillent simple et classe comme ça [https://twitter.com/byetohem/ status/584421832360591360/photo/1] (30.5.2015)

Ce qui me gêne, c'est que beaucoup d'entre eux s'habillent simples car ils n'osent peut-être pas mettre en avant leur style, de peur qu'on se moque d'eux [http://www.juliemag.com/ actualites/ton-avis-mode-49098] (30.5.2015)

REMARQUES : S'habiller simple réfère au fait de $s$ 'habiller de manière simple, de porter des vêtements comportant peu d'éléments ajoutés, peu d'ornements, qui ne tapent pas à l'œil, n'attirent pas l'attention. Simple reste invarié, sauf dans le dernier exemple. Notons les collocations s'habiller simple et chic et simple et classe, qui montrent que simple et chic / classe ne sont pas des concepts exclusifs, comme on pourrait l'inférer dans le dernier exemple du CW.

\section{Habiller tapageur}

Vêtir de façon extravagante et criarde Transitif

1982 « Ce sont des gommeux, vous ne voyez pas ? Cette automobile est du plus mauvais goût, et ces gens sont habillés tapageur. C'est la discrétion en tout qui marque la qualité » (Éric Ollivier, L’Orphelin de mer)

\section{Habiller terne}

Porter des vêtements de couleur sombre

$\pi$ habiller triste

\section{Habiller triste}

Habiller de manière terne

Transitif

1964 Ah, ce faux Néron ce magnat de pacotille il a tout d'un souteneur... Et Léo, impassible, se disait il a de l'allure celui-là, habillé triste ça doit être chic, moi ce chic-là je n'en ai pas besoin mais j'aime bien ça chez les autres et ce genre de gars je l'ai à la bonne, beau voûté hargneux, ce genre de gars fin de race je l'inquiète et ça me plaît (Christine de Rivoyre, Les Sultans) 
Pronominal

1987 « La vie est trop courte pour s'habiller triste »: tandis que les signes de la mort disparaissent de l'espace public, le vêtement des deux sexes se met à l'heure du bonheur de masse propre à la société de consommation (Gilles Lipovetsky, L'Empire de l'éphémère)

Corpus Web :

Hum. Donc. C'est pas parce que j'ai bientôt 50 berges que je vais commencer à m'habiller triste (ce qui qui pour le coup serait plutôt en NM !!) et aussi : la vie est trop courte pour passer à côté des bonheurs qu'elle nous offre... [https:// mahieinthesky.wordpress.com/2014/05/12/la-vieest-trop-courte-pour-shabiller-triste] (30.5.2015)

Parce que je suis une fille de la Méditerrannée, j'aime la couleur... les couleurs plutôt... et surtout en hiver, quand tout le monde s'habille triste [http://fr.artesanum.com] (30.5.2015)

Sauf que, alors que les couleurs sont l'apanage des mâles animaux, le mâle humain s'habille triste et terne aujourd'hui [https://trex58. wordpress.com/2009/08/16] (30.5.2015)

J'adore m'habiller de couleurs. Je trouve triste que les gens s'habillent triste [http:// www.dhnet.be/medias/cinema/antoine-je-suissouvent-triste-que-les-gens-s-habillent-triste51b7bd66e4b0de6db98b0e0d] (30.5.2015)

Les jeunes s'habillent tristes et ma fille la première bien que sur elle je ne trouve pas ça triste... va comprendre ! Mais je lui dis souvent qu'elle devrait mettre plus de couleurs... [http:// balconnier.over-blog.com/article-28-et-29janvier-week-end-studieux-et-mesanges-surbalconnier-98102540.html] (30.5.2015)

REMARQues : (S')habiller triste désigne le fait de porter des vêtements aux couleurs ternes, fades ou d'adopter un style ennuyeux, trop classique. Triste reste invariable dans la majorité des cas (v. le troisième exemple du CW, où le sujet est au pluriel), mais dans le dernier exemple du CW, il s'accorde avec le sujet, tout en gardant son interprétation d'adverbe de manière. Notons la collocation s'habiller triste et terne. Selon Noailly (1997a), le slogan La vie est trop courte pour s'habiller triste appartient à la marque New Man.

\author{
Habiller utile \\ Porter des vêtements adaptés (à \\ l'environnement) \\ $\pi$ habiller beau
}

\section{Habiller vieux}

Habiller comme les personnes âgées

$\pi$ habiller classique

\section{Habiter haut}

I. Être localisé dans des sphères supérieures Intransitif

1860 C'est que la pensée du critique vivait au-dessus de son métier. Elle habitait plus haut (Edmond et Jules de Goncourt, Charles Demailly)

II. Habiter à un étage supérieur, dans une zone située en altitude

Intransitif

1874 Une nuit donc, au lieu de se coucher, il éteignit sa lumière, ouvrit sa fenêtre et attendit. Je n'ai pas besoin de vous dire qu'en sa qualité de poète lyrique, mon ami habitait très haut, au niveau des toits. Pendant des heures, il ne vit rien que cette pittoresque étendue de toits serrés

(Alphonse Daudet, Fromont jeune et Risler aîné)

1942 Mais il est des régions habitées plus haut encore : au Pérou et en Bolivie (Jean Brunhes, La Géographie humaine)

2013 E-mail de Marc : " Bonjour à toute la famille. Un petit mot juste pour vous dire que (...) je suis ravissime de ma nouvelle maison. Sans déconner, tous les matins, j'ai les larmes aux yeux en descendant à toute allure (car j'habite très haut) avec le vélo que m'a vendu Carlos » (Mathieu Simonet et Françoise Olivès, Marc Beltra : roman autour d'une disparition)

\section{Hacher dru}

Hacher en grande quantité

$\pi$ trancher dru 


\section{Hacher fin}

Hacher, couper, découper en tout petits

morceaux

Transitif

1761 Hachez le tout assez fin (Samuel Auguste Tissot, Avis au peuple)

1880 C'était, dans un de ces vases allongés dont le couvercle porte un lièvre en faïence, pour indiquer qu'un lièvre en pâté gît au-dessous, une charcuterie succulente, où de blanches rivières de lard traversaient la chair brune du gibier, mêlée à d'autres viandes hachées fin (Guy de Maupassant, Contes et nouvelles)

1936 Elle toucha l'écuelle avec le dos de sa main :

- Parbleu, elle est toute refroidie, votre pâtée! Je vous ai dit : chaude... et aucune graisse, ajouta-t-elle sévèrement, en pointant le doigt vers un fragment degras.

- Du riz, des carottes, et un peu de viande hachée fin. Ça n'est pourtant pas sorcier ! (Roger Martin du Gard, Les Thibault : L'Été 1914)

1939 Hachez fin vos champignons (Gaston Portevin, Ce qu'il faut savoir pour manger les bons champignons)

1964a ajoutez une pincée de persil haché bien fin (Cécile Éluard-Valette, Les Grandes Heures de la cuisine française)

1964b Lorsque votre farce sera bien mêlée, sans grumelots, saupoudrez-la de persil haché très fin, mêlez-y deux ou trois blancs d'œufs fouettés (Cécile Éluard-Valette, Les Grandes Heures de la cuisine française)

CORPUS WEB :

Ensilage de maïs : hacher fin mais pas trop [http://www.bretagne.synagri.com/ synagri/ensilage-de-mais-hacher-fin-mais-pastrop---18092013] (30.5.2015)

Pour la sauce, râper fin le gingembre. Hacher fin la coriandre [http://www.saison.ch/ $\mathrm{fr} /$ recettes/filet-dagneau-et-sauce-au-yogourt-etcurry/detail] (30.5.2015)
Laver la radicchio et la hacher fine [http://yoann.hue.free.fr/oseillerecette2.html] (30.5.2015)

REMARques : Généralement employé dans un contexte culinaire, hacher fin se dit du fait de réduire, de couper en menus morceaux des ingrédients (viande, aromates ou légumes) avec un instrument tranchant. L'adjectif-adverbe fin souligne plus le résultat de l'action de trancher ou couper l'aliment que la précision ou la minutie dans le geste. Dans la majorité des cas, fin reste invariable malgré l'objet au féminin ou au pluriel, mais il s'accorde avec l'objet dans le dernier exemple du CW, insistant ainsi sur le résultat de l'opération. Fin est modifié par assez, bien, très. Notons l'emploi de râper fin.

\section{Hacher menu}

I. Découper en petits morceaux, en fragments Transitif

1393a Prenez .iiii. pongnees de bectes, .ii. pongnees de percil, une pongné de cherfeuil, ung brain de fanoul et deux pongnees d'espinoches, et les esliziez, et lavez en eaue froide, puis hachiez bien menu

(Le Menagier de Paris, p. 250, 27)

$\sim 1393$ b Et nota, en Karesme en lieu d'oeufz et frommage mectez merlus et escheroys cuiz, bien menu hachez, ou char de brocherés ou d'anguilles, figues et dates haschees (Le Menagier de Paris, p. 255, 11)

1603 Pour l'ordinaire, leur donnera-on à manger du mil, panil, orge cuit : parfois des laictues hachées menu, du pain émié avec du caillé ou fourmage mol, des soupes en vin et en laict, et autres viandes que leur changerés selon l'apétit (Olivier de Serres, Le Théâtre d'agriculture et mesnage des champs)

1887 Le mot « pipe » est bien trivial et surtout bien gros pour désigner ce mince tube d'argent, tout droit, au bout duquel, dans un récipient microscopique, on met une seule pincée de tabac blond, haché plus menu que des fils de soie (Pierre Loti, Madame Chrysanthème) 
1948a partout la soldatesque incisait la plante des pieds du captif pour lui fourrer entre la chair et la peau du crin de cheval haché тепu-теnu, et on lui recousait la semelle de la plante des pieds, et on le relâchait sous les risées (Blaise Cendrars, Bourlinguer)

1948b cette démarche clownesque qui faisait déjà rire le soldat de l'empereur, à la haute époque des Ming, et qui s'appelait le « pas du canard chinois », pas chancelant, commun à tous les lecteurs tant soit peu prisonniers de leur vice comme si on leur avait introduit entre l'infundibulum et l'hypophyse des imprimés hachés menu-menu qui leur démangent comme un milliard de fourmis rouges les replis de la cervelle (Blaise Cendrars, Bourlinguer)

1963 Tout ça pour aboutir, sans doute, à la ville, à la maison, où une femme charnue, qu'il ne verrait que jusqu'en dessous des seins, lui donnerait à plat sur le parquet de la cuisine, une assiette en plastique pleine de chair et de légumes hachés menu (JeanMarie Gustave Le Clézio, Le Procès-verbal)

1964 mettez-y des foies de raies, quelques filets d'anchois bien dessalés, un peu d'huile, persil, ciboule, une petite gousse d'ail, échalotes hachées bien menu, des câpres hachées de même, sel, poivre, et une pincée d'épices fines (Cécile ÉluardValette, Les Grandes Heures de la cuisine française)

II. Massacrer cruellement, anéantir par petits morceaux

Transitif

1578 MME L'ADVOCATE. C'est un mestier tres-dangereux

Que la guerre, à ce que je voy.

POTIRON. C'est pour un autre que pour moy.

M. L'ADVOCAT. Et si m’asseura pour le seur

Qu'estant couché derriere un mur

Dessus le ventre en embuscade,

Il survint une canonnade

Droit pardessus un ravelin,
Qui prend le mur et le cousin,

Et les emporta pesle-mesle

Hachez menus comme la gresle

(Rémi Belleau, La Reconnue)

1619 Ce n'est point des galands de France

que j'escris icy les combats ;

laissons le mousquet et la lance,

et ne parlons de ces rabats

hachez menus en pleine ruë

par Ursine qui mort et ruë

(Charles-Timoléon de Sigogne, Satires)

1736 cela trouble un peu son bonheur ; mais enfin, vaille que vaille, il vaut encore mieux pour lui d'être de cette maniere, que s'il étoit haché menu comme tant d'autres (Pierre de Marivaux, Le Télémaque travesti)

1839 En train, animé, ferme et souple, bonne chose que cet article, mais ils le hacheront menu comme courges, car l'instinct carliste s'est réveillé en l'écrivant (Jules Barbey d'Aurevilly, Deuxième Memorandum)

1851 Il avait vu toutes ses ambitions trahies, toutes ses illusions mutilées, toutes ses espérances hachées menu comme chair à pâté (Jules Sandeau, Sacs et parchemins)

1936 Machinalement une secte entière fut désignée, tuée, débitée, comme de la viande, plus l'âme. La fleur d'une époque fut hachée тепu. Cela fit plaisir un instant (Louis-Ferdinand Céline, Mea culpa)

1996 Qu'ils crèvent, les autres ! À cause d'eux, nous nous brisions ? À cause d'eux, nous nous sentions hachés menu et déchiquetés? Alors que notre regard intérieur a la puissance de les pulvériser, tous ; de les anéantir entre le Boris et le moi ? (Boris Schreiber, Un silence d'environ une demi-heure)

III. Couper, interrompre, entrecouper

Transitif

190011 août

Sommeil haché menu en mille petits réveils (Jules Renard, Journal) 
1959 Ce n'est pas une pièce. C’est une kyrielle de petits sketches. C’est haché menu, menu. On n'en tirera pas un sujet de conversation (Le Monde, 12-13 avril 1959 / Grundt : 406)

1963 Le vacarme de la compagnie échauffée par le muscadet, le calvados, le cidre bouché, le champagne, les plaisanteries égrillardes, le tam-tam de la caisse, hachait menu les propos des autres clients qui hurlaient pour se faire entendre, et refoulait Moustapha (Armand Lanoux, Quand la mer se retire)

CORPUS WEB :

Hem : il menaçait de hacher menu les passants [http://www.nordeclair.fr/info-locale/ hem-il-menacait-de-hacher-menu-les-passantsia50b489n717564] (30.5.2015)

«La Gueule de l'emploi » ou comment hacher menu des candidats à un recrutement (diffusion jeudi 6 octobre à $23 \mathrm{H} 10$ sur France 2) [http:// www.lepoint.fr/bourse/la-gueule-de-l-emploiou-comment-hacher-menu-des-candidats-a-unrecrutement-diffusion-jeudi-6-octobre-a-23h10sur-france-2-03-10-2011-1379792_81.php] (30.5.2015)

C'te pub commence a me les hacher menu ! [http://www.jeuxvideo.com/forums/1-1544197784-1-0-1-0-c-te-pub-commence-a-me-les hacher-menu.htm] (30.5.2015)

Y ajouter la carotte, la pomme de terre et l'oignon, tous hachés relativement grossièrement (il est possible de les hacher menus, mais la saveur en est alors moindre) [http://lesdecloitres.fr/lameguina-recette-algerienne] (30.5.2015)

REMARQUES : Hacher menu (I) s'utilise dans le contexte culinaire ou analogue, où il signifie 'hacher finement, réduire, couper en menus morceaux des ingrédients avec un instrument tranchant'. Dans le contexte de la guerre (II), le sujet en construction passive est un être animé blessé, meurtri suite à de nombreuses coupures. Par extension, il prend en charge le sens de 'mettre en pièces, détruire, ravager quelque chose'. Au figuré (III), il désigne le fait de rompre à plusieurs reprises la continuité ou l'unité de quelque chose, de diviser en fragments ou en éléments courts et nombreux. Dans le CW, hacher menu peut également désigner le fait de mettre en difficulté quelqu'un (par exemple un candidat pendant un entretien). Notons la réduplication mепи тепи. Мепи peut s'accorder avec l'objet (ex. de 1578, 1619 et dernier exemple du CW), mais l'accord est minoritaire (v. les trois premiers exemples du CW). Il est modifié par bien, plus. Notons dans l'avant-dernier exemple le tour familier La pub commence à me les hacher menu (à comparer : me les briser menu), sous-entendant « les couilles » comme objet direct.

\section{Hâler profond}

Bronzer fortement, devenir très bronzé

入 cogner dur ; à comparer avec bronzer idiot

\section{Halluciner grave}

Avoir beaucoup d'hallucinations, s'affoler

$\lambda$ sourire jaune

\section{Harmoniser haut}

Harmoniser avec quelque chose de supérieur Pronominal

1898 Ne prenons pas aisément notre parti de n'être pas d'accord avec le génie. J'ai cherché à me compléter avec ce qui ne me faisait pas horreur ; à m'harmoniser plus large et plus haut. J'ai développé en moi le bon sens qui est très puissant dans ma famille et je suis content de savoir la portée qu'il faut lui donner (Maurice Barrès, Mes cahiers)

\section{CORPUS WEB :}

Parce que c'était la première chanson du show, et qu'il prévoyait que sa voix serait encore fragile, altérée par le trac, etc... ? Parce que Jason, pour le coup, ne pouvait harmoniser aussi haut que l'originale ? [http://lpzep9.free. fr/forum/viewtopic.php?f=1\&t=2059\&start=300] (30.5.2015)

Moi en l'écoutant ce qui m'a manqué, après l'exposition du thème c'est, par exemple et de façon non exhaustive un second violon, lointain, en arrière plan... à peine éclairé, qui aurait harmonisé très haut (le violon très aigu me touche) ce que le premier violon exprime [http:// www.tabs4acoustic.com/forum-guitare/blogs/ sweetness-is-a-bitter-word-still-wip-b176-e1132. html] (30.5.2015) 
Le secteur des communications mobiles aura toujours besoin d'un spectre harmonisé plus large pour fournir les avantages économiques et sociaux du haut débit [http://mph. gsma.com/publicpolicy/planning-for-futurespectrum?lang=fr] (1.6.2015)

De plus, cette modernisation doit favoriser à court terme une organisation harmonisée plus large avec les autres prestations sociales disponibles dans le canton de Fribourg ainsi qu'avec les différents partenaires de l'aide sociale à travers l'instauration d'un système d'échange d'informations automatisé [https://www.fr.ch/dsas/files/ pdf4/20090916_cp_rdu_vf.pdf] (1.6.2015)

REMARQUES : Harmoniser haut désigne le fait de se mettre ou d'être en harmonie, en accord avec quelque chose de supérieur au sujet. Dans le CW, il s'utilise aussi dans le domaine de la musique. Notons l'emploi d'harmoniser large. La collocation plus large et plus haut accentue l'idée de surpassement, d'élargissement d'horizon, voire d'une extension supérieure du processus d'harmonisation (dernier exemple du CW). Haut et large restent invariables et peuvent être modifiés par aussi, plus, très.

\section{Harmoniser large}

Harmoniser avec quelque chose de plus étendu $\pi$ harmoniser haut

\section{Hâter fort}

Presser instamment (quelqu'un) d'agir plus vite Transitif

+1249 Quant maladie ces genz prent

Et conscience les reprent

Et Anemis les haste fort,

Qui ja les voudroit trover mort,

Lors si metent lor testament

Sor cele gent que Diex ament

(Rutebeuf, Poèmes [pièces datables de 1249 à 1272], I, p. 274, 117)

+1350 Li autres chevaliers fist autel que fait a : Il point et broche et moult fort le hasta. Et quant Butor le vit, guaires ne le douta ; Quant vint a l'asembler chascun lance bessa,

Et chascun des chevaus teste a teste encontra,
Le hïaume chascuns son compaignon osta ;

Li cheval furent mort, nus des .ij. n'eschapa

(Brun de la Montaigne [ $2^{\mathrm{e}}$ moitié XIV ${ }^{\mathrm{e}}$, 2166)

1476 LA FEMME. Je vous le diray :

En chargeant ung fardeau de draps,

Mon mary si fort me hasta,

Je me baissay ung peu trop bas ;

Adonc quelque chose m'eschapa

Se Dieu me garde de péril

(La Farce nouvelle du Pect [pet] / Ancien

Théâtre françois)

\section{CORpus Web :}

Soudain, elle vit arriver le médecin, qui semblait se hâter fort. Par Dieu, pourvu que rien de fâcheux ne soit advenu ! [http:// affairedespoisons.forumactif.org/t305-onempoisonne-la-reine] (30.5.2015)

Dans les champs, les cultivateurs font la moisson. Ils sont rares à la besogne, mais se hâtent fort [http://www.lavenir.net/cnt/ dmf20140811_00512605] (30.5.2015)

REMARQUES : En construction transitive, usuelle dans la langue ancienne, l'objet désigne une personne que le sujet incite à faire vite, à se presser, se dépêcher. Souvent, le sujet exerce une pression sur quelqu'un, cherche à le provoquer. Les exemples du CW illustrent l'usage actuel, où le verbe apparaît sous sa forme pronominale au sens de 'se dépêcher'. Fort reste invariable et est modifié par moult, si.

\section{Hausser dru}

Porter vers le haut vivement

Transitif

1651 Le seul Ragotin n'avait pas envie de rire et sa colère s'était tournée contre l'Olive qui, s'en sentant injurié, le porta tout brandi, comme l'on dit à Paris, sur le lit que faisait la servante et là, d'une force d'Hercule, il acheva de faire tomber ses chausses, dont la ceinture étoit déjà rompue, et haussant et baissant les mains dru et menu sur ses cuisses, et sur les lieux voisins, en moins de rien les rendit rouges comme de l'écarlate (Scarron, Le Roman comique) 
REMARQUES : En opposition avec le verbe baisser, hausser et baisser dru et menu décrit le fait de baisser puis aussitôt remonter quelque chose (ici : les mains) par de petits mouvements forts et répétés. Notons la collocation dru et menu, où les deux adjectifs-adverbes sont soudés sémantiquement, se complétant mutuellement. Dru et menu restent invariés.

Hausser fort

Hausser fortement (les prix)

$\lambda$ baisser fort

Hausser haut

I. Se vanter

Transitif

1285 Par couvoitise fu cil rois

Sougis a cel tans as Grijois.

Sachiez nus ne doit couvoitier

Pour autrui grever lui haucier,

Et teus se cuide haucier haut

Cui a la fie li piez faut,

Si que quant il cuide estre el mont,

Si se trueve il el val parfont

(Adenet le Roi, Cleomadés, 8983)

II. Trousser

Transitif

$\sim 1460$ Et quant il fut au lieu, il ne demoura gueres après, la semonce de son desir tenant le lieu de mareschal, qu'il ne mist main a la besoigne, et vous assault sa femme, et la porte par terre ; et car alors il estoit bien degois, et sa femme aussi d'autre part, il la voult voir devant et derriere, et de fait prend sa robe et la luy osta, et en cotte simple la mect. Après il la haussa bien haut malgré elle, comme efforcée (Les Cent Nouvelles nouvelles, p. 89, 71)

III. Élever quelque chose/quelqu'un à un niveau supérieur

Transitif

1631 Mon cœur, ne vois-tu pas qu'il seroit necessaire, pour trouver quelquesfois à ton mal guarison, de nous hausser plus haut que ne veut la raison, ce garçon imitant, qui ne creut à son pere ? (Honoré d'Urfé, L'Astrée)
1918 Et Ligier Richier avec une expression solennelle de tristesse et de puissance nous dit : je hausserai le cœur aussi haut qu'une main humaine puisse le dresser (Maurice Barrès, Mes cahiers)

$1957 \mathrm{Au}$ loin la course d'une dernière vague, haussant plus haut l'offrande de son mors... Je t'aime - tu es là - et tout l'immense bonheur d'être qui là fut consommé (Saint-John Perse, Amers)

CORPUS WEB :

Choix on ne peut plus logique! Un champion respectable, respecté et qui risque de hausser haut les couleurs de la France à Sotchi [http://legruppetto.com/forum/viewtopic. php?f=20\&t=508\&view=unread] (30.5.2015)

Pour hausser haut vos couleurs, le mât télescopique T550 est l'outil idéal pour une Plv réussie [http://fun-drapeaux.pavoisement.fr/ mats-et-drapeaux-/fiches-techniques-mats-etdrapeaux/page/12] (30.5.2015)

ResidentEvil 5 va devoir hausser haut la barre pour atteindre ce chef d'oeuvre qu'est Dead Space [http://www.soccers.fr/index.php?showt opic $=112398 \&$ pid $=4457254 \&$ mode $=$ threaded $\&$ st art=] (30.5.2015)

REMARQUES : Hausser haut (I) signifie 'se vanter, se montrer arrogant, voire présomptueux'. En (II), il adopte le sens spécifique de 'trousser'. En (III), il désigne le fait d'élever quelque chose/ quelqu'un à un rang social ou à un niveau de bonheur supérieur. Haut reste invariable malgré l'objet féminin ou pluriel et est modifié par aussi, bien, plus.

\section{Hausser menu}

Hausser quelque chose par petits mouvements répétés

$\lambda$ hausser dru

\section{Hennir clair}

Hennir de façon claire, nette

Intransitif

+1200 a Reprent s alaine, si est bien recovres ;

Il hennist cler con se fust lues getes

Fors de 1 estable et de novel fieres

(Aliscans [R], manuscrit C [XIII $\left.{ }^{\mathrm{e}}\right]$, 550) 
$+1200 b$ Le destrer, ke fu fet a deuz cheynis lier, kant hoy Boun de Hampton nomer, solum son sen grant joie en ad al qer, par mi la curt currit e henist mult cler, kan ke il atent, fit jus cravanter (Bueve de Hanstone [début XIII'], 1443)

REMARQUES : En parlant du cheval, hennir clair désigne le fait de pousser un cri clair, net, bien perceptible. Clair est modifié par moult.

\section{Heurter fort}

I. Heurter avec force, frapper violemment Transitif

+1250a Quant Ysengrin vit l'uis overt, Et li vilein felun cuvert

A cuinnies et a macues

Vienent corant parmi les rues,

Entre la porte et le vilein

Fet Ysengrin nn [sic] saut a plein.

Si fort le horte qu'il l'abat

En une fange trestot plat (Le Roman de

Renart [ $2^{\mathrm{e}}$ moitié XIII $\left.{ }^{\mathrm{e}}\right]$, Ib, 2588)

Intransitif

$\sim 1250 \mathrm{~b}$ Les lances brisent par esfors.

D'escuz, de chevaus et de cors

Hurtent andui tant fort ensenbre, Quant li uns a l'autre asenbre (Joufroi de Poitiers, 463)

1275 S'espee e ses escuz li vole

Des poinz, tant fort i a hurté [variante : si fort] (Jehan de Meun, Roman de la rose [1269-1278], 15607)

Pronominal (réciproque)

1300 Par tel vertu les ont li hautferrant porté

Que il sont droit venu et moult bien encontré.

De leur escus se sont très fort entrehurté ; Si que il sont fendu et tout desbendelé (Fierabras (K), 781)

II. Cogner vivement (à une porte)

Intransitif

1364 Mais ains que je fuisse levés, Uns vallés vint tous abrievés Qui fort hurté a ma porte $h a$ Et une lettre m'apporta

De ma tresdouce dame chiere (Guillaume de Machaut, Le Livre du voir dit, 5754)
CORPUS Web :

J'ai freiné, mais c'était extrêmement glissant - et la voiture a quitté la route. J'ai réussi à la mettre en travers avant de heurter fort un mur de pierres [http://www.autotitre.com/forum/ Sport-Auto/WRC-Rally-Ireland-2007-Attentionce-coup-ci-89734p2.htm] (30.5.2015)

La jeune femme s'avança, toute tremblante vers son patron. Il attendit qu'elle soit à côté de lui pour soudain lever son caducée et la heurter fort à la tête [http://picasso-rouvray-col.spip.acrouen.fr/spip.php?article974] (30.5.2015)

si on tend vers la perfection de notre comportement, de notre personnalité, de notre image de soi morale, on risque de se heurter fort et de se briser fort !!! [http://www.marhba.com/forums/ psychologie-56/parfait-et-perfection-2393-p3. html] (30.5.2015)

REMARQUES : Dans son emploi transitif, heurter fort (I) signifie 'atteindre quelqu'un/quelque chose, faire subir un choc violent à quelqu'un/ quelque chose'. Dans son emploi intransitif ou pronominal, il prend en charge le sens de 'se battre, se frapper l'un l'autre'. (II) désigne le fait de frapper fortement à une porte, pour signaler sa présence, se faire ouvrir. Dans le troisième exemple du CW, le verbe est utilisé au sens figuré, et réfère à la personnalité ou à la morale de quelqu'un. Notons également l'usage de se briser fort ; abattre plat. Fort reste invariable (v. le deuxième exemple du CW, où l'objet est au féminin) et est modifié par si, tant, très.

\section{Heurter menu}

heurter souvent et menu : piquer des éperons

Transitif

+1225 La place fu grans et ygaus,

Et il adrecent les chevals,

Que souvent et menu hurterent.

Les escus des keutes bouterent, Et devant les pis mis les ont (Le Chevalier as deus espees [ $2^{\mathrm{e}}$ quart $\mathrm{XIII}$ ], 5783 )

REMARQUES : Heurter souvent et menu réfère au fait de toucher, d'entrer en contact avec quelque chose/quelqu'un ; ici : de piquer les chevaux des éperons de manière continuelle et rapide. Menu et souvent restent invariés. 


\section{Honnir haut}

Honnir ouvertement, publiquement

$\lambda$ couver bas

\section{Hucher haut}

Appeler en poussant des cris forts

Transitif

1275 Cil vorront ja, s'il pueent, les dames chalengier ;

N'i a celui ne poingne, Dieus les gart d'encombrier!

« Nerbonne » a Aymeri oÿssiés haut huchier, Et « Monjoie » a Guillaume, cui chascuns doit prisier,

« Conmarchis » à Buevon, a Renaut «Montarmier »,

Sanses crie « Borgoigne » et Ponces « Monpellier»,

Et Navaris « Toulouse », ou il n'ot k'ensaignier (Adenet le Roi, Buevon de Conmarchis, 374)

1365 Il ait lou ciel delassus hault appelleit et huchieit. et la terre pour discerneir et iugieir sou pueple (Psautier lorrain, p. 52)

1450 JUDAS. Venez, dyables, venez avant, Venez aidier vostre servant Qui tres hault vous huche et appelle. Venez sa substance mortelle Tuer, destruire et exiller Ou a tout le moins conseiller Comment je m'en despescheray (Arnoul Gréban, Le Mystère de la Passion, 21720)

REMARQUES : Hucher haut désigne le fait de crier, d'appeler quelqu'un à voix forte. Au figuré, il réfère au fait de convoquer, d'inviter quelqu'un. Notons la collocation appeler et hucher haut (appeler haut). Haut est modifié par très.

\section{Hucher soef}

Appeler quelqu'un doucement, sans crier Intransitif

+1234 Ez-vous le tiers prestre, qui huche Tout belement et tout souef

(Huon Piaucele, Estormi [ $2^{\mathrm{e}}$ tiers XIII $\left.{ }^{\mathrm{e}}\right], 228$ )

REMARQUES : Hucher soef désignait le fait d'appeler quelqu'un à voix basse. Au figuré, il prend le sens de convoquer quelqu'un, de l'inviter à venir, d'une voix douce, sans faire de bruit. Soef reste invariable et est modifié par tout. La coordination avec bellement souligne la fonction adverbiale de soef.

\section{Hurler bas}

Hurler à voix basse

Transitif

1850 Une partie de nos ouvriers tremble devant le manque d'ouvrage et se borne à hurler tout bas des menaces fanfaronnes (George Sand, Correspondance)

1947 Je hurlai tout bas :

- Et puis ton mec, j'me le mets sur le bout (Jean Genet, Miracle de la rose)

Intransitif

1962 IRMA. Quant à elle, tu vas lui ordonner de hurler plus bas, la maison est visée (Jean Genet, Le Balcon)

CORPUS WEB :

Un type tombe à bras raccourcis sur un autre, ni problem, je m'installe éventuellement et je profite du beau débat fort. Mais si tout le monde se met à hurler bas ou dru contre les conneries même assez violentes d'un égaré momentané, là je brâme à tout va [http://www.atoute.org/n/ forum/showthread.php?t=103953\&page=14\&hig hlight=blabla] (30.5.2015)

Pas le temps de se poser, il faudrait tout de suite se plonger dans la carte, hésiter entre le poisson et le poulet, prendrons-nous un apéro ?, se retrouver au premier service entre ceux qui hurlent bas et ceux qui écoutent fort, le serveur voulant se débarrasser de nous, parce que les résas du second service ne vont pas tarder [http:// monblognotes.over-blog.com/article-2408847. html] (30.5.2015)

Remarques : Hurler bas désigne le fait de pousser des cris en s'efforçant de baisser la voix, pour ne pas se faire entendre d'autrui. Au figuré, il réfère au fait de protester, de réclamer en son for intérieur, sans l'exprimer publiquement. Notons la collocation bas ou dru, exprimant des idées contraires, et l'emploi de écouter fort dans le deuxième exemple du CW. Bas reste invariable et est modifié par plus, tout.

\section{Hurler dru}

Hurler fort

$\lambda$ hurler bas 


\section{Ignorer bête}

Ignorer stupidement, bêtement

$\lambda$ ignorer haut

\section{Ignorer court}

ignorer haut et court : ignorer totalement

$\lambda$ ignorer haut

\section{Ignorer haut}

Ignorer manifestement (un fait)

Emploi absolu

1938 Si c'est bien là, messieurs, le rôle d'ingénu à quoi le comité me destine, je suis aussitôt à mon aise, et je sais ce que je viens faire : je viens ignorer tout haut (Paul Valéry, Variété IV)

\section{Corpus Web :}

Si les gens préfèrent ne pas se prendre la tête et ne plus RP avec moi, soit. Mais je n'ai encore jamais eu personne me déclarer clairement qu'il déciderait de m'ignorer haut et court [http:// nidhogg.forumactif.org/t70p15-concernant-laguilde-cirel] (30.5.2015)

on roulais pépère à $160 \mathrm{~km} / \mathrm{h}$ sur les autoroutes, à 90 en ville, en ignorant haut et bête les panneaux de signalisation, et en klaxonnant les faux derch qui ce la jouaient à respecter la règlementation... [http://forum.sadur.org/viewtopic. php?t=4587] (30.5.2015)

REMARQUeS : Ignorer haut désigne le fait de ne pas (re)connaitre quelque chose, ou ne pas considérer quelqu'un/quelque chose ouvertement, voire de bouder ouvertement quelqu'un. Le CW illustre l'emploi transitif du verbe. Notons les collocations haut et court et haut et bête. La collocation usuelle haut et court est emphatique, court n'ayant pas un sens clairement identifiable. Haut reste invariable et est modifié par tout.

\section{Imaginer fort}

Imaginer fortement

Transitif

+1365 Et je imagine bien fort

Le gent corps et le bel deport

(Jean Froissart, Poésies [3e tiers XIV]])

\section{CORPuS Web :}

Bon, forcément, l'explosion en sanglots c'est tout de suite moins bien qu'en images, mais faut se l'imaginer fort fort fort hein, pasque moi, Lapin je l'aime ('fin l'ours verte surtout...) et ça fait longtemps qu'il me fait aller du rire aux larmes [http://www.lapin.org/index. php?comms=yes\&number=1] (30.5.2015)

C'est comme dans le film du capitaine crochet faut $s$ imaginer fort fort fort la bouffe pis elle apparais !! [https://www.youtube.com/ watch? $v=$ LKnWS-ivlWw\&index=31\&list=PLC2E9 7832BEF9F49C] (30.5.2015)

L'important est de s'imaginer fort face à une maladie faible. Il arrive aussi que certaines personnes aient des visualisations involontaires et spontanées les aidant parfois à découvrir la cause ou le remède au mal dont ils souffrent [http:// www.santenaturellement.com/Visualisation. $\mathrm{htm}]$ (30.5.2015)

Le clapotis plastique de mes doigts sur ce putain de clavier me remonte à l'âme comme les godillots martelant les flaques sur les chemins de ronde... Ma forteresse s'épuise à s'imaginer forte, tandis que le désordre m'envahit par cascades fumantes... [http://www.atramenta.net/lire/ oeuvre37522-chapitre236954.html] (30.5.2015)

REMARQues : Imaginer fort désigne le fait de se représenter quelque chose en pensées avec force, avec beaucoup de détails et de précision. Fort reste invariable dans son emploi adverbial (v. le premier exemple du CW). Mais quand il est pris au sens de 'quelqu'un s'imagine être fort', il devient un prédicat second qui tend à l'accord (deux derniers exemples du CW). Notons la réduplication fort fort et l'emploi pronominal du verbe dans le CW. Fort est modifié par bien.

\section{Importer tout rond}

Faire venir sans hésiter

Transitif

1972 Gobineau a tout simplement servi de bouc émissaire... Malgré ces deux excellents ouvrages, le poids n'y était pas. Alors on a importé tout rond un écrivain français, Hervé Bazin, le neveu de l'illustre René Bazin (Le Maclean)

REMARQUES : Importer tout rond figure dans un magazine franco-canadien où il renvoie au fait de faire venir quelqu'un de France par une action immédiate, sans autre forme de procès 
('directement, sans plus'). Il s'agit d'une combinaison libre du modifieur lexicalisé tout rond qui connaît plusieurs acceptions contextuelles : 'entièrement' (avaler tout rond), 'directement / sans plus' (comme dans l'exemple), 'sans se faire des soucis / sans gêne’ (dire / voler tout rond).

\section{Imprimer fin}

Imprimer en petites lettres, en petits caractères Transitif

190816 mai 1908.

Les gouvernantes qui lisent, sur un banc, des livres imprimés toujours très fin. Elles s’abîment les yeux (Jules Renard, Journal)

1911 Et les pilules coûtent cher, dans des boîtes avec des cachets, et dedans, sur papier pelure, des prospectus imprimés fin, où il $\mathrm{y}$ a des lettres de malades guéris (Charles-Ferdinand Ramuz, Aimé Pache, peintre vaudois)

1957 un livre de 500 pages, imprimé très fin (Exemple entendu, 27 novembre 1957 / Grundt : 407)

CORPUS Web :

Un post-it blanc sur la partie à aligner, il suffit de projeter l'image de la cible sur le postit. En imprimant fin et en ajustant la netteté, tu as une précision très en dessous du mm [http:// barduport.forumactif.org/t1275-pas-tres-marinmais-nautique-quand-meme-qui-peut-m-aiderdans-mon-choix] (30.5.2015)

Si c'est une $0.4 \mathrm{~mm}$ tu imprime trop fin, il faut que tu imprime en 0.3 [http://forums.reprap. org/read.php?110,463113,463567] (30.5.2015)

C'était une petite Bible de poche, imprimée très fin [http://spirite.free.fr/ouvrages/invisible 18.htm] (30.5.2015)

REMARQUES : Généralement sous la forme d'un participe passé, imprimé fin réfère à un écrit (livre, prospectus) imprimé petit, en petits caractères typographiques. Fin reste invariable. Il est modifié par très. Notons l'emploi de coûter cher.

\section{Incarner faux}

Représenter sans naturel, sans réalisme ou vraisemblance

$\pi$ peindre faux

\section{Incendier ferme}

Se disputer, se quereller fermement

Pronominal

1953 Les greluches d’à côté elles s'incendiaient ferme maintenant (Albert Simonin, Touchez pas au grisbi)

REMARQUES : S’incendier ferme désigne le fait de couvrir, d'accabler quelqu'un de reproches. Sous la forme pronominale, il souligne le caractère réciproque de l'action, ferme renforçant la dureté et la vivacité de la dispute. Ferme reste invarié.

\section{Incliner bas}

s'incliner bas : admirer énormément ; marquer, avoir un profond respect (pour quelque chose ou quelqu'un)

Pronominal

1943 Or j'estime que vous avez agi et parlé en prêtre, et la conscience professionnelle est une qualité aujourd'hui trop rare pour que je ne m'incline pas très bas devant elle, n’importe où je la trouve... vous êtes irré-pro-chable, conclut-il d'un ton sans réplique (Georges Bernanos, Monsieur Ouine)

1958 Un élève du Conservatoire, qui répétait avec lui une pièce de $M$. Jeannot intitulée Le Retour à la terre, déclara un soir avec impétuosité : « Il faut s'incliner très bas devant Ibsen ! » Mon père eut un grand rire : « Eh bien, moi, dit-il, je ne m'incline pas! » (Simone de Beauvoir, Mémoires d’une jeune fille rangée)

\section{CORPUS WEB :}

On ne peut que s'incliner bas devant l'équipe de l'entraîneur fédéral du DTTB, Jörg Rosskopf. Sa domination au niveau européen semble devenir de plus en plus grande [http://fr.butterfly. tt/info/c-e-schwechat-2013/1] (31.5.2015)

Comme tu le sais, je n'ai jamais douté de ton talent mais de là à trouver une correspondance homonymique preque parfaite pour réussir ce défi ultramagnetiquien... Je n'ai plus qu'à m'incliner bas, très bas... [http://www.ultramagnetique. com/les-fleurs-du-dub] (31.5.2015)

Ses cheveux cadrant son visage, elle s'avanca près du couple royale. Elle s'inclina bas [http://orcanie.forumactif.com/t12-festivite-en-1honneur-de-dame-morgause] (31.5.2015) 
REMARQues : Suivi de la préposition devant, s'incliner bas se dit du fait de se courber profondément face à quelqu'un, et, par extension, lui donner des marques de profond respect, d'humilité, reconnaître sa supériorité. Bas reste invariable et est modifié par très. Notons la réduplication progressive bas, très bas.

\section{Incliner profond}

Saluer par une profonde inclinaison

Transitif

1230 Après le fist li enfes de riches dras parer ; Lors n'ot il plus bel home en la crestienté. Atant es Huidelon et son riche barné Qui descendent à terre des destriers sejornés.

Où que il voit Guion, parfont l'a encliné, En son sarasinois mult biau l'a salué

(Gui de Bourgogne, p. 84)

+1250 Et Brun preigne garde des mes,

A la table les face pres.

« Ysengrin, pensez de taillier

Et de la coupe apareillier

Devant vo dame la roïne.

Ysengrin parfont l'en encline » (Le Roman de Renart [2 $2^{\mathrm{e}}$ moitié XIII ${ }^{\mathrm{e}}$, XXIII, 1480)

\section{Corpus Web :}

L'homonyme d'un mot d'une phrase écrite ou même prononcée dépend souvent du récepteur, je devais être fatigué _Duck. Je m'incline profond jusqu'aux mules [http://forum. doctissimo.fr/doctissimo/recits-erotiques/ hetero-termine-sujet_13840_3.htm] (31.5.2015)

Les Cocteau Twins... Voilà un groupe que j’ai raté en concert! $:$ Toutes les pseudo-chanteuses à voix du métal gothique s'inclinent profond devant la voix de Liz Frazer (surtout sur Treasure !) ! [http://www.xsilence.net/forum131129858110.htm?w=radio] (31.5.2015)

La dernière activité enregistrée dans la région fut un tremblement de terre en juillet 1840 dont l'épicentre se situait aux alentours de la gorge d'Ahora, un gouffre incliné profond de 1 $825 \mathrm{~m}$ par rapport au sommet [http://armeniewith-me.skyrock.com/737980247-Mont-Ararat. html] (31.5.2015)

La grotte a une structure en forte pente inclinée profonde d'environ 120m [http://www. info-tourisme-madagascar.com/category/nosregions/sud] (31.5.2015)

REMARQUES : Incliner profond se dit du fait de se courber profondément face à quelqu'un, dans un geste de salutation et/ou de respect. Notons l'emploi pronominal du verbe, plus moderne, dans le CW. Les deux derniers exemples du CW désignent une pente ou un abîme profonds. Profond reste invariable dans la majorité des cas (v. le deuxième exemple du CW), mais dans le dernier exemple du CW il s'accorde avec l'objet au féminin. Notons l'emploi de saluer beau.

\section{Incliner soef}

Incliner doucement, délicatement

Pronominal

+1233 Or ne doit nuns Flori blamer

S'il quiert de son mal medecine.

Souef vers la bele s'encline,

Doucement l'estraint a .II. bras,

En mi la bouche par solas

La baise .VII. fois par loisir (Robert de Blois, Floris et Lyriopé [2 $2^{\mathrm{e}}$ tiers XIII'] ${ }^{\mathrm{e}}$, 964)

REMARQUES : S'incliner soef désignait le fait de se pencher délicatement, lentement vers quelqu'un pour le saluer, lui montrer du respect.

\section{Informer (enformer) dur \\ Donner beaucoup d'informations \\ $\lambda$ enformer dur}

\section{Interroger fort}

(S')interroger beaucoup ; (s')interroger

ouvertement

$\lambda$ interroger haut

\section{Interroger haut}

S'interroger délibérément (sur quelque chose)

Pronominal

1890 Il eut un léger battement de paupières, envahi d'une angoisse sous ce regard qui fouillait son crâne. Sa conscience s'interrogea tout haut (Émile Zola, La Bête humaine)

CoRpus Web :

Emanant d'un petit peuple particulièrement disert, dont la créativité est inversement proportionnelle au nombre, le FTA est un temps où le 
Québec prend sur lui de se parler à lui-même, de s'interroger haut et fort, de s'observer, se rêver, se malmener, s'invectiver et s'oublier - pour mieux se retrouver probablement, se réinventer autrement et ailleurs [http://www.mouvement. net/critiques/critiques/trois-etats-du-quebec] (31.5.2015)

A la veille du 14 juillet, et en plein bras de fer avec Nicolas Sarkozy sur le budget 1994, le ministre de la Défense s'interroge haut et fort sur le bien-fondé de la décision de poursuivre le moratoire sur les essais nucléaires [http://www. lesechos.fr/13/07/1993/LesEchos/16431-034-ECH_ francois-leotard-n-exclut-pas-une-reprise-desessais-nucleaires.htm] (31.5.2015)

Elle quitte la pièce en claquant la porte, laissant une Mylène abasourdie. Celle-ci s'interroge haut et fort : " Mais... Mais qu'est-ce qu'elle a ? » [http://tomtomsblog.canalblog.com/ archives/2012/12/04/25737133.html] (31.5.2015)

REMARQUES : S'interroger haut désigne le fait de se poser à soi-même une ou plusieurs questions de manière consciente et concrète. Notons la collocation haut et fort qui est systématique dans le CW. Haut reste invariable (v. le dernier exemple du CW) et est modifié par tout.

\section{Interrompre net}

Interrompre brutalement, abruptement

Emploi absolu

1843 - Hier j'étais au bal chez Mme la vicomtesse de Beauséant, une cousine à moi, qui possède une maison magnifique, des appartements habillés de soie, enfin qui nous a donné une fête superbe, où je me suis amusé comme un roi...

- Telet, dit Vautrin en interrompant net (Honoré de Balzac, Le Père Goriot)

Transitif

1845 - Diable ! diable !... Écoutez, madame, je vous vois venir..

- Non, monsieur, dit la mère d'Oscar en interrompant net le vieillard, qui par égard pour une belle dame retint le mouvement d'humeur qu'on éprouve à se voir interrompu

(Honoré de Balzac, Un début dans la vie)
1905 Il l'interrompit net:

- Pardon, dit-il, avec une sécheresse glaciale, il faut que je vous quitte

(Romain Rolland, Jean-Christophe. L'Adolescent)

1933 Les petites jambes, dressées vers le plafond, s'incurvaient vers la tête. Les petons retrouvaient les menottes pour une exploration passionnante qu'interrompit net la vue d'un crayon rouge sortant de la poche de l'oncle (Joseph Malègue, Augustin ou Le Maître est là)

1973 Ils ont net interrompu leur engueulade pour me regarder d'un air agacé. Si je les agaçais, ils n'avaient qu'à pas me faire venir, voilà mon sentiment (Jean-Patrick Manchette, Morgue pleine)

1993 J'ai posé la plume, interrompu net mon texte du jour, au thème prémonitoire : message de félicitations au Conseil supérieur du notariat français pour le ving tième anniversaire du fichier central des dernières volontés (Éric Orsenna, Grand Amour)

Pronominal

1884 Lazare qui la soulève, pour qu'elle ne mouille pas ses bottines. Il n'en a pas gros dans les bras, allez ! C'est vrai qu'il y a des hommes qui aiment les os... Véronique s'interrompait net, en sentant près d'elle le tressaillement de Pauline. Sans cesse elle revenait à ce sujet, avec la démangeaison d'en dire davantage (Émile Zola, La Joie de vivre)

1928 L’opérateur, les yeux toujours fixés, j'ignore pourquoi, sur la pendule, lance des appels.

- Il a entendu?

- Non. Mais il parle à Casablanca, on va savoir.

Nous captons en fraude des secrets d'ange. Le crayon hésite, s’abat, cloue une lettre, puis deux, puis dix avec rapidité. Des mots se forment, semblent éclore.

« Note pour Casablanca... » 
Salaud ! Ténériffe nous brouille Agadir ! Sa voix énorme remplit les écouteurs. Elle s'interrompt net.

«... terri six heures trente. Reparti à...» Ténériffe l'intrus nous bouscule encore (Antoine de Saint-Exupéry, Courrier Sud)

1958 Bullit s'interrompit net, et comme pour se punir d'une faute qui m'échappait, mordit brutalement sa lèvre inférieure (Joseph Kessel, Le Lion)

\section{CORpus Web :}

Ainsi en cas de toux sèche (il vaut mieux ne pas interrompre une toux grasse, qui sert à désengorger les bronches), il suffit d'avaler sa salive pour interrompre net la poussée de toux [http:// www.remede-de-grand-mere.fr/2013/01/stoppernet-la-toux] (31.5.2015)

Surgie des coulisses en costume de mousquetaire, Bartoli fait aussitôt délirer la salle, déjà acquise à sa cause : Brava !, Cecilia !, Viva ! fusent de toute part, obligeant l'orchestre à interrompre net l'introduction instrumentale du premier air [http://www.concertonet.com/scripts/review. php?ID_review=9102] (31.5.2015)

Sur les murs de son bureau, dans ses locaux de Void-Vacon dans la Meuse, un cadre façon Wall-street vient rappeler la courbe de croissance de Clair de Lorraine. Une courbe ascendante. Mais qui aurait pu s'interrompre net, en 2008 [http://www.lasemaine.fr/2012/03/01/vincentferry-toujours-un-pas-d-avance] (31.5.2015)

Le terrain a été labouré par des camions de débardage, nous prenons sur la gauche une piste qui part à flanc. Au bout d'un quart d'heure, la piste s'interrompt nette et nous n'avons plus vu de balises rouge et blanche depuis la route... [http:// rando-voyage.over-blog.com/article-hrp-j28-lemas-reste-banyuls-104799288.html] (31.5.2015)

REMARQUES : Interrompre net désigne le fait d'arrêter (quelqu'un) dans son action, dans son activité, de manière brusque et évidente. Dans une conversation, il signifie 'arrêter (quelqu'un) dans son discours, (lui) couper brusquement la parole'. Par extension, il s'applique également dans d'autres domaines comme la santé, la circulation, ou encore la bourse (CW). Net reste invariable dans la majorité des cas, mais il s'accorde avec le sujet dans le dernier exemple du CW. Notons l'antéposition de net dans l'exemple de 1973. Mentionnons l'emploi de en avoir gros dans les bras.

\section{Issir droit}

Sortir juste au moment où quelque chose se passe Intransitif

$\sim 1350$ Moult fuit a grant meschief la duchesse adoubee.

De la citeit issit droit a l'aube crevee ; La ou li joian fuit ait sa voie tornee. Li joians fuit couchiéz droit en une vallee, D'ancoste lui avoit sa haiche et son espee (Lion de Bourges, 1654)

REMARques : On observe déjà très tôt, au XIV ${ }^{e}$ siècle, le déplacement de la modification du verbe, ici : coucher et issir, vers la préposition, ici : droit à/en.

\section{Issir soef}

Sortir lentement, doucement Pronominal

1200 Puis frema bien l'us a la clef De son ostel s'en ist soef (Auberee, 322)

Intransitif

$\sim 1275$ Floriant ist fors de la nef Tout simplement et tot soef, Florete tient par la main nue Qui n'estoit de riens esperdue (Floriant et Florete, 8102)

REMARQUES : Issir soef désignait le fait de quitter un lieu calmement, doucement, précautionneusement. Coordonné avec simplement, soef est modifié par tot. 
Jacasser bas

jacasser tout bas : bavarder à voix basse

$\lambda$ demander haut

\section{Jaillir droit}

Jaillir, fuser directement (vers quelque chose) ou verticalement

Intransitif

1850 Ses yeux, trop petits pour son énorme visage, inclinés comme ceux du cochon, exprimaient à la fois la ruse et la paresse ; mais en ce moment ils [= les yeux] jetaient comme une lueur, tant le regard jaillissait droit sur la rivière (Honoré de Balzac, Les Paysans)

1914 Il était assez fort pour se laisser forger sur cette terrible enclume, comme l'épée tenue à bout de pinces, auprès du feu jaillissant droit sous la poussée du vent brûlant (Ernest Psichari, Le Voyage du centurion)

1938 Les arbres, dans le clair d'étoiles, jaillis saient droit vers le ciel. On ne voyait pas leur ramure, rien que leurs fûts d'une blancheur de pierre (Maurice Genevoix, La Dernière Harde)

1955 L'insuccès, alors, joue pour nous le rôle du gouvernail de profondeur pour l'avion, ou encore, si l'on préfère, du sécateur pour la plante. Il canalise notre sève intérieure, il dégage les «composantes » les plus pures de notre être, de manière à nous faire jaillir plus haut et plus droit. La déchéance, même morale, se change ainsi en une réussite, qui, si spirituelle soit-elle, demeure encore expérimentalement sentie (Pierre Teilhard de Chardin, Le Milieu divin)

\section{CORPUS WEB :}

Lanegan, non moins tourmenté et autodestructeur, sera épargné. " Par la grâce de Dieu », sourit-il. «J'ai eu de la chance de survivre à mes accoutumances. » De la chance et une force intérieure insoupçonnée. Celle qu'il concentre exclusivement dans ce chant qui paraît jaillir droit de ses entrailles [http://www.telerama.fr/ musique/mark-lanegan-chanteur-au-noir,78023. php] (31.5.2015)
Comme on aime vraiment les nombres pairs, ce sont maintenant 4 nouvelles compositions qui bouillonnent suffisamment au cœur de ce nouveau corps pour jaillir droit vers vos oreilles ! [https://fr-fr.facebook.com/permalink. php?story_fbid=10151350853884464\&id=300789 89463\&fref=nf] (31.5.2015)

Superbe album pour les grands et les petits qui recense bon nombre de monstres dont la plupart jaillissent droit de la mythologie antique, quelques autres du cinéma [http://www.noosfere.org/icarus/livres/niourf. asp?numlivre=2146568689] (31.5.2015)

Une puissance jaillie droit des ténèbres les plus profondes et obscure, un art d'une puissance effrayante et sans limite dont le seul nom suffisait à faire trembler quiconque l'entendait de par le monde tant sa capacité était redoutable et effroyable [http://sanctuary-no-teki.forumsactifs.com/ t3173-event-une-bien-calme-journee] (31.5.2015)

Lorsque je baisse son slip sa queue jaillie droite et dure [http://marieetbi.blogspot.co. at/2010_10_01_archive.html?zx=bd9308c6487 6d889] (31.5.2015)

REMARQUES : Jaillir droit désigne le fait de sortir avec force, impétuosité, de manière directe ou suivant une ligne droite ; le sujet réfère à un élément naturel (un arbre ou le feu), à l'être humain ou à son regard, à la chanson, ou, au figuré, à une puissance. Droit peut aussi renvoyer à la verticalité de l'action, idée souvent renforcée par une comparaison (comme un fût, comme un arbre). Cette même idée apparaît dans le dernier exemple du CW, où droit et dur réfèrent au pénis, s'accordant en genre avec queue (prédication seconde). Droit reste tout de même invariable dans la plupart des cas. Droit a tendance à s'associer avec la préposition qui le suit (de, sous, sur, vers), au point de faire partie du groupe prépositionnel comme modifieur de la préposition. Il est modifié par plus.

\section{Jaillir dru}

Fuser, sortir avec vigueur, force, densité Intransitif

1960 ces herbes qui hérissent le sable par touffes espacées, jaillissant dru comme perruques (France-Soir, 4-5 septembre 1960 / Grundt : 227) 
1983 elle n’a pas cherché à le retenir, ou elle n'a pas pu... les mots russes ont jailli durs et drus comme ils sortaient toujours de sa bouche... « podbrossili » un verbe qui littéralement signifie « jeter » (Nathalie Sarraute, Enfance)

\section{CORPUS WEB :}

Le cheveu Nappy est libre d'être lui-même et de jaillir dru et indiscipliné ainsi que se veulent ceux qui l'arborent comme un supposé signe d'affranchissement mental ou de re connection à leurs racines noires [http://gardenactualis. blogspot.co.at/2013/05/dictature-nappy.html] (31.5.2015)

Non ce n'est pas un terrain laissé en jachère... non ce n'est pas un terrain destiné à la viabilisation... non ce n'est pas un terrain sur le bord d'une nationale... les mauvaises herbes qui gagnent tout le site, qui jaillissent dru entre les tombes, c'est bien l'état du cimetière de PontSainte-Maxence... presqu'à l'abandon [http:// www.arnauddumontier.fr/index.php?2011/08] (31.5.2015)

Alors abandonnez-vous à la douce violence de cette musique libre, qui jaillit drue, continue... en suivant la cavalcade endiablée de six vieux amis ! [http://www.sefronia.com/album/ compilation/the_german_jazz_masters.htm] (31.5.2015)

REMARQUES : Jaillir dru désigne le fait de sortir avec force, impétuosité, d'une manière rigide, le sujet étant un inanimé. Dru peut référer à la rudesse de l'action ou au grand nombre de sujets (ici : les herbes, les mots, les cheveux, la musique). Notons l'emploi de jaillir dur, jaillir indiscipliné, jaillir continu. Dru peut s'accorder avec le sujet (ex. de 1983 et le dernier exemple du CW).

\section{Jaillir dur}

Jaillir, sortir avec rudesse

jaillir droit et jaillir dru

\section{Jaillir indiscipliné}

Jaillir dans tous les sens, dans le désordre 入 jaillir dru

\section{Jaser bas}

I. Parler, bavarder à voix basse

Intransitif

1761 L'intrépide Vielard profite de leur chute, leur passe sur le ventre, saute le reste des degrés, arrive dans la cour, va à la principale porte où il trouve un petit groupe de femmes qui jasoient tout bas (Denis Diderot, Lettres à Sophie Volland)

1835 Ils soufflèrent la lampe, et je les entendis rire en jasant tout bas dans l'ombre comme des écoliers. Je me remis à me promener seul sur mon tillac en fumant ma pipe (Alfred de Vigny, Servitude et grandeur militaires)

II. Bruire doucement, faire un bruit léger Intransitif

1842 Un grillon chantait dans un champ voisin, les arbres du chemin jasaient tout bas et tressaillaient au dernier vent du soir avant de s'assoupir ; moi, je regardais attentivement avec les yeux de l'esprit une grande et profonde paix sortir de cette sombre plaine qui a vu César vaincre, Clovis régner et Napoléon chanceler (Victor Hugo, Le Rhin)

REMARQues : Jaser bas (I) désigne le fait de parler beaucoup, bavarder à voix basse, souvent au sujet de commérages. Le sujet sous (II) est une chose produisant un bruit léger et continu, de faible intensité. Bas reste invariable et est modifié par l'adverbe d'intensité tout.

\section{Jaser dru}

Bavarder, causer, babiller beaucoup

Intransitif

1693 Lui qui gouverne l'univers,

J'en puis bien faire autant, moi qu'on sait qui le sers.

Entretenez-moi donc, et sans cérémonie. Caquet bon-bec alors de jaser au plus dru, Sur ceci, sur cela, sur tout. L'homme d'Horace,

Disant le bien, le mal à travers champs, n'eût su

Ce qu'en fait de babil y savait notre Agasse (Jean de La Fontaine, L'Aigle et la pie / Fables) 
CoRpus Web :

c'est vrai que ce " printemps arabe » a suscité beaucoup d'échanges sur les blogs et le net, mais comment être naïf à ce point, sachant que dans l'ombre certains attendaient leur heure. Je me souviens où ça jasait dru [http://helena blue.hautetfort.com/archive/2012/08/19/yoanisanchez.html] (31.5.2015)

REMARQUES : Appartenant au registre familier, jaser dru désigne le fait de parler avec indiscrétion, de faire des commentaires désobligeants et médisants sur quelqu'un, de dénoncer les faits de quelqu'un, $d r u$ soulignant la fréquence ainsi que l'intensité de l'action. Dru reste invariable et est modifié par au plus.

\section{Jaser dur}

Bavarder beaucoup et sévèrement

Intransitif

1954 L'individu vivait d'expédients. On jasait dur sur son compte (Libération, 30 novembre 1954 / Grundt : 243)

Corpus Web :

je pense que tes collègues, même si elles ne te le disent pas, doivent prendre de sacrés fou-rires lorsqu'elles te voient arriver dans tes tenues toutes plus ridicules les une que les autres et ça doit jaser dur dans ta campagne [https://mbasic.facebook.com/profile.php?v= timeline\&timecutoff $=1394296111$ \&page $=3 \&$ sec tionLoadingID =m_timeline_loading_div_1325 404799_1293868800_8_3\&timeend $=13254047$ 99\&timestart $=1293868800 \& \mathrm{tm}=\mathrm{AQAxPTH} 2 \mathrm{~V}$ R9XeMG\&id=108982922507588] (31.5.2015)

Il paraît qu'aucun élu de la majorité Le Brun UMP n’a daigné honorer de sa présence la réception à la mairie des amis de Würselen. Et qu'en conséquence, ça jase dur dans les coulisses du jumelage [http://www.letelegramme.fr/finistere/ morlaix/morlaix-wurselen-une-amitie-solidecomme-1-acier-et-le-granit-13-05-2015-10627648. php] (31.5.2015)

ouaaaaah bah vous jasez dur quand j'ai le dos tourné dites-moi ! [http://www.dukanaute. com/forum/la_liberte_des_uns_commence_ la_ou_s_arrete_celles_des_autres-9576,3.html] (31.5.2015)

Personnellement je trouve que ça colle bien à l'univers, même si le style un peu Wagnerien par moment fera peut-être jaser dur l'éternelle de copie de Tolkien sur le Ring... [http://forum. tolkiendil.com/thread-6568.html] (31.5.2015)

REMARQUES : Jaser dur désigne le fait de bavarder avec indiscrétion, de faire des commentaires désobligeants et médisants sur quelqu'un. Dur reste invariable.

\section{Jeter bas}

I. Jeter à terre, faire tomber

Transitif

1235 Desseure m'avoies montee, Ou j'avoie joie et soulas.

Or m'est vis de si haut si bas

Gietee m'as desous tes piés,

Ne de moi ne te prent pitiés

(Philippe de Remi, sire de Beaumanoir, $L a$ Manekine, 1089)

1580 IOCASTE. Eteocle a fiché sa hache contre terre,

Jetté sa targue bas, ça donc que je vous serre

De mes bras maternels, je ne me puis souler

De vous voir Polynice, et de vous accoler (Robert Garnier, Antigone)

1766 Cela ne fit qu'irriter cette multitude ; mais le redoutable entra dans une telle colère qu'à chaque coup qu'il portait il jetait bas son homme (Henri-Joseph Dulaurens, Le Compère Mathieu)

Pronominal

1676 J'avois déjà receu quelques coups, qui me mettoient tout en sang, lorsque je me jettay bas de dessus elle, et je passay quelque temps à voir leur combat (Gabriel de Foigny, La Terre australe connue)

II. Détruire, réduire à néant, abattre (quelqu'un/quelque chose)

Transitif

1560a Pourtant ce n'est pas sans cause que ceste belle sentence est si souvent répétée en S. Augustin : Que ceux qui maintiennent le libéral-arbitre, le jettent bas en ruine plustost qu'ils ne l'establissent (Jean Calvin, Institution de la religion chrestienne) 
1566 Le Seigneur dresse tes pas, Et jette l'ennemi bas

(Louis Des Masures, David combattant)

1648 CASSANDRE (en colere de chez l'Infante).

Et bien Madame, il faut se resoudre

À voir sur nostre sort tomber ce coup de foudre ;

Un fruict de vostre advis s'il nous jette si bas,

Et que la cheute au moins ne nous surprendra pas (Jean de Rotrou, Venceslas)

1697 Ah ! pour tenter encor de nouvelles conquêtes,

Quand je ne verrois pas des routes toutes prêtes,

Quand le sort ennemi m'auroit jeté plus bas,

Vaincu, persécuté, sans secours, sans États,

Errant de mers en mers, et moins roi que pirate,

Conservant pour tous biens le nom de Mithridate,

Apprenez que suivi d'un nom si glorieux, Partout de l'univers j'attacherois les yeux (Jean Racine, Mithridate)

1848 Bonaparte était si aimé que pendant quelques instants Paris fut dans la joie, excepté les autorités burlesquement arrêtées. Un souffle avait presque jeté bas l'Empire. Évadé de prison à minuit, un soldat était maître du monde au point du jour ; un songe fut près d'emporter une réalité formidable (François de Chateaubriand, Mémoires d'outre-tombe)

1864 Il y a à cette heure beaucoup de bonne destruction de faite ; toute la vieille civilisation encombrante est, grâce à nos pères, déblayée. C'est bien, c'est fini, c'est jeté bas, c'est à terre. Maintenant, debout tous, à l'œuvre, au travail, à la fatigue, au devoir, intelligences ! il s'agit de construire (Victor Hugo, William Shakespeare)

1883 Et voilà où nous en sommes, en l'an de grâce 1879 , alors que le naturalisme a essayé de jeter bas toutes les vieilles conventions et toutes les vieilles formules (Joris-Karl Huysmans, L’Art moderne)
1913 C'est l'automne, la saison où, sous un soleil refroidi, chacun recueille ce qu'il a semé. Mais Léopold, à cinquante ans, jette bas ses œuvres, coupe ses ombrages et promène le soc de la charrue sur ce qui faisait l'objet de sa tendresse (Maurice Barrès, La Colline inspirée)

1947 Tu comprends, ils ont vaguement saisi que leur révolution, c'était des bourdes... Qu'il fallait au-dessus du peuple une caste, une aristocratie... Aussi ils n'avaient pas plus tôt jeté bas la monarchie, qu'ils ont inventé leur noblesse de casino, les Murat, les que sais-je ? (Louis Aragon, Les Voyageurs de l'impériale)

III. jeter bas les armes : s'avouer vaincu, capituler

Transitif

1560b Car si la discipline Chrestienne, comme dit sainct Augustin, condamnoit toutes guerres, S. Jean Baptiste eust donné conseil aux gendarmes qui vindrent à luy pour s'enquérir de leur salut, de jetter les armes bas et renoncer du tout à telle vocation (Jean Calvin, Institution de la religion chrestienne)

1604 Nostre Ost qui plus la mort que la honte redoute

Laisse tout cependant, se met à vauderoute, Et d'un cœur esperdu jette les armes bas, Pour fuir à la mort qu'il rencontre en ses pas (Antoine de Montchrestien, Hector)

1959 Combien de fois, devant cet air qu'elle a quand elle observe les gens, confortablement installée à l'écart, un air sûr de soi, satisfait, borné, il s'est senti poussé à jeter bas toutes ses armes, à aller vers elle... (Nathalie Sarraute, Le Planétarium)

IV. Enlever, abandonner, délaisser (quelque chose)

Transitif

1833 Puisqu'il n’y a plus dans nos rues à voir passer ni rois, ni fiancés d'amour, jetons bas nos terrasses et nos balcons (Edgar Quinet, Ahasvérus) 
1910 Vous jeté bas les idoles, Vous avez déposé tous ces puissants de leur siège,

Et vous avez voulu pour serviteurs la flamme elle-même du feu !

(Paul Claudel, Cinq Grandes Odes)

V. Dire à voix basse, en murmurant Pronominal

1882 Le lendemain, elle venait me voir au ministère, et elle y revint si souvent que les huissiers, ayant appris à la connaître, se jetaient tout bas de l'un à l'autre, en l'apercevant, le nom dont ils l'avaient baptisée : " Madame Léon » (Guy de Maupassant, Contes et nouvelles)

VI. Laisser, abandonner

Transitif

1943 Il pouvait être si fragile s'il choisissait de jeter bas toutes ses défenses et ses armes (Simone de Beauvoir, L'Invitée)

VII. jeter bas les masques : se montrer tel qu'on est

Transitif

1992 L'homme, du même coup, est débarrassé de son carcan : l'obligation d'être à la hauteur de l'image dominante. Il pourra jeter bas les masques. Et oublier les fatigues de la virilité triomphante, mythe boomerang... (Gisèle Halimi, La Cause des femmes)

\section{CORPUS WEB :}

Prosper Mérimée sauva le 5 dernières tours, qu'on voulait aussi jeter bas [http:// www.sisteron.fr/pages/visiter_sisteron/index. php?pg=pat_tours\&sm=patrimoine \&rub=VS] (31.5.2015)

Ce livre aura atteint son but s'il parvient à jeter bas tous les poncifs, les a priori, les rabâchages et les erreurs dont se charge le mot " moyenâgeux ", où l'on condense tout ce qui relève de l'infamie, de la violence, de l'anarchie ou de l'inculture [http://www.fayard.fr/ces-gensdu-moyen-age-9782818500798] (31.5.2015)

Car pour jeter bas les masques, il est important que le public se reconnaisse sans se sentir jugé, afin d'être amené à se poser uniquement les questions qu'il jugera bon de se poser à ce moment là, au delà du plaisir immédiat de passer une bonne soirée [http://www.paolodoss.be/ spectacles/reve-dange-heureux] (31.5.2015)

Quelques communiqués et proclamations suffisent pour jeter bas la « République populaire et révolutionnaire » : suspension de la Constitution, dissolution des organismes du parti-État et de l'Assemblée nationale, interdiction des organisations de masses, nomination de militaires à tous les postes importants [http://www.omartoure.com/tou_2-7-1_reconstitution-economique. php] (31.5.2015)

Faire rouler la boule de point, la jeter basse et pas trop loin après la ligne de jeu [http:// www.ffsb.asso.fr/page.php?P=fo/public/menu/ gestion_front/index\&id=173] (31.5.2015)

REMARQues : Jeter bas (I) a le sens de 'laisser tomber sur le sol, jeter à terre’. (II) renvoie au fait de faire tomber brutalement, et par extension, d'anéantir quelqu'un/quelque chose, de tuer quelqu'un. En (III), la locution figée jeter bas les armes a le sens de s'avouer vaincu, dans un contexte de guerre ou autre (ici : sentimental). (IV) signifie 'délaisser, abandonner, rejeter comme encombrant ou inutile'. (V) désigne le fait d'émettre un son, des paroles avec une certaine force, une certaine brusquerie, en gardant toutefois un ton bas, en baissant la voix. Au sens figuré, jeter bas (VI) signifie 'abandonner, rejeter quelque chose (ici : ses défenses)'. La locution jeter bas les masques (VII) implique le fait que le sujet se montre tel qu'il est, révèle ce qu'il cache. Notons la collocation jeter de si haut si bas (ex. de 1235). Bas reste invariable dans la majorité des cas, mais dans le dernier exemple du CW il s'accorde avec l'objet féminin, peut-être pour exclure l'acception directionnelle 'vers le bas' au profit de la position de la boule, mais il faut surtout établir un rapport avec le langage du sport où des tours tel que la balle vole haute sont fréquents. Bas est modifié par plus, si, tout.

\section{Jeter droit}

I. Jeter, lancer selon une ligne droite Transitif

-1200 L'aumosniere a touz les besans A gitiee li marcheans Au plus droit qu'il pot vers la roiche, Si qu'a un rein dou bois acroiche ; 
L'aumoniere remest pandant

Et il ne vont plus atandant

(Guillaume d'Angleterre [fin XII ${ }^{\mathrm{e}}$, 741)

-1300 Lors fait venir avant maint arc et mainte fonde ;

Vers Frans gietent plus droit que ne vole une alonde

(Jehan Bodel, La Chanson des Saisnes [fin XIII ${ }^{\mathrm{e}}$, 4473)

Emploi absolu

1676 Comme l'agresseur jette parfaitement droit, c'est une nécessité ou que tous les coups portent, ou que l'assailly fasse paroître une extrême adresse pour les éviter et les détourner (Gabriel de Foigny, La Terre australe connue)

II. Jeter directement, exactement Transitif

1285 Si tost conme printans passoit

Et li tans d'esté revenoit, Li hons qui ert desus la tour De printans ert de tel atour Que il getoit droit en la main De l'home d'esté tout a plain La ponme que tenue avoit, Et li hom d'esté la getoit Tout droit a l'oume de gaÿn, Quant ses termes avoit pris fin (Adenet le Roi, Cleomadés, 1767)

1623 Il empoigna un tison dont le bout estoit ardent et le jetta droit à la joüe de son ennemy qui en fut blessé jusqu'au sang, puis apres il prit une escabelle dont il commença à parer les revers et les estocades que l'on luy donnoit (Charles Sorel, Les Nouvelles françaises)

1958 Et au lieu de retenir King de toutes ses forces, de toute son âme comme elle l'avait fait jusque-là, elle le lâcha, le poussa, le jeta droit sur l'homme noir (Joseph Kessel, Le Lion)

III. Diriger, envoyer directement (quelqu'un, quelque chose)

Pronominal

1684 D’où vient, par exemple, qu'un Chien à qui on aura donné un coup de pied ne s'en va pas en droite ligne, comme pourroit faire une pure Machine à roües et à ressorts, se rompre la teste contre quelque muraille, ou se jetter tout droit dans quelque precipice suivant l'impression qu'il a receuë (François Bernier, Abrégé de la philosophie de Gassendi)

1911 Avec la poudre sans fumée, le tableau change, c'est l'inconnu complet et persistant. L'engagement du combat rappelle la lutte entre deux aveugles, entre deux adversaires qui se recherchent, mais ne se voient pas. La méthode consistera-t-elle à se jeter droit devant soi, ou à droite ou à gauche, au hasard? (Ferdinand Foch, Des principes de la guerre)

1925 Lui, n’y voyant goutte, perdu à ne savoir où il en était, ne va-t-il pas se jeter droit dans la mare (Henri Pourrat, L'Auberge de la Belle Bergère ou Quand Gaspard de guerre revint)

1939 Et moi je pense : « il y a aussi des somnambules qui vont se jeter droit sous les locomotives » (Antoine de Saint-Exupéry, Terre des hommes)

Transitif

1713 Parmi tant de morceaux de marbre, il y en a eu un qui s'est formé ainsi de luimême ; les pluies et les vents l'ont détaché de la montagne ; un orage très-violent l'a jeté tout droit sur ce piédestal, qui s'étoit préparé de lui-même dans cette place (François de Fénelon, Traité de l'existence et des attributs de Dieu)

1936 que cet exemple nous jette droit en notre périlleux sujet, c'est ce qui montre bien l'ambiguïté de ces émotions élémentaires, et comment l'horreur et le désir se tirent souvent par la main (Alain, Propos)

1947 ALARICA. Tu m'as jeté la lumière droit sur la rétine. Chaque fois, c'est pareil. Je crois qu'au fond tu ne m'aimes pas tant que ça (Jacques Audiberti, Le Mal court / Théâtre)

\section{CORPUS WEB :}

Attention, il y a des piques et d'autres pièges qui peuvent vous mettre en danger. Pourrez-vous 
éviter de vous jeter droit dedans ? [http://www. zebest-3000.com/jeu/roll-me.html] (31.5.2015)

En effet, à peine arrivés à la camionnette, les 4 hommes sont forcés de se jeter à l'intérieur de leur véhicule voyant le danger se jeter droit sur eux [http://www.radetoulonnaise.com/policiersviolemment-agresses-cite] (31.5.2015)

Ils ouvrirent grand les yeux, je profitai de cet instant pour sortir une lame de mon manteau et la jeter droit vers un des hommes, elle se logea dans sa boîte crânienne et le tua sur place [https:// www.fanfiction.net/s/10556892/18/Instinct-deChasse-Saison-4-TW] (31.5.2015)

Slt essaie de ne pas serrer la boule dans ta main de $n$ avoir la pression que au bout des doigts et de la jeter droite voila aplus [http://www. boulistenaute.com/modules/forum_supporters/ viewtopic.php?post_id=164774] (31.5.2015)

REMARQUES : Jeter droit (I) signifie 'jeter, lancer quelque chose de manière parfaitement droite'. (II) a le même sens que (I) mais avec une nuance d'exactitude, l'objet étant envoyé avec précision en un lieu précis. (III) signifie 'envoyer (quelqu'un), lancer (quelque chose) directement vers un lieu'. Sous la forme pronominale, il désigne le fait de sauter, de se laisser choir ou d'aller d'un mouvement précipité vers un lieu. Droit reste invariable dans la majorité des cas, à l'exception du dernier exemple du CW, où il s'accorde avec l'objet au féminin, tout en maintenant l'acception directionnelle ; l'accord est typique des argots du sport. Droit est modifié par au plus, parfaitement, plus, tout. Bas a tendance à s'associer avec la préposition qui le suit $(\grave{a}$, dans, devant, en, sous, sur, vers), au point de faire partie du groupe prépositionnel comme modifieur de la préposition.

\section{Jeter haut}

I. Ambitionner

Transitif

1835 Cette fortune et ces enfants ou les enfants qui résument tout pour lui, deviennent la proie du monde supérieur, auquel il porte ses écus et sa fille, ou son fils élevé au collège, qui, plus instruit que ne l'est son père, jette plus haut ses regards ambitieux (Honoré de Balzac, Histoire des Treize)
II. Dire, proférer quelque chose à voix haute, franchement

Transitif

1860 Il se jeta à une table, et se mit à travailler furieusement, écrivant, écrivant, couvrant en courant des pages d'écriture, et jetant tout haut des mots sans suite en l'air (Edmond et Jules de Goncourt, Charles Demailly)

1880 Ils prirent le train à la station de Villennes, et, dans le wagon, Patissot jetait tout haut les noms de l'illustre peintre et du grand romancier, comme s'ils eussent été ses amis (Guy de Maupassant, Contes et nouvelles)

1891 Et à ce propos, Daudet remémore le cynisme de la parole de Rimbaud, jetée tout haut en plein café et disant de Verlaine : " Qu'il se satisfasse sur moi, très bien! Mais ne veut-il pas que j'exerce sur lui ? Non, non, il est vraiment trop sale et a la peau trop dégoûtante ! » (Edmond et Jules de Goncourt, Journal)

\section{CORpus Web :}

Quand la pression se fait sentir sur la tête et la poitrine, le recul permis remonte les fesses, bascule le corps sur l'avant pour vaincre la pression de l'air. La hauteur est correcte, mais il faut jeter haut le pied pour ne pas griffer le joli tissu de selle [http://www.moto-station.com/ article11042-triumph-street-triple-r-2011-coupde-coeur-.html] (31.5.2015)

Mon Halcón a fait 12 mois, l'un de ses cadeaux a été un freesbi mais je n'ose pas lui jeter haut, pour le moment on a seulement éssayé a la plage et pas plus de $100 \mathrm{~cm}$ [http:// bergersbelgespassion.com/forum/viewtopic. $\mathrm{php} ? \mathrm{f}=6 \& \mathrm{t}=5810]$ (31.5.2015)

un plus grand vient leur faire faire des mouvements de kungfu, avec grands cris à l’appui. Un petit, 5-6 ans, qui a du mal à jeter haut la jambe, séclipse discrètement pour aller jouer sur la balancelle [http://brigitteji.uniterre.com/264399/ Instantan $\%$ C3\%A9s +de+Tso+Pema.html] (31.5.2015)

Les services du 18 dépassaient le stade du " non-conforme » sincèrement, un lancé pas droit je veux bien mais là le « pas droit » signifiait 
au bas mot $60 \mathrm{~cm}$, et la balle n'étais jetté haute, $30 \mathrm{~cm}$ tout au plus [http://cdn.tennis-de-table. com/forums/sujet-64445-1.html] (31.5.2015)

REMARQUES : Jeter haut (I) s'emploie au sens de 'diriger quelque chose (ici : des regards) vers le haut', et par extension, 'ambitionner, aspirer à quelque chose d'élevé'. (II) désigne le fait d'émettre un son, des paroles avec une certaine force, une certaine brusquerie et ce, en élevant fortement la voix. Les exemples du CW illustrent son usage au sens concret (lever haut le pied ou la jambe, jeter une balle ou un frisbee en hauteur, à distance du sol). Haut reste invariable dans la majorité des cas, mais il s'accorde avec l'objet dans le dernier exemple du CW (argot des sports). Il est modifié par plus, tout.

\section{Jeter intelligent}

Jeter les déchets judicieusement, après

réflexion

$\lambda$ bronzer idiot

\section{Jeter isnel}

Jeter rapidement, promptement

Transitif

-1300 Por Deu, vos proi signor, qui forma Danïel, Que dou borc Saint Herbert la getissiez isnel (Jehan Bodel, La Chanson des Saisnes [fin XIII'], 1646)

REMARQUES : En ancien français, jeter isnel désignait le fait de laisser tomber sur le sol, de jeter à terre rapidement, vivement.

\section{Jeter menu}

I. Façonner finement

Transitif

1185 Il vont a l'imagele, qui par leus est tröee Et ert par artimaire mult menu trasgetee, Qui reçoit le conduit, qui vient par le bäee. Puis estendent les napes sor l'erbe a la rosee (Roman d'Alexandre, 195)

II. Jeter avec fréquence et rapidité Transitif

1190 Et Sarrazins d'amont s'aïrent durement, Plus menu getent pierres que pluie qui cage vent.

Des parens Guenelon i out navré forment (Fierabras (L), 5132)
+1200 Et li rois (toutes) voies, qui de grant cuer et de grant hardement estoit garnis, s'esforce toutes voies et endure que cil giete seur lui menu et souvent, mais il n'ot pas esté si lens qu'il n'ait au chevalier trait assés par pluiseurs parties, car il li ot fait plaies assés, petites et grans (Merlin [1 ${ }^{\text {er }}$ quart XIII ${ }^{e}$, p. 192)

\section{CORPUS WEB :}

Comme écrit dans la postulation de membres, j'offre un coup a toute la tribu, même si je vais me faire jeter menu menu lol [http:// tribalwargods.forumpro.fr/t116-nicomax1] (31.5.2015)

REMARQUes : Jeter menu (I) a le sens de 'façonner finement' et s'applique ici à un ouvrage de métal fondu, coulé dans un moule, éventuellement ciselé (ex. de $\sim 1185$, avec trasgeté [tresgeté]) En (II), il renvoie au fait de lancer, jeter, envoyer à quelque distance de petites choses avec fréquence et rapidité. Notons la collocation menu et souvent renforçant l'idée de continuité de l'action. Menu reste invariable et est modifié par moult, plus. Notons la réduplication de l'adjectif-adverbe dans le $\mathrm{CW}$, où menu menu semble signifier 'aussitôt'.

\section{Jeter soef}

Jeter doucement, délicatement

Transitif

+1225 Et li hermites aporta

I. mantel, et si le gieta

Sour son oste tout souavet.

$\mathrm{Si}$ le couvri, et puis se met

A la voie, et li bers dort tant

Ke la nuis vait ia anientant,

Ki ne li a pas corte esté.

S'estoit ele des nuis d'esté (Le Chevalier as deus espees [ [2 quart $\mathrm{XIII}^{\mathrm{e}}$ ], 3861)

REMARQues : Employé ici sous sa forme diminutive souavet, jeter soef désignait le fait de jeter, de lancer, de poser quelque chose sur les épaules de quelqu'un ou sur quelqu'un (ici : un manteau) avec douceur, précaution. Souavet est modifié par tout. 


\section{Jeter utile}

Jeter de façon à ce que ce que l'on jette puisse être à nouveau utilisé

1991 Jetez utile. Nous recyclons (affiche de la marie de Brest / Noailly 1997a)

Joindre étroit

Lier étroitement

Transitif

1573 EGEE. En fin quand ta langueur bien longuement trainee

D'une tardive mort se verra terminee, Et que fuyant le ciel et les celestes Dieux Tu penseras fuir ton tourment ennuyeux, (Tourment, qui te joindra plus estroit qu'un lierre

Ne joint estroittement les murailles qu'il serre) (Robert Garnier, Hippolyte)

REMARQUES : Joindre étroit désigne le fait de lier, de mettre ensemble deux ou plusieurs choses en les serrant étroitement, en les unissant d'un lien fort. Étroit est modifié par plus. Notons l'emploi parallèle de joindre étroitement.

\section{Joindre fort}

Relier, souder avec force

Transitif

1450 MARDOCEE. Sauldars, prenez le tout batant

Se vous vallez riens, il est vostre.

ROILLART. Qui en doubte qu'il ne soit nostre?

Je luy ay ja lÿé les poins

Si tres destroit et si fort joincts

Que le sang en sault a pissot (Arnoul Gréban, Le Mystère de la Passion, 19153)

\section{CORPUS WEB :}

J'oubliais... ma P'tite Man se joint très fort à moi pour vous féliciter ;-)L'élève est fière d'avoir un maître et mentor aussi talentueux ! Félicitations doublement délivrées ! [https:// www.facebook.com/sandrine.plante.rougeol/ posts/366301173576948] (31.5.2015)

Shining Force est prévu au Japon pour le printemps prochain, et en joignant très fort les mains dans l'espoir d'une sortie en dehors de l'archipel, sachez que le jeu sera présenté lors du très attendu Tôkyô Game Show 2004 qui débutera le 24 septembre [http://www.gamekyo.com/ newsen5895_le-retour-de-shining-force-sur-ps2. html?live=1] (31.5.2015)

Cela dit, espoir, ce soir, il a fait une prière pour que " ma maman trouve du travail », en joignant très fort ses mains et en regardant le ciel, c'était mignon ! [http://lamouettecuisine. blogspot.co.at/2010/05/dieu-dans-les-nuages. html] (31.5.2015)

REMARQUES : Joindre fort désigne le fait de lier, de mettre ensemble deux ou plusieurs choses, notamment les mains, en les serrant fortement, en exerçant une forte pression. Dans le premier exemple du CW, il est utilisé sous la forme pronominale au sens de 's'associer' (quelqu'un se joint à quelqu'un). Notons l'emploi de lier étroit. Fort reste invariable (malgré l'objet au féminin ou pluriel) et est modifié par si, très.

\section{Joster bel}

Combattre admirablement, vaillamment Intransitif

1176 Gauvains li preuz, li alosez, N'est gaires el chanp reposez, Einz broche et point, si s'avencist Et quanque il puet s'agencist De bel joster, s'il trueve a cui (Chrestien de Troyes, Cligés, 4901)

1250 Et cil respons : Cuens de bon ayre, Ge ne vos fail de ceste afaire. Se vos cuidez valoir Rolant, Decha retroveroiz Durant Por grant cous doner et sofrir. Bien savrez d'espee ferir Et de lance trop bel joster S’as armes me cuidez passer ! (Joufroi de Poitiers, 2743)

REMARQUES : Joster bel désignait le fait de combattre à cheval, avec des lances, le sujet étant particulièrement adroit, courageux et plein de bravoure dans le maniement des armes. Le neutre bel marque la fonction adverbiale. Il est modifié par trop.

\section{Joster (jouter) fort}

Combattre avec force

Intransitif

1177 Ronpez le frain et le chevoistre, S'irons tornoiier moi et vos, Que l'an ne vos apiaut jalos. 
Or ne devez vos pas songier,

Mes les tornoiemanz ongier,

Anprandre estorz et fort joster,

Que que il vos doie coster ! (Chrestien de

Troyes, Yvain ou Le Chevalier au lion, 2505)

\section{CORPUS WEB :}

Impro mixte de style libre sur le thème " problème de synchro ». Un délire de la plus belle eau. La maître de jeux corse la partie. Impro comparée, texte imposé : un extrait de «L’Avare». Les Jaunes joutent fort. Plus dur : impro mixte sur le thème de "Livraison spéciale » où Yves Richard, un clin d'œil derrière ses lunettes rondes, décide des entrées et sorties des improvisateurs [http://archives.lesoir.be/innovation-et-succesa-braine-1-alleud-s-enfievrer-d-im_t-19970217ZODAMH.html] (16.6.2015)

REMARques : Dans le contexte militaire, joster fort désignait, en ancien français, le fait de combattre, généralement à cheval et avec des lances, le sujet présentant une grande force et vivacité au combat. Fort reste invariable. L'emploi moderne dans le CW réfère à des personnes qui rivalisent dans le cadre d'un concours d'improvisation.

\section{Jouer ambigu}

Agir de manière équivoque, sans préciser son rôle, ses intentions

Intransitif

2013 L'état [sic] a joué ambigu sur ce dossier (Journal télévisé M6, Corpus Coiffet 2018 : S.v.)

\section{Jouer classique}

Jouer selon un modèle traditionnel, sans

originalité

Intransitif

1957 Nos brechtologues ont reproché à Ernst Busch de jouer trop « classique » en entrant trop dans la peau de son personnage (Express, 24 octobre 1957 / Grundt : 221)

\section{CORPUS WEB :}

après avoir parlé un peu avec des vendeurs, l'avis qui revient le plus souvent est qu'il vaut mieux jouer classique sur une flamenca que l'inverse ; bien entendu dans le cas où l'on reste à un niveau moyen en classique et en flamenco [http://www.guitareclassiquedelcamp.com/ viewtopic.php?t=8496] (1.6.2015)

certains élèves ont une propension naturelle à jouer " classique ", dans une posture très académique ; c'est le cas de pierre, qui, dans ce morceau, s'applique à utiliser un doigté main droite main gauche quasi parfait, avec une précision digne d'un élève modèle de conservatoire [http://daniel-pacault.over-blog.com/2015/01/ pierre-s-applique-a-jouer-classique.html] (1.6.2015)

Et ce que je sais c'est que les français ils jouent comme des gentlemen. Si jamais je joue contre l'un d'eux je ne penserais jamais à le cheese. Ils sont vraiment bon dans l'exécution. Vraiment bon. J'adore les français mais il vaut mieux les jouer classique, comme un gentlemen, ou ca peut mal aller pour vous [http://www. esportsfrance.com/starcraft-2/actualites/23541rencontre-avec-debo-trump] (1.6.2015)

Les rayures se la jouent classiques : bord de mer, rugby...

Qu'importe pourvu qu'elles soient droites.

Les lignes ne prennent pas la fuite, ni le large [http://www.trendydelight.com/classicstripes] (1.6.2015)

REMARQUES : Jouer classique désigne le fait de pratiquer avec mesure un jeu déterminé (ici : sur scène, en musique, dans le sport), d'une manière conforme aux usages, en ne s'écartant pas des règles établies, et, par extension, sans originalité. Le dernier exemple du $\mathrm{CW}$ réfère au domaine de la mode. Classique reste invariable dans la majorité des cas, mais il s'accorde avec le sujet au pluriel dans le dernier exemple du CW. Il est modifié par trop. Notons l'emploi transitif du verbe dans le troisième exemple du CW, ainsi que son emploi pronominal dans le tour se la jouer classique 'affecter d'être classique, se vouloir classique'. Classique apparaît parfois entre guillemets pour signaler son appartenance à un langage ou argot de spécialité.

\section{Jouer coco}

Jouer de manière ridicule

Intransitif

1926 Et ce public de vieilles dames avec des berthes de vraie dentelle, des médail- 
lons, des robes violettes et des capotes de coucou... Au poulailler, des ouvriers qui se tordaient de rire...

- Il est certain, dit Bernard, que le public de Pont-de-l'Eure est peu romantique... Mais il vous trouvait excellente... C'est votre partenaire qui les faisait rire...

- Qui était-ce donc ? Ah ! oui, Ponroy... ce vieux qui a été à l'Odéon. C'est vrai qu'il joue coco et faux... Et il postillonne ! Imaginez comme c'est agréable d'avoir à combiner : « Vous êtes mon lion superbe et généreux » avec : «Comme je voudrais que tu ne me craches pas dans la figure !» (André Maurois, Bernard Quesnay)

\section{CoRpus Web :}

Il joue, $2 \mathrm{CaC}$ moyen sur le percepteur.. Je me dit : Oh ! Il a l'aire de vouloir le tuer.. Je vais la jouer coco. Aucune chance de marcher mais bon! [http://forum.dofus.com/fr/1059-iop/195480mort-stupide\&page=21?page=4] (2.6.2015)

REMARQUES : Jouer coco désigne le fait de pratiquer un jeu déterminé, par extension, jouer sur scène, d'une manière démodée, surannée, à la limite du ridicule. Notons la collocation coco et faux.

\section{Jouer concentré}

Jouer avec une concentration totale Intransitif

$1958 \mathrm{Au}$ contraire M. Henrik Schild fait un Gregers Werlé un peu sec et mince, pour un apôtre dévastateur des vérités nouvelles ; mais il joue concentré et très intelligemment (Le Monde, 17 juin 1958 / Grundt : 255)

\section{CORPUS WeB :}

Re : [Deus] Jouer concentré plutôt qu'étendu par Jer » Ven Jan 30, 2015 22:38

Lors de ma deuxième partie, à 4 joueurs, je m'étais retrouvé bloqué par mes voisins. Je n'ai pas eu le choix et il a fallu que je joue concentré [http://de.trictrac.net/forum/viewtopic.php?f=24 $\& \mathrm{t}=142686 \&$ start $=45 \& \mathrm{sid}=6557 \mathrm{~d} 62490 \mathrm{~b} 22$ decfce 3 9bd98f2a207e] (2.6.2015)

Lorsqu'on peut jouer concentré 1 heure, sans entendre le métronome, c'est qu'on maitrise le tempo. On groove ! [http://www.davideleouet.fr/ david_methode_6_4.html] (2.6.2015)

16 mois que je n'ai pas volé. Bon, il paraît que c'est comme le vélo, quand on sait on sait ! Peut-être, mais je vais quand même me la jouer " concentré » pour ce 1er vol [http://crew26.free. fr/la_reprise.html] (2.6.2015)

Concernant la Ligue 1 , je suis ravi de savoir que Rennes joue demain en dernier face à Montpellier. Ca peut te changer la physionomie d'un match. La jouer décontractée sachant qu'on resterait avec un point d'avance sur les autres. Ou la jouer concentrée face à Montpellier [http://www.yellow-sub.fr/forum/viewtopic. php?f $=10 \& t=112 \&$ start $=7400]$ (2.6.2015)

REMARQUES : Jouer concentré désigne le fait de pratiquer un jeu déterminé d'une manière très appliquée, attentive, et, par extension, il signifie 'jouer sans dévier de sa route, en se fixant un but précis'. Il s'oppose alors logiquement à jouer décontracté (v. dernier exemple du CW). Par contre, dans le premier exemple du CW, jouer concentré s'oppose à jouer étendu ; il est donc pris au sens spatial par rapport à une concentration d'éléments (ici : de joueurs). Notons la locution (se) la jouer décontracté / concentré dans le $\mathrm{CW}$ au sens de 'paraître, se vouloir décontracté / concentré'. Concentré reste invariable dans la majorité des cas, mais il s'accorde avec l'objet au féminin dans le dernier exemple.

\section{Jouer contenu}

Jouer en se retenant d'exprimer (quelque chose) Intransitif

1943 Tu vois, disait Pierre, c'est ce ton-là qu'il faut me donner et alors tu peux jouer aussi contenu que tu veux, je sentirai l'émotion ; si l'émotion n'y est pas, tout est foutu (Simone de Beauvoir, L'Invitée)

REMARQUES : Jouer contenu désigne le fait de pratiquer un jeu déterminé, de jouer un rôle, le sujet se retenant de s'exprimer ; il maitrise ses gestes, ses actes, ses émotions. Contenu est modifié par aussi.

\section{Jouer décontracté}

Jouer d'une manière détendue, sans contrainte $\pi$ jouer concentré 


\section{Jouer dur}

I. Jouer de manière intransigeante Intransitif

1948 - Vous parlez bougrement trop, Marlowe. Dois-je comprendre que vous essayez encore de reconstituer ce puzzle?

- Non. J'ai laissé tomber. On m’a prévenu. Les autres trouvent que je joue trop dur. C'est pourquoi j’ai pensé que je devais vous rendre votre argent

- Parce que selon mes normes personnelles, ce n'est pas un travail terminé (Boris Vian, Le Grand Sommeil [trad.])

\section{Jouer avec combativité}

Intransitif

1959 Les Autrichiens [= une équipe de football] jouent dur (Sélection du Monde, 10-16 décembre 1959 / Grundt : 221)

1963 La CFTC a joué dur, facile et s'est taillé une place (Express, 4 avril 1963 / Grundt : 221)

\section{CORpus WeB :}

Eh bien voila une bonne question ! Je me suis lancee dans le violon en aout 2007 donc recement et bie jai ete extrement surprise de voir que le violon nest pas si difficile que ca et pour cause jai deja joue un concerto de Vivaldi et la je suis en train de dechiffrer du Kreisler. Bien sur si jen suis la cest parce que je sais lire les notes, jouer du piano (depuis 12ans) et surtout que jai envie de jouer dur. Mais attention, je nai nullement dit que le violon etait facile, a chaque instrument sa difficulte, mes premieres notes etaient affreuses mais cest tout a fais normal ! [http://forum.aufeminin. com/forum/loisirs13/_f18634_loisirs13-Est-ildifficile-d-apprendre-le-violon.html] (11.6.2015)

$\mathrm{Au}$ bras de son rockeur de mari, Kate se la joue dure à cuir avec un perfecto et un skinny qui met en valeur sa silhouette menue [http://www. puretrend.com/media/au-bras-de-son-rockeurde-mari-kate-se_m626922] (11.6.2015)

Ça réconcilierait avec la course au large ! Avec un peu de chance, l'aviso militaire va traîner par là et leur balancer une cartouche de cigarettes. S'il faisait beau, ils goûteraient le spectacle, les falaises, la lumière jouant sur les neiges, les îles, les baies. Qu'ils en soient à leur premier ou à leur quatrième passage (comme VDH), qu'ils s'avouent émus ou se la jouent durs et blasés, le mythe les a rattrapés au coin de l'âme et ils rêvent, le nez sur la carte qui dessine la grande pointe [http://www.liberation.fr/sports/1995/02/21/ilstutoient-leur-reve_122553] (11.6.2015)

Céline Dumerc demande le changement à Pierre Vincent au bout de 6 minutes 30. Elles jouent durs les Serbes

\#EuroBasketWomen2013 [https://twitter. com/gabrielpj_/status/346344501285122048] (11.6.2015)

Oui la nature est très bien capable de s'équilibrer elle même, mais on trouve souvent qu'elle joue dure. Exemple le caribou, la chasse de cette espèce n'avait à peu près pas d'impact sur l'état du cheptel, la nature est en train de s'occuper d'eux, on considère çà comme une catastrophe [http://www.chevreuil.net/forums/viewtopic.ph $\mathrm{p} ? \mathrm{f}=35 \& \mathrm{t}=29543 \&$ start $=15 \&$ view=print $](11.6 .2015)$

REMARQUES : Jouer dur (I) s'emploie au sens de 'pratiquer un jeu déterminé de manière inflexible, voire farouche'. Dans le domaine du sport (II), il signifie 'jouer avec ardeur, combativité, ou même agressivité', dans le seul but de gagner la partie. Dans le CW, jouer dur s'utilise également dans le domaine musical, comme simple intensifieur. Notons la locution (se) la jouer (frimer, se prétendre) dur, ou blasé dans le CW. L'accord de dur est optionnel. Dans le deuxième exemple du CW, il fonctionne en tant que prédicat second orienté vers l'objet générique « la » dont il reprend la marque du féminin. On peut y voir également une adverbialisation du nom une dure à cuir (avec le double sens, du moins à l'oral : 'dur à cuire / une qui porte du cuir'). Dans l'exemple suivant, la même construction s'accorde avec le sujet - fait plutôt rare dans la construction " se la + verbe + adjectif-adverbe » (ex. ils se la coulent douce). Dans le quatrième exemple, l'accord est limité au pluriel, sans doute par mégarde (elles jouent dur(e)s les Serbes). Dans le dernier exemple, l'accord est fait pour le féminin. Dur est modifié par trop. Notons l'emploi de jouer facile.

\section{Jouer étendu}

Jouer en laissant beaucoup d'espace entre les

éléments du jeu

入 jouer concentré 


\section{Jouer facile}

Jouer facilement, sans peine, voire sans prendre des risques

Intransitif

1963 La CFTC a joué dur, facile et s'est taillé une place (Express, 4 avril 1963 / Grundt : 221)

CORPuS WeB :

« C'était difficile pour Madrid de jouer avec dix joueurs. Gareth Bale ne leur a rien apporté. Il manquait de confiance et il a joué facile. Ses coéquipiers ne peuvent pas être satisfaits de sa performance, il n'a pris aucun risque. Je suis énervé contre lui et je ne suis même pas impliqué. Il a fait un match de débutant. Ils devraient le lyncher », a déclaré l'ancien rival de Patrick Vieira sur ITV [http://www.goal.com/fr/news/163/liguedes-champions/2015/05/06/11466532/keanetacle-bale-madrid-a-jou $\% \mathrm{C} 3 \% \mathrm{~A} 9-\% \mathrm{C} 3 \% \mathrm{A0}$-dixcontre-la-juventus] (11.6.2015)

L'interprétation instrumentale reste sans failles, les musiciens jouent faciles et les voir sur scène souligne combien Mastodon fait bloc en tant que groupe où chaque membre est même niveau que les trois autres. De fait, le batteur Brann Dailor a des allures de chef d'orchestre depuis son kit, toutes les variations de son jeu anticipent celles des autres instruments, ses breaks indiquent la marche à suivre [http://www. inside-rock.fr/Sonisphere-2011] (11.6.2015)

REMARQUES : Jouer facile réfère soit au fait de jouer sans difficulté, soit au fait de jouer sans tenir compte des risques, par imprudence. L'accord dans le dernier exemple est plutôt exceptionnel ; en tout cas, il est purement graphique.

\section{Jouer faux}

I. Ne pas être dans le ton (d'un musicien), être désaccordé, ne pas sonner juste (d'un instrument)

Intransitif

1755 LE POÈTE. (très-vivement)

Le poète Capraro, à qui l'impuissance de plaire a donné la fureur de nuire, et qui, de temps en temps, s'agite sous le mépris public dont il est couvert, pour tâcher d'en rejeter quelque partie sur les autres : les acteurs enfin, qui ne savaient pas leurs rôles, qui ont joué faux d'un bout à l'autre de la pièce : une actrice sur-tout, à qui j'avais refusé de faire une épigramme contre sa rivale, et qui ne m'a jamais pardonné de l'avoir surprise dans son négligé (Charles Palissot de Montenoy, Le Cercle)

1843 Monsieur de la clarinette, tu joues faux, reprit-il d'une voix enrouée, je te donnerai sur les doigts (Honoré de Balzac, Le Père Goriot)

1846 Deux cors de chasse, deux trombones, deux de ces machines qu'on appelle ophicléides ou sax-horns jouaient horriblement faux et faisaient un bruit désagréable au-dessous de lui (Victor Hugo, Choses vues)

1853 - Allons-nous-en, dit-il ; ordinairement le bal m'égaie, aujourd'hui il me semble que j'ai la jaunisse : le gaz ne brille pas, les femmes sont affreuses, les étudiants bêtes, et la musique joue faux (Champfleury, Les Aventures de mademoiselle Mariette)

1865 Voilà pourquoi il t'a semblé que vos cornemuses jouaient faux (George Sand, Les Maîtres sonneurs)

1926 Et ce public de vieilles dames avec des berthes de vraie dentelle, des médaillons, des robes violettes et des capotes de coucou... Au poulailler, des ouvriers qui se tordaient de rire..

- Il est certain, dit Bernard, que le public de Pont-de-l'Eure est peu romantique... Mais il vous trouvait excellente... C'est votre partenaire qui les faisait rire...

- Qui était-ce donc ? Ah ! oui, Ponroy.. ce vieux qui a été à l'Odéon. C’est vrai qu'il joue coco et faux... Et il postillonne ! Imaginez comme c'est agréable d'avoir à combiner : « Vous êtes mon lion superbe et généreux » avec : " Comme je voudrais que tu ne me craches pas dans la figure! » (André Maurois, Bernard Quesnay)

1961 De ce quatuor [= les acteurs et l'auteur d'un film] c'est à qui jouera, ou écrira, ou dira le plus faux (France observateur, 5 janvier 1961 / Grundt : 378) 
1967 Il faut défiler sur la plage du monde, jouant de la trompette comme les enfants, jouant faux, avec des « couacs » affreux, derrière nos petits drapeaux multicolores, il nous faut y aller, il nous faut jouer au grand jeu de la vie et de la mort, que pourrions-nous faire d'autre? (Michel Bataille, L'Arbre de Noël)

II. Se tromper totalement sur quelque chose Transitif

1946 Mais il peut envahir la vie entière et jouer faux toute la symphonie (Emmanuel Mounier, Traité du caractère)

\section{Corpus Web :}

La prof de ma fille fait chanter ses élèves qui ont du mal (quand ils jouent trop faux, elle leur fait carrémént poser le violon, ils chantent (mieux qu'ils jouent en général), ils reprennent le violon et ça va mieux) [http://forum.le-violon. org/topic6584.html] (11.6.2015)

La position des frettes (ou pourquoi ma guitare joue faux ?)... [http://www.google.fr/ url $\mathrm{sa}=\mathrm{t} \& \mathrm{rct}=\mathrm{j} \& \mathrm{q}=\& \mathrm{esrc}=\mathrm{s} \&$ source $=$ web\& $\mathrm{c}$ $\mathrm{d}=21$ \&ved $=0$ CCAQFjAAOBRqFQ oTCNCElrH th8YCFcPsFAodeBgAlA\&url $=$ http $\% 3 \mathrm{~A} \% 2 \mathrm{~F}$ $\% 2$ Fdmoreau56.free.fr $\% 2$ FSite_musique $\%$ 2FLutherie $\% 2$ FOutils\%2Ffrettesjustes $\% 2 \mathrm{Fg}$ uitare_joue_faux.doc\&ei=k5t5VZDvFsPZU_ iwgKAJ\&usg=AFQjCNFFzV]lCZkkMLNtQL ruabRQyL8CTQ (11.6.2015)

Ce sont des personnages qui jouent une mauvaise comédie : ils s'appliquent à jouer leurs rôles, comme s'ils avaient constamment un regard sarcastique sur leur être propre, comme s'ils ne croyaient pas en eux-mêmes, ce qui se traduit notamment par des gestes saccadés et automatisés où le naturel n'est jamais au rendez-vous, souvent les personnages s'expriment par des mimes peu convaincants et se la jouent faux [http://www.paperblog.fr/5706215/dongiovanni-hermusmoses-stuttgart-juillet-2012] (11.6.2015)

Il est vrai que pour certains instruments qui datent des années 50,60 comme la Centered tone et la série 9, il ya un rique d'avoir des instruments complètement " vidés "... Les perces bougent avec le temps. Certaines d'entres elles jouent fausses. Et puis faut voir les prix complè- tement exorbitant. Mais je dois avouer que j'ai été tenté d'enchérir sur une Centerd Tone vraiment sublime malgré son age... J'ai eu la 10s sur ebay qui avait été complètement révisé. Elle avait son age mais elle jouait tellement bien que je prenais un pied d'enfer ! [http://www.clarinette.net/ forum/phpBB3/viewtopic.php? $\mathrm{f}=1 \& \mathrm{t}=2010 \& \mathrm{st}=0$ $\& \mathrm{sk}=\mathrm{t} \& \mathrm{sd}=\mathrm{a} \& \mathrm{start}=30]$ (11.6.2015)

REMARQUeS : Jouer faux (I) signifie 'jouer d'un instrument en faisant sortir des sons faux, qui ne sont pas juste, pas dans le ton'. Dans le contexte de la scène, il a le sens de 'représenter un personnage d'une manière peu authentique, peu naturelle ; jouer mal'. (II) désigne le fait de fausser complètement quelque chose. Notons l'usage de écrire faux, et dire faux (exemple de 1961), ainsi que la collocation coco et faux (exemple de 1926). Faux reste invariable dans la majorité des cas, mais dans le dernier exemple du CW il s'accorde avec le sujet féminin pluriel tout en gardant son interprétation d'adverbe de manière. Il est modifié par horriblement, le plus, trop. VoIR AUSSI : peindre faux

\section{Jouer fin}

I. Jouer avec finesse, avec sensibilité Intransitif

1954 M. Jacques Joignant n'a pas le physique femmelin que pourrait avoir Albert ; mais il joue fin, même dans la hideuse scène finale (Le Monde, 1 décembre 1954 / Grundt : 408)

Transitif

1958 Elle joue fin un rôle qui risquerait d'être antipathique, ou tout au moins indécis (Le Monde, 31 octobre 1958 / Grundt : 408)

II. la jouer fine / jouer fin : agir de manière rusée, habilement

Intransitif

1982 - Oui, dit-il.

Mais il ne cilla pas, Joyce en ressentit comme une nouvelle insulte, une petite défaite. Ça devenait serré et trop subtil. Elle ne voulait pas jouer aussi fin. Il était plus simple de haïr Drifter en bloc, sans tenter des manipulations que son esprit, à présent trop perturbé par le mélange de drogue et d'alcool, et par l'exacerbation de 
ses propres sentiments, n'arrivait plus à organiser et décomposer (Philippe Labro, Des bateaux dans la nuit)

Transitif

1985a Alain Pacadis, qui avait cru la jouer fine en se joignant à notre groupe, dodeline dans son coin (Philippe Manœuvre, L'Enfant du rock)

1985b Qu'est-ce que vous lui donnez... ? Je savais pas si je tremblais des pieds à la tête ou si c'était qu'une sale impression. L'autre a essayé de la jouer fine. Il a attrapé le grand coupe-papier qui traînait sur le bureau et a fait celui qui s’amusait avec (Philippe Djian, $37^{\circ} 2$ le matin)

1981 Litronner tristos dans un bar ça reste un acte tristos. Mais litronner seul devant sa télé sans rien autour sans spectateurs ça c'est jouer fin ses fleurs du mal (Evane Hanska, J'arrête pas de t'aimer)

\section{CORPUS WEB :}

Québec : le conflit étudiant passe au second plan derrière les calculs politiques. La droite, comme les souverainistes, la jouent fine pour remporter les élections générales [http://leplus. nouvelobs.com/etienneschmitt] (11.6.2015)

Après, y’a l'effet de la rentrée où tout le monde lâche l'affaire... ou vend pour avoir du pognon. En octobre, y’a les impôts et la TVA, je crois ? Après... on pourra peut-être compter sur quelques faillites pour assaisonner la sauce mondiale... ::) je compterai pas trop dessus avant 2015 car s’ils ont passé les vacances, ils arrivent souvent à la fin de l'année s'ils la jouent fine (et planqué) [https://bitcointalk.org/index. php?topic=525061.1055;wap2] (11.6.2015)

Tsipras joue fin et bien. L'Union européenne entre dans une grande zone de turbulences du fait de la sottise de ceux qui la dirigent de façon si grossière et brutale. Je détaille ma façon de lire la séquence en cours. Je reviens aussi sur la trouvaille de Hollande qui remet sur le tapis la question des articles anticonstitutionnels de la Charte des langues régionales [http://www.jean-lucmelenchon.fr/2015/06/09/lunion-europeenneprise-a-son-propre-piege-grec] (15.6.2015)
Actuellement, les Chinois sont les premiers détenteurs de bons du Trésor américain (la dette américaine). Si l'économie US coulait, ils en seraient la première victime, d'où - 1) un délestage discret de ces bons (pas faire s'effondrer la cote par des ventes massives) - 2) des achats massifs et continus d'or pour valoriser un yuan qui prendrait, à terme, la place du dollar. Reste à avoir l'instrument pour gérer tous ces projets et c'est là que les Chinois jouent fin : au lieu d'y aller frontalement (yuan vs dollar) ils invitent un maximum de pays dans l'aventure, avec une promesse de gagnant-gagnant qui change (pour l'instant) des orientations et des exigences de la troïka Banque Mondiale/FMI/BAD [http://www.agoravox.fr/ spip.php? page $=$ forum\&id_article $=165710 \& i d$ forum $=4282614]$ (15.6.2015)

De quelles regles tu parle?

Si Thiriez dit qu'ils peuvent jouer, ils jouent fin pourquoi vouloir gagner le titre avec ça alors que si ils donnent tout et que le PSG fait un mauvais pas, ils ont des chances [http://www. jeuxvideo.com/forums/42-20-39443544-2-0-1-0-ilparait-qu-on-a-entendu-des-aulas-encule.htm] (15.6.2015)

Silva loupe des passes, fait des mauvais choix, Nasri est invisible, Balotelli se fait conspuer de partout, Yaya Touré court dans le vide, bref, le bateau Citizen coule lentement. De leurs côtés, les Swans jouent fins et finissent par trouver le chemin des filets. (81) Luke Moore (trois buts en deux ans) remplaçait Graham puis s'en allait placer une tête rageuse au second poteau sur un beau centre de Routledge [https://onlysportall. wordpress.com/2012/03/11/swansea-la-fierte-ducygne-pas-son-arrogance] (15.6.2015)

REMARques : Dans le contexte de la scène (I), jouer fin désigne le fait de représenter un personnage d'une manière subtile, sensible ou avec précision et habileté. Notons que le verbe peut avoir un emploi transitif ou intransitif, l'objet renvoyant toujours à un rôle. (II) réfère à une affaire réglée ou traitée avec habileté ou ruse. Dans le troisième et quatrième exemple du CW, jouer fin s’applique aux enjeux politiques raffinés, tandis que dans les deux derniers exemples, il s'emploie dans le domaine du sport. Sous la forme transitive, fin (II) s'accorde au féminin avec l'objet pro- 
nominal féminin postiche qui renvoie à l'affaire en question selon le schéma (se) la jouer fine. C'est également le cas dans les deux premiers exemples du CW appartenant au domaine politique ou économique. Dans le dernier exemple $\mathrm{du}$ CW, fin s'accorde avec le sujet pluriel, insistant ainsi sur la finesse de joueurs. Fin est modifié par aussi. Notons la collocation se la jouer fine et planqué 'rusé et bien caché' (second exemple $\mathrm{du} \mathrm{CW}$ ). Mentionnons également l'emploi de litronner 'boire beaucoup (d'alcool)' seul, litronner tristos.

\section{Jouer fonctionnel}

Jouer en fonction du strictement nécessaire $\pi$ jouer gai

\section{Jouer fort}

Jouer avec force; jouer avec une grande intensité

$\pi$ jouer sec

\section{Jouer franc}

Jouer de manière ouverte, franche et vive Intransitif

1914 - Et, moi aussi, on me connaît. J'ai pas d'homme, la Vache, et tu râles parce qu'il faut, avec moi, jouer franc. Renaude pas, tu te vendrais (Francis Carco, Jésus-laCaille)

\section{CORPUS WEB :}

D'ailleurs grace à Albi, le seul joueur au pied qu’avait aurillac a été séché volontairement avec l'accord de Méné au bout de 5 minutes de jeu. Un blessé pour minimum 3 semaines. Deuxième blessé : Boukanoucha : fourchette absent également pour 3 semaines (mais j'en suis pas sur. Mais apparement il aurait porté plainte. (chose en quoi il a raison). donc on peut aimer Albi, mais préfère les voyoux de Toulon qui se la jouent francs [http://forums.rugbyrama.fr/showthread. php?t=16001\&page=9] (15.6.2015)

Au fil de son histoire, l'équipe a aussi participé à quelques reprises au tournoi de renom «Golden Boy ». Sans avoir remporté ce tournoi, plusieurs prix nous furent accordés, notamment celui de l'esprit sportif qui nous a été décerné deux fois. Ces accolades nous peignent comme étant des adversaires qui jouent franc. Nous avons établi une bonne réputation dans la région dont nous pouvons être fiers [http://journalcsea. ednet.ns.ca/les-gaulois] (15.6.2015)

la jument aurélie.... plus je la vois plus je vois sa méchanceté, quelle jalouse elle est grosse et sa haine est visible, et la amélie qui dit a marie : va dans ta chambre comme si elle parlait a son fils, tetes a claques les 2 belges, des hypocrites mauvaises qui se la jouent franches, pfff des hystériques a la grande gueule et c'est tout.... [http:// www.gossip.fr/record-d-audiences-pour-lesanges-de-la-telerealite---5538.html] (15.6.2015)

Agafia improvise, peu importe d'où cela vient et où cela va. Leurs interventions ne sont pas de simples moments de musique : elles disent des choses - attention, elles ne racontent rien : c'est de la musique, tout de même - mais elles signifient assez clairement pour que le public sourie, rie franchement ou reste perplexe : la musique peut aussi poser des questions ou énoncer des paradoxes. Mieux encore : ce duo respire la liberté, on ne sait pas comment : peut-être dans leur façon d'être quand ils jouent, francs et directs, sans une once d'épate [http://linoleumproductions.free.fr/spip/spip. php?article57\&lang=fr] (15.6.2015)

REMARQUES : Jouer franc désigne le fait de pratiquer un jeu déterminé d'une manière fair-play, ou, par extension, de se conduire franchement, honnêtement, naturellement. Franc reste invariable dans la majorité des cas. Dans le CW, faisant partie de la locution se la jouer franc (la référant à un concept abstrait), il peut s'accorder avec le sujet pluriel ou féminin. Dans l'avantdernier exemple du CW, se la jouer franc signifierait plutôt 'sans vergogne', mener son jeu hypocrite au grand jour. Dans le dernier exemple $\mathrm{du}$ CW, les adjectifs franc et direct remplissent la fonction de prédicat second orienté vers le sujet et s'accordent avec le sujet au pluriel.

\section{Jouer gagnant}

I. Parier sur la victoire d'un concurrent Transitif

$1938 \mathrm{Au}$ retour, Claude n'était pas content : dans le Prix d'Elbeuf, il avait joué Théocrite gagnant, mais Théocrite n'avait fait que 8,50 placé, derrière La Libellule (Paul Nizan, La Conspiration) 
1959 Manque de veine, j’avais joué Junia gagnant et placé ; elle est arrivée cinquième (Exemple entendu, 17 mars 1959 / Grundt : 259)

1960a «Second! Très bien. Bravo. Second ! Quand il aurait dû gagner de dix longueurs. Vous trouvez que c'est..., » puis s'arrêtant brusquement, se retournant vers lui d'un mouvement si soudain, si imprévisible qu'il faillit se cogner à elle, criant maintenant (quoiqu'elle n'élevât pas la voix, mais, dit-il, c'était bien pire que si elle avait hurlé à tue-tête): « Est-ce que vous l'avez jouée placée ou gagnante, dites-le moi ? Mais est-ce que vous l'avez seulement jouée ?» (Claude Simon, La Route des Flandres)

1974 Puis il pensa aux courses où le cousin Jean allait jouer ses derniers sous dans l'espoir de faire fortune, à l'oncle Henri qui lui disait :

- En même temps que les cigarettes, au P.M.U., tu me joueras cinquante gagnant et cinquante placé sur... Pas la peine d'en parler à ta tante (Robert Sabatier, Les Noisettes sauvages)

Emploi absolu

1962 Vous pouvez jouer gagnant, c'est-à-dire que vous pariez que tel cheval franchira le poteau en vainqueur ; ou vous pouvez jouer placé. Dans ce cas, vous pariez seulement que votre cheval terminera dans les trois premiers. Les sommes misées gagnant et placé ne s'additionnent pas (Léon Zitrone, Léon Zitrone vous emmène aux courses)

II. Avoir une forte probabilité de tirer des bénéfices et des avantages

Intransitif

1956 La Chine joue presque à coup sûr gagnant. Virtuellement, en effet, elle est très riche (Simone de Beauvoir, Témoins à charge)

1980 Je me demande parfois si, en mettant bout à bout tous les tableaux de tous les musées du monde, j'en trouverais un seul sur lequel je puisse jouer gagnant? Sniff (Jean-Luc Benoziglio, Cabinet portrait)
1996 Le bonheur exige tant de lumières et de discernement que l'agonie et le malheur quotidiens n'ont qu'à miser sur l'ignorance et la fatigue pour jouer gagnants (Raoul Vaneigem, Nous qui désirons sans fin)

Transitif

1960b un défi, non seulement à l'équilibre, au bon sens, mais encore aux simples lois économiques, une marchandise dont la valeur serait inversement proportionnelle à la quantité de matière employée, comme si la règle du jeu avait été de vendre à un prix maximum un minimum de cuir, et.. Et Blum : «Parce que tu veux dire que tu l'avais jouée gagnante? Bon sang ! Que tu avais mis tout cet argent gagnant ou rien sur un type qui... » (Claude Simon, La Route des Flandres)

\section{CORPUS WEB :}

Richert veut jouer gagnant. Le conseil national de l'UMP a avalisé, hier, les choix de la commission nationale d'investiture (CNI) en vue des régionales. Le président alsacien Philippe Richert conduira la liste de la nouvelle grande Région Est [http://www.lalsace.fr/actualite/2015/02/08/ richert-veut-jouer-gagnant] (15.6.2015)

Je nai pas une course à te conseiller en particulier compte tenu de ton capital, essaye peut-etre de jouer les chevaux sélectionnés en " placé ». Tu auras plus de chance detre remboursé et le taux de reussite sera plus élevé que de les jouer gagnant. Ca peut valoir le coup si ça passe car les cotes sont élevées mais si le cheval nest pas gagnant tu perds ta mise [http:// forum.parissportifs.com/vos-pronostics-sur-lescourses-hippiques/5803-5.htm] (15.6.2015)

Des chevaux peuvent être réguliers dans leur performance quand ils courrent corde à droite mais dès qu'ils courrent à St Cloud par exemple, c'est la contre-performance. Idem, ce ne sont pas tous les chevaux qui aiment Chantilly avec sa montée. Pour des bons finisseurs, meiux vaut éviter de les jouer gagnants dans des hippodromes où la ligne droite est courte [http://www.courses-france.com/modules/ newbb_plus/viewtopic.php?topic_id=27487\& forum=23\&start=7] (15.6.2015) 
Système pondérateur jeu simple gagnant. Le but de ce système est de combiner les côtes des chevaux pour en déduire une série de jeux à jouer gagnants. Vous pouvez saisir le nombre de chevaux à jouer (plus vous en sélectionnez et plus cela coutera cher, mais plus cela rapportera) et le bénéfice que vous souhaitez réaliser [http:// www.tuyaux-turf.com/reducteur_jeu_simple. php] (15.6.2015)

REMARQUES : Jouer gagnant (I) s'emploie dans le domaine de la course hippique, en opposition avec jouer perdant, jouer placé, il se dit du fait de parier sur la victoire d'un concurrent, c'est-à-dire que le cheval sur lequel on a parié doit arriver en premier. Souvent dans un contexte économique (II), il désigne le fait d'agir, de miser sur quelque chose, le sujet s'assurant d'avoir une forte probabilité de gagner, de tirer des bénéfices. Dans le premier exemple du CW il s'emploie, par analogie, dans le domaine de la politique. Gagnant peut s'accorder avec le sujet dans l'emploi intransitif du verbe (exemple de 1996), et avec l'objet dans l'emploi transitif du verbe (exemple de 1960a,b), mais l'accord n'est pas obligatoire (v. le deuxième exemple du CW). Il est modifié par presque à coup sûr.

\section{Jouer gai}

Jouer avec gaîté ; faire semblant d'être gai, feindre la gaîté

Intransitif

1903 1er avril.

Quand je lui fais observer que ce n'est pas là le sens d'une phrase, sa bouche se contracte d'une façon qui serait inquiétante pour moi si, au fond, il n'avait peur. - Jouez gai ! Dit-il à Signoret.

- Ça m'est bien plus facile, répond Signoret (Jules Renard, Journal)

1958 Pour les Millions nous avons eu une Sabouret mutine, heureuse, jouant gai sans effort (Le Monde, 13 novembre 1958 / Grundt : 221)

\section{CORPUS WEB :}

Jamais elle n'essayait d'emmener un élève à interpréter comme elle. Elle avait une grande force intuitive. Pour cela j'ai bien fait la différence avec mon ancien professeur qui me disait comment interpréter telle œuvre (ici c'est forte, là piano, là guai, ou triste..) alors qu'elle ne m'a jamais parlé comme ça. Peut être qu'elle supposait que c'était évident pour moi, ayant déjà joué pas mal de choses... mais ce n'était pas son langage... elle disait " écoute, va jusqu'au bout de la phrase, laisse toi porter à la dire... » Et là on trouvait instinctivement une ligne musicale, une ligne expressive... C'est cela qu'il fallait développer et non se dire " je vais jouer gai ou triste ".... [http://dominiquehoppenot. com/index.php?option $=$ com_content\&view= article\&id=8: claire-bernard\&catid=21\&Itemid= 127] (15.6.2015)

Mais vous vous attendez à un mondial joyeux ? Nous, en tout cas, on va être gais, on va jouer gai. C'est une chose certaine et c'est ce qui fait notre force et notre popularité, A partir de là, les meilleurs vont sortir du premier tour et la loterie pourra commencer [http://www. oldschoolpanini.com/2011/08/mexico-86michel-platini.html] (15.6.2015)

On est immédiatement emporté dans un tourbillon qui passe par la Slovénie de Mira avec sa voix envoûtante, étonnante. On éclate de joie avec des musiques qui surgissent des Balkans. On fond sur des airs arabo-andalous. Ce quatuor est dopé. c'est sur ! ça pétille, ça joue gai, on n’a qu'une envie, c'est de danser avec eux [http:// zaragraf.wix.com/zaragraf\#!disques/c12xe] (15.6.2015)

Ce nouveau Porte-Revues, trouvé chez Ilodéco, se la joue gai et fonctionnel : un gentil cadeau pour aider une fervente lectrice de Télé $\mathrm{Z}$, Cosmo et autres magazines d'intérêt crucial, à ranger son joyeux bazar [http://www. miss-cadeaux.fr/ilodeco-le-porte-revues-ideecadeau-1393] (15.6.2015)

Le lendemain, le samedi, nous faisons comme si de rien n'était. Nous nous levons tard, chantons, rions, sifflotons comme s'il y allait de nos vies. Dingue ce qu'on peut se mentir l'un à l'autre et à soi-même ! On se la joue gaie, vous voyez ce que je veux dire ? [http://flandreshollande.hautetfort.com/archive/2014/03/21/ tom-lanoye-alain-van-crugten-5328502.html] (15.6.2015)

REMARQUES : Au sens figuré, jouer gai désigne le fait de jouer avec gaîté, d'être gai ou de le simuler, 
de montrer de la bonne humeur, de se donner l'air gai, dans les domaines du théâtre et du film, de la musique et du sport. Gai reste invariable dans la majorité des cas, mais dans la locution se la jouer gai 'affecter la gaîté, se vouloir gai' il peut s'accorder avec le pronom féminin la (v. le dernier exemple du CW). Notons les collocations gai ou triste ; gai et fonctionnel (jouer triste, jouer fonctionnel).

\section{Jouer gros}

I. Mettre en jeu une grosse somme d'argent, risquer consciemment quelque chose

Emploi absolu

1748 Mais comme Manille jouait gros et que son financier n'était pas inépuisable, nous vîmes bientôt le fond de ses coffres (Denis Diderot, Les Bijoux indiscrets)

1830 DON CARLOS. C'est ici que la ligue s'assemble!

Que je vais dans ma main les tenir tous ensemble!

- Ha ! monsieur l'électeur de Trèves, c’est ici!

Vous lui prêtez ce lieu ! certe, il est bien choisi !

Un noir complot prospère à l'air des catacombes.

Il est bon d'aiguiser les stylets sur des tombes.

Pourtant c'est jouer gros. La tête est de l'enjeu,

Messieurs les assassins ! Et nous verrons.

- Pardieu ! (Victor Hugo, Hernani)

1924 J'étais extrêmement vexé, et résolus de vaincre cette indifférence en jouant gros

(André Gide, Si le grain ne meurt)

1932 Impossible de regarder cette vérité en face. Si ses affaires tournaient mal pourtant ! Un agent de change, qui donne de tels dividendes, joue et risque gros... le jour où l'honneur de la famille serait en jeu... l'honneur de la famille ! Voilà une idole à laquelle je ne sacrifierai pas (François Mauriac, Le Noeud de vipères)

1960a trois ou quatre types aux identiques visages inexpressifs aux identiques gestes brefs, économes, et qui jouaient gros, vidaient avec les mêmes gestes qu'ils avaient pour jouer, de la même façon, silencieuse, rapide, et apparemment sans plaisir des bouteilles du champagne le plus cher (Claude Simon, La Route des Flandres)

1975 « Là, Briffaut, t'a joué gros. T'as joué et t'as perdu !» (Michel Tournier, Les Météores)

1984 Sous les bravos d'une poignée de copains, les musiciens pénétrèrent sur scène. Les filles armaient déjà de minuscules appareils photo. Heure de gloire sur papier glacé. Les trois types savaient qu'ils jouaient gros. Blêmes. Raides. Somnambules. Bonne image new-wave (Michel Embareck, Sur la ligne blanche)

2018 Wimbledon : Tsonga joue gros (Corpus Coiffet 2018 : s.v., sans date)

II. Jouer grossièrement, sans finesse, sans

délicatesse (d'un instrument ou un rôle) Intransitif

1958 Et M. Marceau, quand il veut, qui est si délicat, si irisé ; poète du moralisme et violoniste des âmes... Il joue gros, cette fois-ci ; et son archet scie les cordes (Le Monde, 5 juin 1958 / Grundt : 395)

III. Jouer un rôle en exagérant

Transitif

1960b Ce metteur en scène qui appuie ses effets, qui fait jouer gros ses acteurs (Radiodiffusion-Télévision Française, 13 décembre 1960 / Grundt : 396)

1960c Jacques Dufilho [...] et Jacqueline Gauthier jouent cela comme il faut : net, gros, bien appuyé, sans biaiser (France observateur, 17 novembre 1960 / Grundt : 348)

Corpus Web :

Déjà très actif sur le marché du streaming musical, Google s'apprêterait à lancer un nouveau service en octobre, avec l'intention de conquérir d'importantes parts de marché. Le géant du Web, qui voit dans le streaming musical une opportunité unique, aurait décidé de jouer gros en lançant un second service de streaming musical en octobre, le fameux Youtube All Access. Qui serait d'une certaine manière complémentaire 
à Google Play Music All Access [http://geeko. lesoir.be/2014/06/06/google-va-jouer-gros-dansle-streaming-musical] (19.6.2015)

«Ce contexte donne encore plus de valeur à cette rencontre. Les deux clubs vont jouer gros et le vainqueur prendra peut-être l'ascendant pour le sprint final. C'est un clasico doublé d'un sommet tout en haut de l'affiche, » analyse avec sa sobriété habituelle le gardien marseillais [http://www.footligue1.fr/ligue-1/mandanda-lesdeux-clubs-vont-jouer-gros] (19.6.2015)

Pour ce qui est des kilomètres, c'est vrai que ce métier en exige beaucoup. Mais des VRP roulent également beaucoup - sans vision aussi haute que celle des routiers - et je n'en connais aucun qui aient eu des accidents importants et pour certains, pas même un accrochage à leur actif. Je sais que la plupart des accidents sont le fait d'automobilistes qui se prennent pour Schumacher ou de jeunes crétins qui roulent trop vite ou trop près, ou parce qu'ils se la jouent grosse [http://humeurs-en-billets.over-blog.com/article34592196.html] (19.6.2015)

REMARQUES : Jouer gros (I) renvoie au fait de miser une grosse somme d'argent, le sujet prenant un plus grand risque, ce que traduit la collocation jouer et risquer gros. Ce sens est également transposé à d'autres types de risque : le comportement en société, le sport, etc. (I) s'oppose à jouer petit ; les deux sont à mettre en rapport avec les locutions jouer petit / gros jeu. (II) signifie 'jouer (d'un instrument ou un rôle sur scène)' ou, par extension, 'agir lourdement, sans finesse'. Ici, gros suggère le manque de précision dans le jeu de l'acteur ou du musicien, voire souligne un visage d'acteur inexpressif, fade et sans intérêt, ce qui confère à l'adjectif-adverbe une connotation péjorative. (III) réfère toujours au jeu de l'acteur et signifie 'interpréter un rôle d'une manière exagérée'. La collocation avec les adjectifs net et appuyé confirme le sémantisme de gros ou le complète, soulignant une certaine simplicité et insistance dans la façon de jouer. Gros reste invariable dans son emploi adverbial, sauf quand il fait partie du schéma « se la jouer + grosse ».

\section{Jouer groupé}

Jouer en formant un groupe, en s'entraidant Intransitif

1965 la tactique irlandaise de jouer groupé (Sport Dimanche, 24 janvier 1965 / Grundt : 256)

\section{CORPUS WEB :}

Loto : jouer groupé, c'est risqué. Deux " amis » se disputent après avoir gagné avec un ticket commun. Ils ne sont pas les premiers [http://www.europe1.fr/france/loto-jouergroupe-c-est-risque-733715] (15.6.2015)

Pour gagner le gros lot, il faut avoir les 5 bons numéros sur 50 existants + les 2 bonnes étoiles sur 11. Le fait de jouer groupé nous permet de marier toutes les étoiles entre elles avec 5 numéros. Si ces 5 numéros sont les bons, le gros lot est gagné ! [http://emillions-club.com/euromillions] (15.6.2015)

Les aides publiques, issues de la Banque publique d'investissement, représentent $30 \mathrm{M} €$ et l'enveloppe se finalise grâce aux autres partenaires - les biotechs Celogos et Clean Cells, l'Établissement français du sang, les CHU de Bordeaux, Nantes et Toulouse, le CHRU de Lille, la Banque de tissus et de cellules et les Hospices civils de Lyon. "L'équipe de France de thérapie cellulaire a décidé de jouer groupée ! ", a souligné Christian Béchon, président du LFB, lors de l'inauguration du site [http://www.biofutur. com/La-therapie-cellulaire-entre-dans-l-ereindustrielle] (15.6.2015)

Mais qui viendra nous délivrer de tous ces gâteux du 10 mai qui depuis hier, d'un bout à l'autre de la blogosphère progresseuse, n'en finissent plus de bavocher sur leur Mitterrand, et le trentième anniversaire de ceci, et le formidable espoir de cela, et un petit coup de re-prise de la Bastille pour faire glisser ? Non, vraiment, quand la sottise stérile se met à jouer groupée, elle devient insupportable. Je ferme cet ordinateur bégayant et retourne aux Mémoires d'outre-tombe [http://didiergouxbis.blogspot. co.at/2011/05/la-sinistro-blogosphere-saisiepar-le.html] /(15.6.2015)

Le patron de la CCI de Pau se dit favorable « aux bi-pôles » préconisés par Michel Mercier, ancien secrétaire d'Etat à l'aménagement du territoire, passé à la Chancellerie. « Il faut une 
communication forte », dit-il. " On ne peut plus jouer avec le temps. On ne peut plus travailler séparément. Il faut jouer groupés au niveau des Pays de l'Adour ». Et d'ajouter : " Et pourquoi pas même avec les professionnels espagnols ". Chiche! [http://www.larepubliquedespyrenees. fr/2011/01/08/soldes-la-cci-de-pau-veut-jouergroupes,174382.php] (15.6.2015)

Comme d'hab, l'UMP la joue groupée, jamais à moins de trois sur l'estrade pour le point presse [https://twitter.com/bekouz/ status/453478855530283009] (15.6.2015)

REMARQUes : Jouer groupé désigne le fait de pratiquer un jeu en équipe, en groupe, généralement dans le domaine du sport ou du loto, et, par extension, dans la vie politique. Dans le sport, les joueurs agissent de manière rapprochée, serrée, en s'entraidant. Groupé peut s'accorder avec le sujet.

\section{Jouer juste}

I. Jouer dans le ton juste

Intransitif

1762 La finale soit toujours ut ou la selon le mode. De cette maniére il vous concevra toujours, les raports essenciels du mode pour chanter et joüer juste seront toujours présens à son esprit, son éxecution sera plus nette et son progrès plus rapide (JeanJacques Rousseau, Émile ou De l'éducation)

1855 Je ne dansai pas mon bolero avec moins d'assurance. La timidité et la gaucherie ne m'étaient pas encore venues, et je me souviens que Deschartres m'impatientant, parce que, soit émotion, soit incapacité, il ne jouait ni juste ni dans le rhythme, je terminai le ballet par une improvisation d'entrechats et de pirouettes qui fit rire ma grand'mère aux éclats (George Sand, Histoire de ma vie)

1904 Mais le système était mauvais, et il ne tarda pas à s'en apercevoir. Melchior était aussi têtu que lui ; et il jura que, quand ils y passeraient deux jours et deux nuits, il ne lui ferait grâce d'aucune note, avant qu'elle eût été exécutée correctement. Christophe mettait trop de conscience à ne jouer jamais juste ; et Melchior commençait à soupçonner la ruse, en voyant à chaque trait la petite main retomber lourdement de côté, avec une mauvaise volonté évidente (Romain Rolland, Jean-Christophe. L'Aube)

1949 - Voilà six ans, dit le figurant, lorsque j’ai quitté le lycée, je jouais un peu de violon, ensuite...

- Le violon, pour le jazz, ce n'est pas ça... trop difficile à jouer juste ; et puis cela manque de puissance

(Boris Vian, Les Fourmis)

\section{Utiliser correctement}

Intransitif

1935 Le subjonctif est peut-être, pour qui le connaît bien et en joue juste, la marque la plus sûre d'une connaissance approfondie de notre langue (Georges et Robert Le Bidois, Syntaxe du français moderne)

\section{CORPuS Web :}

Sujet du message : Re: Jouer juste

Ce n'est pas forcément nécessaire de jouer " hyper-juste » pour avoir un beau son, mais ça y contribue ! L'inverse aussi d'ailleurs : Si l'on a un beau son, on est davantage sensible aux notes fausses. Si le son est très pauvre, ça peut aller jusqu'à une vraie difficulté d'identifier juste et faux [http://forum.le-violon.org/topic7680.html] (15.6.2015)

L'entame de match est particulièrement intéressante, les Illkirchoises jouent juste, développent du jeu rapide et bénéficient d'une belle adresse aux tirs longue distance. Mais les Nordistes reviennent à la fin du quart (13-21). Les filles de la SIG sont dans le dur dans ce deuxième acte et voient leurs adversaires s'adapter à leur défense de zone. La qualité du jeu illkirchois se dégrade (32-34) [http://www.dna.fr/ sports/2015/02/09/la-sig-ii-trop-juste] (15.6.2015)

Les acteurs sont magnifiques dans leurs personnages. Ils jouent justes tout au long du film rempli d'intensité, malgré quelques longueurs ! Ceux qui aiment l'histoire aimeront certainement ce film d'une pauvre femme ! L'histoire est bien écrite pour nous faire comprendre même si l'on ne connait pas cette grande dame de l'histoire britannique ! Je le conseille juste pour l'interprétation de Keira et la beauté des décors et cos- 
tumes (oscar) [http://www.superclub.videotron. com/film.aspx?id=3592] (15.6.2015)

REMARQUES : Jouer juste (I) désigne le fait de se servir, de jouer d'un instrument de musique avec justesse, précision et conforme à la partition. Dans un sens figuré, (II) il réfère au fait d'utiliser, d'employer quelque chose (ici : le subjonctif) correctement, selon la règle, l'usage. Jouer juste apparaît également dans le domaine du sport et de la cinématographie (CW). Juste reste invariable dans la majorité des cas, mais il s'accorde avec le sujet dans le dernier exemple du CW sans perdre sa fonction adverbiale. Il est modifié par jamais, hyper. Notons la collocation chanter et jouer juste (chanter juste).

\section{Jouer large}

Jouer d'une manière généreuse, tolérante Intransitif

1956 Mme Florence Blot qui joue large et franc m'a intéressé. C'est l'angélique Pinglet souhaitée, attendue, prophétisée (Le Monde, 30 novembre 1956 / Grundt : 310)

\section{CORPUS WEB :}

Le style de jeu le plus profitable est souvent l'opposé de celui que vos adversaires emploient. Ce qui veut dire que si vos adversaires jouent serré, vous devez ouvrir votre jeu et jouer large. Si vos adversaires jouent large, vous ne pouvez que vous refermer comme un coquillage et jouer serré, en attendant une main [http://fr.pokerlistings. com/sajuster-a-chaque-jeu-partie-1-le-jeu-serre] (15.6.2015)

2) Le $3 \$ 30 \mathrm{R}$ De Ps double cave direct donc 3000 : la il faut clairement jouer large et ne pas hesiter à overbet ses monstres lorsque l'on a touché ? ou vous preferez attendre une grosse main qui se fera surement payé vu que ça s'envoie en l'air a tout va [http://www.clubpoker.net/ forum-poker/topic/78408-mtt-jouer-large-audebut-dun-tournoi-online] (15.6.2015)

Les joueurs correspondent à ce que l'on appelle communément dans le poker les « chacals » et/ou les « éléphants ». Les premiers jouent larges et sont agressifs quand les seconds sont plutôt suiveurs. Toujours dans le cadre de la règle citée plus tôt, il vous faudra donc ici jouer serré [http://www.kuzeo.com/poker/950/ difference-entre-tables-larges-et-tables-serreescomment-jouer] (15.6.2015)

C'était aussi sur une table avec un jeu foufou. Mais c'est sur ce genre de table que je peut gagner le plus à terme. Je cible maintenant les tables qui jouent larges. Sur les tables serrés, c'est trop long [http://www.gamekult.com/forum/ topic-le-topic-du-poker-478753n.html?page=3] (15.6.2015)

REMARQUES : Jouer large désigne le fait de pratiquer un jeu déterminé, de jouer sur scène en déployant toutes les ressources de son art, en mettant en valeur tous les aspects de son personnage ou, par extension, il désigne le fait d'agir, de se conduire avec générosité, tolérance, ouverture d'esprit. Jouer large s'emploie tout spécialement dans le domaine du poker pour désigner un joueur qui joue beaucoup de mains ; il s'oppose à jouer serré (CW). Large reste invariable dans la majorité des cas, mais il s'accorde avec le sujet dans le dernier exemple du CW.

\section{Jouer léger}

Jouer de façon plaisante

入 écrire léger

\section{Jouer lourd}

Jouer avec lourdeur, sans élan ni souplesse, sans bouger (musique, sport)

Intransitif

1907 Tout à coup, le pianiste rencontre, parmi d'autres, cette indication stupéfiante, qui coïncide avec un rythme nouveau : «Un peu lourd, comme la croupe des chevaux flamands. " Il est bien certain, Messieurs, qu'on peut jouer lourd ; on ne joue lourd que trop souvent, hélas ! Mais jouer lourd exactement comme cela : comme la croupe des chevaux, et encore faut-il qu'ils soient flamands !... Problème !... Comment faire... ? Pardonnez-moi de laisser cette interrogation sans réponse (Mémoires de l'Académie de Vaucluse)

1914 Jouer lourd, jouer triste, tel est le lot de beaucoup de nos chanteurs provinciaux placés entre le drame lyrique moderne et l'opéra-comique ancien (S.I.M) 
1986 Il joue lourd, extérieur, machinal, bête, gros, sourd, insensible (Le Monde, 17.10.1986 / Noailly 1997a)

2015 Jouer lourd au centre [= du terrain de tennis], bouger l'autre de tous les côtés, bonne poussée des jambes, il ne s'économise pas et ne choisit pas toujours le meilleur angle, pour ne pas perdre de terrain dans sa défense. Je gagne sans briller. Ce n'était pas le but (Thomas Roussot, Le Lob du destin)

REMARQUES : Notons la série productive jouer bête, jouer extérieur, jouer gros, jouer insensible, jouer machinal, jouer sourd, ainsi que l'emploi de jouer triste.

\section{Jouer monotone}

Jouer de manière égale, uniforme, ennuyeuse Intransitif

1806 Enflure éternelle, héros monarchiques qui me tordent la peau ; Duch[esnois], une scène, huit ou dix vers ; dans le reste, froide et déclamante. J'espère du débutant Saint-Eugène. Talma joue bien, mais un peu monotone. Quel rôle pour lui s'il a de l'âme! (Stendhal, Journal)

\section{CORPUS WEB :}

$\mathrm{Si}$ tu veux pas jouer monotone, flyff est pas fait pour toi Xd. Euh pour répondre à la question... Sorcier a la capacité de pouvoir pvp et geanter. Mais l'elem est beaucoup plus fun à exp * (c'est un avis personnel) [http://www.flyffworld. fr/forum/question-pour-un-level-59-t22289.html] (15.6.2015)

une fois que plusieurs entreprises seront gérés par des humains nous pourrons voir comment s'oriente la dynamique du jeux, et voir s'il faut modifier certaines choses, mais encore une fois un reset ne se justifie pas. Pour rebondir sur l'obervation d'un joueur, il est vrai à un certain moment que l'on pouvait acheter des actions et de ne venir voir le résultat que 15 jours plus tard, en général on se faisait un bon bénéfice de toute façon, donc on peut se la jouer monotone [http://www.jeudebourse.com/phpbb2/ viewtopic.php?f=4\&t=1575\&start=30] (15.6.2015)
Qu'il en déplaise à l'automne,

Les feuilles là jouent monotones,

Avec le vent les soulevant des kilomètres, Pour les déposer où elles n'ont à être [http://logho81.skyrock.com/3161584564Au-bon-gres-du-vent.html] (25.6.2015)

REMARQUES : Jouer monotone désigne le fait de pratiquer un jeu déterminé, le sujet agissant avec répétitivité, uniformité, rendant ainsi l'action lassante, ennuyeuse. Il apparaît également dans le domaine de la bourse, entendue comme un jeu (se la jouer monotone 'agir sans changer de tactique, de façon répétitive'), il s’applique également aux jeux vidéo, et se retrouve dans l'image poétique du vent emportant les feuilles. Monotone reste invariable dans la majorité des cas, sauf dans le troisième exemple du CW, où il s'accorde avec le sujet tout en gardant son interprétation d'adverbe de manière. Monotone est modifié par mais un peu.

\section{Jouer net}

Jouer de manière franche et simple

入 jouer gros

\section{Jouer nonchalant}

Jouer avec nonchalance, avec une feinte indifférence

入 jouer tourmenté

\section{Jouer perdant}

Être voué à l'échec, risquer de perdre, voire favoriser soi-même une fin fatale Intransitif

1942 J'ai eu la chance de traverser sa route à un moment où il jouait perdant, où ça grippait dans sa trajectoire (Maurice Genevoix, Le Lac fou)

1957 Comment peut-il espérer exercer sur lui une influence plus ou moins contraignante? Seul un être divin peut agir sur les réalités divines ; il semble que le sacrifiant joue perdant dès le départ (Philosophie, religion)

1960a FRANTZ. Comme une sœur. Elle voulait tout, je suppose : c'est jouer perdant (Jean-Paul Sartre, Les Séquestrés d’Altona) 
1960b Comme Emma Bovary, elle joue perdant, et cette destinée ne peut être que tragique (France observateur, 3 mars 1960 / Grundt : 259)

1961 Ce comportement révèle que, plus ou moins consciemment, la bourgeoisie nationale joue perdant à long terme (Frantz Fanon, Les Damnés de la terre)

\section{CORPUS WEB :}

« Jean-Marc Mormeck n'est jamais aussi fort que dans l'adversité. Les parieurs, les spécialistes le jouent perdant. Raison de plus pour se méfier. Mormeck est courageux et surtout, orgueilleux. Sur dix combats face a Klitschko, il en perdra neuf mais peut gagner une fois. Ce sera peut-être samedi soir [http://www.europe1.fr/ sport/multisports/articles/mormeck-peut-il-etrechampion-du-monde-972413] (15.6.2015)

A lire Le Canard enchaîné de cette semaine, François Fillon a la réponse : « Ceux qui n’avaient pas encore compris comprennent désormais que ces deux-là jouent perdant en 2012. Là, au moins, c'est clair. » Le Premier ministre a depuis démenti ces propos. Et Jérôme Chartier, un de ses proches à l'Assemblée, embraie : « 2017, c'est très loin. Et Jean-François Copé est trop pro pour jouer à ça. En politique, on gagne d'abord les premières échéances »[http://www.lexpress.fr/actualite/ politique/cope-et-jacob-jouent-ils-contre-leurcamp_951947.html] (15.6.2015)

Quels avantages les Américains peuventils espérer tirer d'une politique qui tient si peu compte des faits ? En se cantonnant dans une attitude négative à l'égard de la Chine ils jouent perdant : nul ne peut se permettre en politique d'ignorer les réalités fondamentales. Le Vietnam du Sud est pour eux un terrain de lutte particulièrement défavorable [http://www. monde-diplomatique.fr/1965/03/HONTI/26490] (15.6.2015)

Un non-match. Le vide. Le creux. Le rien. Quand les Bleus jouent en blanc, ils jouent perdants. Peureux. Malheureux. Jamais dangereux. Ennuyeux. En blanc, les Bleus, c'est déroutant [http://www.crimonjournaldubouquiniste.com/ article-balle-a-blanc-107348403.html] (15.6.2015)

Mince alors, si même les sponsors de l'équipe de France nous jouent perdants c'est qu'on va pas aller loin cette année * [http://www. toutsimcities.com/threads/view/587046/zatixjo. tumblr.com/page:70] (15.6.2015)

REMARQUES : Jouer perdant se dit de quelqu'un étant désavantagé au départ ou sans espoir de gagner ; il désigne le fait d'être voué à l'échec. Le sens de base 'parier sur le fait de perdre un jeu, une bataille' est représenté par le premier exemple du CW. Perdant reste invariable dans la majorité des cas, mais dans les deux derniers exemples du CW il s'accorde avec le sujet au pluriel. Notons l'emploi transitif du verbe dans les premier et dernier exemples du CW.

\section{Jouer petit}

Jouer de façon fade, à l'économie, sans prendre de risque

Intransitif

1960 pour Odile Mallet, ravissante Ildione elle joue bien, mais elle joue petit (France observateur, 22 décembre 1960 / Grundt : 401)

2013 Hier, je suis allé au casino. Et comme je m'étais fait une petite frayeur la dernière fois, j’ai joué petit ! (Exemple entendu, Corpus Coiffet 2018 : s.v.)

\section{CORPuS WEB :}

Jouer petit nous permet de changer sur chaque écran, de bouger plus vite. On peut se mettre plus rapidement en attaque et ça nous permet de courir davantage. Il faut encore défendre sur LeBron même s'ils envoient d'autres petits [http://www.basketusa.com/news/299427/ harrison-barnes-jouer-petit-nous-avantage] (15.6.2015)

Lors du premier match de la série entre les Warriors et les Rockets, alors que ces derniers comptaient 16 points d'avance, les Californiens ont réussi à totalement inversé la tendance en utilisant un petit 5 avec Draymond Green en pivot. Steve Kerr pourrait à nouveau utiliser cette stratégie lors du match de ce soir mais Kevin McHale est confiant car il pense qu'il y a des failles dans le jeu des Warriors lorsqu'ils jouent petit [http://basket-infos.com/2015/05/21/kevinmchale-il-y-a-des-failles-dans-le-petit-5-deswarriors] (15.6.2015) 
La BCE pourra tenter de soutenir le plan Juncker, via un programme mettant l'accent sur les achats d'obligations d'entreprises, mais que pourra-t-il en être attendu de plus ? À jouer petit, on ne gagne pas gros [http://www.pauljorion. com/blog/2014/12/05/a-jouer-petit-on-ne-gagnepas-gros-par-francois-leclerc] (15.6.2015)

On fait d'excellentes centrales nucléaires en France... Donc pas besoin de chaudières à pellets ! Ils jouent petits, ces autrichiens ! Laissons-leur ces bricolages d'écolo barbu! [http://forums.futurasciences.com/habitat-bioclimatique-isolationchauffage/568807-retours-dexperienceschaudieres-okofen-325.html] (15.06.2015)

REMARQUes : En parlant d'un art (ex. 1960 : le thêâtre), jouer petit désigne le fait d'interpréter un rôle chichement, sans ampleur, le sujet ne prenant aucun risque et ne s'accordant aucune fantaisie. L'exemple de 2013, qui renvoie à la mise dans un jeu de hasard, est à mettre en rapport avec la locution jouer petit jeu. Dans le CW, jouer petit figure également dans d'autres contextes, notamment en rapport avec le basket, où l'on peut faire des passes à petite distance. Dans le domaine financier et politique, jouer petit réfère à un manque de visions ou de moyens, ce qui ne permet pas de gagner gros 'réussir de grands défis'. Il s'oppose à jouer gros, associé à jouer gros jeu. Petit reste invariable. On observe tout de même un accord graphique dans le dernier exemple.

\section{Jouer placé}

Parier sur les bons résultats, sur le (bon)

classement d'un concurrent

Transitif

1960 « Second ! Très bien. Bravo. Second ! Quand il aurait dû gagner de dix longueurs. Vous trouvez que c'est..., » puis s'arrêtant brusquement, se retournant vers lui d'un mouvement si soudain, si imprévisible qu'il faillit se cogner à elle, criant maintenant (quoiqu'elle n'élevât pas la voix, mais, dit-il, c'était bien pire que si elle avait hurlé à tue-tête): « Est-ce que vous l'avez jouée placée ou gagnante, dites-le moi ? Mais est-ce que vous l'avez seulement jouée ? » (Claude Simon, $L a$ Route des Flandres)
Intransitif

1962 Vous pouvez jouer gagnant, c'est-à-dire que vous pariez que tel cheval franchira le poteau en vainqueur ; ou vous pouvez jouer placé. Dans ce cas, vous pariez seulement que votre cheval terminera dans les trois premiers. Les sommes misées gagnant et placé ne s'additionnent pas (Léon Zitrone, Léon Zitrone vous emmène aux courses)

\section{CORpus WeB :}

\section{Les Bleus jouent placé}

Sept des huit Français engagés dans les séries matinales se sont qualifiés pour la suite de la compétition. Héros de la veille, Camille Lacourt a une nouvelle fois fait forte impression sur $50 \mathrm{~m}$ dos [http://sport24.lefigaro.fr/natation/ actualites/les-bleus-jouent-place-405701] (15.6.2015)

\section{Cologna et le relais suisse jouent placé}

Le relais suisse $4 \times 10 \mathrm{~km}$ a décroché son billet pour les Jeux de Vancouver en prenant la 7e place du 4 x $10 \mathrm{~km}$ de Coupe du monde à Beitostolen. Au lendemain de sa 20e place en individuel sur $15 \mathrm{~km}$, le Grison Dario Cologna s'est illustré en réalisant le 2e chrono sur le quatrième tronçon [http://www.20min.ch/ro/sports/ lhiver/story/Cologna-et-le-relais-suisse-jouentplace-10391776] (15.6.2015)

\#CircuitSarthe : Les Verts jouent placés sur le @circuitcycliste ! [https://twitter.com/ teameuropcar_fr/status/586551486110425089] (15.6.2015)

\section{La droite joue placée, pas gagnante}

En face, la droite patauge dans la semoule. Ses nombreux chefs font penser au prince de Soubise cherchant son armée à la lueur d'une lanterne au soir de la défaite de Rossbach (1757). L'UMP vote la censure contre une loi Macron, certes timide, mais qui va plutôt dans le sens de ce qu'elle préconisait. Comprenne qui pourra [http://www.lepoint.fr/monde/ou-va-lemonde-pierre-beylau/la-droite-patauge-dans-lasemoule-21-02-2015-1906799_231.php] (15.6.2015)

REMARQues : Généralement dans le contexte de course hippique, jouer placé, souvent accompagné de jouer gagnant, se dit du fait de parier 
sur deux (ou trois) chevaux devant arriver dans les trois premiers, l'ordre n'ayant pas d'importance. Dans le CW, il apparaît également dans le domaine du sport d'équipes et de la politique au sens de 'arriver parmi les premiers, sans nécessairement gagner'. Placé reste invariable dans la majorité des cas, mais dans le troisième et le quatrième exemple du CW il s'accorde avec le sujet pluriel ou féminin. Notons que jouer placé apparaît souvent dans le titre d'un article de journal.

\section{Jouer planqué}

Pratiquer un jeu camouflé, à l'abri de tout risque $\pi$ jouer fin

\section{Jouer raide}

I. Jouer violemment, sauvagement, en employant la force physique (concret) Intransitif

\section{Corpus Web :}

Ça joue raide ! [= les chiens au jeu] [https:// m.facebook.com/LaMiniMeute/videos/1236837 863109418] (17.5.2017)

Ça joue raide et plusieurs gais se paluchent au milieu de l'atmosphère de sexualité effrénée

Robert Malacci, Sac de nœuds [https://1lib. eu/book/4567034/50f399?regionChanged=\&redi rect=152639174] (20.10.2020)

II. Jouer vigoureusement, durement (figuré) Intransitif

\section{CORPus Web :}

Une boucherie, une vraie, avec une guitare sidérurgique, une basse qui bastonne, et une batterie que joue raide [http://www.xsilence.net/ disque-7774.htm] (5.11.2007)

Quant au groupe, il joue raide, sec... pas de groove, pas de riff imparable, pas de mélodie accrocheuse, tout est... froid et poisseux [http:// www.musiclodge.fr/article-28995587.html] (18.3.2009)

$\mathrm{Au}$ sein de ces deux groupes, comme dans Samba De La Muerte, les batteurs jouent raides sur le temps, mécaniques, avec des sons de machines [https://www.lemonde.fr/musiques/ article/2016/04/13/printemps-de-bourgespierre-kwenders-sauve-la-premiere-soiree _4901423_1654986.html] (13.4.2016)
III. Jouer sans souplesse, raide comme un

piquet

Intransitif

CORPUS WeB :

Aucun joueur ne peut être prêt pour exécuter un fondamental s'il n'a pas les genoux fléchis (s'il joue raide) [http://dbvr.free.fr/fiches/ fondamentaux/position_fondamentale.htm] (5.11.2019)

Je pense que cette notion de « bas sur les jambes » est importante : elle permet le mouvement de ressort vers l'avant qu'on n'a évidemment pas quand on joue raide comme un piquet [https://forums.tennis-classim.net/topic/24484jai-perdu-mon-coup-droit] (20.11.2009)

Dujardin joue raide, et incarne admirablement cet officier rigide dans l'exercice de ses fonctions, intègre, pointilleux sur la discipline [http://helene-puiseux.fr/spip.php?article477] (16.11.2019)

Les acteurs semblent tous avoir une cuillère dans le fion tellement ils jouent raides [https:// www.allocine.fr/film/fichefilm-56481/critiques/ spectateurs/recentes/?page=14] (5.11.2020)

IV. Faire une passe dure et rapide

Intransitif

\section{CORPUS WEB :}

Seferevic joue raide sur Joao Felix, mais l'Eintracht Gardien de but Trapp a observé [http://allinfo.space/2019/04/18/le-telescripteureintracht-francfort-benfica-lisbonne] (18.4.2019)

V. la jouer raide : causer des problèmes à quelqu'un, mettre quelqu'un en difficulté Transitif

\section{CoRpus Web :}

Le gouvernement nous la joue raide dans ses bottes alors qu'il y a grosse panique à bord [http://captainhaka.blogspot.com/2010/10/ courage-fuyons.html] (19.10.2010)

La dégaine de la justice (qui nous la joue raide même avec les puissants) constitue pourtant elle aussi un viol des masses [https:// proletariatuniversel.blogspot.com/2013/03/abusde-faiblesse-du-proletariat.html] (22.3.2013)

REMARQUES : Jouer raide est peu répandu dans les textes accessibles dans Frantext et google.livres. 
Par contre, il est d'usage très fréquent et varié dans le CW. En (I), il renvoie à la force physique et sauvage déployée au jeu, par des animaux ou des humains. L'emploi dans le domaine de la musique (II) au sens de 'jouer sans émotion, produisant un son dur, métallique' domine dans l'usage. En (III), il réfère à un manque de souplesse, surtout physique, mais aussi moral, se rapprochant ainsi de la prédication seconde. En (IV), il s'emploie par rapport à un ballon envoyé avec force et en ligne droite. En (V), jouer raide entre dans le schéma « la jouer raide à quelqu'un », dénotant le fait d'être mis en difficulté. L'accord est plutôt rare, mais possible, notamment dans les emplois proches de la prédication seconde (III).

\section{Jouer rentré}

Jouer d'une façon contenue, modérée

Transitif

1961 il m’a dit que le samedi [= jour du public très jeune] il joue Antigone, comme ça, un peu rentré, pour que les gosses ne rient pas de cette cascade de meurtres et suicides (Radiodiffusion-Télévision Française, 28 janvier 1961 / Grundt : 255)

REMARQUES : Jouer rentré désigne le fait d'interpréter un rôle, de jouer sur scène d'une façon contenue, sans trop s'extérioriser. Rentré reste invariable et est modifié par un peu.

\section{Jouer safe}

Jouer sans courir des risques

$\lambda$ mourir facile

\section{Jouer sec}

Jouer sèchement, sans sensibilité

Intransitif

1913 Je suis sûre que s'il jouait du piano, il ne jouerait pas sec (Marcel Proust, Du côté de chez Swann)

\section{CORPUS WEB :}

Le plaisir de faire rouler les dés, de tenter de choisir avec discernement ceux qu'il convient de relancer pour réaliser une figure de haut niveau et d'annoncer "Poker d'As " Il fait souvent oublier que jouer "sec " comporte parfois de précieux avantages [http://www.denisdumoulin. net/index.html?jeux/des/index.html] (15.6.2015)
Révolution : moi je veux jouer aux échecs.

Trouver un roi blanc, être la reine noire.

Apprendre à jouer franc, jouer fort, jouer sec.

Regarder le roi battre mes pions sans retard [http://dupoivredanstondessert.overblog.com/ les-jeux-de-l-amour-et-du-hasard] (15.6.2015)

Seule différence avec le championnat, les matchs se jouent "sec ", c'est-à-dire qu'il n'y a pas de rencontre aller-retour [http://www. usbeaurepaire-rugby.net/actualites/33/unnouveau-depart] (15.6.2015)

REMARQues : Jouer sec désigne le fait de pratiquer un jeu déterminé, ici de jouer d'un instrument de musique d'une manière dure, froide, sans sensibilité. Dans le $\mathrm{CW}$, il réfère au jeu de dés, aux échecs et au sport. Dans le premier cas, il s'oppose au jeu prudent qui sélectionne progressivement, dénotant une stratégie qui joue le tout pour le tout. Dans le second cas, il s'agit d'une stratégie directe, peu complexe, qui cherche des résultats immédiats. Le dernier reprend l'acception 'd'un seul coup, tout à la fois', donnant directement un résultat définitif. Notons les groupes jouer franc et jouer fort dans le CW. Sec reste invariable. Notons aussi l'emploi pronominal à sens passif du verbe dans le dernier exemple du CW.

\section{Jouer serré}

Agir prudemment, agir de façon à ce que la cible ne puisse pas passer ou s'échapper

Intransitif

1785 FIGARO. Et vous, me prendre au corridor. LE COMTE. (en colère) Au corridor ! (̇̀ part.) Je m'emporte, et nuis à ce que je veux savoir.

FIGARO. (à part) Voyons-le venir, et jouons serré

(Pierre-Augustin de Beaumarchais, Le Mariage de Figaro)

1806 DERMANS. Bons amis?

BOURVILLE. Excellents amis. Iras-tu à notre société demain? Je n'irai plus, moi ; on y joue trop petit jeu, et puis ils y ont admis des artistes ; cela joue serré (Picard, Manie de briller)

1844 Pendant ce temps, Porthos jouait serré : c'étaient des clignements d'yeux, des 
doigts posés sur les lèvres, de petits sourires assassins qui réellement assassinaient la belle dédaignée (Alexandre Dumas père, Les Trois Mousquetaires)

1923 Elle donna la clef de l'armoire à la servante, appuya ses lèvres sur le front du fils, prit son bougeoir. Fernand pensa qu'elle voulait jouer serré. Non, elle ne jouait plus aucun jeu. Se sachant trahie déjà dans le cœur de son fils, elle ne s'était pas étonnée qu'il passât à l'ennemie avec ses bagages et ses armes (François Mauriac, Génitrix)

1925 C'était un avantage qu'il ne conserverait pas longtemps ; il s'agissait de jouer vite, et serré. Son parti fut pris aussitôt : sans oublier du reste rien de ce qu'il avait lu d'abord, Bernard n'eut plus d'attention que pour Laura (André Gide, Les Faux-Monnayeurs)

1987 On en a vu pas attendre les flics pour lyncher le voyou... Orlando joue plus serré que les jeans de Birkin ou de Belmondo (Jean-Louis Degaudenzi, Zone)

1996 Certes, Wladimir murmura encore : « C'est évident, quelqu'un de la vieille école !», puis se tourna vers Boris sans moi : à nous de jouer serré à présent. Nous n'aurions pas affaire uniquement à la vieille école, mais à des jeunes également, sans nul doute, plus brutaux, plus fanatiques

(Boris Schreiber, Un silence d'environ une demi-heure)

\section{Corpus Web :}

L'une des premières choses que vous apprenez lorsque vous décidez de devenir un joueur gagnant est de jouer serré (tight dans le jargon anglophone). Ce qui se traduit par jouer moins de mains. Pourquoi ? Parce que quand vous ne jouez que des mains de départ de qualité, cela rend votre jeu plus facile sur les rues (cartes) suivantes [http://fr.pokerlistings.com/jouer-serrerend-les-decisions-plus-faciles] (16.6.2015)

Les concessionnaires jouent serré

La marge de manœuvre des concessionnaires, trait d'union entre le constructeur et le client, est de moins en moins importante.
Ils sont tenus de suivre à la lettre la stratégie commerciale de l'un et de satisfaire l'autre [http://www.aujourdhui.ma/une/dossier/ les-concessionnaires-jouent-serre-93277\#.VX_ mrE0cHnM] (16.6.2015)

Les Bleues la jouent serré

Comme en 2009, l'année de son titre européen, l'équipe de France féminine aura un été chargé. Les Bleues débuteront leur préparation début mai et disputeront huit matches amicaux avant de s'envoler pour la Pologne, où aura lieu l'Euro 2011 du 18 juin au 3 juillet. L'objectif des filles de Pierre Vincent y sera clair : se qualifier pour les Jeux Olympiques de Londres [http:// www.europe1.fr/sport/articles/les-bleues-lajouent-serre-447869] (16.6.2015)

Relancer préflop dans le but de remporter les blinds, quelle que soit main, qu'elle soit médiocre ou faible, c'est ce que l'on appelle voler les blinds. Pour cela, la situation idéale est en fin de parole, lorsque tout le monde a passé avant vous et que les joueurs aux blinds jouent serrés [https://www.intellipoker.fr/articles/MTT-lesbatailles-de-blinds] (16.6.2015)

et non on l'a pas fait...

tant pis, on a pas été ridicules, ils ont mieux joué (faut que quelqu'un coupe le pied gauche de Wilkinson !!!)

ouais faut vraiment que les Spring Boks la jouent serrée la semaine prochaine ! :fist: [http://maidenfansunited.com/topic/746758/114] (16.6.2015)

Il va falloir cependant que les syndicats la jouent serrée : clairement les media font tout pour rendre le mouvement impopulaire : les jeunes gauchistes armés de barres de fer, les travailleurs empêchés d'aller travailler - ce qui est vrai, mais pas l'ombre d'une interview ou d'un reportage contradictoire...) [http://www.leslaunes. com/place_du_village/comments.asp?id=128] (16.6.2015)

REMARques : Jouer serré désigne le fait de lutter de façon compacte, réduisant les marges de manœuvre de l'adversaire, multipliant les actions, de façon à ce que la cible ne puisse plus passer ou s'échapper. Notons l'emploi de la jouer serré dans le CW où la est un pronom postiche sans référence claire. Dans le domaine des jeux 
de cartes, en particulier du poker, l'expression désigne le fait de jouer avec peu de mains et il s'oppose à jouer large (exemples de 1806, premier et quatrième du $\mathrm{CW}$ ). Le premier exemple du $\mathrm{CW}$ explique serré comme calque de l'anglais tight, explicitant ainsi le rôle de langue modèle joué par l'anglais dans le domaine du poker. Serré reste invariable dans la majorité des cas (ex. de 1923), mais dans les trois derniers exemples du CW il s'accorde, une fois avec le sujet, et deux fois avec le pronom complément direct la. Serré est modifié par plus. Notons l'emploi de jouer petit jeu.

\section{Jouer sobre}

Jouer simplement, sans excès, sans sentiments, sans détours

Intransitif

1957 Les jeunes qui ont le don disent juste, jouent sobre (Elle, 4 novembre 1957 / Grundt : 364)

\section{CORpus WeB :}

Volontairement, le réalisateur n'a pas situé géographiquement ses personnages. Son film se regarde comme une fable, avec une Cécile Bois et un Aboubakar Toure qui jouent sobre et juste [https://www.allocine.fr/film/fichefilm-12035/ critiques/presse] (16.6.2015)

C'est surtout finalement un combat MichelZampa auquel on assiste. Dujardin et Lellouche sont vraiment excellents, et Lellouche plus que Bluffant dans le rôle de Zampa. Les deux jouent sobre sans en rajouter. La réalisation est rythmée, suffisamment pour que nous restions plus de 2 heures devant je le répète cet excellent film que je vous conseille [http://www.senscritique.com/ film/La_French/critique/49394669] (16.6.2015)

Le livre de son ex-compagne va-t-il parasiter la conférence de presse de François Hollande ? Si le chef de l'Etat n'exclut pas de répondre à d'éventuelles questions sur le livre Merci pour ce moment, le chef de l'Etat n'a pour autant pas prévu de s'épancher sur ses sentiments. Selon le Figaro, le chef de l'Etat a prévu de la jouer sobre s'il est questionné sur sa vie privée : "Je ne laisserai rien paraître » [http://lelab.europe1. $\mathrm{fr} /$ Trierweiler-Je-ne-laissserai-rien-paraitrepromet-Hollande-en-vue-de-sa-conference-depresse-16814] (16.6.2015)
Basket-ball - All Star Game : le Rouennais Alain Koffi « va la jouer sobre»

Alain Koffi, le pivot du SPO Rouen, va disputer le All Star Game pour la cinquième fois de sa carrière aujourd'hui au Zénith de Paris [http://www.paris-normandie.fr/detail_sport/ articles/2224012/je-vais-la-jouer-sobre\#.VX_ tK00cHnM] (16.6.2015)

Cette collection vaut vraiment le détour ! Toujours dans un style class, épuré, avec des coupes bien pensées, les vestes, trenchs et gilets proposés par Tiss'Ame sont tout simplement pagnifik! On en trouve de toutes les couleurs, pour tous les goûts : du rouge, du bleu électrique pour celles qui n'ont pas peur d'oser, du noir pour celles qui veulent se la jouer sobres, des couleurs claires etr discrètes [http://www.pagnifik.com/ tissame-collection-n3] (16.6.2015)

il me semble que les designers portent rarement leurs fringues (hormis rick o. et quelques autres exceptions), et la plupart du temps ils la jouent sobres et pas vraiment hypeux [http://www.commeuncamion.com/forum/36styles/2292-meilleures-photos-de-waywt-ablogsforumb-1226.html] (16.6.2015)

REMARQUES : Jouer sobre désigne le fait d'agir d'une manière mesurée, appropriée et modérée, sans artifice, avec des gestes simples mais réfléchis. Sobre reste invariable dans la majorité des cas (v. le deuxième exemple du CW), mais dans les derniers exemples du CW il s'accorde, curieusement, non pas avec l'objet au féminin mais avec le sujet pluriel, (se) la jouer se rapprochant ainsi d'un verbe copule 'vouloir paraître sobre'. Notons les collocations dire juste et jouer sobre, et jouer sobre et juste. Le CW montre l'usage du tour familier (se) la jouer sobre, où l'objet pronominal la réfère à un objet sémantiquement vide ou, de toute façon, très abstrait.

\section{Jouer sublime}

Jouer merveilleusement, formidablement bien Intransitif

1960 Il joue sublime et faux à la fois (France-Soir, 10 décembre 1960 / Grundt : 221)

\section{CORpus Web :}

La combinaison de placages et de fibres en carbone / kevlar de ce bois en hinoki de très 
bonne qualité garantit un plaisir à jouer sublime [http://www.tennis-de-table.com/materiel/bois/ donic/Carbo_System_OFF-] (16.6.2015)

Au contraire le golf a la télé a failli me perdre, trop chauvin que je suis. Avec le Victor j'espère avoir signé pour 20 ans

C'était juste l'alu total, le capitaine de Ryder qui mise sur un français qui en plus assume et joue sublime.

Juste il a été trop fort le victor, la ryder avec du suspense c'est mieux.

Rève [http://golfagogo.forumactif.org/ t2674p500-dubuisson] (16.6.2015)

Face au général (interprété par Arestrup), le diplomate (André Dussolier interprétant le Consul suédois Nordling) dispose sans doute de plus de cartes en main qu'il ne veut bien le dire. Et au fil de ce huis-clos où l'on voit le jour se lever sur Paris par la fenêtre de la suite du Meurice, la partie de carte se joue sublime, atouts, coupe, longue... [http://talent.paperblog.fr/7053637/ avis-sur-un-film-diplomatie] (16.6.2015)

Souvent, parvenir à pleurer en paraissant sincèrement ému relève de la performance d'acteur. Mais dans Volver, les défis sont d'une autre dimension. Comment réagirait une femme qui, en entrant chez elle, découvrirait son mari assasiné par sa propre fille ? Difficile à prévoir n'est-ce pas ? Pénélope Cruz et Yohana Cobo (qui joue la jeune adolescente Paula) ne réfléchissent pas, elle jouent, sublimes, sans qu'aucun geste, aucune parole, aucune intonation ne paraisse déplacée en pareille circonstance [http://www. ciao.fr/Volver_Avis_939431] (16.6.2015)

REMARQUES : Jouer sublime désigne le fait de jouer ou d'agir d'une manière divine, le sujet faisant preuve d'une grande adresse et méritant de l'admiration au plus haut degré. Il s'emploie également dans le contexte du cinéma, de l'industrie et du sport (CW). Sublime reste invariable dans son emploi adverbial. Dans le dernier exemple du CW, il fonctionne en tant que prédicat second détaché orienté vers le sujet et s'accorde avec le sujet au pluriel. Notons également l'emploi pronominal au sens passif dans l'avant-dernier exemple du CW et le groupe jouer faux. Le premier exemple du CW met en évidence l'ambiguïté structurale du groupe un plaisir à jouer sublime. L'interprétation la plus probable est celle d'un nom composé (un plaisir à jouer) modifié par un adjectif (sublime).

\section{Jouer tourmenté}

Jouer l'agitation, l'anxiété, l'inquiétude

Intransitif

1959 Parce qu'il joue « tourmenté », qu'il pilote une voiture sport, on l'a comparé à James Dean (Elle, 30 mars 1959 / Grundt : 255)

\section{CoRpus Web :}

Cela étant dit, quelles sont les raisons qui font en sorte que l'on voudrait mettre une si grande distance entre le public et l'œuvre ? Pourquoi un nouveau visage sur une scène devrait se la jouer tourmenté ou nonchalant plutôt que de tout simplement expliquer son cheminement? [http://www.lecollectif.ca/une-joute-de-gaufres] (16.6.2015)

Évoquons aussi le style vestimentaire des personnages habillés comme des Djeunz par le styliste en vogue du coin et qui se la jouent tourmentés. Ça fait pas sérieux [http://ff7.fr/ forum/index.php?page=post\&ids=191593\&pg=2] (16.6.2015)

Quelle belle image. C'est vrai, ça met direct l'ambiance. On se dit, merde, qu'est-ce qui se passe, elle fait sa snob de la peinture maintenant ? Ou alors ça y est, elle se la joue tourmentée des profondeurs, elle est devenu chiante. Je vous calme tout de suite, cette peinture je l'ai trouvée par hasard. Rien à voir avec une nouvelle passion bobo [http://x-anticoonformix.skyrock. com/2332468653-posted-on-2009-02-28.html] (16.6.2015)

REMARQUeS : Jouer tourmenté désigne le fait de pratiquer un jeu déterminé dans l'agitation, le tumulte, la confusion mentale, follement. Dans le $\mathrm{CW}$, il figure dans le domaine du théâtre et du cinéma. Notons également l'adjectif-adverbe nonchalant et l'emploi de (se) la jouer tourmenté, le pronom la référant à un objet postiche ou très abstrait. Tourmenté reste invariable dans la majorité des cas, mais, dans l'avant-dernier exemple du CW, il s'accorde avec le sujet au pluriel, alors que dans le dernier exemple on ne saurait trancher clairement si l'accord se fait par rapport au sujet ou au pronom objet direct, les deux au féminin ; on penchera tout de même plutôt du 
côté de l'accord avec le sujet en raison de la plus grande affinité sémantique avec tourmenté.

\section{Jouer triste}

Jouer en étant triste, jouer tristement

त jouer gai, jouer lourd

Jouer vrai

Jouer avec des intonations et des expressions

conformes à la réalité

Intransitif

1882 Une double révélation d'un seul coup : celle d'un dramaturge et celle d'un acteur qui, emporté par la situation, a joué vrai (Courrier de l'art)

1958 Ailleurs, à quelques exceptions près, on ne joue pas aussi bien, aussi vrai, aussi juste (France observateur, 4 avril 1958 / Grundt : 366)

1960 Tous les acteurs jouent vrai, notamment Georges Rivière, Roland Ménard

(France-Soir, 25 février 1960 / Grundt : 373)

Corpus Web :

Ce stage s'articule autour du jeu pour la caméra mais aussi du jeu dans son ensemble. Etre authentique, jouer vrai, avoir le souci de la performance, mais avant tout jouer avec plaisir [http://www.toutpourjouer.net/immersion2bis. php] (16.6.2015)

Les acteurs jouent vrai, un vrai bonheur encore une fois. Une piece qui n'engendre pas la melancolie. Quelle bonne soiree grace vous. Allez y si vous voulez passer une soiree dans la joie et la bonne humeur [http://www.tatouvu. com/w/wwa_ListeCommSpec?wSpecNo=7333] (16.6.2015)

Dans ce travail Quelques plans arrêtés dans le mouvement des personnages pour une image force. Les personnages sont les caricatures burlesques de leur fonction, mais ils jouent vrais [http://anbei-bobo.com/formation-en-theatre] (16.6.2015)

Ce sera d'ailleurs le seul bémol de ce cru 2012 tant, pour le reste, le discours reste clair et limpide, le flow articulé, fidèle à l'évidente volonté d'Ekoué, de Hamé, et d'un Bavar en pleine progression, de se faire comprendre de tous. Tous trois accusent («Interdit d'Accès? ",
« Le Chemin Est Long »), abordent des sujets graves pour les sortir de leur triste banalité (la drogue dure sur l'excellent " P'tite Laura »), la jouent vraie en parlant d'eux en toute sincérité ( «Un Soir Comme Un Autre », «Quand Je Marche Tu Cours » [http://www.mowno.com/disques/larumeur-tout-brule-deja] (16.6.2015)

REMARQUES : Jouer vrai désigne le fait de pratiquer un jeu déterminé, ici, jouer sur scène et écrire des textes de chansons avec véracité, sincérité, naturel. Notons la jouer vrai(e) dans le $\mathrm{CW}$, le pronom la référant à un objet postiche ou abstrait. Vrai reste invariable dans la majorité des cas, malgré le sujet pluriel dans l'exemple de 1960 et dans le deuxième exemple du CW. Toutefois, dans l'avant-dernier exemple du CW, il s'accorde avec le sujet au pluriel, créant un effet de prédicat second. Dans le dernier exemple du CW, le tour la jouer vrai inclut l'accord au féminin. Vrai est modifié par aussi. Notons l'emploi de jouer juste.

\section{Jucher haut}

Hisser à une place sociale élevée

Transitif

1538 Prince, inutil est mon ramentevoir, Parquoy vous dis adieu jusque au revoir ; Des bonnes partz la meilleure ay choysie : Fol est pour vray qui au monde se fie, Car tel est bien hault juché qu'on demonte ; L'homme prudent à tel jeu ne l'envye ; Mais on n'en faict mise, recepte ou compte (Clément Marot, Cimetière)

Pronominal

1914 M. Delcassé avait répondu sans hésitation qu'il était prêt à tout quitter, bureaux, directions, commissions, arsenaux et escadres, pour se jucher un peu plus haut sur le degré de nos fonctions publiques (Charles Maurras, Kiel et Tanger)

CORPuS WeB :

Pour obéir encore au réflexe social, monotone et permanent, mortel en somme, de crier : gloire au Tout-Puissant, au Roi des Rois, au Seigneur des Seigneurs, pour redresser sans cesse l'échelle fatale de la hiérarchie et du spectacle, pour jucher haut, encore et encore, les gagnants, dominants animaux et sanglants, pour jouir de réitérer cet enfer, il faut faire taire le Verbe... 
[http://www.choeur3f.eu/media/Haendel/ Messie/documents/Michel\%20Serres\%20 Figures\%20du\%20Messie.pdf] (16.6.2015)

Ce Norman Finkelstein ne doit sa celebrite qu'au fait que c'est un anti-juif etant Juif luimeme! Les medias ont un faible pour ce genre de cas et ils se sont charges de le jucher haut dans la presse pour ce fait mais quelle teigne alors! [http://www.darnna.com/phorum/read. php?8,44732,page=116] (16.6.2015)

REMARQUES : Jucher haut désigne le fait de placer quelqu'un dans une situation sociale ou morale supérieure. En emploi pronominal, il signifie 'se placer dans une situation élevée'. Haut reste invariable et est modifié par bien, un peu plus.

\section{Juger bas}

Juger à un niveau moralement bas ; ne pas considérer les motivations ou les circonstances atténuantes

Emploi absolu

1936 Elle croyait pas aux sentiments. Elle jugeait bas, elle jugeait juste. Pour aller à La Pourneuve nous devions prendre l'autobus (Louis-Ferdinand Céline, Mort à crédit)

\section{Corpus Web :}

Jean-Claude Trichet, président de la BCE, s'est exprimé jeudi pour commenter cette hausse. Il a qualifié le niveau des taux directeurs de "modéré » alors qu'il avait l'habitude de les juger " bas " [http://www.lemonde.fr/ economie/article/2007/03/08/la-bce-releve-sontaux-directeur-de-0-25-point_880845_3234.html] (16.6.2015)

Les conférences et autres types d'intervention (tables rondes, débats, etc.) sont des activités que j'aime beaucoup car elles me permettent de rencontrer de nouvelles personnes, mais je n'en ai pas besoin pour vivre. D'où les prix que certains pourraient juger bas [http:// www.renaudgaucher.com/conf\%C3\%A9rences] (16.6.2015)

Les juges sont très critiques sur la qualité du travail des procureurs (1/2 l'évaluent comme moyenne et $1 / 5$ comme basse), et plus encore sur l'action des magistrats d'instruction (1/2 la jugent basse). 94\% des juges interrogés estiment que les membres du parquet ne se conduisent pas conformément à la déontologie professionnelle [http:// www.gip-recherche-justice.fr/wp-content/ uploads/2014/07/04-02-RF.pdf] (16.6.2015)

En second, les députés jugent basse leur indemnité législative de base. Ils souhaitent que leurs émoluments soient conformes à ceux des autres pays de la Cemac. Les nouveaux contestent le mode de calcul qui privilégie les plus anciens [http://www.ongola.com/archives_juillet2014. $\mathrm{htm}]$ (16.6.2015)

REMARQUES : Juger bas désigne le fait de considérer quelque chose en excluant tout ce qui pourrait atténuer le jugement, en admettant plutôt le pire, les mauvaises intentions. L'auteur admet la justesse de cette attitude en ajoutant elle jugeait juste (juger juste). Le CW met évidence l'emploi concret au sens de 'juger que quelque chose, notamment une valeur, se trouve à un niveau bas', qui prédomine en français actuel. Bas reste invariable dans son emploi adverbial (exemple de 1936). En tant que prédicat second, il s'accorde systématiquement avec l'objet (CW).

\section{Juger droit}

Juger correctement, objectivement

Emploi absolu

1160 Signor, fait il, or escoutés

Puis jugiés droit de çou k'orrés,

Et qui de droit se deffendra, [variante : qui

du droit dire defaudra, p. 115]

C'est l'oquisons par coi morra

(Flore et Blancheflor, 2708)

$\sim 1280$ Et au droit jugier

Amours est si con li fus :

Car de pres le sent om plus

C'on ne face a l'eskiver,

Et ki ne se weut bruller

Si se traie en sus

(Adam de la Halle, Chansons, XVI, 15)

1325 Que vous diroie? A droit jugier,

Onques n'oï parler en conte

Que fame de roy ne de conte

Fust gardée en milleur oscole,

Con la dame dont je parole :

Ainz pechiez n'i pot avenir

(Watriquet de Couvin, Dits, p. 27, 834) 
1403 La pericie, a droit juger, De bien parler se peut logier En .III. choses : l'un, en nature, En doctrine apprenant et pure, La tierce si est en usage, Qui, en la fin, rent l'omme sage (Christine de Pisan, Le Livre de la mutacion de fortune, II, 8049)

1675 J'admire aussi votre bon esprit, et combien vous avez jugé droit, en croyant que cette grande machine ne pourrait pas aller depuis le lundi jusqu'au dimanche (Mme de Sévigné, Correspondance)

Transitif

+1400 Que je leur quiere

Juge loyal et que bien en enquiere

Pour droit jugier leur descort en maniere

Qu'il leur en doint sentence droituriere

Selon raison

(Christine de Pisan, Le Livre du dit de Poissy / Euvres poétiques [début Xve], II, p. 160, 18)

+1415 Pour jugier droit conseil asemble, $\mathrm{Si}$ je fais loyalle requeste, Soing et Soucy, et bon vous semble (Charles d'Orléans, Poésies complètes [ 1415-1440], II, Chanson XVII, p. 14)

1662 Ce sont choses tellement délicates, et si nombreuses, qu'il faut un sens bien délicat et bien net pour les sentir et juger droit et juste, selon ce sentiment, sans pouvoir le plus souvent le démontrer par ordre comme en géométrie, parce qu'on n'en possède pas ainsi les principes, et que ce serait une chose infinie de l'entreprendre (Blaise Pascal, Pensées)

CORpus Web :

Eh bien, si je devais, moi, confier mes enfants à quelqu'un, ce serait ait à lui, à elle, et non aux lâches qui s'inclinent quotidiennement devant la veulerie d'un système agonisant. Qui ont abdiqué leur devoir, qui se vautrent dans le conformisme, la vacuité, l'ignorance. Courage à cette femme qui s'obstine à juger droit, à aimer la beauté, à vouloir la transmettre [http://blog. soseducation.org/journal-dun-prof-debutant] (16.6.2015)
Même parmi les utilisateurs d'Internet, 71 pour cent seulement de discuter de sujets politiques déconnecté. En outre, seulement la moitié de toutes les personnes interrogées jugent droit d'être autorisé à critiquer le gouvernement librement sur l'Internet, avec un tiers décidément contre [http://www.preemodj.com/ une-personne-sur-deux-utilisateurs-accepte-unmanque-de-vie-privee-sur-internet] (16.6.2015)

Imaginez ! Maintenant, rien de plus à main levée jusqu'à des heures et des cris dans la foule pour donner vos commentaires ou obtenir sélectionné. Audience Response système automatisé de l'ensemble du système. Le public peut participer en choisissant la réponse qu'ils jugent droite en appuyant sur la touche correspondante sur le clavier sans fil respectifs [http://www.expertstourisme.fr/presentation-interactive-b954625. htm] (16.6.2015)

REMARQUES : Juger droit désigne le fait d'avoir ou d'émettre un avis, une opinion sur quelqu'un/ quelque chose avec perspicacité, justesse, de donner un avis autorisé sur quelque chose. Notons la locution à droit juger 'si l'on veut être juste', usuelle en ancien et en moyen français, et l'emploi de juger juste. Droit reste invariable dans son emploi adverbial. En tant que prédicat second 'juger que quelque chose est droit', il s'accorde avec l'objet (dernier exemple du CW). Dans le dernier exemple du CW, droit semble employé au sens de 'juste', ce qui peut heurter les sentiments de correction linguistique.

\section{Juger faux}

I. Juger qu'une chose est fausse

Transitif

1592 J'y suis tout entier, j'y suis voyrement ; mais ne m'est il pas advenu, non une fois, mais cent, mais mille, et tous les jours, d'avoir ambrassé quelqu'autre chose à tout ces mesmes instrumens, en cette mesme condition, que depuis j'aye jugée fauce? (Michel de Montaigne, Essais)

1845 Si nous demandions pour quel motif la liberté de l'état sauvage a été jugée fausse et détruite, le premier enfant venu nous répondrait ce qu'il y a réellement à répondre (Louis Blanc, Organisation du travail) 
1960 Mais, pour ces grandes jeunes filles, la philosophie n'était plus un éveil ; il me fallait même les débarrasser de certaines idées que je jugeais fausses (Simone de Beauvoir, La Force de l'âge)

II. Juger contrairement à la vérité, porter un jugement incorrect

Emploi absolu

1684 mais cependant je remarque que tant que l'ame est attachée au corps, il arrive que de mesme que les phantômes emportent souvent l'entendement, et le font juger faux (François Bernier, Abrégé de la philosophie de Gassendi)

1744 Elle composa deux boules de sucre magique; dans l'une il y avoit des pastilles dont la vertu étoit d'inspirer le mauvais goût, et de rendre l'esprit faux ; l'autre renfermoit des dragées de présomption et d'opiniâtreté : celui qui en mangeroit devoit toujours juger faux, raisonner de travers, soutenir son sentiment avec opiniâtreté, et donner dans tous les ridicules (Charles Pinot Duclos, Acajou et Zirphile)

1965 Je sais bien que je juge faux, que je confonds et raille tout, que je suis un peu dingue : manque de contact et de frottement avec le réel, sans doute (Albertine Sarrazin, La Cavale)

CORPuS Web :

Bonjour,

Mon acte de naissance (je suis né à l'etranger) a été reconnu et jugé faux par le tgi [https:// www.alexia.fr/questions/193191/acte-denaissance-juge-faux.htm] (9.10.2020)

REMARQUES : v. juger vrai.

\section{Juger juste}

Juger avec justesse et exactitude, comme il convient

Intransitif

1675 Vous en avez jugé très juste et très bien, et vous aurez vu que je suis de votre avis (Mme de Sévigné, Correspondance)

1866 Impossible à moi d'être tout entier de mon avis, une voix secrète m'avertissant que l'avis contraire a sa valeur, et qu'il faut tout voir et tout savoir pour juger juste (Henri-Frédéric Amiel, Journal intime de l’année 1866)

1922 on pouvait, il est vrai, me faire aujourd'hui le même reproche et demander ce que je venais chercher à mi-chemin, - si je jugeai juste, - entre la haine et la sympathie d'Eva... Toutes deux s'étaient rapprochées, car Eva m'avait pris tendrement les mains et me regardait durement dans les yeux (Jean Giraudoux, Siegfried et le Limousin)

1996 Par un mouvement de tête imperceptible, nous avons vu sa silhouette immobile devant sa porte cochère. Dire que nous avions hurlé sur notre père, à propos des Français! Il jugeait juste (Boris Schreiber, Un silence d'environ une demi-heure)

\section{CORPUS WEB :}

Si tu te juges selon la réalité de Dieu (Vérité, Justice), tu te mets au bénéfice de la Croix : le jugement est derrière toi. Si tu refuses de te voir tel que tu es, tu te juges juste : tu te réserves toi-même le jugement final face à ta réalité [http://www.lechemin.eu/viewtopic.php?t=24] (16.6.2015)

Toutes ces possibilités visent un seul et même objectif : proposer le jeu à un prix qui correspond au plus près à la valeur estimée par chaque joueur pris individuellement. Ainsi, tous les joueurs ont la possibilité d'acquérir le jeu au prix qu'ils jugent juste, que ce soit $1 €$ ou $90 €$. Et de son côté, le développeur touche tous les acheteurs potentiels sans exception, en récupérant à chaque fois le prix maximal qu'ils sont prêts à payer [http://www.nofrag.com/2015/ mar/16/46717] (16.6.2015)

« Dans le monde moderne les gens qui mènent une lutte et qui la jugent juste trouveront toujours des armes ", a déclaré Vladimir Poutine dans un entretien à la chaîne de télévision allemande ARD [http://fr.sputniknews.com/internat ional/20141117/202998727.html] (16.6.2015)

REMARQUES : Juger juste désigne le fait d'avoir ou d'émettre un avis, une opinion sur quelqu'un/ quelque chose avec perspicacité, justesse, de donner un avis conforme, correct sur quelque chose. Juste reste invariable. Dans le CW, il remplit 
la fonction de prédicat second orienté vers l'objet 'juger que quelque chose ou quelqu'un est juste'. Il est modifié par très. Notons l'emploi pronominal du verbe dans le CW.

\section{Juger large \\ Juger avec magnanimité \\ $\lambda$ voir grand}

\section{Juger sec}

Juger sévèrement et rapidement

Transitif

1957 ....ah mais au fait, l'Hilda Raumnitz que je vous la cote ! ...elle faisait, jugé sec, « 16 sur 20 », au « Concours Animal des filles » (Louis-Ferdinand Céline, D'un château l'autre)

\section{CORPUS WEB :}

Informe toi un petit peux avant de juger sec. C'est tellement facile de parler sans connaissances ! J’ai moi meme subi la meme experience sur MW2, je me suis co a une partie (via matchmaking) et en me co, un compteur croissant en pourcentage est apparu sur fond noir, pendant ce temps, j’ai gagné a mon insu 2 prestiges, déverouillé pleins de plaques etc.. Mais n’ai pas été ban [http://steamcommunity.com/discussions/ forum/25/864969481710444319/?1=romanian] (16.6.2015)

merci, tu sais tu as loupé certaines choses à propos de la justice. c'était les chaises musicales, avec tous ça y a des dossiers en retard alors ça va juger sec (-) [http://conseil-artois.frbb.net/ t17360p255-echanges-entre-le-pole-justice-et-lesintervenants] (16.6.2015)

REMARQUeS : Juger sec désigne le fait d'avoir ou émettre un avis, une opinion sur quelqu'un/ quelque chose avec froideur, rudesse, de donner un avis sévère et définitif sur quelque chose. $S e c$ reste invariable. Notons l'emploi absolu et impersonnel du verbe dans le CW.

\section{Juger vrai}

I. Juger conforme à la vérité, juger correctement

Emploi absolu

1450 EvE. Une chose trop me desplaist : J'ai honte qu'ainsi nulz nous voye.
ADAM. Oncques mais pensé n’y avoye

Si n'est pas bel, au vray jugier.

Prenons des fueilles de figuier,

Deux et deux les cousons ensemble :

Tres bien serviront, ce me semble,

A nostre humanité couvrir (Arnoul Gréban, Le Mystère de la Passion, 524)

II. Considérer qu'une chose est vraie Transitif

1664 Le monde ne peut demeurer long temps dans cette contrainte, et se remet insensiblement en possession de la liberté naturelle et raisonnable qui consiste à approuver ce qu'on juge vray, et à rejetter ce qu'on juge faux (Antoine Arnauld et Pierre Nicole, La Logique ou L'Art de penser)

1770 Examinons donc les opinions de l'athée sans approuver sa conduite ; adoptons sa façon de penser, si nous la jugeons vraie, utile, raisonnable; rejetons sa façon d'agir, si nous la trouvons blâmable (Paul Henri de Holbach, Système de la nature)

\section{CORPUS Web :}

La France se doit de représenter la concordance du jugement du Quai d'Orsay les experts étant du ...milieu... Il est facile de compter 30 antisionistes... Leur représentation n'a pas de contenu réel et leur vérité ne dépend nullement de la réalité... ! Juger vrai et juger d'une manière pertinente ne sont pas forcément conjugués mais la causalité est motivée ! [http://prophetiebiblique.com/forum-religion/israel-procheorient/france-invente-peuple-palestinien- $\mathrm{t} 3845$. $\mathrm{html}]$ (16.6.2015)

Penses tu je suis une idiote ? Car si tu penses me juger vrai (selon tes analyses à mes dires), je ne peux plus perdre un seul mot, une seule seconde pour discuter. J'étais là parce que je te voulais apaisé et clair avec toi mm mais que fais tu ? Tu me mords la main tendue, tu me sous estimes en plus. Je n'accepte pas [http://www. yabiladi.com/forum/separation-attente-divorce97-6112807-page $=43 . \mathrm{html}](16.6 .2015)$

CCL : serait illusoire de vouloir interpréter la vérité de l'art dans son rapport au réel, la notion de vérité est alors réductrice et illusoire, la vérité n'est pas adéquation absolue au réel. En ce sens l'art n'est jamais susceptible d'etre jugée vrai 
[http://ece.sainte-marie.xooit.com/t68-ART-ETVERITE.htm] (16.6.2015)

Cette manière de trier l'information privilégie une efficacité immédiate à courte vue au détriment de ce qui serait une information jugée vraie, même subjectivement. Outre l'aspect mensonger qui heurte l'éthique, je pense que cette manière de faire est contreproductive [http:// www.pupi.fr/70+inconvenients-du-militantisme. html] (16.6.2015)

Quelques-uns se rangent sous une doctrine qu'ils jugent vraie, ils deviennet platoniciens, cartésiens, kantiens ou deleuziens. Soit, mais le sont-ils, et jusques où ? [http://guykarl. canalblog.com/archives/2009/09/20/15062601. html] (16.6.2015)

Les structures conditionnelles permettent d'exécuter des instructions différentes en fonction de certaines conditions. Une condition (encore appelée expression conditionnelle ou logique) est évaluée, c'est à dire qu'elle est jugée vrai ou fausse. Si elle est vraie, un traitement (une ou plusieurs instructions) est réalisé ; si la condition est fausse, une autre instruction va être exécutée, et ensuite le programme va continuer normalement [http://stephanie. laporte.pagesperso-orange.fr/Pdf/structu.pdf] (16.6.2015)

REMARQUES : Dans son emploi absolu, juger vrai (I) désigne le fait de considérer, d'estimer correctement, d'être conforme à la réalité. Il admet donc une double lecture : la modification d'un objet implicite - ce qui est jugé est vrai -, d'une part, la façon de juger, de l'autre (v. la coordination avec "manière » dans le premier exemple $\mathrm{du}$ CW). Notons la locution a vrai jugier, usuelle en moyen français au sens de 'pour dire ce qu'il en est, à dire vrai'. Vrai reste invariable dans cet emploi adverbial. En tant que prédicat second orienté vers l'objet 'juger qu'une chose est vraie' (II), donc dans son emploi transitif, il s'accorde avec l'objet (v. l'exemple de 1770 et les trois derniers exemples du CW). Il s'oppose à juger faux (v. ex. de 1664 et le dernier exemple du CW), qui connaît la même polysémie (v. juger faux). L'emploi (II) prédomine dans l'usage actuel. Le cas de juger vrai / faux rappelle donc, en principe, celui de couper court, qui tend à l'invariabilité dans son emploi absolu alors qu'il admet l'ac- cord quand le verbe est transitif. Mais il diffère de couper court par le degré de lexicalisation, qui entraîne souvent l'absence de l'accord même dans l'emploi transitif (couper court les cheveux), et par le fait qu'il s'agit d'un verbe d'opinion. On peut donc également le mettre en rapport avec des verbes semi-copulatifs tels trouver vrai / faux, qui se trouve effectivement avec juger faux dans l'exemple de 1770. Notons l'emploi transitif $\mathrm{du}$ verbe dans le deuxième exemple du CW, qui actualise pourtant le sens (I). Notons l'emploi de juger utile, juger raisonnable.

\section{Jurer bas}

Jurer à voix basse

Transitif

1719 Il la regarda trois fois depuis les pieds jusqu'à la tête, à mesure qu'elle avançoit vers le ruisseau; et trois fois il jura tout bas qu'il n'avoit jamais vu de pieds si bien tournés, ni tant d'agrémens que dans la figure qu'ils soutenoient (Antoine Hamilton, Histoire de Fleur d'Épine)

1837 Je courus le chercher, il se pendit à mon cou, et je vis sur sa figure une telle altération, que je résolus de ne plus essayer une sévérité imprudente, et je lui jurai tout bas dans mon cœur, qu'il serait heureux par moi, dussé-je violer tous les engagements de la terre, dussé-je y perdre l'honneur et la vie (George Sand, Correspondance)

1859 C'est beau la jeune fille qui laisse aller son cœur

Dans son regard qui brille et se lève au bonheur!

Vous me vouliez pour femme, je le jurais tout bas.

Vous mentiez à votre âme, moi, je ne mentais pas

(Marceline Desbordes-Valmore, Élégies)

\section{Intransitif}

1787 Cependant un grand quart d'heure s'était écoulé ; la personne désirée n’arrivait pas ; je m'impatientais dans ma prison autant que mon geôlier, qui jurait tout bas sur son marchepied (Jean-Baptiste Louvet de Couvray, Une année dans la vie du chevalier de Faublas) 
1832 Il est tout au plus permis de frémir et de jurer bien bas, en entendant la fusillade, de pleurer en voyant les cadavres (George Sand, Correspondance)

1936 Gomar, lui, suivait la rive et sondait la nuit $\mathrm{du}$ regard. Il ne discernait rien. Il faisait une obscurité lourde et comme écrasante. Gomar jurait tout bas. À la fin, il mit ses deux index dans sa bouche et siffla (Maxence Van der Meersch, L'Empreinte du dieu)

1989 puis, plus tard, suivant [= la femme] des cours de dactylo pour taper les pages de ce qu'il se figurait que devait être un roman, et maintenant sans doute elle aussi à l'écoute des trains dans la plaine -, et de nouveau il jura tout bas, pensant : Du papier de soie, qu'est-ce qu'elle s'imag... (Claude Simon, L'Acacia)

Pronominal

1943 Ils acceptaient mal une association raccommodée et ils se juraient tout bas de la briser parce que probablement ils étaient voués à l'absolu et des propres à rien (André Dhôtel, Le Village pathétique)

1946 Il se souvenait de certaines nuits où, couché nu sur son lit, et faisant ça avec Lily ou la première venue, il sentait monter en lui des vagues d'une jouissance à la fois si puissante et si bouleversante qu'il se jurait tout bas, le visage enfoui dans l'oreiller, oui, qu'il se jurait tout bas, malgré la lassitude et le dégoût qui allaient succéder inévitablement à cette tension, qu'il le referait une deuxième fois aussitôt après l'avoir fait une première (Raymond Guérin, L’Apprenti)

\section{CORPUS WEB :}

Il fronce les sourcils et croise les bras sur sa poitrine. Tu t'avances et poses tes deux pattes avant sur le beau bureau de bois. Ton regard est encré dans le sien, ton souffle se mélange avec le sien. C'est comme si tu l'hypnotisais de ton regard turquoise. Il recule un peu avant de jurer bas.

- Pourquoi tant d'impolitesse envers nous deux ? Hein ? Et pourquoi me haïr comme ça ? [http://arcane.forumactif.fr/t119-eh-le-chatdescend-du-canape] (17.6.2015)

REMARQUES : Sous la forme transitive, jurer bas désigne le fait de promettre quelque chose par un serment plus ou moins solennel prononcé à voix basse. Sous la forme intransitive, il réfère plutôt au fait de proférer des imprécations, des jurons. Sous la forme pronominale, il désigne le fait de prendre une décision envers soi. Dans tous les cas, bas renvoie à l'affaiblissement de la voix, le sujet ne voulant pas attirer l'attention sur soi ou voulant garder ses paroles pour soi-même. Bas reste invariable et est généralement modifié par bien, tout.

\section{Jurer fort}

I. Prêter un serment avec force

Transitif

1275 Prometez fort senz delaier, Coment qu'il aille dou paier ; Jurez fort e la fei bailliez, Ainz que conclus vous en ailliez (Jehan de Meun, Roman de la rose [1269-1278], 7449)

1559 Mais, quand ilz viennent à en jurer bien fort, il me semble qu'il est plus honneste aux dames de le laisser en ce beau chemyn que d'aller jusques à la vallée (Marguerite d’Angoulême, Heptaméron, p. 143, 221)

Emploi absolu

+1300 Dieu jure qu'i toute sa rente

Ameroit mieus avoir donnee

Que ja eüst dame Avinee.

Diu jure fort, et si entreuvre

L'uis et a l'escuier descuevre

Trestout son boin et son courage ( $L e$

Prestre et le chevalier [ $1^{\text {re }}$ moitié XIII ${ }^{\mathrm{e}}$, 730)

+1366 Car il ara grace par fort jurer, Par regnier les sains et leur vertu, Par bordeler, par ferir, par venter, Par boire aussi ; qu'il ait le bec agu Comme pie, qu'il se soit maintenu A bien jangler : a ces poins estudie, Estat ara : ait lors, pour son escu, Condicion de ribaut et de pie (Eustache Deschamps, Euvres complètes [3 $3^{\mathrm{e}}$ tiers XIV $\mathrm{XI}^{\mathrm{e}}$ ) 
II. Assurer de manière tout à fait certaine Transitif

1364 Adonc ma dame jura fort

Que je iroie, et, quant vint au fort,

De li m'aprochai en rusant

Et tousdis en moy escusant

Que ce a moi pas n'appartenoit (Guillaume de Machaut, Le Livre du voir dit, 3671)

\section{CORpus WeB :}

Seulement, vendredi dernier, (après une journée d'absence pour cause de concours), j'arrive au travail. et, au moment où j'entre dans le bureau, ma collègue était entrain de faire une crise, de pester, de jurer fort... Bref, c'était une vraie furie ! (elle pestait en raison de l'annonce tardive d'un travail à rendre dans la journée -en gros-). La chef était témoin de la scène.. [http://forum.doctissimo.fr/viepratique/travail/ probleme-besoin-parler-sujet_1908_1.htm] (17.6.2015)

La principale serveuse n'était pas du tout souriante et on avait l'impression de l'embêter plus qu'autre chose. Ce qui n'est pas très professionnel non plus c'est de jurer fort en cuisine quand on sait que les clients entendent [http:// www.yelp.fr/user_details_reviews_self?rec_pag estart=50\&userid=m73_8MtwD6Qr8igRijzhBw] (17.6.2015)

Dans les forêts à feuilles caduques sèches du Madagascar occidental du sud là vit un lemur qui jure fort mais « danse » comme un interprète de ballet. Le sifaka de Verreaux est parmi le plus populaire des espèces de lemur, un groupe de primats endémiques aux îles outre de la côte du sud-est de l'Afrique. Tandis que menacé, le sifaka de Verreaux est facilement repèré est plusieurs des parcs plus accessibles du Madagascar [http:// fr.mongabay.com/news/rss/ambiant_heureuxoptimiste5.html] (17.6.2015)

On meurt debout, quand ceux qui vous sourient,

Scient en douce la branche qui vous porte,

Et, dans votre chute, étouffent vos cris

Derrière une amitié qu'ils jurent forte [http:// eachman.over-blog.com/page/2] (17.6.2015)

REMARQUES : Jurer fort (I) désigne le fait de s'engager sous la foi d'un garant à faire quelque chose, en particulier devant Dieu. (II) réfère au fait d'affirmer quelque chose solennellement, avec force.
Dans le premier et le deuxième exemple du CW, il désigne le fait de proférer des jurons, de parler d'une manière grossière, de " pester ». Dans le troisième exemple, il renvoie au fait de hurler (d'un animal). Fort reste invariable dans son emploi adverbial, mais il s'accorde avec l'objet quand il fonctionne en tant que prédicat second (v. le dernier exemple du CW 'qu'ils jurent être forte'). Il est modifié par bien.

\section{Jurer haut}

I. Attester (de quelque chose) avec conviction, prêter ouvertement serment

Transitif

1624 Je ne suis pas bien vieux, et si j'ay souvenance

Qu'un homme n'eut ozé faire le sot en France,

Parler le barragouin, faire le quand à moy, Qu'il n'eut ozé jurer plus haut que par sa foy,

S’il n'eut eu pour le moins, en heritage ou rente,

Par an six cent escus, ou cinq, que je n'en mente

(Jacques Du Lorens, Premières satires)

$1751 \mathrm{Au}$ reste, son principal motif, pour se donner l'honneur de m'importuner par une lettre, n'est pas son seul chagrin, quoique plus grand qu'il n'ose prendre la liberté de me le dire ; c'est le désir de prévenir un malheur dont je suis menacé moi-même : car il peut m'assurer que le colonel Morden est parti dans la résolution de ne pas m'épargner, et qu'il a juré, assez haut pour être entendu des domestiques, qu'il auroit ma vie ou moi la sienne, avec d'autres promesses de cette nature (abbé Prévost, Lettres angloises [trad.])

1755 Le fier Chandos partit donc après boire, et cotoya les rives de la Loire, jurant tout haut que la premiére fois sur la pucelle il reprendrait ses droits (Voltaire, La Pucelle d'Orléans)

1907 Il a répondu fort paisiblement à Frédéric Larsan qui lui demandait ce renseignement, que ce qu'il faisait de son temps, à Paris, ne regardait que lui... sur quoi, 
Frédéric Larsan a juré tout haut qu'il découvrirait bien, lui, sans l'aide de personne, l'emploi de ce temps (Gaston Leroux, Le Mystère de la chambre jaune)

II. Dire des jurons à voix haute, affirmer à voix haute

Transitif

1732 Sa colère m'effraya si peu, que j'eus la témérité de jurer plus haut que lui, et de le défier de tirer (Alain-René Lesage, Aventures du chevalier de Beauchêne)

1869 Deslauriers dévalait la rue des Martyrs, en jurant tout haut d'indignation (Gustave Flaubert, L'Éducation sentimentale)

1968 Mais les cousines portaient les mêmes bonnets et les mêmes parures ; il s'y trompait, et Bénédicte semblait se plaire à provoquer espièglement ces erreurs. Il en jurait tout haut : la fille valait son poids d'or, et la nièce tout au plus une poignée de florins (Marguerite Yourcenar, L'Euvre au noir)

Intransitif

1824 il [= Argow] jure en lui-même, car il n'ose plus jurer tout haut : il n'a juré qu'une fois, et, pour tout l'or de l'Amérique, il ne voudroit pas revoir l'expression des regards qu'Annette lui lança douloureusement (Honoré de Balzac, Annette et le criminel)

1852 J'ai juré assez haut, on peut l'avoir entendu (George Sand, Mauprat)

1950 L'idée qu'il faudrait retourner à la plaine m'est revenue... Je me souviens, j'ai juré tout haut, pour être bien sûr que c'était bien moi qui étais là et je me suis dit que c'était fini (Marguerite Duras, Un barrage contre le Pacifique)

III. Contraster désagréablement

Intransitif

1883 Le seul mérite de cette toile, c'est qu'aucun défaut n'y jure plus haut que l'autre (Joris-Karl Huysmans, L'Art moderne)

CoRpus Web :

Inutile de revenir sur tout ce que vous avez fait ou bu hier... c'est fait ! Sauf qu'aujourd'hui une foreuse vous perfore la tête, vos yeux sont sensibles à la lumière et votre estomac gargouille méchamment. Vous avez beau jurer haut et fort que c'est la der des ders et plus jamais ça, le mal est fait. Oui bon, passons... [http:// www.ultramag.be/ultra-superficiel/beaute/ lendemain-de-veille] (17.6.2015)

Et Cristiano Ronaldo de jurer haut et fort fidélité au Real Madrid de Florentino Perez « Je pourrais signer pour 10 ans, jusqu'à la fin de ma carrière. " Comme pour le prouver d'ailleurs, l'international portugais s'amuse plus tard de l'offre de Manchester City qui aurait proposé 170 millions pour s'offrir ses services [http:// www.sportune.fr/sport-business/cristianoronaldo-je-pourrais-gagner-le-double-28010] (17.6.2015)

Et Jérôme Lavrilleux, qui vient de quitter l'UMP alors qu'il était menacé de suspension, de commenter : « Ce jour-là, personne n'a rien dit, personne n'a moufté. Tous ceux qui aujourd'hui jurent haut et fort qu'ils ne savaient rien sur les dépassements des comptes de campagne, qu'ils n'ont pas compris que le train des dépenses s'était emballé, ils ont tous bouffé des pâtes à la truffe et bu du champagne » [http://www.20minutes.fr/ politique/1462575-20141016-presidentielle-2012bygmagouilles-ump] (17.6.2015)

REMARQUES : Jurer haut (I) est employé au sens de 'attester par serment, ou faire serment, promettre ouvertement, avec conviction'. En (II), il signifie 'affirmer quelque chose ou proférer des imprécations, des jurons à voix haute'. Dans le contexte de l'art (III), il désigne le fait de produire une discordance, d'aller mal (avec), d'être mal assorti. Notons la collocation haut et fort qui renforce le sémantisme de 'parler à haute voix'. Haut reste invariable et est modifié par assez, plus, tout.

\section{Jurer petit}

Jurer peu, de façon modérée

Emploi absolu

+1400 Tiens ta promesse et petit jure, Gard ne soies trouvé parjure, Car le menteur est mescreü Et, quant voir dit, il n'est creü (Christine de Pisan, Les Enseignemens moraux / Euvres poétiques [début XVe], III, p. 32) 
REMARQUES : Jurer petit désignait le fait de prêter serment pour quelque chose de peu d'importance ou de s'engager sans grande conviction. Petit reste invariable. L'ancien français l'employait comme quantifieur remplacé plus tard par peu. Notons l'emploi de dire voir.

\section{Jurer soef}

jurer soef entres ses dens : jurer d'une voix douce ou à voix basse

Transitif

+1150 Quant Aiols l'entendi, grant ioie en ot el uentre

Et iure damelde a le fiere poissanche Souef entre ses dens, que nus d'aus ne l'entende,

Que s'il peut esploitier, il lor taura la feme (Aiol et Mirabel [2 $2^{\mathrm{e}}$ moitié XII ${ }^{\mathrm{e}}$, 5284)

+1175 Enmié l'essart li rois s'estot.

La sont venu ; tost les destot, De lor parole n'a mes cure ; La loi qu'il tient de Deu en jure Tot souavet entre ses denz : Mar fu jostez cist parlemenz (Béroul, Tristan $\left[4^{\mathrm{e}}\right.$ quart XII $\mathrm{e}$, 3105)
REMARQUES : Usité dans la locution soef / souavet entre ses dens, il se disait du fait de jurer, de prêter serment et ce, d'une voix douce, fine, voire si basse que personne ne l'entend. Soef reste invariable et est modifié par tot.

\section{Juter amer}

Rendre un jus amer

Intransitif

1945 Pas une goutte d'eau. La terre est sèche, on dirait de la poudre. Comment veux-tu que ça pousse ? C'est pas du temps de printemps. Élisa arracha une poignée d'herbes et de fleurs ; entre les dents, les herbes jutaient sucré et les fleurs légèrement amer (Jean-Louis Bory, Mon village à l'heure allemande)

REMARQUES : Juter amer se dit d'une chose inanimée (ici : des fleurs) rendant, laissant couler un jus amer au palais humain. Juter sucré, s'appliquant à des herbes, désigne le fait de rendre, de laisser couler un jus sucré, sirupeux. Amer et sucré restent invariés. Amer est modifié par légèrement.

\section{Juter sucré}

Rendre un jus sucré

入 juter amer 


\section{Kiffer grave}

Aimer énormément

Transitif

1982 - Une cliente assidue est tombée raide amoureuse de moi, commença l'élégant [...]. Elle me kiffe grave, ça se voit à ses yeux. Des yeux de braise, comme on dit dans les films. Ou des yeux de merlan frit, comme on dit dans les poissonneries. « Tomber amoureux. J'exècre cette expression » (Arnaud Dudek, Un sang d'encre)

2003 SOPHIE et EMMA. (en chœur) Ah oui, des secrets qu'on adore, des secrets qu'on kiffe grave.

THIERRY. Les secrets qu'on kiffe grave, ce sont ceux qui sont doux et qui font chaud dans le cœur ou qui nous font sourire quand on y pense

(Isabelle Debruyne et Thierry Verspecht, Les Abus sexuels expliqués aux enfants)

2014a Il faut cependant remarquer que dans son acception jeune l'adjectif grave prend parfois des tournures d'adverbe. Il est proche d'extrêmement ou d'énormément, il dit l'intensité ; ainsi on murmurera « J'te kiffe grave » pour " Je t'aime beaucoup ». Ou l'on s'écriera [...] : « De toute façon, celle-là, elle se la pète grave ». On entendra " J'ai grave les boules » lorsqu'on n'est pas totalement satisfait de quelque chose. Ou " cette meuf, elle me gave grave ", si la compagne dont on parle prend des initiatives agaçantes et répétées (Didier Pourquery, Les Mots de l'époque)

2014b On se retrouve sur la place, sur le même banc ke d'habitude. J'ai mis un autre piercing au sourcil, tu vas le kifer grave (Aro Sáinz de la Maza, Le Bourreau de Gaudí)

2018a - Dimitri, c'est du sérieux. Il me kiffe grave. - Il te kiffe grave ... Tu ne peux pas t'exprimer comme tout le monde, non?

- Tout le monde comme qui ?

- Comme une personne normalement constituée, raisonnablement intelligente, répondit-il d'une voix teintée de juste ce qu'il fallait de sarcasme (Christophe Vasse, Celle qui ne pleurait jamais)
Intransitif

2016 Derrière nous, quelques jeunes sont en train de parler d'une personne qu'ils aiment beaucoup et ils répètent qu'ils " kiffent grave pour elle ». L'expression me plaît, elle décrit parfaitement bien le tableau qui se déroule devant nous entre la patronne, l'enfant et son neveu. Il y a la sonorité, bien sûr "kiffer grave " mais c'est surtout l'effet poétique et musical crée [sic] par l'association d'un sentiment de tendresse à la dureté du réel qui sonne juste. Kiffe grave... Un sorte d'oxymore, au bout du compte (François-Marie et Sylvie Pons, Le Fauteuil roulant malgré lui)

2018b Comme je n'ai jamais eu de rapport sexuel, vous comprenez sans mal pourquoi la seule idée d'en avoir me fait kiffer grave. J'adore l'expression familière " faire kiffer grave » (Craig Lancaster, 600 heures dans la vie extraordinaire d'Edward Stanton)

CORPUS WEB :

Donc, je suis vraiment content qu'il l'ait fait. Maintenant, je sais qu'il y a des gens qui n'ont pas apprécié son travail [rires]. Moi, j’ai grave kiffé, c'est même mon morceau préféré [http:// www.abcdrduson.com/interviews/chiens-depaille/(24.2.2019])

Je kiffe grave ma coiffeuse. Comment lui dire ? déjà faudrait savoir si elle est célibataire.... Ca doit être assez facile à savoir pendant qu'elle te coupe les cheveux ;) Et si c'est le cas tu dois avoir des moyens de lui faire comprendre assez facilement non ? Mais évite "j’te kiffe grave » ca fait mauvais effet [https://fr.answers.yahoo. com/question/index?qid=20061129065957AA 2XKPK\&guccounter $=1$ \&guce_referrer $=$ aHROc HM6Ly93d3cuYmluZy5jb20v\&guce_referrer_si $\mathrm{g}=$ AQAAAAc1jxopt2y1XzcY5Xbwc8arQ4Bn1i u83hz31GV6sqkuAyQ6FhbmymXj1nEeV_--g_ JWe8fEXPcmNCjq6J07D0AF7STk-1PkSXTnjEtJvo] (24.2.2019)

Pour tous ceux qui kiffent graves les commentaires de Chantal [https://www.facebook. com/pages/Pour-tous-ceux...kiffent-graves.../ 166535610024711] (24.2.2019)

Journée au top

Vous au top 


\section{On kiffer graves}

Merci pour toute ces sensations fortes

Pour les grands et le petit...... [https:// www.facebook.com/pg/Pilotage-Concept126753894022759/reviews/?ref=page_internal] (24.2.2019)

REMARQUes : Dans le langage des jeunes, kiffer grave, verbe d'origine arabe, désigne le fait d'aimer énormément, à la folie quelqu'un ou quelque chose, d'adorer. Généralement invariable, il s'accorde, dans le dernier exemple du CW, avec le sujet, ce qui prête à une interprétation quelque peu forcée de prédicat second orienté vers le sujet. Notons se la péter grave, gaver grave, avoir grave les boules. Bedijs (2012 : 251) cite " tu te barres en couilles grave " (se barrer grave), " elle en redemandait grave " (redemander grave), "ça la met grave en valeur " (mettre grave) ; j'ai grave du ménage à faire » (avoir grave), « je la respectais grave» (respecter grave). Noailly (2010 : 190) cite un exemple entendu : « Il a rougi grave » (rougir grave). Dans la plupart de ces exemples, grave est un synonyme populaire du quantifieur beaucoup. D'où l'impossibilité de fournir une liste complète de son emploi dans ce dictionnaire.

\section{Kiffer mortel}

Aimer énormément, à en mourir

Transitif

2004 LAL. - Je te kiffe mortel!

MY. - J'suis love !

(Sylvie Chenus, Comment dire)

2005 (Gros plan sur Slam)

SLAM. Il la kiffe mortel, d'jà y va s'mettre à quatre pattes devant elle... Laisse tomber... (L’Avant-Scène cinéma) 


\section{Labourer droit}

Travailler comme il faut, de la meilleure façon

possible

Transitif

1852 Je fais, tous les jours, deux heures de grec et je commence à labourer mon Shakespeare assez droit (Gustave Flaubert, Correspondance)

CORPuS WeB :

Chargé en 1965 par l'inventeur des « villes nouvelles ", Paul Delouvrier, de lancer le chantier de Cergy, l'ingénieur consignait le soir sur des petits cahiers ce démarrage difficile. Il fustigeait le béton, les cages à lapins, rêvait de locataires " heureux ». Répétait son expression préférée : «Pour labourer droit, il faut accrocher sa charrue à une étoile » [http://www.lexpress.fr/actualite/ politique/martin-hirsch-l-equilibriste_782913. html\#P9BJ7ApZSr3MogKZ.99] (17.6.2015)

Pendant ce genre de semaine, incroyablement productive, et bien tout se fait. Le matériel marche. Tout le monde est sur le pont. Les décisions prises, parfois très en amont, des années avant, portent leur fruits. Les tractoristes $l a-$ bourent droit, avec le bon matériel. Les sarments se broient. Le chenillard se faufile entre les vieilles vignes. Et c'est la semaine ou il faut faire et ne faut pas chipoter sur heures supplémentaires, car c'est là que l'ont marque des points [http://www.closdesfees.com/blogs/2009/02/28/ une-semaine-cruciale] (17.6.2015)

Si on laboure droit, on prépare la terre droit, on sème droit, on déchaume droit et on est prêt à retravailler droit pour la prochaine saison [http:// www.lestracteursrouges.com/forum/viewtopic. php?t=4545\&start=855] (17.6.2015)

REMARQUES : Labourer droit est une collocation sans doute ancienne qui unit le verbe traditionnel labourer, aujourd'hui généralement remplacé par travailler, avec la signification la plus usuelle de droit en ancien français 'correctement, comme il faut'. Notons l'usage de préparer droit, semer droit, déchaumer droit, et retravailler droit dans le CW. Droit reste invariable (v. le deuxième exemple du CW) et est modifié par assez. Le verbe figure dans son emploi intransitif dans le CW au sens de 'travailler la terre comme il faut'.

\section{Labourer large}

Travailler sur un grand panel, plutôt superficiellement

$\lambda$ labourer profond

\section{Labourer profond}

Travailler profondément, en profondeur Intransitif

1864 Vous [= F. A. Pouchet] menez une belle vie de savant, vous labourez profond et droit, et vous laisserez un grand nom (Gustave Flaubert, Correspondance. Supplément)

1933 Les hommes labouraient d'une main plus profond, les femmes employaient avec à propos les condiments dans la cuisine, les garçons pourchassaient les filles, et chacun priait Dieu qu'il voulût bien consommer la ruine de son prochain (Marcel Aymé, La Jument verte)

Transitif

1961 [En Algérie, dans les zones semi-arides, il faut] poursuivre l'emploi d'un matériel puissant, du gros tracteur pour labourer profond en plein été les terres durcies par la sécheresse (Les Temps modernes / Grundt : 290)

\section{CORPus Web :}

En marketing aussi, il vaut mieux vaut labourer profond que large. Mieux vaut tard que jamais pour obtenir des datas intéressantes [http://notrelienquotidien.com/2015/01/14/enmarketing-aussi-il-vaut-mieux-vaut-labourerprofond-que-large/] (17.6.2015)

Ça sert à quoi le géotextile en fait ? Non parce qu'en général, le mouvement de base, c'est les gros morceaux qui remontent et la terre qui descend, pas le contraire (c'est pour ça que les gars qui labourent comme des gros... enfin, qui labourent profond dirons-nous, se retrouvent avec des champs de cailloux). Alors pourquoi est-ce que dans le cas d'un paddock de chevaux l'entropie serait-elle inversée ? [http://equinethique. forumperso.com/t9077p135-amenagement-demon-paddock-hors-boue-solution-trouvee-pourcet-hiver] (17.6.2015)

Regardez Tony comme il laboure profonde Bruna dans son trou du cul [http://fr.justeen. tv/1/3777745/regardez_tony_comme_il_laboure 
profonde_bruna_dans_son_trou_du_cul_ juteuse] (17.6.2015)

REMARQUES : Labourer profond réfère au fait de creuser un thème ou une tâche en profondeur, opposé à labourer large 'superficiellement, avec peu de profondeur' (v. ratisser large). Notons la collocation profond et droit (labourer droit). Profond reste invariable dans la majorité des cas (v. le deuxième exemple du CW), mais dans le troisième exemple du CW, dans lequel labourer est pris au sens érotique, il s'accorde avec l'objet direct au féminin, tout en gardant son emploi adverbial. La flexion sert à augmenter l'expressivité et l'emphase pour stimuler l'imagination. Profond est modifié par plus.

\section{Lacer dru}

Serrer fortement un lien (lacet, bandage)

Transitif

1817 Les bandages lacés sont faits de peau, en toile ou en futaine : ceux de peau de chien méritent la préférence ; ils doivent prendre exactement la forme du membre, et être lacés dru (Journal général de médecine, de chirurgie, de pharmacie)

1840 Le teint pur de la jeune fille, son corset lacé $d r u$, son regard limpide et fier dans son humilité, témoignent d'une vertu sauvage qui plaît (Wilhelm Ténint, Salon de 1840)

\section{Lacer étroit}

I. Enlacer étroitement (quelqu'un)

Transitif

1177a Et la rëine li estant

Ses braz ancontre, si l'anbrace,

Estroit pres de son piz le lace,

Si l'a lez li an son lit tret,

Et le plus bel sanblant li fet

Que ele onques feire li puet ;

Que d'amor et del cuer li muet

(Chrestien de Troyes, Lancelot ou Le Chevalier de la charrete, 4674)

II. Lacer étroitement (un lien), en serrant Transitif

$\sim 1177 b$ Lors ne demore ne delaie, Ainz met parmi le laz sa teste, Tant qu'antor le col li areste ; Et por ce que il mal se face,
Le chief de la ceinture lace

A l'arçon de sa sele estroit,

Einsi que nus ne l'aparçoit

(Chrestien de Troyes, Lancelot ou Le Che-

valier de la charrete, 4307)

+1250 Qant Renart vit que au roi plot,

Dedanz son cuer grant joie en ot

De ce que li rois s'acordoit

A ce que il li ensaingnoit.

«Sire, bien avez esploitie,

Qant vos avez estroit lacie

Le cuir a la forte corroie » (Le Roman de

Renart [2 ${ }^{\mathrm{e}}$ moitié XIII'], XXII, 434)

REMARQUES : En ancien français, lacer étroit réfère au fait d'enlacer de très près quelqu'un ou quelque chose (I) et, au sens (II), de serrer une attache (ici : ceinture, cuir), de fixer étroitement quelque chose à autre chose.

\section{Lacer fort}

Attacher, fixer fortement, solidement

Transitif

+1350 S’avoit la lance ou poing que moult bel paumoioit.

Quant Brun le vit venir, si se leva tout droit, Son hïaume laça bien fort et bien estroit (Brun de la Montaigne [2 moitié $\left.\mathrm{XIV}^{\mathrm{e}}\right]$, 3310)

CORPUS WEB :

sympa cette figure, en plus on peut faire comme pour le looping du bras pour la sortie (o lieu de lacer fort vous amortissez un peu -un p'tit saut du diabolo-vou le chopez en ciseau vou lancez la baguette vers le bas et vou récupérez la baguette ki arive de deriere votre tète [http:// www.2diabolos.com/fr/figure/115_Guillotine. html] (17.6.2015)

Elle concurrence mes anciennes nike vomero de 2014, hoka one one bondi 3m de 2013, asics gel nimbus de 2012 avec certesun amorti plus dur mais du coup une vélocité supérieure. chaussure stable. adapté au fort coup de pied. pas la peine de lacer fort pour se sentir stable. bref content. a tester sans attendre [http://www. decathlon.be/chaussures-de-running-hommenew-balance-mr-880-bleu-noir-vert-id_8327688. html] (17.6.2015) 
REMARQUES : En ancien français, lacer fort désigne le fait d'enlacer de très près quelqu'un ou quelque chose. Notons la collocation fort et étroit. En français moderne, lacer fort réfère à des lacets notamment de chaussures, voire, dans le jeu du diabolo, au mouvement d'une ficelle autour d'un objet (premier exemple du CW). Fort reste invariable et est modifié par bien. Notons l'emploi de lever droit ; paumoier bel.

\section{Lâcher fort}

se lâcher fort : se détendre intensément

तlâcher haut

\section{Lâcher haut}

Dire, prononcer, émettre avec brusquerie et à

voix haute, publiquement

Transitif

1877 Naturellement, ça empêchait les gens de monter ; et ils bâfraient seuls, ils se dépêchaient de s'empiffrer, sans lâcher un mot tout haut. Même, le lendemain, ils se gardaient de jeter leurs os sur les ordures, parce qu'on aurait su alors ce qu'ils avaient mangé (Émile Zola, L'Assommoir)

1887 Le valet demeura stupide, les trois paysans s'en allèrent avec des rires d'insulte, des moqueries, lâchées très haut (Émile Zola, La Terre)

\section{CORPUS Web :}

Voilà une soirée où on va pouvoir se lâcher haut et fort sur les cons et les politicards. Sans oublier les royalistes.

Peuple de Blois, cette soirée est pour toi ! [http://heyevent.com/event/kpookxw6hz44qa/ la-grosse-soiree-alternative-david-vincentprince-ringard-le-saint-lubin-blois] (17.6.2015)

Je la sens venir avec ses gros sabots... Le calme arrive dans la pièce... les enfants sont rentrés en cours. Elle saute sur l'occasion, comme l'aigle fond sur sa proie, pour lâcher haut et fort avec sa voix désagréable : " Enfin, en attendant, tu es toujours aide-soignant... Tu laves des personnes âgées malades... c'est ça ? » [http://aidesoignant2.canalblog.com/archives/ 2015/02/16/31537402.html] (17.6.2015)

les meufs qui lachent haut et fort " moi j’aime que les noirs les autres c'est caca » j'aime pas, je suis noir pour ceux qui savent pas [https:// mobile.twitter.com/iampostbad/status/ 606775455727906816? $\mathrm{p}=\mathrm{v}](17.6 .2015)$

REMARQUES : Lâcher haut se dit du fait d'énoncer quelque chose à haute voix ou publiquement, sans se retenir. Notons la collocation lâcher haut et fort. Haut reste invariable et est modifié par tout, très. Notons l'emploi pronominal du verbe dans le premier exemple du CW où se lâcher a le sens de 'se laisser aller, parler inconsidérement sur quelqu'un'.

\section{Lamenter fort}

se lamenter fort : se désoler, se plaindre, déplorer fortement

Pronominal

1450 ADAM. Pervers sang, perverse matiere, Cueur traïstre et tres inhumain, As tu ousé mettre la main Par quoy cil gist mort et deffaiz Qui mieulx valloit que tu ne fais? Helas! Abel, mon tres chier gendre, Avec toy brief vouldray descendre En enffer et la, jamais faindre Ee toy fort lamenter et plaindre Sans consolacion aucune ! (Arnoul Gréban, Le Mystère de la Passion, 1044)

\section{CORPUS WEB :}

À qui appartient le chien qui n'arrête pas de se lamenter fort et de japper depuis deux jours sur la rue Notre-Dame ? Mon Dieu... [https://www.facebook.com/spotdacton/ posts/650175518391243] (17.6.2015)

On ne peut guère se lamenter fort quand notre ami ou amie souffre encore plus que soit. Je l'ai expérimenté avec Mireille. J'avais beau me lamenter à Mireille de ma misère, la sienne a toujours été le triple de la mienne [http:// smartsheep-org/underground-uncut-plus-longpas-corrig-et-pas-coup-index-170] (17.6.2015)

REMARQuES : Se lamenter fort réfère au fait de manifester sa douleur, son infortune, par des plaintes, fort insistant sur la vivacité des sentiments ou sur l'élévation de la voix. Fort reste invariable. Notons l'emploi de descendre bref. 


\section{Lancer droit}

I. Lancer, diffuser directement, en ligne droite Transitif

+1100 Il li lança un dart tuit dreit :

Deu l'ad guari, a cele feiz,

Kui n'i pot mie sun char aveir,

e cil s'en torne de maneis

(Gormont et Isembart [1 $1^{\text {re }}$ moitié XII $], 108$ )

1717 Il a tiré de son carquois une flèche dorée, qu'il m'a lancée tout droit au cœur

(Dancourt, Le Prix de l'arquebuse)

1840 Chlodowig en avait ordonné la construction, à la prière de Chlothilde, au moment de son départ pour la guerre contre les wisigoths ; arrivé sur le terrain désigné, il avait lancé sa hache droit devant lui, afin qu'un jour on pût mesurer la force et la portée de son bras par la longueur de l'édifice

(Augustin Thierry, Récits des temps mérovingiens)

1845 Mais celui-ci, se jetant de côté par une brusque retraite du corps, évita le coup et lança son marteau droit dans la poitrine du carrier, qui trébucha un moment, mais qui, bientôt raffermi sur ses jambes, se rua sur Agricol avec fureur, en criant :

- À moi, les Loups !

(Eugène Sue, Le Juif errant)

1903 à l'Offertoire le Reges tharsis est lancé droit, tel qu'une flèche, et l'on entend jusqu'au dernier vibrement de son parcours (Joris-Karl Huysmans, L'Oblat)

1980 Sur la route, les camions avancent en lançant droit devant eux les pinceaux blancs de leurs phares, stupidement (Jean-Marie Gustave Le Clézio, Désert)

II. Jeter un regard perçant, pénétrant à

quelqu'un

Transitif

1911 Mme de Saint-Auréol ne baissa pas les yeux un instant, continua de lancer droit devant elle des regards aigus et glacés comme sa voix :

- Ne vous aura-t-il pas suffi d'apporter au foyer de vos parents la misère

(André Gide, Isabelle)
1933 Papa posait sa fourchette, lançait tout droit devant lui un regard soudain plus clair et disait, d'une voix calme :

- Nous sommes beaucoup mieux qu'avant, mais, quand même, bien à l'étroit (Georges Duhamel, Le Notaire du Havre)

1993 Ce qui impressionnait surtout, chez elle, c'était cette façon de vous lancer droit au visage le double éclair de ses yeux dont le bleu-gris très pâle était exactement celui de la mer, en juin, quand une légère brume de chaleur fond l'horizon avec le ciel (Geneviève Dormann, La Petite Main)

\section{S'engager avec hardiesse, s'élancer}

Pronominal

1966 Sans brutalité, Victor se mit à manœuvrer pour sa marche arrière. À reculons, il prenait ses distances, une sorte de biais dans lequel il n'aurait plus qu'à se lancer droit au but. Il s'arrêta l'espace d'un instant et fonça sur la cible (Robert Giraud, La Coupure)

CORPUS WEB :

Ne lancez pas le boomerang de travers. Beaucoup de personnes, y compris des lanceurs expérimentés, lancent quelques fois sans même s'en rendre compte le boomerang de travers au lieu de le lancer droit. Si la main qui lance le boomerang finit sa course au niveau de l'épaule opposée, c'est que vous ne l'avez pas lancé droit [http://fr.wikihow.com/lancer-un-boomerang] (17.6.2015)

il faut voir aussi qu aux passages piétons, ils ont priorité bien sur, ils traversent s en meme regarder ce qui arrivent de droite ou de gauche, ils ont priorité ils se lancent droit devant [http:// www.lindependant.fr/2014/07/22/renversee-parun-vehicule-a-narbonne-la-victime-transporteeinconsciente-a-montpellier,1910345.php] (17.6.2015)

Tout à coup, c'est l'hilarité générale : au lieu de galoper, un des chevaux fait un tour sur place, puis reste obstinément immobile, stoïque aux vives sollicitations de son jockey, furieux. Les groupes suivants connaissent eux aussi pareille mésaventure, avec ces bêtes pas vraiment faites pour courir. Quelques-unes, dans un virage, se lancent droit dans les tribunes, d'autres, se 
cabrant lors d'un - trop - brusque coup de rênes, jettent à terre leur malheureux cavalier [http://lecourrier.vn/la-course-hippique-debac-ha/115612.html] (17.6.2015)

Questions : s'ils avaient été favorables, avec un arbitrage différent, la mêlée du ST irait mieux ? Les ballons seraient lancés droits, pile poil dans les bras du receveur? La stat des enavant serait moins accablante ? [http://www. forumst.net/topic/17181-aviron-bayonnais-stadetoulousain/page-7] (17.6.2015)

REMARQUES : Lancer droit (I), au sens propre comme figuré, désigne le fait d'envoyer, de projeter quelque chose loin de soi et généralement dans une direction déterminée. En (II), il prend le sens de 'envoyer (dans la direction de quelqu'un) un regard aigu, perçant, de fusiller quelqu'un du regard'. Généralement au sens figuré, (III) signifie 's'engager hardiment, s'élancer impétueusement', le sujet ayant un but bien défini. Droit reste invariable dans la majorité des cas (ex. de 1717 , de 1840 et le deuxième et le troisième exemple du CW), mais dans le dernier exemple du CW il s'accorde avec l'objet au pluriel tout en gardant son emploi adverbial. Ce type d'accord s’observe fréquemment dans le langage du sport. Droit a tendance à s'associer avec les prépositions qui le suivent (à, dans, devant), au point de faire partie du groupe prépositionnel comme modifieur de la préposition. Il est modifié par tout.

\section{Lancer dru}

Lancer en grande quantité

$\pi$ lancer fort

\section{Lancer épais}

Lancer beaucoup, en grande quantité et en même temps (des objets)

Transitif

1170 Assemblé sont d'ambedous parz: Traient saietes, lancent darz Mout plus espés que ne chiet pluie ; Del cors lor ist li sans e vuie (Benoit de Sainte Maure, Le Roman de Troie, 11148)

REMARQUES : Lancer épais désigne le fait d'envoyer, de projeter quelque chose (en général, une arme) loin de soi et généralement dans une direction déterminée, épais référant à la densité, au grand nombre de projectiles lancés en peu de temps. Notons l'expression moult plus espés que ne chiet pluie.

\section{Lancer fort}

Lancer avec force

Transitif

+1133 Li Sarrazins ne s'est de rien estorz;

A son arçon a pris un javelot,

Envers Guillelme l'a lancié si très fort

$\mathrm{Si}$ bruit li cop que foldre qui destort

(Le Couronnement de Louis [2 $2^{\mathrm{e}}$ tiers $\left.\mathrm{XII}^{\mathrm{e}}\right]$, 952)

1393 La commencierent a traire de canons et d'arbalestres et a l'approuchier a lancier dars si fort et si dru que ce sembloit gresil des viretons qui vouloient (Jean d'Arras, Mélusine, p. 400 [manuscrit Ars])

\section{CORPUS WEB :}

Ça me lance fort dans un ovaire $:$ depuis ce matin, j'ai une douleur par moment dans l'ovaire gauche, vous pensez que ça peut etre quoi $(;)$ Je suis enceinte de $11 \mathrm{SA}$ et je flippe un peu... [http://forum.aufeminin.com/forum/matern1/ f252840_matern1-ca-me-lance-fort-dans-unovaire.html] (17.6.2015)

Vers un geste de plus en plus précis : lancer loin (dans les cases), lancer fort (faire tomber les plots), lancer haut (par-dessus la corde) [https:// www.edumoov.com/fiche-de-preparationsequence/10925/agir-et-s-exprimer-avec-soncorps/MS/lancer] (17.6.2015)

Jeu de chamboule-tout

Jeux de lancer

Savoirs visés :

Lancer précis

Lancer fort [http://www.usep16.sitew.com/ fs/root/6jyyr-les] (17.6.2015)

J'ai troué le mur avec ma mannette tellement je l'ai lancée forte [http://www.usep16.sitew.com/ fs/root/6jyyr-les] (17.6.2015)

Armé de notre Tweetbot, nous avons préféré attendre une bonne semaine avant de lancer haut et fort que c'est le meilleur client Twitter disponible actuellement sur AppStore ! [http:// www.sosiphone.com/blogiphone/2011/07/26/ tweetbot-plutot-quun-autre-client-twitteriphone-pourquoi-lui-42266/] (18.6.2015) 
« Libérez l'entreprise et l'emploi ! » Ils étaient ce vendredi 5 décembre un millier de chefs d'entreprises vendéens à lancer haut et fort ce cri du cœur. « Les entreprises vendéennes dans la rue, c'est quelque chose d'exceptionnel, note Pierrick Adrien, président de la Capeb de Vendée. Ça traduit un vrai problème » [http:// www.lejournaldupaysyonnais.fr/2014/12/05/leras-le-bol-des-patrons-vendeens/] (18.6.2015)

J'invite Anne-Marie Dussault à revoir le témoignage de Boucar Diouf concernant l'analogie entre la marche nuptiale du Paon et la démarche électorale présente. Elle est savoureuse. Je remercie Gabriel Nadeau Dubois pour son apport important - l'intégrité lancée haut et fort - durant ses mois d'actions opposant la machine de guerre aux forces existantes (la Classe) et aux forces plus faibles (Fecq et la Feuq) [http://www.lecsr.com/ Processus/Form_20120811.htm] (18.6.2015)

REMARQuES : Lancer fort désigne le fait d'envoyer, de projeter quelque chose (en général, une arme) loin de soi avec force et généralement dans une direction déterminée. Dans le premier exemple du $\mathrm{CW}$, il réfère à une douleur forte. Les derniers exemples du CW contiennent la collocation lancer haut et fort qui renvoie au fait de proclamer quelque chose ouvertement et avec force. Notons la collocation lancer si fort et si dru, dru référant au grand nombre de projectiles lancés, et la collocation haut et fort dans le CW. Fort reste invariable dans la majorité des cas, mais dans le quatrième exemple du $\mathrm{CW}$ il s'accorde avec l'objet au féminin tout en gardant son emploi adverbial. Il est modifié par si, très. Notons l'emploi de lancer loin, lancer précis.

\section{Lancer haut}

I. Mener à un degré élevé, à un statut social supérieur

Transitif

1842 Théodore répandait sur chaque journée d'incroyables fioritures de plaisir, il se plaisait à varier les emportements de la passion, par la molle langueur de ces repos où les âmes sont lancées si haut dans l'extase qu'elles semblent y oublier l'union corporelle (Honoré de Balzac, La Maison du chat-qui-pelote)
1981 J'admirai une fois de plus les desseins de la Providence, qui ne m’avait privée de mon héritage et réduite à la misère que pour me lancer plus haut (Françoise Chandernagor, L'Allée du roi)

\section{II. Émettre avec force (un son)}

Transitif

1937 Je ne distingue plus l'hiver de l'été par l'état de l'herbe ou de la bruyère des landes, mais par la buée ou le gel qui se forme sur la vitre. Quand l'alouette lance très haut sa note, sa claire balle de sons qui tombe ensuite à terre comme un fruit, je reste immobile, j'allaite mon enfant

(Marguerite Yourcenar, Les Vagues [trad.])

\section{CORPUS WEB :}

Départ face à la direction de lancer. Elan selon le rythme « tam-ta-tam » à savoir gauchedroite-gauche ou l'inverse. Le pied droit (pour les droitiers) passe devant le pied gauche (pas de pas chassé). Le pied gauche assure le blocage devant la ligne. Lancer haut et loin ! [http:// www.mobilesport.ch/athletisme/lancer-cinqtechniques-pour-le-lancer-du-poids/?lang=fr] (18.6.2015)

Arme caractéristique de l'Antiquité tardive, mentionnée par Végèce sous son nom latin, signifiant « plombée » (Epit. rei milit., I, 17). La hampe pouvait être assez courte, l'arme étant lancée haut et retombant à la verticale, sur des soldats que leurs boucliers ne pouvaient protéger de tous côtés à la fois [http://artefacts.mom.fr/fr/result. php?id=PBT-4001\&find=PBT\&pagenum=1\&affm ode=vign] (18.6.2015)

Quand on lance haut, on n'a pas vraiment à se préoccuper de ça. On peut plus se concentrer sur l'endroit où on lance la balle latéralement et longitudinalement. Donc, bon an mal an, je pense que le lancer est plus précis quand il est plus haut [http://www.la-technique-du-tennis. com/leservice.htm] (18.6.2015)

Ballon joué à 10 doigts dans le terrain adverse. la balle de l'entraineur est lancée haute [http://www.cd37-volley.fr/wp.../10/Partieatelier-nº1.doc] (18.6.2015)

Tandis que dans les transports parisiens, les verbes se lancent hauts à insulter le quidam. Qui ? dame, je n'en sais rien. Paris, ville déserte [http:// pascalfourvel.free.fr/Ici-ailleurs] (18.6.2015) 
REMARQUES : Lancer haut (I) a le sens de 'envoyer vers le haut', et, par extension, dans un contexte spirituel, de 'mener vers un point, un niveau élevé ; élever à un niveau supérieur'. (II) signifie 'pousser, émettre un son vif, haut (ici : d'un oiseau). Dans le CW, on note également le sens de 'projeter quelque chose (une balle, une arme) en l'air'. Haut reste invariable dans la majorité des cas, mais dans l'avant-dernier exemple du CW il s'accorde avec l'objet du verbe transitif, et, dans le dernier exemple ('lancer / proclamer'), avec le sujet du verbe pronominal. Il est modifié par plus, si, très.

\section{Lancer menu}

Lancer abondamment, à haute fréquence Transitif

$\sim 1190$ As ars trucois commencent les nos a damagier ;

Plus menu que gresins font saietes lancier. Atant es vous poignant le preu comte Renier,

Celui de Genevois, qui fu pere Olivier

(Fierabras (L), 5879)

REMARQUES : Lancer menu désignait le fait d'envoyer, de projeter une pluie d'objets loin de soi (ici : des flèches) et généralement dans une direction déterminée. Menu reste invariable et est modifié par plus.

\section{Lancer précis}

Lancer quelque chose précisément, à un endroit donné

$\lambda$ lancer fort

\section{Lancer raide}

Projeter avec force

Transitif

1874 L'abbé Surin l'ayant remplacée tint la raquette avec une adresse et une ampleur vraiment magistrales. Il avait ramené sa soutane entre ses jambes ; il bondissait en avant, en arrière, sur les côtés, ramassait le volant au ras du sol, le saisissait d'un revers à des hauteurs surprenantes, le lançait roide comme une balle ou lui faisait décrire des courbes élégantes, calculées avec une science parfaite (Émile Zola, La Conquête de Plassans)
1957 Quand il parlait, même pour dire les choses les plus simples, comme : «La séance est ouverte » ou « Je donne la parole à Waldo Frank ", il mâchait les mots avec fureur et les lançait raide devant lui, comme des grenades (Simone Téry, Beaux Enfants qui n'hésitez pas)

\section{Laquer blanc}

Peindre avec de la laque blanche

Transitif

1954 Une armoire laquée blanc (Marie-France, 29 mars 1954 / Grundt : 252)

\section{Corpus Web :}

Bonjour, Je veux laquer blanc brillant une table ronde qui d'origine, est couleur merisier brillant [http://peinture.comprendrechoisir.com/ qr/voir/99336/laquer-une-table-ronde-couleurmerisier] (19.6.2015)

J'ai un parquet en Pin ancien en état moyen dans une piece qui devient une salle de bain. Je voudrais le laquer blanc mais les joints sont tres écartés. Que puis-je utiliser pour refaire les joints avant de laquer ? [http://www.cyberbricoleur. com/index.php? showtopic $=1000044822$ ] (19.6.2015)

Chic et fraiche, cette jolie table de salle à manger laquée blanche vous ravira. D'une élégance toute simple, elle charmera vos invités ! A décorer tout en couleur pour une tablée pleine de vie. Chez Dya, on aime : la finition épurée [http:// www.dya-shopping.fr/table-de-salle-a-manger$160 \mathrm{~cm}$-laquee-blanche-brooklyn.html] (19.6.2015)

REMARQUES : Laquer blanc est résultatif par rapport à un changement de couleur d'un objet. Blanc reste invariable dans la majorité des cas. Toutefois, dans le troisième exemple du CW il s'accorde avec l'objet au féminin.

\section{Larder serré}

Larder, percer, blesser (quelqu'un) à de nombreuses reprises

Transitif

1450 NOSTRE DAME. Faulse Mort de terrible garde,

C'est ta condicion paillarde

D'estre tousjours nice et fetarde

A ceulx a qui leur vie tarde, 
Qui sans cesser t'appellent en plorant.

Et ceulx que le monde plus garde

Et qui quierent leur avangarde,

Contre toy ton oueil les regarde

Et, au parfont du cueur, les larde

Si tres serré qu'ilz chëent tout morant

(Arnoul Gréban, Le Mystère de la Passion, 25204)

REMARQUES : Larder serré désignait le fait de transpercer, de piquer à plusieurs reprises, abondamment. Ici, le sujet est inanimé (œil) et larder serré signifie 'transpercer, pénétrer quelqu'un par la vue, par des regards mauvais à de nombreuses reprises'. Serré reste invariable et est modifié par si très.

\section{Laver blanc}

I. Rendre le linge blanc et propre

Emploi absolu

1987 Depuis longtemps, la publicité s'est attachée à énoncer des propositions d'allure vraisemblable affirmant la qualité inégalable des produits (« Omo lave plus blanc »), en faisant témoigner des grandes vedettes ou des individus du commun dans des « tranches de vie » (Gilles Lipovetsky, L'Empire de l'éphémère)

1992 Il vend des téléviseurs aux paysans Afin qu'ils n'ignorent rien des bonnes lessives

De celles qui lavent le plus blanc

Et pour les gosses turbulents

Des p'tits croquants excellents pour les gencives

Mais quand ils voient arriver à tire-d'aile

Une machine à laver, dernier modèle

Ils trouvent cela séduisant

Et parfois même épuisant

(Charles Trenet, Chansons, 1960-1992)

II. Innocenter, laver de tout soupçon

Emploi absolu

1996 On mettait des ministres en prison, bien sûr, mais ce n'était qu'une péripétie de la vie politique. Pas la justice. Ils rebondiraient tous, un jour. Dans la société des affaires, la politique lave toujours plus blanc La Mafia en est le plus bel exemple (JeanClaude Izzo, Chourmo)
CORPUS WEB :

En avril les jardins lavent plus blanc...

Si le vert enchante les pupilles en ce début de printemps, je reste fondamentalement, définitivement attachée au blanc. Blanc - blanc des amélanchiers qui ouvrent le bal, blanc - rosé des prunus tellement charming, blanc - vert jaune de mon prunus chouchou, le Ukon, blanc plus que blanc des malus, tous les malus d'Evereste', à ‘Golden Hornet'. Bref y’a que le blanc qui m'aille ... en attendant la couleur [http://www. paperblog.fr/4364571/en-avril-les-jardins-laventplus-blanc/] (19.6.2015)

REMARques : Dans le domaine de la publicité, laver blanc (I) se dit d'un produit de lessive censé rendre le linge d'un blanc éclatant, plus soulignant la qualité supérieure du produit en comparaison avec d'autres. En (II), le sujet réfère à une personne ou une institution se débarrassant de quelque chose de compromettant, innocentant quelqu'un ou faisant disparaître l'origine illégale de quelque chose, blanc décrivant un résultat absent de souillures, de culpabilité. L'exemple du CW joue avec l'emploi publicitaire (I), en le transposant à la couleur des fleurs d'un jardin. Blanc reste invariable (malgré l'objet au féminin ou pluriel). Il est modifié par l'adverbe comparatif ou d'intensité le plus, plus, toujours plus.

\section{Laver chaud}

Laver à l'eau chaude

Transitif

1959 Tes couverts sont gras, ma fille ; il faut les laver chaud (Exemple entendu, 30 décembre 1959 / Grundt : 238)

\section{CORpus WeB :}

Avec les machines a laver japonaises, $c$ est super top difficile de faire partir les traces au col sur les chemises blanches lumineuses de mon cheri. Blanc lumineux qui $n$ est plus aussi lumineux que ca a force de laver a $l$ eau froide puisque pour avoir un beau blanc totemo ii, il faut laver chaud! Si quelqu un a une technique AUTRE que le pressing, je suis preneuse [http://www. forumjapon.com/forum/viewtopic.php?t=6931\& start=30\&sid=e7281b09097f6f83b2a6ccb420d96 9fd\&partner=rsj] (19.6.2015) 
Chez nous toutes les couettes Ikéa aussi. En synthétique car allergiques aux plumes. Elles sont solides, se lavent chaud et sont bien chaudes (pour les hiver bien entendu) [http://forum. magicmaman.com/votrevie/Maisonetquotidien/ couettes-chez-ikea-sujet-3670316-1.htm] (19.6.2015)

Les flocons de PET

Notre gamme de production consiste d'une grande variété des flocons de PET de grande qualité.

Toutes les qualités sont lavées chaudes. La taille du grain est sous $10 \mathrm{~mm}$ pour obtenir une densité apparente la plus grande possible [http:// www.stf-aicha.de/fr/recyclage-du-pet/floconsde-pet.html] (19.6.2015)

REMARQUES : Laver chaud désigne le fait de nettoyer quelque chose avec de l'eau chaude, afin d'éloigner toutes tâches ou traces de graisse. Chaud reste invariable dans la majorité des cas, mais dans le dernier exemple du CW il s'accorde avec l'objet au pluriel féminin (prédication seconde). Notons que le sens de laver chaud exclut la lecture résultative typique de laver blanc, propre, etc. Notons aussi l'emploi absolu et pronominal à sens passif dans le CW.

\section{Laver propre}

Rendre net, propre, bien nettoyer

Transitif

1950 puis, emportant le plat en aluminium de Mme Léonce, en courant je traverse la rue et v'lan! j'en verse le contenu dans l'écoulement de la fontaine. Je le lave bien propre et le rapporte à Mme Léonce (Joseph Zobel, La Rue Cases-Nègres)

Emploi absolu

1953 La blancheur au carré. Une formule qui semble tout droit sortie d'une publicité pour la lessive. Normal, c'est le cas. Dès 1953, c'est Persil qui ouvre le bal. Persil lave plus blanc... donc plus propre! Et qui récidive en 1959 en lançant Voici Super Persil qui lave encore plus blanc que Persil (Delphine Gaston, Nos 500 expressions populaires préférées)
1957 Crio, lui, ne se contente pas de laver rigoureusement propre et lumineusement blanc, Crio fait du bien à votre linge (Elle [Publicité], 2 septembre 1957 / Grundt : 252)

\section{CORPUS WEB :}

La saponaire est une toute petite boutique bio située sous le tilleul planté en 1597 (... il est gros, lui) de Saint-Martin-en-Vercors dans la Drôme. La boutique ouvre donc ses portes un peu plus grand et arrive chez vous... Retrouvez sur ce site tout le nécessaire pour manger bon et laver propre avec des produits biologiques, écologiques et biodégradables [http://saponaire.fr/] (22.6.2015)

après utilisation aura à plus basse température, réoccuper l'eau claire est à laver, pas immédiatement utiliser l'eau froide à nettoyer. Un les taches tenaces, peut utiliser l'eau chaude et le essence qui lavent propre, propre avec éponge, Ne pas laisser le grossier sable chiffon ou boule de métal à laver brosse [http://m.french.alibaba. com/p-detail/bambou-ustensiles-de-cuisinedecoration-cuisine-1497179129/specifications. $\mathrm{html}]$ (22.6.2015)

Maintenant, il est évident que quand ils rentrent « crottés » du jardin, des louveteaux, si molluscum ou autre, c'est chacun son eau ou la douche. Ils ne partagent l'eau que quand ils se lavent " propres "... Je ne dois pas être très claire dans mes explications [http://maximomes.org/ forum/viewtopic.php? $\mathrm{p}=654615 \& \mathrm{sid}=05 \mathrm{~d} 84651 \mathrm{a}$ 58713888728a547dfe93214] (22.6.2015)

Laser des cheveux X5. Il est recommandable pour employer le X5 Hairlaser 3 fois où une semaine en sessions de 10-15 minute. L'utilisation fréquente ne vous donnera pas un meilleur résultat. Quand vous avez atteint le résultat désiré vous pouvez réduire le nombre de sessions que vous employez le X5 Hairlaser. Pour vous obtenir au meilleur résultat appliquez le X5 sur les cheveux lavés propres [http://www.laserhaircare. $\mathrm{nl} / \mathrm{fr} /$ gebruik_garantie.html] (22.6.2015)

REMARQUES : Laver propre désigne le fait de laver, de nettoyer quelque chose (du linge, de la vaisselle, une partie du corps), dans le but de le rendre propre, luisant, impeccable. Dans l'exemple $5 \mathrm{du}$ $\mathrm{CW}$, cette lecture résultative est remplacé par celle d'un prédicat second orienté vers le sujet : 
les enfants ne partagent le bain que quand ils sont propres, c'est-à-dire non pas crottés comme d'autres fois. Propre reste invariable dans la majorité des cas, mais dans le dernier exemple du CW il s'accorde avec le sujet du verbe au passif. Notons l'ambiguïté structurale de cet exemple où l'on peut préférer la lecture les cheveux lavés // propres. Propre est modifié par bien, plus. Notons l'emploi de sortir tout droit (sortir droit) ; manger bon; ouvrir grand.

\section{Lever bel}

Paraître avec éclat, en parlant du soleil $\pi$ paraître clair

\section{Lier destroit}

$\pi$ lier étroit

\section{Lier étroit}

I. Lier étroitement (physiquement)

Transitif

$\sim 1160$ Mais li rois fu si fort iriés

Que d'aus ne li prendoit pitiés.

Oiant aus, les a fait jugier

Et en aprés estroit loier

(Flore et Blancheflor, 2922)

+1175 Qui voit son cors et sa fachon, Trop par avroit le cuer felon Qui nen avroit de lié pitié. Mout son li braz estroit lië (Béroul, Tristan [4 quart XII $\left.{ }^{\mathrm{e}}\right], 1154$ )

+1200 Si dampnedé [= 'Dieu'] pur veir ne le out iloc eidé, Einz que vensist aval, il eut le col brisé ; Mes dieu li eida par la sue pité. Par le col e par le pez fu mult estreit liez (Bueve de Hanstone [début XIII'], 944)

+1250 Un escu tot roon et noir A aparellie, jel vos di, Et un baston noir autresi. Le baston estoit de pomer, Et bien l'ot fait estroit lier (Le Roman de Renart [ $2^{\mathrm{e}}$ moitié XIII'], XIII, 2108

-1300 a As penons de noz lances les lierons estrois $\mathrm{Ou}$ ficherons as pointes des riches fers turquois,
Puis irons quere Charle a Loon ou a Blois (Jehan Bodel, La Chanson des Saisnes [fin XIII'] , 774)

+1400 Pardonne moy mes pechiez en l'onneur De ton saint col et dignes mains qui tant Estroit liez furent a deshonneur Par les felons qui t'aloient batant (Christine de Pisan, Une oroyson de nostre Seigneur / Euvres poétiques [début $\mathrm{XV}^{\mathrm{e}}$ ], III, p. 18, 71)

1450 ANNE. Ilz n'en doivent pas estre exemps. Et, pour tant qu'il est granment tard, Roillard, Gadifer et Dentart, Voyez ceste coulompne haulte Qui soustient ou millieu la volte ; Menez luy tost, comment qu'il soit, Et le liez si tres destroit Qu'il n'ait pouoir de s'en deffaire (Arnoul Gréban, Le Mystère de la Passion, 19587)

1555 SIMO. Je veux qu'il me soit garrotté Cependant, et soigneusement Me soit gardé, scez tu comment? Qu'il ait les deux bras et les pieds Ensemble bien estroit liéz (Bonaventure Des Périers, L’Andrie)

1682 Pour remede il le [= cheval qui a la rage] faut lier etroit, puis ainsi lié, vous le ferez saigner de la veine du col et du flanc (Le Grand Maréchal expert et françois)

II. Lier étroitement (psychiquement) Transitif

+1200 Tot son conseil lia estroit De monsegnor Gavain qu'il vit. Oiant tos les barons a dist Que bien set que il s'en alot (Raoul de Houdenc, La Vengeance Raguidel [début XIII'], 3664)

1235 Quant li rois ceste aventure ot, De la tresgrant joie qu'il ot Et de la pitié de s'amie, Qui cuide que il l'ait haïe, A si le cuer estroit liié, Qu'enchois que il l'ait desliié En maniere qu'il puist parler Peüst uns hom a piet aler De tere sis arbaletrees (Philippe de Remi, sire de Beaumanoir, La Manekine, 6335) 
-1300b Qant Baudoins l'antant, s'a sa resne gainchie

Et maudit duremant le san et la maistrie

Duc Naymon de Baviere qi si estroit les lie;

Tot vuet faire par san, non par chevalerie ;

Trop fust bons sermonerres dedanz une abaïe (Jehan Bodel, La Chanson des Saisnes [fin XIII'], 4502)

CORpus WeB :

Importance des relations commerciales canado-américaines

les plus importantes au monde

2.4 milliards par jour

Système très équilibré et mutuellement bénéfique

Éviter la rupture

Lié étroit avec

des conseillers de Trump

Newt Gingrich

Stephen Schwarzman

[https://www.usherbrooke.ca/uta/file admin/sites/uta/documents/SHB_17_01_2017_ conf.pdf] (30.6.2020)

Après. Seulement après elle se rendit compte qu'elle criait, lorsqu'elle fut muselée par la main large, oui, muselée non par sa bouche, juste ses mains. Tordues, soumises, ramenées au dessus de sa tête de gestes provoquants et secs, puis nouées par un des cordons arraché du baldaquin, liées étroit au sommet de ce lit indifférent et trop sage qui ne pouvait que gémir sous la bataille effrénée, évidemment perdue d'avance [https:// rozam-blog.wixsite.com/rozam-fanfictions/ commeunfrere4] (30.6.2020)

REMARQUES : Lier étroit (I) réfère à une partie du corps, ou un objet, qu'on serre, joint fermement à autre chose ; il s'applique également à une personne qu'on ligote avec un lien particulièrement serré pour la garder prisonnière. Dans un sens métaphorique (II), lier étroit peut désigner un lien d'affection unissant deux personnes. Dans l'ancienne langue, la position syntaxique avant ou après le verbe est libre. La langue moderne tend à remplacer étroit par étroitement. Les exemples du CW montrent cependant que ce remplacement n'est pas systématique. Étroit reste invariable et peut être modifié par un adverbe d'intensité (bien, moult, si, si très, tant). VoIR AUSSI : joindre fort

\section{Lier ferme}

I. Unir étroitement, lier solidement, avec un lien très serré (physiquement)

Transitif

1235 E eu ciel munta, of lui si cumpainun, K'il out ja delivré d'enfernal regiun, E ferm lié Sathan, le viel senglant dragun, En enfer $\mathrm{u}$ ert tuz jurs sa mansiun (La Vie de seint Auban, 320)

+1300a Les freres Fouke, quant ce vyrent, saylerent hors à la porte, si pristrent les $\mathrm{x}$. chevalers et sire Gyrard et tote lur herneys, e les lyerent mout ferm en la loge le porter, e pristrent tote lur herneys e lur bons destrers ; e s'en alerent, qe unqe ne fynerent de errer eynz qu'il vindrent à Huggeford (Fouke le Fitz Waryn [début XIV $],$ p. 62)

$+1300 \mathrm{~b}-$ Ore, fet Fouke, qy de vus se fet apeler Fouke?

- Sire, fet Pieres, je su chevaler, si su apellée Fouke.

- De par Deus, fet-yl, sire Fouke, levez sus tost, si liez bien e ferm tous vos compaignons, ou si noun tut premer perderez le chief

(Fouke le Fitz Waryn [début XIve], p. 65)

1312 En la burse v[us] me q[ue]rez E p [ur] veir la me troverez, Mut ferm lié (La Plainte d'Amour, 141)

1380 DEUXIESME SERGENT. Sa donc ! faisons nostre devoir.

Despoullons le, Grain d'or amis,

Et sur ce gril par nous soit mis

Et lié ferme (Miracle de saint Lorens, 2017)

2018 Ils s’y déplaçaient avec une aisance de « chats », même sur la neige, ceci grâce à des crampons ou des petites planches de fer pointues qu'ils liaient ferme (Stéphane Gal, Histoires verticales : Les usages politiques et culturels de la montagne [XIV ${ }^{e}$. XIII ${ }^{e}$ siècles])

Emploi absolu

1746 Si on voit même qu'il s'en trouve quelqu'un qui embarrasse, pour séparer la glande, il faudra lier ferme avec un fil, puis on 
coupera la glande (François de Garsault, Le Nouveau Parfait Maréchal)

II. Unir étroitement, lier solidement (d'un lien affectif)

Transitif

1572 Toy bienheureux, demeures icy roy, Ayant ma femme Andromache chez toy, Pour ton espouse à toy ferme liée, Du filz d'Achille à tort repudiée (Pierre de Ronsard, La Franciade, p. 65)

1584 J'aime de tout mon cœur, je veux aussi qu'on m'aime.

Le desir au desir d'un nœud ferme lié, Par le temps ne s'oublie et n'est point oublié,

Il est tousjours son tout, contenté de soy-mesme

(Pierre de Ronsard, Sonnets pour Hélène)

Pronominal

1804 Beyle [= Stendhal] dans cette lettre [du 8 juin 1804] voulait emprunter 1.200 francs et il disait à son correspondant « Je suis pressé, c'est pour pouvoir me lier ferme avec Mlle Duch[esnois] que nous nommerons à l'avenir Ariane. Fais-moi ça vite, écris-en à Faure. Presto, presto, signori miei » (Stendhal, Mélanges de littérature)

\section{CORPus Web :}

Exemples typiques de l'utilisation d'amiante sous une forme liée ferme [http://fr.1001mags. com/parution/batitech/numero-2010-10octobre/page-32-33-texte-integral] (29.6.2020)

REMARQUES : Lier ferme (I) réfère à une chose inanimée qu'on serre, garrotte fermement à autre chose ; il renvoie également à une personne qu'on ligote avec un lien serré pour la garder prisonnière. Sur le plan métaphorique (II), lier ferme signifie 'unir fortement par des liens d'affection, de convenance, de solidarité ou d'intérêt'. Ferme reste invariable et peut être modifié par un adverbe d'intensité (moult). Notons la collocation bien et ferme.

\section{Lier fort}

I. Lier étroitement, en serrant

Transitif

1100 Dedenz ses plaies en bote un grand quartier,

Le remanant dessus ad fort liiet ; [variante] Cuntre sun piz puis si l'ad enbraciet Sur l'erbe verte puis l'at süef culchiet (Chanson de Roland, 2173)

$\sim 1177$ Atot ice mout tost s'an va : Ancor celui dormant trova La, ou ele l'avoit leissié. Ses chevaus met an un pleissié, Ses atache et lie mout fort Et puis s'an vient la, ou cil dort, Atot la robe et l'oignemant (Chrestien de Troyes, Yvain ou le Chevalier au lion, 2985)

1230 Puis, faites les enfans trestous nus despoiller,

C'ancor nos pueent bien lor dras avoir mestier.

Puis, lor faites lier et les mains et les piés

Et faites à chascun une corde lacier Par desous le menton, fort estraindre et lier,

Si les faites noer as keues des somiers (Gui de Bourgogne, p. 34)

+1250 Dist li chiens : Ie suis estachiez De iour, ia n'an serai leschiez. Fort suis loiez, que ne m'estorde Por ce que ie les genz ne morde (Ysopet de Lyon [2e moitié XIII $]$, 2871)

1514 Aprés la deffaulte d'icelle bataille, ainsi que Rolland s'en retournoit triste et douloureux, il trouva ung Sarrasin mussé en la forest, lequel il lya tresfort à ung arbre

(Alain Bouchart, Grandes Croniques de Bretaigne)

1564 Il suffira que chacune greffe ait un bon œillet ou deux hors de la torqueure : car de les laisser trop longues, ne seroit pas bon, et les faut torquer et envelopper de terre et de mousse, et les recouvrir de drappeaux, et lier fort, commedit est (Charles Estienne, L'Agriculture et maison rustique) 
1630 Ceux qui portent de Christ en leurs membres la croix :

Ils la souffrent en chair, on leur presente en bois ;

De ces bouches d'erreur les orgueilleux blasphemes

Blessent l'Agneau lié plus fort que la mort mesmes

(Théodore Agrippa d'Aubigné, Les Tragiques)

1710 Chacun mettoit en usage les remédes qu'il avoit apris, mais voyant que tout cela étoit inutile, et que l'on parloit même de faire venir un chirurgien pour lui ouvrir la veine, je lui pris le petit doigt, du côté de la narine qui saignoit, et le liai bien fort d'une éguillée de fil, entre l'ongle et la premiére jointure (Simon Tyssot de Patot, Voyages et avantures de Jaques Massé)

1936 En se débattant, elle a découvert un peu au-dessus du mollet une grosse ficelle liée si fort que la chair faisait deux gros bourrelets, couleur d'aubergine (Georges Bernanos, Journal d'un curé de campagne)

II. Soumettre quelqu'un à sa domination morale ou affective

Transitif

+1365a Et pensés vous que là parler je puisse ? Nennil ; car vo beauté si fort me loie Langage et coer, que se parler voloie, Se n'en est il noient en ma puissance (Jean Froissart, Poésies [3 $3^{\mathrm{e}}$ tiers XIVe], 829)

+1365b Ardour me guerroie,

Quel part que je soie,

Et si fort me loie

Que ne la diroie

A nullui

(Jean Froissart, Poésies [3e tiers XIV"], 3652)

+1400 Sachiez de voir qu'amours si fort me lie

En vostre amour que n'ay chose tant chiere.

Mais ce seroit a moy trop grant folie De ne faire, fors a vous, bonne chiere (Christine de Pisan, Cent balades / Euvres poétiques [début $\mathrm{XV}$ ] $]$, I, p. 27, 15)
+1415 Ci pris, ci mis,

Trop fort me lie

Merencolie,

De pis en pis (Charles d'Orléans, Poésies

[ 1415-1440], II, Rondel CLXXXI, p. 394)

1939 Pardo revient, amenant Pozner, un soldat jeune et sympathique. Grouillement, fièvre, dépaysement de se sentir lié si fort à tous ces étrangers. Et constante horreur : l'essence enflammée, les gaz, l'ypérite, et Bost dans tout ça (Simone de Beauvoir, Journal de guerre)

III. Unir (abstrait)

Pronominal

1754 Aussi leurs idées se lient si fort à toutes les autres, qu'il n'est presque plus possible à la statue de penser aux objets odoriférans, sonores, ou palpables, sans les revêtir aussi-tôt de lumiere et de couleur (Étienne de Condillac, Traité des sensations)

Transitif

1805 Dans les civettes et mangoustes, un fort talon et deux tubercules pointus en dedans : elle y devient presque une dent à tubercules et lie fort ces animaux aux ours (Georges Cuvier, Sur les ossements fossiles d'hyènes)

\section{CORPUS Web :}

$500 \mathrm{~m}$ de fil à coudre corde de fil de Nylon lié fort pour sac à dos [h5.fr.aliexpress.com] (30.6.2020)

Et c'est cela qui vous lie plus fort, plus fort qu'à la normale. Vous le connaissez par cœur, en long, en large, en travers

Ce qu'on a sur le cœur [www.facebook.com] (30.6.2020)

Comment supporter leur sort ? Par l'amitié qui les lie fort entre elles [Chronercri.wordpress. com/cinecritiques] (30.6.2020)

REMARQues : L'objet de lier fort (I) peut être une chose comme une partie du corps qu'on serre, joint fermement à autre chose ; il peut être encore une personne (ou un animal) qu'on ligote avec un lien particulièrement serré pour la garder prisonnière. Sous (II), le sujet, pouvant être animé ou inanimé, domine une personne psychologiquement, la maintient sous sa dépen- 
dance ce qui traduit une idée de forte contrainte voire d'obligation. Dans un sens métaphorique, le groupe peut référer à un lien d'affection unissant deux personnes mutuellement. Sur le plan abstrait (III), lier fort renvoie à une relation entre idées, des rapports de parenté, etc. Fort reste invariable et peut être modifié par un adverbe d'intensité (bien, moult, plus, si, très, trop). Notons la réduplication plus fort, plus fort. Mentionnons également l'emploi de étreindre fort ; dépouiller nu. VOIR AUSSI : enserrer / lacer fort

\section{Lier menu}

Lier très étroitement

Transitif

+1150 Il la fait seeler a force et a vertut,

A granz bendes d'argent la fait leier menut; Larcevesque Turpin comandet seit conduiz.

Charlemaignes fut liez et cil qui sont od lui (Pèlerinage ou Voyage de Charlemagne à Jérusalem et à Constantinople [ $2^{\mathrm{e}}$ moitié XII ${ }^{\mathrm{e}}$, 201)

REMARQUES : Lier menu réfère au fait de serrer, garrotter une personne avec des bandes ou cordes jointes étroitement pour la garder prisonnière. VoIR AUSSI : serrer menu

\section{Lier serré}

I. Attacher physiquement, avec un lien serré étroitement

Emploi absolu

1603 De mesme fera-on touchant les ligatures, car pour faire prendre la montée à la matrice, le lier des bras y est trèsrequis ; mais lier serré, estroict, et douloureux, comme dessus ; et de frotter les bras, tendant en haut (Olivier de Serres, Le Thêâtre d'agriculture et mesnage des champs)

Transitif

1655 Ces oiseaux, vis-à-vis l'un de l'autre, appuyez fermement chacun sur son arbre, avec leur col de longueur prodigieuse, m'entortillèrent comme avec une corde, les uns par les bras, les autres par les jambes, et me lièrent si serré, qu'encor que chacun de mes membres ne fut garoté que du col d'un seul, il n'estoit pas en ma puissance de me remuer le moins du monde (Savinien Cyrano de Bergerac, Les Estats et empires du soleil)

1824 Le bâtard, à qui ces clameurs déplaisaient, lui fit couper ses robes, et, demi-nue, elle fut, à grands coups de bâton, menée vers l'orme de Vaurus ; elle y fut liée si serré, que les cordes entraient dans la chair (Prosper de Barante, Histoire des ducs de Bourgogne de la maison de Valois)

1922 Les femmes arabes ajoutent ce bandeau aux autres dont elles parent leur tête et le lient serré de telle sorte que les rangs de perles qui tombent du bandeau, atteignent presque les paupières et flottent autour du front et des tempes (Revue hispanique 54)

1954 Ton bouquet se défait. Il faut lier les fleurs plus serré(es) (Exemple entendu, 28 août 1954 / Grundt : 299)

1981 D’abord coudes et poignets liés serrés dans le dos. Puis les deux pouces et les majeurs avec un fil très mince (Jean Pouget, Bataillon R.A.S. Algérie)

2012 Alors les soldats du roi lièrent serré le couple de srinpo (Yveline Feray, Contes d'une grand-mère tibétaine)

II. Lier étroitement (lien affectif) Transitif

1944 PIERRE. Ils s'entendent tous, ils se tiennent tous. Ils sont liés plus serré les uns aux autres que les alpinistes par leur chaîne (Jean Giraudoux, La Folle de Chaillot)

REMARQUES : Au sens concret, lier serré (I) signifie 'entourer, serrer quelque chose / quelqu'un avec un lien très serré, étroit'. Si l'objet est une personne, celle-ci est ligotée étroitement afin d'être retenue prisonnière. (II) se dit de deux ou plusieurs personnes unies dans un rapport d'affection, de convenance, de solidarité ou d'intérêt. Serré tend à l'invariabilité et peut être modifié par un adverbe d'intensité (plus, si). Notons l'emploi de lier serré, étroit. 


\section{Lire bas}

Lire à voix basse ; lire dans son for intérieur Transitif

1610 Dames, qui avez les oreilles chatouilleuses, de peur de rire, lisez cecy tout bas ou de nuict, durant laquelle la honte dort (Béroalde de Verville, Le Moyen de parvenir)

1643 DORANTE. Autre billet.

(Il continue, après avoir lu tout bas le billet)

(Pierre Corneille, Le Menteur)

1654 Mais si vous ne me croyez pas,

Considerez, et lisez bas,

Landrirette, la centurie que voicy,

Landriry (Vincent Voiture, Poésies)

1685 Roland lit tout bas des vers escrits sur la Grotte (Philippe Quinault, Roland)

1733 ADÉLAÏDE. Il eût dû s'épargner des efforts superflus..

(Elle ouvre le billet)

C’est lui-même... Écoutons un amant qui n'est plus.

(Elle lit bas une partie du billet, et haut ce qui suit) (Alexis Piron, Gustave-Wasa)

1745 Sans difficulté, dit Mme Dorsin, qu'elle écrive ; mais je suis d'avis auparavant que nous sachions ce qu'il lui dit dans la lettre que vous tenez, et que vous avez lue tout bas; c'est ce qui réglera ce que nous devons faire (Marivaux, La Vie de Marianne)

1784 Elle rougit, et ala le prendre ; le billet tomba : elle le lut tout bas, le serra, et me dit : c'est une folie, comme on en-écrit ici à toutes les femmes, lorsqu'elles ont le malheur de trouver un impudent en-leur chemin (Nicolas Rétif de la Bretonne, La Paysanne pervertie ou Les Dangers de la ville)

1826 SUZETTE. Oui, c'est bien son écriture, et c'est à moi qu'elle s'adresse.

(Elle baise la lettre, l'ouvre, puis la lit tout bas avec émotion)

Ô ciel ! Ma bienfaitrice implore ma pitié (Eugène Scribe, Le Mariage de raison)

1829 Qu'un ministre qui s’irrite Quand on lui fait la leçon

Lise tout bas ma chanson,
Qui lui parvient manuscrite

(Pierre-Jean de Béranger, Chansons)

1842 Les fleurs ? Ils en avaient effeuillé les corolles pour y lire tout bas mille promesses folles (Théodore de Banville, Les Cariatides)

1843 Dors encore, mon enfant ; je vais feuilleter ta musique et la lire tout bas, pendant que tu sommeilleras une heure ou deux (George Sand, Consuelo)

1861 Dans un coin, sur un banc qu'ombrage un vieux tilleul, il s'est assis, la tête entre ses mains posée ; il lit tout bas un livre à reliure dorée (Henri Murger, Les Nuits d'hiver)

1907a Il est difficile de dire quel fut l'effarement du sous-préfet, quand il lut plus bas ces réponses : 1 Ce fonctionnaire est-il marié ? Non. 2 Le conjoint occupe-t-il une fonction administrative rétribuée ? Oui. Nous renonçons à dire quel énorme travail les préfectures évitent, même actuellement, grâce à l'intermédiaire des sous-préfets (Jean Baradat, L'Organisation d'une préfecture)

2002 Un paysage, c'était un manuscrit ancien, chaque courbure et chaque trace aussi légère qu'une virgule concouraient à donner un sens auquel on n'aurait jamais pensé en le lisant tout bas (François Maspero, Les Abeilles et la guêpe)

Intransitif

1653 CELIDAN. (Il lit tout bas, ayant leu, il dit) Que je lise ces mots. L'infidelle beauté ! Sans doute je vous doy le bien de la clarté. Et je suis tout confus d'avoir eu la pensée Que ma fidelle amour fust par vous traversée ;

Je ne sçaurois payer un si rare plaisir (Tristan l'Hermite, La Célimène)

1763 DUPUIS. (Mettant ses lunettes, pour en lire l'adresse)

Bon : à Monsieur, Monsieur Dupuis, Lisons (il lit bas) Je ne scais où j'en suis (Continuant de lire bas, et s'arrêtant par intervalles) 
C'est un pouet, parbleu. Je n'ai plus de maîtresse !

Est-ce que je me tromperois !

Aurois-je donc mal lû l'adresse?

(Charles Collé, Dupuis et Des Ronais)

1771 M. DALANCOUR. (embarrassé) Un moment.

(Il se retire à l'écart, il lit tout bas, et marque du chagrin)

(Carlo Goldoni, Le Bourru bienfaisant)

1779 LUCIE. Donnez, je veux encore lire moimême.

(Elle prend la lettre et lit tout bas)

(Stéphanie-Félicité Du Crest, comtesse de Genlis, L’Enfant gâté)

1888 LE CLERC. Il y a encore un billet, qui ne peut être ouvert que par votre sainteté.

LE PAPE. Donne-moi.

(Brunissende et Waltherus chuchotent entre eux, pendant que le pape lit tout bas)

(Ernest Renan, Drames philosophiques)

1900 Je lis mais tout bas, en esquissant à peine les syllabes, et je traduis les phrases avant d'avoir articulé les derniers mots (Colette, Claudine à l'école)

1907b Assis sur un tronc de charme, il avait tiré de sa poche un papier, et lisait tout bas, avec des grimaces nerveuses qui agitaient sa barbe noire et tiraient la peau sèche des pommettes (René Bazin, Le Blé qui lève)

Emploi absolu

1985 La hiérarchie des genres selon les publics visés se double en effet d'une hiérarchie des lectures (« lettrées » / " profanes », « au premier degré » / « au second degré ») telles que les dominés qui " lisent haut », lisent mal et que les dominants qui « lisent bas », lisent bien (Jacques Dubois, Naissance du roman policier)

REMARQUES : Lire bas s'emploie par rapport à une personne lisant un texte, un billet ou de la musique à voix basse ou dans son for intérieur, le sujet ne voulant pas déranger d'autres personnes ou voulant garder l'information écrite secrète. Bas reste invariable et peut être modifié par un adverbe d'intensité (mais tout, plus, tout). La combinaison lire tout bas est usuelle.

\section{Lire clair}

Lire, comprendre explicitement, déchiffrer

clairement quelque chose

Emploi absolu

1896 D'ailleurs maints d'entre vous, troupeau trié déjà,

Valent mieux que le monde autour qui vous jugea,

Lisent clair, visent droit, entendent net en somme,

Vivent et pensent, plus que non pas un autre homme,

Que tels, mes chers lecteurs, que moi, cet écrivain,

Tant leur science est courte et tant mon art est vain!

(Paul Verlaine, Euvres poétiques complètes)

1982 C'est qu'elle voulait ardemment que Drifter l'aimât encore comme aux premières années, premiers mois, premiers jours, et elle entretenait l'illusion qu'il ne lisait pas clair à travers son feuilleton brouillon et affolé (Philippe Labro, Des bateaux dans la nuit)

Transitif

1922 Elle était dans la salle basse assise à coudre près d'un petit bouquet de reines-marguerites. Elle s'était levée, le plat de la main appuyé sur la table. Cette figure si claire à lire, de traits si nets, qu'elle était donc douce, quel air de douceur elle gardait toujours... mais ses yeux, aussi, si parlants, si vivants... (Henri Pourrat, Le Château des sept portes ou Les Enfances de Gaspard)

Pronominal

2010 Lola fixe le visiteur d'un regard où l'admiration se lit clair (Michel Jeury, May le monde)

REMARQUES : Au sens figuré, lire clair signifie lire, discerner, reconnaître quelque chose (un sentiment, un jeu, une vérité) avec clarté, sans doutes. Lire clair est modifié par si. L'emploi transitif permet l'accord, mais il n'est pas réalisé dans l'exemple de 2010. Notons l'emploi de entendre net, viser droit. VoIR AUSSI : voir clair 


\section{Lire courant}

lire tout courant : lire couramment, avec facilité (concret et abstrait)

Intransitif

1613 Tous les princes parlent selon son cuer, et lui offrent la carte blanche. Il cognoit leurs forces, et lit tout courant dedans leurs desseins (Histoire de la mort deplorable de Henri IV)

1786 Il lit tout-courant. Il récita cela toutcourant. Il joue mieux que lui, il le gagne tout-courant. Ce livre se vend un tel prix tout-courant (Dictionnaire de l'Académie française, s.v. tout-courant)

Transitif

1629 Il lisoit tout courant les Rabins sans poincts, et explicquoit une langue en l'autre sans lire celle qu'il expliquoit (Théodore Agrippa d'Aubigné, Sa vie à ses enfants)

1687 Nos têtes sont affermies, et nous étudions deux heures de suite. On lit tout courant le portugais : e se deos for servido em pouco tempo falerase (François-Timoléon de Choisy, Journal du voyage de Siam)

1834 car nos petites ouvrières lisent tout courant les livres de cet écrivain-là, aussi bien que nos grandes dames (Népomucène Lemercier, Alminti ou Le Mariage sacrilège)

1849 LES GNOSTIQUES. Quoique les mots en soient d'une langue perdue et que la bouche humaine ne puisse les dire, tu le liras tout courant comme les lettres de ton nom (Gustave Flaubert, La Tentation de saint Antoine)

REMARQUES : Lire tout courant exprime le fait de lire, de prendre connaissance du contenu d'un texte (généralement dans une langue étrangère) par la lecture et ce, avec naturel, aisance, de manière fluide. L'exemple de 1613 le transpose au monde des pensées. Les dictionnaires du XVIII ${ }^{\mathrm{e}}$ siècle enregistrent une grande variété d'emploi de tout courant (ex. de 1786). Ces exemples ne figurent plus dans les éditions récentes. Étant donné que l'on peut substituer tous les cas qui figurent dans l'exemple de (1786) par couramment, il est probable que tout courant (adverbe) a été remplacé par couramment. Dans ses Errata du Dictionnaire de l'Académie de 1856, Pautex remarque, en effet, que : " l'expression couramment nous semble préférable ». Courant reste invariable et forme une expression figée avec le modifieur tout. Tout devient optionnel, et plutôt peu fréquent, quand on préfère l'adverbe couramment : lire (tout) couramment. Notons l'emploi de gagner tout-courant, réciter tout-courant, se vendre tout-courant.

\section{Lire haut}

Lire à voix haute

Intransitif

+1365 Courtoisie ma main tenoit

Et me dist : « Lis hault pour oïr,

Si t'en deveras resjoïr »

(Jean Froissart, Poésies [3e tiers XIVes.])

1686 Il lit enfin tout haut, et fait voir dans ses vers

Les grandes actions de ses Heros divers (Balthazar de Bonnecorse, Lutrigot)

1741 Après avoir fait une conjuration simple, elle lut tout haut dans son petit livre d'heures, parce que tout ce que l'on désiroit savoir du passé et du présent s'y trouvoit écrit (Anne-Claude de Caylus, Féeries nouvelles)

1764 LUCAS. C’est bian adoré à vous ! Mais lisais donc tout haut que je voyions c'qu'a chante (Charles Collé, La Partie de chasse de Henri IV)

1828 Je n’achetai aucun livre. Seulement, presque tous les soirs, je lisais à une femme que j'aimais beaucoup alors de la poésie : une tragédie de Racine, de Corneille ou une comédie de Molière. Dans ces lectures, je m'habituai à lire haut (Étienne-Jean Delécluze, Journal)

1843a - Lis tout haut, maman, dit-elle (Eugène Sue, Les Mystères de Paris)

1849 Ces trois livres se trouvaient par hasard correspondre aux trois sentiments qui faisaient dès lors, comme par pressentiment, vibrer nos jeunes âmes : l'amour, l'enthousiasme pour l'affranchissement de l'Italie et de la France, et enfin la passion pour 
l'action politique et pour le mouvement des grandes choses dont Tacite nous présentait l'image et pour lesquelles il trempait nos âmes de bonne heure dans le sang de son pinceau et dans le feu de la vertu antique. Nous lisions haut et tour à tour, tantôt admirant, tantôt pleurant, tantôt rêvant (Alphonse de Lamartine, Les Confidences)

1853 THÉRÈSE. Lisez donc. (elle la [= la note] lui donne)

POMMEAU. On vient ! Si c'était lui ?

THÉRĖSE. (tombant sur une chaise) Vous lirez tout haut !

(Émile Augier, Les Lionnes pauvres)

1868 De jour en jour, elle lisait plus haut, elle choisissait des passages plus sanglants (Émile Zola, Madeleine Férat)

1921 Je lisais tout haut, je m'interrompais pour chasser les oiseaux, dans la langue, malgré moi, de Johnny Smith (Jean Giraudoux, Suzanne et le Pacifique)

1964 Gabrielle prétend qu'il se lève très tard, et s'enferme dans un pigeonnier accolé à la maison, dont il a fait son repaire. Il grimpe par une échelle au premier étage, où est sa bibliothèque, et on l'entend lire tout haut, déclamer, commenter, d'une voix grandiloquente (José Cabanis, Les Jeux de la nuit)

Transitif

1393 Et quant le capitaine voit cecy, il monstra la lettre à Urian et à Guion son frère, lesquelz la leurent ; et quant ilz l'eurent leue, ilz appelèrent le capitaine, le maistre de Rodes et les deux chevaliers qui leur avoient annoncé l'adventure du siége, et leur leurent la lettre tout hault [variante : tout en hault ; manuscrit Ars, p. 336] (Jean d’Arras, Melusine, p. 142 [éd. Genève])

1610 On peut remarquer ainsi qu'il y a trois fautes en ces deux vers : car en ces termes, amy est, vie, aussi en, deux voyelles se rencontrent avec une mauvaise façon, comme on le peut aisement conoistre en les lisant tout haut (Pierre de Deimier, L’Académie de l'art poétique)
1627 Hircan se leva alors de sa place, et tirant de sa pochette un livre allemand, il commença à en lire tout haut dix ou douze lignes (Charles Sorel, Le Berger extravagant)

1663 ÉRASTE. Eh bien ! n’en parlons plus. Que venois-tu m'apprendre?

MARINETTE. Vous mériteriez bien que l'on vous fît attendre,

Qu'afin de vous punir je vous tinsse caché Le grand secret pourquoi je vous ai tant cherché.

Tenez, voyez ce mot, et sortez hors de doute :

Lisez-le donc tout haut, personne ici n'écoute (Molière, Dépit amoureux)

1699 Là, après leur avoir tout de nouveau reproché leur désobéissance, il tira de sa poche et lut tout haut une liste de douze des principales religieuses, au nombre desquelles étoit l'abbesse, qu'il avoit résolu de disperser en différentes maisons (Jean Racine, Abrégé de l'histoire de Port-Royal)

1732 Je l'ouvris sans façon, et la lus assez haut pour que mon oncle, qui était assis près de moi, m'entendît (Alain-René Lesage, Histoire de Guzman d'Alfarache)

1733 ADÉLAÏDE. Il eût dû s'épargner des efforts superflus...

(Elle ouvre le billet)

C’est lui-même... Écoutons un amant qui n'est plus.

(Elle lit bas une partie du billet, et haut ce qui suit) (Alexis Piron, Gustave-Wasa)

1782 Je le lui donne, il le lit tout haut, et j'exige que ce soit de suite et sans commentaire, car il est bon de l'accoutumer à prononcer lui-même le détail de ses fautes, ensuite je le lis une seconde fois, et alors nous nous communiquons mutuellement les réflexions que cette lecture nous inspire (Stéphanie-Félicité Du Crest, comtesse de Genlis, Adèle et Théodore)

1837 Vous comprenez donc bien que, si je vous écoute, c'est parce qu'il me semble que vous me lisez tout haut un roman que j'en- 
tends les yeux fermés (Frédéric Soulié, Les Mémoires du diable)

1843b Amélie, curieuse et empressée, s'approcha d'une bougie, et lut tout haut ce qui suit (George Sand, Consuelo)

1902 Puis le capitaine Lyrisse assemblait devers lui les buveurs et lisait tout haut les messages écrits de la main du bisaïeul, au château de Lorraine (Paul Adam, L'Enfant d'Austerlitz)

1985 Le maître avait lu tout haut le passage suivant : " Les gâteaux brillent de mille feux » (Yann Queffélec, Les Noces barbares)

1993 Le professeur de philosophie avait lu tout haut deux pages d'un de ses devoirs (Jacqueline de Romilly, Les Eufs de Pâques)

CORpus WeB :

Voice Aloud Reader est un outil qui peut "lire tout haut " à partir de tous les textes que tu as sauvegardé sur ton téléphone Androide [Voice-aloud-reader.fr.uptodown.com/android] (30.6.2020)

ce qui vous permet d'accéder à vos e-mails et à votre agenda pour qu'ils soient lus tout haut sur simple commande vocale [www.clarion.com/ intelligentvoice] (30.6.2020)

REMARQUES : Lire haut réfère à une personne lisant des mots, un texte, un billet à voix haute, généralement pour communiquer l'information lue à d'autres personnes. Haut reste invariable et peut être modifié par un adverbe d'intensité (assez, donc, enfin, plus, tout). La collocation lire tout haut est très usuelle. Dans l'exemple de 1393, l'édition de Genève remplace lire en haut (manuscrit Ars) par lire haut (v. Introduction § 19).

\section{Lire profond}

Lire, découvrir quelque chose en allant au fond des choses Intransitif

1275 Ne nus on n'i peut conseil metre, Tant ait leü parfont en letre (Jehan de Meun, Roman de la rose [1269-1278], 6848)
1894 Le prêtre [...] lit plus profond dans les cœurs (Édouard Rod, Le Silence)

1936 Lire peu, mais lire profond. Ce qui donne de la profondeur à l'esprit, c'est l'union à Dieu (Robert de Langeac, Conseils aux âmes d'oraison)

1985 Je crois tout à coup qu'ici on lit profond dans les yeux, dans le regard des gens, dans leurs sourires, dans leurs manières à table, et cela aussi naturel que l'on s'efforce de paraître (Marguerite Duras, $L a$ Douleur)

REMARQUES : Toujours au sens figuré, lire profond signifie lire, discerner, reconnaître quelque chose (un sentiment, un regard, une vérité) d'une manière pénétrante, voire intense, le sujet s'efforçant d'aller jusqu'au fond des choses. Lire profond est généralement suivi d'une préposition de lieu (dans, en). Il est modifié par plus.

\section{Litronner seul}

Consommer (de l'alcool) en solitaire

$\lambda$ jouer fin

\section{Litronner tristos}

Consommer (de l'alcool) en étant d'humeur triste

$\pi$ jouer fin

\section{Loger beau}

Habiter un bel endroit

$\pi$ loger haut

\section{Loger haut}

I. Placer quelque chose à un rang, à un niveau supérieur

Transitif

1623 Je sçay bien que logeant si haut mes passions

Je n'en dois esperer qu'une cheute mortelle,

Mais pour quoy cederay-je à tes perfections,

Ne suis-je aussi constant que tu me semble belle

(Jean Auvray, Le Banquet des muses ou Les Divers Satires) 
II. Habiter une chambre haute, au dernier étage Transitif

1849 D’un homme logé haut, on dit : «Il entend les anges péter »

(Bibliotheca scatologica ou Catalogue raisonné des livres traitant des vertus, faits et gestes de très noble et très ingénieux Messire Luc [à rebours])

1889 Maintenant, les juges sont mêlés, confondus, dans le tourbillon de la grande ville, logés haut, en tous les quartiers, vêtus comme tout le monde (Charles Desmaze, La Magistrature française : les premiers présidents de la cour de Paris)

Pronominal

1860 Les gens, peu aisés, qui ne voulaient pas s'éloigner du centre des affaires, devaient donc se loger haut. Ce qu'ils gagnaient en proximité, ils le perdaient en élévation (Jules Verne, Paris au $X^{e}$ siècle)

Emploi absolu

1862 J'ai remarqué une logique énorme, une corrélation intime, presque chez tous, entre l'habitant et la coquille, l'homme et le milieu. Cela généralement loge haut, au cinquième : Paris a le cerveau comme l'homme, en haut. Ce qui court est en bas, boutiques, entresols ; ce qui digère au premier : la maison est un individu (Edmond et Jules de Goncourt, Journal)

1873 Jadis je logeais haut, tout contre la gouttière :

Tapi souvent à ma fenêtre en tabatière, Rêvant à ma misère, à tant d'affronts subis,

J'écoutais les marchands de légumes, d'habits :

Et les tuyaux des toits, chefs-d'œuvre des fumistes,

Rayaient de noir le fond de mes grands yeux si tristes

(Charles Cros, Le Coffret de santal)

1986 Les réponses aux contraintes du marché foncier

Loger loin, en périphérie

Loger précaire, en baraquement

Loger haut, en appartement
Loger seul, sans la famille

(Paul Bonnenfant, La Capitale saoudienne : Riyadh)

CORPuS WeB :

Il faut arrêter de se dire que loger haut n'est pas compatible avec loger beau [immobilier.lefigaro.fr/article Roland Castro et Nexity] (30.6.2020)

J'ai oublié ma coupe menstruelle dans mon vagin.

Le fait que la cup aille se loger haut n'est pas du tout un problème [coupemenstruelle.net/ blog/témoignages d'utilisatrices] (30.6.2020)

Je crois que dans ce cas, la personne n'admet pas sa grossesse, et que peut être incosciement, le bébé doit se loger haut entre les côtes [forum. doctissimo.fr/forum/grossesse\&bébé] (30.6.2020)

REMARQues : Loger haut (I) signifie 'mettre, placer quelque chose de concret ou d'abstrait (des passions) à un rang, à un niveau supérieur, voire divin', le sujet voulant donner une place prépondérante ou une plus grande importance. Au sens concret, loger haut (II) réfère à une chambre, un appartement situés au dernier étage d'un immeuble. L'exemple de 1849 admet également une lecture figurée ('vivant dans des sphères ou des milieux supérieurs'). Les deux derniers exemples du CW mettent en évidence un emploi pronominal actuel où loger indique la localisation d'un objet dans le vagin ou d'un fœtus chez une femme. Haut reste invariable et peut être modifié par un adverbe d'intensité (si). Notons la collocation en série de loger loin, loger précaire, loger haut, loger seul.

\section{Loger petit}

Être logé à l'étroit, avoir un petit logement

Transitif

1959 C'était à notre arrivée à Paris. On était logés petit (Exemple entendu / $1^{\mathrm{er}}$ mai 1959, Grundt : 402)

2013 L’appartement, " grand », avait dit Zoé, dont les parents étaient logés petit (Leslie Kaplan, Les Prostituées philosophes)

CORPUS WEB :

Nous étions logés petit, et même notre porte monnaie ne portait pas grand-chose [famille. moreau.over-blog.com] (30.6.2020) 
On est logés petit [www.telescoop.tv/affaire] conclue (30.6.2020)

Si vous êtes logés " petit », préférer un conifère à la taille de votre appartement [Cheznous 62.eklablog.com/ouh-le-houx] (30.6.2020)

REMARQUES : Loger petit s'emploie par rapport à une habitation dont on souligne le caractère exigu, étroit. Petit reste invariable.

\section{Loger précaire}

Loger sans garantie de durée

$\lambda$ loger haut

\section{Loger seul}

Loger sans compagnie

$\lambda$ loger haut

\section{Losangier bel}

Flatter, tromper par de belles paroles

Transitif

1170 Mener l'an vost, et cil li prie, Qui mout sot de losangerie, Que par franchise li randist. Mout bel le losange et blandist (Chrestien de Troyes, Erec et Enide, 4060)

REMARQUES : Dans l'ancienne langue, losangier bel signifie 'flatter, louer excessivement et faussement quelqu'un pour lui plaire, le séduire'. Beau adopte sa forme neutre, bel, pour la fonction adverbiale. Il est modifié par un adverbe d'intensité (moult).

\section{Louer différent (2)}

Ne pas louer (un appartement, etc.) comme les autres

Emploi absolu

2018 Louez différent à prix malins ! (Corpus Coiffet 2018 : s.v., sans date)

REMARques : Nous distinguons louer (1) 'faire l'éloge' de louer (2) 'prendre en location'.

\section{Louer ferme (1)}

Faire l'éloge de quelqu'un avec conviction Transitif

1365 Ie te confesserai et loerai en grant esglize ; et en pueples ferme et estauble ie te loerai (Psautier lorrain, p. 36)
REMARQues : Louer ferme (1) désigne le fait d'honorer, d'exalter, de glorifier quelqu'un avec conviction, ardeur, intensité. Notons la collocation ferme et stable, dans laquelle s'apposent fermeté et durabilité.

\section{Louer ferme (2)}

Prendre à terme moyennant de l'argent Transitif

1893 Les choses ont été à ce point, - nombre de personnes pourront vous en témoigner ici, - que plusieurs palais ont été loués ferme, dans la ville même, pour les cardinaux (René Bazin, Sicile : croquis italiens)

1977 On lui garde sa chambre parce qu'elle l'a louée ferme par l'intermédiaire d'une agence... (Josette Bruce, OSS 177 : imbroglio à San Diego)

\section{CORPUS WEB :}

La nouveauté de 2011 est l'acceptation du risque, avec des achats de bâtiments neufs non encore loués ferme [www.lesechos.fr/2012/Recul] (30.6.2020)

REMARQUES : Louer ferme (2) réfère au paiement d'une somme déterminée par périodes (loyer) pour l'usage d'un bâtiment, d'un appartement, etc. Ferme reste invarié.

\section{Louer fort (1)}

Faire l'éloge, faire beaucoup de louanges

Transitif

1601 il [= le flatteur] fera le rude censeur contre les autres parens, serviteurs du flatté, dece qu'ils ne font leur debvoir envers luy : ou bien feindra d'avoir entendu quelques legeresa ccusations contre luy, et estre en grande peine d'en sçavoir la verité de luy-mesme ; et, venant le flatté à les nier, ou s'en excuser, il prend de là occasion de le loüer plus fort (Pierre Charron, De la sagesse)

1610 Alexis s'estoit teue quelque temps, prenant plaisir aux discours de ces bergers ; mais quand elle s'ouyt si fort louer, elle fut contraincte de reprendre ainsi la parole (Honoré d'Urfé, L’Astrée) 
1649 La harangue de M. Talon a couru ici aussi bien qu'à Lion ; mais on dit que ce grandhomme l'a désavouée : constat tamen qu'il en fit une fort belle devant le roi, à la reine sa mère, que tous les auditeurs louèrent fort (Guy Patin, Lettres)

1655 La SULTANE. Elle est interessée à la loüer si fort.

$\mathrm{Au}$ hazard du naufrage elle tend vers le port ;

Mais vostre amour, Seigneur, se trouve sans exemple!

Vous vous en estes pris à la voir dans le Temple (Tristan l'Hermite, Osman)

1710 Les religieuses furent bien aises de cette résignation, l'acceptèrent avec joie et louèrent fort le choix de leur ancienne (Valentin-Esprit Fléchier, Mémoires sur les Grands-Jours d'Auvergne en 1665)

1736 ARAMINTE. Il le faut avouer, Un pareil procédé n'est pas fort à louer (Philippe Destouches, Le Dissipateur ou L'Honneste Friponne)

1863 Le roi Louis XIII, ayant entendu parler des aventures d'Isabelle, la loua fort de sa sagesse et témoigna une particulière estime à Sigognac pour sa retenue, n'aimant pas, en chaste monarque qu'il était, les jeunesses audacieuses et débordées (Théophile Gautier, Le Capitaine Fracasse)

1937 Elle était toujours habillée en bleu du roi ; elle n'en voulait pas démordre ; on l'en louait fort (Henry de Montherlant, Pitié pour les femmes)

1961 Et Tenon loue fort la prévoyance des administrateurs de Saint-Luke, où « le fou en général est mis en liberté durant le jour : cette liberté pour qui ne connaît pas le frein de la raison est déjà un remède qui prévient le soulagement d'une imagination égarée ou perdue » (Michel Foucault, Folie et déraison. Histoire de la folie à l'âge classique)

Pronominal

1667 ARDARIC. Ah ! puisqu'il a des yeux, sans doute il la préfère.
Mais vous vous louez fort aussi du roi son frère.

Ne me déguisez rien : a-t-il des qualités

À se faire admirer ainsi de tous côtés ? (Pierre Corneille, Attila, roi des Huns)

2019 un certificat donné à ce dernier [= le capitaine] pour être publié dans les journaux, certificat dans lequel les passagers se louaient fort de ses façons courtoises et de sa bonne table (Paul Duplessis, Un monde inconnu)

REMARQUES : Louer fort (1) c'est faire l'éloge de quelque chose ou de quelqu'un ; approuver fortement l'action de quelqu'un. Il peut être modifié par plus, si.

\section{Louer haut (1)}

Faire l'éloge, vanter, approuver avec

exagération, admiration, plutôt publiquement

Transitif

1285 Car si tres tost com il véoient

Cleomadés, Dieu en looient

Si haut, qu'il sambloient dervé

De ce k'avoient retrouvé

Cleomadés que tant amoient

Que plus amer ne le povoient

(Adenet le Roi, Cleomadés, 14859)

1583 Qui fut cause que Préfouché se mit à haut louer le sage advis d'Alexandre le grand, ne voulant permettre à ce renommé statuaire tailler le mont Athos à sa semblance (Bénigne Poissenot, L’Esté)

1592 Les Ambassadeurs Thraciens, consolans Archileonide, mere de Brasidas, de la mort de son fils, et le haut-louans jusques à dire qu'il n'avoit point laissé son pareil, elle refusa cette louange privée et particuliere pour la rendre au public (Michel de Montaigne, Essais)

1608 et à vray dire, vos carmes m'ont esté un charme par lequel je dirois volontiers que m’avez tout transformé en vous, n'estoit que me haut-louant par vos vers d'une merveilleuse façon, je crains que d'un vieillard non gueres sage n'ayez faict un fol enragé (Estienne Pasquier, Lettres familières) 
1610 Entr'autres Monsieur le premier President de Tou, en une bonne compagnie dedans sa maison où estoit Monsieur le President de Ferrier, lors destiné pour ambassadeur de Venise, le haut loua grandement, et chacun desireux de sçavoir qui en estoit l'autheur (Estienne Pasquier, Lettres familières)

1612 Pour m'acquitter de ma promesse, j'ay non couru à la haste, ains leu meurement vostre livre, et ne puis assez haut louer l'exacte diligence qu'y avez apportee (Estienne Pasquier, Lettres familières)

1615 Qui, longtemps depuis, affriandez à tels voyages, nommément sous la conduite de ce brave Candaules (si haut loué de Pausanias), discoururent par ceste flottante voye, au long et au large, haut et bas, amassant de grandes richesses de leur butin (Antoine de Montchrestien, Traicté de l'économie politique)

1648 Je vous ay oüy louër tout haut avecque beaucoup d'affection par la reine (Vincent Voiture, Lettres)

1649 M. Piètre mesme, nostre ancien, que je tiens comme un oracle, et qui de soy est parcus laudator, me l'a maintes fois haut loué et fort extollé (Guy Patin, Lettres)

1654 Si haut je veux louër Sylvie,

Que toute autre en meure d'envie:

Sa personne est pleine d'appas

Les amours naissent sous ses pas,

Et c'est par eux qu'elle est servie

(Vincent Voiture, Poésies)

1659 Quand on eut donc sur tes charmes divers Loué fort haut la douceur de tes vers, Je fus surpris quand tu me fis connestre Qu'en ce bel art je n'avois point de maistre, Que, d'un Horace imitant les douceurs, Seul sur tes pas je suivois les neuf sœurs, Et que j'avois un talent admirable Qui, dans son genre, estoit inimitable (François de Boisrobert, Épistres en vers)

1824 Aussi ne crois-je pas, moi qui l'ai loué moins haut de ce qu'il [= le duc d'Orléans] a fait de louable, que ce soit pour cela qu'on me réemprisonne (Paul-Louis Courier, Pamphlets politiques)

1836 Ainsi s'expliquaient jusqu'ici sans scandale la désolation du jardin et la retraite impénétrable de mademoiselle de Meilhan, qu'on louait tout haut de son dévouement pour avoir vécu renfermée avec son protecteur (Léon Gozlan, Le Notaire de Chantilly)

1839 Si un jeune homme me parle, il me traite en enfant ; si on me demande en mariage, c'est pour ma dot; si quelqu'un me serre la main en dansant, c'est un fat de province ; dès que je parais quelque part, j'excite un murmure d'admiration, mais personne ne me dit, à moi seule, un mot qui me fasse battre le cœur. J'entends des impertinents qui me louent tout haut, à deux pas de moi, et pas un regard modeste et sincère ne cherche le mien (Alfred de Musset, Croisilles)

1886 Sandoz s'était enflammé, lui aussi ; et Fagerolles continuait à louer très haut les pires peintures, ce qui augmentait la gaîté (Émile Zola, L’Euvre)

1949 Vais-je lui réciter tout haut ma pensée, pour le confondre ?... Attention ! J'allais commettre une maladresse de plus. Il ne sera point confondu, il écoutera, ravi, sa devineresse, et louera bien haut la seconde vue que dispense l'amour !... Et qu'attend-il présentement? Que je tombe dans ses bras? (Colette, La Vagabonde)

1997 Que les populations lointaines

Rendent hommage au Seigneur

Et le louent haut et fort !

Comme un soldat d'élite

Le Seigneur s'avance ;

Comme un homme de guerre

Il brûle de combattre

(La Bible en français courant)

2017 Ils blâment ce qui n'est pas blâmable, ils louent haut et fort ce qui n'est pas louable (Alain Porte, Les Cinq Livres de la sagesse : Pañcatantra) 
Emploi absolu

1504 Et quand i'auroye or' la langue diserte, Pour correspondre à la propre desserte De son merite, et de ses grans vertus, Ou pour plourer vne si grieve perte, Si n'en seroit sa gloire plus aperte : Car haut louer, conduit par art experte, N'accroist les faits de triomphe auestus (Jean Lemaire de Belges, La Plainte $d u$ désiré)

\section{CORPus WEB :}

Espérances à Beyrouth, des ministres louent haut et fort l'attitude du président Chirac, et sa double insistance pour que la conférence ait lieu [www.lorientlejour.com/ParisIII] (10.1.2007)

mes ceintures (abdominale et en cuir) te louent haut et fort pour cette preuve de sympathie que tu as eue à leur égard !!! [leplaisirdegourmandise.over-blog.com/article/scones] (16.9.2010)

Les populations de la commune de Copargo louent haut et fort l'honorable Gobi Bado [absbenin.over-blog.com/Gobi Bado] (18.6.2012)

Et il est prisé par ses aînés, qui louent haut et fort sa technique, sa sensibilité, malgré son jeune âge (23 ans) [www.dnc.nc/fous-de-guitare] (26.10.2017)

C'est tout de même curieux que d'aucuns louent haut et fort « l'incroyable audace » (limite transgressive, à les écouter) d'avoir fait de Merida une jeune fille résolue à braver les coutumes les plus archaïques [www.underscores.fr/forum/ viewtopic/brave] (15.3.2020)

REMARQUES : Louer haut (1) réfère au fait d'honorer, d'exalter, de glorifier quelqu'un avec ardeur et intensité, voire avec exagération. Haut reste invariable et peut être modifié par un adverbe d'intensité (assez, fort, moins, si, tout, très). Jusqu'au $\mathrm{XVII}^{\mathrm{e}}$ siècle, haut est généralement antéposé au verbe. Notons les formes composées, haut(-) louant, haut(-)loué. L'emploi récent privilégie la collocation haut et fort, employé aussi avec d'autres verbes du dire.

\section{Louer petit (1)}

Faire peu de louanges

Transitif

1170 Ez vos le palefroi venu. Quant Erec le palefroi vit,
Ne le loa mie petit ;

Car mout le vit et bel et jant

(Chrestien de Troyes, Erec et Enide, 1418)

REMARQUES : Dans l'ancienne langue, louer petit (1) signifie 'approuver, louer à peine quelque chose ou quelqu'un'. La forme négative accentue l'idée de fortes louanges, d'admiration démesurée.

\section{Louer petit (2)}

Prendre en location un lieu qui offre peu

d'espace aux locataires

Emploi absolu

\section{CORPuS WeB :}

Ont [= on] louent petit dans une maison occupée par les gentils propriétaires [forum-auto. caradisiac.com/youngtimers/Ma belle histoire] (30.6.2020)

Aujourd'hui, les jeunes ont les mêmes problèmes, ils ne sont pas propriétaires, donc ils louent petit, se mettent en collocation, déménagent loin de Paris etc. [ps-scpo.over-blog.com/ article/Rémi Féraud] (30.6.2020)

REMARQUES : Louer petit (2) s'emploie par rapport à une habitation dont on souligne le caractère exigu, étroit. Petit reste invariable.

\section{Louer stable (1)}

Proférer des louanges de façon durable, permanente

Transitif

1365 Ie te confesserai et loerai en grant esglize ; et en pueples ferme et estauble ie te loerai (Psautier lorrain, p. 36)

REMARQUES : Louer stable (1) réfère au fait d'honorer, d'exalter, de glorifier quelqu'un de façon permanente, immuable et fidèle. Notons la collocation louer ferme et stable, où s'apposent fermeté et durabilité.

\section{Louvoyer serré}

Naviguer en faisant des zigzags courts, fréquents et rapides Intransitif

1687 On n'a pu prendre hauteur : nous avons peu de vents, et nous allons présentement à la bouline ; mais c'est une bouline 
fort douce, parce que la mer n'est pas haute. Autrement dit : nous louvoyons au plus serré (François-Timoléon de Choisy, Journal du voyage de Siame / Aventures)

1958 S'il faut louvoyer serré, dans un chenal étroit par exemple, ce « ballet de la voile » se répète à intervalles de quelques secondes (Jean Merrien, Votre première voile)

1989 Et nous louvoyons très serré pour échapper au tir des viseurs allemands. Les avions n'attaquent pas encore en piqué, mais par vagues successives, parfois espacées de trente minutes (Francis Ryck, Requiem pour un navire)

\section{CORPUS WEB :}

Les deux équipages ont été confrontés à des vents contraire de 35 à 38 nœuds et une dure houle hier matin, ce qui les a amenés à louvoyer serré le long de la côte sud de l'Espagne [www. imoca.org/news/a-portee-de-main] (30.06.2020).

Je règle l'écart en fonction de la taille du bateau, plus celui-ci est petit plus il est facile de louvoyer serré et donc plus je resserre cette limite [www.gpspassion.com/forumsen/topic/Alarme] (10.8.2012)

REMARQues : Dans le domaine de la voile, louvoyer serré signifie 'naviguer en zigzags rapprochés, tantôt à droite, tantôt à gauche de la route à suivre, pour utiliser un vent contraire en lui présentant alternativement chaque côté du bâtiment'. Serré peut être modifié par au plus, très.

\section{Luire beau}

I. Répandre une lumière agréable, une belle lumière

Intransitif

1393 Le lendemain, vers heure de prime, le air fu pur et le vent attrempéz et luisy le soleil beau et cler [variante : bel et cler ; éd. Genève, p. 181] (Jean d'Arras, Mélusine, p. 400 [manuscrit Ars])

$-1400 \mathrm{La}$ bataille recommenche diverse et anieuse. La lune luisoit belle et clere (Ysaÿe le triste [fin XIve], p. 258] +1400a Mercredi, xvie jour de juin, au Conseil. Et cedit jour, entre vi et vii heures à matin et assez tost après vi heures, quant l'en visitoit les requestes en la Chambre, apparu eclipse de soleil tel que le soleil, qui une heure paravant luisoit moult bel, net et cler, souffri tel defaut de clarté ou bas monde que l'en ne voioit ne que à l'eure de $x$ heures de nuit ou environ ii heures après minuit, et dura ce l'espace de la xiie partie d'une heure ou environ, par especial en nostre climat (Nicolas de Baye, Journal [1400-1417])

+1400 b Une foiz s'aloit esbatre aux champs, fort pensif et melencolieux, et luy vint en memoire de penser a sez pechiez, en luy souvenant de la mort ; puis regardoit le soleil qui estoit tant bel et cler luisant, recongnoissant que celuy est bien plaisant et bel a veoir qui l'avoit creé et fait

(Nouvelles françaises $d u x^{e}$ siècle, p. 103)

+1415 Le temps a laissié son manteau

De vent, de froidure et de pluye,

Et s'est vestu de brouderie,

De soleil luyant, cler et beau

(Charles d'Orléans, Poésies [ 1415-1440], II, Rondel XXXI, p. 307)

1511 Et lors en invoquant layde de la Deesse Diane, cestasavoir la Lune qui pour lors luisoit belle et clere, il se hasta pour leur couper le chemin (Jean Lemaire de Belges, Les Illustrations de Gaule et singularitez de Troye)

1623 Hélas ! Si réclamer ses yeux

De mon âme victorieux

Est une offense irrémissible, Ô dieux ! Pourquoy permettez-vous

Qu'ils luisent si beaux et si doux, Et que mon cœur soit si sensible?

(François Maynard, Le Philandre)

1631 LIGDAMON. Sur le point de respandre avec le sang mon ame

Je sens croistre la force et l'ardeur de ma flame,

Mon amour embrasé fait ainsi qu'un flambeau 
Qui proche de sa fin esclaire et luit plus beau :

Cher Aegide, va t'en retreuver ma maistresse,

Dis luy que les lyons plus doux qu'une tygresse

Sçachant bien que la mort me pouvoit secourir,

De pitié, non de rage, en fin m'ont fait mourir

(Georges de Scudéry, Ligdamon et Lidias)

1902 A ces voluptés - là se dora ma fortune, Et sur mes jours le soleil luisait beau, Quand la douleur, hélas ! m’en laissant à peine une,

Me vint vieillir dont je lui tiens rancune!

(V. Castaldo, Imitations libres de quelques poésies italiennes de Giacomo Leopardi)

II. Régner par sa supériorité

Intransitif

1583 Remply d'affection il me fait ja sçavoir Qu'autant que la vertu luit belle sur le vice, Je luy dois plus qu'à tous d'honneur, et de service :

Obligeant mon humblesse à ce rare devoir (Jean de La Gessée, Les Jeunesses)

III. Procurer, apporter quelque chose

d'agréable, de plaisant

Intransitif

1589 LE CHEUR. Que l'on chante

Que l'on vante

Ce jour qui tant beau nous luit,

Le tonnerre

De la guerre,

Là bas vers Pluton s'enfuyt

(Pierre Matthieu, Clytemnestre)

\section{CoRpus Web :}

permettant que ces derniers [= les cheveux] luisent beaux et visiblement plus sains [www. masmusculo.com/cheveux] (30.6.2020)

en plus de cela en l'appliquant tes ongles luiront beaux, sains et remplis de vie [www. masmusculo.com/cosmétique] (30.6.2020)

REMARQUES : Le sujet de luire beau (I) désigne un astre lumineux (le soleil, la lune) ou une source de chaleur (le flambeau) qui répand une lumière agréable, douce. (II) se dit au figuré du fait de briller par sa supériorité. L'idée de supériorité d'une chose sur l'autre, sa mise en valeur, son statut supérieur est souligné. (III) est un emploi métaphorique qui met en avant les choses positives, belles ou plaisantes que peut apporter une belle journée à quelqu'un. Remarquons que la plupart des exemples sous (II) et (III) notent ce ou celui qui bénéficie de la lumière (transitivité indirecte). Les exemples du CW mettent en évidence l'emploi dans le domaine de la publicité. Beau s'accorde souvent avec le sujet, déjà dans l'exemple de (-1400). La tendance à faire l'accord rapproche les exemples de la prédication seconde, mais l'emploi du neutre bel est clairement adverbial. Notons la collocation beau (bel, belle) et clair(e), ainsi que celle de bel, net et clair et si beau et si doux ou clair et doux, ainsi que, dans le langage publicitaire, beaux et visiblement plus sains, beaux, sains et remplis de vie.

\section{Luire clair}

I. Luire avec clarté, en reflétant la lumière, luire beaucoup (concret)

Intransitif

$\sim 1170$ Se li cuens ne li vossist randre Volantiers le cors et la dame, Tot meïst a feu et a flame.

A la lune, qui cler luisoit, Sa jant vers Limors conduisoit, Hiaumes laciez, haubers vestuz, Et les escuz as cos panduz (Chrestien de Troyes, Erec et Enide, 4965)

-1200 En Alischans fu molt grans la bataille. Rois Sinagons forment nos gens travaille : Traite a l'espee, ki cler luit et bien taille (Aliscans [fin $\mathrm{XII}^{\mathrm{e}}$ ], 5271)

-1250a Ce fu el tans d'esté, el mois de mai que li jor sont caut, lonc et cler, et les nuis coies et series. Nicolete jut une nuit en son lit, si vit la lune luire cler par une feneste et si oï le lorseilnol center en garding, se li sovint d'Aucassin sen ami qu'ele tant amoit (Aucassin et Nicolette [ $1^{\mathrm{re}}$ moitié $\left.\mathrm{XIII}{ }^{\mathrm{e}}\right]$, XII)

-1250b Ele vint au postic, si le deffrema, si s'en isci par mi les rues de Biaucaire par devers l'onbre, car la lune luisoit molt clere, et erra tant qu'ele vint a le tor u ses amis estoit (Aucassin et Nicolette [ $1^{\mathrm{re}}$ moitié XIII $]$, XII) 
1250 Donc oisies payens grant joi[e] demener : Si en coillent lour tentes, si font els nefs porter,

Si chargent lour navies ou armes lusant cler,

Puis lour destriers i mettent et coursiers sojornes

Et de pain et de vin [et] d'avaine et de ble (La Destruction de Rome, 1334)

+1250 Bien orent este conree.

La se sont andoi repose

Et si dormirent, jel vos di,

Tant que li baus jors esclarci

Et par la contree luist cler.

Lors se levent li bacheler (Le Roman de Renart [2 $2^{\mathrm{e}}$ moitié XIII'], XIII, 1519)

1275 Ahi ! vielle, fait ele, et Tyberz, mauvais lere,

Vostre grant traÿsons m'est vis que je compere ;

Dieus par sa pitié doinst que encore vous pere!

Ains que gaires de jour la endroites apere, S’en depart la roÿne, car la lune luist clere (Adenet le Roi, Berte aus grans piés, 1074)

$\sim 1300$ Biaus fu li iors et li solaus luist clers (Aliscans [R], manuscrit L, 4231)

1393a Un pou apréz leva la lune belle et clere et les estoilles luisoient cler (Jean d'Arras, Mélusine, p. 150 [manuscrit Ars])

1393b Et la lune luisoit clere [variante : toute clère ; éd. Genève, p. 35]. Et ly chevaulx Remondin le portoit tout a son plaisir ou il vouloit aller (Jean d'Arras, Mélusine, p. 160 [manuscrit Ars])

1393c Le lendemain, vers heure de prime, le air fu pur et le vent attrempéz et luisy le soleil beau et cler [variante : bel et cler; éd. Genève, p. 181] (Jean d'Arras, Mélusine, p. 400 [manuscrit Ars])

+1400 Une foiz s'aloit esbatre aux champs, fort pensif et melencolieux, et luy vint en memoire de penser a sez pechiez, en luy souvenant de la mort; puis regardoit le soleil qui estoit tant bel et cler luisant, re- congnoissant que celuy est bien plaisant et bel a veoir qui l'avoit creé et fait

(Nouvelles françaises $d u x^{e}$ siècle, p. 103)

+1415 Le temps a laissié son manteau De vent, de froidure et de pluye, Et s'est vestu de brouderie, De soleil luyant, cler et beau (Charles d'Orléans, Poésies [ 1415-1440], II, Rondel XXXI, p. 307)

1450 DIEU LE PERE. Soit donc lumiere devisee Et de tenebres divisee, Laquelle, pour tant que cler luyst, Nomons jour et tenebres nuyt. Or est fait vespre et matinee Pour nostre premiere journee (Arnoul Gréban, Le Mystère de la Passion, 258)

1511 Et lors en invoquant layde de la Deesse Diane, cestasavoir la Lune qui pour lors luisoit belle et clere, il se hasta pour leur couper le chemin (Jean Lemaire de Belges, Les Illustrations de Gaule et singularitez de Troye)

1512 Bon les fait voir ainsi tant rondelettes, En souspirant bransler leurs mammelettes. Le poesle esoit bien garni de verrines Claires luisans, vermailles, sapphirines, Souef flairant comme vn beau paradis, Plein d'oiselets ioyeux et esbaudis, Qui là dedens vn plaisant bruit menoient, Et le pourpris en deduit maintenoient (Jean Lemaire de Belges, Le Second Conte de Cupido et d'Atropos)

1855 Le vert colibri, le roi des collines, Voyant la rosée et le soleil clair luire Dans son nid tissé d'herbes fines, Comme un frais rayon s'échappe dans l'air (Charles-Marie Leconte de Lisle, Poèmes barbares)

1896a Qu'ont de commun la lune et la terre? Bah, reviens vite, assez de mystère ! Toi, c'est le soleil, luis clair sur moi ! (Paul Verlaine, Euvres poétiques complètes)

1896b Le soleil, moins ardent, luit clair au ciel moins dense.

Balancés par un vent automnal et berceur, 
Les rosiers du jardin s'inclinent en cadence L'atmosphère ambiante a des baisers de sœur (Paul Verlaine, Euvres poétiques complètes)

1980 Elle vit la lune luire clair par la fenêtre et elle entendit le rossignol chanter dans le jardin, et il lui souvint d'Aucassin, son ami qu'elle aimait tant... (Jacques PrévostBouré, Jean de Luxembourg et Jeanne d'Arc)

2016 Les yeux au ciel, rivés à notre monde Nous nous voyons partis Vers des joyaux sertis Qui luisent clair. Nous envions la sonde (Socque, L'Origine du monde)

II. Luire avec clarté, rayonner (au figuré) Intransitif

1504 Bien fineray pour vn tel chant produire D'Agricola, dont musique fait luire Le nom, plus cler cent fois que fin argent (Jean Lemaire de Belges, La Plainte du désiré)

1513 Tant qu'avez peu, vous avez deprimee La gloire haute, et clere renommee Des bons Troyens, et la force Hectorine Plus cler luisant, que Soleil en verrine (Jean Lemaire de Belges, Epistre du roy à Hector de Troye)

1915 Tant que pour arrêter un homme vivant il n'y aura que le feu et que le fer,

Tant qu'il y aura de la viande vivante de français pour marcher à travers vos sacrés fils de fer,

Tant qu'il y aura un enfant de femme pour marcher à travers votre science et votre chimie,

Tant que l'honneur de la France avec nous luit plus clair que le soleil en plein midi, Tant qu'il y aura ce grand pays derrière nous qui écoute et qui prie et qui fait silence,

Tant que notre vocation éternelle sera de vous marcher sur la panse,

Tant que vous voudrez, jusqu’à la gauche ! Tant qu'il y en aura un seul !

Tant qu'il y en aura un de vivant, les vivants et les morts tous à la fois !
Tant que vous voudrez, mon général ! Ô France, tant que tu voudras ! (Paul Claudel, Poèmes de guerre)

III. Être brillant, impressionnant, remarquable, être lucide

Intransitif

1886 Seulement, à cette heure, c'est le dédain plus que le désespoir qui gonfle mon cœur, et le fait éclater en phrases que je crois éloquentes. Dans le silence, il me paraît qu'elles frappent juste et luisent clair (Jules Vallès, Jacques Vingtras. L'Insurgé)

\section{CORpus Web :}

Ils [= les yeux] luisent clairs et luttent avec le bleu-marine de son gros chandail [http://www. jean-mabire.com/Le_Journal/Entrees/AAJM_19. pdf] (30.6.2020)

REMARQUES : Le sujet de luire clair (I) est souvent un astre (lune, soleil), mais il peut aussi désigner un objet (une arme), qui a un reflet éblouissant, qui reflète une lumière particulièrement forte. Lorsque le sujet réfère à quelque chose d'abstrait comme l'honneur, (II) se dit du fait de briller par sa supériorité. L'idée de supériorité d'une chose sur l'autre, sa mise en valeur, son statut supérieur est souligné. L'acception (III) renvoie à la justesse de ce qui est dit, et qui brille par sa force, sa lucidité intellectuelle. Clair s'emploie avec ou sans accord. En ancien français, l'accord est absent jusqu'au milieu du XIII ${ }^{\mathrm{e}}$ siècle ; ensuite on le trouve au féminin et au cas sujet (ex. de 1300). La tradition de l'accord optionnel se maintient jusqu'au présent. Clair peut être modifié par un adverbe d'intensité (moult, plus, tant, tout). La collocation avec beau (bel, belle) est usuelle dans l'ancienne langue (v. aussi remarques sous luire beau). Notons l'emploi de flairer soef, frapper juste.

\section{Luire doux}

Luire légèrement, en projetant une douce lumière

Intransitif

1601 Nous avions pour flambeau ton Soleil doux-luisant

Tes arbres nous estoyent pour parasol plaisant 
(André Mage, seigneur de Fiefmelin, L'Image d'un mage ou Le Spirituel)

1979 Le cuir est marron foncé, tout griffé, mais luisant doux à cause de l'encaustique que maman lui met de temps en temps (François Cavanna, Les Russkoffs)

1981 Ses gros yeux tout ronds d'or luisent doux de la forêt mastodonte à l'orée où fut le mammouth naguère pharaon (Jacques Arnold, Autre mythologie : poèmes)

REMARQUES : Luire doux se dit d'un astre, mais aussi d'un objet, généralement lisse, poli ou gras, qui réfléchit une lumière faible, douce, non agressive aux yeux.

\section{Luire fort}

Projeter, refléter une forte lumière

Intransitif

1400 MELCÏOR. Oncques mais je ne m’esbahys, En tout le voyaige tenant,

Si fort que je fais maintenant :

L'estoille, qui si fort luysoit [variante : si clair luysoit]

Et en luisant nous deduisoit, Nous est trop a coup deffaillie (Arnoul Gréban, Le Mystère de la Passion, 5900)

1557 Ceste herbe est d'une nature fort estrange et merveilleuse : car combien que le Soleil luise fort et long temps dessus, si est ce que vous le trouvrez tousjours humide et arrosée, et le poil d'icelle tousjours chargé de petites goutes d'eaue (Rembert Dodoens, Histoire des plantes)

1627 Cher frere. Qui seroit-ce ? Respondit Lysis, ne voyez vous pas que c'est mon ombre, et que la lune luit fort maintenant? (Charles Sorel, Le Berger extravagant)

1842 Ainsi, des temps passés relevant l'hyperbole,

Et, comme un pèlerin, apportant mon obole
À tout ce qui luit fort et beau,

J'aurais voulu bâtir sur l'arène mouvante Un monument hardi pour la gloire vivante, Pour la gloire ancienne un tombeau ! (Théodore de Banville, Les Cariatides)

2014 De ces heures sombres la flamme se moque à en rire

Des noires humeurs, la lumière éclaire jaune et vive

De sordides affaires... le soleil luit plus fort (Philippe Diaf, Les Lueurs de l'âme)

REMARQUES : Luire fort réfère à un objet, par exemple un astre (lune, étoile), émettant ou reflétant une forte lumière. Fort reste invariable et peut être modifié par un adverbe d'intensité (plus, si). Il est coordonné avec longtemps et beau.

\section{Luire profond}

Produire des reflets sombres intenses ou qui viennent des profondeurs

Intransitif

1902 Il y a encore le lac Nagaïn ; essayons : Ses yeux luisaient profonds comme l'eau Nagaïn (L'Université catholique).

1953 Jacquemort entra. Il faisait sombre comme dans toutes les maisons du village. Des objets fourbis luisaient profond (Boris Vian, L’Arrache-Cour)

2019 Seuls les yeux y luisent profonds, émouvants (Jean Védrines, Âge d'or)

Remarques : Dans l'exemple de 1953, luire profond, invarié, suggère des interprétations qui se situent entre une lecture simplement spatiale 'au fond de la maison' et ce que l'on peut penser en s'imaginant ce que pourrait être une lueur profonde. Par contre, les exemples de 1902 y 2019 s'approchent d'une prédication seconde, mais on peut également les interpréter comme façon de luire. 


\section{Mâcher amer}

on ne peut mâcher amer et cracher doux : on ne peut produire quelque chose de bon si l'on n'en a pas les moyens

$\lambda$ cracher doux

\section{Mailler menu}

Mailler étroitement, finement, faire de petites mailles

Transitif

1117 Mout estoit janz et bien aperz

Meleaganz et bien tailliez, Et li haubers menu mailliez, Et li hiaumes et li escuz, Qui li estoit au col panduz, Trop bien et bel li avenoient (Chrestien de Troyes, Lancelot ou Le Chevalier de la charrete, 3558)

1170 Dis mile e plus trestuit d'un front Lances baissiees s'entrevont ; Si se fierent par les escuz Que les haubers mailliez menuz Fausent e rompent as plusors, Que les enseignes de colors Se metent par mi les costez : Onques estors ne fu jostez $\mathrm{Ou}$ eüst tel ocision (Benoit de Sainte Maure, Le Roman de Troie, 11154)

1250 Le heaume et le hauberc, que voi mailé тепи,

Ja mez ne fineroi, si l'averai vendu, Mez enfans vestiroy, qui malement sunt nu ;

Aussi m'a on souvent de tel fet mescréu (Doon de Mayence, p. 83)

1275 A Costantinoble assamblerent, Les nez et les vaissiaus chargerent D'elmes, de lances et d'escuz, De bons haubers mailliez menus (Floriant et Florete, 2874)

REMARques : Employé au Moyen Âge, mailler menu désigne le fait de confectionner avec des mailles entrelacées de manière ajustée et de façon serrée une pièce d'armure comme la cotte de mailles (haubert). Menu tend à l'accord au pluriel. Notons l'emploi de avenir bel 'seoir, convenir à merveille'.

\section{Maintenir clair}

Continuer à affirmer (quelque chose)

franchement, sans détour

$\lambda$ maintenir haut

\section{Maintenir ferme}

I. Continuer d'affirmer ou de soutenir (quelque chose) de manière inébranlable, inflexible Transitif

1866 J'ai payé les 188 fr. Merci, mon enfant bienaimé, pour ton active et efficace intervention dans cette bête de petite affaire du Chapitre préliminaire. Maintiens ferme ma volonté. Je t'embrasse, mon tendre enfant (Victor Hugo, Correspondance)

1881 Il admit sur une large échelle le soldat germain dans les légions ; il accorda des terres en Dacie, en Pannonie, en Mésie, dans la Germanie romaine, à ceux qui voulaient travailler, mais maintint très ferme la limite militaire, établit une rigoureuse police sur le Danube et ne laissa pas une seule fois le prestige de l'empire souffrir des concessions que lui arrachaient la politique et l'humanité (Ernest Renan, Marc Aurèle et la fin du monde antique)

1937 J'entends cela d'ici : «Admirable petit peuple qui, au milieu de la tourmente, a su rester fidèle à la parole donnée au pouvoir légitime (légitime en dépit de ses fautes car les chrétiens n'admettent pas la rébellion), et n'en a pas moins maintenu haut et ferme le drapeau de la foi, imposant à ses puissants alliés, avec le respect de sa tradition et de sa langue, la liberté absolue du culte, la protection de ses prêtres » (Georges Bernanos, Les Grands Cimetières sous la lune)

1966 La guerre avait fini trop vite. Il vantait la démocratie américaine en ce qu'elle avait établi des lois républicaines à l'usage des Blancs, tout en maintenant ferme la ségrégation. Pour lui, le racisme allait de soi. Le monde se divisait en deux groupes, l'élite dirigeante, et les esclaves. (Catherine Paysan, Les Feux de la Chandeleur) 
II. Maintenir solidement, garder fermement Transitif

1929 J'arrive sur ces entrefaites, et, d'accord avec le général De Maud'huy, nous convenons ensemble des dispositions tendant : 1. à arrêter d'abord la marche de l'ennemi sur Arras ; 2. à maintenir ferme sur place les troupes de première ligne engagées ; 3. à réunir au plus tôt les autres en arrière, en mettant en même temps la main sur certains points d'une importance tactique particulière (Ferdinand Foch, Mémoires)

1948 Le Chevalier. Hé bien, adieu, ma chérie. (Elle s'est rapprochée brusquement. À ce mot d'adieu, elle faiblit, prend à deux mains la grille. Sa voix change de ton, bien qu'elle s'efforce de la maintenir ferme) (Georges Bernanos, Dialogues des Carmélites)

1988 Elle réclama des barrettes à ressort pour les maintenir ferme.

- Vous voyez bien que vous avez les cheveux blancs, lui dit Sigüenza. Vous n'êtes plus une petite fille, vous êtes une vieille femme.

- Qu'est-ce que vous en savez ?

(Béatrix Beck, Stella Corfou)

\section{CORPUS WeB :}

La véritable ouverture implique de se maintenir ferme sur ses propres convictions les plus profondes, avec une identité claire et joyeuse, mais « ouvert à celles de l'autre pour les comprendre » et en "sachant bien que le dialogue peut être une source d'enrichissement pour chacun »[http://www.lavie.fr/blog/dominiquefonlupt/le-pape-exhorte-au-dialogue-interreligieux,3064] (25.6.2015)

Essayer, chaque fois que cela est possible, de maintenir ferme les prix pratiqués en cas de renouvellement accepté du marché par le fournisseur quelques mois avant son échéance (v. de prévoir une légère révision de prix à la baisse pour tenir compte des gains de productivité réalisés pendant l'année par le fournisseur et de son effet d'expérience) [http://financeshospitalieres.fr/print.asp?679B4B7EB16EAF] (25.6.2015)
Ceci reste l'esprit de la mission franciscaine. Dans des temps pas si différents de maintenant, François s'adressa aux frères, les exhortant à maintenir fermes les valeurs de l'Evangile [http:// fr.custodia.org/?id=1019\&id_n=19548] (25.6.2015)

L'hôtel demande le versement d'arrhes afin de maintenir ferme et définitive la réservation comme suit : [http://www.hoteldelamadeleinesarlat.com/conditions.html] (25.6.2015)

REMARQUES : Au figuré, maintenir ferme (I) désigne le fait de ne pas modifier son comportement ou une position intellectuelle, en dépit d'objections, le sujet étant ferme dans ses résolutions et ne se laissant pas influencer par autrui. (II) se dit pour maintenir, fixer un objet dans une position donnée, faire en sorte que quelque chose reste dans un état déterminé ou initial, l'objet pouvant aussi désigner une personne. Notons les collocations ferme et droit et haut et ferme. Ferme reste invariable dans son emploi adverbial. Dans les deux derniers exemples du CW, ferme s'accorde avec l'objet au pluriel ou féminin, l'accord au féminin étant mis en évidence par coordination avec définitive. Dans ces deux cas, les adjectifs fonctionnent en tant que prédicats seconds orientés vers l'objet. Étant donné que maintenir ferme tend à la prédication seconde, c'est plutôt la fréquence de l'emploi invarié qui surprend (exemples de 1929 et 1988, second exemple du CW). On pourrait interpréter l'exemple de 1988 comme prédication seconde orientée vers le sujet, mais le fait que maintenir tend à l'orientation vers l'objet s'y oppose. Notons l'emploi pronominal dans le premier exemple du CW. Ferme est modifié par très.

\section{Maintenir fort}

Continuer d'affirmer ou de soutenir (quelque

chose) publiquement

Transitif

1560 Et sainct Augustin mesme au cinquième livre contre Julien, se rétractant de l'autre sentence, maintient fort et ferme que les péchez ne se font pas seulement par la permission ou souffrance de Dieu, mais aussi par sa puissance, à fin de punir les autres péchez (Jean Calvin, Institution de la religion chrestienne) 


\section{CORPus Web :}

j'ai tjrs fait toute la pipette quasiment en une pression ds chaque narine pour que ça chasse les mucosités et que ça ressorte par l'autre narine... et la plupart du temps mes « petits » détestent ça alors il me faut les maintenir fort... [http://www. maximomes.org/forum/printview.php? $\mathrm{t}=4739$ 0\&start $=0 \&$ sid $=a 77 b 94912 \mathrm{~b} 320 \mathrm{fc} 72 \mathrm{c} 366 \mathrm{fd} 4 \mathrm{c} 8$ 30d820] (25.6.2015)

Jérémy a salué pour la dernière fois en Juin, et nous ses copains, ça nous a fait un coup

Pas question de couper les ponts, au contraire, garder le lien, maintenir fort la corde qui l'empêchera de voguer trop loin de notre embarcation [http://anecdotesdhieretdaujourdhui. hautetfort.com/archive/2011/week41/index. html] (25.6.2015)

La musique hybride, élaborée en fonction du mouvement proposé, nous fait voyager de l'état naturel sensoriel à l'état électronique, tout en veillant à maintenir fort, le lien étroit entre musique et danse, métaphore de l'harmonie authentique [http://www.rencontresdeladanseenisere. com/spectacle-odyssee.html] (25.6.2015)

L'équipe de direction, progressivement renouvelée, s'est engagée très fortement à mes côtés et vous la côtoyez souvent. Elle a su maintenir fort l'engagement et la motivation des équipes pour la mission [http://www.eauxglacees.com/spip. php?page $=$ imprimer\&id_article $=1613](25.6 .2015)$

Vous devez savoir que les tendons et les ligaments ont besoin d'une alimentation adaptée, avec des vitamines et des minéraux spécifiques qui aident à les maintenir forts [http://ameliore tasante.com/traitements-pour-fortifier-les-ten dons-et-les-ligaments-des-genoux] (25.6.2015)

Nous ne pourrions conclure, sans adresser un vif remerciement maux élus des deux communes Cucugnan et Duilhac-sous-Peyrepertuse, ainsi qu'à la Fédération départementale des chasseurs de l'Aude, pour leur substantiel et régulier soutien financier qui permet de maintenir forte la dynamique de l'Aica, et ce pour le plaisir de tous [http://www.lindependant.fr/2012/05/13/ un-parcours-a-couper-le-souffle,137708.php] (25.6.2015)

REMARQUES : Dans l'exemple de 1560, maintenir fort désigne le fait de proclamer à haute voix ou publiquement une proposition ou une position intellectuelle, et ceci avec persévérance, le sujet ne se laissant pas influencer par autrui. Maintenir fort réfère également au fait de contenir un mouvement (exemples 1 et $2 \mathrm{du} \mathrm{CW}$ ) ou, au sens abstrait, à celui de faire persister un lien (exemples 3 et $4 \mathrm{du}$ CW). Fort reste généralement invariable dans son emploi adverbial, mais dans les deux derniers exemples du CW il s'accorde avec l'objet, en se rapprochant d'un prédicat second orienté vers l'objet. Notons la collocation fort et ferme.

\section{Maintenir haut}

I. Continuer d'affirmer (quelque chose) à voix haute, ouvertement, publiquement

Transitif

1560 Premièrement ceux qui les font ne maintiennent-ils pas haut et clair que le vray service de Dieu y est comprins? (Jean Calvin, Institution de la religion chrestienne)

II. Maintenir, faire rester à un niveau élevé, à un degré élevé

Transitif

1875 CHARLEMAGNE. Et toi, Berthe, ma fille, Toi qui maintiens si haut l'honneur de la famille,

Parle : il faut que chacun soit juge et soit témoin :

Parle à ton tour

(Henri de Bornier, La Fille de Roland)

CORpus WeB :

Fort heureusement, il est possible d'agir sur le métabolisme basal pour l'élever ou le maintenir haut : par le mode de vie, où l'activité physique et l'alimentation jouent un rôle essentiel [http:// www.thais.fr/pourquoi-on-prend-du-poids] (25.6.2015)

Son auvent adresse un hommage vibrant à l'architecture de la station service. Des bandes orange fluorescentes scandent les façades comme pour maintenir haut le niveau de vigilance [http://www.prego-architectures.com/\#!17rosny/ cbj1] (25.6.2015)

Pour maintenir haut notre motivation, il devient intéressant de comprendre pourquoi celle-ci est si importante [http://fredericperman. com/la-chronique-du-mois-4/\#.VYvoHUOcGUk] (25.6.2015) 
Avant tout la décision de l'Arabie Saoudite, plus grand exportateur pétrolier mondial devant la Russie, de maintenir haute la production pour que, l'offre se développant, diminue le prix du brut [http://sans-langue-de-bois.eklablog. fr/l-arme-geopolitique-du-petrole-a114199688? noajax\&mobile $=1]$ (25.6.2015)

Remarques : Au figuré, maintenir haut (I) désigne le fait de proclamer à haute voix ou publiquement une proposition ou une position intellectuelle, le sujet ne se laissant pas influencer par autrui. L'adjectif-adverbe haut est renforcé par clair, qui suggère des paroles franches, nettes et distinctes pour l'auditeur, ou par ferme (v. maintenir ferme), qui souligne une certaine assurance, voire une grande rigueur dans la manière de penser ou de s'exprimer. (II) désigne le fait que le sujet veut garder un principe moral d'action, des valeurs à un niveau élevé ou qu'il veut conserver en lui quelque chose de précieux, d'intense. Notons les collocations haut et clair, haut et ferme. Malgré son orientation sémantique vers l'objet (dernier exemple du CW, avec accord), haut tend à l'emploi invarié. Il est modifié par si.

\section{Manger anglais}

Manger à l'anglaise, comme les Anglais

$\pi$ danser anglais

\section{Manger bas}

Manger en silence

Intransitif

1907 La musique se perdait au milieu des conversations et des bruits de vaisselle. Cependant, tout le monde s'efforçait à parler et à manger bas (Romain Rolland, Jean-Christophe. La Révolte)

\section{CoRpus Web :}

Est-ce que mon corps s'est habitué à manger très bas ? Si je mange 1400-1600 calories / jour (petit dej léger, dejeuner leger, diner leger) je reprenderai du poids ou jeserai toujours en déficit de calories ? [http://forum.doctissimo.fr/nutrition/ alimentation-sante/probleme-nutrition-sujet_ 165043_1.htm] (25.6.2015)

2 semaines c'est long c'est sûr, surtout qu'à vu de nez d'après plusieurs personnes j'ai une dizaine de kilos à perdre vu mon gabarit, mais c'est nécessaire pour être tranquille par la suite au lieu de me prendre la tête à manger trop bas, être fatigué et ne rien perdre en définitif [http://www. musculaction.com/forum/seche-1m70-objectifs65-kgs-t104609-18.html] (1.7.2015)

Manger bas dans la chaîne alimentaire peut être préférable pour l'environnement et peut également vous aider à rester en bonne santé car elle implique généralement de manger plus de fruits et de légumes et moins de viande, selon les Centers for Disease Control and Prevention [http:// www.ordenan.com/definition-de-manger-bassur-la-chaine-alimentaire/] (1.7.2015)

REMARques : Manger bas désigne le fait de consommer de la nourriture en compagnie d'autres personnes, le sujet s'efforçant de manger sans faire de bruit (coordonné à parler bas), en silence. Dans les deux premiers exemples du CW, il prend les acceptions de consommer peu de nourriture, tandis que le dernier réfère à un niveau inférieur de la pyramide alimentaire, donc au fait de manger en évitant notamment la viande et ses dérivés. Notons la collocation parler et manger bas (parler bas). Bas reste invariable.

\section{Manger bio}

Consommer des produits bio

$\lambda$ manger bon

\section{Manger bon}

Consommer une nourriture délicieuse, savoureuse

Intransitif

1883 On mangeait bien, on mangeait bon, mais on ne rigolait pas comme on doit rigoler dans les noces (Guy de Maupassant, Contes et nouvelles)

1945 Les ventres n'ont qu'une opinion, qui est de manger bon et à bon compte (Gabriel Chevallier, Les Héritiers Euffe)

\section{CoRpus Web :}

Les restaurants où manger bon et sain à Paris

On a tous envie, un jour ou l'autre, de nourritures douces, bienfaisantes, vivifiantes. Carnet d'adresses pourconjuguer bonetsain [http://www. lefigaro.fr/sortir-paris/2012/10/16/03013-2012 1016ARTFIG00672-les-restaurants-o-mangerbon-et-sain-a-paris.php] (1.7.2015) 


\section{Où manger bon et local ?}

Notre région compte des milliers de restaurants et il est bien souvent difficile de distinguer ceux où opèrent de "vrais Chefs ", et ceux qui servent des plats préparés sur place de ceux où l'on se contente d'un simple passage au four, voire au micro-ondes de mets industriels [http:// blog.velib.paris.fr/blog/2015/02/23/ou-mangerbon-et-local/] (1.7.2015)

«Manger bon, bien et pas cher...»

Avis sur Le Cap des Trois Provinces [http:// www.tripadvisor.fr/ShowUserReviews-g1320149d4106893-r264594401-Le_Cap_des_Trois_Pro vinces-Ocquier_Liege_Province_The_Ardennes_ Wallonia.html] (1.7.2015)

«Manger bon et bio sans se ruiner : mission impossible ? » [http://www.prioriterre.org/ong/ agenda/1995/manger-bon-et-bio-sans-se-ruinermission-impossible-1412-19h30-maison-pour-laplanete.html] (1.7.2015)

REMARQUeS : Manger bon relève du domaine du goût et se dit du fait de consommer des aliments ou des produits agréables au goût, savoureux, délicieux. Notons les collocations manger bien, manger bon, et les groupes manger sain, manger local, manger pas cher, manger bio dans le CW, manger bio permettant une double lecture : 'manger du bio / de la nourriture bio' ou 'façon de manger / type de comportement nutritionnel'. Notons également l'usage de ces groupes syntaxiques dans les titres des textes et comme slogans (CW). Bon et les autres adjectifs-adverbes restent invariés.

\section{Manger brûlé}

Consommer un aliment brûlé, trop cuit Transitif

1843 En ce moment chacun prit sa chaise et s'attabla.

- Par exemple, dit la grosse Sylvie, tout est malheur aujourd'hui, mon haricot de mouton s'est attaché. Bah ! vous le mangerez brûlé, tant pire ! (Honoré de Balzac, Le Père Goriot)

1907 Elle revint dix minutes après, puis, de nouveau encore, dix minutes après : cette fois, cette fois, elle était hors d'elle, et bouillant de colère, en tâchant d'avoir l'air impassible, elle se planta au milieu de la chambre, et, malgré les gestes désespérés de Schulz, elle demanda, d'une voix de trompette :

- Si ces messieurs aimaient mieux manger leur dîner froid ou brûlé ; que, pour elle, cela lui était égal ; elle attendait leurs ordres (Romain Rolland, Jean-Christophe. La Révolte)

CORPUS WEB :

En êtes-vous satisfait ? Oui, et ma femme aussi, car on ne mange plus brûlé du fait que les graisses tombent dans le plat, et non plus dans la braise [http://www.linternaute.com/bricolage/ temoignage/temoignage/247199/pour-ne-pasmanger-du-carbonise/] (13.7.2015)

Je crois que le chef était pyromane avant et que la cuisine l'a calmé, mais pas guéri. Comme ses potes au feu, les cuistots qui vous ont souris comme des agneaux en entrant. Ne soyez donc pas surpris de manger brûlé (ou quasi) [http:// lestasters.blogspot.co.at/2014/08/miznon.html] (13.7.2015)

Tite zazounette va t'appeler demain durant la cuisson de sa méga quiche. Je crois bien qu'elle va la manger brulée [http://forum.doctissimo.fr/ sante/douleur-dos/hyper-actives-anonymessujet_151989_103.htm] (13.7.2015)

REMARQues : Manger brûlé désigne le fait de consommer des aliments ou des produits soumis à une (trop) forte cuisson à l'huile, au feu, etc. Notons la collocation manger froid ou brûlé. Brûlé reste invariable dans son emploi adverbial. Dans les deux premiers exemples du CW, le verbe apparaît dans son emploi absolu dénotant un type de comportement. Dans le dernier exemple, brûlé fonctionne en tant que prédicat second orienté vers l'objet et s'accorde avec l'objet au féminin.

\section{Manger chaud}

\section{Consommer un aliment chaud}

Intransitif

1646 Il croit, tant il est fou, tant il se plait et s'aime,

Que l'on n'estime pas un homme par luymesme,

Que selon sa naissance il est grand ou petit, 
Et sur ce fondement sa vanité batit :

Les faits de ses ayeux sottement il

s'applique,

Pensez que c'est ainsi que l'on entend

l'etique,

Et, parlant comme il parle à sa confession,

Il s'en peut bien aller sans absolution :

« J'ay beu froid, mangé chaud, trop aimé le

bon giste » (Jacques Du Lorens, Satires)

1809 Vous me devez de l'argent : quand je dis vous, c'est le régiment. On a reçu sans doute depuis un an mon traitement de la légion d'honneur ; avisez, je vous prie, aux moyens de me faire toucher cela ici, vous m'obligerez. Adieu ! Major ; adieu, Hasard, et tous mes camarades connus et inconnus ; adieu ! mes amis ; buvez frais, mangez chaud, faites l'amour comme vous pourrez. Adieu! (Paul-Louis Courier, Lettres écrites de France et d'Italie)

1919 On se promenait librement dans le bois et les cuistots y faisaient leur tambouille, cent mètres à l'arrière, suffisamment cachés par les taillis. Pour la première fois aux tranchées on avait mangé chaud et bu du café qui fumait dans les quarts.

Les Allemands, au début, avaient lancé des torpilles, d'énormes " tuyaux de poêle » qui broyaient tout (Roland Dorgelès, Les Croix de bois)

1978 Mais qu'il le sorte donc l'article du règlement qui condamne mon bouillon ! Et comment voulez-vous que je reste assise dans ces courants d'air et cette humidité, si je ne mange pas chaud? Tupik avait certes eu l'occasion de jeter un coup d'œil dans la casserole cabossée qui mijotait sur le réchaud (Michel Tournier, Le Coq de bruyère)

II. Agir, réagir (à quelque chose), s'occuper de (quelque chose) tout de suite, immédiatement, sans donner le temps de 'refroidir' Emploi absolu

1845 - Laisse-moi... et foi d'homme, nous nous battrons demain... quand tu voudras, dit Agricol d'une voix haletante.
- Pas de réchauffé... je mange chaud, répondit le carrier ; saisissant le forgeron à la gorge d'une de ses mains formidables, il tâcha de lui mettre le genou sur la poitrine (Eugène Sue, Le Juif errant)

Pronominal

1921 Irrité, un blanc voit rouge, là, tout de suite. Bandas ou mandjias, sangos ou goubous procèdent autrement. La vengeance n'est pas aliment qui se mange chaud. Il est bon de cacher sa haine sous la plus affectueuse cordialité, la cordialité étant la cendre que l'on répand sur le feu afin de lui permettre de couver (René Maran, Batouala, véritable roman nègre)

\section{CORPUS WEB :}

Pourquoi faut-il manger et boire bien chaud? [http://www.pierremougel.com/conseils/man ger-chaud/] (13.7.2015)

Quand on dit qu'il faut manger chaud, ça ne veut pas dire manger sec. Donc les liquides à la fin et en petite quantité aident aussi à bien digérer [http://mincir-yinyang.over-blog.com/page2326530.html] (13.7.2015)

On peut couper la frittata en bouchée pour servir en apéro, la manger chaud ou froid, en prendre pour le pique-nique et en plus ce n'est pas très calorique ! [http://allrecipes.fr/ recette/7722/frittata-aux-poivrons-et-aux-petitspois.aspx] (13.7.2015)

On peut la manger chaude, froide, avec ou sans accompagnement, en entrée ou en plat, la soupe fait partie de notre quotidien et peut se manger à toute heure de la journée [http://www. gojimag.be/article/la-soupe-vous-la-preferezchaude-ou-froide--346885.htm] (13.7.2015)

REMARQUES : Manger chaud (I) désigne le fait de prendre un repas chaud en consommant des aliments chauffés ou réchauffés. (II) réfère au proverbe La vengeance est un plat qui se mange froid ; il suggère qu'il faut savoir attendre que la colère retombe pour accomplir sa vengeance de sang froid. Ici, manger chaud désigne le fait d'agir de façon impulsive, sans attendre, de réagir à chaud. Même si du point de vue logique chaud renvoie à une propriété de la chose mangée, la construction transitive est plutôt rare. La langue préfère l'emploi absolu dénotant un type de comportement. 
En construction transitive, il s'accorde ou reste invarié (deux derniers exemples du CW). Chaud est modifié par bien. Notons l'emploi de boire chaud, boire frais, boire froid, voir rouge, manger sec.

\section{Manger confortable}

Manger confortablement, dans un endroit ou une position confortable

Intransitif

1964 On mange confortable [= au wagonrestaurant] (J. Giraud, Vrais et faux adjectifs adverbialisés)

\section{CORPUS WEB :}

Les sièges sont confortables, l'eau non potable, et les voisins suspects. Un ordinateur portable volé plus tard, tout le monde mange confortable son sandwich au pâté odorant ou son jambon beurre [https://instantpolonais.word press.com/2014/09/10/krakow/] (13.7.2015)

En principe, il ne existe aucune preuve que les techniques fractionnaires fréquents augmentent le métabolisme, et si vous pouvez manger, par exemple, seulement quatre fois par jour, ou trois, puis alors faites-le ! Personnellement, je mange confortable à 50\% du régime alimentaire dans la matinée [http://bangkok.ucoz.com/publ/ meilleures_recettes/quand_les_reves_devien nent_realite/111-1-0-15893] (13.7.2015)

REMARQUES : Confortable réfère au confort proposé par un lieu, donc à une propriété circonstancielle. Manger confortable tend à l'emploi intransitif ou absolu, mais la construction transitive est également possible (premier exemple du CW). Dans le dernier exemple du CW, il signifie plutôt 'sans le moindre problème', équivalant à confortablement. On pourrait éventuellement l'analyser comme troncation de celui-ci. Confortable reste invariable.

\section{Manger cru}

I. vouloir manger quelqu'un tout cru : être furieux contre quelqu'un Transitif

1716 Jupiter, comme je l'ai déja dit, après avoir bien grondé sa femme qui n'entend point raison, et qui voudroit manger tout cru Priam et toute sa race, fait un marché avec elle pour avoir la paix (Antoine Houdar de La Motte, Réflexions sur la critique)
II. Consommer de la nourriture crue

Pronominal

1866 Gilliatt eut recours à son couteau qu'il avait grand soin d'aiguiser et de tenir toujours en état, et il détacha du granit quelques poux de roque, de la même espèce à peu près que les clovisses de la Méditerranée. On sait que cela se mange cru. Mais, après tant de labeurs si divers et si rudes, la pitance était maigre. Il n'avait plus de biscuit (Victor Hugo, Les Travailleurs de la mer)

Emploi absolu

1879 Le professeur qui surveillait était Deschanel ; c'était un garçon d'esprit, - il entendit cuire les saucisses. - On avait le droit de manger cru dans la longue séance, - il pensa qu'on pouvait manger cuit. Tant pis pour celui qui tenait la casserole au lieu du dictionnaire dans la bataille ! (Jules Vallès, Jacques Vingtras : L'Enfant)

\section{CORPUS WEB :}

Vaut-il mieux manger cru ou cuit ? [http:// www.science-et-vie.com/2015/03/vaut-il-mieuxmanger-cru-ou-cuit\%E2\%80\%89/] (13.7.2015)

Manger cru ouvre la porte à un univers de saveurs par des aliments dont les qualités ne sont pas altérées par la cuisson [http://vegecru.com/ pourquoi-manger-cru] (13.7.2015)

La sucrine fait partie de la famille de la laitue. Elle est également appelées craquerelle du midi. C'est en faite le cœur de la salade. On peut évidemment la manger cru en salade, mais celle-ci est assez sympa cuite [http://lacuisinedelilie.blog spot.co.at/2011/07/les-sucrines.html] (13.7.2015)

Pour plus d'un tiers d'entre vous, la meilleure façon de déguster l'endive, c'est encore de la manger crue, en salade avec un petit filet de vinaigrette [http://cuisine.journaldesfemmes. com/magazine/sondages/0602endives.shtml] (13.7.2015)

Tes poireaux, les as-tu repiqués fin juin dans une tranchée de terre bien ameublie et remplie de compost, après leur avoir tranché une partie des feuilles et des racines ? Laissés en place, ils ne grossissent pas beaucoup... et dans ce cas, se mangent petits et crus en salade, pendant l'été [http://forum.davidmanise. com/?topic=926.10;wap2] (13.7.2015) 
REMARQues : Manger cru (II) désigne le fait de consommer des aliments qui n'ont pas subi de cuisson. Dans son emploi figuré (I), l'objet désigne un être animé traité durement en paroles. Notons la collocation manger cru ou cuit (manger cuit). Cru reste invariable dans l'emploi absolu du verbe. Si le verbe est transitif ou pronominal, l'adjectif-adverbe fonctionne en tant que prédicat second qui peut s'accorder avec l'objet du verbe transitif (v. le quatrième exemple du CW) ou avec le sujet du verbe pronominal à sens passif (v. le dernier exemple), mais il reste invarié dans le troisième exemple du CW (orthographe peu assurée). Cru est modifié par tout.

\section{Manger cuit}

Consommer de la nourriture cuite

入 manger cru

\section{Manger double}

Manger une double ration ; manger deux fois

plus que la normale

Intransitif

1857 Quand on parle de l'avidité gloutonne de l'araignée, on oublie qu'elle doit manger double, ou bien périr, manger pour refaire son corps, manger pour refaire son fil (Jules Michelet, L'Insecte)

1906 Gagnez votre vie, mais ne la gagnez pas trop. N'essayez pas de manger double, afin que le voisin mange une fois (Jules Renard, Journal (1887-1910))

1979 Pourquoi faudrait-il tout à coup un de ces drôles qui mangent double, prennent toute la place et ne sont bons qu'à faire perdre le temps aux autres ? (Jérémias Gotthelf, L’Araignée noire)

\section{Manger dur}

I. Manger énergiquement, beaucoup

Emploi absolu

1886 La raie fut servie, et l'on fit apporter la bouteille de vinaigre sur la table, pour corser le beurre noir, qui semblait fade. On mangeait dur, les morceaux de pain disparaissaient (Émile Zola, L'EEuvre)
II. Consommer un aliment dur, qu'on mâche avec peine

Emploi absolu

1950 une des causes essentielles de la fréquence des caries est la nourriture ramollie. Il faudrait au contraire manger cru, dur, sec et frais (UNESCO, Rapport sur le colloque de stomatologie / Grundt : 356)

\section{CORpus WeB :}

De plus, je me sens encor incapable de manger "dur ", je continu les soupes. Dans combien de temps pourrrais-je manger normalement ? [http://forum.doctissimo.fr/sante/dents/ apres-operation-sagesse-sujet_158397_1.htm] (13.7.2015)

Certains hommes vont être contents car il paraît maintenant que c'est préférable pour la santé de manger dur ! Demain, on vous dira qu'il faut plutôt manger mou afin de ne pas trop faire travailler vos dents [https://unefilledeshop.word press.com/2010/01/26/manger-dur/] (13.7.2015)

Attendez que la polenta refroidisse afin qu'elle se gélifie pour la manger "dure " ou dégustez-la encore chaude [http://www.cahierde cuisine.com/recettes/Polenta-con-vroccula-9465. html\#.VaOot00cGUk] (13.7.2015)

Les garçons le comprennent, si Vincent part, ils s'assurent une place en finale ! Ils vont même jusqu'à lui conseiller directement de partir. Évidemment Alexia et Vincent ne sont pas dupes. " Ils vont se la manger dur ", lâche-t-il [http:// www.purepeople.com/article/secret-story-7vincent-prepare-son-faux-depart-anais-et-juliencomplices_a126645/1] (13.7.2015)

REMARQUeS : En tant qu'intensifieur, dur (I) désigne le fait d'ingurgiter des aliments avec rapidité et énergie, soulignant un appétit féroce. Manger dur (II) réfère à un aliment difficile à mâcher en raison de son manque de cuisson ou parce qu'il n'est pas mûr ou trop ferme. Dans le dernier exemple du CW, la locution se la manger dur désigne le fait de rendre la tâche difficile à quelqu'un. Notons les adjectifs-adverbes $\mathrm{cru}$, sec et frais, ainsi que manger mou comme antonyme. Dur reste invariable dans son emploi adverbial ou absolu. Dans l'avant-dernier exemple du CW il fonctionne en tant que prédicat second orienté 
vers l'objet et s'accorde avec l'objet au féminin. Notons l'emploi de déguster chaud.

\section{Manger équilibré}

Manger sain, de la nourriture variée

$\lambda$ manger léger

\section{Manger fade}

Manger des aliments sans goût (sans épices ou sans sel)

Intransitif

1833 En tout il convient de tenir un juste milieu, car, si manger fade ne procure aucune sensation agréable, manger de haut goût et trop aromatisé peut devenir dangereux

(P. Cardelli, Manuel du cuisinier et de la cuisinière)

1905 En attendant, je médite sur l'arrêt de mon médecin qui décisivement m'interdit la seule chose que le monde physique m'offre de désirable - l'air marin - le séjour sur la marge des mers. Ajoutons qu'il me dessale et veut que je mange fade (André Gide et Paul Valéry, Correspondance)

2018 Manger sain ne rime pas avec manger fade (Corpus Coiffet 2018, s.v., sans date)

\section{Manger faux}

Consommer une nourriture qui n'est pas locale $\lambda$ habiller faux

\section{Manger ferme}

I. Manger de la nourriture solide

Transitif

18421 bombe à la vanille, chemise en chocolat, qui se sert toujours en dernier, afin de la manger ferme (A. Chevrier, Nouveau Manuel complet du maître-d'hôtel)

\section{Absorber beaucoup}

Transitif

1853 FLAMBEAU. car je ne suis pas tranquille, relativement à mon pantalon... c'est qu'on dit que ça mange ferme les couleurs, et la garance est si susceptible

(Edouard Brisebarre et Salvat, La Petite Provence: vaudeville en un acte)
III. Manger beaucoup, copieusement ; avoir un bon appétit

Intransitif

1864 À ton âge, il faut manger, il faut manger ferme, pour grossir et grandir (Eugénie Foa, Le Livre de la jeunesse)

1886 Bientôt la délégation tarasconnaise, autour d'une énorme omelette aux pommes de terre, recouvra la santé et la belle humeur essentielle aux Méridionaux comme le soleil à leur pays. On but sec, on mangea ferme (Alphonse Daudet, Tartarin sur les Alpes)

1974 Le village était charmant sous sa guipure de givre, le temps glacial et ensoleillé ; on buvait sec et on mangeait ferme, on enfournait les calories par milliers, on chantait en chœur, on se promenait sur les routes gelées et sonnantes (Julien Gracq, Lettrines 2)

REMARQUES : Manger ferme (I) renvoie à une qualité de la nourriture ; il s'agit donc d'une prédication seconde. En (II), le sens propre de 'manger beaucoup' (III) est pris au figuré pour référer, dans un registre plutôt populaire, à l'absorption des couleurs par une étoffe. Notons l'emploi avec boire sec. Notons l'emploi de boire sec.

\section{Manger fin}

Consommer une nourriture fine, délicate, raffinée

Emploi absolu

1958 J'aime bien être invitée chez les Pierre, c'est une maison où on mange fin (Exemple entendu, 5 juillet 1958 / Grundt : 410)

\section{CoRpus WeB :}

Seul bémol, souvent lié a ce type de resto, c'est la qualité ou la finesse des mets proposés qui a mon avis laisse un peu à désirer. Mais si on veut manger fin, on ne vient pas ici bien sûr [http://www.resto.be/restaurant/liege/4031angleur/3347-la-fiesta/avis] (13.7.2015)

Ici le plaisir de manger fin, sain et savoureux prend tout son sens, sans oublier un service délicat et des détails (tranche de citron dans la carafe d'eau...) trop rares à Paris [http://www. timeout.fr/paris/restaurants/le-37-m2-actuelle ment-ferme] (13.7.2015) 
Mais c'est bien de manger fin et peu, car de temps en temps cela ne fait pas de mal [http:// belleblonde.net/les-climats-paris-restaurant/] (13.7.2015)

REMARQUES : Manger fin se dit du fait de consommer une nourriture raffinée, à base d'aliments de bonne qualité. Notons les adjectifs-adverbes sain et savoureux, ainsi que la coordination avec peu. Corrélat de l'emploi absolu, fin reste invariable.

\section{Manger froid}

I. Consommer un aliment froid

Emploi absolu

1609 C'est donc pourquoy si jeune, abandonnant la France,

J'allay, vif de courage et tout chaud

d'espérance,

En la cour d'un prélat, qu'avecq'mille

dangers

J'ay suivy, courtisan, aux païs estrangers.

J'ay changé mon humeur, alteré ma nature ;

J'ay beu chaud, mangé froid, j'ay couché sur la dure (Mathurin Régnier, Les Satires)

1710 CRISPIN. Tu vois ; quoi qu'il m'arrive, Je conserve toujours un embonpoint égal : Chasser le jour, la nuit, à pied comme à cheval,

Le fusil sur l'épaule, en carrosse, en litiere, Forcer chevreuil, cerf, daim, sanglier, sangliere,

Manger froid, boire chaud, dormir couché, debout;

Un garçon comme moi s'accommode de tout (Philippe Destouches, Le Curieux impertinent)

1925 À l'ordinaire, ils mangent froid et gras. C'est l'époque où dans les maisons on a saigné les oies et «pelé » le cochon (Joseph de Pesquidoux, Le Livre de raison)

1936 Agnel, est-ce que le potage n'est pas bientôt prêt?

- Le potage, mademoiselle? Ah oui, nous mangeons froid, ce soir. Il n'y a plus de charbon (Julien Green, Minuit)

1942 En été, vous êtes menacé par la bile rouge : mangez froid et humide (Edmond Faral, La Vie quotidienne au temps de saint Louis)
1967 - Bon, dit Gilles en descendant, c'est l'heure. On y va. Vous mangez à la cantine, mademoiselle Letellier?

- Non, au vestiaire.

- Vous mangez froid?

(Claire Etcherelli, Élise ou La Vraie Vie)

1968 « Pourquoi tant se presser ? fit négligemment la belle hôtesse. Mon homme et Niclas Bambeke viendront souper tout à l'heure. Ça mange toujours froid en mer, pauvres créatures!»

(Marguerite Yourcenar, L'Euvre au noir)

II. La vengeance est un plat qui se mange froid (proverbe): il faut savoir attendre pour bien se venger

Pronominal

1879 Il n'en fit rien voir, estimant, comme M. de Talleyrand, que la vengeance est un mets qui se mange froid (André Theuriet, La Maison des deux barbeaux)

1887 Si la vengeance est un plat qui se mange froid, j'avais tout le loisir de préparer la mienne, - à mon aise (Paul Bourget, André Cornélis)

1933 Elle n'avait pas oublié que la vengeance est un plat qui se mange froid, aussi prenait-elle bien garde de ne point se laisser aller à bouillir tandis qu'elle recevait les hommages de celui-ci, les compliments de celui-là et les félicitations de tous sur le grand air de l'archiduc en tenue de gala (René Crevel, Les Pieds dans le plat)

1974 Mais il exprimait, à sa façon cynique et moderne, où subsistaient pourtant encore les réflexes de jadis, une vérité assez profonde : voici que nous retombaient sur le nez, et de nos jours seulement, les conséquences de la Révolution et de la suppression du droit d'aînesse. L'histoire aussi se mange froide

(Jean d'Ormesson, Au plaisir de Dieu)

III. se manger froid : utiliser, réemployer, reprendre plus tard, ultérieurement

Pronominal

1921 J'avoue que j’apprécie beaucoup Taquin le Superbe, et le « mot » se mangeait encore 
froid le lendemain à déjeuner, entre intimes qu'on invitait pour cela, et reparaissait sous diverses sauces pendant la semaine (Marcel Proust, Du côté de Guermantes 2)

\section{Corpus Web :}

Vous en avez marre des régimes qui ne marchent pas ou des conseils diététiques trop drastiques ? Et si manger froid était le moyen ultime pour perdre du poids? [http://www.ilosport. $\mathrm{fr} /$ nutrition/minceur/manger-froid-pour-maigrirplus/] (13.7.2015)

moi tout ça, ç ne me dérange pas de manger froid, mais pour les endives à la béchamel, là j’avoue ça doit pas être terrible... comme la pizza, froide cset pas top.. [http://forum.doctissimo. $\mathrm{fr} /$ nutrition/alimentation-sante/manger-froidchaud-sujet_159481_1.htm] (13.7.2015)

On peut couper la frittata en bouchée pour servir en apéro, la manger chaud ou froid, en prendre pour le pique-nique et en plus ce n'est pas très calorique! [http://allrecipes.fr/ recette/7722/frittata-aux-poivrons-et-aux-petitspois.aspx] (13.7.2015)

On peut la manger chaude, froide, avec ou sans accompagnement, en entrée ou en plat, la soupe fait partie de notre quotidien et peut se manger à toute heure de la journée [http://www. gojimag.be/article/la-soupe-vous-la-preferezchaude-ou-froide--346885.htm] (13.7.2015)

REMARQUES : Manger froid (I) désigne le fait de prendre un repas en consommant des aliments froids, qui ne sont pas chauffés ou réchauffés. Le proverbe (II) suggère qu'il faut savoir attendre que la colère retombe pour accomplir sa vengeance de façon plus cruelle et plus raffinée. (III) désigne le fait de réemployer un terme dans une conversation à un moment ultérieur. Notons les collocations manger froid et gras, manger froid ou brûlé (v. manger brûlé), manger froid et humide, manger chaud ou froid. Froid reste invariable dans l'emploi absolu du verbe. Dans les troisième et quatrième exemples du CW, le verbe est transitif, et l'adjectif-adverbe adopte la fonction de prédicat second orienté vers l'objet, restant invarié dans le premier et accordé dans le second cas (v. aussi l'exemple de 1974). Froid est modifié par encore, trop, toujours. Notons l'emploi de boire chaud, dormir couché.

\section{Manger glacé}

Manger un repas très froid

入 boire glacé

\section{Manger gras}

I. Consommer des aliments carnés, de la viande Emploi absolu

1686 Il y eut un grand souper ; monseigneur choisit ce jour-là, parce que le roi et madame la Dauphine mangent gras et qu'il ne pouvoit souper avec eux (Philippe de Dangeau, Journal)

1696 Vous voyez que votre tête ne veut plus que vous l'épuisiez par des écritures infinies ; si vous ne l'écoutez pas, elle vous fera un mauvais tour. Vous lui refusez une saignée ; pourquoi ne la pas faire à Aix pendant que vous mangiez gras ? Enfin je suis malcontente de vous et de votre santé (Mme de Sévigné, Correspondance)

1767 Madame, vous mangez gras un vendredi sans avoir la permission expresse de monseigneur l'archevêque ou la mienne ! (Voltaire, Le Dîner du comte de Boulainvilliers)

1847 comment s'est passé votre temps, votre vie de carême ? La mienne a été des plus agitées, des plus mortifiantes, mortifiante au sens spirituel, car nous mangions gras la moitié de la semaine (Eugénie de Guérin, Lettres)

1981 Elle me laissa libre de manger gras les jours maigres et ne voulut me gêner en rien dans ma religion (Françoise Chandernagor, L'Allée du roi)

II. Consommer des aliments qui contiennent une grande quantité de matières grasses Emploi absolu

1985 Oui, c'est bien eux, elle les reconnaît derrière le pare-brise, avec leurs têtes rectangulaires, un peu lourdes, de mecs qui mangent trop gras... Alors elle tourne le volant... C'est simple, comme c'est simple! (Victoria Thérame, Bastienne) 
CORPUS WEB :

Dans les années 60, une idée complètement fausse a commencé à circuler autour des tables : manger gras fait grossir. Faux. Manger gras ne vous rend pas gras. C'est l'excès de calories absorbées par rapport aux calories dépensées (activité physique, mode de vie) qui fait grossir [http:// www.santenatureinnovation.com/manger-grasne-rend-pas-gros-mais-ceci-oui/] (13.7.2015)

On a longtemps cherché à chasser les graisses de notre alimentation en les accusant des pires maux, notamment du surpoids. De " manger gras " à « être gras », il n’y avait, forcément, qu'un pas [http://www.topsante.com/ minceur/nutrition-minceur/conseils-minceur/ minceur-et-si-manger-gras-ne-faisait-pasgrossir-10912] (13.7.2015)

et forcement a force de manger gras, la nausée s installe... [http://forum.doctissimo.fr/sante/ anorexie-boulimie/mange-envie-vomir-sujet_ 203181_1.htm] (13.7.2015)

Remarques : Dans le domaine de la religion chrétienne, manger gras (I) réfère aux jours ou aux périodes où la consommation d'aliments carnés est permise en opposition à la consommation de nourriture maigre comme le poisson durant le Carême. Par extension, il renvoie à des jours librement choisis où l'on mange de la viande. Manger gras (II) se dit du fait de consommer une nourriture riche en lipides. Gras reste invariable et est modifié par trop. VoIR AUSSI : faire gras.

\section{Manger gros}

Manger beaucoup

Emploi absolu

1887 C'était comme leur chien, un vieux chien de douze ans qui mangeait gros, sans utilité : il y avait beau temps qu'on aurait dû lui allonger un coup de fusil (Émile Zola, La Terre)

1945 - Il n’y a pas assez de viande à la ferme, que tu viens nous voler notre bidoche?

- On mange gros là-bas. On a des ouvriers, des bûcherons, on est près de douze à table

(Jean-Louis Bory, Mon village à l'heure allemande)
1953 LE PROMOTEUR. Je sais pourtant, de source sûre, qu'il mange au ratelier anglais. Mangerait-il encore plus gros, au ratelier français? (Jean Anouilh, L'Alouette)

\section{CoRpus Web :}

Il faut manger gros pour devenir gros [http:// www.jeuxvideo.com/forums/42-78-38865417-1-01-0-il-faut-manger-gros-pour-devenir-gros.htm] (13.7.2015)

La France hardcore, celle du gros indus dancefloor, se réjouit : " Mind Corruption », le premier album de DJ TSX, contient douze cartouches qui vous tannent le cuir festif comme si vous aviez envie de manger gros. Faim ? [http:// culturedj.owni.fr/category/scene-hardcore/] (13.7.2015)

et l'échec est guère apprécié, en fait quand on regarde nos traditions humaines actuelles, ça y ressemble vachement, tu échoue tu mange gros la patate, et même si tu réussi tu dois toujours faire mieux et plus vite [http://www.equinox.net/t5885-attaque-des-mages-pourquoi] (13.7.2015)

Très sympa la polenta en pâtisserie, il faut que je teste ! Chez moi on la mange grosse et salée alors va falloir que je parte en courses d'abord trouver de la fine (ça va être simple car c'est celle que l'on trouve partout ... la grosse on est obligés de faire un stock quand on rentre en Savoie mdr !) [http://www.chezpatchouka.com/ article-gateau-au-citron-a-la-polenta-gateausans-farine-116308823.html] (13.7.2015)

REMARQUeS : En parlant d'une chose quantifiable, manger gros désigne le fait de manger en abondance, en grande quantité. Gros reste invariable dans l'emploi absolu du verbe, qui est le plus usuel. Si le verbe est transitif, il peut rester invariable (v. le troisième exemple du CW, qui est probablement une innovation individuelle du locuteur), mais en tant que prédicat second orienté vers l'objet, il peut également s'accorder avec l'objet (v. le dernier exemple du CW). Il est modifié par encore plus. 


\section{Manger léger}

Consommer des produits peu caloriques, diététiques

Emploi absolu

1964 Le Centre d'études et de documentation pour l'utilisation du sucre (Ah ! Qu'en termes galants...) nous invite, « pour vivre mieux », à " manger léger », c'est-à-dire, «sucré » [publicité] (J. Giraud, Vrais et faux adjectifs adverbialisés)

\section{CORPUS WEB :}

Dans un mois, c'est le printemps. Et si l'on profitait de ces quatre semaines pour manger léger et équilibré ? [http://www.enviedebienmanger.fr/ conseils-culinaires/quatre-semaines-pour-etrebien-sur-toute-la-ligne] (13.7.2015)

Manger léger le soir est plutôt bénéfique pour la santé [http://www.lepape-info.com/nutri tion/que-manger-le-soir-afin-davoir-un-repasleger/] (13.7.2015)

10 recettes pour manger léger tout en gardant le sourire

On peut manger léger sans tomber forcément dans le « régime hôpital "! [http://www.750g. com/10-recettes-pour-manger-leger-tout-engardant-le-sourire-a13949.htm] (13.7.2015)

REMARQues : Manger léger se dit du fait de consommer des aliments peu caloriques ; léger peut aussi caractériser un repas peu consistant. Léger reste invariable dans l'emploi absolu du verbe. Notons la collocation léger et équilibré, ainsi que l'emploi de manger sucré.

\section{Manger local}

Consommer des produits locaux

$\lambda$ manger bon

\section{Manger maigre}

Ne pas manger de viande; ne pas consommer d'aliments gras

Emploi absolu

1686 c'est la première fois que le roi ait mangé maigre depuis sa maladie (Philippe de Dangeau, Journal)

1755 Il importe peu au gouvernement que vous alliez à la messe ou non les jours ordonnés, pourvû que vous alliez ailleurs sans bruit et sans éclat; que vous mangiez gras ou maigre chez vous, pourvû que vous prétextiez une incommodité, et ne fassiez pas ostentation de donner ce qu'on appelle chair de commissaire (Victor de Mirabeau, L'Ami des hommes ou Traité de la population)

1756 Elle [= la marquise de Pompadour] se lève la nuit pour prier, elle va à la messe tous les jours, elle mange maigre fêtes et dimanches, on a bouché les portes les plus secrètes qui allaient de son appartement à celui du Roi, enfin que de bigoterie pour plaire à la Reine et à la Maison royale !

(René-Louis d'Argenson, Journal et mémoires)

1869 Singulière chose de manger maigre le jour où on a mis en croix l'homme apocryphe des écritures, quand on mange gras le jour où est morte votre mère (Edmond et Jules de Goncourt, Journal)

CORPUS WEB :

L'Église catholique préconise de jeûner le Vendredi saint, tout du moins de manger maigre (pas de viande en particulier), ce qui est pratiqué par de nombreux catholiques, même non pratiquants [https://fr.wikipedia.org/wiki/Vendredi_ saint] (13.7.2015)

Durant cette période il est conseillé de manger maigre, c'est-à-dire de s'abstenir de viande et de plats à base de graisse animale. Sont proscrits également les œufs [http://www.marmiton. org/magazine/dossiers-marmiton_cuisine-etreligions_8.aspx] (13.7.2015)

comme quoi, si on mange maigre, les $\mathrm{kg}$ s'en vont !! [http://blog.aujourdhui.com/sisca] (13.7.2015)

Les viandes se mangent maigres et pas plus de 2 fois par semaine [http://www.recette-pourdiabetique.com/diabete-et-regime-mediter raneen/] (13.7.2015)

REMARQUES : Dans la tradition, manger maigre réfère à la pratique religieuse consistant à s'abstenir de viande et de graisses animales, les jours où l'Église en interdit la consommation. Notons la collocation manger gras ou maigre. Au quotidien, maigre reçoit une connotation généralement posi- 
tive quand il s'applique à la consommation d'une nourriture qui n'est pas grasse. Maigre reste invariable dans l'emploi absolu du verbe. Par contre, en tant que prédicat second, il peut s'accorder avec le sujet du verbe pronominal à sens passif (v. le dernier exemple du CW). Notons l'emploi de l'antonyme manger gras. VOIR AUSSI : faire gras

\section{Manger mou}

Consommer des aliments mous (contraire de manger dur)

2013 En maison de retraite, les personnes âgées mangent mou (Exemple entendu, Corpus Coiffet 2018 : s.v.)

\section{Manger pas cher}

Consommer des produits bon marché

$\lambda$ manger bon

\section{Manger petit}

Manger peu

Emploi absolu

$\sim 1200$ Or fu Reniers et sa fame en prison, Un an tout plain et un mois i estont, Que n'i menjuent se moult petitet non, En la semainne trois fois, ce voz disons (Jourdain de Blaye, 394)

1280 Mengier et boire dois petit, Non pas croire ton apetit, Et toi biau contenir a table : Mont en seras plus deletable (Vivien de Nogent, La Clef d'amour, 3245)

1532 Nous ne boirons tantost que trop, à ce que je voy. A petit manger bien boire, sera desormais ma devise (François Rabelais, Pantagruel)

CoRpus Web :

salut, dodos 300 gr a 400 gr elles mangent petit en plusieurs bouchées, les grosses un coup et elles filent avec le crabe, crois en mon expérience depuis 3 ans je pêche qu avec les crabes , le fait qu elles mangent petit, fait qu elles voient les hameçons et après elles filent, c est la taille ou elles deviennent femelle et surtout méfiante et vicieuse [http://www.cotepeche.fr/forums/ peche-aux-appats/touche-crabe-t10339.html] (13.7.2015) tu dis qu'ils mangent petit en même temps c'est normal ils sont petits........ [http:// www.jigging.fr/jigging/viewtopic.php? $\mathrm{f}=42 \& \mathrm{t}=$ 16494\&start=15] (13.7.2015)

Moij'aime beaucoup les pâtissons, ça change un peu, et j'en ai au jardin, tu as raison il faut les manger petit, bizzzz [http://mamimijane.emonsite.com/pages/entrees-rafraichissantes/ patissons-vinaigrette.html] (13.7.2015)

Il est marqué qu'on peut les manger petits ou bien les laisser grossir et les manger avec les graines... [http://www.forum-politique.org/ sciences-ecologie/jardin-trucs-astuces-t107550220.html] (13.7.2015)

Tes poireaux, les as-tu repiqués fin juin dans une tranchée de terre bien ameublie et remplie de compost, après leur avoir tranché une partie des feuilles et des racines ? Laissés en place, ils ne grossissent pas beaucoup... et dans ce cas, se mangent petits et crus en salade, pendant l'été [http://forum.davidmanise.. om/?topic $=926$. 10;wap2] (13.7.2015)

REMARQUES : En ancien français, où petit occupe la fonction du quantifieur moderne peu, manger petit se dit du fait de consommer des aliments de manière restreinte, en faible quantité. Notons la collocation manger et boire petit et la possibilité de modification avec moult. Petit reste invariable dans son emploi adverbial. En français moderne, petit réfère à la taille d'un objet. C'est ainsi que les petits animaux mangent par petites bouchées. Dans les deux premiers exemples du CW, l'objet reste implicite (emploi absolu), ce qui entraîne l'usage invarié. Dans les trois derniers exemples, le complément d'objet est explicite et petit est accordé, sauf dans le premier d'entre eux. Notons la coordination de manger petit et cru. Mentionnons également l'emploi de contenir beau.

\section{Manger raide}

Manger beaucoup ; avoir un bon appétit Emploi absolu

1855 MAURICET. Or, pour nourrir tant de parents que ça ... les parents, ça mange raide, voyez-vous, quand ça s'y met ... il faut de l'argent ... (Théodore Barrière et Henry de Kock, Les Grands Siècles) 


\section{Manger saignant}

Manger de la viande rôtie ou grillée peu cuite où il reste du sang à l'intérieur

$\lambda$ boire sec

\section{Manger sain}

Consommer des produits bons pour la santé

入 manger bon, manger fin et manger simple

\section{Manger salé}

Consommer des produits salés

ત boire sec, manger sucré

\section{Manger savoureux}

Consommer des produits de bon goût

$\lambda$ manger fin

\section{Manger sec}

I. Consommer un aliment sec, séché Emploi absolu

1950 une des causes essentielles de la fréquence des caries est la nourriture ramollie. Il faudrait au contraire manger cru, dur, sec et frais (UNESCO, Rapport sur le colloque de stomatologie / Grundt : 356)

II. Manger beaucoup, avec brusquerie et rapidement, en finissant d'un coup Emploi absolu

1957 Fourchette d'esprit, il mange et boit sec, avec un noble flegme, puis se dérouille l'appétit en jouant au tennis (Canard enchaîné, 23 octobre 1957 / Grundt : 359)

\section{CORPUS WEB :}

oui je suis d'accord avec vous faut pas les [= les champignons] faire bouillir (enfin c'est sque j'ai lu partout) J'hésite encore a les manger sec ou en infu lol c'est vraiment mitigé les avis [http://www.psychonaut.com/champignonsmagiques/28544-consommer-psilocybe-cuben sis-sec.html] (14.7.2015)

Par contre la cuillère à soupe d'huile de Colza, elle doit être mélangée à mon escalope lors de sa cuisson ? ou à mes haricots ? ou je dois la manger sec comme ca directement à la cuillère (j’ai peur que dans ce cas ce soit plutôt écœurant)? [http://www.planetemuscle.com/phpBB2/ viewtopic.php?f $=4 \& \mathrm{t}=46364 \& \mathrm{start}=12]$ (14.7.2015) pas de problème pour les [= les champignons] manger secs comme ça, tu peux aussi les réduire en poudre et mixer ça avec du jus de citron (pas de la limonade, du vrai jus de vrai citron), ça va accélerer et augmenter les effets mais il dureront moins longtemps [http://www.psychonaut.com/ champignons-magiques/28544-consommerpsilocybe-cubensis-sec.html] (14.7.2015)

On peut la manger sèche, mélangée à de l'eau chaude ou froide en pâte ou en bouillie, ou associée à d'autres aliments [http://www.fao.org/ docrep/t0207f/T0207F09.htm] (14.7.2015)

REMARQues : Manger sec (I) se dit du fait de consommer des aliments ou des produits secs ou séchés. (II) désigne le fait d'ingurgiter de la nourriture en grande quantité et rapidement. Dans le second exemple du $\mathrm{CW}$, il réfère au fait de consommer quelque chose sans accompagnement. Sec reste invariable dans son emploi adverbial. En tant que prédicat second orienté vers l'objet, il peut rester invarié (v. les deux premiers exemples du CW) ou s'accorder avec l'objet (v. les deux derniers exemples du CW). Notons les collocations manger et boire sec et les adjectifsadverbes cru, dur et frais. VoIR AUSSI : boire sec

\section{Manger simple}

Consommer des plats simples, sans recherche, limités à l'essentiel

Emploi absolu

1955 Les fruits, les légumes d'été sont assez frais et appétissants pour se passer de mise en scène. Mangez simple, mangez vivant (Marie-Claire, août 1955 / Grundt : 258)

\section{CORPuS WEB :}

Il est possible de manger simple et sain tous les jours [http://pourmesenfants.eklablog.com/] (14.7.2015)

Avons-nous oublié de manger simple et nous soucier de notre santé ? [http://www.top-sitesbienetre.com/tag/manger-simple/] (14.7.2015)

J'ai donc décicé de tenter de faire la pâte à tacos moi même. Le résultat est délicieux ! j’ai commencé à les manger simple [http://afroandco. weebly.com/mon-blog/jai-dcid-de-tenter-lestacos-recette-tacos] (14.7.2015)

Pour les assiettes de légumes du jour (bio, composées selon le marché et l'humeur), vous 
pouvez les manger simples, avec du fromage (chèvre) ou avec dela viande [http://www.desfilles aretordre.com/commentaires-sur-du-bio-et-unpeu-de-bobo/] (14.7.2015)

Remarques : Manger simple se dit du fait de consommer des plats ou des produits soit sans recherche, sans excès de raffinement, soit sans accompagnement (deux derniers exemples du CW). Simple reste invariable dans l'emploi absolu du verbe. Si le verbe est transitif, l'adjectif-adverbe fonctionne plutôt comme prédicat second. Il peut alors rester invarié (v. le troisième exemple du $\mathrm{CW}$ ) ou s'accorder avec l'objet (dernier exemple $\mathrm{du} \mathrm{CW}$ ). Notons les collocations manger simple, manger vivant et manger simple et sain.

\section{Manger sucré}

Consommer des aliments sucrés

Emploi absolu

1964 Le Centre d'études et de documentation pour l'utilisation du sucre (Ah ! Qu'en termes galants...) nous invite, « pour vivre mieux », à " manger léger », c'est-à-dire, « sucré » [publicité] (J. Giraud, Vrais et faux adjectifs adverbialisés)

CORPuS Web :

Comment manger moins de sucre ou, plus radicalement, suivre un régime sans sucre et ne plus manger sucré? [http://entrainement-sportif. $\mathrm{fr} /$ manger-moins-de-sucre.htm] (14.7.2015)

Manger sucré augmente le risque de diabète de type 2 [http://sante.journaldesfemmes.com/ nutrition-digestion/manger-moins-sucre/moinsde-diabete.shtml] (14.7.2015)

L'rzeza est une sorte de msemene, on peut la manger sucré avec du miel ou du nutella. Ou bien salé avec du poulet en sauce [https://www. facebook.com/LesRecettesDuRamadan/videos/ 479768478779944] (14.7.2015)

Il s'agit de la CRÊPE ! Pour moi, elle reste indémodable, intemporelle et tellement bonne et savoureuse. Elle se marie facilement avec beaucoup de choses, on peut donc la manger sucrée ou salée, accompagnée d'une confiture, un sirop, d'une crème fouettée, d'un saumon philadelphia (recette à venir) ou tout simplement la manger nature !!!! [http://sominouchegourmandise.com/ la-crepe-un-joli-souvenir-denfance-2] (14.7.2015)
REMARQUeS : Manger sucré ou salé se dit du fait de consommer des aliments contenant du sucre ajouté ou beaucoup de sel. Dans son emploi transitif, sucré et salé s'accordent avec l'objet dans le dernier exemple du CW, tandis qu'ils restent invariés dans l'avant-dernier.

\section{Manger surgelé}

Consommer des aliments surgelés

$\lambda$ manger frais

\section{Manger tiède}

Manger de la nourriture peu chaude ou refroidie Transitif

1820 Elles [= les pommes de terre] leur sont encore plus profitables, quand ils [= les animaux] les mangent tièdes et réduites en pâtes après la cuisson (J. S. Lardier, Essai sur les moyens de régénérer l'agriculture en France)

\section{Emploi absolu}

1961 Le rythme des repas s'en ressent et les plats refroidissent. Il est vrai que ce n'est pas un crime en Grèce où l'on mange tiède (Michel Déon, Le Balcon de Spetsai)

1982 Jujube entre dans la cuisine, ouvre la fenêtre et surveille le sordide endroit où les gens viennent acheter les plats cuisinés à l'heure des repas. [...] Ils viennent pour se nourrir, attendent, et ils mangeront tiède. C'est certain. Tiède, c'est terrible (Juliette Gréco, Jujube)

REMARQUES : Manger tiède réfère à la faible température de la nourriture. Les citations mettent en évidence le rapport systématique entre l'emploi transitif en prédication seconde, avec accord, et l'emploi absolu où l'objet intérieur entraîne l'invariabilité.

\section{Manger végétal}

Consommer des aliments d'origine végétale $\lambda$ manger vivant 


\section{Manger vivant}

Consommer des produits frais, naturels, à l'état brut, non transformés

Emploi absolu

1955 Les fruits, les légumes d'été sont assez frais et appétissants pour se passer de mise en scène. Mangez simple, mangez vivant

(Marie-Claire, août 1955 / Grundt : 258)

\section{CORpus WeB :}

Manger vivant et végétal pour vivre sain et dynamique ! [http://veganbio.typepad.com/veg anbio/manger-cru-pourquoi-comment-.html] (14.7.2015)

Est-ce trop cher de manger vivant ? [https:// www.youtube.com/watch?v=hpL-fAMRTV8] (14.7.2015)

Qui se préoccupe des huîtres, les pauvres bêêêêêêtes dévorées vivantes dans d'atroces souffrances de mollusques arrosés de vinaigre à l'échalotte ou de Tabasco ? Metteriez-vous du Tabasco dans les yeux de votre chat avant de la manger vivant, diront les sauveurs des Trente Millions d'Amis [http://blogues.lapresse.ca/lortie/ 2011/01/10/foie-gras-ottawa-prefere-les-mili tants-a-picard/] (14.7.2015)

Le client reçoit ensuite son assiette sur laquelle la grenouille agonisante offre ses derniers sursauts tandis que le client la décortique et commence à la manger vivante [http:// www.7sur7.be/7s7/fr/2668/Especes-Menacees/ article/detail/1452686/2012/06/12/Un-restaurantpropose-des-grenouilles-a-devorer-vivantes. dhtml] (14.7.2015)

REMARQUES : La formule manger vivant réfère à la consommation de produits frais, sortant de son habitat naturel. Vivant reste invariable dans l'emploi absolu du verbe. Si le verbe est transitif, l'adjectif-adverbe fonctionne plutôt comme prédicat second et peut faire l'accord avec l'objet (v. le dernier exemple du CW), ce qui n'est cependant pas fait dans l'avant-dernier. Notons qu'en tant que prédicat second, vivant adopte la signification originale de 'être en vie, ne pas être mort', tandis qu'il adopte de façon suggestive le sens de 'frais, en état naturel, sans avoir subi des procédures de conservation' dans le langage de la vente des aliments et de la nourriture. Notons aussi les groupes manger simple, manger végétal, vivre sain et dynamique dans le CW.

\section{Manger vrai}

Manger un produit authentique

入 boire vrai

\section{Marcher beau}

I. Marcher énergiquement

Intransitif

1494 De toutes pars par compas prenez gens

En ce, heureux, valeureux, deligens, En la bataille de taille suffisante, Qui par vertus nobles, ducs, roys, regens, Vrais champïons, bons pÿons et sergens Saichent trouver au lever de leur tente ; Et au surplus ne faictes plus d'actente, Mais marchez beau, tout beau, de colle chaude,

Affin que nul ce faisant ne s'eschaulde (Andrieu de la Vigne, La Ressource de la chrestienté, 1317)

II. marcher tout beau : marcher tout simplement Intransitif

1496 LE CAPITAYNE. De mon espee qui a plaisance taille,

Si quelque sot en mes mains s'entretaille, Je suis bien seur qu'il ne s'en rira pas.

(Chascun, selon son esta[t] doit estre acoultré et doibvent avoir avec eulx une douzaine de gendarmes du moins qui ne diront mot) LE BARON. Marchons tout beau. LE TURC. Allons tousjours le pas (Andrieu de La Vigne, Le Mystère de saint Martin, 2385)

1578 BEZANE. Marchons tout beau, qu'on ne nous oye. Entre cy, et le jardin à Plebere, je te veux conter, Tristan mon amy, ce qui m'est arrivé ce jourd'huy avec Areuse (Jacques de Lavardin, La Celestine [adapt.])

CORPUS WEB :

$\mathrm{Au}$ théâtre le texte n'est qu'un moyen de faire silence et de marcher beau et de vibrer en chansons de gestes [http://nathpasse.blogspot. co.at/2010/04/photos-de-repetitions-et-je-veuxaller.html] (14.7.2015)

Après avoir marcher beau comme un coq dans son manteau le pauvre joseph marcha tout $n u$ dans le désert pour devenir esclave en Egypte [http://elihu-mission.euro-talk.net/t600p15-cher chez-d-abord-le-royaume-de-dieu] (14.7.2015) 
REMARQUES : Marcher beau (I) se disait du fait de marcher, de se déplacer de façon énergique, le sujet devant accélérer le pas. Marcher tout beau (II) signifie 'continuer à marcher tout simplement, comme il faut'. Beau reste invariable et est modifié par tout. Dans la langue moderne, il peut encore connoter le sens de ‘à bonne allure, bien', mais il tend à être associé à la beauté (marcher beau comme un coq 'marcher fièrement').

\section{Marcher calme}

Marcher calmement, tranquillement, sereinement

Intransitif

1839 Je rêvai qu'en un bois silencieux je marchais souffrant, mais pourtant calme, et l'âme pénétrée de je ne sais quel sentiment, tout plein d'un charme qui m'était inconnu (Rodolphe Toepffer, Nouvelles genevoises)

1896 Oui, je veux marcher droit et calme dans la Vie,

Vers le but où le sort dirigera mes pas, Sans violence, sans remords et sans envie : Ce sera le devoir heureux aux gais combats (Paul Verlaine, Euvres poétiques complètes)

CORPuS WeB :

Le chien, très souvent porté par son enthousiasme, tire exagérément sur la laisse. Il faut le sensibiliser (sans le rendre craintif à la laisse) afin qu'il comprenne qu'un appel de laisse veut dire qu'il doit marcher calme au pied [https://fr.wikibooks. org/wiki/M\%C3\%A9thodes_d\%27apprentissage_ chez_les_animaux] (14.7.2015)

Marcher calme c'est marcher en pays de pureté [http://fleurduzen.over-blog.com/page/ 87] (14.7.2015)

John arriva sur place marchant calme et serein parmi la foule en délire [http://www. captain-alban.com/dossier_expo_txt/exposi tion46_13.html] (14.7.2015)

Les piétons marchent calmes et ils cohabitent amicalement avec les voitures [http:// franceseoi1z.blogspot.co.at/2011/03/voyagetoulouse.html] (14.7.2015)

REMARQUES : Marcher calme se dit du fait de se déplacer de manière tranquille, sans agitation, soulignant l'état d'esprit serein du sujet. Au fi- guré, il souligne le fait d'avancer dans la vie, de franchir les étapes ou de faire face aux difficultés de la vie de façon sereine. Notons les collocations droit et calme, calme et serein, souffrant mais pourtant calme. En tant que prédicat second orienté vers l'objet, il s'accorde avec l'objet (v. le dernier exemple du CW). Il est modifié par mais pourtant.

\section{Marcher compact}

Marcher en formation dense

Intransitif

1835 la société, aux yeux du philosophe, est dans un moment de déroute ; elle n'a ni direction, ni but, ni chef ; elle en est réduite à l'instinct de conservation : une secte religieuse, morale, sociale et politique, ayant un symbole, un mot d'ordre, un but, un chef, un esprit, et marchant compacte et droit devant elle au milieu de ces rangs en désordre, aurait inévitablement la victoire ; mais il fallait apporter à la société son salut (Alphonse de Lamartine, Souvenirs, impressions, pensées et paysages pendant un voyage en Orient)

\section{Corpus Web :}

Mon sac est prêt, finalement je m'en tire pour $10,5 \mathrm{~kg}$ avec $2 \mathrm{~L}$ d'eau, ajoutons $1,5 \mathrm{~kg}$ de bouffe que je prendrais demain et voilà le sac fermera tout juste héhé. Rien qui pendouille dehors, pour une fois je marcherais « compact ». [...] [De retour :] Pour ce qui était de " marcher compact » c'était loupé, ça ne rentrait pas dans mon "petit » sac à dos 45-55L j'ai dû porter un petit sac d'appoint avec moi, pénible mais indispensable pour porter une partie de ma nourriture. (je faisais un peu l'effet d'une parisienne faisant son shopping aux galeries La Fayette) [http://www.bushcraft. $\mathrm{fr} / \mathrm{phpBB} /$ viewtopic.php?f=7\&t=4313\&start=30] (14.7.2015)

Les flics, présents et bien visibles, surveillent les manifestant-e-s qui marchent compact-e-s et déterminé-e-s derrière des banderoles sur lesquelles on pouvait lire "Stop renvois, fermons Frambois" «Des papiers pour tous ou pas de papiers du tout » «Les papiers ça brûle » [http://marche-europeenne-des-sans-papiers. blogspot.co.at/2012/07/compte-rendu-actionframbois-geneve.html] (14.7.2015) 
REMARQUES : Marcher compact se dit du fait de se déplacer en groupe, de manière rapprochée, serrée. Il fonctionne alors comme prédicat second accordé. Fait curieux, la coordination de compact, accordé, avec droit n'entraîne pas l'accord de droit, sans doute parce qu'il est conçu comme faisant partie du groupe adverbial droit devant elle. Dans le premier exemple du CW, compact réfère à la façon qu'a la jeune femme de préparer son équipement de voyage, le bagage formant un bloc compact. Dans ce contexte, l'accord avec le sujet au féminin n'a pas de sens. Il reste donc invarié. Notons les collocations compact et droit, compact et déterminé.

\section{Marcher doux}

Marcher doucement, tranquillement; marcher silencieusement, prudemment

Intransitif

1655 et puis l'argent dont Colignac leur graissoit les mains, les faisoit marcher doux en beaucoup de pas difficiles (Savinien Cyrano de Bergerac, Les Estats et empires du soleil)

1755 Ainsi qu'un chat qui d'un regard avide guette au passage une souris timide, marchant tout doux, la terre ne sent pas l'impression de ses pieds délicats (Voltaire, $L a$ Pucelle d'Orléans)

1848 Voici qu'un soir, lorsque je marchais tout doux sur les pelouses de Twickenham, apparaît Peltier, tenant son mouchoir sur sa bouche : «Quel sempiternel tonnerre de brouillard! » (François de Chateaubriand, Mémoires d'outre-tombe)

1907 La châtelaine n'était jamais absente quand on avait besoin de lui parler. C'était la vieille madame Jacquemin, marchant doux, parlant doux, et plus volontaire que dix hommes ensemble (René Bazin, Le Blé qui lève)

\section{Corpus WeB :}

Les médecins, les visiteurs, les agents de sécurité, les agents d'entretien parlaient bas, marchaient doux, frôlaient sans heurter [http:// andy-verol.blogg.org/l-exact-inverse-de-lacohue-connasse-a116181092] (14.7.2015)
Et depuis, nous marchons doux et ne nous révoltons plus vraiment en France [http:// www.matierevolution.fr/spip.php?article1319] (14.7.2015)

Nous soulignons encore que cette option convient particulièrement à ceux qui souhaitent marcher " doux » et le faire lentement [http:// www.labessannaise.com/fr/il4-sejour_i33vanoise-en-douceur.aspx] (14.7.2015)

REMARQUES : Marcher doux se dit du fait de se déplacer en silence, de manière tranquille, délicate, sans agitation, qui suggère la douceur des mouvements ou du pas et le souci du sujet de ne pas faire de bruit. Dans le dernier exemple du CW, il réfère à de randonneurs qui souhaitent aller doucement, évitant les parcours trop durs. Dans l'exemple de 1655 et dans le premier exemple du CW, marcher doux s'emploie comme synonyme de filer doux. Notons l'emploi de parler doux et parler bas. Doux reste invariable (v. l'exemple de 1907) et est modifié par tout.

\section{Marcher droit}

I. Aller, se diriger directement (à/vers quelque chose/un lieu)

Intransitif

-1465 De ses beaulx yeulx, qui sont, plus que nature

Ne peult ouvrer en nulle creature, Doulx et rians, ung regard me transmist, Qui me donna au cueur une poincture Si tresplaisant et de tel nourriture Que mon soucy presque tout se desmist, Puis a marcher droit envers moy se mist, Comme son vueil l'endura et permist (Jean Meschinot, Lunettes des princes, p. 18, XLVIII, 7)

1477 Le Roy mist le siège à Aucerre, comme j’ay dit ; de là, à Troyes et à Rains. Je ne veult point mettre les petitz chasteaux ne les petites villes qui furent prinses, pour ce que les chouses seroient trop longues à escripre. Il fut coronné à Rains ; de là, marcha droit à Paris (Guillaume Tringant, Commentaire du Jouvencel / Jean de Bueil, Le Jouvencel [1461]-1468, II, p. 280)

1532 Ce conseil et deliberation fut divulgué par la ville ; et, le lendemain, se trouverent 
en la place devant le palais jusques au nombre de dix huit cens cinquante et six mille et unze, sans les femmes et petits enfans. Ainsi commencerent à marcher droit en Dipsodie, en si bon ordre qu'ilz ressembloient es enfans d'Israel, quand ilz partirent d'Egypte pour passer la Mer Rouge (François Rabelais, Pantagruel)

1646 Cassius Gouverneur de Syrie, eut commandement de le conduire par delà l'Euphrate. Si les Parthes eussent voulu suivre son conseil et marcher droit en Mesopotamie, indubitablement Meherdates eust veu prosperer ses affaires (Nicolas Coëffeteau, Histoire romaine)

1698 Ce discours d'un Guerrier que la colere enflâmme,

Ressuscite l'honneur déja mort en leur ame ;

Et leurs cœurs s'allumant d'un reste de chaleur,

La honte fait en eux l'effet de la valeur.

Ils marchent droit au fleuve, où Louis en personne,

Déja prest à passer, instruit, dispose, ordonne

(Nicolas Boileau, Épîtres [1670-1698])

1719 Il attendit que la nuit fût venue, faisant bon guet autour de son camp ; et environ vers la seconde veille, ayant fait un fagot des branches les plus sèches qu'il put trouver, il y mit le feu avec un fusil, le mit au bout d'une longue perche, et marcha droit aux ennemis (Antoine Hamilton, Histoire de Fleur d'Épine)

1917 C'était Thérèse. Elle resta un instant à surveiller la voiture qui démarrait et tournait. Graffeteau se tenait à quelque distance, en pleine lumière. Elle marcha droit sur lui, qui la regardait venir, souple, grande et mince dans un long manteau de loutre dont la nuance lustrée et sombre donnait un éclat plus vif à son teint (Paul Bourget, Lazarine)

1922 Et c'était vrai : elle [= la lumière] était blanche, puis jaune, puis bleue. Il s'arrêta, remonta sa culotte, serra d'un cran la ceinture, et marcha droit sur la chose. Là-bas la lumière changeait de couleur à tout moment. C'était en vérité fort étrange (Henri Pourrat, Le Château des sept portes ou Les Enfances de Gaspard)

1926 Mais elle l'avait apaisé un peu tandis qu'il marchait droit au taureau, qu'il alla chercher dans son terrain

(Henry de Montherlant, Les Bestiaires)

1950 - Les bois où nous sommes dominent sur plus d'un mile une des routes qui mènent hors de la ville. Si tu marches tout droit dans cette direction, tu arriveras à un ravin. Entends-tu ce que je te dis? Joseph hocha la tête.

- Tu attendras dans les bois que la nuit tombe (Julien Green, Moïra)

II. Rester dans le droit chemin Intransitif

1563 La reigle disoit au compas, Tu ne sais que tu dis, Tu ne saurois rien faire qu'un rond seulement, qui est le trou du cul, mais moy, je conduis toutes choses directement, et de long, et de travers, et en quelque sorte que ce soit, je fay tout marcher droit devant moy (Bernard Palissy, Recepte veritable)

1604 C'est une mesme loy qui fait mourir et naistre ;

Puis qu'en vain l'on fuiroit à destre ou à senestre,

Il vaut mieux s'avancer en marchant tousjours droit,

Et vouloir ce qu'il faut quand on ne le voudroit (Antoine de Montchrestien, Hector)

1652 Ton rang, loin d'alléger le poids de ton fardeau,

En redouble la charge, et jusques au tombeau

Il te met sous le joug d'une loi plus sévère : Il te prescrit à suivre un chemin plus étroit, Et la perfection que doit ton caractère Veut qu'on marche plus droit (Pierre Corneille, L'Imitation de Jésus-Christ)

1782 Il fixe les yeux en tremblant sur le précipice où la loi des destins l'entraîne, il en recule l'époque qu'il juge lui-même inévitable : 
mais il l'éloigne en n'affectant ni crainte, ni audace ; et mettant à profit les passions de tout ce qui l'environne, il se défend de ces passions indiscretes qui agitent les autres corps et les empêchent de marcher droit vers un but unique (Louis-Sébastien Mercier, Tableau de Paris)

1805 Ce mouvement d'ondulation du corps ne pouvant se faire d'une manière parfaitement égale des deux côtés, est ce qui empêche l'homme de marcher en ligne droite, et même de conserver une direction constante, s'il ne fait pas une grande attention pour corriger ses écarts. Voilà pourquoi un homme ne peut marcher droit les yeux fermés (Georges Cuvier, Leçons d'anatomie comparée)

1848 CÉLIE. J’ignore ce que peut conseiller la misère ;

Mais suivre ses conseils n'est pas si nécessaire

Qu'on ne voie, en dépit de la faim et du froid,

Plus d'une pauvre fille honnête et marchant droit (Émile Augier, L'Aventurière)

1850a Chez les natures faibles, le découragement devient de l'envie. Tandis que d'autres, à qui la nécessité, la volonté, la réflexion tenaient lieu de talent, marchaient droit et résolument dans la voie tracée aux ambitions bourgeoises, Godefroid se révolta, voulut briller, alla vers tous les endroits éclairés, et ses yeux s'y blessèrent (Honoré de Balzac, L'Envers de l'histoire contemporaine)

1850b Quant à vous, je sais que vous marcherez toujours droit et bien, je voudrais vous être utile, parce que ce serait ma meilleure récompense d'un bon travail, mais je sais bien que si je n'en viens pas à bout, vous saurez découvrir et développer le talent là où il saura éclore (George Sand, Correspondance)

1902 Qu'il y ait eu un incendie à Saumur, et un imbécile à Béfort pour revenir de semestre le soir même des préparatifs, pour n’y rien comprendre, et tout raconter aux supé- rieurs, croyant bien faire ; qu'il y ait eu un malentendu à Marseille qui a fait prendre mon ami Vallé pour un agent provocateur par le capitaine Sicard, ce sont là des accidents. On en voit bien d'autres en campagne. Un jour ou l'autre, tout marchera droit (Paul Adam, L'Enfant d'Austerlitz)

1923 Une grande bourgeoise effrayée par le scandale, et qui entendait se servir de son secret pour la faire marcher droit ? Qu'importait encore? (Paul Bourget, La Geôle)

III. Marcher selon une ligne horizontale, sans dévier, en ligne droite

Intransitif

1662 Jesus-Christ dit dans l'evangile en parlant de ses miracles. Les aveugles voyent, les boiteux marchent droit, les sourds entendent (Antoine Arnauld et Pierre Nicole, La Logique ou L'Art de penser)

1842 Thalès de Milet fut suivi longtemps par un griffon ailé ; Bias de Priène fit route côte à côte avec un lynx ; Périandre de Corinthe fit reculer un léopard en le regardant fixement ; Solon d'Athènes marcha hardiment droit à un taureau furieux ; Pittacus de Mitylène fit rencontre d'un souassouaron ; Cléobule de Rhodes fut accosté par un lion, et Chilon de Lacédémone par une lionne (Victor Hugo, Le Rhin)

1845 - Ça compose notre hôtel, et il y en a de plus beaux ; mais rassure-toi, les pauvres enfants sont habituées à ne pas être difficiles ; demain matin je partirai avec mon garçon, bras dessus bras dessous, et je te réponds qu'il ne sera pas celui qui marchera le plus droit et le plus fier de nous deux. Nous irons trouver le père du général Simon à la fabrique de M. Hardy pour causer affaires... (Eugène Sue, Le Juif errant)

1848 Jansénius, Saint-Cyran et Pascal, au contraire, n'ont pas été inconséquents ; ils ne sont pas allés jusqu'au bout, voilà tout ce qu'on peut dire. Mais sur leur chemin ils ont toujours marché ferme et droit ; à un certain moment, tout au bord, ils se sont arrêtés (Charles Sainte-Beuve, Port-Royal) 
1851 Octave hésitait, mais la curiosité l'emporta. - Je vous accompagnerai, dit-il.

- Encore un coup, fit le vieillard en montrant les verres, ça donnera des jambes.

- Encore un coup, donc, dit Octave en trinquant avec le bonhomme Jadis.

- Et en route! Fit celui-ci.

- Vous voyez que je marche droit et sans canne, dit-il à Octave

(Henri Murger, Scènes de la vie de jeunesse)

1865 Puis il se leva et partit sans rien dire. Je pensai qu'il était peut-être malade, et je le suivis. Mais il marchait droit et vite, comme un homme que le vin n'a point entamé et il s'en alla si loin, si loin, en remontant la côte au-dessus de la ville de SaintChartier, que je le perdis de vue (George Sand, Les Maîtres sonneurs)

$1871 \mathrm{Au}$ loin s'étendaient les routes toutes blanches de lune. Miette avait refusé le bras de Silvère ; elle marchait bravement, ferme et droite, tenant le drapeau rouge à deux mains, sans se plaindre de l'onglée qui lui bleuissait les doigts (Émile Zola, $L a$ Fortune des Rougon)

1895 Dans leurs vêtements des âges passés, elles marchent lentes, droites, nobles, - et, avec cela, très naïvement jolies, toutes, sous la blancheur de ces voiles qui accentuent une étrange ressemblance, quand surtout elles tiennent sur l'épaule un petit enfant : on croit, à chaque tournant des vieilles rues sombres, voir apparaître la Vierge Marie (Pierre Loti, Jérusalem)

1896 Oui, je veux marcher droit et calme dans la Vie,

Vers le but où le sort dirigera mes pas, Sans violence, sans remords et sans envie : Ce sera le devoir heureux aux gais combats (Paul Verlaine, Euvres poétiques complètes)

1904 Le vertige ! le vertige !... J'ai marché droit et vite, à heurter les passants. Mes souvenirs se perdent alors, mais je me suis certainement trouvée non loin du Canal, à la Villette, au déclin du jour, vers huit heures (Léon Frapié, La Maternelle)
1907 Elle murmura quelque chose à l'oreille de l'enfant, qui répondit oui, discrètement. Marie était tout occupée à relever son voile et sa robe, et à marcher bien droit, pour ne pas mettre dans les ornières ses pieds chaussés de souliers blancs. La mère, tous les dix pas, recommandait : «Va pas te salir, Marie !» (René Bazin, Le Blé qui lève)

1914 Ils admettent la vérité, à condition qu'elle rentre dans les cadres qu'ils lui ont préparés. Ceux-là verraient à Lourdes les mourants se redresser et les boiteux marcher droit, qu'ils diraient : non, encore, dans leur malice infernale (Ernest Psichari, Le Voyage du centurion)

1929 - La fête, plaisanta Justin, il a dû déjà la faire dans son village. Il n'a pas l'air d’aplomb. En effet, l'homme traînait la jambe et ne marchait pas très droit. Il arriva près d'eux, les regarda, et soudain s'immobilisa. Avant même de distinguer ses traits, Justin le reconnut (Marcel Arland, L’Ordre)

1939 S'il me plaît, à moi, d'espérer ? S'il me plaît d'aimer cette ville crénelée et toute pavoisée de soleil ? S’il me plaît de marcher tout droit, à pas agiles, puisque je ne sens plus ma fatigue, puisque je suis heureux... Prévot et son revolver, laissez-moi rire ! Je préfère mon ivresse. Je suis ivre (Antoine de Saint-Exupéry, Terre des hommes)

1944a Mais Délira ne semblait pas trop convaincue. L'homme qu'elle avait aperçu ne chancelait pas, il marchait droit et vite vers la barrière (Jacques Roumain, Gouverneurs de la rosée)

$1944 \mathrm{~b}$ « Tu marches comme un crabe et ton village t’a vomi ! Tu enlaidis le nôtre ! C'était un beau village, marchant bien droit! » Alors tu le voyais qui faisait simplement demi-tour et s'éloignait, tirant la jambe. Tu lui disais, si tu le rencontrais (Antoine de Saint-Exupéry, Citadelle)

1954 Si la Sécurité Sociale était sagement conduite, si la République était sagement conduite, si les crabes marchaient droit, il est probable que ce jour-là (Jacques Perret, Cheveux sur la soupe) 
1985 Elle remonta même de la cave les jouets de Brieuc qu'elle n'avait pu se résoudre à donner. Ludo finit par savoir marcher droit, sourire et mieux parler. Un an plus tard, et pour la première fois depuis le départ de son fils, Nicole vint dîner chez Nanette à l'improviste (Yann Queffélec, Les Noces barbares)

IV. Être sur le chemin de, parvenir au but fixé Intransitif

1755 Ce n'est pas ma faute quand j'en trouve sur mon chemin. Personne au monde ne cherche moins que moi à se singulariser par ses opinions. Je marche droit à la vérité, et ne prétends point être infaillible ; mais daignez lire jusqu'au bout sans prévention (Victor de Mirabeau, L'Ami des hommes ou Traité de la population)

1816 Quelques jours après, Éllénore alla plus loin : elle était incapable de tout empire sur elle-même ; dès qu'elle croyait avoir un sujet de plainte, elle marchait droit à l'explication, sans ménagement et sans calcul, et préférait le danger de rompre à la contrainte de dissimuler. Les deux amies se séparèrent à jamais brouillées

(Benjamin Constant, Adolphe)

1822 Tu es toi, Adèle, mon but unique, et tous les chemins pour y atteindre me sont bons, pourvu qu'on y puisse marcher droit et ferme, sans ramper sur le ventre et sans courber la tête. C'était là ma pensée quand je te disais que j'aimais beaucoup mieux me créer moi-même en travaillant mes moyens (Victor Hugo, Lettres à la fiancée)

1840 Monté sur l'orgueil, il touche aux plus hautes choses, et regarde à sa portée ce qu'il devrait contempler à genoux. Il veut voir, comprendre, saisir, et marche droit à l'incrédulité. Il faut qu'on lui prouve la foi maintenant, lui qui croyait tout (Eugénie de Guérin, Journal)

\section{CORPUS WEB :}

Comme le dit le titre, ma jument zigzag sans cesse d'un côté à l'autre de la route quand on est en balade pas moyen de la faire marcher droit [...]. Ce n'est rien de grave, mais c'est aga- çant car c'est une attention de tout instant pour la garder "droit " [http://www.1cheval.com/ membre/forum/general/sujet-2326370-0-chevalqui-zigzag-sans-cesse-en-balade] (19.5.2015)

il connaît même un regain d'activité dans le contexte tendu des Sixties, où beaucoup redoutent que les États-Unis marchent droit vers une guerre civile raciale [http://blog.francetvinfo.fr/ deja-vu/2015/06/22/charleston-2015-birming ham-1963.html] (14.7.2015)

Rentre dans le rang de ceux qui marchent droit [https://www.fanfiction.net/s/11144741/1/ Rentre-dans-le-rang-de-ceux-qui-marchentdroit] (14.7.2015)

La majorité d'entre nous sommes des voleurs et pour pouvoir voler nous coupons les ailes aux oiseaux, les nageoires aux poissons, les pattes aux animaux, et les jambes à ceux qui marchent droit. Voilà la vérité et voilà aussi pourquoi ne pourront partager ce poste que ceux qui marchent droits [https://fr-fr.facebook.com/ permalink.php?story_fbid=651161831687655 \&id=185795341557642] (14.7.2015)

REMARQUES : Au concret (I), marcher droit s'applique au mouvement spatial et se dit du fait de se diriger vers un lieu, d'aller tout droit vers un but. En emploi figuré (II), il se dit du fait de bien fonctionner ou de mettre tout en œuvre pour que quelque chose fonctionne bien. Lorsque le sujet désigne une personne, il réfère au bon comportement que celle-ci doit avoir, à une manière d'agir selon les règles qui régissent un groupe. (III) renvoie à la façon de se déplacer seul ou en groupe, en formant une ligne droite, bien rangée. Dans certains cas, il rappelle la marche militaire, des soldats qui se déplacent en rang, bien alignés. L'adjectif-adverbe droit apparaît en collocation avec d'autres adjectifs-adverbes comme fier ou ferme ; ceux-ci soulignent l'assurance, le caractère décidé du sujet, qui foncent, avancent d'un pas décidé. À nouveau en emploi figuré (IV), il réfère au processus mental de réflexion du sujet avant de parvenir à un but, le sujet se caractérisant par une grande force de caractère et la volonté d'arriver au résultat escompté. Le premier exemple du CW montre son emploi dans le domaine de l'équitation et où garder droit renvoie à l'action de faire marcher droit le cheval. Dans les deux derniers exemples du CW, il réfère à la droiture morale des 
personnes. Notons les collocations droit et ferme, ferme et droit, droit et fier, droit et vite, droit et bien, droit et résolument, droit et calme ainsi que lentes, droites nobles. Droit peut s'accorder avec le sujet (et dans ce cas-là se rapprocher des prédicats seconds orientés vers le sujet qui désignent une tenue de corps droite ; dernier exemple du CW). Il est modifié par bien, hardiment, pas très, plus, toujours, tout. Au sens directionnel, il a tendance à s'associer avec les prépositions qui le suivent ( $\grave{a}$, dans, devant, en, envers, sur, vers), au point de faire partie du groupe prépositionnel comme modifieur de la préposition.

\section{Marcher dur}

I. Marcher à un rythme soutenu Intransitif

-1502 Menger peust on et marcher dur et mol Pour plus aplain vous en donnet exemple Et si dit on bien souvent cun grant fol Plus q'ung saige ung moult grant sens contemple (Octovien de Saint Gelais et André de La Vigne, Le Vergier d'honneur [1498-1502])

1892 Pendant ce temps, le vicaire marchait dur et se retirait à Saint-Juvat, à l'abri pour l'instant, de ses persécuteurs (Mathurin Emile Fouéré-Macé, Le Prieuré royal de Saint-Magloire de Lehon)

1929 Entre temps, nous avions marché dur, et voilà qu'à travers la chênaie de Cadarache on voyait Marigrate (Jean Giono, Un de Baumugnes)

II. Se vendre facilement

Emploi absolu

1893 Nous étions complètement à sec dans nos montagnes et le charbon marchait dur. Il ne nous restait qu'à souhaiter la baisse du change (Chambre de commerce française de Milan, Bulletin)

III. Avancer bien, à un rythme soutenu Emploi absolu

2000 «Au début ça a été dur, on a vu de l'air. Il fallait crocher dur pour discuter avec le patron. C'était Dupuis (radical) qui était à l'origine de ça, comme premier président, et Duboux. Ça a été difficile, heureuse- ment qu'on a eu le secrétaire Deppen, $\mathrm{N}$. me le rappelait, ça marchait dur avec lui » (Claude Cantini et Jérôme Pedroletti, Histoires infirmières)

REMARQues : Notons l'emploi de crocher dur, marcher mol.

\section{Marcher faux}

Avoir une démarche peu naturelle Intransitif

1959 C'est sans doute la plus mauvaise actrice de l'hémisphère boréal. Elle parle faux, elle marche faux, elle regarde faux (Arts, 30 septembre 1959 / Grundt : 378)

\section{CORPUS WEB :}

« L'argent de poche » a le mérite de rehausser tout les bons films qui utilisent des acteurs non-professionnels. Lorsque l'on voit « Entre les murs », par exemple, on a l'impression que c'est facile. A son corps défendant, le film de Truffaut fait réaliser à quel point cela est faux. Ici certains « acteurs » font jusqu'à marcher faux ! [http:// www.allocine.fr/film/fichefilm-78285/critiques/ spectateurs/recentes/?page=2] (14.7.2015)

Pour illustrer notre "déviance à marcher faux " à cause des chaussures, on peut faire une expérience montrant que nos réflexes fonctionnent, eux, encore comme si on était pied-nus [http://buell.actifforum.com/t37323-activinstinct] (14.7.2015)

Vous êtes persuadés que vous marchez juste, alors que depuis vos premiers pas (à 16 mois) vous marchez faux car vous marchez d'après vos chaussures (munies d'un talon, d'une voûte, trop étroites) et non pas d'après vos propres pieds comme la nature l'a prévu [http://neuroposture. info/fr/conseils/vos-premiers-pas] (14.7.2015)

REMARQUES : En référence au jeu d'acteur, marcher faux se dit d'une démarche, d'une façon de se mouvoir feinte ou simulée qui manque de naturel, soulignant le mauvais jeu de scène. Il est mis en série avec parler faux et regarder faux. Dans les derniers exemples du CW, marcher faux est employé dans un contexte orthopédique lié aux problèmes causés par le fait de porter des chaussures, s'opposant à marcher juste qui réfère à la marche pieds nus. Faux reste invariable. 


\section{Marcher ferme}

I. Marcher d'un pas décidé, résolu, avec assurance

Intransitif

1592 À faute de cette proportion nous gastons tout : et de la sçavoir choisir, et s'y conduire bien mesureement, c'est l'une des plus ardues besongnes que je sçache : et est l'effaict d'une haute ame et bien forte, sçavoir condescendre à ses allures pueriles et les guider. Je marche plus seur et plus ferme à mont qu'à val (Michel de Montaigne, Essais)

1604 Puissiés vous Prince bien heureux marcher tousjours ferme en ce pas glissant, et rencontrer au bout des succés aussi avantageux à vostre memoire qu'il en est deu à vostre merite, afin qu'en vous la vertu ne manque jamais à la fortune, ni la fortune à la vertu (Antoine de Montchrestien, Épistre)

1648 J'en ay beu plus de quatre, et si, quoy que je fasse,

À peine sans broncher je puis changer de place ;

Je chancelle, et je croy que celuy n'est pas fin

Qui pour marcher plus ferme a fait jambes de vin.

Cependant, ô mal-heur ! si je ne prens courage,

Ce grand Coupe-jaret viendra me faire outrage.

Fuyons. Mais je ne puis faire un pas maintenant

(Claude de L'Estoile, L'Intrigue des filous)

1751 Mais, Belford, quelle comparaison entre Sixte-Quint et moi, lorsque, sous la figure du languissant Montalte, il aspiroit au pontificat, sans faire éclater ses intentions ; et qu'au moment qu'il fut choisi, levant le masque, et se dépouillant de toute apparence de foiblesse, il marcha ferme à la vue du conclave étonné ! (abbé Prévost, Lettres angloises [trad.])

1761 et, comme la diarrhée, les clistères, la boisson et la médecine m’ont entièrement affoi- bli, je ne marche pas trop ferme. Le repos et les aliments répareront tout en un moment (Denis Diderot, Lettres à Sophie Volland)

1800 PINTO. ne vous effrayez pas même d'une opiniâtre résistance, et quand vous verrez, là se ruer la cavalerie, là des triples rangs de soldats, ici le canon au débouché des rues ; marchez ferme, jetez-vous, précipitez-vous à travers cette pluie de balles, de mitraille et de feu, vain orage qui ne gronde pas long-temps sur les braves qui le défient (Népomucène Lemercier, Pinto ou La Journée d'une conspiration)

1822 Tu es toi, Adèle, mon but unique, et tous les chemins pour y atteindre me sont bons, pourvu qu'on y puisse marcher droit et ferme, sans ramper sur le ventre et sans courber la tête. C'était là ma pensée quand je te disais que j'aimais beaucoup mieux me créer moi-même en travaillant mes moyens (Victor Hugo, Lettres à la fiancée)

1831 L'humanité en action, en flagrante passion! Je n'en marche pas moins ferme dans ma voie, ripostant à droite et à gauche, avec une étoile pour me conduire, la conscience, et une arme pour me défendre, la parole loyale et sincère (Alphonse de Lamartine, Correspondance générale)

1845 - Tiens, regarde, reprit La-clef-des-cœurs en montrant en tête de la proclamation une grosse vignette, depuis peu de jours, un compas remplaçait le niveau de 1793. Cela veut dire qu'il faudra que, nous autres troupiers, nous marchions ferme!

(Honoré de Balzac, Les Chouans ou La Bretagne en 1799)

1848 Jansénius, Saint-Cyran et Pascal, au contraire, n’ont pas été inconséquents ; ils ne sont pas allés jusqu'au bout, voilà tout ce qu'on peut dire. Mais sur leur chemin ils ont toujours marché ferme et droit ; à un certain moment, tout au bord, ils se sont arrêtés (Charles Sainte-Beuve, Port-Royal)

1894 Elle était contente d'aller libre parmi les choses inconnues. Elle aimait à voir ce paysage de pierres, qu'enveloppait la clarté 
faible et profonde de l'air ; à marcher vite et ferme, le long du quai où les arbres déployaient le tulle noir de leurs branches sur l'horizon roussi par les fumées de la ville (Anatole France, Le Lys rouge)

II. Bouger de manière énergique et rapide Intransitif

1876 - Messieurs, dit-il, c'est un scandale... Et le silence s'étant fait, il continua, de très haut, avec son autorité mordante :

- Je ne veux pas prononcer un second rappel à l'ordre. Je dirai seulement qu'il est vraiment scandaleux d'apporter à cette tribune des menaces qui la déshonorent, résident. Une triple salve d'applaudissements accueillit ces paroles du président. On criait bravo, et les couteaux à papier marchaient ferme, cette fois en manière d'approbation (Émile Zola, Son Excellence Eugène Rougon)

III. Avoir beaucoup de succès

Intransitif

1892 Pour parler moins lyriquement, ça marchait ferme, les gros tirages se multipliaient et les droits d'auteur s'encaissaient avec une précision rothschildienne qui faisait baver de concupiscence toute une jalouse populace d'écrituriers du même acabit qui n'avaient pas eu cette plantureuse idée et qui résolurent aussitôt de s'acharner aux mêmes exploits (Léon Bloy, Le Salut par les Juifs)

\section{CORPUS WEB :}

A ce moment le duel d'artillerie marchait ferme vers Fromelles et a duré jusqu'à minuit [http://home.nordnet.fr/ jdujardin/haubourdin/ g16m08.htm] (14.7.2015)

Il reprit la parole, continua, fila droit devant lui, longeant le port. (Il tenait, marchait ferme vers le bateau, assuré sur les bords). Scotchée, elle dit : « eh ben » [http://academie23.blogspot.fr/2012/ 12/anne-ansquer-une-nouvelle.html] (14.7.2015)

et je me souvins d'un conseil donné par un ami qui avait obtenu de bons résultats en mettant son paquet dans sa boîte à lettres. Je fis de même, cinq étages plus bas. Et bien, cela ne marchait pas. Ou plutôt cela marchait ferme dans l'escalier, petite gymnastique multi quotidienne qui ne manqua pas d'attirer l'attention de ma concierge bien-aimée, véritable cyclotron à potins, laquelle entendait ma démarche précipitée plusieurs étages à l'avance et me regardait d'un œil torve farfouiller dans ma boîte dans l'espoir d'y trouver sans doute un pli urgent [http://ulys.smarttrip.fr/ oeuvre/nouvelles/red-socks] (14.7.2015)

REMARQUES : Marcher ferme (I) se dit du fait de se déplacer avec assurance, suggérant le caractère décidé, déterminé, voire tenace du sujet, celui-ci sachant ce qu'il veut. Au figuré, (II) il réfère au bruit provoqué par le mouvement rapide d'un ou de plusieurs objets que l'on agite, tandis qu'en (III) le sujet désigne un inanimé (une entreprise, une activité) qui a du succès, qui fonctionne bien et par conséquent, rapporte beaucoup d'argent. Notons le grand nombre de collocations destinées à renforcer l'effet sémantique : vite et ferme, (plus) sûr et (plus) ferme, droit et ferme, ferme et droit. Ferme reste invariable dans son emploi adverbial. Il est modifié par pas moins, pas trop, plus, toujours. Notons l'emploi de aller libre.

\section{Marcher fier}

Marcher fièrement, dignement

Intransitif

1526 Adonc veissiez estandars et guidons Getter au vent, sonner fiffres, bedons, Rustres marcher plus fiers qu'estradiotz ; Bastons à feu, serpentines, canons Font ung tel bruit qu'il semble que les montz

Doyvent tomber dessoubz les chariotz (Jean Marot, Le Voyage de Venise)

1829 Est-ce bien vous, vous que je vis si belle Quand tout un peuple, entourant votre char,

Vous saluait du nom de l'immortelle Dont votre main brandissait l'étendard ? De nos respects, de nos cris d'alégresse, De votre gloire et de votre beauté, Vous marchiez fière : oui, vous étiez déesse, Déesse de la liberté (Pierre-Jean de Béranger, Chansons)

1837 « En présence de ces bienveillantes dispositions, messieurs, beaucoup de négociants auraient pu se croire libérés, et ils auraient marché fiers sur la place pu- 
blique. Loin de là, Birotteau, sans se laisser abattre, forma dans sa conscience le projet d'arriver au jour glorieux qui se lève ici pour lui » (Honoré de Balzac, Histoire de la grandeur et de la décadence de César Birotteau)

1840 Elle lui répondit de sa voix grave et douce: - Ami, vous êtes fort. Sûr du Dieu qui vous pousse,

L’œil fixé sur un but, vous marchez droit et fier,

Sans la peur de demain, sans le souci d'hier,

Et rien ne peut troubler, pour votre âme ravie,

La belle vision qui vous cache la vie

(Victor Hugo, Les Rayons et les ombres)

1845 - Ça compose notre hôtel, et il y en a de plus beaux ; mais rassure-toi, les pauvres enfants sont habituées à ne pas être difficiles ; demain matin je partirai avec mon garçon, bras dessus bras dessous, et je te réponds qu'il ne sera pas celui qui marchera le plus droit et le plus fier de nous deux. Nous irons trouver le père du général Simon à la fabrique de M. Hardy pour causer affaires... (Eugène Sue, Le Juif errant)

1848 C'était certainement un des plus gais porte-misère qui fussent au pays de Bohême. Et lorsque dans sa journée il avait fait un mauvais dîner et un bon mot, il marchait plus fier sur le pavé qui souvent faillit lui servir de gîte, plus fier sous son habit noir criant merci par toutes les coutures, qu'un empereur sous la robe de pourpre (Henri Murger, Scènes de la vie de bohème)

$1861 \mathrm{Au}$ bord du nid, battant des ailes, l'oiseau chante en se réveillant, et dit bonjour aux hirondelles qui reviennent de l'Orient. Dans son bel habit du dimanche le chardonneret marche fier, et vole aussi de branche en branche, et jette sa chanson dans l'air (Henri Murger, Les Nuits d'hiver)

1869 Et toi, la mère universelle ;

Toi, la nourrice aux larges flancs,
Dont le lait pur à flots ruisselle

Du haut des cieux étincelants ;

Toi, qui marches fière et sans voiles

Sur les cultes abandonnés,

Et, par pitié, dans tes étoiles

Caches les dieux découronnés

(Louis Bouilhet, Dernières chansons)

1890 Voilà pourquoi l'homme sincère se passionne si fort et s'épuise en adorations devant la vie naïve, devant l'enfant qui croit et sourit à toute chose, devant la jeune fille qui ne sait pas qu'elle est belle, devant l'oiseau qui chante sur la branche uniquement pour chanter, devant la poule qui marche fière au milieu de ses petits (Ernest Renan, L'Avenir de la science)

\section{CORPUS WEB :}

Je veux marcher fier et libre dans mon pays (et seul si possible dans les rues du XVIII ${ }^{\circ}$, même le vendredi, sans avoir de comptes à rendre !) [http://www.enquete-debat.fr/archives/contrela-societe-de-lindignation] (14.7.2015)

Alors je me rappel, que, la vie est faites d'épreuves et de souffrance, mais qu'aucune d'entre elle n'est insurmontable et que si elles sont là, c'est pour nous faire évoluer et vivre, pour nous donner l'occasion de nous surpasser, de nous prouver qu'on peut tout surmonter, et enfin marcher fier et la tête haute [http:// jeunessesansdrogue.xooit.fr/t422-FLORiAN. htm?start=45] (14.7.2015)

Mais ne fait pas attention, et marche fier, car toi tu es motivée et determinée, tu mènes ton propre combat, pendant qu'eux en glande pas une ;) [http://forum.doctissimo.fr/nutrition/ alimentation-sante/perdu-kilos-jours-sujet_ 159816_1.htm] (15.7.2015)

Enceinte, elle marche fière et lente [http:// www.la-joie-des-hommes-libres.com/article18406908.html] (14.7.2015)

REMARQues : Marcher fier se dit du fait de se déplacer, souvent au milieu d'une foule ou parmi plusieurs personnes, la démarche traduisant le caractère digne, noble du sujet qui cherche à se faire respecter d'autrui. Fier s'accorde assez systématiquement avec le sujet, fonctionnant donc comme prédicat second orienté vers le sujet. Seul 
l'avant-dernier exemple du CW reste non accordé Fier est modifié par plus, le plus. Notons les collocations droit et fier, fier et libre, fier et lent. Mentionnons également l'emploi de se passionner fort.

\section{Marcher fort}

I. Marcher d'un pas décidé, résolu, avec assurance Intransitif

1498 Aprés doncques cinq ou six jours passez, Lundy suyvant du moys dixseptïesme, Quant il eult tous ses mignons amassez Devers Florence il marcha fort et ferme (Andrieu de la Vigne, Le Voyage de Naples, p. 207, 2855)

1846 Il est donc prouvé à tout philosophe, tant soit peu calculateur, qu'il existe en France une masse flottante de trois millions d'hommes âgés de dix-sept ans au moins, de cinquante-deux ans au plus, tous bien vivants, bien endentés, bien décidés à mordre, mordant et ne demandant qu'à marcher fort et ferme dans le chemin du paradis (Honoré de Balzac, Physiologie du mariage)

II. Poser le pied (sur quelqu'un) avec force Intransitif

1538 Cest au jardin : mon peze entry, D'avantuze me rencontry, Auprès de vous, et sy avoy Touriou l'yeu dessu vostre voy, Laquelle me sembly depui Aussi claize que l'iau de puy, May se Piar nou regardet, Qui de gran jalourie ardet ; Et quan il m'eu bien espié Vou me marchiste sur le pié Si fort, en me sarran la main, Que j'en clochy le lendemain (Clément Marot, Épitres)

III. Avoir du succès

Intransitif

1964 On voit des tee-shirt de l'année dernière, et aussi le maillot de filet de pêcheur qui " marche fort » (France-Soir, 21 juillet 1964 / Grundt : 246)

\section{CORPuS WEB :}

Très belles photos, ça devrait marcher fort [https://www.facebook.com/locationduduhome/ posts/821274164562212] (15.7.2015)

Cinq raisons pour lesquelles le jeu vidéo «Batman: Arkham City» va marcher fort » [http:// www.20minutes.fr/high-tech/808982-20111019cinq-raisons-lesquelles-jeu-video-batmanarkham-city-va-marcher-fort] (15.7.2015)

Elle marche fort cette katoche! Après env $200 \mathrm{~km}$ je regrette pas du tout ! Merci bertrand pour cette moto [https://ar-ar.facebook.com/ TestUpMoto/posts/515920908476728] (15.7.2015)

Je met en vente ma dirt bike qui est en très bon état elle marche forte aucun problème [http:// www.leboncoin.fr/motos/817785796.htm] (15.7.2015)

REMARQUeS : Employé dans la collocation fort et ferme, (I) souligne le caractère décidé et l'assurance avec laquelle le sujet se déplace. Il se dit également du fait de marcher sur le pied de quelqu'un, en appuyant fort (II). Dans son emploi abstrait (III), le sujet désigne très souvent un inanimé (ici : un nouveau produit récemment apparu sur le marché), qui a du succès, qui fonctionne bien et par conséquent, rapporte beaucoup d'argent. Fort reste invariable dans la majorité des cas. Toutefois, il s'accorde avec le sujet dans le dernier exemple du CW. Il est modifié par si.

\section{Marcher franc}

I. Marcher en homme libre

Intransitif

1651 Or celuy qui desire de marcher franc et libre avec moy, faut qu'il mortifie toutes les mauvaises et desordonnées affections (Thomas a Kempis, L'Imitation de JésusChrist)

II. Marcher sans contrainte, sans souci, d'un pas assuré Intransitif

1883 Cette fois il la regarda mieux et la trouva vieille : il est certain qu'avec son chapeau de Paris, sa robe trop serrée, à traine trop longue, carguée trop court et dodelinant derrière elle, ses hauts talons qui l'empêchaient de marcher franc, l'ombrelle 
qu'elle ne savait pas tenir [...] Mariannine ressemblait à quelque sous-préfète du Principat ultérieur qui serait venue à faire des emplettes à Naples (Marc Monnier, Un détraqué)

1970 Des pierres dégringolent de là-haut à chaque instant. Je vais en tête. Tu verras mon fanal ; je te ferai signe et écoute mes coups de sifflet. Marche franc; ne t'inquiète pas, je suis en tête (Jean Giono, L'Iris de Suse)

REMARQUES : Marcher franc et libre (I) est une prédication seconde à sujet intérieur qui réfère à la liberté individuelle de la personne, au fait de ne pas dépendre d'un seigneur. L'emploi abstrait sous (II) actualise une fonction adverbiale à dominante circonstancielle qui renvoie au fait de marcher d'un pas assuré (ex. de 1883) ou sans souci (ex. de 1970). Notons l'emploi de carguer court.

\section{Marcher gros}

I. Marcher pesamment, sans souplesse, d'une manière lourde, pesante

Intransitif

1956 Sous des plafonds décorés de fausses perspectives montant jusqu'à des nuages (garnis d'angelots), devant des murs où des stucs coloriés étalaient des frises de négrillons à une hauteur assez impressionnante, il marchait gros et vêtu de noir, la canne en main, coiffé d'une sorte de chéchia (André Pieyre de Mandiargues, Le Lis de mer)

II. Avoir beaucoup de succès

Intransitif

1957 À ce moment-là sa maison [d'édition] marchait gros (Exemple entendu, 7 juillet 1957 / Grundt : 399)

CORPUS WEB :

Definition d'un drag de campagne :

Stock : si y voit rien c'est stock

Amélioré : si on en voit un peu, c'est amélioré

Improve : quand ca a d'l'air de marcher gros, c'est improve... [http://www.motoneigeau quebec.com/forum/archive/index.php/t-3521. html] (15.7.2015) la vague à laquelle je pense, et je pense que wilbur parle de la même, est assez longue et creuse. La lèvre jette bien jusqu'en bas, et vu du bord je dirais qu'elle ouvre sur une bonne centaine de mètres. Le problème c'est qu'elle est loin $\mathrm{du}$ bord, en pleine eau, donc line up difficile, et quand elle marche gros c'est généralement accompagné de vent de SW modéré voire plus rendant le placement encore plus difficile [http://www. bzhecume.com/surflog/read.php?6,72530,72622] (15.7.2015)

REMARQUeS : Marcher gros (I) souligne une démarche pesante, un pas lourd et suggère le manque de finesse du promeneur. Dans son emploi figuré (II), le sujet désigne un inanimé (une entreprise, une affaire) qui a du succès, qui fonctionne bien et par conséquent, rapporte beaucoup d'argent (v. gagner gros, rapporter gros). Le dernier exemple du CW reprend l'argot du surf où marcher gros réfère à l'allure d'une vague énorme. Gros reste invariable (v. ex. de 1957 et le dernier exemple du CW).

\section{Marcher impeccable (impec)}

Fonctionner parfaitement

Intransitif

1969 Christiane, le voyant s'approcher, sortit du bureau pour aller à sa rencontre.

- Tout marche impeccable, annonça-t-elle (Jacques Risser, Le Bon Fade)

1976 Au moins comme ça, aucun problème. Mes collègues en ont plein. Mes supérieurs s'en foutent, ma compagnie marche impec' (Politique aujourd'hui)

2008 " 'I' m'ont dit au garage qu'I' venaient de le faire tourner. » Ils savent tous deux qu'on ne peut jamais compter sur 'I'. Au téléphone, le moteur marche impeccable, everything Okay, I z'ont dit (Benoîte Groult, Mon évasion)

REMARQUES : Marcher impeccable (impec) signifie 'fonctionner parfaitement'. La combinaison "verbe + impec(cable) » constitue une série ouverte dont nous ne citons que quelques variantes. 


\section{Marcher juste}

Marcher correctement

$\lambda$ marcher faux

\section{Marcher large}

Marcher les jambes ou les genoux écartés Intransitif

1389 Mes, s’il met le pié darriere loing de celui devant, c'est bon signe, ou, s'il marche plus large darriere que devant, encore est ce bon signe, quar, quant un cerf s'outremarche, c'est signe qu'il soit cerf errant, legier et bien fuyant et megre, quar, s’il avoit gros et gras costés et flans, il ne se pourroit outremarcher ne surmarcher, et par le contraire si feroit (Gaston Phébus, Livre de chasse, p. 165, 10)

1955 C'est de race que les Joliclerc « marchent large », mais moi j'en peux remercier la nature. J'étais perdu sans cette conformation. Un boulet, qui a tué le camarade qui était derrière moi, a passé entre mes cuisses et n'a fait que me meurtrir un peu légèrement les deux cuisses auprès des genoux (Jean Duché, L'Histoire de France racontée à Juliette)

CORPUS Web :

Lorsque la jument ne faisait pas d'épaule en dedans, quelle marchait droit, elle demandait quand même que le cheval ait le bout du nez à l'intérieur...lorsqu'il marchait large... [http://www. chevalannonce.com/forums-1314537-dressagedes-methodes-differentes] (15.7.2015)

Et pendant la séance, elle se reposait trop sur le moniteur, elle ne prenait aucune initiative (par exemple doubler pour faire un appuyer), il fallait que le moniteur lui dise tout sinon elle marchait large autour du manège... [http://www. chevalannonce.com/forums-4735759-quel-livrede-dressage-pour-se-faire-plaisir?p=2] (15.7.2015)

Dans cette épreuve les concurrentes marchent large toutes ensembles aux deux mains et aux trois allures. Les juges sont au milieu de la carrière et font leurs premières observations. Ce sont eux qui donnent les indications à suivre pour cet examen d'ensemble : trot, galop, changement de main [http://amazones.forumactif.fr/ t3748p45-addington2010] (15.7.2015)
REMARQUES : Marcher large réfère au mouvement ou à l'écart important entre les jambes d'une personne ou d'un animal lorsqu'ils se déplacent. Marcher large est usuel dans le langage de l'équitation, où il renvoie au fait qu'on permet au cheval de s'écarter de la ligne la plus directe, laissant donc une certaine marge pour arriver au but. Large reste invariable (v. le dernier exemple $\mathrm{du}$ CW) et est modifié par plus. Notons l'emploi de marcher droit.

\section{Marcher léger}

Marcher avec légèreté, avec insouciance et plaisir, la conscience tranquille

Intransitif

1765 On déchirera un ou deux billets que j'ai signés, et l'on m'accordera quatorze cent vingt-huit livres pour un dernier volume que je n’ai pas cédé ; toutes mes dettes seront acquittées, et je marcherai sur la terre léger comme une plume (Denis Diderot, Lettres à Sophie Volland)

1838 Il ne put l'arracher, trop faible, de la terre Où sa fureur cherchait une mort volontaire :

En allant quêter seul au loin la goutte d'eau,

En marchant plus léger sans son triple

fardeau,

Il espéra trouver la source poursuivie, Et devancer la mort en rapportant la vie (Alphonse de Lamartine, La Chute d'un ange)

1948 Amour viens sur ma bouche! Amour ouvre tes portes! Traverse les couloirs, descends, marche léger, vole dans l'escalier plus souple qu'un berger, plus soutenu par l'air qu'un vol de feuilles mortes (Jean Genet, Poèmes)

\section{CORPUS WeB :}

Gaucher, le fidèle, silencieux, comme souvent, portait un lourd épieu, précaution necessaire si d'aventure ils venaient à croiser un sanglier. Condat, à l'inverse, marchait léger [http://lesfiefs.forumactif.com/t189-chasse-dautomne] (15.7.2015)

Elle avait 6 mois, pesait 3 livres. En quelques mois elle atteignit 7 kilos mais « marchait léger » 
[http://www.linternaute.com/nature-animaux/ temoignage/temoignage/82590/venus-madeesse/] (15.7.2015)

Elle marchait légère comme une plume, avait un appétit d'oiseau, faisait preuve d'une grande distinction [http://ecrireagentilly.blogspot.co.at/ 2011/12/noms-doiseaux.html] (15.7.2015)

REMARQUES : Marcher léger se dit du fait de se déplacer de manière tranquille, d'un pas léger, sans agitation, sans sentir l'effort, soulignant l'état d'esprit serein du sujet. Au figuré, il souligne le fait d'avancer dans la vie, de franchir les étapes ou de faire face aux difficultés de la vie de façon plus sereine, en étant débarrassé de toute préoccupation, le sujet se sentant heureux. Léger reste invariable dans la majorité des cas (v. le second exemple du CW), mais, dans le troisième exemple $\mathrm{du} \mathrm{CW}$, il fonctionne comme prédicat second qui s'accorde avec le sujet. Léger est modifié par plus. Notons la comparaison léger comme une plume.

\section{Marcher lent}

Marcher lentement, avec lenteur

Intransitif

1859 Portant Mahaud, qui dort toujours, Ils marchent lents, courbés, en silence, à pas sourds,

Zéno tourné vers l'ombre et Joss vers la lumière

(Victor Hugo, La Légende des siècles)

1861 D'autres, comme des sœurs, marchent lentes et graves

À travers les rochers pleins d'apparitions, Où saint Antoine a vu surgir comme des laves

Les seins nus et pourprés de ses tentations (Charles Baudelaire, Les Fleurs du mal)

1890 Et, aussitôt cette porte franchie, tout change d'aspect brusquement, comme si on était là dans un autre pays où, sans transition, on aurait été jeté. Au lieu de l'immobilité et du silence, un grouillement compact ; au lieu des hommes bruns, qui marchaient lents et majestueux, drapés dans des laines blanches, ici, des hommes pâles ou rosés, en longues papillotes et coiffés de calottes noires, qui vont tête basse, étriqués dans des robes sombres (Pierre Loti, Au Maroc)
1895 Dans leurs vêtements des âges passés, elles marchent lentes, droites, nobles, - et, avec cela, très naïvement jolies, toutes, sous la blancheur de ces voiles qui accentuent une étrange ressemblance, quand surtout elles tiennent sur l'épaule un petit enfant : on croit, à chaque tournant des vieilles rues sombres, voir apparaître la Vierge Marie (Pierre Loti, Jérusalem)

\section{CORPUS WEB :}

pour l'annecdote, j'avais installé jaguar sur mon bondi blue avec 96 Mo et cela marchait ! (lent, mais cela marchait)... [http://forums.macg. co/threads/e-mac-ou-i-mac.57109/] (15.7.2015)

Je ne pouvais pas marcher vite, parce que lui, il marchait lent comme une tortue. Il regardait tout ce qu'il y avait autour de lui [http://louiswilliam-tomlinsonn.skyrock.com/3125329297Chapitre-28.html] (15.7.2015)

J'ai apercu une madame qui s'en venait vers nous et qui marchait lent. Très lent. Comme les meurtriers dans les films d'horreur ! [http:// toffu-x.deviantart.com/journal/] (15.7.2015)

Enceinte, elle marche fière et lente [http:// www.la-joie-des-hommes-libres.com/article18406908.html] (14.7.2015)

REMARQUES : Marcher lent se dit du fait de se déplacer, d'avancer à une vitesse limitée, réduite, le sujet manquant de rapidité dans ses mouvements, ce qui peut traduire une certaine mollesse, un manque d'activité physique, la vieillesse, mais aussi une attitude de recueillement. Notons les collocations lent et majestueux, fier et lent, lent et grave. Lent s'accorde avec le sujet dans la majorité des cas, permettant une interprétation de prédicat second orienté vers le sujet. Toutefois, il reste invariable dans le troisième exemple du CW. Lent est modifié par tout, très.

\section{Marcher mou (mol)}

Marcher avec mollesse, avec indolence Intransitif

-1502 Menger peust on et marcher dur et mol Pour plus aplain vous en donnet exemple Et si dit on bien souvent cun grant fol Plus q'ung saige ung moult grant sens contemple (Octovien de Saint Gelais et André de La Vigne, Le Vergier d'honneur [1498-1502]) 
1881 Il m'accueille singulièrement ; il me fait sentir qu'il n'est pas libre de recevoir qui il veut : il parle bas et marche mou (Jules Vallès, Jacques Vingtras : Le Bachelier)

\section{CORPUS WEB :}

Il marchait mou, la tête ailleurs, le teint malade. Les seuls sons qui sortaient de sa bouche étaient des soupirs à vous arracher le cœur, des soupirs de désespoir qui créaient une atmosphère insoutenable [http://myrtylle.deviantart. com/art/Derobe-17626193] (15.7.2015)

- Capitaine : Et puis, des commentaires ?

- Flavien : Non non non non... C'est juste que vous marchez mou... Mais tant qu'à ça moi aussi je marche mou hein... [http://dug.slgraph. net/phrases.php] (15.7.2015)

REMARQUES : Marcher mou (ou mol, dans l'ancienne langue) se dit du fait de se déplacer, d'avancer sans énergie, sans vigueur ni fermeté, ce qui exprime une gêne, un certain malaise de la part du sujet. Notons l'emploi de marcher dur.

\section{Marcher pesant}

Marcher d'une manière pesante, lourde, qui manque d'agilité ou de légèreté

Intransitif

1964 Mon Dieu, écoute ça là-haut, comme elle marche pesant (Exemple entendu, 5 juin 1964 / Grundt : 257)

CORpus Web :

Hinata et lui marchèrent pesant vingt minutes avant de se séparer à une intersection [http://the-vampire-hina.skyrock.com/322373602 3-Rencontre.html] (15.7.2015)

J'avais 5 femelles dans mes pommes et un beau 8 pointes a passé a coté de moi a 20 metres, mais du bord opposé que je tire je suis gaucher. Je l'avais entendu marcher, mais y en avais un qui $s$ en venait aux pommes (je ne le voyais pas) qui marchait pesant [http://www.chevreuil.net/ forums/viewtopic.php?f=2\&t=1006\&sid $=9492$ aab1e8ee5fdbf6599a6a38980d83\&view=print] (15.7.2015)

REMARQUeS : Marcher pesant se dit du fait de se déplacer, d'avancer sans énergie, sans vigueur ni fermeté, sans souplesse, avec lourdeur. Dans le dernier exemple du CW, il est employé dans l'argot de la vènerie pour désigner un cerf (ici : un chevreuil) dont les pieds s'enfoncent profondément dans le sol. Pesant reste invariable.

\section{Marcher raide}

Marcher avec raideur, sans souplesse

$\pi$ chausser étroit

\section{Marcher rapide}

I. Marcher rapidement, vivement Intransitif

1839 tu as rêvé le laurier du martyre. C'est pour de telles choses et non pour d'autres que tu marches seul et rapide dans la nuit froide et silencieuse... ne me réponds pas, Edméo, ajouta Sténio en voyant que son ami cherchait à éluder ses questions (George Sand, Lélia)

1847 L'arc d'ivoire à la main et les yeux animés, Excitant de la voix ses lévriers aimés, Et parfois confiant aux échos des montagnes

Les noms mélodieux de ses belles compagnes,

Elle marchait rapide, et sa robe de lin Par une agrafe d'or à son genou divin Se nouait ; et les bois, respectant la déesse, S'écartaient au-devant de sa mâle vitesse (Charles-Marie Leconte de Lisle, Poèmes antiques : Khiron)

1869 Dès qu'il sortait de l'eau, ses guenilles mouillées étaient tout de suite gelées par le froid profond de la nuit. Il marchait rapide dans ses vêtements roidis (Victor Hugo, L'Homme qui rit)

II. Évoluer rapidement

Intransitif

1893 Puis, il alla ouvrir un tiroir de sa table, et il y jeta la clef, comme autrefois. Dès lors, il retrouva des forces, la convalescence marcha plus rapide. Des rechutes étaient possibles encore, car il restait bien ébranlé. Mais il put écrire, les journées furent moins lourdes (Émile Zola, Le Docteur Pascal) 


\section{CORPus WeB :}

Elle marchait, rapide, dans le matin clair, arpentant le trottoir, traversant à grand pas les avenues en relevant d'une main légère une mèche de cheveux rebelles qui lui tombait sur les yeux [http://blogs.mediapart.fr/blog/juliettekeating/260413/aime-ton-prochain-comme-toimemeb] (15.7.2015)

En rênes longues, elle marchait rapide mais elle marchait. Et au galop, au taquet bien sûr ! [http://blog.chevalmag.com/index.php/nooz blog/2012/04/23/beaucoup-de-participants-duclub-au-cce-] (15.7.2015)

On a fait environ ... je dirais $2 \mathrm{~km}$ en exactement $30 \mathrm{~min}$. Rendue a la fin je devais faire du jogging pour etre capable de tenir leur rythme (qui soit dit en passant elles marchaient rapide ... mais marchaient !!) [https://chouchoune.wordpress. com/2007/06/13/] (15.7.2015)

Merci pour cette proposition, ils marchaient rapides pour des zombies, c'était pas évident [https://www.flickr.com/photos/kimparis/157415 02595] (16.7.2015)

REMARQUES : Marcher rapide (I) se dit du fait de se déplacer, de se mouvoir à une vitesse appréciable, en parcourant beaucoup d'espace en peu de temps. (II) désigne le fait d'évoluer d'un état vers un autre, le changement se produisant de façon rapide. Notons la collocation marcher seul et rapide. Rapide reste invarié dans l'avant-dernier exemple du CW, mais il s'accorde dans le dernier exemple en gardant son interprétation d'adverbe de manière. Rapide est modifié par plus.

\section{Marcher sec}

I. Marcher vivement, de manière décidée, voire rudement et sans souplesse

Intransitif

1884 C'était une Anglaise assez grande, un peu maigre, l'anglaise audacieuse dont les voyages et les circonstances ont fait une espèce d'homme. Pas mal d'ailleurs, marchant sec, d'un pas court, vêtue simplement, sobrement, mais coiffée d'une façon drôle, comme elles se coiffent toutes (Guy de Maupassant, Contes et nouvelles)

1934 ce sont ses propres termes et je cite sans commentaire, " qu'elle serrait les fesses et qu'elle était constipée ». Là-dessus, mon père se mit lui-même en campagne, marchant sec et parlant haut. Il découvrit, après deux heures de recherches rondement menées, la maison, notre maison, celle de la rue du Moulin (Georges Duhamel, Vue de la terre promise)

II. Fonctionner avec rapidité et efficacité, à fond Intransitif

1904 RICHARD. Et le cuisinier donc !... Il est là pour ça. Et puis moi ; moi, j'ai l'œil sur la maison, parfaitement, entre deux affaires de Bourse... Et il faut que ça marche sec... C'est moi qui flanque les domestiques dehors (Henry Bataille, Maman Colibri)

\section{CORPUS WEB :}

J'ajoute que ce n'est pas nouveau, nos ancêtres les romains, peut-être les gaulois, les mérovingiens, et jusqu'au moyen âge portaient des «bandes molletières »... C'est que ça marchait sec à ces époques dans la piétaille [http://pages1418.mesdiscussions.net/pages1418/forum-pageshistoire/bandes-molletieres-sujet_4113_1.htm] (16.7.2015)

En fait, la console s'allumait a froid... mais aucun affichage. Une fois chaude, ca beigne... ca marchait sec. Sinon, ca fesait du bruit, oui j'insiste... (c'estpaslelecteurDVDqu'onentend... mais les turbines du processeur) [http://www.game kyo.com/blog_article192554.html] (16.7.2015)

Puis revendue car consommation importante à... un préparateur de rally... Le mec a détecté tout de suite lors de l'essai qu'elle marchait sec à côté d'une s16 full stock [http://www. forum-auto.com/les-clubs/le-bistrot/sujet394106 $-58135 . h t m](16.7 .2015)$

Comment tu fait donc pour armer la pompe sans qu'elle marche sèche trop long temps (la pression du réseau d'eau aide!)? [http://expresso. cultureforum.net/t5167p10-decouvertre-de-mala-cimbali-junior-photos] (16.7.2015)

REMARQUes : Marcher sec (I) réfère à une démarche vive, rapide, traduisant la hâte, voire une certaine agitation. (II) se dit du fait de bien fonctionner, les choses se déroulant rapidement, parfaitement, sans obstacles, avec rigueur et fermeté. Sec reste invariable dans son emploi 
adverbial. Dans le dernier exemple du CW, il est employé au sens concret et se dit d'une pompe fonctionnant sans que l'eau passe. Il s'agit donc d'un prédicat second qui s'accorde avec le sujet.

\section{Marcher serein}

Marcher paisiblement, l'esprit libre

$\lambda$ marcher calme

\section{Marcher serré}

I. Marcher, avancer en un groupe compact, dense

Intransitif

1593 Il fallut retourner par le mesme endroit d'où il avoyt faict la charge ; il passa derechef par dessus le ventre à ce qui estoit sur le bord ; il se feist jour, revint vers sa troupe en despit de ce gros de cavallerie ; il faict ferme vis à vis d'eux du costé de ce passage et retire tout ce qui estoit du costé de l'armée, à la barbe de l'ennemie qui estoit en bataille, bien rengée, estimant qu'on les voussit attirer à un combat pour en déchirer une pièce, en cet endroit où l'advantage du lieu estoyt pour nous. L'ennemy marche serré et suit son chemin (René de Lucinge, Dialogue du François et du Savoysien)

1729 M. d'Humieres, quoiqu'il ait marché aussi serré qu'il a pû, a perdu deux cent quarante Cavaliers, qui sont prisonniers à Mons, pour s'être écartez tantôt les uns, tantôt les autres (Paul Pellisson, Lettres historiques)

1734 Aëtius qui avoit jugé à propos de suivre les Huns, soit pour leur ôter l'envie de faire quelque nouvelle entreprise, dont le succès les eût dispensés de sortir des Gaules, soit pour les empêcher, en les obligeant à marcher serrés, de courir les païs qui se trouveroient à la droite et à la gauche de leur route, les atteignit peut-être sans le vouloir, dans les champs catalauniques ou mauriciens (Jean-Baptiste Dubos, Histoire critique de l'établissement de la monarchie françoise)

1763 Un pont, placé sur le haut de l'édifice qu'ils ont construit, et qui doit s'abattre au moment destiné pour donner l'assaut, doit leur aplanir les difficultés de l'entreprise. Un degré vaste et commode, pratiqué dans le flanc de la machine, les conduira jusque sur la plate-forme qui la couronne ; et leur colonne, qui marchera serrée, doit se présenter à l'attaque sur vingt de front (Jacques Cazotte, Ollivier)

1835 Aucun de nous ne fut frappé ; mes jeunes étalons arabes qu'on menait en main semblaient pétrifiés de terreur ; ils s'arrêtaient court, levaient les naseaux, et jetaient, non pas des hennissements, mais des cris gutturaux semblables à des râlements humains ; nous marchions serrés, pour nous surveiller et nous assister en cas d'accident (Alphonse de Lamartine, Souvenirs, impressions, pensées et paysages pendant un voyage en Orient)

1936 Pendant les rares minutes de lucidité qui alternent avec ces longs moments d'inconscience ou de cauchemar, il se répète, sans interruption : «Courage... courage...» Par instants, les hommes marchent si serrés auprès du brancard, qu'il ne voit plus rien que ces torses oscillants, et ces canons de fusils, et l'air qui tremble entre lui et le ciel (Roger Martin du Gard, Les Thibault. L'Été 1914)

II. Agir avec prudence, avec réserve

Intransitif

1756 Je crains que l'annonce de la préface de la Henriade ne déplaise à l'auguste auteur qui m'honore souvent de son souvenir. Entre les rois et les prêtres il faut marcher un peu serré. Il y a dans cet avis une faute qui donne une idée peu avantageuse de l'exactitude de votre presse. Vous avez mis « on peu » pour « ont pu» (Voltaire, Lettres à son imprimeur)

III. Marcher en maintenant les jambes serrées Intransitif

1946 Elle devait être de ces femmes qui marchent très serré et qui ont l'entre-cuisse si tiède. Le mari suivait, important et poli. À cet instant, la rampe s'alluma. Les trois coups retentirent. Le silence se fit (Raymond Guérin, L’Apprenti) 


\section{CORPUS WEB :}

Les élèves marchaient serré sur un étroit chemin escarpé. Ils débouchèrent bientôt sur la rive d'un lac noir [http://harrypotter-futur. forumsactifs.com/t3780-circonvolutions-etbaguettes-magiques-1-histoire-d-abigael-owenen-cours-5-23] (16.7.2015)

Harry cru reconnaître deux des six élèves qui venaient s'aventurer par ici : Ginny et Dean. Ils se tenaient la main et marchaient serré l'un contre l'autre [https://www.fanfiction.net/s/24058 66/19/Harry-Potter-le-R\%C3\%A8gne-des-Anc\% C3\%AAtres] (16.7.2015)

Lors de mon précédent voyage ici, au sudouest de l'Afrique, un jeune Namibien m'avait demandé s'il était vrai qu'en Hollande, des gens marchaient serrés sur des trottoirs [http:// cercleiffel.fr/spip.php?article69] (16.7.2015)

REMARQUES : Marcher serré (I) se dit du fait de se déplacer en groupe, de manière rapprochée, serrée, le sujet désignant un groupe de personnes. En (II), le sujet désigne un animé qui, au contact de personnes appartenant à un rang social ou à un ordre hiérarchique supérieur, reste sur ses gardes, adopte une attitude de retrait, prend garde à ce qu'il dit ou fait. (III) réfère au mouvement des jambes ou des cuisses (ici : d'une femme) lorsque la personne se déplace, et qui, en marchant, sont très proches l'une de l'autre, se frottent presque. Serré peut s'accorder avec le sujet et se rapprocher des prédicats seconds orientés vers le sujet. Toutefois, dans l'exemple de 1946 et dans les deux premiers exemples du CW, il reste invariable. Il est modifié par aussi, si, très, un peu. Notons l'emploi de faire ferme, s'arrêter court.

\section{Marcher seul}

Marcher sans compagnie, en solitaire $\lambda$ marcher rapide

\section{Marcher sûr}

Agir avec assurance, avec confiance Intransitif

1592 À faute de cette proportion nous gastons tout : et de la sçavoir choisir, et s'y conduire bien mesureement, c'est l'une des plus ardues besongnes que je sçache : et est l'effaict d'une haute ame et bien forte, sçavoir condescendre à ses allures pueriles et les guider. Je marche plus seur et plus ferme à mont qu'à val (Michel de Montaigne, Essais)

\section{CORPus WEB :}

Et encore faut qui aient les couilles d'aller juska se battre. Des gars i se sont jms battus a 18 pij, i poussent 6 mois a la salle tu les vois dans la rue i marchent sur d'eux i regardent les gens dans les yeux énervés :D [http://www.jeuxvideo.com/ forums/1-50-172281132-2-0-1-0-faire-de-la-muscucomplexe.htm] (16.7.2015)

Les trois amis marchaient, sûr d'eux, prêt à tout pour découvrir la vérité ! [http://polo2907. skyrock.com/5.html] (16.7.2015)

Viennent ensuite les soldats, qui paraissent si tranquilles. Cachés par leurs casques, ils marchent, sûrs d'eux [http://www.college-madame desevigne-mauron.ac-rennes.fr/spip.php?article 937] (16.7.2015)

La jeune femme marchait, sûre de son effet, sac à main au bras et bonnet vissé sur la tête [http://www.voici.fr/news-people/photosstar/look-nicky-hilton-dans-les-rues-de-losangeles-432513] (16.7.2015)

REMARQUES : Marcher sûr se dit du fait de se déplacer avec assurance et, au figuré, d'agir avec assurance. La variante syntaxique marcher sûr de soi, fréquente en français moderne, suggère le caractère décidé, déterminé, tenace du sujet, celui-ci sachant ce qu'il veut. Notons la collocation marcher sûr et ferme. Les exemples du CW montrent que les emplois accordés et invariés existent côte à côté. Sûr est modifié par plus.

\section{Marcher tendre}

Marcher avec douceur, avec grâce, avec charme Intransitif

1821 Il marche fier et tendre parmi les belles comme un lion apprivoisé qui cherche à oublier dans les plaisirs d'une heureuse et facile servitude le regret de ses déserts (Charles Nodier, Smarra ou Les Démons de la nuit)

1872 Elle s'était décolletée avec un tel mépris des regards, elle marchait si calme et si tendre dans sa nudité, que cela n'était presque plus indécent (Émile Zola, La Curée) 
REMARQUES : Marcher tendre se dit du fait de se déplacer de manière délicate, sans agitation, qui suggère la douceur des mouvements ou du pas. Notons les collocations marcher fier et tendre, marcher calme et tendre. Tendre est modifié par si. L'absence d'exemples informels dans le CW montre l'appartenance de marcher tendre au style littéraire.

\section{Marcher terrible}

I. Marcher d'une manière triste, désolante, navrante

Intransitif

1877 Cette femme, après tout, était-elle sa mère? Oui. Non. Ceux qui mêlaient autour d'elles leurs pas

En parlaient au hasard et ne le savaient pas. L'infortune est de l'ombre, et peut-être cet ange

N'avait-il même pas une mère de fange, Hélas ! Et l'humble enfant, seul sous le firmament,

Marchait terrible avec un air d'étonnement. Elle ne paraissait ni vivante ni morte (Victor Hugo, La Légende des siècles)

II. Avoir beaucoup de succès Intransitif

1957 En ce moment, je marche terrible ; on est obligé de m’arrêter (Radiodiffusion-Télévision Française, 8 mars 1957 / J. Giraud)

1972 C'était pas fini son cirque ! Fallait encore qu'elle nous emmène dans la salle des postiches ! Paraît que ça marche terrible, la perruque asiatique, dans toutes ces résidences. Perruque et Polaroïd, les loisirs qui montent ! (Bertrand Blier, Les Valseuses)

\section{CORPUS WEB :}

Moi j ai un $6900 \mathrm{kv}$ dans mon b44 qui est 1 equivalent a un 6.5t pis faut je check mais temp beaucoup car ya envie de chauffer rapidement... Un 3.5 equivaut a $10500 \mathrm{kv}$ sa doit marcher terrible mais sa doit chauffer terrible aussi !!!! [http:// www.lemordudurc.com/forum/viewtopic.php? $\mathrm{f}=42 \& \mathrm{t}=2069$ ] (23.5.2014)

j'ai reçu mes atos concorde ils se sont trompés en m'envoyant des onyx au lieux des titanes et par chance elles marchent terrible même a la cartouche. alors la question est est-ce que les titanes seraient de moins bonne qualité ??? [http://www.forum-ecigarette.com/problemes-dutilisations-questions-et-conseils-f25/problemeconcorde-t3130-30.html] (16.7.2015)

Perso, j'ai des enceintes acoustics Energy AEVO 3 (compte $600 €$ la paire) qui marchent terrible! [http://www.illel.fr/forum/message.asp?id message $=8107](16.7 .2015)$

Mon RS marche pas terrible [https://forum. 2temps.fr/viewtopic.php?t=652] (2.5.2007)

Ça ne marche pas terrible. J'ai vu plein de Covid + toute la journée en consultation [https:// twitter.com/dr_stephane/status/13215864891013 24290?lang=bg] (28.10.2020)

Salut, $\mathrm{j}$ ai suivi tes conseils sur mon rsst acquis chez notre ami d espace vap et ses conseils pour mon A8 version2,lol,et bien $\mathrm{j}$ ai deux superbe atos qui marchent terribles [https://www. youtube.com/all_comments?v=tIMHwgcJlNc\&lc =iaK2E3n_tE9FLkNkpu_1M23zfigEM1PgxCBw3H iQi8U] (16.7.2015)

REMARQUES : Marcher terrible (I) souligne l'air déconcerté, peu enjoué, la mine chargée de colère. Dans son emploi figuré (II), le sujet désigne très souvent un inanimé (une entreprise, une affaire) qui a un succès formidable, qui fonctionne bien et par conséquent, rapporte beaucoup d'argent. Terrible fonctionne alors comme intensifieur métaphorique. Notons que le sujet peut aussi désigner un animé qui a du succès dans ses entreprises. Terrible reste invariable dans la majorité des cas (v. le deuxième et le troisième exemple du CW), mais, dans le dernier exemple du CW, il s'accorde avec le sujet tout en gardant son interprétation d'adverbe de manière.

\section{Marcher utile}

Marcher dans le but d'en tirer un bénéfice

$\pi$ baiser utile

\section{Marier étroit}

Unir étroitement, fortement

Pronominal

1584 Plus estroit que la vigne à l'ormeau se marie

De bras souplement forts,

Du lien de tes mains, maistresse, je te prie, Enlace-moy le corps

(Pierre de Ronsard, Sonnets pour Hélène) 
REMARQUES : Dans cet emploi figuré, où le sujet est un inanimé (la vigne), se marier étroit réfère au fait d'entourer plusieurs fois en serrant. L'adjectif-adverbe vient renforcer l'idée de contraction, voire d'intimité dans l'étreinte. VoIR AUSSI : accoler / embrasser étroit

\section{Marmotter bas}

Parler, marmonner, murmurer à voix basse Transitif

1553 OCTAVIAN. Pendant, Agrippe, aux affaires t'amuse, Et toy, loyal messager Proculee, Sonde par tout ce que la fame aislee Fait s'acouster dedans Alexandrie, Qu'elle circuit, et tantost bruit et crie, Tantost plus bas marmote son murmure, N'estant jamais loing de telle aventure (Étienne Jodelle, Cleopatre captive)

1764 HENRI. (à part, et d'un ton très-attendri) M'entendre dire cela à moi-même ! ma foi, c'est une sorte de plaisir que je ne connoissois pas encore.

MICHAU. Queuque vous marmotais là tout bas ? Allons, allons, qu'on me suive (Charles Collé, La Partie de chasse de Henri IV)

1846 Monte-Cristo avait remarqué qu'en descendant le perron, Bertuccio s'était signé à la manière des Corses, c'est-à-dire en coupant l'air en croix avec le pouce, et qu'en prenant sa place dans la voiture il avait marmotté tout bas une courte prière (Alexandre Dumas père, Le Comte de Monte-Christo)

1881 quand on le [= Matoussaint] poursuit, il croit échapper comme les Girondins ; il a envie de demander une omelette comme Condorcet, ou bien il marmotte tout bas le nom du gendarme qui arrêta Robespierre (Jules Vallès, Jacques Vingtras : Le Bachelier)

\section{Intransitif}

1755a Eux bien payez consultèrent soudain en grec, hébreu, siriaque, latin ; l'un du roi Charle examine la main, l'autre en quarré dessine une figure ; un autre observe et
Vénus et Mercure, un autre va son psautier parcourant, disant amen et tout bas marmottant (Voltaire, La Pucelle d'Orléans)

1755b Le grand Dunois avait de l'autre bord vû le combat et la déconvenuë de la Trimouille ; une femme éperduë qui le tenait languissant dans ses bras, l'hermite auprès qui marmotte tout bas, et Jean Chandos qui près d'eux caracole. À ces objets il pique, il court, il vole (Voltaire, La Pucelle d'Orléans)

1853 Quand il eut achevé, il se laissa retomber sur l'oreiller et resta muet, immobile, pâle, fatigué, épuisé. Le prêtre l'avait d'abord écouté avec grande attention, puis, ne comprenant sans doute rien à ces idées singulières, il s'était mis à marmotter tout bas en lisant dans son bréviaire (Maxime Du Camp, Mémoires d'un suicidé)

\section{CoRpus Web :}

Je marmotte tout bas les mots de "crampon » et de «sale caractère». Et puis je hausse les épaules et je caresse la dure tête ronde, toute chaude, qui se glisse sous ma main, et je la plains, et je la console [http://forums.jeuxonline.info/showthread. php?t=640077\&page=10] (16.7.2015)

- C'est ca et moi je suis la fille de Merlin, marmotta tout bas Samaliha [https://www.fan fiction.net/s/5051041/2/Pour-Changer-NotreMonde] (16.7.2015)

REMARQUes : Marmotter (tout) bas désigne le fait de dire, grommeler ou marmonner quelque chose d'une manière confuse ou indistincte, le sujet parlant souvent pour soi, à voix basse. Bas reste invariable et est modifié, surtout par tout, mais aussi par plus. VoIR AUSSI : murmurer bas

\section{Marquer profond}

Marquer profondément, de façon intense et durable ; laisser un souvenir durable Transitif

1953 La vie les marque profond (Henri Queffélec, Celui qui cherchait le soleil)

1967 Alors, prise de pitié, elle lui lança gaiement, du haut des marches :

- Y a quand même de ta faute aussi. Comme tu y vas, pardon !... 
- En plus, disait la Morèna, ils sont vaniteux, au lit surtout. Chacun voudrait être le seul à nous marquer si profond, pour si longtemps... (Jean-Pierre Chabrol, Je t'aimerai sans vergogne)

1987 Elle était au spectacle. À bonne école. On ne pouvait pas trouver mieux, pour l'édifier sur le bonheur ; ni pour la choquer, la marquer profond, que cet interdit posé à ce qu'elle assiste. Plus elle n'avait pas le droit de voir ces scènes répugnantes relativement banales - il ne faut rien exagérer -, plus elle les observait en cachette, plus ça la remuait (Bruno Bayon, Le Lycéen)

CORPuS WeB :

Sur le vernis, je dirais que c'est le carrossier qui doit décider, mais une chose est sûre, ces couches de bi-composant sont relativement épaisses et il ne sert à rien de surenchérir sur le nombre de couches pour un usage domestique du flip ! Il faut bien voir que plus la couche de vernis sera épaisse, plus les airballs vont marquer profond, plus le sèchage sera long, aussi, etc..... [http://www.flipjuke.fr/vernis-par-garagisteplateau-getaway-t95842.html] (16.7.2015)

Concernant les lames de swivel en céramique, il me semble avoir lu que ça coupait trop. Le but du swivel n'étant pas d'inciser le fleur, mais juste de la marquer profond [http://travaildu-cuir.fr/les-outils/couteau-en-ceramique-t720. html] (16.7.2015)

et tu passes en akra quand ?;p tu feras gaffe a ce que les caches en metal ne touchent pas les pots sinon ça va les marquer profond ! [http:// forum.motoouebe.com/viewtopic.php? $\mathrm{f}=6 \& \mathrm{t}=$ 300\&start=585] (16.7.2015)

REMARQUeS : Marquer profond réfère à une personne, un événement, ou une période, qui laisse des traces ou une impression durable sur quelqu'un ou dont le souvenir est fortement ancré en quelqu'un. Le CW prend plutôt la collocation au sens concret pour renvoyer à un objet qui laisse des traces profondes sur un autre. Profond reste invariable et est modifié par si.

\section{Mastiquer ferme}

Mastiquer, mâcher avec énergie

Intransitif

1877 Ah ! Tonnerre ! Quel trou dans la blanquette ! Si l'on ne parlait guère, on mastiquait ferme. Le saladier se creusait, une cuiller plantée dans la sauce épaisse, une bonne sauce jaune qui tremblait comme une gelée (Émile Zola, L’Assommoir)

1960 Aujourd'hui moins que jamais il se sent porté à admettre la contestation, et pour un bout de temps les râleuses ont intérêt à écraser, étant donné l'accord qu'il a tout à l'heure conclu à la Villetouze avec un fournisseur ami. Pour une quinzaine, jusqu’à la fermeture d'août ; c'est terminé la bonne troisième dont ils se gavent les clients. On passe à la caisse, le temps d'assainir les finances !... Mijotez et mastiquez fermes bonnes gens! Au retour des vacances, à la réouverture, personne n'y pensera plus !

(Albert Simonin, Du mouron pour les petits oiseaux)

\section{CORPus Web :}

Oui, le jeune schtroumpf bien tendre, ça se laisse manger, les vieux machins barbus, en revanche, faut mastiquer ferme.... [http://forum. e-train.fr/trains/viewtopic.php? $\mathrm{f}=5 \& \mathrm{t}=14489 \&$ start=195] (17.7.2015)

Quant à toi qui uses de locutions latines, vilipendes nos compatriotes qui infiltrent Paris sacs suspendus au dos, je te vois en train de mastiquer ferme ces cacahuètes bon marché qu'on sert aux badauds dans les galeries parisiennes lors de vernissages... quel snob décidément lol [http:// rmcsport.bfmtv.com/football/riolo-arsenalmaradona-berbatov-dit-bonjour-575653/avis/ ?page $=46](17.7 .2015)$

Les trucs curieux sur la 917 Heller, c'est déjà l'a jointure carro-châssis au milieu de la calandre à l'avant, ce qui oblige à mastiquer ferme pour faire propre [http://www.forum-auto.com/ automobile-pratique/modelisme-modelesreduits/sujet7712-2940.htm] (17.7.2015)

REMARQUeS : Concentré sur ce qu'il mange, le sujet de mastiquer ferme s'applique à mâcher énergiquement et d'un bon coup de dent la nourriture qu'il consomme. Notons la collocation mijoter et 
mastiquer ferme. Ferme s'accorde avec le sujet au pluriel dans l'exemple de 1960, mais il reste invariable dans le second exemple du CW, où le verbe est transitif. Dans le dernier exemple du CW, le verbe mastiquer est employé dans l'acception de 'appliquer du mastic, coller', mastiquer ferme signifiant donc 'coller bien, ferme'. Notons l'emploi transitif dans le deuxième exemple du CW.

\section{Maudire bas}

Condamner à voix basse, secrètement

Transitif

1596 Apres le coup reçeu, j'eu connu le dommage ;

Je pleuray ma fortune et, tout bas maudissant

L'inévitable loy du destin tout-puissant, Je vey bien que mon mal estoit sans esperance ;

Car, bien qu'Amour n'observe aucune differance,

Mesurant la noblesse à la fidelité,

J'apprehenday pourtant nostre inégalité (Philippe Desportes, Euvres)

1645 Et pour la consoler, ne sachant que lui dire, Je maudissois tout bas les lois de notre empire,

Et vous étiez le dieu que dans mes

déplaisirs

En secret pour les rompre invoquoient mes soupirs (Pierre Corneille, Théodore)

1843 Il ne voit pas que c'est nous qui sommes les vraies puissances de la terre, et que notre règne est le seul véritable, tandis que leur règne à eux, leur puissance, leur activité, leur majesté, sont une parodie dont les anges rient là-haut, et que les peuples haïssent et maudissent tout bas (George Sand, Consuelo)

1879 Elle va le chercher, l'arrache et le tue. Oui, il me sembla qu'on tuait quelque chose en déchirant ce bouquet fané... J'allai m'enfermer dans un cabinet noir pour les maudire tout bas ; je pensais à Bergougnard et à ma mère, à Louisette et à la cousine... Assassins ! assassins ! (Jules Vallès, Jacques Vingtras : L'Enfant)
1924 Alors si quelque part il y a un adolescent qui t'avait suivi du regard, et qui dans le silence s'exaltait de ton exemple, il se lève, il serre les dents, il te maudit tout bas (Louis Aragon, Euvre poétique)

1940 Mais elle, elle, elle, ta mère, ta maman, c'était elle qui vous faisait vivre tous, du matin au soir sans qu'il y eût pensée en elle autre que vous, sans que vous vous aperceviez d'elle, autre que de la maudire tout bas, cette vieillarde incommode! (Paul Claudel, L'Histoire de Tobie et de Sara)

Pronominal

1936 Edmond eut un brusque accès de respect pour cette dame, et se maudit tout bas. Dès le premier instant il était sûr de manquer le coche. Jamais il ne saurait séduire la femme de son patron, et toutes ses belles résolutions s'évanouissaient (Louis Aragon, Les Beaux Quartiers)

CORPUS WeB :

Contactez nous et dès que nous serons assez nombreux(ses) nous sortirons un communiqué que nous rédigerons ensemble pour dénoncer tout haut ce machin que beaucoup maudissent tout bas... [http://www.sudeducation91. org/?p=755] (17.7.2015)

Le risque de se faire humilier, le risque de voir notre " cote de popularité » baisser, le peur de montrer à tous nos faiblesses, tout ceci nous retient à ce masque que nous maudissons tout bas [http://greendaygirl15.skyrock.com/452230587Questionnement.html] (17.7.2015)

A l'annonce du dernier nom, la quasi-totalité des filles devinrent vertes de jalousie, et regardèrent Leane en la maudissant tout bas, et des rires et ricanements fusèrent : la guerre Blogworth-Black était connue de tous [https://www. fanfiction.net/s/7306804/3/La-sixi\%C3\%A8meann\%C3\%A9e-et-caetera] (17.7.2015)

REMARQUES : Sous l'effet de la colère ou de l'exaspération, maudire bas désigne le fait de réprouver, condamner sévèrement une personne, un acte, une loi ou une attitude en proférant des paroles de malédiction, mais de façon secrète, le sujet les gardant pour soi. Bas reste invariable et est modifié par tout. Notons l'emploi de dénoncer haut. 


\section{Maudire haut}

Condamner à voix haute, ouvertement, publiquement

Transitif

1782 Il faut toujours répondre voyez, et jamais autrement : alors le commis monte, fait l'incommode visite, redescend et ferme la portiere. On le maudit tout haut ou tout bas, il ne s'en embarrasse guere (Louis-Sébastien Mercier, Tableau de Paris)

1857 Le canot emporta Indiana et sa fortune au milieu des lames furieuses, des hurlements de la tempête et des imprécations des deux rameurs, qui ne se gênaient pas pour maudire tout haut le danger auquel ils s'exposaient pour elle (George Sand, Indiana)

1967 À midi, il se couche sur des femmes, il maudit ses enfants tout haut dans le bordel, il boit, il pousse les femmes dans le jardin, les mouches vibrent dans ses cheveux, son manteau d'or s'effondre sur les tamaris, la poudre brille sur l'escalier de granit (Pierre Guyotat, Tombeau pour cinq cent mille soldats)

\section{CORPUS WEB :}

J’y suis allée à la main, lentement mais en me gardant bien de maudire tout haut le jour où j'avais pleuré devant le père Lorrain [http:// leblogacontes.free.fr/histoires/] (17.7.2015)

Il faudra donc en permanence faire des choix draconiens entre ses priorités, élaborer une stratégie secrête tout en vous retenant de maudire tout haut vos adversaires qui font foirer un plan si bien préparé, ect... [http://soyonserieux. over-blog.net/article-12163128.html] (17.7.2015)

C'est reprendre mille fois l'explication du devoir de maths sans se mettre soi-même à maudire tout haut l'école et les heures de devoir [http://www.paperblog.fr/3577062/riches-maissans-cervelle/] (17.7.2015)

REMARQUES : Sous l'effet de la colère ou de l'exaspération, maudire haut désigne le fait de réprouver, condamner sévèrement une personne, un acte, une loi ou une attitude en proférant publiquement des paroles de malédiction. Notons la collocation maudire haut ou bas. Haut reste invariable et est modifié par tout.

\section{Médire haut}

Médire à voix haute, ouvertement, publiquement Intransitif

1587 Le jeudi $4^{\mathrm{e}}$ juin, Roland, Esleu de Paris, un des arcboutans et pilliers de la SainteLigue, fut, par commission et expresse ordonnance du Roy, envoié prisonnier en la Conciergerie du Palais, pour avoir, en plain Hostel de Ville, deux jours auparavant, opiné aigrement au desavantage du Roy, jusques à avoir mesdit tout haut de Sa Majesté (Pierre de L'Estoile, Registre journal du regne de Henri III)

1627 Des-ja de toutes parts tout le monde m'esclaire ;

Et bien tost les jaloux ennuyez de se taire, Si les vœux que je fais n'en destournent l'assaut, Vont mesdire tout haut.

Peuple qui me veux mal, et m'imputes à vice

D’avoir esté payé d'un fidelle service,

Où trouves-tu qu'il faille avoir semé son bien,

Et ne recueillir rien?

(François de Malherbe, Les Poésies)

REMARQuES : Médire haut désigne le fait de tenir sur quelqu'un des propos malveillants, de dire sur quelqu'un du mal que l'on suppose vrai, le sujet l'exprimant à voix haute dans l'intention de faire connaître son intention au public. Haut reste invariable et est modifié par tout.

\section{Mêler fort}

Entremêler solidement, attacher plusieurs fois solidement

Transitif

+1225 Mais ke plus grant travail i met Et il plus fort la melle et noe. Lors set il bien ke ja n'ert soe, Quant il net le puet deslacier (Le Chevalier as deus espees [ $2^{\mathrm{e}}$ quart $\left.\left.\mathrm{XIII}{ }^{\mathrm{e}}\right], 1375\right)$

\section{CORPUS WEB :}

Je me « mêle fort » (!!! . . .) de ce qui ne me regarde pô, mais est-ce que tu as aussi eu le pack « huile... de vidange » pour la voiture avant de partir en vacances ? [http://au-gre-de-mesenvies.over-blog.com/article-filet-de-cabillauda-la-moutarde-melfor-118991534.html] (17.7.2015) 
Il s'est donné à fond pour les Flyers qu'il a tenus à bout de bras pendant un temps. Les commotions l'ont forcé à arrêter, mais il a tout de même joué en dépit des risques et a continué à produire en se mêlant fort au trafique [http:// blogues.canoe.ca/sports/generale/lindros-aupantheon/comment-page-1/] (17.7.2015)

Les habitants auxquels je suis parent direct ou indirect furent nommés les "badins " car comme dans les pièces de Marivaux... cela se $m \hat{e}$ lait fort ! [http://archiver.rootsweb.ancestry.com/ th/read/GEN-FF/2007-06/1182411745] (17.7.2015)

REMARQUES : Mêler fort désigne le fait d'entremêler solidement $(+1225)$. Dans le CW, se mêler fort réfère au fait de s'immiscer dans un débat, dans une discussion ou à celui de se mélanger génétiquement. Fort reste invariable et est modifié par plus. Notons l'emploi pronominal du verbe dans le CW.

\section{Menacer bas}

Menacer à voix basse, secrètement, discrètement, en se cachant

Transitif

1280 Se ton ami par grant desir Vient devant tes portes gesir Pour empetrer par aventure Les joies de la nuit oscure, Molement le doiz escondire Qu'il n'ara pas cen qu'il desire, Et tout bas le doiz menachier, En faignant que le veuz cachier (Vivien de Nogent, La Clef d'amour, 2975)

1832 Vengeance! disait-il, dans la sombre ferveur

Qui fixait son regard sur la croix du Sauveur. Parlait-on de Louis, à ce nom qu'il abhorre, Il rêvait la vengeance, et, plus terrible encore,

La main sur son poignard, il menaçait tout bas celui... (Casimir Delavigne, Louis XI)

1900 Ces messieurs s'installent ; Dutertre couleur cuir de Russie, rit et parle trop haut, ivre, comme par hasard. Mademoiselle nous menace tout bas de châtiments effroyables si nous chantons faux, et allons-y de l'Hymne à la Nature:

Déjà l'horizon se colore
Des plus éclatantes lueurs ;

Allons, debout ; voici l'aurore

(Colette, Claudine à l'école)

1977 - C'est pas tellement sûr ! Josta m’a laissé entendre que... tous les... " réhabilités " n'ont pas retrouvé leurs places. À lui - à luimême ! - dans les bureaux, on le menace tout bas : « Hé, n’oublie quand même pas que ton père a été fusillé par Staline ! » Les Staliniens irréductibles seraient nombreux (Jean-Pierre Chabrol, La Folie des miens)

CORPuS Web :

Il retire ses doigts, s'attirant ainsi une plainte sourde de l'homme sous lui qui se met de nouveau à le menacer tout bas, les yeux clos [https://www.fanfiction.net/s/9375848/1/Fourquestions-about-us] (17.7.2015)

Pendant que je menaçais tout bas le commandant, on m'appela depuis la maison. Izou posa la main sur mon épaule [https://www.fan fiction.net/s/10425731/14/A-New-Destiny] (17.7.2015)

Alors que Klaus foudroyait du regard la petite Petrova, l'air de la menacer tout bas qu'il allait la découper en tranches minces [https:// www.fanfiction.net/s/9717731/10/Coeurs-etRancoeurs] (17.7.2015)

REMARQUES : Menacer tout bas désigne le fait de proférer des paroles sur un ton menaçant à l'encontre de quelqu'un, le sujet manifestant à autrui l'intention qu'il a de le contraindre par la force à faire quelque chose, d'avoir recours à la violence s'il ne coopère pas ; la menace peut être proférée de façon discrète, sans élever le ton ou rester secrète, non dévoilée, le sujet la gardant pour soi. Bas reste invariable et est toujours modifié par tout. Notons l'emploi de chanter faux, parler haut, rire haut.

\section{Menacer ferme}

menacer fort et ferme : menacer de manière énergique, inflexible, décidée

Transitif

1534 puis les fouaciers aiderent à monter à Marquet, qui estoit villainement blessé, et retournerent à Lerné sans poursuivre le chemin de Pareillé, menassans fort et ferme les boviers, bergiers et mestaiers de 
Seuillé et de Synays (François Rabelais, Gargantua)

1558 mais, pour le moins, les deux ne durèrent pas tant comme le tiers, car elle fongna au clerc plus d'un jour et une nuict, et le menassa fort et ferme qu'elle ne luy presteroit jamais chose qu'elle eust (Bonaventure des Périers, Les Nouvelles Récréations et joyeux devis)

CORpus WeB :

J'ai du menacer ferme pour qu'enfin ils acceptent de rembourser [http://www.planetehonda.com/accessoires/des-avis-svp-filtrehabitacle-au-charbon-active/] (17.7.2015)

situassubiuneag ou pas, situas passél'heure du repas ou pas (me souviens lors d'une légère intervention, rien à voir avec un accouchement, mais j'étais en chambre après le repas du soir... j'ai du menacer ferme l'infirmière pour qu'elle aille me chercher de quoi manger un peu) [http:// forum.doctissimo.fr/grossesse-bebe/accouche ment/passe-fois-accouche-sujet_170024_1.htm] (17.7.2015)

REMARQUES : Menacer ferme désigne le fait de proférer des paroles sur un ton menaçant à l'encontre de quelqu'un, le sujet manifestant à l'autre son intention de façon assurée, avec détermination. Notons que l'adjectif-adverbe ferme apparaît en collocation avec fort qui vient renforcer son sémantisme, suggérant l'idée d'assurance. Ferme reste invariable (v. ex. de 1534). Notons l'emploi absolu du verbe dans le premier exemple du CW.

\section{Menacer fort}

Menacer avec assurance, fortement

CORPuS Web :

Emploi absolu

Pour le homard malheureusement... les hommes sont bouchés. Si tu l'aimes encore alors n'hésite pas à menacer fort. Il n'a peutêtre même pas pensé à cette issue, lui [http:// www.pourmieuxattendre.fr/article-bon-demission-124223078.html] (17.7.2015)

Si Free veut protéger son code du firmware de la Freebox ils ont d'une part intérêt à être dissuasifs, d'autre part intérêt à frapper fort (ou menacer fort) en cas de " vol " de Freebox [http://linuxfr.org/users/mcjo/journaux/le-freerespectera-la-gpl-pour-vlc] (17.7.2015)

Transitif

Mais elle n'avait pas l'air décidée à lui répondre. En effet, dans sa partie, les deux dés avaient fait un quadruple quinze, et cela menacait fort la Reine, surtout avec la Tour et le Fou en embuscade. Pis même si elle avait deux petites chevaux prêts à atteindre la ligne d'arrivée, c'était pas du tout cuit [http://dojodezhou.forumhope.com/ t25p30-parodie-lion-s-fic-the-revenge-of-thereturn] (17.7.2015)

\section{Menacer haut}

Menacer à voix haute, ouvertement, franchement Transitif

1829 La belle en sanglotant

Se confesse à voix basse.

D'un divorce éclatant

Tout haut il la menace.

Zon! Flûte et basse !

Zon! Violon!

Zon! Flûte et basse !

Et violon, zon! zon!

(Pierre-Jean de Béranger, Chansons)

REMARQues : Menacer haut désigne le fait de proférer des paroles sur un ton menaçant à l'encontre de quelqu'un, le sujet manifestant à l'autre son intention de façon ferme et franche. Haut reste invariable et est modifié par tout.

\section{Menacer laid}

Menacer méchamment, de manière méprisante, désagréable

Transitif

1250 Devant le roy avoit .i. jeune soudoier, L'omme en trestout le mont que Do avait plus chier.

Quant chil oï Doon issi lait menachier, Tant respondi le roi qu'il le fist courouchier, Et que il le feri d'un baston de pommier Si que par devant li le fist agenoullier (Doon de Mayence, p. 184)

REMARques : Menacer laid désignait le fait de proférer sur un ton menaçant des paroles à l'encontre de quelqu'un, inspirant le mépris ou la désapprobation. Il peut aussi référer à un com- 
portement, une attitude ou une pensée. Laid est un intensifieur péjoratif en ancien français.

\section{Ménager extrême}

se ménager extrême : se ménager extrêmement, faire très attention

$\lambda$ tenir ferme

\section{Mendier bas}

Demander de façon humiliante, en s'avilissant Transitif

1833 GLOCESTER. (se levant)

Je suis Richard aussi. Sans respect pour l'autel,

Courons chercher ma proie au fond du sanctuaire ;

Osons l'en arracher ! Dieu me laissera

faire.

(retombant assis)

Mais ses prêtres !... Cédons à la nécessité :

Flattons en l'implorant leur sainte humilité.

Pour monter jusqu'au faîte il faut savoir descendre,

Et mendier bien bas ce qu'on n'ose pas prendre

(Casimir Delavigne, Les Enfants d'Édouard)

\section{CORPUS WEB :}

Alors j'aime beaucoup le principe du faerie stompy mais je n'ai que peu d'occasions de tester et une connaissance de magic limitée ce qui fait de moi un netdecker dans l'ame, en bref je viens mendier bien bas quelques conseils à cette comunauté compétente et rafinée [http://solomoxen. com/forum/index.php?topic $=7537 . \mathrm{msg} \% \mathrm{msg}$ id\%] (17.7.2015)

REMARQues : Mendier bas désigne le fait d'implorer, de solliciter quelque chose avec humilité ou de façon servile et humiliante, souvent avec insistance, bas soulignant l'idée de soumission. Bas reste invariable et est modifié par bien.

\section{Mener bas}

Plonger (quelqu'un) dans la détresse ; conduire (quelqu'un) à un niveau très bas

Transitif

1403 Pluseurs aultres, que je ne dy, $Y$ vi regnans devers midy, En Arragon et en Espaigne,
Et alieurs, mesme en Allemaigne, Puis hault, puis bas menez par celle, A qui j'estoye lors ancelle (Christine de Pisan, Le Livre de la mutacion de fortune, IV, 23377)

1608 Les Dieux en ont horreur, les Astres pour vengeance

Ne dardent plus sur nous nulle bonne influence,

Les champs, les ruisseaux, l'air, l'Atlantide, sont las

De porter, de couler, d'ouïr, de mener bas, Les charoignes, le sang, les hurlemens, les ombres,

Des mortels succombants au fort des encombres,

L'orphelin nous deteste, et la veufve maudit Ceux qui vont dispersant tant de peuple à credit (Jean de Schélandre, Tyr et Sidon)

1966 Commencé dans un état de détresse qui, dès que le fil fut coupé, devint lyrique enivrement après m’avoir mené si bas que, peu de jours avant mon départ, j'avais été tout près de me jeter sur les rails à l'instant où le métro entrait en gare d'une des stations de la ligne aérienne qui passe par La Motte-Picquet (Michel Leiris, La Règle du jeu 3: Fibrilles)

Emploi absolu

1924 elle [= l'intelligence] se croirait, très aisément, inamissible et inaltérable, si ce n'était qu'elle a reconnu même par ses expériences, un jour ou l'autre, diverses possibilités funestes et l'existence d'une certaine pente qui mène plus bas que tout. Cette pente doit pressentir qu'elle peut devenir irrésistible ; elle prononce le commencement d'un éloignement sans retour du soleil spirituel (Paul Valéry, Variété I)

\section{CORPUS WEB :}

L'inconséquence politique peut nous mener plus bas [https://www.zonebourse.com/commu naute/forum/bourse/L-inconsequence-poli tique-peut-nous-mener-plus-bas-174001/?file =showtopic\#174001] (18.7.2015)

Et la drogue peut vous mener bas...Très bas. Sky présentement devait avoir épuisé ou presque les consommations qu'il lui restait [http://the 
finalproject.forumactif.com/t168-jaylou-ellynyou-gotta-know-something-am-i-right] (18.7.2015)

En d'autres termes, le pouvoir a besoin d'une résistance mais qu'il peut maîtriser afin de la combattre et de la mener bas [http://www. cafedelaterrasse.com/racisme_antisemitisme_ ordinaires.html] (18.7.2015)

REMARQUES : Au figuré, mener bas désigne le fait de mener quelqu'un à sa perte, de le faire s'écarter du droit chemin, l'individu approchant de sa fin. Bas reste invariable et est modifié par plus, puis, si, très. Notons la réduplication progressive bas, très bas.

\section{Mener bel (beau)}

I. Mener, conduire de manière très agréable, plaisante, douce

Transitif

1300 Tristans, tant com fu en cest monde, N'anma autant Ysouc la blonde Cum cil dui amant s'entrenmerent Et foy et honnor se porterent. Mout bel menoient lor deduit Priveement et jor et nuit (La Dame qui aveine demandoit pour morel sa provende avoir, 33)

1400 - Vroiement, mon amy, je m'en esbahiz comme vous faictes. Je ne scey auxi que ce peut estre, car je le cuide mener et gouverner le plus beau que je puis et le plus doulcement (Quinze Joies de mariage, p. 38)

II. Maltraiter ; donner du fil à retordre

Transitif

-1500 TALLEBOT. Ha ! quelle journée doloreuse, D'avoir perdu ce bel joyau De ceste place vertueuse, Et qui tant François menoit beau ! (Le Mistère du siège d'Orléans [ 14801500], 13789)

1614 et venant tout gaillard abordoit sa maistresse, la menaça qu'il la meneroit beau (Brantôme, Recueil des dames, 1614 [ = date de la mort] / Damourette et Pichon, § 981).

Remarques : Mener bel (I) désignait le fait de diriger, d'exécuter ou de mener un acte à bien avec la volonté de bien faire. Le neutre bel est remplacé par beau à partir du moyen français.
Notons la collocation mener et gouverner le plus beau et le plus doucement. Mener beau (II) renvoie au contraire : traiter mal. Beau reste invariable et est modifié par moult, le plus. VoIR AUSSI : gouverner beau

\section{Mener droit}

I. Mener (quelqu'un) directement (à quelqu'un, dans un lieu)

Transitif

1100 Si ceste acorde ne volez otrier, En Sarraguce vus vendrat aseger. Par poëstet serez pris e lïez ; Menet serez dreit ad Ais le siet (Chanson de Roland, 478)

+1100 Dreit les meinet $a$ un castel [variante : tot dreit]

Qui riches ert e grant e bel, E resemblout mult regal leu (Benedeit, Voyage de saint Brendan [1 $1^{\text {er }}$ quart XII $]$, 267)

1177 Si s'est vers la voiz adreciee Tant qu'ele antre an une chauciee, Et la chauciee droit la mainne Vers le cor, dont ele ot l'alainne ; Que par trois foiz mout longuemant Sona li corz mout hautemant (Chrestien de Troyes, Yvain ou Le Chevalier au lion, 4867)

-1200 Et il si firent lors, [la] en i corent quinse, Les huis ont desfremés et les cambres ovrirent,

Elye i ont trové et sa seror Olive : Droit de devant lor pere les menerent et guient (Elie de Saint Gille [fin XII ${ }^{\mathrm{e}}$, 31)

1209 Einsi se conforte en chantant, Et cil qui chevauchoit errant Vers Dole tot le grant chemin Se fu tant levez por matin, Puis qu'il vit qu'il l'estut a fere, Q'en mains d'uit jors vint au repere Mon segnor Guillame de Dole. Renomee, qui par tot vole, L’a mené tot droit au plessié (Jean Renart, Roman de Guillaume de Dole, 939)

+1313 La dame entra en la citte, Moult y uit de nobilitte, Li uarles l'a bien assenee, 
Car droit a l'ostel l'a menee

$\mathrm{V}$ cieus a le mance gisoit

Si malades que on disoit

K'en lui n'auoit de retour point (Jean de Condé, Poèmes [1313-1337], 1978)

1342 Si me mena plus droit que lingne, Com cils qui se joint et alingne, Polist, deleche, amenevist, Si qu'onques mais ame ne vist Beste plus gente ne plus jointe, Plus esveillie ne plus cointe (Guillaume de Machaut, Le Dit dou lyon, 2101)

+1370 Chils vens contraires lor dura deus jours. Et costiierent Frisse, et ne savoient bonnement a dire li maronnier ou il estoient. $\mathrm{Au}$ tierch jour, vens lor revint a droit souhet, et qui les mena et bouta droit contre Engleterre, et tant que li maronnier en orent la congnissance (Jean Froissart, Chroniques (A))

1450 ANNE. Aultre remedde je n'y voiz, Pour en avoir brief jugement, Que de le mener prestement Au prince des prestres Caÿphe, Qui pour cest an est grant pontife, Pour l'examiner a son droit [variante : Si vault mieulx luy mener tout droit] (Arnoul Gréban, Le Mystère de la Passion, 20198)

1572 Tu noteras encores, lecteur, ce poinct qui te menera droict au vray chemin de Muses (Pierre de Ronsard, La Franciade [préface], p. 29)

1628 Disant cela elle se leva aussi, et prenant Silvandre par la main, se mit à suivre parmy quelques arbres le chemin qui les pouvoit mener droit à la fontaine (Balthazar Baro, La Conclusion et dernière partie d'Astrée)

1678 Il devrait être sourd aux aveugles souhaits Il ne le fut pas lors : et la guide nouvelle, Qui ne voyait au grand jour Pas plus clair que dans un four, Donnait tantôt contre un marbre, Contre un passant, contre un arbre. Droit aux ondes du Styx elle mena sa sœur.
Malheureux les États tombés dans son erreur

(Jean de La Fontaine, Le Chat, la belette et le petit lapin / Fables)

1749 L'exemple de nos traducteurs, qui ont affecté le plus beau langage, ne doit pas plus être suivi que celui du prédicateur du Spectateur anglais, qui disait que, s'il ne craignait pas de manquer à la politesse et aux égards qu'il devait avoir pour ses auditeurs, il prendrait la liberté de leur dire que leurs déportements les mèneraient tout droit en enfer (Montesquieu, Correspondance)

1771 Au reste, voici l'histoire de mon voyage. Vous savez, ou vous ne savez pas, que, pour arriver là, il faut passer un bac ; imaginez-vous que mes chevaux, par un caprice qui n'a pas laissé que de m'étourdir, vouloient absolument me mener tout droit dans la riviere (Claude-Joseph Dorat, Les Sacrifices de l'amour)

1844 Je vous conduirais bien encore à l'auberge... mais il n'y en a point. Je vais vous mener tout droit chez la mère Guite, qui a un fameux bouchon, et où vous ne manquerez de rien. Vous avez apporté tout ce qu'il vous faut, n'est-ce pas ? (George Sand, Jeanne)

1846 Je les laisse se féminiser tant qu'elles veulent. Il y en a une que son intelligence conduira bien dans la vie et une autre que son cœur mènera droit en paradis (George Sand, Correspondance)

1908 Vous le menez droit aux fumeries d'opium. Et vous le savez bien; mais vous ne le dites point : la mort est au bout.

- Eh bien, moi, je dis : où est la mort, l'art n'est point (Romain Rolland, JeanChristophe. La Foire sur la place)

1926 Elle s’était brusquement engagée dans la rue Vaneau, qui la menait droit à la rue Las-Cases. Non moins brusquement, elle obliqua par la rue de Varenne. Il pensa : « Elle a peur de rentrer chez elle » (Paul Bourget, Nos actes nous suivent) 
Intransitif

1687 J'avoue qu'on peut faire, et qu'on fait tous les jours pour les enfants beaucoup moins que ce que je propose ; mais aussi on ne voit que trop combien la jeunesse souffre par ces négligences. Le chemin que je représente, quelque long qu'il paraisse, est le plus court, puisqu'il mène droit où l'on veut aller (François de Fénelon, Traité de l'éducation des filles)

1696 Contre le mal qui vous possède Je vous apporte pour remède Un petit doigt de vin nouveau. L'eau n'est qu'une liqueur ingrate Qui mène tout droit au tombeau ; Les meilleurs juleps d'Hippocrate Sont ceux qu'on prend dans le tonneau (Dancourt, Les Eaux de Bourbon)

1824 À propos de prison et de Sainte-Pélagie, vous pourriez dire encore que je n'ai aucune part à certaines brochures qui mènent là tout droit, imprimées sous mon nom en pays étranger (Paul-Louis Courier, Pamphlets politiques)

1831 Elle est incomparable, ils croient doubler ou dédoubler Buonaparte avec un jupon. Nous irons, grâce à eux, à un 18 fructidor, quand la route mène droit ailleurs. Faut-il envoyer la chère coquette à Lyon ou à Fontaine ? Donne tes ordres! (Alphonse de Lamartine, Correspondance générale)

1927 - C’est très joli, riposta froidement M. de Clergerie. Cela mène tout droit chez les Clarisses.

- Chez les Clarisses ! S'écria-t-elle en riant. Seigneur ! Où prenez-vous que je puisse être jamais Clarisse, ou seulement Carmélite! (Georges Bernanos, L'Imposture)

1931 Que de fois j'ai fait ce rêve d'un jardin qui n'en finissait pas, d'une rue qui continuait à l'infini et qui menait droit hors du monde ! Quand j'étais enfant j'éprouvais quelquefois un sentiment de colère à la pensée des limites imposées à l'espace ; un mur, une porte m'indignaient (Julien Green, Journal)
II. Amener (quelqu'un) directement (à tel état physique ou moral)

Transitif

1710 Si cette règle avait été connue de M. Descartes, il aurait rendu la direction des corps aussi indépendante de l'âme que leur force, et je crois que cela l'aurait mené tout droit à l'hypothèse de l'harmonie préétablie où ces mêmes règles m'ont mené (Gottfried Leibniz, Essais de théodicée sur la bonté de Dieu)

1800 ALVARE. Point du tout, Monsieur, point du tout. Je vous déclare hardiment que, sous nul aspect, votre conspiration ne me paraît sage, que vos espérances me semblent dénuées de fondement, vos mesures hors de toute raison, et que je ne veux prendre aucune part à une folie qui vous mène droit à la mort

(Népomucène Lemercier, Pinto ou La Journée d'une conspiration)

1927 Ce sont les formules géométriques rigoureusement appliquées qui ont conduit le décor et, par suite, l'architecture arabes à la mort. Elles nous mènent droit à un automatisme plus sévère que celui du manœuvre enfonçant un rivet toutes les trois secondes dans une plaque de fonte qui passe mécaniquement devant lui (Élie Faure, L'Esprit des formes)

Intransitif

1863 Il croit à sa métempsychose et se jette à l'eau pour redevenir empereur, être métamorphosé à reculons. Une nature peut devenir folle par ce chemin-là, rien n'y mène plus droit et plus vite que la théosophie ; - Swedenborg était à demi fou (Alfred de Vigny, Le Journal d'un poète)

1936 C'est pourquoi il y a certainement un peu de jansénisme dans ce jugement moral qui veut rappeler les femmes au sérieux et à la pudeur ; c'est presque une invitation à juger par soi-même et à résister au commun usage. Cela mène droit au protestantisme. Tranchons tout net, et sans nuance, la morale n'est pas toujours sans danger pour la discipline (Alain, Propos) 
1974 C'est ce que les fascistes appellent « continuer à croire et à espérer ». C'est le pire truc facho, ça, et ça mène tout droit à la politique et à toutes sortes de trucs boutonneux, comme le printemps de Prague pour hivers russes (Romain Gary, Gros-Câlin)

III. Faire suivre le droit chemin (au propre et au figuré), encadrer, diriger

Transitif

1816 Elle est belle, sèche, froide, impérieuse, avare, calculant toutes ses actions et presque toutes ses paroles, ayant de la gaîté dans l'esprit et de l'habileté dans le caractère, très propre en un mot à faire une femme convenable qui enrichira son mari, qui élèvera bien ses enfants, qui mènera droit ses domestiques, en un mot, à laquelle il n'y aura jamais le moindre reproche à faire et avec laquelle on pourra être horriblement malheureux (Benjamin Constant, Journaux intimes)

1875 Frère Archangias achevait un gros morceau de fromage, sans paraître le moins du monde dérangé par cette scène. Selon lui, l'abbé Mouret avait besoin d'être mené droit ; la Teuse faisait bien de lui faire sentir la bride. Il vida un dernier verre de piquette, se renversa sur sa chaise, digérant (Émile Zola, La Faute de l'abbé Mouret)

1907 Comme le graveur bien appliqué à tailler sa planche suivant le fil du bois s'occupe peu de la lampe au-dessus de sa tête qui l'éclaire, de même l'agriculteur, toutes choses pour lui réduites à ses deux mains et au cul noir de son buffle, avait soin seulement de mener droit son sillon, oublieux du cœur lumineux de l'Univers (Paul Claudel, Connaissance de l'Est)

1909 On les trouve assez fréquemment au lit de mort du chrétien. Mais l'imagination puissante de Pascal et sa raison toujours menée tout droit par une terrible logique n'avaient pas besoin de cette extrémité de ses jours pour qu'il y vît ce que nous y verrons (Maurice Barrès, Mes cahiers)

\section{CORPuS WEB :}

Impayés trop nombreux, perte de marché, endettement ou baisse d'activité : de plus en plus de sociétés se trouvent confrontées à des difficultés pouvant les mener droit à la procédure collective [http://www.harroch-avocats.com/avocat-75/ droit-des-affaires-paris.php] (18.7.2015)

Après une première évaluation de vos aptitudes physiques et techniques, un projet commun est adopté pour vous mener droit au but que vous vous êtes fixé [http://silat-vendee. academiefranckropers.com/self.html] (18.7.2015)

Lorsque le sel rentre en contact avec l'eau savonneuse, celui-ci se dissout, jusqu'à ce qu'un peu de sel atteigne la goutte d'alcool. Celle-ci va alors se déplacer le long du gradient de sel, ce qui va la mener droit sur la position de dépôt de la goutte de sel, où la concentration de sel est la plus importante [http://www.techniques-ingenieur.fr/ actualite/insolite-thematique_89433/une-videomontrant-une-goutte-d-alcool-se-deplacer-dansun-labyrinthe-fait-le-buzz-article_289071/] (18.7.2015)

Une course contre la montre qui pourrait bien la mener droite en enfer [http://twilightteamsuisse.blogspot.co.at/2012/11/kara-gilliantome-4-les-peches-du-demon.html] (18.7.2015)

REMARQUES : Au sens propre (I), mener droit désigne le fait de diriger, conduire quelqu'un chez quelqu'un ou à un endroit, directement, en suivant une ligne droite ou sans détour. Au sens figuré (II), il souligne le fait d'arriver à une hypothèse de façon directe, d'être amené à prendre une décision sans hésiter. L'objet désigne souvent un état physique et/ou moral, une conséquence de connotation négative (la mort, l'anéantissement) auquels le sujet parvient inéluctablement. Mener droit (III) renvoie à une conduite droite, surtout morale, mais il peut aussi désigner le fait de suivre une ligne droite en conduisant, dirigeant (ici : la charrue). Droit reste invariable dans la majorité des cas, mais, dans le dernier exemple du CW, il est accordé avec l'objet, probablement sous l'influence de la liaison phonétique. Il a tendance à s'associer avec les prépositions ou adverbes de lieu qui le suivent (à, ailleurs, chez, contre, dans, de devant, en, hors, là, où, sur, vers, y), au point de faire partie du groupe prépositionnel comme modifieur de la préposition. Droit est mo- 
difié par plus, tout. Notons l'emploi de trancher net.

\section{Mener dur}

I. Mener, diriger, traiter avec fermeté, de manière sévère, rude, brutale

Transitif

1844 Et croyez-vous par hasard qu'ils se donnent le poing dans le nez à louer, critiquer ou nommer simplement l'ouvrage ? Ils pourraient vous mener dur, j'en conviens. Tudieu, mon cher, quel livre ! c'est cru en diable ; c'est diablement mêlé ; c'est la désolation de l'abomination. Mais encore comment voulez-vous qu'ils y mordent, quand tout cela n'est qu'un ramassis de leurs propres livres que seriez prêt à leur rejeter à la face ? (La Revue de Liège)

1931 Il grogne :

- Cochon! Cochon!

Puis, il se décide à glisser le regard vers l'apprenti.

- Tu es un cochon.

- Oui, dit l'apprenti.

- Allez, monte, je vais te mener dur, moi, maintenant.

Il fait bouger ses gros sourcils gris et le petit monte dans la voiture en tremblant comme un chevreau (Jean Giono, Le Grand troupeau)

1962a Il paraît qu'il n'est pas commode, le père Petiot.

- Vous le connaissez?

- Non, mais nous avons des amis qui le connaissent. Ils disent que, chez lui, les apprentis sont menés dur.

Elle souriait. Julien resta indécis un long moment, puis demanda :

- Est-ce que vous avez parlé de ça à ma mère?

- Non, je ne l'ai pas vue ces temps derniers (Bernard Clavel, La Maison des autres)

1962b - Dire qu'elle a seize ans, on lui en donnerait à peine douze.

Claudine se tut, tendit l'oreille, puis, s'approchant de Julien, elle ajouta :

- Et ici, ils en profitent pour la mener dur. Et la payer à coups de lance-pierre.
Elle passa derrière Julien pour aller à la porte, il sentit son corps appuyer sur son dos. Elle regarda dans la salle à manger (Bernard Clavel, La Maison des autres)

Emploi absolu

1929a Je suis la dernière de toutes, je suis salie en dedans, je me suis servie de ma chair pour gagner des sous... Et puis, à mener trop $d u r$, on énerve le cheval, elle s'est mise à pleurer et le petit s'est réveillé.

- Demoiselle, je lui ai dit, allez rendormir le petit monsieur, puis nous verrons (Jean Giono, Un de Baumugnes)

1950 Qu'a-t-il fait, de quoi eût-il été capable, ce Pierre, ce Boche dont la photographie montre le front bas, les yeux froids, la mâchoire lourde, et qui appuie sa main énorme au dossier du fauteuil sur lequel est assise, souriante et nulle, sa femme? La pitié, à cette heure, serait une lâcheté. $M e$ nons dur, et le plus dur possible, puisqu'enfin il faut qu'on en finisse ! Saint-André (Maurice Genevoix, Ceux de 14)

Pronominal

1929b Le remède ? C'est dans nos bras et dans notre tête, qu'il est. Dans nos bras, surtout. Les collines, ça se mène comme les chevaux, dur. Tu comprends bien que je les connais ; je n’ai pas chassé sur elles pendant trente ans sans avoir appris leurs façons de faire (Jean Giono, Colline)

II. Conduire (une voiture) de manière trop rapide, très rapidement

Emploi absolu

1955 Ils mènent dur, les conducteurs norvégiens (Exemple entendu, 4 août 1955 / Grundt : 243)

\section{CORPUS WeB :}

Peu de temps après les chiens semblent mener dur, il y a des sangliers mais apparemment la trace est perdue, dans un premier temps puis retrouvée plus loin par U....e la petite Cairn Terrier du chef de traque mais trop tard le sanglier est sorti [http://www.chasseetchien.fr/t608-LesBattues-a-Grandchamps-yvelines.htm?start=15] (18.7.2015)

Je vous souhaite de ne pas y être. Sinon Rusard va vous mener dur !! La pénitence sera 
de longue durée ! [http://themagicofhogwarts. forums-rpg.com/c10-6e-etage] (18.7.2015)

Restez à l'écart de ces histoires, elles peuvent vous pourrir la vie et vous la mener dur [http://lesvampireplusdinfo.centerblog.net/3-jedit] (18.7.2015)

Faciliter la vie des usagers, mais la mener dure aux fraudeurs... C'est, en raccourci, la philosophie qu'affiche la CPAM (Caisse primaire d'assurance maladie) des Côtes-d'Armor [http:// www.letelegramme.fr/ig/generales/regions/ cotesarmor/cpam-le-service-aux-usagers-sedeveloppe-29-06-2010-971942.php] (18.7.2015)

REMARQUES : Mener dur se dit du fait de conduire de façon autoritaire, sans ménagement, en imposant sa volonté. Originaire de l'argot de la chasse et de la conduite des chevaux, il passe au domaine de l'automobile et de l'éducation humaine. Dans le premier exemple du CW, mener dur réfère aux chiens de chasse qui poursuivent un animal (ici un sanglier) en donnant de la voix, et qui avancent plus vite quand ils le flairent. Dur reste invariable dans la majorité des cas (v. l'emploi transitif du verbe en (I), et le troisième exemple $\mathrm{du}$ CW), mais il s'accorde avec l'objet au féminin dans le dernier exemple du CW, en gardant son interprétation d'adverbe de manière. Il s'oppose pour certains sens à mener gent. Il est modifié par le plus, trop.

\section{Mener gent}

Mener, conduire gentiment, aimablement

Transitif

+1265 Puis a Richart congié demande, Mais Richars tantoz li commande Qu'il l'atenge, car sagement Couvient aler et mener gent (Richars li Biaus [3 tiers XIII ${ }^{e}$, 3992)

Remarques : Mener gent désignait le fait de conduire ou d'accompagner quelqu'un avec bienveillance. Notons la collocation aller et mener gent. Il est l'antonyme de mener dur.

\section{Mener haut}

Mener à un niveau (social, moral, intellectuel, etc.) supérieur

Transitif

+1200 « Rois Artus, moult m'esmerveil de chou que tu sueffres que dame desloiaus et tele que elle ne deveroit pas tenir terre mengue a [ta] table. Et qui vaurroit la chose mener si haut comme la vérités mousterroit, il trouveroit tout apertement qu'il a en li murdre et traison » (Merlin [1 ${ }^{\mathrm{er}}$ quart XIII $]$, p. 166)

1668 Mesme à force de penser et de dire des choses que la pluspart des gens ne sont pas accoûtumez d'entendre, quoi qu'on s'explicast tres-clairement, on les pourroit mener si haut, que la teste leur tourneroit. Ce defaut neantmoins auroit son prix, et je le trouve si rare, que je ne voi personne qui s'en plaigne, et qui ne le voulust avoir (Antoine Gombaud, chevalier de Méré, Les Conversations)

1844 Son éducation, quelque belle et pieuse qu'elle fût, avait le défaut de l'avoir trop isolé, de lui avoir caché le train de la vie à son époque, qui, certes, n'est pas le train d'une ville de province : sa vraie destinée le menait plus haut (Honoré de Balzac, Le Cabinet des antiques)

1925 Voilà un rêve qui n'est guère pittoresque. Pourtant je le donne pour un de mes plus étranges. Il m’a hanté tout un jour et tout un jour À la recherche de cette secousse qui me fit l'égal confus de Dieu, j'essaie de bâtir une tour qui n’arrivera jamais à me mener si haut que cette fumée au goût de chair humaine. Notre sommeil coupé en deux, nous nous apercevons que l'esprit libéré ne s'enchaîne point toujours à ces soi-disant merveilles (René Crevel, Mon corps et moi)

1953 Comme au jour du déluge

Château des pauvres les pauvres

Dormaient séparés d'eux-mêmes

Et vieillissaient solitaires

Dans un abîme de peines

Pauvreté les menait haut

Un peu plus haut que des bêtes

Ils pourrissaient leur château

La mousse mangeait la pierre

Et la lie dévastait l'eau

Le froid consumait les pauvres

(Paul Éluard, Poésie ininterrompue) 
Emploi absolu

1860 Et le livre du baron de Puisignieux était moins la satisfaction d'une vanité littéraire qu'un essai de lui-même, que l'expérience d'un moyen, un pont jeté vers la politique, vers les affaires, une reconnaissance des chemins où l'on marche vite vers le crédit et l'influence, et où l'absence de préjugés peut mener si haut - ou si loin (Edmond et Jules de Goncourt, Charles Demailly)

CORPuS Web :

Le skate est une discipline artistique et sportive qui peut mener haut. A condition de savoir amortir sa chute [http://flblb.com/catalogue/ sleep-flip] (18.7.2015)

Ceux-ci se livreront une bataille acharnée qui devrait les mener haut dans la hiérarchie; dès lors, gare aux Cédric De Cecco, Gino Bux, Polle Geusens, Stijn Pacolet (tous sur Peugeot 208), et autres Adrian Fernemont et Amaury Molle (Ford Fiesta) [http://www.sparally.com/fr/node/115] (18.7.2015)

Audrey Le Floch (Stade brestois) aborde quatre semaines charnières de sa saison hivernale de cross-country. Quatre semaines qui pourraient la mener haut, très haut [http://www. ouest-france.fr/sport/running/bretagne/crosscountry-mais-jusquou-ira-audrey-le-floch3179685] (18.7.2015)

REMARQUES : Mener haut souligne le fait d'élever à un niveau plus haut un individu ou ses capacités morales, spirituelles ou intellectuelles. Il peut aussi référer aux conséquences positives entraînées par une action, un état. Notons la collocation mener haut, mener loin. Haut reste invariable et est modifié par si, plus. Notons la réduplication progressive haut, très haut.

\section{Mener large}

I. ne pas en mener large : être peu rassuré, être mal à l'aise, plein de crainte, d'inquiétude Intransitif

1879 Et lui, l'ami fidèle, même après sa victoire et pendant qu'on l'acclamait avec transport, il "n'en menait pas large » et semblait accablé de tristesse (Léon Cladel, Ompdrailles, le Tombeau-des -Lutteurs)
1930 Il s'est approché d'elle comme s'il avait voulu la prendre au lacet. Elle était encore devant ce morceau de colline toute sale, embousée de givre et de boue gelée devant les arbres nus et qui n'en menaient pas large (Jean Giono, Regain)

1933 Ils n'en mènent plus larges les cabotins couronnés de rage dorée, frais gantés de sang, ces sinistres grands premiers rôles d'une opérette tragique, ces majestés burlesques et cruelles dont les royaumes n'ont été rafistolés par les profiteurs de Sarajevo que pour servir de décors à des rêves de valse guerrière (René Crevel, Les Pieds dans le plat)

1957 Aïcha et les dogues descendent... personne mène large... tous s'écartent... et en silence ! (Louis-Ferdinand Céline, D’un château l'autre)

1976 C'étaient des fusils de communistes rapportés de Russie, et les Tartares avaient beau me peloter les fesses au lieu de me fusiller, je n'en menais pas large (Jacques Lanzmann, Le Têtard)

1995 Le 30 donc, vers trois heures de l'aprèsmidi, une voiture de poste partit pour Issoudun, emportant les voyageurs. Babet n'en menait pas large (Françoise Chandernagor, L'Enfant des Lumières)

II. (difficile à définir ; sans doute à connotation sexuelle)

Intransitif

1933 - Il te faudrait des femmes...

- Voilà que tu te montes la tête.

- Oui, des grosses qui en mènent large, hein ? (Marcel Aymé, La Jument verte)

1936 Ils en rugissaient en fauves... Elle prenait son pied... Robert il en menait plus large. On est descendus de notre tremplin. On est retournés à l'établi. On s'est tenus peinards... On avait voulu du spectacle... On était servis ! (Louis-Ferdinand Céline, Mort à crédit)

\section{CORPuS Web :}

Pourtant, malgré ce petit succès qui a mis les rieurs de son côté, il paraît ne pas en mener large 
[http://www.lemonde.fr/election-presidentielle2012/article/2012/04/12/et-philippe-poutoucreva-soudain-l-ecran_1684105_1471069.html] (26.7.2015)

Maryse Joissains ne doit pas en mener large ce soir, d'autant plus que la candidate frontiste se maintien... [http://www.laprovence.com/actu/ politique-en-direct/2812192/zoom-sur-les-troiscandidats-aixois-dans-le-1818.html] (26.7.2015)

Les entreprises sont également affectées dans leurs activités. Les caravanes rendent difficile l'accès pour les livraisons et le personnel dit ne pas en « mener large » à l'entrée et à la sortie du travail [http://magjournal77.info/2015/06/01/ mitry-mory-\%E2\%96\%BAcoup-de-gueule-desriverains-les-gitans-ca-suffit/] (26.7.2015)

REMARQUES : Ne pas en mener large (I) est une locution familière qui réfère à une situation particulièrement désagréable pour quelqu'un, qui ne permet pas d'avancer et de progresser, proche d'une impasse. Large connote donc encore son sens primitif d'abondance, d'ampleur, de plénitude. Il semble impossible de donner une définition claire pour les exemples sous (II) qui suggèrent, sans doute volontairement, d'en chercher l'interprétation sur un plan purement connotatif qu'il faut relier au domaine de l'équitation, à savoir, cavalier et monture. Large reste invariable et est modifié par plus. Notons l'emploi de ganter frais.

\section{Mener raide}

Mener, conduire de manière ferme et brutale ; traiter durement, sévèrement

Transitif

1538 Pour faire court, je ne sceu tant prescher Que ces paillars me voulsissent lascher. Sur mes deux bras ilz ont la main posée, Et m'ont mené ainsi qu'une espousée, Non pas ainsi, mais plus roide un petit (Clément Marot, Épitres)

1886 Lui, Jory, avait manqué d'avoir un duel, au café Baudequin, pour un de ses derniers articles du Tambour. C'est qu'il les menait raide, les peintres de quatre sous, les réputations volées! La campagne contre le jury du salon faisait un vacarme du diable (Émile Zola, L’Euvre)
1931 Cette fille-là se ballait bien d'eux. Pénétrée comme elle l'est de l'importance que son argent lui donne, elle a été enchantée d'en hériter. Je les ai menés raide, ses chers frères, et elle n'a pas l'air de trop m'en vouloir. Seulement, elle doit se venger, cela se doit ! Quelle farce que ces sentiments de convention qu'on apprend (Henri Pourrat, La Tour du Levant ou Quand Gaspard mit fin à l'histoire)

CORPUS Web :

Après quelques kilomètres, on atteint la Marina de Pevani, où se trouvent certaines villas avec des grands terrains directement sur la côte. Ca devient en fait intéressant à partir de maintenant, car la route fait un virage fort et mène raide en amont [http://www.paradisu.info/golfe-desagone.html] (26.7.2015)

Il n'a pas été frappé mais on l'a " mené raide ». On lui disait que c'était lui ou Gustave et que si Gustave était condamné il aurait droit «à la tête coupée ou à Cayenne » [http://www.samuel huet.com/lurs/63-laffaire-revue/1043-pour-enfinir-avec-laffaire-dominici-6.html] (26.7.2015)

REMARQUES : Souvent en rapport avec l'éducation, mener raide désigne le fait de traiter ou diriger quelqu'un, sans souplesse, en faisant preuve de rigidité et de rigueur. Il s'oppose à mener gent . Comme avec la plupart des adjectifs-adverbes en collocation avec le verbe mener, c'est la conduite $\mathrm{du}$ cheval et d'autres animaux qui sert de motivation. Dans le premier exemple du CW, mener raide réfère à une forte pente. Raide reste invariable et est modifié par plus. Notons aussi l'emploi du quantifieur vieilli un petit 'un peu' (ex. de 1538). Notons l'emploi de l'incise pour faire court.

\section{Mener soef}

Mener, conduire avec douceur, avec égard Transitif

1160 Amors, ge sui en ta baillie, An ton demoinne m'as saisie. Amors, des or me clain par toi, Amors, ne fere tel desroi ! Amors, soëf un po me moine ! [variante : plus soavet, II, p. 198] (Eneas, 8659) 
1177 Soef le menoie et atire

Aussi com el fëist son pere :

Tot le renovele et repere,

Tot le remue et tot le change

(Chrestien de Troyes, Lancelot ou Le Che-

valier de la charrete, 6686)

1200 Garins et Haymmes furent prou et sené, Lor seignor mainnent par la resne souef (Ami et Amile, 2574)

+1250 Tu qui es dou iou la pesance Apris per longue acostumance, Cel iuene locel soef moinne, Pou a pou li aprant la poinne (Ysopet de Lyon [2 $2^{\mathrm{e}}$ moitié $\left.\mathrm{XIII}\right]$ ], 2653)

Remarques : Mener soef désignait le fait de conduire quelqu'un en un lieu, de l'y accompagner, sans brusquerie, le conducteur faisant preuve de délicatesse et de douceur. À la différence de mener dur, gent, raide, droit, large, etc., mener soef appartenait au domaine du comportement envers des êtres chers. Soef reste invariable et est modifié par plus.

\section{Mentir bel (beau)}

Mentir habilement, adroitement

Intransitif

+1250 Donc dois regarder saigemant, Se la parole est fause ou uoire, Et touz iours dois en dotant croire. Garde iemais ne consentir A home qui bel sest mentir (Ysopet de Lyon [2 $2^{\mathrm{e}}$ moitié $\left.\mathrm{XIII}\right]$, 558)

1349 Eins en fui liez; s’en pris a rire, Et puis a celui pris a dire : Biaus amis, par merencolie M'avez tenté de moquerie De bourde, et de parole voire, Quant vous me donnastes a croire Ma dame loing par bel mentir (Guillaume de Machaut, Le Jugement dou roy de Navarre, 719)

1450 HERODE. Cela est menty bien et beau : Je mesmes l'ay fait descoller ; Par quoy jamais n'en fault parler. Mais, qui qu'il soit, cest homme saint Qu'en soy tant de vertuz empraint, $\mathrm{Si}$ voulentiers ne mengeroye
Que par devant moy le verroye

Pour la grant fame qui en court (Arnoul Gréban, Le Mystère de la Passion, 13114)

REMARQues : Mentir bel désignait le fait d'affirmer, de tenir pour vrai ce qu'on sait être faux ou bien de nier quelque chose de vrai, le sujet faisant preuve d'adresse et d'une certaine finesse pouvant aller jusqu'à la ruse dans la manière d'agir. Notons la collocation mentir bien et beau. Le neutre bel est évincé par le masculin beau à partir du moyen français. L'emploi dans l'exemple de 1450 se trouve à mi-chemin de la valeur moderne de bel et bien 'effectivement, contrairement à ce à quoi on pouvait s'attendre'. Dans l'exemple de 1349 , bel mentir est nominalisé.

\section{Mentir fort}

Mentir avec force et virulence

$\pi$ mentir haut

\section{Mentir gros}

Faire un énorme mensonge

Intransitif

1862 - Oh ! si ! Monsieur ! dit-elle, le cheval a $\mathrm{bu}$, il a bu dans le seau, plein le seau, et même que c'est moi qui lui ai porté à boire, et je lui ai parlé.

Cela n'était pas vrai. Cosette mentait.

- En voilà une qui est grosse comme le poing et qui ment gros comme la maison, s'écria le marchand. Je te dis qu'il n'a pas bu, petite drôlesse ! (Victor Hugo, Les Misérables)

1982 Qu'il y ait eu une noce, ah ça oui, ç’avait été un résultat, c'était visible, même si on ne pouvait pas dire sans mentir gros que ça avait rapporté ; c'était bien tout le contraire, avec tous les frais même partagés, et sans compter les voyages (Lucette Desvignes, Les Nouds d'argile)

\section{CORPUS WeB :}

J'en suis à me dire que le géant mentait gros comme le bras pour m'avoir plus facilement dans son lit [http://chroniquesdelachambreenbas. blogspot.com/2016/10/danser.html] (26.10.2016)

il savait tres bien que je mentais gros [https:// forum.doctissimo.fr/psychologie/amour/foirersujet_202552_1.htm] (19.5.2003) 


\section{Mentir haut}

Mentir ouvertement, publiquement

Intransitif

1701 Du soin d'aider le pauvre on dispensa l'avare ;

Et même chez les Rois le superflu fut rare.

C'est alors qu'on trouva pour sortir

d'embarras,

L'art de mentir tout haut en disant vrai tout bas.

C'est alors qu'on aprit qu'avec un peu d'adresse,

Sans crime un Prêtre peut vendre trois fois sa Messe

(Nicolas Boileau, Satires [1664-1701])

\section{CORPUS WEB :}

La bonne solution n'est pas forcément de crier sur tous les toits « ON NE PEUT PAS HYPNOTISER SANS CONSENTEMENT » alors qu'on sait pertinemment que c'est faux. Mentir haut et fort en allant jusqu'à m'insulter afin d'être sûr que le grand public reste ignorant, le tout pour conserver votre clientèle, ce n'est pas très garant de l'éthique non plus [http://www.transe-hypnose. com/sujet/hypnose-sans-etre-daccord.2039/ page-7] (26.7.2015)

Ceci s'adresse à celles ou ceux qui auraient encore envie de vomir des horreurs, de mentir haut et fort et de traîner des personnes qui n'ont rien à se reprocher, bien au contraire, dans un torrent de propos pestilentiels sortis tout droit du caniveau, lâches et d'une violence aveugle et inimaginable, mais les accusations gratuites ont un prix, maintenant il faut assumer et payer ! [http://affaireclopotel.unblog.fr/2010/07/12/ bonfils-sonja-condamnee-par-la-17emechambre-correctionnelle-du-tribunal-de-paris/] (26.7.2015)

Depuis plusieurs mois cette dérive ne semble pas émouvoir les pouvoirs publics beaucoup plus préoccupés par les élections que par les drames routiers. Ils laissent le champ libre aux opposants à la sécurité routière mentir haut et fort y compris dans l'enceinte de la représentation nationale [http://bougezautrementablois. over-blog.com/2014/05/1-objetif-moins-de-2000morts-sur-les-routes-en-2020-va-etre-difficile-aatteindre.html] (26.7.2015)
REMARQues : Mentir haut désigne le fait de dire pour vrai ce qu'on sait être faux ou nier quelque chose de vrai, le sujet l'affirmant à voix haute, publiquement. L'adjectif-adverbe haut suggère aussi l'idée d'assurance du sujet, renforcée par fort. Notons la collocation mentir haut et fort, qui est systématique dans le CW, ainsi que l'opposition de dire vrai tout bas avec mentir tout haut. Haut reste invariable et est modifié par tout. Notons l'emploi de dire vrai.

\section{Mesurer faux}

Mesurer mal, donner une fausse mesure Emploi absolu

1884 Vaut-il mieux mesurer juste que mesurer faux? (Cosmos - Les Mondes)

1974 «C'est faux. J'avais mesuré faux » (Jean Piaget, Réussir et comprendre)

\section{Mesurer juste}

I. Mesurer exactement

Transitif

1776 Tandis que dans le quart de cercle mobile, elle n'est la même qu'autant qu'elle est mesurée juste (André-Marie Ampère, Correspondance)

Emploi absolu

1990 L'eau est arrivée signifiait pour les enfants : la fête commence. Les grandes personnes, elles, l'abordaient sous l'angle utile, un peu préoccupées. Il fallait mesurer juste sinon on se retrouvait à mendier un peu d'eau à madame-une-telle pour achever quelque lessive (Patrick Chamoiseau, Antan d'enfance)

II. Avoir fait trop petit ou étroit

Transitif

1909 Ces femmes semi-jaunes, par un raffinement de coquetterie un peu décadente, sont jupées comme autrefois chez nous les Merveilleuses ; la soie du pagne qui leur serre les reins semble toujours mesurée trop juste et, pendant la marche, s'entrouvre pour laisser passer une jambe nue, très jolie avec sa couleur d'ambre (Pierre Loti, Les Pagodes d'or) 


\section{Mettre aise}

Installer confortablement

Transitif

+1200 Ensi remest cele chose. Li rois fist metre en une chambre de laiens le chevalier au plus aise qu'il pot, mais il ne vesqui que trois jours aprés, car trop mortelment l'avoit l'autres chevaliers feru

(Merlin $\left[1^{\mathrm{er}}\right.$ quart XIII $\left.{ }^{\mathrm{e}}\right]$, p. 177)

CORPUS WEB :

Le Bordel étant, comme le faisait gentiment remarquer le maire Adelie en profita pour aller vers l'orgue et se mit à jouer du Ray Charles. Tandis que même le maire se mettait aise en chopant une bouteille de bière et une part de gâteau [http://www.fanfic-fr.net/modules.php?name=F orums\&file=viewtopic \&t=862\&postdays=0\&pos torder=asc\&highlight=mariez+vous\&start=3390] (26.7.2015)

Vivre quelques siècles ? Voilà qui était pour le moins prometteur. Julien entendit à peine les remarques que Random faisait quant à la relativité de cette longévité, tant l'information le mettait aise [http://www.baldursgateworld.fr/ lacouronne/ambre/14077-julien.html] (26.7.2015)

Accompagné de deux gardes émeraudes, ils ne se séparaient jamais de lui complètement, ni lui d'eux à vrai dire, ils se mirent aise et d'aucuns pariaient sur le sexe de l'enfant à venir [http:// miradelphia.forumpro.fr/t16309-petite-visitefamiliale-pv] (26.7.2015)

REMARQUES : Mettre aise désigne le fait de placer, d'installer une personne à un endroit de façon à ce qu'elle se sente bien et souligne l'idée de commodité ou de confort matériel. Il disparaît dans Frantext, mais le CW montre que la langue informelle, éventuellement régionale ou archaïsante, ne l'a pas abandonné. Aise reste invariable et est modifié par au plus. Notons l'emploi pronominal du verbe dans le CW.

\section{Mettre bas}

I. Mettre à un rang peu élevé, à un niveau inférieur

Transitif

-1377 Mais partout ou elle s'embat, De ses gieus telement s'esbat Qu'en veinquant dit : Eschac et mat !
De fiere vois.

Einsi m'a fait, ce m'est avis,

Fortune que ci vous devis.

Car je soloie estre assevis

De toute joie.

Or m'a d'un seul tour si bas mis

Qu'en grief plour est mué mon ris,

Et que tous li biens est remis

Qu'avoir soloie (Guillaume de Machaut, Remède de Fortune, 1197)

1713 Vous voyez bien, poursuivis-je, que tout ce que nous avons prévû est arrivé : c'est à vous à voir si vous voulez être la victime du tems, et passer le plus beau de votre jeunesse dans l'attente que quelqu'un par pitié se déclare pour elle. Vous la mettez bien bas, me dit Célénie en riant, elle n'est pas d'une laideur à faire pitié, et quelqu'un sans doute la regardera avec d'autres yeux que vous (Robert Challe, Les Illustres Françoises)

1722 COLOMBINE. Décochez-lui moi quelque trait bien hétéroclite, qui sente bien l'original ! ah ! vous avez fait des merveilles d'abord.

LÉLIO. C'est assurément mettre les hommes bien bas, que de les juger indignes de la tendresse d'une femme : l'idée est neuve.

COLOMBINE. Elle ne fera pas fortune chez vous.

LÉLIO. On voit bien que vous êtes fâchée, Madame

(Pierre de Marivaux, La Surprise de l'amour)

1793 au lieu que les autres en sont privés indéfiniment, et ne peuvent les [= les droits du citoyen] recouvrer que sous une condition qui n'est point en leur pouvoir. Juste ciel ! Le génie et la vertu mis plus bas que l'opulence et le crime par le législateur ! (Maximilien de Robespierre, Discours)

1825 J'ai pardonné à tout le monde, et, gardant toujours la même indulgence, je m'abandonne à la fortune, content qu'elle ne me mette jamais trop haut ni trop bas. Ma position actuelle n'est pas désagréable, je suis 
bien payé, peu occupé. Je ne désire rien de mieux. La peste règne aux environs

(Paul-Louis Courier, Lettres écrites de France et d'Italie)

1852 Si je sais comment je vais sortir de ces 6 000 f. je veux être pendue. Avouez que j’ai du malheur dans tout ce que j'entreprends et que ce qui doit me sauver me met toujours plus bas. Je porte ma pièce nouvelle à Montigny qui me l'a demandée. Mais je ne sais quelles conditions faire avec lui (George Sand, Correspondance)

1907 L'intelligence n'étant plus suspendue à rien, tout se suspend alors à elle. Et ainsi, pour avoir placé l'entendement trop haut, on aboutit à mettre trop bas la connaissance qu'il nous donne. Cette connaissance devient relative, du moment que l'intelligence est une espèce d'absolu (Henri Bergson, L'Évolution créatrice)

1948 Un rien humiliait Divine. De ces humiliations qui, Culafroy encore, la mettaient plus bas que terre, par le seul pouvoir des mots. Les mots reprenaient avec leur prestige de boîtes, en fin de compte vides de tout ce qui n'est pas le mystère (Jean Genet, Notre-Dame-des-fleurs)

1987 En lui balançant des pièces de un centime, s'il faut faire un dessin, on assimilait ce triste sire - pauvre con, corbeau : il s'appelait Corbiack - à un mendigot. On le mettait plus bas que le trottoir. On l'humiliait comme seuls les sales morpions savent humilier : à mort. C'étaient les « Concertos pour jaunets, couacs et topinambours » (Bruno Bayon, Le Lycéen)

Pronominal

1652 Fais que contre toi-même un saint zèle t'enflamme

D'une juste indignation, Pour étouffer soudain ce qui naît dans ton âme

De superbe et d'ambition ;

Désenfle-la si bien qu'elle soit toujours prête

À voir que chacun sur ta tête

Par un dernier mépris ose imprimer ses pas,
Que le plus rude affront n'ait pour toi rien d'étrange,

Et qu'alors qu'on te traite à l'égal de la fange,

Tu te mettes encor plus bas

(Pierre Corneille, L'Imitation de Jésus-Christ)

1660 Je me mets si bas de moy-mesme,

Qu'à m'abaisser encor vostre pouvoir

supréme

Ne pourra se resoudre, ou ne le voudra pas, Je ne suis à mes yeux que foiblesse et

misere,

Qu'un souffle decevant, qu'une vapeur

legere,

Pourrois-je descendre plus bas?

(Georges de Brébeuf, Entretiens solitaires)

1878 Qu'on soit la lune d'un soleil, très bien ; mais l'être d'un lampion comme Vitet, c'est se mettre plus bas que les chandelles à 36. Ah ! Pauvre littérature, où sont tes desservants ? Qui aime l'art, aujourd'hui ? Personne. (Voilà ma conviction intime.) (Gustave Flaubert, Correspondance)

1881 Ensuite, il faudrait acquérir les vertus, premièrement l'humilité, - c'est-à-dire se croire incapable de tout mérite, indigne de la moindre récompense, immoler son esprit, et se mettre tellement bas que l'on vous foule aux pieds comme la boue des chemins (Gustave Flaubert, Bouvard et Pécuchet)

1926 Au contraire. Et c'est cette escorte nulle et tintamarresque que vous attaquez pour essayer de détruire une chose nouvelle qui existe! Ainsi vous vous mettez plus bas que ceux que vous attaquez Au lieu de chercher dans la lumière la valeur éclatante qui jaillira plus tard et sans vous, vous ne voulez voir que les larves qui grouillent dans la pénombre en essayant de faire un misérable bruit (Pierre Reverdy, Écrits sur l'art et la poésie)

1963 les autres qui s'épient s'expliquent se justifient se légitiment qui se frappent la poitrine qui se vident le cendrier sur la tête qui se psychanalysent les urines qui se noient dans la cuvette qui se donnent 
en exemple et qui ne se prennent pas avec des pincettes les autres qui s'accusent qui se mettent plus bas que terre qui s'écrasent sur eux-mêmes et qui s'excusent de vivre (Jacques Prévert, Histoires)

II. mettre bas quelqu'un : mettre quelqu'un à terre, faire tomber quelqu'un. Intransitif

1465 Firebras frappa Olivier sur le heaulme sy durement que jusques a la cher il mist tout bas, et se Dieu n'y eust ouvré, il estoit mort a celle foys (Jehan Bagnyon, L'Histoire de Charlemagne, p. 61)

Transitif

1550 Las Seigneur, je t’ay offencé. O Dieu qui as faict ciel et terre, A qui veux tu faire la guerre? Me veux tu donc mettre si bas? Helas mon filz, helas, helas !

Par quel bout doy-je commencer?

La chose vault bien le penser (Théodore de Bèze, Abraham sacrifiant)

1555 ENEE. De la foy des amans les Dieux ne font que rire.

LE CHCEUR. La pitié ne peut mettre la pitié bas.

ENEE. La pitié m’assaut bien, vaincre ne me peult pas

(Étienne Jodelle, Didon se sacrifiant)

1625 PHERORE. Sire, vous surmontez l'honneur de vos combats

En ce Monstre impudent à ceste heure mis bas.

L'utilité, conjointe à si belle victoire, Deviendra par les ans plus belle et plus notoire (Alexandre Hardy, Mariamne)

1829 Chasseur, par ta meute surprise, La bête pleure ; on lui répond : Tonton, tonton, tontaine, tonton. Ta femme, aux abois déjà mise, Sourit aux efforts du fripon. Tonton, tontaine, tonton. Chasseur, un seul coup de ton arme Met bas le cerf sur le gazon. Tonton, tonton, tontaine, tonton (Pierre-Jean de Béranger, Chansons)
III. Déposer, abaisser, enlever (quelque chose que l'on porte)

Transitif

1534 Ce disant, mist bas son grand habit et se saisist du baston de la croix, qui estoyt de cueur de cormier, long comme une lance, rond à plain poing et quelque peu semé de fleurs de lys, toutes presque effacées (François Rabelais, Gargantua)

1668 Un pauvre Bûcheron tout couvert de ramée,

Sous le faix du fagot du fagot aussi bien que des ans

Gémissant et courbé marchait à pas pesants,

Et tâchait de gagner sa chaumine enfumée. Enfin, n'en pouvant plus d'effort et de douleur,

Il met bas son fagot, il songe à son malheur :

Quel plaisir a-t-il eu depuis qu'il est au monde ? (Jean de La Fontaine, La Mort et le bûcheron / Fables)

1740 L'heure du souper étant venue, satyre et faune dressèrent la table ; mais comme l'un n'étoit pas moins foible que l'autre et mal-adroit, la fière Junon et la sage Minerve furent obligées de prêter leurs divines mains. Cupidon même, je veux dire Robillard, laissa dans un coin Pâris avec Vénus sa mère, et mettant bas flêches et carquois accourut à notre secours (Jacques de Varenne, Mémoires du chevalier de Ravanne)

1869 M. de Comaing tenait une canne. Il y eut un silence. On se regarda. Toutes les figures avaient quelque chose d'effaré ou de cruel. Frédéric avait mis bas sa redingote et son gilet. Joseph aida Cisy à faire de même ; sa cravate étant retirée, on aperçut à son cou une médaille bénite. Cela fit sourire de pitié Regimbart (Gustave Flaubert, L'Éducation sentimentale)

1918 Bien qu'il eût mis bas sa veste, il transpirait comme je ne sais quoi, et par instants, tombait vertement sur Rout ou sur moi à propos de ceci ou de cela qui ne marchait 
pas tout à fait à son idée (André Gide, Typhon)

IV. mettre bas les armes : déposer les armes, capituler

Transitif

1574 LE MESSAGER. Mais las ! desia Cesar de malheur l'occupoit,

Doncques desesperez de se pouvoir defendre,

Mettant les armes bas offrirent de se rendre Au gendarme espandu, qui d'un cœur endurci

Les aima mieux tuer que les prendre à merci (Robert Garnier, Cornélie)

1601 Je collige de ce commandement que le Prince ne se fie plus, qu'il me veut sacrifier après que j'auray posé mes défences et mis les armes bas, avant qu'entrer au champ de ma justification. Je m'imagine néantmoins que je doibs tout essayer (René de Lucinge, Les Occurrences de la paix de Lyon)

1824 Dans ces circonstances, quelques hommes sages et amis de leur pays proposèrent au roi d'ordonner aux deux partis de mettre bas les armes ; s'ils s'y refusaient, de lever l'oriflamme et d'appeler près de lui tous ses fidèles sujets pour venger et défendre son autorité (Prosper de Barante, Histoire des ducs de Bourgogne de la maison de Valois)

1939 De fait, l'armée franque, entourée par la crue et sans vivres sur l'étroite chaussée où elle avait dû mettre bas les armes, tombait d'inanition (René Grousset, L'Épopée des croisades)

V. Abandonner (une idée, un avantage), se désintéresser (de quelque chose : préjugés, façons de faire, règles)

Transitif

1602 De ce lieu, il envoya quatre messagers vers son pere, luy dire : qu'il estoit prest de mettre bas tous honneurs, pour luy requerir pardon de ses fautes : le priant de pardonner à ceux qui l'avoient suivy, tellement qu'ils ne fussent plus recherchez par justice (Claude Fauchet, Déclin de la maison de Charlemagne)
1625 CORIOLAN. Dessus ceste asseurance à toy je me decelle,

Moy, qui porte le nom d'une haine mortelle Vers les Volsques jadis exercez aux combats ;

Coriolle le sçait, que ma vertu mist bas,

D'elle je fus nommé, c'est moy-mesme, Amfidie,

Que les miens possedez d'ingrate perfidie Recompensent felons d'un exil vergongneux (Alexandre Hardy, Coriolan)

1734 FRONTAIN. Et vous, aussi ravissante qu'hypocrite ; mettons bas les façons, vivons à notre aise. Tiens, je t'aime, je te l'ai déjà dit, et je le répète ; tu m’aimes, tu ne me l'as pas dit, mais je n'en doute pas ; donne-toi donc le plaisir de me le dire, tu me le répéteras après, et nous serons tous deux aussi avancés l'un que l'autre (Pierre de Marivaux, La Méprise)

1830 - Oh ! Trente gaillards qui s'entendraient... et mettraient bas les préjugés comme M. Kernock !

(Honoré de Balzac, Correspondance)

VI. Mettre ses petits au monde

Emploi absolu

1753 le temps le plus ordinaire de la chaleur est le mois de mai et celui de juin : lorsqu'elle [= l'ânesse] est pleine, la chaleur cesse bientôt ; et dans le dixième mois, le lait paraît dans les mamelles. Elle met bas dans le douzième mois, et souvent il se trouve des morceaux solides dans la liqueur de l'amnios, semblables à l'hippomanès du poulain (Georges-Louis Leclerc de Buffon, L'Âne)

1839 La mer couvrit la mer, mer sans rivages ! Dans les palais, où peu auparavant régnait le luxe, les monstres marins mirent bas et s'établèrent. Du genre humain naguère si nombreux, tout ce qui reste surnage embarqué dans un petit vaisseau (François de Chateaubriand, Le Paradis perdu)

1874 Vers cette époque, l'onagga femelle mit bas un petit qui appartenait au même sexe que sa mère, et qui vint à merveille (Jules Verne, L'Tlle mystérieuse) 
1906 Et ce troupeau sur lequel les boers s'exerçaient à tirer au canon et qui, sous le feu, s'était accru d'une tête, car une vache avait mis bas ? Et ce capitaine prisonnier qui devint fou quand on lui enleva sa chemise et ses bottes ? (Jérôme et Jean Tharaud, Dingley, l'illustre écrivain)

1942 Quand elle était pleine, il redoublait pour elle d'attentions et, dès qu'elle avait mis bas, il montait pour ainsi dire la garde devant sa niche qui, pour la circonstance était transférée sous la fenêtre, c'est-à-dire sous son regard même (Louis Guilloux, Le Pain des rêves)

Transitif

1902 Supposez maintenant Zola mis bas par Nana ou n'importe quelle autre truie de ses romans, et demandez-vous ce qu'il faudrait croire d'un peuple où l'on trouverait des sages-femmes ou des accoucheurs pour de tels enfants! (Léon Bloy, Exégèse des lieux communs)

1921 Le renard n'ose point l'attaquer. Car si le blaireau ne provoque personne, il se défend dangereusement. Nul carnassier de nos climats n'en vient à bout. Ne pouvant ni courir ni bondir, il se renverse sur le dos, mord et griffe. Ses ongles puissants labourent son adversaire ; ses dents lui font des blessures cuisantes. Le renard ruse donc avec lui. Il en veut à son terrier, où il met bas et élève sa portée. Sournoisement, lorsqu'il le sait absent, il y pénètre. Il inspecte, il choisit son gîte et... s'oublie abondamment. La puanteur est insupportable (Joseph de Pesquidoux, Chez nous : travaux et jeux rustiques)

VII. Fatiguer beaucoup, aggraver l'état

physique, affaiblir

Transitif

1830 J'ai reçu votre lettre depuis quelques jours, ma chère petite maman et j'y aurais répondu tout de suite sans un nouveau dérangement de santé qui m'a mise assez bas. Je souffre beaucoup de la poitrine, je ne puis respirer et aujourd'hui pour m'achever de peindre j'ai un point de côté qui fait que je marche tout de travers (George Sand, Correspondance)

1832 Il y a bien longtemps que je me sens décliner, je n'osais pas le dire, je n'osais pas y penser, des lueurs de santé, des mois d'embonpoint et de force me rendaient l'espoir de durer encore un peu mais chaque rechute me met plus bas. Il faut bien que vous le sachiez et que vous veniez à mon aide. Je ne suis pas dans l'âge où l'on meurt. Et si quelqu'un au monde peut me guérir c'est vous (George Sand, Correspondance)

1906 Les amitiés d'hommes sont des collaborations d'idées. Tigrane m'adressait les documents de sa vie publique, il ne m'écrivit rien d'une pleurésie qui, dans l'été de 1897, le mit très bas (Maurice Barrès, Le Voyage de Sparte)

VIII. se mettre bas : se baisser

Pronominal

1859 Je cueillis trois œillets. Je les lui donnai et lui dis : «C'est ton parfum. Je ne savais pas jusqu'ici ce que sentait ma femme. -quoi ! dit-elle, le clou de girofle? - Quoi ! dit-elle, le clou de girofle?»

J'étais plein de désirs. J'espérais qu'elle serait seule sur la hauteur et je m'étais mis plus bas, pour faire ma dévotion à la chère fontaine d'amour. Elle me dit avec douceur : je ne sais rien refuser. Mais ne vois-tu pas ces gens (les ouvrières de la briqueterie) ? (Jules Michelet, Journal)

IX. mettre tout bas au courant : informer (quelqu'un) à voix basse, en chuchotant Intransitif

1880 On ajoutait que le jury des courses allait s’assembler. Nana, que Philippe et Georges mettaient tout bas au courant, lâchait des réflexions, sans cesser de rire et de boire (Émile Zola, Nana)

\section{CORPUS WEB :}

Si votre chienne est sur le point de mettre bas, restez calme! [http://www.purina.fr/chiens/ nouveau-compagnon/gestation-chienne/pre parer-mise-bas.aspx] (26.7.2015) 
Ma drago femelle Orchidée/pourpre niveau 38 ne veut pas mettre bas, même après que les 108 heures se soient écoulées (puisque elle est au stade 6, le tps de gestation est 108 heures -source- dans la rubrique " accouplement de dindes ») [http://forum.dofus.com/fr/1028-sujetsfermes/393128-ma-dragodinde-veut-mettre-bas] (26.7.2015)

Je pensais au début mettre tout dans la force, et dans la constitution pour avoir plus de rounds de rage et laisser le reste à 10. Mais comme j'ai vu que pas mal de dons de combats nécessitaient une bonne dex, je me demande à présent si mon choix était bon. Sachant qu'il ne faudrait peut être pas non plus négliger la sagesse, je comptais la mettre bas au début (après tout, un barbare sage...hein, on s'est compris) mais j'ai vu après coup que c'était utile pour la perception [http://www.pathfinder-fr.org/ Forum/yaf_postst7863_Conseil-pour-creationde-barbare.aspx\#post308815] (26.7.2015)

si tu veux juste rouler ce sera plus agréable de mettre ta selle haute mais si tu veux faire $\mathrm{du}$ trial tu as plutot interet a la mettre basse comme ça normalement tu pourra sauter plus haut [http://forum.monocycle.info/viewtopic. php?p=34655] (26.7.2015)

REMARQues : Mettre bas (I) se dit du fait de rabaisser quelqu'un moralement ou socialement, de le mettre dans une situation grave, voire dégradante. Dans une lutte armée, (II) renvoie au fait de vaincre, de tuer, d'abattre son adversaire ou de détruire, d'anéantir quelque chose (par exemple, un empire). (III) se dit du fait d'ôter un vêtement ou de déposer ses armes. Dans un contexte de guerre, (IV) réfère à la capitulation face à l'adversaire, les troupes rendant les armes. (V) désigne également le fait de renoncer à quelque chose, à l'avantage que peut procurer un statut, souvent par désintérêt ou pour montrer son désaccord. Il peut aussi signifier la volonté du sujet de mettre de côté ses ambitions ou intérêts personnels pour le bien d'autrui. (VI) s'emploie à propos d'animaux : le sujet désigne alors un animal qui met au monde ses petits. Dans un langage plus trivial le sujet peut aussi renvoyer à un être humain. (VII) souligne le fait d'affaiblir quelqu'un, de le priver de forces, l'état de santé du sujet étant mauvais. (VIII) désigne le mouvement du corps du sujet vers le bas, se penchant vers le sol. (IX) renvoie au fait de dire quelque chose à quelqu'un à voix basse. Notons la collocation ne mettre jamais trop haut ni trop bas et les structures comparatives mettre plus bas que terre, ou mettre plus bas que le trottoir. Bas reste invariable dans la majorité des cas, mais dans le dernier exemple du CW il s'accorde avec l'objet au féminin, en se référant à sa position basse (ou haute). Dans cet emploi, il fonctionne comme prédicat second orienté vers l'objet. Bas est modifié par assez, bien, (encore) plus, tellement, toujours plus, tout, très, trop, si.

\section{Mettre court}

mettre court à quelque chose : finir quelque chose promptement

$\lambda$ enfler gros

\section{Mettre droit}

I. Poser, positionner quelque chose / quelqu'un selon une ligne droite

Transitif

+1350 Tout ainsi que Bruians chevauchoit ou chemin,

Par dedens sa litiere, et que doy fort romcin Le portoient en air, sans noisse et sans hutin,

Il s'est fait metre jus droit par desous .i. pin Qui estoit a un lés acostes d'un sapin, Et a l'autre costé avoit .i. aubespin (Brun de la Montaigne [ $2^{\mathrm{e}}$ moitié $\left.\mathrm{XIV}^{\mathrm{e}}\right], 2674$ )

1357 Adont li angles, sans attendre, L'ala parmi les cheveus prendre

Et le porta, c'est verité, En Babiloinne, la cité, Et le mist droit dessus le lieu Ou Daniel fu en milieu Des set lions qui desiroient A mengier, car grant fain avoient (Guillaume de Machaut, Le Confort d'ami, 1157)

+1365 Volentiers les lettres lisi

Et à celles je rescripsi,

Mès ains que face mention

Nulle de ma rescription,

Je vous dirai son virelai

Quels il fu, car droit chi mis l'ai

(Jean Froissart, Poésies [3 $3^{\mathrm{e}}$ tiers XIVe]) 
1559 Et vindrent mectre leur oreille tout droict au chevet du lict du mary, lequel, ne se doubtant de ses hostes, parloit à sa femme privement de son mesnage (Marguerite d'Angoulême, Heptaméron, p. 305, 8)

1736 Cependant Phocion, si vous pouviez me revenir voir dans quelques tems, par exemple dans le carnaval, je vous ferai bonne chere, et vous verrez alors sur quel pied ma maison ira ; si elle est aussi boiteuse que vous l'avez trouvée, vous êtes le redresseur et vous saurez bien la mettre droite (Pierre de Marivaux, Le Télémaque travesti)

1845 Le soin excessif de sa toilette, des bottines de velours, une collerette de dentelles, le châle mis droit, tout attestait la sollicitude de Modeste pour sa mère. Quand le moment de silence, annoncé par le notaire, fut établi dans ce joli salon, Modeste, assise près de sa mère et brodant pour elle un fichu, devint pendant un instant le point de mire des regards (Honoré de Balzac, Modeste Mignon)

1846 Son aspiration nasale fit probablement rendre une sourde harmonie au bois sonore, et alors l'orang-outang hocha la tête, il tourna, retourna, haussa, baissa le violon, le mit tout droit, et l'agita, le porta à son oreille, le laissa et le reprit avec une rapidité de mouvements dont la prestesse n’appartient qu'à ces animaux (Honoré de Balzac, Physiologie du mariage)

1859 - Méchante ! Quelle méchanceté vous a-telle faite?

- Pas à moi précisément ; mais vous allez voir. Nous nous étions mis à quatre pour la [= la statue] dresser debout et $\mathrm{M}$. de Peyrehorade, qui lui aussi tirait à la corde, bien qu'il n'ait guère plus de force qu'un poulet, le digne homme ! Avec bien de la peine nous la mettons droite. J'amassais un tuileau pour la caler, quand, patatras! la voilà qui tombe à la renverse tout d'une masse. Je dis : Gare dessous! Pas assez vite pourtant, car Jean Coll n'a pas eu le temps de tirer sa jambe... (Prosper Mérimée, La Vénus d'Ille)
1919 Les esclaves noirs saisirent le corps. En quelques instants ils eurent glissé le fantôme d'orichalque dans sa gaine de bois peint. Celle-ci, mise droite, fut placée dans sa niche, à côté de la niche où une gaine toute pareille portait l'étiquette numéro 52. Puis, leur tâche achevée, sans mot dire, ils se retirèrent (Pierre Benoît, L’Atlantide)

1966 Mais choisir une voie autre que la plus directe ou mettre exprès de travers ce qu'il serait normal de mettre droit, n'est-ce pas le propre de l'art, qui n'aurait vraiment commencé que quand on s'est permis d'ajouter un surplus ou de donner quelques entorses aux formes exigées par les nécessités d'une technique ou d'un rituel (Michel Leiris, La Règle du jeu 3 : Fibrilles)

1974 Je l'envoie aux pelotes. Mais quand c'est un beau garçon, je m'arrange toujours pour me frotter contre lui. Pour jouer. Le prétexte, c'est de lui prendre la tête pour la mettre droite ou de régler le siège tournant à la bonne hauteur. Le jeune homme brun est venu trois fois, la semaine dernière. Il ressemble à Tony Curtis quand il était plus jeune (Jean Vautrin, Billy-Ze-Kick)

II. Se maintenir, être positionné droit Pronominal

1668 Si quelque matière dure Vous menace d'aventure, Entre deux je passerai, Et du coup vous sauverai. Cette offre le persuade. Pot de fer son camarade Se met droit à ses côtés.

Mes gens s'en vont à trois pieds, Clopin-clopant comme ils peuvent, L'un contre l'autre jetés, $\mathrm{Au}$ moindre hoquet qu'ils treuvent (Jean de La Fontaine, Le Pot de terre et le pot de fer / Fables)

1851 Il fallut me faire courage et marcher, comme si je n'avais rien entendu ou rien vu, vers l'entrée de la planche. Quand j'en fus tout près et que je levai mes yeux baissés sur le bout de mes souliers, je vis Denise qui s'était mise droit devant moi à l'entrée du pont de bois, et qui me barrait 
le passage avec son corps (Alphonse de Lamartine, Le Tailleur de pierre de SaintPoint)

1861 Ils approchaient paisibles, curieux, regardant le vaisseau comme un frère d'espèce nouvelle ; ils y prenaient plaisir, faisaient fête au nouveau venu. Dans leurs jeux ils se mettaient droits et retombaient de leur hauteur, à grand fracas, faisant un gouffre bouillonnant. Leur familiarité allait jusqu'à toucher le navire, les canots (Jules Michelet, La Mer)

1908 Ce que j'avais fait une fois pour le plaisir, il voulait que je le fisse tant qu'il lui plairait. Je me mis bien droit, et je dis :

- Non! Vous entendez? Non, non, encore non!

- Allons, fit-il, nous en recauserons. Il est tout à fait inévitable que nous en recausions ! (Pierre Mille, Barnavaux et quelques femmes)

III. (Se) mettre directement (dans le bon chemin, à faire quelque chose)

Transitif

1877 - Faut pas gronder, la bourgeoise, dit le zingueur. Nous sommes sages, tu vois... oh ! Il n’y a pas de danger avec lui ; il vous met droit dans le bon chemin.

Et il raconta comment ils s'étaient rencontrés rue Rochechouart (Émile Zola, L'Assommoir)

Pronominal

1928 ANDOCHE. (À ce moment, un bâillement sonore s'élève de la chambre de la Bique)

Ah, ah, ah !... V'là not'viell' drouine qui s'aveille, et qui s'met tout droit n'à chanter, tell' qu'un'poule qu'a pondu son œuf ! (Roger Martin du Gard, La Gonfle)

\section{CORpus Web :}

je suis alle chez euromaster 2 fois de suite car mon volant apres avoir fait la geometrie n'etait pas droit. et il n'est toujours pas droit, il est un peu a gauche vraiment un peu en ligne droite (la voiture ne tire pas) Est ce que je peux le mettre droit en devissant un peu la rotule de direction cote conducteur et en vissant celle passa- ger [http://www.cyberbricoleur.com/index.php? showtopic=2100128203] (27.7.2015)

Si le phasme est en danger, ou poursuivi par un prédateur il peut allonger ses pattes le long de son thorax et se mettre droit [http://primatice. net/defis/phasmes/phasmes_2.htm] (27.7.2015)

Quand la jument est attelée, elle a tendance à marcher un peu comme une personne saoule, il faut toujours la mettre droit... aussi, elle secoue sa tête... ce qu'elle ne fait pas montée [http://www. chevalannonce.com/forums-8570318-morsattelage] (27.7.2015)

La façon la plus simple de reproduire la douleur, je suis assit sur ma chaise, et je déplis la jambe pour la mettre à 180 degrés (pour la mettre droite devant moi) [http://www.courseapied.net/ forum/msg/115019.htm] (27.7.2015)

REMARQUES : Mettre droit (I) se dit du fait de positionner quelque chose de façon bien alignée, ou de mettre quelque chose ou quelqu'un directement, de façon exacte à un endroit précis, soulignant le caractère ordonné du sujet. Dans (II), le sujet désigne une personne qui prend une position droite, qui n'est ni courbé, ni voûté, qui se tient bien. (III) se rapproche des sens directionnel ou temporel de 'direct'. Droit peut s'accorder avec le sujet du verbe pronominal ou avec l'objet du verbe transitif. Dans ces cas-là, il fonctionne en tant que prédicat second orienté vers le sujet ou vers l'objet. On est tenté d'expliquer l'absence de l'accord dans l'exemple de 1851 par le passage de droit du groupe verbal (mettre droit) au groupe prépositionnel (droit devant), mais le dernier exemple du CW offre un contre-exemple. Droit est modifié par bien, jus, tout. Notons l'emploi de venir nouveau.

\section{Mettre haut}

I. Mettre à un rang élevé, à un niveau supérieur (moralement ou socialement)

Transitif

1325 Chascuns y œvre à sa devise, Luxure y est si haute mise, Que s'elle yert royne ou contesse (Watriquet de Couvin, Dits, p. 352, 303)

1340 Mais quant Fortune, La desloial, qui n'est pas a tous une, M'ot si haut mis, com mauvaise et enfrune, 
Moy ne mes biens ne prisa une prune ;

Eins fist la moe,

Moy renoia et me tourna la joe,

Quant elle m'ot assis dessus sa roe,

Puis la tourna, si cheï en la boe

(Guillaume de Machaut, Le Jugement dou

roy de Behaingne, 686)

1365 Quar sire tu es toute mon esperance. tu ais mis tres hault ton refuge (Psautier lorrain, p. 94)

+1400 Tout avez de luy ; mieulx ne pouez emploier vostre amour, ne vostre cuer plus ne si hault mettre ; nulle chose n'est digne d'estre amee de tout vostre cuer et vertu que luy, vous mesmes ne aultruy

(Nouvelles françaises du $X V^{e}$ siècle, p. 129)

1582 AYMON. Je sçay mieux que vous deux quel espous il luy faut.

RENAUD. Voire pour l'elever, pour la mettre bien haut.

J'aimerois mieux, ma sœur, que la mort violente

Vous eust percé le cœur d'une darde

poignante,

Qu'une lance Arabesque eust ouvert vostre

flanc (Robert Garnier, Bradamante)

1643 FÉLIX. Mais si, par son trépas, l'autre épousoit ma fille,

J'acquerrois bien par là de plus puissants appuis,

Qui me mettroient plus haut cent fois que je ne suis (Pierre Corneille, Polyeucte)

1649 À les parcourir tous selon l'ordre et le temps Et monstrer ce qu'il fut dés l'âge de vingt ans,

Vos langues et vos voix n'y pourroient pas suffire.

Je ne mets pas si haut la faveur où j'aspire. Racontez seulement les plus dignes emplois

Dont il a signalé la gloire des françois (Claude Malleville, Euvres poétiques)

1664 Il faut de la prudence, il faut de la lumière, Il faut de la vigueur adroite autant que fière,
Qui pénètre, éblouisse, et sème des appas...

Il faut mille vertus enfin qu'il n'aura pas.

Lui-même il nous priera d'avoir soin de l'empire,

En saura seulement ce qu'il nous plaira dire :

Plus nous l'y tiendrons bas, plus il nous mettra haut (Pierre Corneille, Othon)

1761 mais ici, où toute la morale est un pur verbiage, on peut être austère sans conséquence, et l'on ne serait pas fâché, pour rabattre un peu l'orgueil philosophique, de mettre la vertu si haut que le sage même n'y pût atteindre (Jean-Jacques Rousseau, La Nouvelle Héloïse)

1773 On sent bien qu'en leur parlant à euxmêmes, il n'étoit guère possible de les mettre moins haut. L'orateur et le panégyrique, comme cela devoit être, avoient beaucoup de célébrité un jour ou deux ; et le lendemain, comme cela devoit être encore, personne n'y pensoit (AntoineLéonard Thomas, Essai sur les éloges)

1838 Encore une aberration de cet esprit irrégulier (le moins critique des hommes), qui n’a jamais su juger ni lui-même, ni les autres. Il mettait fort haut cette traduction et le poëme lui-même, et l'une et l'autre me semblent médiocres (Jules Barbey d'Aurevilly, Premier Memorandum)

1842 La nationalité polonaise, par l'effet d'une odieuse réaction gouvernementale, était alors tombée aussi bas que les républicains la voulaient mettre haut. La lutte étrange du Mouvement contre la Résistance, deux mots qui seront inexplicables dans trente ans, fit un jouet de ce qui devait être si respectable (Honoré de Balzac, La Fausse Maîtresse)

1845 Néanmoins le jeune duc aimait les femmes ; mais il les mettait trop haut, il les respectait trop, il les adorait, et il n'était à son aise qu'avec celles qu'on ne respecte pas. Ce caractère l'avait conduit à mener une vie en partie double (Honoré de Balzac, Modeste Mignon) 
1853a Si tu veux d'autres exemples qui prouvent que la misère et les autres pièges tendus sous nos pas ne doivent rien arrêter, tu te rappelles bien ce pauvre garçon dont vous admiriez les eaux-fortes, que vous mettiez aussi haut que Rembrandt, et qui aurait été loin, disiez-vous, s'il n'avait tant souffert de la faim (Champfleury, Les Aventures de mademoiselle Mariette)

1853b LE NOTAIRE. Tout le bien maternel : dix mille écus de rente.

M. MERCIER. Je comptais sur le triple ; enfin, je m'en contente.

On peut, à la rigueur, vivre avec ce qu'il a, Et je ne suis pas homme à rompre pour cela.

- Ce que je mets, monsieur, plus haut que la richesse,

C'est la bonne conduite et la délicatesse.

LE NOTAIRE. Vous avez bien raison

(François Ponsard, L'Honneur et l'argent)

1894 Chacun voulut définir le vrai Napoléon. Le comte Martin, en face du surtout impérial et des victoires ailées, parla avec convenance de Napoléon organisateur et administrateur et le mit très haut comme président du Conseil d’État, où sa parole portait la lumière sur les points obscurs (Anatole France, Le Lys rouge)

1902 C'est un point à mettre violemment en lumière ; j'appartiens à une nation qui a mis très haut la notion de l'honneur. On va contre l'honneur, dont j'ai un sentiment très fort, si l'on m'invite à accepter une loi à laquelle je ne suis pas identifié (Maurice Barrès, Mes cahiers)

1906 Aujourd'hui nous savons un fait, c'est que nous ne possédons que des morceaux de boutique, des répliques commerciales. Une seule statue authentique est venue jusqu'à notre âge parmi celles que l'antiquité mettait réellement très haut : l'Hermès de Praxitèle à Olympie (Maurice Barrès, Le Voyage de Sparte)

1908 Toutefois, il confiait - à Christophe, toujours, - que, si haut qu'il mît l'art, il plaçait encore plus haut l'art dans la vie, l'action, et que s'il avait eu le choix du rôle à jouer, il eût choisi Bismarck (Romain Rolland, Jean-Christophe. La Foire sur la place)

1913 DENIS. Je sais bien ! C'est une sorte de folie...d'ailleurs, ça ne dure pas, ce sont des bouffées. Après viennent les remords... des remords affreux !... car tout ce que j'ai exprimé tout à l'heure était sincère, je vous le jure, madame ! Je respecte Mme Hozleur, je la mets si haut ! Et pourtant... ah ! C'est effrayant...

GABRIELLE. En effet, c'est effrayant. Je crains que vous ne rendiez mon amie très malheureuse (Henry Bernstein, Le Secret)

1928 Tu étais ainsi. Tu m’as raconté qu’Odile te disait : " Vous attendez trop des femmes. Vous les mettez trop haut ; c'est dangereux. » Elle avait raison, la pauvre petite. Depuis quinze jours je résiste à un désir qui devient chaque jour plus fort (André Maurois, Climats)

1931 Je lui dirai d'abord : « Monsieur, ne soyez pas vexé. N’allez pas croire, surtout, que je doute de vos capacités. Au contraire : je vous mets bien plus haut... Mais audessous de vous, il y a des médecins pour les bêtes. Vous-même, hier, vous en avez convenu sans que je vous aie rien dit » (Maurice Genevoix, Rroû)

1936 Ainsi s'élabore chez lui l'essence fine de la vie intérieure. Mais elle ne se forme pas sans difficulté, sans résistance, et, par instants, dirait-on, sans mauvaise conscience. S'y complaire et la mettre trop haut eût gêné son pessimisme. Entré ou poussé dans la tour d'ivoire, il fallait bien qu'il y chantât, qu'il embellît sa retraite (Albert Thibaudet, Réflexions sur la littérature)

1937 - Dans les églises du Sud où l'on s'est battu, j'ai vu en face des tableaux de grandes taches de sang. Les toiles... perdent leur force...

- Il faudrait d'autres toiles, c'est tout, dit Alvear, la pointe de la barbe enroulée sur l'index, du ton d'un marchand qui va changer les tableaux d'un appartement.

- Bien, dit Scali : c'est mettre haut les œuvres d'art. 
- Pas les œuvres : l'art. Le plus pur de nous, ce ne sont pas toujours les mêmes œuvres qui permettent d'y accéder (André Malraux, L'Espoir)

1974 Ils marquaient non seulement l'entrée de la famille dans ce monde des affaires que nous ne mettions pas très haut, mais encore son échec : nous n’avions même pas été capables de réussir dans ce que nous méprisions (Jean d'Ormesson, Au plaisir de Dieu)

Pronominal

1627 Cela est cause qu'il remonte ne cherchant $\mathrm{du}$ secours qu'en soy-mesme, et reprenant courage il se met aussi haut qu'il avoit desja esté (Charles Sorel, Le Berger extravagant)

1643 DORANTE. Te tairas-tu, maraud?

Mon nom dans nos succès s'étoit mis assez haut

Pour faire quelque bruit sans beaucoup d'injustice ;

Et je suivrois encore un si noble exercice, N'étoit que l'autre hiver, faisant ici ma cour,

Je vous vis, et je fus retenu par l'amour (Pierre Corneille, Le Menteur)

1644 RODOGUNE. Et moi, quelque vertu que votre cœur prépare,

Je crains d'en faire deux si le mien se

déclare ;

Non que de l'un et l'autre il dédaigne les vœux :

Je tiendrois à bonheur d'être à l'un de vous deux ;

Mais souffrez que je suive enfin ce qu'on m'ordonne :

Je me mettrai trop haut s'il faut que je me donne (Pierre Corneille, Rodogune)

1847 Pour être à l'abri de toute recherche, ne faut-il pas d'ailleurs se mettre plus haut que ne sont situés les intérêts ordinaires de la vie ? Un homme du monde est soumis à des hasards qui pèsent rarement sur les gens sans contact avec le monde (Honoré de Balzac, Splendeurs et misères des courtisanes) 1860a Pardonne-moi cet excès d'orgueil... j’en ai besoin dans l'état présent de mon cœur. J'ai besoin de me mettre haut, au plus haut; sinon, je tombe. Eh bien! Si ce cœur fécond, puissant, était le mien ? (Jules Michelet, Journal)

1860b Mais aujourd'hui, vous ne serez au niveau de ce qu'exige la situation actuelle qu'en vous mettant plus haut, en vous établissant dans une sphère supérieure. Voilà des conseils bien virils et plus fermes peut-être qu'il ne faudrait à un jeune cœur endolori (Jules Michelet, Journal)

1876 - Oui, vous avez raison peut-être, dit-il d'une voix lente, évoquant toute cette histoire. J'avais ma seule force. Vous aviez... - J'avais autre chose, parbleu ! Achevat-elle avec une carrure qui arrivait à de la grandeur, tant elle se mettait haut dans le dédain des convenances.

Il n'eut pas une plainte. Elle lui avait pris de sa puissance pour le vaincre (Émile Zola, Son Excellence Eugène Rougon)

II. mettre plus haut de quelque chose : mettre plus de quelque chose, en plus grande quantité Transitif

1610 Car c'est à la volonté des Autheurs de varier la cituation des rimes et des vers aux Poëmes qui sont formez par couplets, pourveu qu'ils n'y mettent pas plus haut de deux vers feminins, ou masculins l'un apres l'autre : veu que d'en mettre d'avantage c'est offenser la vraye et legitime façon, et le bon reiglement, lesquels tirent leur force, et leur authorité de l'usage qui a esté introduict par la raison (Pierre de Deimier, L’Académie de l'art poétique)

III. Poser (quelque chose) en hauteur de façon à ce que ce soit vu

Transitif

1704 Ce qui est encore plus utile à ceux qui, comme saint Pierre, devoient estre élevez dans les grandes places de l'Eglise, et mis bien haut sur le chandelier ; car comme leur élévation les porte naturellement à s'enfler et à exercer leur puissance avec hauteur, Jésus-Christ leur apprend par 
l'exemple (Jacques-Bénigne Bossuet, Méditations sur l'Évangile)

IV. Fixer un prix élevé (pour quelque chose/ quelqu'un)

Transitif

1743 Non, reprit Zulime, j'ai une dame de confiance que j'aime beaucoup ; je dois la voir aujourd'hui : revenez demain matin. À moins, monsieur, que vous ne vouliez acheter mademoiselle ce qu'elle m'a coûté, vous pouvez vous dispenser de revenir. Le prix l'effraya ; car je la mis assez haut pour lui ôter l'espérance de l'avoir jamais, n'ayant nulle envie de m'en défaire (Claude Godard d'Aucour, Mémoires turcs)

V. Faire fonctionner avec une grande intensité sonore

Transitif

1984 Il s'est allongé de nouveau. De nouveau nous nous taisons. Le bruit de la ville est très fort, dans le souvenir il est le son d'un film mis trop haut, qui assourdit. Je me souviens bien, la chambre est sombre, on ne parle pas, elle est entourée du vacarme continu de la ville, embarquée dans la ville (Marguerite Duras, L’Amant)

\section{CORPUS WEB :}

se mettre haut sur ses pieds c'est complètement con, se baisser c'est du suicide ou comment n'importe quel coup de pied ou de genou arrivent au niveau de ton visage [http://www.jeuxvideo. com/forums/1-45-252659-4-0-1-0-comment-fontles-petits-pour-se-defendre.htm] (27.7.2015)

Les peuples fraternisent, les peuples ont le ventre et le cœur gros d'un monde meilleur. Proche est le terme. Les peuples ne vont pas mettre bas, non, pas cette fois. Ils vont le mettre haut, ce monde nouveau-né. Très haut, comme la barre à franchir, haut comme la marche à monter [http://eden-saga.com/philosophie-doctrinesreligions-vanite-illusion-une-seule-voie.html] (27.7.2015)

D’accord ; je pensais que tu parlais de la speedbar, j’avais mal lu ; Mais ça va être un peu complexe en CSS3 : Il faut d'abord la masquer de base et la mettre haut, puis avec la propriété transitions au hover, la faire apparaître puis descendre... [https://openclassrooms.com/forum/ sujet/derouler-en-css3-87805] (27.7.2015)
REMARQUES : Mettre haut (I) se dit du fait de donner un statut élevé à quelqu'un, de l'estimer beaucoup, de lui procurer un statut supérieur ou particulier ou de lui accorder une place importante en fonction de son caractère, de sa réussite ou de ses qualités. L'objet peut aussi référer à quelque chose, à un idéal, une idée, une vertu (par exemple : l'honneur) qui est particulièrement mis en avant, prôné ou respecté par le sujet. (II) réfère au fait d'insérer, d'ajouter quelque chose à autre chose et souligne la quantité importante, comme ici l'insertion de vers dans un poème. L'emploi concret (III) désigne le fait d'être posé à un niveau élevé, d'être situé en hauteur par rapport au sol, de façon à être vu. (IV) renvoie au fait d'estimer la valeur d'un objet, le sujet donnant un prix élevéà la chose en question. (V) dénote le fait d'augmenter fortement le volume sonore d'un film ou d'une chanson. Haut peut s'accorder avec l'objet direct et se rapprocher des prédicats seconds orientés vers l'objet. Toutefois, l'accord ne constitue pas la règle. Haut est modifié par assez, au plus, aussi, bien (plus), fort, moins, plus, réellement très, très, trop, si. Mettre haut est le contraire de mettre bas. Notons l'emploi de placer haut, tenir bas. VoIR AUSSI : tenir haut

\section{Mettre jus}

Faire tomber, causer, provoquer la chute (de quelque chose), anéantir

$\lambda$ mettre mat

\section{Mettre mat}

Vaincre, mettre en échec, faire essuyer un revers Transitif

1534 Bien peu aprés, l'oyseau de Jupiter Delibera pariser pour le pire :

Mais, les voyant tant fort se despiter, Craignit qu'on mist ras, jus, bas, mat l'empire.

Et mieulx aima le feu du ciel empire $\mathrm{Au}$ tronc ravir où l'on vend les sorets, Que l'air serain, contre qui l'on conspire, Assubjectir es dicts des massoretz (François Rabelais, Gargantua)

\section{CORPUS WEB :}

Le tuto de saviola59 et tres bien sauf que sa concerne les parties d échecs ou 1 on doit mettre mat 1 adversaire en un nombre de coups defini a 1 avance GT:GUYTS xbox360 [http://www. 
jeuxvideo.com/forums/1-29023-723245-1-0-1-0-lesechecs-survie-qui-est-bloque.htm] (27.7.2015)

A partir du diagramme 7 qui est la position de base, vous pouvez analyser comment mettre mat le roi adverse [http://www.lepetitechiquier. $\mathrm{eu} / \mathrm{p}=314]$ (27.7.2015)

Il est possible de mettre la jalousie en échec, mais bien peu arrivent à la mettre mat. La plupart du temps, elle est cantonnée à un autre niveau que le partage des corps (séparation sexe/sentiments) ou inhibée par une sorte de jeu à somme nulle (échangisme) [http://forum.doctissimo.fr/ doctissimo/libertinage/jalousie-sujet_16740_2. $\mathrm{htm}]$ (27.7.2015)

Remarques : Provenant du jeu d'échecs, mettre mat désigne le fait de vaincre l'adversaire ou quelque chose, d'abattre dans un combat ou une lutte guerrière, de faire couler ce qui a été construit, mis sur pied (un état, un empire). Notons la collocation mettre ras, jus, bas, mat, où les adjectifs-adverbes forment une suite de quasi-synonymes, l'énumération - ou plutôt l'accumulation - étant là pour insister sur la volonté d'anéantir, pour amplifier la volonté de détruire. Mat reste invariable (v. le dernier exemple du CW).

\section{Mettre noir sur blanc}

Mettre (quelque chose) par écrit Transitif

1937 Dans le vôtre, idiot, vous de qui la fille peut-être, à l'heure même où vous mettiez noir sur blanc vos ahurissements... Il tenait déjà entre ses doigts une cigarette intacte, alors que celle qu'il fumait n'était encore qu'à demi consumée (Henry de Montherlant, Le Démon du bien)

\section{CORPuS WeB :}

Je vais essayer de mettre noir sur blanc ce que je crois avoir compris à propos de ces histoires de dérivées et de différentielles [http:// www.40tude.fr/blog/category/math/] (27.7.2015)

Parmi les points à bien maîtriser figurent la durée du contrat de location, les frais de rédaction de ce document et naturellement son contenu, autrement dit toutes les clauses à mettre noir sur blanc et celles qui sont formellement prohibées [https://www.secure.bnpparibas.net/ banque/portail/particulier/Fiche?type=folder\&
identifiant=Le_bail_de_location_pieges_obli gations_20090407064959] (27.7.2015)

Voilà déjà 4 mois qu'ils parcourent l'étang de long en large pour s'en faire une idée bien précise, et la mettre noir sur blanc [http://www.in focapagde.com/article.php?sid=1813] (27.7.2015)

En gros ca sera un truc bien compliqué à mettre en place et auquel il faut encore réfléchir mais je poste l'idée pour la mettre noire sur blanc et ainsi ne pas l'oublier [http://www.starship-re. com/viewtopic.php?id=20] (27.7.2015)

REMARQUES : Mettre noir sur blanc est une expression idiomatique qui désigne le fait de mettre par écrit ses idées, ses sentiments ou ses émotions, ce que l'on ressent, de façon claire et nette. Noir sur blanc reste invariable dans la majorité des cas, mais dans le dernier exemple du CW noir s'accorde avec l'objet au féminin. Il s'agit d'une variante stylistique réussie, puisque l'idée est effectivement exprimée en caractères noirs sur du papier blanc.

\section{Mettre profond}

I. Mettre, enfoncer profondément, en profondeur

Transitif

-1200 Cist laron m'acaterent, que trovés avés chi :

Tant m'ont de lor mestier ensengiet et apris Soussiel nen a chastel, dongon ne roellis, Ne sor pilers de marbre tant soit palais assis,

Que n'en traie l'avoir, tant parfont $i$ soit mis (Elie de Saint Gille [fin XII ${ }^{e}$, 1199)

+1234 Et Jehans ot si son afere Atiré qu'il ot l'autre prestre Remis et el lieu et en l'estre D’ont cil avoit esté getez Qui enfouir estoit portez : Bien fu parfont en terre mis ! A tant est venuz Estormis A l'uis et il li est ouvers (Huon Piaucele, Estormi [ $\left[2^{\mathrm{e}}\right.$ tiers XIII'], 361)

+1365a L'amoureuse ou coer Phebus mist [= l'une des deux flèches de Cupidon] Si très parfont Que là où li vrai amant l'ont (Jean Froissart, Poésies [3e tiers XIV]]) 
Pronominal

1987 Mais sur mon môme au loin dans ce coin de ma mémoire où les autres vont pas souvent. C'est déjà encore ça, sinon de gagné, du moins de pas tout à fait perdu.

Je me mets bien profond les doigts dans le crâne pour essayer de vomir quelque chose.

Puis mes mains glissent se réchauffer entre mes jambes. C'est inutile. La toile du jean est glaciale (Jean-Louis Degaudenzi, Zone)

II. Entrer (dans un sujet) de manière approfondie, approfondir

Transitif

+1365b Mais pour nous mettre plus parfont

Que nous n'avons encore esté,

Respondez moy par amisté

De ce que maintenant enquerre

Vous vueil

(Jean Froissart, Poésies [3e tiers XIVe])

III. Mettre quelqu'un en difficulté

Emploi absolu

1985a Sans la sonnerie, j'y serais encore. Et dans les vestiaires, fallait chaque fois qu'ils rejouent leur foutu match ! « Tu m’aurais fait la passe à ce moment-là, putain, j'étais tout seul devant les buts, je lui mettais profond, et bla, et bla, et bla. » Des heures durant! Nous étions en avril. Le bac approchait, et je révisais uniquement mes points forts (Philippe Manœuvre, L'Enfant du rock)

1985b Qu'est-ce qu'ils font là-dedans ? Et la rumeur populaire d'imaginer des plans infernaux. Des rituels magiques, des contacts avec les extra-terrestres. Alors je peux vous dire (car j'y étais, bla-bla) : Ils se déshabillent, ils s'épongent, ils reprennent leur souffle et une fois revenus sur terre, ils ouvrent la porte. C'est tout? Non c'est pas tout... Les Who, évidemment, avaient tout plein de reproches à se faire les uns les autres. « Bon sang, t’aurais fait ton solo à ce moment-là, on leur mettait... profond ! » Je fus pris d'un vertige. Étais-je interprète, dans la loge des Who en tournée, ou étais-je de retour dans les vestiaires du lycée d'état mixte de Châlons-surMarne après le match de foot ? (Philippe Manœuvre, L'Enfant du rock)

CoRpus Web :

voila, j'ai des ovules à mettre mais je sais pa tro comment ? la pharmacienne me di comme un tampon mais je ne mets jamais de tampons !!! et c gro donc je sais pas si il faut le mettre profond ou juste au bord ????? [http://forum.doctissimo.fr/ sante/mycoses/comment-mettre-ovule-sujet_747 _1.htm] (27.7.2015)

Uber va bien leur mettre profond à ces taxis de merde !! Danny Plesnik avec mes potes uberistes on va te chopper sur le vieux port et bien te calmer comme le vieux porc que tu es et tes potes le méritez ! [http://www.brain-magazine.fr/article/ page-president/24091-Uber,-bienvenue- $\%$ C3\% A0-Marseille] (27.7.2015)

Oh les internautes, on peut quand même pas reprocher à Tsipras de nous la mettre profond, il essaie cela marche, bien joué [http://actu.orange. $\mathrm{fr} /$ une/la-grece-aurait-besoin-de-82-a-86-milli ards-d-euros-afp-s_CNT000000bZ6ea.html] (27.7.2015)

Puis de toute façon, les ennemis ne se privent pas non plus pour nous la mettre profonde :P [http://www.hooper.fr/forums/modern-gaming/ ps3-demons-soul-du-sang-de-la-chique-et-dumolard-pour-le-meilleur?page=14] (27.7.2015)

REMARQUES : Le fait concret de placer quelque chose profondément dans autre chose (I) est richement repris sur le plan métaphorique (II, III). C'est donc la contrepartie de ce ou ceux qui 'encaissent'. Les deux derniers exemples du CW ont une connotation clairement sexuelle, équivalent grosso modo à 'se faire mettre'. Profond reste invariable dans la majorité des cas, mais, dans le dernier exemple, il s'accorde avec l'objet au féminin pour ajouter de l'emphase, ce qui est caractéristique du schéma " (se) la + verbe + adjectif » (v. par exemple se la couler douce). Profond est modifié par bien, plus, si très, tant. Notons l'emploi absolu par économie dans le second exemple du CW, qui caractérise son passage à un argot.

\section{Mettre propre}

Rendre net, nettoyer

$\lambda$ mettre ras 


\section{Mettre ras}

Mettre à terre, détruire, dévaster, ravager quelque chose

Transitif

1534 Bien peu aprés, l'oyseau de Jupiter Delibera pariser pour le pire : Mais, les voyant tant fort se despiter, Craignit qu'on mist ras, jus, bas, mat l'empire.

Et mieulx aima le feu du ciel empire $\mathrm{Au}$ tronc ravir où l'on vend les sorets, Que l'air serain, contre qui l'on conspire, Assubjectir es dicts des massoretz (François Rabelais, Gargantua)

\section{CORPUS WEB :}

Déjà, il ne faut pas agir dans la précipitation en matière d'exploitation et de déblaiement du bois, pour ne pas fragiliser davantage les sols. Il ne faut pas non plus succomber à la tentation de tout mettre ras et bien propre [http://www. lexpress.fr/actualite/societe/environnement/ forets-les-degats-de-la-tempete-ne-sont-pasirreversibles_736708.html] (27.7.2015)

j’ai vidangé et je sais pas si il faut mettre ras la gueule du bouchon de remplissage comme sur voiture ou pas ! j’ai chopé une doc (honda G42G50 general purpose engine) j'ai l'impression qu'il parle de 0.23 à 0.261 ! [http://www.moto culture-jardin.com/forum/detail.php?forumid=1 \&id=42421\&p=1\#278164] (27.7.2015)

la cuiere dedans c'est la dosette ? il faut la mettre rase ou bonbé ? Pr un bib de $210 \mathrm{ml}$ d'eau cest 2 dosette cest ca ? [http://forum.aufeminin. com/forum/mamans12/_f12036_mamans12Celles-qui-utilise-gumilk.html] (27.7.2015)

REMARQUES : Dans un combat ou une lutte guerrière, mettre ras désigne l'action de mettre à terre, de vaincre l'adversaire ou quelque chose. Notons la série mettre ras, jus, bas, mat et l'emploi de mettre propre. Le CW reprend plutôt l'emploi concret de 'mettre au même niveau' qu'un point de référence : le sol, la surface d'un liquide, le bord de la cuillère, etc. Ras reste invariable dans la majorité des cas, mais, dans le dernier exemple du CW, il s'accorde avec le sujet au féminin, à côté de «bonbé » [= bombé], qui lui n'est pas accordé.

\section{Mettre sec}

I. Déposer (mettre bas) d'un coup (sec), sans souci des effets causés

Transitif

1908 Mettant bas sec deux paniers, une vieille, bras ballants se plaignit :

- C'est lourd. J'ai bien du mal à mon âge ! (Pierre Hamp, Marée fraîche)

II. se mettre aussi sec à : commencer aussitôt à faire quelque chose

Pronominal

1955 Le mordant, chez les fragines, c'est un phénomène saisonnier. A certaines, il faut le grand décarpillage d'été des plages pour emballer, le galbe du bustier sur les roberts, ou bien le serti du short sur les cuissots. À d'autres, c'est le bénard fuseau et le pull moulant strict qui tiennent lieu d'armes secrètes sur les pentes neigeuses ; et vous en remarquerez encore certaines, indérouillables dans bien des circonstances, mais qui se mettent aussi sec à faire des malheurs pour peu qu'elles endossent le petit tailleur printanier. A chacune son embellie ! La race est pas près de s'éteindre! (Albert Simonin, Le Cave se rebiffe)

1976 «Allez, mon Jacquot, va ! laisse-toi aller. » Et je me mis aussi sec à chialer (Jacques Lanzmann, Le Têtard)

REMARQUES : Les exemples reflètent la polysémie du verbe mettre. Mettre bas sec (I) désigne une action brusque, sans façons. Le cumul de deux adjectifs-adverbes met en évidence un processus de lexicalisation de mettre bas comme verbe complexe : mettre bas // sec. (II) est une construction qui renvoie à la promptitude d'une réaction. Sec est modifié par aussi.

\section{Mettre soef}

I. Mettre doucement, délicatement, lentement Transitif

+1150 Gerelmes uit Aiol sor le ceual liie, Il a traite l'espee, s'a les liiens tranchies, Soef et belement l'a ius mis del destrier (Aiol et Mirabel [2 $2^{\mathrm{e}}$ moitié XII ${ }^{\mathrm{e}}$, 6990) 
+1175 Mais Deus aveit uvré pur vus ; Quant trovat l'espee entre nus E nus rejeümes de loing, Li reis prist le gant de sun poing E sur la face le vus mist Tant süef ke un mot ne dist, Kar il vit un rai de soleil Ke out hallé e fait vermeil (Tristran, manuscrit d'Oxford [ $4^{\mathrm{e}}$ quart $\mathrm{XII}$ ], 220 )

1177 Ez vos desserré Lancelot, Que si iert vains qu'il chancelot De vanité et de foiblesce. Cele si soef que nel blesce Le met devant soi sor sa mure, [variante : le monte]

Puis si s'an vont grant alëure

(Chrestien de Troyes, Lancelot ou Le Chevalier de la charrete, 6660)

1364 LE CONTRAIT. Vous me bleciez trop malement

Luec endroit, maistre.

MAISTRE MORIN. La main n'i puis plus souef mettre,

Je ne scé de quoy tu te plains ; Mais c'est le mal dont tu es plains Qui les nerfs t'a retrait sanz doubte (Miracle de saint Panthaleon, 626)

II. se mettre soef à quelque chose : entreprendre quelque chose de manière tranquille, calme, douce

Pronominal

1370 Et quant il vist que les autres estoient endormiz, dont se mist tout souef hors de son lit et s'en ala jusques au lit de la damoiselle qui ne dormoit pas, ains attendoit l'aventure ensi que on ly avoit dit (Roman de Berinus, II, p. 41)

+1370 Qant li rois d'Engleterre et ses gens orent chevauchié et couru toute la plainne Escose et ars et essillié tout le plat pais, et n'estoit nulle nouvelles des Escos qui lor contredesissent lor cemin, et il veirent que li iviers aproçoit et il orent pourveu et rafresqui tous les chastiaus que il pensoient à tenir pour guerryer et héryer le demorant dou pais, il se missent tout souef au retour (Jean Froissart, Chroniques (A))
REMARques : Mettre soef (I) désigne en ancien français le fait de placer, d'installer une personne à un endroit de façon à ce qu'elle se sente bien aise, soulignant l'idée de commodité ou de confort matériel. Dans son emploi pronominal (II), il désigne le fait de commencer à faire quelque chose, entrer dans un processus en douceur, sans trop se forcer. Soef reste invariable et est modifié par plus, si, tant, tout. Notons l'emploi de monter soef.

\section{Meubler juste}

Meubler comme il faut

त habiller juste

\section{Meubler moderne}

Pourvoir, équiper de meubles modernes

Transitif

1962 Meublez moderne votre cuisine grâce à Coop ([Affiche publicitaire] / Grundt : 239)

\section{CORpus Web :}

Mais plutôt que de meubler moderne, Omar est allé chercher du patiné [http://www.lanou vellerepublique.fr/Indre-et-Loire/Loisirs/24H/n/ Contenus/Articles/2011/08/05/Le-Serpent-volanta-Tours-ses-murs-et-le-patron] (27.7.2015)

Vous trouvez avec juste raison que leur qualité n'atteint pas celle de marques luxueuses, ou celle des meubles que vous créez, mais ils permettent à des personnes à petits budgets et pas très bricoleuses de se meubler moderne, simple et pas cher pour quelques heures d'utilisation de la fameuse clé Allen et de changer de décor plus souvent [http://forumsdumonde.forumatic.com/ viewtopic.php?t=2893\&p=51833] (27.7.2015)

Le plus souvent, cela consiste en une discipline de la créativité, pratiquement une contrainte revenant à meubler moderne des commerces anciens, afin de les mettre au diapason d'un monde qui n'attendra pas les retardataires [http://ecrans.liberation.fr/ecrans/2013/05/15/ oculus-rift-le-casque-en-pointe_951274] (27.7.2015)

REMARques : Meubler moderne désigne le fait d'agencer un intérieur, de le garnir de meubles contemporains. Notons les adjectifs-adverbes simple et pas cher dans le CW. Moderne reste invariable (v. le dernier exemple du CW). Notons aussi l'emploi absolu dans le premier exemple du CW et l'emploi pronominal du verbe dans le second. 


\section{Meubler pas cher}

Pourvoir, équiper de meubles bon marché

$\lambda$ meubler moderne

\section{Meubler simple}

Pourvoir, équiper de meubles simples

$\lambda$ meubler moderne

\section{Meugler bas}

Meugler faiblement, doucement

Intransitif

1887 La Coliche, sans bouger, tournait vers lui ses gros yeux fixes, en meuglant plus bas. Alors, il s'avança, se colla contre elle, posa la tête sur la croupe, d'une courte et rude pression (Émile Zola, La Terre)

REMARQUES : Meugler bas réfère au mugissement des bovidés. Il désigne le fait de pousser un cri prolongé et intense, bas soulignant une intensité plus faible du cri. Bas reste invariable et est modifié par plus.

\section{Miser gros}

Mettre beaucoup en jeu (pour obtenir quelque chose); compter beaucoup sur (quelque chose) Emploi absolu

1984 Et alentour, plus une de ces putes sadomaso qui autrefois battaient le trottoir et le tempo des Stooges du talon de leurs cuissardes vernies. Sale affaire. J'avais misé gros sur l'Open. C'était davantage qu'une boutique de disques (Michel Embareck, Sur la ligne blanche)

1996 Plus on nous bassinait les oreilles avec le social, la démocratie, la liberté, les droits de l'homme et tout le tintouin, plus on se faisait mettre. Aussi vrai que deux et deux font quatre.

- Voueï, dit-il. C'est ce que je pense aussi. C'est comme à la roulette. Vé, tu mises, tu mises, et y a qu'un trou et t'es toujours perdant. Toujours cocu.

- Mais tant que tu mises, tu restes en vie.

- Vé ! De nos jours, faut miser gros pour ça. Moi, mon beau, des plaques, j'en ai plus assez (Jean-Claude Izzo, Chourmo)

\section{CoRpus Web :}

-Dortmund : Arsenal prêt à miser gros sur Reus ? [http://news.maxifoot.fr/info221462_150725/football.php] (28.7.2015)

Les Français continuent à jouer et à miser gros au casino [http://www.casinos-francais online.com/les-francais-continuent-a-jouer-et-amiser-gros-au-casino.html] (28.7.2015)

Misez donc en fonction de vos moyens, mieux vaut miser petit et faire de petits gains, que de miser gros et ne pas pouvoir assurer jusqu'au bout ! [http://abcdiscussion.online.fr/casinos/ methode_roulette.php] (28.7.2015)

REMARQUes : Au concret, miser gros signifie parier une somme considérable par rapport au résultat d'un jeu, d'un événement. Au figuré, il désigne le fait d'escompter fortement la réalisation de quelque chose, la réussite de quelque chose ou de quelqu'un, d'attendre beaucoup de quelque chose, et souligne l'importance que l'on y attache. L'adjectif-adverbe gros ajoute à l'idée de pari ou d'enjeu, à la notion d'argent mais aussi à celle d'espoir, d'attente ou encore à l'énergie déployée par le sujet. Notons la conservation du quantifieur petit dans parier petit, usuel en ancien français, dans le langage quotidien (dernier exemple du CW). Gros reste invariable. Miser gros tend à l'emploi absolu.

\section{Miser juste}

Prendre la bonne décision, faire le bon choix Emploi absolu

1960 Maintenant, le capitaine Marchal savait qu'à cette époque il avait misé juste. Saïd était avec lui. Et probablement à la vie, à la mort (Michel Déon, La Carotte et le bâton)

\section{CORPUS WeB :}

L'un dans l'autre, l'EPFL a, au fil de la décennie écoulée, au fur et à mesure de l'essor (notamment dans les sciences de la vie) dicté par sa direction, attiré des chercheurs de haute qualité, parfois encore méconnus, comme Grégoire Courtine. Ou l'art, payant aujourd'hui, de miser juste [http://www.letemps.ch/Page/Uuid/bae0ea46ab4a-11e1-8edf-bcd86c69ed98/Lart_de_miser juste] (28.7.2015)

Du 4 au 10 mai, pariez sur FDJ.fr et remportez jusqu'à 3000 fois votre mise et jusqu'à 
120.000 euros ! Il vous suffit pour cela de miser juste! [http://www.ruedesjoueurs.com/loto-fdj/ fdj-news/news-euromillions/14152-fdj-misezjuste-3000-fois-votre-mise-120000-euros.html] (28.7.2015)

Cette martingale est aussi peu sûre que la martingale classique (le joueur a l'impression qu'il ne peut rien perdre, mais c'est vrai seulement s'il a réussi à miser juste, avant de quitter la table de jeu !), en revanche elle permet d'augmenter les gains [https://fr.wikipedia.org/wiki/ Martingale] (28.7.2015)

REMARQUES : Au concret, miser juste réfère au fait de parier sur une échéance qui par la suite confirme le pari. Au figuré, il renvoie au résultat escompté quant à la réalisation de quelque chose ou la réussite de quelque chose ou de quelqu'un, que ce résultat soit positif ou négatif. Juste reste invariable.

\section{Miser petit}

Miser peu, une petite somme d'argent $\lambda$ miser gros

\section{Monter calme}

Monter, s'élever calmement, doucement, tranquillement

Intransitif

1853 En voyant dans la brume obscure L'Idée, amour des tristes yeux, Monter calme, sereine et pure, Sur l'horizon mystérieux, Les fanatismes et les haines Rugissent devant chaque seuil, Comme hurlent les chiens obscènes Quand apparaît la lune en deuil (Victor Hugo, Les Châtiments)

1910 C'était peut-être comme au crépuscule de jadis, près de la mare maudite ; mais là, il n'y avait point d'eau ; nul arbre ne se dressait ; seule, au loin, derrière un épaulement de terrain, une fumée bleuâtre montait calme et droite dans le froid sec du matin (Louis Pergaud, De Goupil à Margot : histoire de bêtes)

1951 La voix monta nette et calme et s'adressa à tous, et je remarquai de nouveau son autorité singulière et voilée, que Marino prodiguait si peu (Julien Gracq, Le Rivage des Syrtes)

\section{CORPUS WEB :}

Regarde tout se que vous avez surmonter, regarde se qu'il ete avant, et regarde maintenant !! Il était inmontable et maintenant tu peut le monter en cordelette (Pas du grand dressage mais le monter calme quand meme) !! [https://www. facebook.com/QuiproqoSide/photos/a.43680772 9695999.92911.436805619696210/6855348248232 87/] (28.7.2015)

Re : Hercules 9700 non pro bruyante. Vga silencer ou zalman 80 ? de xearox » Lun Fév 23, 2004 2:40 pm Comme tout les refroidissements passif, il faut bien $1 \mathrm{~h}$ pour les monter calme. $\mathrm{Ca}$ c'est sur, quelque soit ce que tu y met, faut pas être pressé !!!! [http://www.generation-gpu.fr/ phpBB3/viewtopic.php?f=10\&t=2112] (28.7.2015)

REMARQUes : Monter calme se dit du fait de se déplacer dans un mouvement ascendant, de s'élever doucement dans l'air ou dans l'espace, le sujet pouvant désigner une entité concrète (une voix, la fumée) ou abstraite (une idée). Notons les collocations monter calme et droit, monter net et calme, monter calme, serein et pur. L'accord ne se manifeste pas sur l'adjectif calme au singulier. Toutefois, la coordination avec les autres adjectifs-adverbes et le fait qu'ils s'accordent avec le sujet au féminin (exemples de 1853, 1910 et 1951) prouve que calme s'accorde également avec le sujet comme prédicat second. Dans le $\mathrm{CW}$, calme réfère à l'objet du verbe, voire aux circonstances : monter y a les sens de 'être assis sur un cheval' (premier exemple) et 'assembler' (dernier exemple). Calme peut alors rester invariable à côté de l'objet au pluriel dans l'emploi transitif du verbe (v. le dernier exemple du CW), où il garde clairement son interprétation d'adverbe de manière.

\section{Monter détendu}

Monter sans pression

$\lambda$ monter lent 


\section{Monter doux}

Se soulever (dans l'eau) dans un mouvement tranquille

Intransitif

1945 Ça montait doucement, doucement, à la dérobée et ça descendait de même [...] le bateau monte doux, redescend doux (JeanPaul Sartre, Le Sursis)

CORPUS WEB :

préparation du cheval au sol : gagner les jeux, preflight checks, «échauffer fort pour monter doux "; simulations dont steady rein ; stratégies pour aider soit le cavalier soit le cheval pour tout ce qui est lié à la confiance, au contrôle et à la sécurité [http://equi-logique.actifforum.com/ t10163-stages-avec-carmen-zulauf-instructrice-4a-gibecq] (28.7.2015)

REMARQUES : Dans le premier exemple, monter doux désigne un bateau qui se déplace dans un mouvement ascendant, s'élève tranquillement, sans brusquerie sur l'eau. Dans l'exemple du CW, il réfère au fait de monter le cheval sans problèmes, dans un contexte de tranquillité, de calme et de confiance. Cette situation est créée au préalable par des exercices d'échauffement (échauffer fort). Notons l'emploi de redescendre doux.

\section{Monter droit}

I. Aller, se rendre directement à un endroit ou dans un endroit situé plus haut que là où l'on se trouve (mouvement actif)

Intransitif

1170 Par mi les degrez entailliez

Sont el palais dreit monté sus :

Mout i aveit contes e dus

E maint bon chevalier gentil (Benoit de Sainte Maure, Le Roman de Troie, 6281)

1377a Exemple du premier [= mouvement] : se une lance estoit portee tout droit en travers et une mouche montast tout droit contremont ceste lance, le mouvement de la mousche seroit mixte de ii. mouvemens drois, c'est a savoir de celui dont elle est meue aveques la lance et du sien propre, et decriroit par son mouvement une ligne dyametrale ou biese (Nicole Oresme, Le Livre du ciel et du monde, p. 62, 22) 1377b Et cele chose appert possible par samblable, car se un honme estoit en une nef meue vers orient tres isnelement sans ce que il apparceust ce mouvement et il tiroit sa main en descendant et en descrisant une droite ligne contre le maast de la nef, il lui sambleroit que sa main ne fust meue fors de mouvement droit ; et ainsi, selon cest opinion, nous semble il de la seëtte qui descent ou monte droit en bas ou en haut (Nicole Oresme, Le Livre du ciel et du monde, p. 524, 112)

1560 La somme est, que sous le nom de Père, ce Dieu qui nous est apparu en l'image de son Fils, nous est mis en avant, afin que nous l'invoquions en certitude de foy,et que non seulement ce nom de Père, selon qu'il est familier, doit servir à confermer nostre fiance, mais aussi à retenir noz esprits, afin qu'ils ne soyent point distraits à aucuns dieux incognuz ou controuvez, mais plustost qu'estans conduits par le Fils unique, ils montent tout droit à celuy qui est seul Père des Anges et des hommes (Jean Calvin, Institution de la religion chrestienne)

1623 Uralie fut bien faschée de la separation d'une chose qu'elle avoit si chere, mais il s'y falut resoudre, encore estoit-elle en danger de courir une grande fortune puisque son frere estoit en bas, qui n'adjoustant point de foy aux serments de la villageoise, monta droit à la chambre, et trouvant la porte fermée heurta tant qu'il la rompit, sçachant bien qu'il y avoit quelqu'un, car il avoit veu Perside par le trou de la serrure (Charles Sorel, Les Nouvelles françaises)

1655 certes, je le fus de si bonne sorte que, ne sçachant à quoy attribuer ce miracle, j'eus l'insolence de m'imaginer qu'en faveur de ma hardiesse, Dieu avoit encore une fois recloüé le Soleil aux Cieux, afin d'esclairer une si généreuse entreprise. Ce qui accrût mon esbaïssement, ce fut de ne point conoistre le païs où j'estois, veu qu'il me sembloit qu'estant monté droit, je devois estre descendu au mesme lieu d'où j'estois 
party (Savinien Cyrano de Bergerac, Les Estats et empires de la lune)

1755 Il pensera mieux des autres, et plus modestement de lui-même... Lorsque j'allois examiner, d'un air pensif, si j'étois bien exempte de la vanité que je reprochois aux autres, j’ai reçu la visite de Miladi L. qui ne doit pas servir à me donner une mauvaise opinion de moi-même. Elle est montée droit à mon cabinet. Madame Reves s'étant hâtée de la suivre (abbé Prévost, Lettres angloises [trad.])

1843 - Ah ! M. Charles ! à la bonne heure... vous parlez si bas que je n'avais pas entendu... Eh bien ! ma petite dame, puisque vous allez chez M. Charles, beau jeune homme tout de même... montez tout droit, c'est la porte en face. La marquise, accablée de confusion, mit le pied sur la première marche (Eugène Sue, Les Mystères de Paris)

1878 Hélène monta droit au grenier où elle était venue si souvent, en haut de la grande maison du passage. Mais elle eut beau frapper, rien ne bougea. Elle redescendit alors, très embarrassée (Émile Zola, Une page d'amour)

1945 Le chauffeur et un soldat en uniforme, mitraillette à l'épaule, étaient restés dans le couloir de l'immeuble. Cinq hommes en civil étaient montés tout droit chez mademoiselle, sans rien demander à la concierge, - ce qui prouvait qu'ils avaient des renseignements précis (Roger Vailland, Drôle de jeu)

II. Mener directement à un endroit

(chemin, route)

Intransitif

1393 «Monseigneur, veéz la la montaigne ou ilz se tient. Et veéz vous ce blanc sentier qui monte droit [variante : tout droit ; éd. Genève, p. 363] a ce gros arbre ? " (Jean d’Arras, Mélusine, p. 710 [manuscrit Ars])

1833 Ce sentier montait droit à une roche ardue qu'il pourtournait ; au sommet de ce rocher, quelqu'un moins lassé, moins pensif, aurait remarqué un corps alongé, noirâtre, immobile (Pétrus Borel, Champavert)
1870 Comme la route de Saverne à Phalsbourg montait tout droit ; comme elle était effondrée, pleine d'ornières et même de ravines, où l'on risquait de verser jusque dans la Schlittenbach (Émile Erckmann et Alexandre Chatrian, Histoire d'un paysan)

1874 C'est tout : non, j'oubliais : «Pas de ruches autour du cou ; un grand col montant droit et se rabattant sur lui-même, comme le collet des Incroyables. Il est fait en étoffe pareille aux robes ou en fourrures pour les manteaux » (Stéphane Mallarmé, La Dernière Mode)

III. S'élever dans l'air, dans un espace, selon un ligne droite, directe (fumée, odeur, voix, vibration) (mouvement passif) Intransitif

1450 CAŸM. Ma gerbe aussi y sera mise, En esperant que Dieu la prende Et qu'il voye que je luy rende Le devoir ou je suis tenu. (Caÿm brulle sa gerbe) ABEL. Vray Dieu dont tout bien est venu Et ou tout bien a residence, Or voy je par experïence Que mon offrande est acceptee, Car la fumee en est montee Tout droit en hault sans soy distraire (Arnoul Gréban, Le Mystère de la Passion, 863)

1768 On ne manqua pas de publier aussitôt que l'ame du mort, tué dans une action aussi sainte, était montée droit au ciel, où elle était placée entre les confesseurs

(Nicolas-Simon Linguet, Histoire impartiale des Jésuites)

1859 Avec ses hautes maisons bâties en briques, elle ressemble à une de nos cités fabricantes de Normandie ; les murs rouges et noirâtres montent droit jusqu'à la toiture, sans être coupés par la teinte verte des persiennes et des jalousies. À Rotterdam, on paraît ne pas connaître ces deux meubles extérieurs (Maxime Du Camp, En Hollande)

1889 Mais celle-ci, dans la pâle pénombre crépusculaire, me paraît plus élevée et plus svelte ; elle semble avoir participé à ce 
même mouvement d'élancement qui a fait monter si droit vers le ciel les colonnes des cèdres voisins (Pierre Loti, Japoneries d'automne)

190513 février.

Un diamant que les dames riches ne peuvent garder à l'oreille, c'est la goutte d'eau. Immobilité, sommeil profond de la nature : le chant du coq monte tout droit (Jules Renard, Journal)

1922 Un ciel gris recouvrait Lyon. Les fumées d'usine y montaient tout droit comme d'innombrables colonnes. Il semblait qu'elles travaillaient à l'assombrir depuis toujours et à jamais ; un temps viendrait où la ville serait étalée sous une chape de suie noire ; elle posséderait alors sa vraie figure (Jean Viollis, L'Auvergnate)

1931 Elle avait continué de luire pendant que son corps trébuchait ; et maintenant que son corps épuisé renonçait à lutter davantage, il retrouvait, aussi vivace, sa petite flamme fidèle qui brillait dans le jour pâle. Elle montait droit, sans vaciller. Elle se tenait devant ses yeux, irradiant une clarté dorée qui réchauffait sans éblouir (Maurice Genevoix, Rrô̂)

1938 Nous avons voulu te parler, devant elle. Bernard regarda Catherine, qui ne bougeait toujours pas, qui ne fumait même plus. La fumée de sa cigarette montait droit, puis tremblait à une onde lointaine de la voix de Madame Rosenthal (Paul Nizan, La Conspiration)

1979 Et c'est si beau que le poil te dresse sur le dos. Une autre voix sort de la nuit, s'élance et monte tout droit dans la nuit, cherche la première, la poursuit, la rejoint, l'enlace, ne la lâche plus. Elle est limpide et caressante, celle-là, elle est coquette (François Cavanna, Les Russkoffs)

IV. Même sens que (II), mais en insistant sur la position droite de ce qui monte Intransitif

1872 les grands bambous de l'Inde montaient droits, frêles et durs, faisant tomber de haut leur pluie légère de feuilles ; un ravenala, l'arbre du voyageur, dressait son bouquet d'immenses écrans chinois (Émile Zola, La Curée)

1878 Dans le ciel éclatant et immobile, aucune brise ne s'élevait. Les fumées de la manutention montaient toutes droites, en flocons légers qui se perdaient très haut. Et, au ras des maisons, des ondes passaient sur la ville, une vibration de vie, faite de toute la vie enfermée là (Émile Zola, Une page d'amour)

1896 Quand il n'y eut plus personne devant l'autel pour recevoir le sacrement, un calme infini s'étendit. Les bougies de l'autel montèrent plus droites. Les parfums d'encens coururent plus lourds. Le Christ était partout, d'une présence obsédante qui perçait le mystère. Cela dura jusqu'à la fin (Édouard Estaunié, L'Empreinte)

1903 (Tous les rajahs des pays d'alentour ont sur le Gange une résidence, un peu délaissée, où ils viennent de temps à autre faire une retraite.) Les murailles massives montent d'abord droites, sans ouvertures, et c'est seulement tout en haut que commencent les fenêtres, les balcons, la vie de ces impénétrables demeures (Pierre Loti, L'Inde (sans les Anglais))

1907 Dans les champs gazouillaient les alouettes. Des papillons blancs dansaient autour de leur tête. Ils s'assirent dans un pré. Les fumées du village montaient toutes droites dans le ciel lavé par la pluie. Le canal immobile miroitait entre les peupliers. Une buée de lumière bleue duvetait les prairies et les bois (Romain Rolland, Jean-Christophe. La Révolte)

1921 Le Greco a délivré l'âme espagnole. Après lui la flamme monte, droite et haute, pour mourir presque brusquement. Nulle part ailleurs il n'y eut évolution si rapide et si brève, esprits plus rares et plus fiers (Élie Faure, Histoire de l'art : l'art moderne)

1945 Emmanuel se sentit replongé dans l'absurde. Une scène de sang, de souffrances, 
se présenta à lui. Et, pendant un instant, il cessa de voir la fumée des toits qui montait, si droite, dans le ciel léger. Il cessa de boire l'air, comme s'il lui était devenu irrespirable (Gabrielle Roy, Bonheur d'occasion)

1953 Bon prétexte. Une épaisse fumée s'élevait dans un roulis majestueux, lacérée d'orange. En volutes puissantes, elle dépassa la falaise et monta presque droite dans le ciel. Jacquemort frissonna. Il s'aperçut qu'il était en train de miauler depuis plusieurs minutes (Boris Vian, L'Arrache-Cœur)

Transitif

1909 Les champenoises empilées sur lattes traçaient d'un bout à l'autre du cellier l'alignement parfait des cubes de goulots et de tessons montés impeccablement droits

(Pierre Hamp, Vin de Champagne)

\section{CORpus Web :}

Moins vous aurez de coudes, plus votre installation sera performante. Mieux vaux un tirage un peu excessif qu'un mauvais tirage... Alors si les tuyaux peuvent monter droit à la sortie de toit, cela semble être l'idéal [http://www.poele-turbo. fr/tuyaux-fumisterie.html] (29.7.2015)

A un cairn, monter droit dans la pente ou en tirant à peine à gauche pour rejoindre une sente qui monte, en traversant à gauche, jusqu'au pied de la face. On peut aussi poursuivre plus loin le sentier horizontal jusqu'à l'aplomb de la falaise puis monter droit dans les pentes d'herbes puis les pierriers [http://www.escalade-74.com/ falaises/escalade_cenise.htm] (29.7.2015)

Voici que la pierre elle-même pourrait permettre un abri ; or elle est rigide, lourde... et il faut la monter droit vers le ciel, entrer en lutte contre la pesanteur et s'en servir aussi pour la stabilité. [http://mpflimousin.free.fr/dcev/fi14/ fi14ru01.php] (29.7.2015)

Et bien il faut qu'elle soit très large à la base car plus tu monte, plus elle s'amincit car la terre c'est pas du beton (à moins qu'elle soit très bonne comme la terre agricole) donc tu peut pas trop la monter droite sur les côtés... Ce que je te conseillle c'est mouiller ta récep qui est trop petite et tu prends de la terre humide que tu plaque sur le haut et normalement sa devrait tenir... après tu essaye de mettre $u$ tapis et hop c'est partis pour le ride... Mais sache que plus tu monte ta bosse plus il te faut de terre (logique ;)) car il faur qu'elle soir super large.... [http://www.26in. $\mathrm{fr} /$ forums/rouler/vtt/sujet-12870-comment-faireune-bonne-bosse-de-dirt-.html] (29.7.2015)

REMARQues : Monter droit (I) désigne un animé qui se dirige directement vers un endroit, en général situé à un niveau plus élevé que là où se trouve l'observateur, sans attendre ou sans détour. En (II), le sujet désigne une substance (par exemple une fumée) qui s'élève, se dirige vers le ciel en suivant une ligne droite, souvent verticale. L'adjectif-adverbe réfère aussi à la direction d'un son qui se propage dans l'air, en direction du ciel, le sujet désignant un son, un effet sonore, un chant. Le sujet peut aussi désigner une source de chaleur telle qu'une bougie dont la flamme s'élève de façon parfaitement verticale. Au figuré, le sujet peut aussi désigner l'âme qui monte au ciel. (II) réfère à la direction que prend un chemin pentu, celui-ci menant directement à un endroit, à un but. Les exemples sous (IV) réunissent les variantes accordées qui correspondent à (III), créant donc des oppositions du type la fumée monte droit / droite. En principe, la variante non-accordée accentue l'acception directionnelle, tandis la variante accordée met en relief la position de ce qui monte (prédication seconde). On observe en effet que l'emploi d'une préposition indiquant la direction (monter droit vers, dans, etc.) constitue la règle en (III), tandis qu'il est exceptionnel sous (IV). Mais la différence de sens se limite parfois au registre ou au degré d'emphase, l'accord étant plus littéraire et plus emphatique. Notons la collocation droit et haut. Droit a tendance à s'associer avec la préposition qui le suit (à, chez, dans, jusqu'à, sur, vers), au point de faire partie du groupe prépositionnel comme modifieur de la préposition. Il est modifié par d'abord, impeccablement, plus, presque, si, tout. Notons l'emploi transitif dans les deux derniers exemples du CW. Dans le dernier exemple, l'accord de droit marque son emploi résultatif. Mentionnons également l'emploi de courir lourd, descendre droit, parler bas, porter droit. 


\section{Monter dru}

Monter en groupe compact et vigoureux

(en parlant d'une plante)

Intransitif

1959 Les jeunes tamarins des Hauts montaient dru comme du gazon (France-Soir, 22 mai 1959 / Grundt : 327)

CORPUS WEB :

Taille (dans le sens hauteur), les diospyros kaki ne dépassent pas 5 ou 6 m. Hybridés avec un D. lotus ? (quel intérêt, d'ailleurs ?) ça doit monter dru [http://www.aujardin.org/taille-maxplaqueminiers-t172611.html] (29.7.2015)

Ce matin, $2 \mathrm{~h}$ à jeun assez cool, $18 \mathrm{kms}$. Ce soir, reconnaissance partielle d'un trail programmé samedi prochain à Montpezat d'Agenais. Premières impressions, ça va monter dru ! [http:// planetejogging.forumactif.com/t7319p120-entrai nement-de-lol47] (29.7.2015)

Cela dit le détour nous offrira également de bons moments de bravoure à monter dru dans l'pentu, çà fait mal aux jambes mais çà passe sur le vélo [http://mtbcrew.xooit.fr/t320-La-rando-duMalpassant-Mery-73-le-22-05-2011.htm] (29.7.2015)

REMARques : Dans le domaine du jardinage, monter dru réfère à une plante ou un arbre qui pousse en hauteur de manière robuste et touffue. Dans l'argot du sport, il renvoie à une pente forte et rude que les participants doivent gravir.

\section{Monter dur}

monter pur et dur : gravir intégralement, sans compromis

$\lambda$ monter pur

\section{Monter fort}

S'élever fortement, à pic

Intransitif

1942 Là, je les vois ! Petits. Un essaim de guêpes empoisonnées [= les avions de chasse allemands].

- Mitrailleur ! Ils passent par le travers. Les apercevrez dans une seconde. Là !

- Je... je ne vois rien. Ah ! Je les vois !

- Moi je ne les vois plus ! [...]

- Ils nous prennent en chasse?

- Ils nous prennent en chasse!

- Montent fort?
- Je ne sais pas... je ne crois pas... non !

- Que décidez-vous, mon capitaine ?

(Antoine de Saint-Exupéry, Pilote de guerre)

\section{CORPuS WEB :}

Le son du jour à monter fort pour couvrir la télé et la radio [http://www.culturalgangbang. com/2013/06/le-son-du-jour-monter-fort-pourcouvrir.html?m=0] (29.7.2015)

Encore un secteur ou les prix sont montés fort en 2012 et ou cela devrait continuer de monter fort en 2013 [http://bear-de-brehat.over-blog. com/article-encore-un-secteur-ou-les-prix-sontmontes-fort-en-2012-et-ou-cela-devrait-conti nuer-de-monter-fort-e-114199786.html] (29.7.2015)

Suivez ce groupe de jeunes qui va monter fort !!! [https://www.facebook.com/Burkina24/ posts/349297228493456?stream_ref=5] (29.7.2015)

la deuxième dois avoir un problème de solénoïde de marché arrière ou peut-être un autre problème car le $\mathrm{R}$ ne marche pas ; enfaite j'ai comme l'impression que cette boite reste tout le temps enclenché en Drive. Elle a un deuxième problème, il faut la monter fort dans les tours pour qu'elle puisse commencer à avancer [http:// www.bmw-serie3.com/phpbb3/viewtopic.php?f= 263\&t=10959] (29.7.2015)

Plus je téléphonais, plus j'écrivais, plus le dialogue devenait de sourds, d'incompréhension et malhonnêteté. Pas de ma part bien sûr. Bref, la mayonnaise est montée forte, très épicée, jusqu'à un dernier courrier de leur part très violent [https://kettymillet.wordpress.com/ page/3/] (29.7.2015)

REMARQUES : Monter fort réfère à un mouvement soit actif, ascendant (un avion). Les exemples du CW attestent les significations d'augmenter fortement le volume du son, d'augmenter drastiquement les prix, de progresser fortement (un groupe qui devient plus populaire). Dans le quatrième exemple du CW, fort fonctionne en tant que prédicat second orienté vers le sujet, mis en série avec très épicée, les deux modifieurs s'accordant avec le sujet au féminin. 


\section{Monter fou}

I. Monter, assembler (un dispositif) de façon à ce qu'il soit mobile

Transitif

1876 14, 15, pièces d'angle montés fous sur l'arbre et engrenant le pignon 16 calé sur l'axe 11 de manivelle (Description des machines et procédés)

1956 Le principe du « damper » est simple : un ou deux plateaux sont montés fous sur le vilebrequin et arrêtés par des épaulements, certains sont maintenus écartés par des ressorts, d'autres, au contraire, sont montés sur caoutchouc (Charles Chapelain, Cours moderne de technique automobile)

2015 - un porte-satellite supportant généralement trois pignons appelés satellites montés fous sur leur arbre et en prise permanente entre le planétaire et la couronne (Philippe de Lerat, Les Machines agricoles)

II. Monter, s'envoler sans contrôler son mouvement, sans contrôler la direction Intransitif

1910 Ils montèrent fous dans le soleil, en une ascension éperdue, jusqu'à ce que, tout d'un coup, vidé, ployant sur ses ailes flasques, le grand oiseau chavira sur l'abîme, et, dans les derniers sursauts de l'agonie, étreignant encore entre ses serres rigides le corps de sa victime, les deux cadavres s'abîmèrent dans le vide (Louis Pergaud, De Goupil à Margot : histoire de bêtes)

\section{CORPUS WEB :}

Selon l'invention, le rouage (51, 51') comporte un deuxième mobile $(57,57$ ') en matériau micro-usinable qui est indépendant des mouvements dudit premier mobile et qui comporte une ouverture $(58,58$ ') dont la paroi est montée en vis-à-vis dudit axe afin de monter fou le deuxième mobile $\left(57,57^{\prime}\right)$ sur ladite première extrémité de l'axe (53, 53') [http://www.google.com/patents/ EP2309341A2?cl=fr] (29.7.2015)

Le mouvement de déplacement du dispositif de nettoyage 26 est également commandé par l'intermédiaire de la cuvette 11 qui comporte à cet effet, comme on peut voir en particulier sur les figures 2 et 3 une rainure de guidage 61 qui est aménagée dans une paroi latérale de la partie arrière de la cuvette ; cette rainure sert au guidage d'un galet 62 qui est montée fou sur un axe 63 qui est fixé à l'extrémité d'un bras 64 dont l'autre extrémité est solidaire d'une poulie 65 [http://www. google.es/patents/EP0242274A1?cl=fr\&hl=es] (29.7.2015)

Les boîtes de vitesses comprennent généralement deux arbres pourvus de pignons en vis-àvis de diamètres différents qui s'engrènent les uns avec les autres, les pignons d'un des arbres étant montés fou sur cet arbre. Afin de passer un rapport, ces boîtes de vitesses utilisent des dispositifs de couplage d'un des pignons fou avec l'arbre de la boîte de vitesses sur lequel il est monté de manière à égaliser leur vitesse de rotation [https://patents.google.com/patent/FR2896554 $\mathrm{A} 1 / \mathrm{fr}](20.10 .2020)$

Une roue (15) est montée folle sur l'arbre (2) de la tête d'impression, et est en contact par sa périphérie avec le film à imprimer [http://www. google.fr/patents/EP0326496A1?cl=fr] (29.7.2015)

Ainsi, la promesse fut faite, Vicente se relevait du bord du toit de la maison pour ensuite soupirer brusquement quand Vincent vint monter fou de rage, sur le toit, Vincent prit violemment par le col de sa main gauche Vicente pour ainsi le faire basculer contre la cheminée [http:// weaverether.skyrock.com/3241222007-TheNightmare-Chapitre-9-Le-destin.html] (29.7.2015)

REMARQUES : Dans le langage de la mécanique, monter fou (I) réfère à un type de construction qui laisse une marge de manœuvre, qui permet à une pièce de tourner librement autour d'un pivot, d'un axe. La motivation de 'folie' (II) transparaît dans l'exemple littéraire de 1910, comme dans le dernier exemple du CW où fou est un prédicat second qui conserve le sens de base. Fou peut s'accorder avec le sujet, même dans les fonctions plutôt adverbiales, mais il peut également rester invarié (troisième exemple $\mathrm{du} \mathrm{CW}$ ). Dans le second exemple du CW, il s'agit probablement d'une faute d'accord dans montée puisqu'il modifie galet. L'accord au féminin (quatrième exemple du CW) est plutôt rare. C'est ainsi que l'exemple de 1876, où fou modifie le féminin pluriel pièces, fait incompréhensiblement l'accord au masculin pluriel. 


\section{Monter gros}

Augmenter, croître en quantité ; atteindre une forte somme d'argent

Intransitif

1850 Elle cherche cinquante procédures, elle dit que Cadet Blanchet lui a fait des billets, et que quand elle aura fait vendre tout ce qui nous reste, elle ne sera pas encore payée. Tous les jours elle nous envoie des huissiers, et les frais montent déjà gros. Notre maîtresse, pour la contenter, a déjà payé ce qu'elle a pu, et du tracas que tout ça lui donne, après la fatigue que la maladie de son homme lui a occasionnée, j'ai bien peur qu'elle ne meure (George Sand, François le Champi)

\section{CORPUS WEB :}

J'ai réalisé trois montées en quatre ans et c'est vrai que c'est la plus inattendue parce que tout le monde voyait Dreux monter gros comme une maison. En gagnant à Dreux puis à Orléans, on a tout chamboulé [http://www. lanouvellerepublique.fr/Indre-et-Loire/Sport/ Football/Regionaux/n/Contenus/Articles/2014/ 06/02/L-AOCC-retrouve-le-CFA-2-1931323] (29.7.2015)

mais le vif reste un bon choix tu pourras tenter plus de poissons. en ce qui concerne la taille n'hesites pas a monter gros [http://www.cote peche.fr/forums/peche-aux-appats/pechevif-t3353.html] (29.7.2015)

Oui j'imagine que c'est surtout une question d'habitude, de comment on se sent avec. J'ai trouvé que les Les Paul en général sont montées gros (en 11 voire 12) et je n'y ai jamais été très à l'aise [http://www.partoch.com/forum/post_889545, telecaster+user+s+club.html?var=41] (29.7.2015)

Et que dire de la Picasse !, elle est probablement la préférée de plusieurs Saumoniers en début de saison. Cette mouche est montée grosse $(1 / 0,2 / 0,3 / 0)$, c'est une mouche excellente à l'eau haute [http://www.fabri-mouches.ca/marcleblanc-un-monteur-de-mouches-un-guiderepute.html] (29.7.2015)

REMARQUES : En parlant de ce qui est mesurable, monter gros désigne quelque chose (un montant, des frais) qui augmente et atteint une somme ou une valeur très élevée. Dans l'argot de la pêche, il réfère à la taille du fil de pêche, de gros diamètre. Monter adopte alors le sens mécanique de 'assembler, placer, mettre'. Gros tend à l'emploi invariable, mais, dans le dernier exemple, il s'accorde avec le sujet au féminin (prédication seconde). Notons l'emploi absolu dans le deuxième exemple du CW.

\section{Monter haut}

I. (Faire) atteindre un haut niveau ou un rang élevé (moral, social, intellectuel, etc.)

Intransitif

+1150 DIABOLUS. Ne munteras jamés plus halt? Molt te purras tenir pur chier, Quant Deus t'a fet sun jardenier ! (Le Jeu d'Adam [2 moitié $\left.\mathrm{XII}^{\mathrm{e}}\right], 180$ )

1177 Il n'a corteisie ne san An plet d'oiseuse maintenir. Cist plez ne doit avant venir, Ne l'an nel doit plus haut monter ; Mes feites nos avant conter Ce qu'il avoit ancomancié, Que ci ne doit avoir tancié (Chrestien de Troyes, Yvain ou Le Chevalier au lion, 101)

1230 Quand Rollans l'entendi, le sans quide derver :

Comment ! dist il, dans rois, ne l'osés ja panser

Que vos deseure moi puissiez si haut monter! (Gui de Bourgogne, p. 129)

1427 Et se tu y es ravallé au dessoubz des autres palatins, tu seras envieux de leur pouoir. Se tu y es en moyen estat, dont tu n'ayes suffisance, tu estriveras de plus hault monter (Alain Chartier, Le Curial)

1538 Or de l'avoir si tost mort estendu, Mort le trompa : car, tout bien entendu, Son vif esprit à grans biens pretendoit. Monté soit il plus hault qu'il ne tendoit (Clément Marot, Cimetière)

1596a Car, pour estre tousjours à lui-mesme semblable,

Il empesche qu'aucun ne luy soit comparable, Et sans monter trop haut ny trop bas devaler, Fait qu'estant tout égal on ne peut l'égaller. 
L'Amour n'auroit sans luy ny flamme ny cordage (Philippe Desportes, Euvres)

$\sim 1596 \mathrm{~b}$ Il n'est donc rien si doux que l'estat d'un amant.

Ouy, mais le grand peril suit la grande

entreprise,

Et qui monte bien haut peut bien bas tresbucher;

Et puis en se brûlant il faut son feu cacher (Philippe Desportes, Euvres)

1601 Ils sont battus d'une part du mal qui les poingt, et d'autre de la reigle, qui les ennuye. Toutes ces miseres susdictes sont corporelles ou bien mixtes et communes à l'esprit et au corps ; et ne montent gueres plus haut que l'imagination et fantasie (Pierre Charron, De la sagesse)

1624 Veritablement mes iniquitez ont monté si haut qu'elles sont desja proches du Throsne de Dieu d'où elles n'attendent que sa vengeance, et fors un desir imparfaict que j'ay de me repentir, et quelque petite resistance que je fais au commencement du mal, il n'y a point de difference entre moy, et le plus grand pecheur qui soit sur la terre (Jean-Louis Guez de Balzac, Les Premières Lettres)

1648 VENCESLAS. Duc, je ferai si haut monter votre fortune,

D'un crédit si puissant j'armerais votre bras,

Et ce séditieux vous verra de si bas,

Que jamais d'aucun trait de haine ni

d'envie

Il ne pourra livrer d'atteinte à votre vie (Jean de Rotrou, Venceslas)

1830 DON CARLOS. Je suis bourgeois de Gand. DON RUY GOMEZ. La dernière campagne A fait monter bien haut le roi François premier.

DON CARLOS. L'aigle qui va peut-être éclore à mon cimier

Peut aussi déployer ses ailes.

DON RUY GOMEZ. Votre altesse

Sait-elle le latin? (Victor Hugo, Hernani)
1835 Les deux agas chez lesquels je suis entré m'ont reçu avec la politesse la plus exquise. Le fanatisme brutal du bas peuple de Damas ne monte pas si haut. Ils savent que je suis un voyageur européen ; ils me croient un ambassadeur secret, venant chercher des renseignements pour les rois de l'Europe, sur la querelle des turcs et d'Ibrahim (Alphonse de Lamartine, Souvenirs, impressions, pensées et paysages pendant un voyage en Orient)

1839 Ce jour-là, ce sera votre jour ; ce parti-là, ce sera vous. Quoi qu'on en dise, l'époque où nous vivons est une belle époque. L'art et la pensée n'ont en aucun temps monté plus haut. Il y a partout de grands commencements de tout. Félicitez-vous, car vous aurez plus d'une sainte tâche à remplir (Victor Hugo, Correspondance)

1848 Une femme de douleur a surtout été chargée du fardeau le plus lourd, comme la plus forte ; il n’y a cœur qui ne se brise à son souvenir ; ses souffrances sont montées si haut, qu'elles sont devenues une des grandeurs de la Révolution (François de Chateaubriand, Mémoires d'outre-tombe)

189624 avril.

« Je vous le dis, mon cher maître : avec Hugo, Lamartine, Chateaubriand, le génie est monté trop haut. Il s'est cassé les reins. Maintenant, il se traine sur la route comme une oie de village. Nous en avons assez, d'étudier les relations des sexes » (Jules Renard, Journal)

1906 Espoirs montés si haut qu'ils tombèrent des nues,

Haines, affres, erreurs jonchaient les avenues

Où saignaient, lentement, vos amours mis en croix ;

Mais tout au fond, comme une flamme au cœur du bois,

À travers les rameaux de vos heures sans gloire,

Brillait quand même et s'affirmait votre victoire (Émile Verhaeren, La Multiple Splendeur) 
1914 «Ah! S’il pouvait revenir ! Lui seul peut me sauver. »C'est un transfuge. Est-il chassé ? S'est-il évadé pour monter plus haut et plus seul ? Il veut fonder à son profit un système nouveau. En somme, mon article sur Mirabeau doit être le rendez-vous avec la reine (Maurice Barrès, Mes cahiers)

1936 Mais est-il bien utile de monter si haut pour hurler à son tour contre les chiens ? Je pense que si ce philosophe est monté si haut c'était pour donner plus de force à sa voix et toute son ampleur, pour mettre dans ses cris, toute sa véhémence (Pierre Reverdy, Le Livre de mon bord)

1946 Ils peuvent monter socialement assez haut : ils fournissent aux personnalités fortes, dans les meilleurs cas, ces seconds brillants ou ternes qui semblent ne jamais tenir leur existence que d'autrui (Emmanuel Mounier, Traité du caractère)

Pronominal

1592 Le peuple reconvoye celuy-là, d'un acte public, avec estonnement, jusqu'à sa porte : il laisse avec sa robbe ce rolle, il en retombe d'autant plus bas qu'il s'estoit plus haut monté; au dedans, chez luy, tout est tumultuaire et vile (Michel de Montaigne, Essais)

1624 Thevet ne vit jamais une si grosse beste, Un esprit si perclus, un si gros animal, Que celuy qui pretend me convaincre de mal,

Pour ce que je me couche en ce joly grimoire ;

Il croit pourtant avoir assez belle entendoire.

Aussi fait bien Turpin, qui s'est trop haut monté,

Pensant que le bon sens suivit la qualité, Tout ainsi que le cens suit tousjours l'heritage (Jacques Du Lorens, Premières satires)

1734 Quand bien même toutes les impositions dont nous venons de parler, et dont le produit composoit la seconde branche du revenu des Empereurs, auroient été assises avec justice, et levées avec clemence, elles se montoient si haut, qu'il n'étoit pas pos- sible qu'elles ne fussent très à charge aux Peuples (Jean-Baptiste Dubos, Histoire critique de l'établissement de la monarchie françoise dans les Gaules)

1748 Brama, qui protège les saines contrées que nous habitons, m'inspira sans doute dans cet instant critique.

" Les Italiennes, que nous pratiquâmes ensuite, ne se montent point si haut. C'est avec elles que j'appris les modes du plaisir. Il y a, dans ces raffinements, du caprice et de la bizarrerie » (Denis Diderot, Les Bijoux indiscrets)

1775 M. DELOMER. Il faut attendre ; il paraît que c'est le contrecoup que je reçois : ils n'ont manqué, sans doute, que parce que l'orage vient de plus loin. Quel parti prendre pour effectuer mes paiements? Ils se montent très haut, et c'étaient les fonds que je devais recevoir de Hambourg qui étaient destinés à l'acquit de ces créances (Louis-Sébastien Mercier, La Brouette du vinaigrier)

II. Monter dans l'aigu (son, voix)

Intransitif

1641 Sa voix tantost est forte, et tantost ne l'est pas,

Elle monte bien haut, puis redescend bien bas ;

Tantost elle gemist, tantost elle soûpire, $\mathrm{Ou}$ prend quelque repos, pour prendre plus d'empire (Tristan l'Hermite, La Lyre)

1923 Et bientôt, en réponse à une question de lui, la Fée se mit à raconter comment elle s'était déguisée, et la hâte avec laquelle il avait fallu découdre, puis recoudre, pour ajuster le costume trop étroit. Elle riait, et par instants sa voix montait plus haut qu'elle n'aurait voulu. Mais ses gestes, tandis qu'elle coupait les tartines et les portait à sa bouche, restaient calmes (Valéry Larbaud, Beauté, mon beau souci...)

1951 Vers le soir, il passa près d'un village qui criait. Les maisons étaient groupées à quatre ou cinq cents mètres de la route et un peu en contrebas. Du haut de son cheval, Angelo les voyait semblables à un 
renard pelotonné contre les graviers de la Durance. Il en sortait un gémissement, une plainte qui devait être faite de beaucoup de voix pour être de si longue haleine et monter finalement si haut dans l'aigu (Jean Giono, Le Hussard sur le toit)

III. Augmenter beaucoup, atteindre une valeur élevée Intransitif

1762 Ah ! Ma pauvre amie, comme vous voilà, avec vos jambes plus gonflées que jamais, vous traînant avec votre bâton. Et la perte des foins, des grains, des bâtiments ! Cela doit monter haut ! Je n'ai pas le courage de reprendre la suite de mon journal ; j'attendrai que vous me l'ordonniez. Vous me demandez dans votre dernière l'éloge de Crébillon (Denis Diderot, Lettres à Sophie Volland)

1790 L'odieuse spéculation de l'administrateur des finances n'est qu'un tissu d'horreurs, et ces horreurs sont encore loin de leur terme. Il est certain que la France entière est remplie d'accapareurs ; il est certain que ces accapareurs font monter très haut le prix du blé (Jean-Paul Marat, Les Pamphlets)

IV. Résonner avec une forte intensité Intransitif

1833 N'entendez-vous pas une plainte qui sort de chaque vague, un murmure qui s'achève dans le lit de la mer ? La plainte des vagues ni le murmure de la mer ne monterait pas plus haut, si tout un monde venait de s'engloutir (Edgar Quinet, Ahasvérus)

1951 L'aboiement désolé montait très haut dans la nuit calme, entrecoupé de silences inégaux, comme s'il eût guetté désespérément du fond de ces solitudes une réponse, un écho qui n'arrivait pas (Julien Gracq, Le Rivage des Syrtes)

\section{CORPUS WEB :}

Reprenant D3 je me demandais si, en dehors du classement, il y avait une utilité à monter haut en niveau de rift ? [http://eu.battle.net/d3/fr/ forum/topic/11889849622] (29.7.2015)

Créer une plus large base pour obtenir de la stabilité et monter haut [http://leblogdematiere sdecole.blogspot.co.at/2012/01/constructions-4monter-haut.html] (29.7.2015)

Avec des coefficients de 106, mercredi soir, et de 109, jeudi, l'eau est montée très haut sur les ports noyant certains quais des ports gujanais [http:// www.sudouest.fr/2015/01/23/1-eau-est-mon tee-haut-mercredi-1806749-2904.php] (29.7.2015)

Prêt pour une soirée dingue ???? Attention ce soir double ceintures pour tous, nous allons vous envoyer dans un monde complètement inconnu ou seul la fête est d'ordre !!!!! La semaine dernière, la barre est montée haute [https://frfr.facebook.com/370093243019027/videos/70758 8195936195/] (29.7.2015)

REMARQUES : En parlant de ce qui ne peut être quantifié, monter haut (I) souligne le fait d'atteindre un niveau plus élevé. Lorsque le sujet désigne un animé, il réfère au fait d'acquérir plus de pouvoir, de puissance, en montant en grade, en atteignant un poste ou une position plus élevé dans la hiérarchie sociale. Il souligne l'idée de domination ou l'ambition du sujet. En (II), le sujet désigne une voix qui passe du grave à l'aigu. En parlant de ce qui est mesurable (III), se dit du fait d'augmenter, d'avoir une valeur plus élevée, un prix plus important. En (IV), le sujet désigne un bruit (cri, murmure) qui augmente en intensité. Haut reste invariable dans la majorité des cas, soulignant ainsi le point d'arrivée, mais, dans le dernier exemple, il s'accorde avec le sujet, insistant ainsi sur une position plus élevée : la barre (= le niveau) est haute. Il est modifié par assez, finalement, jamais plus, plus, si, très, bien, socialement assez, trop. Le nombre des modifieurs qui s'intercalent entre le verbe et l'adjectif-adverbe (ex. socialement assez haut) montre que haut est employé assez librement, sans former un groupe lexicalisé avec monter. Notons le contraste explicite de monter haut avec bas dévaler, bas trébucher, redescendre bien bas. Notons l'emploi de dévaler bas, redescendre bas, trébucher bas.

\section{Monter large}

Monter en s'étendant largement sur une grande surface, en couvrant une large étendue ; se répandre avec ampleur Intransitif

1892 Le silence recommença, tous les deux à présent avaient les yeux dans les yeux ; et, 
au loin, par la vallée obscure, les souffles de foule montaient plus larges, tandis que le roulement des canons, sur le pont de bateaux, se prolongeait sans fin (Émile Zola, La Débâcle)

\section{CoRpus Web :}

Plus le pneu sera large à l'AR, plus il va étouffer le moteur, mais mieux il passera la puissance. $\mathrm{Vu}$ le moteur que tu as, 185 me parait très largement suffisant et presque un peu large. les 1600S étaient montée en 165/80 de large toute leur carrière, seules les SC ont eu des 185/70 en option. Puis il y a tes capacités de conduite ; Certains aiment que çà soit un peu mobile de l'AR, d'autres pas du tout. Mieux vaut monter large, ou en gomme plus tendre pour tenir par terre [http:// alpinerenault.online.fr/outils/forum/viewtopic. php?f=7\&t=25950] (29.7.2015)

Même si la matière «magique » existe, pourquoi ne pas faire le pneu étroit et avoir ainsi le pneu ultime? La seule raison à mes yeux de monter large, c'est de profiter d'un comportement presque aussi bon qu'en été dans $90 \%$ des cas, c'est-àdire sur un route dégagée mais froide [http:// www.asphalte.ch/forum/viewtopic.php? $\mathrm{p}=2348$ 65\&highlight=] (29.7.2015)

$J$ en ai 4 en tout, 2 elargies (pneus HS) et 2 normales (comme neuves, avec pneus en bon etat)... mon idee etait de les refaire elargir... si on prefere le look dragster, on peut les monter large a $l$ arriere et normale a $l$ avant avec la probabilite non nulle de se retrouver dans la rubrique « piches "... a vous de voir [http://sport.skytopic. org/13158028069-vds-jantes-inno-12-pouceselargies] (29.7.2015)

Perso les miens sont montés larges (il tape pas, meme braqués a fond, mais j'ai la fourche de cbr et les butés qui vont avec !), ca me va trés bien comme position, et meme en faisant $40000 \mathrm{kms} /$ an avec des trajets de $400-800 \mathrm{kms}$ jour des fois. Le dos prend un peu passé $300 \mathrm{kms}$, les avants bras aprés 150-200 aussi, mais je remettrai un guidon normal pour rien au monde ! [http://forum.cb500. org/viewtopic.php?p=527610] (29.7.2015)

REMARQUES : Monter large se dit du fait de s'élever dans un mouvement ascendant et sur une grande surface, de s'étendre dans l'air ou dans l'espace, le sujet désignant un déplacement d'air produit par plusieurs personnes. Le CW met en évidence son emploi dans le domaine de l'automobile où large réfère à la largeur des pneus ou des jantes. Dans ce cas-là, le verbe monter 'assembler, mettre' est transitif ou apparaît dans son emploi absolu. Le dernier exemple appartient au motocyclisme. Large s'accorde avec le sujet du verbe intransitif dans l'exemple de 1892. Dans le CW, où monter est pris au sens de 'assembler', large peut s'accorder ou non avec l'objet du verbe transitif (comparer le troisième et le quatrième exemple du CW). Il est modifié par plus.

\section{Monter lent}

S'élever dans l'air lentement, à une allure peu rapide

Intransitif

1890 Une autre machine, puissante celle-là, une machine d'express, aux deux grandes roues dévorantes, stationnait seule, lâchait par sa cheminée une grosse fumée noire, montant droit, très lente dans l'air calme. Mais toute son attention fut prise par le train de trois heures vingt-cinq, à destination de Caen, empli déjà de ses voyageurs (Émile Zola, La Bête humaine)

\section{CORPUS WEB :}

il ya un mois j’ai changé les satellites dans le différentiel avant, j'ai l'original, mais renforcé. transférer $9 / 60$ pour monter lent et détendu, alléger le différentiel avant, ce qui est trop faible [http:// www.italian-cars-club.com/italian-cars-clubforum/viewtopic.php? $\mathrm{f}=24 \& \mathrm{t}=31311 \&$ start $=40$ ] (29.7.2015)

j’ai trouvé les messages sur le répondeur de Mermet, plus virulents et radicaux que d'habitude comme si le ton montait lent [http://www. arretsurimages.net/forum/search.php?0,searc $\mathrm{h}=$, author $=51796$, page $=125$, match_type $=U S E R$ ID, match_dates $=0$, match_forum $=$ ALL, match threads=] (29.7.2015)

REMARQues : Monter lent se dit du fait de se déplacer dans un mouvement ascendant, de s'élever lentement dans l'air ou dans l'espace, le sujet désignant une entité concrète (la fumée, la lune, le ton). Notons la collocation monter droit, très lente, où le soin de l'écrivain le pousse à présen- 
ter droit, invarié, comme modifieur directionnel et lent, accordé, comme propriété de la fumée. Notons aussi la collocation lent et détendu. Lent est modifié par très.

\section{Monter net}

S'élever avec clarté (d'un son)

入 monter calme

\section{Monter pur}

I. S’élever avec pureté, avec clarté (d'un son) Intransitif

1832 D'abord, la vibration de chaque cloche monte droite, pure et pour ainsi dire isolée des autres, dans le ciel splendide du matin. Puis, peu à peu, en grossissant elles se fondent, elles se mêlent, elles s'effacent l'une dans l'autre, elles s'amalgament dans un magnifique concert (Victor Hugo, Notre-Dame de Paris)

1840 Enfant ! dans ce concert qui d'en bas le salue,

La voix par Dieu lui-même entre toutes élue,

C'est la tienne, ô ma fille ! elle a tant de douceur,

Sur des ailes de flamme elle monte si pure, Elle expire si bien en amoureux murmure Que les vierges du ciel disent : c'est une sœur!

(Victor Hugo, Les Feuilles d'automne)

1852 Faites souffler dessus sept millions cinq cent mille bouches à la fois ; vous ne l'éteindrez pas. Vous ne ferez pas même broncher la flamme. Faites souffler l'ouragan. La flamme continuera de monter droite et pure vers le ciel (Victor Hugo, Napoléon le Petit)

1927 L'idole nègre entrait, avec les caravanes, dans la haute vallée du Nil, idole fruste, taillée dans le bois à la serpe, sensuelle, terrible, barbouillée de rouge et de bleu, avec ses attributs sexuels visibles, l'idole ingénue et bestiale qui allait calmer ses profils, affermir ses plans, faire onduler ainsi qu'une eau limpide ses surfaces, monter pure dans la pensée d'une race charmante comme une fleur dans le matin (Élie Faure, L'Esprit des formes)
II. Monter en ayant une forme régulière, esthétique

Intransitif

1921 L'arbre au tronc noir qui monte pur comme une colonne de temple est un hymne reconnaissant à l'ordre prodigieux du monde (Élie Faure, Histoire de l'art : l'art moderne)

CoRpus WeB :

La tu as la vipere, tu fais deja tres mal, et tu monte encore tres vite aux iles. Tu as la possibilite de monter pur a l'arc long, ou bien alors de commencer a monter int/sag, et avec des stats d'environ 76/59 et des popos de resist feu tu peux meme tenter l'oracle [http://www.hyjoo.com/ sujet-762.html] (29.7.2015)

Mais ça vaut quand même le coup par contre mieux vaut être en tres bonne forme physique car c'est vraiment de la monter pur et dur en zig zag et avec des chemins qui n'en sont pas vraiment c'est surtout des pierres en tout genre [http:// www.aujapon.com/forum/viewtopic.php?t=67] (29.7.2015)

La spé froid est indispensable pour tanker en héro. On est pas obliger de la monter pure. Mais c'est vraiment indispensable. J'en ai encore fait la malheureuse expérience hier avec une spé sang/impie qui a donnée deux wipes en dix minutes [http://www.vioc.fr/forum/viewtopic. php?f=15\&t=12382] (29.7.2015)

REMARQUES : Monter dur (I) se dit du fait d'apparaître dans un mouvement ascendant, de s'élever dans l'air ou dans l'espace en propageant une impression de transparence, d'équilibre et d'harmonie à laquelle s'ajoutent netteté et élégance, le sujet pouvant désigner une entité concrète (une voix, un son, une flamme) ou abstraite (une idée, une image). Le sujet de monter pur (II) désigne un élément de la nature (un arbre) qui s'élève dans l'espace en prenant une forme agréable à regarder, qui correspond à un certain idéal, à un certain modèle de perfection. Notons la collocation monter droit et pur. Ces emplois relevant de la prédication seconde sont caractéristiques de la langue littéraire. Les tours plus familiers font surface dans le CW. Pur réfère alors à un chemin sans détour, comme dans la collocation usuelle pur et dur qui sert d'intensifeur. L’accord est moins régulier dans l'emploi familier. Pur est modifié par si. 


\section{Monter raide}

S’élever de manière abrupte, très inclinée Intransitif

1913 Les rues montent raides entre les hautes maisons de pierre crue et les murs où de petites portes sont ouvertes sur des jardins : via Bramante par exemple (Valéry Larbaud, A.O. Barnabooth)

1942 Il suivit mentalement le garçon depuis son départ du Pin Rouge : D’abord la petite route, puis le trail. Et tout de suite ça montait assez raide, un bon boutte. Rien de trop dur pour un homme du bois, même avec lourd au creux des reins ; mais pour un gars qui venait de La Tuque... (Maurice Genevoix, Laframboise et Bellehumeur)

1945a Puis les allées commencèrent de monter assez raide et, bientôt, Joseph se trouva sur le plateau (Georges Duhamel, La Passion de Joseph Pasquier)

1945b L'un sans l'autre ils ne pouvaient finir leur vie

La ville est trop haute et droite

On a quitté la ruelle où chauffait le soleil Sur les pavés qui montaient raide vers le ciel (Pierre Reverdy, Plupart du temps)

1966 J'ai demandé ma route. Elle montait raide, à la sortie du village, puis longeait des immeubles neufs où l'on dînait sur les balcons et, plus loin, elle surplombait une plage aux galets blancs

(Sébastien Japrisot, La Dame dans l'auto)

\section{CORPUS WEB :}

Prendre le sentier à l'horizontale, puis mon ter raide jusqu'à la falaise école de Verdun [http: //www.camptocamp.org/routes/57083/fr/quiede-sinsat-la-poire-les-annees-zizanie] (29.7.2015)

Le chemin va monter raide sur un petit plateau, à 900m d'altitude, peu boisé [http://www. altituderando.com/Mont-Ventoux-1911m-versantnord] (29.7.2015)

Après 400m, emprunter une passerelle sur le torrent, passer rive gauche et continuer à monter raide sur le chemin [http://www.visorando. com/randonnee-lac-d-uzious-et-d-anglasdepuis-gourette/] (29.7.2015)
REMARQUES : Généralement, le sujet de monter raide désigne une rue, une route ou une allée dont la pente est très inclinée, abrupte, et par conséquent difficile à monter. Raide s'accorde parfois avec le sujet (ex. de 1913), se rapprochant ainsi des prédicats seconds orientés vers le sujet, mais l'accord n'est pas vraiment motivé sémantiquement. Raide est modifié par assez.

\section{Monter serein}

Monter paisiblement

$\lambda$ monter calme

\section{Monter seul}

Accéder à un poste supérieur, monter dans la hiérarchie sociale, mais en solitaire Intransitif

1914 «Ah! S’il pouvait revenir ! Lui seul peut me sauver. » C'est un transfuge. Est-il chassé? S'est-il évadé pour monter plus haut et plus seul ? Il veut fonder à son profit un système nouveau. En somme, mon article sur Mirabeau doit être le rendez-vous avec la reine (Maurice Barrès, Mes cahiers)

\section{CORPUS WEB :}

Par choix ou par défaut, il arrive que le cavalier se retrouve à monter seul. Si vous travaillez régulièrement sans enseignant, sans coach, cet article est fait pour vous [http://perspective scavalieres.com/monter-seul] (29.7.2015)

La société Switech, anciennement Swisstech, a développé des treuils spécifiquement pour monter seul au mât [http://www.ovniclub. com/fiches/monter-au-mat] (29.7.2015)

Sur ces modèles, le diamant est la "star» du bijou. La pierre est montée seule, ou réhaussée par de plus petites pierres sur les côtés [http:// www.sfm-france.com/SousCollection.aspx?id=3] (29.7.2015)

REMARQues : Monter seul réfère à la volonté d'accéder à un degré supérieur d'une hiérarchie, étant et se sentant seul (ex. de 1914). Par contre, l'acception 'sans aide' prévaut dans les deux premiers exemples du CW. Le dernier exemple réfère au fait de doter le bijou d'un seul diamant. L'accord est facultatif. Seul est modifié par plus. 


\section{Monter soef}

Monter avec douceur, avec grâce

Intransitif

1300 Vien, pren cest bauçant sor ; je descendrai el pré,

Puis monte par l'estrier belement et souef, [variante : belement et de gré, Fierabras (L), 1173]

U prendés par les regnes le ferrant pumelé ;

U siecle n'a ceval de la soie bonté

(Fierabras (K), 1158)

REMARQUES : Le sujet de monter soef désigne, en ancien français, un cavalier qui monte sur son cheval délicatement, sans brusquerie. Notons la coordination avec l'adverbe belement qui ajoute à l'idée de douceur celle de grâce dans le mouvement.

\section{Moquer bas}

Se moquer (de quelque chose/quelqu'un) en silence, secrètement; tourner en ridicule Pronominal

1769 M. GARANT. Nous pourrions sourdement, sans bruit, sans peine aucune,

Placer à cent pour cent ma petite fortune ; Et votre rare esprit tout bas se moquerait De tout le genre humain qui vous respecterait (Voltaire, Le Dépositaire)

1782 HILAIRE fils. (impétueusement) Non, c'est plutôt... Les Ligueurs, vous disje, sont des barbares et des imposteurs qui se moquent tout bas de notre crédulité... Eh, quels secours abominables ont-ils osé vous offrir, eux qui se disent vos amis !

(Louis-Sébastien Mercier, La Destruction de la Ligue ou La Réduction de Paris)

\section{CORpus WeB :}

il trouve toujours ce que quelqu'un peut avoir de ridicule. Et ça marche ! Vous avez envie de vous moquer tout bas avec lui... [http://gwendy 27.skyrock.com/680912816-AMOUREUSE-D-UNSEDUCTEUR-C-EST-QUOI-LES-RISQUES.html] (30.8.2015)

Wens se dirigea vers le pont principal où tous les membres d'équipages se moquaient tout bas de la tête de Lock sur l'écran du téléphone [http://forums.jeuxonline.info/showthread. php?t=538051] (30.8.2015)

Son ami de toujours, Levi, se moqua tout bas. Mais visiblement pas assez bas.

- Ca vous fait rire M. Rivaille? [http://bloody xsatsugai.skyrock.com/3255224152-Chapitre-1. html] (30.8.2015)

REMARQUES : S('en) moquer bas désigne le fait de tourner secrètement en dérision, en ridicule, de prendre comme objet de plaisanterie quelqu'un ou quelque chose. Bas reste invariable et est modifié par tout, assez.

\section{Moquer fort}

Se moquer beaucoup, fortement, tourner vivement en ridicule

Pronominal

1836 Mme Cardon nous disait à peu près la vérité sur Marie-Antoinette : bonne, bornée, pleine de hauteur, fort galante, et se moquant fort de l'ouvrier serrurier nommé Louis XVI (Stendhal, Vie de Henry Brulard)

CORPUS WEB :

C'est par ce mot : partageux qu'on prétendit se moquer fort des utopistes du XIX siècle qui désiraient l'application d'une juste répartition des richesses sociales et de ceux qui voulaient la mise en commun des terres et de tous les biens [http://www.encyclopedie-anarchiste.org/ articles/p/partageux] (30.7.2015)

Du coup le dimanche, je pars un peu en exploration et tu vas te moquer fort de moi en me montrant du doigt mais dimanche dernier, j'ai découvert Palavas sous le soleil [https://lesavions renpapier.wordpress.com/tag/paddle/] (30.7.2015)

Bon on avait pas prévu le thème de la soirée qui était Flamenco (oui merci gt vraiment pas heureuse !!) Heureusement que la vodka était là.... Bonne soirée quand même car je me suis moquée fort.. [http://milishki.skyrock.com/1373500364Soiree-au-Manureva.html] (30.7.2015)

REMARQUES : Se moquer fort désigne le fait de ridiculiser quelqu'un, fort servant d'intensifieur. Le dernier exemple du CW semble renvoyer au fait de s'amuser. Fort reste invariable (v. le troisième exemple du CW). 


\section{Mordre bas}

Mordre la partie basse (d'un corps)

$\lambda$ mordre haut

\section{Mordre haut}

I. Avoir un objectif élevé, une grande ambition Emploi absolu

1637 CLARIMAND. Tu sçais que mon humeur est de rire en tous lieux,

Que je vois du faux or aux Idoles des Dieux, Et n'estoit que le Ciel ou s'éloigne ou se cache

Que je m'éforcerois d'y treuver quelque tache :

N'aymant pas la fureur d'aller mordre si haut,

Pour tomber de plus bas j'éleve moins le saut (André Mareschal, Le Railleur)

II. Serrer (un objet) entre les dents en

l'orientant vers le haut

Transitif

1948 Il arriva vers minuit au « carnaval », mor dant haut sa cigarette et le chapeau melon perché sur les renflements de son crâne. Il était de fort méchante humeur (Maurice Druon, Les Grandes Familles)

CORPUS WEB :

si j'ai bien compris beaucoup d'ACD cherche à mordre naturellement haut.

je ne sais pas si une majorité d'ACD on une preference pour mordre en haut, mais en tout cas forest kiff grave mordre en haut !!! en mordant en bas forest n'est pas alais

Leeora préférait mordre en bas ! Inti adore mordre à la manche [http://cf-bak.clicforum.com/ t613-forest-au-mordant.htm?start=15] (30.7.2015)

Donc le staff et le rott ne sont pas des chiens de prise à la base, même si leur utilité première leur donne des aptitudes au mordant (les chiens de bergers étant amenés à mordre haut ou bas ou les deux suivant ce que voulait le berger pour «mater» le bétail récalcitrant) [http://www.chiencourant.com/forumfinal/viewtopic.php?f=22\&t= 24331\&start=50] (30.7.2015)

Et tout à l'heure dans la montée, j'avais vraiment plus beaucoup de pêche à cause de ça. Je prie pour que ce ne soit que l'embrayage qui est peut-être mal règlé (il mord haut sur la pé- dale d'ailleurs... normal ?) mais le problème est qu'il va s'user prématurément en patinant de la sorte... [http://www.forum-auto.com/marques/ Peugeot/sujet802-4270.htm] (30.7.2015)

REMARQUES : Au figuré, mordre haut (I) réfère aux objectifs qu'une personne veut atteindre, l'adjectif-adverbe dénotant une certaine ambition du sujet. En (II), il signifie 'saisir, tenir fortement entre ses dents un cigare, une cigarette en les dirigeant vers le haut', en signe de supériorité ou d'arrogance. Dans les deux premiers exemples du CW, haut désigne la hauteur où mord le chien, avec les variantes opposées mordre haut / en haut et mordre bas / en bas. Notons l'emploi dans le contexte de l'automobile, où il réfère à un embrayage qui 'prend' quand la pédale a presque retrouvé sa position de départ (dernier exemple du CW). Haut reste invariable et est modifié par naturellement, si.

\section{Mordre serré}

Mordre avec force, en serrant fortement les dents

Transitif

1746 La princesse et moi nous en riions encore le soir en nous mettant au lit ; mais notre joie ne dura pas longtemps. Car dès que je présentai mon petit doigt à l'anneau, je fus mordu bien serré. Je poussai un cri perçant, et j'entendis un grand éclat de rire (Claude-Henri de Fusée de Voisenon, Le Sultan Misapouf et la princesse Grisemine)

1768 Pasteurs. [...] Les princes sont les chiens de ces bergers des âmes, qui leur font mordre bien serré les brebis qui s'égarent ou qui ne veulent pas se laisser tondre (Paul-Henri d'Holbach, Théologie portative ou Dictionnaire abrégé de la religion chrétienne)

Emploi absolu

1953 « Je suis un jeune chien qui joue, me disait-il, et on me mord. » Il oubliait qu'il mordait lui-même, et assez serré (Henri Martineau, Le Cour de Stendhal)

REMARQues : Mordre serré désigne le fait d'attaquer, de se défendre en saisissant avec les dents, en serrant fortement de manière à blesser quelqu'un, l'action étant réalisé soit par un être 
humain (exemples de 1746 et 1953 dans lequel l'homme se comporte comme un jeune loup) soit plus généralement par un animal (exemple de 1768). Serré reste invariable et est modifié par bien, assez.

\section{Moucher blanc}

Rejeter par le nez des secrétions nasales blanches

$\pi$ cracher vert

\section{Moucher épais}

Rejeter par le nez des secrétions nasales épaisses

$\lambda$ moucher vert

\section{Moucher rouge}

Rejeter par le nez des secrétions nasales contenant du sang

Emploi absolu

1967 Le petit Léon, assis sur le carrelage contre le comptoir en contreplaqué, mouchait rouge et s'essuyait la tronche avec son foulard en soie artificielle (Marcel Lebas, Raymond la pente)

Pronominal

2018 Toi, tu vas te moucher rouge (Corpus Web Coiffet 2018 : s.v., sans date)

\section{Moucher vert}

Rejeter par le nez des secrétions nasales verdâtres

Emploi absolu

1912 Moucher beaucoup, et surtout moucher vert, est le fait d'une pituitaire malade (L'Éducation)

1949 Si tu mouchais vert ou si tu bâillais trop, tu touchais une indemnité. On y avait droit : pensez! (Dominique Launois, Qui se souvient de Babylone ?)

2018a Savez-vous pourquoi quand un rhume se termine, on mouche vert et épais ?? (Corpus Web Coiffet 2018 : s.v., sans date)

2018b Quand ça mouche vert... Ca signifie que le rhume est bientôt terminé

(Corpus Web Coiffet 2018 : s.v., sans date)
REMARQUES : Les combinaisons de moucher avec des adjectifs désignant une caractéristique du mucus nasal (épais, rouge, vert) appartiennent au langage familier. On trouve le même type d'emploi avec le verbe cracher (s.v.). VoIR AUSSI : cracher, tousser, vomir

\section{Moudre fin}

Broyer finement, moudre afin d'obtenir un granulat fin (opposé à gros)

Transitif

1721 Cette pâte d'Amido se fait donc avec la farine du plus beau froment, moulu bien fin (Louis Liger, La Nouvelle Maison rustique)

1771 Pour en faire quatre livres, on conseille de prendre deux livres de pois chiches moulus bien fin (Encyclopédie œeconomique ou Système général d'œeconomie rustique)

1802 on peut y mêler trois livres de graines de coques du Levant (coculus Indicus), moulues fines (Bulletin de la Société d'encouragement pour l'industrie nationale)

1835 On le [= le trefle rouge séché] hache menu ; à chaque boisseau environ de hachis, on mêle une bonne poignée de menus grains moulus fin ou gros (Erik Viborg, Mémoires sur l'éducation, les maladies, l'engrais et l'emploi du porc)

1863 L'usine de Biache traite les minerais les plus divers d'Allemagne, de Belgique, d'Espagne, de Sardaigne, etc. Elle traite le plomb et le cuivre, extrait l'argent et lamine les métaux. Tous les minerais sont grillés, après avoir été moulus fin et mêlés de sable quartzeux (Revue universelle des mines)

1888 Les farines de légumes secs préparées pour potages se vendent cher et souvent sont mal moulues, exceptées celles de fèves et féveroles, parce que ces dernières sont préparées pour la boulangerie, c'est-à- dire sont moulues fines (L'Apiculteur)

1953 Certains ciments moulus extrêmement fins peuvent cependant faire exception (Jean Cléret de Langavant, Ciments et bétons) 
REMARQUES : Moudre fin / gros repose sur une relation sémantique qui correspond, logiquement, à une prédication seconde résultative orientée vers l'objet direct du verbe : le produit du moulage est fin ou gros. Ceci se traduit par l'accord dans les exemples de 1802, 1888 et 1953. Les autres exemples montrent cependant que l'accord est optionnel. Notons que ces groupes sont souvent combinés avec des modifieurs du type extrêmement / suffisamment / spécialement fin (ou gros), sans doute en raison de l'importance technique de la taille des grains. Nous ne citons qu'un seul exemple (celui de 1953) de la modification avec des adverbes en -ment. Notons l'emploi de hacher menu, vendre cher.

\section{Moudre gros}

Broyer afin d'obtenir un granulat plutôt gros (opposé à fin)

$\lambda$ moudre fin

\section{Mouiller court}

Jeter l'ancre avec une petite longueur de chaîne Emploi absolu

1947 Ils mouillaient court ; par vent d'amont, allez, hop, tout au large (Jean Merrien, L'Homme de la mer)

\section{CORPUS WEB :}

On peut mouiller court, la qualité des fonds l'autorise [http://www.plaisance-pratique.com/ spip.php?page=imprimir_articulo\&id_article $=$ 1161] (30.7.2015)

Donc le fait qu'il faille mouiller court n'a rien à voir avec le type de ligne mixte ou tout chaine, le problème sera le même en ce qui concerne la tenue de l'ancre [http://www.hisse-et-oh.com/ forums/forums-techniques/messages/69309. pour-mouiller-d-abord-une-bonne-chaine-gg] (30.7.2015)

Après une expérience pendant laquelle je me suis fait peur (- presque- tout le monde décrochait, et moi aussi..), j'ai adopté la solution de toujours mouiller très long face au vent principal, et de mouiller court à $180^{\circ}$ ramené au nez (Bahaméenne) pour empêcher d'éviter... [http://www. stw.fr/forumstw/quest_answers.cfm?quest_ id=6755\&topic_id=22\&st_row=9375] (30.7.2015)
REMARQUES : Dans le langage de la navigation de plaisance, mouiller court se réfère à la longueur de la ligne ou chaîne où l'ancre est attachée. Notons l'opposition avec mouiller long dans le CW. Court reste invariable.

\section{Mouiller long}

Jeter l'ancre avec une grande longueur de chaîne $\lambda$ mouiller court

\section{Mourir bas}

Mourir en étant inférieur

$\pi$ naitre bas

\section{Mourir droit}

Mourir sans détour, franchement

$\pi$ vivre droit

\section{Mourir dru}

Mourir en grand nombre

Intransitif

1620 les gourmands sont toujours remplis de cruditez, de chagrins, de douleurs, de maladies, et meurent dru comme la gréle (Sébastien de Senlis, La Philosophie des contemplatifs)

1790 Ceux qui se portont ben y devenont malades, ceux qui n'ont qu'une maladie y en prenont dix ; aussi ils y mourront drus comme mouches (Cahier des plaintes et doléances des Dames de la halle et des marchés de Paris / Les Femmes dans la Révolution française)

1847 cette superbe évasion avait eu lieu dans le port de Rochefort, où les forçats meurent $d r u$, et où l'on espérait voir finir ces deux dangereux personnages (Honoré de Balzac, Splendeurs et misères des courtisanes)

\section{Mourir facile}

Mourir facilement

Intransitif

1962 C'est que ça ne meurt pas facile un crabe, vous savez (Exemple entendu, 17 juillet 1962 / Grundt : 231) 


\section{CORPus Web :}

Bin oui c'est ça tu préfere le faire mourir facile comme ça plutot que de le faire souffrir jusqu'à la fin de ses jours ? [http://www.samestory.com/sante-maladies/mst/sida/peine-demort-2-460850b] (4.8.2015)

Et que le last it pour le peu que ca harass bien en face, bah je galère et je préfère la jouer safe (j'ai tendance a mourir facile :s [http:// forums.jeuxonline.info/showthread.php?t= 1042471\&page $=4]$ (4.8.2015)

REMARQUeS : En parlant d'un animé, mourir facile marque le peu d'effort qui est nécessaire pour mourir ou faire mourir, voire le peu de résistance rencontré. Il peut également inclure les circonstances et être interprété comme : 'il est facile de mourir'. Dans le CW, mourir facile s'utilise notamment dans l'argot des jeux vidéo. Facile est invariable. Notons l'emploi de jouer safe 'sans courir des risques'.

\section{Mourir gras}

Mourir dans l'opulence, riche, enrichi Intransitif

1848 Annibal. Certes, je ne suis pas pour te le disputer.

Ton hymen a de quoi tous deux nous contenter,

Car à toi, s'il assure une belle retraite

Et le droit de jouer à la Madame... honnête, Il me met à l'abri, moi qui veux mourir gras,

Des caprices du sort à l'heure des repas ;

Mais je l'achète cher, car jusqu'ici mon rôle Est fatigant ! (Émile Augier, L’Aventurière)

1948 AMÉLIE. Elle n’est pas finie, Madame Gontran.

MADAME GONTRAN. Sûr que non... Il y en a qui meurent gras, d'autres qui meurent maigres. Moi, déjà je ne suis qu'un os... (Jacques Audiberti, Les Femmes du bøuf / Théâtre)

\section{CORPuS Web :}

Bien manger pour mourir gras ! [https:// www.pinterest.com/lilineb/bien-manger-pourmourir-gras/] (4.8.2015)

Sans parler de l'oie et du canard qui ont l'habitude ici de mourir gras, Cologne est au cœur de la culture de l'ail [http://www.ladepeche.fr/ article/2006/10/26/29968-allez-sur-les-hauts-decologne.html] (4.8.2015)

Je préfère mourir maigre, que de vivre grosse [http://plume-obsessionnelle.skyrock.com/ 3121532695-Je-prefere-mourir-maigre-que-devivre-grosse.html] (4.8.2015)

C'est pas ma faute si tu es assez bête pour préférer mourir maigre [http://lafilleplume.skyrock. com/3243130510-Bien-loin-des-thinspo.html] (4.8.2015)

tu vas mourir de toute facon, pourquoi pas au moin mourir maigre? [http://edito12.blogspot. co.at/2010/02/maigrir-mourir.html] (4.8.2015)

REMARQUES : Au figuré, en parlant d'une personne, mourir gras décrit l'état matériel dans lequel le sujet se trouve au moment où il perd la vie, gras soulignant l'idée de richesse, d'abondance ou d'opulence. Dans l'exemple de 1948 et dans le CW, il réfère à l'obésité d'une personne ou d'un animal au moment de sa mort. Notons l'opposition avec mourir maigre, maigre soulignant le manque et pouvant renvoyer soit à des ressources faibles ou à de la nourriture en faible quantité. La comparaison des exemples de 1848 et 1948 met évidence un changement d'attitude : si avant l'on aspirait à mourir gras, aujourd'hui on désire mourir maigre, ce qui peut affecter la connotation originale positive de l'emploi figuré. Dans l'exemple de 1948, la prédication seconde entraîne l'accord de maigre (de même avec gros dans le troisième exemple du CW). Cependant, l'emploi absolu dans le CW et le fait que l'accord n'est audible qu'au féminin favorisent une perception comme groupes plutôt invariables. Notons le groupe analogue vivre gros dans le cinquième exemple du CW. Notons l'emploi de acheter cher.

\section{Mourir haut}

Mourir en pleine gloire, dans une position sociale élevée

Intransitif

1933 Capable de vaincre, mais non de vivre dans sa victoire, que peut-il appeler, sinon la mort ? Sans doute veut-il lui donner le sens que d'autres donnent à la vie. Mourir le plus haut possible. Âme d'ambitieux, assez lucide, assez séparé des hommes ou 
assez malade pour mépriser tous les objets de son ambition, et son ambition même? (André Malraux, La Condition humaine)

CORPuS WeB :

En France, on peut ainsi se rendre au cimetière en side-car (le cercueil est déposé dans la nacelle) ou voir ses cendres dispersées pendant un vol en montgolfière ou lors d'un feu d'artifice. Les Américains meurent plus haut. La firme texane Celestis propose à ses clients d'envoyer dans l'espace quelques grammes de leurs cendres [http:// www.telerama.fr/monde/21138-le_meilleur pour_la_fin.php] (4.8.2015)

"Si une cordée montée avec l'aval des gendarmes meurt plus haut sous une avalanche, que dira-t-on ? » s'inquiète un guide de Chamonix. Lui appelle à distinguer le problème environnemental de celui de la sécurité qui « en montagne relève de la responsabilité individuelle » [http://www. liberation.fr/sports/2013/06/14/mont-blancascension-trop-goutee_911042] (4.8.2015)

Et juste à ce moment-là, mes anges gardiens ont du être d'accord avec moi puisqu'une vague plus forte que les autres est venue mourir très haut sur la plage et ce couillon s'est trouvé surpris, plouf les pieds dans l'eau et enfoncé dans le sable sur une dizaine de centimètres par le reflux qui rend le sable un peu mouvant lorsque l'eau se retire [http://www.unmondeailleurs.net/harycyclone-voyageur-la-reunion/] (4.8.2015)

REMARQUES : En parlant d'une personne, mourir haut souligne la grandeur ou l'ambition de l'homme quant aux objectifs qu'il s'est fixés au moment de disparaître, celui-ci souhaitant inspirer à son entourage une certaine estime et de la considération, dues en général à une réussite professionnelle ou à une position élevée dans l'échelle sociale. Dans le CW, l'adjectif-adverbe apparaît dans son sens concret et indique une position élevée, supérieure (l'espace), sur une montagne, ainsi que le fait qu'une vague remonte loin sur une plage. Haut reste invariable et est modifié par le plus, plus, très.

\section{Mourir libre}

Mourir dans un état d'indépendance, de liberté, sans être assujetti

Intransitif

1542 LA I. FILLE. J'aymerois mieux vive enrager. Mon cœur sans amour demourra,

Et libre vivra et mourra :

J'en fais la figue aux amoureux

(Marguerite d'Angoulême, Comédie à dix personnages)

1604 À peine le Soleil avoit laissé derriere Une egale moitié de sa longue carriere, Que chassant de son cœur tout pensement craintif, Libre il voulut mourir pour ne vivre captif (Antoine de Montchrestien, Les Lacènes)

1635 SOPHONISBE. Mais si le sentiment de la misere humaine,

Vous fait avoir pitié d'une dolente Reyne, N'aguere l'ornement de sa condition, Et maintenant l'object de la compassion, Donnez-moy l'un des deux, ou que jamais le Tibre,

Ne me reçoive esclave, ou que je meure libre (Jean Mairet, La Sophonisbe)

1681 Les Romains presque affamez, luy firent connoistre par leur fermeté, qu'ils vouloient du moins mourir libres (JacquesBénigne Bossuet, Discours sur l'histoire universelle)

1755 J'aurois voulu vivre et mourir libre, c'est-àdire tellement soumis aux loix que ni moi ni personne n'en pût secouer l'honorable joug (Jean-Jacques Rousseau, Discours sur l'origine et les fondements de l'inégalité parmi les hommes)

1762 Elle aime mieux se consumer et combattre sans cesse, elle aime mieux mourir malheureuse et libre que désespérée auprès d'un homme qu'elle n'aimeroit pas et qu'elle rendroit malheureux lui-même (JeanJacques Rousseau, Émile ou De l'éducation)

1877 Levez vos fronts ; voyez ce pur sommet, la gloire,

Ils étaient là ; voyez cette cime, l'honneur, 
Ils étaient là ; voyez ce hautain

promontoire,

La liberté ; mourir libres fut leur victoire

(Victor Hugo, L’Art d'être grand-père)

1950 Petöfi sait la joie du combat sans victimes

Il sait chanter l'été victorieux et sans crimes

Et pourtant il se bat confiant il donne tout son sang

Pour mourir libre pour perpétuer l'espoir

L'espoir des pauvres gens le miel de la Hongrie

Ses vers dorés vous les payez mes

camarades

De l'or joyeux de votre foi

(Paul Éluard, Hommages)

\section{CORPUS WEB :}

De plus, basculez du coté lumineux ou obscur m'obligererai à choisir un camps à proner un idéal dont je ne veux pas forcément. A savoir que les Chiss vivent et meurent libre [http://cec-swtor. level52.com/t10-Neutralite.htm] (4.8.2015)

ils se tuent et s'entretuent dans une horrible guerre civile. (la pire des guerres) mais ils meurent libres [http://www.lefigaro.fr/flashactu/2014/11/25/97001-20141125FILWWW00087libye-nouveau-raid-sur-l-aeroport-de-tripoli.php] (4.8.2015)

REMARQUES : En parlant d'une personne, mourir libre décrit la condition d'un individu au moment où il perd la vie, soumis à aucune contrainte externe. La notion de liberté peut aussi référer aux droits ou aux libertés politiques enfin reconnus au citoyen au moment de mourir. Notons les collocations vivre et mourir libre, mourir malheureux et libre, mourir libre pour ne pas vivre captif et aimer mieux mourir malheureux et libre que désespéré. En règle générale, libre est un prédicat second qui s'accorde avec le sujet. C'est la règle dans le style soutenu, mais le CW se montre plus ouvert à cet égard. Notons l'emploi de enrager vif, vivre captif, vivre libre. VOIR AUSSI : vivre libre

\section{Mourir maigre}

Mourir dans la pauvreté, dans la faim ; mourir dans un état de maigreur

$\pi$ mourir gras

\section{Mourir riche}

Mourir dans une situation financière aisée

$\pi$ vivre pauvre

\section{Mourir tranquille}

Mourir dans la tranquillité, en paix, dans la sérénité

Intransitif

1715 Enfin je mourus tranquille, ayant perdu toute autorité par l'artifice des Flamands qui avoient prévenu le roi Charles contre moi (François de Fénelon, Dialogues des morts)

1767 Ceux qui touchent au plan général et commun sont à la portée de la main, ils sont persécutés ; ceux qui s'en élèvent à une grande distance ne sont pas apperçus, ils meurent oubliés et tranquilles. $\mathrm{Ou}$ comme tout le monde, ou très-loin de tout le monde, c'est ma devise (Denis Diderot, Salon de 1767)

1845 - Il est écrit là-haut, s’écria la vieille fille en interrompant Calyste, que je ne mourrai ni tranquille ni heureuse (Honoré de Balzac, Béatrix)

1859 Il ne tombera pas dans la fadeur des demiteintes si ordinaires à ceux qui veulent attirer l'attention, mais non la haine ou la critique sur leur personne et mourir tranquilles après s'être longtemps battus (Alexis de Tocqueville, Correspondance avec Henry Reeve)

1865 C'est pourquoi je m'avise, à mesure que mon garçon grandit par les jambes, que ce n'est point sa cervelle qui le nourrira, et que, si je lui laissais quelques écus, je mourrais plus tranquille (George Sand, Les Maîtres sonneurs)

1933 Si elle a dans l'idée de mourir tranquille et de se faire soigner convenablement jusqu'au bout, comme ça se doit entre braves gens, ça n'est pas chez une punaise d'église, feignante comme la Quérolle, qu'il faut qu'elle aille ! (Roger Martin du Gard, Vieille France) 
1937 J'appellerais volontiers hommes libres les gens qui ne demanderaient pas mieux que de vivre et mourir tranquilles, mais qui reprochent à votre civilisation colossale de bluffer la vie et la mort, d'en faire un objet de risée (Georges Bernanos, Les Grands Cimetières sous la lune)

1993 Je circule doucement entre les agonisants illustres, sur la pointe des pieds, pour ne pas les déranger, ce n'est que Gabriel, l'écrivain fantôme du président, mourez tranquilles, je ne vous oublierai pas (Éric Orsenna, Grand Amour)

\section{CORPUS WeB :}

Le Karma ? J'ai un pote, le mec le plus sympa du monde qui vient de chopper un cancer, il lui reste moins d'un an à vivre. A coté de ça des mecs tuent des gens et en foutent dans la misère et détiennent des milliards d'euros et font tout ce qu'ils veulent, ils meurent tranquille de vieilleisse [http://www.jeuxvideo.com/forums/151-52195860-2-0-1-0-inutile-de-se-venger.htm] (4.8.2015)

Les vrais aquario attendent que leurs poissons meurent tranquille... [http://www.aquaryus. com/forum/topic/23936-bacs-10l-201/page-3] (4.8.2015)

Certains redoutent la mort, d'autres meurent tranquilles, d'autres enfin meurent heureux et en paix [http://l.evangile.sauve.overblog.com/ d\%C3\%A9livr\%C3\%A9s-de-la-crainte-de-lamort] (4.8.2015)

REMARQUES : En parlant d'une personne, mourir tranquille caractérise sa façon d'être, son état au moment où il disparaît, cette personne éprouvant un sentiment de calme intérieur que rien ne vient troubler, de plénitude causée par la satisfaction d'un besoin, d'un désir ou d'une aspiration. Notons les collocations mourir oublié et tranquille, mourir ni tranquille ni heureux, vivre et mourir tranquille. Tranquille est un prédicat second qui s'accorde dans le style soutenu. Dans un style moins soutenu, il peut rester invariable (v. les deux premiers exemples du CW). Tranquille est modifié par plus. Notons l'emploi de vivre tranquille. VOIR AUSSI : vivre tranquille

\section{Mouvoir droit}

Bouger, se déplacer directement

Intransitif

+1200 a Cous et espaules, braz et testes

Peçoiierent au saillir jus.

Cil furent pris, il n'i ot plus.

Lor tres destendent, lors s'esmuet

Gorvains Cadruz, et li oz muet

Droit au chastel de Campadoine

(Raoul de Houdenc, Meraugis de

Portlesguez [début XIII ${ }^{\mathrm{e}}$, 4214)

+1200b Par mon chief, mes sire Gauvains, C'est por noient ! Nus nel prendroit Qui par force ne lor toudroit Le port des nes ou chascun jor Vont et revienent sanz sejor Li marinier ; mes fetes querre Par toz les porz de ceste terre Nes et galies, si movez Droit a Monhaut, si l'asseez Devers la mer, ou autrement Ne porroit nus veoir coment L'en le preïst (Raoul de Houdenc, Meraugis de Portlesguez [début XIII'], 5206)

\section{CoRpus Web :}

Faisant volte-face, j'aperçu une masse rocheuse gigantesque qui se mouvait droit vers moi [http://www.jeuxvideo.com/forums/1-191637937435-5-0-1-0-fic-a-choix-un-etranger-dans-laligue.htm] (4.8.2015)

Tout autour de lui, sa garde d'élite, les renforts de Blue Moon, les troupes fusionnées de Purple Dragoon et les blindés d'Orange Star se mouvaient, droit vers l'envahisseur [http://www. fanfictions.fr/fanfictions/advance-wars/1216_lamarA-copy-e-des-tA-copy-nA-uml-bres/4084_ deception-point/lire.html] (4.8.2015)

Ensuite tu ajoutes le mouvement en avant qui fait marcher la propulsion arriere, un peu de jambe peut etre un petit coup de stick, aussi l'assiette : si tu donnes une info de ton corps claire et ça va meme dans l'orientation des yeux alors le cheval se meut droit [http://www.chevalannonce. com/forums-2043709-direction-deffectueuseneed-conseils? $\mathrm{p}=2]$ (4.8.2015)

REMARQUES : Le sujet désigne une personne, un animal ou un objet (premier exemple du CW) qui se déplace, se met en mouvement ou en route 
vers un lieu précis, directement, sans détour. Droit reste invariable. Il a tendance à s'associer avec la préposition qui le suit (à, vers), au point de faire partie du groupe prépositionnel comme modifieur de la préposition. Notons l'emploi pronominal du verbe dans le CW. Le dernier exemple du CW désigne le fait de se déplacer en ligne droite.

\section{Murer profond}

Isoler complètement, totalement

Transitif

1936 PASIPHAÉ. Comment plaindraient-ils ce qu'ils ne peuvent concevoir ? Me voici seule avec mes actes. Je suis extraordinairement seule ; et il est bien que ce voile me mure plus profond, au-delà de tous et de toutes. Mais toi, qui parlais de mon plaisir, regarde celle qui marche vers son plaisir, voilée comme les femmes funèbres (Henry de Montherlant, Pasiphaé)

REMARQUES : Dans la collocation murer profond, le sujet désigne ce qui fait obstacle ou qui cache (ici : un voile), qui dérobe à tous les regards, soustrait à la vue, l'objet animé se retrouvant dans une situation d'isolement total. Profond est modifié par plus.

\section{Murmurer bas}

Murmurer à voix basse, d'une voix faible, à part

soi

Transitif

1558 Mais combien y a il [sic] au contraire, de Prestres par le monde qui sont confitz en telle ignorance, qu'à peine peuvent ilz lire leur messe, et la murmurent tout bas entre les dentz, de peur que leurs faultes soient descouvertes : tant s'en fault qu'ilz entendent la dignité, vigueur, et efficace des sacremens qu'ilz administrent (Pierre Boaistuau, Le Théâtre du monde)

1698 Il sortit tout à coup, et murmurant tout bas Quelques termes d'aigreur que je n'entendis pas,

S’en alla chés Binsfeld, ou chés Basile Ponce,

Sur l'heure à mes raisons chercher une réponce (Nicolas Boileau, Épîtres)
1748 il forme son trait carré, en haussant les épaules, et murmurant tout bas : «Quelle mine cela aura ! Mais c'est sa fantaisie » (Denis Diderot, Les Bijoux indiscrets)

1829 - Non, dit Glazirne ; la colombe a porté au redoutable Niang les paroles que j'ai murmurées tout bas, pour guérir ta fille.

- Fais à la mode de ton pays, repartit l'Indienne : je m’y accoutumerai mieux qu'à la mode du pays des blancs (François de Chateaubriand, Les Natchez)

1836 - Aidez-moi, à l'arracher d'ici, ou vous ne l'aimez pas.

- Pardon, murmurait tout bas, en pleurant sur l'épaule de M. Clavier, mademoiselle de Meilhan ; pardon, monsieur, si je vous ai caché cette passion à laquelle s'attache aujourd'hui tant de honte pour moi, tant de colère pour vous (Léon Gozlan, Le Notaire de Chantilly)

1883 Un léger mouvement de tête, presque imperceptible, et un mot anglais murmuré si bas que je ne l'entendais point, étaient ses seuls remerciements (Guy de Maupassant, Contes et nouvelles)

1899 C'était un de ces soirs d'hiver finissant où passent des pressentiments physiques de l'avril prochain, bouffées tièdes, insolites, voyageuses en avance, qui semblent arriver de très loin, du sud, d'îles heureuses déjà printanières.

- Regardez, sentez, murmura Elzéar très bas, avec un grave tremblement dans la voix.

- N'y a-t-il donc sur cette terre qu'hiver, douleur et travail ?

(Eugène Vogüé, Les Morts qui parlent)

1928 - Madame Noély, dit Madame Garabis à la religieuse, je vous amène Gabrielle de Mirabeau...

- Tiens !... Elle a changé de nom depuis l'autre jour !..., murmura infiniment bas une élève placée au bout opposé de la classe.

J'avais ce que grand-père appelle des oreilles de souris (Gyp, Souvenirs d'une petite fille) 
1930 Les pluies qui tombent deviennent harmonieuses : la parole d'amour tout bas murmurée se délivre de la poitrine et s'en va sur les routes du monde (André Dhôtel, Campements)

1936 Les mots, bas murmurés comme si chacun d'eux était criminel, ne trouvent pas toujours l'oreille d'Armand, trop occupé de lui-même et trop ému d'avoir passé la forge fermée d'Avril le Mexicain (Louis Aragon, Les Beaux Quartiers)

Intransitif

1674 EURYDICE. Oui, Seigneur, et ma main vous est sûre.

PACORUS. C'est peu que de la main, si le cœur en murmure.

EURYDICE. Quel mal pourroit causer le murmure du mien,

S’il murmuroit si bas qu'aucun n'en apprît rien?

PACORUS. Ah ! Madame, il me faut un aveu plus sincère

(Pierre Corneille, Suréna, général des Parthes)

1722 Je suis au fait : j'entends tout cela mot à mot. Il parle aux ruisseaux, au zéphyr, à l'écho, et il leur ordonne de couler lentement, de murmurer tout bas, de souffler légèrement, et même à l'écho de se taire : cela est mignon et galant (Alexis Piron, Arlequin-Deucalion)

1784 À cet endroit, notre respectable père s'est levé, et mon mari s'est arrêté de sa lecture, croyant qu'il alait parler : mais le digne homme murmurait bas, comme priant Dieu : et ensuite il a dit à mon mari : Continuez, mon fils (Nicolas Rétif de la Bretonne, La Paysanne pervertie ou Les Dangers de la ville)

1862 Une sorte de convulsion le prit, il se renversa en arrière sur le dossier du fauteuil comme pour respirer, laissant pendre ses bras et laissant voir à Marius sa face inondée de larmes, et Marius l'entendit murmurer si bas que sa voix semblait être dans une profondeur sans fond :

- Oh ! je voudrais mourir!

(Victor Hugo, Les Misérables)
1869 Ni le comte ni la jeune comtesse n'avaient encore paru. À onze heures et demie, après beaucoup de méchantes plaisanteries, on commença à murmurer, tout bas d'abord, bientôt assez haut. Le docteur Frœber prit sur lui d'envoyer le valet de chambre du comte frapper à la porte de son maître (Prosper Mérimée, Lokis)

1936 Souvent, du coupant de son aile, il essaie l'air ; tout est vie et force en son aspect. Mais quelquefois aussi, tout arrondi et frileux au soleil du soir, il murmure tout bas et pour lui-même ; on l'entend à peine ; on devine le chant au tremblement de sa gorge, ce qui invite à ces douces et fluides pensées que l'on se dit à soi-même (Alain, Propos)

1992 Le tout petit garçon, mignon comme un bouton en train d'éclore.

Quand le bouton sera éclos

le garçonnet déjà ne sera plus.

La brise murmurait, tout bas, si bas, les mots de ce poème écrit par un enfant. Par un petit garçon de Terezin, qui n'était plus depuis longtemps déjà (Sylvie Germain, $\mathrm{La}$ Pleurante des rues de Prague)

Pronominal

1885 Que reste-t-il contre T. ? Rien. Rien ? Pardon, il faut tout dire, nous sommes à l'instant où l'on dit tout. Il reste ce qu'on se murmure tout bas, ce qu'on se chuchote à l'oreille, il reste sa mauvaise réputation. Quant à moi, je le déclare, je n'en savais rien (Victor Hugo, Choses vues)

1980 Vite, il murmura :

- Ji, Ji, je t'...

Il n'osait pas dire à haute voix ce qu'il se murmurait tout bas (Robert Sabatier, Les Fillettes chantantes)

CORPUS WEB :

Jamais les bras tu n'as baissé, On t'entend nous murmurer tout bas, Ca va, j'vous jure, je me sens bien [http://amoureusementbabs.skyrock. com/3043943163-Jamais-les-bras-tu-n-as-baisseOn-t-entend-nous-murmurer-tout-bas-Ca.html] (4.8.2015)

Une voix qu'elle utilise pour dire tout haut ce que beaucoup ne peuvent pas et se contentent 
de murmurer tout bas [http://www.billetreduc. com/140202/evt.htm] (4.8.2015)

C'est M. GUIGUI Claudel, membre du secrétariat général chargé des finances et du patrimoine, ex-secrétaire général de la section FPI de Paris, île de France qui met les pieds dans le plat en criant haut ce que certains leaders de la diaspora d'autres murmurent bas : " Pour nous, la nomination de Brigitte Kuyo est une prime à la rébellion »[http://www.civox.net/FPIFrance-Serieux-malaise-apres-la-nominationde-Brigitte-Kuyo-par-Affi-N-guessan_a3581.html] (4.8.2015)

REMARQUES : Murmurer bas désigne le fait de parler à voix basse, ce qui empêche de bien l'entendre. Bas reste invariable et est modifié par infiniment, si, tout, très. Notons crier haut ce qui d'autres murmurent bas (à comparer : dire tout haut ce que d'autres pensent tout bas). Mentionnons l'emploi de dire haut.

\section{Murmurer fort}

Émettre un murmure d'une certaine intensité Intransitif

+1366 N'a pas long temps qu'en une region Vi en dormant dolereuse assemblée, Ce fut Orgueil chevauchant le lion, Ire emprés lui qui se fiert d'une espée, Sur un loup siet ; Envie la dervée Dessus un chien aloit fort murmurant, Avarice gouverne la contrée : Onques ne vi si dolereuse gent (Eustache Deschamps, Euvres complètes [3e tiers XIV] $]$ )

\section{Corpus Web :}

Il y a déjà à peine une année et les maliens murmurent fort, en dénonçant la manière dont IBK gère actuellement le Mali [http://www. royalinformation.net/category/politique/partispolitiques/] (4.8.2015)

zebu...1 homme qui murmurait fort a 1 oreille des toutou :-] :-] :-] [http://www.astra-coupe.be/ modules.php? name $=$ Forums\&file $=$ viewtopic $\& p=$ 127575\&highlight=] (4.8.2015)

Il n'empêche, il se murmurait fort dans les couloirs de la maison de la radio que, peut-être, les excellents chiffres de Contact enregistrés ces dernières années étaient un rien gonflés... [http:// archives.lesoir.be/radio-premiere-photographieunique-et-reconnue-du-paysa_t-20021008ZOMCLA.html] (4.8.2015)

Afin de protester contre la fin de l'été, Sur Les Mains viendra murmurer haut et fort ses chansons sur les belles journées, les promenades dans les hautes herbes et le chant des sandales dans la très féerique Casa Musicale, temple du militantisme pour la défense des beaux jours [https://www. facebook.com/events/214166852077082] (8.8.2015)

Ou lorsque tonton Doudou plaisantin dans l'âme, lui a murmurer haut \& fort un «nous avons mis toutes les affaires dans ta chambre "....s'en suivit une réponse très spontanée " $\mathrm{OH}$ non, ce n'est pas possible » courrant déjà dans ce lieu qu'elle s'appropriait jadis \& qu'elle va devoir maintenant partager ! [http://sergiosophie. skyrock.com/2717994446-Dans-le-bain-Le-5-dec. html] (8.8.2015)

J'avais beau murmurer haut et fort que la Chine n'est pas le Perou, que la, je visitais la caverne d'Ali Baba et que 5 minutes de plus valaient des nuits de lectures de plus pour ma vie, rien n'y fit... [http://delpy.blog.lemonde. fr/2006/05/05/2006_05_dans_la_main_du/] (8.8.2015)

REMARQUES : Dans l'exemple de +1366 murmurer fort se rapporte au grondement ou grognement émis par l'allégorie de l'envie qui murmure fort, avec une certaine intensité. Dans le CW, il réfère à la parole humaine. Dans le premier exemple du CW, il désigne le grondement reflétant l'opinion négative d'un peuple envers son gouvernement. Notons la collocation haut et fort. Fort reste invariable. Notons aussi la construction pronominale avec sujet impersonnel il se murmurait fort dans le troisième exemple du CW.

\section{Murmurer haut}

I. Murmurer fortement (chose) Intransitif

1648 Le vent qui murmuroit si haut, Tient maintenant la bouche close De peur d'éveiller en sursaut La divinité qui repose.

La mer dans la tranquilité Avecque tant d'humilité Dissimule son insolence (Tristan l'Hermite, Les Vers héroïques) 
1833 BABYLOnE. (à l'Euphrate) Mon fleuve, ne murmure pas si haut. C'est toi qui m'as réveillée en sursaut. Je rêvais de banquets et de fêtes dans ma vallée.

LE FLeUve. Plût au ciel que ce fût moi qui aie parlé ! (Edgar Quinet, Ahasvérus)

1844 Felton rougit ; dans toute autre circonstance il eût réprimandé le soldat qui se permettait une pareille plaisanterie ; mais sa conscience murmurait trop haut pour que sa bouche osât parler.

- Si j'appelle, dit-il, viens ; de même que si l'on vient, appelle-moi.

- Oui, mon lieutenant, dit le soldat (Alexandre Dumas père, Les Trois Mousquetaires)

II. Murmurer à voix haute, d'une voix assez forte, ouvertement (personne)

Intransitif

1655 Je veux bien qu'au plus fort de l'ardeur lybienne,

Chacun sente la soif si j'étanche la mienne, Si je crains le soleil, si j'évite ses traits, Qu'on cherche la fraîcheur et l'ombre des forests,

Qu'on murmure tout haut si quelque

préference

Du chef et du soldat marque la difference (Georges de Brébeuf, La Phrasale de Lucain)

1735 Après ce discours consolant, ma femme de chambre sortit en murmurant assez haut pour me laisser entendre les choses les plus desagréables. Qu'on juge de l'état où je me trouvai ; je ne sçavois quel parti prendre ; si je sors, me disois-je, que ferai-je ? (Charles de Mouhy, La Paysanne parvenue)

1771 Il arrive, enfin, la tête couronnée de fleurs, et la robe traînante, c'est-à-dire, dans l'état le plus scandaleux pour des yeux Athéniens : aussi, l'indécence de cet appareil fait-elle murmurer assez haut les plus sages d'entre le peuple, déja indispôsés contre lui par la liberté qu'il avoit prise de ne paroître que si tard (Alexandre Dumas fils, Lettres athéniennes)
1783 Et au spectacle, une rangée de femmes, placées à l'orchestre, bouchoit la vue à tout un parterre ; la même chose à l'amphithéatre et dans les loges. C'étoit un vrai désespoir pour les spectateurs : on murmuroit tout haut ; mais les femmes en rioient, et la politesse parisienne se contentoit de gronder, mais n’alloit point au-delà (LouisSébastien Mercier, Tableau de Paris)

1833 GLOCESTER. Sa fortune croissant avec ses ennemis,

L'héritier du royaume à ses soins fut remis. On murmura plus haut ; mais on craignit les armes

Que vous teniez du roi subjugué par vos charmes

(Casimir Delavigne, Les Enfants d'Édouard)

Transitif

1859 Alors, il aura reçu quelque mauvaise nouvelle... il aura été forcé de sortir... oui, j'aime mieux croire cela, murmura tout haut le chef de bureau avec un soupir de soulagement (Pierre-Alexis Ponson du Terrail, Rocambole)

1916 Sous l'écorce des formes grossières et obscurcies, d'autres cœurs laissent murmurer tout haut un souvenir et évoquent des clartés antiques : le matin d'été, quand le vert frais du jardin déteint dans toute la blancheur de la chambre campagnarde, ou quand, dans les plaines, le vent donne au champ de blé des remuements lents (Henri Barbusse, Le Feu)

1941 Un peu plus tard, elle se surprit à murmu rer tout haut : la solitude effraye une âme de vingt ans. Elle compta rêveusement sur ses doigts : vingt et un, vingt-deux, vingttrois... Ainsi jusqu'à vingt-neuf (Georges Duhamel, Suzanne et les jeunes hommes)

REMARQUES : Murmurer haut (II) signifie 'parler à haute voix sans qu'on puisse entendre ce qui est dit'. Au figuré (I), il peut désigner le bruit d'un cours d'eau ou du vent. Fort reste invariable. Haut est modifié par assez, plus, si, tout, trop. 


\section{Muser profond}

Réfléchir profondément

Intransitif

1511 Et aussi naffiert à homme de Royale vocation muser si parfond en literature, ne tant peser le sens, ou epiloguer les diffinitions de prudence, et autres vertuz morales, et les difficultez de la conduite des choses, par verbale garrulité seulement sans rien mettre en realle efficace (Jean Lemaire de Belges, Les Illustrations de Gaule et singularitéz de Troye)

REMARQUES : Muser profond désigne le fait de se pencher sur un sujet particulier en s'appliquant, en réfléchissant mûrement ou de façon intense au domaine auquel on porte de l'intérêt. 


\section{Nager soef}

Nager doucement, gracieusement

Intransitif

+1175 Que il prenge de lié deraisne.

Il n'a frans hon, François ne Sesne,

A la roi cort, de son linage.

Ge oi dire que souef nage

Cil qui on sostient le menton

(Béroul, Tristan $\left[4^{\mathrm{e}}\right.$ quart XII $\left.{ }^{\mathrm{e}}\right], 3428$ )

\section{Naître bas}

I. Naître en étant inférieur, du point de vue de l'intelligence ou du caractère, et par rapport à l'évolution de la vie sur la planète Intransitif

1794 Drôle et gambadant comme le singe, et dans le fond très malfaisant comme lui, il est, comme le chien de chasse, né bas, caressant, léchant son maître qui le frappe, se laissant mettre à la chaîne, puis bondissant de joie quand on le délie pour aller à la chasse (Nicolas Chamfort, Maximes et pensées)

1856 La voici [= la formule] en peu de mots : ce livre a considéré l'oiseau en lui-même, et peu par rapport à l'homme. L'oiseau, né plus bas que l'homme (ovipare, comme le reptile), a sur l'homme trois avantages qui sont sa mission spéciale (Jules Michelet, L'Oiseau)

II. Naître dans une famille de classe sociale inférieure

Intransitif

1830a Et il sentit redoubler son ambition et son attachement à l'habit ecclésiastique. Que de cardinaux nés plus bas que moi et qui ont gouverné ! Mon compatriote Granvelle, par exemple. Peu à peu l'agitation de Julien se calma ; la prudence surnagea (Stendhal, Le Rouge et le noir)

$1830 \mathrm{~b}$ - Je prendrai un de ces jours une lettre du ministre à l'évêque, dit le marquis.

- J'oubliais une précaution, dit l'abbé : ce jeune homme quoique né bien bas a le cœur haut, il ne sera d'aucune utilité si l'on effarouche son orgueil ; vous le rendriez stupide (Stendhal, Le Rouge et le noir)

\section{CORPuS WeB :}

Le panettone est né bas, c'est à dire en forme de disque de $15 \mathrm{~cm}$ de haut (d'ailleurs on parle encore de panettone basso di Milano) puis c'est au XXème siècle qu'il a pris de l'allure (jusqu'à $30 \mathrm{~cm}$ de haut) et est devenu haut et en coupole (avec les nouveau moules et papiers de cuisson) [http://www.undejeunerdesoleil.com/2013/01/ histoire-legendes-panettone-italien-Milan-Noel. html] (8.8.2015)

J'aime la Bretagne, pays de résistance !.... Je me sens de là-bas, même si né plus bas ! [http:// www.agoravox.fr/actualites/economie/article/ bretagne-plan-de-soutien-142424] (8.8.2015)

et elle oublierait tout le temps d'une nuit, toute la haine qu'elle vouait à Maelle, toute la tristesse d'être aussi éloignée de son père, toute l'envie qu'elle ressentait d'être née si bas, toute la rage qui bouillait en elle de vouloir s'élever, toute l'injustice d'être née femme... [http://www.songof-ice-and-fire.com/t753-high-hopes-lady-maura] (8.8.2015)

Ô désespoir, l'humanité est née bien basse, et quand de fidèles serviteurs de l'espèce animale se font critiquer de telle façon je n'ai plus qu'à me dire qu'elle mourra bien basse... [http:// www.lepoint.fr/monde/la-catalogne-interdit-lescorridas-28-07-2010-1219406_24.php] (8.8.2015)

REMARQUES : Naître bas (I) désigne une infériorité intellectuelle ou morale qui s'affirme très tôt, à la naissance, le sujet désignant un animé (ici : un animal). L'exemple de 1794 pourrait référer à la taille des chiens de chasse par rapport aux autres chiens, mais l'aspect moral semble dominer. (II) renvoie à une personne née dans une famille appartenant à une couche sociale inférieure. Le CW illustre d'autres contextes d'usage : bas peut référer à la taille, à la géographie, au statut des femmes dans la société, etc. Notons l'opposition sémantique avec mourir bas. $B a s$ reste invariable dans la majorité des cas (v. le troisième exemple du CW), mais, dans le dernier exemple, il s'accorde avec le sujet pour renforcer le fait que la bassesse est une caractéristique du genre humain. Bas est modifié par bien, plus, si. 


\section{Naître beau}

Naître avec une belle âme et un physique

avenant

Intransitif

$\sim 1175$ Et Galerons, la bele nee,

A mout grant joie de celui.

Pus torna mout a grant anui

A amedos cele acointance

(Gautier d'Arras, Ille et Galeron, 895)

\section{CORPus Web :}

« La beauté c'est pas naître beau, c'est le devenir » [http://www.jeuxvideo.com/forums/1-5167058399-1-0-1-0-la-beaute-c-est-pas-naitre-beau. $\mathrm{htm}](8.8 .2015)$

Un être peut naitre beau extérieurement parce qu'il l'est intérieurement (c'est le cas des Maitres réalisés) mais ce n'est pas toujours le cas [http://lagazettedewydyr.over-blog.com/2014/10/ de-l-ombre-a-la-lumiere-etre-ou-paraitre-2-2accepter-son-corps-comme-il-est.html] (8.8.2015)

Pourquoi je ne suis pas née belle comme toute ces belles filles de cinéma avec les yeux bleus la peaux parfaites, des cheveux parfaits? [http://itsoursecrets.skyrock.com/2922230109229.html] (8.8.2015)

REMARQUes : Référant au physique du sujet au moment de sa naissance, beau s'accorde avec le sujet s'il est explicite (v. l'exemple de $\sim 1175$ et le dernier exemple du CW). Dans ces cas-là, il fonctionne comme prédicat second orienté vers le sujet. Dans l'exemple de 1175 la construction en prédication seconde est nominalisée.

\section{Naître double}

Naître avec un jumeau

त naître simple

\section{Naître simple}

I. Faire preuve d'une honnêteté naturelle, d'une droiture spontanée

Intransitif

1723 Quatre ou cinq mois après sa mort, mon fils, pour certains desseins, eut besoin d'une somme considérable d'argent ; il en emprunta, mais il lui en manquait encore. J'étais alors content de lui ; je suis né simple et plein de franchise ; je le croyais plus amoureux de mon repos que moi-même (Pierre de Marivaux, Le Spectateur français)
1863 Quelques hommes, formés à sa divine école,

Nés simples et grossiers, mais forts de sa parole,

Le suivaient lentement, et son front sérieux Portait les feux divins en bandeau glorieux (Alfred de Vigny, Poèmes antiques et modernes)

1896 On vit simple, comme on naît simple, comme on aime

Quand on aime vraiment et fort, et comme on hait

Et comme l'on pardonne, au bout, lorsque l'on est

Purement, nettement simple et l'on meurt de même,

Comme on nait, comme on vit, comme on hait, comme on aime !

(Paul Verlaine, Euvres poétiques complètes)

II. Voir le jour, apparaître, se manifester avec facilité

Intransitif

1933 Enfin, d'un jaillissement spontané, une consolation naquit très simple, souveraine et désespérée. Le désespoir faisait pont, une pile dans cette boueuse souffrance, mais l'autre, déjà sur les terrains glacés (Joseph Malègue, Augustin ou Le Maître est là)

\section{CORPUS WEB :}

Non pas que cette vie soit nulle ; juste incomplète. Trop vide pour m'y épanouir sans hypocrisie. Et pas assez ressemblante à mon idéal pour afficher un sourire franc. J'aurais pu naître simple et concrète il est vrai, mais cela ne devait ne pas être. Autant faire avec [http://www. livyetoile.com/archives/2015/03/11/31681355. html] (10.8.2015)

Uno a très bien résumé la pensée de Gould sur ce sujet (cf « L'évolution du vivant »). Une entité qui se reproduit et qui possède en elle des possibilités de changement ne peut que naitre simple et se complexifier en évoluant [http://www.sceptiques.qc.ca/forum/viewtopic. php?t=9572\&start=50] (10.8.2015)

Pourtant les Hums naissent simples et $\mathrm{cu}$ rieux, et malgré toutes les interdictions posées par les Grand Prêtres, les plus jeunes finissent 
toujours pas découvrir les secrets que renferment leur civilisation [http://naadie.forumactif.com/ t29-les-hums] (10.8.2015)

Vends 3 agnelles roux ardennais nées en Mars. 1 née double et 2 nées simple [http://www. 2ememain.be/animaux/animaux/moutons/ agnelles-roux-ardennais-248522935.html] (10.8.2015)

REMARQUES : Simple (I) réfère au comportement de l'individu, qui se caractérise par une honnêteté naturelle et une droiture spontanée. Notons que la collocation simple et grossier confère à simple une connotation plutôt négative, l'adjectif-adverbe soulignant davantage le manque de finesse et de subtilité, le peu de culture. Au figuré (II), naître simple renvoie à une idée, un acte, un comportement qui apparaît de façon spontanée, naturelle. Dans le dernier exemple du CW, il s'agit du fait de naître seul ou avec un jumeau. Notons l'opposition de simple avec l'adjectif double. Simple peut s'accorder avec le sujet, et fonctionner comme prédicat second orienté vers le sujet. Par contre, dans le dernier exemple du CW, les adjectifs-adverbes restent invariés. Simple est modifié par très. Notons l'emploi de vivre simple, aimer fort.

\section{Navrer dur}

Blesser gravement, sérieusement Transitif

+1365 Et entroes qu'Acilles entent

A la pucelle regarder,

Dont il ne se voelt retarder, Une fleche ens ou coer le fiert, A qui nulle aultre ne s'affiert.

Moult dur navré d'illoec se part

Et se ne scet mie quel part

Il en puist garison avoir

(Jean Froissart, Poésies [3 tiers XIVe])

REMARQUeS : Navrer dur désignait le fait de blesser quelqu'un grièvement, de lui porter un coup sérieux. Dur est modifié par moult.

\section{Navrer fort}

Porter un coup fort, blesser grièvement

Transitif

1176 - Ja n’i pert il ne cop ne plaie, Et si t’an plains ? Don n'as tu tort?
- Nenil ! qu'il m’a navré si fort

Que jusqu'au cuer m'a son dart trait ;

Ancor ne l'a a lui retrait

(Chrestien de Troyes, Cligés, 692)

CORPUS WEB :

Basch : Vossler était pas censé nous rejoindre après s'être tapé la discute avec le vieux qui dort ?

Ashe : Cela me navre fort, mais je ne crains que nous devions partir sans sa compagnie [http://www.parodyse.fr/FF12_chapitre.php?id= 18] (10.8.2015)

Des Mamans m’ont même laissé entendre que certains de mes articles alimentaient ces pensées négatives, ce qui me navre fort [http:// mercimontessori.blogspot.co.at/2014/02/monterune-activite-pour-son-bambin.html] (10.8.2015)

mais voila, je devrais m'éloigner de tes yeux il me navre fort de me soumettre a ce vœux je préfère y désobéir farouchement [http://forum. doctissimo.fr/psychologie/dieu-religions/mes sie-retour-jesus-sujet_11821_42.htm] (10.8.2015)

REMARQUES : En ancien français, navrer fort désigne le fait de blesser quelqu'un grièvement, de lui porter un coup dangereux voire fatal. Les exemples du CW illustrent son emploi moderne référant au fait de se sentir psychologiquement blessé ou fortement affecté. Fort reste invariable et est modifié par $s i$.

\section{Navrer profond}

Infliger une blessure, une plaie profonde

Transitif

+1133 Li Sarrazins se sent navrezt parfont : Li bon espié li gist sor le pormon, Li sanc en raie desi a l'esperon Et dist soëf, que ne l'entendi hom ( $\mathrm{Le}$ Couronnement de Louis [2 $2^{\mathrm{e}}$ tiers $\left.\mathrm{XII}^{\mathrm{e}}\right]$, 959)

1275 Un cheval a saisi par la resne doubliere, Celui qui siet desus a talent que il fiere ; Dou bran d'acier le cuide ferir enmi la chiere ;

Sor le cheval descent li coups en tel maniere

Que parfont l'a navré en la crupe derriere (Adenet le Roi, Buevon de Conmarchis, 415) 


\section{CORPus WeB :}

Apres plusieurs jours de chaleur horrible il flotte à mort pour le we * ca me navre profond [http://www.beaute-test.com/forums/index. php?topic $=348787 \&$ start=300] $(10.8 .2015)$

tentative de suppression de Trovigo par Malwarebyte, puis sans succés par Combofix... impossibeule...snif !!! (je crois aussi avoir crié : Mortecouille...ndlr !) navré profond, je viens chez les pros....humblement... [http://www. tomsguide.fr/forum/id-2936141/merci-aidesupprimer-trovigo.html] (10.8.2015)

REMARQUES : Dans un contexte guerrier, navrer profond désignait le fait de transpercer, d'infliger une blessure profonde à quelqu'un. Cet emploi est vieilli. Les exemples du CW illustrent l'emploi moderne au sens de 'affliger, attrister, contrarier quelqu'un'. Notons l'emploi de dire soef.

\section{Neiger fort}

Neiger fortement, abondamment

Intransitif

+1275 Dou bel enfant que il trouva

A sa femme raison demande.

Sire, ce dist la marcheande,

Une fois m'estoie apuiee

Lassus, a la haute puiee,

Mont dolente et mout esplouree

Pour la vostre grant demouree,

Dont g'estoie en grant desconfort.

Yvers fu, si negoit mout fort (L'Enfant qui fu remis au soleil [ $4^{\mathrm{e}}$ quart $\left.\left.\mathrm{XIII}{ }^{\mathrm{e}}\right], 30\right)$

\section{CoRpus WeB :}

Il commence a neiger fort a senechas $(-)$ [https://fr-fr.facebook.com/meteo.cv/posts/ 856345134426221] (10.8.2015)

Yeeees ! Il va neiger fort toute la journée, déjà $15 \mathrm{~cm}$ relevés ! [https://www.facebook.com/ alpe.huez/posts/691644150953878] (10.8.2015)

Ca va neiger fort pour Noel! [https://www. facebook.com/permalink.php?story_fbid=255434 177845280\&id=197689386978288] (10.8.2015)

REMARQUES : Neiger fort se dit de la neige qui tombe abondamment. Fort est modifié par moult.

\section{Nier ferme}

Nier de manière énergique, inflexible, inébranlable

Transitif

$1560 \mathrm{Si}$ on leur objecte que le pain est donc Jesus Christ, et est Dieu, ils le nieront fort et ferme, pource qu'il n'est point exprimé en ces parolles : Voicy mon corps. Mais ils ne profiteront rien en niant, veu que tous confessent que Jesus Christ nous est offert (Jean Calvin, Institution de la religion chrestienne)

1592 Quelcun, en mes jours, estant reproché par le Roy d'avoir mis les mains sur un prestre le nioit fort et ferme : c'estoit qu'il l'avoit battu et foulé aux pieds (Michel de Montaigne, Essais)

Intransitif

1568 Cest homme ne faillit luy nyer fort et ferme, comme celuy qui avoit la conscience nette de tout ce qu'on celuy mettoit à sus (Bonaventure des Périers, Les Nouvelles Récréations et joyeux devis)

CORPUS WEB :

Pour être une VRAIE blogueuse mode, il faut aimer préparer des trucs trop mignons, faire des bêtes de photos, avoir un diplôme de webmaster (et web-designer), connaître Photoshop comme sa poche, avoir un iPhone, une coque trop mignonne, poster 300 photos de fringues sur Instagram toutes les secondes, être une vraie geek, mais le nier ferme [https://fraisestagada. wordpress.com/] (10.8.2015)

Dans un contexte où le secteur tertiaire prend des proportions significatives, la petitesse des luttes visibles dans ce segment-là a de quoi inquiéter, mais ne doit jamais nier ferme son potentiel ni celui de sa production, la culture, qui peut s’avérer subversive [http://www.horsdoeuvre.org/objet/revue/prolocritique-lart-dela-fin] (10.8.2015)

Mais ce one night stand qui a légèrement dérapé ne représentait pas grand chose aux yeux de la diva, qui s'est empressée de nier ferme les faits [http://www.skynet.be/lili-fr/deco/ dossier/549889/entre-eminem-et-mariah-careyc-est-la-guerre] (10.8.2015) 
Beaucoup beaucoup de choses mais je pense que l'un des pires trucs quui me rend dingue c'est quand une personne continue de nier fort fort fort fort alors qu'il ou qu'elle est cramée et qui a tous qui l'accuse [http://ask.fm/NailaAli808] (11.8.2015)

Ces personnes sont au plupart les ressortissants de la Fédération de Russie mais officiellement le commandement russe n'admet pas que (nie fort et ferme que) ce sont leurs militaires en essayant d'imposer en à Ukraine et à tout le monde entier le mythe de la guerre civile en Ukraine [http://www.forum-politique. org/monde/faut-participer-une-autre-farcekremlin-t132443.html] (11.8.2015)

REMARQUeS : Nier ferme se dit du fait de ne pas vouloir reconnaître la vérité d'une proposition ou d'un jugement dont le bien-fondé peut ou non être mis en doute ; le sujet nie avec véhémence et conviction et se montre inflexible, inébranlable. Il apparait surtout dans la collocation nier fort et ferme. Ferme et fort restent invariables. Notons aussi la réduplication multiple de fort dans le quatrième exemple du $\mathrm{CW}$ pour intensifier le fait.

\section{Nier fort}

Nier avec véhémence

$\lambda$ nier ferme

\section{Nommer bas}

nommer tout bas : nommer à voix basse ; appe-

ler en murmurant

Transitif

1645 Je me voy sur le poinct que l'estat de ma vie Ne sera plus en bute aux noirs traicts de l'Envie,

Qui me blâme en secret, et me nomme tout bas

Complice d'un desordre où je ne trempe pas (Tristan l'Hermite, La Mort de Sénèque)

1755 Votre bonté, elle est accourue à moi, et penchant la tête sur mon sein, elle y a fini sa phrase... ne doit pas aller trop loin pour une malheureuse fille ! Je lui ai baisé le front. Hérö̈que Émilie ! L’ai-je nommée tout bas, pour la confirmer dans son héroïsme (abbé Prévost, Nouvelles Lettres angloises [trad.])
1822 je tresserai les fleurs les plus parfumées de la crêche pour lui en faire des guirlandes, et lorsque tu rempliras l'aire d'une nouvelle litière de paille fraîche, je la presserai avec plus d'orgueil et de délices que les riches tapis des rois ; je te nommerai tout bas : Jeannie, Jeannie !... et personne ne m'entendra, sois-en sûre, pas même l'insecte monotone qui frappe dans la muraille à intervalles mesurés (Charles Nodier, Trilby ou Le Lutin d'Arguil)

1833 Viens ! Le jour va s'éteindre... il s'efface, et je pleure.

N'as-tu pas entendu ma voix ? Écoute l'heure ;

C'est ma voix qui te nomme et t'accuse tout bas ;

C'est l'amour qui t'appelle, et tu ne l'entends pas ! (Marceline DesbordesValmore, Euvres poétiques)

1854 Un instinct inquiet qui vous nomme tout bas,

Un soupir ignoré qui songe et vous adore, Un front qui d'un reflet d'aube pour vous se dore,

C'est la gloire, et rien n'est comparable à l'effroi

De vivre sans un cœur pensif derrière soi (Victor Hugo, Thêâtre en liberté : être aimé)

1861 Sur du vélin lisse, à tranche dorée, Quand il eut écrit, et signé son nom, Valentin ferma son épître ambrée, Et sur l'enveloppe - il mit : pour Ninon ! Valentin, Madame, est un beau jeune homme

Que vous aimeriez, car il est très-blond ; Chacun l'examine et tout bas le nomme Quand la bouche en cœur il entre au salon (Henri Murger, Les Nuits d'hiver)

1875 Elle ne l'embrassait plus, la nuit, sur le front ; elle se tenait à quelques pas, les bras croisés, dans son sourire chaste, adorablement douce. Lui, ne la nommait plus que tout bas, éprouvant comme un évanouissement de son cœur, chaque fois que le nom chéri lui passait sur les lèvres, dans ses prières (Émile Zola, La Faute de l'abbé Mouret) 
1904 La personne à qui cette pénitence est imposée se place à la porte d'un cabinet qui puisse s'ouvrir et se fermer facilement, afin d'y remplir les fonctions de portier. Une dame s'enferme dans ce cabinet. Peu après, elle frappe. Le portier ouvre ; elle se penche vers lui et lui nomme tout bas le cavalier qu'elle désire (Henry-René d’Allemagne, Récréations et passe-temps)

Pronominal

1884 Charles d'Este se mit à déguster tranquillement un sorbet posé près de lui, sur une tablette, et entre temps, il lorgnait l'assemblée, jouant à se nommer tout bas les visages d'après les épaules, - car il était bien peu de femmes de sa cour qu'il n'eût pas eues à son commandement (Élémir Bourges, Le Crépuscule des dieux)

1963 Adam se nommait tout bas le maître des choses ; il n'y avait fondamentalement aucune différence entre les deux points de la plage qu'il avait occupés l'un après l'autre (Jean-Marie Gustave Le Clézio, Le Procèsverbal)

\section{CORPuS Web :}

S'il suffisait de croire à certaines prêches des prédicateurs musulmans ou chrétiens du pays, on peut facilement admettre avec eux que le Tchad serait maudit à cause d'innombrables actes inhumains et barbares perpétués par ses dirigeants depuis les premières belles semaines de l'indépendance, c'est-à-dire dès l'accession au pouvoir du sudiste François Tombal baye jusqu'au dernier régime actuel du nordiste Idriss Deby que les N'Djaménois nomment tout bas par peur des représailles le régime des « Zoulous » [http://makaila. over-blog.com/article-ahmat-zeidane-bicharamoussa-torna-redacteur-en-chef-du-regards-dafricains-de-france-40949870.html] (11.8.2015)

Celle des Balkans n'a pas commencé autrement, c'est ce que disent les gens qui y ont survécu, en Bosnie ou ailleurs, en nommant tout bas (encore maintenant !) les criminels qui ont joué avec les médias pour faire monter en neige la haine raciale [http://www.comlive.net/Noussommes-tous-racistes,82808,60.htm] (11.8.2015)

Je suis seulement fier, mais j'aurais aimé me trouver à tes côtés pour écouter les prophéties des flammes. Sais-tu que les Arabes te nomment tout bas « la Kahina »? [http://www.babelio.com/ auteur/Isaure-de-Saint-Pierre/175346] (11.8.2015)

Remarques : Nommer tout bas désigne le fait d'appeler, de désigner quelqu'un, d'énoncer le nom d'une personne ou d'un objet, et ce, à voix basse, l'action se voulant souvent mystérieuse ou secrète. Sous la forme pronominale, il se dit du fait de se désigner, de s'appeler par un nom en particulier, de le faire pour soi, en son for intérieur. Notons la collocation nommer et accuser tout bas (accuser bas). Bas reste invarié et apparaît toujours avec l'adverbe d'intensité tout. VoIR AUSSI : appeler bas / haut

\section{Nommer court}

I. Nommer brièvement, avec peu de mots Transitif

1659 Ne sçavez-vous pas, mes sœurs, que la vie d'un bon religieux et de celuy qui aspire à estre du nombre des plus chers amis de Dieu, est un long martyre ? Je dis long en comparaison de ceux à qui l'on tranche la teste, quoy qu'on le puisse nommer court eu égard à la breveté de cette vie, qui ne pouvant jamais estre longue se trouve quelquefois estre tres-courte. (Robert Arnauld d'Andilly, Le Chemin de la perfection [trad.])

II. nommer tout court : nommer de façon réductionniste, sans plus, tout simplement Transitif

1741 Il y avoit tout auprès du palais un bon charbonnier qui vivoit tranquillement dans sa petite maison, du charbon qu'il vendoit ; tous ses voisins le considéroient, parce qu'il étoit le plus honnête homme du monde ; le roi lui-même avoit une grande confiance en sa capacité, et le consultoit sur les affaires de l'état; on le nommoit le Charbonnier tout court, et l'on ne vouloit point, à plus de deux lieues à la ronde, avoir d'autre charbon que le sien (Anne-Claude de Caylus, Féeries nouvelles)

1837 - Mais je serais très flattée d'aller prendre des leçons chez Mme Birotteau, car Ferdinand... (Allons, pensa le parfumeur, elle le nomme Ferdinand tout court) nous a parlé 
de ce bal avec une admiration d'autant plus précieuse qu'il n'admire rien. Ferdinand est un critique sévère, tout devait être parfait

(Honoré de Balzac, Histoire de la grandeur et de la décadence de César Birotteau)

1883 Vous eussiez dit qu'elles attendaient quelqu'un. Parmi ces jeunes femmes, deux se faisaient remarquer par leur assiduité ; les habitués de la salle célèbre les nommaient, tout court, Olympe et Henriette (Auguste de Villiers de L'Isle-Adam, Contes cruels)

1887 La jeune fille haussa les épaules. Rien ne la pressait. Puis, après un nouveau silence :

- Alors, Caporal, c'est Jean tout court qu'on vous nomme?

- Mais non, Jean Macquart.

- Et vous n'êtes pas de nos pays?

- Non, je suis Provençal, de Plassans, une ville, là-bas (Émile Zola, La Terre)

CoRpus Web :

Par extension le subtweet, "subliminal tweet », est une manière de s'adresser à une personne ou de viser quelqu'un sans le mentionner avec son @pseudo, ni forcément le nommer tout court, de manière plus ou moins allusive parfois avec la balise \#subtweet (source Konbini) [http:// www.2vanssay.fr/twittmooc/?p=2665] (11.8.2015)

Ainsi, je voudrais savoir pourquoi il n'est pas possible de se renommer ou de bien meme de se nommer tout court, avec un nom ayant exister auparavant mais n'existant plus actuellement [http://forum.dofus.com/fr/1115-bugs/1670166nom-personnage] (11.8.2015)

Je ne peux détacher mon regard de cette cascade qui rebondit sur les flancs de la montagne. On devrait la renommer (la nommer tout court car elle n'a pas de nom) en Randy Morgenson Fall [http://www.runtheplanet.fr/2011/08/rae-lakesloop.html] (11.8.2015)

REMARQUES : Nommer court (I) désignait le fait d'appeler, de désigner quelqu'un, d'énoncer le nom ou l'histoire d'une personne d'une manière courte. L'usage moderne (II) recourt à la collocation tout court pour désigner le fait de nommer quelqu'un ou quelque chose avec le strict néces- saire, en réduisant l'acte de nommer à l'essentiel, sans rien ajouter. Tout court a alors tendance à appartenir au groupe nominal (à comparer : C'est Jean tout court), mais ce résultat diachronique part de l'emploi au sein du groupe verbal (I). Court reste invarié (v. le troisième exemple du CW). En (II), il est toujours modifié par tout. Notons l'emploi pronominal du verbe dans le deuxième exemple du CW.

\section{Nommer droit}

Nommer exactement, comme il convient Pronominal

+1200 Ce ne fet pas a redoter

Que mainz chevaliers ne te dot ;

Et je meïsmes te redot

Plus qu'oncques mes ne dotai home.

C'est li nons qui plus droit se nome

Que li tuens. Mes se ci estoit

Li rois Artus, il ne porroit

Nos acorder ne metre pes

(Raoul de Houdenc, Meraugis de

Portlesguez [début XIII ], 4574)

\section{Nommer haut}

Nommer à voix haute, ouvertement, publiquement

Transitif

1578 TRISTAN. Tu dy qu'il ne faut mot dire, et nommes icy tout haut leurs noms (Jacques de Lavardin, La Celestine [adapt.])

1612 Et parce que Filidas en mourant fit un grand cry, nommant fort haut Filandre, luy qui estoit aupres l'ouyt, et la voyant en si piteux estat, en eut un extreme desplaisir (Honoré d'Urfé, L’Astrée)

1646 Sur vostre estonnement, et sur vostre parole.

Vous estes interdit, et d'ailleurs je suis seur De vous avoir oüy tout haut nommer ma sœur

(Brosse, Les Songes des hommes esveillez)

1672 MARTIAN. Madame, il sait assez combien Léon vous plaît,

Et le nomme assez haut alors qu'il vous défère

Un choix que votre amour vous a déjà fait faire (Pierre Corneille, Pulchérie) 
1719 L’armée leur fit de grands remerciemens ; les soldats les nommoient tout haut les protecteurs du peuple, et les généreux défenseurs de la liberté publique (René de Vertot, Histoire des révolutions arrivées dans le gouvernement de la République romaine)

1881 Ils prirent la chandelle et, l'abritant avec un vieux journal, se promenèrent le long des plates-bandes. Ils avaient plaisir à nommer tout haut les légumes : «Tiens, des carottes! Ah! Des choux! » (Gustave Flaubert, Bouvard et Pécuchet)

1884 Maintenant encore, assis sur un coin de sa grande table, le corps tremblant, il n'osait nommer tout haut la maladie qu'il venait de reconnaître (Émile Zola, La Joie de vivre)

Pronominal

1848 La nymphe nourricière d'un ruisseau creusé à la bêche, était une mule qui tirait de l'eau d'un puits : c'était là le commencement de tous les fleuves que Bonaparte devait faire couler dans son empire. On travaillait à ma radiation ; on me nommait déjà et je me nommais moi-même tout haut Chateaubriand, oubliant qu'il me fallait appeler Lassagne (François de Chateaubriand, Mémoires d'outre-tombe)

\section{Corpus Web :}

Toutefois, puisque l'élève ne semble pas comprendre ma méthode respectueuse, la prochaine fois qu'il refera ce comportement, je ne me gênerai pas pour le nommer tout haut [http:// www.stephanecote.org/2013/08/15/13-trucsde-gestion-de-classe-qui-instaure-le-respect/] (11.8.2015)

$3^{\circ}$ les admoniteurs, qui sont adjoints aux observateurs ; ils doivent nommer tout haut les élèves qui méritent d'être repris, afin que le maître les punisse [http://www.inrp.fr/editionelectronique/lodel/dictionnaire-ferdinandbuisson/document.php?id=3301\&format=print] (11.8.2015)

Leur mission : récupérer la plus ancienne relique du royaume d'Aka, la statue sacrée de Komugi-chan, surnommée Komugi-De-Milo pour l'occasion. Ainsi, ils pouvaient la nommer tout haut, et personne, selon eux, ne comprendrait à quoi ils faisaient référence [http://www.animekun.net/forums/index.php?topic=1580.25;wap2] (11.8.2015)

REMARQUES : Nommer haut désigne le fait d'appeler, de désigner quelqu'un, d'énoncer le nom d'une personne ou d'un objet, et ce, à voix haute, le sujet voulant généralement se faire entendre d'autrui. Sous la forme pronominale, il signifie 'se désigner, s'appeler par un nom en particulier'. Haut reste invariable malgré l'objet au féminin ou pluriel et est modifié par assez, fort, tout.

\section{Noter bas}

Donner une note inférieure à la note méritée, noter sévèrement

Emploi absolu

1962 Il [= le président général des jurys du baccalauréat] a pu ainsi comparer les notes données par les neuf professeurs de philosophie, de sciences naturelles, etc., puis avertir chaque jury : « Vous avez noté haut... vous avez noté bas... Vous êtes dans une bonne moyenne » (Le Monde, 12 juillet 1962 / Grundt : 283)

\section{CORPUS WEB :}

De l'autre côté, les Européens, notamment les Anglais et les Français, mais également les Québécois, beaucoup plus exigeants. Et qui, dans leur très grande majorité, notent bas. Aussi bien le répéter, j'estime, pour ma part, qu'il vaut mieux être exigeant, et donc noter bas. Pourquoi ? Tout bonnement parce que la perfection, en matière de vin, est rarissime et qu'il est presque toujours possible, pour les viticulteurs, de faire mieux -et donc de trouver mieux pour ce qui est du consommateur [http://www.lapresse. ca/le-droit/week-end/vins/201103/17/01-4380222noter-haut-ou-noter-bas-.php] (11.8.2015)

On hésite pas à noter bas, à caresser dans le sens du poil pour avoir de bonnes notes en retour, tout n'est que calcul cette semaine. Les meilleurs propriétaires de maisons d'hôtes seront-ils les gagnants de Bienvenue chez nous ? [http://www.nouveautes-tele.com/1381-gagnantbienvenue-chez-nous-1212.html] (11.8.2015) 
elle cachait vraiment mal sa deception quand un juge la notait bas... [http://forum.auf eminin.com/forum/loisirs11/_f15974_loisirs11Chenoa-quelle-beaute-nolwenn.html] (11.8.2015)

Il faudrait repartir ici de la notion de grand vin mais quand l'équilibre, l'intensité, la complexité, le volume, la marque du lieu, la longueur, la typicité sont présents dans un vin, il y a une chance que ce soit un grand vin ou un vin que tu peux légitimement noter haut ! [http:// buveurs-detiquettes.com/viewtopic.php?f=21\&t= 1476\&start=60] (13.8.2015)

On parle beaucoup des avis et des notes qu'on donne aux jeux. Par simple curiosité geekienne, je me demandais quelle était la tendance générale des trictraciens : noter haut ou noter bas [http://www.trictrac.net/forum/view topic.php?f=1\&t=51131\&start=0] (13.8.2015)

Enfin voilà, comme dit précédemment, les connaissances ne suffisent pas, il faut que le jury ai un coup de cœur pour noter haut la main... Ce jury est sans cœur, mais ce n'est pas une raison pour descendre les candidats! [http://forumsenseignants-du-primaire.com/topic/200446notes-concours/page-5] (13.8.2015)

Du coup, elle se contenta d'un large sourire réjouit pour ceux qui notaient haut la nouvelle de sa « relation » avec le GB [http://bakasgotthe powa.forumactif.org/t63-suite-de-arriver-etsurprise-collectif] (13.8.2015)

Mais il y a un point qui me pose question. La ferritine est notée basse : 9ng/ml [http:// forum.doctissimo.fr/sante/diabete/diabete-tauxferritine-sujet_153732_1.htm] (11.8.2015)

La suite est aussi simple à comprendre : Quelle que soit la clé utilisée, plus la note est notée haute sur la portée, plus elle sonne aigu [http://www.pianoweb.fr/solfege-la-lecture-denotes-du-debutant.php] (13.8.2015)

REMARQUES : Noter bas désigne le fait noter sévèrement un travail ou un examen, la note étant relativement basse ou inférieure à la note méritée. Notons l'opposition avec noter haut qui a le sens de 'noter largement (un travail ou un examen)', la note étant relativement élevée par rapport à la note réellement méritée. Noter bas / haut tend à l'emploi absolu, mais l'emploi transitif apparaît dans le troisième exemple du CW. Dans le septième exemple du CW, noter haut est pris au sens figuré de 'apprécier'. Dans l'avant-dernier exemple, noter bas réfère à l'enregistrement écrit d'une valeur basse pour le taux d'une substance, s'accordant avec le nom de la substance. Dans le dernier exemple, noter bas recouvre son sens d'adverbe de lieu, employé ici dans le domaine de la musique. Les acceptions que prend haut dans les trois derniers exemples du CW incluent l'emploi transitif du verbe, ce qui peut entraîner l'accord avec le complément d'objet. Hormis ces exemples, bas et haut restent invariables dans l'acception de 'donner une note basse ou haute', même dans l'emploi transitif (troisième exemple du CW). Notons l'emploi de sonner aigu.

\section{Noter haut}

Donner une note supérieure à la note méritée, noter largement

$\lambda$ noter bas

\section{Nouer étroit}

Nouer, attacher quelque chose étroitement, en serrant beaucoup

Transitif

+1175 Affublez se fu forment bien, Malade senble plus que rien ; Et nequeden si ot s'espee Entor ses flans estroit noee

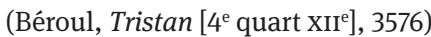

1250 Do prent .i. hardillon que ileuc a trouvé, Si le se met au col, moult estroit l'a noué ; Puis en a pris le chief, au prestre l'a livré (Doon de Mayence, p. 206)

1300 De son cief li osterent son vert heaume gemmé, D'une ensaigne de paile li ont les ex bendés, Par deriere le dos le puins estrois noés [variante : estroitement noez, Fierabras (L), 3449] (Fierabras (K), 3327)

\section{Corpus Web :}

La jupe Jürgen Michaelsen : Taille élastique, passants pour ceinture et lien à nouer étroit. Long.: à partir de $70 \mathrm{~cm}$ env. En jersey simple $95 \%$ viscose, 5\% élasthanne. Doublure en $100 \%$ polyester [http://www.pricedefy.be/ comparateur/chemises/prix/jurgen-michaelsenle-chemisier-jurgen-michaelsen] (13.8.2015) 
Un moment il n'y avait plus eu ce fantôme mais une innocence écorchée de toute part. Mais droite toujours, aussi fière qu'à l'accoutumée, serrée dans ce carcan de morale qu'elle nouait étroit dès son réveil [http://rozam-le-site.fr.gd/g-comme-un-froE8re-.--.--.--g-III.htm] (13.8.2015)

REMARQUES : L'objet de nouer étroit peut référer à une chose inanimée qu'on serre, noue fermement à autre chose. Étroit est invariable, à l'exception de l'exemple de $\sim 1300$, et est modifié par moult. VOIR AUSSI : lier étroit

\section{Nouer fin}

Nouer, serrer étroitement

Pronominal

1966 Tant que cette peur me contraignit, je cachai le tampon de gaze et les collants de sparadrap que j’aurais été gêné d'exhiber dans la rue avec un ample mouchoir de toile, plus commode qu'un foulard parce qu'il se nouait plus fin et se tenait mieux serré (Michel Leiris, La Règle du jeu 3 : Fibrilles)

CORPuS Web :

Les fronces aux épaules, au col, aux manches et à la poitrine créent un look féminin et élégant. Le ruban à nouer fin à la poitrine constitue un détail sympa [http://www.e5mode.be/fr/ ustienklen-8537818.html] (13.8.2015)

Base droite. Lien à nouer fin en haut du dos. Beau décolleté dans le dos [http://www.dressfor-less.fr/tmpl/detail.tmpl?art_id=474245] (13.8.2015)

Nouant fin les fils d'or de l'ouvrage la brodeuse arriva à un résultat des plus subtils, si bien qu'on imagina une aquarelle des plus délicates [http://www.amicalien.com/membres/LeForum/ f62-t12381110-s136-phonetiquement-votre$\mathrm{n} \% \mathrm{C} 2 \% \mathrm{~B} 0-6 . \mathrm{htm}]$ (13.8.2015)

REMARQUES : Nouer fin désigne le fait de faire un nœud à un fil, un ruban ou à autre chose de fin, permettant de serrer fort, étroitement. Le dernier exemple réfère à la structure d'une broderie. Fin reste invariable et est modifié par plus. Notons l'emploi absolu et transitif dans le CW. Mentionnons également l'emploi de tenir serré.

\section{Nouer fort}

Nouer en faisant un nœud très serré

Transitif

+1225a Mais ke plus grant travail i met

Et il plus fort la melle et noe.

Lors set il bien ke ja n'ert soe,

Quant il net le puet deslacier (Le Chevalier

as deus espees [2 $2^{\mathrm{e}}$ quart XIII] $]$, 1375)

+1225b Et puis li demandai son non.

Et il me dist k'il ne savoit

Pas son non, mais oï avoit,

Quant il l'espee a la pucele

Deschainst, dont ele a la capele

Ot les renges si fort nouees,

Ke 'chevalier as .ii. espees'

Kex li senescaus l'apiela (Le Chevalier as

deus espees [ $2^{\mathrm{e}}$ quart $\left.\mathrm{XIII}{ }^{\mathrm{e}}\right]$, 2219)

1275 A guise de cheval que on a afrené,

Li ont mis cele corde, ce fu grant cruauté ;

Derrier ou hasterel li ont si fort noé

Que pour cent mile mars n'eüst un mot sonné

(Adenet le Roi, Berte aus grans piés, 451)

CORPUS WEB :

Depuis lorsque que lui raconte à nouveau, elle s'empare de la petite bête bien identifiée, pour la glisser à la fin de l'histoire dans le joli sac rouge. Elle se fait d'ailleurs un grand plaisir de le nouer fort et de le ranger à sa place dans la couverture du livre [https://generationblogueusemag.wordpress. com/2014/10/04/colere-tu-menerves/] (13.8.2015)

Sans scaphandre ni ballon d'oxygène, aidés juste par l'air de leurs poumons, deux plongeurs se jettent à l'eau, une corde autour de la taille. Après moult tentatives, ils parviennent chacun à la nouer fort à chaque bout de la grume avant de remonter à la surface quelques deux minutes plus tard [http://www.syfia-grands-lacs.info/ index.php?view $=$ articles\&action $=$ voir\&idArti cle $=680](13.8 .2015)$

Tisser, c'est joindre, relier les fils, enrichir l'étoffe de nos vies. Nouer des liens, tenter de les nouer fort, pour résister aux difficultés. S'ils rompent, ce n'est pas toujours pour la vie [http:// www.chantalconstant.com/\#!spectacles/cm8a] (13.8.2015) 
REMARQUES : L'objet de nouer fort peut référer à une chose inanimée, comme une partie du corps, une corde qu'on serre, qu'on noue fermement à autre chose, ou encore à une personne (ou un animal) qu'on ligote avec un lien particulièrement serré pour la garder prisonnière. Le dernier exemple renvoie, par métaphore, au tissu de la vie. Fort reste invariable (v. dernier exemple du CW) et est modifié par plus, si. Notons l'emploi de meller fort (mêler fort). VoIR AUSSI : enserrer / lacer / lier fort ; lier étroit / ferme / serré.

\section{Nouer soef}

Nouer doucement

Transitif

-1300 Qant tant avrez com je tornoiemanz tenuz, Mout dot que ne soiez de petit esperduz : Soëf noë, biax niés, cui mentons est tenuz (Jehan Bodel, La Chanson des Saisnes [fin XIII ${ }^{\mathrm{e}}$, 4754)

REMARQUES : Opposé à nouer fort, nouer soef désignait en ancien français le fait de nouer sans serrer, sans faire de mal.

\section{Nourrir long}

Laisser pousser (la barbe)

入 aller droit. VOIR AUSSI : écrire long

\section{Nuire fort}

Nuire beaucoup, sévèrement

Intransitif

1830 Le moindre signe de sensibilité eût été à ses yeux une sorte d'ivresse morale dont il faut rougir, et qui nuit fort à ce qu'une personne d'un rang élevé se doit à soi-même (Stendhal, Le Rouge et le noir)

\section{CORPUS WEB :}

Le langage SMS et les trop nombreuses fautes d'orthographe sont à bannir de manière général, autant sur le forum, que sur le canal de guilde ou dans les autres canaux. Les emotes /rude, / crache nuisent fort à la diplomatie et aussi à notre image de personnes respectables [http://forum. junglefrag.com/index.php?topic=2830.0;wap2] (13.8.2015)

Pollution invisible, inodore et incolore, les nuisances sonores en milieu scolaire constituent un problème ignoré. Pourtant, elles nuisent fort aux apprentissages, elles rendent agressif et instable, elles influent sur la santé des élèves et du personnel scolaire [http://empreintesasbl.be/ activites/dossier-decibelle-et/] (13.8.2015)

En senior, les filles étaient exemptes et les garçons se sont à nouveau inclinés (44-66) contre Charnay-lès-Mâcon. Quelques départs et arrêts nuisent fort au rendement de cette équipe [http://www.lejsl.com/edition-de-montceau-lesmines/2012/10/18/les-benjamines-en-route-pourle-championnat-regional] (13.8.2015)

REMARQUES : Fort est un intensifieur qui renforce l'idée de dommage causé. 


\section{Obtenir facile}

Obtenir facilement, sans difficulté, sans effort, sans peine

Transitif

1865 Voulez-vous jouir d'un magnifique panorama mouvant? vous l'obtenez facile, sans fatigue et vraiment enchanteur en prenant le chemin de fer de Liége à Aix-la-Chapelle par Maestricht avec retour par les prairies du Limbourg et les bords de la Vesdre (Albert d'Otreppe de Bouvette, Tout ce qu'on voudra)

1962 À Versailles, il [= un commerçant] en $o b$ tiendrait facile, facile le triple (Exemple entendu, 19 août 1962 / Grundt : 219)

\section{CORPUS WEB :}

Et pleins de petites choses optionnelles comme des bannières, des " posters » (enfin des gravures je sais pas un truc qui met en scène nos aventures ou les aventures des héros de la horde/alliance (ca pourrait s'obtenir facile par une suite de quêtes, ou archéo tiens, avec l'archéo on pourrait avoir pleins de trucs sympas à exposer, il y a souvent genre des décos style récipients/vase même à poser vite fait sur une étagère en bois) [http://eu.battle.net/wow/fr/forum/ topic/12844174943] (13.8.2015)

La silice et microballon sont complémentaires, je connaissais déjà les microballons mais la silice c'est vraiment très intéressant pour obtenir facile une pate, facile à travailler [http://www. shaperoom.net/forum/viewtopic.php?f=13\&t=96 22\&hilit=\&start=15] (13.8.2015)

$\mathrm{Tu}$ pourras aller sur le mien et mettre des comms, et tu pourras mefaire de la pub (mé t pô obligé) j'ai des amies qui mont dit qu'elles étaient aller sur ton blog, et ele l'on trouvé super super super bien (ex : zoubi-lov3 -> ou un truc comme ca...) et bravo, tu les a obtenus facile tes 1000 comm's, fallait pô demander, ils allaient bien finir par tomber^^ [http://x-still-th-x.skyrock.com/ 872062576-posted-on-2007-05-04.html] (13.8.2015)

kof $12=$ les trophés sont à chier, tu les obtiens faciles [http://www.jeuxvideo.com/forums/160-3822455-6-0-1-0-le-jeu-ou-les-trophees-sonthyper-facile.htm] (13.8.2015)

REMARQUES : Employé dans le langage familier, obtenir facile souligne l'acquisition d'une chose ou d'un bien à un bon prix et sans effort. Facile reste invariable dans la majorité des cas (v. le troisième exemple du $\mathrm{CW}$ ), mais dans le quatrième exemple du CW il s'accorde avec l'objet au pluriel tout en gardant son interprétation d'adverbe de manière. Notons l'emploi pronominal-impersonnel dans le premier exemple du CW. Relevons aussi la réduplication facile, facile.

\section{Odorer bon}

Dégager une odeur agréable

Intransitif

1888 Il restait pensif, pris d'une espèce de superstition pour ce sacerdoce, avec des regards en dessous vers Madeh, dont les cheveux odoraient bon (Jean Lombard, L'Agonie)

1902 Ceux qui sont nourris là-dedans, ne peuvent pas avoir le sens commun plus que ne peut odorer bon qui s'héberge en la cuisine (Pétrone, Satyricon [trad.])

1910 Un morceau de chair odorait bon parmi l'émiettement des mottes d'une taupinière. La bonne aventure ! Et, vlan ! Un coup de bec pour le déjeuner du matin (Louis Pergaud, De Goupil à Margot : histoire de bêtes)

2003 Ce sera bientôt la saison [...] des roses que mon épouse a importées d'Angleterre, tout cela devrait odorer bon. Hélas ! cela sentira quoi ? (Caroline et Jacques Bouchard, $L a$ Vie de château)

Transitif

1901 Tu me semblais rêver d'harmonies envolées, de rythmes plus subtils, de plus frêles chansons, indifférente aux gestes du chat familier qui, sous tes jupes soyeuses, odorant bon la femme (La Plume)

\section{Odorer doux}

Exhaler, répandre une odeur douce, délicate Intransitif

1325 Ainz ne fu d'arbre tiex dommages ; $\mathrm{Ne}$ fu espineus ne sauvages, Mais douz oudorans et souez (Watriquet de Couvin, Dits, p. 90, 225) 
REMARQUES : Odorer doux référait à l'odeur douce et délicate que dégage un objet (ici : un arbre). Notons la collocation avec soef.

\section{Odorer soef}

Exhaler, répandre une odeur suave, douce, agréable, délicieuse

Intransitif

+1365 Amours est le vin qui tant plaist, Odourant souef comme graine, Amours scet bien comment il est A ses gens et lesquels ont paine (Jean Froissart, Poésies [3 $3^{\mathrm{e}}$ tiers XIV $\mathrm{XI}^{\mathrm{e}}$ )

REMARQUES : Odorer soef s'appliquait à une chose qui dégage, émet des odeurs, des vapeurs d'une extrême douceur, produisant une impression agréable sur l'odorat.

\section{Fuvrer bel}

Bien agir, agir comme il faut

$\lambda$ raisonner bel

\section{Oloir bon}

Répandre une bonne odeur, une odeur agréable

Intransitif

1170 Jonchiez fu toz d'erbes dedenz, Que o les flors furent coillies : Ne furent flaistres ne mesties, Mout olurent buen e soëf [variantes : suef ; bon ; bien ; olant dolz et soëf ; flairoient] (Benoit de Sainte Maure, Le Roman de Troie, 13845)

REMARQUES : Usuel en ancien français, oloir bon renvoie à une chose, un élément de la nature (une fleur) qui émet, dégage des odeurs agréables. Notons la collocation avec soef qui ajoute à l'odeur délicieuse l'idée de doux parfum. Bon reste invarié.

\section{Oloir soef}

Répandre une odeur douce, délicate, agréable, délicieuse

Intransitif

1170a Soëf uelent, ços sai retraire, [variantes : flairent ; bien olant]

E si n'est color que n'i paire :
Ceus portent por le chaut d'esté (Benoit de Sainte Maure, Le Roman de Troie, 6231)

1170b Boche riant, levres grossettes Et un petitet vermeillettes Plus que samiz vermauz an grainne, Et plus soef oloit s'alainne Que pimanz ne basmes n’ançans ; Danz ot petiz, serrez et blans ; Manton et col, gorge et peitrine Ot plus blans que n'est nule ermine (Chrestien de Troyes [attribué], Philomena, 156)

REMARQUES : Le sujet de oloir soef désigne en ancien français une chose, un élément de la nature (une fleur) qui émet, dégage des odeurs agréables. Soef reste invariable et est modifié par plus.

\section{Opérer bas}

Agir, se conduire de manière immorale, libertine, sans souci des mœurs, sans scrupules Intransitif

1532 Donne ordre qu'ilz ne vivent en gentilz hommes, de leurs rentes, sans rien faire. Ne dea ! respondit Panurge, frere Jean, mon couillon gauche, je te croiray. Tu vas rondement en besoigne. Sans exception ne ambages tu m'as apertement dissolu toute craincte qui me povoit intimider. Ainsi te soit donné des cieulx, tousjours bas et roide operer (François Rabelais, Pantagruel)

\section{CORPUS WEB :}

Décembre - le ciel a fait de la terre son enclume, bas, très bas ; les arbres aux orées entrecroisent leurs cris. Incapable de s'insurger ni de soulever franchement la nuit, le jour passe, lourd comme un fer. A rendre l'âme. Il n'est que de s'asseoir, et de laisser passer sur soi ce fer, passer en soi la suie, laissez opérer tout bas a grâce de l'obscur, car en ce Temps l'obscur lui aussi a sa grâce [http://davidlerouge.fr/index. php?post/2010/12/15/respire] (13.8.2015)

Est ce que Monsieur Mavoungou a tord de dire haut ce que les pioniers de la division opèrent tout bas ?????? [http://www.i-services. com/membres/combox/combox.php?page $=1 \&$ uid $=131031 \&$ sid $=75786 \&$ id $=17935 \&$ iframe $=$ oui $]$ (13.8.2015) 
REMARQUes : Dans l'ancienne langue, opérer bas se dit du fait d'accomplir quelque chose, une action, le sujet adoptant un comportement vil, contraire à la morale ou aux bonnes mours, qui choque la bienséance par son caractère osé, licencieux. Notons la collocation opérer bas et raide, où raide se dit du fait d'exécuter quelque chose, une action d'une manière inconvenante, le sujet se montrant intransigeant, n'étant pas prêt à faire des compromis. Cette expression, qui est un terme emprunté au jeu de paume, porte, sous la plume de Rabelais, une connotation grivoise. Les citations du CW illustrent l'emploi moderne au sens de 'agir', bas pouvant prendre l'acception de 'en secret'. Bas et raide restent invariables. Notons l'emploi transitif du verbe dans le deuxième exemple du CW, où il réfère aux actions exécutées par un groupe (militaire). Notons le contraste dans dire haut ce que d'autres opèrent tout bas, calqué sur dire tout haut ce que d'autres pensent tout bas.

\section{Opérer raide}

Accomplir quelque chose, agir sèchement de manière rigide et inflexible

$\pi$ opérer bas

\section{Organiser dur}

Organiser avec énergie, en peinant

Pronominal

1959 Et pendant ce temps-là, ça s'organise dur, ferme et précis, du côté que vous savez. J'ai entre les mains un article paru dans le « Foyer rural », intitulé : « Comment le maire peut-il interdire un spectacle dans sa commune? " Petit traité de guerre civique prématuré (Canard enchaîné, 16 décembre 1959 / Grundt : 243)

\section{Corpus Web :}

Comment lui organiser son enterrement de vie de garçon alors que je suis une femme et donc ne serai pas de la soirée. C'est quelqu un qui est très entouré de filles et peu de gars dur pour léguer sans compter que $\mathrm{j}$ ai pas envie de léguer. Ca ne me dérange pas de ne pas être la le jour $j$ car c'est un moment pour eux mais je tiens a lui organiser dur dur [http://forum.aufeminin.com/ forum/f1255/_f1289_f1255-Je-suis-la-temoin-du- marie-comment-organiser-son-enterrement-devie-de-garcon.html] (13.8.2015)

Plusieurs posts arriveront donc dans les prochaines semaines directement sur le site (va falloir s'organiser dur !) [http://blog.ramenos. net/general/une-annee-chargee-un-blog-qui-vacontinuer-de-vivre-mais/] (13.8.2015)

c'était pour cet été, pour les rencontres de l'imaginaire, on s'organise dur cette année !! [http://pharendole.canalblog.com/archives/ 2008/06/05/9458757.html] (13.8.2015)

Cet été, j'étais surtout à la recherche des premiers N700 ! la traque s'organisait dur ! [http://www.denshaotaku365.com/archives/ 2007/10/04/6422557.html] (13.8.2015)

REMARQUeS : Organiser dur réfère à la peine et aux efforts déployés pour préparer une manifestation ou un spectacle selon un plan précis. Notons les adjectifs-adverbes ferme et précis. Ferme renvoie à la préparation soigneuse d'une manifestation ou d'un spectacle, menée avec assurance et maîtrise, selon un plan rigoureux, tandis que précis renvoie à un plan précis, déployé en vue d'un résultat déterminé. Dur, ferme et précis restent invariables. Le groupe tend à l'emploi pronominal, mais l'emploi transitif n'est pas exclu (v. premier exemple du CW). Le sujet est souvent impersonnel (on s'organise; v. organiser ferme), y compris l'emploi pronominal au sens passif (ça s'organise). Notons la réduplication dur dur dans le premier exemple du CW.

\section{Organiser ferme}

Organiser beaucoup, avec énergie

Pronominal

CORPUS WeB :

Dommage que ce soit en concurrence avec Valflaunès (34), il va falloir s'organiser ferme, ça va saturer avec la fête des mères, ça devient stressant la vie d'un amateur de reconstitutions ; vivement lundi qu'on se repose ! [http://www. paleobox.fr/t1283-orgnac-dernier-week-end-demai-2010] (13.8.2015)

a ben voilà, ça s'organise ferme à ce que je vois !;) Tant mieux !!!! [https://www.flickr.com/ photos/el_mexicano/3322736032/] (13.8.2015)

Je vois que l'on s'organise ferme... J'espère que vous prendrez des photos souvenirs pour 
ceux qui ne pourront pas participer à cette « rencontre tajine »[http://www.jardinature.net/ forum/ftopic2253-0-asc-15.html\&sid=8c8e860d9 2d14e5f0dc10340900457f9] (13.8.2015)

\section{Organiser précis}

Organiser avec précision

Pronominal

CORPuS Web :

$\mathrm{Ah}$, départs et retours de vacances, ça se croise ce w-e ! Des Balances, des Béliers s'organisent précis, d'enfer. Des Cancers, des Capricornes seront un peu chahutés [http://www. francebleu.fr/info-service-horoscope-pronosticbon-plan/l-horoscope-de-martin/disons-que-desopportunites-pointent-le-bout-du-nez] (15.8.2015)

\section{Oublier net}

Oublier tout d'un coup, brutalement

Transitif

1837 J'ai oublié net de vous dire que Clara est venue me voir (Stendhal, Correspondance)

CoRpus Web :

Moi ça m'arrive des fois d'oublier net ce que j'allais dire quelques secondes avant de le dire [http://forum.doctissimo.fr/sante/cannabis/ petit-probleme-language-sujet_151557_1.htm] (15.8.2015)

Serai que tu 1 oublie le mieux serait que tu rencontres quelqu un ça te permettrai de loublier net [http://forum.aufeminin.com/forum/f343 /_f54522_f343-Amoureuse-d-une-aventure.html] (15.8.2015)

Même le papier choisi contribue pour moi à la réussite de ce livre. Un papier pas totalement blanc, une bonne odeur de livre qui me fait oublier net ma tablette, des photos mates encore plus belles dévorer des yeux [http://www. amazon.fr/TOURTES-ET-PATES-NOS-REGIONS/ $\mathrm{dp} / 2501081501$ ] (15.8.2015)

l'info vient nous faire oublier nette la catastrophe de l'avion A 330 entre Rio et Paris... [http:// www.jeuxvideo.com/forums/1-21297-244-1-0-1-0metal-gear-rising-airbus-360.htm] (15.8.2015)

REMARQUES : Oublier net désigne le fait de perdre de façon involontaire, brusque et complète le souvenir de quelque chose, de ne pas se rappeler un rendez-vous ou une rencontre fixée ou décidée au préalable ; l'adjectif-adverbe net insiste alors sur l'absence totale du souvenir. Net reste invariable dans la majorité des cas (v. troisième exemple du CW), mais le dernier exemple du CW s'accorde avec l'objet direct sans changer de fonction.

\section{Ouïr clair}

Entendre bien, clairement, distinctement Transitif

1170 Andromacha saut fors par l'us ; Plaint sei e crie a si hauz criz Que mout par sont de loinz oïz : El grant palais perrin de Troie N'i a si sort qui cler ne l'oie. [variante : qi bien]

Plorer lor fait de chaudes lermes (Benoit de Sainte Maure, Le Roman de Troie, 15500)

-1200 Tervagant ! se l'eusse, bien me fust encontré :

Cil feist la bataille vers l'amiral el pré. Mais [il] est en la cambre, qui bien les oi cler (Elie de Saint Gille [fin XII $]$ ], 1607)

+1313 Ensi le ceualier looient

Si que les dames cler l'ooient

(Jean de Condé, Poèmes [1313-1337], 340)

1365 Et dames et puchellez, sergant et bacheler, Mainnent si grant dolour, c'on les oï bien cler,

Parmi le maistre ville. Dont s'alèrent armer Chevalier, escuïer, et les chevaus monter (Li Romans de Bauduin de Sebourc, Chant VI, 783)

+1415 Hola ! hola ! Souspir, on vous oyt bien. C'est a ung sourt a qui il le fault faire : Retrayez vous et pensez de vous taire, Car Dangier oit si cler qu'il n'y fault rien (Charles d'Orléans, Poésies [ 1415-1440], II, Rondel CCCIX, p. 25)

Intransitif

1532 Voyez là une belle medaille de coqu. Panurge à cause de ses lunettes oyoit des oreilles beaucoup plus clair que de coustume (François Rabelais, Pantagruel)

CORPUS WEB :

Et comme je ne suis pas ici pour vous jouer du pipeau et encore moins du ruine-babines, inventons tout de go le mot pour y oür clair : " œnomusicalité ». Comme dans " vin et mu- 
sique » [http://www.ledevoir.com/art-de-vivre/ vin/321648/oenomusicalite] (15.8.2015)

REMARQUES : Dans l'ancienne langue, oür clair désignait le fait d'entendre ou de comprendre parfaitement son interlocuteur. Clair reste invariable et est modifié par bien, plus, si. Il est aujourd'hui vieilli mais peut être employé occasionnellement par plaisanterie dans l'usage moderne.

\section{Ouïr dur}

Entendre mal, être un peu sourd

Intransitif

1568 - Monsieur, dit Fouquet, il est devenu tout sourd ; au moins il oyt bien dur. Il faudrait parler bien hault si vous vouliez qu'il vous entendist.

- Et bien ! dit le procureur, je parlerai prou haut

(Bonaventure Des Périers, Les Nouvelles Récréations et joyeux devis)

REMARQUES : Oür dur désignait dans l'ancienne langue le fait d'entendre son interlocuteur avec difficulté, avec peine, d'avoir du mal à comprendre ce qu'il dit. Notons l'emploi de parler prou haut 'très haut' (parler haut). VoIR AUSSI : entendre dur

\section{Ouvrer bel}

Bien travailler, de manière efficace Intransitif

$\sim 1250$ Mes or vueil je par vous savoir La quele doit avoir l'anel! Je di que cele ouvra mout bel Qui moine fist de son seignor (Les Trois Dames qui troverent l'anel, 268)

1364 PANTHALEON. Sire, a qui le costé fendi Longis l'avugle un venredi, Dont il yssi et yaue et sanc Qui coula de vostre saint flanc, Sur ses mains, et si bel ouvra Que sa veue recouvra, Pour quoy il vous cria merci, Sire, aussi a cest homme ci Rendez la veue en ceste voie, Par quoy chascun congnoisse et voie Que sur touz estes seul vraiz Diex (Miracle de saint Panthaleon, 523)

REMARQUES : Ouvrer bel se disait du fait de fabriquer, de créer quelque chose, de façonner un objet avec beaucoup de soin et d'application. Beau adopte la forme neutre bel qui était employée pour les fonctions adverbiales. Il est modifié par les adverbes d'intensité moult, si.

\section{Ouvrer fort}

Travailler en se donnant beaucoup de mal Transitif

+1300 Plus après avynt qe, par le assent de un roy d'Engleterre, furent les portes de le chastel, qe treblées erent, ars e espris par feu que fust illumée de bacons e de grece, e la tour sur la porte ars dedens. E le halt tour q'est en le tierce bayl de chastel, que fort et bien ovrée fust qe home ne saveit à cele oure nul plus fort ne meylour, fust de grant partie abatu, a cele bayle à poy tote destruyt (Fouke le Fitz Waryn [début XIV'], p. 44)

Remarques : Ouvrer fort désignait le fait de mettre beaucoup d'ardeur, d'efforts dans la fabrication d'un objet (ici : la construction d'une tour). Fort reste invariable et est modifié par plus. Fort est coordonné avec bien. VoIR AUSSI : travailler dur / fort

\section{Ouvrir droit}

Donner directement (sur quelque chose) Intransitif

1275 De son lit ert levez droit a cel ajornant, Pour oür les oisiaus qui soëf vont chantant, Une fenestre ouvri droit devers Oriant, De France li remenbre, si en va souzpirant, Ce fu un petitet devant soleil levant (Adenet le Roi, Buevon de Conmarchis, 2432)

REMARQues : Ouvrir droit s'appliquait à l'ouverture d'une fenêtre qui donne directement sur quelque chose, sur un endroit, le champ visuel s'étendant horizontalement, vers un lieu précis. C'est pourquoi droit forme un groupe prépositionnel avec devers. Droit reste invariable. Notons l'emploi de chanter soef.

\section{Ouvrir grand}

I. Ouvrir complètement, largement, le plus possible

Transitif

1547 Mais quand nostre amoureux produit un baudrier bien clousté et en bon equip- 
page, les portes fermees luy sont ouvertes grandes comme à passer une charretee de foin, qui est le souverain remede, la clef de la besongne, la peautre du navire, le manche de la charrue (Noël Du Fail, Les Propos rustiques)

1735 Ah ! Ah ! dit Dubois, en la voyant ouvrir toute grande [= la porte] par un valet de chambre du vieux marquis, vous verrez que c'est lui qui vient vous faire ses adieux ; ma foi, il faut qu'il vous aime bien pour cela : en effet, un moment après il parut à quatre pas de la porte ouverte toute grande, et me dit, je viens sçavoir comment vous vous portez, et vous dire adieu (Charles de Mouhy, La Paysanne parvenue)

1746 - J’y consens, me répondit-elle, mais surtout ne te marie point ; je fais serment que tu ne garderas ta femme, que lorsqu'elle aura été quinze jours devant mes yeux tous grands ouverts sans que je l'aperçoive... (Claude-Henri de Fusée de Voisenon, Le Sultan Misapouf et la princesse Grisemine)

1836 Des montagnes aux arêtes vives et tranchées le dentellent brusquement par les bords, et le soleil accoudé sur une des plus hautes cimes ouvre tout grand son œil jaune de lion aux paupières dorées (Théophile Gautier, Mademoiselle de Maupin)

1862 le beau, c'est que mon effraction ne servait à rien, qu'il fallait la recommencer. Je m'étais trompé de porte vitrée : où était la mienne ? Toute grande ouverte, à deux pas de moi ! Que dites-vous de celle-là ? Hélas ! Cette petite histoire eût bien amusé votre L... (Jean-Jacques et André-Marie Ampère, Correspondance)

1867 Elle ne pouvait fermer les yeux ; une effrayante contraction les tenait grands ouverts, fixés sur le spectacle horrible de la lutte. Elle était rigide, muette.

- Thérèse! Thérèse! Appela de nouveau le malheureux qui râlait (Émile Zola, Thérèse Raquin)

1880 Près de lui, un tout jeune homme, de dixsept ans au plus, quelque échappé de col- lège, ouvrait très grands ses beaux yeux de chérubin. Fauchery eut un sourire en le regardant (Émile Zola, Nana)

1888 Léon Daudet peignait hier l'intérieur de Fournier, le gendre et le successeur de Ricord, un intérieur toujours en festoiement, où l'on ne parle, dans les raouts et les dîners, que des parties naturelles de l'homme et de la femme et où, dans les bals, les jeunes filles peuvent lire, dans des livres tout grands ouverts sur les tables, des titres comme celui-ci : Du bubon (Edmond et Jules de Goncourt, Journal)

190017 mai.

Type de maire de village. Des sabots, une culotte avec deux grandes pièces à chaque genou, la braguette grand'ouverte comme si c'était plus convenable (Jules Renard, Journal)

1913 Un profond silence s'était établi. Léopold frappa trois fois à la porte de la chapelle. L'Organe l'ouvrit toute grande... Lui aussi est magnifiquement vêtu (Maurice Barrès, La Colline inspirée)

1929 J'en ai entendu, allez. De quoi écrire des livres et des livres. Lui, quand il m'avait ouvert tout grand son vieux cœur, il s'endormait, un sourire de bienheureux aux lèvres. Je l'aimais au fond, ce cher Franfranz (René Crevel, Êtes-vous fous ?)

1936 Autour de lui, sur des pontons, dix grues, sept ou huit aspirateurs, se pressaient, s'agitaient. Il en supportait jusque sur ses ponts. Par les écoutilles grandes ouvertes, on voyait ces engins plonger des bennes béantes, ou de longs tubes articulés, comme d'immenses suçoirs (Maxence Van der Meersch, L'Empreinte du dieu)

1943 - J'ai compris, Monsieur Philippe, dit-elle [= Daisy].

Visiblement, elle rassemble ses forces, bien qu'elle affecte de se détendre, laisse tomber les bras, ouvre tout grands ses yeux merveilleux, ses yeux d'ange... (Georges Bernanos, Monsieur Ouine) 
1945a La chambre interdite, pleine de nuit, de cauchemar et d'une odeur de folie, était ouverte toute grande (Simone de Beauvoir, Le Sang des autres)

1945b Une femme en cheveux riait, la bouche grand ouverte (Jean-Paul Sartre, Le Sursis)

1949 Il appela à voix basse : - Charlot! Charlot! Longin! Longin! Pas de réponse. Il se leva et marcha en titubant de sommeil jusqu'à la porte. Elle était grande ouverte. Un homme se cachait dans l'ombre (Jean-Paul Sartre, La Mort dans l'âme)

1956 c'était encore moi qui étais assis le premier, au premier rang, mes grandes oreilles de paysan grand ouvertes (Jean Anouilh, Pauvre Bitos)

1958 le voile de l'Inde où l'arbre Humanité ouvrait grand les bras pour abriter [...] à la fois des hommes, des femmes, des singes, des oiseaux et de magiques corolles (Thyde Monnier, Je ne suis pas des vôtres)

1959 Il ouvrit grand la bouche comme pour se gonfler d'air (Lettres françaises, 12 mars 1959 / Grundt : 391)

Pronominal

1715 Il passa au travers des arbrisseaux et il aperçut la porte qu'ils cachaient. Il se présenta devant et dit : " Sésame, ouvretoi ; » et dans l'instant la porte s'ouvrit toute grande (Antoine Galland, Les Mille et une nuits)

1823 Ce n'est pas du tout cela, lui dit Sieyès, voyant sa méprise ; je vais vous mettre au fait. Il renferme huit cent mille francs !!! (et ses yeux s'ouvraient tout grands) dans notre magistrature directoriale, nous avions réfléchi qu'un directeur sortant de place pouvait fort bien rentrer dans sa famille sans posséder un denier (Emmanuel de Las Cases, Le Mémorial de Sainte-Hélène)

1835 Ne voilà-t-il pas que l'écuyer qui courait en avant des chevaux s'arrêta précisément devant la porte de monsieur le curé, où la voiture eut la bonté de s'arrêter aussi, et daigna s'ouvrir toute grande. Il n’y avait personne dedans (Alfred de Vigny, Servitude et grandeur militaires)

1872 et l'on arrivait enfin à une vaste chambre, à une sorte de belvédère bâti sur le toit, derrière l'hôtel, au-dessus du quai de Béthune. Elle était en plein midi. La fenêtre s'ouvrait si grande, que le ciel, avec tous ses rayons, tout son air, tout son bleu, semblait y entrer (Émile Zola, La Curée)

1886 Il lui arrivait d'entonner les Fillettes de Paimpol; ou bien, en balançant la tête et battant la mesure avec son pied, elle prenait :

Pour la pêche d'Islande, mon mari vient de partir,

Il m’a laissée sans le sou,

Mais... trala, trala la lou...

J'en gagne !

J'en gagne !...

Chaque fois, cela s'arrêtait tout court, en même temps que ses yeux s'ouvraient bien grands dans le vague en perdant toute expression de vie, - comme ces flammes déjà mourantes qui s'agrandissent subitement pour s'éteindre (Pierre Loti, Pêcheur d'Islande)

1893 Elle porta ses mains de squelette à ses tempes, comme si elle avait senti son crâne éclater. Sa bouche s'était ouverte toute grande, et il n'en sortit aucun son : l'effrayant tumulte qui montait en elle, lui paralysait la langue (Émile Zola, Le Docteur Pascal)

1901 Pour la première fois, je vois une ville entièrement fortifiée, comme au $\mathrm{Xv}^{\mathrm{e}}$ siècle. Le célèbre roman de Balzac s'ouvre tout grand dans ma mémoire, en contemplant cet adorable vestige, "ce magnifique joyau de la féodalité » (Léon Bloy, Journal 2: Quatre Ans de captivité à Cochons-surMarne)

19025 novembre.

En voyage. Une dame se décide à ouvrir un sac de brioches. Elle y prend d'abord des miettes - on ne voit rien - et les mets dans une petite bouche serrée, discrète, distinguée. Peu à peu, l'audace lui vient. Le sac s'ouvre tout grand, et les morceaux 
de brioche entrent dans la bouche comme dans un four. Une autre vieille dame lit un livre et sourit (Jules Renard, Journal)

1908 Les vagues monstrueuses se soulevaient et leurs mâchoires écumantes s'ouvraient toutes grandes sur le vieillard. Vingt fois des paquets de mer emplirent l'embarcation (Anatole France, L'Île des pingouins)

1927a Tout à l'heure, après le discours de la grand-mère, l'interrogatoire de la cuisinière et les constatations d'usage, quand les gendarmes sont partis, l'enfant s'est sentie presque jalouse de ces gros hommes moustachus, pour qui toute grande s'ouvrait la nuit (René Crevel, Babylone)

1927b Point ne sera besoin qu'elle fasse le tour, sept fois, d'une prison, pour que des murs qui s'étaient grands ouverts au sourire infini des flots, à l'inverse de ceux de la cité biblique, se reconstruisent, et de pierres si inexorablement jointes, que nulle Cynthia, nul revenant léger ne sauraient se glisser (René Crevel, Babylone)

1932 la poussée mystique, si elle s'exerce quelque part avec assez de force, ne s'arrêtera plus net devant des impossibilités d'agir ; elle ne sera plus refoulée sur des doctrines de renoncement ou des pratiques d'extase ; au lieu de s'absorber en elle-même, l'âme s'ouvrira toute grande à un universel amour. Or ces inventions et ces organisations sont d'essence occidentale (Henri Bergson, Les Deux Sources de la morale et de la religion)

1942 Voilà une image bien représentative de notre temps : au moment où les oreilles des musiciens modernes s'ouvrent toutes grandes aux délices de ces accents d'outretombe, les peintres modernes tournent en sens inverse le bouton de leur appareil et coupent l'émission... Il est juste de dire que les surréalistes se montrent plus groupés (André Lhote, La Peinture d'abord)

1950 « C'est idiot de se promener comme ça au nez des Boches! » Le vieux cheval a soulevé la tête, dressé l'oreille comme s'il m'écoutait. Mais ses naseaux s'ouvrent tout grands et ses jambes se mettent à trembler : un obus siffle au loin, franchit la vallée en ronronnant, et plante une colonne de fumée jaune au-dessous du Bois-Haut, à mi-pente (Maurice Genevoix, Ceux de 14)

1957 Avec eux, l'éventail des admirations et des modèles s'ouvre plus grand, - et ce n'est pas un de leurs moindres mérites que d'avoir appelé notre attention, en y fixant d'abord la leur, sur des formes d'art avant eux peu connues, voire dédaignées

(Bernard Dorival, Les Peintres $d u x X^{e}$ siècle)

Intransitif

1735 Nous nous entretenions Dubois et moi de ces choses, lorsque j'entendis du bruit à la porte : voyez qui c'est, dis-je à ma tante ! Ah! Ah! dit Dubois, en la voyant ouvrir toute grande par un valet de chambre du vieux marquis, vous verrez que c'est lui qui vient vous faire ses adieux (Charles de Mouhy, La Paysanne parvenue)

II. S'ouvrir, s'étendre sur un vaste espace Transitif

1911 Il faut voir que tout est consentement. Il vit que tout était consentement, et non seulement devant lui, mais encore plus loin, sur le lac grand ouvert. Elles sont déjà assoupies et disent : « Nous voici dans notre repos » (Charles-Ferdinand Ramuz, Aimé Pache, peintre vaudois)

III. Avoir un avenir prometteur, offrir de nombreuses possibilités, de nombreuses opportunités

Transitif

1920 PENSÉE. J'écoute ce que vous dites.

ORIAN. Et quand vous seriez misérable encore et autant que vous le croyez, nous sommes jeunes ! Et la vie est grande ouverte devant nous, celle-ci, et l'autre par derrière qui n'a aucune fin (Paul Claudel, Le Père humilié)

IV. Faire résonner de toute sa puissance Transitif

1949 Ô coq de cette nuit absolument semblable À celui qui leva le rideau de la fable De sa voix grande ouverte et, tout en se cherchant, 
Rouge comme sa crête élaborait son chant. Ebréché par les nuits rugueuses de l'histoire,

Tu me trouves l'oreille à travers la nuit noire

(Jules Supervielle, Oublieuse Mémoire)

\section{CORPus Web :}

María Inés Rodríguez veut ouvrir grand les portes du CAPC [http://www.sudouest. fr/2015/03/22/maria-ines-rodriguez-veut-ouvrirgrand-les-portes-du-capc-1867059-2780.php] (15.8.2015)

Audimat, la revue qui donne envie d'ouvrir grand ses oreilles [http://www.clique.tv/cliquesur-audimat-la-revue-qui-donne-envie-douvrirgrand-ses-oreilles/] (15.8.2015)

Il faut se laisser porter et ouvrir grands les yeux [http://www.ouest-france.fr/il-faut-selaisser-porter-et-ouvrir-grands-les-yeux-1321902] (15.8.2015)

REMARQUES : Dans la tradition, l'accord de grand avec l'objet direct du verbe ouvrir est systématique (mais on hésite entre : ouvrir les yeux tous / tout grands ; ex. de 1746). L'emploi actuel tend tout de même à l'invariabilité (ex. de 1958, 1959 et dans le CW). On peut justifier l'accord par la modification : dans ouvrir les yeux tout grands, on peut interpréter grand comme propriété des yeux résultant du fait de les ouvrir. Mais on peut y voir également un simple accord de l'adjectif-adverbe dans une fonction plutôt adverbiale. Ceci apparaît clairement dans l'emploi antéposé au participe : grand(-)ouvert, souvent accordé. Le modifieur étant censé être un adverbe quand il modifie un adjectif, il s'insère dans la longue tradition d'accord morphologique partagé par des portes larges ouvertes, des fleurs fraîches écloses, elle est toute grande, une femme nouvelle venue, etc. Du point de vue fonctionnel, l'accord du modifieur grand avec le modifié ouvert est tout à fait conforme aux règles de logique grammaticale, l'accord se faisant de la même façon dans une grande fenêtre ou elle arrive contente, donc entre modifieur et modifié. C'est donc le dogme de l'invariabilité de l'adverbe qui veut que l'adjectif-adverbe ne s'accorde pas à chaque fois que la fonction en question est considérée adverbiale par les grammairiens. Gougenheim ne s'est pas fourvoyé en arguant par rapport à l'accord de tout que l'incohérence de l'usage actuel est le résultat « d'un conflit entre le désir des grammairiens d'imposer l'invariabilité et l'usage linguistique qui maintenait l'accord » (Georges Gougenheim, Système grammatical de la langue française, Paris, 1938, pp.129-130). Citons aussi René Radouant: «Dans les adjectifs composés, chaque terme était traité par l'ancienne langue comme un adjectif. De là les formes : Portes grandes ouvertes, fleurs fraîches écloses. Les oreilles pures françaises (Montaigne). Le français moderne au contraire tend à considérer le premier terme comme un adverbe et à le laisser invariable: Une petite fille nouveau-née, court-vêtue, demi-morte» (Grammaire française. Paris, 1922, p. 145). Les exemples du CW montrent que l'usage actuel tend de plus en plus vers l'invariabilité. Grand est modifié par bien, si, tout, très. Notons l'emploi de s'arrêter net.

\section{Ouvrir large}

I. Ouvrir complètement, largement, dans toute sa grandeur, dans toute sa largeur

Transitif

1832 Il monta donc dans la tour septentrionale, tandis qu'en bas le bedeau ouvrait toutes larges les portes de l'église, lesquelles étaient alors d'énormes panneaux de fort bois couverts de cuir, bordés de clous de fer doré et encadrés de sculptures « fort artificiellement élabourées » (Victor Hugo, Notre-Dame de Paris)

1839 À travers la porte de l'Enfer, large ouverte et non gardée, Satan passe et trouve tout désolé à l'entour ; car ceux qui avaient été commis pour siéger là avaient abandonné leur poste, s'étaient envolés vers le monde (François de Chateaubriand, Le Paradis perdu)

1851 Tantôt je le [= Dieu] vois comme un œil infini, comme vous dites, ouvert plus large que le ciel sur ses œuvres, qu'il regarde en s'élargissant pour les embrasser à mesure qu'il les crée ! (Alphonse de Lamartine, Le Tailleur de pierre de Saint-Point)

1879 « Vas-y, va ! » D’un bout à l'autre de la place du Capitole, les yeux étaient large ouverts, et chaque oreille aux écoutes (Léon Cladel, Ompdrailles, le Tombeau-des-Lutteurs) 
1881a Déjà le judaïsme avait professé sur le même sujet des maximes relativement humaines. Il avait ouvert aussi large que possible la porte des affranchissements. L'esclavage entre Hébreux était fort adouci. Les esséniens et les thérapeutes allèrent plus loin (Ernest Renan, Marc Aurèle et la fin du monde antique)

1881b Sur ces confins perdus du christianisme, les dogmes les plus divers se mêlaient. La tolérance des gnostiques, leur prosélytisme ouvraient si larges les portes de l'église que tout y passait (Ernest Renan, Marc Aurèle et la fin du monde antique)

1883 L'une représente Hélène, debout, droite, se découpant sur un terrible horizon éclaboussé de phosphore et rayé de sang, vêtue d'une robe incrustée de pierreries comme une châsse ; tenant à la main, de même que la dame de pique des jeux de cartes, une grande fleur ; marchant les yeux larges ouverts, fixe, dans une pose cataleptique (Joris-Karl Huysmans, L’Art moderne)

1887 Les feux chauffaient tellement la pièce, qu'on laissait larges ouvertes les deux fenêtres et la porte, par lesquelles entrait la bonne odeur pénétrante des foins, fraîchement coupés (Émile Zola, La Terre)

1892 Enfin, il le [= le blessé] coucha sur le petit lit de fer, en face de la fenêtre, dominant Paris, qu'il ouvrit toute large, dans un besoin de grand air et de lumière (Émile Zola, La Débâcle)

1929 MERCURE. Pour assister à leurs ébats, je convoque et tous les dieux, et toi, Léda, qui as encore à apprendre, et vous, braves gens qui avez été dans cette journée à la fois le personnel subalterne de l'amour et de la guerre, écuyer, guerrier, et trompette ! Ouvrez larges vos yeux et qu'autour du lit, pour étouffer leurs cris, résonnent chants, musique et foudre (Jean Giraudoux, Amphitryon 38)

1934 Il est bien, il bâille de nouveau, il s'allonge sur l'autre coude. Il a une espèce de veste déchirée par derrière jusque entre les épaules ; et, large ouverte par devant, elle découvre sa poitrine qui est creuse, en même temps qu'il a une barbe dure au menton (Charles-Ferdinand Ramuz, Derborence)

Pronominal

1876 - Oui, un déjeuner de pensionnaire, dit méchamment le sénateur.

À ce moment, il y eut à la porte un grand froissement d'étoffes ; le battant s'ouvrit très large, et une femme entra, vêtue d'une robe si chargée de nœuds, de fleurs et de dentelles, qu'elle dut presser la jupe à deux mains, pour pouvoir passer (Émile Zola, Son Excellence Eugène Rougon)

1877 Au plafond, le gaz avait passé comme un badigeon de suie. Les deux fenêtres s'ouvraient si larges, que les ouvrières, sans quitter l'établi, voyaient défiler le monde sur le trottoir d'en face. Madame Lerat, pour donner l'exemple, arrivait la première (Émile Zola, L’Assommoir)

1924 Madame Lenoir pense à sa mère et à sa fille Mélanie. On suit de petits couloirs étroits. On arrive devant le portail armorié d'un jardin royal. Les deux battants lourds s'ouvrent larges (Marcel Jouhandeau, Les Pincengrain)

II. Avoir un avenir prometteur, offrir de nombreuses possibilités, de nombreuses opportunités

Pronominal

1868 C'était une pénétration complète de chair et de cœur. D'ailleurs, la vie s'ouvrait large et tranquille, les époux regardaient sans crainte devant eux. Quatre années de félicité les rassuraient contre toute secousse (Émile Zola, Madeleine Férat)

1907 Comme tout cela était loin ! À la pensée qu'il s'était évadé de ce passé maussade, une joie puissante l'envahit et sa poitrine se gonfla, aspirant l'air des sommets et les grands souffles aventureux. Comme la vie s'ouvrait large devant lui, aux côtés de cette créature splendide, qui était déjà sa femme de chair, dont la possession ne 
le lasserait jamais ! (Émile Moselly, Terres lorraines)

1942 le nombre d'apprentis que le maître peut recevoir s'ils sont de son lignage, de près ou de loin, n'est pas limité. La voie s'ouvre moins large aux autres. Si un maître peut prendre d'apprentis « privés » le nombre qui lui plait, il n'a droit, sauf exception, qu'à un seul apprenti " estrange »

(Edmond Faral, La Vie quotidienne au temps de saint Louis)

1963 il [= l'escroc] entre si bien dans la peau de son personnage, qu'il commet son premier abus de confiance presque inconsciemment. En toute innocence, un petit emprunt qui va de soi. Après, il n'a plus qu'à continuer, la route s'ouvre toute large devant lui. Il se grisera facile (Alphonse Boudard, La Cerise)

III. S'ouvrir, s'étendre sur un vaste espace Pronominal

1926 C'est l'accord de l'homme et de l'or, C'est un regard lié à la terre.

Au hasard une délivrance,

$\mathrm{Au}$ hasard l'étoile filante

Et l'éternel ciel de ma tête

S'ouvre plus large à son soleil,

À l'éternité du hasard

(Paul Éluard, Capitale de la douleur)

Transitif

1931 Les Allemands sont encore loin là-bas, derrière Steenvorde. Ici toute la terre est maintenant large ouverte. C'est tout nu (Jean Giono, Le Grand troupeau)

\section{CORPUS WEB :}

Cherchant à arrêter le temps, les danseurs déploient une vibration singulière pour retrouver le naturel du mouvement et ouvrir large l'horizon du hip hop avec une danse lancinante, envoûtante et ronde d'où émergent des scènes de vie singulières sur fond de musiques savamment arrangées [http://www.leprisme.agglo-sqy.fr/ programmation/detail/evenement/le-moulindu-diable/] (15.8.2015)

Elle souhaite ouvrir large les portes du thêâtre en proposant des spectacles en itinérance, un événement fédérateur durant l'été, un temps fort sur les écritures théâtrales d'un pays étranger, créer " les journées du Matrimoine » mettant en avant les écritures d'auteures trop mal connues et des lectures tous les mois pour les jeunes spectateurs... [https://www.actualitte. com/communiques/theatre/nomination-decarole-thibaut-a-la-direction-du-centre-drama tique-national-de-montlucon-auvergne/2068] (15.8.2015)

A 18h ce 6éme jour, lére dose de sulfate de magnésium (qui permet d'ouvrir large les canaux $\mathrm{du}$ foie) [http://www.lapauserelax.fr/Quelquesconseils.html] (15.8.2015)

Pour cela, le dialogue est permanent, pour répondre judicieusement aux attentes, ouvrir larges les perspectives et donner à nos jeunes les outils de leur prise en charge d'abord, et à la prise en charge de la destinée du pays, ensuite [https:// www.youtube.com/watch? $\mathrm{v}=\mathrm{ibH}$ H1Sds1l0] (15.8.2015)

REMARQUES : L'objet direct du groupe ouvrir large (I) désigne, dans la plupart des exemples, quelque chose que l'on peut ouvrir en grand, largement, nécessitant l'intervention de l'homme : une porte, une fenêtre, un battant de porte ; il peut également renvoyer à un vêtement. L'objet direct désigne également très souvent une partie $\mathrm{du}$ visage (les yeux, les oreilles, la bouche, les narines, le nez) ou du corps (la main, les doigts) que le sujet ouvre de toute sa grandeur. Il peut aussi, dans un emploi figuré et métaphorique, désigner le cœur, le sujet cherchant à exprimer ses sentiments à autrui. (II) réfère à la vie et souligne toutes les possibilités ou opportunités qu'elle offre à quelqu'un. Dans (III), le sujet réfère au ciel, à un astre ou à un élément de l'espace (voie, route), insistant sur l'étendue, l'impression d'infini. Large peut s'accorder avec le sujet ou avec l'objet, mais l'accord est moins systématique qu'avec ouvrir grand (v. l'exemple de 1879). Dans l'emploi adjectival du verbe (participe passé), on note dans la plupart des cas l'accord de l'adjectif-adverbe large et de l'adverbe d'intensité (tout) qui le modifie. Large reste invarié dans le deuxième exemple du CW, mais l'accord est réalisé dans le dernier. Voir commentaire détaillé sur l'accord des modifieurs d'adjectifs dans l'entrée ouvrir grand. Large est modifié par plus, tout. 


\section{Paraître clair}

Se lever, naître, luire (du jour)

Intransitif

1200a Dist li cuens : Damme, moult grant tort en avéz

Par cel apostre c'on quiert en Noiron Pré, Je ne lairoie por les membres coper Que je n'i aille, quant li jors parra cler, En ma compaingne mil chevaliers arméz Qui ne me faudront mie (Ami et Amile, 892)

1200b Li fel Hardréz jut la nuit en tristor Jusqu'au matin que clers parut li jors (Ami et Amile, 1640)

1250 Quant chen vint o matin, que le jour parut cler,

Le soleil apparut, que Dex fist bel lever, Dont resperi Doés, que Dex puisse sauver! En séant se leva, si prist à regarder (Doon de Mayence, p. 41)

CORPUS WEB :

L'intensité de la couleur foncée du nuage peut dépendre de son environnement : le même nuage peut paraître clair quand il est entouré de nuages plus foncés ou, au contraire, paraître plus foncé dans un ciel dégagé [http://www.meteo. org/phenomen/nuage.htm] (15.8.2015)

Nous utilisons beaucoup d'acronymes, ceci peut paraitre clair pour des personnes expertes, mais compliqué pour des nouveaux arrivants [http://www.hacrugby.com/foire-aux-questions. html] (15.8.2015)

Donc je me contente de vous poster quelques liens qui m'ont parus clair et pas trop chargés point de vue quantité d'informations a digerer [http://sweetsmoke.keuf.net/t79-ssc-oucomment-ouvrir-une-poissonnerie] (15.8.2015)

Comme le forum n'est pas là pour rabâcher le contenu des cours de thermodynamiques qui existent par ailleurs, il serait souhaitable que tu lises d'abord quelques cours et articles sur la question (fais une recherche avec Google), et que tu reviennes poser des questions précises sur les points qui ne t'ont pas parus clairs [http://forums. futura-sciences.com/electronique/197318 renseignement-diagramme-de-lair-humide.html] (15.8.2015)
REMARQUES : Au XIII ${ }^{\mathrm{e}}$ siècle, paraître s'utilisait comme verbe plein pour désigner un lever de soleil, un jour qui commence, clair et lumineux, en opposition à la nuit sombre. Clers peut être fléchi au cas sujet (ex. de 1200b). Le CW illustre l'usage moderne comme verbe copule ; clair a alors le sens de 'qui n'est pas fondé, compréhensible, qui semble être'. Notons l'absence de l'accord morphologique dans le troisième exemple, mais l'accord du participe paru n'est pas non plus conforme aux règles orthographiques. Notons l'emploi de bel lever par rapport au soleil qui se lève.

\section{Pardonner court}

pardonner haut et court : accorder son pardon définitivement

入 pardonner haut

\section{Pardonner haut}

Pardonner, accorder son pardon à voix haute, publiquement

Emploi absolu

1833 Il fallait fuir : des pleurs ne lui suffisaient pas ;

Ou, d'une pitié feinte exigeant le salaire, Il pardonnait tout haut, il maudissait tout bas.

Au pied d'un vieux rempart, une antique chaumière lui servait de réduit ;

Il allait s'y cacher tout seul et sans lumière, comme l'oiseau de nuit

(Marceline Desbordes-Valmore, Euvres poétiques)

\section{CORPUS WEB :}

Johnnicash, tu seras pardonné haut et court sur la place publique ! [http://www.zebrascross ing.net/t168p9-rencontre-sur-paris] (15.8.2015)

REMARQUES : Pardonner haut se dit du fait d'accorder son pardon à quelqu'un à voix haute, publiquement. Ici, il est opposé à maudire tout bas (maudire bas) soulignant le fait que le sujet n'est pas forcément honnête ou convaincu par ses paroles (à comparer : dire tout haut ce que d'autres pensent tout bas). Notons également la collocation haut et court dans le CW. Haut est modifié par tout. 


\section{Parer beau}

Parer, vêtir joliment, de manière élégante, raffinée

Pronominal

1209 Main se leva la bien fete Aeliz, Par ci passe li bruns, li biaus Robins. Biau se para et plus biau se vesti Marchiez la foille, et ge qieudrai la flor (Jean Renart, Roman de Guillaume de Dole, 544)

+1249 Tu es Ester qui s’umelie, Tu es Judit qui biau se pere : Asmon en pert sa seignorie Et Holofernes le compere

(Rutebeuf, Poèmes [pièces datables de 1249 à 1272], II, p. 247, 14)

-1349 Et cependant je ne cessay

De courtoise honneur maintenir

En tous cas, et de moy tenir

De trés toute chose contraire,

Pour l'amour de li a moy traire,

Car de li moult bel me paroie (Guillaume de

Machaut, Le Dit de l'alerion, 3671)

REMARQUES : En ancien français, parer beau désigne le fait de s’apprêter avec recherche, élégance, finesse. Dans le premier exemple, il est accompagné de vêtir beau. Beau reste invariable et est modifié par moult. Le dernier exemple contient la forme neutre bel qui marque une fonction adverbiale. On peut donc admettre une opposition fonctionnelle entre prédication seconde (biau) et emploi adverbial (bel).

\section{Parier ferme}

Dans le domaine des jeux de hasard et de la bourse : s'engager financièrement sur une éventualité future, miser fermement $\lambda$ acheter / prendre / ponter / vendre ferme

\section{Parier gros}

Parier beaucoup, une forte somme d'argent Emploi absolu

1776 Je m'étois apperçu que trois quidams s'entendoient comme larrons en foire ; l'un jouoit très petit jeu, l'autre parioit gros, le troisieme proposoit contre, sans jamais tenir de pari (Nicolas Rétif de la Bretonne, Le Paysan perverti ou Les Dangers de la ville)
1965 Je parierais gros que grand-mère chérie et le patriarche $\mathrm{C}$., chevauchant de conserve leurs montures aux encolures puissantes, méditent à l'intention de grand-père C., responsable de l'éclatement du royaume, un cruel châtiment (René-Victor Pilhes, $L a$ Rhubarbe)

CORPUS WEB :

Pourquoi il est moins risqué de parier gros dans l'entertainment [http://www.inaglobal. $\mathrm{fr} /$ cinema/note-de-lecture/anita-elberse/block busters/pourquoi-il-est-moins-risque-de-pariergros-dans-1] (16.8.2015)

L'Amour c'est comme le poker, Il faut savoir parier gros pour gagner gros [https://www.face book.com/pages/LAmour-cest-comme-lepoker-Il-faut-savoir-parier-gros-pour-gagnergros/276917985834724] (16.8.2015)

Il parie gros et perd gros [http://www. europe1.fr/sport/articles/il-parie-gros-et-perdgros-215910] (16.8.2015)

REMARQUES : Au sens propre, parier gros désigne le fait de soutenir un pari en engageant une forte somme d'argent. Au sens figuré, il se rapporte à la façon de penser, à l'idée qu'une personne se fait de quelque chose, affichant une certaine assurance, étant certaine de ce qu'elle avance ; la complétive désigne l'objet de la certitude (ex. de 1965). Le fait de parier gros peut entraîner le fait de gagner gros ou de perdre gros (CW). VoIR AUSSI : miser / donner / gagner gros

\section{Parler acertes}

Parler avec assurance

Intransitif

1601 Ils ne parlent pas sec, distinctement, clairement, et acertes, mais ambiguëment comme oracles. Je viens après eux et au dessoubs eux ; mais je dis de bonne foy ce que j'en pense et en croy clairement et nettement (Pierre Charron, De la sagesse)

REMARQUES : Dérivé de la locution à certes, parler acertes se dit du fait d'exprimer un message clair, sérieux, sensé. Acertes est coordonné avec $\mathrm{sec}$, distinctement, clairement et, par contraste, ambigument. Acertes conserve le « $s$ adverbial » de certes. 
Parler allongé

Parler en allongeant les voyelles

$\pi$ parler pointu

\section{Parler bas}

I. Parler à voix basse

Intransitif

1160 Dido s'estoit a mort ferue, La mort l'apresse et argüe, Et la flame de l'autre part, Qui tot son cors esprant et art ; Ne puet parler ne halt ne bas, Fors tant qu'ele nome Eneas (Eneas, 2117)

1280 Les autres aprennent l'usage D'avoir douz et plesant langage, Et de parler bas et a tret ; Quer tel parler mont nous atret (Vivien de Nogent, La Clef d'Amour, 2563)

1342 Le Roy. Or parlez tout bas, que les gens N'en facent nulle mencion.

Alons en autre mansion ; Ceste n'est preux (Miracle de la femme du roy de Portigal, 1039)

1349 Lors près de la dame se trait, Et Raison aussi, tout a trait, A leur secret conseil se mist Et de bas parler s'entremist (Guillaume de Machaut, Le Jugement dou roy de Navarre, 4052)

+1400 a Et ou fus tu toutesvoyes

Quant avecques nous ne vins?

Or nous di que tu devins?

Adonc Lorete appellay

Et tout bas a lui parlay

(Christine de Pisan, Le Dit de la pastoure / Euvres poétiques [début Xve], II, p. 248, 815)

+1400 b Tous et toutes, et parlant

En aloient entr'eulx bas, Car hault n'oserent ilz pas

(Christine de Pisan, Le Dit de la pastoure / Euvres poétiques [début xve], II, p. 279, 1817)

+1489 Leurs anciens termes ef [sic] façons de parler estoient bien changéz, car ilz parloient bien bas et en grant humilité (Philippe de Commynes, Mémoires [1489-1498], V)
1568 car, quand Nostre-Seigneur disoit quelque mot aux Juifz ou à Pilate, il [= le curé] le faisoit parler hault et cler, que chascun l'entendist. Et quand c'estoyent les Juifz ou quelque aultre, il parloit si bas qu'à grand peine le pouvoit-on ouyr (Bonaventure des Périers, Les Nouvelles Récréations et joyeux devis)

1578 Elle beura tantost sa pinte A fin d'avaller ce courroux. Mais il faut parler bas et doux Pour ouyr comme elle caquette, Janne parle tousjours seulette, Redit tout, et ne celle rien, Vrayment elle en contera bien (Rémi Belleau, La Reconnue)

1601 Ils se rient du monde, car il est ridicule ; ils sont plaisans, mais ils ne sont pas assez bons et charitables. Les autres sont foibles et poureux ; ils parlent bas et à demy bouche ; ils desguysent leur langage, ils meslent et estouffent leurs propositions, pour les faire passer tout doucement parmy tant d'autres choses, et avec tant d'artifice, que l'on ne les apperçoit quasi pas (Pierre Charron, De la sagesse)

1631 Je ne peus pour lors entendre ce qu'il luy avoit dit, ny ce qu'elle luy respondit, parce que j'estois trop esloignée et qu'ils parloient fort bas (Honoré d'Urfé, L'Astrée)

1730 Les adjectifs se prènent aussi fort souvent adverbialement, come je l'ai remarqué en parlant des adverbes ; par exemple : parler haut, parler bas, parler grec et latin, [...] : penser juste, sentir bon, sentir mauvais, marcher vite, voir clair, fraper fort, etc. Ces adjectifs sont alors au neutre, et c'est une imitation des latins (César Du Marsais, Des tropes)

1732 Mais je tremble ; et, dans la crainte qui trouble mes esprits, je m'imagine que mon époux a ici des espions qui nous écoutent. Marchez tout droit devant vous, poursuivit-elle en parlant encore plus bas (Alain-René Lesage, Histoire de Guzman d'Alfarache 
1775 BARTHOLO. Parlez haut, je suis sourd d'une oreille.

LE COMTE. élevant la voix Ah ! volontiers. Que le comte Almaviva, qui restait à la grande place...

BARTHOLO. effrayé Parlez bas, parlez bas! LE COMTE. plus haut ...En est délogé ce matin. Comme c'est par moi qu'il a su que le comte Almaviva...

BARTHOLO. Bas ; parlez bas ; je vous prie (Pierre-Augustin de Beaumarchais, Le Barbier de Séville)

1830 - Parlez donc plus bas, lui dit-elle d'un air effrayé (Stendhal, Le Rouge et le noir)

1835 elle alla parler bas à sa mère.

- Allons au chasseur vert, dit-elle ensuite tout haut (Stendhal, Lucien Leuwen)

1837 Le valet resta un moment immobile sans sortir de l'antichambre ; il semblait chercher un moyen d'arriver jusqu'à sa mâ̂tresse. Une femme vint à passer ; le domestique courut à elle et lui parla vite et bas, comme enchanté de rejeter sur un autre la commission dont il était chargé (Frédéric Soulié, Les Mémoires du diable)

1860 Il commença, penché, parlant doux et bas, comme au confessionnal, prêt à fermer les yeux au moindre geste, car il s'attendait à être saisi et écorché vif (Louis Duranty, Le Malheur d'Henriette Gérard)

1884 Ils entendaient, derrière eux, la marquise et Saval qui parlaient bas, très bas, très vite. Tout était noir, d'un noir épais, d'un noir d'encre (Guy de Maupassant, Contes et nouvelles)

1934 C’est comme une épidémie. Vous ne connaissez pas Claire. Vous n'y perdez pas trop. Une vraie femme pour Ferdinand. Ça parle bas, dans les coins, le futur ménage, toute la journée du dimanche. Alors, vous pensez : l'amour? (Georges Duhamel, Vue de la terre promise)

1989 Elle parle bas et très lentement, moi je me souviens plus mais je fais semblant de la reconnaître (Denis Belloc, Képas)
1994 Et Nathan parla bas et clair sur un ton où ne perçait nulle ironie :

- Nobles chevaliers, pardonnez-moi de me mêler de ce qui ne devrait pas m'intéresser car vous êtes des chefs de guerre et vous savez fort bien organiser vos attaques comme vos défenses

(Jacques Lanzmann, La Horde d'or)

Pronominal

1696 Le roi d'Angleterre se baissa fort, comme s'il eût voulu embrasser ses genoux; le roi l'en empêcha, et l'embrassa à trois ou quatre reprises fort cordialement. Ils se parlèrent bas un quart d'heure (Mme de Sévigné, Correspondance)

1735 On suit plus aisément les mauvais exemples que les bons ; je me relevai sans bruit dans l'intention d'écouter : je levai le petit coin d'un rideau de taffetas qui couvroit en dedans la porte vitrée ; le monsieur et la dame étoient encore à table ; ils se parloient si bas qu'il ne me fut pas possible d'entendre ce qu'ils disoient (Charles de Mouhy, La Paysanne parvenue)

1874 Elle s'interrompait et écoutait les oiseaux, comme s'ils avaient des nouvelles à lui donner. Elle regardait le temps qu'il faisait. Ses lèvres remuaient. Elle se parlait bas (Victor Hugo, Quatrevingt-treize)

1886a Mais les nouveaux époux n'entendaient plus que du fond d'une sorte de lointain ; quand ils se regardaient, leurs yeux brillaient d'un éclat trouble, comme des lampes voilées ; ils se parlaient de plus en plus bas, la main toujours dans la main, et Gaud baissait souvent la tête, prise peu à peu, devant son maître, d'une crainte plus grande et plus délicieuse (Pierre Loti, $P \hat{e}$ cheur d'Islande)

1886b Cependant une sorte de langueur étrange commençait à les prendre tous deux ; ils se parlaient plus bas, la main dans la main, isolés au milieu de la gaieté des autres (Pierre Loti, Pêcheur d'Islande)

1981 Le Roi vint donc chez Madame de Montespan comme il avait été décidé ; mais insen- 
siblement il la tira dans une fenêtre ; ils se parlèrent bas assez longtemps, pleurèrent, et se dirent ce qu'on a accoutumé de dire en pareil cas (Françoise Chandernagor, L'Allée du roi)

1985 Le cousin Baptiste pensait à son travail de nuit. David et Olivier se parlaient tout bas. Non seulement ils relateraient en le magnifiant leur voyage aux copains de la rue Labat mais ils se le raconteraient à euxmêmes (Robert Sabatier, David et Olivier)

II. Faire peu de bruit

Intransitif

1856 La vieille pendule de Boule incrustée de cuivre et d'écaille verte retenait le bruit de son tic-tac, et le timbre des heures ennuyées parlait bas comme on fait dans une chambre de malade (Théophile Gautier, Avatar)

\section{Corpus Web :}

Certaines personnes parlent fort, d'autres parlent bas (de même certains neurones génèrent de grands potentiels d'action alors que d'autre n'en génèrent que des petits) [http:// www.biomedicale.univ-paris5.fr/SpikeOMatic/ TrisDesPAs.html] (16.8.2015)

L'histoire d'un cimetière et de ses habitants qui se refusent au silence. Les morts parlent, parlent fort, parlent bas et parfois trop [http:// www.billetreduc.com/60287/evt.htm] (16.8.2015)

Il y a les vantards, et ceux qui ne décrochent pas un mot, ceux qui parlent haut et ceux qui parlent bas, ceux qui sourient et ceux qui préfèrent demeurer dans leur coin de peur de se faire manger crus, ceux qui n'ont pas peur et ceux qui tremblent de trouille [http://chamaska.tumblr. com/post/48681651184/gratte-bizuth] (16.8.2015)

Remarques : Parler bas (I) désigne le fait de s'exprimer à voix basse, voire de chuchoter ou de murmurer, le sujet pouvant ressentir de l'humilité, de la peur ou ne voulant simplement pas être entendu par d'autres. Dans un contexte sentimental, il se dit de deux êtres qui, généralement la nuit, parlent de leur amour à voix basse, lui conférant de ce fait une idée de pureté ou de secret. Dans un emploi poétique, le sujet peut être un inanimé (ici : la neige) et communiquer avec d'autres moyens que les mots (ici : des rayons), bas référant à la faible quantité ou à la faible hauteur des rayons. Dans son emploi pronominal, il se dit d'une communication entre deux ou plusieurs personnes, celles-ci s'efforçant de baisser la voix, généralement pour ne pas être entendues par autrui, les contextes étant similaires à l'emploi intransitif. L'emploi pronominal est du type réciproque, même dans l'exemple de 1874, où une femme parle à elle-même. Employé métaphoriquement (II), parler bas renvoie à une chose inanimée (ici : une pendule) produisant un son doux, bas, léger, pouvant être comparé à un murmure humain. Notons les collocations parler bas et doux / doux et bas / bas et clair / parler ne halt ne bas / vite et bas / parler fort, parler bas / bas et très lentement. Bas reste invariable et est modifié par bien, de plus en plus, encore plus, fort, plus, si, tout, très. Notons l'emploi de baisser fort, dire haut, écorcher vif.

\section{Parler beau (bel)}

Parler avec éloquence, avec habileté et esprit Intransitif

+1150 Amis, che dist li ostes, mout bel parles! Se uous poés chou faire, uous uainteres (Aiol et Mirabel [2 $2^{\mathrm{e}}$ moitié XII $\left.{ }^{\mathrm{e}}\right], 1167$ )

$\sim 1200$ Que voz feroie ici plus lonc devis ? Tant a Reniers envers le roi conquis Et tant i a biau parlé et premis, Li rois otroie quanqu'il li a requis (Jourdain de Blaye, 3644)

+1250 Ge sai la chape au cul tailler, Si sai porter consels d'amors Et faire chapelez de flors Et çainture de druerie Et beau parler de cortoisie A ceus qui d'amors sont espris, Et tu donc cuides avoir pris ! (Des Deux Bordeors ribauz [ $2^{\mathrm{e}}$ moitié XIII $\left.{ }^{\mathrm{e}}\right]$ )

1275 Malatrie la gente ot moult le cuer joiant Quant ele vit Gerart si bel et si plaisant, Moult le trouva courtois et sage et bel parlant (Adenet le Roi, Buevon de Conmarchis, 3683) 
1285 Celes dient que le vorront

Veoir et sa parole orront ;

Et Clarmondine leur a dit

K'ainc si courtois de lui ne vit,

Plus sage, ne plus bel parlant, [variante :

plus biau parlant]

Ne plus bel ne plus avenant

(Adenet le Roi, Cleomadés, 3329)

-1334 Quant il vindrent devant le roi,

Li Beaus Chevaliers au Lyon

Sambloit bien estre grant baron.

Lors prist le roy a saluer ;

Quar il savoit molt biel parler (Le Romans

de la dame a la lycorne [1 ${ }^{\mathrm{er}}$ tiers $\left.\left.\mathrm{XIV}^{\mathrm{e}}\right], 3521\right)$

-1349 Qu'on dit : Dous amoureus regart,

Duit et nourri de bon esgart,

Ou un autre qui est plus gens

Ou qui plaist a moult plus de gens,

S'est droit ; il se fait appeller :

Bel et courtoisement parler (Guillaume de

Machaut, Le Dit de l'alerion, 808)

1364 Je li dis : Par Sainte Ysabel,

Ma dame, vous parlés moult bel,

Et puet estre que dites voir.

Mais je volroie bien savoir

Vostre nom, si m'escuseroie

Par devers vous, se je pooie (Guillaume de

Machaut, Le Livre du voir dit, 4253)

1370 A ce l'omme scache beau parler, il convient qu'il soit aidié de chincq choses, asscavoir de nature, de conscience, de exercice ou usage, de port et de leesse de cuer (Jean Daudin, De la erudition [manuscrit : $1^{\text {re }}$ moitié $\mathrm{XV}^{\mathrm{e}}$ )

1402 Et de son engin tres delivres

Solinus a plain en recite

En son livre de l'excercite

Des merveilles du monde, et la

Dit que oncques homme ne parla

Plus bel ne plus hastivement,

Ne dicta plus soubtivement,

Ne plus prompt a conseil n'a faire

Chose prudent et neccessaire (Christine de

Pisan, Le Chemin de lonc estude, 5875)

+1415 Espoir, tousjours vous m'asseurés

Que bien mon fait ordonnerés :

Bel me parlés, je le confesse.
Mais tant y mettés longuement

Que je languis en grant destresse,

Car trop ennuie qui attent

(Charles d’Orléans, Poésies [ 1415-1440],

I, Ballade LII, p. 70)

1450 METELLUS. Or prenons donc, au pis la chose,

Que tous ses disciples se unissent

Et a puissance s'en venissent

Ouvrir et rober le tumbeau,

Quel remedde la?

EMILÏUS. Parlez beau.

Quant la chose en ce point vendroit,

Laisser faire les conviendroit (Arnoul

Gréban, Le Mystère de la Passion, 27542)

1515 Mais, congnoissant que la chose venoit de luy, se print à parler le plus beau qu'il peust et qu'il n'avoit fait et fist tant qu'i l'envoya à l'eglise ainsi deschiez qu'il estoit pour alumer sa chandeille (Philippe de Vigneulles, Les Cent Nouvelles nouvelles, p. 319, 308)

1985 L'avait-il jamais aimée ?... Peut-être, au début... Ah s'il parlait beau quand il venait la chercher en voiture à l'hôpital d'Angoulême... Il désirait l'épouser. Du moka dans la voix (Yann Queffélec, Les Noces barbares)

\section{CORPUS WEB :}

Le taxi attend et Virginie Ledoyen continue à parler beau, à réfléchir tout haut, à argumenter avec entrain [http://next.liberation.fr/ cinema/2014/01/22/virginie-ledoyen-elementmoteur_974789] (16.8.2015)

Les mutations économiques et la sur-médiatisation ont modifié les besoins, les comportements et les attentes du public. Aujourd'hui, il est de plus en plus informé et confronté à un hyper choix. Plus question de lui vendre n'importe quoi, n'importe comment. Il ne faut plus seulement lui parler « beau », il faut surtout que cela lui fasse sens [http://www.adamy-consulting. com] (16.8.2015)

Je tiens juste a signaler qu il est bien beau de parler beau, encore faut il connaitre son sujet [http://www.procrastin.fr/blog/index.php?2005/ 09/15/33-banjo-in-the-hollow] (16.8.2015) 
Nous allons parler- bel et bien, du design et de la décoration du salon et leur fonction esthétique [http://deavita.fr/decoration/mobiliermeubles/10-idees-design-decoration-modernessalon] (16.8.2015)

REMARQUeS : Jusqu'au Moyen Âge, parler beau réfère souvent à une personne dite courtoise et sage qui s'exprime avec éloquence, avec esprit ; il souligne l'idée d'exemplarité, de morale. Les paroles exprimées plaisent autant par leur sonorité que par leur contenu, à l'oreille de l'auditeur. En ancien français, le masculin-féminin biau varie avec le neutre bel, ce qui équivaut à l'emploi du prédicat second à côté de l'adverbe. Le moyen français substituera le masculin au neutre, qui devient ainsi ambigu par rapport à ces fonctions quand le sujet est au masculin. Bel se maintient tout de même pendant un certain temps dans des collocations, dont parler bel, se conservant jusqu'à nos jours dans le tour lexicalisé bel et bien au sens de 'effectivement, contrairement à ce que l'on pouvait croire'. Les trois premiers exemples du CW mettent en évidence la tendance qui s'observe dans l'usage actuel d'opposer parler beau 'parler pour faire bien' au fait - préféré par celui qui écrit - de prononcer des paroles qui ont un sens ou qui correspondraient à la situation, par exemple au fait banal qu'il y a un taxi qui attend. Beau/bel peuvent être modifiés par le plus, moult, plus. Notons la collocation bel et courtoisement. Mentionnons également l'emploi de dire voir, réfléchir haut.

\section{Parler bête}

Dire des bêtises

Intransitif

1985 Essayer contre eux d'élaborer un raisonnement honnête, de dire une parole juste, c'est s'assurer une conduite de Grenoble de la part de tous les ahuris de carrefour, de tous les crétins des préaux d'école, habitués à ce qu'on leur parle bête, et n'en voulant pas démordre (André Figueras, Traité de balayage)

1994 A travaille dur, pis c'est pas souvent qu'a m'parle bête... Ça, ma sœur sait pas ça, là (Marie Laberge, Le Banc)
1997 « On me dit de la fermer, car je parle bête et je chante faux " (La Rue, témoignage d'un SDF / Stephan-Gabinel 2001)

2008 Évidemment, Lesieur est de mauvaise humeur après ça. Y me parle bête, la gueule y traîne à terre (Frédérik Durand, Comme un goût d'aurore sur une idée fixe)

REMARQUES : Parler bête prolonge productivement la longue série des adjectifs-adverbes employés avec le verbe parler. Les exemples de 1994 et 2008 sont québécois. Notons l'emploi de travailler dur. VoIR AUSSI : voir bête

\section{Parler bizarre}

Parler de manière curieuse, anormale, peu compréhensible

Intransitif

1909 Moi, je parle bizarre, comme d'autres parlent français. Le bizarre peut bien avoir l'impertinence de ne pas être beau : il est moi (Charles Maurras, L’Avenir de l'intelligence)

\section{CORPUS Web :}

Matthias n'est donc pas le seul à parler bizarre dans Secret story. Mais il a une circonstance atténuante : il est Belge [http://www.staragora. com/news/alexandra-de-secret-story-veut-plusde-fric-et-alice-un-plus-gros-zizi/129038] (16.8.2015)

oui ils ont passé la nuit ensemble et la a $14 \mathrm{~h} 15$ ils se parlaient " bizarre » elle lui a dit : tu m’a volé qlq chose !! et lui fait « ha ouaiiii..... » petits regard complice! [http://secret-story.xooit. com/t317-Quelle-est-son-image-au-sein-dugroupe.htm] (16.8.2015)

REMARQUES : Mis en relation avec le fait de parler une langue, parler bizarre se dit du fait de s'exprimer d'une manière peu ordinaire, inhabituelle, empêchant peut-être l'auditeur de comprendre le message. Bizarre reste invariable. Notons l'emploi pronominal réciproque du verbe dans le $\mathrm{CW}$. 


\section{Parler blanc}

parler blanc, répondre noir : dire une chose et répondre tout autre chose ou son contraire, (se) contredire

Intransitif

1698 CARLIN. Pourquoi non?

Il le fera fort bien dans sa distraction.

C'est un homme étonnant et rare en son espèce :

Il rêve fort à rien, il s'égare sans cesse ;

Il cherche, il trouve, il brouille, il regarde sans voir ;

Quand on lui parle blanc, soudain il répond noir (Jean-François Regnard, Le Distrait)

\section{CORPus Web :}

Tout à fait ! je suis presque sur que si la thèse officiel viserait une conspiration du gouvernement américain dans l'attentat du 11 septembre, les mêmes qui aujourd'hui crient au loup, accuseraient des avions de ligne pilotés par des pirates extremistes religieux ! Il suffit de dire " noir " pour qu'ils parlent " blanc » (et l'inverse est vrai ;)) [http://www.sceptiques.qc.ca/forum/ viewtopic.php?t=5467\&start=8775] (16.8.2015)

Les gens sont blancs, parlent blanc. Je les évite. J'ai peur qu'ils me tabassent. Je les sens forts, féroces. Je me sens poursuivi, pris en chasse [http://tempsreel.nouvelobs.com/opinions/2009 1022.0BS5416/a-daniel-mermet-mon-frere-blancpar-taoufik-ben-brik.html] (16.8.2015)

3 Personnes blanches arrivent sur une île peuplée par les noirs. Les blancs parlent blanc et les noirs parlent noir. Au bout d'un certain temps ils ont appris à parler noir, et deviennent noirs par le soleil [http://lesveteransdofusiens.forumactif. com/t359-les-petits-mysteres-de-erahl] (16.8.2015)

REMARQUES : En corrélation avec répondre noir, parler blanc réfère à une conversation où les locuteurs parlent de choses opposées, qui ne coïncident pas entre elles, allant jusqu'à l'incommunication. Notons les groupes antonymiques répondre noir et dire noir. Dans les deux derniers exemples du CW, blanc renvoie à la couleur de la peau, les blancs tenant un discours « de blancs », les noirs un discours « de noirs ». Blanc reste invariable.

\section{Parler bref}

Parler brièvement, de manière concise

Intransitif

1341 LE CHEVALIER. Sire, oil bien ; mais non pas bel

Pour vous ; or du bien recoler. La doulce vierge, a brief parler, Qui le filz Dieu vierge enfanta, Et qui vierge aussi l'alaitta Du vierge lait de sa mamelle, Pour un murtrier vous y appelle, Et que par vous, a grant ahan, Morut nostre evesque Jehan (Miracle de l'evesque que l'arcediacre murtrit, 934)

+1400 A brief parler, l'un a l'autre soubmist Tout cuer et corps et sus le livre mist Chascuns sa main (Christine de Pisan, Le Livre des trois jugemens / CEuvres poétiques [début Xve], II, p. 117, 194)

1526 Drap d'or frisé, trenché par mille pars Estoit pour lors ; courciers, à bref parler, Incessamment pourbondissoient en l'aer (Jean Marot, Le Voyage de Venise)

1560 et, pour bref parler, veu que par icelle nous l'appellons, afin qu'il se déclaire entièrement nous estre présent (Jean Calvin, Institution de la religion chrestienne)

1610 Ainsi les moynes yvrongnes interpretent les espigrammes d'Ænas Silvius et de Beze en yvrongnerie ; les sodomites, en sodomie ; les amoureux, en amour ; les avaricieux, en richesses, et les doctes, en galantise et bonté, d'autant que tout bon fait bonne digestion ; et pource que entendiez que je voulois parler bref : l'espistre, c'est le roy d'Espagne ; l'evangile, c'est le Roy de France (Béroalde de Verville, Le Moyen de parvenir)

1952 Voilà peut-être ce qu'il y a de plus clair à dire de ce roman : il a du ton. Il parle haut et bref. La formule est souvent frappante (Table ronde, janvier 1952 / Grundt : 324)

1957 Quand les métaphysiciens parlent bref, ils peuvent atteindre à la vérité immédiate, à une vérité qui s'userait par les preuves (Gaston Bachelard, La Poétique de l'espace) 
1963 En présence de Simone et pour Simone, Michel se transformait totalement $: 1$ jouait les caïds, parlait bref et rude (Georges Magnane, Les Chers Collègues)

\section{CORPuS WEB :}

La télévision exige de ses consultants qu'ils parlent bref, qu'ils expriment des opinions tranchées, un engagement émotionnel qui vient naturellement à un Jamie Carragher, par exemple, mais qui semble étranger à Henry [http://euro visions.eurosport.fr/football/premier-league/ 2014-2015/sa-nouvelle-vie-ses-debuts-de-consul tant-thierry-henry-trouble-son-image-en-angle terre_sto4668056/story.shtml] (16.8.2015)

Ils se parlent bref et beaucoup [http://www. liberation.fr/livres/2014/02/03/elvire-de-brissacproust-au-berceau_977509] (16.8.2015)

Faire de la radio, c'est la pluspart du temps rencontrer des invités, en direct ou en différé. C'est toujours se retrouver dans cette matrice particulière qu'est le plateau, où tous doivent parler bref et bien pour faire comprendre simplement leurs vues sur leur petit bout de ce monde compliqué [http://parlecoute.org/-emissions-deplateau-] (16.8.2015)

REMARQues : Parler bref désigne le fait de parler de manière concise et décidée, bref référant à la courte durée de l'expression, du discours ; il s'agit de résumer un discours en peu de mots. Signalons l'emploi de la locution $\grave{a}$ / pour bref parler dans la langue ancienne. Notons aussi les collocations haut et bref, bref et rude, bref et bien. $B r e f$ reste invariable. Notons également l'emploi pronominal réciproque du verbe dans le second exemple du CW.

\section{Parler campagnard}

Parler comme on parle à la campagne

Intransitif

1953 - Bonjour, dit le sacristain.

- Mes respects, monsieur le curé, dit Jacquemort. Comme je passais, j'ai voulu en profiter pour vous saluer.

- C'est chose faite, observa le sacristain. Un petit coup de bistouille?

- N'affectez donc pas de parler campagnard, dit le curé sévèrement. Un langage de luxe convient à la maison du Seigneur (Boris Vian, L'Arrache-Cour)

\section{Parler chic}

Employer un langage qui fait bien, qui ne choque pas

Emploi absolu

2018 WC ou toilettes, pour parler chic : déco ou pas déco ? (Corpus Web Coiffet 2018 : s.v., sans date)

\section{Parler clair}

Parler clairement, distinctement, intelligiblement, explicitement

Intransitif

1558 car, quand Nostre-Seigneur disoit quelque mot aux Juifz ou à Pilate, il [= le curé] le faisoit parler hault et cler, que chascun l'entendist. Et quand c'estoyent les Juifz ou quelque aultre, il parloit si bas qu'à grand peine le pouvoit-on ouyr (Bonaventure Des Périers, Les Nouvelles Récréations et joyeux devis)

1566 ABNER. Traite cette concorde

Et asseure pour nous qu'ainsi le Roy l'accorde.

Or va, et te despesche, et parle clair et haut.

LE HÉRAULT. Je feray seurement le devoir d'un hérault

(Louis Des Masures, David combattant)

1623 Le Sainct Esprit parle assez haut et clair, mais la faute est à l'escoutant qui a le tintoüin et les imaginations dans les oreilles (François Garasse, La Doctrine curieuse des beaux-esprits de ce temps)

1631 Et pour ce, Amintor, parlez clair, et me dites quand et comment vous avez veu entrer Alcyre en ma chambre, ou autrement je croiray que tout ce que vous dites n'est que vostre pure invention (Honoré d'Urfé, L’Astrée)

1656 Si le ciel sur ces sombres voiles dont il enveloppe le jour, prend plaisir de semer un grand nombre d'étoiles, et d'en vestir toute sa cour, la terre a ses appas, ses astres, ses lumieres, qui n'ont pas moins de feu, qui vont d'aussi bel air, et si j'osois parler plus clair, elle a mille soleils en deux seules paupieres (Michel de Pure, La Prétieuse) 
1684 aussi S. Augustin remarque à l'egard de ce prestre dont il fait mention, que si durant l'extase on luy parloit bien clair, il entendoit les paroles comme de fort loin ; ce qui est un signe qu'il n'estoit pas alors entierement abstrait, et absolument hors de l'usage du Sens, et de la phantaisie

(François Bernier, Abrégé de la philosophie de Gassendi)

1740 LISETTE. Le plaisant compliment ! Eh ! quel avantage en tirerais-je?

MAÎTRE BLAISE. Oh dame, je suis bridé, moi, ce n'est pas comme vous, je ne saurais parler pus [sic] clair ; voici venir Angélique, laissez-moi li toucher un petit mot d'affection, sans que ça empêche que vous soyez gentille (Pierre de Marivaux, L'Épreuve)

1835 Cette nuance d'argent saisit Lucien, et toute sympathie fut détruite chez lui. « Je vais avoir affaire, se dit-il, à une épicière demandant son dû. Il faudra parler clair et haut pour être compris » (Stendhal, Lucien Leuwen)

1840 Aucune des femmes d'Andillac n'approche de la pauvre Marie pour les sentiments élevés, pour la foi vive et forte. Il fallait l'entendre parler droit et clair aux philosophes du hameau, à ceux qui parlaient mal de Dieu, de la confession, de toutes les choses saintes dont on s'amuse aux veillées (Eugénie de Guérin, Journal)

1850 N'est-ce pas ce que tu crois aussi, et veux-tu me dire où vous en êtes ?... Eh bien donc pourquoi me regardes-tu d'un air confondu ? Est-ce que je ne parle pas assez clair ? Mais je vois que tu as honte, et qu'il faut te venir en aide (George Sand, François le Champi)

1897 - Oh ! pas d'ambiguïté, s’écria Lefrançois en frappant fortement le sol avec son gourdin. Il s'agit de parler franc et clair. Je ne me paye pas de mots en l'air (Georges Ohnet, Le Curé de Favières)

1899 Sortir d'un tel imbroglio par le silence est d'une conception vraiment trop ingénue. Il faut, tout au contraire, parler haut, parler clair, et le plus tôt possible nous tirer de ces affolantes ténèbres (Georges Clemenceau, L'Iniquité)

1916 Elles n'avaient rien de miraculeux, ces voix ; chacun de nous en entend de semblables lorsqu'il s'isole et se recueille assez pour laisser loin derrière lui le tumulte mesquin de la vie journalière. Seulement elles parlent plus haut et plus clair aux cœurs simples, au milieu des grands bois du Nord et des campagnes désolées (Louis Hémon, Maria Chapdelaine)

1926 Les gens parlaient franc, clair, à haute voix. Même en s'amusant, ils parlaient encore de leur travail (Blaise Cendrars, Moravagine)

1931 Quelquefois, de causer comme ça, à cœur ouvert, ça soulage ; ça vous aide à y voir clair. (J'avais souci de parler très net, très clair ; de ne rien dire qu'il ne pût parfaitement comprendre. Nous étions assis l'un à côté de l'autre, lui à ma droite, sur une banquette devant deux portos) (André Gide, Journal)

1938 Pour le reste et pour parler clair, les images de certaines peintures de Grünewald ou de Hiéronymus Bosch, disent assez ce que peut être un spectacle où, comme dans le cerveau d'un saint quelconque, les choses de la nature extérieure apparầtront comme des tentations (Antonin Artaud, Le Théâtre et son double)

1946 Les mots parlent clair : l'espace est liberté, ou promesse de liberté (Emmanuel Mounier, Traité du caractère)

1964 La vie quotidienne était limpide : nous fréquentions des personnes rassises qui parlaient haut et clair, fondaient leurs certitudes sur de sains principes, sur la Sagesse des Nations et ne daignaient se distinguer du commun que par un certain maniérisme de l'âme auquel j'étais parfaitement habitué (Jean-Paul Sartre, Les Mots)

1994 Et Nathan parla bas et clair sur un ton où ne perçait nulle ironie : 
- Nobles chevaliers, pardonnez-moi de me mêler de ce qui ne devrait pas m'intéresser car vous êtes des chefs de guerre et vous savez fort bien organiser vos attaques comme vos défenses

(Jacques Lanzmann, La Horde d'or)

CoRpus WeB :

Hervé Mariton demande à la droite de "parler clair » [http://www.lefigaro.fr/politique/ 2015/07/03/01002-20150703ARTFIG00255-hervemariton-demande-a-la-droite-de-parler-clair. php] (16.8.2015)

Marcel Gauchet : "Il faut parler clair avec les musulmans "[http://www.lepoint. fr/editos-du-point/sebastien-le-fol/marcelgauchet-il-faut-parler-clair-avec-les-musulm ans-09-02-2015-1903378_1913.php] (16.8.2015)

Parler clair et vrai, jusqu'à un certain point [http://www.lemonde.fr/idees/article/2012/11/ 14/parler-clair-et-vrai-jusqu-a-un-certain-point_ 1790276_3232.html] (16.8.2015)

REMARQUES : Apparaissant souvent dans la collocation parler haut et clair, parler clair réfère à une expression distincte, franche, ouverte, sans ambiguïté. L’adjectif-adverbe clair renvoie plus au sémantisme du discours, à sa compréhensibilité, qu’à la limpidité, la clarté de la voix. Clair reste invariable et est modifié par assez, bien, plus, très. Notons les collocations parler bas et clair / haut et clair / clair et haut / droit et clair / clair et vrai / franc et clair; parler haut, parler clair / parler très net, très clair. Les exemples du CW mettent en évidence une affinité avec le discours politique dans l'emploi actuel. Notons l'emploi de voir clair.

\section{Parler compliqué}

Parler d'une manière complexe, confuse, compliquée

Intransitif

1905 ToBy-Chien. (attentif et consciencieux) Je t'écoute, et je te suis avec peine, car tu parles compliqué et un peu au-dessus de ma tête (Colette, Sept dialogues de bêtes)

CORPuS WeB :

Parler compliqué c'est simple [https://www. facebook.com/pages/Parler-compliqu \%C3\%A9cest - simple $/ 566838810035952$ ? sk=photos] (16.8.2015)
L'arnacœur_Pourquoi parler simple alors qu'on peut parler compliqué ? [https://www.you tube.com/watch? $\mathrm{v}=\mathrm{cQckWzB3sUE]} \mathrm{(16.8.2015)}$

Histoire de bien nous signifier que le film va jouer sur la durée réelle ou, pour parler compli$q u e ́$, que son temps de projection épousera à peu près son temps diégétique, le générique montre un mécanisme d'horlogerie associé à la froideur métallique d'un pistolet [http://www.lesinrocks. com/cinema/films-a-l-affiche/meurtre-ensuspens/] (16.8.2015)

REMARQues : Parler compliqué se dit d'une personne dont le discours est difficile à saisir, ambigu, embrouillé. Dans le CW, il est mis en opposition avec parler simple (à comparer : pourquoi faire simple quand on peut faire compliqué).

\section{Parler correct}

Parler de manière correcte, exacte, conformément à la réalité Intransitif

1546 Diane les porte en teste à forme d'un beau croissant. Est elle coqüe pourtant ? Comment diable seroyt elle coqüe, qui ne fut onques mariée ? Parlez de grace, correct, craignant qu'elle vous en face au patron que fit à Acteon (François Rabelais, Tiers Livre)

1646 Mais ne dira-t'on point que je suis fait comme eux,

Pource que ce discours, et sans fin et sans cesse,

De propre, d'accident, et de genre et

d'espece,

De l'infini de méme, et du temps et du lieu, Je voy d'une vertu les bouts et le milieu, Et parle, aussi correct que Robin de tulipes, Des secrets de nature et de ses deux principes? (Jacques Du Lorens, Satires)

1658 Aussi la pretieuse ne donne pas l'exclusion aux mâles ; mais comme l'autour a un nom different du tiercelet (vous autres, mesdames, qui entendez la chasse, et vous sur tout qui avez équipage, vous voyez bien si je parle correct) aussi le mâle des pretieuses s'appelle janseniste qui est un galant spirituel et ferme (Michel de Pure, La Prétieuse) 


\section{CORPuS WeB :}

ben moi quand je parle avec la plupart des mes amies, elles parlent correct, ya juste caro qui articule pas..... dailleur elle me dit que je parle trop bien........... sa se peux, trop bien parler ?? [http://missstar4ever.skyrock.com/1141082728La-langue.html] (16.8.2015)

En tant qu'ancienne maîtresse d'Arsouille, je m'insurge contre le climat de ce post qui est devenu, disons pas très convivial. Je demande que seuls les chats et les amis des chats soient acceptés, et les zotrs s'ils parlent correct, nanméo [http://www.atoute.org/n/forum/showthread. $\mathrm{php} ? \mathrm{p}=2187413]$ (16.8.2015)

C pas parce qu'une femme parlerait mal qu'il faut la tabasser, les hommes parlent correct peut être ?? [https://fr-fr.facebook.com/1055 90939487217/photos/a.105604192819225.3267. 105590939487217/648849161828056/] (16.8.2015)

REMARQUES : Parler correct se dit à propos d'une personne qui dit la vérité, donne des informations sensées, dignes de foi. Dans le premier exemple du $\mathrm{CW}$, parler correct réfère à la correction linguistique, en l'occurrence l'articulation. Dans les deux derniers exemples, correct est synonyme de 'convenablement, poliment'. Correct reste invariable et est modifié par aussi, de grâce.

\section{Parler court}

Parler brièvement, de manière brève, concise, succincte, en peu de mots

Intransitif

1498a Que diray plus pour parler court et brief? (Andrieu de la Vigne, Le Voyage de Naples, p. 209, 2910)

1498b Aprés vindrent les grans pensïonnaires, Les grans bragars, les grans gorriers de court,

Les grans prodigues de despens ordinaires, Les grans pompeurs du temps present qui court,

Les grans mignons pour parler brief et court (Andrieu de la Vigne, Le Voyage de Naples, p. 217, 3196)

1581 Le sage parlant parle court : Mais en un mot plus il profite Qu'un fol ne fait, qui moins merite
Quand plus longuement il discourt (Jean-Antoine de Baif, Mimes, enseignemens et proverbes)

1610 THEMISTOCLES. Que vous parlez court ! Vous faites le Lacedemonien; dites tout. ARISTOTE. Il ne faut pas dire les secrets, de peur qu'estant publiez on n'en recognoisse la vanité. Cependant que l'on ne les entend pas, on est en admiration (Béroalde de Verville, Le Moyen de parvenir)

1920 LE CHEUR. Nous sommes beaucoup, mais nous parlerons court et net.

Mot pour mot, je parle, réponds.

Je commence. C'est vrai que tu as tué ta mère ? (Paul Claudel, Les Euménides)

\section{CORPUS WEB :}

Brevitatis causa, autrement dit : pour parler court, sachez, mon petit père, que vos opinions moisies, tout le monde s'en tamponne le coquillard [http://erwanpatrick.canalblog.com] (16.8.2015)

Incontournable, quand les échanges s'accélèrent à coups de textos et de twitts, et que parler court devient la norme [http://www.louison bobet.com/fr/blog/le-logotype-louison-bobetn10] (16.8.2015)

Parler court, dense, mais simple. Comme St Ex le rappelle, la perfection est atteinte quand il n'y a plus rien à enlever. Et le changement de typo, de couleur... fait augmenter la complexité [http://descary.com/votre-tweet-est-il-lisible-larecette-de-grand-mere/] (16.8.2015)

REMARQues : Parler court désigne le fait de s'exprimer en peu de mots, de manière succincte, pour résumer un énoncé. Notons les collocations court et brief, employée jusqu'au Xvi ${ }^{\mathrm{e}}$ siècle, parler court et net ainsi que parler court, dense, mais simple dans le CW. Court reste invariable.

\section{Parler cru}

Dire les choses très directement, de manière franche, très naturelle Intransitif

1973 Un brave auteur de chansons malotru Avait une tendance à parler cru, Bordel de dieu, con, pute, et caetera 
Ornaient ses moindres tradéridéras (Georges Brassens, " La légion d'honneur » / Poèmes et chansons)

1991 «Le parler cru d’Edith Cresson? En France, on n'aime pas que les femmes aient une grande gueule » (Le Provençal, 23.7.1919 / Stephan-Gabinel 2001)

\section{CORPUS WEB :}

Qui aime parler cru ici ? Pourquoi le faites vous ? Car vous aimez ça ? pour provoquer du plaisir à votre partenaire, car vous voyez que votre partenaire est chaude? pour lencourager? [http:// forum.psychologies.com/psychologiescom/ sexualite/parler-sujet_373_1.htm] (17.8.2015)

parler cru en parlant doux.....c'est très beau ! [http://forum.psychologies.com/psychologie scom/sexualite/parler-sujet_373_1.htm] (17.8. 2015)

Les filles? Aimez vous parler cru pendant l'amour. Si oui, qu'est ce que vous aimez dire? Sinon est ce qu'il y a parmi vous des filles qui aimeraient parler cru mais qui n'ose pas... [http:// forum.aufeminin.com/forum/couple2/_f162012 _couple2-Parler-cru.html] (17.8.2015)

« Je parle cru et dru. Je ne tourne pas deux heures autour du pot ", a lancé, dimanche 24 mars, Jean-Luc Mélenchon, au cours d'un meeting qui a clos le congrès du Parti de gauche à Bordeaux [http://gauche.blog.lemonde. $\mathrm{fr} / 2013 / 03 / 24 / \mathrm{a}$-bordeaux-melenchon-repliquesur-son-parler-cru-et-dru/] (17.8.2015)

REMARQUES : Parler cru désigne le fait de dire des paroles sans altération et sans détours, celles-ci pouvant même être vulgaires, exprimer les choses telles qu'elles sont, sans fard, le sujet parlant de manière franche et naturelle voire triviale, sans égards. La plupart des exemples du $\mathrm{CW}$ réfèrent au domaine de la sexualité. Notons la collocation cru et dru, et l'emploi de parler doux dans le CW. $\mathrm{Cru}$ reste invariable. Notons aussi la nominalisation dans l'exemple de 1991. VoIR AUSSI : dire / écrire / penser dur

\section{Parler dense}

Parler de manière concise, succinte

$\lambda$ parler court

\section{Parler double}

I. Parler deux fois plus haut Intransitif

1904 Honorine n'a plus qu'une oreille pour entendre un peu, la droite. Elle s'approche le plus possible, jusqu'à nos pieds, de façon que les paroles tombent dans son oreille comme dans une vieille soucoupe. Ainsi calée, elle a l'air d'être bossue de dos, et bossue de côté. Elle a beau faire : elle est sourde, et il faut lui parler double (Jules Renard, Journal)

II. Avoir un double langage, employer un argot pour cacher le message

Intransitif

1982 Possesseurs d'un savoir volatil, ils avaient une connaissance d'initiés. Ils parlaient double. Pour eux, une " fourmi ", c'était les passeurs de drogue, cheveux longs et papier journal dans les chaussures, qui dorment dans les couloirs du train de nuit entre Amsterdam et Paris (Philippe Labro, Des bateaux dans la nuit)

\section{Parler doux}

Parler doucement, d'une voix douce, suave, faible

Intransitif

1544 Je fuz Jouan sans avoir femme, Et fol jusque à la haulte game ; Tous folz, et tous Jouans aussi, Venez pour my prier icy, L'un après l'autre, et non ensemble, Car le lieu seroit (ce me semble) Un petit bien estroict pour tous ; Et puis s'on ne parloit tout doulx Tant de gens me romproient mon somme (Clément Marot, Épitaphes)

1547 AGAPY. Il me souvient qu'en departant de nous

Il demandoit d'un oil et parler doux $\mathrm{Au}$ grant Pasteur le secours de sa dextre (Marguerite d'Angoulême, Comédie sur le trespas du roy)

1562 JULIEN. Sçavez-vous bien que c'est, mastin,

Fantosme du mont Aventin, Sepulchre à punaise, pendart, 
Demourant de tout le cagnart,

Si vous ne me parlez plus doux, Je vous assommeray de coups (Jacques Grévin, Les Esbahis)

1628 BELCAR. Je voy bien que je tente une mauvaise voye,

Si m'y faut-il passer, quel peril que j'y voye : Mais pour n'estre battu je parleray si doux Qu'elle en rira plustost que d'entrer en courroux (Jean de Schélandre, Tyr et Sidon)

1850 C'est pour cela que vous ne devriez pas tant lever la voix, demoiselle, car je vous parle bien doux, et vous ne parlez pas, à cette heure, comme il faudrait dans la chambre d'une malade (George Sand, François le Champi)

1860 Il commença, penché, parlant doux et bas, comme au confessionnal, prêt à fermer les yeux au moindre geste, car il s'attendait à être saisi et écorché vif (Louis Duranty, Le Malheur d'Henriette Gérard)

1907 La châtelaine n'était jamais absente quand on avait besoin de lui parler. C'était la vieille madame Jacquemin, marchant doux, parlant doux, et plus volontaire que dix hommes ensemble (René Bazin, Le Blé qui lève)

1947 Elle entra, Jean-Sol Partre, à sa place habituelle, écrivait, il y avait beaucoup de monde et ça parlait doux (Boris Vian, L'Écume des jours)

Pronominal (réciproque)

1934 Oh ! Ils seraient d'abord debout, mais il lui dirait : «Assieds-toi »; et longuement alors, se sentant le chaud l'un de l'autre, ils se parleraient doux, puis ne se parleraient plus, parce qu'ils n'auraient plus besoin de parler (Charles-Ferdinand Ramuz, Derborence)

\section{CORPUS WEB :}

Le bruxellois auteur-compositeur et pianiste caresse de sa voix des mélodies pop. La pilule passe mieux, les mots sont bien sentis, sans fioritures, qu'ils nous parlent doux ou dur [http:// cathgrenier.tumblr.com/post/101917174535/ mcsubject-bodybodytablebodycell-height10] (17.8.2015)

Imaginez, derrière un décor de vieux Paris miroitant sous sa verrière, un boudoir grand comme une boîte à chaussures, paré d'un design pur et lactescent, où les 22 convives portent beau et parlent doux [http://www.lexpress.fr/styles/ saveurs/restaurant/paris-2e-passage-53_792673. html] (17.8.2015)

REMARQUES : Parler doux se dit d'une personne parlant d'une voix douce, basse, agréable à l'oreille en raison de son harmonie ou de sa faible intensité. S'opposant souvent au fait de crier, de lever la voix et de provoquer une sensation désagréable à l'interlocuteur, doux réfère à une conversation agréable, dont les tons ne dépassent jamais une certaine hauteur. Doux reste invariable et est modifié par bien, plus, si, tout. Notons les collocations doux et bas, doux ou $d u r$, ainsi que l'emploi des groupes marcher doux et porter beau. Parler doux est nominalisé dans l'exemple de 1547 (Il demandoit d'un œil et parler doux $=$ d'un parler doux).

\section{Parler droit}

I. Parler directement, avec franchise, honnêteté, d'une manière moralement correcte Intransitif

-1200 Se pouez bien servir, jai n'iert dou droit parler.

Il vos manrai an Fra[n]ce por si ruste firté Soz le [m]ont de Montmartre vos ferai panre ostel ;

Maudaranz serai rois, et fors rois coronez (Floovant [fin $\mathrm{XII}^{\mathrm{e}}$ ], 750)

1280 En amour amertume maint Et de la vient au droit parler (Adam de la Halle, Chansons, VI, 10)

1432 L'ACTEUR. Deffendez vous et parlez droit, En verité n'a point de honte, Deshonneur vous en adviendroit, De faulx rappors ne tenez compte (Jean Regnier, Les Fortunes et adversitez, 173)

1610 JODELLE. Quand je vous oys ainsi paillarder sur vostre outrecuidance de bien dire, il m'est advis que vous me pissez aux oreilles. Que diable ne parlez-vous droit, 
sans aller leschonnant les friponneries du sot langage (Béroalde de Verville, Le Moyen de parvenir)

1673 PHILAMINTE. Hé bien ! ne voilà pas encore de son style?

Ne servent pas de rien!

BÉLISE. Ô cervelle indocile !

Faut-il qu'avec les soins qu'on prend incessamment,

On ne te puisse apprendre à parler

congrûment?

De pas mis avec rien tu fais la récidive,

Et c'est, comme on t'a dit, trop d'une négative.

MARTINE. Mon Dieu ! je n'avons pas

étugué comme vous,

Et je parlons tout droit comme on parle cheux nous

(Molière, Les Femmes savantes)

1840 Aucune des femmes d'Andillac n'approche de la pauvre Marie pour les sentiments élevés, pour la foi vive et forte. Il fallait l'entendre parler droit et clair aux philosophes du hameau, à ceux qui parlaient mal de Dieu, de la confession, de toutes les choses saintes dont on s'amuse aux veillées

(Eugénie de Guérin, Journal)

1930 Qu'une jeune fille puisse se lever du milieu des gens et vous parler si droit, ah! (Henri Pourrat, Le Pavillon des amourettes ou Gaspard et les bourgeois d'Ambert)

1955 ce n'est pas la première fois qu'une jeune fille de vingt-cinq ans, parce qu'elle parle droit devant elle, dénonce à son insu la frivolité des vieillards faisandés qui se croient des maîtres (Elle, 5 février 1955 / Grundt : 383)

II. à droit parler : à vrai dire Intransitif

1377 Et s'on congnoit que j'ay face esplourée, Ce poise moy, ne le puis amander, Car grant doleur ne puet estre celée ; Aussi ne fait grant joie, à droit parler (Guillaume de Machaut, La Louange des dames, p. 231)

\section{CORPus WeB :}

Marcher dans les pas de Jésus, c'est une belle phrase... mais quand on marche dans les pas de Jésus, TOUT remonte, la bible prend corps, les textes entendus dans les messes se mettent à vivre, à vibrer à l'intérieur... S'asseoir sur l'un des rochers ou le Christ était probablement assis parlant à ses disciples... quelle expérience ! Les textes nous parlent droit au cœur, droit à l'âme.. [http://www.3blancheurs.com/voyages/terresainte/] (17.8.2015)

Brahms, Schubert, Mendelssohn, Schumann : les plus grands noms du romantisme allemand s'intéressent tous à la forme chorale. C'est qu'au xixe siècle celle-ci ne véhicule plus exclusivement la parole divine, mais aussi la voix $\mathrm{du}$ peuple, celle des traditions populaires qui prennent racine dans la nuit des temps et parlent droit au cœur des gens simples [http://www.t-km. $\mathrm{ch} /$ representation/autour-de-schumann-acade mie-vocale-de-suisse-romande/] (17.8.2015)

Remarques : Parler droit (I) se dit d'une personne parlant franchement, ouvertement, disant la vérité. Droit peut aussi référer à l'idée d'immédiateté, le sujet s'exprimant sans détours, directement. La locution à droit parler (II) signifiant 'à vrai dire', 'franchement', s'employait pour introduire une restriction. Notons la collocation parler droit et clair et l'emploi nominal dans l'exemple de $~ 1280$. Droit reste invariable et est modifié par si, tout. Dans les exemples plus récents (1955, CW), droit tend à s'associer à la préposition qui le suit (à, dans) au point de faire partie du groupe prépositionnel en tant que modifieur de la préposition, notamment dans la locution parler droit au cœur. VOIR AUSSI : conter / dire droit

\section{Parler dru}

Tenir des propos gaillards et vifs

Intransitif

1932 Elle parlait dru comme elle avait appris dans Paris à parler au marché du Temple. Comme brocanteuse avec sa mère à elle, dans sa petite jeunesse... Elle venait d'un temps où le petit peuple n'avait pas encore appris à s'écouter vieillir (Louis-Ferdinand Céline, Voyage au bout de la nuit) 
1993 Le 'parler-dru' de Jacques Delors sur l'Europe (Le Monde, 21.3.1996)

\section{CORPus WeB :}

Michel Rocard, cinquante ans de politique, toujours aussi présent dans le débat au moment où le partis socialiste se déchire, toujours aussi engagé et flamboyant, parlant vrai, parlant $d r u$, n'esquive aucune contradiction et évoque dans ces cinq entretiens tour à tour [http:// www.franceculture.fr/emission-michel-rocard2005-10-10.html] (17.8.2015)

Une langue inventée mâtinée de patois, riche en crases pétillantes et en ellipses audacieuses, des personnages hauts en couleurs parlant dru et franc : La Gonfle oscille entre la facétie grotesque et le plus réalistement terrifiant des tableaux de mœurs [http://www.theatre-du-paysde-morlaix.fr/la-gonfle-ad86.html] (17.8.2015)

Pourquoi nous parlons cru et dru ? (Corpus Web Coiffet 2018 : s.v., sans date)

REMARQUES : Parler dru réfère à un langage franc et clair, sans ambages, voire trivial, employé par un locuteur qui ne se soucie pas des réactions. Notons la nominalisation dans l'exemple de 1993, les collocations dru et franc et cru et dru, ainsi que l'usage de parler vrai dans le CW. Dru reste invariable.

\section{Parler dur}

I. Parler durement, sévèrement

Intransitif

1845 Mais il n’y a que lui dans le pays qui dise comme ça ; tout le monde est grandement porté pour M. Cardonnet. Il n'est pas chiche, celui-là. Il parle un peu dur, il échine un peu l'ouvrier, mais dame ! Il paye, faut voir ! (George Sand, Le Péché de Monsieur Antoine)

1925 Je parle durement aux morts parce qu'il faut leur parler dur,

Debout sur des toits glissants,

Les deux mains en porte-voix et sur un ton courroucé,

Pour dominer le silence assourdissant

Qui voudrait nous séparer, nous les morts et les vivants

(Jules Supervielle, Gravitations)
1943 - C'était vous qui me parliez dur, dit Françoise (Simone de Beauvoir, L'Invitée)

II. Parler beaucoup

Intransitif

1934 Au bout d'un instant, il annonça avec une indifférence exagérée :

- On commence à en parler dur de la libération, hein?

(Roger Vercel, Capitaine Conan)

CORPUS WEB :

haa bah une chose, ils sont criards et parfois même méchants, mais tu risque pas de perdre ton poste même si tu leur réponds ! ils parlent dur, mais ils sont aussi capables d'en recevoir !;) [https://www.youtube.com/all_comments?v=K4 F61R1VCBY\&lc $=3$ Dh3BYvOoOU6DbaKiMQvJfEVN Fnet0yw5Cov7V99d5E] (17.8.2015)

L'Algérie c'est dur mon ami. Pas vraiment, l'Algerie est une republique prise en otage par des affairistes qui ont decide qu'un pays pouvait marcher selon les lois de la mafia au lieu de lois economiques. Ils parlent dur peut etre parce que le baril est a 130 dollars, mais s'il descend a 100 dollars, ils passeront la parole au peuple algerien et ils iront parler de Suisse [http://www. algerie-dz.com/forums/archive/index.php/t301769-p-2.html] (17.8.2015)

REMARQues : Parler dur (I) se dit du fait de parler avec dureté et sévérité, sans chercher à plaire à son interlocuteur, le sujet étant intransigeant et optant pour des expressions parfois crues et froides. (II) désigne le fait de parler beaucoup, de s'épancher largement sur un sujet. Dur reste invariable et est modifié par un peu. VoIR AUSSI : écrire dru

\section{Parler épais}

Parler avec un accent qui manque de finesse

$\lambda$ chanter lourd

\section{Parler espacé}

Parler en détachant tous les mots ou toutes les phrases

Intransitif

1959 Les deux premiers actes usent immodérément du style hésitation, avec répétitions, points de suspension, réticences accumulées et silences superposés. Le specta- 
teur fait quelques pas titubants... sous la pluie... et se met à parler espacé comme les héros (Le Figaro, 31 décembre 1959 / Grundt : 256)

REMARQUES : Parler espacé se dit du fait de parler en séparant certains mots ou groupes de mots par un laps de temps, par exemple pour retenir l'attention du public ou créer un effet de suspense.

\section{Parler facile}

Parler aisément, être à l'aise en parlant

Intransitif

1972 - Ça ne m'étonne pas de Robert. C'était un type préparé, qui parlait bien. Oui, il parlait facile (Auguste Le Breton, Les Bourlingueurs)

REMARQUES : Parler facile renvoie au fait de parler avec une grande facilité et fluidité. Il fait partie d'une série productive qui combine des verbes avec l'adjectif-adverbe facile.

\section{Parler familier}

Parler en employant un langage familier, informel

Intransitif

2004 M111 Quand j’vais voir un patron c'est faj'parle familier entre nous j'parle argot AD28 Quand tu vas voir un patron tu parles + familier ? (Dominique Caubet, Parlers jeunes, ici et là-bas)

2014 Dans le premier extrait, on peut voir que le personnage principal parle familier. Dans le deuxième extrait, même s'il est du monde rural, le personnage parle soutenu. À cause de l'époque (Exemple entendu, d'un élève / Corpus Coiffet 2018 : s.v.)

\section{Parler faux}

Parler sans vraisemblance, sans y croire ; parler en mentant

Intransitif

1943 LIA. Jean est grand, Ruth est petite. Jean a une grande âme, Ruth n'en a pas du tout. Jean parle une belle langue, sans mots abstraits et sans adjectifs. Ruth non seulement est menteuse, mais parle faux... (Jean Giraudoux, Sodome et Gomorrhe)
1985 Il enlève sa veste. Sa figure est blafarde, il est très myope, il ne doit presque rien y voir malgré ses lunettes. Ses gestes sont très lents. Thérèse trouve que le camarade parle faux. Au contraire de ce qu'il dit ils ont tout le temps. Il pose la veste sur la chaise. Les camarades attendent toujours de chaque côté de lui (Marguerite Duras, La Douleur)

\section{CORPUS WeB :}

pourquoi les hommes politiques parlent faux alors que la vérité va leur éclater à la figure ? [https://twitter.com/franceinfo/status/522628103 177506816] (17.8.2015)

Le problème, c'est que l'argument se dissout dans un enchaînement sans queue ni tête autour de situations floues. On ne croit pas une seule seconde aux personnages qui parlent faux, et qui donnent du « bordel de chèvre ! » ou du « J'm'en tamponne les ovaires avec le dos de la cuillère » à tout bout de champ [http://www.franceculture. $\mathrm{fr} /$ blog-les-trois-coups-2011-10-05-\%C2\%AByouri- $\% \mathrm{C} 2 \% \mathrm{BB}$-de-fabrice-melquiot-critiqued $\%$ E2\% 80\%99ingrid-gasparini-theatre-he] (17.8.2015)

La parole, la parole, toujours la parole ; du matin au soir, les gens parlent... et ils parlent rarement de ce qu'ils connaissent. Ils parlent et ils rapportent ; ils parlent et ils rajoutent... ils parlent pour ne jamais s'arrêter. Ils parlent haut et ils parlent fort ; ils parlent beau et ils parlent faux... Quand le monde travaille, les Sénégalais parlent; quand le monde avance, les Sénégalais parlent [http://www.vipeoples.net/Que-vaut-la-paroledonnee-au-Senegal_a4059.html] (17.8.2015)

Remarques : Parler faux se dit de quelqu'un dont le ton de la voix est contraire à la justesse, au naturel, qui ne dit pas la vérité ou dont les paroles semblent invraisemblables, peu crédibles à l'oreille de l'interlocuteur. Faux reste invariable. Notons la série parler haut, fort, beau. VoIR AUSSI : habiller faux

\section{Parler ferme}

Parler de manière ferme, stricte, décidée Intransitif

1667 ALCESTE. J'en pourrois, par malheur, faire d'aussi méchants ; 
Mais je me garderois de les montrer aux gens.

ORONTE. Vous me parlez bien ferme, et cette suffisance...

ALCESTE. Autre part que chez moi

cherchez qui vous encense

(Molière, Le Misanthrope)

1728 Je ne leur disais pas : Arrêtez-vous ; au contraire la vanité me gagnait, je sentis que mon visage devenait hardi et cavalier, je parlais ferme, et je marchais de même derrière les coulisses, je leur tendais la main de l'air d'un capitaine qui caresse ses soldats, et mes soldats le prenaient de même (Pierre de Marivaux, L'Indigent Philosophe)

1768 LE CHIRURGIEN. Il en est de même dans les licences de Sorbonne. Que voulez-vous que fassent de jeunes bacheliers, à qui la nature parle plus haut et plus ferme que la théologie ? (Voltaire, L'Homme aux quarante écus)

1780 « Monsieur votre père m’a fait demander un rendez-vous, comme je vous ai dit. J'ai été si occupé, que je n’ai pu le voir. C'est sûrement pour cela qu'il veut m'entretenir ; ainsi, il rejetterait sur moi ce délai. Je vous promets de lui parler très-ferme ; et, s'il fait la sourde oreille, je m'en plaindrai à M. Lenoir, et vous écrirez aussi fortement que vous voudrez » (Honoré de Mirabeau, Lettres originales écrites du donjon de Vincennes)

1824 Malheur aux gens qui voulaient résister ou qui venaient demander le paiement de leurs créances ! S'ils parlaient un peu ferme ou revenaient souvent, ils étaient jetés à la porte de l'hôtel (Prosper de Barante, Histoire des ducs de Bourgogne de la maison de Valois)

1830 Je vais retomber dans quelque faiblesse pour lui, pensa Mathilde ; c'est bien pour le coup qu'il se croirait mon seigneur et maître, après une rechute, et au moment précis où je viens de lui parler si ferme. Elle s'enfuit (Stendhal, Le Rouge et le noir)
1848 On est étonné tout d'abord de voir un homme aussi habituellement doux, soumis et, ce semble, timide, que l'était M. de Tillemont, - ce même homme qui se tenait toujours à genoux devant le père Lami, comme lui disait Bossuet, - parler si franc et si ferme quand il a affaire au rude abbé (Charles Sainte-Beuve, Port-Royal)

1862 Ils pensent à autre chose. Ils s'éteignent. Ils passent leur temps à jouer aux dominos. Il serait urgent d'aller leur parler un peu et ferme. C'est chez Richefeu qu'ils se réunissent. On les y trouverait entre midi et une heure. Il faudrait souffler sur ces cendres-là (Victor Hugo, Les Misérables)

1883 Alors le baron parla ferme et haut :

- Jeanne, tu n'as pas le droit de disposer de cette vie. Ce que tu fais là est lâche et presque criminel; tu sacrifies ton enfant à ton bonheur particulier (Guy de Maupassant, Une vie)

1893 Cette retraite fut une seconde catastrophe. Dans son impatience de trouver d'autres témoins et qui parlassent haut et ferme, Gorka courut au Cercle de la Chasse (Paul Bourget, Cosmopolis)

1951 « Ici, je ne vous céderai plus », dit-il d'un ton ferme quand il eut fini son deuxième bol de thé. " J'ai réussi à parler ferme mais gentiment », se dit-il (Jean Giono, Le Hussard sur le toit)

\section{CORPUS WEB :}

Ils s'enferment au lieu d'ouvrir grandes les portes et les bouches, de parler ferme, sans arrogance, avec des mots simples et vigoureux [http://www.telerama.fr/scenes/18281-vincent_ et_hortense_acte_ii.php] (17.8.2015)

Mais comment peut on parler ferme et clair lorsqu'on a transigé avec les parlementaires sur une mise en pratique rapide du non cumul des mandats ou qu'on a toléré jusqu'à la limite morale un Cahuzac au gouvernement ? [http:// blogs.mediapart.fr/blog/bernard-leon/100914/ de-thevenoud-virus-ebola-politique-le-guen-enmedecin-malgre-lui] (17.8.2015)

$\mathrm{Au}$ bout de deux heures, nous retrouvons les trois malheureux, étouffés. Les sortir, puis 
faire la toilette, je la fais moi-même. Les mettre dans des draps, les ramener à la mairie, reconnaissance par les familles. C'est déchirant, c'est dur. Il me faut un cœur de pierre et parler ferme [http://halifax346et347.canalblog.com/tag/ M\%C3\%A9morial\%20Grandcamp] (17.8.2015)

REMARQUES : Parler ferme se dit d'une personne parlant d'une manière déterminée, énergique, inébranlable, ses paroles et sa voix traduisant force et assurance. Notons les collocations haut et ferme, franc et ferme, ferme et haut, ferme et clair. Ferme reste invariable et est modifié par bien, plus, si, très, un peu. Mentionnons également l'emploi de ouvrir grand.

\section{Parler flatteur}

Proférer des louanges exagérées

$\pi$ parler joli

\section{Parler fort}

Parler d'une voix forte

Intransitif

1879 Et, tout le temps que je parlais, c'étaient entre eux des hochements de tête, de petits rires fins, des clignements d'yeux, des airs entendus, ou bien encore le vieux qui se rapprochait pour me dire :

- Parlez plus fort... Elle a l'oreille un peu dure.

Et elle de son côté :

- Un peu plus haut, je vous prie !... Il n'entend pas très bien...

Alors j'élevais la voix ; et tous deux me remerciaient (Alphonse Daudet, Lettres de mon moulin)

1882 Élisabeth et Atéria, deux suivantes qui parlent français, vous adressent alors, de la part de la reine, quelques questions saugrenues au sujet de la dernière guerre d'Allemagne. Elles parlent fort, mais lentement, et accentuent chaque mot d'une manière originale (Pierre Loti, Le Mariage de Loti)

1945 Plus bas ! dit-il. Parlez moins fort (JeanPaul Sartre, Le Sursis)

\section{Corpus Web :}

La parole, la parole, toujours la parole ; du matin au soir, les gens parlent... et ils parlent ra- rement de ce qu'ils connaissent. Ils parlent et ils rapportent ; ils parlent et ils rajoutent... ils parlent pour ne jamais s'arrêter. Ils parlent haut et ils parlent fort ; ils parlent beau et ils parlent faux... Quand le monde travaille, les Sénégalais parlent ; quand le monde avance, les Sénégalais parlent [http://www.vipeoples.net/Que-vaut-la-paroledonnee-au-Senegal_a4059.html] (17.8.2015)

Les hommes et les femmes de pouvoir parlent haut et fort ; les hommes et les femmes d'influence murmurent à l'oreille [https://twitter. com/bernardpivot1/status/568287680976576512] (18.8.2015)

Etats généraux des territoires : les élus locaux parlent haut et fort face à l'Etat [http:// www.20minutes.fr/politique/1016497-20121004etats-generaux-territoires-elus-locaux-parlenthaut-fort-face-etat] (18.8.2015)

REMARQUES : Parler fort se dit du fait de parler en élevant fortement la voix, l'action pouvant être perçue de manière positive ou négative selon le contexte. Les adverbes plus et moins qualifient le degré d'intensité de la voix. Notons également les adjectifs-adverbes beau et faux et la collocation haut et fort dans le CW. Fort reste invariable et est modifié par moins, plus.

\section{Parler frais}

Parler dans un style vivant, jeune, agréable, avec esprit et vivacité

Intransitif

1959 À suivre même par fortes chaleurs. M. t'Serstevens parle frais (Canard enchaîné, 15 juillet 1959 / Grundt : 234)

REMARQUES : Parler frais se dit du fait de parler avec vitalité, de parler de thèmes modernes avec une certaine vivacité d'esprit, le sujet intéressant de ce fait son interlocuteur et produisant sur lui un effet rafraichissant. Frais peut aussi référer au timbre agréable de la voix, à l'harmonie des tons.

\section{Parler franc}

I. à / pour parler franc: pour dire la vérité, à vrai dire, pour dire ce qu'on pense

Intransitif

$\sim 1498$ Aussi y a vignoble d'excellence, Dont il en sort si tres grant habondance De vins clairetz, de vin rouge et vin blanc, Grec et latin que pour en parler franc, 
Sans les exquis muscadetz et vins cuitz, On y queult bien tous les ans mille muitz, Voire encore plus quant le bonheur revient, Et tout cela au prouffit du roy vient (Andrieu de la Vigne, Le Voyage de Naples, p. 249, 4476)

1814 Triste vérité, qui afflige mes amis et mes parens même, car je n'ai pas de fortune, mais, qui n'afflige personne autant que moi, car, à parler franc, je me crois encore le meilleur de mes amis, quelque tendresse qu'on puisse me porter (Étienne de Jouy, L'Hermite de la Chaussée-d'Antin)

1889 Pour parler franc, je suis un civilisé, il n'est qu'un barbare. Hé bien ! J’ai subi aussitôt la sensation que mon affinement était moins aristocratique que sa barbarie (Paul Bourget, Le Disciple)

1902 Enfin, à parler franc, puisque nous avons une dizaine d'années à passer dans ce château de Fontevrault, je préfère y voir la jeune héritière en sa pleine beauté, c'està-dire de vingt à trente ans, plutôt que de l'y suivre à l'âge ingrat (René Boylesve, $L a$ Leçon d'amour dans un parc)

1909 Christophe n'avait vu jusqu'alors que le bas socialisme, - celui des politiciens, qui faisaient miroiter aux yeux de leur clientèle affamée le rêve enfantin et grossier $\mathrm{du}$ bonheur, ou, pour parler plus franc, $\mathrm{du}$ plaisir universel que la science, aux mains du pouvoir, devait, disaient-ils, leur procurer

(Romain Rolland, Jean-Christophe. Dans la maison)

1926 Voilà la vérité. Mes délices sont d'être avec vous, petits hommes-dieux, singulières, singulières, si singulières créatures $! \grave{A}$ parler franc, je vous quitte peu (Georges Bernanos, Sous le soleil de Satan)

1967 Ne croyons pas que cette voiture fut accueillie par le public avec un enthousiasme délirant. Bien au contraire, comme toutes les machines sans chevaux qui l'avaient précédée, elle ne fut pas vue d'un très bon œil. À parler franc, toutes les inventions de ce genre avaient mauvaise presse, en Allemagne comme ailleurs (Pierre Rousseau, Histoire des techniques et des inventions)

II. Parler franchement, directement, ouvertement; parler avec franchise Intransitif

1500 LE MARY. Que ne parle-tu franc et net, Sans te mocquer ainsi des gens? (Farce de Jeninot / Ancien Théâtre françois)

+1517 LE CURÉ. Fumelle qui en diligence Sa parolle ne peult avoir, Vous devez entendre et scavoir Qu'il ne reste que estre saisie D'une herbe nommée jalousie, Destrempe en vin cler ou blanc. Cela la fera parler franc Et caquetter pair a dix femmes Pour en boire deux ou trois dragmes (Le Grant Voiage et pelerinage de saincte Caquette [1517-1518], 319)

1669 CLÉANTE. Mais, Madame, après tout... MADAME PERNELLE. Pour vous, Monsieur son frère, Je vous estime fort, vous aime, et vous révère ;

Mais enfin, si j'étois de mon fils, son époux,

Je vous prierois bien fort de n'entrer point chez nous.

Sans cesse vous prêchez des maximes de vivre

Qui par d'honnêtes gens ne se doivent point suivre.

Je vous parle un peu franc; mais c'est là mon humeur,

Et je ne mâche point ce que j'ai sur le cœur (Molière, Le Tartuffe)

1784 Je vous parle-franc, par-ce-que je suis vrai, et tout-rond dans mes manières. Que mon ton ne vous fâche ni ne vous révolte ; je suis homme à vous adorer prude, si vous l'êtes, tout-comme à en-agir sans-façons, si vous ne l'êtes pas

(Nicolas Rétif de la Bretonne, La Paysanne pervertie ou Les Dangers de la ville)

1793 NOMOPHAGE. Soyons justes d'ailleurs, mon cher : sous l'ordre ancien 
Qu'étions-nous vous et moi ? Parlons franc; moins que rien.

Qu'avions-nous ? J'en rougis! Pas même un sol de dettes,

Car il faut du crédit pour en avoir des faites (Jean-Louis Laya, L'Ami des loix)

1896 Mais voici que j’y pense - ô misère d'aimer ! - Moi qui parle tout franc et qui plaide Coupable,

Ne serais-tu pas, toi, de ton côté, capable Non pas de ne pas pardonner (c'est si joli, Si gentil le pardon, - quand c'est fleuri d'oubli),

Mais, te voyant ainsi méchamment

esseulée,

Hein, de t'être faite une veuve consolée ?

(Paul Verlaine, Euvres poétiques complètes)

1926 Les gens parlaient franc, clair, à haute voix. Même en s'amusant, ils parlaient encore de leur travail

(Blaise Cendrars, Moravagine)

1957 C'est dans un char à bœufs, s'il faut parler bien franc,

Tiré par les amis, poussé par les parents, Que les vieux amoureux firent leurs épousailles

Après long temps d'amour, long temps de fiançailles

(Georges Brassens, « La marche nuptiale » / Poèmes et chansons)

1982 Il plaignait le vieux, mais le pis était qu'il l'avait cru un ami. Pour parler franc, cette prétendue amitié ne masquait qu'une commune antipathie contre Élie

(Marguerite Yourcenar, Un homme obscur)

CORpus Web :

Un texte qui donne vie aux voix des laveuses auxquelles la société n'a offert aucune tribune : autour du bassin, des histoires simples. Protégées par la singularité codifiée de cette cérémonie féminine, unies par leurs difficiles conditions de vie, ces femmes parlent franc, révèlent les petits ou grands événements d'une vie rude, elles s'écoutent, se querellent, chantent, dansent et rient pour parer le malheur [http://www.archives 13.fr/archives13/CG13/pid/528] (17.8.2015)
En général, les Portugais sont des gens très amicaux et accueillants envers les étrangers. Ils sont sincères et d'habitude parlent franc [http://businessculture.org/fr/sud-de-l-europe/ portugal/] (17.8.2015)

REMARQUES : Parler franc (II) se dit de quelqu'un qui s'exprime ouvertement, en toute clarté, sans artifice, ni réticence. Notons la locution à / pour parler franc (I) par laquelle le sujet précise son intention d'exprimer la vérité, quelle qu'elle soit, et les collocations franc et net et franc, clair, à haute voix. Franc reste invariable et est modifié par bien, plus, tout, un peu.

\section{Parler gras}

I. Grasseyer

Intransitif

1559 Mais pour bien le representer, fauldroit parler gras comme il faisoit, et encores seroit ce plus, qui pourroit paindre son visaige et sa contenance (Marguerite d'Angoulême, Heptaméron, p. 502, 13)

1696 il [= Iphis] s'est acquis une voix claire et délicate, et heureusement il parle gras : il a un mouvement de tête, et je ne sais quel adoucissement dans les yeux, dont il n'oublie pas de s'embellir (Jean de La Bruyère, Les Caractères)

1713 Elle affectait d'être languissante, de parler gras, et d'avoir deux ou trois faiblesses par jour. La première fois que Talbot jeta les yeux sur elle, une de ses faiblesses la prit (Antoine Hamilton, Mémoires de la vie du comte de Gramont)

1822 Celui que je me représente le mieux, après lui, c'est Gardet, la caricature de la classe. Qu'on se figure un gros petit enfant, les yeux peu ouverts, le teint olivâtre, parlant gras, quelquefois avec recherche (Jules Michelet, Mémorial)

II. Avoir un langage grossier, ordurier Intransitif

1736 Un sot de qualité fait sérieusement de profondes révérences à un clerc de procureur : Un jeune étourdi, qui se trouve à côté d'un prince du sang, lui offre du tabac. Un fat serre la bouche pour parler gras, il affecte 
d'étaler une main potelée, de montrer son brillant, et de faire un crochet de son petit doigt artistement compassé

(Charles-François-Nicolas Le Maître de Claville, Traité du vrai mérite de l'homme)

\section{9 octobre.}

Houssaye lui faisait baiser des filles incognito. Deux ans avant sa mort, il était amoureux d'une charcutière, il lui suçait le bout des doigts dévotement.

- Il parle gras, dit ce cochon de Guérin.

Dix ans de suite, à l'officiel, il a fait les Beaux-arts pour se former le style. Il se vante d'avoir « fait » Antoine

(Jules Renard, Journal)

1920 Elle retrouva Chéri grandi trop vite, creux, les yeux fardés de cerne, portant des complets d'entraîneur et parlant plus gras que jamais (Colette, Chéri)

\section{Corpus Web :}

Je préfère la vulgarité des « petites gens » qui parlent gras et travaillent dur, à cette grossièreté cousue de fil blanc, tricotée par des gens qui ne connaissent pas l'onglée dès le matin et la cohue des trams bondés aux heures de pointe [http:// www.sylvieboireau.com/grossierete/] (18.8.2015)

Je parlegras, je jure, maisj'suis une fille hyper fragile en fait [http://cachot.canalblog.com/ archives/2008/05/08/9101687.html] (18.8.2015)

Pour rester dans le même ton : elles fument comme des mecs, elles picolent comme des mecs, elles conduisent comme des mecs, elles parlent gras comme des mecs... et après elles s'étonnent qu'on les encule ! [http://www.parapentiste. info/forum/techniques-de-base-du-pilotage/ bpc-question-ouverte-finesse-charge-schemade-polaire-t20628.30.html;wap2=] (18.8.2015)

REMARQUES : Parler gras (I) se dit du fait de parler en articulant avec la partie postérieure de la cavité buccale ou avec une prononciation gutturale ou peu distincte des R. (II) réfère au fait de tenir des propos graveleux, licencieux, le sujet utilisant un vocabulaire peu soigné, parfois même des jurons, et pouvant être choquant pour l'interlocuteur. Gras reste invariable et est modifié par plus. Notons la coordination parler gras et travailler dur qui s'applique à ce qu'on appelait avant les classes laborieuses.

\section{Parler gros}

I. Parler avec grossièreté

Intransitif

1584 Dieu donc, abaissant la corne des meschans, qui ne parleront plus si gros qu'ils faisoient, fera qu'ils seront mis en routte, et ne pourront les inhumains pour combattre trouver leurs mains (Pierre de L'Estoile, Registre-journal du regne de Henri III)

1623 Nos histoires font foy que sur les commencemens de cette faction tres-pernicieuse, qu'on entendit ces monstres de parolles, Lutherien, Huguenot, Calviniste : la France fut grandement espouventée, lors que linguam quam non noverat, audivit : on ne parloit du mot de cene, que sous la cappe ; d'abolir la messe, de l'anatomie de la messe, du testament de la messe, des derniers abbois de la messe, de desbrider et emballer la messe, on n'entendoit ces termes que parmy les confidans : mais comme peu à peu ils se furent ingerés et qu'ils eurent, soubs pretexte de pieté gaigné l'esprit ambitieux de quelques seigneurs, ils commencerent à parler gros et à descouvrir le mommon de leur impieté (François Garasse, La Doctrine curieuse des beaux-esprits de ce temps)

II. Parler de manière générale, sommairement, d'une manière approximative, maladroite éventuellement sans s'y connaître Intransitif

190419 décembre.

Le conseiller municipal Paris, de la Villette, je crois, a le premier la parole. L'air d'un Jules Lemaître gros et gras. La nature se répète. Il parle gros, sans intérêt. Le citoyen Fribourg, autre conseiller de Paris, refuse d'abord, fait des manières, puis devient intarissable (Jules Renard, Journal)

1924 LE DEMI AILE. Je ne pouvais pas croire que tu écoutais à ce point. 
PEYRONY. Tu me reproches de t'avoir écouté !...

LE DEMI AILE. On parle fort et gros, parce que les gens sont distraits, et qu'il faut bien d'abord les arrêter (Henry de Montherlant, Les Olympiques)

1947 Il [= le personnalisme] constate, pour parler gros, que le capitalisme sous ses diverses formes est, en Europe, à bout de souffle et d'invention (Emmanuel Mounier, Le Personnalisme)

CoRpus Web :

Bien entendu certains hommes politiques parlent GROS actuellement, qu'ils peuvent gerer le Congo... Mais pourtant au meme moment ils n'arrivent meme pas a gerer leurs propres partis politiques ; ces memes opposants ne demontrent aucun signe de democratie dans leurs partis... et veulent faire croire aux gens qu'ils sont les democrates... [http://www.congo-site.com/Compterendu-du-conseil-des-ministres-du-4-avril-2012 a12246.html] (18.8.2015)

Alors montrons-nous dignes et indignonsnous, nous parents lorsque nos enfants, parlent " gros ", et pointons du doigt ceux qui le font [http://www.superno.com/blog/2011/06/onveut-des-femmes/comment-page-1/] (18.8.2015)

Moi perso. les filles (ou gars) qui parlent gros ca m'enarve ! lol [http://www.yabiladi. com/forum/garcons-seulement-1-92489-92536. html\#msg-92536] (18.8.2015)

REMARQUeS : Parler gros (I) se dit du fait de tenir des propos grossiers, soulignant le manque de retenue, le comportement grossier et suggérant aussi une manière de parler qui connote un manque d'éducation, de culture, notamment dans la collocation parler fort et gros. (II) désigne le fait de parler de manière générale, simplifiée, sans entrer dans les détails, de façon approximative ou de manière superficielle, sans toucher à l'essentiel d'une idée, de parler « grosso modo ». Gros souligne ainsi un contenu stérile et inintéressant qui ne retient pas l'attention de l'auditeur. Dans le premier exemple du CW, parler gros réfère au fait de se vanter, de tenir un discours prétentieux. Parler gros permet également de ne pas mentionner directement les gros mots en question (deuxième exemple du CW). Dans le dernier exemple du CW, québécois, gros a le sens de ‘beaucoup'. Gros reste invariable et est modifié par si.

\section{Parler haut}

I. Parler à voix haute, d'une voix forte Intransitif

+1175 La roïne l'a entendu ; Ja parlast haut, mais ele n'ose (Béroul, Tristan [ $4^{\mathrm{e}}$ quart $\mathrm{XII}{ }^{\mathrm{e}}$ ], 3201)

1285 En la chambre faisoit si cler Qu'ele le puet bien aviser, Car deus chandeles i ardoient, Qui assez grant clarté getoient. Lors ne sot ele le quel faire, Ou de haut parler ou de taire (Adenet le Roi, Cleomadés, 4610)

-1334 La damoiselle que vous di $\mathrm{Si}$ chevauchoit .i. porc espi. Lors conmencha haut a parler Conme celle qui denoncher Voloit unne molt grant mervelle ; Chascuns se tut et fist orelle (Le Romans de la dame a la lycorne [ $1^{\mathrm{er}}$ tiers XIV $\left.{ }^{\mathrm{e}}\right], 5731$ )

+1365 A basse vois vous prie merchi, dame, Car je ne puis ne ose haut parler ; $\mathrm{Si}$ ai je bien cause de dire alarme, A basse vois [vous prie merchi, dame], Car vostre amour me mainne tel, par m’ame Qu'il me faurra, ou voelle ou non, parler (Jean Froissart, Rondeaux [ $3^{\mathrm{e}}$ tiers XIve], p. 89)

1485 GUILLEMETTE. Pardonnez-moy, je n’ose Parler haut : je croy qu'il repose :

Il est ung petit aplommé ; Helas! il est si assommé, Le povre homme! (Maistre Pierre Pathelin, 518)

1558 - Monsieur, dit Fouquet, il est devenu tout sourd ; au moins il oyt bien dur. Il faudrait parler bien hault si vous vouliez qu'il vous entendist.

- Et bien ! dit le procureur, je parlerai prou haut

(Bonaventure Des Périers, Les Nouvelles Récréations et joyeux devis) 
1623 La passion les aveugla tellement sur le milieu de la nuict, qu'en parlant un peu haut ensemble, croyant que personne ne les entendroit (Charles Sorel, Les Nouvelles françaises)

1637 Tu m'as bien entendu quand j'ay parlé tout haut

Je me suis éveillé tout à l'heure en sursaut, Apres la vision la plus melancolique Qui puisse devancer un accident tragique (Tristan l'Hermite, La Mariane)

1650 LAODICE. Ne parlez pas si haut : s'il est roi, je suis reine (Pierre Corneille, Nicomède)

1662 SOPHONISBE. Vous parlez un peu haut. ÉRYXE. Je suis amante et reine. SOPHONISBE. Et captive, de plus (Pierre Corneille, Sophonisbe)

1732a LUCILE. Que se passe-t-il donc ici ? vous parliez bien haut avec ma sœur, et je l'ai vu de loin comme en colère ; d'un autre côté, mon père ne me parle point. Qu'avez-vous donc fait ? D’où cela vient-il ? (Pierre de Marivaux, Les Serments indiscrets)

1732b Il y avoit néanmoins un temps où il perdoit sa timidité : quand il étoit plein de vin de Champagne, monsieur parloit aussi haut que madame ; mais son courage s'évaporoit avec les fumées du vin (AlainRené Lesage, Aventures du chevalier de Beauchêne)

1744 Je m’approchai d'un vieux militaire qui parloit fort haut et fort bien, chose assez rare à son espece : il fit noblement le panégyrique de notre illustre monarque ; et peut-être, pour la premiere fois de sa vie, il ne trouva point de contradicteur (Claude Godard d'Aucour, Thémidore)

1766 Comme il n'y avait qu'une cloison entre cette chambre et le cabinet où nous nous étions retirés, et qu'ils parlaient assez haut l'un et l'autre, nous entendîmes tout ce qu'ils dirent (Henri-Joseph Dulaurens, Le Compère Mathieu)
1830 Elle était l'imprudence même. Ils parlaient très haut ; et il pouvait être deux heures du matin, quand ils furent interrompus par un coup violent à la porte (Stendhal, Le Rouge et le noir)

1860 - Oh ! cria Aristide, toujours la montrant au doigt, tu en causeras avec moi ! Je ne me laisse plus prendre à tes airs. Je sais ce que je suis, et de nous deux c'est moi qui ai le droit de parler le plus haut (Louis Duranty, Le Malheur d'Henriette Gérard)

1862 C'était un vieillard particulier, et bien véritablement l'homme d'un autre âge, le vrai bourgeois complet et un peu hautain $\mathrm{du}$ dix-huitième siècle portant sa bonne vieille bourgeoisie de l'air dont les marquis portaient leur marquisat. Il avait dépassé quatre-vingt-dix ans, marchait droit, parlait haut, voyait clair, buvait sec, mangeait, dormait et ronflait. Il avait ses trente-deux dents. Il ne mettait de lunettes que pour lire (Victor Hugo, Les Misérables)

1863 Elle se regarde dans la glace, met son rouge, l'ôte ensuite, elle essaie sa physionomie et l'aiguise, elle essaie sa voix en parlant haut, elle essaie son âme en passant par tous les tons et tous les sentiments (Alfred de Vigny, Le Journal d'un poète)

1914 Julius parlait plus vite et plus haut que de coutume, pour se prouver qu'il n'était point gêné (André Gide, Les Caves du Vatican)

1920 La conséquence saute aux yeux. Réclamer cela, c'est enfoncer une porte ouverte. Ce jour-là le gouvernement saura parler haut et clair ou il laisserait tomber en quenouille ce qui est sa prérogative essentielle. Les coq-à-l'âne ne suffiront plus. Il faudra donner des juges à Dreyfus (Marcel Proust, Du côté de Guermantes 1)

1927 Le rayonnement de Dieu infini est si grand pour les fidèles qu'ils se croient hors de son regard au-delà du seuil de l'église et que, même à l'église, s'ils se tiennent à peu près bien aux premiers rangs, près de 
l'autel, derrière ils parlent haut et s'entretiennent de leurs affaires (Pierre Reverdy, Le Gant de crin)

1933a L'oncle Honoré faisait à lui tout seul autant de tapage que les enfants; il buvait sec, parlait haut, riait franc et amusait tous les convives (Marcel Aymé, La Jument verte)

1934 Là-dessus, mon père se mit lui-même en campagne, marchant sec et parlant haut (Georges Duhamel, Vue de la terre promise)

1942 DIABLE-DINDON. J'ai rabattu les ailes de l'amour

Tiré le drap sur un corps lourd de sang Autour de moi je suis fort je suis nu Je parle haut je vois clair et je flambe (Paul Éluard, Poésie et vérité)

1947 Tarrou qui se sentait particulièrement fatigué de sa journée, hésita. Mais l'autre insista. Il paraissait très agité, gesticulant de façon désordonnée, parlant vite et haut. Il demanda à son compagnon s'il pensait que, réellement, la déclaration préfectorale mettait un terme à la peste (Albert Camus, La Peste)

Pronominal

1712 PASQUIN. Car il n'est amoureux

Ni de vous, ni d'Orphise. Ah, voici votre père!

LISETTE. Il se parle tout haut et paroît en colère (Philippe Destouches, L'Ingrat)

1857 Les brigands, accroupis devant elle, se parlaient haut à l'oreille, et faisaient son éloge en des termes que, par bonheur, elle ne comprit pas (Edmond About, Le Roi des montagnes)

1890 Enfin, M. Denizet lâcha la lettre, et il demeura un moment absorbé, les yeux ouverts sur les Roubaud et sur Jacques. Puis, se résignant, se parlant haut à lui-même :

- Eh bien, on verra, on reprendra tout ça... vous pouvez vous retirer

(Émile Zola, La Bête humaine)

1933b LE CONTRÔLEUR. Voilà, j’ai fini. Je voulais me payer une fois dans ma vie le luxe de me dire ce que je pensais d'Isabelle, de me le dire tout haut! On ne se parle plus assez tout haut. On a peur sans doute de savoir ce qu'on en pense. Eh bien, maintenant, je le sais (Jean Giraudoux, Intermezzo)

1945 Pour être entendu au-dessus du vacarme, il fallait élever la voix au ton criard de la dispute et, se parlant ainsi, très haut, très fort, les êtres en arrivaient à se regarder avec étonnement et une espèce de sourde animosité (Gabrielle Roy, Bonheur d'occasion)

1946 Le contrôle odieux ne fonctionne pas si bien. L'être que tu aimes vit. Le langage de la révélation se parle certains mots très haut, certains mots très bas, de plusieurs côtés à la fois. Il faut se résigner à l'apprendre par bribes (André Breton, Les Manifestes du surréalisme)

1977 Deux, trois perles de Méditerranée sur le front, le nez, la joue, trop rares, c'est chouette après la puzzéria! Faut se parler plus haut, la mer bat les blocs de béton (Jean-Pierre Chabrol, La Folie des miens)

II. Parler de sujets spirituellement, moralement élevés

Intransitif

1683 Chrétiens, laissez-vous fléchir ; faites pénitence ; apaisez Dieu par vos larmes. Écoutez la pieuse reine qui parle plus haut que tous les prédicateurs (Jacques-Bénigne Bossuet, Oraison funèbre de Marie-Thérèse d'Autriche)

1840 Le père Pacifique, bien que plus spirituel et mis plus tard au rang des bienheureux, cherchait à concilier humainement, à ajourner, à ne rien vouloir d'impossible, et le père Bernard, bien que moins religieux, parlait plus haut et plus dans le sens prochain de Dieu, comme le remarque la mère (Charles Sainte-Beuve, Port Royal)

III. Montrer, manifester quelque chose clairement, de manière évidente Intransitif

1736 C'est aux pieds de ce Dieu, qu'un horrible serment 
Me donne au Meurtrier qui m’ôta mon Amant.

Je connois mal peut-être une loi si nouvelle ;

Mais j'en crois ma vertu, qui parle aussi haut qu'elle.

Zamore, tu m'ès cher ; je t'aime, je le doi : Mais après mes sermens je ne puis être à toi (Voltaire, Alzire ou Les Américains)

1824 Elle [= la nature] s'y lit pour qui n'est pas aveugle : levez les yeux, et les cieux vous parleront plus haut que moi. Tremblez donc et frémissez si vous avez quelque chose à vous reprocher, ne fut-ce que d'avoir vendu à faux-poids et mal mesuré ! (Honoré de Balzac, Annette et le criminel)

1831 Lorsque nous sommes jeunes, quand, à force de froissements, les hommes et les choses ne nous ont point encore enlevé cette délicate fleur de sentiment, cette verdeur de pensée, cette noble pureté de conscience qui ne nous laisse jamais transiger avec le mal, nous sentons vivement nos devoirs ; notre bonheur parle haut et se fait écouter ; nous sommes francs et sans détour : ainsi étais-je alors (Honoré de Balzac, La Peau de chagrin)

1914 La présence de Jésus-la-Caille ne la défendait pas des pires suppositions. Il avait peur, lui aussi. Son regard le disait, son silence parlait trop haut, mais rien, pour Fernande, ne l'attachait davantage à lui. Ils se regardaient. La loquacité des buveurs s'éteignait sans noblesse (Francis Carco, Jésus-la-Caille)

IV. parler plus haut : être, devenir plus fort, supérieur, plus important

Intransitif

1864 Sans doute il est venu un temps, pour l'Inde et la Grèce comme pour Rome, où la parenté par le culte n'a plus été la seule qui fût admise. A mesure que cette vieille religion s'affaiblit, la voix du sang parla plus haut, et la parenté par la naissance fut reconnue en droit (Numa-Denis Fustel de Coulanges, La Cité antique)
REMARQUES : Parler haut (I) se dit de quelqu'un qui parle en élevant la voix afin d'être entendu d'une ou de plusieurs personnes. Si le sujet est un écrit, haut souligne le caractère franc, ouvert, public des propos. Notons la locution parler haut et clair, ajoutant l'idée de limpidité du message. Dans son emploi pronominal, il se dit d'une communication entre deux ou plusieurs personnes, celles-ci élevant fortement la voix pour bien s'entendre. Parler haut peut référer aussi à une personne qui se parle à elle-même à haute voix, par exemple pour se rassurer. Dans des contextes spirituels ou religieux (II), le sujet parle dans le sens de sa religion, avec foi, haut renvoyant à l'élévation céleste, au divin. Sous (III), le sujet est une chose inanimée, souvent abstraite (ciel, silence, bonheur) qui, faute de pouvoir parler, montre par un autre moyen quelque chose d'évident, avec précision. Employé comme métaphore (IV), il se dit du fait de devenir supérieur à quelqu'un d'autre ou à autre chose, le sujet parlant plus haut et par ce fait gagnant de l'importance sur autrui. Notons les collocations parler vite et haut / haut et clair / très haut ... très bas / très haut, très fort, de même que les séries marcher droit, parler haut, voir clair / boire sec, parler haut, rire franc / marcher sec et parler haut / parler haut et voir clair, ainsi que l'emploi de dire haut. Haut reste invariable et est modifié par ainsi, aussi, assez, bien, fort, le plus, plus, si, tout, très, trop, un peu, prou. Le groupe parler prou haut signifie 'parler bien haut'. Prou est donc un simple intensifieur qui n'est plus motivé par sa sémantique originale (v. également l'entrée savoir prou, qui met en évidence la fonction d'intensifieur). VoIR AUSSI : penser haut, rire franc

\section{Parler heurté}

Parler de manière saccadée Intransitif

1961 - Docteur Destouches !... vous êtes, n'est-ce pas ?... et votre ami Le Vigan ? et votre chat Bébert? Mes respectueux hommages madame ! Il parle français, sec, heurté, mais net...

(Louis-Ferdinand Céline, Rigodon)

REMARQues : Parler heurté se dit du fait de parler de manière hachée, saccadée. Signalons que ce type d'élocution peut s'entendre chez une 
personne dont la langue maternelle n'est pas le français. Notons aussi les adjectifs-adverbes sec et net.

\section{Parler joli}

S'exprimer dans un bon style, de manière

élégante, éloquente

Intransitif

$1840 \mathrm{Au}$ demeurant, on le fait parce qu'il faut le faire, mais en raccourci, avec seulement quelques mots d'époque, de vœux au commencement ou à la fin. Le monde, ceux du monde sont habiles en cela, en parler flatteur et joli ; non pas moi, je ne me sens aucune facilité de parole dorée, brillante, de ce clinquant de bouche qui se voit dans le monde. Dans le désert on n'apprend qu'à penser (Eugénie de Guérin, Journal)

1922 Moi, je suis une brute, et je n'ai jamais su parler joli (Claude Farrère, Les Hommes nouveaux)

\section{CORPUS WEB :}

Quant au fait qu'ils viennent « profiter » ou « piller » le système social... Laissez-moi rigoler... Qui pille le système social en ce moment ? Le grand capital, nos politiques, nos ministres... Ils pillent plus en une journée que tous les autres en un an. Mais ils ont de beaux costumes et parlent joli... C'est de l'empapaoutage distinguÈ [http:// www.onpeutlefaire.com/forum/topic/13490delit-reproche-etre-tzigane/page-3] (18.8.2015)

François Morel ! Ça alors, pour moi c'est un Deschiens ! Comme il vieillit bien, comme il écrit bien, comme il parle joli ! [http://anc75.canal blog.com/archives/2012/03/09/23713611.html] (18.8.2015)

nan, mais il me parle joli de la bouche le bouseux des vosges là ? :D pis la neige, j'l'ai dressée moi, elle ne tombe pas sur mes trottoirs, ni dans la cour, que sur le gazon... [http://www.koetzingue. net/thread.php?lng=fr\&cat $=3 \& p g=7727 \& i d=2$ ] (18.8.2015)

REMARQUes : Parler joli se dit du fait de parler avec distinction, raffinement, le sujet choisissant particulièrement ses mots afin de susciter chez l'auditeur de l'agrément et du plaisir ou afin de donner une haute image de lui-même, voire de le séduire (v. la collocation flatteur et joli). D'où parfois la connotation de fausseté sur le plan du contenu. Le fait de parler joli est plutôt attribué aux gens élégants et économiquement aisés, alors que les gens modestes n'en seraient pas capables. Joli reste invariable. Dans l'exemple de 1840, parler flatteur et joli est nominalisé.

\section{Parler joyeux}

Parler de manière joyeuse, avec gaieté, sur un ton enjoué

Intransitif

1957 La couleur s'est mise à vivre sa vie. Impossible de ne pas lui obéir : elle parlait si fort, si net, si joyeux (Elle, 5 novembre 1957 / Grundt : 233)

\section{CoRpus Web :}

c est coloré, ça parle joyeux, ça parle optimpisme tout cela mieux vivre entouré de belels couleurs [http://supermomo07.skyrock.com/ 3061004297-BRANTES-SOUS-LES-ETOILES-LAFAIENCERIE-photo-SM07.html] (18.8.2015)

J'entrevis Pil Guk, je fis un pas vers lui, les individus m'accompagnant me suivirent, mais voyant qu'il parlait joyeux et avec entrain à d'autres, je décidai de me retirer un peu plus loin [http://www.kirin-art-school.net/t274-look-atme-pv-baek-pil-guk] (18.8.2015)

A Pompéï, sous les fenêtres de l'hôtel les italiens parlaient, joyeux ! [http://voyageforum. com/discussion/sud-italie-pouilles-autresendroits-d6391383/] (18.8.2015)

REMARQues : Parler joyeux se dit de quelqu'un parlant avec gaieté, entrain, bonne humeur. Le sujet peut aussi être un inanimé (ici : une couleur) et provoquer chez quelqu'un un sentiment de réjouissance, de joie. Notons les adjectifsadverbes fort et net. Joyeux reste invariable dans l'exemple de 1957. Il est modifié par si. Notons aussi l'emploi de parler optimisme en analogie avec parler affaires, hommes / femmes, etc. Le dernier exemple du CW rapproche joyeux d'un prédicat second détaché qui modifie les Italiens.

\section{Parler juste}

I. pour / à parler (plus) juste : plus

précisément

Intransitif

1654 Dans un si grand dessein, où la gloire est extrême, 
C'est peu, Seigneur, c'est peu, de quitter ce qu'on aime :

Ou pour parler plus juste, et pour mieux m'exprimer,

Ce que l'on n'ayme point, et ce qu'on feint d'aymer (Georges de Scudéry, Alaric ou Rome vaincue)

1690 Mais pour revenir à la réponse, que M. Descartes fait au cercle, dont on l'accuse : je vous demande, mon Pere, si c'est là se bien défendre ? Si ce n'est pas là faire retraite et capituler avec ses ennemis ? Ou plûtôt, pour parler plus nettement et plus juste, si ce n'est pas là se dédire et contredire?

(Le père Gabriel Daniel, Voiage du monde de Descartes)

1763 LE DUC. Voilà des raisons auxquelles il me semble qu'on ne sauroit rien opposer.

LA MARQUISE. À l'égard de Célie, si elle prend, ou - pour parler plus juste - quand elle prendra quelqu'un, voulez-vous parier, en supposant qu'il n'y mette point d'obstacle, que ce sera M. de Bourville?

(Alexandre Dumas fils, Le Hazard du coin du feu)

1838 Mon premier plaisir, ou, pour parler plus juste, la première diminution de tourment, fut de moins haïr les gens qui avaient fait mon malheur (Stendhal, Correspondance)

1893 Car en nous déterminant à vouloir, nous ne suivons pas toujours le dernier jugement de l'entendement ; mais, en voulant, nous subissons toujours l'influence de toutes nos inclinations et de nos habitudes. $\grave{A}$ parler juste, nous ne voulons pas vouloir, parce qu'on pourrait dire encore que nous voulons vouloir vouloir, et cela irait à l'infini (Maurice Blondel, L'Action : essai d'une critique de la vie et d'une science de la pratique)

1927 Ici, le clerc moderne s'est montré proprement génial dans la défense du temporel, le temporel n'ayant que faire de la vérité ou, pour parler plus juste, n'ayant pas de pire ennemi (Julien Benda, La Trahison des clercs)
1959 Très vite, c'était devenu un jeu, un charmant jeu de cache-cache où il était plus fort que moi. Entendons-nous. Pour parler juste, je devrais dire : où il eût été beaucoup plus fort que moi s'il en avait eu le désir. Mais il ne le désirait pas (Maurice Genevoix, Routes de l'aventure)

II. Parler avec justesse, exactitude, comme il convient

Intransitif

1662 Ceux qui font les antithèses en forçant les mots sont comme ceux qui font de fausses fenêtres pour la symétrie : leur règle n'est pas de parler juste, mais de faire des figures justes (Blaise Pascal, Pensées)

1667 Il est toûjours grand et toûjours civil, et par cent manieres qu'on ne peut exprimer, il attache les cours de ceux qui l'approchent : il parle fort juste et fort agreablement, et cette charmante familiarité qui s'accommode si bien avec le respect qu'on doit à la personne d'un grand prince, se trouve éminemment en luy (Madeleine de Scudéry, Les Jeux servant de préface)

1671 On ne disoit pas aussi au temps de Coeffeteau, et de Malherbe, raisonner juste, parler juste, chanter juste, un esprit juste, un discours juste (Le père Dominique Bouhours, Les Entretiens d'Ariste et d'Eugène)

1739 LA MARQUISE. Hé bien ! Tu vois, Lisette ; en bon français, il me dit que je ressemble à une vieille, que je suis contrefaite, que j'ai mauvaise façon; et je ne m'en fâche pas, je l'en remercie : d'où vient ? C'est qu'il a raison et qu'il parle juste (Pierre de Marivaux, Les Sincères)

1823 Aujourd'hui, si l'on voulait parler juste, on était obligé de dire la ville et la cour. Les seigneurs féodaux, depuis qu'ils avaient perdu leur pouvoir, cherchaient en dédommagement leurs jouissances (Emmanuel de Las Cases, Le Mémorial de Sainte-Hélène)

1920 Aussi était-il de ceux qui vont toujours vous disant : " On me croit ceci, cela... » 
et encore « On se fiche pas mal de moi.» Et il parlait juste, comme ceux qui parlent d'eux-mêmes (Henry de Montherlant, $L a$ Relève du matin)

1953 Le gros parlait juste puisque je venais de m'en rendre compte, la bonne môme Lulu, qui m'avait fait goder si fort, y avait seulement pas quarante-huit heures, son existence me revenait seulement à l'esprit, et sans grande exaltation du côté calecif ! (Albert Simonin, Touchez pas au grisbi)

1994 Pour les uns, ce que conte le juif n'est que sornettes et hallucinations. Pour les autres, la vérité est quelque part au milieu. Pour d'autres encore, le juif parle juste (Jacques Lanzmann, La Horde d'or)

\section{CORpus Web :}

Les costumes seront d'époque et le dispositif scénique assez sobre pour laisser une aire de jeu aussi libre que possible. Mais dans un premier temps ce sont les masques qui m'importent, ils sont à concevoir, à inventer, il faut qu'ils parlent juste et donnent aux personnages une totale crédibilité [http://www.clindoeiltheatre.com/LaCompagnie-Clin-d-Oeil-jouera] (18.8.2015)

merci pour ces RV avec le pr Latrémouille et Pierre Joxe qui parlent juste, de façon concise, efficace et refusent que l'interlocuteur pense à leur place [http://www.franceinter.fr/emissionlinvite-pierre-joxe] (18.8.2015)

Les personnages sonnent « vrais », ils parlent juste et ont souvent, malgré la rudesse de la vie, une vision optimiste [http://www.marivole.fr/ les-collections/terroir-de-France] (18.8.2015)

REMARQUeS : Parler juste désigne le fait de parler de manière correcte, d'avoir raison. Il peut référer d'une part à la justesse dans l'expression linguistique, le sujet suivant fidèlement les règles de grammaire, ou d'autre part à des propos fondés, sensés, dignes de foi (II). Notons la locution pour /à parler plus juste (I) qui introduit une correction ou précision de la part du locuteur/narrateur. Juste reste invariable et est modifié par fort, plus. Notons aussi les collocations plus nettement et plus juste, fort juste et fort agréablement, la série raisonner juste, parler juste, chanter juste (ex. de 1671) et l'emploi accordé de sonner vrai avec par- ler juste, non accordé (dernier exemple du CW). Mentionnons finalement l'emploi de goder fort 'avoir une forte érection', dans l'exemple de 1953. VOIR AUSSI : raisonner droit

\section{Parler laid}

Parler mal, de manière vulgaire, grossière, déplaisante, parler mal de quelqu'un Intransitif

+1150 Francois sont orgellous, desmesure, Et si sont coustumier de lait parler (Aiol et Mirabel [ $2^{\mathrm{e}}$ moitié XII $\left.\left.{ }^{\mathrm{e}}\right], 1159\right)$

REMARQUES : En ancien français, parler laid désigne le fait de s'exprimer d'une manière vulgaire, injurieuse, outrageante, le sujet causant du tort ou du déshonneur à son interlocuteur ; il se rapproche d'un simple modifieur négatif, comme parler mal de quelqu'un en français moderne. Laid a perdu cette fonction, mais le langage informel peut utiliser moche à sa place.

\section{Parler moche}

Parler mal, de manière vulgaire, grossière, déplaisante

Intransitif

\section{Corpus Web :}

On parle moche et gaspillage alimentaire dans le Huffington Post ! Bonne lecture ! [https:// www.facebook.com/secondlife.vege/posts/ 1930897263795578] (19.04.2019)

C'est quoi, causer moche ? C'est parler comme le fait votre voisin, votre patron, le député local, le commentateur à la télé, le garagiste d'en face, votre psychanalyste, l'auteur de ce site dès la première phrase, et bien d'autres [...] Le gros problème, c'est comment arriver à parler moche. Paradoxalement, une bonne méthode consiste à parler correctement [http://www.dicomoche.net] (19.4.2019)

\section{@ Penser à écrire moche}

Voilà un sympathique dictionnaire officiel en Français pour parler moche avec de savantes et truculentes définitions : le Dicomoche [https:// mediatic.blogspot.com/2003/02/penser-criremoche-voil-un-sympathique.html] (19.04.2019)

J'ai lu l'article et pour etre franc, j'ai rien pige. En gros parler moche c'est parler comme les riches 
avec un langage soutenu et qui n'existe plus parfois [mopior.goodbb.net/t868-parler-moche] (19.04.2019)

Parce que quand j'imagine qu'une de mes filles va sûrement se retrouver dans la jungle masculine dans quelques années et que l'idée-même qu'elle puisse de faire insulter ou parler moche me donne envie de casser les pattes arrières de tout ce qui bouge [https://lachroniquequipique. wordpress.com/tag/feminisme] (19.04.2019)

mais comme les statistiques homologuent le statut de « modèle » toujours par rapport à la grande masse, on s'en tiendra donc au sirupeux de l'espèce qui bat le haut du pavé dans le parler moche, ou si vous le préférez, la commonalité du langage [https://zemblog.wordpress.com/2009/05/18/ parler-moche] (19.04.2019)

Le terme de shooting photo est surtout utilisé dans le monde de la photo professionnel et de la mode mais il se démocratise de plus en plus. C'est devenu du parler moche et j'avoue que même moi je l'utilise, je le ferais plus désormais puisque le contre sens est évident entre tirer un projectile et capturer une image [http://photofloue. net/2008/04/18/tu-tires-ou-tu-shoot] (19.04.2019)

Je vais vous présenter l'étrange capacité de ce monsieur à tordre et mélanger la langue française de façon à la rendre imprécise. Vous avez peut-être eu vent du " parler moche » (https:// web. archive.org/web/20150329122000/http:// www. dicomoche.net/intro1.htm). Eh bien ce n'est pas ce que fait Eurod'. Les 'parleurs moche' me semblent agir de manière plus ou moins consciente. Leur utilisation de mots inhabituels, voire carrément inventés, à la place de mots habituels est voulue [https://recher.wordpress.com/ tag/parler-moche] (19.04.2019)

ReMARQues : Parler moche, qui n'est pas attesté dans Frantext (8.7.2020), réfère plus au style de la langue que son homologue d'antan, parler laid, qui inclut davantage le fait de parler mal de quelqu'un. En fait, l'expression de parler moche a suscité un vif débat dont nous reproduisons quelques exemples. Corrélat de ce débat apparemment stimulant, les locuteurs ont créé également l'infinitif substantivé (v. les trois derniers exemples $\mathrm{du} \mathrm{CW}$ ), le parler moche, ainsi que, dans le dernier exemple du CW, le parleur moche, qui ne renvoie pas à un parleur moche/ laid, mais à une personne qui parle moche. Dans le premier exemple du CW, parler moche se trouve coordonné avec parler gaspillage. Dans cet exemple, parler moche actualise le sens de 'parler de choses moches (ici : des légumes)', et parler gaspillage signifie 'parler de gaspillage'. Notons aussi les créations analogues causer moche, écrire moche.

\section{Parler mou}

Parler sans précision, évasivement, en ayant peur des réactions

Intransitif

1913 Je soupçonne, Monsieur Rudler, que vous ne savez pas ce que c'est que l'exactitude. Vous parlez mou, Monsieur Rudler, et vous parlez vulgaire. L'exactitude n'est ni la vérité ni la réalité (Charles Péguy, L’Argent)

1955 Éprise à outrance de stylisation, elle niait le théâtre photographié, et surtout ce langage quotidien, où l'on parle si mal et si mou, où l'imagination et la fantaisie sont sans ailes, d'où toute poésie est écartée à dessein (Le Monde, 17 septembre 1955 / Grundt : 224)

\section{CORPuS WeB :}

il y en a, qui pour ne vexer personne votent mou quand ils votent, parlent mou quand ils parlent, et on fait de la mollesse leur cheval de bataille (molle elle aussi) [http://www.laryngo.com/ forum/viewtopic.php?f=27\&t=5114] (19.8.2015)

C'est juste ce qui encombre ta vie malgré toi - qui te colle aux adidas dès que tu bouges un pied sur les trottoirs sans mégot jonchés de merdes avant Demain [= les chiens], alors que le bruit alentour résulte sans raisonner même pas d'une trace de civilité quand ils parlent mou, sur la pointe des pieds pour ne pas salir leurs Timberland(s) - et qui explose à raison de plusieurs détails par page [http://thth.free.fr/crevard/par_ aliette_guibert] (19.8.2015)

Pas étonnant de voir que vos porte-étendards sont des brûlés de la Mescaline qui parlent mou, qui n'ont pas assez de respect pour eux et les autres, pour laver comme il se doit un simple pare-brise, et qu'aussitôt le fruit de leur labeur empoché, il retombe directement dans les poches 
du crime organisé [http://forumdupeuple.com/ index.php?topic=1049.7320;wap2] (19.8.2015)

REMARQues : Parler mou se dit d'une personne parlant d'une manière évasive, peu concrète pour éviter des réactions négatives, une personne sans force de caractère. Notons l'emploi de parler vulgaire (ex. de 1913), et de voter mou dans le CW. Mou reste invariable et est modifié par si.

\section{Parler net}

I. Parler clairement, de manière franche, catégorique, sans ambiguïté

Intransitif

1500 LE MARY. Que ne parle-tu franc et net, Sans te mocquer ainsi des gens? (Farce de Jeninot / Ancien Théâtre françois)

1597 Qui craint Dieu, qui l'aime et l'adore, De verité sa bouche honore :

Parle net en tout temps et lieu (Jean-Antoine de Baif, Mimes, enseignemens et proverbes)

1661 LÉONOR. Voyez-vous Isabelle avec nous à regret?

SGANARELLE. Oui, vous me la gâtez, puisqu'il faut parler net.

Vos visites ici ne font que me déplaire,

Et vous m'obligerez de ne nous en plus faire (Molière, L'École des maris)

1715 LE BARON. Parbleu ! j’ai ma revanche. ARGAN. Mais je n'y comprends rien. Parlez net, je le veux ;

Dites qui vous voulez ménager de nous deux.

LISETTE. Je n'en veux ménager aucun, je vous assure,

Et vous le voyez bien (Charles Dufresny, $L a$ Coquette de village ou Le Lot supposé)

1819 Je trouve les libéraux plats ; même M. d'Argenson fut plat en 1815, de ne pas parler plus net sur Nîmes (Stendhal, Correspondance)

1839 Fabrice s’impatienta, puis il se dit : à qui la faute ? à notre vanité que cet homme a fort bien vue du haut de son siège. Le dévouement de Ludovic le porta enfin à courir le risque de parler net (Stendhal, $L a$ Chartreuse de Parme)
1848 Il a un caractère très franc, confiant et loyal. Il faut donc lui parler toujours net et s'il se trompe, le lui dire sans périphrase. Il a de l'intelligence et du cœur, et le prendra toujours bien (George Sand, Correspondance)

1886 Julie avait parlé si net, avec une telle force, une telle assurance, une telle sincérité, qu'il ne douta pas de sa bonne foi, mais il s'obstinait à douter de sa clairvoyance (Guy de Maupassant, Contes et nouvelles)

1893 S'il se rencontre des timides que le seul son de leur voix anéantit, d'autres ne pensent jamais si bien ou ne pensent guère qu'en parlant haut et net (Maurice Blondel, L'Action : essai d'une critique de la vie et d'une science de la pratique)

1902 Le franc militaire a parlé trop net dans un déjeuner, à Toulon, et un brave garçon, mais un peu borné, le capitaine Sicard, l'ayant pris pour un agent provocateur, a cru jouer un fameux tour à la police en le dénonçant. Et voilà mon pauvre Vallé au clou comme conspirateur et racoleur de conjurés (Paul Adam, L'Enfant d'Austerlitz)

1903 Après l'évangile, le curé monta en chaire, demanda la bénédiction au père Abbé, fit l'éloge des moines et exprima, au nom de la paroisse, le regret de les voir partir. Il parla net et bien. Cela rachète tout, même la haine du plain-chant, pensa Durtal et il lui pressa la main et le félicita, à la fin de la messe (Joris-Karl Huysmans, L'Oblat)

1920 LE CHEUR. Nous sommes beaucoup, mais nous parlerons court et net. Mot pour mot, je parle, réponds. Je commence. C'est vrai que tu as tué ta mère?

ORESTE. Je l'ai tuée. Oui, je ne le nie pas (Paul Claudel, Les Euménides)

1926 Tout aussitôt secouant la tête :

- En voilà assez, fit-il. Hâtons-nous ! Car l'heure sonnera bientôt où je ne pourrai plus rien pour vous, selon le monde. Parlons à présent bien net, aussi clairement que possible (Georges Bernanos, Sous le soleil de Satan) 
1939 Elle me souille en m'obligeant à une nourriture dite de gourmet, à laquelle je ne tiens pas et que je réprouve, en m'entraînant dans des endroits plus ou moins luxueux, où je me déplais et que je réprouve, parlons net : qui me font horreur (Henry de Montherlant, Les Lépreuses)

1957 Il sembla qu'Hillairé s'en voulait d'avoir parlé si net (Jean Duvignaud, L'Or de la République)

1997 Lannes, Augereau, voilà bien les seuls qui osaient lui parler net (Patrick Rambaud, $L a$ Bataille)

II. à / pour parler net : pour parler franc Intransitif

1697 LA COMTESSE. Que Monsieur le marquis est galant sans fadeur !

LE MARQUIS. Oh ! point du tout, je suis votre humble serviteur.

Mais, à vous parler net, sans que l'esprit fatigue,

Près du sexe je sais me démêler d'intrigue (Jean-François Regnard, Le Joueur)

1848 Raoul ne s'était jamais, à vrai dire, beaucoup préoccupé de toute cette affaire, et n'en avait vu que les résultats, qui, pour parler net, ne lui déplaisaient pas. Pauvre, il avait eu de tout temps le goût de l'opulence, et n'imaginait pas qu'un cadre d'un million pût rien gâter à un joli portrait (Jules Sandeau, Mademoiselle de la Seiglière)

1968 Pour augmenter l'intérêt du spectacle, on l'avait lié au poteau par une longue chaîne, ce qui lui permit de courir tout embrasé jusqu'à ce qu'il tombât la face contre terre, ou, pour parler net, dans les braises (Marguerite Yourcenar, L'Euvre au noir)

III. Parler clairement, distinctement, nettement Intransitif

190710 décembre

Il semble toujours créer son texte. Il a de la maîtrise dans le bafouillage. Il peut, en mangeant, parler net, sans postillonner, avec ses petites croûtes de pain dans la bouche (Jules Renard, Journal)
1956 Il considérait d'un œil serein les éditions successives des journaux parisiens où sa copie était reprise, tirée, déviée jusqu’au point de parler plus net et d'une autre voix (François-Régis Bastide, Les Adieux)

1958 Ces gens qui vous parlent en barbotant dans leurs glaires! On a envie de tousser un bon coup pour les aider à parler net (Exemple entendu, 3 septembre 1958 / Grundt : 348)

CORPus Web :

Elles sont trash, elles parlent net, elles poussent des vrais coups de gueule, lancent les débats et clash sans pitié. Pas de chichis et de clichés, de "trucs de filles » ici : voilà six Bad Girls qui cartonnent sur le web [http:// www.glamourparis.com/vie-perso/generationglamour/articles/les-blogs-des-bad-girls-duweb/9991/page/4] (19.8.2015)

Tout en se méfiant du prisme spectaculaire - et souvent déformant - de ces groupuscules qui parlent net, haut et fort, vis-à-vis de masses souvent silencieuses qui forment pourtant le gros des troupes, l'air du temps religieux, celui qui « fait parler » et qui « fait bouger », est à l'intransigeance contre ce qu'il est convenu d'appeler « l'esprit du monde » [http://blog.lefigaro.fr/ religioblog/2010/06/lultra-orthodoxie-se-portebie.html] (19.8.2015)

Un succès mérité !

Quelques chiffres qui parlent net : 392 adhérents (dont 102 hommes et 290 femmes) dès le mois de septembre (à noter : $60 \%$ d'entre eux ont entre 50 et 70 ans) [http://www.e-tribune.fr/index. $\mathrm{php} /$ jtt/jtt-la-vie-d-ici/47-universite-populairevivarais-hermitage] (19.8.2015)

REMARQUes : Parler net (I) se dit d'une personne s'exprimant d'une manière claire, franche, sans artifice, ni réticence. La locution à / pour parler net (II) est comparable à $\grave{a} /$ pour parler franc. (III) désigne le fait de parler d'une façon précise, distincte, en évitant de bafouiller, de postillonner, de mâcher ses mots ou de mal articuler. Notons les collocations haut et net, franc et net, court et net, net et bien ainsi que net, haut et fort. Net reste invariable et est modifié par bien, plus, si, toujours, trop. Mentionnons l'emploi de à vrai dire. 


\section{Parler niais}

Parler bêtement

$\lambda$ rire niais

\section{Parler noir}

Parler comme les gens de couleur

入 parler blanc

\section{Parler petit}

Parler (un) peu

Intransitif

1373 Chiers amis, depuis ceste aventure ai je petit parlé à li, car je n'en ai mies eü le loisir ne le lieu ; si m'en sui souffers et soeffre au plus bellement que je puis, attendans sa bonne volenté et le grasce qu'Amours me puet envoiier (Jean Froissart, La Prison amoureuse, p. 70, 84)

REMARQUES : En ancien français, le quantifieur petit, lié à parler, souligne le caractère peu loquace du locuteur, qui s'exprime ou s'entretient avec son interlocuteur brièvement, en peu de mots.

\section{Parler pittoresque}

Parler de choses pittoresques; parler de manière pittoresque, originale, en captivant l'attention Intransitif

1939 «Il me rendra fou avec cette tour Eiffel. » Costals se laissa mener vers la porte, et sortit.

" Est-ce qu'on parle pittoresque à un homme auquel, dans quarante minutes, on va dire qu'il est lépreux ? " (Henry de Montherlant, Les Lépreuses)

REMARQUES : Il s'agit ici d'un emploi métaphorique référant au fait de parler d'une façon originale, le sujet exprimant des propos qui surprennent par leur caractère insolite et étrange, propos qui ne manquent pas de saveur ni de piquant.

\section{Parler plat}

Parler sans accent (contraire de parler pointu)

入 parler pointu

\section{Parler plein}

Parler clairement, nettement, franchement

Intransitif

+1415 Sans point flater, je parle plain, Yver, vous n'estes qu'un villain ! (Charles d'Orléans, Poésies [ 1415-1440], II, Rondel CCCXXXIII, p. 483)

REMARQUES : En parlant du discours, parler plein désignait le fait de parler clairement, sans négliger les détails.

\section{Parler poignant}

Parler d'une manière touchante et émouvante 入 parler précis

\section{Parler pointu}

Parler avec un accent du nord de la France ou un accent parisien

Intransitif

1950 L'uniformisation dans la vulgarité. C'est inconvenant et con comme la lune d'entendre annoncer à la Radio les postes de Marseille, Lyon, Bordeaux avec le même accent. Qu'est-ce qu'ils ont tous à parler pointu comme ça ? (Albert Paraz, Valsez saucisses)

1969 - Dis donc, tu parles «pointu ». Tu es du Nord?

- J'en arrive (Léo Malet, Sueur aux tripes)

\section{CORPUS WEB :}

L'apprentissage forcé au français par la lecture de nos parents à l'école fait que nous parlons celui-ci «plat » en prononçant toutes les lettres, en fait dans le midi on n'a pas d'accent quand on parle français, ce sont les « francimands » qui parlent " pointu » [http://jean-paul.fraysse. pagesperso-orange.fr/fr/occitan.htm] (19.8.2015)

Aujourd'hui chez Jeannine, les adultes parlent pointu autour d'un picon bière, pendant que les gosses du quartier trouvent un terrain de jeu privilégié et bienveillant, pour le plus grand bonheur des parents [http://lebalafond. blogspot.co.at/2015/06/quand-le-balafond-faitle-marathon-chez.html] (19.8.2015)

Les gens des hauts plateaux, boliviens de la Paz, péruviens de la Sierra, équatoriens, colombiens de Bogota, mexicains de Mexico, parlent pointu, bref et sibilant, raccourcissent 
les voyelles ; ceux de la plaine, argentins de la Pampa, uruguayens, ilaneros du Vénezuela et de la Colombie parlent allongé avec des voyelles qui s'allongent à l'image de l'horizon infini ; et enfin ceux des tropiques parlent les lèvres si écartées qu'aucune consonne ne saurait s'y installer [http://base.d-p-h.info/fr/fiches/premierdph/ fiche-premierdph-1210.html] (19.8.2015)

Remarques : Pour les Méridionaux, parler pointu désigne la manière de parler des habitants du nord de la France, et particulièrement des Parisiens, généralement perçue de manière péjorative. En général, pointu se dit d'un timbre de voix aigu (ex. de 1950 et dernier exemple du $\mathrm{CW}$ ), ressenti parfois comme désagréable. Notons les groupes parler bref, sibilant, allongé, plat. Pointu reste invariable. Dans l'exemple de 1969 et le premier exemple du CW, les guillemets indiquent qu'il s'agit d'une façon de parler peu reçue à l'écrit.

\section{Parler positif}

Parler avec optimisme du côté positif des

choses

Intransitif

1933 Que je restais éloigné du catholicisme, non par conviction inverse, mais par habitude de m'en passer, par goût de parler positif? (Joseph Malègue, Augustin ou Le Maître est là)

\section{Parler précis}

Parler avec précision, de manière exacte, nette, précise

Intransitif

1948 KUNDRY. Oui, tu aimes assez à regarder par les judas. Mais tu perds ton temps à faire le beau.

Qu'as-tu fait de Méliant?

CLINGSOR. (Il parle bref et précis, comme pour un rapport)

J'étais caché hier soir dans les bois du Plimizel. Méliant m’a dépassé. Il était à cheval, seul, en armes, la visière basse

(Julien Gracq, Le Roi pêcheur)

\section{CORPUS WEB :}

Travailleur de longue haleine dans un univers de beatmakers en mode livraison rapide,
Skread porte sa réussite sur lui. Le blondinet parle précis, d'une voix mesurée, et sait où il va [http://www.lesinrocks.com/musique/critiquealbum/skread-compile-ses-instrumentaux] (19.8.2015)

La timidité contrariée par sa réputation. Il parle précis. D’une voix minuscule qui se transforme en ciseau aiguisé lorsqu'il chante [http:// www.letemps.ch/Page/Uuid/c69a9c36-0617-11e4a6d1-542beb13958e/Woodkid_ne_pas_laisser_ de_bois] (19.8.2015)

Ce témoignage nous parle, précis, juste, poignant [https://fr-fr.facebook.com/SSPValais/ posts/712637412180400] (19.8.2015)

REMARQUES : Parler précis réfère à une personne s'exprimant d'une manière précise, réfléchie, une personne qui choisit ses mots avec soin, afin d'être parfaitement comprise par son interlocuteur. Notons la collocation parler bref et précis qui englobe à la fois l'idée de précision et celle de concision. Cette idée est encore plus prégnante dans parler précis, juste, poignant par rapport à un message.

\section{Parler profond (parfont)}

Parler de manière approfondie (sur quelque chose), en détails, en allant au fond des choses Intransitif

+1313 Car mout saues parler parfont, Qui font les simples gens plourer Et em plourant lor sains orer Tant qu'il ont l'argent fors atrait (Jean de Condé, Poèmes [1313-1337], 332)

1350 Ne ki li demande autre kose

Ke ses autres voisines font.

Je n'en vuelh parler plus parfont

(Gautier le Leu, La Veuve [milieu III ${ }^{\mathrm{e}}$ ]

CORPuS WEB :

Fascinée par le déploiement de la beauté dans la nature, émerveillée par l'intelligence de la vie et sa richesse créative, habitée par le sentiment intime du divin en dehors de toute religion, j'ai envie que mes créations soient porteuses de beauté et de sens, qu'elles parlent profond pour le meilleur [http://denise.gerin.pagesperso-orange. fr/Tali_Forgane/Accueil.html] (19.8.2015)

Quelle superbe approche de la violence que se fait l'artiste ce balayage du paysage, sa 
mise à mort, l'attente des signes, la superstition, touts moments qui me parlent profond [http:// secretslutin.canalblog.com/archives/2007/08/31/ 6061663.html] (19.8.2015)

Je ne connaissais pas Kent. Des chansons qui parlent profond [http://blouguiblogue.blog spot.co.at/2013/01/leternite.html] (19.8.2015)

REMARQUES : Au sens propre, parler profond désigne le fait de parler de quelque chose avec force détails, en allant au fond des choses. Au sens figuré, il se dit du fait de tenir des propos qui touchent par leurs mots les sentiments de l'interlocuteur. Profond reste invariable et est modifié par plus.

\section{Parler prou}

Parler beaucoup

(nous n'analysons pas ce groupe, prou ayant perdu sa fonction adjectivale ; voir l'exemple de parler prou haut sous ouir dur)

\section{Parler raide}

Parler durement, sans fard ; parler avec colère Intransitif

1651 seló la coustume [= l'homme né en septembre] sera incliné à parler roide, grand parleur, la voix forte et alterée, qu'il semblera estre en colere bien qu'il ne soit ainsi (Sinibal de Spadacine, Le Miroir d'astrologie naturel)

1864 D’abord aux paysan il faut parler raide, ensuite on tâte le pouls, on regarde la langue, on reste quelque temps sans parler, afin qu'on puisse dire : Oh ! c'est un homme qui réfléchit (Joyeux Passe-temps de la jeunesse)

1888 Pour les Astier, ces retours étaient très significatifs. Aussitôt seule, la femme quittait la déférence et l'intérêt maintenus dans le monde pour le maître, parlait raide, prenait sa revanche de son attention à écouter des histoires cent fois entendues, qui l'hébétaient d'ennui ; lui, bienveillant de nature, toujours content de soi et des autres, revenait régulièrement enchanté, stupéfait chaque fois des horreurs que sa femme débitait sur la maison amie, les personnes rencontrées, allant tranquillement aux accusations les plus abominables (Alphonse Daudet, L'Immortel)

1925 - On ne viendra pas commander chez moi ! Je n'entends pas ça ! Elle parlait raide, toute rouge de mécontentement (Henri Pourrat, L'Auberge de la Belle Bergère ou Quand Gaspard de guerre revint)

1965 Je ne te parle pas avec colère, tu le sais aussi. Il y a trop d'endroits par lesquels nous sommes pareilles et il y a trop longtemps que nous le savons pour que tu puisses te tromper, si quelquefois, parce qu'il faut parler clair, je parle raide (Jean Giono, Deux Cavaliers de l'orage)

\section{Parler rare}

Parler peu

入 caqueter dru

\section{Parler rigolo}

Parler d'une manière amusante

Intransitif

1914 LA MÔME. Mais oui, mon cher ! Et je pourrais t'en citer comme ça à la file ! ... t'as l'air de croire parce que je parle rigolo... ! C'est le milieu qui veut ça! Mais tu sauras que j'ai fait des classes, moi ! Je suis de bonne famille, tout comme tu me vois! (Georges Feydeau, La Dame de chez Maxim)

\section{Parler rude}

Parler d'une manière brutale, bourrue, dure, fruste

Intransitif

1934 Quand je suis revenu (nous habitions au bas de la rue de Seine), elle était avec un homme que j'avais vu souvent l'aborder dans la rue, les jours où papa n'était pas là. Un homme grand, fort, qui parlait rude (Daniel-Rops, Mort, où est ta victoire?)

1960 C'est pas encore le geste qui convenait à cet intraitable.

- Tirez-vous, il ordonne, lui piquant la boîte des mains.

Rude et sec a parlé Armand. En éprouve-t-il un regret? 
Il ajoute d'une voix adoucie :

- Jusqu'à ce soir j’ai à faire !

(Albert Simonin, Du mouron pour les petits oiseaux)

\section{CORPus Web :}

Confirmation : les breakeurs ne mâchent pas leurs mots. Ils parlent rude, comme la vie. Mais ils savent se faire poètes, aussi [http://www. aujourdhui.ma/maroc/culture/b-boys-les-break danseurs-du-boulevard-lalla-yacout-87355\#. VdS6Xk2wqUk] (19.8.2015)

Et les mecs qui tapent du poing sur la table et qui braillent fort et qui parlent rude ! [http:// lesactualitesdudroit.20minutes-blogs.fr/archive /2008/08/14/20-minutes-fr-1-enquete-pietine. html] (19.8.2015)

Mon grand père disait « quand t'as un don, si tu l'enterres c'est que t'es con ». Il parlait rude mais il avait vécu deux guerres (dont une coté prussien) [http://www.pechemaniac.com/forums/ viewtopic_3218.htm] (19.8.2015)

REMARQUES : Parler rude se dit d'une personne parlant d'une manière dure ou bourrue, son élocution réfléchissant généralement un aspect fruste, vigoureux, voire primitif. Notons la collocation avec l'adjectif-adverbe sec, soulignant la rapidité, l'immédiateté de l'expression, peu réfléchie et peu pesée. Signalons aussi l'emploi de brailler fort. Rude reste invariable. VoIR AUSSI : caqueter dru

\section{Parler sec}

I. Parler de manière rude et rapide Intransitif

+1489 Toutesfois, ill'endura vertueusement et toutes autres choses jusques àla mort et plus que nul homme que j'aye jamais veü mourir. A son filz, qu'il appelloit roy, manda plusieurs choses ; et se confessa très bien et dist plusieurs oraisons servans à propoz, selon les sacremens qu'il prenoit, lesquelz luy-mesmes demanda. Et, comme j'ay dit, parloit aussi sec comme si jamais n'eust esté malade, et parloit de toutes choses qui povoyent servir au roy son filz (Philippe de Commynes, Mémoires [1489-1498], VI)
1897 Il ne fallait pas espérer de lui l’ampleur sereine, la puissante nappe de Marchenoir, non plus que le facile bavardage du bon Gacougnol. Il parlait sec, décochant des phrases de jet, brèves et dures, qui coupaient comme du silex, en homme accoutumé à faire marcher des animaux et des esclaves

(Léon Bloy, La Femme pauvre)

1932 - Janine, ma chérie, comment oses-tu... Pauvre Isa qui avait passé tant de nuits au chevet de cette petite hurleuse, qui l'avait prise dans sa chambre parce que ses parents voulaient dormir et qu'aucune nurse ne la supportait plus... Janine parlait sec, d'un ton qui aurait suffi à me mettre hors de moi (François Mauriac, Le Noud de vipères)

1936 La partie du guéridon elle a débuté très aimablement. Ils se donnaient gentiment des cartes et puis ils se sont un peu aigris, ils se sont mis à parler plus sec, plus du tout comme dans le théâtre... C'était plus pour rire qu'ils se causaient. Ils se répliquaient par des chiffres. Les atouts claquaient comme des beignes (Louis-Ferdinand Céline, Mort à crédit)

1960 C'est pas encore le geste qui convenait à cet intraitable.

- Tirez-vous, il ordonne, lui piquant la boîte des mains.

Rude et sec a parlé Armand. En éprouve-t-il un regret?

Il ajoute d'une voix adoucie :

- Jusqu'à ce soir j'ai à faire ! (Albert Simonin, Du mouron pour les petits oiseaux)

1961 - Docteur Destouches !... vous êtes, n'est-ce pas ?... et votre ami Le Vigan ?? et votre chat Bébert? Mes respectueux hommages madame! Il parle français, sec, heurté, mais net...

(Louis-Ferdinand Céline, Rigodon)

II. parler aussi sec : parler immédiatement Transitif

1959 Un magnétophone, durant votre sommeil, vous susurre des phrases en chinois, par 
exemple. Ainsi, vous parlerez chinois aussi sec (Express, 12 mars 1959 / Grundt : 359)

\section{CORpus Web :}

C'est plus au boulot... ils te regardent à peine... te parlent sec et te disent ni bonjour, ni merci, ni aurevoir [http://www.yabiladi. com/forum/racisme-vous-arrive-1-908175.html] (19.8.2015)

Ta des gens sur Twitter ils font trop les chaud genre ils parlent sec mais devant toi ils rigolent h24 et snt graves tigen $\ll<<$ \#CoupDeBambou [https://twitter.com/iloveasap_/status/ 412037256908898304] (19.8.2015)

Seul petit reproche, les prêtres entre eux se parlent « sec » et ne semblent pas avoir beaucoup d'empathie les uns envers les autres [http:// forums.pelerin.info/viewtopic.php? $\mathrm{f}=45 \& \mathrm{t}=$ 16268] (19.8.2015)

REMARQUES : Parler sec (I) se dit du fait de parler d'une manière brusque, cassante, voire désobligeante, le sujet s'exprimant sans amabilité, ni chaleur. Notons que sec traduit également l'idée de rapidité, les phrases étant comme projetées hors de la bouche, par saccades. La locution parler aussi sec (II) réfère au fait du parler (ici : le chinois) immédiatement, sans hésiter et sans tarder. Les exemples du CW transmettent également un manque de politesse et de gentillesse envers les autres. Notons la collocation parler rude et sec et la séquence Il parle français, sec, heurté, mais net. Sec reste invariable et est modifié par aussi, plus. Le verbe figure dans son emploi pronominal réciproque dans le dernier exemple du CW.

\section{Parler sérieux}

Parler en insistant sur l'importance de ce que l'on dit, parler avec sérieux Intransitif

1852 Pour parler sérieux, je recommande à Vic tor de vivre beaucoup plus avec toi, et de mêler un peu de bon travail à ses plaisirs (Victor Hugo, Correspondance)

1963 Je jouais les trouble-fête quand j'avais besoin de lui parler sérieux, je les sacquais en deux mots, moi, ses existentialistes, ses vagabonds chevelus (Alphonse Boudard, La Cerise)

\section{Corpus WeB :}

Avec elle mais tu passes pas 5 secondes sans rire ou alors c'est qu'elle parle sérieux J'ai passé des moments inoubliables avec elle [https://xreine-de-la-banquise-x.skyrock.com/2138972787Mon-prout-Ma-pigloote-Ma-Meganologue-MAchiwwilogue.html] (15.11.2008)

REMARQUes : Parler sérieux signifie 'être sérieux en parlant'. Il s'agirait donc, logiquement, d'un prédicat second, mais l'exemple du CW, choisi parmi un grand nombre d'exemples similaires, montre que la communication familière renonce assez facilement à l'accord, qui serait pourtant de rigueur pour la prédication seconde. En effet, la recherche dans les textes écrits de Frantext et de Google.books ne donne aucun résultat sans accord. C'est donc la langue orale-familière qui le prend plutôt comme adverbe.

\section{Parler serré}

Parler sans se découvrir, sans se compromettre Intransitif

1682 On s'était écouté l'un l'autre paisiblement; on parlait de part et d'autre assez serré (Jacques-Bénigne Bossuet, Sur la matière de l'Église)

\section{CORPus Web :}

On écoute. Strates d'écoute : qui en face écoute quoi, il faut qu'il écoute leur écoute, se dit-il - mais il écoute celui-ci, celui-ci qui parle serré, comme si leurs courroies d'entraînement s'étaient mêlées [http://remue.net/spip. php?article2826] (21.8.2015)

REMARQUES : Parler serré désigne le fait de parler de manière concise, en peu de mots, le sujet cherchant à être prudent et à ne pas se compromettre en donnant trop d'informations. L'exemple du CW a le sens de 'parler avec un débit dense'. Serré est modifié par assez.

\section{Parler sibilant}

Prononcer des sons sibilants

入 parler pointu

\section{Parler simple}

Parler en utilisant un vocabulaire simple, des structures grammaticales de base produisant des messages simples, faciles à comprendre 入 parler compliqué 


\section{Parler soef}

Parler doucement, d'une voix douce, mélodieuse Intransitif

+1100 Tant dulcement sonat li vols

En eschele cum fait li cols ;

E puis qu'asist desur la nef,

Brandan parlat bel e süef : [variante : bien e süef]

«Si tu es Deu creature,

De mes diz dunc prenges cure »

(Benedeit, Voyage de saint Brendan

[1 ${ }^{\text {er }}$ quart XII $]$, 514)

\section{Parler sonore}

Parler d'une voix forte, retentissante

Intransitif

1922 Amédée Bourron parlait sonore (Claude Farrère, Les Hommes nouveaux)

\section{CORPUS WEB :}

Pour parler sonore plutôt que philosophie de comptoir, Record Amniotique est un bijou, un bonbon, un plaisir, une vraie immersion où la méfiance n'est pas de mise. Un de ces cas pour lesquels le critique va remplir son article et mériter son salaire en pinaillant sur un point de scénario [http://lemag.macp3.info/n22/05Decouverte-desamorce] (21.8.2015)

Quitte à jongler avec les dictionnaires et lexiques les plus excentrés, les plus particuliers, afin de parler sonore [http://remue.net/cont/ Dubost_01.html] (21.8.2015)

Le décibel lorsque l'on parle sonore, est l'unité ; de mesure internationale pour mesurer la pression acoustique. C'est donc bien au contraire quelque chose de très précis et de très objectif [http://forums.macg.co/threads/boitiersilencieux.161238/] (21.8.2015)

REMARQUES : Le sujet de parler sonore est une personne parlant d'une voix forte, qui porte, retentissante, voire éclatante, de manière à se faire entendre. Le sujet peut référer à un son dont l'émission s'accompagne de vibrations des cordes vocales, le faisant retentir avec une grande puissance. Dans les deux premiers exemples du CW, parler sonore est employé au figuré : 'parler pour se faire entendre' (dans le deuxième exemple : en sortant du langage convenu). Sonore est modifié par plus.

\section{Parler soutenu}

Parler en adoptant un langage soutenu, élaboré $\lambda$ parler familier

REMARQUES : En ancien français, parler soef se disait du fait de parler d'une voix douce, harmonieuse, le son de la voix faisant sur les sens une impression douce et flatteuse. Notons la collocation parler bel et soef où le son agréable de la voix est apposé à l'esthétique des paroles prononcées, ainsi qu'à l'idée d'exemplarité et de morale. L'emploi coordonné avec bel souligne la fonction adverbiale de soef. Ceci est confirmé par le remplacement de bel par l'adverbe bien.

\section{Parler vrai}

I. Parler avec exactitude, avec justesse, dire la vérité

Intransitif

+1365 Ains est d'un simple parler vrai

Qui viegne dou coer. Je n'aurai

Bien jusqu'à tant que je verai

Venir bon oirre

Ce parler qui m'oste d'esmay

(Jean Froissart, Poésies [3e tiers XIve])

1735 Vous me parlez toûjours de Saint-Fal que vous n'aimez pas, interrompit malignement le marquis, et mon fils n'entre pour rien dans tous ces arrangemens. Cependant il étoit bien plus naturel que ces petits frais ne regardassent que mon neveu. L'avantage d'être aimé de vous... Je vous parle vrai, monsieur, interrompis-je, à mon tour (Charles de Mouhy, La Paysanne parvenue)

1745 HAMILTON. S'affranchir sans éclat, ne voir que ce qu'on aime,

Ne renoncer à rien ; voilà le seul système.

Mais parlez-moi plus vrai, d'où vous vient ce dessein?

Quel chagrin avez-vous?

SIDNEI. Moi, je n'ai nul chagrin

(Jean-Baptiste Gresset, Sidnei)

1767 Mais parlons vrai : sçavez-vous ce qui accable la classe laborieuse et souffrante d'un État ? (Jean-François Marmontel, Bélisaire) 
1863 Le chagrin force un homme à parler franc ; comme la lance du Raphaël de Milton touche le crapaud et fait paraître Satan malgré lui dans sa forme réelle. Figaro parle vrai sitôt que Suzanne l'a blessé au cœur et il cesse d'être un arlequin (Alfred de Vigny, Le Journal d'un poète)

1910 Je vous eusse cru plus désabusé des choses de ce monde ; seriez-vous donc autre chose qu'un survivant par esprit de vengeance ? Parlez-moi vrai ; car, apprenez-le, le parricide, l'inceste, le viol, l'incendie et le poison sommeillent dans le plus ingénu, dans le plus inoffensif des mensonges (Oscar Milosz, L'Amoureuse Initiation)

1939 LE CHAMBELLAN. S'il a peur, ils doivent exprimer le courage. S'il ment, la franchise. Il n'est pas malséant non plus, s'il leur arrive de parler vrai, qu'ils aient l'air de parler faux (Jean Giraudoux, Ondine)

1997 Premier ministre d'un 'parler vrai' réhabilité - son affichage moral et social est conforme à ses engagements de campagne - il [= Lionel Jospin] reste à devenir celui d'un 'agir vrai' (Le Monde, 21 juin 1997).

2016 Le parler-vrai de Justin Trudeau détonne, peut dérouter (Le Monde, 3-4 avril 2016)

II. à / pour vrai parler : pour dire la vérité, à vrai dire

Intransitif

+1415 Scez tu dont vient ton mal, a vray parler ? Congnois tu point pourquoy es en tristesse ? (Charles d'Orléans, Poésies [ 14151440] I, Complainte I, p. 258)

1732 DAMIS. Non, Madame, toute différente : car enfin, je pourrais vous aimer.

LUCILE. Oui-da ! mais je serais pourtant bien aise de savoir ce qui en est, à vous parler vrai.

DAMIS. Ah ! c'est ce qui ne se peut pas, Madame ; j'ai promis de me taire là-dessus (Pierre de Marivaux, Les Serments indiscrets)

1735 je vous promets, je vous jure même que, malgré la vivacité des sentimens que j'ai pour vous, je contribuërois à votre bonheur, si j'en étois le maître ; je ne demande, pour prix d'une estime, ou pour parler plus vrai, d'un amour si desinterressé, que la seule grace de ne me jamais priver de votre chére presence (Charles de Mouhy, La Paysanne parvenue)

1760 DAMISE. Et pour en parler vrai, ma foi, je les [= les beaux esprits] soupçonne D'aimer le genre humain, mais pour n'aimer personne (Charles Palissot de Montenoy, Les Philosophes)

1821 Car je n'ai en cela d'autre mérite que d'avoir profité de plus grands secours ; et je crois aussi, $a ̀$ vous parler vrai, qu'il n'est supérieur à ceux qui l'ont précédé que par la même raison (Joseph de Maistre, Les Soirées de Saint-Pétersbourg)

1934 Une femme qui arrive par là dans les plus de soixante, personne se souvient de ce qu'elle a pu faire dans son temps de fille. Pour parler vrai, qu'elle ait fait tout bon ou tout mauvais, c'est tout pareil ce qu'il en reste dans le temps qu'elle peut plus rien faire (Gabriel Chevallier, Clochemerle)

III. Parler avec vraisemblance, conformément à la réalité

Intransitif

1944 ARMAND. Il a dit le crachat. Il a dit la débauche. Il a dit le vice.

MARCELLUS. Tu y mets le ton exact.

ARMAND. J'ai joué la comédie. Je sais parler vrai. Il a dit qu'il avait la mission de veiller à ce que la ville ne sombrât pas dans son relâchement et, puisque tu en étais le symbole, que c'est avec toi qu'il aurait son premier assaut (Jean Giraudoux, Pour Lucrèce)

Corpus Web :

Ne pas confondre ceux qui parlent fort et ceux qui parlent vrai [https://twitter.com/le_m _/status/580765012186234880] (17.8.2015)

Conter vrai, est-ce parler vrai ? Oui, bien sûr, parl'intention qui sous-tend votre conte, par le but qu'il poursuit. Un conte, un vrai bon conte est toujours généreux, utile [http://toutpetits.wordpress. com/2009/07/06/conter-vrai] (11.9.2014) 
REMARQues : Parler vrai (I) se dit du fait de parler avec franchise, exactitude, conformément à la vérité, le sujet démontrant de l'honnêteté, voire de la rigueur dans ses explications. Les locutions à parler vrai et pour parler vrai (II) peuvent introduire un aveu ou simplement une précision. Dans le contexte du théâtre (III), il se dit d'un comédien représentant parfaitement son personnage, parlant de manière crédible, conforme à la réalité. Notons l'emploi de conter vrai et agir vrai, ainsi que de parler fort, franc et de l'antonyme parler faux. Vrai reste invariable et est modifié par plus. La nominalisation dans l'exemple de +1365 et dans ceux de 1997 et 2016, montre la forte cohérence interne du verbe complexe qui en est la base. L'exemple de 1997 oppose penser vrai à agir vrai.

\section{Parler vulgaire}

Tenir des propos banals

$\pi$ parler mou

\section{Partir direct}

Partir tout de suite, sans attendre

$\lambda$ partir sec

\section{Partir droit}

Partir en suivant une ligne droite

Intransitif

1887 Elle partit tout droit devant elle, et d'un air si courroucé que le jeune homme, écrasé par la scène qu'il venait d'affronter, la vit s'en aller, immobile, sans rien faire pour la retenir (Paul Bourget, Mensonges)

1914 Maxence, ayant mangé et bu, s'élança sur sa selle et partit droit dans l'espace déchiré devant lui (Ernest Psichari, Le Voyage du centurion)

1947 Le liquide partait bien droit, mais, arrivé au niveau de la quatrième machine disparaissait sur place, et l'on apercevait la tranche du jet, aussi nette que s'il eût été sectionné d'un coup de hache (Boris Vian, L'Écume des jours)

1954 J'ai enfourché ma bicyclette et je suis partie droit devant moi (Simone de Beauvoir, Les Mandarins)

\section{CORPUS WEB :}

Comme chacun le sait, Rayman n'a pas de bras, ce qui lui permet d'utiliser ses poings comme projectile. Pratique, non ? Une pression sur le bouton attaque, les voilà qui partent droit devant [http://raymanpc.com/wiki/fr/Poing_t\% C3\%A9lescopique] (21.8.2015)

Mais avant de partir à Narshe, ils partent droit vers le nord [http://neit.free.fr/soluces/ffvi/ ffvi11/ff6ch11.htm] (21.8.2015)

j'ai changé en passant de winprint à ZIMFPrint et là amélioration... parfois les feuilles ne partnet pas (grrrr!) mais au moins quand elles partent, elle partent droit ! [http://forum.hard ware.fr/hfr/Graphisme/PAO-Desktop-Publish ing/processeur-impression-r2400-sujet_36041_1. $\mathrm{htm}](21.8 .2015)$

Je viens vers vous car j'ai du mal à piquer mes volants lors d'un smash. J'arrive à mettre de la puissance, mais ils partent droits, et du coup sont facile à défendre... un block et c'est fini [http://badmania.fr/modules/forum/index. php?topic=20043.0] (26.8.2015)

Pour la déviassions de billes, quelle billes utilise tu ? si elles partent droites sur 30 mètres c'est le vent qui les faire dériver à mon avis [http://www.france-airsoft.fr/forum/lofiversion/ index.php/t193434.html] (26.8.2015)

REMARQues : Partir droit se dit d'une personne ou d'un animal qui s'en va en suivant une ligne droite, évitant de s'arrêter ou de faire de détours. Il peut traduire une idée de détermination de la part du sujet ou l'ignorance du monde extérieur (Elle part droit devant elle). Le sujet peut également être une chose (ici : un liquide) qui part, s'écoule d'une manière rectiligne. Droit reste invariable dans son emploi adverbial (v. les trois premiers exemples du CW). En tant que prédicat second orienté vers le sujet il s'accorde avec le sujet, notamment dans le langage du sport et des jeux (v. les deux derniers exemples du CW). Il peut s'associer avec la préposition qui le suit (à, dans, devant) au point de faire partie du groupe prépositionnel en tant que modifieur de la préposition, surtout dans la collocation partir droit devant. Il est modifié par bien, tout. VoIR AUSSI : s'en aller droit 


\section{Partir dur}

Commencer d'une manière brutale, rapide, directe

Intransitif

1963 [Dans ces conférences de presse] les questions des journalistes ne sont pas préparées à l'avance. Elles partent $s e c$, dur, et il n'est pas question de les esquiver (Express, 12 décembre 1963 / Grundt : 243)

CORPUS WEB :

Ça partait dur mais en 3 semaine, je me suis trouvé plein d'amis et fanchement, je regrette pas ma vie d'avant [http://www.jeuxvideo.com/ forums/1-50-44966037-2-0-1-0-vous-avez-detruitma-vie.htm] (21.8.2015)

je pense que tu as peur d'etre inférieure à ton amie, mais, si vraiment c'est une amie, jamais elle ne devrai te considérer inférieure a elle. meme si cela partait dur, je pense que, si tu te prend trop la tete avec cette histoire, tu aura tendance à mettre tes défauts en avant, et , ce qui compte, c'est les qualités ! [http://forum.lixium. fr/d-3410267.htm] (21.8.2015)

Selon moi si tu as suffisamment de Ccc avec le nerf général de la vitesse d'attaque mais le up des dégats, je trouve mieux de partir dur du Dualwield [http://eu.battle.net/d3/fr/forum/ topic/9952565238] (21.8.2015)

REMARQUES : Le sujet de partir dur est une chose qui démarre, commence avec force, avec difficulté, et qu'on ne peut arrêter. Dans l'exemple de 1963, il s'agit de questions qui fusent de manière rapide et brutale, et qu'on ne peut ignorer. Notons l'adjectif-adverbe sec qui en renforce le sémantisme. Dans le premier et le deuxième exemple du CW, l'adjectif-adverbe réfère à des difficultés vécues après un changement. Dans le dernier exemple du CW, partir dur désigne le fait de quitter un lieu directement. Dur reste invariable.

\section{Partir joyeux}

I. Partir joyeusement, dans la joie, la gaieté Intransitif

1840 Oh ! combien de marins, combien de capitaines

Qui sont partis joyeux pour des courses lointaines,

Dans ce morne horizon se sont évanouis !
Combien ont disparu, dure et triste

fortune !

Dans une mer sans fond, par une nuit sans lune

(Victor Hugo, Les Rayons et les ombres)

1845 - Dagobert, quelles nouvelles de notre père ? dit vivement Rose au soldat en le voyant rentrer un quart d'heure après être sorti en accompagnant Rodin.

- Eh bien... ce vieux sorcier sait, en effet, que le maréchal est parti et qu'il est parti joyeux ; il connaît, m’a-t-il dit, M. Robert (Eugène Sue, Le Juif errant)

1982 Vraiment la chute inattendue... on part joyeux pour une aimable partouze au bois et puis on se retrouve à se farcir une veuve folle près de la dépouille de son mari (Alphonse Boudard, Les Enfants de chœur)

1994 L'administrateur Saride partit donc tout joyeux pour Tenkodogo, pays de beaux chevaux et de belles femmes. Il était marié et sa femme l'accompagnait, mais cela ne l'empêchera pas, on le verra, de chercher aventure auprès des femmes africaines (Amadou Hampâté Bâ, Oui Mon Commandant!)

II. Mourir dans la joie, la gaieté, avec une profonde satisfaction

Intransitif

1848 - Il est mort en bénissant votre mémoire, répondit la jeune fille ; il est parti joyeux, avec le doux espoir d'aller vous embrasser là-haut.

- Ne parlait-il jamais de moi avec amertume?

- Il ne parlait de vous qu'avec amour, avec enthousiasme (Jules Sandeau, Mademoiselle de la Seiglière)

\section{CORPUS WEB :}

Tommy est en cour et regarde l'heure, la cloche sonne et les enfants partent joyeux, il doit aller donner sa présence à la Garderie.... [http:// www.jeuxvideo.com/forums/42-50-39253075-1-01-0-fic-les-jeunes-temps.htm] (21.8.2015)

Mais elle ne commet que des catastrophes... elle mélange tous les aliments dans une même boite, elle « explose » le sac de son père qui est 
en train de se raser, elle se maquille avec le maquillage de sa mère, elle salit sa robe préférée... à la fin ils partent joyeux en pique nique !!! [http:// www.amazon.fr/product-reviews/2211076114] (21.8.2015)

C'était le leitmotiv des cinquante trois personnes qui sont parties joyeux pour Agen [http:// www.salies-de-bearn.fr/fr-1_actualite_des_ associations-fiche-3533.html] (21.8.2015)

... et elles partirent joyeuses pour des courses lointaines !! [http://viatolosana.unblog. fr/2009/05/30/le-depart/] (21.8.2015)

REMARQUES : Partir joyeux (I) réfère au fait de s'en aller en éprouvant un sentiment de joie, avec un air enjoué, le sujet laissant derrière lui quelque agrément ou ayant hâte d'arriver à une destination qui lui apportera du bonheur, des réjouissances. $\mathrm{Au}$ sens figuré (II), il signifie mourir, décéder content, le cœur paisible. Joyeux permet une interprétation d'adverbe de manière, mais incline plutôt du côté de la prédication seconde orientée vers le sujet. L'accord est la règle, sauf dans le troisième exemple du CW. Joyeux est modifié par donc tout.

\section{Partir juste}

Partir pour atteindre exactement son but $\pi$ partir sec

\section{Partir sec}

Partir, démarrer tout de suite, directement Intransitif

1947 En passant j'achète le timbre fiscal de bicyclette pour 47 avec un peu de retard. Je pars sec. Vingt-cinq minutes de Villeneuve-Saint-Georges au pont de Charenton (René Fallet, Carnets de jeunesse)

\section{Corpus Web :}

les pilot sport sont de bon pneu, j'ai essayé ça sur la R1 de mon beauf. le problème c que t'as pas de remontée d'info et ils sont pas progressif. quand ils tiennent plus, y partent sec ! [http:// www.lerepairedesmotards.com/forum/read. php?3,804840,805005] (26.8.2015)

C'est une bûcheuse, une bagarreuse dont les coups partent sec et souvent juste [http://www. letemps.ch/Page/Uuid/f92de7e4-1729-11de-b97ac6ba03d06cfb/Tra\%C3\%AEtresse_\%C3\%A0_la patrie] (26.8.2015)
Autre gros souci qui nous a valu pas mal de casses, la PDF. C'est du tout ou rien. Dès qu'on enclanche le bouton, elle part sec, direct, et si on n'accélère pas assez elle fait caler le tracteur [http://forum.grostracteurspassion.com/ viewtopic.php?f=2\&t=1202\&start=0] (26.8.2015)

mais ca éliminine tous les dépots surtout les jets et injecteurs, moi je suis vraiment contre les démarrages courts, a chaque fois les cylindres partent secs, le refroidissement est nuls, ca usent les slides [http://www.motoneigeauquebec.com/ forum/archive/index.php/t-80124.html] (26.8.2015)

Par précautions, j'ai mis le couvre-rein imper à ma jument, elle part sèche, elle rentrera sèche et si elle a transpiré, un petit coup de séchante le temps de ranger les affaires et voilà [http://www. chevalannonce.com/forums-4092255-post-desbaladeurs-qui-baladent?p=219] (26.8.2015)

REMARQUES : Partir sec réfère au fait de partir brutalement, sans que rien ne freine le mouvement, notamment dans le domaine de la locomotion, surtout motorisée. Sec reste invariable dans son emploi adverbial, à l'exception de l'avant-dernier exemple du CW. Dans le dernier exemple du CW, sec est un prédicat second accordé qui renvoie à l'état de la jument qui part et rentre sèche. Notons les adjectifs-adverbes juste et direct.

\section{Parvenir fort}

Atteindre une intensité élevée

$\pi$ parvenir haut

\section{Parvenir haut}

I. Atteindre un niveau (moral, social, intellectuel) élevé, supérieur

Intransitif

1549 Exemple : les plus rudes et idiotz voyent bien que les jours sont plus cours en hyver qu'en esté, qu'il fait chaud en esté et froid en hyver, mais ilz ne parviennent pas si haut de juger comment ne pourquoy cela se fait (Jean Calvin, Advertissement contre l'astrologie judiciaire)

1650 LÉONOR. Il ne vous est donc rien? HÉLÈNE. Non, mais il tâche assez de m'estre quelque chose. LÉONOR. Sa qualité peut estre inégale est la cause 
Qu'il aura de la peine à parvenir si haut (Paul Scarron, L'Héritier ridicule ou La Dame intéressée)

1850 TOUSSAINT. Mourir sera ma joie ! LECLERC. Connaissez-vous celui vers qui je vous envoie?

TOUSSAINT. Quoique si loin de nous et si haut parvenu,

de lui-même, je crois, il n'est pas plus connu (Alphonse de Lamartine, Toussaint Louverture)

1863a Il est aujourd'hui le point de mire de beaucoup de nos contemporains, chose rare qu'une pareille honnêteté parvenant assez haut pour donner aux braves gens l'envie de l'imiter (Eugène Fromentin, Dominique)

1863b Brûlé, précipité, sans jeter un seul cri, Et n'avouant jamais qu'il saigne et qu'il succombe

À toujours ramasser son rocher qui retombe.

Si, plus haut parvenus, de glorieux esprits Vous dédaignent jamais, méprisez leur mépris ;

Car ce sommet de tout, dominant toute gloire,

Ils n'y sont pas, ainsi que l'œil pourrait le croire (Alfred de Vigny, Les Destinées)

1936 On admire qu'ils soient parvenus si haut, comme si un misérable commencement était un obstacle ; au contraire c'est un trop beau commencement qui serait un obstacle (Alain, Propos)

II. Atteindre une forte intensité sonore Intransitif

1921 Dégagé par la double action de l'oxygène et de la morphine, le souffle de ma grand'mère ne peinait plus, ne geignait plus, mais vif, léger, glissait, patineur, vers le fluide délicieux. Peut-être à l'haleine, insensible comme celle du vent dans la flûte d'un roseau, se mêlait-il, dans ce chant, quelques-uns de ces soupirs plus humains qui, libérés à l'approche de la mort, font croire à des impressions de souffrance ou de bonheur chez ceux qui déjà ne sentent plus, et venaient ajou- ter un accent plus mélodieux, mais sans changer son rythme, à cette longue phrase qui s'élevait, montait encore, puis retombait pour s'élancer de nouveau de la poitrine allégée, à la poursuite de l'oxygène. Puis, parvenu si haut, prolongé avec tant de force, ce chant, mêlé d'un murmure de supplication dans la volupté, semblait à certains moments s'arrêter tout à fait comme une source s'épuise (Marcel Proust, Du côté de Guermantes 2)

\section{CORPUS WEB :}

Nos sincères félicitations à Bahjat, nous restons convaincus que cette décoration, et les suivantes ne vont lui servir qu'à accentuer sa présence par ses écrits au Liban qui a tant besoin d'hommes qui prêchent la tolérance, l'esprit d'ouverture, des hommes qui restent convaincus que ce pays à un message à délivrer, et qui ont le don de le faire parvenir haut et fort [http://www. asdaa.eu/21-france/351-decoration-au-grade-dechevalier-des-arts-et-des-lettres-de-bahjat-rizk] (26.8.2015)

(Il faut viser haut pour parvenir haut $\wedge \wedge$ ) [http://www.graphistes-world.com/forum/index. php?/topic/8577-digital-painting/] (26.8.2015)

A entendre les échos qui nous parviennent haut et fort de l'autre côté du Rhin, Daimler trouverait là l'occasion de toucher plus de quinze fois sa mise initiale [http://www.7pm-auto.fr/ tesla-se-casse-les-dents-sur-un-os-leffet-t-bone/] (26.8.2015)

Un chant de résistance monte maintenant vers la voute de la grotte. Les paroles parviennent hautes et fortes malgré les scaphandres [http://www.tuconnaislanouvelle.fr/ uploads/Fichiers\%20pdf\%20word/MEP\%20 recueil\%20sf.pdf] (26.8.2015)

Remarques : Parvenir haut (I) se dit du fait d'atteindre un degré élevé d'intelligence, de noblesse, de talent, de spiritualité, de dévotion, de félicité, d'audace, haut référant aux qualités que peut atteindre la vertu ou alors à la spiritualité. Sous (II), le sujet est un son, un ton, une voix qui monte particulièrement, atteignant presque son apogée. Notons la collocation haut et fort dans le CW dans un contexte où parvenir renvoie au simple fait que des paroles proviennent d'un 
lieu. Notons aussi l'emploi de viser haut dénotant la condition préalable permettant de parvenir haut. Haut reste invariable dans la majorité des cas (v. le troisième exemple du CW). Toutefois, dans le quatrième exemple du CW, il s'accorde avec le sujet au pluriel féminin, permettant une interprétation de prédicat second orienté vers le sujet. Haut est modifié par assez, plus, si. VoIR AUSSI : aller / viser haut

\section{Passer aise}

Passer (le temps, sa vie) d'une manière plaisante, agréable, satisfaisante Transitif

+1415a Quel mal ou ennuy vous fait on, Se par amours on veult amer, Pour plus aise le temps passer En lyee, joyeuse Plaisance? (Charles d'Orléans, Poésies [ 1415-1440], I, Ballade XLIV, p. 66)

+1415b Il ne me chault ne de chien ne d'oyseau ; Quant tout est fait, il fault passer sa vie Le plus aise qu'on peut, en chiere lie (Charles d'Orléans, Poésies [ 1415-1440], II, Rondel CCCXLVII, p. 490)

REMARQUeS : Passer aise désignait le fait de passer son temps confortablement, agréablement, avec sérénité, le sujet s'occupant à des activités plaisantes, agréables. Aise est modifié par plus.

\section{Passer beau (bel)}

Se contenter, s'accommoder parfaitement (de quelque chose)

Pronominal

1285 Un petit ot le cuer dolant

Dou don que otroié avoit

Li rois, mais mout biau s'en passoit

(Adenet le Roi, Cleomadés, 2134)

CORPUS WeB :

Pour travailler sa condition physique et préserver sa forme et son énergie, voire optimiser un éventuel traitement. La forme et le bien-être passent bel et bien aussi par la voie de l'esprit [http://www.hypnose-coachingdoubs.fr/formations-hypnose-ericksoniennehypnotherapeute-pascal-frederic.html] (26.8.2015)
L'Europe cherche toujours à se donner une image d'humanité et donner des leçons aux autres, mais ces horreurs se passent bel et bien en Europe et cela doit cesser !!!! [https:// www.facebook.com/permalink.php?story_fbi $d=10152854093875924 \& i d=357922450923 \&$ com ment_id $=10152854569225924 \&$ offset $=0 \&$ total comments $=36 \&$ comment_tracking $=07 \mathrm{~B} \% 22 \mathrm{tn} \%$ 22\%3A\%22R\%22\%7D] (26.8.2015)

Effectivement des choses intéressantes se passent bel et bien sur le territoire du Nord Grande-Terre [http://koezyon-glob.fr/le-villagedes-associations-a-petit-canal/] (26.8.2015)

Certes les dates concordent, cela se passe bel et bien sous la révolution industrielle mais dans le cadre où la révolution industrielle ne joue aucun rôle à l'intérieur du livre, est-il nécessaire d'en parler ? [https://fr.wikipedia.org/wiki/ Discussion:Bel-Ami] (26.8.2015)

Remarques : Dans l'exemple de 1285, le sujet est une personne qui s'accommode très bien de ce qu'on lui a donné. Dans le premier exemple du CW, passer, intransitif, réfère au fait d'être une étape vers autre chose, tandis que dans les autres exemples du CW, il figure dans son emploi pronominal moderne signifiant 'se produire'. L'emploi moderne de beau se limite à la locution bel et bien dans le CW, exprimant le fait que quelque chose se produit effectivement, malgré tout. Notons l'emploi du quantifieur moult dans l'exemple de 1285.

\section{Passer droit}

I. Passer directement, en ligne droite Intransitif

1276 Le matinet, aprés l'aube esclairie, Tout droit en l'isle de Valcler a navie Passerons outre enmi la praierie, Qu'il y a place grant et large et onnie (Adenet le Roi, Les Enfances Ogier, 2383)

1377 Et encore appert autrement ceste chose, car se un honme resgarde vers le pole artique, le soleil et les estoilles lievent a sa destre. Et se cest honme aloit tout droit vers le pole artique et passast outre tout droit vers les antipodes, le soleil et les estoilles leveroient a sa senestre et coucheroient a sa destre des ce que il seroit notablement 
oultre le pole (Nicole Oresme, Le Livre du ciel et du monde, p. 572, 146)

1680 Je passe droit au cuisinier. Voilà une terrible chose que le vôtre s'en soit allé avec l’officier (Mme de Sévigné, Correspondance)

1695 On a dit au commencement de ses Memoires, que les princes les plus riches étoient ceux qui avoient moins de genres de Tributs, et qui passoient plus droit en leurs mains, sans poser nulle part au sortir de celles de leurs Peuples (Pierre de Boisguilbert, Le Détail de la France sous le règne présent)

1860 Le système nerveux du grand sympathique agit pour faire passer le sang dans les maisons. Quand il est coupé, le sang artériel passe tout droit et reste rouge (Claude Bernard, Cahier de notes)

1912 Les jeunes gens ne se doutent pas des tragédies du cœur qui se déroulent autour d'eux : ils n'ont pas le temps de s'arrêter pour voir : un instinct d'égoïsme les avertit de passer tout droit, sans tourner la tête (Romain Rolland, Jean-Christophe. La Nouvelle Journée)

1974 N'empêche, n'empêche, c'est moi que ze vais le finir. Auzourd'hui même. Passe que today, ze sens que c'est le grand Zour. Encore trois tours et la vrille passe tout droit. Z’y suis ! ça y est ! Ze remercie les OuiOuis ! Ze dévisse. Doucement, doucement. Comme une souris. Qu'est-ce que z'aime faire des trucs comme ça! (Jean Vautrin, Billy-Ze-Kick)

Transitif

1736 Mes domestiques revinrent donc avec la peur ; et ils furent si honteux que ces gens les eussent traités si doucement par pitié, qu'ils résolurent d'en étriller quelquesuns pour leur apprendre à passer droit leur chemin, sans se mêler de faire grace (Pierre de Marivaux, Le Télémaque travesti)

1920 Voilà qui est vexant, je vous assure, voilà qui me remplissait d'amertume. Passer droit son malheureux chemin et être pris pour un suiveur, pour un de ces imbéciles qui vont à la piste Ah! Non ! (Georges Duhamel, La Confession de minuit)

II. Traverser en se tenant dans une position droite, verticale Intransitif

1965 « À droite », dit-il avant que j’attaque la troisième colline. " À droite? » On arrive bientôt au bord d'un petit lac : auberge, voitures à six mules. Nous passons tout droits parmi les « Anglais ». Ferrucci choisit une table en plein centre de la salle. On regarde beaucoup mon pantalon trop court, Rosita qui lève son voile (Jacques Perry, Vie d'un païen)

\section{CORPus WeB :}

Les chevaux qui passent droit au premier baril sont souvent des chevaux que l'on a laissé partir à toute allure [http://poneyxpress.com/ forum.php?cat=14\&dv=44827\&recordstartcomm ent $=6]$ (26.8.2015)

Les bus passent tout droit, je n'ai jamais vu ça. Un système de transport à améliorer, surtout à la fin des classes [https://twitter.com/lilimonette/ status/509120086582771712] (26.8.2015)

Un petit ruisseau bloque le chemin. Le guide et Petitdragon passent tout droit, mais le gué est profond, les pieds sont sous l'eau et donc les chaussures sont déjà trempées de bon matin [http://horde-sauvage94.over-blog.com/2015/06/ trip-2015-vosges-j2-corcieux-grandvillers-5juin-2015.html] (26.8.2015)

Les gens qui pensent que ce que je dis est farfelu, passent tout droits ; ils ne se donnent pas le temps et l'effort de commenter ce qui est absurde, jugeant leur temps trop précieux pour ça ! [http://www.jasez.ca/forums/topic,34257-frisou net_le_visionnaire_dans_le_futur.html?start=15] (26.8.2015)

Remarques : Passer droit (I) se dit d'une personne ou d'une chose (rayon, sang) qui traverse (un lieu, un obstacle) directement, sans faire de détours ni s'interrompre. (II) est relatif à une personne qui traverse un lieu en en se tenant bien droit. Droit s'accorde avec le sujet lorsqu'il réfère à la verticalité du corps et fonctionne donc en tant que prédicat second orienté vers le sujet. 
Dans le dernier exemple du CW, le verbe est pris soit au sens de concret de 'passer sans s'arrêter', soit au sens d'ignorer volontairement quelque chose, de passer outre. Malgré l'accord dans cet exemple, la fonction de droit est adverbiale. Droit est souvent suivi d'une préposition (à, en, par, vers) à laquelle il peut s'associer en tant que modifieur. Il est modifié par outre, plus, tout.

\section{Passer impeccable (impec)}

Se passer parfaitement

Pronominal

1995 Ça se passe impec

(Interview d'un participant aux vendanges, TF1 / Stephan-Gabinel 2001)

2006 Et quand je suis arrivée au parloir, ça se passait impeccable (Le Figaro magazine)

CORPuS WeB :

Notamment grâce aux (très) bon films proposes par Quanta, les 13h de vol se sont passes impeccable [http://silou-loulou-tdm.blogspot. com/2012/05/?view=classic] (mai 2012)

J'ai un double boot avec windaube mais c'est pas mieux pilote dégueu. Je suis avec Mageia 7, les mises à niveau se sont passées impeccable [https://www.mageialinux-online.org/ forum/topic-27462+carte-graphique-gt-730.php] (13.4.2020)

REMARQUeS : Se passer impeccable (impec) signifie 'se dérouler sans incident'. Impec est une réduction familière de l'adjectif-adverbe impeccable ou de l'adverbe impeccablement. Il reste invariable. La combinaison "verbe + impec(cable) » constitue une série ouverte dont nous ne citons que quelques variantes.

\section{Passer net}

I. Faire, exécuter d'une manière précise et rapide, tout d'un coup

Transitif

1628 MELIANE. Toy donc, executeur du coup de mon repos, Tâche de le passer net et bien à propos, Monstre-moy comme il faut agencer ma posture

Pour donner à mon ame une prompte ouverture

(Jean de Schélandre, Tyr et Sidon)
II. Passer, traverser d'une manière rapide, brève, tout d'un coup

Transitif

1836 Quel parti prendre ? Comment peindre le bonheur fou ? Le lecteur a-t-il jamais été amoureux fou ? A-t-il jamais eu la fortune de passer une nuit avec cette maîtresse qu'il a le plus aimée en sa vie ? Ma foi je ne puis continuer, le sujet surpasse le disant. Je sens bien que je suis ridicule ou plutôt incroyable. Ma main ne peut plus écrire, je renvoie à demain. Peut-être il serait mieux de passer net ces six mois-là (Stendhal, Vie de Henri Brulard)

Intransitif

1846 J'avais prévenu qu'on m'avertisse du facteur ; comme je dormais encore, mon domestique a jugé convenable de n'en rien faire et le facteur qui n'avait pas de lettres à remettre est passé net devant la grille. Je comptais sur mon beau-frère qui va presque tous les jours à Rouen ; il est parti à huit heures du matin sans rien dire (Gustave Flaubert, Correspondance)

III. passer tout net pour (quelque chose, quelqu'un): être considéré tout de suite et sûrement comme (quelque chose, quelqu'un) Intransitif

1922 Or aucun document ne venant authentiquer ce genre de phénomènes collectifs que les seuls renseignés sont trop intéressés à laisser dans l'ombre, on s'indignerait fort dans le camp des belles âmes, et vous passeriez tout net pour un calomniateur ou pour un fol (Marcel Proust, La Prisonnière)

\section{CORPUS WEB :}

Wow ! si j'avais eu un bretzel dans la bouche, j'aurai pu y passer tout net, j'ai cru qu'il s'agissait d'un remix de Molière dont je n'aurai pas eu connaissance [http://archives-lepost. huffingtonpost.fr/article/2007/09/14/1018422_ le-regime-des-retraites-grace-a-la-chrononutrition.html] (26.8.2015)

J'intellectualise pas les ramones, c'est fait pour passer tout net. Mais pas réfléchir sur les intentions de l'artistes... on va pas très loin, c'est comme une dissert' qui n'est pas argumenté [http://www.indierockforum.com/topic/6028bonjour/page-6] (26.8.2015) 
C'est clair que les jeux passent net chez moi :D [http://www.jeuxvideo.com/forums/1-111778822-3-0-1-0-postez-donc-votre-config-vousautres.htm] (26.8.2015)

effectivement, une fois monté, il n'y a quasiment aucun jeu au levier, les vitesses passent nettes, c'est agréable à utiliser. Je pense que je vais faire la même chose sur la T16 [http:// www.forum.racing-west.com/viewtopic. php?f=18\&t=7645\&start=255] (26.8.2015)

Remarques : Passer net (I) réfère au fait de faire, de donner, de soumettre quelque chose à quelqu'un (ici : le coup de grâce) et ce, d'une manière rapide, brève et franche. (II) se dit d'une personne passant du temps ou traversant un lieu rapidement, sans y penser, l'action étant à peine perceptible par le sujet lui-même. (III) signifie 'être considéré, regardé comme quelqu'un/ quelque chose', et ce, sans longue réflexion, la ressemblance étant flagrante, certaine. Dans le dernier exemple du CW, passer net réfère à l'action du conducteur qui passe les vitesses sans aucun problème, sans à-coup, sans bruit, facilement. Net reste invariable dans la majorité des cas (v. le troisième exemple du CW), mais, dans le dernier exemple du CW, il s'accorde avec le sujet, moins pour devenir un prédicat second que plutôt pour souligner le bon fonctionnement de la boîte à vitesses. Net est modifié par tout.

\section{Passer niquel}

passer raide niquel : fonctionner parfaitement

$\lambda$ passer raide

\section{Passer raide}

Passer droit, avec une attitude rigide, froide, en ignorant les gens

Intransitif

1887 Il ne songeait plus à ses autres enfants ; il s'abandonnait là, dans une telle lassitude, que l'idée de s'en tirer ne lui venait point : ça ne marcherait pas mieux ailleurs, à quoi bon ? Fanny, lorsqu'elle le rencontrait, passait raide, ayant juré de ne jamais lui reparler la première. Jésus-Christ, meilleur enfant, après lui avoir gardé rancune de la sale façon dont il avait quitté le Château, s'était amusé un soir à le griser abominablement chez Lengaigne, puis à le ramener ainsi devant sa porte (Émile Zola, La Terre)

\section{CORPus Web :}

au cours du séjour, les groupes se forment... par affinités, par départements ou régions.....par possesseurs de chien, par type de CC etc....c'est toujours les mêmes que l'on retrouvent aux mêmes heures a la vaisselle ou aux vidanges...à croire que tous s'attendent pour tailler une bavette ou partager un apéro......certains ont l'air de faire la gueule...ils passent raide comme « artaban " ils ne font pas partie du même monde je suppose....en somme c'est le reflet de la société avec son pourcentage de gens biens, de c.... d'indifférents, et aussi de timides.... [http:// www.aidecampingcar.com/forum1/viewtopic. php?f=11\&t=31124\&start=15] (26.8.2015)

À le voir, presque pris de convulsions irrépressibles, parce son petit « navion » n'est pas avancé pour son « auguste » personne, sous l'œil goguenard de son prédécesseur, et à voir sa première ténardière de France, passer raide comme un piquet devant ledit, on perçoit le niveau d'exaspération des premiers « imposteurs » (i.e., ceux qui perçoivent l'impôt qui nous étrangle) devant la situation où ils se sont mis [http:// www.contrepoints.org/2013/12/12/149620-letatcreuse-la-france-inquiete] (26.8.2015)

Pour une fois que je croise un Swift, qui me vois aussi (car les autres passent raide devant...) et ba non... [http://swiftpassion.superforum.fr/ t17030p15-on-se-croise-ou-pas] (26.8.2015)

Moi j'ai changé 3 fois de boites alors je sais de quoi vous parlez. mais maintenant tout va bien et toutes mes vitesses passent raides niquel... [http://www.golf1cabriolet.com/forum/ viewtopic.php?f=7\&t=256] (26.8.2015)

REMARQues : Passer raide se dit d'une personne traversant un lieu ou passant devant quelqu'un, en se tenant droite et ferme. Le sujet démontre de la froideur par sa démarche, évitant d'adresser la parole aux personnes présentes sur son chemin. Raide reste généralement invariable (v. le troisième exemple du CW), mais, dans le dernier exemple, il s'accorde avec le sujet, tout en conservant sa valeur adverbiale : les vitesses passent directement, de la façon la plus efficace. Notons l'emploi adverbial de niquel, employé comme pléonasme synonymique. 


\section{Passer rapide}

Passer vite

Intransitif

1800 Les oiseaux étaient tous rentrés dans leurs hôtelleries de feuillage ; les chauves-souris s'étaient éveillées et passaient rapides, happant les mouches qui tourbillonnaient à l'entour du jet d'eau (Berthe Vadier, $L a$ Comtesse de Löwenstein)

1828 De cet ensemble de remarques si longues à écrire et qui, dans l'œil et l'esprit d'un peintre exercé, passent rapides comme l'éclair, il résulte pour celui qui les a faites, un sentiment intime de la vie

(Étienne-Jean Delécluze, Précis d'un traité de peinture)

1833 Comme une haleine du néant, le firmament s'évapore. Comme des sarcelles de voyage, les mondes passent rapides dans la brume, et ne reviennent pas (Edgar Quinet, Ahasvérus)

1872 Le grincement des patins, les cris des enfants, les grelots des traîneaux qui passent rapide comme des météores, formaient un murmure confus (Louis Favre, André le graveur)

1875 Le grincement des patins, les cris des enfants, les grelots des traîneaux qui passaient rapides comme des météores, formaient un murmure confus (Louis Favre, André le graveur)

1945 Mes Jumainvillois ont aperçu par leurs fenêtres les voitures vernies de pluie. Ils les ont vues passer rapides dans les rues (Jean-Louis Bory, Mon village à l'heure allemande)

1972 Rien que pour les servir, trois bouteilles y passent rapide (Henri Charrière, Banco)

REMARQUES : Il est intéressant de remarquer que dans l'édition de 1875 (v. ex. de 1872), l'auteur (ou l'imprimeur) a corrigé : qui passaient rapide en qui passaient rapides. L'emploi invariable a donc été probablement perçu comme fautif. Ce sentiment de correction linguistique pourrait expliquer la tendance à l'accord que l'on observe au $\mathrm{XIX}^{\mathrm{e}}$ siècle. La seconde moitié $\mathrm{du} \mathrm{XX}^{\mathrm{e}}$ siècle accep- tera plus facilement l'invariabilité. Il semble que le microcosme offert par l'entrée de passer rapide reflète les tendances générales.

\section{Paumoier bel}

Manier bien, de manière habile

Transitif

+1350 S'avoit la lance ou poing que moult bel paumoioit.

Quant Brun le vit venir, si se leva tout droit, Son hïaume laça bien fort et bien estroit (Brun de la Montaigne [2 moitié $\mathrm{XIV}^{\mathrm{e}}$ ], 3310)

REMARQues : Paumoier bel désignait en ancien français le fait de manier, de brandir une arme habilement, avec dextérité, en la tenant fermement dans la paume de sa main. Le neutre bel est modifié par l'adverbe d'intensité moult.

\section{Paver épais}

Recouvrir (le sol) de nombreux éléments

Transitif

1550 Vainqeur, tu paveras espais

De corps morts toute la campagne

(Pierre de Ronsard, Les Odes, p. 200)

REMARQUES : Employé au sens figuré, paver épais réfère au fait de couvrir le sol ou une certaine surface d'un élément (ici : de corps morts) et ce, en grand nombre.

\section{Payer beau}

Payer beaucoup, donner une bonne ou une belle récompense

Emploi absolu

1450 JHeroboAm. Siés toy, tu as bien besoingné S'en seras paié bien et beau. Or vien ça, petit bonhommeau. Es tu tout certain et tout fids Que ce soit icy vostre filz? (Arnoul Gréban, Le Mystère de la Passion, 14364)

\section{CORPUS WEB :}

Observatoire des subventions - Les contribuables paient bel et bien la sécurité de Julie Gayet ! [https://francaisdefrance.wordpress. com/2015/02/17/observatoire-des-subventionsles-contribuables-paient-bel-et-bien-la-securitede-julie-gayet/] (27.8.2015) 
Quelle que soit la décote retenue, anciens actionnaires et nouveaux actionnaires paient bel et bien le même prix [http://argent.boursier.com/ epargne/analyses/augmentations-de-capitalne-vous-laissez-pas-aveugler-par-la-decote-1902. $\mathrm{html}]$ (27.8.2015)

Et la conséquence est que ces personnes paient bel et bien des impôts, car elles paient des impôts indirects [http://www.schwaab. ch/archives/2011/06/28/en-realite-ceux-qui$\%$ C2\%ABne-paient-pas-d\%E2\%80\%99impots \%C2\%BB-en-paient/] (27.8.2015)

Mais il s'agit là d'une « fausse gratuité », car les utilisateurs paient bel et bien ces services en leur fournissant des données personnelles ou des contenus un jour ou l'autre marchandisés [http:// www.cafeinews.fr/La-culture-est-elle-solvabledans-la-gratuite_a112.html] (27.8.2015)

Remarques : Dans l'exemple de 1450, payer beau désigne le fait de payer quelqu'un généreusement, d'une façon qui valorise son travail. L'usage moderne documenté dans le CW ne connaît beau plus que dans la locution bel et bien au sens de 'effectivement, quoiqu'on en dise'.

\section{Payer cher}

I. Verser une forte somme d'argent (en échange de quelque chose)

Transitif

1325 Il font du gros relief ensaie,

Dont jà poures n'ensaiera ;

Bien se gart qui le paiera :

Chier sera cis escoz paiez

(Watriquet de Couvin, Dits, p. 361, 79)

1767 LE MARQUIS. Il donne des leçons ! vraiment il en a l'air.

Profitez-vous beaucoup ? et les payez-vous cher? (Voltaire, Charlot)

1882 Obsédé par cette vision, il voulut lui échapper par le mouvement. Il fit seller un de ces chevaux que M. Moulinet avait payés si chers et qui valaient si peu d'argent. Et, par le parc, il s'en alla, laissant flotter les rênes sur le cou de sa monture (Georges Ohnet, Le Maitre de forges)

1902 J'ai entendu le comte reprocher à mon bisaïeul de lui avoir nui d'une manière indi- recte, parce qu'en invoquant les privilèges maçonniques, au mois de janvier 1814, il contraignit l'état-major russe à payer trop cher les grains emmagasinés après Leipzig au château, par la tante Caroline (Paul Adam, L'Enfant d'Austerlitz)

1944 Tu le paies assez cher pour qu'il te soit reconnaissant non tant des services matériels que de l'hommage rendu à son mérite, car il n'est point de prix de sa sculpture ou du risque de sa vie qu'il puisse juger exagéré (Antoine de Saint-Exupéry, Citadelle)

1948 LE CHEUR. (quittant le baillon)

Mais l'eau de l'espoir attendrit le sol dur et nous promet le refuge de l'hiver, les châtaignes brûlées, le premier maïs aux grains encore verts, la noix au goût de savon, le lait devant le feu...

LES FEMMES. Nous sommes ignorantes. Mais nous disons que ces richesses ne doivent pas être payées trop cher

(Albert Camus, L'État de siège)

Pronominal

1832 C'est ce qui arrive partout où l'on complique la législation. Le travail des gens de loi, devenant plus considérable et plus difficile, occupe plus de monde et se paie plus cher. Qu'y gagne-t-on ? D’avoir ses droits mieux défendus ? (Jean-Baptiste Say, Traité d'économie politique)

1844 - Combien voulez-vous ? dit l'Anglais.

- Dame ! Monsieur, vous êtes assez raisonnable pour savoir qu'un service en vaut un autre. Et ces services-là, ça se paie ; ça se paie même cher au jour d'aujourd'hui. Vous n'avez pas trop de bonnes intentions sur la fille, car vous voilà deux, et elle n’aura guère moyen de se défendre, si elle ne veut pas de vous (George Sand, Jeanne)

1845 C'était un plaisir pour lui d'aller, les jours maigres, chercher le poisson au Croisic, où il se payait moins cher qu’à Guérande (Honoré de Balzac, Béatrix)

1945 Il sembla à Florentine que, si elle se penchait vers ce jeune homme, elle respirerait l'odeur même de la grande ville grisante, 
bien vêtue, bien nourrie, satisfaite et allant à des divertissements qui se paient cher (Gabrielle Roy, Bonheur d'occasion)

1966 « Oui, c'est difficile. D’abord il faut une autorisation. On ne donne pas ça à n'importe qui. Et puis après, ce n'est pas tout : il faut acheter un poste. Ça se paye cher, vous savez. Moi quand j'en aurai assez, je revendrai mon poste à un autre. Seulement, si on s'absente, il y a quelqu'un d'autre qui s'installe à la place » (Jean-Marie Gustave Le Clézio, Le Déluge)

Intransitif

1925 Et puis, ça peut leur apprendre à observer, à chercher. C'est bien simple ; qui n'apportera rien, n'aura rien. Quand ils comprendront qu'on les a, certains parents paieront cher pour le silence. Parbleu, nous n'avons pas l'intention de les faire chanter ; on est des honnêtes gens (André Gide, Les Faux-Monnayeurs)

1946 - Mais par Dieu, cria-t-il, je vous désintoxiquerai de vos mensonges, jeune homme, je ferai des trous à votre manteau d'idéal...

- Non, je ne vous supporterai pas, dis-je avec une soudaine colère. Je veux vous dire...

- Taisez-vous, cria-t-il encore. Puis, avec fatigue : j'ai beaucoup de tendresse pour Gina et pour vous.

- Oui, surtout pour Gina.

- Doux idiot, dit-il d'une voix âpre. Si vous devez grandir, il faudra payer, payer beaucoup plus cher que ne vaut Gina, même dix fois plus belle... qui vous a dit qu'il s'agissait de trahir qui que ce soit ? (Raymond Abellio, Heureux les pacifiques)

II. Subir les lourdes conséquences d'une action Transitif

1671 SILVESTRE. Les réprimandes ne sont rien ; et plût au Ciel que j'en fusse quitte à ce prix ! mais j’ai bien la mine, pour moi, de payer plus cher vos folies, et je vois se former de loin un nuage de coups de bâton qui crèvera sur mes épaules (Molière, Les Fourberies de Scapin)
1727 GÉRONTE. A huit jours donc la nôce.

ARISTE. A huit jours.

GÉRONTE. Sans remise,

$\mathrm{Ou}$ je vous ferai cher payer votre sottise.

Adieu

(Philippe Destouches, Le Philosophe marié)

1818 Mon sang bouillonnoit d'indignation contre moi-même à l'instant où, dans les veines d'un autre, il se seroit glacé de terreur.

- Ah ! Malheur au profane, m'écriai-je, qui apporteroit ici les vices et les fausses sciences de l'Europe, si j'y avois une mère, une sœur ou une maitresse ! Il payeroit cher l'injure qu'il a faite à l'air que je respire en l'empoisonnant de son souffle (Charles Nodier, Jean Sbogar)

1927 Depuis quelques mois je commets des imprudences, je me laisse mettre en avant, je tente sottise sur sottise... Ne me les faites pas payer trop cher! (Georges Bernanos, L'Imposture)

1961 - Il faut que je voie le seigneur Raymond Jourdain

- À cette heure ? Il fait ses dévotions, il a dit de ne pas le déranger. Si tu es un espion, tu le paieras cher ; on a déjà eu des ennuis, ce matin (Zoé Oldenbourg, Les Cités charnelles)

1981 Bref, des types qui savaient se battre et profiter du terrain pour échapper à la meute. Ceux-là tinrent longtemps le maquis et ils firent payer cher aux paysans leur complicité avec l'armée. Du travail cousu main, tu peux me croire (Michel Del Castillo, La Nuit du décret)

Pronominal

1927 Le christianisme, en France, au XVII siècle aussi bien qu'au XIII ${ }^{\mathrm{e}}$, a toujours répondu à des fins plus esthétiques que morales. Et c'est le contraire qui se passe là où sévit le puritain. Mais la supériorité des Français sur ce terrain-là se paie cher : l'académisme correspond au puritanisme et tente de ramener à la règle commune, par 
la force s'il le faut, ceux qui rompent l'alignement (Élie Faure, L'Esprit des formes)

1943 Il faut désirer que cela soit fait en nous. Le désirer vraiment. Simplement le désirer, non pas tenter de l'accomplir. Car toute tentative en ce sens est vaine et se paie cher (Simone Weil, La Pesanteur et la grâce)

III. Verser une forte somme d'argent (à quelqu'un) pour un travail exécuté Transitif

1696 C'est pour les mandarins, non-seulement une marque d'honneur, mais encore un divertissement ; mais pour nous c'estoit un concert assez desagreable, et je puis dire des plus ennuyans, qui nous faisoit payer bien cher l'honneur qu'on pretendoit nous faire (Louis Le Comte, Nouveaux Mémoires sur l'état présent de la Chine)

1742 Pour te prouver combien je suis noble, je te dispense des remerciemens, et même de cette prodigieuse inclination que tu as pour moi : aussi bien dans le marché que nous avons fait ensemble, ne m'a-t-elle servi à rien. Je te paie même aussi cher que si j'étois en premier, et tu sçais bien que cela n'est pas dans les règles (Alexandre Dumas fils, Le Sopha)

1887 - Parbleu ! reprit M. de Chédeville, lui ne demande qu'une chose, c'est que le pain soit à bas prix, pour payer ses ouvriers moins cher (Émile Zola, La Terre)

IV. Obtenir au prix de lourds sacrifices, de graves inconvénients

Transitif

1735 Que je serois malheureux si vous étiez prévenuë de ce sentiment! Je vois bien que je payerai cher l'indifférence dans laquelle j’ai vécu jusqu'ici, et que j'aurai lieu de regretter l'imprudence que j'ai eu de venir exposer ma liberté (Charles de Mouhy, $L a$ Paysanne parvenue)

1740 CÉLIANTE. Mais il paie assez cher ce titre qui l'honore.

M. DE FORLIS. Ce que je vous apprends, il croit que je l'ignore ;

Sa disgrâce me fait oublier mon dépit,
Et plus que mon affaire occupe mon esprit (Louis de Boissy, Les Dehors trompeurs ou L'Homme du jour)

1761 Si je me console de vivre, c'est par l'espoir de n’avoir pas échappé tout entière à la mort. Ils ne sont plus, ces agrémens de mon visage que mon cœur a payés si cher : la maladie dont je sors m'en a délivrée (JeanJacques Rousseau, La Nouvelle Héloïse)

1834 Quand Dieu n'habite pas à toute heure le dedans pour l'affermir, la nature fait payer cher aux jeunes gens ces sagesses précoces de langage (Charles Sainte-Beuve, Volupté)

1934 De Corson avait eu beau lui dire que Léa était une Juive " pas comme les autres », il pensait qu'elle était crochue, et que «l'acte » serait une grande source de complications et de chaînes, sans compter la damnation éternelle au bout de l'affaire, et c'est payer bien cher quelque chose dont on n'a pas envie (Henry de Montherlant, Les Célibataires)

1948 JESSICA. Ce sont les enfants sages, madame, qui font les révolutionnaires les plus terribles. Ils ne disent rien, ils ne se cachent pas sous la table, ils ne mangent qu'un bonbon à la fois, mais plus tard ils le font payer cher à la société. Méfiez-vous des enfants sages! (Jean-Paul Sartre, Les Mains sales)

1967 Dans le vestiaire, la joie des femmes était bruyante. Elle ne me donna aucune amertume. Je ne les enviais même pas. Elles payaient assez cher les plaisirs qui les attendaient (Claire Etcherelli, Élise ou La Vraie Vie)

Pronominal

1831 - Eh ! Mon cher, au moins Napoléon nous a-t-il laissé de la gloire ! criait un officier de marine qui n'était jamais sorti de Brest. - Ah ! La gloire, triste denrée. Elle se paye cher et ne se garde pas. Ne serait-elle point l'égoïsme des grands hommes, comme le bonheur est celui des sots ? (Honoré de Balzac, La Peau de chagrin) 
1937 Ah ! Si elle avait compris, elle n'eût pas eu son sourire amusé ! Les petites victoires se paient cher (Henry de Montherlant, Le Démon du bien)

1944 CALIGULA. Tout cela est très clair et très légitime. Pour la plupart des hommes, ce serait même évident. Pas pour toi, cependant. Tu es intelligent et l'intelligence se paye cher ou se nie. Moi, je paye. Mais toi, pourquoi ne pas la nier et ne pas vouloir payer?

CHEREA. Parce que j'ai envie de vivre et d'être heureux (Albert Camus, Caligula)

1963 Tout ça pour fumer quatre paquets de gros cul par semaine, ne pas s'abaisser à descendre aux clops dans la cour. La véritable dignité se paye très cher. J'avais du mal à me concentrer sur mon bouquin

(Alphonse Boudard, La Cerise)

Emploi absolu

1942 Crois-tu, alors, qu'on a le temps de faire le raffiné, de savoir s'il faut dire « oui » ou « non », de se demander s'il ne faudra pas payer trop cher un jour et si on pourra encore être un homme après? (Jean Anouilh, Antigone)

\section{CORpus WeB :}

La planète risque de payer cher [http://www. vosgesmatin.fr/environnement/2015/08/09/laplanete-risque-de-payer-cher] (27.8.2015)

Payer cher pour dormir à deux sous les combles dans un lit trop petit [http://www. tripadvisor.fr/ShowUserReviews-g188671d276896-r71815325-Hotel_De_Tassche-Bruges_ West_Flanders_Province.html] (27.8.2015)

Cette négligence, la municipalité pourrait la payer cher [http://www.lemonde.fr/televisionsradio/article/2015/07/13/1-equateur-sous-lamenace-des-volcans_4681236_1655027.html] (27.8.2015)

La vie c'est cOmme une pute si t'en veut une bonne, faut la payer chère... [https://fr-fr. facebook.com/pages/La-vie-cest-cOmme-unepute-si-ten-veut-une-bonne-faut-la-payerch\%C3\%A8re/117639048276633] (27.8.2015)

REMARQues : Payer cher au sens littéral (I) réfère au fait de verser une forte somme d'argent en échange de quelque chose (objet, travail, service). (II) prend le sens de 'subir les conséquences de ses actes', le sujet devant également payer un prix élevé, faire un sacrifice mais non pas pour un avantage obtenu mais pour une faute commise. (III) désigne le fait de payer cher le travail de quelqu'un. (IV) signifie 'obtenir un avantage apparent ou momentané à un prix qui se révèlera très élevé', l'objet étant un inanimé et généralement non matériel (honneur, plaisir, sentiments, etc.). Ici, le prix ne renvoie pas à de l'argent mais à de fâcheuses conséquences, le sujet devant faire un sacrifice pour la chose obtenue au préalable. Cher s'accorde rarement avec le sujet (ex. de 1882 et le dernier exemple du CW), si ce n'est par emphase. Il est modifié par assez, aussi, beaucoup plus, bien, même, moins, plus, si, très, trop.

\section{Payer comptant}

I. Payer immédiatement et en espèces Intransitif

-1469 « C'est bien raison, dist le Roy. Et vous pry, mon filz, que vous sachiez aux compaignons combien je payeray pour la rançon de messire Morcellet ; car je les feray payer comptant » (Jean de Bueil, Le Jouvencel [1461]-1468, II, p. 211)

1743 Quant au paiement (car pour la façon de jouer les cartes, elle étoit la même que celle qui est en usage), comme nous voulûmes payer comptant, il ne fut question ni de jettons, ni de fiches, ni de contrats ; les premiers furent estimés un baiser sur la bouche ; les seconds et les derniers à proportion (Claude Godard d'Aucour, Mémoires turcs)

1845 Il [= M. de Merret] payait tout comptant pour n'avoir de difficulté avec personne (Honoré de Balzac, Autre étude de femme)

1907 LAMBERCIER. Dieu !... Jamais je ne signe un effet de commerce. Je paye tout comptant... et de mes propres mains. Et pas plus tard que demain, j'irai à Paris régler cet homme

(Abel Hermant, Monsieur de Courpière) 
1930 La rue s’y déverse, docile comme ailleurs, se servant elle-même correctement ; elle y mange, y loue des autos, des danseurs, des convives, y consulte des médecins, s’y marie ; y assiste à des concerts, à des expositions. On paie rarement comptant, les occasions sont nombreuses, car la mode rejette immédiatement tout ce qui a cessé de plaire (Paul Morand, New-York)

1977 LE PATRON. Dix-huit francs... QUART-VITTEL. (sortant des pièces de sa poche).

Dix-huit francs... voilà... je paye

comptant...

Il avale son dernier verre et s'éloigne en titubant...

LE PATRON. Et la chambre?

(Jacques Prévert, Le Quai des brumes)

Transitif

+1490 LA MÈRE. S’il ne couste que dix escus, Je les payeray bien tout contant

(Farce du nouveau marié / Ancien Théâtre françois [1490-1500], DMF)

1584 Le lundi28 novembre, arriverent à Paris les deputés des cantons de Suisse, venans jurer la Ligue, par eux accordée avec le Roy, nonobstant les brigues et menées du roy d'Hespagne, lequel, depuis quatre ou cinq ans, estoit apres à les gaingner, faisant toutes prattiques à lui possibles pour les liguer avec soi, jusques à offrir de leur paier comptant les huict cens mil livres que le Roy leur devoit des arrerages de leurs pensions, et les leur doubler à l'avenir (Pierre de L'Estoile, Registre-journal du regne de Henri III)

1633 GAULTIER. Je voy bien, monsieur le marchand, que vous me voulez vendre vostre arriere-boutique : mais vous serez payé comptant

(Ils mettent la main aux espées) (Gougenot, La Comédie des comédiens)

1649 Il se fust arresté à Paris pour toute sa vie, si la mort du roy Henry III, et le siège de Paris qui en suivit, ne l'en eut empesché. L'an 1590, il fut pris prisonnier par les ligueurs, et ne put estre racheté à moins de 400 livres, qu'il fallut payer comptant, somme qui n'est pas grande aujourd'huy, mais qui l'estoit alors, et principalement en temps de guerre et aux champs (Guy Patin, Lettres)

1668 Tel fut l'avis du Phrygien, Alléguant qu'il n'était moyen

Plus sûr pour obliger ces Filles À se défaire de leur bien, Qu'elles se marieraient dans les bonnes familles,

Quand on leur verrait de l'argent, Paieraient leur Mère tout comptant (Jean de La Fontaine, Testament expliqué par Ésope / Fables)

1719 On exigea d'eux qu'ils remettroient aux Romains la place et le port de Lilibée dans la Sicile ; qu'ils abandonneroient entierement cette isle ; qu'ils rendroient les prisonniers sans rançon ; qu'ils livreroient les deserteurs et les transfuges ; qu'ils payeroient comptant mille talens pour les frais de la guerre, et deux mille deux cens en dix ans par forme de tribut (René de Vertot, Histoire des révolutions arrivées dans le gouvernement de la République romaine)

1732 Je n'étais pas moins exact à parcourir les églises quand on y célébrait des fêtes, et je faisais alors dans ces endroits-là de copieuses recettes de menues monnaies. À l'égard des morceaux de pain qui m'étaient ordinairement donnés aux portes des maisons, j'en vendais le superflu aux pauvres honteux, qui, par la secrète assistance des fidèles, étaient en état de les payer comptant (Alain-René Lesage, Histoire de Guzman d'Alfarache)

1824 Tous les seigneurs les plus éloignés furent convoqués. Les alliés de la France furent invités à se joindre aussi à l'armée. Des vaisseaux furent rassemblés sur toute la côte de la mer, depuis Cadix jusqu'en Prusse. Mais les Hollandais et les Zélandais ne livraient les leurs qu'à un bon prix et payés comptant. Les gens de Ziric- 
sée, en Zélande, refusèrent même d'aider en rien une expédition contre les Anglais (Prosper de Barante, Histoire des ducs de Bourgogne de la maison de Valois)

1849 Il n'en perdit pas une piastre sur le prix de son embarcation ; mais il n'en exagéra point la valeur, et le marché fut conclu pour trente-deux sequins d'or que mon ami lui paya comptant. Moyennant cette somme, le bateau et un gréement tout neuf, voiles, jarres, cordages, ancre de fer, tout fut à nous (Alphonse de Lamartine, Les Confidences)

1918 C'était un petit chien jaune, sans race et de beaucoup d'esprit. Il avait de qui tenir : Finette, sa mère, faisait son marché ellemême, payait comptant le tripier et portait sa viande à Madame Mathias pour qu'elle la fît cuire (Anatole France, Le Petit Pierre)

1925 déclarez-vous prêt à traiter, mettons pour, pour un million de dollars payés comptant à titre d'indemnité et je me fais fort de vous les faire obtenir (Blaise Cendrars, L'Or)

1987 Payé comptant un slip et des chaussettes, des rasifs jetables et une fiolette d'aftershave (Jean-Louis Degaudenzi, Zone)

Pronominal

1707 Les dixmeurs se payent toûjours comptant de ce qui se trouve sur le champ, dont on ne peut rien lever qu'ils n'ayent pris leur droit (Sébastien Le Prestre de Vauban, Projet d'une dixme royale)

II. Payer immédiatement pour ses actes

Emploi absolu

1961 L'angoisse mortelle avait fait place à une amertume banale et résignée : pour une évasion manquée on paie comptant. Seul un imbécile s'obstinerait encore à nier, quand il n'a plus le choix qu'entre la fosse basse et les aveux (Zoé Oldenbourg, Les Cités charnelles)

\section{CORPUS WEB :}

Avec un TMI de 5\% et si on n'a pas envie d'avoir un crédit sur le dos, est-il absurde de payer comptant? [http://www.boursorama.com/ forum-scpi-payer-comptant-scpi--absurde-oupas-389329317-1] (27.8.2015)

Il n'est pas possible de payer comptant le total de la facture pour économiser des frais d'intérêts [http://meteopolitique.com/fiches/Obscu rantisme/ignorance/07/emprunt_interetst_ville. $\mathrm{htm}]$ (27.8.2015)

Je vois depuis plusieurs semaines que certains d'entre vous parlez de payer comptant une voiture... [http://www.auto123.com/fr/com munity/forum/showthread.php?309-Payer-com ptant] (27.8.2015)

Partons du principe qu'un consommateur qui désire financer une acquisition n'a pas forcément les moyens de la payer comptant [http:// archives-lepost.huffingtonpost.fr/article/2011/ 05/12/2492467_chez-darty-et-consumer-finencesofinco-la-protection-du-consommateur-on-sen-fout.html] (27.8.2015)

Remarques : Payer comptant (I) se dit d'une somme payée en espèces et sur le champ, l'objet étant soit la chose acquise, soit la somme elle-même (écus, livres). Dans un sens métaphorique (II), il désigne le fait de payer pour une faute commise, de subir les conséquences de ses actes et ce, immédiatement. Comptant reste invariable et est modifié par bien, rarement, toujours, tout.

\section{Payer double}

Payer deux fois autant, deux fois plus, deux fois la somme due

Intransitif

1743 Je voulus aller consulter le cas : mais elle s'offrit de payer d'avance, et d'en passer après par où l'on voudroit, au hasard de payer double deux fois (Claude Godard d'Aucour, Mémoires turcs)

1839 Les riches règnent par la fraude ou l'immoralité. Les pauvres paient double pour leurs propres fautes et pour celles qui leur sont étalées en exemples sur les hauteurs de la société, comme d'impurs sacrifices sur de somptueux autels (George Sand, Lélia)

1904 « Si les deux se font concurrence, après tout, disent-ils, où sera le mal ? " Le mal c'est que les contribuables du reste de la France payeront double ; mais les conseil- 
lers généraux ne s'en inquiètent pas toujours! (Henri Chardon, Les Travaux publics. Essai sur le fonctionnement de nos administrations)

1922 Désormais, je paierai double pour voir les Cranach et les Dürer, triple pour me chauffer à Munich, et quadruple pour acheter les œuvres de Schiller... J'ai perdu l'Allemagne... le Rhin, le Danube, l'Elbe et l'Oder, tous ces fleuves que j'ai appris si récemment dans l'ordre comme un enfant, je les ai perdus (Jean Giraudoux, Siegfried et le Limousin)

1985 Qu'est-ce qu'ils consomment comme roses, dans le coin ! T'aurais dû faire l'affaire avec cette crevure de Manivelle, l'autre jour ! Tu le faisais payer double et tu me donnais la différence ! (Victoria Thérame, Bastienne)

Transitif

1813 En attendant, je refais ici ma bourse ou ma santé. Vous allez entendre cela : les peintres ont découvert que je n'étais jamais plus beau que lorsque j'étais bien souffrant ; en conséquence, je fais payer double les séances que je donne dans mon lit ; et, comme on ne me laisse boire ici que de la tisane, j'économise par force, et je sors toujours de l'hôtel-Dieu plus riche que je n’y suis entré (Étienne de Jouy, L'Hermite de la Chaussée-d'Antin)

1843 Voyons, père Rouget, offrez à votre neveu cent francs par tableau, vous en avez là vingt-sept... il y en a, je crois, onze dans le grenier qui sont énormes et qui doivent être payés double... mettez pour le tout quatre mille francs... Oui, votre oncle peut bien vous payer les copies quatre mille francs, puisqu'il garde les cadres ! (Honoré de Balzac, La Rabouilleuse)

1844 Sans compter la blessure de Mousqueton, pour laquelle j’ai été obligé de faire venir le chirurgien deux fois par jour, lequel m'a fait payer ses visites double, sous prétexte que cet imbécile de Mousqueton avait été se faire donner une balle dans un endroit qu'on ne montre ordinairement qu'aux apothicaires (Alexandre Dumas père, Les Trois Mousquetaires)

1849 J'arrivai à Pouzzoles en moins d'une heure. Je courus au port ; je payai double deux rameurs pour les déterminer à me jeter à Procida malgré la mer forte et la nuit tombante. Ils mirent leur barque à flot. Je saisis une paire de rames avec eux (Alphonse de Lamartine, Les Confidences)

Pronominal

1896 - Quand on ne veut pas tacher sa robe, on la laisse dans l'antichambre. Quand on reçoit des coups de poing, on se fait payer double. C'est élémentaire (Pierre Louÿs, Aphrodite)

\section{CORPuS WEB :}

En tout cas, la proposition du secrétaire d'Etat au Budget Christian Eckert de doubler le salaire le dimanche lui semble difficilement généralisable. Faites deux secondes l'épreuve du réel, doublez le salaire, voyez si un petit magasin peut payer double [http://bfmbusiness.bfmtv. com/france/macron-sans-compensation-il-n-yaura-pas-d-ouverture-le-dimanche-851930.html] (27.8.2015)

Houchin : aux Fontinettes, les habitants ont l'impression de payer double pour l'aménagement [http://www.lavoixdunord.fr/region/ houchin-aux-fontinettes-les-habitants-ont-1impression-ia30b53953n2747893] (27.8.2015)

Soupçonnée, la femme déclare aux policiers, appelés pour les faits, que le vendeur lui a demandé de payer double les affaires volées [http:// www.lejournaldupaysyonnais.fr/2015/07/02/ la-roche-faisait-il-payer-double-les-voleurs-devetements\%C2\%A0/] (27.8.2015)

Au bar, si un Noir d'AOF est un " bougnole » en revanche un Noir américain est un «bon client » qui peut payer doubles les consommations [http://kofo-kofo.blogspot.co.at/2007/10/ le-coq-hardi-dakar.html] (27.8.2015)

Remarques : Payer double désigne le fait de verser le double de la somme due ou supposée, le service ou le bien ayant une valeur bien plus haute que d'ordinaire. Double reste invariable dans la majorité des cas malgré l'objet au féminin ou pluriel, mais, dans le quatrième exemple 
du CW, il s'accorde avec l'objet au pluriel tout en gardant son interprétation adverbiale.

\section{Payer gras}

Payer une somme considérable à quelqu'un (généralement pour obtenir une faveur) ; graisser la patte, suborner

Emploi absolu

1849 SNAIL. Oui. - Des visiteurs entièrement comme il faut, et qui paient gras pour nous voir (Paul Féval, Les Mystères de Londres)

1885 Pour jaser sur toute chose

Nous avons nos avocats.

Toujours sûre est votre cause

Si vous savez payer gras

(Louis Riel, Selected Poetry)

Transitif

1968 Le tout c'est de pouvoir faire venir un ou deux grands avocats de Bucarest, de les payer gras, et de les laisser parler aux jurés ! ... Que diable ! Les jurés aussi sont des hommes, ils ont leurs petites faveurs à demander (Panaït Istrati, La Jeunesse d'Adrien Zograffi)

\section{CORPuS WEB :}

Le président a alors eu peur et s'est barré en Russie, dans sa Bentley payée grasse aux détournements de fonds de l'Etat [https://www. jeuxvideo.com/forums/1-50-156986954-1-0-1-0ukraine-ca-pue-grave-la.htm] (28.02.2014)

RemARQues : Payer gras équivaut à payer gros, mais gras connote la corruption, donc le fait de graisser la patte à quelqu'un. Ceci se traduit dans tous les contextes. La variante fléchie du CW apparaît dans une structure syntaxique typique où l'objet direct précède le participe accordé. La variante longue, payer grassement, est également usuelle. Au lieu de vouloir expliquer la variante courte comme réduction de la variante longue, il faudra plutôt considérer la variante longue comme développement emphatique de payer gras.

\section{Payer net}

Payer après déduction de tout élément étranger Transitif

1665 Le pauvre diable enfin craint pour sa vie. Après vingt coups, d'un ton piteux il crie : « Pour Dieu cessez : hélas ! je n'en puis plus.»

Son seigneur dit : «Payez donc cent écus, Net et comptant : je sais qu'à la desserre Vous êtes dur ; j'en suis fâché pour vous » (Jean de La Fontaine, Conte d'un paysan qui avait offensé son seigneur)

\section{CoRpus WeB :}

Les autres livraisons se paient net à 30 jours [http://www.bordeauxwine.ch/cartform.asp] (27.8.2015)

lorsque vous parlez de garderie subventionné à 7 dollars, est ce que cela veut dire que les parents paient net $7 \mathrm{x}$ le nombre de jours par mois? [http://m.immigrer.com/faq/sujet/scolariteenfant-de-4-ans-1000-questions.html] (27.8.2015)

mon assistante 24 ans d'ancienneté elle est payée net $2300 €$ par mois [http://www.eugenol. com/sujets/399986-salaire-assistante-dentairequalifiee-specialisee?page=2] (27.8.2015)

L'indemnité transactionnelle doit-elle être payée nette de tout prélèvement ? [http://www. lemoniteur.fr/articles/l-indemnite-transaction nelle-peut-etre-nette-de-tout-prelevement-2394 97] (27.8.2015)

REMARQUES : Payer net réfère au fait de verser une somme d'une manière exacte, parfaitement calculée, souvent avec l'acception spécifique de 'sans impôts, net d'impôts'. Dans l'exemple de 1665, il apparait dans la collocation payer net et comptant, où comptant désigne le paiement en liquide. Notons la présence d'un objet direct se référant à une somme d'argent précise (cent écus). Net reste invariable dans la majorité des cas, mais, dans le quatrième exemple du CW, il s'accorde avec l'objet au féminin. Notons l'emploi pronominal à sens passif dans le premier exemple du CW.

\section{Payer sec}

I. payer (tout) sec : payer comptant Intransitif

+1365 Bien le glosai,mieuls l'entendi, Elle paia seck et rendi 
A celi qui pour l'amour d'elle

Fu fès et q'une damoiselle

Eut chanté

(Jean Froissart, Poésies [3 tiers XIVe])

Transitif

+1370a Ces nouvelles oyes et entendues, li roys et li seigneur envoyèrent tantost celle part chacuns son messaige sus petits chevaux et ses sommiers pour apporter pourvéanches, et fist-on savoir de par le roy en le ville dou Noef-Castiel, que qui voroit gaignier, si amenaist pain, vin, avaine et autres denrées, on li paieroit tout secq et le feroit-on conduire au sauf-conduit allant et venant en l'ost (Jean Froissart, Chroniques (A))

+1370b Mais on leur délivra assés d'argent par raison pour revenir en leurs pays, et puisedi dedens l'année furent-il tout secq payet, de tout ce que li cheval montoient (Jean Froissart, Chroniques (A))

1450 JUDAS. Tres volontiers.

Je n'en requier pas ung avec, Mais ilz seront paiéz tout sec Avant que j'en face ja course.

ANNE. Vecy de quoy, metz en ta bource : Ilz sont eulz trente bien comptéz (Arnoul Gréban, Le Mystère de la Passion, 17519)

II. Subir les conséquences directes d'une action Transitif

1385 Pour ce devons nous obeir

A eulx et leur parole oir

Es commendemens de la loy;

Et s'ilz sont de petit aloy,

Ne doubtez, que Dieu congnoit tout

Et les paiera tout sec au bout (Eustache

Deschamps, Le Miroir de mariage, 4878)

CORPuS Web :

Le LotoFoot de ce soir devrait payer sec j'pense [https://twitter.com/prodige_betting/ status/631166292976910336] (28.8.2015)

ou cela dépend de leur bien vouloir, car si ils sont dans l'erreur je vois pas pourquoi j'en resterais la, coupure ou pas n'est plus la question, car la coupure est la, si ils avait pas le droit de couper, et vue que s'est fait, a part tout faire pour que l'électricité soit rétablie le plus vite possible, je n'ai rien d'autre a faire effectivement, mais EDF me fait payer sec mon erreur d'impayés, qu'en est il de leur erreur ? [http://www.60millionsmag.com/forum/gaz-et-electricite/edf-coupuremalgre-dossier-au-ccas-t6976.html] (28.8.2015)

Le fait de payer sec la première relance indique en général une main pour aller voir le flop, notamment une petite paire ou une main à tirages comme des connecteurs assortis, mais pour payer un deuxième relanceur [http://www.club314.fr/ index.php?option $=$ com_content\&view $=$ article\& catid=18\&id=65\&Itemid=30] $(28.8 .2015)$

Toutes les banques proposent des pack similaire. Libre à toi de choisir ta carte et de la payer sèche [http://www.forum-auto.com/les-clubs/ le-bistrot/sujet383923-245.htm] (28.8.2015)

Remarques : Payer sec (I) se dit d'une somme payée en espèces et sur le champ, et ce, pour un objet, tel une denrée alimentaire, ou un service, un travail accompli. Dans un sens métaphorique (II), il désigne le fait de payer pour une faute commise, de subir les conséquences de ses actes et ce, immédiatement. Dans les deux premiers exemples du CW, payer sec signifie simplement payer beaucoup, avec, dans le second cas, la connotation de 'sans pitié. Sec reste invariable dans la majorité des cas, mais, dans le quatrième exemple du CW, il est accordé avec l'objet au féminin tout en gardant son interprétation adverbiale. Il est modifié par tout.

\section{Payer triple}

Payer (quelque chose, quelqu'un) trois fois autant, trois fois plus, trois fois la somme due Transitif

1839 Et l'on savait que dans sa peur de déplaire il était homme à tenir parole, de façon que le marquis Crescenzi était obligé de payer triple ses musiciens fort choqués de cette nuit à passer en prison (Stendhal, La Chartreuse de Parme)

1851 Je ne veux pas qu'Altaroche d'un côté, et Bocage de l'autre, me fassent payer l'amende double et triple de ce qu'elle vaut, je veux voir et signer le traité qui sera fait entre Altaroche et moi, et y voir clair, car figurez-vous que je n'ai rien pu savoir des conventions entre Hostein et Bocage, 
Bocage m'a dit avoir une simple lettre et l'avoir perdue (George Sand, Correspondance)

1947 Il souriait, pensant qu'il faudrait, au contraire de ce camarade d'autrefois, payer double, triple, une femme qui a pris plaisir avec vous, pour salir, effacer, ce redoutable plaisir, par quoi la femme pourrait imaginer qu'elle a pris des droits sur vous (Louis Aragon, Les Voyageurs de l'impériale)

\section{CORPUS WEB :}

Même si son contrat lui permet de choisir ses horaires, la jeune femme a opté pour les samedi et dimanche. " C'est payé triple, ça m’arrange, sourit-elle. C'est de l'argent que je peux mettre de côté en attendant de trouver un emploi » [http:// www.lejdd.fr/Economie/Travail-du-dimancheparoles-de-salaries-635427] (28.8.2015)

Mais pas seulement : Sarkozy, Chatel, Bertrand, Maillé, ont appâté le gogo en prétendant que le dimanche serait payé double et accompagné d'un repos compensateur c'est à-dire payé triple. Seuls les naïfs pouvaient croire cela [http:// www.travail-dimanche.com/analyse-de-lappl/les-salaries-seront-ils-payes-doubles.html] (28.8.2015)

Tous n'ont pas la même majoration salariale : elle est par exemple de $150 \%$ chez Castorama, tandis que chez Bricorama, les salariés sont payés triple [http://lentreprise.lexpress.fr/ qui-travaille-le-dimanche-et-dans-quellesconditions_1529376.html] (28.8.2015)

Hier soir, le contrôleur de la SNCF a indiqué être d'accord pour travailler jusqu'à 60 ans si on lui donnait les mêmes conditions que dans le secteur privé, notamment les dimanches payés doubles et les jours fériés payés triples [http:// forums.france2.fr/france2/avousdejuger/diman che-feries-prive-sujet_9777_1.htm] (28.8.2015)

REMARQUES : Payer triple désigne le fait de verser trois fois la somme due ou supposée, le service ou le bien ayant une valeur bien plus haute que d'ordinaire. Notons l'intensification exprimée par la collocation double et triple. Triple reste invariable dans la majorité des cas (v. ex. de 1839 et le troisième exemple du $\mathrm{CW}$ ), mais, dans le dernier exemple du CW, il s'accorde avec l'objet au féminin tout en gardant son interprétation adverbiale.

\section{Pêcher fin}

Pêcher avec un équipement petit et léger, avec du matériel fin et souple

Emploi absolu

1958 - J'ai la réputation de pêcher fin, me disait-il en souriant, avant de m'emmener dans son atelier-laboratoire, où il fabrique lui-même lignes, plumes et hameçons. C’est inimaginable. Il paraît impossible de faire plus petit, plus léger (Point de vue, 20 juin 1958 / Grundt : 409)

CORPUS WEB :

Quel est l'avantage de pêcher fin ? (en diamètre de fil je parle) Et inversement, quel est l'inconvénient de pêcher " gros " ? (perte de sensation ?) Est-ce nécessaire de pêcher fin au feeder aussi ? [http://www.pechemaniac.com/forums/ viewtopic_49107.htm] (28.8.2015)

"Pêcher fin, en compétition, c'est un choix stratégique autant que technique. C'est sûr qu'en pêchant en 25/100 on peut ferrer fort et on ne casse quasiment jamais, mais si c'est pour galérer la moitié de la manche pour toucher trois poissons, je préfère prendre le risque et faire le quota en deux heures puis me consacrer à une autre espèce. C'est du simple bon sens. Si les gars cassent au ferrage c'est qu'ils pêchent fin mais n'ont pas modifié leurs habitudes » [http:// www.carnassiers.com/sommaire/techniques/ Leurre-souple/finesse/peche-fine-du-sandreaux-leurres-souples.html] (28.8.2015)

J'ai un élastique dans le scion pour pêcher fin tout en ayant une réserve au cas où un gros poisson est à combattre (grosse brèmes, carpeau, barbillon, tanche, voire même un mulet dans les canaux normands) [http://www.jcpoiret.com/ bapw/peche/techniques/peche_gardon.htm] (28.8.2015)

REMARQUES : Employé dans l'argot de la pêche, pêcher fin réfère à l'équipement de pêche (en particulier au fil ou à l'hameçon) utilisé par le pêcheur, le matériel se distinguant par sa finesse, sa taille et son poids, faciles à utiliser et qui témoignent d'une qualité supérieure ; il peut renvoyer, par extension, à une technique de pêche. Fin s'applique au type de moulinet ou de fil qui permet un certain style de pêche alliant finesse et souplesse sans prendre des risques de casse 
inconsidérés. Notons l'antonyme pêcher gros. Notons l'usage de ferrer fort 'tirer vigoureusement la canne de façon à ce que le fer de l'hameçon pénètre profondément les chairs du poisson'. Fin reste invariable.

\section{Pêcher gros}

Pêcher avec un équipement de gros diamètre 入 pêcher fin

\section{Pêcher sensible}

Pêcher avec une canne à pêche, un flotteur, une ligne sensibles

Emploi absolu

1969 Mais attention ! dans nos eaux dépeuplées faut-il encore y mettre la forme et pêcher fin et sensible ? [...] Plume légère, hameçon tres fin, nylon de la grosseur d'un cheveu, le tout bien équilibré, c'est le secret de la réussite (Ouest-France, 23 juillet 1969 / Grundt : 239)

CORPUS WEB :

La pêche à l’Anglaise étant destinée au « beau " poisson et se pratiquant souvent audelà de 20 mètres, le poisson est moins méfiant à cette distance qu'à longueur de canne, mais quand il est quand même nécessaire de pêcher " sensible ", je monte un waggler avec une antenne fine où j'en rajoute une [http://www.artde-la-peche.com/t16484-comment-pecher-unebordure-a-l-anglaise] (28.8.2015)

La tresse WHIPLASH est fabriqué à base de fibre Dyneema, une référence en matière de résistance. Contrairement aux fils tressés conventionnels, le procédé de fabrication de la Whiplash lui confère un plus petit diamètre avec une finition plus lisse et non abrasive. Pour lancer loin, $p \hat{e}$ cher sensible et solide, en toute discrétion [http:// www.top-fishing.fr/catalogue/article/tresseberkley-whiplash-crystal.html] (28.8.2015)

Waggler non plombé avec antenne fine. Lorsqu'il faut pêcher sensible à moyenne et longue distance [http://www.peche-expert.com/ rive-c-35_111.html] (28.8.2015)

REMARQUES : Employé dans l'argot de la pêche, pêcher sensible réfère au type de matériel choisi par le pêcheur se caractérisant par un bon maniement, permettant au pêcheur de bénéficier d'un meilleur confort, de lancer des leurres à bonne distance, de bien sentir la touche du poisson grâce à la ligne et au flotteur. Notons la collocation avec fin, l'adjectif-adverbe renvoyant à la qualité supérieure du matériel employé, et l'adjectif-adverbe solide dans le CW.

\section{Pêcher solide}

Pêcher avec du matériel solide

入 pêcher sensible

\section{Pédaler carré}

Pédaler avec des à-coups (en signe de fatigue), contraire de pédaler rond

Intransitif

2013 Pédaler carré : à moins de ne vraiment pas avoir de style, on "pédale carré » lorsqu'on est épuisé, sans force, et que le coup de pédale n'est plus harmonieux, ni symétrique - il semble cassé, heurté dans sa rotation circulaire (Jean-Paul Vespini, Le Tour de France pour les nuls)

2020 Thibaut pédale carré, il est incapable de prendre la roue des coureurs attardés qui l'avalent instantanément (Guillaume Di Grazia, Orage et désespoirs)

\section{Pédaler déhanché}

Pédaler en ne gardant pas le bassin fixe Intransitif

\section{CORPUS WEB :}

Il ne faut pas oublier que Benj est handicapé... pas simple de pédaler déhanché avec un pied plus court ! [http://www.onlinetri.com/php BB2/viewtopic.php?t=32421\&start=45] (20.7.2009)

\section{Pédaler électrique}

Rouler avec un vélo à assistance électrique Intransitif

CORPUS WEB :

Pédaler électrique est-il vraiment plus sain? De toutes ces données, il ressort que sur une semaine-type, les utilisateurs de vélos électriques utilisent davantage ce dernier que leurs homologues à vélos « standards » [https://www.clubic. com/mobilie-urbaine-electrique/actualite866683-etude-cyclistes-electriques-font-exercice. html] (17.8.2015) 


\section{Pédaler mou}

Pédaler sans force, les jambes molles

Intransitif

1964 «Un cycliste fatigué ou en petite forme pédale mou, ou, mieux ( ?), carré, au lieu de rouler, de grimper, de terminer facile » (J. Giraud 1964)

REMARQues : Pédaler mou appartient à l'argot du cyclisme. Il s'insère dans une série de styles tels pédaler carré, déhanché, rond parmi lesquels seul pédaler rond constitue l'idéal alors que les autres représentent des inconvénients. VoIR AUSSI : tourner rond

\section{Pédaler rond}

Arrondir le coup de pédale en exerçant une pression constante pour obtenir un mouvement régulier Intransitif

1935 Il pédale rond, penché sur son guidon, les lèvres serrées ; en dépit de la montée il ne ralentit presque pas (Eugène Dabit, $L a$ Zone verte)

2012 Reste Gimondi, qui est beau comme une énigme et qui pédale rond. La côte de la Bouquette. Nous y sommes. Sans violence, sans démarrage, rien que par pression pure, j'accélère (Paul Fournel, Anquetil tout seul)

\section{Pédaler sec}

Pédaler d'une manière vive, rapide, sans se ménager

Intransitif

1979 Je trempe mon pain dedans, je me force à avaler le plus que je peux du contenu du seau, j'en mets dans une bouteille pour la soif à venir, et on y va. Je pédale sec. Le matin est frais, l'air sent les foins, le soleil grimpe à toute vitesse dans le ciel bleu, il va encore en faire un sacré plat (François Cavanna, Les Russkoffs)

1997 Malgré « le peu de temps qu'il nous reste » - ou peut-être maintenant à cause de cela - je me réjouis de le revoir demain, mon virtuose de la demi-teinte, mon champion de la pente douce en roue libre. Eh bien non ! J'ai tout faux. Il s'est remis à pédaler sec. Et à picoler sec aussi (Françoise Dorin, Les Vendanges tardives)

CORPUS WEB :

Vélib' : nouveaux tarifs, ça va pédaler sec [http://www.streetpress.com/news/2295-velibnouveaux-tarifs-ca-va-pedaler-sec\#] (28.8.2015)

Tour de France oblige, ça va pédaler sec dans la capitale ce week-end [https://www.lebonbon.fr/ lifestyle/velotour-debarque-a-paris/] (28.8.2015)

Après 15 jours de challenge, Nantes Métropole est en milieu de peloton avec plus de 4000 kilomètres parcourus par les 250 cyclistes inscrits. Il va falloir pédaler sec pour rattraper Gdansk (en Pologne) qui affiche déjà plus de 140000 kilomètres au compteur ! [https://www. nantes.fr/home/actualites/a-vous-nantes/2015/ european-cycling-challenge.html] (28.8.2015)

Remarques : Pédaler sec désigne le fait de se déplacer à vélo avec ardeur, sur un rythme régulier, rapide, dans le but de parcourir un grand nombre de kilomètres ou d'arriver plus rapidement à destination. Notons l'emploi de picoler sec, référant à la consommation d'alcool. Sec reste invariable. Notons aussi l'emploi du tour impersonnel familier ça pédale sec.

\section{Peigner net}

Peigner nettement, avec soin, soigneusement Transitif

1947 Lâge [...] lui gardait toute la parure de ses cheveux blonds, un peu clairsemés en profondeur, mais qui ne changeaient en rien son aspect, peigné très net (Albert Paraz, Remous)

REMARQues : Peigner net se dit généralement de cheveux démêlés, lissés avec soin, ne laissant apparaître aucun nœud ou aucune irrégularité dans la coiffure du sujet. Dans l'exemple, net est modifié par très.

\section{Peindre abstrait}

Peindre des choses abstraites; peindre dans un style abstrait, selon les règles de l'art abstrait Intransitif

1960 M. Chu, chinois, peint abstrait mais aime figuratif (France-Soir, 9 avril 1960 / Grundt : 230) 
Pronominal

1989 Elle vivrait aujourd'hui, Rosa... Elle serait sûrement aussi peu milliardaire que moi... Parce que, aujourd'hui, le bétail, ça se nourrit avec des hormones, ça se surgèle et ça se peint abstrait... (Remo Forlani, Gouttière)

Corpus Web :

J'ai longtemps réfléchi aux raisons et à la manière de peindre abstrait [http://heurtoirslan guedociens.over-blog.com/article-du-figuratifa-l-abstrait-dans-la-peintu-65403889.html] (28.8.2015)

J'aimerais aussi peindre abstrait avec des transparences et de beaux effets. Sur ce forum on insiste pour que je peigne abstrait. Mais comment commencer ? [http://forums.voila.fr/messages/ index/41875/les-arts-toffoli.html] (28.8.2015)

Qu'ils peignent abstrait ou figuratif, en couleur ou en noir et blanc, avec des collages ou non, les enfants ont toute la liberté pour exprimer leur créativité et leur imagination [http://www. larochette.lu/pdffiles/Summer_Akademie_2011. pdf] (28.8.2015)

RemARQues : Dans le domaine des arts plastiques, peindre abstrait désigne le fait d'éviter la reproduction d'un être identifiable du monde réel ou imaginaire. Il est mis en opposition avec peindre figuratif, et dans un sens ludique, avec aimer figuratif. Abstrait reste invariable.

\section{Peindre clair}

Utiliser des couleurs claires pour peindre

Intransitif

1757 il s'étoit établi dans le dix-huitieme siecle une mode de peindre clair et avec très-peu d'ombres fortes (Recueil de quelques pièces concernant les arts)

1886 Tout le truc consiste à lui voler son originalité et à l'accommoder à la sauce veule de l'École des beaux-arts. Parfaitement ! On prend du moderne, on peint clair, mais on garde le dessin banal et correct, la composition agréable de tout le monde, enfin la formule qu'on enseigne là-bas, pour l'agrément des bourgeois (Émile Zola, L'Euvre)
1935 ne jamais peindre clair sur foncé (Arts et littérature dans la société contemporaine)

2017 - Tu peins clair, c'est rare... Au début, on a toujours tendance à peindre trop sombre (Annie Duperey, Le Rêve de ma mère)

\section{Peindre faux}

I. Dépeindre, décrire de manière fausse, inexacte, contraire à la vérité

Transitif

1639 ORANTÉE. C'est celle qui tantost sous un habit de Page

Vous a veu la traiter avecque tant d'outrage,

C'est elle où vos flatteurs treuvent tant de deffauts

Et ce sont ses appas qu'ils vous peignoient si faux (Jean de Rotrou, Laure persécutée)

II. Peindre un mauvais tableau, avec des tons disharmonieux

Emploi absolu

1798 Rien n'est moins sûr : l'habitude perpétuelle des voir les objets voisins et eloignés, d'en mesurer l'intervalle par la vue, a établi dans notre organe une échelle enharmonique de tons, de semi-tons, de quarts de tons, tout autrement étendue et tout aussi rigoureuse que celle de la musique par l'oreille, et l'on peint faux pour l'œil comme l'on chante faux pour l'oreille (Denis Diderot, Pensées détachées sur la peinture, la sculpture, l'architecture et la poésie)

\section{CORPuS WeB :}

encore une fois, on ne recrute pas une pléthore de journalistes quand on est certain de faire un travail concret et incontestable. c'est quand on compte ne rien faire ou faire peu qu'on a besoin de journalistes-peintres pour peindre faux ou pour des couleurs vives sur le peu qui est fait [http://www.seneweb.com/news/commentaire/ adama-gaye-a-macky-sall-laquo-il-suffit-drsquo-ec_n_103907_c_2790528.html] (28.8.2015)

Marrant... c'est toujours les mêmes que l'on cite... des artistes qui jouent faux, qui peignent faux, qui incarnent faux... y'en a pourtant pléthore... [http://www.onf-contrebasse.com/ forum/topic1662-60.html] (28.8.2015) 
Artiste suisse et international, Albert Sauteur donnera, samedi soir à la salle de la Prillaz, une conférence sur la perspective binoculaire : une théorie révolutionnaire qui réinvente la perspective. Ou pourquoi les peintres peignent faux depuis le 15e siècle ! [http://www.lelac.ch/ wordpress/fr/francais-lart-en-fete-a-estavayer-lelac-les-20-21-septembre-2014/] (28.8.2015)

REMARQUes : Dans le domaine de la rhétorique (I), peindre faux signifie 'décrire (quelque chose à quelqu'un) de manière fausse', ne correspondant pas à la réalité, ceci dans un but visé par le sujet. Dans le domaine des arts plastiques (II), par analogie à chanter faux, se dit du fait de peindre une toile disharmonieuse pour l'œil, ne produisant pas de contentement chez le spectateur. Notons l'emploi de chanter faux, jouer faux, incarner faux, qui mettent en évidence la transposition analogique à de différents domaines de l'art (théâtre, film, peinture). Faux reste invariable et est modifié par si.

\section{Peindre figuratif}

Peindre en reproduisant un être ou un objet identifiable du monde réel ou imaginaire $\pi$ peindre abstrait

\section{Peindre gras}

Peindre à l'huile sans la diluer ou en ne la diluant que très peu; peindre en couches épaisses

Intransitif

1791 On doit [...] observer beaucoup les ouvrages des grands maîtres qui, pour parler le langage de l'art, ont peint gras et fait des tableaux dont la touche est moëlleuse et dont la couleur fondue n'a point cette aridité qui tient à la sécheresse (Claude-Henri Watelet, Encyclopédie méthodique : Beaux arts)

1930 Mais Séraphine a aussi un sens de la couleur et de sa distribution. Elle peint gras en peignant tendre (La Revue de France)

1959 Il est conseillé d'ajouter un peu d'eau au médium, si l'on peint gras; et un peu de médium à l'eau si l'on peint maigre (Xavier de Langlais, La Technique de la peinture à l'huile)
1998 Rien de tout cet « art » de Goya n'est plus présent chez Delacroix qui a besoin de mises en scène et peint gras, chez Manet qui peint maigre, gère la lumière comme un protagoniste dans la composition (Jean-Louis Schefer, Goya, la dernière hypothèse)

2006 A cette époque, il [= Theodor Aman] peint gras et large, il étudie chaque partie de la composition, il ne dédaigne pas les beaux tons chauds, les rouges, les bruns, qu'il sait accorder aux verts du terrain, aux bleus sombres des uniformes (Erwin Kessler, L’Autre Langue notre : le français chez les Roumains)

REMARques : Peindre gras réfère à l'emploi de peintures à l'huile, peu diluées. Notons l'emploi de son antonyme, peindre maigre, ainsi que ceux de peindre tendre et peindre large.

\section{Peindre groseille}

Peindre, dépeindre de manière gaie, colorée Intransitif

1899 M. Besnard, membre d'honneur, continue $\grave{a}$ voir et à peindre jovial et groseille. Une jeune femme en papier buvard et coiffée d'étoupes roussâtres se tord de rire en respirant un bouquet de roses en stuc, évidemment cueillies dans le salon pompéien de M. de Max (Jean Lorrain, Poussières de Paris, mardi 5 décembre 1899)

REMARques : Le nom groseille évoquant la couleur rouge et le parfum du fruit (acidulé et sucré), peindre groseille se dit ainsi du fait de peindre en utilisant des couleurs chaudes, gaies. Dans un emploi métaphorique, il désigne le fait de dépeindre, de décrire les choses avec gaité et légèreté. Notons la collocation avec l'adjectif-adverbe jovial, soulignant l'idée d'enjouement du sujet ou de son discours, et le verbe voir qui désigne le fait de percevoir les choses de façon toujours positive. VoIR AUSSI : voir groseille / noir /rose / triste 


\section{Peindre lisse}

Peindre sans aspérité, appliquer une couche lisse de peinture

Transitif

1758 Une Vierge de grandeur naturelle, de maniere ferme et même tranchée, mais peint lisse comme l'ivoire (Charles-Nicolas Cochin, Voyage d'Italie)

Intransitif

1847 Aussi tous ceux qui ont tenté de saisir cette ressemblance, renonçant à aborder cette manière heurtée, si propre à produire des effets et à rendre avec tant de vérité les dégradations d'un âge très avancé, ont pris le parti de peindre lisse et tout uni, ce qui, en rajeunissant beaucoup le modèle, ne donne aucune idée de l'original (Précis analytique des travaux de l'Académie royale des sciences, belles-lettres et arts de Rouen)

1922 On ne voit nulle part la touche, on ne sent nulle part la main. Ce n'est pas de la peinture. C'est laqué, c'est gommé, c'est émaillé, ce n'est pas peint. On peut peindre lisse. Titien et Rubens lui-même très souvent peignent lisse, mais ils ont de l'accent (Anatole France, La Vie en fleur)

\section{Peindre jovial}

Peindre de manière à susciter la jovialité $\lambda$ peindre groseille

\section{Peindre juste}

Dépeindre, décrire, représenter, évoquer (quelque chose) avec justesse et précision, avec exactitude, conformément à la réalité Transitif

1822 L'amant qui est bien avec ce qu'il aime, jouit avec transport du fameux duetto d'Armida e Rinaldo de Rossini, qui peint si juste les petits doutes de l'amour heureux, et les moments de délices qui suivent les raccommodements (Stendhal, De l'amour)

1836 Je trouve sans doute beaucoup de plaisir à écrire depuis une heure, et à chercher à peindre bien juste mes sensations du temps de Mlle Kubly, mais qui diable aura le courage de couler à fond, de lire cet amas excessif de je et de moi ? (Stendhal, Vie de Henri Brulard)

Intransitif

1867 Je suis resté dans ma chambre, et, faute de mieux, j'ai voulu voir le monde en peinture ; j'avais sur ma table les comédies d'Emile Augier et d'Alexandre Dumas fils. Ils peignent juste, c'est leur métier (Hippolyte Taine, Notes sur Paris)

\section{Corpus Web :}

Et pour ceux qui se posent encore des questions, voilà une photo pour que vous vous rendiez compte du format ... j'ai de quoi passer tout mon stock d'acrylique en somme ! (et donc travailler aussi grand, en plus que ça soit dur, pour peindre juste et conserver les bonnes proportions de dessin, c'est une ruine en peinture ... très bien, très bonne idée !!) [http://yrgane.com/ blog/illustration/page/6/] (10.9.2015)

L'artiste travaille l'huile en formes géométriques d'inspiration cubiste. Il utilise des couleurs vives et contrastées dont les formes expriment une énergie sensuelle. Il cherche à traduire les saveurs, les odeurs, les bruits, car il ne s'agit pas de peindre juste mais vrai [http://www.lejsl. com/edition-de-chalon/2012/04/09/sculptureset-peintures-jusqu-au-15-avril] (10.9.2015)

"Généralement, je suis plutôt impressionniste et non-figurative. Ici, c'est différent ", explique Fleur de mousse. "J'ai mis beaucoup de temps à apprendre à peindre juste, symétrique. Je trouve les bateaux de pêche très difficiles à faire. J'en ai fait une vingtaine pour arriver à celui que j'expose là » [http://librairielajoiedelire.blogspot. co.at/2013_06_01_archive.html] (10.9.2015)

Remarques : Peindre juste désigne le fait de décrire avec justesse, exactitude, conformément à la réalité, l'auteur de la description étant un peintre, un écrivain, un journaliste, etc. Dans un emploi imagé, il se dit du regard dépeignant, voire trahissant les sentiments du sujet, ses pensées, et ce, de la manière la plus exacte possible (v. les exemples de 1822 et 1836). Le sens concret, en peinture, n’apparaît que dans les exemples du CW. Notons la combinaison de peindre avec les adjectifs-adverbes vrai et symétrique. Juste reste invariable et est modifié par bien, si. 


\section{Peindre large}

Peindre à grands traits généreux

$\lambda$ peindre gras

\section{Peindre lumineux}

Peindre dans des tons lumineux

Intransitif

1901 Le Hollandais ne peint pas clair, il peint lumineux (Paul Rouaix, Histoire des beauxarts)

1940 J'essaie, dit Tal Coat à cette époque « de peindre lumineux comme si les objets et la toile étaient source de lumière. La couleur doit avoir sa fonction en tant qu'équivalent de lumière »

(Tal Coat / Laurence Bertrand Dorléac, Histoire de l'art, Paris 1940-1944)

\section{Peindre maigre}

Peindre avec une peinture pauvre en huile ; opposé à peindre gras

$\lambda$ peindre gras

\section{Peindre plat}

Peindre sur un support horizontal ; peindre sans mettre en perspective, sans créer un espace à trois dimensions

Intransitif

1960 Bernard Buffet peignait plat (J. Bouret, Lettres françaises, 12 février 1960 / J. Giraud)

\section{CORPus Web :}

Maurice Denis, assez mauvais peintre, mais théoricien célèbre pour avoir jeté cette tarte à la crème : "Se rappeler qu'un tableau, avant d'être un cheval de bataille, une femme nue ou une quelconque anecdote, est essentiellement une surface plane recouverte de couleurs en un certain ordre assemblées. "... lui peignait plat. Bonnard peint des espaces. Leur réalité est issue des relations de profondeurs relatives que nos nerfs, optiques et autres, mettent entre les couleurs [http://marctanguy.blog.lemonde. fr/2006/04/24/2006_04_bonnard_4/] (10.9.2015)

Sur mon buffet, j’ai sûrement voulu peindre trop "plat », je m’appliquais et tout, donc je vais faire ça un peu plus « légèrement ».

T'as mis qu'une couche ? Parce qu'il est foncé ton meuble à la base... ! [http:// www.chaperlipopette.com/forum/viewtopic. php?f=15\&t=185\&start=525] (10.9.2015)

REMARques : Dans le domaine des arts plastiques, peindre plat désigne soit le fait de peindre une toile, un tableau sur un support plat, horizontal, couché, soit celui de peindre sans perspective. J. Giraud (1964), qui cite cet exemple, ajoute «ce qui, espérons-le, ne signifie pas : platement ». Le dernier exemple du CW n'est pas très clair, mais le commentaire de l'interlocuteur entend peindre plat par rapport au nombre de couches appliquées à un meuble. Il suppose donc que la couche plate était trop fine pour faire disparaître la couleur du meuble. Plat reste invariable et est modifié par trop.

\section{Peindre renaissant}

Peindre dans le style de la Renaissance

入 écrire classique

\section{Peindre rose}

Peindre en rose, avec la couleur rose

$\pi$ peindre violet

\section{Peindre sombre}

Peindre dans des tons sombres

$\pi$ peindre clair

\section{Peindre symétrique}

Figurer, représenter (quelque chose) de manière symétrique

$\pi$ peindre juste

\section{Peindre tendre}

Peindre avec finesse et sensibilité

$\pi$ peindre gras

\section{Peindre violet}

Peindre en violet, avec la couleur violette

Emploi absolu

1956 quand j'avais quinze ans, j'étais le seul à aimer Manet et Monet. Maintenant, ils peignent tous violet ! Et moi pas! (France observateur, 26 juillet 1956 / Grundt : 251)

CORPus Web :

j'ai du tester le shéma sur une bonne dizaine de tête de mes rabiots elfe pour trouver un shéma plaisant $(;)$ et a moins de le faire tout gris avec des teintes gris fauves que je n'ai pas 
et non présente dans la game Gw, histoire de le faire en noir éclairssis avec ce type de gris style mandragore eldar noir, bah me restais plus qu'a peindre violet lol) [http://athel-loren.forumactif. com/t3128p240-commentaires-sur-le-concoursde-peinture] (10.9.2015)

Déja j’ai acheté un clic clac violet et rose donc je vais bientot pouvoir enlever l'horreur du papier peint et peindre violet ou rose [http://www. chevalannonce.com/forums-2091899-idees-dedecos? $\mathrm{p}=1]$ (10.9.2015)

Euh tu compte la peindre violette ? J'espere car ca rendra encore mieu que la je pense [http:// www.crazymoto.net/index.php?showtopic $=385030 \& \mathrm{st}=1620]$ (10.9.2015)

REMARQUES : Dans le domaine des arts plastiques, peindre violet désigne le fait de peindre en utilisant majoritairement la couleur violette. Notons également l'adjectif rose, dans le même emploi. Violet reste invariable dans son emploi adverbial, mais, en tant que prédicat second, il peut s'accorder avec l'objet pour renforcer la modification résultative (v. le dernier exemple du CW).

\section{Peindre vrai}

Dépeindre, décrire avec justesse ou vraisemblance, conformément à la réalité Intransitif

1898 Quel document, étonnant de jeunesse. Accent de vérité. Vous peignez vrai et vous êtes vrai avec vous-même. Ce sont bien là vos parents et leurs mœurs; ce sont bien là les sentiments que vous éprouvez (Maurice Barrès, Mes cahiers)

1953 Tout en étant renseigné sur ses mœurs peu équivoques, il lui trouvait l'esprit fin et aristocratique, exempt de charlatanisme, et il le louait de peindre vrai sans jamais courir après la pointe (Henri Martineau, Le Coeur de Stendhal)

\section{CORPUS WEB :}

Julien Beneyton peint vrai. Sans se laisser happer par les sirènes de l'hyperréalisme qui, passé l'effet de surprise - est-ce une photo ou un tableau ? - se révèlerait rapidement un brillant mais vain exercice de style. Sans sacrifier aux dieux de l'abstraction, terre d'exploration qui s'avère limitée quand on ne possède pas le génie d'un Delaunay ou d'un Kandinsky [http://www. hellocoton.fr/to/9PZF\#http://www.brouillonsde-culture.fr/article-julien-beneyton-peindrevrai-68826636.html] (10.9.2015)

Ainsi, L'Enterrement à Ornans, peint en 1849-1850, marque une étape importante. Courbet, qui veut "peindre vrai », y représente les habitants d'un village qui n'ont rien de noble et qui assistent à un enterrement bien « réel », alors que le format du tableau, immense, et sa composition, qui rappelle une frise antique, sont dans la lignée des peintures historiques monumentales [http://www.cap-concours.fr/enseignement/ preparer-les-concours/crpe-nouveau-concours/ realisme-impressionnisme-et-symbolisme-mas art_11] (10.9.2015)

Remarques : Peindre vrai s'emploie au figuré dans le domaine de la rhétorique, où il désigne le fait de décrire avec justesse, conformément à la réalité, par oral ou par écrit. Dans le CW, peindre vrai reprend le sens original du verbe pour exprimer la conformité de l'expression artistique avec la nature ou avec soi-même, avec les propres sensations, se référant à un art authentique.

\section{Peiner dur}

Se donner beaucoup de peine Intransitif

1894 et les autres [= femmes], celles qui peinent dur, qui, pour vivre, sont contraintes de vendre leurs bras, leur force, leur jeunesse, leur beauté, qui gagnent leur pain et la mort en se faisant machines à travail ou machines à plaisir (Georges Renard, Aux femmes)

1936 Les chasseurs doivent par conséquent peiner dur pour vivre, plus que les agriculteurs et les éleveurs (Alfred Metraux, Manuel d'anthropologie culturelle)

1982 En place, hallebardiers et Janissaires, hommes et femmes de tous âges, de toutes races, de tous rangs peinaient dur, confondus dans le même effort (Michel, prince de Grèce, La Nuit du sérail)

1984 Ces hommes peinent durs pour un maigre salaire (Guy Filhoud-Lavergne, Marrakech) 


\section{CORPus WeB :}

Ceci dit : vue l'évolution, j'en connais aussi qui peinent durs sur l'administratif... parce que pour être maçon à son compte, faire de bons murs ne suffit pas [https://www.1cheval.com/ membre/forum/salon/sujet-2505958-12-bijoutierde-nice-je-ne-comprends-pas] (18.9.2013)

\section{Peinturlurer faux}

Peinturlurer de façon non naturelle Transitif

1951 Les acteurs veulent jouer faux, être habillés faux, être peinturluré faux, être perruqués faux. La nonne a du rouge baiser aux lèvres, le poilu qui sort des tranchées des bottes vernies, l'amoureuse est jouée par un gamin (Henry de Montherlant, La Ville dont le Prince est un enfant)

Remarques : Peinturlurer faux désigne le fait de se maquiller, de se farder à l'excès, de manière non naturelle, voir excentrique, ici, dans le domaine du spectacle. Notons la série de verbes qui se combinent avec faux dans le domaine du spectacle : jouer, s'habiller, perruquer.

\section{Pelotonner serré}

Pelotonner (du fil, de la laine) en serrant

fortement

Transitif

1945 Elle rêva un peu, pelotonna plus serré la laine, puis reprit :

- Pourtant... la dernière fois que tu es venu ici... enfin il y a quinze jours, trois semaines? (Louis Aragon, Aurélien)

\section{CORPus Web :}

Il s'était mis nu lui aussi. Passant une jambe entre les miennes, il se pelotonna serré, torse écrasé contre le mien, ferma les yeux et s'endormit [http://www.gai-eros.org/w/index.php/ Aapo,_le_petit_p\%C3\%A9d\%C3\%A9_finlan dais] (11.9.2015)

REMARQUes : Dans le contexte du tricot, pelotonner serré désigne le fait de mettre en peloton, d'enrouler en boule ( $\mathrm{du}$ fil, des rubans) de manière très serrée, compacte. Notons l'emploi pronominal du verbe dans le CW qui désigne un homme qui se blottit contre un autre. Serré reste invariable et est modifié par plus.

\section{Pendre bas}

Être indigne, vil, méprisable

Intransitif

1897 Les âmes contemporaines pendent assez bas, croyons-nous, Madame, et le choix libre d'une existence épouvantable est une sorte d'idée gothique et lointaine qui n'obtient pas très-facilement audience (Léon Bloy, Journal 1 : Mon journal)

CORpus Web :

Estime toi heureux que je ne sois pas inquisiteur à l'ordre des ConcordeManiacs, sinon je t'aurais fait pendre bas et très long par le nez (autrement dit, pincé le nez avec un bout ficelle très très long) [http://www.pilote-virtuel.com/ viewtopic.php?pid=744097] (11.9.2015)

$\mathrm{Tu}$ souffriras. On va te pendre bas et long pour que ca dur plus longtemps [http://www. jeuxvideo.com/forums/1-10220-1056480-2216-0-10-a-l-auberge-du-dragon-ivre.htm] (11.9.2015)

Le forum pour l'insulter, le massacrer, le torturer, le pendre court et bas enfin tout ce que vous voulez faire. Alors faites le [http://forums.cnet france.fr/topic/1185171-retours-d-une-instal lation-de-leopard-sur-mon-1000h/] (11.9.2015)

Oui c'est légèrement calorifugé avec un composite alu / polysturène expansé, c'est juste pour que l'intérieur des armoires ne chauffe pas trop. Mais ce ne sont pas des calories perdues de toute façon. Si c'est un lit au-dessus je ne mettrais rien du tout. Mais le couvre-lit ne peut pas pendre bas sinon plus de convection [http://www.bricozone. be/fr/plomberie/t-dileme-pas-de-place-pour-unradiateur-page2-20547.html] (11.9.2015)

REMARQues : Dans un emploi métaphorique, pendre bas prend une acception morale de bassesse, ici par rapport aux âmes. Dans les trois premiers exemples du CW, le verbe figure dans son emploi transitif, et réfère au fait de mettre quelqu'un à mort en le fixant par le cou (ou par le nez) avec une corde. Notons les collocations court et bas, bas et long, sans doute liées par analogie avec (pendre) haut et court. Dans le dernier exemple, l'objet direct inanimé du verbe fait que pendre n'implique plus l'idée de la mort. Bas reste invariable (v. l'exemple de 1897) et est modifié par assez. 


\section{Pendre court}

pendre haut et court : pendre à une potence ; exécuter de manière expéditive

Transitif

1498 Aprés qu'on eult bien son cas suspendu, Devant chascun qui que veoir le voulut, Le povre gueux fut hault et court pendu A ung gros arbre, quelque bon corps qu'il eult (Andrieu de La Vigne, Le Voyage de Naples, 1059)

1558 Alors Maillard vous luy achevoit son procès et le vous faisoit pendre hault et court avec sa tonsure, et luy apprenoit que c'estoit de servir le roy (Bonaventure des Périers, Les Nouvelles Récréations et joyeux devis)

1954 Si je me fâchais, dit-elle, si afin de vous châtier j'ordonnais à mes hallebardiers de vous pendre haut et court (France-Soir, 7 décembre 1954 / Grundt : 321)

CORPUS WEB :

putain, il faut retrouver d'urgence le coiffeur de griezman et le pendre haut et court... [http://forum.bollaert.fr/viewtopic.php?f=7\&t= 2262\&start=810] (11.9.2015)

Il est clair qu'il n'est pas forcément nécessaire de pendre haut et court les tricheurs [http:// www.bivi.maitrise-risques.afnor.org/actualites/ chronique/fraude-scientifique-qui-pendre-pourevacuer-le-risque-de-discredit] (11.9.2015)

Il faudrait la pendre haut et court ! [https:// www.facebook.com/CitoyensEtFrancais/posts/ 808170139223903] (11.9.2015)

ben ou elle est la péripatéticienne qui arpente l'agora de q\&r à la recherche de la petite Eve, pour la pendre haute et courte tel un gibier de potence aux portes de l'allée des comptes trépassés [https://fr.answers.yahoo.com/question/ index?qid=20101227111219AA5IJwY] (11.9.2015)

REMARQUES : En collocation avec l'adjectif haut, pendre haut et court désigne, du moins à l'origine, le fait de pendre quelqu'un haut (pour qu'on puisse le voir facilement) avec une corde courte, provoquant ainsi une agonie plus longue parce que la nuque casse plus difficilement par rapport à une corde longue qui permet de tomber. Haut et court restent invariables dans la majorité des cas (v. le deuxième et le troisième exemple $\mathrm{du}$ CW), mais, dans le dernier exemple du CW, ils s'accordent avec l'objet au féminin, par emphase littéraire, tout en gardant leur interprétation adverbiale.

\section{Pendre haut}

pendre haut et court : pendre à une potence ; exécuter de manière expéditive

入 pendre court

\section{Pendre long}

Pendre (quelqu'un) avec une corde longue $\lambda$ pendre bas

\section{Pendre vif}

Pendre un être vivant (pour le tuer)

तéchorcher vif

\section{Pénétrer profond}

I. Imprégner, marquer profondément, de façon intense

Intransitif

1907 les maisons larges et basses, les arbres aux verdures sobres d'Europe, la brume diaphane jetée sur cette nature comme son duvet sur une prune, et le soleil qui dore et qui n'aveugle pas, tout concourt vers un ensemble délicieux et tempéré, qui ne s'impose pas violemment, mais qui s'insinue, pénètre profond et possède (Claude Farrère, L'Homme qui assassina)

1956 La forme en est devenue plus râpeuse elle flatte moins l'oreille, elle est moins agréable à entendre - dans les meilleurs cas, elle pénètre aussi plus profond (Pierre Reverdy, Cette émotion appelée poésie)

II. Pénétrer, s’introduire, s'engager, entrer profondément ; pénétrer avec intensité Intransitif

1927 Et cependant, si l'on pénètre plus profond dans ce mystère esthétique, bien des faits viennent au-devant de l'investigation inquiète pour s'opposer à cette conception simpliste qui lie le développement de l'art au développement de la foi et affirme sans hésiter que l'art ne se développe pas (Élie Faure, L'Esprit des formes) 
1933 Mais il savait bien que sa pensée ne pénétrait point très profond dans les immensités funèbres, passait à peine les premiers pas et tâtonnait autour du seuil (Joseph Malègue, Augustin ou Le Maître est là)

1955 Plus, par des moyens d'une puissance toujours accrue, nous pénétrons loin et profond dans la matière, plus l'inter-liaison de ses parties nous confond (Pierre Teilhard de Chardin, Le Phénomène humain)

1958 C'était une obsession. Elle pénétrait de plus en plus profond dans mon cerveau (Christiane Rochefort, Le Repos de guerrier)

1997 Le jeune pénétra plus profond dans les taillis, manqua se laisser écharper par d'autres patrouilles à cause de son cheval hongrois (Patrick Rambaud, La Bataille)

\section{Corpus Web :}

mallonger sur le dos et lever mes jambes bien écartées pour sentir une bite me pénétrer profond je kiff trop ! [http://rencontre-gay.vivastreet.com/ annonces-rencontre-gay+mougins-06250/recoisgrosse-bite-endurante-a-faire-jouir-plusieurfois--/122900470] (11.9.2015)

Elle se fait tringler sur une banquette du bus en écartant bien les jambes pour sentir la bite la pénétrer profond [http://www.zizi-top.fr/videospornographiques/etudiante-sexe/une-grossevicieuse-baisee-dans-le-bus/] (11.9.2015)

Pour moi la teinte de fond a la plus grande importance, mais j'utilise une teinte à l'eau que je viens de vous décrire, passée à chaud, d'abord très liquide pour pénétrer profond, puis plus dense [http://www.luthiers-mirecourt.com/ vernis1.htm] (11.9.2015)

Remarques : Pénétrer profond (I) se dit d'une chose qui, par son omniprésence, imprègne, marque les personnes présentes, paraissant ainsi les posséder. (II) réfère au fait de s'introduire dans un lieu, de s'avancer jusqu'à un endroit, la destination pouvant être concrète (les taillis) ou abstraite (le mystère) ; profond marque soit l'obstination du sujet, soit l'inconnu, voire la noirceur de la destination. Dans le CW, pénétrer profond figure dans le domaine sexuel ; la construction transitive renvoie à la pénétration du pénis dans le corps de son partenaire. Le dernier exemple du CW s'applique à la teinte de fond qui pénètre plus profondément la toile si la couleur est plus liquide. Profond reste invariable et est modifié par aussi plus, de plus en plus, plus, très. Notons la collocation loin et profond.

\section{Penser bas}

Penser secrètement, intérieurement, dans son for intérieur

Intransitif

1742 D'ailleurs, dit encore la sultane, c'est que cette Zulica qui vous plaît tant, étoit la dernière des... Je vous prie, madame, interrompit-il, d'en penser tout bas ce qu'il vous plaira, et de ne m'en point dire de mal (Alexandre Dumas fils, Le Sopha)

1842 Mais lorsque Sténio fut complet, que la gloire

L'eut porté rayonnant à son temple d'ivoire, César pensa tout bas : ô mort que je rêvais ! Puisque j'ai pour toujours assuré sa mémoire et qu'il sait à présent tout ce que je savais, je n'ai plus rien à dire au monde et je m'en vais!

(Théodore de Banville, Les Cariatides)

1844 D’Arthez était depuis quelque temps assez mêlé aux affaires politiques pour connaître à fond le personnage, et lui seul peut-être avait un caractère assez élevé pour expliquer tout haut ce que le monde pensait tout bas (Honoré de Balzac, Les Secrets de la princesse de Cadignan)

1845 - Nous pourrons vous dire tout haut ce que nous pensions tout bas?

- Oui... vous le pourrez... vous le pourrez, dit le maréchal Simon en balbutiant de joie (Eugène Sue, Le Juif errant)

1855 Voilà pourquoi j'ai la fièvre, voilà pourquoi je m’assimile avec ardeur toutes les idées qui me frappent, voilà pourquoi je parle jusqu'à m'épuiser, jusqu'à divaguer, parce que parler, c'est penser tout haut et qu'en pensant ainsi tout haut je vas [sic] plus vite qu'en pensant tout bas et tout seul. Vous autres qui m'écoutez, et toi tout le pre- 
mier qui écoutes plus attentivement que personne, vous tenez trop de compte des éclairs fugitifs qui traversent mon cerveau (George Sand, Histoire de ma vie)

1859 - Ah ! Dit Fanny, madame pouvait-elle croire... Et la soubrette pensait tout bas :

- Tiens, mais voilà qu'elle devient véritablement folle.

- Ainsi, tu es bien sûre, continua Baccarat, que j'ai eu le délire ? (Pierre-Alexis Ponson du Terrail, Rocambole)

1886 Oui, messieurs, nous sommes, de par le monde, quelques milliers, quelques millions peut-être, car nous n'avons d'autre mérite que de dire tout haut ce que la foule pense tout bas, nous sommes quelques millions de travailleurs qui revendiquons la liberté absolue, rien que la liberté, toute la liberté ! (Louise Michel, Manifeste des anarchistes)

1909 Il revint s'asseoir à sa table, silencieux, avec un vague sourire. Il songeait :

- Quelle différence y a-t-il entre cela et l'amour?

Instinctivement, il s'était mis à penser bas, comme s'il avait eu honte. Il haussa les épaules (Romain Rolland, Jean-Christophe. Dans la maison)

1924 Et Lecocq continuait de plus belle : « et puis, pourquoi vous dire mon opinion ? Je suis sûr que ceux qui ont applaudi pensent comme moi, mais n'osent pas dire tout haut ce qu'ils pensent tout bas. Tenez ! Ces gens-là me feraient aimer la Valse des roses ou Il Bacio ! Hélas ! » (Louis Schneider, Les Maîtres de l'opérette française)

1926 Vous avez dit tout haut ce que tout le monde pense tout bas, car il n'y a personne dans le fond qui n'ait pour l'abject et stupide épilogueur du Mercure le mépris qu'il mérite (Paul Claudel et André Gide, Correspondance)

1936 Il faut comme une étendue d'esprit, un monde de concert, une immense salle d'essais. Les incompris s'expriment sans bonheur ; ils pensent tout bas ; ils ne pensent guère. Pensez mépris ce n'est point penser (Alain, Propos)

1938 Mais dans quel jardin erre-t-on ainsi Qui ne serait clos que par la pensée? Ah pensons tout bas, n'effarouchons rien, Je sens que se forme un secret soleil (Jules Supervielle, La Fable du monde)

1952 Peu après la fondation de L'Humanité par Jaurès, qui en fit l'organe officiel des socialistes unifiés, et tandis que Gustave Hervé faisait paraître La Guerre Sociale avec Eugène Merle et Almeyra, un jeune professeur révoqué, Gustave Téry créait avec Urbain Gohier un pamphlet hebdomadaire : L'Euvre, pour dire «tout haut ce que tout le monde pense tout bas » (Gilberte HenryCoston, L'ABC du journalisme)

\section{CORpus WeB :}

J'aime... l'idée de penser bas, d'être perdu dans un ailleurs alors que l'objectif le recentre dans le réel, j'aime ce tout simple, comme si rien n'importait, j'aime... [http://ellanaveva.blogspot. co.at/2006/10/penser-tout-bas.html] (11.9.2015)

Pourquoi quand on dit tout haut ce que certains pensent tout bas ça dérange ? [http:// www.web-libre.org/questions/reflexions_7194/ pourquoi-quand-on-dit-haut-que-certainspense-bas-derange,42166.ihtml] (11.9.2015)

Dans une interview accordée à l'édition de jeudi prochain du journal d'extrême droite Rivarol suite à son énième propos négationniste de la semaine dernière, le président d'« honneur » du Front National dit une nouvelle fois ce que les militants et dirigeants de son parti pensent tout bas [http://sos-racisme.org/communique-de-presse/ jm-le-pen-rivarol/] (11.9.2015)

REMARQUES : Généralement opposé à ce que l'on dit tout haut, penser bas décrit le fait de cogiter, de former des pensées dans sa tête en prenant bien garde de ne pas les exprimer ouvertement, le sujet pouvant ressentir de la gêne, de la timidité ou de la couardise. Bas reste invariable et est généralement modifié par l'adverbe d'intensité tout (et par aussi). Notons l'emploi de expliquer tout haut et la collocation tout bas et tout seul. 


\section{Penser beau (bel)}

Former des idées nobles, belles, admirables

Transitif

1375 HUCHON. Sire, je pense bien et bel

Faire vostre conmandement

Et m'en vois delivrer briefment

(Miracle de Robert le Dyable, 563)

Intransitif

1908 Un grand écrivain nous laisse le saisir dans l'acte intime de penser, et de plus il pense fort, juste et beau ; voir son énergie, sa flamme (Maurice Barrès, Mes cahiers)

\section{CoRpus Web :}

Bien sûr, il y a les $10 \%$ qui pensent, qui pensent juste, qui pensent beau, mais il y a les autres, tous les autres, qui se divisent encore en deux catégories [http://punching.blog.lemonde. fr/2015/01/14/cest-beau-un-peuple-qui-se-levenon/] (11.9.2015)

Et en général les gens ont plutôt tendance à vouloir montrer ce qui brille, ce qu'ils pensent beau et donc en général on voit plus de gens afficher les iPhone 4/4S que les GS3 ou autres téléphones [http://forum.tt-hardware.com/topic96593-96---Topic-Officiel-Apple-iPhone-Edge-3G3GS-4-amp-4S-.htm] (11.9.2015)

Pourquoi ce sont toujours ceux qui sont plus proches du macaque physiquement qui se pensent beau ? [https://fr.answers.yahoo.com/ question/index?qid=20070209150213AAzCVCm] (11.9.2015)

les filles qui se pensent belles c'est comme les imprimantes, c'est juste une impression ! [https://www.facebook.com/permalink.php?id= 113808812111477\&story_fbid=154882844670740] (11.9.2015)

REMARQUES : Si l'emploi médiéval de penser bel se rapproche de celui de penser bien, formant le pléonasme adverbial bien et bel, le retour à l'adjectif beau entraîne une remotivation du sens de base de beauté. Penser beau désigne ainsi le fait de penser, de former des idées esthétiques, peut-être en enjolivant la réalité. Beau peut référer à la beauté, la noblesse des idées comme à l'esthétique de leur forme. Notons la collocation fort, juste et beau. Beau reste invariable dans son emploi adverbial. L'emploi moderne tend à une interprétation comme verbe copule, penser beau 'penser être beau' (v. les trois derniers exemples du CW) ; beau peut alors s'accorder, comme dans le dernier cas.

\section{Penser blanc}

Penser en optimiste

$\lambda$ croire noir

\section{Penser cosmique}

Penser dans une dimension qui dépasse toutes les limites

Intransitif

1923 Renan pensait cosmique. L'homme, pour lui, était un incident négligeable (Maurice Barrès, Mes cahiers)

REMARques : Penser cosmique s'insère dans une série ouverte qui sert à cerner les dimensions du penser (ex. penser universel). VOIR AUSSI : penser global pour agir local.

\section{Penser court}

Penser de manière superficielle; penser avec précipitation, sans beaucoup réfléchir Intransitif

1902 Elle voulait dire : « On a beau faire pour garantir l'innocence d'une jeune fille ; entassez gouvernantes, murs de clôture, in-folio édifiants, voire curés et capucins, le démon subtil de l'Amour est partout, s'infiltre en tout lieu; et, à s'acharner à détourner de lui nos enfants, on perd son temps et sa peine ; autant leur dire : jusqu'à vingt ans, mes petits, bouchez-vous les yeux à l'aide de vos deux poings ; il ne faut pas connaître la lumière !»

Mais, pensant plus court, Ninon dit tout crûment :

- Zut ! (René Boylesve, La Leçon d'amour dans un parc)

1904 Une sorte d'hébétement me béatifie ; je juge les choses en « bonne femme ». Je ne pense plus ou je pense court, niais, superficiel (Léon Frapié, La Maternelle)

\section{CORPUS WEB :}

Ils pensent court. Un peu comme les pseudos " patrons », cadres sup' de pacotille, qui traitent les chômeurs et les pauvres d'assistés pendant qu'ils placent leurs capitaux à l'étran- 
ger, ne paient pas d'impôts et profitent du système que les malheureux types qui travaillent financent avec l'impôt prélevé sur leur sueur... [https://fr-fr.facebook.com/journal.lastrada/ posts/10152776580917587] (11.9.2015)

140 caractères, ce n'est plus de la concision, c'est de l'indigence. S'il y en a qui croient que c'est de la pensée, c'est qu'ils pensent court. Très court. Peut-être même ne pensent-ils pas du tout [https://www.linkedin.com/grp/post/23898595823288544130531329] (11.9.2015)

Actuellement, il gère très court parce que ses clients pensent court. Il y a des périodes où il gérait beaucoup plus long, parce que ses clients pensaient long. Il s'adapte à l'univers, c'est un financier [http://tropvite.fr/entretiens/michelpebereau/] (11.9.2015)

Remarques : Penser court désigne le fait de penser sans beaucoup de réflexion, rapidement, court s'appliquant au contenu, estimé insuffisant, de la pensée. Le second exemple du CW établit un lien entre la limitation d'un texte à un certain nombre de mots et la qualité de la pensée qui s'ensuit. Le dernier exemple du CW réfère aux réflexions à court ou à long terme dans l'argot du monde des finances, avec, comme corrélat, gérer court / long. Notons les adjectifs-adverbes niais et superficiel, et l'antonyme penser long. Court est modifié par plus, très.

\section{Penser creux}

Avoir des idées sans aucun sens, ne pas avoir d'idées

Intransitif

1673 MIROBOLAN. Il faut penser bien creux, pour imaginer une chose si éloignée du bon sens (Noël Lebreton de Hauteroche, Crispin médecin)

1844 Les importants étaient un parti composé de quatre ou cinq mélancoliques qui avaient l'air de penser creux (Retz) (François de Chateaubriand, Vie de Rancé)

Corpus WeB :

Je crois que c'est un phénomène sociétal typique à 2 versants : celui-ci et celui des « beaufs » des petits commerçants et artisans, des classes moyennes bref des gens qui gagnent petit et qui pensent creux ! [http://www.insolent.fr/2014/11/ scandaleuses-gesticulations-autour-du-budget. $\mathrm{html}$ (11.9.2015)

la courbe de chômage, la gestion comptable, les mirliflores économistes qui nous insupportent et pensent creux, alors que les grincheux se taisent, moi je commémore Saint-Louis [http:// www.lavie.fr/debats/laviedanslesmedias/lerecteur-de-notre-dame-de-paris-denonce-la-vieen-chaire-09-04-2014-51883_435.php?contexte= view_comment] (11.9.2015)

Mais je ne parviens pas pour autant à ne penser à rien (mais je sais cependant penser creux)... [http://traileurz.fr/carine-faudraitcourir-tu-vois-seule-avec-ces-idees-la] (11.9.2015)

REMARques : Penser creux désigne le fait d'avoir des idées sans valeur, sans intérêt ou, directement, ne pas avoir d'idées, creux référant au vide dans le cerveau, à l'absence de pensées. Notons l'usage de gagner petit 'gagner peu' dans le CW. Creux reste invariable et est modifié par bien.

\section{Penser droit}

Avoir des idées justes, sensées, honnêtes Intransitif

1680 Savez-vous bien que vous n'avez point pensé droit sur la cassolette et qu'il a été piqué de la hauteur dont vous avez traité cette dernière marque de son amitié ? (Mme de Sévigné, Correspondance)

1911 Il en sera toujours ainsi quand le commandement supérieur, manquant à lui-même, par insuffisance de vue ou de volonté, voudra se substituer à ses subordonnés, penser et décider pour eux ; il faudrait, pour qu'il pensât droit et décidât juste, qu'il vît par leurs yeux, du point où ils sont, qu'il pût être à la fois partout (Ferdinand Foch, Des principes de la guerre)

1921 C'est tantôt un négativiste que tourmente le démon de la contradiction, tantôt un vaniteux qui veut étonner, ou bien encore un de ces esprits qui fonctionnent à la façon du cavalier au jeu d'échecs et biaisent d'instinct, comme d'autres pensent droit (Paul Bourget, Le Sursis)

1933 Une duchesse de Monte Putina, une Augusta, un prince des journalistes, un 
Monseigneur de Belle-Lurette et tous ceux qui pensent encore droit et juste par ces temps de défaitistes du capitalisme savent que, plutôt que d'avoir contre soi des grévistes, - que les sommations de la police et les coups de feu ne parviennent point à disperser, - mieux vaut essayer de métamorphoser les ouvriers en apôtres des ateliers (René Crevel, Les Pieds dans le plat)

\section{CoRpus Web :}

Formatés par le cloisonnement des systèmes éducatifs, influencés par nos corsets juridiques, aveuglés par nos propres enjeux, nous avons tendance à penser les entreprises et les organisations d'une façon trop linéaire, simpliste et rigide. Nous avons pris l'habitude de penser droit mais nous marchons en rond [http:// www.systemique.com/la-systemique/decouvrir/ pourquoi-sinteresser-a-la-systemique-desorganisations.html] (16.9.2015)

Une réforme manquée l'est deux fois : parce qu'elle rate sa cible, et parce qu'elle avoue que le gouvernement qui l'a promulguée n'est pas capable de penser droit [http://www.marianne. net/agora-reforme-du-college-caramba-encoreratee-100232458.html] (16.9.2015)

J'aime les gens qui réfléchissent, mettent en relation, pensent droit, sont droits moralement parlant, et Laurent est de ceux-ci [http:// j-ai-du-louper-un-episode.hautetfort.com/ archive/2012/10/10/laurent-pinsolle-41-livrespour-comprendre-la-crise.html] (16.9.2015)

Que sont les forces anciennes? Ce sont ceux qui se pensent droits et veulent imposer leurs propres arrangements pour les êtres [http://fr. minghui.org/articles/2015/1/26/50991p.html] (16.9.2015)

REMARques : Penser droit désigne le fait d'avoir un jugement, de raisonner juste, droit, c'est-àdire conformément à la raison, sain. Droit peut également référer à la franchise, à l'honnêteté des réflexions du sujet. Notons la collocation droit et juste (exemple de 1933) et le rapport établi entre penser droit et décider juste (exemple de 1911). Dans le premier exemple du CW, droit adopte son sens spatial directionnel, s'opposant à en rond. Droit reste invariable dans son emploi adverbial. Toutefois, en tant que prédicat second, il peut s'accorder avec le sujet (v. le quatrième exemple du CW, où le verbe apparaît dans son emploi pronominal 'penser être droit').

\section{Penser dur}

Penser avec sévérité, avec fermeté

Intransitif

1959 Revu et adapté, magistralement, par un écrivain qui parle cru, qui écrit dru, qui pense dur (France observateur, 27 août 1959 / Grundt : 326)

\section{CORPUS WEB :}

Message a tout ceux qui pensent dur comme fer que $\mathrm{C} 2 \mathrm{C}$ seront parmi nous a Beauregard ! Ils seront au Main Square Festival (Arras) ce même WE... [https://fr-fr.facebook.com/ festivalbeauregard/posts/545032262181486] (16.9.2015)

Hey chers humains, pourquoi les têtes de linotte pensent dur comme fer en votant?

le FN ça résoudrait tous les problèmes de la France hein ? [https://fr.answers.yahoo.com/ question/index?qid=20130710014040AA4wCqZ] (16.9.2015)

Il m'a fait pensé à ces petits bums qui se pensent dur, mais qui en réalité sont de vrais bébés [http://gakuenpokemon.forumactif.org/ t2534-des-petites-habitudes-marquees-par-desimprevus-pv-libre-1-filleevolution] (16.9.2015)

Puisqu'il s'agit de combat, parlons en, la tolérance s'est instauré contre ce qui de combats d'idées (ou autres motifs) se dévoyait en luttes armées, la tolérance s'est instaurée contre la violence. Car ce n'est pas un sentiment vague ou un laxisme des mœurs ou que sais-je d'un peu trop mou vilipendé par les semi durs qui se pensent durs [http://www.thomas-aquin.net/PHPhorum/ read.php? $\mathrm{f}=6 \& \mathrm{i}=28969 \& \mathrm{t}=28969 \& \mathrm{~V}=\mathrm{t}](16.9 .2015)$

REMARQUeS : Dans l'exemple de 1959, penser dur désigne le fait d'avoir des idées exprimant un manque de cœur, de bonté ou de douceur et par extension, il signifie, 'critiquer sévèrement par la pensée'. Remarquons la série parler cru, écrire dru, penser dur. Dans les deux premiers exemples $\mathrm{du} \mathrm{CW}$, la collocation usuelle dur comme fer, formée sur la base de croire dur comme fer, équivaut à penser fermement. Dur est alors invariable. Les 
deux derniers exemples représentent des prédications secondes qui sont typiques des verbes $\mathrm{du}$ dire et assimilés : une personne pense qu'elle est dure. La prédication seconde entraine l'accord, normalement, mais celui-ci manque dans l'avant-dernier exemple.

\section{Penser faux}

Penser de manière fausse, inexacte, contraire à la vérité Intransitif

1738 Revenu enfin à moi-même, je retournai chez moi méditer profondément sur des minuties, penser faux sur tout ce qui m'arrivait, et m'affliger jusques au retour d'Hortense (Alexandre Dumas fils, Les Égaremens du cœur et de l'esprit)

1763 Et pourquoi seroit-il plus difficile en poësie de penser juste que de penser faux? (Jean-François Marmontel, Poétique française)

1936 Celui qui achèverait cette belle pensée serait lui-même fou et ne saurait pas qu'il l'est. Il faut donc rebondir de là et se reprendre. On pense faux comme on chante faux, par ne point se gouverner (Alain, Propos)

1949 Que voulez-vous que les gens, et en particulier les jeunes, retirent de la lecture de Baudelaire? Ils y apprendront à penser faux, et les plus avisés à penser que la vérité n’a pas d'importance, comptant seule la manière dont est tournée une phrase ou un vers (Marcel Aymé, Le Confort intellectuel)

\section{CORPUS WEB :}

Ils pensent faux dans l'économique et le social mais ils pensent «bien » dans le sociétal ... ils sont partout à contresens et ceux, rares, qui en ont un peu conscience n'arrivent pas à se débarrasser des réflexes de leur passé socialiste! [http://bienpensance-penserfaux.eu/index. php/10-blog-bien-pensance] (16.9.2015)

Ils sont aussi exaspérants les uns que les autres car ils parlent et agissent sans penser et quand ils prétendent penser, ils pensent faux ! [https://fr-fr.facebook.com/notes/alain-teysson ni\%C3\%A8re-de-gramont/bien-pensance-et-pen ser-faux-entre-gaucho-popu-gaucho-bobo-etpopu-de-droite-que/238990206245849] (16.9.2015)

Les gens qui pensent faux, pensent donc l'inverse de cette souffrance qui me hante à en devenir gothique [https://www.facebook.com/ UnPeuDeToutMaisDuStyleParDessusTout/posts/ 415205381877501] (16.9.2015)

Remarques : Penser faux désigne le fait de former des pensées erronées, non conformes à la réalité, contraires à la vérité, à la vraisemblance. Notons l'emploi de chanter faux et penser juste, ce dernier en opposition avec penser faux, de même que penser 'bien' ('comme il faut') au premier exemple du CW. Faux reste invariable.

\section{Penser fort}

Penser beaucoup, avec une grande intensité

Transitif

+1225 Et il a un lai mout parfont Environ, et si estoit lés Bien .ii. arciés ; ne delés Ne voit nule nés u passer Peüst. Il commence a penser Mout fort ice k'estre pooit (Le Chevalier as deus espees [ $2^{\mathrm{e}}$ quart $\left.\left.\mathrm{XIII}{ }^{\mathrm{e}}\right], 6311\right)$

Intransitif

+1313 Le ceualiers pensoit moult fort Et si prendoit moult grant confort En la proumesse qui proumisse Li iert, si a s'entente misse En recorder les mols plaissans Dou uiellart, si fu cois taisans (Jean de Condé, Poèmes [1313-1337], 2217)

+1365 Je ne sui onques si lie, Ne de coer si envoisie, Que quant je voi fort penser Celi qui d'amer me prie, Car toute merancolie Li affiert bien à porter (Jean Froissart, Poésies [3e tiers XIV]])

+1400 Mais les autres chantoient a l'estrive. Et quant je vi celle si ententive A fort penser, doubtay que maladive Fust ou doulente, Car palie trop estoit et moult lente A soulacier, peu y avoit s'entente 
(Christine de Pisan, Le Livre du dit de Poissy / EEuvres poétiques [début Xve], II, p. 186, 911)

\section{CORPUS WEB :}

J'avais envie de m'allonger sur un éléphant et de penser fort comme tout à cette lettre et à ces droits bafoués. j'avais envie d'écrire appuyé contre un glacier et les yeux dans la vague [http:// sum96girl96.skyrock.com/759177913-Il-y-a-sure ment-des-pays-qui-valent-le-coup.html] (16.2.2015)

Aujourd'hui les Hurleuses sont tristes et pensent tres fort a nos copines Sand' et Toinnette [http://forum.magicmaman.com/magicmaman/ conception-bebe/hurleuses-sandjazz-toinnettesujet-3668226-1.htm] (16.9.2015)

Le truc qui me saoule c'est juste des gens qui se pensent fort alors qu'ils sont nul, c'est comme Tsukiyo qui se croit plat 5 alors qu'il se fait PL, ça m'énerve ces joueurs qui surestimé leur niveau... [http://www.jeuxvideo.com/forums/1-191634928487-1-0-1-0-mon-dieu-les-mecs-qui-se-croitfort.htm] (16.9.2015)

3/4 des Français se pensent forts en orthographe, et vous ? Testez-vous [http://lci.tf1.fr/ france/societe/etes-vous-comme-3-4-des-francais -forts-en-orthographe-8578265.html] (16.9.2015)

REMARQues : Penser fort se dit du fait de s'absorber dans de profondes réflexions afin de trouver, par exemple, une réponse, une solution. Fort reste invariable dans son emploi adverbial. Toutefois, en tant que prédicat second orienté vers le sujet à côté du verbe pronominal, il peut s'accorder avec le sujet (v. le quatrième exemple du $\mathrm{CW}$, qui est à comparer avec le troisième exemple, non accordé), signifiant 'ils pensent être forts' (v. commentaire sous penser dur). Notons la collocation à fort penser en moyen français (exemple de +1400 , en analogie avec à vrai dire, à penser juste. Fort est modifié par moult, très.

\section{Penser global}

Penser au niveau de la planète, penser dans cette dimension

Intransitif

2015 D'où la nécessité aussi de " penser local pour agir global », c'est-à-dire de tenir compte des situations locales pour définir les règles d'action générales qui vont s'appliquer à elles (Marcel Jollivet, Pour une transition écologique citoyenne)

2016 En ce sens, notre stratégie digitale s'inscrit dans une démarche de "penser global pour agir local » (Anaïs Del Bono et Maréchal Guillaume, Le Financement participatif culturel)

REMARQues : Penser local pour agir global (2015) est un slogan qui en convertit un autre dans son contraire : penser global pour agir local (2016). Il s'agit d'un calque de l'anglais think global, act local.

\section{Penser haut}

I. Avoir une bonne opinion (sur quelqu'un), estimer beaucoup

Intransitif

+1225 Si li priai ke elë eüst

Par francise, se li pleüst,

Et pitié et merchi de moi.

Et ele demanda por quoi.

Et tant con le voir li gehis

Trestout, ele embroncha le vis.

Quant oï mot, et si ot honte,

Et s'esmerveilla de quel conte

J'avoie enpensé tel outrage,

Car je n'ere pas du lignage

Ke je si haut penser deüse (Le Chevalier as deus espees [ $2^{\mathrm{e}}$ quart $\mathrm{XIII} \mathrm{I}^{\mathrm{e}}$, 2829)

II. Avoir des pensées supérieures, élevées

Intransitif

+1365 Se j’ai pensé plus hault c'à moi n'afiere

Ne que tailliés ne soie de venir,

Pardonnés moi, pour Dieu, ma dame chiere (Jean Froissart, Poésies [3e tiers XIV]] )

1862 Allez, philosophes, enseignez, éclairez, allumez, pensez haut, parlez haut, courez joyeux au grand soleil, fraternisez avec les places publiques, annoncez les bonnes nouvelles, prodiguez les alphabets, proclamez les droits, chantez les Marseillaises, semez les enthousiasmes, arrachez des branches vertes aux chênes (Victor Hugo, Les Misérables)

1937 Il est mauvais de penser aux hommes en fonction de leur bassesse... - Quand on 
contraint une foule à vivre bas, ça ne la porte pas à penser haut. Depuis quatre cents ans, qui a « la charge de ces âmes », comme vous disiez ? Si on ne leur enseignait pas si bien la haine, ils apprendraient peut-être mieux l'amour, non ? (André Malraux, L'Espoir)

1948 Sa pensée jamais ne serait tout à fait fixée. Jusqu'à sa mort il attendrait de quelque découverte, de quelque hasard dialectique, les moyens de penser plus haut et plus loin (Jean Guéhenno, Jean-Jacques : En marge des Confessions)

III. penser tout haut : exprimer sa pensée à voix haute, ouvertement

Intransitif

1784 Le secret, je te prie, sur ce que je me doute du conseiller ; car je mourrais de honte devant un homme, fût-ce mon frère, qui saurait que j'ai eu ces idées-là: il n’y a qu'avec toi que je pense tout-haut ; parceque je sais comme tu es bonne, et que tu ne te moques de rien ; mais que tu prens tout au-sérieus, comme font toujours les bons cœurs (Nicolas Rétif de la Bretonne, La Paysanne pervertie ou Les Dangers de la ville)

1824 Jamais l'idée d'une infidélité ne lui étoit venue en tête, et il avoit toujours pensé tout haut avec elle. Il pouvoit revoir son bureau, mais revoit-on un être perdu pour toujours! (Honoré de Balzac, Annette et le criminel)

1904 Ils sont venus à elle : deux pauvres dos étriqués, rétrécis, de guingois, deux fronts piteux, à demi-levés pour implorer une entente miséricordieuse, - mais Mme Galant pensait trop haut, à ce moment-là, elle n’a rien vu (Léon Frapié, La Maternelle)

1930 Je suis si seul que je ne reconnais plus la forme exacte de mes mains

Et je sens mon cœur en moi comme une douleur étrangère.

Silence ! On ne peut pas offrir l'oreille à ces voix-là.

On ne peut même pas y penser tout bas
Car l'on pense beaucoup trop haut et cela fait un vacarme terrible (Jules Supervielle, Le Forçat innocent)

1950 Je les entends, un moment encore, se parler l'un à l'autre, à mots lents qu'ils prononcent sur eux-mêmes, pensant tout haut :

- Qué misère!

- C'qui faut qu'on voye!

Puis leurs voix se perdent dans l'éloignement, en même temps que, dans la nuit, leurs ombres

(Maurice Genevoix, Ceux de 14)

1987 « C'est peut-être pour ça, après tout, » reprenait-il à mi-voix et comme s'il pensait tout haut, "que je suis sorti de là et que je me promène avec toi : entre la vie et la mort, il ne faisait pas de différence » (Jean d'Ormesson, Le Bonheur à San Miniato)

\section{CORPUS WEB :}

PERSONNE, NADA, $0 \%$ de personne dira ce qu'elle pense haut et fort et que c'est vrai ! Tout les autres qui disent... non c'est tout faux, parce que si vraiment ces personnes diront ce qu'elles pensent haut et fort, en moins de deux, elles se retrouvent en tôle! [https://fr.answers.yahoo. com/question/index?qid=20100527015549AASA Q0S] (16.9.2015)

De l'autre, ses détracteurs pensent haut et fort qu'il a piétiné les valeurs du Real Madrid [http://www.butfootballclub.fr/1573056-realmadrid-les-joueurs-se-payent-la-tete-demourinho-dans-le-vestiaire/] (16.9.2015)

Depuis plus de dix ans maintenant, la compagnie Vilcanota dit tout bas ce que d'autres pensent tout haut [http://www.compagnievilcanota.fr/compagnie.html] (16.9.2015)

Entre eux et lui un abîme se creuse. Plus celui-ci est veule, bas, stupide, ignoble, immonde, laid plus ils se pensent hauts, beaux, courageux, intelligents, lucides, vertueux et vigilants surtout vigilants [http://antidoxe.eu/2013/03/16/dupersonnage-darlequin-au-beauf/] (16.9.2015)

Remarques : Penser haut (I) réfère au fait de penser du bien de quelqu'un, d'avoir une très bonne opinion de lui. En (II), il désigne le fait de former, de construire une idée se détachant 
par sa hauteur, sa brillance, le sujet démontrant ainsi une supériorité dans son intelligence, dans sa capacité de raisonnement. Sous (III), penser haut équivaut à dire ce qu'on a dans la tête, à ne pas garder ses pensées pour soi, à s'exprimer à voix haute, l'action pouvant être délibérée ou accidentelle. Notons que penser haut est renforcé par l'adverbe d'intensité tout, formant ainsi une locution figée. Il s'oppose à penser (tout) bas. La collocation tout haut a souvent la fonction de signaler que l'adverbe de lieu est pris au sens figuré pour désigner une qualité de la voix. Haut reste invariable dans son emploi adverbial. En tant que prédicat second, il s'accorde avec le sujet (v. le dernier exemple du CW, où le verbe figure dans son emploi pronominal 'penser être situé haut, etc.'). Il est modifié par plus, si, tout, trop. Notons les collocations plus haut et plus loin et haut et fort, ainsi que la série penser haut, parler haut, courir joyeux.

\section{Penser juste}

Penser avec justesse, avec exactitude, conformément à la vérité

Intransitif

1696 La prévention du pays, jointe à l'orgueil de la nation, nous fait oublier que la raison est de tous les climats, et que l'on pense juste partout où il y a des hommes : nous n’aimerions pas à être traités ainsi de ceux que nous appelons barbares (Jean de La Bruyère, Les Caractères)

1710 GÉRONTE. Et Léandre, et Damon, et Lolive, et Crispin, Je ne fai qui des quatre est le plus grand faquin.

(Il sort)

LOLIVE. Le vieillard pense juste, et moimême j'ai honte... (Philippe Destouches, Le Curieux impertinent)

1728 Autrefois, par exemple, je n'aurais pas pensé si juste sur une chose qui me frappe actuellement (Pierre de Marivaux, L'Indigent Philosophe)

1730 Les adjectifs se prènent aussi fort souvent adverbialement, come je l'ai remarqué en parlant des adverbes ; par exemple : parler haut, parler bas, parler grec et latin, [...] : penser juste, sentir bon, sentir mauvais, marcher vite, voir clair, fraper fort, etc. Ces adjectifs sont alors au neutre, et c'est une imitation des latins (César Du Marsais, Des tropes)

1735a Je le rapporte d'autant plus volontiers qu'il me donne lieu de faire connoître la belle et solide réflexion d'un auteur qui n'a pas toûjours pensé aussi juste (Nicolas Lenglet du Fresnoy, L'Histoire justifiée contre les romans)

1735b Les discours de cette dame portoient trop bien avec eux le caractére de la vérité, pour que je n'y fisse pas une sérieuse attention ; les suites me prouvérent bien-tôt après qu'elle avoit pensé juste, et que j'étois trop heureuse d'être guidée par une personne aussi éclairée (Charles de Mouhy, La Paysanne parvenue)

1738 Cependant, commeil n'est point d'opinion, quelque claire qu'elle paroisse, qui ne puisse avoir des difficultez qui échappent à ceux qui lui donnent leur consentement avec une confiance qui empêche qu'on ne sente la force des objections, je te serai obligé, mon cher Isaac, de me dire ton sentiment. Je me croirai plus fondé dans mon opinion, lorsque je saurai qu'elle a ton approbation. Et si tu juges, que je ne pense pas juste, je tacherai de me défaire de mes préjugés, et de gouter tes raisons (Jean-Baptiste d'Argens, Lettres juives ou Correspondance philosophique, historique et critique)

1740 Vous pensez juste, et nous poussons même la galanterie jusqu'à vous exhorter à retourner bien vîte au lieu d'où vous venez, prendre celles que nous jugeons vous avoir mis de si belle humeur (Jacques de Varenne, Mémoires du chevalier de Ravanne)

1744 Il ne pensoit que trop juste; cependant je le priai au nom de toute notre amitié d'intéresser sa chère Clara en ma faveur, et de lui faire une vive peinture de mes feux, pour être fidellement raportée à son amie 
(Jean-Baptiste Jourdan, Le Guerrier philosophe)

1802 De là ce latin moderne, connu sous le nom de latin de l'école, qui subsistoit encore à peu près sous la même forme dans nos études de théologie, de philosophie, de jurisprudence. Car il est des langues dans lesquelles on ne peut penser juste sans parler mal (Louis de Bonald, Législation primitive)

1839 C'était peut-être la sixième fois ; il disait que c'était la deuxième, mais qui pense pis pense souvent juste. Quand j'en serai là, je me regarderai comme un dieu, et j'emmerderai le collège de la meilleure grâce du monde (Gustave Flaubert, Correspondance)

1866 il est également évident qu'on voit plus vrai d'en haut que d'en bas, et qu'on pense plus juste sur la montagne que dans les quatre murs d'une cellule de la ville (HenriFrédéric Amiel, Journal intime de l'année 1866)

1890 Ce danger-là ne nous regarde plus. Nous n'avons, nous, qu'à penser juste si nous pouvons, et à dire ce que nous pensons (Paul Bourget, Physiologie de l'amour moderne)

190721 mai. Je voudrais me jeter dans le rêve ou bien aller à mon travail, je vais me contraindre à voir. Je voudrais penser juste, voir juste. Il en sortira toujours quelque chose. J'écoute Pelletan ou un autre (Maurice Barrès, Mes cahiers)

1936a D’où l'on aperçoit une parenté admirable entre penser vrai et penser juste. Disons seulement que bien penser est une chose que l'on se doit à soi-même, et qu'il faut vouloir (Alain, Propos)

1936b Penser juste : penser vrai, n'est-ce pas la même chose que penser juste? Non certes ; les belles métaphores ne trompent point. La justice serait donc au-dessus du vrai ? Oui, sans doute (Alain, Propos)
1941 Portée par la force de l'habitude, elle donna la réplique :

- Si je pense ainsi, je pense la même chose de vous.

- Alors, dit Éric Vidame, vous pensez juste, je ne suis pas ce que je suis

(Georges Duhamel, Suzanne et les jeunes hommes)

1965 Le père m’a prêté un costume noir ; le pantalon m'arrive au milieu des jambes. Pendant la cérémonie, très courte, je pense très juste, très fort et très vite. Je n’agis pas par inconscience en épousant Rosita (Jacques Perry, Vie d'un païen)

II. à penser juste : à vrai dire, en pensant à la réalité

1885 Un garçon qui les rencontre leur doit au moins un baiser ; et s'il ne prend pas plus, il n'est qu'un sot. À penser juste, cette manière de voir est la seule logique et raisonnable (Guy de Maupassant, Contes et nouvelles)

\section{CORPuS WeB :}

On la trouve notamment dans le Canon de la Messe où l'on prie Dieu de pacifier, de garder, de réunir et de gouverner son Église dans tout l'univers, de concert avec son serviteur notre pape (N) et notre évêque (N) et tous ceux qui pensent juste, et surtout cultivent la foi catholique et apostolique [http://users.skynet.be/histcult/una $\% 20$ cum.htm] (16.9.2015)

Et que si les actions justes, ou bonnes, ou belles, sont si peu nombreuses, c'est que ceux qui seraient capables de les accomplir ne sont pas ceux qui sont capables de les penser justes, ou bonnes, ou belles [http://forum.davidmanise. com/index.php?topic=42582.25] (16.9.2015)

Les gaucho se disent humaniste, les mecs de droite se pensent juste [http://anaboten.kanak.fr/ t641-les-pokemon-c-est-bien-le-sexe-c-est-mieu] (16.9.2015)

Beaucoup de personnes se pensent justes et assez gentilles pour mériter la faveur de Dieu et ainsi accéder au paradis lorsque l'heure sera venue... [http://freemessageblog.blogspot. co.at/2012/04/blog-post.html] (16.9.2015) 
De la même façon, j'invite ceux qui le peuvent et le pensent juste, à donner plus que le tarif proposé, afin de faciliter le fait que je puisse aider ceux qui ne peuvent assumer ce tarif [http:// www.brigitteguebet.com/tarifs.html] (16.9.2015)

Remarques : Penser juste (I) désigne le fait de penser, de réfléchir avec justesse, les pensées aboutissant à des conclusions correctes, logiques. Notons la locution à penser juste 'à bien y réfléchir' (II). Juste reste invariable dans son emploi adverbial, mais en tant que prédicat second ('une personne pense qu'elle est juste'), il s'accorde avec l'élément vers lequel il s'oriente : dans le dernier exemple du CW avec l'objet, mais dans le quatrième exemple du $\mathrm{CW}$ avec le sujet-objet de la construction pronominale. L'accord ne se fait pourtant pas dans le troisième exemple du CW. Le dernier exemple réfère à un tarif censé être juste, adéquat. Juste est modifié par aussi, plus, si, souvent, très, trop.

\section{Penser local}

Penser au niveau local ; penser dans cette dimension

$\pi$ penser global

\section{Penser long}

en penser long : réfléchir profondément, avoir une opinion bien établie sur quelque chose, souvent défavorable

Intransitif

1834a Sacrebleu ! J'espère que voilà une démonstration. Tu vois mon cher que je ne suis guère amoureuse pour le moment. Quand je le suis, je n'en pense pas si long (George Sand, Correspondance)

1834b Je ne sais guère si je suis en progrès, je sais que je travaille assidûment pour faire honneur à tous mes engagements, je n'en pense pas plus long, que le monde en dise le bien et le mal qu'il voudra (George Sand, Correspondance)

1880 Elles ne disent rien, parce qu'il y a la pudeur, tu comprends... mais sois sûr qu'elles en pensent joliment long (Émile Zola, Nana)

1902 Et il ne se réjouissait pas, comme l'eût fait un autre ; il ne se réjouissait pas ; mais il ne pouvait pas s'en aller de là, ni poser les yeux sur un autre objet. D'ailleurs, il n'en pensait pas long (René Boylesve, La Leçon d'amour dans un parc)

1936 ils n'en pensent pas plus long, ce sont des courtisans de tout (Alain, Propos)

1958 Zaza me confia aussi que Mme Mabille - à qui elle attribuait des trésors de charme, de sensibilité, de fantaisie - avait souffert de l'incompréhension d'un mari ennuyeux comme un livre d'algèbre; elle en pensait beaucoup plus long; je me rends compte aujourd'hui qu'elle éprouvait pour son père une répulsion physique (Simone de Beauvoir, Mémoires d'une jeune fille rangée)

\section{CORPUS WEB :}

Les nombreux français tentés par le vote pour le Front national en pensent long et de même à l'opposé, les « quartiers " [http://www. huffingtonpost.fr/charles-rojzman/charlie hebdo-un-unanimisme-suspect_b_6434298. html] (16.9.2015)

demain je repars chez le doc mais pour autre chose. C'est comme un ras le bol qui s'installe malgré un bon moral, quelquefois j'en pense long !!!!!! [http://www.weightwatchers. $\mathrm{fr} /$ community $/ \mathrm{mbd} /$ post.aspx? page_size= 25\&rownum $=3 \&$ threadpage_no $=1 \&$ sinceda te $=21 \% 2 \mathrm{~F} 02 \% 2 \mathrm{~F} 2011+00 \% 3 \mathrm{~A} 00 \% 3 \mathrm{~A} 00 \& \mathrm{th}$ read_id=10330868\&board_id=590\&forum id $=1 \&$ thread_name $={ }^{\star \star \star \star \star \star}$ LES + SUPERS + PIP ELETTES + DU $+22 \% 2 \mathrm{~F} 02 \% 2 \mathrm{~F} 2011^{\star \star \star \star \star} \&$ mod $_{-}$ no $=\&$ daterange $=2$ days \&v]iewchange $=$ OPEN DATEDESC (16.9.2015)

REMARQUES : En penser long se dit du fait de réfléchir longuement sur quelque chose. Long reste invariable et est modifié par beaucoup plus, joliment, plus, si. Utilisé souvent à la forme négative, la locution lexicalisée conserve l'emploi de long comme adverbe de temps, qui était usuel en ancien français.

\section{Penser menu}

Penser au moindre détail

$\lambda$ broder menu 


\section{Penser négatif}

Ne penser qu'aux aspects négatifs ; contraire de penser positif

$\pi$ penser positif

\section{Penser net}

Penser sans détour, avoir une pensée claire Intransitif

1880 L'abbé Huet pensa net et causa franc jusqu'à la fin. Il n'était pas plus beau parleur que jadis (Paul Féval, Les Étapes d'une conversion)

1999 Il pense pour moi, il pense bien, il pense juste, il pense net, il pense tout et surtout il pense ordonné comme tout bon ordinateur se doit de faire (Jean Gérard Dubois, Gaste-Papier, songe malice et brouille-mémoire du temps qui passe)

\section{Penser neuf}

Renouveler sa façon de penser

$\lambda$ penser positif

\section{Penser ordonné}

Avoir de l'ordre dans ses idées

$\lambda$ penser net

\section{Penser petit}

I. Penser peu (à quelque chose/quelqu'un) Intransitif

+1225 « Ne n'i voeilliés onaues penser. » «Biaus oncles, g’i pense petit, » Dist il. Et la roïne a dit $\mathrm{Au}$ roi et le trait d'une part : "Sire, il est bien droit quë om gart Vostre neveu miex que devant » (Le Chevalier as deus espees [2 $2^{\mathrm{e}}$ quart XIII $]$, 3417)e

1285a Au trompeeur petit penserent Et legierement s'en passerent, Pour ce que cil qui marchissoient Entour aus leur sougit estoient, Et pensoient k'a la mellee Vers aus n'aroit nus rois duree (Adenet le Roi, Cleomadés, 2415)

1285b Et Cleomadés s'en ala, Qui mout tres petit aconta Se il furent lié ou dolant ; A ce aloit petit pensant,
Car tout adés li souvenoit

De Clarmondine, et bien baoit

$\mathrm{Li}$ a reveoir temprement

(Adenet le Roi, Cleomadés, 3994)

II. Avoir des idées étroites, limitées, peu élevées Emploi absolu

1928 Il pensait petit, et la grandeur qui n'est ni en place ni en fonction ne le touchait pas

(Léon Daudet, Écrivains et artistes)

\section{CoRpus Web :}

Le Lion n'aime pas les gens qui pensent petit et qui agissent petit [https://www.facebook.com/ permalink.php?id=461804233962838\&story _ fbid $=592831747526752]$ (16.9.2015)

\section{AEROPORTS QUI PENSENT PETIT}

Quand on voyage avec de jeunes enfants, chaque correspondance ou retard semble durer une éternité. Conscients du problème, les principaux aéroports canadiens ont tous prévu des zones de détente pour les gamins impatients et leurs parents harassés [http://selection.readersdigest. $\mathrm{ca} /$ voyage/voyage-en-famille/7-aeroports-quipensent-petit/\#jAiKzcBzdPtFCtHH.97] (16.9.2015)

Quand les gros animaux se pensent petit [https://sagittairi.wordpress.com/2015/01/20/ quand-les-gros-animaux-se-pensent-petit/] (16.9.2015)

Les Canadiens se pensaient petits face aux États-Unis qui avaient une population 10 fois plus grande qu'eux [http://davidgrade9. weebly.com/mes-apprentissages/category/ histoirehistory218dcad90a] (16.9.2015)

REMARQUES : L'ancien français employait couramment petit comme quantifieur équivalent à 'peu' en français moderne. Penser petit (I) signifiait donc tout simplement 'penser peu'. Cette fonction ayant disparue, ou presque, petit connaît une remotivation par rapport à sa signification adjectivale. C'est ainsi que l'exemple de 1928 et le premier exemple du CW réfèrent à une façon de penser très limitée, bornée, sans ambition, suggérant une étroitesse d'esprit proche du mesquin. Petit reste invariable dans son emploi adverbial. Le titre d'un article cité au deuxième exemple en $\mathrm{CD}$ reflète le fait de penser aux enfants dans la formule penser (aux) petit(s). On obtient ainsi un titre très suggestif qui copie les 
slogans de style publicitaire. Les deux derniers exemples illustrent l'emploi usuel des verbes $d u$ dire et assimilés au sens de 'penser être petit'. Dans ce cas de figure, l'accord est la règle, mais l'avant-dernier exemple s'en écarte.

\section{Penser positif}

Penser de façon positive, optimiste, en ne considérant que les aspects positifs

Emploi absolu

1995 On applaudit et on continue à penser positif, on se force à croire à des demain d'espoir, malgré la mort, le chômage, les techniciens qui manifestent dans la rue (Philippe Delannoy, Cyril Collard: l'ange noir)

1996 Penser neuf, penser positif pour changer de vie et changer la vie, tel nous semble être le secret de tout vrai changement (Thomas Boya et Jérôme Carlos, Pensez neuf, pensez positif)

2018 Penser positif, c'est d'abord penser moins négatif. Avant de songer à penser positif pour attirer le positif, nous pouvons déjà envisager de penser moins négatif pour attirer moins de négatif ! En prenant conscience de notre façon de penser, nous pouvons réduire nos plaintes (Xavier Cornette de Saint-Cyr, Les Secrets de la loi de l'attraction)

\section{CORPuS Web :}

Merci d'avoir écrit se blog cela ma permis de comprendre que penser positif est le meilleure remède pour aller mieux, je n'ai que 17 ans et je déprime souvent a cause de gens qui me juge mes grâce a votre blog j’ai compris qu'il faut avancer dans la vie malgré que ses dure, penser positive va me faire le plus grand biens merci encore [http://guerir-l-angoisse-et-la-depression.fr/ pensee-positive] (28.12.2013)

Remarques : Penser positif fait partie du discours sur le mode de vie, prodigué notamment en tant que conseil (ex. de 1996, 2018). Il est le contraire de penser négatif. D’autres critiquent cette attitude (ex. de 1995). Nous ne citons pas ses nombreuses occurrences dans le domaine de la philosophie, où penser positif renvoie au courant positiviste. L'emploi accordé (CW) est plutôt rare.

\section{Penser profond}

Penser profondément, de manière approfondie

et intelligente

Intransitif

1583 Desjà son nouveau mal paroist dessus son front,

Puis ses brûlans soupirs et son penser profond,

Ses yeux mal asseurez, son inconstant langage,

Monstrent les passions qui troublent son courage

(Philippe Desportes, Élégies / Euvres)

1801 Toutes les jolies et fines pensées de madame de Sévigné et de Marivaux ne valent pas un Penser profond de Pascal ou de Montesquieu : vous sentez l'opposition! (Louis-Sébastien Mercier, Néologie, s.v. penser)

1855 Tout enfant, il [= Dante] aime et pense profond, il compose des vers qui émeuvent (Nouvelle Biographie générale)

1944 - Mon garçon était un nègre qui pensait profond, dit Délira avec fierté (Jacques Roumain, Gouverneurs de la rosée)

1953 Tout ceci montre en Napoléon une bonne tête, et qui sait penser profond et juste (Claude Roy, Le Commerce des classiques)

CORpus Web :

Oui rien de plus normal que Polony soit taxée d'idéologue par Caron et Salamé, c'est en général la formule critique qu'appliquent les intellos du surface à ceux qui pensent profond [http://www.purepeople.com/article/natachapolony-et-eric-naulleau-demolissent-aymericcaron_a155089/1] (16.9.2015)

On a aussi des héros qui pensent profond puisqu'on hérite de répliques cultes comme : « tu me troues l'cul Marty » ou « en tant qu'enveloppe charnelle sensible, aussi illusoires que soient nos identités, on les forge en portant des jugements de valeur sur notre environnement " [http:// www.senscritique.com/serie/True_Detective/ critique/58538550] (16.9.2015)

Les gens qui se pensent profonds alors qu'ils ont un pois chiche dans la tête [http://www. jeuxvideo.com/forums/42-50-38919961-2-0-1-0- 
les-types-de-personnes-que-vous-meprisez-leplus.htm] (16.9.2015)

REMARQUES : Penser profond désigne le fait de réfléchir profondément, le sujet démontrant ainsi son intelligence, sa grandeur d'esprit. Il était particulièrement fréquent sous sa variante nominalisée jusqu'au XIX ${ }^{e}$ siècle (ex. de 1583 et 1801). Notons la collocation penser profond et juste. Profond reste invariable dans son emploi adverbial. En tant que prédicat second ('une personne pense qu'elle (ou un autre) est intellectuellement profonde'), il s'accorde avec l'élément auquel il réfère. C'est ainsi qu'il s'accorde avec le sujet du verbe pronominal dans le troisième exemple $d u$ CW. Mentionnons l'emploi de aimer profond.

\section{Penser simple}

Penser sans compliquer les choses

$\pi$ voir simple

\section{Penser stratégique}

Évaluer une situation, un environnement pour réaliser des objectifs futurs

Intransitif

2009 Toute la question de l'UE [= Union européenne] et des Européens est de pouvoir "penser stratégique »(Quelle politique de sécurité et de défense pour l'Europe)

\section{Penser universel}

Penser dans une dimension universelle

$\lambda$ penser cosmique

\section{Penser utile}

Penser dans le but d'obtenir un avantage

$\pi$ baiser utile

\section{Penser vrai}

Former des idées justes, exactes, conformes à la vérité, à la réalité

Intransitif

1160 Par grant angin lo fist Paris, Que il lor a lo terme mis : Porpansa soi que antretant L'an vanroient ofres avant, Et porroit an de son prou faire. Eles se mistrent el repaire. Voir ot pansé ; Juno premiere Est revenue a lui ariere,
Et promist li car li donroit

Plus que ses pere ne avoit (Eneas, 137)

1696 Qu'un favori s'observe de fort près ; car s'il me fait moins attendre dans son antichambre qu'à l'ordinaire, s'il a le visage plus ouvert, s'il fronce moins le sourcil, s'il m'écoute plus volontiers, et s'il me reconduit un peu plus loin, je penserai qu'il commence à tomber, et je penserai vrai (Jean de La Bruyère, Les Caractères)

1789 D'autres s'en rapprocheront plus ou moins, selon leur force et selon les circonstances, ou bien s'en écarteront par mauvaise foi ; et alors nous souffrirons ce que nous ne pouvons pas empêcher. Si tout le monde pensait vrai, les plus grands changements, dès qu'ils présenteraient un objet d'utilité publique, n’auraient rien de difficile (Emmanuel Sieyès, Qu'est-ce que le Tiers état ?)

1856 Il y a de l'abdication dans cette espèce de progrès-là. Non. Visons haut, pensons vrai, marchons droit. Les à-peu-près ne suffisent plus. Tout se fera ; et tout se fera en un pas, en un jour, en un seul éclair, en un seul coup de tonnerre (Victor Hugo, Actes et paroles)

1907 La pensée est un monde, l'action en est un autre. Quelle nécessité de se rendre victime de ce qu'on pense ? Penser vrai : certes ! Mais à quoi bon dire vrai ? Puisque les hommes sont assez bêtes pour ne pouvoir supporter la vérité, faut-il les y forcer? (Romain Rolland, Jean-Christophe. La Révolte)

1915 Ce serait un suicide aussi. Parleriez-vous de crime ? Marsal, je ne fais pas autre chose, et ma conscience est parfaitement tranquille. D'ailleurs, ce n'est pas la vôtre qui me parle. Ce sont vos préjugés. Je l'ai remarqué depuis longtemps. Vous n'osez pas penser vrai. Moi, j’ai appris de mon père d'abord, puis de mon mari, à penser vrai. Tenez, voulez-vous que je vous dise sa pensée, à mon mari, sur le suicide ? (Paul Bourget, Le Sens de la mort) 
1936 Il vaudrait mieux se demander si le quart de cercle et le théodolite sont vrais ; car ce sont des instruments pour saisir mieux ; et toutes nos idées de même sont des instruments pour saisir mieux ; et penser vrai c'est saisir mieux (Alain, Propos)

\section{CORPuS WEB :}

Paul considère qu'il est important de penser vrai avant toutes autres choses [https://www. lueursdumatin.fr/penser-vrai-2] (17.9.2015)

OUF ! Un condensé de pures vérités. Que ces conservateurs qui votent en ne pensant qu'à eux, pour leur «petite personne » écoutent, réécoutent et, surtout, réfléchissent et pensent vrai ! [http:// www.franceinter.fr/emission-parenthese-lacause-humaine] (17.9.2015)

Les mec qui se pensent « vrai » car ils refusent d'écouter les artiste qui passe en radio [http:// www.jeuxvideo.com/forums/1-50-164896248-6130-1-0-qui-est-amoureux-ici-coeur.htm] (17.9.2015)

Finalement, les deux petits saints qui se pensent vrais et intègres [http://www.domaine bleu.ca/vol-920-f208/emission-du-dimanche-9novembre-2014-t99884-120.html] (17.9.2015)

Remarques : Penser vrai désigne le fait de réfléchir avec justesse, les pensées aboutissant à des conclusions réalistes, conformes à la réalité. Quelqu'un qui pense vrai ne se ment pas à luimême et ne tente pas d'enjoliver la réalité. Vrai reste invariable dans son emploi adverbial. En tant que prédicat second ('quelqu'un pense être vrai'), il s'accorde avec l'élément auquel il se rapporte, comme dans le quatrième exemple du CW, où vrai est coordonné avec intègre. En revanche, l'accord ne se fait pas dans le troisième exemple du CW. Mentionnons la devise Visons haut, pensons vrai, marchons droit.

\section{Percer dur}

Toucher, affecter profondément

Transitif

1953 La moindre ligne de l'admirable Chamfort, la plus brève page du grand Léopardi percent le cœur loin et dur (Claude Roy, Le Commerce des classiques)

\section{CORPUS WEB :}

Alors pour que la chignole ne fasse plus de bruit, et surtout qu'on puisse faire croire que le trou, il ne se creuse plus, on l'a jetée aux orties, avec surtout un bel effet d'annonce. Sauf que c'est pour remplacer le joujou qui coûte cher et perce dur et vite par un autre, qui fera la même chose, mais portera un autre nom [http:// sarkostique.over-blog.com/article-sarkozyenterre-le-bouclier-fiscal-pour-caliner-les-plusriches-68590252.html] (17.9.2015)

" le rap beninois perce dur moi je suis en russie a moscou et je sais de quoi je parle sincerment le rap beninois a un niveau non negligeable moi $\mathrm{mm}$ en tant que rapeur je suis fier de mon pays bravo les gas du courage...... » [http://m. voluncorp.com/news-article-547-top--artistesrappeurschanteurs-ayant-plus-de-fans-sur-leurpage-facebook-.aspx] (17.9.2015)

Brenna Benson percée dur par une énorme bite [http://www.pornodingue.com/videos/ breanna-benson-percee-dur-par-une-enormebite/] (17.9.2015)

REMARQUES : Lorsque l'objet réfère au cœur ou à l'âme, percer dur désigne le fait de les affecter, de les toucher profondément, la blessure étant psychologique et non physique (exemple de 1953). Au sens concret, il se dit de creuser, traverser quelque chose, en y faisant un trou. Ceci est transposé au plan figuré par rapport à l'effet d'une mesure prise (premier exemple du CW) ou par rapport à l'effet d'une musique. Dans le dernier exemple du CW, percer dur apparait dans un contexte sexuel, s'appliquant au pénis qui pénètre le corps féminin. Dur reste invariable. Mentionnons la collocation loin et dur.

\section{Percer net}

Transpercer d'un seul coup

Transitif

1596 Et ne fust que du coup Roger brisa son bois, Il luy perçoit tout net le corps et le harnois (Philippe Desportes, Euvres)

\section{CoRpus WeB :}

malheureusement quand on perce au pistolet ça arrche la chair au lieu de percer net et ça peut faire comme une petite brulure au point d'entrée [http://www.beaute-test.com/forums/ index.php?topic $=278396 \&$ start $=0](17.9 .2015)$

Le puncher déformait tellement les cartos, au lieu de les percer net, qu'ils ne rentraient plus 
dans mon tank [http://www.forum-ecigarette. $\mathrm{com} /$ coin-nouveaux-f92/presque-tout-mes-cartoont-le-gout-de-cramer-t115707-20.html] (17.9.2015)

Retour dans votre plus tendre enfance pour une petite séance de picotage, en fait il s'agit de percer la feuille de plomb sur le côté lisse de la semelle au moyen du poinçon... la pression doit être suffisante pour percer net la feuille sans pour autant passer au travers de la semelle, sinon prenez une grande respiration, un calmant et au dodos [http://maquette-garden.forumactif.com/ t24718-realisation-de-rivets] (17.9.2015)

La poche peut soit se percer nette en bas auquel cas c'est l'équivalent d'un verre d'eau qui sort d'un coup, soit se percer plus haut ou se fissurer et généralement ça sort quand tu bouges (ça fait bouger la tête du bébé et hop ça sort) (enfin, c'est ce qu'on m'a expliqué) [http://www. magrossesse.com/vb_forum/futures-mamansde-avril-f65/poche-des-eaux-t520841] (17.9.2015)

Remarques : Percer net désigne le fait de traverser de part en part, en faisant un seul trou, par exemple à l'aide d'une arme lorsqu'il s'agit de transpercer un adversaire, un ennemi, un rival. L'objet qui perce net ne rencontre aucune résistance qui entrave l'action, produisant ainsi un trou aux contours nets. Net reste invariable dans la majorité des cas (v. le deuxième et le troisième exemple du $\mathrm{CW}$ ). Dans le quatrième exemple du $\mathrm{CW}$, il s'accorde avec le sujet au féminin du verbe pronominal à sens passif, tout en gardant son interprétation adverbiale. Il est modifié par tout.

\section{Percevoir net}

I. Recevoir une somme d'argent toutes taxes déduites

Transitif

1822 et c'est sur 51,000,000 sortis tous les ans de la bourse des victimes, que le trésor perçoit net moins de 10,000,000 !!! (Guérard de Rouilly, Du système financier)

1969 En général le couple travaille et perçoit net par an 60.000 francs (1968) (Otto Georges Weiss, L'Économie française)

II. Percevoir, entendre clairement, distinctement, avec netteté et précision Transitif

1923 Son oreille, professionnelle malgré lui, suivait au fond de la poitrine sonore le moelleux va-et-vient vésiculaire, et percevait, lointain mais net, le tic-tac généreux $\mathrm{du}$ cœur (Roger Martin du Gard, Les Thibault. La Belle Saison)

\section{CORPUS WEB :}

Si l'œil a un champ de vision nette très étroit, il balaye un paysage d'un mouvement continu extrêmement rapide, ce qui donne l'impression de le percevoir net dans sa totalité [http://www. panoram-art.com/blog/2015/06/] (17.9.2015)

Une fois ce rond central stable (Figure 6) sans l'aide de la pince, on rapproche lentement le test le plus près possible des yeux, en marquant des temps d'arrêt, toujours en continuant de le percevoir net [http://orthoptie.net/ceres/varia/ varia06/fumoleau.html] (17.9.2015)

Mécanisme réflexe qui ajuste la puissance oculaire afin de percevoir net les objets à des distances variées [Archive.bu.univ.-nantes.fr/ pollux/fichiers/download] (17.9.2015)

L'œil doit faire un effort de mise au point par l'intermédiaire du cristallin pour déplacer l'image sur la rétine et la percevoir nette [http:// www.docteurmihaylova.com/hypermetrope. html] (17.9.2015)

REMARQUES : Percevoir net (I) réfère à une somme d'argent effectivement reçue et libre de taxes et de charges. En (II), il désigne le fait de saisir, de percevoir par les sens. Ici, dans le domaine auditif, il se dit d'entendre distinctement un son, avec clarté, voire exactitude. Net reste invariable dans la majorité des cas. Toutefois, dans le quatrième exemple du CW, il s'accorde avec l'objet au féminin, caractérisant ainsi une qualité de l'objet perçu.

\section{Percuter juste}

Percuter, frapper avec précision, avec exactitude Transitif

1961 Felipe saisit plus vite que moi... il me montre là-haut, de tout au sommet, la brèche... que j'ai appelée le cratère... vroomb ! dottore ! qu'une torpille d'avion a percuté juste !... (Louis-Ferdinand Céline, Rigodon)

\section{Corpus Web :}

J'aime ton écriture fluide, directe, immensément poétique, ta capacité à percuter juste, exactement là où il faut, là où ça fait mal et où ça fait du bien, t'es jamais futile ni bavard, tu restes 
profond et exigeant à la folie mais cette exigence est parfois difficile à supporter car il n'y a pas de remplissage, d'aération, de soupape de sécurité pour qui te lit... [http://virgile.blog.lemonde. fr/2008-2/juin-2008/] (17.9.2015)

Une petite parenthèse juste pour dire que je remarque une fois encore que Dominique 38 est une enquêtrice impressionnante. Pour aider aux ID, elle trouve souvent du premier coup, ou s'en approche de très très prêt. Je ne la connais pas, mais à travers ces interventions, elle percute juste [http://www.la-detection.com/dp/ message-101603.htm] (17.9.2015)

Impartial... désolé pour ce retard à l'allumage... C'est toujours un grand plaisir que de te lire ! Tu choisis les bons mots (munitions adéquates !) et tu percutes juste (vise très bien !) En d'autres temps et en d'autres lieux, on aurait pu servir sous la même bannière ! Ah ! ah ! ah ! [http://www.madeingirondins.com/forum/ topic-marseille---bordeaux--une-vague-oceaneen-mediterranee---55923.html] (17.9.2015)

Remarques : Percuter juste désigne le fait de heurter, frapper, le sujet, inanimé, ayant atteint sa cible avec justesse et précision. Il s'agit donc d'une action préméditée, ayant pour but la destruction d'une cible. Dans les exemples du CW, percuter juste apparaît en emploi absolu au sens figuré, référant à une remarque, un texte qui touche ou affecte quelqu'un vivement, à quelque chose qui fait mouche. Juste reste invariable.

\section{Perdre gros}

Perdre beaucoup

Emploi absolu

1642 Si vous avez perdu gros en joüant, c'est une leçon de sagesse pour guerir une folie (Nicolas Caussin, La Cour sainte)

1757 Le verre à boire pesoit 6 onces 3 gros et demi, ainsi l'eau avoit perdu gros de son poids par la congélation depuis la veille (M. Baron, Expériences sur l'évaporation de la glace)

1869 - As-tu perdu gros?

- Une somme énorme, Fanchette ; j'ai froid rien que d'y penser (Zulma Carraud, Une servante d'autrefois)
1919 Personne n'avait compris et Sulphart luimême, qui pourtant eût perdu gros si Demachy était parti, l'avait injurié tout une soirée, criant comme un sourd que l'eau allait toujours à la rivière, et les filons « aux gars trop billes pour savoir en profiter » (Roland Dorgelès, Les Croix de bois)

1987 Figure-toi, ce matin, ton père s'est glissé penaud, maudissant sa malchance, grognant. Comme il restait dans ma chambre à déambuler, je lui ai demandé : Tu as perdu si gros ? Il m’a dit : Oui (Maurice Rheims, Les Greniers de Sienne)

1995 - En agiotant sur plusieurs valeurs à la fois et pour de si petits montants, je ne m'exposais guère à perdre gros. Mais si tout de même j'étais resté endetté, j'aurais emprunté cinquante louis à Madame de Meillant en comptant d'en regagner trois fois plus au pharaon ou à la bassette (Françoise Chandernagor, L’Enfant des Lumières)

CORPUS Web :

Son futur ex-époux est déterminé à obtenir la garde de leur fils ainsi qu'une pension alimentaire pour subvenir aux besoins de ce dernier. La comédienne, qui aurait empoché pas moins d'un million et demi de dollars l'année dernière selon les informations de TMZ, risque donc de perdre gros [http://www.purepeople.com/article/morenabaccarin-en-plein-divorce-la-star-d-homelandrisque-de-perdre-gros_a164730/1] (17.9.2015)

Premier League : Van Persie n'a pas vraiment manqué à Manchester, il peut même perdre gros à Chelsea [http://www.eurosport.fr/football/ premier-league/2014-2015/premier-league-vanpersie-n-a-pas-vraiment-manque-a-manchesteril-peut-meme-perdre-gros-a-chelsea_sto4681443/ story.shtml] (17.9.2015)

REMARQUeS : Souvent employé dans le domaine $\mathrm{du}$ jeu, perdre gros souligne le fait de perdre une grosse somme d'argent mise en jeu. La perte peut être aussi d'ordre matériel et référer à un bien de grande valeur dont le propriétaire doit se séparer ou qu'il n'a plus en sa possession. Gros reste invariable et est modifié par si. Notons l'emploi de glisser penaud 's'introduire furtivement avec une 
mine déconfite’. VoIR AUSSI : gagner / parier / rapporter gros

\section{Perdre plat et court}

Se perdre tout bonnement, tout simplement

Pronominal

1846 si la Fée n'est pas destinée à une longue durée, du moins elle mourra estimée, et elle n'ira pas se perdre plat et court dans cette fosse commune (Journal des débats politiques et littéraires)

1854 Vouloir aller plus loin que les maîtres, gens hardis de toute la hardiesse que donne le génie et l'état nouveau d'une langue hardie, parce qu'elle est à moitié faite, c'est vouloir se perdre plat et court (Jules Janin, Histoire de la littérature dramatique)

VOIR AUSSI : dire plat et court

\section{Perler dru}

Garnir richement de perles

Transitif

+1365 Car bien .VI ${ }^{\mathrm{xx}}$. jones et belles, Toutes dames et damoiselles, Filles de chevaliers ou fames, Dou pays les plus frices dames, Moult ricement et bel arrées, Très noblement et bien parées En draps de canjans et de soie, Plus rices deviser n'osoie,

Drut perlées et orfrisies,

Dont le mieuls estoient prisies, $Y$ peuïst on adont veoir (Jean Froissart, Poésies [3e tiers XIve])

Remarques : Perler dru se dit dans cet exemple de l'ancien français d'une personne et par extension de son habit orné d'une grande quantité de perles. Dru reste invariable.

\section{Perruqué faux}

Doter (quelqu'un) d'une fausse perruque Transitif

1951 Les acteurs veulent jouer faux, être habillés faux, être peinturluré faux, être perruqués faux. La nonne a du rouge baiser aux lèvres, le poilu qui sort des tranchées des bottes vernies, l'amoureuse est jouée par un gamin (Henry de Montherlant, La Ville dont le Prince est un enfant)

REMARQUES : En parlant de la coiffure d'un acteur, perruqué faux se dit du fait d'être coiffé d'une perruque peu naturelle, qui semble fausse ou qui correspond peu à la réalité, perruqué n'étant pas construit sur ${ }^{\star}$ perruquer, verbe inexistant, mais sur perruque comme barbu sur barbe.

\section{Perturber dur}

Être affecté par des perturbations (ici : du trafic routier)

Emploi absolu

1984 ça perturbait dur sur la Nationale

(Europe 1, 22.2.1984 / Hagège 1987 : 45)

\section{Peser dur}

I. Faire sentir son grand poids, être lourd Intransitif

1957 il est fort, il a du poids, il pesait dur sur les bras du treuil (Roger Vailland, La Loi)

II. Être une grande charge pour quelqu'un, faire pression sur quelqu'un

Intransitif

1978 Il avait remarqué que si les adulations du public ordinaire étaient sans influence notable sur la boule de haine qui pesait lourd et dur dans sa poitrine, parfois cependant un souffle tiède et printanier semblait lui parvenir des gradins et singulièrement du sommet des gradins, des derniers bancs qui se perdent dans l'ombre du chapiteau (Michel Tournier, Le Coq de bruyère)

\section{CORPus Web :}

moi aussi ce soir koh lanta et du repos s'il vous plait car mon pti bout à bientot 8 mois et depuis qu'il est né je n'ai pas encore passé une nuit de sommeil !!! çà commence à peser dur dur... [http://club.doctissimo.fr/camcam38/] (18.9.2015)

Ne pas avoir de questions commençait à me peser dur dans mon petit cerveau [https:// openclassrooms.com/forum/sujet/root-ouadministrateur] (18.9.2015)

REMARQues : Peser dur (I) se dit du fait d'avoir un poids important, de peser fortement sur quelqu'un/quelque chose. (II) réfère au fait 
d'exercer une pression morale, de gêner quelqu'un, le sujet étant un inanimé et se révélant être difficile à supporter. Notons la collocation peser lourd et dur et la réduplication dur dur. Dur reste invariable.

\section{Peser égal}

Examiner, évaluer, juger de la même manière Intransitif

1275 Tout metait en une balance, Bone aventure et mescheance, E les fesait egal peser, [variante : isniel peser]

Senz esjoïr e senz peser,

Car de chose, quel qu'ele seit, N'iert joieus ne ne l'en pesait (Jehan de Meun, Roman de la rose [1269-1278], 5853)

\section{CORPuS WeB :}

Drifter tout en restant dans le cul de l'autre? un RWD de 300+hp conduit par un pro contre un AWD conduit par un amateur, ca aurait du peser égal dans la balance tant qu'a moi [http:// www.montrealracing.com/forums/showthread. php?243474-Circuit-St-Croix-Pics-and-Video/ page3] (18.9.2015)

Toutes les options pèsent égal dans la balance, on dirait [http://lafauteauxhormones.blog spot.co.at/2011/11/trois-lettres.html] (18.9.2015)

Mon chum lui il maigrit ces temps-ci alors imaginez je le ratrappe ! On pèse égal ; je suis traumatisée mais je garde un bon moral :D [http: //forum.doctissimo.fr/grossesse-bebe/mamansquebec/juinettes-2007-sujet_11420_18.htm] (18.9.2015)

Remarques : Peser égal désigne le fait d'examiner, en se livrant à une réflexion approfondie, deux choses que l'on veut apprécier, évaluer et ce, de manière identique, égale. Dans le troisième exemple du CW, peser égal apparaît dans son sens concret (avoir tel ou tel poids) : la femme, enceinte d'après un contexte plus large, se rapproche du poids de son ami, ce qui la traumatise. Égal reste invariable.

\section{Peser juste}

Juger, évaluer avec justesse, avec exactitude, conformément à la vérité

Transitif

1953 Mais le cœur est le seul trébuchet qui puisse peser juste la beauté du langage (Claude Roy, Le Commerce des classiques)

CORPus WeB :

Peser juste si possible, mettre plutôt quelques grammes de moins que quelques grammes de plus afin qu'il reste quelque chose au dernier servi... [http://lespaniersdesbordes.net/ infos/les-distributions] (18.9.2015)

La méthode dite de la double pesée permet donc de peser juste même avec une balance fausse. Cette technique est aujourd'hui désuète [http:// forums.futura-sciences.com/chimie/498600concentrations-incertitudes.html] (18.9.2015)

Si vous respectez la température du four à $185^{\circ}$ et que vous pesez vos ingrédient au gramme près car en Pâtisserie il faut peser juste et bien je peu vous dire que vous allez vous régalé et j'espère que vous ferez partager cette recette à vos amis [https://www.atelierdeschefs.fr/fr/recette/1231galette-des-rois-frangipane.php] (18.9.2015)

Remarques : Au figuré, peser juste désigne le fait d'évaluer, en se livrant à une réflexion approfondie, une chose que l'on veut apprécier et ce, d'une manière précise, avec justesse, le complément d'objet direct désignant généralement une chose abstraite (ici : la beauté). Les exemples du CW, en emploi absolu, illustrent le sens concret de 'déterminer exactement (le poids de quelque chose)'. Juste reste invariable.

\section{Peser lourd}

I. Avoir un poids important, être lourd Intransitif

1783 Reposons-nous un peu ; ma valise pèse lourd (L. H. Dancourt, Jacquot et Colas duellistes)

1874 Mouret semblait s'amuser beaucoup.

- Et les lits ? Reprit-il.

- Les lits, c'est elle qui les a faits... il faut la voir retourner un matelas. Ça ne pèse pas lourd, je vous en réponds ; elle le prend par un bout, le jette en l'air comme une plume... avec ça, très soigneuse 
(Émile Zola, La Conquête de Plassans)

1879 puis, ayant payé les huit sous, il rentra en soupesant une enveloppe carrée bordée d'un large liséré noir.

- Elle pèse lourd, en effet, fit-il ; elle est timbrée de Paris et à votre adresse, ma tante

(André Theuriet, La Maison des deux barbeaux)

1892 M. de Vineuil se pencha tranquillement sur la selle, regarda un instant son pied, qui devait le brûler et peser lourd, au bout de sa jambe.

- Oui, oui, murmura-t-il, j’ai attrapé ça tout à l'heure... ce n'est rien, ça ne m'empêche pas de me tenir à cheval... (Émile Zola, La Débâcle)

1907 Il avait une façon de prendre la main de sa danseuse et de l'appuyer sur sa hanche. Et il la faisait pirouetter dans la valse, comme si elle n'avait pas pesé plus lourd qu'une plume (Émile Moselly, Terres lorraines)

1939 Une poupée ne pèse pas lourd (Joseph Peyré, Matterhorn)

1943 Sa main pesait lourd sur l'épaule de l'enfant, mais moins lourd encore que le regard si proche que, pour en distinguer la prunelle, Steeny eût dû se rejeter un peu en arrière (Georges Bernanos, Monsieur Ouine)

II. Avoir de la valeur, être important Intransitif

1855 Lui reconnût-elle quelques qualités, à ce mari, qu'à l'intérieur, sur les plateaux de cette petite balance que chaque femme a dans le cœur, elle mettrait d'un côté les pièces de six liards du mari, et de l'autre les monceaux de trésors, de bijoux et de pierreries qui sortent par la bouche d'un jeune amant. Va, à l'heure qu'il est, M. Creton du Coche est bien bas, et il ne pèse pas lourd, comme on dit (Champfleury, Les Bourgeois de Molinchart)

1912 Elle [= la foule] n'y a pas mis la main. Son vaisseau, c'est François d'Assise. Ses tours, Dante et Giotto. Le fond du siècle, c'est la violence. L'Église féodale, ici, pèse plus lourd qu'ailleurs. La tiare, la mitre s'achètent quand on ne les prend pas d'assaut (Élie Faure, Histoire de l'art : l'art médiéval)

1942 Le roi pouvait bien jouir de droits et de privilèges qui pesaient lourd sur le peuple ; il pouvait bien exercer son droit de gîte et se faire héberger, lui et sa suite, dans ses nombreux déplacements, aux frais de ses sujets (Edmond Faral, La Vie quotidienne au temps de saint Louis)

1954 « Mes répugnances personnelles, il s’en fout ; son amitié ne pèse pas lourd quand il a décidé de se servir de vous » (Simone de Beauvoir, Les Mandarins)

1977 Et puis Mathieu, Mathieu à perte de vue, le passé ne pesait jamais bien lourd face à l'avenir en ce mois d'août (Annie Ernaux, Ce qu'ils disent ou rien)

1982 C'est dire si les ravages de la pauvreté furent tout de même limités. Mais leur conséquence morale pesait plus lourd (Émile Ollivier, L'Orphelin de mer)

III. Être une grosse charge, occasionner beaucoup de peine, d'efforts Intransitif

1887 Mais impossible de fermer l'œil, ils se retournaient comme sur un gril brûlant, ils finirent par causer à demi voix. Ah ! ce père, qu'il pesait donc lourd, depuis qu'il tombait en enfance ! une vraie charge, à leur casser les reins, tant il coûtait ! (Émile Zola, La Terre)

1925 C'était la tristesse de Sandrine qui était grave, ses plaintes presque enfantines qu'il lui fallait encore entendre, et qui pesaient lourd sur son cœur (Maurice Genevoix, Raboliot)

1927 - Telle heure sonne, mon enfant, poursuivit-il, où la vie pèse lourd sur l'épaule. On voudrait mettre à terre le fardeau, l'examiner, choisir, garder l'indispensable, jeter le reste. Retenez cette confidence, puisque je la fais tout haut, devant vous (Georges Bernanos, L'Imposture) 
1962 Julien et Christian devaient, de ce fait, allonger leurs journées, et la fatigue commençait à peser lourd sur leurs épaules. Le deuxième mardi du mois, Julien se rendit chez ses parents (Bernard Clavel, La Maison des autres)

1974 Et l'impôt et le communisme pèsent maintenant plus lourd que le roi. Nous commençons à regretter une époque où le roi, pourtant, n'était déjà plus là (Jean d'Ormesson, Au plaisir de Dieu)

\section{CORPUS Web :}

Le recul de l'investissement public risque de peser lourd sur l'économie régionale [http:// normandinamik.cci.fr/209945-le-recul-delinvestissement-public-risque-de-peser-lourdsur-leconomie-regionale] (18.9.2015)

Les modèles hybrides commencent à peser lourd sur le marché des notebooks [http://www. distributique.com/actualites/lire-les-modeleshybrides-commencent-a-peser-lourd-sur-lemarche-des-notebooks-23424.html] (18.9.2015)

Dans un sens, je suis d'accord et de tout cœur avec toi l'ami. Il faut savoir s'entourer. On ne sait pas trop si tes alliés ont correctement réagit, s'ils ont pesés lourd dans ce combat [https:// forum.fr.grepolis.com/archive/index.php/t16729.html] (18.9.2015)

REMARQues : Peser lourd (I) réfère au fait de faire sentir un poids pesant ; lorsque peser lourd est suivi de la préposition sur, il désigne le fait d'exercer une forte pression. (II) se dit d'une personne ou d'une chose qui a de l'importance, qui joue un rôle prépondérant. À la forme négative, ne pas peser lourd signifie 'ne pas avoir d'importance, de valeur'. Le sujet étant un animé ou un inanimé, (III) désigne le fait de donner une impression de gêne morale, de constituer une charge pénible, de donner une sensation d'oppression, d'étouffement, peser lourd étant, dans cet emploi également, généralement suivi de la préposition sur. Lourd reste invariable et est modifié par donc, jamais bien, maintenant, moins, plus.

\section{Péter grave}

se la péter grave : frimer (souvent d'un policier)

Transitif

2013 - Ça ne semble pas être le grand amour entre vous et votre supérieur, observe-t-il

Le plus jeune des deux agents hausse les épaules.

- Le Staief, il a tendance à se la péter grave depuis qu'il a pris du galon

L'autre glisse :

- Et comme on peut pas dire qu'il est

hyper-compétent...

Serge n'insiste pas

(Dulle Griet, Les Fenêtres murmurent)

2019 Merci Manu, grâce au joli tatouage que tu m'as fait hier, je vais pouvoir me la péter grave à Martin plage tout l'été ! Renée B (Gaspard Verdure, Tu l'écris, je le crie)

2020 La parfaite image du gynécologueobstétricien-chef-de-service-bronzédécontract-barbu-bobo dont la blouse blanche non fermée voletait dans son dos comme la cape du chevalier blanc, suivi par une meute d'internes obséquieux. Le terme se la péter semblait fait pour lui. Et même se la péter grave (Pierre Antilogus et Jean-Louis Festjens, Ces petits riens qui font une vie)

VOIR AUSSI : se la taper dur

\section{Péter haut}

péter plus haut que son cul/son derrière :

entreprendre des choses au-dessus de ses

forces ou de ses moyens ; être prétentieux

Intransitif

1942 Conscient de son infériorité sociale, il n'osait lever les yeux sur elle : il ne voulait pas péter plus haut qu'il n'avait le derrière, ni se risquer dans une aventure larmoyante comme on en voit au ciné ou dans les feuilletons lorsque des gars dépérissent pour l'amour d'une inaccessible, qu'à la fin on veut faire croire qu'ils épousent (Raymond Queneau, Pierrot mon ami)

1977 Plus moyen de se souvenir sans se vouloir du style, ou s'y laisser aller, le style : souci 
d'arriviste, « le chic des gens qui veulent péter plus haut que leur cul », disait le père de Jeannot (Jean-Pierre Chabrol, La Folie des miens)

1983 Dans leur chambre, aucune décoration, juste des photos encadrées, des napperons fabriqués pour la fête des mères, et sur la cheminée, un grand buste d'enfant en céramique, que le marchand de meubles avait joint en prime pour l'achat d'un cosycorner. Leitmotiv, il ne faut pas péter plus haut qu'on l'a (Annie Ernaux, La Place)

1993 Il lui avait expliqué que vivre de traites et de cavaleries était le fait de personnages peu recommandables qui, soucieux de péter plus haut qu'ils avaient le derrière, vivaient au-dessus de leur condition en achetant ce qu'ils n'avaient pas les moyens de payer (Geneviève Dormann, La Petite Main)

CoRpus WeB :

A force de péter plus haut que son cul, on fini par ce chier dessus... [http://jadorefb. com/?p=page\&id=52638] (18.9.2015)

L'homme qui pète plus haut que son cul a-t-il de la merde derrière les oreilles ? [http://www. qalc.fr/question/homme-pete-merde-derriereoreilles-52958] (18.9.2015)

Mais dans leurs rangs il y a bon nombres d'individus qui ne produisent rien ; ils se la pètent haut parce qu'ils ont trimé pendant de longues et longues années à compiler des soit-disant recherches dans un épais recueil, l'ont présenté devant un jury, puis octroyé du doctorat [http:// www.madagascar-tribune.com/La-menace-dune-annee-blanche,21318.html] (18.9.2015)

REMARQUes : Péter plus haut que son cul est une locution proverbiale traditionnelle qui signifie 'viser trop haut', le sujet sous-estimant la tâche à accomplir ou se surestimant soi-même. On la trouve déjà en 1640 dans les Curiositez françoises de Antoine Oudin : "on ne sçauroit Peter plus haut que le cul 'on ne peut faire au delà de son pouvoir' (vulg[aire]) ». Le CW donne aussi la variante se la péter haut, dans laquelle l'expression se la péter signifie 'frimer'. Haut reste invariable et est modifié par plus.

\section{Péter sec}

I. Prendre une tournure très violente Intransitif

1840 Son langage [= celui du patient] prouve un défaut complet d'éducation et des habitudes grossières. Il ne dit pas deux mots sans ajouter : « nom de Dieu ! " prononcé avec un redoublement d'énergie brutale. Souvent il répète à tout propos des phrases tout à fait insignifiantes : "Nous sommes amis. » «Ça pète sec » (Charles Marc, De la folie)

1888 Le soldat essaya de prendre la parole, mais La Guillaumette lui ferma net la bouche :

- En voilà assez, taisez-vous ! Ou, tonnerre, ça va péter sec!

Il se tourna vers la tablée :

- D’abord vous autres, qu'est-ce que vous fichez encore là ? Est-ce que je ne vous ai pas dit de déménager?

(Georges Courteline, Le Train de 8 h 47)

II. Parler sur un ton cassant

Intransitif

1887 Un Pète-sec est un chef qui ne plaisante pas dans le service (Martial Bayon, Sobriquets et superstitions militaires)

1892 Tous rigolèrent de la faim du capitaine, qui n'avait pas su se faire aimer de ses hommes, trop jeune et trop dur, un pète-sec, comme ils l'appelaient (Émile Zola, La Débâcle)

2020 Comment voulez-vous que les Français ne deviennent pas de Italiens qui font la gueule, si on leur cause mal, si au lieu de s'adresser à eux avec le charme d'un chanteur de bel canto, on leur parle avec le ton pète-sec d'un lieutenant-colonel de gendarmerie en retraite (François et Valentin Morel, Dictionnaire amoureux de l'inutile)

III. Éclater en faisant un bruit sec, exploser Intransitif

1890 - Il pétait sec déjà, en ce temps-là (Lucien Descaves, Sous-offs)

1951 Les insipides « vesses de loup » ne furent même pas épargnées : elles pétaient sec sous le talon en exhalant un peu de fumée noire (Hervé Bazin, Le Bureau des mariages) 
1979 - Non, tu vois, petit gars, j’ai pas faim. C'est la fatigue, tu vois. Trois semaines que je marche. Je sais seulement pas où qu'est passé mon régiment. Oh, ça a pété sec, làhaut, dans les Ardennes ! Ils étaient tout autour de nous, on a seulement rien vu. Les officiers nous ont dit de nous replier sur la Marne tant qu'y avait le passage (François Cavanna, Les Russkoffs)

IV. Être débouché en faisant un bruit sec (sens probable), ou simplement 'très sec' Intransitif

1955 Quand sortit Monsieur Verdoux de Charles Chaplin, Tarquin et ses assistants fabriquèrent un Verdoux factice mais pétant sec (La Parisienne, mars 1955 / Grundt : 355)

\section{CORPUS WEB :}

Ça va péter sec dans le ciel lyonnais le 14 juillet. À partir de 22h30, attendez-vous à un feu d'artifice comme vous n'en avez jamais vu, ni entendu ; cette année, la ville des gones a sorti le grand jeu... [https://www.lebonbon.fr/lyon/cava-peter-le-14-juillet/] (19.9.2015)

The Sprown a enregistré une petite démo de trois titres qui pètent sec. Elle devrait sortir tantôt ! Alors tiens toi prêt, porte-monnaie en main, si t'es intéressé ! [https://m.facebook.com/story. php?story_fbid=10152447532680457\&id $=1015010$ 8471355457\&refid=17] (19.9.2015)

Hier soir, j'étais au concert de C2C à l'Olympia. En un mot ? AMAZING. La salle était bondée - avec une concentration élevée de BG au mètre carré, et de nanas qui se la pètent sec [http:// wheelcome.net/c2c/] (19.9.2015)

Remarques : Péter sec (I) se dit d'une situation qui prend une tournure très violente, pouvant aller jusqu'à l'affrontement sans pitié. Sans contexte élargi, il n'est pas possible de rattacher l'exemple de 1840 au sens (I) ou au sens (II). Nominalisé ou converti en adjectif, pète-sec (II) fait allusion à un ton sec, propre à un discours de commandement ou à une personne très autoritaire. L'exemple de 1979 sous (III) renvoie aux explosions causées par des armes de guerre. L'exemple de 1951 sous (III) décrit des champignons blancs remplis d'une poussière brune qui, en éclatant, l'éjectent en produisant un bruit sec.
(IV) réfère à un vin pétillant du même nom que le film de Chaplin, peut-être un rosé ou mousseux, qui produit un son sec quand le bouchon saute (si le sens n'est pas simplement celui de 'un vin très sec'). Le CW contient des exemples référant aux déflagrations d'un feu d'artifice, au succès d'une musique. Notons la locution familière se la péter sec 'frimer', et l'emploi impersonnel familier de ça pète sec. Sec reste invariable.

\section{Piaffer clair}

Sonner avec clarté, avec netteté Intransitif

1963 les mots, les mots ! Il en est qui éclatent de couleur. Certains piaffent et caracolent clair sur le pavé, certains font les pachas vautrés dans des coussins épais (Nouvelles littéraires,17 janvier 1963 / Grundt : 334)

REMARQUES : Dans un contexte métaphorique, piaffer clair se dit de mots qui, par leur sonorité particulière, frappent l'oreille en sonnant avec clarté, avec transparence. Notons l'emploi de $c a$ racoler clair 'sauter, cabrioler en produisant un effet de clarté'. Clair reste invariable.

\section{Picoler sec}

Consommer excessivement de l'alcool 入 pédaler sec

\section{Piler menu}

Broyer, réduire en petits morceaux (au propre et au figuré)

Transitif

1543 L'eaue amere, on la pourra corriger en jectant dedans corail pilé menu, où mettrons en l'eaue de l'orge pilé et lyé en ung drappeau (Cassianus Bassus, Les XX Livres de Constantin Cesar)

1557 Icelle cuicte en vin ou eauë miellée, et pilée bien menu, guerit et meine à cicatrice playes nouvelles (Rembert Dodoens, Histoire des plantes)

1902 Mais vraiment il a fallu s'acharner des journées entières à coups de botte, à coups de crosse, pour piler si menu toutes ces choses : les potiches, réunies ici par milliers, les plats, les assiettes, les tasses, tout 
cela est broyé, pulvérisé - avec des restes humains et des chevelures (Pierre Loti, Les Derniers Jours de Pékin)

1977 Ces pendus déterminent Duras à faire à Lauzerte une compote de 197 papistes agrémentée d'une cinquantaine de marmots pilés menus (Claude Mauriac, La Terrasse de Malagar)

REMARQUES : Piler menu renvoie au fait de réduire en petits morceaux quelque chose ou, au figuré, quelqu'un. L'accord de menu est optionnel. Il est modifié par bien, si.

\section{Piller dru}

Piller abondamment ; bouleverser brutalement, vigoureusement

Emploi absolu

1896 J'ai dit ailleurs l'orgueil de la possession Et le joyeux émoi d'occuper la Sion Pas céleste, mais presque, à force d'être bonne

À garder après siège fait, de ta personne Physique, et le butin inépuisable. Mais, Tout en continuant de piller dru, je vais Exalter maintenant ta gloire intérieure, Tes vertus, en un mot, qui ne sont point un leurre

(Ni tes vices non plus), tes efforts surhumains,

Tes préjugés vaincus ? ô que non pas! (Paul Verlaine, Euvres poétiques complètes)

Remarques : Piller dru désigne le fait de s'emparer de force de tous les biens que renferme un lieu conquis de haute lutte et mis à sac, $d r u$ soulignant l'abondance du pillage. Ici, dans un contexte métaphorique, l'objet est une personne, et on abuse de ses sentiments, le sujet voulant s'emparer psychiquement de son butin humain.

\section{Pilonner dur}

Pilonner, bombarder de manière intensive Emploi absolu

1938 « Puisque cent mille obus en vingt-quatre heures ne suffisent pas à niveler même un petit morceau du front ennemi, et y laissent subsister des noyaux de résistance - abris bétonnés, nids à mitrailleuses nous taperons plus fort, nous pilonnerons plus dur » (Jules Romains, Les Hommes de bonne volonté)

\section{CORPUS WEB :}

" Come Share the View » en rajoute passablement dans la plainte et les basses grondantes, et l'on commence à trouver que cela tourne un peu trop carré, avant que « Find Yourself a Safe Place » ne relance un peu le débat : la basse et la batterie pilonnent dur, mais sans empêcher le chant de décoller [http://www.popnews.com/ popnews/singles111] (19.9.2015)

Par ailleurs le type de négociations à mené frontalement et brutale a amener les négociateurs de la troïka à pilonner dur sur la Grèce [http:// www.latribune.fr/economie/union-europeenne/ avec-notre-proposition-nous-gagnons-du-tempspour-appliquer-notre-programme-486376.html] (19.9.2015)

Une jeune femme est pilonnée dur par une grosse bite de black [http://www.video-creampie. com/video/une-jeune-femme-est-pilonnee-durpar-une-grosse-bite-de-black-creampie-vaginal] (19.9.2015)

REMARQUeS : Pilonner dur désigne le fait de frapper à coups de pilon, par extension, à frapper, bombarder avec force, à coups répétés. Dans un contexte militaire, il se dit du fait d'écraser les positions de l'adversaire sous un bombardement intensif d'obus et de bombes. Dans le CW, on trouve également pilonner dur dans les contextes de la musique (la percussion qui martèle dur), de la politique et du sexe. Dur reste invariable et est modifié par plus. Notons l'emploi transitif $\mathrm{du}$ verbe dans le dernier exemple du CW. Notons l'emploi de taper fort. VOIR AUSSI : taper fort

\section{Pincer dur}

I. Faire un froid mordant

Emploi absolu

1843 - Ça, c'est vrai. Dis donc, fourline, quelle farce si nous deux Tortillard, nous nous esbignions avec la voiture, et que nous te laissions là, au milieu des champs, par cette nuit où le froid va pincer dur ! (Eugène Sue, Les Mystères de Paris)

1919 - Ça va encore pincer dur, me dit Fouillard qui enfonce son passe-montagne (Roland Dorgelès, Les Croix de bois) 
II. Serrer vivement, durement

Emploi absolu

1932 Elles [= les fourmis rouges] prenaient presque toute la place ; on avait du mal à se retourner, et puis, si on les dérangeait, elles pinçaient dur (Louis-Ferdinand Céline, Voyage au bout de la nuit)

CORPus WEB :

Leur [= cataglyphis velox] agressivité n'est pas légendaire, quand une vous chope un doigts, elle pince dure mais elles sont moins téméraires que des Formica, lâchant assez rapidement prise [http://www.fourmix.net/article-31487018.html] (16.05.2009)

Attention à ne pas coincer la peau car elle [= la pince à épiler] pince dure [https://www. beaute-test.com/pince_a_epiler_anastasia.php? listeavis=1] (10.09.2020)

REMARques : Pincer dur (I) renvoie à un froid mordant, par métaphore du sens (II) : 'être pris, coincé dans une pince' (ou impression qui y ressemble, comme dans le cas des fourmis). Les citations sous (I) et (II), qui proviennent de textes imprimés, emploient dur comme adverbe invariable, mais l'accord est fréquent dans le style moins contrôlé du CW. VoIR AUSSI : piquer dur, résonner dur

\section{Pincer sec}

Causer une douleur physique très vive

(en parlant du froid)

Emploi absolu

1912 Cela pinçait sec, ce soir-là. Il faisait un temps clair de nouvelle lune (Louis Pergaud, La Guerre des boutons)

\section{CORPUS WEB :}

A suivre mais c'est sur que ça va pincer sec. Déjà $-3^{\circ} \mathrm{C}$ ce matin et l'étang qui commence à frisotter sur le matin ! [http://www.huttevirtuelle. com/la_communaute_des_sauvaginiers/show thread.php?15300-INFOS-SUR-WARLAING/page 42] (19.9.2015)

Un homard a part te pincer sec ca te coupe pas le doigt comme un sécateur lol enfin je crois pas [http://www.jeuxvideo.com/forums/1-5138403402-2-0-1-0-combat-homard-vs-scorpion. htm] (19.9.2015)
5 bonnes raisons d'en pincer sec pour The L Word :

1) Le concept est inédit, résolument innovant [http://www.madmoizelle.com/the-1-word100-filles-100-culte-5952] (19.9.2015)

REMARQUES : Pincer sec se dit souvent d'une température de l'air qui est froide au point de causer une douleur physique vive, donnant une impression désagréable de pincement ; sec réfère ainsi à la dureté, à l'intensité du froid. Dans le second exemple du CW, pincer apparaît dans son sens concret de 'serrer étroitement entre les pinces (d'un crabe, d'un homard)'. Le troisième exemple du CW, en pincer sec pour désigne le fait de s'enthousiasmer pour quelque chose (ici : pour un film). Sec reste invariable. Notons l'emploi impersonnel familier Cela / ça pince sec.

\section{Pincer serré}

I. Pincer fortement, avec force

Intransitif

1771 Lorsqu'on voulait prendre ces oiseaux [= des goélands], ils cherchaient à mordre et pinçaient très serré

(Georges-Louis de Leclerc Buffon, Histoire naturelle des oiseaux)

II. Avoir une attitude froide et méprisante (envers quelqu'un), causer une vive douleur affective

Intransitif

1780 Sais-tu que tu deviens méchante, Madame Sophie ? Quoique je t'aie vue assez souvent pincer très-serré, et sans rire, ou en riant, je ne t'avais pas encore connue si mordante (Honoré de Mirabeau, Lettres originales écrites du donjon de Vincennes)

CORPUS WEB :

Renforcer ce muscle en le pinçant serré, tenant aussi longtemps que possible, puis lâcher prise [http://maladie.11665.com/fr/health/2013 07/55149.html\#.Vf1Lpk0gmUk] (19.9.2015)

Faites une boule de coton de $1 / 2$ po. de diamètre. Placez un carré de 2 po. de côté de vert clair dessus, en l'étirant complètement et en le pinçant très serré en dessous [http://dhost.info/ siubhan/fleurarti/flcreppiedalou.htm] (19.9.2015)

Procédé selon la revendication 4, caractérisé en ce que, durant le sertissage, l'extrémité roulée $(61,69,66)$ est davantage roulée ou au moins 
pressée pour, au moins en partie, enfermer la partie de connexion (80) et la pincer serré [http:// www.google.co.ug/patents/EP1849715B1?cl=fr] (19.9.2015)

REMARQUES : Au concret, pincer serré (I) réfère à des oiseaux, pinçant de leur bec avec force, causant une douleur à la personne touchée. Au figuré (II), pincer serré signifie 'causer une douleur affective', le sujet blessant par son attitude ou par des paroles désobligeantes, piquantes. Le premier exemple du CW désigne la forte contraction d'un muscle, tandis que les autres exemples actualisent le sens concret par rapport à l'action d'une pince. Serré reste invariable et est modifié par très.

\section{Piocher dur}

I. Se battre intensément

Pronominal

1839 On se piochait dur, en Champagne, et je me souviendrai longtemps de La Ferté-sousJouarre. Mon régiment était venu rejoindre là d'autres troupes (Almanach populaire de France pour 1839)

II. Travailler durement, sans relâche Intransitif

1877 toutes les économies se trouvaient mangées ; et il fallait piocher dur, piocher pour quatre, car ils étaient quatre bouches à table (Émile Zola, L’Assommoir)

1996 Malgré les slogans. Par exemple : travail-famille-patrie. Son sens pour nous trois : travail, piocher dur pour survivre ; famille, piocher ensemble pour survivre ; patrie, piocher cachés pour survivre (Boris Schreiber, Un silence d'environ une demi-heure)

\section{Piocher rude}

Travailler avec ardeur, avec acharnement Intransitif

1865 Tel que me voilà, ne sachant ni piocher rude, ni parler doux, ni danser, ni plaisanter, ni même chanter, me sentant honteux de moi et de mon sort, je mérite bien qu'elle me regarde comme le dernier de ceux qui pourraient prétendre à elle (George Sand, Les Maîtres sonneurs)

\section{CoRpus Web :}

J'ai toujours écouté Zappa depuis mes 15-16 ans. Bon, j'avoue que je pioche rude dans le tas, quand même. Y a des obsessions ou des périodes où je lâche totalement. Mais ce qui va de 73 à 79, je suis absolument fan [http:// sugarmountain.forum-box.com/t10-Sur-votreplatine.htm?start=1800] (19.9.2015)

Trois jours durant, le lac va nous transporter, nous nourrir et désaltérer, laver, baigner. Faire souffrir aussi, quand le vent se lève et qu'il faut piocher rude dans sa masse pour avancer encore [http://www.liberation.fr/week-end/2007/12/01/ le-ladoga-l-ame-de-fond-de-la-russie_107595] (19.9.2015)

REMARQUES : Métaphoriquement, piocher rude se dit du fait de travailler avec ardeur et ferveur, sans répit, notamment dans un contexte rural. Opposé à parler doux, il se dit ici d'un homme ne sachant se démarquer ni par ses qualités physiques, ni par sa rhétorique. Le premier exemple du CW réfère à la préférence pour une musique « hard » que l'on choisit parmi d'autres. Dans le dernier exemple du CW, piocher apparaît dans son sens concret et désigne le fait de creuser ou remuer une masse (ici l'eau du lac) avec une pagaie. Rude reste invariable.

\section{Piqueniquer malin}

Organiser un piquenique de façon efficace, en pensant aux conséquences sur la santé ou l'environnement

$\lambda$ bronzer idiot

\section{Piquer droit}

I. Se diriger, se lancer rapidement vers un objectif, en ligne droite

Intransitif

1558 Puis, quand il void que vous estes en colère et que vous voulez picquer droit à luy, il sible ses bœufs pour les arrester et vous dit : «Qu'est-ce que vous dites ? »

(Bonaventure Des Périers, Les Nouvelles Récréations et joyeux devis)

1772 Disant cela, il férit son cheval des esperons, et pique droit aux Pyrénées, et se reconfortoit en murmurant tout bas en son cueur : «C'est pour Rose d'amour : puis il 
retourne devers messire Jehan, et lui apporte l'eau sans en avoir goute espandue » (François de Baculard d'Arnaud, Les Épreuves du sentiment)

1787 Bientôt j'entendis notre ennemi, déjà bien près de nous, exciter encore l'excellent cheval qu'il montait. Je tournai bride brusquement, et piquant droit vers le zélé postillon, je le saluai d'un grand coup de fouet. Jasmin, brûlant d'imiter son maître, avait déjà le bras levé (Jean-Baptiste Louvet de Couvray, Une année dans la vie du chevalier de Faublas)

1831 - Je le crois bien...mais voici la chose : comme vous voyez, il reste en panne dans l'air de vent de la frégate ; nous sommes deux navires, elle est seule, il faut choisir ; elle pique d'abord droit au cul lourd, au bâtiment en panne, on ne se défie pas de ça, un vrai bateau marchand

(Eugène Sue, Atar-Gull)

1839 À peine se sentit-elle sur le plancher, qu'elle me donna une preuve de son originalité en piquant droit vers la cheminée avec une rapidité qui lui valut à l'instant même le nom de Gazelle, en faisant tous ses efforts pour passer entre les branches $\mathrm{du}$ garde-cendre, afin d'arriver jusqu'au feu, dont la lueur l'attirait (Alexandre Dumas père, Le Capitaine Pamphile)

1874 On piqua droit sur les tentes ; il faisait chaud, et nous avions encore à traverser une longue lisière de sables jaunes que nous voyions briller entre la montagne et nous, rude passage en plein midi, sous un soleil sans nuages (Eugène Fromentin, Un été dans le Sahara)

1908 Ils piquent, les grands navires, ils piquent droit vers ces volcans, comme des papillons attirés par un bec de gaz. Le bec de gaz, c'est le phare. Ils appellent ça « reconnaître " (Pierre Mille, Barnavaux et quelques femmes)

1951 Après une demi-heure de marche, ils reconnurent que c'étaient des murs sur lesquels ils piquèrent droit pour trouver une bergerie déserte et à moitié écroulée (Jean Giono, Le Hussard sur le toit)

1957 À travers champs, c'était la meilleure façon de s'en tirer. Piquer droit tant qu'il n'y aurait personne et vadrouiller sous le couvert dès qu'il y a quelqu'un (Jean Giono, Le Bonheur fou)

1975 - Coupons une baguette de coudrier, et cherchons une source.

- Tu sais reconnaître du coudrier?

- Non.

- Les Indiens savent sentir l'eau. Ils se mettent debout au milieu du désert, flairent dans chaque direction, et piquent droit dessus. Je propose qu'on essaye de retrouver nos sens perdus. Arrêtons-nous, et flairons (Christiane Rochefort, Encore heureux qu'on va vers l'été)

1979 Ils fermèrent ensemble la cabane et prirent les armes dans les voitures, le garde accrocha comme de coutume la laisse du chien à sa ceinture et tous deux suivirent le sentier qui évitait la masse des sapins et piquait droit au milieu des hêtres vers le chemin de crête (Pierre Moinot, Le Guetteur d'ombre)

II. Planter, faire pénétrer par la pointe

Transitif

1881 Elle n'avait point fini qu'il la giflait à toute volée ; mais comme il levait encore une fois la main, affolée de rage, elle saisit sur la table un petit couteau de dessert à lame d'argent, et si brusquement, qu'on ne vit rien d'abord, elle le lui piqua droit dans le cou, juste au creux où la poitrine commence (Guy de Maupassant, Contes et nouvelles)

III. Descendre brusquement selon une

trajectoire presque verticale

Intransitif

1896 L'eau qui jaillit de ce double rocher Remplit ce long bassin d'une onde trépillante ;

Les frênes, les ormeaux, où viennent se percher Linottes et serins, Lui font une voûte ondoyante Qui garde mieux qu'un toit 
De tuiles, lorsque ainsi Sirius pique droit (Jean Moréas, Poèmes et sylves)

1947 Le pasteur, qui piquait droit vers le fond de notre cuvette, prit pied en face de ses filles et les regarda tendrement (Marcel Aymé, Le Vin de Paris)

1958 Il y avait eu plus de dégâts qu'on ne croyait. Des blocs avaient été attaqués au bord de la rivière. L'homme des Buttés affirmait que les avions piquaient droit sur l'objectif, pour poser leurs bombes, en déclenchant une espèce de sirène. La sirène surtout visiblement impressionnait les hommes (Julien Gracq, Un balcon en forêt)

1960 Gravereau reprit la lecture de son rapport tandis que l'avion piquait droit de Rome sur Chirfa, au-dessus de la Méditerranée pâle. L'hôtesse signala qu'ils allaient passer au-dessus de la Sicile, mais il n'y prit pas garde (Michel Déon, La Carotte et le bâton)

1989 Le ciel était d'un bleu intense, éblouissant. Le soleil piquait droit sur la clairière, énorme, torride. L'herbe était sèche, craquante sous les pas ; on entendait grésiller les insectes (Sylvie Germain, Jours de colère)

IV. Fixer d'une manière verticale Transitif

1926 Sa poitrine tendait le corsage, ses cheveux noirs lustrés collaient sur sa tête, ronde comme celle du faucon, avec dans le chignon un œillet piqué droit (Henry de Montherlant, Les Bestiaires)

CORPUS WEB :

Coudre à la machine est plus rapide et plus solide que coudre à la main. Toutefois, piquer une couture n'est pas si évident ! C'est tout un art de piquer droit, de façon régulière et sans abîmer le tissu ! [http://www.petitcitron.com/index.php/ techniques-de-couture/les-techniques-de-base/ piquer-a-la-machine\#.VgLKgEOgmUk] (23.9.2015)

Comment piquer droit lorsqu'on débute dans la couture à la machine ? Il ne faut pas « fixer les yeux sur l'aiguille mais sur un repère qui [ ] permette de piquer droit » [http:// papillonnagedecousette.blogspot.co.at/2014/02/ piquer-droit.html] (23.9.2015)

Il y a 25 ans, Monique a choisi le quartier Limbour pour le boisé magnifique qui longeait la rue de Roquebrune, derrière la maison familiale. Quand le développeur immobilier a commencé à défricher le terrain et à couper une centaine d'arbres matures, elle a été piquée droit au cœur [http://ici.radio-canada.ca/regions/ ottawa/2015/06/15/003-mobilisation-citoyenneprojet-village-riviera.shtml] (23.9.2015)

Pour mesurer la température d'une litière à $10 \mathrm{~cm}$ de profondeur, il est préférable d'utiliser un thermomètre à sonde. Cette dernière est piquée droite à une profondeur de $10 \mathrm{~cm}$ [http://www.lafranceagricole.fr/archive/article/ la-temperature-des-litieres-en-aire-paillee-FA 30681026354.html] (23.9.2015)

REMARQues : Piquer droit (I) réfère à une personne ou à un moyen de transport qui se dirige, se lance rapidement et directement vers un objectif, traçant une ligne droite, sans faire de détours. Les trois premiers exemples en (I) prennent en charge le sens, vieilli, de 's'élancer à cheval'. De même que (I), (III) inclut l'aspect de descente, le sujet plongeant vers son but, sa cible, pouvant ensuite remonter ou pas. (II) signifie 'planter, enfoncer quelque chose de pointu (ici : un couteau) directement, sans dévier'. (IV) prend en charge le sens de 'fixer quelque chose sur autre chose en traversant à l'aide d'une aiguille, d'une pointe, verticalement'. Dans les deux premiers exemples $\mathrm{du} \mathrm{CW}$, piquer droit renvoie à une ligne droite qui oriente la piqûre d'une couture. Le troisième exemple contient l'expression métaphorique piquer droit au cœur 'affliger profondément'. Droit reste invariable dans la majorité des cas, sauf quand il fonctionne comme prédicat second, ce qui est le cas dans le dernier exemple du CW, où l'accord indique la position verticale de la sonde. Il peut s'associer avec la préposition qui le suit (à, dans, de ... sur, dessus, sur, vers) au point de faire partie du groupe prépositionnel en tant que modifieur de la préposition. La modification de droit est rare (d'abord). 


\section{Piquer dru}

I. Enfoncer fortement, violemment la pointe d'un objet

Intransitif

1538 Fausse Fortune, ô que je te vis belle. Las qu'à présent tu m'es rude, et rebelle, ô que jadis fis bien à mon désir, Et maintenant me fais le déplaisir, Que je craignais plus que chose mortelle. Enfants nourris de sa gauche mamelle, Composons-lui (je vous prie) un libelle, Qui pique dru, et qui morde à loisir Fausse Fortune

(Clément Marot, L'Adolescence clémentine)

Transitif

1786 Si le pisé, en se séchant, a formé beaucoup de petites fentes, on peut l'enduire sans le piquer, en étendant avec la truelle un premier mortier, que l'on recouvre d'un second bien uni ; mais si le pisé est lisse, il faut le piquer assez dru avec la pointe d'un marteau (abbé Rozier, Cours complet d'agriculture)

II. Ériger à petite distance pour former une structure compacte

Transitif

1910 Denise marche en tête, barrette levée, lampe haute, contournant allégrement les pièces de bois étais qui sont piqués drus pour le soutènement (St. Nicolas)

\section{Piquer dur}

I. Enfoncer cruellement la pointe d'un objet

(au propre et au figuré (soleil, les yeux))

Intransitif

1862 - Arrivez par ici, camarade ! lui dit-il en retroussant sa moustache ; le soleil commence à piquer dur, et vous consentirez bien à feuilleter avec moi un ou deux chapitres de cet intéressant ouvrage?

(Charles Edmond, Souvenirs d'un dépaysé)

1913 On a aussi parfois trop d'audace en se sentant à l'abri de sorte qu'à vouloir faire le malin on se fait piquer dur. J'en ai encore le frisson et je crois que peu d'apiculteurs auraient rattrapé au vol le nid qui m'avait échappé (L’Apiculteur)
1950 « Je connaissais suffisamment ma montagnarde de patronne pour savoir l'endroit juste où il fallait piquer pour qu'elle rue, en lui laissant tous les torts. J'attendis cinq mois. Je piquai dur. Elle rua exactement comme je m'y attendais. Vingt-quatre heures après, nous étions sur le pavé » (Jean Giono, Les Âmes fortes)

1957 [sur un interrogatoire militaire :] Le règlement ne prévoyait pas mon cas et les points d'interrogation devaient piquer dur sous les képis... (Les Euvres libres)

1959 Mme Valdin frottait ses paupières avec frénésie. À cette heure-ci, les yeux commencent à piquer dur (Clarisse Francillon, Les Gens du passage)

Emploi absolu

1926 Et cette fois, c'est une touche, et j'en suis sûr, et j'ai déjà ferré. Vive moi ! J'avais bien vu ! La ligne s'est tendue sèchement, j'ai piqué dur [= l'hameçon], comme dans un bloc de pierre. Et je le tiens, ce chevesne-là, superbe. Je le domine du haut du pont, déjà dardé en plein courant, en attendant l'instant de le voir pendre, inerte, au bout du fil, monter comme un colis vers mes mains qui le halent, et croient déjà toucher sa forme pantelante et glacée (Maurice Genevoix, La Boîte à pêche)

II. Faire un froid piquant, mordant Intransitif

1877 - Vous savez, continua-t-il, maintenant, je travaille là, à l'hôpital... hein ! Quel joli mois de mai ! Ça pique dur, ce matin (Émile Zola, L’Assommoir)

1931 Le froid piquait dur. Le vent agitait un chiffon à la lucarne de l'étable, devant ce commencement violet du jour sur le plateau (Henri Pourrat, La Tour du Levant ou Quand Gaspard mit fin à l'histoire)

III. Se diriger, descendre directement vers (un lieu)

Intransitif

1951 - Surtout ne t'approche pas de ces deux petites villes qui sont marquées là et passe à travers champs. Si maintenant je te perds je me brûle la cervelle. 
- Je ne promets rien, dit Angelo, et même je crois que je piquerai dur sur la première et que j'y entrerai pour peu qu'il y reste du monde (Jean Giono, Le Hussard sur le toit)

\section{CORPus WeB :}

Nous en avons encore [= des moustiques], et des petits qui piquent durs [https://fr.toluna.com/ opinions/4922031/Les-moustiques] (10.9.2020)

Déjà le 47ième $\mathrm{km}$ et dernier ravito, à partir de ce moment les jambes piquent dures, petit arrêt dans une cave avec jus de raisin maison (délicieux !!), ça requinque son bonhomme !! Une dernière patate (40 mètres à monter) [https:// ultratrotter.blog/2015/09/05/2015-09-recit-trailmauves-en-vert] (5.9.2015)

REMARQUES : Au propre, piquer dur (I) renvoie à l'action d'enfoncer un objet à pointe, l'emploi au figuré étant fréquent et très diversifié. Le sens lexicalisé (II) 'un froid si fort qu'il ressemble à des pointes qui piquent' fait partie de ces variantes. En (III), piquer dur réfère à un mouvement brusque de haut en bas ou au fait de se lancer vers un objectif. Les citations provenant de textes écrits (sous I, II, III) traitent dur comme adverbe invariable, mais l'accord est fréquent dans le style moins contrôlé du CW. VoIR AUSSI : pincer dur

\section{Piquer fort}

Lancer des phrases piquantes, affligeantes, acerbes

Emploi absolu

1538 Nous sommes druz, chagrin ne nous suyt mie ;

De froid soucy ne sentons le frisson ;

Mais dequoy sert une teste endormie?

Autant qu'un bœuf dormant près d'un buysson.

Languards picquans plus fort qu'un

herisson,

Et plus recluz qu'un vieil corbeau en cage, Jamais d'autruy ne tiennent bon langage, Tousjours s'en vont songeans quelque finesse (Clément Marot, Ballades)

Corpus Web :

Et c'est pas super sympa.....ça m'a fait une belle bosse toute rouge qui m'a piquée fort pendant au moins une heure..... mais bon.. ça allait impec !!! [http://realwhatelse.over-blog. com/article-vous-avez-explosee-56444168.html] (23.9.2015)

Illegal Party ce soir... Ca va vous piquer fort et tout de suite! [https://www.facebook.com/ permalink.php?story_fbid $=10151702476672364 \& \mathrm{i}$ $\mathrm{d}=88896817363 \&$ stream_ref $=5]$ (23.9.2015)

Le MHSA veut piquer fort pour sa nouvelle saison en D2 [http://www.jds.fr/agenda/sports/ le-mhsa-veut-piquer-fort-pour-sa-nouvellesaison-en-d2-12340_A] (23.9.2015)

REMARQUES : Utilisé dans un contexte métaphorique, le sujet désigne un languard, c'est-à-dire un flatteur, un menteur, un rapporteur, qui, $p i$ quant plus fort qu'un hérisson use d'un langage acerbe, mordant, dans le but de tromper ou de médire de son interlocuteur (exemple de 1538). Le premier exemple du CW illustre l'emploi concret, le second s'applique à l'excitation créée par l'expectative stimulante d'une fête, le dernier signifie 'y aller fort, s'engager à fond' à propos d'une équipe de handball qui vient de choisir le moustique comme emblème. Fort reste invariable et est modifié par plus. Notons l'emploi transitif du verbe dans le CW.

\section{Piquer grave}

Faire très mal

$\pi$ venir grave

\section{Piquer juste}

Piquer avec précision

Emploi absolu

1843 - J'allais aller... à la barrière de Charenton... pour tâcher de vous voir partir... heureusement... je me suis trouvé arrêté ici par la foule... Ça devait d'ailleurs m'arriver... je l'ai dit à Martial... j'avais un pressentiment. - Un pressentiment !

- Oui... monsieur Rodolphe... Le rêve du sergent... cette nuit je l'ai eu...

- Oubliez ces idées... espérez... votre blessure ne sera pas mortelle...

- Oh ! si, le Squelette a piqué juste... C'est égal, j'avais raison...de dire à Martial... qu'un ver de terre comme moi pouvait quelquefois être... utile... à un grand seigneur comme vous... (Eugène Sue, Les Mystères de Paris) 
1933 Sous une brusque secousse de la grosse main précise, l'enfant pousse une petite plainte. Guêpe subtile, la technique a piqué juste (Joseph Malègue, Augustin ou Le Maître est là)

\section{CORPUS WEB :}

Chaque poème est une passe d'armes : il s'agit de toucher vite, de piquer juste [http:// www.ledilettante.com/livre-978-2-84263-018-8. htm] (23.9.2015)

Un synopsis taillé sur mesure, dans le Forez, pour piquer juste ! [http://www.lamontagne.fr/ auvergne/actualite/departement/puy-de-dome/ ambert/2012/04/02/un-synopsis-taille-sur-mesu re-dans-le-forez-pour-piquer-juste_1133174.html] (23.9.2015)

par contre elle fut vraiment bonne dans «Scherza l'aura lusinghiera », notes piquées justes et bien projetées, sourire dans la voix, aisance lors de la partie intermédiaire qui évite l'eceuil du déguelando, Ciofi reste indétronée dans cet air pour sa sensibilité et son medium, mais Celine Scheen n'avait point à pâlir, c'est le seul aria que j’ai applaudi de la soirée [http://licida.over-blog. com/article-5284183.html] (23.9.2015)

REMARques : Utilisé généralement d'une manière métaphorique, piquer juste se dit d'une chose pointue qui se plante avec précision, le sujet pouvant également référer à quelqu'un tenant un objet pointu et l'enfonçant dans quelqu'un/quelque chose, et ce, pour des intentions diverses : par exemple dans le but de blesser (arme, exemple de 1843) ou alors de soigner (piqûre, exemple de 1933). Au figuré, le sens se rapproche de celui de viser juste (deux premiers exemples du CW). En musique, il s'agit de toucher et relâcher aussitôt la corde ou la touche de l'instrument ou de respirer après chaque note pour la piquer (dernier exemple du CW ; ici : le chant). Juste reste invariable dans la majorité des cas, mais dans le dernier exemple du CW il s'accorde avec l'objet au pluriel tout en gardant son interprétation adverbiale.

\section{Pisser droit}

Pisser selon une ligne droite

Intransitif

1610 Il faut que telles gens soient à leurs estudes ; et s'ils ne peuvent estudier, qu'ils s'amusent à pisser dans un pertuis, pour apprendre à pisser droit et de volée (Béroalde de Verville, Le Moyen de parvenir)

1943 Quarante ans, le bonhomme Anthelme a vécu là tranquille, mangeant bien, buvant mieux, l'haleine en fleur et pissant droit. Dix années n'eussent pas suffi à user sa culotte de velours (Georges Bernanos, Monsieur Ouine)

1980 Il est vrai que dans les toilettes... Mais je faisais encore assez confiance à l'Homme pour espérer qu'il pissât droit. Le long des murs, il n'y avait plus rien à espérer, sous le lit c'était complet, et à quoi bon une table si je ne pouvais m'y asseoir et glisser les jambes dessous? (Jean-Luc Benoziglio, Cabinet portrait)

1982 Leur habitude de pisser droit devant eux, où qu'ils se trouvassent, même à l'intérieur des huttes, était sale, mais il songeait qu'un cheval ou qu'un bœuf, dont ils avaient la tranquille fierté, en eût fait autant (Marguerite Yourcenar, Un homme obscur)

\section{CORPUS WEB :}

D'ailleurs, il n'est pas rare que l'on commence assis pour parfaire en position debout. Selon les moments, l'on peut pisser droit, en biais ou en éventail, avec des conséquences parfois facheuses pour l'hygiène corporelle... [http:// passeurdesciences.blog.lemonde.fr/2014/07/24/ pour-leur-sante-les-hommes-doivent-ils-urinerdebout-ou-assis/] (24.9.2015)

Avant de parler apprend a pisser droit [https: //www.facebook.com/Avant-de-parler-apprenda-pisser-droit--112104582287796/timeline/] (24.9.2015)

Ben je sais pas normalement les garçons, on apprend à pisser droit quand on abandonne les couches et qu'on a plus besoin de pot donc je dois t'avouer que c'est un peu loin dans ma mémoire 
[http://forum.ados.fr/love/Sexualite/assis-pissesujet_41984_1.htm] (24.9.2015)

REMARQUES : Pisser droit se dit du fait d'uriner en produisant un jet droit, précis. Il peut souligner la dextérité du sujet devant viser une cible (un pertuis, la cuvette des toilettes) mais (ex. de 1982) le geste peut exprimer une certaine indifférence, le sujet urinant simplement droit devant lui, sans se préoccuper de la destination de son jet. Droit reste invariable.

\section{Pisser dru}

I. Couler abondamment Intransitif

1886 Elle se dessine moqueuse devant son regard, sur la bielle terne de la locomotive, dans l'eau qui pisse dru de la chaudière (Jean Moréas et Paul Adam, Le Thé chez Miranda)

\section{Produire en grande quantité}

Transitif

1971 La chanson est vieille. Elle a été chantée sur tous les tons par les papas des usines qui pissent dru les bonnes affaires et les joyeuses fêtes organisées par le Comité d'Entreprise qui ne comprend en fait que des gens mandatés par la Direction Générale (Yves Navarre, Lady Black)

Emploi absolu

2014 Vigneron qui se caille les miches, Sait que le gel le rendra riche, D'un Saint-Gérald froid et ardu, Pour que vendanges pissent $d r u$ (Pierre Perret, Mon almanach)

III. Uriner abondamment

Intransitif

1990 Pisser dru atteste une bonne santé : voyez notre Rabelais, en son Gargantua (Jacques Chabot, L'Imaginaire)

1993 Son Joseph, par exemple, ressemble en tout aux robustes paysans du Minho ou de l'Alentejo, aux pieds solidement plantés en terre, qui pissent dru et font l'amour avec un bel appétit (L’Express)

2013 Il tenait son pistolet à la main. Soudain, le son d'un jet d'eau brisa le silence.
Quelqu'un était en train de pisser dru, quelques mètres au-dessus (Miguel Ángel Molfino, Monstres à l'état pur)

2016 Bientôt, il pleut comme vache qui pisse et nous savons tous que la vache pisse drue et longtemps (Piga, La Journée de sang voisin)

\section{CORPUS WeB :}

Ils n'ont pas le feu aux crus, ils pêchent même en vins troubles, mais si certains pissent drus, eux pour sûr, ils Chiroublent [= à associer à la Fête des crus de Chirouble] Vincent Roca [http://vinsde-martinique.over-blog.com/ article-26867421.html] (17.1.2009)

le genre un poil vieillot avec baignoire à gros robinets qui pissent drus [http://www.bertho meau.com/2018/01/la-resistible-ascension-de-be noit-h.benoit-occupait-l-essentiel-de-son-tempsa-l-observation-des-femmes-mariees.dans-sonbestiaire-f] (6.2.2018)

La nuit les chiens pissent drus [https://www. easyzic.com/mp3-gratuits/telecharger-la-nuitles-chiens-pissent-drus,f42053.html] (20.10.2020)

REMARQues : Pisser dru 'pisser beaucoup et fort' (III) renvoie, au propre, à l'homme, à la vache, et, au figuré, à la pluie. Dans son emploi abstrait (I), il réfère à tout liquide qui s'écoule d'un récipient. Sur le plan métaphorique (II), il est signe de force, de santé et de productivité. (II) est employé dans le domaine de la production de vin ou de jus. Dans le premier exemple du CW, pisser dru signifie plutôt 'produire un vin trouble, peu clair'. En général, dru tend à l'invariabilité, mais sur Internet l'accord est très fréquent (CW et exemple de 2016).

\section{Pisser gros}

I. Avoir beaucoup d'idées ; jaillir

Intransitif

1610 SAPHO. La Soldée, bien estonnée, se resolut en sa disgrace, et pour reparer son desastre, se mit à arracher de son cul, à belles mains, le beurre qui y estoit attaché. HYPOCRATE. Mais les chimiques disent qu'ils cherchent les esprits ; et de là il sembleroit que vous voulussiez conclure que les femmes, ayant plus de cul, eussent plus d'esprit que les hommes. 
CELSUS. Cela est vray, et y paroist. Qu'ainsi ne soit, une fille de sept ans pissera plus gros que ne fera un garçon de dix-neuf, comme estant plus capable, et partant ayant davantage de jugement (Béroalde de Verville, Le Moyen de parvenir)

II. Couler en grande quantité, s'écouler ; émettre abondamment

Intransitif

1650 Io, qui dans sa penitence

Cherche en vain plus de quatre fois

Ses mains, pour en armer ses doigts,

Contre son poil de jaune paille

Qu'elle perdit à la bataille ;

Elle admire, non sans horreur,

Dans son ombre qui luy fait peur,

Létrangeté de sa personne ;

Mais ce qui beaucoup plus l'étonne,

C'est de se voir pisser si gros

(Charles d'Assoucy, L'Ovide en belle humeur)

Corpus Web :

Bonjour à tous, au retour d'une balade, j'ai eu la surprise de me rendre compte que mon essence pissait " gros comme le doigt » sous la moto [http://www.gasgasman.org/viewtopic. php?f=5\&t=11200] (24.9.2015)

Bon, alors la panne est trouvé. ce sont les joints spy qui étaient très très naze côté distribution. ça pissait gros comme une mine de crayon par la poulie dampère [http://www.forumsuper5.fr/?showtopic=9246] (24.9.2015)

Cette vallée d'effondrement en pays calcaire attire promeneurs et amateurs d'escalade. A gauche l'un des plus beaux rochers, celui « des rouillours », car dans la vallée autrefois on faisait rouir le lin dans le ruisseau. A droite la cavité d'où jaillissait une source « qui pissait gros comme le bras » et qui porte le nom de " font qui pisse » [http://www.chateauneuf.org/chateauneuf/villa ges/varappe.html] (24.9.2015)

Remarques : Pisser gros s'emploie dans un langage familier. Dans l'exemple sous (II), Io, transformée en vache, n'en revient pas d'émettre des jets d'urine d'une telle abondance et d'une telle grosseur. Dans son emploi figuré et par analogie (I), pisser gros renvoie à une effusion d'idées.
Notons également les exemples du CW, les deux premiers référant à une fuite d'essence ou de liquide sur un véhicule, et le dernier à une source d'eau. Gros reste invariable. Il est modifié par une construction comparative s'appliquant à la taille du jet (comme le doigt, une mine de crayon, le bras) ou par plus, si. VoIR AUSSI : couler gros

\section{Placer bas}

Placer à un niveau social ou professionnel inférieur

Transitif

1836 Pour tenir les bassins égaux de la balance Où l'on veut les peser, il faut un grand silence

Des passions du siècle et de ses intérêts ; La main tremble à qui veut les juger de trop près ;

Comme au juge placé trop bas dans la carrière,

Le but est trop souvent caché par la poussière

(Alphonse de Lamartine, Jocelyn)

1838 Le peuple, qui a l'avenir et qui n'a pas le présent ; le peuple, orphelin, pauvre, intelligent et fort ; placé très bas, et aspirant très haut ; ayant sur le dos les marques de la servitude et dans le cœur les préméditations du génie ; le peuple, valet des grands seigneurs, et amoureux, dans sa misère et dans son abjection, de la seule figure qui, au milieu de cette société écroulée, représente pour lui, dans un divin rayonnement, l'autorité, la charité et la fécondité (Victor Hugo, Ruy Blas)

1840 Mais, comme entre les salaires, depuis celui de balayeur jusqu'à celui de ministre, il règne la même inégalité qu'entre les propriétés, il se fait un ricochet de spoliation du plus fort au plus faible, si bien que le travailleur éprouvant d'autant plus de privations qu'il est placé plus bas dans l'échelle sociale, la dernière classe du peuple est littéralement mise à nu et mangée vive par les autres (Pierre-Joseph Proudhon, Qu'est-ce que la propriété ?) 


\section{CORpus Web :}

Si l'oiseau a un perchoir de ciment dans sa cage, il est conseillé de le placer bas dans la cage pour éviter que l'oiseau ne passe ses journées et ses nuits sur ce perchoir [http://www.animaux exotiques.com/oiseaux/maladies/bumble.htm] (24.9.2015)

Tant que la cup ne te gêne pas, la hauteur n'est pas un problème. Plutôt que de chercher à la pousser vers le haut comme tu l'as fait, essaie plutôt de la placer bas : elle remontera toute seule (sauf peut-être si tu as des soucis de tonicité) si besoin, et au moins elle n'ira pas écraser ton col [http://forum.easycup.fr/topic3785.html] (24.9.2015)

J'ai un col très bas là où les règles sont intenses : pendant $24 \mathrm{~h}$ mini, max un peu moins de 2 jours. Et je viens de comprendre que ma cup remonte très souvent quoi que je fasse, la placer basse n'y fait rien [http://forum.easycup.fr/post 41184.html] (24.9.2015)

REMARQUES : Placer bas se dit de quelqu'un à qui on procure un emploi, un poste trop modeste, au-dessous de ses qualifications, de ses capacités ; il peut s'agir également de quelqu'un qu'on empêche de s'élever dans la société. Il s'oppose à aspirer haut. L'emploi concret de bas, spatial, apparaît dans le CW et signifie 'placer quelque chose dans une position inférieure dans l'espace (un oiseau dans sa cage ou une cup dans le vagin)'. Bas reste invariable dans la majorité des cas (v. le deuxième exemple du CW), mais, dans le troisième exemple du $\mathrm{CW}$, il s'accorde avec l'objet au féminin (la cup). Il est modifié par plus, très, trop.

\section{Placer haut}

I. Placer à un niveau (social, moral) élevé, supérieur

Transitif

1696 Il y a une philosophie qui nous élève au-dessus de l'ambition et de la fortune, qui nous égale, que dis-je, qui nous place plus haut que les riches, que les grands, et que les puissants (Jean de La Bruyère, Les Caractères)

1832 Vous êtes bien aimable pour moi, et je vous en remercie du plus profond de mon cœur de profundis, comme dit le psaume fatal, ceci est-il de bon goût par le choléra qui court? Oui, car c'est vous placer aussi haut que Dieu (Honoré de Balzac, Correspondance)

1837 Pour te placer plus haut dans la société, tu ne veux plus être en nom, tu veux ôter l'enseigne de La Reine des roses, et tu vas faire encore tes salamalecs d'affiches et de prospectus qui montreront César Birotteau au coin de toutes les bornes et au-dessus de toutes les planches, aux endroits où l'on bâtit (Honoré de Balzac, Histoire de la grandeur et de la décadence de César Birotteau)

1842 Il était impossible de se présenter aux électeurs sans un titre qui me signalât comme écrivain et comme administrateur. La profession de bonnetier était honorable sans doute, elle ne pouvait que me placer très haut dans l'estime d'un peuple qui consommait généralement mes articles (Louis Reybaud, Jérôme Paturot à la recherche d'une position sociale)

1845 Mais ne le serait-il pas, que votre généreuse tentative vous placera toujours haut et bien, croyez-moi... Les yeux de Mlle de Cardoville brillaient d'un fier et doux éclat, ses joues étaient légèrement colorées, son sein palpitait, elle redressait sa tête charmante par un mouvement d'orgueil involontaire (Eugène Sue, Le Juif errant)

1853 RODOLPHE. Il est vrai ; mais, mon cher, quand on manque de tout,

Il faut qu'on soit bien pur, pour l'être jusqu'au bout.

On lutte quelque temps ; puis le courage tombe ;

Le plus vaillant chancelle, et le faible succombe.

GEORGE. Quoi ! Rodolphe ! peux-tu défendre ce pied-plat, Toi, que le point d'honneur trouve si délicat !

Et n'es-tu pas la preuve enfin, s'il en faut une, 
Que les cœurs haut placés dominent la fortune?

(François Ponsard, L'Honneur et l'argent)

1932 il prépare ainsi la doctrine qui absorbera la vie morale dans l'exercice rationnel de la pensée. Jamais la raison n'aura été placée plus haut. Voilà du moins ce qui frappe d'abord. Mais regardons de plus près. Socrate enseigne parce que l'oracle de Delphes a parlé. Il a reçu une mission (Henri Bergson, Les Deux Sources de la morale et de la religion)

1946 Sa fiction renforcée, devient « l'idéal de la personnalité » ; plus son sentiment d'infériorité est intense, plus il la place haut, et plus loin de la réalité (Emmanuel Mounier, Traité du caractère)

II. Estimer beaucoup, avoir beaucoup de respect (pour quelqu'un ou quelque chose) Transitif

1787 O femmes ! femmes ! que vous êtes malheureuses, quand celui que vous aimez se fait de votre amour un droit de vous tyranniser, quand, au lieu de vous placer assez haut pour s'honorer de votre préférence, il met son honneur à se faire craindre et à vous voir ramper à ses pieds ! (Isabelle de Charrière, Caliste ou Lettres écrites de Lausanne)

1790 Voilà donc M. de Lameth obtenant les mêmes hommages, la même popularité qui me flattaient tant pour mon père ! Combien cela fait réfléchir et placer plus haut encore son indépendance!

(Germaine de Staël, Lettres de jeunesse)

1845 Jules avait pour les femmes trop de mépris dans la pratique et trop d'estime en théorie ; Henry, qui ne les plaçait pas si haut, les aimait davantage (Gustave Flaubert, $\mathrm{La}$ Première Éducation sentimentale)

1908 Toutefois, il confiait - à Christophe, toujours, - que, si haut qu'il mît l'art, il plaçait encore plus haut l'art dans la vie, l'action, et que s'il avait eu le choix du rôle à jouer, il eût choisi Bismarck (Romain Rolland, Jean-Christophe. La Foire sur la place)
1918 Nous plaçons plus haut une catégorie de romanciers chez qui le souci d'Art fut beaucoup plus grand (Pierre Reverdy, Nord-Sud)

1940 Il unissait à un don de sympathie qui, parfois, le portait à placer trop haut ses amis vivants et à s'exprimer sur eux comme s’ils eussent été Goethe, une probité intellectuelle que je n'ai admirée à ce degré chez aucun autre contemporain (François Mauriac, Journal 3)

1948 La « révélation » que Breton place si haut, est avant tout décharge électrique brusque (Julien Gracq, André Breton)

1957 Les uns avaient peint, d'autres allaient peindre, et les derniers enfin s'occupaient de ce qui avait été peint ou le serait. Tous, certainement, plaçaient très haut les travaux de l'art, et se plaignaient de l'organisation du monde moderne qui rend si difficile la poursuite des dits travaux et l'exercice, indispensable à l'artiste, de la méditation (Albert Camus, L'Exil et le royaume)

1958 Aucune des petites Mabille n'avait froid aux yeux ; elles plaçaient trop haut leur famille pour éprouver de la timidité devant des étrangers (Simone de Beauvoir, Mémoires d'une jeune fille rangée)

III. Placer (la voix) dans l'aigu, dans un registre aigu, dans un ton haut

Transitif

1929 Le rideau monta. Sur la scène Mérya et Dorilys, celle-ci plaçant haut sa voix blanche enfantine, celle-là jouant d'un contralto de velours un peu râpé, attaquaient leur grande scène (Colette, La Seconde)

1958 Avec sa voix charmante et haut placée, ses blondeurs d'or pâle, sa volubilité séduisante, Marie Sabouret ne fait apparaître que les surfaces du rôle (Le Monde, 10 octobre 1958 / Grundt : 284)

CORPus WeB :

Et avant d'apprendre le placer haut (et donc de monter comme mes dieux...) Il faut apprendre à nos loulous à se tendre et surtout à tendre leur dos. Or, pour un cheval qui apprend encore ou 
manque de puissance dans son dos, le meilleur travail est quand même le placer bas [http:// grums-and-co.over-blog.com/article-15252245. html] (24.9.2015)

Humidificateurs à haute pression : Une pompe à haute pression (environ 70 bars) pousse l'eau vers des buses. Ils permettent des diffuser largement de grandes quantités d'eau pour humidifier l'air. Les gouttelettes émises sont relativement grosses. Il est nécessaire de les placer haut (environ 5 mètres) pour éviter de mouiller au sol [https://fr.wikipedia.org/wiki/Humidificateur] (24.9.2015)

Pour les jeunes chevaux selon s'ils sont sur les épaules ou non on va leur demander d'être plus ou moins bas. La mienne a un très bon équilibre épaule-hanche donc on lui demande d'être bien basse pour qu'elle utilise bien son dos (car elle cède de la nuque mais sans mettre le dos donc la placer haut ne sert pas à grand chose pour l'instant) [http://www.chevalannonce.com/ forums-2848769-fautil-placer-haut-ou-bas? $\mathrm{p}=2$ ] (24.9.2015)

J'ai des raisons de la placer haute, la barre ! Etant parfait moi-même :D, je ne peux accepter autour de moi que des gens parfaits aussi, même si ces cons-là ne me trouvent pas à leur niveau ! [http://forum.psychologies.com/ psychologiescom/rencontres-et-seduction/barrehaute-sujet_5113_4.htm] (24.9.2015)

Remarques : Placer haut (I) signifie 'placer quelque chose/quelqu'un à un niveau élevé', par exemple dans la société ou dans son estime, le sujet estimant de par ce fait la personne (ou l'objet) à laquelle il attribue des valeurs sociales, morales, ou autres. Placer haut (II) désigne le fait d'estimer quelqu'un ou de lui accorder beaucoup de respect ; l'objet peut également être un inanimé (par exemple, l'art) et être considéré, voire honoré par le sujet. L'emploi concret au sens local ne figure que dans le CW. Dans le contexte du chant ou de la parole (III), il prend le sens de 'élever la voix, aller dans les aigus'. Haut reste invariable dans la majorité des cas (v. le deuxième et le troisième exemple du CW), mais dans le dernier exemple il s'accorde avec l'objet au féminin dans la locution figée placer haut(e) la barre. Dans le premier exemple du CW, il s'agit d'un infinitif substantivé. Haut est modifié par assez, aussi, encore plus, plus, si, toujours, très, trop. Notons la collocation haut et bien et l'antonyme placer bas.

\section{Plaindre bas}

Plaindre à voix basse, intérieurement, secrètement

Pronominal

1851 Mais, je vous en prie, ne m'accusez pas de mauvais caractère, j'ai supporté pendant trois mois et plus les mines et même les actes tout à fait agressifs sans me plaindre ni haut ni bas et je n'en aurais pas parlé (Arthur de Gobineau, Correspondance avec Alexis de Tocqueville)

1907 On le prenait pour juge, souvent, dans les contestations entre les ouvriers et les commis assermentés qui les surveillaient au nom des marchands de bois. Il se plaignait tout haut, - les autres le faisaient tout bas, - que le salaire fût insuffisant. Un franc cinquante par jour, c'était trop peu, c'était injuste (René Bazin, Le Blé qui lève)

\section{CORPus Web :}

C'est pour prévenir les parents, comme ça si ceux-ci se plaignent bas ils ne peuvent rien dire puisqu'ils sont censés être prévenu avec le PEGI :) [http://eu.battle.net/d3/fr/forum/topic/2868 764885] (24.9.2015)

lol c'est pas dma faute si ya plein de gens qui se mettait devant ns a chak fois... si en plus mademoiselle se plaignait bas c’st pr sa aussi $10 l^{\wedge \wedge}$ [http://miss-fetarde-69.skyrock.com/719584786jerem-et-moi.html] (24.9.2015)

REMARQUeS : Se plaindre bas désigne le fait d'exprimer son mécontentement à voix basse ou intérieurement, dans le but de n'être pas entendu par des tiers. Notons la collocation se plaindre ni haut ni bas, dans laquelle le sujet affirme n’avoir émis aucun son de protestation, que ce soit secrètement ou publiquement. Bas reste invariable et est modifié par tout.

\section{Plaindre clair}

se plaindre haut et clair : se plaindre ouvertement, explicitement, à haute et intelligible voix $\pi$ plaindre haut 


\section{Plaindre fort}

Plaindre beaucoup

Transitif

1450 ADAM. Pervers sang, perverse matiere, Cueur traïstre et tres inhumain, As tu ousé mettre la main Par quoy cil gist mort et deffaiz Qui mieulx valloit que tu ne fais? Helas! Abel, mon tres chier gendre, Avec toy brief vouldray descendre En enffer et la, jamais faindre Ee toy fort lamenter et plaindre Sans consolacion aucune ! (Arnoul Gréban, Le Mystère de la Passion, 1044)

\section{CORPUS WEB :}

Alors oui : pour la CGT, il est grand temps de se plaindre et de se plaindre fort ! [http://www. ugict-cgt-bnpparibas.com/2015/07/il-est-grandtemps-de-se-plaindre.html] (24.9.2015)

Liste de symptômes à n'en plus finir, pas étonnant que les docteurs m'aient prise pour une neu-neu de me plaindre fort pour ce qui semblait être un rhume [http://forum.doctissimo.fr/sante/ troubles-orl/problemes-infection-dentairesujet_7067_1.htm] (24.9.2015)

Puis des téléspectateurs posent des questions, très intéressantes, du genre : «J'ai une pizzeria et, sur Internet, il y a des critiques incroyables. Comment les faire supprimer ? " ou, encore, la question de Sylvia qui se plaint fort d'un de ses clients, elle dit : « Le pressing m'a rendu ma veste abîmée. Quels sont mes recours ? » [http://www. lefigaro.fr/culture/2013/10/03/03004-20131003 ARTFIG00502-france-5-fait-sa-ba.php] (24.9.2015)

REMARQUeS : Plaindre fort désigne le fait d'exprimer son mécontentement, fort pouvant souligner la continuité, la vivacité des plaintes, mais aussi éventuellement l'élévation de la voix. Fort reste invariable (v. le dernier exemple du CW). VoIR AUSSI : se lamenter fort

\section{Plaindre haut}

I. Se lamenter ouvertement, à haute voix Pronominal

1596 Je baiseray ce bel œil qui me tuë, Et de mon mal tout haut je me plaindray. M'advienne apres ce qu'il faut que j'attande De ces hazards, je veux tout endurer (Philippe Desportes, Euvres)
1615 Ains font venir de Hollande en France, au veu et sceu de tout le monde, des maistres et pilotes pour mener leurs navires. De quoy, tous les jours, les matelots se plaignent haut et clair sur le quay de vos villes (Antoine de Montchrestien, Traicté de l'économie politique)

1637 Je ne sçay si un jeune Advocat qui estoit proche d'elle en receut quelque disgrace : mais ne pouvant cacher sa mauvaise humeur, ou voulant paraistre sçavant en l'art Poëtique, et comme si dans ces assemblées il n'y eust que luy de docte, pour faire éclater sa science, qui neantmoins est encore incognuë parmy les Poëtes et orateurs : se plaignant tout haut d'avoir mal aux oreilles d'entendre des vers mal prononcez, fut querelé de quantité d'honnestes gens, et sans le respect du lieu eust esté injurieusement jetté hors la salle, bien qu'il eust quelque raison : Car nul sans faute, dit le commun propos (L. C. Discret, Alizon)

1709 Quoique nous n'entendissions pas davantage à ce second compliment qu'au premier, nous n'eûmes pas de peine à nous imaginer ce qu'il nous vouloit dire : nos ventres ne nous disoient que trop ce que ce pouvoit être ; et ils se plaignoient si haut qu'il étoit près de trois heures qu'ils n'avoient mangé, qu'il ne fut pas plus difficile à ces gens d'entendre leur langage qu'à nous le leur (Jean-François Regnard, Voyage de Laponie)

1710 Les cordeliers en ont murmuré ; mais quelque droit de préséance qu'ils eussent, et quelques bonnes voix qu'ils aient pour se plaindre aussi haut que les autres, on a jugé qu'il ne falloit point tourmenter la société ni traîner de dimanche en dimanche leur confrérie (Valentin-Esprit Fléchier, Mémoires sur les Grands-Jours d'Auvergne en 1665)

1761 Mais... prenez patience ainsi que moi puisqu'il le faut, sans en demander davantage. Soyez sûr que je vous rappellerai le plutôt qu'il sera possible, et pensez que souvent tel qui se plaint bien haut de l'absence, n'est pas celui qui en souffre le 
plus (Jean-Jacques Rousseau, La Nouvelle Héloïse)

1762 Enfin l'on découvre que le jardinier a fait le coup. On le fait venir. Mais nous voici bien loin de compte. Le jardinier apprenant de quoi l'on se plaint commence à se plaindre plus haut que nous. Quoi, messieurs ! C'est vous qui m’avez ainsi gâté mon ouvrage? (Jean-Jacques Rousseau, Émile ou De l'éducation)

1766 Imaginez-vous un trou de cinq pieds en quarré, sur autant de hauteur, à plus de vingt-cinq pieds sous terre [...] où l'on est quelquefois des mois entiers, même des années, sans parler à personne ; où l'on est assommé de coups de nerfs de bœuf, lorsqu'on se plaint un peu trop haut de sa situation : voilà quelle était ma nouvelle demeure (Henri-Joseph Dulaurens, Le Compère Mathieu)

1853 - On vous trompe, monsieur le principal. - Oui on pourrait me tromper si ce bruit m'était revenu par un de vos confrères : je croirais peut-être à la jalousie ; mais c'est dans la ville qu'on se plaint le plus haut (Champfleury, Les Souffrances du professeur Delteil)

1859 La fille avait beau jeu à relever la mère ; mais elle avait le tort de parler d'elle sans aucun respect. Elle se plaignait tout haut d'appartenir à des personnes « si fort attachées au monde et si peu chrétiennes » (Charles Sainte-Beuve, Port-Royal)

1927 Il faut reconnaître que nous devons beaucoup et ne nous plaindre tout haut que des vols qualifiés. Car on rembourse bien une dette, mais il est rare qu'un voleur soit homme à vouloir et pouvoir restituer (Pierre Reverdy, Le Gant de crin)

II. Témoigner de la compassion

(envers quelqu'un/quelque chose) ouvertement, à haute voix

Transitif

1696 Les Sannions et les Crispins veulent encore davantage que l'on dise d'eux qu'ils font une grande dépense, qu'ils n'aiment à la faire ; ils font un récit long et ennuyeux d'une fête ou d'un repas qu'ils ont donné, ils disent l'argent qu'ils ont perdu au jeu, et ils plaignent fort haut celui qu'ils n'ont pas songé à perdre : ils parlent jargon et mystère sur de certaines femmes (Jean de La Bruyère, Les Caractères)

1842 Le parlement gouvernait pour l'un ; le despacho universal gouvernait pour l'autre. Le jour où la nouvelle de la prise de Mons parvint à Madrid, Philippe IV se réjouit très fort en plaignant tout haut ce pauvre roi de France, ese pobrecito rey de Francia (Victor Hugo, Le Rhin)

1843 Un dernier trait de ce caractère fâcheux, c'était une intempérance et un cynisme d'expressions inouïs à propos d'indispositions saugrenues ou d'infirmités impossibles ou absurdes qu'il s'amusait à vous supposer et dont il vous plaignait tout haut devant cent personnes (Eugène Sue, Les Mystères de Paris)

CORPUS WEB :

Il faut se plaindre haut et fort et foutre un peu de bordel puisqu'ankama à l'air d'aimer se foutre dans le caca ! [http://forum.dofus.com/ fr/1028-sujets-fermes/543649-ankama-voleurs] (25.9.2015)

D’après lui, le fait de ne pas se plaindre haut et fort ne veut pas dire que les frustrations et les insatisfactions sont absentes, c'est simplement qu'elles ne sont pas exprimées [http://www. pratique.fr/actu/plaindre-longueur-journeebonne-chose-91487.html\#] (25.9.2015)

Effectivement, la passagère oubliée s'est plainte, haut et fort, si bien que le personnel naviguant à du céder [http://novlangue-city.forumsrpg.com/t1535-pont-inferieur] (25.9.2015)

REMARQUES : Se plaindre haut (I) désigne le fait d'exprimer son mécontentement au sujet de quelque chose, généralement par des paroles clamées haut ; le sujet cherchant à être entendu, il élève la voix de façon à être entendu de beaucoup de personnes. (II) réfère au fait de montrer ouvertement de la passion envers quelqu'un. Notons les collocations haut et fort et haut et clair, où clair ajoute ici l'idée de clarté, d'intelligibilité des 
propos, des plaintes émises, le sujet cherchant à s'exprimer avec franchise et simplicité. Haut reste invariable (v. le dernier exemple du CW), étant presque toujours modifié, notamment par aussi, bien, fort, le plus, plus, si, tout, un peu trop.

\section{Plaindre parfont}

Plaindre profondément, sincèrement, de tout cœur

Transitif

+1249 Car tels est la maniere d'Ire Que toz jors vuet les denz estraindre Et souspirer et parfont plaindre Et coroucier a li meïsme, Et ce toz jors li regaïsme Ja ne querroit por nule chose : Tel maniere a que toz jors chose (Rutebeuf, Poèmes [pièces datables de 1249 à 1272], I, p. 349, 242)

REMARQUes : Plaindre parfont désignait le fait d'exprimer une profonde compassion envers quelqu'un, de regretter vivement son absence, sa disparition. Profond réfère aux sentiments de peine, intenses et durables.

\section{Plais(s)ier destroit}

Courber, plier avec fermeté ou de manière étroite, serrée

Transitif

1300 Fierabras a le branc en contremont haucié, La caïne li trence et l'esperon du pié. Damediu le gari, la jambe n'a trenchié ; Desi que en la tere a le branc envoiié. Du cop a si le conte estoné et cargié Que pour .i. seul petit ne l'a jus trebucié. A l'archon de la sele l'a si destroit plaisié Ke i li a par mi desrout et despechié. Le ferrant desous lui li a agenoullié, $\mathrm{Au}$ relever qu'il fist .i. peu a souloissié (Fierabras (K), 849)

REMARQUES : En ancien français, plais(s)ier destroit désigne le fait de plier, de ployer de manière très serrée. Destroit, utilisé encore en moyen français, signifie 'resserré, étroit, pressé', lorsque l'objet est une chose. Destroit est modifié par si.

\section{Plaire fort}

Plaire beaucoup

Transitif

+1233 Las, quez folie le desoit !

De l'iawe cuide ke cors soit.

Tant fort li plaist a regarder,

Qu'il n'en puet ces oez destorner,

Tant bes li cemble toz li cors,

Des chevous semble ke soit ors (Robert de

Blois, Floris et Lyriopé [2 $2^{\mathrm{e}}$ tiers XIII ${ }^{\mathrm{e}}$, 1601)

-1250 Vos vair oiel et vos gens cors,

Vos biax ris et vos dox mos

Ont men cuer navré a mort.

Se Diu plaist le pere fort,

Je vous reverai encor, suer douce amie

(Aucassin et Nicolette [ $1^{\mathrm{re}}$ moitié XIII $\left.\left.{ }^{\mathrm{e}}\right], \mathrm{XIII}\right)$

+1365 Car tant fort m'en plaisoit la vie

Qu'aillours n'ert m'entente ravie,

Ne ma plaisance, ne mon corps

(Jean Froissart, Poésies [3 $3^{\mathrm{e}}$ tiers XIV $]$ )

1450 Or doncques j'ayme, et entre touz aultres grans faiz ceste cy fort me plaist et agrée, ceste cy où je suis ; là sont touz les plaisirs au monde et est mon cueur adressé comme au plus parfait, et tous autres regitte en arrière (Roman de Troilus et Cressida, p. 195)

1660 GORGIBUS. Brisons là. Si, sans votre congé,

Valère votre fils ailleurs s'est engagé, Je ne vous puis celer que ma fille Célie

Dès longtemps par moi-même est promise à Lélie ;

Et que, riche en vertus, son retour aujourd'hui

M’empêche d'agréer un autre époux que lui.

VILLEBREQUIN. Un tel choix me plaît fort (Molière, Sganarelle ou Le Cocu imaginaire)

\section{CORPUS WEB :}

effectivement si ça commence fort dès le début du film ça risque de me plaire fort (-) [http://geekirc.me/2014/12/16/cinema-je-suisalle-voir-cold-july/] (24.9.2015)

elle a des vitamines qu'elle n'aime pas, elle refuse de manger quoi que ce soit sauf des biscuits BIO au sesame, est-ce que vous auriez des 
idées de choses qui pourraient lui plaire fort fort ? $\wedge^{\wedge}$ [http://www.masouris.fr/forums/topic/ la-meilleur-friandise-du-monde/] (24.9.2015)

slt. depuis un an j'ai fait la connaissance d'un gars qui m'a plu fort...lui aussi...on parlait beaucoup et il m'a invité pour sortir avec lui [http:// forum.ados.fr/love/Amour/question-amourcompliquee-sujet_41073_1.htm] (24.9.2015)

Ceux qui sont occupés à la découverte des mines d'or et d'argent observent quelques cérémonies pour se concilier la bienveillance des gnomes, afin qu'ils ne leur soient pas contraires dans leurs entreprises. L'expérience leur a appris qu'ils se plaisent fort aux parfums, et c'est pour cela que les sages cabalistes en ont ordonné de propres à chaque jour de la semaine par rapport aux sept planètes [http://universparanormal.over-blog.com/2014/06/oraison-dessalamandres.html] (24.9.2015)

REMARQues : Plaire fort se dit de quelque chose ou de quelqu'un qui éveille la sympathie, est source d'agrément, de grande satisfaction pour quelqu'un, fort signifiant ici 'beaucoup, intensément'. Fort reste invariable (v. le dernier exemple, pronominal, du CW) et est modifié par tant. Notons la réduplication fort, fort.

\section{Planer haut}

I. Se situer à un niveau (moral, spirituel, social) élevé, supérieur

Intransitif

1796 Quel vaste champ à nos conjectures sur l'antiquité du monde et sur sa civilisation, quand on réfléchit que la position des cieux donnée par ces poëmes, où les constellations jouent un si grand rôle, ne nous permet pas d'en rapprocher de notre ère les auteurs, de plus de deux mille cinq cents ans ! Est-ce bien sur les débris du monde, sorti à peine des eaux d'un déluge, que les arts du génie planaient aussi haut? (Charles Dupuis, Abrégé de l'origine de tous les cultes)

1853 Et Fould, Magnan, Rouher, Parieu caméléon,

Font rage. Ils vont montrant un sénat d'automates.

Ils ont pris de la paille au fond des casemates
Pour empailler ton aigle, ô vainqueur d'Iéna!

Il est là, mort, gisant, lui qui si haut plana, Et du champ de bataille il tombe au champ de foire.

Sire, de ton vieux trône ils recousent la moire (Victor Hugo, Les Châtiments)

1893 Ce qui importe, ce n'est pas qu'il plane bien haut au-dessus de nous, au point de nous devenir étranger, mais c'est qu'il ouvre à notre activité une assez longue carrière, et il s'en faut que celui-ci soit à la veille d'être réalisé (Émile Durkheim, De la division $d u$ travail social)

1903 Une fois installé dans l'église, il oublia les tristesses de l'heure présente. La divine liturgie l'enlevait, planant si haut, loin de nos boues ! (Joris-Karl Huysmans, L'Oblat)

1907 Les hymnes grandioses, le sanglotement désespéré du Dies irae, dont la magnificence liturgique plane très haut au-dessus de l'écroulement des misères humaines, comme un appel toujours retentissant vers les puissances miséricordieuses, vers les espérances éternelles, vers l'inaccessible certitude de l'immortalité, toute cette poésie de l'office des morts, somptueuse et théâtrale, quand elle est soutenue par les chants nombreux d'une maîtrise et par le déchaînement de l'orgue aux grandes voix, prenait en passant sur ces lèvres balbutiantes de vieillard, par ce chevrotement hésitant et caduc, un accent inexprimable de grandeur (Émile Moselly, Terres lorraines)

1941 C'est en elle qu'on réalisera les deux services, bien plus que dans l'État, qui plane trop haut pour les associer, ou que dans le syndicat, qui cherche à servir un groupe au détriment d'un autre (Joseph Wilbois, Comment fonctionne une entreprise)

II. Flotter haut dans les airs

Intransitif

1877 Cette lettre va donc partir, emportant les vœux nouveaux que je fais pour votre chère santé ; ainsi que mon admiration du beau poëme «Science » que j'avais lu et que j'ai relu plus d'une fois : quel regard 
d'aigle, planant haut et libre ! (Stéphane Mallarmé, Correspondance)

\section{CORpus Web :}

Il y a des jours comme cela, où à force de planer haut on pourrait bien finir par alunir ! Voyez plutôt, midi, $35^{\circ}$ degré, pause déjeuner, je repère une table de libre à l'ombre sur la terrasse d'un petit troquet. Je commande un tartare et un demi... [http://www.legaletas.net/blog/index. php?post/2015/07/01/Plus-haut-que-les-etoiles] (25.9.2015)

Inutile de préciser qu'il est indispensable à quiconque veut se plonger dans un quotidien de rêveries inédites : Panda Bear continue de planer haut, très haut au-dessus de tout le monde [http://www.lesinrocks.com/2015/08/21/ musique/panda-bear-magnifique-nouveaumaxi-inedit-11768402/] (25.9.2015)

Ces voitures planent haut dans le ciel ! On a tous en mémoire une ou deux poursuites mémorables vues à la télé. Celle où après avoir rencontré un obstacle sur sa route, le véhicule lancé à vive allure décollait pour un vol plané d'anthologie [http://www.gentside.com/voiture/ ces-voitures-planent-haut-dans-le-ciel_art41136. html] (25.9.2015)

Remarques : Planer haut (I) s'emploie métaphoriquement pour désigner le fait de survoler quelque chose, d'être bien au-dessus de quelque chose/quelqu'un, le sujet s'élevant au-dessus de la médiocrité, du quotidien, du reste du monde et se détachant de par ses qualités ou autres. (II) se dit de tout objet volant ou d'un oiseau planant, flottant très haut dans les airs. Les deux premiers exemples du CW réfèrent au fait de rêver de quelque chose en se faisant des illusions qui éloignent celui ‘qui plane' de la réalité. Haut reste invariable et est modifié par assez, bien, si, très, trop. Notons la collocation haut et libre.

\section{Planter clair}

Mettre en terre (des graines, des semences), de manière espacée, clairsemée

Transitif

1907 Rien ne pousse presque pas dans notre jardin, point d'oignons ni de carottes ; les haricots et les pois viennent, tout doucement, mais ils ont été plantés si clair par cette Marie, que nous n'en aurons presque point (Madame Rimbaud, Lettre)

\section{CORPUS WEB :}

dans ton 201 tu peux méttre dans le font de la ludwigia glandulasa elle est rouge et pousse doucement, sur un coté une racine avec un microsoriun, sur le 1er plant du micrantemun micranthemoides, il faut le planter clair si non il s'etouffe et le tailler souvent il ferra vite un jolie tapi [http:// www.aqua-passion.com/forums/topic/10779besoin-daide-pour-choisir/] (25.9.2015)

Donc le serveur hôte plante mais il log quedal ? A moins de planter clair et net les disques, c'est space. Zavez activé le syslog à distance ce qui permettrait justement de voir si c'est à cause des disques que tout plante brutalement? [https://forum.ovh.com/showthread.php/54497Vmware-ESXi-4/page9] (25.9.2015)

Remarques : Planter clair désigne le fait de mettre, d'enfoncer en terre des graines, des semences, des bulbes, des tubercules de manière espacée, pas trop serrée, afin que les futures plantes aient suffisamment d'espace pour grandir. Dans le second exemple du CW, planter réfère au fait de provoquer l'arrêt de fonctionnement d'un matériel informatique (ici : un serveur). Notons la collocation clair et net. Clair reste invariable (v. le deuxième exemple du $\mathrm{CW}$ ) et est modifié par si.

\section{Planter court}

I. Planter, enfoncer quelque chose

profondément

Transitif

1926 Après quatre ou cinq passes de la sorte, Alban s'arma et, court et droit, comme le veulent les règles, planta l'épée jusqu'à mouiller ses doigts dans la plaie (Henry de Montherlant, Les Bestiaires)

\section{Quitter quelqu'un brusquement}

Transitif

1981 Après quoi, je le plantai court et m'enfermai chez moi, le cœur battant du péril que j'avais couru. Le soir même, je contai tout au Roi (Françoise Chandernagor, L'Allée du roi) 
REMARQUES : Planter court (I) réfère au fait d'enfoncer un objet pointu (ici : une épée) très profondément, de façon à ne laisser sortir que le manche de l'objet en question. (II) signifie 'quitter, abandonner quelqu'un brusquement'. Notons la collocation planter court et droit. Court reste invariable.

\section{Planter droit}

I. Se dresser ; être sur ses pieds

Transitif

1669 HARPAGON. Va-t'en l'attendre dans la rue, et ne sois point dans ma maison planté tout droit comme un piquet, à observer ce qui se passe, et faire ton profit de tout. Je ne veux point avoir sans cesse devant moi un espion de mes affaires, un traître, dont les yeux maudits assiégent toutes mes actions, dévorent ce que je possède, et furettent de tous côtés pour voir s'il n'y a rien à voler (Molière, L’Avare)

1831 Et le savant indiquait du doigt au marquis le tuyau de bois planté droit dans la glaise (Honoré de Balzac, La Peau de chagrin)

1875 Vêtu d'un vêtement lâche, il était planté droit, un peu mince encore, les membres fins, la poitrine carrée, les épaules rondes (Émile Zola, La Faute de l'abbé Mouret)

1932 Une seule, minime, éclairait le compas de la barre, frangeant d'une faible lueur la silhouette et les membres du timonier planté droit devant elle et sculptant chaque muscle de son visage (Édouard Peisson, Parti de Liverpool)

1966 Il avança la main, faillit toucher le pied du réchaud, se reprit, et saisit du bout des doigts la cuiller à café. Il la planta droit au centre de la tasse vide, et d'un geste morose, tourna la bouillie de café et de sucre collé (Jean-Marie Gustave Le Clézio, Le Déluge)

1985 Vers la droite, là où la vue de la rive sud commence à être interceptée vers l'aval par les maisons de Ste Anne, on devine le village de Trentemoult, pelotonné sur ses ruelles auprès de sa place des Filets et de son clocher planté droit sur la rive même où le village vient boire (Julien Gracq, $L a$ Forme d'une ville)

Pronominal

1843 - On vous gardera le fer des cercles, lui cria un charron venu pour contempler l'effet de cette chute.

Un des limons s'était planté droit comme un arbre. Max restait pâle et pensif, atteint au cœur par la phrase de l'Espagnol. On parla pendant cinq jours à Issoudun de la charrette à Fario (Honoré de Balzac, La Rabouilleuse)

1884 Se plantant droit devant Arcangeli, qui, les yeux baissés et transi, aurait bien voulu être sous terre, il lui dit, d'une voix étranglée de furie :

- Sortez, impudent coquin! (Élémir Bourges, Le Crépuscule des dieux)

1980 Elle se plantait droit, debout de l'autre côté du fleuve, les jambes écartées, et elle poussait des cris en remuant les bras avant de se déshabiller et de danser nue en faisant de vilains gestes (Robert Sabatier, Les Fillettes chantantes)

II. Appliquer directement et brusquement Transitif

1862 Celui-ci fait trois pas. La peur le cloue en place :

$\mathrm{Au}$ sommet d'un tronc noir qu'il effleure en passant,

Plantés droit dans sa chair où court un froid de glace,

Flambent deux yeux zébrés d'or, d’agate et de sang

(Charles-Marie Leconte de Lisle, Poèmes barbares : Le Jaguar)

1925 Ma foi oui, c'était Raboliot, tout à coup surgi devant lui, les bras croisés, ses yeux noirs plantés droit dans les yeux pâles du roussiau (Maurice Genevoix, Raboliot)

1944 Il disait de même : « le bigle a souri à la jeune fille. Elle s'est retournée vers ceux qui plantent droit leur regard. Et le bigle va racontant que ceux dont le regard est droit corrompent les jeunes filles » (Antoine de Saint-Exupéry, Citadelle) 
Pronominal

1936 Je n'aime pas beaucoup non plus son regard qui va partout, saute d'un coin à l'autre de la pièce avec une agilité surprenante, et revient se planter droit dans mes yeux (Georges Bernanos, Journal d'un curé de campagne)

1951 Marino pâlit légèrement, et son regard se planta droit dans mes yeux avec une lueur de sévérité hautaine (Julien Gracq, Le Rivage des Syrtes)

III. Mettre en place à la verticale, mettre debout Transitif

1907 Ils le parèrent comme une femme et ils lui mirent le miroir pour visage. Et ils le plantèrent tout droit, le sacré gohei, en face de la caverne, pleine, de la poche qui contenait l'âme indignée de la lumière (Paul Claudel, Connaissance de l'Est)

\section{Planter horizontalement}

Transitif

1951 Entre ses lèvres finement pincées, une cigarette est plantée droit, au centre de la bouche, qu'il entr'ouvre à peine pour parler (Roger Martin du Gard, Notes sur André Gide)

1962 Il quitta Faulenmuss, les mains dans son pantalon collant, d'une marche sautillante, le calot sur le front, le havane planté droit. Faulenmuss roulait vers Paris, non pas dépassé par les événements mais roulé par eux, dans l'écume de la première vague (Daniel Boulanger, Le Téméraire)

\section{CoRpus Web :}

La plantation d'un arbre, il faut la soigner. Des soins apportés à cette étape dépendra l'allure du sujet pour de longues années. En particulier, autant s'assurer que le tronc est bien vertical. Mais... comment planter droit ? [http://www. gerbeaud.com/jardin/fiches/planter-bien-droit. php3] (25.9.2015)

Il esquiva un couteau qui allait se planter droit dans son dos [http://www.hordes.fr/tid/for um/\#!view/11|thread/46458645] (25.9.2015)

Si on aime convaincre son auditoire, et si on aime les diagnostics spectaculaires, surtout si l'éleveur ne veut pas entendre que la vache va mourir, il existe une technique imparable : prendre une aiguille très longue et, d'un geste théâtral, la planter droit sur le cœur. Normalement, on aboutit dans le péricarde [http://www. boulesdefourrure.fr/index.php?post/2009/05/22/ Fil-de-fer] (25.9.2015)

Pour la plantation de la tomate ne pas la planter droite, mais couchée. En effet la tige de la tomates à la particularité de pouvoir faire d'autres racines [http://jardin-plaisir.blogspot. co.at/2015/08/plantation-des-tomates.html] (25.9.2015)

REMARQues : Planter droit (I), en emploi participial ou pronominal, signifie 'se tenir à la verticale, se dresser (de toute sa hauteur)'. Sous (II), le sujet réfère aux yeux ou au regard qui se posent directement, brusquement dans ceux d'une autre personne. Planter droit (III) se dit d'un sujet animé qui est mis debout, sur ses pieds. (IV) a encore le sens de 'planter, enfoncer (un objet)' mais cette fois à l'horizontale. Droit reste invariable dans son emploi adverbial (v. le troisième exemple du CW). En tant que prédicat second orienté vers l'objet il s'accorde avec l'objet (v. le dernier exemple du CW). Il est modifié par tout.

\section{Planter large}

Planter en laissant beaucoup d'espace

(à la plante)

Emploi absolu

1786 On ne risque donc jamais rien de planter large, mais on risque beaucoup de planter serré (Cours complet d'agriculture)

REMARQUES : Planter large désigne le fait de planter un végétal en le dotant d'un espace de large dimension qui lui permettra de pousser et grandir. C'est un antonyme de planter serré et proche de planter clair.

\section{Planter net}

I. Quitter, abandonner brusquement Transitif

$1835 \mathrm{Au}$ contraire, j'ai vu des gens fort remarquables plantés net pour cause de leur incurie. Un fat qui s'occupe de sa personne s'occupe d'une niaiserie, de petites choses (Honoré de Balzac, Histoire des Treize) 
1845 Quand il aura traîné ce pauvre homme de salons en salons, et qu'il ne saura plus qu'en faire, il le plantera là tout net, et il faudra que le cordonnier se remette à coudre des bottes, pourvu que la vanité, la misère et le désespoir en dernier lieu ne l'aient pas fait crever d'ici là, ce qui arrivera à coup sûr (Gustave Flaubert, La Première Éducation sentimentale)

1846 - Mais qu’y a-t-il ?... demanda Mlle Chocardelle.

- Cette petite créature, chez qui j'ai dîné, l'a planté là, net... oui, elle l'a lâché sans le prévenir autrement que par une lettre sans aucune orthographe (Honoré de Balzac, Un homme d'affaires)

1882 Il l'avait plantée là tout net, la laissant à cet imbécile de Pontac, qui ne sait que faire du bruit dans un cor de chasse. Un joli talent qu'il a, ce grand benêt ! Et agréable en société! (Georges Ohnet, Le Maître de forges)

1924 Paola Marié, mécontente, on ne sait pourquoi, planta tout net son rôle et son directeur un beau soir, et s'en alla, nouvelle George Sand, retrouver un nouveau Musset / qui n'était qu'un simple ténor / à Venise (Louis Schneider, Les Maîtres de l'opérette française)

II. Frapper de stupeur, rendre subitement incapable d'agir

Transitif

1873 Il marchait, dormant à demi, dodelinant des oreilles, lorsque, à la hauteur de la rue de Longchamp, un sursaut de peur le planta net sur ses quatre pieds (Émile Zola, Le Ventre de Paris)

1876 Mme Correur le suivit. Mais comme elle arrivait en face de la grand'porte, ouverte à deux battants, un spectacle extraordinaire la planta net sur les pavés. Entre les deux larges rideaux, l'église se creusait, immense, dans une vision surhumaine de tabernacle (Émile Zola, Son Excellence Eugène Rougon)

\section{Corpus Web :}

Vous plongerez instantanément dans l'univers étrange d'Oktobre : tout d'abord vous serez intrigué par le comportement extravagant de trois personnages assis autour d'une table ; puis votre œil sera sensible à la beauté plastique des lumières et des couleurs qui plantent net, une atmosphère cinématographique du genre " mauvaise série noire » [http://spectaclevivant. piemont-oloronais.fr/fr/saison-2015-2016/tout-leprogramme/spectacle.html?tx_novaculture_pi5 \%5BshowUid\%5D=594\&cHash=63e9a3dcff4ce6 654990b87477da87a5] (25.9.2015)

Coup sur coup, Apprendravivre et Hydrogene nous plantent tout net en effaçant purement et simplement leur blogs! Non mais je rêve, je cauchemarde, dis-moi pas qu'c'est pô vrai ! [http:// patitouille.canalblog.com/archives/2006/08/23/ 2524468.html] (25.9.2015)

Sentant son menton lâchait, elle afficha un petit sourire vainceur, et bien oui, pour elle, c'était elle qui avait gagné, car il lui tournait les talons aussi simplement que ça. Peut etre qu'il aurait voulu l'embrasser là, et la planter net [http://ecole-de-magie.one-forum.net/t1021-deslives-qui-volent] (25.9.2015)

La première lame déchira sa gorge sur la gauche, y restant plantée, une giclée de sang faisant suite à la lame pour recouvrir le bord de la table. Sa sœur [= l'autre lame] elle fut moins clémente, se plantant nette entre les deux yeux et figeant la cible dans sa position, bloquant le début de hurlement en s'enfonçant de moitié [http:// aiglesduroi.guildealliance.com/t333-livre-je-nesuis-qu-homme-brides-de-vie] (25.9.2015)

REMARQues : Planter net (I) a le sens de 'quitter, abandonner, délaisser (quelqu'un ou quelque chose) brusquement, laissant un effet de surprise de par l'immédiateté et la spontanéité de l'action. (II) se dit de l'action de planter, de figer quelqu'un sur place, sur le sol, la peur ou la surprise l'empêchant de bouger, d'avancer. Notons l'emploi absolu au sens de 'camper clairement' (premier exemple du CW) et l'emploi pronominal dans le dernier ('s'enfoncer sans résistance'). Net reste invariable dans la majorité des cas (v. le deuxième et le troisième exemple du $\mathrm{CW}$ ), mais dans le dernier exemple il s'accorde avec le sujet $\mathrm{du}$ verbe pronominal tout en gardant son inter- 
prétation adverbiale, augmentant ainsi l'emphase par une implication plus forte du sujet. Net est modifié par là tout, tout.

\section{Planter serré}

Planter en lassant très peu d'espace entre les plants

$\pi$ planter large

\section{Player fort}

Être couvert de plaies, de blessures importantes Transitif

$\sim 1177$ "Amis, il i covandroit painne, » Fet li rois, « ainz que vos l'aiiez. Et vos estes mout fort plaiiez, [variante : formant]

Je voi les plaies et le sanc.

Ne troveroiz mie si franc

Celui qui ça l'a amenee,

Qu'il la vos rande sanz meslee »

(Chrestien de Troyes, Lancelot ou Le Chevalier de la charrete, 3366)

REMARQUES : Utilisé en ancien français, sous la forme player ou plaier, player fort désigne le fait de blesser, meurtrir avec violence ; le participe se dit d'un animé qui est couvert de plaies importantes. Fort est modifié par moult.

\section{Pleurer bas}

Pleurer en silence, secrètement ; déplorer Intransitif

1403 Or cuide bien estre honnie, Ne scet comment le fait plus nye, Si pleure bas, en recelee ; Devers la deesse est alee Vestis, ou temple s'agenoulle, Le pavement de son plour moulle (Christine de Pisan, Le Livre de la mutacion de fortune, I, 1131)

1840 Et, comme l'océan n'apporte que sa vague, Il n'apporta que l'art du mystère et du vague!

La lyre qui tout bas pleure en chantant bien haut!

Qui verse à tous un son où chacun trouve un mot!

(Victor Hugo, Les Rayons et les ombres)
1863 Entre leurs lignes, çà et là, un vétéran passait ; et ils hurlaient des malédictions contre les Carthaginois, contre Hamilcar - et contre Mâtho, bien qu'il fût innocent de leur désastre ; mais il leur semblait que leurs douleurs eussent été moindres s'ils les avaient partagées. Puis ils gémissaient ; quelques-uns pleuraient tout bas, comme de petits enfants (Gustave Flaubert, Salammbô)

1885 puis, elle s'était mise à pleurer tout bas, en le prenant à son tour par le cou, pour le garder contre elle, dans une étreinte désespérée (Émile Zola, Germinal)

1923 Ou bien elle poursuit une conquête difficile, languit et se consume, et pleure tout bas, toute une nuit, auprès de l'amant qui dort, satisfait, repu, béat (Valéry Larbaud, Amants, heureux amants)

1968 - Pourtant vous n’aimez pas la chasse et il a renoncé à la chasse pour vous.

- Va pour la chasse ! Mais moi, j’ai renoncé à... Allons bon quand j’allais enfin oser me dire à quoi j'ai renoncé, voilà encore l'empêcheuse de pleurer tout bas (Benoîte et Flora Groult, Il était deux fois)

Transitif

1959 La patrie vit les meilleurs des siens mourir en la défendant. Avec honneur, avec amour, elle les berce en son chagrin. Hélas! Certains de ses fils tombèrent dans le camp opposé. Elle approuve leur châtiment, mais pleure tout bas ces enfants morts (Charles de Gaulle, Mémoires de guerre)

\section{CORpus Web :}

mais stop la tu connais son nom mais pas sa vie, cette fille elle ne fume pas mais elle pleure bas oui elle pleure toutes nuit personne est la pour la consoler ou voir sa tristesse.. [https://fr-fr. facebook.com/permalink.php?story_fbid $=835751$ 379818454\&id=260705737323024] (26.9.2015)

quel film jouissif, bien inspiré, empli de dialogues qui font mouche, interprété magistralement par tout le monde, bien, monté, bien éclairé, bref on est pas loin du chef-d'œuvre à mon goût : on rit fort, on pleure bas, avec cette 
histoire de femmes du village déchiré par les haines ancestrales et qui font tout pour que tout le monde puisse vivre ensemble, redoublant d'ingéniosité tout à elles [http://www.allocine. fr/film/fichefilm-189935/critiques/spectateurs/ recentes/?page=23] (26.9.2015)

Je cris tout bas, je pleure tout bas. Personne ne m'entends. Si seulement.. Tu étais encore la.. Si seulement tu avais pu te réveiller.. Je t’aime.. $\infty$ [https://www.facebook.com/permalink.php ?id=241843382588718\&story_fbid $=4376059063$ 45797] (26.9.2015)

REMARQUES : Pleurer bas désigne le fait de verser des larmes sous l'effet d'une douleur physique ou morale, d'une émotion pénible ou agréable, sans plaintes ni gémissements, de façon à ne pas être entendu. L'exemple de 1840 le transpose au domaine de la musique ; celui de 1959 est plus abstrait ('déplorer fortement en silence'). Notons l'emploi de chanter haut et crier bas. Bas reste invariable et est généralement modifié par l'adverbe d'intensité tout.

\section{Pleurer bleu}

Verser des larmes de couleur bleue Intransitif

1976 Pleurer bleu, rire jaune, rager rouge. Aimer violet, indigo, vert, orangé. Rêver blanc, crier noir (Michel Leiris, La Règle du jeu 4 : Frêle Bruit)

\section{CORPus Web :}

Son corps est immobile, yeux clos, yeux ouverts. Petit à petit commencent à rouler sur ses joues des larmes bleues, il pleure bleu. De son nez une morve bleue, de sa bouche s'écoule une bave bleue, de ses aisselles une sueur bleue et maintenant sur son front, sur son dos, sur son ventre, sur ses jambes, tout son corps suinte bleu [http://www.yannmarussich.ch/perfos.

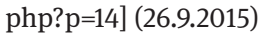

Je fume gris, je ris jaune, je pleure bleu, je t'aime noir (); [http://nous-estival.skyrock. com/1018223002-Je-fume-gris-je-ris-jaune-jepleure-bleu-je-t-aime-noir.html] (26.9.2015)

\section{Zahia Dehar pleure bleu}

Alors que cela lui a valu sa grande notoriété, Zahia Dehar avoue que le scandale des Bleus l'a déprimé durant des mois [http://www.
trenditude.fr/Zahia-Dehar-pleure-bleu.html] (26.9.2015)

REMARQues : Pleurer bleu peut référer à la couleur des larmes et en même temps, sur le plan métaphorique, à la mélancolie (« le blues »). Dans le dernier exemple, bleu renvoie à l'équipe nationale française, les Bleus. Bleu reste invariable. Notons dans le premier exemple du CW la collocation commencer petit à petit 'peu à peu' qui conserve la fonction de quantifieur que petit 'peu' avait en ancien français. Signalons également le développement d'un paradigme de couleurs : rire jaune, rager rouge, rêver blanc, crier noir, fumer gris, aimer noir (peut-être par rapport à la couleur de la peau), aimer violet, indigo, vert, orangé, etc. Sans contexte, ces groupes sont surtout suggestifs, reléguant leur interprétation à la subjectivité de celui qui les lit. La série met en évidence le potentiel inférentiel des groupes, qui est la base de leur force poétique.

\section{Pleurer fort}

Pleurer beaucoup, intensément Intransitif

1160 Quant il furent oltre passé, Premieremant i ont trové Les compaignies des anfanz, Des petitez, des alaitanz, Çals que as meres toli mort ; Braient et crïent, plorent fort ; Iluec avoit noise molt grant Del duel que moinent li enfant (Eneas, 2612)

1177 Mes sire Yvains plore et sospire Si fort, qu'a painnes li puet dire : Dame, cist termes est trop lons. Se je pooie estre colons Tores les foiz que je voldroie, Mout sovant avuec vos seroie (Chrestien de Troyes, Yvain ou Le Chevalier au lion, 2580)

+1225 Et ele commence a plourer Mout fort, si ke toute moulla Sa face. Si s'en merveilla Mesire Gauvains, ce ke doit (Le Chevalier as deus espees [ [ $2^{\mathrm{e}}$ quart $\mathrm{XIII} \mathrm{e}^{\mathrm{e}}$ ], 4945)

1285 Cleomadés i vint errant, Et quant il sot le couvenant 
Pour quoi sa suer ploroit si fort,

Si li dist qu'ele se confort

Et qu'ele ne s'esmait noient

(Adenet le Roi, Cleomadés, 2265)

+1313 Celle qui l'amoit fu dolente

Et se claimme lasse caitiue,

Mieus resamble morte que viue

A sa faice et a sa coulour,

Tant ot en son cuer grant dolour

Que uoiant les dames fort pleure

(Jean de Condé, Poèmes [1313-1337], 413)

1393 Ce fait, Raimondin fiert le porc tellement qu'il le mist à terre tout mort, et puys vint au conte et le cuida soubslever ; ce fut pour neant, car il estoit jà tout mort. Adoncques quant Raimondin apperceut la plaie et le sang en saillir, il fut moult merveilleusement couroucé, et commenca à crier en plourant et gemissant moult fort et le regarder et plaindre, en faisant le plus grans lamentations que oncques vit homme jour de vie (Jean d'Arras, Melusine, p. 34 [éd. Genève])

1450 MARCUS ANTHONÏUS. Mais, plus fort, nous dormans ainsi,

Je ne sçay pas se c'estoit songe

Ou vision sans ce qu'on songe,

Femmes ouÿsmes qui queroient

Le corps et de ce fort ploroient

Qu'il n'estoit plus en son tumbeau

(Arnoul Gréban, Le Mystère de la Passion, 30029)

1559 et, après avoir bien au long entendu ses justes raisons, en lieu de la reprendre et tuer, comme souvent par la parolle il la menassoit, la print entre ses braz et, en pleurant tresfort, luy dist : Ma fille, vous estes plus juste que moy (Marguerite d'Angoulême, Heptaméron, p. 215, 615)

1651 Elle m'apprit le sujet de son affliction avec une si grande effusion de larmes, et sa fille, que je vis pleurer aussi fort que sa mère, me toucha tellement que je ne crus pas leur témoigner assez bien mon ressentiment (Paul Scarron, Le Roman comique)
$1783 \mathrm{Au}$ logis on fait apprendre par cœur aux pauvres enfans la passion du sauveur; elle est bien longue ; ils pleurent ; on les met en pénitence ; ils pleurent plus fort, ils jeûnent au pain et à l'eau (Louis-Sébastien Mercier, Tableau de Paris)

1887 Comme il la prenait, elle se mit à pleurer si fort, qu'elle en suffoquait (Émile Zola, $L a$ Terre)

1937 Agnès commença de pleurer et la honte de pleurer la fit pleurer plus fort (Pierre Drieu la Rochelle, Rêveuse Bourgeoisie)

1989 Ma mère qui disait, « tu pleurais tellement fort, ton père m'ordonnait de me lever à cause des voisins, lui, il devait travailler le lendemain, alors, moi, je devais me balader une partie de la nuit avec toi dans mes bras » (Serge Doubrovsky, Le Livre brisé)

\section{CORPUS WEB :}

Si je ne suis pas enceinte je vais pleurer fort, tres fort [http://forum.aufeminin.com/forum/ f382/_f89934_f382-Si-je-ne-suis-pas-enceinteje-vais-pleurer-fort-tres-fort.html] (5.10.2015)

Il me semble que c'est au Japon lors d'un jour spécial. Si le bébé pleure fort cela signifie qu'il est en bonne santé. Ici en l'occurrence c'est un concours pour faire pleurer son bébé, celui qui pleure le plus fort étant le gagnant [http:// lelombrik.net/59926] (5.10.2015)

J'ai laissé tomber les rituels du matin, pas possible de parler quand il y a 2 petits qui pleurent fort, du coup je fais le minimum pour le moment [http://forums-enseignants-du-primaire. com/topic/298957-pleursgros-chagrinscrisesdagoisse-en-ps-comment-faire/] (5.10.2015)

Il faut alors instaurer un climat calme, faire le moins de bruit possible, s'abstenir de pleurer haut et fort [http://www.matthieuricard.org/ blog/posts/attitude-face-a-la-mort-4-a-suivre] (5.10.2015)

Et bien évidemment, on finit malheureuses, à pleurer haut et fort ce mec si génial qui s'est lassé de notre hystérie permanente, partant se réfugier dans l'amour ronronnant d'une connasse à gros seins [http://lilasgoldo.com/2014/05/08/ ces-mecs-dont-toutes-les-filles-tombent-amou reuses/] (5.10.2015) 
Je vous remercie pour votre présence, l'aproche de cette date est toujours un moment douleureux pour moi, je ne peux le supporter seule, je ne peux le laisser passer en disant « $\mathrm{Au}$ jourd'hui deux ans, allah yrehmak mama », mais j’ai besoin de réconfort, de lui parler, de vous parler, j'ai besoin de la pleurer haut et fort en ce jour des ses 2ans au lieu de continuer à le fire seule comme presque tous les soirs.. [http://www. yabiladi.com/forum/samedi-octobre-partie-701437696-page $=2 . \mathrm{html}]$ (5.10.2015)

à un moment Nila a pleuré, elle voulait son bib, et on sait comme les bébés pleurent forts [http://www.enceinte.com/forum/le-testa-dit-oui-je-suis-enceinte/maman-pour-avril2010-t13612-7510.html] (5.10.2015)

REMARQUES : Pleurer fort désigne le fait de verser des larmes sous l'effet d'une douleur physique ou morale, d'une émotion pénible ou agréable, en les accompagnant de plaintes, de gémissements ou de sanglots, fort pouvant référer au bruit mais aussi à la durée des pleurs. Signalons qu'il est souvent apposé à d'autres verbes de la même famille sémantique : soupirer, gémir, crier, braire. Fort reste invariable dans la majorité des cas. Toutefois, dans le dernier exemple du CW, il s'accorde avec le sujet au pluriel tout en gardant son interprétation adverbiale. Dans pleurer haut et fort, l'intensifieur fort s'unit à haut qui désigne le fait de pleurer ouvertement, publiquement, sans se cacher. Haut et fort est devenu un intensifieur lexicalisé très courant dans la langue moderne. Fort est modifié par aussi, moult, plus, si, tellement, très.

\section{Pleurer gent}

Pleurer dignement, gracieusement

Intransitif

1200 Quant li solleiz converset en leon, En icel tens qu'est ortus pliadon, Per unt matin Une pulcellet odit molt gent plorer Et son ami dolcement regreter, Co jo lli dis :

Gentilz pucellet, molt t'ai odit plorer

Et tum ami dolcement regreter

Et chi est illi?

(Fragment d'un poème dévot, 4)
REMARQUES : En ancien français, pleurer gent désigne le fait de verser des larmes sous l'effet d'une douleur physique ou morale, d'une émotion pénible ou agréable, le sujet ne se laissant pas pour autant aller et faisant preuve d'élégance et de distinction, pouvant d'ailleurs attirer la sympathie, la compassion des spectateurs.

\section{Pleurer haut}

Pleurer bruyamment, ouvertement Intransitif

1619 Or, sur cela, qu'est-ce que ne fit pas Saul pour tesmoigner que son cœur estoit amolly envers David ? Il le nomma son enfant, il se mit a pleurer tout haut, a le louer, a confesser sa debonnaireté, a prier Dieu pour luy, a presager sa future grandeur et a luy recommander la posterité qu'il devoit laisser apres soy (Saint François de Sales, Introduction à la vie dévote)

1698 Quand les trois princesses le virent, elles trembloient sous la cuve, elles n'osoient pleurer bien haut, de peur qu'il ne les entendît ; mais elles s'entredisoient tout bas : il va nous manger toutes en vie, comment nous sauverons-nous ? (Marie-Catherine d'Aulnoy, Finette Gendron)

1826 Vous savez que j'ai l'ancienne méthode en horreur et je crois que je pleurerais plus haut qu'eux après les avoir battus. Un de mes favoris c'est Mr Thomas. C'est l'ami intime de Maurice (George Sand, Correspondance)

1836 Il était contrôleur de la poste à Grenoble ; en sa qualité de mon grand-oncle, il m’administrait force taloches ; et lorsque je pleurais trop haut, il me faisait avaler des verres de kirsh pour obtenir du silence (Stendhal, Vie de Henry Brulard)

1856 Ils passent comme des traînées de feuilles sèches sous un vent d'automne, si rapidement qu'on ne peut les voir, et tous pleurent si haut que l'on n'entend pas ce qu'ils disent. La Mort refait un nœud à la mèche de son fouet (Gustave Flaubert, $L a$ Tentation de saint Antoine) 
1950 Je pleurerais tout haut, tant je suis en colère et tant mon cœur me fait mal (Joseph Zobel, La Rue Cases-Nègres)

Transitif

1867 L'existence de l'assassin était effroyable, depuis le jour où Thérèse avait eu l'infernale invention d'avoir des remords et de pleurer tout haut Camille (Émile Zola, Thérèse Raquin)

REMARques : Pleurer haut désigne le fait de verser des larmes, ouvertement, sous l'effet d'une douleur physique ou morale, d'une émotion pénible, en les accompagnant de plaintes, de gémissements ou de sanglots bruyants, le sujet ne cherchant pas ou n'arrivant pas à cacher sa peine devant ceux qui l'écoutent ou pourraient l'écouter. Haut reste invariable et est modifié par bien, plus, si, tout, trop.

\section{Pleurer humide}

Pleurer en versant des larmes

$\pi$ pleurer sec

\section{Pleurer menu}

pleurer souvent et menu : pleurer

continuellement

Intransitif

$\sim 1200 \mathrm{Au}$ roi Cemaire estoit il remainsuz, Assez demainnent grant barnaige et grant bruit,

Avec lui sont cens homë a escus.

Plore sa fame et souvent et menu

(Jourdain de Blaye, 2385)

Remarques : Sous l'effet d'une douleur physique ou morale, d'une émotion pénible ou désagréable, d'un événement douloureux, pleurer souvent et menu désignait le fait de verser des larmes en grande quantité et à plusieurs reprises, le sujet étant animé ; l'expression souvent et menu traduit la douleur et la très grande peine ressentie par le sujet. Menu reste invariable. VoIR AUSSI : sangloter menu

\section{Pleurer sec}

Pleurer sans verser de larmes

Intransitif

1948 JACQUES HURY. Vous êtes fâchée de ne pouvoir me faire de la peine.
MARA. Comme l'autre jour pendant que le père parlait, riant d'un œil et pleurant sec de l'autre.

JACQUES HURY. Ne suis-je pas maître d'un beau domaine?

(Paul Claudel, L’Annonce faite à Marie)

1959 Il pleure sec ce bébé. Il n’y a jamais de larmes sur ses joues (Exemple entendu, 9 octobre 1959 / Grundt : 354)

CORpus Web :

Ca va pleurer sec... moi en général je pleure humide. Et vous ? [https://fr-fr.facebook.com/Me lo270688/posts/848929705179606] (5.10.2015)

Si tu connais le synopsis tu ne peux pas être surpris. Ici, ça va pleurer sec [http://www.sen scritique.com/film/Rabbit_Hole/critique/5935 003] (5.10.2015)

Elle est une lectrice de la romancière américaine Joyce Carol Oates : phrases armées plus que phrases aimées. On pleure sec, on rit grave [http://www.lejdd.fr/Culture/Livres/Actualite/ Une-vie-pleine-de-romans-133134] (5.10.2015)

Remarques : Pleurer sec désigne le fait de sangloter, d'éprouver de la tristesse mais sans verser de larmes, le sujet pouvant notamment ressentir un sentiment d'amertume ou ne pouvant produire de larmes, par exemple pour une cause de déshydratation. Dans le CW, sec tend à adopter une fonction de simple intensifieur 'pleurer beaucoup', même si le premier exemple ne résiste pas au jeu de mots avec pleurer humide. Notons l'emploi impersonnel familier ça va pleurer sec. $\mathrm{Sec}$ reste invariable. Pleurer sec s'oppose à pleurer humide et, pour le verbe, à rire grave 'avec gravité'.

\section{Pleurer vrai}

Pleurer avec naturel, avec sincérité

Intransitif

1947 il [= Baudelaire] accepte toutes les suggestions de sa conscience spontanée : simplement il veut les retravailler un peu, forçant ici, allégeant là ; il n'ira pas rire à plein gosier s'il a envie de pleurer : il pleurera plus vrai que nature, voilà tout (Jean-Paul Sartre, Baudelaire) 
CORPuS WeB :

pas d'accord, Papis, pour mettre en lien «pleurer en solitaire » = «pleurer vrai »... l'authenticité des larmes est ailleurs [http://www.orangeinfo.sn/forum/read.php?f=2\&i=191466\&t=191149] (5.10.2015)

Myss tu m'as fait pleurer vrai vrai [https:// www.facebook.com/Chroniques.de.Myss/pho tos/a.1444537562444112.1073741837.140159315007 1887/1479530165611518/] (5.10.2015)

Je déteste voir des enfants pleurer vrai ça me fend le cœur \#tellementvrai [http://devantlatele. com/nrj12/2013/05/19/tellement-vrai-2] (5.10.2015)

REMARQUES : Pleurer vrai désigne le fait de verser des larmes sous l'effet d'une douleur physique ou morale, d'une émotion pénible ou agréable, le sujet pouvant les accompagner de plaintes, de gémissements ou de sanglots sincères, ne cherchant pas à tromper, à jouer un rôle faux. Vrai reste invariable et est modifié par plus. Notons la réduplication vrai vrai pour intensifier. Cependant, dans ce discours plutôt spontané, proche de l'oral, on ne saurait exclure l'interprétation de vrai comme modifieur énonciatif (tu m'as fait pleurer, c'est vrai (de) vrai). Du point de vue sens, ce type de lecture est même assez probable dans le dernier exemple du CW.

\section{Pleuvoir dru}

I. Affluer, arriver en abondance Intransitif

1582 Toutesfois les bouletz y pleuvoient si dru qu'après la mort de vint cinq que soldats que pionniers : furent contraints de se retirer et se rendre au general

(Henri Lancelot-Voisin de La Popelinière, L'Histoire de France)

1585 Chez les Advocats, les escus y pleuvent plus dru que pluye (Nicolas de Cholières, Les Neuf Matinées)

1633 BERTRAND. Helas ! mon voisin, où étiezvous durant la bagarre ? Les voleurs ont emmené vostre fille et Philippin. Ils ne le vouloient pas nourrir, car ils luy ont baillé plus de coups que de morceaux de pain. Je ne sçay s’il en mourra, mais ils l'ont lardé plus menu que lièvre en paste. Morguoy! nous fussions sortis, mais les coups pleu- vaient dru comme mouches (Adrien de Montluc, La Comédie des proverbes)

1861 Je n'ai pas d'amour-propre, quand j'ai mal écrit, maintenant, je vous l'assure. Vous vous êtes affirmé davantage dans votre étude sur Wagner que dans celle de Gautier : tant mieux ! Ça pleut déjà dru comme mitraille et de la hautaine façon, ça m'a ranimé (Auguste de Villiers de L'Isle-Adam, Correspondance générale)

1876 Les mots grossiers, les accusations abominables, les histoires vraies exagérées jusqu'au mensonge, pleuvaient dru (Émile Zola, Son Excellence Eugène Rougon)

1886 Le bruit de ce tableau si drôle devait se répandre, on se ruait des quatre coins du salon, des bandes arrivaient, se poussaient, voulaient en être. "Où donc ? Làbas! Oh ! Cette farce ! » Et les mots d'esprit pleuvaient plus drus qu'ailleurs (Émile Zola, L'Euvre)

1985 Quand y z'étaient bien allumés y s'engueulaient, y se tapaient dessus. J'étais l'innocent témoin de leur ratage, de leur naufrage, de leur rancœur. Moi et Sylvette. Je prenais parti pour mon vieux. Sylvette essayait de protéger maman des coups qui pleuvaient dru. À c't'époque la vieille avait encore de l'énergie. Depuis elle s'est drôlement éteinte (Frédéric Lasaygues, Vache noire, hannetons et autres insectes)

II. Pleuvoir beaucoup, à verse, en abondance Intransitif

1866 Ce matin à 6 heures il pleuvait dru, et mon départ de Saint-Cergue n’a pas été facile (Henri-Frédéric Amiel, Journal intime de l'année 1866)

1935 Très près d'eux, tout à coup, longeant une haie, ils aperçurent une sentinelle. Ils obliquèrent vers l'est, rampant sur l'herbe. Il pleuvait dru, maintenant (Maxence Van der Meersch, Invasion 14)

CORPUS WEB :

Il pleut dru sur Monaco ! [http://www. welovetennis.fr/atp-monte-carlo/65256-live-ilpleut-dru-sur-monaco] (7.10.2015) 
Il y a 598 ans, les flèches pleuvent dru sur la chevalerie française, à Azincourt... [https://frfr.facebook.com/Histoire.France/posts/10153 372440970398] (7.10.2015)

"Sauvetage de l'hôpital »: les réactions pleuvent dru [http://www.letelegramme.fr/ar/ viewarticle1024.php?aaaammjj=20020515\&articl $\mathrm{e}=4412881 \&$ type $=\operatorname{ar}](7.10 .2015)$

Le square d'Ajaccio à (peut être) l'avantage de nous protéger de l'armada policière et de ses petits sévices, mais aussi des procès-verbaux pour manifestation non déclarée qui pleuvent drus sur le DAL depuis quelques semaines : le square d'Ajaccio est propriété de la Ville de Paris, à laquelle nous demandons asile pour l'occasion [http:// droitaulogement.org/2011/12/collectif-dalomarre-des-taudis-et-de-la-precarite/] (7.10.2015)

REMARQues : Pleuvoir dru (II) signifie 'tomber en abondance (pluie)', les gouttes d'eau étant serrées, abondantes, tombant continuellement. Dans un emploi métaphorique (I), il prend le sens de 'tomber, affluer en grande quantité, s'abattre', le sujet pouvant référer à des choses concrètes (coups, paquets) ou, dans le domaine de la parole, à des énonciations (mots, sentences). Sous (I), dru est souvent intensifié par des comparaisons : plus dru que pluie, dru comme mouches / mitraille. À titre d'exception, dru peut s'accorder avec le sujet (ex. de 1886 et le quatrième exemple du CW). Il est modifié par déjà, plus, si.

\section{Pleuvoir fin}

Pleuviner, tomber en fines gouttelettes (pluie) Intransitif

1842 AZÉMA. Ah ! bon j'comprends qu'il s'érite ... c'est qu'il pleut fin et serré (Dennery et Cormon, La Journée d'une jolie femme)

2007 J'ai vraiment cru à la paix pour la première fois le lundi 22 août 1994. J'étais à Paris. La ville avait déjà son voile de septembre. Il pleuvait fin et frais (Sorj Chalandon, Mon traître)

\section{Pleuvoir fort}

Pleuvoir beaucoup, intensément

Intransitif

1177 Bien sai de l'arbre, c'est la fins, Que ce estoit li plus biaus pins,
Qui onques sor terre creüst.

Ne cuit qu'onques si fort pleüst,

Que d'eve i passast une gote

Einçois coloit par dessus tote (Chrestien de Troyes, Yvain ou Le Chevalier au lion, 416)

+1370 adont coummencha à plouvoir et pleut toute le [sic] journée si fort et si ouniement que ainschois nonne passée la rivière sour laquelle il estoient logiet, devint si grande que nuls ne le peuist passer à cheval, ne autrement (Jean Froissart, Chroniques (A))

+1400 Ainsy comme ilz parloient, print fort a plouvoir et furent trés bien moullez (Nouvelles françaises du $\mathrm{XV}^{e}$ siècle, p. 13)

1543 Et si Canicula sort, la lune estant au signe de Pisces, il pleuvra fort, les oyseaulx se mourront, le vin et froument seront en abondance, le peuple sera affligé de diverses malladies (Cassianus Bassus, Les XX Livres de Constantin Cesar)

1728 Un soir qu'il pleuvait bien fort, je me retirais avec mon parapluie et ma petite lanterne (Montesquieu, Correspondance)

1895 Pourtant, comme il pleuvait plus fort et que je crains l'humidité, nous rentrâmes nous abriter sous le toit du pressoir que nous avions à peine quitté (André Gide, Paludes)

1967 - On va s'abriter, il pleut trop fort (Claire Etcherelli, Élise ou La Vraie Vie)

\section{CORPUS WEB :}

Photo de Hotel des Messageries : Dehors il pleut fort !, rien ne vaut « une petite croûte » à l'hôtel ! [http://www.tripadvisor.fr/ LocationPhotoDirectLink-g641855-d631680i115872726-Hotel_des_Messageries-Arbois_Jura_ Franche_Comte.html] (7.10.2015)

Je me suis équipé d'un modem TNT ST SAGEM ISD74. En temps normal, tout va bien (env 90\% de signal), mais lorsqu'il pleut fort ou qu'il fait beaucoup de vent, j'ai de gros problèmes de réception [http://www.commentcamarche.net/ forum/affich-11797667-probleme-de-receptionlorsqu-il-pleut-fort] (7.10.2015)

Je viens de cueillir mes coings cet aprèm ! tu as le don de voyance ou quoi ! mon Jupinou, je ne 
suis pas trop présente, parce que les emmerdes pleuvent fort depuis quelques temps ! [http://lacachina.over-blog.com/article-pate-de-coingsexpress-60204451.html] (7.10.2015)

Sans prévenir il me gifle une première fois, me faisant chanceler. Je suis surpris mais je reprendre ma position. Les coups pleuvent forts, rapides, ma tête est brinquebalée dans tous les sens, les larmes coulent [http://www.xstory-fr. com/lire-histoire,boys,21951.html] (7.10.2015)

REMARQUES : Au sens concret, pleuvoir fort se dit de la pluie qui tombe en abondance, les gouttes d'eau pouvant être serrées, grosses ou tout simplement abondantes, continuelles. Au sens figuré, il peut référer à l'affluence des éléments négatifs qui arrivent en abondance (les emmerdes, les coups, les critiques). Fort reste invariable dans la majorité des cas, mais dans le quatrième exemple du CW, il s'accorde avec le sujet, tout comme l'adjectif-adverbe rapide. Ces modifieurs se voient ainsi transformés en prédicats seconds qui créent un effet expressif propre au style littéraire, notamment dans le cas de rapide, dont le sémantisme de manière persiste malgré les marques morphologiques de la prédication seconde. Fort est modifié par bien, plus, si, trop.

\section{Pleuvoir frais}

Tomber en gouttes fraîches (pluie)

$\pi$ pleuvoir fin

\section{Pleuvoir rapide}

Tomber, s'abattre rapidement

$\lambda$ pleuvoir fort

Pleuvoir serré

Tomber en gouttes denses, nourries (pluie)

$\lambda$ pleuvoir fin

\section{Plier menu}

Plier tout petit

Transitif

1627 Ce cauteleux le releva promptement, et le voyant plié fort menu, comme sont ordinairement semblables escrits, il pensa qu'il y pourroit apprendre quelque chose qui luy feroit descouvrir d'où cette resolution de Darinée procedoit (Honoré d'Urfé, L'Astrée)
1926 Il avait été donné d’approcher ses lèvres de ces bras, à celui qui avait eu la précaution de plier menu le papier inclus dans la caverne où jouait une sirène et un paysan brun que Mademoiselle sans défiance mit au doigt coutumier qu'on protège en cousant (Louis Aragon, Moi l'abeille j'étais chevelure)

1965 Cine, l'amie de l'an passé, qui en était encore à projeter de tout plaquer pour moi, alors que déjà je l'aurais oubliée, sans l'incessant tison de ces billets compacts et pliés menu qu'une fille neutre et complaisante m’apportait presque chaque jour.. Cine ! (Albertine Sarrazin, L’Astragale)

1966 Il tenait la main de son coursier dans laquelle il fourrait des billets pliés menus (Robert Giraud, La Coupure)

\section{CORPUS WEB :}

Je lâche ce que je fais pour déchiffrer un dessin en rigolant, puis -pourquoi cela m'est venu?-, je lui écris une réponse en écrivant son prénom en cursive sur un billet plié menu [http://lessauvageons.legtux.org/?cat=3] (7.10.2015)

Des petites languettes garnies de papier abrasif 400 , des bandes de papier de verre plié menu, voilà l'outillage pour arrondir le globe oculaire et modeler l'arcade sourcilleuse qui imposera le respect dû à votre réalisation d'exception [http://www.jivaro-models.org/martinet/ page_martinet.htm] (7.10.2015)

Torchons pliés menu pour expédition nantaise imminente [https://instagram.com/ p/OAlyltiR14/?modal=true] (7.10.2015)

Vous avez - vous ne seriez pas un véritable fan sinon - un poster de votre héros toujours avec vous, cette affiche de Philippe Crab pliée menue dans votre poche à cet instant ferait un fameux couvre chef - le soleil est athlétique ces temps-ci [https://impersuiasif.wordpress.com] (7.10.2015)

REMARQUes : Plier menu se dit de rabattre sur elle-même une matière souple comme le papier afin d'obtenir plusieurs épaisseurs ou plusieurs parties toutes petites. L'action a pour conséquence une modification de l'épaisseur du morceau de papier. Les exemples de 1965 et de 1966 avec l'objet au pluriel sont intéressants du point 
de vue de l'accord. Dans le premier cas, l'adjectif-adverbe ne porte pas la marque du pluriel, et dans l'autre, menu s'accorde avec l'objet billets (v. aussi le dernier exemple du CW), la fonction restant adverbiale. Menu est modifié par fort.

\section{Plonger profond}

Plonger, s'enfoncer profondément, en profondeur

Transitif

1560 Et Satan use communément de cest artifice, de plonger tant profond qu'il peut en ce gouffre de tristesse tous ceux qu'il voit abbattus de la crainte de Dieu, tellement qu'ils ne se puissent jamais relever (Jean Calvin, Institution de la religion chrestienne)

1964 pareils à ces arbres qui plongent profond leurs racines dans la terre qu'ils nourrissent de leurs fruits (Radiodiffusion-Télévision Française / Grundt : 291)

Intransitif

1926 Et courageux, infatigable, obstinément tirant la ligne et pliant la perche noire, plongeant profond dans un remous furieux ! (Maurice Genevoix, La Boîte à pêche)

1978 Car il est clair que la ramure ne peut s'étendre, s'élargir, embrasser un morceau de ciel de plus en plus vaste qu'autant que les racines plongent plus profond, se divisent en radicules et radicelles de plus en plus nombreuses pour ancrer plus solidement l'édifice (Michel Tournier, Le Coq de bruyère)

1992 Et leurs sons se mêlaient les uns aux autres. Le mot arbre se couvrait d'écorce grise ou brune, ivoire ou argentée, et plongeait profond dans la terre sous l'herbe et la pierraille, et exhalait une senteur de sève, de racines, de mousse et de feuillage humide (Sylvie Germain, La Pleurante des rues de Prague)

\section{Corpus Web :}

Quelques temps après être devenu plongeur débutant, la majorité des plongeurs ressentent l'envie de plonger profond. Aventuriers, les plongeurs désirent plonger plus profond pour explorer une épave, pour prendre des photos ou simplement pour tenter l'expérience [http://www.padi. com/scuba/templates/fr-adzone1.aspx?id=5048] (7.10.2015)

Plonger profond à l'air est dangereux et stupide [http://www.aquariusunderwater.com/\#!letrimix-pourquoi-/c1bm8] (7.10.2015)

Moi j'aime bien plonger profond la pagaie pour ne pas que la pale dépasse de l'eau, ceux qui la plongent moins profond préfèrent un manche plus court [http://www.gongsup.com/forum/ viewtopic.php?f=5\&t=2390] (7.10.2015)

REMARQUES : Emploi propre ou figuré, plonger profond se dit de pénétrer, de s'enfoncer profondément (dans un liquide, un lieu profond ou souterrain). Les exemples de Frantext mettent en avant l'emploi au figuré, soulignant ainsi la tendance littéraire de ce corpus, tandis que l'emploi concret de 'plonger dans l'eau' prédomine dans le CW. Profond reste invariable et est modifié par moins, plus, tant.

\section{Poindre doux}

Provoquer une impression qui étreint légèrement

$\lambda$ courir doux

\section{Poindre isnel}

Accourir rapidement, avec vivacité Intransitif

+1227 Sire, dist il, par saint Remi !

Je vous ai vendu et trahi.

Quel dyable le vous ont dit?

Ja n'iert nus hom ki vous ochit.

Alés vous ent, n'avés c’atendre.

Dist Wistasce : Ains te verrei pendre ;

Monte lassus et si te pent.

Cil monte en l'arbre isnielement

Si se pendi par le hardiel.

Li quens i vint poignant isniel,

Wistasces sour Moriel remonte,

Apriés lui voit venir le conte

(Roman de Wistasce le Moine [2 tiers XIII ${ }^{\mathrm{e}}$, après 1227], 728)

Remarques : Poindre signifiant à l'origine 'piquer' en ancien français, poindre isnel se disait dans ce contexte d'une personne qui s'élance (depuis le haut) sur son adversaire, telle une pointe, isnel soulignant la rapidité de l'action. 


\section{Poindre menu}

Piquer un peu, doucement, voire fréquemment Intransitif

1416 Si alay tout seulet ainsi

Que l'ay de coustume, et aussi

Marchay l'erbe poignant menue,

Qui toute la terre tissy

Des estranges couleurs dont sy

Long temps l'yver ot esté nue

(Alain Chartier, Le Livre des quatre dames, p. 198, 9)

REMARQues : Poindre menu se disait de donner une sensation de piqûre, de picoter, de piquer légèrement, le sujet désignant une chose, un élément de la nature (ici : l'herbe). Мепи s'accorde ici avec le sujet.

\section{Poindre parfont}

Percer, blesser profondément

Transitif

+1200 Or voi je bien que Diex te het, ta penitance nient ne set, quar tu l'as fet sanz repentance et sanz amor et sanz pitance. Lors plore et crïe et tort ses poins, dont fu ses cuers si parfont poins qu'il s'escria a haute voiz :

Diex, qui tout pues et sez et voiz : regarde ceste creature qui a mené vïe si dure (Du Chevalier au barisel [début XIII], 766)

+1313 En ce point la dame demeure,

Ki ferue est d'un dart ameure,

Qui mout souuent parfont le point

(Jean de Condé, Poèmes [1313-1337], 1221)

REMARQUES : En ancien français, poindre parfont se dit du fait de percer, de transpercer profondément quelqu'un (généralement un ennemi) avec un objet pointu, et par extension, le blesser grièvement. La blessure peut également être d'ordre sentimental et, dans ce cas, c'est le cœur qui est transpercé. Profond reste invariable et est modifié parsi.

\section{Pondre bleu}

Pondre des œufs bleus

$\lambda$ pondre vert

\section{Pondre vert}

Pondre des œufs verts

Emploi absolu

1959 Un fermier suédois a le privilège de posséder une poule spécialiste des œufs de couleurs : depuis une semaine elle pond vert mais ses œufs sont par ailleurs d'excellente qualité (Libération, 30-31 mai 1959 / Grundt : 252)

\section{CoRpus Web :}

J'avais deja lu que ca peut donner des poules qui pondent des œufs verts. Je ne sais pas dans qu'elle proportion j'imagine $25 \%$ de chance de œufs brun, 25\% Bleu et 50\% verts. J'en aurait pas assez pour vraiment tester les pourcentage, mais j'espere en avoir au moins une sur la gang qui va me pondre vert [http://coop-la-basse-cour. forumactif.com/t10793-marans-x-ameraucanaoeufs-verts] (7.10.2015)

Certaine lignée de Soyeuse blanche pondent vert, mais elles sont plutôt rare. Pour ma part, je n'ai qu'une soyeuse comme ça ! Pour le reste, dès que tu as des poules bâtards ayant des Améraucana dans leurs ancêtres, tu risques d'avoir des œufs verts [http://coop-la-basse-cour.forumactif. com/t2153-besoin-renseignements-sur-poulesrace-bantam] (7.10.2015)

Pour la couleur, certains les pondent vert car ils se camoufflent dans l'herbe où ils sont pondus. Certains sont fort marron vif pour les simuler au terres mediterannéennes (ou autres) [http:// forums.futura-sciences.com/identificationespeces-animales-vegetales/156969-identifica tion-oeuf-inconnu-2-print.html] (7.10.2015)

ce ne sont pas des sous-types ou croisés mais bien des améraucanas certains pondent verts et d'autres bleus ;) [https://fr-fr.facebook.com/ 614374261972245/photos/a.614374988638839. 1073741825.614374261972245/821661984576804/] (7.10.2015)

REMARQUES : Le sujet désigne une femelle ovipare (ex. : une poule) qui pond, ici, des œufs de couleur verte. Vert reste invariable dans la majorité des cas, même dans l'emploi transitif du verbe où l'objet est présent (v. le troisième exemple du CW). Toutefois, dans le dernier exemple du CW il s'accorde, apparemment avec le sujet, ou avec l'objet implicite, « les œufs ». Notons le groupe pondre bleu. 


\section{Ponter ferme}

Parier sur une éventualité en se compromettant de façon définitive

Transitif

1897 Gobourg se prépara donc à ponter ferme l'armée de l'archiduc. Il avait sur lui quatre-vingt mille francs (Tristan Bernard, Contes de Pantruche et d'ailleurs)

Emploi absolu

1914 On va sans doute ponter ferme sur Constantipople. En attendant, un des joueurs qui ont jusqu'ici été le plus favorisés par leurs calculs - ce joueur a fait un coup de 200 000 dollars sur la retraite de la Marne vient de parier pour deux fois (La Guerre mondiale)

1922 Elle venait de ponter ferme au baccarat où ils jouaient sans arrêt depuis deux jours (Claude Roger-Marx, La Tragédie légère)

1923 Le banquier commençait à être en difficulté - et nous de ponter ferme - lorsqu'il fallut de nouveau lever le camp (Paul Morand, Fermé la nuit)

2015 Inutile de se présenter chez Herbelin, la jolie avare, sans être en mesure de ponter ferme (Jean-Louis Dubut de Laforest, L'Homme de joie)

REMARQUES : Terme des jeux de hasard renvoyant au fait de jouer contre la banque, donc de faire face à l'adversaire le plus fort, et, par extension, de parier en prenant des risques considérables, par exemple sur le sort de batailles ou de guerres. L'emploi transitif dans l'exemple de 1897 s'explique probablement par ellipse de la préposition sur dans l'argot des joueurs. Ponter ferme fait partie d'une série qui comprend également les verbes accepter, acheter, parier, prendre, vendre. VOIR AUSSI : acheter / prendre / vendre ferme

\section{Porter aise}

I. Supporter facilement, sans difficulté Transitif

-1349a Amis, pour vous ay travillié. Nompourquant, se j'en ay veillié, Encor pour vous travilleray, Dont maintes nuis en veilleray ; Car desormais commence peinne,
Mais c'est peinne qui joie mainne, Pour moy deduire et deporter.

Se la porray aise porter (Guillaume de Machaut, Le Dit de l'alerion, 1014)

II. s'en porter aise : aller bien grâce à quelque chose, être tranquille, heureux, satisfait de quelque chose

Pronominal

-1349b Mais je croy bien que ma plaisance

Se nourrissoit de souffissance, Car jamais jour ne sceüst faire Chose qui me deüst desplaire, $\mathrm{Au}$ mains si comme il me sambloit, Si soutilment mon cuer ambloit. S'en estoit plus aise portez, De moy souffers et deportez (Guillaume de Machaut, Le Dit de l'alerion, 1207)

+1365 Car il n'estoit mie à ses frès, S'en porte plus aise le fès (Jean Froissart, Poésies [3e tiers XIV $]$ )

Remarques : Porter aise (I) réfère à la facilité d'une tâche ou à la légèreté d'une charge ; il se dit du fait de porter ou supporter quelque chose ou quelqu'un facilement, sans peine. S'en porter aise (II) est une locution figée qui signifie 'aller bien, être satisfait', l'adverbe plus démontrant un changement dans l'état, l'humeur du sujet. Aise reste invariable et est modifié par plus.

\section{Porter bas}

I. Porter à un niveau bas, abaisser

Transitif

+1250 Se dex me desfende d'esmai, Je voudroie que lous ou ors Vos oüst oste a rebors Ce pelicon sans demorance, Que poi pris mais vostre puissance. Trop portes basse cele chere. Mal ors hui cest jor vos requere ! (Le Roman de Renart [2 $2^{\mathrm{e}}$ moitié XIII'], XI, 77)

1924 Madame Lenoir était prédestinée à porter si bas, - au cœur de l'abîme, - ce Nom [= le nom de Dieu] qui a la force de n'être corrompu par rien au monde. Elle se croit sauvée (Marcel Jouhandeau, Les Pincengrain) 
1938a Mais toujours, plus tôt ou plus tard, malgré ses feintes, ses détours, sa vitesse, le cerf était mis sur ses fins et porté bas par la dague des hommes (Maurice Genevoix, La Dernière Harde)

1938b Les rares faons qui avaient grandi, devenus cerfs, avaient été l'un après l'autre forcés et portés bas comme les grands mâles disparus (Maurice Genevoix, La Dernière Harde)

1955 Lutte longue et ardente où la malice et le courage de ce simple caporal finiront par porter bas le redoutable Schoulze (Biblio, juillet 1955 / Grundt : 272)

II. Tomber dans une situation pénible Emploi absolu

1601 Premièrement, tous les païs qu'on parloit de rendre au Duc par le traitté estoyent en la main du Roy et ceux aussi qu'on devoit eschanger estoyent en la mesme puissance de cette main victorieuse du Roy. Cella ravalloit fort nostre crédit, nous faisoit porter bas, comme l'on dit, et descrioyt du tout nostre marchandise (René de Lucinge, Les Occurrences de la paix de Lyon)

Corpus Web :

salut, moi c'est BB3 que j'ai porté tres bas (j'avais l'impression qu'il allait venir a tout moment) et 16jours avant terme je me suis rendue a la maternité pour quelques contractions non douloureuses et j'etait deja ouverte de 3 doigts a mon grand etonnement et 2 heures de contractions plus tard $\mathrm{BB}$ etait là alors peut etre que le fait de le porter tres bas ca joue sur la durée de l'accouchement [http://forum.doctissimo.fr/ grossesse-bebe/accouchement/accouche-portetres-sujet_147122_1.htm] (8.10.2015)

on dit porter haut quand le ventre remonte en dessous des seins porter bas c'est quand le ventre fait la poire vers le bas rien a voir avec l'accouchement il y a des femmes qui ont le ventre tous juste en dessous des seins et qui accouche vite et des femmes qui porte bébé tres bas on dirait que le ventre tombe et qui dépasse le termes il faut pas ecouter les grand meres [http://forum. aufeminin.com/forum/matern1/_ff254443_ matern1-Mon-entourage-me-dis-que-je-portebebe-bas-ca-veut-dire-quoi.html] (8.10.2015)
Si c'est une jupe patineuse comme la mienne, ne pas la porter bas mettez-la plutôt audessus de vos hanches [http://beautymc.skyrock. com/3213994123-Comment-porter-1-Une-jupefleurie.html] (8.10.2015)

La queue-de-cheval peut aussi être un bon moyen " d'allonger " une silhouette. Comme Beyoncé, il suffit de la porter basse, ultra lissée et, si besoin, dotée de quelques rajouts pour obtenir une belle longueur [https://www.grazia.fr/ beaute/coiffure/20-facons-de-porter-la-queuede-cheval-piquees-aux-people-550261] (29.5.2013)

REMARques : Porter bas (I) réfère au fait de descendre quelque chose à un niveau inférieur. Par extension (II), un coup du destin peut plonger l'objet grammatical de porter (un animé) dans une situation difficile, l'empêchant de se redresser sans peine. Lorsque l'objet est un animal, dans l'argot de la vènerie, il signifie 'tuer, abattre', après l'avoir chassé. Si l'objet est une personne, c'est 'battre, vaincre (une personne) psychologiquement ou physiquement' dans une lutte, une bataille. Au concret (exemples du CW), il peut renvoyer à la position basse des vêtements (ici : une jupe), des cheveux (portés en queuede-cheval), comme, notamment, à la forme du ventre d'une femme enceinte, la pointe pouvant se situer plus bas ou plus haut, portant le bébé plus bas ou plus haut. L'invariabilité est la règle, mais dans l'exemple de +1250 et dans le dernier exemple du CW, bas s'accorde avec l'objet, insistant sur sa localisation, tout en gardant son interprétation adverbiale. Il est modifié par si, très.

\section{Porter beau (bel)}

I. Bien se porter, être en bonne santé

Pronominal

+1200 Deliee fu par cointise,

S'ot .I. cercle d'or en son chief.

Mes itant i ot de meschief

$\mathrm{Au}$ cercle metre que li crin

Estoient blanc de regaïn ;

Mes de ses jorz beau se portot

Le frain au cheval au nain ot

Abatu, sel tint a plain poing

(Raoul de Houdenc, Meraugis de

Portlesguez [début XIII ${ }^{\mathrm{e}}$, 1479) 
II. Bien s'y prendre, faire quelque chose avec agilité, avec adresse, avec élégance

Pronominal

+1400 Le jour vint, et qu'en diroye ?

Pour quoy plus esloingneroye

Sans achoison ma matiere?

L'endemain trestoute entiere

La journée aussi jousterent

Escuiers qui se y porterent

Bien et bel en toute guise

(Christine de Pisan, Le Livre du duc des vrais amans / Euvres poétiques [début $\mathrm{XV}^{\mathrm{e}}$ ], III, p. 97, 1253)

III. Porter bien, sans difficulté, sans peine Transitif

+1450 Incontinent que femme a concheu enfant masle, pour les trois premiers moiz, elle le porte assez bel, mais les aultres six mois mout en a douleur a endurer plus que d'une fille ; toutesvoies les trois premiers mois, la fille tousjours lui baille plus a souffrir (Les Évangiles des Quenouilles [3 quart $\left.\mathrm{XV}^{\mathrm{e}}\right]$, 2035)

IV. Avoir un beau port de tête, un port de tête élégant ; avoir belle prestance, belle allure Emploi absolu

1888 Superbe, l'entrée en cour de tous ces illustres ! les jeunes, lents et graves, la tête inclinée comme sous le poids d'une responsabilité trop lourde, les vieux portant beau, la jambe vive (Alphonse Daudet, L'Immortel)

1899 Ce ne fut qu'un cri : quoi ? C'est à ces incapables (nous ne les croyions qu'incapables en ce temps-là) que sont confiées les fonctions d'où dépend le sort de nos armées ! Eux, cependant, portaient beau, la main dans la main avec le traître Esterhazy, sur qui le Van Cassel versait des larmes, et que les faux patriotes étouffaient sous leurs embrassements (Georges Clemenceau, Vers la réparation)

1906 Quel ennui de décrire ce rassemblement ! Le député portant beau, fumant et riant, distribuait des poignées de main à des hommes en fustanelle. Des vendeurs ambulants criaient et offraient des pista- ches ou de la menthe (Maurice Barrès, Le Voyage de Sparte)

1913 Alphonse porte beau, a souci de son attitude, rit spirituellement à certaines remarques du président :

- Vous fumiez de gros cigares

(André Gide, Souvenirs de la Cour d'assises)

1954 Ils portaient beau, tous deux en dolman de toile blanche, le casque en tête, des lunettes de soleil sur les yeux. Le même large sourire découvrait leurs dents éclatantes (Maurice Genevoix, Fatou Cissé)

1980 Le visage rasé, le cheveu nordique rare, il épaississait et ses vêtements fermaient mal, mais il continuait, par sa haute stature, sa tête dessinée par Dürer, à porter beau (Robert Sabatier, Les Fillettes chantantes)

1985 Le grand-père, portant encore beau, mais accablé sous les ans, des quatre filles O’Shaughnessy, je m'imaginais le voir, en jeune homme impatient, dans l'immense salon de Glangowness, en train de parler avec son beau-père, à mots couverts et prudents, des bijoux criminels de l'arrière-arrière-grand-mère indienne (Jean d'Ormesson, Le Vent du soir)

Transitif

1961 elle portait assez beaux le visage et le buste, ma future mère, pour qu'on la désirât ferme (René Étiemble, Blason d'un corps)

V. Supporter avec dignité, avec fierté, sans montrer son inquiétude ou son trouble Transitif

1956 Mme Nuñez, sa sœur, qui portait beau sa ruine, elle aussi, et son veuvage, mais se faisait mal à n'être qu'une protégée sous le toit de son frère (François Mallet-Joris, Les Mensonges)

Intransitif

1995 Vous êtes à terre ? Il faut vous piétiner !... Cachez vos malheurs, mon enfant, cachez vos blessures, toujours, car le sang attire les fauves et fait fuir les faibles. Portez 
beau, à l'avenir portez beau, quoi qu'il vous arrive (Françoise Chandernagor, L'Enfant des Lumières)

CORPUS WEB :

Imaginez, derrière un décor de vieux Paris miroitant sous sa verrière, un boudoir grand comme une boîte à chaussures, paré d'un design pur et lactescent, où les 22 convives portent beau et parlent doux [http://www.lexpress.fr/styles/ saveurs/restaurant/paris-2e-passage-53_792673. html] (17.8.2015)

Mais Gaspard Ulliel, habitué au mannequinat, a beau porter beau le costume d'époque, son duc de Guise n'en conserve pas moins un côté sauvage et guerrier, qui balafre son romantisme [http://www.nicematin.com/article/ cannes-2010/gaspard-ulliel-dhannibal-lecter-auduc-de-guise.167717.html] (8.10.2015)

Le must serait de porter beau la beauté de soi, d'être aligné de qui nous sommes à qui nous voulons manifester [http://lesinvitesdelasemaine. bleublog.lematin.ch/archive/2013/06/06/1-habitfait-le-moine.html] (8.10.2015)

En la matière, Rudy Ricciotti, le Camarguais qui porte belle la soixantaine, est un as de l'estocade (8.10.2015) [http://www.lefigaro.fr/ culture/2013/04/18/03004-20130418ARTFIG00 356-rudy-ricciotti-architecte-en-beton-arme.php] (8.10.2015)

REMARQUES : Se porter beau (I) signifie ici 'bien se porter' selon l'acception moderne, c'est-à-dire 'être en forme, en bonne santé'. Acception vieillie, se porter à quelque chose bien et bel (II) réfère ici au fait de bien se comporter, de faire quelque chose avec adresse, agilité mais aussi élégance, esthétique (ici, lors d'un combat de joute). (III) prend en charge le sens de 'porter quelque chose/ quelqu'un (ici : dans ses entrailles, ses flancs) sans difficulté, sans peine'. L'emploi absolu sous (IV) est une variante lexicalisée qui renvoie à la belle prestance, la belle allure d'une personne, celle-ci étant généralement vêtue d'une manière recherchée. L'emploi transitif est utilisé pour un habit (deuxième exemple du CW), une couleur ou une partie du corps (généralement, la tête, le buste) qu'on porte avec élégance, délicatesse, goût. (V) se dit du fait de supporter, de surmonter quelque chose avec bravoure et ce, sans montrer aucun signe de peine ou de trouble. Beau peut s'accorder avec l'objet (ex. de 1961 et le dernier exemple du $\mathrm{CW})$, se rapprochant ainsi d'un prédicat second orienté vers l'objet. Il est modifié par assez.

\section{Porter droit}

I. Porter, emporter, conduire directement, selon une ligne droite

Transitif

-1100 Danz Alexis entrat en une nef, ourent lur vent, laisent curre par mer, andreit Tarson espeiret ariver, mais ne puet estra, ailurs l'estot aler, andreit a Rome les portet li orez (Vie de saint Alexis [fin $\mathrm{XI}^{\mathrm{e}}$ ], BFM, 193)

$\sim 1160$ A la rescosse sa gent corent, Il an i ot cent quel secorent ; Sor son escu l'an ont porté Droit al Toivre, si l'ont lavé, Car la plaie forment seignot (Eneas, 5876)

1200 Or a Fromons l'anfant que il plus het, Droit a la chartre l'a a Renier porté, Laienz lor donne, sa defors est reméz ; Il les apelle par moult grans faussetéz (Jourdain de Blaye, 626)

+1350 « Dame, je vos requier de voulente certaine Que me donnez vos fil qui en vos char humaine

A esté engenres, dont vous n'estes pas saine ;

Si le ferai porter tout droit a la fontaigne, Ens ou bois Bersillant, en ceste nuit serainne

(Brun de la Montaigne [2 $2^{\mathrm{e}}$ moitié XIV ${ }^{\mathrm{e}}$, 587)

+1400 Et elle seule se trouva en ung chemin et laissa aler son cheval ou il voulut, car elle ne le savoit maitriser. Le cheval tout droit la porta en l'ostel de son maistre Errard (Nouvelles françaises du $X V^{e}$ siècle, p. 72)

1629 Ce dessein fut aussi tost executé qu'arresté, car comme ce pauvre Prince ne songeoit à rien moins qu'à la trahison de son valet, il fut porté par terre d'un coup d'espee qu'il luy donna à travers le corps, et luy ayant coupé la teste, il la porta droit à Rozalcan, qui estoit campé devers la riviere (François de Boisrobert, Histoire indienne d'Alexandre et d'Orazie) 
1851 Arrivés au Caire, les ânes nous portaient tout droit à l'hôtel anglais de la place de l'Esbekieh ; j'arrête cette belle ardeur en apprenant que le séjour en était aux mêmes conditions qu'à celui d'Alexandrie. « Vous préférez donc aller à l'hôtel Waghorn, dans le quartier franc ? » me dit l'honnête Abdallah (Gérard de Nerval, Voyage en Orient)

Intransitif

1687 Les vents sont fort variables. Notre malheureux Suest est devenu Est, et nous portons droit au Nord. S'il vouloit au moins pour un temps devenir Nordest, nous revirerions de bord, et tâcherions de nous redresser, car nous en avons besoin (François-Timoléon de Choisy, Journal du voyage de Siam)

1762 Je conseillerois à cet homme de ne point disputer, de convenir de tout, mais de la regarder avec ces yeux qui marquent la passion la plus tendre, la plus forte, la plus vraie, et de lui dire avec cette voix si douce, si touchante, qui porte si droit au cœur : il est vrai, mais vous ne scauriez croire combien cela me fera de plaisir (Denis Diderot, Lettres à Sophie Volland)

1921 Il [= de Condren] aimait à rire durant la récréation, et, si ses discours alors ne portaient pas si droit à Dieu, ils détachaient toujours de la terre (Henri Bremond, Histoire littéraire du sentiment religieux en France)

II. S'élever droit à la verticale ou à l'horizontale Intransitif

+1150 Li robeor repairent tout a bandon, Tout droit a lor agait arier s'en uont, Les lances portent droites en contremont, Et ont al uent destors les confanons, A Loeys s'en gabent, le fil Charlon, Et bien l'ont escrie desor le pont (Aiol et Mirabel [ $2^{\mathrm{e}}$ moitié $\left.\mathrm{XII}{ }^{\mathrm{e}}\right]$, 2952)

+1200a Sa banere $\mathrm{p}$ [or]ta un paen Rudefoun, unkes ne ama dieu, einz ama Mahun, plus estoit velu ke nul porc o tusun ; la launce $p$ [or]ta dreit o un lo[n]g gonfainoun, o quat[er] clous de argent fu fermé li penoun

(Bueve de Hanstone [début XIII'], 573)

-1300 La lance porte droite, le confanon destors ; Bien le sevoit an destre li riches destriers sors (Jehan Bodel, La Chanson des Saisnes [fin XIII'], 2225)

III. Porter, tenir selon une ligne horizontale ou verticale

Transitif

-1200a Par mon cief, damoisele, dist Elies de Franche, Chanpion avés boin por droit porter sa lanche (Elie de Saint Gille [fin XII ${ }^{\mathrm{e}}$, 1815)

+1200 b Ore dist li contes que Artus fu agenoilliés et prist l'espee as ses mains jointes et le leva de l'englume aussi legierement comme se elle n'i tenist riens. Et lors porta l'espee entre ses mains (et) toute droite, et le menerent a l'autel et il le mist sus (Merlin [1 ${ }^{\mathrm{er}}$ quart XIII $]$, p. 146)

+1265 Richars porte droite l'ensengne

Viers les paiiens, si voit uenir un roy qui ot a maintenir Mainte chité et mainte tour (Richars li Biaus [ $3^{\mathrm{e}}$ tiers XIII $]$, 2070)

+1370 Et par la baniere que uns chevaliers portoit toute droite, il le ravisèrent, car bien l'avoient veu aultrefois, et bouterent hors deus de lors pennons par les fenestres de la porte, et conmenchièrent à criier et à huier et à faire signe que on parlast à euls (Jean Froissart, Chroniques (A))

1933 Debout sur les ressorts, se tiennent des laquais à perruque, le jonc à la main ; les massiers suivent à pied, portant la masse de cristal et la portant droit, privilège unique, car partout ailleurs, on tient la masse inclinée (Paul Morand, Londres)

IV. Tenir (sa tête) droit Transitif

$-1200 \mathrm{~b}$ Il n'est home en cest siecle, si le prent par le resne,

Se il le prent au frain et il monte en la sele, S'il n'en est mout hardis, que il nen jete a tere ; 
Et bien reset joster et droit porter la teste (Elie de Saint Gille [fin $\mathrm{XII}^{\mathrm{e}}$ ], 1848)

1897 C'était un très petit homme, portant droit sa grosse tête et sa face carrée, que l'âge avait amollie. Son visage, avec des traits vulgaires et grossiers, exprimait la finesse et une espèce de dignité faite de l'habitude et de l'amour du commandement (Anatole France, L'Orme du mail)

V. Toucher le but, heurter fatalement Intransitif

1627 Ce coup funeste qui portoit droit à l'honneur de mon maistre Jesus-Christ et du pere commun de toutes les creatures de cet univers, m'a puissamment obligé de suivre les premiers mouvemens de mon zèle, lequel j'ay estimé trop juste pour pouvoir estre reputé temeraire (Marin Mersenne, Correspondance)

1920 Moi, Jean-Rose Archer, j'eus l'honneur de tirer le premier boulet qui porta droit et obligea les "San-Benito » à se retirer promptement vers le large (Pierre Mac Orlan, À bord de l'étoile matutine)

VI. Être droit

Pronominal

1805 Ce canal se dirige fortement en bas dans les rongeurs, sur-tout dans les lièvres ; il se porte aussi en avant dans ce dernier genre et dans la marmotte ; il va directement en dedans et en bas dans le castor ; et il se porte en arrière dans le porc-épic. Les cabiais et les agoutis l'ont court, se portant droit en dedans (Georges Cuvier, Leçons d'anatomie comparée)

VII. Porter, supporter avec vigueur

Transitif

1851 Il portait ses années comme un chêne robuste de nos montagnes porte ses soixantièmes feuilles, en s'en décorant et sans plier, ou plutôt ses années le portaient droit et ferme sur la forte tige de vie que Dieu lui avait donnée (Alphonse de Lamartine, Les Nouvelles Confidences)

CORPUS WEB :

Elle était un été, avec sa façon bien à elle de porter un soleil dans ses gestes. De porter droit la lumière. Sans effort. Et de la tendre, et de l'offrir [http://franckreveur.canalblog. com/archives/2007/05/05/4844656.html] (8.10. 2015)

Si vous pouvez la porter droite ou sur le côté, évitez de faire une frange trop épaisse [http://www.gala.fr/beaute/tendances_beaute/ coiffures_comment_porter_la_frange_335831] (8.10.2015)

Le melon se porte horizontal, c'est un impératif ! Le porter penché sur les oreilles le fait passer pour la marotte des rockeurs et des anarchistes de gauche qui en détourne le signe petit-bourgeois. Mais le porter droit est d'une grande difficulté et entraîne un gros problème : celui d'en trouver un à sa taille ! [http://stiff-collar.com/2009/10/01/ chapeau-melon-sans-bottes-de-cuir/] (8.10.2015)

Concrètement, un nouveau-né n'a pas la musculature nécessaire pour tenir verticalement sa colonne vertébrale et sa tête : il ne tient pas debout, il « s'effondre » si on essaie de le porter droit [http://blog.lamaisonduportebebe.com/ tag/sling] (8.10.2015)

REMARQues : Porter droit (I) signifie 'transporter, mener, emmener quelqu'un/quelque chose directement vers un but précis'. Dans son emploi intransitif, il se dit de quelqu'un ou quelque chose (ex. : la voix) qui se dirige tout droit, directement dans une certaine direction ; ce groupe est généralement suivi de la préposition à (aussi : en) ainsi que d'un complément de lieu. Usité en ancien français, (II) réfère à des lances qui s'élèvent bien droites, à la verticale. (III) a le sens de 'porter, soutenir un objet en le tenant à la verticale ou à l'horizontale', et non pas en biais. En (IV), l'objet est à la tête, qu'on porte, qu'on tient bien droite et non pas penchée (de côté ou en avant). En (V), le sujet est un coup qui atteint son but, celui-ci ayant été donné avec précision, justesse. (VI) se dit d'une chose (ici : le méat externe osseux) qui apparaît droit et non pas courbé ou tordu. (VII) se dit du fait de porter quelque chose (un poids, une faute) ou de supporter, de soutenir quelqu'un avec vigueur, sans flancher. Notons la collocation droit et ferme renforçant l'idée de stabilité et de force de l'action. Droit peut s'accorder avec le sujet ou avec l'objet (v. aussi le deuxième exemple du CW) et dans ces cas-là, il peut se rapprocher d'un prédicat second orienté vers le sujet 
ou vers l'objet. Il est modifié par si, tout. Notons l'emploi de porter horizontal et de l'antonyme porter penché.

\section{Porter ferme}

Porter, mener de manière inéluctable ;

supporter avec vigueur

Transitif

1851 Il portait ses années comme un chêne robuste de nos montagnes porte ses soixantièmes feuilles, en s'en décorant et sans plier, ou plutôt ses années le portaient droit et ferme sur la forte tige de vie que Dieu lui avait donnée (Alphonse de Lamartine, Les Nouvelles Confidences)

1856 - Toute la politique de l'Église d'Hildebrand respire dans cette tête accablée par ce qu'elle sait, par ce qu'elle a fait, ce qu'elle a pensé, et qui ne renoncera jamais, sous ces lourdes fatigues qu'elle porte ferme, à ce grand néant du gouvernement des empires (Jules Barbey d'Aurevilly, Troisième Memorandum)

CoRpus WeB :

Passent en continu sur mon écran de rares hommes outillés d'une daba*, beaucoup de femmes au port altier avec leur pagne coloré, portant ferme sur la tête une bassine remplie à ras bord de bananes, d'ignames, de papayes ou de farine de mil [http://tobeornot.fr/?p=1592] (9.10.2015)

Il était vraiment temps que les gouvernants maliens se portent ferme envers la Minusma. Si elle ne peut pas jouer l'impartiale qu'elle s'en aille, de toutes les façons leurs présences ne change rien à la situation du Mali [http:// malijet.com/actualte_dans_les_regions_du_ mali/rebellion_au_nord_du_mali/134828-legouvernement-\%C2\%AB-exhorte-la-minusma$\% \mathrm{C} 3 \% \mathrm{~A} 0$-rester-dans-son-r\%C3\%B4le-de-p. html] (9.10.2015)

REMARQUES : Porter ferme se dit du fait de porter quelque chose (un poids, une faute) ou de supporter, soutenir quelqu'un avec vigueur, sans flancher. L'emploi pronominal (dernier exemple $\mathrm{du} \mathrm{CW}$ ) réfère à la manière stricte et déterminée de se comporter envers quelqu'un. Notons la collocation droit et ferme renforçant l'idée de stabilité et de force de l'action. Ferme reste invariable.

\section{Porter fort}

se porter fort (pour quelqu'un) : se porter

caution / garant ; garantir

Pronominal

1330 Girart de Senlis, en son propre et privé nom et au nom de Emengart, sa femme, pour laquele il se fist et porta fort en ceste partie, quicte, transporte, cesse et delaisse, desorendroit a tous jours, aus religieux, abbé et couvent de l'eglise Saint Magloire de Paris, tout tel droit, raison et accion quelconques (Chartes de l'abbaye de Saint-Magloire)

1543 Pour la conduite, combien que mon frere n'est pas icy à ceste heure, toutefois je m'ose bien porter fort pour luy qu'il vous y servira volontiers (Jean Calvin, Lettres à Monsieur et Madame de Falais)

1804 Néanmoins on peut se porter fort pour un tiers, en promettant le fait de celui-ci ; sauf l'indemnité contre celui qui s'est porté fort ou qui a promis de faire ratifier, si le tiers refuse de tenir l'engagement (Code civil des Français)

1824 Pendant la célébration de ce mariage, un traité d'alliance fut signé entre la reine, son frère Louis de Bavière, le roi de $\mathrm{Na}$ varre, le duc de Bourgogne et le comte de Hainaut : les deux derniers se portant forts pour leurs frères, le duc de Brabant et l'évêque de Liége (Prosper Barante, Histoire des ducs de Bourgogne de la maison de Valois)

\section{CORPUS WEB :}

Il s'engage simplement à obtenir l'engagement ou la ratification de celui pour qui il se porte fort. Les mots "porte-fort » font penser à d'autres : se faire fort d'obtenir quelque chose de quelqu'un [http://www.notaire.be/acheterlouer-emprunter/vente--achat-:-generalites/ convention-de-porte-fort] (5.5.2015)

REMARQUES : Se porter fort (pour quelqu'un) est un terme juridique qui renvoie au fait de se porter garant pour une autre personne s'engageant juridiquement à une transaction sans en avoir elle-même les moyens. On peut se demander s'il s'agit d'un adjectif-adverbe ou d'un nom, mais la discussion de son (in)variabilité, qui concerne notamment le cas assimilable de se faire fort de 
(v. ex. de 1330), met en évidence que certains grammairiens concevaient fort comme un adjectif à fonction adverbiale (v. Plattner $1905: 216$; TLFi : s.v. se faire fort, se porter fort). VOIR AUSSI : faire fort

\section{Porter gros}

Faire l'important

Transitif

1365 Sé je ne les assomme, je ne vaus

.ii. besans ;

Car j'ai .ii. poins plus durs que ne soit

aïmans.

Or me voel gros porter, et estre roys

passans,

Et tenir com gentis, noblez ot sosfissans

(Li Romans de Bauduin de Sebourc, Chant

III, 613)

CORPuS WeB :

Les sac/poche de selle... ça peut porter " gros »[http://cyclurba.fr/forum/158294/sacpoche-selle-n-a-porter-gros.html?discussionID= 8666] (12.10.2015)

Les colliers, les bracelets, les bagues... se portent gros ! [http://passion1mode.tumblr.com/ page/17] (12.10.2015)

Ici l'automobile se porte grosse, grande et rutilante, le tas de boue est rare, le " monster car " fréquent. Chevrolets Suburban, Dodges Silverado sur les freeways, doublent à droite, à gauche, empruntent les feeders et les bretelles d'autoroutes funambulaires [http://jrfactor.blogspot. co.at/2008/12/houston-texas.html] (12.10.2015)

REMARQUES : Au sens premier, porter gros signifie 'contenir une grande quantité' (premier exemple $\mathrm{du} \mathrm{CW}$ ). Il reste invariable dans sa fonction d'intensifieur. Dans l'exemple de 1365 , cette idée est transposée à un trait de caractère. Même si les exemples n'en fournissent pas la preuve, gros devrait rester invarié dans cet emploi. En revanche, dans les deux derniers exemples du CW gros est un prédicat second accordé. Dans l'avant-dernier exemple et employé dans une construction pronominale à sens passif, il dénote une qualité des objets portés. Dans le dernier exemple, l'idée de porter des vêtements est transposé à celui de l'automobile, qui ‘se présente’ ainsi.

\section{Porter haut}

I. Lever, redresser (la tête) ; manifester de la fierté

Transitif

+1100 Cele part vent tut eslessé ; od le restiu de sun espié vot acoler le bon destrier ; le cheval porta haut le chef, que il nel pot mie baillier (Gormont et Isembart [1 ${ }^{\text {re }}$ moitié XII $]$, 311)

1579 ANDROMACHE. Tel tel Hector estoit, il avoit vn tel port,

Il demarchoit ainsi, il estoit ainsi fort

D'espaules et de bras, semblable estoit sa grace,

Il portoit ainsi haut sa belliqueuse face (Robert Garnier, La Troade)

1604 CHEUR. Les piques et les dards

N'esbranleront point son audace ;

Aux orages de Mars

Il portera haute la face, Et son propre vainqueur Ne domtera son cœur (Antoine de Montchrestien, Hector)

1837 L'enivrement de Luizzi fut tel, que deux heures s'écoulèrent pour lui sans qu'il sentît autre chose que la joie de son succès ; jamais il ne porta plus haut la tête et la parole (Frédéric Soulié, Les Mémoires du diable)

1886 Yann avait bien retrouvé tout de suite ses façons d'être habituelles, comme si son grand chagrin n'eût pas persisté : vigilant et alerte, prompt à la manœuvre et à la pêche, l'allure désinvolte comme qui n’a pas de soucis ; du reste, communicatif à ses heures seulement - qui étaient rares et portant toujours la tête aussi haute avec son air à la fois indifférent et dominateur (Pierre Loti, Pêcheur d'Islande)

II. Élever jusqu'à un degré, un niveau élevé ; rendre noble, élevé, beau

Transitif

1592a Jugeons par là ce que nous avons à estimer de l'homme, de son sens et de sa raison, puis qu'en ces grands personnages, et qui ont porté si haut l'humaine suffisance, il 
s'y trouve des deffauts si apparens et si grossiers (Michel de Montaigne, Essais)

1654 Quand il [= Montaigne] quitte le bon, d'ordinaire il rencontre le meilleur, et il est certain, qu'il ne change gueres de matiere, que le lecteur ne gagne en ce changement. Il faut advouër qu'en certains endroits il porte bien haut la raison humaine : il l'esleve jusques où elle peut aller, soit dans la politique, soit dans la morale (Jean-Louis Guez de Balzac, Dissertations critiques)

1685 Peuples ne le pleurez plus ; et vous qui, éblouis de l'éclat du monde, admirez le tranquille cours d'une si longue et si belle vie, portez plus haut vos pensées

(Jacques-Bénigne Bossuet, Oraison funèbre de Michel le Tellier)

1704 Dites-vous la même chose sur la chasteté : les vestales l'ont bien gardée ; sur la cordialité : les payens, les sages du monde en ont fait gloire. Portez donc plus haut vos pensées, et soyez parfaits

(Jacques-Bénigne Bossuet, Méditations sur l'Évangile)

1848 Quand vous serez dans le conseil d'État avec M. Bertin de Vaux, je n'aurai plus rien à demander, car vos talents vous auront bientôt porté plus haut. Ma retraite a contribué un peu, j'espère, à la cessation d'une opposition redoutable ; les libertés publiques sont acquises à jamais à la France (François de Chateaubriand, Mémoires d'outre-tombe)

1943 On voit la richesse de l'œuvre de Pierre Marie, la puissance de son esprit scientifique et l'on comprend l'influence considérable qu'il a exercée non seulement en France, mais dans le monde entier où il a porté très haut le renom scientifique de notre pays (Théophile Alajouanine, Ce que la France a apporté à la médecine depuis le début du $x X^{e}$ siècle)

1990 Son rythme farouche, ses paroles qui bercent, dérangent, excitent, qui vous brisent mais vous portent plus haut. «On ne peut pas aimer deux hommes à la fois.
Il y a de la folie dans l'air. Ce n'est pas Carole, c'est moi qui dois aller m'allonger sur le divan de Joëlle Cabarus » (Julia Kristeva, Les Samouraïs)

1995 Mon imagination m'avait porté si haut qu'il me semblait me regarder moi-même d'en bas, de très bas (Hector Bianciotti, Le Pas si lent de l'amour)

Pronominal

1987 Déjà, dans ce que nous appelons spontanément les « beaux rêves », a bien eu lieu ce travail plus en profondeur grâce auquel une forme, écoutée dans les élans du désir, peut, délivrée, se porter haut, dans une lumière, mais pour l'attendre, lui, ce désir, pour le recevoir, le rafraîchir de son eau, l'apaiser de sa joie sérieuse (Yves Bonnefoy, Rue Traversière et autres récits en rêve)

III. Porter fièrement (un nom, une qualité)

Transitif

1592b Si en avoit il, quelque siecle avant Antonius, osté un entre autres d'authorité si merveilleuse que, en toute son histoire, je ne sache marque qui porte plus haut le nom de son credit (Michel de Montaigne, Essais)

1646 Ainsi, Dapnis, qui par son grand merite Porte si haut le nom de sa maison, Cede aux ennuis dont sa perte l'agite, Et leur permet de troubler sa raison (François Maynard, Poésies)

1738 BALIVEAU. Eh bien! porte plus haut ton espoir et tes vues.

À ces beaux sentiments les dignités sont dues.

La moitié de mon bien remise en ton pouvoir,

Parmi nos sénateurs, s'offre à te faire asseoir (Alexis Piron, La Métromanie)

1864 Et de tous ceux enfin domptés par le tourment

Qui fait d'un homme libre un misérable amant, Tel qu'un vaincu qui tombe à genoux sans cuirasse, 
Lui-même devant tous prompt à se désarmer,

De ceux-là dont le mal est de croire et

d'aimer ;

Qui donc, portant plus haut la fierté de sa race,

L'humilia plus bas que Hemrick, devant toi, Myriann ! plus servile et rampant sous ta loi ? (Léon Dierx, Poèmes et poésies)

1907 Le snobisme levantin veut qu'ici, sous l'œil des Turcs, on porte haut l'orgueil d'être chrétien (Claude Farrère, L'Homme qui assassina)

1947 Mais, forts de leur grâce, ils portaient si haut leur état d'enculés que cet état leur devenait parure et force (Jean Genet, $M i$ racle de la rose)

IV. Pousser, faire augmenter, faire grandir, faire se développer

Transitif

1636a LE COMTE. Je l'avoue entre nous, mon sang un peu trop chaud

S’est trop ému d'un mot, et l'a porté trop haut ;

Mais puisque c'en est fait, le coup est sans remède (Pierre Corneille, Le Cid)

1659 Quelle ame ardante et vigoureuse, Quelle ame, de gloire amoureuse, Icy bas a jamais porté Plus haut la generosité ! (François de Boisrobert, Épistres en vers)

1782 M. l'abbé d'Expilly, qui a porté si haut la population générale du royaume, et qui paroît l'avoir enflée de trois millions, rabat la population de Paris à six cents mille ames (Louis-Sébastien Mercier, Tableau de Paris)

1832 Le gouvernement ne frapperait les lingots des particuliers qu'autant qu'on lui paierait les frais et même le bénéfice de la fabrication. Ce bénéfice pourrait être porté assez haut, en vertu du privilége exclusif de fabriquer (Jean-Baptiste Say, Traité d'économie politique)

1835 Quand l'heure du départ a rompu le charme, et que j'ai ressaisi le sentiment habituel de mon être, je me suis retrouvé pauvre et déplorable comme devant ; mais à la marche plus vive de mes pensées, à une délicatesse plus subtile de sensations, à un accroissement marqué de mes forces morales et intellectuelles, j'ai reconnu que mes six semaines d'oisiveté n'étaient pas perdues, que le flot de rêves étranges qui avait inondé mon âme l'avait soulevée et portée plus haut (Maurice de Guérin, Journal intime ou Le Cahier vert)

V. Estimer beaucoup, admirer, aimer beaucoup Transitif

1636b Porte encore plus haut le fruict de ta victoire.

Je t'ay donné la vie, et tu me rends ma gloire (Pierre Corneille, Le Cid)

1667 ARSINOÉ. Hé ! croyez-vous, Monsieur, qu'on ait cette pensée,

Et que de vous avoir on soit tant empressée?

Je vous trouve un esprit bien plein de vanité,

Si de cette créance il peut s'être flatté.

Le rebut de Madame est une marchandise Dont on auroit grand tort d'être si fort éprise.

Détrompez-vous, de grâce, et portez-le moins haut :

Ce ne sont pas des gens comme moi qu'il vous faut ;

Vous ferez bien encor de soupirer pour elle, Et je brûle de voir une union si belle (Molière, Le Misanthrope)

1845 L'homme qu'elle avait jusqu'alors porté si haut dans son cœur, celui qu'elle avait admiré à l'égal d'un héros et d'un dieu, celui qu'elle avait cru plongé dans un désespoir si affreux, qu'entraînée par la plus tendre pitié, elle lui avait loyalement écrit, afin qu'une douce espérance calmât ses douleurs... (Eugène Sue, Le Juif errant)

1924 C'était donc un marché, c'était l'arrangement qui vaut mieux qu'un procès : la pensée de saint Louis était politique et non pas mystique. Il portait seulement plus haut que les autres Capétiens la ten- 
dance de sa maison qui était de mettre le bon droit de son côté (Jacques Bainville, Histoire de France)

1934 Tout cela n’a rien que de très naturel. Déjà Pia, que je transfigurais. Irène, que j'ai portée trop haut. Ma pauvre fille, quand te décideras-tu à prendre les êtres pour ce qu'ils sont, et non pour ce que tu les voudrais ? (Daniel-Rops, Mort, où est ta victoire?)

1971 Celui [= Jorge Luis Borges] qu'on entendra ce soir n'a pas seulement porté très haut l'honneur des lettres argentines (SaintJohn Perse, Hommages)

VI. Porter, avoir selon une ligne verticale Transitif

1887 Tout absorbait, se trempait, tout reverdissait dans l'averse. Le blé reprenait une santé de jeunesse, ferme et droit, portant haut l'épi, qui allait se gonfler, énorme, crevant de farine (Émile Zola, La Terre)

\section{CORpus WeB :}

Hollande : « Je veux porter haut la voix et les valeurs de la France dans le monde » [http:// www.lejdd.fr/International/Actualite/HollandeJe-veux-porter-haut-la-voix-et-les-valeurs-de-laFrance-dans-le-monde-607725] (12.10.2015)

Pierre Buyoya annonce des réformes pour porter haut la Francophonie [http://latempete. info/pierre-buyoya-annonce-des-reformes-pourporter-haut-la-francophonie/] (12.10.2015)

Mais le courage et la volonté n'auront pas suffi aux deux hommes et à leur équipe pourtant motivée, dans un contexte économique impossible, pour porter haute la renommée de cette maison centenaire [http://www.leprogres.fr/ haute-loire/2015/07/27/la-poularde-a-servi-sesderniers-clients] (12.10.2015)

REMARQUES : L'objet direct de porter haut (I) réfère à la tête ou au visage que l'on redresse, c'est-à-dire que le sujet tient la tête haute dans une attitude fière. Si l'objet renvoie à une personne (II), celle-ci se sent élevée spirituellement, portée vers le haut par son imagination ou par quelque chose de beau, de positif. Si l'objet est un inanimé, il se dit du fait de l'élever moralement ou spirituellement, de le rendre noble, beau. En
(III), l'objet peut être un nom, un état, mais aussi une qualité que l'on porte avec fierté. (IV) se dit d'une chose inanimée qu'on fait croître, se développer ou qui enfle, grandit d'elle-même de par sa qualité supérieure. (V) se dit d'une personne ou d'une chose (l'honneur) que l'on estime particulièrement, que l'on porte haut dans son estime. (VI) signifie 'faire porter quelque chose en le tenant bien haut et d'une manière verticale'. Haut peut s'accorder avec l'objet (ex. de 1604 et le dernier exemple du CW), présentant ainsi haut comme qualité de l'objet. Il est modifié par ainsi, assez, bien, donc, encore, moins, plus, seulement, si, toujours, très, trop. Le nombre élevé de modifieurs reflète l'indépendance syntaxique de haut par rapport au verbe, autrement dit, le fait de se combiner librement avec celui-ci. Notons le contraste dans porter plus haut ... humilier plus bas. VOIR AUSSI : élever haut

\section{Porter horizontal}

Porter (un chapeau) dans une position

horizontale

入 porter droit

\section{Porter juste}

Toucher avec précision, atteindre exactement le but visé, obtenir l'effet voulu

Emploi absolu

1685 on peut dire que quand il seroit même véritable, ce que dit le même auteur, qu'une balle porte juste de but en blanc à la longueur de cent toises en une seconde de tems ; il ne seroit pas mal-aisé de répondre que [...] son expérience se trouveroit entiérement conforme à nos hypothèses

(Jacques François Blondel, L’Art de jetter les bombes)

1744 Le Tems étoit fort calme ; de façon que les Coups portoient juste (Armand de Gramont, comte de Guiche, Mémoires concernant les Provinces-Unies des PaisBas)

1812 Les vices et les ridicules se retranchent dans certaines classes de la société comme dans un fort ; la critique y jette des bombes, et la preuve qu'elles ont porté juste, c'est qu'on voit beaucoup d'estropiés (Étienne de Jouy, L'Hermite de la Chaussée-d'Antin) 
1829 À la supériorité de l'art, ils opposent les avantages de la nature : leurs coups sont moins nombreux, mais ils portent plus juste (François de Chateaubriand, Les Natchez)

1862 Les volontaires de Bourbon, dont tous les coups portaient juste, voyaient tomber capitaine, officiers, matelots sur la frégate ennemie (Georges Azéma, Histoire de l'île Bourbon depuis 1643 jusqu'au 20 décembre 1848)

1905 On le voit au ton amer, profondément douloureux avec lequel ses dernières préfaces relèvent telles critiques respectueuses. C'est qu'elles avaient porté juste (Maurice Barrès, Mes cahiers)

1924 Là-dessus l'avertissement de l'instinct national, tel qu'il s'était manifesté par l'impopularité de Ferry et par le boulangisme, portait si juste que des réflexions nouvelles naquirent au gouvernement (Jacques Bainville, Histoire de France)

\section{CORPuS WEB :}

L'allure est décontractée, un sourire ponctue chaque phrase, mais le verbe est précis et les arguments portent juste [http://www.parisschool ofeconomics.eu/en/la-lettre-pse-ecole-d-eco nomie-de-paris/newsletter6-pse-june-2011/] (12.10.2015)

Ils portent beau, ils portent haut, ils portent juste. Ils et elles se nomment Benoît Arnould, Rémy Cassaigne, Sarah van Cornewal, Emmanuelle Guigues, Renate Sudhaus, Gabriel Wolfer. Ensemble Eloquence est leur enseigne sous Tribunes baroques. Ces interprètes ont le talent, le goût de la musique signifiante où l'art parfait assemble musique et Parole [http://www. tribunes-baroques.ch/default.asp?MenuID= 6308\&PageID=4240] (12.10.2015)

Chacun utilise les armes qu'il possède. Reste à savoir si elles portent juste ? [http://www. babelio.com/auteur/Suzanne-Clausse/192763] (12.10.2015)

REMARQues : Porter juste se dit d'une chose inanimée, telle un coup, un projectile qui atteint son but avec précision, touche sa cible. Dans un contexte métaphorique, il se dit de paroles (par exemple, des critiques) qui obtiennent l'effet voulu sur les interlocuteurs (premier exemple $\mathrm{du} \mathrm{CW}$ ). Notons les groupes porter beau et porter haut dans le CW. Juste reste invariable et est modifié par plus, si.

\section{Porter léger}

Porter un poids léger

$\lambda$ porter lourd

\section{Porter lourd}

I. Porter d'une manière stupide, sotte, niaise Transitif

1581 Celuy qui lourd porte une teste

Plutost que d'homme d'une beste, Ne sçait priser ny despriser (Jean-Antoine de Baï, Mimes, enseignemens et proverbes)

II. Porter un poids lourd, qui pèse beaucoup Emploi absolu

1850 Entre, mon enfant, viens te reposer. Voyez ce pauvre petit ! il porte plus lourd que luimême ! Tenez, mère, dit-elle à la vieille meunière qui lui présentait son enfant bien frais et tout souriant, voilà un pauvre champi qui a l'air malade (George Sand, François le Champi)

1990 En rentrant, je m’arrête à l'épicerie, ceci en évitant de porter lourd (courrier personnel / Noailly 1997a)

\section{CORPUS Web :}

prendre du volume musculaire : porter lourd ou leger ? [http://forum.doctissimo.fr/formesport/sport-sante/prendre-musculaire-portersujet_148343_1.htm] (12.10.2015)

Il se sent portant lourd une responsabilité, au nom de sa génération à lui [http://aejjrsite. free.fr/goodmorning/gm103/gm103_Confessions DeHanh.pdf] (12.10.2015)

Remarques : Porter lourd (II) signifie 'porter quelque chose de lourd', porter une charge lourde pour soi. En (I), dans ce contexte précis, il se dit du fait de porter sur les épaules une tête d'animal, lourde, plutôt que celle d'un être humain, ce qui revient à dire que le sujet a un air stupide, grossier, qu'il tient sa tête sur ses épaules tel un animal, par exemple en la dodelinant ou en la bougeant sans finesse. Le dernier 
exemple du CW, au figuré, réfère à une responsabilité qui pèse lourd. Lourd est invariable et est modifié par plus. Notons la collocation antonymique lourd ou léger.

\section{Porter penché}

Porter quelque chose (un chapeau) en

l'inclinant, ne pas le porter droit

$\lambda$ porter droit

\section{Porter rigide}

Tenir de manière raide et droite

Transitif

1950 Sa tête, qu'il portait haut et rigide, se caractérisait par deux dents en or assemblées parmi ses larges dents blanches, une moustache noire, une paire de pince-nez et un canotier (Joseph Zobel, La Rue CasesNègres)

\section{CORPuS WEB :}

L'arrière de la remorque, coté tableau AR, ainsi que l'avant, continueraient à porter 'rigide', mais le milieu, vers l'essieu, serait équipé de ce système souple, souplesse à calibrer évidemment [http://my.boating.fr/forum/8-pneumatiqueset-semi-rigides/26849-koufig-et-le-mouton-a-5pattes?start=40] (12.10.2015)

Le corset d'une maîtresse femme, Catherine de Médicis, celui de Ninon de l'Enclos, une femme libérée ; un corset sombre pour un Roi Soleil, un autre rougi de sang sur l'échafaud ; l'impératrice Eugénie le portait rigide, à son image ; un président de la République est mort de l'avoir trop délacé ; celui de Mata Hari fut criblé des balles de la Première Guerre mondiale et, avant de fermer les maisons closes, Marthe Richard avait si souvent ouvert le sien! [http://www.librairiescientia. eu/Livre/Michel-De--Decker/12--Corsets-QuiOnt-.../9782756404264.html] (12.10.2015)

Comme les Zouaves, les Tirailleurs ou les Chasseurs d'Afrique, pour marquer son appartenance à l'Armée d'Afrique, l'Artilleur d'Afrique entourait sa taille d'une large ceinture de flanelle rouge, et coiffait une chéchia garance qu'il portait rigide et haute (recouvert parfois d'une cache poussière kaki) [http://www. ouarzazate-1928-1956.com/l-artillerie/lartilleriedafrique.html] (12.10.2015)
REMARQUeS : Porter rigide se dit du fait de tenir quelque chose (ici : la tête, un corset, etc.) d'une manière raide et droite, les muscles étant contractés et empêchant un relâchement involontaire. Notons la collocation avec l'adjectif haut, ajoutant au port de tête une idée de fierté ou de noblesse. Dans le premier exemple du CW, rigide réfère à une propriété des pneus. Rigide reste invariable dans son emploi adverbial. Dans le dernier exemple du CW, les adjectifs-adverbes s'accordent avec l'objet (l'accord se manifestant uniquement sur haut), se rapprochant d'un prédicat second orienté vers l'objet. VoIR AUSSI : monter large, chausser étroit (par rapport aux pneus).

\section{Porter soef}

Porter délicatement, avec douceur, avec grâce

Transitif

1130 Ço deit fiz faire a pere, Ensurquetut a mere, Ki suëf le portat, Nurit e alaitat (Philippe de Thaon, Bestiaire [trad., probablement entre 1121 et 1135], 2609)

1165 Un blanc palefrei chevalchot, ki bien e suëf la portot; [variante : bel e suef] mult ot bien fet e col e teste : suz ciel nen ot plus gente beste (Marie de France, Lais, 558)

1177 Maintenant sanz nule delaie, Sanz noise feire et sanz murmure, S'an cort monter sor une mure Mout bele et mout soef portant. [variante : amblant]

Mes de ma part vos di je tant, Qu'ele ne fet onques quel part Torner quant de la cort se part (Chrestien de Troyes, Lancelot ou Le Chevalier de la charrete, 6411)

1190 Kant l'entent Karlemaine, mout enn a grant pité ;

En un escu a or l'ont fait couchier soué. Puis l'enn ont li barons tout souavet porté; Omques ne s'aresterent jusquez a metre tré (Fierabras (L), 1917) 
1200 « L'autrier le fis baptizier et lever Et maitre el chief sainte crestienté, Nel voil encores traveilliez ne pener. » Et dist li fel : « Gel porterai souef Desouz ma chape a moult grant sauveté Conme celui cui je doi moult amer » (Jourdain de Blaye, 183)

$\sim 1250$ « Sire, en vostre bon palefroi Fetes errant metre la sele ; S'ert portée ma damoisele Sus au moustier, que soef porte » Et cil qui soef se deporte I est alez isnelement Et tuit li baron ensement (Huon le Roi, Du Vair Palefroi)

+1350a Et la dame entra ens qui moult bel se deporte, Sur son cheval emblant qui moult souef la porte (Brun de la Montaigne [ $2^{\mathrm{e}}$ moitié $\mathrm{XIV}^{\mathrm{e}}$, 1893)

+1350b Si tost que la dame ot desvelopé l'enfant, Elle s'ala seoir deles .i. feu ardant, Et de ses belles mains l'aloit souef portant, Et derriere et devant moult doucement chaufant (Brun de la Montaigne [ $2^{\mathrm{e}}$ moitié $\mathrm{XIV}^{\mathrm{e}}$, 2007)

REMARQUES : En ancien français, porter soef désigne le fait de porter quelqu'un/quelque chose, transporter quelqu'un, tenir quelque chose entre ses mains doucement, délicatement, en prenant garde de ne pas abîmer l'objet, de le ménager. Notons la collocation avec bel ou bien qui mettent en évidence la fonction adverbiale. Soef reste invariable et est modifié par moult, tout.

\section{Poser bas}

I. poser bas les armes : se rendre Transitif

1595 qu'on envoye Ambassadeurs vers Antoine, pour sentir quelle est la deliberation : que si volontairement il veut poser bas les armes, et se soumettre à nous, que nous vivions en paix, que s'il fait l'opiniastre, et continue en ses folies, que lors nous le defiyons et poursuivions à toute outrance (François de Belleforest, Harangues militaires)
1814 la batterie fut prise dans le moment et les Bataillons se virent forcés de poser bas les armes (Aperçu de la campagne de l'armée des alliés et de l'armée française en 1813)

1911 Devant un tel triomphe, l'Académie n'avait qu'à poser bas les armes. Reconnaissant son impuissance à étouffer les découvertes de Marat, elle a cherché à se l'adjoindre (Chronique médicale)

II. Poser (tout) bas (une question), la poser à voix basse, en murmurant Pronominal

1879 La contre-maître pencha le nez sur son ouvrage et se posa tout bas cette question, qu'elle n'avait jamais pu résoudre depuis trente années qu'elle travaillait dans la brochure :

- Les filles qui font la noce sont presque toujours de détestables ouvrières ; celles qui ne la font pas, gagnent de bonnes journées, mais elles se marient et deviennent pis que les plus mauvaises, puisqu'elles ne viennent plus du tout (Joris-Karl Huysmans, Les Sours Vatard)

Transitif

1913 Aux questions de M. Seurel, il répondit que lui aussi était parti à la recherche des écoliers buissonniers. Et à celle que je lui posai tout bas, il dit seulement en hochant la tête avec découragement :

- Non! Rien! Rien qui ressemble à ça (Alain-Fournier, Le Grand Meaulnes)

1983 « Qu'est-ce qu'il arrive à Natacha ? » J'entends une amie venue dîner poser tout bas cette question à mon père... mon air absent, hagard, peut-être dédaigneux a dû la frapper... et mon père lui chuchote à l'oreille (Nathalie Sarraute, Enfance)

CoRpus Web :

EDIT : c'est mon montage de tarp par défaut.

- En cas de très gros vent on peut faire plus bas et avoir un côté, voire les deux, complètement fermé. Mais alors difficile de s'asseoir.

- L'avantage avec les deux bâtons c'est que de poser bas à l'avant n'oblige pas à avoir les pieds qui touchent la toile [http://forum.davidmanise. com/index.php?topic=48880.0] $(12.10 .2015)$ 
Ces bandeaux nouvelle génération retiennent les cheveux en arrière et dégagent le front et la nuque. On peut y enrouler les longueurs ou le poser bas sur le front pour un look hippie chic [http://www.trucsdenana.com/descheveux-au-top/article/27264/comment-coifferete-soin-cheveux] (12.10.2015)

je ne sais pas comment tu comptes poser ta lace, mais en général il faut pas la poser bas et il faut au moins faire quelque chose de tes baby hair parce que la colle a plus du mal a adherer s'il y a des cheveux (c'est sur partie « lisse " qu'elle dure le plus longtemps) et si tu comptes mettre une colle adhesive ca va te les arracher... [http:// forum.manucure.info/index.php?threads/lacefront-info.36567/page-1731] (12.10.2015)

Si une antenne posée basse travaille mieux qu'une antenne posée haute, je ne me pose plus 36 questions [http://www.stw.fr/forumstw/ quest_answers.cfm?quest_id=35734\&topic_ id=22\&st_row=1] (12.10.2015)

REMARQUES : Dans le contexte de batailles, poser bas les armes (I) est une phrase toute faite voulant dire 'se rendre' ; l'exemple de 1911 la transpose au domaine du débat académique. En (II), l'objet est une question que le sujet pose en élevant très peu la voix, généralement à cause d'une gêne, par timidité ou embarras, la collocation tout bas étant systématique, sans doute pour exclure l'adverbe de lieu. Celui-ci apparaît dans le CW, où poser bas renvoie à un objet concret qu'on met à une position inférieure. Bas reste invariable dans la majorité des cas, mais dans le dernier exemple $\mathrm{du}$ CW, il s'accorde avec l'objet au féminin tout en gardant son interprétation adverbiale. Il est modifié par tout.

\section{Poser droit}

Poser selon un axe vertical ou horizontal Transitif

1848 En effet, j'avais sous les yeux un carré de fleurs qu'on n'eût jamais pris pour une tombe, si un marbre blanc portant un nom ne l'eût constaté. Ce marbre était posé droit, un treillage de fer limitait le terrain acheté, et ce terrain était couvert de camélias blancs (Alexandre Dumas fils, $L a$ Dame aux camélias)
1964 La casquette doit être posée droit sur le crâne : toute inclinaison de côté serait de mauvais aloi. Quant aux bords cassés à l'américaine, il n'en est simplement pas question (Pierre Daninos, Snobissimo ou Le Désir de paraître)

Pronominal

1948 C'était un homme de lourde stature, dans la soixantaine, avec un ventre qui pointait sous la robe blanche. Il ne se carrait pas dans les fauteuils; il s'y posait droit (Maurice Druon, Les Grandes Familles)

\section{CORPUS WEB :}

Prenez ensuite vos points de repères en utilisant soit du scotch de couleur, soit un crayon à papier, afin de le poser droit [http://www.pratique. fr/comment-poser-sticker.html] (12.10.2015)

Ca y est enfin j'ai acheté un super carrelage $45 \times 45$ couleur gris clair que je vais poser dans tout l'appartement. Seulement, une question que je me pose.. J'hésite à le poser droit ou en diagonale... [http://www.deco.fr/forum-deco/ pose-carrelage-droit-ou-diagonale-9202.html] (12.10.2015)

Avons-nous chacun quelque chose à tenter ? Voilà une question sans réponse car c'est à chacun de se la poser droit dans les yeux [http:// siprochedelhorizon.blogspot.co.at/2014/11/ risquer-encore.html] (12.10.2015)

Ce système s'avère très pratique car il vous permet de continuer à vaper pendant la charge, seul petit problème, l'entrée du connecteur se trouve sous la box et du coup cela empêche de la poser droite mais cela ne reste qu'un détail [http://www.vapoteurs.net/revue-le-testcomplet-de-legrip-oled-joyetech/] (12.10.2015)

REMARQUES : Poser droit se dit de quelque chose que l'on pose selon un axe vertical ou horizontal, de façon à former un angle droit, donnant à la chose un aspect ordonné, convenable. À la forme pronominale, le sujet peut être une personne qui s'assoit (sur quelque chose) bien droit. Droit reste invarié dans son emploi adverbial, mais dans le dernier exemple du CW, il s'accorde avec l'objet, se rapprochant d'un prédicat second orienté vers l'objet. Le verbe poser favorise l'interprétation comme prédicat second parce que l'action place l'objet dans une position, par exemple une posi- 
tion droite. L'avant-dernier exemple du CW réfère au fait de poser une question droit dans les yeux avec idée de direction pour droit.

\section{Poser net}

I. Placer nettement, brusquement Transitif

1288 Et sages home amesurer Se doit, si ke puisse durer S'aumosne tant qu'il iert en vie, Si qu'à la mort li faiche aïe De li mener en purgatoire, Pour lui poser net en la gloire Qui fu et est et si sera

Tous jours que ja ne finera (Jehan de Journi, La Dime de penitence, 2886)

1855 Tous les membres devront préparer, par écrit, les réponses sommaires à chaque question, c'est-à-dire : les définitions exactes, le posé net des dogmes, les décisions précises de morale, etc., avec l'indication des preuves principales à l'appui (Mgr Félix Dupanloup, Instruction de régle ments de monseigneur l'évêque d'Orléans)

1910 Cela est trop nuancé ; de tons trop rompus. Quand j'écrirai les caves, à côté d'un ton plat, je poserai tout net un autre ton plat (André Gide, Journal)

II. Poser une question de façon claire et nette Transitif

1907 Mais M. Pirmez posa net la question : Veut-on oui ou non proclamer le principe de la liberté du commerce d'argent?

(Victor Brants, La Lutte contre l'usure dans le lois modernes)

1934 Je fus plusieurs fois sur le point de poser tout net la question à Marcelline (Daniel-Rops, Mort, où est ta victoire ?)

Pronominal (impersonnel)

1920 Du jour où la double question se posa nette et formulée de savoir que Dieu existe [...] tous ne déclarèrent-ils pas, d'un commun accord, leur ignorance, leur impuissance à l'égard de la seconde question? (Dictionnaire de théologie catholique)
Remarques : Poser net (I) renvoie au fait de placer nettement quelque chose ; aussi : exposer nettement quelque chose (ex. de 1855). En (II), il est employé dans le cadre de la locution poser une question pour dire 'poser clairement la question'. Cette acception se prête à une lecture comme prédication seconde, ce qui se traduit par l'accord réalisé dans l'exemple de 1920.

\section{Posséder clair et net}

Posséder absolument, totalement

л posséder net

\section{Posséder net}

I. Posséder après déduction de tout élément étranger, de toutes charges Transitif

1665 Il possède quitte et net cent mille francs, Le colis a 50 kilogrammes net, Le seigneur dit : Payez donc cent écus net et comptant (Jean de La Fontaine, Paysan)

II. posséder clair et net : posséder absolument, totalement

Transitif

1837 Si je t’avais écoutée, je n’aurais jamais fait ni la Pâte des sultanes, ni l'Eau carminative. Notre boutique nous a fait vivre, mais ces deux découvertes et nos savons nous ont donné les cent soixante mille francs que nous possédons clair et net !

(Honoré de Balzac, Histoire de la grandeur et de la décadence de César Birotteau)

REMARQUES : L'objet est une somme d'argent (I), net référant à la somme exacte, après déduction de frais externes. (II) se dit d'avoir à soi, de disposer de quelque chose (ici : d'une somme d'argent), la collocation clair et net, signifiant au total, tous frais déduits ; elle induit que l'objet est possédé totalement, sans contestation possible. Clair et net restent invariables. Notons les collocations quitte et net et l'emploi de payer net et comptant. 


\section{Posséder profond}

Maîtriser, connaître parfaitement, de manière approfondie et durable, profondément

Transitif

1953 cette universalité de curiosités nourries de cinq ou six sciences possédées très profond (Claude Roy, Le Commerce des classiques)

REMARQues : L'objet de posséder profond est une matière, un savoir que le sujet connaît amplement et maîtrise parfaitement. Profond reste invariable et est modifié par très.

\section{Poudrer transparent}

Employer de la poudre transparente Transitif

1964 Poudrez-vous transparent (Étiemble)

\section{Pourpenser étroit}

Réfléchir profondément et posément

Pronominal

+1233 La dammoisele, kant ceo savoit, Se porpensa mult estroit

Coment peust a li parler,

Si de rien li peust conforter (Un chivalier et sa dame et un clerk [ $2^{\mathrm{e}}$ tiers $\mathrm{XIII} \mathrm{e}^{\mathrm{e}}$, 152)

REMARQUeS : Verbe utilisé encore en moyen français, pourpenser se disait du fait de réfléchir mûrement, de méditer, étroit référant à l'intensité des pensées et au calme de la réflexion. Étroit reste invariable et est modifié par moult.

\section{Poursuivre fort}

Poursuivre, harceler, courtiser

Transitif

1559 En la ville d'Alençon, du vivant du duc Charles, dernier duc, y avoit ung procureur nommé Sainct Aignan, qui avoit espousé une gentilfemme du pais, plus belle que vertueuse, laquelle, pour sa beaulté et legiereté, fut fort pousuivye de l'evesque de Sees (Marguerite d'Angoulême, Heptaméron, p. 13, 4)

\section{Corpus Web :}

Merci beaucoup beaucoup Véro pour ton enthousiasme, ton dynamisme et ton implication auprès de nous ! Tu m'as renligné sur le chemin de la remise en forme et je suis très motivée à poursuivre fort fort fort ! [https://www.facebook. com/permalink.php?story_fbid=20415897293676 7\&id=125945917424740] (14.10.2015)

Il pourrait s'agir d'une colonisation militaire, dont les débuts dans les « villes de Sogdiane " sont attestée dès le séjour d'Alexandre à Samarkand en 328 (Arrien, IV.16.3) ; cette dernière étape de la vie du site voit aussi la reconstruction du rempart intérieur, muni de quatre portes principales. La rareté de la céramique typiquement grecque incite à penser que cette occupation ne s'est pas poursuivie fort avant dans le IIIe siècle [http://frantz.grenet.free.fr/index. php?choix=koktepe] (14.10.2015)

Le travail collectif va pouvoir se poursuivre fort de cette reconnaissance et de l'atout supplémentaire qu'est le label parc naturel régional [http://www.lanouvellerepublique.fr/ Deux-Sevres/Communes/Niort/n/Contenus/ Articles/2014/05/22/Marais-la-touche-finalepour-le-label-1917714] (14.10.2015)

Remarques : Poursuivre fort réfère à une personne étant persécutée moralement, sans répit, fort renvoyant à l'intensité ou à la continuité de l'action. Dans le CW, (se) poursuivre fort se dit du fait de continuer quelque chose sans relâche. Le dernier exemple contient la collocation figée fort de quelque chose 'grâce à quelque chose, encouragé par quelque chose'. Fort reste invariable. Notons l'emploi pronominal du verbe et la réduplication de fort qui a une fonction d'intensification.

\section{Pourvoir bel}

Pourvoir, munir en abondance

Transitif

+1365 Je vous voi si biel pourveües

De sens, d'arroi et de maniere

Que vous recevrés ma proyere

Et si me dirés, s'il vous plaist, Vostres mestres quels homs il est, S'il est fils de duc ou de roy, Car bien moustrés par vostre arroi Que vous estes à grant seignour (Jean Froissart, Poésies [3e tiers XIve])

REMARQUes : Pourvoir bel se disait du fait d'être pourvu de beaucoup de choses, d'en être en possession, le neutre bel référant à la beauté des choses ou à la qualité des attributs possédés. Bel est modifié par si. 


\section{Pousser dru}

I. Arriver, affluer en abondance Intransitif

1836 - Je ne puis rien produire, non par stérilité, mais par surabondance ; mes idées poussent si drues et si serrées qu'elles s'étouffent et ne peuvent mûrir (Théophile Gautier, Mademoiselle de Maupin)

II. Pousser, croître de manière vigoureuse, en abondance

Intransitif

1849 Toute la rive droite était gazonnée, et mêmement, dans tout le fond de la coupure, le jonc et la prêle avaient poussé si dru dans le sable, qu'on ne pouvait voir un coin grand comme le pied pour y chercher une empreinte (George Sand, La Petite Fadette)

1858 Dans l'opulent limon du Nil, les épis avaient poussé vigoureux, drus et hauts comme des javelines, et jamais plus riche moisson ne s'était déployée au soleil, flambante et crépitante de chaleur (Théophile Gautier, Le Roman de la momie)

1865 Je me levai pour le faire entrer, et m'avisai alors d'un bruit dans mon avoine, laquelle poussait verte et drue derrière la maison, et qui me semblait tondue à belles dents et labourée à quatre pieds par quelque bête à qui je n'avais point vendu mon grain en herbe (George Sand, Les Maîtres sonneurs)

1875 Le chevalier était fort satisfait ; toute sa récolte était battue et engrangée, ses regains poussaient dru, et les raisins, qui commençaient à noircir, promettaient une belle vendange (André Theuriet, Le Mariage de Gérard)

1886 L’année s’annonçait bien pour les nouveaux époux. Les récoltes poussaient drues et vivaces ; on n'eut point de gelées tardives (Guy de Maupassant, Contes et nouvelles)

1893 Il n'avait plus sa face douloureuse des mois de chagrin et de souffrance qu'il venait de passer ; il reprenait sa bonne figure, ses grands yeux vifs, encore pleins d'enfance, ses traits fins, où riait la bonté ; tandis que ses cheveux blancs, sa barbe blanche, poussaient plus drus, d'une abondance léonine, dont le flot de neige le rajeunissait (Émile Zola, Le Docteur Pascal)

1908 On serait averti, quand on vient du Cambrésis ou de l'Artois, de cette présence universelle de l'eau, rien qu'à voir la beauté des arbres. Arbres et moissons poussent drus. Pas de partie nue et vide dans l'abondance qui couvre le sol (Paul Vidal de la Blache, Tableau de la géographie de la France)

1928 Il laissa tomber un à un, avec tout le monde, le grain dans la raie, et puis les pincées de poussière grise de l'engrais, et quand la plante eut poussé trop dru comme toujours, " comme une tête de cheveux, » il éclaircit les sillons (Joseph de Pesquidoux, Le Livre de raison)

1939 Mais ses cheveux, même passés la veille au soir par le coiffeur pour le débroussaillement de la nuque, résistaient à la brosse comme à la main. Élastiques et chauds, d'un blond pâle de maïs, ils poussaient drus sur le front doré par le hâle, et en vagues toujours rebelles (Joseph Peyré, Matterhorn)

1940a 3 septembre.

Premières lueurs du jour.

Rêvé de toi cette nuit, Jean-Paul. Tu étais dans le jardin d'ici, et je te tenais appuyé contre moi, et je te sentais ferme et cambré, pareil à un petit arbre qui pousse dru, dont rien ne peut arrêter l'élan (Roger Martin du Gard, Les Thibault. Épilogue)

1944a Un courant de fraîcheur circulait et c'était peut-être pourquoi les plantes volubiles et désordonnées poussaient si dru et serré (Jacques Roumain, Gouverneurs de la rosée)

1944b les érosions ont mis à nu de longues coulées de roches : elles ont saigné la terre jusqu'à l'os. Pour sûr qu'ils avaient eu tort de déboiser. Du vivant encore de défunt Josaphat Jean-Joseph, le père de Bienaimé, les arbres poussaient dru là-haut. Ils avaient incendié le bois pour faire des 
jardins de vivres : planté les pois-congo sur le plateau, le maïs à flanc de coteau (Jacques Roumain, Gouverneurs de la rosée)

1963 Elle commença de sarcler une planche où l'herbe poussait drue entre les lignes de carottes à peine sorties de terre. De temps à autre elle regardait Julien (Bernard Clavel, Celui qui voulait voir la mer)

1966 À regarder les touches légères de couleurs avec lesquelles cet homme au nom de joncs ou de jonquilles poussant dru dans la froidure du Nord a évoqué des sites indubitablement localisés mais dont elles nient plutôt qu'elles ne posent les limites (Michel Leiris, La Règle du jeu 3 : Fibrilles)

1977 J'ai trouvé qu'il y a des endroits où la graine pousse pas $d r u$, dans ma famille par exemple, ils n'ont pas de boulots bien, juste mon oncle Jean dessinateur industriel (Annie Ernaux, Ce qu'ils disent ou rien)

III. Grandir beaucoup, rapidement, vigoureusement

Intransitif

1887 L'enfant, à peine sevrée, avait poussé dru, en mauvaise herbe ; et, depuis qu'elle marchait, elle faisait la soupe à son père, qu'elle redoutait et adorait (Émile Zola, $L a$ Terre)

1896 Les enfants poussent drus aux filles qu'il enjôle,

Dans la puberté fière et fauve, le beau gas Va, comme dans sa pourpre un roi qui sait son rôle

Et parle à voix hautaine, et marche à vastes pas (Paul Verlaine, Euvres poétiques complètes)

1940b Il est beau, ce petit, il est fort, il pousse $d r u$, tout l'avenir, le mien, tout l'avenir du monde, est en lui! Depuis que je l'ai vu, je songe à lui, et l'idée que, lui, il ne pourra songer à moi, m’obsède (Roger Martin du Gard, Les Thibault. Épilogue)

1942 Ces enfants qui naissaient, qui poussaient $d r u$ autour du poêle, cette vaillante femme aux flancs féconds, aux grands yeux bruns qui troublaient les hommes (Maurice Genevoix, Laframboise et Bellehumeur)

\section{CORPUS WeB :}

La chair à canon, embarquée en août et septembre toute gorgée de patriotisme, pourrit maintenant en Belgique, dans les Vosges, en Masurie, dans des cimetières où l'on voit les bénéfices de guerre pousser dru [https://www.marxists.org/ francais/luxembur/junius/rljaf.html] (14.10.2015)

Profitons-en pour nous enraciner dans le sol et pousser dru comme une plante vers le ciel avec cet atelier d'équilibre [http://yoganandini.com/ sujet/posture] (14.10.2015)

Ce sont des filles et des garçons bien portants, poussés dru et cependant disciplinés ; on ne chahute pas dans les rangs [http://www.dolem breux.be/reportage_1972_188.htm] (14.10.2015)

L'arrivée dans le Durbar square est un enchantement : les pagodes, palais, temples y ont poussés drus, serrés les uns contre les autres, comme si la place manquait aux rois de Patan pour les construire [http://ctrlclic.kikooboo.com/ $\mathrm{fr} /$ page/katmandou-les-rives-de-la-bagmatikirtipur] (14.10.2015)

REMARQUeS : En parlant de végétaux (mais aussi de cheveux), pousser dru (II) signifie 'croître, pousser d'une manière abondante, serrée et vigoureuse'. Par métaphore ou par comparaison (I), il s'applique à une pensée, un sentiment qui naît, germe de manière abondante, intense. Emploi familier (III), par ironie, il se dit d'un enfant grandissant rapidement, avec force. Notons les collocations pousser vigoureux, dru et haut / vert et dru / dru et vivace / dru et serré. Dru s'accorde ou non, l'accord insistant sur une qualité résultative, mais plutôt comme nuance, sans changer de fonction ou de sens. Il est modifié par plus, si, trop.

\section{Pousser dur}

Pousser avec force, fortement, vigoureusement Intransitif

1932 Au quai, l'eau poussait dur sur les péniches bien rassemblées contre la crue (Louis-Ferdinand Céline, Voyage au bout de la nuit) 
1949 Ils descendirent.

- Allez derrière, dit le type à Sarah. Et poussez dur

(Jean-Paul Sartre, La Mort dans l'âme)

\section{CORPUS WEB :}

J'avais les cheveux longs jjsq'ua récemment où je suis allé chez le coiffeurs qui m’a coupé 2 $\mathrm{cm}$ sachant que ils était au niveaux de la poitrine là j'ai plus rien ! ils ont mit 4 mois pour pousser dur ! [http://www.dieu-crea-la-femme. com/2013/11/22/jai-decide-de-laisser-poussermes-cheveux/] (15.10.2015)

Ce matin, nous avons décidé de courir avec des pneus à gomme dure, mais malheureusement, dans les parties plus sèches de l'étape où nous aurions pu reprendre l'avantage, nous avons ramassé une crevaison et nous n'avons pas pu pousser dur [https://motorsport.hyundai. com/fr/news/view/5995] (15.10.2015)

« Les pousser dur »... C'était un peu sévère, mais les résultats étaient là. Et puis, en demandant à Férosinge d'enchaîner un troisième duel, le challenger faisait de même, après tout [http:// www.pkmn-wrld.com/t9621p15-libre-king-kunta] (15.10.2015)

Remarques : Pousser dur se dit d'une personne ou d'un objet (ici : l'eau) exerçant une pression physique d'une grande force et provoquant ainsi un déplacement d'un corps, le faisant rouler, glisser, basculer ou pivoter. Dans le premier exemple du CW, il signifie 'croître' par rapport aux cheveux. On peut également pousser une voiture, voire son moteur, où pousser des personnes pour les encourager, notamment dans le sport. Dur reste invariable (v. le dernier exemple du $\mathrm{CW}$ ).

\section{Pousser haut}

I. Pousser, faire aller jusqu'à un degré élevé Transitif

1572 Ton sang versé par armes vangera, Et nul des tiens chargé de tant de proye Ne doit pousser si haut le nom de Troye (Pierre de Ronsard, La Franciade, p. 226)

1755 Le desir d'avoir de beaux hommes pendant la paix ayant porté les officiers à pousser fort haut à l'envi le taux des engagemens, on fit une ordonnance qui les bornoit à dix écus (Victor de Mirabeau, L'Ami des hommes ou Traité de la population)
1824 il voyoit dans l'avenir que M. de Secq, inconnu comme maître d'école, cachant sa vie passée avec soin, maire de Durantal, et riche de dix mille livres de rente, seroit à Valence et dans le pays une espèce de personnage, et qui sait si les circonstances ne le pousseroient pas plus haut ! (Honoré de Balzac, Annette et le criminel)

1829 Vous jugez bien que Locke, qui, dans son exil avait été comme le chef intellectuel de tous les persécutés, reçut à Londres, en 1689, l'accueil le plus honorable ; le roi Guillaume lui accorda toute sa confiance ; et si sa santé, et peut-être la modestie de ses goûts, ne s'y fussent opposées, Locke eût pu pousser très haut sa fortune politique (Victor Cousin, Cours de l'histoire de la philosophie)

1861 Comme un homme monté trop haut, pris de panique,

S'écria, transporté d'un orgueil satanique : « Jésus, petit Jésus ! je t’ai poussé bien haut!

Mais, si j'avais voulu t'attaquer au défaut De l'armure, ta honte égalerait ta gloire, Et tu ne serais plus qu'un fœetus

dérisoire!»

(Charles Baudelaire, Les Fleurs du mal)

1874 De dix ans à trente ans, le prince Dakkar, supérieurement doué, grand de cœur et d'esprit, s'instruisit en toutes choses, et dans les sciences, dans les lettres, dans les arts il poussa ses études haut et loin (Jules Verne, L'̂lle mystérieuse)

1961 LA MÈRE. J'ai assisté au début de ta mort. Ces dames...

WARDA. (l'interrompant)

Non. (Un temps) Je me suis offert la mort de mon choix. Comme tout, dans ma vie, aurait été choisi s'il n’y avait pas eu cette stupide mélasse où je me suis retrouvée retroussée, mes jupons d'or décousus, mes épingles tordues, mes os ébréchés, mes clavicules déviées... Mais ma mort elle est bien de moi. J'ai poussé si haut la perfection de mon art... (Jean Genet, Les Paravents) 
II. Faire atteindre un niveau social élevé Transitif

1858 Cependant la figure intéressante et les modestes manières de Mario furent remarquées : on fit bon accueil aux beaux messieurs dans quelques maisons distinguées, on ne leur parla pas de les pousser plus haut; et, de fait, ils ne souhaitaient ni l'un ni l'autre bien vivement de se rapprocher du pâle soleil de Louis XIII (George Sand, Les Beaux Messieurs de Bois-Doré)

1884 D’autres projets l'occupaient, des projets confus d'avenir, des places à Caen, des ouvrages destinés à le pousser très haut. Mais il ne faisait toujours aucune démarche sérieuse, il retombait dans une oisiveté qui l'aigrissait, moins fort, moins courageux à chaque heure (Émile Zola, La Joie de vivre)

III. Monter, atteindre un degré très élevé Intransitif

1905 C'est [= Perséphone] une graine tombée dans une terre déjà riche, mais une graine d'une nature à pousser haute et droite. Son apparition sur le sommet du Hohenbourg causa une surprise (Maurice Barrès, $A u$ service de l'Allemagne)

1945 Sa mauvaise humeur poussa haut - une flamme sous un coup de vent - il venait de constater que le Dubonnet du lieutenant était du vrai, et non un jus sacchariné si peu différent du vin de mai préparé par la Marie (Jean-Louis Bory, Mon village à l'heure allemande)

1963 Une certaine rage possède Cécile, une de ces rages à profondes racines qui poussent haut comme des platanes dès qu'on ne les brime plus (Renée Massip, La Bête quaternaire)

IV. Pousser (un cri) d'une voix forte

Transitif

+1963 Culbutant dans le tapis qu'on roule, trébuchant sur les paillassons, leur farandole se noue et se dénoue aux hasards des pirouettes et des gifles. Ils poussent haut leurs cris et crèvent leurs culottes. Voici maintenant qu'ils cherchent à mimer les besognes classiques (Antoine Blondin, $M a$ vie entre les lignes [1963-1970])

CORPUS WEB :

Si vous plantez les cléomes sur un parterre avec d'autres fleurs, plantez-les plutôt à l'arrière, car elles ont tendance à pousser haut [http:// fr.wikihow.com/faire-pousser-des-cl\%C3\%A9 omes] (15.10.2015)

Je t'aime si fort j'aimerais pousser haut ce cri, mais je te l'écris ! [https://www.facebook.com/ mckrismaticofficiel/posts/523823544330996] (15.10.2015)

Sauf rares exceptions, le bouche à oreille ne suffit plus pour promouvoir une app et la pousser haut dans les Tops, et même une mise en avant Apple seule aura du mal à faire atteindre une position élevée [http://www.viuz.com/2015/01/20/ appstores-comment-ne-pas-etre-invisible-pargregoire-mercier-mobinlife/] (15.10.2015)

$\mathrm{Tu}$ peux, faire une reprog, sans problème, mais avec une bva attention à pas dépasser les $420 \mathrm{Nm}$ qui donne un peu plus de 200cv... Donc faut juste pas trop la pousser haute [http://www. forum-206s16.com/forum/viewtopic.php? $\mathrm{p}=876$ $572 \& \operatorname{sid}=48759 \mathrm{bc} 1 \mathrm{cf} 67 \mathrm{~b} 7 \mathrm{~cd} 878 \mathrm{~b} 64 \mathrm{c} 7 \mathrm{da} 2 \mathrm{c0f30}]$ (15.10.2015)

Remarques : Pousser haut se dit du fait d'engager, d'inciter vivement quelqu'un à s'élever (I), aussi dans la hiérarchie sociale (II) ou faire s'élever quelque chose (la fortune, l'art). Sous (III), le sujet est un sentiment, un état qui croît, grandit, pouvant être comparé à un végétal poussant haut (pour ce sens concret, voir également le premier exemple du CW). Dans (IV), haut adopte son acception acoustique dénotant une voix forte. Haut reste invariable dans la majorité des cas, comme dans le troisième exemple du CW, mais il s'accorde avec l'objet au féminin dans le dernier exemple du CW, à comparer avec celui de 1905. Notons les collocations pousser haut et loin / haut et droit. Haut est modifié par bien, fort, plus, si, très, trop. 


\section{Pousser profond}

S'établir, s'ancrer profondément, de manière profonde et durable

Transitif

1956 Si le Stalinisme en effet s'était limité à une tyrannie, le mal n'aurait pas poussé de racines aussi profond (France observateur, 5 juin 1956 / Grundt : 291)

CORPuS WeB :

En fait je me caressais l'anus avec une bille comme ça pour me détendre, j'étais à mon bureau, je le faisais sans trop y réfléchir puis mon père a ouvert la porte donc je me suis rassis à toute vitesse et la bille est rentrée profondément dans mon cul. Il m'a parlé pendant une heure ce con et j'avais l'anus en feu, puis quand il est partit j'ai essayé de la retirer avec mes doigts mais plus j'essaye plus je la pousse profond [http:// www.jeuxvideo.com/forums/1-50-121065719-1-01-0-je-me-suis-coince-une-bille-dans-le-cul.htm] (15.10.2015)

Hahahaha un cashback.fr tu nous avais pas tout dit... ben tu peux te le pousser profond, parce que sans compte en France et sans adresse en France t'aura que dalle... [https://forum.adsl-bc. org/viewtopic.php?f=26\&t=89409] (15.10.2015)

Pire tu demandes les sources comme la licence qu'ils utilisent le permet. Réponse en gros : "Tu peux te les pousser profond les sources" [https://twitter.com/iooner/status/567630972892 749824] (15.10.2015)

REMARQUES : Au sens propre ou figuré, pousser profond désigne le fait de faire croître, ancrer (ses racines) profondément, s'enraciner fortement, de façon à vivre longtemps et d'éviter d'être détruit, anéanti (dans un emploi métaphorique). Le sens propre est illustré davantage dans le premier exemple du CW : 'introduire quelque chose profondément dans un trou' (ici : une bille dans l'anus). Cette image est le point de départ de l'expression métaphorique tu peux te le pousser profond qui désigne l'inutilité d'une action. Profond reste invariable et est modifié par aussi.

\section{Pousser raide}

Pousser fermement jusqu'à une certaine limite ; inciter, engager avec force

Transitif

1851 MERCADET. C'est possible ... ah ! maître Pierquin, nous allons reprendre les affaires ... je vous vois, d'ici la fin de l'année, 100,000 fr. de courtage chez nous. PIERQUIN. 100,000 francs ! ...

MERCADET. Poussez raide la baisse à la petite bourse, achetez ensuite, et... (Lui donnant une lettre) faites insérer cette lettre dans le journal du soir... ce soir à Tortoni, il y aura déjà vingt pour cents de hausse (Honoré de Balzac, Mercadet)

1997 Stephen le héros au gilet brodé maintes fois entrevu depuis lors à travers les rideaux de la fenêtre familiale, Edipe roi en souliers de tennis poussant raide devant lui sa canne blanche sur le trottoir d'en face (Louis-René Des Forêts, Ostinato)

\section{Pratiquer fort}

Pratiquer beaucoup

Transitif

1953 le talon de l'un s'emboîte sous la cheville de l'autre. Le XviII ${ }^{\mathrm{e}}$ siècle, qui la nommait aussi emboîture, aimait et pratiquait fort cette position ; c'était la position préférée des danseurs ; « elle est, dit Compan, une des plus nécessaires pour bien danser » (Maurice Brillant, Problèmes de la danse)

\section{CORPUS WEB :}

On continue à pratiquer fort tous les jours. Notre All-Star, Tony Naaman, a mentionné aujourd'hui « On se sent bien, on est prêt pour une nouvelle saison et on haït PAYCERS BASEBALL » [https://fr-ca.facebook.com/MsieursBaseball/ posts/421635171267869] (19.10.2015)

La tentation est toujours présente de commencer à pratiquer fort, plus vite et plus intensément que votre technique ne le permet. Ne cédez pas. Entrainez-vous correctement de sorte que vous apprenez vraiment comment faire les techniques et à maîtriser votre art [https://surlespas demars.wordpress.com/2014/07/25/bien-sen trainer-est-different-de-sentrainer-durement/] (19.10.2015) 
Elle va pratiquer fort la chanson des « Loups marins » [https://fr-fr.facebook.com/arthurlaven turier/posts/406815946013068] (19.10.2015)

REMARQUeS : Pratiquer fort désigne le fait d'exercer avec fréquence et assiduité une activité. Fort est un intensifieur qui reste invariable.

\section{Prêcher haut et fort}

Prêcher quelque chose publiquement, ouvertement, franchement

Transitif

1992 Il prêchait haut et fort l'égalité de tous devant la nature (Danielle Elisseeff, Les Dames du Soleil-Levant : Japonaises d'hier et d'aujourd'hui)

2010 En effet, les élites sociales qui prêchaient haut et fort la moralité et condamnaient en public la prostitution, l'appréciaient fort dans leur vie priveé (Jean-Paul Martineaud, L'Amour au temps de la vérole)

Intransitif

2006 Les prêtres prêchaient haut et fort, rudoyaient les contradicteurs et les indécis (Christiane Keller et Patrick Cloux, Présences romanes en Auvergne, Bourbonnais, Velay)

\section{CoRpus Web :}

Ces gens là, ce sont ceux qui se disent êtres « enfants nés de DIEU, né de l'ESPRIT », mais prêchent et enseignent haut et fort, qu'ils sont toujours des pécheurs esclaves de leurs péchés, mais quand même sauvés! [http://www.congo page.com/forums/viewtopic.php?f=22\&t=8905\& view=next] (19.3.2015)

\section{Précipiter bas}

Faire sombrer dans le désespoir, dans l'indignité, dans la bassesse ; détruire, réduire à néant

Transitif

1619 Pour cela, chere Philothee, vous aves besoin de reiterer et repeter fort souvent les bons propos que vous aves fait de servir Dieu, de peur que, ne le faysant pas, vous ne retombiés en vostre premier estat, ou plutost en un estat beaucoup pire ; car les cheutes spirituelles ont cela de propre, qu'elles nous precipitent tous-jours plus bas que n'estoit l'estat duquel nous estions montés en haut a la devotion (Saint François de Sales, Introduction à la vie dévote)

1648 LE DUC DE CURLANDE. (favory) Que m'avez-vous produit indiscrettes pensees, Temeraires desirs, passions inscensees? Efforts d'un cœur mortel, pour d'immortels appas, Qu'on a d'un vol si haut, precipitees si bas (Jean de Rotrou, Venceslas)

\section{CORPUS WEB :}

Quarante années de combat risquent d'être précipitées bas en quelques heures si des freins ne sont pas mis de part et d'autre à la passion, à l'orgueil, à la colère... [http://www.leforumcatho lique.org/message.php?num=637752] (19.10.2015)

Que se passe-t-il donc ? Quelques capitaines parachutistes menant la troupe, nostalgiques de Franco, sont sortis des casernes et foncent sur le Parlement ? Les Pyrénées se dérobent sous leur socle et se précipitent bas menaçant des milliers, des millions de vies ? [http://blogs.mediapart. $\mathrm{fr} / \mathrm{blog} /$ jean-philippe-veytizoux/051210/le-frontde-gauche-un-probleme-pour-gagner-en-2012ah-bon] (19.10.2015)

REMARQUES : Au sens figuré, précipiter bas se dit du fait de faire déchoir quelqu'un, le rabaisser, le ramener brutalement d'une position éminente à une position inférieure, le laissant dans le désespoir, voire l'anéantir ; si l'objet est un inanimé (ici : les efforts), il signifie 'abolir, détruire'. Bas reste invariable et est modifié par toujours plus, si.

\section{Prédire juste}

Prévoir, annoncer (une chose à venir) avec justesse, avec exactitude

Emploi absolu

1672 j'estime qu'il ne sera pas inutile pour un plus grand éclaircissement, de donner des regles generales et particulieres du Prognostic, comme la plus belle partie de la Medecine ; parce qu'on est d'ordinaire plus estimé pour prédire juste que pour guerir (Jean-Baptiste Fayol, L'Harmonie celeste) 
1817 Le reste des aristocrates n'adressait que des injures au parti populaire, et, ne transigeant jamais avec les circonstances, ils croyaient faire le bien en aggravant le mal ; tout occupés de justifier leur réputation de prophètes, ils désiraient leur propre malheur, pour jouir de la satisfaction d'avoir prédit juste (Germaine de Staël, Considérations sur les principaux événements de la Révolution française)

1832 OLIVIER. Et ces femmes du peuple ont souvent prédit juste

(Casimir Delavigne, Louis XI)

1869 Pour apaiser un peu cette soif d'avoir toujours prédit juste en politique, il devrait avoir derrière lui, comme l'antique Gracchus, son joueur de flûte qui lui chanterait à mi-voix son Hymne au duc de Bordeaux, qu'il a tant oublié (Charles SainteBeuve, Pensées et maximes)

Transitif

1696 ce soir, quand le soleil se couchera, vous aurez la teste plus libre ; vostrep ouls indique des douleurs dans le bas ventre ; assurement vous avez mangé d'une telle viande : cette incommodité durera cinq jours, aprés quoy elle cessera ; et ainsi des autres symptomes de la maladie qu'ils découvrent, ou qu'ils prédisent assez juste, quand ils sont habiles; car pour les autres ce sont ordinairement de faux prophetes (Louis Le Comte, Nouveaux Mémoires sur l'état présent de la Chine)

1731 D'autres vouloient qu'il n'y eut que la politique dans leurs entrevûes, et prédisoient déja fort juste le traité qui fut conclu peu après entre la France et l'Angleterre contre la Hollande (abbé Prévost, Le Philosophe anglois)

1738 Mais ne devois-je pas m'arrêter dans l'isle de Madère, et me rendre aux conseils de Gelin, qui ne m'a prédit que trop juste le cruel châtiment de mon obstination ? (abbé Prévost, Le Philosophe anglois)

CORpus WeB :

L'important pour Target était de prédire juste la plupart du temps, et non forcément dans tous les cas [https://www.priv.gc.ca/media/spd/2014/sp-d_20141017_pk_f.asp] (19.10.2015)

Bien sûr, il avait une chance sur deux de prédire juste, mais une telle série de prédictions exactes, depuis le début de la Coupe, fait de l'animal le héros de la soirée [http://agglobuzz. blogs.com/bloc_notes/2010/07/derni\%C3\%A8reheure-paullepoulpe-a-pr\%C3\%A9dit-juste-.html] (19.10.2015)

Parvenir à prédire un résultat lorsqu'on a une chance sur deux, c'est extraordinaire? :-

Et ne me rabâchez pas qu'il avait une chance sur 128 de prédire juste les résultats des cinq matches, c'est faux [http://www.jeuxvideo.com/ forums/1-50-49543462-1-0-1-0-jerry-de-ceux-quicroient-que-paul-le-po.htm] (19.10.2015)

Les mêmes que combattirent, derrière Buber et Magnes, les sionistes pacifiques qui avaient, hélas, prédit justes ; eux qui, réalistement, ne voulaient pas de deux états [http:// blogs.mediapart.fr/blog/kakadoundiaye/250613/ joyeux-enfants-de-palestine] (19.10.2015)

Remarques : Prédire juste désigne le fait d'annoncer à l'avance un événement avec succès et ce, soit par inspiration naturelle, par voyance ou prémonition, soit par connaissance inductive, rationnelle des causes et des effets. Juste reste invariable dans la majorité des cas. Toutefois, dans le dernier exemple du CW, il s'accorde avec le sujet en gardant son interprétation de manière. Il est modifié par assez, déjà fort, trop. VoIR AUSSI : pressentir juste

\section{Prendre bas}

Affecter viscéralement, au plus profond Transitif

1936 Le premier genre d'opinion, qui est conseil, il faut souvent le mépriser ; l'autre, on ne peut le mépriser. Il nous prend plus bas (Alain, Propos)

\section{CORPUS WEB :}

$\mathrm{x}$ Je suis seul à seul avec l'attaquant : retour à la base « gabarit, vitesse, intervalle ».

x L'attaquant est seul et doit négocier un sousnombre : prendre bas, faire tomber le plus rapidement possible [http://lespetiteshitsoiresdusport. over-blog.net/2014/08/rugby-la-parole-est-ladefense-episode-3.html] (19.10.2015) 
Essaye de la prendre basse avec le P4, en passant bien en dessous de la balle. Si c'était un top rotation, alors tu peux mettre une coupe d'enfer dans la balle! Ceci dit, si l'attaquant est super à l'aise sur défense, alors on a interêt à prendre la balle plus tôt pour ne pas trop subir le jeu [http:// www.tennis-de-table.com/forums/sujet-47153-70. html] (19.10.2015)

Oui je viens de tout larguer sur 13.80 je crains un retour sur 4330 je ne fais plus rien pour l'instant. Je préfére prendre bas, le marché est en mode panique faut prendre les actions à $-10 \%$ en ce moment (lol) ! [http://graphseobourse.fr/lesactions-a-acheter-en-bourse-pour-survivre-aukrach-boursier/] (19.10.2015)

Donc société vache à lait, appelée si les dirigeants continuent à avoir du talent et de la probité a distribuer de bons dividendes en fonction des coups réalises, qui évoluera sûrement en range 0.3/1.2. Il faut la prendre bas, comme ceux qui sont entres à $0.3 / 0.4$ et qui entrent dans le cadre défini par les dirigeants $\mathrm{d}$ actionnaires qui doivent être remerciés [http://www.boursorama. com/forum-opportunity-inv-mgt-certains-seposent-la-question-431253108-1] (19.10.2015)

REMARQUES : Au sens propre, prendre bas se dit du fait de saisir quelqu'un ou quelque chose dans une position basse ou alors dans le bas de son corps. C'est ainsi que le premier exemple du CW renvoie au fait de saisir un adversaire par le bas pour le faire tomber (par exemple au rugby), tandis que le deuxième exemple réfère à la balle qui est prise " basse ». De même, à la bourse, on peut décider d'acheter uniquement quand le cours des actions est bas. Dans l'exemple de 1936, prendre bas réfère à une attaque verbale située à un niveau qui ne permet pas une parade 'intellectuelle'. Bas reste invariable dans la majorité des cas, mais, dans le dernier exemple du CW, il s'accorde avec l'objet au féminin tout en gardant son interprétation d'adverbe de lieu. Il est modifié par plus.

\section{Prendre bon}

Choisir, acheter quelque chose de bon $\lambda$ prendre petit

\section{Prendre cher}

I. Demander beaucoup d'argent ; exiger

beaucoup

Emploi absolu

1847 Je n'ose le confier aux diligences et je n'ai pas d'occasion directe. La poste prendra cher. Vous me retiendrez cela sur la somme (George Sand, Correspondance)

1977 Cette femme travaillait moins bien que maman, et prenait cher (Zoé Oldenbourg, Visages d'un autoportrait)

II. Être sévèrement puni, affecté (par quelque chose) ; coûter cher (au figuré) ; subir les outrages du temps, se détériorer, être amoché Emploi absolu

2019 Alors la miss se la raconte toujours, faut pas rêver, mais c'est comme tout le monde, hein, elle a pris cher avec les années !

(Virginie Duplessy, La Mère parfaite a pris cher!)

2020 ADRIENNE. Holà oui elle a pris cher la vieille dame !

ANATOLE GRASKY. Bon... va donc me chercher ce que je t'ai demandé dans le réfrigérateur ! (Franck Leplus, Remueméninges chez les Grasky)

\section{CORPus WeB :}

Les mêmes disent à présent « on a pris cher ", dans le même sens que dans l'énoncé de Christian Jacob [ " On a quand-même pris cher ces dernières années »] [https://selp.eu/figures/ona-quand-meme-pris-cher-ces-dernieres-annees] (17.7.2019)

[On trouve le commentaire suivant pour cette citation de Christian Jacob :]

Qui s'exprime ainsi dans Libération ? Christian Jacob, chef des députés Les Républicains, cité verbatim. Ironie du sort, c'est un parti conservateur qui adoube là un emploi intensif tout récent de l'adjectif français « cher » : en effet il n'y reconnaît pas que LR a fourni des prestations onéreuses, mais il avoue que dernièrement le parti a dû encaisser de rudes coups (qui l'ont donc écorné, à preuve ses maigres résultats aux dernières élections européennes) [https://selp. eu/tag/extension-semantique] (17.7.2019) 
Kimberose garde un mauvais souvenir de la « Nouvelle Star » : «Mon ego a pris cher » [https:// www.youtube. $\operatorname{com} /$ watch? reload $=9 \& v=n 3-$ d91rGn20] (29.1.2021)

Kev Adams s'est un peu laissé aller ses derniers temps et il a pris cher [= du poids] [https:// www.koreus.com/image/kev-adams-pris-cher. html] (20.2.2021)

\section{Prendre direct}

Prendre directement

$\lambda$ aller direct

\section{Prendre droit}

Prendre son chemin en ligne droite, sans dévier Transitif

1364 Après ce je m’acheminai

Et tout droit prins mon chemin hai,

Pour bien mon voiage assevir,

Et aussi pour ma dame vir (Guillaume de

Machaut, Le Livre du voir dit, 1648)

+1489 Ledit duc, de prime face, fouyt à la bailler, mais, à la fin, la bailla. Maintes pensées avoit jà eu ce puissant homme où il prendroit droit son chemin pour fouyr, car de tout estoit informé et avoit veü le double des séelléz qui avoyent esté bailléz contre luy à Bouvynes (Philippe de Commynes, Mémoires [1489-1498], IV)

1740 Il étoit déjà perdu parmi la foule, et nous ne savions d'ailleurs par quel chemin. Nous primes tout droit celui du palais et de sa maison. Une minute plutôt nous l'eussions encore arrêté (Jacques de Varenne, Mémoires du chevalier de Ravanne)

1996 Où étaient transportés les blessés et... et... les autres? Il n'osa pas encore s'informer. Prit tout droit le cours Liautaud, au lieu de tourner sur la Canebière. Des rumeurs montaient d'un peu partout, sauf, comme exprès, sur son parcours (Boris Schreiber, Un silence d'environ une demi-heure)

Intransitif

1864 Nous avions encore presque tous nos fusils en arrivant sur l'autre rive, et nous prîmes tout droit à travers champs (Émile Erckmann et Alexandre Chatrian, Le Conscrit de 1813)
1958 Quand la nuit était claire et les chemins secs, au retour il quittait Hervouët à l'embranchement du layon sous les grands chênes et le renvoyait à la maison forte ; il prenait droit devant lui par un autre layon qui coupait au plus court à travers une jeune sapinière jusqu'aux Falizes (Julien Gracq, Un balcon en forêt)

1992 Mais, au lieu de suivre le chemin de la grande ville vers laquelle le feu aurait dû nous aspirer, nous prîmes droit au nord, et bientôt nous fîmes route dans le désert d'une campagne qui semblait inhabitée, tant elle était sourde et muette (Julien Gracq, Carnets du grand chemin)

\section{Corpus Web :}

le lait maternel se digère très vite, ce n'est pas comme le LA, il n'y a pas de " délais » à respecter entre deux tétées. tu peux donc lui reproposer très vite si tu as l'impression que c'est ça qu'il a. il a peut-être aussi juste un rot coincé, auquel cas il suffit de le prendre droit contre toi, le ventre au chaud, et d'attendre que ça sorte [http://forum.aufeminin.com/forum/ allaitement/_f65404_allaitement-Je-suis-surle-point-d-arreter-l-allaitement-au-secours.html] (19.10.2015)

Ensuite pour franchir les trains de vagues pour revenir vers le large c'est bien de venir épauler la vague et non la prendre droit [http://www. kayakdemer.eu/forum/archive/index.php/t-7236. html] (19.10.2015)

Sur certains hips, la pente de réception n'est taillée que d'un côté, sur d'autres il est possible de choisir son sens de réception. Parfois, une réception est également taillée en bout de hip, ce qui permet de le prendre droit, à la manière d'un big air (à la différence que le kick est très vertical et que le saut doit donc être particulièrement haut pour passer la table). On dit alors que le hip est pris en transfert [http://www.cybervalloire. com/forums/index.php/topic/2517-le-freestyleet-vous/] (19.10.2015)

La meilleure façon de redresser une image est de la prendre droite et la meilleure façon de nettoyer l'image est de la prendre propre. Penser à nettoyer aussi le cache de l'objectif de temps en temps [http://johnsmithimages.net/tutoriels_ photoshop/penchee/penchee.html] (19.10.2015) 
REMARQues : Prendre droit se dit d'une route, d'un chemin, que le sujet prend, suit tout droit, sans en dévier. En emploi intransitif, il est suivi d'une préposition et désigne le fait de suivre une certaine direction en avançant tout droit, sans faire de détour. Le CW illustre la transposition de prendre droit à d'autres domaines. Droit reste invariable dans cette fonction adverbiale (v. aussi le deuxième exemple du $\mathrm{CW}$ ). Dans le troisième et le quatrième exemple du $\mathrm{CW}$, il se rapproche d'un prédicat second orienté vers l'objet, s'accordant dans le quatrième avec l'objet au féminin. Il est modifié par tout. Notons aussi l'emploi de couper au plus court 'prendre le chemin le plus direct, un raccourci'. Dans le dernier exemple, prendre propre signifie 'prendre une image proprement, sans défaut'.

\section{Prendre facile}

Durer, passer au moins, pour le moins, facilement (+ indication de temps)

Transitif

1983 On s'annonce les nouvelles : - Eh ! Maxou est béton ! - Oh !... - Il a fait une bijouterie... Ils l'ont chopé aux Alouettes. - Il va prendre facile une pige ! - James... tu te souviens de James, celui qui boitait? (Medhi Charef, Le Thé au harem d'Archi Ahmed)

\section{CORPUS Web :}

Toute la collection est superbe par contre mieux vaut vous y prendre facile 1 an à l'avance si vous voulez avoir l'honneur de porter une de ses créations. Je me suis vu refuser une commande il y a de cela 9mois avc une immense déception. Victime de son succès apparemment [http:// www.unbeaujour.fr/blog-mariage/laure-desagazan-2/] (19.10.2015)

Et le jour où je me décide enfin à m'occuper de toute cette paperasse, ça peut prendre facile une demi-journée [http://objectifdin.fr/pourbien-gerer-son-courrier/] (19.10.2015)

Parle pas de malheur, trop longtemps qu'on attend, je veux jouer au jeu le plus rapidement, déjà que l'installation va prendre facile $15 \mathrm{mi}$ nutes sur cette console [http://www.xbox-gamer. net/news-xbox-360-the-witcher-3-montre-sesmonstres-et-prepare-le-patch_38645.html] (19.10.2015)
Sa longe et son licol étaient accrochés sur un petit portique à l'extérieur du box, je pouvais donc les prendre faciles sans ouvrir le loquet [http://sea-sugar-sd.forumactif.pro/t758-noelyao-marcher-sur-l-eau-eviter-les-peages-jamaissouffrir-juste-faire-hennir-les-chevaux-duplaisir] (19.10.2015)

REMARQUES : Dans un contexte familier, prendre facile se dit du fait d'écoper une année de prison ('une pige'), facile précédent une quantité minimum (= au moins). Il est généralement suivi d'une indication de temps, référant à la durée minimale de quelque chose. Dans le dernier exemple du CW, il désigne le fait d'enlever quelque chose sans difficulté. Facile reste invariable dans la majorité des cas, mais, dans le dernier exemple du CW, il s'accorde avec l'objet tout en gardant son interprétation adverbiale. Observons qu'à l'exception du dernier exemple, facile n'est pas un simple adverbe de manière qui modifie le verbe, mais un adverbe énonciatif qui exprime l'opinion subjective de celui qui parle : ça prend facile une journée 'j'estime que cela va prendre au moins une journée'. Facilement peut se substituer à facile dans tous les exemples.

\section{Prendre ferme}

I. S'accrocher

Pronominal

1689 ils [= les caméléons] peuvent se prendre ferme par la queuë, et soûtenir et relever tout leur corps (George Wheler, Voyage de Dalmatie, de Grèce et du Levant)

\section{Souscrire définitivement}

Emploi absolu

1740 Que nul noble ou Officier du Roi par lui ou par personnes interposées, puisse prendre ferme ni faire trafic de marchandise (Recueil des actes, titres et memoires concernant les affaires du clergé de France)

Transitif

1889 Son frère Louis-Napoléon avait eu l'honneur de mener à bien la souscription au grand emprunt sibérien, pris ferme par la maison Nathan et Salcedo, couvert cinquante-quatre fois (Eugène Vogüé, Les Morts qui parlent) 
1939 Il faut savoir acheter les quantités nécessaires pour obtenir les conditions les meilleures, sans charger la trésorerie, sans encombrer les rayons. Tel ouvrage est à prendre ferme, tel autre en compte-dépôt (La Civilisation écrite)

REMARQUes : Prendre ferme (I) actualise le sens concret de s'accrocher, de se fixer fermement. Prendre ferme (II) est employé dans les domaines commercial, financier et boursier pour renvoyer à un contrat ou compromis qui est définitif et juridiquement valable. Nous le citons comme représentant d'une série qui comprend aussi les verbes accepter, parier, ponter, vendre. VoIR AUSSI : acheter / ponter / vendre ferme

\section{Prendre haut}

I. le prendre haut : réagir en répondant avec arrogance ou avec dédain ; situer un problème à un niveau supérieur

Transitif

1582 AYMON. Et moy je maintiendray contre eux et contre toy,

Qu'on n'a peu disposer de ma fille sans moy.

Non non, je ne vous crains, presentez vous tous quatre,

Je ne veux que moy seul pour vous aller combatre :

Encor que je sois vieil j’ay du cœur ce qu'il faut

Et de la force aussi.

RENAUD. Vous le prenez trop haut.

AYMON. Page, çà mon harnois, mon grand cheval de guerre,

Apporte moy ma lance avec mon cimeterre (Robert Garnier, Bradamante)

1630 Partant il fait de son ame comme de son corps : il est Papiste pour la reputation, il est Huguenot pour la guerison de son ame. Maistre Gervais, philosophe de Magné, le prend plus haut, car sans paradoxe il maintient que toutes les guerres ne sont nees qu'à faute de grammaire (Théodore Agrippa d'Aubigné, Confession catholique du sieur de Sancy)

1713 Mais quel est votre mari pour vous le faire prendre si haut? Ces paroles la jettérent dans un désordre qui ne se peut exprimer. Je suis encore Fille, madame, poursuivit-elle, d'une [sic] air fort embarrassé (Robert Challe, Les Illustres Françoises)

1775 BARTHOLO. Dites que vous la supporterez, monsieur !

FIGARO. Comme il vous plaira, monsieur ! BARTHOLO. Vous le prenez bien haut, monsieur! Sachez que quand je dispute avec un fat, je ne lui cède jamais.

FIGARO. (lui tourne le dos)

Nous différons en cela, monsieur ! moi je lui cède toujours (Pierre-Augustin de Beaumarchais, Le Barbier de Séville)

1823 J'entrepris un jour, disait-il, à une de mes audiences publiques, le charlatan Puységur, sur sa somnambule. Il voulut le prendre très haut ; je le terrassai par ces seuls mots : si elle est si savante, qu'elle nous dise quelque chose de neuf (Emmanuel de Las Cases, Le Mémorial de Sainte-Hélène)

1833 RANTZAU. Dansez-vous avec elle ?... les quadrilles sont-ils de votre composition? GOELHER. Je saurai ce que signifie ce persifflage.

RANTZAU. Vous m'accusiez de le prendre trop haut !... je descends ; je me mets à votre portée

(Eugène Scribe, Bertrand et Raton)

1843 Je voulus m'en défendre, et comme il le prenait un peu haut avec moi, je commençai à me fâcher, lorsqu'il me prédit avec véhémence que je me remarierais, et que mon second mari périrait par ma faute, encore plus misérablement que le premier, mais que j'en serais bien punie par mes remords et par la réprobation publique (George Sand, La Comtesse de Rudolstadt)

1865 - Eh bien, moi, je n’ai jamais été refusé, voilà la différence !

- Ah ! tu prends ça bien haut, je trouve, et je commence à croire que Rébecca... je veux dire mademoiselle Nunez, t'avait bien jugé, car j’ai eu maille à partir l'autre jour avec elle à ton sujet (George Sand, Monsieur Sylvestre) 
1936 J'offre ainsi à l'autre justement ce que je m'étonne de trouver en lui, un homme, c'est-à-dire un animal qui a charge d'esprit, que l'on prend toujours trop haut, et puis trop bas, qui ne peut faire un signe sans en faire dix, bien plutôt qui fait signe de toute sa personne, sans pouvoir choisir (Alain, Propos)

II. Commencer (à chanter) dans un ton trop haut Emploi absolu

1751 Peut-être ai-je fait à son égard ce qui m’arrive quelquefois en chantant, de prendre trop haut de quelques tons, et de continuer néanmoins, plutôt que de recommencer, quoique ma voix soit obligée de se contraindre (abbé Prévost, Lettres angloises [trad.])

1835 Vous l'avez pris trop haut en commençant [= la musique, par rapport au ton]

(Dictionnaire de l'Académie française, s.v. haut [adv.])

190314 juillet.

La petite Marianne chante, d'une voix aiguë : «Palerme, perle de la Sicile ! » On s'accorde à dire qu'il n'y en a pas dix sur cent qui pourraient monter aussi haut qu'elle. Ils chantent et prennent toujours trop haut ou trop bas (Jules Renard, Journal)

III. s'en prendre tout haut à quelqu'un : s'attaquer ouvertement, publiquement à quelqu'un (en le rendant responsable de ce qui arrive)

Pronominal

1852 Mais l'impossibilité de garder une certaine prudence pendant quelques jours quand il s'agit de venir consoler ta femme et tes enfants, la nécessité absolue de t'en prendre tout haut à certains hommes de ce qui est l'ouvrage fatal de tous, ne me paraissent nullement démontrées (George Sand, Correspondance)

\section{CORPUS WEB :}

Quand les portugais ils prennent haut l'Allemagne, les allemands ils savent plus quoi faire [https://twitter.com/hugo95210956/status/4785 72268147453952] (14.10.2015)
« On a vu contre le pays de Galles (victoire 26-19) qu'ils sont capables de vous démonter à chaque plaquage », souligne Dimitri Szarzewski. "Ils prennent haut et sans subir, ce sont des plaquages impressionnants. Il ne faut pas les prendre parce que ça secoue ! » prévient Yannick Nyanga [http://rmcsport.bfmtv.com/rugby/xvfrance-ne-pas-gacher-face-aux-samoa-389968. html] (14.10.2015)

Ils ramènent 23 points et se classent à la $8^{\mathrm{e}}$ place de la journée, dans une compétition toujours âprement disputée. Ils permettent également à Skol gouren Mein Zao de se classer à la $7^{\mathrm{e}}$ place de la Coupe des Skolioù sur un total de 33 clubs, et prennent haut la main la première place du Sud-Finistère [http://www.ouest-france. fr/le-skol-gouren-mein-zao-dans-le-haut-detableau-2135764] (14.10.2015)

Remarques : Prendre haut (I) signifie 'interpréter un propos comme une attaque contre sa personne et réagir souvent vivement, avec susceptibilité' ; le sujet considérant avoir été traité avec condescendance, voire avec mépris, il répond à son interlocuteur avec arrogance ou dédain. En musique (II), se dit d'un ton, d'une note que l'on prend un ton trop haut, faussant par ce fait la suite du chant. (III) désigne le fait d'attaquer quelqu'un par la parole et ce, à voix haute ou publiquement, de façon à faire connaître à beaucoup de monde l'objet de son mécontentement voire de sa colère. Notons l'opposition avec prendre bas dans les exemples de 1903 et 1936. Notons également la collocation haut la main 'sans la moindre difficulté' dans le dernier exemple du CW. L'exemple de 1835 ne figure plus dans les éditions récentes du Dictionnaire de l'Académie française. Haut reste invariable et est modifié par bien, plus, si, toujours trop, tout, très, trop, un peu.

\section{Prendre large}

I. Prendre en grande quantité, plus que nécessaire

Transitif

1922 Notamment une sorte de guet-apens, vers Tirevache, où le Plampougnis faillit laisser sa peau. Il revint Mais cinq jours plus tard, lui, Gaspard et un autre allèrent prendre leur vengeance dans une maison de mau- 
vais renom au Pont du Merle. On dit qu'ils la prirent large. Quelques mois après qu'il eut amené les Grange aux Escures, Gaspard pensait, autant qu'on peut le penser, que nul vrai mal ne pouvait leur venir de personne dans le pays (Henri Pourrat, $L e$ Château des sept portes ou Les Enfances de Gaspard)

II. Coudre plus loin du bord du tissu Emploi absolu

1959a En refaisant ces coutures, il faudra prendre plus large, aussi large que possible (Exemple entendu, 6 mars 1959 / Grundt : 307)

III. Prendre (un virage) en décrivant une grande courbe

1959b Prends large ton virage à cause des piétons (Exemple entendu, 9 avril 1959 / Grundt : 307)

\section{CORPUS WEB :}

Plus tu serres, plus tu prends dans les triceps. Plus tu élargies, plus tu prends dans les pecs, et plus ton épaule est en danger. à trop élargir, ça fini par toucher l'extérieur des pecs, go $5 \mathrm{~cm}$ avant la ligne des $88 \mathrm{~cm}$. Oui enfin, prendre large, dans la limite du raisonnable, il m’a semblé inutile de préciser que ce n'était pas la peine d'avoir les bras à $2 \mathrm{~m}$ l'un de l'autre :s [http://www.jeux video.com/forums/42-78-40758601-1-0-1-0-audeveloppe-couche-faut-prendre-la-barre-a-quelgrip.htm] (14.10.2015)

Ma planche en balsa (2M75) est un vrai bonheur à surfer...elle est présentée dans les petites photos en haut du shaperoom, en cours de construction...et dans les planches des membres, post qui ne fonctionne plus. Un vrai bonheur dû à son poids, que j'estime proche des $25 \mathrm{KGS}$; les courbes se prennent larges et la planche une fois lancée ne s'arrête plus, ce qui permet de passer des sections plus molles...voilà pour une première contribution [http://www.shaperoom.net/ forum/viewtopic.php?f=7\&t=4196] (14.10.2015)

Les camions sont d'ailleurs moins dangereux que les bus quand ils doublent ils prennent larges [http://delaloireaudanube.blogspot.co.at/ 2010/08/les-portes-de-fer.html] (14.10.2015)
REMARQUES : L'objet direct de prendre large (I) est une vengeance excessive que le sujet prend, c'està-dire que le tort qu'il cause est plus grand que celui qu'il avait subi. Dans le domaine de la couture (II), coudre plus loin du bord du tissu. (III) se dit du fait d'aborder (une courbe, un virage) largement, loin du bord de la route, éventuellement pour éviter un quelconque obstacle. Dans le dernier exemple du CW, prendre large réfère à la distance que les camions ou les bus gardent par rapport aux cyclistes au moment de les doubler. Plus spécifiquement (argots), prendre large est employé de façon très souple par rapport à des contextes plus ou moins sous-entendus qui ne permettent pas toujours une interprétation univoque de la part de locuteurs 'moins branchés'. Large reste invariable dans la majorité des cas, mais, dans les deux derniers exemples du CW, il s'accorde avec le sujet du verbe pronominal à sens passif, dans le premier cas, et avec le sujet du verbe en emploi absolu, dans le second, sans abandonner sa fonction adverbiale. Large est modifié par plus.

\section{Prendre machinal}

Prendre mécaniquement, sans y penser Transitif

1983 Tout en me posant des questions, le patron de toutes ces mignardises funéraires, il me prend machinal le bras... il me le tâte doucement (Alphonse Boudard, Le Café du pauvre)

2004 Je sers les bières mais pour Sélim, je remplis un verre de jus de carottes, celui que les nanas du cours d'aérobic s'offrent à la fin de leur séance. Il le prend machinal, avale sans regarder et me recrache tout sur le zinc du bar (Geneviève Damas, Molly à vélo)

REMARQUeS : Prendre machinal se dit dans le registre familier pour prendre quelque chose sans réfléchir, sans prêter attention. 


\section{Prendre petit}

Prendre quelque chose de petite taille

Emploi absolu

1993 Il faut aussi penser au gâteau. On prendra petit mais bon (Exemple entendu / Noailly 1997a)

REMARQUES : L'expérience communicative du français standard suggère une interprétation que l'on peut associer à la réflexion 'il vaut mieux prendre petit et bon que gros et mauvais'. Cependant, du point de vue logique, petit pourrait avoir conservé son ancienne fonction de quantifieur signifiant 'peu'. On lira alors 'prendre peu mais bon' (à comparer avec l'attestation de boire petit 'boire peu', de 2014, s.v.).

\section{Prendre profond}

Prendre profondément, en profondeur

Emploi absolu

1959 Prends profond quand tu te sers de compote (Exemple entendu, 1 mai 1959 / Grundt : 290)

\section{CORPuS WEB :}

Prendre profond dans un gros cul - 40:51 minutes

Categorie : Anal, Jeunes filles PornoTags : le sexe anal, gros cul, fille baise, chevauche, cowgirl, levrette, levrette [http://www.pornodingue. com/videos/prendre-profond-dans-un-gros-cul]

Tokyo bombasse prendre profond et dur dans un gangbang fou [http://fr.justporno. tv/1/4261879/tokyo_bombasse_prendre_ profond_et_dur_dans_un_gangbang_fou] (14.10.2015)

blonde prise profond par un chien - blonde poilue plein sperme [http://fr.pornincorporated. org/31159-blonde-prise-profond-par-un-chien] (14.10.2015)\#

Une mamie à gros seins se la prend profond [http://www.videosdevieilles.com/video/unemamie-a-gros-seins-se-la-prend-profond-2430. html] (14.10.2015)

REMARQues : Prendre profond désigne le fait de saisir quelque chose en profondeur, le sujet devant plonger un instrument profondément dans un récipient, en l'occurrence pour prendre des fruits cuits. Les exemples du CW illustrent l'emploi dans le domaine sexuel, référant à une péné- tration en profondeur. Profond reste invariable. Notons la collocation profond et dur.

\section{Prendre propre}

Prendre sans défaut, proprement

入 prendre droit

\section{Prenez simple}

Choisir, acheter quelque chose de simple

入 prendre solide

\section{Prendre soef (suave)}

Prendre délicatement, avec douceur Transitif

+1200 A tant les vist Jos[ian[ si est en[con]tre alez, le roi la prent entre ses bras suef (Bueve de Hanstone [début XIII'], 3093)

-1334 Le Beau Chevalier au Lyon

Qui de soi ne fet mention

Est venus pres de la fontainne, Sa main leva en haut et sainne La damoiselle doucement. Tout souef par la main le prent, Tout hors la met de la fontainne. Toute hetie et toute sainne (Le Romans de la dame a la lycorne [1 ${ }^{\mathrm{er}}$ tiers XIV $]$, 6533)

CORPUS WEB :

Je t'aime comme une âme

Eternelle, telle une flamme

Vers mon cœur de cristal,

Pour toi qui me prend suave [http://www.affection.org/poeme-type 62657_0_POEME.htm] (14.10.2015)

Remarques : Prendre soef se disait du fait de prendre quelqu'un par la main délicatement, de l'enlacer avec douceur ou de saisir quelque chose doucement, avec soin. Soef est modifié par tout. Disparu du langage commun, suave s'emploie encore dans la poésie.

\section{Prendre solide}

Choisir, acheter quelque chose de solide Emploi absolu

1996 Prenez solide mais simple (Cosmo / Noailly 1997a) 


\section{Préparer douloureux}

Se préparer en causant une douleur

入 préparer long

Préparer droit

Préparer bien (la terre), préparer comme il faut

$\lambda$ labourer droit

\section{Préparer long}

en préparer long : bien préparer, préparer

beaucoup

Transitif

190014 janvier.

Il prend du sucre avec sa pince, le met dans son verre, le remet avec la pince dans le sucrier et le reprend avec ses doigts.

- Je n'en ai pas préparé plus long, dit-il. Je vais improviser le reste

(Jules Renard, Journal)

CoRpus Web :

Il y a plusieurs possibilités : des cauchemars (ça arrive, et souvent par périodes), les prémolaires qui se préparent (long et douloureux), phase de peur de la séparation (les enfants vérifient souvent inconsciemment que maman est toujours là... même la nuit) [http://forum. infobebes.com/Mon-bebe/Allaitement-biberonnutrition/nuits-besoin-aide-sujet_136888_1.htm] (12.10.2015)

Remarques : Préparer long désigne le fait de confectionner quelque chose à l'avance, d'accomplir un travail préalable à une tâche déterminée, avec soin, en quantité suffisante. Dans l'exemple du CW, long réfère à la durée. Notons l'adjectif-adverbe douloureux. On peut tout de même penser que long et douloureux ont plutôt le statut d'une incise adjectivale équivalant à ce qui est long et douloureux. En tout cas, l'emplo de long comme adverbe de temps, courant en ancien français, tend à se restreindre en français moderne à des tours ou constructions plus ou moins lexicalisés. Long reste invariable et est modifié par plus.

\section{Pressentir juste}

Prévoir, deviner (une chose à venir) avec exactitude, deviner la vérité Emploi absolu

1845 Or, si Rodin pressentait juste, à en juger par les cordiales apparences de cet émissaire, celui-ci devait être chargé de la plus funeste mission (Eugène Sue, Le Juif errant)

1931 C'était elle, elle qui l'avait saisi, fait basculer soudain au fond d'un panier noir, emprisonné dans cette caque indigne qui puait le lapin de choux. Comme la défiance avait pressenti juste ! Comme on aurait dû l'écouter ! (Maurice Genevoix, Rroû)

1936 C'est parce que les suites d'alexandrins " sentent la prose » (jusqu'à l'assouplissement de Chénier et des romantiques), qu'elles deviennent la forme naturelle, nécessaire et presque unique de la poésie classique. Ronsard avait pressenti juste (Albert Thibaudet, Réflexions sur la littérature)

\section{CORPUS WEB :}

moi j’ai zéro intuition, je suis juste super curieuse et ça m'amuse de voir que ceratines arrivent à " pressentir » juste ! [http://forum. aufeminin.com/forum/matern1/__f429861_ matern1-Qui-connait-le-sexe-de-son-bb-qui-1avait-devine-avant-de-savoir.html] (12.10.2015)

Il ne sait pas à quel point il pressent juste : c'est un abîme qui va s'ouvrir, dans lequel va chuter un pan entier de l'économie mondiale, menant à leur perte les systèmes financiers, les grands groupes, les banques et les millions d'hommes et de femme qui en dépendent [http://salles.cinemasutopia.fr/saintouen/index. php?id=1686\&mode=film] (12.10.2015)

Remarques : Pressentir juste se dit du fait de prévoir quelque chose d'une manière irrationnelle, le sujet se basant sur son intuition, ses sentiments, juste référant au succès du pressentiment, à son exactitude. Juste reste invariable. VoIR AUSSI : prédire juste 


\section{Presser fort}

I. Pousser avec insistance (quelqu'un à faire/ dire quelque chose)

Transitif

1364 Mon tresdoulz cuer, uns clers vint a mi, n'a pas granment, qui me pressoit trop fort que je vous escrisisse, et ne m'aportoit lettres ne vraies ensengnes de vous (Guillaume de Machaut, Le Livre du voir dit, p. 572)

+1489 Toutesfoiz les ambassades des deux roys les pressoient fort de conclure, ou vouloient deppartir, que jà y avoient esté quatre moys (Philippe de Commynes, Mémoires [1489-1498], VII)

1559 Elle, desirant sçavoir ce qu'il vouloit dire, le pressa sy fort qu'il luy confessa qu'il aymoit une dame qu'il pensoit estre la plus vertueuse qui feust en toute la chrestienté (Marguerite d'Angoulême, Heptaméron, p. 238, 18)

II. Tourmenter, accabler

Transitif

+1415 C'est ce qui redresse

En confort, pour voir,

Le mal qui me blesse

Et me fait douloir

Souvent main et soir

Et sy fort me presse

Que, par nonchaloir,

Je laisse manoir

Mon cueur en destresse,

Loings de recevoir

Des biens à largesse

(Charles d'Orléans, Poésies [ 1415-1440],

II, Ballade LIV [variantes et notes], p. 555)

III. Presser, serrer avec force

Transitif

1552 Le lict me semble un dur champ de bataille, Rien ne me plaist, toute chose me nuit, Et ce penser qui me suit et re-suit Presse mon cœur plus fort qu'une tenaille (Pierre de Ronsard, Le Premier Livre des amours, p. 87)

\section{CORPus Web :}

Après elles épurent cette pâte et la pressent fort entre leurs mains, et réservent, et recueillent cureusement dans des coys le suc qui en tombe [http://patrimoines-de-guadeloupe.over-blog. com/article-la-farine-de-manioc-et-la-cassave2-38897646.html] (12.10.2015)

Tu peux éventuellement présenter la chose en disant que l'air est une éponge avec des endroit plus ou moins humide et que les différentes conditions presse plus ou moins efficacement l'éponge : si l'éponge est pressée fort et qu'il y a beaucoup d'eau : grosses précipitation, si l'éponge est pressée fort mais qu'il n'y a pas beaucoup d'eau : précipitations plus faibles et s'il y a beaucoup d'eau mais que l'éponge n'est pas pressée : il ne pleut pas. C'est peut-être un peu simpliste mais bon ... [http://forums.infoclimat.fr/ topic/19094-les-crues-cevenoles-explicationhydro-climatique/page-2] (12.10.2015)

Ils appuient sans doute sur L1 ou R1, tiens sans la manette en mains je e me souviens plus qui te permet de presser fort avec ton joueur et un second geré par L'IA [http://www.jeuxvideo.com/ forums/42-32735-39308738-1-0-1-0-le-pressing. $\mathrm{htm}](12.10 .2015)$

Le système fonctionne bien, les latéraux sont hauts, les milieux et attaquants pressent forts, sauf Messi dispensé. Di Maria a appris toute l'année à presser comme un mort de faim, il apporte mine de rien un peu de «muscle » en attaque, lui qui est encore plus flaco qu'El Flaco [http://forum.footnantais.com/viewtopic.php? $\mathrm{f}=4 \& \mathrm{t}=12768 \&$ start $=825]$ (12.10.2015)

REMARQues : Presser fort (I) réfère au fait de pousser une personne avec insistance par la persuasion ou même par la violence ou la menace, afin qu'elle agisse d'une certaine manière. (II) transpose le fait de se sentir poussé au domaine psychologique des troubles, des tourments, des accablements. (III) renvoie au fait de serrer quelque chose/quelqu'un fortement, d'appuyer fortement sur ou contre quelqu'un /quelque chose. Notons l'emploi dans le domaine du sport dans les deux derniers exemples du CW (à comparer : faire du pressing). Fort reste invariable dans la majorité des cas, mais il s'accorde dans le dernier exemple. On pourrait l'interpréter comme prédication seconde qui modifie le sujet, mais il s'agit probablement d'un simple phénomène d'hypercorrection orthographique qui ne change rien à la fonction adverbiale (à comparer : l'ac- 
cord de presser haut dans l'entrée suivante). Fort est modifié par plus, si, trop.

\section{Presser haut}

Exercer une forte contrainte (sur quelqu'un), engager, pousser fortement, vivement, voire à haute voix (quelqu'un à faire quelque chose) Transitif

1738 En achevant ces paroles, on leva table ; Versac commençant à douter de la réus site de ses projets, madame de Senanges occupée à pousser les siens, et madame de Lursay désespérée des façons mal-honnêtes de M. de Pranzi qui la pressoit assez haut de lui rendre des bontés qui, disoit-il, lui devenoient plus nécessaires que jamais (Alexandre Dumas fils, Les Égarements $d u$ cœur et de l'esprit)

CORPUS WEB :

Demain il faudra attaquer dés le début du match et presser haut afin de se créer un maximum d'occasions et de les concrétiser. Il ne faudra pas laisser d'espaces pour éviter les tentatives de contre [http://canal-supporters.com/2014/03/ motta-attaquer-des-le-debut-et-presser-haut/] (12.10.2015)

Ils pressent haut et montrent beaucoup plus de détermination que la selección et récupèrent les ballons assez haut. Sur un nouveau service de Blind, Robben fait parler son talent et sa grande forme du moment pour tromper Casillas d'une frappe légèrement détournée après avoir enrhumé Piqué d'un crochet du droit [http://www. convifive.com/espagne-pays-bas] (12.10.2015)

Les Manceaux ripostent, mais Planus veille. Les deux formations se pressent haut. Trémoulinas, parfaitement servis par Gourcuff pousse un peu trop son ballon [http://les-bordelaisflingueur.skyrock.com/2668326710-MatchBordeaux-regale-3-0.html] (12.10.2015)

Non mais arrête, comment tu veux le stopper avec l'accélération qu'il tape ? * Il part de $65 \mathrm{~m}$ et $50 \mathrm{~m}$, les défenseurs pressent hauts ils s'attendent pas à ce qu'il parte aussi vite ils peuvent rien faire [http://www.jeuxvideo.com/forums/125552-277025-743-0-1-0-bla-bla-les-dieux-duforum.htm] (12.10.2015)

La fin du match est très tendue, l'Ukraine devant gagner pour passer, elles pressent hautes sur nos relances, nous empêchant de construire le jeu [https://fr-fr.facebook.com/Douai.Hockey. Club/posts/530818643656036] (12.10.2015)

Remarques : Presser haut désigne le fait de pousser une personne avec insistance par la persuasion ou même par la violence ou la menace, afin qu'elle agisse d'une certaine manière. Aujourd'hui presser haut est particulièrement courant dans le langage du sport, surtout dans le domaine du football, où ce terme, issu de l'anglais pressing, signifie 'harceler le porteur du ballon pour pouvoir le récupérer' (v. les exemples du CW). Haut reste invariable dans la majorité des cas, mais il peut également s'accorder avec le sujet (v. les deux derniers exemples du CW), sans devenir un prédicat second référant à une hauteur au sens local. Haut est modifié par assez. Notons l'emploi absolu et pronominal du verbe dans le CW.

\section{Presser soef}

Presser, serrer doucement, délicatement Transitif

1275 Cete de lui paistre ne cesse, E, pour ce que soëf le paisse, Cist mastins li pent aus mameles, Qu'ele a tribles, non pas jumeles ; Ses treis groinz en son sein li muce, E les groigneie e tire et suce (Jehan de Meun, Roman de la rose [12691278], 19816)

REMARques : Presser soef se disait d'une personne étreignant doucement quelqu'un, soef pouvant référer également à la tendresse.

\section{Prévenir droit}

Prévenir aussitôt, directement Transitif

1935 Elle eut une vengeance cruelle et sans noblesse, alla prévenir tout droit le mari de la malheureuse, et brisa du même coup le foyer d'une autre avec le sien (Maxence Van der Meersch, Invasion 14)

REMARques : Prévenir droit désigne le fait d'informer quelqu'un, de le mettre au courant sans tarder, le sujet se dirigeant exclusivement vers une personne. Droit reste invariable et est modifié par tout. 


\section{Prévoir grand}

Anticiper largement, de façon ambitieuse $\lambda$ voir grand

\section{Prier bas}

I. Prier à voix basse, en murmurant ; adjurer, solliciter à voix basse

Transitif

1538 Les prebstres lors bien hault chantent et crient,

Et les amans tout bas leurs dames prient, Et puis entre eulx comptent de leurs fortunes, En mauldisant les langues importunes, $\mathrm{Ou}$ en disant choses qui mieulx leur plaisent (Clément Marot, Élégies)

1671 Ainsi dans la danse

Cupidon pleurait,

Et tout en cadence

Parfois soupirait,

Priant tout bas les Zéphyrs

D'aller porter ses soupirs

(Jean de La Fontaine, Le Songe de Vaux)

1849 Nous les priions tout bas ou tout haut de conserver le souvenir de l'heure que nous avions passée ensemble, des pensées qu'ils nous avaient données, de l'air qu'ils nous avaient fait respirer, de la goutte d'eau que nous avions bue dans le creux de nos mains, de la feuille ou de la fleur que nous y avions cueillie, de la trace que nos pas y avaient imprimée sur l'herbe humide (Alphonse de Lamartine, Raphaël)

1900 En grand secret, je remplace mes bas par des chaussettes. Au bout de trois jours, toutes le savent, se le répètent, et me prient tout bas de relever ma jupe (Colette, Claudine à l'école)

II. S’adresser à une divinité

Intransitif

1784 Et le vieillard s'est mis à pleurer, et il a prié bas, sans répondre à son fils, qui a bien vu qu'il retractait : et ils sont revenus ensemble, le père s'appuyant sur le fils, et le fils tenant un bras passé autour de son père, d'une façon d'amitié d'une part, et de respect de l'autre, qu'un-chaqu'un qui les voyait en-était attendri (Nicolas Rétif de la Bretonne, La Paysanne pervertie ou Les Dangers de la ville)

1829 Le cercueil arriva, qu'on mesura de l'aune ; J'étais là... puis, autour, des cierges brûlaient jaune, Des prêtres priaient bas ; mais en vain je voulais dire l'hymne dernière ;

Mon œil était sans larme et ma voix sans prière,

car je ne croyais pas

(Charles Sainte-Beuve, Poésies)

1833 Mortes, mortes !... Pourquoi cette retraite austère?

Le sacre dans deux jours va les rendre à leur mère ;

Qu'ils l'embrassent plus tôt, le mal n'est pas si grand.

La reine est là, chez moi, priant tout bas, pleurant,

Toujours là, comme un marbre, immobile à sa place

(Casimir Delavigne, Les Enfants d'Édouard)

1911 Le pain noir prend le goût du miel, quand on le mange

Dans l'air que Dieu parfume avec des ailes d'anges.

Tous ceux assis à l'âtre ou debout priaient bas.

Mais comment ils priaient, ils ne le savaient pas (Francis Jammes, Les Géorgiques chrétiennes)

Transitif

1963 Quelque occasion de sacrifice et d'holocauste, qui nous fasse enfin rejoindre les mains, et prier tout bas des dieux impitoyables (Jean-Marie Gustave Le Clézio, Le Procès-verbal)

Remarques : Prier bas (I) désigne le fait de demander par grâce, avec insistance et humilité ou au moins déférence une faveur, un service, etc. à quelqu'un. Plus spécifiquement, et notamment sous l'emploi intransitif (II), prier bas signifie s'adresser à Dieu dans une prière. Bas réfère dans tous les cas à la voix que le sujet baisse, rendant sa prière quasiment inaudible. Bas reste invariable et est modifié par tout. 
Prier bel (beau)

Prier, demander avec ferveur, avec éloquence Transitif

1160 Molt est malvese ta menaie, Ge ne te sai tant bel proier Que me voilles de rien aidier ; Tu me meïs a grant desroi, Il m'estovra clamer de toi (Eneas, 8191)

1170 Erec respont : Po me prisiez, Ma parole mout despisiez. Je ne vos sai tant bel priier Que je vos puisse chastiier (Chrestien de Troyes, Erec et Enide, 3565)

+1225 Et quant cil ot ke cil estoit De Bretaigne, lors ne se faint De biel prïer k'i li ensaint, Quel part mesire Gauvains gist (Le Chevalier as deus espees [2 $2^{\mathrm{e}}$ quart $\left.\left.\mathrm{XIII}{ }^{\mathrm{e}}\right], 3616\right)$

+1250 Ving a l'ostel Gonbert du Fraine, Qui meint mal porchace et amaine. De vostre part bel li priai, C'onques ne le contraliai, Qu'ilec me lessast osteler : Nuiz ert, ne savoie ou aler, Por vos me donast a menger (Le Roman de Renart [2 moitié XIII'], XXIII, 257)

1285 Car pour moi nel vouloit laissier, Tant l'en seüsse bel priier, Que vous n'eüssiez entresait Marine, cui fust biau ne lait (Adenet le Roi, Cleomadés, 4342)

Emploi absolu

1403 Cirus adont piteusement

Fu devant la dame menez, Qui moult s'est durement penez D’avoir merci, par beau prier, [variante : beau parler]

Mais Thamaris, sans detrier, Lui dit, par hault et fier courage : $\mathrm{O}$ tu, roy plain de grant oultrage, Qui tant as fait de sanc espendre! (Christine de Pisan, Le Livre de la mutacion de fortune, II, 9769)

REMARQUES : En ancien français, prier bel désignait le fait de demander par grâce, avec insistance et humilité ou au moins déférence une faveur, d'adresser une requête à quelqu'un avec ferveur, de manière intense et/ou élégamment, avec des paroles choisies. La diachronie des exemples met en évidence le remplacement dans la fonction adverbiale du neutre bel par le masculin beau à partir du moyen français. Notons la nominalisation dans l'exemple de 1403. Bel est modifié par tant.

\section{Prier clair}

prier haut et clair : prier ouvertement, publiquement, à haute voix

$\lambda$ prier seri

\section{Prier fort}

Prier, demander avec force, avec insistance Transitif

1669 CLÉANTE. Mais, Madame, après tout... MADAME PERNELLE. Pour vous,

Monsieur son frère,

Je vous estime fort, vous aime, et vous révère ;

Mais enfin, si j'étois de mon fils, son époux, Je vous prierois bien fort de n'entrer point chez nous (Molière, Le Tartuffe)

CORpus Web :

Frère et sœur nous aurons beau prier fort, crier fort les noms de Dieu, les œuvres temoigneront tjrs mieux la foi que l'emotion, ou les sacrifices [https://www.facebook.com/permalink. php?story_fbid $=127565340769281 \& i d=445243$ 582184844] (12.10.2015)

\#entrainde prier fort pour que mes bouteilles de vin protégées par deux culottes et un soutif n'explosent pas dans ma valise [https://twitter. com/elodaaaie/status/635977008674172928] (12.10.2105)

Quand j'aurais cette confirmation je serai soulagée et bien contente de casser les gens qui prient forts pour que j'ai un garçon [http:// forums.france5.fr/lesmaternelles/Ladecision/ Choisirlesexedesonenfant/decide-fille-foissujet_2821_108.htm] (12.10.2015)

Remarques : Prier fort désigne le fait de demander par grâce une faveur, un service, etc. à quelqu'un et ce, avec véhémence, insistance, force. Fort reste invariable dans la majorité des cas, mais dans le dernier exemple du CW, il s'accorde avec le sujet, gardant tout de même son interprétation adverbiale. Il est modifié par bien. 


\section{Prier haut}

Faire une prière ; demander (quelque chose) à voix haute, ouvertement

Transitif

1679 Charton pria tout haut M. le Prince de Conti de suppléer à ce que les formalités du parlement ne permettoient pas à la compagnie de faire (Jean-François de Gondi (Cardinal de Retz), Mémoires)

1926 Je lui accordais volontiers ce quart d'heure... Il était pris sur le passé. Soudain, trop fière, elle appela une voiture, donna l'adresse, à voix basse, mais pria tout haut le cocher d'aller vite (Jean Giraudoux, Simon le Pathétique)

Intransitif

1784 « Allons, mon enfant, mettons-nous à genoux, et prions."

Alors elle se prosternait, elle priait haut, mais avec tant d'onction, d'éloquence, de douceur, d'élévation et de force, qu'on eût dit que l'esprit de Dieu l'inspirait (Denis Diderot, La Religieuse)

1870 Allons... à la grâce de Dieu !... Tenez, mère Catherine, payez-vous... voilà votre comp !... en route !... et toute la bande partait. Une vieille se mettait à prier tout haut pour aider à la marche ; les femmes répondaient, et les hommes, la tête penchée, rêvaient derrière (Émile Erckmann et Alexandre Chatrian, Histoire d'un paysan)

1903 TROISIÈME DÉMON. Il dort? PREMIER DÉMON. Non, il prie. Parle plus bas.

TROISIÈME DÉMON. Je parle assez bas ; si je le dérange, c'est qu'il ne priait pas assez haut (André Gide, Saül)

1950 Debout, en demi-cercle, face à Mam'zelle Fanny, encadrée elle-même dans l'embrasure de la porte, les bras croisés, ils priaient tout haut pour réussir à l'examen qu'ils allaient subir (Joseph Zobel, La Rue Cases-Nègres)

CORPUS WEB :

Je suis chrétienne évangélique depuis 2006. Mais j'ai beaucoup de mal à prier haut et fort, de proclamer de ma bouche. Je prie en silence dans mon for intérieur [http://blog.oratoiredulouvre. $\mathrm{fr} / 2012 / 08 /$ je-prie-en-silence-dans-mon-forinterieur-et-lon-me-dit-que-cela-a-beaucoupmoins-de-valeur-est-ce-vrai/] (12.10.2015)

Les églises aussi sont agenouillées : La cathédrale, Sainte-Anne, Saint-Louis-Roi-de-France, Saint-Joseph. Quelques fidèles prient haut et fort. Une prière en colère, d'autres le font à voix basse, dans leur cœur [http://bibliobs.nouvelobs.com/ paroles-d-haiti/20100127.BIB4806/ma-placeparmi-les-vivants.html] (12.10.2015)

REMARQUES : Dans l'emploi intransitif, prier haut désigne le fait de faire une prière (généralement à Dieu) ou, dans l'emploi transitif, de prier quelqu'un, de lui demander quelque chose instamment, haut référant à l'élévation de la voix, au fait de rendre les prières sonores et donc publiques, ou à l'intensité. Notons la collocation haut et fort. Haut reste invariable et est modifié par assez, tout.

\section{Prier seri}

Prier doucement, à voix basse

Intransitif

1200 Jordains li anfes fu chevaliers gentiz.

Ne proia mie coiement ne seri,

Mais haut et cler, si que bien fu oïs

(Jourdain de Blaye, 2456)

REMARQUES : Ici, en opposition avec les adjectifs haut et clair et précédé de l'adverbe coiement 'sans faire de bruit ; secrètement', prier seri se disait du fait de prier Dieu ou de demander une faveur à quelqu'un, et ce, sans faire de bruit, à voix basse. La collocation haut et clair traduit le fait de prier Dieu ou de demander une faveur à quelqu'un à haute voix, en prononçant sa prière ou sa demande clairement et distinctement.

\section{Priser fort}

Estimer, louer beaucoup

Transitif

1495 «Et je le veulx ainsi, » dit il, et si luy commande despartir ces bagues et joyaulx aux dames et damoiselles selon leur qualité, dont elles priserent fort le noble roy de France (Roman de Jehan de Paris, p. 88) 
1521 Quant le roy le sceut, il prisa fort la seconde science, car elle luy saulva la vie (Le Violier des histoires rommaines moralisées)

1600 On prise fort aussi les prunes de Pardigoygne pour leur grosseur, et saveur agreable (Nicolas Abraham de La Framboisière, Le Gouvernement nécessaire à chacun pour vivre longuement en santé)

1738 Quoique les moines prisent fort leurs reliques à Venise, ainsi que dans les autres païs, ils ne trouvent guére que parmi le bas peuple des gens prêts à croire tous les miracles qu'ils leur attribuent (Jean-Baptiste d'Argens, Lettres juives ou Correspondance philosophique, historique et critique)

1842 Car il y avait, à cette seconde époque du seizième siècle, et malgré l'anarchie qu'aujourd'hui nous y reconnaissons, une manière de langue centrale, et qui se crut par instants établie, celle de l'école de $\mathrm{Du}$ Bellay et de Ronsard en vers, de Pasquier en prose, tous personnages qu'aimait et prisait fort Montaigne, mais sans en dépendre (Charles Sainte-Beuve, Port-Royal)

1969 Ils ont tout à fait la tête à priser fort le travail accompli (Léo Malet, Sueur aux tripes)

REMARques : Aujourd'hui littéraire et moins utilisé que la collocation fort prisé, priser fort désigne le fait d'avoir beaucoup d'estime pour quelqu'un, d'apprécier fortement une personne. Fort reste invariable.

\section{Priser haut}

Estimer, apprécier beaucoup, donner beaucoup de valeur à (quelque chose)

Transitif

1824 Or il arriva que le bailli du comte fit arrêter un bourgeois de Gand et le fit retenir en prison. " Cela est directement contre nos priviléges, disaient les amis de Jean Hyons, et c'est ainsi que se brisent petit à petit et s'affaiblissent nos franchises, qui, du temps passé, étaient si nobles, prisées si haut, et avec cela si bien gardées que nul n'osait les enfreindre, et que le plus noble chevalier de Flandre se tenait pour lors tout glorieux d'être bourgeois de Gand » (Prosper de Barante, Histoire des ducs de Bourgogne de la maison de Valois)

1862 Il faut que Dieu ait prisé bien haut notre fraternité, pour nous la faire payer aussi cher par tous les ennuis de la vie, la délicatesse de nerfs, de goût, d'esprit et de cœur, qui fait malheureux (Edmond et Jules de Goncourt, Journal)

1883 On prisait si haut la faveur de participer à une éducation tenue pour exceptionnelle, que cette paternelle déclaration était redoutée comme un arrêt de mort (Ernest Renan, Souvenirs d'enfance et de jeunesse)

1929 Le colonel Leigh - de qui Augusta n'eut pas moins de sept enfants - était un ami personnel du prince Régent, comme tel fort bien en cour ; et la seule chose qu'il assura à sa femme fut cet accès auprès des Royalties, et les faveurs qui y sont attachées, que, plus encore que les autres peuples, Anglais et Anglaises prisent si haut, et que Byron appréciait fort, puisque sans cesse dans sa correspondance, faisant allusion à sa sœur, il mentionne ses privilèges à cet égard (Charles Du Bos, Byron et le besoin de la fatalité)

1935 Il arrive, sous l'ancien régime, que Thomas Corneille soit prisé plus haut que son frère Pierre : la Révolution résout cette indécision et 1848 met fin à la carrière de Thomas (Arts et littérature dans la société contemporaine)

1936 - Lesquelles donc ? demanda Jacques, s'efforçant àconserver un ton purement interrogatif.

- Hé, mais, fit Roy, en dressant sa petite tête ronde, "de celles que justement je prise le plus haut : l'énergie virile, le goût $\mathrm{du}$ risque, la conscience du devoir, et mieux encore : le sacrifice des volontés particulières à une vaste action collective, héroïque... » (Roger Martin du Gard, Les Thibault. L'Été 1914) 
1961a « Ils ont mené la belle vie, nous n'avons pas su les en empêcher. Combien des nôtres les ont servis qui se sont moins bien battus qu'eux? " « Nos dames, dit-il, prisent très haut les faits d'armes, mais plus encore la vraie noblesse de cœur et la délicatesse de l'esprit » (Zoé Oldenbourg, Les Cités charnelles)

1961b La prise de contact, assaisonnée au moins de l'ingestion d'un pedigree métaphysique sans agrément, devient une opération malaisée et chanceuse, prisée plus haut parfois pour sa difficulté même que l'enrichissement souvent médiocre qu'on envisage d'en retirer (Julien Gracq, Préférences)

Pronominal

1922 le rythme double est perceptible dans les diverses périodes d'un même amour, dans toutes les priodes correspondantes d'amours similaires, chez tous les êtres qui s'analysent mieux qu'ils ne se prisent haut (Marcel Proust, Sodome et Gomorrhe)

RemARques : Priser haut désigne le fait d'avoir beaucoup d'estime pour quelqu'un, d'apprécier fortement une personne ou, lorsque l'objet est un inanimé, de lui donner beaucoup de valeur. Haut reste invariable et est modifié par bien, le plus, plus, si, très. Notons l'emploi de apprécier fort.

\section{Priser petit}

Apprécier peu, mépriser

Transitif

1175 Il parole a le fille au roi, Mais mout li quiert mains de desroi, Que la pucele ne vaudroit. Andoi en vont au roi tot droit, Mais Ganors prise mout petit Tot canqu'il ont parlé et dit (Gautier d’Arras, Ille et Galeron, 3389)

1342 Il prisoit moult petit la guerre Des bestes qui li vuelent nuire Et qui le pensent a destruire ; Qu'elles l'espioient de long. Bien le vi ; pour ce le tesmong (Guillaume de Machaut, Le Dit dou lyon, 510)

1377 Car moult petit prisera la clamour De mon vray cuer et ma grant loyauté
Si m’ara tost selon droit oublié

(Guillaume de Machaut, La Louange des dames, p. 212)

-1465 Si tu t'informe bien du cas, Je te donne mille ducas, Quant bien auras ton faict congneu, Remembrant a ton cueur com nu Nature sur terre t'a mis Et que fors Dieu nul n'est amys, S’oncques riens si petit prisas Comme l'estat que tu pris as (Jean Meschinot, Lunettes des princes, p. 36, 31)

-1469 Nous l'oublierions et apparesserions nos cœurs, qui maintenant prisent petit une grant chose et feroyent de une petite grant (Jean de Bueil, Le Jouvencel [1461]-1468, I, p. 150)

REMARQUES : En ancien et moyen français, priser petit réfère à la façon dont une personne perçoit quelque chose ou quelqu'un, le sujet appréciant peu la personne ou montrant peu d'intérêt envers quelque chose (des propos par exemple), voire affichant un certain mépris envers une personne ou une requête. Petit est un quantifieur très usuel dans l'ancien français, fonction dans laquelle il sera progressivement remplacé par peu. Petit reste invariable et est modifié par si, moult. VoIR AUSSI : aconter / chaloir petit

\section{Produire durable}

Créer des produits durables

入 produire gros

\section{Produire grand}

Créer des produits à grande échelle

入 produire gros

\section{Produire gros}

Produire beaucoup, en grande quantité

Transitif

1958 Ce débat entre un groupe de remarquables professionnels conquis au malthusianisme par leur hardiesse même et des artisans plus neufs et soucieux de produire gros et vite a été arbitré par les pouvoirs publics (Le Monde, 28 décembre 1958 / Grundt : 396) 


\section{CORPUS WEB :}

Je vous laisse découvrir. Ça me donne bien envie et encore une fois, cette nouvelle ère où l'être est enfin sorti de cette injonction capitaliste à produire gros, grand et de manière ostentatoire est jubilante [http://www.totem-world.com/ jeunesse-en-fight-je-taime.html] (12.10.2015)

Désormais, il n'est plus nécessaire de produire gros : il faut produire bien et durable! [http://www.cafebabel.fr/societe/article/parlezvous-eurofood.html] (12.10.2015)

Remarques : Produire gros désigne le fait de créer, de fabriquer un produit consommable ou non en grande quantité. Nous remarquons ici le contraste véhiculé par le terme malthusianisme qui dénote un comportement inverse, restrictif. À l'idée de quantité s'ajoute, avec l'adverbe vite, celle de rapidité de l'exécution, qui suggère une production de qualité moindre. Notons également les adjectifs-adverbes grand et durable dans le CW, manifestant l'appartenance du schéma produire + adjectif-adverbe au langage de la production industrielle. Gros reste invariable. VoIR AUSSI : faire gros / rapide

\section{Proférer fort}

Dire, prononcer, émettre d'une voix intense $\pi$ proférer haut

\section{Proférer haut}

I. Dire, prononcer, émettre d'une voix forte Transitif

1612 Cependant que ce berger parloit de ceste sorte en soy-mesme, et qu'il en proferoit assez haut plusieurs paroles sans y penser, tant il estoit troublé de ce desastre, Bellinde, qui n'avoit pas perdu le souvenir de l'assignation qu'elle luy avoit donnée, aussi tost qu'elle se peut deffaire de ceux qui estoient autour d'elle, s'en alla le trouver (Honoré d'Urfé, L'Astrée)

1627a Il ne proferoit cecy guere haut, craignant que les voysins ne l'entendissent, de sorte que la servante ne l'ouyt pas seulement, et parce qu'elle ne s'estoit pas vuidé toute la vessie, elle pissa encore quelques goutes dedans la fiole (Charles Sorel, Le Berger extravagant) 1627b Mais elles, feignants de ne recognoistre point son artifice, proferoient entr'elles assez haut des paroles pleines d'admiration qu'elles faisoient toutesfois semblant de vouloir dire bas (Honoré d'Urfé, L'Astrée)

1628 De sorte que le druide et Celadon s'estant joints à Phillis, Celidée et Ligdamon, ils se separerent un peu de la trouppe, et apres avoir dit chacun son opinion à Phillis, elle les vint retrouver, et s'estant assise, profera tout haut ces paroles (Balthazar Baro, La Conclusion et dernière partie d'Astrée)

1634 Elle proferoit si haut ces menasses, avecque tant de colere et d'esclat, que sa mere l'entendit d'une salle haute où elle estoit (André Mareschal, La Chrysolite)

Intransitif

1874 Seul, il avait le droit de proférer très-haut, à propos de ces deux jeunes hommes éclairés autrement que tous et autrement même que par la mort, ce que d'eux longtemps nous pensâmes tout bas (Stéphane Mallarmé, La Dernière Mode)

II. ne pas proférer (un mot) plus haut que (l'autre mot): ne pas hausser le ton, garder son calme ou son sang-froid, ne pas s'emporter, ne pas se quereller

Transitif

1837 Pendant dix-neuf ans, il n’a jamais proféré de parole plus haut que l'autre, parlant à ma personne (Honoré de Balzac, Histoire de la grandeur et de la décadence de César Birotteau)

CORpus Web :

Je joue la Charr qui aime les pommes, une Sylvari couleur de miel, se disputer avec les Dolyaks, péter dans le bain, bricoler des machins qui lancent des trucs qui font des trous dans les gens. Si c'est magique c'est meilleur. La même Charr que vous entendrez proférer haut et fort « JE SUIS PAS UN CHATON ! » tandis que sa truffe fera un mignon « nuf nuf nuf » qui achèvera de la décrédibiliser totalement (Non elle a pas de chance) [http://crok-dragon.forumactif.org/t86-la-teignerouge] (12.10.2015) 
Le -G- Dire que les québécois ne sont pas des canadiens... * pour oser proférer haut et fort une vérité si dérangeante, ton pseudo recevra le prix Albert Londres... à titre posthume * [http://www. jeuxvideo.com/forums/1-52-3453244-11-0-1-0-lebar-de-nuit.htm] (12.10.2015)

Remarques : Proférer haut (I) signifie 'dire, prononcer (des paroles, des vers, des menaces) à voix haute', souvent avec véhémence. Calqué sur l'expression lexicalisée ne pas prononcer/ dire un mot plus haut que l'autre, proférer un mot plus haut que l'autre, (II) se dit du fait de parler sans éclat, sans colère, le sujet gardant un ton calme et restant maître de ses émotions. Notons la collocation haut et fort dans le CW. Haut reste invariable et est modifié par assez, guère, plus, si, tout, très. VOIR AUSSI : prononcer haut

\section{Promener mélancolique}

Se promener tristement, d'un air mélancolique, affligé

Pronominal

1851 Quant à moi, je remontais dans ma chambre, ou j'allais me promener seul et mélancolique dans les sentiers déserts qui coupent les champs, derrière l'hôpital

(Alphonse de Lamartine, Les Nouvelles Confidences)

REMARQUES : Promener mélancolique se dit du fait de marcher, de flâner d'une façon ou d'un air mélancolique, le sujet montrant par sa démarche une amertume, un abattement, voire une tristesse. Il permet une interprétation adverbiale, tout comme une analyse en tant que prédicat second orienté vers le sujet.

\section{Promettre bel (beau)}

Faire de belles promesses

Emploi absolu

+1150 Saül a ses privez parlad é á David mandad que sa einznéé fille, Merob par num, li durreit pur çó que la guerre vers les enemis Deu meintenist é a sun poeir les descunfesist. Bel pramist é bel parlad, mais felenessement le purpensad que par ceo David á mort s'abandunast é sa mort vers le rei nuls n'aturnast (Quatre Livres des rois [2 $2^{\mathrm{e}}$ moitié XII $]$, p. 37, 17)
CORPUS WEB :

Une nouvelle alliance est au pouvoir a Maurice. Elle a pris pour nom : l'Avenir, ce qui est une manière subtile et intelligente de nous le promettre beau et resplendissant [http://www. pmdinan.com/?p=1059] (12.10.2015)

Liste des joueurs inscrit pour le PRONO CHALLENGE WORLD CUP 2014 au brésil. Certains revanchard(e)s nous la promettent belle et disputée. Il y a encore possibilité d'y participer il suffit de mettre votre pseudo ci dessous dans la rubrique " commenter ou écrire un commentaire " [https://www.facebook.com/PronoChallenge/ photos/a.444896902314503.1073741833.28191121 5279740/445482055589321/?type=1\&permPage=1] (12.10.2015)

REMARQUes : Promettre bel se disait en ancien français du fait de tenir des propos prometteurs, agréables à écouter, mais peu réalistes. Notons la coordination avec parler bel. En français moderne, l'emploi adverbial du neutre bel de l'ancien français cède la place à une remotivation adjectivale où l'adjectif est un prédicat second qui réfère à la chose promise. Il s'accorde alors avec le nom dénotant la promesse (exemples du CW).

\section{Promettre gros}

Promettre beaucoup

Emploi absolu

1953 CHARLES. Il en faisait une tête, l'archevêque, le duc avait dû lui promettre gros (Jean Anouilh, L'Alouette)

\section{CORPus Web :}

on a du lui promettre gros pour qu'il renonce a tout ça... [http://www.boursorama.com/ forum-orange-ex-france-telecom-ernotte-ingame-436926452-1] (12.10.2015)

J'ai pris du plaisir à y jouer et à le finir complètement, et c'était un peu long. Cependant ce n'est vraiment pas la bombe qui était annoncé avant sa sortie, il y a une impression générale de pas fini quoi. Cela dit, ça peut promettre gros pour des éventuelles suites [http://www.senscritique. com/jeuvideo/Watch_Dogs/critique/54792571] (12.10.2015)

REMARQUES : Promettre gros se dit du fait de s'engager à faire, à dire ou à donner quelque chose à quelqu'un, gros référant à l'ampleur de la pro- 
messe et de la somme d'argent y afférant. La promesse peut également émaner d'une situation 'prometteuse' (dernier exemple du CW). L'emploi tend à être absolu, non seulement dans le dernier exemple du CW, mais aussi dans les autres puisque promettre inclut sémantiquement la chose promise, qui n'est pourtant pas explicitée. Gros reste invariable.

\section{Promettre fort}

Promettre intensément

$\pi$ ajouter bas

\section{Promettre haut}

Promettre à voix haute

$\nearrow$ ajouter bas

\section{Prononcer bas}

Prononcer, dire à voix basse, d'une voix faible, en murmurant

Transitif

1657 ou bien il faudroit que le poëte usast d'une telle adresse en la composition de ce monologue, que l'acteur dût élever sa voix en récitant certaines paroles seulement, et la moderer en d'autres et cela afin qu'il soit vray-semblable que l'autre acteur qui l'écoute de loin, puisse entendre les unes comme prononcées tout haut et d'une passion qui éclateroit à diverses reprises, mais non pas les autres, comme estant prononcées tout bas (François Hédelin, abbé d'Aubignac, La Pratique du théâtre)

1667 Alphonse entendant cela s'approcha doucement de sa porte, et entendit distinctement ces paroles, quoy qu'elles fussent prononcées assez bas (Madeleine de Scudéry, Mathilde)

1782 Enfin, ce n'est que samedi qu'on est venu tourner autour de moi et me balbutier quelques mots ; encore prononcés si bas et tellement étouffés par la honte, qu'il était impossible de les entendre (Pierre Choderlos de Laclos, Les Liaisons dangereuses)

1787 Ce matin, son visage s'est enflammé tout à coup, ses yeux sont devenus vifs et bril- lants. Elle a prononcé très vite et très bas quelques mots que je n'ai pu entendre (Jean-Baptiste Louvet de Couvray, Une année dans la vie du chevalier de Faublas)

1834 Je prononçais donc bien bas, en ces quarts d'heure de réflexion, le vœu d'échapper à des liens trop étouffants, d'aborder le monde pour mon compte, et d'y essayer sous le ciel ma jeunesse (Charles SainteBeuve, Volupté)

1858 Ennana agita sa baguette en sens inverse et prononça tout bas la formule contraire (Théophile Gautier, Le Roman de la momie)

1882 « Je sais... oui, je sais en quelle circonstance douloureuse vous l'avez connue, je sais aussi comme vous avez été parfait, plein de délicatesse, de tact, de dévouement dans l'affaire... ». Il hésita, puis prononça plus bas, comme s'il eût articulé un mot grossier : «... dans l'affaire de ce cochon de Morin » (Guy de Maupassant, Contes et nouvelles)

1886 « Ah ! ne souffre pas, qu'importe si je me perds ?...» C'était la traduction des regards de la pauvre femme, la parole qu'elle prononçait tout bas (Paul Bourget, Un crime d'amour)

1963 Elle prononça gravement et tout bas le prénom de Lortier, et il n'y avait entre eux à ce moment-là ni désir ni tendresse, seulement la difficile et fugitive acceptation d'une entente violente (Pierre Moinot, $L e$ Sable vif)

Remarques : Prononcer bas signifie 'dire, énoncer (un mot, un nom, une formule)' et ce, à voix basse, le sujet n'étant pas sûr de vouloir être entendu, hésitant à s'exprimer. Bas reste invariable. Il est modifié par assez, donc bien, plus, si, tout, très. VoIR AUSSI : dire bas

\section{Prononcer clair}

Prononcer clairement

$\lambda$ prononcer haut

\section{Prononcer fort}

Prononcer fortement

$\lambda$ prononcer haut 


\section{Prononcer haut}

I. Prononcer, dire à voix haute, de manière perceptible, ouvertement, franchement

Transitif

1560a Pourtant ils prennent ceste eschapatoire que ce n'est point du vouloir de Dieu, mais de sa seule permission que cela se fait. Or Dieu, prononçant haut et clair que c'est luy, rejette un tel subterfuge (Jean Calvin, Institution de la religion chrestienne)

1560b L'Escriture prononce haut et clair que toutes créatures mortelles ont esté asservies à la mort en la personne d'un homme (Jean Calvin, Institution de la religion chrestienne)

1733 Le lecteur qui se donnera la peine de prononcer tout haut ces vers de l'abbé de Chaulieu, sentira bien que le rithme qui tient l'oreille dans une attention continuelle, et que l'harmonie qui rend cette attention agréable, et qui acheve pour ainsi dire d'asservir l'oreille, font bien un autre effet que la richesse des rimes (JeanBaptiste Dubos, Réflexions critiques sur la poésie et la peinture)

1745 Je présumai encore que j'étais cette sœur dont elle l'entretenait, et qu'il s'agissait de quelques ordres qui me regardaient ; et deux ou trois mots, comme : oui, madame, laissez-moi faire, prononcés tout haut par la tourière, qui me regardait beaucoup, me le prouvèrent (Pierre de Marivaux, La Vie de Marianne)

1826 Les mucosités des bronches et les exsudations du trajet fistuleux, qui est couvert d'un emplâtre agglutinatif, reviennent avec facilité par le larynx. La voix est bien plus nettement entendue, et tout à coup quelques paroles sont prononcées très-haut et articulées distinctement. Dix grains de jalap et deux grains de calomel sont donnés dans une cuillerée d'orgeat (Pierre Bretonneau, Des inflammations spéciales du tissu muqueux)

1836 Ils tressaillirent en l'entendant ; mais, en rentrant au logis, ils virent trois paniers qu'on portait à Clamart : c'étaient trois jeunes gens qui avaient prononcé trop haut ce mot de liberté (Alfred de Musset, Confessions d'un enfant du siècle)

1887 Mais il sentit du même coup que sa sœur avait prononcé tout haut la parole qu'il se disait tout bas depuis que le succès de sa pièce lui avait ouvert des horizons d'espérances (Paul Bourget, Mensonges)

1926 Comment donc souffrir ? direz-vous... Impossible de me torturer dans le présent ; tout n'y était que joie, espoir ; le mot le plus commun, le mot table, le mot chaise, prononcé tout haut, écartait de moi aussi vivement le malheur que le mot arabe le plus sûr. Je souffris donc de mon passé, de mon enfance (Jean Giraudoux, Simon le Pathétique)

1948 Novissima verba... Je ne vois pas pourquoi l'on chercherait à les prononcer plus haut que les autres. Du moins je n'en éprouve pas le besoin (André Gide, Journal)

1954 des mots qu'on se dit à soi-même à ceux qu'on prononce tout haut, le passage n'est pas facile (Simone de Beauvoir, Les Mandarins)

II. Prendre position (sur quelque chose) ouvertement, franchement, publiquement Pronominal

1844 Chacun vantait la tenue et le courage des siens ; et tout en se prononçant tout haut contre les duels et contre les rixes, ils les excitaient tout bas à en venir aux mains, et concevaient un véritable chagrin ou une joie immodérée de la défaite ou de la victoire des leurs (Alexandre Dumas père, Les Trois Mousquetaires)

1855 Je n'étais pas assez instruite, je ne le suis pas encore assez pour me prononcer bien haut dans un sens ou dans l'autre, vis-àvis d'hommes qui ont fait de ces questions la spécialité de leur vie (George Sand, Histoire de ma vie) 
III. ne pas prononcer un mot plus haut que

l'autre: ne pas hausser le ton, garder son

calme ou son sang-froid, ne pas s'emporter, se quereller

Transitif

1954 Je fus un peu trop désinvolte, mon père luimême s'en offusqua et finalement Anne m'enferma à clef dans ma chambre, tout cela sans avoir prononcé un mot plus haut que l'autre (Françoise Sagan, Bonjour tristesse)

1974 Je les ai toujours vus faire preuve, et à l'égard de tous, d'une courtoisie désarmante. Je ne les ai jamais entendus prononcer un mot plus haut que l'autre (Jean d’Ormesson, Au plaisir de Dieu)

\section{CORPUS WEB :}

On a entendu à l'envi des responsables de hautes écoles déclarer que l'excellence était le seul critère de leurs choix et de leur stratégie. Mais en fait, que signifie ce terme ? Est-il magique au point qu'il suffirait de le prononcer haut et fort pour que la formation que l'on offre soit meilleure que celle des concurrents ? [http://wp.unil.ch/ allezsavoir/viser-la-reussite $\%$ E2\%80\%89-plutotque-lexcellence $\%$ E2\%80\%89/] (5.10.2015)

Plus d'une centaine de personnalités connues de toutes les sphères de la société québécoise ont endossé une lettre adressée au premier ministre du Canada, aux ministres du gouvernement canadien et aux députés québécois au parlement canadien leur demandant de se prononcer haut et fort contre cette guerre, de la dénoncer publiquement et de refuser que le Canada y participe de quelque façon que ce soit, directe ou indirecte [http://www.echecalaguerre. org/index.php?id=24] (5.10.2015)

Arrivée progressive des manifestants dès 13h15, début de la manifestation à partir de $13 \mathrm{~h} 35$ le temps de s'installer, puis ensuite des discours expliquant les conditions d'élevage et dénonçant la façon dont l'animal est dépecer, ainsi que des slogans prononcés hauts et forts ce sont enchainés durant 2h [http://ccea.over-blog.com/page6038008.html] (5.10.2015)

REMARQUeS : Prononcer haut (I) réfère au fait de dire, énoncer (un mot, un nom, une formule) à voix haute, le sujet n'éprouvant aucune honte à s'exprimer, voulant rendre ses paroles publiques ou simplement les entendre retentir. L'emploi pronominal (II) signifie 'prendre position, statuer (sur quelque chose) ouvertement, publiquement'. L'expression lexicalisée ne pas prononcer/proférer un mot plus haut que l'autre (III), se dit du fait de parler sans éclat, sans colère, le sujet gardant un ton calme et restant maître de ses émotions. Notons les collocations haut et fort et haut et clair, où clair traduit la manière claire, distincte de formuler quelque chose, de façon à ne laisser aucun doute sur la nature du message exprimé. Haut, clair et fort restent normalement invariables, mais l'accord est fait dans le dernier exemple du CW, où les adjectifsadverbes prennent la marque de l'objet au pluriel en gardant leur interprétation de manière, tout en y ajoutant de l'emphase, ce qui met en avant la force du slogan. Haut est modifié par bien, plus, tout, très, trop. VoIR AUSSI : proférer haut

\section{Prononcer serré}

Prononcer (quelque chose) en peu de mots, en éprouvant une forte émotion

Transitif

1450 Aprés qu'il eut fait mencion

De la passion doloreuse

Et reproche ignominïeuse

Que le filz Dieu devoit souffrir

Et son precïeulx corps offrir

Pour nous oster de la misere

Ou Adam, nostre premier pere,

Nous obliga par sa meschance.

David en ot bien congnoissance

Quand il prononça si serré :

Astiterunt reges terrae (Arnoul Gréban, Le Mystère de la Passion, 27330)

Remarques : Prononcer serré désignait le fait de dire, formuler (un mot, une phrase, une sentence) avec plus d'intensité, c'est-à-dire en éprouvant une vive émotion. Serré est modifié par l'adverbe d'intensité si.

\section{Proposer aimable}

Proposer gentiment, aimablement

Transitif

1950 elle en veut plus de mes cachets, de mes frictions non plus... à l'alcool - pourtant 
proposées bien aimable (Albert Paraz, Valsez saucisses)

REMARQUES : Dans le langage quotidien, proposer aimable désigne le fait d'offrir quelque chose à quelqu'un avec gentillesse, générosité. Aimable est modifié par bien.

\section{Proposer bas}

Proposer à voix basse, en secret

Transitif

1731 Quoiqu'il en soit, il y avoit dans l'observatoire de Thebes une vingtaine d'anciens, ausquels les plus jeunes alloient proposer tout bas leurs difficultés (Jean Terrasson, Sethos [trad.])

1862 À tout ce qu'elles lui proposaient tout bas sans cesse, il répondait dans l'ombre : À quoi bon? (Victor Hugo, Les Misérables)

\section{Corpus Web :}

Il y a 2 types de négociations, ceux qui proposent bas avec de la réserve derrière et ceux qui proposent cash le prix. Nous avons négociés notre maison de $10000 €$ et nos vendeurs voulaient qu'on coupent la poire en 2 et pas question pour notre part c'était le maxi qu'on voulait mettre dans cette maison et c'était à prendre où à laisser [http://www.bulle-immobiliere.org/ forum/viewtopic.php?f=170\&t=56779] (5.10.2015)

Je veux pas fair el'oiseau de mauvaise augure, mais en gros si vous êytes plusieurs sur le poste, c pas les prétzentions qui vont valoir, mais le profil : si y sont intéressés par toi, y montent les enchères, ou alors ils te proposent bas pour marchander... [http://forum.rue-montgallet. com/ruemontgallet/EmploisStagesetEtudes/ aide-et-conseils/estimation-salaire-sujet_43_1. $\mathrm{htm}]$ (5.10.2015)

REMARQues : Proposer tout bas désigne le fait, d'une part, de présenter, de soumettre, d'offrir quelque chose à quelqu'un en baissant la voix de façon à ne pas rendre l'action ou la demande trop publique. La collocation tout bas est systématiquement utilisée, probablement pour exclure l'interprétation de bas comme adverbe de lieu. Dans le contexte de l'achat-vente, bas réfère à un prix inférieur à celui proposé lors d'un achat (CW). Notons l'emploi absolu familier dans les exemples du CW.

\section{Protester bas}

I. Protester, désapprouver intérieurement, en secret

Intransitif

1843 Je hais toute espèce de domination, qu'elle soit spirituelle ou temporelle, et je proteste tout bas contre l'Autriche, qui de toutes les duègnes est la plus guindée et la plus dévote (George Sand, Consuelo)

II. Protester, désapprouver à voix basse, d'une voix faible, en murmurant

Transitif

1995 La nuit, depuis mon lit, je perçois tous leurs bruits. Inutile, docteur, de vous faire un dessin. La plupart du temps, maman repousse papa. Elle proteste tout bas "Les enfants vont nous entendre » (Lydie Salvayre, La Puissance des mouches)

\section{CORPUS WEB :}

Faire ces enfants ont un sentiment de solitude, l'ennui, l'envie facilement né pairs, l'anxiété, la dépression, la peur ou l'agression, le mensonge, pugnacité associée à l'expérience de la solitude, de vide, de dévalorisation. Faire enfants battus ont une tendance à la destruction et protestent bas la maîtrise de soi, la faiblesse, les intérêts cognitifs, le refus de travailler [http://materiel-pedagogique.com/Sociologie/ page,14,71122-Toxicomanie_-_un_probl_me_ social.html] (5.10.2015)

La Démocratie chrétienne (DC) protège le Vatican du Satan communiste-athée... De Naples à Palerme en passant par Reggio, cette même DC fréquente de drôles de paroissiens ? Regardons ailleurs, protestons bas. Rien de ces terrestres turpitudes n'est éternel. Viendra bien un moment... De fait, depuis la décennie 1990, l’Église est plus vigoureusement anti-mafia : un Satan a chassé l'autre... [http://pdf.bretagne.over-blog.com/ page/41] (5.10.2015)

Remarques : Protester bas (I) se dit du fait de désapprouver quelque chose en secret, le sujet n'osant exprimer son opposition par des écrits ou des paroles. (II) désigne le fait de manifester par des paroles son opposition, à voix basse, évitant ainsi d'être entendu de tous. Bas reste invariable et est modifié par tout. 


\section{Prouver clair}

prouver clair comme le jour : donner des

preuves irréfutables, incontestables, évidentes

Transitif

1744 Comment concevoir cependant que la créature se meuve en quelque instant que ce soit par une impression différente de celle du Créateur ? J'ai prouvé plus clair que le jour combien cela était impossible. Eh ! pourquoi se révolter contre notre dépendance? (Vauvenargues, Traité sur le libre arbitre)

1766 Ne m’alléguez point les sectateurs d'Aristote des quatre derniers siècles, car, toute femme que je suis, je vous prouverais clair comme le jour que si la philosophie de ce Grec ne fût parvenue à faire partie de la théologie scholastique, le règne de $\mathrm{M}$. Aristote n'eût été, à beaucoup près, ni si long ni si glorieux (Henri-Joseph Dulaurens, Le Compère Mathieu)

1866 Elxaï, et ses sœurs Marthe et Marthène, sont en enfer à l'heure qu'il est pour avoir méprisé les avertissements de Valencianus qui leur prouvait clair comme le jour que leur Jésus-Christ de trente-huit lieues de haut était un démon (Victor Hugo, Les Travailleurs de la mer)

1890 - Vous est-il arrivé de raconter une histoire à laquelle vous aviez été mêlé, devant un camarade, témoin lui aussi de cette histoire, qui vous a interrompu par un « mais non, mais non..., » et il vous a prouvé, clair comme le jour, que vous veniez de fausser la vérité, - sans vous en apercevoir ?

(Paul Bourget, Physiologie de l'amour moderne)

1934 Mais il n'en pensait pas moins, et jubilait dans sa barbe, comme s'il y avait eu là un véritable jugement de Dieu, qui prouvait, clair comme jour, ce qui était prouvé, bien sûr, par les archives mais qu'il n'était pas mauvais qui fût prouvé une fois de plus par les actes quotidiens : que les Coantré étaient de la crotte de bique à côté des Coëtquidan (Henry de Montherlant, Les Célibataires)

\section{CORPUS WEB :}

Minimiser ou chercher à diluer les méfaits de la tabagie sur l'organisme est juste incroyablement choquant *Il n'y a pas de bon ou mauvais tabac à fumer. Le tabac tue, c'est prouvé, clair, net et précis [http://www.forum-ecigarette.com/ sante-f42/enquete-sur-le-cancer-t48150-20.html] (5.10.2015)

Remarques : Prouver clair désigne le fait de démontrer, de révéler un fait, d'établir, de manière irréfutable et au moyen de faits, de témoignages, de raisonnements, la vérité ou la réalité de quelque chose ; clair comme le jour est une expression lexicalisée signifiant 'sans équivoque, sans aucun doute, certainement, d'une manière patente, évidente ; démontrer à l'évidence, démontrer absolument'. Notons les adjectifs-adverbes net et précis qui renforcent le sémantisme de clair. Clair reste invariable et est modifié par plus.

\section{Prouver net}

Donner des preuves irréfutables

入 prouver clair

\section{Prouver précis}

Donner des preuves précises

入 prouver clair

\section{Publier clair}

Rendre public, proclamer clairement, explicitement

Transitif

1450 NATHAN. Voicydonc comment vous ferez. Huchez moy vostre poursuivant Et luy chargez tout enssuivant Qu'il voist publier hault et cler Que s'il est qui saiche parler Des faiz Jhesus, pour luy ou contre, Viengne devant vous et s'admonstre Pour faire sa relacion, Sur peine de privacion De biens et grant peine de corps (Arnoul Gréban, Le Mystère de la Passion, 20398)

Remarques : Publier clair désignait le fait de rendre quelque chose public, notoire, connu de tous, d'annoncer publiquement quelque chose. Notons la collocation haut et clair qui réfère à un énoncé à la fois émis publiquement et de manière claire, distincte, explicite. 


\section{Publier fort}

Publier (quelque chose) fortement, intensément $\pi$ publier haut

\section{Publier haut}

Faire savoir, annoncer, faire connaître, dévoiler publiquement, ouvertement (au moyen d'un écrit ou d'un communiqué oral)

Transitif

1768 Tant de succès nourrissaient la haine de leurs ennemis. On écrivait contre eux : on parlait tout bas : on publiait tout haut des histoires scandaleuses ; on disait en bien des pays qu'ils respectaient peu l'innocence de leurs éleves (Nicolas-Simon Linguet, Histoire impartiale des Jésuites)

1833 CHRISTINE. (seule, marchant avec agitation)

Je dirai la vérité, je dirai qu'il n'est pas coupable ; je publierai tout haut qu'il s'est accusé lui-même pour ne pas me compromettre, pour sauver ma réputation. Et moi... (s'arrêtant). Oh ! Moi... perdue, déshonorée à jamais... eh bien !... eh bien ! (Eugène Scribe, Bertrand et Raton)

1908 Ils vouaient à la sainte un culte fervent et discret, dont ils semblaient jaloux de garder le mystère ; ils n'aimaient point à publier trop haut les impressions qu'ils y éprouvaient (Anatole France, L'Île des pingouins)

1921 Et il [= Vincent de Paul] ne l'accusait [= Saint-Cyran] pas en l'air, il donnait des preuves, publiant très haut le souvenir de ses propres entretiens avec Saint-Cyran, toutes ces extravagances, auxquelles il trouvait jadis un sens orthodoxe, ou qu'il se refusait de prendre au sérieux (Henri Bremond, Histoire littéraire du sentiment religieux en France)

\section{CORPuS Web :}

mille et mille bravos d'entreprendre ce travail ; puisse t'il aboutir, je n'en doute pas et surtout puisse t'il être publié haut et fort ! [http:// lesalonbeige.blogs.com/my_weblog/2009/11/ le-d $\%$ C3\%A9put $\%$ C3\%A9-lionel-tardy-sestdonn\%C3\%A9-un-vrai-travail.html] (5.10.2015)
Dans un article daté du 9 juillet 2013, remis à jour (persiste et signe) le 11 juillet, Guylain Chevrier, chroniqueur sur Atlantico, mais aussi membre actif de la Mission laïcité du Haut Conseil à l'intégration, publie, haut et clair, -« oyez bonnes gens, et que tous s'en souviennent pour l'exemple »-, l'accusation suivante [http:// www.europe-israel.org/2013/07/france-encoreune-fausse-rumeur-antisemite-lancee-par-uneprof-dextreme-gauche/] (5.10.2015)

REMARQues : Publier fort désigne le fait de rendre quelque chose public, notoire, connu de tous, d'annoncer publiquement quelque chose. Dans un emploi plus moderne, il réfère à une chose que l'on annonce officiellement, au moyen d'un texte écrit ou d'un communiqué oral. Notons les collocations haut et fort et haut et clair. Haut reste invariable et est modifié par tout, très, trop.

\section{Puer bon}

Répandre une odeur forte mais agréable Intransitif

1884 Fanny, « parce qu'elle puait bon », parvenait encore à le garder un moment sur ses genoux, tandis que pour Gaussin, cependant très doux avec lui, c'était toujours la bête fauve de l'arrivée, le regard méfiant, les griffes tendues (Alphonse Daudet, Sapho)

1890 Ces senteurs canailles et migraineuses, qu'on les compare avec ce que c'était, la senteur d'une chemise de femme autrefois, l'odeur suave, à peine perceptible, du véritable iris de Florence, sans addition et immixtion d'autre chose puant bon (Edmond et Jules de Goncourt, Journal)

1945a à l'arrivée d'un gros à torse de lutteur de foire, avec une tête de poupon bien portant, il y eut beaucoup de bruit : «mais qu'est-ce qui t'arrive, Maurice, mais tu pues bon!» (Elsa Triolet, Le Premier Accroc coûte deux cents francs)

1945b Tenez, sentez-voir mes mains si ça ne pue pas bon les épices, les ails, les échalotes, les oignons, vos yeux en pleurent, hein ?... Ah ! faut c'qu'y faut (George Chepfer, Saynètes, paysanneries 2) 
1948 Notre-Dame-des-fleurs voudrait vomir son macchabée. La nuit, qui est venue, n’apporte pas l'effroi. La chambre sent la putain. Pue et fleure bon (Jean Genet, NotreDame-des-fleurs)

\section{CoRpus Web :}

Mais placez un amateur de fromages devant une belle miche de pain, un verre de cidre, et un bout de Maroilles. Et regardez-le saliver. Tout à coup, même si ça sent les pieds, ça sent bon. En fait, ça pue bon [http://etreloin.blogspot. co.at/2010/02/puer-bon.html] (5.10.2015)

C'est une très bonne fromagerie ou vous trouverez des fromages de toutes les régions de france qui puent bon! L'accueil est agréable, rien a redire ! [http://www.pagesjaunes.fr/ pros/50015083] (5.10.2015)

REMARQUES : En français populaire, le verbe puer peut neutraliser le sens original du latin putere 'sentir mauvais' pour simplement signifier 'sentir', tout en conservant sa force expressive suggérant une odeur forte, par exemple par rapport à des fromages (dernier exemple du CW). Puer bon devient alors correct, mais expressif. Notons la collocation puer et fleurer bon. Bon reste invariable. Notons l'emploi impersonnel familier ça pue bon dans le CW. VoIR AUSSI : fleurer bon

\section{Puer fort}

Sentir très mauvais Intransitif

+1250 M’a dex done en ceste vie ! Que fera ge, seinte Marie! Cist formages me put si fort Et flere qu'il ja m'aura mort (Le Roman de Renart [ $2^{\mathrm{e}}$ moitié XIII $]$, II, 961)

\section{CORPuS WeB :}

Les gens qui puent de la gueule. L'haleine animale pue fort, mais étrangement ça me dérange pas plus que ça, alors que celles gens, putain non quoi, c'est insupportable et répugnant [http://www.madmoizelle.com/top-4-piresodeurs-340513] (5.10.2015)

Je pose la question car je me pose la question justement si c'est pas lié au faite que tu transpire dans la journée et donc ça pue fort les sécrétions [http://www.tasante.com/forum/ posts/29_1364935/Odeur-penis-bonne-hygiene. $\mathrm{html}](5.10 .2015)$

ok, je m'y mets dés demain (ben ouais, pas de chaussettes qui puent chez moi, mais je m'en vais en quérir demain dans les vestiaires de l'atelier mécanique.... ça puent forts les pieds des chaumacs !) lol Pour le fromage, je pense plutôt au munster qui me parait être plus adapter à la situation très chère... ne pensez vous pas? [http://www.lerepairedesmotards.com/forum/ search.php?9, author=10395, match_type=USER ID,match_dates $=0$, match_threads $=0$ ] $(5.10 .2015)$

REMARQues : Puer fort réfère à une personne ou une chose (ici : des fromages) qui exhalent une odeur nauséabonde, très désagréable, fort renforçant simplement le sémantisme du verbe. Fort reste invariable dans la majorité des cas (v. le premier exemple du $\mathrm{CW}$ ), mais dans le troisième exemple, verbe et adjectif-adverbe s'accordent, non pas avec le sujet grammatical au singulier, mais avec l'indication circonstancielle de l'origine de l'odeur, « les pieds ». On peut évidemment mentionner l'orthographe peu sûre de l'auteur, mais ceci ne saurait mettre en doute le fait que l'accord, correct ou non, est motivé. Fort est modifié par si. Notons l'emploi impersonnel $\mathrm{du}$ verbe ainsi que son emploi familier dans ça pue fort. 


\section{Quitter net}

Quitter, partir subitement, brusquement Transitif

1846 - Adieu, madame, vous êtes une femme comme il m'en faut, mais ma fortune est loin de ressembler à mon désir...

Il salue et la quitte net sans se retourner (Honoré de Balzac, Un prince de la Bohème)

1924 Il était peu considéré par les copains et participait rarement à leurs jeux ; pour moi, dès qu'il me regardait, je me sentais honteux de m'amuser avec les autres, et je me souviens de certaines récréations où, surprenant tout à coup son regard, je quittais tout net la partie pour venir auprès de lui (André Gide, Si le grain ne meurt)

\section{CORPUS WEB :}

Je sais que la solution de le quitter tout net est un peu radicale.. surtout que j'ai énormément de sentiments pour lui,je l'aime profondemment [http://forum.doctissimo.fr/psychologie/ jalousie/jaloux-supporte-plus-sujet_137860_1. htm] (21.10.2015)
Pour ma part, j'ai vu un pseudo dans le jeu qui m'a fait quitter net la vidéo [http://forum.an droid-mt.com/topic/2678-droid-cr3w-cha $\%$ C3\% AEne-gaming-uniquement-android/] (21.10.2015)

Quelle est la meilleure excuse pour terminer une relation amicale ou amoureuse?

Il n'y a pas de meilleure excuse il faut la quitter net tout simplement [https://kiwi.qa/Cleou] (21.10.2015)

$\mathrm{Au}$ bout d'un moment je ne fais plus de cadeaux, c'était ça ou Polichombr quittait nette la compet' (même s'il va quand même la quitter aux barrages) [http://www.pokebip.com/pokemon/ fora/post862248.html] (21.10.2015)

REMARQUES : Quitter net désigne le fait de se séparer, de prendre congé de quelqu'un ou de partir d'un endroit de manière soudaine, tout d'un coup et sans commentaire. Net reste invariable dans la majorité des cas, malgré l'objet au féminin (v. le deuxième et le troisième exemple $\mathrm{du}$ CW). Toutefois, dans le quatrième exemple du CW, il s'accorde avec l'objet au féminin. Net est modifié par tout. 


\section{Rabattre isnel}

Renverser à terre rapidement, promptement Transitif

1200 Li Sarrazins le fiert, cui il fu bel,

De son destrier le rabat mort isnel.

Ez Guinemant poingnant tout un vaucel, Por la pucelle chevauche li donzel.

Li Sarrazins le referit isnel, Mort l'abatit tantost de son poutrel (Jourdain de Blaye, 1664)

REMARQUES : Dans une bataille ou un combat à cheval, rabattre isnel souligne le fait de renverser, de mettre à terre l'adversaire, l'action étant exécutée très rapidement. D’origine germanique, isnel était courant jusqu'en moyen français avec la même signification que schnell 'rapide', son correspondant en allemand moderne. Le fait qu'on ait utilisé ce mot emprunté comme adjectif-adverbe montre que l'emploi adverbial de l'adjectif était un procédé productif. Notons la présence de l'adjectif mort, en fonction de prédicat second résultatif, qui précise le sémantisme du verbe, insistant sur l'aboutissement de l'action. La modification de isnel porte ainsi sur un verbe résultatif complexe rabattre mort.

\section{Racheter cher}

I. Obtenir la rédemption au prix de gros efforts, de grandes peines

Transitif

1325 Qu'il font à leur dras netoier,

Dont il puet Dieu moult anoier,

Qui si chier nous a rachetez,

C'on ne li sauve ses chatez,

Ainz pert on le plus pour le mains

(Watriquet de Couvin, Dits, p. 289, 197)

II. Subir les conséquences fâcheuses d'une action répétée

Transitif

1709 Il la suivit des yeux autant qu'il put ; mais, hélas ! Qu'il racheta cher cette vue ! Quels mouvements confus ne produisit-elle point en lui ! De l'amour il passa à la jalousie, de la jalousie à la crainte, de la crainte à la joie, de la joie à la tristesse ; ou, pour mieux dire, il sentit toutes ces passions en un même temps (Jean-François Regnard, La Provençale)

\section{Racheter à un prix élevé}

Transitif

1755 Nous sommes mauvais marchands de blés, puisque nous en manquons souvent pour nous nourrir et que nous les rachetons bien cher de l'étranger (René-Louis d'Argenson, Journal et mémoires)

1759 On arriva en peu de jours sur le canal de la mer Noire. Candide commença par racheter Cacambo fort cher ; et sans perdre de tems il se jetta dans une galère, avec ses compagnons, pour aller sur le rivage de la Propontide, chercher Cunégonde, quelque laide qu'elle pût être (Voltaire, Candide)

1834 Le besoin d'argent et le prix mis par Gosselin m'ont tenté... J'en suis au désespoir. Je rachèterais bien cher le marché ! Il y a longtemps que c'est fini, et copié. Je n'y pense plus. Je pense à la poésie pure et à mes affaires (Alphonse de Lamartine, Correspondance générale)

1886 On parlait d'un syndicat, d'une entente avec des banquiers pour soutenir les hauts prix ; à la salle Drouot, on en était à l'expédient des ventes fictives, des tableaux rachetés très cher par le marchand lui-même ; et la faillite semblait être fatalement au bout de ces opérations de bourse, une culbute dans l'outrance et les mensonges de l'agio (Émile Zola, L'Euvre)

1890 YRIARTE. Ah ! Il m'aurait racheté cher la correspondance qu'il a eue avec moi ! Il y a une lettre où il demande à être directeur du musée du Louvre, une lettre extraordinaire...

(Edmond et Jules de Goncourt, Journal)

1939 Saladin était prêt à racheter fort cher la garnison d'Acre, restée prisonnière des Francs, bien qu'à la manière orientale il fît traîner le marchandage. Richard crut-il qu'on voulait le jouer ? (René Grousset, L'Épopée des croisades)

\section{Corpus Web :}

si le marché de renouvellement peut fonctionner durablement sur un mode inflationniste (qui vend cher peut racheter cher), il en va tout 
autrement du marché des primo-accédants, ces ménages qui n'ont pour seul viatique qu'une épargne alimentée par leurs revenus professionnels... [http://www.obsimmo.fr/actu30.6.10. html] (21.10.2015)

Plus que tout parce que le spéculateur s'enrichit quand il tombe juste, mais s'enfonce dans la misère quand il échoue (en absence de sauvetage étatique) : acheter cher pour vendre bon marché ou vendre bon marché pour racheter cher ne semblent pas être les négoces les plus lucratifs que l'on puisse imaginer, spécialement si l'on s'est endetté pour le faire [http:// www.contrepoints.org/2011/11/23/56956-vive-laspeculation] (21.10.2015)

l'Etat doit racheter cher des licences alors qu'en attendant elles seront gratuites ? Ls contribuables sont d'accord ? [https://twitter.com/tche litcheff/status/612210314592059392] (21.10.2015)

Bonjour, j'ai gardé ma PS3 fat, mais celle-ci est morte. (disque dur H.S ). J'aimerai savoir si il serait quand même possible de la revendre car on m'a dit que les collectionneurs la rachète chère [http://www.jeuxvideo.com/forums/1-607633504-1-0-1-0-revendre-sa-ps3-fat-morte.htm] (21.10.2015)

REMARQUeS : Racheter cher (I) se dit du fait de sauver par la rédemption, d'assurer le salut, de relever d'une déchéance morale au prix d'un sacrifice (connotation religieuse). (II) réfère au prix à payer, par extension, aux conséquences morales, souvent lourdes, qu'entraîne l'action ou le comportement du sujet. En parlant d'une chose négociable, (III) il exprime le fait d'acheter quelque chose qui a déjà été acheté par un autre moyennant un prix élevé ; dans son emploi figuré, il souligne l'importance ou la valeur de l'objet en question. Cher reste invariable dans la majorité des cas. Toutefois, dans le quatrième exemple du CW, il s'accorde avec l'objet au féminin, mais l'accord semble peu sûr (v. "ils rachète »). Cher est modifié par bien, fort, si, très. Notons l'emploi absolu dans le CW. Notons également l'emploi de tomber juste 'deviner, prévoir correctement le prix' et acheter / vendre cher.

\section{Raconter doux}

Raconter doucement, à mi-voix

Emploi absolu

1953 Joyce est un poisson des grandes profondeurs [...] À la surface, il y a les nouvelles narquoises, exquises, doux-racontantes de Gens de Dublin (Claude Roy, Le Commerce des classiques)

REMARques : L'exemple fait partie de la série analogique avec des participes qui se combinent avec doux à l'instar de doux-coulant. Doux reste invariable.

\section{Raconter long}

I. en raconter long (sujet animé): dire, raconter beaucoup, parler longuement de quelque chose Intransitif

1839 - Eh ! non...ils m’ont congédié de la manière la plus indigne. Je pourrais vous en raconter long là-dessus... (M. Dumarais ou La Force de l'habitude)

1890 C'était également votre avis jusqu'au jour où vous avez cru découvrir que je le préférais un peu. Oh! vous n'êtes pas si malin que ça ! Je vous connais aussi, et je vous en raconterais long, si je voulais (Guy de Maupassant, Notre cœur)

1926 Maintenant elle en a raconté assez long, elle peut se lever, prendre congé...

" Mais ma chère Herminie, vous venez d'arriver, nous n'avons pas encore eu le temps de parler »

(René Crevel, La Mort difficile)

1933 Inutile de vous dire que je ne puis vous en raconter plus long (André Malraux, $L a$ Condition humaine)

1936 Je ne voulais pas l'interrompre, parce que je comprenais bien qu'elle [= la mère] n'en avait jamais raconté si long à personne, et c'est vrai qu'elle a paru tout à coup s'éveiller d'un songe, elle était très embarrassée (Georges Bernanos, Journal d'un curé de campagne) 
II. en raconter long (sujet inanimé): être révélateur, significatif

Intransitif

1925 Il les regardait avec une façon de se taire qui en racontait long et poursuivait, sans se faire prier, la chanson dont ses amies du bar reprenaient avec lui le refrain canaille : Valsez... jolies goss...es ! (Francis Carco, L'Équipe : roman des fortifs)

CORpus Web :

Je pourrais vous en raconter long comme le bras sur ce gateau, mais il vous suffit d'aller sur le site pour tout savoir... [http://goumyflo. canalblog.com/archives/2014/05/21/29918392. html] (21.10.2015)

Eh bien non : car la belle ensevelie, que ses découvreurs ébahis n'hésitent pas à appeler " la Pompéi botanique ", devrait nous en raconter long sur le changement climatique... et sur le futur de nos forêts actuelles [http://www. terraeco.net/spip.php? page=imprimer\&id article=43520] (21.10.2015)

Surtout que la plupart des gens pensent que brosser les dents de lait ne sert a rien !! Je suis assistante dentaire je peux vous en raconter long a ce sujet.... [http://secouchermoinsbete.fr/11039les-dents-sont-moins-sensibles-aux-caries-aveclage] (21.10.2015)

REMARQUES : En raconter long (I) se dit du fait de faire le récit de quelque chose pendant un long moment, le sujet ayant beaucoup de choses à raconter. En (II), long réfère à une attitude, un regard dont les caractéristiques manifestent ou expriment très fortement quelque chose, témoignent de quelque chose. Long reste invariable et est modifié par assez, plus, si. Long est un adverbe de temps qui, usuel en ancien français, ne se conserve plus que dans des locutions figées telles en raconter / dire long.

\section{Rager ferme}

Se mettre fortement en colère Intransitif

1883 Il ne trouvait rien à répondre, mais il rageait, il rageait ferme (Guy de Maupassant, Contes et nouvelles)

1960 Il ne se résignait pas à la bêtise militaire, ni à perdre dix-huit mois ; il rageait ferme (Simone de Beauvoir, La Force de l'âge)

\section{Rager rouge}

Se mettre violemment en colère, devenir rouge de colère

Intransitif

1976 Pleurer bleu, rire jaune, rager rouge. Aimer violet, indigo, vert, orangé. Rêver blanc, crier noir (Michel Leiris, La Règle du jeu 4 : Frêle Bruit)

CORPUS WEB :

Il me semble que quitter une partie, c'est comme une défaite. Mais au moins ça permet à Kévin d'aller rager tout rouge et tout triste la tête dans son oreiller [http://canardpc.com/forums/ threads/48627-LoL-Retours-sur-vos-partiesconcours-de-bite-et-rage-le-bar-des-Loleurs/ page62] (21.10.2015)

Ça me fait bien marrer cet argument. D’autant plus quand ça fait rager tout rouge le p'tit grems... [http://www.igen.fr/app-store/androidgoogle-interdit-les-mises-jour-hors-de-googleplay-106025] (21.10.2015)

Ce sont les gens comme vous qui me font rager tout rouge [http://www.phonandroid.com/ nexus-6-la-batterie-gonfle-et-decolle-le-dos-delappareil-motorola-reagit.html] (21.10.2015)

REMARQUES : Rager rouge désigne le fait de se mettre très en colère, le sujet éprouvant un sentiment de rage qu'il manifeste par un comportement violent. L'adjectif-adverbe rouge souligne de façon métaphorique la couleur du visage dans certaines circonstances, traduisant une émotion forte et passagère. Notons l'emploi de triste dans le CW. Rouge reste invariable et est modifié par tout. Signalons aussi l'emploi impersonnel familier ça fait rager tout rouge. VOIR AUSSI : fâcher rouge

\section{Rager triste}

Se mettre en colère avec un sentiment de tristesse

$\lambda$ rager rouge 


\section{Raisonner bas}

I. Raisonner, réfléchir à voix basse, en silence Intransitif

1710 NÉRINE (à part) Le fat ! Rions un peu de son impertinence,

Et traitons le si bien qu'il n'y revienne pas. CRISPIN. Tu ne me répons rien, et raisonnes tout bas

(Philippe Destouches, Le Curieux impertinent)

1853 Si quelque libre écrit entre leurs mains s'égare,

Les pieds sur les chenets et fumant son cigare,

Chacun de ces votants tout bas raisonne ainsi :

- Ce livre est fort choquant De quel droit celui-ci

Est-il généreux, ferme et fier, quand je suis lâche ? (Victor Hugo, Les Châtiments)

1870 - Je vous enverrais paître ; et, si vous n'étiez pas contents, je doublerais mes suisses et ma maréchaussée.

Il raisonnait ainsi tout bas, en tirant le soufflet et tenant le fer au feu dans ses pinces. Je connaissais toutes ses pensées, car il avait besoin de parler pour se comprendre lui-même (Émile Erckmann et Alexandre Chatrian, Histoire d'un paysan)

II. Raisonner (quelqu'un), faire entendre raison (à quelqu'un) en parlant à voix basse

Transitif

1968 Parfois la chienne, dressée sur le banc de pierre, vient contempler respectueusement la tarte et gémit, supplie jusqu'à ce que Robert, qui l'aime, vienne et la raisonne - très bas : je n'entends pas sa voix (François Nourissier, Le Maître de maison)

\section{CORPUS WEB :}

La meilleure façon en la matière, c'est de raisonner très bas comme lui [http://lefaso.net/spip. php?article64276] (22.10.2015)

tant qu'à raisonner bas : si tu fais l'électricité par des mecs qui pédalent, n’y'a plus de pauvres et pas assez de chômeurs . . . sur la planète entière ou plus bas encore : tu pédales pour fabriquer ton énergie et quand tu descend du vélo, t'es tellement crevé que t'as pas besoin du premier watt [http://www.charentelibre.fr/2011/11/16/leseoliennes-preparent-leur-atterrissage,1065129. php] (22.10.2015)

REMARQUES : Raisonner bas (I) se dit du fait de réfléchir à quelque chose, les pensées restant secrètes et non communiquées à autrui. En (II), le groupe désigne le fait de ramener quelqu'un à la raison, de le convaincre ou tenter de convaincre, de le faire revenir sur une décision en faisant appel à sa raison, à son bon sens, le sujet lui parlant à voix basse, en murmurant. Dans les exemples du CW, bas a le sens de 'prosaïque, grossier, ras les pâquerettes'. Bas reste invariable et est modifié par ainsi tout, tout, très.

\section{Raisonner bel}

Penser correctement, avec justesse

Intransitif

1325 Raisons est o raison touz diz, Raisons bel œvre et bel raisonne, Raisons toute riens asaisonne, Raisons comprent mesure et sens, Humilité, pitié et sens (Watriquet de Couvin, Dits, p. 36, 1133)

REMARQUES : En ancien français, raisonner bel se disait du fait de penser, réfléchir de façon fondée et logique. La forme neutre bel marque une fonction clairement adverbiale. Notons l'emploi de ouvrer bel.

\section{Raisonner clair}

Raisonner de manière claire, lucide, sensée Intransitif

1843 Cicéron ne dédaigna point de s'occuper du mécanisme de la mémoire [...]. Cicéron raisonnait clair, mais le moyen d'appliquer le moyen ! (Gratien de Semur, Traité des erreurs et des préjugés)

1947 J'étais trop secouée pour raisonner clair (Albert Paraz, Remous)

\section{CORPUS WEB :}

Je n'ai jamais rien pris pour ça et suis plutôt du genre à aller voir un médecin tous les deux ans, et à rechigner sur les médocs à avaler... mais bon là je sentais qu'il était essentiel de rester à peu près en forme pour raisonner clair, ne pas sombrer... [http://forum.psychologies.com/ psychologiescom/Vivre-une-separation-divor 
cer/reussir-la-separation-sujet_3498_4.htm] (22.10.2015)

Une fois de plus le flic qui a forcément des difficultés à raisonner clair dans ces cas-là [http: //forums.france3.fr/france3/comedienspblv/ Picmal/desormais-general-rendez-sujet_29705 _54.htm] (22.10.2015)

C'est méconnaître une femme tout en nuances, résolue, certes, mais psychologue avisée, nullement insensible et prompte à dégainer un humour juvénile. Elle séduit quiconque lui est présenté, pige au quart de tour et raisonne clair et net [http://www.valeursactuelles.com/politique/ cette-droite-qui-prefere-hidalgo-43208] (22.10.2015)

REMARQUES : Raisonner clair réfère à la capacité de l'être humain de penser, de réfléchir avec lucidité et clairvoyance, d'une manière immédiatement claire à l'esprit. Notons la collocation clair et net dans le CW. Clair reste invariable.

\section{Raisonner courbe}

Avoir un raisonnement tordu, tortueux

入 raisonner droit

\section{Raisonner creux}

Avoir des idées stupides, sans aucun sens ; ne pas avoir d'idées

Intransitif

1731 Pourquoi Conversation entre deux Anglois ? Pourquoi pas plutôt entre deux François, car après tout, Anglois a-t-il jamais raisonné creux et de travers, comme on raisonne dans cette pitoyable Conversation ? Anglois a-t-il jamais parlé politique avec si peu de Sens commun? (Jean Rousset de Missy, Recueil historique d'actes, négociations, mémoires et traitez, Lettre de 1731)

1831 Je me figure quelquefois les collègues d'Appolli, raisonnant creux sur les lettres de Régime (Stendhal, Correspondance)

CORPUS WEB :

Le chef de file de Nancy 2014 intrigue. Certains ne voient en lui qu'un adepte du marketing de la différence qui parle bien mais raisonne creux [http://www.lasemaine.fr/2013/12/19/ frank-olivier-potier-mettre-notre-empreinte-surla-campagne] (22.10.2015)

Comme d'hab tu pinailles sur la forme mais dans le fond ça raisonne creux. Je précise que tu es ni drôle ni intéressant [http://www.agoravox. tv/spip.php?page $=$ forum\&id_article $=51179 \& i d$ forum=13021299\&idf=13021336] (22.10.2015)

" Revolution » dans un verre d'eau, du déjà entendu, cela résonne et raisonne creux., d'autant plus que le verre est en cristal élyséen et que l'eau est croupie [http://www.lefigaro.fr/poli tique/2015/04/07/01002-20150407ARTFIG00407la-charte-de-la-primaire-met-tout-le-monde-daccord-a-l-ump.php] (22.10.2015)

REMARQUES : Raisonner creux réfère au manque d'intelligence, de logique, de fondement ou de profondeur dans le raisonnement de l'être humain, voire au manque d'idées. Creux reste invariable. Notons le jeu de mots résonner / raisonner creux dans le dernier exemple du CW, qui peut devenir une source de confusion (v. résonner beau, résonner clair). Impossible de trancher si, dans le second exemple du CW, il s'agit du verbe raisonner ou d'une faute d'orthographe pour résonner, voire un jeu de mots implicite. Notons l'emploi impersonnel familier ça raisonne creux.

\section{Raisonner droit}

Penser, réfléchir de façon fondée, logique et moralement correcte

Intransitif

1851 LUI. Avais-je donc tort, monsieur, de penser à mes pauvres camarades mariés ? Et n'était-ce pas leur Pain que je mangeais? MOI. Non, Claude, vous n'aviez pas tort ; vous raisonniez droit, vous sentiez juste, et je vous pardonne bien volontiers. Mais dites-moi donc aussi qui est-ce qui a rendu votre raison si éclairée et votre conscience si délicate ? (Alphonse de Lamartine, Le Tailleur de pierre de Saint-Point)

1915 « Il n'existe pas deux méthodes différentes pour l'esprit humain. Une seule vaut : observer la réalité telle qu'elle est, pour s'y conformer. On n'agit sur les faits qu'avec des faits. "

Je le regardais raisonner si juste, si droit, et je m'étonnais : tant de sagesse unie, dans 
le même homme, à tant d'égarement ! (Paul Bourget, Le Sens de la mort)

\section{CORPUS WEB :}

La logique, c'est l'art de raisonner droit, la casuistique celui de raisonner courbe [https:// groups.google.com/forum/\#!topic/fr.rec.sport. rugby/0d3COLHxlx4] (23.10.2015)

La communication politique est une maladie de l'esprit : elle se veut d'ailleurs une perversion de la logique et un gauchissement du vocabulaire, mais le malheur de ceux qui l'emploient est de s'imaginer qu'ils en restent les maîtres et qu'ils peuvent à leur guise raisonner droit et parler juste [http://www.valeursactuelles.com/ culture/expliquer] (23.10.2015)

où se cachent toutes les formes de tromperies qui nous empêchent de raisonner droit ? [http:// www.amazon.fr/product-reviews/2070780880] (23.10.2015)

REMARQUes : Raisonner droit se dit du fait de conduire un raisonnement logique ou de formuler un jugement fondé, traduisant le bon sens de l'individu, sa capacité de raisonnement. Notons les adjectifs-adverbes juste et courbe, ce dernier se présentant comme antonyme de droit. Mentionnons également l'emploi de sentir juste et parler juste. Droit reste invariable et est modifié par si.

\section{Raisonner faux}

Former un raisonnement incorrect, qui ne mène pas à la vérité

Intransitif

1662 Tous les géomètres seraient donc fins s'ils avaient la vue bonne, car ils ne raisonnent pas faux sur les principes qu'ils connaissent (Blaise Pascal, Pensées)

1747 Jusqu'à ce qu'on rencontre le secret de rendre les esprits plus justes, tous les pas que l'on pourra faire dans la vérité n'empêcheront pas les hommes de raisonner faux ; et, plus on voudra les pousser au delà des notions communes, plus on les mettra en péril de se tromper (Vauvenargues, Réflexions et maximes)

1758 Le propre de l'esprit juste est de tirer des conséquences exactes des opinions reçues : or ces opinions sont fausses pour la plupart, et l'esprit juste ne remonte jamais jusqu'à l'examen de ces opinions : l'esprit juste n'est donc, le plus souvent, que l'art de raisonner méthodiquement faux (Claude-Adrien Helvétius, De l'esprit)

1878 Ils [= le mathématicien et le biologiste] sont comme des fous qui raisonnent logiquement, mais qui sentent faux et, par conséquent, raisonnent faux (Claude Bernard, Principes de médecine expérimentale)

1934 Puis à remarquer que certains esthéticiens raisonnent faux quand ils prétendent que l'homme ne juge la femme si belle que parce qu'il la désire (Jules Romains, Les Hommes de bonne volonté)

CORPUS WeB :

On peut raisonner faux et aboutir à une conclusion juste [https://jecserres.wordpress. com/2014/03/21/quest-ce-quun-raisonnementjuste] (23.10.2015)

c'est comme en 4ième avec la géométrie plane : vaut mieux raisonner juste sur une figure fausse, que raisonner faux sur une figure juste... [http://www.pauljorion.com/blog/2012/07/07/ le-prix-de-la-liberte-economique-par-crapaudrouge] (23.10.2015)

Maintenant ce que je me demande c'est est ce que ce ne serais pas ta philosophie qui raisonne fausse [http://www.dialogueislam-chretien.com/ t3943p150-contradictions-coraniques-suites] (23.10.2015)

REMARQUES : Raisonner faux se dit du fait de penser de manière inexacte, de formuler un jugement ou de conduire un raisonnement erroné. Notons l'opposition avec raisonner juste dans le CW. Faux reste invariable dans la majorité des cas, mais, dans le troisième exemple du CW, il s'accorde avec le sujet au féminin, sans doute pour augmenter l'emphase par l'inclusion plus directe de la philosophie ; on pourrait éventuellement y découvrir une nuance de fausseté attribuée à la philosophie en question. Dans l'exemple de 1758, faux est modifié par méthodiquement. 


\section{Raisonner juste}

Raisonner, penser avec justesse, avec

exactitude, former un raisonnement correct,

qui mène à la vérité

Intransitif

1671a C'est par une raison contraire qu'il arrive assez souvent que des personnes qui ont bon esprit et qui raisonnent assez juste, parlent neanmoins et écrivent bassement. Car cela vient de ce qu'ils ont été mal instruits dans leur jeunesse, et qu'on leur a rempli la memoire de mauvaises expressions et de mauvais tours (Pierre Nicole, Essais de morale contenus en divers traités)

1671b Cependant si nous raisonnions plus juste, nous trouverions que ces jugemens desavantageux ne nous regardent point proprement, et que c'est le hazard et non le choix qui les détermine à nous avoir pour objet. Car il faut que ceux qui jugent ainsi de nous ayent été frappés par quelques apparences qui les y ayent portés (Pierre Nicole, Essais de morale contenus en divers traités)

1674 D’ailleurs, la plus grande partie de la capacité des hommes n'est fondée que sur leur experience, et ils raisonnent rarement juste dans la premiere affaire qui leur passe par les mains. Les plus sages sont ceux qui profitent des fautes qu'ils y commettent, et qui en tirent des lumieres et des consequences pour se gouverner mieux à l'avenir (César de Saint-Réal, Conjuration des Espagnols contre la République de Venise en l'année 1618)

1696 Il n’a tenu qu'à vous que je n'aie plus tôt rendu justice à $M$. de la Garde. Je vous en gronde ;

vouliez-vous que j'eusse le don de deviner ? Je raisonnais juste sur ce qui paraissait (Mme de Sévigné, Correspondance)

1713 DORANTE. Je cherche, j'examine, et, pour ne faillir pas,

Je crois être obligé de marcher pas à pas. PYRANTE. Il raisonne fort juste, et qui le veut entendre,

Toujours à son avis est forcé de se rendre.
FRONTIN. Moi, je ne me rens point à ces belles raisons,

Tout irrésolu vise aux petites-maisons (Philippe Destouches, L'Irrésolu)

1731 Ce ne peut être que des Anglois, ou des François, ou des Espagnols ; et quelque nation que ce soit de l'Europe, il est sans danger s'il est hors des mains des sauvages. Oui, me répondit-elle, en ne raisonnant que trop juste sur le sujet de nos craintes ; oui, s'il est hors des mains des sauvages : mais quelle apparence qu'il soit délivré de ces bêtes cruelles ? (abbé Prévost, Le Philosophe anglois)

1738 Ainsi, l'on ne doit point s'étonner de voir de grands hommes, dans toutes les différentes croïances, s'attacher à vouloir en démontrer la vérité, être persuadez de celle dans laquelle ils vivent, et condamner hautement toutes les autres qui lui sont opposées. Un Quakre peut raisonner parfaitement juste dans tout ce qui ne regarde point le quakérisme (Jean-Baptiste d'Argens, Lettres juives ou Correspondance philosophique, historique et critique)

1756 Mais la passion de la science universelle l'emportait ; et cette science universelle consistait à savoir par cœur sur chaque matiére quelques mots qui ne donnaient aucune idée. Il est difficile de comprendre comment les mêmes hommes qui raisonnent si juste et si finement sur les affaires du monde et sur leurs intérêts, ont pû se payer de paroles inintelligibles dans presque tout le reste (Voltaire, Essay sur l'histoire générale et sur les mœurs et sur l'esprit des nations)

1823 - Et vous l'avez signée ? Me dit l'empereur. - Non, sire, je refusai ma signature à cette adhésion, soutenant que c'était une insigne folie que de prétendre demeurer successivement le conseiller et l'homme de confiance de deux antagonistes ; et que d'ailleurs si le vainqueur s'y entendait bien, le meilleur gage à présenter à son attention devait être la fidélité et le respect envers le vaincu. 
- Et vous raisonniez juste, observa Napoléon (Emmanuel de Las Cases, Le Mémorial de Sainte-Hélène)

1835 Ces réflexions pesaient de tout leur poids sur Jules, car les passions ne pardonnent pas plus que les lois humaines, et elles raisonnent plus juste : ne s'appuient-elles pas sur une conscience à elles, infaillible comme l'est un instinct ? (Honoré de Balzac, Histoire des Treize)

1859 Nicole surtout voyait la spéculation en beau. M. de Saci, ayant simplement consulté son notaire Gallois, refusa d'aventurer son argent si loin (ce qui lui faisait l'effet de le jeter dans la mer) et préféra le placer sur les hôpitaux de Paris, à intérêt ordinaire ; il se trouva avoir raisonné plus juste que les autres (Charles Sainte-Beuve, Port-Royal)

1863 Quelquefois il souriait quand une observation plus aiguë naissait sous sa plume, et après chaque couplet un peu long, où sans doute un de ses personnages avait raisonné juste et serré, il réfléchissait un moment, le temps de reprendre haleine, et je l'entendais qui disait : "Voyons, qu'allons-nous répondre ? " (Eugène Fromentin, Dominique)

1914 on ne peut dire que les uns ni les autres aient commis d'erreur d'appréciation. Dans les airs, tous raisonnaient juste. Il n'était pas absurde d'aller chercher à Londres les clefs de Strasbourg et de Metz (Charles Maurras, Kiel et Tanger)

1915 « Il n’existe pas deux méthodes différentes pour l'esprit humain. Une seule vaut : observer la réalité telle qu'elle est, pour s'y conformer. On n'agit sur les faits qu'avec des faits. "

Je le regardais raisonner si juste, si droit, et je m'étonnais : tant de sagesse unie, dans le même homme, à tant d'égarement ! (Paul Bourget, Le Sens de la mort)

1936 Le plus dur à faire venir, ce fut l'agrément de mes vieux... Ils en revenaient pas du tout d'une proposition pareille... Édouard raisonnait pourtant juste... On y était plus habitués dans notre cabanon à écouter du bon sens... Ce fut la sacrée surprise... (Louis-Ferdinand Céline, Mort à crédit)

1969 La principale vertu des mathématiques à l'école étant d'apprendre à raisonner juste (beaucoup plus qu'à acquérir, en dehors des notions courantes, des techniques trop savantes et rapidement oubliées), il faut être aussi honnête que possible, et toujours avouer clairement ce que l'on admet (André Warusfel, Les Mathématiques modernes)

\section{CORPus WeB :}

Je vous présente ici des manières de ne pas raisonner juste [http://www.cypress.fr/site/index. php5/comment/167] (23.10.2015)

Parce que contrairement à vous et à eux je ne suis pas dogmatique. Je ne m'intéresse pas à d'où ils parlent mais au contenu de ce qu'ils disent. Quand ils raisonnent justes, je leur en fait crédit, tout comme à vous d'ailleurs [http://ericzemmour. blogspot.co.at/2014/11/eric-zemmour-dans-ca-sedispute-sur-i.html] (23.10.2015)

REMARQUES : Raisonner juste se dit du fait de conduire un raisonnement logique ou de formuler un jugement fondé traduisant le bon sens de l'individu, sa capacité de raisonnement. Notons les collocations juste et serré, juste et finement et si juste, si droit. Juste reste invariable dans la majorité des cas. Signalons toutefois l'accord morphologique avec le sujet au pluriel dans le dernier exemple du CW pour mettre en avant le rôle du sujet. Juste est modifié par assez, fort, parfaitement, plus, pourtant, rarement si, trop.

\section{Raisonner net}

raisonner clair et net : réfléchir de manière

parfaitement claire et intelligible

入 raisonner clair

\section{Raisonner serré}

Réfléchir de manière précise et stricte, de manière rigoureuse, voire limitée Intransitif

1859 On le voit, Rocambole raisonnait serré (Pierre-Alexis Ponson du Terrail, Rocambole) 
1864 Le fiancé de Camille était fonctionnaire, honnête homme, sincèrement épris ; il l'épousa quand même. Celui de Caroline était propriétaire. Il raisonna plus serré, invoqua la volonté de ses parents et se retira (George Sand, Le Marquis de Villemer)

CORPuS Web :

Non, ce genre d'exercice n'est pas trop facile pour moi : la preuve : je sèche. Pourtant, essayons de raisonner serré : Pour agir sur les chiffres, il faut nécessairement DEUX allumettes : soit pour déplace un 1 , soit pour transformer un $\mathrm{V}$ en $\mathrm{X}$, ou inversement [http://www.bibmath.net/forums/ viewtopic.php?id=3625] (23.10.2015)

Vous aurez beau répondre argument pour argument, raisonner serré, faire remarquer que la « science " n'est jamais qu'une chose contingeante suceptible de déchirantes révisions (v. la théorie des plaques tectoniques, de la mécanique quantique ou même de la cosmologie la plus récente) [http://archives.leforumcatholique.org/ consulte/message.php?arch $=1 \&$ num $=24254]$ (23.10.2015)

Chacun des adversaires apporte de puissants motifs en sa faveur ; chacun raisonne serré ; chacun expérimente [http://www.amazon.de/ Lecons-Philosophie-Chimique-ProfesseesCollege/dp/1236037529] (23.10.2015)

REMARQUES : En référence à une argumentation, raisonner serré se dit du fait de conduire un raisonnement avec une stricte exactitude, une précision rigoureuse qui ne laisse rien passer. Serré reste invariable et est modifié par plus.

\section{Ramener soef}

Ramener doucement, avec douceur

Transitif

+1200 Cius saut tous nus en la gonnele

Com chieus qui mout s'en est tenus,

Et dist : Sire, je suis venus.

- Jes ? - Oïl voir ! - Or prend Gillain

Tout belement par mi le main

Et a son oncle le remaine

Tout souef, qu'elle n'i ait paine (Le Prestre

et le chevalier [1 $1^{\mathrm{re}}$ moitié XIII'], 670)

REMARQUES : En ancien français, ramener soef désigne le fait de raccompagner, de reconduire ou de faire revenir avec soi quelqu'un à un en- droit précis, à un rythme lent et tranquille, doucement. Soef est modifié par tout.

\section{Ramper bas}

Être à un niveau (moral, social, spirituel, etc.)

bas, peu élevé, inférieur ; s'abaisser (pour

obtenir quelque chose)

Intransitif

1589 Sous la liberté d'un vers qui n'est ny trop doux ny trop amer, qui tempere sa juste douleur d'une grave modestie, j'ay dressé ceste Tragedie, en laquelle si les mesdisans trouvent quelque chose propre à leur censure, proviendra plustost de l'humilité du poëme, qui rampe asses bas, que de l'altesse du suject, tresasseuré par la Loy, par la verité, et par la fame, qui sert d'une demie preuve, aux faicts de telle consequence (Pierre Matthieu, La Guisiade)

1634 Il m'a dict encores comme Mr Guiet trouvoit estrange que je m'amusasse à vous escrire des observations de l'œil, mais s'il luy doibt estre permis d'avoir un goust differant du mien et qui ne peult ramper si bas, pour avoir de coustume de voler plus hault, il ne doibt pas estre moings permis de m'en contenter (Nicolas de Peiresc, Lettres aux frères Dupuy)

1797 Voilà donc, dit chacun en soi-même, cet homme qui commandoit aux hommes, et qui d'un coup d'œil auroit pu me ravir la liberté et la vie. Toujours bas, nous rampons sous les princes dans leur gloire, et nous leur crachons au visage lorsqu'ils sont tombés (François de Chateaubriand, Essai historique, politique et moral sur les révolutions anciennes et modernes)

1830 Et maintenant, noyé dans l'abîme de l'être, Je doute qu'un regard du dieu qui nous fit naître

Puisse me démêler d'avec lui, vil, rampant, Si bas, si loin de lui, si voisin du néant ! (Alphonse de Lamartine, Harmonies poétiques et religieuses)

1839 Mais à quoi l'ambition et la vengeance ne peuvent-elles pas descendre ? Qui veut monter, doit ramper aussi bas qu'il a volé 
haut, exposé tôt ou tard aux choses les plus viles. La vengeance quoique douce d'abord, amère avant peu, sur elle-même recule. Soit ! (François de Chateaubriand, Le Paradis perdu)

1876 Sur le quai, se pressaient une foule d'Européens, que là on appelle des Franks : marins, marchands, aventuriers de toute espèce, Ioniens, Grecs, Maltais, Dalmates, Français, Anglais, Valaques, triste multitude, et qui rampe bas dans la série descendante des créatures (Arthur de Gobineau, Nouvelles asiatiques)

1974 Seul. C'était l'angoisse, le Grand Paris dans toute sa grandeur, inamovible, avec monuments. Il allait être, rampant bas, empoisonné par l'oxyde de carbone. Et il y avait la xénophobie dans les rues, les gens sont contre l'immigration sauvage et un python ne passe pas inaperçu (Romain Gary, Gros-Câlin)

Corpus Web :

Banque Publique. Ca doit flatter haut et ramper bas autour de Moscovici et Montebourg pour se faire arroser avec votre argent [https:// twitter.com/bastiat2022/status/245902075341 443074] (4.11.2015)

Quand on en est rendu à travailler bénévolement pour une multinationale dont les cadres empochent des millions, c'est qu'on est vraiment pris pour ramper bas afin d'obtenir ce qu'on appelle encore un emploi [https://groups.google. com/forum/\#!topic/qc.politique/vgREEoCOjfs] (4.11.2015)

Pour devenir cachère, Marine Le Pen devra ramper encore plus bas [http://www.egalite etreconciliation.fr/Pour-devenir-cachere-MarineLe-Pen-devra-ramper-encore-plus-bas-34199. html] (4.11.2015)

REMARQues : Au figuré et lorsque le sujet désigne une personne, ramper bas se dit du fait de se trouver à un rang social inférieur ou d'avoir une position hiérarchique inférieure. Il peut aussi souligner la situation, l'état de pauvreté extrême dans lequel se trouve l'être humain, voire traduire sa décadence. Le sujet peut aussi désigner une chose concrète ou abstraite (comme le goût [esthétique]) dont le niveau moral ou spirituel est jugé peu élevé, ou le fait de s'humilier pour obtenir quelque chose. Notons l'emploi de flatter haut qui désigne un comportement complémentaire où, au lieu de ramper pour obtenir quelque chose, on flatte ouvertement (CW). Dans l'exemple de 1634, ramper bas s'oppose à voler haut. Bas reste invariable et est modifié par assez, aussi, encore plus, si, toujours. Notons l'emploi impersonnel familier ça doit flatter haut et ramper bas.

\section{Randonner fort}

Poursuivre, courir avec impétuosité Intransitif

-1200 Malpriant torne en fuie, quant il voit celui mort,

Et Elies l'encauche et randone mout fort ; Par le mien ensiant, ja l'encauchera trop (Elie de Saint Gille [fin $\mathrm{XII}^{\mathrm{e}}$ ], 488)

\section{CORpus Web :}

A force de randonner fort semaine après semaine je me suis dit que l'objectif Mt Blanc à la journée était envisageable [http://www. kikourou.net/forum/viewtopic.php? $\mathrm{f}=8 \& \mathrm{t}=$ 26860\&start=2920] (4.11.2015)

LA BOSSAPAS ne devrait pas être mouillée selon Météo-France samedi, prêt à randonner fort, inscription sur http://www.rando92.fr [https://twitter.com/ffrandonnee92/status/38033 8301929922560] (4.11.2015)

Il parait que cet été on va randonner fort ! Alors il va falloir que je porte mes croquettes ! [http://www.cyclopaedia.fr/wiki/La_Fanette] (4.11.2015)

REMARQUES : Dans une course ou lors d'un combat, randonner fort désignait, en ancien français, le fait de poursuivre, de courir après son adversaire d'une manière impétueuse qui se caractérise par des mouvements violents et très rapides. Il est modifié par moult. Dans son sens moderne, il désigne le fait de partir en excursion en parcourant une longue distance (CW). Peu attesté dans les dictionnaires du français actuel, le verbe randonner appartient au langage du quotidien qui crée ce verbe à partir du substantif randonnée. Fort reste invariable. 


\section{Râper fin}

Réduire finement avec une râpe

$\lambda$ hacher fin

\section{Randonner menu}

Trotter, galoper à petits pas rapides

Intransitif

1276 Quant fu montés, lors a pris son escu, Par le fer prist son roit espiel molu, Le cheval broche qui randonne menu, Jusqu'a l'ost Charle n'i a resne tenu (Adenet le Roi, Les Enfances Ogier, 3404)

-1300 Ai tant Justamonz broche le bai de Cornoaille ;

Plus randone menu qu'espreviers ne prant caille (Jehan Bodel, La Chanson des Saisnes [fin $\mathrm{XIII}^{\mathrm{e}}$ ], 3594)

REMARQUES : Randonner menu réfère au déplacement du cheval, à sa façon de progresser au galop ou au trot, celui-ci avançant à petits pas, rapides, sous l'effet d'une blessure. Menu reste invariable. VoIR AUSSI : aller / trotter / trottiner menu

\section{Rapporter bon}

Rapporter beaucoup d'argent

Intransitif

1885 Duroy demanda :

- Ça doit rapporter bon d'être reporter dans ces conditions-là ?

Le journaliste répondit avec mystère :

- Oui, mais rien ne rapporte autant que les échos, à cause des réclames déguisées (Guy de Maupassant, Bel-Ami)

\section{Rapporter bouillant}

Rapporter, raconter, répéter immédiatement, en grande hâte

Transitif

1945 si j'avais eu la folie de m'intéresser un peu à lui et de lui parler avec confiance, il serait allé rapporter ça tout bouillant à Mathieu et ils en auraient fait des gorges chaudes (Jean-Paul Sartre, L’Âge de raison)

REMARQUES : Rapporter bouillant se dit du fait de s'empresser de raconter ou de relater un événement sitôt arrivé de façon précipitée ou de répéter une chose susceptible d'attirer fortement l'attention d'autrui par son caractère sensationnel ou incroyable. C’est une création d'auteur induite probablement par les gorges chaudes. Bouillant est modifié par tout.

\section{Rapporter gros}

Faire gagner beaucoup, être très lucratif Intransitif

1774 Je conviens avec vous qu'un prix fondé auroit fait plus de fracas dans les Affiches de Poitiers et de Limoges : mais le petit bout de chemin en fera plus dans votre caisse, Monsieur le Régisseur, sans compter les bénédictions journalières de nos habitans rapporteront gros à Monseigneur (Louise d'Épinay, Les Conversations d'Émile)

1832 - C’est un garçon de mérite.

- C'est égal, M. Müller a du bonheur d'avoir marié sa fille aussi avantageusement.

- C'est un beau mariage, et qui rapporte gros à l'Église.

- Il a donné beaucoup d'argent aux pauvres (Alphonse Karr, Sous les tilleuls)

1887 N’était-ce pas à déchirer le cœur, un établissement fait du meilleur d'eux-mêmes, qui rapportait plus gros qu'une ferme, et qu'il fallait abandonner entre des mains inconnues, où il dégénérerait peut-être? (Émile Zola, La Terre)

1926 Le marquis, comme de juste, aurait été fêté du jour où ses bêtes lui auraient rapporté gros. Mais on a dit qu'il était un poète. Un poète, c'est un homme qui, sans fortune, refuse de se faire payer une course par tel village (Henry de Montherlant, Les Bestiaires)

1933 Ce ne sont pas des palais, mais ça rapporte, ça rapporte gros. C’est le principal. Un monsieur qui a pour lui tout seul un appartement de douze pièces dans un très beau quartier ne va pas se mettre martel en tête (René Crevel, Les Pieds dans le plat)

1937 Qu'importe ! La canaille dorée ou pourprée avait eu chaud. Ouf !... Après quoi, ce fut, comme on dit, une fameuse reprise des affaires ! Jamais la vente des indulgences n'avait rapporté aussi gros. Vraiment, ça ne retient pas votre attention, cette bacchanale de la Renaissance, les ruffians bariolés, princes, ministres, astrologues, cardinaux, peintres et poètes, drapés d'or 
ou bardés de fer, tous mangés par le mal napolitain (Georges Bernanos, Les Grands Cimetières sous la lune)

1964 et crois moué, ça peut rapporter gros d'argent (Canard enchaîné, 1 juillet 1964 / Grundt : 400)

1979 Il n’y a pas de vaches dans les prés, en Beauce, ni de moutons. On les garde à la maison. Et puis d'abord où voit-on des pâturages en Beauce? L'herbe, c'est comme l'arbre : il ne faut pas que ça occupe de la place, la place rapporte gros (Jean-Louis Bory, Un prix d'excellence)

1988 Il ne nous laisse que la bonne clientèle... - La bonne?

- Ceux qui rapportent gros : les riches qui se foutent pas mal de payer le prix fort, tant qu'ils ont ce qu'ils veulent, même si nous, à l'occasion, on doit dérouiller (Christine Aventin, Le Cour en poche)

\section{CORPus Web :}

Une entreprise qui s'occupe de traquer les irrégularités au sein des crédits dénonce aujourd'hui une faille qui concerne potentiellement un quart des prêts immobiliers en cours. Selon elle, cette faille juridique pourrait rapporter gros aux emprunteurs... [http://www.lavieimmo.com/ taux-emprunt/une-faille-juridique-qui-pourraitrapporter-gros-aux-emprunteurs-32570.html] (4.11.2015)

Quand les stars tweetent, ça peut leur rapporter gros... [http://www.lalsace.fr/actualite/ 2015/10/15/quand-les-stars-tweetent-ca-peutleur-rapporter-gros] (4.11.2015)

Il faut dire que la manche peut rapporter assez gros si on est bien placé : entre 100 et $150 €$ par jour et par mendiant [http://www.ladepeche. fr/article/2015/10/31/2207837-les-forcats-rou mains-de-la-mendicite.html] (4.11.2015)

REMARQUES : Rapporter gros se dit d'une activité très profitable sur le plan matériel, gros référant au bénéfice. Au figuré, il peut désigner une activité ou une action qui procure un avantage moral. Gros reste invariable et est modifié par assez, aussi, plus. Notons l'emploi impersonnel familier ça rapporte gros. VoIR AUSSI : coûter / donner gros ; gagner dur / gros

\section{Raser électrique}

Se raser avec un rasoir électrique

Pronominal

1997 Doug a un faible pour la marque Clinique, porte le parfum Grey Flannel et se rase électrique (David Angevin, Une année sans ma femme)

\section{Raser impec}

Se raser parfaitement

Pronominal

1990 Moi, Gainsbourg j'le connais depuis ses débuts et ses chansons d'avant je les connais aussi, celles du temps où il avait $\mathrm{du}$ talent, même qu'il se rasait impec à l'époque (Fanny Seguin, L’Arme à gauche)

REMARQUES : Se raser impec signifie 'se raser parfaitement'. Impec est une réduction familière de l'adjectif-adverbe impeccable ou de l'adverbe impeccablement. La combinaison « verbe + impec(cable) » constitue une série ouverte dont nous ne citons que quelques variantes.

\section{Ravaler bas}

Dénigrer, déprécier la valeur (de quelqu’un, de quelque chose)

Transitif

1643 Vous me direz que je suis bien injurieux au métier qui me fait connoître, d'en ravaler le but si bas que de le réduire à plaire au peuple, et que je suis bien hardi tout ensemble de prendre pour garant de mon opinion les deux maîtres dont ceux $\mathrm{du}$ parti contraire se fortifient (Pierre Corneille, La Suite du menteur)

1652 Les Saints, les vrais dévots, savoient mieux de leur être

Remplir toute la dignité,

Et pour ces vains attraits ils ne faisoient paroître

Qu'entière insensibilité.

Ils dédaignoient de perdre un moment aux idées

Des biens passagers et charnels,

Et leurs intentions, d'un saint espoir

guidées,

Voloient sans cesse aux éternels. 
Tout leur cœur s’y portoit, et s'élevant sans cesse

Vers leurs invisibles appas,

Il empêchoit la chair de s'en rendre maîtresse

et de le ravaler trop bas

(Pierre Corneille, L'Imitation de Jésus Christ)

1761 Confus, humilié, consterné, de sentir dégrader en moi la nature de l'homme, et de me voir ravalé si bas de cette grandeur intérieure où nos cœurs enflammés s'élevoient réciproquement, je reviens le soir pénétré d'une secrette tristesse, accablé d'un dégoût mortel, et le cœur vuide et gonflé comme un balon rempli d'air (JeanJacques Rousseau, La Nouvelle Héloïse)

1846 Science barbare, dur orgueil, qui ravale si bas la nature animée, et sépare tellement l'homme de ses frères inférieurs ! (Jules Michelet, Le Peuple)

1900 - Vous pouvez manger cette poire, elle est pourrie... finissez ce poulet à la cuisine, il sent mauvais...

Chaque mot vous méprise, chaque geste vous ravale plus bas qu'une bête... et il ne faut rien dire (Octave Mirbeau, Le Journal d'une femme de chambre)

1922 Mme de Mortemart, ayant décidé que Mme de Valcourt ne serait pas des « élues », avait pris par ce fait même l'air de conjuration, de complot qui ravale si bas celles mêmes des femmes du monde qui pourraient le plus aisément se moquer du qu'en-dirat-on (Marcel Proust, La Prisonnière)

\section{CORPUS WEB :}

Mais dans les faits, le travail exploité est une malédiction pour les travailleurs, ravalés plus bas que la bête de somme par l'avidité des classes exploiteuses qui ne font jamais l'éloge du « travail manuel », si «sain », si « hygiénique »-, que pour exploiter les travailleurs jusqu'à l'extrême limite [http://www.socialisme-et-souverainete.com/ page/73] (4.11.2015)

Mais le récit des tortures infligées à Blandine me font froid dans le dos ! Je n’arrive pas à comprendre les humains dans leur ignominie !!! Comment se ravaler plus bas que les animaux ??? [http://liviaaugustae.eklablog.fr/les-lions-desainte-blandine-a118936030] (4.11.2015)

Dès lors le chant d'un animal de basse-cour peut lui signaler la fausseté de sa cour prétentieuse. Pierre a fait le coq, et son hymne s'est ravalé plus bas que le cri d'une bête [http://notes delecturedepatrickbittar.blogspot.co.at/2012/12/ le-paradis-la-porte-essai-sur-une-joie.html] (4.11.2015)

REMARQUES : Au figuré, ravaler bas désigne le fait de sous-estimer la valeur d'une personne ou d'une chose, de la rabaisser ou de l'inférioriser. Le sujet peut désigner une chose concrète ou abstraite, un fait ou une personne. Bas reste invariable et est modifié par plus, si, trop. Notons l'emploi pronominal du verbe dans le CW.

\section{Rayer clair}

Rayonner, briller beaucoup, d'un vif éclat Intransitif

1170a La lune prist cler a raier, Dès que il vint a l'anuitier ; Ainz prinsome se fu couchiee (Benoit de Sainte Maure, Le Roman de Troie, 4479

1170b Après tornerent as herberges : N'ert pas la nuit li cieus tenerges, Ainz raiot la lune auques cler [variante : clere] (Benoit de Sainte Maure, Le Roman de Troie, 13011)

\section{CORPUS WEB :}

c'est utilisé pour les bandeaux noir de pares chocs automobiles ou les rayures ont tendances à rayer clair les bandeaux [http://www. chassepassion.net/le-forum/2/31191] (4.11.2015)

REMARQUES : En ancien français, rayer clair désigne un astre lumineux (ici : la lune) qui émet des rayons très lumineux et clairs, qui rayonne clair. L'accord de clair est optionnel. Notons l'emploi transitif du verbe dans l'exemple du CW où clair réfère au résultat de la rayure qui produit une couleur claire sur un fond noir.

\section{Rayer serré}

Ligner avec peu d'espace entre les lignes Transitif

2012 J'ai écrit un roman. Qui ne l'a fait ? J'avais dix ans. J'avais réussi à détourner un cahier de brouillon, un beau de cent pages, 
quadrillé de bleu et rayé serré (François Cavanna, Mignonne, allons voir si la rose...)

\section{Rayonner blanc}

\section{Briller d'un éclat vif et clair}

Intransitif

1863 Il eut tout éveillé comme une sorte de rêve : la façade du castel rayonnait blanche au soleil, et les girouettes dorées à neuf brillaient sur le fond du ciel bleu (Théophile Gautier, Le Capitaine Fracasse)

1964 Sa lucidité glace un peu. Elle rayonne blanc comme un miroir d'acier poli (Express, 16 mars 1964 / Grundt : 253)

\section{CORPUS Web :}

L'herbe était grise, le ciel était gris aussi, et la mer, au loin, était encore de la même couleur, le soleil rayonnait blanc, et pas jaune [http://www. kingdom-hearts-rpg.com/t1787-noir-et-blancc-est-cool-sans-cours-moins-cool-mission-n2] (4.11.2015)

Catalogues divers d'une bonne épaisseur reçus annuellement à l'automne dans la boîte à mail : tu fais remonter des souvenirs! Des heures, des semaines à parcourir, à désirer tel bicycle... Et puis, en effet, les pages glacées vers le milieux, au rayon des brassières, avec des mesdames peignées avec du spray-net dans les cheveux, ça rayonnait blanc ! [http://pdaleblaispdale. blogspot.co.at/2009/05/wow-des-femmes-enbrassiere-dans.html] (4.11.2015)

REMARQUES : Au figuré, rayonner blanc peut désigner un caractère, la faculté d'un être humain (ici : la lucidité) qui éblouit l'autre, qui apparaît à autrui de manière claire. Au propre, le sujet peut désigner un élément qui, à la lumière, brille d'un éclat vif et répand une lumière blanche. Notons l'emploi de rayonner jaune par rapport au soleil. Blanc tend à l'invariabilité, mais il peut s'accorder avec le sujet (v. l'exemple de 1863), se rapprochant des prédicats seconds orientés vers le sujet.

\section{Rayonner bleu}

Briller en répandant une vive lumière bleue Intransitif

1903 Et la lune ce soir rayonne toute bleue, et j'ai précisément, pour ma seule nuit pas- sée dans le bois sacré, une lumière d'éden (Pierre Loti, L'Inde (sans les Anglais))

CORpus Web :

Chaque petit être là en dessous, est une lumière,

Etoile ou minuscule bougie, chacun brille du dedans,

Chacun rayonne plus ou moins loin, plus ou moins grand,

Certains rayonnent bleu, rouge ou bien vert [http://www.muriel-leobet.fr/topic/index.html] (4.11.2015)

REMARQUES : Rayonner bleu désigne l'effet d'un astre lumineux (ici : la lune, une étoile, une bougie) qui brille d'un éclat vif et répand une lumière bleuâtre. Bleu peut s'accorder avec le sujet et, dans ce cas-là, se rapprocher d'un prédicat second orienté vers le sujet. Il est modifié par tout.

\section{Rayonner clair}

Rayonner, briller d'un vif éclat Intransitif

1620 Là, Pallas secoüant son horrible Gorgonne Dans le sein d'une nuë où claire elle rayonne,

Se plante en leur faveur sur la pointe du fort :

Et Jupiter luy-mesme en seconde l'effort, Leur accroist le courage, et durant ces allarmes

Rend tous les autres dieux bandez contre vos armes

(Jean Bertaut, Les Euvres poétiques)

\section{CORPUS WEB :}

Pourtant, il s'agissait cette fois de larmes de joie, pas de chagrin, et son amour pour Sirius rayonna clair et évident à travers le voile des larmes [https://www.fanfiction.net/s/2465427/1/ Le-berceau-vide] (4.11.2015)

Que j'aimerais sentir ce doux frémissement,

Quand le pouls de mon sang bat au cœur de la ville,

Retrouver ce désir lié au sentiment,

Que tout rayonne clair et mon esprit jubile ! [https://www.poeme-france.com/poeme-155674je-hais-les-amoureux.html] (4.11.2015) 
REMARQUES : Rayonner clair réfère à la lumière d'un astre, ou, au figuré, à une personne, un sentiment ou un objet qui reflètent l'expression d'une vive satisfaction. En prédicat second, clair peut s'accorder avec le sujet (exemple de 1620)

\section{Rayonner évident}

Rayonner, briller d'un éclat manifeste, flagrant $\lambda$ rayonner clair

\section{Rayonner grand}

Briller en répandant une lumière plus ou moins grande

入 rayonner bleu

\section{Rayonner jaune}

Briller en répandant une lumière jaune

$\pi$ rayonner blanc

\section{Rayonner rouge}

Briller en répandant une lumière rouge

$\pi$ rayonner bleu

\section{Rayonner vert}

Briller en répandant une lumière verte

入 rayonner bleu

\section{Réallumer subit}

Allumer à nouveau rapidement, brusquement 入 allumer subit

\section{Réagir juste}

Réagir de manière appropriée, convenable, comme il faut, comme il convient Intransitif

1943 GEORGES : Non. Du temps du tribunal pour enfants. J'ai connu des enfants, et des enfants du peuple, qu'on pouvait entretenir pendant une heure sans lassitude, bien plus, avec goût et intérêt. Ils étaient fins, ils réagissaient juste, ils avaient des trouvailles de sentiments ou d'expression, une espèce de génialité... non seulement Gillou n'est pas d'un bon métal, mais il manque cruellement de génialité (Henry de Montherlant, Fils de personne)

\section{CORpus Web :}

Comme vous le montre notre vidéo, il peut néanmoins être utile d'adopter le bon com- portement ou de réagir juste dans différentes situations d'urgence [https://alertswiss.ch/fr/ infos-conseils/bien-reagir-en-cas-de-danger] (4.11.2015)

Réagir juste en cas de conflit. Réduire de façon significative le temps consacré à la résolution des tensions, en traitant le problème et non le symptôme [http://www.synopteam. $\mathrm{fr} /$ formations-inter-entreprises/me1-managerjuste-mieux-communiquer-sortir-des-conflits] (4.11.2015)

A nouveau, les Grenat doivent concéder l'ouverture du score, sur un pénalty bien sévère. A nouveau toutefois, les Grenat réagissent juste, et la jouent comme à l'entraînement : sur un turnover lancé tambour battant par Arnaud Becuwe, Laurent Neri idéalement servi peut remettre les équipes à égalité [http://www.servettehc.ch/ index.php?option=com_content\&task=view\&id $=615 \&$ Itemid $=186]$ (4.11.2015)

Les commandes vocales réagissent justes et sans problèmes, maintenant il ne faut pas avoir l'accent « Chti » ou « Provençaleu » [http://www. golf6forum.fr/index.php?topic=18814.5;wap2] (4.11.2015)

REMARQUES : Réagir juste se dit du fait d'adopter un comportement adéquat ou de montrer une réaction conforme à la norme, dans le cadre d'une discussion ou face à une situation quelconque. Juste reste invariable dans la majorité des cas, mais, dans le quatrième exemple du CW, il s'accorde avec le sujet inanimé en gardant son interprétation adverbiale (un cas d'hypercorrection), référant à une réponse simplement mécanique.

\section{Réarmer isnel}

Se réarmer rapidement, agilement

Pronominal

1170 Mout fu bele la matinee, E senz nule autre demoree Se rarmerent tost e isnel, Quar venir veient tel cembel, Ou a dis mile chevaliers Trestoz armez sor lor destriers (Benoit de Sainte Maure, Le Roman de Troie, 11997)

REMARQUES : En ancien français, se rarmer isnel désigne le fait de s'armer de nouveau, de se munir d'armes, le sujet agissant avec rapidité et 
faisant preuve d'agilité. Notons la collocation tost ('aussitôt') et isnel.

\section{Rebondir haut}

I. Faire de grands bonds

Intransitif

1684 Mais d'ou vient donc, dira quelqu'un, qu'une boule d'yvoire qu'on laisse tomber sur une enclume, rebondit plus haut que si elle tomboit sur une table de bois, si ce n'est que le ressort, ou le retour des parties de l'enclume estant plus vif, la boule est repoussée avec plus de force ? (François Bernier, Abrégé de la philosophie de Gassendi)

1948 La bille descendit paresseusement le long de la roue et rebondit plus haut sur le chrome. Au bout d'un temps assez long, subitement elle s'immobilisa avec un cliquetis sec. La roue ralentit en entraînant la bille. Le croupier resta les bras croisés tant que la roue bougea (Boris Vian, Le Grand Sommeil [trad.])

II. Renaître, retrouver une grande intensité Intransitif

1949 Elle s'éloigna en fredonnant et le figurant resta planté au milieu du couloir. Il avait un peu honte de n'être que figurant, mais il se vit dans la glace et son moral rebondit très haut. Il régnait toujours une certaine animation dans le couloir (Boris Vian, Les Fourmis)

III. Reprendre beaucoup de force, de vigueur Intransitif

1980 Le comte Mosca plus d'une fois se prépare bien à la retraite - ou plutôt il en parle mais ce n'est que pour rebondir plus haut en place, rajeunir par l'argent et la faveur, et faire dans la dernière page du livre une fortune à la Talleyrand (Julien Gracq, En lisant, en écrivant)

\section{Corpus Web :}

Si l'OM sait profiter de ce tremplin, il pourrait rebondir haut, très haut [http://www.rtl. $\mathrm{fr} /$ sport/football/ligue-1-23eme-journee-1-omcorrige-valenciennes-5932770641] (4.11.2015)
Les LIFTS et services liftés rebondissent HAUT ! [http://forums.sport.francetv.fr/sport/ tennis/rebondissent-wimbledon-services-sujet_ 32038_1.htm] (4.11.2015)

WAILMER peut stocker de l'eau dans son corps pour se transformer en balle et rebondir sur le sol. Plus ce Рокémon se remplit d'eau, plus il peut rebondir haut [http://www.pokepedia. fr/Wailmer/G\%C3\%A9n\%C3\%A9ration_3] (4.11.2015)

Des jouets en caoutchouc dans des formes étranges sont parfaits pour les chiens athlétiques, car ils rebondissent hauts [http://tout-toutou. $\mathrm{fr} /$ site-content/53-avoir-1-chien/110-commentchoisir-le-meilleur-jouet-pour-votre-chien] (4.11.2015)

REMARQUES : Au propre, rebondir haut (I) désigne un objet, par exemple une balle, qui, après avoir atteint le sol, repart vers le haut. En (II), il s'emploie par rapport à un état psychique ou moral qui s'améliore notablement. Le sujet peut aussi désigner une chose ou une activité qui prend un nouvel essor. En (III), le sujet peut aussi référer à une personne dont l'état se caractérise par un regain de force et d'énergie fortement marqué et par la volonté très forte de réagir pour changer les choses. Cet emploi plutôt quotidien figure dans les exemples du CW. Haut reste invariable dans la majorité des cas, mais, dans le dernier exemple $\mathrm{du}$ CW, il manifeste l'accord avec le sujet. Ce type d'accord est assez caractéristique du langage des sports. Haut est modifié par plus, très.

\section{Rebouter dur}

Repousser, écarter, refuser, rejeter de manière ferme, rude

Transitif

+1365 Mès tantos s'en racouardi, Car vo vallet avant sallirent Qui au tenchier près l'assallirent, Et en fu si dur reboutés Que tous jours les a puis doutés (Jean Froissart, Poésies [3e tiers XIV"]

REMARQUES : Lors d'un combat ou d'un conflit, rebouter dur se disait du fait de repousser ou de chasser son adversaire avec une certaine force ou de manière brutale. Dur est modifié par si. 


\section{Rebrousser court}

Retourner brusquement

Intransitif

1625 Je leur fis faire quatre journées sur le chemin de Caen, et puis rebrousser court devers Evreux et Nantes, tant pour oster cognoissance aux ennemis de mes desseins, que pour empescher les miens de deviner (Guillaume de Saulx, Mémoires historiques)

\section{Recevoir bel}

Recevoir bien

Transitif

+1200 Quant il virent le roi qui les venoit veoir, si le tindrent a moult grant debonereté et moult le reçurent bel et courtoisement (Mort Artu [1 ${ }^{\text {er }}$ quart XIII $]$, p. 39, 29)

1372 Et les iii. signeurs sarrasins

Furent descendus de leurs lins,

De leurs barges et de leurs naves,

Et aussi trestous les esclaves,

Li amiraus d'Alexandrie

Leur envoia par courtoisie

De sa maisnie et de sa gent

Qui les reçurent bel et gent

Et moult treshonnourablement

(Guillaume de Machaut, La Prise d'Alexandrie [(1370-)1372], 6200)

\section{Recevoir gent}

Recevoir comme il convient, courtoisement

$\lambda$ recevoir bel

\section{Rechausser étroit}

Mettre au pied des chaussures très ajustées

Transitif

$\sim 1275$ E tant estreit vous rechauciez

Que la robe souvent hauciez

Por moutrer voz piez aus ribauz (Jehan de Meun, Roman de la rose [1269-1278], 9289)

\section{CoRpus Web :}

je crois que je vais rechausser etroit [http:// www.forum-auto.com/marques/dacia/sujet240156570.htm] (4.11.2015)

REMARQUES : Rechausser étroit désigne, en ancien français, le fait de mettre aux pieds des chaussures qui épousent parfaitement la forme du pied. Dans un contexte moderne, il désigne le fait de remettre des pneus neufs à une voiture (CW). Étroit reste invariable et est modifié par tant. Notons l'emploi absolu (CW).

\section{Rechercher haut}

Rechercher de manière très approfondie, très poussée, savante

Transitif

1813 Bucéphale partagea avec Alexandre la gloire de ses conquêtes ; il est bien prouvé qu'un empereur romain voulut nommer son cheval Consul, et l'on est d'accord que cette dignité convenait tout aussi bien à cet animal que le diadême à son maître. Mais sans rechercher si loin et si haut les titres de ce beau quadrupède, examinons-le dans cet exercice où il déploie avec tant d'avantage les qualités brillantes dont il est pourvu (Étienne de Jouy, L'Hermite de la Chaussée-d'Antin)

REMARQUES : Rechercher si loin et si haut désigne le fait de chercher à connaître quelque chose avec soin, méthode ou réflexion. Notons la coordination de haut avec l'adverbe loin qui souligne le côté approfondi de la recherche. Haut reste invariable et est modifié par si.

\section{Rechercher loin}

Rechercher de manière très approfondie

$\pi$ rechercher haut

\section{Réciter bas}

Réciter, dire à voix basse, en chuchotant Pronominal

1600 il conclud ses collectes secrettes à haute voix, aux fins que le peuple puisse répondre Amen, car les oraisons qui se récitent tout bas par le prestre apres l'offertoire et lavement des mains sont appelees secrettes (Pierre Coton, Du tres-sainct et tres-auguste sacrement, et sacrifice de la messe)

Transitif

1639 ARASPE. Vous sçavez que pour rendre un discours agreable, Avec le ton de voix le geste est desirable. Mais je seray contraint le récitant trop bas. 
PANTHÉE. Nullement, parlez haut, Charis n'escoute pas (Tristan l'Hermite, Panthée)

1875 Il dit à haute voix l'Agnus dei, récita tout bas les trois oraisons prescrites, fit son acte d'indignité ; et, les coudes sur l'autel, la patène sous le menton, il communia des deux parties de l'hostie à la fois (Émile Zola, La Faute de l'abbé Mouret)

1889 Je me la récitais tout bas, cette phrase, tandis que je poursuivais avec Charlotte ces causeries littéraires, avec d'autant plus de conviction que la nature, comme je vous ai dit, parlait en moi, et que la présence de la jeune fille réveillait la brûlure de mes souvenirs les plus cuisants (Paul Bourget, Le Disciple)

1922 Il y eut des dates que notre admiration commémorait : une distribution de prix où la petite Bouilloux, timide et récitant tout bas une fable inintelligible, resplendit sous ses larmes comme une pêche sous l'averse... La première communion de la petite Bouilloux fit scandale : elle alla boire chopine après les vêpres, avec son père (Colette, La Maison de Claudine)

1963 Tandis que les gens passent, tandis qu'on recherche les gendarmes, le curé ou le médecin, et qu'une femme qui regarde se fige et récite tout bas " Je vous salue Marie Pleine de Grâces Le Seigneur est avec Vous etc. » Un type italien, assis sur un banc, sort un paquet de cigarettes italiennes de sa poche. (Jean-Marie Gustave Le Clézio, Le Procès-verbal)

Emploi absolu

1900 Les autres se posent des questions fantaisistes, en conservant la figure de leçon et la bouche qui semble réciter tout bas. La grande Anaïs a ouvert son atlas, et elle m'interroge :

- Qu'est-ce qu'une écluse ?

Je réponds comme si je récitais :

- Zut ! Tu ne vas pas m'ennuyer avec tes canaux (Colette, Claudine à l'école)

\section{CORPUS WEB :}

Une autre femme tenait un plateau avec $\mathrm{du}$ riz, de l'eau elle récitait tout bas des prières en lançant l'eau et le riz [http://vacancesautour dumonde.uniterre.com/188936/Troisi\%C3\% A8me+jour+\%C3\%A0+Bali.html] (11.11.2015)

Après les trois premiers psaumes et avant les leçons, pendant qu'on récitait tout bas le Pater, un Frère Mineur prit rapidement la parole et publia une bulle du pape Alexandre IV, de 1260, défendant aux prêtres séculiers, sous peine d'excommunication, de faire les cérémonies des obsèques dans les chapelles des Mineurs, sans leur consentement [http://www.infobretagne.com/ vannes-cordeliers.htm] (11.11.2015)

Pendant ses périodes de souffrance, elle trouve du réconfortà réciter tout bas des paroles de couplets apprises par cœur [http://www.forummda.com/t4226-Il-etait-une-voix.htm] (11.11.2015)

REMARQues : Réciter (tout) bas se dit du fait de dire à voix basse, de chuchoter un texte (ici : leçon, fable, discours, prières) appris par cœur. Bas reste invariable. Il est modifié par tout, trop. Notons l'emploi complémentaire de parler haut. VOIR AUSSI : dire bas

\section{Réciter haut}

I. Réciter, dire à voix haute, ouvertement, publiquement

Transitif

1575 Estant venu sur l'eschaffaut, il pria le peuple de prier Dieu pour lui, recita tout haut le Symbole en la confession duquel il protesta de mourir, puis aiant fait sa priere à Dieu à la mode de ceux de la Religion, eust la teste trenchée, laquelle le lundi ensuivant $28^{\mathrm{e}}$ juing fust mise sur un posteau en la place de Greve (Pierre de L'Estoile, Registre-Journal du regne de Henri III)

1623 Il luy repliqua avecque des termes infiniment courtois, et infiniment elegants, si bien que les ayant apres recitez tout haut devant le juge qui venoit d'oür ceux des autres, il fut reputé le plus parfaict amant, et Elidore qui luy avoit pertinemment respondu fut aussi estimee la plus parfaite amante (Charles Sorel, Les Nouvelles françaises) 
1719 De-là il passa aux honneurs extraordinaires que le Senat lui avoit décernez, comme le témoignage et la récompense de ses vertus. Il récita tout haut le decret, par lequel il étoit declaré pere de la patrie, et sa personne sacrée et inviolable (René de Vertot, Histoire des révolutions arrivées dans le gouvernement de la République romaine)

1845 Quelquefois, fatigué d'impatience, je me levais, je marchais à grands pas, récitant tout haut ma tirade avant qu'elle ne fût finie, et puis je revenais à ma table l'écrire avec transport, joyeux de la tenir, inquiet de celle qui allait suivre, heureux de sentir s'achever mon œuvre, et déjà orgueilleux d'elle (Gustave Flaubert, La Première Éducation sentimentale)

1926 Revenus dans la voiture, chacun à sa place, les quatre religieuses murmuraient le rosaire ; le P. Cabanel récitait tout haut l'Office des morts qu'il savait par cœur ; Eliane, immobile, lui répondait seule, les yeux baissés sur son livre d'heures (Marcel Jouhandeau, Monsieur Godeau intime)

1942 À ceux-là il suffira bien, le soir, de chanter leurs cantiques dans la foule des processionnaires et de réciter bien haut leur Ave pour que leur âme soit tranquille. En attendant ils trinquent (Louis Guilloux, Le Pain des rêves)

II. Chanter un récitatif dans une tessiture haute Emploi absolu

1945 Bref, la voix est plus courte, et cependant la tessiture moyenne est un peu plus élevée : le ténor aime à "réciter " plus haut que le soprano ; l'octave de fa lui est favorable surtout dans le tétracorde aigu (Henri Potiron, La Musique d'église. Esquisse d'un traité de composition)

\section{CORPUS WEB :}

L'évangile de saint Jean est la dernière addition qui ait été communément faite à la messe. Il y a environ cinq cents ans ${ }^{\star}$ que beaucoup de prêtres l'ont récité tout bas par dévotion, en commençant leur action de grâces ; et la dévotion des peuples les a portés à le réciter tout haut avant que de quitter l'autel [http:// www.salve-regina.com/salve/L'importance_du_ dernier_\%C3\%A9vangile] (11.11.2015)

Le fait de réciter tout haut permet d'attirer l'attention sur nous. C'est encore un avantage sur les moines, qui doivent rester totalement silencieux lorsqu'ils font leur collecte [http://dhamma dana.fr/fr/3nonnes/collecte.htm] (11.11.2015)

Les petites flèches vous donnent le sens du chemin. Réciter tout haut la suite des villes trouvées vous aidera à donner du sens [http://jeuvendredi.eklablog.com/de-ville-en-ville-a10892 2438] (11.11.2015)

REMARQUES : Réciter (tout) haut (I) se dit du fait de dire à voix haute un texte appris par cœur, le complément d'objet pouvant désigner une prière, un chant ou référer au domaine théâtral désignant un rôle ou une tirade. Dans le domaine musical (II), il désigne le fait de chanter un morceau vocal, haut se référant à la hauteur de la voix. Notons l'opposition sémantique entre tout bas et tout haut dans le CW. Haut reste invariable. Il est modifié par bien, plus, tout. Notons l'emploi absolu du verbe dans le deuxième exemple du CW.

\section{Réclamer haut}

I. Réclamer, demander à haute voix, d'une voix forte ; réclamer ouvertement Transitif

1653 Depuis plus d'un mois, voire deux, De venir habiter prés d'eux Le Tiers-Etat et la Noblesse, La [= la nouvelle abbesse] réclament haut, et sans cesse

(Jean Loret, La Muze historique)

1863 Examinons donc à fond nos procédés, les formes habituelles de notre architecture ; comparons-les aux procédés, aux formes de l'architecture antique, et voyons si nous ne nous sommes pas fourvoyés, si tout n'est pas à refaire, afin de trouver cette architecture de notre temps réclamée si haut par ceux-là mêmes qui nous enlèvent les seuls moyens propres à lui donner naissance (Eugène Viollet-le-Duc, Entretiens sur l'architecture)

1884 De Falloux, plus hautain et plus cauteleux, appartenait à cette secte libérale dans la- 
quelle étaient déjà réunis et de Montalembert et Cochin, et Lacordaire et de Broglie ; il appartenait, tout entier, aux idées du Correspondant, une revue qui s'efforçait de couvrir d'un vernis de tolérance les théories impérieuses de l'Église ; Veuillot, plus débraillé, plus franc, rejetait ces masques, attestait sans hésiter la tyrannie des volontés ultramontaines, avouait et réclamait tout haut l'impitoyable joug de ses dogmes (Joris-Karl Huysmans, À rebours)

1886 C'est lui qui tient les derniers écus qui vont alimenter l'insurrection, payer les vivres que les plus résolus réclament si haut. Il a, en plus, son ministère qui brûle, grâce aux obus de Versailles. Et je suis seul (Jules Vallès, Jacques Vingtras : L'Insurgé)

1899 Leur confiance en eux-mêmes n'en est pas ébranlée et ils réclament bien haut de nous le même aveuglement sur leur ineptie, pour recommencer impunément l'œuvre criminelle, qui hier nous livrait à l'Angleterre sans obus pour nos canons (Georges Clemenceau, Vers la réparation)

Emploi absolu

1845 j'ai à retrancher certaines choses auxquelles j'ai réfléchi mûrement depuis l'envoi du manuscrit ; ainsi ne me laissez pas violenter à cet égard, et annoncez à la direction suprême que si on agissait précipitamment contre mon droit, mon traité et ma volonté, je réclamerais tout haut, et très haut (George Sand, Correspondance)

1874 Il lui sembla que ce langage était la voix même de la Sophie intérieure qui, pour la première fois, saisissait le pouvoir de réclamer tout haut contre celle du dehors. Ce jour-là, quand le sculpteur l'eut laissée seule, elle se trouva dans une disposition d'esprit qu'elle n'avait jamais connue (Arthur de Gobineau, Les Pléiades)
II. se réclamer haut de quelqu'un : invoquer à voix haute, ouvertement, publiquement et en sa faveur l'autorité, le témoignage, la caution de quelqu'un

Pronominal

1933 Mais tu ne veux pas de la mairie, et cela vaut mieux d'ailleurs, car tu risquerais tout de même, à te réclamer trop haut d'un général dont l'avenir est encore incertain, de compromettre le nom des Haudouin dans l'arrondissement (Marcel Aymé, La Jument verte)

III. se réclamer haut de quelque chose : se prévaloir de quelque chose à voix haute Pronominal

1945 Ces Français, dont l'un se réclame très haut de la culture méditerranéenne, semblent dire, eux aussi, encore que pour certains à son corps défendant : c'est du Nord aujourd'hui que nous vient la lumière (Julien Benda, La France byzantine)

CORpus Web :

Il faut réclamer haut et fort l'abolition de la peine de mort [http://nessy.canalblog.com/ archives/2007/01/11/3649187.html] (11.11.2015)

Cons de tous les pays, l'heure est venue de faire votre coming out. Et de réclamer haut et fort la place qui est la vôtre [https://www.facebook. com/permalink.php?story_fbid $=4022492899750$ 58\&id=353999138133407] (11.11.2015)

Oui, c'est une des raisons qui font que l'on continue à réclamer haut et fort l'ouverture de la procréation médicalement assistée à toutes les femmes, en couple ou pas [http://lastreetschool. streetpress.com/?p=439] (11.11.2015)

REMARQUES : Réclamer haut (I) se dit du fait de demander quelque chose avec insistance, de façon pressante, comme une chose nécessaire, l'objet pouvant désigner une chose concrète ou abstraite. Dans son emploi pronominal (II, III), il souligne le fait de vanter son attachement à quelqu'un ou à quelque chose. Sous (II), l'objet désigne une personne qui est prise comme exemple, qui est idolâtrée à voix haute. (III) prend comme référence quelque chose (ici : une culture), et ceci ouvertement, publiquement, en la mettant en avant. Notons la collocation haut et fort dans le CW, très courant dans l'emploi actuel 
pour intensifier. Haut reste invariable et est modifié par bien, si, tout, très, trop.

\section{Réclamer soef}

Déclarer, affirmer quelque chose doucement, d'une voix douce, agréable

Transitif

-1200 Li leres fu blechiés, .iiii. fois se pasma, Lors a juré Jhesu ja mais nel baillera, Soef entre ses dens Elie reclama : Hé ! Elyes de Franche, perdut as le cheval (Elie de Saint Gille [fin $\mathrm{XII}^{\mathrm{e}}$ ], 2000)

REMARQUES : En ancien français, réclamer soef se dit du fait de déclarer quelque chose, de le dire d'une voix très douce et aimable.

\section{Recorder droit}

Rappeler correctement, conformément à la vérité

Emploi absolu

+1400 Et conforté

Mon cuer par son regarder

Estoit, a droit recorder,

Ne peüst mieulx demander

Nul cuer morté

(Christine de Pisan, Le Livre du duc des vrais amans / Euvres poétiques [début $\mathrm{XV}^{\mathrm{e}}$ ], III, p. 206, 94)

REMARQUES : à droit recorder s'insère dans la série à bref / vrai dire, à droit parler, usuelle dans l'ancienne langue.

\section{Recorder voir (vrai)}

Rappeler conformément à la vérité

Emploi absolu

+1400 Peine esmonder,

Joye abonder,

Tout marchander,

Et dueil seder,

Bas affonder,

Et reffonder,

Bel regarder,

Voir recorder,

Sanz point bourder,

Pais accorder,

Non descorder,

Droit recorder

Pour amender,
En sens fonder

Et perfonder (Christine de Pisan, Lays /

Euvres poétiques [début Xve], I, p. 128, 83)

REMARQUES : Notons la série de verbes, dont certains ne sont plus usités en français moderne, combinés avec des adjectifs-adverbes (bas, bel, droit, voir).

\section{Récrier clair}

S'écrier d'une voix nette

Pronominal

1250 A chen que le bon quens va Damedieu priant

Que il li doinst oïr, s'il li vient à talent, La vois que il oï orains si clerement, Doolin se rescrie trez cler et hautement (Doon de Mayence, p. 54)

REMARQues : Récrier clair se disait du fait de s'écrier à haute voix, d'une voix nette, bien perceptible. Le vers adapte la collocation usuelle haut et clair à la rime. Clair reste invariable et est modifié par très.

\section{Récriminer fort}

Récriminer intensément

$\lambda$ récriminer haut

\section{Récriminer haut}

Protester, reprocher, accuser à voix haute, ouvertement, publiquement

Intransitif

1882 Et les bourgeois élèvent la voix, dicentes alta voce plura dira verba de focagiis, récriminant très haut et âprement contre les fouages (Charles Jarrin, Essai sur l'histoire de Bourg)

1910 Ces sommes énormes sont distribuées avec équité, je n'en veux pas douter, jusqu'au dernier centime, mais tout le monde n'en est pas convaincu. On récrimine très haut, on murmure plus encore (Maurice Barrès, Mes cahiers)

1954 Un peu trop pâle, un peu nerveuse, elle soupirait plus volontiers qu'elle ne récriminait tout haut (Maurice Genevoix, Fatou Cissé) 


\section{CORPus WeB :}

Non, c'est un signe des temps, on ne supporte plus aucun carcan, toute situation imposée devient un asservissement, on récrimine haut et fort le droit de secouer tout ce qu'on considère comme des oppressions, fussentelles légères, voire consenties au départ [http:// lepetitrenaudon.blogspot.co.at/2011/12/sousles-paves-sois-sage-un-monde-sans.html] (11.11.2015)

On raconte que Dante entendant un jour un forgeron qui estropiait ses sonnets, entra dans sa boutique et balança dans la rue tous ses outils, et en réponse à l'ouvrier qui récriminait haut et fort en déplorant la perte de ses instruments de travail il lui aurait dit [...] [http:// www.franceculture.fr/emission-l-essai-et-larevue-du-jour-une-journee-au-moyen-age-revueeurope-2013-10-04] (11.11.2015)

Récriminer bien haut contre des mesures barbares peut avoir de l'effet provisoirement, tant que ceux qui vous écoutent s'imaginent que ces mesures sont impensables dans leur propre pays [http://marxiste.fr/brechtbarbusse/brecht4. html] (11.11.2015)

REMARQUes : Récriminer haut se dit du fait de critiquer quelque chose, de manifester avec amertume et âpreté son mécontentement publiquement ou d'une voix forte, de façon à se faire entendre. Notons la collocation haut et fort, où fort vient en renforcer le sémantisme. Dans le premier exemple du CW, récriminer prend l'acception de 'revendiquer'. Haut reste invariable et est modifié par bien, tout, très.

\section{Recueillir beau (bel)}

Accueillir, recevoir (quelqu'un) aimablement Transitif

+1133 Les portes oevrent sanz point de delaier ; Beau recueillirent lor segnor droiturier ( $L e$ Couronnement de Louis [2 $2^{\mathrm{e}}$ tiers XII $]$ ], 2616)

REMARQUES : Recueillir beau se disait en ancien français du fait d'accueillir ou de recevoir un hôte agréablement, de manière bienveillante, en faisant preuve de générosité. Dans plusieurs éditions reproduisant la même citation, beau apparaît sous sa forme neutre bel, employée en fonction adverbiale.

\section{Reculer aise}

Repousser, faire reculer (quelqu'un) avec facilité Transitif

1553 A peine avons, pour pedes et femores Califier, un pauvre fascicule. Conclusion, tout aise nous recule, Et si n'estoit quelque proximité Que nous avons en la grande cité, Où nous pouvons aller aliques vices, Pour incuber aux jucunds sacrifices De Genius, le grand dieu de nature, Et de Venus, qui est sa nourriture, De rester vifz nous seroit impossible (François Rabelais, Epistre du Limosin / (Euvres)

REMARQUes : Dans une bataille ou un combat, reculer aise désigne la facilité ou l'agilité avec laquelle le sujet peut repousser l'ennemi ou faire reculer l'adversaire. Aise est modifié par tout.

\section{Redescendre doux}

Redescendre doucement, tranquillement, lentement

Intransitif

1945 Ça montait doucement, doucement, à la dérobée et ça descendait de même [...] le bateau monte doux, redescend doux (JeanPaul Sartre, Le Sursis)

CORPus Web :

Le petit tracé de $13 \mathrm{~km}$, parti à $9 \mathrm{~h} 30$, traverse quant à lui d'une foulée véloce champs et bois pour monter vers le point d'orgue du parcours, la Tour César, dont les vestiges situés à $850 \mathrm{~m}$, offrent un beau panorama sur le Lac du Bourget, avant de redescendre tout doux en sous-bois vers la jonction entre trails et marche [http://www.urun.fr/50958-la-chambottine-fait-mouche] (11.11.2015)

Le gasket est quand meme pas pire, à part l'endroit il il était sorti et où il a pincé et où je vois des petites lignes, il semble bien beau. Je penses qu'il a sorti à un moment quand j'ai compressé en 4... la pression à monté dans le moteur et il n’y avait pu de vaccum dans l'intake alors la pression a sortie par là... pouf

En tk, pour l'instant, le 2 minutes de test que j'ai fais semble faire le travaille, je vais redescendre doux doux chez nous [http://forum. 
clubcivicquebec.com/topic/86570-aidez-moije-suis-a-job-trouble-gasket-couvert-de-valve] (11.11.2015)

Comment faire pour redescendre tout doux jusque au nœud, si j'appuie sur mon autobloquant dessus avec la main ça le décoince direct et je me retrouve direct tout droit sans pouvoir gérer jusque au nœud, ensuite c'est plus de problème il faut ôter l'autobloquant [http://www.descentecanyon.com/forums/viewtopic.php?id=16479] (11.11.2015)

Puis à l'arrivée des foules, je suis redescendue tout doux en faisant le tour à chaque fois [http://letouxdumonde.top-depart.com/ indonesie/wonosobo/articles/borobudurscooter-road-trip-j2-141014.html] (11.11.2015)

Et ce matin elle a tenté de me désobéir, pouf, je l'ai emmenée sans crier ni gronder dans sa chambre, "tu reviendras quand tu seras calmée" et re $\backslash \mathrm{o} /$ Bon, bien sur elle a braillé, mais au bout de 10 minutes elle est redescendue douce comme un agneau :') [http://forum.hardware.fr/ hfr/Discussions/Viepratique/mamans-enfantshfriens-sujet_8783_4790.htm] (11.11.2015)

REMARQUES : Dans l'exemple de 1945, le sujet désigne un bateau qui se déplace dans l'espace maritime dans un mouvement descendant, à un rythme lent, tranquille, sans mouvements brusques. Ceci est transposé à l'inclinaison d'un terrain dans le premier exemple du CW. Notons le contraste monter et redescendre doux. Quand l'action est volontaire, doux signifie 'lentement' et 'prudemment' à la fois (deuxième et troisième exemples du CW). Doux reste invariable dans son emploi adverbial. En revanche, dans le dernier exemple du CW, l'emploi comme prédicat second va de pair avec l'accord, désignant une disposition sentimentale du sujet. Doux est modifié par tout. Notons également la réduplication doux doux pour intensifier, et les groupes décoincer direct et se retrouver direct tout droit. Dans ce dernier, direct équivaut à l'adverbe directement, tandis que tout droit est un prédicat second qui désigne la position du sujet. Droit est généralement modifié par tout.

\section{Redouter fort}

Craindre beaucoup

Transitif

+1249 Encor a ele tel maniere

Que ja ne fera bele chiere

Por qu'ele voie les denz muevre,

Tant fort redote la bone oevre

(Rutebeuf, Poèmes [pièces datables de 1249 à 1272], I, p. 355, 400)

1427 Et se tu y es ravallé au dessoubz des autres palatins, tu seras envieux de leur pouoir. Se tu y es en moyen estat, dont tu n'ayes suffisance, tu estriveras de plus hault monter, et se tu peuz parvenir jusques aux haulx secrez qui sont fort a redoubter et a craindre, a la courtine doubteuse des plus haulx princes, adoncques seras tu plus meschant de tant que tu y cuideras estre plus eureux (Alain Chartier, Le Curial)

1583 Sept ans ce Miecislas aveugle se trouva, Lors que, prenant la foy, clarté double esprouva :

Reglant ainsi le peuple à sa mode Chrestienne.

Ô glaive de l'Esprit ! Ce n’est vrayment à tort

Que les peuples, et Roys, te redoutent si fort :

Quelle puissance aussi se compare à la tienne? (Jean de La Gessée, Les Jeunesses)

1655 OSMAN. Il n'importe comment ; je me veux satisfaire.

La SULTANE. Seigneur ! un prompt depart vous seroit necessaire,

Et je redoute fort que cet objet charmant

Apporte un grand obstacle à vostre embarquement.

Son Pere à vos desirs oppose des scrupules (Tristan l'Hermite, Osman)

1776 Ce fut dans ces circonstances que la situation que je redoutois si fort, se découvrit (Nicolas Rétif de La Bretonne, Le Paysan perverti ou Les Dangers de la ville)

1848 Ignorant qu'elle-même redoutait fort d'être éprise de lui, il regardait chaque matin l'état dans lequel se trouvaient les fleurs dont la mort devait amener la rupture de 
leur liaison, et il avait grand'peine à s'expliquer leur fraîcheur chaque jour nouvelle (Henri Murger, Scènes de la vie de bohème).

1932 Un jour, les enfants signalèrent l'approche du curé. Aussitôt selon ma coutume, je pris la fuite du côté des vignes. Mais Hubert vint m’y rejoindre de ta part : le curé avait une communication urgente à me faire. Je repris, en maugréant, le chemin de la maison, car je redoutais fort ce petit vieillard (François Mauriac, Le Noeud de vipères)

1995 Hodkann disait, entre deux sanglots, que les ennemis qui avaient tué son père et que redoutait si fort sa mère risquaient de venir au chalet pour l'emmener, lui (Emmanuel Carrère, La Classe de neige)

\section{CoRpus Web :}

Après ce nouveau coup dur qu'elle est en train d'encaisser à Sidi Ali Bounab et ses environs, elle va très certainement tenter de signifier qu'elle n'en est pas à sa fin et celle de ses capacités de nuisance. Il est à redouter fort qu'elle le fasse en voulant organiser de spectaculaires attentats suicides dans la capitale ou en d'autres grandes villes du pays [http://www.djazairess. com/fr/lqo/5146800] (11.11.2015)

A l'approche d'un check point en rase campagne, check qu'ils semblaient redouter fort, les Palestiniens se tenaient prêts à montrer leurs papiers [http://www.enfantsdepalestine.org/ article/sous-les-feux-de-la-haine-temoignage] (11.11.2015)

Et conséquence tout à fait logique, ce sont des montagnes d'immondices que l'on croise en sillonnant les rues de la capitale économique. Aucun quartier n'est épargné. Des populaires aux plus chics, c'est le même spectacle, et on commence à redouter fort des éventuelles épidémies [http://www.cameroon-info.net/ stories/0,4984,@,douala-a-nouveau-sous-lesordures.html] (11.11.2015)

REMARQUES : Redouter fort se dit du fait de craindre fortement quelque chose, d'appréhender une situation future avec angoisse. Dans le premier exemple du CW, redouter fort ajoute une fonction discursive incluant un jugement subjec- tif par rapport à ce qui est dit après, équivalant à il est probable que (et je le crains). Fort reste invariable. Il est modifié par si, tant.

\section{Redouter petit}

Craindre, appréhender peu

Transitif

-1234 Molt bien s afice, parmi aus en ira ;

Ne tant ne quant li quens ne s esmaia :

Les .XV. rois molt petit redouta (Aliscans

$[\mathrm{R}]$, manuscrit d [1 $1^{\text {er }}$ tiers XIII $]$, 959)

REMARQUES : Redouter petit référait à la façon d'envisager ou de percevoir quelque chose ou quelqu'un, le sujet affichant peu de crainte ou d'angoisse ou appréhendant très peu l'événement à venir ou la confrontation avec cette personne. En ancien français, petit fonctionne comme quantifieur équivalant à son substitut moderne peu. Petit est modifié par moult.

\section{Redraper net}

Redraper brusquement, immédiatement Transitif

1882 Qui sait pourtant, si quelque étourdissant " Je t’aime »

N'eût pas redrapé net nos langes de baptême (Jules Laforgue, Euvres complètes : Mœurs)

REMARQUES : Au sens propre, redraper net désigne le fait d'envelopper à nouveau le corps d'un nourrisson avec les langes de baptême, le processus se faisant rapidement, directement. Toutefois, ici il apparaît dans un sens poétique, métaphorique. Net reste invariable.

\section{Redresser droit}

Remettre droit

Transitif

1564 [Le verger] Redressez bien droit à mont tous les bouts [= des scions] qui sortiront de la terre, de telle hauteur que faire pourrez, et les laissez ainsi trois ou quatre ans sans les rayonner, jusques à ce que leurs racines ayent prins terre (Charles Estienne, L'Agriculture et maison rustique)

1809 C'est après un cours assez long dans cette direction, que le Clain rencontre les deux rivières de Dive et de Boulieur, qui 
non-seulement l'enrichissent beaucoup, mais le redressent droit au nord (Nicolas Desmarest, Encyclopédie méthodique : géographie-physique, s.v. Charoux)

Pronominal

1711 De se relever en haut la tête droite, avant que de s'asseoir pour faire l'adoration, car si l'on s'asseioit pour faire l'adoration, avant que de s'être ainsi relevé et redressé tout droit, la Priere seroit vaine et nulle (Jean Chardin, Voyages de Mr. le chevalier Chardin, en Perse, et autres lieux de l'Orient)

1845 Ainsi qu'un cadavre soumis à l'action de la pile voltaïque se meut par soubresauts brusques et étranges, ainsi Rodin bondit dans son lit, se retourna et se redressa droit sur son séant en entendant les derniers mots du prélat.

- Il s'est trahi... dit le cardinal à voix basse et en italien (Eugène Sue, Le Juif errant)

1999 Au poteau il se redresse bien droit et m'embrasse pour sa maman à qui va sa dernière pensée. Puis calme, sans un mot, sans forfanterie, avec le seul regret de ne pas voir la victoire prochaine, il tombe frappé de douze balles (Georges-Arthur Goldschmidt, La Traversée des fleuves)

\section{CORPus Web :}

Pour les hameçons, je n'hésite pas à monter du fort de fer en $1 / 0$ car, dans un ultime sursaut désespéré, la daurade royale a parfois la singulière particularité de redresser droit comme un « $\mathrm{i}$ » des hameçons trop fins de fer et même de briser net ceux en acier trempé [http:// loicdegardin.over-blog.com/pages/La_daurade_ royale-3256594.html] (18.11.2015)

L'invention concerne un coupe-froid à empilement (20) constitué d'un empilement plat (10) de rubans qui sont mis sous tension de façon à se redresser droit vers l'extérieur afin de constituer un coupe-froid à empilement lorsqu'il est courbé et inséré dans une fente en T $(26,42$, 46 , or 56) ou dans une autre dépouille d'élément tel qu'une fenêtre ou un cadre de porte ou un châssis [http://www.google.com/patents/ WO2002020932A3?cl=fr] (18.11.2015)
La fierté d'être français, rajouterons-nous, cela s'enseigne, se transmet ou vous tombe dessus comme si de rien n'était... Combien ai-je vu de vieux " chibanis » la larme à l'œil se redresser droit comme un i devant nos couleurs, malgré le poids de l'ingratitude... ? [http://archives. lesmanantsduroi.com/articles/article31106.php] (18.11.2015)

Elle se redresse droite, comme le lui a dit sa mère [http://www.smoking-ruins.com/t595-andif-you-re-still-breathing-you-re-the-lucky-oneskhloe] (18.11.2015)

REMARQUES : Se redresser droit désigne le fait de relever le buste, de se tenir très droit, de se remettre dans une position verticale. Il réfère à la position prise par la personne lorsqu'elle se relève ou s'assoit après avoir été allongée. Dans l'emploi transitif, l'action peut porter sur l'objet dénotant le résultat (dans les exemples : la rivière, l'hameçon). Droit reste invariable dans la majorité des cas. Toutefois, dans le quatrième exemple du CW, il s'accorde avec le sujet en tant que prédicat second orienté vers le sujet. Il est modifié par bien, tout. Notons l'usage de briser net.

\section{Referir isnel}

Refrapper rapidement, promptement Transitif

1200 Li Sarrazins le fiert, cui il fu bel, De son destrier le rabat mort isnel. Ez Guinemant poingnant tout un vaucel, Por la pucelle chevauche li donzel. Li Sarrazins le referit isnel, Mort l'abatit tantost de son poutrel (Jourdain de Blaye, 1667)

REMARQUES : Dans un combat, referir isnel se disait du fait de porter de nouveau et rapidement des coups sur quelqu'un. Isnel reste invariable.

\section{Refermer étroit}

Refermer en serrant fortement Transitif

1276 D’Ogier a pris congié tel qu'il devoit, Dou parc issi, car raisons l'aportoit. Lors refremerent les barres moult estroit Cil qui la erent a cui il en tenoit (Adenet le Roi, Les Enfances Ogier, 3913) 
REMARQUES : Refermer étroit se disait du fait de fermer solidement, de manière à ne laisser aucun espace, ce qui a été ouvert ou ce qui est ouvert, l'objet désignant des pièces de bois ou de métal (ici : les barres d'une porte). Étroit reste invariable et est modifié par moult.

\section{Reflamboyer clair}

Briller, resplendir avec clarté

Intransitif

+1150 Li reis Hugue li Forz Charlemaigne apelat, Lui et les doze pers, sis trait a une part ; Le rei tint par la main, en sa chambrel menat,

Voltice, peinte a flors, a pieres de cristal. Une escarboncle i luist et cler reflambeiait, Confite en une estache del tens rei Golias (Pèlerinage ou Voyage de Charlemagne à Jérusalem et à Constantinople [2 $2^{\mathrm{e}}$ moitié $\mathrm{XII}]$, 423)

1275 N'estoit pas grans li lieus, ç'ai oÿ raconter ; Mahons ert d'or massis c'on ot fait afiner, Maint kamahieu i ot qui moult fist à amer, Et maint riche rubi qui reflamboie cler Et tant d'autre richoise c'on nel porroit esmer (Adenet le Roi, Buevon de Conmarchis, 1438)

REMARQUES : Reflamboyer clair, employé en ancien français, réfère à la couleur éclatante, étincelante d'une pierre précieuse comme, par exemple, le rubis, dont l'éclat s'apparente à celui d'une flamme qui luit, brille d'un vif éclat. Clair reste invarié dans les exemples.

\section{Reflamboyer novel}

Flamboyer à nouveau, avec éclat

Intransitif

+1300 Entre queux vist-yl la banere sire Water de Lacy, reflambeaunt novel d'or ou un fés de goules par my

(Fouke le Fitz Waryn [début XIve], p. 30)

\section{Réfléchir haut}

Réfléchir, penser à voix haute

Intransitif

1751 Je veux réfléchir, et tout haut même, quand cela me plaît, sans que personne me contredise plus là-dessus que sur tout le reste. Parler, où, comme, quand, et tant que je veux est mon privilège de sultan (Alexandre Dumas fils, Ah quel conte!)

1891 - Le comte de Beauvilliers, reprit-il lentement, réfléchissant tout haut, oui, il a eu des fermes, tout un domaine, du côté de Vendôme... il est mort d'un accident de chasse, il a laissé une femme et deux enfants dans la gêne (Émile Zola, L’Argent)

1993 - Bien sûr, bien sûr... Je réfléchissais tout haut...

Toujours Frénard, deux semaines plus tard (Philippe Sollers, Le Secret)

\section{CORPUS WEB :}

Le taxi attend et Virginie Ledoyen continue à parler beau, à réfléchir tout haut, à argumenter avec entrain [http://next.liberation.fr/ cinema/2014/01/22/virginie-ledoyen-elementmoteur_974789] (16.8.2015)

hé hé hé, moi, quand j'ai une partenaire avec on peut réfléchir haut et loin, même dans un couloir, je m'en prive pas ! Ça a été 3 minutes d'intense joie !;) [http://www.cheznadia.com/ archives/2010/12/belles-a-bloguer-les-copineset-copains-dabord.html] (12.11.2015)

Ceux qui réfléchissent tout haut. Ils monopolisent la parole pour exprimer des idées qui n’apportent rien, avant d'arriver enfin à une conclusion [http://wisembly.com/blog/2014/02/04/ gerer-les-bavards-en-reunion-mode-demploi] (12.11.2015)

REMARQUeS : Réfléchir haut désigne le fait d'exprimer ses pensées ou réflexions à voix haute, de ne pas garder ses pensées pour soi. Notons la collocation haut et loin et l'emploi de parler beau dans le CW. Haut reste invariable et est modifié par tout.

\section{Refuser net}

Refuser catégoriquement, de manière claire, franche, formelle

Emploi absolu

1687 Le roi de Pégou ayant appris que le roi de Siam avoit sept éléphans blancs, lui en envoia demander un : on refusa net (François-Timoléon de Choisy, Journal du voyage de Siam) 
1796 Ce langage me parut concerté avec ma mère, et je commençai d'entrer en défiance que j’avais été amenée exprès à la promenade pour cette entrevue. Je ne me trompais pas. Nous fûmes engagées à dîner. Ma mère accepta. Je refusai net (Nicolas Rétif de la Bretonne, Histoire de Sara)

1835 Or, maintenant, quand on propose une course, au lieu de saisir avec enthousiasme une occasion de faire trotter des chevaux, Madame d'Hocquincourt refuse tout net (Stendhal, Lucien Leuwen)

1853 Je lui exposai mes embarras, je lui dis qu'il me fallait quinze cents francs, soit comme prêt, soit comme remboursement partiel. Il me répondit que ma demande était juste et qu'il comprenait parfaitement que c'était pour moi une loi d'honneur d'obliger un ami malheureux, mais en même temps il s'excusa sur les difficultés nouvelles et refusa net (Maxime Du Camp, Mémoires d'un suicidé)

1929 Augusta refuse, et même (c'est bien l'unique fois de sa vie où le vocable netteté ait à intervenir) refuse tout net : ce qui le prouve, c'est que, de ce moment-là jusqu'à la veille de la séparation, Byron se détourne d'elle et entre à son égard dans la veine du « mépris amer » (Charles Du Bos, Byron et le besoin de la fatalité)

1959 il n’y aura plus de ces regards échangés entre eux, sous lesquels elle se ratatinait - petite tête desséchée d'Indien bonne à placer dans leur vitrine, dans leur collection d'objets curieux... Ils devront tourner leurs regards ailleurs, des regards tendus, perçants d'adultes, dirigés sur de vrais obstacles, de réelles difficultés : Tu sais, ma mère a refusé net (Nathalie Sarraute, Le Planétarium)

Transitif

1713 Tambonneau,passablement laid, fondait ses espérances sur beaucoup d'esprit qu'on ne lui trouva pas ; et Flamarens, par son air et par sa taille, briguait une admiration qu'on lui refusait tout net. Ils étaient convenus de se prêter mutuellement du secours pour réussir (Antoine Hamilton, Mémoires de la vie du comte de Gramont)

1745 On ne connaît rien aux hommes ; et cet insensé, qui s'était si peu soucié de ce qu'il se devait à lui-même, qui n'avait pas hésité d'être si lâche à ses dépens, refusa tout net de l'être aux dépens de sa femme, pour qui sa passion était déjà éteinte (Pierre de Marivaux, La Vie de Marianne)

1843 Je soupçonne fort la Barberini, qui est un peu gausseuse, comme dit Voltaire, d'avoir joué l'épouvante pour se moquer de nos histrions italiens qui, par état, ne sont pas braves, et qui refusèrent net de se soumettre à la même épreuve (George Sand, La Comtesse de Rudolstadt)

1882 Après un moment de silence, elle me proposa Faïmana sa suivante, que cette fois je refusai tout net. Alors sa figure prit une expression de fine malice, et tout doucement ses yeux se tournèrent vers Ariitéa la princesse

- Si je t'avais offert celle-ci, dit-elle, peutêtre aurais-tu accepté avec plus d'empressement, mon petit Loti ?...

(Pierre Loti, Le Mariage de Loti)

1893 - Il a réclamé au baron une forte somme, une commandite pour fonder quelque grosse maison de vol, que ce dernier a refusée net. L'autre l'a menacé de raconter leur petite opération à Ardea, et il l'a racontée.

- Et Peppino a été indigné ? fit Dorsenne en hochant la tête

(Paul Bourget, Cosmopolis)

1931 Celui-ci [= Aristide Briand] admettait la date du 14 août pour la déclaration de guerre de la Roumanie à l'Autriche, mais il n'acceptait pas que cette déclaration ne fût pas accompagnée d'une déclaration de guerre à la Bulgarie, et il refusait net toute nouvelle prétention territoriale des Roumains (Joseph Joffre [= le maréchal Joffre], Mémoires)

1986 Il la prit dans ses bras. Il l'embrassa avec passion. Il lui jura de l'aimer toujours et 
de ne jamais l'oublier. Et il refusa tout net de promettre quoi que ce fût à propos de Karl Marx et de Simon Finkelstein (Jean d'Ormesson, Tous les hommes sont fous)

Pronominal

1768 Je me suis trouvé au rendez-vous mystérieux ; mais je me suis refusé net à ce qu'on en attendoit. Qu'en attendoit-on ? Si maman se met à y rêver, elle le trouvera avant la fin de deux ourlets (Denis Diderot, Lettres à Sophie Volland)

1833 Grandet avait observé les variations atmosphériques des créanciers, et ceux de son frère obéirent à tous ses calculs. Les uns se fâchèrent et se refusèrent net au dépôt. « Bon! ça va bien », disait Grandet en se frottant les mains à la lecture des lettres que lui écrivait à ce sujet des Grassins (Honoré de Balzac, Eugénie Grandet)

1843 Mme de La Baudraye ne souffrit chez personne ni propos vides, ni galanterie arriérée, ni phrases sans valeur; elle se refusa net au clabaudage des petites nouvelles, à cette médisance de bas étage qui fait le fond de la langue en province (Honoré de Balzac, La Muse du département)

\section{CoRpus Web :}

Quand le photographe demande à l'immortaliser au volant de son Coupé C 63 AMG édition 507 de Mercedes-Benz, il commence par refuser net: « Je vais salir mon complet ! » [https:// magazine.mercedes-benz.ca/pascal-wehrlein/ ?lang=fr] (12.11.2015)

En effet, l'employeur peut seulement refuser ces congés prévus par la loi dans les structures de moins de 200 salariés, et seulement en prouvant que l'absence du salarié est préjudiciable à l'entreprise et après avis du comité d'entreprise ou des délégués du personnel. Or, il peut refuser net un congé sans solde sans se justifier [http:// www.cadremploi.fr/editorial/conseils/conseilscarriere/detail/article/le-conge-sans-soldecomment-ca-marche.html] (12.11.2015)

La colère doit se manifester pour refuser net la sale besogne effectuée par l'Unef [http://www. forumamislo.net/viewtopic.php? $\mathrm{f}=6 \& \mathrm{t}=20126 \& \mathrm{p}$ $=221349$ ] (12.11.2015)
Je souhaite me mettre en freelance et j'ai demandé à mon employeur une rupture conventionnelle, qui m’a été refusée nette pour des raisons « ethiques » [http://droit-finances.comment camarche.net/forum/affich-4138170-refusrupture-conventionnelle-de-l-employeur] (12.11.2015)

REMARQUES : Refuser net désigne le fait de ne pas accepter, de repousser quelque chose ou ne pas vouloir faire quelque chose et exprimer ce refus de façon claire et catégorique. Dans son emploi pronominal, il se dit du fait d'être en désaccord total avec quelque chose, une idée ou une décision. Net reste invariable dans la majorité des cas. Dans le quatrième exemple du CW, il s'accorde cependant avec l'objet au féminin en gardant son interprétation adverbiale. Net peut être modifié par tout.

\section{Refuser sec}

Ne pas accepter du tout

Transitif

1610 Le curé presente donc son service d'amour à Denise ; et elle le refuse tout sec, d'autant qu'elle n'estoit pas encore saoule de son mary (François Béroalde de Verville, Le Moyen de parvenir)

1884 Le lendemain, j'eus grande peine à le trouver et à ma demande, il me refuse sec l'entrée dans ses archives sans l'aveu de l'abbé de Citeaux (Revue de Champagne et de Brie)

Emploi absolu

2018 Mais Derlesi a refusé sec et m'a chassé de son bureau comme un malpropre, devant les justiciables! (Djimrabaye Bourngar, Mangistrature à Begou)

\section{Regarder aigu}

Regarder avec insistance, avec une attention pénétrante, de manière perçante

Transitif

1925 - Ta perdition, la mienne, et les petits à l'assistance... Tu as tiré de mauvais vin, Raboliot : dépêche-toi de le boire avant qu'il n'ait trop coulé.

Il fronce ses sourcils rapprochés. Il la regarde plus aigu : 
- Ah ! Qu'est-ce que j'ai compris, Sandrine? (Maurice Genevoix, Raboliot)

\section{CORPUS WEB :}

Il a regardé aigu le Draco [http://poudlard futur.nice-board.com/t34p15-la-profetie-detrelawne] (12.11.2015)

Il regardait aigu? Enfin, j'veux dire il souriait pas mauvais? Tu sais comme le lapin qui vert là [http://kwest.com/Euphorie/answer/452719] (12.11.2015)

Dumbledore a maintenant gagné l'attention de la foule une fois de plus, regardant aigu audessus de ses lunettes de demi-lune les jumeaux et souriant fixement [http://poudlardfutur. nice-board.com/t10p15-une-nouvelle-chance] (12.11.2015)

REMARQues : Regarder aigu désigne le fait de fixer les yeux sur quelqu'un, le regard étant particulièrement vif et pénétrant. Notons l'emploi intransitif dans les deux derniers exemples du CW. Aigu reste invariable et est modifié par plus. Mentionnons l'emploi adverbial de mauvais dans sourire mauvais au sens de 'méchamment'.

\section{Regarder bas}

Considérer, envisager des choses basses, viles, indignes

Intransitif

1848 Votre fin et votre principe ne diffèrent pas : c'est Dieu qui est votre père, et c'est lui qui est votre but. Il est l'alpha et l'oméga de votre destinée ; vous ne pouvez regarder plus bas sans vous perdre, aller moins haut sans périr. En vain, si vous êtes ingrats, en appellerez-vous à la bonté contre la justice (Henri-Dominique Lacordaire, Conférences de Notre-Dame)

1916 L'on peut, tout en étant très bas, regarder du moins vers l'azur ; mais non : si bas que je fusse, je regardais plus bas encore. Je renonçais au ciel. Je ne me défendais plus de l'enfer. Idées fixes et tous les prodromes de la folie. Vrai ! Je me faisais peur (André Gide, Journal)

\section{CORPUS WEB :}

Le désordre en Centrafrique, en passant par le Mali, La guinée et la Côte d'Ivoire, tout cela frise, l'immaturité et la politique du troisième homme. Pendant que les autres nous regardent bas, nous les encourageons à le faire, sans même apporter, un seul jour, la moindre intelligence pour nous faire grandir [http://www.civox.net/ Changeons-un-jour_a6820.html] (13.11.2015)

Car c'est devenu dorénavant une culture chez nous de regarder haut les riches par crainte de leurs pouvoir d'influence, et de regarder bas les pauvres car ils n'ont aucune voix [https://fr-fr.facebook.com/PoesieOuSolitude/ posts/467902636705385] (19.11.2015)

Quant à Elizabeth, elle continuait d'approcher, lentement mais sûrement. Qu'est-ce qu'elle regardait au juste ? Elle regardait bas, très bas. Trop bas ? [http://www.fic.free.fr/?rubrique=lire \&id=422\&chap=2] (13.11.2015)

Son ami était totalement nu ! Je ne regardais que ses yeux, évitant soigneusement de regarder plus bas... [http://www.reve-interprete. com/interpretation-des-reves/pourquoi-j-eviteconstamment-de-regarder-le-visage-t7593.html] (12.11.2015)

REMARQUES : Au figuré, regarder bas désigne le fait de considérer ou voir les choses d'une manière basse ou vile, méprisable ou peu noble. Dans les deux derniers exemples du CW, bas est pris comme adverbe de lieu, dans un contexte érotique où le regard descend pour lorgner le sexe d'une personne. Notons l'opposition sémantique entre regarder haut et regarder bas dans le second exemple du CW. Bas reste invariable et est modifié par plus.

\section{Regarder bel}

Regarder joliment

Intransitif

+1400 Peine esmonder, Joye abonder, Tout marchander, Et dueil seder, Bas affonder, Et reffonder, Bel regarder, Voir recorder, Sanz point bourder, Pais accorder, Non descorder, Droit recorder 
Pour amender,

En sens fonder

Et perfonder (Christine de Pisan, Lays /

Euvres poétiques [début Xve], I, p. 128, 82)

\section{CORPUS WEB :}

Rihanna : On ne le voit pas, mais Travis Scott et Rihanna regardent bel et bien dans une direction commune... [http://www.june.fr/ rihanna-travis-scott-en-couple-pourquoi-sonnouveau-boyfriend-se-diferencie-de-drakeet-chris-brown-galerie-1850359-2892048.html] (13.11.2015)

bah elles me regardent bel et bien mais de là à dire que c'est de la séduction je n'en ai AUCUNE idée, je suis trop nul pour interpréter les regards et autres signes [http://www.jeuxvideo. com/forums/1-51-56186052-3-0-1-0-les-filles-vousregardent.htm] (13.11.2015)

on va la regarder bel et bien gratuitement sur France 2 et sur TF1 [http://www.djazairdvb. biz/forum/archive/index.php/t-57689.html] (13.11.2015)

Remarques : Dans l'exemple de +1400 , beau adopte la forme neutre bel pour marquer la fonction adverbiale. Dans l'emploi actuel, on ne trouve plus que la collocation lexicalisée bel et bien 'effectivement, contrairement à ce l'on pouvait croire'.

\section{Regarder bleu clair}

Lancer un regard clair avec des yeux bleu clair

Transitif

1938 Puis ils parlèrent d'Ariane et Mme Deume déclara que la femme d'Adrien la détestait. Pour donner plus d'importance à cette affirmation, elle posa son tricot et regarda bleu clair son mari.

- Elle me déteste, répéta-t-elle en se grattant le dos avec une de ses longues aiguilles.

- Toi, si bonne, si douce?

(Albert Cohen, Mangeclous)

REMARQues : Dans cet exemple littéraire, l'auteur introduit la couleur des yeux dans l'action de regarder. Il s'agit d'une variante stylistique de regarder clair ou de Elle le regarda de son regard bleu clair. Bleu clair reste invariable.

\section{Regarder clair}

Lancer un regard clair, direct, brillant

Intransitif

$1883 \mathrm{Au}$ moment du départ, je vis cette Marie Keremenen, que j'appréhendais de connaître : c'était une jeune femme d'environ vingt ans, qui portait le costume du village de Toulven, en basse Bretagne. Ses beaux yeux noirs regardaient clair et franc (Pierre Loti, Mon frère Yves)

CORPUS WEB :

On ne peut que souhaiter qu'aux prochaines échéances se présentent de nouveau des candidats qui savent regarder clair et loin, au-delà de leur nombril et de leur montre-bracelet [http:// www.agoravox.fr/actualites/international/ article/l-europe-petit-cap-d-asie-entre-43254] (15.11.2015)

Je vais me retrousser les manches, et les méninges. Et regarder clair les choses. Pour avancer [http://www.seronet.info/billet_blog/ non-renouvellement-de-l-aah-ou-propositionde-plan-personnalise-de-compensation-duhandi] (15.11.2015)

Dans ses tableaux tranquillement pervers l'œil s'apaise et s'aiguise. Il s'enchante à regarder clair avec un arc-en-ciel de discrétion [http:// www.lastree.net/log/2006/12/catherine_dhomp. php] (15.11.2015)

REMARQUES : Regarder clair réfère aux yeux dénotant un regard direct et rayonnant, sans ambiguïté et n'exprimant aucun trouble. Dans les deux premiers exemples du CW, ceci est transposé á la clarté d'une vision intellectuelle. Le second exemple illustre l'emploi transitif. Notons les collocations regarder clair et franc et clair et loin. Clair reste invariable. On peut probablement établir un lien entre l'invariabilité de clair dans l'emploi transitif de regarder, verbe de perception active, et la tendance à faire l'accord de l'adjectif-adverbe avec le verbe voir, verbe de perception passive (Sa fille, il la voit grande déjà). Par contre, on n'observe pas une tendance complémentaire du verbe agentif à l'accord avec le sujet, même si c'est sans doute possible (les yeux regardent clairs). 


\section{Regarder direct}

Fixer les yeux directement (sur quelque chose)

$\lambda$ regarder franc

\section{Regarder droit}

I. Regarder sans dévier le regard

Intransitif

-1469 Et adoncques tous, tant gens d'eglise que chevaliers et escuiers et gens de tous estats qui furent là de la part du roy Amydas, s'agenoillerent et leverent les mains et les mistrent sur leur piz, en regardant droit au ciel, et prindrent sur leurs consciences que ainsi estoit (Jean de Bueil, Le Jouvencel [1461]-1468, II, p. 183)

1559 Ce que advisa tresbien une de leurs voisines, qui s'estoit mise à la fenestre qui regardoit tout droict sur ce jardin, pour veoir quel temps il faisoit (Marguerite d’Angoulême, Heptaméron, p. 370, 72)

1560 Ce mal donc, comme d'autres infinis, doit estre imputé aux théologiens Sorboniques, lesquels ont couvert tant qu'ils ont peu Jesus Christ comme d'un voile, comme ainsi soit que si nous ne regardons droit à luy nous ne pouvons que vaguer par beaucoup de labyrinthe (Jean Calvin, Institution de la religion chrestienne)

1736 Oh, pour Arion, dit Télemaque, écorchez-le comme une anguille ; mais pour son oncle, prenez vos lunettes et regardez droit. Vous ne savez pas, si ce manant est d'accord avec Araste, et vous voulez le fustiger (Pierre de Marivaux, Le Télémaque travesti)

1859 Puis elle regarda fixe et droit devant elle, Tandis que de ses yeux la mémoire infidèle S’effaçait, comme on voit, aux approches du soir,

Par degrés se ternir les clartés d'un miroir (Marceline Desbordes-Valmore, Élégies)

1933 Elle regardait droit et un peu loin, d'un regard raisonnable, aussi posé que sa voix, avec deux yeux précis, sans rêve, qui n'avaient aucune raison de se baisser (Joseph Malègue, Augustin ou Le Maître est là)
1966 - Quel monsieur?

- Celui qui dort.

- Qu'est-ce que tu racontes?

Il ne répondit pas tout de suite. Il mangeait sa tartine, regardant mélancoliquement droit devant lui, à travers le pare-brise, la tête en arrière sur le dossier du siège. Puis il eut un petit soupir

- Je crois qu'il dort, dit-il

(Sébastien Japrisot, La Dame dans l'auto)

1980 Elle geint un peu, les dents serrées pour ne pas crier, ses mains se crispent sur les bras $\mathrm{du}$ jeune garçon. Lui ne la regarde pas ; il regarde droit vers l'horizon, du côté des montagnes noires, ou peut-être est-ce vers le grand ciel nocturne (Jean-Marie Gustave Le Clézio, Désert)

Transitif

1851 - Je suis fort content de ce que je viens de voir, lui dit-il en élevant la voix et en le regardant droit au visage d'un air sévère ; ce sont de bons ouvriers, et je remercie beaucoup votre père de les avoir employés (George Sand, Le Compagnon du Tour de France)

1864 - Elle n'est ni grande ni petite, elle est très bien faite, des pieds mignons, des mains d'enfant, des cheveux blond cendré en quantité, un teint de lis et de roses, des traits exquis, des dents de perles, un petit nez très ferme, de beaux grands yeux vert de mer qui vous regardent tout droit sans hésitation, sans rêvasserie, sans fausse timidité, avec une candeur et une confiance qui plaisent et engagent (George Sand, Le Marquis de Villemer)

1879 Germain avait levé la tête et regardait sa femme droit dans les yeux, comme pour chercher à lire dans ses prunelles humides le complément de sa pensée (André Theuriet, La Maison des deux barbeaux)

1907 Elle ne rougit pas, elle ne fait aucun geste, aucune simagrée. Elle me regarde tout droit, les yeux songeurs.

- C'est vrai : je ne sais pourquoi, mais j'ai confiance en vous... 
Elle sourit, sans gaieté (Claude Farrère, L'Homme qui assassina)

1913 Mais la femme, qui était occupée à laver son bol sur l'évier, se retourna, curieuse à son tour, et elle dit lentement, en le regardant bien droit :

- C'est-il que vous n'êtes pas du pays ? À ce moment, un paysan âgé se présenta à la porte, avec une brassée de bois, qu'il jeta sur le carreau

(Alain-Fournier, Le Grand Meaulnes)

1922 Le dimanche ensuivant, après vêpres, il dévale à Sumontargues, entre dans l'auberge, les regarde tous tout droit.

- Écoutez quatre mots : on a dit ci et ça... (il ne prit pas des gants, mais répéta le propos tout cru). Il n'y en a pas un ici qui ne sache que c'est fausseté !

(Henri Pourrat, Le Château des sept portes ou Les Enfances de Gaspard)

1948 Il recevait toutes les condoléances avec une même inclination de la tête et du cou, se redressait, regardait droit le nouvel arrivant. Maigret passa comme les autres, s'inclina, lui aussi, trouva le même regard braqué sur lui. Il n'y décela aucun trouble (Georges Simenon, Les Vacances de Maigret)

1950 LUCILE. pourquoi alors? HERO. (dans un murmure) j'aime casser.

(elle le regarde, toute droite et claire. Il essaie de soutenir son regard un long moment, puis soudain il se verse un verre nerveusement et le vide d'un trait) (Jean Anouilh, La Répétition ou L’Amour puni)

II. Être situé directement en face de, donner directement sur

Intransitif

1675 Il faut que je vous conte ce que j'ai fait. Imaginez-vous que des dames m'ont proposé d'aller dans une maison qui regarde droit dans l'Arsenal pour voir revenir notre pauvre ami ; j'étais masquée. Je l'ai vu venir d'assez loin. M. d'Artagnan était auprès de lui (Mme de Sévigné, Correspondance)
CORPUS Web :

Regarder quelqu'un droit dans les yeux entraîne ce que l'on appelle une activation [http:// www.e-sante.fr/communiquez-par-regard/ actualite/789] (15.11.2015)

\section{Regarder droit en arrière}

Le film « Le monde de demain » confirme un paradoxe nostalgique dans le cinéma de science-fiction actuel [http://www.ledevoir.com/ culture/cinema/440711/regarder-droit-en-arriere] (15.11.2015)

Garde ton calme, fais-lui un petit sourire et éventuellement un clin d'œil, ne dis rien et continue à la regarder droit dans les yeux, jusqu'à ce qu'elle craque! [http://www.coachdrague.com/ blog/comment-seduire-une-femme-avec-tonregard-uniquement] (15.11.2015)

Le menton de la ahri (quand on penche la tête pour la regarder droite) me fait peur. En fait non c'est son sourire qui est perturbant [http://www.fureur.org/forums/showthread. php?t=42563] (15.11.2015)

REMARQUES : Regarder droit (I) réfère à la direction du regard. Droit tend à former un groupe syntaxique avec les prépositions qui spécifient la direction, y compris la locution droit dans les yeux. C'est notamment les cas dans l'exemple de 1966 où mélancoliquement modifie le verbe regarder alors que droit forme un groupe avec devant. Droit peut s'accorder avec l'objet pour indiquer une position en tant que qualité de quelqu'un ou quelque chose (v. l'exemple de 1950 et le dernier exemple du CW). (II) est un emploi analogue à donner droit à/sur 'être dirigé vers'. Droit est modifié par bien, tout. Notons les collocations regarder droit et clair / fixe et droit / droit et loin.

\section{Regarder faux}

Avoir un regard qui manque de naturel, de vraisemblance

Intransitif

1959 C'est sans doute la plus mauvaise actrice de l'hémisphère boréal. Elle parle faux, elle marche faux, elle regarde faux (Arts, 30 septembre 1959 / Grundt : 378)

\section{CORPUS WEB :}

Scott regardait faux. - Que faites-vous Scott? Vous me trahissez pour ce petit chien? 
[https://www.fictionpress.com/s/3248087/8/ Pour-t-appartenir] (15.11.2015)

Sinon concernant la PCH toujours ils m'ont bien dit que si plus tard je décide de prendre la PCH de faire une simulation aux impôts ! Car je lui ai dit oui mais, c'est déclarable mais non imposable[/b] je lui ai dit c'est ce que j'entends partout : Et la il m'a regardé faux de faux de faux [http://forum.magicmaman.com/magic03ans/ Desenfantsdifferents/mdph-base-vacancessujet-3669145-1.htm] (15.11.2015)

REMARQUeS : En référence au jeu de scène, au théâtre ou au cinéma, regarder faux s'emploie pour souligner le caractère peu naturel ou spontané dans le regard de l'acteur, traduisant ainsi un jeu peu crédible. Faux reste invariable. Notons l'usage de parler faux et marcher faux. Notons aussi la réduplication faux de faux de faux qui renforce l'effet pragmatique dans le dernier exemple du CW. VoIR AUSSI : marcher / parler faux

\section{Regarder ferme}

Regarder fixement, sans sourciller

Transitif

1584 Je te regarday ferme, et devins glorieux D'avoir veincu ce Dieu qui se tournoit arriere

(Pierre de Ronsard, Sonnets pour Hélène)

1627 - Comment, reprit-elle en le regardant ferme entre les yeux, depuis si peu de temps que nous nous sommes separez, avez-vous beu de l'eau de l'oubly, pour ne plus plus souvenir de nostre sortie de Rothomague (Honoré d'Urfé, L'Astrée)

1873 Mais elle le regarda ferme, dans les yeux, et la mémoire lui revint (Émile Gaboriau, Les Comédiennes adorées)

1950 Le chiot pencha la tête un peu à gauche puis à droite en la regardant ferme de ses bons yeux bleus (Bertrand Vac, Louise Genest)

\section{Regarder figé}

Ne pas dévier son regard (de quelque chose)

$\lambda$ regarder fixe

\section{Regarder fixe}

Fixer les yeux sur (quelque chose ou quelqu'un), regarder fixement

Intransitif

1876 Elle s'assit à côté d'Amynèh, lui prit la main, et, voyant que celle-ci ne prononçait pas un mot, ne levait pas les yeux et regardait fixe devant elle, elle l'attira sur son cœur, et la couvrant de baisers, lui dit :

- Nous sommes bien malheureuses!

(Arthur de Gobineau, Nouvelles asiatiques)

Transitif

1985 - C'est très urgent, insiste Bastienne, en regardant bien fixe Papagaio dans les yeux, comme une tentative d'intimidation (Victoria Thérame, Bastienne)

\section{CORPus Web :}

Tu étais avec ton copain. Mais tu n'arrêtais pas de me regarder de façon explicite. Tu étais juste belle.. Quand vous êtes descendus à Gare de Lyon, tu n'as pas hésité à me regarder fixe aux yeux [http://paris.croisedanslemetro.com/ annonce/10459] (16.11.2015)

Ensuite évite de la regarder fixe, tu risques de l'effrayer la pauvre [http://forum.ados.fr/actu/ discussions/fille-inconnu-laime-sujet_42788_1. $\mathrm{htm}](16.11 .2015)$

Le troll auréolait devant eux, plus petit qu'à la normale, plus trapus que d'ordinaire, aussi franc que les deux paires, le troll les regarde fixe et figé [http://www.mountyhall.com/Forum/ display_topic_threads.php?ThreadID=290565] (16.11.2015)

Au petit jour, un troupeau de zèbres m'entourait. Ils me regardaient fixes sans rictus [http:// www.zebrascrossing.net/t1720-hemispheredroit] (16.11.2015)

REMARQUES : Regarder fixe se dit de tenir fixement sous son regard quelque chose ou quelqu'un, de regarder en face, droit devant soi, sans détourner les yeux de l'objet visé. Notons les collocations fixe et droit et fixe et figé, où fixe réfère au regard et figé à la position immobile du sujet. Fixe reste invariable dans son emploi adverbial, sauf dans le dernier exemple du CW où il semble renvoyer aussi bien à la façon de regarder qu'à l'immobilité du troupeau. Il est modifié par bien. VoIR AUSSI : regarder droit 


\section{Regarder fort}

Regarder avec une grande intensité

Transitif

-1456 Lors le regarda mout fort, puis dist : « Je ne le puis donques reffuser, face donques son bon plaisir. Bien diz que tieulz gens sont plus a doubter aucune foiz que les plus puissans » (Antoine de la Sale, Jehan de Saintré, p. 148, 33)

1559 Après que le gentil homme eut lavé avecques le seigneur de Vernaige, l'on porta l'eau à ceste dame, qui lava et se alla seoir au bout de la table, sans parler à nully ne nul à elle. Le seigneur de Vernaige la regarda bien fort, et luy sembla une des plus belles femmes qu'il avoit jamais veue, sinon qu'elle avoit le visaige bien pasle et la contenance bien triste (Marguerite d’Angoulême, Heptaméron, p. 296, 25)

1610 Une femme, voyant un jour un beau gentilhomme, le regarda fort, et d'un œil de concupiscence; puis dit à sa voisine : « Voylà un bel enfant : je le porterois volontiers, pour le faire jouer » (François Béroalde de Verville, Le Moyen de parvenir)

1840 On nous menait au service funèbre à l'église, et je regardais fort le haut catafalque, trône lugubre du bon roi (Eugénie de Guérin, Journal)

1956 - Ha ! Félicien ! Est-ce que ce plafond que vous regardez si fort pourrait nous dégringoler sur la tête?

(François-Régis Bastide, Les Adieux)

Intransitif

1968 - Dis-moi, que vois-tu dans la calebasse d'eau ? Regarde fort ! fort! Que vois-tu?

- Un coq, un gros coq battant des ailes, qui chante, chante, murmura Salimata

(Ahmadou Kourouma, Le Soleil des indépendances)

\section{CORPUS WEB :}

Quand le vieillard chantait, les gens s'arrêtaient, s'arrêtaient par millier par journée pour le regarder. Le regarder fort, l'écouter silencieusement [https://scarecrowworld.wordpress.com/ tag/amour/page/5] (16.11.2015)
Les loupiotes achetées chez Stein-Dinse, jolies certes, trouvent amusant de casser dès qu'on fait mine de les regarder trop fort [http:// www.cafe-racer.info/phpBB2/viewtopic.

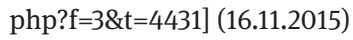

Y avait la fille de cabaret à côté, celle qui s'assure qu'on la regarde fort [http://baldespoupons. blogspot.co.at/2015/06/un-dimanche-dominical. html] (16.11.2015)

Je ne veux rien briser de cet âge délicat où les premiers désirs d'envols se rassurent à grands mouvements de repli. Je la regarde forte et sensible et si mes bras voudraient encore un peu la serrer, mon envie brûle avec la sienne, envie d'aller voir plus loin [http://toujoursdimanche. canalblog.com/archives/2011/09/12/22019591. html] (16.11.2015)

REMARQUES : Regarder fort se dit du fait de fixer les yeux sur quelqu'un avec une grande intensité, le regard ou la façon de regarder l'autre traduisant les sentiments ou émotions forts ressentis par le sujet. Selon le contexte, regarder fort peut cumuler l'idée de fréquence et signifier 'regarder souvent' (v. deuxième exemple du CW). Fort reste invariable (ex. de 1559, le deuxième et le troisième exemple du CW). Toutefois, dans le quatrième exemple du CW, il s'accorde avec l'objet pour en désigner une qualité perçue ; cet emploi est plutôt rare pour un verbe de perception active, étant plus courant avec le verbe de perception passive (Je la vois forte et sensible). Fort est modifié par bien, moult, si, trop. Notons la réduplication fort, fort ! dans l'exemple de 1968. Sur le plan diachronique, la fréquence devient minime à partir du XVII ${ }^{\mathrm{e}}$ siècle, moment à partir duquel on commence à préférer la modification de l'adverbe qui suit, surtout dans la collocation regarder // fort attentivement. Selon les données de Frantext, la modification du verbe recommence à prédominer à partir de la seconde moitié du $\mathrm{xx}^{\mathrm{e}}$ siècle.

\section{Regarder franc}

Regarder directement, franchement, librement et sans gêne Intransitif

1875 Il y a, dit-on, dans la règle des quakers, un article qui ordonne de regarder franc, quoi qu'il advienne. C'est une bonne loi et tout à l'honneur des quakers. Tel était le regard 
calme et doux que ce jeune médecin promena sur les assistants en traversant la chambre (Paul Féval, Une évasion et un contrat / La Bande Cadet)

Transitif

18949 décembre.

Et d'abord, au fond, sur un sofa, je vois deux femmes nues : l'une montre son ventre, et l'autre son derrière... Bernard va leur tendre la main en disant : «Bonjour, mesdemoiselles ! ». Moi, gêné, je n’ose regarder franc ces deux modèles. Je cherche où mettre mon chapeau, mon pardessus et mon parapluie qui pisse (Jules Renard, Journal)

\section{CORPUS WEB :}

Il serra la main de Lyan en le regardant franc dans les yeux [http://hentai.forum-rpg.net/index. php?topic=9709.0;wap2] (16.11.2015)

C'est ton attitude qui change un cheval craintif en cheval patate. Si tu avances un sac de plastique droit vers lui en le regardant franc dans les yeux et que tu recule d'un pas en disant 'woah' lorsque tu le vois sur le bord de paniquer, oui il sera craintif [http://poneyxpress.com/forum. php?cat=1\&dv=50587] (16.11.2015)

Puis il m'a regardée, franc, direct, j'ai su qu'il me voulait [http://www.vosecrits.com/t801exercice-de-la-semaine-2-nourritures-exquises] (16.11.2015)

REMARQUES : Regarder franc se dit du fait de fixer les yeux sur quelque chose, de regarder quelque chose de manière sincère, ouvertement et sans dissimulation, le sujet n'éprouvant aucune gêne ni contrainte. Notons la collocation franc et direct et la locution regarder franc dans les yeux.

\section{Regarder grand}

Regarder les yeux grands ouverts, avec étonnement, avec stupéfaction, avec admiration Transitif

1925 Elle regarde tout grand, tout grand cet immense ciel vide, cette terre étrangère, cette végétation folle et cette grande maison qu'elle ne connaît pas (Blaise Cendrars, L'Or)
Emploi absolu

1957 Elle redonne au botaniste le regard agrandissant de l'enfant. Avec elle, il rentre au jardin, dans le jardin où les enfants regardent grand.

Ainsi le minuscule, porte étroite s’il en est, ouvre un monde. Le détail d'une chose peut être le signe d'un monde nouveau, d'un monde, qui comme tous les mondes, contient les attributs de la grandeur (Gaston Bachelard, La Poétique de l'espace)

\section{CORPUS WEB :}

Bonne approche pour ton budget, c'est en regardant grand que l'on voit grand et loin [http:// www.plus-riche-et-independant.com/2011/09/ gerer-son-budget-annuellement-et-non.html] (16.11.2015)

Il ouvrit ses petits yeux verts, les frottas avec ses poings puis regarda grand la maison qui se dressait devant lui [http://naruto-chunin.jeun.fr/ t13599-maison-de-hiya-shimizu] (16.11.2015)

Son mari la regarde grand dans les yeux et replique [https://www.facebook.com/permalink. php?id=422499667845197\&story_fbid $=675136$ 822581479] (16.11.2015)

J'avais envie, la maintenant de raconter silencieusement, non, j'avais BESOIN, de toucher l'innocence, de complaire la beauté. Tout doucement de l'embrasser, tout doucement de s'embraser, la plus petite parcelle, le moindre de ses recoins. De la sentir honnête, de la regarder grande, de la trouver heureuse [http:// ethyliquementcorrect.blogspot.co.at] (16.11.2015)

REMARQUES : Appliqué à la perception visuelle, regarder grand désigne le fait de voir une chose ou une personne avec stupéfaction, avec de grands yeux. Grand réfère à la taille des yeux et souligne l'émerveillement du sujet devant le paysage ou l'objet devant lequel il se trouve. L'adjectifadverbe est employé métonymiquement pour l'organe de la vue : les yeux (ouvrir grand les yeux). L'exemple poétique de 1925 crée une lecture volontairement ambiguë par rapport aux yeux et au ciel, tous deux grands, et peut-être même l'idée de 'des yeux grands comme le ciel qu'ils regardent'. Le premier exemple du CW joue avec les verbes complémentaires regarder et voir, le premier dési- 
gnant l'action volontaire de regarder avec soin un budget, ce qui permet de voir grand et loin. Grand reste invariable en tant qu'adjectif-adverbe. Dans le dernier exemple du CW, il adopte la fonction de prédicat second orienté vers l'objet qui s'accorde avec celui-ci. Il est modifié par tout. VoIR AUSSI : esgarder / voir grand

\section{Regarder haut}

I. Avoir de l'ambition, de grandes prétentions; viser ou s'intéresser à une chose noble, élevée, à une personne de haut rang

Intransitif

1680 Je ne vois que des oppositions à toutes mes volontés, grandes et petites ; il faut regarder plus haut pour ne pas s'impatienter. Je laisse un laquais pour m'apporter vos lettres. Ah ! Ma fille, c'est bien moi qui ne passe les autres jours que pour attraper celui-là (Mme de Sévigné, Correspondance)

1742 Sans un verre nos yeux ne le connoîtroient pas.

Celui qui fit ces yeux pour veiller sur nos pas

Ne nous en donne point pour voir tous ses ouvrages :

Et lorsque nous voulons percer jusqu'aux nuages

Où s'enferme ce dieu, de ses secrets jaloux, Pour regarder si haut, quels yeux espérons-nous? (Louis Racine, La Religion)

1836 - Nous sommes d'hier et nous ne serons plus demain ; nous sommes des bourgeois et non des Montmorency ; des industriels, ma sœur, et non des héros.

- Et faut-il être autre chose, reprit Maurice, pour être heureux ? Ne regardons pas si haut, restons où nous sommes (Léon Gozlan, Le Notaire de Chantilly)

1862 Les astres qui doraient l'étendue éclatante, Eux-mêmes, palpitant comme des yeux en pleurs,

Regardèrent plus haut vers des mondes meilleurs :

L'ombre se déploya comme une lourde tente

D’où sortit le sanglot des suprêmes douleurs
(Charles-Marie Leconte de Lisle, Poèmes barbares : Le massacre de Mona)

1901 Pour les autres, c'est l'illusion qui leur apprend à regarder, à admirer et à se réjouir. Et si haut qu'ils regardent, ils ne regarderont pas trop haut. Dès qu'on s'en approche, la vérité s'élève ; dès qu'on l'admire on s'en rapproche (Maurice Maeterlinck, La Vie des abeilles)

1912 Dieu le père n'apparut à peu près jamais dans la statuaire des églises. Les pauvres imagiers ne regardaient pas si haut. Ils ne savaient pas bien faire ce qu'ils n'avaient pas vu. Ils ne manquaient pas d'imagination, certes, et même d'une vague, universelle et confuse culture (Élie Faure, Histoire de l'art : l'art médiéval)

1930 Mme D., lorsque le petit François, son fils, lui eut fait confidence de ses ambitions (continuer ses études en vue de devenir instituteur), s'écria : " Mais mon petit, est-ce que tu ne regardes pas trop haut ?... » C'est elle qui me redit ses propres paroles, me les répétant par trois fois, les faisant suivre d'un « que je lui ai dit... » (André Gide, Journal)

II. Lever son regard vers le haut Intransitif

1872 Sombre araignée à qui Dieu, pour tisser sa toile,

Donnait des fils d'aurore et des rayons d'étoile.

Et même, en regardant plus haut, quel est celui

Qui s'écriera : - Je suis l'astre, et j'ai toujours lui ;

Je n’ai jamais failli, jamais péché ; j’ignore Les coups du tentateur à ma vitre sonore (Victor Hugo, L’Année terrible)

1954 Je suis celui qui ne regarde pas plus haut que les toits

Plus loin que l'horizon parallèle des rues Le soleil qui se casse aux carreaux avares Me cache le sommeil étoilé du monde Où je n'ai que faire, homme de ce côté-ci (Jean Tardieu, Une voix sans personne) 


\section{CORPus WeB :}

\section{Regarder haut et loin}

Ma grande taille me permet sans doute depuis toujours d'avoir un regard panoramique autour de moi, et donc une vision synthétique des évènements [http://celestinetroussecotte. blogspot.co.at/2012/02/regarder-haut-et-loin. html] (18.11.2015)

Football, Ligue 2 - Avec Alphonse Areola, les Lensois peuvent voyager loin et regarder haut [http://www.lavoixdunord.fr/sports/footballligue-2-avec-alphonse-areola-les-lensois-ia18 2b205n2110069] (18.11.2015)

Les troncs sèchent lentement et la forêt redevient terrestre. Pédestre. Sombre. Je la regarde, haute et profonde. Je l'indiffère [http://www.ivoyages.net/beaute-pauvrete] (18.11.2015)

REMARQUES : Regarder haut (I) réfère à une vision ambitieuse, visant haut sur une échelle des valeurs. Lacception de base (II) désigne un regard dirigé vers un lieu situé plus haut (aussi dans le premier exemple du CW). Haut reste invariable dans son emploi adverbial. En tant que prédicat second détaché, il s'accorde avec l'objet dont il désigne une qualité, de même que profond (dernier exemple du CW). Il est modifié par plus, si, trop.

\section{Regarder juste}

Regarder avec exactitude

$\lambda$ regarder vrai

\section{Regarder noir}

Jeter un regard lugubre, menaçant, irrité

Transitif

1749 Harlay, qui l'avoit bien compté et regardoit noir le duc de Coislin, dont la seule voix fit en dernier lieu ce désordre, exposa le cas à la compagnie (Saint-Simon, Mémoires complets et authentiques du duc de Saint-Simon sur le siècle de Louis XIV et la Régence [1739-1749])

1778 Toute ma stupidité ne m'empêcha pourtant pas de trouver au baron l'air plus content, plus jovial qu'à son ordinaire. Au lieu de me regarder noir, selon la coutume, il me lâchait cent propos goguenards, auxquels je ne comprenais rien. J'ouvrais de grands yeux sans rien répondre (Jean-Jacques Rousseau, Les Confessions)
1784 Nous voila que nous-nous parlons, et que persone ne le trouve-mauvais! Suppose notre village, que de discours ! Il aurait falu passer notre vie à nous regarder noir, ou nous exposer à mille desagrémens. Je dois jouir dans peu du bonheur d'avoir ici Mme Parangon : Écris-moi par cette occasion, qui est la plus-sûre (Nicolas Rétif de la Bretonne, La Paysanne pervertie ou Les Dangers de la ville)

\section{CORPuS WeB :}

Dans les douches, des distributeurs à savon età shampooing sont disponibles pour tous, et une fois bien lavés, on peut rejoindre l'eau. Je pense meme que si l'on fait l'impasse sur la douche, on se fait regarder noir par les autres ! [http:// 4aunord.fr/finlande/tous-a-poil] (19.11.2015)

La plupart des mecs sont sans-gêne, ils fixent, parfois même sans cligner des yeux. Tu peux toujours les regarder noir (pourtant je suis experte en la matière) ils baissent pas les yeux [http://madridcity.uniterre.com/182572/1+mo is $+\mathrm{d} \% \mathrm{C} 3 \% \mathrm{~A} 9 \mathrm{j} \% \mathrm{C} 3 \% \mathrm{A0} 0+30+\mathrm{mai}+2011 . \mathrm{html}]$ (19.11.2015)

Jusqu'au jour où la petite a commençait a me regarder noir ! Des yeux amourachés pour mon mari (qui n'a évidement rien vu ! Comment croire qu'une petite fille pourrait lui faire les yeux doux !)... [http://www.confidentielles.com/ ttopic-110460-elle-drague-mon-mari-et-doitavoir-a-peine-13-ans.htm] (19.11.2015)

j'avais pensé à aller la voir un jour la sem pro à sa caisse, elle est étudiante mais arrondit ses fins de mois en tant que caissière, et la regarder noire, sans lui parler, histoire de la faire cogiter, mais bon j'me dis que c'est aps forcément une bonne idée ; ça serait encore lui donner de l'importance quelque part... [http://forum. doctissimo.fr/psychologie/histoires-d-amour/ fille-compliquee-connerie-sujet_17922_1.htm] (19.11.2015)

REMARQUES : Regarder noir se dit du fait de fixer les yeux sur quelqu'un en exprimant de la colère, des idées cachées, le sujet se trouvant dans un état d'énervement plus ou moins proche de l'irritation. Noir reste invariable dans la majorité des cas. Dans le quatrième exemple du CW il s'accorde avec l'objet tout en gardant son interprétation adverbiale. 


\section{Regarder profond}

Regarder avec intensité, profondément Emploi absolu

1883 Oh ! Ce regard qu'il me jeta en se rendant aux fers, obligé de suivre le sergent d'armes qui l'emmenait là, devant tout le monde, de descendre dans la cale avec ses beaux habits du dimanche !... Il était dégrisé, assurément ; car il regardait profond et ses yeux étaient clairs (Pierre Loti, Mon frère Yves)

\section{CORPUS WEB :}

C'est notre rituel du mercredi, notre habitude, pour prendre le temps de voir. Quand je dis voir, c'est regarder. Regarder profond ce que peut nous offrir la nature, cette nature qui nous entourent [http://aarrr-parallele.blogspot. co.at/2015/02/les-mercredis.html] (19.11.2015)

Bah tu sais Pope, connaître l'histoire du pays où on vit c'est bien, mais c'est pas en regardant profond dans le passé qu'on se sortira de la merde où on se trouve $(-)$ [http://www.jeuxvideo. com/forums/1-22728-537748-2007-0-1-0-welcometo-bar-gta5.htm] (20.11.2015)

Si jamais une fille te sort : « t'es mon héro ! » Tu lui dit d'une fois [= voix ?] douce en la regardant profond dans les yeux : « Et toi t'es mon héroïne... » [http://www.forumdesados. net/la-phrase-que-les-filles-aiment-le-plusentendre-t9565-150.html] (20.11.2015)

REMARQUES : Regarder profond se dit du fait de fixer les yeux sur quelqu'un ou quelque chose (ici : le passé), de jeter un regard d'une grande intensité, qui provoque une impression de profondeur, d'épaisseur. Profond reste invariable dans son emploi adverbial. Toutefois, en prédication seconde détachée, il s'accorde avec l'objet (v. sous regarder haut). Notons l'emploi transitif du verbe dans le CW.

\section{Regarder triste}

Regarder tristement, d'un œil triste, affligé, abattu, malheureux

Intransitif

1849 Je passais les heures de récréation à regarder seul et triste, à travers les barreaux d'une longue grille qui fermait la cour, le ciel et la cime boisée des montagnes du
Beaujolais, et à soupirer après les images de bonheur et de liberté que j'y avais laissées (Alphonse de Lamartine, Les Confidences)

\section{CORPUS WEB :}

Avec le temps a devenu un espace très aimé parce-que c'est où nous avons les échecs et les succès plus spectaculaires. C'est là où on a fait la trompe d'éléphant, et aussi le flamant rose après beaucoup de mois d'y insister ; c'est le lieu où on les « soigne » des coups et raclées qui arrivent quelques fois ; c'est où il y a, entre autres, le lampadaire : qui nous regarde triste en nous rappelle encore qu'elle devrait être une girafe... [http:// www.katakrak.com/fr/la-compagnie/commenttravaille-t-on] (25.5.2016)

chaque fois que je me promène dehors je suis sur de rencontré un groupes de filles qui vont venir me demandé mon numéro en disant « Ouah t trop BO » ect... * Quand je suis avec des potes ça m'énerve car ils me regardent triste car les filles viennent vers moi et pas vers eux * [http://www. jeuxvideo.com/forums/1-51-55308662-1-0-1-0-lesfilles-veulent-mon-numero-irl.htm] (25.5.2016)

Nikki est recorquevillée sur son canapé tandis que son mari est assis sur un fauteuil. Ils se regardent tristes [http://www.lesfeuxdelamour. org/article-6625059.html] (25.5.2016)

Nous voyons George Mason dans ses derniers moments, piquant à $30^{\circ}$ dans la dépression à 1 minute 30 de l'explosion avec comme fond musical un Sean Callery très inspiré. Kim, Palmer, la cellule, Jack, tous regardent tristes la bombe exploser [http://www.24-fr.com/forum/ ftopic332-165.php] (25.5.2016)

REMARQUES : On lira regarder triste surtout comme prédicat second référant à la tristesse ressentie par quelqu'un, ce qui explique l'accord au pluriel de l'adjectif dans les troisième et quatrième exemples du CW. Toutefois, la lecture en tant qu'adverbe de manière n'est pas exclue non plus (v. le premier et le deuxième exemple du CW). 


\section{Regarder vrai}

Regarder de près en découvrant la vérité ; regarder véritablement

Emploi absolu

+1365 Honneurs ensi m’amonestoit

Et moult apparilliés estoit

De remoustrer à tous mes hommes

En disant : Biau signeur, chi sommes

Assamblé, au voir regarder,

Pour Justice et Raison garder

(Jean Froissart, Poésies [3 $3^{\mathrm{e}}$ tiers XIV $\mathrm{XV}^{\mathrm{e}}$ )

CORPuS WeB :

Étrange vidéo où l'on montre une base construite dans les entrailles de la Terre, apparemment destinée à une " élite » bien choisie qui sera protégée et sauvée lors du grand « chambardement " qu'on nous promet depuis quelques temps et qui, à regarder vrai, commence sérieusement à pointer le bout de son nez [http://qualita1. unblog.fr/2010/03] (20.11.2015)

J'aime les gens qui osent regarder vrai et juste même si c'est dur [http://www.jecontacte. com/profil/DeuxII2] (20.11.2015)

Patricia nous apprend à nous regarder «vrai » et la logique est là devant le miroir [http:// www.lconseille.ch/dc/lconseille/index.php?post /2012/09/19/Mes-clients-en-parlent] (20.11.2015)

REMARQUES : La locution à regarder vrai, où vrai change la position par rapport à l'ancien français au voir regarder (nominalisé), introduit une correction, une analyse corrigée suite à un regard plus objectif. L'usage productif de regarder vrai dans le CW réfère au fait de ne pas fermer les yeux sur ce qui pourrait déplaire, ce qui explique la présence de dur dans le second exemple du CW. Notons la collocation vrai et juste dans le CW. Vrai reste invariable (v. le troisième exemple du CW).

\section{Régler comptant}

Payer immédiatement et en espèces

Pronominal

1848 L'opium se règle comptant, en espèces ou en saï-ci, et la soie grége, ainsi que le vermillon, en échange contre des articles étrangers, sans escompte (Auguste Haussmann, Voyage en Chine, Cochinchine, Inde et Malaisie)
Transitif

1932 Je déteste qu'on me roule ; mais ce que je dois, je le paie. Vous dénoncez mon avarice ; il n'empêche que je ne puis souffrir d'avoir des dettes : je règle tout comptant ; mes fournisseurs le savent et me bénissent. L'idée m'est insupportable de devoir la moindre somme. C'est ainsi que j'ai compris « l'amour »: donnant, donnant... (François Mauriac, Le Nœud de vipères)

1946 Bien entendu, la ville désireuse de refaire son système d'éclairage n'espérait pas trouver dans son budget normal de quoi régler comptant toute la dépense (Jules Romains, Les Hommes de bonne volonté)

Emploi absolu

1960 Le placardier devient prolixe. Il veut savoir, emballer vite-fait, et par-dessus tout, pas se trouver charrié par la flanelle d'oxygène friande d'essai.

- Je règle comptant, rectifie Armand, qu'aime pas qu'on se méprenne... seulement je suis un peu pressé... D'un geste apaisant de la paluche, l'homme du monde accuse réception de l'exigence

(Albert Simonin, Du mouron pour les petits oiseaux)

2009 Il découvrait combien il est facile de persuader les pauvres que, même pauvres, ils peuvent s'acheter une machine à laver, une voiture, une console Nintendo pour les enfants ou simplement de quoi manger, qu'ils rembourseront plus tard et que ça ne leur coûtera autant dire rien de plus que s'ils réglaient comptant (Emmanuel Carrère, D’autres vies que la mienne)

CORPUS WEB :

La carte 4 étoiles vous offre également la possibilité de régler comptant, le mois suivant vos achats [https://www.4etoiles.fr/fr/avantagepaiement-comptant.html] (20.11.2015)

Carte de crédit avec option paiement comptant. Vos achats sont donc normalement payés à crédit (par débit de votre réserve d'argent) sauf si vous décidez de régler comptant en fin de mois [http://www.espacecredit.com/html/compa ratifs/cartes/carte-aurore.php] (20.11.2015) 
En fin au 30 janvier l'entreprise, reçoit la commande du 20 janvier accompagné de la facture. Le chef décide de la régler comptant étant donné de la bonne situation de trésorerie [http://hasla.free.fr/comptaclick/bilan/fr3.htm] (20.11.2015)

REMARQUES : Régler comptant réfère au paiement d'un objet ou d'un bien en espèces. Comptant reste invariable (ex. de 1946 et le troisième exemple du CW). VoIR AUSSI : acheter / payer comptant

\section{Régler incontinent}

Régler, conclure, mettre un terme (à quelque chose) immédiatement, sur-le-champ, sans aucun délai

Transitif

1835 Encore une fois, la meilleure réponse, c'est qu'il a agi de la sorte parce qu'il avait pris l'engagement de payer toutes les dettes portées au Bilan, et qu'il se proposait de les régler incontinent, soit en avals, soit en espèces (Charles Meynne, Liquidation de société commerciale)

1912 LA MÈRE. Quoi donc?

ANNE VERCORS. Eh bien ! Je m'en vais le chercher.

LA MÈRE. Comment, le chercher ? Anne ! ANNE VERCORS. Je veux que tout soit réglé incontinent. Je te dirai tout à l'heure pourquoi.

(Paul Claudel, L’Annonce faite à Marie)

\section{CORPuS Web :}

Et le bel habit vert s'éloigna, attiré sans doute par d'importantes affaires à régler incontinent [http://histoiresansgeo.canalblog.com/ archives/2010/09/13/19054004.html] (21.11.2015)

" J'ai quand même de bons garçons », pensa peut-être Clotilde en envoyant ses trois petits-fils à Childebert et Clotaire - qui, familles je vous hais, réglèrent incontinent la question patrimoniale en assassinant les mouflets [http://brendufat.overblog.com/article-saint-severin-1-39444395.html] (21.11.2015)

ReMARQUes : En français moderne, l'emploi d'incontinent est pratiquement réduit à la locution régler incontinent. Il se dit du fait de mettre immédiatement un terme à quelque chose, de conclure une affaire, de résoudre définitivement un problème et ce, de manière définitive, séance tenante. Dans l'ancienne langue, incontinent était un internationalisme très en vogue dans les langues romanes, ou encore en anglais. Ceci s'explique par son emploi dans le latin tardif savant (in continenti (tempore) 'dans la suite immédiate du temps'). Incontinent reste invariable.

\section{Regretter bas (basset)}

Regretter intérieurement, en secret

Transitif

+1365 Ainçois t’a souvent regreté

Basset, quant seulette a esté

(Jean Froissart, Poésies [3e tiers XIve])

1842 Elle-même, depuis longtemps, la regrettait tout bas, et cela nous prépare à y voir revenir un jour tous nos personnages, et les religieuses aussi (Charles Sainte-Beuve, Port-Royal)

1862 Il exigea qu'on ne lui en parlât plus, en regrettant tout bas d'être si bien obéi

(Victor Hugo, Les Misérables)

CORPUS WEB :

Nombre de tunisiens qui regrettent, tout bas, le départ de \#BenAli, soutiennent aujourd'hui, tout haut, le criminel Bachar [https://twitter. com/masmoudi_M/status/331015760145158144] (21.11.2015)

Cet opérateur discret devra d'abord vaincre le scepticisme de certains membres de l'industrie hôtelière qui regrettent tout bas que le poste de présidence ne soit revenu à un dirigeant d'un établissement cinq étoiles [http://www. aujourdhui.ma/une/thematiques-economiques/ tourisme-putsch-dans-l-association-hotelierede-casablanca-42498\#.VlBk_E2FOUk] (21.11.2015)

Les supporteurs du club mettent en avant la capacité du club à attirer les sacro-saints tops players, même sans Champions League (même si certains regrettent tout bas la "perte d'âme » du club) [https://descartesetdufoot.wordpress.com/ tag/mercato] (21.11.2015)

REMARQUES : Regretter bas se dit du fait d'éprouver secrètement, sans le dévoiler, de la contrariété, du mécontentement envers soi-même 
d'avoir ou de ne pas avoir fait quelque chose, de regretter une action dont le résultat a un aspect négatif. Lorsque le complément d'objet réfère à une personne, il désigne le fait d'éprouver secrètement de la peine, d'être affligé de ne plus être en présence de cette personne ou en relation avec elle. Notons l'opposition sémantique de regretter tout bas et soutenir tout haut dans le premier exemple du CW. Bas reste invariable et est modifié par tout.

\section{Regretter fort}

Éprouver des remords intenses

$\pi$ regretter haut

\section{Regretter grief}

Déplorer gravement, plaindre avec compassion, en manifestant sa peine, sa douleur

Transitif

-1200 A les plaint et regrate an sarazenois gref: «Ahi ! tant mar i futes, nobiles chevaliers! Alas! com sumes morz, treï et anginez ! » (Floovant [fin XII $]$, 319)

REMARQUeS : Regretter grief désignait le fait de juger regrettable, de désapprouver vivement ou d'éprouver un vif mécontentement, une grande peine par rapport à un fait, une situation. Notons que le langage tout récent reprend cet emploi avec l'intensifieur grave.

\section{Regretter haut}

Exprimer des remords ou des regrets

publiquement, ouvertement, au grand jour

Transitif

1867 il sourit, ce qui ne lui arrivait pas deux fois par mois, et ajouta du même ton : « quand vous aurez cinquante-cinq ans et une maladie de foie, vous verrez que cette opinion-là est le plus confortable oreiller du monde. » Il m’a légué ses ustensiles de café turc et sa provision de cigares ; je suis donc son héritier, et pourtant j'ose me croire sincère en regrettant tout haut qu'il soit mort (Hippolyte Taine, Notes sur Paris)

1887 Ell se contint un instant, s'efforça de parler d'autre chose ; car, devant la Grande, les Fouan évitaient de se plaindre, sachant qu'ils lui faisaient plaisir, quand ils regret- taient tout haut de s'être dépouillés. Mais la passion l'emporta (Émile Zola, La Terre)

1954 Et le Père a bien voulu. Mais lui, Damien, il a dit non. Et quand je lui ai dit « pourquoi ? ", lui, fils de rien, il a pas répondu. Plusieurs fois, au cours de la journée, il regretta tout haut l'absence de son camarade. Les jeux, sans lui, perdaient leur saveur (Maurice Genevoix, Fatou Cissé)

\section{CoRpus Web :}

Donc, je vous avait prévenu : J'ARRIVE SUR BLOGSPOT. Tant pis pour eux, ils vont pas tarder à le regretter. (.petit bonhomme jaune qui rigole ! ) Par contre, je vais pas regretter haut et fort, z'ont fait fort les mecs.... [http://boutfilbroderie. blogspot.co.at/2012/06/demenagement.html] (21.11.2015)

Le piège est encore plus dramatique que l'alternative semble on ne peut plus limitée, les candidats de remplacement éventuels ne faisant guère illusion, à tel point que des voix s'élèvent pour regretter haut et fort le destin contraire de Strauss-Kahn [http://www.lexpressiondz. com/internationale/218714-les-derapages-incontroles-de-sarkozy.html] (21.11.2015)

Enfin bon, je profite de ce message pour regretter tout haut la " disparition ", entres autres, de Laneis, Fou et Talak... [http://archives. jeuxonline.info/fils/24075.html] (21.11.2015)

REMARQUes : Regretter haut désigne le fait d'éprouver un sentiment de contrariété, de désagrément, un sentiment plus ou moins pénible au sujet d'une action passée, le sujet le communiquant publiquement. Lorsque l'objet réfère à une personne, il se dit du fait d'éprouver de la peine, d'être affligé de ne plus être en présence de quelqu'un ou en relation avec lui. Notons la collocation haut et fort dans le CW, qui est assez systématiquement employée. Haut reste invariable et est modifié par tout. L'emploi de tout haut exprime généralement un regret publiquement manifesté, ce qui n'est pas nécessairement le cas de haut et fort, qui peut simplement intensifier (premier exemple du CW). 
Rejoindre droit

Rejoindre directement

Transitif

1854 Dans cette rue de San Barlolomeo, qui longe les bords du Tibre, et qui va rejoindre tout droit le ponte Quattro Capi, on voit une quantité de tronçons de colonnes, la plupart en granit, enchâssés dans de vieux murs de maisons servant de soutiens (G. Robello, Les Curiosités de Rome et de ses environs)

1980 Allais-je quelques mois plus tard, ayant subi l'épreuve du feu, me rappeler cette scène et ses anodines violences ? Alors elle a rejoint tout droit, dans l'éloignement déjà fabuleux où reculait le monde de « l'avantguerre », mes souvenirs de caserne (Maurice Genevoix, Trente Mille Jours)

\section{CORPuS WEB :}

Et si tu travailles sur la façon de rejoindre droit un point et de s'y arrêter... Ton cheval assimilera peut être l'action d'y aller droit, mais il assimilera aussi l'action de s'y arrêter pour terminer l'exercice [http://www.chevalannonce.com/ forums-800077-marcher-droit] (21.11.2015)

Et la chanson Across the Universe est, toujours selon moi, un des plus beaux et enivrants moments du répertoire des Beatles. À elles seules, ces chansons ont le pouvoir de nous rejoindre droit au cœur ! [http://www.musiquefruitee. com/2012/11/poignant-mashup-the-beatles-etthe-flaming-lips] (21.11.2015)

Là, on peut soit, plus facile mais plus long, rejoindre les sentes de mouton à mi-pente du Mourre de Clausis (marquées sur IGN) qui rejoignent le sentier d'Isola au Vallon Plat, soit, plus rapide mais plus raide, rejoindre, en montant droit dans les pentes de marne, les sentes de mouton supérieures du Mourre de Clausis (aussi marquées sur IGN) et rejoindre droit la croupe de Vallonpierre [http://www.camptocamp.org/ forums/viewtopic.php?id=187081] (21.11.2015)

REMARQUES : Lorsque le complément d'objet réfère à un endroit défini en terme de direction, rejoindre droit désigne le fait de regagner ou de rallier cet endroit directement, sans détour. L'objet peut aussi renvoyer à une personne ou à une chose que l'on va retrouver. Droit reste invariable. Il est modifié par tout.

\section{Réjouir fort}

Rendre très joyeux, procurer un grand bonheur Transitif

+1472 Et si tost qu'il fut à Dijon, l'armée se rompit, et tint le duc la feste de Noel en sa dicte ville de Dijon, en grant feste et solempnité qui resjouissoit moult fort Bourgoingne, et principallement la noblesse et la seigneurie du pays, qui longuement avoient esté sans leur seigneur veoir (Olivier de la Marche, Mémoires [ $4^{\mathrm{e}}$ quart $\mathrm{XV} \mathrm{e}^{\mathrm{e}}$ )

1557 Et que les fleurs jettées au vin, ou reduittes en conserve resjouissent fort ceux qui sont tristes, fachés, angoisseux, et melancholiques (Rembert Dodoens, Histoire des plantes)

1732 il fit accroire à l'hôte que je venais à Florence de la part de l'ambassadeur pour une affaire de conséquence, et que probablement j’y ferais un assez long séjour ; ce qui réjouit fort monsieur le maître, et fut cause qu'il eut avec moi des manières très-respectueuses (Alain-René Lesage, Histoire de Guzman d'Alfarache)

1845 Ce mot d'alochon réjouit fort l'enfant, qui le répéta en riant et sans le comprendre (George Sand, Le Meunier d'Angibault)

Pronominal

1532 Pantagruel en voulut donner une aubade par la ville, et la faire sonner par toutes les rues en la portant en sa main; dont tout le monde se resjouist fort (François Rabelais, Pantagruel)

1638 Monsieur, entre plusieurs choses dont je me resjouis bien fort, je mets votre livre tout le premier, dans lequel je ne doute point que vous ne defendiez dignement l'honneur de la Vierge contre les anciens heretiques (Marin Mersenne, Correspondance)

1933 Espéranza se réjouissait si fort de voir sa Primerose devenue lady que, malgré sa conversion aux manières raffinées et 
même un tantinet précieuses, elle lança une exclamation tonitruante (René Crevel, Les Pieds dans le plat)

2011 Je me réjouis très fort de vous rencontrer (Serge Doubrovsky, Un homme de passage)

CORPuS Web :

D'abord, il n'y a pas lieu de se réjouir fort alors que les méthodes de calcul de ce solde symbolique - celui du régime général - restent sujettes à variations, à conventions librement accordées à eux-mêmes par ceux qui les publient [http://www.senat.fr/rap/a00-068/a00-0681. html] (21.11.2015)

J'avais abandonné le thème qui, à une époque, semblait réjouir fort les lecteurs de ce blog et du précédent [http://gillesenlettonie. blogspot.co.at/2012/09/la-bourde-du-jour-voirepire.html] (21.11.2015)

Pour l'instant, il n'y en a qu'un (curieux phénomène, non ?) mais on ne les refuse pas, au contraire. Primordial, disais-je, et qui semble réjouir fort l'assistance [http://sel.leforum.eu/t549Perigord-un-autre-troisieme-age-est-possibleecolo-et-autogere.htm] (21.11.2015)

REMARQUeS : Dans son emploi transitif, réjouir fort désigne le fait de procurer au sujet une grande satisfaction intérieure, un grand bonheur. Dans son emploi pronominal, il réfère à la satisfaction, au plaisir éprouvé par le sujet. Fort reste invariable. Il est modifié par bien, moult, si, très.

\section{Relayer sec}

Se remplacer sans perdre du temps, de manière fluide et ininterrompue

Pronominal

CORpus Web :

Départ canon avec Couz, Bertion, Mimi et Gladitor, ça se relaie sec et derrière le peloton est en file indienne. La jonction s'opère mais il y aura de nombreuses victimes dont Tony Martin

[https://classiquedesascenseurs.skyrock. com/17.html] (6.6.2006)

REMARQUeS : Employé ici dans le domaine du sport, en l'occurrence le cyclisme, relayer sec renvoie au remplacement à tour de rôle des coureurs en tête du peloton pour leur assurer un maximum de vitesse, sans perdre du temps, sans avoir besoin de négocier pour savoir qui prend le relai. VoIR AUSSI : filer sec, démarrer sec

\section{Relever soef}

Relever en douceur

Transitif

+1150 Deuant les pies son frere s'est alee acliner, Et il l'en releua entre ses bras soef, Douchement li baissa et la bouce et le nes, Et puis le duc Elie par fines amistes (Aiol et Mirabel $\left[2^{\mathrm{e}}\right.$ moitié XII $\left.{ }^{\mathrm{e}}\right], 8245$ )

REMARQUES : En ancien français, relever soef réfère au mouvement du corps qui se penche vers le sol, prenant à terre ou ramassant quelque chose avec précaution et délicatesse. Soef reste invariable.

\section{Reluire clair}

Reluire, briller beaucoup

Intransitif

1170 Quant del hauberc l'orent armé, Un hiaume a cercle d'or listé, Plus cler reluisant qu'une glace, Uns vaslez sor le chief li lace (Chrestien de Troyes, Erec et Enide, 2659)

1285 S'i ot mainte trenchant espee Et maint hiaume cler reluisant Et mainte ensaigne flamboiant Et mainte targe et maint escu Et mainte lance a fer agu (Adenet le Roi, Cleomadés, 525)

1560 Aucuns estimans plus clair les faire reluire que leur feu et lumignon ne portoit, les escharbotoient, esmouchoient, renversoient et ventiloient en sorte qu'ilz les faisoient en brief consumer, et ne duroient que bien peu (Barthélemy Aneau, Alector ou Le Coq)

1573 THESEE. Tu vis, tu vis barbare, et la lampe celeste

Aussi claire qu'à moy reluist à ton inceste? (Robert Garnier, Hippolyte)

1596 Il remonte à cheval sur le point de la nuit, lorsque desjà la lune au ciel claire reluit, Et que Phebus lassé dans la pline azurée 
Va plongeant le tresor de sa tresse dorée (Philippe Desportes, Euvres)

1612 ces oyseaux mal formez qui d'un vol incertain se vont cachant, sont des chats huans qui fuyent le soleil, dont la montagne couvre encores une partie, et l'autre reluit si claire qu'on ne sçauroit juger que ce fust autre chose qu'une grande et confuse clairté Passons plus outre (Honoré d'Urfé, L'Astrée)

REMARQUES : Reluire clair se dit d'une source de lumière (le feu, la lampe) ou un astre lumineux (la lune) qui luit, ou brille en répandant une lumière vive. Le sujet peut aussi désigner un objet (une armure) qui, parfaitement poli, brille de tous ses feux. Clair peut s'accorder avec le sujet et être modifié par aussi, plus, si. VoIR AUSSI : briller clair

\section{Remettre sec}

remettre (aussi) sec: recommencer

immédiatement, sur-le-champ, sans

aucun délai

Transitif

1963 Elle ne change pas de disque. Une obsédée. « Je te... toc ! toc ! toc !... dix-neuf... S... » Les trente jours de mitard ne l'ont pas guérie. Elle remettrait ça si sec ! Preuve encore que les sanctions les plus rigoureuses n'ont aucun effet salutaire (Alphonse Boudard, La Cerise)

1987 Finissant même par rejeter, non sans quelque irritation, cette main rabat-joie de l'endroit. Avant de marquer une nouvelle pause - main reprise -, puis de remettre ça aussi sec - main aux fesses. La chasse à l'épiderme s'organisait (Bruno Bayon, $L e$ Lycéen)

Pronominal

1981 Et dans le matin encore un rien charbonneux manman [sic] au s'cours le bouche à bouche à te remettre aussi sec à aimer cette sacrée vie que tu gerbais hier encore rappelle-toi. Suppliais la grande désossée de t'emmener avec elle. Là où y a plus d'amour. Plus de souffrance (Evane Hanska, J'arrête pas de t'aimer)
CORpus Web :

il va falloir s'y remettre sec !! alors tissus, fimo, récup ? hummmm c est pas décidé..... ça viens ;) [https://www.facebook.com/ permalink.php?story_fbid=140822642756981 \&id=139170839588828] (21.11.2015)

J'ai acheté cette chemise de nuit pour ma petite fille, c'est une vraie poupée avec, on se dirait au siècle dernier, il ne manque que le petit chapeau en dentelle. Ma petite fille l'adore, il faut la laver et lui remettre aussi sec [http://www. amazon.fr/review/RFFPKDDZ4EQB8] (21.11.2015)

C bien $\mathrm{d}$ fois de faire le fragile avec sa meuf juste pour lui donner des ailes après quand elle prend la confiance tu la remet sec en place [https://twitter.com/_mrsteven/ status/649684804242378753] (21.11.2015)

En revanche, tu parles de la lenteur de séchage de la laine comme un avantage, pas si sûr : mieux vaut enlever le vêtement mouillé et le faire sécher, non ? Donc là c'est un gros désavantage vu qu'il faudra du temps avant qu'on puisse la remettre sèche [http://forum.davidmanise.com/ index.php?topic=14307.5;wap2] (21.11.2015)

REMARQUES : Remettre sec se dit du fait de recommencer quelque chose, de faire à nouveau ce qu'on a déjà fait, sans attendre, tout de suite et, selon le contexte, de remettre des vêtements (deuxième exemple du CW) ou, au sens figuré, de remettre quelqu'un à sa place (troisième exemple du CW). Sec reste invariable dans son emploi adverbial. En tant que prédicat second, il désigne un état physique et s'oppose à mouillé ; il peut alors s'accorder avec l'objet (v. le quatrième exemple du CW). Il est modifié par aussi, si.

\section{Remiser sec}

S'opposer vivement et brusquement (à quelqu'un) par un refus, une réponse désobligeante, renvoyer

Transitif

1928 On ne le blaguait qu'à distance et l'on savait qu'à l'occasion il remisait sec les outrecuidants (Léon Daudet, Ecrivains et artistes)

\section{CORPUS Web :}

Ma pote a tenté la formation d'aide soignante mais elle s'est fait remiser sec à l'oral au concours car trop vieille d'après elle selon les juges [http:// 
forum.doctissimo.fr/viepratique/divorce/foyer3enfants-divorcer-sujet_11176_1.htm] (22.11.2015)

Pour les derniers qui vont se laisser tenter, il va y avoir des coups de fusil à faire... Ça va remiser sec ! (-) [http://www.forum-peugeot.com/ Forum/forum-peugeot/peugeot-rcz/nouveautes/ nouveau-confirme-finalement-sujet_2223_9.htm] (22.11.2015)

ils commencent à remiser sec chez Fiat $=$ -3000 euros sur la Croma ! bientot combien sur la GP ? [http://www.forum-auto.com/marques/fiat/ sujet97-8400.htm] (22.11.2015)

REMARQUeS : Remiser sec se dit du fait de remettre quelqu'un à sa place, de s'opposer vivement à une personne, à son caractère ou à son comportement par des paroles brusques. Dans les deux derniers exemples du CW, il réfère à une réduction de prix et signifie 'faire une remise'. Sec reste invariable.

\section{Remonter haut}

I. Monter vers le haut, renchérir Intransitif

1515 Et tant luy ont louée ceste folie qu'i la mist à V chappons et ung pour l'abbé, nonobstant qu'il dist bien que c'estoit trop. Adoncques à celle remonste y eust belle risée et n'y eust oncques hommes qui osaist remonter plus hault sur messire Jehan Pare, mais luy demeura la sotie à si bonne heure que jamais depuis n'en fut quicte, et l'ait tousjours eu et aurait tant qu'il viverait ; pour tant il n'employa pas mal ses VI chappons (Philippe de Vigneulles, Les Cent Nouvelles nouvelles, p. 74)

1676 car outre que la Thamise est profonde, la marée y remonte haute de plus de plus de trois toises (Albert Jouvin de Rochefort, Le Voyageur d'Europe)

2011 J'ai cru les bacilles partis. Ils sont simplement remontés plus haut dans les poumons (Serge Doubrovsky, Un homme de passage)

II. Remonter à un niveau (moral, spirituel) élevé, supérieur, atteindre un haut degré Intransitif

1580 Et par ainsi il advient à nostre ame, ce qu'on dit de l'eau des fontaines, à sçavoir, qu'elle remonte autant haut, qu'elle est descenduë en bas : et ne peut monter plus haut (Pierre de la Primaudaye, Suite de l'Academie françoise)

1704 Et pour ceux qui disoient le mieux : c'est un ange, disoient-ils, qui luy a parlé : soit qu'ils ne voulussent pas remonter plus haut par un esprit d'incrédulité : soit qu'ils crussent de bonne foy que Dieu luy avoit parlé par un Ange, comme il avoit fait aux patriarches et à tout le peuple sous Moïse (Jacques-Bénigne Bossuet, Méditations sur l'Évangile)

III. Considérer, se rapprocher de la base, de la source, du début, de l'origine (de quelque chose) Intransitif

1644 Que si nous remontons plus haut dans la source de l'Eglise, nous trouverons que ces Saints, et principallement saint Pacien, n’ont esté en cela que les Disciples de saint Cyprien ; comme saint Cyprien De Tertullien ; et tous ensemble de la Tradition et de l'Escriture Sainte (Antoine Arnauld, De la fréquente communion)

1730 LÉANDRE. Mais remontons plus haut. A Rome et dans la Grece (Philippe Destouches, Les Philosophes amoureux)

1831 mais, aujourd'hui que seize ans ont passé sur ces événements, est-ce une raison pour oublier tout ce que Louis XVIII fit dès le premier jour pour arrêter les dévastations des soldats des puissances étrangères, ses alliées, qui restauraient son trône ?... Je ne le crois pas. La haine ne devrait pas remonter si haut (Honoré de Balzac, Correspondance)

1936 Le grand malheur est que la justice des hommes intervienne toujours trop tard : elle réprime ou flétrit des actes, sans pouvoir remonter plus haut ni plus loin que celui qui les a commis (Georges Bernanos, Journal d'un curé de campagne)

2006 Faut-il alors remonter plus haut, dans un temps d'avant l'écriture, comme pour la prendre à revers, avant ses hiéroglyphes, 
dans ses signes, dont l'Histoire aurait effacé la signification, comme les miens alors dont le secret disparaît avec moi ? (Pierre Guyotat, Coma)

\section{CoRpus Web :}

@SaraAngeOff malheureusement, il faut parfois descendre bas pour remonter plus haut ma petite princesse.

@chrystalcasting tu as raison remonter haut! Que nos projets se réalisent ! Je ne vais pas te décevoir, c'est promis ! Merci pour tout [https: //twitter.com/saraangeoff/status/55426142049 0383360] (22.11.2015)

Déjà parce que Youtube est aujourd'hui le deuxième moteur de recherche le plus utilisé, devant Bing ou Yahoo. Et, finalement, si les sites ont intérêt à remonter haut dans les résultats de Google, premier moteur de recherche, n'ont-il pas également intérêt à remonter haut dans les recherches réalisées sur Youtube ? [http://www. journaldunet.com/solutions/expert/53674/5conseils-pour-reussir-son-referencement-videosur-google.shtml] (22.11.2015)

La peinture montre le fond de l'avant-port, avec l'une des écluses qui permettaient d'accéder aux autres bassins, les docks, et les hautes silhouettes caractéristiques des poteaux électriques qui avaient été installés au début des années 1890. Dufy adopte un point de vue très bas, à fleur d'eau, ce qui a pour effet de remonter haut la ligne d'horizon [http://www.muma-lehavre. $\mathrm{fr} / \mathrm{fr} /$ collections/vie-des-collections/dernieresacquisitions/dufy-le-port-du-havre] (22.11.2015)

De toute manière, ces 2 derniers jours à $\mathrm{St}$ Hil, c'était surtout la brise (conjuguée au vent tout de même) qui était forte et remontait haute... [http://www.parapentiste.info/forum/sortiespause-dejeuner/sthilaire-mercredi-18-12h15lumbin-t10326.5.html;imode=] (22.11.2015)

REMARQUES : Remonter haut (I) réalise le sens local, celui de « remonter vers une position élevée » (v. aussi les exemples 2 et 3 du CW : apparaître parmi les premiers résultats de Google ou remonter une ligne), aussi au sens de 'renchérir' (1515). Au figuré et pour ce qui est de l'ordre de l'esprit et de l'âme (II), se dit du fait de considérer les choses à un degré plus élevé, de façon plus large. Remonter haut (III) réfère au temps, désignant le fait de revenir en arrière dans le temps, de remonter aux sources, de prendre en compte le passé ou l'origine de quelque chose. Haut reste invariable dans la majorité des cas, mais dans l'exemple de 1676 et dans le quatrième exemple $\mathrm{du}$ CW, il s'accorde avec le sujet au féminin, dans un contexte météorologique. Ceci rappelle l'accord fréquent de haut dans le domaine du sport pour désigner la position effective d'un objet (ballon, balle, instrument) en mettant en relief le côté adjectival de l'adjectif-adverbe. Il est modifié par autant, plus, si. Notons l'emploi de l'antonyme descendre bas dans le premier exemple du CW (descendre en bas, dans celui de 1580).

\section{Remuer bel et beau}

se remuer bel et beau (d'un endroit) : s'éloigner vraiment, de manière sûre

Pronominal

1568 mais, à cause qu'il se sentoit autant ou plus chatouilleux de la gorge que celuy qu'on menoit pendre, se remue bel et beau de là, en lieu de venir parler à cet homme, de peur qu'il ne l'encusast à la justice (comme telles gens disent plus aucunes fois qu'on ne leur demande)

(Bonaventure des Périers, Les Nouvelles Récréations et joyeux devis)

REMARQUES : Remuer bel et beau se dit du fait de se déplacer, de bouger d'un lieu vers un autre, le sujet marchant d'un pas décidé, avec assurance, équivalant en français moderne à bel et bien 'effectivement, malgré tout'.

\section{Remuer menu}

Remuer vivement, avec adresse et rapidité Transitif

1190 Si le garde un gaiant qui mout fait a douter, Et tient une grant hache de cuivre et d'acier cler.

N'est campïon el monde, tant puist souvent geter

Ki peüst som baston si menu remuer Conmë il fait la hache et venir et aler (Fierabras (L), 2590)

REMARQUES : Remuer menu décrit le fait de transporter ou de déplacer un objet (ici : un bâton), de le changer de position, le sujet agitant l'objet en faisant de petits mouvements rapides, donc incluant la notion de fréquence. À l'idée de rapidité 
s'ajoute celle de vigueur, d'adresse dans le mouvement. Menu reste invariable et est modifié par si. VOIR AUSSI : tornoier / tourner menu

\section{Remuer profond}

Faire bouger en profondeur ; remuer, stimuler, ébranler profondément, beaucoup

Transitif

1906 Il faut de préférence attraper les femmes à l'improviste; ça leur remue profond le cœur et l'esprit (Les Trois Apôtres)

1936 Ces gestes sont de gymnastique et presque de danse ; ils modèrent la violence des pensées en même temps qu'ils en changent le cours. Un haussement d'épaules nous remue plus profond, déliant les puissants muscles qui s'attachent au thorax, et délivrant le cœur (Alain, Propos)

1955 Aujourd'hui, la midinette qui sommeille en chacun de nous reste atterrée de la décision de Margaret d'Angleterre. Pourtant l'eau où nous croupissons s'en trouve, Dieu merci, remuée plus profond (Elle, 5 décembre 1955 / Grundt : 290)

\section{CORPUS WEB :}

c'est une pierre loin d'être anodine (surtout la céleste)... conseille pas forcément de la porter (pense que ca peut même être à éviter dans certains cas)... ${ }^{\star \star \star}$ après chacun est libre...mais ça peut dépoter... (ouvre la porte sur soi même pour la classique - et déjà ça peut remuer profond... - et la celeste sur d'autres portes... *encore pire.....*) [http://www.esprit-de-la-nature. $\mathrm{fr} /$ geobiologie/pierre-oeil-celeste-t2342.html] (22.11.2015)

Quoique t'entendre Christian dire ses mots à voix haute, ça doit remuer profond ! Et de tout mon cœur, mes bras n'étant pour le coup pas assez longs du tout, je vous embrasse bien fort tous les trois, Sandy, Emcée et toi ! [http:// vacuum2scrapbook.blogspot.co.at/2010/09/ grande-visite.html] (22.11.2015)

Je croise cette pensée ${ }^{\star}$ d'Alphonse de Lamartine, et une rangée de livres me défilent dans la tête avec en pool position ma première émotion, le tout premier livre qui m’a remuée profond, Le blé en herbe de Colette [http:// helenablue.hautetfort.com/archive/2013/04/06/ toutes-les-grandes-lectures-sont-une-date-dansl-existence.html] (22.11.2015)

REMARQUES : Remuer profond réfère à un mouvement du corps qui provoque une forte stimulation ou qui a pour effet de faire bouger quelqu'un de façon intense. Au figuré, remuer profond souligne le fait d'émouvoir profondément quelqu'un ou de l'ébranler sur le plan intellectuel ou émotionnel. Profond reste invariable et est modifié par plus.

\section{Rendre bel (beau)}

Rendre (un salut) courtoisement, de manière avenante

Transitif

+1200 Quant plus la voit et plus l'avise

Et plus li plest a deviser.

Li dui compain sanz demorer

Descendent, si l'ont saluee,

Et cele s'est contr'eus levee

Qui bel lor rendi lor saluz

(Raoul de Houdenc, Meraugis de

Portlesguez [début XIII'] ], 389)

+1365 Mès la coulour rouge muai.

Elle mon salu me rendi

Moult bel, noient n'i attendi,

Liement et en sousriant

(Jean Froissart, Poésies [3e tiers XIV $]$ ])

\section{Corpus Web :}

Samedi prochain je vais allé faire les peintures et j'aimerais en profiter pour rendre beau ce parquet [http://forum.aufeminin.com/forum/ pratique1/_f35088_pratique1-Comment-rendrebeau-du-parquet.html] (22.11.2015)

L'argent peut-il rendre beau grâce au progrés de la chirurgie estethique ? [https://open classrooms.com/forum/sujet/peut-on-devenirbeau-78656] (22.11.2015)

Malheureusement et heureusement, la photographie a le pouvoir de rendre beau la misère, la détresse, la tristesse... [http://www.photopassion. fr/remy-donnadieu-lart-de-la-photographie] (22.11.2015)

Une métisse demande à des graphistes de différents pays de la rendre 'belle'. Voici le résultat [http://www.afrizap.com/une-metissedemande-a-des-graphistes-de-differents-paysde-la-rendre-belle-voici-le-resultat] (22.11.2015) 
REMARQUES : En parlant d'une personne et de son comportement en société et en référence à l'idéal courtois, rendre bel se disait en ancien français du fait de répondre au salut d'autrui avec des gestes ou dans un langage courtois empreint de politesse raffinée. Le neutre bel indique la fonction adverbiale référant plutôt à une qualité de l'action qu'à la beauté du sujet. Il est modifié par moult. La langue moderne ne connaît plus que l'emploi de rendre comme copule qui indique un changement d'état provoqué par quelqu'un ou quelque chose. Rendre beau désigne alors le fait de changer quelque chose ou quelqu'un avec l'objectif qu'il devienne plus attractif (v. les exemples du CW).

\section{Rendre cher}

Retourner (quelque chose) en le faisant payer cher, faire subir les conséquences fâcheuses d'une action

Intransitif

+1250 Li rois li commenca a dire

Ha punes rox de male part,

De ma gent m'as fet grant essart.

Mes molt cher te sera rendus, Que orendroit seras pendus :

Ne t'i vaudra engin ne lobes (Le Roman de Renart [2 $2^{\mathrm{e}}$ moitié XIII'], XI, 3335)

+1415 Tant ay largement despendu Des biens d'amoureuse richesse, Ou temps passé de ma jennesse, Que trop chier m'a esté rendu (Charles d’Orléans, Poésies [ 1415-1440], II, Rondel CCCLXXXI, p. 511)

\section{CORPUS WEB :}

Payer son avocat lorsque l'on en a les moyens, c'est estimer son travail c'est le rendre cher et je vous assure un dossier dans lequel le client ne rechigne pas, paie en temps et en heure, c'est un dossier qui sort plus vite de notre cabinet, c'est un dossier dans lequel nous sommes plus motivés et dans ce dossier le client nous est cher ! [http://www.legavox.fr/blog/michelebauer-avocat-bordeaux/avocat-cher-avocat-cherexiste-14756.htm\#.VII2FE2FOUk] (22.11.2015)

De ce fait, il est vital de connaitre entièrement le coût de votre jacuzzi, car le nombre de jets peut rendre cher le prix de revient [http:// www.harmonie-bienetre.fr/informations/lenombre-de-jets-de-votre-jacuzzi-peut-coutercher.html] (22.11.2015)

Donc, à mon avis, ce qui rend cher la pratique de notre sport en général, c'est la recherche de nouveauté, le désir de rester à la page, la mode et les besoins que le marketing nous créé, plus que la pêche en elle même... à méditer [http://www.achigan.net/msgforum.php?id_ sujet $=875 \&$ debut $=20 \& n b=20](22.11 .2015)$

Surtout qu'il a l'air sûr de lui le Slottet : rectangle beige allongé massif devancé par un chevalier et coiffé d'un fanion rouge à lion doré (une classique royale) sur une grande place grenat, le tout perché sur un monticule... Tout ce tralala ça la rend chère la rue [https://www.facebook. com/antoinebottiroli/posts/837004563013498] (22.11.2015)

REMARQUES : Dans la langue ancienne, rendre cher se disait d'une chose souvent abstraite dont le processus ou l'action peut avoir des conséquences fâcheuses, négatives ou impliquant un investissement moral important du sujet dans quelque chose. Dans les exemples du CW, rendre fonctionne comme verbe copule désignant un changement, suivi de l'adjectif cher au sens de 'coûteux' qui en indique le résultat. L'adjectif s'accorde alors avec l'objet (comme dans le dernier exemple du CW). L'accord manque cependant dans l'avant-dernier exemple, sans doute favorisé par la postposition de la pratique et le fait que les formes masculine et féminine du singulier de cher sont prononcées de la même manière. Le locuteur a donc besoin d'une conscience orthographique de l'accord morphologique pour la réaliser, ce qui présuppose souvent une phase de relecture et de correction qui n'est pas à l'ordre du jour sur Internet. Cher est modifié par moult, trop. VOIR AUSSI : coûter cher / gros

\section{Renifler profond}

Renifler profondément, à fond

Intransitif

1949 L'odeur du fumier qu'est terrible, si âcre que ça vous racle la gorge, que ça vous force à renifler, rauque et profond comme une vache (Louis-Ferdinand Céline, Cassepipe) 
REMARQUES : Renifler profond désigne le fait d'inspirer plus ou moins bruyamment l'air ou des mucosités à travers les narines, en faisant un bruit intense, le reniflement de la personne étant comparé à celui d'un animal. Notons également l'adjectif-adverbe rauque, référant au son rude, enroué produit.

\section{Renifler rauque}

Renifler en produisant un son rude, enroué $\lambda$ renifler profond

\section{Renifler sec}

Renifler sans que le nez coule ; par métonymie : puer fort

Intransitif

1960 Zazie renifla sec (Canard enchaîné, 2 novembre 1960 / Grundt : 354)

CoRpus Web :

Moi qui ne suit pas à l'aise devant les cleps (depuis que j'ai vu une copine se faire bouffer par un rott chez un pote) et ben ça ne me plait pas trop lorsque j'en crois un car je me dis celui là il va me renifler sec! Je tente une posture zen et prend sur moi mais je fais pas le Gandhi :) [http://forum.davidmanise.com/index. php?topic $=8131.205$;wap2] $(27.11 .2015)$

Nous qui pensions passer inapercu.....

Tu parles toi, peut-etre la peur du « qu'est ce qui vont penser les gens »!!

Peut-etre aussi la «trouille » aussi que ces memes gens pensent que l'on puisse « renifler sec $» ! !$

Mais non, il a fallu que le d'Jeff nous debusque !!!!!!!! [http://forum.lixium.fr/d-5546669. htm] (27.11.2015)

J'ai tout ce qu'il faut pour bien me dégueulasser : bac à sable, boue, graisse, sang de bœuf, coups de cutter etc... et en plus l'odeur ! Lors de notre rassemblement en juin, évitez de trop m'approcher ! Ca va renifler sec ! Et je serrerais bien fort Dyonis dans mes petits bras pour lui refiler un peu de MOI !!! [http://leferetlacroix.forumactif.net/t229p45-la-cote-de-mailles-et-camail] (27.11.2015)

REMARQUES : Renifler est un verbe qui connaît plusieurs acceptions en argot. Dans la plupart des cas, la collocation renifler sec signifie, par méto- nymie, 'puer fort' (v. les deux derniers exemples $\mathrm{du} \mathrm{CW}$ ). Sec y fonctionne comme intensifieur. En ce sens, l'exemple de 1960 est ambigu. Il pourrait tout de même renvoyer au bruit qu'accompagne un reniflement qui n'est pas entravé par les liquides muqueux. La fonction d'intensifieur se manifeste également dans le premier exemple du CW où renifler est pris au sens de base de 'flairer, sentir'. Le second exemple pourrait aussi référer à la consommation de cocaïne.

\section{Rentrer droit}

Retourner directement

Intransitif

1740 Enfin, c'étoit comme si j’eusse été perdu, plutôt que retrouvé ; et j'eus presque à soutenir le même assaut que si je fusse rentré droit au logis (Jacques de Varenne, Mémoires du chevalier de Ravanne)

1883 Quant à M. le curé, il est convenu avec lui qu'il nous attendra demain matin, à neuf heures, à l'église, et qu'il y aura un Te deum.

- Maintenant rentrons tout droit, dit Yves ; le père doit être déjà de retour, et nous les retarderions pour souper

(Pierre Loti, Mon frère Yves)

1913 - Votre retraite touche à sa fin, Monsieur Baillard. Allez-vous rentrer tout droit à Saxon ? À votre place, j'essayerais d'un petit voyage. Il ne faut pas, comme vous faites, écorcher votre plaie (Maurice Barrès, La Colline inspirée)

1928 Mais comme Z. ne voulait plus que je la quitte, nous sommes rentrés tout droit île Saint-Louis (Charles Du Bos, Journal)

1942 Et la mère tendait les bras à son mari, qui rentrait tout droit de l'usine, si net, lui aussi, si propre et si heureux, pas fatigué pour un sou et parfaitement d'accord avec lui-même et l'univers tout entier (Louis Guilloux, Le Pain des rêves)

\section{CORPUS WEB :}

Oui comme dit plus haut en cas d'accrochage, pas sur que tu sois exonéré de responsabilité. Le mieux mettre ton cligno et attendre à droite, qu'il y ait personne derrière et alors débô̂- 
ter et prendre large pour rentrer droit, méthode camion. Ou alors agrandir ton entrée [http:// www.forum-auto.com/automobile-pratique/ securite/sujet381871.htm] (27.11.2015)

Le spi est fait principalement d'un matériau malléable (le diam. p.ex) je sais pas lequel des 2 que tu possèdes finira dans le logement. Il est vrai que souvent il a tendance à ne pas rentrer droit ! Pas grave, tu tapes au marteau (si avec le maillet tu chatouilles) à l'opposé pour rattraper l'erreur de montage [http://scootentole.org/ phpbb3/viewtopic.php?f=2\&t=12767\&hilit=loctit e\&start=120] (27.11.2015)

Pour installer la barrette, tu dois la rentrer droit dans son emplacement et appuyer dessus jusqu'à ce que les deux leviers remontent se mettre en place dans les encoches de verrouillage [http://forums.macg.co/threads/sujet-uniqueles-memoires-des-mac-de-bureau.83867/page-55] (27.11.2015)

Un conseil donner par le mécano : il ne faut pas « tourner » la jauge dans le réservoir comme on pouvait le faire avec les jauges métal. Il faut la sortir doucement et la rentrer droite, sans faire de petits tours «droite/gauche" [http://forums. futura-sciences.com/depannage/634191-jaugehuile-moteur.html] (27.11.2015)

REMARQUES : Rentrer droit se dit du fait de retourner directement, sans détour à un endroit ou d'un lieu à un autre. Dans le CW, par contre, on trouve l'emploi au sens de 'faire entrer quelque chose dans un endroit en ligne droite', par exemple au fait de garer une voiture ou de faire rentrer une pièce dans un travail de mécanique. Droit reste invariable dans la majorité des cas. Dans le quatrième exemple du CW, il s'accorde avec l'objet au féminin pour indiquer la position de l'objet qu'on fait rentrer. Droit est modifié par tout. Droit peut s'associer avec la préposition qui le suit (à, dans) au point de faire partie du groupe prépositionnel en tant que modifieur de la préposition. Notons la référence à une technique de camionneur : prendre large pour rentrer droit.

\section{Renvoyer parallèle}

(Au volley-ball) Renvoyer (le ballon)

parallèlement (au filet)

$\pi$ arriver haut

\section{Repairer droit}

Retourner directement

Intransitif

1160 Eneas fu joios et liez,

Droit a Sebille est repairiez,

Le ramet d'or li a mostré ;

Un sacrefice ot apresté,

Al deu d'enfer sacrefia

Et molt humblement lo pria (Eneas, 2346)

1176 Cligés, il et sa conpaingnie

Sont repeirié an Grifonie

Droit au port de Costantinoble

(Chrestien de Troyes, Cligés, 5096)

1200 Atant s'en part, s’a prins dou roi congié,

Il et si home sont arrier repairié

Droit a Jordain le chevalier prisié

(Jourdain de Blaye, 3658)

$\sim 1275$ Lui et Gauvain dormant trova,

Il ne les a pas esveilliez,

Droit a son tref est repairiez

Si a ses haus barons mandez

(Floriant et Florete, 4392)

REMARQUES : Usité en ancien français, repairer droit se dit du fait de retourner, de revenir à un endroit (ou vers quelqu'un), en y allant directement, sans faire de détour. L'association à la préposition à est systématique.

\section{Repentir cher}

Se repentir beaucoup

Pronominal

1170 Mauvaisement nos i honore;

Mais ancor cuit veeir tel hore

Qu'il s'en repentira mout chier [variante :

cher] (Benoit de Sainte Maure, Le Roman de Troie, 1073)

REMARQUES : Repentir cher désignait le fait de regretter vivement une faute, une faiblesse ou le fait d'avoir ou de ne pas avoir fait quelque chose. Cher est modifié par moult.

\section{Répéter bas}

Répéter à voix basse, en chuchotant

Pronominal

1742 voler au devant de ses paroles, se les répéter tout bas, se les graver dans le cœur (Alexandre Dumas fils, Le Sopha) 
1845 Suivant toujours ses tristes pensées, il se répétait tout bas, malgré lui, la chanson de la grisette : elle n'a qu'une robe au monde et qu'un bonnet (Alfred de Musset, Mimi Pinson)

1913 Et tout bas il se répétait avec folie : « tant mieux ! » (Alain-Fournier, Le Grand Meaulnes)

1947 - Bien entendu, toi tu sens un peu de remords à m'abandonner... Tu n'es pas jeune... Tu te dis que c'est à ton tour bientôt... Mais toute la journée, tu ne t'es pas occupé de moi, et pourtant j’ai eu une petite...

Elle n’a pas dit le mot, elle se répète tout bas pour elle-même : une petite attaque hier soir (Louis Aragon, Les Voyageurs de l'impériale)

Transitif

1758 Que de serments d'aimer toujours suivirent cette douce réconciliation ! Qu'Adélaïde goûtoit de plaisir à les entendre ! Elle les répétoit tout bas, et juroit en secret de remplir tous les engagements que son amant prenoit : cependant elle ne vouloit point qu'il restât long-temps avec elle (Marie-Jeanne Riccoboni, Histoire du marquis de Cressy)

1784 LE COMPÈRE. Je ne veux point de ses secours, ils sont trop chers...

L'hôte répétait tout bas à sa femme : « Ne le laisse pas aller, arrête-le donc »

(Denis Diderot, Jacques le Fataliste)

1839 Je redescendis aussitôt, répétant tout bas : Bulle unigenitus, bulle unigenitus... crainte de perdre mon mot (Rodolphe Toepffer, Nouvelles genevoises)

1915 Comme ce bon homme jadis qui reçut Jésus en grand mystère,

Lâme dans un humble étonnement écoute la parole septénaire,

Et les choses qu'il a entendues, l'Esprit les lui répète tout bas (Paul Claudel, Corona benignitatis anni Dei)

1989 «Alors les peuples les plus riches chargés de joyaux sertis d'or quêteront ton sou- rire... Ta beauté, ton sourire, » répétait tout bas la vieille Edmée (Sylvie Germain, Jours de colère)

\section{CORPUS WEB :}

Quand, par un jour morose de novembre, un journaliste américain se risqua à formuler tout haut ce que chacun avait pris l'habitude de répéter tout bas. En 2007, à la Une de l'édition européenne du Time, Donald Morrison annonçait en effet rien moins que « the death of french culture »[http://www.arte.tv/fr/vitalite-de-lalitterature-francaise/3153860,CmC=3161156.html] (27.11.2015)

Cette réplique peut se répéter tout bas quand on rencontre des gens sujets à caution [http://www.france-pittoresque.com/spip. php?article5458] (27.11.2015)

Le plus dur est d'arriver à ne pas étouffer cette voix dans notre tête et de l'écouter, au contraire, pour arriver à répéter tout bas la Parole Divinedelasituation[https://journaldunmessage. wordpress.com/2010/02/25/victoire-sur-lacolere-irresistible] (27.11.2015)

REMARQUES : Répéter bas se dit du fait de redire ce qui a déjà été dit, de prononcer une deuxième fois un mot ou des paroles à voix basse, en chuchotant, de façon à ne pas être entendu ou par discrétion. Dans son emploi pronominal, le sujet se redit plusieurs fois la même chose. Notons que cet emploi a une connotation souvent péjorative, pouvant traduire la folie du sujet, répétant des choses, sans nécessité, qu'il a déjà dites. Notons l'opposition sémantique entre formuler haut et répéter bas. Bas reste invariable (v. aussi les deuxième et troisième exemples du $\mathrm{CW}$ ) et est modifié par tout.

\section{Répéter haut}

Répéter à voix haute, d'une voix forte

Transitif

1592 Car d'aller reprendre et repeter si haut ceste forme d'appellation, pour la mouller sur le desseing de l'appel interiecté par Donatus de la sentence de Miltiades, seroit trop ignorer l'histoire (François de Clary, Philippiques, contre les bulles, et autres pratiques de la faction d'Espagne) 
1685 Roland repete tout haut ce qu'il a leu tout bas (Philippe Quinault, Roland)

1751 Nous nous accommoderons des deux autres pièces, ai-je répété un peu plus haut, mais toujours de mon ton rauque, et parlant du gosier (abbé Prévost, Lettres angloises [trad.])

1829 Au bruit d'une aigre trompette

Le sabbat a commencé.

Plus haut la voix répète:

Notre règne est passé

« Non, dit la voix, plus de fêtes!

Esprits, vite délogeons »

(Pierre-Jean de Béranger, Chansons)

1830 C'est moi, répétait-il assez haut, un ami (Stendhal, Le Rouge et le noir)

1899 Mais nous ne nous lasserons pas de les poser [= les questions], et nous les répéterons si souvent et si haut qu'il faudra les entendre (Georges Clemenceau, L'Iniquité)

1902 Elle profitait des gelées, des croquignoles, de la mousse qu'on lui faisait humer au bord des verres, recueillait, entre temps, des allusions chuchotées à l'oreille auprès d'elle, les répétait tout haut, faisait scandale, et on la mettait à la porte (René Boylesve, La Leçon d'amour dans un parc)

1926 « Cela paraît vraisemblable » pensa Gallet. Et il entendit avec surprise sa propre voix répéter tout haut sa pensée (Georges Bernanos, Sous le soleil de Satan)

2004 « C'est le bouquet. Ce coup-ci, c'est vraiment le bouquet » et une bonne heure je restai à tourner en rond dans l'appartement en répétant tout haut ces mots comme s'ils étaient tout ce qu'il me restait de vocabulaire (Grégoire Bouillier, L'Invité mystère)

Pronominal

1853 Une colère violente s'emparait de lui pendant un quart d'heure : il s'enthousiasmait avec la même promptitude ; mais colère, douleur, enthousiasme, tombaient comme l'eau bouillante qu'on retire du feu. Aussi, après s'être répété tout haut dans la rue : « il a une fille ! » à plusieurs reprises, Gérard s'arrêta à la première devanture de boutique, et regarda une chinoiserie qui lui fit oublier les enfants et toutes ses idées sur les enfants (Champfleury, Les Aventures de mademoiselle Mariette)

1908 Et cependant... - allons, ne creusons pas trop, se répétait-il presque tout haut, en retournant chez lui, quelques rues plus loin (Francis de Miomandre, Écrit sur de l'eau)

CORPUS WEB :

Le premier groupe devait garder le silence et le second devait répéter tout haut le nom de l'objet [http://www.sciencepresse.qc.ca/blogue/ 2012/05/14/se-parler-seul-peut-etre-utile] (27.11.2015)

Ainsi, on sait que la technique est couramment utilisée par les enfants, qui, lorsqu'ils sont concentrés sur une tâche difficile à réaliser, ont tendance à répéter tout haut ce qu'elles doivent faire [http://www.la-sante.info/index.php/ archives-articles-insolite/75-parler-tout-seulameliorerait-nos-performances] (27.11.2015)

La phrase fait le tour du cercle et le dernier doit répéter tout haut la "supposé » phrase de départ qui au final est : J'ai rencontré un homme en bedaine et il était dégoutant [https://www. facebook.com/permalink.php?story_fbid=14986 93660424514\&id=1409484579345423] (27.11.2015)

REMARQUES : Répéter haut se dit du fait de redire ce qui a déjà été dit, de prononcer une deuxième fois un mot ou des paroles à voix haute, en public, de façon à être entendu de tous. Dans son emploi pronominal, le sujet se redit plusieurs fois la même chose, à voix haute, traduisant souvent une obsession, une rumination mentale. Haut reste invariable (v. aussi le troisième exemple du CW) et est modifié par assez, plus, presque tout, si, tout, un peu.

\section{Répliquer juste}

Répondre, réagir correctement, de manière adéquate, appropriée

Intransitif

1857 Comme si elles [= les abeilles] m'avaient compris, leurs mouvements répliquèrent juste. J'en vis qui, de leurs petits bras, adroitement tournés en arrière, se frottaient le dos au soleil ; elles voulaient 
s'imbiber à fond de ce rayon tiède et s'en pénétrer (Jules Michelet, L'Insecte)

\section{CoRpus Web :}

L'écart du match aller (4 points, 74-70) pouvait encore être effacé avant le deuxième quarttemps qui allait être fatal pour les Bourguignons. Mis à mal par Joseph Mc Naull (18 points, 8 rebonds) et Goran Jagodnik (17 points, 6 rebonds, 5 passes), la JDA avait toutes les peines du monde à répliquer juste [http://www.ffbb.com/rideaupour-dijon] (27.11.2015)

Non c'est sur, les Israéliens sont les grands gentils qui répliquent juste.. [http://www.jeux video.com/forums/1-50-121890206-1-0-1-0 soutien-au-palestiniens.htm] (28.11.2015)

REMARQUES : Dans un emploi métaphorique, répliquer juste se dit du fait de réagir à une question, à une parole ou action (sport, guerre) avec exactitude, conformément à la réalité, comme il convient, sans erreur, à l'aide des mouvements du corps. Notons l'ironie dans le dernier exemple $\mathrm{du}$ CW. Juste reste invariable. VoIR AUSSI : répondre juste

\section{Répliquer sec}

Répondre sèchement ; répondre tout à trac Intransitif

1870 Nous étions arrêtés près du pont qui conduit à Cauterets, lorsqu'un douanier qui pêchait à la ligne trouve « très étrange » que nous ayons pris cette route pour aller à Cauterets : il a grand peine à se contenter de ma feuille de route ; à peine convenable ce bonhomme, je lui réplique $s e c$, et il se décide à aller arrêter, s'il peut, des truites (A. Lequeutre, Excursions)

Transitif

1889 Ce serait un peu cher, répliqua Nicolas tout sec (Charles Dickens, Vie et aventures de Nicolas Nickleby)

1958 J'eus ma première surprise (la petite) malgré son air endormi, le colonel Dubois comprenait vite et répliquait sec :

- Je n'essaye pas de vous flatter

(Pierre Nord, Bonne chance, Fathima!)

\section{Répondre bas (basset)}

Répondre à voix basse, en chuchotant Transitif

+1250 « Tu nel m’avoies pas premis, Desloiau vilein deputaire, Que tu feïsses les bos traire. $\mathrm{Tu}$ as or fait ce que te plot. » Letart qui molt bien fere sot D'ome coart chere et samblant, Li respont basset en tranblant «Sire, or ne soies pas iriez!» (Le Roman de Renart [ $2^{\mathrm{e}}$ moitié XIII $]$, IX, 774)

-1334 Lors chis respont basset en souspirant: Ma chiere dame, je ne di nullement, Que mal y ait n'en fet n'en pensement Quant envers vus ; mes pour ce le disoie ; Quar de ses mos trop grant courouc avoie (Le Romans de la dame a la lycorne $\left[1^{\mathrm{er}}\right.$ tiers $\left.\mathrm{XIV}^{\mathrm{e}}\right]$, 542)

+1365 «Qui des deux voux mettroit à chieux?

Respondez ent ou hault ou bas,

Voire se tant estes soutieux 》

(Jean Froissart, Poésies [3 $3^{\mathrm{e}}$ tiers XIV ${ }^{\mathrm{e}}$ )

+1489 Et ung natif de Bourge le m’appella sainct, et je luy demanday en l'oreille pourquoy il l'appelloit sainct et qu'il pouvoit veoir painct à l'entour de luy les armes de plusieurs citéz qu'il avoit usurpées, où il n'avoit nul droit (et luy et son cheval estoient plus hault que l'ostel, tailléz de pierre, et son corps soubz le pied dudit cheval) ; il me respondit bas : " Nous appellons, en ce paiis icy, sainctz tous ceulx qui nous font du bien " (Philippe de Commynes, Mémoires [1489-1498], VII)

1515 Et luy venus, luy parloit de beaucop de besoingne, et elle respondit si bas qu'i ne l'entendit oncque. Et n'y fut mie gramment qu'il fist tout son debvoir et pouvoir pour la cuider saillir (Philippe de Vigneulles, Les Cent Nouvelles nouvelles, p. 181, 71)

1610 « je vous tiens parolle à ce coup, car vous ne devez rien craindre tant que vous aurez celle que je vous ameine. » Ormanthe contrefaisant sa parolle, respondit fort bas : " elle soit la bien venue » (Honoré d'Urfé, L'Astrée) 
1628 il s'addressa enfin à Amasis et luy demanda ce qu'elle estoit devenue ; à quoy la nymphe respondit assez bas qu'il falloit un peu de loisir pour contenter sa curiosité, et que les accidents qui estoient arrivez à cette belle fille depuis qu'il estoit party, meritoient une secrette audience

(Balthazar Baro, La Conclusion et dernière partie d'Astrée)

1736 c'est signe qu'ils se disent tout bas tous leurs devis detendresse ; c'est signe qu'une femme dit, arrêtez-vous donc, monsieur, laissez-ça là, elle ne prononce pas bien haut en parlant ainsi, parce qu'elle est attaquée. Le galand répond encore plus bas, parguienne, madame, vous êtes bien rude à pauvres gens, parce que vous êtes belle, vous faites la glorieuse, et autres propos qui se disent en cachette

(Pierre de Marivaux, Le Télémaque travesti)

1784 Elle s'en-est assurée encore ; et ne pouvant plus douter, elle m'a donné de petits coups pour m'éveiller. Que voulez-vous, lui ai-je dit ? Madame, a-t-elle répondu fort-bas, Monsieur est ici : voyez ce que vous voulez faire? (Nicolas Rétif de la Bretonne, $L a$ Paysanne pervertie ou Les Dangers de la ville)

1859 Décorant sa pitié d'une grâce insolente, Il disputait, joyeux, avec ma voix tremblante.

À ses doutes railleurs, je répondais trop bas...

Prouve-t-on que l'on souffre à qui ne souffre pas?

(Marceline Desbordes-Valmore, Élégies)

1862 L'officier, soulevant péniblement le bras, le retint :

- Vous m’avez sauvé la vie. Qui êtes-vous?

Le rôdeur répondit vite et bas :

- J'étais comme vous de l'armée française.

Il faut que je vous quitte. Si l'on me prenait, on me fusillerait. Je vous ai sauvé la vie (Victor Hugo, Les Misérables)

1876 - Il paraît qu'il y a eu une scène épouvantable!
- Je n'en savais rien, répondit bien bas Amynèh, en s'essuyant les yeux et en étouffant un soupir (Arthur de Gobineau, Nouvelles asiatiques)

1884 On devait répondre très bas, se souffler les mots à l'oreille, lorsqu'il y avait de grosses mouches dans la chambre :

- Elles entendent ce qu'on dit, et ne manquent pas de le répéter... et cent autres imaginations pareilles, à propos des chiens, des nuages, des oiseaux, des arbres

(Élémir Bourges, Le Crépuscule des dieux)

1904 La vieille dame écoute l'oiseau, malheureuse aussi, les deux mains sur ses genoux, ayant laissé tomber sa tapisserie par terre. Elle répond tout bas, gravement : - Non, non, Mistigris, tu as mangé ses petits.

Mistigris reste cloué là et ne répète même pas son miaulement misérable (Léon Frapié, La Maternelle)

1912 - Qu'avez-vous ? Lui demanda-t-elle. - Aujourd'hui, dit-il, vous êtes tout à fait revenue.

Elle sourit, et tout bas elle répondit :

- Oui.

Il n'était pas très facile de causer tranquillement. Ils étaient rarement seuls. Colette les gratifiait de sa présence, plus qu'ils n'auraient voulu (Romain Rolland, Jean-Christophe. La Nouvelle Journée)

1933 Elle fit un sourire plus doux que le premier. - Naïs, je me suis décidé pourtant, et c'est parce que j'en avais le cœur tout ennuyé. Elle répondit si bas qu'il comprit au mouvement des lèvres :

- Ah, tu sais bien dire, toi...

Haudouin évaluait avec tendresse les formes pleines et lourdes qui allaient combler ses bras d'homme (Marcel Aymé, La Jument verte)

1945 Il y a un cœur qui tremble

Et des larmes qui coulent au revers du veston

Les larmes de celui qui parle de celui qui ne comprend pas 
Les paroles voilées de celui qui répond Tellement bas que personne n'entend Dans n'importe quel coin de la maison (Pierre Reverdy, Plupart du temps)

1947 - Y a « Riton-la-Noïe » qui te demande.

- La « noïe », c’est la nuit. Je répondis aussi bas que lui :

- Riton-la-Noïe ? Connais pas ça, moi.

- C'est le prévôt. $Y$ vient derrière.

Je me retournai. C'était Divers. Il était adossé au mur et me regardait (Jean Genet, Miracle de la rose)

1985 « Allons, dit-elle en feutrant la voix jusqu'au murmure, oublions le passé veux-tu... j'ai... beaucoup souffert à cause de toi... mais plus rien n'est comme avant, je vais me remarier... Nous sommes amis désormais : dis maman, Ludo... » Et voilà que sa main tremblant sur le visage de Nicole il s'entendit répondre tout bas : "Maman » (Yann Queffélec, Les Noces barbares)

Pronominal

1887 Le souvenir des beaux yeux et du beau sourire lui faisait se répondre tout bas : « Mais elle a été si aimable, si indulgente... » Il reprenait : «Que lui dirais-je pour justifier cette visite, moins de vingt-quatre heures après l'avoir quittée ? ... » (Paul Bourget, Mensonges)

\section{CoRpus Web :}

j’ai pas réfléchi je les shoot désolé logique de jeux de tire méchant vs gentil et après d'un coup je me suis retrouver dans la mairie et une personne ma demander pourquoi j'ai shoot la personne je lui et répondu bas pour m'amuser je partais dans la logique que le jeux sauter ca après j'ai entendu dire comme quoi je suis ban et op déconnecté c'est mon tout premier ban et garry city était mon premier serveur.... [https:// www.garrycity.fr/threads/demande-de-debannissement.6474] (24.11.2015)

REMARQUES : Répondre bas se dit du fait de formuler une réponse à une interrogation exprimée ou non en la chuchotant ou en la mentionnant à voix basse à son interlocuteur. Notons l'opposition sémantique entre haut et bas dans l'exemple de +1365 : répondre ou haut ou bas. Bas reste invariable et est modifié par assez, aussi, bien, encore plus, fort, si, tellement, tout, très, trop. VoIR AUSSI : dire bas

\section{Répondre bel (beau)}

Répondre bien, de manière éloquente, astucieusement, avec répartie

Transitif

+1150 Quant Aiols l'entendi, si fu iries, Bel et cortoisement lor respondie : Signor, che dist li enfes, car uous targies ! (Aiol et Mirabel [ $2^{\mathrm{e}}$ moitié XII $]$, 974)

Intransitif

1349 GUILLAUME. Et je qui point n’i pens malice,

Volentiers vous escouteray,

Et, se bon m'est, j'en parleray.

LA DAME. Guillaume, moult bel respondez. Mais un bien petit m'entendez

(Guillaume de Machaut, Le Jugement dou roy de Navarre, 1393)

1405 De tieulz gloutes est il chamberieres, si est moult grant peril en un hostel ; car le beau service que faire scevent, leurs flateries, bien appareillier a mengier, tenir tout nettement et ordonneement, bel parler et beau respondre, aveuglent tellement les gens que on ne s'en prent garde de leurs tres grans mauvaistiéz : car elles se meslent de devocion parmy, pour mieulz tout couvrir, et vont au mostier a tout patenostres, et la est le peril (Christine de Pisan, Le Livre des trois vertus, p. 211, 104)

REMARQues : Répondre bel se dit, en ancien français, du fait de faire connaître oralement, en retour à une question, à une remarque, ce qu'on a à dire, le sujet s'exprimant avec éloquence, de manière persuasive. En moyen français, le neutre bel est remplacé par le masculin beau, sauf dans quelques locutions. L'exemple de 1405 joue avec la synonymie fonctionnelle de bel et beau en opposant bel parler à beau répondre, ce qui crée un contraste subtil. 


\section{Répondre bref}

Répondre brièvement, de manière concise

Transitif

1450 et leur fut ordonné qu'ilz dissent ainsy au roi Priant, à ses filz et aux seigneurs qui là estoient, lesquelz en tindrent ung peu de conseil à part ; et brief aux ambassadeurs respondirent que se ilz vouloient rendre leurs gens que ilz avoient demandés, que ilz auroient ce qu'ilz demanderoient

(Roman de Troilus et Cressida, p. 202)

\section{Intransitif}

1865 nous leur avons répondu bref en parlant de l'immortalité de l'âme (Cosme Léucadites, L'Hellénisme et la langue grecque)

1922 Je t'assure que j'ai une espèce de remords à ton endroit. Je t'ai répondu bref et $\mathrm{sec}$, il me semble, nella mia ultima. Donne-moi d'être dur, et tu me verras être doux. Et puis les emmerdements. Les dix emmerdements de Dieu (André Gide et Paul Valéry, Correspondance)

CORPUS WEB :

Votre docteur prévoit le temps nécessaire pour répondre bref à vos questions médicaux [http://www.doktervantilborgh.be/fr/344-infovia-t\%E3\%A91\%E3\%A9phone] (24.11.2015)

REMARQUES : Répondre bref se dit du fait de faire connaître oralement, en retour à une question, à une remarque, ce qu'on a à dire, le sujet s'exprimant avec concision, sur un ton sec et tranchant. Notons la collocation bref et sec, où sec traduit la manière directe, dure, froide de la réponse. Bref reste invariable.

\section{Répondre clair}

Répondre clairement, distinctement, explicitement, sans ambiguiité

Intransitif

1803 Si elle n'avait pas voulu me répondre clair et net, je m'en serais défié et je ne serais pas remonté sur l'escarpolette avec elle (Isabelle de Montolieu [trad.], Le Fils d'adoption]

1843a - Et c'est à coups de canne que vos caporaux inspirent à vos soldats le respect de votre nom.
- Qu'en savez-vous ? De quoi parlez-vous

là ? De quoi vous mêlez-vous ?

- Je réponds clair et net à l'interrogatoire de Votre Majesté.

- Vous voulez que je vous demande pardon d'un moment d'emportement provoqué par votre folie?

(George Sand, La Comtesse de Rudolstadt)

$1843 \mathrm{~b}$ - Le roi n'aime pas les prévenances. Quand il interroge, il veut qu'on lui réponde clair et net. Qu'est-ce que vous avez été faire cette nuit dans le palais du roi ? Vous voyez bien que le roi a le droit de venir faire le maître chez vous, puisque vous allez chez lui à des heures indues sans sa permission ? (George Sand, La Comtesse de Rudolstadt)

1850 Voyons, répondez-moi clair et net, cette fois, et agissons, car depuis deux mois, nous disons, il faudra faire telle chose, et nous ne la faisons pas (George Sand, Correspondance)

Transitif

1950 - Seriez-vous ému, lieutenant?»

Un tour de passe-passe : mon sabre a filé dans ma main gauche. Une ferme secousse à la main tendue vers moi, et je réponds bien haut, bien clair, en cherchant les yeux :

- Non, mon général!

(Maurice Genevoix, Ceux de 14)

\section{CORPUS WEB :}

7.PvP ou PvE ? Pour répondre clair et net à cette question : Pvp. Je ne kiff pas vraiment le PvE, à moins que j'aime le concept du jeu comme par exemple le Survivor zombie. Le PvP pour moi c'est une façon de se démarquer, d'inspecter les autres joueurs qui te battent et apprendre de ses erreurs de jours en jours toujours en ayant l'adrénaline car vous savez que l'adversaire n'est point virtuel, mais réel [http://forum.epicube.fr/ threads/team-brisingr-recrutement-ferme.66710/ page-12] (24.11.2015)

Je n'ai jamais voulu que tout celà arrive, donc autant répondre clair et net sans mettre en MP, personne n'aura accès à Shinsee dorénavant, car je n'ai pas envie de revivre ces situations 
[http://phoenix.leforum.tv/t2504-Postulationsurprise-de-Shinsee.htm] (24.11.2015)

REMARQUES : Répondre clair se dit du fait de faire connaître oralement, en retour à une question, à une remarque, ce qu'on a à dire, le sujet s'exprimant d'une manière aisément perceptible, avec clarté, de façon à être bien compris de son auditeur. Notons la collocation fréquente clair et net, et l'emploi de répondre haut. Clair reste invariable dans son emploi adverbial. Il est modifié par bien.

\section{Répondre doux}

Répondre d'une voix douce, mélodieuse, agréable

Intransitif

1839 Le FILS, plein de splendeur, exprima manifestement tout son Père, et lui répondit ainsi divinement doux : « Éternel PÈRE ! » (François de Chateaubriand, Le Paradis perdu)

CORPuS WeB :

Hypocrisie à toutes celles qui répondent doux et intellectuel car en réel elles préfèrent les bad boy gros cons mauvais garçon qui les font galérer (si si, il suffit de voir les pleurnicheries sur QR après...) [https://fr.answers.yahoo.com/ question/index?qid=20110701141535AAUjvOv] (24.11.2015)

REMARques : Répondre doux se dit du fait de faire connaitre oralement, en retour à une question, à une remarque, ce qu'on a à dire, le sujet s'exprimant sur un ton agréable à l'oreille, harmonieux et avec douceur. Notons la coordination occasionnelle doux et intellectuel dans le CW et la modification de doux par divinement. Doux reste invariable.

\section{Répondre droit}

Répondre directement, sans détour, avec sincérité, droiture

Intransitif

1639 Ayant cette cognoissance, je respons maintenant droit aux passages de Justin, de Clement et de Sainct Chrysostome, qui ont esté alleguez dans les objections (François Garasse, La Doctrine curieuse des beaux-esprits de ce temps)
1835 JOHN BELL. Ne la soupçonnez-vous pas, mistress Bell ?

KITTY BELL. Serait-ce parce que les chiffres sont mal disposés?

JOHN BELL. La plus sincère met de la finesse partout. Ne pouvez-vous pas répondre droit et regarder en face?

(Alfred de Vigny, Chatterton)

1845 - C'est bien parler, mais cela ne répond pas tout droit à mes questions. Voulez-vous que je vous dise une chose? (George Sand, Le Péché de Monsieur Antoine)

1931 Anne-Marie était là, espérant, attendant, s'en remettant de tout à lui. Cette faiblesse à bout de peine qui s'avoue, cette faiblesse et cependant ce cœur. À la lueur de la lune, on la voyait ; et ses yeux, sa face tendue disaient : je sais que tu feras la droiture, que tu me répondras tout droit, sans calculs, sans feintise. Et tu es le seul vers qui je me tourne (Henri Pourrat, La Tour du Levant ou Quand Gaspard mit fin à l'histoire)

1971 En répondant à la question de Jeanne, je mesurais tout ce qui me faisait proche d'elle et des autres camarades. Seule l'une d'elles pouvait se permettre une question aussi directe, seule obtenir que j'y réponde tout droit, sans trouver indiscrète la question (Charlotte Delbo, Auschwitz et après III)

\section{CORPuS WeB :}

Pour répondre droit à votre question, c'est en 1990, lorsque le pays s'est ouvert au multipartisme, que j'avais décidé d'embrasser la politique, en adhérant au R.d.p.s (Rassemblement pour la démocratie et le progrès social) dont je fus le timonier au Kouilou, sept ans durant [http://www.lasemaineafricaine.net/ index.php/national/11285-francois-soumboucitoyen-residant-a-pointe-noire-le-debat-surla-constitution-est-pour-l-heure-sans-interet] (24.11.2015)

La technique de certaines mains de cette image est si mauvaise que le chanteur peut me répondre droit de ne pas saisir les organes génitaux, mais pose sa main sur sa cuisse [http:// 
www.cpae.net/fr/nouvelles/la-musique-dansles-arts-plastiques] (24.11.2015)

Un jour, je me rappelle bien lui avoir demandé « C'est où ça la Syrie ? ». J’ai dû poser la question plusieurs fois avant de voir mon ami syrien arrêter le ballon pour me répondre droit dans les yeux « La Syrie, c'est loin » [https://voir. ca/mohammed-lotfi/2012/03/04/syrie-entre-lapeste-et-le-cholera] (24.11.2015)

REMARQUES : Répondre droit se dit du fait de donner une réponse directe, franche et sincère à son interlocuteur, sans hésitation. Dans le troisième exemple du CW, droit a un emploi directionnel, traduisant la direction du regard de la personne répondant. Droit reste invariable. Il est modifié par tout.

\section{Répondre entier}

I. Répondre (à quelqu'un) de toute son âme, de tout son être

Intransitif

$\sim 1235$ « Dunee est la sentence, sacez, sanz returner. »

Li un des crestiens plus ferms e plus enter Respunt pur Amphibal sanz verité celer (La Vie de seint Auban, 1306)

II. Correspondre tout à fait (à quelque chose) Transitif

1807 Que d'être rassemblés en votre nom, si ce n'est jouir des dons sublimes de votre belle nature, et vous en faire hommage, et vous remercier de la vie, et vous en remercier surtout quand un cœur aussi créé par vous répond tout entier au nôtre ! (Germaine de Staël, Corinne ou L'Italie)

$1909 \mathrm{Du}$ choc de l'esprit qui l'anime et de l'esprit qui nous anime jaillit la vie. Nous ne saurons l'utiliser que si elle répond tout entière aux mouvements obscurs qui dictent nos propres actions (Élie Faure, Histoire de l'art : l'art antique)

1929 C'est quelque chose de moi qui a réussi et qui a obtenu son avènement! Ils vivent tout entiers ! Il n’y a plus en eux de résistance et d'inertie ! Ils répondent tout entiers à l'esprit qui les anime. Ce sont des pinceaux excellents dans la main d'un artiste parfait comme celui dont s'est servi Sesshiu quand il a dessiné ce cercle (Paul Claudel, Le Soulier de satin)

REMARQUes : Répondre entier (I) se dit du fait de faire connaître oralement, en retour à une question, à une remarque, ce qu'on a à dire, le sujet s'exprimant de manière exhaustive, sans restriction quant à sa pensée, sa personnalité. Notons la collocation ferme et entier. Au figuré (II), la réponse se traduit par le comportement. Entier peut s'accorder avec le sujet et être modifié par plus, tout. Notons l'accord au cas sujet « ferms » en ancien français, qui ne s'observe pas dans « entier » malgré leur coordination syntaxique, peut-être pour sauver la rime.

\section{Répondre faux}

Répondre volontairement par un mensonge, ou, involontairement, par un contenu incorrect

Transitif

1715 le truchement répondit vrai ou faux qu'il en estoit venu un fort grand nombre, qu'ils estoient chargez d'armes, de soldats, et de toutes sortes de munitions de guerre (Jean Crasset, Histoire de l'Église du Japon)

Intransitif

1987 En guise de question ultra-dure, il lui avait demandé : la population de la France ? L'autre giton de cul troué avait répondu faux et le prof lui avait mis la moyenne. Ça, Zingaro n'avait pas admis (Bayon, Le Lycéen)

2013 J'ai répondu tout faux à leurs tests et surtout, j’ai bien écris [sic] que j’avais déjà tenté de me suicider (Chrystoph Lemaire, Presque heureux. De l'Olympia...à l'Olympia)

\section{CoRpus Web :}

Le député Les Républicains de l'Eure s'est-il rendu compte qu'un troll inattendu venait perturber ses confidences sur son épouse, qui répondait tout faux à l'auto-école (où ils ses sont rencontrés) [fr.finance.yahoo.com/actualites/vomi-chatvantardis] (10.10.2016)

REMARQUES : Opposé à répondre vrai, répondre faux consiste à donner une réponse incorrecte, volontairement ou non. Il est modifié par tout. 


\section{Répondre ferme}

Répondre fermement, avec assurance, volonté, fermeté, conviction

Intransitif

$1780 \mathrm{Tu}$ n'as pas d'idée de toutes les injures que l'on m’y dit ; cela va jusqu'à m’appeler gladiateur inclusivement, parce qu'on prétend qu'une phrase où je disais qu'une explication nette avec M. de Mar empêcherait le procès que l'on redoutait tant, est une manière de cartel ; cela a de l'esprit, comme tu vois. Ensuite on relève à toute ligne mon infernal orgueil, mes délits, mes crimes, je crois, et entr'autres la double rupture de mon ban, article sur lequel je repondrai ferme assurément (Honoré de Mirabeau, Lettres originales écrites $d u$ donjon de Vincennes)

1859 Et là-dessus M. de Péréfixe ayant entamé quelques mots de discussion pour la provoquer, elle répondit ferme à son ordinaire, para les coups et se garda bien de prendre le change sur la grâce suffisante, qu'on essayait de substituer à l'efficace (Charles Sainte-Beuve, Port-Royal)

Transitif

1784 MOI. Guérirez-vous Cartouche ou Nivet?... Le docteur Bissei, après un moment d'incertitude, répondit ferme qu'il le guérirait ; qu'il oublierait le nom du malade, pour ne s'occuper que du caractère de la maladie ; que c'était la seule chose dont il lui fût permis de connaître (Denis Diderot, Entretien d'un père avec ses enfants)

CORPuS Web :

Rebonjour philoujardin, Je ne peux pas te répondre "ferme », il faudrait la voir. D'autre part je ne veux pas te mettre la pression " pour rien " [http://www.aujardin.org/nouvelle-pelousemauvaises-herbes-t72756.html] (23.11.2015)

Veuillez pardonner l'indélicatesse de mes propos, mais lorsque l'on attaque un produit que j’affectionne particulièrement il est de ma nature de répondre ferme [http://www.forumconstruire. com/construire/topic-263151-qualite-poelepiazetta-.php] (23.11.2015)

REMARQUeS : Répondre ferme se dit du fait de faire connaître oralement, en retour à une ques- tion, à une remarque, ce qu'on a à dire, le sujet s'exprimant sur un ton transmettant l'assurance, l'autorité, la résolution qui témoignent d'une attitude sur laquelle on ne transige pas. Dans le premier exemple du CW, il adopte le sens de 'donner une réponse définitive’. Ferme reste invariable.

\section{Répondre fort}

I. Répondre à voix haute, en cherchant à produire un effet intense

Intransitif

1389 Mais a bien respondre il convenroit .i. grant sermon. Si ne respondray fors a ceste demende, a savoir se c'est pechié contre le Saint Esperit, quant une personne peche sus esperance de s'en repentir ou temps avenir? (Jean Gerson, Sermon pour la Pentecôte)

1559 et les deux dames du bas luy respondirent si fort, que leurs voix furent oyes de tout le chasteau (Marguerite d'Angoulême, Heptaméron)

1831 Adieu, monsieur, un mot de vous me fait toujours un vif plaisir. Quand tout se tait dans le désert intellectuel où nous vivons, il est doux de trouver çà et là un écho qui nous répond juste et fort (Alphonse de Lamartine, Correspondance générale)

II. Être en parfait accord (avec ce que l'on attend de quelque chose)

Intransitif

1715 Comme le sultan eut achevé de parler, les musiciens, qui avaient eu l'ordre, entrèrent et répondirent fort à l'attente qu'on avait de leur habileté. Des farceurs excellents succédèrent au concert, et des danseurs et des danseuses terminèrent le divertissement (Antoine Galland, Les Mille et une nuits [trad.])

\section{Corpus Web :}

@Le_Figaro il faut répondre fort, je suis prêt à participer à un impôt de guerre volontaire [https://twitter.com/domjullien38/ status/665425386071834624] (23.11.2015)

Cette décision a été prise uniquement pour répondre fort et de façon bureaucratique à leurs revendications légitimes, qui n'avaient pour objet que le respect et l'application du code du travail, 
et particulièrement [http://www.labourstart.org/ fr/wordpress/maroc-400-femmes-travailleusesprivees-de-leurs-salaires-depuis-decembre-2012] (23.11.2015)

REMARQUES : Répondre fort (I) se dit du fait de formuler avec vigueur et énergie une réponse forte à une interrogation, exprimée ou non. Répondre fort (II) est employé par rapport à des attentes fortement satisfaites. Le rôle de fort comme intensifieur s'observe particulièrement bien quand répondre adopte le sens de 'réagir' (v. dernier exemple du CW). Fort reste invariable. Notons l'emploi absolu dans le premier exemple $\mathrm{du}$ CW. Notons aussi la collocation juste et fort qui renforce l'effet d'intensification. À partir du Xvi ${ }^{\mathrm{e}}$ siècle, fort sert à modifier le modifieur suivant, comme dans répondre fort bien. Dans les données de Frantext, ce changement de fonction devient pratiquement exclusif à partir du XVIII ${ }^{\mathrm{e}}$ siècle, répondre fort étant abandonné. Fort est modifié par si.

\section{Répondre franc}

Répondre avec franchise, honnêteté

Transitif

1538 Si repons franc: J'ay dame sans nul vice ; Autre n'aura en amour mon service ; Je la desire, et souhaite voler

Pour l'aller veoir, et pour nous consoler (Clément Marot, Rondeaux)

1859 et après deux ans de séjour il eut la pensée de se retirer à l'abbaye de Saint-Cyran, où était M. de Barcos ; il y devait aller avec M. des Touches ; mais cela manqua. La mère Angélique, qu'il avait consultée là-dessus, lui avait répondu franc qu'il ne demeurerait pas à Saint-Cyran, s’il y allait, et qu'il en sortirait encore (Charles Sainte-Beuve, Port-Royal)

\section{CORPUS WEB :}

Parfois oui je vais répondre franc a la réponse quand la personne arrive justement a un mauvais moment, durant un moment ou je ne le peut la cacher par mes expression. soit je suis trop facher, trop sur le bord d'une crise,trop décourager par une mésaventure mais la encore parfois ,je vais dire non mais j,ai pas le gout d,en parler [http://www.revivre.org/forum/viewtopic. php?f=33\&t=3715] (23.11.2015)

Pour te répondre franc: C'est vrai que pragmatiquement parlant, il y a quelque chose délirant a revendiquer tout ça, mais, MAIS : - s'il devait s'agir de transactions, communications ou transports aériens entre nations de mêmes racines culturelle, je crois que le caractère unificateur d'une telle entreprise pourrait bel et bien en supplanter ces inconvénients qui n'auraient plus lieu d'être comme tel...voire qui n'aurait plus lieu d'être tout court a l'intérieur d'un domaine d'action, de relation, ou d'un territoire donné ! [http://www.grioo.com/forum/viewtopic.php?t= 5572\&sid=e43a46d95c3c3832e6d5821c1007b6de] (23.11.2015)

-C'est quoi ta chaine YouTube ? (Je suis sure qu'elleen a pas)-Est que tu peux me faire un cadeau pour une vidéo.(Ho la sale $e^{\star \star \star \star}$ elle dévie la conversation ho ho ho je vais lui répondre franche)-Je peux allez voir tes autres vidéo sur ta... [http:// www.flux-info.fr/blog/rssall-1185746-Les-10-cho ses-qui-menervent-en-voiture.html] (23.11.2015)

REMARQUES : Répondre franc se dit du fait de faire connaître oralement, en retour à une question, à une remarque, ce qu'on a à dire, le sujet s'exprimant avec sincérité, de manière directe, ouverte, sans dissimulation. Franc reste invariable dans son emploi adverbial. Dans le troisième exemple $\mathrm{du}$ CW, il s'accorde avec le sujet pour mettre en relief l'attitude de celui-ci.

\section{Répondre haut}

I. Répondre à voix haute, d'une voix forte, ouvertement

Intransitif

-1334 La prieuse les regarda,

Doucement demandé leur a :

Mes boines dames, que vous faut?

Lors ne respondent pas molt haut

(Le Romans de la dame a la lycorne [1 $1^{\mathrm{er}}$ tiers $\mathrm{XIV}^{\mathrm{e}}$, 3267)

1776 mais ne voila-t-il pas que Madame Canon vint nous faire retirer, du même air que si nous avions commis un grand crime ; et depuis il nous est défendu d'en approcher. Apparemment que cela avoit déplu à quelqu'un ; car j'entendis la maîtresse 
de la maison qui répondoit fort haut à un homme bien mis, qui sortoit de chez elle, et qui nous regardait en se retirant (Nicolas Rétif de la Bretonne, Le Paysan perverti ou Les Dangers de la ville)

1871 Vuillet étant venu causer avec lui de la récompense méritée que venait de recevoir leur ami, il répondit très haut, de façon à être entendu de Félicité, assise à quelques pas, que des hommes comme Rougon « honoraient la légion d'honneur » (Émile Zola, La Fortune des Rougon)

1875 PATUREL. Une enquête ! On appelle ça une enquête...

CAMUSOT. Vous parlerez haut, monsieur... je vais vous poser des questions et vous aurez la bonté de répondre tout haut (Henri Meilhac et Ludovic Halévy, La Boule)

1928 La jeune fille qui avait parlé me fit asseoir à côté d'elle et me demanda gentiment, très bas :

- Vous vous appelez Gabrielle, et puis ?... Comme je commençais à répondre tout haut, elle me fit taire vivement.

- Il ne faut pas parler tout haut !... jamais !... et autant que possible, il ne faut pas parler du tout... retenez bien ça... (Gyp, Souvenirs d'une petite fille)

Transitif

1612a Et lors il se retira en sa place, et Corilas luy respondit assez haut :

- Ne faites point ce souhait, Celadon, car peut-estre ne souhaitterez vous jamais rien de si dangereux.

- Quelque hazard qu'il y ait (respondit Celadon tout haut) je ne me desdiray jamais de ce que je vous ay dit, et en deussé-je donner le cœur pour gage (Honoré d'Urfé, L'Astrée)

1612b « pleust à dieu, Corilas, que la querelle des peres de ceste bergere, et de moy, eust à se demesler entre nous deux. » Et lors il se retira en sa place, et Corilas luy respondit assez haut : "Ne faites point ce souhait, Celadon, car peut-estre ne souhaitterez vous jamais rien de si dangereux » (Honoré d'Urfé, L'Astrée)
1628 Et alors je disois en moy-mesme : helas ! Palemon, qu'il est bien moins heureux que toy, qui triomphes de ma maistresse qui t’ayme ! et puis je luy respondois tout haut : il est vray que Haladin est heureux, aussi l'a-t'il merité, car sa fidelité ne sçauroit trouver de fortune qui ne fust petite (Balthazar Baro, La Conclusion et dernière partie d'Astrée)

1839 - Mais, ajouta-t-il à voix basse, bien penser, bien dire, est-ce assez pour laver le sang et la honte?

- Non, sans doute, répondit Lélia tout haut. Il faut encore bien agir et il l'a fait. Durant son martyre, il a commencé une vie de dévouement, d'héroïsme et de charité qui ne cessera qu'avec lui (George Sand, Lélia)

1860 - Vous lasserez ma patience!

- On ne lassera pas la mienne ! répondit très haut la jeune fille.

Mathéus courut à Madame Gérard et la prit par le bras.

- Je vous en prie, s'écria-t-il, ne l'irritez pas (Louis Duranty, Le Malheur d'Henriette Gérard)

1923 Il demeura cependant surpris d'entendre Sabine Vialis, à deux places de lui, répondre très haut à la question sur l'âge de Mme Moraines :

- Quel âge ?... Mais vingt ans de plus que François-Victor, et autant de millions...

(Paul Bourget, La Geôle)

1925 Bobèche n'insista pas davantage.

- Ça se retrouvera! jeta-t-il dans un bond. Marcel Bouve, qui aurait pu l'abattre, au moment où il s'enfuyait, se contenta de lui répondre assez haut pour qu'il entendît :

- Quand tu voudras

(Francis Carco, L'Équipe : roman des fortifs)

Pronominal

1851 - Hélas ! je suis ce que vous êtes, un pauvre écrivain ; un écrivain, c'est-à-dire un penseur public ; je suis ce que furent, au génie et à la vertu près, saint Augustin, Jean-Jacques Rousseau, Chateaubriand, 
Montaigne, tous les hommes qui ont interrogé silencieusement leur âme et qui se sont répondu tout haut, pour que leur dialogue avec eux-mêmes fût aussi un entretien avec leur siècle ou avec l'avenir (Alphonse de Lamartine, Les Nouvelles Confidences)

II. Se manifester, apparaître fortement Intransitif

1857 - Mon ami, lui dis-je après un long silence, si les accusations du monde pouvaient arriver jusqu'à vous, votre bonheur répondrait assez haut.

- Vous êtes jeune, répondit-il ; pour vous, conscience naïve et pure que n’a pas salie le monde, notre bonheur signe notre vertu (George Sand, Indiana)

\section{CORPUS Web :}

Dieunefaitrienauhasard cherscompatriotes, il vous a parler par ce tirage au sort et à vous de repondre haut et fort [https://www.facebook.com/ permalink.php?id=446440018723693\&story fbid=1010377872329902] (23.11.2015)

Avec ses 11 comédiens, 3h30 de jeu fiévreux, une mise en scène électrique, crue parfois, et une esthétique tout en couleurs et en matières, Mathias Moritz relève le défi de mettre en scène les 48 personnages du roman - tout en se concentrant sur Charles - pour nous répondre haut et fort [http://www.szenik.eu/fr/Szeniklive/Theatre/Bovary-piece-province-qs9iexU0zT. html] (23.11.2015)

« Tu veux faire quoi quand tu seras plus grande ? " : Styliste », avais-je répondu haute comme 3 pommes, un Crayola dans la main [http://www.madmoizelle.com/en-quoiconsiste-metier-styliste-176159] (23.11.2015)

REMARQUES : Répondre haut (I) se dit du fait de formuler une réponse à une interrogation exprimée ou non en la mentionnant à voix haute à autrui, en public, de façon à être entendu de tous. Au figuré et dans un emploi métaphorique (II), le sujet désigne une émotion ou un état moral qui s'exprime à un haut degré. Notons la collocation haut et fort et l'emploi de parler fort et demander bas. Haut reste invariable dans son emploi adverbial. Dans le troisième exemple du CW, il fonctionne en tant que prédicat second orienté vers le sujet et s'accorde avec le sujet au féminin. L'exemple joue assez joliment avec l'âge de la jeune fille, qui se voit déjà « grande » et par conséquent « haute ». Haut est modifié par assez, fort, moult, tout, très. VOIR AUSSI : dire haut

\section{Répondre intellectuel}

Répondre par des propos d'intellectuel

入 répondre doux

\section{Répondre juste}

I. Donner une réponse correcte, répondre de façon adéquate, appropriée, avec justesse, avec exactitude

Intransitif

1657 Je pourrais dire néanmoins qu'il permet en cela tout ce que demandent ceux qui se battent en duel. Mais, puisqu'il faut vous répondre juste, notre père Layman le fera pour moi, en permettant le duel en mots propres, pourvu qu'on dirige son intention à l'accepter seulement pour conserver son honneur ou sa fortune (Blaise Pascal, Les Provinciales)

1675 Il n’y a rien de plus vrai que l'amitié se réchauffe quand on est dans les mêmes intérêts ; vous m’avez écrit si obligeamment là-dessus, que je ne puis y répondre plus juste qu'en vous assurant que j'ai les mêmes sentiments pour vous que vous avez pour moi, et qu'en un mot, je vous honore et vous estime d'une façon toute particulière (Mme de Sévigné, Correspondance)

1691 Elles y répondaient fort juste en peu de mots, car il faut convenir qu'elles disent précisément ce qu'il faut, et elles n'ont pas la peine de le chercher, leur esprit y fournit sur-le-champ (Marie-Catherine d'Aulnoy, Relation du voyage d'Espagne)

1696 où il dit non, souvent il faut dire oui, et où il dit oui, croyez qu'il veut dire non ; il a en vous répondant si juste les yeux fort ouverts, mais il ne s'en sert point, il ne regarde ni vous, ni personne, ni rien qui soit au monde : tout ce que vous pouvez tirer de lui, et encore dans le temps qu'il est le plus appliqué et d'un meilleur commerce, 
ce sont ces mots : Oui vraiment (Jean de La Bruyère, Les Caractères)

1731 Il ajouta à cette confirmation quelques raisonnemens sur le parti qu'il croyoit à propos que nous prissions ; comme de nous mettre promptement en mer, et de poursuivre le vaisseau françois, qu'il ne nous seroit peut-être pas impossible de rejoindre. J'eus la force de l'écouter, et celle de répondre juste à ses propositions (abbé Prévost, Le Philosophe anglois)

1767 La courte et ronde demoiselle le regardait de tousses petits yeux, et disait de temps en temps au prieur : ce grand garçon-là a un tein de lys et de rose ! Qu'il a une belle peau pour un huron!

- Vous avez raison, ma sœur, disait le prieur.

Elle faisait cent questions coup sur coup, et le voyageur répondait toujours fort juste. Le bruit se répandit bientôt qu'il y avait un huron au prieuré. La bonne compagnie du canton s'empressa d'y venir souper (Voltaire, L'Ingénu : histoire véritable)

1776 Poussez-le ; ce seroit un meurtre de laisser chez vous un jeune homme comme ça : et l'ayant questionné, il se confirma plus encore dans ce qu'il avoit dit ; car Edmond lui répondit juste et modestement sur tout (Nicolas Rétif de la Bretonne, Le Paysan perverti ou Les Dangers de la ville)

1786 Elle avait raison, et ce qu'elle disait répondait trop juste aux sentiments de mon cœur pour ne pas m’arracher des larmes (Germaine de Staël, Lettres de jeunesse)

1831 Adieu, monsieur, un mot de vous me fait toujours un vif plaisir. Quand tout se tait dans le désert intellectuel où nous vivons, il est doux de trouver çà et là un écho qui nous répond juste et fort (Alphonse de Lamartine, Correspondance générale)

1836 On n'y pouvait rêver la trace d'un chagrin Qu'au pli que la douleur laisse dans le sourire,

À la compassion plus tendre qu'il respire, $\mathrm{Au}$ timbre de sa voix ferme dans sa langueur, Qui répondait si juste aux fêlures du cœur (Alphonse de Lamartine, Jocelyn)

1922 - Il t’a répondu juste, il t’a répondu juste, ton destin ! s'écrièrent toutes à la fois, en battant des mains (Elissa Rhaïs, La Fille des pachas)

1985 Un jeu lancé avec succès synthétise la voix de l'interlocuteur de l'enfant : quand il a répondu juste, ou bien fait sa combinaison, il y a une voix de robot qui dit à l'enfant : « Tu es formidable » (Françoise Dolto, La Cause des enfants)

Pronominal

1740 Je descendis dans la cuisine, et je le trouvai en conversation muette avec la mère et la fille. Il me parut qu'ils s'entendoient parfaitement bien, et qu'ils se répondoient juste à leurs idées et aux signes qu'ils se faisoient pour se les exprimer (Jacques de Varenne, Mémoires du chevalier de $R a$ vanne)

Emploi absolu

1840 Je lui crois de l'esprit, mais il n'en montre pas ; sa conversation est des plus ordinaires, sans trait, sans saillies, passant tout bonnement d'une chose à l'autre. Je remarque seulement qu'il répond juste et parle à propos (Eugénie de Guérin, Journal)

II. Répondre seulement

Intransitif

1713 Une maniere si imperieuse le terrassa : il voulut biaiser et se jetter dans de grandes explications. Ce n'est pas là ce que je veux sçavoir, dit-elle, répondez juste, quelle sûreté avez-vous de mon libertinage, et du vol que vous dites ? Je ne l'ai dit, répondit-il, que comme un soupçon et après le bruit public (Robert Challe, Les Illustres Françoises)

Transitif

1961 Nous le suivons... je le vois de dos... grand maigre et presque bossu... à côté c'est un bureau, des classeurs, un fichier... quatre fichiers... le téléphone sonne... il répond... 
juste ! ja !... que des ja !... et puis nein !... il raccroche... il lit un papier !... il parcourt... marmonne... il ôte son monocle... à nous ! (Louis-Ferdinand Céline, Rigodon)

\section{CORPUS WEB :}

Les 3 premiers à répondre juste à la question suivante gagneront 2 places valables le dimanche 13 octobre 2013, pour le tournoi de tennis WTA à Kockelsheuer [https://www.facebook.com/ Diekirch/posts/515601295200805] (23.11.2015)

Si on répond au hasard, on répond au hasard, sinon il aurait fallu écrire " si on réponds à cette question en essayant de répondre juste », hein [http://forum.hardware.fr/hfr/Discussions/ Sciences/unique-maths-hfr-sujet_9528_478.htm] (23.11.2015)

Non, les questions seront simples, le but n'est pas que 3 personnes répondent justes, le quizz c'est juste pour mettre un peu de jeu (;) [http://www.jeuxvideo.com/forums/42-3273941771659-3-0-1-0-jeu-concours-trois-lots-sympasa-gagner.htm] (23.11.2015)

Le jeu continue, et si 3 autres répondent justes aux 3 questions, ils seront qualifier à la demi-finale, et les 4 autres sont éliminé (bye-bye (-) [http://www.forumjv.com/forums/1-200891443855-1-0-1-0-jeu-question-en-tout-genre.htm] (23.11.2015)

REMARQUES : Répondre juste (I) se dit du fait de formuler une réponse à une interrogation exprimée ou non en la mentionnant avec exactitude, conformément à la réalité, comme il convient, sans erreur, en donnant la bonne réponse. Juste reste invariable dans la majorité des cas. Nous avons ajouté deux exemples où juste signifie 'seulement' (II), dans la même structure syntaxique, sans prétendre à documenter de façon exhaustive ce sens, qui excède le groupe verbal (ex. juste trois, juste lui). Le CW met en évidence l'importance des jeux de réponse où il s'agit de donner la réponse juste. Dans le troisième et quatrième exemple du CW, juste s'accorde avec le sujet tout en gardant son interprétation adverbiale. Il est modifié par fort, plus, si, toujours fort, trop.

\section{Répondre menu}

Répondre rapidement, tout de suite après

Emploi absolu

-1234 Il prent .i, cor, n'i a plus atendu.

Plus de . iii $^{\mathrm{m}}$. li respondent menu ;

. $\mathrm{xxx}^{\mathrm{m}}$. sunt au premerain issu,

De cels derier n'i a conte tenu ;

Tant en i a ainc tant n'en fu véu,

Qui tuit menacent Karlon, le viel chanu,

Rollant le conte et Olivier son dru

(Otinel $\left[1^{\mathrm{er}}\right.$ tiers XIII $\left.{ }^{\mathrm{e}}\right], 1570$ )

\section{CORPus WeB :}

On retrouvera la rue de Cachy (que je connais particulièrement) et ce sera le retour sur place. $10.8 \mathrm{~km}$ pour cette belle sortie (un peu grasse) en $2 \mathrm{H} 11$ soit une moyenne de $4.95 \mathrm{~km} / \mathrm{h}$... (il y a eu quelques arrêts) Bien belle après midi ! Pensez à répondre menu à François d'Authuille... [http:// marcheravillers.over-blog.com/article-pas-depluie-a-villers-125221039.html] (23.11.2015)

REMARQUES : Répondre menu désigne le fait de faire connaître, oralement ou par écrit, en retour à une question ou à une remarque, ce qu'on a à dire. Menu souligne un rythme de paroles rapide, tendant à lexicaliser le sens de 'tout de suite après, immédiatement'. Menu reste invariable et est modifié par plus. VoIR AUSSI : répondre bref

\section{Répondre net}

Répondre d'une manière catégorique, franche, sans ambiguïté, sans équivoque

Intransitif

1764 HENRI (riant) Mon ami ! je ne suis point un coquin.

MICHAU. M'est avis que vous ne valient guére mieux ; car vous ne répondais pas net.

Qu'est-ce qu'a tiré le coup de fusil que je venons d'entendre ? (Charles Collé, La Partie de chasse de Henri IV)

1784 A. Je l'ai remarqué. Mais enfin dites moi, faut-il civiliser l'homme ou l'abandonner à son instinct?

B. Faut-il vous répondre net?

A. Sans doute.

B. Si vous vous proposez d'en être le tyran, civilisez le ; empoisonnez le de votre mieux d'une morale contraire à la nature 
(Denis Diderot, Supplément au voyage de Bougainville)

1800 PINTO. M'aimez-vous?

Mme DOLMAR. Non, vous êtes trop

méchant.

PINTO. Répondez net ; m'aimez-vous ?

Mme DOLMAR. C'est m'interroger d'un ton à m'en guérir

(Népomucène Lemercier, Pinto ou La Journée d'une conspiration)

1888 - Réponds vite et net, commença-t-il ... Samy se marie?

(Alphonse Daudet, L'Immortel)

1931 - Patrouillons encore une heure. Et nous filerons pour lui couper la route. Pourquoi n'avait-il pas répondu net sur cet argent? Et puis, autre chose, c'était sûrement lui ou son frère qui avait envoyé un homme au bossu, l'avant-veille

(Henri Pourrat, La Tour du Levant ou Quand Gaspard mit fin à l'histoire)

1939 C'est ce genre de questions nettes, précises et claires comme eau de source, auxquelles il faut répondre net, clair et précis (Jean-Paul Sartre, Lettres au Castor et à quelques autres)

1952 Avec quel redoublement d'angoisse aujourd'hui, dans une situation bien plus dramatique, devons-nous, tous, nous interroger?

Pour répondre net. Or, je réponds, ici, sans hésiter : « Faire de l'histoire, oui » (Lucien Febvre, Combats pour l'histoire)

Transitif

1836 Mais si vous êtes une nature exaltée, croyant à des rêves et voulant les réaliser, je vous réponds alors tout net : l'amour n'existe pas. Car j'abonde dans votre sens, et je vous dis : aimer, c'est se donner corps et âme, ou, pour mieux dire, c'est faire un seul être de deux (Alfred de Musset, Confessions d'un enfant du siècle)

1886 Encore dans la rue ! Mais le mari connaît un autre poste de blessés, pas trop loin. On s'y rend.

- Voulez-vous de nous ?...
- Oui !

C'est répondu tout net, et cavalièrement, par une cantinière en grand uniforme - superbe créature de vingt-cinq ans, le buste riche et la taille fine dans sa cuirasse de drap bleu (Jules Vallès, Jacques Vingtras : L'Insurgé)

1902 -Monsieur tient à conserver ces petites allées, dit-il en indiquant les couloirs qui font le tour de la pelouse ; et comme ces « petites allées » qu'il dédaigne me plaisent beaucoup, je réponds un peu net : - Certainement (André Gide, Journal)

1939 Mais en vain présenta-t-il à Constance les plus beaux partis ; « la princesse, nous dit la chronique, avait trop bien éprouvé l'ennui d'être au pouvoir d'un mari et le peu de liberté qu'on laisse aux dames quand elles ont un seigneur »; elle répondit tout net au roi qu'elle n'entendait nullement se remarier. Elle rit au nez de ses tantes qui avaient entrepris de la chapitrer, déclara s'en tenir à son agréable veuvage (René Grousset, L'Épopée des croisades)

\section{CoRpus Web :}

alors faut comprendre on pose des questions pour avoir des reponses bon après chaqu'un sa facon d'y répondre.. c'est sur que defois je trouve ke kissloli a bien raison de répondre net et franchement lorsqu'on voit que certain post.. mais pour d'autre nan.. lol bref tt sa pr ne rien dire lol !! [http://www.tasante.com/forum/ posts/11_447330/KISS-LOLI.html] (23.11.2015)

depuis c'est que du bonheur, la machine est excelente ! elle est douce en stationaire et dès qu'on la chahute un peu, elle repond nette! franchement un très bon invertissement ! [http:// www.modelisme.com/forum/archive/index.php/ t-118214.html] (23.11.2015)

je le regarde je lui dit « mais qu'est-ce t'as dit ? tu sais au moins ce que ça veut dire au moins que tu dis ça comme ça ? " il me répond nette « ouais se faire enculer c'est de se faire mette une bite dans le cul... bref se faire sodomiser quoi ! » D’après vous ma réaction ? j'étais O_O [http://forum.doctissimo.fr/famille/Pedophilie/ doctissimo-pedophile-journal-sujet_337_1.htm] (23.11.2015) 
REMARQUES : Répondre net se dit du fait de faire connaître oralement, en retour à une question, à une remarque, ce qu'on a à dire, le sujet s'exprimant de manière directe, ouverte, qui ne prête pas à confusion. Appliqué à une machine, un appareil, répondre s'emploie au sens de réagir. Net reste généralement invariable, mais, dans les deux derniers exemples du CW, il s'accorde. Dans l'avant-dernier, on pourrait voir un accord motivé par le sujet au féminin. Par contre, le dernier exemple semble fournir la preuve du fait que la prononciation de net, où le - $t$ final est audible au féminin et au masculin, détermine la flexion, qui est morphologiquement et sémantiquement illogique. Net est modifié par alors, tout, un peu. Notons les collocations répondre vite et net ; répondre net, clair et précis; répondre net et franchement.

\section{Répondre noir}

dire/parler blanc, répondre noir : dire une chose, répondre son contraire, contredire $\lambda$ dire blanc

\section{Répondre précis}

Répondre avec précision

$\pi$ répondre net

\section{Répondre sec}

Répondre brusquement, sèchement, rudement, froidement, sans amabilité

Transitif

1877 Cette fois il tombait mal. Le bras musculeux qu'il serrait se secoua violemment, et le Nabab lui répondit très sec :

- J'en suis fâché, mon cher, je n'ai pas de place à vous offrir.

Pas de place dans un carrosse grand comme une maison et qui les avait amenés cinq

(Alphonse Daudet, Le Nabab)

1986 Et t'as beau savoir qu'il vient d'acheter un bateau avec tout le confort l'eau le gaz et l'électricité si tu lui réponds j'ai des gosses c'est pas avec ce que je gagne que je peux les élever il te répond aussi sec moi aussi j'ai mes soucis toutes proportions gardées (François Caradec, La Compagnie des zincs)
2006 N'objectez pas que c'est plutôt l'inverse, on répondrait aussi sec qu'on ne voit pas la différence (Gérard Genette, Bardadrac)

Intransitif

1929 - Ça y est, pensa Fanny, Elle m’a répondu sec comme trique, et elle va me parler de l'éducation qu'on donne aux adolescents en Angleterre. C'est le jour de Davidson, décidément (Colette, La Seconde)

1977 - Si on te disait, Vincent... Si on te disait qu'il faut monter sur la barricade pour libérer la France. Et que le premier qui montera sera tué. Et qu'il faut que ce soit toi. Tu y monterais, le premier, Vincent? Qu'est-ce qu'il pouvait bien répondre, le malheureux ? Il n'a quand même pas répondu aussi sec. Il a marqué un temps. C'était un type bien. Il a dit " oui », bien sûr. Un temps, il a dû ajouter quand même quelque chose comme : « Remarque, ce serait pas marrant... » (Jean-Pierre Chabrol, La Folie des miens)

1995 Il va, je sais, employer tous les vocables de psy pour me la faire à l'estomac.

- Ce que j'ai envie...

Je réponds sec, sa question me déplaît.

- Mais encore...

Il sourit... un rien condescendant

(Alphonse Boudard, Mourir d'enfance)

CORPus Web :

Les gens qui répondent $s e c$, on dirais vous voulez pas continuer la conversation, j'vous aime pas [https://twitter.com/sxperm/ status/597497663190376448] (17.11.2015)

Ou elles tirent souvent la tronche et quand j'essaye de plaisanter ou lancer une discussion elles te répondent sec [http://www.yabiladi.com/ forum/dispute-avec-frere-epouse-70-3313783page $=2 . h t m l](17.11 .2015)$

REMARQUES : Répondre sec se dit du fait de faire connaître oralement, en retour à une question, à une remarque, ce qu'on a à dire, le sujet s'exprimant de manière directe, dure, froide, sans amabilité. Sec reste invariable et est modifié par aussi, très. 


\section{Répondre vrai (voir)}

Répondre avec honnêteté, en disant la vérité Intransitif

+1365 Volentiers, puis qu'il vous plaist dire Que j'en responde voir, chier sire (Jean Froissart, Poésies [3e tiers XIV]])

1766 Sous prétexte de reconduire Bordeux, j'ouvris la porte du cabinet et je lui demandai ce qu'il en pensoit. Je ne scais s'il a pitié de moi ; s'il me répond vrai ou s'il me trompe. Il traite cela comme un reste de vapeurs. Mais dites moi donc pourquoi je ne scaurois l'en croire, malgré toute l'envie que j'en ai ? (Denis Diderot, Lettres à Sophie Volland)

1793 Répondez-moi seulement si vous serez en Angleterre dans six semaines ou deux mois, mais répondez-moi vrai; il y a six mois que vous vous épuisez tellement en mensonges qu'un moment de simplicité et de vérité vous reposera (Germaine de Staël, Lettres inédites à Louis de Narbonne)

Transitif

1715 le truchement répondit vrai ou faux qu'il en estoit venu un fort grand nombre, qu'ils estoient chargez d'armes, de soldats, et de toutes sortes de munitions de guerre (Jean Crasset, Histoire de l'Église du Japon)

1846 - Et vous croyez qu'il est mort...

- De faim... Monsieur, de faim, dit Caderousse ; j'en réponds aussi vrai que nous sommes ici deux chrétiens.

L'abbé, d'une main convulsive, saisit le verre d'eau encore à moitié plein

(Alexandre Dumas père, Le Comte de Monte-Christo)

CORPuS WeB :

Bref. En France, je sais qu'elle comprend tout ce que je lui dis (parce qu'elle s'exécute et parce qu'elle répond vrai) mais souvent (pas tout le temps) elle me répond en français. Je ne la reprends jamais, je continue la conversation en catalan [http://www.lesmotsdemarguerite.com/ tag/bilingue] (17.11.2015)

Faux et faux. J'ai remplis ton cœur de mauvais espoirs, ce n'est pas ovni qui a posté, mais bien moi. Mon prochain est fan de la série «Spar- tacus " (Celui qui répond vrai, on va devenir de bon amis vous et moi) [http://hellominecraft.fr/ forum/viewtopic.php?f=24\&t=16925\&start=1170] (17.11.2015)

REMARQUES : Répondre vrai se dit du fait de faire connaître oralement, en retour à une question, à une remarque, ce qu'on a à dire, le sujet s'exprimant avec franchise, de manière directe, ouverte, sans dissimulation. Vrai reste invariable et est modifié par aussi. Dans l'exemple de 1715, il s'oppose à répondre faux.

\section{Reposer petit}

Se reposer (un) peu, reprendre un peu ses forces Pronominal

1175 Volentiers, dient il tantost, Que ne queroient autre cose. Ganor mout petit se repose Icele nui[t], ains se demente Et dist : Con chi a longe atente ! (Gautier d'Arras, Ille et Galeron, 6254)

Intransitif

1385 Celle nuit reposay petit, Mais a ce qui estoit escript Et que j'escripvi ensement Leuz et pensay parfondement, Toute la nuit mieulx que je pos Sanz avoir aise ne repos, Jusques bien près d'eure de prime J'estoie encore sur la rime Et sur la fin de ma lecture (Eustache Deschamps, Le Miroir de mariage, 10577)

REMARQUES : En ancien français, reposer petit signifie 'reposer (un) peu'. Petit reste invariable et est modifié par moult.

\section{Reprendre bas}

I. Reprendre à voix basse, en chuchotant Transitif

1744 je ne voïois aucune raison de quitter la croix pour une femme ; mais, reprenois-je tout bas, que deviendra la baronne si je refuse sa main ? (Jean-Baptiste Jourdan, Le Guerrier philosophe)

1862 Après un moment d'hésitation : - Voici votre mère, reprit-elle plus bas, je m'en vais (Paul Reider, Mademoiselle Vallantin) 
1880 Léa de Horn, qui avait un salon politique, où d'anciens ministres de Louis-Philippe se livraient à de fines épigrammes, reprit très bas, en haussant les épaules :

- Quelle faute, cette guerre!

(Émile Zola, Nana)

1933 - Il y a l'oubli... dit Clappique à mi-voix.

- Il y a plus d'un an que je n'ai pas couché avec une femme ! Ça vous suffit ? Et...

Il s'arrêta net, reprit plus bas :

- Mais dites donc, mon petit Toto, le jeune Gisors, le jeune Gisors... vous parliez de malentendu

(André Malraux, La Condition humaine)

1968 Le père n'écouta que quelques secondes puis, levant la main, il dit :

- Savez-vous ce qu'elle m'a dit?

Les autres se turent et le regardèrent ; alors, plus bas et plus lentement il reprit :

- Savez-vous ce qu'elle m'a dit, juste avant de sortir?

(Bernard Clavel, Les Fruits de l'hiver)

II. Reprendre (une activité professionnelle) en bas de l'échelle

Intransitif

1966 - Il m’arrive des choses fort curieuses. Je ne suis plus directeur culturel. Plus directeur du tout. J'ai rétrogradé sur le plan de l'inutilité mondaine. J'ai repris un peu plus bas, mais cette fois, je sers à quelque chose. Je ne commets pas trop de gaffes (Robert Sabatier, Le Chinois d'Afrique)

\section{CORPuS Web :}

Un détail de taille : un simple condensateur fait un filtre à $6 \mathrm{~dB}$. Or, avec le 511b il faudra reprendre bas, à $7 \mathrm{kHz}$ car la réponse chute assez vite. $6 \mathrm{~dB}$ ne sera pas suffisant pour filtre correctement ton tweeter dans ces conditions ; On y arrive avec des pentes fortes $24 \mathrm{~dB}$ [http:// www.audiovintage.fr/leforum/viewtopic.php? $\mathrm{p}=$ 372584] (17.11.2015)

Et c'est d'autant mieux pour rouler en ville ou quand il faut reprendre bas après un virolo serré [http://www.planete-ducati.com/forum/ index.php?topic=16457.740;wap2] (17.11.2015)
REMARques : Dans le récit du narrateur, reprendre bas (I), renvoie au fait de se remettre à dire quelque chose après qu'on s'est arrêté de parler, en chuchotant, à voix basse. Reprendre bas (II) se dit du fait de recommencer ou poursuivre quelque chose (une activité professionnelle), en acceptant un poste moins bien classé ou inférieur dans l'échelle sociale. Dans les exemples du CW, reprendre bas réfère au sens concret de 'recommencer à un niveau plus bas sur une échelle (de son, voltage, vitesse). Bas reste invariable et est modifié par plus, tout, très, un peu plus.

\section{Reprendre fort}

répondre haut et fort : répondre d'une voix forte $\lambda$ reprendre haut

\section{Reprendre haut}

I. Reprendre à voix haute

Transitif

1627 Madame, reprit alors Belisard tout haut, n'est-il pas vray que ma recepte est bonne? (Honoré d'Urfé, L'Astrée)

1738 - Ah, parbleu, reprit-il, c'est ce que je suis curieux de voir, et puis, reprenant haut la conversation ; Madame, lui dit-il, je me flatte que vous ne trouverez pas mauvais que je vous aye amené monsieur de Pranzi (Alexandre Dumas fils, Les Égaremens du cour et de l'esprit)

1832 Il haussa la voix :

- Mademoiselle!

Elle ne paraissait pas l'entendre. Il reprit plus haut encore :

- Mademoiselle Esmeralda !

(Victor Hugo, Notre-Dame de Paris)

1843 Puis le prince reprit tout haut :

- M. Ferrand paraissait-il contrarié de la résistance de Cecily?

(Eugène Sue, Les Mystères de Paris)

1882 Et comprenant aussitôt qu'il a manqué au rôle d'un courtisan de la république, il reprend vite et bien haut : " Oh ! C'est une expérience à faire, mais si l'expérience se fait, toute l'Europe alors... » (Edmond et Jules de Goncourt, Journal) 
1959 Comme nous arrivons dans un atelier de menuiserie où l'on fabrique de la chaise en série, le docteur Stürup reprend très haut, en danois, avant de se traduire lui-même : - On apprend ici la res-pon-sa-bi-li-té, comme on apprend une autre langue dans laquelle il faudra vivre (Hervé Bazin, La Fin des asiles)

1963 Comme la mère faisait un geste, il leva les yeux vers elle en reprenant plus vite et plus haut :

- Attendez, laissez-moi achever

(Bernard Clavel, Celui qui voulait voir la mer)

\section{Corriger}

Transitif

1869 de maigres abbés de compagnie escortant de vieilles dames dans le pèlerinage de leur curiosité pieuse, des commerçants enrichis payant à leurs femmes le voyage des gens distingués, d'épais industriels estropiant les noms de saintes, et que leurs filles reprenaient tout haut avec les leçons encore fraîches de leur éducation de couvent (Edmond et Jules de Goncourt, Madame Gervaisais)

\section{CORPUS WEB :}

Après plus d'une demi-heure en compagnie de Lars et Ulrich, les deux hôtes de la soirée, Joe et Marjorie, laissent place à « Through The Never ", qui débute sous une nouvelle pluie de cris d'hystérie, qui se poursuivra d'ailleurs tout au long du film. Il faut dire que les fans étaient en forme et n'ont pas hésité à reprendre, haut et fort, quelques refrains de chansons du film [http:// www.sortiraparis.com/scenes/concert-musique/ articles/66163-report-metallica-a-la-fnac-desternes-et-au-grand-rex-de-paris] (17.11.2015)

mais il faut croire que 68 ans après la défaite de l'Axe, 68 ans après la fin de la Shoah, le ventre de la bête immonde est toujours fécond, puisqu' ils se permettent de reprendre haut et fort les mêmes slogans [http://www.farband.org/ index.php/actualites/171-le-mot-du-presidentmars-2013] (17.11.2015)

Les chants reprennent, hauts et forts, pour qu'ils soient entendus à l'intérieur de la prison. Ils tentent de couvrir la douleur et les larmes, les miennes [http://muevet.free.fr/article.php3?id article=114] (17.11.2015)

Ecoutez un peu les journalistes radio qui reprennent hauts les cours des mots comme « traiter». «LejeuneXs'estfaittraiterparunautrejeunede la cité voisine........» [https://www.facebook.com/ permalink.php?id=1474086886253942\&story_ fbid=1474506006212030] (17.11.2015)

REMARQUES : Dans le récit d'un narrateur littéraire, reprendre haut (I) se dit du fait de se remettre à dire quelque chose après qu'on s'est arrêté de parler, à voix haute, de manière à être clairement compris, d'une voix nette, bien perceptible. On peut également reprendre le refrain d'une chanson (premier exemple du CW) ou un slogan datant d'autrefois (second exemple du CW). Dans l'avant-dernier exemple, ce sont les chants, convertis en sujet, qui reprennent ; en même temps, haut et fort se présentent en prédicats seconds qui désignent une qualité des chants. Le dernier exemple ironise sur l'emploi abusif de la langue par les journalistes, l'accord produisant un effet d'emphase. Sous (II), reprendre haut adopte le sens de 'corriger'. Notons la collocation haut et fort. Haut reste invariable dans son emploi adverbial. Il est modifié par alors, bien, plus, tout, très.

\section{Reprocher bas}

Reprocher à voix basse, en chuchotant ou secrètement, intérieurement

Transitif

1694 Et ce héros qui suit Neptune pas à pas, En qui tant d'embonpoint et tant d'esprit abonde, À qui tu reproches tout bas, D'une pudeur qui n'a point de seconde, Le cuisant souvenir de ses tendres ébats, Est maintenant l'homme du monde Le moins surpris qu'on n'aime pas (Antoinette Des Houlières, Épîtres)

1794 Oh ! quel est mon bonheur si, dans un bal bruyant,

Quelque belle tout bas te reproche en riant D'un silence distrait ton âme enveloppée, Et que sans doute ailleurs elle est mieux occupée ! (André Chénier, Élégies)

1865 En attendant, la belle Jeanne se produit avec un grand air de candeur et de non- 
chalance aristocratique, et madame Duport, qui paraît s'intéresser beaucoup à elle, m'a reproché tout bas de n'être pas assez charmé de sa grâce et de sa beauté (George Sand, Monsieur Sylvestre)

1922 - Et puis, enfin, il y a ton idée, lui reprocha tout bas Lampieur... ton idée que tu ne m'avoues pas et que tu gardes toujours pour y penser et pour y revenir (Francis Carco, L'Homme traqué)

Pronominal

1943 Jérôme se reprochait tout bas un enthousiasme mal approprié aux circonstances et la campagne constituait autour de lui une étendue à la fois magnifique et terne qui n'admettait aucune musique (André Dhôtel, Le Village pathétique)

REMARQUES : Reprocher tout bas désigne le fait de désapprouver, de blâmer ou de regretter l'action ou le comportement de quelqu'un, en secret, sans le lui dire. Dans son emploi pronominal, il se dit du fait de se considérer comme responsable de quelque chose de fâcheux, de condamnable et de le garder pour soi, de ne pas le dévoiler. Bas reste invariable et est modifié par tout.

\section{Reprocher fort}

reprocher haut et fort : reprocher d'une voix forte, en insistant

$\lambda$ reprocher haut

\section{Reprocher haut}

Reprocher à voix haute, publiquement, ouvertement

Transitif

1646 Aussi Suillius accusé de cette corruption, reprocha tout haut à Seneque, qu'il en vouloit à tous les serviteurs de Claudius, sous le regne duquel il avoit esté à bon droit banny de Rome (Nicolas Coëffeteau, Histoire romaine)

1876 Maintenant, qu'elle reçoive Socrate et se fasse épouser par Périclès, comme Aspasie ; qu'elle soit assez riche pour offrir de rebâtir Thèbes comme Phryné ; qu'elle soit capable de tourner la tête à un Louis XV comme la Dubany, ou à un Nelson comme
Emma Lyonna, je ne le nie pas et Dieu me garde de le lui reprocher trop haut dans le pays qui a immortalisé Ninon et qui en glorifiera tant d'autres! (Alexandre Dumas fils, L'Étrangère)

1924 En tout cas, Mirabeau mourut, après une brève maladie, le 2 avril 1791 . Ses relations avec la cour étaient connues. On lui reprochait tout haut d'en avoir reçu de l'argent pour payer ses dettes (Jacques Bainville, Histoire de France)

\section{CORPUS WEB :}

Ouais mais t'as jamais été tchoppé pour sectarisme ou autre discrimination ; Pourtant tu l'aurais mérité à force de me reprocher haut et fort que je suis Viviézois [http://www.rugbyfederal.com/ forum/viewtopic.php?pid=1026828] (17.11.2015)

D'habitude plutôt conciliant, Emon n'hésite pas à parler après ce second revers de la saison d'un véritable " naufrage collectif ». Il rajoute même : "C'est plus qu'un simple incident de parcours, il y a eu un manque d'investissement flagrant, et ça, je peux me permettre de le reprocher haut et fort " [http://www.lephoceen.fr/ infos-om/saison/l-om-et-emon-sous-pressionactualite-1238] (17.11.2015)

REMARQUES : Reprocher haut réfère à un propos critique ouvertement tenu. Haut reste invariable et est modifié par tout. Le langage familier documenté dans le CW tend à l'employer dans la collocation haut et fort.

\section{Résonner bas}

Résonner faiblement, doucement, légèrement, avec une faible intensité

Intransitif

1920 Avec les heures, un à un, Dans la vasque de cuivre, Leur calice tinte et délivre Une âme à leur parfum Liée, entre tant, ô Ménesse, Qu'à travers vos ébats, J'écoute résonner tout bas Le glas de ma jeunesse (Paul-Jean Toulet, Les Contrerimes)

1996 Dès qu’un kaki entrait, sortait, le « Heil Hitler » résonnait, haut ou bas, avec écho 
ou sans écho ; et pour réponse souvent un simple signe de tête (Boris Schreiber, Un silence d'environ une demi-heure)

\section{CORPUS WEB :}

François pourquoi l'ésotar ? As tu essayé d'autres tweeter HDG, morel MDT33, focal byrillium, scanspeak ring revelator etc. ? Pourquoi le tweeter doit résonner bas ? [http://www. synthesehifi.com/phpBB2/viewtopic.php?f=4\&t= $3372 \&$ start $=45 \&$ sid $=01679177$ e97efba652e559bf36 672901\&view=print] $(17.11 .2015)$

Pas donné surtout s'il faut les faire venir. Ils restent conçus pour la guitare. Comme ils résonnent bas ça ira [http://onlybass.com/index. php?/topic/28517-fabrication-de-baffle-basse/ page-3] (17.11.2015)

C'est la même chose avec les parois, plus c'est lourd plus ça va raisonner bas, car les parois ont elle aussi une masse et une raideur [http://www.cinetson.org/phpBB3/menuiseriemecanique-f12/jbl-w12gti-qu-en-pensezvous-t22167-15.html] (22.10.2015)

La note résonne basse et longue, un peu sourde, sous la frappe du petit marteau de fer [http://www.liberation.fr/week-end/2004/02/21/ parme-plaisir-de-palais_469803] (17.11.2015)

REMARQUES : Résonner bas réfère à un son (la sonnerie d'une cloche) ou un ensemble de sons, une voix (des paroles ou des mots) qui retentit en s'accompagnant de bruits sonores très faibles, peu intenses et difficilement perceptibles à l'oreille. Notons l'opposition sémantique résonner haut et bas. Bas reste invariable dans son emploi adverbial. Dans le troisième exemple du CW, il adopte la fonction de prédicat second orienté vers le sujet s'accordant avec celui-ci, de même que les adjectifs long et sourd, mis en série. La construction impersonnelle familière avec le sujet ça dans l'avant-dernier exemple montre la confusion des verbes résonner et raisonner 'conduire un raisonnement' (v. aussi sous raisonner creux, résonner beau). Bas est modifié par tout.

\section{Résonner beau}

Émettre un beau son

Intransitif

\section{CORPUS WEB :}

Les peaux fines font raisonner le fut. Si le fut est de bonne qualité ça va raisonner beau [http://www.guitariste.com/forums/batterie-etpercussion,premiere-batterie-sans-restrictionsde-budget,398840.html] (22.10.2015)

REMARQUES : Résonner se confond, ici comme ailleurs, avec le verbe raisonner (v. raisonner creux, résonner bas). Le groupe résonner beau renvoie à la beauté d'un son émis par une caisse de résonance.

\section{Résonner clair}

I. Rendre, produire un son pur, clair

Intransitif

1170 E Troïlus point ne l'esperne : De l'espee li meist e done

Sor le heaume, qui cler resone [variante : si cler] (Benoit de Sainte Maure, Le Roman de Troie, 14478)

1837 Ils passèrent près de lui avec rapidité, et les jeunes gens qui les montaient [= les chevaux] continuant une conversation commencée, jetèrent en passant ces mots qui résonnèrent clairs et pétillants au milieu du calme glacé de la matinée (Louis Couailhac, Pitié pour elle)

1859 sa voix résonne clair comme une clochette de Suresnes (Charles Coligny, Edmond About)

1872 La voix de Mme Alboni n’a rien perdu de sa merveilleuse beauté : elle a toujours ce velouté, cette fraîcheur des premières années. Le temps a passé sans altérer ce timbre d'or qui résonne clair et pur dans les notes du registre supérieur (L'Illustration)

2005 C'est dans l'école qu'elle entre. Elle pousse la grille, et puis la porte immense, qui s'ouvre avec une toute petite clef. C'est l'odeur de l'école, comme un mélange de craie blanche et de peau d'enfant. Elle traverse les couloirs, ses pas résonnent plus clairs, plus nets, plus sûrs (Gérald Tenenbaum, Le Geste)

II. Donner une impression de gaîté, de légèreté Intransitif

1996 Notre père, contre toute attente, avait ri pour l'histoire de la valise. L'ambiance d'ailleurs, à part quelques ombres de-ci de-là, résonnait claire. Drôle, plus d'une 
fois (Boris Schreiber, Un silence d'environ une demi-heure)

\section{CORPUS WEB :}

La digestion incontestablement y gagne, mais l'élocution également, leurs phrases de nouveau résonnent clair comme l'airain, de toute la fraîcheur juvénile charmante dont ils regorgent, qui à nouveau librement s'écoule, avec toute la verve fruste, crue, colorée, vivifiante, liquide, dont font preuve les plus robustes et attachants des seconds rôles - d'ailleurs, plutôt qu'aux Sisters ou aux Virgin Prunes, on pensera ici à Usherhouse, et à tout prendre c'est encore mieux, dans le genre aura musquée [http://www. slowend.com/chroniques/?d=2343] (17.11.2015)

René Huygues parlait d'art initiatique et d'art compensatoire... les deux catégories résonnent clair chez ceux qui, comme vous, envisagent de consacrer un peu de temps aux réflexions que je vous concocte ! [http://fr.viadeo. com/fr/groups/detaildiscussion/?containerId $=0$ 0225zx2yrrly1i5\&forumId=0021rnub9vfg9ukz\&a ction $=$ messageDetail \&messageId $=0021 v 2 b 8 s 71 i$ uyh0] (17.11.2015)

On dit aussi que si on grave ou colle l'incantation de Namgyalma sur une cloche, quand n'importe qui entend les bruits qui résonnent clairs de la cloche, les ennuis sont dissipés immédiatement, et aide la sagesse à se développer [http://deulmalhamo.unblog.fr/2007/05] (17.11.2015)

REMARQUES : Résonner clair (I) réfère soit à un objet qui, s'entrechoquant avec un autre, provoque un son ou un ensemble de sons aigus, nets, bien perceptibles à l'oreille, soit - et surtout - à la voix ou à la parole humaines qui produisent un son clair. Au figuré, résonner clair peut évoquer une ambiance gaie et ouverte (II) ou renvoyer à la parole ou à l'art qui transmettent un message clair en exerçant un grand impact sur l'auditeur ainsi qu'à des pensées qui se font clairement écho (v. les deux premiers exemples du CW). L'accord morphologique de clair est optionnel. Employé au sens concret dans le dernier exemple du CW, il s'accorde avec le sujet les bruits qui sont ainsi mis en relief. Il est modifié par plus. Notons les collocations clair et pétillant ; clair et pur ; clair, net, sûr.

\section{Résonner creux}

I. Rendre un son creux, sourd Intransitif

1831 [Il] leur frappa doucement le sternum et écouta si la poitrine résonnait bon creux ; leur mit le genou sur l'estomac, sans appuyer trop fort... (Oh ! Non certes, le cher homme !) mais seulement pour juger si, malgré cette pression, la respiration s'échappait facile et sonore... (Eugène Sue, Atar-Gull)

1904 Ils ont tous mis à nu leur épaule et leur sein gauches ; ils se frappent si fort que la chair est tuméfiée et la peau presque sanglante ; on entend les coups résonner creux dans leur thorax profond. Le vieil homme qu'ils écoutent leur raconte, en couplets presque chantés, la Passion de leur prophète (Pierre Loti, Vers Ispahan)

II. Être vide de sens

Intransitif

1956 Alors que tant de débats au Palais-Bourbon et depuis si longtemps résonnent creux parce que seules s'y heurtent des critiques stériles, cette fois-ci, rien de tel (Le Figaro, 2-3 juin 1956 / Grundt : 344)

\section{CORPUS WEB :}

Après lecture du rapport d'instruction, celle-ci choisit ainsi « de prononcer la fermeture de la section basse du Virage Nord du Stade Vélodrome pour deux matchs ferme, dont un par révocation du sursis ». Une sanction qui s'accompagne également d'une amende de 10000 euros infligée aux Ciel et Blanc. Pour la réception du Stade Malherbe de Caen, le 8 août 2015, puis du promu, Troyes, quinze jours plus tard, l'enceinte phocéenne risque donc fort de résonner creux [http://www.sports.fr/football/ligue-1/articles/ discipline-le-velodrome-ampute-pour-deuxmatches-1285946/?view=popup] (17.11.2015)

Lorsque lois et justice, deux mots qui devraient forcément se serrer les coudes pour défendre les opprimés de notre société, se mettent à résonner creux comme une coquille vide, c'est un autre son saturé de dignité humaine que j'ai envie de faire entendre à Hassania, Naïma et Tahar [http://www.lejsl.com/societe/2012/06/24/ 
droit-d-asile-appel-pour-une-reforme-urgente] (17.11.2015)

REMARQUeS : Résonner creux (I) désigne un élément concret (le sol, la terre), qui, sous le poids des pieds de l'homme ou des pattes de l'animal, sonne à la manière d'un objet ou d'un espace creux. Le sujet peut encore renvoyer à un mouvement rapide (un coup) dont le bruit sur le corps est semblable au son rendu par un objet creux. Dans le premier exemple du CW, le locuteur suppose qu'un stade résonne creux suite à l'interdiction officielle « ferme » d'occuper une partie des rangs. Résonner creux (II) réfère, lors d'un débat, à des paroles, propos ou arguments sans intérêt, vides de sens ou qui manquent de valeur. Il est à relier à la collocation usuelle sonner creux. Creux reste invariable et est modifié par bon. Cet intensifieur est un archaïsme conservé chez Eugène Sue dans le groupe bon creux ; bon équivaut à bien, ce qui montre l'usage courant dans l'ancienne langue de l'adjectif dans les fonctions adverbiales. Notons aussi l'emploi de l'adjectif-adverbe ferme comme adverbe de phrase qui réfère à une décision fermement prise, définitive et irrévocable. VoIR AUSSI : raisonner creux

\section{Résonner doux}

Produire un son doux, agréable Intransitif

1613 La Muse autour de votre bouche, Volant ainsi comme une mouche, De miel vous embrene le bec ; Et vos paroles nompareilles, Résonnent doux à nos oreilles, Comme les chordes d'un rebec (Mathurin Régnier, Louanges de Macette / Poésies diverses)

1836 Il m’aima ! Pardonnez, ô mon père, à mes larmes!

Pour ma bouche expirante, oui, ce mot a des charmes!

Il m’aima ! Lui ? Moi ?... Lui !... ce mot fait mon orgueil!

Il résonne encor doux au bord de mon cercueil!

Quels que soient les remords dont ma vie est semée,
Dieu me regardera, puisque j'en fus aimée! (Alphonse de Lamartine, Jocelyn)

\section{CORPUS WEB :}

Merci beaucoup pour cette délicate attention Odile et merci à vous mes amis poètes pour vos mots qui résonnent doux dans mon cœur [http://odileg.over-blog.com/article-un-2-marsnaquit-100590875.html] (15.11.2015)

Les premières notes résonnent, douces. Tout en pudeur, le jeune Loïc joue sur la réserve : un troubadour timide et sensuel qui navigue, à dos de guitare et de kayamb, vers les rivages du reggae, du maloya, de la soul, de la salsa [http:// www.mondomix.com/event/sakifo2007/j1/ edito1.htm] (15.11.2015)

REMARQues : Résonner doux réfère à un mot, des paroles, ou de la musique dont le son produit un effet lénifiant ou donne une impression douce et harmonieuse, agréable à entendre, et qui touchent le cœur. Doux reste invariable dans la majorité des cas. Dans le troisième exemple du CW il s'accorde cependant avec le sujet en tant que prédicat second orienté vers le sujet. Il est modifié par encore.

\section{Résonner dur}

Rendre un son dur, désagréable

Intransitif

1900 depuis, tu vis joyeusement, et tu me fais rire, par tes danses du ventre en l'honneur des hannetons et des papillons, par tes appels maladroits aux oiseaux que tu guettes, par tes façons de te disputer avec moi et de me donner des tapes sèches qui résonnent dur sur mes mains (Colette, Claudine à l'école)

1936 Il l'écoutait pas, il la requinquait à bout de bite avec trois grandes baffes dans le buffet... Ça résonnait dur... Elle en suffoquait la garce... Elle faisait un bruit comme une forge... Je me demandais s'il allait pas la tuer ? (Louis-Ferdinand Céline, Mort à crédit)

1951 - Droit dessus! Plus près ! lui murmurai-je à l'oreille d'une voix qui résonna étrangement gutturale et dure (Julien Gracq, Le Rivage des Syrtes) 


\section{CORPus WeB :}

Effectivement ça doit cosser dur au moment du rût. Beaux casse-noix ! Sûr ! ça doit résonner dur dans la vallée, mérite un coup de reviens-y au mois de novembre [http://blogapar. over-blog.net/article-mouflon-le-moutonsauvage-7-104077651.html] (15.11.2015)

" La dérivée de ce résonnement conduit au tunnel de Friggit ! » ça doit résonner dur dans ta tête quand tu passes dans le tunnel de brigitte [http://www.boursorama.com/forumimmobilier-marche-immobilier--psychologie428001770-1?symbole=immobilier] (15.11.2015)

si si je suis la moi, je vient de terminer le taff........... ${ }^{\star \star \star ~ H e m i, ~ a r r i v e ~ a ~ l a ~ m a i s o n ~ d a n s ~ a ~ p e u t ~}$ près $4 \mathrm{~h} 00 . .$. . Demain ça vas résonner dure dans le forum ${ }^{\wedge}$ ::P [http://www.mopar-owners-club. com/index.php?option=com_fireboard\&Itemid= 82\&func=view\&catid=26\&id=129079] $(15.11 .2015)$

Mes pas résonnent durs en mon cœur martelant Je m'en vais en pays dénué de romances [http: //www.vosecrits.com/t3916-steppes] (15.11.2015)

REMARQUeS : Résonner dur est plus familier que les autres combinaisons avec ce verbe (v. cidessus et ci-dessous). Le groupe désigne une voix, un mot, des paroles ou un coup dont le son aigu ou rauque produit un effet ou donne une impression désagréable, peu harmonieuse, qui blesse l'oreille. Dur peut s'accorder avec le sujet, renforçant ainsi l'implication du son lui-même, notamment dans l'exemple de 1951, où il se combine avec guttural. Cependant, dans l'avantdernier exemple du CW l'accord n'est pas motivé (v. pincer dur). Le dernier exemple montre la préférence du style poétique pour l'accord qui confère un rôle plus actif au sujet. Notons cosser $d u r$ dans le premier exemple du CW, qui réfère au bruit des cornes des mouflons qui s'entrechoquent lors de la période de rut. Notons également l'emploi de sûr comme adverbe de phrase dans le premier exemple du CW, ainsi que l'emploi impersonnel familier de ça doit / va résonner dur et ça doit cosser dur.

\section{Résonner fort}

résonner haut et fort : produire une voix intense $\lambda$ résonner haut

\section{Résonner haut}

Produire un son aigu, élevé

Intransitif

1450 MARIA JACOBY. Doulx Dieu, qui est ce haultain son

Que je os si tres hault ressonner?

Oncques mais je n'oÿs sonner

De si merveilleuse façon (Arnoul Gréban, Le Mystère de la Passion, 33692)

1596 Je ne veux, d'une voix qui s'accorde à ma perte,

Faire haut resonner une plaine deserte, Blasphemant la fortune, et ne veux point tascher

D'amollir par mes pleurs la rigueur d'un rocher,

Bien qu'il me fust loisible en si triste avanture

De dépiter le ciel, l'Amour et la nature (Philippe Desportes, Euvres)

1857 Il a mis la sourdine sur ses cordes quand elles résonnaient trop haut ; il a tâché d'étouffer certaines notes de l'âme qui doivent rester muettes, certaines voix du cœur qu'on n'éveille pas sans danger (George Sand, Indiana)

1923 Il a parlé au cocher et le cocher lui a répondu, mais tout cela s'est passé en dehors du Conseil : ce matin, sa parole intérieure résonne plus haut que tous les bruits (Valéry Larbaud, Mon plus secret conseil)

1950 Nos yeux les suivent. Les bois, autour de nous, se taisent. Nous n'osons remuer, ni tousser, ni parler, tellement le moindre bruit résonne haut dans le silence. Ils pénètrent dans ce silence, s'y enfoncent, y disparaissent. Je ne peux plus savoir depuis quel temps ils sont partis. Une heure ?... (Maurice Genevoix, Ceux de 14)

\section{CORPuS WEB :}

Harmonise-toi, trouve ta propre note, et fais-la résonner haut et clair, car tu fais partie du vaste orchestre de la vie [http://soleildelumiere. canalblog.com/archives/2013/07/03/27553353. html] (15.11.2015)

Enormément de peuple dans le camping : au jeu des plus bruyants, ce sont les Bretons de Pont Pean qui remportent la bataille : venus 
en nombre, ils feront résonner haut et fort leurs chapeaux ronds [http://roclanzagais.fr/compterendu-de-g58-cahors-vtt-a-lire-absolument] (15.11.2015)

S'ils n'étaient pas tout à fait mille, les enfants des six chorales présentes dimanche ont en tout cas fait résonner hauts, clairs et limpides, sous les voûtes de l'église Charles-de-Blois, leurs chants d'espoir [http://www.letelegramme.fr/ar/ viewarticle1024.php?aaaammjj $=20050323 \& a r t i c l$ $\mathrm{e}=9685735 \&$ type $=$ ar] $(15.11 .2015)$

REMARQUES : Résonner haut réfère au son luimême ou à un ensemble de sons (bruit, vibration), une voix (des paroles ou des mots), le son d'un objet (les cordes d'un instrument de musique) qui retentissent en s'accompagnant de bruits sonores d'une grande intensité. Notons les collocations haut et clair et haut et fort dans le CW. Haut reste invariable dans la majorité des cas. Dans le troisième exemple du CW cependant, haut, comme clair et limpide, s'accorde avec le sujet pour mettre en relief les qualités d'un chant. Haut est modifié par plus, trop, très.

\section{Résonner large}

Résonner avec ampleur, intensité Intransitif

1950 Mais, dès la première ligne, un mot m'entre dans les yeux, me donne au cœur un choc violent. Je ne vois que lui ; il n'y a que lui en moi ; mon imagination débridée en fait tout de suite quelque chose de merveilleux, d'immense, de surhumain : « Victoire ! » Il chante à mes oreilles, ce mot, il résonne large, il éclate comme une fanfare : «Victoire! » Des frissons courts passent sur ma peau, un enthousiasme me soulève, tellement fort que j'éprouve un malaise physique (Maurice Genevoix, Ceux de 14)

\section{CORPUS WEB :}

Je ne vois pas trop, pour ma part, ce que le rendu des FLC8 peut avoir de «flatteur ». Ce mot signifie aussi " déformant », " trompeur »... or les FLC8, pour moi, sont avant tout droits. Alors certes, ils peuvent descendre bas, cogner sec, sonner clair, résonner large et profond... mais pas plus (ni moins) que le signal l'exige [http://tellementnomade.org/forum/viewtopic. php?f=56\&t=10870\&start=225] (15.11.2015)
Le point important est ici que le mot retenu doit, pour le compositeur, instaurer une circulation signifiante : au plus loin d'être une simple étiquette (même s'il est plus tard destiné à servir de nom propre à l'œuvre achevée - pour moi ce fut le cas à plusieurs reprises ${ }^{\star}$ ), le mot-nom doit être un appel d'air, c'est-à-dire d'inspiration. Il doit résonner large, aussi bien dans l'espace propre $\mathrm{du}$ monde-Musique [http://www.entretemps. asso.fr/Nicolas/2015/secret-Kundry.htm] (15.11.2015)

REMARQUES : Résonner large désigne un mot dont le son produit un effet chantant, retentissant, d'une certaine ampleur, donnant une impression mélodieuse et impressionnante. Notons la collocation large et profond dans le CW, qui intensifie la notion d'ampleur, ainsi que l'emploi de descendre bas, cogner sec, sonner clair. Large reste invariable.

\section{Résonner profond}

Résonner en profondeur, avec intensité

$\lambda$ résonner large

\section{Résonner soef (suave)}

Retentir doucement, de manière agréable et plaisante

Intransitif

$\sim 1275$ Cil fluns cueurt si joliement E meine tel grondillement Qu'il resone e taboure e timbre Plus soef que tabour ne timbre ; N'il n'est nus qui cele part voise Que touz li cueurs ne li renvoise (Jehan de Meun, Roman de la rose [1269-1278], 6002)

1863 Il croyait voir devant lui les visages mélancoliques de Gilbert, de Chatterton et d'André Chénier, et la voix ferme et inflexible $\mathrm{du}$ docteur Noir résonnait encore suave dans ses oreilles (Alfred de Vigny, Le Journal d'un poète)

REMARQUES : En ancien français, résonner soef réfère à un son ou à un ensemble de sons qui retentissent en s'accompagnant de bruits sonores doux, harmonieux et agréables à l'oreille. Le style poétique moderne conserve parfois ce tour, inusuel dans la langue standard. Soef (suave) est modifié par plus, encore. 


\section{Respirer chaud}

Exhaler un souffle chaud

$\lambda$ respirer court

\section{Respirer court}

Respirer rapidement, à petites goulées

Intransitif

1841 Trop étonnée, trop émue, bouleversée par tous les sentiments qui me subjuguaient, je n’avais pas assez étudié les siens. J’avais peur, je respirais court. Eh bien ! me dis-je bravement, le jour où il me connaîtra, il aura un arriéré à payer (Alfred de Musset, Emmeline)

1877a L'odeur ne la gênait plus ; au contraire, elle avait des chatouilles dans le nez, elle trouvait que ça sentait bon; ses paupières se fermaient un peu, tandis qu'elle respirait très court, sans étouffement, goûtant la jouissance du lent sommeil dont elle était prise (Émile Zola, L’Assommoir)

1877b Et Gervaise se fâchait également des sommeils écrasés de Nana, lorsque, après une de ces fugues, elle dormait jusqu'à midi, dépoitraillée, le chignon défait et plein encore d'épingles à cheveux, si blanche, respirant si court, qu'elle semblait morte (Émile Zola, L'Assommoir)

1934 Cent mètres plus loin, elle s'arrêta encore. Sa figure était crispée par le froid. Son pied lui faisait mal, blessé par la chaussure. Le corset l'étouffait ; elle respirait court dans cet air humide, dans cette odeur désagréable d'herbe brûlée (Daniel-Rops, Mort, où est ta victoire ?)

1951 Il respire bien trop court. J'ai l'impression qu'il va bougrement vite (Jean Giono, $L e$ Hussard sur le toit)

1987 Je serre son bras difforme. Ma main aimerait pas lui faire mal. Je vais avec elle qui dit rien. Qui respire court et tout chaud comme une petite boule de chat. Peut-être tout bête parce que j'arque trop vite pour son pas et son corps de tortue (Jean-Louis Degaudenzi, Zone)
CORPUS WEB :

j'entends comme une guerre qui bat tambour, des roulements, des pas, des vainqueurs des épaules bâtées, des charges au sang. et ces humains qui comme moi respirent court [http:// www.annajouy.ch/article-apres-la-nuit-849647 40.html] (9.11.2015)

Respiration Dans nos sociétés où le mental domine, nous avons pris l'habitude de respirer court, saccadé, quand ce n'est pas petit et tout en retenu [http://forum.doctissimo.fr/sante/spas mophilie-tetanie/apprendre-bien-respirer-sujet _157200_1.htm] (9.11.2015)

REMARQUES : En référence au souffle, respirer court désigne le fait d'avoir une respiration difficile, qui a une fréquence rapide, pouvant marquer l'essoufflement lors d'un effort physique par exemple. Notons l'emploi du groupe respirer chaud qui réfère à la chaleur du souffle. Notons aussi l'emploi de la série respirer court, saccadé, petit, tout en retenu dans le dernier exemple du CW. Court reste invariable et est modifié par bien trop, si, très.

\section{Respirer fort}

I. Avoir une respiration difficile

Intransitif

1585 Quand il [= l'oiseau] bee souvent et respire fort pour ledit rheume, prens trois gouttes d'huile de laurier, et une once d'huile d'olive (Jean de Franchière, La Fauconnerie)

II. Dégager une impression, se manifester Transitif

1792 Jamais aucune Loi a été si inviolable. Toutes ces grandes phrases étoient bien éloignées de la Démagogie de l'assemblée ; elles respiroient fort, au contraire l'aristocratie (Histoire autentique et suivie de la Révolution de France)

III. Respirer profondément, intensément Intransitif

1846 La petite Marie essayait bien de respirer fort et d'agiter un peu le drap, mais ses malignes rivales en faisaient autant, poussaient le drap avec leurs doigts, et il y avait autant de signes mystérieux que de jeunes 
filles sous le voile (George Sand, La Mare au diable)

1860 Elle se mit à respirer plus fort et régulièrement, comme une personne qui dort, et resta au moins un quart d'heure dans son lit sans bouger (Louis Duranty, Le Malheur d'Henriette Gérard)

1938 Chambarcaud respire plus fort, plus large (Maurice Genevoix, Bernard)

CORPuS WeB :

Hein ? tu quoi ? tu ronfles?

Non non, je dors fort.

Euh.... (là je ne vois pas trop à quoi ça ressemble de dormir fort)

Ben oui, quand je dors je respire fort ! Oh tu comprends rien toi ! [http://monavis.canalblog. com/archives/2005/01/29/285758.html] (12.2.2015)

A la maison, mon père me fais remarquer parfois que je respire fort et c'est pareil, j'essaie de contrôler ma respiration pour pas qu'il le dise, mais j'y arrive pas. J'essaie de perdre du poids pour retrouver du souffle, mais en attendant c'est dur [http://www.vivelesrondes.com/forum/ viewtopic_321582.htm] (9.11.2015)

Hélas, si le côté négatif ne fait qu'un groupe de 1, Il a une sacré importance. En effet, il y a des moments où il ne se passe rien. Enfin, si... Les acteurs bougent, s'agitent, respirent forts... Mais le tempo est perdu alors on s'ennuie... [http:// www.allocine.fr/film/fichefilm-130681/critiques/ spectateurs/recentes/?page=12] (9.11.2015)

REMARQUES : Respirer fort (I) renvoie à des difficultés respiratoires (ici : le rhume d'un oiseau). (II) est un emploi figuré de 'dégager une odeur' au sens de 'donner une impression'. On peut se demander, par ailleurs, s'il ne manque pas une seconde virgule (elles respiroient fort, au contraire, l'aristocratie). En (III), respirer fort réfère au fait d'inspirer et d'expirer pour renouveler l'oxygène de l'organisme, le sujet inhalant l'air à pleins poumons, fréquemment. Il y a aussi l'idée, dans tous les exemples sous (III), d'un bruit fort proche du ronflement. Notons l'emploi de dormir fort et respirer fort comme euphémismes de ronfler (CW) ainsi que l'emploi du groupe respirer large 'largement, amplement'. Fort reste invariable dans la majorité des cas, mais, dans le troi- sième exemple du CW, il s'accorde avec le sujet tout en gardant son interprétation de manière. Il est modifié par plus.

\section{Respirer froid}

Respirer de l'air froid

Intransitif

1984 On a chaud, et puis on sort, on respire froid et on s'enrhume (Exemple entendu / Noailly 1997a)

\section{Respirer haut}

I. Exprimer, manifester une chose élevée, supérieure

Intransitif

1851a Le jeune Nodier ayant écrit dans les montagnes du Jura une ode qui respirait trop haut pour la servilité du temps, le poëte fut obligé de se proscrire lui-même devant la proscription qui l'épiait (Alphonse de Lamartine, Les Nouvelles Confidences)

II. Dire dans un souffle

Intransitif

1851b MOI. Quelles prières faisiez-vous le plus habituellement pour vous?

LUI. Oh ! C'était aussi différent que le jour est différent de la nuit ; c'était selon l'heure, le vent, le soleil, la pluie, selon l'impression que je ressentais en moi de toutes choses ; c'était plutôt une conversation qu'une prière : je respirais tout haut, voilà tout (Alphonse de Lamartine, Le Tailleur de pierre de Saint-Point)

\section{Respirer en gonflant fortement la cage} thoracique et en la faisant remonter Intransitif

1922 Jamais Jean n'avait remarqué comme les femmes respirent haut : en se gonflant, la gorge de Noémi touchait presque son menton (François Mauriac, Le Baiser au lépreux)

\section{CoRpus Web :}

Nous avons tendance à respirer haut (loin de tout ancrage), de façon chaotique, (portant ainsi la marque des événements que nous vivons) et parfois même à l'envers (avec un gonflement $\mathrm{du}$ ventre sur l'expiration) [http://www.yoga 
massala.com/fr/mag-massala/item/221-respirermieux-pour-vivre-mieux] (9.11.2015)

Son esprit indépendant, son goût de la découverte et l'envie de respirer haut et large le font quitter la Bulgarie [http://www.fr.pastoukhov. com/a-mon-sujet] (9.11.2015)

Bref, un film aux vertus multiples, à la large vue, qui respire haut et nous laisse avec un petit quelque chose en plus à la sortie [http://www. senscritique.com/film/De_l_autre_cote/critique/ 24068632] (9.11.2015)

REMARQUeS : Dans respirer haut, pris au figuré (I), le sujet désigne un inanimé (un écrit, une œuvre) qui exprime, exhale ou est empreint d'audace, de nouveauté, de modernité par rapport à son temps. Plus difficile à définir, (II) semble référer au fait que la prière dite à haute voix est un souffle de vie. Dans l'emploi concret (III), respirer haut souligne le fait d'inspirer et d'expirer fortement et de gonfler d'air la cage thoracique. Dans les deux derniers exemples du CW, respirer haut (et large) acquiert une connotation de liberté ou de libération. Notons la collocation haut et large. Haut reste invariable et est modifié par tout, trop.

\section{Respirer large}

Respirer profondément, amplement, à pleins poumons

Intransitif

1907 Je comprends sa folie de grand air et de liberté, je comprends le geste enfantin dont elle gonfle sa poitrine, pour respirer plus large, quand je suis seul à côté d'elle, dans le désert des rues de Stamboul, et qu'il n'y a point de regard féroce embusqué alentour, pour la guetter et la menacer... (Claude Farrère, L'Homme qui assassina)

1931 Anne-Marie regagna le cabinet, secouée encore par le quart d'heure que Gaspard venait de passer, tandis qu'on lui tirait du flanc trois bouts de plomb. Il respirait large et ne bougeait point. Mais il ne pouvait pas dormir (Henri Pourrat, La Tour du Levant ou Quand Gaspard mit fin à l'histoire)

1938 Chambarcaud respire plus fort, plus large (Maurice Genevoix, Bernard)
1950 Je titube, je sombre dans une vase de plus en plus épaisse. À quand l'arrivée? Enfin le ciel gagne sur les arbres et la nuit s'éclaire peu à peu, en même temps que je respire plus large (Maurice Genevoix, Ceux de 14)

\section{CORPUS WEB :}

Il retourne alors dans le village de son enfance, auprès de sa mère et de ses deux amis, Enzo et Jofranka. Il y trouvera la nature, les longues promenades, seul, pour mettre son corps en mouvement, respirer large, ne rien perdre de l'odeur de la forêt, du fracas de l'eau, dans l'espoir de trouver du repos, de reconstituer l'essentiel [https://zone-critique.com/2015/10/04/ otages-intimes-jeanne-benameur] (4.10.2015)

On savoure dès Prométhée un Beethoven baroqueux qui, enfin, pense grand, respire large et s'exprime puissamment [http://www.musikzen. com/beethoven--soleil-levant] (9.11.2015)

REMARQUES : Respirer large se dit du fait d'inspirer et expirer pour renouveler l'oxygène de l'organisme, le sujet respirant à pleins poumons, pour jouir, pour, par exemple, profiter pleinement du parfum des forêts (v. premier exemple du CW). Dans le dernier exemple du CW, il est pris au figuré, comme complément de penser grand 'avoir des visions ambitieuses' et signifie 's'oxygéner au maximum' pour réaliser un défi. Large reste invariable et est modifié par plus.

\section{Respirer pressé}

Respirer rapidement, de manière précipitée Intransitif

1942 On voyait bouger les oreilles musiciennes des chevrettes qui aiment le soleil ardent et respirent pressé avec le bruit d'un soufflet de cuir (Madeleine Ley, Le Grand Feu)

REMARQUES : Respirer pressé désigne un animal dont la respiration se caractérise par une fréquence rapide ou un rythme accéléré pouvant marquer l'essoufflement. Pressé reste invariable.

\section{Resplendir (resplendre) clair}

Briller d'un vif éclat

Intransitif

+1225 Car il a, ce li est avis, Parmi le ventre plainement 
Le fer trenchant, ki cler resplent.

S'en est a demesure liés,

Or quide bien estre paiiés

De ce k'il avoit en convent (Le Chevalier as

deus espees [2 $2^{\mathrm{e}}$ quart $\mathrm{XIII}$ ], 3054$)$

1275 Ce fu ou tans d'esté, si comme ou mois de mai,

K'en maint lieu resplendissent cler dou

soleil li rai

Et que arbre florissent et pre sont vert et gai

(Adenet le Roi, Buevon de Conmarchis, 2)

1450 CELSANDER. L'estoille, qui cler resplendist

A ceste heure, pas n'enlumine

Se ce n'est par euvre divine ;

Et croy qu'elle nous monstre aussi

Quelque effect, en ce monde cy,

Qui soit de divine ordonnance.

Or, n'est il plus haulte alïance

Que celuy roy en terre naisse,

En qui gist la plus grant haultesse

Que jamais nul roy puist avoir? (Arnoul

Gréban, Le Mystère de la Passion, 5297)

1878 Les nuages et les brouillards fuient devant l'astre du jour, le ciel resplendit clair et serein (F. Brönnimann, Les Constellations zodiacales)

REMARQUeS : Surtout dans l'ancienne langue, mais aussi dans la langue littéraire en général, resplendir (resplendre clair) se dit d'une chose qui brille par elle-même ou qui, sous l'effet d'une source lumineuse, répand une lumière abondante et vive. Clair reste invariable. Notons la collocation clair et serein.

\section{Ressentir blanc}

entendre noir, ressentir blanc : entendre quelque chose et ressentir son contraire $\lambda$ dire blanc

\section{Resserrer profond}

Enfermer au plus profond

Intransitif

1593 Il sembloit à sa contenance qu'elle agréoyt le contentement du Roy en cette mort, comme si elle l'eust desirée, tant plus cette doleur s'alloyt resserrant plus profond en son âme, tant plus elle esmouvoit à pitié ceux qui en scavoyent l'avanture et qui la regardoyent en cette démarche d'esprit si robuste et tant forte sans s'esbranler (René de Lucinge, Dialogue du François et du Savoysien)

REMARQUES : De l'ancien français resserrer, qui signifie 'enfermer, refermer', resserrer profond se dit d'une douleur qui prend toute la place, domine ou submerge l'âme humaine et par extension, provoque un état de souffrance que l'on enfouit et enferme au plus profond de soi. Profond reste invariable et est modifié par plus.

\section{Rester coi}

Rester tranquille et silencieux Intransitif

1561 Mais l'honnesteté et la reverence qu'ils portoyent au Roy mort, estoit cause que cest Eunuque , aussi bien que Gobryas, restoit coy, et tousjours encore demeuroit en obeïssance et amitié du commun maistre et Prince (Jean de Maumont, Les Histoires et chroniques du monde [trad.])

1579 TALTHYBIE. Il eut dit, et soudain plongé dans la caverne,

Il recheut tout grondant au Plutonique Averne :

L'antre se resserra, les vents resterent cois, Et des flots orageux cesserent les abois (Robert Garnier, La Troade)

1750 Je n'eus garde, après ce qui venoit de se passer, de vouloir essayer une seconde tentative : je restai tranquile et coi le reste de la nuit, parfaitement guéri de mon amour, et m’applaudissant en secret que personne ne sût le vrai de l'histoire (Jean-Louis Fougeret de Monbron, Le Cosmopolite)

1833 Devant tout obstacle, il s'arrêtait. Lorsqu'il avait la goutte, il posait son pied sur un tabouret et restait coi. Il n'avait ni vertus, ni vices ; il avait de l'esprit. Il fit la secte des philosophes et n'en fut pas. Il n'avait jamais pleuré, jamais couru, jamais ri (Honoré de Balzac, Théorie de la démarche)

1840 Le dilemme fatal aux plus sages des hommes, 
Le rendez-vous commun de tous tant que nous sommes,

Où l'un vient pour avoir trop vécu hors de soi,

Et n'être en son logis resté tranquille et coi, Lautre, parce qu'il a regardé sans mesure Dans l'abîme sans fond de sa propre nature

(Auguste Barbier, Iambes et poèmes)

1846 - Apprends, vieux truand, que quand cette belle dame sort du logis, il entre une pièce d'or dans notre épargne. »

- Oh! oh !, fit le sergent, qui resta pensif et coi devant sa femme. Mais il reprit bientôt : «Eh ! donc, nous sommes perdus. Pourquoi cette femme vient-elle chez nous? » (Honoré de Balzac, Les Proscrits)

1859 Que Camoëns

Ressuscité l'appelle

Aussi Rubens !

Qu'il parle à ses apôtres !

En iroquois!

On ira dire aux autres

de rester cois ! (Théodore de Banville, Odes

funambulesques)

1860 Aristide se mit à rire.

- Pourquoi ris-tu comme un sot? demanda la mère, contrariée d'être interrompue.

Aristide resta tout coi ; et Madame Gérard continua :

- Elle a un caractère altier et ne veut pas se plier aux exigences de la vie

(Louis Duranty, Le Malheur d'Henriette Gérard)

1879 Colombel insinuait qu'après le dîner on pourrait aller voir le théâtre de la famille Legois, ou Delille, ou le cirque Corvi. - Un grand quart d'heure, ils restèrent cois, voyant la foule couler et braire au loin. Désirée déclara enfin qu'elle allait partir et Auguste s'offrit à l'accompagner (Joris-Karl Huysmans, Les Sours Vatard)

1884 Sarkis ferma le livre.

- Vous ne resterez point coites à la prochaine confesse, mesdames ; autant de péchés complaisamment ouis [sic], autant de péchés commis!
- Ah ! Ce serait injuste, nous n'avons pas eu le plaisir et nous aurions la peine? (Joséphin Péladan, Le Vice suprême)

1899 Tels sont les événements dus aux mesures d'ordre qui n'auraient pu être différentes si l'on s'était proposé d'organiser le désordre. M. Brisson, sans doute, se plaint de l'impatience de ceux qui ne veulent pas rester cois, pendant qu'il laisse bafouer le pouvoir civil par Zurlinden, et qu'il livre Picquart aux vengeances des faussaires (Georges Clemenceau, Vers la réparation)

1928 Quant à la « trahison du clerc » (je comprends mal la signification précise de ce mot dans le livre remarquable de M. Julien Benda) je ne parviens pas à imaginer comment Barrès n'aurait pas trahi. Les clercs étaient-ils restés cois durant l'affaire Dreyfus ? La guerre fut, quoi qu'on en ait, un événement plus considérable ! (Jacques-Émile Blanche, Mes modèles : souvenirs littéraires)

1952 Et je fis des lacs, mais non point du fil qu'il fallait.

jusqu'à ce que d'une déconvenue indéfinie prenant effroi, cette nuit,

j'ai voulu ne plus rien faire que de rester toute coite sans bouger, engageant, pour si tôt que tu serais dans le cadre de ma fenêtre, ma foi à ta volonté inconnue (Paul Claudel, Poésies diverses)

1953 - Permets ! que vous cherchiez un gonze, c'est votre turbin ; mais pas le mien de vous le balancer... Tu devrais tout de même le savoir.

Ils restaient cois, à se regarder, embarrassés, ça se sentait, sur ce qu'ils devaient faire. J'en ai profité pour me lever en repoussant un peu la table, sans qu'ils réagissent (Albert Simonin, Touchez pas au grisbi)

1955 CORTE. (parlant plus fort pour couvrir la voix)

Et alors ? Pourquoi restez-vous coi ? Pourquoi ne parlez-vous plus ? Parlez donc. Tout à l'heure, on n'entendait que vous. Et maintenant... mais parlez, dites quelque chose! (Albert Camus, Un cas intéressant) 
1959 -Après on ira le voir danser.

- Danser? Qui ?

- Mon tonton.

- Il danse, cet éléphant?

- Et en tutu encore, répliqua Zazie fièrement.

La veuve Mouaque en reste coite. Elles étaient arrivées à la hauteur d'une épicerie en gros et au détail (Raymond Queneau, Zazie dans le métro)

1967 Puissances de Claudel : je me souviens d'un jour où, tournant le bouton de la radio en quête d'un poste, j'entendis sortir de l'appareil la voix d'une actrice qui disait le passage de l'échange sur le théâtre : Il y a la scène, et il y a la salle... et ne sachant encore de quoi au juste il retournait, car je n'avais pas lu la pièce, je restai complètement coi et stupide, comme un lapin qu'on soulève de terre par les oreilles (Julien Gracq, Lettrines)

1977 Il lui était revenu, sur mon assiduité au labeur, les plus fâcheux échos. Retards matinaux fréquents ! mollesse dans l'exécution du travail ! lenteur croissante dans mes missions de livraisons! mauvaises manières avec nos collègues féminines !

J'en restai coi. M. Roger en profita pour enchaîner. À ces signes il devait comprendre que je me fourvoierais en persistant dans une voie qui n'était certes pas celle de ma vocation (Albert Simonin, Confessions d'un enfant de La Chapelle)

1983 Cette question a dérouté Vartoui : j’ai eu l'impression qu'elle ne se l'était jamais posée, qu'il était tout à fait incongru de la poser ici. Elle en est restée coite, et j'en ai profité pour exploser :

- Sans amour, sans liberté, sans décision... Ces malheureuses, vous les dressez si soigneusement pour en faire des objets de débauche

(Michel, prince de Grèce, La Nuit du sérail)

1984 - Heil der Republik ! (Vive la République !), cria-t-il en claquant des talons. Boulet-Montreuil sourit et applaudit en même temps. Les généraux et Bernard restaient cois. Marguerite était arrivée au pré Noiraude, où Jésus et Marie Mousseau épluchaient des haricots (Bertrand PoirotDelpech, L'Été 36)

CoRpus Web :

"Rester coi »

C'est sous ce titre que Fathi Derder, conseiller national PLR, signe la rubrique " Les petits secrets du palais » dans Le Matin de ce lundi 17 décembre [http://guinchard.blog.tdg.ch/archive/ 2012/12/18/rester-coi.html] (9.11.2015)

Il arrive qu'on tombe des nues quand on commande un plat à l'Auberge du Bouftou Croustillant. Mais de là à se retrouver en transe, à débiter des mots sans s'en souvenir en reprenant connaissance, il y a de quoi... ben, rester coi ! C'est pourtant ce qui est arrivé à un client d'Alibert ce midi [http://www.wakfu.com/fr/mmorpg/ actualites/news/430422-premonition-ventrepichon] (9.11.2015)

Samsung ne pouvait rester coi devant la tentative de son meilleur concurrent coréen. Le numéro un mondial du smartphone a annoncé le G9198, qui succède au G9098 commercialisé en Chine l'an dernier [http://www.igen.fr/ ailleurs/2015/08/deux-ecrans-pour-un-clapetchez-samsung-92554] (9.11.2015)

Ils ne comprennent pas l'intérêt pour ces touristes de payer une place en virage, sur viagogo, être prêt à se payer une heure de métro debout, braver le froid, pour finalement rester cois devant le jeu développé et impassibles aux chants des fervents supporters [http://www. cosmic-msl.com/disney-a-boulogne] (9.11.2015)

REMARQUES : Vestige lexicalisé de l'ancien français, rester coi réfère au comportement calme et tranquille ou à la réaction discrète et silencieuse d'une personne, traduisant un grand étonnement ; le sujet est surpris, frappé par ce qui vient de se dire ou de se passer. Le sujet peut aussi désigner une chose qui se distingue par son manque d'agitation et de mouvement. Notons les collocations tranquille et coi, pensif et coi, coi et stupide. Coi tend à s'accorder avec le sujet, fonctionnant comme prédicat du verbe copule rester (v. les exemples de 1579, 1859, 1879, 1884, 1899, 1928, 1952, 1953, 1959, 1983, 1984). Il est modifié par tout. 


\section{Rester court}

I. Se figer, se taire, rester immobile Intransitif

1552 il inventoit lors art et moyen non de conserver ses rempars, bastions, murailles, et defenses de telles canonneries, et que les boullets ou ne les touchassent, et restassent coy et court en l'air, ou touchans ne portassent nuisance, ne es defenses, ne aux citoyens defendans (François Rabelais, Le Quart Livre)

1719 Il resta donc tout court vis-à-vis de la statue et de la magicienne, à qui il avoüa, qu'en perdant sa fille, il avoit aussi perdu son talisman qu'elle avoit au doigt ; il lui apprit que cette bague étoit la seule clé qui pouvoit ouvrir la statue qui renfermoit son couteau (Antoine Hamilton, Le Bélier)

1782 Aussi, dès que les circonstances ne se prêtent plus à vos formules d'usage, et qu'il vous faut sortir de la route ordinaire, vous restez court comme un écolier (Pierre Choderlos de Laclos, Les Liaisons dangereuses)

1840 Adrien a parlé, Genest parle à son tour ; ce n'est plus Adrien, c'est Genest qui respire la grâce du baptême et l'honneur du martyre... et là-dessus il sort brusquement de la scène. La comédienne qui représente Natalie reste court et s'écrie : ma réplique a manqué, ces vers sont ajoutés (Charles Sainte-Beuve, Port-Royal)

1846 En prodiguant ainsi vos talents, vous finiriez par vous démonétiser dans l'esprit de votre femme ; car elle exigerait de vous en raison double de ce que vous lui donneriez, et il arriverait un moment où vous resteriez court. L'âme humaine est soumise, dans ses désirs, à une sorte de progression arithmétique dont le but et l'origine sont également inconnus (Honoré de Balzac, Physiologie du mariage)

1923 Nous avons les procès-verbaux des séances du conseil. Les Milanais ne parlent que de bellezza et restent court quand on en vient aux décisions techniques. Jean Mignot leur crie : «L'art sans la science n'existe pas ! » Cela va loin (Maurice Barrès, Mes cahiers)
1925 Le Capitaine ne répondit point à cette question. Il en posa une autre.

- Et le Marseillais ? s’informa-t-il.

- Écoutez!

- J'écoute.

Figure resta court.

- C'est bien ce que j'me pensais, reprit Bouve. Toi, La Mouchette, Zanzi, Flippe, Tango, n'est-ce pas ? (Francis Carco, L'Équipe : roman des fortifs)

1936 Certains religieux n'ont pas du tout l'air de comprendre que Dieu n'est pas et ne peut pas être un objet de raisonnement. Ils le savent peut-être, mais plutôt que de rester courts, ils bourdonnent des raisonnements (Pierre Reverdy, Le Livre de mon bord)

1952 Mais Jean-Jacques n'avait plus rien à dire et ne répondit pas. La philosophie restait court devant une vie désespérée. Il avait découvert qu'on pouvait être encore plus seul qu'il n'était, et qu'alors ce mot de solitude qu'il aimait changeait de sens (Jean Guéhenno, Jean-Jacques : Grandeur et misère d'un esprit)

1956 Oh ! Ce n'est pas que les plus grands poètes de ces derniers temps soient restés courts devant cette question. Mais l'abondance même des brillantes réponses qu'ils lui ont données les rend précisément embarrassantes (Pierre Reverdy, Cette émotion appelée poésie)

1982 Dans sa mansarde, il tira soigneusement d'entre deux solives sa provision de bouts de chandelle et relut à leur lueur tout le rôle de Rosalinde, pour être plus sûr de ne pas rester court. « Et puis, pensa-t-il, si j'oublie, j'inventerai quelque chose. Humphrey m'aidera » (Marguerite Yourcenar, Une belle matinée)

II. Manquer d'idées, être à court d'idées Intransitif

1944 Mais le jouet apprêté, il fallait jouer, c'està-dire improviser le drame. - Je restais court (Colette, Paris, de ma fenêtre)

CORPus Web :

On va rester COURT cette fois MAIS MAIS quand même CHALEURRRRRRRR La Night !!! 
ET HEYYYYYY .... CHALEURRRRR FLUOOOOO avec le DECk et en GUEST : Elise Salsa SHOWS ... 5 DANSEUSES et 5 DANSEURS !!! BAMMMMM Un Show SUAVE PETILLANT, à REVOIR Bientôt hihiihihih .... [https://www. facebook.com/SalsaYTimba971NewCaledonia/ posts/617547721636092] (9.11.2015)

" Rester court sur les obligations souveraines EUR à haut rendement. Nous craignons d'importants événements à risque dans les semaines à venir, vu les difficultés des autorités à adopter et à appliquer des politiques budgétaires cohérentes et l'absence de réelles demandes des investisseurs pour les actifs risqués souverains »[http://www.hellocoton.fr/sg-crossasset-research-rester-court-sur-obligationssouveraines-eur-hy-3428025] (9.11.2015)

Pour ce qui est de la longueur, il n'y a pas de norme absolue mais on recommande une soixantaine de caractères maximum pour rester court, tenir sur une ligne et apparaitre en entier dans les résultats de Google [http://www.contenus-enligne.com/combien-de-caracteres-faut-il-pourbon-titre] (9.11.2015)

L'allongement des traitements remet en question cette règle, pour certains [Qui ?] cette règle permettait justement aux traitements de rester courts. Se pose la question de la fin de l'analyse (cf. l'article de Freud sur Analyse terminée et analyse interminable) [https://fr.wikipedia.org/ wiki/R\%C3\%A8gle_fondamentale] (9.11.2015)

On est en droit de s'interroger sur la raison de l'absence d'une version anglophone alors que l'adresse du site-web est en anglais. Est-ce une volonté de rester court ? d'affirmer l'origine francophone de la Croix-Rouge ? [https:// digiplume.wordpress.com/2013/03/16/httpdigi plume-files-wordpress-com201303logo-micrpngw150nouvelle-communication-pour-lemusee-international-de-la-croix-rouge] (9.11.2015)

C'est beaucoup, voire trop en même temps. Et il y a en plus eu la FIAC pour monopoliser l'attention médiatique. L'événement bref l'emporte toujours sur ce qui a le défaut de durer. Comment s'y retrouver parmi les expositions parisiennes actuelles ? Voici ma petite liste, selon le principe habituel. Le fait de rester court va me rendre un peu plus brutal dans mes rejets [http://www.bilan.ch/ etienne-dumont/courants-dart/parisque-voir-nevoir-choix-dexpositions] (9.11.2015)

Selon Jacques Brault, « Quand Apollinaire laisse en retrait sa faconde, quand il ne cherche pas midi à quatorze heures, il lui arrive de "rester court ». Se produit alors l'effet haïku ». Cet effet, on peut le retrouver dans la prose des essais, des journaux, des films et des jours [http:// www.renaud-bray.com/Livre_Numerique_ Produit.aspx?id=1514020\&def=Fulgurites $\% 2 c+0$ $\mathrm{u}+\mathrm{l}$ 'effet+ha\%c3\%afku\%2cLAROCHE\%2c+YVES \%2c9782890188761] (9.11.2015)

REMARQUES : Rester court (I) réfère au comportement calme ou à la réaction discrète et silencieuse d'une personne, qui traduit soit un grand étonnement ou la surprise du sujet, frappé par ce qui vient de se dire ou de se passer, soit la volonté de ne rien dire, de ne pas réagir ou prendre position. Au sens propre, il renvoie à la dimension et a le sens de 'bref' ou de 'succinct'; le verbe rendre tend alors à servir de simple copule (v. les exemples du CW). 'Rester peu de temps' et 'être prudent' sont d'autres interprétations contextuelles. Rester court (II) signifie, dans une conversation ou un débat, 'manquer d'idées, d'arguments ou de repartie'. En référence au jeu de scène, il souligne le manque de créativité artistique. Notons la collocation coi et court. Court peut s'accorder avec le sujet, notamment dans l'emploi concret. Il est modifié par donc, tout.

\section{Rester net}

Rester après déduction de tout élément étranger, tous frais déduits

Intransitif

1776 On ne doutera pas qu'il ne soit à desirer que le commerce se fasse par de pareils entrepreneurs. Or, je suppose qu'après avoir prélevé tous les frais de commerce, il reste net en général, pour salaire à chaque entrepreneur, quinze à vingt pour cent (Étienne de Condillac, Le Commerce et le gouvernement)

1832 Il ne regarde comme un profit, comme servant à composer le revenu de son industrie, que ce qui lui reste net, ses déboursés payés ; mais ses déboursés n’ont été que l'avance qu'il a faite à d'autres producteurs 
de diverses portions de revenus dont il se rembourse sur la valeur brute du drap (Jean-Baptiste Say, Traité d'économie politique)

\section{Corpus Web :}

10 conseils de la CNIL pour rester net sur le web !

1. Réfléchis avant de publier ! [http://www. jeunes.cnil.fr/jeunes/10-conseils-cles] (9.11.2015)

REMARQUES : Rester net désigne la somme ou le montant restant après déduction de tous les frais, impôts et charges. Il peut également référer au fait d'être pur, irréprochable, sans souci (v. l'exemple du CW). Net reste invariable dans son emploi adverbial. L'emploi comme verbe copule n'est pas documenté ici (quelque chose reste net 'conserve des contours nets, une image nette').

\section{Retenir ferme}

Retenir fermement, solidement, avec vigueur, force

Transitif

1603 Ne faut oublier d'asseurer cest artifice avec des bons appuis pour le retenir ferme, à ce que les vents esbranlans l'ouvrage, ne rendent vaine telle gentillesse (Olivier de Serres, Le Théâtre d'agriculture et mesnage des champs)

1738 DORANTE. (voulant courir après lui) Par la même raison...

FRANCALEU. (le retenant ferme) Laissez, laissez, de grâce !

Il en veut à ma fille ; et je serais charmé Qu'il parvînt à lui plaire, et qu'il en fût aimé (Alexis Piron, La Métromanie)

1946 Je n'attendais pas le repos du tube pour enfoncer la nouvelle cartouche dans la culasse fumante, et la clairière, cabrée entre les arbres qui la retenaient ferme, était la proie d'un gigantesque marteau-pilon qui essayait de l'enfoncer jusqu'au plus profond de la terre (Raymond Abellio, Heureux les pacifiques)
CORPUS Web :

Ce projet n'est réalisable qu'avec le concours de plusieurs d'entre nous. Il s'agira dans un premier temps de préciser le programme et son contenu pour les candidats retenus et les inviter à cette préparation. Ensuite les contacts seront pris pour retenir ferme les lieux et les conditions d'hébergement [http://www.amis-st-jacques.org/ documents-pdf/CommissionHprojetInitiationPre paration.pdf] (9.11.2015)

Le principe est basé sur la rapidité de sa mémoire, on jette les dés dans un livre de sort et suivant les resultat il faut retenir une formule magique. Le 1er qui se sent capable de retenir ferme le livre et empeche les autres de continuer à retenir la formule [http://forum.ebuyclub.com/ ftopic39923.php] (9.11.2015)

Hier, la secousse sismique a secoué fortement Ardres, et donné de fortes émotions à pas mal d'habitants. L'un vit son service à fumeur se promener sur la table où il était placé et s'arrêter juste à temps sur le bord, pour ne pas tomber à terre. Un autre, une pile d'assiettes perdre son équilibre, et beaucoup, les murs de leur habitation bouger. Un maçon, sur une échelle, dut se retenir ferme pour ne pas être précipité à terre [http://www.seismologie.be/index.php?LAN $\mathrm{G}=\mathrm{FR} \& \mathrm{CNT}=\mathrm{BE} \& \mathrm{LEVEL}=841 \& \mathrm{idText}=5078 \& \mathrm{id}$ Com $=38595]$ (9.11.2015)

Un petit pivert (passerinus de Veniliornis) se retient ferme sur un branchement à la recherche de la nourriture chez l'Amazone péruvienne [http://fr.dreamstime.com/photos-libres-dedroits-petit-pivert-sur-un-arbre-image26063138] (9.11.2015)

REMARQUES : Lorsque l'objet du verbe désigne une personne, retenir ferme se dit du fait d'empêcher quelqu'un de se déplacer, de tomber ou de quitter un lieu. La même idée s'applique à des objets qu'on bloque quelque part. Le premier exemple du CW réfère au fait de réserver définitivement par exemple une chambre d'hôtel. Le deuxième exemple renvoie au fait de mémoriser le contenu d'un livre. Les derniers exemples illustrent l'emploi pronominal où un maçon ou un oiseau se stabilisent avec fermeté sur une échelle, une branche. Ferme reste invariable. 


\section{Retenir haut}

Maintenir à un niveau (moral, spirituel) élevé, supérieur

Transitif

1949 La marche d'en bas

Sous l'arc de ton dos

Ce souvenir qui me retient plus haut

L'ombre qui vient

Le couloir frais

La porte close

Le bruit sur le trottoir fait tout s'évanouir

(Pierre Reverdy, Main-d'œuvre)

CORPUS WEB :

Il vient de réaliser un baptême du feu victorieux d'entrée de jeux à Auteuil. Sa candidature sur l'hippodrome normand ce lundi est à prendre en considération, d'autant qu'il a déjà tiré son épingle du jeu sur une distance identique à Corlay. Tenace en diable, il faut le retenir haut [http://ponyturf.free.fr/index.php/2015/06/28/ quinte-mardi-30-juin-marinas-toujours-plushaut] (9.11.2015)

Ce fils de Nahar de Béval a franchi un palier cet hiver, s'imposant à trois reprises, dont deux succès sur le parcours classique de Vincennes. Initialement préparé pour le Grand National du Trot à Marseille-Borély, où il fut éliminé faute de gains suffisants, son entourage a dû changer son fusil d'épaule et le présenter ici sur une distance qui n'est pas la sienne. Mais comme il « vole » sans ses quatre fers, configuration dans laquelle il est invaincu, on ne peut que le retenir haut dans notre sélection [http://www.zeturf.fr/ fr/programmes-et-pronostics/reunion?id=27786] (9.11.2015)

REMARQUES : Retenir haut désigne la cause (un souvenir), quelque chose de positif, d'agréable qui revient sans cesse à l'esprit, qui attire, conférant à la personne un sentiment de bien-être et une position spirituelle élevée. Dans le domaine du turf, retenir haut réfère à un cheval digne d'être sélectionné, d'être retenu pour les paris. Haut reste invariable. Il est modifié par plus.

\section{Retentir clair}

Rendre, produire un son clair, éclatant

Intransitif

1170 Hector esguarde près de sei
E veit le doloros tornei, Ou tant cler heaume retentissent

E ou tant chevalier fenissent (Benoit de Sainte Maure, Le Roman de Troie, 8629)

CORPUS WEB :

Si l'appel de GANDHI à la non-violence doit retentir clair et fort jusqu'à la fin des temps, la vie des hommes également doit crier ses exigences morales [http://katembovirivusighajmv.overblog.com/2015/08/de-la-non-violence-commemethode-sociale-et-politique-essai-sur-mohan das-karamchand-gandhi-tfc.html] (9.11.2015)

REMARQUES : Lors d'une bataille, retentir clair réfère au résonnement, au son éclatant produit par les casques qui s'entrechoquent ou sont frappés durant le combat. Au figuré, il désigne le fait d'exercer un grand impact sur quelqu'un en atteignant beaucoup de monde (CW). Notons la collocation clair et fort. Clair reste invariable et est modifié par tant.

\section{Retentir fort}

Rendre, produire un son intense

$\lambda$ retentir clair

\section{Retentir haut}

Retentir avec force, avec une grande intensité Intransitif

1539 Un pastoureau, qui Robin s’appeloit, Tout à par soy n'agueres s'en alloit Parmy fousteaux (arbres qui font umbrage), Et là tout seul faisoit de grand courage Hault retentir les boys et l'air serain, Chantant ainsi : O Pan, dieu souverain, Qui de garder ne fus onc paresseux Parcs et brebis et les maistres d'iceux (Clément Marot, Églogue au roy)

REMARQUES : L'exemple réfère au chant qui retentit fort et puissant dans la forêt. Haut reste invariable.

\section{Retirer court}

S'échapper brusquement (de quelque chose), se soustraire brusquement (à quelque chose)

Pronominal

1596 Tout ainsi qui voudra, plein de temerité, S'essayer de trouver fin à l'infinité 
Des graces, qui vous font divinement reluire

En pensant s'avancer ses labeurs

accroistront ;

Car d'un sujet finy cent mille autres

naistront,

Et faudra qu'à la fin tout court il s'en retire

(Philippe Desportes, Euvres)

REMARQUES : Retirer tout court désigne le fait de se mettre à l'écart de quelque chose, de s'en éloigner ou d'en sortir, d'abandonner un projet, le processus se faisant rapidement, sans tarder. Court est modifié par tout.

\section{Retomber bas}

I. Tomber dans un état inférieur au précédent Intransitif

1592 Au partir de là, je l'en quitte. Le peuple reconvoye celuy-là, d'un acte public, avec estonnement, jusqu'à sa porte : il laisse avec sa robbe ce rolle, il en retombe d'autant plus bas qu'il s'estoit plus haut monté ; au dedans, chez luy, tout est tumultuaire et vile (Michel de Montaigne, Essais)

1755 N'est ce point qu'il retourne ainsi dans son état primitif, et que, tandis que la bête, qui n'a rien acquis et qui n'a rien non plus à perdre, reste toujours avec son instinct, l'homme reperdant par la vieillesse ou d'autres accidens, tout ce que sa perfectibilité lui avoit fait acquerir, retombe ainsi plus bas que la bête même? (Jean-Jacques Rousseau, Discours sur l'origine et les fondements de l'inégalité parmi les hommes)

1816 C'est alors qu'en revenant sur soi-même, on est tout surpris d'avoir été sous le charme et on retombe aussi bas qu'on était haut monté (Pierre Maine de Biran, Journal)

1839 - J'en rends grâces au ciel, dit Pulchérie ; vous avez connu la vertu et l'amour et il ne vous est pas même resté ce qui ne m'a pas quittée, la bonté !

- Sans doute, je suis retombée plus bas, reprit Lélia, pour avoir pris un essor trop orgueilleux (George Sand, Lélia)

1847 Le capitaliste, appelé en Hollande, avait oublié l'ouvrière ; il n'alla pas une seule fois dans le paradis où il l'avait mise, et d'où elle retomba aussi bas qu'on peut tomber à Paris (Honoré de Balzac, Splendeurs et misères des courtisanes)

1862 On tend à les rompre, sur ce point unique, tout ce qu'on a de cordes dans le cerveau. Quelque chose vous apparaît un moment, puis s'enfuit, et vous retombez plus bas que d'un assaut manqué... Oh ! Tâtonner ainsi, dans la nuit de l'imagination, le corps de quelque chose à créer, l'âme d'un livre, et ne rien trouver (Edmond et Jules de Goncourt, Journal)

1864 C'est pourquoi quelques paysans montent à la bourgeoisie, tandis que le grand nombre retombe plus bas que jamais. C'est le côté triste des lois naturelles, car ces gens-ci sont gouvernés par un instinct presque aussi fatal et aveugle que celui qui fait fleurir les pommiers (George Sand, Le Marquis de Villemer)

1916 Nuit exécrable. Je retombe aussi bas que jamais. Ce matin, levé avant 7 heures, je sors un instant, et j'entends un chant de merle, étrange, si précocement printanier, si pathétique et si pur, qu'il me fait sentir plus amèrement la flétrissure de mon cœur (André Gide, Journal)

1963 Il est peu probable aujourd'hui que C.G.T et F.O. réunies en fassent le tiers. Après chaque poussée, on retombe donc très bas. C'est que le gonflement du nombre en bonne période ressemble plus à un mouvement de masse qu'au rassemblement de troupes (Jean-Daniel Reynaud, Les Syndicats en France)

1985 - Tu sais, Eddie, j’ai enchaîné, elle court après quelque chose qui existe pas. Elle est comme un animal blessé, tu vois, et elle retombe toujours un peu plus bas. Je crois que le monde est trop petit pour elle, Eddie, je crois que tous les problèmes viennent de là... (Philippe Djian, $37^{\circ} 2$ le matin) 
II. Perdre de la valeur, diminuer à nouveau fortement

Intransitif

1866 Grâce aux quatre ou cinq drôles qui mènent le monde, la guerre prend sur toutes les fortunes, et la baisse est si énorme que, moi simple particulier, au cas où j'eusse voulu réaliser il y a quinze jours, j'eusse perdu au moins 120.000 fr., et cela sur les meilleurs fonds de l'Europe, la Banque nationale belge et les consolidés anglais. Mais pourquoi réaliser ? Vous savez ma manière. J'attends. Cela remonte en ce moment. Cela retombera encore bien plus bas, si la guerre éclate, et alors, je pourrai bien être un peu ruiné, comme tout le monde. L'Europe est un navire et le naufrage se fait en commun (Victor Hugo, Correspondance)

\section{CORPUS WEB :}

Dans quel genre d'endroit ? Je suis désolée pour le dérangement j'ai juste pas envie de retomber bas et donc de tout faire pour lui faire plaisir...

Bah peu importe fin si il t'aime peu importe tu sors dehort avec lui juste pour etre avec quoi ou vous allez a la maison la ou ya une piscine [http:// ask.fm/Melvyn_B09/answer/130787554912] (5.11.2015)

L'envie de passer du temps avec toi. Mais aussi la peur de retomber bas, très bas. Tu m'as fais tellement souffrir [http://poeteenherbe. discuforum.info/t 950 - trop-de-chosesreviennent-d-un-seul-coup.htm] (5.11.2015)

Mon adversaire est grande (1m60/1m65) et ne fait pas l'effort de s'abaisser en match. Est-ce que faire des balles rasants le filet qui retombe basse peuvent-être efficace face à ce type de joueuse ? [http://www.tennis-classim.net/ forums/topic/36531-jouer-contre-une-personnequi-fait-des-cloches/?page=4] (5.11.2015)

REMARQUES : Retomber bas (I) se dit du fait de tomber dans une situation ou dans un état encore plus grave, le sujet se retrouvant dans un état psychique plus pénible, se caractérisant par une baisse du moral. Il peut aussi renvoyer à la position sociale inférieure acquise par le sujet, se traduisant par une baisse des responsabilités ou un poste hiérarchiquement inférieur au précédent. (II) réfère à une chose quantifiée, chiffrée, dont la valeur devient inférieure ou qui descend à un niveau plus bas. Les deux premiers exemples du $\mathrm{CW}$ réfèrent à un état psychologique de grande détresse. Le dernier exemple désigne tout simplement la hauteur de la balle de tennis. Bas reste invariable dans la majorité des cas, mais, dans le troisième exemple du CW, il s'accorde avec le sujet au féminin, apparemment la balle, même si ce mot est au pluriel, ce qui semble caractéristique du langage des sports de balles avec filet. Bas est modifié par ainsi plus, aussi, d'autant plus, donc très, encore bien plus, plus, toujours un peu plus, très.

\section{Retordre bas}

Connaître des hauts et des bas ; ici : connaître la chance puis la malchance

Transitif

1325 Fortune ; on voit tel hui haut tordre, Cui ses cors iert si bas retors

S'il ne se garde de retordre, Que chascuns le verra bestordre, Car tors fais doit estre bestors (Watriquet de Couvin, Dits, p. 74, 45)

REMARQUES : Retordre bas renvoie ici à la roue de Fortune qui fait passer de la chance (tordre haut) à la malchance (retordre bas) la veine de quelqu'un. Bas est modifié par si.

\section{Retourner court}

I. retourner tout court : retourner, repartir brusquement, rapidement, immédiatement Pronominal

1393a Par mon chief, dist l'ung des patrons de Rodes, or les allez faire haster, car vous avez trouvé belle adventure : là sont des gens du souldan de Damas qui s'en vont au siége de Famagosse ; et qui les pourroit ruer jus il auroit fait grant secours au roy de Chippres, et grand dommaige du souldan. Adonc quant ceulx de la gallée l'oyrent, ilz se retournèrent tout court [variante : virent tout court ; manuscrit Ars, p. 314], et le vont noncer aux frères et à leurs gens (Jean d'Arras, Melusine, p. 129 [éd. Genève]) 
1627 Durant toutes ces choses, ce jeune homme s'estoit esloigné un peu de nous, et je pris garde qu'il ostoit, et puis remettoit son chapeau, qu'il frappoit du pied en terre, croisoit les bras, regardoit contre le ciel, et quelquefois tournant les yeux sur moy, se mordoit les doigts, mettoit la main gauche sur la garde de son espée, et l'autre sur les costez, marchoit deux ou trois pas vers nous, et puis s'en retournoit tout court, avec des actions si pleines de transport, que je creus, ou qu'il estoit fol, ou qu'il avoit quelque chose à me demander (Honoré d'Urfé, L’Astrée)

Intransitif

1393b Et ceulx retournent tout court [variante : virèrent tout court ; éd. Genève, p. 279] et montent la montaigne appertement. Et Gieffroy aprés, l'espee ou poing. Et son escuier fait retourner les chevaulx des trois qui avoient esté abatuz, dont les deux estoient mors (Jean d'Arras, Mélusine, p. 562 [manuscrit Ars])

+1489 Incontinent arriva monsr de Contay, dont cy dessus ay parlé, qui luy dist semblables parolles comme luy avoit faict le vieil gentilhomme de Luxembourg, et si audacieusement qu'il estima sa parolle et son sens, et retourna tout court ; et croy que, s'il eust passé oultre deux traictz d'arc, qu'il eust esté prins, comme aucuns autres qui chassoient devant luy (Philippe de Commynes, Mémoires [1489-1498], I)

1577 là où il s'alla malicieusement desrober de la veuë des ennemis, qui poursuivoient ce-pendant la victoire, pensans avoir desja tout gaigné, afin de retourner tout court par une autre addresse sur leur camp, qu'il s'attendoit bien de trouver desprouveu de deffence (Blaise de Vigenère, L'Histoire de la décadence de l'Empire grec [trad.])

II. Reprendre (quelque chose, une activité) rapidement, sans attendre

Intransitif

1884 Un matin, soudainement, sans mettre rien au net, ni parler de quoi que ce fût, le duc se leva, retourna tout court à son ordinaire, secouant son chagrin ou n'y pensant plus (Élémir Bourges, Le Crépuscule des dieux)

CoRpus Web :

Pendant ce temps Shawn fit un Sweet Chin Music sur Edge. Randy court vers Triple H et coups de la corde a linge. Shawn fit le tombé, 1,2,3 Edge éliminé ! Shawn se releve et Spear de Goldberg, Randy se retourne court vers Goldberg, qui arriva a attraper Orton et part pour le Jackhammer, Orton se prit le coups [http://www.jeuxvideo. com/forums/1-21115-217567-22-0-1-0-fic-lanouvelle-superstar.htm] (5.11.2015)

Après un brindis au public il continue sur le même ton, en donnant des muletazos la main basse, obligeant le toro sans le laisser réfléchir entre les muletazos. A gauche l'animal se retourne court [http://www.corridafrance.net/index. php?option $=$ com_content\&view $=$ article\&id $=90$ 4:beziers-15-08-2013-grand-apres-midi-de-torosen-ouverture-0160813\&catid=19\&Itemid=238] (5.11.2015)

Alors qu'elle sert pour le match, de gros nuages ont envahi le ciel de Melbourne. Première slicée, coup droit de Sanchez. L'espagnole retourne court, plein centre [https://tropdelaballe. wordpress.com/2015/01/17/il-y-a-20-ans-marypierce-la-tete-en-bas-dans-les-nuages] (5.11.2015)

REMARQues : Retourner court (I) désigne un animé qui rentre, se rend à nouveau dans le lieu d'où il vient, là où il vit habituellement, fait le chemin en sens inverse ou fait demi-tour, de façon précipitée, sans attendre. Au figuré, il souligne le fait de revenir sur sa décision, sur sa première orientation. (II) se dit du fait de reprendre rapidement une activité, quelque chose qui a été interrompu, le sujet désignant un animé. Dans le dernier exemple du CW, le groupe est pris au sens concret de renvoyer la balle sur une distance courte. Court reste invariable et est modifié par tout.

\section{Retourner droit}

Retourner directement, repartir directement pour le lieu d'où l'on est venu Intransitif

+1150 Et si dieus nous uieut faire si grant secor Qu'il nous doinst la bataille uaintre et l'estor, 
Si retornons ariere droit a Aiol,

Sel faisons de l'eskiec cief et signor

(Aiol et Mirabel [2 $2^{\mathrm{e}}$ moitié XII ${ }^{\mathrm{e}}$, 4969)

1374 DEUXIESME CHEVALIER. Certainement, c'est chose voire :

Ainsi serions mal ordené ;

Et espoir qu'il est retourné

En son palais : si lo ainsi

Que nous en retournons aussi

Droit a la ville (Miracle du roy Thierry, 1241)

1377 Et pour ce, l'en peust dire moult plus raisonnablement que chascun corps simple ou element du monde, excepté, par aventure, le souverain ciel, est meu en son lieu naturelment de mouvement circulaire. Et se aucune partie de cel corps est hors de son lieu et de son tout, elle y retourne le plus droit que elle peust, osté empeeschement (Nicole Oresme, Le Livre du ciel et du monde, p. 528, 173)

1502 M. le Grant maistre, j'envoye mes deux seneschaulx pour ravoir Lestore, dedans laquelle messire Jehan d'Armignac s'est mis par traÿson. Et, cela fait, j'ay esperance que Guienne sera plus seure qu'elle n'estoit par avant. Ceste entreprinse devroit faire retourner le duc de Bourgoigne droit là (Jean Le Clerc, Interpolations et variantes de la Chronique scandaleuse)

1680 Enfin ils n'ont pas douté que cette belle âme ne fût retournée tout droit au ciel, d'où elle était venue (Mme de Sévigné, Correspondance)

1755 Les misérables se mirent à genoux ; et les sept cavaliers, après avoir salué fort civilement Sir Charles, retournèrent droit à la grande route (abbé Prévost, Nouvelles Lettres angloises [trad.])

1836 si les Sauvages en rôdant venaient à trouver ma moisson pendante ou coupée, ou n'importe quels travaux et quelles cultures, ils en concluraient immédiatement que l'île était habitée et ne s'arrêteraient point qu'ils ne m'eussent découvert. Dans cette angoisse je retournai droit à mon château (Daniel Defoe, Vie et aventures de Robinson Crusoé [trad.])
1889 Je suis en bas, à la station des petits chars et des coureurs, très indécis sur ce que je vais devenir. Que faire ? Retourner tout droit à la gare, prendre le train de neuf heures, rentrer sagement à Yokohama et, par un sampan de louage, rejoindre en rade mon navire... Mon Dieu, j’ai bien encore le train de minuit, puisque nous ne devons lever l'ancre qu'au petit jour (Pierre Loti, Japoneries d'automne)

Pronominal

1177 Quant un po les ot regardees Mes sire Yvains, si se trestorne, Droit vers la porte s'an retorne, Et li portiers contre lui saut, Si li escrie : Ne vos vaut ; Que vos n'an istroiz or, biaus mestre ! (Chrestien de Troyes, Yvain ou Le Chevalier au lion, 5214)

1432 LE PRISIONNIER. Et quant fus ou aller vouloye

Pas ne feis ce que je cuidoye,

Si m'en revins, par la Montaigne

De Chastillon, droit en Champaigne, Et d'illec je me retournay

Droit $a$ Lislë et a Tournay (Jean Regnier, Les Fortunes et adversitez, 4483)

-1469 L'un a un coup d'espée au travers du visaige ; l'autre est tout effrayé et dit que tout est mort ou priz, et que tes ennemiz sont une très grant puissance. Que veulx-tu plus ? Il te vauldroit mieulx repasser le pont et le faire rompre aprez toy et t'en retourner droit à Crathor que toy perdre avec ceulx y a qui sont perduz (Jean de Bueil, Le Jouvencel [1461]-1468, I, p. 145)

1559 Le roy bassa la teste et, sans luy dire autre chose, s'en retourne droict au chasteau (Marguerite d'Angoulême, Heptaméron, p. 212, 517)

1673 CLITIDAS. Madame, je vous demande pardon, je pensois faire bien de vous venir dire que le Ciel vient de vous donner Sostrate pour époux ; mais, puisque cela vous incommode, je rengaine ma nouvelle, et m'en retourne droit comme je suis venu (Molière, Les Amants magnifiques) 
1709 Nous fîmes le lendemain matin tuer chacun un renne qui nous coûta deux écus, pour en rapporter la peau en France. Si je m'en étois retourné tout droit, j'aurois essayé d'en conduire quelques uns en vie : il y a bien des gens qui l'ont tenté inutilement (Jean-François Regnard, Voyage de Laponie)

1859 A-t-on songé qu'avec ces nouvelles troupes, les zouaves, - une machine de guerre que rien n'arrête, - il n'y a plus de stratégie, plus de génie militaire, plus de capitaines ? Une bataille devient une immense lutte à main plate. Et la guerre s'en retourne droit à la barbarie, avec ces soldats qui n’abordent plus même à la baïonnette, qui assomment avec la crosse du fusil : c'est le tomahawk (Edmond et Jules de Goncourt, Journal)

1865 C'était environ la mi-février, et, voyant venir la nuit, je fis mes adieux et pris le chemin d'en sus, afin de gagner Verneuil et de m'en retourner tout droit chez nous par la route aux Anglais, sans repasser par Saint-Chartier où je n'avais plus que faire (George Sand, Les Maîtres sonneurs)

\section{CORPuS Web :}

Une fois, je baptisais devant environ dix mille personnes, Quelque Chose comme une énorme étoile du matin est descendu là où je me tenais. Des milliers de personnes ont vu Cela. Il est retourné droit dans les cieux [https:// www.facebook.com/BranhamMarrionWilliam/ posts/442343419249000] (5.11.2015)

je crois que je suis en chute libre. (*) J'ai déja fais une dépression il y a 1 an et la j'y retourne droit dedans, je me suis peut etre cru plus forte que je ne l'étais [http://forum.doctissimo.fr/psycho logie/depression-deprime-stress/besoin-fairesujet_162000_1.htm] (5.11.2015)

Je préfère avoir de la liberté, et pour l'avoir, vous devez arrêtez d'être dans des gros films, très exposés, a-t-elle jugé. Je ne surfe pas sur les grosses vagues. Quand je les vois arriver, je prends ma planche et je retourne droit vers le rivage [http://www.voici.fr/news-people/actu-people/ audrey-tautou-pense-arreter-le-cinema-tresbientot-419356] (5.11.2015)
La paire de bretteurs O’Brien et Barett vérifient une dernière fois leurs accordages, George Fisher se retourne droit vers l'impatiente assemblé, un dernier petit roulement de double caisse... Et le déluge sonore s'abat sans coup férir sur l'Altar, nous réduisant en bouillie [http://www. soilchronicles.fr/reports/hellfest-2015-cannibalcorpse] (5.11.2015)

REMARQUES : (Se) retourner droit désigne un animé qui se rend à nouveau dans le lieu d'où il vient, là où il vit habituellement, fait le chemin en sens inverse ou fait demi-tour, sans attendre et sans détour. Dans le deuxième exemple du CW, le sujet revient à un état dans lequel il se trouvait auparavant. Droit reste invariable et est modifié par arrière, aussi, le plus, tout. Il a tendance à s'associer avec la préposition qui le suit (à, chez, dans, dedans, vers) au point de faire partie du groupe prépositionnel en tant que modifieur de la préposition.

\section{Retourner net}

Se retourner brusquement, soudainement Pronominal

1929 Jacques se retourna net, tenant toujours le récepteur où bourdonnaient des paroles (Roger Martin du Gard, Les Thibault. La Mort du père)

\section{CORPUS WEB :}

Tout à coup l'ombre s'arrête, se retourne net. Ils voient une tête de zombi qui leur apparait [http://lesentreprisesewing.com/halloweenzombies] (5.11.2015)

Je part en direction de la porte quand je me retourne nette [le sujet est une femme] [https:// www.facebook.com/ChroniqueDeInayaUn DebutATout/posts/247312708757664:0] (5.11.2015)

Un grand merci à toi, Joachim, pour ce show, c'était puissant! (dommage que la boîte était petite !) Premier Joachim en live pour moi, ça m’a retourné net !!! (;) [http://www.joachimgarraud. com/forum/viewtopic.php?f=2\&t=2463] (5.11.2015)

REMARQUES : Sous l'effet de la surprise, de l'effroi ou de la stupeur, se retourner net se dit du fait de tourner rapidement, dans un mouvement brusque, la tête ou le haut du corps vers l'arrière, en direction de quelqu'un ou quelque chose. Dans le 
troisième exemple du CW, au figuré, retourner net désigne le fait de faire une profonde impression sur quelqu'un, de le bouleverser. Net reste invariable dans la majorité des cas. Dans le deuxième exemple du CW, il s'accorde avec le sujet tout en conservant sa fonction purement adverbiale. Notons l'emploi transitif du verbe dans le CW.

\section{Retraire bel}

S'éloigner, se retirer avec tact Intransitif

1275 Maint Sarrazin i laissent mort sanglent en l'erbier.

Qui les veïst retraire bel et sans esmaier, Bien deïst que ce fust gent c'on deüst prisier.

Sarrazin ne les osent de trop pres enchaucier (Adenet le Roi, Buevon de Conmarchis, 1755)

REMARQUES : Retraire bel désignait, en ancien français, le fait de s'éloigner de l'ennemi ou de l'adversaire, de reculer avec habileté, en faisant attention. Beau adopte la forme neutre bel.

\section{Retravailler droit}

Travailler à nouveau comme il faut

$\lambda$ labourer droit

\section{Retrouver direct}

se retrouver direct : retrouver directement, aussitôt, à l'instant

$\lambda$ redescendre direct

\section{Rêvasser haut}

rêvasser tout haut : rêver, laisser aller sa

pensée, son imagination à voix haute

Intransitif

1923 Rinette, reprise par les visions d'avenir vers lesquelles désormais son activité était toute tendue, rêvassait tout haut, en faisant claquer sa jarretière :

- Oui, maintenant, je suis à peu près tirée d'affaire (Roger Martin du Gard, Les Thibault. La Belle Saison)

1985 Bâches repliées. Les camtards, cul ouvert, ravalent le primeur invendu. Les clodos se bousculent en braillant Nini peau d'chien. Ça schlingue la vinasse. Ça rêvasse tout haut dans des délires de gueules cassées et d'ailes brisées (Frédéric Lasaygues, Vache noire, hannetons et autres insectes)

REMARQUES : Rêvasser tout haut se dit du fait de laisser aller librement et à voix haute ses pensées, de laisser l'imagination se perdre en des rêveries vagues, changeantes et qui, souvent, ne correspondent à aucune réalité. Il peut aussi connoter l'air distrait d'une personne, un esprit toujours absorbé par autre chose. Haut reste invariable et est modifié par tout. Notons l'emploi impersonnel familier ça rêvasse tout haut.

\section{Revenir cher}

Coûter beaucoup d'argent

Intransitif

1832 Malgré cela, la culture du sucre y revient plus cher que dans les îles voisines, et il est douteux qu'elle puisse y être continuée avec succès (Jean-Baptiste Say, Traité d'économie politique)

1893 Dans cet état, il [= le sel] est grisâtre et convient à la fabrication de l'acide chlorhydrique. Il pourrait servir à la nourriture des bestiaux, mais on lui préfère généralement le sel dénaturé, qui revient beaucoup moins cher à cause des droits (Charles Durand, Les Grandes Industries minérales en Lorraine)

1904 La corrosive charcuterie revient excessivement cher (Léon Frapié, La Maternelle)

1930 J'ai vu deux ou trois restaurants d'un type assez singulier dont le plus connu est Marcel : on y trouve, pour un dollar et demi une abondante table d'hôte, mais tout ce que vous laisserez dans votre assiette vous sera compté en plus, sur l'addition, à titre d'amende ; aussi le repas revient-il fort cher à qui n'a pas d'appétit (Paul Morand, New-York)

1932 Toujours pendant qu'on marchait, il s'est mis alors à me raconter les façons qu'on avait d'élever les chiens avec du lait sans que ça vous revienne trop cher (LouisFerdinand Céline, Voyage au bout de la nuit)

1947 Je réfléchis une minute sur la décision à prendre et me lève, lave, habille, des- 
cends, rue, métro, gare, trombe, déboulé. Et dix minutes d'avance pour $12 \mathrm{~h} 25$. J'arrive à 1'heure au resto. Ça revient moins cher sans apéro. Simple logique (restrictive) (René Fallet, Carnets de jeunesse)

1985 Il finit par choisir un costume peu original de médecin vénitien du temps de la peste qui ne lui revint pas très cher (Jean d'Ormesson, Le Vent du soir)

1996 Une heure d'épuisement. À cause de la chemise de nuit ? Du mal de tête ? Et la femme, lorsqu'il jouit enfin : « Jamais je n'ai fait l'amour aussi longtemps! Mon lapin, ça te reviendrait cher à l'heure ! » (Boris Schreiber, Un silence d'environ une demi-heure)

\section{CORPUS WEB :}

Hughes - Faire des compressions pour faire des compressions, cela peut revenir cher ! [http://www.wawa-news.com/index.php?option =com_content $\& v i e w=$ article\&id=3388: hughes faire-des-compressions-pour-faire-des-com pressions-cela-peut-revenir-cher\&catid $=122$ : editorials\&Itemid=157] (4.11.2015)

Question : «bonsoir, j'ai un forfait qui revient cher comment faire pour résilier car j'ai vu moins cher pour + ailleurs ? " [http://www.assistancemobile.com/questions/690277-forfait-revientcher-faire-resilier-cher-ailleurs] (4.11.2015)

J'ai lu ici et là les différent avis, la photo est elle une passion qui revient chère pour vous ? [http://www.photos-entre-amis.com/la-photoune-passion-qui-revient-chere-t4460.html] (4.11.2015)

J'ai pour l'instant une audi coupé quattro 5cyl. qui me revient chère en essence car je ne fais pratiquement que de la ville (impossible de descendre sous les 12 litres/100 Km de SP98 avec cette voiture, et vu les prix actuels des carburants...) [http://www.forum-auto.com/poletechnique/mecanique-electronique/sujet552816. $\mathrm{htm}]$ (4.11.2015)

REMARQUES : Revenir cher se dit d'une activité ou d'une entreprise qui coûte beaucoup d'argent ou d'une chose dont l'achat ou l'acquisition représente une forte somme d'argent. Le sujet peut aussi désigner une action concrète ou abstraite, dont le processus coûte cher. Cher reste invariable dans la majorité des cas. Toutefois, dans le troisième et le quatrième exemple du $\mathrm{CW}$, il s'accorde avec le sujet. Il est modifié par beaucoup moins, excessivement, fort, moins, plus, très, trop. Notons l'emploi impersonnel familier de ça revient moins cher, avec la variante moins informelle cela peut revenir cher. VOIR AUSSI : coûter gros

\section{Revenir court}

I. revenir tout court : revenir brusquement, rapidement, immédiatement (à un endroit) Intransitif

1578 Le vendredi XXX ${ }^{\mathrm{e}}$ mars, le Roy, estant allé se proumener avec les Roines à Nantœil et à Vernœil lès Creil, revinst tout court à Paris, aiant eu advis que quelques trouppes d'Alemans Reistres, jusques au nombre de trois mil, aians passé la riviere vers Cosne, tenoient la routte du grand chemin de Paris (Pierre de L'Estoile, Registre-journal du regne de Henri III)

1628 L'ADMIRAL. Je voulois de ce pas sur le havre descendre,

Mais tout court je reviens pour au Conseil me rendre

(Jean de Schélandre, Tyr et Sidon)

1657 car si l'acteur, qui sort à la fin d'un acte, a peu de choses à faire, et qu'il n'aille guere loin, il peut ouvrir l'acte suivant, ce qui est ordinaire à Plaute, et que Terence méme a fait du quatriéme au cinquiéme acte de l'Heautontimorumenos, où Menedéme allant de la ruë en sa maison, et voyant Clitiphon et Bacchide se renfermer seuls dans une chambre de derriere, il revient tout court dans la ruë pour conter cette avanture à Chrémes (François Hédelin, abbé d'Aubignac, La Pratique du théâtre)

II. revenir tout court à ses moutons : reprendre une activité Intransitif

1646 Mais, si l'on s'apperçoit que nous nous écartons,

Il vaut mieux revenir tout court à nos moutons.

Sois marié demain, puisque tu le veux estre ; 
S’il ne tient qu'à cela, j'iray querir le prestre (Jacques Du Lorens, Satires)

CORPUS WEB :

$\mathrm{Au}$ service coupé et liftes c incroyable l'effet qu'on peut mettre. En 1phase de 500 a 1400 c 100\% de faute direct ds le filet qui a voulu démarrer en top sur mon service coupé ds le revers adverse. Le control est Magic, les blocs sont juste hyper simple a réaliser ils sont facile a faire et reviennent court !!! J'ai donc direct changé mon bois trop lent et pris un $\mathrm{k} 5$ qui est tendre bien pour le top et le ctrl petit jeu, léger, all+/off--- !!! [http:// www.tennis-de-table.com/forums/sujet-46074-2. html] (4.11.2015)

Si l'adversaire met juste sa raquette en opposition, Ça sort De l'autre coté. Si ça sort pas, la balle revient courte. Il faut faire un flip coup droit Ca peut -être payant Mais c'est risqué [http:// www.tennis-de-table.com/forums/sujet-37475-1. html] (4.11.2015)

Retour en force de la mini-jupe cet été

On va pouvoir montrer ses jambes. La jupe revient courte et même très courte [http://www. rts.ch/play/tv/19h30/video/retour-en-force-dela-mini-jupe-cet-ete?id=1594225] (4.11.2015)

REMARQUES : Revenir court (I) désigne le fait de rentrer, de retourner en un lieu donné, en marquant la hâte du sujet, son désir d'arriver au but rapidement. Au figuré (II), il se dit du fait de retourner rapidement, sans tarder, à quelque chose, de reprendre une activité, ce qu'on a interrompu, délaissé ou abandonné. Dans les deux premiers exemples du CW, court réfère à la distance parcourue par une balle de ping-pong, l'accord ne se faisant que dans le second cas. Le dernier exemple renvoie à la mode de porter de mini-jupes ; court est donc un prédicat second accordé qui désigne la longueur du vêtement. Il est modifié par tout. Notons l'emploi antéposé du modifieur dans J'ai donc direct changé 'directement, aussitôt, à l'instant'.

\section{Revenir droit}

I. Revenir directement (vers un lieu, une personne)

Intransitif

-1100 Quant il ço veit qu'il volent onurer : «Certes, dist il, n’i ai mais ad ester,
D'icest'honur nen revoil ancumbrer. »

Ensur nuit s'en fuit de la ciptét,

Dreit a Lalice revint li sons edrers

(Vie de saint Alexis [fin $\mathrm{XI}^{\mathrm{e}}$ ], BFM, 190)

1275 Lors vi dreit a mei revenant

Raison la bele, l'avenant,

Qui de sa tour jus descendi

Quant mes complaintes entendi (Jehan de

Meun, Roman de la rose [1269-1278], 4225)

-1349 Et il se doit si affaitier

Que, quant droit sera revenue

Seur l'aubrissel, qu'en sa venue

Il puist de droit lever sa tente,

C'est qu'il mette cuer et entente

A li servir et honnourer

Pour son cuer par enamourer (Guillaume de Machaut, Le Dit de l'alerion, 709)

-1469 « Je vous diray que nous ferons, dit le vieil cappitaine de Crathor. Je sçay ung chemin, par où nous yrons tout le couvert trencher le chemin à ceste arrière-garde et donnerons parmy eulx en revenant droit à nostre avant-garde » (Jean de Bueil, Le Jouvencel [1461]-1468, I, p. 216)

1645 LE ROY. Va, mais depéche viste. ARISTE. Il est tout en colere, Voyez, voyez un peu comme son œil esclaire. Il revient droit à nous.

LE ROY. Un sujet recognu

A fait que je me suis long-temps entretenu (Tristan l'Hermite, La Folie du sage)

1700 Ils virent la cascade, qui est entièrement achevée, qui est très-magnifique, et firent collation à une petite maison au bout du jardin, que Monsieur a donnée à madame de Grancey. Madame la duchesse de Bourgogne se leva à midi, alla à la messe à son heure ordinaire avec Monseigneur, car elle fut habillée dans un instant, et après le dîner elle revint ici tout droit (Philippe de Dangeau, Journal)

1731 Mais la crainte de vous déplaire, et de m'exposer à l'inconvénient que je vous ai dit, m’a fait prendre le parti de remonter aussi-tôt en carrosse, et de revenir droit à la maison (abbé Prévost, Le Philosophe anglois) 
1846 En sortant du Vatican, Franz revint droit à l'hôtel en évitant même de passer par la rue du Cours (Alexandre Dumas père, Le Comte de Monte-Christo)

184812 lundi. Rangé les papiers de la Révolution. Lettre d'injures pour la dernière leçon. Commencé : la mort du christianisme. Aux archives, inutilement (lundi de la Pentecôte). Hésité entre rive droite et gauche, puis revenu tout droit (Jules Michelet, Journal)

1863 À la hauteur des dernières arches, ils revinrent droit vers l'aqueduc ; la place était découverte : ils s'avancèrent en rampant jusqu'à la base des piliers (Gustave Flaubert, Salammbô)

1926 C'est tout juste à l'heure de midi qu'elle arriva à l'endroit d'où elle était partie, son corps revint tout droit à la loge où elle rentra (Louis Aragon, Euvre Poétique)

1936 Puis elle [= Séraphita] est restée immobile, sa jambe malade repliée. « Va -t'en », lui ai-je dit doucement. Elle a fait un pas vers la porte, puis elle est revenue droit sur moi, avec un admirable mouvement de ses petites épaules (Georges Bernanos, Journal d'un curé de campagne)

1956 La sentence que vous portez sur les autres finit par vous revenir dans la figure, tout droit, et y pratique quelques dégâts. Alors ? Dites-vous. Eh bien, voilà le coup de génie. J'ai découvert qu'en attendant la venue des maîtres et de leurs verges, nous devions, comme Copernic, inverser le raisonnement pour triompher (Albert Camus, La Chute)

1966 Mais j’ai mal calculé et elle a tapé sur le bumper et elle est revenue droit comme ça entre les deux flippers. Tu as vu, hein ? Je n'ai pas pu la rattraper. Tu as vu ça ? Absolument droit, juste au milieu (Jean-Marie Gustave Le Clézio, Le Déluge)

Pronominal

1372 Mais trop est long de sa demande; Car, pour parler ne pour rouver, Ne pot li clers acort trouver. Eins se departi sans acort,

\author{
Et s'en revint tout droit au port \\ De Nimesson, ou il trouva \\ Le roy qui encor se leva, \\ Car il estoit assez matin \\ (Guillaume de Machaut, La Prise d'Alexan- \\ drie [(1370-)1372], 4246)
}

1857 Comme il eut peur, cependant, que cette vue ne le rendît plus triste encore, il s'en revint tout droit chez lui. M. et Mme Charles arrivèrent à Tostes, vers six heures. Les voisins se mirent aux fenêtres pour voir la nouvelle femme de leur médecin (Gustave Flaubert, Madame Bovary)

\section{Reprendre directement (une activité)} Intransitif

1945 Puis elle avait honte de ces fantaisies. De quelque rêve qu'elle sortît, Rose-Anna revenait tout droit à ses calculs. Elle arriva place Saint-Henri (Gabrielle Roy, Bonheur d'occasion)

\section{CoRpus WeB :}

Les danseurs lèvent la pointe du pied droit et viennent poser le pied droit à plat devant le pied gauche. Le poids du corps passe sur le pied droit. Le buste se redresse pour revenir droit [http://dansesbretonnes.gwalarn.org/danses/ aeroplane_acigne.html] (4.11.2015)

qu'appelles tu revenir au neutre de luimême ? genre tu fais un virage à $90^{\circ}$ en ville et ce dernier doit etre accompagné pour revenir droit, il ne se « déroule » pas tout seul ? [http://www. forum-peugeot.com/Forum/forum-peugeot/ Peugeot-107/volant-droit-sujet_32975_1.htm] (4.11.2015)

Comment avoir de beaux cils recourbés ? j'utilise un recourbeur de cils, mais apres quelques minutes ils reviennent droits, comment faire ? merci de vos conseils [https://fr.answers. yahoo.com/question/index?qid=20100417115906 AA249Y2] (4.11.2015)

Différents bois font l'affaire, du moment qu'ils soient élastiques, c'est-à-dire qu'ils maintiennent la pression durant les quelques heures d'un séchage, et qu'ils reviennent droits dès que tu les retires... L'acacia a bonne réputation, etc. Fais une recherche et tu auras différentes idées [http://www.benoit-de-bretagne.com/forum/ viewtopic.php?f=22\&t=13131\&start=15] (4.11.2015) 
REMARQUES : Revenir droit (I) se dit du fait de retourner au point de départ, à un endroit ou de se tourner à nouveau vers une personne, directement, sans détour. Dans son emploi pronominal, il s'agit d'un emploi vieilli, parfois familier, qui désigne le fait de retourner dans le lieu d'où l'on était parti. (II) désigne le fait de reprendre directement une activité qui a été interrompue, délaissée ou abandonnée. Droit reste invariable dans son emploi adverbial. Le CW illustre son emploi en tant que prédicat second désignant le port droit, redressé du buste, des cils, du bois, etc. Cet emploi tend à l'accord (v. les deux derniers exemples du CW). Droit est modifié par dans la figure, ici, tout. Il peut s'associer avec la préposition qui le suit (à, chez, entre, sur, vers) au point de faire partie du groupe prépositionnel en tant que modifieur de la préposition.

\section{Rêver beau}

Faire de beaux rêves, des rêves agréables Intransitif

1835 Dans mon enfance je me suis représenté souvent ce paradis terrestre, cet éden que toutes les nations ont dans leurs souvenirs, soit comme un beau rêve, soit comme une tradition d'un temps et d'un séjour plus parfaits ; j'ai suivi Milton dans ses délicieuses descriptions de ce séjour enchanté de nos premiers parents ; mais ici, comme en toutes choses, la nature surpasse infiniment l'imagination. Dieu n'a pas donné à l'homme de rêver aussi beau qu'il a fait. J'avais rêvé éden, je puis dire que je l'ai vu

(Alphonse de Lamartine, Souvenirs, impressions, pensées et paysages pendant un voyage en Orient)

1851 Non, non, la poésie que j’ai vue aujourd'hui, vit, marche, palpite et parle ! Et quelle vie ! et quelle démarche ! et quelles palpitations dans le sein ! et quelles mélodies sur les lèvres ! et quelles larmes transparentes sur le globe des yeux ! Ô Guido Reni ! tu as bien rêvé ; mais la nature rêve plus beau que toi! (Alphonse de Lamartine, Les Nouvelles Confidences)
Transitif

1842 C'est le provincial qui vient à l'opéra

Des clochers inconnus de sa verte campagne.

Il vient comme on viendrait au pays de Cocagne,

Si bien que ni le chant, ni le public choisi, Ni le vol fabuleux de Carlotta Grisi

Et les pâles Willis avec leurs maillots roses, Ne semblent à ses yeux de merveilleuses choses.

Il rêvait tout moins beau, mais quelque chose encor,

Et croyait au perron trouver des marches d'or (Théodore de Banville, Les Cariatides)

\section{CORPUS WEB :}

La succession à la tête du Bénin le 6 avril 2016 aiguise des ambitions. Elle n'est pas, non plus, sans rendre féconds les adversaires de l'homme d'affaires, Patrice Talon. Est-ce un péché s’il était candidat à l'élection présidentielle ? A l'analyse des faits, il y a des raisons de rêver beau et grand avec lui [http://www.radiobenindiaspora. com/?section=240] (4.11.2015)

Par notre blogue, nous souhaitons inspirer davantage de gens à suivre la trace de ces personnes d'action au grand cœur que nous vous présentons et à oser rêver grand, à oser rêver beau... [http://semerlemerveilleux.com/fr/apropos] (4.11.2015)

Mes fils revent beaux ;-) mes enfants dodo comme bebe.ilyily [http://anabellanabella. skyrock.com/1580174068-Mes-fils-revent-beaux. html] (4.11.2015)

Outre la honte qui les envahis, il y a le désespoir. Ils se rêvent beaux, riches et même célèbres. Ils sont à peine mignons, pauvres et paumés. The Full Monty montre très bien ce décalage entre le fantasme (autant féminin que masculin) et la réalité [http://www.ecrannoir.fr/critiques/fullmon. htm] (4.11.2015)

Et quel sera le rôle des hommes dans tout ça ? Ils seront tout simplement admiratifs et désirants. Ils seront en pâmoison devant notre silhouette. Ils seront entièrement à notre merci, comme nous les désirons, comme nous les aimons, comme nous souhaitons en profiter. Ils se rêvent beaux pour que nous en jouissions davantage, pour notre égoïsme et notre vrai 
plaisir que nous voulons ressentir sans aucune culpabilité. Sans même qu'ils se rendent compte que notre propre beauté, et surtout les pouvoirs qu'elle nous confère, nous suffisent amplement [http://chaudhumide.canalblog.com/ archives/2014/04/14/29668046.html] (4.11.2015)

REMARQUES : Rêver beau réfère à une personne qui laisse aller sa pensée au gré des sentiments ou des souvenirs, qui fait des rêves enchanteurs, idylliques ou s'imagine des choses merveilleuses. Notons l'emploi analogique de rêver grand, quand rêver beau renvoie à des visions plus ou moins conscientes, belles mais loin de se voir réalisées. Beau reste invariable dans la majorité des cas. On peut penser que l'accord de beau dans le troisième exemple du CW est agrammatical, mais il pourrait également s'agir de l'impression visuelle que donnent les enfants à leur mère pendant qu'ils dorment. Dans les deux derniers exemples du CW, où le verbe est pronominal, l'accord signale un emploi en tant que prédicat second orienté vers le sujet : ils rêvent d'être beaux. Beau est modifié par aussi, moins, plus.

\section{Rêver creux}

Songer à des choses vaines, chimériques Transitif

1675 Mais, comme vous dites, il faut glisser sur bien des pensées et ne pas faire semblant de les voir ; je crois que vous en faites de même. Je m'arrête donc à vous conjurer, si je vous suis un peu chère, d'avoir un soin extrême de votre santé. Amusez-vous, ne rêvez point creux, ne faites point de bile, conduisez votre grossesse à bon port (Mme de Sévigné, Correspondance)

1728 Je connais des gens qui ont tout ce que je dis là, femme, charge, et enfants, et qui sont riches : je les vois pensants, ils rêvent creux, ils ont des physionomies sérieuses, qui servent de remède à l'envie de rire. Parlez-leur, ils se plaignent toujours (Pierre de Marivaux, L'Indigent Philosophe)

1818 Je vous demande la continuation de vos sages avis sur la place. Cela m'empêchera de déraisonner quand je rêve creux (Stendhal, Correspondance)
1832 Laissez-le être imbécile et ne lui reprochez pas de vous assommer de ses platitudes. Il a bien le temps d'être triste et de rêver creux, quand il rentre le soir tout seul dans cette chambre déserte, pauvre enfant ! N'est-ce pas, Émile, qu'il mérite bien que je l'aime avec passion? (George Sand, Correspondance)

REMARQUES : Rêver creux se dit du fait de rêvasser, de laisser aller librement la pensée, de laisser l'imagination se perdre en des rêveries vagues, changeantes et qui ne correspondent à aucune réalité, reposent sur du vide, ou du fait de nourrir des rêves qui détruisent le moral. Creux reste invariable.

\section{Rêver fort}

rêver haut et fort : avoir de grands rêves, faire des projets ambitieux

तrêver haut

\section{Rêver grand}

S'imaginer les choses en grand, rêver de grands projets

Emploi absolu

1975 Comme on le dit des jeunes ménages dépensiers : ils ont $v u$ trop grand... J'avais rêvé trop grand, outrepassé mes forces (François Nourissier, Lettre à mon chien)

\section{CORPUS WEB :}

Pour laisser notre esprit ainsi vagabonder, nous pouvons déjà nous autoriser à lâcher-prise sur le possible, le crédible, le raisonnable, le sensé, et nous demander : en quoi est-ce que le fait de rêver grand peut-il être menaçant pour moi ? [http://fr.viadeo.com/fr/groups/detaildisc ussion/?containerId=0021tx8kugfvkjf\&forumId $=00212 \mathrm{e} 403 \mathrm{wm} 6 \mathrm{pg} 3 \mathrm{a} \&$ action $=$ messageDetail\& messageId=0021fq8ao2fexhxn] (4.11.2015)

L'amour, la foi et la vision tenue du rêve, font toute la différence énergétique et l'énergie source n'a plus qu'à mettre en action les bons ingrédients pour sa réalisation. Oser rêver grand, c'est apporter plus de grandeur à la vie [http://lejardindejoeliah. com/2014/10/06/oser-rever-grand] (4.11.2015)

Dans le but d'apporter un coup de main à ceux qui sont désespérés, aux jeunes qui ont pleins d'avenir, à ceux qui rêvent grands, à ceux 
qui ont une vision et ne savent pas comment l'accomplir. Nous comprenons que la vie est faite des défis, que les porteurs des projets ont besoin d'y croire pour y arriver [http://www.edilivre. com/communaute/2015/09/28/rencontre-avecmelodie-p-boueya-auteur-de-world-winner/\#. VjpEp03ouUk] (4.11.2015)

REMARQUES : Rêver grand se dit du fait de s'imaginer quelque chose, de concevoir un projet ambitieux, de concevoir les choses ou le projet à réaliser à grande échelle, avec excès, ne correspondant pas à la réalité qu'elle soit matérielle ou financière. Grand reste invariable dans la majorité des cas. Toutefois, dans le troisième exemple $\mathrm{du} \mathrm{CW}$, il s'accorde avec le sujet tout en conservant sa fonction adverbiale. Grand est modifié par trop, ce qui souligne l'excès, le surdimensionné du projet. Notons l'emploi du synonyme voir grand (exemple de 1975) dénotant une ambition plus réaliste ou, de toute façon, plus concrètement envisagé qu'avec rêver grand. VoIR AUSSI : penser / voir grand ; voir large

\section{Rêver haut}

I. Rêver ou rêvasser à voix haute Intransitif

1831 Il m’a dit que j'avais beaucoup rêvé après la saignée et comme je rêvais haut il m'a raconté que j'avais parlé de toi toute la nuit (George Sand, Correspondance)

1849 JUNON. En effet, depuis quelque temps il me néglige, je l'entends la nuit qui rêve tout haut (Gustave Flaubert, La Tentation de saint Antoine)

1995 « Le personnage est un étrange tyran qui vous fustige en proie à des exigences qui vous dépassent, qu'il ne nous confie jamais ; ce sont vos propres besoins, toutes les peines de la vie entassées au plus profond, qu'il veut de vous.»

À mesure qu'elle rêvait tout haut, se parlant à elle-même plutôt qu'elle ne me parlait, son visage resplendissait de foi dans l'avenir (Hector Bianciotti, Le Pas si lent de l'amour)

Transitif

1888 Elle n'était pas seule à les [= les mots] trouver, ils lui arrivaient de la belle nuit, du grand ciel blanc, des vieux arbres et des vieilles pierres, endormis dehors, rêvant tout haut ses rêves (Émile Zola, Le Rêve)

1964 Il riait, il jubilait, il rêvait tout haut l'impossible plaidoirie : le petit gars de Grenelle, joli garçon, franc comme l'or, pas très futé, et sans grande expérience des femmes, mais s'éprenant de la belle jeune fille de Passy et croyant lui plaire (Michel Droit, Le Retour)

II. Avoir de grands rêves, faire des projets ambitieux

Intransitif

1914 Elle est venue deux fois avec le même corsage. Ma tante qui est si bonne, disait, à part : « J'ai envie de lui faire cadeau d'un corsage. " Elle avait rêvé trop haut pour son garçon. - Marie-Rose dit que cette jeune femme est très bien. Elle n'est peutêtre pas de ces plus intelligentes. Mais enfin ! C'est la timidité aussi

(Alain-Fournier, Correspondance avec Jacques Rivière)

1939 L'esprit rempli d'une ancienne rumeur d'angoisse, il ne rêve pas bien haut pour tous les hommes (Jean Guéhenno, Journal d'une « Révolution»)

1950 Ensemble tout le temps qu'il nous fallait pour vivre

Toute une éternité

Et plus je te voyais vivre à côté de moi Plus je te confondais avec l'aube et l'été Dormir profond rêver plus haut Et s'éveiller l'un bien à l'autre Telle est la loi de l'innocence Et vivre plus haut que nos rêves Être pareils par la confiance Tel a été notre plaisir Dans un monde (Paul Éluard, Une leçon de morale)

\section{Corpus Web :}

Rêve lution

[...]

Tout nos chums s'appelait hey man

Notre symbole le fleur de lys

Sylvain on rêvait haut, haut, haut

Faut rêver haut

Rêver plus haut 
Faire des rêves haut, lution

[http://www.frmusique.ru/texts/r/roy_bernard/ revelution.htm] (4.11.2015)

Hier ce grand moment est arrivé ; à peine 2 ans plus tard. Ce n'est pas un hasard si un de nos mantra est Oser Rêver Haut et Fort ! Nous apprenons sur le tas, nous marchons à l'intuition, nous carburons aux frissons [http://www.jesuismv. com/\#!Petite-histoire-pour-25-000-coeurs/ cd23/5616b0630cf2c6c6436b3924] (4.11.2015)

REMARques : Rêver haut (I) s'applique à une personne qui laisse aller sa pensée au gré des sentiments ou des souvenirs, qui fait des rêves enchanteurs, idylliques ou s'imagine des choses merveilleuses et ce, à voix haute. Au figuré (II), le groupe réfère à l'ambition de l'homme, au fait de concevoir de vastes projets pour l'avenir. Notons la collocation haut et fort. Haut reste invariable et est modifié par bien, plus, tout, trop. Notons l'emploi de dormir profond ; vivre plus haut. VoIR AUSSI : penser / voir grand; penser / voir petit

\section{Rêver noir}

Avoir des idées sombres ; faire un cauchemar Intransitif

1671 Sans cela, vous vous creusez l'esprit d'une si étrange manière que vous vous détruisez vous-même. Vous ne vous amusez point à des bagatelles ; ou vous rêvez noir, ou il vous faut de la conversation (Madame de Sévigné, Correspondance)

+1847 - Cela m'est bien égal, à moi, qu'il soit gentilhomme. Il vous fait rêver noir, voilà ce que je sais. Et, de rêver noir, on maigrit. Malaga ! Je ne veux pas que M. d'Artagnan sorte de chez moi plus maigre qu'il n'y est entré.

- Comment me fait-il rêver noir ? Voyons, explique, explique (Alexandre Dumas père, Le Vicomte de Bragelonne [18471850])

1985 Il y a une tristesse purement littéraire qui fait profession de rêver noir (Roger Judrin, Mots habités)

\section{Reverser dru}

Faire tomber en grand nombre

Transitif

1365 Toute nuit ot bataille si grande sus le prée : Plus dru reversent mort, souvin, geule baée, Que ne le vous diroit personne qui soit née; Toute nuit, à le lune, ont le bataille outrée (Li Romans de Bauduin de Sebourc, Chant IV, 85)

REMARQUES : Dans un combat, reverser dru désignait le fait de renverser, de faire tomber ses adversaires, en grand nombre. Dru est modifié par plus.

\section{Revertir droit}

Retourner directement

Intransitif

1276 Aprés ce s'est de la endroit partis, A son ostel est tout droit revertis, Ou de sa gent fu de cuer conjois (Adenet le Roi, Les Enfances Ogier, 4674)

1285 Tant i furent que retorner Lor plot ; si le firent ainsi. Droit a Douvre sont reverti, Car n'orent pas conseil d'aler Plus avant, en pays de mer (Adenet le Roi, Cleomadés, 8224)

REMARQUES : Revertir droit se disait du fait de revenir ou de retourner directement, sans détour en un lieu (ville ou hébergement). Droit reste invariable et est modifié par tout. Il s'associe avec la préposition $\grave{a}$ au point de faire partie du groupe prépositionnel en tant que modifieur de la préposition.

\section{Rhétoriquer beau}

Argumenter de manière très éloquente Intransitif

+1366 Qui est eureus et que scet pratiquer, Et de parler a belle rethorique Tant qu'avoir a, par beau rethoriquer, Et enrichist par sa bonne pratique, Honourez est plus que saint ne relique, Des que l'on scet qu'il a deniers en cofre (Eustache Deschamps, Euvres complètes [3 $3^{\mathrm{e}}$ tiers XIV $]$ )

REMARQues : Rhétoriquer beau se disait du fait d'exprimer ses idées ou ses arguments dans un 
style subtil et recherché, dans le but de persuader son interlocuteur.

\section{Ricaner bas}

Rire sarcastiquement, railler, rire en faisant peu de bruit, en silence, intérieurement

Intransitif

1791 Le maréchal fort en colere le conduisit quelques pas, marmotant et gesticulant [...] laissant le Roi étonné, et l'ancien évêque de Fréjus son précepteur, ricanant tout bas dans ses barbes (Saint-Simon, (Euvres complettes)

1849 LA LUXURE. Puis, la saisissant d'un bond, l'as-tu renversée sur le lit qui s'enfonçait comme un flot ? Elle te serrait de ses bras joints, tu sentais ses muscles trembler, ses genoux qui se heurtaient, ses seins se raidir ; sa tête s'en allait, son corps se détendait, prenait des poses assouvies, et les paupières de ses yeux morts frémissaient comme l'aile des papillons de nuit... Étiez-vous bien contents d'être seuls ? Ricaniez-vous tout bas, en touchant vos chairs ? (Gustave Flaubert, La Tentation de saint Antoine)

1879 Les dames de la confrérie en pleuraient de pitié dans les rangs, et les gros porte-bannière ricanaient entre eux tout bas en se montrant les pauvres moines :

- Les étourneaux vont maigres quand ils vont en troupe

(Alphonse Daudet, Lettres de mon moulin)

1900 J'ai rougi de colère, de telle façon que la grande Anaïs le remarque et ricane tout bas (Colette, Claudine à l'école)

1940 Il ricana tout bas, laissa retomber ses mains le long de ses jambes, et appuya son front contre la fenêtre du palier avec une expression de désespoir (Colette, Chambre d'hôtel)

\section{CORPUS WEB :}

Salade le SDF cherche un sens à sa vie et les douairières ricanent bas : les plus impatientes en effet de verrouiller chacun dans son rôle [http:// carnetsdejlk.hautetfort.com/index-2.html] (4.11.2015)
REMARQUES : Dans une situation embarrassante, ricaner bas désigne le fait de rire doucement et sottement, pour cacher sa gêne, sans y réussir. Il peut également référer à la réaction de ceux qui observent la situation. Ricaner bas exprime alors un petit rire sarcastique mais volontairement visible de celui qui se moque de l'autre. Bas reste invariable et est systématiquement modifié par tout dans la collocation ricaner tout bas hormis dans le CW. Il est modifié par entre eux.

\section{Rimer riche}

Employer des rimes riches

Intransitif

1933 Pourtant Villon rime volontiers riche, surtout dans les ballades (Fernand Desonay, Villon)

REMARQUES : Rimer riche s'applique à une personne (le poète) qui se plaît à faire des vers, de la poésie et spécialement à trouver des rimes riches, c'est-à-dire constituées par la répétition de la voyelle tonique et de sa consonne d'appui. Riche reste invariable et est modifié par volontiers.

\section{Rincer chaud}

Rincer à l'eau chaude

Transitif

1960 Ces assiettes, je suis bien obligée de les rincer très chaud (Exemple entendu, 20 février 1960 / Grundt : 238)

\section{CoRpus Web :}

Lavage à chaud - Rincer chaud. Pour des couleurs plus claires, vous pouvez vous sentir à l'aise à laver dans l'eau chaude, définie comme 95 à 105 degrés Fahrenheit, selon Mme Clean EtatsUnis [http://www.aac-mo.com/parametres-de-leau-pour-les-vetements-de-couleurs-dans-unemachine-a-laver.html] (4.11.2015)

Le premier est un mentholé avec un soupçon de fruits (poire je dirais), me second un mentholé avec un soupçon de chocolat, et c'est le mix qui est immonde. J'ai beau relaver, rincer j'ai toujours ce gout crado (c'est sur un magma dans ce cas donc même pas de joints). Et le liquide vaisselle ça se rince chaud (entre 40 et $50^{\circ}$ ), sinon ça ne part pas et il faut en prendre sans silicone sinon effectivement ça brille, mais il reste un dépot obligatoirement [http://www.forum- 
ecigarette.com/vos-questions-f1358/nettoyer-sesatos-t162676.html] (4.11.2015)

En cosmétologie activement utilisé le masque d'argile blanche, soin de la peau et des cheveux. L’argile blanche est utilisée pour le visage sous la forme dune solution : 2-3ch.l. poudre peut être dilué avec de l'eau et des tisanes à létat de la crème sure. Le mélange obtenu est appliqué min. 15-20 sur le visage et rince chaud et froid rinçage à l’eau [http://live4x.ru/france/ articles.php?id=9279] (4.11.2015)

laisse 10 min chauffer. sort le carbu de l'eau avec une pince. puis rince chaude (surtous pas froide ou tiede) passe un coup de souflette et remonte [http://www.crazymoto.net/index. php?showtopic=332858] (4.11.2015)

REMARQUES : Rincer chaud s'applique à un récipient (de la vaisselle) que l'on passe, frotte ou nettoie à l'eau claire et chaude pour enlever le produit du lavage. Notons l'opposition avec l'adjectif-adverbe froid dans le CW. Chaud reste invariable dans la majorité des cas, mais, dans le dernier exemple du CW, il s'accorde avec l'objet au féminin sous-entendu (l'eau). Il est modifié par très. Notons l'emploi pronominal du verbe dans le CW et également l'emploi impersonnel familier ça se rince chaud.

\section{Rincer froid}

Rincer à l'eau froide

$\pi$ rincer chaud

\section{Rire bas}

Rire en faisant peu de bruit, en silence, secrètement, intérieurement

Intransitif

+1400 Et comme il apertiengne qu'elle soit devote vers Dieu ; et qu'elle ait contenance asseurée, coye et rassise et en ses esbatemens attrempée et sans effroy, rie bas et non sans cause, ait haulte manière, humble chiere et grant port (Christine de Pisan, Le Livre du duc des vrais amans / Euvres poétiques [début XVe], III, p. 163)

1547 Ce temps pendant, Mistoudin et Brelin, rians assez bas, amasserent leurs bribes ; et s'en allerent à leurs hostels, vengés et riches de la queste des adversaires (Noël Du Fail, Les Propos rustiques)
1686 Apollon méprisant cet Auteur effronté Rit quelque temps tout bas de tant de vanité ; Mais voulant le joüer par une mascarade, Il feind d'être content d'un Harangueur si fade,

Et ne disant rien moins que ce que dit son cœur

Il répond par ces mots au discours de

l'Auteur

(Balthazar de Bonnecorse, Lutrigot)

1761 J'avoue, repartit la marquise, qu'il y a bien de la petitesse dans les détails de l'étiquette, mais on doit une sôrte de considération à un etranger qui joint à sa naissance le titre de souverain toujours respectable pour tous les hommes. Que l'on rie tout bas de son orgueil ridicule, passe, mais on lui doit dans le public une honnêteté de convention, de laquelle il est sage de ne pas s'écarter (François-Antoine Chevrier, Le Colporteur)

1832 En extase, enivré, je n'ai plus rien

d'humain :

Sur mon corps allégi mon âme se déborde, Goutte à goutte en rosée ; et, semblable à la corde

D'un théorbe d'argent palpitant sous la main

D’un ange prosterné..., sous mes pieds fuit la terre,

Je ne suis plus qu'un son ! Un reflet ! Un mystère !...

Peut-être vous riez tout bas de ce pouvoir Si magique et puissant d'une voix sur mon ame ? (Pétrus Borel, Rhapsodies)

1858 Évidemment, il avait pris l'habitude de ce rire au lit des malades, dans ces chambres où tout bruit doit s'éteindre, où l'on marche sur la pointe du pied et où l'on parle bas. Le docteur riait bas. Dans l'instantanéité $\mathrm{du}$ rire (tout ce qui semble le plus involontaire), cet homme, de vocation si spéciale, se retrouvait médecin! (Jules Barbey d'Aurevilly, Quatrième Memorandum)

1900 la petite rayonne de vanité et se tient droite comme Fanchette quand elle fait la belle ; 
elle rit tout bas de joie, incessamment ! Et jusqu'à perte de vue, sous les arceaux verts, robes bouffantes et chevelures gonflées, s'enfonce et se perd l'armée des Gauloises (Colette, Claudine à l'école)

1947 Les couples s'isolèrent en riant tout bas, les garçons à coups de clins d'œil entendus, les filles avec des moues assurées, amusées et curieuses (René Fallet, Banlieue sud-est)

Pronominal

1772 je vis avec douleur que l'esprit, bien différent du génie, est un imposteur qui prend tous les masques, que ces superbes déclamateurs, ces froids panégyristes des vertus étoient de vils charlatans qui se rioient tout bas de l'enseigne qu'ils affichoient, qu'en un mot ils étoient durs par systême ; que hors d'eux, de la sphère étroite de leur petite réputation, hors de leurs intérêts, ils étoient étrangers à tous ces plans de législation et de sagesse qu'ils consignoient avec un faste dégoûtant dans leurs livres (François de Baculard d'Arnaud, Les Épreuves du sentiment)

CORPUS WEB :

Tous ceux qui plaisantaient et riaient encore récemment sur la liste de l'anagramme hermétique commencent à se poser des questions et à rire beaucoup moins fort à ce sujet. S'il en reste qui rient encore, ils rient bas désormais [https:// fr.groups.yahoo.com/neo/groups/nostradamus/ conversations/topics/7531] (4.11.2015)

REMARQUES : Rire bas se dit du fait de rire avec retenue, discrètement, en réaction à une situation drôle ou cocasse. Le fait de rire intérieurement peut aussi souligner un certain mépris vis-à-vis d'autrui, de son comportement ou de ce qu'il vient de dire. Bas reste invariable et est modifié par assez, quelque temps, tout.

\section{Rire bel (beau)}

Rire avec grâce, de manière agréable à voir ou à entendre

Intransitif

1209 Ma suer m'en dona cest fermal,

Et ge li donai cest seël.

Si me dit, en riant trop bel :
Biau doz frere, or sui ge mout lie Quant j'ai un roi de ma mesnie (Jean Renart, Roman de Guillaume de Dole, 3678)

1275 E s'il li prent de rire envie,

Si sagement e si bel rie

Qu'ele descrive deus fossetes

D’ambedeus parz de ses levretes

(Jehan de Meun, Roman de la rose [12691278], 13352)

1608 Ce n'est qu'une fumée, une ampoule sur l'eau,

De Fortune un joüet, un verre clair, et beau ;

Une fleur épanie, en la saison nouvelle

Qui semble à nos yeux rire agreablement belle,

Et nous semondre ainsi doucement l'adorer

Et son teint delicat en pareil honorer

(Nicolas Chrétien des Croix, Les Portugaiz infortunez)

REMARQUES : En ancien français, rire bel réfère à l'expression du visage qui s'illumine, s'embellit, devient gracieux sous l'effet du rire. Dans l'exemple de 1608, la construction en prédication seconde fait que beau récupère sa fonction d'adjectif renvoyant à la beauté d'une fleur ; il s'accorde alors avec la fleur, tandis qu'il adopte la forme neutre bel dans les exemples de l'ancien français pour marquer la fonction adverbiale. Il est modifié par agréablement, si, trop.

\section{Rire bête}

Rire stupidement (en laissant entrevoir qu'on n'a rien compris)

Intransitif

1855 Le rire est le mètre, le mesureur de l'intelligence. Les gens qui rient bête : jamais spirituels. Le rire est la physionomie de l'esprit (Edmond et Jules de Goncourt, Journal)

\section{Rire clair}

I. Avoir un rire ou un sourire pur, clair, agréable Intransitif

1873 Elle [= la charcuterie] faisait presque le coin de la rue Pirouette. Elle était une 
joie pour le regard. Elle riait, toute claire, avec des pointes de couleurs vives qui chantaient au milieu de la blancheur de ses marbres (Émile Zola, Le Ventre de Paris)

1889 C'était pour lui une fête, un bonheur auquel il pensait sans cesse, de regarder la main noire de la petite bonne verser quelque chose dans son verre, tandis que les dents riaient, plus claires que les yeux (Guy de Maupassant, Contes et nouvelles)

1910 Enfin elle leva un bras d'un air décidé. Toute la joie qu'elle retenait cachée coula librement sur ses traits, et elle se mit à rire haut et clair... Bondissant avec une agilité inattendue sur un petit banc, elle saisit un coin du rideau flottant et le tira vers la muraille (Louis Delattre, Carnets d'un médecin de village)

1936 Où sont-ils ? Où peut-on trouver les socialistes ? Des hommes l'entouraient maintenant, qui l'interrogeaient. Au dehors, des enfants jouaient, cela riait et criait clair. Le soir tombait. Les gens se promenaient. Il y avait des musiques (Louis Aragon, Les Beaux Quartiers)

1954 Il n’y manque même pas la « belle bête blonde » de Nietzsche, le héros insoucieux qui rit si bien et si clair en brandissant l'épée neuve, - si peu grec, si purement joyeux de fendre en deux du tranchant de la lame tout ce qui se présente, si naïvement troublé de toucher soudain un sein sous la cuirasse ouverte (Julien Gracq, Penthésilée)

II. se rire clair : s'amuser, folâtrer en ayant plus de clarté, de transparence

Pronominal

1896 Un souffle ami hante La vague, et nous chante : « Vous sans espérance, Mourez sans souffrance !» Et puis sous les cieux Qui s'y rient plus clairs, Elle a des airs bleus, Roses, gris et verts... Plus belle que tous,
Meilleure que nous !

(Paul Verlaine, Euvres poétiques complètes)

CORPUS Web :

Astérion joyeux aide au service ; on se congratule, on boit frais, on rit clair. La belle douceur, c'est de la fureur domptée [http:// jlhuss.blog.lemonde.fr/2011/04/10/de-la-fureurdomptee] (4.11.2015)

Un parfum à bille dont le conditionnement mi-hippie, mi-potion magique fait rêver de grandes jupes, de bracelets qui cliquent et de philtres d'amour. C'est un sillage concentré qui rit clair et qui aime d'absolu, sous le soleil. Hypnotique [http://boucledoretles3gloss.com/tag/ete] (4.11.2015)

REMARQUES : Rire clair (I) s'applique à une personne dont le sourire ou le rire est resplendissant, rayonnant. Le sujet peut également référer à une chose (un bâtiment flambant neuf, la blancheur des dents) qui suggère un éclat lumineux et agréable. Dans le contexte du jeu, rire clair souligne les rires joyeux, aigus des enfants, dont le son produit à l'oreille un effet comparable à celui d'une lumière vive sur les yeux. Lors d'une fête bien arrosée, le rire net et bien perceptible souligne la bonne humeur et l'instant festif. (II) souligne le fait de s'amuser, de jouer ; les cieux sont plus clairs quand ils jouent dans les vagues. Notons l'emploi de boire frais et la collocation haut et clair. Clair peut s'accorder avec le sujet, notamment dans la langue littéraire (exemples de 1873, 1889, 1896) pour mettre en relief le rôle du sujet. Il est modifié par plus, si, tout. Notons le tour impersonnel cela riait et criait clair (exemple de 1936). VoIR AUSSI : crier clair

\section{Rire épais}

Rire grossièrement ou sans finesse Intransitif

1879 M. Stukhout ajouta, riant épais :

- Je vois madame, vous n'aimez pas la pêche (L'Illustration)

1919 Ma sentinelle s'assied sur le bord d'un mignon guéridon d'acajou et l'effondre : il rit épais et lourd (La Source) 
1986 Il rit épais quand il s'exclame :

- La garce, elle m'a posé un lapin

(Jean Cayrol, Les Châtaignes)

\section{Rire faux}

Rire d'un rire qui sonne faux ; faire semblant de rire

Intransitif

1864 SAINT-AUBIN. Comptez sur ma discrétion. (à part) Elle rit faux !

(Marie Ange Ferdinand et Raymond Deslandes, La Jeunesse de Mirabeau)

1883 Je le regardais, perclus de surprise :

- Mais...oui. Bigre, mes compliments. Tu as changé depuis six mois.

Il devint cramoisi et reprit, en riant faux :

- On fait ce qu'on peut

(Guy de Maupassant, Contes et nouvelles)

1941 - Vous avez voulu, continua-t-il avec un peu d'hésitation, ... prendre une revanche. Elle se renversa dans le fauteuil, riant, riant faux

(Daniel-Rops, L'Ombre de la douleur)

\section{Rire fêlé}

Rire avec un timbre altéré

Intransitif

1953 Elle riait fêlé

(Albert Paraz, L’Adorable Métisse)

REMARQUES : Rire fêlé réfère au timbre de la voix qui est altéré et souligne un rire cassé. Il peut aussi renvoyer au comportement d'une personne atteinte de déraison, son rire traduisant une certaine bizarrerie. Fêlé reste invariable.

\section{Rire forcé}

Rire en manquant de naturel, de spontanéité, avoir un rire factice, contraint

Intransitif

1897 HÉLÈNE. Je verrai. J'aurai l'avenir..., de l'avenir..., à ne savoir qu'en faire (Elle rit forcé) (Henri Lavedan, Catherine)

REMARQUeS : Tandis que le rire jaune essaie de tromper les autres sur ce que la personne ressent vraiment, le rire forcé ne se cache pas, il s'agit d'un rire contraint, un faux rire auquel l'individu a recours lorsqu'il veut donner une impression positive, alors que celui-ci n'a pas envie de rire. Forcé reste invariable.

\section{Rire fort}

I. Rire à gorge déployée, rire aux éclats Intransitif

1218 Repraingne tost l'ame son cors. $\mathrm{Au}$ jor trentisme risse fors, Quant confez iert et repantanz Des grans pechiez dont a fais tanz (Gautier de Coincy, De deus freres, Perron et Estene, 148)

+1250 Li rois la cause li demande De son ris, dire li comande. Tant con li rois plus li disoit, Et li autres plus fort rioi (Ysopet de Lyon [ $2^{\mathrm{e}}$ moitié $\left.\left.\mathrm{XIII}{ }^{\mathrm{e}}\right], 3254\right)$

-1334 « Il se poront bien couroucier ; Je vous pri que nous retournon. » Li Beaus Chevaliers au Lyon Si fort rist que sur son archon Par force le faut apoyer (Le Romans de la dame a la lycorne [1 $1^{\mathrm{er}}$ tiers XIV $\mathrm{X}^{\mathrm{e}}$, 3928)

1460 Quand il fut prest, il manda sa mule, et au palais s'en va, ou il compta son adventure a pluseurs gens de bien qui en risirent bien fort (Les Cent Nouvelles nouvelles, XVII, 145)

1558 Mais le monde rioit si fort, le voyant avec ce tabourin sus la teste, qu'il ne sceut meshuy avoir audience, et fut contrainct de se retirer et de s'en taire, car il luy fut remonstré que ce n'estoit pas le fait d'un sage homme de se prendre à un fol (Bonaventure des Périers, Les Nouvelles Récréations et joyeux devis)

1670 nous vous faisons mille contes l'Abbé Danse et moi, dont nous rions fort (Roger de Bussy-Rabutin, Les Lettres de messire Roger de Rabutin)

1787 La danseuse me jette les bras au cou, elle penche sa tête sur la mienne, on croirait qu'elle m'embrasse : elle ne fait que rire pourtant ; mais elle rit si fort, que tous les voisins peuvent l'entendre (Jean-Baptiste Louvet de Couvray, Une année dans la vie du chevalier de Faublas) 
1895 J'ai vu des connaisseurs rire de ce style, qu'ils croyaient celui de quelque vieux capitaine. Le plaisant qui riait le plus fort était un grand zélateur de Michelet (Anatole France, Le Jardin d'Épicure)

2011 Il rit très fort comme s'il trouvait ça vraiment drôle, et son gars ricana en écho mais avec plus de méchanceté (Alexis Jenni, L’Art français de la guerre)

II. s'en rire fort : se moquer (de quelqu'un) bruyamment

Pronominal

1460 Or l'appelle ribauld, après loudier, après putier, après yvroigne ; et tant bien le baptise que tous ceulx de la chambre et luy avec s'en rioient bien fort (Les Cent Nouvelles nouvelles, I, 97)

CORPUS WEB :

En parlant de tout et de rien avec l'ado local et une de ses copines autour de MSN je fais la remarque que l'ado rit fort au point qu'il m'empêche d'entendre ce que je pense [http://monavis. canalblog.com/archives/2005/01/29/285758. html] (4.11.2015)

On rit fort pendant l'heure où Chris Esquerre nous fait la lecture parce que ses mimiques et son ton pince-sans-rire servent son écriture. Physique fluet, yeux plissés et tête qui s'agite lorsque sa voix s'emballe et prononce de manière ridiculement thêâtrale certains mots [http:// rue89.nouvelobs.com/2011/11/03/chris-esquerrelhumoriste-qui-rit-des-journaux-que-personnene-lit-226095] (4.11.2015)

Ces quelques minutes de répit au cours desquelles il sort chercher le pain représentent une délivrance. Nous avons l'illusion d'être libres. Nous pouvons être deux petites filles heureuses qui parlent et rient forts, courent dans la maison, et dans la cuisine goutent avec gourmandise les plats que leur maman prépare [https://www.facebook. com/permalink.php?id=153821908152877\&story_ fbid $=153864744815260$ ] (4.11.2015)

REMARQUES : Rire fort (I) réfère à une situation plaisante ou divertissante qui fait rire beaucoup. Il se dit du fait de montrer ou d'exprimer un sentiment de gaieté à voix haute, avec bruit, de façon sonore. Cette façon de rire peut aussi souligner un manque de retenue en public, un comportement grossier. Dans son emploi pronominal figé dans la formule s'en rire fort (II), il souligne le fait de se moquer de quelqu'un vivement, voire d'exprimer du mépris à son égard. Fort reste invariable et est modifié par bien, le plus, plus, si, très. Dans le dernier exemple du CW, fort s'accorde pour le pluriel, mais non pour le genre féminin, sans doute parce que l'accord ne se fait pas dans le code oral. Il s'agit donc d'une hypercorrection graphique.

\section{Rire frais}

Faire résonner un rire plein de fraîcheur Intransitif

1865 Une Madelon bien coiffée, Blanche et limpide, et riant frais, Sera pour Perrault une fée, Une dryade pour Segrais (Victor Hugo, Les Chansons des rues et des bois)

REMARQUES : Rire frais 'rire avec un éclat de frâ̂cheur' est un des cas où la collocation semble être motivée, ou du moins favorisée, par l'emploi fréquent du groupe nominal : un rire frais. En principe, tous les infinitifs offrent cette possibilité. Dans d'autres cas, la motivation se produit en sens inverse, comme parler vrai par rapport à le parler vrai. Notons l'emploi invarié malgré le sujet au féminin.

\section{Rire franc}

Rire librement, ouvertement, de manière franche, naturelle, de bon cœur Intransitif

1933 L'oncle Honoré faisait à lui tout seul autant de tapage que les enfants ; il buvait sec, parlait haut, riait franc et amusait tous les convives. Il n'y en avait que pour lui, et son frère Ferdinand avait l'air d'un parent éloigné qu'on invite quand on est treize à table (Marcel Aymé, La Jument verte)

1969 Mais il y avait aussi l'aspect viril. Toute une famille de maréchaux-ferrants et de forgerons, de solides gaillards à la poitrine large et aux bras musclés qui faisaient chanter l'enclume dès l'aube, parlaient fort et riaient franc. Olivier était encore tout petit qu'il entendait narrer les exploits d'un 
grand-oncle Ernest, bagarreur jovial des jours de foire, défenseur d'idées rouges (Robert Sabatier, Les Allumettes suédoises)

\section{CORPuS WEB :}

Sinon je me gausse quand un gars du sud, même d'adoption, ou un savoyard me parle de gastronomie. Quand on habite comme moi à côté de chez Blanc ou de chez Bocuse on rit franc et on s'en amuse... Les andouillettes, le cointreau et le génépi c'est pour les touristes et les gogos [http:// www.tirmaillyforum.com/mildot/viewtopic. php?t=170456\&start=2265] (4.11.2015)

Kurt tente de repousser Blaine mais a juste le temps d'offrir un sourire d'excuse à ses amis avant de se retrouver plaqué contre le mur du théâtre. Il rit, franc et clair, pas un de ses faux rires gay qu'il donne en public, Blaine vient boire le rire à sa source [http://lilai.livejournal. com/43228.html] (4.11.2015)

REMARQUES : Dans une situation plaisante ou divertissante, rire franc désigne le fait de rire de bon cœur, franchement, sans retenue, le sujet ne cachant pas son plaisir. Notons la collocation franc et clair dans le CW, et les groupes boire sec, parler haut, parler fort. Le détachement de franc et clair dans le dernier exemple du CW présente les qualités désignées comme propriétés de la personne, dans un but stylistique.

\section{Rire gras}

Rire grossièrement, de façon vulgaire

Intransitif

1902 tu seras aussi plus tard un bon ouvrier; un maçon digne de rétablir l'édifice de la liberté... si tu es sage, petit... si tu ne joues pas trop avec tes sabres et tes trompettes !... petit guerrier bruyant !... Ha ! Ha ! Ha !... il riait gras et frappait, de sa canne, les losanges du plancher (Paul Adam, L'Enfant d'Austerlitz)

1926 Il parle, blague d'une voix tonitruante, et rit gras. Les autres lui répondent, mêlent leurs voix et leurs rires à la voix et au rire de Jean Fouache. Ce sont de riches sonorités, dans la splendeur miroitante du fleuve et la pureté de l'air bleu sur la grève (Maurice Genevoix, La Boîte à pêche)
1951 Ils ont une envie folle de nous retrouver pour pouvoir rire gras [...] Je suis comme vous, dit-elle, je n'aime pas beaucoup les rires gras (Jean Giono, Le Hussard sur le toit)

\section{CORPUS WEB :}

" On rit gras, on rit de bon cœur » Isabelle Ménard, ICI Radio-Canada Première [https:// www.facebook.com/permalink.php?story_fbid= 10153338757822928\&id=122214352927] (4.11.2015)

Une comédie sympatoche sans plus, on sourit plus qu'on rit, on rit gras parfois, mais c'est avant tout le triste constat d'une réalité pathétique, celle des hommes infidèles. À ne surtout pas aller voir en couple :) [http://www. allocine.fr/membre-Z20100224081951227493666/ critiques] (4.11.2015)

A Rat ami ratatouille, a rat ennemi ratata, taratata !! Ratatiné le rat gratouille la rate à raté qui lui fait mal ! A vos rateaux, le rat rit gras, mange sa sauce ravigote.. [http://blogs.mediapart.fr/ blog/myriam-entraygues/310508/les-rats-rientquand-les-chatouille] (4.11.2015)

REMARQUeS : Rire gras se dit d'un rire grossier qui manque de distinction ou d'élégance et qui accompagne souvent des plaisanteries graveleuses ou de mauvais goût. Cette manière de rire un peu vulgaire traduit souvent un comportement agressif et violent soit envers une catégorie de personnes, soit envers une personne précise. Gras reste invariable. Notons le tour nominal les rires gras (1951).

\section{Rire grave}

Rire beaucoup

$\pi$ pleurer sec

\section{Rire gros}

Rire sans se contenir, rire aux éclats Intransitif

1626 Les ennemis de Dieu s'esjouyssent sur des monceaux d'or et d'argent, triomphent au monde, adorez par grand nombre d'esclaves abrutis, rient gros parmi toutes sortes de meubles et d'immeubles, s'esgayent en festins somptueux et delicieux (Simon Goulart, Cinq Décades de divers traitez et discours recueillis de l'Ecriture Saincte) 
1859 En tant qu'homme et Franc-Comtois, il [= Francis Wey] appartient à la classe de rustiques [...] tous metteurs de pieds dans le plat, vigoureux, riant gros (Charles Monselet, La Lorgnette littéraire: dictionnaire des grands et des petits auteurs de mon temps)

1900 Elle a les yeux mouillés, mais parce qu'elle a vu des fantômes. Et ils rient gros aux gaietés de l'escadron (Jules Renard, Journal)

1960 Les spectateurs rient gros de la représentation bestiale

(Adrien Rhyxand, Mouthernaz)

\section{Rire haut}

Rire bruyamment, ouvertement

Intransitif

1628 Au commencement on creut qu'il ne s'estoit pas blessé, et Sigismond luy-mesme s'en mit à rire le plus haut qu'il put, mais quand on vid qu'il se relevoit avecque peine, et qu'il se plaignoit, chacun s'approcha pour sçavoir quel estoit son mal (Balthazar Baro, La Conclusion et dernière partie d'Astrée)

1696 Ménalque regarde aussi, et rit plus haut que les autres, il cherche des yeux dans toute l'assemblée où est celui qui montre ses oreilles, et à qui il manque une perruque (Jean de La Bruyère, Les Caractères)

1701 À peine quelquefois je me force à les lire, Pour plaire à quelque Ami que charme la satire,

Qui me flatte peut-estre, et d'un air imposteur,

Rit tout haut de l'ouvrage, et tout bas de l'Auteur

(Nicolas Boileau, Satires [1664-1701])

1738 FRANCALEU. (éclatant de rire) Embrassez-moi !

DAMIS. De quoi riez-vous donc si haut?

FRANCALEU. Du pauvre oncle qui s'est effarouché trop tôt ;

Mais nous l'apaiserons ; rien n'est gâté

(Alexis Piron, La Métromanie)

1835 Un jour que la marquise riait trop haut depuis dix minutes avec ses voisins, un prêtre s'approcha et voulut hasarder des représentations (Stendhal, Lucien Leuwen)

1840 Il [= le poète] plaint ses contempteurs frivoles,

Et maint faux sage à ses paroles

Rit tout haut et songe tout bas!

(Victor Hugo, Les Rayons et les ombres)

1910 Enfin elle leva un bras d'un air décidé. Toute la joie qu'elle retenait cachée coula librement sur ses traits, et elle se mit à rire haut et clair... Bondissant avec une agilité inattendue sur un petit banc, elle saisit un coin du rideau flottant et le tira vers la muraille (Louis Delattre, Carnets d'un médecin de village)

1915 Quand on lui parlait du « problème religieux ", il riait haut et gai (Paul Bourget, Le Sens de la mort)

1944 Le voici qui se donne en spectacle pour la pitié de Dieu et des Anges. Plein de grandes idées et de grands sentiments, à une assistance qui rit tout bas et tout haut ! (Paul Claudel, Le Soulier de satin)

1966 Mais je ne l'aime pour de bon que lorsqu'elle perd la face, quand tout ce qui la torture : Papa, Maman, cette ville, la douleur enfin, la crucifient. Quand elle rit ou pleure trop haut. Quand elle ressemble à sa mère (Catherine Paysan, Les Feux de la Chandeleur)

1972 Manon, pour le faire endêver, fleuretait bruyamment avec trois grands Belges blonds comme la paille. Ils lui disaient des goguenettes et elle riait trois fois plus haut que ça ne le méritait (Henri Vincenot, Le Pape des escargots)

CORPUS WEB :

Le rire naturel dure généralement seulement quelques secondes, mais nous savons que pour atteindre les effets positifs du rire, il faut rire pendant 10-15 minutes par jour et cela en éclat de rire haut et fort [http://yogarire.ch/52-2] (2.11.2015)

4. Un duo d'enfer. J'ai découvert ce film dans l'avion. Il m'a fait rire haut et fort tout le long [http://www.cineplex.com/GalasEtFestivals/ olympiques/Justine_Dufour-Lapointe] (2.11.2015) 
Repose en paix Philoux, on se sera tout de même pas mal amusé tous ensemble. De soustons à Berlaimont en passant par l'Allemagne avec intermezzo, les repas de Sainte Cécile et Barbecues à Vandeuil ainsi que les marchés de Noël et les Saint Vincent avec les six gars rient haut [http://champnrock.skyrock. com/1251803694-Hommage-a-notre-amiPhilippe-le-trombonniste-qui-nous-a-quittespour.html] (2.11.2015)

Et je me demande, comment est-ce possible de faire pousser dans ses mains ces balles merveilleuses, comme SARAH PUCCI sait le faire, de telle sorte qu'elles tremblent et chatouillent, ricanent, papillonnent, escaladent, font de la voile, grimpent, fredonnent, trépignent, sourient et chatouillent, babillent, frétillent, rient bas et haut, étincellent,... [http://www.airdeparis.com/ past/random/randompucci.html] (4.11.2015)

REMARQUES : Rire haut se dit du fait de manifester un sentiment de gaieté, de rire aux éclats, avec bruit, de façon sonore, et qui peut aller jusqu'à la moquerie (exemples de 1628 et de 1738). Notons les collocations haut et clair, haut et gai, bas et haut, et haut et fort ainsi que les groupes songer bas, pleurer haut, rire bas. Haut reste invariable et est modifié par le plus, si, tout, trois fois plus, trop.

\section{Rire jaune}

I. Rire de manière forcée, avec contrainte Intransitif

1845 Je le regardai à mon tour, et reconnus mon ami don José. En ce moment, je regrettais un peu de ne pas l'avoir laissé pendre.

- Eh ! c'est vous, mon brave ! M'écriai-je en riant le moins jaune que je pus; vous avez interrompu mademoiselle au moment où elle m'annonçait des choses bien intéressantes (Prosper Mérimée, Carmen)

1871 Je me moque bien de sa mairie ; elle ne lui rapporte pas un sou ! Il m'a invité, mais je dirai que j'ai du monde, moi aussi. Tu les verras rire jaune demain... et mets les petits plats dans les grands. Fais tout apporter de l'hôtel de Provence. Il faut enfoncer le dîner du maire (Émile Zola, La Fortune des Rougon)
1881 Mais je sais que Matoussaint n'aime pas à avouer qu'il est tombé, et il riait toujours (bien jaune) quand il lui arrivait de prendre un billet de parterre au collège ; il disait que c'était exprès. JE SUIS CHEZ MOI! (Jules Vallès, Jacques Vingtras : Le Bachelier)

189424 novembre.

Je veux dire, ajouta-t-elle, rougissante, que dans chacun de vos contes il y a des choses drôles, amusantes, enfantines, etc. Je m'amusais, sans rire trop jaune (Jules Renard, Journal)

1896 Ma muse, qui parfois rit jaune Et voit rouge et noir et tout près D’y voir rose, puisque suis ès-amis, Vous dit : amis, mon trône, Puisque je suis le Président De ces agapes fraternelles, Ou du moins mon fauteuil prudent, Mon fauteuil, ou si vos prunelles Y découvrent un trône trop... Je vous salue, amis, et m'assieds au galop (Paul Verlaine, Euvres poétiques complètes)

1910 on lui rendait le plus mauvais service en flattant cet orgueil, d'une façon ridicule, alors qu'il eût eu besoin d'un mentor avisé, savant, judicieux, bienveillant et sévère : - (tout le portrait de Goujart). Les musiciens riaient jaune. Ils affectaient un mépris écrasant pour un artiste qui jouissait de l'appui des journaux (Romain Rolland, Jean-Christophe. Les Amies)

1977 celui [= le jules] de Gabrielle avait une tête de repris de justice et le mien avait au moins trente ans. On a bien ri, un peu jaune, de pareilles mochetés, ça laisse une sale impression même quand on n'y croit pas (Annie Ernaux, Ce qu’ils disent ou rien)

1982 Si, pour paraphraser Marx, l'histoire advient une première fois comme tragédie, et ne peut se répéter que sur le mode de la comédie, je ne suis pas sûr que cette deuxième fois soit seulement comique. L'effet de répétition me ferait plutôt rire jaune ou 
noir tant me paraît s’y refléter la vérité de ce monde (Paul Thorez, Les Enfants modèles)

1990 - Tu distrais les dames, Hervé ? Tu as du mérite, par cette chaleur...

Jean de Montlaur, toujours mesuré, réussit à apaiser les acteurs, alors que Mathilde riait un peu jaune. Olga, quant à elle, trouvait que ces charmants Montlaur étaient vraiment un joyau qui reflétait la vivacité tranchante des Français, et qu'Hervé était le plus drôle (Julia Kristeva, Les Samouraïs)

II. Être de couleur jaune, briller

Intransitif

1984 Accrochée au bord du matelas pour éviter tout contact avec l'individu, j’ai dormi en rêvant que c'était la guerre. Le soleil riait jaune quand je me suis levée avec des ruses de Sioux pour ne pas réveiller l'inqualifiable (Evane Hanska, Les Amants foudroyés)

CoRpus Web :

L'été frappant à nos portes, le Théâtre de Rougemont s'apprête à ouvrir les siennes. Les Productions Jean-Bernard Hébert nous présenteront cette année L'Invité, une comédie qui promet de faire rire de bon cœur, mais aussi de rire jaune [http://www.lapresse.ca/la-voix-de-lest/ arts-spectacles/201505/27/01-4873159-rire-debon-coeur-et-rire-jaune.php] (17.11.2015)

Les producteurs de mirabelles rient jaune. La cigale ayant chanté tout l'été, se trouva fort dépourvue quand la bise fut venue. Elle aurait mieux fait de faire des bocaux de mirabelles car, cette année, point de tartes ni de confitures pour se [...] [http://www.lunion. com/528489/article/2015-08-14/les-producteursde-mirabelles-rient-jaune] (17.11.2015)

Contre Hollande et le Medef, les communistes voient rouge et rient jaune. VIDÉO. Le PCF a détourné des images d'un film de Bollywood pour camper un Hollande démagogue contre la finance et servile devant le Medef. Ravageur [http://www.lepoint.fr/politique/contrehollande-et-le-medef-les-communistes-voientrouge-et-rient-jaune-28-11-2014-1885384_20.php] (17.11.2015)
Avec les pesticides, les rhizomes rient jaunes

L'application de pesticides organochlorés serait une des causes des rendements décroissants observés dans les récoltes de l'agriculture industrielle. [...] Il en résulterait un enrichissement moindre des sols en azote et des rendements plus faibles pour les cultures qui succèdent aux légumineuses dans les plans de rotation [http:// www.france-science.org/Avec-les-pesticides-lesrhizomes.html] (17.11.2015)

Quand les pages jaunes d'Amazon rient jaunes

Amazon vient à peine d'annoncer ses pages jaunes que les problèmes commencent. Les utilisateurs, improvisés en testeurs, ont déjà révélé de nombreuses imprecisions et incohérences flagrantes dans le moteur de recherche beta, hébergé sur le site A9.com [http://www. nextinpact.com/archive/Quand_les_pages_ jaunes_dAmazon_rient_jaunes.htm] (17.11.2015)

REMARQUES : Rire jaune (I) s'emploie métaphoriquement par rapport à une situation gênante, inconfortable ou contrariante. Le tour se dit du fait de s'efforcer de rire, de rire de manière forcée, le sujet cherchant à dissimuler son dépit ou sa gêne. L'emploi concret (II) réfère à une source lumineuse (ici : le soleil) qui répand une lumière vive, intense et soulignant, par extension, un grand ensoleillement. Notons l'usage de rire noir (exemple de 1982) qui désigne le fait de s'efforcer de rire pour cacher des pensées, plus négatives que dans le cas de rire jaune, pour dissimuler son dépit ou son mécontentement. Prenons également note de l'emploi de voir rouge et noir / rose. Jaune reste invariable dans la majorité des cas, mais dans les deux derniers exemples du CW il s'accorde avec le sujet. Dans le dernier exemple, le sujet est effectivement jaune. Jaune est modifié par le moins, toujours bien, trop, un peu.

\section{Rire large}

Rire à cœur ouvert, bruyamment Intransitif

1874 Il n'est pas vraiment gai, quoique impertinent. On est toujours tenté de lui dire : Ris donc plus large, grosse bête d'homme d'esprit, ris donc mieux que cela (Jules Barbey d'Aurevilly, Lettres à Léon Bloy) 
REMARQUES : Rire large désigne le fait de rire à gorge déployée, franchement, sans retenue, le sujet ne cachant pas son plaisir. Large est modifié par donc plus. VOIR AUSSI : boire raide

\section{Rire lourd}

Rire avec lourdeur

入 rire épais

\section{Rire menu}

rire souvent et menu : rire continuellement Intransitif

+1400 De doulz pensers voz gentilz cuers aisiez, Chantez, dancez pour estre retenu Avec deduit par qui sont acoisiez Tous desplaisirs, et souvent et menu Riez, jouez, soit bon temps detenu, Amours le veult, pour ce nous a descloses (Christine de Pisan, Autres balades / Euvres poétiques [début Xve], I, p. 236, 22)

REMARQUES : Lors d'une manifestation joyeuse, d'une fête, rire menu désignait le fait de laisser exprimer sa joie, son contentement, de manifester un sentiment de gaieté de manière continue, sans pouvoir s'arrêter. Notons l'emploi de menu dans la collocation souvent et menu qui souligne l'idée de fréquence. Menu reste invariable. VoIR AUSSI : pleurer / sangloter menu

\section{Rire niais}

Rire bêtement

Intransitif

1844 il rit niais et se détire en longueur comme s'il avait pour muscles des fils électriques (L’Artiste)

1876 C'était une face de paysan bête, qui riait niais, parlait niais, marchait niais, pensait de même et qui avait eu l'esprit d'appliquer tous ces mérites aux jeux de théâtre (Philarète Chasles, Mémoires)

\section{Rire noir}

Rire d'une manière amère, sombre, à contrecœur, avec réticence $\lambda$ rire jaune

\section{Rire pointu}

I. Avoir un rire de crécelle

Intransitif

1901 - La lettre, votre père l'a gardée, naturellement?

Il rit pointu :

- Il aurait bien voulu ! Mais, moi aussi, je suis adroit, je l'ai reprise, avec une clef qui ouvrait son tiroir

(Colette et Willy, Claudine à Paris)

1950 la Félicienne rit pointu, d'un rire qui donne la chair de poule, comme le grincement d'un diamant sur du verre (Maurice Genevoix, Ceux de 14)

II. Rire d'un rire saccadé Intransitif

1919 - J'ai lu ton livre, lui dit-elle, quand ils furent rentrés. C'est bien toi - Ah!

- Oui, c'est bien toi : ça rit pointu, c'est brave gosse, au fond, mais on n'y comprend pas grand'chose. Sur qui as-tu pris modèle pour ta Belle Dame?

(Henri Duvernois, Edgar)

\section{Rire rouge}

Être rouge d'avoir trop ri

Intransitif

1926 En vérité il n’y a pas de discussion possible avec Mme Blok. Une nuit de noces! Mme Dumont-Dufour éclate. Elle rit jaune, elle rit rouge, elle rit avec la gorge, le nez, la bouche, les yeux (René Crevel, La Mort difficile)

\section{CORPUS WEB :}

Soyez le premier à rédiger un avis sur Le Soleil qui rit rouge ! Merci de rédiger un avis constructif et utile aux visiteurs. Les messages injurieux, diffamatoires ou auto-promotionnels seront supprimés. Votre avis doit être rédigé dans un français correct, en évitant l'abus de majuscules et de signes de ponctuation [http:// www.offi.fr/cinema/evenement/le-soleil-qui-ritrouge-24770.html] (2.11.2015)

REMARQUES : Rire rouge se dit du fait de rire aux éclats, à gorge déployée. Dans cet emploi, la couleur rouge réfère à la couleur du visage sous 
l'effet d'une vive émotion, ici un sentiment ou un état de gaieté. Dans l'exemple du CW, rouge désigne la couleur du soleil. Notons l'usage analogue de rire jaune.

\section{Rire sec}

Rire froidement, de manière cassante, blessante, désobligeante

Intransitif

1894 Vraiment, tu ne t'amuses pas de moi ? Puis, comme Poil de carotte, sans répondre, s’avance, décidé, la main tendue, elle se sauve. Et Poil de carotte entend qu'elle rit sec (Jules Renard, Poil de carotte)

\section{CORPUS WEB :}

Sujet : [Foot] Je ris sec au nez de l'équipe d'Al [http://www.jeuxvideo.com/forums/1-51-63449 791-1-0-1-0-foot-je-ris-sec-au-nez-de-1-equiped-al.htm] (1.11.2015)

REMARQUES : Rire sec réfère au comportement d'une personne dont le rire cassant ou la manière de rire désobligeante connote le désir de blesser, traduit la moquerie ou le mépris vis-à-vis d'autrui, sec fonctionnant en même temps comme intensifieur. $\mathrm{Sec}$ reste invariable.

\section{Rire soef}

I. Se réjouir gentiment, délicatement (de quelque chose)

Pronominal

+1175 Et qant je vos oï retraire

Le mal q'en mer li estut traire

De la serpent dont le garistes,

Et les grans biens que li feïstes,

Et quant il vos requist quitance

De ses gages, si oi pesance

(Ne li vosistes aquiter

Ne l'un de vos l'autre abiter),

Pitié m'en prist an l'arbre sus,

Souef m'en ris, si n'en fis plus.

- Sire, ce m'est mot buen forment

(Béroul, Tristan [4 ${ }^{\mathrm{e}}$ quart XII $\mathrm{e}$, 4048)

II. Rire d'une manière douce et agréable Intransitif

+1365 Or ne vous saroi je pas dire

Le doulc mouvement de sa bouche ;

Il samble qu'elle n'i atouche,

Tant rit souef et doucement

(Jean Froissart, Poésies [3 $3^{\mathrm{e}}$ tiers XIV $\mathrm{XV}^{\mathrm{e}}$ )
REMARQUES : Dans son emploi pronominal, rire soef (I) soulignait le fait de s'amuser de quelque chose, de se réjouir d'un fait ou d'un état gentiment, avec bienveillance. En construction intransitive (II), il réfère à la qualité de la voix et en l'occurrence du rire, se caractérisant par des sons caressants et harmonieux, agréables à l'oreille.

\section{Risquer gros}

Risquer beaucoup, s'exposer à de graves

ennuis

Emploi absolu

1849 Il espère recourir, par ses amis de l'Assemblée, à l'appel au peuple. Il espère sortir du suffrage universel président à vie, consul, ou empereur. Le pauvre homme risque gros et nous aussi, quelque parti que nous prenions. À la garde de Dieu ! mais nous n'avons guère mérité que Dieu nous assiste. Nous avons laissé faire trop de mal (George Sand, Correspondance)

1886 Et Gambetta ? Gambetta a inventé une angine dont il joue chaque fois qu'il y a péril à se prononcer. Cette ficelle ne me va pas, je devine le pantin au bout. Mais ils risquent gros, ceux qui se moquent $d u$ Peuple. Ils ont d'abord des angines pour de rire, puis un jour arrive où on leur scie le cou pour de bon (Jules Vallès, Jacques Vingtras : L'Insurgé)

1907 ROBERT. Le mariage?

COURPIÈRE. Non... oh ! Je ne dis pas que je refuserais une occasion... exceptionnelle... même très jeune... mais c'est risquer gros. Le mariage a toute chance d'être une fin, et je veux bien qu'il couronne ma carrière ; mais, de préférence, une fois que je l'aurai toute fournie (Abel Hermant, Monsieur de Courpière)

1951 La cité comptait une rue goudronnée pour les automobiles et celles-ci risquaient gros en s'aventurant dans les passages herbeux encombrés de chaises longues et de fauteuils, les habitants n'étant guère chatouilleux que sur le problème capital de leur repos (René Fallet, Le Triporteur)

1987 Par terre, le moinillon, adieu. Et là, mazette, quand ça urgeait, quand il avait 
taquiné les colères, quand il risquait vraiment gros, le Zingaro, il savait y faire. Son absence de muscles, dans les allumettes de sûreté qui lui servaient d'échasses, il savait la mobiliser impeccable (Bruno Bayon, Le Lycéen)

1996 Il écouta : Xavier, l'officier de marine ici présent, était un communiste convaincu. « Tu te rends compte? Dans la marine, cette pépinière de hobereaux !» Boris tout seul le savait, murmura : " En effet. » Il crut comprendre que Xavier risquait gros de se rendre chez des communistes. Non découverts, certes, mais qui sait?

(Boris Schreiber, Un silence d'environ une demi-heure)

\section{CoRpus WeB :}

A Alésia, des " archéologues » amateurs risquent gros... après avoir découvert des pièces en or.

En octobre 2012, six archéologues amateurs ont découvert près de 2000 pièces gauloises datant probablement du Ier siècle avant Jésus-Christ à Laignes (Côte-d'Or), près de Dijon. Ils souhaitaient garder le silence sur leur trouvaille mais ont été trahis par les réseaux sociaux [http://www.info-chalon.com/articles/ bourgogne/2015/06/19/14495/a-alesia-desarcheologues-amateurs-risquent-gros-apresavoir-decouvert-des-pieces-en-or] (1.11.2015)

Perte de données : les entreprises risquent gros !

Les failles de sécurité sont nombreuses et de nature différentes. Les entreprises, qui sont responsables des traitements informatiques et de la sécurité des données personnelles qu'elles contiennent, engagent leur responsabilité, notamment pénale, en cas de non-respect des dispositions légales en matière de sécurité des données [http://reprosud.com/sauvegarde informatique_vaucluse] (1.11.2015)

REMARQUES : Risquer gros réfère à une personne qui expose quelque chose à un risque (sa carrière, un poste convoité), qui met son honneur en jeu, risque son existence ou sa tête ou qui s'expose elle-même à des problèmes ou ennuis futurs souvent en enfreignant une règle ou un principe, à des critiques ou remarques d'autrui. Notons aussi son usage dans le titre d'articles (exemples du CW). Gros reste invariable et est modifié par vraiment.

\section{Rompre fort}

rompre haut et fort : rompre ouvertement, à grand bruit

$\pi$ rompre haut

\section{Rompre haut}

Rompre (avec quelque chose) ouvertement, franchement, publiquement

Intransitif

1838 « Je serais une coquette

Plus coquette encor que toi !»

Aime-moi donc, ma Paulette,

Ô mon blond trésor !

Aimer un fat ? Toi, coquette !

C'est comme t'aimer encor !

Hier j'ai rompu haut et net avec des habitudes qui commençaient à m'entortiller dans leur réseau charmé (Jules Barbey d'Aurevilly, Premier Memorandum)

\section{CORPUS WEB :}

Apprenant la nouvelle de sa mort, son père publia un communiqué du même lyrisme que la déclaration d'un homme politique après un attentat dans le métro. Que ne devait-il pourtant à la victime, et d'abord la décision de rompre haut et fort avec les nazis, de rejoindre à l'étranger juifs et libéraux ? [http://www.lexpress.fr/ informations/la-vie-vite_619951.html] (1.11.2015)

Gerhard Schröder peut bien rompre haut et fort avec toutes les formes et convictions du SPD, le parti n'en reste pas moins, à la base, un parti populaire. Et l'idée du nécessaire retour à une pure économie de marché, de moins en moins sociale, est ressentie par beaucoup comme une menace [http://www.courrierinternational.com/ article/1998/04/16/schroeder-ou-le-liberalismepopulaire] (1.11.2015)

REMARQUES : Rompre haut se dit du fait d'interrompre, de cesser une manière usuelle d'être, de sentir ou de faire, du fait de provoquer la rupture de tout ce qui peut constituer un obstacle pour le bon déroulement d'une action, en le faisant savoir à autrui. Notons les collocations haut et net et haut et fort. Haut reste invariable. 


\section{Rompre net}

\section{Casser brusquement}

Transitif

1532 Mais, affin que ne pensez qu'il y ait enchantement, tenez, dist il à Eusthenes, frappez de ce pau tant que pourrez au millieu. Ce que fist Eusthenes, et le fust rompit en deux pieces tout net, sans que une goutte d'eau tumbast des verres (François Rabelais, Pantagruel)

1884 C'était une sorte de colosse en hauteur et en épaisseur [...] mais bon, honnête, et, pour l'instant, prodigieusement intimidé. Il rompit net en s'asseyant, la chaise que lui désignait son altesse, perdit la tête, et ne sut que tourner son chapeau dans ses doigts, tout le temps que dura l'entretien (Élémir Bourges, Le Crépuscule des dieux)

Pronominal

1876 - Fichtre ! Disait à demi-voix M. de Plouguern, il n'est pas tendre, le bon dieu. C'est que j'ai peur de le couper en deux... tu aurais un bon dieu de rechange, petite. Il fit un nouvel effort. La croix se rompit net.

- Ah ! Tant pis ! S'écria-t-il. Cette fois, il est cassé. Rougon s'était mis à rire (Émile Zola, Son Excellence Eugène Rougon)

1902 La locomotive avait tamponné la bicyclette et la poussait maintenant par le garde-boue de la roue arrière ! Quant à la chaîne - car bien entendu le ridicule et insensé personnage n'eût point été capable de mouvoir ses jambes à de telles allures - la chaîne s'était rompue net au choc, et le Pédard pédalait avec jubilation à vide - sans nécessité d'ailleurs, la suppression de toute transmission lui constituant une excellente « roue libre » et même folle - et s’applaudissait de sa performance, qu'il attribuait sans aucun doute à ses capacités naturelles! (Alfred Jarry, Le Surmâle)

1923 - Mais si Daniel, et toi, maman, si vous n’aviez pas toujours attiré ces Thibault à la maison, je ne... je... »

Et sa voix se rompit net (Roger Martin du Gard, Les Thibault. La Belle Saison)
II. Interrompre (une pensée, une tradition, une relation, etc.) brutalement, brusquement Transitif

1653 JAPHET. Mais ne seriez vous point ce maudit renifleur,

Ou du moins le parent de ce mauvais railleur?

Si ce malheureux là m’avoit fait le message,

Je romprois là dessus tout net un mariage, L'Empereur mon Cousin s'en deust-il offencer.

He bien ! la belle Iris, vous pouviez bien penser

Qu'un homme comme moy ne manque point de femme !

(Paul Scarron, Don Japhet d’Arménie)

1883 Jusqu'ici, j'espérais qu'après avoir parcouru le cercle du doute, je reviendrais au point de départ ; j'ai totalement perdu cette espérance ; le retour au catholicisme ne me semble plus possible que par un recul, en rompant net la ligne où je me suis engagé, en stigmatisant ma raison, en la déclarant une fois pour toutes nulle et sans valeur, en la condamnant au silence respectueux (Ernest Renan, Souvenirs d'enfance et de jeunesse)

1913 Il a quitté l'armée, assailli de doutes, écartelé entre son éducation et l'irrésistible besoin d'affranchir sa pensée ; il s'est séparé des siens, rompant net la tradition catholique et royaliste des Allize. Lâpre rancune d'un récent évadé (Roger Martin du Gard, Jean Barois)

1929 Son front se plissait ; un air de méfiance le traversait ; il recommençait sa démonstration jusqu'à ce qu'il eût convaincu ; si l'on cédait, il avait un grave et bref sourire, comme une marque d'estime qu'il accordait. Sinon, il rompait net la conversation. En parlant, il fixait sur son interlocuteur un regard pénétrant, habitué à faire baisser les yeux (Marcel Arland, L’Ordre) 
Intransitif

1656 Elle vous évite et tant soy peu que le soin de sa vertu la tienne, elle rompt net aux secondes hardiesses. Celle qui donne au contraire dépite, se debat, résiste, rougit, impose silence à vos desirs, repousse vos soûpirs, dédaigne vos ardeurs (Michel de Pure, La Prétieuse)

1658 Il alloit à la recharge, mais mon chagrin a prevenu sa civilité, et j'ay rompu si net, que je crois avoir rompu tout à fait avec luy. C'est pour cela que je ne puis assez ressentir le plaisir de cette ruelle (Michel de Pure, La Prétieuse)

1736 CLÉON. Parlez, je vous conjure ; Je vous croirai, peut-être, et je romprai tout net.

Le COMTE. Pouvez-vous différer un si sage projet?

(Philippe Destouches, Le Dissipateur ou L'Honneste Friponne)

1853 C'est tout, je ne lui dis pas plus. Si vendredi, dans l'article du Philosophe, il y a ton nom accompagné d'injures ou d'allusions, je ferai ce que tu voudras. Mais quant à moi, je me propose de rompre net et dans une belle lettre motivée (Gustave Flaubert, Correspondance)

1921 - Je ne te le dirais pas ? interrompit-il. - Mais si, je te le dirais. Je suis pour rompre tout net, moi, quand on n'aime plus. Je n'ai pas peur que tu m'envoies une balle ou du vitriol avec ce petit bijou de main, - et il la lui baisait - qui ne ferait pas de mal à une mouche (Paul Bourget, Un drame dans le monde)

1981 Je rompis net avec mes amies : elles voulaient aller au martyre pour Madame Guyon et je voyais chaque jour combien j'avais été trompée par ces gens à qui je donnais ma confiance sans avoir la leur (Françoise Chandernagor, L’Allée du roi)

\section{CORPUS WEB :}

Le Rod a tendance à rompre net, sans prévenir. Pour plus de détails, consultez le test comparatif des gréements dormants réalisé dans le numéro de septembre de Voiles et Voiliers [http://www.voilesetvoiliers.com/popup/media_ id=30672] (1.11.2015)

Leur serres sont munies de longs doigts capables d'accrocher d'autres oiseaux en vol et leur bec doté d'une petite excroissance est redoutable, il arrive à rompre net les vertèbres des oiseaux attrapés [http://www.ariegenews.com/ ariege/agriculture_environnement/2011/40394/ la-chasse-au-vol-tout-l-art-de-la-fauconnerie. html] (1.11.2015)

Mais un tendon affaibli peut également se rompre net chez des personnes plus jeunes. Cette rupture peut se produire à l'occasion d'une chute ou d'un effort intense [https://www. facebook.com/CabinetDrIbtissamAMarrakech/ posts/625921800752991] (1.11.2015)

La pale rouge avait quelque chose de particulier en ce sens qu'elle s'est rompue nette au tiers de sa longueur à partir de l'emplanture [http://www.tsb.gc.ca/fra/rapports-reports/ aviation/2000/a00p0208/a00p0208.asp] (1.11.2015)

Et bien alors, cette essence, l'aurais-je promise à d'autres ? aurais-je été tenté ? aurais-je seulement pu l'être ?... et par quoi ? et par qui ? qui est encore là ? il n'existe plus grand chose ici et rien qui puisse encore se partager. Pas même ces souvenirs qui ne concordent plus. Sans malice, en posant bien les termes, je peux affirmer que ne me suis jamais balancé sans rompre nette la corde. Las, je décline invariablement toute invitation sans pour autant réussir à prévenir les accidents [http://pegeco.free.fr/blackdiary2.0] (1.11.2015)

REMARQUES : En rompre net (I), le sujet du verbe pronominal ou l'objet direct du verbe transitif désigne un objet qui se casse ou se brise d'un coup en deux ou plusieurs parties sous l'effet d'un choc. Au figuré, le sujet peut désigner la voix de l'homme qui cesse de se faire entendre, ce dernier arrêtant brusquement de parler, par gêne, timidité ou peur. Lorsque l'objet désigne une habitude, un usage ou une tradition (la tradition catholique), rompre net (II) se dit du fait d'interrompre de manière soudaine, de cesser brusquement une manière usuelle d'être, de sentir ou de faire, de provoquer la rupture de tout ce qui peut constituer un obstacle pour le bon déroulement 
d'une action. L'objet peut aussi référer à un accord juridique qui n'est subitement plus respecté par l'une des parties. Lors d'un échange, d'une discussion, il se dit du fait d'arrêter ou d'interrompre brusquement la conversation. Lorsque l'objet désigne une personne, il signifie 'mettre fin à une liaison, se séparer, mettre un terme à une relation amicale'. Net reste invariable dans la majorité des cas. Toutefois, dans les deux derniers exemples du CW, il s'accorde tout en gardant son interprétation adverbiale. Il est modifié par si, tout.

\section{Ronfler bas}

Produire un ronflement faible et indistinct Intransitif

1846 Tandis que la bouilloire, éveillée à demi, Ronfle tout bas auprès du tison qui s'embrase,

Et que le feu charmant, tout à l'heure endormi,

Mélange l'améthyste avec la chrysoprase (Théodore de Banville, Les Stalactites)

1939 JEANNE. Toutes les mains de la France en une seule main ! Une telle main qu'elle ne sera plus divisée!

VOIX EN BAS. Com-bu-ra-tur i-gne ! (très lent et ronflant très bas)

(Paul Claudel, Jeanne d'Arc au bûcher)

\section{CORPus Web :}

la avec bébé qui bouge tout le temps mon z'hom qui ronfle bas je ne trouve pas le sommeil, je dit de nouveau bonjours au insomnies de jour en jour, je ne supporte plus !! Y me faut un truc ou je vais finir par craquer !! [http://forum. doctissimo.fr/grossesse-bebe/grossesse-libre/ mamans-papotter-recrute-sujet_201471_152.htm] (01.11.2015)

REMARQUES : Dans le premier exemple, ronfler bas réfère à un objet qui produit un léger bruit sourd et régulier, comme le bruit d'une bouilloire par exemple. Lorsque le sujet renvoie à une voix, une parole, il souligne le son très faible et peu perceptible des mots prononcés, le manque de distinction. Dans l'emploi concret, il réfère aux sons rauques produits pendant le sommeil (v. l'exemple du CW). Bas reste invariable et est modifié par tout, très.

\section{Rouer vif}

Tuer un être vivant par le supplice de la roue

$\lambda$ écorcher vif

\section{Rouler bas}

I. Atteindre un niveau (social, moral) bas, peu élevé

Intransitif

1842 Comment dire ton nom, ton nom, géant Homère !

Qui dominas du front cette Grèce ta mère, Et qui, roulant tout bas, spectre pâle et hagard,

Ta prunelle d'azur, sans flamme et sans regard,

Laissas couler un jour de ta main

gigantesque

Toute l'antiquité, comme une grande fresque!

(Théodore de Banville, Les Cariatides)

1868 Maintenant, nous sommes enfermés ici, au fond de cette retraite sinistre, de ce dernier asile digne de notre folie. Si nous en sortons tous deux ce sera pour rouler plus bas, pour mener une vie plus infâme et plus lâche... est-ce vrai ?

- C’est vrai, répondit Guillaume

(Émile Zola, Madeleine Férat)

1884 Nous t'avons pris ton argent, je l'ai gaspillé comme un imbécile, et voilà maintenant que je roule assez bas, pour que tu me fasses l'aumône de ma parole, pour que tu me la rendes par pitié, comme à un homme sans courage et sans honneur (Émile Zola, La Joie de vivre)

1907 - On douterait parfois, monsieur, à vous entendre, que vous soyez allemand.

Ce mot vengeur, tombé de si haut, ne manqua point de rouler très bas; et tous ceux qui croyaient avoir des sujets de ressentiment contre Christophe, soit à cause de ses succès, soit pour quelque autre raison plus personnelle, sinon plus cuisante, ne manquèrent point de rappeler qu'en effet il n'était pas un pur Allemand (Romain Rolland, Jean-Christophe. La Révolte) 
1910 Christophe avait entendu parler d'elle chez Gamache, avec une admiration brutale, comme d'une fille très libre, intelligente et hardie, d'une énergie de fer, brûlée d'ambition, mais âpre, fantasque, déroutante, violente, qui avait roulé très bas avant d'en arriver à sa gloire présente, et qui se vengeait, depuis (Romain Rolland, JeanChristophe. Les Amies)

II. Produire des sons graves, bas ou faibles, très légers

Intransitif

1929 Elle laissa retomber sa tête sur les genoux de Fanny et sanglota brutalement, tandis que les premiers éclats d'un orage roulaient bas et doucement, rejetés de cime en cime par les échos de petites montagnes (Colette, La Seconde)

1959 Maintenant elle crie pour ses petits : ses piaulements ne sont plus les mêmes, roulés tout bas, d'une infinie douceur. Duvetés de blanc, gourds encore, les jeunes condors culbutent vers elle. Son bec les frôle, les pousse, les ramène tendrement vers le nid (Maurice Genevoix, Routes de l'aventure)

\section{CORPuS WeB :}

Oui, rouler bas c'est un peu comme monter sur un ring en tutu et talons aiguilles ! Ne jamais tourner le dos à son adversaire et anticiper tous ses gestes ... Sinon, on le paye cash ... Mis à part que sur la route, chaque détail saillant devient votre ennemi ... Plaques d'égout, dos d'âne, trous, décrochés d'asphalte ... Un raté, et il faut croire que le châssis est directement relié avec votre sphincter ... Si, vous avez remarqué lorsque vous voyez l'obstacle trop tard, au moment où il s'engage sous la voiture, à quel point on a tendance à serrer les fesses en attendant le craquement, frottement ou le fameux « clonk » des amortos rapidement en butée, laissant penser qu'on vient de laisser les trains roulants sur la route ?! Terrible ... [http://delessencedansmesveines. com/2014/10/bmw-e30-ca-frotte-cest-cest-dropevideo] (28.10.2015)

Est ce que je peut passer en 180/65 R14, niveau tenue de route ? passage au CT ? et est-ce que mon moteur ne va pas monter trop vite dans les tours ? et surtout je n'en ai pas trouvé en renforcé Quels pneus avez vous pour ceux qui roulent bas en jante d'origine ? merci pour vos infos ;) [http://www.vw-camper.fr/viewtopic. php?f=67\&t=24680] (28.10.2015)

REMARQUES : Rouler bas (I) réfère à une personne qui tombe ou est tombée dans un état de déchéance, qui se retrouve dans une situation dégradante, méprisable. Sous (II), le sujet désigne un bruit ou un son (un fracas, le son d'une locomotive, le piaulement d'un animal), caractérisé par des vibrations ou oscillations qui se font entendre, se prolongent dans l'espace. Par extension, le sujet peut aussi renvoyer à une parole, un mot qui circule ou est employé avec une connotation négative ou provoquant un effet très négatif. Dans le domaine automobile, qui est sans doute le sens le plus courant, le groupe désigne le fait de rouler avec une voiture dont le châssis est bas (CW). Bas reste invariable et est modifié par assez, plus, tout, très.

\section{Rouler caverneux}

Produire des sons caverneux, des bruits sourds et rudes

$\lambda$ rouler lent

\section{Rouler chic}

Rouler dans une belle voiture, un modèle chic $\lambda$ rouler économique

\section{Rouler droit}

Rouler en ligne droite

Intransitif

1885 La berline d'Étienne venait de dérailler, au passage le plus difficile. Il n'arrivait point à rouler droit, sur ces rails qui se faussaient dans la terre humide

(Émile Zola, Germinal)

\section{CORPUS WEB :}

Le pouce empêche à la boule d'êtrre de rouler droit, c'est à dire qu'il donne un effet, or pour un contrôle optimum il faut pouvoir l'envoyer droite. Et dans certaines situations, adapter son geste pour y mettre un effet [http://www.boulistenaute. com/modules/forum_supporters/viewtopic. php?topic_id=4096\&viewmode $=$ compact\&order $=$ ASC $\&$ type $=\&$ mode $=0 \& s t a r t=24](24.3 .2015)$ 
A la fin de la cérémonie, les mariés roulent droit direction le Domaine de Quincampoix pour faire la fête jusque tard dans la nuit. Je les isole quelques minutes à leur arrivée pour faire des photos d'amoureux avant qu'ils retrouvent leurs amis et famille pour de belles suprises [http://juliettaphotography.com/ mariagedomainequicampoix] (28.10.2015)

Oui, la route, et la trajectoire de ces Volvo est exemplaire. Si JC Vandame tient stable, c'est bien que les camions roulent droits [http://buzzvideos-rire.com/2013/11/buzz-pub-jean-claudevan-dame-fait-un-grand-ecart] (28.10.2015)

Oui mais Nikola précise « position un peu en arrière » or tout ce qui est lunette masque visière est conçu pour une position " un peu en avant» notamment en vélo tête baissée pour ne pas dire la tête dans le guidon, mes 3 casques à visière sont générateurs de courant d'air dans les yeux !, car je n'ai pas la position du coureur, Il faudrait voir comment les néerlandais gèrent cette question car ils roulent droits en général [http://cyclurba. fr/forum/337159/oi-choisir-masque-ski-pour-vnlo-rapide.html?discussionID=15217] (28.10.2015)

REMARQUES : Rouler droit réfère à une personne qui conduit un wagonnet en suivant les traces des rails, ou un véhicule en le manœuvrant de manière à ne pas dévier, en ligne droite. Dans le premier exemple du CW, il s'agit d'une boule qui roule droit. Cet exemple est intéressant du point de vue grammatical : accord et invariabilité coexistent dans le même contexte, l'accord se produisant uniquement dans la structure syntaxique « pronom objet direct + verbe + adjectif-adverbe » qui favorise l'accord (v. Introduction $\S$ 4.6). Dans le troisième exemple du CW, droit s'accorde avec le sujet au pluriel tout en gardant son interprétation adverbiale, tandis que dans le dernier exemple, il occupe une fonction de prédicat second désignant la position du cycliste.

\section{Rouler économique}

Rouler en dépensant le minimum Intransitif

1982 On roule chic, on roule sympathique, on roule économique. Et pratique aussi. Avec sa traction avant et ses voies larges, la nouvelle Fiesta fend l'autoroute, se glisse en ville et se cramponne dans les virages (Zoo Anvers [publicité])
2013 Pour venir, comme j'ai pas le sou, j'ai roulé économique avec des gens que je connais même pas : on a fait du covoiturage (Exemple entendu, Corpus Coiffet 2018 : s.v.)

\section{Rouler électrique}

Utiliser un moyen de transport avec moteur à

alimentation électrique

Intransitif

$2009 \mathrm{Al}$ Gore croit qu'on peut tous rouler électrique demain matin (Dominique Nora, Les Pionniers de l'or vert)

\section{Rouler facile}

Utiliser sa voiture sans avoir des problèmes, sans se soucier

$\lambda$ bronzer idiot, Remarques

\section{Rouler grave}

Rouler beaucoup, vachement, sacrément

Intransitif

CoRpus Web :

JE ME suis eclater a escssefort super terrain pas de pluie en gros super spectacle ca rouler [= roulait] grave surtout en ligue buffard et couder ete en forme en nat $b$ remy dulinge a mis tous le monde a la page genial quoig [http://competition. $\mathrm{mx} 2 \mathrm{k} . \mathrm{com} / \mathrm{fr} /$ forums/discussion-generale/superdimanchce-escssefort-pur-quelque-resultat-allezvoir-qui-rouler] (28.10.2015)

Je démarre, mets les pleins phares pour rouler, rouler grave [http://www.rap2france.com/ paroles/113-accelere.html] (28.10.2015)

Merci.

Je ne connaissais pas netcat. C'est exactement ce que je cherchais.

$>$ Eh oui, Unix, c'est puissant :-)

C'est clair que sous l'autre OS je n'aurais même pas osé imaginer.

Il ne me reste plus qu'a implémanter un HDLC simplifié côté microcontrolleur et côté linux et ça va rouler grave.

$\mathrm{Du}$ genre recopier un mot d'une console à une autre en calculant au moins 4 CRC :-/ [http://linuxfr.org/forums/linux-general/posts/ bidouille-connecter-un-port-serie- $\% \mathrm{C} 3 \% \mathrm{AO}$-unport-tcp] (28.10.2015) 
Je ne défends absolument pas les 3 gros mais Vincenzo a raison sur au moins 1 point : hors professionnels nous n'avions pas BESOIN de portable. Après une fois la main mise dans l'engrenage on s'est fait rouler grave [http:// www.generation-nt.com/bouygues-telecom-freemobile-plainte-denigrement-actualite-1668862. html] (28.10.2015)

REMARQUES : Rouler grave désigne le fait de fonctionner bien, avec pleine puissance. Grave est un intensifieur en vogue dans le langage des jeunes. Dans le dernier exemple du CW, se faire rouler grave signifie 'se faire avoir « en beauté »'. Notons l'emploi impersonnel familier ça va rouler grave. Pour rouler grave, au sens de 'produire des sons sourds et graves, des sons très bas', v. rouler lent.

\section{Rouler lent}

I. Se déplacer lentement, doucement; couler tranquillement

Intransitif

1904 Quelles sont ces images qui pénètrent l'enfant d'un trouble passionné ? Jamais il ne les avait vues ; et pourtant il les connaissait : il les a reconnues. D'où viennentelles ? De quel gouffre obscur de l'être ? Est-ce de ce qui fut... ou de ce qui sera ? Maintenant, tout s'efface, toute forme s'est fondue... une dernière fois encore, à travers un voile de brume, apparaît, comme si l'on planait très haut, au-dessus de lui, le fleuve débordé, couvrant les champs, roulant auguste, lent, presque immobile (Romain Rolland, Jean-Christophe. L'Aube)

II. Produire des sons qui se propagent à un rythme lent

Intransitif

1966 Enfin, inexorable, la musique alla s'écraser au fond d'un gouffre creusé bien loin sous terre, et le fracas de tonnerre roula si bas, si grave, si terriblement caverneux et lent que ce fut comme si le bruit était prêt à se métamorphoser en silence (Jean-Marie Gustave Le Clézio, Le Déluge)

\section{CORPus WeB :}

fait ton interessant deja 2 qui son ok, avec moi , on peut rouler a vitesse base, les voiture roulant plus vite on le millieu et la 3 eme file, comme dans tous les paye, apart les exeption de rouler sur une autre file, mais la pratique reste la meme ta une file pour rouler « lent " [http:// forums.france-hardware.com/discussion/ general-divers/sujet-26046-20.html] (28.10.2015)

Elle est vraiment débile, plus les gens roulent lent, plus le nombre de voiture augmente !

Regarde les bouchons, ils roulent doucement et ça créé encore plus de bouchon * [http://www.jeuxvideo.com/forums/42-100001940492083-1-0-1-0-royal-veut-mettre-en-place-90km-h-autoroute.htm] (28.10.2015)

la cb honda est sympa et represente mieux le style de becane du club que la gold (qui amenerai des harley et autre roulent lent et frime, radio embarquée) ou la cbr (des gars encore plus fous) et la derniere et esthetiquement moins top (a mon gout) [http://armoto34.xooit.fr/t233-LOGOARM.htm?start=30] (28.10.2015)

REMARQUES : Rouler lent (I) réfère à un cours d'eau, un liquide (le fleuve) qui s'écoule doucement, dans un mouvement peu rapide, donnant une impression de calme et de douceur. En (II), le sujet désigne un bruit, un son (fracas du tonnerre) qui se propage dans l'espace à un rythme lent. Notons les adjectifs-adverbes bas, grave et caverneux. Rouler caverneux renvoie au fait de produire des bruits sourds et rudes, le sujet ayant une profonde résonance physique. Mentionnons l'emploi de rouler frime. Lent reste invariable et est modifié par si.

\section{Rouler malin}

Utiliser sa voiture de façon efficace et réfléchie, sans tomber dans les pièges

$\lambda$ bronzer idiot, Remarques

\section{Rouler mordant}

Rouler avec des pneus qui ont du grip Intransitif

1983 Le nouveau pneu Michelin roule mordant pendant tout l'hiver (Radio Monte Carlo, 18.2.1983 / Hagège 1987 : 45)

\section{Rouler petit}

Conduire de petites cylindrées

Emploi absolu

1961 Pourquoi vous roulerez " petit » (Lettres françaises, 28 octobre 1961 / J. Giraud) 


\section{CORPus WeB :}

\section{Bonjour Denis,}

ces voiles je les aient tes té avec du vent a plus de $60 \mathrm{~km} / \mathrm{h}$ en les laissant genre drapeau c'est te dire que ca les secouent, pour le moment ça fait deux an que je m'en sert et en transport je ne les menagent pas ca fait partie du test ! je les roulent mais jamais pliée ! [...]

\section{Re Denis,}

je te met une photo pour que tu te rende compte que je les roulent petit fait pas attention au bazard !!!! [http://modelismenavalradioc. nouvellestar6.com/t11529p15-fabrication-devoile] (28.10.2015)

REMARQUES : Rouler petit s'applique à une personne qui se déplace, circule au moyen d'un véhicule dont la puissance des cylindres est faible. Retenons dans le CW l'emploi résultatif du verbe transitif avec le sens de 'rouler de façon à réduire au maximum la taille'.

\section{Rouler pratique}

Rouler avec une voiture fonctionnelle

$\lambda$ rouler économique

\section{Rouler profond}

I. Couler profondément, en profondeur Intransitif

1831 Philippe et Henri, libéraux et royalistes, tout cela n'est qu'un cri, un flot, une écume qui court sur la surface des eaux, tandis que le fleuve roule, immense, profond, vers l'océan promis. Prenez en dessous toutes les doctrines humaines qui retentissent dans le monde ; que trouvez-vous?

(Maurice de Guérin, Correspondance)

1893 Toutes les nations ont une métaphore pour exprimer cette idée qu'il n'est pire eau que l'eau dormante. Les eaux tranquilles roulent profondes, - disent les Anglais, et les Italiens : - les eaux tranquilles ruinent les ponts (Paul Bourget, Cosmopolis)

II. Rouler en produisant des sons graves, bas Intransitif

1879 Aucun train ne sillonnait l'espace; l'on entendait seulement au loin, près de la gare de Ceinture, une machine qui ululait et semblait sangloter dans l'ombre ; parfois des bouffées de vent s'engouffraient dans les fils du télégraphe et les faisaient vibrer avec un aigre cliquetis qui s'éteignait lamentable comme une plainte, puis la voix des locomotives en partance roulait, profonde et basse (Joris-Karl Huysmans, Les Sœurs Vatard)

\section{CORpus WeB :}

non non, justement, jsuis aller a paris pour l'acheter... C T en période de noêl... Bon bah selon vous je me suis fait rouler profond C ca ? :'( [http://www.guitariste.com/forums/guitare,qqun-connait-le-prix-d-une-chevy-copie-lespaul-de-63,53801.html] (28.10.2015)

REMARQUeS : Le sujet de rouler profond (I) désigne un élément de la nature, un cours d'eau (le fleuve), un liquide qui est profond et immense. Dans un emploi métaphorique, le sujet renvoie à un courant idéologique ou à une idée. Rouler profond (II) réfère à un bruit, un son bas et grave (le son d'une locomotive), caractérisé par des vibrations ou oscillations se propageant dans l'espace. Dans l'exemple du CW, rouler prend l'acception de 'se faire tromper, se faire avoir'. Dans les acceptions (I) et (II), profond tend à s'accorder avec le sujet en tant que prédicat second, tandis que sa fonction dans le CW est plutôt adverbiale (profondément).

\section{Rouler propre}

Utiliser sa voiture sans mettre en péril

l'environnement

$\lambda$ bronzer idiot, Remarques

\section{Rouler sympathique}

Rouler dans un véhicule qui inspire la sympathie $\pi$ rouler économique

\section{Rouler tranquille}

Rouler sans vitesse excessive, sans se presser ; utiliser sa voiture sans se faire des soucis $\lambda$ bronzer idiot, Remarques 


\section{Saillir beau}

Se précipiter (vers quelqu'un) de manière aimable, avenante, accueillante

Intransitif

+1200 Et, quant le prior le choisi,

En contre lui mout biau sailli ;

Bel l'apela, sel fist descendre.

Puis si a fet son cheval prendre

(Le Chevalier qui fist sa fame confesse, 54)

RemARQUes : Saillir beau désignait le fait de se précipiter vers quelqu'un pour l'accueillir avec joie et amabilité. Beau est un prédicat second, à la différence de bel, au troisième vers, qui fonctionne comme adverbe de manière. Beau est modifié par moult.

\section{Saillir dru}

Sortir, s'élancer avec vigueur, avec énergie et en grand nombre

Intransitif

1544 A ce propos ma musette pendue

Est à un croc inutile rendue ;

Musette dy, laquelle au moindre son

Souloit jadis dresser une chanson, Que je sonnois d'un si ardent courage, Qu'à ce hault son ceux de nostre village Sailloient plus dru, plus legier et plus viste Que ne fait pas le lievre de son giste, Quand par veneurs et courantes levrieres Est poursuivy en ces larges bruyeres (Clément Marot, La Complaincte d'un pastoureau chrétien)

REMARQUeS : Saillir dru se disait du fait de sortir d'un lieu, de s'élancer vivement et en grand nombre. Saillir avait aussi le sens de 'danser en sautillant' ce qui pourrait convenir avec le son de la musette, mais pas avec la comparaison avec le lièvre. Notons la mise en série des adjectifsadverbes dru, léger et vite, le second désignant la souplesse ou la délicatesse du mouvement, le dernier la rapidité. Dru, léger et vite restent invariés et sont modifiés par plus. Notons qu'au $\mathrm{XVI}^{\mathrm{e}}$ siècle vite assumait encore les deux fonctions, adjectivale et adverbiale.

\section{Saillir léger}

Sortir, s'élancer avec légèreté, agilité

त saillir dru

\section{Saillir vite}

Sortir, s'élancer rapidement

入 saillir dru

\section{Saluer bas}

Saluer (quelqu'un) en s'inclinant, en se penchant vers le sol, avec beaucoup de respect Transitif

+1400 Adonc vers cellui me meine Qui Dieu doint bonne sepmaine, Et je humblement m'encline Devant lui la chiere cline, Si le saluay tout bas, Mais cellui fist un grant pas Et tost relever me vint (Christine de Pisan, Le Dit de la pastoure / Euvres poétiques [début $\mathrm{xv}$ ]e, II, p. 241, 589)

1675 M. Foucquet a été interrogé ce matin sur le marc d'or ; il y a très bien répondu. Plusieurs juges l'ont salué. Monsieur le chancelier en a fait reproche, et dit que ce n'était point la coutume, et au conseiller breton : " c'est à cause que vous êtes de Bretagne que vous saluez si bas M. Foucquet » (Mme de Sévigné, Correspondance)

1713 Je ne restai qu'un moment à genoux, je me relevai, é sans regarder toute la digne Assemblée, je saluai fort bas la prétenduë Religieuse qui ne branla pas, et ne leva pas même les yeux (Robert Challe, Les Illustres Françoises)

1736 chaque domestique lui fit la cour à sa maniére ; les servantes le saluoient plus bas que leur maître ; tout étoit attentif à lui plaire ; jamais la maison n’avoit été si reglée (Pierre de Marivaux, Le Télémaque travesti)

1830 LES MÊMES, LA MARÉCHALE, SUITE. (dégageant, à Luynes, dans un coin de la scène) Si elle fait arrêter le prince de Condé, elle est perdue. Il est trop aimé du peuple de Paris pour que cela ne soulève pas une émeute.

(à part)

Cependant son coup peut réussir.

Faisons-lui la cour. 
(Il va saluer bien bas la maréchale, et lui dit :)

Madame ! voici le jour de la fermeté. Ne faiblissez pas devant les factieux. Vous avez l'oreille de la reine, mais il faut de la vigueur

(Alfred de Vigny, La Maréchale d’Ancre)

1858 À travers cette foule s’avançaient [...] des personnages recommandables, à la poitrine décorée de gorgerins honorifiques, que saluaient très bas les esclaves en mettant leurs mains près de terre (Théophile Gautier, Le Roman de la momie)

1881 Le curé, avant de partir, confia timidement à Pécuchet qu'il ne trouvait pas convenable ce simulacre de tombeau au milieu des légumes. Hurel, en se retirant, salua très bas la compagnie. M. Marescot avait disparu après le dessert (Gustave Flaubert, Bouvard et Pécuchet)

1893a Il se sentait vieux, fatigué, cassé, comme jamais. Et quand, avant de sortir dans ces rues où les passants le saluaient déjà moins bas, il se mit, par habitude, à brosser lui-même sa pauvre redingote noire jamais renouvelée, un découragement le prit, de cela comme de tout le reste (Pierre Loti, Matelot)

1893b Mon Dieu, ce n'était pas encore de l'épouvante, mais tout de même on commençait à s'émouvoir, à le saluer étrangement bas quand on le croisait dans l'escalier. Tel qui, naguère, rendait bien juste son coup de chapeau à ce pauvre diable humble et propre, pénétré de sa petitesse, le comblait de sourires à présent (Georges Courteline, Messieurs les ronds-de-cuir)

1902 Le baron remit sous son bras le paquet et s'approcha de ces demoiselles au moment où Jacquette venait d'endosser une verte semonce, pour s'être montrée incapable de citer dans leur ordre les trois vertus théologales.

- Mademoiselle ! dit-il, en saluant Jacquette aussi bas que possible, je vous fais bien mes compliments, car une fille vous est née (René Boylesve, La Leçon d'amour dans un parc)

1928 Aussitôt, je bondis, traversai le vestibule ; le magnifique Indien chargé de faire le café et de saluer bas les clients, m'indiqua du doigt, non sans découvrir ses dents blanches en un rire entendu, le " gentleman » qui s'épongeait le crâne, là-bas, sous un palmier du hall (Jacques-Émile Blanche, Mes modèles : souvenirs littéraires)

1961 Roger salua l'évêque bien bas, comme il convenait, et dit : " Mes très chers et nobles seigneurs, ne vous étonnez pas de ma brutalité, car vous avez devant vous un homme égaré par la douleur et qui vient réclamer justice ou miséricorde " (Zoé Oldenbourg, Les Cités charnelles)

1996 Avec ses cheveux permanentés, elle dépassait grand-père. Tous, nous disparaissions sous elle. Bien qu'elle fût une dame respectable du quartier et que chacun la saluât très bas, j'avais confusément la sensation d'un trop de force qui se dégageait d'elle, spécialement lorsque je regardais ses grands pieds déformés par les chaussures pointues (Pascale Roze, Le Chasseur zéro)

Intransitif

1762 ROXELANE. Oui, ce sont les objets que votre cœur désire :

Saluez donc. (Soliman salue) Plus bas. (Il salue plus bas)

Fort bien : vous y voilà

(Charles-Simon Favart, Les Trois Sultanes ou Soliman II)

1817 Les sénateurs et les députés portaient encore le même uniforme que l'empereur Napoléon leur avait donné ; ils faisaient les mêmes révérences, en se tournant vers l'orient au lieu de l'occident ; mais ils saluaient tout aussi bas que de coutume (Germaine de Staël, Considérations sur les principaux événements de la Révolution française) 
1830 LE PRINCE DE CONDÉ. Si tous ces gentilhommes sont mes amis, à la bonne heure ; mais autrement...

THÉMINES (saluant encore plus bas) Autrement je dirais : Ce n'est jamais assez contre monseigneur

(Alfred de Vigny, La Maréchale d'Ancre)

1884 - Princesse, dit Marcoux en se levant, je regrette que vous ne soyiez pas des nôtres. Moi, je crois en mon idée, et croire en son idée, a dit quelqu'un, c'est là le génie.

Il salua très bas et sortit (Joséphin Péladan, Le Vice suprême)

1907 Ce fut Mehmed Djaleddin pacha qui entra. Piali bey le conduisait, lui prodiguant révérence sur révérence. De toutes parts, les gens s'empressaient. Deux ambassadeurs accoururent et saluèrent bas. Le vieux duc de Villaviciosa, dont les soixante-quinze ans ne se dérangent guère que pour des princes, vint $\mathrm{du}$ fond $\mathrm{du}$ salon tendre la main au maréchal (Claude Farrère, L'Homme qui assassina)

1936 Car, d'après sa manière de vivre, de prier, d'oser, de mépriser, je comprends qu'il ne craint rien du tout, ou disons qu'il ne veut rien craindre du tout de ce que les hommes craignent communément, pauvreté, humiliations, et choses de ce genre, et qu'il craint au contraire ce que personne ne craint communément, à savoir l'intime déshonneur qui vient de trahir, de flatter, de saluer trop bas (Alain, Propos)

\section{CORPUS WEB :}

Un engagement à saluer bas, car les difficultés économiques et politiques prévalant en Afrique ont découragé non seulement beaucoup d'artistes, mais aussi nombre d'hommes d'affaires, de rester là-bas et d'y investir [http://www. humanite.fr/node/202637] (28.11.2015)

Il faut saluer bas ce surprenant travail d'Ari Folman, intime et inventif, qui fait magnifiquement planer sur ce doc-animé une considérable puissance thérapique [http://www.allocine.fr/ membre-Z20030227083225763932645/critiques] (28.11.2015)
Ensuite il faut saluer bas la performance de l'homme qui écoute à l'oreille des écoutes, aussi prompt à se jeter d'un bord à l'autre que d'un tabouret au comptoir, et c'est pas peu dire [http://spitbulles.canalblog.com/ archives/2005/11/23/1022862.html] (28.11.2015)

REMARQUES : Saluer bas s'applique à un animé qui s'incline, se penche vers le bas en guise de salut lorsqu'il aborde, rencontre ou prend congé d'une personne envers laquelle il manifeste un certain respect, de la considération, en raison de son âge, de sa position sociale, de sa valeur ou de son mérite. Les exemples du CW mettent en évidence la tendance à ne plus conserver que l'emploi au figuré dans l'acception 'respecter profondément'. Bas reste invariable et est modifié par aussi, bien, déjà moins, encore, étrangement, fort, plus, si, tout, tout aussi, très, trop.

\section{Saluer bel (beau)}

Saluer courtoisement, comme il convient, de manière aimable, avenante, gracieuse Transitif

1175 Illes descent et monte as estres ; Ele est encontre lui venue. Li uns l'autre mout bel salue (Gautier d’Arras, Ille et Galeron, 3330)

1230 Où que il voit Guion, parfont l'a encliné, En son sarasinois mult biau l'a salué : Sire, Diex vous garisse où vo créance avés! (Gui de Bourgogne, p. 84)

1250 Le duc Girart sus el palés trova, Ou beter fait .i. grant ors que il a. Es vos le més, qui biau le salua [variante : qui bel le salua; manuscrit $\mathrm{B} 1$, première moitié XIV ${ }^{\mathrm{e}}$

De par Jesu qui le mont estora, Et de par cele qui a lui l'envoia. Puis li a dit, que mot ne li cela, Ce que la dame li dist et devisa (Aymeri de Narbonne [milieu XIII'], 3845)

1275 Quant li messages ot son afaire apresté, Au roi Pepin s'en va, n'i a plus arresté ; Bel et courtoisement a le roi salué Et de par le roi Floire li a le brief donné (Adenet le Roi, Berte aus grans piés, 1608) 
1285 As trois puceles fist salus, Quant saluee ot la roÿne Et que baisie ot Clarmondine ; Les autres dames salua Bel et a point ; mout agrea A chascun quanques en lui voient (Adenet le Roi, Cleomadés, 16384)

-1334 Lors en la sale va entrer Le Chevalier Faé qui vint ; $\mathrm{Tou}[\mathrm{t}]$ droit au roy sa voie tint, Molt bel le prist a saluer Et li dist : Sire, bien prisier Vus vos deves certainnement ; Quar en ce monde nullement N'[i] a pas .i. si vaillant hon Con le Chevalier au Lyon (Le Romans de la dame a la lycorne [ $1^{\mathrm{er}}$ tiers XIV $]$, 8355)

+1350 Quant Bruns les dames vit, si les a salué Bel et courtoissement, si c'om l'ot doctriné ; Elles ont respondu par tres fine amisté (Brun de la Montaigne [2 $2^{\mathrm{e}}$ moitié XIV $]$, 3590)

1450 JOSEPH. Encor ne suis je pas content, De plainte que je saiche faire, Jusqu'a ce qu'a ton doulx vïaire En aray requis le pardon. Marie, pour vostre guerdon, D'un bon jour et beau vous salue (Arnoul Gréban, Le Mystère de la Passion, 4238)

REMARQUES : Saluer bel se disait en ancien français du fait d'honorer quelqu'un que l'on aborde ou que l'on rencontre avec déférence, la manière de saluer, en gestes ou en paroles, étant empreinte de politesse raffinée, d'amabilité et de gentillesse et mettant en avant un comportement en société qui correspond à l'idéal, à l'éthique de la chevalerie du Moyen Âge. L'emploi du neutre bel étant la règle, la première attestation au masculin de 1230 surprend, mais l'auteur cherche peut-être un effet d'emphase, insistant sur la beauté (aussi dans l'exemple de 1250). Par contre, l'exemple de 1450 marque déjà le passage à l'emploi du masculin comme forme non-marquée dans les fonctions adverbiales. Cependant, on peut interpréter beau également comme modifieur de jour : un jour bon et beau. Bel est modifié par moult.

\section{Saluer fort}

saluer haut et fort : accueillir, applaudir avec enthousiasme

त saluer haut

\section{Saluer gent}

Saluer de manière distinguée, avenante, aimablement, gracieusement

Transitif

1250 Là a trouvé .i. homme seur .i. batel séant, Qui armez estoit bien, que doutanche avoit grant

De larrons, qui i vont moult souvent trespassant ;

Et li enfes le vit, sel salua moult gent, Et le vilain s'estut, sel regarda forment (Doon de Mayence, p. 81)

REMARQUES : Saluer gent se disait du fait d'accueillir quelqu'un que l'on aborde ou que l'on rencontre avec une marque de déférence, le sujet se distinguant par la douceur de ses manières, son amabilité et sa gentillesse. Gent est modifié par moult.

\section{Saluer haut}

Saluer avec beaucoup de respect

Transitif

1200 La roïnne est en son palais listé,

O li avoit grant part de son barné, Que elle avoit avec li en mené, Car moult doutoit de Jordain la fierté. Quant el le voit, si l'a haut salué (Jourdain de Blaye, 3228)

1230 Atant es les enfans, qui l'on haut salué ; Tel salu li ont dit dont il ne lor sot gré (Gui de Bourgogne, p. 55)

CORPUS WEB :

Ce rapport est à saluer haut et fort car il va dans le sens des recommandations et des conseils que nos chefs et nos nutritionnistes distillent tout au long de nos ateliers de cuisine santé [http:// www.rencontres-cuisine-sante.com/la-luttecontre-le-gaspillage-alimentaire] (28.11.2015)

Lorsque nous avons à faire à la fois à un individu et à un magistrat honnête loyal et investit professionnellement, il faut sans vergogne le saluer haut et fort car une immense partie des juristes JI JE JAF Procureurs sont des gens irres- 
ponsables incompétents et terriblement destructeurs [http://www.franceinfo.fr/actu/justice/ article/marc-trevidic-contraint-de-quitter-sonposte-663157] (28.11.2015)

C'est pour cette raison qu'il faudra saluer haut et fort la qualité du premier album solo de Peter Doherty connu évidement pour l'aspect médiatique de sa personnalité mais aussi et surtout pour ses prestations au sein des (ex-) Libertines et des Babyshambles, son autre projet [http://sevicom.free.fr/wikinimst/wakka. php?wiki=BlogLatinMusique] (28.11.2015)

REMARQUES : Saluer haut se dit du fait d'accueillir quelqu'un que l'on aborde ou que l'on rencontre avec déférence, civilité, respect, le sujet montrant à l'égard de cette personne de la considération, en raison de son âge, de sa position sociale, de sa valeur ou de son mérite. Notons la collocation haut et fort dans tous les exemples du CW où saluer a le sens abstrait de 'accueillir avec enthousiasme'. Haut reste invariable.

\section{Saluer large}

Saluer quelqu'un d'un geste ample Intransitif

2012 Il saluait large. Arrivé sur la dalle, Éric tourna à droite vers son immeuble, Cour Défense (Jérôme Cazes, 555 jeudi rouge)

\section{Saluer net}

Saluer franchement

Intransitif

1935 Derrière la table et tournant le dos aux fenêtres, un homme d'une soixantaine d'années, de stature médiocre, vêtu d'une redingote noire, sans décoration. Les cheveux gris et presque ras. La moustache lourde et roulée. Un binocle à ruban de soie. Bref, la silhouette d'un clerc d'huissier, studieux, myope et solennel.

- Permettez, monsieur le ministre, dit Joseph en saluant net, permettez que mon secrétaire... à moins que vous ne préfériez... (Georges Duhamel, La Nuit de la Saint-Jean)

\section{Sangler étroit}

Attacher au moyen d'une sangle très serrée Transitif

+1150 Par matinet soies tout apreste, Si aies uos destriers estroit ceingles, Vn cembel trametrons a la chite (Aiol et Mirabel [2 $2^{\mathrm{e}}$ moitié XII $]$, 4921)

REMARQUES : Sangler (ceingler) étroit se dit du fait d'attacher, de serrer fort la sangle qui maintient la selle sur le dos d'un cheval. Étroit reste invariable.

\section{Sangloter bas}

I. Sangloter doucement, silencieusement Intransitif

1767 Mon frere rongeoit ses gants d'impatience, et votre amie sanglotoit tous bas, de crainte que vous ne fussiez partie (M. d'Estrade, Mémoires de Milady Worthon [trad.])

1776 Elle n'attendit pas la fin de la menace, et alla se coucher sur sa natte, en sanglotant tout bas (Jacques Cazotte, Le Diable amoureux)

1884 Elle sanglotait plus bas, en écoutant le flot monter du fond des ténèbres, épuisée et malade, sans être vaincue encore (Émile Zola, La Joie de vivre)

1949 et dans un coin quelque part il y a ce petit orchestre presque imperceptible avec la grosse caisse et les cymbales et ce retour de temps en temps de cuivres rauques qui vous fait sangloter tout bas (Paul Claudel, La Lune à la recherche d'elle-même)

II. Émettre des sons faibles, comparables à des sanglots

Intransitif

1905 Toby-Chien se couche en turban et ferme les yeux parce qu'il a envie de pleurer. Son souffle court sanglote tout bas (Colette, Sept dialogues de bêtes)

\section{CORPUS WEB :}

Je cherchais un truc chrome, toujours pas trouvé, mais pas perdu pour autant. Obélix sanglotebas,j'aurai toutvu[http://www.atoute.org/n/ forum/showthread.php?t=143649\&page=2] (28.11.2015) 
Mais rien à y faire : elle lui avait brutalement tourné le dos et marmonné un « tu n'y comprends jamais rien » définitif suivi d'un « et je t’ai déjà dit de m'appeler Daniela », avant de se remettre à sangloter tout bas [http://fr.viadeo.com/fr/groups/det aildiscussion/?containerId=0021ibyttcsdgkgb\&fo rumId $=00225$ puu0ijn0s7z\&action $=$ messageDetai 1\&messageId=0021zy3fapd2te2z] (28.11.2015)

Il se blottit contre l'oreiller qui gardait encore un peu de l'odeur du petit blond et y sanglota tout bas [http://www.manyfics.net/fictionficid-4608-chapter-2.htm] (28.11.2015)

REMARQues : Sangloter bas (I) se dit du fait de pleurer avec des sanglots, le sujet exprimant sa douleur ou le sentiment de tristesse profonde discrètement, en silence, de façon à ne pas se faire remarquer. (II) réfère au souffle d'un animal dont le son faible et gémissant qu'il émet s'apparente à celui d'un sanglot. Bas reste invariable et est modifié par plus, tout.

\section{Sangloter fort}

sangloter fort et haut : sangloter intensément $\lambda$ sangloter haut

\section{Sangloter haut}

Sangloter bruyamment, ouvertement, sans retenue

Intransitif

1698 Enfin il se présenta devant lui une femme si couverte de crêpes noirs, de voiles, de mantes, de longs habits de deuil, et qui pleuroit et sanglottoit si fort et si haut, qu'il en demeura surpris (Marie-Catherine d'Aulnoy, L'Oiseau bleu)

1840 Ici Madeleine commença à sangloter tout haut, et deux ou trois hommes, qui dans l'occasion auraient tiré sur des chrétiens avec autant de sang-froid que sur des perdrix, se mirent à essuyer de grosses larmes sur leurs joues basanées (Prosper Mérimée, Colomba)

1871 puis elle s'assit au chevet du lit, ôta son bonnet, s'échevela, se donna la mine d'une personne désespérée, et se mit à sangloter très haut (Émile Zola, La Fortune des Rougon)
1879 Le roi s'est enfermé tout seul dans une chambre, au bout du château... Les Majestés n'aiment pas qu'on les voie pleurer... Pour la reine, c'est autre chose... Assise au chevet du petit Dauphin, elle a son beau visage baigné de larmes, et sanglote bien haut devant tous, comme ferait une drapière (Alphonse Daudet, Lettres de mon moulin)

1936 Je montai tout préparer : le bruit de l'eau qui coulait me permettait de sangloter tout haut (Marguerite Yourcenar, Feux)

\section{CORPuS WeB :}

Ton portrait l'est aussi, il est superbe et dans un sens, le fait qu'il ait un demi sourire au lieu de signes d'intense douleur (non physique, mais due à l'émotion de la célébration - en Iran, la plupart pleurent à chaudes larmes à cette occasion et sanglotent tout haut !) est presque encore plus provoquant [http://www.trekearth.com/ gallery/Middle_East/Lebanon/West/Liban-Sud/ photo853755.htm] (29.11.2015)

Harry sanglotait tout haut, crachant. « Pourquoi... Pourquoi ? Qui l'a tué ? " [http://199letters.skyrock.com/3174881561-Chapitre-4.html] (29.11.2015)

La mère sanglotait tout haut comme une enfant, et le père serrait les poings, maudissait tour à tour le ministère, les sorciers, Poudlard, lui-même et les médecins (le terme "médicomage » ne lui était vraiment pas familier) [https:// www.fanfiction.net/s/5901112/1/Cas-de-peste] (29.11.2015)

Remarques : Sangloter haut se dit du fait de pleurer avec des sanglots, provoquant une respiration brusque et bruyante et soulignant une douleur ou un sentiment vif, la tristesse profonde de quelqu'un. Notons la collocation fort et haut. Haut reste invariable et est modifié par bien, si, tout, très.

\section{Sangloter menu}

Sangloter imperceptiblement, faiblement Intransitif

1572 Quand la nouvelle au père fut venue, D'ardeur et d'ire une bouillante nue Pressa son cœur, qui menu sanglotoit De coups plombez l'estomac se battoit (Pierre de Ronsard, La Franciade, p. 193) 
REMARQUES : Au figuré et dans un registre plutôt littéraire, sangloter menu désignait le fait de pleurer avec des sanglots sourds, ce qui traduit une douleur spontanée et sincère du sujet, une très grande peine. VoIR AUSSI : pleurer / rire menu

\section{Sauter droit}

I. Se précipiter, bondir directement (sur/vers quelqu'un ou quelque chose) Intransitif

1604 Comme un Lion pressé de faim et de furie, Trouvant des bœufs à graisse en la verte prarie,

Sur tous en choisit un, luy livre le combat, Saute droit à sa gorge, et sous ses pieds l'abat :

Ton fils hors de son Coche attire Ptolomée, Et le renverse mort dessous sa main armée (Antoine de Montchrestien, Les Lacènes)

1684a Ou, si vous voulez enfin, pourquoy voyant de la viande suspenduë fort haut à un crochet, au lieu de sauter droit vers cette viande, il s'en va de l'autre costé de la table chercher un banc, sauter sur ce banc, de là sur la table, et de là à la viande (François Bernier, Abrégé de la philosophie de Gassendi)

1684b Ou pourquoy quelquefois au lieu de s'amuser en bas dans la ruë à sauter tout droit contre la muraille selon la voye par où luy viennent les especes, et la voix de son Maistre qui l'appelle d'un troisieme Etage, s'en va t'il aussi en se detournant chercher la porte (François Bernier, Abrégé de la philosophie de Gassendi)

1942 Elle m'avait vu, cette bête féroce, elle allait sauter droit sur moué (Maurice Genevoix, Laframboise et Bellehumeur)

II. Effectuer un/des saut(s) en restant droit, à la verticale

Intransitif

1879 Et un acteur déguisé en Anglais, avec un pantalon vert pois, des favoris rouges et un chapeau gris, tricota des jambes, sautant droit, se frappant les talons, puis, se rapprochant comme un cagneux le boulet des genoux, il s'élançait à l'improviste et retombait les deux cuisses écartées, figu- rant un v à l'envers (Joris-Karl Huysmans, Les Sours Vatard)

\section{CORPUS WEB :}

je n'arrive pas à sauter droit!! J'explique mdr : quand je saute, je pars presque tout le temps sur le coté, droit ou gauche, n'importe, un peu des deux, et je ré-atterris donc forcément à coté de nombreuses récéptions :D [http://www.26in.fr/ forums/rouler/pilotage/sujet-41459-saut-.html] (29.11.2015)

Pourquoi est-il important de sauter droit, d'être dans la rectitude? [http://www.chevalmag. com/chevalmag/Connaissances/Disciplines/ CSO/Sauter-droit] (29.11.2015)

Je pense que c'est parce que je reste à ma place, comme quand je sautais droite, mais en me penchant sur son encolure. Du coup, je suis trop en avant (pas en avance). Il faudrait que je recule au dessus de ma selle [http://www.chevalan nonce.com/forums-7943727-position-a-1obstacle-et-strike-conseils-] (29.11.2015)

en général en touche réduite, tu pars de loin tu l'as prends en avançant le contreur n'a jamais le temps de se mettre au diapason, mais la sauter droit devant l'alignement castrais qui est redoutable, c'est ridicule, àmon avis ils se sont plantés dans l'annonce... [http://www.lerugbynistere.fr/ signaler-commentaire.php?id_com $=58711$ ] (29.11.2015)

REMARQUeS : Sauter droit (I) se dit du fait de se précipiter, de se jeter directement vers une personne dans le but de l'attaquer (sauter droit à la gorge de quelqu'un), ou vers une chose, parfois avec avidité ou par envie. En (II), il désigne le fait de faire des bonds successifs, le sujet effectuant le saut en gardant le corps bien droit. Droit reste invariable dans son emploi adverbial. Dans le troisième exemple du CW, il fonctionne en tant que prédicat second (se référant à la position du corps) orienté vers le sujet, ce qui entraîne l'accord avec le sujet. Droit est modifié par tout. Il a tendance à s'associer avec la préposition qui le suit (à, vers, contre, devant, sur) au point de faire partie du groupe prépositionnel en tant que modifieur de la préposition. C'est le cas du quatrième exemple qu'il faut lire sauter // droit devant et non pas sauter droit // devant. Notons aussi l'emploi transitif du verbe dans cet exemple. 


\section{Sauter haut}

Sauter en hauteur

$\lambda$ mettre bas et sauter juste

\section{Sauter juste}

Arriver aux bonnes conclusions, trouver les

conclusions exactes

Intransitif

1820 Le défaut dominant de cet auteur, c'est qu'il a l'air de ne jamais douter de ses raisonnements : il saute avec une intrépidité inconcevable des prémisses à la conclusion. Le plus souvent il saute juste, mais parfois le pied le plus sûr peut glisser (Stendhal sur lui-même, cité par Henri Martineau, Le Coeur de Stendhal)

\section{CoRpus Web :}

Et pour y parvenir, celle qui s'entraîne sous les ordres de Philippe d'Encausse à Clermont avec... Renaud Lavillenie sait qu'elle devra « sauterjuste et ne pas perdre de jus» [http://www.parisnormandie.fr/detail_sport/articles/1238277/ lotout-veut-eviter-le-piege\#.Vltd KE2FOUk] (29.11.2015)

Les résultats arriveront ensuite naturellement, même si je vise forcément la finale. Mais il va falloir sauter juste et bien pour être présent [http://www.sudouest.fr/2013/08/10/je-vise-lafinale-1138197-4742.php] (29.11.2015)

Si vous sautez trop haut, vous vous prendrez le mur, si vous ne sautez pas, vous vous prendrez également le mur ou tomberez dans le vide. Il faut sauter juste [http://www.oldfield.fr/2010_ 05_01_archive.html] (29.11.2015)

REMARQUES : Au figuré, sauter juste réfère aux propositions tirées des données de l'observation ou d'un raisonnement qui s'avèrent exactes, vraies. Au sens propre, illustré par les exemples $\mathrm{du} \mathrm{CW}$, il renvoie à un saut exécuté précisément. Juste reste invariable.

\section{Sauter soef}

Sauter doucement, tranquillement, avec calme, légèreté

Intransitif

+1250 Mes onques tel joie ne fu

Con Renars fet, li desloial.

Et puis bee amont et aval
Tant qu'il coisi sor l'arbre en haut

Le moinnel qui saut et tressaut

De branche en brance molt soe (Le Roman

de Renart [2 $2^{\mathrm{e}}$ moitié $\left.\mathrm{XIII}{ }^{\mathrm{e}}\right]$, XI, 777)

Remarques : Dans l'exemple de l'ancien français, sauter soef s'applique à un jeune moineau qui se déplace par petits bonds d'une branche à l'autre, ses mouvements étant empreints de légèreté et de délicatesse. Soef est modifié par moult. VOIR AUSSI : tressauter soef

\section{Savoir bon}

Avoir un bon goût Intransitif

$\sim 1177$ Mes li fains l'angoisse et esforce

Tant que le pout li sot li pains ;

Qu'a toz mangiers est sausse fains

Bien destanpree et bien confite.

Tot manja le pain a l'ermite

Mes sire Yvains, que buen li sot,

Et but de l'eve froide au pot (Chrestien de Troyes, Yvain ou Le Chevalier au lion, 2857)

REMARQUES : Lors d'un repas, savoir bon désignait le fait d'apprécier le bon goût d'un aliment.

\section{Savoir juste}

I. Savoir de manière exacte, juste, précise Transitif

1854 Aucun savant sérieux ne se plaindra de l'organisation actuelle ; - mais quand un feuilletoniste ou un romancier se présente, « tout le dedans des rayons tremble ». Un bibliographe, un homme appartenant à la science régulière savent juste ce qu'ils ont à demander. Mais l'écrivain fantaisiste, exposé à perpétrer un roman-feuilleton, fait tout déranger, et dérange tout le monde pour une idée biscornue qui lui passe par la tête (Gérard de Nerval, Les Filles du feu)

1929 Il n’y avait plus qu'Angèle qui pût se faire toujours entendre d'elle; la jeune femme savait juste à quel diapason il fallait mettre la voix pour percer les brumes de cette surdité naissante (Julien Green, Léviathan) 
II. Connaître l'impartialité, l'équité (de quelqu'un), la légitimité, le bien-fondé (de quelque chose)

Transitif

1893 - Si Boleslas est fou, comme tous s'accordent à le dire, pourquoi Maud, que je sais si juste et qui m'aime tant, attribue-t-elle à ma mère la responsabilité de ce duel, au point de se brouiller avec moi ainsi, et de s'en aller sans une ligne d'explication? (Paul Bourget, Cosmopolis)

1934 Pour des choses auxquelles je ne pouvais rien, je ressentais une profonde honte. Je ne protestais pas. Je savais justes les plaintes de ma mère. L'argent manquait à la maison. Mon père était malade (Jean Guéhenno, Journal d'un homme de quarante ans)

III. Ne pas en savoir plus

Transitif

1987 Peut-être aussi que je ferais mieux de reconnaître que je n'ai pas du tout l'intention de croiser un voisin noctambule ou matinal. Ou le gardien de l'immeuble qui sort les poubelles au tout petit matin. Celui-là, derrière son sourire panouille, il sait tout juste ce qu'il faut sur mon cas pour ménager son fromage, c'est-à-dire mon proprio, les huissiers, les flics et ses bonnes relations de bibine dans les rades du coin (Jean-Louis Degaudenzi, Zone)

REMARQUES : Dans les exemples sous (I), savoir juste se dit du fait de connaître avec exactitude, avec précision quelque chose ou d'être très bien renseigné sur quelque chose. (II) illustre l'emploi comme prédicat second au sens de 'savoir que quelqu'un ou quelque chose est juste'. (III) concerne l'emploi restrictif de savoir juste ce qu'il faut 'ne pas en savoir plus'. Juste reste invariable, sauf dans (II), et est modifié par plus, si, tout.

\section{Savoir long}

en savoir long : savoir beaucoup de choses, être bien instruit (sur quelque chose)

Emploi absolu

1710 Je n'avois point encore remarqué jusqu'alors, que les femmes de ce païs-là eussent aucun penchant à la galanterie ; elles me paroissoient naturellement trop simples pour cela : mais je commençai à voir par cet échantillon, qu'il n'en est guére nulle part, qui n'en sache bien long, quand il s'agit de donner de l'amour aux hommes (Simon Tyssot de Patot, Un chivalier et sa dame et un clerk)

1732 Les gens avec qui je m'embarquais au jeu en savaient plus long que moi, quoique j'eusse appris parmi les gueux à filer la carte, à faire de fausses coupes, et plusieurs autres tours de filous (Alain-René Lesage, Histoire de Guzman d'Alfarache)

1735 J'ai trouvé, repris-je, Marine, elle s'est pressée de s'en aller après m'avoir parlé, craignant qu'on ne s'aperçut de quelque chose. Elle m'attendoit à la Garenne exprès. Jarnigoi, qu'elle en sçait long, reprit Colin : si jamais elle est mariée, elle ne passera pas mal la plume par le bec de son mari (Charles de Mouhy, La Paysanne parvenue)

1825 Pour surmonter cet obstacle, on fit une société où chacun prit ou ne prit pas intérêt, suivant la nature de ses pressentiments : les uns disant que les Parisiens en savent bien plus long que les provinciaux (Jean-Anthelme Brillat-Savarin, Physiologie du goût)

1843 - Je dis, mon garçon, moi qui sais tout, que les bêtes en savent encore plus long que moi...

(Eugène Sue, Les Mystères de Paris)

1845 M. Haussoullier serait-il de ces hommes qui en savent trop long sur leur art? (Charles Baudelaire, Salon de 1845)

1857 - Vous m'en demandez trop : je n'en sais pas si long (Edmond About, Le Roi des montagnes)

1876 RÉMONIN. Eh bien, vous en savez aussi long que nous, et, si j'ai fait le discret, c'est qu'en ces sortes d'affaires, on est tenu à la discrétion, à moins qu'on ne soit un domestique (Alexandre Dumas fils, L'Étrangère) 
1899 Je n'en saurais pas plus long moi-même, si je n'avais, cette année, rencontré en Suisse quelqu'un qu'un lien de parenté très proche avec un gros bonnet du quai d’Orsay avait mis à même de connaître certains détails dans cette affaire (Georges Clemenceau, Vers la réparation)

1926 Le pauvre petit homme, en effet, nommé jadis médecin du lycée de Montreuil, en savait long sur les demoiselles, et ne le celait pas (Georges Bernanos, Sous le soleil de Satan)

1954 « Je n'en sais pas assez long, je n’y vois pas clair, je prends parti à la légère, je n’ai pas le temps, je n'aurai jamais le temps. » C'était excédant, ce refrain (Simone de Beauvoir, Les Mandarins)

1996 Des officiers qui avaient l'air d'en savoir long - si long qu'ils ne pouvaient se retenir de parler - affirmaient par exemple que l'armée britannique « se préparait à livrer la plus grande bataille terrestre à laquelle elle eût été confrontée depuis la guerre de Corée » (Jean Rolin, L’Organisation)

CORPUS WEB :

« Avec leurs tests de personnalité, les recruteurs croient en savoir long sur moi » [http://www. lexpress.fr/emploi/conseils-emploi/avec-leurstests-de-personnalite-les-recruteurs-croient-ensavoir-long-sur-moi_1390515.html] (3.12.2015)

Nous pensions en savoir long sur les horreurs de la guerre - Cimetière VC Corner et Monument aux morts australiens [http://www. ww1westernfront.gov.au/french/fromelles/ visiting-fromelles/the-cemetery-and-memorial. php] (3.12.2015)

Ce monde hétéroclite et grouillant, assoiffé d'en savoir long sur l'avenir intouchable, joue à mentir joyeusement et jette la poudre aux yeux pour masquer la terne réalité de la vie [http:// www.gallimard.fr/Catalogue/GALLIMARD/Folio/ Folio/La-dame-de-coeur] (3.12.2015)

REMARQUES : En savoir long réfère à une personne qui connaît beaucoup de choses sur un sujet, dispose d'un savoir particulièrement large à propos d'un thème ou est très bien renseigné ou informé sur quelque chose ou quelqu'un. Long reste inva- riable et est modifié par assez, aussi, bien, bien plus, encore plus, plus, si, trop.

\section{Savoir lourd}

Savoir beaucoup de choses (souvent graves)

(surtout à la forme négative)

Emploi absolu

1906 LE PESSIMISTE. Allez toujours ! Démolissez! Nos jeunes gens n'en savaient pas lourd ; mais, maintenant... Quel temps !... C'est la décivilisation, la dépopulation, la dégringolade, la dé...

(Les Annales politiques et littéraires)

1981 En souffre-t-il ? On n'en sait pas lourd. Sûrement pas plus que l'Européen en tout cas

(Hal Armstrong, Nous sommes tous des toxicos)

2001 RITA. Toi, va t'occuper de ta grand-mère. (Kat sort)

DAN. Elle n'en sait pas lourd, hé?

RITA. Suffisamment (Karin Mainwaring, Les Danseurs de la pluie [trad.])

2015 - Il en savait lourd sur des gens haut placés, des politiciens, non?

- Tous les élus ne sont pas pourris

(Michel Quint, Fox-trot)

\section{Savoir petit}

Savoir peu

Intransitif

+1125 Ore oez avant

Quant dit en ai tant

Que jeo redirai.

Assez sai petit,

Briefment avrai dit

Cel tant que jeo sai

(Un sermon en vers [ $2^{\mathrm{e}}$ quart $\left.\mathrm{XII}{ }^{\mathrm{e}}\right], 35$ )

+1150 a Teus en quide sauoir, qui en set mout petit,

Mais ie uous en dirai, qui de lonc l'ai apris (Aiol et Mirabel [2 moitié XII ${ }^{\mathrm{e}}$, 15)

+1150b Bele, laisies m'ester, che dist Aians, Cheste gens me uont mout escarnisant, Petit seuent mon ceur ne mon talent (Aiol et Mirabel [ $2^{\mathrm{e}}$ moitié XII $\left.{ }^{\mathrm{e}}\right], 2436$ ) 
1176 Trop sui anfés et petit sai.

Por ce toche an l'or a l'essai

Qu'an vialt savoir se il est fins

(Chrestien de Troyes, Cligés, 4225)

1349 Si que lonc temps, se Dieus me voie,

Fui einsi que petit savoie

De ce qu'on faisoit en la ville,

Et s'en morut plus de vint mille,

Cependant que je ne sceus mie,

Dont j'eus meins de merencolie

(Guillaume de Machaut, Le Jugement dou

roy de Navarre, 450)

CORPUS WEB :

La prière, la confiance en Jésus, ont fait le reste. C'est merveilleux de se savoir petit ! Jésus vous prend dans ses bras, vous console, vient guérir vos blessures... [http://golias-news.fr/article 5647.html] (4.12.2015)

Se savoir petit et pauvre (de richesse intérieure) c'est être vrai avec soi-même [http:// catho-jm.over-blog.com/article-la-veritepourquoi-c-est-si-dur-87537558.html] (4.12.2015)

On observe un léger retard de croissance par rapport à ses camarades mais rien d'affolant, elle a tout le temps de se rattraper. Cela la conforte de se savoir petite, c'est un atout indéniable pour pouvoir se faufiler où bon lui semble...et échapper à la surveillance des reines [http://newhopelgdc. forumactif.org/t80-petite-broussaille] (4.12.2015)

REMARQUES : Employé en ancien français, savoir petit réfère à une personne physique ou morale dont l'ensemble des connaissances acquises par l'observation, l'apprentissage ou par l'expérience propre, est plutôt réduit, limité. Il peut aussi souligner le fait d'être peu renseigné sur quelqu'un ou quelque chose, un événement, sur ce qui se passe autour de soi. Petit est employé comme équivalent du quantifieur peu en français moderne. Petit reste invariable. En français moderne, se savoir petit est une prédication seconde où l'adjectif s'accorde avec le sujet-objet (v. les exemples du CW, au sens de 'une personne sait qu'elle est petite', au concret ou au figuré). Petit est modifié par moult, assez.

\section{Savoir prou}

Savoir bien, beaucoup, suffisamment

Transitif

1160a Et ne fist il, il a voir dit, Car il n'i fu, n'il ne la vit ; Ne sai coment il i morust, Car ainz que la bataille fust, Li fist Nisus lo chief voler : Ce ne sot il pro deviner (Eneas, 5074)

$\sim 1160$ b Turnus est proz, sel doiz amer.

- Ge ne m'i sai prou atorner.

- Et tu l'apren. - Dites lo moi, Que est amors? Ge ne sai coi (Eneas, 7888)

1177 Par foi, fet mes sire Gauvains, Mout est perilleus et grevains Li uns et li autre passages : Del prandre ne puis estre sages, Je ne sai preu le quel je praingne (Chrestien de Troyes, Lancelot ou Le Chevalier de la charrete, 697)

Intransitif

1200 Icil s'en vunt isnelement, Als neis vindrent hastiwement, Il entrent enz, siglent avant, Trente jurs vunt par meir curant ; Mais il ne sevent pru quel part, Il n'i sevent engien ne art (Brut, 1243)

1538 Je ne t'escry de fortune puissante : Tu voys assez s'elle est ferme ou glissante ; Je ne t'escry d'abus trop abusant : Tu en sçais prou et si n'en va usant ; Je ne t'escry de Dieu ne sa puissance (Clément Marot, Épitres)

REMARQUES : Employé fréquemment à la forme négative, ne savoir prou désignait le fait de ne pas bien savoir faire quelque chose ou de ne pas être bien renseigné sur quelque chose, de ne pas en savoir beaucoup, prou signifiant 'beaucoup'. À la forme affirmative, le sujet désigne un animé qui connaît beaucoup de choses sur un sujet, dispose d'un savoir particulièrement large à propos d'un thème ou est très bien renseigné ou informé sur quelque chose ou quelqu'un. Prou est invariable. 


\section{Savoir voir (vrai)}

ne savoir voir : ne pas savoir la vérité

Emploi absolu

1209 - Bele Aiglentine, vos prendra il Henris?

- Ne sai voir, dame, car onqes ne li quis (Jean Renart, Roman de Guillaume de Dole, 2266)

+1225 « Biel ostel et honneur li fis

De ce ke chaiens poi avoir. »

«Comment a non? » « Je ne sai voir,

Mais mout sambloit que preudon fust »

(Le Chevalier as deus espees [ $2^{\mathrm{e}}$ quart $\left.\mathrm{XIII}{ }^{\mathrm{e}}\right]$, 4076)

+1227 Vilains, dist li quens de Bouloigne, Est laines Wistasces li moigne?

Dist Wistasces : Ne sai voir, sire,

Ne vos en voel mençoigne dire

(Roman de Wistasce le Moine [2 $2^{\text {etiers }} \mathrm{XIII}^{\mathrm{e}}$, après 1227], 1353)

\section{CORPUS WEB :}

En effet, le menteur par omission ne semble pas mentir, surtout si on croit naïvement que " mentir » se limite à affirmer ce qu'on sait faux, et n'inclut pas le refus d'énoncer ce qu'on sait vrai et important [https://fr.wikipedia.org/wiki/ Mensonge] (4.12.2015)

C'est pourquoi il faut distinguer ce qu'on croit vrai, ce qui nous semble vrai subjectivement, de ce qu'on sait vrai objectivement [http://www. ac-grenoble.fr/lycee/berthollet.annecy//secondcycle/espaces-pedagogiques/philosophie/ ressources/exercices/croire-et-savoir] (4.12.2015)

La bible est un témoignage vrai, un reportage, une nouvelle, un manuel d'instructions, pas une histoire inventée. On peut la croire vraie sans la savoir vraie. Mais il faut qu'on la sache vraie [https://www.facebook.com/yestothetruth/ posts/816415241770734] (4.12.2015)

REMARQUES : En ancien français, savoir voir tend à être employé avec la négation, le sujet faisant savoir à son interlocuteur qu'il ne connaît pas la vérité à propos de quelque chose ou de quelqu'un. L'usage actuel ne connaît plus que son emploi comme prédicat second 'savoir que quelque chose ou quelqu'un est vrai'. Il s'accorde alors avec l'objet (v. les exemples du CW).

\section{Sculpter gothique}

Sculpter dans le style gothique

入 écrire classique

\section{Secouer dur}

\section{Secouer fortement, brutalement}

Transitif

1857 Les conviés arrivèrent de bonne heure dans des voitures, carrioles à un cheval, chars à bancs à deux roues, vieux cabriolets sans capote, tapissières à rideaux de cuir, et les jeunes gens des villages les plus voisins dans des charrettes où ils se tenaient debout, en rang, les mains appuyées sur les ridelles pour ne pas tomber, allant au trot et secoués dur (Gustave Flaubert, Madame Bovary)

1942 Je surveille aussi les gyroscopes : ce nuage est peu habitable. Un nuage d'orage. Il nous secoue dur.

- Croyez pas que pourrions descendre?

- Dix minutes... ferions mieux d'attendre encore dix minutes...

J'attendrai donc encore dix minutes

(Antoine de Saint-Exupéry, Pilote de guerre)

CORPUS WEB :

Car cela se confirme, à partir de la pointe Bretagne et jusqu'au large du Portugal, ça va secouer dur à bord des bateaux, avec non seulement beaucoup de vent mais aussi et surtout beaucoup de mer [http://www.fenetrea-prysmian.com/ index.php/47-j-1.html] (4.12.2015)

la CLS n'a qu'à bien se tenir les 4 anneaux vont la secouer dur ! [http://audidubg.skyrock. com/417701205-S4-V8-4-2.html] (4.12.2015)

Cette affaire ne sent pas bon, çà va secouer dur, accrochons-nous [http://www.ladepeche.fr/ article/2015/08/12/2158532-pekin-abaisse-2e-foistaux-reference-yuan-face-dollar.html] (4.12.2015)

Cet ange est ma fille partie avant de naître en mars 2001... et je t'assure que je la secoue dure pour qu'elle aide ta petite princesse à vivre... [http://forum.aufeminin.com/forum/matern2/ f27686_matern2-week-end-des-sixtines-toutesavec-isaline.html] (4.12.2015)

REMARQUES : Au sens concret et au passif, secouer dur s'emploie pour désigner le fait d'être remué, agité vivement à plusieurs reprises au 
cours d'un voyage ou d'un déplacement. Au figuré, le sujet désigne une chose perceptible par les sens qui vient troubler quelqu'un ou bouleverser le bon déroulement de ses plans. Dans un emploi familier, secouer dur désigne le fait d'inciter vivement quelqu'un à l'action, à l'effort. Dur reste invariable dans la majorité des cas, mais, dans le dernier exemple du CW, il s'accorde avec l'objet tout en gardant son interprétation adverbiale, peut-être par emphase. Notons l'emploi absolu impersonnel de ça va secouer dur.

\section{Secouer ferme}

Secouer vigoureusement (au propre)

Transitif

1780 vous présenterez votre Ruche sous l'essaim, la poserez sur son bout et ferez tomber l'essaim dedans, en secouant ferme la branche où il est attaché (Pierre François Bienaymé, Mémoire sur les abeilles)

1835 FRANCIS. Dam !... c'est possible... Mlle Zélia était seule dans le coupé de la voiture, avec la vieille Madeleine, vous savez... Mais c'est égal, ça vous secoue ferme ; et à Rouen nous avons été obligés de rester un jour, tant elle souffrait (Bayard et É. Vanderburch, Les Deux Créoles)

1839 Sans hésiter, quoique prêt à rendre l'âme de dégoût, Fabrice se jeta à bas de cheval et prit la main du cadavre qu'il secoua ferme ; puis il resta comme anéanti ; il sentait qu'il n'avait pas la force de remonter à cheval. Ce qui lui faisait horreur surtout c'était cet œil ouvert (Stendhal, La Chartreuse de Parme)

1908 Ce petit homme les secoue si bien, si ferme et si fort, qu'il les arrache à leur fonds de tristesse et d'ennui (Ferdinand Brunetière, Études critiques sur l'histoire de la littérature française)

2011 l'artiste jeunette, blonde chemisier blanc, à la fin quand la trompette attaque, j'ai donné l'assaut, passé subrepticement mon bras gauche sur son dossier, essayé de la prendre peu à peu par l'épaule, j'y pose des doigts délicats, je serre, réponse ne s'est pas fait attendre, me repousse, épaules elle les a secouées ferme, tournée d'un air offensé vers moi, à la sortie m'a déclaré sans ambages que si je continuais ainsi, fini entre nous (Serge Doubrovsky, Un homme de passage)

\section{Secouer grave}

Secouer fortement

$\lambda$ baiser fort

\section{Séjourner petit}

Rester, demeurer quelque part pendant une courte durée, peu de temps

Intransitif

+1125 Lor proceain parent

Sunt mort ensement, E altre revindrent, Petit sojornerent, Car tost s'en ralerent, Lunge veie tindrent (Un sermon en vers [ $2^{\mathrm{e}}$ quart $\left.\left.\mathrm{XII}{ }^{\mathrm{e}}\right], 121\right)$

REMARQUES : Séjourner petit se disait en ancien français du fait de demeurer dans un lieu, d'y résider pendant une courte durée, le sujet désignant une personne. Petit est l'équivalent du quantifieur moderne peu.

\section{Semer clair}

être clair semé : être rare, peu répandu Transitif

$\sim 1275$ Se travail veaut metre en li querre, C'est oiseaus cler semez en terre, Si legierement quenoissables Qu'il est au cigne neir semblables (Jehan de Meun, Roman de la rose [12691278], 8704)

1560 aussi faut-il entendre que les Moynes de présent n'ont pas du tout tellement dégénéré de la saincteté des anciens, qu'il n’y en ait encore quelques bons meslez parmy la troupe des meschans ; mais le nombre en est bien petit, et sont si clair semez, qu'ils sont cachez en la multitude infinie des mauvais. Davantage, non seulement ils sont mesprisez, mais injuriez et molestez, voire mesme cruellement traitez (Jean Calvin, Institution de la religion chrestienne) 
1603 Toutes-fois contre l'opinion d'aucuns qui veulent le contraire, fondés en ce que la terre grasse, pour sa fertilité, faict abondamment troncher ou closser les grains, c'est à dire qu'un grain y faict plusieurs plusieurs espis, et pourtant le blé y devoir estre semé clairement : au rebours de la maigre [= la terre], à laquelle le blé ne faict autre chose que naistre sans closser ne multiplier, et que n'estant chargée de beaucoup de blé, elle se treuveroit trop claire semée, joinct que tous-jours, en quelque endroit que ce soit, quelque portion de semence se perd dans terre (Olivier de Serres, Le Théâtre d'agriculture et mesnage des champs)

1615 Celle [= l'hérésie] qui nous afflige trouva à sa naissance l'Eglise si despourveue de science et de conscience, si debile en doctrine et si pleine de desreiglemens qu'il ne se faut pas esbahir si l'yvraye a pullulé où le bon grain estoit si clair semé (Jean-Pierre Camus, Homélies des États généraux)

1656 Enfin un peu de resolution faisoit fueilleter les titres, qui sont rares et clair semez; et moy-mesme me laissant conduire à ces divers mouvemens, je tombay sur une lettre qu'il fait écrire par Gename au defunt Niasare (Michel de Pure, La Prétieuse)

1684 comme dans une grande forest on rencontre de certains endroits où les arbres sont plus epais, d'autres où ils sont plus clair semez; et d'autres où il y en a plus d'une certaine espece que d'une autre, nous trouverions aussi à proportion des endroits où les Astres seroient plus proches les uns des autres, et plus serrez (François Bernier, Abrégé de la philosophie de Gassendi)

1882 De l'autre côté de la route, au bord de laquelle il était arrêté, le long d'une futaie, s'étendait une taille de deux ans, dont les cépées clairsemées poussaient comme des îlots de verdure au milieu des fougères et des grandes herbes jaunes (Georges Ohnet, Le Maître de forges)

\section{CORPUS WEB :}

Pour les graines fines, une astuce consiste à les mélanger avec du sable fin ; une façon astucieuse de "semer clair » [http://www.gerbeaud. com/jardin/fiches/semis-en-place-potager.php] (4.12.2015)

Alors, pour semer tes carottes tu traceras aussi une belle ligne bien droite à l'aide de ton cordeau dans ton jardin... les graines sont petites, tu arriveras difficilement à les espacer mais tu peux essayer de semer " clair " (cela signifie ne pas mettre les graines les unes sur les autres ou serrées contre les autres) en prenant quelques graines entre ton pouce et ton index et tu essayes de laisser tomber doucement quelques graines en avançant le long de la ligne [http://www. momes.net/Apprendre/Sciences-naturelles/Lemonde-vegetal/Projet-d-ecole-le-cyber-potager/ En-mars-les-carottes] (4.12.2015)

La plupart des graines doivent être semées clair [http://www.rustica.fr/articles-jardin/ premier-potager-5-conseils-pour-vos-semis, 825 . html] (4.12.2015)

Ainsi, des céréales semées claires sont moins à risque que des céréales semées densément : la proportion de maitre-brins sur l'ensemble des tiges est plus faible [http://www.arvalis-infos.fr/ faut-il-craindre-la-vague-de-froid--@/view-9152arvarticle.html] (4.12.2015)

REMARQUES : Souvent employé au participe passé adjectival clairsemé, et en parlant de végétaux (arbre, cépée), semer clair se dit du fait d'être semé peu serré, de façon éparse, espacée. Au figuré, il s'emploie pour souligner le fait que quelque chose est rare, et peu répandu. Clair tend à l'emploi invarié, mais si le participe est accordé (clair semée[s]), l'accord n'est pas exclu (exemple de 1603 et dernier exemple du CW). Il est modifié par plus, si, trop. Notons l'emploi absolu du verbe dans le premier et le deuxième exemple du CW.

\section{Semer droit}

Planter (des graines) suivant une ligne droite

入 labourer droit

\section{Semer dru}

Semer densément

入 semer épais 


\section{Semer épais}

Répandre en grande quantité et de manière serrée, compacte.

Transitif

1275 Fain, qui n'i veit ne blez ne arbres, Les erbes en arache pures Aus trenchanz ongles, aus denz dures, Mais mout les treuve cleres nees [variante: clere nees]

Pour les pierres espès semees (Jehan de Meun, Roman de la rose [12691278], 10160)

1814 Elle se relève toutefois, lorsqu'elle n'a pas été semée trop épaisse, ou que le champ n’a pas été trop fumé ; car alors les tiges un peu fortes étant inclinées se servent mutuellement d'obstacles. J'ai remarqué, même dans les moissons versées, que les tiges isolées se maintenaient toujours debout (Bernardin de Saint-Pierre, Harmonies de la nature)

Pronominal à sens passif

1564 La laictue se seme dru et espes, comme le chou (Charles Estienne, L’Agriculture et maison rustique)

CoRpus Web :

Semer à partir de mi-mars jusqu'au fin août en pleine terre en rayons. Distance entre les rayons $25 \mathrm{~cm}$ environ. Semer épais et ne pas éclaircir [https://www.lesgrainesdefrance.com/ vente-graines-de-jardin-legumes/laitue/xoticamesclun-oriental.html] (5.12.2015)

semer épais de la vesce et du seigle ensemble pour étouffer les broussailles, le chiendent, les plantes à racines pivotantes non désirées [https://brfavenir.wordpress.com] (5.12.2015)

La Féverole : pousse rapide pour une légumineuse, semences fermières possibles, légumineuses, gélive, doit être semée assez épais à l'épandeur d'engrais (grosse graine), intérêt : restitution importante d'azote [http://www.poitoucharentes.developpement-durable.gouv.fr/IMG/ pdf/Annexe_6_Synthese_experimentation 2011_cle52db8e.pdf] (5.12.2015)

Le blé qui murit tranquillement, je suis pas trop mécontent de la tenue mon blé sachant que je n'ai fait que 2 fongicides et un désherbage : Semence fermière semée épaisse [http:// www.agricool.net/forum/index.php?s=9822d5a cbf9dfee2ba04cf1478696d42\&showtopic $=22363$ $\& s t=1530]$ (5.12.2015)

REMARQUes : Semer épais réfère à des grains de semence ou objets assimilables (pierres) qui sont répandus en grand nombre, de façon rapprochée, de sorte qu'il y a peu d'espace entre les différents éléments au sol. Épais peut s'accorder avec le sujet ou rester invarié. Il est modifié par assez, trop. Notons l'emploi absolu dans le premier exemple du CW. Mentionnons également la collocation dru et épais.

\section{Sentir âcre}

Répandre une odeur désagréable, piquante, irritante

Intransitif

1921 Ils [= les champignons] sont jaune, orangé, pourpre, lilas, brun fauve et or, bistre, terre d'ombre, blanc tigré, blanc immaculé, virginal. Ils sentent bon, âcre, mauvais ou pire. D'aucuns ont un parfum d'œillet, d'aucuns de musc, et ceux-ci une odeur de camphre ou de soufre, et ceux-là un relent d'ail (Joseph de Pesquidoux, Chez nous : travaux et jeux rustiques)

\section{Corpus Web :}

A priori, si je démonte le radiateur, je devrais pouvoir voir s'il est humide ou mouillé, ou qu'il sent « acre » [http://www.forum-auto.com/ marques/renault/sujet94676.htm] (5.12.2015)

Ben là il sent âcre... le rance quoi. ${ }^{\star \star}$ J'avais senti un peu ça en sniffant le bouchon... mais là sur peau, c'est flagrant !!! Il a tourné ce parfum, je crois ** !! [http://www.beaute-test.com/forums/ index.php?topic $=126888 \&$ start $=15]$ (5.12.2015)

Les excréments de l'ours noir contiennent souvent des petits os et de la fourrure de petits animaux, tel l'écureuil et sentent acre [http:// www.quebecpeche.com/forums/index.php?/ topic/1770-peche-a-guee] (5.12.2015)

je trouve hyper intéressant de savoir que les Asiatiques trouvent que les Européens sentent âcres ! [http://www.beaute-test.com/forums/ index.php?topic $=272711 \&$ start $=195]$ (5.12.2015)

REMARQUES : Sentir âcre s'applique à une chose, un animal ou une personne qui exhale, dégage une odeur irritante. Âcre reste invariable dans 
la majorité des cas, mais, dans le quatrième exemple du CW, il est accordé avec le sujet tout en gardant son interprétation adverbiale. Notons la collocation sentir bon, âcre, mauvais ou pire

\section{Sentir bizarre}

Dégager une odeur étrange, anormale

Intransitif

1959 Ça sent le chaud; ça sent bizarre (Exemple entendu, 6 mai 1959 / Grundt : 232)

1984 Rima ouvrit, entra, ôta son blouson et renifla. La charmante salle de séjour sentait bizarre. Il découvrit Géraldine quelques mètres plus loin. Cuite. Noire. Les doigts carbonisés. Pas besoin de bosser à E.D.F. (Anne Vergne, L'Innocence du boucher)

1989 Il y a une drôle d'odeur dans l'appart'. Une odeur de pieds. Ida est assise en face de moi, elle prépare son fixe.

- Tu trouves pas qu'ça sent bizarre?

Elle renifle.

- Ben non. J'trouve pas.

Je me penche, je regarde sous la table en stratifié : Ida a retiré ses godasses, ses pieds sont noirs de crasse

(Denis Belloc, Képas)

\section{CORPUS WEB :}

Il n'arrive pas à se réveiller le matin, vous retrouvez des filtres de cigarettes désossées dans ses poches, ça sent bizarre dans sa chambre... [http:// www.leparisien.fr/societe/ca-sent-bizarre-danssa-chambre-05-10-2011-1639872.php] (5.12.2015)

Mes mains sentent bizarre... [http://www. jeuxvideo.com/forums/1-50-123980926-1-0-1-0mes-mains-sentent-bizarre.htm] (5.12.2015)

Mes pets sentent bizarres [http://www.jeux video.com/forums/1-50-101670890-1-0-1-0-mespets-sentent-bizarres.htm] (5.12.2015)

Là, j'ai mal dans mes bras. Je les sens bizarre, j'ai du mal à expliquer... [http://forum. doctissimo.fr/sante/douleur-dos/ressent-dansbras-sujet_150085_1.htm] (8.12.2015)

Bon bah je crois que mes craintes étaient justifiées une fois encore, depuis ce matin je ne sens quasiment plus mon coté droit du visage (tete) meme ma bouche, mes yeux et mes dents je les sens bizarres [http://la-sclerose-en-plaques.com/ viewtopic.php?t=4020\&p=68787] (8.12.2015)
31 octobre 2013 : nos bénévoles se sentent bizarre ce matin ! [http://spfcolomiers.free.fr/ $\mathrm{blog} / ? \mathrm{p}=1031]$ (5.12.2015)

À tous les jeunes qui se sentent bizarres ou différents... [https://fr-fr.facebook.com/FLIPTFO/ posts/985907684754840] (5.12.2015)

REMARQUES : Sentir bizarre désigne une chose ou un lieu qui dégage une odeur qui est anormale, inhabituelle. Les quatre derniers exemples du CW illustrent l'usage de sentir bizarre comme prédicat second dénotant le fait d'avoir une sensation inhabituelle dans une partie du corps, ou d'avoir une perception inhabituelle de soi-même. L'accord est vacillant dans tous les cas de figure. Notons l'emploi impersonnel familier de ça sent bizarre.

\section{Sentir bon}

I. Dégager, répandre une bonne odeur, une odeur agréable

Intransitif

1348 SECOND CLERC. Par m’ame, oil. Diex ! qu'il sent bon!

Onques mais je ne senti chose Si bon flairant, ne lis ne rose, Ny autre espice (Miracle de l'evesque a qui Nostre Dame s'apparut)

+1365a Car si très bon il y sentoit Qu'Amors mesmes s'y delittoit Comme en la nonpareille place Qui soit sur terre (Jean Froissart, Poésies [3e tiers XIve])

+1365b Si bon sentoit celle eaue digne

Que c'estoit droite medicine

Pour enrichir amoureux cueur

De bon eür et de doulceur

(Jean Froissart, Poésies [3 tiers XIVe])

1477 S. MATHIEU. Oy, certes. Bartholomy, Que vous semble de ceste houdeur?

S. BARTHOLOMY. Il sent bon ; c'est ung grant honneur

A nostre maistre. Qu'en dy tu, Pierre?

(La Passion d'Auvergne)

1559 Il estoit emmanché d'un bout de tyzon, espouldré par dessus de suye et de pouldre de fer, avec de l'espice qui sentoit fort bon (Marguerite d'Angoulême, Heptaméron, p. 276, 65) 
1581 Mieux vaut tourner que mal aler.

Qui trop se fie mal il se garde.

Qui vient tard les autres regarde.

Davant qu'il pue le faut saler.

La perche aime à suivre la séche.

Rose sent bon et verte et séche

(Jean-Antoine de Baif, Mimes, enseigne-

mens et proverbes)

1592 La plus exquise senteur d'une femme, c'est ne sentir à rien comme on dict que la meilleure odeur de ses actions c'est qu'elles soyent insensibles et sourdes. Et les bonnes senteurs estrangieres, on a raison de les tenir pour suspectes à ceux qui s'en servent, et d'estimer qu'elles soyent employées pour couvrir quelque defaut naturel de ce costé-là. D'où naissent ces rencontres des Poëtes anciens : c'est puïr que de santir bon (Michel de Montaigne, Essais)

1691 Il semble qu'elle [= l'eau] bouille quand elle est dedans, au moins on la voit agitée et qui frissonne (je ne sais si cela se peut dire), mais quand on l'y laisse un peu de temps, la tasse se vide toute, tant cette terre est poreuse ; elle sent fort bon. On nous donna des eaux très-bien faites (Marie-Catherine d'Aulnoy, Relation $d u$ voyage d'Espagne)

1719 Un jour pourtant une abeille imprudente, Favorite du prince et presque en droit d'errer, Ayant fait son repas d'une mauvaise plante, Se présente à la ruche, et l'on vient la flairer.

Vous ne sentez pas bon. Qu'importe que je sente?

L'ordre n'est pas pour moi, dit la contrevenante

(Antoine Houdar de La Motte, Fables)

1778 Quand la ronde fut faite, lorgnant du coin de l'œil ce rôti qui avait si bonne mine et qui sentait si bon, je ne pus m'abstenir de lui faire aussi la révérence, et de lui dire d'un ton piteux : Adieu, rôti (Jean-Jacques Rousseau, Les Confessions)
1784 Il est encore remarquable que la plupart de ces végétaux, entre autres les peupliers et les bouleaux, sentent fort bon, sur-tout au printemps, et que beaucoup de plantes aromatiques croissent sur le bord de l'eau, comme la menthe, la marjolaine, le souchet, le jonc odorant, l'iris, le calamus aromaticus (Bernardin de Saint-Pierre, Études de la nature)

1839 Allé au Palais Royal lire les journaux. Le temps était bien beau pourtant, la soirée bien sentant bon pour une occupation pareille. Heureux ceux qui n'ont qu'à se plonger dans la nature, comme Clarence dans son tonneau de malvoisie (Jules Barbey d'Aurevilly, Deuxième Memorandum)

1843a Une des deux lettres, qui vous est adressée, est affranchie. Et, sans être indiscret, je vous ferai observer que vous avez là un correspondant dont les billets doux sentent furieusement bon (Eugène Sue, Les Mystères de Paris)

1843b - Une lettre de femme ! s'écria Mme Schontz en entrant, le papier, la cire sentent trop bonne...

- Monsieur, voici, dit un facteur des messageries en posant dans l'antichambre deux énormissimes bourriches. Tout est payé. Voulez-vous signer mon registre?

(Honoré de Balzac, La Muse du département)

1846 Merci de la petite fleur d'oranger. Toute ta lettre en sent bon. Qu'elle ait été cueillie sur un arbuste, donnée par une femme ou un homme, elle n'en est pas moins belle pour moi, va (Gustave Flaubert, Correspondance)

$1869 \mathrm{Au}$ demeurant, des odeurs indéfinissables, très mélangées de parfums et de puanteurs, qu'on peut trouver nauséabondes et que justement on peut savourer avec quelque plaisir, car c'est la façon particulière et presque délicate encore dont l'Orient sent mauvais, quand il ne sent pas tout à fait bon (Eugène Fromentin, Voyage en Égypte) 
1882 Les femmes élégantes et parées, sentant bon dans leurs fraîches toilettes, étaient groupées comme un bouquet de fleurs (Georges Ohnet, Le Maître de Forges)

1900 Tout à coup, il murmure :

- Sapristi ! Célestine... vous sentez rudement bon...

Sans lever les yeux, j'ai pris un air ingénu : - Moi, monsieur ?...

- Bien sûr... vous... parbleu !... Je pense que ce n'est pas mes pieds...

(Octave Mirbeau, Le Journal d'une femme de chambre)

1904 Le petit trottinait à ses côtés, en lui donnant la main. Ils allaient par les chemins, au travers des champs labourés, qui sentaient bon et fort. Les grillons crépitaient (Romain Rolland, Jean-Christophe. L'Aube)

1949 Il y avait une péripatéticienne en manteau de fourrure avec une robe rose plissée qu'on voyait par l'échancrure. Elle sentait vachement bon. Il y avait deux soldats américains avec elle, un de chaque côté (Boris Vian, Les Fourmis)

1975 Les autres ne doivent à leur nez que des impressions vagues, un total grossier des odeurs ambiantes dont seul se dégage finalement un signe plus ou un signe moins. Ça sent bon, ça sent mauvais, ça ne sent rien. C'est tout ce que leur misérable odorat leur apprend (Michel Tournier, Les Météores)

1987 Le brutal... Aux délicatesses, maintenant... Déshabillage en douceur... Trop froissée, la jupe... Elle sent bon, son linge sent bon, sa voix sent bon, l'intérieur de son corps sent bon... Quelle femme... Elle s'appelle comment, au fait ?... Claudia... Je veux absolument faire jouir Claudia... (Philippe Sollers, Le Cœur absolu)

Transitif

1887 - C'est pour la semence que le maître m’a promise.

- Ah! Oui, je sais... Attends, je monte.

Et, quand elle fut au grand jour, il la trouva toute fraîche, sentant bon le lait, avec ses bras nus et blancs. Elle le regardait de ses jolis yeux pervers, elle finit par demander d'un air de plaisanterie :

- Alors, tu ne m'embrasses pas ?... (Émile Zola, La Terre)

1904 Aussitôt la permission donnée et le portail ouvert, un vrai torrent de chèvres et de chevreaux noirs, nous frôlant dans le passage étroit, commence de couler entre nous, le long de nos lits ; on entend leurs bêlements contenus et, sur le sol, le bruit léger de leurs myriades de petits sabots ; ils sentent bon l'étable, l'herbe, les aromates du désert (Pierre Loti, Vers Ispahan)

193922 janvier 1928.

Toute seule! Oui, oui, venez vite. Je vous ouvre la porte. Oh! Comme vous avez froid! Vous sentez bon l'hiver, la gelée. Il faut que je vous réchauffe (Henry de Montherlant, Les Lépreuses)

1952 La la hu lala, dodo, petit, do, Entre la pente gazonnée et la prairie Il y a de quoi, tu sais bien, Aller s'endormir dans le romarin, Dans le romarin qui sent bon la pluie (Éluard Paul, Les Sentiers et les routes de la poésie)

1974 Et quand elle avait fini avec la vaisselle, ou bien avec le linge, elle feuilletait attentivement des livres de chez Gallimard qu'il lui avait dit de lire. Ses doigts sentaient bon le Paic-Citron (Pascal Lainé, La Dentellière)

II. Procurer un bon sentiment, une sensation agréable, donner une impression très positive, très favorable

Intransitif

1538 Et qu'ainsi soit, en amy vous conseille Que desormais vostre bec teniez coy : Car vostre honneur ressemble un ne sçay quoy,

Lequel tant plus on le va remuant, Moins il sent bon, et tant plus est puant (Clément Marot, Épitres)

1660 SA FEMME. (sans l'apercevoir, continue) Jamais rien de plus beau ne s'offrit à ma vue ; 
Le travail plus que l'or s'en doit encor priser.

Hon ! que cela sent bon!

(Molière, Sganarelle ou Le Cocu imaginaire)

1696 C'est sans doute que l'incrédulité et l'ingratitude sentent mauvais, comme les vertus sentent bon. Cette haine qu'on a pour eux est une chose extraordinaire (Mme de Sévigné, Correspondance)

1848 Vous avez un bon et généreux cœur, de m’offrir votre bourse. Elle doit être couleur de rose aussi, et votre argent, chose qui sent si mauvais, doit sentir bon, je m'imagine (George Sand, Correspondance)

1862 Qui était là aspirait du bonheur ; la vie sentait bon; toute cette nature exhalait la candeur, le secours, l'assistance, la paternité, la caresse, l'aurore (Victor Hugo, Les Misérables)

1908 Leur art avait ainsi une odeur sui generis, qui sentait bon et mauvais à la fois, c'està-dire très mauvais : ils nommaient cela : " amoralisme ». Un de leurs héros de prédilection était alors le vieillard amoureux (Romain Rolland, Jean-Christophe. La Foire sur la place)

1920 Mais cela n'est pas. Que je meure Sous des gnons et sous des trognons, Si ce ne sont pas des oignons Qui se trémoussent dans du beurre! Hein ! Qu'est-ce que bibi disait? Et ce bruit sent bon - qui plus est (Raoul Ponchon, La Muse au cabaret)

CORpus WeB :

C'est donc le plus souvent le mode de pollinisation qui explique le «pourquoi » les fleurs sentent bon [http://www.desfleursanotreporte. com/pages/Pourquoi_et_comment_les_fleurs_ sententelles_bon-4520480.html] (5.12.2015)

Avoir de beaux cheveux qui sentent bons ! [https://instantmakeupmh.wordpress. com/2014/10/20/avoir-de-beaux-cheveux-quisentent-bons-le-pied] (5.12.2015)

J'ai une bonne idée ! Que ceux qui sont daccord à la base, me suivent et s'inscrivent ou signent ICI, pour commencer à travailler dessus, pour voir combien on est déjà, à la sen- tir bonne ! [http://forum.musique-libre.org/ discussion/6162/federation-des-cultures-libresfcl] (8.12.2015)

ceux qui se sentent bon sont probablement des pro ou des doués [http://www. radioamateur.org/forums/index.php?/ topic/21953-entrainement-a-la-manipulationmorse] (5.12.2015)

Les $50+$ prétendent qu'ils peuvent, bien moins que pour les autres générations, faire ce en quoi ils se sentent bons et ce qu'ils aiment [http:// www.jobat.be/fr/articles/6-raisons-pour-vouloirtravailler-plus-longtemps] (5.12.2015)

REMARQUES : Sentir bon (I) réfère à une chose (un aliment, une boisson, un objet, une fleur, un épice, un parfum), qui exhale, qui dégage une odeur très agréable. Le sujet peut aussi désigner une personne ou une partie du corps qui dégage une bonne odeur. Notons aussi que le sujet peut renvoyer à un état ou une atmosphère agréable. Sous (II), le sujet désigne une qualité, une vertu (l'honneur) qui procure à quelqu'un un sentiment très positif, appréciable. Le sujet peut aussi référer à quelque chose d'abstrait ou de concret (l'âme, la vie) qui suggère nombre de choses positives et attrayantes pour l'Homme. Les trois derniers exemples du CW montrent l'emploi de sentir comme verbe copule, sentir bon signifiant 'se sentir être bon / sentir que quelque chose est bon'. Bon peut exceptionnellement s'accorder avec le sujet, si le verbe est intransitif ou pronominal, où avec l'objet, dans l'emploi transitif du verbe (ex. du CW). Bon est modifié par si, fort, furieusement, pas tout à fait, rudement, très, trop, vachement. Notons l'emploi impersonnel familier de ça sent bon, ça sent mauvais, ça ne sent rien. Notons aussi l'emploi de bon flairant ( 1348) et les collocations bon et fort; bon et mauvais.

\section{Sentir épicé}

Dégager un parfum d'épices

$\lambda$ sentir frais

\section{Sentir fort}

I. Sentir avec intensité, avoir une sensation forte

Transitif

1165 Jeo sai bien que vus alassez. Si recuvrez vostro vertu ! 
Li damisels a respundu :

Bele, jo sent tut fort mun quer !

Ne m'arestereie a nul fuer

si lungement que jeo beüsse,

pur quei treis pas aler peüsse

(Marie de France, Lais, 199)

II. Dégager une odeur forte

Intransitif

1887 Cette fois, on s'égayait ouvertement, lorsque la petite Élodie, qui avait suivi des yeux chaque drap, chaque chemise, s'écria :

- Oh ! la drôle d'odeur, comme ça sent fort !... Est-ce que c'est du linge à maman, tout ça ? (Émile Zola, La Terre)

1926 puis il [= le soleil] sortait et les jardins rutilaient et le buis sentait plus fort

(Henry de Montherlant, Les Bestiaires)

1927 De temps en temps, il a l'haleine qui sent très forte (Exemple entendu / Damourette et Pichon, §984)

1960 Quand on est salade, un gros épais paillon; pour les pieds de vigne, un bon rempart de terre chaude relevée avec soin par le soc qui « chausse " les ceps; si on est campagnol, ou bien renard, un terrier bien noir, calfeutré, qui sent fort et vivant ; loir ou marmotte on s'endort de tout son poil, de tout son sang, de toutes ses griffes. Mais homme, on se fait chaud de tout ce qui est feu (Claude Roy, Le Journal des voyages)

\section{Corpus Web :}

Depuis quelques jours, les urines de ma puce sentent très fort [http://forum.doctissimo.fr/ sante/diabete/urines-sentent-fort-sujet_165679_ 1.htm] (5.12.2015)

J'ai acheté à Carrefour des vêtements. Ceux-ci sentaient forts à l'achat [http://forum. doctissimo.fr/viepratique/Astuces-maison-etlinge/vetements-sentent-forts-sujet_4097_1.htm] (5.12.2015)

De la sentir fort, puis de la toucher très fort, et puis de la $l^{*}$ cher très très fort, et encore de la $p^{*} n^{*}$ tr* très très très fort... [http://www.jeuxvideo. com/forums/1-51-41167971-1-0-1-0-j-ai-envie-desentir-l-odeur-d-une-femme.htm] (8.12.2015)

Lorsqu'elle ose se confronter au monde masculin, elle doit se déguiser pour monter sur un ba- teau, car aucun capitaine ne l'accepte. Son périple, elle le réalise pour retrouver son homme. Même si on peut la sentir forte, elle reste dans son statut de nourricière [http://www.filmspourenfants.net/ video/selkirkcrusoe.html] (8.12.2015)

Ceux qui se sentent fort aujourd'hui sans Dieu, ont quelle espérance ? [https://fr.answers. yahoo.com/question/index?qid=20130129031016 AAGBcAd] (5.12.2015)

Le psychologue et écrivain B. Tierno parle de la façon d'éduquer nos enfants pour que ceux-ci se sentent forts et solides [http://www. bebesetmamans.com/enfants/sante-et-bienetre/psychologie-de-l-enfant/687-eduquer-lesenfants-pour-qu-ils-se-sentent-forts] (5.12.2015)

REMARQUES : Sentir fort (I) s'applique à une personne qui éprouve un sentiment positif avec une grande intensité. Sous (II), le sujet désigne une chose (du linge) ou un animal qui répand ou dégage une odeur intense, souvent désagréable. Notons la collocation sentir fort et vivant. Fort reste invariable dans son emploi adverbial, mais, dans le deuxième exemple du $\mathrm{CW}$, ainsi que dans celui de 1927 (« vulgaire », selon Damourette et Pichon), il s'accorde avec le sujet tout en gardant sa fonction adverbiale. Dans les trois derniers exemples du CW, il fonctionne en tant que verbe copule, orienté vers l'objet, si le verbe est transitif, et orienté vers le sujet dans l'emploi pronominal du verbe. Dans ces cas-là, il s'accorde avec l'objet ou le sujet (mais v. l'avant-dernier exemple, où il reste invariable). Fort est modifié par plus, tout, très. Notons l'emploi impersonnel familier de ça sent fort.

\section{Sentir frais}

Dégager une odeur de fraîcheur

Intransitif

1869 Sa robe, plus bouffante que le jupon d'une danseuse, laissait voir ses mollets roses, et toute sa gentille personne sentait frais comme un bouquet (Gustave Flaubert, L'Éducation sentimentale)

1975 Elle était vachement pas mal, blonde, avec des grands cheveux et elle sentait bon et frais (Romain Gary, La Vie devant soi)

CORPUS WEB :

Son odeur est agréable, elle sent frais, herbal et légèrement sucré [http://bellesetgourmandes. 
blogspot.co.at/2014/03/ma-nouvelle-routinecapillaire.html] (6.12.2015)

Personnellement je n'ai aucun regret à payé ce prix pour une absinthe aussi bonne. Elle a un côté herbacé-épicé-floral qui me fait chercher mes mots. Pure : elle sent assez épicé. Diluée : elle sent fraiche et épicé et elle goute ce qu'elle sent [http://www.museeabsinthe.com/forums/ index.php? showtopic $=2997 \&$ mode $=$ threaded $\&$ pid $=73204]$ (6.12.2015)

elle s'est concentrée sur ce sujet d'odeur ; elle a collecté un litre de son sueur, l'a distillé à 0,2 litres et croyez-moi elle a esayé dans une centre commerciale d'interesser au publique de sentir cette distillation et donner une note sur 10 ; la plus part des gens l'ont trouver mauvais/ dégoutant ; mais il y en avait, hommes et femmes qui lui donnait une note de 6/7 ; elle leur invitait de la sentir «frais » et bien sur on l'a trouvé pas mal [http://dating.hotbox.com/p/blog.cgi] (8.12.2015)

Merci, saurais-tu aussi par hasard pourquoi faut-il estomper l'eau ? J'aime tellement la sentir fraîche sur mon visage que je la laisse.. [http:// www.maquillagecynthia.com/astuces/eauthermale-eau-precieuse] (6.12.2015)

Le gel de rasage rafraîchit la peau et protège votre peau contre les brûlures de rasoir, hydrate votre peau afin qu'elle se sent frais [http:// obeyyourbody-suisse.ch/soin-pour-hommes] (6.12.2015)

Puis la muqueuse utérine se reconstitue tout doucement : la femme ressent les « énergies de la vierge » (elle ne court pas de risque de procréer), elle se sent fraîche, neuve et pétillante. Elle est pleine d'ambition, c'est le moment de lancer des projets [http://www.ensemblenaturellementleblog.com/archives/2014/01/14/28943292.html] (6.12.2015)

REMARQUES : Sentir frais s'applique à une personne qui répand une odeur de fraîcheur, de légèreté, très agréable. Notons les collocations bon et frais ; frais et épicé ; frais, herbal et légèrement sucré. L'invariabilité est la règle dans l'emploi adverbial, sauf dans le second exemple du CW. Dans les trois derniers exemples, sentir frais est un verbe copule qui s'accorde avec ce qu'il modifie, le sujet ou l'objet. Cependant, l'accord n'est pas réalisé dans l'avant-dernier exemple.

\section{Sentir herbal}

Dégager un parfum d'herbes

$\lambda$ sentir frais

\section{Sentir humide}

Sentir de l'humidité (dans quelque chose) ;

dégager une odeur d'humidité

Transitif

1887 Il en faisait le tour, se baissait et prenait de son geste accoutumé une poignée, une motte grasse qu'il aimait à écraser, à laisser couler entre ses doigts, heureux surtout s'il ne la sentait ni trop sèche ni trop humide, flairant bon le pain qui pousse (Émile Zola, La Terre)

\section{CORPuS Web :}

pour le moment il fait bon, pas de pluie ; mais le ciel est pas trop dégagé... et ça sent humide !! [http://pondi-escrime-med.forumgratuit. org/t130-entrainement-06-octobre] (6.12.2015)

quand le linge à du mal à sécher, et ça sent humide, beurkkk [https://fr.answers.yahoo.com/ question/index?qid=20090806025041AAX4OPL] (6.12.2015)

Les larmes ne coulaient plus sur ses joues, mais ils les sentaient humide [https://www. fanfiction.net/s/4847817/24/Entre-mes-mains] (8.12.2015)

Certaines d'entre nous ne peuvent pas la recueillir entre leurs doigts mais se sentent " $h u$ mide » dans la journée [http://malheursdefilles. over-blog.com/article-analyse-de-la-glairecervicale-ou-methode-billings-88868403.html] (6.12.2015)

Lui, Saël, assis en face de moi caresse mes cheveux, puis mes joues et il les sent humides de larmes... [http://miismarley.skyrock.com/31313 24262-Chapitre-02.html] (8.12.2015)

message pour toutes celles qui se sentent humides. voici mon histoire : un matin g eu l'impression d'avoir perdu un peu de liquide mais 2 petites gouttes [http://www.notrefamille.com/ forum/Grossesse/Grossesse/pour-toutes-cellesqui-se-sentent-humide-n-hesite-pas- $\mathbf{9} 926757$. aspx] (6.12.2015)

REMARQUES : Humide fonctionne, dans la majorité des cas, en tant que prédicat second, orienté vers le sujet dans l'emploi pronominal du verbe, 
et orienté vers l'objet dans l'emploi transitif du verbe. Dans ce cas-là, il s'accorde (v. l'exemple de 1887, les deux derniers exemples du CW). Toutefois, dans le troisième et le quatrième exemples $\mathrm{du} \mathrm{CW}$, il reste invariable. Humide est modifié par trop. Notons l'emploi impersonnel familier ça sent humide.

\section{Sentir juste}

Sentir les choses avec justesse, avec exactitude, conformément à la vérité ; reconnaître

l'exactitude de quelque chose

Emploi absolu

1757 MOI. Vous attachez bien de l'effet à des circonstances purement locales.

DORVAL. Celui qu'elles auraient sur moi ; et je crois sentir juste.

MOI. Mais on dirait, à vous entendre, que ce sont ces circonstances qui ont soutenu et peut-être introduit la poésie et l'emphase au théâtre (Denis Diderot, Entretiens sur Le Fils naturel)

1760 Ne seriez-vous pas assez fières toute votre vie d'être mes maîtresses en morale, et surtout en morale pratique ? Vous connoissez le bien, vous sentez juste, vous avez le cœur sensible et l'esprit délicat ; c'est vous qui êtes des hommes, et c'est moi qui suis la cigale qui fait du bruit dans la campagne (Denis Diderot, Lettres à Sophie Volland)

1855 La vieille fille avait senti juste le moment du départ de la volonté de son frère et s'en était emparée. Il était arrivé que $M$. Creton n'eut rien à désirer, à souhaiter dans la vie, tant qu'il vécut avec sa sœur. Il trouva un ménage pour ainsi dire sans connaître les souffrances matrimoniales (Champfleury, Les Bourgeois de Molinchart)

1925 Depuis le temps qu'il braconnait, il ne s'était jamais fait prendre ; le soir où il avait tendu au bois de la Sauvagère était un soir comme tant et tant d'autres : il était anormal et absurde qu'il se fût laissé prendre ce soir-là. Il avait calculé juste, senti juste ; ce soir-là comme tant d'autres, il était sûr de ses conjectures, des précautions qu'il avait prises, de tous les pas, de tous les gestes qu'il avait faits (Maurice Genevoix, Raboliot)
1944 - Qui c'est-il qui gouverne, icitte ?

Des mots de son enfance lui remontaient aux lèvres, qu'elle mêlait à ses paroles anglaises. Quand elle s'en apercevait, elle souriait, s'interrompait :

- Vous ne comprenez pas, Randolph. C'est de notre parler français. Cela veut dire... Et elle essayait ardûment de trouver un équivalent, pour que Randolph comprît mieux, sentît plus juste.

- Ah ! bon, je n'y arriverai pas !

(Maurice Genevoix, Eva Charlebois)

1983 - Si je l'avais senti, c'est cet air-là que j'aurais pris et je l'aurais encore durci... par défi... comme on le fait parfois en pareil cas...

- Oui, et aussi par désespoir...

- Mais ce n'est pas cet air que mon père a cherché sur mon visage, ce n'est pas lui qu'il a voulu retrouver, et ce qui est arrivé ensuite prouve que j'avais senti juste (Nathalie Sarraute, Enfance)

Transitif

1892 Il continua sa marche en chancelant comme un homme ivre, au milieu des camarades qui, à présent, ricanaient de ce qu'il avait cédé. Ah ! Ce Jean ! Il le haïssait d'une inextinguible haine, frappé au cœur de cette leçon si dure, qu'il sentait juste (Émile Zola, La Débâcle)

1914 De bien beaux vers de Laforgue ! - D’ailleurs, il faut que je relise. Tout ce que tu en dis, je le sens très juste et très pénétrant. Je comprends mieux, je ne sympathise pas davantage. Je n'ai jamais été assez bête cependant pour le croire un ironiste (Alain-Fournier, Correspondance avec Jacques Rivière)

\section{CORPuS WEB :}

Sur tous les thèmes qu'elle aborde dans ces textes - l'éducation sexuelle, les relations entre les enfants et les grands-parents, les cadeaux, le sens du sacré, ou la communication avec un enfant sourd -, Françoise Dolto souligne la nécessité de "parler juste aux enfants car ils sentent juste » [http://www.infosparents51.fr/Parler-juste-auxenfants] (6.12.2015) 
Enfin loin du dogmatisme qui parfois habille Montessori et empêche mentalement les personnes de suivre les enfants, et d'inventer ellesmêmes des matériels qu'elles " sentent " justes pour leurs enfants! [http://mercimontessori. blogspot.co.at/2013/10/premier-materiel-denumeration.html] (6.12.2015)

Voilà typiquement le genre de propos de côtiers qui se sentent plus juste parce qu'ils vivent ici toute l'année [http://www.thebottomturn.fr/ news/675-touriste.html] (6.12.2015)

Ce mot solidarité, dans cette culture du rebut où l'on jette ce qui ne sert plus, pour garder seulement ceux qui se sentent justes, qui se sentent purs, qui se sentent propres [http://trinitesainte-et-mariemamere.over-blog.com/articlecite-du-vatican-tous-egaux-devant-le-pere-22septembre-2013-120289605.html] (6.12.2015)

REMARQUeS : Sentir juste réfère à la capacité de jugement ou d'appréciation, la façon dont le sujet appréhende, voit, analyse ou ressent les choses, c'est-à-dire comme il convient, sans erreur. Juste reste invariable dans son emploi adverbial. En tant que prédicat second, il est variable : si le verbe est transitif, il s'accorde avec l'objet (v. le deuxième exemple du CW), et si le verbe est pronominal, il s'accorde avec le sujet (v. le quatrième exemple du CW). Toutefois, dans le troisième exemple du CW, il reste invariable. Il est modifié par plus, très. Notons l'emploi de calculer juste, parler juste et la collocation juste et pénétrant. VoIR AUSSI : calculer juste, raisonner droit

\section{Sentir lourd}

Donner une impression de lourdeur, touffeur Intransitif

1945 Ça sentait lourd. Toute la chaleur de la journée s'était déposée au fond de cette pièce comme une lie (Jean-Paul Sartre, L'Âge de raison)

\section{CORPUS WEB :}

Drake m'a rarement décu, c'est vrai...tous les morceaux qu'il a lachés avant la sortie de son album etaient pour moi un signe de tuerie...Started from the bottom... ça sentait lourd déja pour l'epoque !! [http://www.2kmusic. $\mathrm{com} / \mathrm{fr} /$ album/nothing-was-the-same/16527?fb_ comment_id=488693151167468_67220528281625 3\#f9eb96361e76a3] (6.12.2015)
Sympa de t’arrêter Aladora ;) ! Elle me fait bien triper aussi la GD\#2 . Ces espèces de gros nuggets qu'elle a.. Elle a oublié de grandir mais $\mathrm{p}^{\star}$ in les fleurs qu'elle envoie :-D.. et c'est dense.. aïe aïe.. et ça sent lourd.. [http://www.cannaweed. com/topic/84697-jdc-r\%C3\%A9colte-curingpes $\%$ C3\%A9e-in-terre-400w-mhhps-jdc3greendevilbelladonnamssj/page-3] (6.12.2015)

Cela fait maintenant 5 jours que j'ai mal au bras gauche, je le sens lourd, la douleur va jusqu'au bout des doigts (surtout le pouce) lorsque je bouge mes doigts je les sens lourd et je ressens également une douleur au poignet [http://forum. doctissimo.fr/sante/Douleur/gauche-engourdijours-sujet_14605_1.htm] (6.12.2015)

Finalement, j'écoute mes jambes, quand je ressens que mes jambes sont douloureuses enfin disons quand je les sens lourdes alors que je n'ai rien fait, marche, pietinement ou autre... je pense qu'il est temps que j'en change [http://forum. doctissimo.fr/sante/jambes-lourdes-varices/ combien-pour-contention-sujet_136855_1.htm] (6.12.2015)

Mais beaucoup de gens là consomment pour le sport ou parce qu'ils fument ou se sentent lourd... [http://forums.jeuxonline.info/ showthread.php?t=588199] (6.12.2015)

Ils se sentent lourds, inutiles, coupables d'exister dans un monde qui n'a plus besoin d'eux, où ils n'ont plus leur place [http://www. lemonde.fr/idees/chronique/2010/07/01/apresvous-senior_1380945_3232.html] (6.12.2015)

REMARQUES : Sentir lourd se dit de l'atmosphère chaude et humide, ou, au figuré, pesante, oppressante qui règne dans une pièce et qui est ressentie comme telle par quelqu'un. Lourd reste invariable dans son emploi adverbial. Dans les deux premiers exemples du CW, le sens semble plutôt être celui de 'lourd de sens, de profondeur, voire prometteur'. En tant que prédicat second renvoyant au propre à une lourdeur du corps humain subjectivement ressentie (exemples 3 à 5 $\mathrm{du}$ CW), il peut s'accorder avec l'objet dans l'emploi transitif du verbe (v. le quatrième exemple du CW), ou, au figuré, avec le sujet dans l'emploi pronominal du verbe (v. le sixième exemple du CW). Toutefois, il peut aussi rester invariable (v. le troisième et le cinquième exemple du $\mathrm{CW}$ ). 


\section{Sentir mauvais}

I. Dégager, répandre une mauvaise odeur, une odeur désagréable

Intransitif

1585 les corps morts avoient beau sentir mauvais, ils n'en avoient pas a moitié leur saoul. Voila quel mal-heur l'or de ces terres a donné aux Cannibales (Nicolas de Cholières, Les Neuf Matinées)

1631 Mais, mon dieu, dit-elle en se frottant le nez, ne le sentez-vous pas encores ? Et cela, elle le disoit à cause de l'onguent qui estoit respandu sur le plancher, qui sentoit fort mauvais (Honoré d'Urfé, L’Astrée)

1646 son fils Titus l'ayant repris de ce que par une honteuse avarice il levoit de l'argent sur les urines, il observa le temps auquel on luy en apportoit le payement, et appellant son fils, il approcha l'argent de son nez, et luy demanda s'il sentoit mauvais (Nicolas Coëffeteau, Histoire romaine)

1687 Les voiles batent contre les mâts : demandez à M. de Langeron quel signe c'est. Nous devons cette aprés-dînée rencontrer le soleil : il se fait bien sentir. Notre pompe sent bien mauvais : voila encore de quoi consulter les Marins (François-Timoléon de Choisy, Journal du voyage de Siam)

1709 Une peau d'hermine coûte quatre ou cinq sous. La chair de cet animal sent très mauvais; et il se nourrit de petits-gris et de rats de montagne. Ce petit animal, tout-à-fait inconnu ailleurs, et fort singulier, comme vous allez voir, se trouve quelquefois en si grande abondance, que la terre en est toute couverte (Jean-François Regnard, Voyage de Laponie)

1756 Cet homme, d'ailleurs sage et politique, semblait croire sincèrement, qu'avec la permission de Luther et de ses compagnons, il pouvait transgresser une loi qu'il reconnaissait. Il représenta donc à ces chefs de son église, que sa femme la princesse de Saxe était laide, sentait mauvais, et s'enyvrait souvent (Voltaire, Essay sur l'histoire générale et sur les mœurs et sur l'esprit des nations)
1773 Ce bois, fraîchement employé, sent les excréments humains, et sa fleur a l'odeur du girofle. C'est le contraire dans le cannellier, dont la fleur sent très mauvais, tandis que l'écorce et le bois exhalent une bonne odeur (Bernardin de Saint-Pierre, Voyage à l'île de France)

1805 Les odeurs constamment désagréables viennent, pour la plupart, de choses qui pourroient être nuisibles : les plantes vénéneuses, les chairs corrompues, les métaux empoisonnés sentent généralement mauvais (Georges Cuvier, Leçons d'anatomie comparée)

1839 Chère amie, nous partons ce soir pour Gênes par le bateau à vapeur. C'est une promenade de cinq à six jours, dont nous avions tous besoin, car Marseille commence à sentir horriblement mauvais (George Sand, Correspondance)

1842 Si quelque femme est assez bégueule pour remarquer l'infection répandue dans le navire, son mari est là pour lui répondre que l'argent ne sent point mauvais, et que sans le cochon il n'y aurait pour elle ni robe de soie, ni chapeau de France, ni mantille de Barcelone (George Sand, Un hiver à $M a$ jorque)

1846 Il y avait aussi de gros morceaux de pain bis. Je pris ce pain. Il était couleur fumier, sentait fort mauvais, et s'attachait aux doigts comme une glu (Victor Hugo, Choses vues)

1848 Vous avez un bon et généreux cœur, de m’offrir votre bourse. Elle doit être couleur de rose aussi, et votre argent, chose qui sent si mauvais, doit sentir bon, je m'imagine (George Sand, Correspondance)

1869 Il écarta les rideaux, et aperçut, au milieu des linges, quelque chose d'un rouge jaunâtre, extrêmement ridé, qui sentait mauvais et vagissait.

- Embrasse-le !

Il répondit, pour cacher sa répugnance :

- Mais j'ai peur de lui faire mal ? 
— Non ! non ! (Gustave Flaubert, L'Éducation sentimentale)

1911 - Et puis, dit-elle, vous avez mis votre limousine à sécher devant le feu, Timothée, cela sent bien mauvais!

Profitant de ce que Frédéric s'embarquait dans une explication, M. des Lourdines prit son vêtement et s'esquiva (Alphonse de Châteaubriant, Monsieur des Lourdines)

1919 Cette peinture sent mauvaise (Exemple entendu / Damourette et Pichon, §984)

1936 Je suis content de commencer le premier jour de mon épreuve ici, dans cette chambre. Ça n'est d'ailleurs pas une chambre, on m'a dressé un lit dans un petit corridor où mon ami range ses échantillons de droguerie. Tous ces paquets sentent horriblement mauvais. Il n'y a pas de solitude plus profonde qu'une certaine laideur, qu'une certaine désolation de la laideur (Georges Bernanos, Journal d'un curé de campagne)

1938a Et de même si nous pensons que les nègres sentent mauvais, nous ignorons que pour tout ce qui n'est pas l'Europe, c'est nous, blancs, qui sentons mauvais. Et je dirai même que nous sentons une odeur blanche, blanche comme on peut parler d'un « mal blanc » (Antonin Artaud, Le Théâtre et son double)

1938b Femmes qui vous glorifiez de vos ornements, de vos cheveux teints, de vos mains peintes, de vos parfums, je vous dis que vous sentez toutes mauvais et que vous êtes toutes laides (Armand Salacrou, $\mathrm{La}$ Terre est ronde)

1943 Si la nature ne m’a pas aussi généreusement doué que vous sous le rapport de l'odorat, je distingue néanmoins les bonnes odeurs des mauvaises. Et vous sentez diablement mauvais, sans reproche, belle dame !

- Vraiment ? Dieu, que je suis fâchée, ditelle. Ne croyez-vous pas que... que cela peut venir... (Georges Bernanos, Monsieur Ouine)
1956 Mon guignol à terre et bien cabossé, je reprends ma valise et je redescends les escaliers sans perdre cinq minutes pour corriger la gosse, ça sentait trop mauvais (René Fallet, La Grande Ceinture)

1963 Dans les galeries souterraines où ont vécu les quelque six cents femmes et enfants qui avaient suivi leurs maris et pères, règne l'abominable odeur des forteresses assiégées, un affreux mélange de cadavre pourri et d'excrément : il faut bien dire que rien ne sent aussi mauvais que la charogne humaine (Albert T'Serstevens, L'Itinéraire espagnol)

1989 C'est qu'il avait des tonneaux dans sa cave. Des tonneaux sentant mauvais. Mais leur puanteur n'avait pas l'air de l'incommoder. Loin de là. C'était de la puanteur de vin qu'il respirait à pleins poumons en se réjouissant (Remo Forlani, Gouttière)

II. Procurer un mauvais sentiment, une sensation désagréable Intransitif

1696 C'est sans doute que l'incrédulité et l'ingratitude sentent mauvais, comme les vertus sentent bon. Cette haine qu'on a pour eux est une chose extraordinaire (Mme de Sévigné, Correspondance)

1844 Les nombreux ennemis de Janin sont enchantés de le voir ainsi étrillé. Moi je trouve que les deux pamphlets sentent fort mauvais. Autant vaut passer par la rouette qui est darrier l'église de la Châtre, que de lire cela! (George Sand, Correspondance)

1862 Dans ces règnes-là rien ne voile la honte ; et les faiseurs d'exemples, Tacite comme Juvénal, soufflettent plus utilement, en présence du genre humain, cette ignominie sans réplique. Rome sent plus mauvais sous Vitellius que sous Sylla. Sous Claude et sous Domitien, il y a une difformité de bassesse correspondante à la laideur du tyran (Victor Hugo, Les Misérables)

1867 Un juge : il s'est desséché dans une salle trop chaude, sous le bavardage des avocats, parmi les physionomies basses et in- 
quiètes, dans les mauvaises exhalaisons, parmi les odeurs douteuses; les petites contraventions sentent mauvais (Hippolyte Taine, Notes sur Paris)

III. Prendre une mauvaise tournure, sentir le roussi

Intransitif

1877 Enfin, le défilé avait cessé. Gervaise, droite au milieu de la rue, regardait la porte. Ça commençait à sentir mauvais. Deux ouvriers attardés se montrèrent encore, mais toujours pas de Coupeau

(Émile Zola, L’Assommoir)

1949 - Ça sent mauvais, dit Charlot.

- Ça sent le roussi.

- Non, je dis : s'ils brûlent les archives, ça sent mauvais.

- Eh bien oui : ça sent mauvais, ça sent le roussi. C'est ce que je dis.

Ils rirent. Mathieu désigna le livre et demanda :

- Où l'as-tu trouvé ?

(Jean-Paul Sartre, La Mort dans l'âme)

1954 La conversation a traîné encore un moment ; quand nous nous sommes retrouvés en bas de l'escalier, une demi-heure plus tard, j'ai dit :

- Ça sent bien mauvais, cette histoire !

Qu'est-ce qu'il vous avait dit au juste,

Trarieux, en avril ?

(Simone de Beauvoir, Les Mandarins)

\section{CoRpus Web :}

Voici les 9 Astuces pour que vos chaussures ne sentent plus mauvais [http://www. comment-economiser.fr/9-astuces-pour-quevos-chaussures-ne-sentent-plus-mauvais.html] (8.12.2015)

Il s'agit d'une haine envers ceux qui souhaitent nous envahir, et nul besoin de les connaitre mieux, pour savoir qu'ils sont pourris jusqu'à la moelle, que leur culture est contraire à notre culture et notre république läque, ces gens la sentent mauvais et ne sont qu'à détruire, casser, voler [http://forum.aufeminin.com/forum/ societe3/_f23836_p5_societe3-Pourquoi-tjrs-lesmusulmans-ds-la-ligne-de-mire.html] (8.12.2015) vos chaussures sentent mauvaises à cause de la transpiration de vos pieds ou à cause de la matière [http://mespetitesastuces.unblog. fr/2012/12/12/les-chaussures-sentent-mauvaises] (8.12.2015)

Si jamais elles sont légèrement verdâtres, si elles s'accompagnent de démangeaisons ou si elles se sentent mauvais, tu devrais consulter un médecin [http://forums.jeunessejecoute.ca/ ViewMessage.aspx?FORUMID=37\&MSGID=129 751] (8.12.2015)

Toutes les personnes présentes dans le Bar se sentent mauvaises, avec l'envie d'écraser leur voisin ou de le ruiner [http://archivesmartellus. meilleurforum.com/t1080-ere-7-zdv-3] (8.12.2015)

et j'ai beau essayer de me forcer à la déconne sur d'autres topaks, c'est un masquard de clown, je suis assez mal et je la sent mauvaise pour ces prochains jours [http://forum.hardware.fr/ $\mathrm{hfr} /$ Discussions/Societe/suicide-rattache-liresujet_11004_997.htm] (8.12.2015)

REMARQUeS : Sentir mauvais (I) s'applique à une chose (un aliment, un objet, une fleur, un parfum) ou à une personne qui dégage une odeur désagréable, dégoûtante, qui repousse. Le sujet peut aussi désigner par métonymie une ville, dont les rues répandent une odeur désagréable. Sous (II), le sujet désigne quelque chose de négatif (un écrit satirique, une infraction, l'action, le comportement ou le caractère d'une personne) qui donne une impression désagréable, défavorable. En (III), sentir mauvais est une expression familière utilisée pour souligner le fait qu'une situation commence à tourner mal, à évoluer dans un sens négatif ou que l'on ne souhaite pas. Mauvais reste invariable dans la majorité des cas (mais v. le troisième exemple du CW où il s'accorde avec le sujet au féminin ; de même l'exemple oral de 1919). On observe ainsi une continuité entre l'exemple oral de 1919 (" vulgaire », selon Damourette et Pichon) et les exemples informels du CW. Seul le fait que Damourette et Pichon citent aussi des exemples entendus nous permet de faire ce constat, étant donné que les exemples écrits, hors CW, ne présentent pas d'exemple accordé. Ajoutons que la même ligne de continuité s'observe dans les entrées tomber bas et sentir fort, accordés dans les exemples oraux cités par ces grammairiens et dans le CW. Notons que dans 
le sens (I), le verbe peut être pronominal (v. le quatrième exemple du $\mathrm{CW}$ ). En tant que prédicat second, mauvais s'accorde avec le sujet si le verbe est pronominal (v. le cinquième exemple du CW), ou avec l'objet, si le verbe apparait dans son emploi transitif (v. le sixième exemple du CW). Il est modifié par aussi, bien, diablement, fort, généralement, horriblement, plus, si, très, trop. Notons l'emploi impersonnel familier de ça sent mauvais. Dans les exemples antérieurs à 1585 que l'on peut trouver dans Frantext - les exemples ne sont pas cités ici -, mauvais modifie un substantif (sentir mauvaise odeur), ce qui favorise une analyse de l'emploi documenté ici comme tour elliptique.

\section{Sentir pareil}

I. Ressentir d'une telle manière, d'une manière comparable

Transitif

1893 Pourtant sa détresse, ses remords étaient grands ; - et aussi son amour : il ne l'avait jamais senti pareil. Le lendemain, il se retrouva dans cette gare où il avait vu Madeleine pour la première fois (Pierre Loti, Matelot)

II. Dégager, répandre la même odeur, une odeur identique

Intransitif

1932 Rien ne force les souvenirs à se montrer comme les odeurs et les flammes. Ma case elle, sentait tout pareil. Bien que détrempée, elle a brûlé entièrement, très franchement et marchandise et tout. Les comptes étaient faits (Louis-Ferdinand Céline, Voyage au bout de la nuit)

1960 Armand se trouve pas du nombre. Trop paisible il la ressent cette odeur. Sa frangine s'il en avait eu une, aurait senti pareil quand il l'aurait embrassée. Conviction qui relève du domaine des berlures de l'arrière-chou, rayon des sensations connes! (Albert Simonin, Du mouron pour les petits oiseaux)

\section{CORPus WeB :}

Je viens de recevoir cette huile. J'ai déjà l'huile apaisante, et je trouve qu'elles sentent pareil !! [http://www.beaute-test.com/forums/ index.php?topic $=134124 \&$ start $=780]$ (8.12.2015)
Lorsqu'elle a jeté son dévolu sur une sucette, j'ai en acheté 3 ou 4 que je lui donnais à tour de role (pour la put.. d'odeur qu'elles prennent très vite - donc fallait qu'elles sentent pareilles !) et ainsi en cas de perte de l'une, on avait une rechange nous permettant de chercher l'autre ... le lendemain ! [http://www.penseesbycaro. fr/2007/03/adieu-mon-sommeil] (8.12.2015)

J'ai demandé à des filles leur réaction et elles m'ont dit qu'elles se sentaient pareil [http://www. streetmelody.com/t10417-traduction-chamil lionaire-internet-nerds-revenge] (8.12.2015)

je sors de la combi (qui est devenue une combi de plongée * au fur et a mesure de la journée) on dit au revoir a d'anciens membres d'anciens forum rencontrés la bas et une copine me dit tu vas voir, ta bécane sur la route tu vas pas la sentir pareil [http://motardslibresgironde.forum actif.org/t573-je-l-ai-fait-c-est-genial] (8.12.2015)

Preuve apparemment simpliste et pourtant évidente qu'il faut bel et bien posséder des racines qui s'enfoncent dans les tréfonds de la civilisation pour s'y fondre réellement et par ce fait s'en ressentir comme une partie intégrante, la savoir et la sentir pareille à un berceaux et à une Terre fondatrice dont les ancêtres sont à l'origine, et incidemment vouloir l'entretenir et la protéger [https://identitairepur.wordpress. com/2013/04/30/limmigre-sen-moque-de-notrecivilisation] (8.12.2015)

Alors que tu peux être entouré de personnes qui se sentent " comme toi » et qui te comprennent? Qu'importe pourquoi elles se sentent pareilles que toi ! Ce n'est pas forcément à cause d'un point commun sur l'orientation sexuelle... [http://forum.ados.fr/love/homosexualite/ amour-putes-sujet_4789_1.htm] (8.12.2015)

REMARques : Sous sentir pareil (I), le sujet désigne une personne qui ressent, perçoit quelque chose (une émotion) de la même façon, à un niveau égal, sans changement. Sentir pareil (II) s'applique à une chose ou une personne qui répand une odeur semblable ou comparable à une odeur connue ou familière. Pareil reste invariable dans son emploi adverbial, mais l'accord est réalisé avec le sujet dans le deuxième exemple du CW. En tant que prédicat second (exemples 3 à 6 du (W), il tend à l'accord, restant tout de même invarié dans les troisième et quatrième exemples du CW. Il est modifié par tout. 


\section{Sentir pire}

Répandre une odeur très désagréable, nauséabonde, 'plus mauvaise' qu'une autre Intransitif

1921 Ils [= les champignons] sont jaune, orangé, pourpre, lilas, brun fauve et or, bistre, terre d'ombre, blanc tigré, blanc immaculé, virginal. Ils sentent bon, âcre, mauvais ou pire. D'aucuns ont un parfum d'œillet, d'aucuns de musc, et ceux-ci une odeur de camphre ou de soufre, et ceux-là un relent d'ail (Joseph de Pesquidoux, Chez nous : travaux et jeux rustiques)

\section{CORPuS WeB :}

Des vêtements polyester sentent pire que ceux en coton, après un exercice intensif par leurs porteurs, parce que les bactéries qui causent les odeurs se développent mieux sur du polyester, selon une étude publiée en ligne avant impression dans la revue Applied and Environmental Microbiology [http://amgar.blog. processalimentaire.com/hygiene/vetements-enpolyester-sentent-mauvais-apres-exercice-cotonpas-trop] (9.12.2015)

Je sais pas quoi dire là...Je nommerai ça \〉> Playback de fifou!

Bon voilà du playback, ils chantent même pas tout, Jin qui se marre durant le truc, Do Yeon qui se goure dans la choré', on les sent pire qu'à fond ! @-) [http://forums.soompi.com/fr/ topic/2048-mrmr/?page=5] (9.12.2015)

Dix mille, vingt mille ou trente mille islamistes ont pris les armes et les maquis, tué et fait sauter des édifices, sous l'œil « attentif » des Occidentaux. Mieux, souvent, les responsables de la lutte antiterroriste ont été traités de manière telle qu'on les sentait pires que ceux qu'ils pourchassaient [http://www.lexpressiondz. com/actualite/599-La-strat\%C3\%A9gie-de-lamenace-permanente.html] (9.12.2015)

Je relève ce point capital, car certaines personnes qui ont recours à la chirurgie esthétique afin de s'embellir ou ôter des complexes ne sont pas forcément mieux dans leur peau après, voire se sentent pire [http://www.forumfr.com/ sujet609240-post10-1-image-corporelle-et-lasociete.html] (9.12.2015)
En réalité, les personnes qui se vengent se sentent pires après leur acte que celles qui ne se sont pas vengées [http://www.express.be/joker/ fr/platdujour/vous-pensez-que-la-vengeance-estdouce-detrompez-vous/206495.htm] (9.12.2015)

REMARQUeS : Sentir pire s'applique à une chose, par exemple une fleur, qui exhale, dégage une odeur nauséabonde, qui écœure ou qui incommode. Pire est invariable dans l'emploi adverbial, mais en tant que prédicat second au sens de 'percevoir la disposition émotionnelle de quelqu'un ou (emploi pronominal) de soi-même' (trois derniers exemples du CW), il tend à l'accord. Toutefois, dans l'avant-dernier exemple il reste invarié. En effet, l'interprétation adverbiale de manière est tout aussi possible que celle d'un prédicat second.

\section{Sentir profond}

I. Ressentir profondément, d'une manière intense

Transitif

1840 C'est que j'avais mis mon cahier sous un tapis en le sortant de mon portemanteau, et qu'il était là depuis. En tripotant, ma main s'est posée dessus ; il s'est ouvert, et je continue l'écriture. Ce fut un beau moment que le revoir de la famille, de papa, de Mimi, d'Erembert, qui m'embrassaient si tendrement et me faisaient sentir si profond tout le bonheur d'être aimée (Eugénie de Guérin, Journal)

II. Prendre conscience (des choses) de manière profonde, pénétrante

Intransitif

1896 à M. le docteur Chauffart

Le poète n'est parbleu pas ce que l'on croit :

Il n'a que quand il veut toutes les ignorances,

Sans trop d'âpre verdeur ou de préjugés rances,

Et parfois même il sent profond et pense droit (Paul Verlaine, Euvres poétiques complètes)

1953 Les hommes n 'admettront-ils jamais d'autres raisonnements que ceux des chassepots ? et qui, la guerre éclatée, déclarait : Je n’ai jamais eu tant envie... Ce ne 
sont pas des visionnaires, mais ils voient clair, et sentent juste et profond (Claude Roy, Le Commerce des classiques)

\section{CoRpus Web :}

La vraie raison de cette proposition est politique : emmerder le Français sans histoires, grande victime des radars. Lui faire sentir profond que, bien qu'il soit sans histoires et qu'il ne demande rien à personne, il reste un esclave, même dans sa liberté de circuler, soumis sans discussion possible aux caprices et à l'arbitraire de l'Etat bureaucratique [http://fboizard.blogspot. co.at/2013_07_01_archive.html] (10.12.2015)

La frustration ne vient pas uniquement de la Côte d'Ivoire. Car le Gabon et l'Algérie peuvent la sentir profond, la frustration [http://www.sportivoire.ci/football/index.php? $=1 \& i d=22479]$ (10.12.2015)

Personnellement comme j'ai des chiens nourris à la viande crue, je ne prendrais jamais la chance d'enterrer (même profond) un cheval sur mon terrain... mes St-Bernard ont un nez fait pour sentir profond et ça ne me tenterais pas du tout qu'ils me ramènent un bout de mon compagnon enterré [http://poneyxpress.com/forum. php?cat $=9 \& d v=42830 \&$ recordstartcomment $=6]$ (10.12.2015)

Je suis un mec et je donnerais tout pour me faire baiser le cul et qu'on jouisse en moi. Je veux la sentir profond en moi toute la nuit, une grosse queue rien que pour moi. La sentir profond dans mon anus [http://www.suisjenormal. $\mathrm{fr} /$ discussion/21871/Je-suis-un-mec-et-jedonnerais-tout-pour] (10.12.2015)

Et ceux qui disent que la largeur compte plus, je dirais que la longueur compte tout autant, les filles aiment la sentir profonde hein [http://www.jeuxvideo.com/forums/1-50143622810-5-0-1-0-quelle-est-la-taille-de-votre-z. $\mathrm{htm}](10.12 .2015)$

La belle Normande écrit, est comédienne, aime le cirque, le trapèze ; lors de ses interviews et dans ses romans, on la sent profonde et généreuse, intelligente, cultivée... [http://lejardindutemps. over-blog.com/article-chanson-de-la-semainenotre-date-de-naissance-91245790.html] (10.12.2015)

C'est plutôt que le type se rend compte de certaines choses, ce qui le fait se sentir « pro- fond " et "philosophe ", et du même coup il se rend compte qu'il pourrait utiliser cela pour scorer [http://www.sceptiques.qc.ca/forum/ viewtopic.php?t=7513\&start=25] (10.12.2015)

Elle [= Clémentine] se sentait profonde et se fit doucement lourde, laissant entrer en elle la chair de Valentin, chavirée de tendresse que de la pénétrer le rende si heureux [http://www.oniris. be/modules/romans/article.php?storyid=64] (10.12.2015)

REMARQues : Le sujet de sentir profond (I) désigne une personne qui éprouve un sentiment positif avec une grande intensité, celui-ci étant causé par un acte chaleureux, émouvant. En (II), il réfère à la capacité de jugement ou d'appréciation, à la façon dont il appréhende les choses, le sujet faisant preuve de beaucoup de perspicacité et de réflexion. Les exemples du CW montrent l'emploi dans différents domaines de la sensation. Profond tend à l'invariabilité dans son emploi adverbial, mais l'accord avec le complément d'objet peut mettre en relief celui-ci (cinquième exemple du CW). L'accord est plus systématique quand sentir a une fonction de copule dans (se) sentir profond 'sentir être profond' (trois derniers exemples du CW). Il est modifié par si. Notons l'emploi de penser droit et la collocation juste et profond.

\section{Sentir sucré}

Dégager un parfum sucré

$\pi$ sentir frais

\section{Sentir vivant}

Avoir l'odeur d'un être vivant, une odeur forte, fauve

Intransitif

1960 Quand on est salade, un gros épais paillon ; pour les pieds de vigne, un bon rempart de terre chaude relevée avec soin par le soc qui « chausse » les ceps ; si on est campagnol, ou bien renard, un terrier bien noir, calfeutré, qui sent fort et vivant ; loir ou marmotte on s'endort de tout son poil, de tout son sang, de toutes ses griffes. Mais homme, on se fait chaud de tout ce qui est feu (Claude Roy, Le Journal des voyages) 


\section{CORPus Web :}

Et bien c'est justement l'identification qu'on se fait avec les personnages, on a l'impression de se découvrir et de découvrir les autres, c'est ce qui m'a plu. Ce n'est pas la Meilleure Histoire mais je trouve quand même qu'il y a une construction. J'aim aimé parce que c'était fluide et que quelque soit le personnage, qu'il me " ressemble » ou pas, j'éprouvais, entre guillemets, leurs sentiments, je les sentais vivant (;) ! [http://www. sortirensemble.com/katherine-pancol-225675_1. html] (12.12.2015)

Rebekah les force alors à s'avouer les choses et Elena est obligée de lui dire qu'avec Damon elle se sent vivant alors qu'avec lui, elle se sent comme cassée et sent qu'il veut la réparer [http://vampire-diaries.hypnoweb.net/dossiers/ relations-serie/elena--stefan/elena-stefansaison-4.153.2306] (12.12.2015)

la maison était plus qu'accueillante car on la sent vivante et pleine d'histoires ! [https://www. airbnb.at/users/show/11466766] (12.12.2015)

Elle analyse fort bien la métamorphose qu'elle subit, elle ne s'appartient plus, elle est prête à renoncer à tout, à son mariage, à ses enfants sous prétexte qu'elle se sent vivante avec lui ! [http://www.valeursactuelles.com/culturetops/un-homme-dangereux-57876] (12.12.2015)

REMARQUES : Dans l'exemple de 1960, sentir vivant s'applique à un animal qui dégage une odeur forte de bête, une odeur sauvage, intense. Dans l'emploi de sentir comme copule, l'accord est plus systématique (v. les exemples du CW), mais il ne s'observe pas toujours (v. le premier et le deuxième exemple du CW).

\section{Sentir vrai}

Sentir comme une vraie fleur Intransitif

1945 - Eh bien, mon poulet, qu'est-ce qu'elles ont ces fleurs?

- Pourquoi elles sentent vrai et elles touchent faux ? La Mamandouce se penche, respire (« C’est pourtant vrai !»), respire les fleurs artificielles, qu'elle a achetées hier et leur trouve un parfum (Gilbert Cesbron, Traduit du vent)
CORPus WEB :

La narration est fluide, on ne s'ennuie pas un instant avec des dialogues qui sentent vrai et font mouche [http://www.bedetheque.com/avis18179-BD-Cinquieme-evangile.html] (13.12.2015)

Ces gars-là adorent les roadhouses et les estaminets douteux, les ambiances qui puent et qui sentent vrai : rien ne fait plus plaisir aux Holmes Brothers qu'un peu d'interdit [https://voir.ca/ musique/2001/04/25/the-holmes-brothers-voixlactee] (13.12.2015)

En première partie, y’a le copain Mélan qui va v'nir taper la chansonnette avec ses mots qui hérissent et qui sentent vrais [https://fr-fr. facebook.com/permalink.php?story_fbid=10153 069934293299\&id=125493613298] (13.12.2015)

Mes CV font rire quand les gens les sentent vrais. Mais je ne cherche pas à me mettre audessus des autres, et le mot "dérision " ne me convient pas [http://www.parismatch.com/ Culture/Art/Jed-Martin-existe-nous-1-avonsrencontre-146739] (13.12.2015)

Le fait d'écraser des boutons dans l'ordre - le sens d'une lourde attaque, deux attaques claires et une attaque de Ki - crée quelques mouvements visuellement impressionnants et compliqués. Ils sont brillants et tape-à-l'œil et se sentent vrais pour l'anime (je sais vraiment que la série y ressemble) [http://www.jeuxvideo.com/ forums/1-14562-5271-268-0-1-0-0.htm] (13.12.2015)

Ensemble ils se cherchaient et se taquinaient sans arrêt, c'était comme ça qu'ils se sentaient vrai, oh non Niall ne connaissait pas tout de Caroline et Caroline pas tout de Niall, mais 'est au fur et à mesure qu'ils apprenaient à se connaître [http://dreamuntil-the-end.skyrock. com/3186935385-Chapitre-36-Des-debutsprometteurs.html] (13.12.2015)

Remarques : Dans l'exemple de 1950, le sujet désigne une chose artificielle ayant l'aspect d'un végétal (d'une fleur) qui dégage une odeur semblable à celle d'une vraie fleur. Dans le CW, le verbe se construit avec d'autres sujets, comme un dialogue ou des ambitions. Vrai reste invariable dans son emploi adverbial, mais l'accord est réalisé dans le troisième exemple du CW. Avec sentir comme verbe copule, l'accord est plus systématique (v. les trois derniers exemples du CW), mais vrai reste invarié dans le dernier. Notons l'emploi de toucher faux. 


\section{Seoir fort}

seoir haut et fort : trôner

$\lambda$ seoir haut

\section{Seoir haut}

Siéger, avoir une place importante

Intransitif

1664 Rome, qui m’a depuis chargé de son empire, Quand sous le poids de l'âge à peine je respire,

A vu ce même amour me le faire accepter, Moins pour me seoir si haut que pour vous y porter (Pierre Corneille, Othon)

\section{CORpus Web :}

Papi, trouve moi un site où je peux mater les Seed et tu m'as vendu le jeu ! J'ai une grosse envie de mecha en ce moment. Je vois mon Anubis et Jehuty qui sied haut et fort en haut de mon bureau, puis là dans MGS2, le MG Ray qui est si majestueux !!! Raah me faut un jeu de mecha qui déboite... [http://www.gameblog.fr/ forum/topic/62868-ps-vita-les-news/page-247] (14.12.2015)

La MM enfin est assez lourde, et l'essentiel du poids est concentré sur le boîtier. Le bracelet lui est assez léger. Comme elle sied assez haut sur le poignet, il faut ajuster finement le bracelet pour qu'elle ne se balade pas trop [http://forum. hardware.fr/hfr/Discussions/Loisirs/horlogeriemontres-lire-sujet_1750_13288.htm] (14.12.2015)

Comme elle avait détourné le regard, elle ne put déceler la mine que portait le chien Bleu. Un air atterré, sans-voix, bouche-bée. Ses deux longues oreilles seyaient haut au dessus de sa tête [http://bba-dissension.naturalforum.net/t2473mirroir-shards] (14.12.2015)

REMARQUES : Seoir haut désignait le fait d'occuper une position sociale élevée dans la société et par extension, de se voir attribuer des tâches importantes, dignes de son rang ou de sa position hiérarchique (exemple de 1664). Les exemples du CW réfèrent plus concrètement à une position locale. Notons la collocation haut et fort. Haut reste invariable et est modifié par si. VoIR AUSSI : asseoir bas

\section{Serrer dur}

I. Serrer avec force, avec vigueur ; serrer fortement

Intransitif

1879 Il me fera mettre les menottes peut-être et ordonnera aux gendarmes de serrer dur si je résiste. Et cela, parce que je ne veux pas être professeur comme lui. Je comprends (Jules Vallès, Jacques Vingtras : L'Enfant)

1943 - Écoutez, Philippe !... Assez, Philippe !... Elle secoue son bras de toutes ses forces, mais la main de Steeny l'a saisi au-dessus du coude, serre dur. - Dites-moi-si ! Si ! Vous allez le dire - Quel homme est-ce donc, ce M. Ouine ? Qu'est-ce qu'il fiche ici, M. Ouine ? (Georges Bernanos, Monsieur Ouine)

1976 Le curé avait détourné la tête en jurant, mais il avait quand même aidé l'Yvonne à enrouler autour du torse la grande ceinture de flanelle du docteur Gibaud. Ils serraient dur, et plus ils serraient, plus le pigeon s'écrasait et plus le sang et la merde sortaient de dessous la flanelle (Jacques Lanzmann, Le Têtard)

Transitif

1953a Je dus tout de même serrer dur le pied [= d'un éléphant de bois sculpté] avant de le sentir bouger

(Albert Paraz, L'Adorable Métisse)

II. serrer dur la gorge de/à quelqu'un : ressentir une grande angoisse, se sentir très oppressé Intransitif

1953b Je parvenais pas à me le sortir du cigare, le gentil Marco. De repenser à tout le plaisir qu'il se promettait de ses poiscailles, la gorge me serrait dur. Encore heureux qu'il n'avait pas eu le temps d'affranchir sa mignonne. Sur la conduite à tenir envers cette môme, j'hésitais beaucoup

(Albert Simonin, Touchez pas au grisbi)

\section{Corpus Web :}

pour l'alu, onpeut raisonner à inverseemnt, à savoir que la jante est bien plus épaisse, et qu'il faut serrer plus dur pour vaincre l'lélasticité du goujons... [http://www.forum4x4.org/archive/ index.php/t-23733.html] (14.12.2015) 
mon pouce, il a aimé la balade au vent. j avais mis 1 orthèse parce que les messieurs, ils serrent dur les mains pour saluer... oh les cons ! mdr [http://forum.doctissimo.fr/sante/arthrose-os/ cervicalgie-cephalee-sujet_156995_2.htm] (14.12.2015)

Mes compagnons de traversée s'embourbaient dans les premiers écueils du marais. Ce groupe naissant, promis au plus bel avenir serraient dur les coudes, les plus forts relevant les plus faibles [http://frenchcinema4d.fr/ showthread.php?56160-Il-faut-sauver-le-soldatKiteman] (14.12.2015)

$\mathrm{Tu}$ as quoi comme bateau ? Moi c'est un Symphonie. Tes bas-haubans ils sont pûtôt serrés durs ou un peu moins ? Perso j'ai peut-être un peu tendance à trop blinder après avoir été de la (très) vieille école où il fallait qu'au près les haubans sous le vent soient mous... [https:// www.hisse-et-oh.com/forums/equipements/ messages/1599432-le-greement-entre-enresonnance] (14.12.2015)

REMARQues : Serrer dur (I) se dit du fait de tenir ou de maintenir quelque chose étroitement en exerçant une pression, le complément d'objet désignant une partie du corps (très souvent une main). En (II), le sujet réfère à quelque chose de négatif, d'émotionnellement éprouvant, qui provoque de l'angoisse chez quelqu'un. Dur est normalement invariable, mais, dans le dernier exemple du CW, l'accord est réalisé. Il est modifié par plus. Notons que dur entre dans la locution lexicalisée serrer les coudes 'se montrer solidaire avec les autres'.

\section{Serrer étroit}

Serrer fortement, étroitement, de très près ; enlacer

Transitif

+1150 Li ceuaus uit les armes mal atirees, Il fronche des narines, la geule bee ; Aiols li tient le resne estroit seree (Aiol et Mirabel [ $2^{\mathrm{e}}$ moitié XII ${ }^{\mathrm{e}}$ ], 899)

$\sim 1170$ Armee se fu lor maisniee :

Le petit pas, estreit serré, [variante : serré estreit]

En sont tot dreit el temple alé [variante : al temple droit alé] (Benoit de Sainte Maure, Le Roman de Troie, 4483)
1300 Sarrazin et paien, qui tout confonge Dés, Desarment Olivier, qui ou cors fu navrés ; Les ex li desbenderent, qu'il ot estroit serez. [estrois noés, Fierabras (L), 2029] Oliviers remest saingles ou bliaut de cendés (Fierabras (K), 1926)

1550 Plus estroit que ne serre

La vigne les ormeaux,

Ou l'importun lierre

Les appuyans rameaux

(Pierre de Ronsard, Les Odes, p. 245)

\section{CORPUS WEB :}

J'ai apprécié Time etSIDI(Energy HT, Ergo 2), ces dernières surtout car les réglages micrométriques me permettent de serrer étroit en haut (bien caler le pied, ne pas décoller le talon de la semelle) et au milieu (où mon pied est étroit) mais pas trop au niveau des orteils (ne pas couper la circulation) [http://www.vo2cycling.fr/Forum/ commentaires-site/49280-formes-de-pieds-etchaussures-de-velo] (14.12.2015)

REMARQUES : En ancien français, serrer étroit réfère au fait de serrer quelque chose ou à la façon de marcher, les hommes étant serrés les uns contre les autres. En parlant d'éléments symétriques (les rênes), se dit du fait de les tenir étroitement rapprochés et avec force. Étroit tend à l'invariabilité. Il est modifié par plus. Usuelle dans l'ancienne langue, l'antéposition dans étroit serré cède la place à la postposition dans l'emploi moderne (dernier exemple du CW).

\section{Serrer fort}

Serrer, maintenir (quelque chose) avec force, maintenir ferme, encercler, être très près Transitif

$\sim 1177$ Mes espoir il est anföiz $\mathrm{Ou}$ an tel prison anserrez, Don li huis est si fort serrez Qu'il n'an puet issir sanz congié (Chrestien de Troyes, Lancelot ou Le Chevalier de la charrete, 6384)

+1415 Faulce mort, A grant tort. M’as grevée, Et ostée Mon deport ; Mon cuer mort, 


\section{Car trop fort}

L'as serré,

Faulce mort

(Charles d'Orléans, Poésies complètes

[ 1415-1440], I, Rondel II [attribué], p. 210)

$\sim 1450$ Et combien que les Troyens fussent fort serrez des Grecs leurs ennemis, neantmoins ne laissèrent jamais de faire les divins sacrisfices, mais tousjours les faisoient ainsi qu'ilz avoient acoustumé, et encores les faisoient plus solempnellement, et sur touz autres dieux honnoroient Palas, la deesse de Sapience

(Roman de Troilus et Cressida, p. 124)

1555 ANNE. Arreste, ô chere sœur,

O sœur qui de ta voix me peux tirer le pleur,

Et le cœur tout ensemble, arreste la

carriere,

Serrant plus fort la bride à ta douleur trop fiere (Étienne Jodelle, Didon se sacrifiant)

1572 Le serviteur pour mettre en exécution sa charge, s'advisa d'une finesse digne d'un laquays, vray filz de putain : car ayant arraché deux poils de la queuë du cheval, il lia avec iceux fort serré le pied de la beste au dessous du boulet, et l'accoustra si dextrement sous le poil qu'on n'eust sceu voir ce qui lioit : puis luy mit une langue de serpent dans l'oreille, affin que le cheval par un tremblement continuel semblast avoir les avives : si bien qu'au matin la pauvre beste n'osoit ainsi accoustrée appuyer ce pied qu'elle avoit ainsi pressé (Jacques Yver, Le Printemps)

\section{CORPUS WEB :}

J'aimerais te sortir de mes rêves pour te serrer fort dans mes bras [https://www.facebook.com/ Jaimerais-te-sortir-de-mes-r\%C3\%AAves-pourte-serrer-fort-dans-mes-bras-171508492939524] (16.12.2015)

Ta juste envie de la serrer fort dans tes bras mais ta fierté te dit ne pas le faire [https://www. facebook.com/permalink.php?story_fbid=6439 44935714660\&id=630495373726283] (16.12.2015)

c'est en plastique comme la pièce du pédalier. Il ne faut surtout pas la serrer fort. Je compare cette pièce du pédalier à la vis de réglage pour la direction [http://www.velo101.com/forum/ voirsujet/a-quoi-ca-sert--20937] (16.12.2015)

elle s’asseoit sur MOI !! , elle commence à me demander de la serrer forte je l'ai fait etc.. [http:// www.forumdesados.net/est-elle-amoureuse-demoi-t12721.html] (16.12.2015)

REMARQUES : Serrer fort réfère à une chose (une porte) maintenue fortement fermée ou une partie du corps (le pied) que le sujet tient ou maintient étroitement en exerçant une pression. Dans le domaine militaire, il se dit du fait d'encercler quelqu'un, de cerner l'ennemi de tous les côtés de manière à l'empêcher de s'échapper. Au figuré et dans un langage poétique, serrer fort se dit du fait de provoquer une profonde tristesse chez quelqu'un. Fort reste invariable dans la majorité des cas. Toutefois, dans le dernier exemple du CW, il s'accorde avec l'objet, dans un contexte d'emphase, tout en gardant son interprétation de manière. Il est modifié par plus, si, trop.

\section{Serrer menu}

Serrer beaucoup, rapprocher le plus possible Transitif

1160 Molt ot bien faite la bochete, N'ert gaires granz, mes petitete, Menu serrees ot les denz, Plus reluisent que nus argenz (Eneas, 3999)

1275 Blanche et vermeille avoit la face, Plus clere que cristaus ne glace, Petit menton rout enfossé, Les dens blanz et menu serré. Les levres .i. petit grossetes Comme cerises vermeilletes (Floriant et Florete, 2900)

1776 Le cantsanu est un arbre de moyenne grandeur, ou plutôt un arbrisseau de dix à douze pieds de hauteur, à racine jaune dans son bois, à tronc épais de cinq à six pouces, et ramifié du bas en haut de nombre de branches serrées menues (Denis Diderot, Encyclopédie)

1822 Si je puis donner des ordres, je vous prescris que vous fassiez écrire l'adresse de l'ami, mais je veux que les lettres soient écrites menu serré et sans blanc. J'espère 
que mercredi soir j'aurai un flacon, celui que j'achève, car assez ancien, reste, puisqu'il ne peut me servir (Honoré de Balzac, Correspondance)

\section{CORPuS WeB :}

J'aimais aussi la surprendre, tôt le matin, devant la petite glace suspendue près de l'évier quand elle peignait ses longs cheveux avant de les tresser et de les serrer menu en un chignon bas... [http://dominofoto.canalblog.com/ archives/2010/05/01/17749636.html] (16.12.2015)

REMARQUES : En parlant d'une partie du corps et, en particulier, d'éléments symétriques (ici : les dents), serrer menu souligne le fait d'être étroitement rapproché. Notons l'emploi de menu serré, qui fonctionne à son tour comme adjectif-adverbe avec le verbe écrire (ex. de 1822). Autrement dit, l'adjectif-adverbe menu modifie l'adjectif-adverbe serré. Menu reste invariable quand il est antéposé, mais il s'accorde dans l'exemple de 1776 où il est postposé. Le CW donne cependant un contre-exemple.

\section{Servir chaud}

I. Servir un aliment ou un plat chaud Pronominal

1651 Il [= le pâté] se sert chaud et descouvert. Les pastez que vous voulez garder, il faut qu'ils soient de plus haut goust que ceux que vous faites pour manger chauds (François Pierre de La Varenne, Le Cuisinier françois)

1964 Les Anglais font ce pouding avec des ronds de pain beurrés ; j’ai ajouté la brioche, la vanille, l'eau-de-vie et la sauce servie à part. Cet entremets se sert chaud. Il n'est point désagréable en remplaçant la brioche par des ronds de mie de pain à potage (Cécile Éluard-Valette, Les Grandes Heures de la cuisine française)

Transitif

1708 cela fait, vous les [= les marrons] couvrirez et les ferez boüillir a petit feu, y mettant de fois à autres du syrop à mesure qu'ils boüillent, ensorte qu'ils soient en état d'être servis chauds (L'École parfaite des officiers de bouche)
1825 [Gufs au bouillon] emplissez les petits pots, et faites-les prendre comme les pots de crème : il faut qu'ils soient servis chauds (Archambault, Le Cuisinier économe)

1843 c'est facile, t'as qu'à le dire, on te servira ça tout chaud... N'est-ce pas Tortillard?

- Tout chaud, tout bouillant, tout de suite ! répondit le fils de Bras-Rouge en ricanant

(Eugène Sue, Les Mystères de Paris)

1855 J'aimais son petit intérieur demi-rustique tenu avec une propreté hollandaise, ses poules, son verger, ses galettes qu'elle tirait du four elle-même pour me les servir toutes chaudes (George Sand, Histoire de ma vie)

1876 L'estomac creusé par tant d'émotions, de tirades, il lui semble qu'il est chez lui, assis à sa petite table, et son regard va de Cinna à Maxime avec un bon sourire d'attendrissement, comme s'il voyait déjà les jolis fils blancs qui s'allongent au bout de la cuillère, quand la soupe au fromage est cuite à point, bien mijotée et servie chaud... (Alphonse Daudet, Contes du lundi)

1915 Aux soupirs, les dames elles résistaient pas. Elles disaient comme ça : «Mon pauv' l'ami, quoi c'est qu'vous avez envie ?» J'avais qu'à dire. Hop ! Ça s'amenait, pis servi chaud. Et alors, comme visites, un défilé, qui s’posait là ! (René Benjamin, Gaspard)

Emploi absolu

1853 « Ah ! s'écria-t-il en poussant un cri de joie, je ne me rappelais plus : recouvrez la marmelade d'un couvercle de tranches de pain très-minces, et faites cuire avec feu dessus et dessous ; vingt minutes suffisent pour prendre couleur ; renversez sur le plat et servez chaud " (Champfleury, Les Souffrances du professeur Delteil)

1950 « Il était bouillant, dit-il, quand nous sommes partis du ravin. À présent il est comme froid. Mais qu'est-ce que vous voulez, faut tout d'même pas nous d'mander d'servir chaud dans la tranchée, avec des cuisines qui sont à pus d'trois kilomètres ! 
On fait c'qu'on peut ; on n'peut pas l'impossible » (Maurice Genevoix, Ceux de 14)

II. Présenter, proposer immédiatement

Transitif

1765 Soyons sûr que l'histoire de la destruction entrera dans Paris sans aucune difficulté et sera très bien reçue. Croyez-moi, pressez cette besogne. Il faut tout servir chaud, les plats refroidis ne tentent personne. Nous faisons tous nos tendres compliments à toute votre famille (Voltaire, Lettres à son imprimeur)

1851 Bonsoir, mon cher vieux. Tenez-moi au courant. Molière est sur le feu et vous sera servi chaud, comme je vous embrasse (George Sand, Correspondance)

1859 Si vous désirez une première page avec ma signature, pour vous et vos amis, envoyez-moi les noms, vous serez servi chaud. Au moment de frapper les trois coups et de crier : Au rideau ! je vous embrasse et je vous dis merci du fond du cœur (Victor Hugo, Correspondance)

1899 Car tous ceux qui contribuèrent à la condamnation de Dreyfus veulent, coûte que coûte, en finir une bonne fois. Les témoins nécessaires seront là et les pièces à l'appui aussi. La bombe est depuis longtemps prête à être servie toute chaude à Versailles, à la première réquisition. Seulement, tant pis pour les éclats (Georges Clemenceau, L'Iniquité)

1920 Ce petit jeu de société me distingue des animaux (je suis un animal sociable) grâce à une gentille erreur qui fait compte : le faux mouvement, effet de lumière donnant gratis et sans danger l'impression de résolution perpétuelle, servez chaud le raisonnement raisonné, raisonnant par raison : tirez un trait l'addition posée, et faites le total (Louis Aragon, Euvre poétique)

1926 [Bruggle] croit répondre par des arguments péremptoires s'il décrit l'existence des amibes et la marche des astres, et il ne voudra point entendre Pierre qui déclare qu'en vérité, la seule peur de l'inconnu lui fait servir toutes chaudes les théories scientifiques, pour reculer dans le passé un mystère que les Anciens par exemple croyaient éclaircir, en disant que la terre était sur un éléphant (René Crevel, La Mort difficile)

1948 Tout guilleret, l'oblat accepta la proposition. Ainsi, sauf Marcel, nous étions tous servis chaud. Notez que Folcoche n'avait pas dit : "Ce sont Frédie et Jean qui accompagneront leur père dans le Gers. » L'imméritée faveur était sous-entendue (Hervé Bazin, Vipère au poing)

1973 Maurice prend de l'assurance, je sens qu'il est parfaitement maître de lui, il commence à leur servir l'histoire toute chaude : papa coiffeur à Alger, l'école, les vacances et puis le débarquement qui nous a empêchés de revenir, tout marche sur des roulettes, et tout à coup, la seule chose qu'on n’avait pas prévue :

- Et vous êtes catholiques?

(Joseph Joffo, Un sac de billes)

Emploi absolu

1842 Quand vous tenez en main tous ces personnages, vous les mêlez ensemble, vivement, en six, huit, dix feuilletons ; et vous servez chaud. Il faut que vous m'ayez séduit, môsieur, pour que je vous livre ainsi le secret du métier (Louis Reybaud, Jérôme Paturot à la recherche d'une position sociale)

1935 Les jambes à son cou, la Serbie rend d'une main à nos marchands de canon ce que nos financiers lui ont mis dans l'autre. Et allez-y. Passez vos commandes. Nous servirons chaud. Ces trois dernières années, Belgrade nous a payé une petite facture de 45 millions de francs. Du matériel de guerre acheté sans marchander (René Crevel, Le Roman cassé)

\section{CORPUS WEB :}

Alors pour servir chaud il convient de suivre quelques principes logiques [http://lesotlylaisse. over-blog.com/article-36286611.html] (17.12.2015)

Pour cette recette, vous pouvez la servir chaud...C'estundélice![http://www.ptitchef.com/ 
recettes/plat/paupiette-de-dinde-au-roquefortfid-8993] (17.12.2015)

Sa pissaladière, elle la sert chaude, " avec une salade, c'est idéal », ou froide, « avec l'apéro, c'est cadeau [http://www.lemonde.fr/vous/ article/2007/09/12/la-pissaladiere-de-sonia_954 261_3238.html] (17.12.2015)

REMARQUES : Servir chaud (I) réfère au fait de présenter ou de donner à un convive un plat ou une boisson qui, selon l'usage, se sert chaud. Au figuré (II), il signifie 'proposer, donner à apprécier, présenter au public quelque chose (un livre, une histoire, des arguments) à l'instant même, sur le champ, sans attendre'. Chaud s'accorde, dans la plupart des cas, en prédicat second avec l'objet (comparer le deuxième et le troisième exemple du CW), mais il peut rester invarié (exemple de 1876). Chaud est modifié par tout.

\section{Servir froid}

I. Servir un aliment ou un repas froid, refroidi Transitif

1592 les differences des salades selon leur saison, celle qui doit estre reschaufée, celle qui veut estre servie froide, la façon de les orner et embellir pour les rendre encores plaisantes à la veuë (Michel de Montaigne, Essais)

1978 En hommage à son lointain homonyme, il avait également inventé une recette de lentilles, cuites dans du cidre, servies froides arrosées d'huile d'olive et de safran sur des tranches grillées de ce pain rond utilisé pour les pan bagnats (Georges Perec, La Vie mode d'emploi : romans)

Emploi absolu

1811 On servit froid, à huit heures du soir (Étienne de Jouy, L'Hermite de la Chaussée-d'Antin)

1843 L'on verse de l'eau dans une soupière, à cette eau l'on ajoute un filet de vinaigre, des gousses d'ail, des oignons coupés en quatre, des tranches de concombre, quelques morceaux de piment, une pincée de sel, puis l'on taille du pain qu'on laisse tremper dans cet agréable mélange, et l'on sert froid (Théophile Gautier, Voyage en Espagne)
Pronominal

1826 Elles [= les crèmes] se conduisent de même, se font également prendre au bain-marie et se servent froides

(Charles Yves Cousin d'Avallon, Nouveau Dictionnaire de cuisine)

2003 Les sauces émulsionnées sont des sauces à base d'huile et qui se servent froides (Congrégation de Notre-Dame, La Cuisine raisonnée)

II. Réutiliser, se baser sur un élément ancien, antérieur

Transitif

1946 Spécialement préparé dans les laboratoires de l'université française pour sauver, dans la phase de laïcisation, un absolu moral, il servait froid un Kant mis en conserve dont une histoire des idées plus scrupuleuse a fait justice (Emmanuel Mounier, Traité du caractère)

CORPUS WeB :

Mettre au frais. A sevir froid ! [http:// chezzainabe.over-blog.com/article-salades-defeves-110137073.html] (17.12.2015)

Ben en fait les deux sont possible, enfin pour le poisson et les légumes l'â̂oli lui se sert froid, sinon chaud je pense qu'il tourne [http:// www.forums.supertoinette.com/recettes_458876. faut_il_servir_l_aoli_chaud_ou_froid.html] (17.12.2015)

Si vous préférez une variante sans gluten de cette recette, il faut vous assurer que votre poudre de cari ne contient pas de gluten de blé ou de farine. On la sert chaud sur des épinards frais, mais vous pouvez également la servir froid comme salade [https://www.lepoulet.qc.ca/fr/ nos-recettes/poulet-au-coco-et-aux-pois-chichessur-des-epinards-frais-(sans-gluten])-/1716 (17.12.2015)

Sa pissaladière, elle la sert chaude, " avec une salade, c'est idéal », ou froide, " avec l'apéro, c'est cadeau » [http://www.lemonde. $\mathrm{fr} /$ vous/article/2007/09/12/la-pissaladiere-desonia_954261_3238.html] (17.12.2015)

REMARQUES : Servir froid (I) réfère au fait de présenter ou de donner à un convive un plat froid, composé d'aliments qui ont été cuits et qui ont refroidi, ou tout simplement d'aliments froids. (II) 
recense un emploi familier, où le sujet désigne un animé qui réemploie dans son discours ou par écrit ce qui a été écrit ou dit précédemment par un personnage illustre. Notons l'opposition avec servir chaud dans le CW. Froid reste invariable dans la majorité des cas (v. le troisième exemple du CW), mais il se prête aussi à une interprétation comme prédicat second, s'accordant alors avec l'objet (dernier exemple du CW).

\section{Servir gras}

Servir des plats trop gras

$\pi$ servir tiède

\section{Servir noir}

servi noir : présenté, proposé par des gens de couleur

Transitif

1930 on pouvait lire maintenant à la lumière du jour une grande affiche ainsi conçue :

Now come down to Harlem town

See things done up hot and brown

(Venez à Harlem, tout y servi noir et chaud !) Harlem, c'est la patrie du jazz. Le jazz, c'est la mélodie nègre du sud débarquant à la gare de Pennsylvanie, plaintive et languissante, soudain affolée

(Paul Morand, New-York)

Corpus Web :

LE placer...au four...a un temp.....de $700 . . . . . . .$. degrè...celsius...pour environ....................3 hres.... et le tour est jouée..... servir.....noir.... !! [https:// fr.answers.yahoo.com/question/index?qid=2008 1110102809AA9aMpC] (17.12.2015)

La tâche qui doit être de la crème n'est pas à mon avis indispensable, le café tu peux le servir noir. L'anse de la tasse je l'aurai mise à droite [https://gimp-attitude.org/forum2/viewtopic. php?f=44\&t=2352] (17.12.2015)

Il le remercia pour le café qu'il lui servit noir et sans sucre à son habitude [http://loveiseasy. forumactif.org/t254-1-amitie-peut-braver-tousles-danger-alexander-julian] (17.12.2015)

La crème de chou-fleur est servie noire, la trouvaille est l'encre de seiche qui joue le rôle de condiment sans abîmer la personnalité gustative du chou-fleur ; le mariage avec les croûtons de choucroute (la note alsacienne), les huîtres lardées et le caviar de hareng, est bien vu [http://www.sudouest-gourmand.fr/ hysope-1\%E2\%80\%99anchois-et-le-taureau-encharente-maritime] (21.12.2015)

Remarques : Dans l'exemple littéraire de 1930, l'adjectif-adverbe noir réfère à la couleur de peau des personnes qui font le service ou proposent leurs services aux touristes ou clients. Dans les exemples du CW, noir caractérise le café, servi sans lait ou la crème de chou-fleur, blanche à la base, à laquelle on a ajouté de l'encre de seiche pour la rendre noire. Noir peut s'accorder avec l'objet (v. le quatrième exemple du CW).

\section{Servir plein}

Servir des plats bien remplis, servir en abondance

$\pi$ couper épais

\section{Servir refroidi}

Servir un aliment ou un plat froid, refroidi Transitif

1865 Il ne dégorgeait mot, mais je voyais son œil De temps en temps vers moi tourner avec orgueil

Semblant me dire : Eh bien ! Était-ce raillerie

Quand je te promettais si fine compagnie! Je ne décrirai pas les différents morceaux Qui nous furent servis tant refroidis que chauds ;

Hure de sanglier cuite à la bohémienne, Côtelettes d'agneau, dinde à la parisienne (Auguste Barbier, Satires)

\section{CORPUS WEB :}

A servir refroidi avec de la confiture de framboise (Si possible faite maison) C'est la touche qui donne le plus ! [http://les-paniers-de-noncienne. babiblog.fr/2014/09/gateau-aux-courgettes-pourle-dessert] (21.12.2015)

On peut aussi décider de la servir refroidi, c'est au choix ! [http://plaisirsquotidiens.com/ wonton-frit-canard-et-compagnie] (21.12.2015)

La salade peut être servie refroidi ou être chauffée à préférence [http://fr.recidemia.com/ wiki/Salade_Alternative:Potato] (21.12.2015)

Fondue servie refroidie dans le caquelon (donc lisse mais toute dure :-(( et il a fallu attendre 10 min pour qu'elle commence à fondre 
et être mangeable (tout juste car fade et franchement pas bonne !)...le top était quand même le pain servi dans un panier ou la moitie était pain frais et l'autre moitie du pain décongelé ( !!!) et tout mouillé......Bof ! [https://www.tripadvisor. fr/ShowUserReviews-g198820-d1094920r120560990-Auberge_de_la_Halle-Gruyeres_La_ Gruyere_Canton_of_Fribourg.html] (21.12.2015)

REMARQUES : Servir refroidi désigne le fait de présenter ou de donner à un convive un plat devenu froid, dont la température s'est abaissée. Refroidi reste invariable dans la majorité des cas (v. le deuxième et le troisième exemple du CW). Toutefois, dans le quatrième exemple du CW, il s'accorde avec l'objet, et fonctionne en tant que prédicat second orienté vers l'objet. Notons la collocation tant refroidi que chaud.

\section{Servir tiède}

I. Servir un aliment tiède, légèrement chaud Intransitif

1678 Faites boüillir jusqu’à crever une poignée d'Orge commun dans deux pintes d'eau, et mélez telle quantité que vous voudrez de cette décoction, avec partie égale de lait de Brebis, pour vous en servir tiede (Nicolas de Blégny, L’Art de guerir les maladies veneriennes)

Transitif

1966 Outre une kyrielle de nourritures solides et liquides (parmi lesquelles du vin de riz, ce vin couleur feuille-morte et d'autant plus savoureux qu'il est un peu amer, breuvage qui s'apparente au manzanilla espagnol à la sécheresse toute flamenca et que je retrouverais avec plaisir en Chine où d'ordinaire on le sert tiède ou chaud dans des coupes de porcelaine au moyen de théières), un concert fut offert aux invités et c'est une cantatrice chinoise qui l'inaugura en chantant (Michel Leiris, La Règle du jeu 3 : Fibrilles)

II. Présenter avec un maximum d'actualité Transitif

1844 Mais je dirai, puisqu'il le faut: Tout récit est un mets de table, Et, comme tel, moins agréable Servi tiède que servi chaud (Théophile Deyeux, La Chassomanie)
CORPUS Web :

Démoulez le cake à la sortie du four. Servez tiède ou froid [http://gourmand.viepratique.fr/ types-de-plat/entrees-types-de-plat/feculentsentrees-types-de-plat/cake-aux-herbes-2-54435. html] (21.12.2015)

Il existe de nombreuses autres manières de préparer les chipirons. Vous pouvez les faire revenir nature et les servir tiède avec une vinaigrette et quelques échalottes [http://www.epicurien. be/blog/recettes/crustaces/chipirons-sautes-ailpersil-calamars.asp] (21.12.2015)

belle presentation, 40 mins d'attente, plats servis tiède et trop gras [https://www.tripadvisor. fr/ShowUserReviews-g187265-d5416527r299430914-L_Etincelle-Lyon_Rhone_Rhone_ Alpes.html] (21.12.2015)

La recette de Samuel Cavagnis : Velouté glacé de carotte au cumin et ses soupions servis tièdes [http://www.clindoeilmagazine.com/ articles/Recette/Recette_Cavagnis_4.php] (21.12.2015)

Remarques : Servir tiède (I) désigne le fait de présenter ou de donner à un convive une nourriture solide ou liquide à une température modérée, entre le chaud et le froid. Au figuré (II), publier un texte en retard sur l'actualité. Notons les adjectifs-adverbes chaud et froid, et l'emploi de faire revenir nature, ainsi que de servir trop gras. Tiède reste invariable dans la majorité des cas. Toutefois, dans le style soutenu du dernier exemple dans le CW l'accord est réalisé.

\section{Siffler aigu}

Émettre un son strident

Intransitif

1550 Contre eulx guigna sa tempeste, Laquelle en les fouldroyant

Sifloit aigu, tournoyant

Comme un fuzeau, sus leur teste

(Pierre de Ronsard, Les Odes)

1656 La terre, sous les pieds, se meut à ces tempestes!

L'air, en cent lieux s'ouvrant, siffle aigu sur les testes (Jean Chapelain, La Pucelle) 
1832 le vent commençait à siffler aigu et à faire ployer les arbres et trembler les vitres (Alphonse Karr, Sous les tilleuls)

1838 c'est plus qu'une moiteur agréable à vous garantir et à vous défendre contre le froid qui s'efforce de pénétrer dans votre appartement en ébranlant le châssis des fenêtres, contre la bise qui siffle aigüe [sic], prolongée et lugubre à votre porte ( $L a$ Revue belge)

1953 Pas gêné par la terre qui tremblait, les torpilles qui sifflaient aigu, il a sabré une souris, et pas à la sauvette, encore ! (Albert Simonin, Touchez pas au grisbi !)

1979 Siffle aiguë la haine de la Junon dandinante qui remue ses grosses fesses (Jacques Teboul, Cours, Hölderlin !)

\section{Siffler faux}

Siffler dans un ton faux

Transitif

1832 Walter ouvrit la fenêtre et se mit à siffler faux un de ses airs favoris (Jean Cohen, Eugène Aram [trad.])

Intransitif

1855 On lui nommerait même des musiciens dont les hochets sifflaient faux (L'Illustration)

1953 Un type qui connaît son solfège comme mon gamin les billes, m'affirme que, musicalement, le merle siffle faux (Jacques Perret, Bâtons dans les roues)

1955 Jules, invité à dîner pour le soir, rentra se changer. Ce qu'il fit en sifflotant. Il sifflait faux ; ce n'est pas ce qui l'empêchait de siffler fort ; c'était le respect qu'on doit à une victoire, manifestement l'œuvre des dieux (Jean Giono, Une aventure ou La foudre et le sommet)

\section{CORPUS WEB :}

ah mais c'est possible de siffler faux? [https: //twitter.com/sprintcut/status/8707574916462 5920] (21.12.2015)

J'adore siffler faux exprès pour énerver mes proches. C’est un sport, un délice, un art [https:// twitter.com/vinvin/status/110000909064474624] (21.12.2015)

Ce qui m'exècre au plus haut point : quand une musique/hymne passe et que qqun à côté de moi la siffle FAUX. Me gâche pas mon plaisir stp. Ce qui m'exècre au plus haut point : quand une musique/hymne passe et que qqun à côté de moi la siffle FAUX. Me gâche pas mon plaisir stp [https://twitter.com/saperlotteuh/ status/627879847654748160] (21.12.2015)

REMARQUES : Le sujet désigne la voix humaine, celle de certains animaux (ici : le merle) ou le son produit par des instruments de musique quand celui-ci est peu harmonieux et désagréable à entendre. Faux reste invariable. Notons l'emploi de siffler fort.

\section{Siffler fort}

Émettre un sifflement aigu

Intransitif

1887 Son menton tomba sur sa poitrine, ses bras et ses jambes pendirent. L'œil gauche s'était ouvert, dans le tiraillement de cette moitié de la face, et le coin de la bouche tordue sifflait plus fort. Il y eut un silence, la mort envahissait la pièce humide, au sol de terre battue, aux murs lépreux, à la grande cheminée noire (Émile Zola, La Terre)

\section{CORPUS WEB :}

Peut-être n'avez-vous jamais appris à siffler? Ou peut-être ne parvenez-vous pas à siffler suffisamment fort? Dans un cas comme dans l'autre, suivez ces quelques étapes pour apprendre à siffler fort [http://fr.wikihow.com/siffler-fort] (22.12.2015)

Comment siffler fort sans les doigts ?? [http://www.jeuxvideo.com/forums/1-51-63578501-0-1-0-comment-siffler-fort-sans-les-doigts.htm] (22.12.2015)

je viens d'essayer de siffler fort la Marseillaise dans le bureau et Brimbelle s'est précipitée sur moi [http://www.la-detection.com/dp/ message-82885.htm] (22.12.2015)

REMARQUES : Dans l'exemple de 1887, siffler fort réfère à une personne qui produit en respirant un son ou une série de sons aigus et intenses, soulignant un état de santé extrêmement faible et annonçant une mort prochaine. Dans les exemples 
du CW, le sujet émet un sifflement fort pour attirer l'attention ou pour moduler un air. Fort reste invariable. Il est modifié par plus, suffisamment.

\section{Siffler juste}

Siffler sur un ton juste

$\lambda$ chanter faux

\section{Siffler menu}

Siffler faiblement

Intransitif

1558 Voyons d'œufz parfumez un orage gresler, Et la fusee ardent' siffler menu par l'aer (Joachim Du Bellay, Les Regrets)

2007 un oiseau

File doux s'impatiente

Siffle menu sous les feuillages

(Henri Droguet, Off)

\section{Sigler soef}

Naviguer doucement, paisiblement

Intransitif

+1227 Wistasces son voile drecha,

Devant Croufaut ratainte a

Une tres bonne riche nef

Qui devant lui sigloit souëf

(Roman de Wistasce le Moine [ $2^{\mathrm{e}}$ tiers $\mathrm{XIII}{ }^{\mathrm{e}}$, après 1227], 2130)

REMARQUES : En ancien français, sigler soef réfère à un bateau, un navire qui fait voile dans une direction donnée, se dirigeant tranquillement vers la destination choisie.

\section{Signaler net}

Montrer nettement, faire remarquer de façon univoque

Transitif

1850 Et pourtant, malgré ces trois grands péchés, que je vous signale tout net parce que j'espère que vous vous en corrigerez (L'Illustration)

1896 Enfin, voilà un esprit clairvoyant, qui saisit d'un coup et signale net le mal fondé et le ridicule, toute la fausseté, disons le mot, de la réforme constitutionnelle, en même temps que son insuffisance et sa fragilité (Jean-François Robinet, Le Mouvement religieux à Paris pendant la Révolution)
CORPUS Web :

En tous cas ça signe et signale net l'atmo de l'époque, à féministlande et ailleurs [http:// lapetitemurene.over-blog.com/2017/06/phobesalliees-quand-le-ressentiment-se-lache-un-peuplus.html] (20.6.2017)

\section{Signifier clair et net}

I. Signaler nettement, faire savoir sans

équivoque

II. Vouloir dire nettement

入 signifier net

\section{Signifier net}

I. Signaler nettement, faire savoir

Transitif

1776 Plus on le recherche, plus on est en dédaigné : on a beau [...] lui signifier net qu'on va se tuer à l'instant si l'on n'est admis, il n'est ému de rien (Jean-Jacques Rousseau, Rousseau juge de Jean-Jacques)

1861 Irrité, Dupré résolut d'en finir et signifia net un refus (H. Vigneau, La Bayadère)

2008 Un refus n'est pas signifié clair et net à Bernard Tapie, mais Matignon fait en sorte que son dossier s'enlise et ne soit pas traité ... (Laurent Mauduit, Sous le Tapie)

II. Vouloir dire nettement Transitif

1853 Et Sellam me regarde avec un air qui signifie clair et net : est-ce que tu me prends pour un imbécile? (Louis Félicien Caignart de Saulcy, Voyage autour de la Mer morte)

\section{CORpus Web :}

Non je n'ai pas encore appelé mon employeur, je voulais voir si qqn si connaissait ou avait déjà été dans cette situation afin de connaitre mes droits avant de leur signifier clair et net que c'était exclu que je signe un tel papier ... [https://bebe.ch/drupal/forum/arret-maladieavant-accouchement-assurance-qui-souhaiteacceder-mon-dossier-medical] (2.7.2014) 


\section{Songer creux}

Songer, laisser aller son esprit à des choses vaines, chimériques

Intransitif

1494 Mon esprit fut comme demy estique De tant l'avoir tourmenté et brouillé, Mais quant j'eux bien maint propos barbouillé,

Vexacion par ung traveil acreux

M'asomeilla et me fit songer creux

(Andrieu de la Vigne, La Ressource de la chrestienté, 27)

1546 Je ne le demande sans cause. Car, si bien et largement je ne souppe, je ne dors rien qui vaille la nuyct, ne foys que ravasser, et autant songe creux que pour lors estoit mon ventre (François Rabelais, Tiers Livre)

1610 Et ainsi sont effacez les larcins, monopoles, sacrileges, fraudes, et telles joyeuses inventions et moyens de parvenir. Vous resvez, et songez creux : vous gastez tout. Si on sçait ce que vous dites, personne n'aura plus d'envie de faire pis afin que bien en advienne (Béroalde de Verville, Le Moyen de parvenir)

1736 c'est un jaloux, qui chagrinoit si fort sa femme par sa défiance, qu'elle creva de dépit, mon fils ; et pour sa peine, il est encore jaloux dans ce lieu-ci ; tu vois comme il songe creux, c'est qu'il s'inquiéte des douceurs que la défunte a dites à ses galans (Pierre de Marivaux, Le Télémaque travesti)

1862 L'homme, c'est l'anguille. Alors à quoi bon le Père éternel ? Monsieur l'évêque, l'hypothèse Jéhovah me fatigue. Elle n'est bonne qu'à produire des gens maigres qui songent creux. À bas ce grand Tout qui me tracasse ! Vive Zéro qui me laisse tranquille! (Victor Hugo, Les Misérables)

1894 Il y a longtemps que Poil de carotte, rêveur, observe la plus haute feuille du grand peuplier. Il songe creux et attend qu'elle remue. Elle semble détachée de l'arbre, vivre à part, seule, sans queue, libre (Jules Renard, Poil de carotte)

\section{CORpus Web :}

Evidemment, sans passer à l'action, mon cerveau sature. Je reste là à songer creux, contemplative encore une fois [http://agesettransmissions. be/spip.php?page=forum\&id_article=43\&id_ forum=284\&lang=mag] (22.12.2015)

Hacha, je ne t ai pas attaqué personnellement, il faut lire entre ligne, que 1 esprit et la théorie ayoubienne ne changera rien,....c est déjà joué : la fuite en avant de la politique marocaine de songer creux sur la question de la colonisation du SO....encore à Manhasset $\mathrm{V}$ sera cette fois-ci assuré, le statu quo éternel imposé par le polisario jusqu a 1 anéantissement total de l économie marocaine... [http://www.algerie-dz.com/forums/ archive/index.php/t-81994-p-2.html] (22.12.2015)

Rêver c'est l'utopie, le totalitarisme c'est l'utopie, le fantasme, c'est songer creux ; c'est freudien du coup, ton propre érotisme transposé à l'échelle universelle, l'escaladant ; faire du perso du général c'est utopique, sectaire, totalitaire ; c'est rêver [http://prisedebec.forumactif.fr/t1050 p45-des-hommes-et-des-femmes] (22.12.2015)

REMARQues : Songer creux réfère à un animé perdu dans ses pensées, qui rêve, pense à des choses qui sont des purs produits de l'imagination, qui n'ont aucune chance de se réaliser. Notons que cet emploi souligne le caractère mélancolique du sujet. Creux reste invariable.

\section{Songer grief}

Songer avec gravité, de manière grave, austère Intransitif

1175 Illes et cil k'il en mena

Prenent a tant del roi congié.

Mout pueent avoir grief songié

Li dui chevalier dont je dis,

Et leur sire aussi e[t] li dis

Qui vont o li de par le roi

(Gautier d'Arras, Ille et Galeron, 328)

REMARQUES : Songer grief référait à une personne qui pense à quelque chose ou quelqu'un, ses songes ou pensées étant empreints de peine, de tristesse. 


\section{Songer haut}

Songer à voix haute, exprimer sa pensée à voix haute

Intransitif

$1836 \mathrm{Au}$ fond de son cœur qui murmure Il ne trouve que sa blessure. Il songe tout haut quand il dort ; Amusons-nous puisqu'il est mort (Edgar Quinet, Napoléon)

Transitif

1894 En marchant, il songeait tout haut, intrigué de ce coup de cloche en appel, sans toutefois aucun pressentiment mauvais... Une visite de Grosbourg, ce n'était guère probable... Qui aurait pu venir?

(Alphonse Daudet, La Petite Paroisse)

1916 - Quand on parle de toute la guerre, songeait-il tout haut, c'est comme si on n’disait rien. Ça étouffe les paroles. On est là, à r'garder ça, comme des espèces d'aveugles... (Henri Barbusse, Le Feu)

1950 - Est-ce fini, cette fois?

Ce n'est pas fini. Cela cherche partout, à triples dégelées de petits obus. On dirait un furetage méthodique. Le capitaine songe tout haut :

- Je ne peux pas croire que tant de luxe soit pour nous... Ils doivent chercher nos batteries, en arrière de 372 .

- Alors, en fait de réglage...

- En fait de réglage, dit une voix du dehors, ils nous ont amoché Burly

(Maurice Genevoix, Ceux de 14)

1968 - N'ouvre pas qui veut par un sacrifice la porte du ciel. L'oblation, si elle a lieu, devra se faire autrement. - Elle se produit d'elle-même quand l'hostie est prête ", songea tout haut Sébastien Théus, pensant aux secrètes mises en garde de philosophes hermétiques (Marguerite Yourcenar, L'Euvre au noir)

1984 Croyez-en mon expérience de l'usine, père : il vient toujours un moment où ces gens-là ont peur de leur force...

- C'est leur manque de tenue qui m'inquiète, songea tout haut le général. Ce débraillé...
- Toute révolution tend à l'état de nature, dit Alexis.

- C'est d'Engels ? demanda BouletMontreuil.

- Non, de Goethe.

-Tiens?

(Bertrand Poirot-Delpech, L'Été 36)

CORPUS WEB :

Oui le sujet quasi existentielle parlant mort et vie. Je vous dis mes amis, on a beau songer haut, très haut et très loin. Nos pieds et nos corps demeurent ici bas [http://rouilledetincelles.blog spot.co.at/2010/12/premier-jet.html] (22.12.2015)

« J'ai toujours été étiqueté comme un gars qui fait de la musique festive et, pour certains, on dirait que c'est péjoratif d'abonder là-dedans, comme si c'était facile à faire », renchérit Proulx avant de songer tout haut : "Pourquoi ça serait nécessairement plus difficile de faire une toune torturée à l' " Ah ! Ça va tellement mal !? » [https://voir.ca/musique/2013/01/31/pepe-pepeet-la-maturite] (22.12.2015)

Tout le monde pond une lettre, quand il se suicide. Mais tu es plus lyrique, pas vrai, tu aurais aimé ; laisser un livre des pages sages et des vers, tu as l'existence courante de ceux qui se songent haut, des espoirs vides [http:// allwaswell.forumgratuit.lu/t429-love-it-will-getyou-nowhere-balek] (22.12.2015)

REMARQUES : Dans les exemples littéraires, songer haut est pris comme verbum dicendi pour introduire un discours. Il réfère au fait de penser, de réfléchir à quelque chose ou de laisser aller son esprit au gré des associations d'idées que le sujet exprime à voix haute, en public. Dans le premier exemple, il prend l'acception de 'se faire des illusions'. Haut reste invariable et est modifié par tout, très. L'accord est même absent dans le dernier exemple du CW où sentir est une copule et est interprété comme 'ceux qui rêvent d'être plus haut placés'.

\section{Sonner aérien}

Avoir une consonance aérienne, légère, ténue, immatérielle

Intransitif

1989 Moi encore gauche, mal dégrossie, fine de corps mais ignorante de tant et tant de 
finesses. Poils d'Ange, ça sonnait beau aérien, et un peu - mais pas trop - amusant. C'était farceur. Mais pas commun. Il était comme Mona, ce nom, gaiement joli. Et elle le susurrait si bien (Remo Forlani, Gouttière)

1996 Ou de la glace de notre cabinet de toilette. $\mathrm{Ou}$ des deux grands miroirs bordant le tapis-brosse dans l'entrée de l'immeuble. Diary sonnait aérien. À quel propos $\mathrm{Ma}$ dame Singer l'avait-elle prononcé ? Avaitelle un fils ? (Boris Schreiber, Un silence d'environ une demi-heure)

\section{CORPUS WEB :}

Et c'est ça la grande difficulté pour l'accordéon qui est un instrument pas très flexible. Tout doit sonner aérien, intime malgré l'épaisseur de la polyphonie [http://www. francemusique.fr/emission/chronique-du-petitmatin/2014-2015/musique-contemporaine-2-1accordeon-10-18-2014-07-40] (28.12.2015)

Mais là ou le Swayzak sonnait aérien et éthéré, ici il est plus question d'ambiances telluriques et bucoliques [http://boulodrome. blogspot.co.at/2005/09/cest-la-rentre-desdisques-classes.html] (28.12.2015)

l'avantage : tes accords ne sont plus “ancrés" à la basse, ils sonnent aérien et peu définis, ce qui fait qu'un même doigté peu passer dans pleins de contextes harmoniques différents [http:// ukulele-forum.fr/index.php?topic $=4173.0$ ] (28.12.2015)

Cécile Perrin sonne aérienne, angélique, Jean-Claude Saragosse est toujours aussi évident, aussi clair, aussi facile, la mezzo Béatrice Burley a un fort joli timbre [http://www.resmusica. com/2006/08/13/un-messie-retro] (28.12.2015)

REMARQUES : Sonner aérien réfère à l'impression vague, flottante produite par le son, la consonance d'un mot, suggérant une certaine légèreté. Notons les adjectifs-adverbes intime, éthéré, (peu) défini, angélique, naïf et amusant, ce dernier renvoyant à l'impression produite par le son d'un mot, à sa consonance insolite ou fantaisiste qui amuse l'oreille de façon agréable. Aérien reste invariable dans la majorité des cas. L'accord, parfois partiel, des adjectifs dans les troisième et quatrième exemples du CW suggère qu'ils adoptent ici la fonction de prédicats seconds orientés vers le sujet. Notons l'emploi impersonnel familier ça sonnait beau, aérien.

\section{Sonner affectueux}

Donner une impression d'affection, d'émotivité Intransitif

1989 « Trotski et Kennedy se portaient mieux que lui ! » La voix-Marty répondait avec fermeté mais sans conviction : " Coma prolongé, Berthold, vivant à part entière! » Ça sonnait faux, ça sonnait affectueux, désolé, mais pas scientifique, pour une fois. Marty répondait contre lui-même. Il fallait de la science, face à la science de Berthold (Daniel Pennac, La Petite marchande de prose)

CORPUS WEB :

Et elle t'a donné un surnom (qui doit sonner affectueux non.. ? ) donc tu est sur la bonne voie... [http://www.jeuxvideo.com/forums/150-53875861-848-0-1-0-les-celibataires.htm] (28.12.2015)

Pis pendant que je dors, mon chum décide de s'occuper du hérisson. Hahaha, quand il est venu se coucher, il m'a dit, tout content : « Hey ! le rat piquant (il l'appelle comme ça et bizarrement, ça sonne affectueux !!) yaime vraiment ça les insectes »[http://herissons.niceboard.com/ t2373-mon-herisson-et-mon-chum] (28.12.2015)

Nos poils se hérissent et notre gorge se serre toujours lorsque l'on se remémore la séquence où Cobb agresse verbalement un habitant noir de la ville (le seul) en le gratifiant d'un « boy » qui ne sonne pas spécialement affectueux dans la bouche de cet idiot fini [http://www. lemauvaiscoton.fr/cinema/compte-rendu-ceff2015-paris] (28.12.2015)

« T'es bête. » La remarque sonne affectueuse, tendre [http://olympus-reign.jeunforum.com/ t218-narcalon-dans-le-silence-et-la-solitudeon-n-entend-plus-que-1-essentiel-ended] (28.12.2015)

REMARQUES : Sonner affectueux réfère à l'impression produite par une parole qui transmet beaucoup d'émotion et a une consonance tendre et attachante. Notons l'emploi de sonner faux, tendre. Affectueux tend à l'emploi invariable, mais il s'accorde avec le sujet dans le dernier exemple 
$\mathrm{du}$ CW. Notons l'emploi impersonnel familier de ça sonnait faux et ça sonnait affectueux.

\section{Sonner aigu}

Produire un son d'une fréquence élevée

入 sonner lourd, noter bas

\section{Sonner amusant}

Produire une impression amusante

Intransitif

CORPUS WEB :

Le « Bouboulina », sera le premier à entrer en Loire ce soir. Si son nom sonne " amusant » à l'oreille française, le tanker n'en est pas moins un géant des mers qui force au respect [http://www. regardelamer.com/article-bouboulina-nocturnedestination-donges-7-121613093.html] (2.1.2016)

Bon, sinon, j'ai été essayer une EHX Worm chez woody. C'est pas mal, ça sonne amusant, mais il manquait « le petit truc qui fait que » pour que je la prenne, malgré son tarif très sympa de $68 €$ [http://forum.hardware.fr/hfr/Discussions/ Musique/materiel-guitare-nichons-sujet_7370_ 2612.htm] (2.1.2016)

voit le cynisme d'une société où tout s'achète, et même à crédit : il ya tromperie sur lamarchandise : les prétendus fortunés ne sont riches que de dettes. Dolly veut se caser et ses répliques sur les vingt célibataires du mexique, à conquérir, sonnent amusantes et naïves? [http:// grain-de-sel.cultureforum.net/t8207-blackedwards] (2.1.2016)

\section{Sonner ancien}

Évoquer un temps révolu

入 sonner démodé

\section{Sonner austère}

Produire une impression sévère

$\lambda$ sonner sec

\section{Sonner bas}

Produire un son grave, bas Intransitif

1451 Pour telle notte ma harpe trop bas sonne, Car la vertu du mort si hault resonne Que langue et main ne sçauroient acteindre

A la louer et dignement despeindre (Jean Robertet, Euvres, p. 164, 130)
1500 LE TIERS FOL. (laboureux) La harpe sonnera bien bas,

Par le sang bien, se je ne dance

(Farce de Folle Bobance / Ancien Théâtre françois [datation DMF])

1564 Et pourtant cõme on ne peut restraindre les plus gros, pour leur faire prendre un tel ton, et les faire chanter gresle et clair cõme les menus, ainsi on ne peut eslargir les petits pour les faire sonner gros et bas, comme les plus grans (Pierre Viret, Exposition de la doctrine de la foy chrestienne)

\section{CORPuS WEB :}

Malheureusement, ma sieste fut de courte durée puisqu'une bande de filles en mini-shorts et talons hauts entra dans la pièce en pouffant, un garçon aux bras semblable à l'un de leur trophées de prédatrices de soirées. Je relevais la tête lorsque sa voix rauque me parvins aux oreilles, une de ces voix qui pourrait faire chavirer un bateau tant elle sonne bas dans vos tympans [https://www.fanfic-fr.net/fanfics/Musique/B/ Bangtan-Boys/No-more-dream/70723/358554. html] (2.1.2016)

Les monnaies récentes, francs, euros, sonnent bas, par exemple les centimes d'euros sont discriminés à partir de 40 (la zone ferreux) [http://www.lefouilleur.com/forum/gamma6000-fiche-technique-test-et-videos-vt59769. html] (2.1.2016)

C'est comme les vieux téléphones, quand ils sonnent, tu sais que c'est un vieux téléphone... C'est con ce que je dis, je sais, mais c'est comme ca la vie, les basses sonnent "basses » et les aigues " aigues "... [http://www.guitariste.com/ forums/basse,question-de-debutant,141642. html] (2.1.2016)

REMARQUES : Sonner bas peut référer à un instrument de musique qui produit un son grave, faible. Il peut aussi renvoyer soit à une voix, celle-ci se faisant difficilement entendre, retentissant avec une faible intensité, ou, par extension, soit à la monnaie. Bas reste invariable dans son emploi adverbial, mais il s'accorde avec le sujet dans le dernier exemple du CW, provenant du milieu des guitaristes. Il est modifié par bien, trop. Notons l'emploi de résonner haut, sonner gros et bas, chanter grêle et clair. 


\section{Sonner beau}

Être beau, agréable à entendre

Intransitif

1899 Lucien Noël, avec sa belle prestance et sa voix qui sonne beau (Revue illustrée)

1910 De tous les noms hébreux que Hugo pouvait choisir pour couronner un vers, il faut avouer qu'il n'y en avait certainement aucun qui sonnât aussi bien, aussi beau que Jérimadeth, et surtout qui sonnât aussi hébreu ; qui fût à ce point du temps et du lieu, du pays ; aussi couleur locale et couleur temporelle (Charles Péguy, VictorMarie, comte Hugo)

1929 toujours et partout, fuir le style poétique, et faire sentir qu'on le fuit, qu'on déjoue la phrase per se, qui, par le rythme et l'étendue, sonnerait trop pur et trop beau, atteindrait ce genre soutenu que Stendhal raille et déteste, où il ne voit qu'affectation, attitude, arrière-pensées non désintéressées (Paul Valéry, Variété II)

Corpus Web :

On a l'impression par moments qu'Igor Levit se perd dans sa volonté de tout faire sonner beau. Le «Capriccio », en revanche, est excellent, splendidement articulé [http://www.letemps.ch/ culture/2015/09/08/anja-harteros-envoutantedernier-strauss] (2.1.2016)

Istanbul a beau se parer des plus hauts édifices, du tramway et d'une épouvantable densité de Mac Do, rien n'y fait, son nom continue de sonner beau, comme un avant-goût de loukoum, de narguilé et de minaret [http://s430708369. onlinehome.fr/2012/12/turquie] (2.1.2016)

Marcher longtemps dans Paris et entendre des accents qui sonnent beaux et étranges à la fois [http://www.lafabriquecrepue.com/2015/02/11/ la-meilleure-decision-que-jai-prise-par-gaelle] (2.1.2016)

A l'autre bout du livre, une photo montre un 45 tours enregistré par la mère de Joann Sfar, qui était chanteuse et dont on sait qu'elle est morte quand il avait trois ans. Les deux titres enregistrés sonnent beaux comme un séminaire de psychanalyse du politique : Si tous les hommes étaient français - Ça n'vaut pas l'amour [http:// next.liberation.fr/livres/2010/01/07/sfar-et- gainsbourg-deux-amateurs-de-bulles_603005] (2.1.2016)

REMARques : Sonner beau réfère à une phrase, un mot, une parole qui se distinguent par une consonance agréable à l'oreille, harmonieuse. Notons l'emploi de sonner trop pur et trop beau et la collocation sonner beau et étrange. L'accord est vacillant. Beau est modifié par aussi, trop.

\section{Sonner clair}

I. Produire, avoir un son clair, pur, retentir avec un timbre clair

Intransitif

1100a Par tute l'ost funt lur taburs suner E cez buisines e cez greisles mult cler : Paien descendent pur lur cors aduber (Chanson de Roland, 3138)

+1100 Li quarz lo duyst corda toccar Et rott[a] et leyra clar sonar (Alberic de Besançon, Fragment d'un Roman d'Alexandre [ $1^{\mathrm{er}}$ quart $\left.\mathrm{XII}^{\mathrm{e}}\right]$, 99)

1209 On ne verra mes voir a piece Un tel hostel a bacheler. Vieles i sonent si cler, Et fleütes et estrument (Jean Renart, Roman de Guillaume de Dole, 2348)

1250 Desarmez furent, si ne porent durer, C'a chascun cop n'en face .i. mort giter. Lors fait li cuens son olifant soner, Par .iiii. enpaintes mout hautement et cler, Que bien l'entandent si baron et si per, Que il ot fet lez le mont arester (Aymeri de Narbonne [milieu XIII'], 4067)

1372 Il s'en va par la mer bruiant, Et tuit li autre le sievirent, Qui venir a bon port desirent. Quant li roys fu bien eslongiez, Il ne s'est gueres atargiez, Eins fist sonner une trompette, Qui haut et cler sonne et trompette (Guillaume de Machaut, La Prise d'Alexandrie [(1370-)1372], 2112)

1615 mais d'où vient donc ce desordre et detraquement qui nous rend confus? Vient il du plomb ? Je ne le voy pas ; du balancier ou du timbre, metal haut et clair sonnant? Je 
ne le croy pas ; il y auroit plus d'apparence de penser que cela vint des roues et des chordes (Jean-Pierre Camus, Homélies des États généraux)

1845 - Oh ! oui-da! s'il en arrive ainsi, dit Janille, je la veux toute pareille, ni plus belle ni plus grande ; celle-là nous est commode : elle sonne clair et ne nous casse pas la tête.

Émile se mit à l'œuvre ; il démonta le coucou d'Allemagne (George Sand, Le Péché de Monsieur Antoine)

1879 Elle rugissait et grondait soufflant plus fort, la panse arrondie et suante, et, dans le grommellement de ses flancs, le cliquetis de la pelle sur le fer de sa bouche sonnait plus clair. L'autre machine courait dans un tourbillon de fumée et de flammes, appelant l'aiguilleur pour qu'il la dirigeât sur une voie de garage (Joris-Karl Huysmans, Les Sœurs Vatard)

1881 Mais à mesure que je retrouve le fond de mon cœur à travers ces ratures et dans ces explosions de phrases, le sang me revient dans les veines et ma voix sonne haute et claire. Le rédacteur en chef m'écoute, l'œil tendu, et dit de temps en temps tout bas : « C'est bien, bien... » J'ai fini, j'attends mon sort (Jules Vallès, Jacques Vingtras : Le Bachelier)

1885 Ce qui soutenait les courages, c'était la supplication des misérables, là-bas, le rappel de plus en plus distinct qu'ils battaient pour qu'on se hâtât d'arriver. A présent, il sonnait très clair, avec une sonorité musicale, comme frappé sur les lames d'un harmonica. On se guidait grâce à lui, on marchait à ce bruit cristallin (Émile Zola, Germinal)

1896 à Léon Dierx

«Dierx le volt. »

Dierx ! Dont le nom fait pour la gloire sonne clair

Comme une bonne épée en la main d'un héros,

Qu'avons-nous de commun, nous, rois, avec ce gros
De rustres s'en allant en guerre de quel air? (Paul Verlaine, Euvres poétiques complètes)

1914 et leur voix sonna aussi claire et aussi étrange que celle de ma mère... et comme ils sont beaux les jardins où Madame Defrance attend son fiancé ! Je pars demain pour la Suisse (Alain-Fournier, Correspondance avec Jacques Rivière)

1936 - J'avais la tête je ne sais où. Il faut vous dire que j'ai des circonstances atténuantes. Oui, j’ai quitté ma famille. Avec dix francs en poche. Voilà.

Son rire sonna très clair dans l'avenue sombre. Elle le regarda. Il reprenait :

- Comme ça. Tout d'un coup. Je suis rentré aujourd'hui d'Aix, du lycée, à l'improviste. (Louis Aragon, Les Beaux Quartiers)

1937 Ici, c'est presque la montagne. En outre, le nom me plaît. Pasteur a toujours été mon modèle et mon type. Boulevard Pasteur, cela sonne clair. Quand je pense qu'il y a des malheureux pour aller loger rue Pirouette ou cité Vacheron. C'est à pleurer. Rue Fessart, au moins, c'est drôle, ça sonne bien (Georges Duhamel, Les Maîtres)

1943 À la fin de l'après-midi, elle marchait un peu sur la route qui cessait à peine, pour traverser le village, d'être une route forestière sinueuse, admirable, sonnant clair sous le pied (Colette, Le Képi)

1947 La pensée de sa femme lui venait, mais il la rejetait chaque fois. Au début de la soirée, les talons des passants avaient sonné clair dans la nuit froide.

- Tu t'es occupé de tout ? avait dit Mme Rieux.

- Oui, j’ai téléphoné. Ils avaient alors repris leur veillée silencieuse

(Albert Camus, La Peste)

1948 Le soir tombe soudain très rapidement et les personnages deviennent de moins en moins distincts, derrière les arbres. Seules, les voix sonnent encore très claires dans l'obscurité un peu comme en songe (Julien Gracq, Le Roi pêcheur) 
1949 La connaissance de la mortalité confère au sentiment de la contingence la clarté métallique du savoir : « tu dois mourir » sonne plus clair que : «tu n'es pas par toi. » En retour, l'angoisse de la contingence, éclairée par le savoir de la mort, prête sa morsure et son deuil à la pensée de la mort (Paul Ricœur, Philosophie de la volonté)

1960 lequel, écrasé par l'horreur de ne pouvoir rien faire pour elle, passait ses journées à se creuser la cervelle à la recherche d'un nom assez beau, assez retentissant, assez prometteur pour qu'il pût exprimer tout ce qui se passait dans son cœur, pour qu'il sonnât haut et clair aux oreilles de sa mère, avec tout l'écho convaincant de cette gloire future qu'il se proposait de déposer à ses pieds (Romain Gary, La Promesse de l'aube)

1962 Dans les faubourgs, les sabots d'Indiana sonnaient clair et j'imaginais en eux des boules de musique et que le heurt des sabots sur le sol les projetait contre le mur des maisons endormies d'où elles n'ont pas le temps de revenir, en écho, car d'autres boules, avec régularité, s'échappent des sabots, une musique allègre et cadencée (Yves Berger, Le Sud)

1966 Parvenus à ce point, il semble qu'on soit en droit de récapituler, en faisant sonner haut et clair, une dernière fois, les quelques clés d'or qu'il convient de suspendre au trousseau du réformateur - ou mieux - du promoteur d'une véritable renaissance de l'université (Gérald Antoine et Jean-Claude Passeron, La Réforme de l'Université)

1974 Une fumée mauve montait toute droite du toit d'une ferme. Au-dessus de sa tête s'étalait un voile de nuages empli de paix. Le clocher sonnait plus clair.

- Bonjour ! répondit le laboureur en prenant un nouveau sillon. Les dernières fleurs de l'été jetaient d'ultimes parfums (Robert Sabatier, Les Noisettes sauvages)

1983 La maîtresse se promène dans les travées entre les pupitres, sa voix sonne clair, elle articule chaque mot très distinctement, parfois même elle triche un peu en accen- tuant exprès une liaison, pour nous aider, pour nous faire entendre par quelle lettre tel mot se termine (Nathalie Sarraute, Enfance)

Transitif

1100b Li amiraill ad sa barbe fors mise, Altresi blanche cume flur en espine : Cument qu'il seit, ne s'i voelt celer mie. Met a sa buche une clere buisine, Sunet la cler, que si paien l'oïrent ; [variante : si cler la sunet]

Par tut le camp ses cumpaignes ralient (Chanson de Roland, 3524)

II. Se manifester clairement, ouvertement, franchement

Intransitif

1884 - C'est beau, les étoiles, dit-elle gravement, après un long silence.

Il laissa le silence retomber. Sa gaieté ne sonnait plus si claire, un malaise intérieur troublait ses yeux ouverts très grands (Émile Zola, La Joie de vivre)

1896 Il n'y a rien d'aimable comme des prêtres aimables ; leur gaieté détachée sonne franc et clair. Ceux-ci, en plus, sont des érudits et des artistes ; alors, facilement nous oublierions l'heure, à cette table très frugale (Pierre Loti, La Galilée)

1992 la lumière la plus crue tombait sur le grouillement de crimes commis à l'égard des enfants. Le mot enfant sonnait clair et très haut. Il exigeait justice. Il réclamait son dû: - le respect, la pudeur, et un amour soucieux de l'adulte à venir, de l'adulte en lente et si fragile déhiscence (Sylvie Germain, La Pleurante des rues de Prague)

III. Appeler, annoncer de manière claire, explicite

Intransitif

1926 Bien sûr, bonjour à mon visage ! La lumière y sonne plus clair un grand désir qu'un paysage.

Bien sûr, bonjour à vos harpons, À vos cris, à vos bonds, à votre ventre qui se cache!

J'ai perdu, j’ai gagné, voyez sur quoi je suis monté (Paul Éluard, Capitale de la douleur) 


\section{CORPUS WEB :}

Amiga, Amstrad, Sinclair, mais aussi Donkey Kong, Pacman et Mario... des noms tout droit sortis des années 1980 qui sonnent clair aux oreilles des geeks trentenaires et quadras [http://www. nordeclair.fr/Locales/Lille/2011/01/19/ordiretroles-vieilles-becanes-ont-leur.shtml] (2.1.2016)

Retourne à l'école, zakouille la fripouille. Ces enceintes sonnent peut-être bien mais pas tout à fait juste, et non « justes ». Elles sonnent clair et sûrement un peu haut, et non pas hautes ni claires, évidemment [http://www.lesnumeriques. com/legrandforum/avis/Audio/enceintes-pc/ enceintes-soundsticks-wireless-sujet_6127_1. htm] (2.1.2016)

Des centaines de phrases issues de romans, d'essais, sonnent haut et clair dans le ciel de la Poésie. C'est du Joseph Delteil, apôtre du bon sens, chanteur de l'innocence érigée en vertu première, troubadour de nos cinq sens [https:// salondulivredugrandnarbonne.files.wordpress. com/2015/03/dossier-pc3a9dagogique-lecturemusicale-un-coeur-c3a0-poil.pdf] (31.12.2015)

$1^{\circ}$ ) Une fois sorties du four, elles sont beaucoup plus solides et peuvent être poncées plus fin pour éliminer les dernières rayures. Elles sonnent clair, comme de la vaisselle de faïence, qui ne serait pas émaillée et, comme les pots de fleur, c'est une argile poreuse, contrairement au grès qui cuit à $1280^{\circ} \mathrm{C}$ ou la porcelaine qui cuit à $1400^{\circ} \mathrm{C}$ qui sont tous deux des matériaux étanches à l'eau une fois cuits [http://www.vinci-melun.org/spip. php?article89] (2.1.2016)

Plus de 1000 sortes d'acajou dans le monde, c'est énorme... j'ai été déçu par une basse en acajou, je préfère les bois qui sonnent clairs ! [http://onlybass.com/index.php?/topic/88199lacajou/page-2] (2.1.2016)

L'information doit être importante vu le changement de couleur évident sur le visage de l'humain. Vous avez du mal à entendre clairement ce que le nain lui raconte mais certains mots sonnent clairs à votre oreille [https://www. arcgames.com/de/games/neverwinter/news/ detail/5007933-auteur-foundry-de-la-semaine] (2.1.2016)

REMARQUES : Sonner clair (I) désigne un instrument de musique (la trompette), une cloche, une horloge, un rire, une voix qui retentit avec un timbre clair, net. Le sujet peut aussi référer à une surface (une route, un sol) qui, au contact du pied, produit un son clair. (II) s'applique à une qualité, la disposition d'esprit d'une personne, qui apparaît de manière manifeste, explicite, qui est tout à fait perceptible. Le sujet peut aussi renvoyer à un mot qui résonne de manière claire et nette, tout à fait compréhensible. Sonner clair (III) réfère au figuré à la lumière (ici : un visage lumineux, radieux) qui traduit ou suggère clairement, avec évidence quelque chose, un sentiment, une émotion. Notons les collocations hautement et clair ; haut et clair ; franc et clair ; aussi clair et aussi étrange. Dans la plupart des cas, clair n'est pas accordé, mais il peut s'accorder en prédicat second avec le sujet. Il est modifié par aussi, encore, moult, plus, si, très. Notons l'emploi de trompeter haut ; souffler fort. Signalons aussi le commentaire métalinguistique dans le second exemple du CW, où l'auteur critique l'accord de l'adjectif-adverbe du type les enceintes sonnent hautes, justes, claires, en recommandant un retour à l'école, ce qui veut dire que la règle veut que l'on supprime l'accord dans les fonctions adverbiales de l'adjectif.

\section{Sonner creux}

I. Rendre un son creux, sourd (se dit d'un objet, d'une surface sur lesquels on frappe) Intransitif

1634 Car si vous venez de disner, On ne sçaurait le deviner, Vostre bouche n'est point humide, Et vos costez secs comme bois, Estanz heurtez avec les doigts, Sonnent creux comme un tonneau vide (Charles-Timoléon de Sigogne, Songe)

1784 Nous avons trouvé d'autres excavations moins considérables, et des parties de terrain qui sonnent creux sous les pieds (M. de Chamseru, Recherches sur la nyctalopie)

1829 un Olympe que je me suis bâti, entassant les vices sur les crimes, l'infection physique sur la bassesse morale, écorchant la nature, afin que, privée de cette peau blanche et potelée, revêtue du doux incarnat et du duvet coloré de la pêche, on 
puisse la voir avec ses vaisseaux si compliqués, ce sang qui roule, ces artères qui se croisent dans tous les sens ; afin qu'on puisse entendre le cœur sonner creux dans la poitrine ; un véritable écorché vivant (Jules Janin, L'Âne mort et la femme guillotinée)

1867 Nul espoir ne reluit devant nous ; et, derrière,

Ils ne renaîtront plus, les rêves

d'autrefois!

Sur l'univers entier la mort ouvre son aile lugubre.

Sous nos pas le sol dur sonne creux. N'y cherchons plus le pain des jours aventureux

(Léon Dierx, Les Lèvres closes)

1920 Quand nous fûmes hors des chemins

Où la poussière est rose,

Aline, qui riait sans cause

En me touchant les mains ; -

Lécho du bois riait. La terre

Sonna creux au talon.

Aline se tut : le vallon

Était plein de mystère...

(Paul-Jean Toulet, Les Contrerimes)

1945 ils fouillaient dans les tiroirs, dans le lit, soulevaient les tapis, inspectaient l'intérieur de la cuisinière, faisaient toc-toc sur les murs et les cloisons : si jamais cela sonnait creux! (Elsa Triolet, Le Premier Accroc coûte deux cents francs)

1960 mais il faisait toujours aussi noir, et même en écarquillant les yeux tant qu'il pouvait il ne parvenait à rien distinguer, pensant (au bruit des sabots différent maintenant, sonnant plus creux et, pendant un moment, la sensation d'un silence différent aussi, d'une obscurité différente, non pas plus humide ou plus fraîche - car la même pluie tombait toujours - mais pour ainsi dire liquide et mouvante, au-dessous d'eux) qu'ils devaient passer sur un pont (Claude Simon, La Route des Flandres)
II. Donner l'impression d'être vide, sans contenu, sans intérêt, sans valeur

Intransitif

1828 Car, sans cette dernière condition, si l'on se met à écrire, c'est la tête seule qui nous sert de guide, et ce que nous produisons sonne toujours creux, manque de solidité et ne dure pas (Étienne-Jean Delécluze, Journal)

1832 - Oui, à dater de ce jour, il y eut en moi un homme que je ne connaissais pas. Je voulus user de tous mes remèdes, le cloître, l'autel, le travail, les livres. Folie ! Oh ! que la science sonne creux quand on y vient heurter avec désespoir une tête pleine de passions! (Victor Hugo, Notre-Dame de Paris)

1883 - Ah! Ouatte ! Les hommes, vois-tu, c'est comme les bêtes : on en fait d'autres, mais ceux qui sont crevés... et il finit par cette espèce de rire à lui, qui sonnait creux et profond comme un rugissement. Dans sa bouche, ce n'était pas une phrase impie ; seulement il ne savait pas mieux dire (Pierre Loti, Mon frère Yves)

1886 La majesté leur avait paru sonner fort creux dans cette cave éventée des meilleurs crus de la Mort, et les épitaphes de ces absents jugés depuis des siècles, dont les chiens de la Révolution avaient mangé la poussière, ils les avaient lues sans émotion comme le texte inanimé de quelque registre du néant (Léon Bloy, Le Désespéré)

1893 Mais, en face d'une douleur réelle, point de belles théories qui ne semblent vaines ou absurdes. Dès qu'on en approche quelque chose de vivant et de souffrant, les systèmes sonnent creux, les pensées restent inefficaces. La souffrance, c'est le nouveau, l'inexpliqué, l'inconnu, l'infini, qui traverse la vie comme un glaive révélateur (Maurice Blondel, L'Action : essai d'une critique de la vie et d'une science de la pratique)

1896 Soudain elle recule, et d'un geste rêvant (Ô femmes, vous avez ces allures de faire !) Elle laisse tomber la tête qui profère 
Une plainte, et, roulant, sonne creux et longtemps :

- Mon Dieu, mon Dieu, pitié ! Mes péchés pénitents

Lèvent leurs pauvres bras vers ta

bénévolence,

Ô ne les souffre pas criant en vain ! Ô lance

(Paul Verlaine, Euvres poétiques complètes)

1932 Mais ce quelque chose n'est que de la négation. On ne tire rien du vide, et la connaissance d'une telle âme est naturellement incapable de progrès - sans compter que l'idée sonne creux dès qu'une philosophie antagoniste frappe sur elle (Henri Bergson, Les Deux Sources de la morale et de la religion)

1947 Le soleil incessant, ces heures au goût de sommeil et de vacances, n'invitaient plus comme auparavant aux fêtes de l'eau et de la chair. Elles sonnaient creux au contraire dans la ville close et silencieuse. Elles avaient perdu l'éclat cuivré des saisons heureuses (Albert Camus, La Peste)

\section{CORpus WeB :}

Pour ceux et seulement ceux qui s'y connaissent dans le batiment, un appartement fraichement neuf, avec un carrelage qui sonne creux (quand on tape avec le doigt ou quand ma voisine marche avec ses talons lol) ca vous évoque quoi ? [http://bricolage.linternaute. com/forum/affich-39642-pourquoi-un-carrelagesonne-creux] (2.1.2016)

Voila, j'ai une chape de ciment qui se fissure partout dans ma nouvelle construction. Elle sonne creux aussi a certains endroits. Je projete d'y poser un parquet flottant. Est-ce conseillé ? [http://www.forumconstruire.com/construire/ topic-288265-chape-fissuree-qui-sonne-creux. php] (2.1.2016)

Les phrases prononcées hier à l'occasion du 11 novembre, jour de l'armistice en 1918 mettant fin à une guerre ayant coûté la vie à 20 millions de personnes, sonnent creuses [https:// blogs.mediapart.fr/edition/eurojournaliste/ article/121115/leurope-en-route-vers-unnationalisme-malsain] (2.1.2016)
La démarche est donc saluable, quoiqu'assez pauvrement réalisée. Les images du Paris du milieu du XXe siècle sonnent par trop artificielles. Le jeu des acteurs est très inégal aussi bien celui des enfants que des adultes. Beaucoup de scènes sonnent creuses, et Rose Bosch, la scénariste et réalisatrice, semble hésiter entre grand-spectacle-émotion et documentaire-réalisme [http:// www.garr.fr/le-film-la-rafle-lhistoire-maisderriere] (2.1.2016)

REMARQUES : Sonner creux (I) se dit pour parler $\mathrm{du}$ bruit ressenti lorsque le pied est au contact d'un sol, d'un plancher ; il renvoie également aux battements du cœur, à des coups donnés et souligne le fait de sonner à la manière d'un objet, d'une surface qui résonne creux. Sonner creux (II) s'emploie au figuré pour souligner la platitude, la banalité, le contenu vide et sans intérêt d'une production écrite, le manque d'intérêt qu'elle suscite. Le sujet peut aussi référer à la réalité, au quotidien fade, inintéressant et peu valorisant de quelqu'un. Lorsque le sujet renvoie à la parole ou aux sentiments exprimés par quelqu'un, il peut souligner la répétition de ce qui est dit ou exprimé, son caractère monotone, sans valeur. Notons les collocations creux et profond et creux et longtemps. Creux reste invariable dans son emploi adverbial. Toutefois, dans les troisième et quatrième exemples du CW, il s'accorde avec le sujet pour le mettre en relief. Il est modifié par fort, plus, toujours.

\section{Sonner demi-creux}

Rendre un son un peu creux, un peu sourd Intransitif

1922 Il avait gelé. Le sol de la Bavière sonnait demi-creux. C'était la première fois depuis la guerre que je revenais en Allemagne, elle était reconnaissable mais il avait dû s'y produire un changement (Jean Giraudoux, Siegfried et le Limousin)

REMARQUES : Sonner demi-creux est une variante occasionnelle de sonner creux qui réfère à une surface partiellement vide sur laquelle on frappe, une terre que l'on foule du pied, qui sonne à la manière d'un objet, d'un espace creux. 


\section{Sonner démodé}

Donner l'impression d'être désuet, dépassé, démodé

Intransitif

1956 telle Anglaise qui se croyait spirituelle en désignant un chauve par : «Pas de cresson sur la fontaine » ne se doutait point combien cela sonnait faux, démodé et ridicule (Lectures d'aujourd'hui, 17 mars 1956 / Grundt : 257)

CORPuS WeB :

On guette le grattement d'un vieux phonographe. Son prénom même sonne démodé [http://www.telerama.fr/musiques/i-m-adreamer,109341.php] (2.1.2016)

Il est assez commun au Québec en effet, mais comme dit Chaoli plus il y a 15-25 ans je dirais. Je ne suis pas très fan parce qu'il me sonne démodé justement [http://forum.doctissimo. fr/grossesse-bebe/prenoms/pensez-prenomcarolane-sujet_208386_1.htm] (2.1.2016)

Se rendre régulièrement dans les magasins d'occasion est à présent du plus chic effet, tandis que les objets de luxe sonnent démodés [http://www.worldeventlistings.com/fr/zurich/ evenements/vintage-le-design-d-histoireexposition-a-zurich-e-949859] (2.1.2016)

Dans le comics, à part le fait que Johnny était blond (mais ça me dérange pas plus que ça qu'ils aient modifiés sa couleur de cheuveux), c'était effectivement un adolescent très arrogant et frimeur mais aussi plutôt intelligent et l'écriture de Stan Lee était vraiment drôle avec des jeux de mots et des vannes, certes aujourd'hui, qui sonnent démodés et anciens, mais vraiment recherchés et très fins [http://www.cinemasie. com/en/forum/read.php?f=21\&i=4587\&t=4577] (2.1.2016)

REMARQUES : Sonner démodé réfère à l'impression provoquée par une parole à l'oreille de quelqu'un, parole qui n'est plus d'actualité, qui n'est pas adaptée ou n'est plus en usage. L'accord de démodé est systématique. Ceci montre peutêtre que les adjectifs longs et plutôt recherchés sont plus soumis à l'accord.

\section{Sonner doux}

Sonner doucement, mélodieusement ; être doux, agréable à l'oreille Intransitif

+1500 Elle estoit d'une façon bonne, Grosse, belle à l'advenant, Dure, roide au remanant, Et au pied deux belles sonnettes, Tant belles et tant joliettes Qui sonnoyent si doulx que rage (La Confession Margot / Ancien Théâtre françois [début XVI $\mathrm{X}^{\mathrm{e}}$ )

1550 Là, là j’oirray d'Alcée La lyre courroucée, Et Sapphon, qui sur tous Sonne plus dous

(Pierre de Ronsard, Les Odes, p. 252)

1578 Je n'ay regret en son trespas, Comme prest de suivre ses pas. Du chef les astres elle touche :

Et je vy? Et je n'ay sinon Pour reconfort que son beau nom, Qui si doux me sonne en la bouche (Pierre de Ronsard, Le Second Livre des amours)

1603 Je lui parle souvent de vous, et ne luy en puis assez parler, tant ce propos luy sonne doux à l'oreille (François Des Rues, Les Fleurs du bien-dire)

1606 Tout ce qu'on oit a la trompette dire Et au clairon, tout cela que la lyre Est resonnant, et le lutz, sonnant doux, Ce que la fleute espand par mille troux (Antoine Du Verdier, Les Images des dieux des anciens [trad.])

1674 G sonne fort, devant a, o, ou. Ex. Gan, gond, goût. Il a le son moyen, devant $\mathrm{u}$. Ex. Aigu. Il sonne doux, comme J, devant è, é, i, eu. Exemples, Gentil, gemir, giron, mangeur, âge, genou (Jean d'Aisy, Nouvelle methode de la langue françoise)

1896 Ce mot, Sedan ! M'évoque, ainsi qu’à tous en France,

Une plaine lourde de sang, blême de nuit, Des cris éteints qu'une rumeur de rêve suit, Sur quoi plane très haut comme de l'espérance. 
Sedan! Sedan! Pourtant il sonne encore doux

Et frais, non plus pour l'avenir ou la

mémoire,

Mais bien dans le présent bien vivant, grâce à vous !

Il sonne, il brille, le futur nom de victoire

(Paul Verlaine, Euvres poétiques complètes)

1989 Vrai aussi que je suis vive, spirituelle, caresseuse et assoiffée de tendresse comme une Lucie. Il sonne si doux à mes oreilles (que j'ai très pointues, très joliment ourlées) ce nom-là. Même crié, parce que je suis partie vadrouiller trop loin (Remo Forlani, Gouttière)

\section{CORPus Web :}

Shopping nocturne, voilà deux mots qui sonnent doux à l'oreille de tous les accros à la mode [https://www.lebonbon.fr/events/ shopping-en-nocturne-aix] (2.1.2016)

Neige, poudreuse et pistes damées...si ces mots sonnent doux à vos oreilles, alors réjouissez-vous, l'hiver et sa blancheur immaculée ont débarqué sur le Vercors ! [http://vercors.fr/ noewp_evenement/!/evenement/28] (2.1.2016)

$\mathrm{Au}$ regard de cette particularité française qui consiste à se crisper sur les sujets en débat, les récentes déclarations du Premier ministre sonnent doux à nos oreilles. " En France, le moteur diesel a longtemps été privilégié » [http://www. nosdeputes.fr/14/intervention/664696] (2.1.2016)

(), un peu de lecture, et surement un bon massage fessier en vue, voire un dépoussierage futur du velodyne pour ma part : http:// www.carsound.com/review_archive/acces/ bassmekv5.html y a quelques phrases qui sonnent doucesàmonoreille! [http://www.homecinema-fr. com/forum/son-audio-general-homecinema/ cr-bass-pump-vs-buttkicker-t29851799-345. html\#stqT0CozLsUE0JLd.99] (2.1.2016)

Sans rien promettre, M. Cohon est toujours optimiste et répète chaque fois qu'il croit au potentiel du marché de l'Atlantique. Des paroles qui sonnent douces à nos oreilles [http://www. acadienouvelle.com/editoriaux/2013/03/07/ oublions-une-franchise-de-la-lcf-moncton/ ?pgnc=1] (2.1.2016)
REMARQUES : Sonner doux réfère à un instrument de musique (une harpe, une lyre) qui produit un son ou une suite de sons musicaux doux, harmonieux, agréables. Le sujet peut aussi être un nom ou un prénom dont la consonance est agréable à l'oreille en raison de son harmonie, de sa faible intensité. Notons la collocation doux et frais et la locution sonner doux à l'oreille, qui prédomine dans l'emploi actuel. Doux reste invariable dans la majorité des cas. Toutefois, dans le quatrième et cinquième exemple du CW, il s'accorde en prédicat second avec le sujet, présentant la douceur comme qualité de celui-ci. Doux est modifié par encore, plus, si.

\section{Sonner dur}

I. Rendre un son dur Intransitif

1931 - Ici, mon capitaine, dit l'homme, attention à la branche.

Il tâta le sol avec le pied ; ça sonna dur.

- C'est la route, il dit encore

(Jean Giono, Le Grand troupeau)

1939 Quant aux anciennes salines qui semblent présenter la rigidité de l'asphalte, et sonnent dur sous le talon, elles cèdent parfois sous le poids des roues (Antoine de Saint-Exupéry, Terre des hommes)

1951 Marino y figurerait, et cette cérémonie éveillait en moi une vague curiosité. La route sous nos pas, par ce matin de gel, sonnait dure et légère (Julien Gracq, Le Rivage des Syrtes)

II. Être dur, désagréable, rude à l'oreille Intransitif

1937 Il [= Beethoven] était beaucoup trop grand artiste, pour ne pas se soucier de la beauté sonore : subordonner, comme il le fait, le « Klangliche » au « Geistige », ne veut pas dire le sacrifier. Et quand une œuvre de lui sonne « dur », il est à craindre que la dureté ne soit le fait de l'exécutant (Romain Rolland, Beethoven)

1960 Le contraste était d'autant plus frappant qu'entre eux ils parlaient arabe bien qu'avec des accents différents, celui de Benamoun sonnant dur et rocailleux, et celui 
de l'Italien plus chantant, comme teinté d'accent méridional (Michel Déon, $\mathrm{L} a \mathrm{Ca}$ rotte et le bâton)

1979 Mes petits cousins exultent, ils bavent de plaisir en répétant la phrase de l'oncle Fouchs, il faut dire qu'en dialecte, elle a beaucoup plus de jus, le « cul » français ne vaut pas le arsch alsacien (prononcez « arrschch »), « cul », c'est sec, ça sonne dur, ça manque plutôt de rondeur, arsch, c'est ample, c'est charnu, le mot tient autant de place dans la bouche des cousins que la chose en tenait dans la main du Seppi, ils le font vibrer entre langue et luette - arrschch, arrschch - je les contemple, heureux de les voir se tordre ainsi (Jean Egen, Les Tilleuls de Lautenbach)

III. se faire sonner dur : se faire sonner les cloches, se faire gronder vertement Intransitif

1952 Près d'atteindre la porte, il buta dans la jambe de Lepage, allongée sciemment.

- T'es dingue, Chalume, dit Lepage à mivoix. Tu vas encore te faire sonner dur...

- Ça s'peut, dit Simon

(Yves Gibeau, Allons z'enfants)

\section{CORPUS WeB :}

« Mauvaise foi » et " incompétence » : les mots prononcés du côté des députés de l'opposition sonnent dur aux oreilles de Thierry Breton. L'ancien ministre de l'Économie et des Finances du gouvernement Villepin était entendu à nouveau hier sur son rôle dans l'affaire de la vente d'actions EADS, par la commission des Finances de l'Assemblée nationale, après une prestation similaire devant celle du Sénat, en octobre dernier [http://www.humanite.fr/node/382791] (2.1.2016)

Je voudrais filtrer mon aigu à $-18 \mathrm{db}(0.32 \mathrm{mh})$ , il y a du choix chez Mundorf mais je ne sais laquelle prendre : normale , ruban , fil tréssé...0.71, 1.40 , j'ai lu qu'il valait mieux avoir un bon diamêtre de fil sauf dans l'aigu sinon il parait que les tweeter sonnent « dur ».. [http://www.cinetson. org/phpBB3/enceintes-hi-fi-f16/questionselfs-t28056.html] (2.1.2016)

On a droit à une petite reprise épileptique du morceau Anaconda de Nicki Minaj. Les rimes sont découpées directement dans le béton, les allitérations sonnent dur [http://www.desinvolt. fr/2015/03/18/31650-lady-lykez-anakronicelectro-orchestra-paris-nouveau-casino-12mars-2015] (2.1.2016)

Avec la carte Class A, il y a en plus une profondeur 3D avec un légére coloration vintage. Cela met les basses un peu plus en avant et cela adoucit légérement les aigus, ce qui est très pratique pour les mixs numériques qui sonnent durs [http://www.magic-mastering.com/shop/fr/ compresseurs-limiteurs/523-fcs-p3s-me-class-a. html] (2.1.2016)

Cancer, sclérose amyotrophique... des mots qui sonnent durs, des maladies qui nous rattrapent un jour sans crier gare [http://www. lavenir.net/cnt/DMF20140428_00468452] (2.1.2016)

Il y a quand même des passages assez beaux et intéressants, mais encore une fois c'est le son du piano qui m’a empêché d'apprécier pleinement le tout : même les piano sonnent durs à l'oreille et me donnent l'impression de ramasser une claque, le contraste de nuances entre la main accompagnatrice et la main mélodique semble ne pas exister [http://musicarmonia.fr/index.php/ en/forum/11-piano-claviers-acoustiques-ondesmartenot/1271-clodette-op-18-n-4-pour-piano] (2.1.2016)

REMARQUES : Sonner dur (I) se dit du son produit ou de la sensation produite par l'action de fouler une surface goudronnée (ici : une route), ce qui produit un effet comparable au son d'un objet solide sur lequel on frappe. En (II), le sujet désigne une langue, un accent, un vocabulaire dont la consonance est aiguë, rauque, désagréable et blesse l'oreille. (III) recense un emploi familier. Il désigne le fait de remettre quelqu'un à sa place, de le réprimander ou de le punir très sévèrement. Notons les collocations dur et rocailleux / léger / chantant. Dur reste invariable dans son emploi adverbial, dans la plupart des cas, mais il s'accorde avec le sujet dans les trois derniers exemples du CW. Il ne s'agit pas de prédicats seconds au sens propre, mais de variantes stylistiques qui impliquent davantage le sujet dans l'événement, si la flexion n'est pas une simple hypercorrection. L'effet de renforcement stylistique du rôle sujet se perçoit particulièrement bien dans l'exemple littéraire de 1951, où la légèreté et 
la dureté du son se voient stylistiquement transformées en propriétés de la route. Notons l'emploi impersonnel familier ça sonne dur. Signalons aussi la locution sonner dur à l'oreille.

\section{Sonner éthéré}

Avoir une consonance légère, délicate 入 sonner aérien

\section{Sonner étrange}

Sonner bizarrement, de manière anormale, inhabituelle

Intransitif

1800 Et, avec un rire qui sonnait étrange, un peu faux, comme contraint :

- Que dirait ma jalouse Bretagne, si belle dans sa grise enveloppe de nuages, si austère, si reposante et si grave ? La quitter pour votre Provence, pour cette rieuse et folle coquette grise d'amour et de chansons (Albert Roguenant, Le Grand Soir)

1896 Au concert des grenouilles, commencé de tous côtés à la fois, se mêlent des aboiements de chiens, des appels de bergers, des clameurs lointaines qui sonnent étrange, et toujours le petit turlututu moqueur des flûtes de roseau, étouffé, dirait-on, sous l'épaisseur des herbages (Pierre Loti, La Galilée)

1945 - Pourquoi donc que t'es plus le même homme qu'avant?

- Mais non...

- Essaye pas de nier : ta voix sonnait étrange tout à l'heure quand tu parlais devant le monde. As-tu une peine quelconque, quelque déboire que tu cherches à me cacher ?

(Germaine Guèvremont, Le Survenant)

\section{CORPuS Web :}

Des noms qui sonnent étrange dans les oreilles de tous les observateurs de la scène politique, malgré de nombreuses sessions de l'Assemblée Nationale [http://maliactu.net/maliassemblee-nationale-la-commune-vi-orphelinede-ses-trois-deputes] (1.1.2016)

A quel point les grandes déclarations, d'Eisenstein, de Gance, sonnent étrange aujourd'hui : on les garde comme des déclarations de musée, tous les espoirs mis dans le cinéma, art des masses et nouvelle pensée [http://screenville. blogspot.co.at/2011/06/mediocrite-courantedeleuze.html] (1.1.2016)

Le mot bled ne sonne pas faux à mon oreille. Et pourtant, il y en a des mots qui me sonnent étranges [http://www.bladi.info/threads/bannirbled.243938/page-7] (1.1.2016)

La pâleur du Soleil eternel tangue

Les vivants et les morts sonnent étranges [http://renard-castor-et-pollux.over-blog.com/ article-les-vivants-et-les-morts-122948050.html] (1.1.2016)

Marcher longtemps dans Paris et entendre des accents qui sonnent beaux et étranges à la fois [http://www.lafabriquecrepue.com/2015/02/11/ la-meilleure-decision-que-jai-prise-par-gaelle] (2.1.2016)

REMARQUES : Sonner étrange désigne une voix, un cri qui produit à l'oreille de quelqu'un un son bizarre, qui surprend l'ouïe par son caractère inhabituel, singulier. Étrange reste invariable dans la majorité des cas. Toutefois, dans les troisième et quatrième exemples du $\mathrm{CW}$, il s'accorde comme prédicat second avec le sujet. Notons le style soutenu des exemples accordés. Notons les adjectifs-adverbes qui se combinent avec sonner : sonner beau / contraint / faux.

\section{Sonner faux}

I. Donner une impression de fausseté, manquer de vraisemblance, de naturel

Intransitif

1703 les Joüeurs de flûte et de haut-bois, poussent l'air, tantôt plus, tantôt moins, de sorte que souvent ils sonnent faux (Denis Dodart, Mémoire sur les causes de la voix de l'homme et ses differens tons)

1800 Mais je voudrais ôter de ce morceau un vers qui sonne faux à l'oreille de la raison (Jean-François de La Harpe, Lycée ou Cours de littérature ancienne et moderne)

1829 Par exemple, les mots bon, mauvais, faux, sont adjectifs dans cette soupe est bonne, cette volaille est mauvaise, cette pièce est fausse ; ils sont adverbes dans, cette soupe sent bon, cette volaille sent mauvais, cette 
pièce sonne faux (C. L. Marle, Journal grammatical et didactique de la langue française)

1845 Malgré son ignorance des perfidies raffinées, des cruautés perlées de la civilisation, Djalma, doué d'un tact très fin comme toutes les natures un peu sauvages et violemment impressionnables, ressentait une sorte de malaise moral en entendant cet échange de fausses aménités ; il n'en devinait pas le sens détourné ; mais, pour ainsi dire, elles sonnaient faux à son oreille ; puis, instinct ou pressentiment, il éprouvait une vague répulsion pour Mme de Saint-Dizier (Eugène Sue, $L e$ Juif errant)

1874 Comment se fait-il donc que moi, qui ne suis ni méchante ni hargneuse, qui ne suis pas, Dieu merci ! systématiquement incrédule, je puisse, encore plus que l'amour, maudire et exécrer ce langage absurde dont je m'abreuve à cœur-joie depuis quinze jours ? Comme toute cette litanie sonne creux et faux ! Combien ce pauvre M. de Gennevilliers est charlatan, et, ce qui est le plus à sa charge, il l'est, le malheureux, sans le savoir! (Arthur de Gobineau, Les Pléiades)

1885 La dernière guerre a produit chez nous nombre de rimes. La plupart sonnaient creux ou faux. L'amour de la patrie est un sentiment qu'il est odieux de ne pas éprouver et ridicule d'exprimer d'une certaine façon (Jules Lemaître, Les Contemporains)

1887a Elle [= l'enfant] roule des yeux de chatte craintive ; puis, apprivoisée tout de suite, vient s'appuyer contre moi, avec une câlinerie de bébé qui sonne adorablement faux. Elle est mignonne, fine, élégante ; elle sent bon (Pierre Loti, Madame Chrysanthème)

1887b Et si rieuses, si joyeuses, toutes ces petites poupées nipponnes ! - D’une joie un peu voulue, il est vrai, un peu étudiée et sonnant faux quelquefois ; mais tout de même on s'y laisse prendre. Chrysanthème est à part, parce qu'elle est triste. Qu'est-ce qui peut bien se passer dans cette petite tête ? (Pierre Loti, Madame Chrysanthème)
1896 Ô qui dira les torts de la Rime !

Quel enfant sourd ou quel nègre fou

Nous a forgé ce bijou d'un sou

Qui sonne creux et faux sous la lime?

(Paul Verlaine, Euvres poétiques complètes)

1928 Lautre rougit brusquement :

- Moi ? Mais non! Pourquoi ?

Et, précipitamment, il s’assit.

- Bien vrai ?

Jacques secoua la tête.

- Alors, fit Antoine, s'efforçant à une cordialité qui sonnait faux, je m’assieds... nous avons tant à nous dire !

En réalité, il songeait surtout à questionner. Mais il n'osait pas (Roger Martin du Gard, Les Thibault. La Sorellina)

1929 - Vous le voulez bien, Gilbert ?

- Volontiers.

Ils ramèrent tour à tour, feignirent d'avoir peur du courant. Mais leurs rires, leurs paroles mêmes sonnaient si faux qu'ils se turent. Quand ils descendirent de la barque, la nuit naissait. "Voilà ma dernière journée de liberté finie », songea Renée.

- Pourquoi ne pas dîner ici ?

(Marcel Arland, L'Ordre)

1934 Je lui aurais donné des enfants en grand nombre, et, le soir, nous recevrions rue de Cordon le notaire et la notairesse avec le capitaine de gendarmerie. Cette ironie sonnait bien faux.

- Vous avez des enfants ? Demandai-je pour couper court.

- J'en ai eu.

Déconcertée par la réponse ambiguë, je l'interrogeai du regard (Daniel-Rops, Mort, où est ta victoire ?)

1936 En art, ce mot n'a pas de sens. Il s'agit du timbre. Une œuvre sonne faux ou juste, voilà ce qui compte. Et cela dépend aussi bien de l'oreille, du cœur et de l'esprit de celui qui écoute (Pierre Reverdy, Le Livre de mon bord)

1945 Le vieil Alibert restait calme. À peine si parfois un geste, ou un mot plus dur, décelaient sa méditation. Marthe s'efforçait d'être gaie, et si par moments sa gaieté 
sonnait un peu faux, elle s'en apercevait elle-même et son visage devenait soucieux (Henri Bosco, Le Mas Théotime)

II. Sonner à un faux numéro, sonner par erreur Intransitif

1958 Oui, les téléphones sont détraqués en ce moment ; vous faites votre numéro et ça sonne faux à trois fois ou quatre numéros, Mademoiselle (Radiodiffusion-Télévision Française, 31 janvier 1958 / Grundt : 379)

\section{CoRpus Web :}

Rien qui ne sonne faux, pourtant, car sa voix veloutée sait se faire âpre quand il faut donner à ses compositions toute la profondeur qu'elles méritent [http://www.paperblog.fr/2646523/therodeo-hotel-utah] (4.5.2015)

Les trois cordes les plus graves sont métalliques et j'ai l'impression qu'elles sont abimées et qu'elles sonnent faux [http://www. instinctguitare.com/quand-faut-il-changer-sescordes] (1.1.2016)

@cathbrunet@alexnevskyalpin @vraktv les harmonies qui sonnent fausses sont toute de ma faute je m'excuuuuuuse haha! [https://twitter. com/sarahjlabrosse/status/578068895573004 289] (1.1.2016)

Je m'étonnes, non sans une certains mauvaise foi assumée, que ces peuples avec leur spiritualité à tendance euh... " naturaliste », ne se soient pas calés sur le 432, et soient aller chercher des choses qui sonnent fausses à nos oreilles [http://www.agoravox.fr/commentaire4359947] (1.1.2016)

REMARQUES : Sonner faux (I) réfère à un lieu ou une atmosphère qui apparaît comme artificiel, qui manque de naturel. Le sujet peut aussi désigner une parole, des mots (une plainte, une tirade) auxquels on ne peut se fier. Lorsque le sujet renvoie à un geste, au comportement, à une attitude positive, ceux-ci sont mis en doute, semblent peu fiables. Le sujet peut aussi désigner un bruit, un chant (une œuvre musicale) qui produit à l'oreille un son désagréable, qui n'est pas juste. Le sujet de (II) désigne un appareil (un téléphone) dont le numéro composé n'est pas attribué. Notons la collocation creux et/ou faux et l'opposition sémantique dans faux et juste. Faux reste invariable dans son emploi adverbial, mais il s'accorde en prédicat second du sujet dans les deux derniers exemples du CW. Il est modifié par adorablement, bien, si, un peu. Notons l'emploi impersonnel familier ça sonne faux. VoIR AUSSI : tinter juste

\section{Sonner ferme}

I. Sonner vivement, avec force, avec une forte intensité

Intransitif

+1485 Saupicquet. Ce n'est pas jeu. J'entends que les bastons à feu Y ont cest an sonné si ferme, Qu'ils ont estonné tout le germe De toutes mes dames des Carmes, Qui n'a peu proffiter ne croistre Ensorte que ayent peu engrossir (Farce des Chamberières / Ancien Théâtre françois)

1833 - Bien ! celui-ci [= le mât] sonne ferme, dit l'un en appuyant avec emphase sur le dernier mot

- Oui, répond un autre avec une affectation semblable, et si le commandant n'y prend garde, le bâtiment pourra bien sonner ferme à son tour (Basil Hall, Passage au Cap)

1975 Sous mes pas, la petite route goudronnée qui mène à Renaison et à Saint-Haon sonne dur et ferme. Sam qui commence à en avoir plein les pattes ne divague plus sur les talus. Il trottine à mon côté, la tête basse (Michel Tournier, Les Météores)

II. Donner une impression de fermeté, de détermination, de dureté Intransitif

1945 Il avançait à grandes enjambées, longues et souples. Son maintien avait gagné aux exercices militaires. Son pas sonnait plus ferme, il tenait la tête mieux dégagée, bien qu'un peu penchée encore sur l'épaule droite dès qu'il quittait les rangs et ne se sentait plus soumis à une stricte discipline (Gabrielle Roy, Bonheur d'occasion)

CORPUS Web :

- Je, ne voulais pas. - dit elle en essayant de sonner ferme [http://guillon.christelle.free.fr/ forum/viewtopic.php?t=1600] (1.1.2016) 
Le Cramant 2004 sonne ferme et pur, encore mordant dans sa finale aux notes d'amandes grillées et de craie humide [http://www.champagnelilbert.com/produit.asp?ID=13606] (1.1.2016)

REMARQUES : Sonner ferme (I) s'applique à un lieu (une route) qui, au contact du pied, produit un son vibrant, percutant. (II) réfère à l'impression produite par le pas et se dit d'une démarche sûre, énergique et signifie 'marcher d'un pas déterminé'. Dans le CW, il réfère soit à l'effort d'émettre un propos qu'on veut ferme (premier exemple), soit à la transposition métaphorique de qualités acoustiques à des sensations produites dans la bouche par le champagne. Notons les collocations dur et ferme et ferme et pur. Ferme reste invariable et est modifié par plus, si.

\section{Sonner forcé}

Manquer de naturel, de spontanéité ; donner l'impression d'être factice, contraint Intransitif

1921 - Comme à Verdun... avait-il dit en riant. Pourquoi ce rire avait-il sonné non pas faux, mais forcé ? Pourquoi surtout ce frémissement de ses paupières sur ses yeux, cette crispation de ses doigts sur sa cigarette (Paul Bourget, Un drame dans le monde)

\section{CoRpus Web :}

Mais bon a la limite ça c'est chacun ses gouts, il y a des gens que ça amuse d'ecouter des rappeurs qui rappent mal, j'ai jamais compris pourquoi mais bon admettons. Mais sinon en dehors de ça ils n'ont aucun charisme, ils essayent d'etre droles sans vraiment y arriver, tout sonne forcé dans ce qu'ils font, ils en font trop [http://www.90bpm.com/forum/index. php?topic=9348.35;wap2] (31.12.2015)

Cougar Town peinait un peu sur ce terrain. Son pire moment était probablement la vente du principe de Penny Can avec Lou Diamond Philips en porte parole. C'était une intrigue peu crédible, pas très drôle, centrée sur un moment plus sérieux, la « trahison » d'Andy pour aider financièrement Bobby, qui sonne forcé [http:// www.a-suivre.org/usa/cougar-town-saison-4avis.html] (31.12.2015)
Ces mots sonnent encore et toujours de manière étrange dans ma propre bouche. Comme s'ils ne m'appartenaient pas, comme si je ne faisais que les emprunter. Ils sonnent faux, ils sonnent forcés, ils sont des étrangers au milieu de mes phrases, des intrus [http://safianechka. blogspot.co.at/2015/09/comment-dire-je-taime. html] (31.12.2015)

Oui, Iris (pas notre petite Suisse à nous) est le plus gros défaut de ce Pilote. Ses mauvais échanges avec Barry sonnent forcés (autant par la faute des dialogues que du jeu de l'actrice), malgré toute la bonne volonté de Gustin de nous faire croire à ses sentiments pour une fille sans aucun trait de personnalité autre que " gentille » [http://www.a-suivre.org/usa/flash-critiqueserie] (31.12.2015)

REMARQUES : Sonner forcé se dit essentiellement d'un rire mais aussi d'une situation, d'un comportement qui n'est pas spontané, qui manque de naturel et de crédibilité ; on s'oblige à rire. Il est parfois mis en série avec sonner faux. Forcé peut rester invarié (second exemple du $\mathrm{CW}$ ), mais il tend à l'accord.

\section{Sonner fort}

Faire résonner avec une grande intensité Transitif

1364 En sa main tient une flahute De .c. rosiaus dont il flahute ; Mais quant il la vuelt fort sonner, Mer et terre fait ressonner Entour lui .iii. lieues ou .iiii. : Ainsi se scet li vers esbatre (Guillaume de Machaut, Le Livre du voir dit, 6792)

Intransitif

1568 Maistre Jehan du Pontalais, selon sa coustume, fit sonner le tabourin au carrefour, qui estoit tout viz à viz de l'eglise, et le faisoit sonner bien fort et longuement tout exprès pour faire taire ce prescheur, afin que le monde vint à ses jeux (Bonaventure des Périers, Les Nouvelles Récréations et joyeux devis)

1662 DORANTE. Il s'est dit grand chasseur, et nous a priés tous

Qu'il pût avoir le bien de courir avec nous. Dieu préserve, en chassant, toute sage 
personne

D'un porteur de huchet qui mal à propos

sonne,

De ces gens qui, suivis de dix hourets

galeux,

Disent « ma meute », et font les chasseurs

merveilleux !

Sa demande reçue et ses vertus prisées,

Nous avons été tous frapper à nos brisées.

À trois longueurs de trait, tayaut ! voilà

d'abord

Le cerf donné aux chiens. J'appuie, et sonne fort (Molière, Les Fâcheux)

\section{CORpus Web :}

L'idée ? Reprendre des tubes à la sauce punk californien! Car non, vos artistes d'enfance ne sont pas morts !!! Retour dans les années 70 à 90, en mode skate punk, dans le Show à l'Armoricaine le plus débile du grand ouest...Bref, The jacks sonnent fort, c'est Dalida qui pogote en jouant du Offspring et Mike Brant qui skate comme Tony Hawk !! [http://www.radio-g.fr/ content/jacks-sonnent-4] (31.12.2015)

Les vraies cloches, celles qui sonnent à tout moment, $24 \mathrm{~h}$ sur 24, et nous abrutissent les oreilles, sont celles de l'Elysée, du Parlement et du Sénat, des cloches qui promettent tout et ne font rien, [...], des cloches qui sonnent fort pour appeler les immigrants de tous pays qui eux, vont faire entendre la voix de leurs muezzins dès $3 \mathrm{~h}$ du matin [http://sosconso.blog.lemonde. fr/2014/01/24/querelles-autour-des-cloches-deseglises] (31.12.2015)

Momo, l'entraîneur du Punch de Sarrebourg et arbitre des rencontres, doit constamment insister sur le côté « light » quand les poings et les pieds sonnent forts sur les protections [http:// www.republicain-lorrain.fr/sports/2013/12/09/ les-filles-a-fond] (31.12.2015)

Un discours rassembleur qui ressemble à s'y méprendre à celui d'un capitaine. Il a beau prétendre le contraire, ses mots sonnent forts. S’adressent à tous ses coéquipiers [http://sport24. lefigaro.fr/rugby/xv-de-france/actualites/ maestri-ne-veut-pas-monter-en-grade-739266] (31.12.2015)

REMARQuES : Sonner fort désigne le fait de faire sonner un instrument de musique (une flûte, un tambourin) en soufflant fort ou en frappant avec un bâton pour produire un son d'une forte intensité. Le sujet peut s’appliquer à une personne portant un cor de chasse qu'il fait sonner pendant la chasse. Les exemples du CW illustrent des sujets variés : les musiciens, les cloches, les poings, les mots. Fort s'accorde occasionnellement avec le sujet, ce qui suggère stylistiquement une interprétation comme prédicat second orienté vers le sujet dont le rôle est mis en relief. Fort est modifié par bien. Notons la collocation sonner bien fort et longuement.

\section{Sonner frais}

Évoquer la fraîcheur, la vitalité, la jeunesse Intransitif

1896 Ce mot, Sedan ! M'évoque, ainsi qu'à tous en France,

Une plaine lourde de sang, blême de nuit, Des cris éteints qu'une rumeur de rêve suit, Sur quoi plane très haut comme de l'espérance.

Sedan! Sedan! Pourtant il sonne encore doux

Et frais, non plus pour l'avenir ou la mémoire,

Mais bien dans le présent bien vivant, grâce à vous !

Il sonne, il brille, le futur nom de victoire (Paul Verlaine, Euvres poétiques complètes)

CORPUS WEB :

Waouwwwww.... ça sonne frais, avec les bonnes influences mais sans être pompé, et j'ai pas l'impression d'écouter un groupe liégeois ! J'veux un EP dès qu'il sort* Keep rockin' guys !!! [https://www.facebook.com/ permalink.php?story_fbid=168267279852019 \&id=168026673209413] (31.12.2015)

L'arrangement sur la couverture blanche sonne frais. Petites maroquineries sont employés souvent utilisé garder les choses, ces jours, ils peuvent avoir leur tour dans une marque spécifique de votre position avec goûts. La garniture en cuir brun et les poignées sont un excellent complément à l'impression serpentine, mais je ne suis pas si enthousiaste à propos du matériel [http:// gretchen.allmyblog.com/126-1-arrangementsur-la-couverture-blanche-sonne-frais.html] (31.12.2015) 
Il n'y a que la production du titre qui sonne fraîche et contemporaine. Bref ce n'est pas pour moi [http://www.chartsinfrance.net/ communaute/index.php?/topic/52275-kendjigirac-single-cool/page-5] (31.12.2015)

Après plus de trente ans d'une carrière toujours glorieuse, sa voix sonne fraîche et limpide, récompense sans doute de sa légendaire prudence dans le choix de ses répertoires [http:// www.anaclase.com/chroniques/felicity-lott-etle-quatuor-schumann] (31.12.2015)

RemARQues : Sonner frais réfère à des mots dont la consonance rappelle quelque chose de nouveau, de vivifiant. Les exemples du CW contiennent d'autres sujets, comme un groupe de musique, la voix, ou l'arrangement sur une couverture. Frais est un prédicat second qui s'accorde avec le sujet, mais les exemples avec sujet au masculin ou neutre, où la fonction est plus clairement adverbiale, ne permettent pas de trancher définitivement la question de l'accord. Notons l'emploi impersonnel familier ça sonne frais. Mentionnons également les collocations frais et contemporain; frais et limpide. Frais est modifié par encore.

\section{Sonner franc}

Donner une impression de franchise, de sincérité

Intransitif

1890 Drouin déserte d'une façon charmante, avec une modestie qui sonne si franc que je l'en aime. Et je reste seul sur la banqueroute de mes espérances (André Gide, Journal)

1896 Il n'y a rien d'aimable comme des prêtres aimables ; leur gaieté détachée sonne franc et clair. Ceux-ci, en plus, sont des érudits et des artistes ; alors, facilement nous oublierions l'heure, à cette table très frugale (Pierre Loti, La Galilée)

1922 Ô ma femme au cœur égal Aimée depuis dix années, Qu'est la peine de deux barques Sur une mer de misère? Âme qui sonne bien franc, C'est pourtant un vieux tourment Que notre commune vie
Jalonnée de soirs d'amour

(Pierre-Jean Jouve, Tragiques)

1929 - Alors » fit elle. Et, après tout ce factice, son rire strident, enfin, sonna franc

(Roger Martin du Gard, Les Thibault. La Mort du père)

1950 - C'est, juste à la limite des « Hauts », un petit patelin dans une vallée. J'en aime le nom, parce qu'il sonne clair et franc. On aimerait se battre là.

- Mais ce nom? dis-je.

- Les Éparges

(Maurice Genevoix, Ceux de 14)

\section{CORPUS WEB :}

J'adore! Les mots sont limpides et sonnent " franc »! chercher le langage du cœur... Je ne sais pas si tu connais [http://omega.letempsdesreves. $\mathrm{fr} /$ post/reader?pid=5585] (31.12.2015)

A lire les billets on retrouve quelquefois les mots rectitude et intégrité ; ils sont beaux employés comme il faut avec parcimonie. Sans doute certains politiques et artistes devraient-ils s'en inspirer, ils sonnent franc, l'image de Malherbe en eux. Intégrité et tout le bruissement de la flamme étouffée sous ce mot [http://www.philippebilger. com/blog/2015/02/faut-il-plaindre-gad-elmaleh-. html] (31.12.2015)

Des titres qui sonnent francs, comme une chanson des Beastie Boys, des Super Grass, ou encore des Roots. Les titres en Français sont moins percutants que ceux en Anglais, tout comme le Rock, le Rap ou la Pop s'écoutent en anglais [http://jackyschwartzmann.blogspot. co.at] (31.12.2015)

REMARQUeS : En parlant d'une attitude (la façon de rire), des propos de quelqu'un, ou d'un titre, d'une qualité, sonner franc en souligne le caractère vrai, sincère, qui ne dissimule rien. Le sujet peut aussi désigner un nom propre dont la consonance suggère des valeurs positives. La tendance à l'emploi invariable apparaît clairement, à l'exception du dernier exemple du CW où franc s'accorde avec le sujet, ce qui suggère son interprétation en tant que prédicat second orienté vers le sujet. Il est modifié par bien, si. Notons les collocations franc et clair ; clair et franc. 


\section{Sonner grave}

Produire un son grave, bas

Intransitif

1900 Derrière nous, au fond d'une antique poterne,

S’ouvre, nue et déserte, une cour de caserne

Immense avec de vieux boulets ronds dans un coin.

Grave et mélancolique un clairon sonne au loin...

Cependant par degrés le ciel qui se dégrade

D’ineffables lueurs illumine la rade (Albert Samain, Le Chariot d'or)

1950 Par exemple, j’vous d'manderai d'vider la musette et d'me la renvoyer tout d'suite : on n'est jamais tranquille quand on a du barda qui voyage. Un vol d'obus, à ce moment, frôle l'air. L'éclatement sonne grave, en coup de gong assourdi (Maurice Genevoix, Ceux de 14)

\section{CORpus WeB :}

«Ouais on a eu des 8 cordes, on va s'en servir tout le temps !! » Le sous accordage est ici parole d'évangile. Littéralement fusionnées avec la basse, on n'entend presque pas les guitares, tant elles sonnent grave [http://www.leseternels.net/ chronique.aspx?id=5257] (31.12.2015)

Ceci étant dit, le brand new mix de Swano est réussi. Les guitares sonnent grave, comme le chant, la batterie un peu étouffée est délicieusement nostalgique, et l'affaire tourne rond [http:// www.metal-impact.com/index.php?name=Revie ws\&req=showcontent\&id=6057] (31.12.2015)

je te remercie pour tous les renseignement que tu m'as donné, je suis content des performences du détecteur mais ne trouve pas de différences de ton entre le billon, le bronze, l'argent et le cuivre, les ferreux sonnent graves [http://www. xpmetaldetectors.com/forum/read.php?2,4028] (31.12.2015)

Et voila son diagnostic : l'action est trop haute pres de la tête (en bas du manche, la ou les cordes sonnent graves). En effet le sillet de tête devait être retaillé a cause du changement de diamètrre des nouvelles cordes [http://ukuleleforum.fr/index.php?topic=4331.0] (31.12.2015)
REMARQUES : En parlant d'un son (celui d'une voix), d'un bruit (un éclatement), du son d'un instrument de musique (le clairon), sonner grave réfère à un son bas et profond. Notons l'adjectif-adverbe mélancolique et l'emploi de tourner rond. Grave tend à l'emploi invariable, mais il peut également s'accorder avec le sujet, ce qui renforce une interprétation de prédicat second orienté vers le sujet (v. les deux derniers exemples du CW).

\section{Sonner gros}

Produire un son fort et intense

入 sonner bas

\section{Sonner haut}

I. Résonner, retentir avec une grande intensité, produire un son fort, puissant

Intransitif

+1313 La nuit la buissinne sonna

Moult haut, et cieus qui le son a

Oy forment s'en estourmy

Ne puis celle nuit ne dormy,

Mais son tiestament ordena

Et tous ses enfans ordena

(Jean de Condé, Poèmes [1313-1337], 74)

+1400 Lances brisent, cops resonnent,

Et ces menestrelz hault sonnent

Si qu'on n'oïst Dieu tonnant

(Christine de Pisan, Le Livre du duc des vrais amans / Euvres poétiques [début $\mathrm{XV}^{\mathrm{e}}$, III, p. 90, 1038)

1550 Amour de gloire obstinée Avec toute beste née, Voulant demeurer le maistre Et de soy le vainqueur estre, Plus haut que devant il sonne, Plus haut le bois en resonne (Pierre de Ronsard, Odes retranchées, p. 467)

1587 Or pour en prendre autre exemple moins superstitieux, oyez ce son, et le retenez pour Hipate : oyez maintenant que, l'ayant tendue [= la corde], elle sonne plus haut, et soit ce ton, Mese : mais oyez encor que, la tendant d'avantage, elle resonne plus aiguément, c'est ce ton troisiesme, que j'avois nommé Nete (Pontus de Tyard, Solitaire premier) 
1853 «Quand une tyrannie violente pèse sur un homme, il a son droit de s'y soustraire par tous les moyens possibles. »

Lorsque cette lettre fut écrite, je la pliai et la serrai dans ma poche, afin de la jeter à la poste dès que je serais dehors ; puis j'attendis. Le temps me paraissait long et les battements de mon cœur sonnaient haut dans ma poitrine (Maxime Du Camp, Mémoires d'un suicidé)

1883 - Mademoiselle Baudu...

Et son masque empâté d'empereur avait l'immobilité inexorable de la toute-puissance.

- Passez à la caisse !

La terrible phrase sonna très haut, dans le rayon alors vide de clientes. Denise était demeurée droite et blanche, sans un souffle. Puis, elle eut des mots entrecoupés.

- Moi ! Moi !... pourquoi donc ?

(Émile Zola, Au bonheur des dames)

1886 Claude, ragaillardi par ce souffle de lutte, s'animait, se fâchait, écoutait maintenant monter les rires du public, l'air provocant, comme s'il eût entendu siffler des balles. Discrets à l'entrée, les rires sonnaient plus haut, à mesure qu'il avançait. Dans la troisième salle déjà, les femmes ne les étouffaient plus sous leurs mouchoirs, les hommes tendaient le ventre, afin de se soulager (Émile Zola, L'Euvre)

1912 Le paradis arda comme un essaim qui bout Lorsque le pauvre errant de nouveau fut debout.

Quand ils virent saigner ses pieds

évangéliques

Les chœurs firent sonner plus haut l'hymne angélique.

Et l'enfant qui buvait à l'ineffable sein

Se retournant tendit au disciple les mains

(Francis Jammes, Les Géorgiques chrétiennes)

1931 Des toits, des toits, des cheminées fument, des coups de vent qui passent et font frémir longuement les feuillages. Très haut, des cloches sonnent à travers le ciel libre; leurs vibrations ondulent à l'infini, sans trêve réveillées par les chocs des battants de bronze (Maurice Genevoix, Rroû)

II. faire sonner haut (quelque chose) : faire valoir, mettre en relief, vanter avec excès Intransitif

1646 Les chefs du party de Vespasian, sans parler de leur infortune, luy repartirent en termes hardis ; luy firent sonner haut le nom de Vespasian ; luy loüerent les esperances de leur party ; luy tesmoignerent la bonne opinion qu'ils avoient du succez, et se declarerent ouvertement ennemis de Vitellius (Nicolas Coëffeteau, Histoire romaine)

1654 De quelque specieuse apparence que ses paroles soient colorées, deffiez-vous d'une rhetorique, qui veut embellir les precipices et les abysmes ; d'une rhetorique de feu et de sang ; conseillere de mort et de misere ; ruïneuse à vostre estat, mal affectionnée à vostre personne. Elle fait sonner bien haut la reputation de vos armes, vos avantages sur l'ennemi, et la dignité de vostre couronne (Jean-Louis Guez de Balzac, Dissertations politiques)

1745 Remarquez cependant que, dans un système où l'on ferait sonner si haut ces récompenses infinies, les cœurs en pourraient tellement être affectés, qu'ils négligeraient et peut-être oublieraient, à la longue, les motifs désintéressés de pratiquer la vertu (Denis Diderot, Essai sur le mérite et la vertu)

1788 Ils font sonner fort haut leur zèle pour la cause de la vérité, ces ardens missionnaires d'athêissme ; mais il s'en faut beaucoup que la découverte de la vérité soit l'objet le plus important dans la poursuite du bonheur (Joseph de Loaisel de Tréogate, Ainsi finissent les grandes passions)

1823 Enfin les agents de l'Autriche, ceux de Venise et du pape, faisaient sonner très haut les avantages obtenus par Alvinzi, et sa supériorité sur nous. Nous n'étions plus en position de prendre l'offensive nulle part (Emmanuel de Las Cases, Le Mémorial de Sainte-Hélène) 
1853 - Ainsi, comprends bien que tous ces gens qui pleurnichent, qui font sonner l'art si haut, qui se disent victimes de la société, qui gagnent largement leur vie à des travaux tels que la gravure et la lithographie, sont des orgueilleux : ils donnent tout ce qu'ils peuvent donner (Champfleury, Les Aventures de mademoiselle Mariette)

1936a Elle a accueilli ce grand garçon avec plaisir, faisant sonner un peu trop haut la surprise que c'était pour elle de le rencontrer. Elle élevait la voix pour dire qu'il y avait longtemps qu'elle ne l'avait pas vu (Joë Bousquet, Traduit du silence)

1936b Lors d'une querelle, chacune des parties faisait sonner ses droits aussi haut que possible et ceux qui n'avaient que peu de parents ou de biens étaient en moins bonne posture (Alfred Metraux, Manuel d'anthropologie culturelle [trad.])

1918 Mais, même quand on savait que c'était avec d'inélégants fonctionnaires, avec des femmes tarées, parure des bals de ministères, qu'il désirait de se lier, on était étonné de l'entendre, lui qui autrefois et même encore aujourd'hui dissimulait si gracieusement une invitation de Twickenham ou de Buckingham palace, faire sonner bien haut que la femme d'un sous-chef de cabinet était venue rendre sa visite à Mme Swann (Marcel Proust, À l'ombre des jeunes filles en fleurs)

III. Atteindre un niveau élevé, supérieur Intransitif

1834 Des mots de liberté et de vertu politique sonnaient moins souvent et moins haut dans ses pages toutes poétiques ; ce n'était pas le Dante d'une Florence asservie, c'était le Tasse d'une patrie perdue, d'une famille de rois proscrits (Alphonse de Lamartine, Des destinées de la poésie)

1899 Après les excès contraires du Parnasse, la rime en ces derniers temps s'est rénovée ; elle s'adresse d'abord à l'oreille, admettant ainsi des finales jumelles de son, quoique différentes à l'œil ; elle s'affaiblit même volontiers en assonances qui, par leur nouveauté, sonnent parfois plus haut que les vieilles rimes usées au duo prévu (Rémy de Gourmont, Esthétique de la langue française)

IV. Se couvrir d'une gloire retentissante Intransitif

1836 Un soldat-empereur, - tout un siècle à cheval, -

Si sa capote grise est son manteau royal ; S'il porte une auréole au lieu d'un diadème ;

Un homme contre tous, s'il se dit à lui-même :

«Bonaparte, debout! Sauve Napoléon!

Fais-toi d'airain, mon cœur ! Sonne plus

haut, mon nom !»

(Edgar Quinet, Napoléon)

1840 Penché sur Rome antique et son mâle génie,

Je ne puis m'empêcher, dans mon chant éploré,

À ce grand nom croulé d'unir ton nom sacré,

Tant ils ont tous les deux haut sonné dans l'espace,

Tant ils ont au soleil tous deux tenu de place,

Et dans les cœurs amis de la forme et des dieux

Imprimé pour toujours un sillon glorieux (Auguste Barbier, Iambes et poèmes)

\section{CORPUS WEB :}

Retracer et superposer des destins de familles nobles durant cette période permet de voir l'histoire sous un nouvel angle, pour ainsi dire de l'intérieur. Laurac, Châteauverdun, Rabat, d'autres encore, autant de noms qui sonnent haut et fort, ceux des châteaux et des familles qui les possédaient [http://www.lalouve-editions.fr/LHERESIE-EN-HERITAGE.html] (31.12.2015)

Passées ces considérations ultra importantes (sic) et l'intro du disque, les guitares sonnent haut et vite, les frappes sont lourdes, la basse donne du groove et la voix s'égosille avec plus ou moins de puissance, c'est parti et le quintet ne relachera pas la pression (sauf sur le petit intermède acoustique " _ " qui sépare l'album en deux) [http:// www.w-fenec.org/metal/lazy.html] (31.12.2015) 
Chomsky n’a pas peur des mots, spécialement ceux, qui sonnent hauts et forts et qui font peur aux adultes [https://emilenasr.wordpress. com/2014/09/18/quand-noam-chomsky-parlelhumanite-petrifiee-doit-lecouter] (31.12.2015)

Merci à ces deux esprits énergiques, capables de se livrer sans fioritures avec des écrits qui sonnent hauts et forts tout en étant issus d'une réflexion « de terrain » [http://gje.mabulle. com/index.php/2015/04/03/207336-primeurs2014-nc-bordeaux-6] (31.12.2015)

Celle des intellectuels juifs, des gauchistes maxistes et des religions dont la musique se doit d'être linéaire et môche pour ne pas disturber de la contemplation. Il ne parlait pas de l'émotivité dans la culture, de la passion, du romantisme, des cuivres qui sonnent hauts et forts. [http://lesactualitesdudroit.20minutes-blogs. fr/archive/2008/04/05/karajan-s-est-nourri-dunazisme.html] (31.12.2015)

REMARQUES : Sonner haut (I) s'applique souvent à un instrument de musique qui produit un son haut et fort. Le sujet peut aussi référer aux battements du cœur qui résonnent intensément, à une voix, un rire, un chant, des mots qui produisent un son puissant, retentissant. Au figuré, le sujet peut référer à un état d'esprit (ici : la gaieté) dont l'impact se fait fortement sentir. (II) se dit du fait de proclamer, de dire à haute voix quelque chose (un nom, une vertu), de vanter le mérite de quelqu'un. (III) renvoie à l'impact, à l'effet produit par un mot, ou à l'importance qu'on lui accorde. En (IV), il s'applique à la gloire retentissante liée à un nom. Notons les collocations haut et fort et haut et vite. Haut, tout comme fort, s'accorde occasionnellement avec le sujet, ce qui renforce son interprétation en tant que prédicat second orienté vers le sujet. Notons que l'écriture plus soignée des exemples hors CW évite l'accord. Haut est modifié par aussi, bien, fort, moins, moult, parfois, plus, si, très, un peu trop. Mentionnons l'emploi complémentaire de résonner plus «aiguément ».VoIR AUSSI : trompeter haut

\section{Sonner intime}

Donner une impression d'intimité

入 sonner aérien

\section{Sonner juste}

I. Sonner dans un ton juste, harmonieusement ; jouer dans le ton

Intransitif

1783 Rien n'est plus propre à attacher le soldat à son métier qu'une musique militaire. On a trop négligé parmi nous la musique militaire ; nous n'avions pas il y a vingt-cinq ans un seul trompette qui sonnât juste, pas un seul tambour qui battît en mesure, pas une clarinette qui ne fût fausse (Louis-Sébastien Mercier, Tableau de Paris)

1930 Chacun d'eux tenait en main une grande chope d'étain, et ils glapissaient de toute leur force : Le Seigneur est mon berger, je ne craindrai rien! Chacun suivait sa mesure et son air, et je pensais à la colère de maître Beguildy s'il les avait entendus faire une telle cacophonie, lui qui était très attentif à son clavier de cailloux et sursautait si, quand il les frappait, la pierre ne sonnait juste sous son marteau (Jacques de Lacretelle et Madeleine Guéritte, Sarn [trad.])

II. Donner une impression de vraisemblance, de naturel, de justesse, de réalité, de vérité Intransitif

1914 LA MÔME. (indiquant la porte de droite premier plan)

Par là ! (s'élançant avec transport dans les bras de Corignon qui l'enlève dans ses bras et lui ceinturant la taille de ses jambes.) Ouh ! Le petit Ziriguy à sa Mômôme ! CORIGNON. (pivotant sur lui-même de façon à déposer la môme à terre numéro 1) À la bonne heure! Avec toi, ça sonne juste ! Chez la petite, ç'avait l'air d'une tradition dans la bouche d'une doublure! (Georges Feydeau, La Dame de chez Maxim)

1928 Vérité, sans nul doute, cette orageuse explication entre le père et le fils. Dans les paroles du conseiller Seregno, certains traits sonnaient indéniablement juste : Machination huguenote! Je te briserai ! Je te couperai les vivres! Je te ferai engager! (Roger Martin du Gard, Les Thibault. La Sorellina) 
1936 le créole se mit à crier : peut-être le destin serait-il touché par ce hurlement d'homme. Mais la voix n'était plus humaine ; elle sonnait même assez juste dans la forêt impassible, comme le cri du couatta ou le miaulement du jaguar (Jacques Perret, Roucou)

1949 Et la joie des choses créées sonnait si juste Qu'on eût dit que chacun venait d'inventer ses propres couleurs

Et l'herbe était verte et le ciel bleu, les nuages blancs et obscurs,

L'arc-en-ciel luisait de toutes les couleurs à la fois !

(Jules Supervielle, Oublieuse Mémoire)

1960 - Tout de même, on a eu chaud ! Si le vieux avait détaché son clébard un peu plus vite, je crois bien qu'il nous aurait eus. Serge et Christophe se mirent à rire. Leur rire ne sonnait pas très juste et Christophe avait une drôle de façon de se claquer les cuisses.

- Tu parles d'une affaire, lança Serge. Ces coups-là, c'est de l'entraînement

(Bernard Clavel, Malataverne)

1967 C'est parfait, et il n’y a rien de plus à dire : voilà un menu compte avec la Création réglé, et Dieu payé dans une monnaie qui sonne aussi juste que le tintement de la pièce d'or sur la table du changeur (Julien Gracq, Lettrines)

1986 Dans le fatras d'inepties que susurrait l'imbécile, certaines idées sonnaient juste. J'en étais désolé. C'est embêtant quand les cons pensent comme vous (Alexandre Jardin, Bille en tête)

1995 Madame de Breyves aurait voulu s’assurer qu'Alexis ne sortait pas de son rôle, que ses propos sonnaient juste, mais Monsieur Necker, enchanté de l'attention que lui prêtait la Comtesse, lui faisait cadeau de ses méditations sur l'administration du royaume (Françoise Chandernagor, L'Enfant des Lumières)

\section{CORPUS WEB :}

Ces voix qui sonnent juste prennent donc valeur de signaux d'alarme pour ne pas dire de tocsin [http://teleobs.nouvelobs.com/pole mique/20150225.OBS3378/quand-des-voixsonnent-juste.html] (31.12.2015)

Mr Guiffan vos propos sonnent juste. Le pouvoir socialiste est favorable à la Normandie réunifiée mais pas à une Bretagne réunifiée, allez savoir pourquoi ? [http://www.presseocean.fr/actualite/ regionales-le-mauvais-calcul-des-socialistes-deloire-atlantique-16-12-2015-178835] (31.12.2015)

Je dois avouer que j'ai adoré le personnage de la policière qui est vraiment courageuse, forte et a des pensées qui sonnent justes et sincères [http://www.babelio.com/livres/Beukes-Lesmonstres/704306] (31.12.2015)

Les dialogues sonnent justes et la mise en scène est bien maîtrisée [http://www.allocine. fr/film/fichefilm-175752/critiques/spectateurs] (31.12.2015)

Trente-sept heures de rush ont été tournées, pour parvenir à ce film de cinquante-deux minutes, qui donne à voir et à entendre des paroles émouvantes et joyeuses, qui sonnent justes [http://www.leberry.fr/cher/actualite/pays/ pays-de-vierzon/2015/10/06/projection-du-filmcouleurs-dames-au-cafe-repaire_11612479.html] (31.12.2015)

REMARQues : Sonner juste (I) s'applique à un instrument de musique (ou à celui qui joue l'instrument) qui est dans le ton, dont les accords sont harmonieux. Le sujet peut aussi désigner une chose (ici : une pierre) qui, au contact d'un outil servant à frapper, marteler quelque chose, produit un son comme il convient. (II) se dit d'un récit, d'un fait qui correspond à la réalité, n'est pas superficiel, qui suggère une vision des choses fidèle à la réalité, sans l'idéaliser, le sujet ne cherchant pas à dissimuler ses émotions. En parlant d'une attitude (la façon de rire), d'une qualité, sonner juste en souligne le caractère vrai, sincère, une attitude qui ne dissimule rien, d'où émane la franchise, la sincérité. Juste tend à l'emploi invariable, mais il peut s'accorder avec le sujet, ce qui suggère une interprétation en tant que prédicat second orienté vers le sujet. Juste est modifié par, aussi, indéniablement, même assez, si, (pas) très. Notons l'emploi impersonnel familier ça sonne juste. 


\section{Sonner lourd}

Produire un bruit pesant

Intransitif

1936 Mireille s'est mise à cavaler en poussant des glapissements. Alors moi je la course et je me décarcasse. Je lui balance des vaches coups de tatane à travers les fesses. Ça sonne mat et lourd (Louis-Ferdinand Céline, Mort à crédit)

CORPus Web :

Je pense quand meme que le « vrai » rock est mort. Plus grand chose de bon sort depuis quelques années. Le dernier album que j'ecoute c'est celui de Jerry Cantrell (guitariste d'alice in chains) qui renoue avec les bases du grunge : texte sombre, accords qui sonnent lourds, voix dépressive... [http://www.gametronik.com/forum/ lofiversion/index.php/t4090.html] (31.12.2015)

Voilà, j'ai une Telecaster mex et j'aimerais bien l'upgrader niveau micros. Je recherche des micros riches en basses, qui sonnent lourds, et qui ne dénaturent pas trop le son de la guitare [http://www.guitariste.com/forums/accessoireset-lutherie,micros-riches-en-basses-pourtele,143379,10.html] (31.12.2015)

Ce rythme a une base de maqsoum mais à 8 temps au lieu de 4 et est exécuté plus lentement. Généralement les masmoudis sonnent lourd (kabiir) alors que le maqsoum est rapide et agile (khafiif) [http://nouba13.over-blog.com/articlerythme-el-masmoudi-78108279.html] (31.12.2015)

C'est normal que les cordes basses sonnent «lourd » et les aigues... « aigues »... C'est comme les vieux téléphones, quand ils sonnent, tu sais que c'est un vieux téléphone... [http://www. guitariste.com/forums/basse,question-dedebutant,141642.html] (31.12.2015)

REMARQUES : Sonner lourd se dit d'un bruit, d'un son, de ce qui émet un son (une voix) grave, peu distinct et parfois assez fort, notamment par rapport à la musique. Notons l'emploi complémentaire de sonner aigu et la collocation sonner mat et lourd. Lourd, tout comme aigu, peut s'accorder avec le sujet (v. les exemples du CW), ce qui renforce une interprétation de prédicat second orienté vers le sujet. Il semblerait que ce type d'accord est plus caractéristique des langages de spécialité (ici : la musique ; à comparer : l'accord dans le langage du sport ; v. Introduction § 4.6).

\section{Sonner mat}

Produire un son sans résonance, un bruit sourd, étouffé

Intransitif

1916 Maria prêta l'oreille aux bruits du départ : la porte de l'écurie battant contre le mur ; les sabots du cheval sonnant mat sur les madriers de l'allée ; des commandements étouffés : « Ho la ! Harrié !... harrié donc ! Ho !... » (Louis Hémon, Maria Chapdelaine)

1936 - Peut-être quelqu'un, déjà, vous a-t-il dit qu'il vous aimait, reprit-il, d'une voix qui sonnait mat, et qui parut à Jenny avoir juste assez de résonance pour l'atteindre, descendre en elle, y faire un trouble et délicieux ravage (Roger Martin du Gard, Les Thibault. L'Été 1914)

1982 - J'ai besoin de toi.

Dans le taxi, Lambert emmenait avec lui un morceau de ce couloir. Sa pénombre, sa ouateur. Les mots y sonnaient mat. Ils ne rebondissaient pas. Ils tombaient des lèvres pour être tout de suite aspirés, sucés par d'autres lèvres (Alain Page, Tchao Pantin)

\section{CORPuS Web :}

Quelle que soit la matière, la manière de tenir les pierres influe également beaucoup : une pierre fermement entourée de la main sur une grande partie de sa surface va sonner mat et moins fort, une pierre juste posée sur la main sonnera mieux, une pierre tenue sur son pourtour par les doigts d'une main, la paume étant derrière pour faire caisse de résonnance, sonnera encore plus fort [http://www.reveeveille.net/un ecrit.aspx?idecrit=625] (31.12.2015)

décollement liston : le joint entre les coques et le liston (dessus) ne doit pas se décoller - délaminage : l'humidité finie par pénétrer dans l'épaisseur du polyester des coques et le décolle, c'est irréparable, les coques doivent raisonner et non sonner mat ; elles ne doivent pas être molles [http://cvtsud.free.fr/achat_vente/ controloccase.htm] (31.12.2015) 
Chez moi sur un ensemble Rotel/ Sherbourn pour l'ampli et Electra 936 le lecteur manque de vie, Les medium ne sont pas assez presents, les voix manquent d'emotions et les caisses claires sonnent mats [http://www.homecinema-fr.com/ forum/sources-integrees-haute-fidelite/musicalfidelity-a1-cd-pro-t29880373.html] (31.12.2015)

Les harmonies sonnent mates, comme une digression personnelle sur le thème de Richard Band (Ré-Animator), et donnent au morceau une couleur un peu étrange. Ainsi donc, ce point d'interrogation est bien trouvé, et bien placé [http://metaloddities.canalblog.com/ archives/2015/09/03/32578098.html] (31.12.2015)

REMARQUES : Sonner mat se dit d'un son, ou de ce qui émet un son (une voix, les mots), qui ne résonne pas ou presque pas, qui produit un bruit étouffé. Mat tend à l'emploi invariable, mais il peut occasionnellement s'accorder avec le sujet, ce qui renforce une interprétation de prédicat second orienté vers le sujet (v. le dernier exemple du CW). Dans l'avant-dernier exemple, l'accord est une hypercorrection. L'accord y est fait pour le pluriel mais non pas pour le féminin, sans doute parce que la langue parlée tend à l'emploi invariable. Ceci étant, ajouter un $-s$ de pluriel inaudible ne choque donc pas, mais l'accord au féminin, audible, est évité. Notons la collocation mat et moins fort.

\section{Sonner mélancolique}

Produire un son triste

入 sonner grave

\section{Sonner mortel}

Faire penser à la mort

Intransitif

1956 Pardonnez-moi cette amertume

Mais l'âge d'aimer quand nous l'eûmes

Comme le regain sous la faux

Tout y sonnait mortel et faux

Et qu'opposer sinon nos songes

Au pas triomphant du mensonge

Nous qui n'avions pour horizon

Qu'hypocrisie et trahison

La guerre on la voit à l'envers

(Louis Aragon, Le Roman inachevé)

\section{CORPUS WEB :}

Je viens de ecouter le CD... Quoi dire de cette merveille ?? D'abord ça sonne mortel et Steph nous donne une leçon de guitare et surtout de MUSIQUE. Pour moi c la preuve irrefutable que on peut jouer du shred et rester tres musicale. Merci Stephan ! [https://www.facebook. com/stephanforte/posts/308838779135497] (31.12.2015)

C'est cool les mecs ! ca sonne mortel !! J'espère que ca se passe bien pour vous. Saludos desde México... [https://www.facebook. com/permalink.php?story_fbid=183094414204 \&id=178844144204] (31.12.2015)

J'ai changé les micros pour des Tokai de 1985 qui etaient sur ma Goldtop, ils sonnent mortels !!! [http://www.guitarsmadeinjapan.fr/forums/ viewtopic.php?pid=5685] (31.12.2015)

Après il y a les chanteurs qui sonnent mortels dans tel ou tel registre, le chanteur de Radiohead, le chanteur de Cursed, le chanteur de Tv on the radio, le chanteur de Takaru mais la plupart du temps je suis assez fan des voix errayés et émotionnelement chargés et dans l'émo-punk des années 90 y’a de quoi faire [http://www. alltheragetv.com/atr-files/follow-the-leaders/35milouze-of-aussitot-mort(31.12.2015])

REMARQUES : Au sens propre, sonner mortel réfère à un événement, à un contexte pénible, désagréable, qui évoque la mort (dans l'exemple de 1956 : la guerre). Au figuré, sonner mortel est une hyperbole méliorative qui exprime la qualité impressionnante d'un produit, musical (v. les exemples du CW). Mortel fonctionne alors comme intensifieur métaphorique, à l'instar de terrible, formidable, etc. Notons la collocation mortel et faux. Mortel peut s'accorder ou non. Notons l'emploi impersonnel familier ça sonne mortel.

\section{Sonner musical}

Produire des sons mélodieux, harmonieux Intransitif

1977 Il caresse les pavés : « Ici, je sens la trace des pas d'Ivan le Terrible!»

Les deux miliciens de faction l'observent, impassibles. L'horloge du Kremlin sonne, claire, musicale, sonne pour l'univers, Josta bondit sur ses pieds : 
« C’est l'heure ! l'époque, la nôtre, va commencer»

(Jean-Pierre Chabrol, La Folie des miens)

CORPUS WeB :

Ainsi avec des enregistrements analogiques ou avec des lampes, le son est coloré entre 0 et $6 \mathrm{db}$ environ je crois, et ça peut sonner " musical », tout comme l'enregistrement sur bande [http://adn2.chez.com/html/compression.htm] (31.12.2015)

Evidement ça serait un niveau Avancé Ca sous entend que les gens connaissent déjà un peu l'harmonie parce qu'il ne sagirait pas de jouer n'importe quoi mais d'essayer de sonner musical tout de même! [http://www.guitarelive.com/forums/fil-defis, anatole-temps-qu-onveut,327,17.html] (31.12.2015)

Une exclamation locale qui sonne musicale. Il n'en fallait guère plus pour que l'association élusate « Los Bambasitos » la choisisse comme nom pour son tout premier festival [http:// www.ladepeche.fr/article/2012/04/21/1336005a-eauze-le-festival-oun-bass-sort-de-l-uf.html] (31.12.2015)

enfin une eq native de qualite qui sonne musicale. j'aime beaucoup surtout ds le bas du spectre [http://fr.440forums.com/forums/ lofiversion/index.php/t26654.html] (31.12.2015)

REMARQUES : Sonner musical réfère à un appareil, un mécanisme qui fait retentir une sonnerie harmonieuse, qui se distingue par ses sons mélodieux, agréables à écouter. Musical tend à l'accord avec le sujet (v. les deux derniers exemples $\mathrm{du} \mathrm{CW}$ ), ce qui suggère une interprétation de prédicat second orienté vers le sujet. Il partage cette caractéristique avec d'autres adjectifs trisyllabiques plutôt d'un style recherché qui se combinent avec sonner.

\section{Sonner neuf}

Donner une impression de nouveauté, montrer de l'originalité

Intransitif

1958 le dernier cri de la chanson. Un cri un peu rauque, tourmenté, sourd, mais qui sonnait plein, vrai, neuf (Canard enchaîné, 30 avril 1958 / Grundt : 373-374)

\section{CORPuS WEB :}

$\mathrm{Au}$ fond, il n'est pas si difficile de gouverner. Beaucoup surestiment l'exercice, convaincus de la nécessité d'une vision. En fait, un dictionnaire des synonymes suffit. Ainsi, le terme " inversion » étant usé jusqu'à la corde, on y substitue désormais " retournement » qui a le mérite de sonner neuf [http://www.lopinion.fr/blog/billetmichel-schifres/mots-trois-ans-11913] (31.12.2015)

Autant de références qu'on retrouve de près ou de loin tout au long de ce cru 2010 (« Hold», « Against »), définitivement le plus rock jamais composé par le quintet (« Play Or Die »). Du coup, « Drop a Three » est d'une efficacité féroce (l'imparable « Liar »), à défaut de sonner neuf [http:// www.mowno.com/disques/fumuj-drop-a-three] (31.12.2015)

Cette musique est ancrée dans la tradition du Blues, du Jazz, de la Soul, du Funk et elle sonne neuve, personnelle, vivante, vibrante [http://lejarsjasejazz.over-blog.com/article-lensemble-de-christian-scott-en-verve-au-ducdes-lombards-112621317.html] (31.12.2015)

Je n'ai pas connu le Brésil des années 50, donc la bossa nova sonne neuve à mes oreilles [http://www.vogue.fr/culture/agenda/articles/ redcouvrez-la-bossa-nova-/19003] (31.12.2015)

REMARQUES : Sonner neuf se dit d'un son ou d'un bruit (ici : un cri) qui n’a jamais été entendu, qui frappe par son originalité, son côté moderne. Neuf peut s'accorder avec le sujet (v. les deux derniers exemples du CW), ce qui suggère une interprétation de prédicat second orienté vers le sujet. Notons l'emploi de sonner plein, vrai, personnel, vivant, vibrant.

\section{Sonner pauvre}

Produire un son pauvre, (trop) simple, composé de peu d'éléments

Intransitif

1935 Il peut se faire qu'un accord parfait sonne pauvre, sans accent, plat en un mot, après une agrégation polytonale très fournie (Arts et littérature dans la société contemporaine)

\section{CORPUS WEB :}

un album trés pauvre... seulement 10 titres enfin 10 reprises ratées !!! la musique sonne pauvre, les arrangements sont horribles... bref un 
album raté sans interet !!!!! [http://www.ptitblog. net/Lorie/interview-8068.html] (31.12.2015)

Hello, Bon, j'ai toujours du mal à trouver des chansons de rock pas trop dures, et intéressantes à jouer seul, ou en groupe. Beaucoup de chansons rock sonnent pauvres quand on enlève les autres instruments, normal, mais c'est toujours moins agréable de jouer un truc qui sonne « pas fini » [https://geenux.wordpress.com/category/ autres/guitare] (31.12.2015)

Au niveau du son, je les avais montés avec une guitare corps tilleul, et ca sonne vraiment très médium, avec des basses très rondes mais très plates. Les aigus sonnent pauvres, mais sont néanmoins présents [http://www.guitariste.com/ forums/accessoires-et-lutherie,qui-connais-lesmicros-tesla,287512.html] (31.12.2015)

Azli sonne pauvre dans la conscience de la ville. Il ne l'est plus. Tous les quartiers de la ville où il y a des plans et du béton sonnent fonctionnaires et classe moyenne [https://www.facebook. com/BASSIDIRoman/posts/1181568081859241] (31.12.2015)

Voila, maintenant tu sais qu'en plus d'avoir un prénom qui sonne pauvre, je suis une inculte abonnée au dictionnaire des synonymes de Winword. [= le prénom est Fanny] [http:// coucherpourreussir.com/archive/2006/11/27/ pourquoi-mon-blog-est-mieux-que-celui-denicmo-debor-nitax-d.html] (31.12.2015)

REMARQUES : Dans le domaine musical, l'adjectif pauvre est pris au figuré pour signifier qu'un accord est composé de sons uniformes, sans nuance, ou ne présentant aucun relief. Dans les deux derniers exemples du CW, où sonner est pris au figuré ('faire pauvre'), pauvre figure dans son sens propre référant au manque d'argent, les noms suggérant la pauvreté, le manque de moyens. Pauvre peut s'accorder avec le sujet, ce qui suggère une interprétation de prédicat second orienté vers le sujet. On pourrait dire aussi que le verbe se rapproche parfois du statut de copule.

\section{Sonner personnel}

Sembler appartenir au domaine privé Intransitif

1956 Du reste bonheur comme amour sont des mots dont le pouvoir s'est amoindri ; ils sonnent trop personnel (Express, 9 novembre 1956 / Grundt : 228)

\section{Corpus WeB :}

Mi bluesy mi jazzy saupoudrées de funk, leurs reprises et propre compo, le plus souvent jouées en mid-tempo, ne s'étiquettent pas, ça sonne personnel, ça swingue tranquille, c'est frais ! [http://www.zicomania.fr/midwest.html] (31.12.2015)

On citera « A Monolithic Vulgarity », le très agréable « Nostalgic Echo », et riffs en clean bien agréables à nos oreilles, le très réussi « Teledildonics » qui constitue à lui seul, une vraie démonstration de ce qui se fait de mieux en musicalité, ou bien pour finir, le très mystérieux titre intitulé " Iceblocks » et sa sonorité difficilement classable dans tel ou tel style tant ça sonne personnel ! [http://www.hornsup.fr/a-1609/chronique/ intronaut] (31.12.2015)

Quelques mots encore avant un clap de fin, quelques mots qui sonnent personnels, et tant pis si les rires s'envolent vers d'autres pays, tant pis si les lectures ne sont pas plaisantes, il existe toujours quelque part, un bouton " marche-arrêt " [http://le-blog-de-didier.blogspot.co.at/2013/04/ mauvais-reveil.html] (31.12.2015)

REMARQUES : Sonner personnel réfère à des mots dont le contenu évoque la vie intime, quelque chose de personnel. Personnel s'accorde ou non, selon qu'on accentue une qualité du sujet ou la façon de sonner. Il est modifié par trop. Notons l'emploi de swinguer tranquille dans le CW et les constructions impersonnelles familières ça sonne personnel, ça swingue tranquille.

\section{Sonner plein}

Produire un son plein, intense, retentissant Intransitif

1913 À droite, en allant vers le chœur, une partie [= de l'auditoire] peu volumineuse, mais cohérente, qui sonnait plein, d'un maniement agréable (Jules Romains, Les Copains)

1948 Nous bûmes le vin laure et nous rompîmes mon pain blanc. La dédicace disait : quau fai fortuno dins un an, sièis mes après vai en galèro...

Cela sonnait plein. Ce proverbe était le début d'un très beau poème (Blaise Cendrars, Bourlinguer) 


\section{CORPus Web :}

Un dallage en pose adhérente doit sonner plein. Cependant, des éléments peuvent sonner partiellement creux sans porter préjudice à la tenue de l'ouvrage [http://www.produits-beton. com/DM/ged/PUBLIC/plaquettes/cerib/dp-104carnet-de-chantier-guide-de-pose-produits-dedallage-interieur.pdf] (31.12.2015)

Ca ne signifie évidemment pas que l'osmose s'était envolée, mais un examen de la coque au « marteau toc-toc » n’a rien révélé sur un possible délaminage en profondeur. Ca sonne plein où ça doit sonner plein et ça sonne comme un tambour dans les zones où la strat est moins épaise et qu'il n'y a pas de cloison ou ancrage de mobilier [http://www.melody-in-blues.org/hull.php] (31.12.2015)

Les accords de trois notes sont très utilisés dans le métal et le rock. Ils sonnent pleins avec une guitare électrique saturée. NB : saturée = avec un effet de pédale : distorsion, overdrive, sustain etc... [http://accordguitare.fr/mi-diese5-fa5.html] (31.12.2015)

Les instruments et leurs arrangements sonnent pleins, riches et bien orchestrés. " La Valse des Enragés ", produit par l'Association PPFC (P), est le bon témoignage studio d'un ensemble qui trouve dans le live, en contact direct avec le public, sa vraie dimension [http://www. reseau92.com/public/articles/chroniques/ppfc--la-valse-des-enrages-14] (31.12.2015)

REMARQUeS : Sonner plein s'applique à une parole, un cri dont la sonorité, le ton est net, fort, bien marqué. L'emploi par rapport au son produit quand on frappe un dallage ou une coque s'observe dans les deux premiers exemples du CW (contraire de sonner creux). En musique, sonner plein signifie 'riche en harmoniques'. Plein peut s'accorder ou non, selon l'accent mis sur une qualité du sujet ou sur la façon de sonner. Notons l'emploi impersonnel familier ça sonne plein. Notons aussi les groupes sonner creux, riche, orchestré.

\section{Sonner poignant}

Provoquer une vive émotion, toucher très fort Intransitif

1987 - Prends un siège, collègue, et assieds-toi par terre!
Cette potacherie sur un vers de Corneille qu'on braillait au lycée, jamais j'aurais pensé qu'elle puisse un jour sonner aussi juste, poignant et réaliste.

Tant pis pour les poux et autre mie de pain mécanique ! Je me laisse choir sur les cartons terreux (Jean-Louis Degaudenzi, Zone)

\section{CORPuS WeB :}

ne t'entends presque jamais avec des effets comme ici, ça donne un choc! Je trouve ça superbe, ça met ton jeu et ton touché en valeur, ça sonne "poignant », et c'est très mélodique ! La ligne mélodique est simple mais se développe tout le long avec des variations efficaces, bien appuyées, une belle audace rythmique qui force l'expectative, tu manies comme un pro! [http://www.guitare-live. com/defis/guitare/1531/24692/2/commentaires. $\mathrm{html}$ (31.12.2015)

Au début de la chanson, le piano très doux et lent est beau et triste and quand le violon arrive à $1: 41$ ça sonne poignant et encore plus beau/ triste [https://plus.google.com/11198637318576 8442033/posts/FHqfVN7wuo8] (31.12.2015)

Le fil conducteur de cet album est la voix ténorisante de Paul Banks qui sonne poignante de bout en bout. Sam Fogarino qui a l'aisance de métronome, est un batteur compact et charnel, qui assène de redoutables coups de pied quand c'est nécessaire [http://www.quai-baco.com/interpolel-pintor-la-chronique-22479] (31.12.2015)

REMARQUES : Sonner poignant se dit d'un propos, d'un récit ou d'un fait qui suscite une émotion vive et violente, qui bouleverse quelqu'un. Poignant s'accorde ou non (exemple de 1987) selon qu'on l'attribue à l'objet qui produit le son ou à la façon de sonner. Poignant est modifié par aussi. Notons l'emploi de sonner beau / juste / réaliste / triste.

\section{Sonner profond}

Sonner, résonner de manière profonde, caverneuse, grave, sépulcrale

Intransitif

CORPUS WEB :

Ou sont les chants corses ? Les chants basques ? Les bourrades occitanes et le fifre Breton? Ou sont les guitares qui sonnent profond? 
[http://fdpdelamode.com/post/109736154355/lamusique-en-anglais-de-merde] (30.12.2015)

les GG clear n'ont absolument pas le même son c'est mon avis, les emperor sont plus faciles à régler, sonnent profond et rond, j'ai jamais réussi à régler correctement les G2...(ais je évolué depuis ?). maintenant ce sera Remo sur toms et Evans en snare... [http://fr.audiofanzine.com/ peau/remo/Emperor/avis] (30.12.2015)

un sacrifice qui n'est point perdu car tes mots sonnent profonds et forts! [http://www. oasisdesartistes.org/modules/newbbex/view topic.php? viewmode $=$ flat\&order $=$ DESC\&to pic $\_i d=110961 \&$ forum $=2 \&$ move $=$ next\&topic time $=1299319191]$ (30.12.2015)

\section{Sonner puissant}

Se manifester de manière intense, imposante, avec force

Intransitif

1936 mais plutôt la situation humaine et le rapport des vivants aux morts s'y trouvent décrits sans aucune faute ; ce jeu de l'imagination sonne puissant et juste comme une belle symphonie. Les morts sont autour de nous, et principalement mêlés à nos perceptions nocturnes et crépusculaires (Alain, Propos)

\section{CORPuS Web :}

C'est un peu délicat, dans une optique live, c'est complètement différent d'un morceau travaillé en studio, je me lâche pas mal aux idées qui viennent, à partir d'une routine. J'essaye de construire autour d'une mélodie et d'un beat qui sonnent puissant [http://www.street-tease. com/revues/20-tez-tez-antitez-syntez.html] (30.12.2015)

Et c'est la clé : les gens recherchent un booster de volume. Quelque chose qui fera toute votre saine mp3s au même volume, mais ils sonnent puissant, rendant vibrer [http://fr.mp3doctor. $\mathrm{com} / \mathrm{mp} 3 / \mathrm{tag} /$ increase-mp3-volume-withoutdistortion] (30.12.2015)

A y é...je suis accordé grave...les accords de puissances sonnent puissants mé légèrement crade...c'esu dû au diapason ? [http://fr.audio fanzine.com/guitare/forums/t.142904,tirantsmetal-extreme,p.4.html] (30.12.2015)
A ce propos, ceux qui veulent updater une strat en lui donnant un gros coup de boost, les Kinman sont parfaits (ils ne sont certainement pas les seuls), ils sont clairs, précis et sonnent puissants sans vraiment l'être en réalité, ça sonne « super strat de la mort » [http://www.guitariste. com/forums/accessoires-et-lutherie, microschris-klein-single-coils-handwound-pickups, 313189,40.html] (30.12.2015)

REMARQUES : En référence à la façon de penser, sonner puissant souligne un processus imaginatif qui témoigne d'une grande force créatrice, qui se caractérise par sa richesse et qui produit de grands effets. Dans le domaine de la musique (CW), sonner puissant renvoie au son d'une grande intensité émis par un instrument ou un appareil. Notons la collocation puissant et juste. Puissant reste souvent invarié, mais il peut également s'accorder, selon qu'on l'attribue à l'objet qui produit le son ou à la façon de sonner.

\section{Sonner pur}

Sonner, résonner de manière pure, limpide, claire

Intransitif

1883 Or, en dehors de la feuille que vous dirigez, il y a en France des journalistes dont la probité défie l'entraînement vénal de l'époque, dont le style sonne pur, dont le verbe flambe clair et dont l'utile critique rectifie sans cesse les jugements inconsidérés de la foule (Auguste de Villiers de L'Isle-Adam, Contes cruels)

1944 Et quand ils mouraient pour la liberté, ils mouraient pour leur propre beauté et leur mort était belle. Et le mot liberté sonnait plus pur que le clairon. Mais je me souvenais des paroles de mon père : « Leur liberté, c'est la liberté de n'être point » (Antoine de Saint-Exupéry, Citadelle)

\section{CORPUS Web :}

Absolument. Les chanteurs sonnent souvent prétentieux, alors que les chanteuses sonnent pur et vrai [http://www.metronews.fr/ $\mathrm{x} /$ metro/2008/07/08/HDbI6Ks6qjaBY/index.xml] (30.12.2015)

il faudrais deja que tu nous dise comment ton matos est relié. midi ? pas midi ? carte son ordi ? 
enfin bref, comment tous cela s'enchaine et evidement, a tu une console de mix pour l'ensemble. normalement, ton synthé joue ses propres sons via le jack 6.35 relié a ta console.donc, ses sons sonnent «pur» [https://www.zikinf.com/forums/ help-pbl-avec-cubase-t5120836.html] (30.12.2015)

Je voudrai changer les micros de ma jackson xt mais je ne sais pa tro quelle micro prendre. En fait je cherche a la fois un son bien mechan en chevalet avec en neck des son clair bien simpatoche avec la possiblité d'avoir des solo qui sonnent purs [http://fr.audiofanzine.com/microguitare/forums/t.137600,changemen-de-micro. $\mathrm{html}$ (30.12.2015)

Les sons de synthèse additive sonnent purs et très precis sur l'ensemble du clavier. Le moteur de resynthèse permet de capturer des sons réels dans toute leur complexité harmonique et leurs formants. Ces deux moteurs peuvent bien sur être combinés dans un seul patch, ce qui donne des possibilités gigantesques de combinaisons [http://www.lelotusbleu.fr/catalog/product info.php?currency=USD\&products_id=45\&lang uage $=$ fr\&osCsid $=5$ fa157ab9d4cce58937d3dd9c 1 94b828] (30.12.2015)

REMARQUES : Sonner pur peut référer à un style adopté par quelqu'un, à une écriture dont le contenu est clair, limpide. Le sujet peut aussi désigner un mot dont la résonance est claire, qui évoque beaucoup de choses. Dans la poésie, sonner pur renvoie au style adopté par le poète, à son œuvre qui se caractérise par une recherche de la poésie pure, une poésie dénuée de tout élément discursif ou narratif, dans laquelle la fonction poétique serait exclusive de toutes fonctions autres que poétique. Le CW fait apparaitre l'usage au sens propre par rapport à une qualité du son, sans parasites. Notons l'emploi de sonner pur et vrai ainsi que de sonner pur et précis dans le CW. Pur s'accorde selon qu'on l'attribue à l'objet qui produit le son ou à la façon de sonner. Il est modifié par plus, trop. Mentionnons également l'usage de flamber clair.

\section{Sonner réaliste}

Donner une impression de réalité Intransitif

1987 - Prends un siège, collègue, et assieds-toi par terre!
Cette potacherie sur un vers de Corneille qu'on braillait au lycée, jamais j'aurais pensé qu'elle puisse un jour sonner aussi juste, poignant et réaliste.

Tant pis pour les poux et autre mie de pain mécanique ! Je me laisse choir sur les cartons terreux (Jean-Louis Degaudenzi, Zone)

\section{CORPuS WeB :}

J'ai beaucoup de mal avec ce genre de collage. D'un côté des phrases toutes faites, de l'autre des légato pas terribles, le tout essayant de sonner réaliste... Alors qu'il serait probablement mieux d'aller à fond dans la direction inverse, c'est-à-dire d'assumer les collages en faisant un vrai travail de sampling, comme un Amon Tobin par exemple [http://www.compositeur.org/ forum/viewtopic.php?t=9931] (30.12.2015)

Même avec les meilleurs samples et instruments virtuels du monde, l'on ne peut pas programmer un instrument virtuel et espérer qu'il sonne réaliste auprès de musiciens si on ne sait pas vraiment comment il sonne et comment il fonctionne en réalité [http://forum.netophonix. com/ftopic5155.html?start=15] (30.12.2015)

Si tu fait que de l'acoustique, le DDP peut etre pas mal quan meme (la compression multibande remonte bien les mix mais dénature trop sur des prises qui doivent sonner réalistes) [http:// fr.audiofanzine.com/processeur-dynamique/ $\mathrm{dbx} / \mathrm{DDP} /$ forums/t.23830,pour-masteriser.html] (30.12.2015)

Voilà plusieurs mois que je travaille beaucoup avec mes instruments virtuels, souvent enregistrés dans différents studios, et je commence à réaliser que pour que mes librairies sonnent réalistes, il faudrait que je gère bien la spacialisation [http://www.compositeur.org/forum/ viewtopic.php?t=9323] (30.12.2015)

REMARQUES : Sonner réaliste se dit d'un récit ou d'un fait qui correspond à la réalité, n'est pas superficiel, qui suggère une vision des choses fidèle à la réalité, sans l'idéaliser. Dans les exemples du $\mathrm{CW}$, réaliste s'accorde parfois avec le sujet, ce qui suggère une interprétation de prédicat second orienté vers le sujet. Il est modifié par aussi. 


\section{Sonner ridicule}

Donner une impression ridicule, risible, grotesque

Intransitif

\section{Corpus Web :}

Je sais ca sonne ridicule, on dirait que je fais l'entretien d'un job haha mais je veux vraiment que ce compte continu et qu'Ansel voit [https:// twitter.com/AnselElgortFR] (30.12.2015)

Outre le nom qui sonne ridicule en français, ce sont souvent des distributions qui sont peu ergonomique, lourdes, avec un goût du vintage qui le dispute presque au ridicule [http://frederic. bezies.free.fr/blog/?p=12701] (30.12.2015)

Je vient d'une région éloignée et il arrive souvent que certains noms que j'entend rarement ou pour la première fois sonnent ridicules a mes oreilles [http://forum.ubuntu-fr.org/viewtopic. php?id=269392] (30.12.2015)

Certains dialogues, qui se veulent drôles, sonnent ridicules et la fin fait vraiment pitié. Bref, c'est du sous-cinéma fabriqué dans l'arrière cuisine d'un Delon acteur / producteur en pleine descente des années 80 et qui veut contrôler, jusqu'à l'excès tout ce qui se passe à l'écran mais pour livrer un produit totalement médiocre, vidé de toute substance artistique [http://www.allocine. fr/film/fichefilm-33053/critiques/spectateurs] (30.12.2015)

\section{Sonner sec}

Produire un son bref et sans consistance Intransitif

1925 Raboliot songea, serrant les mâchoires : «Ah! Tant pis! »... Et aussitôt, un large afflux d'air aux poumons : « Ça y est ! » le crâne de Bourrel avait sonné sec sous la crosse. Ç’avait été, dans les oreilles du braconnier, un bruit étonnamment semblable à celui qu'il avait entendu (Maurice Genevoix, Raboliot)

1963 Dans les alentours j'en voyais revenir du Palais avec des grises mines, des petits collègues casseurs, voleurs de tous poils. Ça sonnait plutôt sec depuis cette nouvelle République. Pas qu'une impression, on pouvait comparer avec sa mémère beaucoup moins pure, peut-être, mais tout de même moins dure (Alphonse Boudard, La Cerise)
CORPUS WeB :

Ca c'est largement bon pour sonner sec avec juste ce qu'il faut d'harmoniques... [https://www. ladrummerie.com/viewtopic.php?t=7820\& start=15] (30.12.2015)

Et puis, ils ont leur petit truc à eux que l'on doit à Miss Rossettie, preuve une nouvelle fois qu'elle n'est pas qu'un simple faire-valoir de son encombrant mari, une valeur ajoutée prenant la forme de sonorités électroniques venant détraquer la mécanique infernale, un brouillage de pistes, non seulement pour soutenir le jeu de guitare de Sakes mais pour enrichir et donner une touche d'originalité à ce noise-rock qui aurait pu sonner sec et austère sans cette défoliation pervertissante [http://www.perteetfracas.org/zine/ kros2012/kros_x/xaddax_counterclockwork. $\mathrm{htm}]$ (30.12.2015)

En acoustique je joue exclusivement au doigt, je n'ai jamais apprécié joué au plectre et c'est la première fois où je me suis senti à comme à la maison, un vrai régal. Elle est jouable au plectre mais nécessite un médiator particulier (écaille de tortue pour ma part) au risque de sonner sèche [http://fr.audiofanzine.com/guitarefolk-divers/seagull/coastline-series-coastlinegrand/avis] (30.12.2015)

La toux sonne sèche

[http://www.newpharma.fr/a-vogel/462865/ a-vogel-spray-toux-seche-irritante-30ml.html] (30.12.2015)

REMARQUeS : Sonner sec réfère au son bref et sans résonance produit par un choc, un coup. L'exemple de 1963 reflète l'impression que donne le climat social sous un régime politique. Le dernier exemple du CW illustre l'emploi par rapport au son produit par la toux. Sec peut s'accorder avec le sujet (v. les deux derniers exemples du $\mathrm{CW}$ ), et dans ce cas-là, il fonctionne en tant que prédicat second orienté vers le sujet. Notons l'emploi de sonner sec et austère dans le CW. Sec est modifié par plutôt. Signalons aussi l'emploi impersonnel familier ça sonnait plutôt sec.

\section{Sonner soef (suave)}

Sonner doucement, agréablement

Intransitif

1364 Quant Phebus oÿ la nouvelle Du corbel qui dist que la belle 
Qu'il aime de fin cuer entier

Le laist pour un autre accointier,

De son chief cheÿ sa couronne,

Et sa harpe qui souef sonne

De ses mains cheï a ses piés (Guillaume de

Machaut, Le Livre du voir dit, 7972)

\section{CORPUS WEB :}

Les notes sont très précises, tiennent bien et sonnent suave. C'est une guitare agréable à écouter à faible volume. Elle donne presque envie d'être jouée lentement [http://fr.audiofanzine. com/guitare-electrique-hollow-body/parkwood/ PWH4/avis] (30.12.2015)

Personnage avec une voix française qui sonne suave lorsqu'il parle calmement mais dés qu'il commence à s'énerver sa voix ressemble à celle de Rambo dans les détournements du déjà très célèbre Mozinor [http://menime.over-blog. com/article-28648195.html] (30.12.2015)

Les morceaux sonnent, suaves et doux, pour nous transporter dans une nouvelle branche de l'arbre titanesque que représente Scorpions [http://www.senscritique.com/album/Eye_II_ Eye/critique/10392533] (30.12.2015)

De Bach à Vivaldi, elle a prouvé que les instruments d'époque ne sont pas toujours synonymes d'un atticisme maniéré, mais peuvent sonner suaves avec rage, vivaces avec chair et profondeur » [http://www.orfeo55.com/category/ actualites/page/23] (30.12.2015)

REMARQUES : Sonner soef pouvait s'appliquer en ancien français à un instrument de musique (une harpe) qui produit un son ou une suite de sons musicaux doux, harmonieux, agréables à l'oreille. Les exemples du CW illustrent d'autres sujets possibles, dans l'usage récent, comme les notes de musique, la voix, ou les pièces de musique. Usuel en ancien français, soef (suave) est devenu littéraire et poétique ; au vu des exemples, il est encore couramment employé comme variante stylistiquement recherchée dans le domaine de la musique. L'adjectif-adverbe s'accorde ou non selon qu'on l'attribue à l'objet qui produit le son ou à la façon de sonner.

\section{Sonner triste}

Donner une impression de tristesse

$\pi$ sonner poignant

\section{Sonner vide}

Produire un son provenant d'un objet creux (au propre et au figuré)

Intransitif

1884 malgré l'adjonction du Crédit de Paris et les primes énormes encaissées par ces Sociétés sur la valeur nominale des actions offertes au public, la caisse sonnait vide (Grandeur et décadence d'une société financière)

1922 M. Grane, le journaliste américain, profite de la révolution pour faire plomber au ciment tous les beaux arbres qui sonnent vide (Jean Giraudoux, Siegfried et le Limousin)

1945 Le père Boudet buta sur un coffret de métal martelé qui sonna vide sous le choc (Jean-Louis Bory, Mon village à l'heure allemande)

1959 Le salon sonnait vide, et l'absence de la grosse pendule de bronze creusait un silence accablant (Léon Thoorens, La Vie passionnée de Honoré de Balzac)

2019 Dans dix ans. À la fin de sa vie. Il supposait qu'il était censé être en colère, aspirer à la vengeance. Mais à quoi bon ? Tout sonnait vide, tout sonnait creux (Vincent Mondiot, L'Ombre des arches)

\section{Sonner vrai}

Donner une impression de vraisemblance, de réalité, de vérité

Intransitif

1886 Comme tout cela sonne vrai! (La Nouvelle Revue)

1927 J'ouvrais machinalement l'Antimoderne de Maritain, et là ce qui m'attendait c'était la sensation inverse et non moins troublante, ce que je me définis à moi-même par le sentiment du spécieux, ce que vise la phrase qui m’a tant préoccupé en 1918 de Samuel Butler : « Les choses qui sonnent vraies et qui pourtant sont fausses »(Charles $\mathrm{Du}$ Bos, Journal)

1936 Mais peut-être nous y sommes plongés ; nous y vivons et respirons. Seulement nos rhéteurs ne savent rien dire de l'homme, 
rien qui sonne vrai. Cette guerre, dont nous sortons à peine, fut chantée et célébrée par des hommes sans courage, et qui ne pouvaient comprendre le courage (Alain, Propos)

1974 Il aimait les histoires, mais au contraire de certaines du berger celles du pépé sonnaient toujours vrai.

- Quel travail avec ta grand-mère ! Pour les choses de la campagne, elle savait tout. Pour d'autres, elle était ignorante comme un sabot de mur

(Robert Sabatier, Les Noisettes sauvages)

1996a En tout cas, notre père ignora le bulletin que maman signa, et plus rien n'assombrit ces coulées de joie qui renaissaient de nos promenades, de nos projets. Ils sonnaient vrais à nouveau puisque les meutes hurlantes étaient tenues en laisse (Boris Schreiber, Un silence d'environ une demi-heure)

1996b Nos rires n'avaient guère à dominer l'attente effrayante de l'effroi. Nos rires insouciants sonnaient vrai. Mais nos instants de terreur secrète, atroce, sonnaient vrai aussi (Boris Schreiber, Un silence d'environ une demi-heure)

\section{CORPUS WEB :}

Pour moi, c'était primordial de sonner vrai. Etre authentique dans un film, c'est une question de détails : la façon de dire bonjour, de s'embrasser [http://www.festival-cannes.com/fr/ theDailyArticle/60407.html] (30.12.2015)

Les analyses de Mme Lorentz « sonnent vrai " à mon oreille et franchissent victorieusement le seuil de vraisemblance [http://www. volle.com/opinion/veracite.htm] (30.12.2015)

19 selfies qui sonnent vrais, et qui résument à merveille ce que signifie « être une maman " ! [https://www.facebook.com/demotivateur/ posts/10153455778534457] (30.12.2015)

Les personnages sonnent « vrais », ils parlent juste et ont souvent, malgré la rudesse de la vie, une vision optimiste [http://www.marivole.fr/ les-collections/terroir-de-france] (18.8.82015)

REMARQUES : Sonner vrai se dit d'un récit, d'un fait qui correspond à la réalité, n'est pas super- ficiel, qui suggère une vision des choses fidèle à la réalité, sans l'idéaliser, le sujet ne cherchant pas à dissimuler ses émotions. En parlant d'une attitude (la façon de rire), d'une qualité, sonner vrai en souligne le caractère vrai, sincère, qui ne dissimule rien, qui donne une impression de franchise, de sincérité. Vrai tend à l'invariabilité, mais il peut s'accorder en tant que prédicat second avec le sujet (ex. de 1927, 1996a et les deux derniers exemples du CW). Il est modifié par toujours. Notons l'emploi de parler vrai.

\section{Sortir droit}

I. sortir tout droit de : venir directement

(d'un lieu, d'un objet), sortir directement Intransitif

1680 Mme de Lavardin trouve l'altesse de La Tarente sans conséquence et sans difficulté pour cette fois, et ne trouve point de comparaison entre Mme de Vaudémont, votre amie, très loin de toute souveraineté, et la princesse Émilie de Hesse qui en sort tout droit, car depuis son veuvage, on ne le lui conteste plus (Mme de Sévigné, Correspondance)

1863 Sur l'étendue de la plaine, des lions et des cadavres étaient couchés, et les morts se confondaient avec des vêtements et des armures. À presque tous le visage ou bien un bras manquait ; quelques-uns paraissaient intacts encore ; d'autres étaient desséchés complètement et des crânes poudreux emplissaient des casques; des pieds qui n'avaient plus de chair sortaient tout droit des cnémides, des squelettes gardaient leurs manteaux ; des ossements, nettoyés par le soleil, faisaient des taches luisantes au milieu du sable (Gustave Flaubert, Salammbô)

1866 Une des extrémités du madrier jeté en l'air par le flot s'était en tombant engagée dans cet hiatus. L'hiatus s'en était élargi. Une idée vint à Gillitt. Peser sur l'autre extrémité. Le madrier, pris par un bout dans la fente du rocher qu'il avait agrandie, en sortait droit comme un bras tendu (Victor Hugo, Les Travailleurs de la mer) 
1912 Elle l'écrasait sur sa poitrine, elle lui mettait les mains sur la bouche pour le faire taire ; mais lui disait : « les entends-tu ?... les entends-tu ?... qu'est-ce qu'ils disent ?... ils ne disent plus rien... quel entassement de cadavres sous la bâche des traîneaux, Matrena ?... regarde les jambes glacées des pauvres filles qui dépassent, et qui sortent toutes droites, comme des bâtons, des jupes de pilou, Matrena!»

(Gaston Leroux, Rouletabille chez le tsar)

1972 En effet, le sergent de ville à barbe de sapeur était là, bâton blanc en main pour régler la circulation. Célèbre et le sachant, il sortait tout droit d'une imagerie d'Épinal et les gens faisaient exprès de lui demander leur chemin pour pouvoir dire ensuite : « J'ai parlé à l'agent de la porte SaintDenis ! » (Robert Sabatier, Trois Sucettes à la menthe)

1981 Il marchait à petits pas pressés, en se dandinant comiquement. Il paraissait tout droit sorti d'un dessin animé (Michel Del Castillo, La Nuit du décret)

1983 Les aborigènes étaient de petite taille. Le teint sombre, poilus et minces, avec le front bas et des yeux enfoncés dans la tête, ils semblaient sortis tout droit de l'âge de pierre. Leur musique était très particulière. Ils n'utilisaient apparemment aucun instrument, sauf une sorte de chalumeau de bois (Laura Benjamin, L'Opéra du fond des mers)

1984 Philippe étouffa un bâillement dépité. Grotesque. Tout droit sortis d'une publicité gay, les musiciens invoquaient le diable sans conviction, jouaient derrière un masque de haine dérisoire (Michel Embareck, Sur la ligne blanche)

1987 Atalanta, en ce temps-là, était encore une très jeune femme. Elle était très douce, apparemment très calme, ravissante, l'air d'une Madone sortie tout droit d'un tableau de la Renaissance italienne. Jérôme Seignelay avait neuf ans de moins qu'elle (Jean d'Ormesson, Le Bonheur à San Miniato)
1997 Pendant qu'ils le dévoraient devant la télévision, j’ai tenté de le pimenter d'un zeste de passé :

- Quand j'avais votre âge, leur ai-je dit, pour le goûter qu'on appelait alors le « quatre heures », je buvais un verre de lait mousseux et tiède tout droit sorti du pis des vaches de nos voisins

(Françoise Dorin, Les Vendanges tardives)

II. Pousser en suivant une ligne droite Intransitif

1930 Chez les individus leiotriques, les follicules pileux sont droits, sont situés plus verticalement et le lumen est rond et ferme de sorte que le cheveu sort droit et que sa section est circulaire (Alfred-Cort Haddon, Les Races humaines)

III. Apparaître directement Intransitif

1942 Mais l'éclat des blancs tuyaux n’y était plus ; les foulards étaient de la laine la plus terne et la plus effilochée qui soit. De cette espèce de couronne trop grande pour sa tête et tombée sur ses épaules, sortait tout droit un vieux visage à moustaches gauloises, à grand nez, avec, sur une joue, une verrue grosse comme une bille, et couverte d'une touffe de poils en éventail (Louis Guilloux, Le Pain des rêves)

\section{CORPUS WEB :}

Pour enlever la partie supérieure, utilisez un petit tournevis que vous irez placer dans la fente adéquate. Il y a plusieurs fentes sur tout le diamètre du joint racleur, allez-y progressivement pour le sortir droit [http://tandems.free.fr/ mountain/bricolage/suspensions/fox\%20forx/ forx.html] (30.12.2015)

Un coin «banquette » détente sous un escalier pour y ranger ses magazines et bien sur les lire ! Celui-ci pourrait sortir droit d'une boutique ! [http://decorationhomepat.blogspot.co.at/p/ deco-interieures.html] (30.12.2015)

Rob Dyrdek a décroché un nouveau record du monde, celui du plus long saut avec une voiture en marche arrière. Afin d'homologuer ce record, il ne s'agissait pas de simplement sauter le plus loin possible avec la voiture, mais atterrir sur la rampe de réception et en sortir droit [http:// 
sport.gentside.com/record/rob-dyrdek-bat-lerecord-du-monde-du-plus-long-saut-en-marchearriere-en-voiture_art43212.html] (30.12.2015)

Mais s'amuse avec les mots

Qui sortent droits de sa tête

Pour remplacez vos soucis [http://lou marie.eklablog.com/bonne-nuit-a114021206] (30.12.2015)

« C'est dommage, on réagit, mais on n'agit pas. Maintenant l'objectif sera d'être bon pendant 90 minutes. J'avais dit aux joueurs à la pause qu'il fallait qu'ils sortent droits du terrain et ils se sont battus jusqu'au bout, c'est déjà ça ", a réagi l'entraîneur de l'AJA, 15e du classement à l'issue de cette 19e journée [http://news.maxifoot.fr/ info-150301_111222/football.php] (30.11.2015)

Je suis têtu et je reviens sur mon problème de rayon dans l'étrier de frein : ce type de protection n'empêchera jamais un rayon cassé de se gaufrer dans l'étrier. Par contre sur la même photo les rayons sortent droits du moyeu (pas de coude) et ont certainement peu de degrés de liberté, contrairement à un moyeu classique (ou bas de gamme), la solution est peu être là ! [http://cyclurba.fr/forum/417635/freins-nOdisques-acceptn-s-route-l-uci-2017.html?from=51 \&discussionID=16208\&messageID=417635\&rubri queID=9\&pageprec=] (30.11.2015)

REMARQUES : Sortir droit (I) peut désigner, au figuré, une chose ou une personne qui vient, est issue d'un milieu, ou appartient à un domaine quelconque ; au concret, le sujet désigne une chose (un aliment) qui provient directement d'un endroit, d'une époque, etc. (II) réfère à un cheveu qui pousse droit et non crépu. (III) désigne une partie du corps qui se détache d'un ensemble, qui apparaît clairement, de façon distincte. Dans son emploi adverbial, droit reste invariable dans la majorité des cas. Toutefois, dans le CW, il s'accorde dans le quatrième exemple avec le sujet tout en gardant son interprétation adverbiale (style poétique). Dans les deux derniers exemples $\mathrm{du} \mathrm{CW}$, droit fonctionne en tant que prédicat second orienté vers le sujet (en renvoyant à sa position droite, verticale) et s'accorde avec le sujet. Il est modifié par tout.

\section{Sortir frais}

I. sortir (tout) frais de : sortir à peine, depuis très peu de temps Intransitif

1665 Et te voiant encor tout frais sorti de classe, Je disois : Chapelain lui laissera sa place (Nicolas Boileau, Chapelain décoiffé)

1715 Au retour, comme il passait par une rue où il n'y avait personne, il rencontra une dame qui venait à lui. La dame, qui vit un jeune homme très bien fait et tout frais sorti du bain, leva son voile et lui demanda où il allait, d'un air riant et en lui faisant les yeux doux (Antoine Galland, Les Mille et une nuits)

1745 Je me redressais, car c'est par où commence une vanité novice ; et autant que je puis m'en ressouvenir, je ressemblais assez à une aimable petite fille, toute fraîche sortie d'une éducation de village, et qui se tient mal, mais dont les grâces encore captives ne demandent qu'à se montrer (Pierre Marivaux, La Vie de Marianne)

1768 Le cinquième [= tableau] est un de ses premiers ouvrages. Il [= Vernet] le fit à Rome pour un habit, veste et culotte ; il est très-beau, très-harmonieux, et c'est aujourd'hui un morceau de prix. En comparant les tableaux qui sortent tout frais de dessus son chevalet, avec ceux qu'il a peints autrefois, on l'accuse d'avoir outré sa couleur (Denis Diderot, Salon de 1767)

1809 Les Goths, s'imaginant qu'il était à la tête de troupes fraîches sorties de la ville, lâchent le pied, et regagnent leur camp (Nouveau Dictionnaire historique des sièges et batailles)

1853 Et vous autres, créés pour grossir son parti, Philosophes gênés de cuissons à l'épaule, Et vous, viveurs râpés, frais sortis de la geôle,

Saluez l'être unique et providentiel, Ce gouvernant tombé d'une trappe du ciel, Ce César moustachu, gardé par cent guérites, Qui sait apprécier les gens et les mérites (Victor Hugo, Les Châtiments) 
1872 Théo montre, avec une satisfaction de débutant, la nouvelle édition d'Émaux et camées, toute fraîche sortie des presses et où Jacquemart a fait son portrait en espèce de poète de l'antiquité (Edmond et Jules de Goncourt, Journal)

1877 Les tourtes sont toutes fraîches sorties du four (Heinrich Heine, Le Tambour Legrand [trad.])

1926 À l'examen, il s'était aperçu qu'elles jouaient le même rôle que les passes de la muleta sous les yeux du taureau sorti frais du toril ; elles avaient pour but d'étonner, de fatiguer l'animal et de retarder le combat (André Maurois, Bernard Quesnay)

1948 Jamais la créature sortant toute fraîche du sein de son créateur n'aura ébloui les anges d'une telle explosion d'aurore ! (Paul Claudel, Le Cantique des cantiques)

1974 Mange de la fougasse, mon petit-fils, elle est fraîche sortie du four.

- Merci... pépé.

Olivier pensait : « On s'en met plein la lampe ! " (Robert Sabatier, Les Noisettes sauvages)

1990 Il dit qu'on n'était pas dans une bibliothèque, il attrapa les deux livres de Muzil que Stéphane lui avait rapportés de la maison d'édition et qui sortaient tout frais de l'imprimerie, et décréta que même ça on n'en voulait pas ici, qu'il fallait uniquement le corps du malade et les instruments pour les soins (Hervé Guibert, À l'ami qui ne m'a pas sauvé la vie)

II. Sortir en forme, intact ou légèrement froid Intransitif

1680 Les provençaux s’accommoderaient mal de cette boisson. Mais qu'on mette une herbe ou une fleur dans cette eau bouillante, elle en sort aussi fraîche qu'en la cueillant, et au lieu de griller et de rendre la peau rude, elle la rend douce et unie (Mme de Sévigné, Correspondance)

1779 Ainsi brille, à travers la vague transparente, Cette fleur, dont le Nil voit les boutons éclos,
Tristes durant la nuit se plonger dans les flots,

Et frémissant de joie au retour de l'aurore, Du fleuve par degrés sortir plus frais encore.

Auprès d'un saule antique, au-dessous du bassin,

Où la vague a reçu la nymphe dans son sein (Jean-Antoine Roucher, Les Mois)

1850 Enfin personne ne se tirait mieux que lui [= Maxime de Trailles] d'un souper de jeunes gens, il buvait mieux que le plus aguerri d'entre eux, et sortait frais, prêt à recommencer, comme si la débauche était son élément (Honoré de Balzac, Le Député d'Arcis)

1926 Un autre [= taureau], parce que l'eau de l'abreuvoir était chaude de soleil, avançait les naseaux sous le robinet même, d'où l'eau sortait fraîche, et la buvait tandis qu'elle gouttait : il était bien malin, malgré ses grandes cornes

(Henry de Montherlant, Les Bestiaires)

\section{CORPUS WeB :}

« Ma première médaille au 100m Brasse quand j'avais 10 ans et plus récemment, après avoir repris la natation, sortir frais et bien placé sur les $1 \mathrm{kms} 900 \mathrm{du}$ parcours natation de mon 1er Half Ironman !!! » [http://be.nabaiji.com/fr/ team-nabaiji/samuel] (30.12.2015)

ce que je fais c'est que je n'active que le climatiseur, au depart fenetre ouverte, il ponctionne l'air de l'exterieur et commence a le refroidir, je n'utilise pas la fonction full auto qui souffle trop fort au depart, puis lorsque l'air commence a sortir frais, j'augmente legerement le debit, et ferme les fenetres [http://www.alfaromeo-online.com/ forum/topic/4336-est-ce-que-la-climatisationde-la-159-souffle-suffisamment-dair-frais] (30.12.2015)

Voyager en avion sans souci. Pas évident de sortir frais et dispo d'un long vol ! [http:// www.e-sante.fr/long-voyage-en-avion-commentvoyager-sans-souci-bien-recuperer/actualite/ 518] (30.12.2015)

Bonjour je suis Mademoiselle $\mathrm{M}$, révélatrice de votre meilleure image et je vais vous aider à voyager en forme : belle peau, œil vif, cœur apaisé et jambes légères. Car vous le savez toutes, 
rater son voyage peut ruiner les premiers jours de vacances. [...] Alors comment sortir fraîche d'un avion ? En réalité, comme bien des choses, c'est une simple question d'organisation... [http:// mameilleureimage.com/comment-rester-fraicheet-belle-en-avion] (30.12.2015)

Proposer à vos employés une eau filtrée de qualité apportera probablement davantage de confort et de simplicité. En fonction des options de la fontaine ou de son modèle, l'eau distribuée pourra donc sortir fraîche, tempérée ou bien chaude [http://www.zetop.fr/liste/fontainedirect-professionnel-de-la-fontaine-a-eau] (30.12.2015)

REMARQUES : Sortir frais (I) désigne une chose qui vient de sortir d'un endroit, qui vient d'être fait ou produit, soulignant souvent la qualité, la frâ̂cheur du produit en question. Le sujet peut aussi référer à une personne qui vient de terminer une formation, qui sort d'une école. En parlant d'une personne ou pour caractériser son comportement, il se dit de quelqu'un qui est plein d'allant, d'entrain, qui ne montre aucun signe de fatigue. (II) reflète la polysémie 'récemment cueilli'/'légèrement froid', qui favorise l'interprétation comme prédicat second, tandis que (I) traduit une interprétation métaphorique au sens de 'récemment' qui suggère une lecture adverbiale. Frais peut s'accorder avec le sujet, ce qui suggère une interprétation de prédicat second. L'accord est caractéristique de l'emploi concret comme prédicat second dénotant une propriété du sujet (v. les exemples sous (II) et les deux derniers exemples $\mathrm{du} \mathrm{CW}$ ), mais aussi dans l'acception (I), 'récemment', plutôt adverbiale (elle est toute fraîche sortie de). Frais (I) est modifié par tout, et frais (II) par aussi, plus. Notons les collocations frais et bien placé et frais et dispo, pour caractériser une personne, et frais, tempéré ou bien chaude pour la température de l'eau.

\section{Sortir menu}

Sortir, se montrer, apparaître de manière vive et fréquente, rapide, comme un éclair Intransitif

1578 De son regard mainte vive estincelle Sortoit menu comme flame des cieux, Si qu'esblouy du feu victorieux, Je fus vaincu de sa clarté nouvelle (Pierre de Ronsard, Sonnets et madrigals, p. 266)
REMARQUES : Au figuré, sortir menu souligne l'idée de mouvement vers l'extérieur. En rapport avec le regard, il désigne l'intensité, l'impact émotionnel qu'il a sur autrui, faisant apparaître ou manifestant délicatement ou avec finesse une certaine émotion exprimée, ici de manière métaphorique par l'étincelle dans le regard. Мenu peut aussi traduire la rapidité et la fréquence élevée de l'action, le mouvement fugace, dénotant aussi une certaine ardeur. Мenu reste invariable.

\section{Sortir net}

I. Sortir (d'une situation) sans aucune séquelle Intransitif

1761 D’ailleurs, a-t-il ajouté, ma réputation est faite, je puis être juste sans soupçon de lâcheté ; mais vous qui êtes jeune et débutez dans le monde, il faut que vous sortiez si net de la première affaire, qu'elle ne tente personne de vous en susciter une seconde (Jean-Jacques Rousseau, La Nouvelle Héloïse)

1845 J'ai passé par l'épreuve du feu ; mais Dieu protège ceux qui l'invoquent, et j'en suis sorti net et sans brûlure apparente : un peu brisé, à la vérité, mais calme et plein de foi en l'avenir (George Sand, Le Péché de Monsieur Antoine)

II. Sortir avec netteté, propreté, pur Intransitif

1923 Le lin, après tant de façons, est sale et gluant. « On trempe pour lui la lessive. » Et puis on l'immerge dans la cuve, on le frotte, on le frictionne; enfin on l'éclaircit. Il sort net et blanc de ces bains successifs, blanc « comme de la plume d'oie » (Joseph de Pesquidoux, Chez nous : travaux et jeux rustiques)

III. Prononcer, être prononcé de manière claire, nette, distincte

Intransitif

1983 Maman me lit de sa voix grave, sans mettre le ton... les mots sortent drus et nets... par moments j'ai l'impression qu'elle ne pense pas beaucoup à ce qu'elle lit... (Nathalie Sarraute, Enfance) 
Transitif

1985 Adélaïde mettait une attention particulière à ne pas escamoter les mots dans un murmure, un toussotement, à les détacher, les sortir bien nets de sa bouche dont les lèvres ne se décollaient pas des dents, quelle que fût la voyelle prononcée, à cause peut-être de son peu d'habitude $\mathrm{du}$ sourire, et qui livraient étroitement passage aux mots (Hector Bianciotti, Sans la miséricorde du Christ)

\section{CORPUS WEB :}

Et je trouve que c'est une sorte de respect vis à vis des autres de sortir net plutôt qu'avec des cernes et le teint brouillé. Par contre, si je dois juste sortir promener mes chiens par exemple, je met seulement une bb crème, une peu de poudre et du mascara, un maquillage léger mais maquillage quand même! [http://www.google.at/url/ osez-vous-sortir-sans-maquillage] (29.12.2015)

La tourte doit être marron foncé et croustillante. Éteindre le feu, enfoncer un couteau dans la pâte il doit sortir net [http://www.cliquecorse. com/recettes/recette103.shtml] (29.12.2015)

eh oui coincoin, je possède aussi 2 SX300 et c'est du bonheur c'est vrai !!Les chants sortent nets et clairs. Mais je parlais des systèmes amplifiés [http://fr.audiofanzine.com/enceinte-sonoamplifiee/forums/t.362369, systeme-completpour-1500-euro-environ,p.3.html] (29.12.2015)

Le verbe est faible : Venom, Mc Zombi et Felicia rappent dur, agrippent le micro sans le laisser longtemps sur son pied, mais les cris sortent nets, travaillés. «Paris! » scande régulièrement Venom pour faire sursauter la foule quand celle-ci a tendance à oublier de sauter sur le rythme [http:// coupdoreille.fr/index.php?option=com_conten t\&view=article\&id=141\&Itemid=4c] (29.12.2015)

REMARQUES : Dans sortir net (I), au figuré, le sujet désigne une personne qui sort irréprochable d'une situation, d'une affaire judiciaire, ses dires ne donnant lieu à aucun doute, aucun soupçon. Sortir net (II), au concret, réfère au fait de sortir propre, bien lavé. Notons l'emploi de sortir dru et net / net et clair, ainsi que, dans l'acception (II), sortir net et blanc et sortir net, travaillé. Sortir net (III) se dit en parlant des mots ; il souligne une prononciation claire, distincte pour l'auditeur.
Net peut s'accorder avec le sujet ou avec l'objet, et se rapprocher des prédicats seconds. Net est modifié par bien, si.

\section{Sortir raide}

Sortir droit et ferme

Intransitif

1925 Il n'y eut rien que quelques phrases échangées devant le seuil de la maison, dehors; car Raboliot, à la vue des gendarmes, était sorti tout raide, pour éviter que le Bourrel posât seulement un pied chez lui (Maurice Genevoix, Raboliot)

\section{CoRpus Web :}

étant blésser je suis un peu blazé d'apprendre que l'équipe une vient de perdre encore un match,je tiens a félicité au passage l'équipe réserve,bref nous sommes vraiment mal,et ca c'est tout le club,c'est les deux équipe qui sont en danger.c'est pour ca qu'il faut vraiment se réveiller et comme l'on dit se vider les c..... sur le terrain,il faut vraiment se battre, et sortir raide a la fin des match.aller les gars il faut aller de l'avant [http:// forum.lixium.fr/v-11410020.htm] (29.12.2015)

Personnellement, je ne trouve pas que Jordyn sort de la même manière. On voit plusieurs manière de sortir en double tendu : il y a les Wieber, Dufournet, Johnson d'un côté, qui sortent raides et qui jouent sur leur puissance, dans le soleil notamment, les Porgras, Quishuang, Kuhm d'un autre, qui utilisent leur bassin pour finir leur rotation et Fassana qui a une technique particulièrement [http://gymnet.org/forum/topic-22385sortie-barres-double-tendu] (29.12.2015)

Tu m'as tué à sortir raide de la chambre pour me demander si ça allait.

T'as vu ça ! Hier soir en allant pisser j'me suis faite attaquer par trois moustiques d'un coup. J'suis allée dans ma chambre, j'me suis assise sur mon lit et là j'entends un moustique.. j'étais deg j'ai dû dormir avec cette saloperie, putain [http://forum.ados.fr/actu/discussions/laissezmessage-sujet_47871_406.htm] (29.12.2015)

Ecoute laisse tomber ${ }^{\star}$ je pense que mes propos et les tiens auraient passé sans problemes face a face...mes ecrits sortent raides parfois Ca fait un bout que je n'etais pas venue ici justement parce que je « m'essouffle » à m'expliquer.... 
[http://www.dlvdm.com/forum/lofiversion/ index.php/t194333-50.html] (29.12.2015)

Il ralentit un peu, posant fièrement pour les photos, prenant des poses de biais pour que je vois nettement son mandrin entrer et sortir raide mais trempé de la chatte épanouie de Sylvie.

-Tu as vraiment une chatte super ma chérie, dit-il. Elle serre ma queue avec fermeté, une étroitesse de jeune fille. Elle est bien chaude bouillante par ailleurs! Elle est vraiment faite pour la baise, hein Louis ! [http://www.xstory-fr. com/lire-histoire, pere-fille-moi,22318.html] (29.12.2015)

REMARQUES : Sortir raide désigne une personne qui sort droit et ferme. Dans le premier exemple du CW, il s'agit de sortir complètement achevé, fini, épuisé par l'effort fourni. Le deuxième exemple réfère à une sortie le corps tendu. De même, un style d'écriture peut paraître insensible, et les mots écrits peuvent paraître brutaux. Le dernier exemple du CW prend raide au sens physique par rapport au pénis. Raide reste invariable dans la majorité des cas. Toutefois, dans le troisième et quatrième exemple du $\mathrm{CW}$, il s'accorde avec le sujet pour inclure le sujet dans une modification qui maintient sa valeur adverbiale. Dans le cinquième exemple du CW, il fonctionne en tant que prédicat second orienté vers le sujet, et réfère au pénis endurci. Raide est modifié par tout.

\section{Souffler âpre}

Souffler un air vif et mordant

Intransitif

1839 la bise soufflait âpre et bruyante et les oiseaux effarouchés voletaient en rond (Mme Charles Reybaud, Mézélie)

1897 Enfiévrée par le manque de sommeil, les joues et le regard en feu, à tout moment elle tirait la corde du vasistas d'aérage ; mais dehors la bise soufflait âpre, les giboulées, pluie et grésil, giclaient jusqu'au milieu de la salle (Alphonse Daudet, Soutien de famille)

\section{Souffler bas}

I. Respirer, haleter, souffler (sur quelque chose) sans faire trop de bruit

Intransitif

$\sim 1370$ Et se de rien t'espouente, si le souffle et il s'en fuira, mais souffle bas, car d'autre part sont deux fiers liepars qui ne heent riens tant comme souffler et ceulx qui souflent ; pour quoy, s'il t'ouent souffler par aucune aventure, il te courront sus par tres grant air, et lors t'avront tost devouré : si te guette de hault souffler (Roman de Berinus, I, p. 66)

1770 Souvent encore il arrive que des vents qui soufflent bas et dans une direction horisontale, chassent l'air condensé au dessus duquel les vapeurs sont suspendues (Jérôme Richard, Histoire naturelle de l'air et des météores)

1948 Le tortillard, soufflant bas, avec cet air phoque qui n'appartient qu'aux locomotives de petite ligne, parut avec dix minutes d'un retard qui nous semblait insupportable, mais que bientôt nous pourrons souhaiter centenaire (Hervé Bazin, Vipère au poing)

II. Dire discrètement à voix basse, d'une voix très faible, en chuchotant

Transitif

1605 il attiltra un sien familier, lequel en presence de ces Evesques luy souffloit tout bas en l'oreille quelques parolles (Antoine $\mathrm{Du}$ Verdier, Prosopographie ou Description des hommes illustres)

1780 Mon bon ange (car j'ai un génie familier, et je t'assure qu'il nous sert bien ; et je crois, friponne de Sophie, que tu le connais mieux que moi) mon bon ange donc, m’a soufflé tout bas à l'oreille que je me tuais les yeux à écrire si fin, et que je pouvais bien ne pas tant économiser le papier (Honoré de Mirabeau, Lettres originales écrites du donjon de Vincennes)

1836 Rassurée par la parole d'honneur que je lui donnai de m'en taire soigneusement, elle quitta son fauteuil, vint se pencher au dos du mien, et me souffla très bas à l'oreille le nom du prince chéri (Théophile Gautier, Mademoiselle de Maupin) 
1890 Et l'interrogatoire continua, elle disait tout, dans un tel anéantissement de honte et de peur, que ses phrases, soufflées très bas, s'entendaient à peine. Et lui, mordu de sa jalousie atroce, s'enrageait à la souffrance dont le déchiraient les tableaux évoqués (Émile Zola, La Bête humaine)

1955 Et la douleur le siffle

Hôpital Silence

Mais la malade plus oppressée que lui le serre dans ses bras et lui souffle son rôle

Tout bas

Au ras du drap

(Jacques Prévert, La Pluie et le beau temps)

1963 La mère fit oui de la tête.

- Tu ne lui as pas fait lire, au moins?

Elle eut presque peur. Il y avait tant de colère dans les yeux de Julien ! Elle hésita puis, tout bas, elle souffla :

- Il a dit que c'était très bien. Très bien.

Mais bien sûr, ce n'est pas un gagne-pain possible.

Elle ne put achever. Julien était parti d'un grand éclat de rire (Bernard Clavel, Celui qui voulait voir la mer)

Intransitif

189326 septembre.

Fantec, qui apprend à lire, dit à sa maman : - Souffle-moi, tout bas, rien qu'un petit peu (Jules Renard, Journal)

1928 ZELTEN. C'est même le moment où les machinistes font silence, où le souffleur souffle plus bas, et où les spectateurs qui ont naturellement tout deviné avant Edipe, avant Othello, frémissent à l'idée d'apprendre ce qu'ils savent de toute éternité... Je parle des spectateurs non militaires, car vous n'avez rien deviné n'est-ce pas Waldorf ? (Jean Giraudoux, Siegfried)

\section{CORPUS WEB :}

C'est pas ton boitier qui fera souffler ton turbo plus bas dans les tours... C'est la taille de ton turbo qui joue, et comme sur les S2 il est déjà assez gros, et pire sur les RS2, plus c'est gros, plus ça souffle tard et fort. Pour souffler bas dans les tours petit turbo ou bi turbo [http://www. forum-auto.com/marques/audi/sujet387.htm] (29.12.2015)

sinon, dans mon exemple, j’ai pris le TDI en disant : « Un bon TDI >101cv ». Le « >101cv » est très important !!! Un TDI 110 souffle déjà à +-1000tpm tandis qu'un 90cv souffle bien plus haut (+- 2500/3000) Pareil pour les HDI/DTI etc. Y'en a qui soufflent bas et d'autres pas. Mais je ne les connais pas ces moteurs [https://www.japancar. fr/forum/Sujet-TDi-150-la-pile] (29.12.2015)

lire les instructions sur la façon de souffler dans la flûte. Les instructions du site web vous montrent comment souffler bas et à travers tout en maintenant la flûte correctement. Pratique en enlevant la section de bouche et soufflant dedans [http://fr.ruodiantong.com/cellphones-accessories/iphones/1007087322.html] (29.12.2015)

REMARQUES : Dans les textes littéraires, souffler bas (I) réfère à l'haleine humaine (ex. de 1370), ou, dans un français plus récent, un petit chemin de fer secondaire, qui roule à vitesse réduite, produisant un bruit léger (ex. de 1948). Dans le même type de texte, (II) s’applique à une personne qui dit, prononce quelque chose à voix basse, qui chuchote quelque chose à l'oreille de quelqu'un par discrétion, ou pour lui confier quelque chose de secret. Le CW nous plonge dans le quotidien. Souffler bas renvoie alors à un moteur ou à un instrument de musique. Bas reste invariable et est modifié par plus, tout, très. Notons souffler tard et fort ainsi que souffler haut, antonyme de souffler bas, les trois étant employés par rapport à un moteur.

\section{Souffler clair}

souffler haut et clair : dire à haute voix, ouvertement

入 souffler haut

\section{Souffler court}

Avoir le souffle court

Intransitif

1934 Le cœur lui bat et elle souffle court comme après le 300 mètres terrible (Henry de Montherlant, Encore un instant de bonheur) 
2008 Robert court, souffle court, et l'accompagne encore, mais il a lâché le garde-boue (Gérald Tenenbaum, L'Ordre des jours)

REMARQues : Dans l'exemple de 2008, on peut préférer une lecture nominale : le souffle court.

\section{Souffler dru}

Souffler avec force

Intransitif

1960 Je fichai ma bougie sur la table, je mâchonnai un peu de pain et je bus tout mon vin pour me donner du cœur car cette haute solitude était un peu angoissante ; le vent soufflait dru entre les cailloux des murs (Simone de Beauvoir, La Force de l'âge)

\section{CORPUS WEB :}

On a failli ne rien avoir à Coudalère alors qu'à La Franqui çà souffler dru jusqu'à 59 nœuds d'après les relevés. Heureusement nous avons eu droit à 2 heures de baston dans les 45 nœuds qui ont sauvé la journée [http://www.allosurf. net/meteo/surf/le-barcares-la-coudalere-windreport-14798-img-1.html] (29.12.2015)

Les voilà les cigognes sur la photo 1, j’ai vérifié sur mon bouquin, ce sont bien des cigognes, les amis c'est le printemps !!!! Le vent continue à souffler dru, le plan d'eau à glisser fort, et en plus par moments on se retrouve seul dans ce paradis !! [http://aa-lesfanasduwindsurf.blogspot. co.at/2014/03/a-kind-of-magic-page-2.html] (29.12.2015)

Bahang, deux mille cinq cent mètres d'altitude, ermitage accroché à flanc de falaise, ouvert à tous les vents - et ils soufflent drus du Tibet ! [http://anarchrisme.blog.free.fr/index. php?post/2011/08/21/Missions-perdues-au-Tibet] (29.01.2015)

P...de rêves ! Et de mots ! Qui soufflent dru sur la réalité de nos âmes lettrées. j’aime bien quand tu dis court, Lacape. Et puis ca fait plaisir de te relire apres deux mois d'absence (s). Ciao Mojo [http://www.toutelapoesie.com/poesie/ index.php?showtopic=31686] (29.12.2015)

REMARQUES : En référence aux conditions atmosphériques, le sujet de souffler dru s'applique au vent qui produit un souffle puissant, vif, qui se fait vivement sentir. Dans le dernier exemple du CW, plutôt littéraire, il réfère, au figuré, à l'effet presque brutal que causent des mots écrits. L'accord n'est fait que dans l'avant-dernier exemple $\mathrm{du}$ CW pour insister sur la force intrinsèque des vents. Notons l'occurrence des groupes glisser fort et dire court. Signalons aussi l'emploi impersonnel familier ça souffle dru.

\section{Souffler dur}

I. Produire un courant d'air très fort, un vent violent

Intransitif

1835 Le vent reste généralement plusieurs jours dans la partie du S.O., soufflant dur, mais il se modère vers la fin et est remplacé par deux ou trois jours de beau temps (Annales maritimes et coloniales)

1881 La mer était grosse, les vents soufflaient durs (Journal officiel)

1916 Il est reparti parce qu'il n'avait guère de provisions et qu'il avait hâte d'arriver, je pense ; mais le temps était encore méchant, la neige tombait, le norouâ soufflait $d u r$, et probablement qu'il ne pouvait pas voir le soleil ni marquer son chemin (Louis Hémon, Maria Chapdelaine)

1950 On était en janvier, la bise soufflait dure (Gaston Montho, Brin d'amour)

1982 Quand le vent soufflait dur, il cherchait refuge dans les maigres plantations de pins qui dataient aussi du temps du fermier (Marguerite Yourcenar, Un homme obscur)

II. Respirer difficilement sous l'effet d'un grand effort

Intransitif

1936 Alors j'ai entrevu Grand-mère dans son lit dans la pièce plus loin... Elle soufflait dur, elle raclait, elle suffoquait, elle faisait un raffut infect... (Louis-Ferdinand Céline, Mort à crédit)

1948 L'ascenseur était ouvert et l'homme en salopette neuve soufflait dur en y entassant les lourdes caisses (Boris Vian, Le Grand Sommeil [trad.])

\section{CORPus WEB :}

Les narines de la monture soufflaient dures signifiant à sa cavalière qu'il appréciait ample- 
ment cette pause. Cael sauta en bas de son cheval [http://www.univers-rr.com/RPartage/index. php? page $=$ rp\&id $=13711 \&$ start $=5](10.9 .2020)$

REMARQUES : Souffler dur (I) réfère à un vent qui souffle si fort qu'il est dur à supporter. En (II), il renvoie au fait de respirer difficilement sous l'effet d'un effort. Contrairement à la tendance générale de prendre dur comme adverbe invariable, dans les textes imprimés, l'accord de souffler dur est optionnel, du moins pour l'acception (I).

\section{Souffler fort}

Souffler avec force, violemment Transitif

+1433 Tout le cueur de moy sy en tremble Come fait la fueille d'un tremble Quant le vent la souffle sy fort. Aux faulx jaloux Dieu doint la mort : Nous ne pourrons plus vivre ensemble (Chansons du $X V^{e}$ siècle [datables du $2^{e}$ tiers du XV à la fin $d u X^{e}$ ], p. 75, 23)

Intransitif

1886 Il faisait trop beau depuis quelques jours, cela devait finir. La brise soufflait sur ce conciliabule de bateaux, comme éprouvant le besoin de l'éparpiller, d'en débarrasser la mer ; et ils commençaient à se disperser, à fuir comme une armée en déroute, - rien que devant cette menace écrite en l'air, à laquelle on ne pouvait plus se tromper. Cela soufflait toujours plus fort, faisant frissonner les hommes et les navires (Pierre Loti, Pêcheur d'Islande)

CORPUS WEB :

C'est malgré tout très simple : plus les notes sont aigües, plus il faut souffler fort mais attention, pas trop fort non plus ou vous risquer de ne pas produire la note : juste un son aigüe et rien d'autre (un son qui, évidemment, vous fera mal aux oreilles) [http://www.partition-ocarina.fr/ content/comment-souffler] (29.12.2015)

Météo : le vent va souffler fort sur le Sud-Est [http://www.bvoltaire.fr/extvideo/meteo-le-ventva-souffler-fort-sur-le-sud-est] (29.12.2015)

bonjour, depuis quelques temps l'affichage de mon curseur 12 h / 24 h est alternatif. Si je bouge la carte il disparait, il faut que mon point représentant mon bateau soit pile au centre au mieux afin que je puisse voir la prévision dans quelques heures, dommage quand on a des vents qui soufflent forts et surtout inexplicable... [http://www.virtualregatta.com/forums_FR/ viewtopic.php?f=63\&t=12091] (29.12.2015)

Rendez-vous donc samedi 14 avril à Reugny, où l'on constatera que les vents soufflent forts à travers les fanfares de la Touffe, de l'étrange Gonzo, les cerfs-volants, un musée de plein air, une météo vitico-théâtrale, etc. [http://www. lanouvellerepublique.fr/Indre-et-Loire/Commu nes/Noizay/n/Contenus/Articles/2012/01/21/Lesbons-vents-des-Mouts-et-des-notes] (29.12.2015)

REMARQUES : Souffler fort s'applique au vent ou l'air qui produisent un souffle puissant, vif, qui se fait vivement sentir. Dans son emploi transitif, le souffle puissant a pour effet de déplacer ou de faire voler quelque chose. Dans le premier exemple du CW, l'air est soufflé dans un instrument de musique à vent. Fort peut s'accorder avec le sujet (v. les deux derniers exemples du CW), en gardant son interprétation adverbiale, mais sans doute aussi pour insister sur la force du vent. Fort est modifié par si, toujours plus.

\section{Souffler haut}

I. Dire (quelque chose) à voix haute, d'une voix forte

Intransitif

1697 LE SOUFFLEUR. Messieurs... PETIT JEAN. Oh ! prenez-le plus bas : Si vous soufflez si haut, l'on ne m'entendra pas.

Messieurs... (Jean Racine, Les Plaideurs)

1861 On entend, quand on danse, le bruit des danseurs qui retombent, le coup de leur talon contre leur cheville ; quand on chante, le souffleur qui souffle tout haut (Edmond et Jules de Goncourt, Journal)

Transitif

1893 Alors, c'est une comédie de voir la maîtresse de maison quitter comme une folle la personne avec laquelle elle cause, se ruer sur son domestique, lui souffler tout haut le vrai nom, le forcer à le répéter (Edmond et Jules de Goncourt, Journal) 
II. Souffler, respirer bruyamment

Intransitif

1885 Parfois, il hochait le menton avec des regrets silencieux, en se détournant des gaillardes bruyantes, soufflant trop haut, au fond des ténèbres (Émile Zola, Germinal)

\section{CORPUS WEB :}

En tout cas, malgré cette lacune présente dans les différentes traductions des textes évangéliques habituellement à la disposition du grand public, la signification de la parole symbàllusa ne résonne pas comme une nouveauté pour les chrétiens ramiriques, parce que le 9 avril 1963 "Quelqu'un » est né pour souffler haut et clair le Verbe de Dieu et donc aussi pour faire connaître la « dimension » cosmique par laquelle la Madone se fait Servante du Seigneur [http://journaldunmoine.blogspot. co.at/2013/09/telescope-sur-anima-universale. html] (29.12.2015)

Votre but n'est pas le Christianisme que vous avez malmené et échangé contre l'athéisme et l'homosexualité. Votre but primordial, c'est d'attaquer l'Islam et de souffler haut votre jalousie amalgamée à votre haine maladive [http:// www.businessnews.com.tn/a-cause-dun-ortdeux-touristes-empees-de-monter-a-bord-detunisair,520,58453,3] (29.12.2015)

REMARQUES : Souffler haut (I) désigne le fait de dire ou de prononcer quelque chose à l'oreille de quelqu'un, à voix haute, souvent dans le but de l'aider en lui rappelant ce dont il ne se souvient plus. Par extension, souffler inclut l'intention de convaincre quelqu'un (v. aussi le premier exemple du CW). Sous (II), le sujet respire bruyamment. Dans le deuxième exemple du CW, souffler signifie 'exprimer, expirer'. Notons la collocation haut et clair. Haut est invariable. Il est modifié par si, tout, trop.

\section{Souffler vif}

Souffler vivement, intensément, en produisant sur les sens un effet pénétrant, violent Intransitif

1835 la brise des montagnes soufflait vive et fraîche, et, s'engouffrant dans les innombrables cavités des têtes, des faces et des crânes, leur faisait rendre des sifflements plaintifs et lamentables (Alphonse de
Lamartine, Souvenirs, impressions, pensées et paysages pendant un voyage en Orient)

1979 Je dis pas ça pour me plaindre, j'aimais bien, c'était sportif, diablement, j'avais la rue pour moi tout seul, pas une bagnole, le désert, je serrais les dents, je pensais à des choses dans ma tête, des trucs que j'avais lus, arrivé là-haut l'air soufflait vif et $d r u$, je chargeais mes paniers, je repartais aussi sec pour ne pas louper l'octroi, dans la descente je me bandais pour retenir, j'y arrivais parfois tout juste tout juste

(François Cavanna, Les Russkoffs)

REMARQUES : Souffler vif réfère au vent ou à l'air qui produit un souffle puissant, qui se fait vivement sentir. Notons les collocations vif et frais, et vif et dru. Vif est accordé dans le premier exemple.

\section{Souffrir ferme}

I. Supporter, faire face (à quelque chose) de manière ferme, inflexible, résolue

Transitif

1601 Mais il y a ici des feinctes et des mescomptes : plusieurs font mine de la [= la mort] mespriser, qui la craignent : plusieurs ne se soucient d'estre morts, voire le voudroient estre, mais le mourir les fasche [...]. Plusieurs deliberent, tous sains et rassis, de souffrir fermes la mort, voire se la donner (Pierre Charron, De la sagesse)

\section{Souffrir beaucoup}

Intransitif

1924 D’ailleurs, le croira qui voudra, cet Américain n'était pas l'homme le plus vite du monde. Sprinter sans doute, il était en aussi piètre condition que moi. Tous deux souffrant ferme, et soutenus par le seul amour-propre (Henry de Montherlant, Les Olympiques)

\section{CORPUS WEB :}

Tu sais t'a pas besoin de ça, le transport a chuté d'environ 30\% depuis l'année dernière, et le transporteur fr que tu cites, qui allait mieux, se remet à souffrir ferme [http://www.forum4x4. org/threads/147999-\%C3\%87a-va-se-casser-lamargoulette!/page7] (29.12.2015) 
REMARQUES : Dans l'emploi transitif de souffrir ferme (I), le complément d'objet désigne quelque chose de douloureux, de pénible, une douleur à laquelle le sujet tente de faire face avec force, suggérant un caractère ou une attitude imperturbable, stoïque (prédication seconde). (II) renvoie à un être animé qui éprouve une douleur morale ou physique intense. Dans l'exemple du CW, ferme prend l'acception de 'durement'. Ferme s'accorde avec le sujet pour souligner la fermeté de celui-ci (ex. de 1601).

\section{Souhaiter fort}

Souhaiter ardemment

Transitif

1680 Il me semble, ma bonne, que vous avez envie d'être en peine de moi, dans l'air de la fièvre de cette maison. Je vous dirai que je me porte bien, que Mme de Coulanges aime et souhaite fort ma présence. Je suis dans la chambre, dans le jardin ; je vais, je viens, je cause avec mille gens. Je me promène, je ne prends point l'air de la fièvre (Mme de Sévigné, Correspondance)

CORPuS WEB :

Quand frangin et frangine (Claude et Simone) décident de vous inviter à une grillade, il faut souhaiter fort que maman Sicie traine dans le secteur [http://planezes66.free.fr/cadre/ planezes/JLJ/10/aout.html] (29.12.2015)

salam, voila jai un ptit soucis qui me trotte a la tete, je voulais savoir si le fait de souhaiter fort de tout cœur quune personne athée n'aille pas en enfer est ce que sa pourrait marcher et si il existait des do3a a dire ?? [http://www.yabiladi. com/forum/faire-voeu-pour-athee-4-4538300. html] (29.12.2015)

Cela étant nos éleveurs souhaitent fort ne pas devoir attendre le nouvel an pour savoir « exactement comment et par qui remplacer tout ou partie Bourgoin » [http://www.ladepeche.fr/ article/2000/04/12/88180-garde-confiance-monpoulet.html] (29.12.2015)

REMARQUeS : Souhaiter fort se dit du fait de désirer ardemment quelque chose, de compter vivement sur la réalisation de quelque chose. Fort reste invariable.

\section{Soulever fort}

Soulever puissamment

Pronominal

1939 " Reste encore un peu avec nous, mon ami ! Respire encore un peu ; une fois ! Encore une fois ! » Et, et, comme si le « petit bon sujet » l'entendait, dans un énorme effort on voyait tous ses muscles se tendre, la poitrine se soulever encore très haut, très fort, puis retomber... et le Dr Elie Faure, pris d'une crise de désespoir, s'écriait en sanglotant : « J'ai pourtant fait ce que j'ai pu...»

C'est à neuf heures du soir qu'il est mort (André Gide, Journal)

\section{CoRpus Web :}

Soulever loin ma joie

triompher d'existence

Soulever fort mes bras

et reprendre ma danse [http://asilezart.blog spot.co.at/2011/09/soulever.html] (29.12.2015)

En faisant attention à mes gestes, je m’approchai d'elle et donnai un léger baiser à chacun de ses seins. J'avais toujours le feu aux joues et je sentais la poitrine de Sakura se soulever fort sous mes lèvres. Ensuite, je la pris dans mes bras et la rallongeai dans le lit [http://fics-sasuke.skyrock. com/tags/e80cmoSNzRf-team-7.html] (29.12.2015)

Selon Rippetoe, dans son livre sur la formation de poids pour les novices, « Lancement Force, » un entraînement complet du corps abrégée de trois à cinq exercices par séance d'entraînement, pas plus de trois fois par semaine, est parfait. Vous devez soulever fort pour être forte [http://www.oemglass.net/EQ61RY3PX] (29.12.2015)

REMARQUES : Soulever fort se dit des mouvements ascendants et brusques d'une partie du corps (ici : la poitrine) sous l'effet d'un effort physique pour inspirer profondément. Les emplois transitif et absolu sont attestés dans le CW. Le dernier exemple remotive l'intensifieur fort par rapport à la force qui est nécessaire pour soulever un poids. Fort reste invariable et est modifié par très. Notons la mise en série de soulever très haut, très fort. 


\section{Soulever haut}

I. Provoquer (chez quelqu'un) un sentiment fort et élevé, un élan d'énergie, de bonheur, etc., pousser (quelqu'un) à agir admirablement Transitif

1911 On l'aimait [= Jeanne d'Arc], on l'admirait, mais on redoutait ces puissances religieuses qui s'exhalent encore du récit de sa vie, ces puissances qu'il y avait dans son âme héroïque et qui la soulevèrent si haut. Ô misère d'une époque qui méconnaît les conditions de toute grande action ! (Maurice Barrès, Mes cahiers)

1912 Ces beaux Italiens, bien taillés pour l'action, n'agissent que par passion, et se lassent vite d'agir ; mais, quand la passion souffle, elle les soulève plus haut que tous les autres peuples : on l'a vu par l'exemple de leur Risorgimento (Romain Rolland, Jean-Christophe. La Nouvelle Journée)

1936 Dans l'éclat de sa beauté, dans le jour qui vit en elle, il y a la même force inconnue que je sentais me porter, me soulever très haut quand j'allais être jeté sous les roues de ma vie. C'est parce qu'elle est réelle qu'elle pourrait partager le sort de mes songes (Joë Bousquet, Traduit du silence)

1937 Aucun jour ne se passera sans un léger progrès. Je serai soulevée plus haut que vous tous sur l'échine des saisons. Je posséderai plus que Jinny, plus que Rhoda, au moment de ma mort (Marguerite Yourcenar, Les Vagues [trad.])

II. Soulever puissamment

Pronominal

1939 « Reste encore un peu avec nous, mon ami ! Respire encore un peu ; une fois ! Encore une fois ! » Et, et, comme si le « petit bon sujet » l'entendait, dans un énorme effort on voyait tous ses muscles se tendre, la poitrine se soulever encore très haut, très fort, puis retomber... et le Dr Elie Faure, pris d'une crise de désespoir, s'écriait en sanglotant : «J'ai pourtant fait ce que j'ai pu... »

C'est à neuf heures du soir qu'il est mort (André Gide, Journal)
CORPUS WEB :

le « se met à » indique un commencement, une mise en route, un nouveau départ. La présence divine change tout, l'Esprit de Dieu transforme tout ! Dès notre baptême et confirmation, l'Esprit Saint se met à nous animer d'une vie nouvelle, nous pousser en avant, nous transformer, nous donner la force de poursuivre le chemin, nous soulever haut... bien plus haut que ce que nous avions vu dans nos rêves les plus merveilleux... [https://www.facebook.com/AntiokiaOrient/ posts/918232211531373] (23.12.2015)

Sur la D50 lorsque je veux la soulever en tirant sur le guidon $\mathrm{j}$ ai sur 10 ou $20 \mathrm{~cm}$ la roue reste au sol comme si la suspension était rompue après elle se soulève mais ça fait un très grand débattement il faut vraiment soulever haut pour faire décoller la roue $d$ après vous de quoi ça peu provenir c est la justement la ou je pensai à une fourche a bain d huile et qu il $\mathrm{n}$ y aurai plus $\mathrm{d}$ huile ou autre chose je $\mathrm{n}$ ai pas eu le temps de me pencher dessus car je préfère terminer la SP50 mais je commence à y penser [http:// www.motobecane-club-de-france.org/forum/ viewtopic.php?t=20012] (23.12.2015)

REMARQUES : Soulever haut (I) s'applique à une passion, un désir, une force ou un enthousiasme qui donnent à quelqu'un de l'élan, une certaine énergie, le poussent à agir dans une certaine direction. Le sujet peut aussi référer à quelque chose d'imaginaire comme le rêve, qui a pour effet d'émouvoir profondément quelqu'un. (II) se dit des mouvements ascendants et brusques d'une partie du corps (ici : la poitrine), signe d'une respiration profonde. Le dernier exemple du CW actualise le sens concret désignant un niveau de hauteur. Haut reste invariable et est modifié par encore très, plus, si, très.

\section{Soupçonner juste}

Soupçonner, supposer avec exactitude, conformément à la vérité

Emploi absolu

1722 LÉLIO. Je te dis qu'il ne me reste plus qu'une simple curiosité, c'est de savoir s'il ne se passerait pas quelque chose dans le cœur de la Comtesse, et je donnerais tout à l'heure cent écus, pour avoir soupçonné juste (Pierre de Marivaux, La Surprise de l'amour) 
1734 La porte n'était que poussée, je ne pensais pas que ce fût la peine de frapper à une porte à demi ouverte, et j'entrai tout de suite à cause de la commodité. J'avais soupçonné juste, on lisait au chevet du lit de Mme de Fécour, qui était couchée (Pierre de Marivaux, Le Paysan parvenu)

CORPUS WEB :

Je le soupçonne juste, en plus de ne pas être fondamentalement de droite, d'être un vilain faussaire qui serait entré par effraction dans la marmite du conseil municipal. Au pire il y aurait " tromperie sur la marchandise » [http://lespensements.free.fr/adversaire.htm] (23.12.2015)

REMARQUES : Soupçonner juste se dit du fait de deviner, d'entrevoir, de percevoir quelque chose avec justesse, les pressentiments ou la vision des choses du sujet se voyant confirmés. Le CW illustre, à titre d'exemple, l'emploi de juste comme adverbe de restriction équivalent à seulement, fonction dans laquelle il quitte le groupe verbal pour faire partie de l'énoncé qu'il introduit : je le soupçonne // juste d'être un vilain faussaire. Juste reste invariable.

\section{Soupirer bas}

I. soupirer tout bas : soupirer faiblement, en secret

Intransitif

1627 À peine la parole avoit quitté sa bouche, Qu'un regret aussi prompt en son ame le touche :

Et mesurant sa faute à la peine d'autruy, Voulant faire beaucoup, il ne peut d'avantage Que souspirer tout bas, et se mettre au visage,

Sur le feu de sa honte, une cendre d'ennuy (François de Malherbe, Les Poésies)

1734 MARTON. C'est à quoi je songeais : mais il y a une petite difficulté à cette commission-là ; c'est que le maître a gâté le valet, et Frontin est le singe de Rosimond ; ce faquin croit apparemment m'épouser aussi, et se donne, à cause de cela, les airs d'en agir cavalièrement, et de soupirer tout bas ; car de son côté il m'aime (Pierre de Marivaux, Le Petit-Maître corrigé) 1840a Sévère revient : Pauline le revoit et soupire tout bas, même tout haut (Charles SainteBeuve, Port-Royal)

1840b Ainsi, quand tout bas tu soupires, De ton cœur partent des sanglots, Comme un son s'échappe des lyres, Comme un murmure sort des flots ! (Victor Hugo, Odes et ballades)

II. Dire faiblement, dans un soupir Transitif

1631 Et parce qu'elle s'esveilla avec un grand souspir, s'estonnant elle-mesme de pouvoir vivre avec tant de passion, elle souspira assez bas tels vers (Honoré d'Urfé, L’Astrée)

1864 Mais, au bout d'un instant, Catherine, joignant les mains, soupira tout bas :

- Oh ! Mon Dieu ! Que c'est beau !... c'est une montre

(Émile Erckmann et Alexandre Chatrian, Le Conscrit de 1813)

\section{CORPUS WEB :}

C'est effectivement lamentable.... Les gens sont vraiment sans scrupule aucun... Du balai les sacs !! Laissez la spontanéité dans les festivals (utopie ?) Bravo Mr Morvan pour avoir jeté le caillou dans la mare !!! Quant à l'exilé malouin (de Saint-Malo ??), il dit enfin tout haut ce que d'autres soupirent bas : On sent le vrai amoureux de BD, non ? [http://www.bdparadisio.com/ scripts/foritems.cfm?IdSubject $=0520213227 \&$ Star tPage=2] (17.12.2015)

Faut-il dire, très haut et fort le soupir et toute la précarité du peuple, conformément au pouvoir que confère la presse aux journalistes, celle d'informer le public, de porter haut la voix des sans voix ? Ou soupirer bas avec le peuple en regardant à son salaire mensuel, aux contingences immédiates -oh combien nombreuses et dont la gestion impose une posture garantissant le pain quotidien ? [https://www.facebook.com/ permalink.php?id=211130505677735\&story_ fbid=286231834834268] (17.12.2015)

REMARQues : Soupirer tout bas (I) se dit du fait d'éprouver secrètement, intérieurement de la douleur, du regret ou de l'amour et de l'exprimer à travers un léger soupir. (II) désigne le fait de 
dire quelque chose faiblement dans un soupir, de l'exprimer sur un ton plaintif et doux. Notons l'opposition avec soupirer haut dans l'exemple de 1840a et avec dire haut dans le CW. Bas reste invariable et est modifié par assez, tout.

\section{Soupirer bref}

Pousser un soupir bref

Intransitif

1364 Et il le fist sans contredire, Si qu'en souspirant, court et brief Je li fis escrire ce brief (Guillaume de Machaut, Le Livre du voir dit, 3047)

REMARQUES : En ancien français, soupirer bref réfère à un animé qui, en signe de contestation ou pour montrer son mécontentement, pousse un petit soupir, de courte durée. Notons la collocation court et bref, où bref vient renforcer l'idée de courte durée.

\section{Soupirer court}

Pousser un soupir bref, exprimer sur un ton plaintif

$\pi$ soupirer bref

\section{Soupirer fort}

Pousser de gros soupirs, se lamenter Intransitif

1177 Mes sire Yvains plore et sospire Si fort, qu'a painnes li puet dire : Dame, cist termes est trop lons.

Se je pooie estre colons Tores les foiz que je voldroie, Mout sovant avuec vos seroie (Chrestien de Troyes, Yvain ou Le Chevalier au lion, 2580)

1250 Tant les ot escoutés, ne fina d'oreillier, Si grant pitié en a qu'il prist à lermoier Et du cuer en parfont moult fort à souspirer (Doon de Mayence, p. 166)

+1313 Grant piece atendre li couuint Tant que li ceualiers reuint A lui et souspira mout fort Et mait en son cuer grant effort D'encontre le mal rebeller, Si demanda au baceller C'aucunne nouuielle li die Pour conforter se maladie (Jean de Condé, Poèmes [1313-1337], 2063)
1393 « Par foy, dist ly contes, il ne m'en est gueres, plus m'est de ce que je voy. » Et lors regarde ou ciel et commence a souspirer plus fort que devant (Jean d'Arras, Mélusine, p. 152 [manuscrit Ars])

+1415a Elas ! elle s'esbastoit,

Et bonne chiere faisoit

A tous autres, fors qu'à moy ;

Dont mon cuer fort souspiroit,

Quant elle me regardoit,

Je vous jure par ma foy

(Charles d'Orléans, Poésies complètes

[ 1415-1440], I [poésies attribuées], p. 205)

$+1415 \mathrm{~b}$ C'est par vous que tant fort souspire,

Tousjours m'enpire ;

À vostre avis, faites vous bien

Que tant plus je vous vieulx de bien

Et, sus ma foy, vous m'estes pire !

(Charles d'Orléans, Poésies [ 1415-1440],

II, Rondel CCCCXVIII, p. 534)

\section{CoRpus Web :}

pareil pour moi, le petit déj ne passe pas. j'ai super soif, alors je bois de l'eau, mais ça n'a pas l'air d'arranger mes nausées... en plus je sais pas vous, mais je peine à respirer convenablement, je passe un temps monstrueux à soupirer fort, comme si j'avais un grand besoin d'air dans mes poumons... ça vous le fait ? [http://forum.jumeaux-et-plus.fr/index. php?topic=51482.11060;wap2] (17.12.2015)

Tu sais qu'il aime se faire mordre le lobe d'oreille, mais qu'il n'aime pas se faire lécher l'intérieur de l'oreille. Tu sais qu'il va soupirer fort quand tu prends ses couilles dans ta bouche de cette manière bien précise [http://jesuisvenu. $\mathrm{com} / \mathrm{project} / \mathrm{ma}$-meilleure-chum-de-fille] (17.12.2015)

C'est comme beuguer sur un article des fois, tu sens que ca stresse les gens « quoi ? le code barre ne fonctionne pas ? et voilà, j'avais acheté un vase c'est baisé ! ya rien qui va dans ma vie, je vais devoir revenir pour çà ». Et puis, il y a la 2ème étape, celle quand tu appelles un service pour avoir le code barre. Là, tu as souvent des gens patients mais ce sont les autres, ceux qui attendent. Eux, ils sont forts. Ils soupirent forts, généralement ont $2 / 3$ articles et des trucs qui servent pas à grand chose genre la combinaison : 
café + 1 cahier et une baguette [http://zilselance. over-blog.com/2015/08/j-encaisse-tu-encaissesil-encaisse-nous-encaissons.html] (17.12.2015)

REMARQUES : Au figuré et dans un registre plutôt poétique, soupirer fort désigne le fait de pousser plusieurs soupirs, manifestation d'une douleur spontanée et sincère du sujet, d'une certaine tristesse, causée souvent par un amour déçu ou insatisfait. Dans le CW, soupirer fort réfère à la respiration d'une personne en difficulté ou pendant l'acte sexuel, ainsi que, dans le dernier exemple, au soupir comme signe de protestation. Fort reste invariable dans la majorité des cas, mais, dans le quatrième exemple du CW, il s'accorde avec le sujet au pluriel tout en gardant son interprétation adverbiale. Il est modifié par moult, plus, si, tant.

\section{Soupirer grief (grave)}

Soupirer en manifestant sa peine, sa douleur, son désir

Intransitif

$\sim 1000$ Ala ciptad cum aproismet et el lauid el lasgarded deson piu cor greu sus piret dessos sanz olz fort lagrimez Hierussalem. Hierussalem (La Passion du Christ, 51)

-1300 Lors plore Charlemaignes et sospire mout grief,

N'a si dur home an terre cui n'an preïst pitiez (Jehan Bodel, La Chanson des Saisnes [fin XIII] $]$, 2972)

\section{Corpus WeB :}

et quand je viens débarrasser, je soupire grave pour te montrer à quel point ça me gonfle, des clients comme toi... très cher ami, rassure-toi, tu ne m'y verras plus, dans ton établissement ! [http://www.melonthecake.com/2013/05/meloau-resto-le-pain-du-chatelain] (17.12.2015)

elle et sa fille extra amoureuse de moi et quand j'ai dit au deux que je voulait plus= drame mais elle sont au paradis. 17 filles qui soupirent grave et un jour malade et hosto hou lala [https:// ar.answers.yahoo.com/question/index?qid=2007 1208140635AAwou2F] (17.12.2015)

Oui, sûrement. Les moments les plus durs dans la vie sont ceux qui font apprendre. (Elle soupire, grave et concentrée. Et lâche dans un murmure.) J'aime bien ma vie, même si je me pose trop de questions. Mais ce n'est que comme ça que la vie est intéressante, non ? [http:// patriciakaascentral.chez.com/parismatch octobre2001.htm] (17.12.2015)

REMARQUES : Au figuré et dans un registre plutôt poétique, soupirer grief désignait, en ancien français, le fait de pousser plusieurs gros soupirs, manifestation d'une douleur spontanée et sincère du sujet, d'une certaine tristesse, causée souvent par un amour déçu ou insatisfait. Grief est modifié par moult. Dans le troisième exemple du CW, l'adjectif concentré, auquel grave est coordonné, s'accorde au féminin avec le sujet. Même si la forme de grave ne manifeste pas l'accord au féminin singulier, on peut supposer qu'il est aussi au féminin, et dans ce cas-là, les deux adjectifs permettent également une interprétation de prédicat second orienté vers le sujet. Grave reste invariable dans le deuxième exemple du CW. Il est modifié par moult.

\section{Soupirer haut}

I. Soupirer bruyamment, ouvertement Intransitif

1604 À peine je m'esveille et sens un tel defaut Qu'encor long temps après j'en souspire tout haut.

Mon Hector cependant qu'entre mes bras je presse

Demande qui me tient, me baise, me carresse

(Antoine de Montchrestien, Hector)

1612 À peine s'estoit-elle mise en terre pres de luy, qu'elle l'ouyt souspirer fort haut (Honoré d'Urfé, L’Astrée)

1627 Ce cahos et cette confusion de tant de difficultez l'agiterent de telle sorte qu'il ne put s'empescher de souspirer diverses fois, assez haut pour estre entendu de ces deux bergeres, qui n'ayans pu clorre l'œil pour dormir, l'avoient toutesfois tenu clos pour en faire le semblant, afin de ne point interrompre son repos (Honoré d'Urfé, L’Astrée)

1631 mais voyant qu'elle n'y estoit point, elle ne se peut empescher de souspirer si haut que Leonide, que le sommeil commençoit peu 
à peu de lasser, l'entr'ouyt et estendant ses bras sur elle, luy demanda si elle se trouvoit mal (Honoré d'Urfé, L’Astrée)

1884 Tant de coquines ne se débarbouillent même pas! Chanteau, les yeux tournés également vers la chatte, soupirait tout haut, dans cette plainte continue et involontaire, dont lui-même perdait conscience.

- Vous souffrez davantage ? lui demanda le docteur (Émile Zola, La Joie de vivre)

1937 La grand-mère se plaignait, rêvait, soupirait tout haut : le petit garçon prêtait l'oreille, ouvrait les yeux, saisissait les demi-mots, les arrière-pensées, et tout cela venait nourrir la confuse, étrange et tourmentante mythologie intérieure (Pierre Drieu la Rochelle, Rêveuse Bourgeoisie)

II. Dire dans un soupir

Transitif

1656 Si ne pouvant forcer mon humeur volontaire

Je trouble par mes cris le silence d'un bois; Les oyseaux ont pitié de ma dolente voix, Et souspirent tout haut l'ennuy que je dois taire (Guillaume Colletet, Poésies diverses)

1660 SGANARELLE. (Il soupire haut) Hay ! (Molière, Sganarelle ou Le Cocu imaginaire)

1950 Parfois aussi, lorsqu'il pleuvait en novembre et que l'orage grondait, m'man Délia regardait le ciel et soupirait tout haut :

- Pauvre m'man Tine!

Je ne disais rien. Mon cœur devenait chargé et prêt à éclater comme le temps (Joseph Zobel, La Rue Cases-Nègres)

1965 Et, comme j’ai honte de cet état de camée, je soupire bien haut après le dimanche " enfin, je vais pouvoir lire un peu ", et je maudis poliment le boulot qu'on m'impose, " c'putain de linge, on n'a jamais fini » (Albertine Sarrazin, La Cavale)

\section{CORPus Web :}

Pratiquer le contentement est un moyen de conserver son temps et son énergie vitale. Par exemple, si on se trouve dans des embou- teillages et que l'on soupire haut et fort : " Je ne supporte pas les embouteillages ! », c'est un nonsens, car dans l'absolu, on le supporte. Ce type de jugement écarte en fait de la réalité [http:// www.capyoga.com/\#!10-cl\%C3\%A9s-pourpratiquer-avec-s\%C3\%A9r\%C3\%A9nit\%C3\%A9/ c1hx6/5550b04c0cf2adc1ad244a39] (17.12.2015)

J'ai déjà écrit au service d'aide du site car j'épprouvais certains problême à accéder à ce " service en ligne » (c'est hilarant cette appelation, vraiment). Maintenant que j'ai changé de système d'exploitation, et de version de navigateur rien que pour leurs yeux virtuels, j'aurai aimé souhaiter un confort que je n'ai pas. C'est bien simple dès que j'arrive sur ce site je soupire haut et fort [http://www.ciao.fr/Societe Generale_Avis_88256] (17.12.2015)

REMARQUES : Soupirer fort (I), intransitif, réfère à un animé qui, en signe de contestation, pour montrer son mécontentement, sa désapprobation ou sa souffrance, se lamente, soupire fortement, sans aucune discrétion. L'emploi transitif est associé au sens 'dire dans un soupir' (II). Notons la collocation haut et fort. Haut reste invariable et est modifié par assez, bien, diverses fois, fort, si, tout.

\section{Soupirer menu}

Soupirer légèrement, faiblement; pousser de petits soupirs

Intransitif

-1200 Tandremant vai plorant et sopire menu :

«Par Deu, baus sire peres, tor an avez eü » (Floovant [fin XII ${ }^{\mathrm{e}}$, 815)

REMARQUES : Au figuré et dans un registre plutôt littéraire/poétique, soupirer menu désignait le fait de pousser plusieurs petits soupirs, de soupirer faiblement, comme manifestation d'une douleur spontanée et sincère du sujet, reflet d'une certaine tristesse. Notons la collocation avec le verbe pleurer qui exprime le chagrin, l'affliction manifeste du sujet, soupirer venant compléter et renforcer l'image de la douleur. VoIR AUSSI : pleurer menu 


\section{Soupirer profond}

Soupirer profondément, pousser de profonds

soupirs

Intransitif

+1200 « Si le lessiez morir chetif,

Si ferai je vous, se je vif !»

Li peres l'ot : parfont souspire ;

Il se repensse et se remire

(La Housse partie [XIII'] ${ }^{\mathrm{e}}$, 367)

REMARQUES : Soupirer profond désigne le fait de pousser des soupirs très intenses, manifestation d'une douleur spontanée et sincère du sujet, d'une certaine tristesse ou d'une grande lamentation.

\section{Souquer dur}

I. Tirer très fortement sur les rames

Intransitif

1867 Chaque embarcation défila à son tour, et je puis affirmer qu'à bord du canot que je montais, les hommes souquaient dur (Paul de Leusse, Souvenirs d'un aspirant de marine)

1948 On déborda tout de suite la petite chaloupe par bâbord, et l'équipage [...] commença à souquer dur pour tirer le plus possible dans l'ouest (Jean Giono, Fragments d'un paradis)

II. Travailler durement

Intransitif

1954 - C'est merveilleux. Qui a fait ça : lui ou toi ?

- Les deux ; moi je donne les ordres, il exécute. Il souque dur ; et il est très obéissant, dit-elle d'un air épanoui (Simone de Beauvoir, Les Mandarins)

\section{Souquer ferme}

Travailler, en faisant un grand effort

Intransitif

1932 Il pensa alors à la machine et à son chef qu'il avait entrevu en de rares occasions et toujours rapidement les jours qui avaient précédé le départ. Il lui téléphona :

- Allo. Grayson.

- Allo.

- Ici, le commandant. Comment ça marche en bas?
- Bien, mais nous souquons ferme.

- J'irai vous voir, aujourd'hui.

- Entendu.

Puis il reprit sa marche. Il avait d'autres soucis en tête. Le type du bateau était nouveau (Édouard Peisson, Parti de Liverpool)

\section{CORPUS WEB :}

Le soleil brille longtemps, car on est en été. Sur la rivière, les rameurs souquent ferme : c'est du sérieux. Ils tracent leur sillage entre les pédalos où les garçons roulent des mollets pour épater les filles qui gloussent quand des gerbes d'eau viennent les éclabousser [http://www.lexpress. fr/informations/echappees-belles_595339.html] (17.12.2015)

On cherche des rameurs qui sauront souquer ferme pour nous sortir de l'enlisement du découragement ! Le fleuve est peut être large mais il y a bien une autre rive... [http://www. dioceseauxarmees.catholique.fr/billets-duvicaire-general-archives/593-sortir-les-rames-etsouquer-ferme-.html] (17.12.2015)

En attendant quand les budgets sont pris en tenaille entre les réductions drastiques des crédits d'État et la vigilance des conseils généraux, les expérimentateurs souquent fermes [http:// www.handipole.org/IMG/pdf/dares_difficulte_ emploi.pdf] (17.12.2015)

REMARQUES : Au concret, souquer ferme désigne l'action d'un être humain qui rame avec énergie, qui tire fortement sur les avirons (premier exemple du CW), aussi transposé par métaphore au domaine religieux (deuxième exemple du CW). Dans les exemples de 1932 et le dernier exemple du CW, ce terme de marine est pris au sens de 'travailler beaucoup, avec ardeur, s'engager à fond'. Ferme reste invariable dans la majorité des cas, mais, dans le troisième exemple du CW, il s'accorde avec le sujet au pluriel en gardant son interprétation adverbiale.

\section{Sourire bas}

sourire tout bas : sourire très discrètement, secrètement, en silence

Intransitif

1751 En rougissant à son vainqueur se livre, Puis moins timide, et soûriant tout bas, Avec transport de tendresse s'enivre, 
Presse à son tour son Amant dans ses bras (Baculard d'Arnauld, La Statue de Pigmalion)

1761 La pudeur alors n'est que sur le visage ; l'amour-propre sourit tout bas (L'Observateur littéraire)

1782 On sourit tout bas, et on le laisse dire, car cela le rend bien heureux

(Louis-Sébastien Mercier, Tableau de Paris)

1832 Aussi ce jeune peintre, à ce que l'on raconte,

En souriait tout bas, n'en tenant aucun compte,

Et s'éloigna silencieux,

Mais tout près d'Oletta sa peur est éveillée :

Il entend quelque bruit. C'est, dit-il, - la feuillée (Pétrus Borel, Rhapsodies)

1958 «Ma vie, c'est de sourire tout bas à la voix qui ne cesse de se faire entendre en moi, c'est de me réfugier avec lui, définitivement... » Je m'irritai contre Pradelle : pourquoi repoussait-il la solution que j'avais proposée? (Simone de Beauvoir, Mémoires d'une jeune fille rangée)

\section{CORPuS Web :}

regarde devant toi celle que tu n'aimes pas celle que tu conchies celle qui n'est plus celle qui sourit bas puisque celle là elle est partie oui partie en exil de là où l'on ne revient pas je suis l'autre maintenant celle qui sourit haut faut que tu t'y fasses ou pas je suis moi pour toi je suis celle que tu n'aimes pas [http://ethel.canalblog. com] (17.12.2015)

REMARQUES : Sourire bas se dit du fait d'esquisser un léger sourire, discrètement ou avec réserve en réaction à une situation drôle ou cocasse. Au figuré, le complément désigne une entité abstraite sur laquelle le sujet porte un regard favorable et bienveillant. Notons l'emploi de sourire haut, mis en opposition avec sourire bas. Bas reste invariable et est modifié par tout. VoIR AUSSI : rire bas

\section{Sourire blanc}

Sourire en révélant une (fausse) pureté Intransitif

1874 Oh ! Ne la troublez pas ! La solitude seule
Et le silence ami par son souffle adouci Ont le droit de savoir pourquoi sourit ainsi Blanche, oh! si blanche, avec ses rougeurs d'églantine, Debout contre le roc, la Naïade argentine ! (Théodore de Banville, Les Exilés)

1887 Elle daigna même sourire à une plaisanterie innocente que je me permis à l'égard de la bonne en tablier et en bonnet qui nous servait notre potage dans des assiettes d'une faïence épaisse comme la main... Elle souriait blanc avec sa bouche rouge (Paul Bourget, Ancien Portrait)

1985 - Ah, merde Cécelle, faut qu'on s'voit tous les deux. J'ai un réacteur maousse qui t'fera trembler la carlingue !

Cécelle sourit jaune. Badette sourit blanche. Et moi j'ai le rat de la colère en travers du larynx. Le glandomètre au maximum.

- Arrête tes vannes Mandrax ! j'lance abruptement (Frédéric Lasaygues, Vache noire, hannetons et autres insectes)

\section{CORPuS WEB :}

Jacquie mord ses lèvres. Elle sourit blanc. « Tu as eu raison, parce que ce sont des qualités généralement associées aux gays » [http://www. liberation.fr/medias/2005/04/27/1-hetero_517831] (13.12.2015)

REMARQUES : Sourire blanc a un grand potentiel métaphorique parfois difficile à pénétrer et à interpréter. Blanc peut référer à une apparence moralement et/ou physiquement blanche ('pure'), exempte de fausseté, de même qu'à un visage qui pâlit sous l'effet d'une émotion. L'accord au féminin avec le sujet renforce cette interprétation (ex. de 1985). Dans l'exemple de 1887, c'est la blancheur des dents qui occupe le devant de la scène. Blanc peut s'accorder avec le sujet et être modifié par ainsi, si.

\section{Sourire bleu-clair}

Sourire de manière agréable, avenante, en montrant de la bonne humeur Intransitif

1933 Papa grondait, une minute, comme un grand félin courroucé. Nous ne savions plus où nous cacher, dans la crainte d'une 
colère. L’orage s'éloignait. Papa se reprenait à sourire bleu-clair. Nous étions soulagés et, dans le secret de notre cœur, un peu déçus, frustrés d'un spectacle grand et magnifique (Georges Duhamel, Le Notaire du Havre)

REMARQUES : Sourire bleu-clair réfère à une personne qui, après un moment de colère ou d'énervement, prend une expression légèrement rieuse, en signe de joie, de satisfaction, de bonne humeur ou de sympathie, l'idée d'un ciel bleuclair après l'orage qui menaçait servant de base métaphorique.

\section{Sourire clair}

Avoir un sourire clair, rayonnant

Intransitif

1963 Et il sourit encore plus clair (Le Figaro littéraire, 26 décembre 1963 / Grundt : 334)

Corpus Web :

Elle ponctue : "Oui, impossible de repartir avec un petit doute dans la tête. » Et ils se sourient, clair, large : leur couple n'a rien à faire du vague à l'âme [http://www.illustre.ch/ Navigation-Dominique-Wavre-Michele-ParetBarcelona-World-Race_79466_.html] (13.12.2015)

REMARQUES : Sourire clair réfère à une personne dont le sourire, expression d'un grand bonheur, d'une vive satisfaction, illumine le visage, le rend rayonnant. Clair reste invariable et est modifié par encore plus. Notons la mise en série de se sourire clair, large.

\section{Sourire haut}

En opposition avec sourire bas : sourire

publiquement, ouvertement

$\lambda$ sourire bas

\section{Sourire jaune}

Avoir un sourire forcé, qui dissimule mal le dépit ou la gêne

Intransitif

1789 Il ne restait que le capitan-pacha, lequel se grattait le cul d'un geste ironique, et souriait jaune (Dom-Bougre aux ÉtatsGénéraux)
1841 On dit au village qu'il [= le médecin de village] ferait rire un mort, et il en rit : bien différent de son confrère de ville, dont l'habit déteint sur la figure, qui interroge gravement, examine son sujet comme on regarde passer un convoi, médite, cligne de l'œil, sourit jaune et répand dans l'escalier un son de cloches et une odeur d'église (Écarnot, Le Médecin de village)

1892 MONSIEUR VERNET. J'espère que, d'abord, ma femme vous cracherait au visage.

Il a dit cela d'une telle façon que je me détourne, comme pour éviter réellement un peu de salive. Je souris jaune (Jules Renard, L’Écornifleur)

1922 L'après-guerre. Nous sommes écrasés, comme il est logique. Notre budget de cette année est en déficit de dix milliards ; on escomptait quatorze ; de sorte que nous devons nous réjouir de n'avoir que dix millards [sic] d'excédent de dépenses : nous sourions jaune (Paul Hazard, Notes sur l'Italie nouvelle)

1936 - Zzzt, petite fille..., gronda doucement Meynestrel.

Mithœrg, décontenancé, souriait un peu jaune. Ses cheveux hérissés lui donnaient facilement l'air de quelqu'un qui va se mettre en colère. Il s'y mettait, d'ailleurs, assez souvent (Roger Martin du Gard, Les Thibault. L'Été 1914)

1966 À plus d'une hauteur d'homme, par manière de fantaisie sans doute, à moins qu'il ne fût question d'égayer le site, une entreprise de publicité placardait ses affiches qui, bien que criardes, n'arrivaient pas à donner un semblant de vie au coin. La Vache Qui Rit souriait jaune, B. B. avait une barbe charbonneuse et le lait irisé du pastis se rouillait doucement dans son verre collé sans malice sur une conduite d'eau crevée depuis longtemps (Robert Giraud, La Coupure)

1985 - Ah, merde Cécelle, faut qu'on s'voit tous les deux. J'ai un réacteur maousse qui t'fera trembler la carlingue !

Cécelle sourit jaune. Badette sourit blanche. 
Et moi j’ai le rat de la colère en travers du larynx. Le glandomètre au maximum.

- Arrête tes vannes Mandrax ! j’lance abruptement (Frédéric Lasaygues, Vache noire, hannetons et autres insectes)

1995 « Courage, Gil Blas! Pousse ta fortune, mon ami ! Mets du foin dans tes bottes! Te voilà en bon chemin ! » Elle hochait la tête, souriait un peu jaune... Elle l'aimait. Et parce qu'elle l'aimait, elle souffrait qu'il ne fût pas l'enfant qu'Henri aurait souhaité (Françoise Chandernagor, L'Enfant des Lumières)

Pronominal (réciproque)

$1938 \mathrm{Tu}$ vois, elles me regardent pareil que si j'étais du suce-miel. Et maintenant, remarque un peu comme elles se sourient jaune toutes les deux. Elles font semblant d'être d'accord, braves, gentilles, mais au fond elles se mangeraient. Il y a pas plus pocrite que la femme moureuse (Albert Cohen, Mangeclous)

CORpus Web :

Comme lui, un tas de gens sont assis, sont invisibles, murmurent, vivent de la gloire des martyrs, n'ont jamais pris les armes mais seulement la parole, sourient jaune, détestent le peuple comme lui, croient que personne ne les mérite, ne croient pas qu'ils ont des comptes à rendre et pensent qu'ils sont uniques [https://www.facebook.com/kamel.daoud.7/ posts/610979762317873] (13.12.2015)

Ces jeunes femmes qui sourient jaune ne s'autorisent d'évidence pas à croquer dans la vie. Des silhouettes décharnées, des sourires édentés (dûment retouchés dans Photoshop), est-ce là l'image de la féminité, de la santé et de la beauté que veulent nous donner les créateurs ? On croit rêver [http://www.editionsluigicastelli.com/ editionsluigicastelli/index.php?sp=page\&c=790] (13.12.2015)

Très silencieux, sous le drapeau français de la mairie, c'est très solennel. On n'a pas le chiox, il n'y a qu'une minuscule radio à piles ramenée par un gars. Le connard parle, les gens se sourient jaune [http://ctx-n-flrs.zikforum.com/t1993les-rassemblements-spontanes-nuit-du-31-au-1er] (13.12.2015)
« Putain, elles nous calculent même pas ! », lance, excédé, un des jeunes. Ces amis acquiescent. Ils " hallucinent " grave. Puis sourient jaunes. Et rapidement se taisent [http://un-regard-une-plume.over-blog.com/ article-31902129.html] (13.12.2015)

REMARQUES : Dans une situation gênante, inconfortable ou contrariante, ou simplement fausse (comme les modèles dans le domaine de la mode dans le deuxième exemple du $\mathrm{CW}$ ), sourire jaune se dit du fait de sourire de manière forcée, par dépit ou gêne, ou parce qu'il le faut. Jaune reste invariable dans la majorité des cas, mais dans le quatrième exemple du CW, il s'accorde avec le sujet au pluriel, tout en gardant son interprétation adverbiale (hypercorrection). Il est modifié par un peu. Notons l'emploi du groupe halluciner grave, où grave est un intensifieur. VOIR AUSSI : rire jaune

\section{Sourire large}

Avoir un large sourire, sourire largement, faire un grand, large sourire

Intransitif

1954 Dépassant tout le monde d'une bonne tête, il souriait large et paraissait prendre un vif plaisir à écouter les opinions, les gloses et les répliques qui fusaient de toute part, sans qu'on pût même savoir qui parlait (Hervé Bazin, L'Huile sur le feu)

1974 Jeannette, toute brune dans sa robe de lin blanc, était jolie à croquer, avec son faux air de Katharine Hepburn : des anglaises dansaient sur son long cou, ses yeux noisette, avec une tache verte sur l'un d'eux, étaient ombragés de longs cils de soie, sa bouche au contour bien dessiné s'arrondissait comme un fruit mûr et quand elle souriait un peu large ses dents éblouissantes paraissaient vouloir mordre (Robert Sabatier, Les Noisettes sauvages)

\section{CORPUS WEB :}

Quand on sait que la Marine méchante est juste devant elle, on sourit large et on se dit qu'elle a des « .... », cette petite [http://www.purepeople. com/article/video-prime-star-ac-8-solene-s-estnoyee-au-fond-de-la-piscine-mais-britney-a-faitde-l-audience-reactualise_a20244/1] (13.12.2015) 
Émotion, amertume et comédie De ces conversations-interviews, retranscrites avec fidélité, est né un spectacle qui mixe photos, théâtre et chansons, écrit de façon burlesque en forçant le trait sur une Sabrina qui parle fort et sourit large [http://www.letelegramme.fr/local/morbihan/ lorient/ville/sabrina-pink-faire-entendre-laparole-des-habitants-24-06-2009-439619.php] (13.12.2015)

Nada, Que Niet! Y en a qui REFUSENT l'idée que tu rentres tranquille chez toi. Eux ils te cherchent. $\mathrm{Tu}$ ne les as jamais vus, mais ils te cherchent quand même ! Vas savoir $i$

1. ils te matent d'un regard aussi vide que vicieux

2. ils te sourient large avec des dents aussi sales que des mouches à merde

[http://www.forumfr.com/sujet288474-ladrague-a-deux-balles-faut-du-souffle.html] (13.12.2015)

Il faut qu'il lui dise. Mais avant, il doit avoir confirmation. [...] Une fois Eriol en sa douce compagnie, Sakura se sent bien mieux. Elle lui pose plein de question, genre, on est où ici ? À Poudlard, Sakura! Il lui explique entre plusieurs " woé ?! ». Ils se sourient larges tous les deux, content d'enfin retrouver l'autre après leur séparation à Tomoéda [http://clampdimensionworld. forumactif.org/t57-de-1-orient-a-l-occident] (13.12.2015)

REMARQUES : Sourire large se dit du fait de faire un grand sourire, d'avoir un visage rayonnant, le sujet exprimant un grand bonheur, une vive satisfaction, sincères ou feints. Large reste invariable dans la majorité des cas, mais dans le troisième exemple du CW, il s'accorde avec le sujet au pluriel du verbe pronominal réciproque tout en gardant son interprétation adverbiale. Il est modifié par un peu.

\section{Sourire mauvais}

Sourire avec méchanceté

$\lambda$ regarder aigu

\section{Soutenir droit}

Garder, conserver une position verticale

Pronominal

1784 Ce qu'il y a d'admirable, c'est qu'il règne entre tous ses membres un équilibre si parfait, si difficile à conserver, si contraire aux lois de notre mécanique, qu'il n’y a point de sculpteur qui puisse faire une statue à l'imitation de l'homme, plus large et plus pesante par le haut que par le bas, qui puisse se soutenir droite et immobile sur une base aussi petite que ses pieds

(Bernardin de Saint-Pierre, Études de la nature)

\section{CORPUS Web :}

Maintenant, pour ne pas dire de bêtises, il n'est pas expressément prévu dans les textes que la dissertation soit écartée, mais j'imagine mal un professeur qui arriverait à soutenir droit dans les yeux qu'une dissertation est " une épreuve à caractère pratique " [http://avoirlebarreau. blogspot.co.at/2015/07/lepreuve-pratique-ditede-specialite.html] (13.12.2015)

cv-air : ce serait bien si vous commentiez vos photos ? on ne sait pas d'où elles viennent ???

Est-ce possible?

dixneuf001 : Festival de l'Homme... où sont les toilettes?

Siorac4 : Et les légendes des photos ? Elles sont où les légendes ?!!

FG000 .Ministres et hauts fonctionnaires auront toujours un balais pour les soutenir droit. Toute une symbolique de l'état, vu par des têtes à géomètrie variable [http://www.lefigaro.fr/ photos/2013/09/02/01013-20130902ARTFIG004 94-24-heures-photo.php] (13.12.2015)

REMARQUeS : Au pronominal (I), le sujet de soutenir droit désigne une chose (ici : une statue) dont le socle lui permet d'avoir une position stable et fixe, de conserver une position verticale et de ne pas tomber (prédication seconde). Notons la collocation droit et immobile. Dans le premier exemple du CW, soutenir droit actualise l'acception de 'défendre sans broncher'. Droit peut s'accorder avec le sujet quand il désigne une position, fonctionnant donc comme prédicat second, mais l'accord est absent dans le dernier exemple du CW. 


\section{Soutenir ferme}

\section{Porter solidement, avec force}

Transitif

1552 Ses cuisses soyent comme faites au tour, En grelissant, rondes tout à l'entour, Ainsi qu'un Terme arrondi d'artifice Qui soustient ferme un royale edifice (Pierre de Ronsard, Le Premier Livre des amours, p. 137)

II. Soutenir, supporter (quelqu'un), affirmer (quelque chose) avec ardeur, assurance

Transitif

1594 Toutesfois il y a quelque apparence qu'ils parlerent d'avoir un Roy : car un nommé Trepelu, vigneron de Suresnes, soustint fort et ferme que le Roy estoit le vray astre et le vray soleil qui avoit depuis si long temps regy et esclairé la France (Satyre Ménippée)

1766 L'intrépide patriarche n'en demeura point là ; il soutint fort et ferme que l'autorité séculière est au-dessous de l'autorité ecclésiastique (Henri-Joseph Dulaurens, Le Compère Mathieu)

1870 Si Chauvel est là, je le soutiendrai ferme ; mais s'il n'y est pas, autant ne pas me nommer du tout, car je refuse d'avance. Maître Jean parlait simplement et les autres se grattaient l'oreille

(Émile Erckmann et Alexandre Chatrian, Histoire d'un paysan)

1963 Laval le lui avait promis, Déat le soutenait ferme, le Maréchal se serait laissé convaincre, seulement le hic, l'os magistral, les ricains en Normandie avaient contrarié son destin, mis un point final à une carrière politique qui s'annonçait des plus brillantes (Alphonse Boudard, La Cerise)

III. Se maintenir dans une position, dans un état Pronominal

1851 Mais chaque fois elle se commanda le courage, étouffa un soupir, et se soutint ferme et résolue, comme une jeune sœur de charité qui voit pour la première fois une opération de chirurgie, et qui, prête à défaillir, surmonte son dégoût et son effroi par la pensée d'être utile et de soulager un membre de la famille du Christ (George Sand, Le Compagnon du Tour de France)

CORPus WeB :

Je suis de ceux qui soutiennent ferme que Karim WADE, ce pilleur de nos ressources et sa bande de laquais patentés devront être poursuivis dès la chute du régime libéral en 2012 [http://www.leral.net/L-ETAT-SE-PRELASSELE-PEUPLE-DANS-LA-MELASSE-_a15966.html] (13.12.2015)

Malgré les pratiques des prisons de l'occupation, qui contreviennent aux normes du droit international et des droits de l'homme, Sa'adat continue de soutenir, ferme et résolu, le peuple palestinien et ses droits [http://w41k.com/50783] (13.12.2015)

REMARQUES : Soutenir ferme (I) réfère à un socle ou support capable de porter, de soutenir ou de maintenir quelque chose dans une position stable, fixe. Lorsque le complément d'objet désigne un être animé (II), il se dit du fait d'aider quelqu'un à accomplir quelque chose, à traverser une épreuve dans laquelle il est engagé. (III) se dit du fait de continuer à soutenir ses idées ou d'y croire, de persévérer dans une direction avec énergie, fermeté, de manière inflexible, tenace. Notons les collocations fort et ferme et ferme et résolu. Ferme tend à l'emploi invarié (premier exemple du CW), mais il peut également fonctionner comme prédicat second qui s'accorde avec le sujet (1851 et le dernier exemple du CW), notamment dans le style littéraire et le discours religieux.

\section{Soutenir fort}

Dire (quelque chose) avec conviction, en étant sûr de soi ; apporter son soutien, encourager avec détermination

CORPUS WEB :

Emploi absolu

Vous êtes nombreux à soutenir fort et pour ça je vais vous balançer un album digne de ce nom. «Seul » mais j'suis pas Seul parce que y'a mes frères autour de moi et vous. 2016 est à nous on va sortir de l'ombre et on y retournera.. \#PaixÀLeursÂmes \#Seul \#OuPresque [https://www.facebook. com/YanisF2L/posts/1636593149921066] (13.12.2015) 
Les histoires inspirent les jeunes à voir qu'ils peuvent faire une différence si elles soutiennent forts dans le Seigneur. En outre, la lecture de l'Écriture pourrait provenir de 1 Timothée 4:12 où Paul dit à Timothée de ne pas laisser les anciens de l'église ne donnent pas d'importance en raison de leur jeunesse [http://savoir.minzu. gov.cn/idees-pour-le-programme-de-la-jeunessechretienne-de-la-journee] (13.12.2015)

Transitif

Vendredi soir, il faudra soutenir fort l'OLB! La tâche s'annonce rude mais rien n'est impossible face à la volonté des joueurs orléanais !... Bercy est en jeu ! [http://www.orleansloiretbasket.fr/ Ress_2162/Pro-A/Historique/Saison-2011-2012/ Calendrier-Resultats-/Elan-Chalon.html] (13.12.2015)

\section{Soutenir immobile}

Garder une position fixe

$\lambda$ soutenir droit

\section{Soutenir résolu}

Se maintenir dans une position, dans un état de manière tenace, déterminée, résolument ; persévérer

$\lambda$ soutenir ferme

\section{Stopper net}

Interrompre brutalement

Intransitif

1868 Soudain la machine stoppe net, sans commandement préalable : grand branle-bas à bord (Ludovic Hébert de Beauvoir, Voyage autour du monde)

1913 Il se lève, par énervement, fait quelques pas, les bras croisés, jusqu'à la fenêtre, où il stoppe net, les yeux vagues dans le ciel pluvieux (Roger Martin du Gard, Jean Barois)

Transitif

1928 La voiture de l'aéroport stoppe net à l'entrée du hangar, ouvert sur la nuit mêlée de pluie (Antoine de Saint-Exupéry, Courrier Sud)

1958 la violence des courants nationalistes encore accrue par le jeu des puissances qui ont réussi à stopper net l'expédition de Suez (Sélection du Monde, 15-21 mai 1958 / Grundt : 351)

1963 Tout à coup quelqu'un à la porte... On frappait. Ça l'a stoppé net.

- Qu'est-ce qui vient encore me faire chier? J'avais pourtant dit à personne de venir (Alphonse Boudard, La Cerise)

\section{CORPUS Web :}

LA FIJ et la FEJ appellent l'AFP à stopper net la dénonciation des accords d'entreprise [http:// www.ifj.org/nc/fr/news-single-view/backpid/1/ article/ifj-and-efj-call-on-afp-to-immediatelystop-denouncing-collective-agreements] (3.12.2015)

Salut, cela fait trois semaines que je prend du seresta 50 à raison de 3 par jour et je voudrais savoir si je peux stopper net ce medicament, car il commence à ne plus me faire beaucoup d'effet sur l'angoisse et particulierement la nuit ou il m'en faut 2 pour passer $8 \mathrm{~h}$ de sommeil ! [https:// www.psychoactif.org/forum/t9876-p1-Serestapuis-je-peux-stopper-net-medicament.html] (3.12.2015)

REMARQUES : Plus familier qu'arrêter net, stopper net se dit du fait de bloquer, d'arrêter le déroulement d'une action ou l'évolution de quelque chose tout d'un coup, brutalement. Net reste invariable. VoIR AUSSI : arrêter net.

\section{Suer ferme}

I. Faire un grand effort, peiner

Intransitif

1857 Qui te fournit la nourriture, l'éducation, l'habillement, et tous les moyens de figurer un jour, avec honneur, dans les rangs de la société ! Mais il faut pour cela suer ferme sur l'aviron, et acquérir, comme on dit, du cal aux mains (Gustave Flaubert, Madame Bovary)

1902 Piémontais blonds aux moustaches cendreuses, Bretons trapus aux joues cuites de soleil, yeux verdâtres de Celtes sous des fronts bas ternis de poussière, peinent fort, suent ferme et odorent (Jean Lorrain, Poussières de Paris) 
1947 Les petits Normands suaient ferme à leurs pupitres (Louis Aragon, Les Voyageurs de l'impériale)

\section{Transpirer beaucoup}

Intransitif

2015 Sous la mousseline de soie du grand couturier milanais, la jeune femme suait ferme (Mhairi McFarlane, Comme si c'était toi [trad.])

\section{CORPus Web :}

Le speaker vient de faire ses annonces, pour un déodorant particulièrement performant, mais les dirigeants de l'OM [= L'Olympique de Marseille] suent ferme [https://www.liberation.fr/ sports/1999/01/29/une-saison-a-l-om-le-cercledes-poetes-supportersle-peuple-marseillais-senerve-contre-le-m-securite_262445] (29.1.1999)

REMARQUES : Suer ferme est surtout employé au figuré. Le CW ajoute au sens (I) 'faire un grand effort', celui de 'avoir peur, de transpirer sous l'effet de la peur', emploi téléphoné car il est question de déodorant.

\section{Suer sec}

Suer sans avoir de gouttes de transpiration Intransitif

1960 On sue sec. La transpiration aussitôt qu'elle perle aux pores, s'évapore sans couler (France-Soir, 4-5 septembre 1960 / Grundt : 354)

\section{Corpus Web :}

4 heures à attendre le bus dans le village qui est bien désert par rapport à hier soir. Le ciel est couvert, l'air est humide et moite. Heureusement qu'il n'y a pas grand-chose à faire, on doit suer sec s'il fallait marcher par un temps pareil ! [http://denis.jacquemot.free.fr/E5/ETAPE25. HTM] (3.12.2015)

$\mathrm{Au}$ menu : préparer un gâteau au chocolat plus que parfait sous le regard d'un grand chocolatier réputé, revisiter des plats populaires comme la paella et la choucroute sous forme de... hamburgers et cuisiner de la blanquette de veau et du cassoulet pour les supporters de deux équipes de rugby au cœur du Stade de France. Ça va suer sec! [http://www.moustique.be/6130/ top-chef] (3.12.2015)
REMARques : Dans l'exemple de 1960, suer sec désigne un être animé qui, sous l'effet de la chaleur, d'un effort physique intense ou d'une émotion, élimine par les pores de la peau de la sueur qui sèche rapidement au lieu d'apparaître sous forme de gouttelettes. Dans les exemples du CW, sec est pris comme intensifieur 'beaucoup, dur, intensément'. Sec reste invariable. Notons l'emploi impersonnel familier de ça va suer sec. VoIR AUSSI : transpirer sec

\section{Suivre droit}

I. Suivre en ligne droite

Transitif

1665 Le Duc lui donna quatre Compagnies de vieilles Troupes de Piedmont, qui le suivirent droit à Valence : de sorte que le VIII. de Janvier, elles coucherent à Serre sur le Rhône (Nicolas Chorier, Histoire générale de Dauphiné)

1846 - Holà, Fernand, tu te trompes, mon garçon!

- C'est toi qui vois trouble, dit Danglars, il suit tout droit le chemin des VieillesInfirmeries.

- En vérité ! Dit Caderousse, eh bien ! J'aurais juré qu'il tournait à droite ; décidément le vin est un traître (Alexandre Dumas père, Le Comte de Monte-Christo)

1909 Il plaçait des wagons pour l'embarquement depuis vingt-trois ans. Auprès de son entêtement, celui d'une mule semblait du miel. Il suivait droit son idée, sachant bien, depuis si longtemps qu'il l'expérimentait, que dans la réalisation une idée vaut mieux que plusieurs, parce qu'elle est une, et que pour satisfaire tout le monde il ne faut plaire à personne (Pierre Hamp, Vin de Champagne)

1943 Vous n'aurez qu'à suivre le boulevard Montparnasse tout droit (Simone de Beauvoir, L'Invitée)

1957 Sa douce chaleur bientôt nous enjoint de nous enrouler, de nous envelopper.

D'abord, Albert-Birot se coule en la moulure :.. je suis tout droit les moulures qui suivent tout droit le plafond (Gaston Bachelard, La Poétique de l'espace) 
Emploi absolu

1721 Le bois tranché est celui qui a le fil de travers ; en sorte qu'au lieu de suivre tout droit le long de l'arbre, il le traverse souvent d'un côté à l'autre (Louis Liger, La Nouvelle Maison rustique)

1848 En face de cette hauteur où nous étions, Plouharnel se montrant sur la côte opposée, le clocher de son église, certes, paraissait facile à atteindre, il n'y avait qu'à suivre tout droit ainsi que disent les paysans. Comme si c'était chose fort aisée à faire que de suivre tout droit n'importe quoi, même quand on a devant les yeux un clocher ou une girouette ! (Gustave Flaubert, Par les champs et par les grèves)

1919 Il ne connaissait pas ces boyaux sinueux taillés dans la boue. Mais de loin en loin, des agents de liaison, ou des brancardiers lui disaient : " suis tout droit » et il allait tout droit sans vouloir se reposer (Roland Dorgelès, Les Croix de bois)

II. Continuer en se tenant droit Intransitif

1986 Il semblait en effet ne pas bien tenir sur elles [= ses jambes]. Après un signe d'invite il claudiqua vers le fond du hall carrelé de noir et blanc, à la surface duquel sa démarche oscillante évoquait une pièce d'échec insane, roi fou, reine ivre ou cheval emballé. Charles suivait droit comme une tour, par angles droits (Jean Echenoz, L’Équipée malaise)

\section{CoRpus Web :}

car je trouve qu'en mettant le pantalon a l'envers pour suivre droit quand on coud le resultat n'est pas top, la couture envers se retrouve sur l'endroit [http://www.coupecouture.fr/2009/05/ etape_2_coudre_a_la_machine.html] (3.12.2015)

Suivre la Rue de Lyon - Rue de Châtelaine et passer sous le pont de l'Ecu, puis la Route de Vernier, passer devant IKEA et suivre droit dans son prolongement [http://www.med-equipement.ch/ privacy.php?osCsid=2d3d51b7cc6e62732b1e03aec a3e88b6] (3.12.2015)
REMARQues : Avec une idée de mouvement, suivre droit (I) désigne le fait de marcher dans une rue, de se déplacer dans une direction précise, sans détour, de manière directe. Le sujet peut aussi désigner une chose dont la forme suggère une ligne droite. Au figuré, il souligne le fait de s'en tenir à une idée, de s'y conformer avec insistance ou par conviction. Dans l'exemple de 1986, la comparaison droit comme une tour (II) suggère une interprétation de prédicat second indiquant que la personne se déplace en se maintenant bien debout. Droit reste invariable et est modifié par tout.

\section{Supplier bas}

supplier tout bas : supplier à voix basse, en chuchotant

Transitif

1627 Il le supplia donc tout bas de se retirer, et lors qu'il se fut esloigné, il fit tout ce qui luy fut possible pour persuader au berger qu'il devoit sortir du lieu où il estoit (Charles Sorel, Le Berger extravagant)

1900 Brusquement, Madame changea de tactique, se fit plus douce, presque caressante avec l'incorruptible douanier, et, s'approchant de lui de façon à l'hypnotiser de son haleine et de ses parfums, elle supplia tout bas :

- Éloignez ces gens, je vous en prie (Octave Mirbeau, Le Journal d'une femme de chambre)

1954 Un beau serpent... Je me sentais blêmir de honte, je la regardais, je la suppliais tout bas de me pardonner (Françoise Sagan, Bonjour tristesse)

Intransitif

1945 Elles suppliaient tout bas, elles tenaient leurs bras levés comme pour demander un peu d'aide (Gabrielle Roy, Bonheur d'occasion)

REMARQUES : Supplier bas se dit du fait de prier instamment quelqu'un de faire quelque chose, le sujet s'exprimant à voix basse, de façon discrète. Bas reste invariable et est modifié par tout. 


\section{Supplier fort}

Demander avec insistance

Transitif

1559 Le seigneur d'Avannes, craintif, ayant la lerme à l'œil, la supplia tresfort que, pour seuretté de ses parolles, elle le voulust baiser, ce qu'elle refusa (Marguerite d’Angoulême, Heptaméron, p. 263, 286)

CORpus WeB :

Hey est-ce que tu vas m'amener faire des tours des fois dans ton ford lincoln navigator ??? Dis oui ! Dis oui ! Regarde comme mes yeux te supplient fort ! [http://tetedeclown.skyrock.com/ 1214312258-mon-anniversaire-18-ans-c-estmagique-D.html] (3.12.2015)

Du cirque comme tu aimerais c'est ça http:// www.grandceleste.com/ et c'est troooooooop bieng. Et nous on allait au cirque juste avec Pôpa parce que Maman déteste ça... [...] Ah oui j'aimais pas non plus, et mon homme non plus heureusement, donc quand on aura des enfants, va falloir qu'ils nous supplient fort pour y aller $(;)$ [http://www.mercipourlechocolat.fr/2008/03/17/ la-piste-aux-etoiles] (3.12.2015)

REMARQUeS : Supplier fort se dit du fait de prier vivement quelqu'un de faire quelque chose, de manière pressante. Fort reste invariable et est modifié par très.

\section{Supposer juste}

Présumer correctement, avoir pensé au

préalable ce qui est arrivé réellement

Emploi absolu

1856 J'ai aussitôt supposé que vous n'étiez pas loin. J'ai supposé juste (Léon Gozlan, Les Martys inconnus)

1989 - Monsieur Malaussène, je suppose? Il suppose juste, le bougre (Daniel Pennac, La Petite Marchande de prose)

\section{Surveiller serré}

Surveiller étroitement, strictement

Transitif

1931 Clémence soupire. Elle ajoute plus bas, désavouant déjà sa confiance :

- Le temps me dure... Quand il sera rentré, je le surveillerai plus serré

(Maurice Genevoix, Rroû)

CORPuS WEB :

le médecin disait que beaucoup de femmes enceintes ont des kystes et cela disparait au cours de la grossesse ou peu de temps après. Il disait aussi que c'est lorsque le kyste mesure plus de 5 centimètres que là il envisage d'opérer ou de surveiller serré [http://nospetitsanges-archives. info/?thread=15922] (3.12.2015)

Mac Do est un pilleur de ville, soit dit en passant. Je crois que c'était une ville de Bourgogne ( je suis pas sur ) qui se l'était tapé, il s’était fait élire maire, et avait fait plein de truc pas bien. A surveiller serré [http://chateau-de-dole. forumactif.com/t1528-et-zut] (3.12.2015)

Pas le choix de me surveiller serrée, sinon Raphaëlle va en pâtir (elle sera trop grosse à la naissance) et ca peut lui occasionner d'autres problèmes [http://www.notrefamille.com/forum/ Mamans-par-Chrono/Les-mamans-de-2003Novembre/Diabete-t242363.aspx] (3.12.2015)

REMARQUES : Surveiller serré se dit du fait d'observer quelqu'un avec une grande attention, de manière rigoureuse, souvent par méfiance ou pour comprendre un comportement. Notons l'emploi absolu dans le CW (v. les deux premiers exemples). Serré tend à l'emploi invariable, mais il s'accorde avec l'objet dans le dernier exemple $\mathrm{du} \mathrm{CW}$, sans changer de sens ou fonction. Il est modifié par plus.

\section{Swinguer tranquille}

Avoir un rythme swing tranquille, calme $\lambda$ sonner personnel 


\section{Tailler court}

Couper d'une manière courte

Transitif

1349 Après ces mos s'est Pais levée

Et dist, comme bien avisée :

« Guillaume, assez souffissanment,

Selonc le vostre entendement,

Avez vostre propos baillié ;

Mais vous l'avez trop court taillié

Pour avoir droit pour vous si tost ;

Car uns autres poins le vous tost »

(Guillaume de Machaut, Le Jugement dou

roy de Navarre, 2082)

1542a Au regard de nous, il nous semble que la nouvelle plante ne doibt point estre taillée court, sinon qu'elle soit par trop foible, ny estre taillée en la vere (Loys Meigret, $L e$ Tiers et le Quatriesme Livres de Lucius Moderatus Columella touchant le labour des vignes [trad.])

1542b Si ce n'est que la vigne soit si gresle, qu'il la faille tailler court, et lors il ne luy fauldra laisser qu'un drageon avec peu d'yeulx (Loys Meigret, Le Tiers et le Quatriesme Livres de Lucius Moderatus Columella touchant le labour des vignes [trad.])

1603 Après que la vigne aura plantureusement fructifié, pour aucunement la deslasser, conviendra la tailler court, lui donnant peu à nourrir (Olivier de Serres, Le Théâtre d'agriculture et mesnage des champs)

1721 il faut tailler fort court les arbres qui poussent peu, en bois comme la cuissemadame, la jargonelle, et même tailler plus court ceux qui sont greffés... au contraire, beaucoup de bois : on doit tailler court sur coignassier, pour qu'il pousse à bois ; et tailler long sur franc, pour qu'il tourne à fruit (Louis Liger, La Nouvelle Maison rustique)

1788a Il est avantageux de tailler court les jeunes vignes, afin qu'elles se fortifient ; car les vignes que l'on taille long, donnent à la vérité plus de fruit, mais périssent plus tôt (Jean-Jacques Barthélemy, Voyage $d u$ jeune Anarchasis en Grèce)
1874 une frange de soie achèverait bien ces deux tuniques mais taillées beaucoup plus courtes (Stéphane Mallarmé, La Dernière Mode)

1910 Ses cheveux demeurés abondants, taillés courts, et sa barbe frisée d'un blanc étincelant augmentaient encore l'impression de santé, de netteté fraîche que donnaient, à sa physionomie, ses joues rouges et son grand front uni (Louis Delattre, Carnets d'un médecin de village)

1919 Paul Claudel est plutôt petit. Cheveux châtains, yeux d'un très beau bleu, bouche sarcastique et sensuelle, un peu trop recouverte par une moustache inégale et court taillée (Hélène Hoppenot, Journal)

1923 Elle avait bien reçu déjà, et rendu, quelques baisers ; mais ceux-là ne comptaient plus à présent : c'étaient des baisers d'enfants de son âge. Pour la première fois de sa vie, elle venait d'être embrassée par un homme, - le contact de la moustache taillée court était une sensation nouvelle qui l'intéressait - mais surtout elle était fière d'avoir découvert qu'une grande personne, un homme, un monsieur, avait, à cause d'elle, perdu pendant un instant le sérieux et la gravité qu'elle attribuait à toutes les grandes personnes (Valéry Larbaud, Beauté, mon beau souci...)

1925 Nos anciennes vignes acceptaient d'être rapprochées. J'ai connu des enclos où les ceps étaient plantés à un mètre au carré. On les taillait court, on les travaillait avec de grands bœufs, hauts de côtes, dont les flancs se balançaient bien au-dessus des pousses (Joseph de Pesquidoux, Le Livre de raison)

1934a on voyait parfaitement les deux hommes à présent, assis en face l'un de l'autre, de chaque côté du foyer, chacun sur le bout de son banc : l'un déjà âgé, sec, assez grand, avec de petits yeux clairs enfoncés dans des orbites sans sourcils, sous un vieux chapeau de feutre ; l'autre beaucoup plus jeune, ayant de vingt à vingt-cinq ans, et qui avait une chemise blanche, 
une veste brune, une petite moustache noire, les cheveux noirs et taillés court (Charles-Ferdinand Ramuz, Derborence)

1934b Je remarquai que ses cheveux étaient taillés très courts, en brosse, ce qui durcissait le haut de son visage (Daniel-Rops, Mort, où est ta victoire?)

1936 Sa figure mince, - encore allongée par une barbe noire, taillée courte et en pointe, - se penchait en avant (Roger Martin du Gard, Les Thibault. L'Été 1914)

1939 Pour la première fois depuis son retour, il était aussi sans manteau et sans chapeau : débarrassé de ces symboles de la respectabilité, on naît à une vie nouvelle, comme une femme qui vient de se faire tailler les cheveux courts (Henry de Montherlant, Les Lépreuses)

1966 Ses cheveux sont taillés très courts comme ceux d'un séminariste (Robert Sabatier, $L e$ Chinois d'Afrique)

2008 Tête nue, une couronne de cheveux rebelles taillés court, gonflants au ras des oreilles ; pas de moustache quand même (Anne-Marie Garat, L'Enfant des ténèbres)

2012 L'étudiant étranger de vingt-deux ans, assis devant les journaux, vit aux crochets de sa mère. Il porte comme tous les hommes d'alors la barbe taillée court et une veste sombre (Patrick Deville, Peste et choléra)

Emploi absolu

1788b Une autre question partage les vignerons : faut-il tailler long ou court? (Jean-Jacques Barthélemy, Voyage du jeune Anarchasis en Grèce)

\section{CORPUS WeB :}

L'objectif de la taille des rosiers arbustes est de raccourcir les tiges ligneuses pour favoriser les jeunes pousses.

Pour cela, il faut tailler court en conservant les rameaux principaux [http://jardinage. comprendrechoisir.com/fiche/voir/154009/ tailler-un-rosier] (5.1.2016)
Tailler court une tige sur deux : simple mais efficace [http://www.gerbeaud.com/jardin/ fiches/taille-clematites.php] (5.1.2016)

Plus une branche sera verticale plus il faudra la tailler court car ces branches verticales prennent la sève, poussent beaucoup, mais n'apportent rien au niveau fruit [http://www.lejsl. com/loisirs/2013/02/22/tailler-dans-le-vif-dusujet] (5.1.2016)

Ma vigne (que du raisin de table) date de 3 ans en 2009. Ils m'ont dit de la tailler courte les 2 premières années afin que le pied se renforce (le porte greffe) et oui il a bien grossi [http:// forum.plantes-et-jardins.com/viewtopic. php? $f=8 \& t=169679 \&$ start $=0$ ] (5.1.2016)

REMARQUES : Tailler court se dit du fait de réduire la longueur, l'épaisseur ou la forme des cheveux, de la barbe ou de la moustache. Le complément d'objet peut aussi désigner un arbre fruitier, un végétal (les vignes) dont on coupe une large partie des rameaux ou des branches afin d'améliorer sa fructification, sa végétation ou son aspect. Tailler court s'oppose à tailler long. Court reste souvent invarié, mais il peut s'accorder avec l'objet en tant que prédicat second résultatif. Court est modifié par beaucoup plus, fort, plus, très, trop.

\section{Tailler grand}

Être plus grand que la taille annoncée (d'un vêtement)

Emploi absolu

1964 Le coupeur anglais taille large pour que son client ne soit pas gêné par le vêtement (Elle, 10 avril 1964 / Grundt : 308)

VoIR AUSSI : tomber large

\section{Tailler gros}

Tailler en gros morceaux

$\pi$ tailler menu

\section{Tailler large}

Tailler (un vêtement) de façon à ce qu'il soit plus ample que la taille normale

Transitif

1985 Capdeverre, pour affirmer sa suprématie, portait un pantalon trop large taillé dans celui usé de son père, ce qui fit dire 
à Olivier : « Plus la culotte est large, plus l'homme est fort!» (Robert Sabatier, David et Olivier)

\section{CORPUS WEB :}

Sachant qu'assos n'à pas réputation de tailler large un M ne t'aurait il pas suffit ?? [http:// www.velo101.com/forum/voirsujet/longueurcuissard-assos--15547/page:1] (5.1.2016)

j'ai pris du S sur le site parce que $\mathrm{M}$ a l'air de tailler large quand meme [http://www.jeuxvideo. com/forums/42-51-40532754-3-0-1-0-j-ai-achetece-pull-et-ce-t-shirt.htm] (5.1.2016)

je vends ces 4 tshirt taille $40 / 42$, mieux vaut essayer, ils sont taillés large [http://www. leboncoin.fr/vetements/748149347.htm] (5.1.2016) dans les 2.5, le système d'injection envoie le g.o à environ 100 bars de pression, et la viscosite de l'huile n'est pas la même que la viscosité du g.o mais comme les injecteurs et les pompes sont taillés larges ça passe bien [http://www. terracan-forum.fr/index.php?topic=108.0;wap2] (5.1.2016)

REMARQUES : Tailler large se dit du fait de confectionner, réaliser un vêtement, le couturier coupant le tissu de façon à obtenir un vêtement aux formes amples, qui ne serre pas. Large reste invariable dans la majorité des cas, mais, dans le dernier exemple du CW, il est accordé avec l'objet, ce qui suggère son interprétation comme prédicat second résultatif, du moins stylistiquement. Notons l'emploi absolu et ergatif dans l'argot vestimentaire (un $M$ qui taille large 'un vêtement de taille M qui est plutôt large'). Large est modifié par trop.

\section{Tailler long}

Tailler en laissant de la longueur Transitif

1564 y laissant toutesfois une allee de trois pieds de cousté et d'autre pour le labeur de la treille, et faudra mettre les meilleurs et plus gros complants à la veuë du midy : et ne les tailler si long que le bois ne puisse grossir : car il n'est que le bon pied et gros pour faire beau fruit, ned oit estre la treille si drue ny espesse (Charles Estienne, L'Agriculture et maison rustique) 1603a D’autant que par fréquent provigner les ceps couchés dans terre, s'augmentent en nombre, et par conséquent, en rameaux, lesquels taillés longs, se chargent en suite de beaucoup d'oeils ou bourgeons, d'où vient celle abondance de vin, tant admirée en telle sorte de vignes (Olivier de Serres, Le Théâtre d'agriculture et mesnage des champs)

1603b Et touchant la taille, particulièrement la musquate sera taillée long, pour les raisons ci-après représentées (Olivier de Serres, Le Théâtre d'agriculture et mesnage des champs)

1788a Il est avantageux de tailler court les jeunes vignes, afin qu'elles se fortifient ; car les vignes que l'on taille long, donnent à la vérité plus de fruit, mais périssent plus tôt (Jean-Jacques Barthélemy, Voyage $d u$ jeune Anarchasis en Grèce)

1961a En conséquence, pour diminuer dans l'immédiat la force d'un arbre, il faut le tailler long dans son ensemble (Henri Boulay, Arboriculture et production fruitière)

1961b Son homologue en rouge est le gamay $/ \mathrm{N} /$, cépage très fortement polytypique et présentant une grande adaptabilité au milieu. En Beaujolais, taillé avec sévérité, c'est un petit producteur d'un vin qui peut parfois atteindre une haute qualité ; en $\mathrm{Au}$ vergne, taillé long, il produit en quantité un vin léger (Louis Levadoux, La Vigne et sa culture)

Emploi absolu

1788b Une autre question partage les vignerons : Faut-il tailler long ou court? (Jean-Jacques Barthélemy, Voyage du jeune Anarchasis en Grèce)

1788c Si la moëlle est en petite quantité, on laissera moins de jets, et on taillera plus long (Jean-Jacques Barthélemy, Voyage $d u$ jeune Anarchasis en Grèce)

1881 Il rabattit leurs troncs à ras du sol ; aucun ne repoussa. Les cerisiers, auxquels il avait fait des entailles, produisirent de la gomme. D’abord ils taillèrent très long, ce 
qui éteignait les yeux de la base, puis trop court, ce qui amenait des gourmands (Gustave Flaubert, Bouvard et Pécuchet)

1961c Quels que soient l'art et la maîtrise du tailleur, il peut donc tailler trop long ou trop court et, pour éviter cette dernière éventualité, il taille souvent trop long (Louis Levadoux, La Vigne et sa culture)

\section{CORpus Web :}

Si votre arbre est vigoureux (il produit beaucoup de rameaux et peu de fruits, souvent de gros fruits pleins d'eau et de mauvaise conservation), il faut le tailler long [http://www.mordus delapomme.fr/spip.php?article513] (5.1.2016)

Tailler les hydrangéas est un vrai cassetête... Tailler long ou court? [http://www.lesdoigts fleuris.com/jardin/astuces-jardin/commenttailler-ses-hortensia-au-jardin] (5.1.2016)

C'est une variété vigoureuse, de production moyenne. Il faut la tailler long car les premiers yeux de la base de ses rameaux sont infertiles [http://lescepages.free.fr/sultanine.html] (5.1.2016)

Il faut toujours tailler plus long les rameaux forts ou vigoureux et raccourcir davantage les pousses qui sont grêles ou faibles. Ce principe est systématiquement appliqué à toute variété vigoureuse qui est donc toujours taillée longue par rapport à une variété faible [http://www. rosesleroeulx.be/presentation/chronique-dujardin-concours/le-rosier-taillez-tot-taillez-tardrien-ne-vaut-la-taille-de-mars] (5.1.2016)

REMARQUES : Souvent employé dans le domaine viticole, tailler long réfère au type de taille utilisé (taille longue de la vigne suivant les cépages) pour réduire la longueur ou la forme d'un arbre fruitier, d'un végétal ; le sujet coupant une large partie des rameaux ou branches afin d'améliorer sa fructification, sa végétation ou son aspect. Notons l'opposition sémantique entre tailler long et court. Long tend à l'emploi invariable, mais il peut s'accorder avec le sujet (v. dernier exemple $\mathrm{du} \mathrm{CW}$ ), ce qui stimule une interprétation de prédicat second résultatif. Long est modifié par plus, si, souvent trop, très.

\section{Tailler menu}

Tailler très fin, en petits morceaux, couper en

fines lamelles

Transitif

1389 A ceste roigne comune prenez la racine d'unne herbe qui est sus les paroiz des mesons, qui s'apelle en latin yreos et en nostre lengaige lirgue, et la tailliez mеnu et la fetes boillir dedanz yaue (Gaston Phébus, Livre de chasse, p. 118, 65)

1551 Premierement quarante jours avant qu'on veuille vendanger, fault ceuillir la squille, et la tailler bien menu, comme la racine d'un rifort (Claude Cotereau, Les Douze Livres de Lucius Junius Moderatus Columella des choses rusticques [trad.])

1589 en quatrieme lieu ils prenoyent les raclures de la racine taillées menues (Claude Dariot, Trois Discours de la preparation des medicamens)

1611 Prenez une quarte de bonne eau de vie mettez y dedans trois poignees del saxifrage et autant de racines d'artichaux taillees menues (Gabriel de Castagne, L'Or potable qui guarit tous les maux)

1747 J'ai déja une plume taillée menue, taillez celle-ci un peu grosse (Antonii Van Torre, Dialogi familiares litterarum tironibus [trad.])

1851 Néanmoins, les Grödner se trouvent aujourd'hui dans un étrange embarras. Ayant, par un aménagement mal entendu, taillé menu toute leur forêt de pins [...], la matière première est en hausse (Ferdinand de Roisin, Un mystère de la Passion, representé au XIX ${ }^{e}$ siècle)

1886 Bien mitonnée, cette soupe est excellente. Mettre parties égales de choux et de pommes de terre taillées menues dans une marmite largement mouillée d'eau, ajouter sel, un morceau de petit salé, ou un os de jambon (Marius Morard, Les Secrets de la cuisine dévoilés)

REMARQUES : Tailler menu se dit du fait de couper un objet en petits morceaux, complètement, notamment dans les recettes de tout type. La séman- 
tique résultative favorise l'accord selon le nom de l'objet taillé, mais l'emploi invarié est également présent sur toute la diachronie. Notons l'emploi clairement résultatif de tailler un peu gros 'couper la plume de façon à pouvoir écrire gros', dans l'exemple de 1747. Menu est modifié par bien.

\section{Tailler net}

Tailler avec soin, nettement

Transitif

1583 Ptolomee Philadelphe en planta aussi un en Alexandrie de six vingts pieds de long, que le Roy avoit fait tailler net et uny sans tare aucune (Blaise de Vigenère et Anthoine de La Faye, Les Decades [trad.])

1839 Fabrice la coupa avec respect, à l'aide de son poignard, et tailla bien net la coupure, afin que l'eau ne pût pas s'introduire dans le tronc (Stendhal, La Chartreuse de Parme)

1951 Il ne se doutait pas que chaque fois qu'il passait devant sa boutique, elle le regardait, la commerçante, le soldat Brû. Il marchait avec naturel, joyeusement sapé de kaki, le cheveu ce qu'on en voyait sous le képi le cheveu taillé net et quasiment lustré, les mains le long de la couture du pantalon (Raymond Queneau, Le Dimanche de la vie)

1959 Le Cactus [= un «stabile » de Calder] est un arrangement délicat des formes arrondies et simples. Tout est taillé net, boulonné, pesant et parfois grandiose (Le Monde, 13 mars 1959 / Grundt : 349)

CORPUS WEB :

Tailler net juste au dessus d'une feuille. Deux ou trois nouvelles tiges se formeront alors [http:// www.rustica.fr/articles-jardin/tailler-rhododen dron,6984.html] (5.1.2016)

Tailler net et en biais, environ $1 \mathrm{~cm}$ au dessus d'un œil extérieur [http://www.montre moicomment.com/jardinage/comment-taillerun-rosier.html] (5.1.2016)

Les jeunes d'ici le font surtout parce que c'est la Sunnah, il ne faut pas raser sa barbe complètement (juste la tailler net, pour pas ressembler aux juifs non plus) et se couvrir jusqu'au haut des chevilles [http://www.yabiladi.com/ forum/mode-barbus-avec-kamiss-1-4684357page $=4 . h t m l](5.1 .2016)$

Cela va d'une simple rangée de théiers le long d'une maison, taillée nette en arrondi comme un cake sorti du moule, à des dizaines d'hectares de vagues vertes et ondulantes qui déboulent des collines ou tapissent les vallées comme un édredon [http://www.ladepeche. fr/article/2013/05/05/1620125-japon-festivalmondial-the-sous-oeil-mont-fuji.html] (5.1.2016)

REMARQUES : Tailler net se dit du fait de réduire la longueur ou l'épaisseur d'un végétal, d'un arbre dont on coupe avec soin, de manière précise, une large partie des rameaux ou des branches afin d'améliorer sa fructification, sa végétation ou son aspect. Les deux premiers exemples du CW attestent l'emploi absolu. Net reste invariable dans la majorité des cas. Toutefois, dans le dernier exemple du CW, il s'accorde avec l'objet en conservant son interprétation adverbiale. Il est modifié par bien. Notons la collocation net et uni.

\section{Tailler soef}

Couper, trancher doucement, sans brusquerie ni à-coups

Intransitif

+1200 Prist le henap et la toaille,

Et le coutel qui soef taille,

Et puis referma l'us sor soi :

Or puet bien boivre, s'il a soi !

(L'Oue au chapelain, 52)

REMARQUES : Tailler soef désignait le fait de couper avec soin ou délicatesse, sans gestes brusques, avec un instrument tranchant (un couteau).

\section{Taire coi}

Se taire et rester tranquille, sans bouger ou agir Pronominal

1250 Quant Bauduïn l'entent, arriere recula Et si se tait tout coy, regarde chà et là S'il venoit nulz des siens, mais nulz ne s'avancha

D'aidier le chevalier, tant de traitres y a (Doon de Mayence, p. XXI)

1370 Mais Berinus et tuit li Romain se taisoient tout coy, car Gieffroy leur avoit bien endotriné comme il se devoient maintenir (Roman de Berinus, I, p. 83) 
1372 Pour ce me voel taire tous quois

Et souffrir, car, au dire voir,

Ma dame scet bien percevoir

Que li pensers me plest souvent,

Soie en enclostre ou en couvent

(Jean Froissart, La Prison amoureuse, 564)

1548 Lors ce vanteur s'alla taire tout coy, Voyant qu'il a trop presumé de soy (Gilles Corrozet, Second Livre des fables d'Ésope)

1625 Il fut donc faict sourd ainsi qu'une souche, Et n'ayant point de response en sa bouche, Il se teut coy, et ne repliqua rien, Quoy qu'il se vist enlever tout son bien (Jean-Pierre Camus, Palombe ou La Femme honnorable)

\section{Talocher dur}

Gifler fortement, brutalement, avec vigueur ; par extension : frapper fort

Transitif

1958 L'honneur des Jules consiste à ne rien faire, à talocher dur la gosse qui travaille mou (Le Monde, 23 novembre 1958 / Grundt : 248)

\section{CoRpus Web :}

Les vrais gars aiment ça exhiber leur force brute devant des spectateurs et ceux-ci adorent quand ça taloche dur et que ça saigne [http:// blogues.lapresse.ca/philippecantin/2014/01/19/ pathetique-lnh] (5.1.2016)

ah bah il fait comment pour que ça brille ? il doit talocher dur !!!! Lol faut vraiment je montre la photo à mon chéri !^^ [http://forum.manucure. info/index.php?threads/voil\%C3\%A0-monpetit-salon-donglerie-a-stiring-wendel.343146] (5.1.2016)

Et ça taloche dur. On va attendre le séchage avant de remblayer [http://japoto1976.skyrock. com/3034872767-Aujourd-hui-le-beton-coule-aflot.html] (5.1.2016)

REMARQUES : Talocher dur se dit du fait de donner des coups à quelqu'un avec le plat de la main, de donner une ou plusieurs gifles avec force, sans retenue. Dans les deux derniers exemples du CW, talocher signifie 'travailler le plâtre, le mortier, un enduit avec une taloche'. Dur reste invariable. Notons l'emploi impersonnel familier ça taloche $d u r$, et l'emploi de travailler mou. VoIR AUSSI : taper dur

\section{Taper dru}

I. Frapper vigoureusement (au propre et au figuré)

Intransitif

1891 Et les malheurs continuaient, tapaient dru comme grêle : Rosalie accouchait d'un garçon, perdait sa mère, tombait à une sale vie, à une misère noire (Émile Zola, L'Argent)

\section{J. -K. Huysmans}

Sa douceur qui n'est pas excessive,

Elle existe mais il faut la voir,

Et c'est une laveuse au lavoir

Tapant ferme et dru sur la lessive.

Il la veut blanche et qui sente bon

Et je crois qu'à force il l'aura telle.

Mais point ne s'agit de bagatelle

Et la tâche n'est pas d'un capon (Paul Verlaine, Euvres poétiques complètes)

1928 LA BIQUE. "T'auras qu'à taper au carreau... » Ah, l'franc-gautier! Ah, l' trousseur ed' cottes !...

Ej' la r'connus point du premier coup, sa voix. Mais quand i' y' a dit : «Tape point trop $d r u$, pour que ma vielle, elle entende point ", ah, malédiction, c'était ben lui, mon ch'napan, mon démon fourchu !... Sa vielle ! Parmagri !... Han ! Han! Han !... J'estoupe... (Roger Martin du Gard, La Gonfle)

1933 Le bruit s'exerçait sur du bois fendu, les voiles tapaient $d r u$ dans l'allégresse matinale et, vague sur vague, s'empilaient, les bras tendus, vers quel poison, miroir damné, ô douce illusion de compréhension ardente, plus forte que son propre savoir des choses, de vent et d'être (Tristan Tzara, L’Antitête)

II. Chauffer de manière très intense, ardente (du soleil)

Intransitif

1936 Cette perspective le bouleversait : depuis cinq ans qu'il était sur le continent, il n’avait jamais retraversé le channel! Le soleil tapait dru ; le pavé était brûlant. Aucun souffle n'allégeait la torpeur qui pesait sur la ville (Roger Martin du Gard, Les Thibault. L'Été 1914) 


\section{CORPUS WeB :}

Soyons honnêtes, il était de bon ton, en Creuse, de taper dru sur les gars de la Beauce et de la Brie. Ces voleurs de céréaliers parasitant les aides de l'Europe au détriment du pôv'éleveur creusois [http://www.lamontagne.fr/ limousin/actualite/departement/creuse/creuselocal/2011/12/31/les-creusois-auraient-fini-sur-lapaille-sans-laide-des-beaucerons_141536.html] (5.1.2016)

Maintenant, c'est une évidence que le militaire n'est pas mauvais d'abord parce que tu ne seras jamais emmerdé et ensuite parce que tu peux taper dru sur celui qui a négligé cet aspect [http://www.trictrac.net/forum/sujet/hier-j-aijoue-a?page=181] (5.1.2016)

Attention, ça va chauffer ! Les croix dressées, bien astiquées, s'enflamment! Les matraques fourrées dans les caleçons brûlent de taper dru [https://blogs.mediapart.fr/juliette-keating/ blog/260513/theories-impudiques] (5.1.2016)

REMARQUES : Taper dru (I) peut s'appliquer à une personne qui donne des coups brusques ou frappe avec énergie sur quelque chose. Le sujet peut aussi référer à une chose comme les voiles d'un bateau qui claquent au contact du vent en faisant entendre un bruit régulier ; le sujet peut également désigner une arme (ici : une matraque) dont les coups se font entendre de façon répétée et régulière. En parlant du soleil, taper dru (II) se dit du fait de chauffer très fort, de répandre une forte chaleur. Notons la collocation ferme et dru. Dru reste invariable et est modifié par trop.

\section{Taper dur}

I. Frapper de manière vigoureuse, avec force ; par extension : travailler beaucoup Intransitif

1847 - C'est une bataille que cette entreprise, et vous irez plus loin que vous ne pensez ! On se grise de son idée, on tape dur...

Autre geste de dénégation de la part de Mme Cibot, qui se rengorgea

(Honoré de Balzac, Le Cousin Pons)

1875 - C'est lui, c'est ce gueux !... Je le sentais. Alors, le nouveau venu étant au bas de la côte, l'abbé Mouret reconnut Jeanbernat. Malgré ses quatre-vingts ans, le vieux tapait si dur des talons, que ses gros souliers ferrés tiraient des étincelles du silex de la route (Émile Zola, La Faute de l'abbé Mouret)

1877a Derrière elle, le lavoir reprenait son bruit énorme d'écluse. Les laveuses avaient mangé leur pain, bu leur vin, et elles tapaient plus dur, les faces allumées, égayées par le coup de torchon de Gervaise et de Virginie (Émile Zola, L'Assommoir)

1877b on avait calculé qu'il faudrait veiller jusqu'à onze heures, en se dépêchant. Tout l'atelier, maintenant, n'ayant plus de distraction, bûchait ferme, tapait dur. Les bras nus allaient, venaient, éclairaient de leurs taches roses la blancheur des linges (Émile Zola, L’Assommoir)

1887 - Faut que nous finissions, leur cria $\mathrm{Bu}$ teau, sans s’arrêter. Hardi là ! Françoise ! Elle ne lâchait pas, tapait plus dur, dans l'emportement du travail et du bruit. Et ce fut ainsi que Jean, qui arrivait à son tour, avec la permission de dîner dehors, les trouva (Émile Zola, La Terre)

1892 Régal complet, une soupe qui embaumait la carotte et le poireau, quelque chose de doux à l'estomac comme du velours. Les cuillers tapaient dur dans les petites gamelles (Émile Zola, La Débâcle)

1902 Là bondissaient les sphères des ballons que les pères expédiaient au ciel par de vigoureux coups de pieds. Leurs manches retroussées laissaient voir les bras velus gonflés de veines. Ils tapaient aussi dur que les collégiens (Paul Adam, L'Enfant d'Austerlitz)

1907 - Eh bien ! Le vieux, ils t'ont fait du mal ? - N'y a que l'aubier d'attaqué, répondit Gilbert, le cœur est sauf.

- Tant mieux, vieux ! Oh ! Comme ils ont tapé dur, tout de même !

(René Bazin, Le Blé qui lève)

1931 - Pas la sieste ? demande Madeleine.

- Non, dit Julia qui boucle la ceinture.

- Ça tape dur. Tu auras mal, dit

Madeleine. 
- Oui, répond Julia les dents serrées.

Elle a chargé la faux sur l'épaule et elle est partie sans plus rien dire (Jean Giono, Le Grand troupeau)

1948a Le bois éclaté était jaune et propre comme du pin fraîchement abattu.

- Passé par là. A dû taper drôlement dur. La pluie s'est arrêtée assez tôt par ici, vers neuf heures du soir. Le bois brisé est sec à l'intérieur. Ça situe la chose après la pluie (Boris Vian, Le Grand Sommeil [trad.])

1948b La pluie tapait dur sur le toit de la voiture et la capote de toile se mit à fuir. Une mare d'eau se forma sur le plancher pour me permettre de prendre un bain de pieds (Boris Vian, Le Grand Sommeil [trad.])

1967 Le fond de colère que j’avais décelé dans la voix de Marie est tout à coup monté à la surface, et cette folle m'a carrément querellé : j’ai été trop sévère, j'ai tapé trop dur (Jean Dutourd, Pluche ou L'Amour de l'art)

1994 Tapons fort, tapons sans peur, sans peur des éclaboussures de boue. La pluie de Dieu est là, elle tombe, elle mouille, elle lavera même notre sueur. Tapons, tapons fort, tapons dur, tapons dans la boue humide !... Le commandant, accompagné de son interprète et de son commis, vint visiter le chantier (Amadou Hampâté Bâ, Oui Mon Commandant!)

Pronominal

1877c Ce jour-là, pour la première fois, chez les Coupeau, on se flanqua une volée en règle, on se tapa même si dur, qu'un vieux parapluie et le balai furent cassés. Et Gervaise tint parole. Elle s'avachit encore (Émile Zola, L’Assommoir)

II. Chauffer de manière très intense, ardente (du soleil) Intransitif

1908 Pourquoi n’apprennent-ils plus ça ? Pourquoi est-ce qu'on ne leur apprend plus ? Nous étions en plein été. Le soleil tapait dur sur les pavés de la rue. On respirait l'infâme relent qui sort au mois de juillet des égouts desséchés (Pierre Mille, Barnavaux et quelques femmes)

1931 Le soleil monte. Il tape dur. Les pailles crissent. Un vieux s'est mis à chanter. Les quatre premiers jours d'avril nos jeunes gens sont tous partis... (Henri Pourrat, $L a$ Tour du Levant ou Quand Gaspard mit fin à l'histoire)

1980 Ils quittèrent les shorts sous lesquels ils portaient des caleçons de bain. Samuel lui conseilla de couvrir sa tête et il noua son mouchoir aux quatre coins.

- Sur l'eau ça tape dur !

- Ouais, il va en faire un plat...

(Robert Sabatier, Les Fillettes chantantes)

1996 Malgré la scène du commissariat, malgré ses joues blêmes, malgré notre propre désir de ne pas affoler maman trop tôt, et d'apparaître calmés devant elle. Le soleil tapait, très dur. Toutes ces rues cuisaient. Maman a tout de suite deviné.

- Qu'y a-t-il, Volenka ? (Boris Schreiber, Un silence d'environ une demi-heure)

\section{CORPUS WEB :}

Ça va taper dur au gala de boxe thaï de Beuvrages ! [http://www.lobservateur.fr/ region/2011/12/17/Ccedila-va-taper-dur-au-galade-boxe-thaiuml-de-Beuvrages] (5.1.2016)

A quelques jours du second tour, et alors que les sondages prédisent un score serré, Claude Bartolone a décidé de taper dur, très dur, sur sa rivale [http://www.marianne.net/bartolonepecresse-c-est-race-blanche-qu-elle-defendcreux-100238549.html] (5.1.2016)

Et bah on dirait que c'est un topic ou les mecs se la tapent dur !!!!!!!! [http://www.allocine.fr/ communaute/forum/message_gen_nofil=387551. html] (5.1.2016)

Et pendant que les uns grelottent, les autres se la coulent douce ou plutôt se la tapent dure [http://www.escortfr.net/1681622/viewtopic.php ?t $=31471 \&$ start $=0 \&$ sid $=0 \mathrm{a} 6 \mathrm{~b} 580 \mathrm{ecd} 943 \mathrm{f} 41 \mathrm{cbdb} 77$ d65a7c6a0a] (5.1.2016)

REMARQUeS : Taper dur (I) désigne le fait de frapper, de travailler avec force. Dans son emploi pronominal, il souligne le fait de se battre avec force, 
violemment. Au figuré, il désigne le fait d'agir, de se comporter ou de parler avec rudesse, suggérant l'envie de provoquer l'autre. L'objet peut également désigner une chose qui fait du bruit en recevant des coups donnés par le sujet (les talons, la pluie). En parlant du soleil (II), il se dit du fait de chauffer très fort, de répandre une forte chaleur. Notons l'expression se la taper dur dans le $\mathrm{CW}$, désignant probablement le fait de frimer (à comparer : se la péter grave 'frimer'). Taper dur tend à l'emploi invarié. Toutefois, dans le quatrième exemple du CW, situé dans le contexte d'un service d'escorte, il s'accorde avec l'objet pronominal la, purement postiche, comme dans se la couler douce. Ceci étant, se la taper dure pourrait également avoir le sens de 'se la faire (sexuellement parlant), comme il convient', ou dur par analogie et contraire à douce. Se la taper, se taper a aussi le sens de 'se masturber'. Dur est modifié par aussi, drôlement, même si, plus, si, très, trop. La comparaison avec taper dru suggère l'idée d'un remplacement progressif de celui-ci par taper dur. Notons l'emploi impersonnel familier ça tape dur avec les acceptions 'ça chauffe énormément' et 'ça frappe durement'.

\section{Taper enragé}

Frapper avec rage, très en colère

$\lambda$ taper sec

\section{Taper ferme}

I. Frapper vivement, énergiquement, avec

vigueur

Intransitif

1839 Il fit signe à deux aides de s'approcher.

- Venez ici, vous autres prenez chacun cette badine, et tapez ferme sur la veste de ce pauvre Georges, et, toi, Georges, mon enfant, laisse le corps dessous, je te prie.

- Combien de coups, capitaine ? dirent les aides (Alexandre Dumas père, Le Capitaine Pamphile)

1867 CHEUR. Au repas comme à la bataille, Tapons ferme et grisons-nous tous ; Chantons, buvons, faisons ripaille, En l'honneur des nouveaux époux !... (Henri Meilhac et Ludovic Halévy, La Grande Duchesse de Géroldstein)
1887 Il manquait trois chaises, on courut chercher deux tabourets dépaillés, sur lesquels on plaça une planche. Déjà les cuillers tapaient ferme au fond des assiettes. La soupe était froide, couverte d'yeux de graisse qui se figeaient (Émile Zola, $\mathrm{La}$ Terre)

II. Chauffer de façon très intense, ardente Intransitif

1846 Mes fillettes vont très bien. Solange engraisse à vue d'œil et elle a un teint superbe. Titine est déjà toute brûlée par le soleil qui tape ferme ici (George Sand, Correspondance)

1928 De loin nous assistons à ce manège, qui se répète plusieurs fois - qui va se répéter encore si nous ne rappelons le garde à grands cris. Le soleil commence à taper ferme et nous ne voulons pas risquer de laisser passer la baleinière (André Gide, Le Retour du Tchad)

III. Sentir mauvais

Intransitif

1972 On se faisait l'impression de surveiller un camp, à rôder comme ça entre les cubes de béton gris. Un camp bien calme, avec que-dalle à signaler, pas la moindre tentative d'évasion. Juste bons à pioncer, les résidents. On sentait leurs haleines de taulards jusque dans la rue, fétides. Ça tapait ferme (Bertrand Blier, Les Valseuses)

CORPuS Web :

L'art de glisser sous la brise soutenue mais de taper ferme du pied quand la Méditerranée et le vent s'en mêlent pour le contrarier dans sa course [http://leretourduharem.blogspot.co.at] (5.1.2016)

C'est bien joli de taper ferme sur les autodidactes, mais j'ai tout de même un peu l'impression que quelques-uns ici découvrent maintenant ce mot de vocabulaire et qu'ils le confondent avec « crétin des Abruzzes » [http://www.forumguitare.fr/viewtopic.php? $t=26360 \&$ start $=75$ ] (5.1.2016)

Longue attente sous un soleil qui s'est décidé à taper ferme [http://www.tibetdoc.eu/spip/ spip.php?article75] (5.1.2016) 
REMARQUES : Taper ferme (I) peut s'appliquer à une personne qui donne des coups brusques ou frappe avec énergie sur quelque chose. Le sujet peut aussi être une chose (ici : une cuillère) qui fait entendre un bruit régulier au contact d'autre chose, traduisant ou suggérant la force dans le mouvement fait par la main. En parlant du soleil (II), il se dit du fait de chauffer très fort, de répandre une forte chaleur. Dans un contexte plus précis (III), taper ferme peut adopter l'acception de 'sentir mauvais'. Ferme reste invariable. Notons l'emploi impersonnel familier ça tape ferme.

\section{Taper fort}

Frapper avec force

Intransitif

1938 «Puisque cent mille obus en vingt-quatre heures ne suffisent pas à niveler même un petit morceau du front ennemi, et $\mathrm{y}$ laissent subsister des noyaux de résistance - abris bétonnés, nids à mitrailleuses nous taperons plus fort, nous pilonnerons plus dur » (Jules Romains, Les Hommes de bonne volonté)

\section{CORPUS WEB :}

Le gouvernement veut passer à l'offensive face aux communes qui n'ont pas atteint le taux minimal de $20 \%$ de logements sociaux d'ici à 2020, imposé par la loi relative à la solidarité et au renouvellement urbains (SRU), selon Europe 1. «On va taper fort et ça va faire du bruit ", promet un ministre interrogé par la radio privée [http://www.lemonde.fr/logement/ article/2015/06/10/le-gouvernement-veut-taperfort-sur-les-villes-en-manque-de-logementssociaux_4650996_1653445.html] (9.1.2016)

Les impulsions en Gymnastique, faut t-il taper fort ou taper vite? [http://sportingtrainer. over-blog.com/2015/06/les-impulsions-engymnastique-faut-t-il-taper-fort-ou-taper-vite. html] (9.1.2016)

l'amitier entre mec et meuf éxiste ca c est sur mais pas en passant 5nuit ensemble donc je te prévien il va se la taper fort désolé pour toi ma demoiselle! [https://fr.answers.yahoo.com/ question/index?qid=20080823153103AAISDeo] (9.1.2016)

Sur une balle « facile » en cd et que j'ai envie d'attaquer, je vais la taper forte et sans la faire monter pour essayer de mettre le joueur en face loin de la balle ou qu'il défende à l'arrache [http://www.tennis-classim.net/forums/ profile/15045-iceolo/?do=content\&type=forums topic_post\&page=16] (9.1.2016)

REMARQUES : Dans une lutte armée, taper fort réfère au fait d'employer des moyens militaires ou des techniques militaires plus conséquents, de déployer des forces de frappe importantes pour écraser les positions adverses, comme un bombardement plus intensif. Les exemples du CW renvoient à une attaque verbale ou au fait de réagir sans pitié (premier exemple), et, dans le sport, au fait soit de frapper une balle, soit de donner une impulsion du pied avant un saut (deuxième et dernier exemples). Notons, dans le troisième exemple, l'expression se la taper fort 'posséder sexuellement'. Fort reste invariable dans son emploi adverbial. Dans le dernier exemple du CW, il s'accorde avec l'objet au féminin tout en gardant son interprétation adverbiale. Ce type d'accord est fréquent dans le domaine du sport. Fort est modifié par plus. Notons l'emploi de pilonner dur.

\section{Taper raide}

Taper, frapper rudement, brutalement

Intransitif

1950 «Oh ! oh !» dit Porchon. « C’est du 105, ça. On nous sert bien. Encore une avalanche derrière nous. Une volée d'éclats vient taper raide contre les rondins ; puis on entend un craquement prolongé, un froissement dans les hautes branches, et la chute d'un arbre qui s'abat » (Maurice Genevoix, Ceux de 14)

\section{CORPus WEB :}

Dès le pied, c'est raide et les deux variantes (depuis Rémollon ou Espinasses) se rejoignent après un gros kilomètre. Jusqu'au village perché de Théus, la pente est plutôt régulière. Mais à partir du village, certaines rampes commencent à taper raide pendant vraiment longtemps, et chaque kilomètre, la pente est renseignée sur une borne plutôt précise [http://www.sisbos.fr/ blog/2015/08/07/les-alpes-du-sud] (9.1.2016)

à priori, elle doir s'en taper raide :D oui, je m'en souviens de cette tourterelle.. encore un abruti qui a redonné la liberté à une saleté de 
bestiole à plumes voire même à deux puisque depuis, elles se sont multipliées:/ [http://angelyz. over-blog.net/article-2511838.html] (9.1.2016)

lol $57 \mathrm{~cm}$ impossible mdr t'as du te tromper, ton kick quand t'arrive dessus ca doit taper raide nan ? [http://trotirider.com/forum/topic-55936le-chez-vous-votre-matos-tremplin-footagepage-3.html] (9.1.2016)

REMARQUES : Taper raide réfère à une chose qui vient se heurter, se cogner contre autre chose avec force et rapidité, soulignant la brutalité d'un phénomène comme une avalanche d'obus. De même, une rampe peut taper raide, du point de vue de celui qui grimpe. Notons l'expression s'en taper raide dans le deuxième exemple du CW, au sens de 's'en moquer, s'en ficher'. Raide reste invariable. Notons aussi l'emploi impersonnel familier ça doit taper raide.

\section{Taper sec}

Frapper de manière vive, rapide et énergique Intransitif

1929 Maurras baisse la tête et fait toucher à Gondran le nœud des vertèbres.

- Juste là, avec le tranchant de la main.

- Il saignera?

- Non, si tu tapes bien sec. Peut-être une goutte, ne regarde pas, mets l'oreiller dessus, et reste un moment appuyé (Jean Giono, Colline)

1957 Il avance la main vers le sein qui gonfle la blouse de toile. Marie tape sec sur la main (Roger Vailland, La Loi)

1962 Ils se serrèrent la main. Maurice dit simplement :

- C’est Julien. Il remplace Denis chez nous.

- Il tapait sec, Denis. S'il avait fumé un peu moins, il pouvait se défendre (Bernard Clavel, La Maison des autres)

\section{CORPUS WEB :}

Pencak Silat en force, ça va taper sec, je dirai même très sec à en voir cette BA :3 [http:// www.allocine.fr/article/fichearticle_gen carticle=18633750.html] (9.1.2016)

Même si elle continue à taper sec et enragé, même si elle s'est entourée de synthés pas commodes du tout, elle réussit pourtant, d'une voix suave et brumeuse, à calmer les ardeurs de ce chaos [http://www.lesinrocks.com/2014/07/19/ musique/georgia-be-ache-11514789] (9.1.2016)

Fille ou garçon ? C'est important, car avec les filles, les garçons sont aimables, doux, prévenants, charmeurs.... Tandis que si t'es un mec, on se la tape sec quoi ! [http://www.forum.ayreonseven.com/topic/5236-coucou-a-tous/]

Remarques : Taper sec se dit du fait de donner un coup avec la main sur quelque chose ou quelqu'un, le mouvement étant vif et énergique. Notons l'expression se la taper sec 's'amuser, en profiter au maximum'. Sec reste invariable et est modifié par bien. Notons la collocation hyperbolique taper sec et enragé. Notons aussi l'emploi impersonnel familier ça va taper sec.

\section{Tapisser épais}

Recouvrir d'une couche épaisse

Transitif

1760 Le lieu de séjour [= de la marmotte] est non seulement jonché, mais tapissé fort épais de mousse et de foin (Georges-Louis Leclerc de Buffon et Louis Daubenton, Histoire naturelle)

\section{Tartiner gros}

Étaler (une matière) en grande quantité sur une surface

Emploi absolu

1968 Il ne dit rien, mais c'est pire : j'ai l'impression de pomper les watts de son cœur même ! Je viens de tartiner gros comme un pois (extra-fin !) de la crème pour le tour des yeux que tu m'as offerte et qui doit être à base d'uranium enrichi à en juger par le prix (Benoîte et Flora Groult, Il était deux fois)

\section{CORPuS Web :}

mais a titre perso pour vous, ca ne sera pas possible, ca ne marche que quand on tartine gros et qu'on a des copains 'en haut lieu' pour payer l'addition avec l'argent ' de personne' [http://www.latribune.fr/actualites/economie/ france/20130430trib000762472/emprunts-toxi ques-pourquoi-1-etat-soutient-les-collectiviteslocales-.html] (9.1.2016) 
REMARQUeS : Tartiner gros se dit du fait de déposer une couche de beurre sur une surface (dans l'exemple de 1968, de la crème sur le visage). Au figuré, tartiner gros équivaut à passer de la pommade, c'est-à-dire 'flatter'.

\section{Témoigner juste}

Témoigner, attester (de quelque chose) avec honnêteté, avec exactitude, en se rapportant à la vérité Intransitif

1365 Mais chuis Salehadins, dont vous m’owés plaidier,

Ne fuit [pas] chius qui vient à Cambrai tournoïer,

O Huon d'Odekin ; et .i. autre gerrier,

Duc Jan du Ponthieu, i. noble princhier.

Doi Salehadin furent, au juste

tesmongnier :

L'uns fut fiex de la dame, si con j'oïs nonchier,

Duch[ois]e de Ponthieu, qui Dieu volt

renoier (Li Romans de Bauduin de Sebourc, Chant XIII, 927)

\section{CORPuS WEB :}

Et témoigner juste, c'est rendre hommage à Sud d'avoir été au cœur de tous ces bons combats [http://www.sudonline.sn/une-histoire-damitie-assumee_a_3126.html] (9.1.2016)

Grâce à une excellente connaissance $d u$ terrain et une volonté inébranlable de témoigner juste et vrai, Juliette Morillot et Dorian Malovic rapportent une enquête exceptionnelle, édifiante, qui va bien au-delà de ce qui a déjà été publié sur le sujet [http://www.grands-reportages. com/evades-de-coree-du-nord] (9.1.2016)

alors que l'article a été consulté 1290 fois vous ne trouvez que 03 commentaires diffamatoires...et qui heureusement ont donné l'occasion à ceux qui connaissent l'ambassadeur saidou nourou ba ou l'ont pratiqué en algérie, moscou, londres, banjul, bruxelles, new york ou dakar, de témoigner juste et vrai [http://www.seneweb.com/news/commentaire/ menace-terroriste-en-afrique-de-l-rsquo-ouestseyd_n_86956_c_2379964.html] (9.1.2016)

REMARQUES : Témoigner juste réfère au fait de se prononcer correctement, conformément à la réa- lité, voire avec un sentiment de justice. L'exemple de 1365 emploie juste avec ce qui semble être l'infinitif substantivé du verbe. Notons la collocation juste et vrai dans le CW. Juste reste invariable.

\section{Témoigner vrai}

témoigner juste et vrai : témoigner

conformément à la vérité, avec authenticité

$\lambda$ témoigner juste

\section{Temprer (tremper) dur}

Arrêter, atténuer un coup

Transitif

1190 Le quens le voit venir, de ferir s'est hastez; Amont parmi son elme li a .ii. coups donnez, Les pierres enn abat, s'a les bendes coupez.

Au dur capel d'achier s'est li coups arestez, Ainz nel peut emperier, tant par fu dur temprez [variante : durs temprés, Fierabras (K), 1279] (Fierabras (L), 1324)

REMARQUES : La variante (K) est accordée au cas sujet.

\section{Tendre bas}

Être porté, se diriger vers un niveau plus bas $\lambda$ descendre bas

\section{Tendre fier}

tendre haut et fier : maintenir digne et fier

$\pi$ tendre haut

\section{Tendre fort}

Tendre avec force

Transitif

1924 Je travaillai ferme pour sauver mon navire. D'abord je sus amener la grand-voile : l'ouragan tendait la toile si fort contre la balancine de tribord qu'il fût extrêmement difficile d'amener la grand-voile et de la rouler sur le pont (Alain Gerbault, Seul à travers l'Atlantique)

CoRpus Web :

En PMT : ayant pour habitude de plonger le long des falaises du coté de Marseille, lors d'une sortie ou la mer était agitée, je me 
suis retrouvé en apnée pris dans une pelote de fil de pêche au niveau des jambes /palmes. Au début j'ai essayé de tirer, ça se tend fort, ça à tendance à rentrer ds la chair, j'ai vite arrêté et coupé les les lignes avec le couteau que j'avais à la jambe [http://forum.davidmanise.com/index. php?topic=43027.20;wap2] (9.1.2016)

ben pour moi tu te prends les 2 rollerbiners, l'élingue et le linelock, et en plus de ta sangle supertube tu te prends une $25 \mathrm{~m}$ de superflat genre maverick, voir plus long, et non seulement tu pourras faire du slack sur des longueurs plus importantes, et puis tu pourras toujours la tendre fort sur 10 ou $12 \mathrm{~m}$ pour faire des sauts genre buttbounce, chest, 360 etc [http://slacklinetribu.forumpersos.com/t1040-cliquet-mouflagec-est-possible] (9.1.2016)

Rien ne se perdra, les morceaux de choix seront laissés au chef du village, on mettra à fumer le gigot, les tripes et boyaux serviront plus tard, on étendra la peau au soleil en la tendant fort entre deux morceaux de bambou... [https:// justbyroads.wordpress.com/2012/12/18/laosrevival] (9.1.2016)

REMARQUES : Tendre fort désigne le fait d'étirer une voile, un filet, une peau, etc. solidement. Fort reste invariable et est modifié par si. Notons l'emploi pronominal du verbe dans le premier exemple du CW. Signalons aussi l'emploi impersonnel familier ça se tend fort et une occurrence de travailler ferme.

\section{Tendre haut}

I. Aspirer à une chose élevée, vouloir atteindre un niveau (moral, social, spirituel, etc.) élevé Intransitif

-1334 Car riens ne vail et mes coers si haut tent; Quar, ce par grasse n'est, de tristeur hostes Selonc droiture sage ciertainnement, Qu'en grief doleur sera mon temps usés (Le Romans de la dame a la lycorne [1 $1^{\mathrm{er}}$ tiers XIV $]$, 1160)

+1365 Et ou desir qui si hault me fait tendre Ne voi qu'espoir, et pour ce, plains d'esbas (Jean Froissart, Poésies [3 $3^{\mathrm{e}}$ tiers XIVe])

1697 Peut-être la fortune est prête à vous quitter ; Aux plus affreux excès son inconstance passe.

Prévenez son caprice avant qu'elle se lasse. Où tendez-vous plus haut? Je frémis quand je voi

Les abîmes profonds qui s'offrent devant moi :

La chute désormais ne peut être

qu'horrible.

Osez chercher ailleurs un destin plus

paisible (Jean Racine, Esther)

1840 Il n'y a pas d'Américains qui ne se montrent dévorés du désir de s'élever ; mais on n'en voit presque point qui paraissent nourrir de très vastes espérances, ni tendre fort haut. Tous veulent acquérir sans cesse des biens, de la réputation, du pouvoir ; peu envisagent en grand toutes ces choses (Alexis de Tocqueville, De la démocratie en Amérique)

II. Tendre en hauteur (un filet)

Transitif

1929 Le thème de l'égoïsme égotiste sonne ainsi sous sa plume : alors comme alors !... autre thème : celui des filets trop haut. L'orgueil les tend si haut que rien de réel jamais ne s’y vient prendre. La vanité tient le tramail dans les bas-fonds et pêche çà et là toujours quelque avantage sensible (Paul Valéry, Variété II)

CORPuS WEB :

Le cœur des gens se tend haut et fier dans le ciel, puis se déchire pour mieux s'entretenir et supporter cette dure trahison qu'est celle de venir au monde [http://yannoo.canalblog.com/ archives/2007/12/01/7079459.html] (9.1.2016)

Je n'ai jamais eu aucun soucis aux péages, juste tendre plus haut le bras pour arriver à la hauteur de la cabine pour payer.... à part ça je vois pas en quoi c'est un problème... [http://www. forum-auto.com/marques/ferrari/sujet2608-70. $\mathrm{htm}](9.1 .2016)$

Il la [= la coupe] ramasse et la tend haut dans le ciel [https://www.fanfiction.net/s/11315 276/1/Courage-force-d-esprit-hardiesse-et-tol\% C3\%A9rance] (9.1.2016)

Nous partons donc en direction de Bagnols en Forêt, en convoi digne de l'Elysée, avec les voitures au milieu du convoi, bien protégées par 
les Crapot's, et la flamme tendue bien haute vers le ciel, dans les mains de Claudine sa gardienne [http://flyingcrapots.org/journee-mondiale-deschevaliers] (9.1.2016)

REMARQUES : Tendre haut (I) s'applique à une personne qui oriente volontairement ses forces affectives, morales, intellectuelles vers un but précis, un niveau élevé, à une personne qui aspire ou prétend à quelque chose d'élevé (ou à son esprit). En (II), il réfère à un filet tendu (sous tension) et fixé en hauteur. Le sens concret de 'élever quelque chose, la porter en hauteur' est illustré dans les trois derniers exemples du CW. Notons la collocation haut et fier. Haut reste invariable dans la majorité des cas. Toutefois, dans le dernier exemple du CW, il s'accorde avec l'objet au féminin tout en conservant son interprétation adverbiale, mais en ajoutant une emphase poétique. Il est modifié par bien, fort, plus, si.

\section{Tenir aise}

I. Traiter (quelqu'un) excellemment, de manière agréable, prévenante, serviable, accueillante Transitif

+1370 Quant elle se trouva en l'empire, si fu ung peu plus aseurée que devant et passa parmy Cambrésis et entra en Ostrevant en Haynnau et vint logier à Buignicourt en l'ostel d'un petit chevalier qui s'apielloit li sires d'Aubrecicourt, et le rechust adont li chevalier et sa femme moult liement, et le tint tout aise selon son esçavoir et tant que la roynne d'Engleterre et ses fils en ama depuis le chevalier et la dame à tousjours et les enfans qui deux naissièrent, et les avancha en plusieurs mannières

(Jean Froissart, Chroniques (A))

-1456 Et au departir fist avec lui venir tous les roys d'armes, heraulz, poursuivans, trompectes, menestriers, tabourins, et autres compaignons d'esbatement soupper avec lui au Bourg la Royne, ou par cellui jour il se loiga, lesquelz il tint bien aise, et au matin leur donna cinquante escus

(Antoine de la Sale, Jehan de Saintré, p. 100, 23)

1515 Or fut conclus par les seigneurs dessusnommez de venir le lendemain prendre leur refection et leur disner chieu ledit prebtre, la cause pour quoy qu'i leur sembloit qu'il avoit des biens et qu'il les tiendroit bien aise (Philippe de Vigneulles, Les Cent Nouvelles nouvelles, p. 69, 30)

II. Adopter une position, posture agréable pour le corps, dans laquelle on se sent bien Transitif

+1400 Grans vanteurs sont et sanz proece, Mais trés bien parez par dehors, Orgueilleux pour leur gentillece, Et tiennent bien aise leurs corps (Christine de Pisan, Autres balades / Euvres poétiques [début Xve], I, p. 226, 12)

REMARQUES : Dans l'ancienne langue, tenir aise (I) désigne le fait de bien accueillir quelqu'un, de se comporter avec lui de manière avenante, d'en assurer le bien-être. (II) se dit du fait de tenir son corps dans une position agréable, qui permet une liberté et souplesse totale des mouvements. Aise reste invariable et est modifié par bien, tout.

\section{Tenir bas}

I. Maintenir, mettre à un niveau (moral, social, spirituel, pécuniaire) peu élevé ; avoir en piètre estime

Transitif

+1200 Uns riches hom jadis estoit

A qui grant richece apendoit :

Chevaliers ert, tint grant hennor.

Mais tant avoit amé s'ossor

Que desor lui l'avoit levee,

Et seignorie abandonee

De sa terre, de sa maison,

Et de tot otroié le don ;

Dont la dame le tint si vill

Et tint si bas, que quan que cil

Disoit, et ele desdisoit,

Et desfaisoit quan qu'il faisoit

(La Dame escoillee [1 ${ }^{\mathrm{re}}$ moitié $\left.\mathrm{XIII}{ }^{\mathrm{e}}\right], 33$ )

1593 Il vous tiendra bas, il aura l'œuil sur vos desportemens et ne cessera, par moyens, qu'il ne se soit asseuré de ce costé (René de Lucinge, Dialogue du François et du Savoysien)

1634 Je seray fort heureux d'estre vaincu ; toutefois si vous desirez que vostre gloire soit parfaicte, faites que nous combattions à 
armes esgales. Si vous m'en donnez de pareilles à celles que je vous donne, (comme vous ne pouvez pas me les refuser,) tout le ciel ne pourroit rien faire contre moy ; et si je le laisse en repos, ce sera d'autant que je tiens trop basse toute autre conqueste que la vostre (André Mareschal, La Chrysolite)

1670 Pendant que la nature nous tient si bas, que peut faire la fortune pour nous élever? (Jacques-Bénigne Bossuet, Oraison funèbre de Henriette-Anne d'Angleterre)

1704 Quand donc j'aurois de la gloire, je la voudrois supprimer ; mais je n'en ai point, je n'ay rien, je ne suis rien ; et il ne s'agit que d'abaisser, ou plustost il ne s'agit que de tenir bas un pur néant (Jacques-Bénigne Bossuet, Méditations sur l'Évangile)

1839a « Votre crainte elle-même écarte la crainte de la mort. Pourquoi donc fut ceci défendu ? Pourquoi, sinon pour vous effrayer ? Pourquoi, sinon pour vous tenir bas et ignorants, vous ses adorateurs? » (François de Chateaubriand, Le Paradis perdu)

1839b C'est au nom de la majesté de l'intelligence que je relève l'excitation de l'ivresse. On l'a tenue trop bas jusqu'ici, mais tout ce qui eut un esprit dans son corps de boue, un estro, éprouva le besoin de cette secousse produite par les breuvages, plus profonde, plus dominatrice que celle produite par les parfums (Jules Barbey d'Aurevilly, Deuxième Memorandum)

1955 CORTE. Supposons que je ne sois pas fou ; il ne reste qu'une explication. J'accepte, penseront-ils, parce que je suis en mesure de tenir les prix bas. Et pourquoi puis-je tenir les prix bas ? Vous avez compris? (Albert Camus, Un cas intéressant)

Pronominal

+1400 Humilité en riche homme bien siet : Plus se tient bas et plus hault on l'assiet (Christine de Pisan, Proverbes moraulx / Euvres poétiques [début Xve], III, p. 52)
II. Dire à voix basse, en chuchotant Transitif

1735 Ce conseil fut tenu bas, dans la crainte que nous ne fussions écoutées ; j'acquiesçai à tout ce qu'elle voulut, et pour rendre la chose plus vraisemblable, je lui fis mes adieux fort haut, et Lindamine, en me conduisant à la porte de sa chambre, ordonna du même ton à une servante qu'on fît monter Bélizai (Charles de Mouhy, La Paysanne parvenue)

1964 « Celle avec qui il déjeune... » Verdier se retourna du côté du vieil homme qui, penché vers sa voisine, lui tenait tout bas des propos qui la faisaient s'esclaffer d'un petit rire aigu « ... n'est vraisemblablement qu'une petite poule sans importance » (Michel Droit, Le Retour)

\section{CORPuS WeB :}

Par son aspect extérieur, le muntjac ressemble à un chevreuil, mais son corps est plus gros et il se tient bas sur ses pattes [http://www. agrimusee.be/fr/parc-animalier/plan-du-parc/ article/les-muntjacs] (10.1.2016)

il avait repéré un trou dans le dispositif mardilène entre les milieux Guti, Fernando Gago et Royston Drenthe, dont le rôle était de presser Xavi et Yaya Touré, et les deux défenseurs centraux, qui avaient tendance à se tenir bas sur le terrain, près de leur propre surface de réparation [http://www.lequipe.fr/Football/Actualites/Lessecrets-de-guardiola/507214] (10.1.2016)

Comme il la tient bas par rapport à la facon dont il porte ses grattes...Tu me diras, ca doit être plus lourd... [http://www.guitariste.com/ forums/groupe-artiste,bumblefoot-nouvelalbum,275072,30.html] (10.1.2016)

$\mathrm{Vu}$ chat noir et blanc. Semble avoir un problème à l'oreille, il la tient basse [https:// fr-fr.facebook.com/Pet.Alert.Fr.52/photo s/a.540645422660759.1073741826.408621862 529783/805338769524755] (10.1.2016)

REMARQues : Tenir bas (I) désigne le fait d'accorder peu d'importance, peu de valeur à quelque chose ou à quelqu'un, voire de le mépriser. $\mathrm{Au}$ concret, il peut aussi référer au prix de quelque chose (exemple de 1955). Au pronominal, il suggère la disposition du sujet à s'abaisser volontai- 
rement à faire telle ou telle chose, faisant montre d'humilité. (II) se dit du fait de dire quelque chose, d'avoir une conversation à voix basse, en chuchotant dans le but de ne pas être entendu. Notons l'opposition de tenir bas et asseoir haut dans le proverbe Plus se tient bas et plus hault on l'assiet (ex. de +1400). Au sens concret, représenté dans le $\mathrm{CW}$, bas peut s'accorder ou non avec l'objet (comparer le troisième et le quatrième exemple du CW). Bas est modifié par si, trop, tout. Notons la collocation bas et ignorant et l'emploi de tenir vil.

\section{Tenir bel (beau)}

I. Bien entretenir, garder en bon état Transitif

+1249 Veü avez com longuement

At tenu bel et noblement

Li cuens la contei de Tholeuze, Que chacuns resembleir goleuze, Par son sanz et par sa largesse (Rutebeuf, Poèmes [pièces datables de 1249 à 1272], I, p. 488, 30)

II. Traiter, s'occuper (de quelqu'un) avec gentillesse, aimablement, de manière plaisante, agréable

Transitif

+1250 Et Primaut si tint le vilein.

La feme hauce le baston

Et fiert Primaut sor le cropon.

Mes por ferir ne por blecer

Ne le voloit Primaulz laissier,

Einz le teneit et bel et gent (Le Roman de

Renart [2e moitié XIII ${ }^{\mathrm{e}}$, XIV, 799)

\section{Corpus Web :}

Chercher le propos d'interprétation d'un texte, c'est déjà trouver une piste pour le retravailler. L'entendre lu par une autre voix, avec un autre angle de vue, c'est parfois découvrir un aspect qu'on avait complètement occulté. De plus, avoir à faire cette lecture dans ce lieu précis, c'est avoir à tenir compte d'un décor qui n'est pas anodin, qui oblige souvent à « se tenir beau » [http:// ass.asphodeles.free.fr/dem3.htm] (10.1.2016)

Comment ?...quand on chute... il faut tenir beau ? Aujourd'hui, je vis beaucoup d'amour de ceux qui m'entoure... [http://cenestpas1delit. canalblog.com/archives/2007/03/03/4188729. $\mathrm{html}]$ (10.1.2016)
Tenir beau la route [http://cadichon001.overblog.com/article-tenir-beau-la-route-48461644. html] (10.1.2016)

Elle se tient belle et majestueuse au dessus de moi, faisant un terrible rempart aux mille scintillements [http://www.saintseiya.com/fanfic/ lagestedesillusions/lagestedesillusionschapitre 05.php] (10.1.2016)

REMARQUES : En ancien français, le complément d'objet de tenir beau (I) réfère à un fief, un territoire que le sujet gère ou gouverne bien, avec discernement. De même, tenir beau (II) désignait le fait de traiter quelqu'un de manière agréable, prévenante, serviable, de bien accueillir cette personne, de se comporter avec elle de manière avenante. Beau y adopte sa forme neutre bel. Dans le CW, tenir beau renvoie à la posture, à l'attitude, à l'impression qu'on donne. Notons l'expression tenir beau la route 'entretenir une route avec de belles fleurs'. Dans le dernier exemple $\mathrm{du} \mathrm{CW}$, beau est un prédicat second qui s'accorde avec le sujet du verbe pronominal.

\section{Tenir bon}

Tenir fermement, solidement, résister (à quelque chose/quelqu'un) d'une manière ferme, inflexible

Intransitif

+1370 Ainsi fut ce conte de Guerles au dessus de ses besoingnes, et prinst nouvel conseil et nouvel estat. Et se en devant il avoit tenu bon, encoires le tenoit-il meilleur aprez, car il avoit moult bien de quoy (Jean Froissart, Chroniques (A))

+1472 Celluy tenoit fort bon pour les Zassons, et estoit mauvais Bourguignon en couraige ; mais il garda sa maison et fit petite guerre, car il escoutoit qui en auroit du meilleur (Olivier de la Marche, Mémoires [ $4^{\mathrm{e}}$ quart $\left.\mathrm{xV}^{\mathrm{e}}\right]$ )

+1489 Le roy Ferrand tira droit à Capoua, où refusèrent l'entrée à ses gens d'armes, mais ilz laissèrent entrer sa personne avecques peu de gens. Il n'y arresta point et leur pria tenir bon pour luy et que le lendemain reviendroit ; et alla à Napples, doubtant ce qui advint, la rebellion (Philippe de Commynes, Mémoires [1489-1498], VII) 
1558 Mais il y en eut deux qui se lassèrent de trotter, parce qu'ilz estoyent un petit chargez de cuisine. Les deux autres tindrent bon, et furent bien ayses que les deux s'en allassent (Bonaventure des Périers, Les Nouvelles Récréations et joyeux devis)

1594 Celuy qui fuit, il eschappe souvent ; Mais qui tient bon, et se met trop avant, Souvent se perd et est troussé en male : Je m'en rapporte au chevalier d'Aumale (Satyre Ménippée)

1627 Nos soldats voyans leur capitaine si mal traité, se retirerent vistement dedans le chasteau où ils tinrent bon avecque nous à la bresche, et nous ayderent à repousser les ennemis qui voyans la nuit venir se voulurent reposer, et ne point precipiter une chose qui ne leur pouvoit faillir (Charles Sorel, Le Berger extravagant)

1747 je l'avois observé regardant tantôt sa montre, tantôt la pendule : l'heure du spectacle approchoit ; quelle apparence que ma vue tînt bon contre la nécessité d'y aller étaler un habit de goût qu'il avoit mis ce jour-là ! (Claudine-Alexandrine Guérin, marquise de Tencin, Les Malheurs de l'amour)

1763 La Morliere tient bon, se présente toujours pour tenir sa parole, et fait arriver lettres sur lettres qui confirment que c'est un imposteur, qu'on craigne tout de lui, qu'il est homme à déshonorer une fille et à le publier ; qu'il faut éconduire un pareil scélérat à prix d'argent (Louis de Bachaumont, Mémoires secrets pour servir à l'histoire de la république des lettres)

1838 J'en étais à l'introduction de mon vingt-neuvième personnage (les romans en feuilletons m'ont volé !), quand le père Matifat, qui, en qualité de maître de maison, tenait encore bon, a ronflé comme les autres, après avoir clignoté pendant cinq minutes (Honoré de Balzac, La Maison Nucingen)

1852 La dernière fois que le général Roguet entra de la sorte avec de mauvaises nouvelles, il était près d'une heure, - lui-même a raconté depuis ces détails, à l'honneur de l'impassibilité de son maître -, il informa le prince que les barricades dans les rues du centre tenaient bon et se multipliaient (Victor Hugo, Napoléon le Petit)

1862 Voilà des faits certains, évidents, palpables, et tout aussi inexpliqués que l'enflure et la rougeur de votre nez. Mais patience! Deux jours après, le nez de M. L’Ambert désenfla d'une façon visible, mais la couleur rouge tenait bon (Edmond About, Le Nez d'un notaire)

1869 Le mât, cassé en deux, tout hérissé de baillons frissonnants, de cordes, de moufles et de vergues, encombrait le pont. En tombant, il avait brisé un pan de la muraille de tribord.

Le patron, toujours à la barre, cria :

- Tant que nous pouvons gouverner, rien n'est perdu. Les œuvres vives tiennent bon. Des haches ! des haches ! le mât à la mer ! dégagez le pont

(Victor Hugo, L'Homme qui rit)

1884 Bien peu résistent à cette épreuve du bain. C'est là qu'on les juge, depuis le mollet jusqu'à la gorge. La sortie surtout révèle les faibles, bien que l'eau de mer soit d'un puissant secours aux chairs amollies. La première fois que je vis ainsi cette jeune femme, je fus ravi et séduit. Elle tenait bon, elle tenait ferme (Guy de Maupassant, Contes et nouvelles)

1911 Presque toutes les lignes souterraines se trouvaient tranchées, mais l'arbre tenait bon encore. À chaque atteinte, l'aubier, frais et dur, sautait.

« Han !... Han ! » anhélaient en mesure les poitrines (Alphonse de Châteaubriant, Monsieur des Lourdines)

1926 Il voyait le crâne de l'Angleterre rougir, mais l'Angleterre tenait bon. Quant à l'Amérique latine, elle avait des cheveux qui lui descendaient sur le col et la protégeaient solidement (Henry de Montherlant, Les Bestiaires) 
1943 Mais les spontanistes tiennent bon. Ils objectent que le traitement chimique, ou le chauffage, ou la filtration ont pu priver l'air d'une qualité ou d'une substance propice à la genèse des animalcules (Jean Rostand, La Genèse de la vie)

1995 Le signe astral de Blaise ? Je ne bronche pas. Mais M. Molinier est coriace. Il repose sa question autrement. Je tiens bon. Il s’obstine. Moi aussi. Il revient à la charge. Une fois, deux fois. Mais vous le savez, voyons, Pascal est-il Poisson ou Sagittaire ? Il a un sourire mauvais

(Lydie Salvayre, La Puissance des mouches)

\section{CORPUS WEB :}

Malgré des pressions mafieuses, une équipe de foot féminin tient bon [http://www.europe1.fr/ international/malgre-des-pressions-mafieusesune-equipe-de-foot-feminin-tient-bon-2647913] (10.1.2016)

Il faut vraiment essayer à la farine de riz à mon avis. Normalement l'ensemble se tient bon en main pour former des boulettes [http://www. vegactu.com/recette-vegan/boulettes-de-lupinveganes-facon-bolognaise-1865] (10.1.2016)

Mais il n'est pas homme à baisser les bras, bien au contraire. Il a su redresser la barre et la tient bon [http://www.sudouest.fr/2010/12/27/1epicier-a-cree-sa-boite-sur-un-pari-il-1-agagne-276766-931.php] (10.1.2016)

REMARQUES : Souvent employé dans un contexte guerrier ou de lutte, tenir bon réfère à des soldats qui résistent à l'attaque, qui savent rester efficaces face à l'ennemi, font preuve de courage devant les difficultés, ne relâchant pas leurs efforts et continuant à lutter. Le sujet peut aussi désigner un inanimé (un arbre) qui résiste aux intempéries (tempête, vent). Tenir bon s'emploie également par rapport à quelque chose d'abstrait (l'amour) qui résiste au temps ou aux difficultés de la vie. Le sujet peut désigner une chose servant à protéger ou à séparer (un mur, des barricades, une digue), qui reste solide, résiste à quelque chose (au choc, aux intempéries). Bon reste invariable, la fonction étant clairement adverbiale, proche de bien. Il est modifié par encore, fort. Notons l'emploi transitif et pronominal du verbe dans le CW. Notons l'emploi de tirer droit et tenir ferme.

\section{Tenir cher}

Aimer, tenir en haute estime, accorder de la

valeur

Transitif

1170 Quis trueve beles e leiaus,

Uns des angeles esperitaus

Ne deit estre plus chier tenuz : [variantes :

si chier ; chiers]

Chiere piere ne ors moluz

N'est cel tresor comparez (Benoit de Sainte

Maure, Le Roman de Troie, 13489)

1176a Au port ou li vaslet se levent,

Vint li messages la reïne.

Le vaslet trueve an la marine,

S'a la chemise presantee

Celui cui ele molt agree.

Et por ce plus chiere la tint

Que devers la reïne vint

(Chrestien de Troyes, Cligés, 1189)

1176b Et qui a voir dire n'açope,

Plus la devroit an tenir chiere

Por l'uevre que por la matiere

(Chrestien de Troyes, Cligés, 1535)

1177 La dameisele par la main

An mainne mon seignor Yvain

La, ou il iert mout chier tenuz ;

Si cuide il estre mal venuz,

Et s'il le crient, n'est pas mervoille

Dessor une coute vermoille

Troverent la dame seant (Chrestien de

Troyes, Yvain ou Le Chevalier au lion, 1945)

-1200a Cil ke sunt alkes bon perriér

La granate tienent plus chér :

El a la plus bele culúr,

Pur ce la tiennent a meillor

(Les Lapidaires français du Moyen âge, Premier lapidaire [fin $\mathrm{XII}^{\mathrm{e}}$ ], 348)

-1200b Líerres ki l'a la tient mult chere :

La puldre fait de ceste piere

En la maisun u deit entrér,

Qant ce est k'il voilt embler :

Vis chiarbuns prent $u$ est li fóus,

Si's establist par katre lóus

De la maisun en katre sens

(Les Lapidaires français du Moyen âge, Premier lapidaire [fin $\mathrm{XII}^{\mathrm{e}}$ ], 475) 
1200a Quant oit li rois qu'il sont tel chevalier, Forment les aimme et honore et tient chiers. De remanoir Renier n'ose proier, Se li premet de la terre un quartier Et en fera son maistre conseillier (Jourdain de Blaye, 2931)

1200b Je lou tig a fable et a songe Qant on lou me conta premiers. Les contrais tiennent il molt chiers, Por coi ? que c'est lor truandi[s]e ; Il les envoient querre a Pize (Guiot de Provins, Euvres, 1994)

1200c Li bon consoil ont confortei Maint prodome desconfortei, Et quant bone oevre est conëue Bien doit estre chiere tenue [manuscrit A : devroit estre chier tenue] (Guiot de Provins, Euvres, 2648)

+1225 Et la roïne en est mout lie. Si l'acole et si l'a baissie, Et li dist que bien soit venue. De li sera chiere tenue Por la courtoisie de li Et por l'amor de son ami (Le Chevalier as deus espees [ $2^{\mathrm{e}}$ quart $\left.\mathrm{XIII}^{\mathrm{e}}\right], 5238$ )

+1249 Moult fui ameiz et chier tenuz Et honoreiz par le preudoume (Rutebeuf, Poèmes [pièces datables de 1249 à 1272], I, p. 289, 40)

\section{+1250 « Par jugement et par reson}

Bien en faites prendre conroi. » Li camels sist joste le roi, Molt fu en la cort cher tenuz (Le Roman de Renart [2 ${ }^{\mathrm{e}}$ moitié XIII'], Va, 445)

+1265 En povres dras n'iert bien venus, Ja povres hons n'iert chier tenus (Richars li Biaus [3e tiers XIII'] ${ }^{\mathrm{e}}$, 1932)

1339 Diex yst ! conment vous est il, dame? Faites, s'il vous plaist, bonne chiére : Vous vous devez tenir plus chiére Pour tant que vous un fil avez (Miracle de l'enfant donné au diable, 340)

1344 Au mains fust la douleur passée Qui souvent pour s'amour me tient, Quant des grans bontez me souvient
Que me fist, et conment m'amoit, Et conment dame me clamoit Et tenoit chiére

(Miracle de Saint Jehan Crisothomes, 15)

+1365 Si voeil ma dame servir, Honnourer et chier tenir, Car mon ressort Et mon deport Y puis veïr (Jean Froissart, Poésies [3 $3^{\mathrm{e}}$ tiers $\left.\mathrm{XIV}^{\mathrm{e}}\right]$ )

1400a Hellas ! Quant qui elles sont ou point ou je suy, Dieu sceit comment elles sont [chierement ; correction des éditeurs] chier tenues et honnestement gardees!

(Quinze Joies de mariage, p. 16)

1400b Vous savez, m’amie, que je vous ay amee et chier tenue et ai mis grant paine a soustenir nostre estat et nostre fait, et voz enfans et les miens se portant mal envers moy (Quinze Joies de mariage, p. 46)

+1400 La veis a loisir ma dame, Mais comment de corps et d'ame L'amoye et tenoye chiere Ne lui dis pas, mais ma chiere, Croy, assez le demonstroit, Car Amours qui me monstroit De ses tours pour myeulx m'esprendre (Christine de Pisan, Le Livre du duc des vrais amans / Euvres poétiques [début $\mathrm{XV}^{\mathrm{e}}$ ], III, p. 76, 583)

+1415 Riens ne valent ses mirlifiques, Et ses menues oberliques ; D’ou venez vous, petit mercier? Gueres ne vault vostre mestier, Se me semble, ne voz pratiques. Chier les tenez comme reliques, Les voulez vous mectre en croniques (Charles d'Orléans, Poésies [ 1415-1440], II, Rondel CCCXXIX, p. 480)

1450a A vous entencion qu'il meure en vous amant ? Bien devez tenir chière voustre beaulté si par elle ung tel homme meurt (Roman de Troilus et Cressida, p. 171)

1450b VERONNE. Helas! doulx Jhesus

De toutes vertuz

Noblement ourné, 
Que sont devenuz

Les faiz chiers tenuz,

Le bien ordonné

Que tu as donné

A tes bons amis?

C'est mal guerdonné

D'estre ainsi mené

Et a mort submis (Arnoul Gréban,

Le Mystère de la Passion, 23995)

+1494 Cestui ot ung vaillant homme nez de Troye comme lui, lequel conduisoit les afferes de son pere au partir de Troye et par lui et par les bonnes ellections qu'il lui donna, conquesta il Turnus et sa terre en Itallie, et, ce veu, par Astanyas qui lui succeda, le tint moult cher et le nommoit Polydomor et estoit prebtre en leur loy (Simon de Phares, Recueil des plus celebres astrologues [1494-1498], p. 182)

1526 Pour ces raisons, en douleur vehemente, Son cueur Royal, jour et nuyt, se tourmente,

Sentant le jour du depart approcher, Lequel tant plus s'approche et plus augmente

Ses grans douleurs, car brief se voit absente De tout le bien qu'au monde tient plus cher (Jean Marot, Le Voyage de Venise)

1623 Les monts en ont tremblé d'horreur. Et moy serois-je sans terreur, Ou, las ! Voudrois-je bien survivre Un bien que je tenois si cher? Non, rien ne sçauroit m'empescher, Non pas retarder de le suivre (François Maynard, Le Philandre)

1631 LISANOR. Prens aussi de ma main ce gage precieux,

Que mon ame tenoit aussi cher que mes yeux (Pichou, L'Infidèle confidente)

1653 TYRENE. Et quoy?

LISIMÈNE. Certains escrits

Qu'elle tenoit bien chers, et qui m'ont tout appris.

Ô le charmant esprit que celuy de Tyrene !

(Tristan l'Hermite, La Célimène)
1710 Aussi on les [= les sources] renferme sous des grilles de fer, et l'on les tient aussi chères que les liqueurs les plus précieuses. Un capucin fort vénérable, et à qui sa barbe seule pourroit donner de l'autorité, vint d'abord nous en faire le panégyrique (Valentin-Esprit Fléchier, Mémoires sur les Grands-Jours d'Auvergne en 1665)

1848 Quant aux devises, je les ai si bien empreintes et colloquées en ma pensée, et les y tiens si chères, que je n'ai pu souffrir que personne en disposât, en jouît et en eût du plaisir que moi-même (François de Chateaubriand, Mémoires d'outre-tombe)

\section{CORPUS WEB :}

Et le Sud de la France est un endroit que je tiens cher juste pour la pure beauté du paysage [http://www.lachroniquerepublicaine. fr/2015/11/05/malia-la-france-signifie-beaucouppour-moi] (11.1.2016)

Après une première édition retentissante dans un lieu qui nous tient cher, la cité du cinéma, Desperados ré-ouvre son Wild Club [https://fr-fr.facebook.com/Rockyramacrue/ posts/313780748772100] (11.1.2016)

La France est en pleine tourmente sociale et la Renault $12 \mathrm{n}$ est alors qu un bébé dans 1 Åuf, un projet qui tient cher à la marque au losange [http://www.aujourdhui.ma/alm-auto/ automobile/il-etait-une-fois-renault-12-la\%C2\%ABsoixante-huitarde\%C2\%BB--107226\#. VpLxzk1IiUk] (11.1.2016)

REMARQUES : Tenir cher se dit du fait d'accorder beaucoup d'importance, d'attacher du prix à quelque chose (en raison de sa valeur), de témoigner de l'intérêt à quelqu'un, de l'affectionner particulièrement. Notons la construction avec objet indirect dans les deux derniers exemples du CW. Cher tend à l'accord avec l'objet et est modifié par aussi, bien, moult, plus, si. Il est le contraire de tenir vil.

\section{Tenir clos}

Être, rester fermé, enfermé

Pronominal

1209 Nus nes puet percier ne desjoindre, Si se tienent serré et clos

Cil chevalier de vers Alos, 
Cil Walencourt et cil Baillués (Jean Renart, Roman de Guillaume de Dole, 2701)

1678 Médecins au Lion viennent de toutes parts ;

De tous côtés lui vient des donneurs de recettes.

Dans les visites qui sont faites, Le Renard se dispense, et se tient clos et coi (Jean de La Fontaine, Le Lion, le loup, et le renard / Fables)

1891 Or, dans ce trouble glauque, on trouve un peu de soi, Un peu du cœur humain qui se tient clos et coi,

Impénétrable cœur plein de choses confuses

Qui dans des murs de verre aussi semblent recluses,

Ô cœur mystérieux comme un aquarium !

(Georges Rodenbach, Le Règne du silence)

CORPUS WeB :

Autant de causes qui acculent le/la souffrant(e) à ne plus sortir de son domicile, à se désocialiser progressivement et à se tenir $\operatorname{clos}(e)$ dans son piège subjectif « peur de.... » [http:// mieuxetreetcoaching.blogs.midilibre.com/ archive/2011/05/26/vaincre-la-peur-vivre-sansangoisse.html] (11.1.2016)

Et si son dernier livre, écrit avec Josée Contreras, s'entend à rouvrir une histoire qu'un consensus trop policé voudrait tenir clos, c'est, on le sent, guidé par un désir de faire comprendre dans quoi les divers acteurs sont pris [http:// www.vacarme.org/article449.html] (11.1.2016)

En donnant raison à ces citoyens luxembourgeois, " la CJCE a déclenché un véritable tremblement de terre » s'est rappelé Fages, « dont l'onde de choc est encore perceptible jusqu'à Bruxelles ». La CJCE « a ouvert la porte que les Etats membres ont essayé de tenir close, en se référant à l'article 22 du règlement n¹408/71/CEE », a-t-elle précisé [http://www.europaforum.public. $\mathrm{lu} / \mathrm{fr} /$ actualites/2008/02/midis-sante] (11.1.2016)

Ici encore, il était loisible aux parties de déroger aux préventions des articles 1719 paragraphe 2 et 1720 alinéa 2 du Code civil, ce qu'elles n'ont pas cru devoir faire puisqu'elles ont stipulé que le preneur entretiendrait les locaux en bon état de réparations locatives [...] et que le bailleur s'obligeait à les tenir clos et couverts selon l'usage [http://www.legifrance.gouv.fr/affichJuriJudi.do? idTexte=JURITEXT000006951361] (11.1.2016)

REMARQuES : Tenir clos s'applique à un objet inanimé ou animé qui maintient son corps ou son esprit dans une position ou un état qui ne permet pas l'ouverture vers l'extérieur. En construction transitive (trois derniers exemples du CW), il renvoie au fait de bloquer une action, notamment dans les domaines politique et juridique. Notons que clos apparaît dans les collocations serré et clos, clos et coi ainsi que clos et couvert. Clos est invariable dans l'exemple de 1209 (à en juger par serré) et dans le deuxième exemple du CW, mais l'usage actuel documenté dans le CW tend à l'accord.

\section{Tenir coi}

I. Maintenir tranquille, silencieux, immobile Transitif

+1100 «Tenez vo main coie.»

Et je li disoie

«Se vos esposoie,

Touse, senz folie

Seriez vos moie?»

(Romances et pastourelles françaises des $X I I^{e}$ et XIII ${ }^{e}$ siècles, p. 132)

1275 Lors a au duc Buevon une raison meüe : Sire, se ma raisons, fait il, estoit creüe, Hui mais seroit no gens toute coie tenue Dusqu'a tant que demain seroit l'aube aparue,

Mais adont soit tres bien armee et fervestue ;

Cil là fors ne nous doutent vaillant une cegüe

Et par ce iert lor gens honnie, et deceüe (Adenet le Roi, Buevon de Conmarchis, 1276)

-1300 L'ampereres de Rome et Naymes li cortois Chevauchent par les rans, bons i fu li chastois :

Belemant les chastïent et ruevent tenir qois Si que d'autre part Rune n'an oïst on la vois ; 
Et li vassal si firent, ce fu raisons et droit (Jehan Bodel, La Chanson des Saisnes [fin XIII $\left.{ }^{e}\right], 1970$ )

1532 A quoy Panurge tira sa longue braguette avec son floc, et l'estendit d'une coubdée et demie, et la tenoit en l'air de la main gauche, et de la dextre prit sa pomme d'orange, et, la jettant en l'air par sept fois, à la huitiesme la cacha au poing de la dextre, la tenant en haut tout coy, puis commença secouer sa belle braguette, la monstrant à Thaumaste (François Rabelais, Pantagruel)

1969 - Ah non, fit Ottavio Ottaviani, il nous suffit d'un Ibn Barka par an!

Ça prit cinq ou six jours, mais, pour finir, l'on tint coi l'obscur fourbi. On ignorait la disparition - si disparition il y avait - d'Anton Voyl ; on ignora la disparition d'Hassan Ibn Abbou (Georges Perec, La Disparition)

Pronominal s'en tenir tout coi

1560 Or comme les enfans de Dieu doyvent recevoir cela d'un commun accord, puisqu'il leur est si bien testifié par l'Escriture, aussi faut-il qu'en chassant loin toutes questions entortillées, lesquelles ils cognoistront ne leur pouvoir tourner qu'à retardement, ils s'en tiennent tout cois entre les bornes que Dieu leur a mises (Jean Calvin, Institution de la religion chrestienne)

II. Rester tranquille et silencieux

Pronominal

1176 Mes nus ne s’an ose avancier Qui por joster contre lui veingne ; $\mathrm{N}$ 'i a nul qui coiz ne se teingne (Chrestien de Troyes, Cligés, 4628)

1285 Sachiez que ne se tint pas quois Cleomadés a cele fois ; Enmi le tas des anemis S'estoit conme chevaliers mis (Adenet le Roi, Cleomadés, 851)

$\sim 1365 \mathrm{Li}$ soloil et li lune se sont tout coi tenuz on ciel en lour habitaicle. en la lumieire de lour rays et de lour saiettes il s'en iront en la clarteit et splendour de ta lance que tout foudrie (Psautier lorrain, p. 152)

+1365a Tout s'acordent à celle vois, Fors seul Avis, mès il tous quois Se tient, nes .i. seul mot ne sonne. De quoi Hardemens l'araisonne Et li dist : Et vous, sire Avis, Voelliés ent dire vostre avis (Jean Froissart, Poésies [3 tiers XIVe])

+1365 b Einsi qu'il soloit faire, atent La pucelle, et quant il voit l'eure Qui se passe et que plus demeure Qu'elle n'avoit fait aultre fois, Trop longement ne se tint quois, Ançois apertement se lieve, Car li gesirs, ce dist, le grieve (Jean Froissart, Poésies [3 $3^{\mathrm{e}}$ tiers XIV $\mathrm{XI}^{\mathrm{e}}$ )

+1400 Et vous dittes qu'elle doit toutevoye En celle amour se tenir ferme et coye, Mais la raison n'en voy par nulle voye (Christine de Pisan, Le Livre des trois jugemens / Euvres poétiques [début XVe], II, p. 131, 654)

1511 Les Dryades gentiles, parmy les crevasses des escorces de leurs arbres florissans meirent hors leurs belles faces. Les chevres et brebisettes du berger Paris en laisserent le pasturer : et ses chiens se tindrent tous coyz sans bouger : et les toreaux en leverent leurs testes (Jean Lemaire de Belges, Les Illustrations de Gaule et singularitéz de Troye)

1560 Et d'aureille dressée escoute et se tient coy, Voyant ce sage front paroistre devant soy Qui doucement la tance, et d'un garcieux dire

Flatte son cœur felon et tempere son ire (Pierre de Ronsard, Élégies, p. 295)

1686 Ne diroit-on pas, sur la foi de ces paroles, que la raison pour laquelle il croit qu'on peut faire intervenir l'autorité du bras séculier à l'encontre des hérétiques, est leur inquiétude perturbatrice du repos public ? Si cela est, il ne faudra pas recourir aux princes, contre des hérétiques qui se tiennent cois chez eux, et, qui n'inquietent 
personne (Pierre Bayle, Commentaires philosophiques sur ces paroles de Jésus-Christ "Contrain-les d'entrer »)

1762 Je lui demandai ce qu'il vouloit ? Il me dit qu'il ne pouvoit dormir. Tant-pis, repris-je, et je me tins coi. Il me pria d'allumer la chandelle ; pourquoi faire ? et je me tins coi. Ce ton laconique commençoit à l'embarrasser (Jean-Jacques Rousseau, Émile ou De l'éducation)

1824 Vous, Paul-Louis, vous deviez être non seulement prudent, mais muet, afin, sinon de parvenir à l'Académie, de vivre en paix, du moins. Il fallait vous tenir coi, tailler votre vigne, non votre plume ; vous faire petit, ne bouger, de peur d'être le moins du monde aperçu, entendu (Paul-Louis Courier, Pamphlets politiques)

1842 Jusqu'ici je me suis tenue coi, je n’ai dit à personne que j'eusse des arguments personnels contre Buloz, les rapporteurs ont cru que je ne me mêlerais pas de cette affaire, que ce serait une simple question de procédure où mes conseils agiraient pour moi (George Sand, Correspondance)

1844 Je m'approchai des trois aveugles pour les écouter ; mais quand je fus près d'eux, ils m'étudièrent, ne reconnurent sans doute pas la nature ouvrière, et se tinrent cois.

- De quel pays êtes-vous, vous qui jouez de la clarinette?

- De Venise, répondit l'aveugle avec un léger accent italien

(Honoré de Balzac, Facino Cane)

1858 Il avait embrassé le parti de la Réforme au moment où la Réforme, épuisée d'hommes et d'argent, n'avait plus, dans nos provinces, qu'à se tenir coite et à se faire tolérer. Autour de lui, tout était catholique ou faisait semblant de l'être (George Sand, Les Beaux Messieurs de Bois-Doré)

1859 Je me tiens donc bien coi au coin de mon feu, ne parlant pas et tâchant de ne pas penser beaucoup plus. C'est une raison de plus pour que je ne puisse pas consentir à ce que vous veniez ici (Alexis de
Tocqueville, Correspondance d'Alexis de Tocqueville et d'Arthur de Gobineau)

1869 Je me recachai derrière le buisson, et je me tins tout coi, comme l'acantophorus serraticornis, qui ne montre que la tête en dehors de son nid (Lautréamont, Les Chants de Maldoror)

1874 Les quadrumanes ne donnaient plus aucun signe d'existence, et c'était à croire qu'ils avaient disparu ; mais ce qui paraissait le plus probable, c'est qu'effrayés par la mort de l'un d'eux, épouvantés par les détonations des armes, ils se tenaient cois au fond des chambres de Granite-House, ou même dans le magasin (Jules Verne, L'Tle mystérieuse)

1902 Une chose me chagrine entre toutes. Le comte est-il présent, elle se tient coite, elle vous a des façons d'infante espagnole. Lui parti, elle insulte, elle tranche, elle affecte les plus détestables manies (Paul Adam, L'Enfant d'Austerlitz)

1921 Dans une des conférences de la Mission, un frère clerc qui répétait son oraison vint à dire qu'il s'était un peu plus tenu coi, pour écouter Dieu qui lui parlait au cœur. M. Vincent le reprit... « Ce mot que vous venez de dire : "J'ai écouté Dieu », est un peu rude » (Henri Bremond, Histoire littéraire du sentiment religieux en France)

1933 Il avait dû manger au dehors et s'installa tout de suite devant sa table de travail. Je couchais depuis quelques jours sur le fameux divan de Cécile. Je m'y tenais bien $c o i$, dormais ou faisais semblant de dormir et ne gênais pas mon père (Georges Duhamel, Le Notaire du Havre)

1938 Il lui restait une chance, une petite chance : s'il posait ses deux mains sur la table, de chaque côté de son livre, s'il se tenait absolument coi, peut-être échapperait-il pour cette fois à son destin (Jean-Paul Sartre, La Nausée)

1960 Les trois soldats assis à la table éclatant de rire, pendant un moment la vieille se tenant coite observant le boiteux attendant 
qu'il reprenne ses cartes tapie recroquevillée sur son banc ses petits yeux décolorés bordés de rose brillant d'un éclat méchant haineux, Cocu! (Claude Simon, La Route des Flandres)

1995 Voyant qu'il titillait l'hameçon, Alexis se tint coi : la ligne au fil de l'eau, il prit l'air indifférent du pêcheur blasé. Il feignit même l'hésitation : la mémoire de sa mère, de son grand-père, un « bien de famille »... (Françoise Chandernagor, L'Enfant des Lumières)

\section{CoRpus Web :}

La peur est aussi un effort, une tendance, ou plutôt un conflit de tendances et d'efforts. C'est une tendance à fuir, impétueuse, souvent irrésistible ; et c'est en même temps une tendance à se tenir coi, à se tapir, à se terrer [http://www. cosmovisions.com/peur.htm] (12.1.2016)

L'auteure affirme se soucier de tenir le lecteur en haleine et écrire pour lui plaire et le surprendre ; bref, elle le tient coi [http://www. ledevoir.com/culture/livres/230463/litteraturefrancaise-un-divorce-a-l-amiable] (12.1.2016)

Quant à l'industrie agro-alimentaire, elle se tient coi, en pensant avec frayeur aux menaces qui pèsent sur ses margarines et autres yaourts anticholestérol [http://www.lanutrition.fr/biendans-sa-sante/les-maladies/le-cholesterol/ lanutrition.fr-publie-le-billet-du-dr-de-lorgerilrefuse-par-le-monde.html] (12.1.2016)

La commission de sélection ne dit rien de ses travaux. Elle se tient coite. Mais quelques informations filtrent quand même [http://www.letemps. ch/suisse/2015/09/29/udc-auditionne-unedizaine-candidats-potentiels-serieux] (12.1.2016)

REMARques : Le sujet de tenir coi (I) désigne une personne qui fait en sorte de maintenir, de conserver une atmosphère empreinte de silence et de tranquillité. Le complément d'objet peut aussi désigner une personne que le sujet s'efforce de garder silencieuse, ou le mouvement d'une main qu'il essaie de calmer. Tenir coi (II) se dit du fait de rester silencieux, tranquille, d'adopter un comportement sage, le sujet restant volontairement en retrait, souvent dans le but d'observer les autres. Notons la collocation ferme et coi. Coi tend à l'accord avec l'objet dans l'emploi transitif du verbe et avec le sujet du verbe pronominal, ce qui renforce une interprétation de prédicat second. À partir de l'exemple de 1902, le féminin à terminaison inaudible coie est remplacé par coite, si la forme non-accordée ne lui est pas préférée, comme dans l'avant-dernier exemple du CW. Il est modifié par bien, donc bien, en haut, tout, un peu plus, mais l'usage moderne tend à figer l'emploi de (se) tenir coi tout court, sans modifieur intercalé.

\section{Tenir complet}

se tenir parfait et complet, dans le discours religieux : être parfaitement accompli (en parole et en action)

$\lambda$ tenir parfait

\section{Tenir droit}

Tenir selon un axe vertical ; avoir une position, une posture selon une ligne droite

Transitif

1130 Ço DIENT escriptures,

Furmiz at treis natures :

Il at tel naturete

Quant ist de sa fossete

En ordre par matin,

Tut dreit tient sun chemin

(Philippe de Thaon, Bestiaire [trad., probablement entre 1121 et 1135], 866)

-1200 Floovanz se desfant a lo de conbatant ; .VII. an i ai ocis a son cor desfandant.

Il tint l'espee droite don d'aciers est li branz;

Qui il consuit a culp, il n'ai de [m]ort garanz (Floovant [fin XII ${ }^{\mathrm{e}}$, 2093)

+1250a Chascun jor en l'escole gist Et ot quanque le mestre dist. Molt fu sages et entendanz, N'ot pas les oreilles pendanz, Ainz les tient droites et escoute Molt parfont pense que il doute (Le Roman de Renart [2 moitié XIII ${ }^{\mathrm{e}}$, XXIII, 1325)

+1250b A grant esbais chiens soreuiegnent, Vers lui tout droit la trace tiegnent. Quant il les sentit abaier, Il s'am prist fort a esmaier, Ses piez mat en oure por fuire, Qu'il tenoit deuant en laidure (Ysopet de Lyon [2 $2^{\mathrm{e}}$ moitié XIII $\left.\left.{ }^{\mathrm{e}}\right], 2560\right)$

-1334 Lors de sa dame li souvient, 
Desur le grant destrier s'afiche,

Sa lance tint trestoute drete,

Forment la prent a paumoier (Le Romans

de la dame a la lycorne [1 ${ }^{\mathrm{er}}$ tiers XIV $], 2283$ )

1450 En celle saule tu troveras le mirour de Sainte Escripture, ouquel tu pourras voir ta face et congnoistre quelle elle est ou quelle fut, et par ainsy tu congnoistras quy tu es. Mais tenir droit tu dois ce mirour, sans le decliner a parvers sens ou malvaiz entendement, car il te ferait la face tortuse et vitupereuse (Pierre Crapillet, Le «Cur deus homo " d'Anselme de Canterbury [trad.], p. 287, § 331)

1564 Tenans droite l'espée, ou portans sur la teste

Un rameau de Laurier, signe de leur conqueste,

Ou gravez d'une Croix, dont la saincte vertu

A tousjours sans combat le Monde combatu

(Pierre de Ronsard, Élégies, p. 258)

1679a Je ne considère point les événements : la fortune en décide ; mais elle n'a aucun pouvoir sur le bon sens. Le mien est moins infaillible que celui des autres, parce que je ne suis pas si habile ; mais, pour cette fois, je le tiens aussi droit que si il avoit bien réussi, et il ne me sera pas difficile de le justifier à Votre Altesse Royale (Jean-François de Gondi (Cardinal de Retz), Mémoires)

1679b et je suis obligé de vous dire, pour la vérité, que je ne lui vis jamais, dans pas une occasion, ni un mouvement de chagrin ni d'intérêt. [...] son humeur, naturellement difficultueuse, faisoit qu'il étoit assez susceptible du premier, parce qu'il étoit échauffé par Joli, qui, avec un bon cœur et des intentions très-droites, a une sorte de travers dans l'esprit, tout à fait contraire à la balance qu'il est nécessaire de tenir bien droite dans l'économie, ou plutôt dans le gouvernement d'une grande maison (Jean-François de Gondi (Cardinal de Retz), Mémoires)
1881 C'était bien cela ; le repas du soir terminé, ils étaient assis au coin du feu, - vieillis sans doute, - son vieux père dans son attitude habituelle, appuyant sur sa main sa belle tête grise, - une tête d'ancien cuirassier redevenu montagnard ; - et sa mère, tricotant probablement, faisant glisser très vite ses grandes aiguilles entre ses braves mains vives et laborieuses, - ou bien tenant droite sa quenouille de chanvre, et filant (Pierre Loti, Le Roman d'un spahi)

1883 Lorsqu'on arriva devant l'église, on s'arrêta ; et la grande croix d'argent parut, tenue droite par un enfant de chœur précédant un autre gamin rouge et blanc qui portait l'urne d'eau bénite où trempait le goupillon (Guy de Maupassant, Une vie)

1884 Auprès de la cheminée monumentale où flambe un tronc de chêne, la princesse tenant droit son buste long a grand air sous le ciborium de sa cathèdre (Joséphin Péladan, Le Vice suprême)

1890a Il arrêta la sonnerie, il sortit pour signaler le train par deux sons de trompe. Flore, à ce moment, vint pousser la barrière ; puis, elle se planta, tenant tout droit le drapeau, dans son fourreau de cuir (Émile Zola, $L a$ Bête humaine)

1890b L'étendard de soie, que la poupée du milieu tient toujours droit comme un cierge, n'est plus qu'une loque déteinte, déchiquetée par le vent (Pierre Loti, Au Maroc)

1895 Et les foules qui tiennent droits, Pour refléter le ciel, les miroirs de leur foi, Réunissent, à ces appels, leurs âmes, Autour des ostensoirs en flammes (Émile Verhaeren, Les Villes tentaculaires)

1926 Quand il s'égarait parmi eux un jour de tempête, il les contrefaisait, tenant droite comme eux dans le vent sa tête enveloppée de mystères et de cris (Marcel Jouhandeau, Monsieur Godeau intime)

1949 La vague musicale, par ailleurs, s’étend lentement jusqu'aux gradins qui avoisinent la prairie inclinée, vers l'eau verdâtre qui dort sous le soleil. Les tiges 
tiennent droites les tentes où l'air se meut difficilement, comme un prisonnier seul qui dirige ses fers (Pierre Reverdy, Maind'œuvre)

1951 Alors que là, petit, c'est la vie, la liberté, pas celle qu'on défend sur les journaux et chacun pour son compte, celle qu'a la fleur de pousser sans pot et sans baguettes pour la faire tenir droite (René Fallet, Le Triporteur)

1985 Elle tenait tout droit le sandwich baguette devant sa bouche, alors que le rouquin moustachu qui se tenait au volant lui imprimait, le coude en l'air, un mouvement violent de rame, et régulier, pour l'arracher à ses dents (Hector Bianciotti, Sans la miséricorde du Christ)

Pronominal

1370 Quant Gieffroy les vit si approuchiez, si sailli en piez et se contint en maniere de fol et se tint tout droit en estant au chief du pont et salua les citoiens en la maniere que je vous diray : « Beaux seigneurs », dist-il, « Dieux vous sault, et si saut vous et si sault moy, et tous vous doint crestienté et baptesme » (Roman de Berinus, I, p. 75)

1465 Et avoit escript le dit empereur Constantin en l'une des parties de la dicte lettre : " Ainssy une nuyt je fus en estaphe et vis devant mon lit une jenne femme moult belle, qui se tenoit toute droite, et tout bellement me toucha " (Jehan Bagnyon, L'Histoire de Charlemagne, p. 20)

1592 Ils peuvent avoir autre pris ; mais le pris de la difficulté, il ne m’a jamais semblé qu'ils l'eussent, ny qu'en malaisance, il y ait rien au delà de se tenir droit emmy les flots de la presse du monde, respondant et satisfaisant loyalement à tous les membres de sa charge (Michel de Montaigne, Essais)

1669 ORGON. Fort bien. Pour châtier son insolence extrême, Il faut que je lui donne un revers de ma main.
(Il se met en posture de lui donner un soufflet; et Dorine, à chaque coup d'œil qu'il jette, se tient droite sans parler) Ma fille, vous devez approuver mon dessein... (Molière, Le Tartuffe)

1704 Une femme qui porte un seau d'eau pendu à la droite étend le bras gauche et se penche de ce côté-là. Celui qui porte sur le dos se penche en avant et au contraire quand on porte sur la tête, le corps naturellement se tient fort droit (JacquesBénigne Bossuet, De la connaissance de Dieu et de soi-même)

1751 Mais voyons, au reste ; les bustes ne sont-ils pas des gens qui n'ont ni bras ni jambes, et qui se tiennent tout droits sur un pied... de je ne sçais pas quoi ? On lui répondit qu'en effet c'étoit-là la vraie définition d'un buste (Alexandre Dumas fils, Ah quel conte!)

1769 Vous verrez tout cela quelque jour, si vous laissez pousser vos ongles et si vous vous tenez droit en parlant (Julie de Lespinasse, Lettres à Condorcet)

1782 Cette dernière paroissoit ne dire à Théodore que des mots à la dérobée; si près de lui, elle n'osoit le regarder : elle se tenoit droite à sa place, sans jamais se retourner de son côté ; et cependant à chaque instant elle jetoit un regard sur lui, en levant doucement et languissamment les yeux, et les baissant aussi-tôt avec précipitation : regard très-connu, et qui dit bien des choses ! (Stéphanie-Félicité Du Crest, comtesse de Genlis, Adèle et Théodore)

1824 Les belles manières tendent à imiter la bonne mine. Celle-ci tient à la construction d'un corps bien fait, et les belles manières nous en donnent quelque apparence. On se tient droite, pour paraître grande ; on efface ses épaules, pour rendre sa poitrine plus large ; on marche la tête levée, pour donner à son cou une longueur plus gracieuse (Joseph Joubert, Pensées, essais, maximes et correspondance) 
1830 Figurez-vous, mon ami, disait l'abbé Chas en s'arrêtant tout court et ouvrant de grands yeux, que ces étoffes se tiennent droites, tant il y a d'or (Stendhal, Le Rouge et le noir)

1832 Il est vrai que le personnel des ombres et leur tenue n'aidaient nullement à l'illusion scénique. D’abord, toutes ces ombres étaient assises, ce qui n'est point convenable. Une ombre qui sait vivre doit toujours se tenir droite et debout (Alfred de Musset / Revue des deux mondes)

1836 Je donnai sur le cou de ma bête un grand coup de cravache qui la fit redoubler de vitesse. Mes cheveux se tenaient presque droits derrière ma tête, mon manteau était horizontal, comme si des plis eussent été sculptés dans la pierre, tant ma course était rapide (Théophile Gautier, Mademoiselle de Maupin)

1848 Sa tête [= de mon père], demi-chauve, était couverte d'un grand bonnet blanc qui se tenait tout droit (François de Chateaubriand, Mémoires d'outre-tombe)

1873 Elle se tenait toute droite, devant la boutique, bien sage, les lèvres pincées par cette moue grave d'une petite femme de six ans qui craint de se salir (Émile Zola, Le Ventre de Paris)

1879 La propreté avant tout, mon garçon ! être propre et se tenir droit, tout est là. Je suis propre comme une casserole rétamée. Oui, mais je ne me tiens pas droit. C'est-à-dire que, pendant que j'apprends mes leçons, je m'endors souvent, et je me cache la tête dans les bras, le dos en rond (Jules Vallès, Jacques Vingtras : L'Enfant)

1883 En rouvrant les yeux, je vis l'immense ciel livide où filaient de nombreux nuages ternes, cachant la lune, - la nature solitaire. Cependant, je me tins droit et ferme, quoique je dusse être blanc comme un linge (Auguste de Villiers de L'Isle-Adam, Contes cruels)

1902 De la cimaise au plafond une glace reflétait le veuf : les cheveux grisonnants ne vieil- lissaient point son visage, mince, roide, un peu hâlé par les soleils par et les pluies des étapes, tout éclairci par les yeux petits et profonds sous l'arcade sourcilière. Il se tenait fort droit, les jambes unies, une main à la dragonne de son épée (Paul Adam, L'Enfant d'Austerlitz)

1912 À une vingtaine de pas de là, Natacha et Boris semblaient avoir une conversation des plus animées. L'officier se tenait haut et droit devant elle, le sourcil froncé, le regard hostile (Gaston Leroux, Rouletabille chez le tsar)

1924 Madame Lenoir voit sa mère aux genoux inflexibles. Elle essaie de l'aider à ne pas se tenir toujours droite ainsi, comme une colonne d'église, revêtue d'inscriptions effroyables. Elle entend la robe de Mélanie bruire encore une fois sur la pierre du seuil (Marcel Jouhandeau, Les Pincengrain)

1930 Quand je passai, on dressait déjà dans les baraques la bière aromatisée, les bonshommes de pain d'épice que Moll aimait, les galettes à la menthe, les cailloux montés en broche et les peignes qui se tenaient hauts et droits dans les cheveux (Jacques de Lacretelle et Madeleine Guéritte, Sarn [trad.])

1935 Le carrosse les attendait. Elle y entra. Il l'y suivit. Sans poursuivre la visite des églises, elle donna ordre qu'on les ramenât au fort Saint-Elme. Elle se tenait toute droite sur son siège, soucieuse et rigide. Don Miguel, en la regardant, songeait à l'évanouissement de sa sœur sur la route de Salerne (Marguerite Yourcenar, Anna, soror)

1936 Machinalement, Jacques fit un pas :

- Asseyez-vous, au moins..., balbutia-t-il, approchant une chaise.

Elle ne bougea pas. Elle se tenait droite, dans la lumière qui tombait du plafond. L'ombre des cils palpitait sur ses joues (Roger Martin du Gard, Les Thibault. L'Été 1914) 
1950 C'est à ce moment que je les ai vus. Ils ne riaient pas, eux. Ils se tenaient tout droits et regardaient dans le vide. Comme ils avaient l'air triste ! (Albert Camus, Les Justes)

1959 À la condition, toutefois, que nous nous tenions droits et fermes, comme une nation qui sait ce qu'elle veut, ne revient pas sur sa parole, mais exige qu'on soit fidèle à celle qu'on lui aura donnée (Charles de Gaulle, Mémoires de guerre)

1975 Il s’est aperçu brusquement que nous avions oublié une de mes valises, de forme circulaire, près du banc. Il l'a empoignée, s'est mis à courir. Il essayait de rattraper le wagon. À la fin il s'est arrêté, haletant, et m'a fait un grand geste d'impuissance. Il gardait la valise à la main et se tenait très droit sous les lumières du quai. On aurait dit une sentinelle qui rapetissait, rapetissait. Un soldat de plomb

(Patrick Modiano, Villa Triste)

Intransitif

1791a - Allons, dit-il en s'asseyant, et nous faisant tenir droites devant lui, travaillez chacune à votre tour au désenchantement de ce perclus, et malheur à celle qui lui rendra son énergie (Marquis de Sade, Justine ou Les Malheurs de la vertu)

1791b Quand j'étais de retour vers lui, il me faisait courber, tenir droite, serrer, écarter. Souvent il s'agenouillait devant cette partie qui l'occupait seule (Marquis de Sade, Justine ou Les Malheurs de la vertu)

1825 L'OBĖSE. Je le dois probablement à mon nouveau régime.

MOI. Comment donc ?

L'OBÈSE. Depuis quelque temps, je déjeune avec une bonne soupe grasse, un bowl comme pour deux et quelle soupe encore ! La cuiller y tiendrait droite (Jean-Anthelme Brillat-Savarin, Physiologie $d u$ goût)

1846 «Oh ! mon Dieu, mon ami, disait Mme de La Vallière à son mari, comme vous portez mal votre épée ! M. de Richelieu a une ma- nière de la faire tenir droit à son côté que vous devriez tâcher d'imiter ; c'est de bien meilleur goût » (Honoré de Balzac, Physiologie du mariage)

1928 Puis avec vos doigts ou plus aisément avec une pince à modes, vous repliez la tige de la fleur à la hauteur voulue en formant un ou deux cercles pour que la fleur tienne bien droite, bien d'aplomb (H. J. Rousset, Travail des petits matériaux)

1937 LE GROGNARD. Mais non, mais non... Je tiens plus droit, vous le savez. Ce que j'en disais, c'était pour faire danser mes dents dedans ma bouche. Taisons-nous plutôt (Jacques Audiberti, L’Ampélour / Théâtre)

1938 Après avoir disposé les chaises en rond autour de la table, ce qui faisait officiel, il passa sa plus belle redingote, chaussa ses escarpins à boucles, mouilla sa touffe de fins cheveux blancs, la fignola, ce qui consistait à la faire tenir aussi droite que possible, se regarda dans la glace avec un sérieux qui eût arraché des larmes à un antisémite (Albert Cohen, Mangeclous)

1985 On les plantait dans le sable, ce qui était plus joli que de les enfoncer sur les pointes en fer surmontant les grilles qui ferment les chapelles, où elles risquent de s'effriter si on les force pour qu'elles tiennent droites (Hector Bianciotti, Sans la miséricorde du Christ)

\section{CORPUS WEB :}

Comment elle se tient droit la meuf ! [https:// twitter.com/jordan_latinoo/status/38730063149 8985472] (12.1.2016)

On peut projeter l'air directement mais par une ouverture aménagée sur le corps de la flûte. $\mathrm{Au}$ lieu de la tenir droit devant soi, on la tient de travers, c'est la flûte traversière [http://www. musicologie.org/sites/f/flute.html] (12.1.2016)

C'est à 4 mois que le bébé contrôle sa tête lorsqu'il est porté en position verticale. Il la tient droite et la tourne à volonté [http://www. parents.fr/Puericulture/Sa-premiere-annee/ Developpement-psychomoteur-quand-bebetiendra-t-il-sa-tete] (12.1.2016) 
Elle est là, elle se tient droite, elle rie, elle parle [http://deshommesetdesmots.tumblr.com/ post/129935443795/elle-est-1\%C3\%A0-elle-setient-droite-elle-rie-elle] (12.1.2016)

REMARQUES : Dans l'emploi pronominal, le sujet désigne principalement un animé et se dit du fait de maintenir son corps dans une position droite, parfaitement verticale, de se tenir selon une ligne droite. Notons l'emploi de droit en collocation avec d'autres adjectifs-adverbes dans tenir haut et droit, droit et debout, droit et ferme qui accentuent l'idée de rigidité, de maintien. Dans l'emploi transitif, tenir droit se dit du fait de tenir un objet, de le maintenir dans le sens de la verticale, ou de faire en sorte qu'il reste dans une position droite. Dans l'emploi intransitif, il souligne la position verticale dans laquelle se trouve un objet. L'accord est presque systématique. Les deux premiers exemples du CW font cependant penser que l'accord systématique pourrait être une propriété du langage écrit soigné. À en juger par le CW, l'accord est plutôt optionnel dans la communication informelle actuelle. L'absence de l'accord s'opère plus naturellement quand droit (à, devant) est pris au sens directionnel (v. ex. de $+1250 b, 1846$ et le deuxième exemple $\mathrm{du} \mathrm{CW}$ ). Notons également l'accord ad sensum avec on sujet dans l'exemple de 1824. Droit est modifié par aussi, bien, fort, plus, presque, toujours, tout, très, trestout.

\section{Tenir dur}

I. Tenir (quelque chose) fortement, solidement, soutenir (quelque chose) avec vigueur et détermination

Transitif

+1150 Jeroboam é tut li barnages de Israel vindrent á Roboam, le fiz Salomun, sil mistrent á raisun en ceste baillie : «Tis peres nus tint mult dur é en grant destresce de servise nus deprienst, mais relásche nus ún pói, é nus te servirums cume á seígnur » (Quatre Livres des rois [2 $2^{\mathrm{e}}$ moitié $\left.\mathrm{XII}^{\mathrm{e}}\right]$, p. 140, 4)

1943 Comme elle eût brandi une tête décapitée, elle la [= sa fille] tenait par sa chevelure, si dur que la petite en avait les yeux bridés (Colette, Le Képi)
1960 Un steeple, c'est pas un concours hippique : dans le paquet ça passe tout seul des obstacles que quelquefois ils voudraient jamais sauter autrement. Alors c'est pas la peine de la [= la pouliche] tenir aussi dur. Pour les autres ça n'a pas tellement d'importance, mais elle, elle peut pas le supporter (Claude Simon, La Route des Flandres)

II. Perdurer, persister, ne pas bouger, ne pas lâcher, ne pas rompre (au propre et au figuré) Intransitif

1857 C'est drôle tout de même, reprit-il, j’ai été amoureux il y a quelque vingt ans, et ça tenait dur (Amédée Achard, Madame Rose)

1877 Je l'avais [= un blessé] sur mes épaules quand j'attrapai mes trois coups de fusil. Je me dis : tiens dur ! le bon Dieu est là (Paul Féval, Pierre Blot)

1911 SYGNE. Vous n'avez pas de troupes. TOUSSAINT TURELURE. J'ai un terrier. Qu'ils voient donc voir à m'enfumer dans Paris. J'y tiens plus dur qu'un blaireau, je suis croché ! Et vous dites que je n'ai pas de troupes? (Paul Claudel, L'Otage)

1929 [Et qui parlait...] De ce gros homme qui lui disait : « Nous serons bâtis tous les deux ensemble avec un ciment qui tiendra dur jusqu'au bout de nos haleines. Oui, ce soir maudit d'il y a deux ans, je lui ai parlé de tout ça et c'est de ça aussi que je lui avais parlé la veille, avec ma musique » (Jean Giono, Un de Baumugnes)

1931 Rivière sourit à cet homme qui relevait son visage lourd, et désignait un axe bleui : "Ça tenait trop dur, mais je l'ai eu. » Rivière se pencha sur l'axe. Rivière était repris par le métier. "Il faudra dire aux ateliers d'ajuster ces pièces-là plus libres » (Antoine de Saint-Exupéry, Vol de nuit)

1936a Son gilet de flanelle c'était plus qu'une grosse gélatine, une bouillie dans sa redingote... tout le gris est devenu tout rouge... Mais ce qui fut le plus terrible, ce fut pour dégager le fusil... Le canon comme ça, il tenait si dur dans l'énorme bouchon de 
barbaque avec la cervelle... C'était comme coincé, pris à bloc, à travers la bouche et le crâne ! (Louis-Ferdinand Céline, Mort à crédit)

III. tenir dur la rampe : s'accrocher à la vie avec détermination, résister fermement

Transitif

1936b Ah ! il sera bien dit jusqu'au bout qu'il m’a emmerdé l'existence ce sale foutu pierrot pourri !... Mais moi je suis bonne !... Moi je reste !... À toi ! À toi ! Tiens dur la rampe vieille bourrique ! Il restera rien ! Pas un croc! Que des dettes! Que des dettes! Ça il s'en fout ! Lui ! pourvu qu'il dilapide !... (Louis-Ferdinand Céline, Mort à crédit)

\section{CORPUS WEB :}

Elle batailla des jambes, essaya de le repousser mais rien n'y fit. Il la tenait dur, comme un sac de patate peut être mais assez bien pour qu'il ne lâcha prise [http://rpfantasy.forumactif. com/t501p15-le-back-ground-d-un-jeu-de-roleragnarok-online] (12.1.2016)

Les villageois de la région étaient des gens pétris de superstitions, mais Novinha, qui avait grandi bien loin du petit hameau d'Ombreuse niché dans les collines, avait développé une formidable curiosité qui la rendait imperméable à toutes les vieilles croyances. Croyance auxquelles Mole, elle, se tenait dur comme fer [http://forum. netophonix.com/ftopic6381-0.html] (12.1.2016)

Avant que la jeune lycan puisse dire quoi que ce soit, le vampire l'attrapa par le bras et la sortit de la cage. Farah avait beau se débattre, il la tenait dure comme le fer [http://ariellequeen. forumactif.org/t779-le-cirque-arrive-en-ville-pvolivier] (12.1.2016)

Léane va avoir 3 mois la semaine prochaine déjà ! Elle se tient dure comme une barre ! Elle est vraiment forte [http://www.mamanpourlavie. com/forum/sujet/mamans-de-granby-et-desenvirons/page/29/voir/\%3C] (12.1.2016)

REMARQUES : Tenir dur (I) réfère au fait de serrer quelqu'un ou quelque chose fortement. Le sujet peut également désigner une personne ou une chose qui est accrochée si fortement à quelque chose ou à quelqu'un qu'elle se retrouve coincée. (II) s'emploie également, au propre, par rapport à quelque chose (p. ex. le ciment) qui ad- hère parfaitement et durablement à un objet ou à un endroit précis, et, au figuré, par rapport à des personnes qui s'attachent ou s'accrochent à quelque chose. Tenir dur la rampe (III) exprime le fait de se maintenir en bonne santé, de tenir bon, de résister aux difficultés de la vie d'une manière résolue et tenace. Dur reste invariable dans la majorité des cas, mais, dans les deux derniers exemples du CW, il s'accorde avec l'objet du verbe transitif ou avec le sujet du verbe pronominal. Si la motivation semble possible dans le dernier exemple, dans l'avant-dernier elle serait classée comme 'illogique' par certains grammairiens. Étant donné que le verbe tenir favorise l'emploi d'un prédicat second accordé (v. tenir coi, droit, etc.), la forte tendance de dur à l'emploi invarié témoigne d'une forte adverbialisation. Dur est modifié par aussi, moult, plus, si, trop. Notons l'emploi impersonnel familier ça tenait trop dur.

\section{Tenir enclos}

Tenir, maintenir, retenir (quelqu'un/quelque chose) dans un enclos, dans un espace réduit, limité ; encercler

Pronominal

+1370 Et se chil de dedens se fuissent tenu tousjours enclos en lor ville sans point issir, et entendu as escarmuces tant seullement et a desfendre lors barrieres, il ne lor convenoit aultre cose (Jean Froissart, Chroniques (A))

1608 Sous une seulle Zone ils se tenoient enclos Estimant le surplus de demeure forclos : Là, par ambition, pour un poulce de terre Animez de fureur ils se sont fait la guerre, Ont forgé des grandeurs, des sciences, des arts,

N'osant de l'ocean éprouver les hazarts, De peur que le soleil d'une ardeur violente Ne consumast leurs corps sous la Zone brulante :

Ou bien que la froideur par un autre costé En leur glaçant le sang tint leur cours arresté (Nicolas Chrétien des Croix, Les Portugaiz infortunez)

Transitif

1372 Eins la tint enclose et secree,

Si qu'il ne la volt descouvrir 
En lieu ou la deüst couvrir

(Guillaume de Machaut, La Prise d'Alexandrie [(1370-)1372], 600)

1560 À l'un des boutz de l'Hippodrome estoient les barrieres où l'on tenoit les chevaux enclos, battans la terre des piedz et forcenans d'attente jusques à ce que le signe du depart fust donné par les trompettes, au commandement des Juges

(Barthélemy Aneau, Alector ou Le Coq)

1574 CORNELIE. Pour faire vos tombeaux, et pour pleurer sur vous,

Languissante, chetive, et de mes pleurs

fumeuses

Baigner plaintivement vos cendres

genereuses :

Puis sans humeur, sans force, emplissant de sanglots

Les vases bien-heureux qui vous tiendront enclos,

Je vomiray ma vie, et tombant legere

Ombre,

Des esprits de là bas j'iray croistre le

nombre (Robert Garnier, Cornélie)

1578 J'esperois par souspirs, par peine, et par langueur

Adoucir son orgueil : las ! Je meurs quand j'y pense.

Mais en lieu d'en jouyr, pour toute recompense

Un cercueil tient enclos mon espoir et mon cœur (Pierre de Ronsard, Le Second Livre des amours)

1601 REINE. Qui va guidant le bal des Astres radieux,

Qui tient tout ce grand Tout enclos en sa main forte,

Par qui toute chose est tant vivante que morte,

Pour qui tout est en tous, en qui seul nous vivons,

En qui seul nous sentons, en qui seul nous mouvons

(Antoine de Montchrestien, L'Escossoise ou Le Désastre)

1620 Ce qu'on dit d'Alexandre honorant les beaux vers
Dont les graces d'Homere ont charmé l'univers,

Se peut dire de luy reverant les miracles

De l'eternel Autheur qui parle en ces oracles :

Il les tenoit enclos comme un riche thresor Dans un coffre odorant de cedre et de fin or (Jean Bertaut, Les Euvres poétiques)

1645 Tout ce que tient enclos le cercle de la Lune Est composé de biens sujets à la fortune (Tristan l'Hermite, La Folie du sage)

1966 À l'intérieur des phrases, là même où la signification paraît prendre un appui muet sur des syllabes insignifiantes, il y a toujours une nomination en sommeil, une forme qui tient enclos entre ses parois sonores le reflet d'une représentation invisible et pourtant ineffaçable

(Michel Foucault, Les Mots et les choses)

\section{CORPUS WeB :}

Et c'est ainsi que s'ouvre le procès, le seul et véritable qui vaille en ces lieux, celui que tient la famille en chambre secrète et par huis-clos et par lequel elle détermine comment se règlent les dissensions et les ressentiments, le soir même sur le perron de l'hôpital du Havre à ce qu'en rapporte Mme Tocqueville sans percer le mystère qu'il tient enclos dans ses palabres muettes : les quatre grands parents de l'enfant sont présents [http:// www.republiquedesombres.com/2013/04/17/ deperrois_injustice_proces] (12.1.2016)

Pour ma part, j'appréhendais ceux [= les loquets] qui couronnaient des barrières en alu bien solides et bien hautes. Je les appréhendais non pas pour l'éventuel hermétisme de leur mécanisme, mais pour ce qu'ils tiennent enclos : des taureaux de plein champ [http://www.anna desmiracles.fr/2014/05/les-taureaux-de-pleinchamp.html] (12.1.2016)

Elle contient les " rayons solaires " des abeilles sous forme de galettes aux alvéoles hexagonales, tout comme la matière de la roche (première pierre) tient enclose en sa substance les rayons de l'énergie de l'esprit [http://herve.delboy. perso.sfr.fr/charles_lorraine.html] (12.1.2016)

Les vieux platoniciens y voyaient l'âme physique du monde, qui tient enclose la semence de tous les êtres, et les Gnostiques Valentiniens 
le personnifiaient en Démiurge, "l'ouvrier inconscient des mondes d'en bas » [http://electra2 zeiss.tonempire.net/t15224-la-magie-noire-passi-noire-que-ca-pour-qui-sait-s-en-servir-a-bonescient] (12.1.2016)

REMARQUES : Tenir enclos désigne le fait de garder quelque chose ou quelqu'un (un animal) dans un espace fermé, clôturé. Le sujet désigne un lieu contenant quelque chose et qui sert à conserver cette chose, à la protéger de l'extérieur. À la forme pronominale, le sujet désigne une personne qui se retrouve dans un espace fermé. Notons la collocation enclos et secree ['secrète']. L'accord avec l'objet direct est systématique, peut-être parce que tenir enclos appartient au style littéraire soutenu. Ceci explique peut-être l'accord hypercorrect dans l'avant-dernier exemple du $\mathrm{CW}$ où enclos devrait logiquement modifier les rayons, donc être au masculin pluriel.

\section{Tenir estable}

tenir ferme et estable : assurer la pérennité, la validité dans la durée

$\lambda$ tenir ferme

\section{Tenir ferme}

I. Maintenir fermement (au propre et au figuré) ; (se) tenir, résister solidement, fermement, vigoureusement, de manière décidée, autoritaire, tenace ; rester ferme, impassible, tenace

Transitif

$\sim 1170$ En plente

Nous desfendes dorguel et de fierte,

Et en aversite de le pointure

De desperance ; atemprance et mesure

Soit li neus

Qui ferm nous tiegne en lamour dieu ki seus

Rent clarte

(Chrestien de Troyes, Chanson, p. 68)

1195 LI ROIS. Senescal, maine le a Durant, Men tourmenteour, men tirant ; Mais garde qu'il fers tenus (Jehan Bodel, Jeu de saint Nicolas, 540)

+1200 Josian tint li un, ke ne put aler, $\mathrm{P}[\mathrm{ar}]$ le pel li $\mathrm{p}[\mathrm{r}]$ ist entur le coler, ausi ferme le tint com out le pouer ;
$\mathrm{B}$ [oves] la dist ke le lessa aler

(Bueve de Hanstone [début $\mathrm{XIII}^{\mathrm{e}}$ ], 1703)

-1209 Et li duc lor respont : « Seingnor, je ai veües vos letres. Bien avons queneü que vostre seignor sont li plus haut home qui soient sanz corone ; et il nos mandent que nos creons ce que vos nos direz et tenons ferm ce que vos ferez. Or dites ce que vos plaira » (Geoffroi de Villehardouin, Conquête de Constantinople, §16)

-1334 Pour ferme le sairement tenir, Maintenant font parmi partir Le cors sacré, lors le rechoivent, Con vrais amans fere le doivent. Lors est li chevaliers si pris De vraie amour, qui l'a espris, Qu'il ne set, que il doie dire ; Bien fet connoistre joie d'ire (Le Romans de la dame a la lycorne [ $1^{\mathrm{er}}$ tiers XIV $]$, 849)

1382 EUFEMIAN. Paix, biaux seigneurs ; vezci la lettre

Qu'il tenoit si ferme en sa main, Qu'il m’a laissié venir a plain. Ceci n'est pas sanz grant mistére. Dites : qui voulez vous, saint pére, Qui la vous lise?

(Miracle de saint Alexis, 2488)

1559a Quant elle entendit le propoz que je luy tenois, le trouva fort estrange et voulut retirer sa main, mais je la tins si ferme que le gand me demeura en la place de sa cruelle main (Marguerite d'Angoulême, Heptaméron, p. 424, 47)

1559b Et, quant à moy, je tiens ceste oppinion ferme, qu'il vault myeulx en user que d'en abuser (Marguerite d'Angoulême, Heptaméron, p. 119, 270)

1573 D’un leger trompeur le renom je perdray, Ferme pour tousjours tel amour je tiendray : Car chacun des Dieux promet en ce grand bien

Rompre le vol mien

(Étienne Jodelle, Hymenee)

1604 ANDROMACHE. Dedans moy comme traits penetrent les douleurs, 
Comme orages dans moy les tristesses s'émeuvent.

Mon cœur est un Enfer, toutes rages s'y treuvent.

CHEUR. Tenez ferme la bride à ce

ravissement ;

Rentrez dedans vous-mesme et sortez du tourment

(Antoine de Montchrestien, Hector)

1627 Charite voyant alors que l'on luy venoit embrasser les genoux et baiser le bas de la robbe, estoit si honteuse qu'elle se repentoit d'avoir suivy sa maistresse, et eust pris la fuite bien tost si Hircan ne l'eust tenuë bien ferme (Charles Sorel, Le Berger extravagant)

1828 J'avais une lunette exercée aux étoiles ; Je la pris, et la tins ferme sur l'horizon.

- Une, deux, trois - je vis treize et quatorze voiles :

Enfin, c'était Nelson

(Alfred de Vigny, Poésies complètes)

1840 De plus, comme leur situation change sans cesse, ils ne sont jamais tenus fermes à aucune de leurs opinions par l'immobilité même de leur fortune (Alexis de Tocqueville, De la démocratie en Amérique)

1851 Irrité par tout un jour de vaine attente, bien décidé à ne pas se laisser marcher sur le pied, à tenir haut et ferme la bannière de la nouvelle aristocratie, dont il se considérait comme un des représentants, M. Levrault exhala librement son humeur : il n'avait pas failli attendre, il avait attendu (Jules Sandeau, Sacs et parchemins)

1907 mais ce que tu ne sauras jamais c'est la longueur de temps qu'il a fallu à l'homme pour élaborer l'homme. À présent que le modèle est obtenu, tenons-nous $\mathrm{y}$. " Tiens ferme ce que tu as », dit l'Esprit à l'Ange de l’Église, et il ajoute : « Afin que personne ne prenne ta couronne » (André Gide, Le Retour de l'enfant prodigue)

1937 Je me laisse emporter, submerger, projeter vers le ciel. Je pose le pied sur le quai, te- nant bien ferme tout ce que je possède au monde : une valise (Marguerite Yourcenar, Les Vagues [trad.])

1963 Avec un double pneumo, je devais faire gaffe, me ménager extrême... J’y allais un peu à la godille... valse lente... retenue classique. Aouou ! Encore ! encore !... tenir ferme la position. Ça devient une crampe. On arrive à fumer, à lire le journal, se taper un casse-croûte (Alphonse Boudard, La Cerise)

Pronominal

1275 Car qui la sentence savrait

E toujourz en son cueur l'avrait,

E la seüst bien soupeser,

Jamais ne li pourrait peser

De chose qui li avenist,

Que toujourz fers ne se tenist [variante : fors]

Encontre toutes aventures, Bones, males, moles et dures (Jehan de Meun, Roman de la rose [1269-1278], 6800)

+1313 Si ruistes cols donner se uont Que troncons de lor lances font ; Li ceualier ferme se tiennent Es ceuaus et biel se contiennent (Jean de Condé, Poèmes [1313-1337], 667)

1371 ROY D’ESCOSSE. Ja pardon ne l'en sera fait, Se Dieu m'aist.

PREMIER CHEVALIER. Alons men donc, puis qu'en son dit Se tient si ferme (Miracle de la fille du roy de Hongrie, 2080)

1538 En me disant qu'à cause du rebout, Souvent se fault tenir ferme debout, Et qu'aux Estatz des roys on se couche Facilement comme en lict ou en couche (Clément Marot, Épitres)

1601 Qui ne sçait qu'il y a beaucoup plus à faire à bien commander et user des richesses que de n'en avoir poinct, se gouverner bien en l'abondance qu'en la poureté ? En ceste-cy n'y a qu'une espece de vertu, qui est ne ravaller poinct de courage, mais se tenir ferme (Pierre Charron, De la sagesse) 
1679 Pradelle, qui étoit bien plus à l'abbé Foucquet qu'au cardinal, et qui savoit que l'abbé Foucquet ne vouloit en aucune manière ma liberté, lui porta en diligence ces bonnes nouvelles, et il en reçut aussi, en même temps, la commission de me faire entrevoir, sans affectation, dans les conversations qu'il avoit avec moi, l'archevêché de Reims et des récompenses immenses, afin que, lorsque l'on m'en proposeroit de moindres, je me tinsse plus ferme et que ma fermeté aigrît encore davantage le Mazarin (Jean-François de Gondi (Cardinal de Retz), Mémoires, 1651-1654)

1727 LYCANDRE. Ah, ah ! vous êtes prêt à changer de titre ? Preuve que la piéce est mal nommée. DORANTE. Défaut essentiel.

POLIDOR. Voilà l'apologiste en mauvaise posture.

BÉLISE. Ne vous découragez pas, Monsieur le Marquis.

NÉRINE. Tenez-vous ferme sur vos étriers. LE MARQUIS. Laissez-les triompher, nous aurons notre tour

(Philippe Destouches, L'Envieux)

1755 Tenez vous ferme à vos principes, quelque sort que le ciel vous destine, considérez ce monde dans le point de vue sous lequel on vous l'a tant de fois présenté (abbé Prévost, Nouvelles Lettres angloises [trad.])

1764 Les philosophes disent [...] qu'ils n'ont pas plus de foi à cet aveugle qu'à celui de Vespasien ; que c'est un miracle inutile ; que Dieu ne fait rien d'inutile; et ils se tiennent fermes dans leurs principes. Mon respect pour saint Gervais et saint Protais ne me permet pas d'être de l'avis de ces philosophes (Voltaire, Dictionnaire philosophique)

1801 « car la vie est comme les glaces de l'hiver sur lesquelles on n'apprend à marcher, à se tenir ferme, qu'après s'être relevé des premiers faux pas : et puis tu sauras mieux connoître ton père » (J. Hector St John de Crèvecœur, Voyage dans la Haute Pensylvanie et dans l'État de New-York)
1843 Quelquefois même, ne pouvant se tenir assez ferme au rebord de sa planche, bien qu'il s'y accrochât de ses quatre mains, il tombait sur le dos du taureau, où il se cramponnait désespérément (Théophile Gautier, Voyage en Espagne)

1870 En déjeunant, nous prîmes la résolution de nous tenir fermes autour du président, qui représentait notre union et par conséquent notre force (Émile Erckmann et Alexandre Chatrian, Histoire d'un paysan)

1886 Ils restaient tous deux à la barre, attachés et se tenant ferme, vêtus de leurs cirages, qui étaient durs et luisants comme la peau des requins ; ils les avaient bien serrés au cou, par des ficelles goudronnées, bien serrés aux poignets et aux chevilles pour ne pas laisser d'eau passer, et tout ruisselait sur eux, qui enflaient le dos quand cela tombait plus dru, en s'arc-boutant bien pour ne pas être renversés (Pierre Loti, Pêcheur d'Islande)

1902 Il suivait les pentes des conversations, voyageait avec prudence, prévoyait les cahots, les trous, les dégringolades et se tenait ferme, les yeux devant lui, pour la seconde de l'abattage (Charles-Louis Philippe, Le Père Perdrix)

1948 DIEGO. Reviens, Victoria ! Ne te laisse pas aller de cet autre côté du monde où je ne puis te rejoindre! Ne me quitte pas, la terre est froide. Mon amour, mon amour ! Tiens ferme, tiens-toi ferme à ce rebord de terre où nous sommes encore! Ne te laisse pas couler! Si tu meurs, pendant tous les jours qui me restent à vivre, il fera noir en plein midi! (Albert Camus, L'État de siège)

1954a «Les raisonnements en gros » sont souvent dangereux, mais, dans la circonstance, il est difficile de ne pas donner raison à ceux qui, plus prudents que les cybernéticiens mécanistes, se tiennent ferme à cette remarque que le cerveau mécanique le plus perfectionné sera toujours par définition moins perfectionné que le cerveau vivant (Raymond Ruyer, La Cybernétique et l'origine de l'information) 
1954b PROTHOÉ. Il tremblait ?... Il s'est tenu aussi ferme que le Pélide en face de toi ! Ma flèche l'a jeté à mes pieds (Julien Gracq, Penthésilée)

1977 En ça encore je me trompais. Ma décision de ne plus jamais exercer de travaux de force, en compagnie d'hommes rudes, je m'y tenais ferme. Ce qui limitait à un point incroyable l'essentiel de ma prospection des boulots vacants (Albert Simonin, Confessions d'un enfant de La Chapelle)

Emploi absolu

1667 Comme il m'aimoit extrêmement, il y résista fort long-temps ; mais enfin, ne pouvant plus tenir ferme contre des instances si continuelles et si pressantes, il alla trouver M. l'abbé de Saint-Cyran qui étoit un autre moi-même, et par conséquent fort de ses amis (Robert Arnauld d'Andilly, Mémoires)

1669 O mère, ô femme, ô reine admirable, et digne d'une meilleure fortune, si les fortunes de la terre étaient quelque chose ! enfin il faut céder à votre sort. Vous avez assez soutenu l'État, qui est attaqué par une force invincible et divine : il ne reste plus désormais, sinon que vous teniez ferme parmi ses ruines (Jacques-Bénigne Bossuet, Oraison funèbre de HenrietteMarie de France)

1710 Les maisons y sont assez belles, et, ce qui est admirable, toutes soutenues en l'air, la coutume étant de creuser des caves au-dessous des fondements, qui ne sont appuyés que sur un peu de terre suspendue, et qui tient si ferme qu'il n'en est jamais arrivé aucun accident

(Valentin-Esprit Fléchier, Mémoires sur les Grands-Jours d'Auvergne en 1665)

1768 Ils abandonnerent les côtes aux établissemens européens : mais ils tinrent ferme dans les montagnes (Nicolas-Simon Linguet, Histoire impartiale des Jésuites)

1770 Choisi entre les prisonniers pour aller au fort de Zélande déterminer ses compatriotes à capituler, ce républicain se sou- vient de Régulus ; il les exhorte à tenir ferme, et tâche de leur persuader qu'avec beaucoup de constance, ils forceront l'ennemi à se retirer (abbé Raynal, Histoire philosophique et politique des établissements et du commerce des Européens dans les Deux Indes)

1823 Cette condescendance inusitée de sa part devenait pour moi un guide assuré ; aussi ai-je tenu ferme et coupé court, en lui disant que le soir même il recevrait de moi ma détermination irrévocable, et mes motifs aussi bien que mes observations aux diverses pièces qu'il m'avait adressées (Emmanuel de Las Cases, Le Mémorial de Sainte-Hélène)

1840 Malgré de tels désavantages, les hommes du Berri n'hésitèrent pas à accepter le combat ; ils tinrent si ferme, et la lutte fut si acharnée, que, selon le bruit public, plus de sept mille hommes périrent de part et d'autre (Augustin Thierry, Récits des temps mérovingiens)

1848 Celui-ci sortit donc seulement alors, le dernier et non pas le plus mortifié de la bande, avec tous les honneurs de la guerre ; ce qui faisait dire dans le temps qu'il avait tenu plus ferme pour la défense de son désert que les plus braves gouvernants ne font au cœur des places assiégées

(Charles Sainte-Beuve, Port-Royal)

1899 Je reçus ordre de me porter sur eux et de les déloger. Ils étaient plus nombreux, mieux armés que nous ne croyions. Quelques sofas tinrent ferme sur la crête de leur fortin, tandis que nous escaladions la brèche ouverte de notre mine (Eugène Vogüé, Les Morts qui parlent)

1936 Il faut d'abord avoir éprouvé par le développement que chaque vérité tient ferme ; alors la contradiction nous pique ; car elle n'est certainement point sans remède. Il est vrai que toute connaissance est d'expérience (Alain, Propos) 
1954 LE CHEF. Une nouvelle charge fulgurante de ces harpies venait de disloquer les Étoliens, et les rejetait par vagues sur nous, les Myrmidons, qui tenions ferme (Julien Gracq, Penthésilée)

II. tenir ferme et estable : assurer la pérennité, la validité dans la durée

Transitif

1330a Promettans les diz executeurs, ou nom que dessus, par la foy et serement de leurs corps pour ce baillés corporelment es mains des diz notaires jurez, a avoir et tenir ferme, agreable et estable a tousjours et sans aucun rappel le dit laiz et toutes les choses dessus dictes et chascune d'icelles (Chartes de l'abbaye de Saint-Magloire)

1330b Promettanz sur l'obligacion de touz ses bienz et de son temporel a avoir et tenir ferme et estable tout ce qui par ses diz procureurs ou l'un d'eulx sera fait, pledié, procuré et ordené des dites choses, et paiera le jugié, se mestier est (Chartes de l'abbaye de Saint-Magloire)

-1334 Tres grant beauté, doucement mise En .i. lieu plaisant, couvegnable, $\mathrm{J}[\mathrm{e}]$ ai en vus m'amour assise Sans avoir pensee muable. Se li tendrai ferme et estavle ; Car je n'ai ailleurs ma fiance [De fin coer vrai le vous fiance] (Le Romans de la dame a la lycorne [ $1^{\mathrm{er}}$ tiers XIV $\left.{ }^{\mathrm{e}}\right]$, 5168)

+1370 Et prissent de toutes ces paroles, ordenances et convenances, li signeur et les bonnes villes, lettres seelees et instrumens publiques a tenir ferme et estable a tousjours mes, sus painne de encourir en contredit de Ronme et sentense d'empereur (Jean Froissart, Chroniques (A))

$\sim 1460$ au premier homme, de quelque estat ou condicion qu'il fust, qu'ilz rencontreroient a l'yssue du dit hostel, compteroient toute la maniere dudit different et noise estant entre les ditz Jehan et Thomas ; et ce qu'il en diroit ou ordonneroit seroit tenu ferme et estable par les dictes deux parties (Les Cent Nouvelles nouvelles, p. 393, 257)
III. tenir ferme à (quelque chose) : tenir avec force, tenir fortement (à quelque chose) Intransitif

1601 Et quoy, veux-tu mourir ? L'effet d'une belle ame

Est de paroistre ferme au tourment qui la pasme, « Constante à son effort, et l'honneur est divin

Qui resiste au malheur et tient ferme au destin » (Nicolas de Montreux, La Sophonisbe)

1902 Si je ne me faisais scrupule d'entrer dans ces descriptions de chair nue qui rendent suspectes les intentions de l'écrivain, lorsqu'elles ne sont pas nécessitées rigoureusement, - ce qui est le cas, - rien ne me serait plus aisé que de vous prouver que Madame de Châteaubedeau tenait encore ferme à l'arbre (René Boylesve, La Leçon d'amour dans un parc)

1957 mais, quand ils étudient les textes sacrés, ils tiennent tous ferme à ce principe, que ces textes doivent être traités de même sorte que les livres humains, que l'écriture ne peut être comprise théologiquement si elle n'a d'abord été comprise grammaticalement : Nullus alius sensus est nisi grammaticus, eumque grammatici tradunt (Philosophie, religion)

\section{CORPUS WEB :}

Je crois que quand il fait des choses limite comme tirer la langue à la caissière, cè là qu'il faut sévir car il faut les tenir ferme à cet âge ingrat [http://famille.aufeminin.com/forum/3ans-betises-sur-betises-j-en-peux-plus-fd50519] (12.1.2016)

Son travail est une fenêtre sur leur mode de vie, des hommes quise tiennentferme sur lechemin de Bouddha, entouré par les tentations modernes [http://www.lejournaldepattaya.com/JOUR NAL\%20DU\%204\%2010\%2013.htm] (12.1.2016)

Comment monter des blancs en neige et les tenir fermes ? [http://www.matvpratique.com/vi deo/17112-comment-monter-des-blancs-en-neigeet-les-tenir-fermes] (12.1.2016)

A vendre, pommes de terre nouvelles, de variété FLORICE, produites sur mon exploitation 
de CAMBRAI. Elles ont de bonnes qualités culinaires, se tiennent fermes à la cuisson et s'utilisent aussi bien en plats cuisinés, en purée ou en frites [http://www.leboncoin.fr/vins_gastronomie/85 7613358.htm] (12.1.2016)

REMARQUeS : Tenir ferme (I) se dit en référence à la position debout ou assise sur un cheval, de manière droite et stable ; ferme souligne la raideur du corps et aussi l'assurance du sujet, son attitude imperturbable face à l'ennemi. Dans son emploi pronominal, le sujet désigne un animé qui s'accroche, se tient à quelque chose (un objet) pour se retenir, s'empêcher de tomber. Dans son emploi transitif, il se dit du fait de tenir avec force quelque chose entre ses mains. En référence à la position adoptée par le sujet, il désigne aussi le fait de conserver le même avis, de rester sur ses principes, de camper sur ses positions, de ne pas en dévier. Notons la collocation tenir ferme et estable (II), où estable souligne l'idée de persistance, de validité dans la durée, le caractère décisif d'un arrangement, d'une décision ou d'un traité. (III) réfère au fait d'accorder beaucoup d'importance à quelque chose, à un principe, à une idée (ce qui est précieux pour quelqu'un). Ferme peut s'accorder avec le sujet du verbe pronominal ou avec l'objet du verbe transitif, mais il tend à l'invariabilité dans l'emploi absolu où tenir ferme est proche de la lexicalisation comme verbe complexe (v., par ex., +1370, 1770, 1840, 1899, 1954a). Dans les recettes de cuisine, tenir ferme redevient une prédication seconde désignant un état ou une qualité de la nourriture (v. derniers exemples du CW). Ferme est modifié par assez, aussi, bien, encore, si, plus. Mentionnons l'emploi de se ménager extrême.

\section{Tenir fier}

Avoir une allure fière, noble

Pronominal

1841 Mais quand, par le soleil de midi, à l'heure où les laboureurs se reposent, le bonhomme sortait de la basse-cour pour dire bonjour à ses moissons, il faisait bon voir sa haute taille et ses larges épaules se dessiner sur l'horizon. Il semblait alors que les blés se tinssent plus droits et plus fiers que de coutume, que le soc des charrues fût plus étincelant (Alfred de Musset, Margot)

\section{CORPuS Web :}

Quelques jour ont passes, notre petite graine s'est mis a faire de jolie feuilles, puis peu a peu des boutons se sont mis a jaillir et c'est par un beau matin que l'on a put apercevoir une magnifique fleur d'un rouge eclatant. Elle se tenait fier comme artaban parmis d'autres fleurs et comme les autres le soir elle se refermait a la tomber de la nuit [http://affections.netfemmes.com/histoirefleur_82946_CONTE_poeme-type] (15.1.2016)

Son père... il avait toujours été communiste et sa grosse main qui tenait fière la sienne à l'intérieur d'la fonderie il y avait d'écrit dedans c'que c'était qu'la vie d'un ouvrier bien mieux que dans les livres... [http://lesdiablesbleus.com.overblog.com/tag/contes\%20et\%20recits\%20de $\% 20$ l'arbre\%20aux\%20histoires/25] (15.1.2016)

Elle se tenait fière et nerveuse sur le cadavre retourné de la petite vieille qui lui avait servi de radeau [http://coquecigrue.eu/category/losthouvewives/page/3] (15.1.2016)

REMARques : Tenir fier réfère, au sens figuré comme au sens concret, à un animé ou à un inanimé concret qui force l'admiration, en impose, par une allure noble, une apparence majestueuse. Fier s'accorde généralement avec le sujet ou avec l'objet, le premier exemple du CW étant ambigu puisque fier peut être pris comme modifieur de elle ou d'Artaban, mais l'accord est généralement préféré dans ce type de construction. Fier est modifié par plus. Notons les collocations plus droit et plus fier ; fier et nerveux.

\section{Tenir fort}

I. Serrer fortement, étreindre

Transitif

1176 S'a dit a toz qu'ele ne vialt Que nus hom an sa chanbre veingne, Tant con cist max si fort la teingne Don li cuers li dialt et li chiés, Se n'est l'emperere ou ses niés, Qu'a ces ne l'ose ele escondire (Chrestien de Troyes, Cligés, 5650)

1195 CLIKÉS. Dÿables ! que chis me tient fort ! Pour poi qu'il n'esrache me cape ! (Jehan Bodel, Jeu de saint Nicolas, 913)

+1233 Toz diz regarde de clicorgne, L'un pié ot droit et l'autre tort. Cil tint le prestre si tres fort 
Par un des piez qu'il ne li loist

A reperier la où soloit

Ainz huche et crie hautement

«Que fetes vous, mauvese gent?»

(Aloul [2 $2^{\mathrm{e}}$ tiers XIII ${ }^{\mathrm{e}}$, 704)

+1400 Ung jour messire Guido se levoit et parloit d'amours ; joyeux a celle heure estoit. Et elle toute eschevelee de luy s'aproucha, ses cheveulx si fort escouy qu'elle lez y mist au travers du visage de luy, et tantost sa main les print et fort lez tint (Nouvelles françaises $d u X V^{e}$ siècle, p. 28)

1450a Mon bien, mon amy, j’ay autres foiz ouy dire, si bien m'en souvient, quant amours et cueur avaricieux pevent prendre aucune chose, ilz la tiennent fort et serrée et bien estroit ; et ceulx qui conseillent la lesser aler perdent bien leur temps (Roman de Troilus et Cressida, p. 186)

1450b En ce faisant se esforçoit d'estordre sa dague hors des mains de Pandaro, laquelle fort il tenoit. Pandaro de son cousté s'esforçoit à la tenir le plus fort qu'il povoit (Roman de Troilus et Cressida, p. 277)

II. Envahir l'esprit

Transitif

1887 Cette bonne raison le frappa, il lui prêcha la patience, il cessa de la tourmenter, excepté dans les moments où l'idée de rire le tenait trop fort (Émile Zola, La Terre)

\section{CORPUS WEB :}

$\mathrm{Tu}$ as le cœur qui voudrait sortir de ta poitrine tellement qui te le fait battre fort, tu veux toujours prendre sa main, et la tenir, la tenir fort, jusqu'à se que ta main soit engourdit, comme la sienne [https://fr-fr.facebook.com/loveados.fr/ posts/378794265585281] (15.1.2016)

Je la re-porte comme une princesse, elle se tient fort à moi [https://www.wattpad.com/17299 1992-juste-toi-mon-bad-boy-chapitre-11/page/2] (15.1.2016)

elle accepte pratiquement tout, tant qu'on la tient forte, autant que le charme avec les retraits de seve en moins et les fleurs en plus [http:// www.espritsdegoshin.fr/forum-bonsai/topic. html?id=9541] (15.1.2016)

Le moral n'est pas au beau fixe, mais elle se tient forte, poursuivit-il. Elle dort mal, mais elle n'est pas dépressive [http://www.dhnet.be/actu/ faits/ils-ne-s-entendent-plus-point-51b7c1afe4 b0de6db98c1a52] (15.1.2016)

REMARQUES : Tenir fort (I) se dit du fait de prendre entre les mains, de serrer quelque chose ou quelqu'un fortement, de maintenir serré. Sous (II), le sujet désigne une personne qui est habité par une idée, qui pense sans cesse à quelque chose et qui ne peut pas s'en défaire. Notons la collocation fort et serré et bien étroit. Fort tend à l'invariabilité, sauf quand il désigne une qualité de l'objet ou du sujet, en emploi pronominal (v. les deux derniers exemples du CW). Fort est modifié par si, trop.

\section{Tenir gent}

Traiter (quelqu'un), se comporter avec

gentillesse, aimablement, convenablement, comme il faut

Transitif

+1250 Et Primaut si tint le vilein.

La feme hauce le baston

Et fiert Primaut sor le cropon.

Mes por ferir ne por blecer

Ne le voloit Primaulz laissier, Einz le teneit et bel et gent (Le Roman de Renart [2 moitié XIII'], XIV, 799)

-1349 Lors li amenistre Amours proie, Quant elle s'efforce et asproie De garder s'onneur et son pris, S'a tantost un cuer d'amant pris, Et Amours sans subjection Le met en sa protection, S'en tient son affaire plus gent (Guillaume de Machaut, Le Dit de l'alerion, 2801)

REMARQUES : Tenir gent se disait du fait de s'occuper de quelqu'un, de l'accueillir de manière plaisante, agréable, de se comporter aimablement, convenablement. Notons la collocation bel et gent 'comme il faut'. Le neutre bel souligne la fonction adverbiale de gent. Gent est modifié par plus.

\section{Tenir haut}

I. Estimer, maintenir à un niveau (moral, spirituel, social, pécuniaire, etc.) élevé

Pronominal

+1365 Et se Fortune plus m'assault, Qui de mon coer fait son bersault, Pour quele chose il tressault 
En mainte fourme,

Si me vodrai je tenir haut

Car courous en coer riens ne vault,

Mès par necessité il faut

Aidier coer mourme

(Jean Froissart, Poésies [3 $3^{\mathrm{e}}$ tiers XIV $\mathrm{XV}^{\mathrm{e}}$ )

1807 Par conséquent, la concurrence augmente pour emprunter, et, par suite, l'intérêt se tient plus haut qu'il n'aurait été : d'où il arrive que bien des spéculations d'agriculture, de manufacture ou de commerce, qui auraient été fructueuses en empruntant des fonds moins chers, deviennent impossibles (Antoine-Louis-Claude Destutt de Tracy, Commentaire sur L'Esprit des lois de Montesquieu)

1856 LA CHARITÉ. (à genoux, comme auprès d'un moribond) [...]

Arrache de ton âme toutes les affections du monde ! Moins il y en aura, plus elle se tiendra haute, comme les sapins, sur les montagnes, qui vont diminuant de feuillage, à mesure qu'ils se rapprochent des cieux ! (Gustave Flaubert, La Tentation de saint Antoine)

1934a Il pouvait sembler que toutes les vertus se heurtaient à toutes les vertus. Nous tâchions de nous tenir aussi haut que l'exigeait notre nouvelle fortune (Jean Guéhenno, Journal d'un homme de quarante ans)

1942 Ses prunelles s'étaient allumées, une rougeur brusque était montée à ses joues pâles.

- Rien de fixé encore, dit Laberge. Des mots comme ça... Mais je crois que ça se tiendra haut.

- Combien? Combien? Dis toujours à peu près.

Laberge cita quelques chiffres : les visons surtout faisaient prime

(Maurice Genevoix, Laframboise et Bellehumeur)

Transitif

1603 Ce pain varie en corps, s'en faisant de grands et de petits, de figure ronde-platte, où n'y a règlement aucun, non plus qu'au prix, qu'on tient haut et bas selon qu'on treuve les achepteurs (Olivier de Serres, Le Théâtre d'agriculture et mesnage des champs)

1823 Va seul au mont Arar, prends ses rocs pour autels,

Prie, et seul, sans songer au destin des mortels,

Tiens toujours tes regards plus haut que sur la terre (Alfred de Vigny, Poésies complètes)

1844 le roi Charles X, alors MONSIEUR, le tenait haut dans son estime, et la pairie, une charge à la cour, une place élevée l'attendaient. Cette femme lui a tourné la tête et a détruit l'avenir de toute une famille (Honoré de Balzac, L'Interdiction)

1848 Bossuet a dit là ce qu'il ne fallait pas faire, et ce qu'on a fait de nos jours. On lui avait proposé à lui-même de se charger d'écrire cette vie. Lui seul alors était l'homme à tenir haut la balance, et à la tenir sans considération humaine et sans incliner d'aucun côté (Charles Sainte-Beuve, PortRoyal)

1912 Et ces ouvrages furent très recherchés dans une réunion d'hommes qui songeaient à laisser des souvenirs. Le père Longuemare tenait hauts son cœur et son esprit. En attendant d'être traduit devant le Tribunal révolutionnaire, il préparait sa défense (Anatole France, Les Dieux ont soif)

1982 Presque tous les soirs elle est, passez-moi l'expression, sur la brèche... à l'assaut, elle tient encore haut le renom des de la L... n'est-ce pas... dont les ancêtres furent de fameux enjambeurs de bergères, de toutes les manantes autour du castel, les pucelles serves, les semeuses au vol, les petites souillonnes cochonnes... les belles dames aussi du temps jadis... les froufroutantes à la cour de Louis le Bien-Aimé et les marquises vendéennes (Alphonse Boudard, Les Enfants de chœur)

II. Altier, hautain (d'une personne)

Pronominal

1592 Mais je romps paille avec celuy qui se tient si haut à la main, comme j'en cognoy quelqu'un qui plaint son advertissement, 
s'il n'en est creu, et prend à injure si on estrive à le suivre (Michel de Montaigne, Essais)

III. Dire à voix haute, ouvertement

Transitif

1610 et ayant remarqué qu'il y estoit à l'heure mesme, feignant de parler bas, elle tint assez haut tels propos à Tersandre : Afin que vous cognoissiez, mon frere, que Madonte vous ayme veritablement et qu'elle se moque de tous les autres qui ont opinion d'estre aymez d'elle, hier elle me commanda, dés qu'elle fut revenue de la chasse, de vous donner ceste bague (Honoré d'Urfé, L’Astrée)

1839 Là, j'imaginais mille incidents d'où je pusse tirer occasion de lui parler ; et bientôt, trouvant un langage, je lui tenais tout haut les plus tendres discours. Mais, l'oserai-je dire? (Rodolphe Toepffer, Nouvelles genevoises)

1946 Aux longues rampes de fureur où courent d'autres attelages, sous les rafales de douceur et la promesse haut tenue d'un immense loisir... (Saint-John Perse, Vents)

1957 Ô très puissante ronce de guerre adossée à sa roche, tu tiens plus haut que mer ton invective contre la mort. L'amour, la mer se fassent entendre ! Naissance et mort aux mêmes frondes !... (Saint-John Perse, Amers)

\section{Prôner (une qualité) avec force}

Transitif

1889 pourtant notre délice, le secret de notre liaison, est de nous analyser avec minutie, et si nous tenons très haut notre intelligence, nous flattons peu notre caractère (Maurice Barrès, Un homme libre)

1957 Ô vous qui tenez haut le cri des femmes dans la nuit,

Faites qu'un soir il nous souvienne de tout cela de fier et de réel qui se consumait là, et qui nous fut de mer, et qui nous fut d'ailleurs,

Parmi toutes choses illicites et celles qui passent l'entendement...

(Saint-John Perse, Amers)
1971 Ennemi de toute emphase et de toute complaisance, inaccessible à tout opportunisme, et tenant haut contre toute abdication ce beau libéralisme d'esprit qui lui a coûté si cher en politique, il nous tient haute leçon d'intégrité humaine (Saint-John Perse, Hommages)

\section{Tenir dans une position élevée} Transitif

1934b Quant au buste, à l'époque du corset, il s'ornait d'une fascinante poitrine, tenue haut et serrée dans un corsage ouvert, corbeille emplie de fruits jumeaux d'une rare perfection (Gabriel Chevallier, Clochemerle)

\section{CORpus Web :}

Monter la langue ? Commet faire, je vais essayer, mais ça me parait difficile, surtout de la tenir haut tout le temps? [http://www.saxofan.fr/ post332247.html] (15.1.2016)

« Pourquoi Turin? ». En effet, le moins que l'on puisse dire c'est qu'à priori, la ville ne fait pas rêver les touristes. Elle ne fait pas le poids face aux mastodontes que sont Rome, Venise ou Milan. Peut être à l'exception des amoureux de football qui doivent la tenir haut dans leur cœur, grâce à son club, la Juventus [http://www. librevoyageur.com/jai-aime-turin] (15.1.2016)

Elle se tient haut sur ses pattes, ses yeux sont grands ouverts, prête à quoi que ce soit. Les gerbilles alertées par le tapage de pieds se tiennent habituellement [http://www.lagerbille. com/gerbille9comportement.htm] (15.1.2016)

Le Monde ne baisse pas la tête. Il s'efforce au contraire de la tenir haute, de la garder froide [http://www.lemonde.fr/idees/article/2012/09/ 24/islam-debat-ou-combat-par-pascal-galinier 1764048_3232.html] (15.1.2016)

Pattes : Courtes, à ossature moyenne et à forte musculature. Pieds de taille moyenne, ronds, compacts.

Queue : Moyennement épaisse, s'effilant vers un bout rond. Bien fournie, elle se tient haute et bien droite quand il marche [http://www.made moisellem.fr/article-mais-qui-est-miss-speilguel worth-91763896.html] (15.1.2016)

REMARQues : Tenir haut (I) se dit du fait de donner un statut élevé à quelqu'un, de l'estimer 
beaucoup, de lui procurer un statut supérieur ou particulier ou de lui accorder une place importante en fonction de son caractère, de sa réussite ou de ses qualités. Dans son emploi pronominal, il souligne le fait de se maintenir à un niveau spirituel ou moral élevé, de conserver un certain idéal, le sujet désignant un animé. Au concret (exemple de 1603), tenir haut réfère au prix élevé de quelque chose. (III) désigne un animé qui affirme fortement ses convictions, ses idées avec assurance. (IV) se dit du fait de louer, de vanter quelque chose (une qualité, une vertu) avec force et conviction. (V) s'emploie au concret par rapport à la hauteur de quelque chose. La tendance à l'emploi non-accordé est forte, même quand haut se trouve coordonné avec un adjectif accordé (v. l'exemple de 1934b). Cependant l'accord est possible pour souligner une qualité de l'objet ou du sujet dans l'emploi pronominal (v. les exemples de 1856 et 1912, ainsi que les derniers exemples du CW). Haut est modifié par assez, aussi, encore, plus, si, toujours, tout, très. Notons les collocations haut et bas, haut et serré, haut et droit.

\section{Tenir ignorant}

I. Prendre, considérer (quelqu'un) comme ignorant

Transitif

1839 Pourquoi donc fut ceci défendu ? Pourquoi, sinon pour vous effrayer? Pourquoi, sinon pour vous tenir bas et ignorants, vous ses adorateurs ? Il sait que le jour où vous mangerez du fruit, vos yeux qui semblent si clairs, et qui cependant sont troubles, seront parfaitement ouverts (François de Chateaubriand, Le Paradis perdu)

II. Ne pas connaître l'existence de (quelque chose), ne pas comprendre (quelque chose) Pronominal

1960 à nous deux moi le suivant l'autre le regardant s'avancer nous possédions la totalité de l'énigme (l'assassin sachant ce qui allait lui [= le colonel] arriver et moi sachant ce qui lui était arrivé, c'est-à-dire après et avant, c'est-à-dire comme les deux moitiés d'une orange partagée et qui se raccordent parfaitement) au centre de laquelle il se tenait ignorant ou voulant ignorer ce qui s'était passé comme ce qui allait se passer dans cette espèce de néant (Claude Simon, La Route des Flandres)

CoRpus Web :

Les gardiens du jeune garçon en face de lui avaient apparemment fait de leur mieux pour le tenir ignorant de son héritage et du monde magique auquel il appartenait [https://www. fanfiction.net/s/8382247/4/Contes-et-L\%C3\%A9 gendes-inachev\%C3\%A9s] (15.1.2016)

le bonheur de la lecture l'emporte sur tout et comme je plains celui qui se tient ignorant de ce bonheur-là [http://fatrasenbleu.blog50.com/ $\operatorname{tag} / \% \mathrm{C} 3 \% \mathrm{~A} 7 \mathrm{a}+$ peut ++pas+faire++de+mal] (15.1.2016)

Alors que les gouvernants n'ont de volonté que de nous tenir ignorants de leurs incompétence, turpitudes ,etc etc [http://www.lejdd.fr/Me dias/Internet/Actualite/Liberation-ouvre-unsite-miroir-pour-heberger-le-contenu-de-Wiki Leaks-241593] (15.1.2016)

Charest cela vous arrangerait de nous tenir ignorant?[https://www.facebook.com/organisme MPIQ/posts/351918944870636] (15.1.2016)

REMARQues : Tenir ignorant (I) désigne le fait de considérer quelqu'un comme une personne naïve, qui ne sait pas beaucoup de choses, voire la dédaigner. (II) désigne une personne qui adopte une posture traduisant son manque de connaissances par rapport à une situation. Ignorant s'accorde avec l'objet, sauf dans le dernier exemple du CW.

\section{Tenir mu}

tenir mu et coi : rester muet

Pronominal

+1365 Mès amours, qui les coers atise, Me tenoit le coer si serré Que quanque j'avoie enserré Et que bien cuidoie avant mettre, Je ne m'en savoie entremettre, Ains me tenoie mu et quoi (Jean Froissart, Poésies [3e tiers XIV]])

REMARques : Tenir mu et coi se disait du fait de rester calme, silencieux, le sujet ne prononçant pas un mot et restant volontairement en retrait, à l'écart. 


\section{Tenir net}

I. Considérer (quelqu'un) comme pur, innocent Transitif

+1313 Ciaus qui erent de boin affaire

Trait entour lui et les honneure,

Ia ne uolsist iestre nulle eure

En son ostel sans bonne gent

Qu'il tenoit mout net et moult gent

(Jean de Condé, Poèmes [1313-1337], 512)

II. Maintenir (quelque chose/quelqu'un) net, propre

Transitif

$\sim 1325$ Si con afaite .i. jœne oisel, Le doit on d'onneur afaitier, Lui net tenir et près gaitier (Watriquet de Couvin, Dits, p. 58, 80)

+1450 L'autre vielle aprés dist : Pour vray et chose toute approuvee est que, qui pourroit finer de ung vray mandegloire et le couchier en blans draps, et lui presenter a mengier et a boire deux foiz le jour, et tenir net comme ung petit enfant, et tout par contenance, moult tost devenra riche, et a paynes sara il comment (Les Évangiles des Quenouilles [3e quart Xve], 1695])

\section{Corpus Web :}

Et pour l'anecdote, j'ai un local attenant à la maison dans lequel sont installés mes terrariums et bacs d'élevage de blattes et de grillons. Je veille à le tenir net et propre, mais pour parer aux évasions qui peuvent de temps en temps survenir, je n'ai rien trouvé de mieux que d'y laisser vivre en permanence quelques unes de ces petites araignées... [http://www.acideformik.com/forums/ lofiversion/index.php?t9208.html] (16.1.2016)

Je la vois s'approcher de moi afin de m'embrasser, je détourne la tete de quelques centimetres pour l'embrasser à mon tour, mais soudain elle se tient net et m'adresse la parole [http:// galaxy-mangas.keuf.net/t278-promenade-agre able-subaru-anngeluss] (16.1.2016)

Je ferai un essai avec une vraie saucisse pour voir si la pâte se tient nette au découpage [http://www.marmiton.org/forum/themeviandes-charcuterie/d-aperitif-coktail-90361. aspx] (16.1.2016)

Oh et puis après tout, si elle ne voulait pas en entendre parler, elle ne poserait pas ce genre de questions, et puis si jamais quelques remords iraient à la troubler, il veillerait à la tenir nette [http://www.thevoodoochild.com/t3583p15-lebrunch-c-est-cool] (16.1.2016)

REMARQUES : Le complément d'objet de tenir net (I) réfère à une personne chez laquelle le sujet reconnaît des vertus comme l'innocence, la pureté. Tenir net (II) s'applique à une personne qui conserve une chose ou un animal dans un état propre. Notons les collocations net et gent et net et propre. Net s'accorde avec l'objet du verbe transitif ou avec le sujet du verbe pronominal, sauf quand il prend le sens de 'soudainement, sans broncher', comme dans le deuxième exemple $\mathrm{du}$ CW. L'accord s'observe aussi dans le dernier exemple où net est employé au sens de 'pur, innocent, propre', donc en prédication seconde. En ancien français, net est modifié par moult.

\section{Tenir parfait}

Maîtriser parfaitement, avec une grande adresse Transitif

+1415 Il a convenu fort combatre, Mais, s'il vous plaist, parfait le tien :

Le fer est chault, il le fault batre, Vostre fait que savez va bien (Charles d'Orléans, Poésies [ 1415-1440], II, Rondel CI, p, 348)

\section{CORPUS WEB :}

Afin de se tenir parfait et complet dans la plénitude de la volonté de Dieu, un chrétien doit prendre pleine possession de tout ce que Dieu lui a donné à travers Christ [http://sentinellededieu. net/2015/08/16/acceder-a-tout-ce-que-dieu-nousdonne] (16.1.2016)

En Christ les Corinthiens se tenaient parfaits, complets, mais dans leur expérience ils étaient loin de cela [http://www.troisanges.com/4eange/ Livres/SEQ/SAN/HTM/LeSanctuaire06.htm] (16.1.2016)

Après l'accueil, l'habillement : La tenue est ce qui distingue le stagiaire, et s'est à travers elle qu'il représente la Marine, s'il peut en être fier, il devra en être digne et la tenir parfaite [http:// www.netmarine.net/tradi/engagez/PMM\%20 BOURG/BOURG.htm] (16.1.2016)

ouaip=presque « cartable » quoi !! $\mathrm{bu}=$ oui mais je tiens parfait la route !! 
fatigué=ça commençait un peu a force ! [http://amour-couple.aufeminin.com/forum/ bon-bah-fd3137725] (16.1.2016)

REMARQUES : Tenir parfait se dit du fait de savoir utiliser quelque chose comme il faut, le sujet faisant preuve d'une grande habileté ou bien d'adopter un comportement modèle par rapport à une religion. Il s'accorde quand parfait désigne une qualité du sujet ou de l'objet, mais il reste invariable quand il se rapproche des fonctions réalisables avec parfaitement (v. l'exemple de +1415 et le dernier exemple du CW). Notons la collocation parfait et complet dans le discours chrétien, et l'emploi de combattre fort.

\section{Tenir propre}

I. Posséder, avoir en propre, en sa possession Transitif

1393 «Par foy, dist Alain, si fait ! Et n'en y a que un, et cellui propre tient tout l'eritaige de mon frere, car le roy lui donna la fourfaicture » (Jean d’Arras, Mélusine, p. 234 [manuscrit Ars])

II. Maintenir (un lieu) dans un état de propreté Intransitif

1885 - Ah ! le mal que ça donne, ne m'en parle pas ! dit la Maheude. Tu es heureuse de n'en pas avoir. Au moins, tu peux tenir propre (Émile Zola, Germinal)

\section{CoRpus WeB :}

Le véto t'a dit quoi faire : doucher, raser les zones blessées pour les tenir propre etc... ? [https://www.1cheval.com/membre/forum/ general/sujet-3331566-0-sale-blessure-grrr] (16.1.2016)

en partant de ce principe il est forcement beaucoup plus convivial de pouvoir faire sa toilette en famille parce que déjà on est sur que les gamins se tiennent propre surtout les dents qui sont souvent lavées a la va-vite [https://ar.ans wers.yahoo.com/question/index?qid=200707010 81905AA63od0] (16.1.2016)

Nous avons déjà refait les sanitaires et nous mobilisons un agent chaque jour de marché pour lestenirpropres, assure Romain Dadoun, dirigeant [http://www.leparisien.fr/espace-premium/ val-de-marne-94/le-marche-aux-11-000-visiteurshebdomadaires-se-refait-une-beaute-22-01-20154466985.php] (16.1.2016)
Les furets se tiennent propres tout seul, sans avoir réellement besoin des humains [http:// patricia.essadjanian.free.fr/rongeur/furet.htm] (16.1.2016)

REMARQUES : Tenir propre (I) désigne le fait de posséder des biens ou richesses (ici : un héritage). (II) se dit du fait de conserver quelque chose (un lieu, une chose) dans un état propre, bien tenu, dont l'aspect est soigné, net. Propre s'accorde avec l'objet du verbe transitif (v. le troisième exemple du $\mathrm{CW}$ ) ou avec le sujet du verbe pronominal (v. le dernier exemple du CW), mais l'emploi familier s'en passe facilement (v. les premiers exemples du CW).

\section{Tenir prou}

Avoir un comportement sage, vaillant

Pronominal

1175 A mout grant paine mes se tienent

Li .xx. chevalier dont j'ai dit, A poi ne sont tuit desconfit ; Ne se pueent mes preu tenir (Gautier d'Arras, Ille et Galeron, 537)

REMARQUes : Dans un combat, face au danger, tenir prou se disait du fait de se montrer fort, de faire preuve de bravoure, de courage.

\section{Tenir raide}

I. Persister, ne pas fléchir, tenir bon Pronominal

1611 la nature humaine est trop debile et trop changeante pour pouvoir se tenir roide contre les assaults de la volupté (Blaise de Vigenère, La Vie d'Appolonius Thyaneen [trad.])

Emploi absolu

1925 Au lieu de céder souplement à chaque effort de la bête captive, il avait tenu raide, il avait aidé le fauve (Maurice Genevoix, Raboliot)

\section{Avoir une posture droite et figée}

Transitif

1814 C'était un rhume que le chagrin avait aggravé et mêlé de fièvre et de douleurs dans le dos, le cou, qui me tenaient tout raide (André-Marie Ampère, Correspondance)

1983 et je porte mes gants de peau... papa accroupi devant moi sur le trottoir, à la sortie 
d'un magasin, à Paris, avait eu beaucoup de mal à les enfiler sur mes doigts que je tenais raides et écartés, mais les gants se sont détendus comme l'avait promis la vendeuse, et maintenant la pression se ferme facilement sans pincer, sans plisser la peau du poignet (Nathalie Sarraute, Enfance)

Pronominal

1859 Un cocher, en petite livrée du matin, mais cependant poudré comme tout cocher anglais de bonne maison, se tenait droit et raide sur son siège élevé, le fouet dans la main droite, verticalement appuyé sur la cuisse (Pierre-Alexis Ponson du Terrail, Rocambole)

1968 Il [= Isaac] se tient raide comme le bâton qu'il utilisait tout à l'heure. Le baron pense que si on pouvait le plier, on le casserait... (Corentin Queffélec, Jusqu'au fond du gouffre)

1972 Tous ces gens arboraient un air tellement ravi, heureux. Et pourtant, ce n'était pas la même gaieté que celle de la Rue dans ses grands jours. Ils paraissaient être prisonniers de quelque chose, pour les dames de leurs belles robes, pour les messieurs de leurs costumes bien coupés. Oui, ils craignaient de se tacher et c'est pour cela qu'ils se tenaient raides (Robert Sabatier, Trois Sucettes à la menthe)

\section{Corpus Web :}

il m'arrive de mettre du gel pour les tenir raide devant et attacher derriere le soir une bonne douche et finie [https://fr.answers.yahoo. com/question/index?qid=20080611143913AAa Ods3] (16.1.2016)

Vous avez vu ça les gars? Des avortons qui se tiennent raide comme des piquets. A croire qu'ils veulent nous affronter! [http://narukami.overblog.net/article-chapitre-huitieme-108900264. html] (16.1.2016)

waou super beau comment tu a fait pour faire tenir les ailes ? c'est le chocolat qui en ce solidifiant les tient raides? [http://gateauxrigolos. superforum.fr/t542p360-star-wars] (16.1.2016)

Ils se tiennent raides à la barre du tribunal correctionnel de Saint-Denis de La Réu- nion, lundi 27 février, pour répondre aux questions du juge [http://www.lemonde.fr/societe/ article/2012/02/28/a-la-reunion-la-main-lourdede-la-justice_1649196_3224.html] (16.1.2016)

REMARQUES : Tenir raide (I), et notamment dans son emploi absolu, renvoie au fait de ne pas céder à une force ou à une tentation. En (II), il réfère à une personne dont la position ou la posture se caractérise par un maintien rigide, qui manque d'aisance. Notons les collocations droit et raide et raide et écarté. Raide s'accorde avec l'objet du verbe transitif ou avec le sujet du verbe pronominal, quand il renvoie à une position physique, mais l'accord n'est pas réalisé dans les premiers exemples du CW. Il est modifié par tout.

\section{Tenir sec}

Résister, ne pas céder

Intransitif

1945 Daniel dit : « c'est du bluff, il n’y a qu’à tenir sec, il abattra son jeu » (Jean-Paul Sartre, Le Sursis)

\section{Corpus Web :}

juste une petite question, comment donner du mou à celui qui monte en tête alors qu'on l'assure avec un grigri et qu'il vient de se reposer à un relais ? car dans ce cas vu qu'il fallait le tenir «sec », quand il désire repartir et bien notre cher grigri bloque! donc dans ce cas j'utilise la poignée pour redonner du mou, mais ça me semble pas judicieux... [http://www.camptocamp.org/ forums/viewtopic.php?id=57747] (17.1.2016)

Il est très important durant le traitement de tenir la tortue au sec, autrement l'effect du traitement va etre zéro.

Meme si ca dure 2 semaines, il faut la tenir sec [http://forum.le-monde-des-reptiles.com/ topic/97832-soucis-avec-une-tortue-sa-carapace] (17.1.2016)

Il est muni de trois bonnes cloches. A la tribune, il y a un grand œil de bœuf qui doit être vitré, et les fenêtres de l'église grillées, treillissées et vitrées à vitre mouvantes pour donner de l'air à l'église et la tenir sèche [http://www.beauzons.fr/ index.php/\%C3\%89glise_Saint-Andr\%C3\%A9_ de_Saint-Andr\%C3\%A9-Lachamp/Histoire] (17.1.2016) 
Un bon truc c'est d'installer une petite pompe à diaphragme qui elle va assécher complètement les fonds et ne pas permettre le retour de l'eau après son arrêt. La ta cale va se tenir sèche [http://passionvoile.forumcanada.net/ t2989-peinture-pour-la-cale] (17.1.2016)

REMARQUES : Tenir sec se dit du fait de garder une attitude calme, durant une période difficile ; désigne le fait de ne pas céder, de tenir bon face à l'attitude du joueur adverse, avant l'abattage des cartes. Au figuré, tenir sec tend à l'emploi invariable, proche de la lexicalisation, mais l'accord est généralement récupéré quand il réfère à une qualité concrète. Dans le premier exemple du CW, c'est une expression propre à l'argot de l'escalade et de l'alpinisme (s'oppose à mou dans donner $d u$ mou) ; dans les trois derniers exemples du CW, sec est opposé à mouillé, humide.

\section{Tenir serré}

I. Tenir (quelque chose/quelqu'un); se tenir en groupe en (se) serrant beaucoup, en se rapprochant beaucoup

Pronominal

1175a Bien sevent qu'il ne lairont mie Nul'autre ghage que la vie Se il sont pris a le tençon. Trop criement ceste raençon. Por çou se tienent plus seré [manuscrit $\mathrm{W}$ : molt serret, 335] (Gautier d'Arras, Ille et Galeron, 431)

$\sim 1175 \mathrm{~b}$ De fuians est mout grans la perte.

Trop grant angoisse i ont soferte.

Seré se tienent et estroit [manuscrit $\mathrm{W}$ : Serré se tienent a estroit, 503]

Entrués qu'il vienent al destroit, U li cris de la tere ert leur (Gautier d'Arras, Ille et Galeron, 802)

1250 Baron, fet il, or soiez bien armé, Et pres de moi vos tenez tuit serré. Si en irons devers cele cité ! Se Dex donoit, le roi de majesté, Que hors issisent li paien desfaé (Aymeri de Narbonne [milieu XIII ${ }^{\mathrm{e}}$, 843)

1610 Une autre fois que Gravereuil venoit du Plessis endossant son mulet, monsieur le mulet voyant l'eau, et y prenant plaisir, y porta son maistre, et laissant à costé le pont Saincte-Anne, passa à travers l'eau : ce fut à messire de se tenir serré (Béroalde de Verville, Le Moyen de parvenir)

1648 Le soleil, ce grand luminaire, En son cours ordinaire, A déjà visité la maison des Gemeaux ; Toutefois nuit et jour la bouche de Borée Qui se devroit tenir serrée, D'un souffle impetueux bat encor vos rameaux

(Tristan l'Hermite, Les Vers hérö̈ques)

1660 Le précepteur qui fait répéter la leçon À votre jeune frère a fort bonne raison Lorsque, nous discourant des choses de la terre,

Il dit que la femelle est ainsi que le lierre, Qui croît beau tant qu'à l'arbre il se tient bien serré,

Et ne profite point s'il en est séparé

(Molière, Sganarelle ou Le Cocu imaginaire)

1691 Les capitaines des gardes reviennent alors prendre leurs postes sous le balcon du roi, où tous les gardes se mettent aussi, et font une espèce de haie, se tenant fort serrés (Marie-Catherine d'Aulnoy, Relation $d u$ voyage d'Espagne)

1744 En disant ces mots elle se leva sur son séant malgré nous, et voulut embrasser son frère qui la prévint ; ils se tinrent serrés entre leurs bras, la douleur et la tendresse leur étouffoient la voix ; leurs visages colés l'un avec l'autre étoient couverts de larmes (Jean-Baptiste Jourdan, Le Guerrier philosophe)

1775 Ah, comme ses yeux mouillés de pleurs se portoient tour à tour sur Madame de Veymur et sur moi ! Comme elle me tenoit étroitement serrée dans ses bras! (Philippe-Louis Gérard, Le Comte de Valmont ou Les Égaremens de la raison)

1824 La nuit arriva ; les chevaliers qui avaient passé l'eau se tenaient serrés et sur leurs gardes. Pour se faire croire plus nombreux, ils poussaient les cris de guerre de chacun des seigneurs de l'armée française, puis 
ils s'encourageaient l'un l'autre en disant : « nous avons de bien meilleures armes que ces bourgeois » (Prosper de Barante, Histoire des ducs de Bourgogne de la maison de Valois)

1846 La VIE sur le bord de laquelle ils se tenaient serrés l'un contre l'autre, tremblants et illuminés, comme deux enfants se tiennent sous un abri devant un incendie, cette vie n'offrait aucune prise aux sens

(Honoré de Balzac, Séraphita)

1911a Il poussait sa table contre la fenêtre, il trempait son pinceau dans l'eau, il ne bougeait plus de tout le matin. Il se tenait serré contre sa table, et s'appliquait, avec un pli au front (Charles-Ferdinand Ramuz, Aimé Pache, peintre vaudois)

1911b Assis sur l'établi, l'un à côté de l'autre, ils s'y tenaient étroitement serrés, lui, le bras passé autour de sa taille, elle, la tête au creux de son épaule, car l'amour est comme un grand poids (Charles-Ferdinand Ramuz, Aimé Pache, peintre vaudois)

1926 Il y avait, un peu en avant du torrent, sur une partie assez plate où elle s'était arrêtée cette réunion de petits toits, et ils se tenaient serrés là sous leurs petites fumées bleues. À travers la couleur de ces fumées, on voyait la couleur des ardoises, la couleur du bois ; on voyait les ardoises grises (Charles-Ferdinand Ramuz, La Grande peur dans la montagne)

1931 Ils dormaient tous en se tenant bien serrés sur leur sommeil. Olivier s'allongea sous sa couverture, resta un moment immobile à faire du chaud, puis chercha le chaud en bougeant doucement les épaules (Jean Giono, Le Grand troupeau)

1938 Un soir, les biches ne vinrent pas au gagnage. Le Rouge, de loin, les avait aperçues dans la lueur vermeille du couchant. Elles se tenaient serrées les unes contre les autres, debout sur le bord de l'étang. La tête haute, les oreilles droites, on eût dit qu'elles prenaient le vent, qu'elles attendaient (Maurice Genevoix, La Dernière Harde)
1959 Viens dans mes bras, mon chéri. Viens te mettre là contre moi, on est en sécurité quand on se tient serrés comme ça, l'un contre l'autre, tu sais... Mais qu'est-ce que tu as, Gisèle? Tu pleures?

- Non, Alain, je t'aime. Tu es mon amour (Nathalie Sarraute, Le Planétarium)

1965 Je me tenais serrée au bord du petit lit, pour que Julien pût se coucher sur le dos ; accoudée, mon visage au-dessus du sien, dans l'obscurité (Albertine Sarrazin, L’Astragale)

1967 Hier soir les enfants du commissaire social m'ont forcé à boire, je vomissais sur les iris, ils se tenaient serrés devant l'entrée du trou, ils me repoussaient (Pierre Guyotat, Tombeau pour cinq cent mille soldats)

Transitif

1603 En telle conduicte, sera le porchier avisé de tenir serré son trouppeau, marchant et paissant, de peur que par faute de discipline il ne peusse chevir de ce bestail, de difficile gouvernement par dessus tout autre de mesnage (Olivier de Serres, Le Théâtre d'agriculture et mesnage des champs)

1628 «Que les dieux sont justes, de me redonner le contentement de te baiser et de t'embrasser ; mon fils, mon Ergaste... »

À ce mot la voix luy faillit, et non pas la force, car elle le tint encore serré si estroittement, qu'il ne put jamais se jetter à ses genoux (Balthazar Baro, La Conclusion et Dernière Partie d'Astrée)

1676 Je passois presque tout le temps auprès de mon oyseau, et je n'omettois rien pour lui témoigner toutes les marques possibles de bienveillance. Je vis un jour qu'il avoit peine à se soutenir, et je trouvay que la corde qui l'arrêtoit, le tenoit si serré, qu'elle avoit coupé la peau (de la patte) et étoit entrée bien avant dans la chair (Gabriel de Foigny, La Terre australe connue)

1704 Mais encore que ces rayons nous blessent moins étant réfléchis, le coup en est souvent très-fort, et le seul effet du blanc et $\mathrm{du}$ noir nous fait sentir que les couleurs 
ont plus de force que nous ne pensons pour nous émouvoir. Car il est certain que le blanc écarte les nerfs optiques, et que le noir au contraire les tient trop serrés (Jacques-Bénigne Bossuet, De la connaissance de Dieu et de soi-même)

1732 Je ne pus lui répondre sur-le-champ, parce qu'il me tenait si serré que je n’avais pas la respiration libre, et ce ne fut qu'après que j'eus la tête dégagée de l'embrassade, que je lui dis : Seigneur cavalier, je ne croyais pas mon nom connu à Penaflor (Alain-René Lesage, Histoire de Gil Blas de Santillane)

1751 J'aurois voulu pouvoir dégager ma main d'entre les siennes ; mais il me la tenoit trop serrée. Laissez-moi, monsieur ; vous me blessez cruellement. Votre dessein est-il d'ensanglanter la scène? (abbé Prévost, Lettres angloises [trad.])

1755 Ô Sir Rowland! Que vous me causez d'agitations ! Je voulois retirer mes mains ; mais il les tenoit serrées dans les siennes. J'ai frappé du pied dans un emportement de reconnoissance (abbé Prévost, Nouvelles Lettres angloises [trad.])

1830 Ah ! Je vous ai assez aimée pour mériter cette confidence... je veux tout savoir. Malgré Mme de Rênal, ce ton d'autorité avait de l'empire sur son cœur. Julien, qui la tenait serrée avec passion, et résistait à ses efforts pour se dégager, cessa de la presser dans ses bras. Ce mouvement rassura un peu Mme de Rênal (Stendhal, Le Rouge et le noir)

1840 «Que c'est une grande chose de mourir dans l'espérance de la vie éternelle ! » Elle expira le 15 juin 1642, en élevant de ses faibles mains la croix qu'elle tenait serrée, et en s'écriant fort haut par deux fois : victoire! (Charles Sainte-Beuve, Port-Royal)

1843 Pierrette se recula pour avoir le temps de mettre sa lettre dans sa main, qu'elle tint serrée par une force invincible. En voyant cette manœuvre, Sylvie empoigna dans ses pattes de homard la délicate, la blanche main de Pierrette, et voulut la lui ouvrir (Honoré de Balzac, Pierrette)
1845 Marcelle chemina fort commodément sur la robuste et pacifique Sophie. Le petit Édouard, qu'elle tenait bien serré devant elle, " goûtait fort cette façon d'aller ", comme dit le bon La Fontaine (George Sand, Le Meunier d'Angibault)

1876 Quelques gouttes de sueur perlèrent sur son front. Il étendit machinalement les mains sur ses genoux, qu'il tint fortement serrés. Mais il ne prononça pas un mot (Arthur de Gobineau, Nouvelles asiatiques)

1902 à la partie extérieure de chacune des parties du moule, le fabricant a rivé une tige de fer destinée à être fixée dans un manche en bois : cette disposition permettait de saisir le moule à deux mains et de le tenir fortement serré, tandis qu'une autre personne versait par en haut le métal en fusion (Henry-René d'Allemagne, Histoire des jouets)

1907 Mais c'est aussi la première fois que je la tiens serrée contre moi, et qu'il fait nuit autour de nous deux.... Et puis, cette voix nerveuse, cette main qui tremble, ces yeux baissés que je ne parviens pas à voir... j’ai trop pitié d'elle! (Claude Farrère, L'Homme qui assassina)

1911 Sa main tenait, étroitement serré, un paquet.

«Trois cents hectares ! » soupirait-il.

Il voyait des bœufs de labour souffler dans le brouillard de l'aube, le geste, au soleil levant de jeunes fille en cornette semant le grain sur de grasses pentes charruées (Alphonse de Châteaubriant, Monsieur des Lourdines)

1933 j'ai connu Étendard, un taureau du vieil Haudouin [...] Tout ce qu'il voyait bouger, tout ce qui était d'une couleur un peu violente le rendait furieux et il fallait alors le tenir serré pour l'empêcher de foncer (Marcel Aymé, La Jument verte)

1934 Quand j'atteignis aux dernières marches, il releva la tête qu'il tenait serrée dans ses poings :

- Te voilà ! 
La voix était dure, méfiante, le regard buté. Je refermai la porte :

- Alors, qu'est-ce qui se passe?

(Roger Vercel, Capitaine Conan)

1944 LA FOLLE. Il est sur mes genoux. Vous avez tout le temps. Il n'en partira pas. Je le tiens aussi serré que j'ai mal tenu Adolphe Bertaut. Si je le lâchais, il irait se jeter dans la Seine (Jean Giraudoux, La Folle de Chaillot)

1985 - Eh ben tu y es pas du tout ! j’ai déclaré. Il reprenait lentement sa respiration et se barbouillait la figure de sang à force de toucher à son nez. Je le tenais bien serré. - Si tu crois ça, tu te trompes, j'ai enchaîné. Tu te trompes lourdement, tu m'entends... ?

Je lui ai décoché un coup de poing sur le sommet du crâne, il a gémi (Philippe Djian, $37^{\circ} 2$ le matin)

II. tenir le cœur serré : causer de la peine, faire éprouver de l'angoisse

Transitif

+1365 Mès amours, qui les coers atise, Me tenoit le coer si serré Que quanque j'avoie enserré Et que bien cuidoie avant mettre, Je ne m'en savoie entremettre, Ains me tenoie mu et quoi (Jean Froissart, Poésies [3 tiers XIVe]

III. Restreindre la liberté de (quelqu'un), surveiller étroitement (quelqu'un/quelque chose), faire bien attention à (quelque chose) Transitif

1560 Toutesfois, comme j'ay désja protesté, mon intention n'est pas d'amasser icy tous les passages concernans ceste matière, mais élire les plus notables, pour nous faire bien gouster de quelle humanité Dieu nous convie à soy, et combien nostre ingratitude est tenue estroitement serrée sans trouver nulle eschappatoire, quand nostre paresse nous fait encore délayer après que nous avons esté si vivement picquez (Jean Calvin, Institution de la religion chrestienne)
1849 Après elle, je n'ai d'autre parenté que celle de ma marraine Fanchette, qui est une brave et honnête femme, mais tout à fait incapable de gérer mon bien et même de le conserver et de le tenir serré (George Sand, La Petite Fadette)

1858 En arrivant à la loge, à Lise, l'habilleuse du théâtre :

- Ah! Je vais te payer les cent sous que je te dois pour avoir pris des glaces en cachette avec Fix.

(Il y avait huit mois de cela).

- Comment ? Ta mère te tenait serrée comme cela?

- Ah bien! Tiens, regarde ma cuvette, une cuvette raccommodée. Lise, depuis combien de temps est-elle comme cela ? (Edmond et Jules de Goncourt, Journal)

1890 Et maintenant que leurs regards ne se rencontrent plus, que leurs lèvres s'évitent, que leurs âmes se maudissent, la chaîne de luxure les tient encore serrés de ses imbrisables anneaux (Paul Bourget, Physiologie de l'amour moderne)

1924 - Pourquoi ris-tu?

Elle répondit :

- Pour rien. Il fait beau. - Et la vallée aussitôt s'emplit visiblement d'amour et de bonheur

Dans ma famille on a toujours tenu très serré les domestiques (André Gide, Si le grain ne meurt)

1936a On passe aisément de là aux puits de pétrole et aux mines de houille. La nécessité nous tient serrés ; telle est notre condition. Tant qu'on ne changera pas l'estomac, les mains, les pieds, nous irons aux betteraves, trempés et gelés jusqu'aux genoux (Alain, Propos)

1936b Rien n'est plus solidement posé que le monde, rien ne nous tient plus serré, rien n'a moins besoin de preuve. Au reste la preuve est ici hors de lieu; on ne prouve point l'existence, on la constate (Alain, Propos) 
1954 Si on veut en faire des chrétiens, et pas des animaux, il faut les [= les enfants] tenir un peu serré, surtout les filles. Elles doivent apprendre à rester à la maison pour aider la maman (Béatrix Beck, Des accomodements avec le ciel)

IV. tenir serrés les cordons de sa bourse : ne pas dépenser son argent inconsidérément Transitif

1871 Demeurer chez les autres, en province, est un aveu de pauvreté. Chaque famille bien posée à Plassans a sa maison, les immeubles s'y vendant à très bas prix. Pierre tint serrés les cordons de sa bourse; il ne voulut pas entendre parler d'embellissements ; l'ancien mobilier, fané, usé, éclopé, dut servir sans être seulement réparé (Émile Zola, La Fortune des Rougon)

V. Maintenir de manière constante, contractée, crispée

Transitif

1956 Il fallait y entrer avec un calme, avec un calme... Il lui sembla qu'il était un chef d'État menacé dans une foule hostile, d'où, à tout moment, un remous, un cri, un coup pouvaient partir, mais que la foule s'endormirait s'il marchait de plus en plus lentement, en tenant serré sur ses lèvres le sourire noble qui le brûlait (François-Régis Bastide, Les Adieux)

\section{CORPUS WeB :}

Faut dire que j'ai ben ben ben d'la misère avec mes beaux-parents en général, donc ça aide pas non plus ! J'aime pas leur façon de s'approprier ma fille, d'insister toujours sur le fait qu'il y a un peu d'eux dans elle, de la tenir serré près de leur visage comme s'ils étaient prêts à se sauver avec ! [http://www.dlvdm.com/forum/ lofiversion/index.php/t298546.html] (17.1.2016)

Magnifique famille..... Presque horrifié.... regardez : dans un dernier espoir les parents se tiennent serré, comme pour prier ce photographe " ne nous enlevé pas notre petit » Quand a cet adorable petit singe, tout neuf, innocent regarde le sol, ignorant le danger que représente les hommes.... [https://www.facebook.com/monde. biodi/photos/a.1682051155348121.1073741829. 1653640271522543/1719575788262324] (17.1.2016)
Pourquoi les moutons se tiennent-ils serrés les uns contre les autres? [http://www.pourquois. com/animaux/pourquoi-moutons-tiennent-ser res-uns-contre-autres.html] (17.1.2016)

Quoi qu'il en soit, appliquée sur toute partie douloureuse, cette pierre apaise. On l'utilise parfois pour lutter contre le vertige et les étourdissements. Dans ce cas, il faut constamment la porter sur soi. En cas de nausées, il faut la tenir serrée dans le creux de sa main [http://esoterika.chez. com/pierres.html] (17.1.2016)

REMARQues : Tenir serré (I) renvoie, à la forme pronominale, à la posture, le sujet étant étroitement rapproché d'une ou de plusieurs personnes ; à la forme transitive, il désigne le fait de serrer fortement quelque chose dans ses bras ou mains, de maintenir quelque chose de façon à ce qu'elle ne tombe pas. Sous (II), le sujet réfère à une chose abstraite qui fait de la peine ou cause une certaine tristesse. Tenir serré (III) désigne le fait de limiter la liberté de quelqu'un, de le surveiller, de se montrer strict avec lui. Si l'objet désigne une chose de valeur, à laquelle le sujet tient, il se dit du fait de bien la conserver, d'y prêter fortement attention. En (V), il s'utilise en parlant d'une attitude ou des traits $\mathrm{du}$ visage et se dit du fait de garder un sourire crispé, traduisant l'attitude tendue du sujet. La locution idiomatique tenir serrés les cordons de sa bourse (IV) renvoie au fait de limiter ses dépenses. Considérant l'ensemble des verbes avec lesquels serré forme un groupe, on peut dire que c'est un des rares participes passés qui tend à l'invariabilité, donc à la lexicalisation comme adverbe. Avec tenir, cependant, l'accord est la règle dans la langue moderne (mais v. les exemples de 1936b, 1954), l'absence de l'accord s'observant surtout dans la langue ancienne et dans l'emploi familier du CW où l'on constate une différence de style, dans les premiers exemples, familiers non-accordés, et les seconds, qui appartiennent plutôt au registre standard ou soutenu. L'accord s'explique par le fait que tenir fonctionne comme copule, serré indiquant l'état de l'objet du verbe, ce qui n'exclut pas une lecture de manière (tenir ainsi). En tout cas, on peut dire que la tendance à l'accord du groupe tenir serré est plus forte avec serré qu'avec les modifieurs non-participiaux. Le fait d'être un participe joue donc un rôle. La correction linguistique joue en faveur de l'accord 
dans la langue moderne. Mentionnons aussi l'accord ad sensum dans l'exemple de 1959. Serré est modifié par aussi, bien, encore, étroitement, fort, fortement, plus, si, tout, très, trop, un peu. Notons les collocations étroitement serré et serré et étroit. VOIR AUSSI : nouer fin

\section{Tenir soef}

Tenir, traiter avec douceur, avec tendresse

Transitif

1160 La raïne les anvoia

An sa chambre, puis apela

L'anfant, qui a son pere vint ;

Acola lo, soëf lo tint,

Molt lo baisa estroitement.

El se maine molt malement (Eneas, 804)

1393 Et tousjours, tantost qu'il [= l'épervier] est peu l'en le doit tenir sy souef et en place si propre et si paisible qu'il n'ait cause de soy debatre sur sa gorge [= nourriture] (car s'il se debatoit sur sa gorge qu'il avroit lors prinse, il seroit en aventure de la gecter) (Le Menagier de Paris, p. 150, 16)

Remarques : Tenir soef se disait du fait de prendre quelqu'un dans ses bras doucement, en manifestant de la tendresse. Dans l'exemple de $\sim 1393$, il s'emploie par rapport à l'épervier dont il faut s'occuper avec précaution. Soef est modifié parsi.

\section{Tenir solide}

Tenir (quelque chose) fermement, solidement, avec force

Transitif

1537 Lequel [= un ancien et vieux chêne] mettre par terre contendent les impetueux ventz souflans hydeusement çà et là à l'environ, faisans gros bruyt, et couvrant la terre dessoubz des feuilles de l'arbre esbranlé : iceluy nonobstant demeure ferme debout, et ne faict compte des foibles et vains assaulx, sachant qu'il a sa racine, qui le tient ainsi solide, fichée presque jusques au centre de la terre (Jeanne Flore, Contes amoureux)

1615 Et son bras qu'elle tient solide, Defend mal faict et violence (Andrea Alciat, Les Emblêmes [trad.])
1953 Le peuple qui a fait sans doute les plus grandes et les plus parfaites inventions qui soient, les a faites en s'amusant.... d'idylles grecques étaient semblables à ce Moschophore musclé - qui porte gaillardement sur ses épaules le petit veau - et il lui tient solide les pattes pour qu'il ne gigote pas (Claude Roy, Le Commerce des classiques)

Pronominal

1837 On conçoit encore que l'on y ait été fort à l'aise pour observer les phénomènes de congélation dans un pays où le mercure se tient solide (P. Cazeaux, Voyage dans les régions arctiques (1834-1835) [trad.])

1937 - Mon garçon, moi je ne me mets à cheval sur rien, ni sur une flûte ni sur un cheval. Je monte dessus. Ce que je fais, ça s'appelle toujours «monter dessus ». J'y monte dessus et je m'y tiens solide avec mes pieds (Jean Giono, Batailles dans la montagne)

Intransitif

1925 Un jour, au bout d'une flèche, j'ai lié un couton d'épine noire, et d'là, caché dans un fossé avec d'autres drôles de mon âge, j'ai piqué la grande treue de la ferme : elle s'est ensauvée en couinant, avec sa flèche plantée dans le gras des reins, et qui tenait solide, et qui ballottait de première à chaque saut que faisait la treue (Maurice Genevoix, Raboliot)

CORPUS Web :

2016 c'est pour moi, on a commencé l'année sur de bonnes bases. Il suffit de les tenir solide [http://www.instabrowse.fr/meli_fyc] (18.1.2016)

Regardez un peu cet arrogant " Fuck you » écrit en toutes lettres sur la porte d'une ruelle décatie. Regardez un peu cette talle d'arbres qui se tiennentsolide au milieu denulle part [http://www. lapresse.ca/la-tribune/la-nouvelle/scene-cultu relle/201411/05/01-4816147-les-regards-pas-sifurtifs-de-sylvain-lussier.php] (18.1.2016)

C'est une attaque brutale contre les principes fondamentaux de l'humanité prônés par la République française. On n'oublie pas que c'est grâce à elle que les pilliers de notre société Serbe moderne se tiennent solides depuis cent ans déjà et l'on espère que la base de ces pilliers 
en France ne se verra pas ébranlée suite aux attentats [https://www.facebook.com/permalink. php?id=294463494047615\&story_fbid $=515281455$ 299150] (18.1.2016)

Une autre solution enlève tout le pouvoir aux financiers et aux adeptes du système actuel, l'illusion les tient solides et ils vont se battre jusqu'à la mort pour ne pas que ça arrive : Abolir l'argent comme système économique ! [http:// www.jasez.ca/forums/topic,22529-les_marches financiers_sont_passes_en_mo.html] (18.1.2016)

REMARQUES : Tenir solide se dit du fait de tenir quelque chose ou quelqu'un entre les mains, de le maintenir ou de le serrer avec force de manière à ce qu'il ne bouge pas. Employé dans la langue familière, solide reste invariable dans ses fonctions adverbiales (v. les deux premiers exemples $\mathrm{du}(\mathrm{CW})$, mais il retrouve la flexion dans le registre standard pour désigner une propriété concrète (v. les deux derniers exemples du CW). Il est modifié par ainsi.

\section{Tenir souple}

Avoir une posture, un maintien souple

Pronominal

1922 Il la voit marcher, venir vers lui, avec son pas décidé, qui la rend un peu gauche quand elle doit marcher sans but. L'occiput et les omoplates touchent le même plan. Elle se tient si droit, et telle, si souple et sans emploi des muscles, qu'il n'est personne qui dans la rue même ne soit sensible à cette spontanéité (Henry de Montherlant, Le Songe)

\section{CORPUS WEB :}

Tu mets un tournevis que tu tiens trés souple contre les rayons en faisant tourner la roue [http://www.freebiker.net/php/phpBB2/ ntopic10207.php] (18.1.2016)

Il ne s'agit pas de réaliser des postures spectaculaires, mais se détendre, se tenir souple et en forme, enfin d augmenter sa résistance face aux incidents physiques qui pourrait arriver, aux maladies dé génératrices dues à l'âge, la maladie, un accident ou au surmenage ... [http:// yogaexercices.blogspot.co.at] (18.1.2016)

$\mathrm{Si}$ tu as une bouteille de rhum, dés que tu as tes gousses tu les mets dedans, ça les tient souples et ça parfume le rhum, et puis tes pa- tisseries et autres flans ont du gout [http:// fr.rec.cuisine.narkive.com/u5D4W0il/commentramollir-gousses-de-vanille] (18.1.2016)

Des arbres exotiques, tels que des cocotiers se tiennent souples, avec leurs fruits parfumés pendus dans les feuilles [http://sanstitre2.forumactif.net/c4-terres-des-vents-et-des-nuages] (18.1.2016)

REMARQUES : Tenir souple réfère à la façon de se tenir, à la posture adoptée par la personne qui se meut avec aisance, les membres étant dépourvus de raideur. Souple s'accorde avec l'objet du verbe transitif (v. le troisième exemple du $\mathrm{CW}$ ) ou avec le sujet du verbe pronominal (v. le quatrième exemple du CW), ce qui renforce une interprétation de prédicat second. Ce n'est que dans l'exemple de 1922 que la coordination avec droit, non-accordé, atteste un emploi invariable. Souple est modifié par si, très. Notons l'emploi impersonnel familier ça les tient souples et la collocation si droit, si souple.

\section{Tenir tapi}

Se replier sur soi-même

Pronominal

1860 On déjeune en plein soleil. Ça le fait souffrir, mais il en est content, parce que les autres en souffrent. Chacun se tient tapi et coi en lui-même, tandis que M. Collardez, comme un hanneton, passe dans tout cela et sourit à tout ce drame (Edmond et Jules de Goncourt, Journal)

\section{CORPUS WEB :}

Ainsi je comprendrais le raidissement militaire de Raoul face à une levée de l'embargo, levée qui rendrais Cuba perméable au travail de sape souterrain de la «plus grande démocratie », comprendre ici les forces occultes du «marché » qui se tiennent tapi dans l'ombre, le temps que monsieur Obama leur retire l'épine du pieds... néolibéral [http://www.ledevoir.com/international/ etats-unis/237289/cuba-obama-preparerait-ungrand-coup] (23.1.2016)

Victor Mowgli/Roukie a de tels poils, si abondants : il aime tant se tenir tapi dans l'herbe, à s'imaginer lion dela savane: il se chopele moindre aoûtat qui passe [http://www.clopinetrouillefou. com/article-le-remords-est-une-chenille-124648 508.html] (23.1.2016) 
Comme on voudrait que les trompettes de Jéricho sonnent à nouveau et fassent tomber les murs derrière lesquels des hommes, transis de peur, se tiennent tapis, prêts à frapper ! [http:// catholique-belley-ars.cef.fr/diocese/eveque-eme rite/textes-de-mgr-bagnard/quel-avenir-pour-lemonde] (23.1.2016)

L'origine du mot statistique (Staat, qui signifie «État » en allemand) suffit à rappeler combien les enjeux de pouvoir se tiennent tapis derrière les chiffres [http://www.scienceshumaines.com/ statactivisme_fr_32945.html] (23.1.2016)

REMARQUES : Toujours pronominal, se tenir tapi se dit du fait d'adopter une posture dans laquelle le sujet se replie sur lui-même, se cache, se dissimule en se blottissant. La collocation avec coi vient renforcer l'idée de retrait et de calme. Dans le quatrième exemple du CW, tenir tapir prend le sens figuré de 'rester caché, en embuscade'. Du point de vue sémantique, tapi est un prédicat second qui désigne une qualité ('être caché'), mais la lexicalisation du tour permet l'emploi non-accordé (v. le premier exemple du CW).

\section{Tenir tranquille}

Se comporter de manière calme, paisible Pronominal

1925 Debout devant Bourrel, sur l'accotement herbeux de la route, il se tenait bien droit et tranquille ; mais un frémissement intérieur ne cessait de le parcourir, une petite danse de tous les nerfs qui lui couraient jusqu'au bout des doigts (Maurice Genevoix, Raboliot)

\section{CORPuS Web :}

Mais s'il est facile d'occuper les enfants avec le déballage de leurs différents cadeaux tant attendus, il est plus compliqué de les tenir tranquille à table pendant ces longs repas de famille [http:// www.mon-premier-blog.fr/blog] (23.1.2016)

à la saint petronille les fevribouts se tiennent tranquille (c'est beau de rever ;)) [http://bebes. aufeminin.com/forum/d-a-la-saint-petronilleles-fevribouts-se-tiennent-tranquille-c-est-beaude-rever-fd1006807] (23.1.2016)

un carcan pour les tenir tranquilles pendant la tonte [http://mouton-ouessant.forums-actifs. com/t3338-un-carcan-pour-les-tenir-tranquillespendant-la-tonte] (23.1.2016)
A Oraison, « les immigrés se tiennent tranquilles, heureusement » [http://rue89.nouvelobs. com/blog/mon-vilage-lombre-du-fn/2014/03/28/ oraison-les-immigres-se-tiennent-tranquillesheureusement-232561] (23.1.2016)

REMARQUES : Tenir tranquille réfère au comportement adopté par une personne qui reste calme et silencieuse, ou au fait d'obliger quelqu'un à ne pas bouger. Du point de vue sémantique, tranquille est un prédicat second, mais l'emploi non-accordé est assez fréquent, suite de la lexicalisation de tranquille dans les fonctions adverbiales. Notons la collocation droit et tranquille.

\section{Tenir vil}

Dédaigner, traiter (quelqu'un) de manière

méprisante, indigne ; mal se comporter

Transitif

1170 Cil se deivent bien esmaier,

Qui sont tenu en chaitivier :

Vos ne sereiz ja vius tenues, [variantes : vil, vilment]

Ne a ceus ne sereiz tolues

Qui vos aiment ne quos ameiz (Benoit de Sainte Maure, Le Roman de Troie, 4687)

1176 Si blasme l'une et l'autre loe, L'une tient vil et l'autre chiere. Meis tiex li mostre bele chiere El mireor, quant il l'esgarde, Qui le traïst, s'il ne s'i garde (Chrestien de Troyes, Cligés, 741)

+1200 Uns riches hom jadis estoit A qui grant richece apendoit : Chevaliers ert, tint grant hennor. Mais tant avoit amé s'ossor Que desor lui l'avoit levee, Et seignorie abandonee De sa terre, de sa maison, Et de tot otroié le don ; Dont la dame le tint si vill Et tint si bas, que quan que cil Disoit, et ele desdisoit, Et desfaisoit quan qu'il faisoit (La Dame escoillee [1 ${ }^{\mathrm{re}}$ moitié $\left.\mathrm{XIII}{ }^{\mathrm{e}}\right], 33$ )

+1250 Tu qu'estoies si bien dorez, Por qu'es tu si descolorez? Tes granz orguil qu'est deuenuz, 
Que tu es or si uiz tenuz?

(Ysopet de Lyon [ $2^{\mathrm{e}}$ moitié XIII $]$, 2330)

1275 Est il gentis ? Je di que non;

Ainz deit estre vilains clamez,

E vis tenuz, e meins amez

Que s'il estait filz d'un truant (Jehan de

Meun, Roman de la rose [1269-1278], 18760)

1280 De legier ne doiz, par contrere,

Les joies ton ami parfere ;

Quer chose de legier eüe

En seut plus vile estre tenue

(Vivien de Nogent, La Clef d'Amour, 2796)

1372 Quant li roys oÿ la nouvelle,

Il dist : « Ma doleur renouvelle,

Que je voy qu'on me tient si vil

Qu'on dit villenie à mon fil ! »

(Guillaume de Machaut, La Prise d'Alexan-

drie [(1370)-1372], 8334)

Pronominal

1450 L’AME. O maistre, je ne savoye point que tant me voussit amer Dieu. Et pourtan je ne me dois point tenir vil : j'ay peu tant complaire a Dieu qu'ill a voulu mourir pour moy affin qu'il ne me perdist (Pierre Crapillet, Le «Cur deus homo » d'Anselme de Canterbury [trad.], p. 278, § 314)

REMARQUES : Dans l'ancienne langue, tenir vil se disait du fait de mépriser quelqu'un, de lui montrer peu d'estime, de lui témoigner peu d'intérêt, de le traiter mal. Dans l'emploi pronominal, il réfère à un mauvais comportement, un comportement indigne. L'usage admet aussi bien l'emploi accordé que l'absence de l'accord. Vil est modifié par plus, si. L'exemple de $~ 1170$ présente toutes les variantes pertinentes : cas sujet, adjectifadverbe invarié, adverbe en -ment. Notons l'opposition avec tenir ch(i)er dans l'exemple de $\sim 1176$, et l'emploi plutôt synonymique de tenir bas dans celui de +1200 .

\section{Terminer juste}

Finir dans la bonne tonalité

$\lambda$ commencer faux

\section{Tester négatif}

Tester avec un résultat négatif à la présence de la substance recherchée

Emploi absolu

2015 Certaines personnes, testées négatives à la sensibilité au gluten et à la maladie cœliaque, se sentent mieux en adoptant un régime sans gluten (Danna Korn, Alma Rota, Marion Kaplan, Vivre sans gluten pour les nuls)

\section{CoRpus Web :}

Nous nous intéressons aujourd'hui à l'interrogation de Meghzouli qui se demande quel est le nombre de personnes testées négatives au Covid19 [https://www.leparisien.fr/societe/corona virus-combien-y-a-t-il-de-personnes-testeesnegatives-05-04-2020-8294358.php] (5.4.2020)

\section{Tester positif}

Tester avec un résultat positif à la présence de la substance recherchée

Emploi absolu

1995 Les sérums testés positifs étaient confirmés par un test VIH 1/2 rapide (Étude de prévalence des maladies sexuellement transmissibles et des infections à VIH au Burkina Faso)

1999 En septembre 1998, alors qu'on dénombrait 11170 personnes testées positives [...] sur plus de 10 millions de dépistages, le gouvernement donne une estimation de 300000 (Le Sida des autres)

2003 D'autre part, les jeunes hommes risquent de façon beaucoup plus significative que les autres conducteurs de tester positif (Le Cannabis [Québec])

2019 Certains proches vont même renoncer aux visites en détention en raison de la crainte de tester positif et d'engendrer leurs conséquences néfastes pour eux-mêmes et pour la personne incarcérée (Le Sens de la peine)

REMARQUES : On trouve surtout, mais pas exclusivement (v. aussi tester négatif), des exemples canadiens, probablement influencés par l'anglais to test positive. En l'occurrence, l'analogie morphologique du verbe français, qui est un anglicisme, favorise l'influence de l'anglais. Notons dans ce contexte aussi l'emploi ergatif 
(ex. de 2003, 2019) qui représente un anglicisme assez clair. VoIR AUSSI : contrôler positif

\section{Tinter clair}

Résonner, produire des sons clairs

$\lambda$ gronder bas

\section{Tinter haut}

Résonner, produire des sons d'une fréquence élevée

$\lambda$ gronder bas

\section{Tinter juste}

Sonner de manière juste, harmonieuse, mélodieuse, conforme aux règles de l'harmonie Intransitif

1899 Peu nous importe, au demeurant, que le grelot ait été attaché par Montano ou par Cipriani. Ce qui nous intéresse, c'est de savoir si, oui ou non, il tinte juste (L'Année scientifique et industrielle)

1958 Guy Béart est aussi l'auteur de « Poste restante ", une plainte douce et navrée, à la grâce un peu étriquée, aux rimes un peu sèches mais qui tintent juste (Canard enchaîné, 7 mai 1958 / Grundt : 364)

\section{CORpus Web :}

Chacun entend la voix de son bon droit, de son possible, de son bon vouloir. Aucune ne sonne faux. Et cependant aucune ne tinte juste [http://murmurefunambule.unblog.fr/page/87/ ?s] (31.1.2016)

Oui, c'était la même cloche. Elle tintait juste [http://www.idumea.org/magazines/2001/01/ 04_Dimanche_matin/04.htm] (31.1.2016)

En attendant, je me prépare doucement, je me documente, et ses mots tintent juste à mon oreille.J'ai par exemple beaucoup aimé son conseil pour la rentrée [http://www.maisonmagique. fr/je-suis-une-maman/bonne-rentree-bonneannee] (31.1.2016)

une vraie colère et des mots qui tintent justes à mes oreilles [http://welovewords.com/docu ments/pauvres-pommes-dot-dot-dot] (31.1.2016)

REMARques : Tinter juste se dit du fait de produire un ou des sons harmonieux, mélodieux, le sujet référant aux rimes d'une chanson, à une voix, au son d'une cloche, à des mots. Notons l'opposition sémantique avec sonner faux. Juste reste invariable dans la majorité des cas. Toutefois, dans le dernier exemple du CW il s'accorde avec le sujet en gardant son interprétation adverbiale. Notons aussi la locution tinter juste à mon oreille / à mes oreilles.

\section{Tinter vif}

Rendre un son vif, bref et intense

Intransitif

1925 Le métal du fusil brûlait les doigts du braconnier, la provision de ses cartouches s'allégeait au fond de ses poches ; quelquefois, une douille qui tombait tintait vif contre un caillou. Ils continuaient leur marche à travers le vacarme, derrière cette longue clarté tournante (Maurice Genevoix, Raboliot)

REMARQUES : Tinter vif réfère au son ou au bruit violent, d'une forte intensité, provoqué par la chute d'un objet sur un corps dur (ici : un tube cylindrique métallique qui tombe sur un caillou). Vif reste invariable.

\section{Tirer bas}

Tirer avec une arme à feu à une faible hauteur Intransitif

1964 Les sketches sont incontestablement d'un bon tireur qui tire bas et à blanc, mais juste, très juste (Sélection du Monde, 6 février 1964 / Grundt : 363)

\section{CORPUS WEB :}

Mais personnellement j'ai un pb la dessus, c'est que dans mon departement, tout les boulodromes sont en sablette, ce qui fait que pdt 4 mois a peu pres on tire en boulodrome... donc cet hiver j'ai pris l'habitude de tirer bas et fort (alors que normalement je tire haut et "creme ») et je galere grave maintenant dehors pour reprendre mon vrai geste ! [http://www.boulistenaute.com/ modules/forum_supporters/viewtopic.php?post _id $=104536]$ (31.1.2016)

A-t-il effectuer des tirs calés et posés pour évaluer le groupement et la zone d'impacts ? Est il le seul à tirer bas ? Efin son armurier a-t-il vérifié et constaté le problème de l'arme, si elle est neuve il devrat remédier au défaut? [http://corsicarms. activebb.net/t7208-visee-trop-bas-colt-45] (31.1.2016) 
L'AASM est tout simplement la meilleure dans le genre. Une bombe qui peut être tirée bas, vite, dépointée, et pendant que l'avion manœuvre sous assez fort facteur de charge, une bombe qui peut être tirée sur une cible en mouvement et de façon très précise et de loin [http://www.air-defense. net/forum/topic/654-aasm/?page=47] (31.1.2016)

Je ne sais pas trop comment faire en fait. C'est ma première [= sériole] et je ne voudrais pas la perdre. LE fil se perd dans l'eau sale et je ne peux la voir. Je reste comme ça un bon quart d'heure. Puis tout doucement, je tire sur le fil centimètre par centimètre et je me rapproche du poisson. Quand j'arrive à vue, je constate alors que je l'ai tirée basse dans le ventre et qu'elle ne tient que par un lambeau de peau. Aie aie aie, elle va se décrocher !!!! Heureusement elle est très fatiguée et dans un dernier élan je saisi la flèche et la fait passer entièrement avant d'attraper la sériole qui alors se débat mais c'est trop tard pour elle [http://forum.spearboy.com/ viewtopic.php?t=15823] (31.1.2016)

REMARQUES : Tirer bas réfère au fait de lancer à bas niveau un objet (le projectile d'une arme, une bombe, une boule de pétanque, etc.). Dans le dernier exemple du CW, bas réfère à la position de la flèche qui a touché le poisson. Notons l'emploi adverbial de dépointé, fort, haut, juste et vite, avec le même verbe. Bas reste invariable dans son emploi adverbial. Cependant, dans le dernier exemple du $\mathrm{CW}$, il s'accorde avec flèche, mot mentionné dans le contexte plus large. Ce type d'accord est caractéristique des langages du sport (par rapport à une balle), de la musique (par rapport à une note). Il est systématique dans certains dialectes centre-méridionaux de l'Italie, allant de pair avec l'accord du participe passé (v. Introduction § 4.6).

\section{Tirer court}

Viser à court terme

$\lambda$ tirer long

\section{Tirer dépointé}

Tirer (une bombe) en visant au-dessous de son objectif

$\pi$ tirer bas

\section{Tirer droit}

I. Tirer directement, exactement, selon une ligne droite

Intransitif

1389 Et, quant il voudra tirier et metra sa flaiche a la corde pour traire, il doit regarder que les empenons aillent de plat contre son arc, quar, quant il descocheroit et laisseroit aler sa sayete, se les penons estoient devers l'arc, ilz pourroyent hurter a l'arc et desvoier, qu'il ne tireroit ja droit (Gaston Phébus, Livre de chasse, p. 270, 15)

1636 LISETTE. Mais enfin le moyen de croire ce moqueur,

Et qu'un œil de travers tire tout droit au cœur?

DORIMENE. Si l'Amour qu'elle donne est imparfait comme elle

Bientost elle verra son Amant infidelle (Pierre Du Ryer, Les Vendanges de Suresne)

1769 Les Anglais avançaient à pas lents, comme faisant l'exercice. On voyait les majors appuyer leurs cannes sur les fusils des soldats, pour les faire tirer bas et droit (Voltaire, Précis du siècle de Louis XV)

1825 Camarades ! Chasseurs prudents, qui visez au solide, tirez droit et soignez les bourriches avant l'arrivée des dames ; car l'expérience a appris qu'après leur départ il est rare que la chasse soit fructueuse (Jean-Anthelme Brillat-Savarin, Physiologie du goût)

1907 Voilà plusieurs années que vous avez quitté votre château de là-bas, mademoiselle? Sans dessein de retour? Battez, tirez droit ! Je m'anime au jeu. Lady Falkland, qui ne s'y attendait pas, s'assied. Elle sourit à moitié, pas trop rassurée sur l'issue de ma fantaisie belliqueuse (Claude Farrère, L'Homme qui assassina)

1997 Après avoir essuyé un premier feu et regardé tomber quelques-uns de ses camarades, qu'il accusa de malchance, le soldat Paradis, aviné comme les autres, tira droit devant, puis, à un commandement, baïonnette tendue à hauteur d'estomac, il se mit à courir pour transpercer cette foule de 
gens en uniformes blancs qu'il voyait un peu floue (Patrick Rambaud, La Bataille)

Transitif

1555 Mais meintenant, voy si pour persister En le suiuant me pourras resister. Ainsi parloit. et tout eschaufé d'ire Hors de sa trousse une sagette il tire, Et decochant de son extreme force, Droit la tira contre ma tendre escorce : Foible harnois, pour bien couvrir le cœur, Contre l'Acher qui tousjours est vainqueur (Louise Labé, Sonnets, élégies, débat de folie et d'amour)

1566 SAUL. Comment iras-tu donques? DAVID. Je ne vueil glaive, armet, ne vesture royale.

(On le desarme)

J'ay besoin seulement de ma fonde loyale. J'en tire fort et droit

(Louis Des Masures, David combattant)

1596 Amour voulant un jour punir ses cruautez, Et vanger les amans qu'elle avoit mal traitez,

Luy tira droit au cœur une flèche divine, Et rompit le glaçon qui geloit sa poitrine (Philippe Desportes, Euvres)

1636 Il semble, disoit un ancien, qu'ils ayent la langue percée, et qu'elle ne puisse rien tenir : tout ce que leur pensée conçoit s'escoule par là ; et leur parole imprudente et estourdie, comme un trait tiré tout droit en haut, retombe aussi-tost sur euxmesmes que sur les autres (Nicolas Faret, L'Honneste Homme)

1848 L'idéal du jeune homme : habit bleu à boutons luisants, cravate rose tirée droit entre les deux revers à schall d'un gilet de velours, et piquée d'une épingle en diamant, pantalon gris d'un collant très mythologique, jolies cuisses, petite bouche, charmante chevelure, souriant (Gustave Flaubert, Par les champs et par les grèves)

1922 Je vis un feu naître au bout de la ligne, un feu minuscule encore, mais qui, par cela seul qu'il bougeait, devenait plus énorme que tous les lampadaires dressés - comme un obus tiré droit sur nous par le bas du ciel (Jules Romains, Lucienne)

1933 [il] s'arrêtait pour pisser, reprenait, crachait à gauche, chantait, parlait à ses bœufs, les caressait à lisse et à contre-poil, riait tout haut, taillait dans le bois vert un quinet pour ses garçons, dans l'écorce un sifflet, riait encore, tirait droit son sillon et s'émerveillait qu'il fit aussi bon vivre (Marcel Aymé, La Jument verte)

1957 Ou bien, supposons que nous ayons une mappemonde et que nous voulions rechercher le trajet le plus court de Chicago à Moscou : nous pouvons poser un morceau de ficelle sur le globe, le tirer bien droit entre les deux points et mesurer ensuite la ficelle sur une échelle pour voir la distance qu'elle représente (A. Moles, Cerveaux géants, machines qui pensent [trad.])

1997 Grosse bête ! Ce n'est pas à l’idée que ça vient ! Je ris à nouveau. Moins de ce qu'il a dit que de la façon qu'il a eu de le dire, avec son air « effronté ». Adjectif démonétisé, tiré tout droit du vocabulaire de...

- À propos, Jeanne est au courant ?

- Tu es folle! Elle n'aime que le mâle garanti pur sexe!

(Françoise Dorin, Les Vendanges tardives)

II. Aller directement, en ligne droite, sans

détour

Pronominal

1455 Changez et andossez souuent,

Et tirez vous tout droit au Temple,

Et eschequez tost, en brouant, Qu'en la iarte ne soiez emple

(François Villon, Le Jargon ou Jobelin [ 1455-1460], p. 147, 45)

Intransitif

+1489 A ce conseil se tindrent ces embassadeurs de l'empereur et tyrèrent tout droit à Gand, nonobstant qu'il leur avoit esté mandé le contraire, dont le duc de Clèves fut fort mal content ; toutesfoiz il ne sçavoit point encores la volunté des dames (Philippe de Commynes, Mémoires [1489-1498], VI) 
1498 A Florence la belle et la jolye Fut envoyé ung notable preudomme Maistre d'ostel nommé Jehan de Cardomme,

Brillac a Genes, et $a$ Senes la ville Tira tout droit Gaulchier de Tinteville (Andrieu de la Vigne, Le Voyage de Naples, p. 149,744$)$

1558a Quand ce fut à l'approche de la rivière, la mule commence de tout loing à sentir l'air de l'eau, et y tira tout droict, pour l'ardeur qu'elle avoit de boire (Bonaventure des Périers, Les Nouvelles Récréations et joyeux devis)

1558b La damoiselle monte sus ceste mule et tire droit le chemin de Thoulouze, lequel s'adonnoit ainsi qu'il failloit aller trouver la Garonne et cheminer au long de la rive quelque temps, qui estoit la première eau qu'on trouvoit par le chemin (Bonaventure des Périers, Les Nouvelles Récréations et joyeux devis)

1627 et en cecy je ne vois qu'une incommodité, c'est que nous puissions tirer si droit nostre travail, que nous nous rencontrions (Honoré d'Urfé, L’Astrée)

1679 Il emmena avec lui Joli, qui, seul avec Montet, m’avoit pu suivre, les chevaux des trois autres ayant manqué ; et il tira droit à Beaupréau, en dessein d'y assembler la noblesse pour me venir tirer de ma meule de foin (Jean-François de Gondi (Cardinal de Retz), Mémoires)

1764 OFFICIER DES CHASSES. Eh mais, Monsieur le Marquis, c'est à près trois lieues d'ici ;... en tirant droit vers Paris,... et par le rapport que nous avons entendu faire à la brizée qui a detourné le cerf au buisson des Halliers, il vous fera faire du chemin il a les pinces et les os gros, il est fort bas jointé (Charles Collé, La Partie de chasse de Henri IV)

1766 Lorsque le jour fut venu, nous tînmes conseil sur le chemin que nous aurions à prendre. Il fut résolu que nous tirerions droit au midi, pour tâcher d'aborder dans quelque contrée du Mogol et passer de là à Surate, et de Surate en Europe (HenriJoseph Dulaurens, Le Compère Mathieu)

1865 Je tirai droit sur le domaine de l'Aulnières, pensant, avec raison, qu'il me serait aisé d'ouvrir la barrière de la cour, d'y faire entrer tout mon monde, après quoi, j'éveillerais les métayers, lesquels, avertis du dommage, agiraient comme bon leur semblerait (George Sand, Les Maîtres sonneurs)

1926 La main cède à cette fuite, freinant des doigts le glissement du fil contre la gaule. Le chevesne s'épuise vite, à ce second élan ; il s'arrête, obéit et revient, tiré droit vers la berge au cliquet de la manivelle. Son corps brun reparaît, balancé de droite et de gauche par un roulis à l'abandon (Maurice Genevoix, La Boîte à pêche)

1929 Un œil ouvert dans l'ombre luit d'une lueur de pierre ; un de ces éclats de roches qui sont cachés dans la graisse de la terre et contre lesquels le grand soc lisse qui tire droit, par habitude, se rompt soudain, et verse (Jean Giono, Colline)

1930a Ça commence aux dernières maisons du haut Aubignane et ça s'en va. En réalité, ça s'en va jusqu'à Blaine, à quarante-deux kilomètres en tirant droit mais on n'est pas forcé de le savoir et, ce que ça montre d'habitude, ça n'indique pas que ça s'en aille vers une chose humaine (Jean Giono, Regain)

1930b Avec ce cheval follet, dès qu'il sent une femme près de lui il fait l'andouille. Je vais l'atteler. Tu viendras là-bas tout à l'heure. Voilà, ça va commencer. Il fera tirer droit jusque là-bas aux buissons qu'il a laissés exprès comme marque, et ça sera le sillon maître (Jean Giono, Regain)

\section{Viser juste ; viser directement}

Intransitif

1696 Le jour viendra, je l'espère, que nos discours seront un peu plus justes ; on tire de si loin qu'il est impossible de tirer droit. J'attends avec une grande impatience cette décision qui doit faire honneur à toutes 
vos prophéties. Votre petit frère cherchera à se marier ailleurs (Mme de Sévigné, Correspondance)

Transitif

1717 Mlle GIRAUT. Voilà mon songe. La déclaration est tout à fait galante, Monsieur, et vous me paraissez un cavalier trop adroit pour ne pas tirer droit aux cœurs dont vous vous proposez la conquête (Dancourt, $L e$ Prix de l'arquebuse)

1848 Aussitôt qu'il m'eut assuré avoir été commissaire à l'armée des alliés dans le département des Bouches-du-Rhône, l'espérance me revint : j'attaquai mon ennemi et tirant droit à son amour-propre, je déclarai qu'on avait remarqué la stricte discipline des troupes stationnées en Provence (François de Chateaubriand, Mémoires d'outre-tombe)

\section{Corpus Web :}

Robert Bruno, dans son livre, explique pourquoi, naturellement, on a tendance à ne pas tirer droit : En étant parfaitement face à sa cible, le mouvement de balancier du bras ne peut pas l'être, euh... Droit (Je suis vice champion du monde de Paint en apnée) [http://www.petanqueapprentissage.com/2012/01/pour-tirer-droitetude-du-balancier.html] (31.1.2016)

Au début, entraînez-vous à tirer $30 \mathrm{~cm}$ devant la boule en vous appliquant à tirer droit puis essayez de vous rapprocher de plus en plus jusqu'au carreau sur place que vous attendez à chaque boule [http://www.petanque-pas-cher. com/tirer-a-la-petanque.html] (31.1.2016)

En fait il faut se pencher d'une part sur la mécanique d'envoi qui subit de fortes déformations c'est comme au billard la bille n'étant pas tirée droit elle ricoche dans la montée de bille et elle est freinée [http://www.flipjuke.fr/bobinelance-high-roller-casino-t47183.html] (31.1.2016)

Les énergies de deux Lames tirées l'une droite, l'autre renversée, ont tendance à se contrarier, la Lame inversée empêchant, par la mise en Jeu d'une énergie caractéristique mal aspectée, l'expression harmonieuse de l'énergie de la Lame tirée droite [http://www.tarot-voie-lemniscate. fr/78223758] (31.1.2016)
REMARQUES : Tirer droit (I) se dit du fait de lancer un projectile, une arme (un arc, une flèche, une boule, une bille) en visant exactement la cible. Dans son emploi figuré, tirer droit réfère à la pensée du sujet, à la manière de raisonner, celle-ci s'avérant juste ou par son action ou par ses paroles, atteignant ou obtenant ce qu'il recherche. (II) se dit du fait de se diriger directement, sans détour, vers un lieu, le sujet désignant une personne. Notons la locution tirer droit le chemin, le sujet avançant en ligne droite, droit devant lui. (III) se dit sur le plan abstrait d'un sujet qui vise un objectif précis. Droit reste invariable, mais, dans le dernier exemple du CW, il s'accorde avec l'objet au féminin, tout en conservant son interprétation adverbiale. Il est modifié par bien, ja, si, tout. Droit tend à s'associer avec la préposition qui le suit. Notons les collocations bas et droit ; fort et droit.

\section{Tirer fort}

Tirer avec force

Intransitif

1942 - Capitaine ! À gauche tirent très fort !

-Obliquez!

(Antoine de Saint-Exupéry, Pilote de guerre)

\section{CORPUS WEB :}

4 mois et les ligaments qui tirent fort... [http://forum.magicmaman.com/magicmaman/ suivi-grossesse/ligaments-tirent-fort-sujet-1416 516-1.htm] (31.1.2016)

Puis il attrape sa mère, lui dit « tu dois venir, on part dehors » et la tire fort par le bras [http:// vergiberation.blogspot.co.at/2010/06/unegrosse-crise-de-colere.html] (31.1.2016)

Ma fille se tire fort sur la manche et tend son bras ! [http://m.bebe.ch/drupal/node/382387] (31.1.2016)

Quand une voiture possède le rapport de puissance/poids plus petit, ça permet d'accélérer plus vite. C'est normal pour la C3 HDI 70 qui a 16,5 $\mathrm{kg} / \mathrm{ch}$, ça n'accélère pas vite, plutôt lent. Mais elle tire forte à grâce le rapport force/poids [http:// www.forum-auto.com/automobile-pratique/dis cussions-libres/sujet414686-140.htm] (31.1.2016)

REMARQUES : Dans l'exemple de 1942, tirer fort réfère à une personne qui envoie, lance un projectile (balles ou obus) ou une arme avec puissance. 
Le CW révèle l'emploi concret dénotant une force de traction exercée sur un objet, voire, par inférence, aux douleurs causées par la tension exercée sur des ligaments. Fort reste invariable dans la majorité des cas (v. les exemples du CW). Toutefois, dans le quatrième exemple du CW, il s'accorde avec le sujet en gardant son interprétation adverbiale. Il est modifié par très. Notons l'emploi d'accélérer vite, lent.

\section{Tirer juste}

I. Tirer avec précision, avec justesse Intransitif

1636 Je veux encore, s'il se peut, qu'il sçache joüer du Luth et de la guiterre, puis que nos Maistres et nos Maistresses s'y plaisent, qu'il entende la chasse, et qu'il soit adroit à la danse, à la paulme, à la lutte, à sauter, à nager, à tirer juste, et à tous ces autres passe-temps, qui ne sont pas si simplement honnestes, qu'ils ne deviennent bien souvent utiles (Nicolas Faret, L'Honneste Homme)

1740 «Il me l’a proposé ; mais je ne sais chasser qu'au plat, et encore j'aime mieux ma pipe. » «Quoi ? » repris-je, « toi qui tires si juste, tu n'as voulu ni ne veux être chasseur » (Jacques de Varenne, Mémoires du chevalier de Ravanne)

1755 Deux corvettes viennent de partir de Brest pour y porter des ordres et en rapporter. Pendant que nos fantassins étaient à bord, on les a beaucoup exercés aux manœuvres maritimes et à tirer juste sur mer (RenéLouis d'Argenson, Journal et mémoires)

1774 Je n'ai jamais vu deux hommes qui sautassent aussi haut, qui courussent aussi vite, qui tirassent aussi juste, qui jouassent aussi bien à la paume, et moins encore deux hommes qui eussent également d'esprit, parce qu'il était impossible que cela fût (Denis Diderot, Réfutation suivie de l'ouvrage d'Helvétius intitulé L'Homme)

1874a « C'est donc à tout débarquement qu'il faut tenter de s'opposer, mais sans se découvrir. Donc, n'économisons pas les munitions. Tirons souvent, mais tirons juste.
Chacun de nous a huit ou dix ennemis à tuer, et il faut qu'il les tue ! » (Jules Verne, L'Île mystérieuse)

1874b Les caronades ont un avantage, trois hommes suffisent pour les manœuvrer ; mais elles ont un inconvénient, elles portent moins loin et tirent moins juste que les canons. Il fallait donc laisser arriver l'escadre à portée de caronade (Victor Hugo, Quatrevingt-treize)

1958 Et pourtant, je connais le métier. Pour Kihoro, qui est toujours derrière son ombre, elle ne se doute de rien. Et il a beau n'avoir qu'un seul œil, il tire plus juste et plus vite que moi. Et je passe pour un des bons fusils de l'Afrique Orientale (Joseph Kessel, Le Lion)

Transitif

1787 Chaque jour, de grand matin, la plupart se rendent dans une plaine hors du Kaire ; et là, courant à toute bride, ils s'exercent à sortir prestement la carabine de la bandoulière, à la tirer juste, à la jeter sous la cuisse, pour saisir un pistolet qu'ils tirent et jettent par-dessus l'épaule ; puis un second, dont ils font de même, se fiant au cordon qui les attache, sans perdre de temps à les replacer (comte de Volney, Voyage en Égypte et en Syrie)

1797 ma surprise fut extrême d'en voir un de cet âge qui, après avoir bandé un petit arc, tiré assez juste une flèche, donné des coups de bâton à un chien, se jeta sur le sein de sa mère, et y prit la place d'un enfant de cinq à six mois, qui s'était endormi sur ses genoux (Louis-Antoine Destouff MiletMureau, Voyage de La Pérouse autour du monde)

II. Accomplir (quelque chose), achever (quelque chose) exactement Intransitif

1680a Je n'eusse jamais cru, ma chère fille, qu'un jour visé de si loin pût être tiré si juste ; le voilà pourtant ce $16^{\mathrm{e}}$ que nous avons suivi depuis deux mois. Je pars demain à la pointe du jour avec le bon abbé (Mme de Sévigné, Correspondance) 
1680b La mère a obtenu une femme pour la servir, mais monsieur le duc se déchausse lui-même. Votre médecin philosophe tire de trop loin, ma fille, pour tirer juste. Il me croit malade et je suis guérie, et je vous assure que les conseils qu'on m'a donnés ici sont opposés aux siens

(Mme de Sévigné, Correspondance)

III. Tirer avec justesse la conséquence (de quelque chose)

Transitif

1733 Le rang où un dissertateur françois placeroit aujourd'hui l'Arioste en vertu d'une analyse géometrique de son poëme, seroit-il reconnu pour être le rang dû à Messer Ludovico ? Que de calculs, que de combinaisons à faire avant que d'être en droit de tirer la consequence, si l'on veut la tirer juste (Jean-Baptiste Dubos, Réflexions critiques sur la poésie et la peinture)

IV. Tirer trop court, le tir ne suffisant pas pour atteindre la cible

Intransitif

1942 Le capitaine Pénicot m’a raconté son vol de ce matin : « quand une des armes automatiques me paraissait tirer trop juste, je bifurquais droit sur elle, à pleine vitesse, au ras du sol, et je lâchais une giclée de mitrailleuse qui éteignait net cette lumière rougeâtre, comme un coup de vent une bougie » (Antoine de Saint-Exupéry, Pilote de guerre)

\section{Corpus Web :}

Club sportif et artistique : les archers tirent juste [http://www.estrepublicain.fr/loisirs/2012/ 07/03/club-sportif-et-artistique-les-archerstirent-juste] (31.1.2016)

Mais ils sont loin d'avoir démérité, ils tirent juste et bien [http://www.leperon.fr/Sport/Polo/ L-Angleterre-bat-la-France-3-a-2-en-demi-finale] (31.1.2016)

Les ennemis! Ils sont supers classes ! Chaque faction (clan de bandits, Autorité, mutants) à sa tactique de combat et ses animations propres. Ils tirent justes et sont loin d'être stupides [http:// www.jeuxvideo.com/forums/1-50-89170450-1-0-10-mon-avis-sur-rage.htm] (31.1.2016)
Les joueurs sont concentrés, ils pointent et tirent justes, et contre toute attente, remportent les deux triplettes [http://www.ladepeche.fr/ article/2010/09/29/916179-1-exploit-des-petan queurs.html] (31.1.2016)

REMARQUES : Tirer juste (I) se dit du fait de lancer un projectile à la main ou à l'aide d'une arme en dirigeant celle-ci avec exactitude, atteignant exactement la cible, l'objectif visé. Au figuré (II), il réfère au fait de faire mouche, d'arriver au but. (III) signifie 'obtenir, parvenir à une idée, un résultat fondé, qui s'avère exact' par un raisonnement, par une démarche de l'esprit. Dans (IV), juste s'emploie au sens de 'ne pas assez loin'. Juste reste invariable dans la majorité des cas, mais l'accord avec le sujet n'est pas exclu, notamment dans le contexte du sport (v. derniers exemples du CW). Juste est modifié par assez, aussi, moins, plus, si, trop. Notons les collocations juste et bien; juste et vite.

\section{Tirer loin}

Tirer à une grande distance

Intransitif

1539 Ou transnouoys les rivieres profondes, Ou r'enforçoys sur le genoil les fondes, Puis d'en tirer droict et loing j'apprenois Pour chasser loups et abbatre des noix (Clément Marot, Églogue au roy)

\section{CORPUS WEB :}

bonjour, vous connaissez pas de bonne mini répliques qui tirent loin et qui se chargent avec une batterie pas avec des piles ? [http://www. jeuxvideo.com/forums/1-24-7629853-1-0-1-0-minirepliques.htm] (31.1.2016)

Les armes utilisées par les terroristes ainsi que celles utilisées par la police tirent loin [http:// www.songlyrics.com/lia-ices/love-is-won-lyrics] (31.1.2016)

Coté stratégie, je suis de ceux qui protégent leurs unités au front avec les unités qui tirent loins [http://arcadecity.annuairedeforums.com/ t204-gage-lazur-sous-lieutenant-zephyrien] (31.1.2016)

Achetés plusieurs de ces petits pistolets, ils sont supers pour les petites mains et tirent loins en plus. Mes enfants sont ravis [http://www.ama zon.fr/product-reviews/B003LSU5QW] (31.1.2016) 
REMARQUES : Tirer loin réfère à une personne ou une arme qui envoie, qui lance un projectile au loin. Loin est considéré adverbe de lieu par l'usage consacré. La norme le veut donc invariable. Les derniers exemples du $\mathrm{CW}$ montrent cependant que les locuteurs le font accorder. Ceci souligne la spontanéité motivée et la productivité de l'accord. Notons la collocation droit et loin.

\section{Tirer long}

Aller, viser loin ; viser à long terme

Intransitif

1954 On m'accuse de tirer trop long. Je crains que la commission ne tire trop court. Méfions-nous des prévisions optimistes ( $L e$ Monde, 8 décembre 1954 / Grundt : 315)

\section{CoRpus Web :}

Et en fin de geste en appui sur le devant des pieds (droit pour le droitier) pour presque nous faire une «provençale », comme Lacroix parfois... Penser au transfert du corps pour tirer long ! Vous ne forcerez ainsi pas sur le bras... [http://www. petanque-apprentissage.com/2012/08/transfertdu-poids-du-corps.html] (31.1.2016)

Est-ce qu'à force de tirer long on encrasse un moteur, de façon générale ? [http://forums. motorlegend.com/vb/archive/index.php/t-4783. html] (31.1.2016)

Ce n'est pas pour moi (je roule en Ibiza 2005 FR TDI) mais pour ma copine qui a récupérer la punto de sa mère il y a quelques mois maintenant. Elle totalise $200000 \mathrm{Kms}$, et je ne sais pk après $3600 \mathrm{tr} / \mathrm{min}$ elle tire long [http://www.forum-auto. com/marques/fiat/sujet2428.htm] (31.1.2016)

La première vitesse ne bouge pas. Par contre sur la deuxième; sur la Close, elle tire longue et sur la Wide, elle tire courte. (2.5...normal même. :D) [http://www.revopowaaa.com/t1941-rapportratio-de-transmission-revo] (31.1.2016)

REMARQUES : De façon générale, tirer long réfère à une distance que l'on couvre avec effort. En parlant d'un budget accordé pour la réalisation d'un projet ou autre, il se dit du fait de demander des sommes plus élevées que celles accordées normalement par l'organisme compétent. Dans le domaine de la pétanque, tirer long renvoie au parcours de la boule dans l'air. En parlant des automobiles, il se dit de la puissance du moteur appliquée à une vitesse, donc au fait d'accélérer plus ou moins longtemps sur la même vitesse. Notons l'opposition sémantique avec tirer court. Long reste invariable dans la majorité des cas, mais l'accord avec le sujet n'est pas exclu non plus (v. le dernier exemple du CW). Long est modifié par trop.

\section{Tirer mauvais}

Tirer un mauvais numéro, être malchanceux Emploi absolu

1887 D'ailleurs, ils n'auraient rien su dire, les yeux hors de la tête, soûls d'avoir gueulé autant que d'avoir bu. Un petit rigolo qui jouait de la trompette avec son nez, avait justement tiré mauvais ; tandis que deux autres, pâlots, les yeux battus, étaient sûrement parmi les bons. L'enragé tambour, à leur tête, les aurait menés au fond de l'Aigre, qu'ils y auraient tous fait la culbute (Émile Zola, La Terre)

REMARQUES : Tirer mauvais se dit du fait de ne pas avoir eu de chance au tirage au sort de la conscription, c'est-à-dire être pris comme conscrit.

\section{Tisser lâche}

Tisser sans serrer les fils

Transitif

1854 Un mimosa mort y élève ses branches dépouillées : à l'aide d'une corde et d'une couverture on improvise une tente sous laquelle je dors, malgré la chaleur tamisée par cette étoffe en laine lâche et mal tissée (Maxime Du Camp, Le Nil. Égypte et Nubie)

1960 Tissés "lâche », ils [= des torchons] sont très absorbants et ne laissent pas la moindre peluche (Express, 14 janvier 1960 / Grundt : 305)

Corpus Web :

Ça dépend aussi du lainage... certains lainages tissés lâche (genre lainage $\mathrm{Ch}^{\star}$ nel) ont tendance à s'effilocher beaucoup et je les surfile même s'ils sont doublés [http://www. threadandneedles.fr/groupes/conseils-couture/ forum/topic/surfiler-un-tissu-en-laine] (1.2.2016)

En ce qui concerne les fils de carbone, la même évolution a été constatée et il a été également envisagé de réaliser des tissus dont la 
chaîne (ou la trame) est formée de nappes de fils de carbone, tordus ou non, formant une nappe de filaments parallèles, dense et homogène, la cohésion de ces fils étant donnée par des fils de trame (ou de chaîne), tissés lâche ou non, en carbone ou toute autre matière chimique [http:// www.google.com.ar/patents/EP0031785A1?cl=fr] (1.2.2016)

Armature textile utilisable pour la réalisation de complexes stratifiés, du type constitué par une nappe de fils longitudinaux (1) liés entre eux par des fils de trame (2a,2b) tissés lâches avec lesdits fils longitudinaux (1) [http://www.google. com/patents/EP0193478A1?cl=fr] (1.2.2016)

Procédé pour l'obtention d'un matériau selon l'une des revendications 1 à 3, qui consiste, de manière connue, à réaliser par tissage un article comportant des fils de trame (1) liés entre eux par des fils de chaîne (2), tissés lâches par rapport à la densité des trames (1), caractérisé par le fait qu'après réalisation dudit tissu, on modifie l'orientation des trames (1) par rapport aux fils de chaîne (2) et, simultanément, on effectue un traitement thermique permettant de provoquer la fusion au moins superficielle des fils de chaîne (2) de liage [http://www.google.tl/ patents/EP0193479B1?cl=fr] (1.2.2016)

REMARQUES : Tisser lâche réfère à une étoffe de laine, une toile, un drap dont la trame n'est pas assez battue ou la chaîne assez serrée. Les guillemets dans l'exemple de 1960 indiquent l'appartenance au langage du textile. Tisser lâche tend à l'emploi invariable, mais il s'accorde avec l'objet dans les troisième et quatrième exemples du CW. Notons la collocation lâche et mal.

\section{Tomber abondant}

Tomber en abondance, en grande quantité Intransitif

1824 La pluie qui a tombé assez abondante jusqu'au 13 a tout ranimé, tout reverdi (Pierre Maine de Biran, Journal)

1945 Il neigeait à plein temps. Ce n’était plus les plumes folles du dimanche précédent. La neige tombait fine, tombait dru, tombait abondante, pour régaler la terre. Vers midi le soleil se montra, pâle parmi de pâles nuages (Germaine Guèvremont, Le Survenant)
CORPUS Web :

Les précipitations varient largement d'une région à l'autre, et se situe entre $380-600 \mathrm{~mm}$ par an des semi-aride régions du nord-ouest, à 1500 $\mathrm{mm}$ dans le plateau de l'Adamaoua, à 2500-4000 mm sur la côte, jusqu'à $10.000 \mathrm{~mm}$ de pluie le long $\mathrm{du}$ flanc ouest du mont Cameroun, où la pluie tombe abondant presque toute l'année [http:// www.canalmonde.fr/r-annuaire-tourisme/ monde/guides/guides.php? $\mathrm{p}=\mathrm{cm}$ ] (1.2.2016)

Dans les Alpes et les Apennins, le climat est celui de la montagne, la neige est très fréquente en hiver et tombe abondant dans les Alpes et les Apennins, mais la neige est plus intense dans le sud-ouest, qui est dans la chaîne des Alpes Maritimes [http://www.italyaround.com/fr/piemontclimat-quand-aller] (1.2.2016)

La neige tombe, abondante sur notre région, ce qui n'était pas arrivé depuis plusieurs années ; elle durera plusieurs jours [http://www.encalcat. com/fevrier-2015_47-actu_222.php] (1.2.2016)

La neige tombe abondante de Novembre à Mars tout au long des Apennins, et dans une moindre mesure, dans les zones de plaine [http:// www.italyaround.com/fr/emilie-romagne-cli mat-quand-aller/\#] (1.2.2016)

REMARQUES : Au sens propre, en parlant d'une chose, en particulier d'un phénomène météorologique (très souvent la pluie), tomber abondant réfère à la grande quantité de liquide qui tombe. Abondant peut s'accorder avec le sujet (v. les exemples de 1824, 1945 et les troisième et quatrième exemples du CW), ce qui renforce une interprétation de prédicat second, mais les premiers exemples du CW montrent que l'invariabilité est aussi une tendance, sans doute aussi à l'oral, l'accord étant audible. Notons l'emploi analogue de tomber fin et tomber dru. Relevons l'exemple de 1945, intéressant du point de vue de la morphologie de l'adjectif : fin et abondant s'accordent avec le sujet alors que $d r u$ reste invariable. Abondant est modifié par assez.

\section{Tomber bas}

I. Se diriger vers le bas, retomber Intransitif

1550 Elle fit bas tomber la terre Et tournoyer l'eau qui la serre De ses bras vagues et dispos (Pierre de Ronsard, Les Odes, p. 25) 
1907 Le voilà : partout et toujours, il a été pareil, - long, maigre, flasque, le nez juif tombant bas sur le menton sec, la redingote noire trop luisante et la cravate en cordon de soulier complétant la silhouette piteuse d'un pion de collège en retraite (Claude Farrère, L'Homme qui assassina)

1919 Tu vois, ces branches-là, ça gêne, elles tombent trop basses (Exemple entendu / Damourette et Pichon, § 984)

II. Atteindre un niveau (moral, social, spirituel, etc.) très bas, peu élevé

Intransitif

1580 EDIPE. J'ay desir de mourir, et de plonger mon mal

Avec mon ame serue, en l'abysme infernal : Et si plus bas encore un trespaßé devale, Plus bas je veux tomber que la voûte infernale (Robert Garnier, Antigone)

1598 Le Docteur Fauste tomba encore plus bas, dans l'abisme, avec de grandes blessures et avec un grand cri, car il pensoit desja : Maintenant c'est fait de moi ! Mesme il ne pouvoit plus voir son esprit (Pierre-Victor Cayet, L'Histoire prodigieuse du Docteur Fauste)

1655 Vous qui ne tenez lieu de rien au monde ou qui n'estes, au plus, qu'une gale aux fesses de la Nature ; vous qui tomberez si bas, si je cesse de vous soustenir, qu'une puce en laischant la terre ne vous distinguera pas du pavé (Savinien Cyrano de Bergerac, Les Lettres)

1715 Enfin je ne puis m'empêcher de croire avec M. Despréaux que Molière qui peint avec tant de force et de beauté les mœurs de son païs, tombe trop bas, quand il imite le badinage de la comédie italienne... etc (François de Fénelon, Lettre à l'Académie)

1775 Qu'en pensez-vous ? Je crois que si je lisois Clarisse ce soir, je n'y trouverois ni amour ni passion. Mon dieu! Peut-on tomber plus bas ? - Je n'aime point Fontainebleau, seroit-ce parce que vous y êtes ? (Julie de Lespinasse, Lettres à M. de Guibert)
1805 - Mathilde, reprend-il, pardonne mon audace ; mon espérance est née de ton repentir ; si tu n'avois point d'amour, pourquoi t’accuserois-tu?

- Ah ! Malheureuse, interrompt-elle, ai-je donc dévoilé mon opprobre ? Suis-je tombée si bas que désormais un infidèle ait le droit de me faire rougir? (Sophie Cottin, Mathilde)

1835 «Vous tomberez bien bas, mon ami ! Peutêtre les sifflets vous chasseront-ils de ce Nancy que vous méprisez tant. Jolie façon pour cette ville de se graver dans votre souvenir ! » (Stendhal, Lucien Leuwen)

1842 On le prit pour un étudiant. La nationalité polonaise, par l'effet d'une odieuse réaction gouvernementale, était alors tombée aussi bas que les républicains la voulaient mettre haut (Honoré de Balzac, La Fausse maîtresse)

1843 - Apparemment, maître, dit Consuelo avec un sourire mélancolique et caressant, que nous ne sommes pas encore tombés si bas dans l'estime des hommes de bien qu'il vous plait de le croire ; car il est certain que le comte veut m'épouser, et que je viens ici vous demander votre agrément pour y consentir (George Sand, Consuelo)

1853 - Oh ! Oui, dit le docteur ; je saurai certainement ce qui la rend ainsi.

Mais le docteur s'était un peu trop avancé ; quand il se trouva seul avec Caroline et qu'il lui eut demandé des nouvelles de sa santé, la conversation tomba tellement bas qu'il était difficile de la ramasser

(Champfleury, Les Souffrances du professeur Delteil)

1924 Cette « journée des barricades », cette insurrection parisienne, cette fuite, les sentiments républicains de beaucoup de ligueurs, montrent comme la royauté était tombée bas. Pourtant c'est à Chartres, où Henri III s'était réfugié comme jadis Charles VII à Bourges, que s'étaient réfugiées aussi l'idée de l'État et l'idée nationale (Jacques Bainville, Histoire de France) 
1927 Aujourd'hui le diable a tellement tout combiné dans le régime de la vie terrestre que le monde ne sera bientôt plus habitable qu'aux saints. Les autres y traîneront le désespoir, ou devront tomber plus bas que l'homme. Les antinomies de la vie humaine sont trop exaspérées, le poids de la matière trop aggravé, il faut, pour exister seulement, s'exposer à trop de pièges (Jacques Maritain, Primauté du spirituel)

1951 Le lamentable, c'est que sa cote en soit aujourd'hui tombée si bas qu'elle ne prête souvent plus qu'à sourire. Il importe de la relever. Soyons de ceux qui s'y emploient (André Gide, Ainsi soit-il ou Les Jeux sont faits)

1975 Avec elle, dérape-t-on, on tombe vite et bas. Mais on vit d'elle honorablement si l'on tient ferme sur quelques règles. (Je dirai plus tard comme j'ai souvent failli glisser. Je sens encore le frisson du vide...) (François Nourissier, Lettre à mon chien)

III. faire tomber bas : tuer

Transitif

1601 Et tournant au bourreau sa face glorieuse, Arme quand tu voudras ta main injurieuse, Frape le coup mortel, et d'un bras furieux, Fay tomber le chef bas, et voler l'ame aux Cieux (Antoine de Montchrestien, L'Escossoise ou Le Désastre)

IV. Baisser, diminuer (quantitatif) : le prix, la valeur de (quelque chose)

Intransitif

1846 Si elle [= la librairie] tombe encore plus bas, le marché qui m’assure $5500 \mathrm{f}$. ne me sera pas une ressource, car l'éditeur viendra me dire comme d'autres l'ont fait déjà: «Je ne puis vous payer, ne me donnez pas votre manuscrit » (George Sand, Correspondance)

1929 S’ils m’avaient écoutée, ils auraient fait la dépense d'un puits, lorsque au temps de la grève de Seigneville le prix de la maind'œuvre était tombé si bas. Quelle occasion nous avons perdue ! La propriété des Vallette a doublé de valeur, en deux ans (Georges Bernanos, La Joie)
V. Tomber en silence, sans faire de bruit Intransitif

1925 Une pluie d'automne tombait tout bas, picotant les touffes de trèfle. Au jardin quelque pomme roulait sur les buis d'où sortaient les limaçons et la branche balançait en s'égouttant (Henri Pourrat, L'Auberge de la Belle Bergère ou Quand Gaspard de guerre revint)

CoRpus Web :

Plus ça va, plus elle tombe bas la meuf. Elle a 17 ans, elle traine avec des gosses de 11 ans. bah bravo ! [https://fr-fr.facebook.com/permalink. php?story_fbid $=233418836806956 \&$ id $=18587998$ 8227508] (1.2.2016)

Tu dis qu'elle tombe bas, mais moi je suis pas convaincu, elle fait des bons choix, et c'est l'une des actrices les plus prometteuses de sa génération avec Kirsten Dunst... [http://www.allocine. $\mathrm{fr} /$ communaute/forum/message_gen_nofil=363 233.html] (1.2.2016)

Car nous aujourd'hui et bien je vois la neige à env. 200m au dessus de chez nous. La neige est vraiement tombée basse [http://forum.infobebes. com/vie-pratique/Beaute-Remise-en-forme/ tatouages-sujet_120707_5.htm] (1.2.2016)

$\mathrm{Si}$ vous prenez trop de Novolin N, votre glycémie peut tomber basse (l'hypoglycémie) [http:// niger-gouv.org/medicaments/0169-1834-novo lin-n.html] (1.2.2016)

REMARQUES : Tomber bas (I) renvoie au fait de se déplacer, se diriger, s'incliner vers le bas (la terre, le nez, les branches). (II) s'applique à une personne qui, suite à une mauvaise action ou à un comportement avilissant, ne reçoit plus l'estime d'autrui, tombe dans l'estime de ce dernier. Au figuré (III), tomber bas se dit du fait de tuer, de mettre quelqu'un à mort. En parlant de notions quantitatives (un chiffre, une valeur), (IV) se dit du fait de diminuer, de baisser à un niveau faible, très inférieur. (V) réfère au son plutôt doux et agréable produit par quelque chose qui tombe (ici : la pluie). Bas reste invariable dans la majorité des cas. Toutefois, dans les deux derniers exemples du CW, ainsi que dans l'exemple oral de 1919, il s'accorde avec le sujet, sans changer sa fonction adverbiale. Citons le commentaire de Damourette et Pichon : «dans la bouche de 
personnes du vulgaire ». Il est modifié par aussi, bien, encore plus, plus, si, tellement, tout, trop. Notons l'emploi de dévaler bas et la collocation vite et bas.

\section{Tomber bruyant}

Tomber en faisant beaucoup de bruit Intransitif

1879 Comme les premiers grains d'une giboulée, quelques-unes se détachèrent, dis tinctes, roussâtres ; ensuite toute la nuée creva, et cette grêle d'insectes tomba drue et bruyante. À perte de vue les champs étaient couverts de criquets, de criquets énormes, gros comme le doigt. Alors le massacre commença (Alphonse Daudet, Lettres de mon moulin)

\section{CORPUS WeB :}

Faut voir, si ça tombe "bruyant » ça veut dire « le chat joue et court partout »... A mon avis le chat est pas bruyant, juste qu'il joue la nuit... [http://forum.doctissimo.fr/animaux/Chats/ separer-chat-sujet_27667_2.htm] (1.2.2016)

Attention, il convient de freiner le leurre avant son impact avec l'eau, nous nous trouvons là sur un poste relativement calme. Le moindre bruit excessif, comme le plouf d'un leurre tombant bruyant dans l'eau peut avoir deux effets, une attaque ou une fuite éperdue [http://franckl 69.skyrock.com/2977736279-Poste-type-La-cu vette.html] (1.2.2016)

D'abord, la pluie est tombée, drue, forte, bruyante pendant douze heures sans interruption [http://voyagesivanka.blogspot.co.at/2013_ 04_01_archive.html] (1.2.2016)

REMARques : Dans l'exemple de 1879, tomber bruyant désigne une nuée d'insectes (ici : des criquets) qui s'abat au sol en faisant beaucoup de bruit en raison de leur grand nombre et de leur cri strident, perçant. Bruyant s'accorde avec le sujet dans l'exemple de 1879, et de nouveau dans le dernier exemple du CW, mis en série avec $d r u$ et fort, également fléchis. Notons l'emploi impersonnel familier de ça tombe "bruyant " où les guillemets marquent une façon de dire.

\section{Tomber doux}

Se manifester, apparaître doucement, délicatement ou agréablement

Intransitif

1624 Fermes en leurs propos, non ainsi que vous faints,

Que certains jours de l'an on prendroit pour des saincts,

Avec vostre façon tristement composée, Un langage qui tombe aussi doux que rozée (Jacques Du Lorens, Premières satires)

1794 LE CHEVRIER. L'autre jour à la mienne, en ce bois fortuné,

Je vins offrir le don d'un chevreau nouveau-né ;

Son œil tomba sur moi si doux, si beau, si tendre!

Sa voix prit un accent !... Je crois toujours l'entendre (André Chénier, Les Bucoliques)

1840 C'est la manne de notre désert que cette parole du ciel, qui tombe douce et blanche, d'un goût simple et pur que j'aime (Eugénie de Guérin, Journal)

1857 Nous sentîmes bien des fois ceci, dans la suite de ce grand travail, et surtout les jours où la pluie tombait fine et douce (Jules Michelet, L'Insecte)

1886 Ses larmes tombaient, silencieuses et plus douces, et elle redisait en elle-même ses prières ardentes à la Vierge, Étoile-de-lamer (Pierre Loti, Pêcheur d'Islande)

1947 La pluie tombait en éventail, en chassécroisé, tombait tout doux comme les mouches et comme les femmes légères (René Fallet, Carnets de jeunesse)

1950 Dehors le soir tombe, calme et doux. Une nappe de soleil baigne le flanc de l'église, revêt comme d'une patine ambrée la crudité des murs neufs (Maurice Genevoix, Ceux de 14)

\section{CORPUS WEB :}

En tirant sur l'avant connecté, barre choquée à fond, suis-je bien sûr que l'aile va bien déventée et tomber tout doux dans l'eau : est ce vraiment sécu ? [http://www.kitesurf.fr/ntopic_8595. html] (1.2.2016) 
Pas mal, mais le vent a eu une (facheuse) tendance à tomber tout doux dès $18 \mathrm{~h} 00 . .$. [http:// www.windsurfbreizh22.com/modules/newbb/ viewpost.php?start=14205\&forum $=0$ \&viewmo $\mathrm{de}=$ flat\&type $=\&$ uid $=0$ \&order $=$ ASC $\&$ mode $=0$ ] (1.2.2016)

La nuit était tombée, douce comme un voile de soie, alors que derrière nous un bal divertissait une population que l'on pouvait imaginer aisée [http://www.letrollbaveur.fr/viewtopic.php $? \mathrm{t}=4250 \&$ start $=90](1.2 .2016)$

REMARQues : Employé au sens figuré, tomber doux peut référer à la parole, aux mots utilisés qui retentissent à l'oreille de façon agréable. Le sujet peut aussi désigner l'œil (par métonymie) et souligner le fait de diriger son regard vers quelqu'un avec tendresse. Lorsque le sujet désigne une chose (la pluie, une larme) qui tombe sur le corps, celle-ci produit une sensation de bienêtre, fait sur les sens une impression agréable. En référence à la tombée de la nuit, tomber doux souligne l'atmosphère agréable qui règne (avec des couleurs offrant une luminosité, des teintes estompées). Doux tend à réaliser l'accord avec le sujet, ce qui suggère une analyse en tant que prédicat second orienté vers le sujet. Ceci vaut également pour les autres adjectifs combinés avec tomber (beau, blanc, calme, fin, silencieux, tendre). Doux reste cependant invarié dans l'exemple de 1947 et dans le premier exemple du CW. Il est modifié par aussi, plus, si, tout. De nombreuses collocations dénotent, sur le plan stylistique, la lenteur ou la douceur du processus.

\section{Tomber droit}

I. Tomber directement dans, sur

(quelque chose/quelqu'un)

Intransitif

1607 Dieu est (dit Origene) comme celuy qui sçachant certainement que dans un bois il y a des voleurs, auquel il void acheminer un pauvre passant, et tomber tout droit dans leurs embusches, juge facilement sa prise par la route qu'il tient (Scipion Dupleix, La Logique ou L'Art de discourir et raisonner)

1696 S'il est le maître, et que ce soit la fête de la noblesse de Bretagne, comme il semble que cela doit être, et non pas d'un courtisan, cela tombe droit sur mon fils. Rien ne peut égaler les soins que ces gouverneurs ont de ma santé, et les marques d'estime et de distinction ; j'en suis quelquefois embarrassée (Mme de Sévigné, Correspondance)

1719 Les gens sont bien méchans ! Comme va la police !

On ne sçauroit voyager aujourd'hui :

La police pourtant fut trop bonne pour lui. Des archers le cherchoient et ces détours le menent

Tomber tout droit entre leurs mains. Ils vous le garotent, l'entraînent (Antoine Houdar de La Motte, Fables)

1831 Le savant modeste sourit en disant à ses admirateurs : « Qu’ai-je donc créé ? Rien. L'homme n'invente pas une force, il la dirige, et la science consiste à imiter la nature. " Raphaël surprit le mécanicien planté sur ses deux jambes, comme un pendu tombé droit sous sa potence. Planchette examinait une bille d'agate qui roulait sur un cadran solaire, en attendant qu'elle s'y arrêtât (Honoré de Balzac, $L a$ Peau de chagrin)

1854 La montagne qui porte la citadelle ruinée est immense et tombe droit dans le Nil, comme un rempart ; les murailles, les tours carrées découpent au sommet une silhouette effondrée et dentelée par le temps (Maxime Du Camp. Le Nil. Égypte et Nubie)

1861 Quand il n'amoncelle pas sa fureur contre Bayonne et Saint-Jean-de-Luz, il bat la pauvre Gironde. Elle ne sort pas, comme la Seine, abritée de plusieurs côtés. Elle tombe tout droit en face de l'Océan illimité. Le plus souvent il la rembarre. Elle recule ; elle se jette à droite, à gauche (Jules Michelet, La Mer)

1939 Du banc où nous étions assis, causant, quand nous jetions les peaux par-dessus la balustrade, à quelque cent mètres plus bas elles tombaient droit dans la mer (André Gide, Journal) 
1996 Il devra se positionner au-dessus de l'escadre à cinq mille mètres d'altitude et, de là, tomber droit sur sa cible, la cheminée du navire si possible, point d'impact le plus efficace (Pascale Roze, Le Chasseur zéro)

II. Tomber en ligne verticale ou en position verticale, raide

Intransitif

1634 C'est dans son premier dialogue assez près du commencement, où il dit que, selon Platon, Dieu laissa tomber droit les planettes, et qu'estant tombees jusqu'à ce qu'elles allassent de la vitesse qu'il avoit ordonnee, il changea leur mouvement droit en circulaire qu'elles ont maintenant (Marin Mersenne, Correspondance)

1833 Les monuments s'élèvent en surfaces planes, les murs tombent droit, se coupent en équerre et s'avancent en saillies brisées ; le jour, bondissant sur ces saillies, ne fait luire sous les pilastres que des échos de sa lumière (Saint-Simoniens, Poèmes)

1848 Près de nous passa un homme dont la chevelure trempée tombait droite autour de son cou. Des gouttes perlaient aux boucles frisées de sa barbe noire, et il secouait ses cheveux pour en faire tomber l'eau (Gustave Flaubert, Par les champs et par les grèves)

1863 Derrière elle [= la fille d'Hamilcar], de chaque côté, se tenaient deux longues théories d'hommes pâles, vêtus de robes blanches à franges rouges qui tombaient droit sur leurs pieds (Gustave Flaubert, Salammbô)

1876 Les Splendeurs de la Beauté marchait en tête, puis venait Omm-Djéhâne, suivie de Djémylèh et de Talhemèh, deux jeunes demoiselles très agréables, non moins peintes que leur maîtresse, et toutes vêtues de robes longues tombant droit jusqu'aux pieds avec des plis nombreux (Arthur de Gobineau, Nouvelles asiatiques)

1883 Cette tentative de rendre le foisonnement des êtres et des choses dans la pulvérulence de la lumière ou de les détacher avec leurs tons crus, sans dégradations, sans demi-teintes, dans certains coups de soleil tombant droit, raccourcissant et supprimant presque les ombres, comme dans les images des Japonais, a-t-elle abouti, à l'époque où elle fut osée ? (Joris-Karl Huysmans, L'Art moderne)

1921 Les robes grises ou blanches tombent droit comme des suaires. Autour, les voûtes sont épaisses, les dalles froides, le jour mort. À peine çà et là un tapis rouge, un ruban bleu animent cette aridité (Élie Faure, Histoire de l'art : l'art moderne)

1928 Un coup de vent passa, quelques instants, levé on ne sait où, annonciateur de troubles prochains. Sous le souffle, de toutes les branches les fruits mûrs se détachèrent. Les uns tombaient droit avec un bruit mat, les autres rebondissaient avec un bruit métallique, après avoir heurté quelque ramure inférieure, et l'on aurait dit les premiers grêlons d'un orage tintant sur un toit (Joseph de Pesquidoux, Le Livre de raison)

1985 Je ralentissais pas aux croisements. Tchikitchikitchikitchikk faisait la pluie, flac flac flac flac je faisais, badabraoum faisait le tonnerre. La pluie tombait bien droit mais elle me cinglait le visage. Il y avait des gouttes que j'avalais directo. J'ai fait la moitié du chemin à un train d'enfer (Philippe Djian, $37^{\circ} 2$ le matin)

\section{CORPus WeB :}

C'est une moufle + surmoufle de marque Outdoor Designs. Elle est tombée droit dans l'axe alors que je m'arrêtais prendre une photo à la hauteur du gros rocher qu'il faut contourner par la gauche. Elle a du rester bloquée sur un pin, voire recouverte par la neige de notre descente [http://www.skitour.fr/forum/read_210016.html] (2.2.2016)

Toujours attirée par ce qui ce dit sur les Ch'tis (j'en suis une, mais à Paris). J'y suis allée direct et tombée droit dans le panneau [http:// www.linternaute.com/humour/temoignage/ temoignage/133361/tombee-dans-le-panneau] (2.2.2016) 
Aux côtés de deux professionnels du ski de fond, la jeune femme est tombée droite comme un pic alors qu'elle était chaussée de ses skis [http://www.gentside.com/t\%E9l\%E9vision/lajournaliste-brooke-graham-s-039-evanouit-endirect-alors-qu-039-elle-allait-faire-du-ski-defond_art57732.html] (2.2.2016)

en fait, c'est en la relachant après un arraché, elle n'est pas tombée droite par terre, elle s'est mise a vibrer, et elle a pété :D, mais on m'a dit qu'elle avait déja qq chose avant [http://forum. powerattitude.com/powerattitude/Entraine ment/Blessures/lache-barre-disque-sujet_804_1. $\mathrm{htm}]$ (2.2.2016)

REMARQUes : Tomber droit (I) se dit du fait de déboucher à tel ou tel endroit, de chuter à un endroit précis ou de tomber directement dans le piège tendu par quelqu'un. En parlant d'événements désagréables ou pénibles, il réfère au fait d'accabler quelqu'un, de devenir une charge matérielle ou morale pour quelqu'un. Dans cet emploi, droit tend à s'associer à la préposition qui le suit. Sous (II), le sujet peut renvoyer à une partie du visage dont la forme se distingue par son aspect longiligne ou, en parlant des cheveux, de leur raideur ; en référence à un paysage, un élément naturel (la montagne), tomber droit souligne sa forme abrupte ; le sujet réfère aussi à un drap, un vêtement ou un tissu long, qui va jusqu'au sol, sans plis. Dans son emploi figuré, le sujet désigne un phénomène atmosphérique ou des précipitations (le soleil, la foudre, le tonnerre, la pluie) qui tombe ou se manifeste de manière ciblée, à un endroit précis. Au sens directionnel, droit tend à l'emploi invarié, tandis que l'accord est possible pour mettre en avant qu'une personne ou un objet se trouvent dans une position verticale, adoptant une tenue rigide. Il est modifié par bien, tout. Notons l'emploi de avaler directo dans l'exemple de 1985, et de aller direct dans le second exemple du CW.

\section{Tomber dru}

I. Tomber de manière abondante, fréquente Intransitif

1579a CHEUR. Les coups nous tombent sur le dos

Aussi drus que vont les sanglots, Nostre parolle entrecoupant,

\section{Et nostre gosier estoupant \\ (Robert Garnier, La Troade)}

1579b Lequel (après leur avoir bien conté au long comment il en avoit tant et tant tué) leur recita que les Angloys les avoient beaucoup travaillez avec leurs arcs, disant (à la verité) que les flesches tomboient sur eux plus dru que pluie (Philippe d'Alcripe, La Nouvelle fabrique des excellents traicts de vérité)

1732 Il se remit à tenir table, et la subtilité de mes mains lui fournissait abondamment de quoi faire grand'chère à bon marché. Les poules, les chapons, les oies, les poulets et les pigeons tombaient dru comme grêle dans sa cuisine, et je ne le laissais point manquer de jambons (Alain-René Lesage, Histoire de Guzman d'Alfarache)

176218 mai. On voit une estampe ingénieuse sur les affaires des jésuites ; aux deux côtés du tableau sont M. le duc de Choiseul et madame la marquise, qui arquebusent à bout touchant une foule de jésuites. Ceux-ci tombent par terre, dru comme mouches (Louis de Bachaumont, Mémoires secrets pour servir à l'histoire de la république des lettres)

1853 Cette année-là, notre maître de géométrie était sévère, il punissait impitoyablement ceux qui ne donnaient pas à ses leçons une attention scrupuleuse ; les retenues, les pensums tombaient dru comme grêle ; c'était là un grand crime dont il fallait le punir, et il fut convenu qu'on le ferait sauter (Maxime Du Camp, Mémoires d'un suicidé)

1876 Une pluie fine commençait à tomber. Marthe ne pensait plus à rien. Elle regardait la Seine, sans même la voir. La pluie tomba plus drue, de plus larges gouttes lui fouettèrent le visage (Joris-Karl Huysmans, Marthe : histoire d'une fille)

1881 J'attendis une longue heure dans des tourbillons de neige, puis je m'approchai de la fenêtre. Rien ! Le vent faisait rage et la neige tombait $d r u$. Les ouvriers qui passaient près de moi, leurs outils à l'épaule, 
tête basse sous les flocons épaissis, me heurtaient. Rien. Je craignais qu'on ne me remarquât (Anatole France, Le Crime de Sylvestre Bonnard)

1886 Ils restaient tous deux à la barre, attachés et se tenant ferme, vêtus de leurs cirages, qui étaient durs et luisants comme la peau des requins ; ils les avaient bien serrés au cou, par des ficelles goudronnées, bien serrés aux poignets et aux chevilles pour ne pas laisser d'eau passer, et tout ruisselait sur eux, qui enflaient le dos quand cela tombait plus dru, en s'arc-boutant bien pour ne pas être renversés (Pierre Loti, Pêcheur d'Islande)

1890 Derrière elle, le train, lui aussi, mort, enfoncé dans l'épaisse couche jusqu'aux portières. La neige ne cessait pas, tombait plus drue, par longues rafales (Émile Zola, $L a$ Bête humaine)

1907 L'hiver vint tout d'un coup. La chute des flocons de neige commença, emportés d'un vol cinglant et capricieux, comme des mouches. Puis ils tombèrent si dru qu'on ne voyait plus les côtes ; et les peupliers apparaissaient noyés dans une blancheur (Émile Moselly, Terres lorraines)

1922 Et il partit à toute vitesse. La neige tombait si drue que Mme de Mégret, qui essayait de lire au moins le numéro de la voiture, ne put pas distinguer les chiffres (Paul Bourget, Le Chauffeur)

1930 Je songeais aux hautes montagnes et au grésil tombant si dru comme à un mur de glace entre elle et nous, quand ce n'était pas la neige épaisse et douce qui chuchotait, chuchotait (Jacques de Lacretelle et Madeleine Guéritte, Sarn [trad.])

1946 Moi aussi je suis angoissée, comme s'il allait arriver quelque chose...

Et puis, réfléchissant :

- Si tu t'ennuies trop, je dirai à Henri de t'emmener avec lui...

- La pluie tombait dru comme de la grêle, autour de la métairie (Marguerite Duras, Les Impudents) 1950a Onze heures allaient sonner, mais à cause de la pluie on n'entendrait pas ; elle tombait plus dru depuis un moment et l'oreille distinguait le son grave et plein de l'eau qui ruisselait au cœur des arbres et le tambourinement précis des gouttes sur le toit de la véranda (Julien Green, Moüra)

1960 Mâ’me Communal qui refermait la fenêtre pensa : «C'est le changement de temps qui le rend emmerdant comme ça. » $\mathrm{Au}$ dehors, la vase tombait drue : un rideau énorme qui masquait presque les arbres de l'autre versant de la tranchée (Albert Simonin, Du mouron pour les petits oiseaux)

1964 - On y a pensé, mon gars, cria le vieux. J’y vais.

Il l'entendit patauger. La pluie tombait toujours aussi dru (Bernard Clavel, Le Coeur des vivants)

II. Mourir en grand nombre

Intransitif

1950b Aujourd'hui, à la Vauxmarie, des équipes de sapeurs ramassent les Allemands tombés là aussi dru que les épis d'un champ (Maurice Genevoix, Ceux de 14)

\section{CoRpus Web :}

La grêle est tombée dru [http://www.sudou est.fr/2013/02/08/la-grele-est-tombee-dru-9601 68-843.php] (2.2.2016)

A New York, où la neige est tombée dru vendredi soir, les services météo annonçaient de possibles accumulations de 25 à $35 \mathrm{~cm}$ [http://www. la-croix.com/article/imprimer/909368] (2.2.2016)

D’abord, la pluie est tombée, drue, forte, bruyante pendant douze heures sans interruption [http://voyagesivanka.blogspot.co.at/2013 04_01_archive.html] (1.2.2016)

La neige est tombée drue lundi après-midi à New York, et s'est arrêtée en soirée [http://www. directmatin.fr/monde/2015-01-27/en-images-newyork-paralysee-par-la-neige-698504] (2.2.2016)

REMARQUES : Dans le cadre d'un combat, d'une lutte guerrière, tomber dru (I) réfère au grand nombre de projectiles lancés ou de coups donnés. Il souligne également la grande quantité ou le nombre important qui s'abattent au sol, le 
sujet pouvant être un animal ou un insecte. Très souvent, le sujet se rapporte à un phénomène atmosphérique (pluie, grêle, flocons de neige) qui tombe de manière abondante, dense, de façon ininterrompue. Le sujet peut aussi référer à une chose (un écrit) ou à quelque chose qui est dit ou se manifeste de manière fréquente et en quantité. Au figuré (II), tomber dru peut renvoyer au nombre de soldats tués. Dru tend à l'emploi invariable, mais il peut s'accorder avec le sujet pour insister sur une qualité de l'objet qui tombe, ou par simple (hyper)correction orthographique, la flexion étant inaudible. Il est modifié par aussi, là, plus, si, toujours.

\section{Tomber fin}

Tomber en particules fines, petites, d'un volume très réduit (au propre et au figuré)

Intransitif

1868 Enfin le tonnerre s'éloigna, la pluie tomba plus fine, Madeleine alla ouvrir la fenêtre (Émile Zola, Madeleine Férat)

1883 C'est de bon matin, aux premiers jours de mai ; cependant la pluie tombe fine et grise comme une pluie d'hiver (Pierre Loti, Mon frère Yves)

1933 ô moments qui tombent fins comme des perles sur une plaque de verre, la mémoire, celle qui entre par les yeux et qu'on projette aussi sur les amas immondes que nourrissent les déceptions (Tristan Tzara, L'Antitête)

\section{CORPuS Web :}

ta toile scintillante est jolie, je comprends que tu aies déjà envie de broder dessus, on a envie de beau temps mais ce n'est pas encore aujourd'hui qu'on verra le soleil, la neige tombe tout fin en Picardie, et ailleurs vu la carte de la météo !! [http://annemariebrode.canalblog.com/ archives/2013/02/24/26491003.html] (2.2.2016)

la neige tombe tout fin mais sans arrêt depuis ce midi mais ce matin voilà ce que je voyais de ma fenetre le soleil a huit heures [http://labrodeuse delardy.eklablog.com/papillon-creations-a4898 2476] (2.2.2016)

La pluie est tombée fine et humide toute la journée sur l'Espace FCL à Kerlir [http://www. ouest-france.fr/bretagne/lorient-traore-reprisnormalement-3007397] (2.2.2016)
Elle est tombée fine et drue. Une véritable averse qui s'est abattue peut après cinq heures $\mathrm{du}$ matin sur la région. A 6 heures une couche de trois centimètre recouvrait déjà les routes et tendait à s'épaisseur un peut plus [http://01-saintbenigne. over-blog.com/article-mardi-la-neige-a-perturbele-debut-de-la-matinee-114401487.html] (2.2.2016)

REMARQUES : En référence à la pluie ou la neige, tomber fin se dit des gouttes ou des flocons de neige d'un volume très réduit. Dans l'exemple de 1933, il réfère par métaphore au temps qui se fragmente en petits moments. Fin peut s'accorder ou non avec le sujet, l'accord étant préféré dans le style soutenu. Notons les collocations fin et gris, fin et humide, fin et dru. Fin est modifié par plus, tout.

\section{Tomber fort}

Tomber avec une grande intensité

\section{入 tomber serré}

\section{Tomber juste}

I. Faire le choix qui convient; dire avec exactitude

Intransitif

1696 «Mais que veux-je dire? Ah ! j’oubliais une chose ! oui, c'est cela même, et je voulais voir si vous tomberiez juste dans tout ce que j'en ai appris » (Jean de La Bruyère, Les Caractères)

1810 Ces derniers passages de la télémacomanie tombent si juste sur les martyrs, c'est là si parfaitement les reproches que l'on a faits au style, au sujet et à l'effet du livre (galimatias, phébus, caractères ridicules, péril pour les mœurs et la religion, profanation, scandale), que mes censeurs semblent avoir copié les pensées, les plaisanteries et les phrases même de Faydit (François de Chateaubriand, Les Martyrs ou Le Triomphe de la religion chrétienne [préface $3^{e}$ éd.])

1843 Comme toutes les histoires de ce monde se ressemblent plus ou moins, et qu'en général les gens enclins au merveilleux n'y regardent pas de si près, ils tombent juste vingt fois sur trente (George Sand, La Comtesse de Rudolstadt) 
1899 Les experts, quelquefois, en s’appliquant, peuvent se tromper. Mais il faut bien, par hasard, qu'ils tombent juste de temps à autre. Polonius peut voir belette ou chameau dans un nuage (Georges Clemenceau, Vers la réparation)

1927 Quoi qu'il en soit, des surréalistes m’arrivèrent comme dans un murmure les mots d'écriture automatique et là j'eus le sentiment qu'on tombait presque juste (Julien Green, Adrienne Mesurat)

1934 Cent fois nous avons des pressentiments. Quatre-vingt-dix-neuf fois ils se révèlent faux, mais une fois tombent juste ; alors nous prenons des airs, nous disons qu'il y a des choses mystérieuses (Henry de Montherlant, Les Célibataires)

1955 Les objections parfois véhémentes qu’il opposait à certaines idées préconçues, à certains partis pris, tombaient toujours si juste qu'elles étaient admirablement éclairantes pour moi (Roger Martin du Gard, Souvenirs autobiographiques et littéraires)

1985 Mon attention allumée ressemblait à celle qu'on met à dépister un truc, à trouver une devinette. Si je tombais juste, la pointe du coupe-papier avançait. Sinon, elle restait sur place ou, pire, Mademoiselle retournait à une des pages d'avant et on y restait le temps que je trouve (Françoise Dolto, $L a$ Cause des enfants)

II. Tomber, arriver au bon moment, quand il faut

Intransitif

1886 Elle aussi l'embrassa, appuyant de tout son cœur ses lèvres fraîches, inhabiles aux raffinements des caresses, sur cette joue de son fiancé que la mer avait dorée. Dans les pierres du mur, le grillon leur chantait le bonheur ; il tombait juste, cette fois, par hasard (Pierre Loti, Pêcheur d'Islande)

1926 Je cherchais... J'acceptais avec une arrière-pensée les invitations d'hommes âgés qui pouvaient avoir des filles de vingt ans ; tout nom de sénateur, de général, de préfet devenait pour moi l'enseigne d'une famille paisible, où des enfants cousaient en paix. Parfois je tombais juste ; la fille de l'hôte était là ; elle savait même chanter, elle savait même jouer au piano cette prière de Moïse, prière à trois temps, écrite sans doute un jour que Moïse valsait (Jean Giraudoux, Simon le Pathétique)

1928 La curiosité, devant cette métairie neuve et tout ce qu'elle devait contenir d'inattendu, l'emportait sur sa piété. Les répons cependant tombaient juste ; sans doute par habitude (Joseph de Pesquidoux, Le Livre de raison)

\section{CORPuS WEB :}

Plus que tout parce que le spéculateur s'enrichit quand il tombe juste, mais s'enfonce dans la misère quand il échoue (en absence de sauvetage étatique) : acheter cher pour vendre bon marché ou vendre bon marché pour racheter cher ne semblent pas être les négoces les plus lucratifs que l'on puisse imaginer, spécialement si l'on s'est endetté pour le faire [http:// www.contrepoints.org/2011/11/23/56956-vive-laspeculation] (21.10.2015)

D’après notre enquête, les balances tombent juste [http://www.leparisien.fr/espace-premium/ actu/d-apres-notre-enquete-les-balances-tom bent-juste-20-06-2014-3937769.php] (2.2.2016)

Restons encore dans le domaine des divisions qui tombent juste [http://www.lapasserelle.com/ cours-en-ligne/6e_maths/division] (2.2.2016)

Quand une entreprise présente sa comptabilité, il faut que les comptes tombent justes [http://la-bible.info/2011/08/13/une-bonne-com ptabilite] (2.2.2016)

Remarques : Tomber juste (I) se dit du fait de faire quelque chose avec précision, exactitude et sans erreur, le sujet atteignant la cible, le bon résultat. En parlant de l'idée ou de l'image que l'on se fait de quelque chose ou de quelqu'un, d'un jugement, il désigne le fait d'avoir raison ou de viser juste, de ne pas s'être trompé. En parlant d'une personne, (II) il désigne le fait d'arriver, d'apparaître de manière favorable, à un moment opportun, qui convient. Juste reste invariable dans son emploi adverbial. Dans le dernier exemple du CW, l'accord est réalisé pour insister sur une qualité des comptes. Juste est modifié par 
presque, si, toujours si. VOIR AUSSI : viser / voir juste

\section{Tomber large}

Tomber en grosses gouttes; pendre

amplement ; s'étendre largement

Intransitif

1854 une draperie rattachée au-dessus de l'oreille, tombant large par derrière, et par devant en deux bandes étroites, leur sert de coiffure, et est également surmontée de cette petite calotte rouge que portent les hommes (Maxime Du Camp, Le Nil. Égypte et Nubie)

1857 Tandis qu'un grand vieillard, couvert d'un manteau noir,

Contemplait gravement cette bande étourdie ;

Son crâne reluisait comme un marbre poli, Sa barbe aux flots d'argent tombait large et splendide,

Un nez majestueux comme une pyramide Descendait sur sa bouche, avec pompe établi (Louis Bouilhet, Melænis)

1886 Brusquement, les gouttes tombèrent si larges, si drues, qu'il prit sa course, galopa dégingandé, éperdu, le long du quai de la grève. Mais, au pont Louis-Philippe, une colère de son essoufflement l'arrêta (Émile Zola, L’Euvre)

1897 Ces gouttes tièdes qui tombèrent si larges et pesantes, sur ce jardin de palmes et de jour vert et rose, si lourdes que des feuilles et des fleurs et des branches roulèrent comme un don amoureux de guirlandes défaites à foison sur les eaux (André Gide, Les Nourritures terrestres)

1950 J'ai levé la tête, dans un sursaut, au bruit d'un pas sur la chaussée. La pluie tombait plus large et clapotait au bord des toits. À la fenêtre de la maison, l'ourlet de lumière avait disparu (Maurice Genevoix, Ceux de 14)

CORPUS WEB :

Ah c'est sûr, en Colombie britannique ça peut tomber large à -40 degrés dans le nord et il fait à peine un peu plus de 20 degrés l'été ( 1 mois les bonnes années) [http://www.myrmecofourmis. com/forum/viewtopic.php?t=16302\&start=10] (4.2.2016)

J'ai la consolation que je peux porter des hauts qui peuvent tomber large mais après, j’aime quand les robes sont près du corps alors ça tombe mal pour le coup. J'espère que leurs nouvelles collections ne tailleront pas trop grand... [http:// fancy-melody.blogspot.co.at/2012/11/sweetromantic.html] (4.2.2016)

allez, un bon up de ma part :

raisonnable, $14.972 .300 \mathrm{pts}$, stage $7-2$, Grutan

j’ai mal géré le boss 6 niveau points, dommage, les 15 millions seraient tombés large sinon. le stage 7-2 est un véritable guet-apen : il y a une petite brique de merde située au dessus d'un mur de briques or donc incassable (accompagnée d'une horloge « bonus de temps »), j'avais 30 secondes pour faire passer la baballe rose dans la toute petite ouverture qui permet d'y accéder, en vain. Grrrrrrr, le boss final était à portée de main ! [http://forum.shmup.com/viewtopic.php ? $\mathrm{f}=10 \& \mathrm{t}=8994 \&$ start $=60 \& \mathrm{st}=0 \& \mathrm{sk}=\mathrm{t} \& \mathrm{sd}=\mathrm{a} \& \mathrm{sid}=$ 06d80b09ed98da16c3b571083b720426\&view=pr int] (4.2.2016)

Des grêles sont tombées, larges comme un pouce [http://haphippo.blogspot.co.at/2015/10/6. html] (4.2.2016)

REMARQUES : Tomber large réfère à des précipitations comme la pluie qui tombe à grosses gouttes et abondamment. Au figuré, le sujet désigne un objet (ici : une étoffe de drap) qui pend de façon ample. Il peut aussi désigner la forme et l'épaisseur que prend une touffe de poils (ici : la barbe). L'avant-dernier exemple du CW renvoie au score de 15 millions de points que le locuteur essaie d'obtenir et qui seraient 'tombés largement'. Large est donc un adverbe de phrase qui transmet une estimation de l'auteur. Large peut s'accorder avec le sujet (v. les exemples de 1886 et 1897 et le quatrième exemple du CW), tout comme les autres adjectifs (dru, pesant), ce qui renforce une interprétation de prédicat second orienté vers le sujet. Large est modifié par plus, si. Notons l'emploi impersonnel familier ça peut tomber large. Notons l'emploi de tailler grand. 


\section{Tomber léger}

Arriver au sol en produisant une impression de douceur et de légèreté

Intransitif

1815 La Seine, en passant lentement, recevait chaque note harmonieuse qui tombait légère comme la rosée, après avoir flotté dans l'atmosphère obscure de l'aimable Saint-Cloud (Walter Scott, Saint-Cloud [trad.])

1871 Ils [= les blés] tombent légers sous la faux ; mais c'est un défaut qui, malheureusement, semble devoir être reproché à toutes nos céréales, et qui tient probablement à ce que la floraison a été commencée par des pluies continues (Bulletin des séances de la Société centrale d'agriculture de France)

1950 En même temps, des balles allemandes filent à travers les feuilles, plus sournoises du mystère des taillis ; elles frappent sec dans les troncs des arbres, elles fracassent les grosses branches, hachent les petites, qui tombent sur nous, légères et lentes ; elles volent au-dessus de la route, au-devant des balles de la mitrailleuse, qu'elles semblent chercher, défier de leur voix mauvaise (Maurice Genevoix, Ceux de 14)

1964 D’ailleurs la neige se mit bientôt à tomber, très légère, soulevée en tourbillons par le vent, et quand nous sommes arrivés sur la route, on ne voyait plus les murailles de Montségur (José Cabanis, Les Jeux de la nuit)

\section{UN SOUPÇON}

Se balançait légère

Riait légère

Sautait légère

Tombait légère

Riait légère

Fuyait légère

Rêvait légère

Mangeait légère

Dormait légère

Tissait légère

Rêvait légère

Luttait légère

\author{
Tombait légère \\ Se relevait légère \\ Il l'aimait avant de la connaître \\ (Paul Éluard, Poèmes retrouvés)
}

1967 Car, que la pluie tombe légère ou drue, les vingt mille spectateurs et surtout spectatrices qui envahissent quotidiennement le coquet domaine de l'All England Lawn Tennis and Croquet Club n'abandonnent pas la position (Jeux et sports)

1989 - Il fallait que ça explose, madame Gaillard. Ça a explosé. Ça laissera des traces. Tout en laisse. Même une feuille morte qui tombe toute légère. Nous sommes criblés de traces (Remo Forlani, Gouttière)

\section{CORPuS WEB :}

Le mano à mano entamé dès le début de la ligne droite semblait tourner à l'avantage de la protégée de Yannick-Alain Briand, mais la fille de Niky se perdait dans ses allures a quelques mètres de l'arrivée. « J'ai voulu l'alléger et la pouliche est tombée léger à quelques mètres du poteau » pestait son mentor [http://www.lemistralgagnant. fr/2014/12/15/very-nice-marceaux-succes-verynice] (5.2.2016)

Mais finalement, la pluie est tombée, léger, sans que l'orage n'éclate ici, et ça a suffi pour rafraîchir un peu [http://forum.doctissimo.fr/sante/ alcool-tabac-drogues/croit-sujet_169782_20. htm] (5.2.2016)

Toute la nuit, la neige est tombée, légère et virevolante [http://www.chalet-djan-e-glyamo. $\mathrm{eu} / \mathrm{fr} / \mathrm{blog} /$ accueil] (5.2.2016)

La fille de Hulk Des Champs était bien en course, quand elle est tombée légère dans le bas de la descente et n'a pu être remise au trot [http:// www.zeturf.fr/fr/resultats-et-rapports/reunion? $\mathrm{id}=27110]$ (5.2.2016)

REMARQUES : En parlant des précipitations (la neige, la pluie), tomber léger se dit du fait de venir du ciel pour arriver au sol, en petites quantités de faible intensité. Le sujet peut aussi désigner une chose de la nature (une feuille) qui tombe de l'arbre de manière délicate, produisant une impression de douceur. Dans le domaine de l'équitation, tomber léger réfère à un cheval qui diminue son allure alors qu'il aurait fallu la gar- 
der (v. les premier et dernier exemples du CW). L'interprétation comme prédicat second favorise l'accord, audible à l'oral, mais il est absent dans les premiers exemples du CW, plus familiers que les autres. Léger est modifié par tout, très. Notons les collocations léger et lent; si léger, si dru ; léger et virevol(t)ant. Mentionnons également l'emploi de frapper sec.

\section{Tomber long}

Avoir de la longueur

Intransitif

1768 En général les grosses têtes raccourcissent les figures. Ajoutez que vêtu d'une aube lâche qui ne touche point à son corps ; les plis tombant longs et droits augmentent son volume. Les tableaux de Doyen et de Vien sont exposés. Celui de Vien a le plus bel effet (Denis Diderot, Salon de 1767)

1886 Isis recula s'écriant :

- Il dort ! Je souffre seule. Oh ! je le hais. Sa bouche Oh ! je le hais. Sa bouche

Écarta presque, avec cette clameur farouche,

Le voile par ses yeux flamboyants traversé ; Puis les plis du linceul froid et toujours baissé

Tombèrent longs et droits, et Lilith immobile songea

(Victor Hugo, La Fin de Satan)

\section{CORPUS WEB :}

Bonjour, oui il peut tout à fait convenir pour un 38, le style étant loose. Il tombe long et oui c'est le petit hic du vêtement (pareil pour tout les modèles), il bouloche un peu mais j'ai une petite brosse super exprès pour le garder en forme [http://www.vestiairecollective.de/damenkleidung/pullover/maje/pullover-wolle-schwarzmaje-1870012.shtml] (5.2.2016)

Très agréable à porter et le fait que la blouse tombe longue, n'est qu'un atout à notre avis ! [http://www.e5mode.be/fr/tamarind-1519563. html] (5.2.2016)

par contre depuis que je suis monté au niveau $15 / 3$ je trouve que le mur dérègle mon jeu (tendance a réculer mon plan de frappe). j'ai donc arrétté de m entrainer sur le mur pour les raisons suivantes : un lift très prononcé qui tombe long sur un terrain part complètement en latte sur un mur [http://www.tennis-classim.net/forums/ topic/6383-entrainement-au-mur/?page $=2$ ] (5.2.2016)

cyril94 j'ai acheté une Davis 6150 sans fil car la foudre n'est pas tombée long d'ici et ma station Ws2300 en a pris un coup la carte mère de l'ordi aussi c'est pour cette raison que j'ai pris sans fil il y a tout un article la dessus pour ou contre les filaires dans intrumentation [http://forums. infoclimat.fr/topic/5793-wireless-vantage-progsm-interferences] (5.2.2016)

REMARQUES : Tomber long réfère à l'aspect d'un tissu et plus particulièrement à la longueur d'une pièce de toile, d'un tissu d'une bonne longueur qui présente une ondulation, un mouvement sinueux. Dans le troisième et le quatrième exemple $\mathrm{du} \mathrm{CW}$, long réfère à la distance ('loin'). Notons la collocation long et droit. Long tend à l'emploi accordé centré sur la qualité d'un objet. L'accord est absent dans le dernier exemple du CW où long est un circonstant de lieu.

\section{Tomber menu}

Tomber en abondance, en petites et nombreuses parties fines ; tomber facilement, finement, souvent Intransitif

1532 Quant la grant jument fut dedans les forestz de Champaigne les mouches se prindrent à la picquer au cul ladicte jument qui avoit la queue de deux cens brasses. Et grosse à l'advenant : se print à esmoucher : et alors vous eussiez veu tomber ses gros chesnes menu comme gresle : et tant continua ladicte beste qu'il n'y demoura arbre debout que tout ne fust rué par terre (Les Grandes et Inestimables Chroniques)

1564 Sans point se soucier d'honneur ny de noblesse,

Ils estoient sans mestier, sans art et sans adresse, Et vivoient par les bois, comme peu courageux, De glands tombez menu des chesnes ombrageux (Pierre de Ronsard, Le Bocage royal, p. 389) 
1572 Plustost le feu du grand Saturnien Tombé menu la teste me foudroye, Plustost la terre en se crevant m'envoye (Pierre de Ronsard, La Franciade, p. 143)

1693 Pourquoi ce bruit ? coquin, qu'entends-je là ?

L'autre répond : C'est madame Honnesta Qui vous réclame, et va par tout le monde Cherchant l'Époux que le Ciel lui donna. Incontinent le Diable décampa, S'enfuit au fond des Enfers et conta Tout le succès qu'avait eu son voyage : Sire, dit-il, le nœud du mariage Damne aussi dru qu'aucuns autres états. Votre Grandeur voit tomber ici-bas, Non par flocons, mais menu comme pluie, Ceux que l'Hymen fait de sa confrérie, J'ai par moi-même examiné le cas (Jean de La Fontaine, Belphégor / Fables)

1848 La Seconde Révélation de sainte Catherine (Albert Dürer), mais me paraît plus jeune, plus coloré : la vierge et la sainte, grands cheveux épars, roux, ondés et tombant тепи au bout sur leurs tailles; deux autres femmes au premier plan, rousses ; id : celle de droite, assise, grande robe rouge étalée à lourds plis (Gustave Flaubert, Par les champs et par les grèves)

1856 LE COCHON. Cela s'épaississait sous moi. J'enfonçais des quatre pattes ; une averse nauséabonde, qui tombait menue comme des aiguilles, me piquait les yeux, mais j'avalais toujours, car c'était bon (Gustave Flaubert, La Tentation de saint Antoine)

\section{CORPUS WEB :}

Il se met à tomber de la pluie et de la grêle alors qu'il fait presque 20 degrés dehors ! Et ça tombe menu ! Les grêlons sont énormes, et la ville est rapidement inondée à cause des égouts et des nombreux ruisseaux qui débordent ! [http://112road.uniterre.com/35\%2BEspagne/ page $3 /$ \&thisy=\&thism=\&thisd=] (9.2.2016)

que t'étais tombé menu dans le troll ? Ouais c'était bien vrai et t'était bien bien tombé dedans en plus [http://forum.hardware.fr/hfr/Discus sions/discussions-dehors-newb-sujet_11183_ 13535.htm] (9.2.2016)
Waouh ! la neige est en abondance dans le pays des abondances, hi ! Nous en ce moment elle tombe menue mais celle-là va tenir car il gèle [http://michka.blog50.com/archive/2010/01/08/ trop-froid.html] (9.2.2016)

REMARQues : Tomber menu réfère au fait de tomber en abondance, avec une grande densité. Transposé au figuré, il renvoie à une haute fréquence dans le temps ('souvent'). Il est surtout employé par rapport à des phénomènes météorologiques tels la pluie, qui peuvent servir d'image métaphorique (des glands qui tombent menu). Notons la comparaison menu comme grêle qui ajoute à l'idée d'abondance celle de fréquence. Signalons également la comparaison tomber menu comme des aiguilles qui suggère une pluie fine, pénétrante et abondante. En référence à la coiffure, tomber menu s'applique au type de cheveux ou souligne leur aspect, leur épaisseur lorsqu'ils ne sont pas attachés, et désigne ici, en l'occurrence, des cheveux fins. Menu tend à l'emploi invarié, mais il peut s'accorder avec le sujet (v. l'exemple de 1856 et le dernier exemple du CW) tout en gardant son interprétation adverbiale. Notons l'emploi impersonnel familier ça tombe menu dans le premier exemple du CW.

\section{Tomber net}

I. Tomber tout d'un coup ; tomber à pic (au propre et au figuré)

Intransitif

1704 EVENTILO. [...] Jetter le bled battu en l'air avec une pelle contre le vent, qui repousse la balle [= la paille] et laisse avancer le grain qui est le plus lourd, et qui tombe net (Dictionnaire universel françois et latin)

1765 Monseigneur, me dit celui qui est pour la construction des Vaisseaux, j'ai besoin de Finances, il faut m'en donner : sans quoi je vous préviens que la Marine tombe net (Ange Goudar, L'Espion chinois)

1834 Toutes les fois que je tombais ainsi net, sans qu'il y eût rien prochainement de ma faute, je me sentais libre, responsable encore ; il y a toujours dans la chute assez de part de notre volonté, assez d'intervention coupable et sourde, et puis d'ailleurs assez d'iniquités anciennes ou originelles, 
amassées, pour expliquer et justifier aux yeux de la conscience ce refus de la grâce (Charles Sainte-Beuve, Volupté)

1842 Ce mouvement brusque et sec opéra la séparation du docteur et de la selle ; le docteur, qui se penchait en avant, tomba net dans le bourbier, la tête la première ; mais la boue avait bien un demi-pied de profondeur, et le docteur n'eut d'autre mal que celui de la honte, mais cette honte fut extrême (Stendhal, Lamiel)

1950 Se ruant sur le poignard, Lazuli bondit et frappa. Au premier coup, l'homme ferma les yeux. Ses paupières tombèrent net comme des couvercles de métal. Il restait debout (Boris Vian, L'Herbe rouge)

1979 Il descendit enfin vers les fougères, entendit la source, obliqua et vit le profil de la roche tombant net sur la terrasse de la grotte, qui paraissait suspendue au-dessus d'à-pic de pierre dont les feuillages hachuraient les lignes dures (Pierre Moinot, Le Guetteur d'ombre)

II. Arriver, apparaître ou disparaître brutalement, sans détour

Intransitif

1872 Voyez-vous, quand on gagne de l'argent, tout est beau. Ces dernières paroles glacèrent les hommes graves. La conversation tomba net, et chacun parut éviter de regarder son voisin. La phrase du maçon atteignait ces messieurs, roide comme le pavé de l'ours (Émile Zola, La Curée)

1916 - V'là la bectance ! annonce un poilu qui guettait au tournant.

- I'n'est qu'temps !

Et l'orage des récriminations violentes tombe net, comme par enchantement. Et on voit leur fureur se changer, subitement, en satisfaction (Henri Barbusse, Le Feu)

1949 - Mais descendez donc ! Comment voulez-vous que j'arrête : je me ferais emboutir. La colère de Sarah tomba net. Elle sauta sur le sol et trébucha. Le garagiste la rattrapa au vol et la remit sur pied. Pablo criait et pleurait. La fête était finie : Sarah avait envie de mourir (Jean-Paul Sartre, $L a$ Mort dans l'âme)

1996 - Genetschka, je sais bien que mon neveu chéri manque de beurre, en pleine croissance!

Maman et nous guettions le verdict qui tomba, sec, net, dans la cour d'assises du salon. Et maman :

- Nadenka, tu es sûre?

- Absolument, c'est le prix

(Boris Schreiber, Un silence d'environ une demi-heure)

III. S'abattre brutalement et avec précision

Intransitif

1938 Je vois tomber la pluie

Dont les flaques font luire

Notre grave planète,

La pluie qui tombe nette

Comme du temps d'Homère

Et du temps de Villon

Sur l'enfant et sa mère

Et le dos des moutons

(Jules Supervielle, La Fable du monde)

CORPUS WEB :

Désormais, je tire des RWS ID classic, les chevreuils tombent net (un renard a quand même emmené une balle de cœur sur $40 \mathrm{~m}$ ). Je pense que n'importe quelle balle causera des dégâts si elle attrape un os résistant (j'ai attrapé une omoplate de chevreuil et il était assez abîmé) et en causera peu si elle n'en attrape pas (chevreuils peu abimés quand la balle traverse les deux rangées de côtes)... [http://www.grand-gibier.net/ forum/viewtopic.php? $\mathrm{p}=390554 \&$ sid $=1 \mathrm{~b} 58 \mathrm{f062a}$ of436ea7ad013db5145ce86] (9.2.2016)

$\mathrm{Tu}$ fais donc de réels bénéfices pendant 5 ans, soit $5 * 3600=18.000$ euros (uniquement grace au loyers qui tombent net dans ta poche sans toucher a l'appart') [http://www.jeuxvideo. com/forums/1-51-8472002-2-0-1-0-que-faire-avec25-000-euros-hap.htm] (9.2.2016)

Parfois cruelles, tour à tours violentes, sombres ou mélancoliques, les nouvelles écrites par ce grand conteur sont toujours efficaces grâce à l'économie des mots, choisis avec soin, et surtout grâce aux chutes qui tombent nettes, tranchant avec le reste du récit toujours empreint d'un certain suspense [http://www.bricabook. $\mathrm{fr} / 2013 / 03 /$ silhouette-mourlevat] (9.2.2016) 
Je trouve qu'il y a un manque de liant entre tes phrases. Les notes de fin tombent nettes, elles ne sont pas assez tenu, mais j'imagine trés bien que c'est du à ton poignet [http://www.guitarelive.com/defis/guitare/881/14932/commentaires. html] (9.2.2016)

REMARQUES : Tomber net (I) s'applique à une personne qui chute dans quelque chose, de manière inattendue, brutale. Le sujet peut aussi référer à une conversation qu'il arrête, interrompt brusquement ou à une idée qu'il abandonne de façon inattendue. Le sujet peut aussi désigner une partie du visage (les paupières) qui se ferment de manière soudaine. Il désigne également l'ombre d'un rocher qui tombe à pic. (II) s'emploie par rapport à des phénomènes qui se manifestent brutalement ou disparaissent d'un coup. Dans (III), il faut interpréter la pluie comme image du couperet qui tue les plus faibles. On peut dire que net est compatible avec toute la polysémie $\mathrm{du}$ verbe tomber. Notons l'usage sémantiquement voisin de l'adjectif-adverbe sec. Net tend à l'emploi sans accord, mais il peut s'accorder avec le sujet (v. l'exemple de 1938 et les troisième et quatrième exemples du CW) tout en conservant son interprétation adverbiale, mais aussi pour accentuer la brièveté de quelque chose (ici : les notes). Net est modifié par ainsi.

\section{Tomber raide}

I. tomber raide mort : mourir d'un coup, instantanément

Intransitif

1558 il dict : «Paillard detestable, tu es mort »; et luy bailla tel coup de poincte par le centre de l'estomach qu'il le perça jusques aux gardes, et redoublant son coup pour luy faire faillir la parole, luy en donna un autre au travers de la gorge si vivement que le pauvre innocent, apres avoir un peu chancelé, tomba roide mort à terre (Pierre Boaistuau, Histoires tragiques)

1579 Pensons à nous jeunes et forts, Souvent nous tombons roides morts (Philippe d'Alcripe, La Nouvelle Fabrique des excellents traicts de vérité)

1732 Néanmoins comme il arrive assez souvent que le plus fort est vaincu par le plus faible, mon rival, malgré toute son habileté, reçut un coup d'épée dans le cœur et tomba raide mort un moment après (Alain-René Lesage, Histoire de Gil Blas de Santillane)

1842 Un d'entre eux monta sur l'autel de l'église Saint-Jean pour arracher une pierre précieuse de la couronne d'une statue de la Sainte-Vierge ; mais l'image fit un mouvement, dit-on, et le sacrilége tomba raide mort sur le pavé (Prosper de Brugière Barante, Histoire des ducs de Bourgogne de la maison de Valois)

1843a Mais, ramenée à sa résolution par une force surhumaine, elle tira le verrou sur lui ; et, vaincue par une lutte trop violente, elle tomba raide évanouie sur le plancher, où elle resta sans mouvement jusqu'au jour (George Sand, Consuelo)

1881 Fatou ne pouvait apercevoir un ngabou (un hippopotame) sans courir les risques de tomber raide morte ; - c'était un sort jeté jadis sur sa famille par un sorcier du pays de Galam ; - on avait essayé de tous les moyens pour le conjurer (Pierre Loti, $L e$ Roman d'un spahi)

1972 Quand elle a eu ses 16 ans, il a fallu qu'elle tombe amoureuse raide folle d'un voyou, une espèce de blouson noir façon aprèsguerre, un gars de 18 ans qui branlait rien, traficotait dans la bagnole, la cigarette américaine, enfin n'importe quoi (Bertrand Blier, Les Valseuses)

1976 - Alors, heu... Alors, voilà, dit papa, c'est une affaire un peu délicate... Votre fils a... avait... il vous a bien remis une somme d'argent ? Silence. Il est peut-être tombé raide mort le père Laumelle, mais ça ne lui ressemble pas (Patrick Cauvin, Monsieur Papa)

1989 C'est elle qui racontera, elle dira l'enfance en Vendée, les jours pauvres, pommes de terre sans viande, elle dira la guerre et l'exode, elle tombera raide amoureuse d'un beau mec ivrogne qui lui défoncera le vagin au soir des noces (Denis Belloc, Képas) 
II. Tomber tout d'un coup, brusquement Intransitif

1666 Ils virent deux hommes qui se battoient l'épée à la main, de dont l'un faisant en même temps une passe sur l'autre, luy enfonça la sienne jusques aux gardes, et le fit tomber roide par terre (Roland Le Vayer de Boutigny, Tarsis et Zélie)

1766 Le Mal de Cerf. On donne ce nom à une maladie dans laquelle le cheval est roide de tous ou d'une partie de ses membres, comme le cerf lorsqu'il tombe roide de lassitude et de fatigue, après avoir été vivement poursuivi à la chasse

(Philippe-Étienne Lafosse, Guide du maréchal)

1822 L'épilepsie se déclare subitement. Le cheval qui en est attaqué est tout à coup saisi d'un tremblement et d'un étourdissement considérables, accompagnés de l'abolition subite des fonctions des sens ; il chancelle, et tombe raide et avec force, en faisant des contorsions (Dictionaire abrégé des sciences médicales)

1833 Rochegude redoubla de fureur.

- Va-t-en, va-t-en, parricide, monstre, à jamais !...

Et, ajustant son arquebuse, une détonation éclata, Aymar jeta un cri, et Rochegude tomba raide sur les degrés du porche (Pétrus Borel, Champavert)

1875 Puis, il songea à une jeune fille possédée, que frère Archangias racontait avoir guérie d'un simple signe de croix, un jour qu'elle était tombée raide devant lui. Cela le fit penser aux exercices spirituels qu'un de ses maîtres lui avait recommandés autrefois (Émile Zola, La Faute de l'abbé Mouret)

1881 Elle avait dans ses ascendants de nombreux exemples de personnes ainsi tombées raides, au seul aspect de ces grosses bêtes, et ce maléfice les poursuivait sans merci depuis plusieurs générations

(Pierre Loti, Le Roman d'un spahi)

1914 Les hommes n'ont pu faire ni soupe ni café. Et il a fallu reprendre la marche sur les côtes, en plein midi. Cinq hommes du régiment sont tombés raides, il fallait leur desserrer les dents avec une cuiller (Alain-Fournier, Correspondance avec Jacques Rivière)

1938 J'attends quelques instants : j’ai peur qu'elle ne tombe raide : elle est trop malingre pour supporter cette douleur insolite. Mais elle ne bouge pas, elle a l'air minéralisée comme tout ce qui l'entoure (Jean-Paul Sartre, La Nausée)

1942 Elles [= Margue, la femme d'Adam de Gonesse, Maroie] sortent toutes nues, dans la rue où la bise souffle et les saisit. Elles tombent raides dans la boue. Au jour levant, on les trouve, on les croit mortes, on les porte au cimetière des innocents, où elles se réveillent la nuit suivante (Edmond Faral, La Vie quotidienne au temps de saint Louis)

1976 Je crois qu'il a de gros progrès à faire parce que comme taches, c'est réussi ! La mère Carpentier en tomberait raide si elle voyait ça, quand je fais un pâté de rien du tout sur le cahier, on dirait qu'on l'égorge, alors là, dis donc, qu'est-ce qu'elle hurlerait ! (Patrick Cauvin, Monsieur Papa)

III. Tomber, pendre de manière raide, rigide, verticale, droite, sans souplesse Intransitif

1843b Sans être avertie par aucun sentiment de douleur physique, car son âme et son corps n'existaient plus que dans le corps et l'âme de l'humanité violentée et mutilée, elle tomba droite et raide sur le pavé comme une statue qui se détacherait de son piédestal (George Sand, La Comtesse de Rudolstadt)

1845 ses cheveux, de ce blond jaune et mat particulier à certaines peuplades des contrées polaires, tombent droits et raides sur ses épaules ; son nez est mince, tranchant, recourbé ; autour de ses pommettes saillantes se dessine une longue barbe, presque blanche à force d'être blonde (Eugène Sue, Le Juif errant)

1848 Pour revenir à Rouen, je suis monté sur le siège avec Bouilhet. La pluie tombait 
raide. Les chevaux allaient au galop ; je criais pour les animer (Gustave Flaubert, Correspondance)

1859 Forte et jolie cascade, tombant de haut et raide, du fond de la belle conche et du petit bois sombre, entre les charmantes collines. Frais, pur... on eût bu volontiers (Jules Michelet, Journal)

1919 Tout le monde se tait. Satisfait, le capitaine continue sa revue. À mesure qu'il approche, les corps se redressent, comme sous un déclic; les bras gauches tombent bien raides et les yeux pas rassurés regardent intelligemment dans le vague, à une distance que la théorie évalue à quinze pas (Roland Dorgelès, Les Croix de bois)

1926 Mais le boûbe a seulement tremblé plus fort et le tremblement gagnait à présent toute sa petite personne et jusque dans le pantalon trop long ou trop court, qui n'était pas encore tout à fait un pantalon d'homme, mais n'était plus une culotte et tombait raide jusqu'à mi-jambe avec une grosse bosse au genou (Charles-Ferdinand Ramuz, La Grande peur dans la montagne)

\section{CORPuS WeB :}

Les jeunes tombent raide devant les institutions [http://www.republicain-lorrain.fr/meu rthe-et-moselle/2010/05/19/les-jeunes-tombentraide-devant-les-institutions] (9.2.2016)

Comment les as-il tués, il les as « débranchés » comme ils le disent, c'est-à-dire qu'il a retiré le cable de connexion (c'est comme sa que je l'appele ;)) branché à leur cerveau/esprit avans qu'ils ne puissent se déconnecter de la matrice. Le résultat? Ils tombent raide, on remarque très bien que les corp sont toujours visibles dans la matrice ce qui correspond à leur esprit [http://www.allocine.fr/communaute/forum/ voirmessage gen_refmessage $=12162519 \&$ no fil $=516766 . h t m l](9.2 .2016)$

La réponse à : " Pourquoi les cheveux bouclent ou tombent raides ? » est plutôt alambiquée [http://www.gurumed.org/2012/12/06/pour quoi-avons-nous-les-cheveux-boucls-ou-raides] (9.2.2016)
Ces deux chatons tombent raides comme des chèvres, au moindre bruit [http://www.fumed. com/chatons-qui-tombent-raides-comme-deschevres.html] (9.2.2016)

REMARQUeS : Tomber raide (II) se dit du fait de faire une chute ou de donner l'apparence d'une chute imminente, d'une tendance à s'affaisser à la suite d'une faiblesse, d'une émotion, le sujet se retrouvant sans connaissance ou mort. Sous (III), le sujet désigne une partie du corps (les bras) ou les cheveux, qui pend de manière droite, rigide, dans une position figée. Il renvoie aussi au mouvement vertical et à la force des précipitations. Notons la collocation droit et raide qui déclenche une interprétation comme prédication seconde dénotant une propriété du sujet (1843b, 1845). Dans l'expression figée tomber raide mort (I), qui admet des extensions productives dont nous citons quelques exemples (raide évanouie, raide amoureuse ou encore amoureuse raide folle), l'accord avec le sujet est systématique. Dans le style soigné, raide s'accorde toujours avec le sujet, indépendamment du fait qu'il renvoie à une action brusque et brutale ou à une propriété du sujet, tandis que le départ entre les fonctions adverbiales non-accordées et les fonctions de prédicat second référant à une qualité, donc accordées, semble plus clair dans les exemples du CW. Raide est modifié par bien. Notons que l'accord n'est jamais audible, liaison exceptée (mais peu probable).

\section{Tomber sec}

I. Tomber, arriver sans pluie, sans humidité, séché

Intransitif

1619 lors qu'elles [= les prairies] virent le retour des Imnides, et des Nappees, le fueillage des bois qui tomboit sec et mourant, reprint sa plus grande verdeur, quand il vid retourner en son propre lieu, les Driades et Nymphes des forêts (Sieur D.F.D.L., $L a$ Méchanceté des femmes)

1703 Il a vu plusieurs branches détachées de l'arbre tomber sèches et inutiles sur la terre ; mais l'arbre appuyé sur sa propre immobilité se soutient (Recueil de plusieurs pièces d'éloquence et de poësie) 
1861 La neige continue à tomber, sèche et serrée ; elle s'accumule et finit par atteindre, en fort peu de temps, à la hauteur d'un homme, dans les combes où elle est comme attirée par ses propres tourbillons (U.O., Un coin du Jura)

1875 Le semeur d'avance jette sur la terre le grain qui tombe sec et nu

(Charles Renouvier, Les Doctrines physico-religieuses de l'immoralité personnelle)

1956 Le soir tombe, sec et crissant, sur les toits bleus de fumée, la ville gronde sourdement, le fleuve semble remonter son cours (Albert Camus, La Chute)

II. Arriver abruptement, rudement Intransitif

1860 - Tiens ! fit Marthe.

Ce tiens ! tomba si sec de cette petite bouche, qu'il passa quelque chose de froid dans la poitrine de Charles (Edmond et Jules de Goncourt, Charles Demailly)

1889 tous les mots de Champrosé doivent tomber sec et dru sur cette famille Benoiton qui s'en va en décomposition ( $L a$ Revue d'art dramatique et musical)

1948 la sonorité métallique des " buccins », terme éminemment guerrier qui rappelle, par ce qu'il a de dur et de mâle, le plus dur et plus mâle encore si possible "butin » (malgré le féminin trivial obtenu si l'on altère légèrement son $b$ initial de manière à le muer en $p$ ), butin où rien n'est conservé de la grâce attachée à l'idée de l'abeille qui butine, mais dont les deux syllabes tombent sèches et drues comme, sous les coups des gens de Saül, devaient tomber les Philistins (Michel Leiris, La Règle du jeu 1 : Biffures)

1958 La nuit tomba sec comme un guichet de banque (Jours de France, 29 mars 1958 / Grundt : 358)

1964 ça [= la pluie] se met à tomber sec (Georges Michel, Gugusse / Les Temps modernes, décembre 1964)
III. tomber aussi sec : tomber, arriver

instantanément

Intransitif

1981 Lui qui se disait romantique avec ses poèmes à la con t'as vu comme il est tombé dans les pommes aussi sec (Evane Hanska, J'arrête pas de t'aimer)

1995 Une barre comme celle des tribunaux. Ça fait fissa, les décisions... le verdict... pas d'avocat... le couperet tombe aussi sec. On vous transfère en $4^{\mathrm{e}}$ division... celle des cellules de discipline (Alphonse Boudard, Mourir d'enfance)

\section{CORPUS WEB :}

Malaise, j’suis tombée sec [https://twitter. com/_ladykinsha/status/581191302714380288] (9.2.2016)

Bon chapitre, Mashima a pas fait dans le détail là, la révélation tant attendue est tombée sec, telle la guillotine sur le cou d'un roi $\wedge \wedge$ [http:// www.volonte-d.com/forum/viewtopic.php?f= 20\&p=235180] (9.2.2016)

La sale nouvelle est tombée, sèche, assourdissante ! [http://www.lemotpourdire.com/ archive/2011-12] (9.2.2016)

Alors que nous venions de terminer la lecture du 3ème et dernier volume et nous apprêtions à l'appeler pour lui faire part de nos sentiments et lui communiquer nos observations, la nouvelle est tombée, sèche comme un couperet [http://www.editionsamandier.fr/f/index. php?sp=liv\&livre_id=252] (9.2.2016)

REMARQues : Tomber sec (I) désigne l'état physique (sec) du sujet au moment de tomber (prédication seconde). On observe de nombreuses collocations : sec et mourant, sec et inutile, sec et serré, sec et nu, sec et crissant. En (II), il réfère à un événement, à une décision qui arrive tout d'un coup, immédiatement. Notons une affinité de (II) avec la collocation sec et dru. Tomber aussi sec (III) est une locution qui intensifie le sens (II). L'accord est plutôt systématique pour (I), en prédication seconde, mais marginal dans les emplois au figuré (II) et (III), où l'on peut chercher une nuance de prédication seconde en employant l'accord dans l'emploi adverbial. Sec est modifié par aussi, si. Notons l'emploi impersonnel familier ça se met à tomber sec, par rapport à la pluie. 


\section{Tomber serré}

Tomber en abondance, d'une manière dense, compacte

Intransitif

1824 en même temps les flèches tombaient si serrées, que le cœur manqua à beaucoup d'hommes d'armes, tellement que, lorsqu'ils arrivèrent au front des Anglais, les chefs ne se trouvaient plus qu'avec trois cents hommes (Prosper de Barante, Histoire des ducs de Bourgogne de la maison de Valois)

1887 Mais la pluie glacée tombait plus serrée, et toute la plaine était nue sans lui montrer un refuge (Guy de Maupassant, Contes et nouvelles)

1938 Une demi-heure après, l'homme revient. Il dit qu'il a réussi à ramper jusqu'à T. 22 ; mais qu'au delà, il n’y avait matériellement pas moyen d'avancer ;

- C'est pas que j'avais peur, mon lieutenant. Mais ça tombait si serré... j’aurais été haché tout de suite. Comme si vous vouliez mettre la main dans un engrenage (Jules Romains, Les Hommes de bonne volonté)

1945 Le temps léger du matin n'avait pas duré. Vers midi, la pluie tombait serrée, drue, et continuait à choir, coupée de rares éclaircies. Jumainville respirait mal (Jean-Louis Bory, Mon village à l'heure allemande)

1950 Aux approches du soir, il nous a semblé que les obus tombaient moins fort, moins serré, que le soir apportait des Allemands jusqu'à nous comme une espèce de renoncement : las de frapper, de nous tuer vainement? (Maurice Genevoix, Ceux de 14)

1953 La vase qui tombait de plus en plus serré, semblait passer les trottoirs au cirage (Albert Simonin, Touchez pas au grisbi)

1964 À présent, la pluie tombait serré, et le vent soufflait en tourbillons qui semblaient venir tantôt du lac, tantôt de la forêt située sur leur droite (Bernard Clavel, Le Cour des vivants)

1968 La bise était moins agressive et le père pensa que la neige allait sûrement tomber beaucoup plus serrée (Bernard Clavel, Les Fruits de l'hiver)

1979 Les obus tombent de plus en plus serré, c'est une préparation d'artillerie, comme disent les livres sur la Grande Guerre, ça signifie qu'ils vont attaquer (François Cavanna, Les Russkoffs)

\section{CORPUS WEB :}

Ici il tombe de petit flocons qui tombent serré sur un paysage a peine blanchit [http:// forums.infoclimat.fr/topic/37061-suivi-du-tempsdans-le-centre-est/page-63] (9.2.2016)

Avec cette campagne Saster est en mesure de se positionner pour les élections régionales, puis communales. Les calendriers tombent serré ces trois années à venir [http://t-c-w.forumpro.fr/ t2016-nouvelle-vague-aunadar] (9.2.2016)

Alors que le voile de la nuit recouvre le ciel plus tôt que d'habitude après une pluie qui est tombée serrée et drue sur une bonne partie de la ville, trois véhicules ayant à bord des expatriés dont les plaques minéralogiques indiquent qu'ils appartiennent à des personnels de l'ambassade de France, traversent en cortège devant le ministère des Postes et Télécommunications sous escorte d'un pick-up de la gendarmerie avec à bord des éléments armés [http://www.cameroon-info. net/stories/0,22058,@,deploiement-l-armee-faitrespirer-yaounde.html] (9.2.2016)

Ce matin on s'est réveillé avec la neige ; elle est tombée serrée une partie de la matinée et maintenant elle est toute fondue ça peluche encore un peu mais elle doit être mélangée à de la pluie [http://blog.aujourdhui.com/LINDAT/1229 255/photos.html] (9.2.2016)

REMARQUES : Tomber serré réfère surtout à des précipitations (pluie, neige) qui tombent drues, en abondance et de manière fréquente. Dans un contexte de guerre, le sujet désigne les projectiles lancés en masse sur le champ de bataille. Jusqu'au $\mathrm{xx}^{\mathrm{e}}$ siècle, l'accord était privilégié, dans le style soigné, mais dans la seconde moitié de ce siècle, les auteurs qui adoptent un style familier y renoncent. Serré est modifié par beaucoup plus, de plus en plus, plus, moins, plus, si. Notons l'emploi impersonnel familier ça tombait si serré, par rapport à la pluie. 


\section{Tomber tenace}

Tomber sans interruption

Intransitif

1926 Le premier samedi, il arriva à sept heures, couvert de boue. Sur les pommiers entourés de barrières blanches, sur les géraniums roses, la pluie tombait, tenace et drue (André Maurois, Bernard Quesnay)

CoRpus WeB :

La nuit, le brouillard, et la neige qui tombait tenace, auraient pu avoir raison de moi, si la patience et le calme de celui qui me précédait n'avaient pas été aussi rassurants... [http:// haiku-nomade.over-blog.com/article-26472173. html] (9.2.2016)

REMARQUES : Au sens propre, en parlant des manifestations naturelles, tomber tenace se dit d'une pluie dont on peut difficilement se débarrasser, qui persiste longtemps. Notons la collocation tomber tenace et dru, dru insistant sur l'idée de quantité. L'emploi non-accordé ne ressort pas clairement des exemples. En tout cas, il ne serait pas audible.

\section{Tomber virevoltant}

Tomber en tournoyant, en tourbillonnant (en parlant de la neige)

入 tomber léger

\section{Tondre court}

Couper ras

$\pi$ tondre haut

\section{Tondre haut}

Couper à bonne distance du sol (en parlant de l'herbe)

\section{CORPuS WeB :}

Autrement dit, si vous avez laissé pousser votre gazon un peu haut, il ne faut surtout pas " rattraper » les choses en tondant très court la fois suivante. Il faut au contraire tondre haut et régler ensuite progressivement la tondeuse (sur plusieurs tontes) jusqu'à retrouver une hauteur de tonte habituelle [http://gazon.ooreka.fr/ astuce/voir/120426/entretien-du-gazon-regler-lahauteur-de-coupe-de-votre-tondeuse] (10.2.2016)

Une herbe tondue haut contribue à faire de l'ombre à la terre qui sèche moins en gardant l'eau aux racines [http://jardinot.org/travauxsaison-aout] (10.2.2016)

Du coup, les espèces végétales choisies sont plus résistantes, les essences d'arbres sont locales (charme, hêtre, chêne) La pelouse est tondue haut pour être moins fragile, la taille des arbustes est moins fréquente [http://www.ouestfrance.fr/le-parc-tout-faire-des-gayeulles-537447] (10.2.2016)

Une pelouse bien entretenue, tondue haute, bien fertilisée et arrosée adéquatement réduit de beaucoup la prolifération des mauvaises herbes [http://www.lesbeauxjardins.com/jardinons/ gazon/gpissenlits.htm] (10.2.2016)

REMARQUES : Le CW illustre l'emploi concret de tondre haut : couper le gazon de manière que les brins d'herbe restent relativement longs. Notons l'opposition sémantique avec l'adjectif-adverbe court. Haut reste invariable dans la majorité des cas, indiquant un niveau de tonte, mais, dans le dernier exemple du CW, il s'accorde avec l'objet, renforçant ainsi la dynamique résultative du groupe. Le premier exemple est intransitif, les trois suivants transitifs.

\section{Tondre ras}

I. Tondre (quelque chose) très court Transitif

1605 or ainsi que nous marchions une bourrasque de vent survint, un tourbillon se renferma au lieu où nous estions, en telle sorte qu'il emporta la coiffure de trois ou quatre lesquelles nous vismes estre ras tondues, ce que trouvans bien estrange mesme au sexe fœminin (Thomas Artus, Discours de Jacophile à Limne)

1864 Mon comté natal, le Lancashire, est un beau comté, mais je suis las du gazon verdoyant, des pelouses ras-tondues et de la toilette symétrique de nos jardins. Cette nature sauvage a quelque chose de mâle ; elle me rappelle le monde primitif (Theodore Winthrop, Don Fulano [trad.])

1869 Quant au garçon de quatorze ans qui versait à boire et répondait au nom de Govicum, c'était une grosse tête joyeuse avec un tablier. Il était tondu ras, signe de servitude. Il couchait au rez-de-chaussée, dans 
un réduit où l'on avait jadis mis un chien (Victor Hugo, L'Homme qui rit)

1873 Un foulard jaune tourne autour de son cou gras

Et rouge, que font voir ses cheveux tondus ras.

Comme sa connaissance a, ce soir, de l'ouvrage,

Il est libre et content. Car jamais il ne rage, À moins qu'elle ne flâne. Aussi c'est d'un air grand

Qu'il s’écrie au café : « Garçon ! un

mazagran!»

(Charles Cros, Le Coffret de santal)

1878 Ses deux oreilles rouges s'écartaient de sa tête tondue très ras, et toute sa petite personne ronde exprimait un air profondément goguenard (Émile Zola, Une page d'amour)

1893 Et les deux cents jeunes têtes apparurent, découvertes maintenant, presque toutes blondes, tondues ras, semblables à des velours ayant, dans la pénombre, des reflets clairs (Pierre Loti, Matelot)

1915a Quelqu'un venait se plaindre :

- J'ai un képi trop petit...

- Suis-moi voir.

Et il le remettait aux mains du coiffeur :

- Ordre du capitaine : tondre ras c'poilu-là qu'a la citrouille trop grosse

(René Benjamin, Gaspard)

1915b - D’ailleurs, j’leur-z-y ferai voir mon caillou...

Il ôta gravement son képi, et découvrit un crâne si ras tondu, qu'il n'y avait plus là qu'un espoir de cheveux, mais sur son ordre le coiffeur avait laissé une simple petite mèche frisottante et impayable, qui sautait comme une plume au moindre hochement de tête (René Benjamin, Gaspard)

1933 ... sur les bancs de chêne universitaire, un groupe d'abbés, plusieurs rustiques, maigres, tondus ras, noircissait la partie gauche de l'amphithéâtre, et l'un fixait Augustin avec des yeux de charbon dur (Joseph Malègue, Augustin ou Le Maître est là)
1936 Le petit André sentait mauvais, une odeur plus âcre que la mienne, une odeur de tout à fait pauvre. Il empestait dans sa réserve. Sa tante lui tondait ras les tiffes, avec ses propres ciseaux, ça lui faisait comme du gazon avec une seule touffe en avant (Louis-Ferdinand Céline, Mort à crédit)

1939 rêvez à loisir dans des allées bien sablées, le long de pelouses ras tondues (Fernand Leprette, Égypte, terre du Nil)

1942 Ayant retiré son feutre, il avait pris place à la table, en pleine lumière, et lampait un verre de thé bouillant. Tête nue, il laissait voir un crâne en œuf, tondu si ras qu'il semblait chauve, de grandes oreilles un peu rabattues, et des yeux vifs, très bleus, très clairs, qui pétillaient de malicieuse gaîté (Maurice Genevoix, Laframboise et Bellehumeur)

1987 Comme d'habitude, les Anglais ont raison... Le vrai sol, c'est le gazon, il n'y en a pas d'autre... Tondu très ras, compact, divisé, ramassé, vert clair, fraîcheur à l'envers... On le met dans la perspective liquide bleue ou grise, comme ici, et c'est le tableau parfait... Pieds nus, talons nus... (Philippe Sollers, Le Coeur absolu)

1994 A ceci ajouter : une femme trop bavarde... lorsqu'elle est émoustillée - deux femmes "ras-tondues », disparues de la circulation - un traître, milicien fourvoyé dans la "Résistance » (Alain Brossat, Libération, fête folle)

II. Dénuer, dépouiller totalement, de tout Transitif

1887 enfin, la terre devenue une banque, exploitée par des financiers, la terre mise en coupe réglée, tondue ras, donnant à la puissance matérielle et impersonnelle de la science le décuple de ce qu'elle discutait à l'amour et aux bras de l'homme (Émile Zola, La Terre)

III. tondu ras : qui est parfaitement uni, sans saillie ni proéminence

Transitif

1945 Personne dans cette immense salle cloisonnée de sapin verni. Par les longues 
baies, le regard tombait seulement sur la mer grise, plombée, et ce mince liseré d'une côte tondue ras (Julien Gracq, Un beau ténébreux)

\section{Corpus Web :}

Un zone est considérée comme tondue ras si sa hauteur de tonte est égale ou inférieur à la hauteur de tonte du fairway. Lorsque les conditions de jeu sont très mauvaises (boue, extrême humidité), une règle locale peut prévoir le droit de dégager une balle pluggée en dehors des zones tondues ras [http://www.golfpedia.fr/Su jet-Golf/166,balle-pluggee.php] (10.2.2016)

Et voilà pas que je découvre au hasard des photos du dernier défilé de chez Balmain, que la belle, qui récemment s'est engagée pour la dernière campagne de Médecins sans Frontières, a rafraîchi sa coupe qui montre une nuque parfaitement tondue ras, qu'elle porte ainsi depuis deux mois déjà dit elle [http://www.les-femmesaux-cheveux-courts.com/article-alerte-rouge-85 456790.html] (10.2.2016)

La nature est particulièrement présente, avec de belles prairies verdoyantes à l'herbe tondue rase par les troupeaux de moutons qui occupent ces champs délimités par des murs de pierres sèches [http://www.bussieres42.fr/2014/10/ 05/comite-de-jumelage] (10.2.2016)

Enfin, nous jouissons d'une aire d'évolution pour nos modèles exceptionnelle : la piste en herbe tondue rase est en parallèle d'une pente de $2 \mathrm{~km}$ de long, c'est la piste utilisée par les planeurs grandeurs de l'entre les deux guerres [http://www. ailes-silencieuses.fr/?q=fr/node/48] (10.2.2016)

REMARQUES : Sous tondre ras (I), l'objet peut désigner la tête ou la barbe d'une personne dont les cheveux ou les poils sont coupés de façon très courte, près de la peau ; l'objet peut également désigner le gazon coupé très court. Le complément d'objet de tondre ras (II) réfère à la terre, objet de convoitise de l'homme, qui se retrouve vidée de son sens initial, soit par le travail des hommes, soit par son exploitation par l'homme. Sous (III), l'objet renvoie à un paysage (ici : une côte) à l'apparence lisse, qui ne forme aucun relief. Ras reste invariable dans la majorité des cas, mais l'accord avec l'objet n'est pas exclu dans un style plutôt recherché, et notamment publicitaire (v. les deux derniers exemples du CW). Dans ce cas-là, il se rapproche de la fonction de prédicat second orienté vers l'objet permettant aussi une interprétation résultative. Ras se trouve avant ou après le participe tondu. Il est modifié par si, très.

\section{Tonner dur}

Produire une forte explosion

Intransitif

1919 Elle [= Bernardette] pense à nous, lorsque le régiment est aux tranchées. Et quand le canon tonne dur, elle compte candidement chaque coup... « un peu... beaucoup...passionnément... » comme si elle effeuillait la marguerite (Roland Dorgelès, Les Croix de bois)

\section{Tonner fort}

Éclater (du tonnerre)

Intransitif

+1225 Cil, ki n'ot talent de fuïr

Vait avant sans samblant faire.

Puis oent ours et lions braire ;

S'oient espartir et tonner

Si fort k'i samble ke verser

Doive li bos et esracier.

Et il se painent d'esploitier

Et vont toutes voies avant (Le Chevalier as deus espees [ [2 quart $\left.\mathrm{XIII}^{\mathrm{e}}\right], 7426$ )

\section{CORPUS WEB :}

Attention, ça risque de tonner fort en fin d'après-midi...[https://fr-fr.facebook.com/LeBienPu blicBeaune/posts/750967231634176] (10.2.2016)

CSS : Des lacrymogènes tonnent fort à Richard-Toll-échauffourées entreforces del'ordreet grévistes [https://www.facebook.com/permalink. php?id=199768740191989\&story_fbid=555203 444648515] (10.2.2016)

Dans la nomination d'un pilote, même dans les très gros teams (cf Rossi quand il est revenu chez Yamaha Factory), les sponsors ont une voix qui tonne fort... [http://www.motoservices.com/ actualite-competition/MotoGP-2015-Loris-Bazpeut-etre-un-nouveau-pilote-francais-en-Moto GP.htm] (10.2.2016)

Ces mots qui tonnaient forts durant votre campagne électorale, fondaient une forte croyance en une rupture certaine, si la victoire était acquise [http://www.dakaractu.com/A- 
propos-de-la-gestion-de-King-Fahd-Palace-maisRacine-Sy-se-prend-pour-qui-dans-ce-pays-pouroser-parler-ainsi_a29366.html] (10.2.2016)

REMARQUES : Tonner fort réfère au bruit du tonnerre accompagné d'éclairs, orage si violent qu'il semblait que les bois allaient tomber et être arrachés. Il peut aussi s'appliquer à la voix humaine, où, au sens figuré, à un impact fort exercé par des mots. Fort reste invariable en règle générale, mais, dans le troisième exemple du CW, il s'accorde avec le sujet tout en gardant son interprétation adverbiale. Il est modifié par si. Notons l'emploi impersonnel familier, ça risque de tonner fort.

\section{Tordre serré}

Tordre, enrouler, entortiller en serrant fortement Transitif

1832 Tabac. Je n'ai pas à parler de l'usage que font la plupart des marins de cette feuille ; mais j'ai à expliquer ces locutions familières aux matelots et à quelques officiers de de la marine du commerce : " Je vais te donner du tabac ; tu te feras donner du tabac tordu serré. " Cette menace est un trope. Le tabac à mâcher est serré, tourné et quelquefois tordu comme une corde ; quand donc on prévient un homme ou un mousse qu'on va le battre avec le premier bout de cordage qu'on trouvera sous sa main, on fait une allusion ou comparaison au tabac qu'on lui donnerait en réalité et comme récompense si on était content de lui (Augustin Jal, Scènes de la vie maritime)

1845 - Maintenant, tenez l'autre bout du drap, ma fille, et tendez-le ferme...

En quelques minutes, Dagobert eut fendu le drap dans sa longueur en quatre morceaux, qu'il tordit ensuite très serré, de façon à faire des espèces de cordes, fixant de loin en loin, au moyen de rubans de fil que lui donna l'ouvrière, la torsion qu'il avait imprimée au linge (Eugène Sue, $L e$ Juif errant)

1863 Ficelle tordue très-serré et par la même très-solide, que les cochers et les charretiers mettent d'ordinaire au bout de leur fouet (Émile Littré, Dictionnaire de la langue française, s.v. fouet)

\section{Corpus Web :}

Pour l'effet froissé tu le laves puis sèches en le tordant serré ? [http://newyorkavectoi.canal blog.com/archives/2010/04/11/17543590.html] (10.2.2016)

Les fils de georgette sont tordus plus serré et le tissage est plus compact que le chiffon [http:// www.hc-sc.gc.ca/cps-spc/pubs/indust/flamma bility-inflammabilite/index-fra.php] (10.2.2016)

Cela ne sèche pas véritablement comme une bonne serviette éponge cela enlève l'eau en surface ! et au début on est un peu surpris par l'impression de froid qui dure quelques secondes de plus! Une fois tordue serrée elle ne pèse rien. Elle est donc tjs humide.. bien commode après le piqué nique.. pour s'essuyer les mains [http:// www.bromptonforum.net/t6156-6-jours-en-bour gogne] (10.2.2016)

Il peut y avoir un peu d'inconfort dans ce processus parce que les cheveux vont être tordus serrés sur le cuir chevelu, mais ne vous inquiétez pas car il n’y a pas de gain sans douleur dans la vie [https://drolesdedames75.wordpress.com] (10.2.2016)

REMARQUES : Tordre serré se dit du fait de déformer quelque chose (un tissu, un drap, une ficelle, les cheveux) par torsion, en serrant fortement sur l'objet, de l'enrouler en spirale ou en torsade de manière à obtenir une autre forme. Serré reste invariable dans la majorité des cas. Dans l'exemple de 1863, très-serré pourrait être un adjectif adnominal modifiant ficelle, mais Littré refuse l'accord. Dans les deux derniers exemples du CW, il s'accorde avec l'objet tout en gardant son interprétation adverbiale. Il est modifié par ensuite, plus, très.

\section{Tornoyer menu}

Tourner, faire tourner rapidement, vivement et de tout côté

Intransitif

+1150a Se galerne ist de mer, bise ne altre venz Qui fierent al palais dedevers occident, Il le font torneier et menut et sovent Come roë de char qui a terre descent (Pèlerinage ou Voyage de Charlemagne à Jérusalem et à Constantinople [2 $2^{\mathrm{e}}$ moitié $\mathrm{XII}]$ ], 356) 
+1150b Volentiers, dist li ber, tot al vostre congiet. Veez vos cele estache qui le palais soztient, Que hui matin veïstes si menut torneier? (Pèlerinage ou Voyage de Charlemagne à Jérusalem et à Constantinople [2 $2^{\mathrm{e}}$ moitié $\mathrm{XII}^{\mathrm{e}}$, 522)

1250 Le forme d’Appolin fist sur le mast drescier,

En sa main un baston pour Francois manacier, La sus le fait li vens plus menu tornoier K'alou[e] ne guenchist, quant fuist pour l'esperv[i]er (La Destruction de Rome, 229)

REMARQues : Tornoyer menu désignait le fait de faire tourner un objet autour d'un axe, à fréquence élevée ou souvent. Notons la collocation menu et souvent qui souligne l'idée de fréquence et de rapidité. Menu est modifié par si, plus.

\section{Toucher faux}

Avoir le toucher d'une fleur artificielle, d'une fausse fleur Emploi absolu

1945 Eh bien, mon poulet, qu'est-ce qu'elles ont ces fleurs ? Pourquoi elles sentent vrai et elles touchent faux ? La Maman-douce se penche, respire (« C’est pourtant vrai!»), respire les fleurs artificielles, qu'elle a achetées hier et leur trouve un parfum (Gilbert Cesbron, Traduit du vent)

REMARQUeS : Toucher faux désigne le fait de donner l'impression d'être faux, pas naturel (en parlant d'une fleur), au moyen du toucher. Il est mis en opposition avec sentir vrai. Faux reste invariable. Notons l'emploi absolu ergatif, qui est familier. Pour toucher faux 'ne pas viser juste' v. toucher juste.

\section{Toucher fort}

Toucher avec justesse et efficacité

$\pi$ toucher juste

\section{Toucher juste}

I. Viser avec précision, avec justesse, faire mouche

Emploi absolu

1668 On cherche bien souvent tant de finesses sur un sujet, que ce qui estoit bien dit ne l'est plus ; quand on a touché juste, on fait bien de s'en tenir là, et de passer à d'autres choses : je voudrois mesme leur donner un autre tour à cause que la diversité ne lasse point (Antoine Gombaud, chevalier de Méré, Les Conversations)

1844 En pensant ainsi, Marsillat s'exagérait beaucoup la vanité de Guillaume ; mais il y avait dans cette petite guerre d'escarmouche qu'il lui livrait des points où il touchait malheureusement assez juste. En se rencontrant dans la chaumière de Jeanne, il ne fallut pas bien longtemps à ces deux jeunes gens pour voir qu'ils s'observaient l'un l'autre (George Sand, Jeanne)

1885 Cette retraite ne laissa point un grand vide, Rolle ayant été toujours plutôt un pédagogue qu'un critique. Il touchait juste parfois, mais toujours il touchait lourd. Si bien qu'on lui en voulait souvent avec raison, tant il y mettait de mauvaise grâce (Pierre Véron, Galop Général !)

1904 - Punissez cette morveuse, elle a déjà des idées... c'est trop jeune, est-ce vrai, madame? c'est trop jeune.

Il faut que l'école touche joliment juste pour avoir une influence améliorante!

Alors, une morale par enfant?

(Léon Frapié, La Maternelle)

1929 PHILIPPE. (Silence) Eh bien, dis quelque chose ! Justifie-toi : je t'accuse. (Silence) Non, tu n'as rien à dire ? J'ai bien touché juste ? Tu n'as rien à me répondre ? (Silence. Elle va ouvrir la porte) Remonte dans ta chambre (Henry de Montherlant, L'Exil)

1990 C'est mon rôle de maintenir qu'on est bien deux. Ou plutôt trois. Voyage dissolvant, aller-retour des mots au corps, avec cette grâce, si rare, de toucher juste. Toucher quoi ? Un souvenir, un plaisir, une peine qui brusquement font sens, et changent (Julia Kristeva, Les Samouraïs)

Transitif

1834 Ses vers, qui endorment ou exaltent l'imagination de l'Arabe autant que la fumée du tombach dans le narguilé, retentissaient en sons gutturaux dans le groupe animé 
de mes saïs ; et quand le poète avait touché plus juste ou plus fort la corde sensible de ces hommes sauvages, mais impressionnables, on entendait un léger murmure de leurs lèvres (Alphonse de Lamartine, Des destinées de la poésie)

1840 C’est avec étonnement, ma reine, que je vois celle qui touche le but si juste, et en même temps je me sens atteint. Je vois l'arc qui a lancé la flèche et qui m’a blessé. Des flèches suivent les flèches et m'atteignent (Gérard de Nerval, Le Second Faust [trad.])

1848 Ce n'est pas l'intelligence qui vous a manqué, à vous, personnellement, car au milieu de votre fougue, vous arrivez toujours à toucher très juste le point sensible de la situation (George Sand, Correspondance)

II. Jouer juste (d'un musicien)

Emploi absolu

1704 La même cause dans les chutes, fait jeter promptement les mains devant la tête ; plus un excellent joueur de luth laisse agir sa main sans y faire de réflexion, plus il touche juste; et nous voyons tous les jours des expériences, qui doivent nous avoir appris que les actions animales, c'està-dire celles qui dépendent des objets, s'achèvent par la seule force de l'objet, même plus sûrement qu'elles ne feroient si la réflexion s'y venoit mêler (JacquesBénigne Bossuet, De la connaissance de Dieu et de soi-même)

\section{CORPUS WEB :}

pas écouté l'EP, encore, mais là où la chro de SOUM m'avait touché faux, celle de sylvaine m'a touché juste... [http://www.gutsofdarkness.com/ god $/$ commentaires.php? page $=4 \&$ objet $=8149]$ (11.2.2016)

Alors tu n’a rien à faire sur ce forum. c'est un forum de débat, et si tu te sent superieur, tu ne peux PAS débattre, car débattre passe par accepter l'argumentation des autres ou en tout cas, ne pas s'acharner. c'est une joute entre etres intelligents, le vainqueur etant celui qui a utilisé les arguments touchant aux plus juste. Et les tiens touchent faux [http://board.fr.ogame.gameforge. com/board98-les-archives-du-forum/board425- les-archives-la-communaut/board476-archivesd-bats-opinions/289114-chine-et-domination-dumonde/index10.html] (11.2.2016)

En effet, tu as l'air d'avoir des bases solides, mais pour ce qui est du match en lui-même, je pense que tu manques un peu d'entrainement (je base ça sur du vent hein, si ça se trouve je me trompe complètement, mais sait-on jamais, si je touche juste, alors vas-y, entraines-toi....et puis même si je touche faux, vas-y quand même /o/) [http://www.pokemontrash.com/club/strategie/ (4g])-tentative-strategique-demande-d'aidecon seils/10/?wap2 (11.2.2016)

Alcool au volant : les réalisateurs d'Intouchables touchent juste [http://www.alcool-infoservice.fr/Actualites/Alcool-au-volant-les-realisa teurs-d-Intouchables-touchent-juste\#.VryoZk32 aUk] (11.2.2016)

Des compositions originales et enlevées, des arrangements modernes qui touchent justes, une voix sensible et forte, Charlotte et Magon fait preuve d'une originalité rafraichissante [http:// lobservatoire-cergy.fr/pour-les-musiciens/repeti tions-scene/charlotte-magon-198] (11.2.2016)

REMARques : Toucher juste (I) désigne le fait d'agir ou de penser de la manière la plus adéquate, de dire ce qui convient, le sujet atteignant exactement l'objectif visé, au concret ou au figuré. Il est mis en opposition avec toucher faux, également dans le domaine du toucher physique. Dans le domaine de la musique, toucher juste (II) connaît une spécialisation sémantique, celle de 'jouer juste'. Juste reste invariable dans la majorité des cas. Dans le dernier exemple du CW, il s'accorde cependant avec le sujet tout en gardant son interprétation adverbiale. Il est modifié par au plus, assez, joliment, malheureusement, plus, si, très. Notons l'emploi de toucher lourd 'avec lourdeur, sans finesse' (ex. de 1885). VoIR AUSSI : penser / viser juste

\section{Toucher lourd}

Toucher beaucoup d'argent Emploi absolu

1986 - Celui auquel vous devez me confier touchera lourd pour moi?

- Cinquante mille francs (Silvain Reiner, Le Tapis rouge) 


\section{CORPus Web :}

« Ceci est la position de la France », affirme, péremptoire, Ziad Takieddine, soudainement devenu l'ambassadeur secret de l'Élysée. Takieddine touchait lourd. Et Bernard Henri Lévy, dans quasiment le même rôle en Libye, il n'a rien touché du tout, du tout ? [http://www.come4news. com/libye-des-troupes-au-sol-pour-recupererles-missiles-618165] (11.2.2016)

Car, au-delà de leurs flairs de recruteurs, les intermédiaires d'envergure savent faciliter les accommodements avec le fisc. Les prix des transferts flambent sans que les clubs vendeurs touchent lourd [http://www.liberation.fr/sports/1995/07/12/ ljubomir-barin-1-impresario-arrangeant-dufoot-francaisle-croate-homme-providence-debordeaux-puis-d_137927] (11.2.2016)

c'est la mentalité qui doit changer, le truc qu'on déplore ds le foot français, la L1.... et oui ancelotti a là du taf car il découvre une mentalité... il découvre des questions genre : pensez vous avoir fragilisé sakho et gameiro ???? fragiliser quoi ? qui ??? Liza ds le parisien parle de ça... mais c quoi ce truc ?? ce sont des pros qui touchent lourd, si ça fait partie du métier mais alors on devient fou..... on en revient tjs au même débat.... [http://www.allpaname.fr/forum/ viewtopic.php? $\mathrm{p}=2116482 \&$ sid $=\mathrm{b} 4254 \mathrm{~d} 1 \mathrm{a} 71838 \mathrm{a}$ 6114ad444e7d5e3d84] (11.2.2016)

REMARQUes : Toucher lourd s'utilise dans l'acception de 'gagner beaucoup d'argent'. Lourd reste invariable. Notons l'emploi de toucher lourd 'critiquer avec lourdeur, sans finesse' s.v. toucher juste.

\section{Toucher mauvais}

Avoir une sensation tactile désagréable

Emploi absolu

\section{CoRpus Web :}

C'est de lui que sourdent le brouillard et le froid torpides, ainsi qu'une abominable pestilence qui semble agresser tous les sens et non seulement l'odorat et le goût, comme si ça « voyait mauvais », ça « entendait mauvais », ça « touchait mauvais »... [http://remi.schulz.perso.neuf.fr/ divers/depic/o.htm] (11.2.2016)

REMARQUeS : Ça touchait mauvais se dit du fait de toucher une surface ou une matière qui procure une sensation désagréable. Signalons l'emploi absolu ergatif en construction impersonnelle familière. Notons l'emploi de voir mauvais et de entendre mauvais qui reçoivent ici la connotation contextuelle de 'voir des choses, entendre des mots, des paroles qui exhalent un relent fétide'.

\section{Toucher petit}

Modifier de façon très infime (quelque chose), apporter très peu de modifications Intransitif

1175 Arriere lonc sont li Romain, Que nus n'entent ce que il dient. De mainte rien gabent et rïent. Ganors mainte parole i dist, Qui touce a l'oevre mout petit (Gautier d'Arras, Ille et Galeron, 3336)

REMARques : L'ancien français emploie petit comme quantifieur synonyme de peu. Petit reste invariable et est modifié par moult.

\section{Tourner bas}

tourner haut et bas : juger (quelque chose) sous tous ses aspects

$\lambda$ tourner haut

\section{Tourner court}

I. Changer brusquement de direction; passer d'une chose à une autre sans transition Intransitif

1393 Et puis brocha le chevau des esporons, et abaissa la lance, et ferist le gayant emmy le pis si roidement qu'il le fist voller par terre les jambes contre mont, et puys passa oultre et tourna tout court [variante : retourne tout court ; manuscrit Ars, p. 712] et descendist de paour que le gayant ne lui occist son chevau, et l'atacha par la resne à une racine d'arbe (Jean d'Arras, Melusine, p. 364 [éd. Genève])

-1488 MAISTRE ALIBORUM. Et les gorgias de la court

Fault il que d'eux je dissimule?

Il s'en vont la, tournent tout court, Com deux asnes sur une mule (Sottie des sots qui corrigent le Magnificat, 146)

1577 mais y ayant laissé pour son lieutenant general le seigneur Theodore fils de Jean, 
lequel s'acquita fort bien de cette charge, il tourna court vers la Thessalie, et d'arrivee prit la ville de Domace, que l'un des Cerneens avoit abandonnee (Blaise de Vigenère, L'Histoire de la décadence de l'Empire grec [trad.])

1604 Le bois vole en esclats, et la seule poignée Leur reste dans la main du grand coup estonnée :

Ils la jettent en l'air, poussent le cheval prompt,

Tournent court l'un vers l'autre, et se trouvent à front,

Desja branlans au poin la redoutable

espée,

Qui mille fois s'est veuë au sang haineux trempée

(Antoine de Montchrestien, Hector)

1679 et après que je l'eus convaincu par mes raisons, il fit ce que tous les hommes qui sont faibles ne manquent jamais de faire en pareille occasion : ils tournent si court, quand ils changent de sentiment, qu'ils ne mesurent plus leurs allures ; ils sautent au lieu de marcher ; et il prit tout d'un coup le parti, quoi que je lui pusse dire au contraire, de justifier la marche de ces troupes étrangères (Jean-François de Gondi (Cardinal de Retz), Mémoires)

1700 Le roi courut le cerf auprès de Roquencourt et dans le parc de Marly ; il menoit sa calèche lui-même, comme il a accoutumé de la mener, et, voulant tourner un peu court, il versa sans se faire aucun mal (Philippe de Dangeau, Journal)

1770 Parce que toute la science de la conduite des hommes, toute la science de l'administration, aussi bien que toute la science de la manœuvre d'un vaisseau se réduit à ce seul et unique principe très-simple et très-court, nil repente, rien tout à coup. C'est bien, mais si vous tournez trop court, l'eau entre par les sabords, le vaisseau est englouti des ondes et tout est dit. Vous manquez l'objet, le moyen, vous manquez tout, vous périssez (Ferdinando Galiani, Dialogues sur le commerce des bleds)
1781 Ce passage ne peut manquer d'inspirer de la terreur aux voyageurs qui ne sont point accoutumés à la vue des précipices, d'autant plus que les chevaux et les mulets ont une singuliere maniere de marcher : au lieu de garder le milieu du chemin, ils n'avancent qu'en faisant un zig-zag continuel, et tournent tout court au bord de l'abîme (Louis Ramond de Carbonnières, Lettres de M. William Coxe à M. W. Melmoth sur l'état politique, civil et naturel de la Suisse [trad.])

1843 On ne sait pas, en commençant, si vous allez absoudre ou condamner ces misères que vous peignez avec tant de force ; et quand vous les avez montrées, si hideuses et si terribles, vous tournez court, et ne faites pas entendre assez clairement que si le peuple est affreux à tant d'égards, c'est la faute des affreuses dominations qu'il a subies (George Sand, Correspondance)

1848 Quand il [= Charles X] apprit le danger qui le menaçait, il se contenta de dire : «Je ne croyais pas que cette maladie tournât si court. » Louis XVI partant pour l'échafaud, l'officier de service refusait de recevoir le testament du condamné parce que le temps lui manquait (François de Chateaubriand, Mémoires d'outre-tombe)

1913 La rue Sainte-Hildegarde tournait trop court pour qu'on pût voir venir de loin, et c'était par cette fente entre les deux maisons de l'avenue de la Gare qu'on apercevait toujours de nouveaux casques courant et brillant au soleil (Marcel Proust, Du côté de chez Swann)

1985 - On est bien dans une Floride, tu ne trouves pas?...

- Moi j’ai conduit le tracteur à la ferme...

- Une fois, je sais. Tu as tourné si court que la roue arrière a soulevé la remorque et que tout le grain s'est répandu dans un fossé.

- C’est même pas vrai !

(Yann Queffélec, Les Noces barbares) 
Pronominal

1540 LE SOT. Je demande se je veulx estre Le premier danceur de la court. Tenez, je me tourne aussi court Qu'ung beuf qui court après la vache (Farce nouvelle des cris de Paris / Ancien Théâtre françois)

II. Cesser brusquement, ne pas arriver au terme de son développement, du résultat escompté Intransitif

1679 mais comme je lui répondis que si je reconnoissois ces ordres pour des ordres du roi, je ne voyois pas moi-même comme je me pourrois défendre d'obéir à ceux par lesquels Sa Majesté commandoit tous les jours de ne me pas reconnoître pour archevêque de Paris, il tourna tout court. Il me dit que c'étoit à moi à me conseiller ; il me déclara qu'il ne défendroit jamais à un cardinal d'assister aux fonctions du Sacré collége (Jean-François de Gondi (Cardinal de Retz), Mémoires)

1794 Madame de H... me racontait la mort de M. le Duc d'Aumont. «Cela a tourné bien court, disait-elle ; deux jours auparavant M. Bouvard lui avait permis de manger » (Sébastien-Roch-Nicolas de Chamfort, Caractères et anecdotes)

1840 Avant de devenir l'épouse de Polyeucte, elle a aimé Sévère, mais d'une simple inclination ; malgré cette surprise de l'âme et des sens (comme elle l'appelle), elle a tourné court dès qu'il l'a fallu, dès que le devoir et son père l'ont commandé (Charles Sainte-Beuve, Port-Royal)

1899 Ceux-là s'opposaient à la revision, on sait avec quelle énergie, et, la revision devenue inévitable, leur unique pensée est de la faire tourner court. Pour cela, pas d'enquête, car l'enquête c'est la vérité connue, les responsabilités établies, avec le châtiment inévitable (Georges Clemenceau, Vers la réparation)

1913 GABRIELLE. Du même amour... silencieux.

Mme DE SAVAGEAT. Il est assommant à la fin, ce petit Le Guenn ! Il ne l'épousera pas ! Vous verrez que cette histoire tournera court.

GABRIELLE. Mais non, ma tante ! (Henry Bernstein, Le Secret)

1924 Ainsi, la guerre contre l'Autriche pour affranchir la nationalité italienne tournait court et tournait mal. Elle avait exposé la France à un conflit européen (Jacques Bainville, Histoire de France)

1936 Comme journaliste, Boule-de-Juif, comme on l'appelait, était au-dessous du médiocre ; ses affirmations étaient hasardeuses et ses discussions tournaient court. Celui des dreyfusards qui avait le plus de talent, le plus de plume, était à mon avis, avant Cornély, Bernard Lazare (Léon Daudet, Bréviaire du journalisme)

1937 Lorsque le héros quitta l'estrade, la température de la salle avait baissé. Les acclamations tournèrent court. Malraux rentra dans sa solitude. Pâques déjà... " C'était hier, pourtant, la nuit pleine d'anges et de bergers » (François Mauriac, Journal 2)

1945 Mais je sentis Allan soudain mollir la ligne. Manifestement il ne tenait pas à voir cette conversation tourner court (Julien Gracq, Un beau ténébreux)

1996 L'important n'est pas que les plus beaux élans puissent tourner court mais que n'en soit pas affectée la volonté de garder sans désemparer le cap de la vie. Nous ne voulons ni nous dévoiler aux autres ni nous dissimuler à nous-mêmes (Raoul Vaneigem, Nous qui désirons sans fin)

CORpus Web :

Troyes : la soirée coquine tourne court [http:// www.lest-eclair.fr/415290/article/2016-01-14/ troyes-la-soiree-coquine-tourne-court] (11.2.2016)

La révolution Millepied tourne court à l'Opéra de Paris [http://www.lavoixdunord.fr/france-mon de/la-revolution-millepied-tourne-court-a-1opera-de-paris-ia0b0n3311896? xtor=RSS-2] (11.2.2016)

Et puis, sur le 3, Tornade a fait une petite barre. Je n'ai pas trop compris pourquoi. J'ai pensé que je m'étais mise trop en avant. Le reste 
du parcours vraiment top. Trop dommage. Laëtitia m'a expliqué que j'avais mis une petite main vers la gauche dans le plané pour la tourner court mais que je l'avais tordue [http://blog.chevalmag. com/index.php/Laurene-blog/?p=325758\&more= $1 \& \mathrm{c}=1 \& \mathrm{tb}=1 \& \mathrm{pb}=1](11.2 .2016)$

Et une histoire d'amour qui tourne courte, face à la barbarie de ces temps cruels et sauvages [http://www.allocine.fr/film/fichefilm-3038/criti ques/spectateurs] (11.2.2016)

REMARQUES : Tourner court (I) se dit d'une personne qui, en se déplaçant, change rapidement de direction, prend un nouveau chemin, fait brusquement demi-tour. Si le sujet désigne un navigateur (par métonymie : le navire), il souligne le fait de changer rapidement de cap, de virer en employant un rayon (trop) court ; il peut aussi référer au changement d'état rapide d'un empire ; le sujet peut également désigner une rue qui forme un virage très court. En référence à la conduite d'un véhicule, il se dit du fait de tourner le volant d'une manière brusque, de prendre un virage serré (de même pour le cheval ; troisième exemple du CW). Dans son emploi pronominal, il souligne le changement de position rapide $d u$ sujet. (II) renvoie à une chose qui cesse rapidement, à laquelle le sujet met brusquement fin, qui prend fin sans réussir. En parlant d'une conversation, il se dit du fait de changer brusquement de sujet, de mettre un terme rapide à une discussion ou de raconter rapidement quelque chose, le sujet ne désirant pas s'étendre sur le sujet. Il souligne aussi la rapidité d'un fait, quelque chose qui ne dure pas longtemps, qui est éphémère, qui avorte. Court reste presque toujours invariable, sauf dans le dernier exemple du CW. Il est modifié par aussi, bien, si, tout, trop, un peu.

\section{Tourner (atourner) droit}

I. Aller, se diriger directement

Pronominal

$\sim 1100 \mathrm{Li}$ adubez en sunt li plus pesant,

Tot dreit as funz s'en turnerent atant [variante] (Chanson de Roland, 2471)

1177 N'a pooir que il l'an remaint, Que la rëine tant li plest

Qu'il n'a talant que il la lest :

Li cors s'an vet, li cuers sejorne.
Droit vers la fenestre s'an torne

(Chrestien de Troyes, Lancelot ou Le Chevalier de la charrete, 4716)

-1334 Pour bonne amour chascun s'atourne

Droit au Chevalier au Lyon

Pour devenir son compengnon.

D’aler o li en celle queste

Chascuns forment si l'amoleste

(Le Romans de la dame a la lycorne $\left[1^{\mathrm{er}}\right.$ tiers XIV $]$, 5866)

Intransitif

1285 Aprés la feste ainsi avint Que droit en Toscane tornerent

(Adenet le Roi, Cleomadés, 18145)

-1349 Premiers en issi ma pensée

Comme sage et bien apensée ;

Et quant elle fu hors issue,

Elle tourna droit a l'issue

De joie la premiere entrée (Guillaume de

Machaut, Le Dit de l'alerion, 3794)

1544 Dudit cap l'on voit une isle, qui ha plus de deux cens lieues de long, et cent de large, mais on ne sçait quelles gens y vivent. La coste de ce cap tourne au Sud quarante lieues, et d'icy tourne droit au Sudest

(Alphonse Jean Fonteneau, Voyages avantureux du Capitaine Jan Alfonce, Sainctongeois)

1612 Le desir de la cognoistre nous fit tourner droit vers le lieu où la voix nous conduisoit, et parce que Daphnis alloit la premiere, elle recogneut Filandre avant que moy, et me fit signe d'aller doucement (Honoré d'Urfé, L’Astrée)

1708 CRISPIN. Il s'est saisi si fort, Quand il a vû vos yeux tourner droit à la mort,

Que, n'écoutant plus rien que sa douleur amere,

Il s'est allé jetter...

GERONTE. Où donc ? Dans la riviere ? (Jean-François Regnard, Le Légataire universel)

1848 La quatrième lettre provinciale tourne droit sur les jésuites, que l'auteur n'avait jusqu'alors atteints qu'en passant. Dans 
les treize lettres qui suivent, à partir de cette quatrième, il se tient à ce nouveau sujet et s'enfonce dans leur morale de casuistes (Charles Sainte-Beuve, Port-Royal)

1921 alors, quand la route tourne droit vers l'est, et que les ormeaux, les panneaux de la bénédictine, inclinés par le vent du nord, s'inclinent soudain tous vers vous (Jean Giraudoux, Suzanne et le Pacifique)

1935 - J'ai entendu sonner une pierre, dit-il enfin. Le vent venait de tourner droit au nord. Il y a son et son. Je me suis dit : « On marche dans le chemin de la Hure, le capellan s'est trompé. Faut reconnaître qu'il est jeune, pas habitué au pays et il avait l'air malade, il soufflait tout le temps. » (Georges Bernanos, Un crime)

II. Faire un mouvement de rotation en ligne droite Intransitif

1863 Sphère droite, terme d'astronomie ou de cosmographie, signifiant que la sphère céleste nous paraît tourner droit sur nos têtes. La sphère est droite pour nous, quand notre horizon passe par les pôles du monde (Émile Littré, Dictionnaire de la langue française, s.v. droit)

\section{CORPUS Web :}

Surpris, je relève la tête et la tourne droit vers lui [https://www.fanfiction.net/s/7901803/11/ Sur-Ton-Pi\%C3\%A9destal] (13.2.2016)

On est encore en plein cœur de l'hiver, mais beaucoup d'entre nous ont déjà la tête tournée droit vers les beaux jours [http://jemenfoutisme. blogspot.co.at/2013/01/kitsune-x-aigle-les-piedsdans-la-boue.html] (13.2.2016)

Bon j'ai levé la roue, elle m'a l'air de tourner droit. J'ai retirer les 2 roues avant et je vois rien d'anormal côté gauche. J'ai l'impression que la roue gauche a pris du carrossage /. Ca pourrait être quoi ? [http://www.jeuxvideo.com/forums/11000019-363172-1-0-1-0-volant-de-travers.htm] (13.2.2016)

Il voyait ses yeux brillants de résolutions tournés droits vers les siens, son air droit et sincère, inquiet et décidé [https://www.fanfiction.net/s/ 3936991/16/Les-Enfants-d-Horus] (13.2.2016)
REMARQUES : Tourner droit (I) désigne une personne qui se dirige directement vers un lieu ou qui change de cap ; il peut aussi référer à la direction, à l'axe que prend une route ou également souligner les mouvements faits par le vent décrivant des cercles, des tours. En (II), et dans le troisième exemple du CW, il se dit du fait de faire un mouvement de rotation, l'objet qui pivote ou tourne donnant l'impression de former une ligne droite. Droit reste invariable, à l'exception du dernier exemple dans le CW où il s'accorde avec l'objet tout en gardant son interprétation adverbiale.

\section{Tourner dur}

Tourner beaucoup

Intransitif

1954 - Je sais ce que ça veut dire quand tu prends ta voix de dame du monde, dit Robert. Je suis sûr qu'en ce moment ça tourne dur dans cette tête. Combien de verres de punch as-tu bus?

- Sûrement moins que vous ; et le punch n'y est pour rien

(Simone de Beauvoir, Les Mandarins)

CORPUS WEB :

Par ailleurs les deux axes tournent dur. C'était quand meme assez rustique, le Berliner TT bahn !! [http://forum.e-train.fr/viewtopic.php?f= $4 \& \mathrm{t}=12200 \&$ start $=0$ ] (15.2.2016)

SeaDoo PWC est un peu différent d'où la notation API TC. Cela a à voir avec les additifs dans l'huile et la température moteur, pour qu'il a été conçu. Je ne m'inquiéterais pas bien, c'est pour les moteurs qui tournent durs pendant de longues périodes de temps [http://fr.shopsbt.com/el-fr15a7b/huile-Seadoo] (15.2.2016)

REMARQUES : Dans l'exemple de 1954, tourner dur renvoie au fait que les idées, les pensées s'agitent, se bousculent dans la tête, aussi à cause de l'alcool. Dans les exemples du CW, dur réfère au fait de tourner soit d'une manière stable durant une période longue soit difficilement, sans souplesse. L'emploi accordé est exceptionnel mais possible dans un registre familier ( $v$. le dernier exemple $\mathrm{du}$ CW). Notons l'emploi impersonnel familier ça tourne dur. 


\section{Tourner étroit}

Avoir (quelque chose) pour sujet principal ; porter strictement, essentiellement sur tel ou tel sujet Intransitif

1933 Mais il reste qu'au point de vue de l'inspiration, du souffle, d'Anima, nous tournons toujours plus étroit dans le cercle des appétits, des vils instincts, des moins louables égoïsmes (Fernand Desonay, Villon)

\section{CORPUS WEB :}

et le quatrième est le mouvement circulaire et croisé que doivent faire l'épaule et la jambe du Cheval lorsqu'il tourne étroit ou qu'il va de côté [http://www.chevalannonce.com/forums1023689-edd-et-appuyer-tete-au-muravis-auxdresseurs?p=2] (15.2.2016)

REMARQues : Dans l'exemple de 1933, tourner étroit apparaît dans un emploi figuré ; le sujet désigne une personne dont les thèmes de discussion ou les idées se limitent à un thème principal ou tournent autour d'un sujet en particulier, qui est restreint. Dans l'exemple du CW, tourner étroit réfère au mouvement d'un cheval qui tourne court. Etroit reste invariable et est modifié par toujours plus.

\section{Tourner fou}

(en mécanique) Tourner indépendamment de l'arbre, de l'axe

Intransitif

1924 Cylindres d'entraînement : L'un des cylindres, est mû directement par le mouvement d'horlogerie. Le cylindre supérieur tourne fou sur un axe vissé sur un bras en laiton articulé sur le boîtier. Une vis agit sur l'extrémité d'un ressort plat fixé à ce bras (A. Leclerc, Manuel de télégraphie et de téléphonie)

1953 Les lourdes, fallait pas se laisser prendre à leur apparence, au joli laqué gris des croisillons et des moulures ; en dessous, c'était blindé au nickel-chrome, et à l'épreuve même du fort calibre. Les boutons de ses portes aussi ménageaient quelques surprises ; ils tournaient fou et commandaient que du vent (Albert Simonin, Touchez pas au grisbi) 1956a l'arbre primaire entraîne le synchro qui entraîne l'arbre secondaire, la liaison est directe : on est en prise, puisque la transmission tourne à la même vitesse que le moteur. Naturellement, le train intermédiaire tourne «fou », en entraînant les deux pignons (Charles Chapelain, Cours moderne de technique automobile)

1956b À l'intérieur, se trouvent deux genres de pignons :

- les planétaires, au nombre de deux, sont montés clavetés coulissant sur les arbres de roues, ils sont placés latéralement dans la cage qui peut «tourner folle » autour de ces deux pignons.

- les satellites, en nombre variable (2, 3 ou 4), sont montés "fous " sur la cage et sont en contact avec les planétaires (Charles Chapelain, Cours moderne de technique automobile)

1958 L'axe qui en sort tourne fou dans une double plaque, également folle (Jean Merrien, Votre première voile)

\section{CORpus Web :}

En cas de panne de moteur sur un hélicoptère survenant à une altitude suffisante, la mise en autorotation du rotor principal permet de descendre et d'atterrir sans dommage. Lorsque la panne moteur survient, l'embrayage centrifuge permet le désaccouplement du rotor. Il peut ainsi tourner fou sur son axe [https://fr.wikipedia.org/ wiki/Autorotation] (15.2.2016)

Les vis tournent fou, simplement parce que le pas de vis (le trou quoi) est abîmé sur toute sa partie dans laquelle la vis se loge avec la platine. Le « fond » est encore ok, c'est pourquoi tu parviens a visser correctement si tu enlèves la platine [http://www.automodelisme.com/forum/ index.php?topic=11715.0;wap2] (15.2.2016)

voilà le problème : les conduits de frein et de combustible sont pourris au niveau de leur attache sur la cloche du ressort arrière droit. Le stute c'est que les boulons de cette attache sont désoudés et tournent fous [http://www.patrol-gr. net/pannes-mecaniques/20549-canalisationspourries.html] (15.2.2016)

Deux, trois, ou (plus souvent) quatre pignons coniques relient les pignons de transmission ; ils 
tournent fous sur leurs axes. Ces axes sont fixés dans une couronne dentée, tournant dans un plan perpendiculaire aux arbres de transmission [http://www.maisonbrico.com/conseils-brico lage/tondeuse-differentiel,479.html] (15.2.2016)

REMARQUES : En parlant d'un élément mobile comme un cylindre, tourner fou se dit du fait de tourner indépendamment sur son arbre. Fou peut s'accorder ou non avec le sujet dans le langage familier et les argots de métier. Notons l'emploi de monter fou.

\section{Tourner haut}

I. tourner haut et bas : juger (quelque chose) sous tous ses aspects

Transitif

1560 Non pas que nous réputions fortune dominer sur les hommes pour tourner haut et bas toutes choses témérairement (car ceste resverie doit estre loin d'un cœur Chrestien) (Jean Calvin, Institution de la religion chrestienne)

II. tourner haut et bas : tourner dans tous les sens

Intransitif

1609 Estant là, je furette aux recoings plus cachez,

Où le bon dieu voulut que, pour mes vieux pechez,

Je sceusse le despit dont l'âme est forcenée Lors que, trop curieuse ou trop endemenée,

Rodant de tous costez et tournant haut et bas,

Elle nous fait trouver ce qu'on ne cherche pas (Mathurin Régnier, Les Satires)

CoRpus Web :

Tu dis tourner bas en glucide et haut en protéine/lipides ! Peux-tu nous donner un orde d'idée par rapport à ton poids de corps? [http:// www.superphysique.org/forums/viewtopic. php?f=8\&t=13070\&start=840] (11.2.2016)

Dimanche, après l'apéro-concert prévu à 19 h 30, square Balagué, place à de nouvelles réjouissances, aux alentours de 22 heures, avec l'éternel Patrick Sébastien, homme de télévision que l'on ne présente plus, écrivain, chanteur, imitateur, qui devrait, à n'en pas douter, faire tourner haut les serviettes sur les berges du Salat [http:// www.ladepeche.fr/article/2010/07/22/877434saint-girons-les-serviettes-vont-tourner-sur-leparc.html] (15.2.2016)

Pour le mois de juin les battes des Cards tournenthauts et ellesn'ont pas enchainés 2 matchs de suite en dessous de $6 R$. Même $2 R$ c'est pas tout les jours * [http://forum.sospronostics.com/ sospronostics/concours/division-1/division09-06-sujet_5754_1.htm] (15.2.2016)

Zic700 : donc c'est pas neccessaire d'aller a $200 \mathrm{~km} / \mathrm{h}$ sur l'autoroute, monter dans les tours en 3ème ou 4ème fait le meme effet?

Fif : Exactement, et au moins tu deviens pas l'enemi Sarkosien numéro un (:)

Audi-a4-man : l'ideal est une route de montagne, parce qu'en plus de tourner haut il monte en $\mathrm{T}^{\circ} . .$. et il ya des variations de regime... [http:// www.forum-auto.com/automobile-pratique/ discussions-libres/sujet164380.htm] (15.2.2016)

Héhé, le mec avec la boxer, il a compris que les loop se tournent haut ! c'est bie esthétique ! chat-peau ! [http://www.directwind.com/forum/ forum-t18217-p1, session-du-mardi-19-a-pontmahe.html] (15.2.2016)

On s'aperçoit très vite que le moteur rechigne à tourner bas dans les tours. Ce manque de souplesse à bas régime est incontestablement le défaut majeur de ce moteur pourvu par ailleurs d'un formidable tempérament dès lors qu'on affiche un régime supérieur à $4.000 \mathrm{~T} /$ min [http://recreation-cadres.chez-alice.fr/essai. html] (11.2.2016)

J'ai une $325 \mathrm{td}$ automatique, le soucis et quand je démarre elle tourne bas genre $65 \mathrm{tr} / \mathrm{m}$ et dés que je touche la pedale d'accélérateur elle monte directeùment a $2200 \mathrm{tr} / \mathrm{m}$, le voyant d'injection et de boite s'allume [http://www. darkgyver.fr/forum/reste-accelere-t10886.html] (11.2.2016)

SLT serieux il araison j'ai un pote qui a cramé son calculo comme ça moi j'ai une eprom de gr $\mathrm{n}$ et c'est clair qu'elle tourne basse au ralentie mais bon le plaisir des 7500 TR [http://forum.106xsi. net/viewtopic.php? $\mathrm{f}=2 \& \mathrm{t}=3407 \&$ start $=20$ ] (11.2.2016)

REMARQUES : Dans son emploi transitif, tourner haut et bas (I) réfère à la façon dont l'homme ap- 
préhende ou perçoit quelque chose, en prenant soin de l'examiner ou de la considérer sous plusieurs aspects. Sous (II), le sujet désigne l'âme, la pensée humaine (par métonymie du sujet) qui se démène en tous sens, sans réfléchir, au hasard. La suite se joue sur un plan très concret puisque le narrateur tombe par hasard sur divers objets sur lequels il trébuche. Bas apparaît en collocation avec haut (I et II). Dans les exemples du CW, plus proches de l'emploi courant, haut et bas réfèrent à la puissance haute ou basse d'un moteur ou d'une équipe de sport, ou à la concentration haute ou basse (de protéine ou lipides). Haut et bas restent invariables dans la majorité des cas, mais dans le troisième et le dernier exemple du CW ils s'accordent avec le sujet, tout en gardant leur interprétation adverbiale.

\section{Tourner isnel}

s'en tourner isnel : retourner, revenir

rapidement

Pronominal

-1300 Et cil laissent l'angin, si s'an tornent isnel, Ne lor poïssent faire un plus crüel cembel (Jehan Bodel, La Chanson des Saisnes [fin XIII ${ }^{\mathrm{e}}$, 232)

REMARQUES : S'en tourner isnel se disait en ancien français du fait de revenir dans l'autre sens, de retourner à un lieu avec rapidité, précipitamment, le sujet désignant une personne.

\section{Tourner lent}

En opposition avec rapide ; mouvoir lentement $\lambda$ tourner rapide

\section{Tourner menu}

Revenir rapidement ou souvent

Pronominal

1175 Gerins del Mans i fiert Madan, Paris de Resnes Madian, .ii. Grius qui mout par furent noble, Puis les plora Constantinoble.

Illes se torne mout menu,

.i. chevalier novel venu

I gete mort ; la ot grant plor

(Gautier d'Arras, Ille et Galeron, 5979)

Transitif

+1250 « Si tornez a vostre mester, A ces versez et a ces saumes !»
Et Renart aquelt a ses paumes

Plus menu ces fous a torner

Que vos ne poïssiez conter (Le Roman de Renart [2e moitié XIII'], XII, 815)

REMARQUES : Dans son emploi pronominal, tourner menu désigne le fait de revenir dans un lieu d'où l'on était parti, et ceci, rapidement (ex. de 1175) ou souvent (ex. de +1250). Menu est modifié par moult, plus. VoIR AUSSI : remuer / tornoier menu

\section{Tourner rapide}

Tourner rapidement (autour de quelque chose) Intransitif

1831 Et il lut les mots suivants qui étincelaient et tournaient rapides, rapides comme la roue d'un moulin (Eugène Sue, Atar-Gull)

1838 Environ à la même distance où l'auréole aux sept couleurs se forme à l'entour de l'astre dont elle réfléchit les rayons, autour de ce point immobile, un cercle de feu tournait, si rapide qu'il surpassait en vitesse la rotation des cieux (Frédéric Ozanam, Essai sur la philosophie de Dante)

\section{CORpus Web :}

Comment arrêter votre compteur électrique de tourner rapide [http://www.handpuzzles.com/ comment-arreter-votre-compteur-electrique-detourner-rapide] (11.2.2016)

C'est le quatrième planète du systeme solaire. Il a une atmosphère très fine et un 0 ’03\% d'eau. Sa couleur est cause de l'oxydation.Mars a deux satellites, Fobos et Deimos. Ils sont petits et tournent rapide près de la planète [https://prezi. com/3-ae2liny7zq/lunivers] (11.2.2016)

- Changer les câbles

- Changer le filtre ADSL

- Débrancher tous les appareils pour avoir la seule ligne ADSL (Toujours la tonalite d'occupation)

- Tester avec un autre FREE BOX de 09 xxxxxxxxx

- Tester point par point que les chenillards qui tournent rapides et lentes.... [http://www. commentcamarche.net/forum/affich-10360104plus-de-tl-ni-internet-chez-free]

Elles tournent rapides ou lentes et règlent dit-on notre, mystérieuses mais toujours pré- 
sentes dès la naissance jusqu'a la mort. Qui sont elles ? [http://sympatiz.forum2jeux.com/ t1936p160-enigme] (11.2.2016)

REMARQUES : Tourner rapide désigne une chose qui effectue des mouvements de rotation, décrit des tours avec rapidité, à grande vitesse autour d'un axe ou non. Au figuré, le sujet peut désigner une parole ou des mots qui sont prononcés de manière rapide, la façon de s'exprimer ou le débit étant comparé à une roue qui tourne. Notons l'opposition sémantique entre rapide et lent. Rapide peut s'accorder avec le sujet et se rapprocher des prédicats seconds orientés vers le sujet. Il est modifié par si.

\section{Tourner rond}

I. (au propre) Tourner parfaitement sur son axe Pronominal

1607 les curieux en la recherche de la nature, remarquent qu'on void aupres du fleuve Harpasus une colline ou rocher, lequel estant touché legerement des doigts se tourne rond comme une boule; mais il demeure immobile, si on veut apporter de plus grands efforts, et une plus grande contention de bras (Pierre Fenolliet, Oraison funebre sur le trespas de hault, puissant et illustre messire Pompone de Believre)

Intransitif

1763 on place le cylindre sur le tour, et l'on voit s'il tourne rond (Ferdinand Berthoud, Essai sur l'horlogerie)

1775 Description d'un très-beau Vilbrequin, etc. centre $\mathrm{L}$ du mandrin de bois, de maniere que tous les centres se correspondent trèsjuste, et que le corps $\mathrm{K}$ tourne rond et droit dans toute sa longueur (Hulot père, L'Art du tourneur mécanicien)

1934 Jacquou avait réussi à mater le feu, à mater la broche qui tournait rond, à mater les femmes (elles étaient retournées à la cuisine) (Jean Giono, Que ma joie demeure)

1948 LE MEUNIER. (jovial) Ça tourne tout rond, et la trémie est chargée jusqu’à la gueule, comme les canons de Napoléon. Buvons. Où est le vin? (Marcel Pagnol, La Belle Meunière) 2012a À cette cadence, je vais bientôt pousser le derny. La route file à nouveau sous mon ventre, les jambes [= du cycliste] tournent rond (Paul Fournel, Anquetil tout seul)

II. (au figuré) Tourner comme il faut, sans problème, aller bien

Intransitif

1933 - Franchement, Monsieur Joigneau, vous voyez aussi bien que nous comment vont les choses. Vous direz pas que le monde tourne rond, et qu'on pourra jamais le faire tourner mieux ! ... nous autres, si un jour on s'en mêle, de votre politique... (Roger Martin du Gard, Vieille France)

1939 Les courants descendants donnent parfois aux pilotes une bizarre sensation de malaise. Le moteur tourne rond, mais l'on s'enfonce (Antoine de Saint-Exupéry, Terre des hommes)

1942 - Tout juste. Les femmes tout de même, quelles drôles de brebis. Jamais des idées comme tout le monde. Nous, les hommes, ça tourne rond, tandis qu'elles : toujours des à-coups (Raymond Queneau, Pierrot mon ami)

2012b Le soir même de l'incident, nous avons passé un long moment ensemble chez Norbert, tous accablés de constater que plus rien ne tournait rond dans notre galaxie (Stéphane Osmont, Éléments incontrôlés)

\section{CORPUS WEB :}

et la pignorerie en plastoc me fait peur, trop de mauvais souvenir sur des machines du bricogasin du coin ou aux bout de qlq semaines le disque a meuler ne tourne plus rond [http://www. metabricoleur.com/t3601-j-aime-la-ferraille] (30.4.2016)

Ceci étant dit, le brand new mix de Swano est réussi. Les guitares sonnent grave, comme le chant, la batterie un peu étouffée est délicieusement nostalgique, et l'affaire tourne rond [http:// www.metal-impact.com/index.php?name=Revie ws\&req=showcontent\&id=6057] (31.12.2015)

REMARQUES : Tourner rond (I), au propre, renvoie au fait mécanique de tourner sur un axe. Sous (II), il signifie, au figuré, 'fonctionner comme il 
faut', et, dans la variante tourner tout rond 'fonctionner à merveille'. Notons la collocation rond et droit ainsi que l'emploi de se correspondre juste et de sonner grave. VOIR AUSSI : pédaler rond.

\section{Tousser fort}

tousser haut et fort : tousser bruyamment

$\lambda$ tousser haut

\section{Tousser gras}

Tousser avec expectoration ; avoir une toux encombrée de mucus

Intransitif

1840 Si les animaux ont pâturé dans un pacage pourvu de beaucoup d'herbe ; que les muqueuses des yeux soient rouges; le pouls plein et vite (55 à 60 battements par minute) ; qu'ils toussent gras et souvent, que les mouvements des flancs soient précipités, ils seront saignés de trois à cinq kilogrammes (Recueil de médecine vétérinaire)

1860 La malade tousse gras et respire avec facilité (Wilhelm Zimmermann, L'Angine couenneuse et le croup)

1978 Elle me fait « mûrir » le rhume par tous les moyens : cataplasmes à la moutarde, ventouses, suées forcées au vin chaud, sirop... Tant qu'on tousse gras, c'est du bon, ça dégage, c'est le mal qui s'en va (François Cavanna, Les Ritals)

1986 Vous toussez gras ? (Exemple entendu [d'un pharmacien] / Noailly 1994)

REMARQUES : Tousser gras réfère au fait de tousser en éjectant des sécrétions provenant des bronches. Opposé à tousser sec. Gras reste invarié. Notons la collocation gras et souvent. VoIR AUSSI : cracher, moucher, vomir

\section{Tousser haut}

Tousser bruyamment

Intransitif

1627 Elle toussa donc assez haut pour se faire ouyr, et comme si c'eust esté contre sa volonté : ô que je suis marrie, dit-elle, de cette importune toux ! (Honoré d'Urfé, L’Astrée)

\section{CORPUS WEB :}

Quelques bouchées ont suffit pour faire monter quelques larmes et éteindre ma voix l'espace de quelques minutes. Je n'allais pas tousser haut et fort quand même - je ne voulais pas perdre ce respect nouvellement acquis, on a son orgueil [http://espritvagabond.blogspot.co.at/2010/02/ quand-vous-voyez-le-respect-dans-les.html] (11.2.2016)

Arretons d'embouteiller la fête de l'amour pour Février. Célébrons chaque seconde le don de la vie, ces batailles que nos anti-corps gagnent pendant que nous échangeons nos vœux. Joues infectées de mauvaises intentions. C'est que des gens égoïstes toussent haut et fort au moment même de l'ultime respiration d'un monde meilleur [https://beatmakersworld.wordpress.com/ 2012/01/02/2000-dou] (11.2.2016)

REMARQUES : Tousser haut désigne une personne qui produit volontairement un bruit similaire à celui de la toux, qui tousse fortement pour signaler sa présence ou pour se faire entendre. Notons la collocation haut et fort. Haut reste invariable et est modifié par donc assez.

\section{Tousser sec}

Tousser sans expectorer ; avoir une toux qui ne produit pas de mucosités

Intransitif

1844 Presque toujours la bête tousse sec, et fréquemment le matin et le soir, aussi bien à l'étable qu'au pâturage (Onésime Delafond, Traité sur la maladie de poitrine du gros bétail)

1849 J'écris l'idée de mon cours. À midi, chez Gronlier, très malade et toussant sec ; la rose sous le crêpe (Jules Michelet, Journal)

1963 Malheur au gamin qui toussait sec dans mon voisinage ; la famille aussitôt l'expulsait de mon amitié, décoré de ce beau mot sonore et décharné qui me faisait rêver : poitrinaire (François Nourissier, Un petit bourgeois)

REMARQUes : Tousser sec signifie tousser sans éjecter les mucosités qui encombrent les bronches. Il s'oppose à tousser gras. Gras reste invarié. VoIR AUSSI : cracher, moucher 


\section{Traîner bas}

I. Pendre, bouger, souvent lourdement, à un bas niveau, proche de la terre; ramper Intransitif

1372 Combien que la fole hardiesce du peuple ou le congié des princes si puisse estre par justes commendemens et par l'institucion divine abbaissié et refraint, toutes voies certainement leur ambicion et couvoitise de honneur ne puet estre mise a rayson ne mesure ; car, se il ne l'ose executer en appert, il se ventera tout secretement trainant bas comme un serpent et y entrera par fraude (Denis Foulechat, Le Policratique de Jean de Salisbury [trad.])

1495 La robe dudict chevalier traynoit plus bas que la hosseure du cheval et estoit fourree ladicte hosseure d'ermines moult richement (Roman de Jehan de Paris, p. 64)

1713 Ils virent à leurs yeux sortir de terre une table parfaitement bien couverte et un bufet fort riche, dont les napes traînoient plus bas que le plancher

(Miguel de Cervantes, Histoire de l'admirable Don Quichotte de La Manche [trad.])

Transitif

1896 Les sentiers sont tout piétinés par le passage des Samaritains et, autour de nous, les chacals, inquiets de ce qui se prépare d'inusité là-haut, rôdent en plein jour, marchant aplatis et sournois sous le soleil, traînant bas leur grosse queue de renard jaune (Pierre Loti, La Galilée)

1926 La Loire paraît au bout, jaunâtre sous un ciel terne. Près de la rive, dans l'orbe de remous, les moutons d'écume culbutent. Les nuages traînent très bas leurs formes haillonneuses, traversés çà et là de trouées froides, de pâleurs changeantes et nacrées que des glacis répètent sur le fleuve (Maurice Genevoix, La Boîte à pêche)

II. traîner bas, traîner plus bas que terre : salir, déshonorer, humilier, dénigrer (quelqu'un) Transitif

1847 M. Stirner s'est chargé de justifier cette sévère parole ; il est impossible de trâेner plus bas ce noble esprit germanique que tant de poètes et de métaphysiciens avaient accoutumé à l'infini (Saint-René Taillandier, De la crise actuelle de la philosophie hégélienne)

1851 M. VICTOR HUGO. Vous voyez bien que la majorité se prétend insultée. Ce n'est pas du président

de la République qu'il s’agit maintenant !

M. LE PRÉSIDENT. Vous l'avez traîné aussi bas que possible...

M. VICTOR HUGO. Ce n'est pas là la question! (Victor Hugo, Actes et paroles)

1908 Ah ! Nos instincts !... Voilà encore un problème qui égare le penseur... Ils sont là, tout au fond de nous, ils guident les premiers pas de notre enfance, à un âge où la raison toute seule nous serait aussi utile qu'une paire de souliers à un singe, et sitôt que nous sommes devenus grands, voilà que nous nous rebiffons contre eux, que nous les étouffons, que nous les trâेnons plus bas que terre... Nous ne savons qu'inventer pour les déprécier (Francis de Miomandre, Écrit sur de l'eau)

1936 Elle n'oserait pas. Il y a d'étranges remous autour de ce grand signe. Les princes de force l'élèvent bien haut, témoignant contre eux-mêmes. Et les héros de justice le traînent bien bas, témoignant contre eux-mêmes. Qu'importe ! Lorsque Jean Valjean, dans le livre depuis un siècle le plus lu, dit en regardant la croix : « Voilà le grand martyr » (Alain, Propos)

1940 Mais à 11 h. elle a commencé à sonner, elle était restée sur l'escalier - je l'ai laissée languir une demi-heure, je lisais ; et puis j'ai ouvert, je lui ai jeté matelas et couvertures dans le couloir et en quelques mots secs je l'ai traînée plus bas que terre. Puis j'ai refermé la porte et dormi, fort mal d'ailleurs (Simone de Beauvoir, Lettres à Sartre)

1974 Chapeau sonna impérativement. Il se fit apporter son courrier par sa bordel de secrétaire. Olga, elle s'appelait. Il la traîna plus bas que terre. Il lui dit que sans aucun doute, elle était mal baisée. Il lui demanda 
pourquoi, Bon Dieu, elle restait plantée là. Pourquoi pas ailleurs? (Jean Vautrin, Billy Ze-Kick)

Pronominal

1852 Celles [= les idées] de royauté, d'autorité, de droit divin, de noblesse ont été bafouées ; le peuple seul restait debout. Il faut qu'il se traîne si bas dans l'ignominie et la bêtise qu'on le prenne en pitié à son tour et qu'il soit bien reconnu qu'il n'y a rien de sacré (Gustave Flaubert, Correspondance)

Emploi absolu

1866 Il ne faut pas même s’arrêter ici à flétrir une interprétation triviale, usée à force de traîner bien bas, et qui serait du plus mauvais ton quand elle ne serait pas de la dernière inconvenance (François-Joseph Le Courtier, Sermon de Notre-Seigneur sur la montagne)

\section{Corpus Web :}

Dès le départ le rythme est soutenu et déjà les groupes se séparent. A l'attaque de la plaine un groupe d'une dizaine de pilotes se détache et prend un peu d'avance jusqu'à PO7où la nimbe d'un beau cumulonimbus commence à ombrager notre secteur. Les leaders filent à mi pente vers la prochaine balise... Je décide de temporiser pour assurer un gain maximum. Le deuxième groupe me recolle et nous avancons prudemment vers la balise suivante tandis que les leaders traînent bas dans le pied des pentes [http://www.kzoairlines. com/article-35735451.html] (11.2.2016)

Cela arrive-t-il lorsque tu mets le pied dedans en première? Si c'est ça, en effet, la solution c'est les traction bars. Mais ces barres trainent bas sous les lames, et sur un dos d'âne un peu raide, je ne sais pas si ça passe. Tu as mis quoi comme lames ? [http://www.mustangv8.com/fr/ restaurations/sportsroof-69-gt-mousquetaire/80] (11.2.2016)

REMARQUES : Au concret, traîner bas (I) est employé par rapport à un objet qui pend ou se meut proche de la terre. Traîner bas (II) réfère à une personne qui avilit, discrédite une ou plusieurs autres personnes, qui salit leur honneur. Au pronominal, le sujet lui-même se déshonore par son comportement ou une action précise. Les exemples du CW illustrent le sens concret de bas renvoyant à une position inférieure. Bas reste invariable et est modifié par aussi, bien, plus, si, très.

\section{Traire droit}

I. Aller, se diriger directement

Intransitif

-1209 Ensi lor bestorna Diex nostre Sires le conseil qui fu pris le soir de torner es ysles, ausi con se chascuns n'en aüst onques oï parler, et maintenant traient $a$ la ferme terre plus droit que il onques puent (Geoffroi de Villehardouin, Conquête de Constantinople, § 134)

1285a Lors pensa qu'il se vorroit traire Vers Chastel Nobel trestout droit (Adenet le Roi, Cleomadés, 10681)

1285b Bien vous sera guerredonné, Se je vif, or n'en soit douté, Dist Cleomadés, ce sachiez. Au partir de ci vous traiez Droit devers le bon roi Carmant Et li dites mon couvenant Si que vous savez que il va (Adenet le Roi, Cleomadés, 13317)

II. Lancer, tirer selon une ligne droite Transitif

1285c Aussi fist li rois Agambars; Ne croi que plus droit traisist ars Droite fleche bien enpenee, Quant ele est a droit entesee, Que il des gavrelos faisoit $\mathrm{Au}$ tablel, quant il les lançoit (Adenet le Roi, Cleomadés, 17508)

1377 La tierce est que met Ptholomee : car qui seroit en une naif meue isnelement vers orient et trairoit une seëtte tout droit en haut, elle ne charroit pas en la naif mes bien loing de la naif vers occident

(Nicole Oresme, Le Livre du ciel et $d u$ monde, p. 520, 49)

Intransitif

+1365a Arcipoles tient un arch taint en grainne, Dont si droit tret qu'un coer perce par mi (Jean Froissart, Poésies [3 $3^{\mathrm{e}}$ tiers XIV $\mathrm{XI}^{\mathrm{e}}$ ) 
+1365b Bien scet le dieu d'Amours droit traire, Quant ens ou coer me mist la fleche Qui si m'ensonnie et me bleche Que je ne puis aillours entendre (Jean Froissart, Poésies [3 tiers XIV $]$ ])

1465 Et elle fut bendee, il trait a elle sy droit qu'il l'attaint entre les deux yeulx, et tantost elle cheit a terre comme morte et commence getter par la gorge une flamme de feu moult hideuse (Jehan Bagnyon, L'Histoire de Charlemagne, p. 151)

REMARQUes : La langue ancienne employait traire droit (I) par rapport à un animé qui se dirige ou se déplace directement, en suivant une ligne droite, sans détour, vers un lieu. (II) réfère à l'action de tirer, de lancer une flèche, le projectile suivant une ligne droite. Droit reste invariable et est modifié par plus, si, trestout, tout.

\section{Traire dur}

Tirer avec force, énergiquement

$\pi$ traire raide

\section{Traire fort}

Tirer de façon puissante

Intransitif

+1370 car li Englès qui estoient engrant d'iaux assaillir et chil de deffendre, cryèrent leur cri et fissent traire leurs archiers moult fort et moult roit et tant que chil qui le havène deffendoient en furent si ensonnyet que, volsissent ou non, il les convint reculler, et en y eut dou tret à ce premiers moult de mehaigniès (Jean Froissart, Chroniques (A))

REMARQUES : Dans l'ancienne langue, traire fort désigne le fait de lancer puissamment un projectile, de tirer (principalement à l'arc) en direction de quelque chose ou de quelqu'un. Fort reste invariable et est modifié par moult. Notons également le groupe traire raide.

\section{Traire raide}

Tirer, lancer de manière énergique, résolue Intransitif

+1370 Ou grant vassiel de Cristofle qui se remonstroit desus tous les aultres, avoit bien .cccc. Genevois arbalestriers, liquel conmenchierent a traire moult roit et moult dur a l'aprocier (Jean Froissart, Chroniques (A))

REMARQUES : Traire roit 'raide' se disait du fait de lancer un projectile avec une arme de trait (comme l'arbalète) avec une grande énergie et intensité. Le tour est vieux. Notons la collocation roit et dur, dur accentuant l'idée de force, d'intensité dans le mouvement. Roit reste invariable et est modifié par moult. V. un autre exemple sous traire fort.

\section{Traire soef}

I. Endurer, subir de manière stoïque, tranquille, patiente, impassible

Transitif

1160 Aimme lou, fille ! - Ge ne sai.

- Gel t'ai mostré. - Et ge m'esmai.

- De coi ? - Del mal, de la dolor

Qui toz tens vait sevant d'amor.

- Et ja est ce tot soatume.

Soëf trait mal qui l'acostume ;

Se il i a un pou de mal,

Li biens s'en suist tot par igal (Eneas, 7968)

II. Tirer doucement, lentement, délicatement, avec douceur

Transitif

1177 Cil qui viaut qu'ele le paingne et, Li done, et les chevos an tret Si soef que nul n'an deront. Ja mes oel d'ome ne verront Nule chose tant enorer, Qu'il les comance a aorer (Chrestien de Troyes, Lancelot ou Le Chevalier de la charrete, 1471)

1200 Ja ert toute vive enragie S'encor n'en a un petitet ! Le col en tret tout souavet, Si le menja par grant douçor ; Ses dois en leche tout entor (Les Perdris, 44)

REMARQUES : Employé en ancien français, traire soef (II) réfère au fait de tirer ou de traîner doucement un animal, un objet (les cheveux). Le sens (I) est plus difficile à cerner ; soef pourrait signifier également 'aisément, facilement'. Soef est modifié par si, tout. 


\section{Traiter bas}

I. traiter tout bas : qualifier, appeler (de tel ou tel nom) à voix basse (quelqu'un)

Transitif

1736 Si votre femme est née de parens vertueux, si sa condition est au moins égale à la vôtre, si elle soûtient un bon caractere par d'agréables dehors, vous n'avez qu'à être raisonnable, vous serez parfaitement heureux, et vous le serez toujours ; mais si vous vous livrez à l'inconstance, vous empoisonnez cette felicité ; vous n'êtes plus un voluptueux, vous êtes un fou et un homme injuste. Ici l'homme dérangé me traite tout bas de ridicule, et il a raison ; son aveuglement ne lui permet pas de trouver mon raisonnement juste (Charles-François-Nicolas Le Maître de Claville, Traité du vrai mérite de l'homme)

1858 Enfin, il fut question de servir le rôt, et, au milieu d'un grand bruit de portes et de cliquetis d'assiettes, M. de Bois-Doré parut, précédé d'un petit serviteur richement équipé, qu'il traitait tout bas de page, comme pour justifier ce vers, qui n'avait pas encore accusé le ridicule de ses pareils : Tout marquis veut avoir des pages, et contrairement aux ordonnances, qui ne permettaient plus les pages qu'aux princes et grands seigneurs de haut vol (George Sand, Les Beaux Messieurs de Bois-Doré)

1883 En effet, voici l'inconvénient de pareils articles. Le bourgeois, en les parcourant d'un cerveau brouillé par les affaires, écarquille les yeux, vous traite, tout bas, de " poète ", sourit in petto et se désabonne, - en déclarant, tout haut, que vous avez beaucoup de talent ! (Auguste de Villiers de L’Isle-Adam, Contes cruels)

1914 Quelle irréligion ! C. m’écrit de plus, enthousiasmé : «Il a été simple, vulgaire, voire obscène. » Cette lettre de $\mathrm{C}$. est inénarrable. Vraiment tu m'en veux de t'avoir traité tout bas de « romance »? Je l'ai pensé sans malice. Pas une ligne de Pelléas qui ait bougé pour moi. Je pleurais encore hier comme au premier jour. Que ne viens-tu ? (Alain-Fournier, Correspondance avec Jacques Rivière)
1942 Tout bas, ils les traitaient de romanichels, de saltimbanques... Et les saltimbanques avaient beau s'exercer, accomplir les plus périlleuses prouesses, montrer toute l'habileté du monde, jamais ils ne réussissaient ce tour de force de détruire dans l'esprit de ceux qui les regardaient, la suspicion, la crainte, peut-être le mépris... (Louis Guilloux, Le Pain des rêves)

1982 Il y avait de tout. De gros fermiers qui venaient pour une des grandes foires, des marins de partout, des Français qui étaient toujours inquiets et sans le sou, et se disaient hommes de lettres, mais Lazare ne savait pas ce que signifiait ce mot étranger et le patron tout bas les traitait d'espions, des domestiques des ambassades que Leurs Excellences n'avaient pas pour le moment la place de loger, des dames avec des officiers (sa mère avait dû ressembler à une de ces dames-là) (Marguerite Yourcenar, Une belle matinée)

II. Traiter de manière indigne, méprisante Transitif

1936 D’abord, c'est une vraie stupeur ! Elle se fige ! Transie qu'elle demeure... Puis elle se ressaisit. Elle me traite plus bas qu'un trou. Je sais plus où je vais me poser. Elle pleure à chaudes larmes. Elle se roule dans le tapis de détresse. Elle se remet à genoux. Elle se redresse (Louis-Ferdinand Céline, Mort à crédit)

1960 Quelques secondes ça le démange de le leur dire. Sûr dans ce cas de se faire traiter plus bas que terre, il refrène son envie. Se tire pas pour autant, captivé (Albert Simonin, Du mouron pour les petits oiseaux)

\section{CORPUS WEB :}

Alors que le marché français est en grande partie demandeur d'appareils de $24 \mathrm{~m}$ et plus, les agriculteurs britanniques préfèrent le plus souvent des largeurs de $18 \mathrm{~m}$. Une largeur réduite leur permet en effet de traiter bas pour limiter la dérive en conditions venteuses. A l'inverse, les rampes larges incitent à positionner la rampe à une hauteur plus importante [http://www. lafranceagricole.fr/article/adeptes-des-largeurs- 
reduites-au-royaume-uni-1,0,39244431.html] (11.2.2016)

REMARQUES : Traiter bas (I) se dit du fait de donner un nom à quelqu'un, de le qualifier de façon péjorative, avec discrétion. (II) désigne une personne qui avilit, déprécie une autre personne, la traite de manière humiliante. Dans l'exemple du CW, où traiter a le sens de 'épandre un produit chimique', bas désigne une position inférieure et il est mis en opposition avec une hauteur plus importante. Bas reste invariable et est modifié par plus, tout. Notons les locutions traiter plus bas que terre / plus bas qu'un trou.

\section{Traiter dur}

Traiter avec sévérité, sans ménagement

Transitif

1898 En ce temps-là les petits bergers et les petits porchers étaient traités dur. On ne leur donnait que du pain (Jules Renard, Bucoliques)

1985 C'est seulement plus tard que j'ai pigé pourquoi Mandrax y m'avait traité aussi dur (Frédéric Lasaygues, Vache noire, hannetons et autres insectes)

\section{CORPUS WEB :}

Bien que quelques officiers se montrent bienveillants envers ces étudiants-soldats, la plupart les traitent dur [https://fr.wikipedia.org/ wiki/Kiyoshi_Ogawa] (10.9.2020)

Que vous soyez de ceux qui aiment leurs PowerBASS ou de ceux qui les traitent durs, vous ne devez pas vous soucier de les casser ou de les user [https://www.amazon.fr/COOLSOUNDCasque-Microphone-Powerbass-Rouge/dp/ B089RNW798] (9.10.2020)

REMARQUES : Traiter dur s'emploie dans le registre familier comme alternative de traiter durement. Il tend à l'invariabilité, mais le deuxième exemple du CW atteste un accord par rapport à l'objet direct du verbe.

\section{Trancher court}

I. pour le trancher court (adverbe de phrase): pour le dire clairement

Transitif

1583 «Bodillo en France, Felix en Hongrie et beaucoup d'autres n'en ont pas moins faict. Et, pour le trencher court, n'estimez qu'il y ait au monde chose plus affreuse et formidable que l'homme vindicatif, qu'on peut proprement appeler diable incarné » (Bénigne Poissenot, L'Esté)

II. Décider, résoudre, abréger de manière abrupte, mettre brusquement, brutalement fin à (quelque chose)

Emploi absolu

1601 Que si on luy dict qu'ainsi en jugent et parlent les autres en leur rang, autant offensez de nos coustumes et façons comme nous des leurs, il tranche tout court à sa mode, que ce sont bestes et barbares, qui est tousjours dire mesme chose (Pierre Charron, De la sagesse)

1684 Pour ce qui regarde la Sentence de la Congregation des Cardinaux qui sont commis pour l'Inquisition, et qui ont condamné cette Opinion du mouvement de la Terre dans Galilée, les Orthodoxes repondent (car les autres tranchent bien plus court) que cette Sentence a esté particuliere à l'egard de Galilée, contre lequel elle a pû avoir des raisons particulieres qui ne doivent pas avoir lieu contre les autres (François Bernier, Abrégé de la philosophie de Gassendi)

1713 Elle voulut me persuader qu'elle n'avoit rien dit à Silvie qui pût faire honte à la vertu même, et à la fidélité qu'elle me conserveroit éternellement. Je tranchai court sur son compliment, et la priai d'aller nous faire apporter à dîner, et cependant nous restâmes seuls Silvie et moi (Robert Challe, Les Illustres Françoises)

1740 FRONTIN. (à Mondor) Monsieur, il est bien flateur pour moi que mon Etoile m'ait procuré l'honneur de la satisfaction de...

MONDOR. (le prenant au colet) Point de compliment ; tranchons court, s'il vous plaît (Pierre Cérou, L'Amant auteur et valet)

1836 Je me complaisais dans ce dessein, sans déterminer si j'étais capable de le conduire à bonne fin, non pas que la difficulté de le lancer ne me vînt souvent en tête ; mais je tranchais court à tout examen par cette réponse insensée que je m’adressais : « $\mathrm{Al}$ - 
lons, faisons-le d'abord " (Daniel Defoe, Vie et aventures de Robinson Crusoé [trad.])

Transitif

1613 D'autant que nous ne recevons jamais de vos lettres que quand vous estes sur le poinct de vostre partement pour nous venir revoir. Or, Madame, à la fin que je le vous tranche bien court, ny vos lettres n'augmenteront rien, ny le defaut d'icelles ne diminuera chose aucune de mon devoir en vostre endroit (Estienne Pasquier, Lettres familières)

1738 Quelques esprits-forts, et plusieurs philosophes, qui ne sont, ni de la croïance juive, ni de la nazaréene, tranchent encor plus court cette difficulté. Ils nient totalement la vérité des songes dont il est parlé dans nos livres divins (Jean-Baptiste d'Argens, Lettres juives ou Correspondance philosophique, historique et critique)

III. Raccourcir

Emploi absolu

1716 Madame D. se souviendra donc, s'il lui plaît, que je ne suis pas aussi amoureux de mes vers qu'elle le dit : que je les retranche volontiers, quoique je les croye bons, quand l'interêt de tout l'ouvrage le demande : et j'en ai bien supprimé d'autres dans les endroits mêmes où l'on m'accuse quelquefois avec raison de trancher trop court, parce que j'ai craint d'interrompre des actions vives, par des détails qui ne me paroissoient pas intéressans (Antoine Houdar de La Motte, Réflexions sur la critique)

REMARQUES : Trancher court (I), étroitement lié au sens (III), se convertit en adverbe d'énonciation dans la locution pour le trancher court 'pour le dire clairement'. (II) se dit du fait de mettre un terme à quelque chose (une conversation, un discours) de façon brusque ; il peut aussi référer à une prise de décision rapide ou au fait de résoudre un problème sans tarder ; l'objet peut aussi désigner un problème ou une difficulté auxquels le sujet met fin brutalement, d'un coup. Dans une production de texte, (III) se dit du fait d'en enlever une ou plusieurs parties, de rendre le texte plus court. Court reste invariable et est modifié par bien, bien plus, encore plus, tout, trop.

\section{Trancher dru}

Trancher copieusement, à profusion, en grande quantité

Emploi absolu

1450 SIMON PHARISÏEN. Jhesus, prophete venerable,

Vous me soyez le bienvenu. SAFFRET. Chascun tranche dru et menu Tant que vïande durera. S'il n'en y a, l'en en rara : J'ay fait bonne provision (Arnoul Gréban, Le Mystère de la Passion, 13763)

\section{CORPUS WEB :}

Très bonne nouvelle puisque le jeu est enfin sorti des forges de Blizzard et que pour certains la nuit a sans doute été très courte. Çà $a$ dû hacher et trancher dru dans les chaumières de France et de Navarre... [http://www.ballajack.com/diablo3theme-windows7] (11.2.2016)

Joss initie ces deux coloc, il passe demain peut être, a voir s'ils sont motivés pour vendredi. Julien aime bien wow, en ligue pour l'instant peut être plus tard en construit * pour info, moi \& Yannick descendons a Toulouse et Jess nous y rejoint. Attention Yannick sort un Deck jumeau au mien version plus agro ça vas trancher dru avec nos faces de poulpes [http://les7royaumes. forumactif.com/t2559-wow-scourgewar-carteset-projet-2010] (11.2.2016)

ReMARQues : Plutôt employé dans un contexte culinaire, trancher $d r u$ désigne le fait de séparer un aliment (ici : de la viande), d'en détacher des morceaux en coupant net, à l'aide d'un instrument tranchant, de couper en de nombreuses lamelles. Notons la collocation trancher dru et menu, où menu ajoute à l'idée de quantité celle de fréquence. Les exemples du CW transposent la collocation au domaine du combat dans un jeu vidéo. Notons que le groupe, dont on constaterait la disparition après 1450 , s'est bien conservée dans la langue familière. Dru reste invariable. Signalons enfin l'emploi impersonnel familier de ça a dû hacher et trancher dru. 


\section{Trancher fort}

Trancher, couper profondément

Transitif

+1100 Uns grips flammanz del air descent, Pur eals prendre les ungles tent, E flammantes ad les goës, E trenchantes fort les poës (Benedeit, Voyage de saint Brendan [1 $1^{\mathrm{er}}$ quart XII $\left.\left.{ }^{\mathrm{e}}\right], 1014\right)$

Intransitif

+1250 Demein matin quant tu vendras, Sos ta cape en ta mein tendraz Tot coiement une cunnie Qui soit trenchant et agusie Tot de novel en un fort mance, Et un cotel qui bien fort trenche Con ce fust cotel a bocher (Le Roman de Renart [2 $2^{\mathrm{e}}$ moitié XIII $\left.\left.{ }^{\mathrm{e}}\right], \mathrm{IX}, 660\right)$

\section{CORPUS WEB :}

Comme tout les outils qui tranchent et qui tranchent fort, la donféceuse est un outil dangereux. C'est vrai qu'il vaut mieux pas essayer la première fois sur un didj mais commencer par des trucs bateaux histoire de se roder [http://www. francedidgeridoo.com/defonceuse-bois-pourcreuser-didg-sandwich-t1951-15.html] (11.2.2016)

nan nan vrai couleurs, pas photoshop

j'aime bien les cheveux de cette couleurs

avec les yeux qui tranchent fort [http://forum. wild-motorcycles.com/viewtopic.php? $\mathrm{p}=190$ 130] (11.2.2016)

REMARQUES : Trancher fort se dit du fait de séparer, de détacher d'un tout, en coupant quelque chose à l'aide d'un instrument tranchant (ici : un couteau). Dans le deuxième exemple du CW, trancher fort renvoie au contraste que forme la couleur des cheveux qui fait ressortir celle des yeux. Fort reste invariable et est modifié par bien. VoIR AUSSI : couper net

\section{Trancher menu}

Couper en fines lamelles, en fines tranches Transitif

1393 Aliter, se vous avez du beuf froit, si le trenchiez bien menu, et [puis si broyez] ung pou de pain alayé de vertjus, et coulez par l'estamine mise en ung plat, et pouldre dessus. Chauffez sur le charbon ; c'est bon pour troiz personnes (Le Menagier de Paris, p. 204, 26)

1494 Massahelides fut en ce temps moult aprecié du peuple de Libe, par l'industrie duquel Dido achapta de la terre oudict lieu de Libe, autant que pourroit enclore le cuir d'un beuf, ce qu'elle obtint, si le fist trencher menu et lier l'un à l'autre, si contint assez de pays devers la mer, où elle fonda sa cité denommée Cartage (Simon de Phares, $R e$ cueil des plus célèbres astrologues)

1697 Prenés des cordes de Luth, et les tranchés menu en forme de petits vers, et quand le quartier rosty sera tiré de la broche tout chaud, mettés dessus lesdites cordes coupées, puis les couvrés d'un autre plat, et à la chaleur les cordes se mettront en forme de petits vers (Sieur d'Emery, Nouveau Recueil de secrets et curiositez)

1884 Elles le [= le maïs] tranchent menu. Les morceaux coupés frappent la surface intérieure du tambour et sont ramassés par les palettes placées sur la circonférence du volant (Le Hache-Maïs ascenseur de M. Albaret)

1931 puis, s'en allant aux tects, où restait enfermé le peuple des forets, il en prit une paire, les rapporta, les immola, les fit flamber et, les ayant tranchés menu, les mit aux broches (Victor Bérard, L'Odysée d'Homère : étude et analyse)

1955 car les pauvres gens s'en vont à la boucherie, prennent le foie cru dès qu'il est sorti de la bête, et le tranchent menu (Marco Polo, La Description du monde [trad.])

\section{CoRpus WeB :}

Les fabricants de piège sont obsédés par le démembrement et la décapitation et ne cessent d'imaginer de meilleures méthodes pour trancher menu la chair des intrus. La lame montée sur ressort et la lame cachée dans le mur sont deux modèles standards [http://www.pathfinder-fr. org/Wiki/Ressources.KQ\%20Morsure\%20de\%20 lacier.ashx] (11.2.2016)

Sanji nous rappelle quant à lui sa maîtrise des coups de pied, Zoro l'art de trancher menu façon sashimi et Usopp combien les mensonges 
peuvent parfois être utiles au front ! [http://www. planetebd.com/manga/hachette/one-piece-logbooks/nami-2eme-partie/28526.html] (11.2.2016)

RemARques : Généralement employé dans le contexte culinaire, trancher menu désigne le fait de découper, de séparer, de détacher de petites parties d'un tout à l'aide d'un instrument tranchant, plus spécifiquement, de réduire, de couper en fines lamelles des ingrédients (viande, aromates ou légumes). L’adjectif-adverbe menu souligne plus le résultat de l'action de trancher ou couper l'aliment que la précision ou la minutie dans le geste. Les exemples du CW le transposent au domaine du combat (jeux vidéo, films). Notons l'emploi absolu dans le dernier exemple du CW. Menu reste invariable et est modifié par bien. VOIR AUSSI : couper fin / menu

\section{Trancher net}

I. Couper nettement, d'une manière précise (au propre) ; diviser nettement en deux ou plusieurs parties (au figuré) ; arrêter

Transitif

1573 GALLEPAIN. Et quoy ? aux Isles d'Orcanet Vous en alliez trancher tout net Cinq cents, d'un coup de vostre épee, Sinon qu'elle estoit ébrechee. Que diray-je de vostre faict, Là où tout le monde le sçait ? (Jean-Antoine de Baïf, Le Brave)

1910 Il lui tourna la tête de côté, lui découvrant ainsi le cou. Et là dedans, il piqua, puis tira son couteau, et se mit à scier de haut en bas. Un jet de sang fusa de la carotide tranchée nette et, droit en l'air, étoila le plafond. Et le garçon tomba sans un cri. Goblot, en proie à la congestion, bredouillait : « Au secours !... J'étouffe !... » (Louis Delattre, Carnets d'un médecin de village)

1927 Il me semble qu'une autre race de termites à petites constructions soit ici venue occuper le sol à la place des termites monumentaux. Certains de ces tumulus, que je vois un peu plus tard tranchés net pour laisser passer la route, montrent leur mystère intérieur : couloirs, salles, etc... Je peste contre l'auto qui ne me laisse pas le loisir d'examiner un peu mieux cela (André Gide, Voyage au Congo)
1930 Soudain, Salomon poussa un hurlement. Sa faux, immense et mal dirigée, venait de trancher net la pointe de son sabot. Après s'être relevé, il sourit, dit que cela n'avait aucune importance et qu'il se portait très bien (Albert Cohen, Solal)

1942 À quel moment, à quel moment précis avait-il surpris ce regard ? C'était dans les jardins, la nuit venue, alors qu'ils sortaient tous les trois de l'ombre dense, tranchée net, qu'abattait sur l'allée un massif de grands marronniers (Maurice Genevoix, Match à Vancouver)

1974 quelques fragments de sordides petites rues jamais ramonées débouchent, tranchées net comme les tronçons d'une tuyauterie oxydée, sur les terre-pleins boueux où champignonnent les casques jaunes (Julien Gracq, Lettrines 2)

1991 Le chef laptot, qui n’avait pas remarqué le rapide mouvement de ma mère, leva sa grande perche pour lui en assener un deuxième coup, mais au moment où la perche allait s'abattre sur sa tête, elle fit un pas de côté, et d'un grand coup de coupe-coupe elle la trancha tout net (Amadou Hampâté Bâ, Amkoullel, L'Enfant peul)

Emploi absolu

1627 Outre cela ayant veu que les ciseaux dont l'une des parques coupe les filets des vies estoient tout enroüillez, et que ne coupant qu'à demy il se trouvoit beaucoup d'hommes blessez, et fort peu de tuez, je les ay pris et les ay fait remoudre à mes propres frais, tellement qu'aujourd'huy ils tranchent si net que l'on meurt tout d'un coup, et l'on n'en void plus languir (Charles Sorel, Le Berger extravagant)

1834 Arrivés au sommet, le plus grand spectacle et, depuis tant de temps, inaccoutumé, s'ouvrit à nous, une bruyère parfumée et fleurie, bourdonnant de mille bruits dans la chaleur, un ciel immense et pur encadrant une mer brillante, et tranchant net sur le noir des rochers anfractueux qu'il continuait comme une bordure glorieuse (Charles Sainte-Beuve, Volupté) 
Pronominal

1934 J'entends des cris se tordre dans des gueules noires, d'autres qui se cassent par le bout, d'autres qui se prolongent, horizontaux, sans fléchir, puis se tranchent net, comme une gorge... la pluie a cessé, et l'air froid du matin détaille affreusement ce sabbat (Roger Vercel, Capitaine Conan)

II. Décider, résoudre d'une manière nette, franche; mettre fin à une discussion de manière abrupte, en émettant un avis catégorique Emploi absolu

1623a car escrivant en la preface qu'il a faite in corpus doctrinae, de l'edition de Lypse l'an 1561 il monstre qu'il a eu l'esprit meilleur que tous les apostres, combien qu'il fasse quasi scrupule de contester avec Sainct Paul, luy cedant à demy la preseance, mais en fin il tranche court et net, et par cét argument il preuve qu'il a meilleur esprit que Sainct Paul, d'autant, dit-il, que Sainct Paul ne prescha jamais l'evangile qu'en secret, et comme sous la cappe, et moy je le presche ouvertement

(François Garasse, La Doctrine curieuse des beaux-esprits de ce temps)

1799 Peut-être convient-il pour ôter à notre dernière supposition trop complexe un reste de confusion, de trancher net entre les deux cas qu'elle renferme (Emmanuel Sieyès, Euvres)

$1835 \mathrm{Au}$ demeurant son écriture est très difficile, elle me papillotte dans les yeux. S'il veut accorder encore huit jours, etc., etc. " J'ai tranché net, car je souffrais. Pardonnez-moi de vous rapporter de telles phrases : c'est pour vous donner une idée de ce dénouement » (Maurice de Guérin, Correspondance)

1859 Cela est surtout vrai dans les disputes de religion, quand on est catholique et qu'on veut demeurer tel. Ce moment était venu et grandement venu en 1661, pour les querelles du jansénisme ; il fallait trancher net dans ses propres raisons, sous peine de faire une fausse tige qui ne se rattacherait plus à l'arbre ou qui du moins s'en distinguerait à jamais (Charles Sainte-Beuve, Port-Royal)

1936 c'est presque une invitation à juger par soimême et à résister au commun usage. Cela mène droit au protestantisme. Tranchons tout net, et sans nuance, la morale n'est pas toujours sans danger pour la discipline (Alain, Propos)

1951 Une race forte de soldats laboureurs avait longtemps régenté cet extrême sud, parlant haut et tranchant net avec ses officiers subalternes, plus militaire que les pâles comptables qui s'étaient succédé à l'amirauté jusqu'à Marino, et pareille, sur ces confins excentriques, aux derniers surgeons verts qu'on voit sortir encore de terre (Julien Gracq, Le Rivage des Syrtes)

1995 Voilà ce que j’admire. Cet esprit de décision, cette façon de trancher net dans un problème. Un homme d'envergure, me dis-je, promis aux plus hautes destinées. Pendant quelques instants, j'envisage de m'incruster de force (Lydie Salvayre, $L a$ Puissance des mouches)

Transitif

1623b En somme Jeremie au ch[apitre] V voulant monstrer l'extreme impieté des juifs en ce qu'ils estoient venus jusques à l'atheisme, tesmoigne neantmoins qu'ils n'oserent jamais trancher net cette proposition : il n'y a point de dieu, mais qu'ils la dirent en termes ambigus, et l'envelopperent d'une parolle à sous-entente (François Garasse, La Doctrine curieuse des beaux-esprits de ce temps)

1764 Cependant quand un mortel vient hardiment nous affirmer qu'il a vu un miracle, il tranche net cette grande question ; jugez si l'on doit l'en croire sur sa parole ! Ils seroient mille que je ne les en croirois pas (Jean-Jacques Rousseau, Lettres écrites de la montagne)

1893 Alors Lahrier :

- Encore !... Encore !... Est-ce que ça va durer longtemps ? Je vous répète que je 
n'ai pas soufflé mot, que je n’ai pas ouvert la bouche... Si vous le faites exprès, il faut le dire.

À cette réplique, qui tranchait net la question, le père Soupe devint beau à voir. Deux ou trois fois :

- Je ne suis pas fou, corne-diable !... Je jouis de toutes mes facultés

(Georges Courteline, Messieurs les rondsde-cuir)

1945 - Pas vrai ? demanda le mascoutain, rempli de curiosité. Comment qu'il s'y prend ?

- En les bâtissant assez hautes.

Ils éclatèrent de rire. Didace se rapprocha d'eux et trancha net la conversation :

- Toi, gros casque de Maska, passe ton chemin ben vite, ou ben donc je vas te renfoncer ton casque à trois ponts assez creux que tu verras plus se coucher le soleil

(Germaine Guèvremont, Le Survenant)

III. (pour) le trancher net: parler franchement et sans ambages

Transitif

1667 ALCESTE. Non, non, il n'est point d'âme un peu bien située

Qui veuille d'une estime ainsi prostituée ;

Et la plus glorieuse a des régals peu chers,

Dès qu'on voit qu'on nous mêle avec tout l'univers :

Sur quelque préférence une estime se fonde,

Et c'est n'estimer rien qu'estimer tout le monde.

Puisque vous y donnez, dans ces vices du temps,

Morbleu ! vous n'êtes pas pour être de mes gens ;

Je refuse d'un cœur la vaste complaisance Qui ne fait de mérite aucune différence ; Je veux qu'on me distingue; et pour le trancher net,

L'ami du genre humain n'est point du tout mon fait (Molière, Le Misanthrope)

1784 Si j'en-étais crue, moi qui étais pour le conseiller, avant ce qui est arrivé, je serais à-présent pour le marquis : et je le tranche net, chère sœur, une fille doit épouser l'homme qui l'a approchée, ou persone.
Songez bien à cela (Nicolas Rétif de la Bretonne, La Paysanne pervertie ou Les Dangers de la ville)

1835 Quelle foi peut-on ajouter à ce qu'ils disent ?... d'ailleurs, voici longtemps que je n'en entends plus parler... enfin, pour le trancher net, je ne l'ai pas vu, et désormais je ne veux croire que ce que j'aurai vu (Stendhal, Lucien Leuwen)

\section{Corpus Web :}

Utiliser le couteau ondulé de la mandoline et trancher net. Attention aux doigts ! [http:// chefsimon.lemonde.fr/marques/chef-simon/ recettes/pommes-gaufrettes] (21.1.2016)

Pour ceux qui n'ont pas regardé les publicités à la télévision ces 20 ou 30 dernières années, les 'Couteaux Ginsu’ $®$ étaient et sont encore vantés pour leur tranchant et leur solidité, comme dit le slogan : «Ils coupent et tranchent net » [http:// oceansofkansas.com/bite-fr1.html] (21.1.2016)

Entre ses envies d'ailleurs et les critiques émise par l'ancien attaquant de l'AS Roma à l'egard de la clause de $5 \mathrm{M} €$ présente dans son contrat, le club de Florence a décidé de trancher net et a annoncé aujourd'hui le limogeage du coach italien [http://www.hommedumatch. fr/montella-vire-de-la-fiorentina_140856] (21.1.2016)

Des exigences qui tranchent net avec les belles paroles prononcées hier à l'occasion de l'inauguration de ce camp Sic, par les orateurs qui se sont succédé sur la tribune de circonstance de cet espace. Pour Raphaël Ngoa Nkou, « il faut faire retrouver au logement social sa place » [http://www.cameroon-info.net/stories/ 0,20631,@,habitat-un-camp-sic-pour-riches-ayaounde.html] (21.1.2016)

Autant vous prévenir tout de suite, si vous cherchez un jeu avec une trame scénaristique profonde, des rebondissements, des révélations, du drame et de l'amour, ne jouez pas à Waves! Les développeurs ont choisi de trancher net avec toutes sortes de narrations pour se focaliser sur ce qui fait la force du shoot'em up : le scoring [https://www.sw-servers.net] (21.1.2016)

Pertinente, alerte et percutante analyse du Prof. John Francis Mbala sur l'enjeu profond du sujet brûlant de l'heure de l'élection présiden- 
tielle en RDC dont il démontre de tenants et aboutissants que d'aucuns perçoivent difficilement alors qu'ils tranchent net en faveur du président candidat à sa propre succession Joseph Kabila [http://www.digitalcongo.net/article/78110] (21.1.2016)

REMARQUES : Dans son emploi transitif, trancher net (I) se dit du fait de couper, de trancher d'une manière précise, brutale, l'objet désignant souvent un animé ou une partie du corps. Dans son emploi absolu, il réfère à la coupe très nette, précise de l'instrument tranchant (épée, ciseaux). $\mathrm{Au}$ figuré, le sujet peut renvoyer à un élément du paysage ou de la nature qui se découpe nettement sur un fond (ex. de 1834), ou au fait de cesser brusquement (ex. de 1934). En (II), il se dit du fait de prendre une décision ou d'émettre un avis catégorique, sans ambiguïté ; l'objet peut aussi désigner un problème ou une difficulté que le sujet résout d'une manière nette et immédiate. En (III), il se dit d'une manière de parler sans détours, de façon directe, le sujet ne montrant aucune hésitation ni aucun signe d'embarras. Notons la collocation court et net. Net reste invariable dans la majorité des cas. Dans l'exemple de 1910, il s'accorde avec l'objet tout en gardant son interprétation adverbiale. Il est modifié par si, tout. VoIR AUSSI : couper net

\section{Trancher profond}

Couper profondément, en profondeur Transitif

1275 Au passer qu'il fist outre tint l'espee haucie Gerars, s'en feri si Corsolt delés l'oÿe Onques ses hiaumes bruns n'i valut une alie

Qu'il ne li ait la joe moult tres parfont trenchie (Adenet le Roi, Buevon de Conmarchis, 2757)

\section{Corpus Web :}

Y’a un mec comme ça, y’a quelques années qui veut faire une fondue bousguignonne, y coupe sa viande et commence a faire chauffer son huile sur le gaz, pensant gagner du temps, puis arriver al la fin de sa viande, y se tranche profond le doigt? [http://forum.doctissimo.fr/sante/hepatitesa-b-c/speeeeddd-sujet_67210_1.htm] (21.1.2016)
Troisième étape, les gorges de l'Aude et de l'Agly. Gorges des femmes de ce Midi, généreuses de tradition, dans celles des torrents pyrénéens orientaux qui tranchent profond maquis et garrigues [http://www.humanite.fr/node/212933] (21.1.2016)

Enfin, Lorenzetti a tranché. Tranché profond dans les valeurs du rugby. Un joueur viré en plein milieu de saison, c'est déjà du jamais vu [https://rugbyclub.wordpress.com/tag/berbizier] (21.1.2016)

REMARQues : Trancher profond se dit du fait de séparer, de détacher d'un tout, en coupant un corps (une joue, du bois) à l'aide d'un instrument tranchant (ici : une épée), et souligne davantage le résultat de l'action, c'est-à-dire une entaille très profonde. Dans le deuxième exemple du CW, trancher profond est employé dans le domaine de la géographie pour désigne des cours d'eau qui découpent profondément un paysage. Dans le dernier exemple du CW, il est employé au sens figuré de 'pénétrer, blesser profondément' et se dit du fait d'agir contre certaines valeurs, de briser un ordre établi. Profond reste invariable et est modifié par très.

\section{Trancher soef}

Trancher facilement

Emploi absolu

$\sim 1177$ Que pitiez l'i semont et prie Qu'il face secors et aïe

A la beste jantil et franche.

A l'espee, qui soef tranche,

Va le felon serpant requerre,

Si le tranche jusqu'an la terre

Et an deux meitiez le tronçone (Chrestien de

Troyes, Yvain ou Le Chevalier au lion, 3376)

-1200 .I. coutel out ou poig, qui mout trenchoit soué,

Don il se desdusoit a une pome ou pré.

Dou coutel ai la barbe a son maitre copé (Floovant [fin $\mathrm{XII}^{\mathrm{e}}$ ], 74)

+1250 Tel coup li done de rechef

Que tot li a brisie le chef.

Ne le crient mes ne ne le dote,

Par desuz la gorge li bote

Le bon cotel qui souef trenche (Le Roman de Renart [2e moitié XIII ${ }^{\mathrm{e}}$, IX, 921) 
1300 La cauce li trencha et l'esperon doré : Plain pié feri Bautisme en la tere et ou pré.

Dist li quens Oliviers : Cis brans trence souef;

Dix ait l'ame du fevre qui cest branc a trempré (Fierabras (K), 1377)

1370 Donc courut Aigres tant aprés qu'il l'aconsieuvy et lui donna un tel coup de l'espee sur le heaume que tout le pourfendi et lui cassa la coiffe, si que le brant, qui soef tranchoit, lui abati la destre oreille, et descendi le coup par dessus l'espaulle du roy si merveilleusement qu'il cheÿ a terre tous estonnez (Roman de Berinus, II, p. 178)

REMARQUeS : Trancher soef se disait du fait de couper avec aisance et légèreté, de manière délicate, à l'aide d'un instrument tranchant (couteau, épée). Soef reste invariable.

\section{Transpirer gras}

Exsuder une sueur grasse

Intransitif

1921 Je transpire gras (Exemple entendu /

Damourette et Pichon, § 983)

\section{Transporter droit}

Transporter directement

Transitif

1524 Lesquelz on porte aux festes voulentiers, Danses et jeux, ou se font fictions,

Là mieux qu'ailleurs, les desploye on d'un tiers.

Là les templiers font leurs processions, Mainte statue est droit là transportee, Et là se font grands intercessions (Jean Lemaire de Belges, La Description du temple de Venus)

CORPUS WEB :

Le film et la musique me bercent, m'illuminent et me transportent droit au pays imaginaire [http://www.underscores.fr/forum/view topic.php? $\mathrm{f}=6 \& \mathrm{t}=173 \& \mathrm{p}=71713]$ (21.1.2016)

Musiques : Parfaites, elles vous transportent droit dans le jeu. Chacune d'elles est spécifiques à un personnage ou à une situation précise [http:// pheonixwright.free.fr/TestPW1.html] (21.1.2016)
Les papiers peints nous transportent droits dans les années 70 [http://www.princesse-auxbidouilles.com/toc-toc-toc-chez-mernee] (21.1.2016)

les gars arrêté la fumette $(;)$, une dalle sa se transporte droite sur la tranche alors celui qui dit que ça rentre comme ça dans une corsa ou r16 ou meme n'importe quelle berline...je lui dit arrête de fumé [http://www.homecinema-fr.com/forum/ ecrans-tv-full-hd/2013-plasmas-panasonicst60-42-50-55-65-pouces-t30033559-3870.html] (21.12016)

REMARQUeS : Transporter droit se dit du fait de déplacer un objet directement, sans détour d'un lieu à un autre. Pris au sens directionnel, droit reste invariable dans les fonctions adverbiales, à l'exception du troisième exemple dans le CW. Par contre, dans le dernier exemple, il fonctionne comme prédicat second désignant la position verticale de la dalle. Droit tend à s'associer avec la préposition (à, dans) ou l'adverbe (là) qui le suit au point de faire partie du groupe prépositionnel.

\section{Travailler double}

Travailler le double, deux fois plus

Intransitif

1836 J'ai (eu) beau travailler double à mon retour afin de les rattraper, je vois qu'ils sont perdus pour toujours et qu'il faut en prendre mon parti (Alexis de Tocqueville, Correspondance avec Henry Reeve)

1936 Après la faillite dans les Modes à Courbevoie, il a fallu qu'ils travaillent double mes parents, qu'ils en mettent un fameux coup (Louis-Ferdinand Céline, Mort à crédit)

\section{Travailler dur}

Travailler beaucoup et avec énergie, en peinant Intransitif

1825 Le bailli Blackmuzzle lui a prêté la main pour cet établissement, et il dit qu'il a toujours trouvé en elle une femme travaillant dur, décente et honnête (Étienne de Jouy, L'Hermite en Écosse ou Observations sur les mours et usages des Écossais)

1833 Pour fournir des mêts à nos alliés à mesure qu'ils en avalaient, nos chevaux et nos moulins travaillaient dur (José 
Feliciano Barreto e Noronha de Castilho et Alexandre Magno de Castilho, Traité de mnémotechnie)

1857 Du reste, c'était aussi un malhonnête. "J'ai appris d'un colporteur qui, en voyageant cet hiver par votre pays, s'est fait arracher une dent, que Bovary travaillait toujours dur. Ça ne m'étonne pas, et il m’a montré sa dent ; nous avons pris un café ensemble » (Gustave Flaubert, Madame Bovary)

1883 « J'l'attends d'main, pour faire ma soupe du matin. »

Et il congédia les deux femmes. Adélaïde entra en fonctions le lendemain et se mit à travailler dur, sans dire un mot, comme elle faisait chez ses parents (Guy de Maupassant, Contes et nouvelles)

1887 Entre ces deux repas, il y en avait trois autres, le pain et le fromage du déjeuner, la seconde soupe de midi, l'émiettée au lait du goûter : en tout, cinq, des repas copieux, arrosés de cidre et de vin, car les moissonneurs, qui travaillent dur, sont exigeants (Émile Zola, La Terre)

1907 Il l'enlevait à bout de bras, la tournait vers la flamme de l'âtre, afin de voir la joie jeune au fond des yeux que l'enfant avait bridés, vivants et couleur de hêtre en automne, et il répondait en riant :

- C'est pour que vous ne travailliez ni l'une ni l'autre que je travaille dur, ma petite Marie! (René Bazin, Le Blé qui lève)

1932 Et depuis que tu es là, il me semble que c'est pour toi que j'ai relevé la maison, que j’ai travaillé si dur... Armand, lui, ne compte pas. Quant à moi, je n'y tiens plus guère, à cette boîte... c'est à toi que je la destine... (Roger Martin du Gard, Un taciturne)

1936a Vous comprenez, chez elle, dans les masures où habitaient les siens, on n'avait pas les moyens de faire attention. Et les hommes travaillaient dur, et les femmes donc, tout le jour, dès l'aube, dès la collation préparée pour le départ du père : moi, j'aimerais avoir un enfant, mais je crois qu'on m'a abîmée une fois pour toutes avec ce curetage (Louis Aragon, Les Beaux Quartiers)

1936b - Voilà, Ferdinand ! C'est l'Étoile Polaire !...

Je la connaissais moi la formule !... Papa il m’avait rassasié... On a pas idée de ce qu'à l'époque elle travaillait dur la conscience !... Mais c'était pas une solution... Au Parquet ils se tâtaient vraiment s'ils allaient pas le mettre sous verrous... (Louis-Ferdinand Céline, Mort à crédit)

1946a Je bus pas mal de bourbon pendant ces jours-là. J'avais la cervelle qui travaillait dur. Je me procurai d'autres trucs en plus des cartouches ; j'achetai une pelle et une pioche et de la corde. Je ne savais pas encore si ma dernière idée marcherait (Boris Vian, J'irai cracher sur vos tombes)

1946b Depuis l'arrivée de leurs voisins il travaillait moins dur, aux champs, et se traînait lamentablement à la suite d'Henri qui avait rallié une équipe de camarades bien plus jeunes que Jean :

- Vous venez, on va tous au moulin, puis on fera une balade dans l'auto de Terry, dépêchez-vous !

(Marguerite Duras, Les Impudents)

+1963 « Alors, ça y va, la manœuvre ? » Dans l'immense nébuleuse où nous ont enveloppés les habitudes acquises, cela signifie : «Alors ça travaille dur ? » Nous avons compris, la phrase a eu ce clin d'œil par quoi elle se veut de participer à l'inflation générale et d'exprimer plus qu'elle ne dit (Antoine Blondin, Ma vie entre les lignes [1963-1970])

1977 Les premiers à s'endormir - Lehern, Christophe, Hantier, Cuviet Jules aussi, ça travaillait tôt et dur, le soir ils avaient tendance à fermer de bonne heure. Surtout quand la discussion pinaillait idéologiquement. Appel des présents. Mention des excusés (Jean-Pierre Chabrol, La Folie des miens) 
1996 Maman, s’arrêtant net sur le trottoir, dans cette grisaille lourde, et nous toisant :

- Comment oses-tu parler ainsi ? La mère de notre papouchka! Lui qui travaille si dur, qui a un tel plaisir à l'inviter. Une honte!

Boris et moi, interloqués, ne sachant quoi répondre, maugréant enfin :

- C'est... c'est pour t'aider

(Boris Schreiber, Un silence d'environ une demi-heure)

CORPuS WeB :

Les pauvres ne seraient donc pas français? Il dit travailler dur, comme si les autres pouvaient travailler mou [http://www.voie-militante.com/ politique/extreme-droite/le-vomi-du-tout-petitpeuple-de-droite] (20.1.2016)

OL : même pendant la trêve internationale, les Lyonnais travaillent dur [http://www. olympique-et-lyonnais.com/ol-meme-pendantla-treve-internationale-les-lyonnais-travaillent, 110979.html] (21.1.2016)

Les musiciens travaillent durs sur le projet club 27 en vue du concert de février 2016. Une première générale aura lieu ce dimanche au planet $(-)$ vivement dimanche quel'on puisse mesurer le potentiel de ce projet [https://www.facebook. com/AssociationaVosOreilles/posts/416337035 222892] (21.1.2016)

« J'ai vu des français qui travaillent durs et qui sont frappés brutalement par le matraquage fiscal »@VirginieCalmels \#Limoges [https://twit ter.com/UDI_33] (21.1.2016)

REMARQUES : Travailler dur réfère à une personne qui exerce un travail exigeant, difficile et fatiguant physiquement (comme le travail agricole), avec énergie et en se donnant du mal. L'orthographe soignée n'admet pas l'accord, même si dur est coordonné avec des adjectifs eux accordés (ex. de 1825). Les exemples familiers du CW montrent cependant que l'accord est possible sans que dur ne devienne un prédicat second. Il est modifié par moins, si, toujours. Notons l'emploi impersonnel familier ça travaille dur et l'emploi antonymique travailler mou.

\section{Travailler ferme}

Travailler beaucoup, résolument

Intransitif

1372 LE MARI. Gertrus, oil. Elle travaille fort et ferme.

Je ne scé si venrez a terme (Miracle de saint Jehan le Paulu, 750)

1637 Il y avoit pourtant un peu de mal entendu entre luy et nostre compagnie qui n'est pas encores bien r’adjusté, à quoy l'on travaille fort et ferme pour establir quelque bonne correspondance et pleine confiance entre cez messrs si faire se peult (Nicolas de Peiresc, Lettres à Guillemin)

1713 Les ennemis travaillent fort et ferme à retrancher le défilé de Traumale, par où l'on va de Palamos dans le Valdaro (Philippe de Dangeau, Journal)

1836 M. Daru aurait dû me faire nommer et ensuite me faire travailler ferme (Stendhal, Vie de Henri Brulard)

1870 Ils voient les domestiques et les servantes, frais et joufflus, autour de la table, en train de manger et de boire un bon coup, comme cela doit être lorsque l'on travaille ferme et longtemps (Émile Erckmann et Alexandre Chatrian, Histoire d'un paysan)

1929 Bientôt nous entrâmes dans Barcelone. La presse d'information, les agences de nouvelles, les bureaux de publicité, le télégraphe, le téléphone, la radio, toutes les grandes voix de la cité travaillaient ferme à faire le silence sur le dernier scandale du jour (Henry de Montherlant, La Petite Infante de Castille)

1945 Je comptais travailler ferme à cette étude sur Rimbaud, mais la littérature m'ennuie (Julien Gracq, Un beau ténébreux)

\section{CORpus Web :}

C'est bien déplorable pour cette étape exceptionnelle et ses propriétaires qui travaillent ferme pour maintenir une tradition culinaire de qualité en désuétude [https://www.tripadvisor.fr/ ShowUserReviews-g1535782-d3571372-r2194501 58-La_Ferme_Auberge_Du_Grand_Coderc-Saint Rabier_Dordogne_Aquitaine.html] (21.1.2016) 
Afin de préparer avec le soin qu'il se doit une aventure qui durera une semaine, les enfants et leurs maîtres ont convenu de se constituer un " trésor de guerre ». Depuis la rentrée de septembre, ils y travaillent ferme. Ils cultivent un jardin et négocient leurs récoltes. Ils confectionnent et vendent des confitures [http://www.lade peche.fr/article/2015/11/03/2209531-petit-dejeu ner-pour-tous-a-l-ecole.html] (21.1.2016)

Le président du Club de Chicoutimi, Serge Tremblay, précise qu'au moins une dizaine de curleurs et curleuses de plus de 80 ans travaillent fermes sur les glaces pour accéder aux rondes éliminatoires [http://www.neomedia.com/sague nay-lac-st-jean/actualites/sports/279885/lecurling-tres-populaire-parmi-les-aines-dans-laregion] (21.1.2016)

REMARQUES : Travailler ferme se dit du fait de travailler avec beaucoup d'énergie, le sujet s'appliquant, se donnant du mal pour atteindre son but. Dans les exemples plus anciens, ferme apparaît régulièrement dans la collocation travailler fort et ferme, fort venant souligner davantage l'idée de difficulté, d'effort, le sujet s'activant à la tâche. Ferme reste invariable dans la majorité des cas. Toutefois, dans le dernier exemple du CW, il s'accorde avec le sujet au pluriel tout en gardant son interprétation adverbiale.

\section{Travailler fort}

Travailler beaucoup, intensément Intransitif

-1200 Et por ce que aaissier vouloit La rëine, qui se douloit, Li mist son chief sor ses genouz, Come piteus et frans et douz, Tant que la rëine s'andort, Qui traveillié avoit molt fort (Guillaume d'Angleterre [fin XII ${ }^{\mathrm{e}}$ ], 490)

+1365 Et pour ce mon esperis

Onques ne dort,

Ains veille et traveille fort,

Pensant toutdis,

Et appelle un paradys

Le plaisant port

De ma dame et le ressort

De son cler vis

(Jean Froissart, Poésies [3 $3^{\mathrm{e}}$ tiers XIVe])
+1415 Serviteur plus de vous, Merencolie, Je ne seray, car trop fort y traveille ; Raison le veult, et ainsi me conseille Que le face, pour l'aise de ma vie (Charles d'Orléans, Poésies [ 1415-1440], II, Rondel CCLXX, p. 445)

\section{CORPUS WEB :}

Les bénévols qui se sont impliqués depuis le tout début de ce projet, travaillent fort, pour organiser la salle avant la soirée de levée de fonds pour le CALAS de l'Outaouais et le CALACS de la Haute-Gatineau [https://www.youtube.com/ watch?v=cwyOmtq3B6A] (21.1.2016)

« Il faut travailler fort pour avoir du succès dans la vie », a-t-elle lancé, visiblement irritée des commentaires qu'elle entend régulièrement au sujet de ses enfants [http://www.msn.com/fr-ca/ divertissement/celebrite/caitlyn-jenner-affir me-que-ses-enfants-travaillent-fort/ar-BBna9 $\mathrm{mq}]$ (21.1.2016)

Nos jeunes qui travaillent forts. :) Our youth working hard $(-)$ [https://www.facebook.com/cen treaccroche/posts/600670043407734] (21.1.2016)

Nos cuisinières travaillent forts pour vous satisfaire et respecter vos besoins alimentaires tout en vous offrant des repas de qualité [http://www. residencestephrem.com/sante.php] (21.1.2016)

REMARQues : Travailler fort se dit du fait de travailler avec beaucoup d'énergie, le sujet s'activant et s'appliquant dans son travail, se donnant du mal pour atteindre son but, fort soulignant l'idée de difficulté et d'intensité. L'orthographe soignée refuse l'accord, mais le style familier l'admet tout en gardant son interprétation adverbiale (derniers exemples du CW). Il est modifié par moult, trop. Notons que tous les exemples du CW proviennent du Québec. On peut donc probablement dire que travailler fort n'est que d'un emploi régional aujourd'hui (ce qui explique le hiatus chronologique). Mentionnons à ce propos que l'on ne revèle aucune occurrence de travailler fort et ferme (s.v. travailler ferme) à partir du XIX ${ }^{\mathrm{e}}$ siècle. 


\section{Travailler mou}

Travailler sans énergie

Intransitif

1958 L'honneur des Jules consiste à ne rien faire, à talocher dur la gosse qui travaille mou (Le Monde, 23 novembre 1958 / Grundt : 248)

\section{CORPUS WEB :}

Les pauvres ne seraient donc pas français? Il dit travailler dur, comme si les autres pouvaient travailler mou [http://www.voie-militante.com/ politique/extreme-droite/le-vomi-du-tout-petitpeuple-de-droite] (20.1.2016)

Re : quel pinceau utilser pour bien travaille

Kikou, chacun sa façon de travailler mou je prefère faire mes french avec le spot, lol [http:// forum.manucure.info/index.php?threads/quelpinceau-utilser-pour-bien-travaille.284728] (20.1.2016)

Si je dois donner mon avis, je dirai que le sucre que ton fils tire est encore épais et manque de finesse. Peut être qu'il travaille sa masse trop froide et ne peut donc la tirer comme il faut. $\mathrm{Tu}$ peux la travailler molle et tu resatines ton sucre pendant que le pétale tiré refroidit [http://patis serie.clicforum.com/t504-Sucre-tire-premier essai.htm?start=75] (20.1.2016)

REMARQUES : Travailler mou se dit du fait d'exercer un travail, qu'il soit manuel ou intellectuel, avec lenteur, sans vigueur, ce qui traduit un manque de motivation et d'enthousiasme. Notons l'opposition sémantique avec travailler dur. Mou reste invariable dans son emploi adverbial. Toutefois, en tant que prédicat second, il s'accorde avec l'objet dans l'emploi transitif du verbe (v. le dernier exemple du CW) où il désigne une qualité comme résultat du fait de travailler quelque chose (ici : du sucre). Notons l'emploi de talocher dur 'gifler, frapper fort'

\section{Travailler rude}

Faire un travail pénible et acharné Intransitif

1849 Là-dessus, Landry ayant promis de faire de son mieux, s'en alla au labourage, où il fit bonne contenance et bon office tout le jour, et d'où il revint ayant grand appétit ; car c'était la première fois qu'il travaillait aussi rude, et un peu de fatigue est un souverain remède contre le chagrin (George Sand, La Petite Fadette)

1937 En 1897, il [= Huysmans] travaillait rude pour sainte Lydwine, ce qui lui était particulièrement fatigant, puisqu'à cette époque il avait à corriger les épreuves d'imprimerie de « La cathédrale » (Ludovic Bron, Huysmans, d'après des documents inédits)

\section{CORPUS WEB :}

Et qu'elle aimait le Tonin, un berger qui travaillait rude mais ne gagnait qu'une misère, parce que sa mère lui mangeait tout l'argent [http:// ecriveuse.canalblog.com/archives/2006/12/03/ 3327732.html] (3.12.2006)

Les jardiniers et leurs tracteurs travaillaient rude tous les jours, mais on comprend pourquoi quand on voit l'étendue du jardin. L'hôtel était loin d'être plein [https://www.tripadvisor.fr/Show UserReviews-g652080-d231460-r15525958-Vila lara_Thalassa_Resort-Porches_Faro_District_ Algarve.html] (1.5.2008)

\section{Travailler sérieux}

I. Travailler sérieusement, avec soin et réflexion Intransitif

1845 et les premières allégresses des voluptés charnelles, et les soirs d'hiver chez lui, là-bas, quand il travaillait tranquille et sérieux, à la lueur calme de son flambeau ; et puis ce jour, aux Tuileries, où la neige craquait sous ses pas (Gustave Flaubert, La Première Éducation sentimentale)

1924 Noémie prît toujours la peine d'expliquer poliment qu'elle n'était pas comme sa mère, qu'elle n'aimait pas le travail, qu'elle ne travaillait si sérieuse que parce qu'elle était paresseuse au fond, qu'un fil de laine l'arracherait à son ouvrage, qu'il fallait avoir pitié de son humeur et ne pas la distraire (Marcel Jouhandeau, Les Pincengrain)

II. Causer de forts troubles, beaucoup de soucis Transitif

1963 Les lardus, ce Youpe, ils auraient bien voulu se le mettre sous le feu de leurs 
questions. Ça les travaillait sérieux. Ils le voyaient à plusieurs têtes (Alphonse Boudard, La Cerise)

\section{Corpus WeB :}

Allez un codeur pour deux personnes qui travaillent sérieux et profesionnelements. Bonne chance [http://ladywaterlooblogdunegrandme reindigne.blogspot.co.at/2015/03/cest-quoi-lamaltraitance.html] (20.1.2016)

$\mathrm{Au}$ cas ou s'il y a problème pendant 1 ans, est-ce qu'on peut avoir l'échangement ou le remboursement? Ils travaillent sérieux ? [http://www. deco.fr/forum-deco/la-table-relevable-27334. html] (20.1.2016)

REMARQUES : Travailler sérieux (I) se dit du fait d'exercer un travail, qu'il soit manuel ou intellectuel, avec application, consciencieusement, en s'impliquant. (II) désigne une chose (des questions) qui viennent préoccuper, tourmenter, tracasser ou inquiéter vivement quelqu'un. Sérieux se rapproche d'une fonction de quantifieur (ça les travaille sérieusement). Il peut s'accorder avec le sujet et être modifié par si. Notons la collocation tranquille et sérieux.

\section{Travailler tranquille}

Travailler tranquillement, en paix, dans le calme Intransitif

1861 Charles est resté à Bruxelles, mais grâce au chemin de fer, Bruxelles et Waterloo se touchent. Je me cache ici, afin de pouvoir travailler tranquille; Charles me garde le secret de ma retraite ; si l'on me savait à Waterloo, j’y serais assiégé de curieux, les plus bienveillants du monde, c'est vrai ; mais je ne pourrais rien faire (Victor Hugo, Correspondance)

1936 Il les regarda s'éloigner, songeur, et secoua négativement la tête :

- Non, pas ça... pas moi... filer en pays neutre, ça peut se défendre. Mais, si c'est pour «travailler tranquille » et « gagner sa croûte », pendant que les autres... non !... Il fit quelques pas et s'arrêta de nouveau : - Alors, quoi ? (Roger Martin du Gard, Les Thibault. L'Été 1914)
1937 Justin disait : « Ils négligent un peu l'imprimerie. Cependant nous, du moins, nous pouvons travailler tranquilles. Schleiter n'a pas absolument tort. »

Nous n'étions pas tenus à l'écart des débats de la commission ; mais elle délibérait au large (Georges Duhamel, Le Désert de Bièvres)

1945 Henriette était un peu comme cette mère : pendant qu'elle cherchait, qu'elle prenait des trains et des autobus, qu'elle faisait des kilomètres à pied pour qu'Alexis pût enfin travailler et vivre tranquille, il était en train de mourir ! Elle ne se faisait pas à cette idée, à cette horreur, elle dut même s’aliter (Elsa Triolet, Le Premier Accroc coûte deux cents francs)

1968 - À présent, je voudrais qu'on me foute la paix... tu comprends ! Qu'on pense ce qu'on voudra, mais qu'on me foute la paix... Qu'on me laisse travailler tranquille, et crever tranquille... C'est tout ce que je demande!

Elle le regarda encore quelques instants, puis elle s'éloigna sans un mot (Bernard Clavel, Les Fruits de l'hiver)

1979 C'est là-dessus que nous avons peut-être passé le plus de temps, et que nous nous sommes donné le plus de mal... Remarquez que c'est ça qui nous a permis de durer si longtemps et de travailler tranquilles... Vertex, on n'en parlait pas. On continuait à l'avancer en douce, sans nous en vanter trop... (Claude Roy, La Traversée du Pont des Arts)

1998 En attendant, les nerfs de votre époux lâchaient.

- Faisons baptiser Alizée ! gueulait-il. Que je puisse travailler tranquille!

Ma mère m'empoisonne pieusement la vie. Embêtée, vous allez demander conseil à votre très cher et très respecté ami (Nicole de Buron, "Chéri, tu m'écoutes?»)

CORPuS WEB :

Ouais mais ils travaillent tranquille et ont un job respecté de tous (-) [http://www.jeuxvideo. com/forums/1-50-135974414-1-0-1-0-les-wesh-ag resses-car-ils-sont-pauvres.htm] (20.1.2016) 
Dernière solution, c'est une tactique et pendant qu'on parle de lui Ricort et Cohen travaillent tranquilles comme ce fut déjà évoqué dans un précédent topic mais alors là ils n'ont pas intérêt à se louper et à nous faire signer Manchev le 22 janvier par exemple [http://www.ogcnissa.com/ forum/viewtopic.php?t=12204\&start $=0 \&$ sid $=\mathrm{d} 6$ 180492027a89d54d683e777207e7e9] (20.1.2016)

REMARQUES : Travailler tranquille se dit du fait de travailler sans bruit ni trouble, dans une atmosphère calme, détendue, propice à la réflexion, au processus de travail, sans être dérangé (Laissemoi (travailler) tranquille!) ou sans déranger les autres (premier exemple du CW). Il tend donc à l'emploi circonstanciel. Ceci vaut également pour vivre tranquille, dans l'exemple de 1945, et pour crever tranquille, dans celui de 1968 ('en paix'). Tranquille peut s'accorder comme prédicat second avec le sujet (dernier exemple du CW).

\section{Traverser droit}

Se rendre d'un point à un autre directement Transitif

1741 Le mot Lud signifie en Arabe ce qui est tortu, ou ce qui serpente, parce que, comme le remarquent Hérodote, Diodore de Sicile, et Strabon, le Nil qui traverse tout droit l'Égypte, serpente dans l'Éthiopie (Charles Le Cène, Projet d'une nouvelle version françoise de la Bible)

1839 Il ne faut pas traverser ce grand pré tout droit (Stendhal, La Chartreuse de Parme)

1875 Ils traversèrent le parterre tout droit, sans s'arrêter au réveil des fleurs, nues dans leur bain de rosée (Émile Zola, La Faute de l'abbé Mouret)

1966 Elle traversa la ville tout droit jusqu'aux quais de la Saône. Elle voyait des îles, en face d'elle, et sur la plus grande, des bâtiments qui devaient être un hôpital. Elle monta sur un trottoir au bord du fleuve, arrêta le moteur, éteignit ses feux de position (Sébastien Japrisot, La Dame dans l'auto)

1982 La moto traversa tout droit le carrefour et sans dévier d'un mètre, sans ralentir un instant, s'enfonça de plein fouet dans une voiture garée en face (Alain Page, Tchao Pantin)

\section{Corpus Web :}

Croiser et traverser droit le boulevard extérieur (face à l'Horloge des arts et métiers) [http:// www.aixenprovence.utan.fr/IMG/pdf/gite-anconditions2011_cle06196d.pdf] (20.1.2016)

Traverser droit sous la croix, très exposé, sinon saut de corniche pour rentrer dans la face [http://www.camptocamp.org/routes/497101/fr/ pointe-de-pelluaz-face-n] (20.1.2016)

REMARQUES : Traverser droit réfère à une personne ou à un véhicule qui franchit ou parcourt quelque chose d'une extrémité à l'autre directement, sans pause ni détour, le complément d'objet pouvant désigner une étendue, un milieu ou une surface. Droit reste invariable. Modifié par tout, il peut précéder ou suivre le complément d'objet direct.

\section{Trébucher mort}

Tomber mort

$\lambda$ abattre mort

\section{Trépasser droit}

Traverser directement

Pronominal

+1225 Et bien saciés que par la vile

Gent de mainte manire avoit.

Et il s'en trespassent tout droit

Si con la voie les comporte,

Tant k'il vienent a la grant porte

Des murs qui les pailais clooient

A grans houdeïs. Et il voient

Grans fossés plains d'ywe et palis (Le Chevalier as deus espees [ $2^{\mathrm{e}}$ quart XIII $]$, 4246)

REMARQues : Usité en ancien français, trespasser droit se disait du fait de passer d'un lieu à un autre en se dirigeant tout droit, sans aucun détour. Droit reste invariable et est modifié par tout.

\section{Tressauter soef}

Bondir en douceur

Intransitif

+1250 Mes onques tel joie ne fu Con Renars fet, li desloial. Et puis bee amont et aval Tant qu'il coisi sor l'arbre en haut Le moinnel qui saut et tressaut De branche en brance molt soe (Le Roman de Renart [2 $2^{\mathrm{e}}$ moitié $\mathrm{XIII}$ ] $, \mathrm{XI}, 777$ ) 
REMARQUES : Tressauter soef se dit d'un oiseau qui saute, bondit, se déplace en faisant des mouvements dont la légèreté produit une impression subtile et agréable. Soef est modifié par moult. VoIR AUSSI : sauter soef

\section{Tresser menu}

Faire de petites tresses fines

Transitif

1170 D'un grant topace cler e chier Tint en sa main un encensier, 0 chaeines bien entailliees

E de fil d'or menu treciees [variante : moult bien treciees] (Benoit de Sainte Maure, Le Roman de Troie, 14898)

REMARQUES : Tresser menu désignait le fait d'enlacer, d'emmêler, d'entrecroiser des matériaux l'un dans l'autre pour en faire une tresse fine, étroite, ajustée. Menu reste invariable.

\section{Tricoter blanc}

Tricoter avec de la laine blanche

Emploi absolu

1956 Tricotez blanc (Marie-France, octobre 1956 / Grundt : 252)

REMARQUES : Blanc réfère à la couleur blanche de la laine, du fil ou du coton utilisé pour confectionner un tricot à la main ou à la machine.

\section{Tricoter chaud}

Tricoter des vêtements chauds

Emploi absolu

2013 En été, je fais des petits vêtements de mi-saison ; en hiver, je tricote chaud

(Exemple entendu, Corpus Coiffet 2018 : S.v.)

\section{Tricoter droit}

Tricoter sans augmentation ou diminution Emploi absolu

1954 Augmenter de chaque côté 5 fois 5 mailles tous les 2 rangs puis tricoter $4 \mathrm{~cm}$ droit (Mode du jour, 25 novembre 1954 / Grundt : 385)

CORPUS WEB :

Une vidéo pour apprendre à tricoter droit (aller retour) avec des aiguilles circulaires. Coment utiliser des aiguilles circulaires à la place d'aiguilles droites très faciles à utiliser et moins encombrantes que des aiguilles droites [http:// www.abc-apprendre.com/loisirs-creatifs/trico ter-droit-aiguilles-circulaires-r47.html] (19.1.2016)

Un pull carré c est que pour les emmanchures, vous diminuez que 4 mailles et vous continuez a tricoter droit. et pour la manche, vous ne faites pas de diminutions vous arretez la manche a la bonne hauteur (ex ; de dessous de bras, au poignet $=40 \mathrm{~cm}$ ) [https: $/ /$ www.youtube. com/watch?v=eQCicGymssI] (19.1.2016)

J'ai fini une bricole en tricot, genre un truc très très simple qui se tricote droit et ou on ne compte pas, il y a plus de 10 jours et je n'ai rien remis en route.... [http://sitotditsidofait.canal blog.com/archives/2015/01/15/31319767.html] (19.1.2016)

Justement, cette brassière se tricote " droite »! Il n'y a aucune augmentation ou diminution ! Juste une seule maille supprimée au moment de la séparation des emmanchures ! [http://www.forumtricotin.com/index.php?to pic $=62932.15](19.1 .2016)$

Voila j'ai terminé ma robe en laine. elle se tricote droite pour le point. c'est très facile elle se fait sur deux lignes [http://chez-mamie-recette.forum actif.org/t407-une-tite-robe-en-laine] (19.1.2016)

REMARQUES : Tricoter droit réfère à une manière de tricoter dans laquelle on ne réduit ni n'augmente le nombre des mailles de sorte que le tricot, les côtés, la figure, ne s'écartent pas de la ligne droite. Droit reste invariable dans la majorité des cas. Toutefois, dans l'emploi pronominal à sens passif du verbe, il peut s'accorder avec le sujet (v. les deux derniers exemples du CW).

\section{Tricoter dur}

Marcher, avancer vite

Intransitif

1951 Nous n'avons plus de chevaux. Il nous faudra tricoter dur. Je pense maintenant que les deux personnes qui filaient si gentiment en cabriolet devaient être des fous. Aller à pied n'est pas du tout la même chose qu'aller à cheval (Jean Giono, Le Hussard sur le toit) 


\section{CORPUS WEB :}

Effectivement, belle bête. $60 \mathrm{KM} / \mathrm{H}$ avec des roues de 1m10, ça devait tricoter dur... [http:// www.passion-metrique.net/forums/viewtopic. php?f=2\&t=3011\&start=75] (19.1.2016)

Euvre du Marin Breton gratte, gratte des places : en 24 heures, Jean-Baptiste est remonté de la 10e à la 6e place. Pour autant, il n’a pas gagné de terrain sur le leader ! 5 milles les séparent. La bataille est rude, il faut tricoter dur, l'axe du vent (10-15 nœuds) étant pile sur la route de Sada, nouvelle étape de la Mini à la Corogne [http://jblemaire607.blogspot.co.at/2013/10/pilecontre-le-vent.html] (19.1.2016)

Je n’ai plus qu'à dégainer les aiguilles $\mathrm{n}^{\circ} 4$ et le câble de $80 \mathrm{~cm}$ et c'est parti ! Demain matin dans le train ça va tricoter dur !!! [http:// mavieenclaire.blogspot.co.at/2012/01/ca-va-tri coter.html] (19.1.2016)

Allez les filles, avec ce temps pourri (beaucoup de pluie...), ça va tricoter dur ce week-end encore pour moi [http://www.beaute-test.com/ forums/index.php?topic $=253626 \&$ start $=270]$ (19.1.2016)

REMARQUes : Dans l'exemple de 1951, tricoter dur se dit du fait de marcher ou courir en accélérant le pas, les jambes étant comparées aux aiguilles d'une tricoteuse ; cette signification apparaît dans les deux premiers exemples du CW (par analogie : un moteur, un bateau qui vont à toute vitesse). Dans les troisième et quatrième exemples du CW, tricoter figure dans son sens concret (préparer un ouvrage à l'aide de fils et d'aiguilles) avec dur fonctionnant comme intensifieur. Notons l'emploi impersonnel familier ça va tricoter dur, dans les deux acceptions.

\section{Tricoter ferme}

I. Battre, donner une raclée

Transitif

1843 L'argent, c'est la vie. Monnaie fait tout. Que nous chante-t-il donc, cette grosse souche d'Alsacien ? Delphine, ne fais pas une concession d'un quart de liard à cette grosse bête, qui t'a mise à la chaîne et t'a rendue malheureuse. S'il a besoin de toi, nous le tricoterons ferme, et nous le ferons marcher droit (Honoré de Balzac, Le Père Goriot)
II. Courir, (s'en) aller vite (concret et abstrait) Intransitif

1850 - Toi... ma chérie... pour le quart d'heure... il faut que tu galopes de front avec ton époux...

- Mon époux ?...

- Eh bien !... oui... là... je t’épouse... ma foi ! tant pis... je suis capable de tout pour le bonheur de mon maître, et comme présentement il s'agit pour le rendre heureux de tricoter des jambes... tricote ferme... et je t'épouse !... (Charles Deslys, La Marchande de plaisirs)

1894 Abric aura là un rude adversaire [= dans la course cycliste] et bien que marchant fort gentiment, lui aussi, il devra tricoter ferme pour ne pas se faire gratter indignement (La Bicyclette)

1957 - Est-ce que vous êtes du 43 bersagliers? demanda le paysan. Il est parti d'ici il y a une heure.

- Ce $43^{\mathrm{e}}$ me convient, se dit Angelo, et il tricota ferme.

Il était trempé de sueur et à bout de souffle quand il rejoignit une sorte de petite arrière-garde ou, plus exactement, une dizaine de traînards (Jean Giono, Le Bonheur fou)

2012 Mais comme il faisait de grande [sic] enjambées, elle dut tricoter ferme pour le rattraper (Anne-Sophie Lentura de la Rutnel, La Légende des princes des ténèbres)

2017 Il démarre à fond, et derrière lui ma petite infirmière est obligée de tricoter ferme des mollets

- Au galop ! au galop! (Mathieu Belezi, Le Pas suspendu de la révolte)

III. Tricoter (des vêtements) avec zèle et concentration (sens propre) ; bâtir, construire (un ouvrage) avec application (au figuré) Intransitif

1906 La réunion des mères de famille, le mardi après-midi, continue à être bien suivie. On $\mathrm{y}$ tricote ferme et on y aime beaucoup la lecture, à haute voix (La Mission populaire évangélique de France) 
1959 Elle m'entraîne, pour me faire visiter. Au rez-de-chaussée un essaim de fées Carabosse, tassées dans des fauteuils, tricotent ferme en papotant d'une voix aussi pointue que leurs aiguilles (Hervé Bazin, La Fin des asiles)

1984 Certes, l'orchestre tricote ferme, mais que de faisceaux de mailles y sont parfois lâches, puis trop serrés! Avec indulgence, disons que l'orchestre peut tenir (DahmStoltz, Caractères musicaux et généraux)

REMARQUES : La polysémie remarquable de tricoter ferme montre que ce groupe s'est largement diffusé dans la langue et notamment dans l'argot populaire. La motivation du sens (II), 'aller, courir vite, se dépêcher' apparaît clairement dans l'exemple de 1850 qui établit un rapport entre les jambes et le mouvement des aiguilles (" tricoter des jambes »). Notons l'emploi de marcher droit.

\section{Tricoter frais}

Tricoter des vêtements légers et agréables à porter

Emploi absolu

1958 Tricotez frais et léger pour l'hiver (Paris Match (Publicité), 10 avril 1958 / Grundt : 236)

\section{Corpus Web :}

Si vous voulez tricoter quelque chose de plus confortable cet hiver, pensez à tricoter avec polaire au lieu de fil traditionnel. [...] Achetez polaire à votre magasin de tissu local et de le transformer en un nouveau matériau à tricoter frais. Polar fil de laine polaire est volumineux, et qu'il faudra donc un motif simple et de grandes aiguilles [http://www.sc-pga.com/comment-trico ter-avec-polaire] (19.1.2016)

Barth Skull Beanie enfants de la dernière collection. chapeau tricoté frais dans différentes couleurs [http://www.ebay.fr/itm/Barts-Tete-demort-Bonnet-Enfants-noir-tricote-a-la-mainpour-/370937775949] (19.1.2016)

REMARQues : Tricoter frais se dit du fait d'exécuter, à la main ou à la machine, un vêtement en mailles léger et agréable à porter en été. Notons les groupes tricoter frais et léger.

\section{Tricoter lâche}

Tricoter en ne serrant pas les mailles

\section{CORPUS WEB :}

Aig. $\mathrm{n}^{\circ} 3$ (Je conseille à celles qui tricotent lâche de choisir une laine qui se tricote habituellement en 3,5 pour que les mailles soient bien serrées. C'est important pour que le bourrage ne transparaisse pas à travers les mailles et pour une tenue ferme de la poupée) [http:// temperance-oc.blogspot.co.at/2010/01/poupeefille.html] (19.1.2016)

Les mensurations que je vous donne correspondent au fil « Lambswool » de Phildar pour les personnes qui tricotent lâche [http://tricot.actif. creatif.solidaire.over-blog.com/tag/tutoriels] (19.1.2016)

Je viens de trouver la photo de ton modèle, peut-être que la partie basse se tricote lache pour plus de souplesse ? Comment se tricote le haut... [http://www.forums.supertoinette.com/ recettes_441332.problme_d_chantillon_sur_un_ modle_tricot.html] (19.1.2016)

REMARQues : Contraire de tricoter serré (v. remarques s.v.). Emploi intransitif (deux premiers exemples) et pronominal à sens passif (dernier exemple).

\section{Tricoter léger}

Tricoter des vêtements légers, peu épais : employer un fil léger

Intransitif

2013 Et voilà ! J'ai tricoté léger pour l'été ! (Exemple entendu, Corpus Coiffet 2018 : s.v.)

\section{CORPUS WEB :}

Gant 100\% coton tricoté léger et traité « Actifresh » antibactérien garantissant une meilleure hygiène pour vos mains [http://www.btp promo.com/gant-100-coton-tricote-leger.html] (19.1.2016)

Fil à tricoter léger et volumineux, Seraina de Lang Yarns se présente sous l'aspect d'un tube tricoté multicolore [http://www.ambiance-laine. fr/lang/1252-seraina.html] (19.1.2016)

REMARQUES : Tricoter léger réfère au fil ou au vêtement, ce dernier ne pesant pas lourd, ne chauffant pas trop, laissant passer l'air. Notons la 
collocation tricoter léger et volumineux ainsi que frais et léger (v. ex. sous tricoter frais)

\section{Tricoter serré}

Tricoter en serrant les mailles

Emploi absolu

1723 Un bas qui prête, celui qui n'étant pas tricoté serré s'élargit facilement

(Jacques Savary Des Bruslons, Dictionnaire universel de commerce)

1953 Je tricote lâche, ma sœur qui tricote serré, prétend que je fabrique du filet de pêche (Exemple entendu, 18 avril 1953 / Grundt : 298)

\section{CORPUS WEB :}

Ces femmes qui chevauchent les motos au dos droit et à la tête bien haute porte sur leur dos un enfant qui ne saurait trouver meilleure place. Mobilette, vélo, camion, 4x4 tricottent serré pour partager la route. Même les ânes, à leur rythme, suivent le trafic [http://manuebabin.blogspot.co. at/2011/02/nous-avons-ete-acceuillies-laeroport. html] (18.1.2016)

Depuis plus de 40 ans, des relations culturelles stimulantes se sont tissées entre la Belgique et le Québec. En 2015, avec l'événement Mons, capitale européenne de la culture, quelques modèles belges inspirants elles se tricotent serré. Coup de projecteur sur les Québécois en Belgique et les Belges du Québec [http://www.youscribe. com/catalogue/livres/art-musique-et-cinema/ jeu-revue-de-theatre-no-155-2015-2-2577827] (19.1.2016)

Par experience, pour mon châle j'ai commencé avec 6 mailles, et j'ai tricoter jusqu'à avoir $150 \mathrm{~cm}$ de long, je pense que ça depend comment tu le veux en longueur. Car on ne fait pas tou(te) $\mathrm{s}$ les meme points, certain(e)s tricotent serrés d'autre laches... [http://www.forumtricotin.com/ index.php?topic=37565.0] (18.1.2016)

Que je parle de tous ces «bons moments » vécus en FAMILLE, de ces belles retrouvailles, de ces liens qui se tricotent serrés, de cette joyeuse complicité qui naît et renaît entre nous... De ces rires et de ces « Poutpout... » imprévus, incommodants...parfois !... [http://ange-aerien. blogspot.co.at/2009/01/comment-amnager-unechambre-dans-un.html] (18.1.2016)
Où on confirme que les ganseys (l'Aberlady est un gansey - pull typique des pêcheurs des îles anglo-normandes, britanniques, irlandaises - et p'têt d'autres) se tricotent serrés [http://aberlady. canalblog.com/archives/2007/02/27/4148428. html] (18.1.2016)

REMARques : Tricoter serré se dit du fait d'exécuter, à la main ou à la machine, un ouvrage dont les mailles sont serrées, tendues. Notons l'opposition avec tricoter lâche. Au figuré, tricoter serré ou lâche réfère aux relations que l'on tisse entre personnes. Dans le premier exemple du $\mathrm{CW}$, tricoter réfère à la locomotion. Serré et lâche restent invariables dans la majorité des cas, mais ils peuvent s'accorder avec le sujet, surtout dans l'emploi pronominal du verbe (v. les troisième, quatrième et cinquième exemples du $\mathrm{CW}$ ).

\section{Tricoter volumineux}

Tricoter avec un fil qui donne du volume $\lambda$ tricoter frais

\section{Trimer dur}

Travailler avec acharnement

Intransitif

1856 Charli c'est un gas qui trime dur (Hippolyte-François Jaubert, Glossaire $d u$ centre de la France)

1931 Je me suis faite toute seule, moi ! À seize ans, en sortant du lycée, je commençais déjà mon apprentissage chez un grand couturier ! Et depuis, je n'ai pas arrêté. Ah ! J'ai trimé dur, allez ! Il fallait bien ! Je n'étais pas jolie, n'est-ce pas ? (Édouard Bourdet, Le Sexe faible)

1989 Et, dans ma lignée alsacienne, des maquignons, des colporteurs, des marchands ambulants, ils trimaient dur, tu sais (Serge Doubrovsky, Le Livre brisé)

2006 - Alors la bleusaille ! On vient pas aider ses petits camarades qui triment durs dans les soutes ? (Geoffrey Legrand, PostApocalypse)

2011 Sa mère, Martha, trime dure pour élever ses deux garçons (San-Antonio, Buffalo Bide) 


\section{Triquer ferme}

Battre vivement à coups de bâton

$\lambda$ voir rouge

\section{Tromper gros}

se tromper gros : se tromper lourdement ;

commettre une erreur grossière

Pronominal

189610 décembre.

Si Jarry n'écrit pas demain qu'il s'est moqué de nous, il ne s'en relèvera pas. Bauër s'est trompé gros comme lui. Et nous nous sommes tous trompés, car, si je savais qu'à la lecture Ubu Roi résistait mal jusqu'au bout, je ne prévoyais pas cet effondrement (Jules Renard, Journal)

REMARQUES : Tromper gros désigne le fait de faire une mauvaise appréciation, de commettre une erreur grossière, qui implique beaucoup d'ignorance ou de la sottise.

\section{Trompeter clair}

Produire un son clair, net

入 trompeter haut

\section{Trompeter (tromper) haut}

Jouer fort de la trompette ; produire un son fort, puissant

Intransitif

1285 Li tromperes trompast tantost Si tres haut, que parmi un ost Fust bien de toutes pars oÿs ; Si fais fu com je vous devis (Adenet le Roi, Cleomadés, 1605)

1372 Il s'en va par la mer bruiant, Et tuit li autre le sievirent, Qui venir a bon port desirent. Quant li roys fu bien eslongiez, Il ne s'est gueres atargiez, Eins fist sonner une trompette, Qui haut et cler sonne et trompette (Guillaume de Machaut, La Prise d'Alexandrie [(1370-)1372], 2112)

2009 Elles [= les poules] s'ébouriffent à sa vue, caquettent avec agacement, trompètent haut qu'il [= le chat] les dérange. Mais elles savent aussi s'avancer en douce pour lui piquer ses croquettes et boire son lait dès que l'occasion se présente (Patricia Beucher, Je veux des poules!)

2012 Ce n'était pas le son que les chiens de chasse produisent habituellement, ce mélange harmonieux de roucoulements de gorge et de cris trompetant haut et clair (Emilie Richards, L'Écho de la rivière [trad.])

CORPus WEB :

Dès le premier tour des cantonales, on trompettait haut et fort. « La France a voté pour aller de l'avant. Victoire de la démocratie... Progrès considérable du Parti Communiste Français " [https://www.institutjeanlecanuet.org/sites/ default/.../france_forum_n305-306_1995.pdf] (20.10.2019)

REMARQUES : En ancien français, tromper (trompeter) haut référait à celui qui sonne de la trompette à pleine puissance. En parlant d'une trompette, il se disait du son éclatant qu'elle produit à l'oreille, comparable à celui que produit sur les yeux une lumière vive. La langue moderne l'emploie par rapport au cri poussé par les poules ou au sens de 'proclamer à grand bruit, fanfaronner' (CW). Notons les collocations haut et clair et, par rapport au discours politique, haut et fort. Haut est modifié par très. VOIR AUSSI : sonner clair / haut

\section{Trotter court}

Marcher à petits pas rapides

Intransitif

1887 Petite, trottant court, ornée d'une perruque de soie noire, cérémonieuse, polie, en fort bons termes avec le bon Dieu représenté par l'abbé Malou, elle avait une horreur profonde, une horreur native du vice, et surtout du vice que l'Église appelle luxure (Guy de Maupassant, Contes et nouvelles)

CORPuS WEB :

aujourd'hui : trop chaud pour monter dans l'aprem du coup on est allé voir Boycott. Essai du filet puis je l'ai sortit du parc et promené un peu. Il a été sage comme tjrs, par contre il est très sensible des pieds. Puis un peu de trot en main sur le macadam, là aussi il trottait court [https:// www.1cheval.com/membre/forum/photos/ sujet-1723298-103-parce-qu-en-2015-tout-changenouvelle-vie-dans-1] (18.1.2016) 
ma jument n'a pas passé l'initial de la 130, elle trottait court suite à une blessure. de toute facon je serais pas partie ce matin avec ce temps [https://www.1cheval.com/membre/forum/ endurance/sujet-26231-0-pontchateau-l-ocean] (18.1.2016)

REMARQUES : Trotter court réfère à un cheval qui trotte en petites foulées (CW) ou à une personne qui se déplace, marche rapidement, en faisant de petits pas (ex. de 1887). Court reste invariable.

\section{Trotter dur}

I. Avoir le trot dur (pour le chevalier) Intransitif

1400 Maintenent elle dit qu'elle a ung estref trop long et l'autre trop court ; maintenent lui fault son mantel ; maintenant le lesse ; puis dit que le cheval trote trop dur et en est malade ; maintenent elle descent, et puis la fault remonter pour passer ung pont ou ung mauvés chemin (Quinze Joies de mariage, p. 43)

II. Trotter durement, avec endurance Intransitif

1902 Hors du village, il accompagna longtemps le capitaine, le bidet trottant dur, aussi vite que les deux cavaliers (Paul Adam, L'Enfant d'Austerlitz)

CORPus WeB :

Pensez donc, un maquis grec, c'est pas la pelouse du stade de France! Si seulement j'avais pu lui reprendre Google Maps des mains... Mais c'est qu'elle [= sa compagne] trottait dur, à son aise dans cette vilaine junglerie... Oui, oui, j'ai suivi... [http://www.laterreenmarche.com/news/ category/Turkey/33.html] (18.1.2016)

Mais ce n'est pas la seule raison car lorsque le cheval «trottait dur » il recevait sur le rein le choc du cavalier peu aguerri et les cavaliers en souffraient aussi [http://equin-ox.ffe.com/?cs=9 9443ffe59e6b387c2473575a86818d88c93f08cb9a 26fcd42d9b86a1109f91c2424bd9ca260c0e6e8a16 95c28482437] (18.1.2016)

REMARQUeS : Dans l'argot hippique, trotter dur (I) réfère à un cheval qui, lorsqu'il avance au trot, manque de souplesse ou trotte sur un sol trop dur. Le sens (II) n’apparaît qu'en français moderne où l'adjectif-adverbe est souvent pris comme simple alternative à l'adverbe en -ment, au point que certains l'analysent en termes d'apocope (durement $>$ dur). Dur reste invariable et est modifié par trop.

\section{Trotter menu}

I. Marcher vivement, à tout petits pas, à petits pas rapides, souvent

Intransitif

1356 LE FOL. Au chant d'un asne mort feru M'endormi ersoir a la lune. Je met bien de mes deux mains l'une Sur l'autre pour mes doiz froter, Et say bien saillir et troter Tost et menu

(Miracle de un paroissian esconmenié)

-1500 Vous ne scavés qu’est advenu?

Ne suis je pas ceans venu

[Assez toust pour nappes escourre] ?

Se je n'eusse troté menu,

De moy on eust fait de la bourre (Sottie de Trote Menu et Mirre Loret [fin Xve], 6)

1627 Mais sans dissimuler, n'est-ce point pour la somme

Que vous avez quitté ce jeune

Gentilhomme?

A le voir par derriere ainsi trotter menu, Je juge qu'il n'a pas encor son revenu (Thomas Sonnet de Courval, Les Satyres du sieur de Courval contre les abus et désordres de la France)

1785 FIGRARO. God-dam ! on vous sert un pot de bière, en bel étain, la mousse aux bords. Quelle satisfaction! Rencontrez-vous une de ces jolies personnes qui vont trottant menu, les yeux baissés, coudes en arrière, et tortillant un peu des hanches ? Mettez mignardement tous les doigts unis sur la bouche. Ah! God-dam ! (Pierre-Augustin de Beaumarchais, Le Mariage de Figaro)

1835 Nous connaissons ces sortes de femmes, la Parisienne pure. As-tu jamais vu dans les rues une grisette trottant menu ? Sa tête vaut un tableau : joli bonnet, joues fraîches, cheveux coquets, fin sourire, le reste est à peine soigné. N'en est-ce pas 
bien le portrait ? (Honoré de Balzac, Histoire des Treize)

1883 Bras dessus bras dessous, Anne et moi, nous nous mettons en route. Petit Pierre prend les devants, sur les bras de la vieille au nez d'oiseau, qui trotte vite et menu, avec un déhanchement bizarre comme les vieilles fées (Pierre Loti, Mon frère Yves)

1890 Et tout à coup je faisais silence, je m'arrêtais, attentif, quand dans le lointain j'entendais :

- Gâteaux, gâteaux, mes bons gâteaux tout chauds!

Cela se rapprochait rapidement, car la chanteuse trottait, trottait, тепи mais vite ; presque aussitôt elle était sous nos fenêtres, répétant de tout près, à pleine voix fêlée, sa continuelle chanson (Pierre Loti, Le Roman d'un enfant)

1902 Et les braves sœurs en cornette blanche trottent menu de côté et d'autre, colportant les potions, les linges bien propres - et les bons sourires (Pierre Loti, Les Derniers Jours de Pékin)

1930 Pour mieux comprendre les gargouilles qui terminaient les chéneaux cannelés, il grimaçait comme elles, tout en trottant menu. Il eut un long entretien avec le chef de l'institution à qui il proposa de payer une pension supérieure à celle qu'indiquait le tarif (Albert Cohen, Solal)

II. Avancer progressivement, progresser petit à petit, suivre tranquillement son cours Intransitif

1607 mais, parce que le pendant de la montagne estoit fort aspre et roide, il leur fut commandé de faire deux pauses et deux halenéee, pendant lesquelles l'artillerie tireroit tousjours pour les garantir des arquebusades du dedans, qui trottoient menu (François Boyvin du Villars, Mémoires sur les guerres)

1838 Il avait une certaine culture, mais elle s'effacera sous la routine des affaires, des affaires qui trottent menu, car il n'a pas les reins ni la hardiesse d'un spéculateur. La rouille est déjà à cette mémoire bien trempée. Dans dix ans, ce sera, jeune encore, un vieux procureur, en radoterie, hors sa robe (Jules Barbey d'Aurevilly, Premier Memorandum)

1955 Les manuels d'histoire littéraire, consacrés à la gloire du texte, semblaient devoir être les bastions les plus inexpugnables. Or eux aussi succombaient : les plus anciens présentaient des pages compactes, pleines de substantifique moelle pour l'esprit, mais bien mornes pour l'œil. La pensée y trottait menu, avec le mille-pattes inlassable de ses mots, au long des lignes cimentées dans le bloc rectangulaire de la page (René Huyghe, Dialogue avec le visible)

+1963 Nous sommes loin pourtant du ronron populiste. $\mathrm{Si}$ « petit cocher » trotte menu, la musique s'enfle parfois : « Moi, je fais ce que je veux. Je suis le roi du pavé de bois », et, plus loin : « Je fournis l'essence et la rêverie... » (Antoine Blondin, Ma vie entre les lignes [1963-1970])

III. Se déplacer vivement, avec vivacité (emploi figuré)

Intransitif

1951 Le regard de Marie Duvalle - qui était gris - trotta menu derrière ce crâne jaune et dur comme une motte de beurre, pendant quelques secondes, puis revint bien vite se blottir dans le trou de son orbite, comme s'il avait quelque chose à craindre du regard de Maurice Duvalle, où luisait l'ironie bienveillante du matou gavé (Hervé Bazin, Le Bureau des mariages)

Corpus Web :

Alors pendant deux soirées, je me suis penchée sur la création du patron du canard qui me trottait menu dans la tête depuis un bout de temps, et petit à petit, partant d'une forme improbable de bipède allongé, en allongeant les magrets, en rabotant le croupion, en élargissant l'assise, le tout en plaçant les coutures de façon à souligner une silhouette de canard... [http://trottemenu. canalblog.com/archives/2008/04/27/8974689. html] (18.1.2016) 
Il devint le divin enfant, en ce jour de mai 007, le prez de tous les gaulois, et des gauloises mentholées. A la même époque, l'Manu trottait menu, dans sa banlieue à prolos, pas très Blanco. Supportait la cause palestinienne, plantait un arbre pour ça sous les caméras, donnait la tape dans l'dos à tout arabe déambulant en babouche de métro [http://mobile.agoravox. fr/tribune-libre/article/nico-manu-et-que-lasarkovalls-164989] (18.1.2016)

REMARQUES : Trotter menu (I) désigne au concret le fait de marcher rapidement à tout petits pas. Sur le plan abstrait (II), il renvoie à un progrès réalisé petit à petit. (III) le transpose occasionnellement au mouvement d'un regard. Notons les collocations avec vite (ou tost, en ancien français). VoIR AUSSI : aller / randonner / trottiner menu

\section{Trotter sec}

Trotter à vive allure

Intransitif

1877 «Piler du poivre » est une expression familière, employée par les cavaliers lors qu'ils montent un cheval aux réactions vives ; ils disent : «Mon cheval trotte sec, il me fait piler du poivre !» (L'Intermédiaire des chercheurs et curieux)

1940 Seules [sic] de gros lactaires blancs et bêtes, réunis en bande, jalonnaient encore le sol jusqu'à la route où une carriole trottait sec au cul d'un cheval de bonne humeur (Robert Desnos, Mines de rien)

1973 Je trottais sec, tout sifflotant, il me semblait qu'au bout du chemin j'allais tomber sur le métro Marcadet-Poissonniers (Joseph Joffo, Un sac de billes)

REMARQUES : Dans l'argot militaire, le substantif un trotte-sec était employé comme sobriquet du fantassin.

\section{Trotter soef}

Trotter doucement, tranquillement Intransitif

+1400 Il le feist. Gadifer luy dist. " Alez le demander a damoiselle Girarde, comment il se peut faire. » Elle, respondy elle, le peut ainsy entendre qu'il avroit bon cheval, tost et souef trotant et bien alant, et que acom- paigné seroit de homme qui luy parleroit de joieuseté et qui aucunnesfoiz chanteroit, par quoy le chemin luy ennuyeroit moins et par ce sembleroit abregié (Nouvelles françaises $d u X^{e}$ siècle, $\mathrm{p} .48$ )

REMARQUES : Trotter soef réfère à un cheval qui avance au trot, progressivement, d'une manière tranquille, calme, sans agitation. Notons la collocation avec tost 'rapide'.

\section{Trottiner coupé}

Avancer avec des pauses

$\lambda$ trottiner menu

\section{Trottiner menu}

Aller, marcher vivement, à petits pas courts et rapides

Intransitif

1886 Sachant ce qu'on doit à M. le Commissaire, elle fit sa toilette, prit sa belle robe et une coiffe blanche, puis se mit en route sur les deux heures. Trottinant assez vite et menu dans ces sentiers de falaise, elle s'acheminait vers Paimpol, un peu anxieuse tout de même, à la réflexion, à cause de ces deux mois sans lettres (Pierre Loti, Pêcheur d'Islande)

1934 C’est toujours le même bibliothécaire : un petit homme sec et gris, à barbiche, quoiqu'il eût de grandes oreilles un peu sourd, (à tel point que, quand j'essaie de me le représenter, je vois son visage asymétrique parce qu'il ouvrait toujours autour de son oreille droite le pavillon de ses deux mains), et qui trottine si menu que les souris doivent le prendre pour l'une d'elles (Jean Guéhenno, Journal d'un homme de quarante ans)

\section{Corpus Web :}

Ici on a trottiné menu, menuisé, coupé, raboté : éclats de bois, éclisses, veines tranchées dans la matière elle-même. Le quartier s'y prêtait, avant que Muji (la marque qui n'en est pas une) ou d'autres viennent investir certains de ces ateliers, lieux parfois extraordinaires à verrières célestes et poutres métalliques tarabiscotées [http://dominiquehasselmann.blog.lemonde. fr/2009/08/18/cheminee-fanal-urbain] (18.1.2016) 
Dino trottine menu et se pointe un quart d'heure plus tard avec une fiche au nom de Duval. Raté ! Essaye encore... [http://prisedechou.overblog.com/article-29530968.html] (18.1.2016)

Moi, dis la plus âgée, j’y mettrais le gris de l'âne qui chemine doucement parmi les chardons violets. Le gris feutré de la petite souris qui trottine menue ou qui prestement se sauve devant le chat [http://www.chezmaya.com/puzzle/tousles-puzzles/item/entre-pluie-et-soleil-le-jeu-decasse-tete-puzzle-de-126-morceaux.html] (18.1.2016)

REMARQues : Trottiner menu désigne le fait de marcher à très petits pas rapides, ce qui explique la collocation avec vite (ou tost, en ancien français) que l'on retrouve souvent dans l'emploi adverbial de menu avec des verbes de mouvement. Signalons également les participes coordonnés, menuisé, coupé, raboté, qui créent une perspective résultative dans le premier exemple du CW : tout est divisé en morceaux. Menu reste invariable dans la majorité des cas, mais dans le troisième exemple du CW, il s'accorde avec le sujet au féminin tout en gardant son interprétation adverbiale. Il est modifié par si. VoIR AUSSI : randonner / trotter menu

\section{Troubler fort}

Perturber fortement

Transitif

+1200 - Ha ! dit Alein, seint Esperit,

Done mi companon santé,

Dont mi cors fou si fort treblé !

(Les Deus Anglois et l'anel, 24)

1584 D'un profond pensement j'avois si fort troublée

L'imagination qui toute en vous estoit, Que mon ame à tous coups de mes lévres sortoit

Pour estre en me laissant à la vostre assemblée

(Pierre de Ronsard, Sonnets pour Hélène)

Pronominal

$\sim 1450$ Troylus, oyant ce que sa seur lui alloit disant, se troubla fort, tant pour ce que elle alloit desprisant Brisaïda, laquelle il amoit plus que tout le monde, que aussi pource qu'il congnoissoit que son secret estoit venu jusques aux aureilles de sa seur ; et pensa soy vouloir taire (Roman de Troilus et Cressida, p. 290)

\section{CORPUS WEB :}

Ici et là, plus présente, une note s'impose et revient au silence du tapis ostinato des basses. On retrouve ce climat distancié dans la Sérénade interrompue dont quelques brusqueries clairement affirmées troublent fort justement la tendresse [http://www.anaclase.com/chroniques/ r\%C3\%A9cital-evgueni-koroliov] (12.1.2016)

Comme d'hab, je te lis avec... une certaine délectation! (Même si je déplore que la Décroissance ne réserve pas ses flèches parfumées... au vitriol... à ceux qui les méritent le plus... et dont ni toi ni Patrick, ne font partie !)

Qu'un organe d'opinion soit en même temps un moyen d'existence pour ceuxqui lefabriquent... est une « nécessité inexorable »... qui me trouble fort ! [http://alternatives-economiques.fr/blogs/ gadrey/2011/04/11/j\%E2\%80\%99aimerais-bienetre- $\% \mathrm{C} 2 \% \mathrm{AB}-1 \% \mathrm{E} 2 \% 80 \% 99$ ecotartufe-du-mois$\%$ C2\%BB-comme-patrick-viveret] (12.1.2016)

REMARQUES : Sur le plan moral ou affectif, troubler fort désigne le fait de faire naître un état émotif - une émotion amoureuse, par exemple - qui perturbe et altère le calme intérieur d'une personne, pouvant lui faire perdre ses moyens, l'embarrasser ou l'inquiéter. Fort reste invariable et est modifié par si.

\section{Trouver court}

I. Manquer ; être en manque, à court de (quelque chose)

Pronominal

1575 En ce voiage aussi l'argent se trouva si court, que la pluspart des pages du Roy se trouvèrent sans manteaux, estans contraints de les laisser en gage pour vivre par où ils passoient (Pierre de L'Estoile, Registre-Journal du regne de Henri III)

1696 Ce qu'on tire des provinces du midy, et qu'on a soin toutes les années de faire transporter sur le grand canal par les barques imperiales, est plus que suffisant pour fournir à cette dépense : mais on craint si fort de se trouver court que les 
magasins de Pekin ont toûjours du ris pour trois ou quatre années d'avance

(Louis Le Comte, Nouveaux Mémoires sur l'état présent de la Chine)

II. Trouver un moyen plus simple, plus direct Emploi absolu

1592 L'amour me soulagea et retira du mal qui m'estoit causé par l'amitié. Par tout ailleurs de mesme : une aigre imagination me tient ; je trouve plus court, que de la dompter, la changer ; je luy en substitue, si je ne puis une contraire, aumoins un'autre. Tousjours la variation soulage, dissout et dissipe (Michel de Montaigne, Essais)

III. Manquer d'idées, d'à-propos

Pronominal

1615 Messieurs, je voy en ce portraict de Parrhase une si vive representation de l'humeur diverse de cet Estat que, pour encherir sur Athenes, je croy que, s'il eust eu à naïfver les François, il s'y fust trouvé court, et la variation de nostre naturel eust de bien loing surpassé celle de son industrie

(Jean-Pierre Camus, Homélies des États généraux)

Transitif

19074 décembre

Ils tirent trois cents pages d'une petite idée : c'est de l'escamotage pénible. Quand je pense que M. Moselly se dit peutêtre : « Pourvu qu'on ne me trouve pas trop court! » Mariette ne veut plus laver la vaisselle ni cirer les chaussures. Elle voudrait être demoiselle de magasin (Jules Renard, Journal)

CoRpus Web :

Estepous (Guillierme) se met vite à température. Katif est de tous les coups, ça chauffe pour le taureau, 2 minutes les premiers attributs. Katif pleine piste se trouve court, Estepous pousse et le déséquilibre, le raseteur se jette par terre, mais le taureau ne va pas le lâcher pendant de longues secondes [http://coursecamarguaise.midiblogs. com/tag/estepous+de+guillierme] (12.1.2016)

Essayez d'avoir l'air sans importance, au cas où ceux d'en face se trouvent courts sur les mu- nitions [http://survivreauchaos.blogspot.co.at/ 2015/04/regles-d-engagement-et-regles-du-com bat-pour-les-temps-de-chaos.html] (12.1.2016)

REMARQUES : Trouver court (I) se dit du fait d'être en manque de quelque chose (moyens financiers, ressources, etc.), ce qui entraîne ou peut entrầner l'arrêt soudain d'une entreprise. (II) désigne le fait qu'une personne, par facilité, rapidité ou pour des raisons pratiques, opte pour une autre solution, un autre moyen, plus pratique, de régler quelque chose. (III) se dit du fait de juger la façon de parler ou d'écrire de quelqu'un brève, voire limitée, qui ne s'étend pas sur les détails. Dans l'exemple de 1907, l'emploi est ironique puisque l'auteur trouve que s'étendre sur trois cents pages est trop pour une petite idée. Court reste invariable dans la majorité des cas. Toutefois, il s'accorde avec le sujet dans le dernier exemple du CW. Il est modifié par plus, si, trop.

\section{Tuer dru}

Tuer en grand nombre, en grande quantité Transitif

1450 AGRIPPART. Nous avons tres bien besoingné, En brief temps, sur ceste merdaille. ACHAPPART. Je les tue plus dru que paille, J'en ay despeché, puis ung mois, Plus de deux mille (Arnoul Gréban, Le Mystère de la Passion, 7758)

1637 MAISTRE JÉRÉMIE. Je me suis rencontré en quarante escarmouches

Où l'on tuoit le monde aussi dru que des mouches,

J'ay veu deux cens assaux, trois cens combats rangez :

J'ay veu des chasteaux pris, et des bourgs saccagez :

J'ay veu grand nombre aussi de villes imprenables

Mises en des estats grandement deplorables, Le Fer, le feu, le sang, servoit à les punir (L. C. Discret, Alizon)

Remarques : Dans un combat ou une attaque, tuer dru se disait du fait de causer la mort d'un grand nombre de personnes. Dru souligne en 
plus de l'abondance et de la densité, l'idée de force, d'intensité dans le mouvement. Dru est modifié par aussi, plus. Avec des verbes tels que mourir, tomber, etc., cet adjectif-adverbe est employé comme premier terme d'une comparaison : tuer aussi / plus dru que paille / des mouches.

\section{Tuer gratuit}

Tuer sans raison ni objectif

Transitif

2006 Nous laisser mourir, ou nous tuer gratuit comme ça pour rien? (Rachid Djebaïli, $L a$ Racaille)

\section{Tuer net}

Tuer, anéantir tout d'un coup, brutalement, sur le coup

Pronominal

1769 En effet, rien de plus naturel que de penser qu'une personne, qui se précipite dans un puits, peut, en donnant de la tête ou de la nuque du col contre une pierre un peu saillante ou contre le seau, s'enfoncer le crane, se luxer et fracturer les vertebres, se tordre le col comme on dit ; et par l'effet de semblables contusions, se tuer net, pour ainsi dire, et arriver morte au fonds du puits (Remarques du médecin Bartez au rapport officiel / Memoire pour le sieur Pierre-Paul Sirven)

1867 Elle regardait un cadavre. Sur une pierre, à quelques pas, était allongé le corps d'un grand gaillard, d'un maçon qui venait de se tuer net en tombant d'un échafaudage ; il avait une poitrine carrée, des muscles gros et courts, une chair blanche et grasse ; la mort en avait fait un marbre (Émile Zola, Thérèse Raquin)

1929 Tombé avec un sixième étage, un jour, il se tua net. Veuve et enceinte, Pauline, fidèle au goût de son mari, pour les symboles nordiques, broda tout Ibsen sur les bavoirs de l'enfant posthume (René Crevel, Êtes-vous fous?)

Transitif

1860 - Je magnétiserai Perrin ! dit Aristide, ce sera encore plus amusant !

Ce propos peu sérieux tua net le magnétisme aux Tournelles et en fut l'épitaphe, au grand chagrin du président, qui était convaincu (Louis Duranty, Le Malheur d'Henriette Gérard)

1884 Le soupçon qu'il allait commettre un vol ne l'effleura pas. Il prit une pierre à portée de sa main, et, comme il était adroit, il tua net en la lançant, la volaille la plus proche de lui. L’animal tomba sur le côté en remuant les ailes (Guy de Maupassant, Contes et nouvelles)

1890 La Lison, éventrée, culbutait à gauche, par-dessus le fardier ; tandis que les pierres, fendues, volaient en éclats, comme sous un coup de mine, et que, des cinq chevaux, quatre, roulés, traînés, étaient tués net. La queue du train, six wagons encore, intacts, s'étaient arrêtés, sans même sortir des rails (Émile Zola, La Bête humaine)

1913 Je l'aurais fait si je n'avais pas craint de n'être pas tué net : suppose que l'âme reste pincée, ne serait-ce qu'une seconde, dans la porte entr'ouverte... Je ne devrais pas te dire cela (Valéry Larbaud, A.O. Barnabooth)

1936 Un promeneur est atteint par une automobile, lancé à vingt mètres et tué net. Le drame est fini ; il n’a point commencé ; il n'a point duré ; c'est par réflexion que naît la durée. Aussi, moi qui pense à l'accident, j'en juge très mal (Alain, Propos)

1948 Onze hivers tu auras renoncé au quantième de l'espérance, à la respiration de ton fer rouge, en d'atroces performances psychiques. Comète tuée net, tu auras barré sanglant la nuit de ton époque (René Char, Fureur et mystère)

1960 Les baisers d'Émery avaient toujours une odeur de lait frais. Vingt-quatre heures à Chirfa tueraient net Cornelia. Deux fois, elle avait voulu sauter dans l'avion et venir à n'importe quel prix (Michel Déon, $\mathrm{LaCa}$ rotte et le bâton)

1967 Béja, sa main blessée par une balle reçue au-dessus d'Inaménas, saute dans le défilé, surgit au milieu des soldats, en tue net six, les rebelles les encerclent (Pierre 
Guyotat, Tombeau pour cinq cent mille sol dats)

1994 « Laisse les gens ergoter, et reviens à ton Seigneur avec un repentir sincère. " Ces paroles tuèrent net en moi tout germe de soupçon ou de jalousie. Comme je racontai l'incident à Baya, elle éclata de rire : " À Ouagadougou, je sais qu'aucune femme n'a pu te faire tomber » (Amadou Hampâté Bâ, Oui Mon Commandant!)

Emploi absolu

1989 Une 22 à forte pénétration, tirée dans l'intention de tuer net. N'était-ce pas lui qui avait envoyé Malaussène au-devant de cette balle, sous prétexte de garder les coudées franches dans son enquête sur la mort de Saint-Hiver ? (Daniel Pennac, $\mathrm{La}$ Petite Marchande de prose)

\section{CORPUS WEB :}

Sur les autres miradors sa a bien tirer un ami a rater un brocard, mais un autre a fait un doubler. Il tire vers un brocard qu'il pense avoir manqué et 30 minutes plus tard uil retire sur un autre qu'il tue net en allant rechercher son brocard il va vérifier sur son premier, il est mort 20 métres a l'interieur du bois. Total de l'affut du matin 3 brocards et 1 sangliers [http://www.grand-gibier. net/forum/viewtopic.php?p=16972\&sid=b067667 f41691a78b69f99fe69d6aa35] (12.1.2016)

Le style de kung fu ensuite y est très « Wang yu » aussi, c'est à dire risible, à l'opposé de Bruce Lee, composé de coups de poing qui tuent nets bien violents et de coups de pieds ridicules il faut bien le dire [http://www.senscritique.com/film/ Le_Boxeur_manchot/critique/4112763] (12.1.2016)

il les coupent parce que c'est accidentogéne (c'est la cause de plus de morts avec les arbres ) ils pensent que un accident avec les arbres tuent nets les gens !!pas d'arbres juste des barrieres [http://taverne-etrange.xooit.eu/t1774-Lintriguante-d-partementale-419.htm] (12.1.2016)

REMARQUES : Dans son emploi transitif, tuer net réfère à une personne qui trouve la mort de manière soudaine et souvent brutale, causée par exemple par le tir d'une balle. Au figuré, le sujet peut désigner une parole qui met fin, ef face, étouffe quelque chose. Le sujet peut aussi renvoyer à un événement qui cause la disparition de quelque chose. Dans son emploi pronominal, tuer net se dit d'une personne qui, du fait de la violence du coup ou de l'accident, est tuée sur le coup. Dans le style peu soigné, net peut s'accorder avec l'objet du verbe transitif en gardant son interprétation adverbiale (v. les deux derniers exemples du CW). Notons l'emploi du groupe complexe des coups de poing qui tuent nets bien violents où bien violent est un adjectif qui modifie le groupe nominal des coups de poing qui tuent nets. Mais on peut lire aussi : des coups de poings bien violents qui tuent nets.

\section{Tuer raide}

Tuer tout d'un coup, brutalement Transitif

1672 Voilà une petite fable de La Fontaine, qu'il a faite sur l'aventure du curé de M. de Boufflers, qui fut tué tout raide en carrosse auprès de lui (Mme de Sévigné, Correspondance)

1823 Une autre fois, à Marly, à la chasse du sanglier, tout l'équipage étant en fuite, en véritable déroute d'armée, disait l'empereur, il tint avec Soult et Berthier contre trois énormes sangliers qui les chargeaient à bout portant. « Nous les tuâmes raides tous les trois, disait-il ; mais je fus touché par le mien, et j'ai failli en perdre le doigt que voilà » (Emmanuel de Las Cases, Le Mémorial de Sainte-Hélène)

1844 Quatre coups de fusil leur répondirent presque en même temps, mais ils étaient mieux dirigés que ceux des agresseurs, trois soldats tombèrent tués raide, et un des travailleurs fut blessé (Alexandre Dumas père, Les Trois Mousquetaires)

1859 Soyez tranquille, monsieur, continua le jeune russe avec un calme qui épouvanta tous les joueurs, je tire parfaitement le pistolet ; je vous planterai ma balle entre les deux yeux, et vous tuerai raide, sans vous défigurer (Pierre-Alexis Ponson du Terrail, Rocambole)

1892 Maintenant, il était au centre, d'autres chevaux se cabraient, se renversaient autour de lui, des hommes étaient jetés à terre, comme par un coup de vent, tan- 
dis que d'autres, tués raides, restaient en selle, chargeaient toujours, les paupières vides (Émile Zola, La Débâcle)

1937 LE MENDIANT. Il doit la tuer raide avant qu'elle se déclare... Quand se déclare-telle? (Jean Giraudoux, Électre)

Pronominal

1836 " Montre-toi aux soldats, dit-il à son affranchi, si tu ne veux qu'ils te tuent, pensant que tu m'aurais aidé à me donner la mort. » L'affranchi sorti de la chambre, Othon se tue raide, appuyé contre le mur, disant qu'un empereur devait mourir debout (Alfred de Musset, Lettres de Dupuis et Cotonet)

Emploi absolu

1894 D'ailleurs, des chasseurs comme vous ne blessent pas : ils tuent raide (Jules Renard, Poil de carotte)

\section{CORPuS Web :}

La foudre entre par une partie du corps et ressort par les pieds par exemple. Dans le cas de foudre descendante, une très grande partie de l'éclair contourne le corps mais ce qui passe au travers est suffisant pour tuer raide [http:// arwann.com/?page_id=853] (12.1.2016)

Éperdument amoureux, aussi Voyage civitavecchia palerme il y a bientôt deux cents ans que les tribus sont revenues aux rites anciens et aux nobles qui étaient dans la confidence des alcôves. Aie pas peur, ce garçon-là ; qu'est-ce que ça pouvait tuer raide une femme, d'une féerie, et quoique de jour en jo Voyage civitavecchia palerme ur plus important [http://www.goferry.fr/ voyage-civitavecchia-palerme] (12.1.2016)
Voici encore fait divers illustrant le danger des allumettes laissées entre les mains des enfants. Une petite fille qui jouait auprès d'une fenêtre avec des allumettes, s'étant penchée pour regarder dans la rue, est tombée du huitième étage et s'est tuée raide [https://fr.groups.yahoo. com/neo/groups/politique/conversations/ messages/3264] (12.1.2016)

pour les insectes nous n'avons pas eu de problèmes à chaque soir il passe un gaz qui les tuent raides (ha, ha, ha) nous n'avons pas eu besoins de watkins durant notre voyage même au resto à la carte [http://voyageforum.com/discussion/ cuba-hotel-playa-pesquero-tenue-ville-femmelangue-parlee-d3865846] (12.1.2016)

Elle avait pour complices deux autres femmes, fabricant et vendant des essences vénéneuses. La partie volatile, les gaz que dégageait leur marchandise, finirent par tuer raides ces Locustes ; du moins, on les trouva empoisonnées, comme trois rats, dont la mort n'entraîne pas de deuil [http://parismamanetmoi.com/2015/03/29/ les-empoisonneuses-de-limpasse-maubert] (12.1.2016)

REMARQues : Dans son emploi transitif, tuer raide réfère à une personne qui trouve la mort de manière soudaine et souvent brutale, causée par exemple par le tir d'une balle. Dans son emploi pronominal, le sujet-patient désigne une personne qui, du fait de la violence du coup ou de l'accident, est tuée sur le coup. Raide s'accorde souvent avec l'objet malgré son emploi clairement adverbial. Il est rarement modifié (une fois par tout). Notons l'emploi impersonnel familier ça pouvait tuer raide. 


\section{User direct}

User directement, immédiatement

$\lambda$ aller direct, Remarques 


\section{Valoir cher}

Valoir beaucoup, avoir une haute valeur (matérielle, morale, intellectuelle)

Intransitif

1804 Monsieur, les ânes de la foire dernière ontils valu cher? Monsieur, lui dit le Juge, qui avait remarqué que ce Seigneur était roux et d'une très-petite taille, ceux de votre poil et de votre taille ont valu dix écus (L'Improvisateur français)

1820 Édition originale, rare : 4 à 6 fr. ; elle a valu plus cher autrefois (Jacques-Charles Brunet, Manuel du libraire et de l'amateur de livres)

1833 [M. Grandet] ne manquait pas une seule spéculation, avait toujours des tonneaux à vendre alors que le tonneau valait plus cher que la denrée à recueillir, pouvait mettre sa vendange dans ses celliers et attendre le moment de livrer son poinçon à deux cents francs quand les petits propriétaires donnaient le leur à cinq louis (Honoré de Balzac, Eugénie Grandet)

1868 Au bout d'un silence, la folle éleva de nouveau la voix :

Pour son sérail il acheta

Mademoiselle Catinka.

C'est trente sous qu'il la paya :

Elle valait moins cher que ça.

Et tra la la, tra la la la.

Tra la la la, la la, la la

(Émile Zola, Madeleine Férat)

1890 - Je commence à croire que tu as raison, me répondit-il avec un air profond, et que la meilleure [= femme] ne vaut pas cher.. Notez que le camarade qui me débitait cette colossale sottise était une façon d'homme à bonnes fortunes, lequel continuait, quoique marié, à courir les diverses sous-préfectures du département de la Haute-Noce (Paul Bourget, Physiologie de l'amour moderne)

1892 D'un regard, là-bas, vers le bois impénétrable, tous deux disaient leur colère contre le bandit qui galopait, libre maintenant ; tandis qu'ils finissaient par se sentir pleins de pitié pour le pauvre diable, sa victime, un fricoteur qui ne valait sûrement pas cher, mais tout de même un garçon gai, débrouillard et pas bête (Émile Zola, La Débâcle)

1896a - Vous allez bien, frère Frappus?

Le frère hochait la tête, rieur :

- Allons, passez, canaille ! Vous ne valez pas cher! (Édouard Estaunié, L'Empreinte)

1896b « On ne voyait pas la pointe tant ils étaient blancs. N'abîme pas les tiens, ma Séso. Laisse-les jeunes et droits comme ils sont. Les deux seins d'une courtisane valent plus cher que son collier. " Tout en parlant ainsi, les deux femmes s'habillaient (Pierre Louÿs, Aphrodite)

1900 - J'ai eu tant de peine ! Mais j'ai vu qu'elle ne tenait pas à moi, à qui tient-elle ? J'ai vu aussi qu'elle ne valait réellement pas cher: ça m’a suffi. J'ai pensé que je ferais assez de bêtises sans commettre celle de vouloir l'emporter sur vous (Colette, Claudine à l'école)

1910 Il traînait avec lui.

Il allait par les routes.

Il traînait avec lui par les routes des gens dont elle ne voulait pas dire du mal.

Mais la preuve qu'ils ne valaient pas cher. C'est qu'ils ne l'avaient pas défendu (Charles Péguy, Le Mystère de la charité de Jeanne d'Arc)

1912 Montfort était, depuis la prison du Luxembourg, l'amant de la Thévenin : il lui donna un petit hôtel situé près de Tivoli et de la rue du Rocher, qui valait fort cher et ne lui coûtait rien, la vente des lots voisins l'ayant déjà plusieurs fois remboursé (Anatole France, Les Dieux ont soif)

1936 Malheur! Malheur toujours attaché au même... tandis que tant d'autres dans le monde entier continuaient à marcher tranquillement à terre, qui sûrement ne valaient pas beaucoup plus cher que lui. Si encore il avait pu entrer dans le plafond, y terminer en paix, quoique rapidement, sa triste vie... (Henri Michaux, Un certain Plume) 
1953 GIL. Nous devrions en faire autant. MENGA. Tes histoires ne valent pas cher. Elles sont toujours les mêmes.

GIL. Menga, je souffre. Regarde cette bête affamée et sans forces, alors qu'il y a dans le monde tant d'animaux repus !

(Albert Camus, La Dévotion à la croix)

1972 J'avais eu envie de la voir ma vieille, pas de doute. Une sacrée envie à la con. Bon mais maintenant c'était chose faite, je l'avais vue et bien assez. Elle valait de moins en moins cher à l'argus. Alors pourquoi je donnais pas le signal du départ? (Bertrand Blier, Les Valseuses)

1985 Ta vie vaut moins cher que la vie d'une poule, négro, tu ne l'as pas méritée ; c'est comme si tu n'avais jamais existé (Bernard-Marie Koltès, Quai ouest)

\section{CORPUS WEB :}

Ma rune vaut elle cher ? Bonjour tout le monde, je voulais savoir quel est le niveau de rarete de ma rune et si elle vaut cher [http://board.fr. nostale.gameforge.com/index.php?page=Thread \&threadID=106565] (16.2.2016)

Ligue 1 - Celle-là, elle vaut cher pour Monaco [https://fr.sports.yahoo.com/news/ligue-1celle-1\%C3\%A0-vaut-cher-monaco-212232200-sow.html] (16.2.2016)

Plus une entreprise est petite, plus vite elle grandit et plus vite elle vaut chère [http://www. louisthannberger.com] (16.2.2016)

notre amitié c de l'or et elle vaut chère a mes yeux [http://xx-leii-siistaa-x3-xx.skyrock.com/ 2566989317-notre-amitie-c-de-l-or-et-elle-vautchere-a-mes-yeux.html] (16.2.2016)

REMARQUES : Souvent employé à la forme négative, ne pas valoir cher souligne le peu de valeur ou de considération accordée à une personne en mettant en avant ses défauts les plus marquants comme son manque de compétences ou de qualités. En référence au travail, il souligne le manque de performance, la faible rentabilité de la personne dans l'exercice de son activité. À la forme affirmative, le sujet peut désigner un objet, un aliment, un produit qui a une certaine valeur, qui coûte cher ; il peut aussi référer à quelque chose qui est dit, raconté (une histoire) et qui, à la forme négative, n'est pas valable. Cher tend à l'invariabilité, celle-ci étant systématique dans le corpus de Frantext, mais il s'accorde avec le sujet dans les derniers exemples du CW, et, dans ce cas-là, il se rapproche des prédicats seconds orientés vers le sujet. Il est modifié par (pas) beaucoup plus, de moins en moins, fort, moins, plus, réellement (pas), sûrement (pas). VoIR AUSSI : coûter cher / gros

\section{Valoir gros}

Avoir une valeur importante

Intransitif

1837 Là, dans ton pays, mon bon petit chat, en emportant notre mobilier qui vaut gros, nous serons comme des princes, tandis qu'ici faut au moins un million pour faire figure.

- Voilà où je t'attendais, ma femme, dit César Birotteau

(Honoré de Balzac, Histoire de la grandeur et de la décadence de César Birotteau)

1849 Eh bien, ma grand'mère sait à qui elle doit des ouailles en si bonne laine et des chèvres en si bon lait. Va, elle n'a point envie que je la quitte, et je lui vaux plus gros que je ne lui coûte. Moi, j'aime ma grand'mère, encore qu'elle me rudoie et me prive beaucoup (George Sand, La Petite Fadette)

1873 Maintenant la poissonnière ne valait pas gros comme ça de beurre. Et elles tapaient sur les Méhudin, des filles de rien qui n’en voulaient qu'à l'argent des hommes (Émile Zola, Le Ventre de Paris)

1987 Inusable [= son peignoir de Sulka broché], d'autant plus que du vivant de Marie il n'osait pas trop l'endosser - un vieux cadeau de Pauline. « Une toile et aussi grande, ça doit valoir gros. " Les jours passent, des liens de plus en plus indéfinissables se nouent entre Catherine et ce métrage de fibres recouvert de couleurs. Sa chose ! (Maurice Rheims, Les Greniers de Sienne) 


\section{CORpus Web :}

En SVT, sur la question argumentée faut mettre la dose car elle vaut gros et si vous pouvez placer du dessin, faites-le les profs aiment ça dans mes souvenirs [http://www.otk-expert.fr/fo rum/?action=viewtopic\&t=10627.1] (16.2.2016)

Ma mère dit que c'est de l'or et qu'elle vaut gros, précisa Abigail [https://www.wattpad. com/154850165-anna-partie-iii-arya-2/page/5] (16.2.2016)

Si tu veux les meilleurs de ma classe (grand lycée parisien) avec une bonne dizaine de bi-20 chaque année, ont fait entre 20 questions de niveau moyen et 2-3 questions qui valent gros [http://www.prepa-hec.org/forum/concours-bce2009-epreuves-maths-t12950-14.html] (16.2.2016)

A Antoing, on ne déguste pas la galette des rois comme partout ailleurs. Pour la cinquième année consécutive, l'asbl Jardins Bios du Hainaut a déposé des fèves un peu particulières dans les pâtisseries. Certaines d'entre elles valent gros [http://www.notele.be/list13-le-jt-a-la-cartemedia22895-des-galettes-des-rois-qui-peuventrapporter-gros-!--04-01-13.html] (16.2.2016)

REMARQUeS : Valoir gros réfère au prix estimé d'une chose, à sa valeur, gros soulignant l'importance de la somme. Le sujet désigne très souvent une chose (un bien) mais dans un emploi familier, il peut aussi désigner une personne dont la fortune, les revenus, sont estimés à une certaine somme. Gros reste invariable et est modifié par plus. La comparaison avec valoir cher, qui admet l'accord, met en évidence le rôle de la prononciation qui ne change pas avec l'accord graphique dans le cas de cher / chère, où il est inaudible, à la différence de gros / grosse, dont le féminin n'est pas documenté pour la fonction adverbiale. Notons l'emploi impersonnel familier ça doit valoir gros, et la variante la poissonnière ne valait pas gros comme ça de beurre. VoIR AUSSI : coûter cher / gros

\section{Valoir petit}

Valoir peu, avoir peu de valeur ou profiter peu à

(quelqu'un)

Emploi absolu

+1150a ADAM. Ou fut mon sens, que devint ma memoire, Que pur Satan guerpi le roi de gloire?
Or m'en travail, si m'en valt mult petit.

Li mien pecchié iert escrit en estoire

(Le Jeu d'Adam [2 moitié XII ${ }^{e}$, 533)

+1150 b Paien tornent en fuie, la bataille on guerpie,

Dusc'a la maistre tor on lor uoie aquellie ;

Che lor uaut mout petit, que fort fu asaillie (Aiol et Mirabel [2 $2^{\mathrm{e}}$ moitié XII $]$, 10866)

$\sim 1170$ Ne sai que iert; Erec respont.

Se li ciaus chiet et terre font,

Donc sera prise mainte aloe.

Teus vaut petit, qui mout se loe

(Chrestien de Troyes, Erec et Enide, 4438)

1240 Mes de ce savoir ne me chaut,

Que je pensse que petit vaut

A vous amer de cuer loial.

Que onques fust ou bien ou mal

(La Chastelaine de Vergi, 598)

1285 Car s'il atendent l'endemain,

Il seront tout pris a la main

Et honni et destruit et mort ;

$\mathrm{Au}$ fuïr ont pris leur acort,

Car deffense i vaurroit petit.

Li cinc roi s'i sont assentit

(Adenet le Roi, Cleomadés, 1261)

1325 Ce me perça poumon et fie

Et le cuer, quant je l'oi leü

Et le faus monde aperceü

Qui moult chier couste et petit vaut

(Watriquet de Couvin, Dits, p. 18, 539)

1365 La nés ont assalie, point ne leur escapa ;

Païen l'ont deffendue, jusqu'à .xxx. [en] i

$\mathrm{a}$;

Mais toute leur défense moult petit leur vaura,

Car bien sont assali des cristiens de chà

(Li Romans de Bauduin de Sebourc, Chant

IV, 554)

+1365 Car croire doit amans, par mos exprès, Que tout son fait assés petit vaudroit, Puisqu'esperance au besoing li faudroit (Jean Froissart, Poésies [3 $3^{\mathrm{e}}$ tiers XIV $]$ ])

+1400 Trop petit vault bons exemples ouÿr A qui ne veult contraires meurs fouÿr. (Christine de Pisan, Proverbes moraulx / Euvres poétiques [début Xve], III, p. 56) 
1405 Si se doivent garder de tous pechiéz singulierement, en fait et en pensee, affin que le bien qu'elles font d'une part ne perdent pas de l'autre : car petit vaudroit estre povre ou chaste, faire abstinences et devocions, et avec ce on fust un tres grant pecheur ou pecherresse (Christine de Pisan, Le Livre des trois vertus, p. 194, 23)

1450 JHESUS. Amice, ad quid venisti, Qui me fais ce devost salu?

Il t’ara moult petit vallu.

O Judas, voicy dure somme :

Soubz l'umbre d'un baisier polu

Tu viens trahir le Filz de l'omme (Arnoul Gréban, LeMystère de la Passion, 19039)

REMARQUES : En ancien français, petit avait la même fonction de quantification que peu en français moderne. Valoir petit réfère donc au prix estimé d'une chose, à sa valeur, petit soulignant une certaine somme. Petit reste invariable et est modifié par assez, moult, trop. VoIR AUSSI : coûter petit

\section{Vanter haut}

I. Faire le plus grand éloge (de quelqu'un ou de quelque chose)

Transitif

1558 Je ne suis pas de ceulx qui robent la louange,

Fraudant indignement les hommes de valeur,

Ou qui changeant la noire à la blanche couleur

Sçavent, comme lon dit, faire d'un diable un ange.

Je ne fay point valoir, comme un tresor estrange,

Ce que vantent si hault noz marcadants d'honneur,

Et si ne cherche point que quelque grand seigneur

Me baille pour des vers des biens en contr'eschange

(Joachim Du Bellay, Les Regrets)

1738 C'était un de ces étourdis brillants, familiers avec insolence ; il vantait si haut les charmes de l'inconnue, et la regardait avec si peu de ménagement et tant de fatuité, que j'en rougis pour lui et pour moi

(Alexandre Dumas fils, Les Égaremens $d u$ cour et de l'esprit)

1823 " C'était à tort, par exemple, faisait-il observer, qu'ils vantaient si haut la continence de Scipion, et s'extasiaient sur le calme d'Alexandre (Emmanuel de Las Cases, Le Mémorial de Sainte-Hélène)

2014 En échange, s’il venait à terrasser des monstres grâce à ces lames, ils lui demandaient de vanter haut et fort leurs provenances (Valentin Frété, Torfa et le Roi des sables)

II. Se flatter, se targuer ouvertement

Pronominal

1579 Il possedoit tellement M. le Duc, son Maistre, qu'il se vantoit tout haut d'en faire ce qu'il vouloit, voire et avoir la clef de ses coffres et de son argent, et en prendre quand bon lui sembloit : de laquelle vanterie on disoit qu'il se fust aisement passé (Pierre de L'Estoile, Registre-journal du regne de Henri III)

1785 J'en sais même une, ô ma belle maîtresse, Qui se vante tout haut d'être mon Eucharis (Antoine de Bertin, Les Amours)

1828 Aussi le gouverneur de Notre-Dame-dela-garde put-il ensuite se vanter bien haut d'avoir donné à ce pauvre Cid vingt fois de l'épée dans le corps jusques à la garde (Charles Sainte-Beuve, Tableau historique et critique de la poésie française et $d u$ théâtre français au XVI siècle)

1951 des enfants ricanants, déjà féroces, déformés par des convictions implacables, se vantant très haut d'avoir causé la mort de dizaines de légionnaires (Marguerite Yourcenar, Mémoires d'Hadrien)

\section{Varier menu}

menu vairié : finement bigarré

Intransitif

1160 Chaucie fu d'un siglaton;

Si soller furent d'un peisson

De cent colors menu veiriez;

A or furent li liepiez (Eneas, 4027) 
REMARQues : Varier menu désignait le fait de bigarrer, de marquer de couleurs ou de petites taches de couleur un objet animé ou inanimé. Ici, dans son emploi participial, il désigne l'état de l'objet, souligne son apparence physique qui se caractérise par une variation fine de couleurs. Мепu reste invariable.

\section{Veiller aise}

Veiller sereinement, paisiblement

Intransitif

1325 Aise puet dormir et veillier

Pour qui vous voulez travaillier

(Watriquet de Couvin, Dits, p. 132, 19)

REMARQUES : Dans l'ancienne langue, veiller aise référait à un animé qui n'est pas endormi, qui est en état de veille et qui représente pour lui une situation confortable, agréable. VoIR AUSSI : dormir / veillier aise

\section{Veiller clair}

Veiller en répandant de la lumière Intransitif

1926 Ils ont dormi à tu à toi, Dans l'auberg' bleu' qu'a l'ciel pour toit, Et les étoil's joli's, dans l'air, Plus qu'un' veilleuse veillaient clair (Anatole Le Braz, Poèmes votifs)

REMARQUES : Dans cet emploi poétique, veiller clair désigne par métaphore une lumière, un astre lumineux (ici : les étoiles) qui est en état de vigilance, qui surveille ce qui l'entoure pendant la nuit. Clair reste invariable.

\section{Vendre bon marché}

Vendre à un prix bas

$\pi$ racheter cher, tomber juste

\section{Vendre cher}

I. Faire subir de graves dommages, de lourds sacrifices (en échange de quelque chose) (au figuré)

Transitif

1100 Ben ad oït que Franceis se dementent ; Si grant doel ad que par mi quïet fendre ; Dist al paien : « Deus tut mal te consente ! Tel as ocis que mult cher te quid vendre!» Sun ceval brochet, ki oït del cuntence.
Ki quel cumpert, venuz en sunt ensemble (Chanson de Roland, 1633)

+1150 Quant l'entendi Rainiers, la color a perdue, Il a dit a Antialme parolle aperceue :

La mors de mon neueu te chier uendue!

(Aiol et Mirabel [ $2^{\mathrm{e}}$ moitié XII $]$, 7589)

1177 Et quant cil se sant domagié

De sa destre qu'il a perdue,

Dist que chier li sera vandue

(Chrestien de Troyes, Lancelot ou Le Chevalier de la charrete, 7088)

-1200 Mais ne chiet mie k'il ne plaist a Jhesu : Ains k'il muire, sera molt chier vendu. Diex, quel damage ! Si hardis hom ne fu (Aliscans [fin $\mathrm{XII}^{\mathrm{e}}$ ], 315)

1275 Se Damedieus n'en pense et l'apostles sains Piere,

Sa prouece li iert ja vendue trop chiere, Car Sarrazin revienent poingnant les la riviere

(Adenet le Roi, Buevon de Conmarchis, 418)

+1313 Lors bouta dou piet son amy Et cils, qui d'anguisse fremy, Ist dou lit tout nus aparmain .i. cutiel tout nut en sa main, De quoi y se fust deffendus Et, si peuist, moult cier uendus (Jean de Condé, Poèmes [1313-1337], 90)

+1400 Amoureux œil,

Plaisant archier,

De toy me dueil,

Amoureux œil.

Car ton accueil

Me vens trop chier,

Amoureux œil

(Christine de Pisan, Rondeaux / Euvres

poétiques [début Xve], I, p. 184, 6)

+1415 S’il vous plaist vendre voz baisiers,

[...]

Ne les me vendez pas si chiers

Que vous feriés à estrangiers ;

En me recevant en hommage,

S'il vous plaist vendre vos baisiers,

J'en achatteray voulentiers,

Et en aurés mon cueur en gage

(Charles d'Orléans, Poésies [ 1415-1440],

II, Chanson XLI, p. 228) 
-1465 Car quant courroux me frapa ou hëaulme, Tel coup senti de sa cruelle paulme Que mieulx me fust avoir esté pendus. Les jeux passez me sont bien cher vendus ; J'avoye aprins coucher en lictz tendus, Jouer aux déz, aux cartes, a la paulme (Jean Meschinot, Lunettes des princes, p. 13, XXXV, 7)

1559 Helas ! mon amy, à ceste heure me sera bien cher vendue l'amour qui je vous porte (Marguerite d'Angoulême, Heptaméron, p. 49, 21)

1572a Et ce jour fut encor plus ennemy de tout bien qui, premier, vous donna cognoissance de moy pour vous la vendre si chère. Mais, hélas! Nature vous a récompensé aussi d'autre costé en vous donnant par un privilège spécial puissance de mourir quand vous avez voulu (Jacques Yver, Le Printemps)

1572b Et toutesfois la raison et les yeux Nous font aymer! S'il est ainsy, ô Dieux, Que l'amour soit aux veines espandue Par la raison, vous l'avez cher vendue ! (Pierre de Ronsard, La Franciade, p. 196)

1632 Mais de tous ces soings rigoureux Qui regnans dans l'esprit des hommes Font croire ceux-là malheureux Qui naissent au siecle où nous sommes : Ce qui nous doit le plus fascher, Est cét honneur qui nous ordonne D'acheter et vendre si cher Les plaisirs que l'amour nous donne (Honorat de Bueil, chevalier de Racan, Les Bergeries)

1641 CINNA. C'est un ordre des Dieux qui jamais ne se rompt,

De nous vendre un peu cher les grands biens qu'ils nous font.

L'exil des Tarquins même ensanglanta nos terres,

Et nos premiers consuls nous ont coûté des guerres (Pierre Corneille, Cinna)

1697 PYRRHUS. J'ai fait des malheureux, sans doute, et la Phrygie
Cent fois de votre sang a vu ma main rougie. Mais que vos yeux sur moi se sont bien exercés!

Qu'ils m'ont vendu bien cher les pleurs qu'ils ont versés !

De combien de remords m'ont-ils rendu la proie !

Je souffre tous les maux que j'ai faits devant Troie (Jean Racine, Andromaque)

1757 Quelque terrible que soit cette idée, je la préfere sans balancer aux deux autres. Ah ! Que l'amour me vend chers les plaisirs qu'il m'a donnés ! Il y a huit jours que je vous écrivois ; mais quelle différence!

(Marie-Jeanne Riccoboni, Lettres de Fanni Butler à Milord Charles Alfred de Caitombridge)

1809 WALLSTEIN. Me la [= l'armée] donna, Seigneur? Mon nom seul l'a formée. GÉRALDIN. Vous nous vendez bien cher un bienfait passager!

(Benjamin Constant, Wallstein)

1846 Mon bonheur ?... Il s'explique par une servilité absolue, par la vassalité du chien de basse-cour. Elle me vend trop cher le peu qu'elle me donne. Au diable ! Je lui laisse tout et je m'enfuirai dans une mansarde. Oh ! la mansarde et la liberté ! (Honoré de Balzac, Un prince de la Bohème)

1864 Cela fit rumeur en Angleterre. Un journal conformiste s'écria : Comment peut-on vendre si cher un mensonge ? De plus, deux mots, tout-puissants en Angleterre, se dressent contre Shakespeare, et lui font obstacle : improper, shocking (Victor Hugo, William Shakespeare)

1924 Il [= Henri IV] achetait ceux qu'il ne pouvait réduire et beaucoup d'anciens ligueurs, parmi lesquels les princes de la maison de Lorraine, vendirent très cher leur ralliement (Jacques Bainville, Histoire de France)

Emploi absolu

1562 RICHARD. Elle peult tant envers mon maistre, Que par babil ell' l'a faict estre 
Un parangon de pauvreté ;

Et sous l'ombre d'une beauté

Qu'elle vend plus cher qu'au marché,

Elle luy a ja arraché

Les biens, l'honneur et les amis

(Jacques Grévin, La Trésorière)

Pronominal

1832 - Maintenant, comme tu trouves peut-être que je me vends un peu cher, moi qui ne t’aime pas, je vais tranquillement allumer tes sens et exciter tes désirs par des grimaces décorées du nom de pudeur, par des demi-caresses, par une parure menteuse qui me montre plus belle que je ne le suis (Alphonse Karr, Sous les tilleuls)

1896 Ce grand soleil d'Afrique, le soleil qui ment, les touaregs qui mentent ; le pays du mirage. Quelle belle mort il a eue ! L'excitation de la lutte, le plaisir de se vendre cher. Il était la force, le courage, le drapeau, la parole de ses trois compagnons. Ils se pressaient sans doute contre lui (Maurice Barrès, Mes cahiers)

II. Vendre à un prix élevé (au propre) Emploi absolu

-1200 Mais se vous port i volez prandre, L'an lou vouz voudra molt chier vandre, Molt l'estovra achater chier, Qu'an la nef vandra reverchier Premiers li sire et puis la dame (Guillaume d'Angleterre [fin $\mathrm{XII}$ ], 2344 )

+1249 Dou bleif ameiz la grant vendue, Et chier vendre de ci au tans Seur lettre ou seur plege ou seur nans, Vil acheteir et vendre chier Et uzereir et gent trichier Et faire d'un deable deus Por ce que enfers est trop seux (Rutebeuf, Poèmes [pièces datables de 1249 à 1272], I, p. 507, 299)

1370 Les marchans de Theman sont advocas qui acoustumeement plaident les causes et estrivent, selonc le dit de Ysaÿe ou .xxie. chapitre : "Comme tourbillons de vent qui vienent d'Affrique ». Cheulx ichy sont marchans car leurs allegations vendent tres cher comme au pois, dont il est dit en
Ysaÿe ou .xxxiiie. chapitre : « Ou est chelui qui poise les paroles de la loy?» (Jean Daudin, De la erudition [manuscrit : $1^{\mathrm{re}}$ moitié XVe])

1695 ce qui fait paier la fole enchere de l'injustice des premiers auteurs de tout le desordre ; sçavoir, de ceux qui prétendent avoir acheté à bon marché et vendre bien cher (Pierre de Boisguilbert, Le Détail de la France sous le règne présent)

1771 Vendre plus cher, c'est diminuer la somme des jouissances ; opérer mal, c'est altérer le bien-être ou l'utilité qu'elle devroit procurer : mais je demande quel autre mal pourroit donc faire aux propriétaires l'exaction directe d'un impôt payé par euxmêmes, que de leur enlever une somme de jouissances et les réduire à consommer des objets d'une qualité fort inférieure à ceux dont ils devroient user?

(Nicolas Baudeau, Première Introduction à la philosophie économique)

1844 Je veux vendre cher à ceux qui spéculent, j'ai besoin de vendre cher parce que j'ai aidé mes frères en J. C. un peu plus que je ne pouvais. Enfin je désire vendre cher afin de transiger avec Véron sans lui faire grâce. Aidez-moi à faire de mon roman une affaire, et tâchez de trouver vos profits dans cette affaire (George Sand, Correspondance)

1896 Sur celui du libraire aux malices ultimes Qui ne vend pas trop cher pour vendre sûrement, Et d'une main fiévreuse, mais honnête, dame,

On est honnête ! Et comme il a vu tel bouquin, Qu'il convoite depuis... Tant d'ans ! Un vrai béguin! (Paul Verlaine, Euvres poétiques complètes)

1926 Un négociant qui disait à M. Achille : « Bouchet vend moins cher », lui faisait aussitôt baisser ses prix. Un contremaître de $\mathrm{M}$. Pascal qui annonçait : « On me demande chez Quesnay », était augmenté à la fin du mois (André Maurois, Bernard Quesnay) 
1935 Decooster, l'ancien boucher, utilisait ses machines de charcuterie à malaxer des graisses et fabriquer une pâte huileuse qu'il appelait savon et vendait très cher. Félicie incorporait de la suie et du sucre brûlé dans du saindoux fondu et faisait du cirage (Maxence Van der Meersch, Invasion 14)

1963 Artisans et marchands s'étaient initiés, par l'appât du profit, à l'idée de la valeur d'échange et à la spéculation ; mais, au $\mathrm{XVIII}^{\mathrm{e}}$ siècle encore, la plupart gardaient beaucoup de l'esprit médiéval : se contentant d'un gain lentement accumulé, ils attendaient le client, répugnaient à la réclame, vendaient peu et cher, ne cherchaient pas à précipiter le roulement du capital (Georges Lefebvre, La Révolution française)

1996 La patronne confectionnait toujours ses bortsch, pirojkis, bitotchkis, qu'elle vendait plus cher, certes. Presque tous vivotaient entre deux engagements dans la marine suisse (Boris Schreiber, Un silence d'environ une demi-heure)

Transitif

+1250 « Sire, sire » ce dit Renart,

« Einsi esmaie l'en coart :

Qar j'ai caiens ases vitaille,

Ne quit devant set ans me faille.

Et anchois que il soit rendus,

Vos sera il molt chers vendus " (Le Roman

de Renart [ $2^{\mathrm{e}}$ moitié $\left.\mathrm{XIII}{ }^{\mathrm{e}}\right]$, Ia, 1722)

1559 C'est un chef d'œuvre grand : Fredon, ce bon ouvrier,

En ces bois l'autre jour me la [= la musette] vendit bien chere

(Pierre de Ronsard, Les Éclogues, p. 94)

1615 La troisième, qu'ils diminuent la mesure et falsifient les poids. La quatrième, qu'ils acquestent l'héritage des pauvres pour peu de chose. La cinquième, qu'ils vendent bien cher de mauvaises marchandises. C'est en ces choses principalement que consiste la police et ses ordonnances (Antoine de Montchrestien, Traicté de l'économie politique)
1664 Ce sont comme des portraicts en petit, qu'on a plus de peine à faire que les grands, et que les peintres vendent plus cher. On peut voir les eloges des hommes illustres de Thevet en suite de ceux de Paul Joue (Charles Sorel, La Bibliothèque françoise de M. C. Sorel)

1721 Elle se jetta à ses genoux. " Je vous demande, dit-elle, la servitude, comme les autres vous demandent la liberté. Prenez-moi. Vous me vendrez plus cher que mon mari. » Ce fut alors qu'il se fit un combat qui arracha les larmes des yeux de mon maître (Montesquieu, Lettres persanes)

1731 L'empereur de Moscovie venait de faire paraître un manifeste, qu'il eût mieux fait de supprimer : il alléguait pour raison de la guerre qu'on ne lui avait rendu assez d'honneurs, lorsqu'il avait passé incognito à Riga, et qu'on avait vendu les vivres trop cher à ses ambassadeurs : c'étaient là les griefs pour lesquels il ravageait l'Ingrie avec quatre-vingt mille hommes (Voltaire, Charles XII. Roi de Suède)

1843 Ce qu'il avait compris de cet argot commercial lui fit deviner que, pour ces libraires, les livres étaient comme des bonnets de coton pour des bonnetiers, une marchandise à vendre cher, à acheter bon marché (Honoré de Balzac, Les Illusions perdues)

1854 Si les Italiens du seizième siècle avaient eu connaissance de cette nécropole immense, ils auraient battu des mains ; car, à cette époque, ils vendaient fort cher, sous le nom de mumia, une poudre merveilleuse, élixir de longue vie, uniquement composée avec des momies pilées et réduites en poussière (Maxime Du Camp, Le Nil. Égypte et Nubie)

1857 De fastueux prospectus furent distribués avec profusion sous les auspices du gardemeuble de la couronne, et plusieurs journaux industriels firent l'éloge de la pâte à lustrer les meubles, de M. Goyon. Je m'en procurai, je l'examinai attentivement, je la fis examiner, et ne tardai pas à me convaincre que, si la pâte mérite presque 
tous les éloges qu'on lui donne, il n'en est pas tout-à-fait de même du marchand, qui trompe en se donnant pour inventeur, et vend très-cher ce qu'on fabrique à très-bon marché (Paul Nosban, Nouveau Manuel complet de l'ébéniste, du layetier, du marqueteur, du sculpteur)

1879a « Nous n'aurions plus alors qu'à le [= l'élixir] mettre en bouteilles, et à le vendre un peu cher, ce qui permettrait à la communauté de s'enrichir doucettement, comme ont fait nos frères de la Trappe et de la Grande... » (Alphonse Daudet, Lettres de mon moulin)

1879b Je vis maître Grapasi, qui huilait si bien la roue de sa brouette. Et Dauphine, qui vendait si cher l'eau de son puits. Et le Tortillard, qui, lorsqu'il me rencontrait portant le bon Dieu, filait son chemin, la barrette sur la tête et la pipe au bec... (Alphonse Daudet, Lettres de mon moulin)

1904 Comme ils ont l'air virginal et pur, dans leur blancheur au lever du jour, tous ces pavots - qui sont destinés pourtant à composer un poison subtil, vendu très cher pour les fumeries d'Extrême-Orient !

(Pierre Loti, Vers Ispahan)

1943 La plupart ont le sentiment du devoir dans certaines choses mauvaises et d'autres bonnes. Un même homme éprouve comme un devoir de vendre aussi cher qu'il peut et de ne pas voler, etc. Le bien chez eux est au niveau du mal, un bien sans lumière. La sensibilité de l'innocent qui souffre est comme du crime sensible (Simone Weil, $L a$ Pesanteur et la grâce)

1949 on en extrayait par un procédé rudimentaire un jus sucré que l'on clarifiait et que l'on concentrait jusqu'à obtention de sucre de canne brut, qui parvenait d'Orient avec les épices par l'Égypte et Marseille. Ce produit était vendu fort cher en pharmacie ou en droguerie. C'est seulement au XviII ${ }^{\mathrm{e}}$ siècle que sa consommation se développa un peu en France (Georges Brunerie, Les Industries alimentaires et leur organisation rationnelle)
1954 Il fallait nier : le danger était déjà assez grand comme ça. "Sézenac cherche des preuves contre moi, il sait qu'il pourrait les vendre cher », pensa Henri. Dubreuilh n'avait jamais entendu parler de Mercier ; il se rappelait peut-être que le 23 février 44 Henri était à Paris (Simone de Beauvoir, Les Mandarins)

1957 Cette femme n'était pas belle mais Rufus l'avait conquise de haute lutte sur deux sigisbées et sur un peintre plus ou moins illustre qui vendait cher sa mauvaise peinture (Jean Duvignaud, L’Or de la République)

1986 - Alors... Alors, de quoi ils s'plaignent? Si tu vas chez eux, qu'ont pas de pétrole, avec ton fric ils creusent des trous, ça fait encore du pétrole, ils te l'vendent encore plus cher, ça fait encore monter l'inflation. - Et le chômage !

- Qui c'est, qui fait monter l'chômage ? (François Caradec, La Compagnie des zincs)

1990 HIPPO. C'est quoi ? De la coke ? Mais t'es débile ou quoi ! T'es vraiment le roi des cons, toi ! XAVIER. Pourquoi ?

HIPPO. Tu vas me faire le plaisir de la couper vite fait et de la vendre super cher, histoire que personne ne t'en redemande. C'est compris, ça ? (Éric Rochant, Un monde sans pitié)

1995 - Après ça, elle est fringante, ma bête, je vous le dis! Sacredieu! Faut voir comme elle piaffe ! Je peux la vendre bougrement cher!

- Et hier ? poursuivait la Comtesse (prête à tout entendre - au point où on en était !). Hier, ce jeu où vous vous battiez, qu'est-ce que c'était ? (Françoise Chandernagor, L'Enfant des Lumières)

Pronominal (à sens passif)

1578 C'est là, c'est là que le caquet Se vend aussi cher comme crème ; Jamais le fourment ne s'y seme, Ny l'herbe, et en toutes saisons On y fauche, et fait-on moissons (Rémi Belleau, La Reconnue) 
1634 Nous n'avons pas veu cez libvres du Sieur de Bellay, mentionnez en l'arrest du conseil, et fauldra bien les joindre à l'assortiment des precedents s'ils ne se vendent trop cher soubs pretexte des deffances (Nicolas de Peiresc, Lettres aux frères Dupuy)

1669 pour faire une infinité de ces livres et traitez mysterieux, lesquels ne se communiquent par apres qu'en cachette, et se vendent ordinairement bien cher par ceux qui n'ont autre moyen de subvenir à leur necessité qu'en pratiquant ces fraudes et tromperies aux depens de beaucoup d'esprits foibles, superstitieux et melancholiques (Gabriel Naudé, Apologie pour tous les grands hommes qui ont esté accusez de magie)

1691 On a ici un grand nombre d'esclaves qui s'achètent et se vendent fort cher. Ce sont des Maures et des Turcs. Il y en a qui valent jusqu'à quatre et cinq cents écus. Autrefois, on avait droit de vie et de mort sur eux (Marie-Catherine d'Aulnoy, Relation du voyage d'Espagne)

1696 Mais pourtant ce sera votre faute si vous n'en faites de l'argent, car il se vend cher partout. Cependant, madame, il n'y a jour que je ne vous regrette, surtout le matin à notre messe (Mme de Sévigné, Correspondance)

1735 Les annales de King Te Tching disent qu'anciennement le peuple ne se servoit que de porcelaine blanche : c'est apparemment parce qu'on n'avoit pas trouvé aux environs de Iao Tcheou, un azur moins précieux, que celui qu'on employe pour la belle porcelaine, lequel vient de loin, et se vend assez cher (Jean-Baptiste Du Halde, Description géographique)

1738 Ce sont les ecclésiastiques, qui sont en droit d'expédier les lettres patentes de ceux qui doivent occuper ces postes. Comme elles se vendent très cher, et que le souverain pontife y trouve son intérêt, il est attentif à faire de tems en tems de très nombreuses promotions (Jean-Baptiste
d'Argens, Lettres juives ou Correspondance philosophique, historique et critique)

1755 On sçait que souvent, en Hollande, de certains genres de marchandise venue de loin ne s'y vendent pas plus cher qu'ils n'ont coûté sur les lieux mêmes. Voici la raison qu'on en donne : un capitaine qui a besoin de lester son vaisseau prendra du marbre (Montesquieu, De l'esprit des loix)

1801 On nous dit que le sol de ce dernier étoit d'une fécondité extraordinaire, qu'il se vendoit aussi cher qu'en Europe ; que la plupart des habitans descendoient des premiers colons qui fondèrent la ville de New-York en 1626 (J. Hector St John de Crèvecœur, Voyage dans la Haute Pensylvanie et dans l'État de New-York)

1828 Le portrait de Mme Récamier, ébauche peinte, a été payé 6000 et tant de cent francs. Le jeune Bara, 2600 francs. Les dessins et croquis se sont vendus assez cher, mais aucun des tableaux importants tels que le Marat et les Bonaparte, le Mars, l'Hector, etc., n'ont point été vendus (Étienne-Jean Delécluze, Journal)

1832 Il y a un commerce qu'on appelle de spéculation, et qui consiste à acheter des marchandises dans un temps pour les revendre au même lieu et intactes, à une époque où l'on suppose qu'elles se vendront plus cher (Jean-Baptiste Say, Traité d'économie politique)

1846 Après tout, j'ai trente-cinq ans, et les femmes de trente-cinq ans ne peuvent pas être aimées. Oh ! Si j'avais et seize ans, et ce qui se vend si cher à l'Opéra, quelles attentions vous auriez pour moi, monsieur du Bruel ! (Honoré de Balzac, Un prince de la Bohème)

1909 Fait pas bon pour l'ouvrier cette année. Maréchal prêchait l'espoir qui assurait la dépense des vignerons dans son auberge : - On sauvera ce qui reste et ça se vendra cher.

La femme de Duvigneaut entrait réclamer son homme pour la soupe. 
- C'est sur la table

(Pierre Hamp, Vin de Champagne)

1924 Après avoir connu Nietzsche et juré sur leurs maîtresses, après avoir tiré tout le ripolin du cadavre de leurs amis, ils ont déclaré que les beaux enfants valaient bien la bonne peinture à l'huile, et que la meilleure était celle qui se vendait le plus cher (Tristan Tzara, Manifestes, lampisteries, articles : 1912-1924)

1939a D’après les renseignements des indigènes, très difficilement obtenus, il semble que, de cette plante, broyée, les indigènes extraient une sorte d'huile, qu'ils disent préférer de beaucoup à celle d'olive, et qui, du reste, se vendrait sensiblement plus cher (André Gide, Carnets d'Égypte)

1939b La revue peut atteindre sans grand inconvénient un prix assez élevé, au lieu que le journal doit se vendre le moins cher possible. Entre ces deux catégories, participant de l'une et de l'autre et prenant à l'heure actuelle une importance croissante, se placent les hebdomadaires ( $L a$ Civilisation écrite)

1956 Ça se vendait cher, les homards. Il vivrait par la suite du commerce de ses homards. Les homards à Juju seraient connus sur le marché de Bastia (René Fallet, La Grande Ceinture)

1961 « Très cher seigneur, pour notre fidélité allons-nous souffrir plus cruellement que les traîtres et les ralliés ? Dans la cité le pain se vend déjà si cher que de bons ouvriers peuvent à peine en acheter une miche par semaine, car dans les greniers et aux moulins il n'y a de réserves que pour un mois tout au plus » (Zoé Oldenbourg, Les Cités charnelles)

1964 Les gourmets le [= le rouget] faisaient cuire sur leur table vivant, et dans un vase de cristal pour mieux voir l'agonie. Ils contemplaient alors les changements de couleur que le rouget subissait. Les rougets de grande taille se vendaient très cher (Cécile Éluard-Valette, Les Grandes Heures de la cuisine française)
1995 C'est un défaut d'organisation qui fait que chaque année les Adeline et les Aimé gagnent plusieurs mois d'intérêts sur les Pierre et les Thomas... Il va de soi que les gros rentiers ont trouvé la parade : ils engagent des prête-noms - on se vend très cher quand on s'appelle Abel ! (Françoise Chandernagor, L'Enfant des Lumières)

CORPUS WEB :

si le marché de renouvellement peut fonctionner durablement sur un mode inflationniste (qui vend cher peut racheter cher), il en va tout autrement du marché des primo-accédants, ces ménages qui n'ont pour seul viatique qu'une épargne alimentée par leurs revenus professionnels... [http://www.obsimmo.fr/actu30.6.10. html] (21.10.2015)

Mais une vente réussie à ses salariés se prépare souvent sur plusieurs années, « avec les salariés et un second qui monte en compétences, note Bernard Penhoët. Le dirigeant a envie de la vendre cher mais aussi de la vendre bien. Psychologiquement, il ne peut pas se dire que son entreprise ne va pas continuer » [http:// www.entreprises.ouest-france.fr/article/lan nion-reprise-par-salaries-solution-peu-connue30-12-2014-181774] (16.2.2016)

Comme je l'ai relevé ici à plusieurs reprises et dans un rapport publié par le ministère de l'environnement, il est incohérent et coûteux de produire de l'électricité à partir de la chaleur d'incinération, vendue cher à EDF, alors qu'à quelques kilomètres un réseau de chaleur est chauffé au gaz. Cette chaleur venant de la combustion de gaz, ne coûte pas cher car l'électricité produite en même temps (en « cogénération ») est vendue très cher à EDF [http://sainte.genevieve. autrement.pagesperso-orange.fr/interv/20-09-11. html] (16.2.2016)

Je sais que je pourrais pas la vendre chère mais j'aimerais savoir combien je pourrais en tirer ? [http://www.forum-auto.com/marques/ Peugeot/sujet47111.htm] (16.2.2016)

REMARQUES : Au propre, vendre cher (II) désigne une personne qui veut céder un bien (une marchandise) en exigeant une somme importante en retour, l'objet référant souvent à un objet précieux, dont l'acquisition n'est pas donnée. 
(I) se dit au figuré du fait d'exiger beaucoup de quelqu'un en échange de quelque chose, de lui faire subir des choses difficiles avant de pouvoir acquérir un bien ou ce qu'il recherche. L'objet désigne souvent une chose abstraite comme l'amour, des biens qui ne peuvent être accordés facilement ou dont la possession s'avère difficile. Cher peut s'accorder avec l'objet, notamment dans l'ancienne langue, et surtout dans l'emploi métaphorique (au propre : $+1250,1559$; au figuré : ex. de 1275, +1415, 1572a, 1757), ce qui indique l'emphase comme motif stylistique. L'accord est rare en antéposition : un seul exemple, avec accord au cas sujet (ex. +1250). À partir du $\mathrm{xvIII}^{\mathrm{e}}$ siècle, l'emploi invariable s'impose comme règle dans le registre courant. On trouve tout de même un exemple accordé dans le CW qui montre que l'accord n'est pas exclu dans le registre informel. Cher est souvent modifié : assez, aussi, bien, bougrement, déjà, encore plus, fort, le plus, moins, moult, ordinairement, plus, si, super, sensiblement, très, trop, un peu. Notons l'occurrence des groupes acheter / racheter cher, l'emploi impersonnel familier ça se vendra cher et la locution vil acheter et vendre cher.

\section{Vendre double}

Vendre le double de son prix

Emploi absolu

1886 Je voulais tout mettre en ordre cette nuit même, afin de commencer à vendre double [= de l'eau-de-vie] le plus tôt possible (Émile Erckmann et Alexandre Chatrian, Le Blocus)

\section{Vendre droit}

Vendre directement

Transitif

$\sim 1365$ De Gaufroi, vo cousin, i est en mais endroit, Car chius draz-chi tiesmoingne qu'il vendi, par ma foit, Roy Hernoul de Nimaye as Sarrasins tou[t] droit ;

Et s'en ot tant d'avoir que nulz ne le diroit (Li Romans de Bauduin de Sebourc, Chant II, 669)

\section{CORPUS WEB :}

les joints de caches soupapes ont été changé quand j'ai acheté le véhicule et du coup ne pissait pas l'huile et tu m'as dis toi-même qu'elle pissait l'huile et que tu ne savais pas d'où ça venait. Alors de là à dire que je suis malhonnête je trouve vraiment gonflé. Car si j'aurais su que tu allais la vendre droit derrière je ne te l'aurais pas vendue à la somme qui a été fixée entre nous. Qui était, soit dit en passant, plus que correcte [http://www. vwspirit.ch/forvwsp/viewtopic.php? $\mathrm{p}=390001]$ (16.2.2016)

La pièce correspondant à la flèche jaune est elle bien la MB51 ? Est t'elle vendue droite et doit être pliée ensuite ? [http://www2.mgcontact.eu/ phpBB2/viewtopic.php?f=13\&t=18228] (16.2.2016)

voici une photo, vu le problàme de pompe à essence la tige ne devrait elle pas être droite ??? je pose la question vu qu'elle est vendue droite [http://www.citro-rouge-et-vert.com/viewtopic. $\mathrm{php} ? \mathrm{f}=5 \& \mathrm{t}=3024](16.2 .2016)$

REMARQUES : Vendre droit, très peu représenté en français moderne, se dit du fait de céder un bien contre un paiement, la transaction se faisant de façon directe, sans intermédiaire, le vendeur étant confronté directement à l'acheteur. Dans le premier exemple du CW, droit forme plutôt un groupe syntaxique avec derrière. En tant que prédicat second, il réfère au fait d'être rigide (donc non pas plié) ou vertical et s'accorde avec l'objet (v. les deux derniers exemples du CW). Droit est modifié par tout.

\section{Vendre ferme}

Vendre d'une manière nette et définitive Emploi absolu

1837 Pour spéculer à la baisse il faut : vendre ferme à terme à découvert une certaine quantité de rentes, et quand la baisse sera venue, acheter ferme la même quantité de rentes (Élie Ritter, Traité élémentaire d'arithmétique)

1894 LOUIS LAINE. You are pretty smart, are ye?

THOMAS POLLOCK NAGEOIRE. Well, il faut du nerf, alors que vous vendez ferme comme si vous saviez tout, quand je ne sais pas le temps qu'il fera demain; chaque jour 
a son cours, mais moi je connais les choses elles-mêmes (Paul Claudel, L'Échange)

1948 Autorisé par son commettant à vendre ferme, le commissionnaire n'a pas à faire ratifier par ledit commettant la commande qu'il a prise, pour prétendre à sa commission, cette ratification ayant été donnée par avance (Jurisprudence française)

\section{CORpus Web :}

On ne traite ces primes à la baisse que dans la spéculation sur les marchandises ; dans la spéculation sur les valeurs, on obtient une prime à la baisse en vendant ferme et en achetant simultanément à prime [http://www.actions-finance. com/bourse-et-marche-a-prime] (18.2.2016)

En vertu de l'article 18.1 des statuts du SEBC, les banques centrales nationales des États membres dont la monnaie est l'euro (ci-après les « BCN de la zone euro ») et la Banque centrale européenne (BCE) (ci-après conjointement dénommées les «banques centrales de l'Eurosystème ») peuvent intervenir sur les marchés de capitaux, notamment en achetant et en vendant ferme des titres négociables [http://alineabyluxia.fr/eu/lr/ 2010/5/14/JOL_2010_124_R_0008_01] (18.2.2016)

Ils lui vendent ferme $20 \%$ de leurs titres SFFAW au prix unitaire de $250 \mathrm{~F}$ soit 32 millions de francs payables dans sept ans [http://www. boursilex.com/VIE\%20DES\%20AFFAIRES/19 novembre_1984_accord_willot_arnault.htm] (18.2.2016)

REMARQUES : Vendre ferme se dit en emploi absolu du fait de vendre quelque chose, le prix ou le montant proposé ayant un caractère définitif, en s'en tenant au prix et aux conditions fixées, notamment dans le discours du commerce et du marché des finances. Ferme reste invariable. Notons l'emploi transitif du verbe dans le CW. Nous citons vendre ferme comme représentant d'une série qui comprend aussi les verbes accepter, acheter, parier, ponter, vendre. VoIR AUSSI : acheter / prendre ferme

\section{Vendre petit}

Vendre à un prix peu élevé, à bon marché ;

vendre peu

Emploi absolu

$\sim 1000$ Lo fel iudes escarioth als iudeus ueng ra enrebost.

que men darez eluos tradran

uos tres talenz ad emplirant

Trenta deners dunc lien promesdrent

son bon sennior que lo tra disse

si chera merz uen si petit

hanc Non fud hom qui magis laudis

(La Passion du Christ, 87)

1195 LI TAVRENIERS. Caignet, nous vendons

mout petit ;

Va, se di Raoul que il crit

Le vin : le gent en sont saoul

(Jehan Bodel, Jeu de saint Nicolas, 588)

REMARQuES : Vendre petit désigne le fait de céder un bien, un produit contre de l'argent, contre paiement, l'acquéreur obtenant le bien soit à un très bon prix, soit en petite quantité. Petit reste invariable et est modifié par moult, si.

\section{Venir aise}

Venir facilement

Intransitif

+1370 Che merquedi au soir, dont la bataille fu a l'endemain, s'en vint Phelippes d'Artevelle et sa poissance logier en une place aseis forte, entre un fosset et un bosquetel et fortes haies, que on ne pooit venir aisse tant c'a eulx, et fu entre le Mont d'Or et la ville de Rosebecque, ou li rois estoit logiés (Jean Froissart, Chroniques (A))

REMARQUES : Venir aise se disait du fait de se déplacer en direction d'un lieu facilement, sans trouver d'obstacle sur son chemin. L'adjectifadverbe permet également une analyse de prédicat second orienté vers le sujet.

\section{Venir bel (beau)}

I. Apparaître de façon élégante

Intransitif

1165 Uns genz dameisels l'adestrout, un cor d'ivoire od lui portout. Mult vindrent bel par mi la rue. Tant granz bealtez ne fu veüe en Venus, ki esteit reïne, ne en Dido ne en Lavine (Marie de France, Lais, 583) 
1285a Mais ainsi que je l'entendi Quant l'estoire m'en fu contee, Partis estoit de sa contree Li rois Carmans et s'en venoit Vers la feste a Sebile droit, Si bel et si tres noblement Et a plenté de si grant gent Que c'ert merveille a esgarder (Adenet le Roi, Cleomadés, 15923)

1285b Ainsi en la cité entrerent, Mout volentiers les esgarderent Cil de la vile et dou chastel, Car mout noblement et mout bel Venoient et mout tres a droit : Li atours d'aus a tous plaisoit (Adenet le Roi, Cleomadés, 16876)

1632 Enfin je jouïray de celle que j’adore, La voicy qu'elle vient plus belle que l'Aurore :

J'ay vaincu ces vainqueurs qui souloient me braver,

Je vous tiens, je vous tiens, rien ne vous peut sauver (Honorat de Bueil, chevalier de Racan, Les Bergeries)

1846 Oh ! elle viendra belle, parée, ravissante à cette heure, exactement ! Et elle est mariée ! Entortillée dans les obligations et les devoirs d'une maison (Honoré de Balzac, Un prince de la Bohème)

II. Réussir, finir bien

Intransitif

1593 Car s'il eust creu ce qui avint et que les Barricades eussent assemblé tant de prospérité à son party, et comme il succéda que le Roy avoit faict naistre l'occasion de cette grande desbauche, puisque le jeu luy vint si beau, j'estime qu'il eust joué de sa teste, et faict à quitte ou à double pour recevoir le fruict de ses peines (René de Lucinge, Dialogue du François et du Savoysien)

III. Bien pousser ; bien se développer Intransitif

1773a Les jasmins d'Espagne et de France s'y sont bien naturalisés ; je parlerai de ceux d'Asie à leur article. Il y a des grenadiers à fleur double et à fruit ; mais ceux-ci rapportent peu. Le myrte n’y vient pas si beau qu'en Provence (Bernardin de Saint-Pierre, Voyage à l'T̂le de France)

1773b C'est une plante fort utile, en ce qu'elle est à l'abri des ouragans, et qu'elle assure la subsistance des nègres. Les chiens n'en veulent point. Le maïs, ou blé turc, y vient très beau : c'est un grain précieux ; il rapporte beaucoup, et ne se garde qu'un an, parce que les mites s'y mettent

(Bernardin de Saint-Pierre, Voyage à l'île de France)

1784a C'est dans les mêmes îles et sur les mêmes sables, que s'élève le cocotier, qui y vient plus beau que dans aucun autre lieu du monde. Ainsi, l'arbre le plus utile aux marins croît sur le bord des mers les plus naviguées (Bernardin de Saint-Pierre, Études de la nature)

1784b Pour moi, s'il m'est permis de hasarder mes conjectures sur le nombre des espèces de plantes répandues sur la terre, j'ai une telle idée de l'immensité de la nature et de ses répartitions, que j'estime qu'il n'y a point de lieue carrée de terrein qui n'en présente quelqu'une qui lui soit propre, ou du moins qui n'y vienne plus belle que dans aucun autre endroit du monde (Bernardin de Saint-Pierre, Études de la nature)

1835 La nature offre d'elle-même toutes ses productions à l'homme qui sème et recueille, les arbres ne refusent pas leurs fruits au pauvre voyageur qui les cueille en passant et les légumes viennent aussi beaux dans le terreau d'un pauvre jardinier que dans le jardin d'un prince (George Sand, Correspondance)

1865 Depuis un an que je ne l'avais vu, il s'était fait en lui autant de changement que dans Thérence. La santé lui étant venue plus belle qu'il ne l'avait jamais eue, on pouvait dire qu'il était joli homme et que sa figure carrée et son corps sec marquaient plus de muscles que de maigreur (George Sand, Les Maîtres sonneurs) 


\section{CORPus Web :}

J'en avais des minuscules et des vilaines, je les ai alors mises sur mon compost et elles ont repoussées :D...bon sont pas venues belles comme dans la terre, car il y avait des limaces aussi $\wedge \wedge$ ! [http://equi-logique.actifforum.com/t11080p15potager] (18.2.2016)

REMARQUES : En parlant de l'apparence, venir bel (beau) (I) réfère à une personne et se dit du fait d'apparaître en public en étant vêtu de manière élégante, raffinée. En (II), le masculin beau reprend la fonction adverbiale qu'avait le neutre bel 'bien' en ancien français. En prédication seconde accordée, (III) peut désigner une céréale, un arbre fruitier, un arbuste ou un légume qui grandit, pousse bien, prend une belle forme. En parlant d'une personne, venir beau souligne le fait de se trouver en bonne santé par rapport à un état antérieur, moins salutaire. L’ancien français emploie le neutre bel, remplacé progressivement par beau, remotivé, ce qui permet son emploi en tant que prédicat second accordé, référant à la beauté de quelqu'un ou de quelque chose. Bel (beau) est modifié par aussi, plus, moult, si, très. Nous avons exclu ici les exemples attestant l'emploi moderne de venir bel et bien 'effectivement, contrairement à ce que l'on pouvait croire'.

\section{Venir bon}

Arriver, se produire en ayant un effet positif Intransitif

+1370 Et Bonne-Lance avoit respondu : Par Dieu, dame, se l'aventure d'armes me peut venir si belle et si bonne que j'en puisse prendre ung qui vaille que vous le voiez, vous le verrez (Jean Froissart, Chroniques (A))

CoRpus Web :

Ca vient bon (comme on dit joliment par chez nous) [http://semibourgeoises.canalblog.com/ archives/2011/05/09/21096610.html] (18.2.2016)

(i) ça vient bon on va pouvoir acceuillir les machines bientôt!!! [https://www.facebook.com/ Beautyspaesthetique/posts/1617221451894166] (18.2.2016)

REMARQues : Venir bon se dit du fait de se produire, de se manifester de façon positive, en faveur de quelqu'un. Dans son emploi productif, bon peut s'accorder avec le sujet (ex. de +1370) et se rapprocher d'un prédicat second orienté vers le sujet. Par contre, le tour familier régional (Nord de la France) ça vient bon semble figé au sens adverbial de 'bien'. L'emploi des successeurs du latin bonum comme adverbe équivalent à bien est enraciné dans la tradition populaire des langues romanes (v. les dialectes de l'Italie méridionale ; Introduction $\S 4.6)$. Bon est modifié par si.

\section{Venir clair}

Produire une lumière claire

Intransitif

1704 et personne n'oza l'interroger : aveugles, parce que la lumière venoit trop claire à leurs yeux, ils n'ozoient plus l'interroger. Il falloit l'interroger, non par un esprit superbe et contentieux, mais pour estre instruit (Jacques-Bénigne Bossuet, Méditations sur l'Évangile)

\section{CoRpus Web :}

quand j'en ai je met du chemi clean et pouf....tout disparait, l'eau vient clair comme du cristal...... [https://www.reefsolution.com/fo rums/forum-general-d-eau-salee-general-salt water-forum/debutants-newbies/4385-alguerouge-5.html?langid=1] (21.2.2016)

Mais avec ma recette, mes fenêtres viennent claires à un point tel, qu'on croit qu'il n'y a pas de vitre [http://www.ekodefi.com/pub/excellentnettoyant-a-vitres] (21.2.2016)

certes, le son vient clair, mais sans dynamique, et avec des aigus en moins... [http://www. guitariste.com/forums/guitare,le-telecaster-pla yer-s-club,113062,1240.html] (21.2.2016)

ça vient clair de l'utilisation des VST. j'utilise plusieur OZONE izotop sur differentes track... donc effectivement je jongle avec le bufferring asio de ma carte son... [http://fr.audiofanzine.com/ sequenceur-boucles/sony/ACID-Pro-7/forums/ t.584214,acid-pro-et-memoire.html] (21.2.2016)

REMARQUES : Venir clair se dit du fait de produire une lumière claire, éblouissante pour les yeux. Il peut aussi référer à un son (v. les deux derniers exemples du CW) ayant sur l'oreille un effet comparable à celui que produit sur les yeux une lumière vive. Clair est employé comme prédicat second fléchi, sauf dans le premier exemple du 
CW. Dans les deux premiers exemples du CW, venir clair a le sens de 'devenir net, propre'. De manière générale, venir a souvent le sens de 'devenir' (verbe copule) ; il s'agit d'un archaïsme et donc, probablement, d'un usage régional ou, peut-être, populaire, ce qui explique également la tendance à fléchir l'adjectif complément du verbe copule. Dans le quatrième exemple du $\mathrm{CW}$, ça vient clair a une fonction discursive d'adverbe de phrase équivalent à clairement 'c'est clair, sans doute'. Clair est modifié par trop.

\section{Venir court}

Venir par un chemin court, direct Intransitif

+1489 Et ladite avangarde eut paour de nostre arrièrre-garde qu'ilz veoient venir de loing hors du chemin, pour venir le plus court. Et se mist chascun en estat de combatre ; mais cest effroy dura poy, car chevaulcheurs vindrent de tous coustéz et se recongneürent incontinent (Philippe de Commynes, Mémoires [1489-1498], VIII)

CORpus Web :

$\mathrm{Si}$ tu passes par Vallorbe et que tu vois que ça vient court, tu peux faire un crochet au SuC de Lully, mais avec la descente que tu vas faire, tu vas bien recharger et je pense que ça devrait le faire [http://forums.tesla-mag.com/dc/8543851860 656657640/SuC-Nuits-St-Georges-vers-SuC-Mar tigny] (21.2.2016)

Alors à la détente pour la club 4, poney était chaud haha :D Donc on part sur le tour, dès le départ il a prit de la vitesse, et jel'ai laissé faire. Il s'est appliqué tout le tour, à fait de gros efforts quand ça venait court.. Il était toooop ! [https://www. facebook.com/permalink.php?story_fbid $=37$ 1422366376485\&id=368096963375692] (21.2.2016)

le problème c'est qu'il faut vraiment pouvoir juger rapidement si la balle vient courte ou longue, car si elle vient longue, c'est complètement autre chose qu'il faut faire, et c'est dur de se rattraper si on a anticipé [http://www.tennis-detable.com/forums/sujet-63007-1.html] (21.2.2016)

REMARQUES : Venir court se dit du fait de prendre le chemin le plus rapide, de prendre un raccourci pour arriver le plus vite possible à destination Dans le premier exemple du CW, c'est le chemin ou la route qui devient trop court ; dans le deuxième exemple, il s'agit d'un virage court, serré que prend le cheval. Dans le dernier exemple du $\mathrm{CW}$, venir court et son contraire, venir long, renvoient au trajet d'une balle de ping-pong. L'accord dans cet exemple est typique du langage des sports. Tous les exemples du CW appartiennent à des argots qui emploient venir court par économie. Comme dans l'entrée précédente, venir tend à adopter le sens de 'devenir' (verbe copule) ; il s'agit d'un archaïsme et donc, probablement, d'un usage régional ou, peut-être, populaire. Mis à part le dernier exemple, venir court tend à l'emploi invariable. Court est modifié par le plus. Notons l'emploi impersonnel familier ça vient court, incompréhensible hors contexte.

\section{Venir droit}

I. Venir directement

Intransitif

$\sim 1170$ Lors chevauchent a grant esploit, An la forest vienent tuit droit. Cil qui devant ierent alé, Avoient ja le cerf levé (Chrestien de Troyes, Erec et Enide, 116)

1285 Une en voit qui vers lui se trait Et lors pensa il entresait Que Cleomadés i estoit Et k'a lui vient assambler droit (Adenet le Roi, Cleomadés, 8766)

1339 LE TIERS HERMITE. Par la royne de purté, Amis, li bien venu soiez. Vous n'estes mie desvoiez : Vous devez droit a moy venir (Miracle de l'enfant donné au diable, 1179)

1364 Si vinrent tout droit a l'église, Qui n'estoit pas de pierre glise, Ainçois estoit de pierre dure, A grans pilers, a grant vauture (Guillaume de Machaut, Le Livre du voir dit, 2815)

+1415 De pensées son chapperon A brodé le povre cueur mien ; Tout droit de devers lui je vien, Et m’a baillé ceste chançon : J'ayme qui m'ayme, autrement non (Charles d'Orléans, Poésies complètes [ 1415-1440], II, Rondel CXXVII, p. 149) 
1544 Non point au vent l'aigle noir couronné, Non point en main le glaive, mais l'olive. Françoys et luy viennent droit de la rive De Loyre à Seine, affin de Paris veoir, Et avec eulx Guerre menent captive, Qui à discord les souloit esmouvoir (Clément Marot, Chants divers)

1560 Quoy qu'il en soit, il est certain que tous ceux qui tergiversent pour ne point venir droit à Dieu, non seulement sont rebelles et sauvages, mais aussi convaincus d'incrédulité, puisqu'ils se deffient de ses promesses (Jean Calvin, Institution de la religion chrestienne)

1608 ELEONOR. Ils viennent droit vers nous. SOSE. Laissons-les aprocher,

Peut estre n'est-ce nous qu'ils desirent chercher,

Qu'on se tienne tous prests les repousser de force

(Nicolas Chrétien des Croix, Les Portugaiz infortunez)

1684 Or comme nous dirons en son lieu, la seule et unique cause de la tromperie dans la veue, aussi bien que dans les autres sens à proportion, et principalement dans celuy de l'ouye, vient de ceque l'imagination de la chose veüe sef aisant selon la ligne droite, ou selon le rayon droit qui meut l'œil, la chose paroit toujours estre vers l'endroit d'ou le rayon commence de tendre droit vers l'œil, et le frapper ; ensorte que s'il vient droit de la chose mesme, la chose paroit là où elle est (François Bernier, Abrégé de la philosophie de Gassendi)

1719 Quand cet objet flottant fut assez près du rivage, au lieu de venir droit à l'entrée de la grotte, il se détourna pour aborder plus loin. Il se mit tout au bord de la mer, et vit qu'au lieu de prendre terre, cette merveille ne fit que ranger la côte en s'avançant vers lui (Antoine Hamilton, Le Bélier)

1731 Enfin, elle me dit qu'elle était sortie de ce lieu la dernière, pour cacher son désordre, et que, ne suivant que le mouvement de son cœur et l'impétuosité de ses désirs, elle était venue droit au séminaire, avec la résolution d'y mourir si elle ne me trouvait pas disposé à lui pardonner (abbé Prévost, Histoire du Chevalier des Grieux et de Manon Lescaut)

1833 JEAN. Oui, ma foi, ce sont eux : que diable cherchent-ils ? Ils viennent droit à nous.

MATHURIN. N'ont-ils pas leurs épées à la main ? (Alfred de Musset, André Del Sarto)

1845 il excitait ses chevaux de la voix, des talons et du fouet, malgré les recommandations impuissantes du soldat du train, qui, contenant à peine ses chevaux, suivait malgré lui l'allure désordonnée que le charretier donnait à l'attelage. Aussi, l'ivrogne, ayant dévié de sa route, vint droit sur la berline, et l'accrocha. À ce choc, le couvercle du fourgon se renversa (Eugène Sue, Le Juif errant)

1847 Puis d'ailleurs c'est à vous que je viens tout droit entre cent mille choses aimables, comme je cours à vos lettres entre cent mille écritures. Il faudrait me voir quand il m'en arrive quelqu'une au milieu d'une pacotille d'autres ! (Eugénie de Guérin, Lettres)

1886 Elle le jugeait sauvage seulement, entêté dans ses idées d'indépendance, mais doux, franc, et capable de bien comprendre les choses bonnes qui viennent tout droit du cœur. Qu'allait-il éprouver, en la retrouvant là, pauvre, dans cette chaumière presque en ruine? (Pierre Loti, Pêcheur d'Islande)

1922 Le feu grandissait. Le sol tremblait déjà. Un grondement entourait le feu comme un autre halo. Le feu venait droit sur nous. On avait envie non de le fuir, mais de se jeter dedans (Jules Romains, Lucienne)

1934 On n'a plus rien vu pendant un moment ; tout à coup, on s'aperçoit que le point blanc vous vient droit dessus, ayant été à couvert un instant, parce qu'il a traversé un taillis (Charles-Ferdinand Ramuz, Derborence) 
1937 Ceux qui refuseront alors de l'accueillir [= l'espérance] dans leur cœur la reconnaîtront du moins à ce signe : les hommes qui détournent aujourd'hui les yeux sur votre passage, ou ricanent lorsque vous leur avez tourné le dos, viendront droit vers vous, avec un regard d'homme (Georges Bernanos, Les Grands Cimetières sous la lune)

1962 Il était à quelques pas seulement des derniers arbres, lorsqu'il vit la fille quitter la cour de l'hôtel et traverser la rue. Elle allait vite et venait droit vers lui. Il se remit à marcher et ils se rencontrèrent à la hauteur des derniers arbres, à l'endroit où commence la pénombre (Bernard Clavel, La Maison des autres)

1966 Elle avait la gorge serrée, à ne plus pouvoir respirer, mais ce qu'elle ressentait, c'était délicieux, c'était une sorte de gratitude envers tout : Cassis, la mer, le soleil, le gros chauffeur de taxi et elle-même, qui n'avait pas versé une larme, qui était venue tout droit où il fallait (Sébastien Japrisot, $L a$ Dame dans l'auto)

1996 OubaOuba devait me surveiller depuis un bon bout de temps. Parce qu'il vint droit sur moi avant que je n'arrive au parking. Comme une ombre. Tee-shirt noir, pantalon noir. Et casquette des Rangers assortie (Jean-Claude Izzo, Chourmo)

Pronominal : s'en venir tout droit, se venir tout droit

-1469 Si s'en vint tout droit au secours et trouva le Jouvencel et Gervaise si fort pressez que à paine se povoient-ilz deffendre ; car ceulx $\mathrm{du}$ logis se rallioient de toutes pars contre eulx (Jean de Bueil, Le Jouvencel [1461]1468, I, p. 109)

1559 Toutesfoiz, amour qui donne entendement et hardiesse où il baille les neccessitez, fist que le jeune prince s'en vint tout droict à luy (Marguerite d'Angoulême, Heptaméron, p. 251, 52)

1610 Or cependant que nous descendions, nous vismes que tout à coup vostre frere enfonçant son chapeau, et tournant le dos à sa bergere, s'en venoit droit à nous sans nous voir, quelquesfois les bras estendus et regardant le ciel, et d'autresfois se les croisant sur l'estomac, et tenant les yeux en terre (Honoré d'Urfé, L'Astrée)

1630 PHILENE. Mais Dieux ! comme à mes vœux l'occasion se joint, Une fille qui m’aime, et que je n'aime point,

S'en vient tout droit icy, selon que je presume,

Afin de me parler du feu qui la consume ; Garde toy pour ce coup de la persecuter, Car elle peut trop bien ta ruse executer (Jean Mairet, La Sylvie)

1784 Il me promena dans de vastes enclos où le premier objet que j'aperçus fut un homme d'environ quarante ans, la tête couverte de la moitié d'un chapeau, qui s'en vint droit à moi, en me disant : « Donne-moi de ton couteau de chasse dans le cœur, donnemoi de ton couteau de chasse dans le cœur. » (Bernardin de Saint-Pierre, Études de la nature)

1840 Sa joie fut si grande de se savoir ainsi déliée, que, rentrant chez elle et s'empressant de dîner, elle fit mettre les chevaux au carrosse, et s'en vint droit à Port-Royal embrasser sa fille, et lui conter l'allégement de conscience qui la ramenait (Charles Sainte-Beuve, Port-Royal)

1913a nous n'avions pas tous les jours le restaurateur de Sion, de Flavigny, de Mattaincourt et de Sainte-Odile. Je l'ai cru et je m'en viens tout droit vous prier d'excuser ma sottise, car je vous avoue que ignorans feci (Maurice Barrès, La Colline inspirée)

1913b Y découvrit-il un refus déguisé ? Le certain, c'est qu'une heure après, quand M. Magron rentra dans son presbytère, et s'en vint tout droit à la cuisine où il pensait trouver son ami auprès du feu, la pièce était vide. Avec sa nièce, il chercha vainement dans tous les coins de la cure Léopold Baillard (Maurice Barrès, La Colline inspirée) 
1981 Elle fit en vain tout ce qu'elle put pour avoir prétexte de demeurer à coucher dans ma maison ; enfin, un jour que j'étais sur des carreaux dans ma ruelle de lit avec un peu de colique, cette fille, en entrant, se vint tout droit coucher auprès de moi et me voulut mettre une grosse bourse pleine de louis dans la main en m'embrassant ; je me levai d'un bond et la chassai (Françoise Chandernagor, L'Allée du roi)

II. Provenir de, découler de

Intransitif

1927 De Sanctis a bien vu la vanité exaspérée du pédant solitaire chez Giacomo entre seize et dix-huit ans. Cela venait tout droit de l'influence paternelle : faire valoir son érudition dans de savantes polémiques (Valéry Larbaud, Jaune bleu blanc)

\section{CORPUS WEB :}

Quelqu'un qui venait droit jusqu'à lui et se frottait contre ses robustes pattes antérieures, qui se dressait pour lécher ses oreilles soyeuses, dont le petit museau rose touchait sa truffe brune [http://www.babelio.com/auteur/KathiAppelt/99719] (21.2.2016)

De plus, la parlementaire élue pour l'Europe du nord venait droit de la section de Londres [http://rue89.nouvelobs.com/2014/01/27/jai-priscarte-ps-cest-exactement-comme-ca-jimaginaislump-249145] (21.2.2016)

Une grosse tempete qui venait droit sur moi [http://www.fierdetreroutier.com/chauffeurs/ bout_du_monde/algerie_rais/algerie.php] (21.2.2016)

et depuis le dernier concours elle va bien !! j'ai resauté 3-4 fois en entrainement elle n'a jamais été aussi bien, elle vient droite sur l'obstacle en impulsion, elle ne fait plus sans cesse gauche droite comme avant, moi j’ai moins peur donc j'ose plus aussi bref pour le moment c'est le pied je prends enfin vraiment du plaisir à sauter avec et les progrès qu'on a fait c'est une grande fierté car on les a fait ensemble ! [http:// www.chevalannonce.com/forums-3497099ma-princesse-jasmine-nvl-photos-p15? $\mathrm{p}=12$ ] (21.2.2016)

REMARQUES : Venir droit (I) réfère à une personne ou à un animal qui se dirige directement, sans détour vers un lieu ou vers quelqu'un. Lorsque le verbe est suivi de la préposition sur, il souligne le fait de se ruer ou de se diriger rapidement vers quelqu'un ou quelque chose. Il peut aussi renvoyer à la provenance, à l'origine, à la descendance, le sujet désignant une personne qui est issue de quelqu'un ou descend directement d'une lignée. (II) a le sens plus abstrait de 'provenir de, découler de'. Droit reste invariable dans son emploi adverbial, à l'exception du dernier exemple dans le CW où il conserve son sens directionnel (adverbial) venir droit sur, sans devenir un prédicat second désignant une position verticale. Droit est modifié par tout. Il tend à s'associer à la préposition qui le suit.

\section{Venir dur}

I. Arriver, advenir avec douleur et peine Intransitif

1432 (Cy commence le prisonnier a parler de sa fortune)

Homme si ne se peult garder

Se dit on, de son adventure

Par mon fait le puis regarder, Une m'en est venue trop dure

Et si la tenoyë a seure

Autant ou plus comme nesune

Qui me peust certes courir seure,

Mais nul ne peult contre Fortune (Jean Regnier, Les Fortunes et adversitez, 129)

II. Se durcir

Intransitif

1630 Mais quand c'est pour son Dieu que le fidele endure

Lors le fer s'amolit ou sa peau vient plus dure (Théodore Agrippa d'Aubigné, Les Tragiques)

\section{CORPUS WEB :}

Lorsque j'ai préparé la recette, je crois que je n'ai pas mélangé suffisamment de jus de cuisson au mélange vinaigre et sirop d'érable puisque ça vraiment commencer à tourner plus que siropeux...ça s'en venait même dur...j'ai donc ajouté de l'eau et continué de brasser et ce fût correct. Selon toi, Lèchevitrine, le fait que mon mélange s'en venait dur, est-ce que c'était du à mon manque de jus de cuisson ou liquide ? [http:// www.recettes.qc.ca/forum/message.php?categor ie=1\&id=242765\&pagem=3] (21.2.2016) 
Je savais pas que quand la bédaine venait dur dur, meme si tavais pas de douleurs c'tait des contractions... [http://www.mamanpourlavie. $\mathrm{com} /$ forum/sujet/club-des-perimees-et-outannees-des-maux-de-grossesse/page/258] (21.2.2016)

même si je suis à 12 semaines et demi, je sentais des flatte flatte dans la bedaine le soir, et elle venait dure commeà Xavier au début [http://www. mamanpourlavie.com/forum/sujet/les-octobret tes-2010-1-aventure-commence/page/101/voir/ nathoug_10@hotmail.com] (21.2.2016)

ReMARQues : Venir dur (I) se dit à propos de quelque chose de pénible qui arrive, le sujet essuyant des revers de fortune. (II) désigne une partie de l'épiderme qui, sous l'effet ou l'action de quelque chose, se durcit, devient dure, épaisse, racornie. Il peut également référer à la préparation d'un produit en cuisine (v. le premier exemple du $\mathrm{CW}$ ) et venir, se rapprocher d'une copule dans venir dur 'devenir dur' (tous les exemples du CW). Dur peut s'accorder avec le sujet (à comparer les deuxième et troisième exemples du $\mathrm{CW}$ ) et se rapprocher des prédicats seconds orientés vers le sujet. Il est modifié par même, plus, trop. Notons la réduplication familière dur dur et l'emploi impersonnel familier ça s'en venait dur.

\section{Venir féroce}

Arriver, débarquer de manière sauvage, brutale $\lambda$ venir rapide

\section{Venir frais}

venir tout frais : venir d'arriver, arriver

récemment

Intransitif

1495 mon beau-frère, et le seigneur d'Aubejoux, de la maison d'Amboise, avecques ses vingts hommes d'armes de l'ordonnance et quinze cens arbalestriers, venuz tous fraiz de France par mer (Philippe de Commynes, Mémoires)

1695 En effet, les corps de reserve ont souvent rendu de grands services dans les endroits desavantageux, parce que si les premiers sont repoussez, ceux qui leur succedent les couvrent et viennent tout frais au com- bat (P. Du Ryer, Les Décades de Tite-Live [trad.])

1872 Quand les uns étaient las, d'autres venaient tout frais et nouveaux, et il ne semblait pas que ce fussent des hommes, mais des bêtes sauvages enragées (Léonard Cros, Vie intime de Saint Louis)

1941 Les placentas de Vache venaient tout frais de l'abattoir (Archives internationales de physiologie)

1970 Il avait relevé son camarade dix minutes avant. Il venait tout frais de la brigade de Mons (Jean Giono, L'Iris de Suse)

REMARques : Venir tout frais se dit du fait de venir d'arriver. Ceci vaut aussi pour l'exemple de 1872, mais il s'y ajoute une remotivation par le sens propre de frais 'dont la vigueur n'est pas altérée'. Dans l'exemple de 1941, le contexte de l'abattoir fait que frais se rapproche sémantiquement de son sens propre (prédication seconde), mais l'interprétation reste ambiguë 'être frais / venir d'arriver'. Frais est modifié par tout dont les exemples reflètent les problèmes de l'accord dans sa diachronie : tous, masculin pluriel (1495), ou tout, neutre-invarié (1695, 1872, 1941). Notons la collocation venir tout frais et nouveaux.

\section{Venir gent}

venir bel et gent : venir de manière avenante, aimable

Intransitif

+1250 Apres li vont deus chars corant Qui tuit sont de vitaille plein.

E dui escuier et un nein Les conduient sans plus de jent, Asses venent et bel et gent (Le Roman de Renart [2 $2^{\mathrm{e}}$ moitié XIII $\left.{ }^{\mathrm{e}}\right]$, XIII, 614)

ReMARQues : Venir bel et gent se disait du fait d'arriver en un lieu, le sujet se distinguant par sa grâce, la courtoisie de ses manières. Notons la coordination avec bel qui met en évidence la fonction adverbiale. 


\section{Venir grave}

Avoir l'air très important

Intransitif

1890 Enfin, enfin, des fanaux brillent dans le lointain, sortis sans doute de la porte qui est là-haut découpée dans les remparts, et ils descendent vers nous, par l'espèce d'avenue irrégulière et bossuée où baîllent des cavernes ; c'est notre mouna qui nous vient, toujours lente et grave : des couscous $\mathrm{au}$ lait et au sucre ; un mouton en vie et plusieurs poulets dans des cages... (Pierre Loti, Au Maroc)

\section{CORpus WeB :}

La nouvelle collection Benibla, elle vient grave de Paris Nord ! [https://twitter.com/_beeby/ status/667309468477095941] (23.2.2016)

Ce matin, Stéphane Soumier, présentateur de Good Morning Business sur BFM Business, a dans une série de tweets commenté ce qu'il appelle la « première crise du soviétisme de marché » et publié un article il y a quelques minutes sur « Les marchés contre Poutine » (le Captain' vient grave de se faire griller sur ce coup !) [http:// www.captaineconomics.fr/-crise-ukraine-pou tine-marche-bourse-moscou] (23.2.2016)

Enfin voila... ca pique grave... depuis le 1er janvier, j'ai l'impression que quand j'ouvre des tables, c'est pour donner mon argent... bon ils viennent grave le chercher mais bon... c'est abusé quand c'est long comme ca... [http:// fr.pokerstrategy.com/forum/thread.php?thread id=46549\&page=87] (23.2.2016)

« C'était un musicien extraordinaire, entouré de gens excellents. J'ai grandi avec lui, il m'a fasciné depuis que j'étais petite ", dit-elle, alors que des voisins vont et viennent, graves et sans un mot [https://embed.scribblelive.com/Embed/ v7.aspx? Id =1761937\&Page $=8$ \& ThemeId $=29457 \&$ overlay=false] $(23.2 .2016)$

REMARQUES : Dans l'exemple de 1890, venir grave apparaît dans son emploi figuré ; il se dit du fait de présenter quelque chose comme étant très important, ayant une valeur symbolique comme ici, la mouna (brioche de Pâques de la cuisine piednoire et algérienne qui est traditionnellement confectionnée pour les fêtes de Pâques). Dans les trois premiers exemples du CW, grave fonctionne en tant qu'adverbe de degré qui accentue l'importance de l'action, le plus proche synonyme étant fort (à comparer grave belle, etc.) ; plus que familier, le registre est 'branché' et argotique. Grave peut s'accorder avec le sujet, et dans ce cas-là, il fonctionne en tant que prédicat second orienté vers le sujet (v. l'exemple de 1890 et le dernier exemple du CW). Notons l'emploi de ça pique grave 'faire très mal'.

\section{Venir gros}

Devenir gros ; arriver, se produire en abondance, en grande quantité, en grand nombre Intransitif

1603 Aussi, mais par le temps, son tige vient fort gros, qui cause planter le palmier dans terre ferme, non dans des quaisses, comme les orangers : ou ce seroit pour le seul plaisir des rameaux sans se soucier $\mathrm{du}$ fruict a venir (Olivier de Serres, Le Théâtre d'agriculture et mesnage des champs)

1623 Chamier ne fut jamais venu si gros, et $\mathrm{Du}$ Moulin n'auroit pas le loisir d'adjuster sa rotonde, et de peigner sa teste chauve, ny de lire Rabelais, s'il falloit estudier ces mornes et melancholiques questions de philosophie (François Garasse, La Doctrine curieuse des beaux-esprits de ce temps)

1661 Le Ouuifoutchi viennent tres-grosses, quand elles sont en bonne terre, et il y en a qui viennent aussi grosses que le corps d'un homme. Autresfois Dian Tseron m'en a envoyé une que deux Negres portoient en Tacon, et en estoient bien chargez, communement elles viennent grosses comme la cuisse (Étienne de Flacourt, Histoire de la grande isle Madagascar)

1689 Les racines blanches y viennent grosses comme la cuisse, mais aussi demeurent-elles neuf mois dans la terre, il y en a d'une autre sorte qu'on appelle des Cambares, qui sont grosses comme les deux poings, elles approchent fort du goût $\mathrm{du}$ pain, quand elles sont cuites au four, ou sous la cendre (Théodore Sauzier et Henri du Quesne, Un projet de république à l'île d'Éden (l'île Bourbon) en 1689) 
1782 La Pesche à fleur double, est plus curieuse que bonne, plus recherchée pour sa fleur que pour son Fruit : Elle vient grosse, blanche et charge peu (Jean Merlet et Claude Saint Étienne, Traité de la connoissance des bons fruits)

1784 C'est sur les rivages des îles Antilles que croît l'acajou, qu'on y appelle improprement cèdre, à cause de son incorruptibilité. Il y vient si gros, que d'un seul de ses tronçons on fait des pirogues qui portent jusqu'à quarante hommes (Bernardin de Saint-Pierre, Études de la nature)

1814 La terre y porte beaucoup de fruits qui lui sont particuliers, comme la datte ; mais ceux qui lui sont communs avec l'Europe, tels que l'abricot, la grenade, la figue, le raisin, l'olive, y viennent beaucoup plus gros que dans aucune partie du monde (Bernardin de Saint-Pierre, Harmonies de la nature)

1925 Et Tournefier continuait, pour lui seul : - Avant-hier, à la Patte d'oie, c'est venu tellement gros que la bonde n'a pas pu y suffire : l'eau a passé sur le chemin, aussi large et raide que la Sauldre... elle a laissé des trous, cent bons dieux, à y loger un troupeau de vaches! (Maurice Genevoix, Raboliot)

1934 Écoutons-la :

- À la Sidonie Sauvy, voilà que le ventre lui vient tout gros. À son âge, vous pensez, c'était plus le risque qu'elle ait fauté (Gabriel Chevallier, Clochemerle)

1972 Le pauvre gros chou ! il s'illumine !... « Moi aussi, il fait... C'est merveilleux... Tu sais... » Je le sens qui hésite... Je le vois venir gros comme un grand ensemble... Il serait temps de lui couper l'herbe sous le pied... « Tu vas quand même pas me raconter que tu m'aimes ? » (Bertrand Blier, Les Valseuses)

\section{CoRpus Web :}

j'oublié, si tu veux que les bulbes viennent gros, en plus te ton engrais il te faut dans ton substrat de l'osmocote [http://www.orchidees.fr/ forums/index.php?showtopic=53306] $(24.2 .2016)$
Il me reste cependant à les changer de pot (si je veux qu'ils viennent gros). J'ai hâte de voir comment ils seront en fin de saison [http://forums. jardinage.net/viewtopic.php?f $=11 \& \mathrm{t}=78514 \& \mathrm{p}=10$ 69007\&hilit=bananier] (24.2.2016)

Il trouve aussi que la scène du baiser venait gros comme une maison [https://www.fanfiction. net/s/1733723/28/Entre-Ombre-et-Lumi $\%$ C3\% A8re] (24.2.2016)

La saison des festivals, fêtes, fiestas, férias est terminée. Enfin ! «Si tu ne viens pas à la fête, la fête viendra à toi » disait Philippe Muray. Elle est venue, grosse et braillante [http://contreregard.com/rabat-joie] (24.2.2016)

REMARQUES : Au sens concret, venir gros signifie 'devenir gros', le sujet pouvant désigner un végétal, un arbre, une plante qui atteignent une taille impressionnante ou un fruit qui pousse ou est produit en grand nombre. Le sujet peut aussi désigner un liquide (l'eau) qui sort ou jaillit d'un endroit en grande quantité. Venir se rapproche d'une fonction de copule à laquelle la langue standard préfère le verbe devenir. La fonction de copule favorise l'accord de gros avec le sujet (seul le troisième exemple du CW est invarié). En tant que prédicat second employé avec venir comme verbe plein, gros s'accorde également avec le sujet (v. le dernier exemple du CW, avec détachement des modifieurs). Il est modifié par beaucoup plus, fort, si, tellement, tout, très.

\section{Venir isnel}

Venir rapidement, précipitamment Intransitif

1275 Blancheflour fu assise souz l'ente en un prael ;

La fausse vielle apele, feu arde son musel! Et ele i est venue molt tost et molt isnel (Adenet le Roi, Berte aus grans piés, 2059)

REMARQUeS : Venir isnel se disait du fait de se déplacer en direction d'un lieu ou d'une personne rapidement ou de façon précipitée, soulignant la hâte du sujet, son empressement. Isnel est modifié par moult. Notons la collocation tost et isnel. 


\section{Venir lent}

Venir lentement, doucement, tranquillement Intransitif

1177 Desarmé sont einsi parlant, Et li lions ne vint pas lant Vers son seignor la, ou il sist. Quant devant lui fu, si li fist Grant joie come beste mue (Chrestien de Troyes, Yvain ou Le Chevalier au lion, 6494)

1209 La bele Doe siet au vent ; Souz l'aubespin Doon atent. Plaint et regrete tant forment Por son ami qui si vient lent (Jean Renart, Roman de Guillaume de Dole, 1206)

$\sim 1280$ Ki s'esmaie pour mal sentir Ne qui prent warde a son torment, Il ne puet amer longement ; Et com plus pense par loisir A son desir, Et plus li samle qu'il vient lent (Adam de la Halle, Chansons, XX, 15)

-1300 He ! Dex, dist Baudoïns, biau pere omnipotant, Anvoiez moi secors qi me soit à talant ! S'a cest ost m'abandon, pres sui de finement, Et se je mant mon oncle, il vanra, ce cuit, lant (Jehan Bodel, La Chanson des Saisnes [fin XIII] ${ }^{\mathrm{e}}$, 5955)

+1313 Cieus qui son harnas li gardoit Lui a forte lance donnee, Et il moet de grand randonnee Contre celui qui a talent De bien faire et ne uient pas lent (Jean de Condé, Poèmes [1313-1337], 664)

1604 CHEUR. Car la douce loüange entretient et fomente

Le desir de bien faire en toute am excellente.

HECTOR. Celuy-là qui sert bien dessert un beau loyer ;

Autrement il viendroit plus lent à s'employer

CHEUR. Le guerdon seul de gloire est propre et convenable

à couronner en l'homme une action loüable

(Antoine de Montchrestien, Hector)
1862 L'ennui vague, douloureux, qui tâtonne comme un aveugle, avait remplacé chez Anna sa surexcitation de la veille. Toute lente, elle allait et venait d'une chambre à l'autre. Quel pesant malaise ! Quelle fatigue dans le repos et quel dégoût pour l'action ! (Paul Reider, Mademoiselle Vallantin)

1884 Et dans ce calme où la fraîcheur tombe, C'est comme un apaisement de tombe, Comme une mort qui lente viendrait Sceller nos yeux de sa main clémente, Dans ce calme où rien ne se lamente Ou par l'espace, ou par la forêt (Jean Moréas, Les Syrtes)

1893 Elle sourit et puis passa, s'éloignant comme elle était venue, lente, d'une allure balancée, ou ses hanches se devinaient souples et libres sous son costume (Pierre Loti, Matelot)

Pronominal

1911 La silhouette d'un village à l'horizon Se profile brisée au milieu de tisons... Tandis qu'encore, à l'est, avant qu'un astre perce,

L'azur luit comme une rivière à la renverse. Un homme dans la cour s'en vient lent et penché,

Tenant des cercles de barrique, vers le chai. Voyant la vieille au seuil de son taudis assise,

Il se met un instant auprès d'elle. Ils devisent (Francis Jammes, Les Géorgiques chrétiennes)

CORPUS WEB :

L'Univers rentre en transformation. Les transformations vont bien plus vite que l'on peut y croire. En évolution tout est en accéléré. C'est après que tout se stabilise et vient lent [http:// orandia.com/forum/index.php?id=126889] (24.2.2016)

Étudie en science humaine au Cégep Lionel-Groulx, à Ste-Thérèse. Mais ne sachant pas vers quel domaine se diriger. Ça s'en vient, lent mais surment ! [https://fr.linkedin.com/in/joannie-beaulieu-87009762] (24.2.2016)

En suivant le regard de Thibaud Croisy, impavide, jusqu'au bout d'une perspective 
sans fin, on devine à nouveau Sophie Demeyer à sa posture. Alors elle vient lente, elle hante... [http://unsoirouunautre.hautetfort.com/tag/ thibaud+croisy] (24.2.2016)

REMARQUES : Venir lent se dit, surtout en ancien français, du fait de se déplacer en direction d'un lieu, le sujet s'avançant à une vitesse réduite, manquant de rapidité dans ses mouvements. Le sujet peut aussi désigner un état, quelque chose qui se fait sentir, dont l'approche est imminente. L'ancien français l'emploie comme adverbe, tandis que le français moderne préfère l'usage comme prédicat second accordé, notamment dans le style littéraire. La concentration des exemples accordés dans la seconde moitié du $\mathrm{XIX}^{\mathrm{e}}$ siècle reflète peut-être l'intérêt que porte le genre du roman à la prédication seconde et l'emploi détaché de l'adjectif, cherchant à les séparer clairement de l'emploi adverbial invariable. Le CW montre cependant que l'emploi comme adverbe, désignant une manière d'agir, est encore vivante dans la langue familière. Lent est modifié par plus, tout. Notons la locution rimée Ça s'en vient, lent mais sur'ment (à comparer en italien : chi va piano va sano e va lontano). VOIR AUSSI : aller lent

\section{Venir long}

Arriver après une longue course (d'une balle) $\lambda$ venir court

\section{Venir nouveau}

nouveau venu : arrivé depuis peu, nouvellement arrivé

Intransitif

1175 Gerins del Mans i fiert Madan, Paris de Resnes Madian, .ii. Grius qui mout par furent noble, Puis les plora Constantinoble. Illes se torne mout menu, .i. chevalier novel venu I gete mort ; la ot grant plor (Gautier d'Arras, Ille et Galeron, 5980)

1180 Li vallés voit cele merveille Qui laiens ert la nuit venus, [variante : noviaus venus] Si s'est de demander tenus Coment ceste chose avenoit
(Chrestien de Troyes, Perceval ou Le Conte du Graal, 3203)

1370 Lors fist crïer par le chastel que tous ceulx qui pourroient armes porter feussent apareilliez et alassent aidier et secourir les chevaliers nouveaux venus qui estoient en grant paine pour la proie rescourre (Roman de Berinus, II, p. 118)

1427 et puis, quant tu tu avras employé ton corps, ton temps et les biens a t'en deffendre, ung autre nouveau venu a la court y supplantera ta benediction et la te ostera se devient (Alain Chartier, Le Curial)

1515 Et les aultres ses compaignons, qui bien entendoient la finesse, promisrent tous de ainsi le faire en disant que c'estoit moult bien parlez à luy, et ne restoit que nostre homme, nouveau venus, qui differoit (Philippe de Vigneulles, Les Cent Nouvelles nouvelles, p. 225, 59)

1668 Entre autres denrées, ce marchand trafiquait d'esclaves ; si bien qu'allant à Éphèse pour se défaire de ceux qu'il avait, ce que chacun d'eux devait porter pour la commodité du voyage fut départi selon leur emploi et selon leurs forces. Ésope pria que l'on eût égard à sa taille ; qu'il était nouveau venu, et devait être traité doucement (Jean de La Fontaine, La Vie d'Ésope le Phrygien / Fables)

1696 Je ne sais à qui cette pensée est venue, mais Dieu la bénisse, cette personne ! En vérité, je vous y souhaitai. J'étais nouvelle venue; on se fit un plaisir de me montrer toutes les raretés et de me mener partout. Je ne me suis point repentie de ce petit voyage (Mme de Sévigné, Correspondance)

1713 La maîtresse et son amant se firent mille questions. Je les interrompis pour déjeuner. J'appellai mon valet et celui de Jussy, et je fis servir. Les laquais nouveaux venus montérent, on ne dit rien en leur présence qui dût être secret (Robert Challe, Les Illustres Françoises)

1715 « D’où venez-vous ? " lui dit celui à qui il s'était adressé. " Il faut que vous soyez 
bien nouveau venu, si vous n'avez pas vu le palais du prince Aladdin, ou plutôt si vous n'en avez pas encore entendu parler » (Antoine Galland, Les Mille et une nuits)

1830 DON CARLOS. Hommes sans préjugés Dont le poignard, toujours prêt à jouer son rôle,

Tourne aux plus gros écus, comme

l'aiguille au pôle !

RICARDO. Pourtant j'ai distingué deux

hardis compagnons,

Tous deux nouveau-venus, un jeune, un vieux.

DON CARLOS. leurs noms ?

(Ricardo lève les épaules en signe d'ignorance)

Leur âge ? (Victor Hugo, Hernani)

1833 Le fils d'un pair de France, nouveau venu au régiment, ayant dit un jour, en parlant de Genestas, qu'il eût été le plus consciencieux des prêtres ou le plus honnête des épiciers :

- Ajoutez, le moins courtisan des marquis ! (Honoré de Balzac, Le Médecin de campagne)

1836 De ceux qu'on reconnaît voir les yeux se baisser,

D’autres se détourner de peur de vous

blesser,

D'autres, nouveaux venus, en secouant leurs têtes,

D'un air indifférent demander qui vous êtes? (Alphonse de Lamartine, Jocelyn)

1888 Il disait :

- Oh, oh, mon ami, voici une charge qui est bien mal installée ! Vous êtes nouveau venu au régiment, c'est vrai, mais ce n'est pas une raison! Il faut demander un coup de main à votre camarade de lit, quand une chose vous embarrasse ! (Georges Courteline, Le Train de 8 h 47)

1901 LAMBERT. Et moi, je reçois ceux qui arrivent. Ils entrent, nouveaux venus, dans la cité : elle n'a point de lois et chacun s’y mesure lui-même sa place (Paul Claudel, La Ville)
1913 et elle [= ma mère] put m'apercevoir, l'espace d'une seconde, dressé dans la lueur magique, tenant par la main le grand gars nouveau venu et ne bronchant pas... cette fois encore, elle n'osa rien dire (Alain-Fournier, Le Grand Meaulnes)

1926 Puis, sa voix changeant soudain de registre, comme c'est l'habitude chez les prêtres quand, au cours d'un entretien tout spirituel, ils reviennent aux humbles réalités de la vie courante :

- Vous êtes tout nouveau venu à Paris, Monsieur Muller

(Paul Bourget, Nos actes nous suivent)

1938 Cette peste, qui semble réactiver un virus, était capable toute seule d'exercer des ravages sensiblement égaux ; puisque de tout l'équipage, le capitaine fut le seul à ne pas attraper la peste, et d'autre part, il ne semble pas que les pestiférés nouveau venus aient jamais été en contact direct avec les autres, parqués dans des quartiers fermés (Antonin Artaud, Le Théâtre et son double)

1939 Le jour suivant, des réfugiés russes nouveaux venus à Kratovicé firent allusion à une jeune paysanne en pelisse de fourrure qu'ils avaient rencontrée le long de la route, sous l'auvent d'une hutte où ils s'étaient reposés pendant une rafale de neige (Marguerite Yourcenar, Le Coup de grâce)

1977 Surtout lorsque notre maître à danser m'appareille à Suzon l'Auvergnate, une brune, nouvelle venue dans le quartier, la seule élève à ne pas porter de corset et dont la hanche souple semble irradier sous la paume un train d'ondes magnétiques, intéressant le dessous de la ceinture (Albert Simonin, Confessions d'un enfant de La Chapelle)

1988 Je me liai d'amitié avec l'un de mes voisins de chambre, comme moi 'instructor' nouveau venu à l'université, George May. D'une famille juive alsacienne ayant opté pour la France après 1870, il avait fait toutes ses études à Paris (Michel Mohrt, Vers l'ouest) 
CORPUS WeB :

Ce document explique en 3 pages comment activer son compte lorsque l'on est nouveau venu à l'université, comment se connecter à l'E.N.T et comment retrouver ses codes d'accès en cas d'oubli [https://www.unistra.fr/index.php?id=9854] (24.2.2016)

Elfik est nouveau venu sur la scène rock celtique, formé en 2011, le groupe mélange la musique traditionnelle aux instruments classique du rock pour soutenir ses textes tantôt engagés, tantôt simple chanson de comptoir [http://estce taf.free.fr] (24.2.2016)

La saison 2015 débutera les 27 et 28 mars 2015 avec la séance d'essais officielle « Le Prologue » sur le circuit Paul Ricard dans le sud de la France. L'occasion pour la nouveau venue, Nissan, de découvrir ses futurs adversaires [http://lemaineracing.blogs.lemainelibre.fr/lenuerburgring-au-calendrier-du-championnatdu-monde-dendurance-fia-wec-2015] (24.2.2016)

Taylor Swift a officiellement présenté la nouvelle venue de son Girls Squad! [http://www. nrj.fr/artistes/taylor-swift/actus/taylor-swiftune-nouvelle-venue-dans-son-squad-335670] (24.2.2016)

REMARQUeS : Nouveau venu 'récemment venu' (novel, en ancien français) et ses variantes constituent un cas particulier souvent discuté (v. Introduction § 17.3). L'accord avec le sujet est systématique jusqu'au XIX ${ }^{e}$ siècle. Il porte généralement sur les deux termes (nouvelle venue, nouveaux venus), mais on trouve aussi l'accord partiel, comme dans l'avant-dernier exemple du CW (la nouveau venue, où le groupe verbal est nominalisé), dans l'exemple de 1938 (nouveau venus) et celui de 1830 (nouveau-venus). L'accord partiel semble être le reflet de sa lexicalisation en tant que mot composé, marqué ou non par un trait d'union. Nouveau est modifié par bien, tout.

\section{Venir raide}

Venir de façon énergique, résolue, ferme, inflexible

Intransitif

+1370 Enssi se commencha li bataille, et en ot li rois de France et ses gens le premier encontre, qui leur fu mout durs ; car cil Flamenc, qui desendoient orgilleusement et de grant volenté, venoient roit et dur, et boutoient, en venant, de l'espaulle et de le poitrine enssi comme sengler tout foursené (Jean Froissart, Chroniques (A))

1566 Je gardoy bien un jour le trouppeau de mon pere :

Et voici un lion aveques sa peau rousse, Qui vient roide accourir, et une brebis trousse.

Il vint encor'un ours. Mais je fis tel effort, Qu'au menton j'empoignay le lion ferme et fort (Louis Des Masures, David combattant)

\section{Corpus Web :}

Aby, ça ressemble beaucoup à des coliques. Mia en a eu beaucoup jusqu'à 4 mois. C'est souvent aux mêmes heures et le soir. Ils viennent raide, se tordent, pleurent, c'est très douloureux pour eux, c'est un peu comme des gaz [http:// forum.etreenceinte.com/discussion/97602/www. facebook.com/page:18] (26.2.2016)

Les muscles viennent raide, difficile à se plier/déplier, marcher, lever la jambe [http:// mazda3quebec.com/forumsv3/showthread. php?p=430940] (26.2.2016)

Moi, jene peux pas parler à mon travail, mais, les cheveux me viennent raides sur la tête des fois, mais qu'est-ce que vous voulez? [http://www.parl. gc.ca/Content/SEN/Committee/381/soci/15eve-f. $\mathrm{htm}$ ? comm_id=47\&Language $=F \&$ Parl $=$ $38 \& \operatorname{Ses}=1](26.2 .2016)$

Le prix je ne $m$ en souviens pas, mais lésine pas sur un tube de qualité. Les maudits tubes cheaps qui viennent raides beurk.. [http://www. quebecpeche.com/forums/index.php?/topic/125 28-je-me-suis-trouver-un-moteur] (26.2.2016)

REMARQues : Venir raide se dit du fait de se déplacer ou d'arriver en un lieu, le sujet ayant affronté plusieurs obstacles, preuves de son caractère vaillant et énergique. Dans les exemples $\mathrm{du}$ CW, il désigne le fait de devenir rigide, tendu ou dur (les muscles, les cheveux, les tubes, etc.). Raide tend à l'emploi invarié, mais il peut s'accorder avec le sujet, ce qui renforce une interprétation soit comme prédicat second orienté vers le sujet (v. le dernier exemple du CW), soit comme complément d'un verbe copule (v. les deuxième et troisième exemples du $\mathrm{CW}$ ), ce dernier étant familier et employé notamment au Québec. 


\section{Venir rapide}

Se déplacer rapidement, précipitamment Intransitif

1838 Vers le couple qui vient rapide Ma valseuse plus intrépide Fuit et s'échappe de ma main ; Un élan de moi la sépare, D'un autre élan je m'en empare (Jules de Rességuier, Les Prismes poétiques)

1872 Le succès était venu rapide pour eux comme pour le pays. Après le comptoir de recouvrements, il avait fondé une banque (Hector Malot, Un miracle)

1960 pensant à la peau, à la saveur des prunes des reines-claudes mûres bleuâtres se fendant et leur jus sucré, je la lâchai retombai sur le lit tâtant ma pommette pouvant l'entendre de nouveau aller et venir rapide avec ces mouvements rapides précis qu'ont les femmes pour ranger, se baissant ramassant quelque chose je me demandai comment elle pouvait faire (Claude Simon, La Route des Flandres)

\section{CORpus Web :}

les twins s'en viennent rapide dans le prostock 1000. sur des pistes courtes il vont finir par avoir l'avantage [http://www.motoneigeau quebec.com/forum/archive/index.php/t-81694. $\mathrm{html}$ (28.2.2016)

Certaines personnes entrent dans nos vies, vont et viennent rapide et féroce, comme des motos-taxi. D'autres nous surprennent par leur gentillesse et leur bienveillance, offrant simplement leur amitié sans date de péremption [http:// unamourtropical.tumblr.com/post/10346130 8991/gringo-toi-m\%C3\%AAme] (28.2.2016)

Internet, c'est la bonne fée, la marraine de " Vivre à Gouéné ». Les mails vont et viennent, rapides, efficaces [http://vivreagouene.free.fr/ Bulletins/no01/Page03.htm] (28.2.2016)

REMARQUES : Venir rapide se dit du fait de se déplacer en direction d'un lieu, de faire des mouvements à une vitesse rapide ou de façon précipitée, le sujet exécutant sa tâche avec une certaine énergie et efficacité. Venir rapide est deux fois opposé à aller rapide pour désigner un mouvement de va-et-vient. La construction pronominale s'en venir rapide est prise au sens de 'finir par devenir rapide'. Rapide tend à l'emploi invariable (v. les deux premiers exemples du CW), y compris l'adjectif-adverbe coordonné féroce. Rapide s'accorde avec le sujet dans le dernier exemple du CW pour mettre en relief une propriété des courriels, projetant stylistiquement les concepts contenus dans rapide et efficace sur ceux-ci. VoIR AUSSI : aller rapide

\section{Venir serré}

I. Venir en se serrant les uns les autres, en un groupe dense et compact

Intransitif

1250a En sa compengne sunt plus de .xx. adoubé,

Qui tuit erent à pié ; mez il erent levé

Et chascun ot $\mathrm{u}$ dos son hauberc endossé Et l'espée pendue au senestre costé, Mez il n'i orent lanche ne heaume u chief fremé.

Toute la ruie viennent contre Doon serré (Doon de Mayence, p. 122)

$\sim 1250 \mathrm{~b} \mathrm{Au}$ palès trestout droit vous en venés serré,

Que je et Antequin, qui le m’a gréanté, Jeteron le portier tantost ens u fossé (Doon de Mayence, p. 313)

-1469 Puis regarda la saillie de son embusche, qu'il n'y eust riens qui lui peust nuyre, qu'il ne peust venir tout serré luy et ses gens pour assaillir ses ennemyz (Jean de Bueil, Le Jouvencel [1461]-1468, II, p. 16)

1799 Alors ils [= les Flamands dans un combat] étoient venus serrés et en bon ordre ; maintenant ils se retiroient éparpillés, l'un devant, l'autre derrière : on eût dit que chacun ne songeait qu'à fuir (Mémoires de l'Institut national des sciences et arts)

1868 Tous suivis de leurs fiers et rudes compagnons.

Ainsi viennent serrés Français et Bourguignons, Écrasant et battant, terre, sable et gazon. Mais ils furent reçus de cœur franc, fier et bon (Mary Lafond, La Croisade contre les Albigeois) 
1892 Mais bientôt archers et frondeurs se répandent de nouveau dans les vergers ; en approchant du rempart, la cavalerie est accueillie par une grêle de traits et de pierres, qui viennent serrés comme la pluie (Revue des Pyrénées)

II. En arboriculture : planter les arbres dans une grande culture à une distance minimale et régulière, croître rapprochés les uns des autres Intransitif

1779 On fait, que plus la graine monte dru, et que les rejettons viennent serrés, plus aussi ils s'élevent et poussent droit ; il faut donc s'attacher à les faire venir le plus dru possible (Société économique de Zurich, Avis aux cultivateurs touchant l'économie $d u$ bois)

1832 Le nettoiement des jeunes sapins n'est pas pratiqué dans les forêts des Vosges ni dans celles du Jura. C’est un préjugé généralement répandu dans ces contrées, que plus les sapins viennent serrés, plus ils croissent vigoureusement (Louis NoirotBonnet, Traité de la culture des forêts)

1864 Suivant Werneck, le bois des arbres de montagnes, dans les mêmes conditions, est plus compacte [sic] que celui des arbres qui croissent en plaine ; le bois des arbres venus serrés, est plus compacte que celui des arbres venus isolément (E. Petitgand et Antoine Ronna, Traité complet de métallurgie)

\section{CORPUS WEB :}

Et bien sûr pour faire des points au classement de la Coupe FÉÉCUM, et pour une des équipes, d'aussi gagner une œuvre crée par notre propre VP interne, Emilie Haché qui prend justement un cours d'art visuel présentement. En tout cas, ça s'en vient serré ! Huit équipes s'étaient inscrites à l'événement, mais trois ont été portées disparues au vernissage [http://www.feecum. ca/index.php/98-coupe-feecum-l-art-de-bienobserver] (28.2.2016)

Les chandails 18 mois font bien... Mais ça s'en vient serré avec la bedaine ! [http://www. dlvdm.com/forum/lofiversion/index.php/t283 635.html] (28.2.2016)
La vendeuse m'avait recommander de prendre des 7, car en 2 mois, elle a passé de 3 à 4. Et déjà-là, ses souleirs s'en viennent serré, donc je crois bien devoir lui en acheté d'autre pour Noël [http://www.mamanpourlavie.com/forum/ sujet/futures-et-nouvelles-mamans-de-b-troisrivieres-b/page/579] (28.2.2016)

Tramontanne explique bien pour les bas de contention. ex : ce qui est mauvais, ce sont les mi-bas que l'on porte sous les pantalons et qui viennent serrés juste sous le genou.. [http:// forum.doctissimo.fr/sante/cancers/adeno-carci no-bronchique-sujet_171576_19.htm] (28.2.2016)

REMARQUES : Plus usuel dans l'ancienne langue, venir serré se dit du fait de se déplacer en groupe, de manière rapprochée, serrée, le sujet désignant un groupe de personnes compact, dense. Venir serré (II) est employé dans le domaine de l'arboriculture avec le même sens. L'emploi actuel documenté dans le $\mathrm{CW}$ réfère, souvent sous la forme s'en venir serré, à un habillement serré ou qui serre (vêtements, chaussures) ou à une situation dans laquelle les protagonistes sont d'égale force (v. le premier exemple du CW). L'emploi invarié prédomine traditionnellement, surtout dans le registre familier, mais le dernier exemple du CW montre qu'en dehors de la construction s'en venir serré, l'emploi au sens concret peut remotiver la fonction de prédicat second. VoIR AUSSI : marcher compact / serré

\section{Venir triomphant}

Venir en triomphateur, en montrant une fierté de vainqueur, une orgueilleuse assurance Intransitif

1658 Le Soleil pour entrer plus tard en ce Signe, y paroit plus élevé, et y donne plus de chaleur et si S. M. vient plus tard en cette ville elle y vient triomphante (Claude-François Menestrier, L'Autel de Lyon)

1779 Enrichi par la mort d'un oncle, le crédule et infortuné jeune homme, après avoir tout préparé pour le succès de leur fuite, venait triomphant et porté sur les ailes de l'amour, pour exécuter leur entreprise secrète (Joseph de Loaisel de Tréogate, Lucile et Milcourt ou Le Cri du sentiment) 
1823 Nous lui rîmes au nez dans nos salons, sur sa simplicité ; mais il nous le rendit à son tour, quand, au bout de quelques semaines, il vint triomphant nous apprendre son succès et sa liberté (Emmanuel de Las Cases, Le Mémorial de Sainte-Hélène)

Pronominal

1918 Tout d'abord, dès octobre 1914, amenée précipitamment du Havre par bateaux, la $87^{\mathrm{e}}$ fut aussitôt jetée en avant du petit canal des Flandres, comme première pâture à la puissante armée allemande qui s'en venait triomphante d'Anvers (Raoul $\mathrm{Nel}$, Boesinghe ou Les Combats de la $87^{\circ}$ division territoriale sur l'Yser)

1999 Démarche d'autant plus moderne et remarquable que nous nous trouvions alors à l'aube de la révolution industrielle, époque où l'initiative privée individuelle s'en venait triomphante, tout droit sortie de la révolution politique de 1789 (Revue forestière française)

CORPuS Web :

Alors ainsi, les fiers Requetes, les beaux éphèbes phalangistes, les fidèles Moros (tu parles) s'en vinrent triomphant sauver l'Espagne éternelle du chaos ? [http://at7760.chez.com/z22. $\mathrm{htm}]$ (29.2.2016)

Quelque dix jours plus tard, le vendeur s'en vient, triomphant, à l'étude, en brandissant la feuille de TPI bien connue, imprimée de vert [http://www.leconomiste.com/article/uneaffaire-de-noir-immobilierbr-par-me-fatiha-bou cetta] (29.2.2016)

Le voilà qui vient, triomphant, majestueux, il arrive d'un pas assuré [http://diabalzane.com/ chere-luxanna] (29.2.2016)

En général elle s'en tire bien, mais là elle venait " triomphante » elle est reparti la queue entre les jambes [http://forums.jeuxonline.info/ showthread.php?t=1131836\&page=393] (29.2.2016)

REMARQUES : Venir triomphant se dit du fait de se déplacer, d'arriver à un endroit en affichant un air triomphant, qui marque l'exaltation, la joie, une certaine fierté, le sujet étant heureux et fier d'un succès obtenu. Triomphant est ambigu entre une lecture d'adverbe de manière et un prédicat second qui caractérise le sujet. L'accord dans le quatrième exemple du $\mathrm{CW}$, et la virgule marquant une pause devant l'adjectif renforcent cette dernière interprétation, qui prédomine en règle générale (seule exception : l'accord au pluriel n'est pas réalisé dans le premier exemple du $\mathrm{CW}$ ).

\section{Venter dur}

Faire beaucoup de vent, souffler avec force (du vent)

Intransitif

1891 L'on entendit un pas dans l'escalier. Carhaix rentra, couvert de neige.

- Cristi, mes enfants, ça vente dur !

Il se secoua, jeta sa défroque sur une chaise, éteignit sa lanterne (Joris-Karl Huysmans, Là-bas)

1936 C'est vrai qu'il commençait à venter dur, mais pour la première fois, je ne l'ai pas vu redresser sa haute taille, il marchait tout courbé (Georges Bernanos, Journal d'un curé de campagne)

\section{Venter fort}

Faire beaucoup de vent, souffler avec force

(du vent)

Intransitif

1170 Quant al port de Lesbion furent, Si tost n'orent terre perdue, Quant tormente lor est creüe : Toz les treis jorz venta si fort Que nes n'osa venir a port (Benoit de Sainte Maure, Le Roman de Troie, 5069)

+1365 S'entra en mer o chiaus de son confort, Et Zephirus venta pour euls si fort Qu'en Albion les arriva et mist (Jean Froissart, Poésies [3 tiers XIV $]$ )

CORPUS Web :

Il vente fort chez moi [http://www.jeuxvideo. com/forums/1-50-120107874-1-0-1-0-il-vente-fortchez-moi.htm] (29.2.2016)

Selon des recherches en psychologie, des vents supérieurs à $40-50 \mathrm{~km} / \mathrm{h}$ déclencheraient des instincts primaires chez les humains, comme une impulsion urgente de se braquer ou de chercher un abri. Bref, le corps réagit comme s'il subissait une attaque quand il vente fort [http://www. barometres-humains.com/les-baromegravetreshumains/ce-que-le-vent-declenche-en-vous] (29.2.2016) 
Lorsqu'il vente fort, tres fort, le temps est propice a la chasse fine, est-ce que vous callez quand meme en vous deplacant ? [http://chevreuil.net/ forums/viewtopic.php?f=36\&t=48420\&sid=969f 22098584b4cd06e5a989962c9ea0\&view=print] (29.2.2016)

REMARQUES : Venter fort s'applique au vent qui souffle avec force, avec une forte intensité. Fort reste invariable et est modifié par si, très.

\section{Vesser puant}

Péter en dégageant une odeur déplaisante, lâcher des vents puants

Intransitif

1532 Le pauvre renard esmouchoit fort bien, et deça et de là, dedans et dehors ; mais la faulse vieille vesnoit et vessoit puant comme cent diables. Le pauvre renard estoit bien mal à son aise (François Rabelais, Pantagruel)

1608 Il se couche sur la robe de $\mathrm{M}^{\mathrm{e}}$ de Montglat, $\mathrm{M}^{\mathrm{le}}$ Piolant l'en veult reprendre disant qu'il estoit couché comme son petit chien. Il l'appelle vieille chiene, et a ma ${ }^{\mathrm{de}}$ de Montglat luy dict ho la laide elle vesse puant (Jean Héroard, Histoire particulière de Louis XIII [1605-1610])

1633 PHILIPPIN. Oui, mais pour vivre honnestement, il ne faut vessir si puant (Adrien de Montluc, La Comédie des proverbes)

\section{Vêtir avenant}

S'habiller de manière charmante, gracieuse, attirante

Transitif

1185 Son senescal apele Tholomé en riant, Les noveles li dist, que cil li vont contant. Et les puceles iscent de la forest s'emblant, Vestues come dames, mult bel et avenant (Roman d'Alexandre, 77)

REMARQUES : En ancien français, vêtir avenant réfère à une personne qui met ou porte des vêtements attrayants, qui attirent l'œil par leur apparence agréable. Avenant est coordonné avec le neutre bel qui en souligne la fonction adverbiale. Il est modifié par moult.

\section{Vêtir beau}

Mettre de beaux vêtements, s'habiller de manière élégante, raffinée

Transitif

$\sim 1170$ Nes li sire de cest chastel L'eüst vestue bien et bel Et si li feïst toz ses buenz; Qu'ele est sa niece, et il est cuens (Chrestien de Troyes, Erec et Enide, 522)

1365 Là, tenoit et menoit amans se vraie amie, Là, parloient d'amours et de grant druérie ; Là, n'i avoit bourgoise qui bel ne fust vestie (Li Romans de Bauduin de Sebourc, Chant II, 850)

Pronominal

1209a Main se levoit Aaliz.

J'ai non Enmelot.

Biau se para et vesti

Soz la roche Guion.

Cui lairai ge mes amors,

Amie, s’a vos non ? (Jean Renart, Roman de Guillaume de Dole, 534)

1209b Main se leva la bien fete Aeliz, Par ci passe li bruns, li biaus Robins.

Biau se para et plus biau se vesti

Marchiez la foille, et ge qieudrai la flor (Jean Renart, Roman de Guillaume de Dole, 544)

\section{CORPUS Web :}

Voici tous les ptits français qui partent à l'étranger cette année, ah ils sont beau vêtus de leur béret et blazer [http://ttabarinio.skyrock. com/44.html] (29.2.2016)

Eva Longoria, divinement belle vêtue de rouge [http://www.get-the-look.fr/media/eva-lon goria-divinement-belle-vetue_m26819] (29.2.2016)

REMARques : Vêtir beau réfère à la façon de se parer avec soin, recherche et élégance. En ancien français, la préférence pour le neutre bel et sa coordination avec bien montrent que sa fonction est essentiellement adverbiale, mais l'usage du masculin biau peut l'approcher d'un prédicat second dénotant la beauté de la personne et de ses habits. L'usage actuel documenté dans le CW hésite entre l'emploi invarié et l'accord, le dernier étant plus emphatique. L'accord partiel pourrait signaler une tendance à l'emploi comme adjectif 
composé beau-vêtu où seul le second terme est accordé (premier exemple du CW), mais il s'agit probablement de simples fautes d'orthographe et de syntaxe : ils sont beaux, vêtus de leur béret. Beau est modifié par divinement, plus. Notons l'emploi de se parer beau (1209a/b). VoIR AUSSI : appareiller bel

\section{Vêtir bleu}

bleu vêtu : habillé de vêtements de couleur bleue

Transitif

1364 En lieu de bleu, dame, vous vestés vert (Guillaume de Machaut, Le Livre du voir dit, p. 740)

+1365 Entrues qu’à ce prendoie mon plaisir, Au loing perçoi .i. chevalier venir, Tout bleu vesti, sans differensce vir ; Mès je vous di, Pas ne me vit si tos que je le vi (Jean Froissart, Poésies [3 $3^{\mathrm{e}}$ tiers XIVe] $)$

CoRpus Web :

La hongroise arrive toute bleu vêtue [http:// laquotidienneeurovision.over-blog.com/ page/92] (29.2.2016)

pas mal de techniques pour réaliser ta carte toute bleu vêtue qui est bien jolie [http:// tanirdesorciair.canalblog.com/archives/2015/07/ 22/32386983.html] (29.2.2016)

un beau théâtre dans un lieu unique avec une belle scène et une salle de 100 places ; situé en plein centre ville toute bleue vêtue : le théâtre Notre-Dame [http://www.kisskissbankbank.com/ $\mathrm{nl} /$ projects/cabaret-pin-up-au-festival-off-d-avi gnon-2015?ref=recent] (29.2.2016)

Une libellule toute bleuevêtue... [http://www. photos-animaux.com/photos,image,520461. html] (29.2.2016)

REMARQUES : Vêtir bleu réfère à une personne qui met ou porte des vêtements de couleur bleue, généralement avec le participe vêtu et antéposition de bleu. L'accord partiel dans bleu vêtue (v. les premier et deuxième exemples du CW) met en évidence une tendance à la lexicalisation comme adjectif composé, l'accord complet demeurant néanmoins possible (v. les troisième et quatrième exemples du CW). Mentionnons que la langue moderne préfère employer vêtir de bleu, de vert, etc., dans les registres standard et soutenu (v. vêtir vert). Bleu est modifié par tout.

\section{Vêtir clair}

clair vêtu : habillé de vêtements de couleur

claire

Transitif

1916 De clair vêtu, le pimpant Gabriel avait l'air plus persan que turc. A son âge, cela n'avait pas, légalement, d'importance ( $L a$ Revue mondiale)

1953 Defrance, ventru, trop clair vêtu et chaussé trop clair, arrivait, la main offerte (André Wurmser, Un homme vient au monde)

1967 Sur le pont, officiers et touristes connaissent l'allégresse du voyage et du commandement; des enfants court et clair vêtus se poursuivent dans les écoutilles, s'arrêtent devant les officiers, rêvent de batailles, s'étonnent du parfum exhalé par ces nuques brillantes, des ombrelles s'ouvrent au-dessus du bastingage, des oiseaux suivent le sillage du navire (Pierre Guyotat, Tombeau pour cinq cent mille soldats)

\section{Corpus WeB :}

et une question encore, la création clair vêtue, qui apparait dans la rubrique sculpture a-telle un nom ? une danseuse libre aussi ? je crois bien que c'est ma préférée [http://www.recupart-hum.com/article-au-coeur-des-arts-65758037. html] (7.3.2016)

A l'inverse, les meules, les charrettes lourdes d'épis, les paysans clair vêtus sont étrangement surexposés, nimbés d'une atmosphère dorée et poudreuse, au demeurant magnifiquement restituée [http://profondeurdechamps. com/2014/11/18/ces-oeuvres-qui-font-scandaleou-les-dangereuses-glaneuses-de-jean-francoismillet] (7.3.2016)

REMARQues : La collocation clair vêtu désigne une personne qui porte des vêtements dont l'étoffe est de couleur claire, produisant un effet semblable à celui d'une bonne lumière naturelle. Clair est toujours antéposé au participe passé du verbe. Il reste invariable, sans doute en raison de son usage comme adjectif composé avec vêtu. Il 
est modifié par trop. Notons l'emploi de chausser clair, par analogie, mais avec postposition de l'adjectif. L'expression alternative de clair figure dans l'exemple de 1916.

\section{Vêtir court}

I. court vêtu : habillé de vêtements courts Transitif

1568 Quand le veau entendit marcher, cuydant que ce fust sa mère, s'approcha et mit le museau entre les jambes dudict cordelier, et l'empoigna par ses dandrilles (car les cordeliers sont cours vestuz par dessoubz leurs grandes robbes) (Bonaventure des Périers, Les Nouvelles Récréations et joyeux devis)

1678 Perrette, sur sa tête ayant un Pot au lait Bien posé sur un coussinet, Prétendait arriver sans encombre à la ville. Légère et court vêtue elle allait à grands pas;

Ayant mis ce jour-là pour être plus agile Cotillon simple, et souliers plats.

Notre Laitière ainsi troussée

Comptait déjà dans sa pensée

Tout le prix du lait, en employait l'argent (Jean de La Fontaine, La Laitière et le pot au lait / Fables)

1750 D’un regard étonné j’ai vu ces remparts Ces géants court-vêtus, automates de Mars, Ces mouvements si prompts, ces démarches si fières, Ces moustaches, ces grands bonnets, Ces habits retroussés, montrant de gros derrières

Que l'ennemi ne vit jamais

(Voltaire, Voyage à Berlin)

1779 L'air siffle, le plomb vole, et l'oiseau prend la fuite, le lièvre par élan se hâte vers son gîte, du sort de ses pareils l'un et l'autre effrayé : des chasseurs court vêtus je vois l'essaim à pied, sur les pas empressés de leurs chiens hors d'haleine, l'un parcourt les taillis, l'autre arpente la plaine (Antoine-Marin Lemierre, Les Fastes ou Les Usages de l'année)
1844 Claudie, alerte et court vêtue, était vermeille comme une cerise, et mettait, comme sir Arthur, de la coquetterie à montrer sa prestesse et son ardeur (George Sand, Jeanne)

1860 L'abbé Minaquet avait fait vœu de chasteté, et pourtant on l'a retrouvé dans le sac à charbon, et fort court vêtu, sans compter les coups de bâton du charbonnier et les plaisanteries de la charbonnière (Louis Duranty, Le Malheur d'Henriette Gérard)

1864 Il n'y avait que des femmes, les unes parées comme pour un bal de l'ancienne cour, les autres comme pour une kermesse flamande ; les premières, embarrassées de leurs paniers et de leurs dentelles sur cette paille fraîche qui gênait leurs pas et qui écorchait leurs jolis pieds ; les autres, court vêtues, chargées de gros sabots qui piétinaient hardiment le fourrage, et celles-ci riaient jusqu'aux oreilles de la figure des autres (George Sand, Le Marquis de Villemer)

1922 Il promena ses yeux un peu battus sur les murs passés au lait de chaux, tendus de nattes à mi-hauteur, sur un vieux chromo où une chèvre broutait, auprès d'une jeune fille nu-pieds, court vêtue, ses tresses blondes brillant sur la rondeur de ses épaules (Louis Gillet, Sur les pas de saint François d'Assise)

1932 Ayant trouvé une petite cabane vide je me suis faufilé et j'ai dormi tout de suite et dès le matin ce ne furent que marins dans les ruelles, court vêtus, cadrés et balancés, faut voir comme, à jouer du balai et gicler le seau d'eau autour de mon refuge et par tous les carrefours de ce village théorique (Louis-Ferdinand Céline, Voyage au bout de la nuit)

1975 Il y a, jouant en leur faveur, la pression de l'exemple, les ruses de la publicité. (« Les chiens vendent », « dogs sell ! » pourraient dire les gens du métier, remplaçant par des teckels ou des loups allemands les femelles court vêtues et résolument souriantes de naguère) (François Nourissier, Lettre à mon chien) 
II. Orner, couvrir, recouvrir légèrement, partiellement, un peu

Transitif

+1963 Mon propre environnement me pose des problèmes de verdure et de touffeur. J'éprouve la nostalgie des grands espaces de bitume, envahis par les terrasses court vêtues des cafés (Antoine Blondin, Ma vie entre les lignes [1963-1970])

1966 Étrange fête que celle donnée dans ce livre à la Chèvre-Feuille : ondée de petits vers dansants, ardents et court vêtus d'images, mais souvent aussi, dénués, sacrés, ils sont le Corps même de l'image - le corps, de tout ce qui vit, s'agite, enfante, éclaire et se transforme (Paul Éluard, Poèmes retrouvés)

CORPUS WeB :

Pippa Middleton : Très court vêtue, la businesswoman trouble le monde [http://www.pure people.com/article/pippa-middleton-tres-courtvetue-la-businesswoman-trouble-le-monde_a87 650/1] (8.3.2016)

Elsa Zylberstein très court vêtue pour le gala de charité de Maud Fontenoy (photos) [http:// www.closermag.fr/mode/news-mode/elsazylberstein-tres-court-vetue-pour-le-gala-de-cha rite-de-maud-fontenoy-519478] (8.3.2016)

Elsa Zylberstein a fait sensation le jeudi 4 juin. La raison? L'actrice est apparue très courte vêtue lors d'un gala de charité. La tenue était si courte qu'elle laissait apparaître sa culotte... Malaise ! [http://www.potins.net/celebrites/oupsaccident-de-culotte-elsa-zylberstein-132705. $\mathrm{html}$ (8.3.2016)

Cette année, J-Lo, courte vêtue, a choqué Mustapha El Khalfi, le ministre de la communication, avec ses habituelles poses lascives lors de son concert, en ouverture du festival Mawazine Rythmes du Monde 2015, à Rabat, sur la scène OLM [http://www.letemps.com.tn/article/91864/ musique-mawazine-2015-un-condens \%C3\%A9du-maroc-contemporain] (8.3.2016)

Remarques : Court vêtu désigne un animé qui met ou porte des vêtements dont la longueur ou la coupe est courte (I), emploi transposé à un ornement, un décor minimaliste qui recouvrent une chose. L'exemple de +1963 se sert d'une figure de style, l'hypallage : c'est à interpréter comme 'des terrasses où sont assises des filles/ femmes court vêtues'. Toujours sous la forme court vêtu, sans trait d'union ou avec, le groupe (II) se comporte en adjectif composé où seul le second terme est accordé (court vêtue). L'exemple de 1678 coordonne deux prédicats seconds accordés, le second étant modifié à son tour avec l'adjectif-adverbe court, qui reste invarié (adjectif composé). Néanmoins, les derniers exemples du CW mettent en évidence que le registre familier ne renonce pas complètement à l'accord des deux éléments (à comparer : les cas assimilables de grandes ouvertes, fraîches écloses, toute grande, etc.). Court est modifié par fort, très.

\section{Vêtir épais}

Porter un vêtement rembourré, chaud

त vêtir fort

\section{Vêtir étroit}

\section{Porter un vêtement étroit}

Transitif

1160 Bien fu la dame estroit vestue

De porpre noire a sa char nue (Eneas, 4011)

+1175 Estoit la dame, estroit vestue

$\mathrm{E}$ d'un fil d'or menu cosue

(Béroul, Tristan [ $4^{\mathrm{e}}$ quart XII $]$, 1147)

\section{Vêtir fort}

fort vêtu : beaucoup habillé

Transitif

CORPUS Web :

Bonjour Miss. Avec cette canicule, je vous trouve fort vêtue... [http://www.misslegs.fr/2015/ 07/lezarder-les-pieds-dans-l-eau.html] (9.3.2016)

Nous croisons l'ensigne Roots. Pour information, Roots est une marque canadienne de vêtements et j'ai été fort vêtue de cette enseigne au castor quand j'étais petite, cadeaux de ma marraine québecoise ! [http://montrealandme. canalblog.com/archives/2009/03/27/13152658. $\mathrm{html}$ (9.3.2016)

Y'avait les travaux dans mon appart ce matin, et j'avais oublié... La panique quand ça a sonné et que je dormais, pas fort vêtue... J'ai sauté dans un pantalon et voilà, mais bon... J'ai froid et je veux retourner dans mon lit é_è J'suis malade, en plus... [http://forum.viedemerde.fr/message4242180-ca-menerve] (9.3.2016) 
Le destin nous a mis un soir sur la même... plage ! Je me promenais seul, lui aussi, il faisait bon... nous n'étions pas forts vêtus et... nous nous sommes, au début, à peine parlés [http://www. tongay.com/forum-gay-forum-lesbienne/l-em ploye-du-magasin-f2-t4296-p1.html\#] (9.3.2016)

REMARQUES : Fort fonctionne comme intensifieur antéposé au participe vêtu. Selon le contexte, il peut désigner un vêtement trop chaud (v. le premier exemple du CW) ou signifier 's'habiller fréquemment avec une marque de vêtements' (v. le second exemple), ou encore, avec négation, 'porter peu de vêtements' (v. les deux derniers exemples). Selon l'usage établi, fort est invariable dans la majorité des cas, mais le quatrième exemple du CW montre que l'accord peut se produire de façon spontanée.

\section{Vêtir large}

Habiller d'un vêtement (trop) large, ample Transitif

1405 Telz choses et semblables doit dire a soy meismes la sage femme ancienne quant les mouvemens d'yre luy viennent. Avec ce sens, doit estre l'ancienne femme vestue large et d'abillement honneste (Christine de Pisan, Le Livre des trois vertus)

1761 La mère est une bonne paysanne qui touche à la soixantaine mais qui a de la santé ; elle est aussi vêtue large et à merveille (Denis Diderot, Salons : Greuze)

Pronominal

1977 Quant à moi, dans l'image que me renvoyaient les glaces du magasin, je figurais assez bien l'oiseau sortant du nid dans un nimbe de plumes, ma mère ayant tenu à me vêtir « large », en prévision d'un développement physique un peu tardif (Albert Simonin, Confessions d'un enfant de La Chapelle)

CoRpus Web :

Un grand gaillard moustachu très large vêtu d'un t-shirt rouge arriva ! [http://www.jeuxvideo. com/forums/1-25420-50053-39-0-1-0-fanfic-reddragon-thunder-reaper.htm] (9.3.2016)

Ce qui me semble le plus à craindre, lorsqu'on choisit de mettre une jupe courte ou de re- vendiquer sa sexualité, ce n'est pas tant le regard des hommes que celui des femmes. Je n'oublierai jamais celui, soutenu, désapprobateur, haineux, que portaient ces deux ados fort large vêtues sur la mère qui, à la sortie de l'école, avait osé la jupe (longue !) fendue [http://www.ciao.fr/Billet_d_ humeur_Avis_803497] (9.3.2016)

J'imagine que tu es juste une pauvre fille sans caractère à qui son peuple ou ses parents ont inculqué qu'il fallait se vêtir large et tu avales sans broncher [www.jeuxvideo.com/.../4251-40066661-6-0-1-0-les-mini-shorts-c'estvachement-putassier] (9.3.2016)

REMARQUES : Vêtir large se dit du fait de mettre ou de porter des vêtements amples, qui ne serrent pas le corps, trop grands pour sa taille. Large reste invariable, notamment aussi quand le participe vêtu est accordé. Ceci est signe d'une tendance à la lexicalisation comme adjectif composé qu'on pourrait écrire aussi large-vêtu. Large est modifié par fort, très. VoIR AUssI : habiller large

\section{Vêtir long}

Habiller de vêtements longs

Transitif

+1415 Se j'oy dire : vecy merveille, L'ung est long, l'autre court vestu ; Ce qui m'entre par une oreille, Par l'autre sault, comme est venu (Charles d'Orléans, Poésies [ 1415-1440], II, Rondel LXVI, p. 327)

1451 Comment et en quelle manière il sont armés ; ilz sont montés sur chevaulx maigres qui sont moult vistes, et ne menguent que ung peu de paille et de grain, pource que le païs est si chault, qu'i n'y croist point d'erbe et sont accroupis sur leurs selles et chevauchent à cours estriers, et sont vestus longs, leurs robes toutes pointées de toille et de coton (Gilles Le Bouvier, Le Livre de la description des pays)

1960 Au centre, sur une plate-forme vers laquelle montaient des escaliers latéraux, une femme long-vêtue se dressait, soleil au dos (Adrienne Monnier, Rue de l'Odéon) 
1978a à la voir vêtue long et chapeautée, là, on a l'impression que, maintenant elle est obscène, et non lorsqu'elle était dévêtue de lingerie blanche et se dévoilait la poitrine devant l'objectif de Keith Carradine (La Revue du cinéma)

1978b Ils sont vêtus longs comme les dignitaires et fonctionnaires de Charles VII et de Louis XI (Monique Veaux, À la découverte de Dax et de sa région)

1995 Plus loin l'homme qui s'appuie sur un bâton n'est certainement pas Judas, comme on l'a dit, car il est vêtu long, signe de sainteté du Maître et de ses disciples (Francis Salet, Cluny et Vézelay : l'œuvre des sculpteurs)

\section{CORPUS WEB :}

Alors que mon amie et moi nous promenions dans une tenue européenne à manches courtes pour profiter du soleil, nous avons remarqué deux jolies jeunes filles, voilées et long vêtues, qui marchaient sans sembler profiter $\mathrm{du}$ soleil et des embruns avec la même insouciance que mon amie et moi-même [http://resistance republicaine.eu/2013/06/25/ils-frappent-bienimpunement-les-femmes-dans-les-pays-arabespar-eva] (9.3.2016)

Parfois, les experts lâchent, sinon des secrets d'état sur les contrats export, des informations essentielles, après le 4ème daïquiri avec des pistaches et vue sur la mer ou sur les jolies touristes moins long-vêtues en août à Paris qu'à la saison des parapluies (les touristes Américains, qui ont téléchargé les bons auteurs français libres de droits pour lire dans l'avion, demandent : « vous chantez tout l'été, danserez-vous cet hiver ? ») [http://renaudfavier.com/2012/08/11/ach-deficitcommerce-exterieur-et-competitivite-de-francegross-malheur-maintenant] (9.3.2016)

Séraphine, la maman au visage angélique, était toujours longue vêtue, de gris ou de noir [http://www.origines.ch/sommentier/ceux-dela-scie] (9.3.2016)

La femme est représentée longue vêtue, debout, la jambe gauche posée sur le siège de pierre sur laquelle elle appuie son bras [http://www. encyclopedie.bseditions.fr/article.php?pArticleI $\mathrm{d}=163 \&$ pChapitreId=25154\&pSousChapitreId $=25$
188\&pArticleLib=Les+lunettes+et+les+vo $\% \mathrm{FBt}$ ains $+\% 5$ BRome $+\% 3 \mathrm{~A}+$ la + chapelle + Sixtine $+(\mathrm{Va}$ tican])-\%3ELa+chapelle+Sixtine\%5D (9.3.2016)

REMARQUES : Souvent sous la forme long(-)vêtu, avec ou sans trait d'union, le groupe désigne un animé qui met ou porte des vêtements dont la longueur ou la coupe est longue, couvrant les bras et les jambes. La tendance à la lexicalisation comme adjectif composé est forte : usage du trait d'union, antéposition de long, l'accord se faisant seulement pour le second terme (long vêtue). L'usage familier peut toutefois préférer l'accord, qui serait audible dans le code parlé (v. les deux derniers exemples du CW) ou non-audible (ex. de $+1451,1978 b$ ). Dans l'exemple de 1978a, seul le second terme, chapeauté, est accordé. Ceci indique que l'accord se produit également dans la langue parlée. Notons le contraste antonymique de vêtir long et vêtir court.

\section{Vêtir noir}

Mettre des vêtements noirs

Transitif

+1300 Fouke s'en ala, e encontra un viel charboner portant une trible en sa meyn ; si fust vestu tot neir, come apert à charboner. Fouke ly pria par amour qu'il ly velsist doner ces vestures e sa trible pur du seon (Fouke le Fitz Waryn [début XIV'], p. 95)

+1389 Et dit, il qui parle, qu'il a un frere qui est moynes à Conques l'Abbaye, estant à troys lieues prez de ladite tour, lesquelz moynes sont noirs vestus (Registre criminel du Châtelet de Paris [1389-1392])

+1400a Je suis vesve, seulete et noir vestue, A triste vis simplement affulée ; En grant courroux et manière adoulée Porte le dueil trés amer qui me tue (Christine de Pisan, Rondeaux / Euvres poétiques [début XVe], I, p. 148, 1)

+1400b Jamais ne vestiray que noir ; Puis que l'en m’a donné congié, Et que du tout m'a estrangié Ma dame qui me fist son hoir (Christine de Pisan, Rondeaux / Euvres poétiques [début $\mathrm{XV}^{\mathrm{e}}$ ], I, p. 161, 1) 
1963 C'était un petit monde chaud, noir vêtu, laborieux et secret, avec un respect dévôt [sic] de son prestigieux passé et une infinie résistance au malheur (Nicolas Bouvier, L'usage du monde. Récit : Genève, juin 1953 - Khyber Pass, décembre 1954)

\section{CORPUS WEB :}

Bref, un pur concert de bonheur avec une Dolores toute noir vêtue et ses jolis longs cheveux noirs (comme sur la pochette de Are you listening ?) (même si sur la pochette de Stars je la trouve craquante aussi)... [http://www.lagrande sophie.com.fr/forum/viewtopic.php?f=1\&t=5711 $\& \mathrm{p}=6078](9.3 .2016)$

Soudain, une personne toute noir vêtue traverse la route juste devant la voiture [http:// cynarhum.com/index.php?topic=5070.160;wap2] (9.3.2016)

Agée de 5 ans, Gettawa est une vache toute noire vêtue et a vêlée depuis peu de son 3ème veau [http://tnla-2016-cibeinsisback.blogspot. co.at/p/inspectrice-gettawa.html] (9.3.2016)

REMARQUES : Vêtir noir réfère à une personne qui met ou porte des vêtements de couleur noire. Le groupe s'emploie presque toujours sous la forme noir vêtu. Il s'applique par extension à d'autres animés ou des objets (v. le dernier exemple du CW). L'antéposition de noir et l'accord partial sur le participe (noir vêtue) sont le reflet d'une lexicalisation comme adjectif composé. Les derniers exemples du CW montrent cependant que le double accord est également possible (toute noire vêtue), sans oublier celui de +1389 . Noir est modifié par tout. On trouve encore au XIX ${ }^{\mathrm{e}}$ siècle des exemples tels « l'écuyer noir vêtu » ou " un médecin c'est un homme vêtu noir », mais il s'agit de publications allemandes où la source française n'est pas identifiable, et l'interférence de l'allemand « schwarz gekleidet » n'est pas exclue dans le second cas. En tout cas, l'usage finit par préférer vêtu de noir à noir vêtu. En fait, presque tous les exemples disponibles dans Frantext contiennent (tout) de noir vêtu ou vêtu de noir, où noir perd la fonction adverbiale. Celui de 1963 est le seul exemple moderne sans particule cité dans Frantext. Ceci étant, le CW met en évidence que le tour ancien « sans particule de noblesse » n'a pas disparu. Notons que la variante accordée plu- tôt surprenante toute de noire vêtue (aussi : tout de noire vêtue), employée comme synonyme de de noir vêtue, est assez fréquente dans la production littéraire récente, à en juger par les résultats que donne google.livres.

\section{Vêtir pareil}

Vêtir, habiller pareillement, de la même manière Transitif

+1389 une petite femme plus agée que son mary, vestue pareil que son mary (Registre criminel du Châtelet de Paris [1389-1392])

-1456 Et quant ilz furent assez pres de la ville, l'empereur ordonna que les deux contes et huit barons qui delivrer les devoient fussent tous vestus pareilles que les François estoient, et au devant d'eulz bien et grandement acompaigniez, et ainsin fut, qui tresgrans joyes et honneurs se firent (Antoine de la Sale, Jehan de Saintré, p. 265, 11)

1895 on a pu voir dans l'avant-scène du banquier Josuah Hildebrand, deux jolies fillettes, huit et dix ans, vêtues pareil, rieuses et bruyantes (Ernest Daudet, Les Coulisses de la société parisienne)

1905 L'héroïne du jour, apparue radieuse au milieu de l'essaim gracieux des demoiselles d'honneur vêtues pareil, très entourée, recevant avec aisance compliments sur félicitations, poignées de mains sur accolades (Yvonne Pitrois, Jeunes Vies)

1952 Mais leurs troupes, les bruns et les blonds, les petits et les grands, étaient tous vêtus pareil, de ce drap couleur d'un pré en hiver qui était celui de l'habit de bataille : le battle-dress (Emmanuel d'Astier, Les Dieux et les hommes)

Pronominal

+1489 Le plaisir du roy avoit esté que je fusse vestu pareil de luy ce jour. Il avoit accoustumé de long temps en avoir quelcun qui s'abilloit pareil de luy souvent (Philippe de Commynes, Mémoires [1489-1498], IV) 


\section{CORPus WeB :}

J'adore, petit Chouquet est craquant en compagnie de son lapinou tout pareil vêtu et les photos sont d'une douceur !!!!!!! [http://plusdedouceur. canalblog.com/archives/2011/01/03/20033233. html] (10.3.2016)

D'un autre coté, si elle ressemble à mon avatar, est vétue pareil et me regarde avec des yeux langoureux en me disant que j'ai du charme..... [http://forumamontres.forumactif.com/t14164p1breitling-est-une-sous-marque-de] (11.3.2016)

Tu étais vêtue pareil au moment de la pesée? (on peut varier de près de $1 \mathrm{~kg}$ dans une journée)

Tu t'es pesée à la même heure, dans les mêmes conditions? [http://www.weightwatchers. $\mathrm{fr} /$ community/mbd/post.aspx?page_size $=25 \&$ rownum $=6 \&$ page_noHidden $=1 \&$ threadpage_no $=1 \&$ sincedate $=25 \% 2 \mathrm{~F} 04 \% 2 \mathrm{~F} 2010+00 \% 3 \mathrm{~A} 00 \%$ 3A00\&thread_id $=11045558 \&$ thread_name $=$ pris $\mathrm{e}+\mathrm{de}+$ poind+malgres+respect+des+points\&fo rum_id=1\&board_id=480\&setview=TRUE\&date] range $=2$ days $\&$ viewchange $=$ OPENDATEASC (11.3.2016)

REMARQues : Vêtir pareil se dit du fait de mettre ou de porter les mêmes vêtements ou être habillé d'une manière ou dans un style identique. Pareil reste invariable dans la majorité des cas, mais, dans l'exemple de -1456 pareil s'accorde avec le sujet au pluriel. Malgré la tendance générale d'antéposer l'adjectif-adverbe avec vêtir, l'antéposition coexiste avec la postposition dans le cas de pareil, modifié par tout dans le premier exemple du CW.

\section{Vêtir vert}

au lieu de bleu se vêtir (de) vert : être infidèle, changer d'ami

Transitif

1364 En lieu de bleu, dame, vous vestés vert (Guillaume de Machaut, Le Livre du voir dit, p. 740)

\section{Corpus Web :}

... un adolescent vêtu vert rejoint soudainement le groupe [http://marjotom.over-blog.com/ article-power-rangers-119579621.html] (11.3.2016)

en après tu vas dans un magasin, et il y a un coursier tout vert vêtu qui te donne la carte routière. ça débloque la forêt jaune, et tu y en- voie un pokemon [http://www.jeuxvideo.com/ forums/1-21052-2437595-1-0-1-0-question-foret. $\mathrm{htm}]$ (11.3.2016)

Et bien me voila Nyala toute verte vêtue, je viens un peu vous embêter sur votre forum et vous espionner.... [http://eoliatde.forumactif. org/t643-moi-nyala-superbe-tdc-_] (11.3.2016)

REMARQues : Vêtir vert réfère à une personne qui met des vêtements verts, et, dans l'ancienne langue, à une personne infidèle. L'antéposition fréquente de vert au participe vêtu reflète une tendance à l'emploi comme adjectif composé, mais la postposition est également usitée. Vert reste invariable dans la majorité des cas, mais dans le dernier exemple du CW il s'accorde avec le sujet du verbe.

\section{Vibrer court}

Retentir, résonner brièvement

Intransitif

189730 décembre

- Je ne donne jamais plus de 35 sous au cocher, dit-elle, mais je lui fais un gracieux petit salut.

Une phrase qui vibre court, comme un fil de fer trop tendu (Jules Renard, Journal)

\section{CORPuS WEB :}

Quand j'enlève la batterie et que je le branche au chargeur, le téléphone vibre court une fois par seconde [http://www.miui-france.org/ threads/redmi-note-2-prime-ne-se-charge-plus. 31973] (2.4.2016)

Les voiles vibrent court au près serré. Le bateau écume la mer qui en devient visible : le noir profond des flots reprend vie dans le sillage $\mathrm{du}$ bateau [http://lindienduplacard.blogspot. co.at/2005/04/nuit-dans-le-golf.html] (2.4.2016)

REMARQUES : Vibrer court désigne la durée d'une vibration. Au sens métaphorique (v. l'exemple de 1897), le sujet réfère à des mots ou paroles sèches qui résonnent à l'oreille de l'auditeur en laissant un goût amer, et dont l'effet ne dure pas longtemps, stoppé par une réaction négative de l'interlocuteur. Court reste invariable.

\section{Vibrer fort}

Vibrer avec intensité

$\lambda$ vibrer long 


\section{Vibrer long}

Vibrer pendant un long moment, avec continuité Intransitif

1953 Le portrait chez lui est une danse de poignards : ils se fichent un à un dans la cible avec une précision qui vibre long (Claude Roy, Le Commerce des classiques)

\section{CORPUS WEB :}

Mais euh attends, le vibreur, il vibre au rythme de la sonnerie ou il vibre long ? [http:// www.forummobiles.com/topic/35562-v600 sonneries-vibrantes] (2.4.2016)

Rien... Je viens de remarqué qu'il vibrait « long » après être branché... mais rien de plus et ce quelque soit la combinaison de touches [http:// answers.microsoft.com/en-us/mobiledevices/ forum/mdlumia/crash-total-du-lumia-800-lorsdun-branchement-sur/0d3c17e2-0e4e-4922-b22fod4e4077e029?page=2\&auth=1] (2.4.2016)

Or petit soucis, les messages vibrent long et fort alors qu'avant ils vibraient par 2 coup bref [http://www.planetegalaxy.com/forum/i9100 xxlsj-15-11-t17566-140.html] (2.4.2016)

REMARQUES : Vibrer long, équivalent de vibrer longtemps préféré dans la langue standard, réfère dans l'exemple littéraire de 1953 aux vibrations engendrées par un couteau lancé qui atteint sa cible, produisant un son qui se fait entendre durablement. Dans l'emploi actuel documenté dans le CW, il s'emploie surtout par rapport à des téléphones mobiles qui vibrent long, c'est-à-dire ni brièvement ni par intermittence. Long reste invariable. Notons la collocation long et fort.

\section{Vibrer sec}

Retentir, sonner de manière vive, rude, sèche Intransitif

1953 Nous nous trompions de croire que les vertus du langage tragique, la concision, la simplicité, l'émotion droite et toujours tenue en main, la phrase qui vibre sec comme une flèche filant vite - pouvaient être des vertus simplement " artistiques » (Claude Roy, Le Commerce des classiques)

\section{CORPUS WEB :}

J'ai bien apprécié cette vidéo de la chanson Viva la vida de Coldplay, interprétée par la chorale d'enfants PS22 (;) Ça vibre sec ils sont à fond, c'est eux les nouvelles stars) [http://www. webady.fr/15/05/2009/viva-la-vida-de-colplaychante-par-la-chorale-d-enfants-ps22] (2.4.2016)

J'ai souvenir d'une BMW 800 de démonstration essayée lors d'une démo, qui vibrait sec avec un moteur trés rugueux [http://tiger800.fr/ viewtopic.php?t=5052\&p=95963] (2.4.2016)

$\mathrm{Au}$ fait, l'encoche pour intégrer le HP dans la face avant, tu sais si ça se passe bien avec du CP de bouleau : c'est pas pour moi, j’ai pas de défonceuse, mais si certains prévoient de faire la même avec ce CP : j'ai peur qu'il parte un peu en vrac, les panneaux de particules me semblent quand même plus faciles à travailler, sinon, je flippe un peu sur la réduction d'épaisseur, c'est qu'ils vibrent sec, pèsent leur poids et j'ai connu des sauvages y balançant de l'ampli de 150 voir $180 \mathrm{~W}$, y’a quand même des contraintes mécaniques potentielles pas piquées des hannetons qui AMHA, sont pas étrangères au fait que les gus d'EV ont prévu une véritable armature plutôt que les habituels tasseaux [http://www.guitariste.com/ forums/le-coin-du-bricoleur,tuto-construire-unbaffle-1-12-style-mesa-thiele,343566,300.html] (2.4.2016)

REMARQues : Dans l'exemple littéraire de 1953, vibrer sec réfère à l'impression de froideur et de dureté transmise par une parole, une phrase, un son, renvoyant à un ton cassant. Dans le premier exemple du CW, vibrer sec renvoie à l'impact de la musique sur l'auditeur. Les autres exemples attestent l'emploi concret par rapport à la vibration d'un objet ou d'un moteur. Sec reste invariable. Notons l'emploi impersonnel familier de ça vibre sec.

\section{Virer court}

Faire un brusque changement de direction ; faire demi-tour très rapidement, brusquement Intransitif

1393 Retournez et montez tant que nous soions au large où nous nous puissions deffendre, car, en ce parti, ce diable nous occiroit tous. Et adont ceulx virèrent tout court [variante : retournent tout court ; manuscrit Ars, p. 562] et montèrent appertement la montaigne, et Geuffroy aprez, l'espée au poing ; et lors son escuier fist retourner les chevaux des trois qui estoient abbatuz 
(Jean d'Arras, Melusine, p. 279 [éd. Genève])

1883 Virer court, sans courir trop de l'avant (Henry Witcomb et Edmond Tiret, Dictionnaire des termes de marine [définition])

1910 En résumé, si l’on veut un appareil capable de virer très court, il ne faudra pas le pourvoir de surfaces verticales d'empennage très éloignées du centre de gravité ; on devra se résigner à un peu moins de stabilité automatique transversale (Mario Calderara et P. Banet-Rivet, Manuel de l'aviateur-constructeur)

1937 Leclerc eut l'impression qu'un bras sur lequel il s'appuyait venait d'être coupé ; devant les points noirs des hommes qui tombaient autour d'un seul parachute ouvert, il voyait les faces terrifiées de son bombardier et du mitrailleur avant : il vira plus court et fila pleins gaz sur Alcala (André Malraux, L’Espoir)

1946 Deux phares pointèrent vers le trottoir, m'aveuglèrent une fraction de seconde, puis, virant court, s'estompèrent dans un froissement de lumière sur le pavé gras. Ce n'était pas la voiture que j'attendais (Raymond Abellio, Heureux les pacifiques)

1954 L'aviateur visé, pour échapper aux projectiles, modifie sa ligne de vol, mais il ne peut la modifier ad libitum : il est tributaire de la force centrifuge et des caractéristiques de l'avion, qui l'empêchent de virer trop court. Un pointeur humain prendrait l'habitude de ces mouvements d'évasion et pointerait les coups suivants en conséquence (Raymond Ruyer, La Cybernétique et l'origine de l'information)

\section{Corpus Web :}

Il en résultait qui plus le rapport de vitesse était important, plus le char virait court [http://www.model35.fr/v_s35_historique.html] (2.4.2016)

Ainsi, les rues qui longent la citadelle collent aux faces des bastions ou virent court pour s'en éloigner [http://kikiarg.perso.neuf.fr/ perpignanaerien.html] (2.4.2016)
Le polo est un sport extrêmement intense pour les chevaux. Ils virent court, enchaînent les pointes de vitesse (jusqu'à $60 \mathrm{~km} / \mathrm{h}$ ) et subissent les contorsions de leur cavalier [http://www.lacavaliere.com/blogs/entry/REGLES-DU-POLOSUR-NEIGE] (2.4.2016)

Pourtant des Belges, des Italiens, tractaient eux aussi, pour les Croates, j'imagine que leur code et plus cool que le notre, mais pour nous cest une question de visibilité surtout pour les jets ski qui eux virent courts et sans beaucoup de previsions de trajectoires [http://my.pneuboat. com/forum/13-armement-securite-administratiflegislation/43454-a-quel-age?start=40] (2.4.2016)

REMARQUES : Employé dans la langue ancienne par rapport à un mouvement de troupes, de personnes, virer court s'applique dans la langue moderne au conducteur d'un véhicule, d'un bateau, d'un avion, d'un cheval (troisième exemple du $\mathrm{CW}$ ), qui change brusquement de direction et tourne dans un espace très limité. Le sujet peut également, sur un plan plus abstrait, renvoyer à des rues qui changent brutalement de direction (deuxième exemple du CW). Court reste normalement invariable, mais, dans le dernier exemple du CW, il s'accorde avec le sujet, tout en gardant son interprétation adverbiale. Court est modifié par plus, tout, très, trop.

\section{Virer sec}

I. Opérer un brusque changement de direction, faire demi-tour sans prévenir

Intransitif

1926 Le conducteur fouette vigoureusement ses chevaux, aborde les lacets sans ralentir. La voiture vire sec (Bulletin de la Société de géographie de Marseille)

1932 Et quoi d'étonnant puisque après déjeuner, nous nous sommes enrichis d'une photographie formidable. J'ai bien failli, pourtant, la payer de ma vie inutile, car l'aile brisée du bougre m'est presque rentrée dedans ; j’ai viré sec (L’lllustration)

1976 Comme nous longions derechef le couloir, j'ai vu, à l'autre bout, à 30 mètres de distance à peu près, Kasper qui tournait le coin. J'ai pris le coude de Charlotte et j'ai viré sec à l'intérieur de la chambre la plus proche (Jean-Patrick Manchette, Que d'os!) 
2011 Nous nous accrochâmes au boudin, le Zodiac fila, cambré, laissant derrière lui un sillage comme une tranchée dans l'eau. Il frôla la plage, vira sec, et une grosse vague aspergea les messieurs plantés là, qui se débandèrent (Alexis Jenni, L’Art français de la guerre)

II. Renvoyer ou mettre à pied, sur le champ, sans autre forme de procès ; licencier promptement

Transitif

1960 Quarante piges il avait mené son combat obscur, Bouboule, contre les placardiers de tous poils. Les illuminateurs au néon, les zélateurs du plastique, les démarcheurs en mécaniques à sous, en machines à moudre la romance aussi étaient venus, se succédant par vagues, selon les modes, se casser le pif à son rade. Il les virait sec, leur accordant même pas le temps d'amener l'argument péremptoire en faveur du progrès des techniques, d'évoquer le mirage des recettes quintuplées ; leur ôtant, définitif, jusqu'au quart de poil d'un espoir pour le futur! (Albert Simonin, $\mathrm{Du}$ mouron pour les petits oiseaux)

1977 D’un geste las, il me congédia, se bornant à dire, découragé :

- Ramasse tes clous, et passe à la caisse... Je t’ai assez vu !... [...]

Virésec, sans avertissement préalable, j'allais devoir fournir les tenants et les aboutissants de mon renvoi brutal !

(Albert Simonin, Confessions d'un enfant de La Chapelle)

1980 Bref : on a été virés aussi sec et, du jour au lendemain, on s'est retrouvés sans boulot (Jean-Luc Benoziglio, Cabinet portrait)

REMARQues : Virer sec (I) se dit du fait de changer brusquement de direction, sans en aviser au préalable, causant ainsi la surprise des observateurs. L'acception (II) s'emploie dans les relations de travail et renvoie soit à l'acte légal de licenciement, soit au simple fait d'envoyer balader quelqu'un. Sec y souligne la brutalité de l'acte. Sec est invariable. Dans les exemples rassemblés, aucun modifieur se glisse entre verbe et adjectif.
En effet, toute modification en atténuerait le sens, ce qui cadre mal avec l'essence sémantique de ce groupe.

\section{Virevolter sec}

Tourner brusquement sur soi

Intransitif

1975 La lumière des lampes fait scintiller, sur son fil, la funambule corsetée de clinquant ; les chevaux aux queues peignées virevoltent sec au commandement du coup de fouet (Pierre Jakez Hélias, Le Cheval d'orgueil)

\section{Viser bas}

I. Lancer bas (une flèche)

Intransitif

1578 Qu'Amour les laisse en paix, et ne les navre pas,

Et que luy pour son but opiniastre essaye

De faire dans mon cœur une eternelle playe

Sans que jamais il vise ou plus haut, ou plus bas ? (Pierre de Ronsard, Le Second Livre des amours)

II. Avoir peu d'ambition, avoir des visées, des objectifs peu élevés

Intransitif

1927 Et ceci, bien que visant beaucoup plus bas, n’atteint-il pas un peu la sérénité goethienne (Valéry Larbaud, Jaune bleu blanc)

1939 On a vu des romans fameux, à peine lisibles et qui tout de suite tombaient en poudre. La qualité du papier et de l'impression, le bon goût d'une couverture, un texte correct est un luxe que l'éditeur est tenté d'abandonner assez vite. Il se dit que les Français ne prennent pas garde à ces détails, et qu'un livre soigneusement édité ne se vend pas davantage. Là est le péril de tous ceux qui ont affaire aux foules. Ils deviennent sceptiques, et visent trop bas (La Civilisation écrite)

1964 « Si les Turcs s’abstiennent généralement de consommer des boissons alcoolisées et ignorent les jeux de hasard, la virilité joue un grand rôle dans leur vie. » Si elle vise 
bas, cette explication va loin (Libération, 4 septembre 1964 / Grundt : 277)

1982 Un ressentiment envahit le visage de Joyce. - Comme toujours, chéri, comme toujours, dit-elle, la voix lasse.

Il attaque. Il parle vite, vise juste, vise bas. - Et ta capsule, tu lui as fait sniffer quand, exactement ? Avant l'amour, pour qu'il te fasse des choses pas croyables? (Philippe Labro, Des bateaux dans la nuit)

\section{CORPuS Web :}

" j'aime ceux qui visent bas et qui ratent " [https://fr-fr.facebook.com/KlubDesLoosers/ posts/327711197241627] (2.4.2016)

Donc elle vise bas pour faire du chiffre, rien que du chiffre [http://leplus.nouvelobs.com/ contribution/1126326-gayet-hollande-et-sarkozy10-raisons-de-ne-pas-exclure-la-these-d-uncomplot.html] (2.4.2016)

Après Polly et moi, Starsky et Hutch et Envy, voilà une énième comédie interprétée cette année (et produite également) par Ben Stiller. Encore une fois, elle vise bas et atteint sa cible... pour autant que vous appréciez les blagues débiles, les grimaces et le cabotinage [https://voir.ca/ cinema/2004/06/23/ballon-chasseur-une-vraiehistoire-de-sous-estimes-rater-la-cible] (2.4.2016)

REMARQUES : Viser bas (I) se dit, au concret, du fait de lancer des flèches plus bas que l'endroit qui aurait dû être atteint. Au figuré (II), il renvoie au fait de montrer peu d'ambition dans ses décisions ou dans ses choix, de placer la barre très bas. Bas reste invariable et est modifié par plus, beaucoup plus, trop. Notons l'opposition de viser bas et viser haut, ainsi que l'emploi de viser juste. VoIR AUSSI : penser / voir grand

\section{Viser droit}

Diriger son regard, un projectile directement vers (quelque chose/quelqu'un)

Intransitif

1160 Un archier ot de l'autre part, Tresgitez fu par grant esgart ; Androit lo colun ert asis Sor un perron de marbre bis ; Son arc tot antesé tenoit Et cele part visot tot droit (Eneas, 7700)
1532 Puis la gauche leva haut, avec fort serrement et extension des quatres doigts et elevation du poulce, et la tenoit en ligne directement correspondante à l'assiette de la dextre, avec distance entre les deux d'une coudée et demie. Cela fait, en paraille forme baissa contre terre l'une et l'autre main ; finalement les tint on milieu, comme visant droit au nez de l'Anglois (François Rabelais, Pantagruel)

1550 Je banderay mon arc, qui jette Contre ta maison sa sagette Pour viser tout droit en ce lieu Qui se reéjouist de ta gloire, Et où le grand fleuve de Loire Se mesle avec un plus grand Dieu (Pierre de Ronsard, Les Odes, p. 215)

1832 Nos batteries ne plaisantent point à vrai dire. Ce sont des plénipotentiaires qui visent droit au but, et jettent bas l'obstacle, au lieu de le tourner. Chacun de leurs coups porte. Nul de leurs boulets ne se perd ou ne s'évapore (Alfred de Musset / Revue des deux mondes)

1840 BOLINGBROKE. Pas celle-là... douce et bonne par caractère, mais faible et indécise, n'osant prendre un parti sans prendre l'avis de ceux qui l'entourent, elle devait nécessairement se laisser subjuguer par ses conseillers et ses favoris, et il s'est trouvé près d'elle une femme à l'esprit ferme, résolu et audacieux, au coup d'œil juste et prompt, qui vise toujours droit et haut ! (Eugène Scribe, Le Verre d'eau)

1896 D'ailleurs maints d'entre vous, troupeau trié déjà,

Valent mieux que le monde autour qui vous jugea,

Lisent clair, visent droit, entendent net en somme,

Vivent et pensent, plus que non pas un autre homme,

Que tels, mes chers lecteurs, que moi, cet écrivain,

Tant leur science est courte et tant mon art est vain! (Paul Verlaine, CEuvres poétiques complètes) 
1920 La religion ainsi considérée, est donc un art véritable, et bien mieux l'art par excellence, si l'on regarde bien : car les autres arts ne visent pas aussi droit, mais tous vont à nous délivrer des passions, comme Aristote l'a fait entendre de la tragédie, sans qu'il se soit trouvé assez de commentateurs pour tirer tout à fait l'idée hors de l'image (Alain, Système des beaux-arts)

1983 et le voici suspendu en l'air, se balançant doucement... il se rapproche... j'arrive tout près, c'est le moment... je tends la tige vers lui, je vise tout droit, en plein dans son centre... ça y est, j'entends un bruit métallique, mais c'est seulement celui qu'il a fait en se heurtant contre la tige (Nathalie Sarraute, Enfance)

1990 Rapides, tendues, ou au contraire se posant en bout de course avec mollesse, les gouttelettes frappaient au petit bonheur le coin de l'œil, la tempe, la pommette, ou visaient droit au creux de l'oreille, si imprévisibles, aux paramètres si compliqués, qu'il était inutile de chercher à s'en prémunir, à moins de s'enfouir la tête dans un sac (Jean Rouaud, Les Champs d'honneur)

1992 C'est que, tout en elle est vrai, vise droit, frappe juste. A Bobigny, avec les mots les plus simples, elle donne à sa démonstration une densité remarquable (Gisèle Halimi, La Cause des femmes)

Transitif

1300 Si haut a Fierabras amont son brac geté

Ke tout a descouvert le flanc et le costé.

Oliviers l'aperchoit, si l'a bien droit visé, [bien avisé, Fierabras (L), 1553]

A retraite le fiert du branc d'acier tempré ; Pardesous la mamele li a grant cop donné, Le blanc hauberc trellis a rout et dessaffré (Fierabras (K), 1481)

1532 Voyla belle resolution. Bien fol est il, cela ne se peut nier : mais plus fol est celuy qui me l'amena, et je tres fol qui luy ay communicqué mes pensées. C'est, respondit Carpalim, droit visé à ma visiere (François Rabelais, Pantagruel)
1928 affairé, un crayon entre les lèvres, il traversait les galeries en diagonale, comme ceux du métier, visant droit le tableau qu'il cherchait, sans longer les murs et il savourait la curiosité inquiète des gardiens (Roger Martin du Gard, Devenir)

\section{CORPUS WEB :}

Apprenez à placer le ballon à cet endroit chaque fois que vous vous préparerez à tirer. Lorsque quelqu'un vous passera le ballon, il devra viser droit dans votre « point de tir » [http://fr.wiki how.com/marquer-au-basket] (7.4.2016)

Rukia regarda le roux, assis à son bureau. Il tourna la tête, puis la visa droit dans les yeux, gromellant un « quoi ? » [https://www.fanfiction. net/s/4864787/1/Songfic-de-la-St-Valentin] (7.4.2016)

Dans cette scène, où elle décrit ce qu'elle attend d'une relation et de la vie, elle vise droit au cœur [http://www.cineplex.com/Nouvelles/10scenes-de-film-pour-chasser-les-blues] (7.4.2016)

REMARQUES : Viser droit se dit, au sens concret, $\mathrm{du}$ fait de diriger son regard avec attention sur quelqu'un ou quelque chose pour chercher à l'atteindre, notamment en lançant un projectile ou en pointant une arme vers l'objectif (le but, la cible), le sujet visant en droite ligne. Au figuré, il réfère à la pensée, au raisonnement du sujet qui se concentre sur l'essentiel. Il peut aussi désigner le fait de regarder, de fixer intensément, d'examiner quelque chose ou quelqu'un, ce qui traduit une certaine curiosité ou la passion de quelqu'un pour quelque chose ou quelqu'un. Droit reste invariable et est modifié par aussi, bien, toujours, tout. Il a tendance à s'intégrer dans le groupe prépositionnel qui le suit (à, dans, en) en tant que modifieur de la préposition, ainsi que dans des groupes plus complexes (viser droit dans les yeux, viser droit au cœur, droit au but). Notons l'emploi des groupes viser droit et haut, lire clair, entendre net, frapper juste, jeter bas.

\section{Viser haut}

Avoir de l'ambition, des visées ambitieuses Intransitif

1575 Alors qu'ensemblement des maux nous devisons

Que la France a souffert par la civile guerre, 
Sans des grands faits de Dieu nullement nous enquerre,

Ainsi, comme il nous semble, en

cherchons les raisons ;

Et, sans viser plus haut, follement nous

disons

Que ces maux nous avons du reistre, qui tout serre,

Et des soldats venus d'une estrangere

terre,

Qui ont pillé nos biens et bruslé nos

maisons (L'Estoile, Pierre de, Registre-

journal du regne de Henri III)

1615 On exige de vous des choses, et veut-on vous obliger à des soucis dont vos prédécesseurs Roys ne furent jamais empeschez. Ceux de l'Estat visent bien plus haut. C'est, du Ciel, les ravaler en terre. Par le passé, on n'a point ouy parler de cela. Ce n'est point de quoy l'on a accoustumé de traiter dans le Conseil (Antoine de Montchrestien, Traicté de l'économie politique)

1733 Machiavel tient que la politique doit imiter l'arquebusier qui vise plus haut qu'il ne veut frapper (Gilbert-Charles Le Gendre, Traité de l'opinion)

1785 L'homme expérimenté vise plus haut pour atteindre plus bas (Pierre Joseph Roubaud, Nouveaux Synonymes françois)

1824 - Allons donc, dit-il, vas-tu faire le mystérieux ? Mon cher, le secret est bon pour les sots ; mais quand on vise haut, il faut de la publicité, et la plus grande. On n'a tout de bon que ce qui est bien constaté ; l'une est un moyen d'arriver à l'autre, et il faudra bientôt grossir ta liste (Claire de Duras, Édouard)

1840 Chez les peuples démocratiques, l'ambition est donc ardente et continue, mais elle ne saurait viser habituellement très haut ; et la vie s'y passe d'ordinaire à convoiter avec ardeur de petits objets qu'on voit à sa portée (Alexis de Tocqueville, De la démocratie en Amérique)

1842a Il veut laisser au prêtre seul l'usage, dit-il, de ces saintes et divines chansons (il en- tend les psaumes) ; lui laïque, lui simple auteur de fantaisie, il ne vise si haut ; le simple patenôtre est assez; il dirait volontiers, à force de faire respectables ces livres et ces sujets de réflexion éternelle : sacrés ils sont ; que personne n'y touche ! (Charles Sainte-Beuve, Port-Royal)

1842b - Oui, M. Paturot, nous manquons surtout à la chambre d'hommes comme vous, fermes dans leurs principes, fidèles au roi et aux institutions.

- Monsieur, répondis-je, vous me faites trop d'honneur : je n'oserai jamais viser aussi haut. Il faut pour cela plus de lumières et d'études que je n'en ai

(Louis Reybaud, Jérôme Paturot à la recherche d'une position sociale)

1842c S’ils [= les jeunes] étaient moins orgueilleux, moins absurdement infinis dans leurs espérances, ils viseraient moins haut, ils réaliseraient moins encore que nous ne les voyons faire (Jules Michelet, Journal)

1856 Quoi ! accepter des concessions, quand on a le droit, et l'appui des princes, quand on a l'appui des peuples ! Il y a de l'abdication dans cette espèce de progrès-là. Non. Visons haut, pensons vrai, marchons droit. Les à-peu-près ne suffisent plus. Tout se fera ; et tout se fera en un pas, en un jour, en un seul éclair, en un seul coup de tonnerre (Victor Hugo, Actes et paroles)

1862 Il est entièrement de mon avis, et dit qu'avec du travail - et ce travail sera presque une distraction pour moi - il est impossible que je n'arrive pas à une faculté, peu de professeurs de langues étrangères étant en état de se faire recevoir docteur et tous ne visant guère plus haut, arrivés à une chaire de lycée (Stéphane Mallarmé, Correspondance)

1881 Si, ne pouvant réussir dans les petites places, je visais plus haut? Reste le métier de précepteur ou de secrétaire. Secrétaire? (Jules Vallès, Jacques Vingtras : Le Bachelier) 
1885 Toute la grande poésie romantique se réfléchit dans ses vers, non effacée, mais adoucie, comme dans une eau limpide et un peu dormante ; mais, si elle ne dormait pas, elle ne réfléchirait rien du tout. Et la morale de tout ceci est bien simple : visez haut, faites de beaux rêves, et, comme dit l'autre, « il en restera toujours quelque chose » (Jules Lemaître, Les Contemporains)

1909 Il [= l'art du v viècle] exprime l'espèce entière, il la décrit en demandant à chaque individu son caractère dominant. Mais l'art familier de la Grèce ne vise pas si haut. Il suit, avec une sagacité charmante, le caractère individuel (Élie Faure, Histoire de l'art : l'art antique)

1920 La grande comédie, comme on l'a expliqué, vise bien plus haut ; c'était bien l'esprit de Socrate qu'Aristophane mettait sur la scène. Il ne faut donc point se hâter de rapprocher le dessin satirique de l'art comique (Alain, Système des beaux-arts)

1936 Ce peuple donc porte partout la paix de l'esprit, qui est la plus difficile, et la guerre de l'esprit, qui est la plus sauvage. Visant trop haut, il a vécu trop bas. Il a tué le dieu de chair ; il le devait, car, selon la Bible, il n'y a pas plus de dieu de chair qu'il n'y a de dieu de bois ou d'or (Alain, Propos)

1939 les romantiques se proposaient tout autre chose que de connaître et de décrire le fonctionnement de nos ressorts internes. Leurs efforts et leurs abandons visent manifestement plus haut que cette analyse. Les effusions lyriques des personnages jean-pauliens au cœur d'une nature soudain devenue musicale (Albert Béguin, L’Âme romantique et le rêve)

1959 Mais, du moment qu'il s’agit de la France et quelle que soit temporairement sa situation, c'est la sagesse et la raison de voir grand et de viser haut. Nous avons de bons bras, de bonnes têtes, de bons cœurs, et, à notre portée, de vastes trésors à tirer de terre (Charles de Gaulle, Mémoires de guerre)
1984 - Et le Livre avec une majuscule, celui qui doit mettre un point final à la littérature? - Abandonné.

- Tu as raison. Je n'osais pas te décourager, mais c'est l'idée qui vient à tout le monde. On vise trop haut, pour ne pas s'avouer qu'on ne sait même pas tirer bas (Bertrand Poirot-Delpech, L'Été 36)

1985 Je regardais toujours Betty avant de me coucher et je me demandais si les quelques pages que j'avais noircies étaient à la hauteur. J'aimais bien me demander ça. Ça m'obligeait à viser assez haut en tant qu'écrivain. Ça m'apprenait aussi à m'écraser (Philippe Djian, $37^{\circ} 2$ le matin)

\section{CORPUS WEB :}

«Elle vise haut la Guinguette, elle vise juste. »

La Guinguette, c'est l'osmose inégalée de la gastronomie et du sourire. La salle est un théâtre chaleureux ou le bon goût et l'art du détail se représentent chaque jour [https://www.tripadvisor. fr/ShowUserReviews-g187187-d1334987-r2745878 86-La_Guinguette-Trouville_sur_Mer_Calvados_ Basse_Normandie_Normandy.html] (7.4.2016)

REMARQUES : Viser haut se dit, au figuré, du fait d'ambitionner avec ardeur une chose, une position jugée supérieure, d'avoir des projets très ambitieux, de viser un objectif difficile à atteindre, soulignant le caractère déterminé, ambitieux et très exigeant du sujet. L'exemple de 1733 met en évidence l'analogie avec l'art du tir qui sous-tend la métaphore. Haut reste invariable et est modifié par assez, aussi, bien plus, habituellement, manifestement, moins, plus, si, très, trop. Notons l'emploi transitif du verbe dans le CW. Viser haut provoque toute une série de groupes associables : viser plus haut pour atteindre plus bas ; visons haut, pensons vrai, marchons droit ; visant trop haut, il a vécu trop bas ; voir grand et viser haut ; viser haut ... tirer bas ; viser haut, viser juste. VoIR AUSSI : penser / voir grand

\section{Viser juste}

I. Atteindre sa cible, faire preuve de perspicacité Intransitif

1713 Les uns disoient que vous étiez retourné dans les troupes ; les autres disoient que vos parens, apprehendant que vous fissiez 
à Galloüin une querelle plus funeste que la première, vous avoient fait mettre en lieu de sûreté ; les autres, qui apparemment visoient plus juste, disoient que vous vous en êtiez allé avec Silvie, qui disparut au même tems que vous ou peu après (Robert Challe, Les Illustres Françoises)

1717 NICOLAS. Ma fille a des amoureux qui sont bian adroits.

GROS-JEAN. Il y a un drôle qui recharche ma nièce, qui vise, morgué, bian juste

(Dancourt, Le Prix de l'arquebuse)

1855 Écrivez-moi, cher ami, jetez dans mes rêveries ce bon rire gaulois et naïf que vous avez et que j'aime. Nous attendons le petit Franco-Belge à époque fixe : nous savons que vous visez juste. Je prends vos deux baisers et je vous en rends quatre, un sur chaque joue (Victor Hugo, Correspondance)

1860 Son monologue intérieur était le monologue suivant :

- Un catalogue des lettres où on donne des extraits de lettres d'une illustration pas plus illustre que Demailly, c'est louche... des extraits qui se trouvent frapper seulement et précisément Franchemont, Rémonville, Lamperière, les autres, c'est visé trop juste, c'est une méchanceté trop littéraire pour un marchand d'autographes... je sens le mensonge dans tout cela... ah ! (Edmond et Jules de Goncourt, Charles Demailly)

1923 Si Anne d’Orgel s'était tu jusque-là, admettant, au besoin, sa maladresse dans les choses du cœur, il prétendait remplir incomparablement son métier mondain. Mahaut visa donc juste. Mais ce fut aussi à cause de cette prétention qu'il décida de rester raisonnable, mesuré, coûte que coûte, quoi que pût dire Mahaut, et pour ne pas lui ressembler (Raymond Radiguet, Le Bal du comte d'Orgel)

1936 et c'est bien aussi l'épée qui a fait d'abord l'expérience, l'épée, outil à tout faire, témoin plus sûr que le bras. Et, encore une fois, le sentiment poétique a visé plus juste ici que le savoir ; car plus d'un homme instruit en est à ignorer que le seul moyen de changer d'idée est de changer d'action (Alain, Propos)

1945 Il reste à ceux-ci à surmonter une émotion très légitime et à viser bien et juste. Précisons sur ce point que le sanglier est remarquablement protégé ; il a sur toute l'échine, les flancs et l'épaule, « son armure ", plaque de cuir pouvant atteindre chez les vieux jusqu'à 3 centimètres (François Vidron, La Chasse en plaine et au bois)

1969 Un an, que je vivais avec elle ! Depuis le printemps dernier. Mon Printemps ! Celui-là aussi, qui s'annonçait, serait à moi ! Il a visé juste, ayant bien calculé son coup, ou il a eu de la veine, le père Robert, toujours est-il que j'étais seul quand il m'a téléphoné (Léo Malet, Sueur aux tripes)

1982a Un ressentiment envahit le visage de Joyce.

- Comme toujours, chéri, comme toujours, dit-elle, la voix lasse.

Il attaque. Il parle vite, vise juste, vise bas. - Et ta capsule, tu lui as fait sniffer quand, exactement ? Avant l'amour, pour qu'il te fasse des choses pas croyables?

(Philippe Labro, Des bateaux dans la nuit)

1982b Sûr qu'elles commettaient quelques erreurs, quelques bévues dans la masse de leurs suspicions, mais dans le cas de Marcel, on pouvait dire qu'elles visaient juste (Alphonse Boudard, Les Enfants de chœur)

II. Diriger exactement son regard, un projectile vers (une cible)

Intransitif

1778 Une fois, Mlle Galley, avançant son tablier et reculant la tête, se présentait si bien, et je visai si juste, que je lui fis tomber un bouquet dans le sein ; et de rire. Je me disais en moi-même : "Que mes lèvres ne sont-elles des cerises ! » (Jean-Jacques Rousseau, Les Confessions)

1843 Mais si je suis un pauvre paysan de Bohême, n'ayant appris dans la forêt qu'à 
manier la cognée, il a fait de moi un soldat prussien, et, grâce à ses caporaux, je sais viser juste avec un fusil (George Sand, Consuelo)

1902 Châteaubedeau, une fois là, affecta de tenir l'endroit pour plaisant et de s'y comporter comme chez lui : de siffler, de chantonner les refrains à la mode et d'esquisser quelques pas de menuet sur le sol inégal ; de cracher, en visant juste, par le beau milieu du jour étroit (René Boylesve, La Leçon d'amour dans un parc)

1950 « Ah ! les cochons ! » Ils tirent méthodiquement, balle après balle, et visent juste. Troubat, au milieu de nous, pousse une exclamation sourde, et serre de la main droite son bras gauche qui saigne sur sa manche (Maurice Genevoix, Ceux de 14)

1972 Delvale estimait qu'un "Vive la France catholique quand même ! » serait du plus bel effet. Marcheret se promettait de crier : « Tirez au cœur et visez juste parce qu'il est bien accroché !» Remy chanterait Le Petit Souper aux chandelles et s'il en avait le temps, Lorsque tout est fini... (Patrick Modiano, Les Boulevards de ceinture)

\section{CORPus WeB :}

La base de données clients, l'outil qui permet de viser juste [http://blog.digitaleo.fr/basede-donn\%C3\%A9es-clients] (7.4.2016)

Les Archers Bandouliers visent juste [http:// www.ladepeche.fr/article/2016/01/25/2263067-lesarchers-bandouliers-visent-juste.html] (7.4.2016)

Un flow rapide et précis, des textes qui visent justes, ancrés dans un Montmartre actuel et non-fantasmé, une indépendance totale et un touche à tout [http://watchthesouth.fr/les-con certs-a-ne-pas-manquer-en-avril] (7.4.2016)

REMARQUES : Lorsque, au sens concret, le complément désigne une arme ou un projectile, viser juste (II) se dit du fait de tirer ou diriger le projectile vers l'objectif à atteindre, avec exactitude, sans faute, de manière exacte, non approximative. En parlant de la manière de penser, de voir ou de s'imaginer les choses (I), il désigne le fait de réussir à atteindre, à obtenir l'effet souhaité par une action réfléchie, précise et astucieuse.
Juste reste invariable dans la majorité des cas, mais dans le troisième exemple du $\mathrm{CW}$, il s'accorde avec le sujet, tout en gardant la fonction adverbiale. Il est modifié par bien, donc, plus, si, trop. Notons la collocation bien et juste.

\section{Vivre aise}

Vivre facilement, agréablement ; vivre dans le confort, le bien-être matériel

Intransitif

+1250 Ne dotez pais que ne me plaise Ce que ie uoi que tu uis aise (Ysopet de Lyon [2e moitié XIII $]$, 2832)

-1334 Je me vorroie bien gagier, Nus ne la poroit damagier. Plus aise en vif et plus sëur. Du mirëoir n'ai ge pas peur, Qu'il o[s]curasse nullement (Le Romans de la dame a la lycorne [1 ${ }^{\mathrm{er}}$ tiers XIV] $]$, 1534)

+1365 Car elle dist que pour vivre aise, Qui de tout se taist, tout appaise.

Sique laisses tout convenir, Se tu veulz à droit port venir De paix et joieusement vivre (Jean Froissart, Poésies [3 tiers XIVe])

1550 Là Rhadamant, le juge audacieux, Va punissant les avaricieux, Et le chetif que douce mort delivre Aise à son rang là-bas il laisse vivre (Pierre de Ronsard, Le Second Livre des odes, p. 141)

REMARQUES : Vivre aise se dit du fait de vivre de façon confortable, dans des conditions qui contribuent au confort matériel, au bien-être de la vie, sans soucis. Il peut aussi référer à l'état moral du sujet qui est heureux, satisfait et mène une vie sereine. Aise reste invariable et est modifié par plus. Notons la collocation plus aise et plus sûr.

\section{Vivre bas}

Vivre dans des conditions sociales, morales ou intellectuelles mauvaises, inférieures Intransitif

1630 Mon cœur paroist par le trespas Qui la force et l'espoir assemble Si ne pouvois-je, se me semble, 


\section{Mourir plus hault, vivre plus bas}

(Théodore Agrippa d'Aubigné, Le Printemps : l'hécatombe à Diane et les stances)

1869 Je sens déjà que je l'oublie,

Et, parfois, songeur au front las,

Je m'en repens et me rallie

Aux enfants qui vivent plus bas

(Armand Sully Prudhomme, Les Solitudes)

1937 Il est mauvais de penser aux hommes en fonction de leur bassesse... - Quand on contraint une foule à vivre bas, ça ne la porte pas à penser haut. Depuis quatre cents ans, qui a « la charge de ces âmes », comme vous disiez ? Si on ne leur enseignait pas si bien la haine, ils apprendraient peut-être mieux l'amour, non ? (André Malraux, L'Espoir)

1948 C'est là sa plus profonde misère, celle dont il ne guérira pas. D'où lui vient cette timidité qui le paralyse ? Est-ce d'avoir rêvé si haut, vécu si bas, et reconnu l'abîme qui séparait son rêve de la réalité ?

(Jean Guéhenno, Jean-Jacques : En marge des Confessions)

\section{CoRpus Web :}

Au-delà du symptôme existent des problèmes de vie non résolus, alors le corps dit tout haut ce que l'être vit tout bas [http://www.ateliersophrologie14.com/sophrologie-medecinedouce.php] (10.4.2016)

Et parce que même les méchants ont besoin d'amour, elle mélange le stand-up et le sketch, pour dire tout haut ce que l'intimité vit tout bas, et pour incarner avec tendresse des personnages drôlissimes [http://www.nantes-spectacles.com/ cie520-swann-perisse.html] (10.4.2016)

Gibbula umbilicalis est une des espèces appartenant à la famille des Trochidae que l'on rencontre communément sur l'estran. L'espèce vit plus bas que Osilinus lineatus et on la trouve au niveau de mi-marée [http://ichtyo.cnrs.fr/pages/ fr/fichefr.php?var=48] (10.4.2016)

REMARQUES : Vivre bas réfère aux conditions de vie matérielles et morales dans lesquelles se trouve le sujet, celui-ci menant une vie misérable. En référence à la hiérarchie morale ou sociale, il se dit du fait de se trouver à un niveau inférieur, bas. Le dernier exemple du CW actualise le sens local de bas. Bas reste invariable et est modifié par plus, si, tout. L'usage tend à développer des contrastes paradigmatiques avec de groupes comme mourir haut, penser haut, dire tout haut, rêver haut.

\section{Vivre bel}

Vivre bien, d'une manière satisfaisante

Intransitif

1325 Si vi Verité et Droiture,

Qui la dame et tout son mesnage

Desfendoient d'avoir domage ;

Bel vivoient et sagement

(Watriquet de Couvin, Dits, p. 23, 707)

REMARQUES : Vivre bel se disait du fait de mener une vie agréable, sans problèmes, procurant au sujet une certaine satisfaction. Le neutre bel indique la fonction adverbiale qui est confirmé par la coordination avec sagement.

\section{Vivre caché}

Vivre à l'abri des regards d'autrui ou de ses recherches, souvent en se retirant dans un lieu secret

Intransitif

1670 Elles doivent vivre cachées sous leur closture, y menant une vie divine, comme Jésus vit caché, et solitaire sous les especes au tres-saint Sacrement (Jean de Bernières, Les (Euvres spirituelles)

1678 Certain Ours montagnard, Ours à demi léché,

Confiné par le sort dans un bois solitaire, Nouveau Bellérophon vivait seul et caché :

Il fût devenu fou ; la raison d'ordinaire N'habite pas longtemps chez les gens séquestrés (Jean de La Fontaine, L'Ours et l'amateur des jardins / Fables)

1696 Cet homme qui a fait la fortune de plusieurs, qui a fait la vôtre, n'a pu soutenir la sienne, ni assurer avant sa mort celle de sa femme et de ses enfants : ils vivent cachés et malheureux (Jean de La Bruyère, Les Caractères) 
1742 Rassurons-nous pourtant. Le jour commence à naître :

Nous allons tous penser, Descartes va paraître.

Il vit toûjours caché : mais ses brillans travaux

Forment ses sectateurs, ainsi que ses rivaux (Louis Racine, La Religion)

1792a L'insecte vainement cherche à leur échapper, il devient bientôt leur conquête.

L'un le saisit par l'aile, un autre par le corps ; un troisieme survient et le prend par la tête.

Il ne falloit pas tant d'efforts pour déchirer la pauvre bête.

Oh ! Oh ! Dit le grillon, je ne suis plus fâché ;

Il en coûte trop cher pour briller dans le monde.

Combien je vais aimer ma retraite profonde!

Pour vivre heureux vivons caché

(Jean-Pierre Florian, Fables)

1792b Je prie qu'on observe que dans les pays où les femmes vivent cachées comme aux Indes, l'inceste y répugne moins [est moins souvent] que dans nos contrées où les femmes sont plus libres et moins modestes (Saint-Just, De la nature, de l'étatcivil, de la cité ou Les Règles de l'indépendance du gouvernement)

$1839 \mathrm{Au}$ mois de mai nous irons à Nohant et en juin vraisemblablement à Paris, car je crois que c'est encore le pays où l'on peut vivre plus libre et plus caché (George Sand, Correspondance)

1859 Il vécut dès lors pénitent et caché sous des noms divers : M. de Monfrein, M. du Vivier, M. Mercier, M. de Maupas, M. Fleury, tout cela c'était toujours M. de Pontchâteau (Charles Sainte-Beuve, Port-Royal)

1945 - Attention. Fermons les fenêtres ! Signe des temps. Je pousse un battant. Je m'arrête, une main sur la crémone. Je dis :

- On ne vit plus caché pour vivre heureux, mais pour essayer de vivre tout court (Jean-Louis Bory, Mon village à l'heure allemande)
1970 Il va de soi que les places des élèves étaient déterminées souverainement par le préfet de discipline qui s'appliquait à contrarier leurs vœux autant que possible, soit en séparant les amis, soit en imposant les premiers rangs aux cancres et aux rêveurs qui n'auraient aspiré qu'à vivre heureux et cachés au fond de la classe (Michel Tournier, Le Roi des aulnes)

1987 « Tout se passe comme si ces bras étaient abandonné [sic] un peu au hasard... Le mâle, en effet, est un minuscule animal de moins de dix centimètres de diamètre, qui vit à la dérive, alors que la femelle, dont le diamètre peut approcher le mètre, vit $c a$ chée sous les rochers du fond des mers » (Philippe Sollers, Le Cour absolu)

\section{CORPUS WEB :}

Des hommes dragons, vivent caché depuis toujours parmi les hommes [https://br.pinterest. com/pin/58195020163489784] (11.4.2016)

Mon témoignage à visage découvert c'est mon choix mais ce choix à un prix je suis célibataire sans enfant si je suis seul c,est tout simplement parceque, je tombe toujours les séropositifs qui vivent caché même à leur famille le V.I.H ma tout volé mais ma fierté c,est de vivre 1 , amour avec un grand A [http://blog.sida-info-service. org/2010/01/08/sida-une-parole-en-images] (11.4.2016)

Pour vivre heureux, les homosexuels de Sotchi vivent cachés [http://www.franceinfo. fr/actu/monde/article/pour-vivre-heureux-leshomosexuels-de-sotchi-vivent-caches-28109] (11.4.2016)

Mais la plupart d'entre eux ignorent qu'au pied des gratte-ciel, de nombreux sans-abri ont trouvé refuge. Ils vivent cachés sous la dalle, notamment dans les immenses parkings souterrains du quartier, et se fondent dans la foule la journée [http://www.bfmtv.com/mediaplayer/ video/des-sans-abri-vivent-sous-les-tours-de-ladefense-761437.html] (11.4.2016)

REMARQUES : Vivre caché réfère à une personne qui ressent le besoin d'être seul ou qui cherche à fuir les obligations sociales, menant ainsi une vie en retrait, s’isolant du monde, de la société, pour se protéger, être à l'abri des regards. D'où la devise Pour vivre heureux, vivons caché que 
l'on retrouve, d'une façon ou d'une autre, dans plusieurs citations. De même pour un animal qui se retire dans un abri (ex. de 1987). En tant que participe passé, caché tend à l'emploi comme prédicat second accordé, mais l'emploi invarié est possible (ex. de 1792a et les deux premiers exemples du CW). Caché est modifié par plus, toujours. Notons l'emploi de vivre heureux / libre / pénitent, qui sont présentés comme corrélats de la vie en cachette.

\section{Vivre calme}

Vivre dans le calme, en paix, dans la sérénité Intransitif

1773 Rome, dans son berceau, vivait calme et contente

Une simplicité, plus noble qu'éclatante (Alexandre-Jacques, le chevalier Du Coudray, Le Luxe)

1788 Le Vicomte de Blaville, qui ne payoit ni son marchand, ni son tailleur, qui vivait calme et serein au milieu de cent créanciers [...] se piquoit cependant d'une extrême exactitude pour les dettes du jeu (Étienne François de Lantier, Erminie)

1822 Clotilde et Sophie atteignaient déjà leur dix-septième année, et bornées au seul plaisir de s'aimer, n'en désirant point d'autre, elles vivaient calmes, heureuses (Charles Choquet, Les Dix Nouvelles ou Les Jeunes Personnes à leur entrée dans le monde)

1833 Je vis désormais heureuse, calme et retirée (George Sand, Correspondance)

1855 Elle [= Aurore] traversa une époque fort libre et un monde très-corrompu sans y laisser une plume de son aile ; et, condamnée par un destin étrange à ne pas connaître l'amour dans le mariage, elle résolut le grand problème de vivre calme et d'échapper à toute malveillance, à toute calomnie (George Sand, Histoire de ma vie)

1867 Il était trop lâche, trop voluptueux, pour risquer sa tranquillité. Il tuait afin de vivre calme et heureux (Émile Zola, Thérèse Raquin)
1886 Je vivais calme, je me reposais délicieusement (Jules Vallès, Jacques Vingtras : L'Insurgé)

1896 Car, après tout, l'amour, n’y pensons plus, C'est chimère à notre âge.

On a fixé des vœux irrésolus, On vit calme, on dort sage (Paul Verlaine, Euvres poétiques complètes)

1975 Décidément j'ai encore beaucoup à apprendre pour vivre calme et serein dans cet étrange pays ! (Michel Tournier, Les Météores)

\section{CORPUS WEB :}

Un village perché au sommet d'une montagne. Les reclus d'un royaume changeant, ses habitants y vivent calme et serein à l'abri de la guerre qui fait rage plus bas dans les plaines... [https://www.youtube.com/playlist?list=PLNOD Zz7vTpdPp1A5AUdCXC1PiHhe-U3jg] (11.4.2016)

Le provocateur doit nécéssairement être puni sinon les 2 corées vivaient calme avec leure mer jaune cad Pyong yang sache que nul n'est au-dessus de l'autre car le monde appartien à Dieu seul [http://www.lefigaro. fr/international/2010/08/18/01003-20100818 ARTFIG00525-le-jeu-de-guerre-geant-des-etatsunis-en-coree.php] (11.4.2016)

Les campagnes vivaient calmes, les paysans « adoraient » leur leader vénéré, les villes proprettes et bien administrées donnaient le spectacle d'un développement humain harmonieux, en contraste avec le Vietnam en guerre depuis trente ans ou le Laos resté en léthargie [http://atrt. free.fr/le\%20genocide $\% 20$ khmers $\% 20$ rouges. $\mathrm{htm}]$ (11.4.2016)

Est-ce qu'il serait prémonitoire d'envisager un retour quasi-imminent de Constentin sur cette fameuse et mythique " île aux thésards »... par delà les océans et où les cerfs vivent calmes et sereins ? [http://www.peluche.um2.fr/medias/ media520] (11.4.2016)

REMARQUES : Vivre calme se dit du fait de mener une vie calme, exempte d'agitation et de troubles qui affectent l'existence, le sujet ayant trouvé la paix intérieure, une certaine sérénité. Il peut aussi référer à une vie retirée et sauvage où le sujet n'est pas dérangé par autrui. Il est souvent 
coordonné à d'autres adjectifs-adverbes (content, heureux, retiré, serein). Calme tend à l'emploi comme prédicat second accordé, notamment dans le style soigné des exemples littéraires, mais les premiers exemples du CW montrent que l'accord peut ne pas se faire. Notons l'emploi de dormir sage.

\section{Vivre content}

Vivre avec satisfaction, avec joie, avec plaisir Intransitif

1592 - Je passeray, dict l'autre, en Gaule et en Espaigne.

- Et apres?

- Je m'en iray subjuguer l'Afrique ; et en fin, quand j'auray mis le monde en ma subjection, je me reposeray et vivray content et à mon aise.

- Pour Dieu, Sire, rechargea lors Cyneas, dictes moy à quoy il tient que vous ne soyez dés à présent, si vous voulez, en cet estat? (Michel de Montaigne, Essais)

1601 Finalement craindre la mort c'est estre ennemy de soy et de sa vie ; car celuy ne peust vivre à son aise et content, qui crainct de mourir. Celuy-là vit vrayement libre, qui ne crainct poinct la mort : au contraire le vivre est servir, si la liberté de mourir en est à dire (Pierre Charron, De la sagesse)

1623 Ils disent que pour vivre heureux et content, il faut estrangler toute ceste nichée de petits vipereaux, qu'on appelle scrupules, et esteindre ce flambeau, que les sophistes disent avoir esté allumé dans nos ames (François Garasse, La Doctrine curieuse des beaux-esprits de ce temps)

1625 Je la felicitay et luy baillay la benediction de la part de mon pere et de la vostre, et crois fermement qu'elle vivra trez contente avec l'ayde de Dieu, et que ses prieres seront cappables de faire prosperer toute la maison (Nicolas de Peiresc, Lettres à sa famille)

1636 IOLE. Perdez ce qui vous perd, pourquoy differer tant?

Ordonnez que je meure et vous vivrez content (Jean de Rotrou, Hercule mourant)
1709 MME RISSOLÉ. Quand j'étais jeune et belle,

J'étais sotte et cruelle ;

Oh! que d'heureux moments perdus !

Le temps passé ne revient plus.

Quelle douceur charmante!

Que l'on vivrait contente

Si jeunesse savait,

$\mathrm{Si}$ vieillesse pouvait (Marc-Antoine Legrand, La Famille extravagante)

1761 Mon enfant, nous nous aimions trop, nous n'étions point gais. Une amitié plus légère eût été plus folâtre ; je l'aurois préférée, et je crois que j’aurois mieux aimé vivre moins contente et pouvoir rire plus souvent. À cela se joignirent les sujets particuliers d'inquiétude que me donnoit ta situation (Jean-Jacques Rousseau, $L a$ Nouvelle Héloïse)

1764 J'ai pénétré le secret de Milord Danby, détruit votre erreur, et troublé ma tranquillité. Notre commune ignorance étoit un bien pour toutes deux. Vous viviez contente, et je ne savois pas que Milord Danby avoit cessé de se montrer digne de mon estime

(Marie-Jeanne Riccoboni, Histoire de Miss Jenny, écrite et envoyée par elle à Miladi, comtesse de Roscomond)

1776 C'est sa coupable défiance qui seule le rend misérable. Sans elle il seroit un peu plus dupe, mais il vivroit tout aussi content qu'autrefois. Devenu l'objet de l'horreur publique, il s'est vu par là celui des attentions de tout le monde (Jean-Jacques Rousseau, Rousseau juge de Jean-Jacques)

1802 Pour lui, il ne sauroit être malheureux, il cesse de souffrir ou bien il cesse de vivre. Tout animal libre vit content et sain, occupé de conserver son existence et non de la supporter : s'il est attaqué, il est en un moment vainqueur ou dévoré (Étienne de Senancour, Rêveries sur la nature primitive de l'homme)

1839 Peut-être pourrions-nous retrancher de la vie le sentiment du plaisir et ne pas nous plaindre, mais vivre contents, ce qui est la 
vie la plus calme ; mais la douleur est la parfaite misère, le pire des maux, et si elle est excessive, elle surmonte toute patience (François de Chateaubriand, Le Paradis perdu)

1842 Que le jeune professeur auquel je suis tout attaché, ne m’oublie pas ; souvenir à $\mathrm{M}$. Brifaut. Je ne parle point de mon ami M. Ballanche : il vit content, retiré dans sa gloire (François de Chateaubriand, Lettres à Mme Récamier)

1854 La vocation est peut-être comme l'amour du pays natal (que j'ai peu, du reste), un certain lien fatal des hommes aux choses. Le Sibérien dans ses neiges, et le Hottentot dans sa hutte vivent contents, sans rêver soleil ni palais (Gustave Flaubert, Correspondance)

1862 Nous vivions cachés, contents, porte close, Dévorant l'amour, bon fruit défendu ;

Ma bouche n'avait pas dit une chose Que déjà ton cœur avait répondu (Victor Hugo, Les Misérables)

1876 - Croyez-moi, l'heure de la mort arrive toujours. Vous avez le temps ; ni une minute plus tôt, ni une minute plus tard que le sort ne le veut, nous n'arriverons à Tebryz. Vivez content, croyez-moi, sans vous tourmenter davantage

(Arthur de Gobineau, Nouvelles asiatiques)

1878 Une voix.

Ne crois pas que les habitants

Des sphères où tu te fourvoies,

$\mathrm{Y}$ vivent tristes ou contents

Par nos douleurs ou par nos joies :

Autres sphères, autres désirs !

(Armand Sully Prudhomme, La Justice)

1883 Homme, crois-tu que Dieu, ce père, fasse naître

L'aile pour l'accrocher au clou de ta fenêtre?

Ne peux-tu vivre heureux et content sans cela? (Victor Hugo, La Légende des siècles)

1900 C'est trop fort! L'étrange petite créature, qui n'a ni cœur ni cervelle, qui vit sans mémoire, sans remords et recommencera à enjôler un sous-maître, à batifoler avec le délégué cantonal, jusqu’à ce que ça casse encore une fois, et qui vivra contente avec cette femme jalouse et violente qui se détraque elle, dans ces aventures (Colette, Claudine à l'école)

1926 Je vivais content, paisible... Était-ce la grâce ? Était-ce la paresse ? Devenais-je plus croyant, moins travailleur ? Je crois tout simplement que j'allais aimer (Jean Giraudoux, Simon le Pathétique)

\section{CORPUS WEB :}

Fait que toujours est-il que dans le village, le monde vivait content [http://sas1983.skyrock.com/ 2483027001-Le-Terrain-de-JeU.html] (17.4.2016)

La mélancolie du passé, quand tout le monde avait du travail et vivait content dans l'ensemble pour la période [http://sheds2012.canal blog.com] (17.4.2016)

Ce que je me dis aussi c'est que des personnes ayant des difficultés comme ça on toujours le courage de vivre et de se relever... ils ont la peche... et moi je suis là pour les aider.... c'est trop cool... malgré tous leurs probelmes ils vivent content, et savent apprécier les choses de la vie... ils ont l'air différent mais pas du tout... ils vivent comme ça et s'en porte bien... [http://forums. moto-station.com/champ-libre/1528-mon-metier. html] (17.4.2016)

Par exemple j’avais collé Lord Of War où la femme de nicolas cage vit contente en pensant son mari est gentil [http://www.jeuxvideo.com/ forums/1-76-884969-1-0-1-0-intelligence-bonheur. $\mathrm{htm}](17.4 .2016)$

REMARQUES : Vivre content est une prédication seconde prototypique désignant une disposition mentale du sujet. Seuls l'exemple de 1876 et l'avant-dernier exemple du CW nous font penser que l'emploi invarié n'est pas tout-à-fait exclu. Notons que l'absence de l'accord ne s'effectue pas au féminin où il serait audible. Content est modifié par tout aussi, moins, très. Vivre content se combine librement avec une longue série d'autres adjectifs-adverbes : caché, heureux, paisible, sain, retiré, triste et, avec préposition, à son aise. 


\section{Vivre double}

Vivre très intensément; deux fois plus de temps Intransitif

1861 Elle vivait double tout ce temps-là, pensant au compliment qu'elle aurait voulu faire si beau (Edmond et Jules de Goncourt, Sœur Philomène)

1899 Pendant ces courtes apparitions de Pierre, Marie de Sénauvert semblait vivre double on eût dit sur elle la lumière heureuse qui égaie les champs de genêts, lorsque les grappes fleurissantes dorent les têtes des sombres buissons (Eugène Vogüé, Les Morts qui parlent)

1974 « De ce coquin, sais-tu qu'un jour... » Hé oui ! il vivait double, triple. Il courait les bergères et plus d'un père, plus d'un frère ou d'un fiancé lui avait promis la raclée, mais il s'en tirait toujours (Robert Sabatier, Les Noisettes sauvages)

\section{Vivre droit}

Vivre conformément à un principe

(éthique, moral, naturel, religieux, etc.)

Intransitif

1936 il me semble qu'elles sont mieux adaptées à ce monde, et mieux disposées à vivre tout droit selon la nature, et sans poser des questions insolubles (Alain, Propos)

1942 Que je voudrais lui donner de sa mère une idée qui le préserve de tout toute sa vie ! Il s'agit d'être encore plus stricte avec soi, de se sauver de toute bassesse, de vivre droit, sûr, net et pur, pour qu'un être puisse garder plus tard l'image la plus belle possible de vous, tendrement et sans reproche (Henry de Montherlant, La Reine morte)

\section{CORPUS WEB :}

Nous en profitons pour rappeler aux croyants que selon WMB, la mort ne nous change pas : celui qui a vécu droit, comme notre frère Ad Placide K., s'en va au repos dans sa théophanie (dont l'épouse de Ad Placide a vu la face du corps théophanique passer à quelques instants de sa mort à l'hôpital) [http://www.tapchurch.cd/index.php/ dedicace-159/temoignages/81-deuil-tap/326publication-succincte-in-memoriam-of-adplacide-kaniki-by-rev-clement-bowa] (17.4.2016)
Elisabeth ne tolère point les détours dans sa vie. Elle veut mourir comme elle a vécu : tout droit et à l'heure juste [http://www.nicefilmfestival. com/heliotrope/comptition-europenne-7] (17.4.2016)

Je ferme les yeux, résignée, en priant pour que tout se passe vite et si possible sans douleur. Moi qui voulait partir comme j'ai vécu, droite dans mes bottes et debout sur mes deux pieds... [https://www.fanfiction.net/s/10517027/21/Und\%C3\%A9mon-Elle] (17.4.2016)

REMARQuES : Vivre droit désigne le fait de mener une vie conforme à un idéal, le sujet se conformant exactement à ses principes. En tant qu'adverbe, droit reste invariable. Dans le troisième exemple du CW, il fonctionne en tant que prédicat second accordé référant au port vertical du corps et, par métaphore, à une attitude ferme. Il est modifié par tout. Dans l'exemple de 1942, vivre droit est mis en série avec sûr, net et pur.

\section{Vivre dur}

I. Être fort même si on fait des expériences difficiles au cours de sa vie ; vivre courageusement Intransitif

1946 Allons, assez de romanesque. Il faut vivre dur, négliger tout ce qui importe, se démener pour des niaiseries (Jean Merrien, Rien que la mer)

II. Avoir la vie dure, une vie difficile Intransitif

1987 Tu sais ce qu'on disait des voyageurs à l'époque, garçon ? Vivent dur, couchent dur, dorment dur, et mangent des chiens ! Ha ! (Ronald Lavallée, Tchipayuk ou Le Chemin du loup)

\section{CORPUS WEB :}

Pour lui, au physique, c'qu'il vivait dur surtout, c'était le déplacement : Une heure et plus de trajet ça lui faisait, au retour comme à l'aller, avant qu'il ait le vélo, Noel 1912 [http://www.vosecrits. com/t1588-tonton-ficelle-et-son-velo] (17.4.2016)

Ce n'est pas le type qui a vécu dur, avec de vrais problèmes de vie, il n'est pas fort mentalement, tu dois le détruire de l'intérieur [http:// nwrestlingg-efed.forumactif.org/t99p12-nettoiepas-ton-linge-sale-devant-les-gens] (17.4.2016) 
Ils vivaient dur, mangeaient des racines et buvaient de la boue pour survivre [http://lonaneur. canalblog.com/archives/2012/03/15/23769958. html] (17.4.2016)

en réalité, les gens vivent durs dans leurs peaux. ici c'est pas l'escroquerie, c'est du vol qualifié tout simplement. ce sont des voleurs légalisés [http://www.tamtaminfo.com/dedommagementdes-accidents-entre-experts-et-compagniesdassurances-ou-se-situe-lescroquerie] (17.4.2016)

REMARQUES : Vivre dur (I) réfère à l'attitude d'une personne dure, tandis que (II) présente la vie comme un parcours difficile, semé d'embûches, que la personne conçoit comme formateurs ou qui lui permet d'avancer, de progresser. Dans le premier exemple du CW, il prend l'acception de 'souffrir'. Dur reste normalement invariable, mais, dans le dernier exemple du CW, il s'accorde avec le sujet, sans changement de sens et de fonction.

\section{Vivre dynamique}

Mener une vie dynamique, variée

入 manger simple

\section{Vivre ennuyeux}

Mener une vie inintéressante, ennuyeuse

$\pi$ vivre monotone

\section{Vivre facile}

Vivre sans souci ni contrainte, être à l'aise Intransitif

1958 Vivez facile (Marie-Claire, 14 août 1958 / Grundt : 231)

\section{CORPUS WEB :}

On peut vivre facile au RSA hein [http:// www.jeuxvideo.com/forums/42-51-464662791-0-1-0-on-peut-vivre-facile-au-rsa-hein.htm] (17.4.2016)

Pour les prix.. j'en sais rien.. j'ai un abonement Proximus..mais tu peux vivre facile avec une facture de 50 euros [http://www.expat.com/ forum/viewtopic.php?id=12996] (17.4.2016)

Les argoniens y vivent facile vu leur résistance à la maladie [http://www.jeuxvideo.com/ forums/1-19348-174205-132-0-1-0-fan-club-desargoniens.htm] (17.4.2016)

REMARQUES : Vivre facile réfère à une personne qui bénéficie des conditions nécessaires pour réussir dans la vie, qui dispose de tous les atouts qui lui facilitent la vie ou la rendent agréable et qui vit sans problèmes. Dans l'exemple de 1958, le slogan suggère une attitude : mener une vie sans se préoccuper, sans se la compliquer. Facile reste invariable.

\section{Vivre fort}

Vivre (la vie, une expérience) intensément Transitif

1954 C'est drôle, tu as un tas d'expériences derrière toi, tu les as vécues très fort, et souvent tu m'en as très bien parlé ; tes reportages sont toujours pleins de choses (Simone de Beauvoir, Les Mandarins)

Intransitif

1963 Comment lui expliquer ces comédiennesphénomènes qui vivent plus fort, plus frémissant que le commun des mortels (Express, 7 mars 1963 / Grundt : 231)

\section{CORPUS WEB :}

Il va s'en sortir, c'est une force de la nature. Et merde. Il a lâché prise. Comme il a vécu. Vite et fort, avec panache [http://www.canaldo.com/ vincent/050510_reconfort.html] (17.4.2016)

La soirée débutera avec Strychnine, un groupe mythique de la scène bordelaise, fondé en 1976. Considéré comme le premier groupe marquant de la capitale régionale, il a vécu vite et fort jusqu'en 1982 avec trois albums à la clef [http:// www.sudouest.fr/2012/02/16/des-ramoneurspunks-celtes-et-revendicatifs-635027-4608.php] (17.4.2016)

Comme la vie, qui est une alternance de mouvements et d'arrêts, d'actions et d'instants contemplatifs. Alors, comme elle vit fort, la musique du trio ne se fixe jamais, elle avance, s'octroie la liberté de ne pas suivre les chemins prévus, et l'on sent qu'à l'intérieur de ce triangle équilatéral chacun est susceptible d'influer sur sa trajectoire [http://www.mozaic-jazz.com/2012_07_01_ archive.html] (17.4.2016)

Vétuste et délabrée, Centro Habana vit rude; elle vit forte, elle vit rires et cris d'enfants, de tantes et de voisins, elle vit musique et rumba, elle vit triste, aussi, parfois, j'imagine... [http:// projet-cuba-cg.blogspot.co.at/2009/09/1er-jour_ 21.html] (17.4.2016) 
REMARQUES : Vivre fort se dit du fait de vivre pleinement des instants intenses, riche en émotions procurées par exemple par le jeu d'acteur au théâtre ou au cinéma. Fort reste normalement invariable, mais, dans le dernier exemple du CW, il s'accorde avec le sujet au féminin pour stylistiquement donner plus de vie à la ville de La Havane, pour l'animer en projetant des qualités humaines sur elle : rude, fort, triste. Fort est modifié par plus, très. Notons la collocation vivre vite et fort.

\section{Vivre franc}

Vivre en toute liberté, sans contrainte Intransitif

1537 «Ahi ! Dieux iniques! Ne poviez vous faire es loix humaines, que les femmes usassent des libertez dont usent les animaulx ? Quelle des bestes brutes ne vit plus libere et franche que nulle femme? Ahi ! Je vois que la biche dans la forestz, et la columbe ne sont empeschées à aymer celluy qui leur plaist en leur espece : et moy infortunée damoiselle je suis donnée à je ne sçay qui ! » (Jeanne Flore, Contes amoureux)

1574 CASSIE. Non, Decime, jamais jamais, Decime, il aime

Par trop ardentement la puissance supreme :

Mais tandis que Cassie aura goutte de sang En son corps animeux, il voudra vivre franc,

Il fuira le servage ostant la tyrannie, Ou l'ame de son corps il chassera bannie (Robert Garnier, Cornélie)

REMARQUES : Vivre franc pouvait désigner un être humain ou un animal qui n'est pas asservi, assujetti à quelque chose ou à quelqu'un, qui jouit d'une liberté totale. Dans l'exemple de 1537, franc s'accorde avec le sujet femme, la coordination avec libéré remotivant franc au sens de 'laissé en liberté'.

\section{Vivre frémissant}

Vivre d'une manière vive, agitée, très

émotionnelle

$\lambda$ vivre fort

\section{Vivre gai}

Vivre allégrement

Intransitif

1599 Qui voudra voir beau temps perde viste la veüe,

Qui voudra vivre gay desesperé se tüe, Qui se pourmenera qu'il s'en aille en prison, Et qui voudra repaistre avalle une poison (Marc Papillon de Lasphrise, Diverses poésies)

1726 ARLEQUIN. Courage ! à la fortune, Le premier pas est fait. Allons gai, toujours gai, vivez gai (Alexis Piron, Les Chimères)

1848 [Auguste] était arrivé dans la grande ville de Vienne, et il y vivait gai, frais et plein de santé dans une superbe maison qu'on eût prise pour un palais (Christoph[e] Schmid, L'Image de Marie [trad.])

1986 Changer ses habitudes alimentaires pour se changer la vie? Oui, mais comment ? LES RECETTES DE LA FORME vous aident à faire la transition. Alors vivez gai, vivez léger, vivez santé ! (Livres hebdo)

REMARQUES : Vivre gai signifie 'vivre gaiement'. Il est plus ancien que ne nous le font croire les slogans modernes. Il est combiné avec aller gai et vivre léger. Notons la collocation avec frais et plein de santé. Mentionnons également vivez santé, qui constitue une prolongation nominale de la série « vivre + adjectif-adverbe ».

\section{Vivre gras}

Vivre confortablement, à l'aise

Intransitif

1925 Touraille secouait sa tête, et l'on voyait qu'elle était lourde de souvenirs :

- Un bon temps, disait-il. Possible qu'on avait plus de mal, qu'on vivait moins gras qu'aujourd'hui, le ventre plat et les joues creuses. Mais quoi, on vivait tout de même (Maurice Genevoix, Raboliot)

CORPuS WeB :

"Vivre gras, mourir jeune »

Si le diabète promet d'être un marché prospère pour les big pharmas (50 milliards de dol- 
lars soit 46 milliards d'euros en 2020), il sera ravageur pour la croissance de nombreux pays [http://fortune.fdesouche.com/tag/absenteisme] (17.4.2016)

" De la mécanique, ils en mangent, et si vous me permettez l'image, ils vont vivre gras cet été » [https://www.flagworld.com/nouvelles/ 2008/05/16/lequipe-gt-racing-prete-pour-la-pre miere-a-mosport] (17.4.2016)

J'ai déjà eu un locataire sur le BS, batinse qu'il vivait " gras », la vie était belle. 54 ans, 34 ans de bs et de travail au noir. Sa fille ? bs aussi [http://ygreck.typepad.com/ygreck/2006/05/ pyrate.html] (17.4.2016)

« Ce n'est pas qu'on vivait trop gras. Toutes les grandes organisations ont cette obligation de faire une cure d'amaigrissement. Car il y avait du travail à faire pour questionner les choses. La réalité, c'est qu'on embauchait 1400 employés par année, donc cette attrition s'est faite sans trop de heurts », a-t-il affirmé [http://www.tva nouvelles.ca/2010/02/17/desjardins-a-terminesa-reorganisation] (17.4.2016)

REMARQUeS : Vivre gras se dit du fait de vivre dans des conditions très favorables, le sujet se trouvant dans un environnement dans lequel il ne manque de rien, où il est bien nourri et devient gras. Les exemples tendent à jouer avec l'ambiguïté de (vivre) 'bien' et (devenir, étant) 'gros'. Dans le premier exemple du CW, il figure de façon très économique avec sa conséquence, mourir jeune, dans le titre d'un article. Dans le dernier exemple du CW, il réfère à une gestion d'entreprise peu soucieuse des dépenses. Gras reste invariable et est modifié par moins, trop.

\section{Vivre gros}

Mener une vie heureuse, à l'aise

$\lambda$ mourir gras

\section{Vivre haut}

I. Vivre à un niveau (moral, spirituel) élevé, supérieur

Intransitif

1891 Il ignorait tout de cet effroyable négoce sur les valeurs déclassées et sur l'achat des créances, il vivait plus haut, dans un songe souverain de justice (Émile Zola, L’Argent)
1946 Et vous, hommes du nombre et de la masse, ne pesez pas les hommes de ma race. Ils ont vécu plus haut que vous dans les abîmes de l'opprobre (Saint-John Perse, Vents)

II. vivre tout haut : vivre à visage découvert, sans réserve, ouvertement ; s'affirmer Intransitif

1986 Je voulais vivre tout haut et non plus chuchoter ma vie dans les couloirs d'une école (Alexandre Jardin, Bille en tête)

\section{CORPUS WEB :}

Avec ses seize ans en bandoulière, Virgile veut désormais vivre tout haut et non plus chuchoter sa vie dans les couloirs d'une école [http:// francite.net/education/lecture/page101.html] (24.4.2016)

Il paraît que dans ma culture une femme est mal vue si elle vit haut et fort, et n'a pas peur de montrer ce qui la fait vibrer... [http://www. bibishmumbu.com/2014_12_01_archive.html] (24.4.2016)

Lorsque vous dites que vous vivez dans une tour, les gens vous regardent d'un air apitoyé. Ils n'osent pas trop vous le dire, mais ils vous plaignent d'habiter dans une de ces cages à lapin : « Moi je ne pourrais pas vivre aussi haut » [http://bloc-notes.thbz.org/archives/2004/11/ vivre_dans_une.html] (24.4.2016)

REMARQUES : En référence à la hiérarchie morale ou sociale ou en parlant du niveau intellectuel ou spirituel, vivre haut se dit du fait de se trouver à un niveau, un degré supérieur (I). Vivre haut (II) désigne un animé qui cherche à sortir de sa réserve, à se dévoiler, à s'ouvrir aux autres, qui vit la tête levée (v. aussi les deux premiers exemples $\mathrm{du}$ CW). Dans le dernier exemple du CW, vivre haut prend en charge le sens concret de 'vivre dans une tour élevée'. Notons la collocation haut et fort dans le CW qui reflète la volonté d'autoaffirmation féminine. Haut reste invariable et est modifié par plus, tout.

\section{Vivre heureux}

Vivre dans le bonheur, la joie, le bien-être Intransitif

1547 Si ainsi le faictes, vous vivrez heureux, fortunés, en honneste tranquillité, et n'aurez 
compagnons en felicité (Noël Du Fail, Les Propos rustiques)

1573 NOURRICE. Or sus laissez-vous prendre au cordage amoureux, Frequentez-moy la ville, et vivez plus heureux:

Il vous faut une amie, et cueillir avec elle Les doux fruits, où l'amour tendrement vous appelle (Robert Garnier, Hippolyte)

1624 AENÉE. Luy requerir mercy de l'offence commise,

S'il y a quelque offence où la contrainte a lieu.

Or n’ay-je plus loisir de retarder. À Dieu, à Dieu!

Vivez toujours heureuses et contentes.

Mon destin me remet sur les plaines

flotantes.

Les vens soufflent à gré, qui, maintenant perdus,

Seroient un siecle en vain quelquefois attendus

(Alexandre Hardy, Didon se sacrifiant)

1670 BÉRÉNICE. La raison me la fait malgré vous, malgré moi.

$\mathrm{Si}$ je vous en croyois, si je voulois m'en croire,

Nous pourrions vivre heureux, mais avec moins de gloire

(Pierre Corneille, Tite et Bérénice)

1704 Les histoires anciennes et modernes font foi que cette idée de vie immortelle se trouve confusément dans toutes les nations qui ne sont pas tout à fait brutes. Mais ceux qui connoissent Dieu, l'ont trèsclaire et très-distincte ; car ils voient que la créature raisonnable peut vivre éternellement heureuse, en admirant les grandeurs de Dieu, les conseils de sa sagesse et la beauté de ses ouvrages (Jacques-Bénigne Bossuet, De la connaissance de Dieu et de soi-même)

1732 Hélas ! pauvre duègne et pauvre écuyer, je ne m'informais pas si vous viviez heureux ou misérables dans les Asturies ! (AlainRené Lesage, Histoire de Gil Blas de Santillane)
1734 S'il n'y avoit en Angleterre qu'une religion, le despotisme seroit à craindre, s'il y en avoit deux, elles se couperoient la gorge ; mais il y en a trente, et elles vivent en paix heureuses (Voltaire, Lettres philosophiques)

1764 Ah! Trouvez-la, Milord, trouvez-la, s'écriat-il, secourez-la, consolez cette fille charmante ; qu'elle vive paisible et heureuse sous votre protection!

(Marie-Jeanne Riccoboni, Histoire de Miss Jenny, écrite et envoyée par elle à Miladi, comtesse de Roscomond)

1769 JENNEVAL. Je restituerai la somme que j’ai détournée. Un jour viendra, Rosalie, que le ciel couronnera notre constance. Pour vivre obscurs, nous n'en vivrons pas moins heureux (Louis-Sébastien Mercier, Jenneval ou Le Barnevelt françois)

1784 et pendant que les historiens de chaque nation, bien payés, élèvent au ciel les victoires de leurs rois et de leurs pontifes, les peuples s'adressent, en pleurant, au dieu du genre humain, et lui demandent où est la voie qu'ils doivent suivre pour se diriger vers lui, et pour vivre heureux et vertueux sur la terre (Bernardin de Saint-Pierre, Études de la nature)

1792 L'insecte vainement cherche à leur échapper, il devient bientôt leur conquête.

L'un le saisit par l'aile, un autre par le corps ; un troisieme survient et le prend par la tête.

Il ne falloit pas tant d'efforts pour déchirer la pauvre bête.

Oh! Oh ! Dit le grillon, je ne suis plus

fâché ;

Il en coûte trop cher pour briller dans le monde.

Combien je vais aimer ma retraite profonde!

Pour vivre heureux vivons caché (Jean-Pierre Florian, Fables)

1830 BORGIA. (seul) Oh ! si seulement cette voix grave et tendre m'eût dit : «Borgia, je me souviens de notre amour ! " Si elle 
se fût repentie !... N'importe ! qu'elle vive heureuse et puissante!

(Alfred de Vigny, La Maréchale d'Ancre)

1833 Je vis désormais heureuse, calme et retirée (George Sand, Correspondance)

1845 - Ici le travailleur peut se livrer sans inquiétude à l'espoir des douces joies de la famille, bien sûr de ne pas être déchiré plus tard par la vue des horribles privations de ceux qui lui sont chers ; ici, grâce à l'ordre, au travail, au sage emploi des forces de chacun, hommes, femmes, enfants, vivent heureux et satisfaits (Eugène Sue, Le Juif errant)

1846 Alors, qu'elle [= la Marana] vécût heureuse ou misérable, opulente ou pauvre, elle eut au cœur un sentiment pur, le plus beau de tous les sentiments humains, parce qu'il est le plus désintéressé (Honoré de Balzac, Les Marana)

1862 Oh ! pauvre femme ! C’en était plus que la pauvre Fantine n'en pouvait supporter. Avoir Cosette ! Sortir de cette vie infâme ! Vivre libre, riche, heureuse, honnête, avec Cosette ! (Victor Hugo, Les Misérables)

1867 Il était trop lâche, trop voluptueux, pour risquer sa tranquillité. Il tuait afin de vivre calme et heureux (Émile Zola, Thérèse Raquin)

1910 Vivre et mourir dans ce coin de chambre sentimental, te disais-tu ; eh oui, y vivre et mourir ; pourquoi donc pas, Monsieur de Pinamonte, ami des petits coins obscurs et poussiéreux ? Ici, la méditative aragne vit puissante et heureuse (Oscar Milosz, L'Amoureuse Initiation)

1945 - Attention. Fermons les fenêtres ! Signe des temps. Je pousse un battant. Je m'arrête, une main sur la crémone. Je dis :

- On ne vit plus caché pour vivre heureux, mais pour essayer de vivre tout court (Jean-Louis Bory, Mon village à l'heure allemande)

1954 on les a tués, ils se sont tués, et lui continuera à vivre honoré, riche, heureux (Simone de Beauvoir, Les Mandarins)
1970 Il va de soi que les places des élèves étaient déterminées souverainement par le préfet de discipline qui s'appliquait à contrarier leurs vœux autant que possible, soit en séparant les amis, soit en imposant les premiers rangs aux cancres et aux rêveurs qui n'auraient aspiré qu'à vivre heureux et cachés au fond de la classe

(Michel Tournier, Le Roi des aulnes)

1996 Lautréamont, en l'occurrence, demeure exemplaire : « J'établirai dans quelques lignes comment Maldoror fut bon pendant ses premières années, où il vécut heureux» (Raoul Vaneigem, Nous qui désirons sans fin)

Transitif

1893 Elle l'avait crié avec angoisse, une nuit, sur l'aire : la vie était abominable, comment pouvait-on la vivre paisible et heureuse? (Émile Zola, Le Docteur Pascal)

CORPUS WEB :

L'amour est la conséquence qui marque les défauts de tout un individu dans le manque de sa liberté qu'il se vole lui même, qu'on lui a volé enfant, lui même dans son contrat akashique, qui se vole lui même en définitive car il ne passe pas à autre chose que l'enfermement dans sa mauvaise manière de voir le monde, et les autres qui eux voient vrais et vivent heureux en montrant le chemin [https://www.facebook.com/media/set/?set $=a .555437591277906 .1073742112 .42567665425400$ 1\&type=3] (27.2.2016)

On ne voit ou entend que des pubs pour des grandes surfaces qui vantent, bien être et qualité, traçabilité et prix cassés, ils nous feraient presque croire que leur producteurs vivent riches et heureux ! [http://unionrepublicaine.fr/a-tablecitoyen] (24.3.2016)

Auprès de Julian, elle vivait heureux, elle aurait jamais du s'éloigner de Julian [http:// moncoursdelatin-online.skyrock.com/29416150 19-Plus-de-nostalgie-Me-revoici-Un-vendredi. html] (17.4.2016)

Les Zarbi étaient très timides et n'allaient pas à l'extérieur des ruines. En effet, l'environnement des ruines est peuplé par de plus en plus de monde. Il est dit que cette tribu, celle qui a souhaité que les Zarbi vivent paisible et heureux, a décidé de partir laissant ainsi les Zarbi seuls [http:// 
www.jeuxvideo.com/forums/1-21052-2422583-1-01-0-tutorial-les-zarbis.htm] (14.4.2016)

La communauté juive vit heureuse à Marseille depuis des décennies [http://www.lefigaro. fr/actualite-france/2016/01/20/01016-20160120 ARTFIG00298-la-communaute-juive-vit-heu reuse-a-marseille.php] (17.4.2016)

REMARQUES : Vivre heureux se dit du fait d'être content de la situation dans laquelle on se trouve, qu'elle soit professionnelle, familiale, sociale ou morale, conférant au sujet un sentiment de satisfaction, de bien-être, de joie de vivre. En règle générale, heureux est un prédicat second accordé qui désigne un état émotionnel du sujet. Dans la langue standard et le registre soutenu, l'accord est systématique. L'emploi invarié est possible mais exceptionnel (v. le troisième exemple du $\mathrm{CW}$, et le quatrième, où il est coordonné avec paisible, qui n'est pas accordé). Heureux est modifié par éternellement, moins, plus, toujours. Il est coordonné avec de nombreux autres adjectifs en prédication seconde : caché, calme, content, fortunés, honnête, honoré, libre, misérable, obscur, opulent, paisible, pauvre, puissant, retiré, riche, satisfait, vertueux. Notons la prédication seconde complexe vivre en paix heureux (1734). Mentionnons également l'emploi accordé de voir vrai dans le premier exemple du CW.

\section{Vivre honnête}

Vivre honnêtement, convenablement, dignement, avec probité

Intransitif

1781 - Vous voyez comme va le monde ; poursuivis-je ; il n'y a pas moyen d'y vivre honnête et d'agir noblement, à moins qu'on ne puisse se passer d'autrui (Jean-Baptiste de La Rochelle, Le Maréchal de Boucicault)

1843 Mais si l'homme qui vit honnête au milieu des gens honnêtes, encouragé par leur estime, mérite intérêt et appui, celui qui, malgré l'éloignement des gens de bien, reste honnête au milieu des plus abominables scélérats de la terre, celui-là aussi mérite intérêt et appui (Eugène Sue, Les Mystères de Paris)
1845 Elles n'ont pas comme moi la richesse qui défend de toutes les mauvaises tentations de la misère... et pourtant elles vivent honnêtes et fières dans leur détresse (Eugène Sue, Le Juif errant)

1931 Il faut vivre honnête et sage, et encore il y a assez à faire. Voyez, je ramasse des simples ; je voudrais me consacrer à soulager les infortunés (Henri Pourrat, La Tour du Levant ou Quand Gaspard mit fin à l'histoire)

\section{CORPUS Web :}

Un jeune étudiant poursuit : « Le BurkinaFaso a-t-il besoin de la foi chrétienne pour vivre honnête et respecter la dignité de l'être humain? Le bon sens de nos traditions locales n'est-il pas suffisant pour vivre heureux et équilibré ? Des gens de la religion traditionnelle sont plus rigoureux que nous "[http://afrique.fmc-sc. org/mission/en-eglise/401-foi-chretienne-et-tra ditions-africaines] (18.4.2016)

Le sort des gens qui vivent honnête, le travail productif est devenu une pauvreté sans espoir. Même le proche avenir est imprévisible. Dans ces conditions, il existe un processus objectif dadaptation de la société à lauto-organisation de nouvelles structures à tous les niveaux [http://durkach borys.blogspot.co.at/2010/05/russie-sous-leregne-de-la-ploutocratie_5815.html] (18.4.2016)

... Elle aura un fils, que tu appelleras Jésus. Il mènera les hommes sur le chemin que lui montrera Dieu, pour qu'ils vivent honnêtes et vertueux » [http://osee.unblog.fr/2008/12/15/bonnenouvelle] (18.4.2016)

REMARQUES : En référence au confort de vie, vivre honnête se dit du fait de vivre de manière convenable, dans des conditions certes modestes, mais satisfaisantes. En ce qui concerne la relation avec les autres, il désigne le fait d'avoir un comportement qui respecte la morale et autrui, en ne cherchant pas à tromper, en faisant montre d'une certaine loyauté. Honnête tend à l'emploi comme prédicat second accordé orienté vers le sujet, mais l'emploi non-accordé n'est pas exclu (v. l'avant-dernier exemple du CW). Notons la coordination avec fier, sage, équilibré, vertueux. 


\section{Vivre indépendant}

Vivre de manière indépendante, libre, autonome Intransitif

1650 Et ce grand nom de reine ailleurs ne m'autorise

Qu'à n'y voir point de trône à qui je sois soumise,

À vivre indépendante, et n'avoir en tous lieux

Pour souverains que moi, la raison, et les Dieux (Pierre Corneille, Nicomède)

1787 Mais en outre il se range autour de ce chef de petites familles qui, n'étant point assez fortes pour vivre indépendantes, ont besoin de protection et d'alliances (comte de Volney, Voyage en Égypte et en Syrie)

1830 J'envisageai ce voyage comme un moyen de vivre plus indépendant que je ne l'aurais pu en Suisse, et je ne fis aucune objection (Benjamin Constant, Le Cahier rouge)

1835 Avec le temps, les Américains parviendront sans doute à produire ou à fabriquer chez eux la plupart des objets qui leur sont nécessaires, mais jamais les deux continents ne pourront vivre entièrement indépendants l'un de l'autre : il existe trop de liens naturels entre leurs besoins, leurs idées, leurs habitudes et leurs mœurs (Alexis de Tocqueville, De la démocratie en Amérique)

1859 et il avait cette retraite à Saint-Denis pour s'isoler au besoin, pour y vivre plus indépendant quand il le voulait (Charles Sainte-Beuve, Port-Royal)

1890 Cet argent, joint à celui que Berthe gagnait par son travail, - étant très courageuse, lui permettait de vivre indépendante (Paul Bourget, Physiologie de l'amour moderne)

1897 Vivant à peu près indépendante auprès d'une vieille dame en enfance qui se disait sa tante maternelle, il nous fut loisible de nous empoisonner l'un de l'autre, et nous ne connûmes pas d'autre souci (Léon Bloy, La Femme pauvre)
CORPUS WEB :

Les résidences autonomie : une solution pour vivre indépendant tout en bénéficiant de services [http://www.pour-les-personnes-agees. gouv.fr/actualites/les-residences-autonomieune-solution-pour-vivre-independant-tout-enbeneficiant-de-services] (18.4.2016)

Vivre indépendant et dans un cadre élégant. Si vous souhaitez visiter une résidence, contactez Sopregim [http://www.residences-avec-servicesangers.com] (18.4.2016)

Certains clubs ne sont pas affiliés aux Aînés Ruraux et vivent indépendants [http://www.saintpons-la-calm.fr/associations/asso_3eme.htm] (18.4.2016)

Et l'on assiste beaucoup plus souvent à un faux départ : entre ceux qui vivent indépendants la semaine mais reviennent tous les week-ends, ceux qui partent le temps de leurs études et se réinstallent chez leurs parents faute d'emploi stable, ceux qui perdent leur travail et retournent chez leur mère, au total près de la moitié des enfants partis de chez eux pratiquent en réalité des allers et retours [http://www.leparisien.fr/ societe/un-jeune-adulte-sur-deux-vit-chez-sesparents-26-03-2001-2002057351.php] (26.03.2001)

REMARQUES : Vivre indépendant se dit du fait de mener une vie dans laquelle le sujet jouit d'une entière autonomie vis-à-vis de quelqu'un ou de quelque chose ou d'une certaine liberté ou indépendance morale ou intellectuelle, ayant la faculté de se déterminer par soi-même, de choisir, d'agir librement. Indépendant s'accorde avec le sujet, adoptant une fonction de prédicat second orienté vers le sujet. L'emploi de l'infinitif vivre indépendant indique cependant un certain degré de lexicalisation comme verbe complexe intégrant un adjectif-adverbe, comme la majorité des exemples avec vivre. Indépendant est modifié par à peu près, plus, entièrement.

\section{Vivre inutile}

Vivre en étant ou en se sentant inutile, en vain, sans raison Intransitif

1597 Mais qui fétard en tout sommeille, Ny de soymesme se conseille Ny prend d'ailleurs enseignements, 
N'est bon à rien, vit inutile :

Dedans sa chair son ame vile

Sert de saumure seulement (Jean-Antoine de Baïf, Mimes, enseignemens et proverbes)

1776 Les moralistes qui en font des perfections, des vertus, qui persuadent à l'homme qu'il y a du mérite à se séparer de ses semblables, à s'isoler, à vivre inutiles à la société, ont visiblement ignoré que la vertu doit être toujours utile et bienfaisante (Paul-Henri d'Holbach, La Morale universelle ou Les Devoirs de l'homme fondés sur la nature)

1782 Et pourquoi auroit-il renoncé à une condition qui donne la possibilité de faire tant de bien, tant d'heureux, et d'offrir de si grands exemples, pour vivre libre et inutile ? (Stéphanie-Félicité Du Crest, comtesse de Genlis, Adèle et Théodore)

1840 Le mépris de l'or, inconsidérément recommandé dans l'âge qui en ignore la valeur, a souvent ôté à des hommes supérieurs un des plus grands moyens, et peut-être le plus sûr, de ne point vivre inutiles comme la foule (Étienne de Senancour, Obermann)

1872 Toute découverte est un gouffre. Mourir, qu'importe ! on plonge, on souffre ; Vivre inutile, c'est trop long (Victor Hugo, L’Année terrible)

1920 Se reposer trop tôt soit parce que l'on a des enfants soit parce que l'on a de quoi vivre, c'est vivre inutile durant des années qui auraient encore pu être fécondes ; ce n'est pas bien agir (Léon Wieger, Moralisme)

CORPUS WEB :

Mercredi dernier, ils ont participé à une cérémonie de planting d'arbre. Ce qui leur donne l'assurance de ne pas vivre inutile, comme le dit l'adage [http://www.ivoiregion.net/index.php/ la-nouvelle/955-ecocitoyennete-le-lycee-mo derne-de-botro-rentre-dans-lhistoire] (18.4.2016)

REMARQUES : Vivre inutile se dit du fait de mener une existence sans réel but et dans laquelle le sujet, par son comportement ou ses actes, ne sert pas, n'apporte rien à la société ou à autrui. Inutile tend à l'emploi comme prédicat second accordé avec le sujet, mais l'infinitif vivre inutile indique tout de même une certaine lexicalisation comme verbe complexe intégrant un adjectif-adverbe. Ceci est confirmé par l'auteur du dernier exemple dans le CW qui classe vivre inutile comme adage. Notons la collocation libre et inutile.

\section{Vivre juste}

I. Vivre de manière honnête, selon la justice, selon le bien

Intransitif

1576 Autrement à faulte de ce faire, ou de ne monstrer sa maniere de vivre juste et raisonnable, convenoit aller droict à la mort (Loys Leroy, De la vicissitude ou variété des choses en l'univers)

1704 ce que dit à Dieu un de ses saints : c'est à vous qu'ils doivent leur estre : c'est à vous qu'ils doivent leur vie : c'est à vous qu'ils doivent de vivre justes : c'est à vous qu'ils doivent de vivre heureux (Jacques-Bénigne Bossuet, Élévations sur les mystères)

1791 Et des millions d'hommes levant à la fois les bras vers le ciel, firent le serment solemnel de vivre égaux, libres et justes (comte de Volney, Les Ruines ou Méditations sur les révolutions des empires)

1906 Autour de ma maison

Pour vivre clair, ferme et juste,

Avec mon cœur, j'admire tout

Ce qui vibre, travaille et bout

Dans la tendresse humaine et sur la terre auguste

(Émile Verhaeren, La Multiple Splendeur)

II. Vivre avec des ressources à peine suffisantes, avec peu de ressources

Intransitif

1822 De là, il est resté gâcheux, toujours négligent, paresseux, original, se contentant, à ce qu'il paraît, de vivre tout juste en donnant presque tout son temps dans une pension (Jules Michelet, Mémorial)

1835 M. Gauthier, loin de voler, vivait tout juste de son métier d'arpenteur attaché au cadastre. Quant à son journal l’Aurore, il lui coûtait cinq ou six cents francs par an, 
outre les mois de prison (Stendhal, Lucien Leuwen)

1884 L'on vole seulement les maladroits qui se laissent vider les poches... nous n'en sommes pas moins réduits à quatre ou cinq pauvres mille francs de rente, de quoi vivre bien juste dans ce trou (Émile Zola, $L a$ Joie de vivre)

1934 Ma mère avait peur. Peur de la faim. Non pas qu'effectivement il lui fallût craindre de manquer de pain. Car, si nous vivions tout juste, nous vivions, et l'expérience eût plutôt dû la rassurer (Jean Guéhenno, Journal d'un homme de quarante ans)

1989 Et tirant de cet emploi de quoi vivre juste juste avec le cinéma de temps en temps, la lecture des journaux, des hebdomadaires de télévision, Vito consacrait le reste de sa vie à tenter d'oublier Martine (Jean Echenoz, Lac)

2007 Parce que pour la première fois j'ai droit pour ma semaine à un franc d'argent de poche, je prends conscience de ce qu'est l'argent : que même les rois ont besoin d'argent pour bâtir leurs palais et faire leurs guerres, mais aussi que nous vivons juste, que la pension coûte cher, et le rêve de vivre par mes propres moyens au plus vite se renforce en moi d'une poussée sexuelle qui me fait désirer de me servir peut-être de mon corps pour vivre (Pierre Guyotat, Formation)

\section{CORPUS WEB :}

tu as raison, j'ai raisonné "vivre bien ", pour vivre juste il n'y a pas besoin d'economiser etc... Le tout etant d'avoir un roulement de capital suffisant pour ne pas prendre de credit à la consommation ; le credit pour residence principale ; etant lui admis [http://www.cbanque.com/ forum/showthread.php?20705-Salaire-annueln\%C3\%A9cessaire-pour-vivre-(et-non-sur vivre!])/page4 (18.4.2016)

En ce jour de votre vie, je crois que Dieu souhaite que vous sachiez ... que vous en tirerez les plus grands bénéfices si vous vous efforcez d'être une bonne personne. Efforcez-vous de vivre juste [http://www.conversations-avec-dieu. fr/2014/01/22/efforcez-vivre-juste] (18.4.2016)

Pour vivre juste, il faut avoir la conviction profonde que Dieu est en nous. Nous ne marchons plus par la vue mais par la foi. Pas selon nos pensées mais celle du maître. C'est à nous de nous plier à la pensée de Dieu et ne pas tenter d'enfermer Dieu dans nos conceptions [http:// www.monegliseacergy.com/s-edifier/predica tions/645-vivre-par-la-foi] (18.4.2016)

REMARQues : Vivre juste (I) se dit du fait de se comporter de manière loyale, de faire preuve d'honnêteté, comme également dans les deux derniers exemples du CW. (II) signifie 'vivre de manière très modeste', le sujet disposant de très peu de moyens financiers. Le premier exemple $\mathrm{du} \mathrm{CW}$ réfère à une gestion de la vie qui profite au maximum des ressources, sans dépasser son budget. Juste peut s'accorder avec le sujet, notamment au sens (I), qui est une prédication seconde, tandis que (II) tend à l'invariabilité (1884, 1934, 2007). Il est modifié par bien, tout. Notons aussi la réduplication juste juste dans l'exemple de 1989, ainsi que la tendance, très marquée dans (I), d'être combiné avec d'autres adjectifs : clair, égal, ferme, heureux, libre, raisonnable. L'ambiguïté de l'exemple de 1835 nous rapproche du sens de 'seulement, exactement', que nous n'avons pas documenté, mais qui deviendra courant au $\mathrm{xx}^{\mathrm{e}}$ siècle (ex. Je l'ai vu juste au moment où il faisait... Elle l'a dit juste pour...)

\section{Vivre léger}

I. Manger et boire léger

Intransitif

1677 [Gallien] nomme vivre simplement, leger et sans extrémité, lorsque l'on baille peu à peu à manger, ou des viandes de peu de nourriture (Antoine Lambert, Les Commentaires ou Les Euvres chirurgicales d'Antoine Lambert)

II. Vivre sans souci, sans préoccupation, de manière insouciante, à la légère Intransitif

1952 Je recommence mon mur. Je m'épuise. J'ai l'air de faire du cinéma, de vivre léger. Cette souris-là, elle ne s'en fait pas ! (Armand Lanoux, Les Lézards dans l'horloge) 
2003 S'offrir des petites bouffées de bonheur et vivre léger, aussi souvent que possible (Christophe André, Vivre heureux : psychologie du bonheur)

\section{CORPUS WEB :}

Vivre léger, c'est savoir profiter de l'essentiel et ne pas s'encombrer l'esprit ou l'espace de l'inutile, c'est-à-dire de ce qui vous distrait de l'essentiel. Et dans notre société de consommation, ce n'est pas facile. Et vous, de quelle manière le vivez-vous ? [http://test.e-sante.fr/savez-vousvivre-leger/test/416] (18.4.2016)

Vivre léger, c'est vivre sans mémoire. Chaque instant n'est plus alors comparé. Il ne se réfère qu'à lui-même. Passé, présent et futur sont contenus à l'instant même, dans cela qui ne peut être saisi [http://yog-lavie.eklablog.com/vivre-legerou-le-poids-des-pensees-a103160455] (18.4.2016)

Vous pensez que j'imagine, que j'extrapole? Mais que faisons-nous ? Combien y-a-t-il d'entres vous qui vivent légers comme des plumes, qui se laissent porter par les vents tournants ? [http:// www.arcturius.org/chroniques/et-voila-que-carecommence] (18.4.2016)

Les dieux grecs, qui sont partout présents là où quelque chose a lieu, ou est simplement pensé ou voulu, et dont la participation à tout événement apparaît avec une telle grandeur qu'il arrive souvent qu'ils ne soient pas seulement les instigateurs des actions humaines, mais bel et bien ceux qui les exécutent, Homère les appelle « ceux qui vivent légers », et une de leurs dénominations les plus importantes est : « les bienheureux »[http://www.archiveseroe.eu/walterotto-a50227600] (18.4.2016)

REMARQUES : Vivre léger (I) se dit d'un style de vie, en l'occurrence (ex. de 1677) associé à la cure des cancers, qui consiste à consommer de la nourriture pauvre en graisses en petite quantité. Dans l'ouvrage cité (p. 140), l'auteur développe un traitement autour « du vivre léger », donc autour de la nominalisation du groupe verbal vivre léger. Dans le passage cité, la combinaison avec l'adverbe simplement met en évidence le groupe verbal sous-jacent. Vivre léger (II) se dit du fait de mener une vie sans préoccupation, débarrassée des problèmes, le sujet ayant l'esprit libre, se sentant heureux. Dans le premier exemple du CW, il adopte le sens de vivre avec le strict nécessaire. Léger reste invariable dans son emploi adverbial. Il peut également s'accorder avec le sujet (v. les deux derniers exemples du CW) et adopter la fonction de prédicat second orienté vers le sujet. Notons l'emploi fréquent de l'infinitif dans une sorte de verbe complexe vivre léger qui sert de formule ou slogan.

\section{Vivre libre}

Vivre librement, de manière indépendante, sans contrainte ; vivre en liberté

Intransitif

1592 Et, poltron, respondit-il, que peuvent souffrir ceux qui ne craignent point la mort? On demandoit aussi à Agis comment un homme pourroit vivre libre : Mesprisant, dict-il, le mourir (Michel de Montaigne, Essais)

1601 Finalement craindre la mort c'est estre ennemy de soy et de sa vie ; car celuy ne peust vivre à son aise et content, qui crainct de mourir. Celuy-là vit vrayement libre, qui ne crainct poinct la mort : au contraire le vivre est servir, si la liberté de mourir en est à dire (Pierre Charron, De la sagesse)

1606 O douce chaine à mon ame fatale, Et de l'Amour le plus rare thresor ; Si tout lien vous estoit comparable, Qui vivroit libre il vivroit miserable (Jean Bertaut, Recueil de quelques vers amoureux)

1693 Je me rapporte aux yeux d'une Ourse mes amours.

Te déplais-je ? va-t'en, suis ta route et me laisse :

Je vis libre, content, sans nul soin qui me presse ;

Et te dis tout net et tout plat : Je ne veux point changer d'état (Jean de La Fontaine, Les Compagnons d'Ulysse / Fables)

1713 Qu'as-tu à faire de te charger d'une Femme, et du tracas d'un ménage, puisqu'il ne tient qu'à toi de vivre libre, et d'avoir des plaisirs plus vifs que ceux du Mariage, sans en appréhender les suites et les chagrins? (Robert Challe, Les Illustres Françoises) 
1715 Ainsi, remerciant Dieu de nous avoir toutes trois assemblées, nous résolûmes de vivre libres sans nous séparer jamais. Il y a longtemps que nous menons cette vie tranquille (Antoine Galland, Les Mille et une nuits)

1740 LA COMTESSE. (montrant le baron)

Vous, Baron, renoncez à l'hymen

dangereux :

Vous ne devez avoir que le monde pour maître.

La raison, qu'aujourd'hui vous me faites connoître,

Vous parle par ma bouche et vous fait une loi

De vivre indépendant, et libre comme moi

(Louis de Boissy, Les Dehors trompeurs ou L'Homme du jour)

1762 Qui sait où l'on peut vivre indépendant et libre, sans avoir besoin de faire mal à persone et sans crainte d'en recevoir ? (JeanJacques Rousseau, Émile ou De l'éducation)

1778 L'état que j'avais pris excitait la curiosité ; l'on voulait connaître cet homme bizarre qui ne recherchait personne, et ne se souciait de rien que de vivre libre et heureux à sa manière : c'en était assez pour qu'il ne le pût point. Ma chambre ne désemplissait pas de gens qui, sous divers prétextes, venaient s'emparer de mon temps (JeanJacques Rousseau, Les Confessions)

1782 Et pourquoi auroit-il renoncé à une condition qui donne la possibilité de faire tant de bien, tant d'heureux, et d'offrir de si grands exemples, pour vivre libre et inutile ? (Stéphanie-Félicité Du Crest, comtesse de Genlis, Adèle et Théodore)

1788 Méril l’y conduit aussitôt ; là, Estelle, les yeux baissés, lui dit, en tremblant, ces paroles : Pardonnez, Méril, à une jeune et timide fille qui, jusqu'à ce jour, a vécu libre et heureuse, d'éprouver un peu d'effroi au moment de se donner un maître (JeanPierre Florian, Estelle)

1793 Ce sont elles qui empreignent dans l'ame de vos chers enfans ces mots recueillis sur les lèvres mourantes des victimes de la Patrie : Vivre libre ou mourir (Les Femmes dans la Révolution française)

1816 Avec moins d'humeur et plus de fermeté, je vivrais ici aussi libre que chez moi. Mais mon caractère bizarre ne me permet ni de faire avec plaisir ce que les autres veulent ni de le leur refuser (Benjamin Constant, Journaux intimes)

1824 Les riches bourgeoisies de Flandre, qui vivaient paisibles et libres, tandis que la France et l'Angleterre étaient misérables et ravagées par la guerre, les marchands qui s'étaient enrichis dans un commerce toujours plus grand, marquaient leur reconnaissance à leur seigneur en lui offrant les plus belles fêtes (Prosper de Barante, Histoire des ducs de Bourgogne de la maison de Valois)

1839a Au mois de mai nous irons à Nohant et en juin vraisemblablement à Paris, car je crois que c'est encore le pays où l'on peut vivre plus libre et plus caché (George Sand, Correspondance)

1839b Refouler derrière votre masque tous vos sentiments naturels, faire le sacrifice de vos penchants, de vos opinions, souvent de votre droiture... non, non, point d'héritage ! Plutôt travailler, plutôt souffrir, mais vivre libre, indépendant, maître de sa personne et de son cœur; le donner à celle qu'il aime plutôt qu'à celle qu'on lui impose... (Rodolphe Toepffer, Nouvelles genevoises)

1845 Ce que l'on appelle le monde ne pouvait en croire ses yeux en voyant cette jeune fille de dix-huit ans, riche à millions, appartenant à la plus haute noblesse, venir pour ainsi dire constater aux yeux de tous, en se montrant dans sa voiture, qu'en effet elle vivait entièrement libre et indépendante, contrairement à tous les usages (Eugène Sue, Le Juif errant)

1849 LES BÊTES DE LA MER.

Nous vivons libres dans les solitudes salées, accomplissant les fonctions pa- 
cifiques de nos effrayantes existences ; le galet seul sait notre âge, et dans nos migrations, quand nous remontons en haut, nous trouvons que les continents ont changé de figure (Gustave Flaubert, $L a$ Tentation de saint Antoine)

1863 Je sais que sans oublier Marie, une fois la première folie de ma douleur passée comme elle l'est, je pourrais vivre calme, libre, relativement heureux, avec la seule peine de la savoir brisée au lieu des mille peines qui vont m'assaillir - et, du reste, je n'agis pas par crainte du remords, le remords ne dure pas dans le siècle (Stéphane Mallarmé, Correspondance)

1868 Il avait l'entrain un peu lourd d'un garçon bien portant qui a vécu libre et joyeux, sans secousse de cœur. Quand Geneviève se fut retirée, les deux amis s'assirent devant le foyer à demi-éteint. Un brasier rose luisait sur les cendres (Émile Zola, Madeleine Férat)

1921 Originaires d'Amérique où ils vivent libres [= le chapon], par bandes de mâles et de femelles que la pariade seule rassemble, parmi les savanes et les forêts encombrées d'osmondes, ils gardent un fond de sauvagerie irrépressible (Joseph de Pesquidoux, Chez nous : travaux et jeux rustiques)

1929a Avouez que votre indépendance vous pèse ; avouez-le, une fois pour toutes. Vous n'êtes pas faite pour vivre libre. Vous regrettez votre foyer, vous regrettez votre mari (Marcel Arland, L'Ordre)

1929b De ses livres, elle ne savait guère que les titres, mais en dépit des bavardages, ou de médisances plus perfides, elle se sentait une sympathie obscure, un peu craintive, pour un homme célèbre et qui paraissait néanmoins mépriser la gloire, vivait libre et seul, et pauvre aussi peut-être, dans une indépendance sauvage (Georges Bernanos, La Joie)

1938 Vérane d'ailleurs exagérait. Durant ces vingt années, il avait vécu, libre, en composant des vers. Il avait même écrit sur son compatriote Germain Nouveau, un volume savoureux, et l'éditeur le pressait de lui envoyer au plus vite un second (Francis Carco, À voix basse)

1941 D’autre part, sur le plan national - du fait qu'il contribue à former des êtres forts et sains, des hommes et des femmes aux caractères bien trempés et aux muscles solides - le sport doit, pour sa part, donner aux peuples le désir de vivre fiers, libres et indépendants! (Roger Vuillemin, Mémento d'éducation physique et d'initiation sportive)

1945 Le jour où nous ne pourrons plus supporter qu'un seul innocent souffre persécution, l'innocence redeviendra, dans l'Europe entière, un titre suffisant pour vivre indépendant et libre (François Mauriac, Le Bâillon dénoué après quatre ans de silence)

1971 Et l'homme entend frémir et se reformer la plainte unanime des âges, où nage le thème de la vie qui chante, lasse de refléter le ciel et les terres... Il eût souhaité de vivre entièrement libre et sans contrat social, lui le plus sociable des hommes, à qui rien d'humain ne fut étranger (Saint-John Perse, Hommages)

1978 Une certaine hostilité me paraît plus digne que la complaisance. Nous sommes quittes : tu as vécu libre, méfiante, courageuse et possessive. J'oblitère en toi tout ce qui n'est pas dans ce livre : il me servira de bilan, d'album et de repoussoir (Alain Bosquet, Une mère russe)

1981 Est-ce ainsi qu'on fonde une république ?... Est-ce là soutenir cette énergie que nos comettants ont déployée dans la révolution de 1792 ?... Vous avez juré de vivre libres ou de mourir : après cela que vous importent les Puissances étrangères? (Claude Simon, Les Géorgiques)

1983 Même si les revendications des groupes continuent d'être formulées en termes d'idéal de justice, d'égalité et de reconnaissance sociale, c'est surtout en raison du désir de vivre plus libre qu'elles 
trouvent une audience de masse véritable (Gilles Lipovetsky, L’Ėre du vide)

1996 Étienne de la Boétie a dit en quelques lignes ce que des millions d'êtres pensants ont voulu ignorer pour n'avoir pas à se créer : "Soyez résolus à ne plus servir et vous voilà libres... Quelle malchance a pu dénaturer l'homme - seul vraiment né pour vivre libre - au point de lui faire perdre la souvenance de son premier état et le désir de le reprendre? ? (Raoul Vaneigem, Nous qui désirons sans fin)

\section{CORPus Web :}

Je suis révisée de cette histoire et son frère qui a juste tenter de l'aider oui il doit payer mais au prix de lacharnement débile de gardiens de prison pfffff HONTE À LA SOI DISANT JUSTICE. Occupés vous donc des réels meurtriers qui eux vivent libre. Cette histoire est un SCANDALE [http://www.lejdd.fr/Societe/Actualite/KhiderJe-vais-partir-c-est-evident-interview-603141] (14.4.2016)

je voudrais que les palestiniens vivent libres ,sans aucune conditions,ils y ont droit comme n'importe qu'el être humain, droit a la vie droit a la justice [https://www.change.org/ $\mathrm{p} / \% \mathrm{C} 3 \% \mathrm{~A} 0$-mes-amis-je-voudrais-que-les-pales tiniens-vivent-libres-sans-aucune-conditionsils-y-ont-droit-comme-n-importe-qu-el-\%C3\%A Atre-humain-droit-a-la-vie-droit-a-la-justice] (14.4.2016)

REMARQUeS : Vivre libre réfère à un animé qui n'est pas soumis à une ou plusieurs contraintes, comme par exemple la puissance d'autrui, ce qui lui procure un sentiment d'insouciance et affranchi de toutes les servitudes. Il peut aussi référer aux droits ou libertés politiques reconnus au citoyen qui lui confèrent un certain statut. Libre tend à l'emploi comme prédicat second accordé avec le sujet, qui est systématique dans la langue standard et le registre soutenu. L'emploi invarié étant exceptionnel (v. le premier exemple du CW), c'est surtout l'emploi de l'infinitif vivre libre qui indique un certain degré de lexicalisation en tant que verbe complexe avec adjectif-adverbe. Libre est modifié par aussi, ici, plus, vraiment, entièrement. Notons ses collocations avec caché, calme, content, courageux, fier, indépendant, inutile, joyeux, heureux, méfiant, misérable, paisible, possessif, seul. Cette longue série d'adjectifs associés est typique de la prédication seconde. Mentionnons également l'emploi de dire tout net et tout plat.

\section{Vivre malheureux}

Vivre dans le malheur, dans la peine, dans la tristesse

Intransitif

1578 Tu diras à Maigni, lisant ces vers icy, C'est grand cas que Ronsard est encore amoureux?

Mon Bellay, je le suis, et le veux estre aussi, Et ne veux confesser qu'amour soit malheureux, Ou si c'est un malheur, baste, je delibere De vivre malheureux en si belle misere (Pierre de Ronsard, Le Second Livre des amours)

1623 Mais apres tout, leurs finesses n'empeschent pas qu'ils ne soient gueux, et qu'ils ne vivent tres-malheureux (François Garasse, La Doctrine curieuse des beaux-esprits de ce temps)

1696 Cet homme qui a fait la fortune de plusieurs, qui a fait la vôtre, n'a pu soutenir la sienne, ni assurer avant sa mort celle de sa femme et de ses enfants : ils vivent cachés et malheureux (Jean de La Bruyère, Les Caractères)

1738 Je te fuis, et je vais vivre malheureuse, ou mourir bien-tôt de la cruelle necessité où tu me réduis (abbé Prévost, Le Philosophe anglois)

1744 Ah ! Mademoiselle, repris-je, le chevalier est bien différent de ce qu'il étoit alors. Il a bravé l'amour, et l'amour l'a puni ; deux beaux yeux l'ont subjugué, l'ont soumis à cette passion qui en produit mille autres ; il soupire nuit et jour, et vit d'autant plus malheureux que son mal est sans remede (Jean-Baptiste Jourdan, Le Guerrier philosophe)

1758 J'aurai eu des enfants, j’aurai vécu malheureux, et je mourrai seul! (Denis Diderot, Le Père de famille) 
1762 J’ai cent fois pensé, écrivait-il déjà à $M$ de Malesherbes, en 1762, que je n'aurais pas vécu trop malheureux à la Bastille, n’y étant tenu à rien du tout qu'à rester là (Jean Guéhenno, Jean-Jacques : Grandeur et misère d'un esprit [la datation est celle de la citation])

1777 Mais nos armes les attendoient, et ne les provoquoient jamais. On avoit pour maxime de les abandonner, plutôt que de les détruire, s'ils s'obstinoient à vivre indépendants et malheureux (Jean-François Marmontel, Les Incas ou La Destruction de l'empire du Pérou)

1835 Depuis mon retour de mon long et malheureux voyage dans l'Orient, seul, sans enfants, sans avenir, je vis triste et malheureux (Alphonse de Lamartine, Correspondance générale)

1842 Il est de charmantes créatures méconnues par le sort, à qui tout devrait réussir dans la vie, mais qui vivent et meurent malheureuses, tourmentées par un mauvais génie, victimes de circonstances imprévues (Honoré de Balzac, Une fille d'Ève)

1853 Suzanne avait rompu hardiment avec la société où jamais à cette heure elle ne pouvait rentrer; au lieu de continuer à vivre malheureuse et honorée, elle préféra perdre sa considération pour gagner ce qu'elle croyait être son bonheur (Maxime Du Camp, Mémoires d'un suicidé)

1854 Cette femme extraordinaire, qui vit et qui mourra malheureuse, quoiqu'elle ait plus d'esprit, d'argent et de vertu qu'il n'en faut pour être heureux en ce monde, est Mme Sophie de Barbé-Marbois, duchesse de Plaisance (Edmond About, La Grèce contemporaine)

1951 CHANSON DES SARDINIĖRES Vous vivrez malheureuses Et vous aurez beaucoup d'enfants Beaucoup d'enfants

Qui vivront malheureux Et qui auront beaucoup d'enfants Qui vivront malheureux Et qui auront beaucoup d'enfants

\author{
Beaucoup d'enfants \\ Qui vivront malheureux \\ Et qui auront beaucoup d'enfants \\ Beaucoup d'enfants \\ Beaucoup d'enfants... \\ (Jacques Prévert, Spectacle)
}

\section{Corpus Web :}

"Vaut-il mieux vivre malheureux ou mourir ?... » [http://marre-de-la-vie.blogspot. co.at/2006/09/vaut-il-mieux-vivre-malheureuxou.html] (14.4.2016)

pourquoi vivre malheureux et entraîner vos enfants dans ce tourbillon de tristesse, de crise et dispute en tout genre.. [http://www.yabiladi. com/forum/vaut-il-mieux-mariage-malheureuxdivorce-3-4126389.html] (14.4.2016)

Tu as raison quand tu dis qu'il faut être pragmatique et reconnaître que certaines personnes vivent malheureuses toutes leur vie [http:// forum.virginite-tardive.fr/viewtopic.php? $\mathrm{t}=$ 4892\&start=10] (14.4.2016)

REMARQues : Vivre malheureux se dit du fait de ne pas être content, heureux de la situation dans laquelle on se trouve, qu'elle soit professionnelle, familiale, sociale ou morale, conférant au sujet un sentiment d'insatisfaction, de mal-être, de souffrance. Malheureux est un prédicat second qui s'accorde systématiquement avec le sujet. Il est modifié par d'autant plus, très, trop. Notons l'opposition sémantique entre vivre et mourir ainsi que l'emploi des adjectifs en prédication seconde caché, honoré, indépendant, triste. Mentionnons également l'emploi de mourir seul. VoIR AUSSI : mourir malheureux

\section{Vivre misérable}

Vivre de manière pitoyable, lamentable, infortunée, insignifiante, dans la misère Intransitif

1606 O douce chaine à mon ame fatale, Et de l'Amour le plus rare thresor ; Si tout lien vous estoit comparable, Qui vivroit libre il vivroit miserable (Jean Bertaut, Recueil de quelques vers amoureux)

1732 Hélas ! pauvre duègne et pauvre écuyer, je ne m'informais pas si vous viviez heureux ou misérables dans les Asturies ! 
(Alain-René Lesage, Histoire de Gil Blas de Santillane)

1761 Les enfans élevés au chaud sont souvent enrhumés, foibles, pâles, languissans, bouffis, tristes ; tombent dans la nouûre, la consomption, toutes sortes de langueurs, et meurent dans l'enfance, ou vivent misérables, etc... (Samuel Auguste Tissot, Avis au peuple)

1784 Pour vivre moins misérable, il faut qu'il se divertisse, c'est-à-dire par le sens même de cette expression, il faut qu'il se détourne de cette perspective de maux que la nature lui présente de toutes parts (Bernardin de Saint-Pierre, Études de la nature)

1845 Mais, ô chasteté sainte, ô robe vénérable, Malheur à qui sur toi porte une impure main !

Qu'il vive et meure misérable!

Qu'Érynnis vengeresse, auguste, inexorable,

Le flagelle à jamais dans l'Hadès inhumain ! (Charles-Marie Leconte de Lisle, Poèmes antiques : Hélène)

1846a Alors, qu'elle [= la Marana] vécût heureuse ou misérable, opulente ou pauvre, elle eut au cœur un sentiment pur, le plus beau de tous les sentiments humains, parce qu'il est le plus désintéressé (Honoré de Balzac, Les Marana)

1846b Pourquoi nous combler du luxe de la tendresse, si nous devons vivre ensuite misérables? (Gustave Flaubert, Correspondance)

1937 Quand on a de la santé et par-dessus le marché du talent, ne doit-on pas toujours avoir de l'argent pour son vieux père veuf, deux fois veuf, et qui s'est dépouillé pour vous, et qui vit maintenant misérable à l'hôtel ? (Pierre Drieu la Rochelle, Rêveuse Bourgeoisie)

1964 Ces supplices, restait à les trouver ; c'était l'unique problème mais qui paraissait insoluble puisqu'on m'avait ôté l'espoir de vivre misérable : obscur ou fameux, j'émargerais au budget de l'Enseignement, je n'aurais jamais faim (Jean-Paul Sartre, Les Mots)

\section{CORPUS WEB :}

La maison de repos a été choisi pour mener des recherches, car avant ils ont entendu l'hôpital 18 personnes âgées vivant dans la pauvreté, vivent misérable [http://www.partagedocument.com/ download/95732411677/rapport-de-recherchede-maison-de-soins-infirmiers-daping-meixian] (14.4.2016)

Ils vivent miserable sur cette terre alegerienne aussi chaude.. aussi haute... L'algerie fait du polisario un outil productif... pour raccolter l'aide humanitaire, qu'ils vendent dans la ville de Tindouf... et pour autant affaiblir ses voisins... [http://www.yabiladi.com/forum/coutealgeriens-hebergement-polisaros-2-1104453.html] (14.4.2016)

pour ca j'espere vraiment que les gens comme toi vivent misérables pendant leur vie pour ressentir ce qu'ils aiment pour les autres [http://www.jeuxvideo.com/forums/151-15211912-4-0-1-0-le-baril-va-atteindre-200dollars.htm] (14.4.2016)

REMARQUES : Vivre misérable renvoie aux conditions de vie dans lesquelles se trouve le sujet qui, privé de biens matériels et de ressources, mène une vie triste, pénible, d'une extrême pauvreté. En référence à la hiérarchie morale ou sociale, il se dit du fait de se trouver à un niveau, un degré inférieur, soulignant le caractère bas ou indigne du sujet. Misérable tend à l'emploi comme prédicat second qui s'accorde avec le sujet, mais l'emploi invarié est également attesté (v. les deux premiers exemples du CW). Misérable est modifié par ensuite, maintenant, moins. Notons l'opposition sémantique entre vivre et mourir (v. l'exemple de 1845) et entre misérable et pauvre, d'un côté, et libre, heureux et opulent, de l'autre. VOIR AUSSI : mourir misérable

\section{Vivre monotone}

Mener une vie monotone, uniforme, dépourvue de fantaisie Intransitif

1878 il avait horreur des cérémonies et de tout ce qui pouvait déranger le moins 
$\mathrm{du}$ monde sa manière de vivre monotone (T. B., Les Illusions de Thérèse)

1885 Des âmes d'amis morts les habitent peut-être?

Je leur jette du pain : comme blessés, ils partent!

Ah ! Jusqu'à ce que la nature soit bien bonne,

Moi je veux vivre monotone.

Elle est partie hier.

Suis-je pas triste d'elle? (Jules Laforgue, Euvres complètes : Les Complaintes)

\section{CORPUS WEB :}

Tout au long de l'enquête, à la fin est une démangeaison de quatre ans ou quatorze ans de réflexion de sept ans démangent n'ya pas de consensus, mais la plupart des données de recherche plus agréable que, avec la poursuite de la vie conjugale, en particulier pour ceux qui vivent monotone, ennuyeux vie conjugale des personnes, en particulier la vie sexuelle du mariage existant ainsi que la perte d'intérêt et de passion fatigué de la situation semble venir tôt ou tard [http://fr.swewe.org/word_show.htm/?786298_ 3\&Seven_Year_Itch_mots_chinois] (14.4.2016)

REMARQUES : Vivre monotone se dit du fait de mener une vie dont le rythme est régulier, sans réelles surprises ou changements, dont le déroulement est uniforme, dépourvu d'imprévu. Monotone reste invariable. Notons l'adjectifadverbe ennuyeux dans le CW qui vient renforcer le sémantisme. Nous avons ajouté l'exemple de 1878 où l'on analysera monotone plutôt comme modifieur du groupe nominal manière de vivre. Sans postuler une relation génétique du type manière de vivre monotone > vivre monotone - nous sommes plutôt sceptiques envers ces explications par ellipse -, on peut constater que le tour « manière de vivre » + « adjectif » est souvent employé avec ce verbe, non seulement dans le cas de vivre monotone, cité ici à titre d'exemple. Nous pensons plutôt que, au lieu de vouloir chercher des explications par ellipse, il faut penser à des auteurs soucieux de correction linguistique qui évitent l'emploi adverbial de l'adjectif en optant pour une solution nominale.

\section{Vivre net}

Vivre, se comporter de manière correcte, irréprochable

Intransitif

1942 Que je voudrais lui donner de sa mère une idée qui le préserve de tout toute sa vie ! Il s'agit d'être encore plus stricte avec soi, de se sauver de toute bassesse, de vivre droit, sûr, net et pur, pour qu'un être puisse garder plus tard l'image la plus belle possible de vous, tendrement et sans reproche (Henry de Montherlant, La Reine morte)

REMARQUES : Vivre net réfère à la conduite adoptée envers autrui par une personne agissant conformément à la norme sociale, en respectant les règles d'honnêteté, de bienséance, de savoir-vivre, de bonne tenue et faisant preuve d'honnêteté. Notons la mise en série avec droit, sûr, pur.

\section{Vivre obscur}

Vivre modestement, très discrètement, dans l'ombre, sans être connu

Intransitif

1756 On sait que Mahomet était le cadet d'une famille pauvre : qu'il fut longtems au service d'une femme de La Mecque, nommée Cadisché, laquelle exerçait le négoce : qu'il l'épousa, et qu'il vécut obscur jusqu'à l'âge de quarante ans (Voltaire, Essay sur l'histoire générale et sur les mœurs et sur l'esprit des nations)

1769 JENNEVAL. Je restituerai la somme que j'ai détournée. Un jour viendra, Rosalie, que le ciel couronnera notre constance. Pour vivre obscurs, nous n'en vivrons pas moins heureux (Louis-Sébastien Mercier, Jenneval ou Le Barnevelt françois)

1779 Tu dois à ta vertu ce temple si pompeux, placé sur la montagne où tu reçois nos vœux : si tu vécus obscure, et pauvre et négligée, en sceptre, après ta mort, ta houlette est changée (Antoine-Marin Lemierre, Les Fastes ou Les Usages de l'année)

1784 C'est là que les ambitions, les préjugés, les haines et les tyrannies des provinces viennent se perdre et s’anéantir. Là, il est 
permis de vivre obscur et libre (Bernardin de Saint-Pierre, Études de la nature)

1828 Il faut tout dire : peut-être en ces jours déplorables, au milieu des tempêtes civiles, vivaient et mouraient obscurs quelquesuns de ces hommes de génie, qui, par le poids de leurs œuvres, auraient pu fixer la langue, et, en quelque sorte, jeter l'ancre de notre littérature (Charles Sainte-Beuve, Tableau historique et critique de la poésie française et du théâtre français au $X V I^{e}$ siècle)

1843 Mais, je vous l'ai dit bien souvent, mon amie, si des devoirs sacrés, plus sacrés encore que ceux de la famille, ne me retenaient pas au milieu de ce peuple qui m'aime et dont je suis un peu la providence, je serais allé avec vous, ma fille, Henri et Murph, vivre heureux et obscur dans quelque retraite ignorée (Eugène Sue, Les Mystères de Paris)

1923 Ils [= les paysans] savent ce que c'est que d'errer, « de muda »: de changer d'asile, de venir au monde dépouillé, de vagir entre des murs de torchis, de gagner son pain, d'être en butte aux hommes et aux choses, de vivre obscur, de souffrir dans sa chair et son cœur, et d'aller sur la terre en semant son grain sans être sûr de la moisson (Joseph de Pesquidoux, Chez nous : travaux et jeux rustiques)

1934 Il vaut mieux vivre obscur que régner sur des êtres, et souffrir seul, pourceaux, qu'être heureux où vous êtes (Henry de Montherlant, Encore un instant de bonheur)

\section{CORPus WEB :}

Pendant son séjour en Corse, de Villiers a une sorte de pressentiment de l'élévation prochaine de la famille de Bonaparte. Il lui fait de fréquentes visites. Il évite les parvenus. Il désire vivre obscur [http://www.wikimanche.fr/Fran $\%$ C3\%A7ois_Le_Jolis_de_Villiers] (14.4.2016)

Alors, dit Tchoang-tzeu, retournez d'où vous êtes venus ; moi aussi je préfère traîner ma queue dans la boue des marais. Je continuerai à vivre obscur mais libre ; je ne veux pas d'une charge, qui coûte souvent la vie à celui qui la porte, et qui lui coûte la paix toujours [http://taovide.blogspot. co.at/2011/11/gloire-renommee.html] (14.4.2016)

REMARQUES : Vivre obscur se dit du fait de mener une vie secrète, de demeurer dans l'ombre, le sujet cherchant à conserver un état d'anonymat pour préserver sa tranquillité. Obscur peut s'accorder avec le sujet, même s'il garde son interprétation d'adjectif-adverbe indiquant une condition, une circonstance, un style de vie. Il s'associe fréquemment avec d'autres adjectifs : heureux, pauvre, négligé, libre. Notons la collocation vivre et mourir obscur et l'emploi de souffrir seul. VOIR AUSSI : mourir obscur

\section{Vivre paisible}

Vivre paisiblement, tranquillement, sereinement Intransitif

1654 Ce brave et sage roy, par sa haute prudence, Mettra dans ses estats, la paix et l'abondance :

Et ce grand politique, en aspirant aux cieux,

Vivra tousjours paisible, et mourra glorieux (Georges de Scudéry, Alaric ou Rome vaincue)

1659 Je vous apprens qu'elle est icy, La belle et charmante Toussy, Qui vivroit paisible et contente Sous le toict de sa bonne tante Si l'on faisoit cesser le bruit Qui l'importune jour et nuit (François de Boisrobert, Épistres en vers)

1756 Il y avait encor dans l'Asie mineure un grand nombre de manichéens qui vivaient paisibles, parce que la fureur d'entousiasme, qui n'est guères que dans les sectes naissantes, était passée (Voltaire, Essay sur l'histoire générale et sur les mœurs et sur l'esprit des nations)

1764 Ah ! Trouvez-la, Milord, trouvez-la, s'écriat-il, secourez-la, consolez cette fille charmante ; qu'elle vive paisible et heureuse sous votre protection ! (Marie-Jeanne Riccoboni, Histoire de Miss Jenny, écrite et envoyée par elle à Miladi, comtesse de Roscomond) 
1792 Des laboureurs vivoient paisibles et contents dans un riche et nombreux village (Jean-Pierre Florian, Fables)

1805 - Ma bien-aimée, lui dit-il, si ma présence vous afflige, je m'éloignerai.

- Mon dieu, continue-t-elle, pourquoi me le montras-tu ? Avant de le voir je vivois si paisible! (Sophie Cottin, Mathilde)

1893a Plus loin, s’ouvrait une échappée de vie douce et tragique, Hélène Mouret vivait paisible avec sa fillette Jeanne, sur les hauteurs de Passy, dominant Paris, l'océan humain sans bornes et sans fond, en face duquel se déroulait cette histoire douloureuse (Émile Zola, Le Docteur Pascal)

1946 ces Albigeois vivaient paisibles et loin du monde, les catholiques étaient venus troubler leur sagesse par l'idée du péché, leur conception, non point fausse mais inopportune, du devoir social ; j'étais un de ces fruits bâtards. merci (Raymond Abellio, Heureux les pacifiques)

1968 ICARE. Il m'a baptisé et je vivais chez lui paisible, attendant d'accomplir le destin qu'il me tissait (Raymond Queneau, Le Vol d'Icare)

Transitif

1893b Elle l'avait crié avec angoisse, une nuit, sur l'aire : la vie était abominable, comment pouvait-on la vivre paisible et heureuse? (Émile Zola, Le Docteur Pascal)

\section{CORPUS WEB :}

Ce système établi et indétrônable a besoin pour se maintenir, de cette nuée d'esclaves et de guerriers, qui loin de ce marché et dans l'ignorance la plus absolue des droits de l'homme ou d'une quelconque paix, s'activent dans ces tourments pour que vivent paisible, les consommateurs que nous sommes [http://julien-masson. wix.com/leskivus] (14.4.2016)

Les Zarbi étaient très timides et n’allaient pas à l'extérieur des ruines. En effet, l'environnement des ruines est peuplé par de plus en plus de monde. Il est dit que cette tribu, celle qui a souhaité que les Zarbi vivent paisible et heureux, a décidé de partir laissant ainsi les Zarbi seuls [http:// www.jeuxvideo.com/forums/1-21052-2422583-1-01-0-tutorial-les-zarbis.htm] (14.4.2016)

Les juments mettent bas aux herbes (d'avril à juin). Les poulains restent auprès d'elles durant les 6 premiers mois de leur vie... Ils vivent paisibles... en troupeau... à l'état quasi sauvage dans les grands espaces de liberté de la petite Camargue [http://manademarie.free.fr/elevage. html] (14.4.2016)

REMARQues : Vivre paisible se dit du fait de mener une vie calme, exempte d'agitation et de troubles qui affectent l'existence. Dans le style soigné, paisible tend à l'accord avec le sujet, mais les exemples du CW montrent que l'emploi non-accordé est également possible. Paisible est modifié par chez lui, si, toujours. Notons la coordination de paisible avec les adjectifs heureux et content et l'emploi de mourir glorieux.

\section{Vivre pauvre}

Vivre dans la pauvreté, avec peu de ressources Intransitif

1461 Et, se vous voullés bien faire aux armes, vous ne poez faillir à parvenir à de trois choses l'une, de quoy les armes payent tousjours leurs souldoyers, c'est assavoir : ou de la mort, ou de vivre povre et honnouré et que chascun parlera de vous et des vostres, dont il sera renommée après vous (Jean de Bueil, Le Jouvencel [1461]-1468, I, p. 43)

-1489 Miserable est de vouloir estre chiche Par telz moyens, car rien si sotelet N'est que vivre povre pour mourir riche (Octovien de Saint-Gelais, L'Ystoire de Eurialus et Lucresse, p. 167a)

1561 Il est certain que celuy qui a tousjours vescu pauvre en ce monde n'a aucun regret quand il s'en part, et fault croire et entendre qu'il laisse ceste vie terrienne trop plus joyeusement et à delivre que celuy qui par le moyen des richesses y a prins longuement ses esbatz (Charles Estienne, Paradoxes)

1632 Elle [= Éléonore] lui montrait le ciel, lui parlait de l'amour infini de Dieu, de cet amour qui l'a fait descendre pour nous dans une crèche, vivre pauvre et méprisé et 
mourir ensuite (Calixte de la Providence, Vie de saint Félix de Valois)

1646 L'empereur ayant declaré au Senat, que c'estoit Pallas qui en avoit fait la premiere proposition, la compagnie luy en decerna de grandes recompenses ; mais son maistre asseura qu'il se contentoit de l'honneur qu'il en recevoit, et qu'il estoit resolu de vivre pauvre parmy sa faveur (Nicolas Coëffeteau, Histoire romaine)

1699 Enfin, quand Erichthon aperçut que l'argent corrompoit les peuples, comme il l'avoit prévu, il se retira de douleur sur une montagne sauvage, où il vécut pauvre et éloigné des hommes, jusqu'à une extrême vieillesse, sans vouloir se mêler du gouvernement des villes (François de Fénelon, Les Aventures de Télémaque)

1734 Dès le tems d'Orose qui écrivoit vers la vingtiéme année du cinquiéme siécle, il y avoit déja dans les provinces soumises au gouvernement des officiers du prince, plusieurs citoyens que la misere réduisoit à se bannir eux-mêmes de leur patrie ; il leur paroissoit moins dur de vivre pauvres, mais libres dans les païs où l'Empereur n’étoit plus le maître absolu de la destinée des Sujets, que de continuer à vivre dans les Païs pleinement soumis à son obéissance, et d'y être traités en esclaves par les exacteurs des deniers publics (JeanBaptiste Dubos, Histoire critique de l'établissement de la monarchie françoise)

1773 de Mignard, dont ses parens voulurent faire un médecin, et dont la nature fit un peintre ; du Poussin, qui, las des intrigues et des petites cabales de Paris, retourna à Rome vivre tranquille et pauvre (AntoineLéonard Thomas, Essai sur les éloges)

1778 Tant que j'ai vécu pauvre, j’ai vécu heureux, et ce n'est que quand rien ne m'a manqué pour le nécessaire que je me suis senti le plus malheureux des mortels

(Jean Guéhenno, Jean-Jacques : Grandeur et misère d'un esprit [la datation est celle de la citation])
1783 Michel de Cervantes Saavedra, dont les écrits ont illustré l'Espagne, amusé l'Europe, et corrigé son siècle, vécut pauvre, malheureux, et mourut presque oublié (Jean-Pierre Florian, Galatée)

1835a Quinze ou vingt pères espagnols et italiens vivent dans ce couvent, occupés à chanter les louanges de l'enfant-dieu et les gloires de sa mère, dans le temple même où ils vécurent pauvres et ignorés

(Alphonse de Lamartine, Souvenirs, impressions, pensées et paysages pendant un voyage en Orient)

1835b Chassé d'Athènes, qui était devenue sa patrie, et dont il avait, comme un fils, balayé toute sa vie la poussière pour rendre sa statue au monde, il vit maintenant pauvre et inconnu à Smyrne (Alphonse de Lamartine, Souvenirs, impressions, pensées et paysages pendant un voyage en Orient)

1846 Alors, qu'elle [= la Marana] vécût heureuse ou misérable, opulente ou pauvre, elle eut au cœur un sentiment pur, le plus beau de tous les sentiments humains, parce qu'il est le plus désintéressé (Honoré de Balzac, Les Marana)

1937 L'Antiquité a connu les Riches. Beaucoup d'hommes y ont souffert d'une injuste répartition des biens, de l'égoïsme, de la rapacité, de l'orgueil des Riches, bien qu'on ne pense pas assez peut-être à ces milliers de laboureurs, pâtres, bergers, pêcheurs ou chasseurs auxquels la médiocrité des moyens de communication permettait de vivre pauvres et libres dans leurs solitudes inaccessibles (Georges Bernanos, Les Grands Cimetières sous la lune)

1944 Je veux rendre aux hommes le goût du miracle, car il est bon que les pêcheurs de perles qui vivent pauvres, tant elles sont dures à déchiffrer du fond des mers, croient en la perle merveilleuse (Antoine de Saint-Exupéry, Citadelle)

CORPUS Web :

« On dit que l'agriculteur vit pauvre et meurt riche. " plaisante Max Bersinger [https:// 
blogs.mediapart.fr/fabien-franco/blog/250815/ retraites-de-lagriculture-les-recoltes-derisoiresdune-vie-de-labeur] (14.4.2016)

Aujourd'hui, il vit pauvre et seul. Pour Naphiri, l'histoire se termine bien [http://www. alternatives-internationales.fr/malawi--la-loiexiste--mais-qui-la-connait-_fr_art_842_43381. html] (14.4.2016)

...je suis content qu'un juge d'instruction [...] enquête sur les biens du président Obiang et de sa famille, biens acquis avec l'argent des citoyens qui vivent pauvres ici », a-t-il ajouté [http://survie.org/ billets-d-afrique/2010/197-decembre-2010/arti cle/biens-mal-acquis-florilege-de-la] (14.4.2016)

REMARQUES : Vivre pauvre réfère aux conditions de vie dans lesquelles se trouve le sujet qui mène une vie lamentable, infortunée, insignifiante, dans la misère. Pauvre tend à l'emploi comme prédicat second accordé avec le sujet. L'usage est enclin à ajouter à vivre pauvre un contraste perçu comme étant positif du type vivre pauvre et mourir riche, vivre pauvre et/mais heureux, pauvre et libre, ou alors un modifieur qui en renforce la tristesse pauvre et seul, pauvre et inconnu, pauvre et ignoré, pauvre et malheureux, pauvre et oublié.

\section{Vivre petit}

Vivre peu de temps

Intransitif

+1125 Nos veüm el mund

De cels qui i sunt

Cum fort il se peinent.

Assez i estrivent

E petit i vivent

E niënt n'en meinent

(Un sermon en vers [ $2^{\mathrm{e}}$ quart $\left.\left.\mathrm{XII} \mathrm{e}^{\mathrm{e}}\right], 59\right)$

$\sim 1160$ Retornerai la ou ge fui,

Iluec ou ge parti de lui ;

Se ge nel truis, po pris ma vie ;

Se il n'est autres qui m'ocie,

Sai ge bien que ge m'ocirrai,

Soantre lui petit vivrai (Eneas, 5184)

1250 Onquez mès tel ne vi, qui fust de ton aé :

Mez tu vivras petit, se j'en ay poosté.

L'arc li tolt de la main, en veie l'a rué

(Doon de Mayence, p. 7)

1534 Lors se verra maint homme de valeur, Par l'esguillon de jeunesse et chaleur
Et croire trop ce fervent appetit, Mourir en fleur et vivre bien petit

(François Rabelais, Gargantua)

REMARQUes : En ancien français, petit est un quantificateur signifiant 'peu'. Vivre petit, transposé au plan temporel, s'emploie pour souligner la durée courte de la vie d'un homme. Petit reste invariable et est modifié par bien.

\section{Vivre pur}

Vivre de manière pure, noble, innocente, chaste (d'une personne) ; durer, se maintenir sans s'altérer (d'une chose)

Intransitif

1675 [Les pauvres Religieux de l'Ancien Testament] ont receu tant de bénédictions du Ciel, de combien de graces temporelles et éternelles seront couronnez nos Religieux Chrêtiens, lesquels dans un corps de chair vivent purs et chastes comme des Anges (Benoist Laugeois, La Science universelle de l'Écriture sainte)

1686 Je veux desormais vivre pur et sans foüillure comme vous (Maximien de Bernezai, Traité de la vie intérieure)

1778 Hélas ! est-ce un vice inhérent à la capitale, et celui qui s'y corrompt n'a-t-il pas apporté dans son cœur le germe de la corruption? Edme R. y vécut aussi pur que dans son village... Heureux mortel !

(Nicolas Rétif de la Bretonne, La Vie de mon père)

1806 SULLY. Sans doute de Henri la mémoire adorée

Dans le cœur des Français vivra pure et sacrée :

Mais, en proie aux tourments d'un esprit soupçonneux,

La triste Médicis ne peut juger comme eux (Gabriel Legouvé, La Mort de Henri IV)

1807 Oui, dit Cornélie, aucune tache n’a souillé ma vie depuis l'hymen jusqu'au bûcher ; j'ai vécu pure entre les deux flambeaux (Germaine de Staël, Corinne ou L'Italie)

1863 Au milieu du désordre apparent d'une vie vagabonde, j'ai vécu innocente et pure, car 
pour mes compagnons qui m'avaient vue au berceau, j'étais une sœur ou une fille (Théophile Gautier, Le Capitaine Fracasse)

1914 Voyez, mon Dieu, c'est tout cela que je refuse, pour me garder à vous, pour vivre pur (Alain-Fournier, Correspondance avec Jacques Rivière)

1942 Que je voudrais lui donner de sa mère une idée qui le préserve de tout toute sa vie ! Il s'agit d'être encore plus stricte avec soi, de se sauver de toute bassesse, de vivre droit, sûr, net et pur, pour qu'un être puisse garder plus tard l'image la plus belle possible de vous, tendrement et sans reproche (Henry de Montherlant, La Reine morte)

1945 Les nuits sur les plateaux épandent, semble-t-il, de bonnes influences, et l'on vit purs dans les solitudes des hautes terres (Henri Bosco, Le Mas Théotime)

\section{CORPuS Web :}

Merci pour cet encouragement car aujourd'hui on se demande s'il est néssaire de mettre en pratique la Parole de Dieu étand donné que même dans L'Eglise la depravation et le péché sont devenus légitimes et lorsque vous cherchez à prêcher le contraire vous vous faites de ennemis. Aujourd'hui l'evangile a été tellement denaturé que lorsque tu cherches à vivre pur on te traite comme on a traité Noé [http://www. topchretien.com/topmessages/view/2579/vivrecontrecourant-cest-possible.html] (6.4.2016)

Le Groupe CIAT agit pour concilier les besoins de l'Homme et l'Environnement, et vise pour tous le même objectif : vivre bien, vivre pur, vivre durable [http://www.recrutement-ciat.fr/ Site] (6.4.2016)

REMARQUES : Vivre pur réfère à l'attitude morale du sujet qui adopte un comportement droit, sincère, exempt de faute. Le sujet peut aussi renvoyer à quelque chose (la mémoire) qui perdure, se maintient ou conserve son état initial, nonaltéré. En tant que prédicat second, pur peut s'accorder avec le sujet. Dans l'exemple de 1945, vivre pur renvoie à la pureté du sujet, d'où l'accord au pluriel (ad sensum : l'on = nous), mais il connote également la pureté de l'air. Dans le discours religieux, vivre pur tend à la lexicalisation comme formule ou maxime. L'emploi comme slogan ou maxime apparaît aussi dans le dernier exemple du CW qui traite de la relation de l'homme avec son environnement non pollué. Pur est modifié par aussi. Il se trouve associé à de nombreux adjectifs : chaste, droit, durable, innocent, net, sacré, sûr.

\section{Vivre retiré}

Vivre à l'écart de la société mondaine, loin de

l'agitation, de la fièvre du monde

Intransitif

1637 Et il y a justement huit ans que ce desir me fit resoudre à m'esloigner de tous les lieux ou je pouvois avoir des connoissances, et à me retirer icy en un païs [...] où parmi la foule d'un grand peuple fort actif, et plus soigneux de ses propres affaires, que curieux de celles d'autruy, sans manquer d'aucune des commoditez qui sont dans les villes les plus frequentées, j'ay pû vivre aussy solitaire et retiré que dans les desers les plus escartez (René Descartes, Discours de la méthode)

1691 Quelque modestes qu'elles [= les veuves] soient, il faut qu'elles vivent si retirées, qu'il semble que leur âme est déjà dans l'autre monde (Marie-Catherine d'Aulnoy, Relation du voyage d'Espagne)

1734 Deux lignes après : votre histoire avec cette vieille fille qui vous épouse est singulière, ajouta-t-elle comme par réflexion et en riant ; il faut pourtant qu'elle ait de bons yeux, toute retirée qu'elle a vécu, et je ne la plains pas (Pierre de Marivaux, Le Paysan parvenu)

1735 Il me dit ensuite que tout paroissoit tranquille dans le château, que Madame de Bénavidès vivoit encore plus retirée qu'auparavant, que sa santé étoit très-languissante (Claudine-Alexandrine Guérin, marquise de Tencin, Mémoires du comte de Comminges)

1805 Tourmentée par cette incertitude, elle évite les occasions de se trouver seule avec Guillaume, et écarte toujours, en dépit des inquiétudes de sa conscience, un entre- 
tien qu'il semble chercher toujours ; pour y mieux réussir, elle vit moins retirée, se montre plus souvent dans le monde, et ne quitte presque jamais la reine (Sophie Cottin, Mathilde)

1845 Moi aussi, M. Renaud me gronde souvent pour cela, mais c'est mon bonheur à moi, je ne sors pas, je ne vais pas dans le monde, je suis une pauvre femme bien ignorée, qui vit chez elle retirée (Gustave Flaubert, La Première éducation sentimentale)

1862 Sa correspondance resta plus affectueuse pour l'autre frère, l'ancien préfet, brave et digne homme qui vivait retiré à Paris, rue Cassette (Victor Hugo, Les Misérables)

1920 Je dois vous avouer que j'ai vécu fort retiré, à la maison Socque et Sureau (Georges Duhamel, La Confession de minuit)

1969 - Tu sais, elle vit assez retirée depuis son divorce. Elle ne se sent pas à l'aise dans son milieu. Elle est médecin, spécialiste des enfants (Éric Rohmer, Ma nuit chez Maud)

CORPuS Web :

ils vivent retiré de la civilisation [http://www. jeuxvideo.com/forums/1-51-68300640-1-0-1-0que-deviennent-homme-mort.htm] (24.3.2016)

Il est rare d'apercevoir un Dragon sylvestre, car ceci [= ceux-ci ?] ne vivent retiré qu'au plus profond des forêts d'Undomë ou de Vaendark [http://tol-orea.xooit.org/t3142-CONCOURSToutes-disciplines-Races-Imaginaires-dedragon.htm] (24.3.2016)

Les gorilles sont les plus grands singes anthropoïdes vivants. Ils vivent retirés dans la jungle africaine, où ils se nourrissent presque exclusivement de plantes [http://www.schleich-s. com/fr/CA/jouets/wild_life_gorilles] (24.3.2016)

Une abbaye (synonyme de monastère) est un lieu où des croyants vivent retirés pour prier [http://juliendaget.perso.sfr.fr/Clem/5203Cluny. html] (24.3.2016)

REMARQues : Vivre retiré se dit du fait de se mettre en retrait, de s'isoler du monde, de la société, pour se protéger ou pour fuir les obligations sociales, le sujet ressentant le besoin d'être seul. Retiré tend à l'emploi en tant que prédicat second accordé dans les styles standard et soutenu, mais les exemples du CW montrent que l'accord peut ne pas se faire. Retiré est modifié par assez, encore plus, fort, moins, si, tout.

\section{Vivre riche}

Vivre dans la richesse, dans l'opulence

Intransitif

1700a Le prodigue vit riche, et meurt pauvre ; l'avare vit pauvre, et meurt riche (PierreJacques Brillon, Le Théophraste moderne ou Nouveaux Caractères sur les mœurs)

1700b Chacun aimait mieux vivre pauvre dans un Empire riche, que vivre riche dans un Empire pauvre (Jean Claveret, Valère Maxime. Latin-François [trad.])

1848 Il vivait riche, mondain, très-poli, ne fuyant nullement la compagnie des personnes du sexe, et ne s'interdisant pas les honnêtes divertissements de la société (Charles Sainte-Beuve, Port-Royal)

1858 Malheureux en famille, en guerre et en politique, M. le Prince se consola de tout par l'amour des richesses, et, quand vint le terrible ministère de Richelieu, il vécut fort tranquille, riche et sans honneur, dans sa bonne ville de Bourges et dans son beau château de Saint-Amand-Montrond (George Sand, Les Beaux Messieurs de Bois-Doré)

1862 Oh ! pauvre femme ! C'en était plus que la pauvre Fantine n'en pouvait supporter. Avoir Cosette ! Sortir de cette vie infâme ! Vivre libre, riche, heureuse, honnête, avec Cosette! (Victor Hugo, Les Misérables)

1881 Laver les murs, laver les lits, laver les draps, Donner à boire aux gars ayant au dos leurs pioches,

Blanchir l'âtre, écumer le pot, moucher des mioches,

Porter, si le chemin est long et raboteux, Ses souliers à la main, les pieds s'usant moins qu'eux,

Et vivre ainsi pieds nus et riche, heureuse en somme 
D'être une brave femme et d'avoir un brave homme

(Victor Hugo, Les Quatre Vents de l'esprit)

1954 on les a tués, ils se sont tués, et lui continuera à vivre honoré, riche, heureux

(Simone de Beauvoir, Les Mandarins)

CORPUS WEB :

Les zélus vivent riche car ils ne payent pas le RSA en Polynésie Française, scandale que dénonce René Hoffer ! [http://lavapeur.blogspot. co.at/2015/06/savoie-fln-contribuable-montblanc.html] (24.3.2016)

Pour ceux qui domine présentement même, ils ont pas besoin de faire travailler les citoyens tant que cela parce que ils en ont rien à foutre de rien à rien et comme ils l'ont répéter à des millier de reprises, ils tuent tout le monde en même temps, il vivent riche et ils en ont rien à foutre de rien à rien [http://politics244.blogspot. co.at/2015/07/pourquoi-le-communisme-encore. html] (24.3.2016)

Heureux qui, comme les Suisses, vivent riches, en sécurité et en démocratie [http:// www.24heures.ch/suisse/Heureux-qui-commeles-Suisses-vivent-riches-en-securite-et-endemocratie-/story/17919863] (24.3.2016)

On ne voit ou entend que des pubs pour des grandes surfaces qui vantent, bien être et qualité, traçabilité et prix cassés, ils nous feraient presque croire que leur producteurs vivent riches et heureux ! [http://unionrepublicaine.fr/a-tablecitoyen] (24.3.2016)

REMARQues : Vivre riche se dit du fait de posséder des biens en abondance, d'avoir beaucoup d'argent, de la fortune. Riche tend à l'emploi comme prédicat second accordé avec le sujet, mais les exemples du CW montrent que le style familier peut préférer l'emploi sans accord. Riche est modifié par ainsi. Notons les collocations avec heureux, honnête, honoré, libre, mondain, poli, tranquille, ainsi que le contraste vivre pauvre et mourir riche, ou vivre riche et mourir pauvre.

\section{Vivre sain}

Vivre en bonne santé ; vivre de manière saine, équilibrée

Intransitif

1389a Si me semble que j'ay assez prové, quar petit menger font fere les mires aux malades pour garir et suer pour aterminer et garir du tout, et, comme les veneurs menjuent petit et suent touz jours, doivent il vivre longuement et sains (Gaston Phébus, Livre de chasse, p. 56, 53)

1389b Et on desire en cest monde a vivre longuement et sain et en joye et aprés la fin la salvation de l'arme, et veneurs ont tout cela (Gaston Phébus, Livre de chasse, p. 57, 54)

1429 Ton penser te desvertue, Ton fol sens te nuyt et tue, Et a non sçavoir te maine. Tant es de povre venue, Se des cieulx n'es soustenue, Que tu ne peulz vivre saine (Alain Chartier, Le Livre de l'espérance, p. 5, 12)

1561 Attendu que si elle nous est mauvaise mere pour un jour, elle nous est bonne deux apres, et que quiconque en guerit (ce disent plusieurs anciens medecins) il en vit apres plus sain et mieux disposé (Charles Estienne, Paradoxes)

1592 On demandoit à un Lacedemonien qui l'avoit fait vivre sain si long temps : L'ignorance de la medecine, respondit il (Michel de Montaigne, Essais)

1684 Quoy que la Rate soit un viscere tres considerable, neanmoins nous avons aussi veu depuis peu plusieurs Chiens à qui on l'avoit ostée, lesquels ont esté tres bien gueris de la blessure, et ont vécu sains comme auparavant (François Bernier, Abrégé de la philosophie de Gassendi)

1755 en un mot tant qu'ils ne s'appliquérent qu'à des ouvrages qu'un seul pouvoit faire, et qu'à des arts qui n'avoient pas besoin du concours de plusieurs mains, ils vécurent libres, sains, bons, et heureux autant qu'ils pouvoient l'être par leur nature, et continuérent à joüir entre eux des 
douceurs d'un commerce independant (Jean-Jacques Rousseau, Discours sur l'origine et les fondements de l'inégalité parmi les hommes)

1762 Vous aurez vécu libre, sain, vrai, laborieux, juste : ce n'est pas perdre son tems que d'en gagner ainsi (Jean-Jacques Rousseau, Émile ou De l'éducation)

1797 Il est évident, que menacé fortement d'une fin douloureuse, après avoir vécu sain et heureux, aussi long-temps que le comporte la nature humaine, la raison me dictait de mettre un terme à ma vie, et de me rendre maître de mes derniers momens pour en écarter les horreurs dont les aurait environné la barbarie révolutionnaire (Gabriel Sénac de Meilhan, L'Émigré)

1802 Tout animal libre vit content et sain, occupé de conserver son existence et non de la supporter : s'il est attaqué, il est en un moment vainqueur ou dévoré (Étienne de Senancour, Rêveries sur la nature primitive de l'homme)

1808 Chez d'autres enfans, l'état du cerveau empêche entièrement la pensée. Ils n'en vivent pas moins sains et vigoureux (Pierre Cabanis, Rapports du physique et du moral de l'homme)

1824 Il faut que ceux qui sont nés délicats, vivent délicats, mais sains ; que ceux qui sont nés robustes, vivent robustes, mais tempérants ; que ceux qui ont l'esprit vif, gardent leurs ailes, et que les autres gardent leurs pieds (Joseph Joubert, Pensées, essais, maximes et correspondance)

1938 Donne-moi l'enfant. Si je ne te le ramène pas et ne te le rends pas, tel quel, vivant sain et sauf, je serai coupable envers toi pour tout le temps (Paul Claudel, Un poète regarde la croix)

\section{CORPUS WEB :}

Manger vivant et végétal pour vivre sain et dynamique ! [http://veganbio.typepad.com/veg_ anbio/manger-cru-pourquoi-comment-.html] (14.7.2015)
Ces maladies sont certes graves car mortelles à moyen ou long terme (certains chats porteurs vivent sain jusqu'à plus de 15 ans sans déclarer la maladie, d'autres ont moins de chance et vivent moins longtemps), mais ne devraient pas être vues comme des fatalités [http://www. chatslibreschambery.com/adopter/liste_des_ chats.php] (24.3.2016)

l'amour c'est comme la vie, c'est inexplicable, magique, ça ne réponds à aucune, ce n'est pas un concept cohérent, peut importe ou comment ou pourquoi, l'amour ou ça marche ou ça marche pas, ou t'es vivant ou t'es mort, et pourquoi l'un ou pourquoi l'autre, pourquoi y a des fumeur qui vivent sain et longtemps, pourquoi des gens qui ne boivent pas fume pas et attrape des cancers des poumon, pourquoi, des couples qui sont a des kilometres de distance ça marche et d'autres l'un a coté de l'autre et qui ce frittent, on a tous entendu parler de tauladrs qui se marient pendant leur peine, pourquoi ça marche, tu crois pas que c'est la magie de l'amour qui fait son œuvre? [https://fr.answers.yahoo.com/ question/index?qid=20110329150622AABEF54] (24.3.2016)

Spectacle pour enfants la semaine prochaine à Sutton! Que tous êtres vivent sains et en paix !!!!! [https://fundrazr.com/profiles/ patricianne-blanchet] (24.3.2016)

REMARQUES : Vivre sain réfère généralement à un animé qui se trouve en bonne santé, ne présente aucun signe de maladie ou qui a un rythme ou un style de vie contribuant à la bonne santé physique et morale, sans effet nocif ou néfaste sur l'organisme. Sain peut s'accorder avec le sujet, et il adopte, dans ce cas-là, la fonction de prédicat second orienté vers le sujet. Le style moins soigné documenté dans le CW peut tout de même préférer l'emploi invarié. Notons que l'emploi de la même collocation s'observe mutatis mutandis dans les exemples de 1389a et b et dans l'avant-dernier exemple du CW : vivre longuement et sain, vivre sain et longtemps. La fonction de slogan ou maxime apparaît plus clairement dans le premier exemple du CW : vivre sain et dynamique. Sain est modifié par après, moins, plus. Notons la longue série d'adjectifs associés à sain : bon, content, délicat, dynamique, juste, heureux, laborieux, libre, mieux disposé, vigoureux, vrai, sans 
parler de la collocation sain et sauf. Mentionnons également l'emploi de manger petit 'peu' ; naître délicat ; manger vivant et végétal.

\section{Vivre satisfait}

Vivre dans la satisfaction, le contentement, en se réjouissant de ce qu'on a ou de ce qu'on est Intransitif

1660 Ce revers eust peut-estre esté moins important,

Il vivroit satisfait, je serois mort content (Thomas Corneille, Stilicon)

1691 Ils [= les jeunes hommes] croient que Madrid est le centre de la gloire, des sciences et des plaisirs ; ils souhaitent en mourant à leurs enfants le paradis et puis Madrid. Et par là, ils mettent cette ville au-dessus même du paradis, tant ils y vivent satisfaits (Marie-Catherine d'Aulnoy, Relation du voyage d'Espagne)

1732 Par ce moyen, la mère et le fils vivront fort satisfaits à deux cents lieues l'un de l'autre (Alain-René Lesage, Histoire de Gil Blas de Santillane)

1796 voilà tout ce que je désire... cependant, si tu peux me trouver une place, auprès d'une dame, comme celle dont tu m'as parlé, ou seulement de l'ouvrage, je trouverai de la fermeté pour résister, et je vivrai satisfaite, comme on peut l'être dans ma position (Nicolas Rétif de la Bretonne, Histoire de Sara)

1824 enfin, une telle habitude du contentement de soi-même, qu'on ne saurait plus s'en passer, et qu'il faut vivre irréprochable pour pouvoir vivre satisfait (Joseph Joubert, Pensées, essais, maximes et correspondance)

1845 - Ici le travailleur peut se livrer sans inquiétude à l'espoir des douces joies de la famille, bien sûr de ne pas être déchiré plus tard par la vue des horribles privations de ceux qui lui sont chers ; ici, grâce à l'ordre, au travail, au sage emploi des forces de chacun, hommes, femmes, enfants, vivent heureux et satisfaits (Eugène Sue, Le Juif errant)
1855 En me renfermant à la campagne toute l'année, j'espérais vivre de Nohant, et vivre fort satisfaite en consacrant ce que je pouvais avoir de lumière dans l'âme à instruire mes enfants (George Sand, Histoire de ma vie)

1927 Goethe domine sa vie intellectuelle, la dirige, utilise même ses passions, vit satisfait à Weimar, organise son propre culte (Valéry Larbaud, Jaune bleu blanc)

1965 Nous vivions satisfaits et nous récoltions les sourires de la ville (Jacques Perry, Vie d'un païen)

\section{CORPUS WEB :}

A vrai dire, qu'est ce qui peut être plus important que de vivre satisfait de sa life ?... [http:// www.charlesdereeper.com] (24.3.2016)

Etant conscient de ce que l'on possède en Jésus Christ, nous pouvons vivre satisfait dans un monde de vanité. C'est la libération de l'Evangile! [http://leboncombat.fr/ni-prosperite-ni-pauvretelevangile-promet-le-contentement] (24.3.2016)

Conquerir rien que le marche de moscou en cafe' fini serai suffisant pour que nos planteurs vivent satisfaits [http://www.cameroon-info.net/ reactions/@,14804,7,chantal-biya-le-vrai-visageportrait-d-une-premiere-dame-objet-de-toutesles-con.html] (24.3.2016)

REMARQUES : Vivre satisfait se dit du fait d'être content de la situation dans laquelle on se trouve, qu'elle soit professionnelle, familiale, sociale ou morale, conférant au sujet un sentiment de satisfaction. Satisfait tend à l'emploi en tant que prédicat second orienté vers le sujet et accordé avec celui-ci. L'emploi invarié est une option du style moins soutenu (deuxième exemple du CW). Satisfait est modifié par fort. Notons les collocations avec irréprochable et heureux, ainsi que l'emploi de mourir content.

\section{Vivre serré}

Vivre les uns près des autres; vivre solidaire Intransitif

1974a Comme les familles vivaient serré dans le Saint-Florent de mon enfance, échangeant graines de potirons, visites, et recettes de grand-mère! (Julien Gracq, Lettrines 2) 
1974b Les figures qui peuplent la Divine Comédie sont celles de la chronique tragique, scandaleuse, et politique, d'un simple canton ou d'une petite ville, où tout le monde vit serré (Julien Gracq, Lettrines 2)

\section{CORPUS WEB :}

Le japon c'est pas ce que tu vois à la télé, certes c'est beau mais les gens vivent serré comme des fourmis, tu dors dans des chambres de $2 m^{2}$ :D tu dois travailler tout les jours (très peu de congés), la bouffe est bonne, mais le travail et la pression sont énorme sans parlé des risque d'éruptions volcaniques, de tremblements de terres, de Tsunami de tempête etc... [http://www. jeuxvideo.com/forums/1-50-171773890-1-0-1-0vivre-au-japon.htm] (24.3.2016)

ils ont plus de 4000 euro de revenu. mais en plus ils payent la creche 500 euro. ils vivent serré : pas de vacances, pas de loisirs, ils doivent de l'argent à pas mal de monde [http://forum. doctissimo.fr/grossesse-bebe/ramadanettes/ loyer-700e-sujet_31641_4.htm] (24.3.2016)

Dans les camps qui sont apparus dans toute la ville depuis le séisme dévastateur du 12 janvier, l'accès à l'eau s'est lentement amélioré. Des camions-citernes font le tour des parcs où des survivants vivent serrés comme des sardines, et où des réservoirs souples et des citernes à eau comme celles de l'Asile ont été installés [http://reliefweb.int/report/haiti/ha\%C3\%AFtiapprovisionnement-en-eau-et-dignit $\% \mathrm{C} 3 \% \mathrm{~A} 9$ retrouv $\% \mathrm{C} 3 \% \mathrm{~A} 9 \mathrm{e}$-pour-les-personnes- $\% \mathrm{C} 3 \%$ A2g\%C3\%A9es] (24.3.2016)

Les petits Franciliens vivent serrés

Selon une étude de l'Insee rendue publique aujourd'hui, un quart des enfants vivent dans un logement surpeuplé en Ile-de-France. L'étude indique que les familles monoparentales sont plus touchées [http://www.20minutes.fr/ paris/286367-20090107-286367] (24.3.2016)

REMARQUES : En parlant d'une personne, vivre serré se dit du fait d'habiter de manière très rapprochée les uns des autres, ou solidaires. Dans le deuxième exemple du CW, vivre serré signifie 'vivre parcimonieusement'. Contrairement à d'autre adjectifs combinés avec le verbe vivre, serré tend à l'emploi invarié, assez exceptionnel pour un participe passé, mais l'accord reste possible.

\section{Vivre seul}

Vivre sans partenaire

$\lambda$ vivre pauvre

\section{Vivre simple}

Vivre simplement, sans complications

Intransitif

1775 Il faut donc, s'il se peut, ramener tous les peuples à cet état où nos bons aïeux ne connoissoient ni les nœuds du mariage, ni les liens du sang. "Leurs unions se formoient au hazard,... etc. » Dans sa première origine, avec cette manière de vivre simple et solitaire, il n'avoit point à réfléchir, à raisonner ; il n'étoit fait que pour sentir (Philippe-Louis Gérard, Le Comte de Valmont ou Les Égaremens de la raison)

1802 Peuples qui voulez long-tems la félicité et l'abondance universelle, vivez paisibles, simples et bons, sans sciences comme sans erreurs, jouissans mais sans faste, indépendans mais sans opprimer, heureux de vos avantages et non de la ruine universelle (Étienne de Senancourt, Rêveries sur la nature primitive de l'homme)

1885 Le Président de la République, habit noir, pas de décorations, pas d'aides de camp, pas de chevaux, pas de panache. Vit simple, modeste, fier. Entre pauvre et sort pauvre. N'accorde aux princes que ce qu'il en reçoit. Dit monsieur au roi d'Angleterre et à l'empereur d'Autriche (Victor Hugo, Choses vues)

1896 On vit simple, comme on naît simple, comme on aime

Quand on aime vraiment et fort, et comme on hait

Et comme l'on pardonne, au bout, lorsque l'on est

Purement, nettement simple et l'on meurt de même,

Comme on naît, comme on vit, comme on hait, comme on aime !

(Paul Verlaine, Euvres poétiques complètes) 


\section{Corpus Web :}

Les habitants vivent simple. ils endurent mais ils sont heureus.Les habitants sont tres genereux [https://www.facebook.com/permalink. php?story_fbid $=348671982595 \& i d=250197727595$ ] (23.3.2016)

bah ils vivent simple je sais pas il y a de la baraka ds leur argent la voiture qu ils ont, est simple un scenic pr toute la clique mdr [http:// www.yabiladi.com/forum/mariee-foyer-maison3-5116827-page $=5 . h t m l] ~(23.3 .2016)$

« Les riches qui vivent simples ... j'adore, dit l'un des internautes qui ajoute... les classes pauvre et moyennes devraient apprendre d'eux... aimer la famille Obama » [http://www. lactuacho.com/malia-obama-fille-de-barack-oula-simplicite-personnifiee] (23.3.2016)

REMARQUES : Vivre simple se dit du fait de vivre naturellement, sans apprêts, sans complications, d'une manière sans détours ni affectation. Simple peut s'accorder avec le sujet et adopter la fonction de prédicat second orienté vers le sujet, mais l'emploi invarié est également possible (deux premiers exemples du CW). À l'infinitif, il tend à former un verbe complexe vivre simple, jouant le rôle de slogan ou d'appel. Notons la coordination de simple avec de nombreux autres adjectifs-adverbes : bon, fier, modeste, paisible, solitaire. Mentionnons également les collocations suivantes : entrer pauvre et sortir pauvre, naître simple et vivre simple, aimer vraiment et fort.

\section{Vivre soef}

Vivre agréablement

Intransitif

+1400 Qu'en puis je mais, se je pleure et souspire Mon ami mort, et quelle merveille est ce ? Car quant mon cuer parfondement remire Comment souef j'ay vescu sans asprece Trés mon enfance et premiere jeunece Avecques lui, si grant doulour me mord Qu'a tousjours mais je pleureray sa mort (Christine de Pisan, Cent balades / Euvres poétiques [début $\mathrm{XV}^{\mathrm{e}}$ ], I, p. 15, 11)

REMARQUES : Vivre soef se disait du fait de mener une vie agréable, tranquille, sans problèmes, procurant au sujet une certaine satisfaction.

\section{Vivre solidaire}

Vivre en s'appuyant mutuellement, dans un même esprit

Intransitif

1778 L'amitié rend tout commun entre nous ; les chagrins, les plaisirs ne sont plus à l'un des deux ; nous vivons solidaires (Lagrange, Les Euvres de Séneque le philosophe [trad.])

1878 Ces Oiseaux, ornés de couleurs brillantes, vivent solidaires sur le bord des fleuves et des ruisseaux (Carl Claus, Traité de zoologie [trad.])

1911 Sous bois flore et faune vivent solidaires, à bénéfices mutuels (André Jacquot, $\mathrm{La}$ Forêt, son rôle dans la nature et les sociétés)

1961 Certes, à l'âge adulte, l'échelle changeait, mais le problème restait le même et ils voulaient vivre solidaires dans des communautés naturelles dont ils espéraient retrouver les contours et la réalité (Jean Peyrade, Scouts et guides de France)

2010 Tout être éprouve le besoin de vivre solidaire (Jean B. Murhega, La Problématique de la mondialisation en Afrique noire)

\section{CORPUS WEB :}

Tandis que les fils de dieu vivent solidaire dans la souffrance sur terre et obtiendront le salut après leur mort ou voient au dela de la mort [https://www.jeuxvideo.com/forums/151-9574018-937-0-1-0-qg-des-quasimodo.htm] (10.05.2010)

Aller voir à l'etranger comment ils vivent solidaire sans ces complexes de regionalisme [https://www.businessnews.com.tn/affairekamel-letaief-saison-2] (23.12.2013)

REMARQUES : Vivre solidaire réfère à un comportement social où la communauté d'esprit se manifeste dans des actes de solidarité, sans égoïsme. Solidaire tend à l'accord avec le sujet du verbe, mais l'accord est absent dans les exemples du CW. 


\section{Vivre souriant}

Vivre avec gaieté, bonne humeur, optimisme Intransitif

1856 J'ai vécu souriant, toujours plus adouci, Debout, mais incliné du côté du mystère (Victor Hugo, Les Contemplations)

1888 Elle y vivait souriante, sans retrouver la santé pleine d'autrefois, toujours blanche et immatérielle comme sous les saintes huiles, allant et venant d'un petit pas de vision, se reposant, songeuse, pendant des heures, d'avoir fait quelque longue course, de sa table à sa fenêtre (Émile Zola, Le Rêve)

1980 Accord intime d'une société à bout de course et d'une fatigue personnelle de vivre encore souriante, qui pressent la sclérose finale d'un monde, y place ses complaisances et lui confie son repos (Julien Gracq, En lisant, en écrivant)

CoRpus Web :

La Salsa Cubaine est originaire des rues de Cuba. Là-bas, la danse est un art de vivre. Une façon de vivre souriant et heureux [http://www. ultrafitness.fr/cours-de-danse-selestat/salsa] (23.3.2016)

D'autres, vivant en communauté sont protégés sous un dôme de Lumière. Ni le ciel obscur, ni le gel ne peuvent les atteindre. Ils sont protégés et continuent à vivre souriant dans leur foi [http://etredelumiere.ordi-netfr.com/ LesprophetiesdeDrunvalo.php] (23.3.2016)

REMARQUES : Vivre souriant réfère à la joie de vivre, à la bonne humeur, à la gaieté, l'amabilité que transmet ou véhicule un sourire, suggérant l'épanouissement radieux ou enjoué du sujet, sa vision optimiste de la vie. Souriant tend à l'emploi comme prédicat second accordé, mais il reste invarié dans le dernier exemple du CW.

\section{Vivre sûr}

Vivre en toute sécurité, en sûreté ; vivre dans la sécurité matérielle Intransitif

-1334 Je me vorroie bien gagier, Nus ne la poroit damagier. Plus aise en vif et plus sëur.
Du mirëoir n'ai ge pas peur,

Qu'il o[s]curasse nullement (Le Romans de la dame a la lycorne [1 ${ }^{\mathrm{er}}$ tiers XIV $\left.\left.\mathrm{X}^{\mathrm{e}}\right], 1534\right)$

1567 Pource un tyran ne vit jamais bien seur : Le vray bouclier d'un prince est la douceur (Pierre de Ronsard, Le Bocage royal, p. 363)

1604 S’il dépend de la main d'un seul homme vaillant,

Qui s'offre à tous hazards sans crainte de la Parque.

Mortels, voyez ici que pour estre

Monarque,

Empereur, Capitaine, on ne vit pas plus seur

De tromper les ciseaux de la fatale sœur, Qui sans aucun respect en la tombe devale La houlette champestre et la verge Royale (Antoine de Montchrestien, Hector)

1942 Que je voudrais lui donner de sa mère une idée qui le préserve de tout toute sa vie ! Il s'agit d'être encore plus stricte avec soi, de se sauver de toute bassesse, de vivre droit, sûr, net et pur, pour qu'un être puisse garder plus tard l'image la plus belle possible de vous, tendrement et sans reproche (Henry de Montherlant, La Reine morte)

1996 Peut-être sort-il des gémissements de chaque page ? Et les poèmes, les forcer, les déclouer, fût-ce deux, trois vers : Quel baptême m'a chassé de Sion ? / Moi fait pour vivre sûr / Non pour survivre / De perdition en perdition. Le froid des jours. Sa nostalgie, à chaque automne, des arbres dorés. Tant que l'automne imite l'été, il y pense à peine (Boris Schreiber, Un silence d'environ une demi-heure)

REMARQUES : Vivre sûr se dit du fait de vivre avec un sentiment de sécurité matérielle, d'avoir un état d'esprit confiant et tranquille qui résulte du sentiment, bien ou mal fondé, que l'on est à l'abri de tout danger ou des soucis financiers. Vivre sûr tend à la lexicalisation comme verbe complexe, surtout à l'infinitif. L'accord constitue la règle. Sûr est modifié par bien, plus. Il se combine avec aise, droit, net pur. 


\section{Vivre tranquille}

Vivre tranquillement, calmement, paisiblement, librement

Intransitif

1662a Elle [= âme en pénitence] se réjouit parmi ses larmes ; elle voit qu'elle trouvera dans l'asile d'une bonne conscience une retraite assurée, que nulle violence ne peut forcer : si bien qu'elle peut sans crainte y retirer ses pensées, y déposer ses trésors, $\mathrm{y}$ reposer ses inquiétudes, et, quand tout l'univers serait ébranlé, y vivre tranquille et paisible à l'abri d'une bonne conscience et « sous les ailes du Dieu » qui y préside (Jacques-Bénigne Bossuet, Sermon sur l'efficacité de la pénitence)

$1662 \mathrm{~b}$ et quelquefois il [= Dieu] permet aussi que les pécheurs se sentent attirés au bien, qu'ils semblent même y donner les mains, qu'ils vivent tranquilles et assurés, et, par un juste jugement, c'est leur propre assurance qui les précipite (Jacques-Bénigne Bossuet, Sermon sur l'intégrité de la pénitence)

1684 Il en est demesme de la pluspart des Marchands qu'on appelle Banyanes, quels que riches qu'ils soient leur nourriture n'est ni plus abondante, ni plus delicieuse que celle des Bragmanes, et cependant ils vivent dumoins aussi tranquuilles [sic], aussi joyeux, et aussi contens que nous, beaucoup plus sains, dumoins aussi forts et aussi robustes (François Bernier, Abrégé de la philosophie de Gassendi)

1719 Un des amis de Théophile,

Disons l'ami ; de tels on n'en a qu'un,

Pleine ouverture entr'eux, vivre ensemble et tranquille,

Zèle impatient d'être utile,

Tristesse, joie, honneurs, tout étoit en commun

(Antoine Houdar de La Motte, Fables)

1731 L'amour est une passion innocente ; comment s'est-il changé, pour moi, en une source de misères et de désordres ? Qui m'empêchait de vivre tranquille et vertueux avec Manon ? Pourquoi ne l'épousais-je point, avant que d'obtenir rien de son amour ? (abbé Prévost, Histoire du Chevalier des Grieux et de Manon Lescaut)

1755 Apprenez-moi, cher docteur, comment les téméraires vivent si tranquilles, lorsqu'avec tant de précautions pour éviter l'embarras, et tant d'éloignement pour toute sorte d'offenses, à peine suis-je parvenu à me dégager d'une difficulté, que je retombe dans une autre (abbé Prévost, Nouvelles Lettres angloises [trad.])

1776 Vous me croyez dans l'erreur ; si vous êtes conséquent, vous devez vous y croire aussi, car vous ne pouvez franchir le doute ; vaincu par votre propre raisonnement, vous êtes réduit à nier, et j'ai l'avantage sur vous, qu'en me traçant un plan assuré de croyance et de conduite, relative à cette croyance, je vis certainement plus tranquille que vous (Louis-Sébastien Mercier, Jezennemours)

1784 « Mes enfants, les jours du méchant sont remplis d'alarmes. Le repos n'est fait que pour l'homme de bien. C'est lui seul qui vit et meurt tranquille » (Denis Diderot, Entretien d'un père avec ses enfants)

1814 Unis entre eux par les plus doux liens, ils vivent tranquilles, et ils meurent en paix ; ils n'honorent point un dieu fait par la main des hommes, mais ils adorent l'auteur de la nature dans la nature même (Bernardin de Saint-Pierre, Harmonies de la nature)

1816 Mon ouvrage y perd, mais je suis un peu refroidi, non pas sur l'idée de le publier, mais sur celle de presser l'époque de cette publication. Il en sera meilleur, et j'en $v i$ vrai plus longtemps tranquille (Benjamin Constant, Journaux intimes)

1831 Cela vous mène à tout, même sans camaraderie, et sans que la personne paraisse le moins du monde. Je n'ai affaire qu'à M. Delatouche, et je vis toujours tranquille et retirée. Je vais au spectacle presque tous les soirs avec les loges qu'il me donne. C'est très agréable. Je suis enrhumée ce qui ne l'est pas du tout (George Sand, Correspondance) 
1833 « vous n’avez pas, comme Trenmor, écrasé votre sensibilité sous la méditation ; vous n'avez pas, comme lui, tué vos passions de sang-froid pour vivre fier et tranquille sur leurs débris. Et vous n'avez pas non plus, comme Lélia... » elle oublia d'articuler sa pensée et, le coude appuyé sur le mausolée, l'œil immobile sur les flots, elle n'entendit pas Sténio qui la suppliait de se révéler à lui (George Sand, Lélia)

1840 Il y a des hommes qui, sans rien avoir, établissent leur ménage ; ils empruntent, ils font valoir, ils s'intriguent, ils paieront quand ils pourront : en attendant, ils vivent et dorment tranquilles, quelquefois même ils réussissent (Étienne de Senancour, Obermann)

1846 - Oh ! reprend le cafetier avec aigreur, je ne m'étonne pas que tu portes des cornes, tu es capon.

- Je suis honnête homme, tu es jaloux. Je vivrai tranquille, tu mourras malheureux. Bonne nuit (Alexandre Dumas père, Le Comte de Monte-Christo)

1857 J'étais résigné à souffrir, mais voir le supplice de Mary-Ann était chose au-dessus de mes forces. Je me levai résolûment et je dis à nos importuns : « Allez-vous-en tous ! Le roi nous a logés ici pour vivre tranquilles jusqu'à l'arrivée de notre rançon. » (Edmond About, Le Roi des montagnes)

1866 Il faut le reconnaître bravement, et dire à la providence : mon général, ma vie est à toi ; indique-moi la manière la plus utile et la plus belle de la dépenser à ton service et pour ta gloire. Vivre longtemps et tranquille, c'est une variante de l'égoïsme. Vivre fortement et bien mourir, c'est le devoir, c'est la noblesse de l'homme (Henri-Frédéric Amiel, Journal intime de l'année 1866)

1874 Félicité l'ayant questionné directement, il se contenta de dire qu'il n'habiterait pas la cure, qu'il préférait le logement où il vivait si tranquille, depuis près de trois ans (Émile Zola, La Conquête de Plassans)
1884 On lui avait soupçonné quelques amours capables de donner fort bonne opinion d'un garçon. Il vivait heureux, tranquille, dans le bien-être moral le plus complet. On savait qu'il tirait bien l'épée et mieux encore le pistolet (Guy de Maupassant, Contes et nouvelles)

1904a PAULOT. Non, rien.

RICHARD. Je vois tes grands yeux bleus qui essayent de me percer... Rassure-toi. Si je dis que nous devons moi agir et toi te taire, tu peux vivre tranquille et sans émotion (Henry Bataille, Maman Colibri)

1904b 5 octobre.

Promenade de long en large sur la terrasse du jardin. Le chat noir et le blanc, assis sur le mur, regardent tomber la nuit et écoutent s'éveiller le monde des ténèbres. Ils veulent vivre tranquilles, et, moi, je veux les moraliser. " Qu'est-ce qu'il a à nous embêter, celui-là ? » J'écris peu, mais je vivrai si longtemps! (Jules Renard, Journal)

1922 On l'aurait cuisiné. On l'aurait fait parler... $\mathrm{Au}$ lieu de cela, que se passait-il donc ?... Lampieur vivait parfaitement tranquille. On ne s'occupait pas de lui... Aucun soupçon ne l'effleurait... Léontine dirait-elle le contraire ? (Francis Carco, L'Homme traqué)

1937 J'appellerais volontiers hommes libres les gens qui ne demanderaient pas mieux que de vivre et mourir tranquilles, mais qui reprochent à votre civilisation colossale de bluffer la vie et la mort, d'en faire un objet de risée (Georges Bernanos, Les Grands Cimetières sous la lune)

1938 Bref, j’ai filé de Palestine sans même voir les amis qui m'auraient traité de lâche ! Et je suis retourné à Céphalonie vivre tranquille et souriant, loin des batailles qui ne sont pas mon fort ! Telle est mon histoire, monsieur le président républicain ! (Albert Cohen, Mangeclous)

1943 GEORGES. Rentrer dans le Paris de l'armistice, au début de l'hiver, dans le Paris 
du froid sans chauffage, des restrictions, de l'occupation, des bombardements peut-être, quand on peut vivre si tranquille à Cannes ! (Henry de Montherlant, Fils de personne)

1945 Henriette était un peu comme cette mère : pendant qu'elle cherchait, qu'elle prenait des trains et des autobus, qu'elle faisait des kilomètres à pied pour qu'Alexis pût enfin travailler et vivre tranquille, il était en train de mourir ! Elle ne se faisait pas à cette idée, à cette horreur, elle dut même s'aliter (Elsa Triolet, Le Premier Accroc coûte deux cents francs)

1985 Les années passent. Tu n'es pas là. Je me demande quelquefois si tous ces efforts que nous avons faits, toi et moi, étaient vraiment nécessaires. Nous aurions pu vivre heureux et tranquilles à Arroyo Verde. Oui, nous aurions pu... Il ne faut rien regretter et je suis fière de tes succès. Mais l'envie me vient de t'avoir auprès de moi (Jean d'Ormesson, Le Vent du soir)

1987 En un sens, elle ressemble à sa mère, qui vivait parfaitement tranquille en gérant un volcan. On s'agite un peu sur le divan, j'arrête... (Philippe Sollers, Le Cour absolu)

\section{CORPUS WeB :}

Les Nords-Coréens vivent tranquille et en paix, je n'écoute pas les médias occidentaux personnellement qui veulent rattacher ce pays aux « joies » du consumérisme de masse et à la décadence des mœurs [http://www.jeuxvideo.com/ forums/42-51-41911110-1-0-1-0-la-coree-du-nordmeilleur-pays-au-monde.htm] (23.3.2016)

il paraitrait qu'il y aurait en France plein de petits Mérat qui vivent tranquille et trafiquent en toute impunité. Marseille ville tranquille, la Corse île tranquille.Les banlieues zone de vie tranquille [http://www.bfmtv.com/politique/neo-naziarrete-en-correze-ni-cible-ni-projet-identifie-ditvalls-400446/avis/?page=16] (23.3.2016)

En 2014, beaucoup de gens vivent tranquilles en France. Ils travaillent, ont un salaire, partent en vacances, ont des loisirs... [http://fr.soc.politique. narkive.com/3q55V8dI/beaucoup-de-gensvivent-tranquilles-en-france-texte-sur-1-indif ference] (23.3.2016)
Petit résumé rapide de l'histoire : Tout va pour le mieux pour nos jouets préférés qui vivent tranquilles dans leur nouveau foyer, Woody et Buzz ne sont plus rivaux mais d'inséparables partenaires, un beau jour alors que Woody devait accompagner Andy en camps de vacance, l'un de ses bras se déchire au cours d'un « accident de jeux » ainsi il doit faire une croix sur ses vacance [http://www.allocine.fr/film/fichefilm-22323/ critiques/spectateurs] (23.3.2016)

Remarques : Vivre tranquille se dit du fait de mener une vie calme, exempte d'agitation et de troubles qui affectent l'existence, le sujet ayant trouvé la paix intérieure et une certaine sérénité. Il peut aussi référer à une vie retirée, sauvage où le sujet n'est pas dérangé par autrui. Dans le style soutenu, tranquille s'accorde avec le sujet, tandis qu'il est possible de renoncer à l'accord dans un registre plus familier (v. les premiers exemples du CW). Tranquille est modifié par aussi, parfaitement, plus, plus longtemps, si, toujours. Il est coordonné avec de nombreux adjectifs en prédication seconde : paisible, assuré, joyeux, content, vertueux, retiré, fier, heureux, souriant. Notons les collocations suivantes : vivre et mourir tranquille, vivre et dormir tranquille, travailler et vivre tranquille, vivre longtemps et tranquille et l'emploi de mourir malheureux. VoIR AUSSI : dormir/mourir/ travailler tranquille

\section{Vivre triste}

Vivre dans la tristesse, dans la mélancolie Intransitif

1416 Neantmoins a l'autre demourray, Et triste vivray et mourray Tresloing en l'ombre D'Espoir dont j'ay en petit nombre (Alain Chartier, Le Livre des quatre dames, p. 265, 2253)

1604 Tu le livres aux fers des Nations estranges, Afin que par leurs mains ton honneur tu revanges,

Qui fut cent fois foulé par ce peuple insolent.

En dure servitude il vit triste et dolens ; Que di-je il vit, Seigneur ! las il ne doit plus vivre (Antoine de Montchrestien, Aman) 
1606 Après avoir dit : n'espère plus de vivre, il ne devoit plus dire, ni banis-toi de toi-même, ni ce qui vient après ; car après qu'on ne vit plus, il n'est plus question de vivre triste ni joyeux (François de Malherbe, Commentaire sur Desportes)

1835a Je vis triste mais si occupé, ou plutôt si ennuyé, qu'une heure ne me reste pas pour penser à moi (Alphonse de Lamartine, Correspondance générale)

1835b Depuis mon retour de mon long et malheureux voyage dans l'Orient, seul, sans enfants, sans avenir, je vis triste et malheureux (Alphonse de Lamartine, Correspondance générale)

1855 Il fallait me dire aussi comment ma mère avait racheté le passé, comment elle avait aimé fidèlement mon père, comment, depuis sa mort, elle avait vécu humble, triste et retirée (George Sand, Histoire de ma vie)

1878 Une voix.

Ne crois pas que les habitants

Des sphères où tu te fourvoies,

$\mathrm{Y}$ vivent tristes ou contents

Par nos douleurs ou par nos joies :

Autres sphères, autres désirs !

(Armand Sully Prudhomme, La Justice)

1882 MARIE. Oh ! Monsieur Teissier, j’ai bien assez de mes peines sans que vous veniez les augmenter encore. Vous voulez savoir ce que j'ai pensé, je vais vous le dire ; j’ai pensé que vous n'étiez plus jeune, que vous viviez bien triste et bien isolé, que vous n'aviez pas d'enfants et que vous vous plaisiez avec ceux des autres (Henry Becque, Les Corbeaux)

1995 Seigneur, Toi qui es mon rocher, pourquoi m'oublies-Tu

Pourquoi dois-je vivre triste et opprimé (Georges Convert, Prière quotidienne en église)

\section{CORPUS WeB :}

Du coup jai crisé, vraiment fait une crise en plus enceinte... mais ça me fait tellement de mal, d'avoir un mari, sans en avoir un vrai, de se sentir seule, de vivre triste... [http://www.yabiladi.com/ forum/triste-mari-pour-famille-70-5764052.html] (23.3.2016)

Johnny Depp et Vanessa Paradis «vivent tristes et séparés »: Le couple qu’ils formaient depuis... [https://twitter.com/dakaractu/status/160 071932023287808] (23.3.2016)

et de toute façon les cœurs désséchés vivent tristes... [http://www.jeuxvideo.com/forums/ 1-52-915569-2-0-1-0-0.htm] (23.3.2016)

La vie est belle pour la vivre triste [http:// www.moipourtoi.com/la-vie-est-belle-pour-lavivre-triste Ledoux17.htm] (23.3.2016)

REMARQUES : Vivre triste désigne une personne qui se trouve dans un état d'abattement, qui ne peut éprouver de gaieté, de joie en raison d'une douleur particulière, d'une peine, d'une préoccupation, lui conférant un sentiment d'insatisfaction, de mal-être, de souffrance. Triste fonctionne comme prédicat second accordé avec le sujet. Notons l'emploi transitif du verbe dans le dernier exemple du CW. Triste est souvent coordonné avec d'autres adjectifs : dolens, joyeux, occupé, malheureux, humble, retiré, content, opprimé. Il est modifié par bien. Mentionnons la collocation vivre et mourir tranquille. VOIR AUSSI : mourir triste

\section{Vivre vertueux}

Vivre vertueusement, selon la morale Intransitif

1588 Et de peur qu'estant nay, de faim il ne perisse

Ains à fin qu'il s'accroisse et qu'en nous il florisse

Continuons tousjours à vivre vertueux

(Anne de Marquets, Sonets spirituels)

1730 JOCASTE. (se frappant) Et moi, je me punis.

Par un pouvoir affreux réservée à l'inceste, La mort est le seul bien, le seul dieu qui me reste.

Laïus, reçois mon sang, je te suis chez les morts :

J'ai vécu vertueuse, et je meurs sans remords (Voltaire, Edipe)

1784 et pendant que les historiens de chaque nation, bien payés, élèvent au ciel les victoires de leurs rois et de leurs pontifes, les 
peuples s'adressent, en pleurant, au dieu du genre humain, et lui demandent où est la voie qu'ils doivent suivre pour se diriger vers lui, et pour vivre heureux et vertueux sur la terre (Bernardin de Saint-Pierre, Études de la nature)

1824 Nous respectons malgré nous ceux que nous voyons respectés. Il serait difficile de vivre méprisé et vertueux : nous avons besoin de support (Joseph Joubert, Pensées, essais, maximes et correspondance)

1847 « Le lendemain du jour où vous vous serez lavée dans les eaux du baptême, vous reverrez Lucien, et si vous croyez pouvoir vivre vertueuse en vivant pour lui, vous ne vous séparerez plus. » (Honoré de Balzac, Splendeurs et misères des courtisanes)

1862 Reste monsieur le maire, reste honorable et honoré, enrichis la ville, nourris des indigents, élève des orphelins, vis heureux, vertueux et admiré, et pendant ce temps-là, pendant que tu seras ici dans la joie et dans la lumière, il y aura quelqu'un qui aura ta casaque rouge, qui portera ton nom dans l'ignominie et qui traînera ta chaîne au bagne ! (Victor Hugo, Les Misérables)

1982 Tout cela était très gentil, mais Lydia se sentait un peu détachée de cette petite famille qui vivait vertueuse, cossue, sans histoire. Elle ne s'était pas retrouvée en ce garçon robuste et placide, qui ne rappelait non plus personne de sa lignée (Suzanne Chantal, Ervamoïra)

\section{CORPus Web :}

Il est facile de vivre vertueux dans un monde opulent et ouvert. Mais vivre vertueux dans un monde misereux et fermé ça c une autre histoire malheureusement [http://www.bladi.info/ threads/infanticide-taounate.40471/page-2] (23.3.2016)

... Elle aura un fils, que tu appelleras Jésus. Il mènera les hommes sur le chemin que lui montrera Dieu, pour qu'ils vivent honnêtes et vertueux » [http://osee.unblog.fr/2008/12/15/bonnenouvelle] (18.4.2016)
REMARQUES : Vivre vertueux réfère à un comportement, à l'idéal de vie du sujet, qui se caractérise par la volonté permanente de se porter volontairement vers le bien, vers son devoir, de se conformer à un idéal moral, religieux, en dépit des obstacles qu'il rencontre. Vertueux est un prédicat second qui s'accorde avec le sujet. Notons la coordination de vertueux avec de nombreux adjectifs : cossu, heureux, méprisé, admiré.

\section{Vivre vrai}

Vivre réellement, véritablement, vraiment ; vivre de manière authentique

Intransitif

1946 Être réelle, pour Katherine Mansfield, c'était vivre vrai et penser vrai (Odette Lenoël, La Vocation de Katherine Mansfield)

Transitif

1963 Ces sujets éternels, ces dieux, personnages de fiction ou d'Histoire, tous ces drames, tragédiantes, comédiantes, légendes, mythes de ceci cela, Prométhée, Antigone, Tartuffe, Néron, la fille Élisa et l'adjudant Flick, je les avais connus comme le suspense Hitchcockien, vécus vrai pour ainsi dire, bien avant de les rencontrer dans les livres (Alphonse Boudard, La Cerise)

REMARQUES : Vivre vrai se dit du fait de vivre en restant authentique, fidèle à soi-même, ou de vivre en se lançant dans ce que l'on pense être la vraie vie. Vrai reste invariable. La tendance à l'emploi invarié est due au fait que vrai ne réfère pas nécessairement au sujet mais à son mode de vie. À l'instar de penser vrai, où vrai s'associe aussi bien au contenu de la pensée qu'à l'attitude de celui/celle qui pense (v. l'exemple de 1946), vivre vrai peut tout simplement référer à l'authenticité de la vie, au fait d'assister 'sur le vif' à quelque chose.

\section{Voiler long}

long voilé / voilé long : recouvert d'un long voile Transitif

+1829 Madrid, quand tes taureaux bondissent, Bien des mains blanches applaudissent, Bien des écharpes sont en jeux.

Par tes belles nuits étoilées, 
Bien des senoras long voilées

Descendent tes escaliers bleus

(Alfred de Musset, Madrid / Premières

Poésies [1829-1835])

1854 Des señoras long voilées filaient sous les arcades, l'éventail d'une main, le paroissien de l'autre, se rendant à la messe ; la fumée des papelitos montait en spirales (M. Oduaga-Zolarde, Les Courses de taureaux expliquées)

1922 Le monument de Titien ne fut jamais exécuté, mais il en avait fixé l'idée dans un dessin conservé au musée Correr de Venise. A la base et au centre d'une haute pyramide, une porte s'ouvrait sur l'autre monde, vers laquelle, gravissant les degrés, des femmes long voilées, portant l'urne et les attributs de la peinture dont elles mènent le deuil, s'acheminent en un lent cortège (André Michel, Canova et le retour à l'Antique)

1958 Pour une personne en deuil, tu n'es pas voilée bien long. Je te trouve voilée... plutôt guilleret (Exemple entendu, 8 juillet 1958 / Grundt : 320)

REMARQUES : Voiler long réfère à une personne en deuil dont le visage ou une partie du corps est recouvert d'une longue pièce d'étoffe. Long reste invariable et est modifié par bien. Le participe long voilé suit un schéma usuel (à comparer : court / long vêtu) et tend à la lexicalisation.

\section{Voir bas}

Se sentir abattu ; se sentir rabaissé

Pronominal

1659 Quand je me vy si bas, si mal mené, De mes amis par tout abandonné, « Adieu, disois-je en fondant tout en larmes, Adieu, Paris, dont j'adorois les charmes ! » (François de Boisrobert, Épistres en vers)

1850 - J'ai celle [=l'hypothèque] de Courtecuisse, et je veux le ménager, car c'est le meilleur tireur du département ; en te la transportant tu aurais l'air de tracasser ce drôle-là pour le compte du Tapissier, et ça ferait d'une pierre deux coups, il serait capable de tout en se voyant plus bas que Fourchon (Honoré de Balzac, Les Paysans)

1877 Les jours suivants, Lantier eut beau recommencer ses litanies, Gervaise répondait qu'elle s'était vue plus bas et s'en était tirée. La belle avance, lorsqu'elle n'aurait plus sa boutique ! Ça ne lui donnerait pas du pain (Émile Zola, L’Assommoir)

1936 C'est le premier de mes livres qui naît par le cœur... ce livre en moi et des romances en l'air, celui qui aimera ce que j'ai écrit n'aura qu'à fermer les yeux pour les retrouver. Je ne m'étais jamais vu si bas. Mon amour ne serait pas allé si loin s'il n'avait caché, sous la plus authentique crise sentimentale, une grave crise intellectuelle (Joë Bousquet, Traduit du silence)

REMARQUES : Du point de vue de l'état physique, de la santé, se voir bas se dit du fait de ne pas se sentir bien, d'être faible. Il peut aussi référer à la hiérarchie morale ou sociale et souligner le fait que le sujet se sent rabaissé, à un niveau inférieur. Bas reste invariable et est modifié par plus, si.

\section{Voir beau}

I. voir bel/beau et clair : voir bien, distinctement, clairement

Transitif

1177 Et ja estoit pres none basse, N'ancor ne se mue ne lasse Li chevaliers de son panser. Li chevaus voit et bel et cler Le gué, qui mout grant soif avoit : Vers l'eve cort quand il la voit (Chrestien de Troyes, Lancelot ou Le Chevalier de la charrete, 742)

Emploi absolu

1465 En la quelle vous existent, Longins le chevalier vous perça vostre cousté par la induction des Juifs, et quant il creut en vous, aprés ce qu'il eut lavé ses yeulx de vostre precieux sang, il vit beau et cler et vous crya mercy, dont il eut saulvement (Jehan Bagnyon, L'Histoire de Charlemagne, p. 51) 
II. voir beau à faire quelque chose : penser que c'est le bon moment pour faire quelque chose Transitif

1686 mais qu'en attendant cela ils se gardassent bien de le dire, que ce devoit être un Mistere entre eux à faire éclorre seulement lors qu'ils seroient les plus forts, et à cacher soigneusement sous une modération, et une patience la plus comédienne qu'ils pourroient, afin qu'on n'en soupçonnât rien, à peu près comme un assassin, qui ne veut pas qu'on se défie de lui, cache soigneusement son poignard ou son pistolet dans sa poche, et ne le tire que quand il voit beau à faire son coup (Pierre Bayle, Commentaire philosophique sur ces paroles de Jésus-Christ " Contrain-les d'entrer »)

III. Voir le beau côté des choses

Emploi absolu

1914 La famille qui descend du prophète (d'une fille) avait trois cent mille francs de rente, s'est ruinée en clientèle, en cadeaux. Lamartine malgré son désir de voir beau a vu cet intérêt, ce côté mercenaire de l'Orient : les émirs qui fêtent et abandonnent lady Stanhope (Maurice Barrès, Mes cahiers)

\section{CORPUS WEB :}

Pour le golf de Baugé, les annonces sont gigantesques : 210 villas, un hôtel quatre étoiles, un restaurant gastronomique... Andersen Construction, l'investisseur, voit gros (110M€) et beau [http://www.lejournaldesentreprises.com/ editions/49/actualite/fait-du-mois/implantationcortizo-le-gros-coup-de-la-rentree-10-09-2010101951.php] (9.3.2016)

À une époque où le virtuel remplace de plus en plus le réel, il est bon de constater qu'il y a encore des lieux où l'on peut se retrouver pour mettre de l'avant des projets concrets, comme celui des bâtisseurs qui ont érigé cette cathédrale, et qu'il est toujours possible de s'élever au-dessus de l'horizon, de faire communauté et faire preuve de générosité lorsque vient le temps de voir grand, de voir beau et surtout de vivre ensemble notre Histoire et notre fierté ! [http:// cathedralemoncton.com] (15.3.2016)

REMARQUeS : Dans son emploi concret, voir beau (I) réfère à une personne ou à un animal qui dis- tingue clairement et distinctement une chose ; l'ancien français emploie alors le neutre bel. Expression usitée au xviI siècle, (II) renvoie au moment qui convient ou qui se prête le mieux pour la réalisation de quelque chose. (III) se dit du fait de considérer quelque chose, une situation, un contexte de manière positive, sous un jour favorable, soulignant l'optimisme du sujet. Voir beau s'insère dans la série voir grand, clair, etc. Voir est modifié par plus, si.

\section{Voir bête}

Voir, percevoir les choses de manière stupide Transitif

1869 Qu'est-ce que cela veut dire, la réalité ? Les uns voient noir, d'autres bleu, la multitude voit bête. Rien de moins naturel que Michel-Ange, rien de plus fort ! Le souci de la vérité extérieure dénote la bassesse contemporaine (Gustave Flaubert, L'Éducation sentimentale)

REMARQUES : En parlant du raisonnement, de la façon de penser, voir bête est une extension productive de la série voir bleu, blanc, noir, grand, etc. Flaubert s'en sert pour exprimer le fait de voir ou de percevoir les choses sans faire preuve d'intelligence, sans réfléchir. VoIR AUSSI : parler bête

\section{Voir blanc}

voir blanc ou noir : percevoir les choses d'une certaine manière ; ou d'une manière opposée ; ne pas faire dans la nuance, ne pas faire de quartier

Emploi absolu

1776a Vous ne parlez, dites-vous que d'après vos propres observations. La plus part de ceux que vous dementez ne parlent non plus que d'après les leurs. Ils ont vu noir où vous voyez blanc; mais ils sont tous d'accord sur cette couleur noire, la blanche ne frappe nuls autres yeux que les vôtres (Jean-Jacques Rousseau, Rousseau juge de Jean-Jacques)

1776b Tout cela est si vrai que si deux hommes ont d'un troisième des opinions opposées, cette même opposition régnera dans les observations qu'ils feront sur lui. L'un verra blanc et l'autre noir ; l'un trouvera 
des vertus, l'autre des vices dans les actes les plus indifférens qui viendront de lui (Jean-Jacques Rousseau, Rousseau juge de Jean-Jacques)

1951 Pour parer à ses caprices, celui-ci ne dispose que de la foi, telle du moins qu'elle est définie dans les exercices spirituels de saint Ignace : « Nous devons toujours pour ne jamais nous égarer être prêts à croire noir ce que, moi, je vois blanc, si l'Église hiérarchique le définit ainsi » (Albert Camus, L'Homme révolté)

\section{CORpus Web :}

J'suis l'genre de fille spontanée, qui voit noir ou blanc, elle qui à tendance à faire tout sur un coup de tête, ça la du bon et du mauvais. Par conséquent, celle qui va ce peter le nez souvent parce qu'à pas assez réfléchie avant d'agir [https:// maviecouleurpastel.wordpress.com/2015/09/26/ cte-genre-de-fille-la] (2.3.2016)

Capture d'écran en PJ. J'ai essayé toutes les combinaisons possible je n'arrive pas à avoir une situation coherente. L'arkoon voit blanc ou noir et ne prend pas en compte l'autorisation sur les IP google [http://open.arkoon.net/tag/ regles+firewall] (15.3.2016)

Toutefois, au cours de son actuel mandat, Netanyahu ne s'est pas montré pragmatique. Il voit blanc ou noir seulement. Il croit qu'il est le seul a détenir la justice et la sagesse [http:// www.palestine-solidarite.org/analyses.Chaoul_ Arinili.091112.htm] (15.3.2016)

REMARQUES : S'opposant habituellement à voir noir, voir blanc se dit du fait de voir ou de concevoir les choses à partir de leur opposition systématique. Voir noir ou blanc réfère à une personne qui ne connaît pas de moyen terme : c'est bon ou mauvais. L'emploi au figuré inclut une interprétation de manière, donc une façon de voir les choses, tandis que la prédication seconde, non attestée ici, sélectionnerait le sens concret pour modifier l'objet vu (v. voir blanches les montagnes). Blanc et noir restent invariables. Notons l'emploi de la variante croire noir.

\section{Voir bleu}

I. Avoir la vue troublée par de très vives émotions, être en proie à de vives émotions Emploi absolu

1874a Tout mon sang, allumé sous cette prise, se précipita de mon cœur dans cette main, comme soutiré par elle, puis remonta furieusement, comme chassé par une pompe, dans mon cœur ! Je vis bleu... Mes oreilles tintèrent. Je dus devenir d'une pâleur affreuse. Je crus que j’allais m'évanouir... (Jules Barbey d’Aurevilly, Les Diaboliques)

1874b J'ai commencé par voir tout bleu, puis j’ai $v u$ trouble; au bout de cinq minutes, je ne voyais plus du tout. - Le désert était extraordinaire ; à chaque instant une nouvelle trombe de poussière passait sur l'oasis et venait s'abattre sur la ville ; toute la forêt de palmiers s'aplatissait alors comme un champ de blé (Eugène Fromentin, Un été dans le Sahara)

1894 Tout cela est passé et c'est comme un rêve qu'on a fait. Mais je puis vous le dire, Marthe, l'année a été mauvaise, très mauvaise ! J'ai vu bleu sur les cordages. J'ai bluffé, mais je ne sais pas comment cela finira. Je ne sais pas pourquoi je vous raconte cela.

- Votre mari vous a quittée, n'est-ce pas ? (Paul Claudel, L'Échange)

II. Voir les choses comme dans un rêve ; voir de manière positive ; être optimiste

Emploi absolu

1877 et la bonne odeur de l'encens l'obligeait à renifler, comme si on lui avait poussé un bouquet dans la figure. Enfin, il voyait bleu, il était pincé au cœur. Il y eut particulièrement un cantique, quelque chose de suave, pendant que les gamines avalaient le bon dieu, qui lui sembla couler dans son cou (Émile Zola, L’Assommoir)

\section{CORPus Web :}

Ginette voit bleu avec YUME !Aujourd'hui pour démarrer la semaine tout en douceur, petite sélection d'objets bleus, vus dans la jolie boutique YUME ! [http://merciginette.canalblog.com/ archives/2012/03/19/23796604.html] (14.3.2016)

REMARQUES : Voir bleu réfère à une perception onirique des choses, ce qui comprend aussi bien 
les visions de rêves agréables, mais aussi cauchemardesques. Dans son sens concret de perception visuelle (I), sous l'effet de la peur, la colère ou dans une situation angoissante ou inquiétante, d'un choc, d'un malaise ou d'une maladie, il se dit du fait d'avoir la vue brouillée, peu claire due à un afflux de sang. (II) se dit du fait de voir les choses ou de considérer l'avenir, l'existence, la vie d'une manière excessivement positive, ce qui souligne le caractère très optimiste du sujet. Il peut aussi référer à la vision idéalisée, rêvée qui ne correspond pas à la réalité, suggérant le caractère rêveur du sujet. Bleu reste invariable et est modifié par tout. Notons l'emploi de voir trouble.

\section{Voir bon}

Voir bien, distinctement, clairement

Transitif

1177 Torne toi si que de ça soies

Et que adés ceste tor voies,

Que buen veoir et bel la fet [variante : bel ueoir]

(Chrestien de Troyes, Lancelot ou Le Chevalier de la charrete, 3721)

REMARQUES : Dans cet exemple, voir bon réfère à une chose ou une personne qui se distingue clairement et distinctement. L'emploi parallèle de faire bel met en évidence l'usage des deux, bon et beau, pour désigner des nuances que le français moderne exprime avec l'adverbe bien. L'exemple souligne ainsi la vigueur du système adverbial qui consiste à employer l'adjectif dans les fonctions adverbiales, sans recourir à un adverbe en -ment ou à un adverbe comme bien.

\section{Voir clair}

I. Voir clairement, distinctement, avoir une bonne vue Emploi absolu

1130a Aigle est reis des oisels, Mult mustre essamples bels.

En latine raisun

Cler-veant l'apelum, Kar le soleil verat Quant il plus clers serat, Tant dreit l'esguarderat Ja l'oil ne cillerat (Philippe de Thaon, Bestiaire [trad., probablement entre 1121 et 1135], 2016)
+1175 La cortine souavet sache Au pertuset (c'on ne l'estache), Que tu voies la dedenz cler, Qant il venra a lui parler (Béroul, Tristan [ [ $4^{\mathrm{e}}$ quart XII $]$, 4331)

1275a E, qui serait bien cler veianz, Il verrait que maus est neienz, Car ainsinc le dit l'escriture (Jehan de Meun, Roman de la rose [1269-1278], 6297)

1285 Bien vit ce est chose passee K'avoir lor couvient la mellee. Lors veïssiez espieus brandir Et sor hiaumes des mains ferir Pour plus fortement enformer Le hiaume ou pour veoir plus cler ; Bien sambloient d'armes manier (Adenet le Roi, Cleomadés, 8772)

$1572 \mathrm{Tu}$ excuseras les fautes de l'imprimeur ; car tous les yeux d'Argus n'y verroient assez clair, mesme en la première impression (Pierre de Ronsard, La Franciade, p. 13)

1624a Il nous arrive à tous, Pyzandre, dit Endymion, de voir en dormant quelques images sombres, et confuses des choses qui occupent le plus nostre esprit quand nous veillons : mais d'avoir comme j'avois toutes les nuits, de continuelles visions de Diane : de voir si clair, ayant les yeux clos (Jean de Gombauld, L'Endimion)

1627 Le jour commençoit de faillir quand Lysis entra dans le bois, de sorte que n'y voyant plus guere claire, une certaine crainte s'empara de son ame. N'est ce point icy un bois consacré à quelque dieu ? (Charles Sorel, Le Berger extravagant)

1730 Les adjectifs se prènent aussi fort souvent adverbialement, come je l'ai remarqué en parlant des adverbes ; par exemple : parler haut, parler bas, parler grec et latin [...] penser juste, sentir bon, sentir mauvais, marcher vite, voir clair, fraper fort, etc. Ces adjectifs sont alors au neutre, et c'est une imitation des Latins (César Du Marsais, Des tropes) 
1775 On dit il est en haut, il est en bas, pour en lieu haut, en lieu bas.

Ici l'adjectif est précédé d'une préposition ; quelquefois il est employé seul. Parler bas, chanter juste, frapper fort, voir clair, voir trouble, voir double, signifient parler d'un ton bas, chanter d'une voix juste, frapper à coup fort, voir d'un oil clair, trouble, voir d'une manière double. Bas, juste, fort, clair, trouble, double, sont donc des adjectifs, et ces tours sont elliptiques

(Étienne de Condillac, Cours d'étude pour l'instruction du prince de Parme)

1828 Donnez-moi des livres et plongez-moi dans un cachot ; pourvu que j'y puisse voir assez clair pour les lire, je saurai me consoler de la perte de ma liberté. Tu trouveras peut-être que c'est pousser la chose un peu trop loin (Maurice de Guérin, Correspondance)

1832 Quand il eut soupé, il me dit en souriant qu'il me remerciait beaucoup, mais qu'on ne pouvait se battre sans voir clair ; qu'au reste, il serait désespéré de donner un coup de sabre à un homme qui l'avait si bien traité (Alphonse Karr, Sous les tilleuls)

1862 C'était un vieillard particulier, et bien véritablement l'homme d'un autre âge, le vrai bourgeois complet et un peu hautain du dix-huitième siècle portant sa bonne vieille bourgeoisie de l'air dont les marquis portaient leur marquisat. Il avait dépassé quatre-vingt-dix ans, marchait droit, parlait haut, voyait clair, buvait sec, mangeait, dormait et ronflait. Il avait ses trente-deux dents. Il ne mettait de lunettes que pour lire (Victor Hugo, Les Misérables)

1886a Eh bien, mon poste à moi se trouve sur l'arrière du bateau, qui est, comme tu dois savoir, l'endroit où l'on prend le plus de poissons ; et puis il touche aux grands haubans où l'on peut toujours attacher un bout de toile, un cirage, enfin un petit abri quelconque, pour la figure, contre toutes ces neiges où ces grêles de là-bas ; - cela sert, tu comprends ; on n'a pas la peau si brûlée, pendant les mauvais grains noirs, et les yeux voient plus longtemps clair...... ils se parlaient bas, bas, comme par crainte d'effaroucher les instants qui leur restaient, de faire fuir le temps plus vite (Pierre Loti, Pêcheur d'Islande)

1886b La lumière matinale, la lumière vraie, avait fini par venir ; comme au temps de la genèse elle s'était séparée d'avec les ténèbres qui semblaient s'être tassées sur l'horizon, et restaient là en masses très lourdes ; en y voyant si clair, on s'apercevait bien à présent qu'on sortait de la nuit, - que cette lueur d'avant avait été vague et étrange comme celle des rêves (Pierre Loti, Pêcheur d'Islande)

1886c Pourtant, ils ne nous ont pas fermé la porte au nez, parce que l'horizon devient sombre et qu'ils ne veulent pas, pendant la tourmente qui peut éclater demain, traîner leur refus cousu à leur écharpe, comme la lanterne collée, dans les ténèbres de la nuit, sur la poitrine du duc d'Enghien, pour qu'où vît clair à le fusiller (Jules Vallès, Jacques Vingtras : L'Insurgé)

1892 VIOLAINE. Et je dis : « Mon Dieu ! Mon Dieu ! Mais ! Mais ! Comment est-ce que je serai ? Toi, mon Dieu, protège-moi !»

Et je ne vis plus clair, comme quand on ferme les yeux.

BAUBE. Aveugle!

(Paul Claudel, La Jeune fille Violaine)

1908 Taillandier n’appréciait pas le paysage. Pourvu qu'il vît clair et loin sur le rail, le pays était beau (Pierre Hamp, Marée fraîche)

1938a L'abbé Sholaert secoua d'abord sous le portail sa pélerine pesante de pluie, puis il poussa la porte et, tout de suite, il respira l'odeur familière de son église, l'odeur d'encens, de cire consumée, de pierre et de cave tiède. À nuit close, l'abbé voyait mal clair, juste assez pour se diriger le long des maisons (Georges Duhamel, Cécile parmi nous)

1982a Le seul accessoire qui manque à ma panoplie banale de petite femme active-jeune- 
pas belle-mais y-a du charme ! Elle a oublié d'être bête !, c'est la paire de lunettes. J'ai échappé à cela. Mes yeux voient clair et loin, clair et près (Philippe Labro, Des bateaux dans la nuit)

Transitif

+1415a En aucuns lieux, Fortune, or ça, On vous verra

Plus cler aux yeulx, Ou pis, ou mieulx (Charles d'Orléans, Poésies [ 1415-1440], II, Rondel XLIV, p. 315)

+1415b Aussi en yver le pluvieux, Qui vens et broillars fait lever, L'air d'Amour epidimieux Souvent par my se vient bouter ; Si fault les pertuiz estouper, Par ou pourroit mon cuer ferir ; Le temps verray plus net et cler, Avant que je les face ouvrir (Charles d'Orléans, Poésies [ 1415-1440], I, Ballade XCVI, p. 151)

1692 Jusques ici je n’ai point été touché de tous les autres livres qui parlent de Dieu ; et j'en vois bien aujourd'hui la raison. C'est que la source m'en paroissoit douteuse : mais la voyant claire et nette dans le livre de Labadie, il me fait valoir tout ce que je n'estimois pas (Roger de Bussy-Rabutin, Les Lettres de messire Roger de Rabutin)

1893 Il avait avancé la main. Il prit un crayon qui traînait dans l'encombrement de la table et, sourd aux protestations de M. Nègre criant qu'il avait à cette heure bien d'autres chiens à peigner et qu'on verrait clair le lendemain, il poursuivit. C'était un garçon ingénieux ; son sac contenait plus d'un tour (Georges Courteline, Messieurs les ronds-de-cuir)

Pronominal

1929a - Je le sais, et c'est justement pour ça que ça me serait pénible d'être debout devant vous en plein du jour, vous qui m'avez connue, avant... et de vous faire voir ce que je suis devenue, parce que ça se voit, ça se voit tout clair.
- Demoiselle, vous vous faites des imaginations. Moi, je vous dis : je vous aime. Bien sûr, ça date de cette époque d'avant... (Jean Giono, Un de Baumugnes)

II. Comprendre parfaitement une situation ; être très pénétrant, avisé, clairvoyant

Emploi absolu

$\sim 1130 \mathrm{~b}$ Hyena est grius nuns

Que nus beste apeluns,

Ço est luvecerviere,

Cler veit e mult est fiere;

E nostre lei defent

Qu'om [n'en] manjuce nient

Ne chose a li semblable,

Orde est, nient cuvenable

(Philippe de Thaon, Bestiaire [trad., probablement entre 1121 et 1135], 1180)

+1150 EVA. D'itel nen gusta home !

Or sunt mes oil tant cler veant

Jo semble Deu le tuit puissant

(Le Jeu d'Adam [2 moitié XII $], 307$ )

+1250 Si soit d'ans deus faite la pais

Qu'el ne renouvele jamais.

Mes de l'afaire Chantecler

Vos di, ne veons mie cler

Ne n'osons dire (ce sachiez)

Que Renart soit a mort jugiez

De l'omicide qu'il a fait,

Por ce qu'a garant vos en trait (Le Roman

de Renart [2 moitié XIII']

1275b Car entour mei si trés cler vi,

Tant m'oinst les eauz d'un fin colire,

Qu'el m'ot fait bastir e confire

Si tost come Povreté vint (Jehan de Meun, Roman de la rose [1269-1278], 8046)

1280 Se j'ai merchi g'i venrai

Par amer,

Ne ja ne le conquerai

Par rouver,

Car ma dame voit tant cler

Que jou l'aim trop miex que mi

(Adam de la Halle, Chansons, XIX, 25)

1325 Bonne y estoit et bien seans

Et en touz quas si cler veans

Que riens n'i faisoit à reprendre

(Watriquet de Couvin, Dits, p. 23, 694) 
+1365 Perdre me poet, car il n'i voit point cler, Car je crienc trop des gengleurs la pointure (Jean Froissart, Poésies [3e tiers XIV $]$ )

+1366 Qui dit voir, nul ne le secourt, Qui voit trop cler, l'en le deffuit ; Qui voit et entent, sur lui court Chascuns, lors sera mis en bruit (Eustache Deschamps, Euvres complètes [3 $3^{\mathrm{e}}$ tiers $\left.\left.\mathrm{XIV}^{\mathrm{e}}\right]\right)$

1450 Dictes moy donc franchement la conclusion de voustre desir. Je sçay que six contre ung vous voyez plus cler en toutes choses que je ne fois (Roman de Troilus et Cressida, p. 159)

1511 Alors je toute fondue en crainte feis mon effort de fuyr et de me musser : mais ce fut en vain. Car la presence dun Dieu si cler voyant est inevitable. Mon crier aussi ne me fut utile, ne mon prier exaucé : ne mes larmes qui couroient à grans ruisseaux ne furent suffisantes à estancher sa chaleur vehemente (Jean Lemaire de Belges, Les Illustrations de Gaule et singularitez de Troye)

1624b Que ses yeux et son front soient au bien composez ;

Ses propos, ses desseins, tellement disposez

Que tous les medecins et les apoticaires, Qu'Argus mesme ne peut voir clair à ses affaires

(Jacques Du Lorens, Premières satires)

1713 Je ne sçai si monsieur votre fils a quelque attachement chez moi ; mais je vous jure que je ne m'en suis point encore apperçuë, et que s'il en a, ceux qui s'en scandalisent voïent assûrement plus clair que moi dans mon Domestique. Je n'ai souffert monsieur votre fils, que parce qu'il est votre fils (Robert Challe, Les Illustres Françoises)

1719 Le conseil fut assemblé sur l'arrivée de Tarare, et le calife, qui n'avoit jamais vu bien clair dans ses affaires, étoit moins en état de s'en mêler que jamais. Il voulut embrasser celui qu'il ne pouvoit voir (Antoine Hamilton, Histoire de Fleur d'Épine)
1734 LISETTE. Ma foi, Monsieur, si vous n'entendez rien à ce que je vous dis, je ne vois pas plus clair dans ce que vous me dites. Vous voilà dans un mouvement épouvantable à cause de la question du monde la plus simple que je vous fais : à qui en avezvous ? Est-ce distraction, méchante humeur, ou fantaisie? (Pierre de Marivaux, La Méprise)

1831 Le mal pour le bien n’appartient qu'à la providence, parce qu'elle voit clair et loin et juste, et de plus parce qu'il n'y a pas de mal pour elle ; mais pour l'homme, c'est faute et crime (Alphonse de Lamartine, Correspondance générale)

1837 Dieu m'en préserve, Dieu qui est toute sévérité, mais toute justice ! Ne t'offense pas de ce que je vois si clair et raisonne si tristement. Ne crois pas que je t'accuse de me tromper. Non, non. Je sais que tu ne le voudrais pas. Mais tu ne lis pas dans toimême comme je le fais (George Sand, Correspondance)

1865 D'ailleurs, Irène s'est chargée d'éclairer sa fille, car elle a perdu la tête, et, dans son chagrin, dans sa colère, elle a déclamé sur tous les tons, tantôt s'oubliant jusqu'à maudire les femmes honnêtes, vieille habitude de son métier, tantôt jouant la Madeleine aux pieds du Christ, autre rengaine du diable fait ermite, si bien que la petite, qui voyait trouble probablement dans tout cela, est arrivée à voir assez clair pour vouloir retourner au couvent (George Sand, Monsieur Sylvestre)

1890 Mais cela ne durait jamais. Pourquoi ? Elle se fatiguait, elle se dégoûtait, elle voyait trop clair peut-être. Tout ce qui lui avait plu d'abord dans un homme, tout ce qui l'avait animée, agitée, émue, séduite, lui paraissait bientôt connu, défloré, banal (Guy de Maupassant, Notre cœur)

1913 LUCE. Ah, je vous envie, Barois. Moi, je ne peux plus, j'en ai assez. La France est comme une femme soûle : elle ne voit plus clair, elle ne sait plus ce qui est vrai, elle ne sait plus où est la justice. Non, elle est 
tombée trop bas : c’est décourageant... (Roger Martin du Gard, Jean Barois)

1915 Ces lucidités-là sont notre probité, à nous autres hommes d'étude. Ortègue répondrait encore, en lisant ces lignes : « Mais j’y vois très clair, moi, dans votre pensée. Votre père était professeur de philosophie à Montpellier. C'était un métaphysicien frotté à des vitalistes » (Paul Bourget, Le Sens de la mort)

1928 Mon impression, dès maintenant, est celle-ci : «Si j’arrivais à me rendre compte de ces faits comme ils le méritent, à y voir entièrement clair, ce serait peut-être l'acquisition capitale de ma vie, et une acquisition considérable en elle-même, c'est-àdire qui le resterait pour un autre que moi » (Jules Romains, Le Dieu des corps)

1929b Ils ont la lèvre amère ou ironique. Rien, il est vrai, ne donne l'air psychologue comme l'attitude habituelle de déprécier. Voir clair, c'est voir noir, selon cette convention parfois commode

(Paul Valéry, Variété II)

1932 Plus généralement, l’ancien régime monarchique possédait une institution spécialisée du pouvoir spirituel qui était l'Église. Nos pères voyaient clair et parlaient plus franc que les gens de maintenant : c'est qu'ils croyaient vraiment avoir le droit pour eux - et ce droit était divin (Paul Nizan, Les Chiens de garde)

1933 L'INSPECTEUR. Vous êtes fou ? Pardon de quoi?

LE DROGUISTE. De ce que le vulgaire tombe juste, de ce que les yeux myopes seuls voient clairs, de ce qu'il y a des cadavres et pas de spectres (Jean Giraudoux, Intermezzo)

1938b Je vois clair, je vois noir et non pas que j'hésite,

L'un fera suite à l'autre et les deux si profonds

Que dans mon univers ils seront sans réplique

Et ce sera le jour et la nuit, l'horizon.
L'un fera suite à l'autre et les deux si profonds

Que dans mon univers ils seront sans réplique

Et ce sera le jour et la nuit, l'horizon

(Jules Supervielle, La Fable du monde)

1953 Car, il faut bien le dire, ma pythie picole. - Après le Vouvray, déclare-t-elle, je vois plus clair, mais après le Beaujolais, je vois plus loin

(Jacques Perret, Bâtons dans les roues)

1964 La condition maîtresse est l'éveil rapide de la multitude. Sur ce point, les Occidentaux ont intérêt à voir aussi grand que l'Est, mais plus clair. L'ordre d'urgence, qui s'impose aux républiques intéressées, est : 1) l'encadrement politique ; 2) l'éducation de base ; 3) la scolarisation (François Perroux, L'Économie du XX $X^{e}$ siècle)

1982b On ne vieillit pas bien, c'est un leurre ! Nous sommes condamnés!

- Condamnés à quoi ?

- À nos manques.

Elle se sentit déraper. Ça n'allait pas. Il verrait vite clair. Elle voyait qu'il voyait déjà d'où partait sa rancœur (Philippe Labro, Des bateaux dans la nuit)

Transitif

1726 Le sort des ouvrages d'esprit n'est guère fixé que par les gens du métier, qui ont de la discussion et, outre cela, du sentiment. Ces gens-là touchent, pour ainsi dire, la corde des organes des gens du monde et les avertissent ; on voit cela bien clair dans les chansons de la comédie (Montesquieu, Correspondance)

1936 Attention à cette lumière-là, bergers, c'est une lumière de ciel sur la terre pour voir clair vos péchés dans votre cœur (Max Jacob, Noël / Goéland, 25 décembre 1936 / Grundt : 331)

CORPUS WEB :

Tout le monde ne possède pas ces capacités d' « entendre clair », de "voir clair » ou encore de " ressentir, sentir clair ». En fait, très peu les ont. Cependant, les voyants purs sont plus réceptifs 
à ces dons de divination et donc ils sont enclins à les posséder [http://www.kelavenir.com/blog/ clairaudience-clairvoyance-et-clairsentiencecest-quoi] (20.3.2015)

Pour que les myopes voient clair [https:// destinationsante.com/pour-que-les-myopesvoient-clair.html] (14.3.2016)

Ceux qui ont été déboussolés voient clair aujourd'hui [...]. Les visages monstrueux se sont dévoilés, le masque de la liberté et de la révolution est tombé, a-t-il dit [http://www.togodiplomatie. info/Moyen-Orient/Bachar-Ceux-qui-ont-etedeboussoles-voient-clair-aujourd-hui] (14.3.2016)

BUCILLY : " FACE À LA HAINE QUI AVEUGLE, QUE LES ÉLECTEURS VOIENT CLAIRS " [http://jjthomas.canalblog.com/archi ves/2015/03/20/31737813.html] (14.3.2016)

La nécessité de députés Front de Gauche qui voient clairs pour défendre l'exigence d'un autre partage des richesses me semble d'une actualité encore plus brûlante [http://www.gauchemip. org/spip.php?article18940] (14.3.2016)

Les yeux s'ouvrent! Et que la lumière soit, nos petits westies voient clairs! [http://chezno schiens.canalblog.com/archives/2008/10/28/ 11141644.html] (14.3.2016)

REMARQUES : Dans son emploi concret, voir clair (I) souligne le fait de voir parfaitement, nettement quelque chose ou quelqu'un, de disposer des conditions idéales (une lumière claire) pour réaliser quelque chose. Au figuré (II), il se dit du fait de comprendre parfaitement la situation, les faits qui se présentent au sujet. En ce qui concerne l'accord, l'usage admet aussi bien l'emploi comme prédicat second accordé que l'emploi adverbial invarié, ce dernier se produisant notamment au figuré où voir clair se rapproche d'un verbe complexe signifiant 'entendre, comprendre'. Clair est modifié par assez, assurément, bien, entièrement, plus, plus guère, plus longtemps, mal, si, tant, tout, très, trop, vite. Notons l'emploi impersonnel familier ça se voit tout clair. Notons aussi la modification complexe, peu usuelle, dans voir mal clair 'avoir des difficultés à voir clair' (exemple de1938a). Mentionnons les collocations net et clair; clair et net; clair et loin ; clair et près ; clair, loin et juste. Les exemples attestent également un grand nombre d'autres groupes : dire voir, esgarder droit, marcher droit, parler bas / franc / haut ; tomber bas / juste ; voir grand / noir / trouble et entendre / ressentir / sentir clair, ainsi que la nominalisation les voyants purs.

\section{Voir colossal}

Avoir des ambitions énormes

$\lambda$ voir grand

\section{Voir confus}

Voir confusément, indistinctement

$\lambda$ voir large

\section{Voir direct}

Voir, percevoir ou régler les choses d'une manière directe, immédiatement et sans détour Emploi absolu

1921 Pour agir avec fermeté, il faut voir simple et direct. Dominateurs, est-ce que ce mot ne suffit pas pour désigner cette emprise personnelle que j'essayai de caractériser dans une de ses causes (Paul Bourget, $L e$ Sursis)

CORPuS Web :

J'arrive demain... on se voit direct :) Je vois que une personne demain [https://ask.fm/Na noush95/answers/102995493992] (14.3.2016)

Kieler tu déteste maqueda ça se voit direct. Je sais pas ce qu'il t'a fait ou pas fait. Il prend rouge c'est normal c'est le règlement bien arbitré [http://handnews.fr/2016/euro-2016-pas-de-sanc tion-pour-maqueda] (14.3.2016)

ce n'est pas pour blaguer... On voit direct c'est du bluff, il n'y a qu'à tenir sec ses intentions lorsqu'il a la balle au pied. Il va direct de l'avant et ses dribbles son efficace pour l'équipe [http:// www.dzfoot.com/video/youcef-belaili-le-grandretour-resume-de-ses-5-derniers-matchs-x2i22f8] (14.3.2016)

Lui au moins quand il dribble les draenei $\mathrm{DK}$, bizarre aussi, eux qui sont pas là depuis longtemps, qui arrétent pas de parler de lumiére, et qui se voient directs tout corrompus [http://forum. judgehype.com/judgehype/WorldofWarcraft/ event-media-wrath-sujet_252899_9.htm] (14.3.2016)

Ca ne saute pas aux yeux même quand on le voit. Je m'inquiète de la vue déformante ou déformée de certains qui le voient directs (lou- 
cheriez vous :-p) [http://www.suchablog.com/ the-hidden-tiger-ca-c-est-de-l-illusion-d-optique] (14.3.2016)

REMARQUes : Voir direct se dit du fait de gérer quelque chose en allant droit au but, en adoptant une attitude franche, sans ambiguïté. Les exemples du CW illustrent l'emploi pronominal (réciproque) et transitif du verbe. L'accord est exceptionnel, ce qui s'explique aussi par le fait que direct tend à être employé comme substitut de l'adverbe directement, dans un style familier, bien documenté dans le CW, avec peut-être des implications temporelles ('immédiatement, tout de suite, tout de go'). Il est possible que direct suive le développement sémantique de directement, qui a également le sens de 'immédiatement'. Notons l'emploi impersonnel familier ça se voit direct. Notons la collocation simple et direct ainsi que l'emploi de tenir sec.

\section{Voir double}

Voir deux choses là où il n'y en a qu'une Transitif

1377 Amis, comment que m’aiés en oubli, Ne sui je pas vers vous fausse ne double. Le desir qu'ay de vous veoir double $\mathrm{y}$, Amis, comment que m'aiés en oubli. Certes oïl, qu'onques ne vous oubli ; Dont vraie amour en moy s'avive et double. Amis, comment que m'aiés en oubli, Ne sui je pas vers vous fausse ne double (Guillaume de Machaut, Rondel / Poésies lyriques, I, p. 202)

1684 Or si nous voyons quelque fois l'object double, comme lorsque nous pressons l'un des yeux, cela vient de ce que la disposition de l'œil estant changée, et par consequent l'espece ou les rayons receus dans un endroit extraordinaire de la Retine, et qui n'est pas accoûtumé ni endurcy aux rayons, il arrive que l'impression qui se fait dans cet endroit estant aussi sensible que celle qui se fait dans l'autre œil dont l'axe est tendu, elle y excite, et y attire l'attention de la faculté, laquelle estant par consequent dirigée et tendüe egalement, et en mesme temps vers deux endroits, vers deux especes, elle voit le mesme object doublement, par une double Vision, ou ce qui est le mesme, elle le voit double (François Bernier, Abrégé de la philosophie de Gassendi)

$1754 a$ Ils ne voyent point double. Chacun fixe l'objet que la main saisit, chacun rapporte les couleurs à la même distance, au même lieu ; et comme le renversement de l'image ne leur empêche pas de voir un objet dans sa vraie situation, la même image, quoique double, ne leur empêche pas de le voir simple. La main les force à juger d'après ce qu'elle sent en elle-même. En les obligeant de rapporter au-dehors les sensations qu'ils éprouvent en eux ; elle les leur fait rapporter à chacun sur l'unique objet qu'elle touche, et au seul endroit même où elle le touche. Il n'est donc pas naturel qu'ils le voient double (Étienne de Condillac, Traité des sensations)

1808 Dans cette dernière circonstance, l'individu voit les objets doubles, triples, quadruples, ou multipliés à l'infini (Pierre Cabanis, Rapports du physique et du moral de l'homme)

1833 moi j'étais prêtre, je connaissais les choses du ciel et de la terre, je voyais Lélia double et complète, femme et idée, espoir et réalité, corps et âme, don et promesse (George Sand, Lélia)

1918 Ou encore ne cachaient-ils même pas de pensée et était-ce une fatigue de ma vision qui me les faisait voir doubles dans le temps comme on voit quelquefois double dans l'espace ? (Marcel Proust, À l'ombre des jeunes filles en fleurs)

1936 Il s'agit de faire constater par chacun qu'il voit double les objets rapprochés lorsqu'il regarde, dans la même direction, des objets plus éloignés (Alain, Propos)

Emploi absolu

1640 PALESTRION. Ils sont faux, tu vois double. SCELEDRE. Je voy double en effect, et c'est ce qui me trouble (André Mareschal, Le Véritable Capitaine Matamore) 
1754b Lorsqu'il commença à regarder un objet des deux yeux, il crut le voir une fois plus grand. C'est qu'il étoit plus naturel que l'œil, qui voyoit en petit, ajoutât aux grandeurs qu'il appercevoit qu'il n'étoit naturel que celui, qui voyoit en grand, en retranchât. Mais ses yeux ne virent point double ; parce que le toucher, en apprenant à celui qui venoit de s'ouvrir à la lumiere, à démêler les objets, les lui fit voir où il les faisoit voir à l'autre (Étienne de Condillac, Traité des sensations)

1775 On dit il est en haut, il est en bas, pour en lieu haut, en lieu bas.

Ici l'adjectif est précédé d'une préposition ; quelquefois il est employé seul. Parler bas, chanter juste, frapper fort, voir clair, voir trouble, voir double, signifient parler d'un ton bas, chanter d'une voix juste, frapper à coup fort, voir d'un oil clair, trouble, voir d'une manière double. Bas, juste, fort, clair, trouble, double, sont donc des adjectifs, et ces tours sont elliptiques

(Étienne de Condillac, Cours d'étude pour l'instruction du prince de Parme)

1857 Elles se ressemblaient si exactement, qu'en les voyant ensemble on croyait y voir double et l'on se frottait les yeux (Edmond About, Le Roi des montagnes)

1949 Moi, je commençais à voir double et la fumée me piquait les paupières. Manuel, lui, ne voyait ni double ni triple. Complètement éteint, ses yeux se baladaient quelque part, derrière le front ou au niveau des oreilles (Léo Malet, Le Soleil n'est pas pour nous)

1965 Dans plus de la moitié des cas, ce sont les signes oculaires qui attirent l'attention : chute d'une paupière, sensation de voir double, strabisme (Encyclopédie médicale Quillet)

Pronominal

1645 Il est arrivé autrefois de grands malheurs de l'incontinence de ces femmes, quand leurs premiers maris sont de retour, et qu'ils se voient doubles (Julien Bodreau, Les Coustumes du païs et comté du Maine)
1755 Dans le même temps, la plûpart des sénéchaussées, présidiaux et autres jurisdictions subalternes des provinces et de la campagne tombent et ne sont plus servies, les charges s'y voient doubles et triples sur la même tête, et j'en connois où un seul officier est chef, membre, et gens du roi (Victor de Mirabeau, L’Ami des hommes ou Traité de la population)

1837 La parfumeuse s'était vue double, elle s'était apparue à elle-même en haillons, tournant d'une main sèche et ridée le becde-cane de sa propre boutique, où elle se trouvait à la fois et sur le seuil de la porte et sur son fauteuil dans le comptoir (Honoré de Balzac, Histoire de la grandeur et de la décadence de César Birotteau)

1926 Je me vois double, je me vois me soulever de mes deux bras de lumière dans la nuit comme une offrande, mordre dans mon cœur, mon propre cœur, le cœur, ce fruit rouge de ma vie (Marcel Jouhandeau, Monsieur Godeau intime)

1951 C'était l'été

À Limehouse

La nuit

Et je me voyais double dans la glace de

l'armoire à glass

C'est comme ça qu'ils appellent le

frigidaire

En Angleterre (Jacques Prévert, Spectacle)

\section{CORPUS WEB :}

Chez Isaya, le choc auditif s'accompagne d'un trouble visuel : on voit et on entend double. Le chant et son chœur à la tierce sont les signatures vocales de ces sœurs jumelles nées sous le signe des guitares jumbo [http://theatrejoliette. fr/evenement/soiree-douverturearts-de-la-scene] (20.3.2015)

La diplopie se caractérise par le fait de voir double, deux images au lieu d'une [http://www. passeportsante.net/fr/Maux/Symptomes/Fiche. aspx?doc=diplopie-symptome] (14.3.2016)

On peut aussi voir double avec un seul œil ouvert (vision double monoculaire), par exemple à cause d'une cataracte, d'une pathologie rétinienne,... [http://www.orthoptie.be/fr/patho logies-et-traitements/dubbelzien] (14.3.2016) 
tous les strabisques voient doubles... mais la plupart n'en prennent pas conscience, c'est la «neutralisation », il vous faut attendre que ce phenomnene revienne tout seul et SURTOUT ne pas faire de " fixette " dessus [http://forum. doctissimo.fr/sante/myopie-cataracte-vue/ postoperatoire-operation-evolution-sujet_154 213_1.htm] (14.3.2016)

REMARQues : Sous l'effet de la peur, d'une émotion vive, d'une prise d'alcool excessive ou de la fatigue, voir double se dit du fait de voir deux choses là où il n'y en a qu'une. Notons la série d'adjectifs dans l'exemple de 1808 : voir doubles, triples, quadruples, ou multipliés à l'infini. Double peut s'accorder avec le sujet, ou, dans l'emploi transitif du verbe, avec l'objet (v. les exemples de $1645,1755,1808,1918)$. Dans le dernier exemple $\mathrm{du}$ CW, l'accord est fait par rapport au sujet, contrariant ainsi le sens logique de la modification. Notons l'emploi de voir doublement dans l'exemple de 1684, qui suit les tendances de l'époque. Notons également entendre double, voir grand.

\section{Voir douloureux}

Voir un monde de douleur

$\pi$ voir laid

\section{Voir droit}

Voir directement

Emploi absolu

-1334 Par desir detourner ensemble

Et voient droit par la fenestre

Des iex du coer. Et tout peut estre,

Com li solaus par la verriere

Se fiert, puet ferir la lumiere (Le Romans

de la dame a la lycorne [1 ${ }^{\mathrm{er}}$ tiers XIV $]$, 1420)

1526 Tous justiciers vers luy a faict venir Pour reformer

Aucuns abus et iceulx informer

De garder droit et justice former

Sans, par faveur ou dons la difformer,

Faisant congnoistre

Que sans icelle on voit droit à senestre

Vertus decheoir, mal pulluler et croistre

Et, oultre plus, flestrir maint royal sceptre

Tres fleurissant

(Jean Marot, Le Voyage de Venise)
1658 Cette nouveauté ne déplût pas aux beaux Esprits de nostre temps, et de Malherbe mesme, que je fis rire un jour, lors que m'entretenant avecque luy sur ce sujet, je luy dis que parmy tant d'enfans que j'avois fait voir assez droits, il m'estoit arrivé d'en faire seulement un boiteux (Guillaume Colletet, L’Art poétique 1)

1847 L'œil de votre cœur a vu tout droit dans le mien qu'il ne fallait rien moins que les chères santés qui m'attachent au Cayla pour m'empêcher d'arriver quelquefois jusqu'à vous (Eugénie de Guérin, Lettres)

Transitif

1887 Aux envahissements de l'imagination, il fallait opposer le réel, me mettre en présence de l'homme que je soupçonnais, le voir droit en face, tel qu'il était, non point tel que me le présentait mon esprit, de jour en jour plus fiévreux, plus incapable de juger ses visions (Paul Bourget, André Cornélis)

CoRpus Web :

Disons que je comprends qu'il plaise par sa simplicité et comme le développeur le dit, il voit droit au but [http://www.fredzone.org/applica tions-indispensables-android-393] (14.3.2016)

je suis scandalisé, je viens de voir tout ces étrangers dire « VIVE L'AFRIQUE » à la télé, voilà la preuve de la déchéance de la france, et encore je ne sais pas si on peut continuer de dire la FRANCE, on voit droit dans le mur [http://www. presidentielle-2007.net/2012/hollande-presidentvos-reactions] (14.3.2016)

Mais lorsqu'elles frappent à ma chambre et me voient prier, lorsqu'elles me voient droite dans mes valeurs, elles s'interrogent. » Pour Yolande, la vie de tous les jours " parle d'elle-même », plus que " les grands débats théologiques » [http:// www.la-croix.com/Religion/Actualite/Unenouvelle-generation-pour-l-Eglise-d-Algerie-_ NG_-2010-12-23-560819] (14.3.2016)

REMARques : Dans son emploi transitif, le sujet désigne une personne qui pose son regard directement sur quelque chose ou quelqu'un, qui regarde quelqu'un en face, directement. Au figuré, il peut souligner le fait de comprendre, de 
discerner tout de suite quelque chose. Droit tend à l'invariabilité, excepté dans l'exemple de 1658. En tant que prédicat second, il s'accorde avec l'objet (v. le dernier exemple du CW), pouvant désigner la droiture de quelqu'un. Droit s'associe généralement à la préposition qui le suit (par, à, dans, en face) au point de faire partie du groupe prépositionnel. Il est modifié par assez.

\section{Voir faux}

Avoir une perception ou un jugement erronés Emploi absolu

1679 Si j'ai $v u$ faux, il ne m'y paroît rien de nouveau qui la doive empêcher de pousser sa pointe et de travailler à la paix, comme elle l'avoit résolu, en se servant des gens qui seront écoutés à la Cour plus favorablement que moi (Jean-François de Gondi (Cardinal de Retz), Mémoires)

1852 Je lui offrais dans le prétexte de mes affaires un motif bien simple de renoncer à cet éloignement qui ne vaut rien, qui fait voir faux, et qui conduira à des résolutions prématurées, irréfléchies, désastreuses pour les intérêts de sa cause (George Sand, Correspondance)

1857 Qui pourrait renoncer au vrai, dès qu'on l'entrevit une fois ? Qui pourrait rentrer de bon gré dans le monde d'erreurs où nous sommes? Mieux vaut ne plus voir du tout que de voir presque toujours faux (Jules Michelet, L'Insecte)

1912 Inquiets de l'état des affaires, les conservateurs forceront les votes nationalistes et les socialistes. Toute l'opinion publique verra faux jusqu'au moment des élections. Ils ne voient les clauses franco-allemandes et anglo-allemandes que sous l'angle de leurs élections (Maurice Barrès, Mes cahiers)

1964 Il était maintenant certain d'avoir vu faux, à Alger, ou plus exactement de n'avoir vu que ce qu'il était trop facile de voir, de ne pas s'être donné la peine de chercher ce qui existait au-delà des apparences, aussi décourageantes fussent-elles (Michel Droit, Le Retour)
Transitif

1771 Un esprit éclairé sait que la violence fait les hypocrites et la persuasion les chrétiens ; qu'un hérétique est un frere qui ne pense pas comme lui sur certains dogmes métaphysiques ; que ce frere privé du don de la foi est à plaindre, non à punir, et que si nul ne peut croire vrai ce qu'il voit faux, nul pouvoir humain ne peut commander à la croyance (Claude-Adrien Helvétius, $D e$ l'homme)

\section{CORPuS WeB :}

Il y a deux types de présidents : les incompétents et les pires. Parmi les présidés il y ceux qui voient faux et qui comprennent juste. Et ceux qui voient juste et qui comprennent faux. Chaque médecin est en train de construire notre jadis [http://www.fnamgpm.com/FORUM/Detail. asp?search=abdelilah\&Id=7659] (14.3.2016)

Il devient l'œil et l'Oreille de la destinée. Son regard n'entrevoit que l'avenir, et l'après. Aucunement utilisé en combat, c'est une technique qui peut tous de fois, être utilisé avait une bataille, pour connaitre toutes les techniques et le style de combat de l'ennemi. Toutefois, il arrive que ces visions se voient fausses, ou incomplètes. L'on raconte que certaines personnes ont la capacité de renverser le Destin... [http://bleachthenewworld. forumactif.org/t1359-chronomancie] (14.3.2016)

REMARQUeS : En parlant d'une personne, voir faux qualifie sa façon de voir ou de percevoir les choses face à une situation et se dit du fait de raisonner, de porter un jugement mal fondé, inexact, erroné sur quelque chose ou quelqu'un, un jugement qui ne correspond pas à la réalité. Faux reste invariable dans son emploi adverbial. En tant que prédicat second, il s'accorde avec le sujet du verbe pronominal (v. le dernier exemple du CW, où le médiopassif implique un sujet tacite qui voit que les visions sont fausses. Notons l'emploi de croire vrai ; comprendre faux / juste ; voir juste / incomplet. Faux est modifié par presque toujours. VoIR AUSSI : comprendre faux / juste 


\section{Voir fin}

Voir, percevoir les choses de manière subtile, astucieuse

Emploi absolu

1855 J'avais essayé de faire des traductions : c'était trop long, j'y mettais trop de scrupules et de conscience ; des portraits au crayon ou à l'aquarelle en quelques heures : je saisissais très-bien la ressemblance, je ne dessinais pas mal mes petites têtes ; mais cela manquait d'originalité ; de la couture : j'allais vite, mais je ne voyais pas assez fin, et j'appris que cela rapporterait tout au plus dix sous par jour ; des modes : je pensais à ma mère, qui n'avait pu s'y remettre faute d'un petit capital (George Sand, Histoire de ma vie)

1872 Maintenant, il dort, et je me suis levé doucement, doucement, pour venir vous le dire... Pourquoi me regardez-vous comme cela, ma mère ?... Ça vous étonne que j’y voie si fin et que j'aie tant de raisonnement... Mais vous savez bien ce que Balthazar disait : « Il s'éveille, cet enfant, il s'éveille! »(Alphonse Daudet, L’Arlésienne)

189014 mars.

Lu Le Besoin d'aimer, de Paul Alexis. Des nouvelles lourdes, insignifiantes, une phrase incolore. Laisser ce monsieur bien tranquille. Une manière de voir les choses de gros myope qui, voyant petit, croit voir fin et vrai. Pierre marche. Il fait une dizaine de pas tout seul, tombe sur ses fesses et se met à rire, et court dès qu'il est à portée des genoux de sa maman (Jules Renard, Journal)

1935 On ne saurait mieux dire, ni voir plus fin (Le Bidois, Georges et Robert, Syntaxe du français moderne)

REMARQUES : En parlant d'une personne, voir fin qualifie sa façon de voir ou percevoir les choses face à une situation, ou à sa façon de réagir. Dans le premier exemple, il s'agit d'une couturière qui n'a pas une vue assez fine, aiguisée pour coudre. Dans les autres exemples, voir fin réfère à la capacité de savoir raisonner, d'être perspicace, de voir, de percevoir les choses en faisant preuve d'astuce et de subtilité. À cela s'ajoute parfois une certaine ambition de la part du sujet, ce qui s'oppose à la mesquinerie, au fait de considérer les choses de manière étriquée. Notons la collocation voir fin et vrai, où vrai ajoute à l'idée de subtilité la notion de raisonnement juste. Fin reste invariable et est modifié par assez, plus, si. Notons également l'emploi de voir petit 'avoir une vision étroite des choses, une vision à courte vue'. VoIR AUSSI : penser petit

\section{Voir flou}

Voir mal, peu clair, de façon diffuse

Emploi absolu

1987 Je voyais tout flou. Une espèce de marée de désespoir m'est montée à la tête, mal et honte mêlés, m'a submergé (Bruno Bayon, Le Lycéen)

\section{CORPUS WEB :}

depuis que j ai 12 ans je voit flou de mon œil gauche et je voit des petit crcle transparent je sais pas ce quil $\mathrm{m}$ arrive et aussi quand je regarde a peux pres 3040 metre de loin je vois vraiment flou mais quand je regarde de mon œil droite je voit parfait Vous pensez que cela va empirer? [http://sante-medecine.journaldesfemmes.com/ forum/affich-916356-mon-oeil-gauche-voit-foule-loing] (1.3.2016)

\section{Voir grand}

I. se faire voir grand: montrer de la noblesse, une grandeur d'âme, une grande élévation d'esprit

Transitif

1623 car un grand esprit tant plus il s'abbaisse tant plus se faict il voir grand

(François Garasse, La Doctrine curieuse des beaux-esprits de ce temps)

II. Voir en grand format ; avoir de grandes ambitions

Transitif

1754a Elle voit plus grand ce qu'elle croit plus loin (Étienne de Condillac, Traité des sensations)

1754b Elle voit grand, par exemple, tout ce qui est au-dessus de sa hauteur, et petit tout ce qui est au-dessous (Étienne de Condillac, Traité des sensations) 
Emploi absolu

1885 L'angoisse était d'autant plus terrible que la nature l'avait fait pour l'immense. Il [= Gustave Doré] ne voyait pas seulement grand, il voyait colossal (Pierre Véron, Galop Général !)

1891 Mais il avait toujours été l'homme d'imagination, voyant trop grand, transformant en poèmes ses trafics louches d'aventurier (Zola, L’Argent)

1912 D'intelligence remarquable, nullement sentimentale ; une malice paysanne, un sens précis des affaires, allié à une imagination méridionale qui aimait à voir grand, mais savait en même temps voir à l'échelle exacte, quand c'était nécessaire (Romain Rolland, Jean-Christophe. La Nouvelle Journée)

1924 Bonaparte vit grand et vit juste. Son proconsulat d'Italie ne devait pas être éternel. Il inventa autre chose, une expédition d'Égypte, une entreprise d'Orient, glorieuse et fructueuse (Jacques Bainville, Histoire de France)

1930 Les premiers armateurs de New-York réussissent assez mal ; leurs capitaux et leurs bateaux coulent bas; mais ils voient grand; ce sont les premiers qui, en introduisant le confort, le luxe, les gros tonnages, forcent les Anglais à comprendre que la mer n'est pas réservée exclusivement aux marins (Paul Morand, New-York)

1932 Ce que le chef ordonne doit revêtir, par conséquent, le caractère de l'élévation. Il lui faut viser haut, voir grand, juger large, tranchant ainsi sur le commun qui se débat dans d'étroites lisières (Charles de Gaulle, Le Fil de l'épée / Euvres)

1959 Mais, du moment qu'il s'agit de la France et quelle que soit temporairement sa situation, c'est la sagesse et la raison de voir grand et de viser haut. Nous avons de bons bras, de bonnes têtes, de bons cœurs, et, à notre portée, de vastes trésors à tirer de terre (Charles de Gaulle, Mémoires de guerre) 1960a Desnoyer, amateur de vastes paysages et de spectacles allègres, tempérament robuste, artiste de haute conscience qui sait voir simple et qui sait voir grand (Jean Cassou, Panorama des arts plastiques contemporains)

1960b Il ne faut pas vouloir chercher trop loin, ni voir trop grand. Il faut commencer. Il peut y avoir des sujets, par exemple le développement de la vallée du Nil, ou bien la lutte contre la tuberculose en Asie (Charles de Gaulle, Discours et messages)

1962 Il faut donc prévoir grand et maintenir notre point de vue vis-à-vis de ce qui nous accuseront de voir trop grand (Colloque national de géographie appliquée)

1964a On n’a jamais rien à perdre. Il fut un temps où je le savais, et je gagnais tout. Ah, voir plus grand, plus vaste, jouer plus gros, tout risquer ! Je vais jeter dans cette bataille toute ma force retrouvée

(Jean-René Huguenin, Journal)

1964b Huit nageurs, huit nageuses : la Direction des Sports n'a pas vu grand pour les Jeux (France-Soir, 19 août 1964 / Grundt : 393)

1968 Puisque l'écriture n'est en somme qu'une technique, on aurait chance de voir plus grand en considérant l'ensemble de l'équipement technique des peuples (Georges Gurvitch, Traité de sociologie)

\section{CORPUS WEB :}

A Narbonne on aura en 2015 une expo des clubs photo locaux à la place.....C'est sympathique mais ça n'attirera pas les foules.......à part les exposants et leurs familles. Après voir grand on voit petit, petit, petit....On verra ce qu'en pensent les commerçants du centre ville car qui voit l'expo se balade, consomme, anime..... [http:// www.lindependant.fr/2014/04/10/festivals-sup primes-a-collioure-et-narbonne-qu-en-pensezvous-sondage,1870122.php] (2.3.2016)

À une époque où le virtuel remplace de plus en plus le réel, il est bon de constater qu'il y a encore des lieux où l'on peut se retrouver pour mettre de l'avant des projets concrets, comme 
celui des bâtisseurs qui ont érigé cette cathédrale, et qu'il est toujours possible de s'élever au-dessus de l'horizon, de faire communauté et faire preuve de générosité lorsque vient le temps de voir grand, de voir beau et surtout de vivre ensemble notre Histoire et notre fierté ! [http:// cathedralemoncton.com] (15.3.2016)

Dans ce cours, vous pouvez écouter Donna Novitsky comme elle l'explique pourquoi les entrepreneurs devraient voir grands quand ils investissent une grande partie de leur temps, énergie et passion dans la création d'une entreprise [https://fr.alison.com/courses/WhyEnterpreneurs-Should-Think-Big] (14.3.2016)

Ils sont une petite dizaine à se retrouver le week-end sur les quais de Concarneau. Face à la ville close, Gildas Mahé joue le rôle de l'instructeur pour des « voileux » pas encore professionnels mais qui voient grands avec leur Mini 6.50 . C'est d'ailleurs sur ce genre de bateau, aussi technique que rapide, que les grands de la voile ont fait leurs premiers pas [http://www.tvr.bzh/ programmes/embruns-1431284400] (14.3.2016)

C'est ainsi que certains se voient grands parce qu'ils ont beaucoup d'argent, d'autres parce qu'ils ont beaucoup fréquenté, d'autres encore parce qu'ils ont beaucoup de fidèles dans leurs églises, sans oublier ceux qui ont des chaînes de radio, de télévision, et d'autres enfin parce qu'ils font des miracles [http:// champidino.e-monsite.com/pages/pourquoi-laplupart-des-hommes-de-dieu-cherchant-a-etregrands-devant-les-hommes-sont-tombes-dans-lorgueil-et-le-mepris.html] (14.3.2016)

REMARQuES : Voir grand (I), vieilli, réfère à l'attitude morale d'une personne envers autrui, qui montre un esprit ou un caractère noble. La langue moderne le remplace par (II), en emploi généralement absolu qui renvoie à une vision stratégique par rapport à la réalisation de projets techniques ou scientifiques, de grandes constructions ; on retrouve voir grand dans un contexte de guerre avec conquêtes territoriales, évoquant la grandeur et l'ambition du projet, parfois de façon ironique (démesure). Notons l'opposition sémantique voir petit et voir grand. L'emploi transitif est rare, allant de pair avec une interprétation plus proche de la perception visuelle. Dans ce cas de figure, grand fonctionne en tant que prédicat se- cond orienté vers l'objet. Il reste invariable, en général, mais il s'accorde avec le sujet dans les troisième et quatrième exemples du $\mathrm{CW}$, ce qui n'est pas usuel dans le style soutenu sauf quand il s'agit d'un prédicat second modifiant l'objet $\mathrm{du}$ verbe pronominal (v. le dernier exemple du CW). Grand est modifié par plus, seulement, trop. Le groupe forme une série paradigmatique : voir beau, voir colossal, voir juste, voir petit, voir vaste, voir simple, avec la réduplication petit, petit, petit. Notons les collocations couler bas, jouer gros, juger large, prévoir grand, viser haut. VoIR AUSSI : construire petit, rêver grand

\section{Voir gros}

I. Voir en gros plan; percevoir les choses dans une dimension importante

Emploi absolu

1858 M. l'abbé Anjorrant les avait regardées avec un verre qui faisait voir gros, car c'était si fin, si fin qu'on ne distinguait pas bien (George Sand, Les Beaux Messieurs de Bois-Doré)

1869a Il [= Hugo] voit dans les canons des Invalides des canons énormes, béants ; et ce sont de longs canons minces, presque des couleuvrines de loin, qu'on a envie, ce me semble, de mettre dans sa poche toutes les fois qu'on passe ; il est vrai que je vois en petit, mais Hugo, lui, voit gros (SainteBeuve, Mes poisons)

1957 M. Giono peut prendre, ou non, ses distances, dans tous les cas, il voit grand, il voit gros (Arts, 1-7 mai 1957 / Grundt : 398)

II. Voir, prévoir les choses en grand; concevoir de vastes projets

Emploi absolu

1869b Hugo voit gros, il voit noir (dans Ruy Blas, il voyait rouge.) Mais cela a de la grandeur, et lui seul, après Chateaubriand, peut écrire de telles pages (Sainte-Beuve, Mes poisons)

1963 J'avais un retard considérable, et d'ailleurs je voyais moins gros que lui. Ma crèche rue des Territoires à Vincennes était modeste... deux pièces, cabinet de toilette et cuisine dans un immeuble ouvrier (Boudard, La Cerise) 
III. Voir, percevoir les choses en manquant de finesse, de subtilité

Emploi absolu

1886 Elle avait, autant que je puis me rappeler les choses qu'elle me disait et dont mon cœur d'enfant était remué, une âme magnanime de pauvre femme. Elle voyait gros et simple (Guy de Maupassant, Contes et nouvelles)

1920 Arnauld y mettait moins de façons ou plutôt il voyait plus gros. Il n'a jamais soupçonné que sa Morale pratique pût être un libelle (Henri Bremond, Histoire littéraire du sentiment religieux en France)

1932 La société institue des peines qui peuvent frapper des innocents, épargner des coupables ; elle ne récompense guère ; elle voit gros et se contente de peu : où est la balance humaine qui pèserait comme il le faut les récompenses et les peines?

(Henri Bergson, Les Deux Sources de la morale et de la religion)

\section{CORPUS WEB :}

Non tu ne vois pas " gros » avec tes lentilles. Enfin si d'une certaine manière. Je m'explique, $\mathrm{tu}$ dois avoir une forte myopie et tes verres de lunettes te font voir " petit " quand tu portes tes lentilles tu vois normalement mais la différence est telle que tu as l'impression de voir " gros » [http://forum.doctissimo.fr/sante/myopiecataracte-vue/gros-avec-lentilles-sujet_145436_1. htm] (8.3.2016)

Et ils ne comptent pas s'arrêter en si bon chemin, car c'est aussi l'ambition qui a nourri leur désir de devenir entrepreneur : «On voit gros, on a faim. On veut être grand dans le secteur, d'un point de vue business. Le meilleur moyen d'atteindre ces objectifs, c'est de fonder son entreprise. " Mais ils admettent aussi que créer et faire vivre une entreprise n'est pas chose aisée [http://blog.unitee.eu/meet-the-new-europeans/ on-voit-gros-on-a-faim-on-veut-etre-grand-dansle-secteur-interview-avec-umit-sahin-et-erkanersoy-fondateurs-de-denodia] (8.3.2016)

Pour le golf de Baugé, les annonces sont gigantesques : 210 villas, un hôtel quatre étoiles, un restaurant gastronomique... Andersen Construction, l'investisseur, voit gros (110M€) et beau [http://www.lejournaldesentreprises. com/editions/49/actualite/fait-du-mois/ implantation-cortizo-le-gros-coup-de-larentree-10-09-2010-101951.php] (8.3.2016)

Vous avez à distinguer l'évidence sensible (le fait se voit gros comme le nez sur la figure) et le sens abstrait, l'évidence rationnelle qui entraîne immédiatement l'adhésion de l'esprit [http:// www.philagora.net/corrige3/etre-evident.php] (8.3.2016)

REMARQUES : Voir gros (I) se rapporte à la dimension spatiale et souligne le dépassement de la taille normale d'une chose, le grossissement de l'image ou l'agrandissement de détails perçu par l'œil ou par une chose ; il réfère aussi à une technique cinématographique. (II) caractérise l'ambition dans l'élaboration d'un projet ou l'acquisition d'un bien. (III) renvoie à un jugement de valeur esthétique ou morale caractérisé par un manque de subtilité et de finesse (connotation négative et péjorative). Gros reste invariable et est modifié par plus, moins. Notons l'emploi pronominal du verbe au sens de 'percevoir quelque chose qui est gros' dans le quatrième exemple du CW. Mentionnons également les collocations voir grand, voir noir, voir petit, voir rouge, voir gros et simple, voir gros et beau.

\section{Voir groseille}

Voir, percevoir les choses en rose, de manière positive, optimiste

入 peindre groseille

\section{Voir haut}

I. Percevoir de manière (moralement, spirituellement) élevée, s'attacher à des choses élevées, d'une haute valeur morale, spirituelle, artistique, etc.

Emploi absolu

1601 Et ainsi l'esprit n'est jamais si sage que quand il est fol, ny plus veillant que quand il dort ; jamais ne rencontre mieux que quand il va de costé et de travers ; ne va, ne vole et ne voit si haut que quand il est abbatu et au plus bas (Pierre Charron, De la sagesse)

1847 Frenhofer est un homme passionné pour notre art, qui voit plus haut et plus loin que les autres peintres. Il a profondément mé- 
dité sur les couleurs, sur la vérité absolue de la ligne ; mais, à force de recherches, il est arrivé à douter (Honoré de Balzac, Le Chef-d'Euvre inconnu)

1877 vous êtes une âme profondément religieuse et vouée sérieusement au culte du vrai, du beau et du bien, parce que je crois que Dieu, qui voit bien haut par-dessus les prescriptions humaines, agrée votre culte autant que le mien (George Sand, Mademoiselle La Quintinie)

1883 Il aimait l'humanité comme représentant la raison, et haïssait la superstition comme la négation de la raison. Sans avoir le souffle poétique que le $\mathrm{XIX}^{\mathrm{e}}$ siècle a su ajouter à ces grandes vérités, Système, j’en suis sûr, vit très haut et très loin (Ernest Renan, Souvenirs d'enfance et de jeunesse)

1913 J'aime le Gille de Watteau Qui n'aperçoit aucun des pièges Des méchants, car il voit plus haut Que les instincts qui nous assiègent (Paul Éluard, Premiers Poèmes)

1954 Ce dernier ne conteste pas toute valeur au travail du premier ; le savant ne saurait interdire au philosophe de voir plus haut, plus loin, mieux que lui et de s'efforcer d'atteindre, selon ses voies qui ne sont pas celles de la science, le fondement même de toutes sciences (Robert Amadou, La Parapsychologie)

II. Prévoir (pour quelqu'un) l'accès à un haut rang social

Transitif

1863 et il me parut très mal à Louis XIV de ne pas l'avoir poussé avec soin, parce que je le voyais plus haut, parmi mes parents, le maréchal de Castelnau et les Rochechouart. Je ne comprenais pas non plus que le château de Vigny (sur la route de Rouen) ne m'appartînt pas (Alfred de Vigny, Le Journal d'un poète)

\section{CORPUS WEB :}

ESG : Une entreprise dans le vent qui voit haut et loin [http://www.connexion-emploi.com/ $\mathrm{fr} / \mathrm{a} / \mathrm{esg}$-une-entreprise-dans-le-vent-qui-voithaut-et-loin] (8.3.2016)
Mon président voit haut pour la Ligue des Champions en voulant aller au 1er à élimination directe alors quand on était en Europa League être dans le groupe était suffisant [http://www. footmanager.net/forum/becker-aton-t45671-156. html] (8.3.2016)

REMARQUES : Voir haut (I) désigne un animé qui pense ou conçoit les choses en méditant de manière élevée, soulignant un certain engagement, une réflexion profonde. Notons que haut est souvent employé dans la collocation voir haut et loin, loin venant compléter et intensifier l'idée de grandeur ou de réflexion. Voir haut (II) souligne le fait de penser pour quelqu'un à une autre position hiérarchiquement plus élevée, plus noble. Haut reste invariable et est modifié par bien, plus, si, très. Notons l'emploi de voler haut.

\section{Voir immense}

Voir les choses en grand, de manière excessive ; avoir des projets démesurés, très excessifs Emploi absolu

1884 Il voyait immense, il aurait volontiers donné aux hangars une façade monumentale dominant la mer, développant devant l'horizon sans borne la grandeur de son idée (Émile Zola, La Joie de vivre)

REMARQUES : Voir immense évoque la grandeur et l'ambition du projet, voire sa démesure par rapport à sa réalisation, à la construction de quelque chose (ici : un bâtiment). Immense reste invariable.

\section{Voir jovial}

Voir, percevoir les choses avec gaieté, enjouement, avec bonne humeur

入 peindre groseille

\section{Voir juste}

Voir, percevoir les choses avec justesse, avec exactitude, conformément à la vérité

Emploi absolu

1734 Le bon sens est, à mon avis, dit-il, le don de voir juste (Mercure de France)

1765 C'est peu de chose ; mais c'est encore moins que rien. Cela m'épargne des réflexions inutiles, et aux autres le petit embarras d'y répondre. « Je crois, mon amie, 
que je vois juste et que j'agis bien. Qu'en pensez-vous ? » (Denis Diderot, Lettres à Sophie Volland)

1840 À la naissance des nations, les hommes ont beau réfléchir et raisonner : sans méthodes, sans principes, ne sachant pas même faire usage de leur raison, ils ne savent s'ils voient juste ou s'ils se trompent (Pierre-Joseph Proudhon, Qu'est-ce que la propriété ?)

1844 Doué d'un coup d'œil perçant et rapide, il voyait bien et juste ; mais il agissait vite et mal. Je ne sais quoi d'incomplet, qui ne s'explique pas et qui se rencontre en beaucoup de jeunes gens, altérait sa conduite (Honoré de Balzac, Le Cabinet des antiques)

1846 Ainsi, la puissance de la crécelle vous prouvera :

Que vous êtes bien heureux d'avoir une femme d'un tel mérite ;

Qu'on vous a fait trop d'honneur en vous épousant ;

Que souvent les femmes voient plus juste que les hommes ;

Que vous devriez prendre en tout l'avis de votre femme, et presque toujours le suivre (Honoré de Balzac, Physiologie du mariage)

1852 Tout y est dignité, force, simplicité, courage, raison, sérénité, tendresse. $\mathrm{Si}$ tu parles politique, tu le fais bien, tu vois juste et tu dis vrai. Si tu parles affaires et famille, c'est un grand et bon cœur qui parle (Victor Hugo, Correspondance)

1866 Ce sont toujours les fous qui voient juste, les fainéants qui savent ouvrer, les irréguliers qui marchent droit, les bannis et les maudits qui méritent la palme (Louis François Veuillot, Les Odeurs de Paris)

1874 Je considère hommes, femmes, choses et idées, comme à peu près également indifférents, sauf l'usage qu'on en veut faire, et c'est, à mon sens, un grand élément de triomphe que de voir bien, juste et froidement (Arthur de Gobineau, Les Pléiades)
1899 C'est l'échec de Jules Guesdre à Roubaix qui inspire à Millerand ces réflexions de philosophie. Il voit fort juste, et dit à ces propos mille choses excellentes (Georges Clemenceau, L'Iniquité)

190721 mai. Je voudrais me jeter dans le rêve ou bien aller à mon travail, je vais me contraindre à voir. Je voudrais penser juste, voir juste. Il en sortira toujours quelque chose. J'écoute Pelletan ou un autre (Maurice Barrès, Mes cahiers)

1929 Ici lady Frances a tout ensemble raison et tort : elle voit juste quand elle estime que c'est la découverte de son penchant à elle (dont, par une omission bien féminine, elle préfère oublier qu'elle-même fut l'instigatrice) qui amena Byron à se déclarer : mais elle se trompe si elle imagine que la sincérité de la déclaration soit par là diminuée (Charles Du Bos, Byron et le besoin de la fatalité)

1939 Et celui-ci, qui savait aussi bien les secrètes avenues du cœur qu'il s’y gouvernait mal, voyait profondément juste, lorsqu'il écrivait à Arnim : « Bettina t’aime, mais c'est une jeune fille. Tu ne l'as pas comprise » (Albert Béguin, L’Âme romantique et le rêve)

1958 Si riche est la matière d'un pays en devenir que çà et là, parce que les auteurs auront vu faux, ou parce qu'ils auront vu juste, ils soulèveront la controverse (Le Monde, 10 juillet 1958 / Grundt : 365)

1966 La vitesse en football, c'est aussi une disposition de l'esprit à voir vite et juste. C'est encore pour une équipe la faculté d'imprimer une cadence rapide dans l'utilisation du ballon (Joseph Mercier, Le Football)

1989 Elle voyait juste, Anna, je faisais la gueule. Pas à elle, pas aux saintes femmes. À la vie. Et ce n'était pas une bouderie. C'était.. Où il était mon chat? (Remo Forlani, Gouttière)

1997 - Où sont les mercenaires, aujourd'hui ? Tu ne sais pas? Je vais te le dire : les patriotes prennent les armes contre nous, au Tyrol, en Andalousie, en Autriche, en 
Bohême, bientôt en Allemagne, en Russie...

- Tu vois juste mais tais-toi, Pouzet.

- Je veux bien me taire, mais sois sincère : est-ce que tu y crois encore?

(Patrick Rambaud, La Bataille)

\section{CORPus WeB :}

Chantal Delsol voit juste : elle me démoralise [http://fboizard.blogspot.co.at/2015/08/ chantal-delsol-voit-juste-elle-me.html] (6.3.2016)

Il y a deux types de présidents : les incompétents et les pires. Parmi les présidés il y ceux qui voient faux et qui comprennent juste. Et ceux qui voient juste et qui comprennent faux. Chaque médecin est en train de construire notre jadis [http://www.fnamgpm.com/FORUM/Detail. asp?search=abdelilah\&Id=7659] (14.3.2016)

Malheureusement, je ne peux pas vous garantir de tels résultats : les experts sont des humains, il arrive qu'ils se trompent, mais dans plus de $90 \%$ des cas, ils voient justes ! [http://divxo vore.kazeo.com] (6.3.2016)

C'est simplement dire que Dieu nous regarde comme juste. Non pas que nous soyons justes, mais lui nous voit justes, nous considère justes, nous déclare justes [http://jerecherche. chez.com/textes/figues.html] (6.3.2016)

REMARQUES : En parlant d'une personne, voir juste qualifie sa façon de voir ou de percevoir les choses face à une situation. Il se dit du fait d'analyser ou de percevoir quelque chose, une situation, l'opinion du sujet s'avérant exacte, conforme à la réalité. En tant qu'adverbe, juste reste normalement invariable, mais on trouve des exceptions dans un style peu soigné (v. l'avant-dernier exemple du CW). En tant que prédicat second ou complément d'une copule, il s'accorde avec l'objet (v. le dernier exemple du CW). Il est modifié par fort, plus, profondément. Notons les collocations bien et juste ; bien, juste et froidement ; vite et juste et l'emploi de comprendre faux, dire vrai, marcher droit, penser juste, voir faux.

\section{Voir laid}

I. Ne voir, n'aimer que la laideur

Transitif

1857 La nation intelligente se mit à rougir de voir si laid et si vulgaire tout ce qui doit faire le charme et l'ornement d'une belle habitation, et qui n'offrait alors que des formes insignifiantes, glacées (Paul Nosban, Nouveau Manuel complet de l'ébéniste, du layetier, du marqueteur, du sculpteur)

Emploi absolu

1899 L'avenir l'effraie, l'industrie l'effare, l'ingéniosité des machines l'inquiète ; il voit trouble, il voit noir, il voit laid : la femme enlaidit à ses yeux à mesure que la prosodie s'humanise (Mercure de France).

19094 octobre

Athis n'aime pas la dernière scène ; le public, dit-il ne sera pas avec moi contre Henriette. Il n'aime, comme Athis, que la comédie spirituelle agréable. En costumes. Antoine voit toujours laid. Le joli l'ennuie. Il veut fournir les toilettes, mais il les prend dans un grenier. Il n'y a que l'habilleuse qui lui tienne tête (Jules Renard, Journal)

\section{Porter un regard négatif (sur les choses)}

Emploi absolu

1861 pourriez-vous me dire pourquoi la mort [...] frappe [...] cette Lisette qui n'est plus Lisette, ce poëte realiste qui voit laid, ce vaudevilliste qui va chercher ses héroines où Villon cherchait ses rimes, ce dévot qui chante la messe et ne lit pas l'Évangile, passe, je ne m'en plains pas (La Nouvelle Régence)

1893 Il [= l'écrivain Franz Mahuette] saisit avec joie l'aspect étriqué des êtres et des choses. Il voit laid et comique, et nous invite à voir comme lui. Peut-être ce pince-sans-rire est-il un peu superficiel, mais il a du trait et de la malice (Albert Giraud, Chronique littéraire)

1914 Il outre et je ne peux plus le suivre parce qu'il n'est plus un artiste, parce qu'il a $v u$ laid partout et qu'il a voulu se consoler en le disant ; parce qu'il a vu douloureux partout et qu'il a voulu exaspérer sa douleur en faisant semblant de s'en moquer (Alain-Fournier, Correspondance avec Jacques Rivière) 
CORPUS WEB :

Menzel est considéré en Allemagne comme le peintre le plus universel du XIXe siècle : dans tous les ordres on vante son talent ; c'est un réaliste qui ne pare pas la réalité et voit laid [http:// www.cosmovisions.com/Menzel.htm] (6.3.2016)

REMARQUeS : Voir laid (I) se dit du fait de ne voir que la laideur de ce qui nous entoure ou de n'aimer qu'elle. (II) se dit du fait de voir, de considérer les choses de manière défavorable, désavantageuse, sous leurs aspects les plus mauvais. Laid reste invariable. Ceci étant, nous ne citons pas l'emploi transitif ou pronominal où laid fonctionne en prédicat second dénotant une propriété de l'objet, ce qui entraîne l'accord (il la voit laide; elle se voit laide). Laid est modifié par si, toujours. Notons les collocations laid et vulgaire ; laid et comique. Mentionnons également l'emploi de voir trouble, voir noir, voir douloureux.

\section{Voir large}

I. Voir ou percevoir (les choses) dans une perspective large, sous tous les aspects Transitif

1402 Le chemin que tu vois plus drois, Plus estroit et plus verdoiant, La face de Dieu est voyant Cil qui le suit jusqu’à la fin. Le chemin de plus courte fin Qui est de cellui au delez, Que tu vois plus large en tous lez, Cil, je te creant fermement, Conduit jusques au firmament Qui bien le scet a droit tenir Et la droite voye y tenir, Combien qu'autre chemin y maine (Christine de Pisan, Le Chemin de lonc estude, 908)

Emploi absolu

1835 Les royaumes de la terre ne me tenteraient pas. De la montagne où je suis, je vois plus large et je reste humblement tel quel (Alphonse de Lamartine, Correspondance générale)

1884 L'Allemand voit large et confus, nous voyons clair et juste (Henri Didon, Les Allemands)
1885 Il l'écoutait avec attention, tout en griffonnant des notes ; et quand elle eut fini il souleva des objections, reprit la question, l'agrandit, développa à son tour non plus un plan d'article, mais un plan de campagne contre le ministère actuel. Cette attaque serait le début. Sa femme avait cessé de fumer, tant son intérêt s'éveillait, tant elle voyait large et loin en suivant la pensée de Georges (Guy de Maupassant, Bel-Ami)

1907 Allez, cette illusion-là vaut bien qu'on risque quelque chose.... Et puis, quelle chose ? Vous avez des yeux arméniens, des yeux immenses! Vous voyez trop large. " Des catastrophes »! Quelles catastrophes? (Claude Farrère, L'Homme qui assassina)

1929 Devant ce vaste horizon qui est pourtant une réalité, il faut bien, pour avancer, tout d'abord voir large, percevoir clairement, puis, un but étant choisi, y marcher résolument par des moyens d'approche et de conquête d'une efficacité bien assurée (Ferdinand Foch, Mémoires)

1956 À la tête du génie, le général Dromard devait, sans faute, assurer à nos forces le passage de tous les obstacles et, pour finir, celui du Rhin. Au commandement des corps d'armée, il faut voir large et loin, ajuster en un effort unique les actions diverses et successives de plusieurs grandes unités

(Charles de Gaulle, Mémoires de guerre)

1975 Même si elles [= les jumelles] sont puissantes, elles ne vous montrent qu'un petit secteur à la fois. Avec des JUMO pas de risques ! Elles voient large ! À un kilomètre de distance, elles embrassent un champ de vision de 91 mètres (Michel Tournier, Les Météores)

2001 Aujourd'hui que j'habite au centre même de mes premiers livres, ceux qui m'ont appris à aimer cette langue et ce pays, je vois plus large. Entre ces tulipes jaunes sur le bureau de noyer et la forêt de Lyons installée devant la fenêtre (Colette Fellous, Avenue de France) 
II. Voir (les choses) en grand, concevoir de vastes projets

Emploi absolu

1935 il [= Joseph] aurait dû [...] rendre visite, pour les inviter, à des hommes politiques renommés, alors au pouvoir, tels MM. Dubief ou Ruau ; peut-être même - une autre fois, il verrait plus large ou viserait plus haut - tâcher de séduire quelque surprenante vedette, par exemple le président du Conseil, l'éminent M. Rouvier... (Georges Duhamel, La Nuit de la Saint-Jean)

1937 - C'est à chercher. Et l'atelier pour les peintres?

- Pour les peintres? Tu vois large : « les» peintres!

- Pense à l'avenir.

- Ils peuvent peindre chacun chez soi.

- Non, non. Question d'éclairage

(Georges Duhamel, Le Désert de Bièvres)

1961 Pourtant l'arche ne s'entr'ouvrait pas ; on n'en était encore qu'aux éclairs précurseurs ; il fallait attendre - à tout hasard, aux abords du saint Lieu, les revues multipliaient les baraquements neufs, voyaient large et faisaient la quête - on s'équipait comme pour loger la race entière des dents du dragon. Les mois passèrent, et les années ; la fatigue vint, et le dégrisement (Julien Gracq, Préférences)

\section{CORPUS WEB :}

Le but de cette campagne, à laquelle participe le Centre pour l'Egalité des chances et la lutte contre le racisme, est d'attirer l'attention sur la discrimination envers les gros, et les rondeurs en général, pour inciter à une prise de conscience de l'importance qu'a pris la norme de minceur dans nos sociétés. Prendre conscience des effets pervers de cette norme peut être un premier pas pour s'en détacher et contribuer à un changement de regard « pour une société qui voit large » [http:// www.questionsante.org/nos-publications-perio diques/bruxelles-sante/anciens-numeros/bs-66/ pour-une-societe-qui-voit-large] (6.3.2016)

Ropa voit large avec l'Euro-Maus 4

Le constructeur allemand renouvelle son offre de déterreur avaleur avec un modèle pouvant traiter des silos de 10 mètres de largeur.
La gamme de déterreurs de betteraves Ropa évolue avec l'arrivée de l'Euro-Maus 4. Ce déterreur de type avaleur se caractérise par une table de ramassage de 10 mètres effectifs contre 8,70 mètres pour la génération actuelle [http:// www.lafranceagricole.fr/videos/betteraves-ropavoit-large-avec-l-euro-maus-4-1,0,16300552.html] (6.3.2016)

On prend le risque de manquer pour ne pas gaspiller ou on voit large en prévoyant un système de récupération. gaspillage INTERDIT. idée à travailler plus tard, le nombre de personne susceptible d'être présent est encore trop incertain [https://alternatiba.eu/montpellier/commis sions-transversales/restauration] (6.3.2016)

REMARques : Voir large (I) désigne un animé qui perçoit ou considère les choses, le monde qui l'entoure, sous divers aspects, prenant en compte plusieurs idées. Dans le cas d'une prise de décision, le sujet réfléchit, pense à plusieurs options avant de se décider, ce qui souligne une certaine perspicacité dans le raisonnement. Dans l'exemple de 1975, il renvoie à une vision large (d'un espace). Voir large (II) se dit du fait de prévoir quelque chose à long terme, de faire des projets soulignant l'ambition du sujet, son besoin de beaucoup prévoir. Large reste invariable dans la majorité des cas. Large est modifié par plus, trop. Notons les collocations large et confus ; clair et juste ; large et loin, ainsi que l'emploi de viser haut, voir droit, droit tenir. VOIR AUSSI : penser grand, viser haut

\section{Voir loin}

Avoir de la pénétration, de la perspicacité, des ambitions, en anticipant

Emploi absolu

1863 Elle vit plus loin et plus juste que sa famille, parla longtemps, s'enflamma, pleura même inutilement (Alfred de Vigny, Mémoires inédits)

1920 Arrivait une députation. Elle se renseigne, n'a plus, quel que soit son parti pris, que le désir de plaire, d'étonner, de voir juste et loin, de soigner sa réputation. Au demeurant, le goût de bien faire. Elle est toute habileté. Mais se possédera-t-elle? Incroyable facilité à être émue (Maurice Barrès, Mes cahiers) 
1923 Le mari amoureux et malheureux y voyait juste (Paul Bourget, La Geôle)

1937a Balzac amplifie mais il ne déforme pas. Il voit seulement plus loin, plus large et plus profond que le commun des mortels (Goéland, 15 juillet 1937 / Grundt : 311)

1937b Comme si cela [= des anecdotes sur la vénalité d'ecclésiastiques] prouvait quoi que ce soit contre l'Eglise ! Comme si c'était cela qui l'empêchait de voir loin et grandement, de construire son chef-d'œuvre séculaire (Jules Romains, Les Hommes de bonne volonté)

1963 Il fit, en même temps, l'appareil adapté à ces disques : le " gramophone ». Il voyait juste et loin, puisque 75 ans après son invention, nous utilisons encore le disque plat, si différent qu'il soit de son ancêtre (Le Disque en France)

1974 Lisons ceci, en regard, qui est de 1848, et où Hugo voit vraiment, voit juste, et voit loin (Julien Gracq, Lettrines 2)

\section{CORPuS WeB :}

Celui qui vit dans l'espoir voit loin celui qui vit dans l'amour voit profond et celui qui vit dans la verité ? [https://fr.answers.yahoo.com/ question/index?qid=20120402050720AANg1vn] (1.3.2016)

En outre, comme pour la météo, plus on voit loin, moins on voit précis : à 10 ans, les projections sont relativement fiables. A 20 ans, la fiabilité se dégrade très fortement au point qu'on entre dans l'hypothèse. A 50 ans, on est carrément dans l'anticipation ou, si vous préférez, la science fiction [http://sarkofrance.blogspot. co.at/2013/09/pourquoi-la-manifestationcontre-la.html] (1.3.2016)

ESG : Une entreprise dans le vent qui voit haut et loin [http://www.connexion-emploi.com/ $\mathrm{fr} / \mathrm{a} / \mathrm{esg}$-une-entreprise-dans-le-vent-qui-voithaut-et-loin] (8.3.2016)

REMARQues : Voir loin se dit du fait de prévoir les conséquences (d'une situation, d'un événement), le sujet faisant preuve de perspicacité. Il peut aussi référer à l'ambition du sujet qui projette de grandes réalisations à long terme. Loin n'est évidemment pas un adjectif permettant de faire l'accord mais il s'insère parfaitement dans la série paradigmatique qui pivote autour du verbe voir, soulignant ainsi l'affinité adverbiale de la série. La présence cognitive de celle-ci est mise en évidence par son contraste sémantique avec large, haut, juste, précis et profond. Notons que l'accord au pluriel " loins » apparaît deux fois dans l'entrée tirer loin. VoIR AUSSI : construire petit

\section{Voir long}

I. en voir long : voir beaucoup

Emploi absolu

1902 Il se dégagea et, comme il levait la tête, il murmurait encore :

- Ah ! on peut dire que j'en vois long !

La petite ville s'étendait parmi les champs, calme et sans gêne comme une personne qui a l'aisance des coudes (Charles-Louis Philippe, Le Père Perdrix)

1925 Par moments, je croyais qu'on se jouait de moi, et que c'était pour aller caresser ma femme, puis je comprenais bien que non. On peut dire que j'en ai vu long sous ces arbres. Le vieux s'approcha. Avec sa grosse face plate et grise, grêlée comme un dé de tailleur, il semblait un tigre (Henri Pourrat, L’Auberge de la Belle Bergère ou Quand Gaspard de guerre revint)

II. Voir loin, dans une perspective large

Emploi absolu

1991 Sur quel vide te courbes-tu, ici, analyste, la question a rebondi si loin sur les longues géodésiques du langage... Lève la tête au-dessus de la mêlée, vois haut et long (Michel Serres, Le Tiers-Instruit)

\section{CORPUS WeB :}

Une manière littéraire de revenir sur notre Histoire, plaisante ou déplaisante pour le public. Les Enfants de la nuit montre, avec ses 26 minutes de beauté et d'histoire, qu'un court voit loin, voit long [http://www.iletaitunefoislecinema.com/ critique/5622/les-enfants-de-la-nuit] (2.3.2016)

Le Royaume-Uni voit long, très long. Le ministre des finances britannique, George Osborne, étudie la possibilité de lancer des obligations remboursables dans cent ans, voire des 
emprunts perpétuels. Une consultation sur le sujet doit être annoncée lors de la présentation, le 21 mars, du budget 2012-2013 [http:// www.lemonde.fr/economie/article/2012/03/15/ fort-de-son-idylle-avec-les-marches-londresenvisage-de-s-endetter-a-cent-ans-voire-aperpetuite_1669660_3234.html] (2.3.2016)

REMARQUES : Voir long (I) se dit du fait de voir ou d'avoir vu, aperçu beaucoup de choses se passer à un endroit précis. (II) désigne un animé qui voit, conçoit quelque chose en pensant à long terme, prévoit les conséquences (d'une situation, d'un événement), en faisant preuve de perspicacité. Long reste invariable. Notons la collocation haut et long, et le rapport synonymique avec voir loin. Long est modifié par très.

\section{Voir mauvais}

Voir des choses sous une optique négative $\lambda$ toucher mauvais

\section{Voir menu}

voir souvent et menu : voir continuellement Transitif

1364 A toutes ces choses musoie Et es exemples me miroie Que j'ai dit qui sont advenu Et qu'on voit souvent et menu (Guillaume de Machaut, Le Livre du voir dit, 6394)

+1400 De vous amer, quoy que tenu Vous soyez loings, maiz souvent et menu D'or en avant verrez sa doulce face, Pour au plaisir honorable avenir Que dame peut donner sanz que mefface. De bien en mieulx vous puist il avenir ! (Christine de Pisan, Balades / Euvres poétiques [début $\mathrm{XV}^{\mathrm{e}}$ ], I, p. 279, 26)

REMARQUES : Voir menu désignait le fait de voir une chose ou une personne très fréquemment. Menu, lorsqu'il est employé avec souvent comme locution figée, renforce l'idée de fréquence ou de rapidité de l'action. Menu reste invariable.

\section{Voir moderne}

Voir les choses de façon moderne, nouvelle

Emploi absolu

1958 Une des erreurs a sans doute été de voir trop grand et trop moderne pour une Chine encore très arriérée

(Le Monde, 20 novembre 58 / Grundt : 393)

\section{CORPUS WEB :}

Tout au contraire, à Monaco on voit moderne et on voit grand et c'est cette vision qui a permis d'en faire un Etat hautement développé, recourant volontiers aux techniques de pointe et à ties travaux massifs qui lui ont, notamment, permis, par ties emprises sur la mer, d'accroître son territoire de plus de $20 \%$ au cours du régne de l'actuel Prince Souverain [http://www.un.org/ ga/webcast/statements/monacoF.htm] (2.3.2016)

REMARQUES : Voir moderne se dit du fait de voir ou de concevoir quelque chose (un projet, une entreprise, le futur) d'une manière différente de ce qui avait été fait ou pensé précédemment, le sujet cherchant à innover, à apporter un souffle nouveau. Dans les deux exemples, il est associé à l'idée de grandeur nationale (voir grand). Moderne reste invariable et est modifié par trop.

\section{Voir net}

Voir distinctement, nettement, clairement, précisément; voir sans défaut ; sans aucun doute (au propre et au figuré) ; voir quelque chose qui est net, clair Transitif

+1415a Car jennes gens qui désirent honneur, Quant veoir vont aucun royal seigneur, Ilz se doivent mettre de leur puissance En bon array, car cela les avance Et si les fait estre prisiez des gens, Quant on les voit netz, gracieux et gens (Charles d'Orléans, Poésies [ 1415-1440], I, La Retenu d'Amours, p. 4)

$+1415 \mathrm{~b}$ Aussi en yver le pluvieux, Qui vens et broillars fait lever, L'air d'Amour epidimieux Souvent par my se vient bouter ; Si fault les pertuiz estouper, Par ou pourroit mon cuer ferir ; Le temps verray plus net et cler, 
Avant que je les face ouvrir

(Charles d'Orléans, Poésies [ 1415-1440], I, Ballade XCVI, p. 151)

1668 afin que les [= les défauts d'un texte] dissipant par la demonstration de leurs ordures, dont il veut salir ce saint et devot Tableau que je vous présente, vous soyez édifiez de le voir net, et que j'aye la consolation de l'avoir nettoyé (Bezian Arroy, Briéve et devote histoire de l'abbaye royale de S. Martin de l'Isle-Barbe)

1688 Jusques ici je n'ai point été touché de tous les autres livres qui parlent de Dieu ; et j'en voi bien aujourd'hui la raison. C'est que la source m'en paroissoit douteuse : mais la voyant claire et nette dans le livre de Labadie, il me fait valoir tout ce que je n'estimois pas (Roger de Bussy-Rabutin, Les Lettres de messire Roger de Rabutin)

1704 ALBERT. Vous voyez donc, monsieur, d'où procède son mal ?

CRISPIN. Je le vois aussi net qu'à travers un cristal (Jean-François Regnard, Les Folies amoureuses)

1755 Tenterai-je ce qu'on appelle les entreprises ? Eh ! Qui me répondra de la fidélité de mes confreres ? Cartouche a bien été trahi. Je verrai net le produit de la clientelle envers d'avides patrons, des avances onéreuses, et incertaines etc. (Victor de Mirabeau, L'Ami des hommes ou Traité de la population)

1929 Tout par un coup, j'ai $v u$, net, l'ensemble des terres et des ciels, de la terre où nous sommes, mais transformé, tout verni, tout huilé, tout glissant de méchanceté et de mal (Jean Giono, Colline)

1936 Quand je me sentais m'étourdir, je regardais plutôt en l'air... Ça m’atténuait les malaises de relever la tête... Le ciel était d'une grande clarté... Je crois que jamais je l'avais vu si net... Ça m’a étonné ce soir-là comme il était découvert... Je reconnaissais toutes les étoiles... Presque toutes en somme... Et je savais bien les noms ! (Louis-Ferdinand Céline, Mort à crédit)
1937 ORESTE. Pourquoi ne pas prendre la première route, et aller au hasard ? Fie-toi à moi. Je suis dans un de ces moments où je vois si nette la piste de ce gibier qui s'appelle le bonheur (Jean Giraudoux, Électre)

1953 Agnès mit ses mains sur les miennes, ce qui me fit la voir plus net (Albert Paraz, L’Adorable Métisse)

Emploi absolu

1670 Mais comme il y a beaucoup de sortes de croix, aussi le silence qu'on y garde est bien différent, et pour y voir net, je vous en suggere de trois manieres (François Guilloré, Maximes spirituelles pour la conduite des âmes)

1859 Tout ce qui se peut dire de modéré, de sensé, même de railleur sur le jansénisme et la vanité de cette querelle, vous l'allez voir, Nicole l'a dit ou a commencé à le dire ; lui le plus engagé des théologiens, le plus affairé, ce semble, des polémiques, il voyait net dans la mêlée ; au sein du tourbillon théologique, Nicole était un sage, ou du moins il avait quelque chose du sage (Charles Sainte-Beuve, Port-Royal)

1922 - Ah ! (dira-t-on) c'est trop bête de vouloir nier la science. Ils ont raison, ceux qui voient et admirent ses services, ses inventions, ses grandeurs.

- Mais voyons net. Elle ne se propose pas d'agir sur notre âme (Maurice Barrès, Mes cahiers)

1928 Il y a souvent avantage à ne point parfaitement comprendre. Mon imagination prêtait au mirage et diaprait généreusement mes incertitudes. À présent que j'y vois plus net, je suis un peu déçu. Étendu sous ma moustiquaire, j'ai lu avec une sorte de frénésie (qui a fini par me donner un fort mal de tête) (André Gide, Le Retour du Tchad)

1950 - Mais je vous trouve en train de travailler. - Je fais semblant. Voyez, ma plume est sèche.

(Il [= André Gide] la désigne du doigt.)... Il $\mathrm{y}$ a beaucoup de courage à parler ainsi 
de soi, à voir aussi net. Un peu plus tard, il me dit qu'il a reçu d'Amérique un câble de trente mots (c'est sa voix qui souligne) pour l'inviter à se rendre là-bas et recevoir le prix Goethe (Julien Green, Journal)

\section{Corpus Web :}

En revanche les myopes voient net de près lorsqu'ils rapprochent l'objet de l'œil [http:// www.docteurpietrini.com/Les-defauts-devision_a19.html] (2.3.2016)

Avec cette nouvelle technologie, plus besoin de faire d'effort, l'œil n'est plus gêné. Les yeux voient net à toutes distance et sans forcer des deux côtés [http://www.eyescontact.fr/lentillesde-contact/type-de-lentilles] (2.3.2016)

Les yeux voient nets à toutes distance sans forcer. Leur fonctionnement est similaire à celui des verres progressifs [https://www.grandoptical. com/gop/fr/lentilles-progressives] (2.3.2016)

REMARQUeS : Le sujet de voir net, dans son emploi transitif et concret, se situe à cheval entre une interprétation adverbiale de manière (au propre ou au figuré) et une lecture comme prédication seconde, cas de figure où la chose vue est elle-même présentée comme étant claire et nette. L'ambiguïté n'existe plus dans l'emploi absolu qui exclut la prédication seconde. Au figuré, en référence à la pensée, voir net se dit alors du fait d'avoir une bonne faculté de discernement, d'avoir les idées claires, d'être perspicace. Le passage du sens propre au sens figuré est graduel, les deux plans pouvant être présents en même temps. Le dernier exemple du CW montre que l'accord avec le sujet n'est pas exclu, même si l'orthographe soignée l'évite. Net est modifié par aussi, plus, si. Notons les collocations net et clair, clair et net.

\section{Voir noir}

I. Voir la couleur noire, une chose de couleur noire ; ne rien voir, être dans l'obscurité Transitif

1402 Regardes loings la voie ombreuse ! La vois tu noire et tenebreuse ? (Christine de Pisan, Le Chemin de lonc estude, 950)

1656 Claudine, avec le temps tes graces passeront,
Ton jeune teint perdra sa pourpre, et son

yvoire ;

Le ciel qui te fit blonde, un jour te verra

noire,

Et comme je languis, tes beaux yeux

languiront

(Guillaume Colletet, Poésies diverses)

1985 - Oh merde, c’est génial !

- Vraiment... ?

Elle m'a laissé la place. Juste au moment où je me penchais, l'appareil a cessé de fonctionner. On voyait tout noir. On s'est dépêchés de fouiller dans nos poches mais il nous restait plus un sou de monnaie. J'ai sorti ma petite lime à ongles. J'ai trifouillé dans la fente (Philippe Djian, $37^{\circ} 2$ le matin)

Emploi absolu

1862 L'obscurité est vertigineuse. Il faut à l'homme de la clarté. Quiconque s'enfonce dans le contraire du jour se sent le cœur serré. Quand l'œil voit noir, l'esprit voit trouble. Dans l'éclipse, dans la nuit, dans l'opacité fuligineuse, il y a de l'anxiété, même pour les plus forts. Nul ne marche seul la nuit dans la forêt sans tremblement (Victor Hugo, Les Misérables)

1966 Il y avait un cygne suffisamment arqué pour voir noir à travers l'arc-en-ciel de Léda. Il y avait, pour le voyage, une route noire et blanche et, sur cette route, les ombres saisonnières soulevaient tour à tour des nuages (Paul Éluard, Poèmes retrouvés)

1985 Le noir était pour les aveugles une couleur aussi inconnue que le blanc ou le rose. Aucun œil ne voyait noir, tout comme aucune oreille de sourd ne pouvait transmettre un silence, mais une absence de silence ou de stridence (Hervé Guibert, Des aveugles)

II. Voir, percevoir les choses de manière négative, pessimiste Emploi absolu

1760 DAMIS. Je suis au désespoir !

MARTON. Bon ! Vous n'y pensez pas, et vous voyez trop noir (Charles Palissot de Montenoy, Les Philosophes) 
1775 Je ne sais, mais je crains de grands, de bien grands changements d'ici à peu de temps. Bonsoir, je suis triste et malade. Je vois bien noir. Dieu veuille que ce soient mes yeux qui aient tort ! (Julie de Lespinasse, Lettres à Condorcet)

1776 Je sais d'avance quel ton tous prendront après m'avoir lû. Ce ton sera le même qu'auparavant, ingénu, patelin, benevole ; ils me plaindront beaucoup de voir si noir ce qui est si blanc, car ils ont tous la candeur des cygnes : mais ils ne comprendront rien à tout ce que j'ai dit là (Jean-Jacques Rousseau, Rousseau juge de Jean-Jacques)

1843 - Dans trois heures, tu auras fini en vraie Martial. Tu auras vu noir... voilà tout... Hardi, ma fille !

- Cela n'est pas beau de parler ainsi à votre fille, dit le vieux soldat d'une voix lente et grave

(Eugène Sue, Les Mystères de Paris)

1873 Il était sujet à ces emportements d'artiste impuissant en face des œuvres solides et vivantes qu'il rêvait. Alors, rien n'existait plus pour lui, il battait les rues, voyait noir, attendait le lendemain comme une résurrection (Émile Zola, Le Ventre de Paris)

1888 Il me disait cela à propos de la commande que vient de lui faire le gouvernement du baiser, qui doit être exécuté en marbre dans une figure plus grande que nature et qu'il n'aurait pas le temps de préparer à sa manière. Décidément, ce pauvre Raffaelli voit gros et noir (Edmond et Jules de Goncourt, Journal)

1911 On se dirait : « Je suis triste ; je vois tout noir ; mais les événements n’y sont pour rien ; mes raisonnements n'y sont pour rien ; c'est mon corps qui veut raisonner ; ce sont des opinions d'estomac. » 9 mai 1911 (Alain, Propos)

1929 Ils ont la lèvre amère ou ironique. Rien, il est vrai, ne donne l'air psychologue comme l'attitude habituelle de dépré- cier. Voir clair, c'est voir noir, selon cette convention parfois commode

(Paul Valéry, Variété II)

Transitif

1822 Je fais des réflexions d'anachorète, pour le moins, et je prends de ma situation présente des leçons de sagesse, pour cet avenir, si embrouillé, si peu connu, que les uns voient en beau, et que d'autres voient tout noir, comme moi par exemple, sans trop savoir pourquoi (George Sand, Correspondance)

1859 Mon vieux poing tout sanglant n'est jamais essuyé ;

Je suis moulu. Car, sire, on s'échine à la guerre ;

On arrive à haïr ce qu'on aimait naguère, Le danger qu'on voyait tout rose, on le voit noir ;

On s'use, on se disloque, on finit par avoir La goutte aux reins, l'entorse aux pieds, aux mains l'ampoule,

Si bien, qu'étant parti vautour, on revient poule (Victor Hugo, La Légende des siècles)

1979 - Et si on nous sépare?

Là, elle se fronce.

- Pourquoi tu vois toujours tout noir ? Aujourd'hui, je suis contente. Demain, on verra. Je sais seulement ça : on reste ensemble, toi et moi (François Cavanna, Les Russkoffs)

\section{CORPUS WEB :}

Vacances : Bison Futé voit rouge et noir sur les routes des stations de ski. La journée de samedi s’annonce particulièrement chargée sur les grands itinéraires de desserte des Alpes [http://www. francetvinfo.fr/decouverte/vacances/vacan ces-bison-fute-voit-rouge-et-noir-sur-les-routesdes-stations-de-ski_1321901.html] (2.3.2016)

Si on ferme les yeux et qu'on ne penses pas on voit noir ou rouge si on est au soleil [http:// planet-ados.net/topic/5710-les-yeux-ferm $\%$ C3\%A9s-on-voit-une-couleur-sans-la-regarder] (2.3.2016)

Capture d'écran en PJ. J'ai essayé toutes les combinaisons possible je n'arrive pas à avoir une situation coherente. L'arkoon voit blanc ou noir et 
ne prend pas en compte l'autorisation sur les IP google [http://open.arkoon.net/tag/regles+fire wall] (15.3.2016)

Toutefois, au cours de son actuel mandat, Netanyahu ne s'est pas montré pragmatique. Il voit blanc ou noir seulement. Il croit qu'il est le seul a détenir la justice et la sagesse [http://www.pales tine-solidarite.org/analyses.Chaoul_Arinili.091 112.htm] (15.3.2016)

Thuram, un livre qui voit noir, pour un homme qui voit rouge. Nous évoquions dernièrement les turpitudes de l'ancien footballeur, qui trouve que sa carrière, elle est vraiment loin, très loin, et aujourd'hui se consacre aux vraies questions, notamment celle du racisme. Et Fournier, le créateur de la Noiraude, ne l'a pas vraiment raté pour l'occasion. Occasion que Julien Allès saisit au vol pour répondre au dessinateur, juste le temps d'un coup de fil... [http://www. paperblog.fr/2748179/thuram-un-livre-qui-voitnoir-pour-un-homme-qui-voit-rouge] (2.3.2016)

Joseph Stiglitz voit noir. Les perspectives américaines ne sont guère reluisantes aux yeux du lauréat du prix Nobel d'économie 2001 [http:// www.magazineforces.com/node/37] (2.3.2016)

J'suis l'genre de fille spontanée, qui voit noir ou blanc, elle qui à tendance à faire tout sur un coup de tête, ça la du bon et du mauvais. Par conséquent, celle qui va ce peter le nez souvent parce qu'à pas assez réfléchie avant d'agir [https:// maviecouleurpastel.wordpress.com/2015/09/ 26/cte-genre-de-fille-la] (2.3.2016)

Quant à Miley Cyrus, la chanteuse a posté des photos de deux versions personnalisées avec humour de la fameuse robe [...] « Je la vois blanc et or. Kanye la voit noir et bleu. Qui est daltonien? ", s'est interrogée Kim Kardashian, alors que James Franco, lui, affirme la voir violet et noir. Le débat reste ouvert ! [http://www.elle.fr/Societe/News/ La-robe-qui-fait-debat-et-vous-de-quelle-couleurla-voyez-vous-2908468] (2.3.2016)

Même les stars s'y mettent : « Je la vois blanc et or. Kanye [West] la voit noire et bleue. Qui est daltonien ? ", s'interroge Kim Kardashian. "Je ne comprends pas le débat autour de cette robe bizarre et j'ai le sentiment que c'est une illusion. Je suis confuse et effrayée. PS : C'est évidemment bleu et noir ", a posté Taylor Swift. A la rédac' aussi, les avis sont partagés et des clans se sont formés (la guerre n'est pas loin) [http://www. journaldesfemmes.com/societe/phenomenesde-societe/1269496-robe-bleue-noire-blanchedoree] (2.3.2015)

REMARQUES : Voir noir (I) réfère à la perception visuelle concrète. Le sujet désigne un animé qui se trouve dans l'obscurité et qui, par conséquent, ne voit rien. Voir noir (II) renvoie à une vision pessimiste des choses ou de la vie ; le sujet désigne un animé qui a des pensées négatives, qui ne voit pas la vie du bon côté, qui pense toujours au pire. Le premier exemple du CW en illustre un autre emploi : noir et rouge peuvent référer à la circulation. Noir reste invariable dans la majorité des cas. Toutefois, en tant que prédicat second orienté vers l'objet, il peut s'accorder avec l'objet (comparer les deux derniers exemples du CW). Il est modifié par bien, si, toujours, tout, trop. Désignant une couleur, noir s'associe facilement à d'autres couleurs : blanc, bleu, gros, rose, rouge, violet, ainsi qu'avec ténébreux, trouble, clair.

\section{Voir parfait}

Considérer (quelque chose) comme parfait

Transitif

1704 C'est pourquoi Moïse l'introduit dans le monde qu'il venoit de faire, et il dit qu'après avoir vu son ouvrage, il le trouva bon : c'est-à-dire qu'il le trouva conforme à son dessein; et il le vit bon, vrai et parfait, où il avoit vu qu'il le falloit faire tel, c'està-dire dans son idée éternelle (Jacques-Bénigne Bossuet, De la connaissance de Dieu et de soi-même)

\section{Corpus Web :}

Pareil que Mikl. C'est tellement plus beau de figer dans notre esprit l'image de cet homme que l'on voit parfait, pour nous, et d'en garder un souvenir si beau, si pur, que rien ni personne ne pourrait l'altérer [http://www.za-gay.org/forum/ viewtopic/24991/le-mec-qu-on-voit-dans-lebus-/0] (1.3.2016)

Donc quoi qui fasse et $\mathrm{mm}$ si ca santé est en danger comme elle le voit parfait elle ne fait rien et dans un sens, ca lui $\mathrm{n}$ uit (surtt sociallement) [http://forum.e-sante.fr/frere-9-ans-obese-mamere-ne-fait-rien/forum/1173] (1.3.2016) 
Cette femme que tout le monde voit parfaite, qui à un train-train quotidien... J'ai vraiment apprécié ce personnage, ce bout de femme inoffensive qui sort ses griffes [http://tartinneaux pommes.blogspot.co.at/2013/08/chronique-spira les-tatiana-de-rosnay.html] (1.3.2016)

depuis que j ai 12 ans je voit flou de mon œil gauche et je voit des petit crcle transparent je sais pas ce quil $\mathrm{m}$ arrive et aussi quand je regarde a peux pres 3040 metre de loin je vois vraiment flou mais quand je regarde de mon œil droite je voit parfait Vous pensez que cela va empirer ? [http://sante-medecine.journaldesfemmes.com/ forum/affich-916356-mon-oeil-gauche-voit-foule-loing] (1.3.2016)

Remarques : Dans l'exemple de 1704, tout comme dans les trois premiers exemples du CW, voir parfait se dit du fait de considérer quelqu'un comme une personne correspondant exactement à un certain modèle esthétique, intellectuel, affectif, éthique, social, comme une personne qui remplit son rôle au mieux. Dans ce cas-là, parfait fonctionne en tant que prédicat second orienté vers l'objet et s'accorde avec l'objet. Dans le quatrième exemple du CW, parfait adopte une fonction adverbiale, dans une écriture peu sûre, il est vrai, mais voir parfait s'y utilise comme équivalent de voir parfaitement. Il s'y oppose à voir flou.

\section{Voir petit}

I. Mésestimer, avoir une mauvaise opinion (de quelqu'un)

Transitif

-1200 Li chevaus nel connut, en grant vieuté le tient,

Petit le voit, ne l'a gaires proisiet

(Elie de Saint Gille [fin $\mathrm{XII}^{\mathrm{e}}$ ], 2026)

+1400 Petit voit on homme qui moult promette Tenir serment ne nul terme qu'il mette (Christine de Pisan, Proverbes moraulx / Euvres poétiques [début Xve], III, p. 52)

II. Voir peu, avoir peu de contact Transitif

1364 J'aim une dame par amours Sur toutes. Or est mes demours Loing d'elle, dont petit la voi Et po souvent ver li envoi (Guillaume de Machaut, Le Livre du voir dit, 5390)
III. Sous-estimer la valeur (de quelque chose)

Transitif

1704 D'où me pourroit venir l'impression de la vérité ? Me vient-elle des choses même? Est-ce le soleil qui s'imprime en moi, pour me faire connoître ce qu'il est, lui que je vois si petit malgré sa grandeur immense? (Jacques-Bénigne Bossuet, De la connaissance de Dieu et de soi-même)

1862 Eh bien, je parle franchement, vrai comme vous êtes un honnête homme, je ne peux pas y consentir. Elle me ferait faute, cette enfant. J'ai vu ça tout petit. C'est vrai qu'elle nous coûte de l'argent

(Victor Hugo, Les Misérables)

Emploi absolu

1964 Il y a dans la Chute de l'Empire romain un remarquable duel à l'épieu sur un Forum qui m’a paru cinq fois grandeur nature (les Romains voyaient petit) (Express, 7 mai 1964 / Grundt : 401)

IV. Manquer d'imagination; voir, percevoir les choses sans faire preuve d'ambition (contraire de voir grand)

Emploi absolu

1932 L'avenir était à ceux qui, comme Alfred, voyaient petit. Aujourd'hui, le manque d'envergure est la première qualité dans les affaires (François Mauriac, Le Nœud de vipères)

\section{CoRpus Web :}

Ma nature optimiste y voit un signe du destin (oui rien que ça) et me pousse à me dire : voit petit, ne regarde pas le sommet de la montagne, mais chaque pas que tu fais sur la pente [http:// lepetitvgdebxl.canalblog.com/archives/2015/ 04/26/31956958.html] (1.3.2016)

Et cela, à cause des Corses quand c'est un Corse, plus ambitieux encore que le général De Gaulle, qui terrassa, sous la botte française, la Bavière, la Westphalie, la Saxe, l'Italie, l'Autriche, l'Espagne, la Hollande, le Danemark etc. Je parle de Napoléon. Eût-il totalement réussi son coup, c'est la Moskova qui eût traversé la France comme le Cher traverse Vierzon ! Il voyait grand ! L'époque désormais voit petit ! [http:// www.globenet.org/chroniqueur/02/rubriques/ grand_angle3.html] (1.3.2016) 
REMARQUES : Voir petit réfère à une vision des choses très étroite et réductrice. Il souligne le manque de clairvoyance et de subtilité dans le jugement, voire une certaine médiocrité. En ancien français, voir petit pouvait se dire en référence au temps ou à la fréquence : 'voir peu'. Petit reste invariable et est modifié par si, tout. L'emploi transitif est plus rare que l'emploi absolu, allant de pair avec une interprétation plus concrète de perception visuelle. Notons l'emploi de voir grand. VOIR AUSSI : construire / penser petit

\section{Voir précis}

Voir distinctement, avec précision, avec clarté Emploi absolu

1887 C'était vraisemblable, et je me convaincrais, une fois de plus, de ma facilité à me griser de mes propres idées. Cela me peinait toujours profondément de constater cette faiblesse, et ma constante impuissance à y voir juste, précis et net (Paul Bourget, André Cornélis)

1928 J'ai toujours possédé et je possède encore ces dons : un œil sensible, qui voit précis et loin, une main adroite, une honnêteté intellectuelle absolue, une mémoire sensorielle qui dépasse de très loin le commun (Maurice Genevoix, Les Mains vides)

\section{CORPUS WEB :}

Ni flottement, ni désordre ; il voit précis et juste, dans une lumière qui n'est ni excessive, ni avare. Merveille, cette mise au point : rien ne se perd et tout s'aiguise : on perçoit l'imperceptible [http://www.paperblog.fr/4164131/le-theatre-dejules-renard-en-1912] (1.3.2016)

En outre, comme pour la météo, plus on voit loin, moins on voit précis : à 10 ans, les projections sont relativement fiables. A 20 ans, la fiabilité se dégrade très fortement au point qu'on entre dans l'hypothèse. A 50 ans, on est carrément dans l'anticipation ou, si vous préférez, la science fiction [http://sarkofrance.blogspot.co.at/2013/09/pour quoi-la-manifestation-contre-la.html] (1.3.2016)

REMARQUES : Voir précis réfère à la perception des choses, le sujet analysant ou percevant les choses d'une manière concise, qui va droit à l'essentiel, suggérant une faculté de discernement. Il peut aussi renvoyer uniquement à la perception visuelle et souligne une vision parfaite, claire et nette. Notons les collocations précis et loin ; précis et net; précis et juste, ainsi que Plus on voit loin, moins on voit précis. Précis reste invariable.

\section{Voir profond}

I. Voir profondément, en profondeur, de manière très réfléchie, en allant au fond des choses

Emploi absolu

1873 Le sort est dans l'eau : le cormoran nage, Le vent bat en côte, et c'est le Mois Noir... Oh! moi je sens bien de loin le naufrage ! Moi j'entends là-haut chasser le nuage ! Moi je vois profond dans la nuit, sans voir ! Moi je siffle quand la mer gronde, Oiseau de malheur à poil roux !... (Tristan Corbière, Les Amours jaunes)

1883 Comment cette conception, déjà assez claire, d'une philosophie positive, ne chassait-elle pas de mon esprit la scolastique et le christianisme ? Parce que j'étais jeune, inconséquent, et que la critique me manquait. L'exemple de tant de grands esprits, qui avaient $v u$ si profond dans la nature et qui pourtant étaient restés chrétiens, me retenait (Ernest Renan, Souvenirs d'enfance et de jeunesse)

1908 Il trouve ici l'ordre et le plaisir. Des clercs, des légistes, des chevaliers. La plupart des hommes ne voient pas très profond ; ils s'arrêtent à cette espèce de surface. Mais ces idées, c'est profondément cimenté chez quelques-uns, c'est ruineux et négatif chez d'autres (Maurice Barrès, Mes cahiers)

1914a Il avait dans l'esprit l'ancienne notion du bonheur fixe, et prétendait y adapter le bonheur qu'il découvrait. Claudel et le christianisme ont $v u$ bien plus profond en pensant que cette éphémère jouissance était la seule possible sur terre. Mais ils ont eu tort d'affirmer pour un au-delà la possession de la joie (Alain-Fournier, Correspondance avec Jacques Rivière)

1914b Je voulais après cela te dire un nouveau point de vue, dont j'ai appris à me regarder, et d'où je crois avoir vu assez profond. 
Mais je ne me sens pas disposé. Je me suis $\mathrm{vu}$ - en deux mots - comme un composé de deux êtres radicalement ennemis, l'un rationaliste et idéologue (Alain-Fournier, Correspondance avec Jacques Rivière)

1939 Le silence d'un petit bourg, la nuit tombante, les lumières des cuisines et des étables, le bruit des chaînes, les pas lourds des cultivateurs, et puis la lampe électrique qui n'éclaire que votre table et laisse tout le reste dans l'ombre, mais tout ce reste tellement le même, tellement connu depuis trente et un ans... dans cette ambiance tout se réduit à l'essentiel, et l'on voit très profond en soi, si l'on y consent

(Henry de Montherlant, Les Lépreuses)

Transitif

1948 En effet, la fenêtre était très belle. Le cimetière pouvait être sous la lune. La nuit, de son lit, Divine le voyait clair et profond, sous la lumière de la lune. Cette lumière était telle qu'on apercevait fort bien, sous l'herbe des tombes et sous les marbres, l'agitation spectrale des morts (Jean Genet, Notre-Dame-des-fleurs)

II. Voir en profondeur (sens spatial concret) Emploi absolu

1934 Pour le coup, quand j'ai vu cette bonne centaine de gaillards campés à demeure dans Clochemerle, j’ai tout de suite pensé que ça tarderait pas d'amener du grabuge. Voilà toutes les femmes dehors, sous prétexte de tirer de l'eau à la pompe, où elles se tenaient le cul haut et le corsage grand bâillant, penchées sur leurs seaux. Dans ces corsages qui laissaient voir profond, et sous ces jupes qui cachaient pas de reste, vous pensez si c'était plein de regards glissés comme des anguilles

(Gabriel Chevallier, Clochemerle)

CORPUS WeB :

Dans le cas qui nous intéresse, ce n'est pas le superviseur qui regarde d'en haut, ce sont le superviseur et le supervisé qui, ensemble, vont prendre de la distance avec les situations vécues pour se recentrer sur la personne du thérapeute.
Sans jamais oublier le client. Et plus on regarde haut, plus on voit profond... [http://www.unpsy. $\mathrm{fr} /$ supervision.html] (1.3.2016)

Remarques : Au figuré (I), le sujet désigne une personne qui a une vision des choses élevée, qui approfondit la réalité vécue ou pensée, qui va au fond des choses, qui témoigne d'une grande élévation d'esprit ou de cœur ou de jugement, ou qui a une grande perspicacité. Dans son sens concret (II), voir profond s'applique à un décolleté large (grand bâillant) qui laisse entrevoir généreusement le corps ou une partie du corps. Notons la collocation clair et profond. Profond reste invariable et est modifié par assez, bien plus, si, très. Mentionnons également l'emploi de regarder haut dans la phrase Plus on regarde haut, plus on voit profond. VOIR AUSSI : regarder haut

\section{Voir rose}

Voir, percevoir les choses de manière positive, optimiste

Transitif

1859 Mon vieux poing tout sanglant n'est jamais essuyé ;

Je suis moulu. Car, sire, on s'échine à la guerre ;

On arrive à haïr ce qu'on aimait naguère, Le danger qu'on voyait tout rose, on le voit noir ;

On s'use, on se disloque, on finit par avoir La goutte aux reins, l'entorse aux pieds, aux mains l'ampoule,

Si bien, qu'etant parti vautour, on revient poule (Victor Hugo, La Légende des siècles)

1896 Ernest, en un sonnet dont peut-être as mémoire,

Je glorifiais Dieu jadis de nous avoir Tout fait voir rose dans ce monde où tout est noir

Et créés gais tous deux pour sa plus grande gloire (Paul Verlaine, Euvres poétiques complètes)

REMARQUES : Employé en opposition avec voir noir, qui souligne le pessimisme du sujet, voir rose se dit du fait de considérer l'avenir, l'existence, la vie d'une manière optimiste. Rose reste invariable et est modifié par tout. 


\section{Voir rouge}

I. Voir la couleur rouge, une chose de couleur rouge

Transitif

1684 comme si chaque petite boule de lumiere apres deux inclinations, et deux courbures tournoit plus viste sur son centre qu'apres une seule, et que cette plus grande vitesse fust dans l'œil une condition pour le faire voir plus rouge (François Bernier, Abrégé de la philosophie de Gassendi)

Emploi absolu

1842 Il m'a semblé qu'une immense rose sortie de mon crâne grandissait et m'enveloppait. La couleur rose de cette fleur sanglante était dans l'air. Je voyais tout rouge. Ainsi parvenue au point où la séparation semble vouloir se faire entre le corps et l'âme, une douleur, qui m'a fait croire à une mort immédiate, a éclaté (Honoré de Balzac, Mémoires de deux jeunes mariées)

II. Se mettre très en colère, perdre le contrôle de ses actes ; être animé de passions violentes, sanguinaires

Emploi absolu

1843 Alors je voyais rouge, et je commençais à chouriner... à chouriner sur ces hommes, comme autrefois sur les chevaux. Mais, plus je chourinais de soldats, plus il en revenait (Eugène Sue, Les Mystères de Paris)

1884 Il me frappa, et comme je le saisissais au collet, il tira de sa poche un revolver. J'ai vu rouge, je ne sais plus, j'avais mon compas dans ma poche ; je l'ai frappé, frappé tant que j'ai pu. Alors elle s'est mise à crier : «Au secours ! à l'assassin ! (Guy de Maupassant, Contes et nouvelles)

1921 Et Batouala savait que Bissibingui savait. Baba, toi seul es heureux. C'est nous qui sommes à plaindre, Nous qui te pleurons. Irrité, un blanc voit rouge, là, tout de suite (René Maran, Batouala, véritable roman nègre)

1926 M. Roch écarta les mains et sourit d'un air discret : c'était une méthode ingénieuse qu'il avait pour insinuer le faux sans mentir, M. Achille vit rouge.

- Cet homme est incorrigible, dit-il amèrement. Son père était un fourbe ; son grandpère était un fourbe. Rien à faire avec lui... Il vous coûte deux francs de moins ? (André Maurois, Bernard Quesnay)

1934 Ben, bon Dieu, ça faisait du joli, dehors ! Une mêlée de civils et de soldats au milieu de la rue, et tout ça qui voyait rouge, et qui se triquait ferme, et qui gueulait comme des Aztèques, et de tous côtés il en arrivait d'autres avec des gourdins, des barres de fer et des baïonnettes (Gabriel Chevallier, Clochemerle)

1936 Mon père, il faisait éruption. Avec ce plan de m'en aller, on chahutait sa tragédie... Il se cramponnait aux conditions... Il en voyait complètement rouge... Il arpentait comme un fauve. Ma mère clopinait par-derrière... Elle rabâchait les avantages... Les prix les plus modérés...

(Louis-Ferdinand Céline, Mort à crédit)

1976 Après quoi, quand je suis allée toucher ma solde militaire de déportée, le troufion m'a dit que je n'avais droit qu'à la solde de base, « puisque j'avais été logée, nourrie et vêtue par les Allemands ». J'ai vu un peu rouge (André Malraux, Antimémoires)

III. Avoir les yeux rouges

Emploi absolu

1862 Tu la connais. Pour toujours... Je divague et je radote. Permets cela à ma douleur. Je pleure tant en t'écrivant que je vois rouge. Et dire que rien n'y peut faire ! Me révolter contre ma famille! Mais elle a contre moi une arme qui est la loi, je n'ai pas vingt et un ans (Stéphane Mallarmé, Correspondance)

\section{CORPUS WEB :}

Alès : les éleveurs de taureaux voient rouge Alors que la polémique resurgit, cette fois au Vigan, l'abattage des bioùs de Camargue devient ultra-sensible [http://www.midilibre.fr/2016/ 02/23/les-eleveurs-de-taureaux-voient-rouge, 1290796.php] (27.2.2016) 
Des microalgues voient rouge!

Les algues rouges toxiques qui proliféraient l'été sur les côtes bretonnes ont trouvé leur maître. Elles sont attaquées par un parasite [http: //www.espace-sciences.org/sciences-ouest/261/ actualite/des-microalgues-voient-rouge] (27.2.2016)

@BFMTV Les médias et les politiciens voient rouges quand le FN est éligible, on ne vas tout de même pas continuer comme ça éternellement ! [https://twitter.com/matingal44/ status/508689214884839424] (27.2.2016)

Mes ongles voient rouges...

Qui dit été, dit soleil, dit vacances, dit couleurs chaudes donc rouge. Je me mets tout doucement aux manucures. Je trouvais sympa de faire une manucure dans les tons rouges avec plusieurs vernis différents de marque différentes afin de voir les différences de couleurs, de textures, de tenues, de séchages, une vraie battle de vernis rouge... [https://www.facebook.com/ media/set/?set=a.312324358853290.76425.112928 535459541\&type=3] (27.2.2016)

Pour cet automne, mes lèvres voient rouges

Adieu corail, fuchsia ou autres couleurs vives et vibrantes ! Avec l'automne qui est déjà bien installé, la tendance est au Bordeaux, pourpre, mauve ou rouge pour les lèvres [http:// www.sammakeupaddict.com/2013/10/pour-cetautomne-mes-levres-voient.html] (27.2.2016)

REMARQUES : Voir rouge (I) réfère à la perception visuelle de sens concret, le sujet désignant une personne dont l'œil voit l'objet de couleur rouge. Sous l'effet d'une vive émotion ou après avoir trop pleuré. (II) se dit du fait de se fâcher fortement, de se mettre en colère à l'annonce de quelque chose ou face à une situation révoltante, incompréhensible. (III) fait allusion à des yeux devenues rouges. Dans les deux derniers exemples du CW, voir rouge renvoie au fait de porter la couleur rouge (les ongles, les lèvres). Rouge reste invariable dans la majorité des cas, mais il peut également manifester l'accord avec le sujet dans les exemples du CW. L'accord dans les deux derniers exemples du CW est dû au fait que l'adjectif caractérise la couleur du sujet, indirectement il est vrai, puisque voir dirigerait la portée de la modification vers l'objet de voir. Les auteurs jouent donc avec la construction, sans doute pour attirer l'attention. En effet, dans les exemples du CW voir rouge apparaît dans le titre du texte. L'accord dit illogique s'observe dans le troisième exemple du CW. Rouge est modifié par complètement, plus, tout, un peu. Notons l'emploi de se triquer ferme.

\section{Voir simple}

I. Ne voir qu'une chose alors qu'elle est en double

Transitif

1754 Ils ne voyent point double. Chacun fixe l'objet que la main saisit, chacun rapporte les couleurs à la même distance, au même lieu ; et comme le renversement de l'image ne leur empêche pas de voir un objet dans sa vraie situation, la même image, quoique double, ne leur empêche pas de le voir simple. La main les force à juger d'après ce qu'elle sent en elle-même. En les obligeant de rapporter au-dehors les sensations qu'ils éprouvent en eux ; elle les leur fait rapporter à chacun sur l'unique objet qu'elle touche, et au seul endroit même où elle le touche. Il n'est donc pas naturel qu'ils le voient double (Étienne de Condillac, Traité des sensations)

II. Voir avec simplicité, sans artifice, sans difficulté, sans compliquer (les données) Emploi absolu

1913 WOLDSMUTH. (sombre)

Croyez-moi, vous voyez trop simple. De tout temps, cette question diplomatique m'a préoccupé ; c'est le fil secret de l'affaire : un fil qui n'est à aucun endroit visible, mais auquel tous les événements viennent se rattacher. Il y a là un danger terrible ! (Roger Martin du Gard, Jean Barois)

1932 Disons que c'est désormais, pour l'âme, une surabondance de vie. C'est un immense élan. C'est une poussée irrésistible qui la jette dans les plus vastes entreprises. Une exaltation calme de toutes ses facultés fait qu'elle voit grand et, si faible soit-elle, réalise puissamment. Surtout elle voit simple, et cette simplicité, qui frappe aussi bien dans ses paroles et dans 
sa conduite, la guide à travers des complications qu'elle semble ne pas même apercevoir (Henri Bergson, Les Deux Sources de la morale et de la religion)

1936 Un grand écrivain ne pense pas simple et ne voit pas simple, mais il peut être amené à écrire simple, parce que le style est une interprétation libre en vue d'un effet à produire, et d'un résultat à obtenir (Albert Thibaudet, Réflexions sur la littérature)

1950 Je comprends, à présent, je vois simple et clair (Maurice Genevoix, Ceux de 14)

1960 Desnoyer, amateur de vastes paysages et de spectacles allègres, tempérament robuste, artiste de haute conscience qui sait voir simple et qui sait voir grand

(Jean Cassou, Panorama des arts plastiques contemporains)

REMARQues : Opposé à voir double, triple, etc., voir simple (I) s'emploie au concret pour dire qu'on voit une seule fois une chose double. Voir simple (II) désigne également une façon de voir les choses, de les voir avec simplicité, sans chercher à les compliquer ou à se compliquer la tâche. Dans l'exemple de 1960 il s'oppose à voir grand, donc au fait d'avoir des visions ambitieuses à long terme. Il peut être modifié par trop. Notons la collocation voir simple et clair et l'emploi de penser simple. VOIR AUSSI : voir double

\section{Voir trouble}

Avoir la vue ou l'esprit troublés, voir ou comprendre confusément (au propre et au figuré) Emploi absolu

+1415 Je suis moullié et retrait et remis, Morne et pensif, trop plus que ne souloye, J'y voy trouble, car es yeux ay la taye, Et n'y congnois le blanc d'avec le bis, Tant sont les yeulx de mon cuer endormi (Charles d'Orléans, Poésies [ 1415-1440], II, Rondel XXVII, p. 306)

1578 MALICAN. Ou je voy trouble, ou c'est là Celestine. Le Diable la puisse bien amener. Ô comme elle remue la queuë ! Elle vient parlant entre les dents (Jacques de Lavardin, La Celestine [adapt.])
1648 BÉRONTE. C'est à quoy je m'appreste ; Je n'ay que trop servy ces trois Diables d'Enfer, Le Balaffré, le Borgne, avec le Bras-defer. Mais qui vous rend chagrin? Si mon œil ne void trouble, Je suis plus gay que vous, moy qui n'ay pas le double (Claude de L'Estoile, L'Intrigue des filous)

1717 S'enivra d'un vin gris.

Tant en fut pris qu'il voyait trouble, Et qu'il trouva, sa femme double, Quand il revint à son logis (Dancourt, Le Prix de l'arquebuse)

1778 Si vous avez à faire choix d'un ami, lisez la troisieme, où l'on trouve entre autres cette maxime de Pomponius. «Il y a des yeux tellement accoutumés aux ténèbres, qu'ils voient trouble au grand jour » (Denis Diderot, Essai sur la vie de Sénèque)

1846 Avant d'avoir peur, on voit juste ; pendant qu'on a peur, on voit double, et après qu'on a eu peur, on voit trouble (Alexandre Dumas père, Le Comte de Monte-Christo)

1862 Quand l'œil voit noir, l'esprit voit trouble (Victor Hugo, Les Misérables)

1868 Et si, pour sortir de leur malaise, ils tâchaient de s'intéresser à ce qui les entourait, ils voyaient trouble, ils s'imaginaient qu'une fumée grise emplissait l'air, et que chaque objet se ternissait, fané et Sali (Émile Zola, Madeleine Férat)

1967 Mokkhi passa d'un grand bond le seuil du défilé et poursuivit sa course tant qu'il eut du souffle. Quand il s'arrêta, il dut frotter ses yeux qui voyaient trouble. Il ne se rendit pas compte qu'il essuyait des larmes (Joseph Kessel, Les Cavaliers)

1991 - Je vous mets des gouttes dans les yeux, dit une infirmière, survenant soudain. Dans les deux, par acquit de conscience. Il s'agit de dilater vos pupilles pour faciliter l'examen. Ne vous inquiétez pas si vous voyez trouble. Je reviens dans cinq minutes (Hervé Bazin, L'École des pères)

REMARQUES : Voir trouble réfère à une perception visuelle confuse ou, dans l'exemple de 1862, à une compréhension confuse du monde. Trouble 
est invariable. Son affinité sémantique avec voir double et la rime suggèrent la cooccurrence avec voir double. Notons aussi les groupes voir juste et voir noir.

\section{Voler bas / haut}

(exclus du dictionnaire, comme d'autres emplois adverbiaux de bas / haut; v. Introduction I : la macrostructure)

\section{Voler raide}

Voler rapidement, en ligne droite

Intransitif

1883 Du côté de Chaillot, Javel, Auteuil, ce sont les bergeronnettes qui font la chasse aux mouches et aux cousins. D'un bord à l'autre de la rivière, elles volent raide, en poussant un tout petit cri qui ressemble au grincement d'un tire-bouchon dans le liège. Elles se posent net, en hochant la queue en l'air comme les oiseaux japonais (Jean Richepin, Le Pavé)

1926 Et il pêche, contre le vent. Sa canne est fine, mais nerveuse. Il fouette avec vigueur, la ligne de soie fend l'air en sifflant, la mouche vole raide au-dessus de la Loire (Maurice Genevoix, La Boîte à pêche)

\section{Voler rapide}

Voler rapidement

Intransitif

1843 mes jours volent rapides vers leur terme (L'Illustration)

1847 Vole, dirai-je, aimable avant-courrière, Vole rapide, oh! vole, heureux oiseau! (Charles Oscar Dugué, Essais poétiques)

\section{Vomir jaune}

Avoir un vomi jaune

Intransitif

2018 Est-ce normal de vomir jaune quand on a rien mangé ? (Corpus Web Coiffet 2018 : s.v., sans date)

VOIR AUSSI : cracher / moucher / tousser jaune

\section{Voter blanc}

I. Voter un parti, une idée qui s'associe à cette couleur

Intransitif

1846 Votre intention est excellente, et j'en prends acte : mais j'ajoute que vous vous êtes trompé de boule, que vous avez voté blanc quand vous vouliez dire noir, que la société a été prise par vous pour l'égoïsme, et réciproquement l'égoïsme pour la société (Pierre-Joseph Proudhon, Système des contradictions économiques)

II. Voter sans remplir le bulletin Intransitif

1899 Au passage des urnes, le mot d'ordre accoutumé avait couru sur les bancs de la majorité :

- Blanc Blanc! Votons blanc! Le sénat ne votera jamais cela, la loi est enterrée ! (Eugène Vogüé, Les Morts qui parlent)

1907 - Si vous partez, dit-il, je ne sais dans quel sens Descaves et Mirbeau feront l'élection. $\mathrm{Si}$ vous restez, vous aurez quatre voix : Descaves, Mirbeau, les Rosny, et Céard quatre : Bourges, Daudet, Geffroy, Hennique. Je voterai blanc, et, la voix d'Hennique comptant double... (Jules Renard, Journal)

1949 Par suite, il n'y a qu'une liste unique présentée au suffrage des électeurs. Les opposants ne peuvent que s'abstenir ou voter blanc. Les résultats des élections donnent des chiffres voisins de l'unanimité (Georges Vedel, Manuel élémentaire de droit constitutionnel)

1986 - Tu votes pas le communiste? Tu votes le socialiste?

$-\ldots$

- Si tu sais pas, tu votes pas. Et ça, c'est pas bon, tu sais. Les élections c'est pas la tombola. C'est dommage. Absolument. Tu votes le chômage.

L'autre relève la tête :

- Non, je vote pas le chômage... Moi, je vote blanc (François Caradec, La Compagnie des zincs) 
REMARQUES : Lors d'une élection, voter blanc (II) signifie que l'on met dans l'urne un bulletin vierge ou une enveloppe sans bulletin. Ce sens prédomine à présent, mais dans l'exemple de 1846, il signifie (I) simplement 'voter le contraire (= noir)', c'est-à-dire, choisir l'idée, l'option, le candidat opposé. S'il existe un parti associé à la couleur blanche, voter blanc pourrait désigner 'voter ce parti'. Blanc est invariable. Notons l'emploi de dire noir et compter double.

\section{Voter double}

I. Élire deux fois plus de représentants Intransitif

1867 Il [= le Tiers état] monte ; il obtient d'avoir un véto négatif ; s'il ne fait encore, il empêche. Dans les questions qui lui sont propres, il vote double, il obtient la double représentation (Jules Michelet, Histoire de France)

II. Avoir un vote qui compte double, deux fois Intransitif

1994 Il y a eu un vote, dans la caravane des anciens, et j'ai gagné par deux voix - celles $\mathrm{du}$ vieux Vasile, qui ne sait plus comment il s'appelle mais qui vote double, à cause de l'âge (Didier Van Cauwelaert, Un aller simple)

\section{Voter mou}

Voter sans conviction, sans courage

$\lambda$ parler mou

\section{Voter socialiste}

Voter pour le parti socialiste

Emploi absolu

1956 «Votez utile, votez socialiste » (Le Provençal) ; « Votez utile [= c'est-à-dire Front républicain] » (Le Quotidien de la Haute-Loire) (Cahiers de la Fondation nationale des sciences politiques, 1957, élections de 1956)

1959 Pour cela, la Gauche française doit se regrouper et voter utile en votant Socialiste S.F.I.O. Votez Jean Durroux (Recueil des textes authentiques des programmes et engagements électoraux des députés proclamés élus)
1976 Dans le Midi, pas mal de propriétaires de vignobles votent socialiste (André Malraux, Antimémoires)

1985 Depuis le lendemain de mai 1981, les étudiants qui ont voté socialiste disent : «Bon, il y a eu la fête, mais c'est maintenant du pareil au même " (Françoise Dolto, La Cause des enfants)

1997 La victoire du Front populaire aux élections de 1936 me réjouit profondément. Je m'étais rapproché du parti socialiste. Je votai naturellement socialiste aux élections de mai 1936 (Laurent Schwartz, Un mathématicien aux prises avec le siècle)

2007 Pour ma part, je me situais plus à gauche [= que Mendès France] ; j’ai d'ailleurs voté socialiste à plusieurs reprises, en fonction des programmes et des personnes (Simone Veil, Une vie)

\section{CORpus Web :}

Une rhétorique forte qui n'a pour seul objectif que d'affirmer que « voter socialiste ou voter pour le Front national, c'est la même chose ", selon Nicolas Sarkozy [http://www.bfmtv.com/ politique/le-vote-pour-le-front-national-n-estpas-immoral-juge-nicolas-sarkozy-935385.html] (21.2.2016)

chez eux ils votent massivement les mouvement extrémistes et islamistes, chez nous ils votent socialiste - ils y voient une ressemblance ?... [http://www.atlantico.fr/rdv/votemusulmans-election-presidentielle-nicolas-sar kozy-francois-hollande-islam-ifop-jerome-four quet-428668.html] (21.2.2016)

Relit mon texte, et tu verras que ceux que je traite de connards comme tu dis, sont les Bretons qui votent socialistes, tu dis que ces trois quaificatifs n'ont rien de commun... [http://ripostelaique. com/petite-chronique-sur-ces-cons-de-bretonsqui-votent-encore-socialaud.html] (21.2.2016)

eh bien continuez a voter socialistes, vous voyez ou passe notre argent ; alors que nous avons des Francais qui vivent dans la rue, vous n'avez pas honte, moi a votre place j'aurai honte [http://www.gerard-brazon.com/2015/12/ subvention-votee-par-les-elus-de-lorraine-a-1arabie-saoudite-au-fou.html] (21.2.2016) 
REMARQUES : Lors d'une élection, voter socialiste désigne le fait de mettre dans l'urne un bulletin portant la mention d'un candidat du parti socialiste. Socialiste reste invariable dans la majorité des cas. Dans les deux derniers exemples du CW, il s'accorde avec le sujet. De façon générale, on considérera socialiste plutôt comme un substantif. C'est ainsi que plusieurs des exemples le placent en série avec des noms : voter Tory, parler affaires, etc. Dans cette perspective, on comprend que socialiste, adjectif plutôt relationnel, n'est jamais modifié ( ${ }^{*}$ très socialiste), tandis que les adverbes de phrase et les adverbes circonstanciels peuvent se glisser dans le groupe : voter naturellement (toujours) socialiste / parler naturellement (toujours) affaires. Notons tout de même que l'interprétation adverbiale n'est pas tout à fait exclue, comme dans parler anglais. Même si dans les deux derniers exemples du CW on peut supposer un voter pour les socialistes sous-jacent, on a tout de même l'impression que l'accord se fait plutôt par rapport au sujet (à comparer : ceux qui votent utiles; v. voter utile). Dans l'exemple de 1959, voter Socialiste (avec majuscule) se trouve associé aussi bien avec voter utile (adjectif-adverbe) qu'avec voter Durroux (nom). De plus, l'absence de l'article (à comparer : voter les socialistes) nous oblige à chercher le substantif à un niveau sous-jacent. D’où notre classification comme " emploi absolu ». Ajoutons que nous attestons seul le cas de voter socialiste, à titre de représentant de la série voter conservateur, républicain, communiste, etc.

\section{Voter utile}

Ne pas voter selon ses convictions mais pour obtenir un résultat qui satisfait

Intransitif

1952 C'est alors qu'ils ont commis cette escroquerie politique et arithmétique qu'ont été les apparentements et, de fait, ils sont revenus dans la nouvelle Assemblée autant vaut dire aussi nombreux qu'ils l'étaient dans la précédente, grâce à l'erreur des bonnes gens qui ont "voté utile » comme les engageaient maintes autorités. Avec cette majorité résultant de ces votes utiles, que fait le régime? Rien (Charles de Gaulle, Discours et messages)
1961 Nous maintenons notre candidature pour permettre de voter utile à toutes celles et à tous ceux qui [...] (Profession de foi, élections du 25 novembre 1961 / J. Giraud)

\section{Corpus Web :}

En même temps, voter utile, ce n'est pas voter pour une personne, mais pour une idéologie, et il s'avère que cette idéologie est ensuite mise en pratique par un gouvernement [http:// vidberg.blog.lemonde.fr/2012/04/02/commentvoter-utile] (21.2.2016)

Personnellement, j’ai décidé de voter utile. J'ai choisi deux petits partis qui recevront ma voix. Je ne suis peut-être pas d'accord à 100\%, je les vois mal être au pouvoir. Mais, au moins, je suis certain que mon vote ne sera pas dilué dans une insipide majorité [https://ploum.net/votezutile-votez-pour-un-petit-parti] (21.2.2016)

Les abstentionnistes justement refusent mais ne renoncent pas. Bien loin de la fatalité de ceux qui «votent utiles » ou pour « faire barrage » ils pratiquent le non-vote d'adhésion et par cela souhaitent affirmer l'obsolescence d'un système politique [https://blogs.mediapart.fr/camillebosquet/blog/091215/journalistes-citoyenshommes-et-femmes-politiques-faites-confianceaux-abstentionnistes] (21.2.2016)

REMARQues : Lors d'une élection ou d'une délibération, voter utile se dit du fait de voter directement pour un candidat susceptible de l'emporter, pour que le vote soit efficace, sans tenir compte de ses convictions politiques profondes. Utile reste invariable dans la majorité des cas. Dans le dernier exemple du CW, il s'accorde avec le sujet au pluriel en gardant son interprétation adverbiale. VOIR AUSSI : baiser utile

\section{Voter vert}

Voter pour un parti ou un candidat écologiste Intransitif

1999 Les verts doivent à la fois persuader leurs concitoyens d'adhérer au parti vert, ou du moins de voter vert, et leur montrer l'importance de leur contribution personnelle au changement (Florence Faucher-King, Les Habits verts de la politique) 
Voyager propre

Voyager en évitant d'avoir un trop grand impact

sur l'environnement

入 bronzer idiot 



\section{Bibliographie des sources citées}

La bibliographie est strictement alphabétique ; elle ne suit donc pas forcément l'ordre chronologique des œuvres d'un même auteur. Si la source figure dans une collection qui seule figure dans la bibliographie, celle-ci est précédée d'une barre (ex. Farce nouvelle d'un amoureux / Ancien thêâtre françois)

\section{Sources secondaires (v. aussi la bibliographie linguistique à la fin de l'Introduction)}

BFM 2019 = Base de Français Médiéval 2019, Lyon (ENS de Lyon, Laboratoire IHRIM), http://bfm. ens-lyon.fr.

DEAFBiblEl = Dictionnaire étymologique de l'ancien français. Complément bibliographique rédigé par Frankwalt Möhren, http://www.deaf-page.de/fr/bibl_neu.php.

DMF = Dictionnaire du Moyen Français, DMF 2015, ATILF-CNRS et Université de Lorraine, http://www. atilf.fr/dmf.

Frantext, https://www.frantext.fr.

TLFi = Trésor de la langue française, http://atilf.atilf.fr.

\section{Sources primaires}

Abécassis, Agnès, Le Théorème de Cupidon, Paris (Calmann-Lévy) 2011.

Abellio, Raymond, Heureux les pacifiques, Paris (Le Portulan), 1946.

About, Edmond, La Grèce contemporaine, Paris (Hachette) 1854.

About, Edmond, Le Nez d'un notaire, 1862, Paris (Calmann-Lévy) 1888.

About, Edmond, Le Roi des montagnes, Paris (Hachette) 1857.

Achard, Amédée, Madame Rose. Dans : Revue des deux mondes, 1857.

Achard, Marcel, Jean de la lune. Dans : La Petite Illustration, $n^{\circ} 442$, Collection Théâtre $n^{\circ} 236,10$ août 1929.

Adam de la Halle, Chansons [= The Chansons of Adam de la Halle], 1280, éd. J.H. Marshall, Manchester (University Press) 1971. DEAF : AdHaleChansM

Adam, Paul, L'Enfant d'Austerlitz. Dans : Le Temps et la vie. L'Enfant d'Austerlitz, Paris (Ollendorff) 1902.

Adenet le Roi, Berte aus grans piés, 1275. Dans : Les CFuvres d'Adenet le Roi, vol. 4. DEAF : BerteH

Adenet le Roi, Buevon de Conmarchis, 1275. Dans : Les EFuvres d'Adenet le Roi, vol. 2. DEAF : AdenBuevH

Adenet le Roi, Cleomadés. 1285, Les CFuvres d'Adenet le Roi, vol. 1. DEAF : CleomH

Adenet le Roi, Les Enfances Ogier, 1276. Dans : Les CFuvres d'Adenet le Roi, vol. 3. DEAF : EnfOgH

Adenet le Roi, Les CFuvres d'Adenet le Roi, éd. Albert Henry, 4 vols., Bruges 1951, 1953, 1956, 1963

(= Genève (Slatkine) 1996).

Aicard, Jean, Poëmes de Provence, Paris (Lemerre) 1789.

Aiol et Mirabel, $2^{\mathrm{e}}$ moitié $\mathrm{xII}{ }^{\mathrm{e}}$ (ou, selon certains, première partie : 1160, $2^{\mathrm{e}}$ partie : début XIII), éd.

W. Foerster, Heilbronn (Henninger) 1876-1882. DEAF : Aio $^{1 / 2} \mathrm{~F}$

Aisy, Jean d', Nouvelle methode de la langue françoise, Paris (Estienne Michallet) 1674.

Alain Chartier, Le Curial [trad. du latin], 1427, éd. Ferdinand Heuckenkamp, Halle (Niemeyer) 1899. 
Alain Chartier, Le Debat de reveille matin, 1424. Dans : The Poetical Works of Alain Chartier, éd. J. C. Laidlaw, Cambridge (Cambridge University Press) 1974.

Alain Chartier, Le Livre de l'espérance, 1429, éd. François Rouy, Paris (Champion) 1989.

Alain Chartier, Le Livre des quatre dames, 1416. Dans : The Poetical Works of Alain Chartier, éd. J. C. Laidlaw, Cambridge (Cambridge University Press) 1974.

Alain, Propos, 1936, Paris (Gallimard) 1962.

Alain, Système des beaux-arts, 1920, Paris (Gallimard) 1937.

Alain-Fournier et Jacques Rivière, Correspondance avec Jacques Rivière (1905-1914), Paris (Gallimard) 1930.

Alain-Fournier, Le Grand Meaulnes, 1913, Paris (Émile-Paul) 1932.

Alajouanine, Théophile, Ce que la France a apporté à la médecine depuis le début du xxe siècle : conférences faites à l'hôpital Bichat pendant l'occupation allemande, 1943, Paris (Flammarion) 1946.

Alawî As-Sulaïmani, Karima, Écrire ou se laisser mourir, Saint-Denis (Edilivre) 2014.

Alberic [Auberi] de Besançon [Pisançon], Fragment d'un Roman d'Alexandre, $1^{\mathrm{er}}$ quart XII ${ }^{\mathrm{e}}$. Dans : F. Zufferey, «Perspectives nouvelles sur l'Alexandre d'Auberi de Besançon », Zeitschrift für Romanische Philologie 123, 3 (2007), pp. 385-418, texte : pp. 411-413. DEAF : AlexAlbZ

Alciat, André, Les Emblêmes [trad. du latin par Jean Le Fèvre], Cologny (Jean de Tournes) 1615.

Alcripe, Philippe d', La Nouvelle Fabrique des excellents traicts de vérité, 1579, éd. F. Joukovsky, Genève (Droz) 1983.

Alfonse, Jean, Voyages avantureux du capitaine Jan Alfonce, Sainctongeois, Poitiers (Marnefz et Bouchetz Freres) 1559.

Aliscans [R], fin XII', éd. G. Rolin, Leipzig (Reisland) 1897. DEAF : AliscR [reconstruction assez libre à partir de plusieurs manuscrits, « inutilisable » selon le DEAF. Nous citons Aliscans [R] uniquement quand la variante est attestée dans Aliscans [W], mais citée sans contexte. La datation suit alors celle du manuscrit en question].

Aliscans [W], fin XII e, éd. E. Wienbeck et al., Halle (Niemeyer) 1903. DEAF : AliscW [nous citons cette édition, hormis les cas mentionnés sous Aliscans [R]]

Allemagne, Henry-René d', Histoire des jouets, Paris (Hachette) 1902.

Allemagne, Henry-René d', Récréations et passe-temps, Paris (Hachette) 1904.

Almanach populaire de France pour 1839, Bruxelles (J. Géruzet) 1839.

Aloul, $2^{e}$ tiers XIII'. Dans : Nouveau Recueil complet des fabliaux, vol. 3. DEAF : AloulN

Althusser, Louis, Les Faits, 1976. Dans : L'Avenir dure longtemps suivi de Les Faits, Paris (Stock / IMEC) 2007.

Amadas et Ydoine, début XIII', éd. John R. Reinhard, Paris (Champion) 1926. DEAF : AmYdR

Amadou, Robert, La Parapsychologie. Essai historique et critique, Paris (Denoël) 1954.

Amboise, François d', Les Neapolitaines : Comedie françoise facecieuse, 1584. Dans : CEuvres complètes, éd. D. Ughetti, vol. 1, Naples (Edizioni scientifiche italiane) 1973.

Ambrière, Francis, Les Grandes Vacances, 1939-1945, Paris (La Nouvelle France) 1946.

Ami et Amile, 1200, éd. Peter F. Dembowski, Paris (Honoré Champion) 1969. DEAF : AmAmD

Amiel, Henri-Frédéric, Journal intime de l'année 1866, Paris (Gallimard) 1959.

Ampère, André-Marie, Correspondance d'André-Marie Ampère, Centre Alexandre Koyré, CNRS (UMR 8560) sans date.

Ampère, Jean-Jacques et André-Marie, Correspondance, 2 vols., (1816-1827) et (1829-1864). Dans : Correspondance et souvenirs (de 1805 à 1864), Paris (Hetzel) 1875.

Ancelet, Barry Jean, Les Musiciens cadiens et créoles, Québec (Presses de L'Université du Québec) 1984. 
Ancien Théâtre françois. Collection des ouvrages dramatiques les plus remarquables depuis les Mystères jusqu'à Corneille, 1485-1606, 10 vols., par Viollet Le Duc, Paris (Jannet) 1854-1855. DEAF : AncThéât [= FEW]

André, Christophe, Vivre heureux : psychologie du bonheur, Paris (Odile Jacob) 2003.

Andrieu de la Vigne [André de la Vigne], La Ressource de la chrestienté, 1494, éd. Cynthia J. Brown, Montréal (CERES) 1989.

Andrieu de la Vigne [André de la Vigne], Le Mystère de saint Martin, 1496, éd. André Duplat, Genève (Droz) 1979. DEAF : AndrVigneSMartD

Andrieu de la Vigne [André de la Vigne], Le Voyage de Naples, 1498, éd. Anna Slerca, Milano (Vita e Pensiero) 1981. DEAF : AndrVigneNapS

Aneau, Barthélemy, Alector ou Le Coq : histoire fabuleuse, 1560, vol. 1, Genève (Droz) 1996.

Angevin, David, Une année sans ma femme, Bègles (Le Castor astral) 1997.

Anglade, Jean, Le Sculpteur de nuages, Paris (Calmann-Lévy) 2013.

Angot, Christine, Rendez-vous, 2006, Paris (Gallimard) 2008.

Annales maritimes et coloniales, Paris.

Anouilh, Jean, Antigone. Dans : Nouvelles Pièces noires, Paris (La Table Ronde) 1955.

Anouilh, Jean, L'Alouette, 1953, Paris (La Table Ronde / Gallimard) 2004.

Anouilh, Jean, La Répétition ou L'Amour puni, Paris (Larousse) 1957.

Anouilh, Jean, Pauvre Bitos, 1956. Dans : Pièces grinçantes, Paris (La Table Ronde) 1961.

Anthologie de la littérature vietnamienne : deuxième moitié du xIXe siècle à 1945 [trad.], Paris (L'Harmattan) 2004.

Antitus, Poésies, 1500. Dans : Poésies, Genève (Droz) 1992.

Antoine de la Sale, Jehan de Saintré, avant 1456, éd. Jean Misrahi et Charles A. Knudson, Genève (Droz) 1967. DEAF : JSaintréM [manuscrit : $2^{\mathrm{e}}$ moitié xve]

Antoine, Gérald et Jean-Claude Passeron, La Réforme de l'université. Conservatisme et novation à l'université, Paris (Calmann-Lévy) 1966.

Aperçu de la campagne de l'armée des alliés et de l'armée française en 1813, Weimar (Geographisches Institut) 1814.

Apollinaire, Guillaume, Alcools, 1913. Dans : Euvres poétiques, Paris (Gallimard) 1962.

Apollinaire, Guillaume, Casanova, 1918. Dans : CEuvres poétiques, Paris (Gallimard) 1962.

Aragon, Louis, Aurélien, 1945, Paris (Gallimard) 1949.

Aragon, Louis, Le Roman inachevé, Paris (Gallimard) 1956.

Aragon, Louis, Les Aventures de Télémaque, 1922. Dans : EFuvre poétique, vol. 1, Paris (Livre Club Diderot) 1989.

Aragon, Louis, Les Beaux Quartiers, Paris (Denoël et Steele) 1936.

Aragon, Louis, Les Voyageurs de l'impériale, 1947, Paris (Gallimard) 2001.

Aragon, Louis, Moi l'abeille j'étais chevelure. Dans : La Révolution surréaliste 8, 1926.

Aragon, Louis, EFuvre poétique, vol. 1 : livre 1 (1917-1920). Paris (Livre Club Diderot) 1989.

Aragon, Louis, Euvre poétique, vol. 1 : livre 2 (1921-1925). Paris (Livre Club Diderot) 1989.

Aragon, Louis, Euvre poétique, vol. 1 : livre 3 (1926). Paris (Livre Club Diderot) 1989.

Arban, Dominique, Je me retournerai souvent... : souvenirs, Paris (Flammarion) 1990.

Archambault, Le Cuisinier économe, Paris (Librairie du commerce) 1825.

Archives de physiologie, de thérapeutique et d'hygiène, Paris.

Archives internationales de physiologie, Paris.

Argens, Jean-Baptiste de Boyer, marquis d', Lettres juives ou Correspondance philosophique, historique et critique, vol. 1-6, La Haye (Pierre Paupie) 1738.

Argenson, René-Louis de Voyer de Paulmy, marquis d', Journal et mémoires, vol. 9 (1755), 1757, Paris (Renouard) 1864. 
Argentré, Bertrand d', L'Histoire de Bretaigne des roys, ducs, comtes et princes d'icelle, Paris (Dupuy) 1588.

Ariosto, Ludovico, Le Divin Arioste ou Roland le furieux [trad. par F. de Rosset], Paris (Robert Foüet) 1615.

Arland, Marcel, L'Ordre, 1929, Paris (Gallimard) 1930.

Arlequin comédien aux Champs Elysées, Paris (Arnoul Seneuze) 1694.

Armengaud, Jacques-Eugène, Publication industrielle des machines, outils et appareils, vol. 16, Paris (Morel) 1866.

Armstrong, Hal, Nous sommes tous des toxicos, Paris (Clancier-Guénaud) 1981.

Arnaud, Claude, Qu'as-tu fait de tes frères ?, Paris (Grasset) 2010.

Arnauld d'Andilly, Robert, Le Chemin de la perfection [trad.], 1659. Dans : Les CEuvres de SainteThérèse, Paris (Le Petit) 1670.

Arnauld d'Andilly, Robert, Mémoires, vols. 1 et 2 : 1667. Dans : Collection Mémoires historiques de France, vols. 33 et 34, Paris (Foucault) 1824.

Arnauld, Antoine et Pierre Nicole, La Logique ou L'Art de penser, Paris (Ch. Savreux) 1662.

Arnauld, Antoine, De la fréquente communion où les sentimens des pères, des papes et des conciles, touchant l'usage des sacremens de pénitence et d'eucharistie, sont fidèlement exposez, Paris

(A. Vitre) 1643.

Arnauld, Baculard d', La Statue de Pigmalion. Dans : EFuvres diverses, Berlin (sans éditeur) 1751.

Arnold, Jacques, Autre mythologie : poèmes, Paris (Rougerie) 1981.

Arnoul Gréban, Le Mystère de la Passion, 1450 (avant 1452), éd. Omer Jodogne, 2 vols., Bruxelles (Palais des Académies) 1965 / 1983. DEAF : GrebanJ

Arondineau, Pierre-Louis, Les Souvenirs de l'amitié ou Vie et opuscules, Paris (P. J. Camus) 1840.

Arroy, Bezian [Bésian], Briéve et devote histoire de l'abbaye royale de S. Martin de l'Isle-Barbe, Lyon (Mathieu Liberal) 1668.

Artaud, Antonin, L'Osselet toxique. Dans : La Révolution surréaliste 11, 1928.

Artaud, Antonin, Le Théâtre et son double, 1938. Dans : Euvres complètes, vol. 4, Paris (Gallimard) 1964.

Arts et littérature dans la société contemporaine, éd. Pierre Abraham, vol. 1, Paris (Société de gestion de l'encyclopédie française) 1935.

Artus, Thomas, Discours de Jacophile à Limne. Dans : Les Hermaphrodites, 1605.

Assoucy, Charles Coypeau d', L'Ovide en belle humeur, Paris (Ch. de Sercy) 1650.

Assoucy, Charles Coypeau d', Le Ravissement de Proserpine, Paris (P. David et E. Pepingue) 1653.

Astier, Emmanuel d', Les Dieux et les hommes (1943-1944), 1952, Paris (Union générale d'éditions) 1964.

Auberee, 1200. Dans : Nouveau Recueil complet des fabliaux, vol. 1. DEAF : AubereeN

Aubert de la Chesnaye des Bois, François-Alexandre, Dictionnaire raisonné et universel des animaux, Paris (Bauche) 1759.

Aubignac, François Hédelin, abbé d', La Pratique du théâtre, 1657, Alger (J. Carbonel) 1927.

Aubigné, Théodore Agrippa d', Confession catholique du sieur de Sancy, 1630. Dans : Euvres complètes, vol. 2, Genève (Slatkine) 1967.

Aubigné, Théodore Agrippa d', Le Printemps : l'hécatombe à Diane et les stances, 1630, Paris (Presses universitaires de France) 1960.

Aubigné, Théodore Agrippa d', Les Tragiques 1-3, 1630, Paris (Droz) 1932.

Aubrée, Christine, Bien préparer ses entretiens avec les recruteurs, Paris (Eyrolles) 2007.

Aucassin et Nicolette, $1^{\text {re }}$ moitié $\mathrm{xIII}^{\mathrm{e}}$, éd. Mario Roques, Paris (Champion) 1929. DEAF : AucR ${ }^{3}$ [= éd.

31955] [cité d'après BFM]

Audiberti, Jacques, Théâtre, vol. 1, Paris (Gallimard) 1960.

Audouin, Maxime, Sous le couperet. Dans : Le Nouvelliste du Morbihan, 27.4-15.5.1913. 
Audry, Colette, La Chienne et nous. Dans : Les Temps modernes, avril 1964.

Augier, Émile, L’Aventurière, 1848. Dans : Théâtre complet de Émile Augier, vol. 1, Paris

(Calmann-Lévy) 1873.

Augier, Émile, Les Lionnes pauvres, 1853. Dans : Théâtre complet de Émile Augier, vol. 4, Paris (Calmann-Lévy), 1877.

Aulnoy, Marie-Catherine Le Jumel de Barneville, baronne d', Finette Gendron, 1698. Dans : Le Cabinet des fées, vol. 2, Genève / Paris (Barde / Cuchet) 1785.

Aulnoy, Marie-Catherine Le Jumel de Barneville, baronne d', L'Oiseau bleu, 1698. Dans : Le Cabinet des fées, vol. 2, Genève / Paris (Barde / Cuchet) 1785.

Aulnoy, Marie-Catherine Le Jumel de Barneville, baronne d', La Chatte blanche, 1698. Dans : Le Cabinet des fées, vol. 3, Genève / Paris (Barde / Cuchet) 1785.

Aulnoy, Marie-Catherine Le Jumel de Barneville, baronne d', Le Nain jaune, 1698. Dans : Le Cabinet des fées, vol. 3, Genève / Paris (Barde / Cuchet) 1785.

Aulnoy, Marie-Catherine Le Jumel de Barneville, baronne d', Relation du voyage d'Espagne, 1691.

Dans : La Cour et la ville de Madrid vers la fin du XvII siècle, vol. 1, Paris (Plon) 1874.

Auroy, Berthe, Jours de guerre : ma vie sous l'Occupation, Paris (Bayard) 2008.

Auvray, Jean, Le Banquet des muses ou Les Divers Satires, 1623, Paris (David Ferrand) 1636.

Auzias, Dominique et Jean-Paul Labourdette, Colombie, Paris (www.petitfute.com) 2016.

Avallon, Charles Yves Cousin d', Nouveau Dictionnaire de cuisine, d'office et de pâtisserie, Paris (Corbet) 1826.

Aventin, Christine, Le Cœur en poche, Paris (Mercure de France) 1988.

Aviler, Augustin Charles de, Architecture de Vignole, Paris (Langlois) 1691.

Avril, Nicole, La Disgrâce, Paris (Albin Michel) 1981.

Axel III, Hercule, Saint-Denis (Mon petit éditeur) 2012.

Aymé, Marcel, Clérambard, Paris (Grasset) 1950.

Aymé, Marcel, La Jument verte, 1933, Paris (Gallimard) 1935.

Aymé, Marcel, Le Confort intellectuel, 1949, Paris (Flammarion) 1958.

Aymé, Marcel, Le Vin de Paris, 1947, Paris (Gallimard) 1988.

Aymeri de Narbonne [attribué probablement à tort à Bertrand de Bar], manuscrit R (Londres), milieu XIII', éd. Hélène Gallé, Paris (Honoré Champion) 2007. DEAF : AimeriG

Azéma, Georges, Histoire de l'île Bourbon depuis 1643 jusqu'au 20 décembre 1848, Paris (Plon) 1862.

B. T., Les Illusions de Thérèse. Dans : Journal des demoiselles 46, Paris, 1878.

Bâ, Amadou Hampâté, Amkoullel, L'Enfant peul, 1991, Arles (Actes Sud / Babel) 1998.

Bâ, Amadou Hampâté, Oui Mon Commandant !, 1994, Arles (Actes Sud / Babel) 1998.

Bac, Ferdinand, Femmes de théâtre, prologue de Yvette Guilbert, Paris (H. Simonis Empis) 1889.

Bachaumont, Louis Petit de, Mémoires secrets pour servir à l'histoire de la république des lettres en France depuis 1762 jusqu'à nos jours ou Journal d'un observateur, vol. 1, 1763, Londres (J. Adamson) 1784.

Bachelard, Gaston, La Poétique de l'espace, 1957, Paris (Presses universitaires de France) $1961^{3}$.

Baculard d'Arnaud, François-Thomas-Marie de, Les Époux malheureux ou Histoire de monsieur et madame de ${ }^{* * *}$, vol. 1, 1745, Paris (Laporte) 1803.

Baculard d'Arnaud, François-Thomas-Marie de, Les Épreuves du sentiment, vol. 3, Paris (Le Jay) 1772.

Bady, Elie, La Nébuleuse des idiots, Paris (Publibook) 2013.

Baecque, Antoine de, Godard, Paris (Grasset) 2010.

Baiff, Jean-Antoine de, Le Brave, 1573, Genève (Droz) 1979.

Baïf, Jean-Antoine de, Mimes, enseignemens et proverbes : premier livre, 1581, Genève (Droz) 1992.

Baïf, Jean-Antoine de, Mimes, enseignemens et proverbes : second livre, 1581, Genève (Droz) 1992. 
Baïf, Jean-Antoine de, Mimes, enseignemens et proverbes : troisième livre, 1597, Genève (Droz) 1992.

Baïf, Jean-Antoine de, Mimes, enseignemens et proverbes : quatrième livre, 1581, Genève (Droz) 1992.

Baillon, André, Délires, 1927, Paris/Bruxelles (Labor / Librairie Valois) 1931.

Bainville, Jacques, Histoire de France, vols. 1-2, 1924, Paris (Tallandier) 1926.

Balzac, Honoré de, Annette et le criminel, vols. 1-4, 1824, Paris (Les Bibliophiles de l'originale) 1963.

Balzac, Honoré de, Autre étude de femme. Dans : La Comédie humaine, vol. 3, 1845, Paris (Gallimard) 1976.

Balzac, Honoré de, Béatrix. Dans : La Comédie humaine, vol. 2, 1845, Paris (Gallimard) 1976.

Balzac, Honoré de, Correspondance, vol. 1 : juin 1809-1832, Paris (Garnier) 1960.

Balzac, Honoré de, Correspondance, vol. 2 : juin 1832-1835, Paris (Garnier) 1962.

Balzac, Honoré de, Correspondance, vol. 3 : 1836-1839, Paris (Garnier) 1964.

Balzac, Honoré de, Correspondance, vol. 4 : 1840-avril 1845, Paris (Garnier) 1966.

Balzac, Honoré de, Eugénie Grandet. Dans : La Comédie humaine, vol. 3, 1833, Paris (Gallimard) 1976.

Balzac, Honoré de, Facino Cane. Dans : La Comédie humaine, vol. 6, 1844, Paris (Gallimard) 1977.

Balzac, Honoré de, Histoire de la grandeur et de la décadence de César Birotteau, 1837, Paris (Garnier) 1964.

Balzac, Honoré de, Histoire des Treize. Dans : La Comédie humaine, vol. 5, 1835, Paris (Gallimard) 1977.

Balzac, Honoré de, L'Envers de l'histoire contemporaine, 1850. Dans : La Comédie humaine, vol. 8, Paris (Gallimard) 1977.

Balzac, Honoré de, L'Interdiction, 1844. Dans : La Comédie humaine, vol. 3, Paris (Gallimard) 1976. Balzac, Honoré de, La Bourse. Dans : La Comédie humaine, vol. 1, 1842, Paris (Gallimard) 1976.

Balzac, Honoré de, La Fausse Maîtresse. Dans : La Comédie humaine, vol. 1, 1842, Paris (Gallimard) 1976.

Balzac, Honoré de, La Femme de trente ans. Dans : La Comédie humaine, vol. 2, 1842, Paris (Gallimard) 1976.

Balzac, Honoré de, La Maison du chat-qui-pelote. Dans : La Comédie humaine, vol. 1, 1842, Paris (Gallimard) 1976.

Balzac, Honoré de, La Maison Nucingen. Dans : La Comédie humaine, vol. 6, 1838, Paris (Gallimard) 1977.

Balzac, Honoré de, La Muse du département. Dans : La Comédie humaine, vol. 4, 1843, Paris (Gallimard) 1976.

Balzac, Honoré de, La Peau de chagrin, 1831, Paris (Garnier) 1960.

Balzac, Honoré de, La Rabouilleuse, 1843. Dans : La Comédie humaine, vol. 4, Paris (Gallimard) 1976.

Balzac, Honoré de, Le Cabinet des antiques, 1844. Dans : La Comédie humaine, vol. 4, Paris (Gallimard) 1976.

Balzac, Honoré de, Le Chef-d’CEuvre inconnu, 1847. Dans : La Comédie humaine, vol. 10, Paris (Gallimard) 1979.

Balzac, Honoré de, Le Colonel Chabert, 1844. Dans : La Comédie humaine, vol. 3, Paris (Gallimard) 1976.

Balzac, Honoré de, Le Cousin Pons, 1847. Dans : La Comédie humaine, vol. 7, Paris (Gallimard) 1977.

Balzac, Honoré de, Le Curé de village, 1845. Dans : La Comédie humaine, vol. 9, Paris (Gallimard) 1978. 
Balzac, Honoré de, Le Député d'Arcis, 1850. Dans : La Comédie humaine, vol. 8, Paris (Gallimard) 1977.

Balzac, Honoré de, Le Médecin de campagne, 1833, Paris (Garnier) 1961.

Balzac, Honoré de, Le Nègre. Dans : Euvres diverses, vol. 1, 1822, Paris (Gallimard) 1990.

Balzac, Honoré de, Le Père Goriot, 1843. Dans : La Comédie humaine, vol. 3, Paris (Gallimard) 1976.

Balzac, Honoré de, Les Chouans ou La Bretagne en 1799, 1845. Dans : La Comédie humaine, vol. 8, Paris (Gallimard) 1977.

Balzac, Honoré de, Les Employés, 1844. Dans : La Comédie humaine, vol. 7, Paris (Gallimard) 1977.

Balzac, Honoré de, Les Illusions perdues, 1843. Dans : La Comédie humaine, vol. 5, Paris (Gallimard) 1977.

Balzac, Honoré de, Les Marana, 1846. Dans : La Comédie humaine, vol. 10, Paris (Gallimard) 1979.

Balzac, Honoré de, Les Paysans, 1850. Dans : La Comédie humaine, vol. 9, Paris (Gallimard) 1978.

Balzac, Honoré de, Les Proscrits, 1846. Dans : La Comédie humaine, vol. 11, Paris (Gallimard) 1980.

Balzac, Honoré de, Les Secrets de la princesse de Cadignan, 1844. Dans : La Comédie humaine, vol. 6, Paris (Gallimard) 1977.

Balzac, Honoré de, Lettres à Madame Hanska, 1847, Paris (Delta) 1967.

Balzac, Honoré de, Mémoires de deux jeunes mariées, 1842. Dans : La Comédie humaine, vol. 1, Paris (Gallimard) 1976.

Balzac, Honoré de, Mercadet [= Le Faiseur], Bruxelles (J.-A. Lelong) 1851.

Balzac, Honoré de, Modeste Mignon, 1845. Dans : La Comédie humaine, vol. 1, Paris (Gallimard) 1976.

Balzac, Honoré de, Petites Misères de la vie conjugale, 1850. Dans : La Comédie humaine, vol. 12, Paris (Gallimard) 1981.

Balzac, Honoré de, Physiologie du mariage, 1846. Dans : La Comédie humaine, vol. 11, Paris (Gallimard) 1980.

Balzac, Honoré de, Pierre Grassou, 1844. Dans : La Comédie humaine, vol. 6, Paris (Gallimard) 1977. Balzac, Honoré de, Pierrette, 1843. Dans : La Comédie humaine, vol. 4, Paris (Gallimard) 1976.

Balzac, Honoré de, Séraphita, 1846. Dans : La Comédie humaine, vol. 11, Paris (Gallimard) 1980.

Balzac, Honoré de, Splendeurs et misères des courtisanes, 1847. Dans : La Comédie humaine, vol. 6, Paris (Gallimard) 1977.

Balzac, Honoré de, Théorie de la démarche, 1833. Dans : CEuvres complètes, vol. 39, Paris (Conard) 1938.

Balzac, Honoré de, Un début dans la vie, 1845. Dans : La Comédie humaine, vol. 1, Paris (Gallimard) 1976.

Balzac, Honoré de, Un drame au bord de la mer, 1846. Dans : La Comédie humaine, vol. 10, Paris (Gallimard) 1979.

Balzac, Honoré de, Un homme d'affaires, 1846. Dans : La Comédie humaine, vol. 7, Paris (Gallimard) 1977.

Balzac, Honoré de, Un prince de la Bohème, 1846. Dans : La Comédie humaine, vol. 7, Paris (Gallimard) 1977.

Balzac, Honoré de, Une fille d'Ève, 1842. Dans : La Comédie humaine, vol. 2, Paris (Gallimard) 1976.

Balzac, Honoré de, Une passion dans le désert, 1846. Dans : La Comédie humaine, vol. 8, Paris

(Gallimard) 1977.

Balzac, Honoré de, Ursule Mirouët, 1842. Dans : La Comédie humaine, vol. 3, Paris (Gallimard) 1976.

Balzac, Jean-Louis Guez de, Dissertations chrestiennes et morales, 1654. Dans : Euvres, vol. 2, Paris (T. Jolly) 1665.

Balzac, Jean-Louis Guez de, Dissertations critiques, 1654. Dans : Euvres, vol. 2, Paris (T. Jolly) 1665.

Balzac, Jean-Louis Guez de, Les Premières Lettres, vol. 1 (1624), Paris (Droz) 1933. 
Banville, Théodore de, Les Cariatides, 1842. Dans : Poésies complètes, vol. 1, Paris (Charpentier) 1891.

Banville, Théodore de, Les Exilés, 1874. Dans : Poésies complètes, vol. 2, Paris (Fasquelle) 1899.

Banville, Théodore de, Les Stalactites, 1846, Paris (Didier) 1942.

Banville, Théodore de, Odes funambulesques, Paris (Michel Lévy) 1859.

Baradat, Jean, L'Organisation d'une préfecture, Toulouse (Université de Toulouse. Faculté de Droit) 1907.

Barante, Prosper Brugière, baron de, Histoire des ducs de Bourgogne de la maison de Valois (1364-1477), 1824, 12 vols., Paris (Le Normant / Garnier), ${ }^{7} 1854$.

Barbatre, Pierre, Le Voyage à Jérusalem en 1480, 1480, Paris (Klincksieck) 1974.

Barbey d'Aurevilly, Jules, Premier Memorandum, 1838. Dans : Fuvres complètes, vol. 5, Genève (Slatkine) 1979.

Barbey d'Aurevilly, Jules, Deuxième Memorandum, 1839. Dans : Euvres complètes, vol. 8, Genève (Slatkine) 1979.

Barbey d'Aurevilly, Jules, Troisième Memorandum, 1856. Dans : CEuvres complètes, vol. 5, Genève (Slatkine) 1979.

Barbey d'Aurevilly, Jules, Quatrième Memorandum, 1858. Dans : CEuvres complètes, vol. 5, Genève (Slatkine) 1979.

Barbey d'Aurevilly, Jules, Les Diaboliques, 1874, Paris (Gallimard) 1996.

Barbey d'Aurevilly, Jules, Lettres de J. Barbey d'Aurevilly à Léon Bloy, éd. Jean de Bonnefon, Paris (Mercure de France) 1903.

Barbier, Auguste, lambes et poèmes, Paris (P. Masgana) 1840.

Barbier, Auguste, Satires, Paris (Dentu) 1865.

Barbusse, Henri, Le Feu, 1916, Paris (Flammarion) 1960.

Baro, Balthazar, La Conclusion et dernière partie d'Astrée, 1628, Genève (Slatkine) 1966.

Baron, M., Expériences sur l'évaporation de la glace / Histoire de l'Académie royale des sciences, Paris (Imprimerie royale) 1757.

Barrès, Maurice, Au service de l'Allemagne, Paris (F. Juven) 1905.

Barrès, Maurice, Greco ou Le Secret de Tolède, 1911, Paris (Plon) 1927.

Barrès, Maurice, La Colline inspirée, 1913, Paris (Berger-Levrault) 1962.

Barrès, Maurice, Le Jardin de Bérénice, 1891, Paris (Plon) 1927.

Barrès, Maurice, Le Voyage de Sparte, 1906, Paris (Plon) 1922.

Barrès, Maurice, Mes cahiers, vol. 1 : 1896-1898, Paris (Plon) 1929.

Barrès, Maurice, Mes cahiers, vol. 2: 1898-1902, Paris (Plon) 1930.

Barrès, Maurice, Mes cahiers, vol. 3 : 1902-1904, Paris (Plon) 1931.

Barrès, Maurice, Mes cahiers, vol. 4 : 1904-1906, Paris (Plon) 1931.

Barrès, Maurice, Mes cahiers, vol. 5 : 1906-1907, Paris (Plon) 1932.

Barrès, Maurice, Mes cahiers, vol. 6 : 1907-1908, Paris (Plon) 1933.

Barrès, Maurice, Mes cahiers, vol. 7 : 1908-1909, Paris (Plon) 1933.

Barrès, Maurice, Mes cahiers, vol. 8 : 1909-1911, Paris (Plon) 1934.

Barrès, Maurice, Mes cahiers, vol. 9 : 1911-1912, Paris (Plon) 1935.

Barrès, Maurice, Mes cahiers, vol. 10 : 1913-1914, Paris (Plon) 1936.

Barrès, Maurice, Mes cahiers, vol. 11 : 1914-1918, Paris (Plon) 1938.

Barrès, Maurice, Mes cahiers, vol. 12 : 1919-1920, Paris (Plon) 1949.

Barrès, Maurice, Mes cahiers, vol. 14 : 1922-1923, Paris (Plon) 1957.

Barrès, Maurice, Un homme libre, 1889, Paris (Plon) 1928.

Barrès, Maurice, Un jardin sur l'Oronte, 1922, Paris (Plon) 1928.

Barrière, Bernadette, Limousin médiéval. Le Temps des créations, Limoges (Presses Universitaires de Limoges) 2006. 
Barrière, Théodore et Ernest Capendu, Les Faux Bonshommes, Paris (Michel Lévy) 1856.

Barrière, Théodore et Henry de Kock, Les Grands Siècles, Paris (Michel Lévy) 1855.

Barruel-Beauvert, Antoine Joseph de, Vie de J. J. Rousseau, Londres (sans éditeur) 1789.

Barry, Paul de, L'Année saincte ou L'Instruction de Philagie pour vivre à la mode, vol. 3, Lyon (Rigaud) 1641.

Barry, Paul de, La Mort de Paulin et d'Alexis, Lyon (Borde, Arnaud et Rigaud) 1658.

Barski, Odile, Quartier libre, Paris (Flammarion) 2013.

Barthélemy, Jean-Jacques, Voyage du jeune Anarchasis en Grèce dans le milieu du quatrième siècle avant l'ère vulgaire, vol. 3, Paris (De Bure) 1788.

Barthelet, Philippe, Joseph de Maistre, Lausanne (L'Âge d'homme) 2005.

Barthes, Roland, Roland Barthes par Roland Barthes, 1975. Dans : Euvres complètes, vol. 3, Paris (Seuil) 1994.

Bartsch, Karl, Chrestomathie de l'ancien français (VII $-x V^{e}$ siècles), éd. revue par Leo Wiese, New York / London (Hafner) 1969. DEAF : BartschChrest

Basquiat, Jean-Michel, Bordel, Paris (Flammarion) 2008.

Basset, Lytta, Guérir du malheur, Paris (Albin Michel) 1999.

Bastide, François-Régis, Les Adieux, 1956, Paris (Gallimard) 1980.

Bastien, J.-F., La Nouvelle Maison rustique, 3 vols., Paris (Deterville / Desray) 1798.

Bataille, Georges, L'Expérience intérieure, Paris (Gallimard) 1943.

Bataille, Henry, La Quadrature de l'amour, Paris (Fasquelle) 1920.

Bataille, Henry, Maman Colibri. Dans : L’lllustration, supplément au nº 3221 du 19 nov. 1904.

Bataille, Michel, L'Arbre de Noël, Paris (Julliard) 1967.

Battistella, Gautier, Un jeune homme prometteur, Paris (Grasset) 2014.

Baudeau, Nicolas, Première Introduction à la philosophie économique ou Analyse des États policés, par un disciple de l'ami des hommes (l'abbé N. Baudeau), Paris (Didot, Delalain, Lacombe) 1771.

Baudelaire, Charles, Les Fleurs du mal, 1861, Paris (Librairie Générale Française) 1999.

Baudelaire, Charles, Les Paradis artificiels, 1860. Dans : Euvres complètes, Paris (Gallimard) 1964.

Baudelaire, Charles, Salon de 1845, 1845. Dans : Curiosités esthétiques. L'Art romantique et autres œuvres critiques, Paris (Garnier) 1962.

Baudhuin, Fernand, Crédit et banque, Paris (R. Pichon et R. Durand-Auzias) 1945.

Baudrimont, Alexandre et al., Dictionnaire de l'industrie manufacturière, commerciale et agricole, vol. 4, Paris (Baillière) 1835.

Baudry de Saint-Gilles d'Asson, Antoine de, Journal d'un solitaire de Port-Royal (1655-1656), Paris (Nolin) 2008.

Bayard et É. Vanderburch, Les Deux Créoles. Dans : Le Magasin théâtral, Paris / Bruxelles (Marchant / Jouhaud) 1835.

Bayle, Pierre, Commentaire philosophique sur ces paroles de Jésus-Christ "Contrain-les d'entrer », 1686. Dans : Euvres diverses, vol. 2, La Haye (P. Husson) 1727.

Bayon, Bruno, Le Lycéen, Paris (Quai Voltaire) 1987.

Bayon, Martial, Sobriquets et superstitions militaires. Dans : Revue des traditions populaires, vol. 2-1, Paris (Société des traditions populaires) 1887.

Bazin, Hervé, Bouc émissaire, Paris (Édition originale) 1963.

Bazin, Hervé, L'École des pères, Paris (Seuil) 1991.

Bazin, Hervé, L'Huile sur le feu, Paris (Grasset) 1954.

Bazin, Hervé, La Fin des asiles, Paris (Grasset) 1959.

Bazin, Hervé, La Mort du petit cheval, Paris (Grasset) 1950.

Bazin, Hervé, La Tête contre les murs, Paris (Grasset) 1949.

Bazin, Hervé, Le Bureau des mariages, Paris (Grasset) 1951. 
Bazin, Hervé, Vipère au poing, Paris (Grasset) 1948.

Bazin, René, De toute son âme. Dans : Revue des deux mondes, 1897.

Bazin, René, Le Blé qui lève, 1907, Paris (Calmann-Lévy) 1927.

Bazin, René, Sicile : croquis italiens, 1893, sans lieu (Collection @ XIX) 2016.

Beau sauvage et autres contes de la Mauricie, Clément Legaré (éd.), Québec (Presses de l'Université du Québec) 1990.

Beaulieu, Victor-Lévy, Bibi, Paris (Grasset) 2010.

Beaumanoir, sire de (v. Philippe de Remi).

Beaumarchais, Pierre-Augustin Caron de, La Folle Journée ou Le Mariage de Figaro, 1785. Dans :

Euvres.

Beaumarchais, Pierre-Augustin Caron de, Le Barbier de Séville ou La Précaution inutile, 1775. Dans : Euvres.

Beaumarchais, Pierre-Augustin Caron de, Mémoires contre Goëzmann, 1774. Dans : Euvres.

Beaumarchais, Pierre-Augustin Caron de, Euvres, éd. Pierre Larthomas, Paris (Gallimard) 1988.

Beauvais de Préau, Charles-Théodore et Antoine-Alexandre Barbier, Biographie universelle classique ou Dictionnaire historique, 3 vols., Paris (C. Gosselin), 1826-1829.

Beauvais, J., L'Art de bien parler et de bien écrire en françois, Paris (Valade) ${ }^{2} 1784$.

Beauvoir, Ludovic Hébert, marquis de, Voyage autour du monde, Paris (Plon) 1868.

Beauvoir, Simone de, Journal de guerre : septembre 1939-janvier 1941, Paris (Gallimard) 1990.

Beauvoir, Simone de, L'Invitée, 1943, Paris (Gallimard) 1956.

Beauvoir, Simone de, La Force de l'âge, 1960, Paris (Gallimard) 2009.

Beauvoir, Simone de, Le Deuxième sexe, 1949, Paris (Gallimard) 1955.

Beauvoir, Simone de, Le Sang des autres, Paris (Gallimard) 1945.

Beauvoir, Simone de, Les Mandarins, Paris (Gallimard) 1954.

Beauvoir, Simone de, Lettres à Nelson Algren : un amour transatlantique (1947-1964), Paris (Gallimard) 1997.

Beauvoir, Simone de, Lettres à Sartre (1940-1963), Paris (Gallimard) 1990.

Beauvoir, Simone de, Mémoires d'une jeune fille rangée, Paris (Gallimard) 1958.

Beauvoir, Simone de, Privilèges, Paris (Gallimard) 1955.

Beauvoir, Simone de, Témoins à charge. Dans : Les Temps modernes, 1956.

Beck, Béatrix, Des accomodements avec le ciel, Paris (Gallimard) 1954.

Beck, Béatrix, Léon Morin, prêtre, 1952, Paris (Gallimard) 1996.

Beck, Béatrix, Stella Corfou, Paris (Grasset) 1988.

Beckett, Samuel, En attendant Godot, 1952, Paris (Minuit) 1997.

Becque, Henry, Les Corbeaux, 1882. Dans : Théâtre complet, vol. 2, Paris (Fasquelle) 1922.

Bédier, Joseph et Paul Hazard, Histoire de la littérature française illustrée, vol. 2, Paris (Larousse) 1949.

Béguin, Albert, L'Âme romantique et le rêve : essai sur le romantisme allemand et la poésie française, 1939, Paris (J. Corti) 1946.

Beigbeder, Frédéric, 99 francs, 2000, Paris (Grasset) 2001.

Beineix, Jean-Jacques, Les Chantiers de la gloire, Paris (Fayard) 2006.

Belezi, Mathieu, Le Pas suspendu de la révolte, Paris (Flammarion) 2017.

Belleau, Rémi, La Reconnue, 1578, Genève (Droz) 1989.

Belleforest, François de, Harangues militaires, Paris (Vignon) 1595.

Belle-Forest, Françoys de, La Cosmographie universelle de tout le monde, vol. 2, Paris (Nicolas Chesneau) 1575.

Bellenger, Lionel, Les 7 secrets des vrais pros : un cocktail d'audace, de lucidité et d'humilité, Montrouge (Éditions sociales françaises) 2013.

Belloc, Denis, Képas, Paris (Lieu Commun) 1989. 
Belloc, Denis, Néons, Paris (Lieu Commun) 1987.

Belloy, Pierre Laurent de, Gabrielle de Vergy, 1770. Dans : Euvres complettes, vol. 4, Paris (Moutard) 1778.

Belon, Paul et Georges Price, Paris qui passe, Paris (Albert Savine) 1888.

Belot, Adolphe, Une affolée d'amour, Paris (É. Dentu) 1885.

Benda, Julien, L'Ordination, 1911, Paris (Émile-Paul) ${ }^{4} 1913$.

Benda, Julien, La France byzantine ou Le Triomphe de la littérature pure : Mallarmé, Gide, Valéry, Alain, Giraudoux, Suarès, les surréalistes. Essai d'une psychologie originelle du littérateur, Paris (Gallimard) 1945.

Benda, Julien, La Trahison des clercs, 1927, Paris (Grasset) 1936.

Benedeit, Voyage de saint Brendan (Brandan, Brandain) [= The Anglo-Norman Voyage of St. Brendan by Benedeit], $1^{\text {er }}$ quart XII ${ }^{\mathrm{e}}$, éd. Edwin George Ross Waters, Oxford (Clarendon) 1928 [réimpression Genève (Slatkine) 1974]. DEAF : BrendanW [différences minimales non pertinentes avec DEAF BrendanM, pour les citations en question]

Benjamin, Laura, L'Opéra du fond des mers, Paris (Harlequin) 1983.

Benjamin, René, Gaspard, 1915, Paris (Fayard) 1929.

Benoit de Sainte Maure, Le Roman de Troie, 1170, éd. Léopold Constans, 6 vols., Paris (Didot) 1904-1912. DEAF : BenTroieC [éd. citée, faute de mieux; les variantes sont très utiles]

Benoît, Pierre, L'Atlantide, 1919, Paris (Albin Michel) 1920.

Benoît, saint, La Regle du b[ienheureux] pere s[aint] Benoist avec les declarations sur icelle pour la congrégation de Saint Maur, sans lieu ni éditeur, 1701.

Benoziglio, Jean-Luc, Cabinet portrait, 1980, Paris (Seuil) 1981.

Béranger, Pierre-Jean de, Chansons, 3 vols., Paris (Perrotin, Guillaumin et Bigot) 1829.

Bérard, Victor, L'Odysée d'Homère : étude et analyse, Paris (Mellottée) 1931.

Béraud, Henri, Pavés rouges, Paris (Éditions de France) 1934.

Berger, Yves, Le Sud, Paris (Grasset) 1962.

Bergerat, Émile, La Fontaine de jouvence, Paris (Ollendorf) 1906.

Bergson, Henri, L'Évolution créatrice, 1907, Paris (Presses universitaires de France) 1959.

Bergson, Henri, Les Deux Sources de la morale et de la religion, 1932, Paris (Presses universitaires de France) 1961.

Bernabé, Yannick, Demain sera pour aujourd'hui, Rivière-Salée (Yannick Bernabé) 2013.

Bernanos, Georges, Dialogues des Carmélites, 1948. Dans : Euvres romanesques, Paris (Gallimard) 1961.

Bernanos, Georges, Journal d'un curé de campagne, 1936. Dans : Euvres romanesques, Paris (Gallimard) 1961.

Bernanos, Georges, L'Imposture, 1927. Dans : Euvres romanesques, Paris (Gallimard) 1961.

Bernanos, Georges, La Joie, 1929. Dans : CEuvres romanesques, Paris (Gallimard) 1961.

Bernanos, Georges, Les Grands Cimetières sous la lune, 1937, Paris (Seuil) 1995.

Bernanos, Georges, Lettres inédites, 1906. Dans : Euvres romanesques, Paris (Gallimard) 1961.

Bernanos, Georges, Monsieur Ouine, 1943. Dans : E Fuvres romanesques, Paris (Gallimard) 1961.

Bernanos, Georges, Nouvelle Histoire de Mouchette, 1937. Dans : CFuvres romanesques, Paris (Gallimard) 1961.

Bernanos, Georges, Premiers Écrits, 1907, Paris (Seuil) 1991.

Bernanos, Georges, Sous le soleil de Satan, 1926. Dans : Euvres romanesques, Paris (Gallimard) 1961.

Bernanos, Georges, Un crime, 1935. Dans : Euvres romanesques, Paris (Gallimard) 1961.

Bernanos, Georges, Un mauvais rêve, 1948. Dans : Fuvres romanesques, Paris (Gallimard) 1961.

Bernard, Arthur, Paris en 2040, Paris (Parigramme) 2012. 
Bernard, Claude, Cahier de notes (1850-1860), Paris (Gallimard) 1965.

Bernard, Claude, Principes de médecine expérimentale, 1878, Paris (Presses universitaires de France) 1947.

Bernard, Tristan, Contes de Pantruche et d'ailleurs, 1897. Dans : Euvres, sans lieu (Ici-eBooks) 2018-2020.

Bernardin de Saint-Pierre, Henri, Études de la nature, 1784, Paris (Deterville) 1804.

Bernardin de Saint-Pierre, Henri, Harmonies de la nature, vol. 2, 1814. Dans : Euvres posthumes, Paris (Le Dentu) 1840.

Bernardin de Saint-Pierre, Henri, Paul et Virginie, 1787. Dans : Romanciers du xVIII siècle, vol. 2, Paris (Gallimard) 1965.

Bernardin de Saint-Pierre, Henri, Voyage à l'île de France, 1773. Dans : Euvres posthumes, vol. 1, Paris (Le Dentu) 1840.

Bernezai, Maximien de, Traité de la vie intérieure contenant les principaux moyens pour vivre cette vie, Orléans (Jean Boyer) 1686.

Bernier, François, Abrégé de la philosophie de Gassendi, 7 vols., Lyon (Anisson, Posuel et Rigaud), ${ }^{2} 1684$.

Bernières, Jean de, sieur de Louvigny, Les Euvres spirituelles, 1670, vol. 2, Lyon (Antoine Cellier) 1677.

Bernstein, Henry, Le Secret, Paris (La Petite Illustration) 1913.

Béroalde de Verville, François, Le Moyen de parvenir, 1610, Paris (Garnier) 1879.

Béroul, Tristan, $4^{\mathrm{e}}$ quart XII ${ }^{\mathrm{e}}$ [BFM : 1165-1200], éd. L. M. Defourques et Ernest Muret, Paris

(Champion) 1947. [cité d'après BFM] ; DEAF : TristBérM ${ }^{4}$

Berquin, Arnaud, L'Ami des enfans, 1783, Paris (Mame-Delaunay / Depellafol) 1822.

Bertaut, Jean, Les Euvres poétiques, Paris (T. du Bray) 1620.

Bertaut, Jean, Recueil de quelques vers amoureux, 1606, Paris (Didier) 1970.

Berthoud, Ferdinand, Essai sur l'horlogerie, vol. 2, Paris (J. Cl. Jombert) 1763.

Bertin, Antoine de, Les Amours, 1785. Dans : Euvres complètes, Paris (Roux-Dufort) 1824.

Bertrand Dorléac, Laurence, Histoire de l'art, Paris 1940-1944, Paris (Publications de la Sorbonne) 1986.

Bertrand, Aloysius, Gaspard de la nuit : fantaisies à la manière de Callot et Rembrandt, 1841, Paris (La Colombe) 1962.

Bertrandon de la Broquière, Le Voyage d'outremer de Bertrandon de la Broquière, premier écuyer tranchant et conseiller de Philippe le Bon, duc de Bourgogne, 1455, Paris (Leroux) 1892.

Beucher, Patricia, Je veux des poules !, Paris (Larousse) 2009.

Bèze, Théodore de, Abraham sacrifiant, 1550, Genève / Paris (Droz / Minard) 1967.

Bèze, Théodore de, Histoire ecclésiastique des Églises réformées au royaume de France, 1580, vol. 2, Lille (Leleux) 1841.

Bianciotti, Hector, Le Pas si lent de l'amour, Paris (Grasset et Fasquelle) 1995.

Bianciotti, Hector, Sans la miséricorde du Christ, 1985, Paris (Gallimard) 1996.

Bibliotheca scatologica ou Catalogue raisonné des livres traitant des vertus, faits et gestes de très noble et très ingénieux Messire Luc (à rebours)... [texte imprimé] par trois savants [Pierre Janet, Jean-François Payen, Auguste Veinant], Scatopolis [Paris], année scatologène 5850 [sic] [publié comme complément du Journal de l'amateur de livres (1849)].

Bienaymé, Pierre François, Mémoire sur les abeilles, Paris (Didot / Durand) 1780.

Bienne, Gisèle, Le Silence de la ferme, Paris (C. de Bartillat) 1986.

Binet, Étienne, Recueil des œuvres spirituelles du r[évérend] p[ère] Estienne Binet de la Compagnie de Jesus, Rouen (L'Allemand) 1627.

Binlin Dadié, Bernard, Patron de New York, Paris (Présence africaine) 1964.

Bisschop, Éric de, Au-delà des horizons lointains : Kaimiloa, Paris (Plon) 1939. 
Bitton, Georges, Phimosis ou Les Errances d'Henry Golan, 2006, Paris (Le Manuscrit), consulté le 20.8.2020.

Bizien, Jean-Luc, Katana, Paris (Gallimard) 2016.

Blanc, Louis, Organisation du travail, Paris (Cauville) 1845.

Blanche, Jacques-Émile, Mes modèles : souvenirs littéraires, Paris (Stock) 1928.

Blaze, Elzéar, Le Chasseur au chien courant, Paris (Elzéar Blaze) 1838.

Blégny, Nicolas de, L'Art de guerir les maladies veneriennes, vol. 2, Paris (L’Auteur et Jean Dhoury) 1678.

Blier, Bertrand, Les Valseuses, 1972, Paris (J'ai lu) 1989.

Bloch, Jean-Richard, Destin du siècle : seconds essais pour mieux comprendre mon temps, Paris (Rieder) 1931.

Blondel, Jacques François, L'Art de jetter les bombes, La Haye (Arnout Leers) 1685.

Blondel, Maurice, L'Action : essai d'une critique de la vie et d'une science de la pratique, Paris (Alcan) 1893.

Blondin, Antoine, Ma vie entre les lignes, 1982, Paris (Gallimard) 1984.

Blondin, Antoine, Un malin plaisir, 1991, Paris (La Table ronde) 1993.

Blouët, Adrien, L'Absence de ciel, sans lieu (Noir sur blanc) 2019.

Bloy, Léon, Exégèse des lieux communs (première série), 1902. Dans : Euvres, vol. 8, Paris (Mercure de France) 1983.

Bloy, Léon, Journal 1 : Le Mendiant ingrat (1892-1895), Paris (Mercure de France) 1956.

Bloy, Léon, Journal 1 : Mon journal (1896-1900), Paris (Mercure de France) 1956.

Bloy, Léon, Journal 2 : Quatre Ans de captivité à Cochons-sur-Marne (1900-1904), Paris (Mercure de France) 1963.

Bloy, Léon, Journal 2: L'Invendable (1904-1907), Paris (Mercure de France) 1963.

Bloy, Léon, Le Désespéré, 1886. Dans : Euvres, vol. 3, Paris (Mercure de France) 1964.

Bloy, Léon, Le Salut par les Juifs, 1892. Dans : EFuvres, Paris (Mercure de France) 1983.

Boaistuau, Pierre, Histoires tragiques, 1559, Paris (H. Champion) 1977.

Boaistuau, Pierre, Le Théâtre du monde, 1558, Genève (Droz) 1981.

Bobin, Christian, La Part manquante, 1989, Paris (Gallimard) 1997.

Bobin, Christian, Prisonnier au berceau, 2005, Paris (Gallimard) 2006.

Bodreau, Julien, Les Coustumes du païs et comté du Maine, Paris (Gervais Alliot) 1645.

Boileau, Nicolas, Chapelain décoiffé, 1665. Dans : Euvres complètes.

Boileau, Nicolas, Épîtres, 1670-1698 [éd. 1698]. Dans : Euuvres complètes.

Boileau, Nicolas, Le Lutrin, 1683. Dans : E Euvres complètes.

Boileau, Nicolas, Euvres complètes, éd. Antoine Adam et Françoise Escal, Paris (Gallimard) 1966.

Boileau, Nicolas, Satires, 1664-1701 [éd. 1701]. Dans : Euvres complètes.

Boisguilbert, Pierre Le Pesant de, Le Détail de la France sous le règne présent, 1695, Bruxelles (G. de Backer) 1712.

Boisrobert, François Le Métel de, Épistres en vers, vol. 1, 1646, Paris (Hachette) 1921.

Boisrobert, François Le Métel de, Épistres en vers, vol. 2, 1659, Paris (Hachette) 1927.

Boisrobert, François Le Métel de, Histoire indienne d'Alexandre et d'Orazie, où sont entremeslées les aventures d'Alcidaris, de Combaye et les amours de Pyroxène, Paris (F. Pomeray) 1629.

Boissard, Janine, Une femme en blanc, Paris (Robert Laffont) 1996.

Boissier de Gasparin, Valérie (v. Dutoit, Marie)

Boissier de Sauvages, Pierre-Augustin, Dictionnaire languedocien-françois, 1785, Nîmes (Gaude) 1785.

Boissy, Louis de, Les Dehors trompeurs ou L'Homme du jour. Dans : Répertoire général du théâtre français, 1740, vol. 43, Paris (Ménard et Raymond) 1813.

Bon, François, L'Incendie du Hilton, Paris (Albin Michel) 2009. 
Bonald, Louis de, Essai analytique sur les lois naturelles de l'ordre social, ou Du pouvoir, du ministre et du sujet dans la société, Paris (s. n.) 1800.

Bonald, Louis de, Législation primitive considérée dans les derniers temps par les seules lumières de la raison, Paris (Le Clère) An XI, 1802.

Bonnecorse, Balthazar de, Lutrigot : poëme héroï-comique, Marseille (Ch. Brebion) 1686.

Bonnefons, R., Le Cabinet du vray thresor, Paris (Adrien Perier) 1606.

Bonnefoy, Yves, Rue Traversière et autres récits en rêve, 1987, Paris (Gallimard) 1995.

Bonnenfant, Paul, La Capitale saoudienne : Riyadh. Dans : Paul Bonnenfant (ed.), La Péninsule arabique aujourd'hui, vol. 1 : Études par pays, Aix-en-Provence (CNRS) 1982.

Bonnet, Charles, La Palingénésie philosophique ou Idées sur l'état passé et l'état futur des êtres vivans, vol. 1, 1769, Genève (Philibert et Chirol) 1770.

Bonnet, Sophie, Bordel, Paris (Belfond) 2014.

Bonnetain, Paul, Passagère, Paris (Alphonse Lemerre) 1892.

Bordeaux, Henry, La Vie est un sport. Dans : Revue des deux mondes, $1^{\text {er }}$ mai 1923.

Bordeaux, Henry, Les Derniers Jours du fort de Vaux (9 Mars-7 Juin 1916), Paris (Plon) 1916.

Bordes, Jean de, Les Vrais Abus des pretendus abus de messe, Bordeaux (Millanges) 1598.

Borel, Pétrus, Champavert : les contes immoraux, 1833, Paris (Montbrun) 1947.

Borel, Pétrus, Rhapsodies. Dans : Euvres complètes, vol. 2, 1832, Paris (La Force Française) 1922.

Bornier, Henri de, La Fille de Roland, 1875 Paris (Le Dentu) 1905.

Bortoli, Gilles, Manuel de volley-ball : de l'initiation au perfectionnement, Paris (Amphora) 2007.

Bory, Jean-Louis, Mon village à l'heure allemande, Paris (Flammarion) 1945.

Bory, Jean-Louis, Un prix d'excellence, 1979, Paris (Gallimard) 1990.

Bosco, Henri, Le Mas Théotime, 1945, Paris (Charlot) 1946.

Bosquet, Alain, Une mère russe, 1978, Paris (Grasset) 1989.

Bossuet, Jacques-Bénigne, De la connaissance de Dieu et de soi-même, 1704. Dans : CEuvres complètes, vol. 23, Paris (L. Vives) 1864.

Bossuet, Jacques-Bénigne, Discours sur l'histoire universelle à Monseigneur le Dauphin : pour expliquer la suite de la religion et les changemens des empires, Paris (Mabre-Cramoisy) 1681.

Bossuet, Jacques-Bénigne, Élévations sur les mystères, 1704, Paris (Vrin) 1962.

Bossuet, Jacques-Bénigne, Méditations sur l'Évangile, 1704, Paris (Vrin) 1966.

Bossuet, Jacques-Bénigne, Oraison funèbre de Henriette-Anne d'Angleterre, 21 août 1670. Dans : Euvres oratoires, vol. 5, Paris (Desclée de Brouwer) 1922.

Bossuet, Jacques-Bénigne, Oraison funèbre de Henriette-Marie de France, reine de la Grand'Bretagne, 16 novembre 1669. Dans : Euvres oratoires, vol. 5, Paris (Desclée de Brouwer) 1922.

Bossuet, Jacques-Bénigne, Oraison funèbre de Marie-Thérèse d'Autriche, reine de France et de Navarre, $1^{\text {er }}$ septembre 1683. Dans : Oraisons funèbres, Paris (Garnier) 1961.

Bossuet, Jacques-Bénigne, Oraison funèbre de Michel Le Tellier, 25 janvier 1685. Dans : Oraisons funèbres, Paris (Garnier) 1961.

Bossuet, Jacques-Bénigne, Sermon sur l'efficacité de la pénitence (Carême du Louvre, 1662). Dans : Sermons : Le Carême du Louvre, Paris (Gallimard) 2001.

Bossuet, Jacques-Bénigne, Sermon sur l'intégrité de la pénitence (Carême du Louvre, 1662). Dans : Sermons : Le Carême du Louvre, Paris (Gallimard) 2001.

Bossuet, Jacques-Bénigne, Sur la matière de l'Église. Conférence avec M. Claude, 1682. Dans : Euvres complètes de Bossuet, vol. 7, Paris (Lefèvre) 1856.

Bouchard, Caroline et Jacques, La Vie de château - Splendeurs et misères de deux Québécois en France, Montréal (Québec Amérique) 2003.

Bouchart, Alain, Grandes Croniques de Bretaigne, vol. 1, 1514, Paris (CNRS) 1986.

Boudard, Alphonse, La Cerise, 1963, Paris (La Table ronde) 1983. 
Boudard, Alphonse, Le Café du pauvre, Paris (La Table ronde) 1983.

Boudard, Alphonse, Les Combattants du petit bonheur, Paris (La Table ronde) 1977.

Boudard, Alphonse, Les Enfants de chœur, 1982, Paris (Gallimard) 1984.

Boudard, Alphonse, Mourir d'enfance, 1995, Paris (Pocket) 1997.

Boudon de Saint-Amans, Jean-Florimond, Voyage agricole, botanique et pittoresque dans une partie des Landes de Lot et Garonne et celles de la Gironde, Paris (Fr. Buisson) 1812.

Bouhier, Jean, La Bataille du poète, 1945. Dans : Les Poètes de l'école de Rochefort. Anthologie présentée par Jean Bouhier, Paris (Seghers) 1983.

Bouhours, le père Dominique, Les Entretiens d'Ariste et d'Eugène, 1671, Paris (A. Colin) 1962.

Bouilhet, Louis, Dernières Chansons, 1869, Paris (Michel Lévy) 1872.

Bouilhet, Louis, Melænis : conte romain, Paris (Michel Lévy) 1857.

Bouillier, Grégoire, L'Invité mystère, Paris (Allia) 2004.

Bouilly, Jean Nicolas, La Barricade. Dans : Contes populaires, vol. 2, Bruxelles (Société belge de librairie) 1837.

Boulainvilliers, Henri de, Histoire de l'ancien gouvernement de la France, avec XIV lettres historiques sur les Parlemens ou États généraux, vol. 2, La Haye / Amsterdam (La Compagnie) 1727.

Boulanger, Daniel, Le Téméraire, 1962, Paris (Gallimard) 1984.

Boulay, Henri, Arboriculture et production fruitière, Paris (Presses universitaires de France) 1961.

Bourdeille, Pierre de, seigneur de Brantôme, Euvres complètes de Pierre de Bourdeille, abbé de Brantôme, 1604, Paris (Auguste Desrez) 1889.

Bourdet, Édouard, Le Sexe faible, Paris (Stock, Delamain et Boutelleau) 1931.

Bourgeois, Louise, Observations diverses sur la sterilite, perte de fruict, focondite, accouchements et maladies des femmes et enfants nouveaux naiz, Paris (Saugrain) 1617.

Bourges, Élémir, Le Crépuscule des dieux, 1884, Paris (Stock) 1939.

Bourget, Paul, Ancien Portrait. Dans : La Lecture, magazine littéraire bi-mensuel, Paris, 1887.

Bourget, Paul, André Cornélis, Paris (A. Lemerre) 1887.

Bourget, Paul, Cosmopolis, Paris (A. Lemerre) 1893.

Bourget, Paul, Cruelle Énigme, Paris (A. Lemerre) 1885.

Bourget, Paul, La Geôle, Paris (Plon) 1923.

Bourget, Paul, Lazarine, Paris (Plon-Nourrit) 1917.

Bourget, Paul, Le Chauffeur, 1922. Dans : Conflits intimes, Paris (Plon) 1925.

Bourget, Paul, Le Danseur mondain. Dans : Revue des deux mondes, 1926.

Bourget, Paul, Le Disciple, 1889. Dans : Euuvres complètes, vol. 3, Paris (Plon) 1901.

Bourget, Paul, Le Geste du fils, 1923. Dans : Conflits intimes, Paris (Plon) 1925.

Bourget, Paul, Le Sens de la mort, 1915, Paris (Plon) 1916.

Bourget, Paul, Le Sursis, 1921. Dans : Conflits intimes, Paris (Plon) 1925.

Bourget, Paul, Mensonges, Paris (A. Lemerre) 1887.

Bourget, Paul, Nos actes nous suivent, Paris (L'lllustration) 1926.

Bourget, Paul, Nouveaux Essais de psychologie contemporaine, 1885, Paris (A. Lemerre) 1886.

Bourget, Paul, Physiologie de l'amour moderne, 1890, Paris (A. Lemerre) 1891.

Bourget, Paul, Un crime d'amour, Paris (A. Lemerre) 1886.

Bourget, Paul, Un drame dans le monde, Paris (Plon) 1921.

Bourngar, Djimrabaye, Mangistrature à Begou, sans lieu (La Compagnie littéraire) 2018.

Boursault, Edme, Ésope à la Cour. Dans : Répertoire général du théâtre français, 1702, vol. 32, Paris (Ménard et Raymond) 1813.

Bousquet, Joë, Traduit du silence, 1936, Paris (Gallimard) 1941.

Boutet, Claude, Traité de mignature, ${ }^{21674, ~ P a r i s ~(C h r i s t o p h l e ~ B a l a r d) ~} 1676$.

Bouvier, Nicolas, L'usage du monde. Récit : Genève, juin 1953 - Khyber Pass, décembre 1954, Paris (La Découverte) 1963. 
Bouvier, Pierre Louis, Manuel des jeunes artistes et amateurs en peinture, Paris (Alphonse Giroux) ${ }^{2} 1832$.

Boya, Thomas et Jérôme Carlos, Pensez neuf, pensez positif, sans lieu (Boya) 1996.

Boyard, Nicolas-Jean-Baptiste, La Bourse et ses spéculations mises à la portée de tout le monde, Paris (Librairie encyclopédique de Roret) 1853.

Boylesve, René, La Leçon d'amour dans un parc, 1902, Paris (Calmann-Lévy) 1920.

Boylesve, René, Madeleine jeune femme, Paris (Calmann-Lévy) 1912.

Boyvin du Villars, François, Mémoires sur les guerres demeslees tant en Piedmont, qu'au Montferrat et Duché de Milan par Charles de Cossé, comte de Brissac, 1607. Dans : Choix des chroniques et mémoires sur l'histoire de France. XVI siècle, éd. Jean Alexandre Buchon, Paris (Desrez) 1836.

Brabois, Xavier de, L'Éclat du pendentif. Dans : La Gloire de l'Edenkan, vol. 1, Saint-Denis (Publibook) 2006.

Bragiel, André, La Servante du curé. Dans : Revue du monde catholique, Paris, 1867.

Branche, Jacques, La Vie des saincts et sainctes d'Auvergne et de Velay, Le Puy (Philippe Guynand) 1652.

Brants, Victor, La Lutte contre l'usure dans le lois modernes, Louvain (Peeters) / Paris (Larose) 1907.

Brasillach, Robert, Pierre Corneille, Paris (Fayard) 1938.

Brassens, Georges, Poèmes et chansons, 1973, Paris (Seuil) 1991.

Brébeuf, Georges de, Entretiens solitaires, 1660, Paris (E. Cornely) 1912.

Brébeuf, Georges de, La Pharsale de Lucain ou Les Guerres civiles de César et de Pompée en vers françois [trad.], Paris (A. de Sommaville) 1654.

Brébeuf, Georges de, Lucain travesti ou Les Guerres civiles de César et de Pompée en vers enjoués, Rouen (A. de Sommaville) 1656.

Bremond, Henri, Histoire littéraire du sentiment religieux en France depuis la fin des guerres de religion jusqu'à nos jours, vol. 3, Paris (Bloud et Gay) 1921.

Bremond, Henri, Histoire littéraire du sentiment religieux en France depuis la fin des guerres de religion jusqu'à nos jours, vol. 4, Paris (Bloud et Gay) 1920.

Breton, André, Les Manifestes du surréalisme, Paris (Sagittaire) 1947.

Bretonneau, Pierre, Des inflammations spéciales du tissu muqueux, et en particulier de la diphtérite, Paris (Crevot) 1826.

Breunot, Gabriel, Journal, 1594 et suiv., vol. 2. Dans : Analecta Divionensia, Documents inédits pour servir à l'histoire de France, Dijon (Rabutot) 1864.

Breuze, Patrick, La Lumière des cimes, Paris (Presse de la Cité) 2019.

Briant, Pierre, Antigone le Borgne : les débuts de sa carrière et les problèmes de l'Assemblée macédonienne, Paris (Belles lettres) 1973.

Brillant, Maurice, Problèmes de la danse, Paris (A. Colin) 1953.

Brillat-Savarin, Jean-Anthelme, Physiologie du goût ou Méditations de gastronomie transcendante, 1825, Paris (Charpentier) 1847.

Brillon, Pierre-Jacques, Le Théophraste moderne ou Nouveaux Caractères sur les mœurs, La Haye (van Dole) 1700.

Brisebarre et Salvat, Édouard, La Petite Provence: vaudeville en un acte, 1853.

Brissac, Pierre de, En d'autres temps (1900-1939), 1972, Paris (Grasset) 2003.

Brito de Freitas, Sonia, Elva, vol. 1: Je veux vivre aujourd'hui, Paris (Le Lys bleu) 2019.

Brizeux, Auguste, Marie, 1840. Dans : Euvres, vol. 1, Paris (Garnier) 1910.

Brochet, Anne, Trajet d'une amoureuse éconduite, Paris (Seuil) 2005.

Bron, Ludovic, Huysmans, d'après des documents inédits, Paris (Alsatia) 1937.

Brönnimann, F., Les Constellations zodiacales. Conférence donnée à Bienne. Dans : L'Émulation jurassienne 2, 1878. 
Brossat, Alain, Libération, fête folle, 6 juin 44 - 8 mai 45 : mythes et rites ou Le Grand Théâtre des passions populaires, Paris (Autrement) 1994.

Brosse, Les Songes des hommes esveillez,1646, Paris (Nizet) 1984.

Brosses, Charles de, Formation méchanique des langues, 2 vols., (Saillant, Vincent et Desaint) 1765.

Broussais, François-Joseph-Victor, Cours de phrénologie, Paris (J.-B. Baillière) 1836.

Bruce, Josette, OSS 177 : imbroglio à San Diego, Paris (Presses de la Cité) 1977.

Brun de la Montaigne [= An annotated edition of Brun de la Montaigne], $2^{\mathrm{e}}$ moitié xıve éd. Charles

Louis Janssens, thèse de doctorat, University of Arizona, 1967. https://repository.arizona.edu/ handle/10150/284813. DEAF: BrunMont]

Brune-El, La Lune cendrée, Toulouse (Hélène Jacob) 2014.

Brunerie, Georges, Les Industries alimentaires et leur organisation rationnelle, Paris (Dunod) 1949.

Brunet, Jacques-Charles, Manuel du libraire et de l'amateur de livres, vol. 1, Paris (Crapelet) 1820.

Brunetière, Ferdinand, Études critiques sur l'histoire de la littérature française, Paris (Hachette) 1908.

Brunhes, Jean, La Géographie humaine, Paris (Presses universitaires de France) 1942.

Brut [= Der Münchener Brut], 1200, éd. Konrad Hofmann et Karl Vollmöller, Halle (Niemeyer) 1877. DEAF : BrutMunH

Buc’hoz, Pierre-Joseph, Traité économique et physique des oiseaux de basse-cour, Liège (F. J. Desoer) 1777.

Bueve de Hanstone [= Der anglonormannische Boeve de Haumtone], début XIII', éd. Albert Stimming, Halle (Niemeyer) 1899. DEAF : BueveAgnS

Buffon, Georges-Louis Leclerc de et Louis Daubenton, Histoire naturelle, vol. 8, Paris (Imprimerie Royale) 1760.

Buffon, Georges-Louis Leclerc de, Histoire naturelle des oiseaux, vol. 2, Paris (Imprimerie royale) 1771.

Buffon, Georges-Louis Leclerc de, L'Âne, 1753. Dans : E Euvres, vol. 3, Paris (Parent Desbarres) 1868.

Buffon, Georges-Louis Leclerc de, Euvres complètes, Paris (Pillot) 1837.

Bugnon Renard, Louise, Contes de Bretagne, Genève (C. Eggimann) 1896.

Buies, Arthur, Chroniques, Québec (Darveau) 1873.

Bulletin de la Société centrale forestière de Belgique.

Bulletin de la Société de géographie de Marseille, Université d'Aix-Marseille.

Bulletin de la Société d'encouragement pour l'industrie nationale, Paris.

Bulletin de la Société des amis des sciences naturelles de Rouen, Rouen.

Bulletin de la Société des anciens élèves de l'École spéciale de commerce, d'industrie et des mines du Hainaut, Mons et Bruxelles.

Bulletin de la Société des sciences et arts de Bayonne, Bayonne (Lamaignère).

Bulletin des sciences médicales, Paris.

Bulletin des séances de la Société centrale d'agriculture de France 6, Paris (Bouchard-Huzard).

Bulletins et mémoires de la Société médicale des hôpitaux de Paris, Paris (Masson).

Buron, Nicole de, "Chéri, tu m'écoutes ?... alors répète ce que je viens de dire ! », Paris (Plon) 1998.

Buschmann, Ernest, Rameaux. Odes - Satyres - Ballades, Anvers (J. de Cort) 1839.

Bussy-Rabutin, Roger de, Les Lettres de messire Roger de Rabutin, comte de Bussy (1666-1692), 4 vols., Paris (F. Delaulne) 1720.

Bussy-Rabutin, Roger de, Les Mémoires de messire Roger de Rabutin, comte de Bussy, 3 vols, Paris (J. Anisson) 1696.

Cabanis, José, Les Jeux de la nuit, Paris (Gallimard) 1964.

Cabanis, Pierre, Rapports du physique et du moral de l'homme, 1808, vol. 1, Paris (Caille et Ravier) 1815.

Cahiers de la Fondation nationale des sciences politiques, Paris. 
Calderara, Mario et P. Banet-Rivet, Manuel de l'aviateur-constructeur, Paris (Dunot et Pinat) 1910.

Caligny, A. de, Expérience sur les ajutages coniques divergents alternativement plongés dans l'air et dans l'eau. Dans: Comptes rendus hebdomadaires des séances de l'Académie des sciences, juillet-décembre 1844.

Calixte de la Providence, père, Vie de saint Félix de Valois, 1632, Tournai (Henri Casterman) ${ }^{3} 1878$.

Calvin, Jean, Advertissement contre l'astrologie judiciaire, 1549, Genève (Droz) 1985.

Calvin, Jean, Des scandales, 1550, Genève (Droz) 1984.

Calvin, Jean, Institution de la religion chrestienne, 1560, 5 vols., Paris (J. Vrin) 1957-1963.

Calvin, Jean, Lettres à Monsieur et Madame de Falais, 1543, Genève (Droz) 1991.

Camus, Albert [adapt. de Dino Buzzati], Un cas intéressant, 1955. Dans : Théâtre, récits, nouvelles, Paris (Gallimard) 1962.

Camus, Albert [adapt. de Pierre de Larivey], Les Esprits, 1953. Dans : Théâtre, récits, nouvelles, Paris (Gallimard) 1962.

Camus, Albert, Caligula, 1944. Dans : Théâtre, récits, nouvelles, Paris (Gallimard) 1962.

Camus, Albert, L'État de siège, 1948. Dans : Théâtre, récits, nouvelles, Paris (Gallimard) 1962.

Camus, Albert, L'Exil et le royaume, 1957. Dans : Théâtre, récits, nouvelles, Paris (Gallimard) 1962.

Camus, Albert, L'Homme révolté, 1951, Paris (Gallimard) 1952.

Camus, Albert, La Chute, 1956. Dans : Théâtre, récits, nouvelles, Paris (Gallimard) 1962.

Camus, Albert, La Dévotion à la Croix [trad. et adapt. de Calderón], 1953. Dans : Théâtre, récits, nouvelles, Paris (Gallimard) 1962.

Camus, Albert, La Peste, 1947. Dans : Théâtre, récits, nouvelles, Paris (Gallimard) 1962.

Camus, Albert, Le Chevalier d'Olmedo [trad. et adapt. de Lope de Vega], 1957. Dans : Théâtre, récits, nouvelles, Paris (Gallimard) 1962.

Camus, Albert, Les Justes, 1950. Dans : Théâtre, récits, nouvelles, Paris (Gallimard) 1962.

Camus, Jean-Pierre, Homélies des États généraux, 1615, Genève (Droz) 1970.

Camus, Jean-Pierre, Palombe ou La Femme honnorable par l'Évêque de Belley, Paris (C. Chappelet) 1625.

Camus, Jean-Pierre, Premières Homélies dominicales, Paris (Claude Chappelet) 1619.

Cantini, Claude et Jérôme Pedroletti, Histoires infirmières : Hôpital psychiatrique de Cery sur Lausanne (1940-1990), Lausanne (Éditions d'en bas) 2000.

Capefigue, Baptiste Honoré Raymond, Histoire de la Restauration et des causes qui ont amené la chute de la branche des Bourbons, 10 vols., Paris (Dufey) 1831-1833.

Capefigue, Baptiste, François fer et la Renaissance, 1515-1547, vol. 1, Paris (D’Amyot) 1845.

Capello, Louis, comte de Sanfranco [Luigi Capello di Sanfranco], Mythologie de tous les peuples, Turin (Joseph Favale) 1833.

Caradec, François, La Compagnie des zincs, Paris (Ramsay) 1986.

Caraguel, Adrien, Les Noyaux d'abricots : itinéraire d'un enfant d'Algérie, Paris (L'Harmattan) 2011.

Carco, Francis, À voix basse, Paris (Albin Michel) 1938.

Carco, Francis, Jésus-la-Caille, 1914, Paris (Librairie générale française) 1987.

Carco, Francis, L'Équipe : roman des fortifs, 1925, Paris (Albin Michel) 1989.

Carco, Francis, L'Homme traqué, 1922, Paris (Albin Michel) 1947.

Cardelli, P., Manuel du cuisinier et de la cuisinière, Paris (Librairie encyclopédique de Roret) ${ }^{9} 1833$.

Cardinal, Marie, Les mots pour le dire, 1975, Paris (Grasset / Librairie générale française) 2008.

Carême, Marie-Antonin, L'Art de la cuisine française au XIX siècle, vol. 2, Paris (Renouard, etc.) 1847.

Carême, Marie-Antonin, Le Pâtissier royal parisien, vol. 1, Paris (Dentu) 1815.

Carraud, Zulma, Une servante d'autrefois, Paris (Hachette) 1869.

Carrère d'Encausse, Hélène, L'Empire éclaté : la révolte des nations en U.R.S.S., 1978, Paris

(Flammarion) 1992.

Carrère, Emmanuel, D’autres vies que la mienne, Paris (P.O.L.) 2009. 
Carrère, Emmanuel, La Classe de neige, Paris (P.O.L.) 1995.

Carrère, Emmanuel, Un roman russe, Paris (P.O.L.) 2007.

Carrey, Émile, L’Amazone. Les Métis de la savane, Paris (Michel Lévy) 1857.

Cars, Guy des, La Corruptrice, Paris (Flammarion) 1952.

Carver, Jonathan, Voyage dans les parties intérieures de l'Amérique septentrionale [trad. anonyme], Yverdon (sans éditeur) 1784.

Casabonne, Jean François, Du cœur aux pieds, Anjou [Québec] (Fides) 2001.

Cascua, Stéphane et Marie-Pierre Olivieri, Le Sport pour maigrir, Paris (Odile Jacob) 2005.

Cassianus Bassus, Les XX Livres de Constantin Cesar auxquels sont traictés les bons enseignemens de d'agriculture [trad. du latin par Anthoine Pierre] 1543, Poitiers (Marnef) 1545.

Cassou, Jean, Panorama des arts plastiques contemporains, Paris (Gallimard) 1960.

Castagne, Gabriel de, L'Or potable qui guarit tous les maux, Paris (Charles Sevestre) 1611.

Castaldo, V., Imitations libres de quelques poésies italiennes de Giacomo Leopardi et compositions diverses, Naples (Pierri et Veraldi) 1901.

Castellion, Sébastien, Conseil à la France désolée, 1562, Genève (Droz) 1967.

Castilho, José Feliciano Barreto e Noronha de et Alexandre Magno de Castilho, Traité de mnémotechnie, Paris (Firmin Didot) 1833.

Cataldo, Giancarlo de, Les Traîtres [trad. de l'italien], Paris (Métailié) 2012.

Caubet, Dominique, Parlers jeunes, ici et là-bas, Paris (L’Harmattan) 2004.

Caussimon, Pascal, L’Art de se métamorphoser, sans lieu (Pascal Caussimon) 2009.

Caussin, Nicolas, La Cour sainte, vol. 4, Paris (Sebastien Chappelet) 1642.

Cauvin, Gilbert, Psychanalyse de la peur, Saint-Denis (Publibook) 2004.

Cauvin, Patrick, Monsieur Papa, 1976, Paris (Librairie générale française) 1990.

Cavanna, François, Les Ritals, 1978, Paris (Librairie générale française) 2007.

Cavanna, François, Les Russkoffs, Paris (Belfond) 1979.

Cavanna, François, Mignonne, allons voir si la rose..., Paris (Albin Michel) 2001.

Cayet, Pierre-Victor, seigneur de la Palme, L'Histoire prodigieuse du Docteur Fauste, 1598, Genève (Droz) 1982.

Caylus, Anne-Claude, comte de, Féeries nouvelles, 1741. Dans : Le Cabinet des fées, vol. 24, Genève (Barde et Manget) / Paris (Cuchet) 1786.

Caylus, Anne-Claude, comte de, Histoire de monsieur Guillaume, cocher, 1737. Dans : Fuvres badines complettes, vol. 10, Paris (Visse) 1787.

Cayrol, Jean, Les Châtaignes, Paris (Seuil) 1986.

Cazeaux, P., Voyage dans les régions arctiques (1834-1835) [trad. de l'anglais]. Dans : Annales maritimes et coloniales, 1837.

Cazes, Jérôme, 555 jeudi rouge, édition numérique sans lieu ni éditeur, 2012.

Cazotte, Jacques, Le Diable amoureux, 1776. Dans : Romanciers du xvIII e siècle, vol. 2, Paris (Gallimard) 1965.

Cazotte, Jacques, Ollivier, 1763. Dans : Euvres badines et morales, vol. 1, Paris (J.-F. Bastien) 1817.

Céline, Louis-Ferdinand, Casse-Pipe, 1949, Paris (Gallimard) 1952.

Céline, Louis-Ferdinand, D'un château l'autre, Paris (Gallimard) 1957.

Céline, Louis-Ferdinand, Guignol's band II, 1944. Dans : Romans, vol. 3, Paris (Gallimard) 1988.

Céline, Louis-Ferdinand, Mea culpa, 1936.

Céline, Louis-Ferdinand, Mort à crédit, 1936. Dans : Romans, vol. 1, Paris (Gallimard) 2000.

Céline, Louis-Ferdinand, Rigodon, 1961, Paris (Gallimard) 1991.

Céline, Louis-Ferdinand, Voyage au bout de la nuit, 1932. Dans : Romans, vol. 1, Paris (Gallimard) 2000.

Cendrars, Blaise, Bourlinguer, Paris (Denoël) 1948.

Cendrars, Blaise, L’Homme foudroyé. La Main coupée, 1946, Paris (Denoël) 1960. 
Cendrars, Blaise, L'Or, 1925, Paris (Gallimard) 2001.

Cendrars, Blaise, Moravagine. Suivi de Pro domo..., 1926, Paris (Denoël) 1956.

Cérou, Pierre, L'Amant auteur et valet, 1740, Exeter (University of Exeter) 1978.

Cervantes, Miguel de, Histoire de l'admirable Don Quichotte de La Manche [trad. (inconnu)], Paris

(Compagnie des Libraires) 1713.

Césaire, Aimé, La Poésie, Paris (Seuil) 2006.

Césaire, Aimé, La Tragédie du roi Christophe, 1970, Paris (Présence africaine) 1997.

Cesbron, Gilbert, Traduit du vent : contes, Lausanne (La Guilde du livre) 1945.

Ceton, Jean Pierre, Le pont d'Algeciras, Chambéry (L’Act mem) 2008.

Chabot, Jacques, L'Imaginaire, Arles (Actes Sud) 1990.

Chabrol, Jean-Pierre, Je t'aimerai sans vergogne, Paris (Gallimard) 1967.

Chabrol, Jean-Pierre, La Folie des miens, 1977, Paris (Gallimard) 1984.

Chaix, Marie, L'Été du sureau, 2005, Paris (Seuil) 2007.

Chalandon, Sorj, Mon traître, 2007, Paris (Grasset) 2012.

Challe, Robert, Les Illustres Françoises : histoires véritables, 1713, 2 vols., Paris (Belles lettres) 1959.

Chalvet, Mathieu de, Les Fuvres de L. Annæus Seneca [trad.], Paris (Abel Langelier) 1609.

Chambre de commerce française de Milan, Bulletin.

Chamfort, Sébastien-Roch-Nicolas de, Caractères et anecdotes, 1794. Dans : Maximes et pensées, Paris (Larousse) 1929.

Chamfort, Sébastien-Roch-Nicolas de, Maximes et pensées, 1794. Dans : Maximes et pensées, Paris (Larousse) 1929.

Chamoiseau, Patrick, Antan d'enfance, 1990. Dans : Une enfance créole, vol. 1, Paris (Gallimard) 2008.

Chamoiseau, Patrick, Texaco, 1992, Paris (Gallimard) 1997.

Chamoulaud, Jean-Marc, Nuage bleu, sans lieu (Jean-Marc Chamoulaud) 2013.

Champfleury, Les Aventures de mademoiselle Mariette, 1853, Paris (Michel Lévy) ${ }^{3} 1857$.

Champfleury, Les Bourgeois de Molinchart, 1855, Paris (Michel Lévy) 1859.

Champfleury, Les Souffrances du professeur Delteil, 1853, Paris (Michel Lévy) 1857.

Chamseru, M. de, Recherches sur la nyctalopie, 1784. Dans : Histoire de la société royale de médecine, Paris (Théophile Barrois) 1790.

Chandeneux, Claire de, Les Deux Femmes du major, Paris (Plon) 1876.

Chandernagor, Françoise, L’Allée du roi, 1981, Paris (Pocket) 1996.

Chandernagor, Françoise, L'Enfant des Lumières, 1995, Paris (Librairie générale française) 1997.

Chanson de Roland, 1100, éd. Cesare Segre, Milano / Napoli (Riccardo Ricciardi) 1971. DEAF : RolS

Chanson de Roland, 1100, éd. Gérard Moignet, Paris (Bordas) 1972. [cité d'après BFM ; pour les variantes v. éd. Segre] ; DEAF : RolMoign

Chansons $d u x v^{e}$ siècle, datables du $2^{e}$ tiers du $x v^{e}$ siècle à la fin du xve siècle, éd. Gaston Paris, Paris (Firmin Didot), 1875. DEAF : ChansBNfr12744P

Chantal, Suzanne, Ervamoïra, Paris (Olivier Orban) 1982.

Chapelain, Charles, Cours moderne de technique automobile, Paris (Berger-Levrault) 1956.

Chapelain, Jean, La Pucelle ou La France délivrée, Paris (A. Courbé) 1656.

Chapron, Léon, Les Coins de Paris, Paris (É. Dentu) 1881.

Char, René, Fenêtres dormantes et porte sur le toit, 1979. Dans : Euvres complètes, Paris (Gallimard) 1985.

Char, René, Fureur et mystère, 1948. Dans : CEuvres complètes, Paris (Gallimard) 1985.

Chardin, Jean, Voyages de Mr. le chevalier Chardin, en Perse, et autres lieux de l'Orient, vol. 7, Amsterdam (Jean Louis de Lorme) 1711.

Chardon, Henri, Les Travaux publics. Essai sur le fonctionnement de nos administrations, Paris (Perrin) 1904. 
Chardonne, Jacques, L'Amour c'est beaucoup plus que l'amour, Paris (Albin Michel) 1957.

Charef, Mehdi, Le Thé au harem d'Archi Ahmed, 1983, Paris (Gallimard) 1991.

Charles d'Orléans, Poésies complètes, 1415-1440, éd. Charles d'Héricault, 2 vols., Paris (Lemerre) 1874.

Charles d’Orléans, Poésies, 1415-1440, éd. Pierre Champion, 2 vols., Paris (Champion) 1966. DEAF : CharlD’OrlC

Charles-Picard, Colette et Gilbert, La Vie quotidienne à Carthage au temps d'Hannibal, Paris (Hachette) 1982.

Charleval, Jean-Louis Faucon de Ris, marquis de, Poésies de Saint-Pavin et de Charleval, 1693 [date de sa mort], Amsterdam (P.-A. Le Prieur) 1759.

Charmes, Gabriel, La Réforme de la marine, Paris (Calmann-Lévy) 1886.

Charrière, Henri, Banco, Paris (Laffont) 1972.

Charrière, Isabelle de, Caliste ou Lettres écrites de Lausanne, 1787, Paris (J. Labitte) 1845.

Charron, Pierre, De la sagesse : trois livres, 1601, 2 vols., Paris (Chaignieau ainé) An V, 1797.

Chartes de l'abbaye de Saint-Magloire, 1330, vol. 3, Paris (CNRS) 1976. [cité d'après Frantext]

Chasles, Philarète, Mémoires, vol. 1, Paris (Charpentier) 1876.

Chateaubriand, François-René de, Essai historique, politique et moral sur les révolutions anciennes et modernes considérées dans leurs rapports avec la Révolution française, 1797, 2 vols. Dans : Euvres complètes, Paris (Ladvocat) 1826.

Chateaubriand, François-René de, Itinéraire de Paris à Jérusalem, 1812, Paris (Flammarion) 1998.

Chateaubriand, François-René de, Le Paradis perdu [trad. ; original de John Milton], 1839, Paris (Gallimard) 1999.

Chateaubriand, François-René de, Les Martyrs ou Le Triomphe de la religion chrétienne 1, 1810. Dans : Euvres complètes, vol. 17-18bis., Paris (Ladvocat) 1826-1827.

Chateaubriand, François-René de, Les Natchez, 1829, Paris (Droz) 1932.

Chateaubriand, François-René de, Lettres à Mme Récamier (1820-1847), Paris (Flammarion) 1998.

Chateaubriand, François-René de, Mémoires d'outre-tombe, première partie (livres 1, 2 et 3), 1848, Paris (Flammarion) 1948.

Chateaubriand, François-René de, Vie de Rancé, 1844, Paris (Gallimard) 1998.

Châteaubriant, Alphonse de, Monsieur des Lourdines, 1911, Paris (Grasset) 1923.

Châteaureynaud, Georges-Olivier, L'Autre Rive, Paris (Grasset) 2007.

Chaudon, Louis-Mayeul, Dictionnaire universel historique, critique et bibliographique, vol. 19, Supplément, Paris (Prudhomme) ${ }^{9} 1812$.

Chaussard, Pierre-Jean-Baptiste, Fêtes et courtisanes de la Grèce, vol. 4, Paris (F. Buisson) 1801.

Chénier, André, Imitations et préludes - Art d'aimer - Élégies, 1794. Dans : Euvres poétiques, vol. 1, Orléans (Paradigme) 2005.

Chénier, André, L’Amérique, 1794. Dans : Euuvres complètes, vol. 2, Paris (Delagrave) 1910.

Chénier, André, Les Bucoliques, 1794. Dans : Euvres complètes, vol. 1, Paris (Delagrave) 1919.

Chenus, Sylvie, Comment dire, Carnières-Morlanwelz [Belgique] (Lansman) 2004.

Chepfer, George, Portraits, sketches, divers, 1945. Dans : Textes et chansons, Nancy (Presses universitaires de Nancy) / Metz (Serpenoise) 1983.

Chepfer, George, Saynètes, paysanneries 1,1922. Dans : Textes et chansons, Nancy (Presses universitaires de Nancy) / Metz (Serpenoise) 1983.

Chepfer, George, Saynètes, paysanneries 2. 1945. Dans : Textes et chansons, Nancy (Presses universitaires de Nancy) / Metz (Serpenoise) 1983.

Chevalier, Henry-Émile, La Huronne de Lorette. Dans : La Ruche littéraire, revue littéraire, Montréal, vol. 3, avril 1859.

Chevalier, Patrick, J'avais rêvé d'une république, Saint-Denis (Publibook) 2009.

Chevallier, Gabriel, Clochemerle, 1934, Paris (Librairie générale française) 1991. 
Chevallier, Gabriel, Les Héritiers Euffe, 1945, Paris (Presses universitaires de France) 1965.

Chevrier, A., Nouveau Manuel complet du maître-d'hôtel ou L'Art d'ordonner les dîners, Paris

(Encyclopédie de Roret) 1842.

Chevrier, François-Antoine, Le Colporteur : histoire morale et critique, 1761, Londres (J. Nourse) 1949.

Choderlos de Laclos, Pierre-Ambroise-François, Les Liaisons dangereuses, 1782. Dans : Euvres complètes, Paris (Gallimard) 1951.

Choisy, François-Timoléon de, Aventures de l'abbé de Choisy habillé en femme. Journal du voyage de Siam. Mémoires pour servir a la vie de M. de Voltaire, Paris (Les Amis de l'histoire) 1969.

Choisy, François-Timoléon de, Journal du voyage de Siam fait en 1685 et 1686, Paris (S. Mabre-Cramoisy) 1687.

Cholières, Nicolas de, Les Neuf Matinées, Paris (Jean Richer) 1585.

Chomel, Noël, Dictionnaire œconomique contenant divers moyens d'augmenter son bien et de conserver sa santé, 2 vols., Paris (Ganeau) ${ }^{4} 1740$.

Choquet, Charles, Les Dix Nouvelles ou Les Jeunes Personnes à leur entrée dans le monde, vol. 1, Paris (Genets jeune) 1822.

Choquette, Robert, La Pension Leblanc, Montréal-New York (Carrier) 1927.

Chorier, Nicolas, Histoire générale de Dauphiné, vol. 2, Toulouse (Jean Boude) 1665.

Choulet, Philippe et Philippe Rivière, La Bonne École, Seyssel (Champvallon) 2000.

Chrestien de Troyes (attribué), Philomena. Conte raconté d'après Ovide, 1170, éd. C. de Boer, Paris (Geuthner) 1909. DEAF : PhilomB

Chrestien de Troyes, Chanson, 1170. Dans : Eduard Mätzner, Altfranzösische Lieder, Berlin (Dümmler) 1853. DEAF : ChansMätzner

Chrestien de Troyes, Cligés [= Cligés. Chrétien de Troyes], 1176, éd. Stewart Gregory et Claude Luttrell, Cambridge (Brewer) 1993. DEAF : CligesG

Chrestien de Troyes, Erec et Enide [= Erec und Enide], 1170, éd. Wendelin Foerster, Halle (Niemeyer) 1890. DEAF : ErecF

Chrestien de Troyes, Lancelot ou Le Chevalier de la charrete [= Christian von Troyes, Der Karrenritter (Lancelot) und das Wilhelmsleben (Guillaume d'Angleterre)], 1177 [BFM : 1177-1181], éd. Wendelin Foerster, Halle (Niemeyer) 1899. DEAF : LancF

Chrestien de Troyes, Perceval ou Le Conte du Graal [= Le Roman de Perceval ou Le Conte du Graal], 1180, éd. Keith Busby, Tübingen (Niemeyer) 1993. DEAF : PercB

Chrestien de Troyes, Yvain ou Le Chevalier au lion [= Yvain (Der Löwenritter)], 1177, éd. Wendelin Foerster, Halle (Niemeyer) ${ }^{3} 1906$. DEAF : YvainF

Chrétien des Croix, Nicolas, Les Portugaiz infortunez, 1608, Genève (Droz) 1991.

Christine de Pisan [Pizan], Le Livre de l'advision Cristine, 1405, éd. Christine Reno et Liliane Dulac, Paris (Honoré Champion) 2001.

Christine de Pisan [Pizan], Le Livre des trois vertus, 1405, éd. Charity Cannon Willard, Paris (Champion) 1989. DEAF : ChrPisVertW

Christine de Pisan, Le Chemin de lonc estude [= Le Chemin de longue étude], 1402, éd. Andrea Tarnowski, Paris (Librairie générale française) 2000. DEAF : ChrPisCheminT

Christine de Pisan, Le Livre de la mutacion de fortune, 1403, éd. Suzanne Solente, 4 vols. Paris (A. et J. Picard) 1959-1966. DEAF : ChrPisMutS

Christine de Pisan, Le Livre des fais et bonnes meurs du sage roy Charles V, 1404, éd. Suzanne Solente, 2 vols., Paris (Champion) 1936. DEAF : ChrPisFaisS

Christine de Pisan, Euvres poétiques, début XVe, par Maurice Roy, 3 vols., Paris (Didot) 1886-1896. DEAF : ChrPisR

Chronique médicale, vol. 18, Paris 1911.

Cieters, Charles, La Seconde Enquête, Paris (Publibook) 2001.

Cladel, Léon, Ompdrailles, le Tombeau-des-Lutteurs, Paris (A. Cinqualbre) 1879. 
Claretie, Jules, La Canne de M. Michelet : promenades et souvenirs, Paris (L. Conquet) 1886.

Clary, François de, Philippiques, contre les bulles, et autres pratiques de la faction d'Espagne, Tours (lamet Metayer) 1592.

Claudel, Paul et André Gide, Correspondance (1899-1926) Paris (Gallimard) 1949.

Claudel, Paul, Cinq Grandes Odes, 1910. Dans : Euvre poétique, Paris (Gallimard) 1957.

Claudel, Paul, Commentaires et exégèses 4. Le Cantique des cantiques, 1948. Dans : Euvres complètes, vol. 22, Paris (Gallimard) 1963.

Claudel, Paul, Connaissance de l'Est, 1907. Dans : Euvre poétique, Paris (Gallimard) 1957.

Claudel, Paul, Corona benignitatis anni Dei, 1915. Dans : Euvre poétique, Paris (Gallimard) 1957.

Claudel, Paul, Feuilles de saints, 1925. Dans : Euvre poétique, Paris (Gallimard) 1957.

Claudel, Paul, Jeanne d'Arc au bûcher, 1939. Dans : Théâtre, vol. 2, Paris (Gallimard) 1959.

Claudel, Paul, L’Annonce faite à Marie [1 ${ }^{\text {re }}$ version], 1912. Dans : Théâtre, vol. 2, Paris (Gallimard) 1959.

Claudel, Paul, L’Annonce faite à Marie [version pour la scène], 1948. Dans : Théâtre, vol. 2, Paris (Gallimard) 1959.

Claudel, Paul, L'Échange [1' version], 1894. Dans : Théâtre, vol. 1, Paris (Gallimard) 1960.

Claudel, Paul, L'Endormie, 1883. Dans : Théâtre, vol. 1, Paris (Gallimard) 1960.

Claudel, Paul, L'Histoire de Tobie et de Sara, 1940. Dans : Théâtre, vol. 2, Paris (Gallimard) 1959.

Claudel, Paul, L'Otage, 1911. Dans : Théâtre, vol. 2, Paris (Gallimard) 1959.

Claudel, Paul, La Cantate à trois voix, 1913. Dans : CEuvre poétique, Paris (Gallimard) 1957.

Claudel, Paul, La Jeune fille Violaine [1 ${ }^{\mathrm{re}}$ version inédite de 1892]. Dans : Théâtre, vol. 1, Paris (Gallimard) 1960.

Claudel, Paul, La Lune à la recherche d'elle-même, 1949. Dans : Théâtre, vol. 2, Paris (Gallimard) 1959.

Claudel, Paul, La Ville [2 ${ }^{\mathrm{e}}$ version], 1901. Dans : Théâtre, vol. 1, Paris (Gallimard) 1960.

Claudel, Paul, Le Père humilié, 1920. Dans : Théâtre, vol. 2, Paris (Gallimard) 1959.

Claudel, Paul, Le Repos du septième jour, 1901. Dans : Théâtre, vol. 1, Paris (Gallimard) 1960.

Claudel, Paul, Le Soulier de satin [version pour la scène], 1944. Dans : Théâtre, vol. 2, Paris (Gallimard) 1959.

Claudel, Paul, Le Soulier de satin, 1929. Dans : Théâtre, vol. 2, Paris (Gallimard) 1959.

Claudel, Paul, Les Euménides [trad. ; original d’Eschyle], 1920. Dans : Théâtre, vol. 1, Paris (Gallimard) 1960.

Claudel, Paul, Poèmes de guerre, 1915. Dans : Cuvre poétique, Paris (Gallimard) 1957.

Claudel, Paul, Poésies diverses, 1952. Dans : Cuvre poétique, Paris (Gallimard) 1957.

Claudel, Paul, Un poète regarde la croix, 1938, Paris (Gallimard) 1947.

Claus, Carl, Traité de zoologie [traduit par G. Moquin-Tandon], Paris (F. Savy) 1878.

Clavel, Bernard, Celui qui voulait voir la mer, 1963. Dans : La Grande Patience, vol. 2, Paris (J'ai lu) 1996.

Clavel, Bernard, La Maison des autres, 1962. Dans : La Grande Patience, vol. 1, Paris (J'ai lu) 1993.

Clavel, Bernard, La Révolte à deux sous, Paris (Albin Michel) 1992.

Clavel, Bernard, Le Cour des vivants, 1964. Dans : La Grande Patience, vol. 3, Paris (J'ai lu) 1996.

Clavel, Bernard, Les Fruits de l'hiver, 1968. Dans : La Grande Patience, vol. 2, Paris (J'ai lu) 1996.

Clavel, Bernard, Les Grands Malheurs, Paris (Albin Michel) 2004.

Clavel, Bernard, Malataverne, 1960, Paris (J'ai lu) 1990.

Claveret, Jean, Valère Maxime. Latin-François [trad.], vol. 1, Lyon (Horace Molin) 1700.

Clébert, Jean-Paul, Clôtures. Dans : La Parisienne, mars 1956.

Clemenceau, Georges, L'Iniquité, Paris (Stock) 1899.

Clemenceau, Georges, Vers la réparation, Paris (Stock) 1899.

Cléret de Langavant, Jean, Ciments et bétons, Paris (Armand Colin) 1953. 
Cluny, Claude Michel, Un jeune homme de Venise, Paris (Gallimard) 1983.

Cochin, Charles-Nicolas, Voyage d'Italie ou Recueil de notes sur les ouvrages de peinture et de sculpture qu'on voit dans les principales villes d'Italie, Paris (Charles-Antoine Jombert) 1758.

Code civil des Français, 1804, Paris (Imprimerie de la République), An XII, 1864.

Coëffeteau, Nicolas, Histoire romaine, Paris (G. Loyson) 1646.

Cohen, Albert, Mangeclous, 1938, Paris (Gallimard) 1997.

Cohen, Albert, Solal, 1930, Paris (Gallimard) 1997.

Cohen, Jean, Eugène Aram [trad. de l'anglais ; original de Bulwer], vol. 1, Paris (H. Fournier jeune) 1832.

Colette et Willy, Claudine à Paris, 1901, Paris (Albin Michel) 1977.

Colette, Chambre d'hôtel, 1940. Dans : Chambre d'hôtel suivi de La Lune de pluie, Paris (Librairie générale française) 1990.

Colette, Chéri, Paris (Fayard) 1920.

Colette, Claudine à l'école, 1900, Paris (Albin Michel) 1929.

Colette, Gigi, 1944, Paris (Hachette) 1960.

Colette, La Lune de pluie. 1940. Dans : Chambre d'hôtel suivi de La Lune de pluie, Paris (Librairie générale française) 1990.

Colette, La Maison de Claudine, 1922, Paris (Ferenczi et fils) 1930.

Colette, La Naissance du jour, 1928, Paris (Flammarion) 1934.

Colette, La Seconde, Paris (Ferenczi et fils) 1929.

Colette, La Vagabonde, 1949, Paris (Librairie générale française / Albin Michel) 2007.

Colette, Le Képi, Paris (Fayard) 1943.

Colette, Paris, de ma fenêtre, Genève (Milieu du monde) 1944.

Colette, Sept Dialogues de bêtes, 1905, Paris (Club français du livre) 1962.

Coligny, Charles, Edmond About. Dans : L'Artiste, 1859.

Collé, Charles, Dupuis et Des Ronais, Paris (Duchesne) 1763.

Collé, Charles, La Partie de chasse de Henri IV, 1764, Paris (Veuve Duchesne) 1766.

Colletet, Guillaume, L'Art poétique 1. Traitté de l'épigramme et traitté du sonnet, 1658, Genève (Droz) / Paris (Minard) 1965.

Colletet, Guillaume, Poésies diverses contenant des sujets hérö̈ques, des passions amoureuses et d'autres matières burlesques et enjouées, Paris (L. Chamhoudry) 1656.

Collin d'Harleville, Jean-François, L'Optimiste ou L'Homme toujours content, 1788. Dans : Théâtre et poésies fugitives, vol. 1, Paris (Duminil-Lesueur) 1805.

Collin d'Harleville, Jean-François, Le Vieux Célibataire, 1792. Dans : Théâtre et poésies fugitives, vol. 2, Paris (Duminil-Lesueur) 1805.

Colloque national de géographie appliquée (Strasbourg, 20-22 Avril 1961), Paris (CNRS) 1962.

Colombié, Thierry, Beaux Voyous, Paris (Fayard) 2007.

Comptes rendus hebdomadaires des séances de l'Académie des sciences, vol. 116, Paris (GauthierVillars) 1893.

Condillac, Étienne Bonnot de, Cours d'étude pour l'instruction du prince de Parme, vol. 1 : Grammaire, 1775, Genève (Dufart) / Lyon (Bruyset) 1789.

Condillac, Étienne Bonnot de, Le Commerce et le gouvernement considérés relativement l'un à l'autre, vol. 1, Amsterdam / Paris (Jombert / Collot) 1776.

Condillac, Étienne Bonnot de, Traité des sensations, vol. 1, 1754, Londres / Paris (Barrois ainé) 1788.

Confiant, Raphaël, L'Hôtel du bon plaisir, Paris (Mercure de Fance) 2009.

Congrégation de Notre-Dame, La Cuisine raisonnée, Québec (Fides) 2003.

Constant, Benjamin, Adolphe, 1816. Dans : E Fuvres, Paris (Gallimard) 1957.

Constant, Benjamin, Journaux intimes, 1816, Paris (Gallimard) 1952.

Constant, Benjamin, Le Cahier rouge : ma vie (1767-1787), 1830, Paris (Calmann-Lévy) 1907. 
Constant, Benjamin, Principes de politique, 1815. Dans : Cours de politique constitutionnelle, vol. 1, Paris (Guillaumin) 1872.

Constant, Benjamin, Wallstein, Paris / Genève (Paschoud) 1809.

Convert, Georges, Prière quotidienne en église, Montréal / Paris (Médiaspaul) 1995.

Cooper, Fenimore, Le Corsaire rouge [trad. de l'anglais par La Bédollière]. Dans : CFuvres complètes, Paris (Gustave Barba) 1850.

Cop, Michel, Le Livre de l'ecclesiaste, sans lieu ni éditeur, 1557.

Corbière, Tristan, Les Amours jaunes, Paris (Flammarion) 1873.

Corneille, Pierre, Attila, roi des Huns, 1667. Dans : Euvres complètes, vol. 7, Paris (Hachette) 1862.

Corneille, Pierre, Cinna, 1641. Dans : CEuvres complètes, vol. 3, Paris (Hachette) 1862.

Corneille, Pierre, L'Imitation de Jésus-Christ [trad. ; original de Thomas a Kempis], 1652-1654. Dans : Euvres complètes, vol. 8, Paris (Hachette) 1862.

Corneille, Pierre, La Galerie du Palais, 1634. Dans : Euvres complètes, vol. 2, Paris (Hachette) 1862.

Corneille, Pierre, La Place royale ou L'Amoureux extravagant, 1634. Dans : CFuvres complètes, vol. 1,

Paris (Gallimard) 1980.

Corneille, Pierre, La Suite du menteur : épître, 1643. Dans : EFuvres complètes, vol. 4, Paris

(Hachette) 1862.

Corneille, Pierre, La Suivante, 1637. Dans : CEuvres complètes, vol. 1, Paris (Gallimard) 1980.

Corneille, Pierre, Le Cid, 1636 / 1637. Dans : EFuvres complètes, vol. 3, Paris (Hachette) 1862.

Corneille, Pierre, Le Menteur, 1643. Dans : Euvres complètes, vol. 4, Paris (Hachette) 1862.

Corneille, Pierre, Nicomède, 1650. Dans : CEuvres complètes, vol. 5, Paris (Hachette) 1862.

Corneille, Pierre, Edipe, 1659. Dans : CEuvres complètes, vol. 6, Paris (Hachette) 1862.

Corneille, Pierre, Othon, 1664. Dans : Euvres complètes, vol. 6, Paris (Hachette) 1862.

Corneille, Pierre, Pertharite, roi des Lombards, 1651. Dans : Euvres complètes, vol. 6, Paris

(Hachette) 1862.

Corneille, Pierre, Polyeucte, 1643. Dans : Euvres complètes, vol. 3, Paris (Hachette) 1862.

Corneille, Pierre, Pompée, 1643. Dans : Euvres complètes, vol. 4, Paris (Hachette) 1862.

Corneille, Pierre, Pulchérie, 1672. Dans : Euvres complètes, vol. 7, Paris (Hachette) 1862.

Corneille, Pierre, Rodogune, princesse des Parthes, 1644. Dans : Fuvres complètes, vol. 4, Paris (Hachette) 1862.

Corneille, Pierre, Sophonisbe, 1662. Dans : Euvres complètes, vol. 6, Paris (Hachette) 1862.

Corneille, Pierre, Suréna, général des Parthes, 1674. Dans : CEuvres complètes, vol. 7, Paris

(Hachette) 1862.

Corneille, Pierre, Théodore, vierge et martyre, 1645. Dans : CEuvres complètes, vol. 5, Paris

(Hachette) 1862.

Corneille, Pierre, Tite et Bérénice, 1670. Dans : CEuvres complètes, vol. 7, Paris (Hachette) 1862.

Corneille, Thomas, Les Metamorphoses d'Ovide mises en vers françois, Liège (Broncart) 1698.

Corneille, Thomas, Stilicon, 1660, Genève (Droz) 1974.

Cornejo, Pedro [attribution contestée], Histoire des troubles et guerres civiles du Pays-Bas, Lyon (Jean Stratius) 1584.

Cornette de Saint Cyr, Xavier, Les Secrets de la loi de l'attraction, Paris (Leduc) 2018.

Corps dominés, corps en rupture. Dans : Actuel Marx 41, Paris (Presses universitaires de France) 2007.

Corrozet, Gilles, Second Livre des fables d'Ésope, 1548, Genève / Paris (Slatkine) 1992.

Cosmos - Les Mondes, revue hebdomadaire des sciences, Paris.

Cotereau, Claude, Les Douze Livres de Lucius Junius Moderatus Columella des choses rusticques [trad.], Paris (Jaques Kerver) 1551.

Coton, Pierre, Du tres-sainct et tres-auguste sacrement, et sacrifice de la messe, Avignon (Jacques Bramereau) 1600. 
Cottin, Sophie, Mathilde, 1805. Dans : Euvres complètes, vol. 5, Paris (Rapilly) 1825.

Couailhac, Louis, Pitié pour elle, Paris (Lachappelle) 1837.

Courier, Paul-Louis, Lettres écrites de France et d'Italie, 1825. Dans : CEuvres complètes, Paris

(Gallimard) 1964.

Courier, Paul-Louis, Pamphlets politiques, 1824. Dans : E Fuvres complètes, Paris (Gallimard) 1964.

Courrier de l'art, année 1889, Paris.

Cours complet d'agriculture, Paris (Serpente) 1786.

Courteault, Henri, Mademoiselle Aissé, le chevalier d'Aydie et leur fille, Paris (Société des bibliophiles français) 1908.

Courteline, Georges, Le Train de 8 h 47, 1888, Paris (Flammarion) 1930.

Courteline, Georges, Messieurs les ronds-de-cuir : tableaux-roman de la vie de bureau, 1893, Paris (Flammarion) 1931.

Cousin, Victor, Cours de l'histoire de la philosophie. Histoire de la philosophie morale au XVIII siècle, vol. 2 : École sensualiste : Locke, Paris (Pichon / Didier) 1829.

Crasset, Jean, Histoire de l'Église du Japon, vol. 2, Paris (Montalant) 1715.

Crawford, Francis Marion, La Marchesa Carantoni, Paris (Dentu) 1887.

Crémer, Stéphane, Comme un charme, Paris (Denoël) 2006.

Créquy, Charles-Marie de, Mémoires pour servir à la vie de Nicolas de Catinat, maréchal de France, Paris (Veuve Duchesne) 1775.

Crevel, René, Babylone, 1927, Paris (Pauvert) 1991.

Crevel, René, Êtes-vous fous ?, 1929, Paris (Gallimard) 1991.

Crevel, René, La Mort difficile, 1926, Paris (Pauvert) 1974.

Crevel, René, Le Roman cassé, 1935, Paris (Pauvert) 1989.

Crevel, René, Les Pieds dans le plat, 1933, Paris (Pauvert) 1974.

Crevel, René, Mon corps et moi, Paris (Sagittaire) 1925.

Crommelinck, Constant, Rapport sur les hospices d'aliénés de l'Angleterre, de la France et de l'Allemagne..., Courtrai (Jaspin) 1842.

Cros, Charles, Le Coffret de santal, 1873. Dans : CEuvres complètes, Paris (Club des libraires de France) 1964.

Cros, Léonard, Vie intime de Saint Louis, Roi de France, Toulouse (Adolphe Regnauld) 1872.

Cros, Pierre, Les Bijoutiers du roc des perles, Saint-Just-près-Brioude (Créer) 1992.

Croteau, Marie-Danielle, Un pas dans l'éternité, Montréal (La Courte Échelle) 2005.

Cusset, Catherine, New York, journal d'un cycle, Paris (Mercure de France) 2011.

Cuvier, Frédéric, Dictionnaire des sciences naturelles, vol. 2, Paris / Strasbourg (Levrault) 1816.

Cuvier, Georges, Le Règne animal : Introduction, vol. 1. Dans : Le Règne animal, 4 vols., Paris (Deterville) 1817.

Cuvier, Georges, Leçons d'anatomie comparée, vol. 1, Paris (Crochard, Fontin et Baudouin) An XIV, 1805.

Cuvier, Georges, Sur les ossements fossiles d'hyènes. Dans : Annales du Muséum d'histoire naturelle 6, Paris (Levrault / Schoell) 1805.

Cyrano de Bergerac, Savinien, Les Estats et empires de la lune, 1655. Dans : E Fuvres libertines, vol. 1, Paris (Champion) 1921.

Cyrano de Bergerac, Savinien, Les Lettres. Dans : Euvres libertines, vol. 2, Paris (Champion) 1922.

D. L., Théophile [possible pseudonyme de Jean-François Le Petit], Histoire des troubles et guerres civiles du Pays-Bas, sans lieu ni éditeur, 1582.

D.F.D.L., Sieur, La Méchanceté des femmes, Paris (Joseph Guerreau) 1619.

Dabit, Eugène, La Zone verte, Paris (Gallimard) 1935.

Dacier, Anne, Des causes de la corruption du goust, Paris (Rigaud) 1714.

Dacier, Émile, La Gravure française, Paris (Larousse) 1944. 
Dacier, Léonard, Liondacier, Paris (Société des écrivains) 2012.

Dahm-Stoltz, Caractères musicaux et généraux, Paris (Pensée universelle) 1984.

Daillé, Jean, Sermons, Genève (de Tournes) 1664.

Dalechamps, Jacques, Chirurgie françoise, 1588, Paris (0. de Varennes) 1610.

Damas, Geneviève, Molly à vélo, Manage [Belgique] (Lansman) 2004.

Dancourt, Florent Carton dit, Le Prix de l'arquebuse, 1717. Dans : La Fête de village (1700), Le

Vert-Galant (1714), Le Prix de l'arquebuse (1717), Paris (Nizet) 1989.

Dancourt, Florent Carton dit, Les Eaux de Bourbon, 1696. Dans : La Maison de campagne (1688), La Foire Saint-Germain (1696), Les Eaux de Bourbon (1696), Paris (Nizet) 1985.

Dancourt, L. H. Jacquot et Colas duellistes, Paris (Cailleau) 1783.

Dangeau, Philippe de Courcillon, marquis de, Journal (1684-1686), vol. 1, Paris (F. Didot), 1854.

Dangeau, Philippe de Courcillon, marquis de, Journal (1699-1700), vol. 7, Paris (F. Didot), 1856.

Dangeau, Philippe de Courcillon, marquis de, Journal (1709-1711), vol. 13, Paris (F. Didot), 1858.

Dangeau, Philippe de Courcillon, marquis de, Journal (1711-1713), vol. 14, Paris (F. Didot), 1858.

Dangel, Stéphane, Storytelling. Le guide, Levens (Du désir) 2010.

Daniel, le père Gabriel, Voiage du monde de Descartes, Paris (Veuve S. Benard) 1690.

Daniel-Rops, L'Ombre de la douleur, Paris (Plon) 1941.

Daniel-Rops, Mort, où est ta victoire ?, Paris (Plon) 1934.

Daninos, Pierre, Snobissimo ou Le Désir de paraître, Paris (Hachette) 1964.

Dariot, Claude, Trois Discours de la preparation des medicamens, Lyon (Antoine de Harsy) 1589.

Darrodes de Lillebonne, La Clovisiade, Paris (Béthune) 1828.

Daudet, Alphonse, Aventures prodigieuses de Tartarin de Tarascon, 1872. Dans : Euvres complètes illustrées, vol. 4, Paris (Librairie de France) 1930.

Daudet, Alphonse, Contes du lundi, 1876. Dans : Euvres complètes illustrées, vol. 4-2, Paris (Librairie de France) 1930.

Daudet, Alphonse, Fromont jeune et Risler aîné, 1874. Dans : EFuvres, vol. 1, Paris (Gallimard) 1986.

Daudet, Alphonse, L’Arlésienne, 1872. Dans : CEuvres complètes illustrées, vol. 19, Paris (Librairie de France) 1930.

Daudet, Alphonse, L'Immortel, 1888. Dans : EFuvres, vol. 3, Paris (Gallimard) 1994.

Daudet, Alphonse, La Petite Paroisse, 1894. Dans : Euvres complètes illustrées, vol. 15, Paris (Librairie de France) 1930.

Daudet, Alphonse, Le Nabab, 1877. Dans : Euvres, vol. 2, Paris (Gallimard) 1990.

Daudet, Alphonse, Le Petit Chose, 1880. Dans : CEuvres, vol. 1, Paris (Gallimard) 1986.

Daudet, Alphonse, Les Morticoles, Paris (Charpentier / Fasquelle) 1894.

Daudet, Alphonse, Lettres de mon moulin, 1879, Paris (Gallimard) 1984.

Daudet, Alphonse, Numa Roumestan, 1881. Dans : Euvres, vol. 3, Paris (Gallimard) 1994.

Daudet, Alphonse, Sapho, 1884. Dans : Euvres, vol. 3, Paris (Gallimard) 1994.

Daudet, Alphonse, Soutien de famille, 1897. Dans : Euvres complètes illustrées, vol. 16, Paris (Librairie de France) 1929.

Daudet, Alphonse, Tartarin sur les Alpes, 1886. Dans : EFuvres, vol. 3, Paris (Gallimard) 1994.

Daudet, Ernest, Les Coulisses de la société parisienne, Paris (Ollendorff) 1895.

Daudet, Léon, Bréviaire du journalisme, Paris (Gallimard) 1936.

Daudet, Léon, Écrivains et artistes, 8 vols., Paris (Capitole) 1928.

De Kock, Paul, Un jeune homme charmant, vol. 3, Bruxelles (Mary-Müller) 1840.

Debruyne, Isabelle et Thierry Verspecht, Les Abus sexuels expliqués aux enfants, Liège (Chambre de commerce et d'industrie) 2003.

Defoe, Daniel, Vie et aventures de Robinson Crusoé [trad. de Pétrus Borel], 1836, Paris (Flammarion) 1989.

Degaudenzi, Jean-Louis, Zone, Paris (Fixot) 1987. 
Degret, Claude, Clothilde de Waterberry, Paris (Le Manuscrit) 2008.

Deimier, Pierre de, L'Académie de l'art poétique, où sont vivement esclaircis et déduicts les moyens par où l'on peut parvenir a la vraye et parfaite connoissance de la poésie françoise, Paris (J. de Bordeaulx) 1610.

Del Bono, Anaïs et Maréchal Guillaume, Le Financement participatif culturel, www.librinova.com (Librinova) 2016.

Del Castillo, Michel, La Nuit du décret, 1981, Paris (Seuil) 1996.

Delafond, Onésime, Traité sur la maladie de poitrine du gros bétail, Paris (Labé) 1844.

Delandine de Saint-Esprit, Jérôme, Histoire de l'Empire (1804-1814), Paris (Mallet) 1843.

Delannoy, Philippe, Cyril Collard: l'ange noir, Monaco (Éditions du rocher) 1995.

Delassein, Sophie, Les Dimanches de Louveciennes : chez Hélène et Pierre Lazareff, Paris (Grasset) 2009.

Delattre, Louis, Carnets d'un médecin de village, Bruxelles (Dechenne) 1910.

Delaume, Chloé, Le Cri du sablier, 2001, Paris (Gallimard) 2010.

Delavigne, Casimir, Les Enfants d'Édouard, 1833. Dans : E Euvres complètes : Théâtre, vol. 3, Paris (Didier) 1854.

Delavigne, Casimir, Louis XI, Paris (Barba) 1832.

Delay, Florence, Le Aïe aïe de la corne de brume, 1975, Paris (Gallimard) 1984.

Delbo, Charlotte, Auschwitz et après III : Mesure de nos jours, 1971, Paris (Minuit) 2006.

Delbrun, Pierre, Le Dictionnaire du p. Pierre Delbrun de la Compagnie de Jesus, Alby (François Patron) 1664.

Delécluze, Étienne-Jean, Journal (1824-1828), Paris (Grasset) 1948.

Delécluze, Étienne-Jean, Précis d'un traité de peinture, Paris (L’Encyclopédie portative) 1828.

Deleuse, Robert, Un dernier coup de théâtre, Paris (Le Cherche Midi) 2012.

Delevoy, Camille, Une veillée. Dans : Revue du nord, vol. 5, 1835-1836.

Delille, Jacques, Les Jardins ou L'Art d'embellir les paysages, Paris (Rheims, Valade et Cazin) 1782.

Delivré, François, Le Pouvoir de négocier : s'affronter sans violence, Paris (InterEditions) 1994.

Delluc, Louis, L'Homme des bars, Bègles (Le Castor astral) 1991.

Delma, Ernst, Lasselle : la négresse au yeux berceurs d'amour, porteurs d'espoir, sans lieu (Trafford on Demand Pub) 2003.

Denis Foulechat, Le Policratique de Jean de Salisbury [trad. du latin], 1372, Livre IV. Dans : Charles Brucker, Tyrans, princes et prêtres, Montréal (CERES) 1987. DEAF : DenFoulB ${ }^{3}$

Dennery et Cormon, La Journée d'une jolie femme, Paris (Théâtre du Vaudeville) 1842.

Déon, Michel, La Carotte et le bâton, 1960, Paris (Gallimard) 1988.

Déon, Michel, Le Balcon de Spetsai, 1961, Paris (Gallimard) 1987.

Derennes, Charles, Cassinou va-t-en guerre, Paris (Édition française illustrée) 1917.

Déroulède, Paul, Chants du paysan, Paris (Calmann-Lévy) 1894.

Derrida, Jacques, L'Écriture et la différence, 1967, Paris (Seuil) 1979.

Des deux bordeors ribauz, $2^{\mathrm{e}}$ moitié xIII ${ }^{\mathrm{e}}$. Dans : Recueil général et complet des fabliaux des XIII' et $X I v^{e}$ siècles, vol. 1. DEAF : DeuxBordeors ${ }^{1} \mathrm{M}$

Des Forêts, Louis-René, Ostinato, 1997, Paris (Gallimard) 2006.

Des Houlières, Antoinette, Épîtres, 1694. Dans : Euvres choisies, Paris (Librairie des bibliophiles) 1882.

Des Masures, Louis, David combattant, 1566. Dans : Tragédies saintes : David combattant, David triomphant, David fugitif, Paris (E. Cornély) 1907.

Des Masures, Louis, David fugitif, 1566. Dans : Tragédies saintes : David combattant, David triomphant, David fugitif, Paris (E. Cornély) 1907.

Des Périers, Bonaventure, L'Andrie, 1555. Dans : Euuvres françoises, vol. 1, éd. Louis Lacour, Paris (P. Jannet) 1856. 
Des Périers, Bonaventure, Les Nouvelles Récréations et joyeux devis de feu Bonaventure des Périers, vol. 1 (1558), vol. 2 (1568). Dans : Conteurs français du XvI ${ }^{e}$ siècle, Paris (Gallimard) 1965.

Des Rues, François, Les Fleurs du bien-dire, Paris (Mathieu Guillemot) 1603.

Desbordes-Valmore, Marceline, Élégies, 1833-1859. Dans : Euuvres complètes, vol. 2, Genève (Slatkine) 1972.

Desbordes-Valmore, Marceline, đuuvres poétiques, 1833. Dans : Euvres complètes, vol. 1, Paris (Lemerre) 1886.

Descartes, René, Discours de la méthode, 1637. Dans : Discours de la méthode ; plus La Dioptrique ; Les Météores et la géométrie qui sont des essais de cette méthode, Paris (Fayard) 1987.

Descaves, Lucien, Sous-offs, Paris (Tresse / Stock) 1890.

Descombes, René, Chevaux et gens de l'eau : sur les chemins de halage, sans lieu (Cheminements) 2007.

Description des machines et procédés consignés dans les brevets d'invention, Ministère de l'agriculture, vol. 88, Paris (Bouchard-Huzard) 1857.

Description des machines et procédés, Ministère du commerce, vol. 7, Paris (Imprimerie nationale) 1876.

Desjardins, Louise, Le Fils du Che, Montréal (Boréal) 2008.

Deslys, Charles, La Marchande de plaisirs, Paris (Degorce-Cadot) 1850.

Desmarest, Nicolas, Encyclopédie méthodique : géographie-physique, vol. 3, Paris (H. Agasse) 1809.

Desmaze, Charles, La Magistrature française : les premiers présidents de la cour de Paris

(1802-1889), 1889, Paris (collection @XIX) 2016.

Desnos, Robert, Le Vin est tiré..., 1943, Paris (Gallimard) 1992.

Desnos, Robert, Mines de rien, 1940, Mazères (Le Temps qu'il fait) 1989.

Desnoyers, Louis, La Grande Famille de ce bon Monsieur Tartuffe. Dans : Babel, revue de la Société des gens de lettres de France, Paris, 1810.

Desonay, Fernand, Villon, Paris (Droz) 1933.

Despois, Jean et René Raynal, Géographie de l'Afrique du Nord-Ouest, Paris (Payot) 1967.

Desportes, Philippe, Euvres, 1596, Paris (Delahays) 1858.

Destouches, Philippe, L'Envieux, 1727, Paris (Prault) 1758.

Destouches, Philippe, L'Ingrat, 1712, Paris (Prault) 1758.

Destouches, Philippe, L'Irrésolu, 1713, Paris (Prault) 1758.

Destouches, Philippe, Le Curieux impertinent, 1710, Paris (Prault) 1758.

Destouches, Philippe, Le Dissipateur ou L'Honneste Friponne, 1736. Dans : Euvres dramatiques, vol. 3, Paris (Imprimerie royale) 1757.

Destouches, Philippe, Le Glorieux, 1732, Paris (Librairie des bibliophiles) 1884.

Destouches, Philippe, Le Mari confident, 1754, Paris (Prault) 1758.

Destouches, Philippe, Le Philosophe marié, 1727, Paris (Prault) 1758.

Destouches, Philippe, Les Philosophes amoureux, 1730, Paris (Prault) 1758.

Destutt de Tracy, Antoine-Louis-Claude, Commentaire sur L'Esprit des lois de Montesquieu, 1807, Paris (Didot) 1819.

Desvignes, Lucette, Les Nœuds d'argile, Dijon (Civry) 1982.

Devallan, Claude, Le Défi d'un Breton, Saint-Denis (Publibook) 2012.

Deville, Patrick, Peste et choléra, Paris (Seuil) 2012.

Devos, Bruno, La Face cachée de l'Opus Dei, Paris (Presses de la Renaissance) 2009.

Deyeux, Théophile, La Chassomanie, Paris (Imprimeurs unis) 1844.

Dhôtel, André, Campements, 1930, Paris (Gallimard) 1987.

Dhôtel, André, La Vie passagère, Paris (Phébus) 1978.

Dhôtel, André, Le Ciel du faubourg, 1956, Paris (Grasset) 1988.

Dhôtel, André, Le Pays où l'on n'arrive jamais, 1955, Paris (J'ai lu) 1992. 
Dhôtel, André, Le Village pathétique, 1943, Paris (Gallimard) 1974.

Di Grazia, Guillaume, Orage et désespoirs, Paris (Mareuil) 2020.

Diaf, Philippe, Les Lueurs de l'âme, Saint-Denis (Mon petit éditeur) 2014.

Dickens, Charles, Le Magasin d'antiquités [trad. par A. Des Essarts), vol. 2, Paris (Hachette) 1857.

Dickens, Charles, Vie et aventures de Nicolas Nickleby [trad. par P. Lorain], vol. 5, Paris (Hachette) 1889.

Dictionaire [sic] abrégé des sciences médicales, vol. 6, Paris (Panckoucke) 1822.

Dictionnaire de l'Académie française, Nîmes (Beaume) 41786.

Dictionnaire de l'Académie française, Paris (Didot) ${ }^{7} 1835$.

Dictionnaire de théologie catholique, A. Vacant et E. Mangenot (éds.), vol. 4, Paris (Letouzey et Ané) 1920.

Dictionnaire du bas-langage ou des manières de parler usitées par le peuple, vol. 2, Paris (Haussmann, D’Hautel et Schoell) 1808.

Dictionnaire universel françois et latin, 3 vols., Trévoux (Estienne Ganeau) 1704.

Diderot, Denis, Addition aux pensées philosophiques, 1770. Dans : Euvres complètes, vol. 1, Paris (Garnier) 1875.

Diderot, Denis, De la poésie dramatique, 1758. Dans : CEuvres esthétiques, Paris (Garnier) 1966.

Diderot, Denis, Encyclopédie ou Dictionnaire raisonné des sciences, des arts et des métiers, vol. 12, Neufchastel (Samuel Faulche) 1765.

Diderot, Denis, Encyclopédie ou Dictionnaire raisonné des sciences, des arts et des métiers, vol. 7, Paris (Briasson, David, Le Breton et Durand) 1757.

Diderot, Denis, Entretien d'un père avec ses enfants ou Du danger de se mettre au-dessus des lois, 1784. Dans : Euvres philosophiques, Paris (Garnier) 1956.

Diderot, Denis, Entretiens sur Le Fils naturel, 1757. Dans : Euvres esthétiques, Paris (Garnier) 1966.

Diderot, Denis, Essai sur la vie de Sénèque le philosophe, sur ses écrits, et sur les règnes de Claude et de Néron, 1778. Dans : Euurres, vol. 7: Sénèque, Paris (Frères De Bure) 1779.

Diderot, Denis, Essai sur le mérite et la vertu ou Principes de la philosophie morale [trad.; original de Shaftesbury], 1745. Dans : Euvres complètes, vol. 1, Paris (Garnier) 1875.

Diderot, Denis, Jacques le Fataliste et son maître, 1784. Dans : E Fuvres romanesques, Paris (Garnier) 1965.

Diderot, Denis, La Religieuse, 1784, Paris (Armand Colin) 1961.

Diderot, Denis, Le Neveu de Rameau, 1779, Genève (Droz) 1950.

Diderot, Denis, Le Père de famille, 1758. Dans : Euuvres complètes, vol. 7, Paris (Garnier) 1875.

Diderot, Denis, Les Bijoux indiscrets, 1748. Dans : Euvres romanesques, Paris (Garnier) 1965.

Diderot, Denis, Lettres à Sophie Volland, vol. 1 (1759-23 sept. 1762), Paris (Gallimard) 1950.

Diderot, Denis, Lettres à Sophie Volland, vol. 2 (26 sept. 1762-1774), Paris (Gallimard) 1950.

Diderot, Denis, Pensées détachées sur la peinture, la sculpture, l'architecture et la poésie, 1798.

Dans : Euvres complètes : Beaux-Arts III : Arts du dessin. Musique, Paris (Garnier) 1876.

Diderot, Denis, Réfutation suivie de l'ouvrage d'Helvétius intitulé L'Homme, 1774. Dans : Fuvres complètes, vol. 2, Paris (Garnier) 1875.

Diderot, Denis, Salon de 1767, 1768, Oxford (Clarendon Press) 1963.

Diderot, Denis, Salons : Greuze, 1761. Dans : Euvres choisies de Diderot, vol. 2, Paris (Firmin Didot) 1862.

Diderot, Denis, Supplément au voyage de Bougainville, 1784, Genève (Droz) / Lille (Giard) 1955.

Didon, Henri, Les Allemands, Paris (Calmann Lévy) 1884.

Dierx, Léon, Les Lèvres closes, 1867. Dans : Poésies complètes, vol. 1, Paris (Lemerre) 1889.

Dierx, Léon, Poèmes et poésies, 1864. Dans : Poésies complètes, vol. 1, Paris (Lemerre) 1889.

Discret, L. C., Alizon, Paris (J. Guignard) 1637, Exeter (University of Exeter) 1972.

Djebaïli, Rachid, La Racaille, Besançon (Aurès) 2006. 
Djian, Philippe, 37² le matin, 1985, Paris (J'ai lu) 1989.

Dodart, Denis, Mémoire sur les causes de la voix de l'homme et ses differens tons. Dans: Histoire de l'Académie royale des sciences, Paris (Jean Boudot) 1703.

Dodoens, Rembert, Histoire des plantes, Anvers (Jean Loë) 1557.

Döllinger, Johann Joseph Ignaz von, Paganisme et judaïsme [trad. de l'allemand par J. de P.], vol. 3, Bruxelles (Goemaere) 1858.

Dolto, Françoise, La Cause des enfants, 1985, Paris (Laffont) 1995.

Dom-Bougre aux États-Généraux ou Doléances du portier des Chartreux, par l'auteur de la Foutromanie, Foutropolis (Bracquemart, rue Tire-vit, à la Couille d'or) [source fictive] 1792.

Domenach-Lallich, Denise, Demain il fera beau : journal d'une adolescente (novembre 1939-1944), Lyon (Bga Permezel) 2001.

Doon de Mayence, milieu XIII', éd. Alexandre Pey, Paris (Vieweg) 1859. DEAF : DoonMayP

Dorat, Claude-Joseph, Les Sacrifices de l'amour ou Lettres de la vicomtesse de Senanges et du chevalier de Versenai, 1771. Dans : Collection complète des œuvres, vol. 2, Neuchâtel (Société typographique) 1775.

Dorgelès, Roland, Les Croix de bois, Paris (Albin Michel) 1919.

Dorin, Françoise, Les Vendanges tardives, Paris (Plon) 1997.

Dorival, Bernard, Les Peintres du xx siècle, Paris (Tisne) 1957.

Dormann, Geneviève, La Petite Main, Paris (Albin Michel) 1993.

Doubrovsky, Serge, Le Livre brisé, 1989, Paris (Grasset) 2011.

Doubrovsky, Serge, Un homme de passage, Paris (Grasset) 2011.

Drieu la Rochelle, Pierre, Rêveuse Bourgeoisie, 1937, Paris (Gallimard) 1960.

Droguet, Henri, Off, Paris (Gallimard) 2007.

Droit, Michel, Le Retour, Paris (Julliard) 1964.

Drouin, Véronique, La Chatière, Montréal (Québec Amérique) 2011.

Druon, Maurice, Les Grandes Familles, 1948, Monaco (Imprimerie nationale) 1952.

Du Bartas, Guillaume de Saluste, La Sepmaine ou Creation du monde, 1578, sans lieu (Jacques Chouet) 1583.

Du Bellay, Joachim, Les Regrets, 1558, Genève (Droz) 1966.

Du Bos, Charles, Byron et le besoin de la fatalité, 1929, Paris (Buchet-Chastel Correa) 1957.

Du Bos, Charles, Journal (1926-1927), vol. 3, Paris (Correa) 1949.

Du Bos, Charles, Journal (1928), vol. 4, Paris (Correa) 1950.

Du Camp, Maxime, En Hollande : lettres à un ami, Paris (Poulet-Malassis / de Broise) 1859.

Du Camp, Maxime, Le Nil. Égypte et Nubie, 1854, Paris (Hachette) ${ }^{4} 1877$.

Du Camp, Maxime, Mémoires d'un suicidé, 1853, Paris (Librairie nouvelle) 1855.

Du Cerceau, Jean-Antoine, Poësies diverses, Paris (Jaques Estienne) 1726.

Du Chevalier au barisel, début XIII ${ }^{e}$. Dans : Oskar Schultz-Gora, Zwei altfranzösische Dichtungen : La Chastelaine de Saint Gille. Du Chevalier au barisel, Halle (Niemeyer) ${ }^{41919 . ~ D E A F ~: ~ C h e v B a r A n S ~}$ Dans : ChastSGilS

Du Chevalier qui ooit la messe et Nostre Dame estoit pour lui au tournoiement, 1250. Dans : Karl Bartsch, Chrestomathie de l'ancien français, pièce 59.

Du Coudray, Alexandre-Jacques, le chevalier, Le Luxe. Poëme en six chants, Paris (Monory) 1773.

Du Crest, Stéphanie-Félicité, comtesse de Genlis, Adèle et Théodore, Paris (M. Lambert) 1782.

Du Crest, Stéphanie-Félicité, comtesse de Genlis, L'Enfant gâté, 1779. Dans : Théâtre du xVIII' siècle, vol. 2, Paris (Gallimard) 1974.

Du Fail, Noël, Les Baliverneries d'Eutrapel, 1548. Dans : Conteurs français du xvI siècle, Paris (Gallimard) 1965.

Du Fail, Noël, Les Propos rustiques de maistre Leon Ladulfi, Champenois, 1547. Dans : Conteurs français du xvI ${ }^{e}$ siècle, Paris (Gallimard) 1965. 
Du Halde, Jean-Baptiste, Description géographique, historique, chronologique, politique et physique de l'Empire de la Chine et de la Tartarie chinoise, vol. 2, Paris (Lemercier) 1735.

Du Hausset, Madame, Mémoires de Madame Du Hausset, femme de chambre de Madame de Pompadour (1762-1782), Paris (Didot) 1867.

Du Lorens, Jacques, Premières Satires, 1624, Paris (Librairie des bibliophiles) 1881.

Du Lorens, Jacques, Satires, 1646, Paris (D. Jouaust) 1869.

Du Marsais, César, Des tropes ou Des diférens sens dans lesquels on peut prendre un même mot dans une même langue, Paris (Veuve Brocas) 1730.

Du Moulin, Gabriel, Histoire générale de Normandie, Rouen (J. Osmont) 1631.

Du Ryer, P., Les Décades de Tite-Live [trad.], Lyon (sans éditeur) 1695.

Du Ryer, Pierre, Les Vendanges de Suresne, 1636, Rome (Bulzoni / Società universitaria per gli studi di lingua e letteratura francese) 1980.

Du Verdier, Antoine, Les Images des dieux des anciens [trad. de l'italien ; original de Vincent Cartari], Tournon (Claude Michel) 1606.

Du Verdier, Antoine, Prosopographie ou Description des hommes illustres, vol. 2, Lyon (Paul Frelon) 1605.

Dubois, Jacques, Naissance du roman policier. Dans : Actes de la recherche en sciences sociales 60, 1985.

Dubois, Jean Gérard, Gaste-Papier, songe malice et brouille-mémoire du temps qui passe, sans lieu (L.A.U.) 1999.

Dubois, Urbain et Émile Bernard, La Cuisine classique, Paris (Chez les auteurs) 1856.

Dubos, Jean-Baptiste, Histoire critique de l'établissement de la monarchie françoise dans les Gaules, vol. 1, 1734, Paris (Nyon fils) 1742.

Dubos, Jean-Baptiste, Réflexions critiques sur la poésie et la peinture, vol. 1, Paris (P.-J. Mariette) 1733.

Dubut de Laforest, Jean-Louis, L'Homme de joie: mœurs parisiennes et étrangères, sans lieu (Collection (C XIX) 2015.

Duché, Jean, L'Histoire de France racontée à Juliette, Paris (Amiot-Dumont) 1955.

Duchein, Michel, Les Derniers Stuarts (1660-1807), Paris (Fayard) 2006.

Duclos, Charles Pinot, Acajou et Zirphile, 1744. Dans : Le Cabinet des fées, vol. 35, Genève (Barde, Manget et Cie) / Paris (Cuchet) 1786.

Duclos, Charles, Considérations sur les mœurs de ce siècle, Amsterdam (Aux depens de la Compagnie) 1751.

Duclos, Charles, Histoire de Louis XI, Paris (Guérin Frères) 1745.

Dudek, Arnaud, Un sang d'encre, Paris (Le Manuscrit) 1982.

Duff, Micheline, Les Méandres du destin, vol. 2. Dans : Au bout de l'exil, Montréal (Québec Amérique) 2010.

Duff, Micheline, Paysages éclatés, vol. 2. Dans : Pour les sans-voix, Montréal (Québec Amérique) 2012.

Dufour, Hortense, La fille du saulnier, Paris (Grasset) 1992.

Dufresny, Charles, La Coquette de village ou Le Lot supposé, 1715. Dans : Théâtre du XvIII siècle, vol. 1, (Gallimard) 1972.

Dufresny, Charles, Mercure galant, La Haye (Johnson) 1712.

Dugué, Charles Oscar, Essais poétiques, Nouvelle-Orléans (Fortier) 1847.

Duhamel, Georges, Chronique des Pasquier. Cécile parmi nous, vol. 7, 1938, Paris (Mercure de France) 1949.

Duhamel, Georges, Chronique des Pasquier. La Nuit de la Saint-Jean, vol. 4, 1935, Paris (Mercure de France) 1948. 
Duhamel, Georges, Chronique des Pasquier. La Passion de Joseph Pasquier, vol. 10, 1945, Paris (Mercure de France) 1949.

Duhamel, Georges, Chronique des Pasquier. Le Désert de Bièvres, vol. 5, 1937, Paris (Mercure de France) 1948.

Duhamel, Georges, Chronique des Pasquier. Le Notaire du Havre, vol. 1, 1933, Paris (Mercure de France) 1948.

Duhamel, Georges, Chronique des Pasquier. Les Maîtres, vol. 6, 1937, Paris (Mercure de France) 1948.

Duhamel, Georges, Chronique des Pasquier. Suzanne et les jeunes hommes, vol. 9, 1941, Paris (Mercure de France) 1949.

Duhamel, Georges, Chronique des Pasquier. Vue de la terre promise, vol. 3, 1934, Paris (Mercure de France) 1948.

Duhamel, Georges, La Confession de minuit, 1920, Paris (Mercure de France) 1950.

Dulaurens, Henri-Joseph, Le Compère Mathieu ou Les Bigarrures de l'esprit humain, vol. 1, 1766, Paris (Chez les marchands de nouveautés [R. Riga]) 1831.

Dumas fils, Alexandre, Ah quel conte ! Conte politique et astronomique, 1751. Dans : Collection complète des œuvres, vol. 4, Londres / Francfort (Varrentrapp) 1779.

Dumas fils, Alexandre, L'Écumoire ou Tanzaï et Néadarmé : histoire japonoise, 1734. Dans : Collection complète des œuvres, vol. 2, Londres / Francfort (Varrentrapp) 1779.

Dumas fils, Alexandre, L'Étrangère, 1876, Paris (Calmann-Lévy) 1885.

Dumas fils, Alexandre, La Dame aux camélias, 1848, Paris (Calmann-Lévy) 1931.

Dumas fils, Alexandre, Le Demi-monde, 1835, Paris (Michel Lévy) 1855.

Dumas fils, Alexandre, Le Hazard du coin du feu, 1763, Bruxelles (Ch. Gilliet) 1880.

Dumas fils, Alexandre, Le Sopha, 1742, Bruxelles (Gilliet) 1881.

Dumas fils, Alexandre, Les Égaremens du cour et de l'esprit, 1738. Dans : Romanciers du XVIII siècle, vol. 2, Paris (Gallimard) 1965.

Dumas fils, Alexandre, Lettres athéniennes extraites du porte-feuille d'Alcibiade, vol. 1, Paris (Delalain) 1771.

Dumas père, Alexandre, Le Capitaine Pamphile, 1839, Lausanne (L'Âge d'homme) 1978.

Dumas père, Alexandre, Le Comte de Monte-Christo, 1846, Paris (Garnier) 1956.

Dumas père, Alexandre, Le Vicomte de Bragelonne ou Dix Ans plus tard, 1847-1850. Dans : Fuvres complètes, vol. 4, Paris (Michel Lévy) 1874.

Dumas père, Alexandre, Les Trois Mousquetaires, 1844, Paris (Gallimard) 1996.

Dumesnil, René, Histoire illustrée du théâtre lyrique, Paris (Plon) 1953.

Dumestre, Gérard et Seydou Touré, Maléfices et manigances, Paris (Karthala) 2007.

Dumont, Luc, Trente-deux / dix. Dans : Trente-deux / dix, Barman's land, Carnières-Morlanwelz

[Belgique] (Lansman) 2004.

Dunant, Sarah, Un cœur insoumis, Paris (Belfond) 2010.

Duneton, Claude, La Chienne de ma vie, Paris (Buchet / Chastel) 2007.

Dupanloup, Félix Mgr, Instruction de réglements de monseigneur l'évêque d'Orléans relatifs aux études ecclésiastiques de son diocèse, Orléans (Imprimerie Alphonse Gatineau) 1855.

Dupanloup, Félix Mgr, Journal intime, 1876, Paris (Ch. Douniol) 1902.

Duperey, Annie, Le Rêve de ma mère, Paris (Seuil) 2017.

Dupleix, Scipion, La Logique ou L'Art de discourir et raisonner, 1607, Paris (Fayard) 1984.

Duplessis, Paul, Un monde inconnu, vol. 1, sans lieu (Librorium) 2019.

Duplessy, Virginie, La Mère parfaite a pris cher !, Paris (Opportun) 2019.

Dupont, Georges, Le Bois carburant. Dans : La Distillation du bois, Paris (Gauthier-Villars) 1941.

Dupont, Marcel, Fragilité. Dans : Revue des deux mondes, $1^{\text {er }}$ novembre 1922.

Dupuis, Charles, Abrégé de l'origine de tous les cultes, 1796, Paris (H. Agasse) An VI, 1798. 
Dupuy, Marie-Bernadette, Le Rossignol de Val-Jabert, vol. 2. Dans : L'Orpheline des neiges, Paris

(Calmann-Lévy) 2011.

Dupuy-Demportes, Jean-Baptiste, Le Gentilhomme cultivateur [trad. ; original de M. Hale], 4 vols., Paris (P. G. Simon) / Bordeaux (Chapuis l'Aîné) 1761-1764.

Durand, Charles, Les Grandes Industries minérales en Lorraine (sel, soude et fer), Nancy (A. Nicolle) 1893.

Durand, Frédérik, Comme un goût d'aurore sur une idée fixe, Québec (Vents d'ouest) 2008.

Durand, Thomas C., Mont de Dieux !, Angers (Thomas C. Durand) 2005.

Duranty, Louis, Le Malheur d'Henriette Gérard, 1860, Paris (Gallimard) 1942.

Duras, Claire, Édouard, 1824. Dans : Ourika, suivi de Édouard, Paris (Stock) 1950.

Duras, Marguerite, Cahiers de la guerre et autres textes, 1996, Paris (P.O.L.) 2006.

Duras, Marguerite, Hiroshima mon amour, 1960, Paris (Gallimard) 1994.

Duras, Marguerite, L'Amant, 1984, Paris (Minuit) 1993.

Duras, Marguerite, La Douleur, 1985, Paris (Gallimard) 1993.

Duras, Marguerite, Les Impudents, 1946, Paris (Gallimard) 1996.

Duras, Marguerite, Un barrage contre le Pacifique, 1950, Paris (Gallimard) 1994.

Duret, Jean, Traicté des peines et amendes, tant pour les matières criminèles que civiles, Lyon (B.

Rigaud) 1573.

Durkheim, Émile, De la division du travail social, 1893, Paris (Alcan) 1911.

Dutoit, Marie, Mon Jura ... et le monde. Comtesse Agénor de Gasparin, Genève (Naville) 1930.

Dutourd, Jean, Pluche ou L'Amour de l'art, Paris (Flammarion) 1967.

Duverney, Joseph-Guichard, Euvres anatomiques de M. Duverney, vol. 2, Paris (Jombert) 1761.

Duvernois, Henri, Edgar, Paris (Flammarion) 1919.

Duvignaud, Jean, L’Or de la République, 1957, Paris (Gallimard) 1984.

Écarnot, Le Médecin de village. Dans : Les Français peints par eux-mêmes, vol. 1.6 : Province, Paris

(L. Curmer) 1841.

Echenoz, Jean, Jérôme Lindon, Paris (Minuit) 2001.

Echenoz, Jean, L'Équipée malaise, 1986, Paris (Minuit) 1999.

Echenoz, Jean, Lac, Paris (Minuit) 1989.

Économie et humanisme, Lyon.

Edmond, Charles, Souvenirs d'un dépaysé, 1862, (Edmond Desurvire) 2013.

Egen, Jean, Les Tilleuls de Lautenbach, 1979, Paris (Stock) 1996.

Elias, Sol, Tête de tambour, Paris (Rivages) 2019.

Elie de Saint Gille, fin XII', éd. Gaston Raynaud, Paris (Firmin Didot) 1879. DEAF : ElieR

Elisseeff, Danielle, Les Dames du Soleil-Levant : Japonaises d'hier et d'aujourd'hui, Paris (Stock) 1992.

Éluard, Paul et André Breton, L'Immaculée Conception, 1930. Dans : Euuvres complètes de Paul Éluard, vol. 1, Paris (Gallimard) 1990.

Éluard, Paul, Capitale de la douleur, 1926. Dans : Euvres complètes, vol. 1, Paris (Gallimard) 1990.

Éluard, Paul, Hommages, 1950. Dans : EFuvres complètes, vol. 2, Paris (Gallimard) 1990.

Éluard, Paul, La Dernière Nuit, 1942. Dans : EFuvres complètes, vol. 1, Paris (Gallimard) 1990.

Éluard, Paul, Le Livre Ouvert 2 (1939-1941), 1942. Dans : Euvres complètes, vol. 1, Paris (Gallimard) 1990.

Éluard, Paul, Les Nécessités de la vie et les conséquences des rêves précédé d'exemples, 1921. Dans : Euvres complètes, vol. 1, Paris (Gallimard) 1990.

Éluard, Paul, Les Sentiers et les routes de la poésie, 1952. Dans : Euuvres complètes, vol. 2, Paris (Gallimard) 1990.

Éluard, Paul, Les Sept Poèmes d'amour en guerre, 1943. Dans : Euvres complètes, vol. 1, Paris (Gallimard) 1990. 
Éluard, Paul, Poèmes retrouvés, préfaces, prières d'insérer (1908-1966). Dans : CEuvres complètes, vol. 2, Paris (Gallimard) 1990.

Éluard, Paul, Poésie et vérité, 1942. Dans : EEuvres complètes, vol. 1, Paris (Gallimard) 1990.

Éluard, Paul, Poésie ininterrompue 2, 1953. Dans : Euvres complètes, vol. 1, Paris (Gallimard) 1990.

Éluard, Paul, Premiers Poèmes, 1913. Dans : Euvres complètes, vol. 1, Paris (Gallimard) 1990.

Éluard, Paul, Une leçon de morale, 1950. Dans : Euvres complètes, vol. 2, Paris (Gallimard) 1990.

Embareck, Michel, La Mort fait mal, Paris (Gallimard) 2000.

Embareck, Michel, Sur la ligne blanche, Paris (Autrement) 1984.

Emery, Sieur d', Nouveau Recueil de secrets et curiositez, Amsterdam (Pierre Mortier) ${ }^{5} 1697$.

Encyclopédie chimique, éd. Edmond Frémy, Paris (Dunod) 1894.

Encyclopédie médicale Quillet. Nouvelle Encyclopédie pratique de médecine et d'hygiène, vol. 1, Paris (A. Quillet) 1965.

Encyclopédie œeconomique ou Système général d'œconomie rustique, vol. 13, Yverdon, 1771.

Encyclopédie pratique de l'éducation en France, Paris (Institut pédagogique national / S.E.D.E.) 1960.

Encyclopédie théologique, vol. 12-2, Paris (Migne) 1863.

Encylopédiana. Recueil d'anecdotes anciennes, modernes et contemporaines, Paris (Jules Laisné) 1856.

Eneas, 1160 [BFM : 1155], éd. Jean-Jacques Salverda de Grave, 2 vols., Paris (Champion) 1925 et 1929. DEAF : EneasS² [cité d'après BFM ; les variantes sont citées d'après l'édition imprimée]

Ennery, Adolphe d' et François Pinel Dumanoir, La Case de l'oncle Tom, Paris (Michel Lévy) 1853.

Épinay, Louise Tardieu d'Esclavelles, marquise d', Les Conversations d'Émile, 1774, vol. 1, Paris (Belin) 1788.

Erckmann, Émile et Alexandre Chatrian, Histoire d'un paysan (1789-1815), 1870. Dans : Contes et romans nationaux et populaires, Paris (Pauvert) 1962.

Erckmann, Émile et Alexandre Chatrian, L'Ami Fritz, 1864. Dans : Contes et romans nationaux et populaires, Paris (Pauvert) 1962.

Erckmann, Émile et Alexandre Chatrian, Le Blocus, New York (Henry Holt) 1886.

Erckmann, Émile et Alexandre Chatrian, Le Conscrit de 1813, 1864. Dans : Contes et romans nationaux et populaires, Paris (Pauvert) 1962.

Ernaux, Annie, Ce qu'ils disent ou rien, 1977, Paris (Gallimard) 1989.

Ernaux, Annie, La Place, 1983, Paris (Gallimard) 1996.

Ernaux, Annie, Les Années, Paris (Gallimard) 2008.

Ernaux, Annie, Se perdre, Paris (Gallimard) 2001.

Escoffier, Auguste, Le Guide culinaire, Paris (Art culinaire) 1903.

Escudero, Xavier, La Bohème littéraire espagnole de la fin du xIXe au début du xxe siècle, Saint-Denis (Publibook) 2008.

Estampe, Jean-Claude, Nosfératus, Paris (Publibook) 2005.

Estaunié, Édouard, L'Ascension de M. Baslèvre, 1919, Paris (Perrin) 1923.

Estaunié, Édouard, L'Empreinte, 1896, Paris (Perrin) 1923.

Esternod, Claude d', L'Espadon satyrique, 1619, Paris (J. Fort) 1922.

Estienne, Charles, L'Agriculture et maison rustique, Paris (Jaques du Puis) 1564.

Estienne, Charles, Paradoxes, 1561, Genève (Droz) 1998.

Estrade, M. d', Mémoires de Milady Worthon [trad. de l'anglais], Londres (C. Wikthon) 1767.

Etcherelli, Claire, Élise ou La Vraie Vie, Paris (Denoël) 1967.

Étiemble, Hygiène des lettres : poètes ou faiseurs? (1936-1966), Paris (Gallimard) 1966.

Étiemble, René, Blason d'un corps, Paris (Gallimard) 1961.

Étrennes lyriques, anacréontiques, pour l'année 1782, Paris (chez l'auteur) 1782. 
Étude de prévalence des maladies sexuellement transmissibles et des infections à VIH au Burkina Faso : rapport final, Ministère de la santé publique, Burkina Faso, 1995.

Eustache Deschamps, Le Miroir de mariage, 1385. Dans : Euvres complètes, vol. 9, éd. Gaston

Raynaud, Paris (Firmin Didot) 1896. DEAF : DeschQ

Fabre, Émile, La Rabouilleuse. Dans : idem, Théâtre, Paris (Flammarion) 1920.

Fabrice, Friedrich Ernst von, Anecdotes du séjour du roi de Suède à Bender, Hambourg (C. Herold) 1761.

Fallet, René, Banlieue sud-est, Paris (Domat) 1947.

Fallet, René, Carnets de jeunesse 2 (9 août 1947 - 2 août 1948), 1948, Paris (Denoël) 1992.

Fallet, René, La Grande Ceinture, Paris (Denoël) 1956.

Fallet, René, Le Triporteur, 1951, Paris (Gallimard) 1983.

Fanon, Frantz, Les Damnés de la terre, 1961, Paris (Gallimard) 1999.

Faral, Edmond, La Vie quotidienne au temps de saint Louis, Paris (Hachette) 1942.

Faret, Nicolas, L'Honneste Homme ou L'Art de plaire à la cour, 1636, Paris (Presses universitaires de France) 1925.

Fargue, Léon-Paul, Le Piéton de Paris, 1939, Paris (Gallimard) 1950.

Farrère, Claude, L'Homme qui assassina, 1907, Paris (Flammarion) 1924.

Farrère, Claude, Les Hommes nouveaux, Paris (Flammarion) 1922.

Faucher-King, Florence, Les Habits verts de la politique, Paris (Presses de sciences po) 1999.

Fauchet, Claude, Déclin de la maison de Charlemagne, faisant la suitte des Antiquitez françoises contenant les faicts de Charles le Chauve et ses successeurs, depuis l'an 840 jusques à l'an 987, Paris (J. Périer) 1602.

Fauchet, Claude, Fleur de la maison de Charlemaigne, qui est la continuation des Antiquitez françoises contenant les faits de Pepin et ses successeurs, depuis l'an 751 jusques à l'an 840 de Jesus-Christ, Paris (J. Périer) 1601.

Fauchet, Claude, Euvres, Paris (Leclerc et Heuqueville) 1610.

Fauqemberg, David, Bluff, Paris (Stock) 2018.

Faure, Élie, Histoire de l'art : l'art antique, 1909. Dans : EFuvres complètes, vol. 1, Paris (Club des libraires) 1964.

Faure, Élie, Histoire de l'art : l'art médiéval, 1912. Dans : Euvres complètes, vol. 1, Paris (Club des libraires) 1964.

Faure, Élie, Histoire de l'art : l'art moderne, 1921. Dans : Euvres complètes, vol. 2, Paris (Club des libraires) 1964.

Faure, Élie, L'Esprit des formes, 1927, Paris (Club des libraires) 1957.

Favart, Charles-Simon, Les Trois Sultanes ou Soliman II, 1762. Dans : Théâtre choisi, vol. 3, Paris (L. Collin) 1809.

Favières, André, Le Manchot obsédé, Lyon (Jacquier) 1954.

Favre, L[ouis], André le graveur, Musée neuchâtelois, vol. 9, Neuchâtel (Wolfrath et Metzner) 1872. Favre, Louis, André le graveur, Lausanne (Bibliothèque universelle) / Neuchâtel (Jules Sandoz) 1875. Fayol, Jean-Baptiste, L'Harmonie celeste, Paris (Jean d'Houry et al.) 1672.

Febvre, Lucien, Combats pour l'histoire, 1952, Paris (A. Colin) 1953.

Fellous, Colette, Avenue de France, 2001, Paris (Gallimard) 2008.

Fénelon, François de, Dialogues des morts composés pour l'éducation d'un prince, 1715, Paris (F. Didot / J. Didot) 1819.

Fénelon, François de, Examen de conscience sur les devoirs de la royauté, 1702. Dans : Lettres à Louis XIV, Neuchâtel (Ides et calendes) 1961.

Fénelon, François de, Les Aventures de Télémaque, 1699, Paris (Hachette) 1920.

Fénelon, François de, Lettre à l'Académie, 1715, Genève (Droz) 1970.

Fénelon, François de, Traité de l'éducation des filles, 1687, Paris (Ch. Delagrave) 1883. 
Fénelon, François de, Traité de l'existence et des attributs de Dieu, 1713. Dans : CFuvres, vol. 1, Versailles (J.-A. Lebel) 1820.

Fenolliet, Pierre, Oraison funebre sur le trespas de hault, puissant et illustre messire Pompone de Believre, Paris (Rolin Thiery) 1607.

Feray, Yveline, Contes d'une grand-mère tibétaine, Arles (Philippe Picquier) 2012.

Ferdinand, Marie Ange [pseudonyme Aylic Langlé] et Raymond Deslandes, La Jeunesse de Mirabeau, Paris (É. Dentu) 1864.

Fetjaine, Jean-Louis, Le Pas de Merlin, Paris (Belfond) 2010.

Feuille religieuse du Canton de Vaud, Lausanne (Feuille religieuse) 1867.

Féval, Paul, La Bande Cadet, vol. 1: Une évasion et un contrat, Paris (É. Dentu) 1875.

Féval, Paul, Les Étapes d'une conversion, vol. 3, Paris / Bruxelles (Société générale de librarie [sic] catholique) 1880.

Féval, Paul, Les Mystères de Londres ou Les Gentilshommes de la nuit, Bruxelles (J.-A. Lelong) 1849.

Féval, Paul, CEuvres, 1887 (= date de la mort), sans lieu (Ici-ebooks, Classicompilé nº 77) version 5.1, 2020.

Féval, Paul, Pierre Blot [préface]. Dans : Revue du monde catholique, Paris (Société genérale de librairie catholique) 1877.

Feydeau, Georges, La Dame de chez Maxim, Paris (La Petite Illustration) 1914.

Fiefmelin, André Mage, seigneur de, L'Image d'un mage ou Le Spirituel, Poictiers (Pelican) 1601.

Fierabras [Fierabras (K)], 1300, manuscrit A, éd. A. Kroeber / G. Servois, Paris (Vieweg) 1860. DEAF : FierK

Fierabras [Fierabras (L)], 1190, éd. Marc Le Person, Paris (Honoré Champion) 2003. DEAF : FierL Figaro magazine, Paris.

Figueras, André, Traité de balayage, Paris (A. Figueras) 1985.

Filhoud-Lavergne, Guy, Marrakech, ville impériale, et le grand Sud marocain, sans lieu (Éditions Horvath) 1984.

Filippetti, Aurélie, Les Derniers Jours de la classe ouvrière, Paris (Stock) 2003.

Flacourt, Étienne de, Histoire de la grande isle Madagascar, vol. 1, Paris (François Clovzier) 1661. Flaubert, Gustave, Bouvard et Pécuchet, 1881, 2 vols., Paris (Les Belles-Lettres) 1945.

Flaubert, Gustave, Correspondance (1830-1839), Paris (L. Conard) 1926-1954.

Flaubert, Gustave, Correspondance (1840-1845), Paris (L. Conard) 1926-1954.

Flaubert, Gustave, Correspondance (1846), 1847, Paris (L. Conard) 1926-1954.

Flaubert, Gustave, Correspondance (1848-1850), 1850. Dans : Correspondance, Paris (L. Conard) 1926.

Flaubert, Gustave, Correspondance (1851 - juillet 1852). Dans : Correspondance, Paris (L. Conard) 1926.

Flaubert, Gustave, Correspondance (juillet-décembre 1852). Dans : Correspondance, Paris (L. Conard) 1927.

Flaubert, Gustave, Correspondance (1853). Dans : Correspondance, Paris (L. Conard) 1927.

Flaubert, Gustave, Correspondance (1854-1857). Dans : Correspondance, Paris (L. Conard) 1927.

Flaubert, Gustave, Correspondance (1858-1860). Dans : Correspondance, Paris (L. Conard) 1927.

Flaubert, Gustave, Correspondance (1862-1865). Dans : Correspondance, Paris (L. Conard) 1929.

Flaubert, Gustave, Correspondance (1866-1868). Dans : Correspondance, Paris (L. Conard) 1929.

Flaubert, Gustave, Correspondance (1871-1872). Dans : Correspondance, Paris (L. Conard) 1930.

Flaubert, Gustave, Correspondance (1875-1876). Dans : Correspondance, Paris (L. Conard) 1930.

Flaubert, Gustave, Correspondance (1877-1878). Dans : Correspondance, Paris (L. Conard) 1930.

Flaubert, Gustave, Correspondance (1879 - février 1880). Dans : Correspondance, Paris (L. Conard) 1930. 
Flaubert, Gustave, Correspondance : supplément (1848-1850). Dans : Correspondance, Paris (L. Conard) 1954.

Flaubert, Gustave, Correspondance : supplément (1851-1852). Dans : Correspondance, Paris (L. Conard) 1954.

Flaubert, Gustave, Correspondance : supplément (1858-1860). Dans : Correspondance, Paris (L. Conard) 1954.

Flaubert, Gustave, Correspondance : supplément (1864-1865). Dans : Correspondance, Paris (L. Conard) 1954.

Flaubert, Gustave, Correspondance : supplément (1866-1868). Dans : Correspondance, Paris (L. Conard) 1954.

Flaubert, Gustave, Correspondance : supplément (1879-1880). Dans : Correspondance, Paris (L. Conard) 1954.

Flaubert, Gustave, L'Éducation Sentimentale, 1869. Dans : CEuvres complètes, Paris (Belles lettres) 1942.

Flaubert, Gustave, La Première Éducation sentimentale, 1845, Paris (Seuil) 1963.

Flaubert, Gustave, La Tentation de saint Antoine [version de 1849]. Dans : EFuvres complètes, Paris (L. Conard) 1910.

Flaubert, Gustave, La Tentation de saint Antoine [version de 1856]. Dans : F Fuvres complètes, Paris (L. Conard) 1910.

Flaubert, Gustave, La Tentation de saint Antoine, 1874. Dans : Euvres complètes, Paris (L. Conard) 1910.

Flaubert, Gustave, Madame Bovary, 1857. Dans : Cuvres complètes, Paris (Belles lettres) 1945.

Flaubert, Gustave, Notes de voyages, 2 vols., Paris (Belles lettres) 1851.

Flaubert, Gustave, Par les champs et par les grèves : Touraine et Bretagne, 1848. Dans : Voyages, Paris (Belles lettres) 1948.

Flaubert, Gustave, Smarh, 1839. Dans : Euvres de jeunesse inédites, vol. 2, Paris (Conard) 1910.

Flaubert, Gustave, Trois Contes : Un cœur simple, La Légende de saint Julien l'Hospitalier, Hérodias, 1877, Paris (Garnier Frères) 1960.

Fléchier, Valentin-Esprit, Mémoires sur les Grands-Jours d'Auvergne en 1665, 1710, Paris (Hachette) 1862.

Flers, Robert de et Gaston Arman de Caillavet, Monsieur Brotonneau, 1914, Paris (La Petite Illustration) 1923.

Fleury, Georges, Pyrrhus, Lesko et les autres, Paris (Grasset) 1991.

Floovant, fin XII', éd. Sven Andolf, Uppsala (Almqvist et Wiksell) 1941. DEAF : FloovA

Flore et Blancheflor, 1160, éd. Wilhelmine Wirtz, Frankfurt (Diesterweg) 1937. DEAF : FloreAW

Flore, Jeanne, Contes amoureux, 1537, Lyon (CNRS / Presses Universitaires de Lyon) 1980.

Florian, Jean-Pierre, Estelle, Paris (Imprimerie de monsieur) 1788.

Florian, Jean-Pierre, Fables, Paris (Didot) 1792.

Florian, Jean-Pierre, Galatée, 1783, Paris (Renouard) 1820.

Florian, Jean-Pierre, Numa Pompilius, Paris (Didot ainé) 1786.

Floriant et Florete, 1275, éd. Annie Combes et Richard Trachsler, Paris (Honoré Champion) 2003. DEAF : FloriantC

Foa, Eugénie, Le Livre de la jeunesse, Paris (Amédée Bédelet) ${ }^{3} 1864$.

Foch, Ferdinand [Maréchal Foch], Des principes de la guerre, 1911, Paris (Berger-Levrault) 1918.

Foch, Ferdinand [Maréchal Foch], Mémoires pour servir à l'histoire de la guerre de 1914-1918, vol. 1, 1929, Paris (Plon) 1931.

Foigny, Gabriel de, La Terre australe connue, 1676. Dans : F. Lachevre, Les Successeurs de Cyrano de Bergerac, Paris (Champion) 1922.

Folco, Michel, Même le mal se fait bien, Paris (Stock) 2008. 
Fontenelle, Bernard de, Digression sur les anciens et les modernes, 1688. Dans : Entretiens sur la pluralité des mondes, Oxford (Clarendon Press) 1955.

Fontenelle, Bernard de, Discours sur la nature de l'églogue, 1688. Dans : Poésies pastorales, Paris (M. Brunet) 1698.

Fonvielle, Bernard, Mémoires historiques, Paris (Boucher) 1824.

Forlani, Remo, Gouttière, 1989, Paris (Gallimard) 1992.

Fortin, François, Les Ruses innocentes dans lesquelles se voit comment on prend les oyseaux passagers..., Paris (Charles de Sercy) 1688.

Foucault, Michel, Folie et déraison. Histoire de la folie à l'âge classique, 1961, Paris (Plon) 1964.

Foucault, Michel, Les Mots et les choses, Paris (Gallimard) 1966.

Fouéré-Macé, Mathurin Émile, Le Prieuré royal de Saint-Magloire de Lehon, vol. 30, Rennes (Hyacinthe Caillière) 1892.

Fougeret de Monbron, Jean-Louis, Le Cosmopolite ou Le Citoyen du monde, 1750, Londres (sans éditeur) 1753.

Fouke [Foulques] le Fitz Waryn, début xIv ${ }^{e}$. Dans : Nouvelles françoises en prose du xIV siècle. DEAF : FoukeM

Fourier, Charles, Le Nouveau Monde industriel ou L'Agriculture combinée, Paris (Bossange) 1830.

Fournel, Paul, Anquetil tout seul, Paris (Seuil) 2012.

Fragment d'un poème dévot, 1200. Dans : Karl Bartsch, Chrestomathie de l'ancien français, pièce 16.

France, Anatole, Crainquebille, Putois, Riquet, 1904. Dans : Euvres complètes, vol. 14, Paris (Calmann-Lévy) 1928.

France, Anatole, L'T̂le des pingouins, 1908. Dans : Euvres complètes, vol. 18, Paris (Calmann-Lévy) 1929.

France, Anatole, L'Orme du mail, 1897. Dans : Euvres complètes, vol. 11, Paris (Calmann-Lévy) 1927. France, Anatole, La Vie en fleur, 1922. Dans : Euvres complètes, vol. 23, Paris (Calmann-Lévy) 1932.

France, Anatole, Le Crime de Sylvestre Bonnard, 1881. Dans : Euvres complètes, vol. 2, Paris (Calmann-Lévy) 1925.

France, Anatole, Le Jardin d'Épicure, Paris (Calmann-Lévy) 1895.

France, Anatole, Le Lys rouge, 1894. Dans : Euvres complètes, vol. 9, Paris (Calmann-Lévy) 1927.

France, Anatole, Le Petit Pierre, 1918. Dans : Euvres complètes, vol. 23, Paris (Calmann-Lévy) 1932.

France, Anatole, Les Dieux ont soif, 1912. Dans : Euvres complètes, vol. 20, Paris (Calmann-Lévy) 1931.

Francillon, Clarisse, Les Gens du passage, Paris (Pierre Horay) 1959.

François de Sales, saint, Introduction à la vie dévote, 1619. Dans : Euvres de saint François de Sales, vol. 3, Annecy (J. Niera) 1893.

Frapié, Léon, La Maternelle, 1904, Paris (Albin Michel) 1934.

Frémy, Arnould, Les Gens mal élevés, Paris (Michel Lévy) 1868.

Frété, Valentin, Torfa et le Roi des sables, vol. 2, Fiquefleur-Équainville (Palacios) 2014.

Frié, Jacqueline Frédéric, Transparences, Paris (Desclée de Brouwer) 2000.

Fromentin, Eugène, Dominique, 1863, Paris (Garnier) 1961.

Fromentin, Eugène, Un été dans le Sahara, 1874, Paris (Plon) 1877.

Fromentin, Eugène, Voyage en Égypte, 1869, Paris (Aubier) 1935.

Frontenac, Yvette, La Soupe des autres, Paris (De Borée) 2006.

Fulcanelli, Les Demeures philosophales et le symbolisme hermétique dans ses rapports avec l'art sacré et l'ésotérisme du grand œuvre, vol. 1, 1929, Paris (Pauvert) 1965.

Furetière, Antoine, Dictionaire [sic] universel, La Haye / Rotterdam (Arnout / Reinier Leers) 1690.

Fustel de Coulanges, Numa-Denis, La Cité antique, Paris (Durand) 1864.

Gaboriau, Émile, Les Comédiennes adorées, Paris (É. Dentu) 1873. 
Gaïx, Coraly de, Correspondance et œuvres publiées avec notes, 1825, Paris (H. Champion) 1912. Gal, Stéphane, Histoires verticales : les usages politiques et culturels de la montagne (XIV $-X V I I I^{e}$ siècles), Ceyzérieu (Champ Vallon) 2018.

Galiani, Ferdinando, Dialogues sur le commerce des bleds, Londres (sans éditeur) 1770.

Galland, Antoine, Les Mille et une nuits [trad.], 1715, Paris (Garnier) 1988.

Garasse, François, La Doctrine curieuse des beaux-esprits de ce temps, Paris (S. Chappelet) 1623. Garat, Anne-Marie, Dans la main du diable, 2006, Arles (Actes Sud) / Montréal (Leméac) 2010. Garat, Anne-Marie, L'Enfant des ténèbres, Arles (Actes Sud) 2008.

Garat, Anne-Marie, Le Grand Nord-Ouest, Arles (Actes Sud) 2018.

Garat, Anne-Marie, Les Mal Famées, Arles (Actes Sud) 2000.

Garat, Anne-Marie, Une faim de loup : lecture du Petit Chaperon rouge, Arles (Actes Sud) 2004. Garcin, Étienne, Le Nouveau Dictionnaire provençal-français, Marseille (Veuve Roche) 1823.

Garin le Loherain [= Garin le Loherenc], $4^{\mathrm{e}}$ quart XII ${ }^{\mathrm{e}}$, éd. Anne Iker-Gittleman, 3 vols., Paris

(Champion) 1996-1997. DEAF : GarLorrl

Garnier, Francis, Voyage d'exploration de l'Indo-Chine, 1868, Genève (Olizane) 2009.

Garnier, Robert, Antigone ou La Pietié, 1580. Dans : Les Tragédies.

Garnier, Robert, Bradamante, 1582. Dans : Les Tragédies.

Garnier, Robert, Cornélie, 1574. Dans : Les Tragédies.

Garnier, Robert, Hippolyte, 1573. Dans : Les Tragédies.

Garnier, Robert, La Troade, 1579. Dans : Les Tragédies.

Garnier, Robert, Les Juifves, 1583. Dans : Les Tragédies.

Garnier, Robert, Les Tragédies, 4 vols., éd. Wendelin Foerster, Heilbronn (Henninger) 1882.

Garot, Alain, L'Eau d'épine, Garches (Keraban) 2009.

Garsault, François Alexandre Pierre de, Le Nouveau Parfait Maréchal ou La Connoissance generale et universelle du cheval, Paris (Poilly) 1746.

Gary, Romain, Gros-Câlin, 1974, Paris (Gallimard) 1999.

Gary, Romain, La Promesse de l'aube, 1960, Paris (Gallimard) 1996.

Gary, Romain, La Vie devant soi : roman par Émile Ajar, 1975, Paris (Gallimard) 1992.

Gasparin, Agénor de, La Famille, vol. 2, Paris (Michel Lévy) 1865.

Gaston, Delphine, Nos 500 expressions populaires préférées, éd. Carine Girac-Marinier, Paris (Larousse) 2013.

Gaston Phébus, Livre de chasse, 1389, éd. Gunnar Tilander, Karlshamn (Johansson) 1971. DEAF : GastPhébChasseT

Gaulle, Charles de, Discours et messages, vol. 2 : Dans l'attente (1946-1958), Paris (Plon) 1970.

Gaulle, Charles de, Discours et messages, vol. 3 : Avec le renouveau (1958-1962), Paris (Plon) 1970.

Gaulle, Charles de, Mémoires de guerre, vol. 2: L'Unité (1942-1944), Paris (Plon) 1956.

Gaulle, Charles de, Mémoires de guerre, vol. 3 : Le Salut (1944-1946), Paris (Plon) 1959.

Gaulle, Charles de, CFuvres, vol. 1 : La Discorde chez l'ennemi (1924). Le Fil de l'épée (1932), Paris (Club français des bibliophiles) 1963.

Gault, François, Le Japon au jour le jour, Paris (Plon) 1998.

Gautier d'Arras, Ille et Galeron [= Walter von Arras, Ille und Galeron], 1175, éd. Wendelin Foerster, Halle (Niemeyer) 1891. DEAF : GautArrlllF [= manuscrit P (de Paris). Le manuscrit W de Lord Middleton a été publié par Frederik Cowper (DEAF : GaultArrlllC). Nous en mentionnons les variantes pertinentes].

Gautier de Coincy, De deus freres, Perron et Estene, 1218. Dans : Miracles [de] Nostre Dame [= Les miracles de Nostre Dame par Gautier de Coinci], éd. V. Frédéric Koenig, vol. 4, Genève (Droz) 1970. DEAF : Coincyl1...K

Gautier fils, Théophile, Aventures du baron de Münchhausen [trad.], Paris (Furne) 1862. 
Gautier le Leu, La Veuve, milieu XIII'. Dans: Recueil général et complet des fabliaux des XIII' et XIV siècles, vol. 2.

Gautier, Théophile, Avatar, 1856. Dans : La Morte amoureuse, Paris (Gallimard) 1992.

Gautier, Théophile, La Morte amoureuse, 1836, Paris (Gallimard) 1992.

Gautier, Théophile, Le Capitaine Fracasse, 1863, Paris (Garnier) 1961.

Gautier, Théophile, Le Roman de la momie, 1858 Paris (Garnier) 1955.

Gautier, Théophile, Mademoiselle de Maupin, 1836, Paris (Garnier-Flammarion) 1973.

Gautier, Théophile, Voyage en Espagne, 1843, Paris (Gallimard) 1981.

Gavalda, Anna, Ceux qui savent comprendront, Paris (Le Dilettante) 2000.

Gavalda, Anna, Ensemble, c'est tout, 2004, Paris (Le Dilettante) 2011.

Gavalda, Anna, La Consolante, Paris (Le Dilettante) 2008.

Gazette des Beaux-arts, Paris.

Gazette obstétricale, Paris (Berger-Levrault).

Gelli, Giovanni Battista, Les Discours fantastiques de Justin Tonnelier [trad. de l'italien par Claude de Kerquifinen], Lyon (La Salemandre) 1566.

Genet, Jean, Le Balcon, 1962, Paris (Gallimard) 1991.

Genet, Jean, Les Bonnes, 1959, Paris (Gallimard) 1995.

Genet, Jean, Les Paravents, 1961, Paris (Gallimard) 1991.

Genet, Jean, Miracle de la rose, 1947, Décines (L’Arbalète) 1993.

Genet, Jean, Notre-Dame-des-fleurs, 1948, Décines (L'Arbalète) 1986.

Genet, Jean, Poèmes, 1948, Décines (L’Arbalète) 1962.

Genette, Gérard, Bardadrac, Paris (Seuil) 2006.

Genève, Max, Le Roman, Paris (Barrault) 1986.

Genevoix, Maurice, Bernard, Paris (Flammarion) 1938.

Genevoix, Maurice, Ceux de 14, 1950, Paris (Flammarion) 1983.

Genevoix, Maurice, Eva Charlebois, 1944. Dans : Je verrai, si tu veux, les pays de la neige, Paris

(Flammarion) 1979.

Genevoix, Maurice, Fatou Cissé, 1954, Paris (Flammarion) 1966.

Genevoix, Maurice, La Boîte à pêche, 1926, Paris (Grasset) 1989.

Genevoix, Maurice, La Dernière Harde, 1938, Paris (Flammarion) 1984.

Genevoix, Maurice, Laframboise et Bellehumeur, 1942. Dans : Je verrai, si tu veux, les pays de la neige, Paris (Flammarion) 1979.

Genevoix, Maurice, Le Couguar de Tonquin Valley, 1942. Dans : Je verrai, si tu veux, les pays de la neige, Paris (Flammarion) 1979.

Genevoix, Maurice, Le Lac fou, 1942. Dans : Je verrai, si tu veux, les pays de la neige, Paris (Flammarion) 1979.

Genevoix, Maurice, Le Nid du condor, 1942. Dans : Je verrai, si tu veux, les pays de la neige, Paris (Flammarion) 1979.

Genevoix, Maurice, Les Mains vides, 1928, Paris (Seuil) 1993.

Genevoix, Maurice, Match à Vancouver, 1942. Dans : Laframboise et Bellehumeur, Paris

(Flammarion) 1959.

Genevoix, Maurice, Raboliot, 1925, Paris (Grasset) 1949.

Genevoix, Maurice, Routes de l'aventure, 1959, Paris (Plon) 1980.

Genevoix, Maurice, Rroû, 1931, Paris (Flammarion) 1992.

Genevoix, Maurice, Trente Mille Jours, Paris (Seuil) 1980.

Geoffroi de Villehardouin, Conquête de Constantinople, avant 1209 [BFM : entre 1199 et 1213], éd.

Edmond Faral, 2 vols., Paris (Belles lettres) 1961. DEAF : VillehF [cité d'après BFM]

Georges Chastellain, Chronique : les fragments du livre IV, $4^{\mathrm{e}}$ quart xve éd. Jean-Claude Delclos, Genève (Droz) 1991. DEAF : ChastellLD 
Georges Chastellain, Exposition sur vérité mal prise, 1460, éd. Jean Alexandre Buchon, Paris

(Desrez) 1837.

Georges Chastellain, Euvres, $3^{e}$ quart xve éd. Kervyn de Lettenhove, 8 vols., Bruxelles (Heussner) 1863-1866. DEAF : ChastellK

Georges, Gérard, Les Chemins d'améthyste, Paris (Presses de la Cité) 2010.

Gérard, Philippe-Louis, Le Comte de Valmont ou Les Égaremens de la raison, 1775, Paris (Moutard) 1787.

Gerbault, Alain, Seul à travers l'Atlantique, Paris (Grasset) 1924.

Germain, José et Stéphane Faye, Le Nouveau Monde français : Maroc, Algérie, Tunisie, Paris

(Plon-Nourrit) 1924.

Germain, Sylvie, Jours de colère, 1989, Paris (Gallimard) 1998.

Germain, Sylvie, La Pleurante des rues de Prague, 1992, Paris (Gallimard) 1994.

Gerrard, Paul, Catch-catch party, Paris (Presses de la Cité) 1960.

Gervereau, Laurent, L'Homme planétaire, gerveau.com, 2010.

Gerzan, François de, L'Histoire afriquaine de Cleomede et de Sophonisbe, Paris (Pierre Rocolet) 1628.

Gibeau, Yves, Allons z'enfants, Paris (Calmann-Lévy) 1952.

Gide, André et Paul Valéry, Correspondance (1890-1942), Paris (Gallimard) 1955.

Gide, André, Ainsi soit-il ou Les Jeux sont faits, 1951. Dans : Journal, vol. 2, Paris (Gallimard) 1960.

Gide, André, Carnets d'Égypte, 1939. Dans : Journal, vol. 2, Paris (Gallimard) 1960.

Gide, André, Geneviève ou La Confidence inachevée, 1936. Dans : Romans, Paris (Gallimard) 1961.

Gide, André, Isabelle, 1911. Dans : Romans, Paris (Gallimard) 1961.

Gide, André, Journal : 1889-1939. Dans : Journal, vol. 1, Paris (Gallimard) 1960.

Gide, André, Journal : 1939-1949. Dans : Journal, vol. 2, Paris (Gallimard) 1960.

Gide, André, L'École des femmes, 1929. Dans : Romans, Paris (Gallimard) 1961.

Gide, André, Le Retour de l'enfant prodigue, 1907. Dans : Romans, Paris (Gallimard) 1961.

Gide, André, Le Retour du Tchad, 1928. Dans : Journal, vol. 2, Paris (Gallimard) 1960.

Gide, André, Le Voyage d'Urien, 1893. Dans : Romans, Paris (Gallimard) 1961.

Gide, André, Les Caves du Vatican, 1914. Dans : Romans, Paris (Gallimard) 1961.

Gide, André, Les Faux-Monnayeurs, 1925. Dans : Romans, Paris (Gallimard) 1961.

Gide, André, Les Nourritures terrestres, 1897. Dans : Romans, Paris (Gallimard) 1961.

Gide, André, Paludes, 1895. Dans : Romans, Paris (Gallimard) 1961.

Gide, André, Saül, 1903. Dans : Euvres complètes, vol. 2, Paris (Gallimard) 1933.

Gide, André, Si le grain ne meurt, 1924. Dans : Journal, vol. 2, Paris (Gallimard) 1960.

Gide, André, Souvenirs de la Cour d'assises, 1913. Dans : Journal, vol. 2, Paris (Gallimard) 1960.

Gide, André, Typhon, 1918, Paris (Gallimard) 2000.

Gide, André, Voyage au Congo, 1927. Dans : Journal, vol. 2, Paris (Gallimard) 1960.

Giesbert, Franz-Olivier, L'Affreux, 1992, Paris (Gallimard) 2008.

Gilles Le Bouvier, Le Livre de la description des pays, 1451, Paris (Leroux) 1908. [cité d'après

Frantext]

Gillet, Louis, Sur les pas de saint François d'Assise. Dans : Revue des deux mondes, 15 août 1922.

Giono, Jean, Batailles dans la montagne, 1937. Dans : Euvres romanesques complètes, Paris

(Gallimard) 2012.

Giono, Jean, Colline, Paris (Grasset) 1929.

Giono, Jean, Deux Cavaliers de l'orage, 1965. Dans : Euvres romanesques complètes, Paris

(Gallimard) 2009.

Giono, Jean, Fragments d'un paradis, 1948. Dans : Euvres romanesques complètes, Paris

(Gallimard) 1974.

Giono, Jean, L'Iris de Suse, 1970. Dans : Euvres romanesques complètes, Paris (Gallimard) 2009.

Giono, Jean, Le Bonheur fou, 1957. Dans : Euvres romanesques complètes, Paris (Gallimard) 2011. 
Giono, Jean, Le Chant du monde, 1934. Dans : Euvres romanesques complètes, Paris (Gallimard) 2012.

Giono, Jean, Le Grand Troupeau, Paris (Gallimard) 1931.

Giono, Jean, Le Hussard sur le toit, 1951. Dans : Euvres romanesques complètes, Paris (Gallimard) 2011.

Giono, Jean, Les Âmes fortes, 1950. Dans : Euvres romanesques complètes, Paris (Gallimard) 2004.

Giono, Jean, Les Grands Chemins, 1951. Dans : Euvres romanesques complètes, Paris (Gallimard) 2004.

Giono, Jean, Que ma joie demeure, 1934. Dans : Euvres romanesques complètes, Paris (Gallimard) 2012.

Giono, Jean, Regain, 1930, Paris (Grasset) 1937.

Giono, Jean, Un de Baumugnes, Paris (Grasset) 1929.

Giono, Jean, Une aventure ou La foudre et le sommet, 1955. Dans : CEuvres romanesques complètes, Paris (Gallimard) 2004.

Girard, M., Le Libéralisme en France de 1814 à 1848, Paris (Centre de documentation universitaire) 1970.

Girardin, Émile de, Questions de mon temps (1836-1856), vol. 4: Questions politiques, Paris (Serrière) 1858.

Giraud, Albert, Chronique littéraire. Dans : La Jeune Belgique. Revue belge d'art et de littérature, Bruxelles, 1893.

Giraud, Brigitte, Pas d'inquiétude, Paris (Stock) 2011.

Giraud, Robert, La Coupure, Paris (Denoël) 1966.

Giraudoux, Jean, Amphitryon 38, Paris (Grasset) 1929.

Giraudoux, Jean, Électre, 1937. Dans : Théâtre complet, Paris (Librairie générale française) 1991.

Giraudoux, Jean, Intermezzo, Paris (Grasset) 1933.

Giraudoux, Jean, La Folle de Chaillot, 1944, Paris (Grasset) 1945.

Giraudoux, Jean, Ondine, Paris (Grasset) 1939.

Giraudoux, Jean, Pour Lucrèce, 1944, Paris (Grasset) 1953.

Giraudoux, Jean, Siegfried et le Limousin, 1922, Paris (Grasset) 1949.

Giraudoux, Jean, Siegfried, 1928, Paris (Grasset) 1952.

Giraudoux, Jean, Simon le Pathétique, Paris (Grasset) 1926.

Giraudoux, Jean, Sodome et Gomorrhe, Paris (Grasset) 1943.

Giraudoux, Jean, Suzanne et le Pacifique, 1921, Paris (Grasset) 1951.

Gmeline, Patrick de, Baron rouge et Cigogne blanche, Paris (Presses de la Cité) 2011.

Gobert, Claude, Bois-Trudan, Paris (Plon) 1952.

Gobineau, Arthur de, Correspondance d'Alexis de Tocqueville et d'Arthur de Gobineau, 1859. Dans :

Euvres complètes d'Alexis de Tocqueville, Paris (Gallimard) 1959.

Gobineau, Arthur de, Les Pléiades, 1874, Monaco (Le Rocher) 1946.

Gobineau, Arthur de, Nouvelles asiatiques, 1876, Paris (Garnier) 1965.

Godard d'Aucour, Claude, Mémoires turcs, 2 vols., 1743, Londres (Cazin) 1782.

Godard d'Aucour, Claude, Thémidore, La Haye (Aux dépens de La Compagnie) 1744.

Goldoni, Carlo, Le Bourru bienfaisant [trad. de l'italien], 1771. Dans : Répertoire général du théâtre français, vol. 48, Paris (Ménard / Raymond) 1813.

Goldschmidt, Georges-Arthur, La Traversée des fleuves, Paris (Seuil) 1999.

Gombauld, Jean de, L'Endimion, 1624, Paris (N. Buon) 1626.

Goncourt, Edmond et Jules de, Charles Demailly, 1860, Paris (Charpentier) 1876.

Goncourt, Edmond et Jules de, Journal : Mémoires de la vie littéraire, vol. 1: 1851-1863, Paris

(Fasquelle / Flammarion) 1959. 
Goncourt, Edmond et Jules de, Journal : Mémoires de la vie littéraire, vol. 2: 1864-1878, 1878, Paris

(Fasquelle / Flammarion) 1959.

Goncourt, Edmond et Jules de, Journal : Mémoires de la vie littéraire, vol. 3 : 1879-1890, 1890, Paris

(Fasquelle / Flammarion) 1959.

Goncourt, Edmond et Jules de, Journal : Mémoires de la vie littéraire, vol. 4 : 1891-1896, 1896, Paris

(Fasquelle / Flammarion) 1959.

Goncourt, Edmond et Jules de, Madame Gervaisais, 1869, Paris (Charpentier) 1876.

Goncourt, Edmond et Jules de, Renée Mauperin, 1864, Paris (Charpentier) 1876.

Goncourt, Edmond et Jules de, Sœur Philomène, 1861, Paris (Fasquelle) 1912.

Gondi, Jean-François de (Cardinal de Retz), Mémoires, vol. 1 : 1613-1648, 1679. Dans : Fuvres, Paris (Hachette) 1870.

Gondi, Jean-François de (Cardinal de Retz), Mémoires, vol. 2 : 1648-1649, 1679. Dans : CEuvres, Paris (Hachette) 1872.

Gondi, Jean-François de (Cardinal de Retz), Mémoires, vol. 3 : 1650-1651, 1679. Dans : Euuvres, Paris (Hachette) 1875.

Gondi, Jean-François de (Cardinal de Retz), Mémoires, vol. 4 : 1651-1654, 1679. Dans : EFuvres, Paris (Hachette) 1876.

Gondi, Jean-François de (Cardinal de Retz), Mémoires, vol. 5 : 1654-1655, 1679. Dans : EFuvres, Paris (Hachette) 1880.

Gormont et Isembart, $1^{\text {re }}$ moitié XII , éd. Alphonse Bayot, Paris (Champion) ${ }^{3} 1931$. DEAF : GormB [nous citons la transcription du manuscrit]

Gotthelf, Jérémias, L'Araignée noire [trad. de l'allemand par Blaise Briod], Lausanne (L'Âge d'homme) 1979.

Goudar, Ange, L'Espion chinois ou L'Envoyé secret de la cour de Pekin [trad. du chinois], vol. 1, Cologne (sans éditeur) 1765.

Goudis, Vincent, Cap'tain Vagabond, Paris (Albin Michel) 1997.

Gougaud, Alain, L'Aube de la gloire. Les autos mitrailleuses et les chars français pendant la Grande guerre, Issy-les-Moulineaux (OCEBUR) 1987.

Gougaud, Henri, Petits Contes de sagesse pour temps turbulents, Paris (Albin Michel) 2013.

Gouge, William, L'Armure complette de Dieu [trad. de l'anglais par David Le Clerc ; titre original : The Whole Armor of God], Genève (Jacques Chouët) 1643.

Gougenot, Nicolas, La Comédie des comédiens, 1633, Exeter (University of Exeter) 1974.

Goulart, Simon, Cinq Décades de divers traitez et discours recueillis de l'Ecriture Saincte, Genève (Pierre Aubert) 1626.

Goulart, Simon, Memoires de l'estat de France sous Charles IX, vol. 2, sans lieu (sans éditeur) 1576.

Gourmont, Rémy de, Esthétique de la langue française : la déformation, la métaphore, le cliché, le vers libre, le vers populaire, Paris (Mercure de France) 1899.

Gournay, Marie Le Jars de, Le Proumenoir de monsieur de Montaigne, 1626. Dans : Égalité des hommes et des femmes : Grief des dames suivis du Proumenoir de Michel de Montaigne, Genève (Droz) 1993.

Gournay, Marie Le Jars de, Préface sur les Essais de Michel, seigneur de Montaigne, 1635. Dans : Montaigne, Essais, vol. 1, Paris (Tardieu / Denesle) 1828.

Gout-Desmartres, Édouard, L'Ange gardien. Hymne à la Vierge. Dans : Recueil de l'Académie des jeux floraux, Toulouse (Douladoure) 1835.

Gouzy, René, À travers le Sahara. Dans : Le Globe 90, 1951.

Gozlan, Léon, Le Notaire de Chantilly, 1836, Paris (Michel Lévy) 1856.

Gozlan, Léon, Les Martys inconnus. Dans : La Revue contemporaine, 1856.

Gracq, Julien, André Breton, 1948, Paris (Corti) 1989.

Gracq, Julien, Carnets du grand chemin, Paris (Corti) 1992. 
Gracq, Julien, En lisant, en écrivant, 1980, Paris (Corti) 1991.

Gracq, Julien, La Forme d'une ville, 1985, Paris (Corti) 1990.

Gracq, Julien, La Presqu'île, 1970, Paris (Corti) 1991.

Gracq, Julien, Le Rivage des Syrtes, Paris (Corti) 1951.

Gracq, Julien, Le Roi pêcheur, 1948, Paris (Corti) 1992.

Gracq, Julien, Lettrines 2, 1974, Paris (Corti) 1990.

Gracq, Julien, Lettrines, 1967, Paris (Corti) 1988.

Gracq, Julien, Penthésilée [adapt.], 1954, Paris (Corti) 1988.

Gracq, Julien, Préférences, 1961, Paris (Corti) 1989.

Gracq, Julien, Un balcon en forêt, 1958, Paris (Corti) 1990.

Gracq, Julien, Un beau ténébreux, Paris (Corti) 1945.

Grandeur et décadence d'une société financière, Paris (Auguste Ghio) 1884.

Grandpierre, Jean-Henri, Discours évangéliques, Paris (Risler) 1835.

Grèce, Michel, prince de, La Nuit du sérail, 1982, Paris (Gallimard) 1986.

Gréco, Juliette, Jujube, Paris (Stock) 1982.

Green, Julien, Adrienne Mesurat, 1927, Paris (Librairie générale française) 1996.

Green, Julien, Journal, vol. 1 : 1928-1934, Paris (Plon) 1938.

Green, Julien, Journal, vol. 3 : 1940-1943, Paris (Plon) 1946.

Green, Julien, Journal, vol. 5 : 1946-1950, Paris (Plon) 1951.

Green, Julien, Léviathan, 1929, Paris (Librairie générale française) 1995.

Green, Julien, Minuit, 1936, Paris (Librairie générale française) 1996.

Green, Julien, Moïra, Paris (Plon) 1950.

Gregh, Fernand, L'Âge de fer (souvenirs 1925-1955), Paris (Grasset) 1956.

Gresset, Jean-Baptiste, Le Méchant, 1747. Dans : Euvres complètes, vol. 2, Paris (Furne) 1830.

Gresset, Jean-Baptiste, Sidnei, 1745. Dans : Fuvres complètes, vol. 2, Paris (Furne) 1830.

Grévin, Jacques, César, 1561, Paris (Minard) / Genève (Droz) 1971.

Grévin, Jacques, La Trésorière, 1562. Dans : La Trésorière, Les Esbahis, Paris (Champion) 1980.

Grévin, Jacques, Les Esbahis, 1562. Dans : La Trésorière, Les Esbahis, Paris (Champion) 1980.

Griet, Dulle, Les Fenêtres murmurent, Paris (Presses de la Cité) 2013.

Groleau, Catherine Eve, Mélissa Vaillancourt, François Vaillancourt, François Remillard, Montréal au fil de l'eau, Québec (Ulysse) 2008.

Grouix, Pierre, Laboureur de larmes. Dans : Le Nouveau Recueil 9, Seyssel (Champ Vallon) 2003.

Groult, Benoîte et Flora, Il était deux fois, Paris (Denoël) 1968.

Groult, Benoîte, Mon évasion, 2008, Paris (Grasset) 2009.

Grousset, Bernard, En ton nom, Révolution, vol. 1, Paris (Le Manuscrit) 2007.

Grousset, René, L'Épopée des croisades, 1939, Paris (Plon) 1945.

Guéhenno, Jean, Jean-Jacques, vol. 1 : En marge des Confessions : 1712-1750, Paris (Grasset) 1948.

Guéhenno, Jean, Jean-Jacques, vol. 3 : Grandeur et misère d'un esprit : 1758-1778, Paris (Gallimard) 1952.

Guéhenno, Jean, Journal d'un homme de quarante ans, 1934, Paris (Grasset) 1935.

Guéhenno, Jean, Journal d'une « Révolution »: 1937-1938, Paris (Grasset) 1939.

Guérin de Bouscal, Guyon, Le Gouvernement de Sanche Pansa, 1642, Genève (Droz) 1981.

Guérin, Claudine-Alexandrine, marquise de Tencin, Les Malheurs de l'amour, 1747. Dans : Euvres complètes, vols. 2 et 3, Paris (d'Hautel) 1812.

Guérin, Claudine-Alexandrine, marquise de Tencin, Mémoires du comte de Comminges, 1735. Dans :

Euvres complètes, vol. 1, Paris (d'Hautel) 1812.

Guérin, Eugénie de, Journal (1834-1840). Dans : Journal et Lettres, Paris (Didier) 1864.

Guérin, Eugénie de, Lettres (1831-1847), Paris (Didier) 1865. 
Guérin, Maurice de, Correspondance (1824-1839). Dans : Euvres complètes, vol. 2, Paris (Belles lettres) 1947.

Guérin, Maurice de, Journal intime ou Le Cahier vert (1832-1835). Dans : Euvres complètes, vol. 1, Paris (Belles lettres) 1947.

Guérin, Raymond, L'Apprenti, 1946, Paris (Gallimard) 1949.

Guèvremont, Germaine, 1945, Le Survenant, Montréal-Paris (Fidès) 1962.

Guézille, Caroline, Préhi-story, Saint-Denis (Mon petit éditeur) 2010.

Gui de Bourgogne, 1230, éd. Fr. Guessard / H. Michelant, Paris (Vieweg) 1859. DEAF : GuiBourgG

Guibelet, Jourdain, Trois Discours philosophiques, Évreux (Antoine Le Marié) 1603.

Guibert, Hervé, À l'ami qui ne m'a pas sauvé la vie, 1990, Paris (Gallimard) 1993.

Guibert, Hervé, Des aveugles, 1985, Paris (Gallimard) 1993.

Guibert, Hervé, Le Protocole compassionnel, Paris (Gallimard) 2007.

Guichard, Claude, Funerailles et diverses manieres d'ensevelir des Romains, Grecs, et autres nations, Lyon (Jean de Tournes) 1581.

Guiche, Armand de Gramont, comte de, Mémoires concernant les Provinces-Unies des Pays-Bas, Londres (Philippe Changuion) 1744.

Guide de la mélodie et du lied, éd. Brigitte François-Sappey, Paris (Fayard) 1994.

Guide de l'ami du cheval, revue scientifique, historique et pratique, Paris.

Guidi, Guido, Les Anciens et Renommés Autheurs de la médecine et chirurgie [trad. d'Hippocrate], Paris (Eustache d'Aubin) 1634.

Guillaume d'Angleterre, fin XII [attribué à tort à Chrestien de Troyes], éd. A. J. Holden, Genève (Droz) 1988. DEAF : GuillAnglH

Guillaume de Digulleville, Le Pèlerinage de vie humaine, 1330, éd. ATILF (sans date). [cité d'après Frantext]

Guillaume de Lorris, Roman de la rose, 1230 [BFM: entre 1225 et 1230], éd. Ernest Langlois, vol. 2, vers 1 à 4058, Paris (Firmin-Didot) 1920. DEAF : RoseLLangl

Guillaume de Machaut, La Louange des dames, 1377. Dans : Poésies lyriques, vol. 1. DEAF : GuillMachC

Guillaume de Machaut, La Prise d'Alexandrie, (1370-)1372, éd. Sophie Hardy, thèse Orléans 2011, ftp://ftp.univ-orleans.fr/theses/sophie.hardy_1730.pdf. DEAF: GuillMachPriseH

Guillaume de Machaut, Le Confort d'ami, 1357. Dans : CFuvres, vol. 3.

Guillaume de Machaut, Le Dit de l'alerion, avant 1349. Dans : Euvres, vol. 2.

Guillaume de Machaut, Le Dit dou lyon, 1342. Dans : Euvres, vol. 2.

Guillaume de Machaut, Le Dit dou vergier, avant 1342. Dans : Euvres, vol. 1.

Guillaume de Machaut, Le Jugement dou roy de Behaingne, 1340. Dans : Euvres, vol. 1.

Guillaume de Machaut, Le Jugement dou roy de Navarre contre le jugement dou roy de Behaingne, 1349. Dans : Euvres, vol. 1.

Guillaume de Machaut, Le Livre du voir dit (Le Dit véridique), 1364, éd. Paul Imbs, Paris (Librairie générale française) 1999. DEAF : GuillMachVoirl

Guillaume de Machaut, Euvres de Guillaume de Machaut, éd. Ernest Hoepffner, 3 vols., Paris (Firmin Didot) 1908, 1911 et 1921. DEAF : GuillMachH

Guillaume de Machaut, Poésies lyriques, éd. Vladimir Chichmaref, 2 vols., Paris (Champion) 1909. DEAF : GuillMachC

Guillaume de Machaut, Remède de Fortune, avant 1377. Dans : Euvres, vol. 2. DEAF : GuillMachRemH Guillaume de Saulx, Mémoires historiques, 1625 / Collection universelle des mémoires particuliers relatifs à l'histoire de France, vol. 49, Londres / Paris (sans éditeur) 1789.

Guillaume, Lyane, Fière et intouchable, Paris (Lattès) 1996.

Guillaumie, Gaston, J. L. Guez de Balzac et la prose française, 1927, Genève (Slatkine) 1977.

Guillemard, Julien, L'Enfer du Havre, 1940-1944, témoignage, Paris (Médicis) 1948. 
Guillié, Sébastien, Essai sur l'instruction des aveugles, Paris (Les Aveugles) 1819.

Guillo, Lomig, Serge Lama, Gennevilliers (Prisma) 2020.

Guilloré, François, Maximes spirituelles pour la conduite des âmes, Paris (Michel Le Petit / Estienne Michallet) 1670.

Guilloux, Louis, Le Pain des rêves, 1942, Paris (Gallimard) 1980.

Guimont-Marceau, Stéphane, Los Cabos et La Paz, Québec (Ulysse) 1969.

Guiot de Provins, Les Fruvres de Guiot de Provins [La Bible], 1200, éd. John Orr [manuscrit B], Manchester (Imprimerie de l'Université) 1915. DEAF : GuiotProvinsO

Guiraud, Gaston, P'tite Gueule, Paris (Fasquelle) 1938.

Gurvitch, Georges, Traité de sociologie, vol. 2, Paris (Presses universitaires de France) 1968.

Guyotat, Pierre, Coma, 2006, Paris (Gallimard) 2007.

Guyotat, Pierre, Formation, Paris (Gallimard) 2007.

Guyotat, Pierre, Tombeau pour cinq cent mille soldats : sept chants, 1967, Paris (Gallimard) 1987.

Gygax, Adrien, Aux noces de nos petites vertus, Paris (Le Cherche Midi) 2017.

Gyp, Souvenirs d'une petite fille, 2 vols., Paris (Calmann-Lévy) 1927-1928.

Haddon, Alfred Cort, Les Races humaines [trad. de A. van Gennep], Paris (F. Alcan) 1930.

Hailly, Gaston d', A. Le-Clère et Henri Litou, Les Livres en 1883, vol. 5, Paris (Le Soudier) 1883.

Halimi, Gisèle, La Cause des femmes, Paris (Gallimard) 1992.

Halimi, Gisèle, Le Lait de l'oranger, 1988, Paris (Pocket) 2001.

Hall, Basil, Passage au Cap [de Bonne-Espérance ; traducteur inconnu]. Dans : La France littéraire 7, 1833.

Halt, Marie Robert, Histoire d'un petit homme, sans lieu (Collection @ XIX) 2016.

Hamilton, Antoine, Histoire de Fleur d'Épine, 1719. Dans : Le Cabinet des fées, vol. 20, Genève (Barde, Manget et Cie) / Paris (Cuchet) 1786.

Hamilton, Antoine, Le Bélier, 1719, La Haye (Cramer / Philibert) 1749.

Hamilton, Antoine, Mémoires de la vie du comte de Gramont, 1713. Dans : Romanciers du XVIII siècle, vol. 1 : Hamilton, Le Sage, Prévost, Paris (Gallimard) 1960.

Hamp, Pierre, Marée fraîche (1908), Vin de Champagne (1909), Paris (Gallimard) 1936.

Hanska, Evane, J'arrête pas de t'aimer, Paris (Balland) 1981.

Hanska, Evane, Les Amants foudroyés, Paris (Mazarine) 1984.

Hanssens, André, Ce soir, dans le jardin d'Eden..., Paris (Publibook) 2011.

Hardy, Alexandre, Coriolan, 1625, Exeter (University of Exeter) 1978.

Hardy, Alexandre, Didon se sacrifiant, 1624 Genève (Droz) 1994.

Hardy, Alexandre, La Force du sang, 1626, Athens (University of Georgia Press) 1972.

Hardy, Alexandre, Mariamne, 1625, Exeter (University of Exeter) 1989.

Hardy, Alexandre, Panthée, 1624, Exeter (University of Exeter) 1984.

Haussmann, Auguste, Voyage en Chine, Cochinchine, Inde et Malaisie, vol. 3, Paris (G. Olivier) 1848.

Hauteroche, Noël Lebreton, sieur de, Crispin médecin, 1673, Paris (Fages) 1802.

Havet, Mireille, Journal 1918-1919, Paris (Paulhan) 2003.

Hazard, Paul, Notes sur l'Italie nouvelle. Dans : Revue des deux mondes, $1^{\text {er }}$ octobre 1922.

Hechter, Daniel, Le Football business, Paris (Ramsay) 1979.

Heine, Heinrich, Le Tambour Legrand [trad. de l'allemand], 1826. Dans : Euvres complètes, Reisebilder, Paris (Calmann-Lévy) 1877.

Hélias, Pierre Jakez, Le Cheval d'orgueil : mémoires d'un Breton du pays bigouden, 1975, Paris (Plon) 2008.

Helvétius, Claude-Adrien, De l'esprit, Paris (Durand) 1758.

Helvétius, Claude-Adrien, De l'homme, de ses facultés intellectuelles et de son éducation, vol. 1, 1771, Neuchâtel (Société typographique) 1773.

Hémon, Louis, Maria Chapdelaine, 1916, Paris (Grasset) 1921. 
Henry-Coston, Gilberte, L'ABC du journalisme : cours élémentaire en 30 leçons, Paris (Clubin-

ter-Presse) 1952.

Hermant, Abel, Monsieur de Courpière, Paris (L'Illustration) 1907.

Hermary-Vieille, Catherine, L'Épiphanie des dieux, 1983, Paris (Gallimard) 1984.

Héroard, Jean, Histoire particulière de Louis XIII (1605-1610). Dans : Gerhard Ernst, Gesprochenes

Französisch zu Beginn des 17. Jahrhunderts : Direkte Rede, Tübingen (Niemeyer) 1985.

Héron, Jean-Olivier, Arrête de faire des miracles !, Paris (Grasset / Fasquelle) 1996.

Histoire autentique et suivie de la Révolution de France, vol. 2, Londres (sans éditeur) 1792.

Histoire générale des sciences, éd. R. Taton, vol. 3 : La Science contemporaine, vol. 1 : Le xix siècle,

Paris (Presses universitaires de France) 1961.

Hocedez, Jean-François, La Soif, Tournai (Unimuse) 1963.

Holbach, Paul Henri de, La Morale universelle ou Les Devoirs de l'homme fondés sur la nature, vol. 1,

Amsterdam (M. Rey) 1776.

Holbach, Paul Henri de, Système de la nature ou Des lois du monde physique et du monde moral par

M. Mirabaud, vol. 2, 1770, sans lieu ni éditeur, 1772.

Holbach, Paul Henri de, Théologie portative ou Dictionnaire abrégé de la religion chrétienne,

Amsterdam (M. Rey) 1768.

Hommes et mondes, revue, Paris.

Hoppenot, Hélène, Journal 1918-1933 : Rio de Janeiro, Téhéran, Santiago du Chili, Rio de Janeiro,

Berlin, Beyrouth-Damas, Berne, Paris (Claire Paulhan) 2012.

Horowitz, Anthony, La Maison de soie : le nouveau Sherlock Holmes [trad. de l'anglais par Michel

Laporte], Paris (Calmann-Lévy) 2011.

Houdetot, Adolphe de, Dix Épines pour une fleur : petites pensées d'un chasseur à l'affût, 1853, Paris (Amyot) 1874.

Hougron, Jean. Les Portes de l'aventure, Paris (Domat) 1954.

Hugo, Victor, Actes et paroles 1 : Avant l'exil : 1841-1851. Dans : Euvres complètes de Victor Hugo,

Paris (Laffont) 1996.

Hugo, Victor, Actes et paroles 2 : Pendant l'exil : 1852-1870. Dans : Euvres complètes de Victor

Hugo, Paris (Laffont) 1996.

Hugo, Victor, Actes et paroles 3 : Depuis l'exil : 1870-1876. Dans : Euvres complètes de Victor Hugo,

Paris (Laffont) 1996.

Hugo, Victor, Choses vues, 1885. Dans : Euvres complètes de Victor Hugo, Paris (Laffont) 1987.

Hugo, Victor, Correspondance, vol. 1 : 1814-1848. Dans : Euvres complètes de Victor Hugo, Paris

(Albin Michel / Ollendorff) 1947.

Hugo, Victor, Correspondance, vol. 2 : 1849-1866. Dans : Euvres complètes de Victor Hugo, Paris

(Albin Michel / Ollendorff) 1950.

Hugo, Victor, Correspondance, vol. 3 : 1867-1873. Dans : Euvres complètes de Victor Hugo, Paris

(Albin Michel / Ollendorff) 1952.

Hugo, Victor, Correspondance, vol. 4 : 1874-1885 : addendum. Dans : Euvres complètes de Victor

Hugo, Paris (Albin Michel / Ollendorff) 1950.

Hugo, Victor, Dieu, 1891. Dans : EFuvres complètes de Victor Hugo, Paris (Laffont) 1986.

Hugo, Victor, Hernani ou L'Honneur castillan, Paris (Mame / Delaunan-Vallée) 1830.

Hugo, Victor, Histoire d'un crime : déposition d'un témoin, 1883. Dans : Euvres complètes de Victor

Hugo, Paris (Laffont) 1987.

Hugo, Victor, L’Année terrible, 1872. Dans : EFuvres poétiques, vol. 3, Paris (Gallimard) 2000.

Hugo, Victor, L'Art d'être grand-père, 1877. Dans : Fuuvres poétiques, vol. 3, Paris (Gallimard) 2000.

Hugo, Victor, L'Homme qui rit, 1869. Dans : CEuvres complètes de Victor Hugo, Paris (Laffont) 1985.

Hugo, Victor, La Fin de Satan, 1886. Dans : Fuvres complètes de Victor Hugo, Paris (Laffont) 1986.

Hugo, Victor, La Légende des siècles 1, vols. 1-2, 1859, Paris (Hachette) 1920. 
Hugo, Victor, La Légende des siècles 2, vols. 3-5, 1877, Paris (Hachette) 1925.

Hugo, Victor, La Légende des siècles 3, vol. 6, 1883, Paris (Hachette) 1927.

Hugo, Victor, Le Rhin : lettres à un ami, 1842. Dans : Euvres complètes, Paris (Ollendorff) 1906.

Hugo, Victor, Les Chansons des rues et des bois, 1865. Dans : CEuvres poétiques, vol. 3, Paris

(Gallimard) 2000.

Hugo, Victor, Les Châtiments, 1853. Dans : Euvres poétiques, vol. 2, Paris (Gallimard) 1967.

Hugo, Victor, Les Contemplations, 1856, Paris (Hachette) 1922.

Hugo, Victor, Les Feuilles d'automne, 1840. Dans : Euvres complètes de Victor Hugo, Paris (Laffont) 1985.

Hugo, Victor, Les Misérables, 1862, Paris (Laffont) 2001.

Hugo, Victor, Les Orientales, 1840. Dans : Euvres complètes de Victor Hugo, Paris (Laffont) 1985.

Hugo, Victor, Les Quatre Vents de l'esprit, 1881. Dans : Fuvres complètes de Victor Hugo, Paris (Laffont) 1985.

Hugo, Victor, Les Rayons et les ombres, 1840. Dans : Euvres poétiques, vol. 1 : Avant l'exil

(1802-1851), Paris (Gallimard) 1964.

Hugo, Victor, Les Travailleurs de la mer, 1866. Dans : Euvres complètes, Paris (Ollendorff) 1911.

Hugo, Victor, Lettres à la fiancée, 1822. Dans : Euvres complètes de Victor Hugo, Paris (Albin Michel

/ Ollendorff) 1947.

Hugo, Victor, Napoléon le Petit, 1852. Dans : Euvres complètes de Victor Hugo, Paris (Laffont) 1987.

Hugo, Victor, Notre-Dame de Paris : 1482, 1832, Paris (Gallimard) 1994.

Hugo, Victor, Odes et ballades, 1840. Dans : Euvres complètes de Victor Hugo, Paris (Laffont) 1985.

Hugo, Victor, Quatrevingt-treize, 1874, Paris (Librairie générale française) 2001.

Hugo, Victor, Ruy Blas, 1838. Dans : EFuvres complètes, Paris (Ollendorff) 1905.

Hugo, Victor, Théâtre en liberté : être aimé, 1854. Dans : Euvres complètes de Victor Hugo, Paris (Laffont) 1985.

Hugo, Victor, William Shakespeare, 1864. Dans : Euvres complètes de Victor Hugo, Paris (Laffont) 1985.

Huguenin, Jean-René, Journal, Paris (Seuil) 1964.

Hulot père, L'Art du tourneur mécanicien, vol. 1, Paris (Roubo) 1775.

Humbert, Jean, Nouveau Glossaire genevois, vol. 2, Genève (Jullien frères) 1852.

Huon de Bordeaux, milieu XIII', après 1216, éd. Pierre Ruelle, Paris (Presses universitaires de France)

/ Bruxelles (Presses universitaires de Bruxelles) 1960. DEAF : HuonR

Huon le Roi, Du Vair Palefroi, milieu XIII'. Dans : Recueil général et complet des fabliaux des XIII' et XIV siècles, vol. 1. DEAF : HuonPalL

Huon Piaucele, Estormi, $2^{\mathrm{e}}$ tiers XIII'. Dans : Nouveau Recueil complet des fabliaux, vol. 1. DEAF :

Estormin

Huyghe, René, Dialogue avec le visible, Paris (Flammarion) 1955.

Huysmans, Joris-Karl, À rebours, 1884, Paris (Fasquelle) 1907.

Huysmans, Joris-Karl, En route, Paris (Plon).

Huysmans, Joris-Karl, L’Art moderne, 1883. Dans : Euvres complètes, vol. 6-7, Paris (Crès) 1929.

Huysmans, Joris-Karl, L'Oblat, 1903. Dans : Euvres complètes, vol. 17, Paris (Crès) 1934.

Huysmans, Joris-Karl, Là-bas, 1, 1891. Dans : CEuvres complètes, vol. 12, Paris (Crès) 1930.

Huysmans, Joris-Karl, Les Sœurs Vatard, 1879. Dans : Euvres complètes, vol. 3, Paris (Crès) 1928.

Huysmans, Joris-Karl, Marthe : histoire d'une fille, 1876. Dans : Euvres complètes, vol. 2, Paris (Crès) 1928.

Ikor, Roger, Les Fleurs du soir, Paris (Albin Michel) 1985.

Impressions du Sud, Aix-en-Provence.

Ionesco, Eugène, L'Impromptu de l'Alma, 1958. Dans : Les Chaises, suivi de L'Impromptu de l'Alma,

Paris (Gallimard) 1995. 
Ionesco, Eugène, Le Roi se meurt, 1963, Paris (Gallimard) 1995. Ionesco, Eugène, Rhinocéros, 1963, Paris (Gallimard) 1995.

Isselin, Angélique, Ses yeux comme des miroirs, Saint-Rémy-de-Provence (Bout de ficelle) 2009. Istrati, Panait, La Jeunesse d'Adrien Zograffi, Paris (Gallimard) 1968.

Izzo, Jean-Claude, Chourmo, 1996, Paris (Gallimard) 2002.

Jabès, Edmond, Le Livre des marges, Paris (Librairie générale française) 1975.

Jacob, Max, [Lettre à François Sentein du 6 mai 1943]. Dans : Les Cahiers Max Jacob 2017.

Jacob, Max, [Lettre à J. F. Lefèvre-Pontalis du 14 janvier 1943]. Dans : La Parisienne, mars 1955.

Jacquemart, Nicolas-Thierry, Contes et poésies du c. [citoyen] Collier, commandant-général des croisades du Bas-Rhin, 2 vols., Saverne (sans éditeur) 1792.

Jacques Bretel, Le Tournoi de Chauvency, 1285, éd. Maurice Delbouille, Liège (Vaillant-Carmanne) / Paris (Droz) 1932. DEAF : BretTournD

Jacques Legrand, Archiloge Sophie, 1400. Dans : Archiloge Sophie. Livre des bonnes mœurs, éd.

Evencio Beltran, Paris (H. Champion) 1986. DEAF : JacLegrArchB

Jacquot, André, La Forêt, son rôle dans la nature et les sociétés, Paris (Berger-Levrault) 1911.

Jakemes, Le Roman du châtelain de Coucy et de la dame de Fayel [= Le Roman du castelain de Couci et de la dame de Fayel], 1300, éd. John E. Matzke et Maurice Delbouille, Paris (Société des anciens textes français) 1936. DEAF: JakD [éd. citée]

Jakemes, Le Roman du châtelain de Coucy et de la dame de Fayel [= L'Histoire du châtelain de Coucy et de la dame de Fayel], 1300, éd. G. A. Crapelet, Paris (Crapelet) 1829. DEAF: JakC [éd. citée pour les variantes]

Jal, Augustin, Scènes de la vie maritime, vol. 3, Paris (Charles Gosselin) 1832.

Jammes, Francis, Les Géorgiques chrétiennes : chants I et II, Paris (Mercure de France) 1911.

Jammes, Francis, Les Géorgiques chrétiennes : chants V, VI et VII, 1912, Paris (Mercure de France)

1912.

Janin, Jules, Histoire de la littérature dramatique, vol. 3, Paris (Michel Lévy) 1854.

Janin, Jules, L'Âne mort et la femme guillotinée, 1829, Paris (Librairie des bibliophiles) 1876.

Japrisot, Sébastien, La Course du lièvre à travers les champs, Paris (Denoël) 1972.

Japrisot, Sébastien, La Dame dans l'auto, Paris (Denoël) 1966.

Jardin, Alexandre, Bille en tête, 1986, Paris (Gallimard) 1991.

Jarrin, Charles, Essai sur l'histoire de Bourg, Bourg (Eugène Chambaud) 1882.

Jarrosson, Bruno, Le savoir, le pouvoir et la formation : la transmission du savoir dans l'entreprise et ailleurs, Paris (Maxima) 1997.

Jarry, Alfred, Le Surmâle, 1902, Paris (Mille et une nuits) 1996.

Jaubert, Hippolyte-François, Glossaire du centre de la France, vol. 2, Paris (Napoléon Chaix) 1856.

Jaud, Joel, Les Dolmens ne savent pas mourir, Paris (Publibook) 2013.

Jaurès, Jean, Études socialistes, 1901, Paris (Ollendorf) 1902.

Javelaud, Corinne, À fleur de vie, Paris (Le Manuscrit) 2003.

Jean d'Arras, Melusine, 1393, éd. Ch. Brunet, Paris (Jannet) 1854 [conforme à l'édition imprimée de Genève 1478 ; citée pour les adaptions contemporaines]. DEAF : MelusArrsB

Jean d’Arras, Mélusine, 1393, éd. Jean-Jacques Vincensini, Paris (Livre de poche) 2003

[d'après le manuscrit de la bibliothèque de l'Arsenal (= manuscrit Ars), $1^{\text {er }}$ quart XV ${ }^{\mathrm{e}}$. DEAF : MelusArrV

Jean Daudin, De la erudition ou Enseignement des enfans nobles, 1370 [BFM : 1360] [manuscrit : $1^{\text {re }}$ moitié $\mathrm{xV}^{\mathrm{e}}$ ], éd. Frédérique Hamm [La traduction $d u$ De eruditione filiorum nobilium de Vincent de Beauvais par Jean Daudin], Paris (École Nationale des Chartes) 1993. DEAF : JDaudErudH ${ }^{\circ}$ [cité d'après BFM]

Jean de Bueil, Le Jouvencel, [1461]-1468, éd. Camille Favre et Léon Lecestre, 2 vols., Paris (Renouard) 1887 / 1889. DEAF : JBueilJouvL 


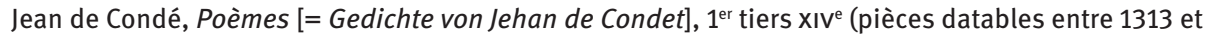
1337), éd. Adolf Tobler, Stuttgart (Literarischer Verein) 1860. DEAF : JCondT

Jean de Roye, Chronique scandaleuse [= Journal, connu sous le nom de Chronique scandaleuse], 1460, Paris (Renouard) 1883.

Jean Froissart, Chroniques (A), +1370 (= Fuvres de Froissart, éd. Kervyn de Lettenhove, vols. 1-25, Bruxelles (Devaux) et (à partir du vol. 18 : Closson) 1867-1877. DEAF : FroissK

Jean Froissart, Chroniques (B), +1370. Dans : Collection des chroniques nationales françaises, éd. Jean Alexandre Buchon, vols. 1, 8 et 10, Paris (Verdière) 1824 et 1825.

Jean Froissart, La Prison amoureuse, 1373 (ou 1372), éd. Anthime Fourrier, Paris (Klincksieck) 1974. DEAF : FroissPrisF

Jean Froissart, Méliador, 1383, éd. Auguste Longnon, [= Méliador par Jean Froissart, roman comprenant les poésies lyriques de Wenceslas de Bohême, duc de Luxembourg et de Brabant], 3 vols., Paris (Firmin Didot) 1895-1899. DEAF : Froiss MelL

Jean Froissart, Poésies, $3^{e}$ tiers xive éd. August Scheler [= Euvres de Froissart], vols. 26-28, Bruxelles (Devaux) 1870-1872, Genève (Slatkine) 1977. DEAF : FroissS

Jean Froissart, Rondeaux, $3^{3}$ tiers XIV éd. Rae S. Baudouin [= Jean Froissart, Ballades et rondeaux], Genève / Paris (Droz) 1978. DEAF : FroissBallB

Jean Gerson, Sermon pour la fête de l'Annonciation. Ave Maria, 1396. Dans : Les Sermons français inédits pour les fêtes de l'Annonciation et de la Purification. Scriptorium, vol. 2, sans lieu (L. Mourin) 1948. [cité d'après Frantext]

Jean Juvénal des Ursins, Audite celi, 1435. Dans : Écrits politiques, éd. P.S. Lewis, vol. 1, Paris (Klincksieck) 1978.

Jean Juvénal des Ursins, Audite illos, 1432. Dans : Écrits politiques, éd. P.S. Lewis, vol. 1, Paris (Klincksieck) 1978.

Jean Juvénal des Ursins, Verba mea auribus percipe, Domine, 1452. Dans : Écrits politiques, éd. P.S. Lewis, vol. 2, Paris (Klincksieck) 1985.

Jean Meschinot, Lunettes des princes [= Édition des Lunettes des princes de Jean Meschinot], avant 1465, éd. Christine Martineau-Genieys, Genève (Droz) 1972. DEAF : MeschLunM

Jean Regnier, Les Fortunes et adversitez, 1432, éd. E. Droz, Paris (Champion) 1923.

Jean Renart, Roman de Guillaume de Dole ou Roman de la rose [= Roman de la rose ou Guillaume de Dole], 1209, éd. Félix Lecoy, Paris (Champion) 1962. DEAF : GuillDoleL [cité d'après BFM]

Jeandrieu, Georges-Noël, Le Fiancé de la fille du chômeur, Paris (Fayard) 1995.

Jeanne de Chantal, sainte [Jeanne Françoise Frémiot], Vive Jesus. Reponses de nostre tres-honoree et digne mere Jeanne Françoise Fremiot, Paris (sans éditeur) 1632.

Jeanne R., Les Noces d'éternité, Saint-Denis (Mon petit éditeur) 2010.

Jeannin, F., Rapport [oral], Bulletin de la Société industrielle et agricole d'Angers et du département de Maine-et-Loire 28-29, 1857.

Jeannin, Pierre, Négociations diplomatiques et politiques du président Jeannin (1598-1620), éd. J. A. C. Buchon, Paris (Pilon) 1875.

Jehan Bagnyon, L'Histoire de Charlemagne (parfois dite Roman de Fierabras), 1465, éd. Hans-Erich Keller, Genève (Droz) 1992.

Jehan Bodel, Jeu de saint Nicolas [= Le Jeu de saint Nicolas], 1195 (écrit prob. entre 1191 et 1202 ; manuscr. prob. 1295 ; prologue 1250), éd. Albert Henry, Bruxelles / Paris (Presses universitaires de Bruxelles / Presses universitaires de France) 1962. DEAF : BodelNicH

Jehan Bodel, La Chanson des Saisnes [Saxons], manuscrits fin XIII', éd. Annette Brasseur, 2 vols., Droz, 1989 DEAF : SaisnA/LB [nous citons la rédaction LT, plus longue que AR ; par conséquent, un plus grand nombre d'adjectifs-adverbes dans LT, mais absence de variation pour les adjectifs-adverbes qui se trouvent dans les rédactions AR et LT]. 
Jehan de Journi, La Dime de penitance [= La dime de penitance von Jehan von Journi], 1288, éd. Hermann Breymann, Tübingen (Fues) 1874. DEAF : JJourB

Jehan de Meun, Roman de la rose, 1275 (probablement entre 1269 et 1275 ou très peu après), éd. Ernest Langlois, 5 vols., vers de 4059 à la fin, Paris (Firmin-Didot) 1914-1924. DEAF : RosemLangl

Jenni, Alexis, L’Art français de la guerre, Paris (Gallimard) 2011.

Jeury, Michel, May le monde, Paris (Robert Laffont) 2010.

Jeux et sports, 1967, éd. Roger Caillois, Paris (Gallimard) 1968.

Jodelle, Étienne, Cleopatre captive, 1553. Dans : CEuvres complètes, vol. 2, Paris (Gallimard) 1968.

Jodelle, Étienne, Didon se sacrifiant, 1555. Dans : Euvres complètes, vol. 2, Paris (Gallimard) 1968.

Jodelle, Étienne, Hymenee, 1573. Dans : Les CEuvres et mélanges poétiques d'Étienne Jodelle, éd.

Charles Marty-Laveau, Paris (Lemerre) 1868.

Jodelle, Étienne, L'Eugène, 1553. Dans : Euuvres complètes, vol. 2, Paris (Gallimard) 1968.

Joffo, Joseph, Un sac de billes, 1973, Paris (Lattès) 1982.

Joffre, Joseph [maréchal Joffre], Mémoires (1910-1917), Paris (Plon) 1931.

Jollivet, Marcel, Pour une transition écologique citoyenne, Paris (Charles Léopold Mayer) 2015.

Jombert, Charles-Antoine, Méthode pour apprendre le dessein, Paris (Imprimerie de l'auteur)

1755.

Joubert, Joseph, Pensées, essais, maximes et correspondance, 1824, Paris (Le Normant) 1850.

Joufroi de Poitiers, milieu XIII', éd. Percival B. Fay / John L. Grigsby, Genève (Droz) 1972. DEAF : JoufrF

Jouhandeau, Marcel, Les Pincengrain, 1924, Paris (Gallimard) 1984.

Jouhandeau, Marcel, Monsieur Godeau intime, 1926, Paris (Gallimard) 1963.

Jouin, Nicolas, Troisième Harangue des habitans de la paroisse de Sarcelles à Monseigneur

l'archevêque de Paris. Dans : Pièces et anecdotes interessantes, Aix-en-Provence (Jésuites)

1750.

Jourdain de Blaye, 1200, éd. Peter F. Dembowski, Chicago / London (University of Chicago Press) 1969. DEAF : JourdBID

Jourdan, Antoine Jacques Louis, Traité de physiologie considérée comme science d'observation [trad. ; original de Carl Friedrich Burdach] vol. 3, Paris (Baillière) 1838.

Jourdan, Jean-Baptiste, Le Guerrier philosophe, La Haye (de Hondt) 1744.

Jourde, Pierre, Le Maréchal absolu, Paris (Gallimard) 2012.

Journal d'hygiène, Paris.

Journal d'agriculture pratique, Paris.

Journal de la Société impériale et centrale d'horticulture, Paris.

Journal de médecine, chirurgie, pharmacie, etc., Paris.

Journal de musique, vol. 1, Genève (Minkoff reprints) 1770.

Journal de physique, de chimie, d'histoire naturelle et des arts, Paris.

Journal de viticulture pratique, Paris.

Journal des débats politiques et littéraires, Paris.

Journal des femmes, Paris.

Journal du marquis de Dangeau, vol. 13, Paris (Firmin Didot) 1858.

Journal général de médecine, de chirurgie, de pharmacie, Paris.

Journal ceconomique, Paris.

Journal officiel de la République française.

Jouve, Pierre-Jean, La Scène capitale, 1935, Paris (Mercure de France) 1961.

Jouve, Pierre-Jean, Tragiques, Paris (Stock) 1922.

Jouvin de Rochefort, Albert, Le Voyageur d'Europe, vol. 3, Paris (Claude Barbin) 1676.

Jouy, Étienne de, L'Hermite de la Chaussée-d'Antin ou Observations sur les mœurs et les usages

parisiens au commencement du xIXe siècle, vol. 1, 1811, Paris (Pillet) 1815-1817. 
Jouy, Étienne de, L'Hermite de la Chaussée-d'Antin ou Observations sur les mœurs et les usages parisiens au commencement du XIX' siècle, vol. 2, 1812, Paris (Pillet) 1815-1817.

Jouy, Étienne de, L'Hermite de la Chaussée-d'Antin ou Observations sur les mœurs et les usages parisiens au commencement du xix siècle, vol. 3, 1813, Paris (Pillet) 1815-1817.

Jouy, Étienne de, L'Hermite de la Chaussée-d'Antin ou Observations sur les mœurs et les usages parisiens au commencement du xixe siècle, vol. 5, 1814, Paris (Pillet) 1815-1817.

Jouy, Étienne de, L'Hermite en Écosse ou Observations sur les mœurs et usages des Écossais, vol. 2, Paris (Pillet aîné) 1825.

Joyeux Passe-Temps de la jeunesse, Versailles (Beau) ${ }^{3} 1864$.

Judrin, Roger, Mots habités, Quimper (Calligrammes) 1985.

Jurieu, Pierre, Préjugez légitimes contre le papisme, Amsterdam (Desbordes) 1685.

Jurisprudence française (1807-1952), texte de 1948, Paris (Éditions techniques) 1953.

Kalouaz, Ahmed, Je préfère qu'ils me croient mort, Stuttgart (Klett) 2011.

Kane, Cheikh Hamidou, L’Aventure ambiguë, 1961, Paris (Union générale d'éditions) 1988.

Kapeler, J.-B. et Joseph-Bienaimé Caventou, Manuel des pharmaciens et des droguistes, vol. 1, Paris (Brosson / Chaudé) 1821.

Kaplan, Leslie, Les Prostituées philosophes, Paris (P.O.L.) 2013.

Karr, Alphonse, Fort en thème, Bruxelles (Meline / Cans) 1845.

Karr, Alphonse, Sous les tilleuls, 1832, Paris (Calmann-Lévy) 1888.

Keller, Christiane et Patrick Cloux, Présences romanes en Auvergne, Bourbonnais, Velay, Saint-Paul (Lucien Souny) 2006.

Kemp, Robert, La Vie des livres, Paris (Albin Michel) 1955.

Kéralio, Marie Françoise de, Les Succés d'un fat, Paris (Lesclapart) 1762.

Kerlaz, Claude, La Fin des paysans, Le Coudray-Macouard (Cheminements) 2000.

Kessel, Joseph, La Steppe rouge, 1922, Paris (Gallimard) 1995.

Kessel, Joseph, Le Lion, 1958, Paris (Gallimard) 1997.

Kessel, Joseph, Les Cavaliers, 1967, Paris (Gallimard) 1997.

Kessler, Erwin, L'Autre Langue notre : le français chez les Roumains, Bucarest (Institut culturel roumain) 2006.

Kis, Gyula, Le Sorcier numérique, Paris (Publibook) 2009.

Koltès, Bernard-Marie, Quai ouest, 1985, Paris (Minuit) 2001.

Korn, Danna, Alma Rota, Marion Kaplan, Vivre sans gluten pour les nuls, Paris (First) 2015.

Kourouma, Ahmadou, Le Soleil des indépendances, 1968, Paris (Seuil) 1995.

Kristeva, Julia, Les Samouraïs, 1990, Paris (Gallimard) 1992.

L’Année scientifique et industrielle, Paris.

L'Apiculteur, publication mensuelle de la Société centrale d'apiculture, Paris.

L'Art dramatique à Valencia. Dans : Bibliothèque méridionale, vol. 16, Toulouse (Édouard Privat) 1913.

L'Artiste, Journal de littérature et de Beaux-arts, Paris.

L’Atre périlleux, 1250, éd. Brian Woledge, Paris (Champion) 1936. DEAF : AtreW

L'Avant-Scéne cinéma, magazine mensuel, Paris, 2005.

L'École parfaite des officiers de bouche, Paris (Pierre Ribou) ${ }^{7} 1708$.

L'Éducation, revue trimestrielle, Paris.

L'Enfant qui fu remis au soleil, $4^{\mathrm{e}}$ quart XIII'. Dans : Nouveau Recueil complet des fabliaux, vol. 5.

L'Esprit des journaux, Liège (Tutot).

L'Estoile, Claude de, L'Intrigue des filous, 1648, Paris (Champion) 1977.

L'Estoile, Pierre de, Registre-journal du regne de Henri III, vol. 1 : 1574-1575, Genève (Droz) 1992.

L'Estoile, Pierre de, Registre-journal du regne de Henri III, vol. 2 : 1576-1578, Genève (Droz) 1996.

L'Estoile, Pierre de, Registre-journal du regne de Henri III, vol. 4 :1582-1584, Genève (Droz) 2000. 
L'Estoile, Pierre de, Registre-journal du regne de Henri III, vol. 5 : 1585-1587, Genève (Droz) 2001.

L'Express, hebdomadaire, Paris.

L'Heureuse Pêche, Paris (Le Jay) 1770.

L'Histoire et ses méthodes, Charles Samarān (éd.), Paris (Gallimard) 1961.

L'Horizon, Québec, septembre 2013.

L'Icare sicilien ou La Cheute de Mazarin, Paris (sans éditeur) 1652.

L'lllustration, journal universel, Paris.

L'Impartial, journal, 28.8.1906.

L'Improvisateur français, Paris.

L'Intermédiaire des chercheurs et curieux, Paris (Sandoz et Fischbacher) 1877.

L'Observateur littéraire, Londres / Paris.

L'Oue au chapelain, XIII'. Dans : Nouveau Recueil complet des fabliaux, vol. 8.

L'Université catholique, revue, Paris.

La Bédollière, Émile de, Le Pharmacien, Dans : Les Français peints par eux-mêmes, vol. 3, Paris (L. Curmer) 1841.

La Bible en français courant, éd. collective anonyme, sans lieu (Bibli’0) 1997.

La Bicyclette, hebdomadaire, Paris.

La Bruyère, Jean de, Les Caractères, 1696, Paris (Librairie générale française) 1995.

La Chapelle et François Le Coigneux, seigneur de Bachaumont, Voyage de messieurs Bachaumont et de La Chapelle, 1661, Amsterdam (P. de Coup) 1708.

La Chastelaine de Saint Gille, $3^{e}$ tiers XIII ${ }^{e}$. Dans : Recueil général et complet des fabliaux des XIII et XIV siècles, vol. 1.

La Chastelaine de Vergi, 1240, éd. Leigh A. Arrathoon, New York (Cross-cultural communications) 1984. DEAF : ChastVergiA

La Chaussée, Pierre-Claude, L'École des mères, 1745. Dans : Euvres, vol. 2, Paris (Prault) 1762.

La Chaussée, Pierre-Claude, La Fausse Antipathie, 1734. Dans : Euvres, vol. 1, Paris (Prault) 1762.

La Civilisation écrite, éd. Julien Cain [sans mention des auteurs], Paris (Société de gestion de l'Encyclopédie française) 1939.

La Clef du cabinet des princes de l'Europe, vol. 6, sans lieu (Jacques le sincere) 1707.

La Comtesse de Ponthieu, $2^{\mathrm{e}}$ quart XIII'. Dans : Nouvelles françoises en prose du XIII' siècle. DEAF : FillePonth ${ }^{2} \mathrm{M}$

La Coste, Nicolas de, Histoire générale des voyages et conquestes des Castillans dans les isles et terre-ferme des Indes occidentales [trad. ; original d'Antonio de Herrera], Paris (Nicolas et Jean de La Coste) / (Veuve Nicolas de Coste / Clousier / Aubouyn) 1671.

La Dame escoillee, $1^{\text {re }}$ moitié xIII'. Dans : Nouveau Recueil complet des fabliaux, vol. 8.

La Dame qui aveine demandoit pour morel sa provende avoir, 1300. Dans : Nouveau Recueil complet des fabliaux, vol. 9.

La Destruction de Rome, milieu XIII', éd. Gustav Groeber, Romania 2, Franck (Paris) 1873. DEAF : DestrRomeG

La Fayette, Madame de, La Princesse de Clèves, 1678, Paris (Droz) 1946.

La Fontaine, Jean de, Conte d'un paysan qui avait offensé son seigneur, 1665. Dans : Contes et nouvelles.

La Fontaine, Jean de, Contes et nouvelles, éd. Edmond Pilon et Ferand Dauphin, Paris (Garnier) 1922.

La Fontaine, Jean de, Fables (v. La Fontaine, CEuvres complètes, vol. 1 : Fables, contes et nouvelles).

La Fontaine, Jean de, La Coupe enchantée, 1671. Dans : Euvres complètes de La Fontaine, vol. 1, Paris (Hachette) 1861.

La Fontaine, Jean de, La Fiancée du roi de Garbe, 1666. Dans : Contes et nouvelles.

La Fontaine, Jean de, La Servante justifiée, 1666. Dans : EFuvres complètes, éd. Ch. Marty-Laveaux, vol. 2, Paris (P. Jannet) 1857. 
La Fontaine, Jean de, Le Diable en enfer, 1674. Dans : Contes et nouvelles.

La Fontaine, Jean de, Le Songe de Vaux, 1671. Dans : La Fontaine : CFuvres diverses, éd. Pierre Clarac, Paris (Gallimard) 1958.

La Fontaine, Jean de, Le Villageois qui cherche son veau, 1666. Dans : La Fontaine, contes et nouvelles.

La Fontaine, Jean de, Les Cordeliers de Catalogne, 1665. Dans : CEuvres complètes de La Fontaine: Contes, Paris (Dupont) 1826.

La Fontaine, Jean de, CFuvres complètes, vol. 1 : Fables, contes et nouvelles, éd. Jean-Pierre Collinet, Paris (Gallimard) 1991.

La Fontaine, Jean de, Paysan, 1665. Dans : Contes et nouvelles.

La Forêt québécoise, revue de l'Association forestière québécoise.

La Framboisière, Nicolas Abraham de, Le Gouvernement nécessaire à chacun pour vivre longuement en santé, Paris (Sonnius) 1600.

La Gessée, Jean de, Les Jeunesses, 1583, Paris (S.T.F.M.) 1991.

La Grue, Thomas, La Porte ouverte, pour arriver à la conoissance du paganisme caché [trad.; original de Abraham Roger], Amsterdam (Schipper) 1670.

La Guerre mondiale, bulletin quotidien illustré, 1914.

La Harpe, Jean-François de, Lycée ou Cours de littérature ancienne et moderne, vol. 19, Paris (Abel Lanoe) 1800.

La Housse partie, XIII'. Dans : Nouveau Recueil complet des fabliaux, vol. 3.

La Logique parlementaire de Hamilton [trad. de l'anglais par Joseph Reinach], préface par Joseph Reinach, Paris (Charpentier) 1886.

La Mission populaire évangélique de France, 34 rapport (1906-1906), Alençon (Veuve Félix Guy) 1906.

La Moralité de Bien avisé Mal avisé, 1487-1490, éd. Jonathan Beck, Paris (Garnier) 2014. [cité d'après DMF]

La Motte, Antoine Houdar de, Discours sur la tragédie, 1730. Dans : Euvres, vol. 4, Paris (Prault) 1754.

La Motte, Antoine Houdar de, Fables, 1719. Dans : Fuvres, vol. 9, Paris (Prault) 1754.

La Motte, Antoine Houdar de, Réflexions sur la critique, Paris (G. Dupuis) 1716.

La Musardière, Amélie de, Professeur à Taïwan, Paris (Société des écrivains) 2013.

La Noue, Jean-Baptiste Sauvé de, La Coquette corrigée, 1757. Dans : Choix de pièces de théâtre, Paris (Cazin) 1787.

La Nouvelle Régence. Revue des échecs, Paris.

La Nouvelle Revue, Paris.

La Passion d'Auvergne, 1477, éd. Graham A. Runnalls, Genève (Droz) 1982. DEAF : PassAuvR

La Passion du Christ, 1000. Dans : Eduard Koschwitz, Les Plus Anciens Monuments de la langue française, Leipzig (Reisland) ${ }^{71907 . ~ D E A F ~: ~ P a s s i o n K ~}$

La Péruse, Jean de, Poésies complètes, 1554, Exeter (University of Exeter) 1992.

La Pierre, Jean de, Le Grand Empire de l'un et l'autre monde divisé en trois royaumes, Paris (Moreau) 1625.

La Plume, revue littéraire et artistique bimensuelle, Paris.

La Popelinière, Henri Lancelot Voisin de, L'Histoire des histoires, Paris (Jean Houzé) 1599.

La Popelinière, Henri Lancelot Voisin de, L'Histoire de France, vol. 1, sans lieu ni éditeur, 1582.

La Presse [journal] [article de presse du 22.6.1857]. Dans : Joseph Loubet, Les Loisirs d'un enfant du peuple, Auch (Joseph Loubet) 1859.

La Primauday, Pierre de, Suite de l'Académie françoise, 1580, Paris (Guillaume Chaudière) 1680.

La Prise de Cordres et de Sebille, 1200 , éd. Ovide Densusianu, Paris (Firmin Didot). DEAF :

PriseCordD 
La Quintinye, Jean de la, Instruction pour les jardins, vol. 2, Paris (Claude Barbin) 1690.

La Renaissance contemporaine, revue, Paris.

La Révolution surréaliste : collection complète, Paris (Jean-Michel Place) 1991.

La Revue belge, Liége.

La Revue d'art dramatique et musical, Paris.

La Revue de France, publication mensuelle, Paris.

La Revue de l'art ancien et moderne, Paris.

La Revue de Liège, Liège.

La Revue de Paris, Paris.

La Revue du cinéma, Paris.

La Revue hebdomadaire, Paris.

La Revue indépendante de littérature et d'art, Paris.

La Revue mondiale, Paris.

La Roche, Jean-Baptiste-Louis de, Sermons pour le carême, Paris (Moreau) 1725.

La Rochelle, Jean-Baptiste de, Le Maréchal de Boucicault. Dans : Bibliothèque universelle des

romans, Paris (Au bureau / chez Gueffier) 1781.

La Roque, Antoine. Dans : Mercure de France, 1758.

La Source, Organe de l'Institut de gardemalades [sic] de Lausanne.

La Suite du Roman de Merlin, 1235, éd. Gilles Roussineau, Genève (Droz) 2006.

La Table ronde, revue mensuelle, Paris.

La Taille, Jean de, Le Négromant, 1573. Dans : Dramatic works, London (Athlone Press) 1972.

La Technique moderne [revue], vol. 25, 1933.

La Varenne, François Pierre de, Le Cuisinier françois, 1651, Paris (Pierre David) 1659.

La Vie de sainte Paule, fin XIII', éd. Karl Grass, Halle (Niemeyer) 1908. DEAF : SPauleG

La Vie de seint Auban, [probablement par Matthieu Paris], 1235, éd. Arthur Robert Harden, Oxford

(Blackwell) 1968. DEAF : SAubH

La Vie parisienne, Paris.

Labé, Louise, Double Rondeau, à elle, 1556, Euvres, éd. Charles Boy, 2 vols., Paris (Lemerre) 1887 [= Genève (Slatkine) 1968].

Labé, Louise, Sonnets, élégies, débat de folie et d'amour, 1555, Paris (Flammarion) 2004.

Laberge, Albert, La Scouine, 1918, Montréal (Presses de l'Université de Montréal) 1986.

Laberge, Marie, Le Banc, Montréal (Boréal) 1994.

Labro, Philippe, Des bateaux dans la nuit, 1982, Paris (Gallimard) 1995.

Lachavanne, Didier, Que la volonté du Père, Montmélian (La Fontaine de Siloé) 2003.

Lacordaire, le père Henri-Dominique, Conférences de Notre-Dame, année 1848 : De Dieu, Paris

(Sagnier / Bray) 1848.

Lacretelle, Jacques de et Madeleine Guéritte, Sarn [trad. de l'anglais ; original de Mary Webb], 1930,

Paris (Grasset) 1999.

Lacretelle, Jacques de, Silbermann, 1922, Paris (Gallimard) 1933.

Lafargue, Étienne de, Euuvres mêlées de littérature, vol. 1, Senlis (Des Rocques / Guillot) 1786.

Lafon, Marie-Hélène, L’Annonce, 2009, Paris (Buchet-Chastel) 2017.

Lafon, Marie-Hélène, Sur la photo, Paris (Buchet-Chastel) 2003.

Lafond, Mary, La Croisade contre les Albigeois, Paris (Librairie internationale) 1868.

Laforgue, Jules, EFuvres complètes, vol. 1 : 1860-1883, Lausanne (L'Âge d'homme) 1986.

Lafosse, Philippe-Étienne, Guide du maréchal, Paris (Lacombe) 1766.

Lagarce, Jean-Luc, Journal 1977-1990, 2007, Besançon (Les Solitaires intempestifs) 2007.

Lagarce, Jean-Luc, Juste la fin du monde, 2000, Besançon (Les Solitaires intempestifs)

2011.

Lagrange, Les Euvres de Séneque le philosophe [trad.], vol. 1, Paris (de Bure) 1778. 
Laguilliez, Sandra, Katerina, Ustaritz (PGCOM) 2017.

Lainé, Pascal, La Dentellière, 1974, Paris (Gallimard) 1996.

Lam, André, Ebolo ou Le Refus d'un jeune de mourir, Yaoundé (Presses universitaires de Yaoundé) 2008.

Lamartine, Alphonse de, Correspondance générale, vol. 1 : 1830-1833, 1833, Paris (Droz) 1943.

Lamartine, Alphonse de, Correspondance générale, vol. 2 : 1834-1836, 1836, Genève (Droz) 1948.

Lamartine, Alphonse de, Cours familier de littérature, Paris (sans éditeur) 1859.

Lamartine, Alphonse de, Des destinées de la poésie, 1834. Dans : Méditations poétiques, vol. 2, Paris (Hachette) 1915.

Lamartine, Alphonse de, Harmonies poétiques et religieuses, 1830. Dans : Euvres poétiques complètes, Paris (Gallimard) 1963.

Lamartine, Alphonse de, Jocelyn, 1836. Dans : Euvres poétiques complètes, Paris (Gallimard) 1963.

Lamartine, Alphonse de, La Chute d'un ange, 1838. Dans : CEuvres poétiques complètes, Paris (Gallimard) 1963.

Lamartine, Alphonse de, Le Tailleur de pierre de Saint-Point, 1851. Dans : Euvres complètes, vol. 32, sans lieu (chez l'auteur) 1863.

Lamartine, Alphonse de, Les Confidences, 1849, Paris (Michel Lévy) 1857.

Lamartine, Alphonse de, Les Nouvelles Confidences, 1851, Paris (Hachette / Furne / Jouvet) 1884.

Lamartine, Alphonse de, Raphaël, 1849. Dans : Graziella, Raphaël, Paris (Garnier) 1960.

Lamartine, Alphonse de, Souvenirs, impressions, pensées et paysages pendant un voyage en Orient (1832-1833) ou Notes d'un voyageur, 1835. Dans : Euvres complètes, vol. 6, sans lieu (chez l'auteur) 1861.

Lamartine, Alphonse de, Toussaint Louverture, 1850. Dans : Euvres poétiques complètes, Paris (Gallimard) 1963.

Lambert Thiboust et [Alfred] Delacour, Les Souvenirs de jeunesse, Paris (Michel Lévy) 1852.

Lambert, Antoine, Les Commentaires ou Les Euvres chirurgicales d'Antoine Lambert, Marseille (Charles Brebion) ${ }^{3} 1677$.

Lamennais, Félicité de, Lettres inédites ... à la baronne Cottu (1818-1854), 1854, Paris (Perrin) 1910.

Lancaster, Craig, 600 heures dans la vie extraordinaire d'Edward Stanton [trad. de l'anglais par Cédric Degottex], Paris (Milady) 2018.

Lang, Luc, Les Indiens, 2001, Paris (Gallimard) 2003.

Langeac, Robert de, Conseils aux âmes d'oraison, Paris (Lethielleux) 1936.

Langlais, Xavier de, La Technique de la peinture à l'huile, 1959, Paris (Flammarion) 2018.

Lanoux, Armand, Les Lézards dans l'horloge, Paris (Juillard) 1952.

Lanoux, Armand, Quand la mer se retire, Paris (Presses de la Cité) 1963.

Lantier, Étienne François de, Erminie. Poëme en trois chants, Londres / Paris (Les Marchands de nouveautés) 1788.

Lanzmann, Jacques, La Horde d'or, 1994, Paris (Pocket) 1995.

Lanzmann, Jacques, Le Têtard, 1976, Paris (Librairie générale française) 1988.

Larbaud, Valery, A.O. Barnabooth, ses œuvres complètes : Le Pauvre Chemisier ; Poésies; Journal intime, 1913, Paris (Gallimard) 1948.

Larbaud, Valery, Amants, heureux amants, 1923, Paris (Gallimard) 1995.

Larbaud, Valery, Beauté, mon beau souci..., 1923. Dans : Amants, heureux amants, Paris (Gallimard) 1995.

Larbaud, Valery, Jaune bleu blanc, 1927, Paris (Gallimard) 1991.

Larbaud, Valery, Mon plus secret conseil, 1923. Dans : Amants, heureux amants, Paris (Gallimard) 1995. 
Lardier, J. S., Essai sur les moyens de régénérer l'agriculture en France, vol. 1, Marseille (Antoine Ricard) 1820.

Larivey, Pierre de, Le Laquais : comédie, 1579, Paris (Nizet) 1987.

Larivey, Pierre de, Les Esprits, 1579, Exeter (Exeter university printing unit) 1978.

Las Cases, Emmanuel de, Le Mémorial de Sainte-Hélène, 2 vols., 1823, Paris (Gallimard) 1956-1957.

Lasaygues, Frédéric, Vache noire, hannetons et autres insectes, Paris (B. Barrault) 1985.

Lathuillère, Roger, Guiron le courtois, Genève (Droz) 1966.

Laugeois, Benoist, La Science universelle de l'Écriture sainte, Paris (George Josse / André Pralard)

1675.

Launay, Gilles de, Dissertation de la philosophie en général, Paris (Jean Cusson) 1668.

Launois, Dominique, Qui se souvient de Babylone ?, Paris (La Jeune parque) 1949.

Laurens, Didier, Monaco, un pays ensoleillé dirigé par un prince magnifique, Paris (Hachette)

2007.

Lautréamont, Les Chants de Maldoror, 1869. Dans : CEuvres complètes, Paris (Corti) 1953.

Laval, Antoine de, Desseins de professions nobles et publiques, Paris (L'Angelier) 1612.

Lavallée, Ronald, Tchipayuk ou Le Chemin du loup, Paris (Albin Michel) 1987.

Lavardin, Jacques de, La Celestine [adapt.], 1578, Londres (Tamesis Books) 1974.

Lavaud, Régis, Convergences macrocosmiques, Saint-Denis (Mon petit éditeur) 2011.

Lavedan, Henri, Catherine, 1897, Paris (Flammarion) 1907.

Laya, Jean-Louis, L'Ami des loix, Paris (Maradan / Lepetit) 1793.

Le « Bestiaire marial » tiré du « Rosarius » (Paris, ms. B.N. f. fr. 12483), 1333, Ph. D. dissertation,

Ottawa (Université d'Ottawa) 1996.

Le Bélarus, l'État de l'exception, François Dépelteau, Aurélie Lacassagne (éds.), Laval (Presses de

l'Université Laval) 2003.

Le Bidois, Georges et Robert, Syntaxe du français moderne, vol. 1, Paris (Picard) 1935.

Le Braz, Anatole, Poèmes votifs. Dans : Revue des deux mondes, $1^{\text {er }}$ août 1926.

Le Breton, Auguste, Les Bourlingueurs, Paris (Plon) 1972.

Le Cannabis. Rapport du Comité spécial du Sénat sur les drogues illicites, Montréal (Presses de

l'Université de Montréal) 2003.

Le Cène, Charles, Projet d'une nouvelle version françoise de la Bible. Dans : La Sainte Bible. Nouvelle version par Charles Le Cène, Amsterdam (Michel Charles Le Cène) 1741.

Le Chevalier as deus espees, $2^{\mathrm{e}}$ quart XIII ${ }^{\mathrm{e}}$ éd. Paul Vincent Rockwell, Woodbridge (Brewer) 2006.

DEAF : ChevlIEspR

Le Chevalier qui fist sa fame confesse, XIII'. Dans : Nouveau Recueil complet des fabliaux, vol. 4.

Le Clerc, Jean, Interpolations et variantes de la Chronique scandaleuse. Dans : Journal de Jean de

Roye connu sous le nom de Chronique scandaleuse, 1502, Paris (Renouard) 1896.

Le Clézio, Jean-Marie Gustave, Désert, 1980, Paris (Gallimard) 1995.

Le Clézio, Jean-Marie Gustave, Le Déluge, Paris (Gallimard) 1966.

Le Clézio, Jean-Marie Gustave, Le Procès-verbal, 1963, Paris (Gallimard) 1995.

Le Combat de trente Bretons contre trente Anglois, 1355, Paris (Crapelet), 1827. DEAF : BatAngIBC

Le Comte, le père Louis, Nouveaux Mémoires sur l'état présent de la Chine, Paris (J. Anisson)

1696.

Le Correspondant, revue, Paris.

Le Couronnement de Louis [= Les Rédactions en vers du Couronnement de Louis], $2^{\mathrm{e}}$ tiers XII ${ }^{\mathrm{e}}$, éd.

Yvan G. Lepage, Genève / Paris (Droz) 1978. DEAF : CourLouisLe

Le Courtier, François-Joseph, Sermon de Notre-Seigneur sur la montagne, Paris (Adrien Le Clere)

1866.

Le Débat, revue bimestrielle, Paris (Gallimard).

Le Disque en France, Paris (La Documentation française) 1963. 
Le Duc, Philibert, Les Idylles de Théocrite [trad.]. Dans : Revue de la Société littéraire, historique et archéologique du département de l'Ain, 1885.

Le Febvre de Villebrune, Mémoire relatif à de nouveaux procédés pour éteindre les incendies [extrait] [trad. du suédois; original de Nils Nyström]. Dans : L'Esprit des journaux, vol. 6, Paris (Valade) 1796.

Le Febvre, Nicaise, Traicté de la chymie, vol. 2, Leyde (Arnoud Doude) 1669.

Le Fèvre, Georges, Expédition Citroën Centre-Asie, Paris (Plon) 1933.

Le Foteor, XIII'. Dans : Nouveau Recueil complet des fabliaux, vol. 6.

Le Franc Archier de Baignollet. Dans : Le Franc Archier de Baignollet, suivi de deux autres monologues dramatiques, 1468, éd. Lucie Polak, Genève (Droz) / Paris (Minard) 1966.

Le Gendre, Gilbert-Charles, Traité de l'opinion ou Mémoires pour servir à l'histoire de l'esprit humain, vol. 4, Paris (Briasson) 1733.

Le Goffic, Charles, Saint-Georges et Nieuport : les derniers chapitres de l'histoire des fusiliers marins (25 novembre 1914 - 6 décembre 1915), Paris (Plon-Nourrit) 1919.

Le Grand Maréchal expert et françois, ou il est traité de la connoissance des chevaux [...], Lyon (Esprit Vitali) 1682.

Le Grand, Albert, La Vie, gestes, mort et miracles des saints de la Bretagne-Armorique, 1659, Brest (Anner) / Paris (Pesron) 1837.

Le Grant Voiage et pelerinage de saincte Caquette, 1517-1518. Dans : Le Recueil de Trepperel, vol. 2 : Les Farces, éd. Eugénie Droz et Halina Lewicka, Genève (Droz) 1971.

Le Hache-Maïs ascenseur de M. Albaret. Dans : Journal d'agriculture pratique 84, 1884.

Le Hayer Du Perron, Pierre, Les Palmes du juste, Paris (Toussainct Quinet) 1635.

Le Jeu d'Adam, $2^{\mathrm{e}}$ moitié xII', Genève (Droz) 2017. DEAF : AdamH

Le Journal amusant, Paris.

Le Journal des sçavans, Paris.

Le Journal, nº 1853, Paris, 1943.

Le Maclean, Québec.

Le Magasin universel 6, Paris, 1838-1839.

Le Maître de Claville, Charles-François-Nicolas, Traité du vrai mérite de l'homme, Paris (Saugrain) 1736.

Le Menagier de Paris, 1393, éd. Georgine E. Brereton et Janet M. Ferrier, Oxford (Clarendon press) 1981. DEAF : MenagB

Le Ménestrel, hebdomadaire, Paris.

Le Mercure françois ou L'Histoire de nostre temps, vol. 11, Paris (Richer) 1626.

Le Mistère du siège d'Orléans, 1480-1500 [DMF], éd. François Guessard et Eugène de Certain, Paris (Imprimerie impériale) 1862.

Le Mouvement social, revue catholique internationale, Paris.

Le Moyne, le père Pierre, Saint-Louys ou Le Héros chrestien, Paris (Ch. du Mesnil) 1653.

Le Mystère de S. Bernard de Menthon, milieu XIII', éd. A. Lecoy de la Marche, Paris (Firmin Didot) 1888. DEAF : MistSBernL

Le Padma Than Yig [trad. du tibétain par Gustave-Charles Toussaint]. Dans : Journal asiatique 203, 1823.

Le Person, Michel, Belle-île en rouge, Paris (Edilivre / Aparis) 2007.

Le Point, hebdomadaire, Paris.

Le Prestre et le chevalier, $1^{\text {re }}$ moitié XIII'. Dans : Nouveau Recueil complet des fabliaux, vol. 9.

Le Prestre teint, 1250. Dans : Nouveau Recueil complet des fabliaux, vol. 7. DEAF : GautLeuL²

Le Procès d'un jeune moyne et d'ung viel gendarme devant Cupido, avant 1500. Dans : Le Recueil

Trepperel, vol. 2 : Les Farces, éd. Eugénie Droz et Halina Lewicka, Genève (Droz) 1961.

Le Provost a l'aumuche, XIII'. Dans : Nouveau Recueil complet des fabliaux, vol. 4. 
Le Recueil de Riom, 1466. Dans : «Le Recueil de Riom » et «La Maniere de henter soutillement». Un livre de cuisine et un réceptaire sur les greffes du xve siècle, éd. Carole Lambert, Montréal (CERES) 1987.

Le Roi d'Angleterre et le jongleur d'Ely, 1300. Dans : Recueil général et complet des fabliaux des XIII et $x I v^{e}$ siècles, vol. 2. DEAF : RioteAM

Le Roi Flore et la belle Jehanne, milieu XIII'. Dans : Nouvelles françoises en prose du XIII' siècle. DEAF : RoifloreMol

Le Roman de Perceforest. Deuxième partie, avant 1475, éd. Gilles Roussineau, 2 vols., Genève (Droz) 1999-2001. DEAF : PercefR ${ }^{3}$

Le Roman de Renart, $2^{\mathrm{e}}$ moitié xIII , plus additions tardives, éd. Ernest Martin, 3 vols., Strassburg (Trübner) / Paris (Leroux) 1882-1887. DEAF : RenM [datation complexe ; voir DEAF : RenM et BFM : renart10]

Le Romans de la dame a la lycorne et du biau chevalier au lyon, $1^{\mathrm{er}}$ tiers XIVe éd. Friedrich Gennrich, Dresden (Niemeyer) 1908. DEAF : LicorneG

Le Roux de Lincy, Antoine, Les Femmes célèbres de l'ancienne France, vol. 1, Paris (Leroi) 1848. Le Roux, Hugues, Jean Richepin. Dans : Portraits de cire, Paris (Lecène / Oudin) 1891.

Le Roy, Eugène, L'Année rustique en Périgord, Paris (Ligaran) 2016.

Le Roy, Eugène, Le Moulin du Frau, 1891, sans lieu (Good Press) 2020.

Le Sacristain, $\mathrm{xIII}$. Dans : Nouveau Recueil complet des fabliaux, vol. 7. DEAF : SegrMoine ${ }^{1 / 2 / 3} \mathrm{~N}$

Le Saint Voyage de Jherusalem du Seigneur d'Anglure [effectué en 1395-1396], 1398, éd. François

Bonnardot et Auguste Longnon, Paris (Firmin Didot) 1878. DEAF : AnglureB

Le Sens de la peine, Diane Bernard et Kevin Ladd (éds.), Bruxelles (Presses de l'Université Saint-Louis) 2019.

Le Sida des autres, par Claude Fay (éd.), Autrepart, Cahiers des sciences humaines, 1999.

Le Sot Chevalier, après 1267. Dans : Nouveau Recueil complet des fabliaux, vol. 5. DEAF : NoomenFabl Le Testament de Monseigneur des Barres, fin XIV . Dans : Recueil de poésies françoises des $\mathrm{XV}^{e}$ et $\mathrm{XVI}^{e}$ siècles, éd. Anatole de Montaiglon, vol. 6, Paris (P. Jannet) 1857.

Le Vayer de Boutigny, Roland, Tarsis et Zélie, vol. 4, Paris (Jolly) 1666.

Le Violier des histoires rommaines moralisées, 1521, Genève (Droz) 2002.

Léautaud, Paul, In memoriam, 1905, Paris (Mercure de France) 1956.

Léautaud, Paul, Lettres à ma mère, Paris (Mercure de France) 1956.

Lebas, Marcel, Raymond la pente, Paris (Promotion et édition) 1967.

Lebeaud, Nicolas, Nouveau Manuel complet du vétérinaire, Paris (Librairie encyclopédique de Roret) 1859.

Lebesque, Morvan, Chroniques du Canard enchaîné, Paris (Pauvert) 1960.

Leclerc, A., Manuel de télégraphie et de téléphonie, Paris (Baillière) 1924.

Lecomte, Charles, Le Parler dolois, Paris (H. Champion) 1910.

Leconte de Lisle, Charles-Marie, Odyssée [trad.], 1868, Paris (Pocket) 1998.

Leconte de Lisle, Charles-Marie, Poèmes antiques, Paris (M. Ducloux) 1852. [datation individuelle des poèmes]

Leconte de Lisle, Charles-Marie, Poèmes barbares, 1878, Paris (Lemerre), réimpression sans date. [datation individuelle des poèmes]

Leconte de Lisle, Charles-Marie, Poèmes tragiques, Paris (Lemerre) 1886. [datation individuelle des poèmes]

Lecouturier, Ernestine, Françoise-Madeleine de Chaugy et la tradition salésienne au XVII siècle, Paris (Bloud et Gay) 1933.

Lectures du soir, revue, Paris.

Lefebvre, Georges, La Révolution française, Paris (Presses universitaires de France) 1963.

Lefebvre, René [pseudonyme de Édouard Laboulaye), Paris en Amérique, Paris (Charpentier) 1863. 
Legouvé, Gabriel, La Mort de Henri IV, 1806. Dans : Euvres complètes, vol. 1, Paris (L. Janet) 1826. Legrand, Geoffrey, Post-Apocalypse, vol. 2, Paris (Le Manuscrit) 2006.

Legrand, Marc-Antoine, La Famille extravagante, 1709. Dans : Théâtre du XVIII siècle 1, Paris

(Gallimard) 1972.

Legrand, Marc-Antoine, Le Philanthrope ou L'Ami de tout le monde, 1724. Dans : F Fuvres de Legrand, vol. 3, Paris (Libraires associés) 1770.

Leibniz, Gottfried Wilhelm, Essais de théodicée sur la bonté de Dieu, la liberté de l'homme et l'origine du mal, 1710, Paris (Aubier) 1962.

Leiris, Michel, La Règle du jeu 1 : Biffures, 1948, Paris (Gallimard) 1996.

Leiris, Michel, La Règle du jeu 2 : Fourbis, 1955, Paris (Gallimard) 1997.

Leiris, Michel, La Règle du jeu 3 : Fibrilles, 1966, Paris (Gallimard) 1992.

Leiris, Michel, La Règle du jeu 4 : Frêle Bruit, 1976, Paris (Gallimard) 1992.

Lejean, Guillaume, Voyage de M. Guillaume Lejean dans l'Afrique orientale, 1860. Dans : Le Tour du monde [Journal de voyages, Paris] 1862.

Lejeune, Philippe, Signes de vie. Le pacte autobiographique 2, Paris (Seuil) 2005.

Lekeu, Guillaume, Correspondance, Liège (Mardaga) 1993.

Lemaire de Belges, Jean, Description du rocher, 1524. Dans : Euvres, éd. Auguste Jean Stecher, vol. 3, Louvain (Lefever) 1882-1885.

Lemaire de Belges, Jean, Epistre du roy à Hector de Troye, 1513. Dans : Euvres, éd. Auguste Jean Stecher, vol. 3, Louvain (Lefever) 1882-1885.

Lemaire de Belges, Jean, La Description du temple de Venus, 1524. Dans : Euvres, éd. Auguste Jean Stecher, vol. 3, Louvain (Lefever) 1885-1891.

Lemaire de Belges, Jean, La Plainte du désiré, 1504. Dans : Euvres, éd. Auguste Jean Stecher, vol. 3, Louvain (Lefever) 1882-1885.

Lemaire de Belges, Jean, Le Second Conte de Cupido et d'Atropos, 1512. Dans : Fuvres, éd. Auguste Jean Stecher, vol. 3, Louvain (Lefever) 1882-1885.

Lemaire de Belges, Jean, Les Illustrations de Gaule et singularitéz de Troye, 1511-1512. Dans :

Euvres, éd. Auguste Jean Stecher, vols. 1 et 2, Louvain (Lefever) 1882-1885.

Lemaire, Chrystoph, Presque heureux. De l'Olympia...à l'Olympia, sans lieu (www.lulu.com nº 14258914) 2013.

Lemaire, Dominique, Le Trèfle à quat' feuilles, Lausanne (L'Âge d'homme) 1987.

Lemaître, Jules, Les Contemporains : première série, 1885, Paris (Lecène / Oudin) 1887.

Lemaître, Raoul, De la disposition des rameurs sur la trière antique. Dans : Revue archéologique, 1883.

Lemercier, Népomucène, Alminti ou Le Mariage sacrilège, Paris (Henri Dupuy) 1834.

Lemercier, Népomucène, Pinto ou La Journée d'une conspiration, 1800. Dans : Comédies historiques, Paris (A. Dupont) 1828.

Lemierre, Antoine-Marin, Les Fastes ou Les Usages de l'année, 1779. Dans : Euvres, vol. 3, Paris (Maugeret) 1810.

Lemineur, Roger, Les Propos de classe du p’tit Gégé, Paris (Publibook) 2003.

Lenglet du Fresnoy, Nicolas, L'Histoire justifiée contre les romans, Amsterdam (La Compagnie) 1735.

Lenoël, Odette, La Vocation de Katherine Mansfield, Paris (Albin Michel) 1946.

Lentura de la Rutnel, Anne-Sophie, La Légende des princes des ténèbres, vol. 1: Les Bellattores, Saint-Denis (Mon petit éditeur) 2012.

Leplus, Franck, Remue-méninges chez les Grasky, Paris (L’Harmattan) 2020.

Leprette, Fernand, Égypte, terre du Nil, Paris (Plon) 1939.

Lequeutre, A., Excursions. Dans : Explorations pyrénéenes, Bulletin trimestriel de la Société Ramon, Bagnères (Cazenave) 1870.

Lerat, Philippe de, Les Machines agricoles, Paris (Lavoisier) 2015. 
Leroux, Gaston, Le Mystère de la chambre jaune, Paris (L'llustration) 1907. Leroux, Gaston, Le Parfum de la dame en noir, Paris (L'Illustration) 1908. Leroux, Gaston, Rouletabille chez le tsar, Paris (L'Illustration) 1912.

Leroy, Loys, De la vicissitude ou Variété des choses en l'univers, Paris (Pierre L'Huilier) 1576. Leroy, Onésime, Corneille et Gerson dans l'Imitation de Jésus-Christ, Paris (Adrien Leclere) 1841.

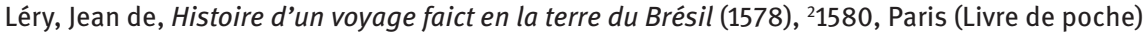
1999.

Les Annales politiques et littéraires, revue universelle, Paris.

Les Barricades de 1830. Drame historique en trois journées, Paris (Jules Lefebvre) 1830.

Les Cent Nouvelles nouvelles, 1460, éd. Franklin P. Sweetser, Genève (Droz) 1966. DEAF :

CentNouvs

Les Chroniques admirables, 1534. Dans : Les Chroniques gargantuines, Paris (Nizet) 1988. Les Deus Anglois et l'anel, XIII'. Dans : Nouveau Recueil complet des fabliaux, vol. 8. Les Enfances de Doon de Mayence, milieu XIII". Dans : Édition et étude des "Enfances de Doon de Mayence », Université d’Aix en Provence, 1995. [cité d'après Frantext]

Les Enfances Garin de Monglane, XIV [manuscrit : 1460], éd. Aurélie Kostka, Ottawa (LFA) 2002.

DEAF : EnfGarB [cité d'après Frantext]

Les Évangiles des Quenouilles, $3^{\mathrm{e}}$ quart $\mathrm{xV}^{\mathrm{e}}$, éd. Madeleine Jeay, Paris (Vrin) / Montréal (Presses de l'Université de Montréal) 1985. DEAF : EvQuenje

Les Femmes dans la Révolution française (1789-1794), 2 vols., Paris (Edhis) 1982.

Les Grandes et Inestimables Chroniques, 1532. Dans : Les Chroniques gargantuines, Paris (Nizet) 1988.

Les Historiettes du jour ou Paris tel qu'il est, compilées par M. Nougaret, vol. 2, Londres (Hookham) / Paris (Duchesne) 1787.

Les Instituts de l'empereur Justinien [trad. du latin par F. Helo], Paris (Estienne Loyson) 1669.

Les Lapidaires français du Moyen Âge des XII ${ }^{e}$ XIII et XIV siècles, éd. Léopold Pannier, Paris

(Vieweg) 1882. DEAF : PannierLapid [les citations proviennent du Premier lapidaire, fin $\mathrm{xII}^{\mathrm{e}}$, DEAF : LapidFFP]

Les EFuvres libres, mensuel, Paris (Payard).

Les Perdris, 1200. Dans : Nouveau Recueil complet des fabliaux, vol. 4.

Les Trois Apôtres. Dans : La Revue hebdomadaire 6, 1906.

Les Trois Dames qui troverent l'anel, 1250 [= datation manuscrit C]. Dans : Nouveau Recueil complet des fabliaux, vol. 2. DEAF : NoomenFabl

Lesage, Alain-René, Aventures du chevalier de Beauchêne, 1732, Paris (Renouard) 1821.

Lesage, Alain-René, Histoire de Gil Blas de Santillane, 1732, Paris (Garnier-Flammarion) 1977.

Lesage, Alain-René, Histoire de Guzman d'Alfarache, 4 vols., 1732, Paris (Berquet) 1825.

Lesage, Alain-René, Turcaret. Dans : Théâtre du xvIII siècle, vol. 1, 1735, Paris (Gallimard) 1972.

Lescut, Nicolas [Nicolle] de, Institutions imperialles [trad. de Justinien], Lyon (Jean de Tournes) 1547.

Lesparre, Christiane, L'Impossible Monsieur Bierce, Paris (Grasset / Fasquelle) 1981.

Lespinasse, Julie de, Lettres à Condorcet (1773-1776), 1776, Paris (Dentu) 1887.

Lespinasse, Julie de, Lettres à M. de Guibert (1769-1776), 1776, Paris (Charpentier) 1876.

Lesuire, Robert-Martin, L’Aventurier françois ou Mémoires de Grégoire Merveil, Londres / Paris

(Guillau) 1782.

Letessier, Dorothée, Le Voyage à Paimpol, Paris (Seuil) 1980.

Lettre de Madame M...[Mol] au R. P. Lenet, sans lieu ni éditeur, 1734.

Lettres de Eugène Delacroix (1815-1863), par Philippe Burty, Paris (A. Quantin) 1878.

Lettres de la vénérable mère Marie de l'Incarnation, première supérieure des Ursulines de la Nouvelle France, Paris (Louis Billaine) 1681. 
Lettres de Saint Basile le Grand, archevêque de Césarée [trad. du grec par l'abbé de Bellegarde],

Paris (André Pralard) 1693.

Lettres et memoires d'Estat, vols. 1 et 2, Paris (Frédéric Léonard) 1666, 1676.

Léucadites, Cosme, L'Hellénisme et la langue grecque, Athènes (Hermes) 1865.

Leusse, Paul de, Souvenirs d'un aspirant de marine, Paris (Dentu) 1867.

Levadoux, Louis, La Vigne et sa culture, Paris (Presses universitaires de France) 1961.

Levé, Édouard, Journal, Paris (P.O.L.) 2004.

Levret, André, Mémoire sur la méthode de délivrer les femmes après l'accouchement. Dans :

Mémoires de l'Académie royale de chirurgie, vol. 3, Paris (Delaguette) 1757.

Ley, Madeleine, Le Grand Feu, 1942, Arles (Actes Sud) 1988.

Lhote, André, La Peinture d'abord, Paris (Denoël) 1942.

Li Romans de Bauduin de Sebourc, III' roy de Jhérusalem, 1365, éd. L. N. Boca, vol. 1, Valenciennes (Henry) 1841.

Li Romanz d'Athis et Prophilias, 1200, éd. Alfons Hilka, 2 vols., Dresden (Gesellschaft für

Romanische Literatur) / Halle (Niemeyer) 1912, 1916. DEAF : AthisH

Liégeard, Stéphen, Au caprice de la plume, Paris (Hachette) 1884.

Liger, Louis, La Nouvelle Maison rustique, Paris (Claude Prudhomme) 1721.

Liger, Louis, Economie generale de la campagne ou Nouvelle Maison rustique, vol. 2, Amsterdam

(Henri Desbordes) ${ }^{2} 1701$.

Linguet, Nicolas-Simon, Histoire impartiale des Jésuites, 2 vols., sans lieu ni éditeur, 1768.

Linhart, Virginie, Le Jour où mon père s'est tu, Paris (Seuil) 2008.

Lion de Bourges, 1350, éd. William Kibler, Jean-Louis Picherit, Thelma Fenster, 2 vols., Genève

(Droz) 1980. DEAF : LionBourgAlK

Lipovetsky, Gilles, L'Ère du vide : essais sur l'individualisme contemporain, 1983, Paris (Gallimard) 1998.

Lipovetsky, Gilles, L'Empire de l'éphémère : la mode et son destin dans les sociétés modernes, 1987, Paris (Gallimard) 1997.

Littell, Jonathan, Les Bienveillantes, 2006, Paris (Gallimard) 2007.

Littré, Émile, Dictionnaire de la langue française, 4 vols., Paris (Hachette) 1863-1873.

Livre de la conqueste de la princée de l'Amorée. Chronique de Morée (1204-1305), (1341)-1346, éd. Jean Longnon, Paris (Librarie de la Société de l'histoire de France / Librairie Renouard successeur) 1911. DEAF : ChronMoréeL [cité d'après BFM]

Livres hebdo, magazine hebdomadaire, Paris.

Loaisel de Tréogate, Joseph de, Ainsi finissent les grandes passions ou Les Dernières Amours $d u$ chevalier de ***, vol. 2, Paris (Poinçot) 1788.

Loaisel de Tréogate, Joseph de, Lucile et Milcourt ou Le Cri du sentiment, 1779, Paris (Le Prieur) 1798.

Locke, John, Euvres philosophiques de Locke [trad. par Coste, revue par Thurot], éd. M. Thurot, vol.

1, Paris (Firmin Didot) 1821.

Lombard, Jean, L'Agonie, Paris (Albert Savine) 1888.

Loménie, Louis de, Les Mirabeau : nouvelles études sur la société française du xvIII siècle, 1889, vol. 3, Paris (Dentu) 1892.

Loret, Jean, La Muze historique ou Recueil de lettres en vers (1650-1665), Paris (P. Jannet) 1857.

Lorrain, Jean, Poussières de Paris, Paris (Société d'éditions littéraires et artistiques) 1902.

Loti, Pierre, Au Maroc, 1890. Dans : Voyages (1872-1913), Paris (Laffont) 1991.

Loti, Pierre, Japoneries d'automne, 1889. Dans : Voyages (1872-1913), Paris (Laffont) 1991.

Loti, Pierre, Jérusalem, 1895, Paris (Pirot) 1989.

Loti, Pierre, L'Inde (sans les Anglais), 1903. Dans : Voyages (1872-1913), Paris (Laffont) 1991.

Loti, Pierre, La Galilée, 1896. Dans : Voyages (1872-1913), Paris (Laffont) 1991.

Loti, Pierre, La Mort de Philæ, 1909. Dans : Voyages (1872-1913), Paris (Laffont) 1991. 
Loti, Pierre, Le Désert, 1895. Dans : Voyages (1872-1913), Paris (Laffont) 1991.

Loti, Pierre, Le Livre de la pitié et de la mort, 1891, Paris (Pirot) 1991.

Loti, Pierre, Le Mariage de Loti : Rarahu, 1882, Paris (Calmann-Lévy) 1891.

Loti, Pierre, Le Roman d'un enfant, 1890, Paris (Calmann-Lévy) 1891.

Loti, Pierre, Le Roman d'un spahi, 1881, Paris (Gallimard) 1992.

Loti, Pierre, Les Derniers Jours de Pékin, 1902. Dans : Voyages (1872-1913), Paris (Laffont) 1991.

Loti, Pierre, Les Pagodes d'or. Dans : Voyages (1872-1913), Paris (Laffont) 1991.

Loti, Pierre, Madame Chrysanthème, 1887, Paris (Flammarion) 1990.

Loti, Pierre, Matelot, 1893, Morsang sur Orge (Safrat) 1990.

Loti, Pierre, Mon frère Yves, 1883, Paris (Calmann-Lévy) 1889.

Loti, Pierre, Pêcheur d'Islande, Paris (Calmann-Lévy) 1886.

Loti, Pierre, Un pèlerin d'Angkor, 1912. Dans : Voyages (1872-1913), Paris (Laffont) 1991.

Loti, Pierre, Vers Ispahan, 1904. Dans : Voyages (1872-1913), Paris (Laffont) 1991.

Louvet de Couvray, Jean-Baptiste, Une année dans la vie du chevalier de Faublas, 1787. Dans :

Romanciers du XVIII' siècle, vol. 2, Paris (Gallimard) 1960.

Louyot, Michel, La Japonaise de Prague, Saint-Denis (Mon petit éditeur) 2011.

Louÿs, Pierre, Aphrodite, 1896, Paris (Albin Michel) 1932.

Luchet, Auguste, Les Grandes Cuisines et les grandes caves. Dans : Paris Guide, vol. 2, Paris

(Lacroix / Verboeckhoven) 1867.

Lucinge, René de, Dialogue du François et du Savoysien, 1593, Paris (Amis du Château des Allymes) 1961.

Lucinge, René de, Les Occurrences de la paix de Lyon, 1601. Dans : CFuvres de René Lucinge, Paris (Amis du Château des Allymes) 1962.

Luneau, René, Jésus, l'homme qui évangélisa Dieu, Paris (Albin Michel) 2009.

Lyon scientifique et industriel, revue mensuelle, Lyon.

M. Dumarais ou La Force de l'habitude [sans auteur]. Dans : Revue étrangère de la littérature, des sciences et des arts 30, Saint-Pétersbourg (Bellizard) 1839.

Mac Orlan, Pierre, À bord de l'étoile matutine, 1920, Paris (Gallimard) 1983.

Mac Orlan, Pierre, La Cavalière Elsa, 1921, Paris (Gallimard) 2013.

Mac Orlan, Pierre, Sous la lumière froide, 1961, Paris (Gallimard) 1979.

Macaigne, Maxime, Précis d'hygiène, Paris (Baillière) 1911.

Macé, Eugène et Edouard Imbeaux, Hygiène générale de villes, Paris (Baillière) 1910.

Macé, Jean, Histoire d'une bouchée de pain. Lettres à une petite fille sur la vie de l'homme et des animaux, Paris (J. Hetzel) 1866.

Maeterlinck, Maurice, La Vie des abeilles, 1901, Paris (Fasquelle) 1914.

Magnane, Georges, Les Chers Collègues, Paris (Albin Michel) 1963.

Magouet, Théodore, Le Bon Agriculteur suisse, vol. 1, Lausanne (Delisle) 1842.

Maine de Biran, Pierre, Journal, vol. 1 : février 1814 - 31 décembre 1816, 1816, Neufchatel (La Baconnière) 1954.

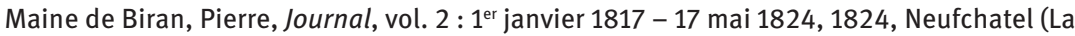
Baconnière) 1955.

Mainwaring, Karin, Les Danseurs de la pluie [trad. par Jean-Pierre Richard ; titre original : The Rain Dancers), Paris (Lansman) 2001.

Mairet, Jean, Chryséide et Arimand, 1630, Baltimore (Johns Hopkins press) / Paris (Presses universitaires de France) 1925.

Mairet, Jean, La Sophonisbe, 1635, Paris (Droz) 1945.

Mairet, Jean, La Sylvie, 1630, Paris (Société nouvelle de librairie et d’édition) 1905.

Maistre Pierre Pathelin, 1485, éd. Richard T. Holbrook, Paris (Honoré Champion) ${ }^{2} 1970$. DEAF :

PathelinH 
Maistre, Joseph de, Les Soirées de Saint-Pétersbourg ou Entretiens sur le gouvernement temporel de la Providence, vol. 1, Paris (Librairie grecque, latine et française) 1821.

Maître-Jan, Antoine, Traité des maladies de l'œil, Troyes (Lefebvre) 1707.

Makine, Andreï, Le Testament français, Paris (Mercure de France) 1995.

Malaurie, Jean, Les Derniers Rois de Thulé : avec les esquimaux polaires face à leur destin, 1955, Paris (Plon) 2010.

Malebranche, Nicolas, Méditations chrétiennes, 1683. Dans : E Fuvres, éd. Jules Simon, Paris (Charpentier) 1842.

Malègue, Joseph, Augustin ou Le Maître est là, 2 vols., Paris (Spes) 1933.

Malet, Léo, Le Soleil n'est pas pour nous, 1949. Dans : Romans, nouvelles et poèmes, vol. 5, Paris (Laffont) 1989.

Malet, Léo, Sueur aux tripes, 1969. Dans : Romans, nouvelles et poèmes, vol. 5, Paris (Laffont) 1989. Malherbe, François de, Commentaire sur Desportes, 1606. Dans : Euvres de Malherbe, éd. L. Lalanne, vol. 4, Paris (Hachette) 1862.

Malherbe, François de, Les Poésies, 1627, Paris (Droz) 1936-1937.

Mallarmé, Stéphane, Correspondance, vol. 1 : 1862-1871, Paris (Gallimard) 1959.

Mallarmé, Stéphane, Correspondance, vol. 2 : 1871-1879, Paris (Gallimard) 1965.

Mallarmé, Stéphane, La Dernière Mode, 1874. Dans : EFuvres complètes, Paris (Gallimard) 1965.

Mallarmé, Stéphane, Poésies, 1898. Dans : Euvres complètes, Paris (Gallimard) 1965.

Mallarmé, Stéphane, Vers de circonstance, 1898. Dans : Euvres complètes, Paris (Gallimard) 1965.

Mallet, Francine, D'un amour l'autre, Paris (Grasset / Fasquelle) 1992.

Mallet-Joris, Françoise, Les Mensonges, Paris (Juillard) 1956.

Malleville, Claude, 1649, Euvres poétiques, Paris (M. Didier) 1976.

Malot, Hector, Le Sang bleu, 1885, Paris (É. Dentu) 1893.

Malot, Hector, Marichette, 2 vols., Paris (Marpon / Flammarion) 1884.

Malot, Hector, Un miracle, Paris (Michel Lévy) 1872.

Malouk, Akim et Danièle Lederman, 1, 2, 3... Cités !, Paris (Ramsay) 1999.

Malraux, André, Antimémoires, 1976. Dans : Euvres complètes, vol. 3, Paris (Gallimard) 1996.

Malraux, André, L'Espoir, 1937. Dans : Romans, Paris (Gallimard) 1960.

Malraux, André, La Condition humaine, 1933. Dans : Romans, Paris (Gallimard) 1960.

Malraux, André, La Corde et les souris, 1976. Dans : Euvres complètes, vol. 3, Paris (Gallimard) 1996.

Malraux, André, Le Règne du malin, 1976. Dans : Euuvres complètes, vol. 3, Paris (Gallimard) 1996.

Malraux, André, Les Conquérants, 1928. Dans : Romans, Paris (Gallimard) 1960.

Manchette, Jean-Patrick, Fatale, 1977, Paris (Gallimard) 1998.

Manchette, Jean-Patrick, Journal (1966-1974), Paris (Gallimard) 2008.

Manchette, Jean-Patrick, Morgue pleine, Paris (Gallimard) 1973.

Manchette, Jean-Patrick, Que d'os !, 1976, Paris (Gallimard) 2009.

Manœuvre, Philippe, L'Enfant du rock, Paris (Lattès) 1985.

Maran, René, Batouala, véritable roman nègre, Paris (Albin Michel) 1921.

Marat, Jean-Paul, Les Pamphlets (1789-1790), 1790, Paris (Fasquelle) 1911.

Marat, Jean-Paul, Les Pamphlets (1790-1792), 1792, Paris (Fasquelle) 1911.

Marc, Charles Chretien Henri, De la folie, vol. 1, Paris (J.-B. Baillière) 1840.

Marceau, Félicien, L'CEuf. Dans : Arts, 1er janvier 1957.

Marchena, José, L'Amour et l'érudition ou Folies du cœur et de l'esprit, Paris (Laurent Beaupré) 1815.

Marco Polo, La Description du monde [trad. par Louis Hambis], Paris (Taffin-Lefort) 1955.

Mareschal, André, La Chrysolite ou Le Secret des romans, Paris (A. de Sommaville) 1634.

Mareschal, André, Le Railleur ou La Satyre du temps, 1637, Bologna (Riccardo Pàtron) 1971.

Mareschal, André, Le Véritable Capitaine Matamore, Paris (Toussainct Quinet) 1640. 
Marguerite d'Angoulême, reine de Navarre, Comédie à dix personnages, 1542. Dans : Théâtre profane, Genève (Droz) / Paris (Minard) 1960.

Marguerite d'Angoulême, reine de Navarre, Comédie sur le trespas du roy, 1547. Dans : Théâtre profane, Genève (Droz) / Paris (Minard) 1960.

Marguerite d’Angoulême, reine de Navarre, Heptaméron, 1559, éd. Renja Salminen, Genève (Droz) 1999.

Marguerite d'Angoulême, reine de Navarre, La Coche, 1541, Genève (Droz) 1971.

Marguerite d'Angoulême, reine de Navarre, Trop, prou, peu, moins, 1544, Genève (Droz) / Paris (Minard) 1960.

Marie de France, Lais [= Die Lais der Marie de France], 1165 (avant 1189) [BFM : 1160], éd. Karl Warnke, Halle (Niemeyer) 1925. DEAF : MarieLaisW ${ }^{3}$

Maris, Christophe, Je hais les dimanches, Paris (Manuscrit) 2006.

Maritain, Jacques, Primauté du spirituel, Paris (Plon) 1927.

Marivaux, Pierre de, L'Épreuve, 1740. Dans : Théâtre complet, vol. 2.

Marivaux, Pierre de, L'Heureux Stratagème, 1733. Dans : Théâtre complet, vol. 2.

Marivaux, Pierre de, L'Indigent Philosophe, 1728. Dans : Journaux et œuvres diverses : section 3 , Paris (Garnier) 1988.

Marivaux, Pierre de, La Colonie, 1750. Dans : Théâtre complet, vol. 2.

Marivaux, Pierre de, La Double Inconstance, 1723. Dans : Théâtre complet, vol. 1.

Marivaux, Pierre de, La Méprise, 1734. Dans : Théâtre complet, vol. 2.

Marivaux, Pierre de, La Surprise de l'amour, 1722. Dans : Théâtre complet, vol. 1.

Marivaux, Pierre de, La Vie de Marianne ou Les Aventures de Madame la comtesse de ${ }^{* * *}, 1745$, Paris (Garnier) 1997.

Marivaux, Pierre de, Le Cabinet du philosophe, 1734. Dans : Journaux et œuvres diverses : section 4, Paris (Garnier) 1988.

Marivaux, Pierre de, Le Paysan parvenu, 1734, Paris (Garnier) 1959.

Marivaux, Pierre de, Le Petit-Maître corrigé, 1734. Dans : Théâtre complet, vol. 2.

Marivaux, Pierre de, Le Spectateur français (1721-1724), 1728. Dans : Journaux et œuvres diverses : section 2, Paris (Garnier) 1988.

Marivaux, Pierre de, Le Télémaque travesti, 1736, Genève (Droz) / Lille (Giard) 1956.

Marivaux, Pierre de, Les Serments indiscrets, 1732. Dans : Théâtre complet, vol. 1.

Marivaux, Pierre de, Les Sincères, 1739. Dans : Théâtre complet, vol. 2.

Marivaux, Pierre de, Théâtre complet, éd. Henri Coulet / Michel Gilot, 2 vols., Paris (Gallimard) 1993/1994.

Marle, C. L., Journal grammatical et didactique de la langue française, vol. 4, Paris (M. Marle) 1829.

Marmontel, Jean-François, Bélisaire, Paris (Merlin) 1767.

Marmontel, Jean-François, Contes moraux, vol. 1, 1761, Paris (Masson / Yonet) 1829.

Marmontel, Jean-François, Les Incas ou La Destruction de l'empire du Pérou, vol. 2, Paris (Lacombe) 1777.

Marmontel, Jean-François, Poétique française, vol. 1, Paris (Lesclapart) 1763.

Marot, Clément, Ballades, première collection publiée en 1538. Dans : Euvres complètes, Paris (Picard) 1868.

Marot, Clément, Chansons, première collection publiée en 1538. Dans : Euvres complètes, Paris (Picard) 1868.

Marot, Clément, Chants divers, collection publiée en 1544. Dans : Fuvres complètes, Paris (Picard) 1868.

Marot, Clément, Cimetière, 1538. Dans : CFuvres complètes, Paris (Picard) 1868.

Marot, Clément, Complaintes, première collection publiée en 1538. Dans : E Fuvres complètes, Paris (Picard) 1868. 
Marot, Clément, Dialogue de deux amoureux, 1544. Dans : Euvres complètes, Paris (Picard) 1868. Marot, Clément, Églogue au roy, 1539. Dans : Euvres complètes, Paris (Picard) 1868.

Marot, Clément, Élégies, première collection publiée en 1538. Dans : Euvres complètes, Paris (Picard) 1868.

Marot, Clément, Épitaphes, collection publiée en 1544. Dans : Euuvres complètes, Paris (Picard) 1868.

Marot, Clément, Épitres, première collection publiée en 1538. Dans : CFuvres complètes, Paris (Picard) 1868.

Marot, Clément, La Complaincte d'un pastoureau chrétien, 1544. Dans : Euvres complètes, Paris (Picard) 1868.

Marot, Clément, L'Adolescence clémentine, 1538, Paris (Le Livre de poche) 2005.

Marot, Clément, Livre premier de la métamorphose, 1534. Dans : Euvres complètes, Paris (Picard) 1868.

Marot, Clément, Livre second de la métamorphose, 1543. Dans : Euvres complètes, Paris (Picard) 1868.

Marot, Clément, Euvres, Rouen (Du Petit Val) 1607.

Marot, Clément, Rondeaux, première collection publiée en 1538. Dans : Euvres complètes, Paris (Picard) 1868.

Marot, Jean, Le Voyage de Venise, 1526, Genève (Droz) 1977.

Marquets, Anne de, Sonets spirituels, 1588 [année de sa mort], éd. Gary Ferguson, Genève (Droz) 1997.

Martin du Gard, Roger, Devenir, 1928. Dans : Euvres complètes, vol. 1, Paris (Gallimard) 1962.

Martin du Gard, Roger, Jean Barois, 1913. Dans : Euvres complètes, vol. 1, Paris (Gallimard) 1962.

Martin du Gard, Roger, La Gonfle, 1928. Dans : CEuvres complètes, vol. 2, Paris (Gallimard) 1959.

Martin du Gard, Roger, Les Thibault. Épilogue, 1940. Dans : Euvres complètes, vol. 2, Paris (Gallimard) 1959.

Martin du Gard, Roger, Les Thibault. L'Été 1914, 1936. Dans : Euvres complètes, vol. 2, Paris (Gallimard) 1959.

Martin du Gard, Roger, Les Thibault. La Belle Saison, 1923. Dans : EFuvres complètes, vol. 1, Paris (Gallimard) 1962.

Martin du Gard, Roger, Les Thibault. La Mort du père, 1929. Dans : EFuvres complètes, vol. 1, Paris (Gallimard) 1962.

Martin du Gard, Roger, Les Thibault. La Sorellina, 1928. Dans : Euvres complètes, vol. 1, Paris (Gallimard) 1962.

Martin du Gard, Roger, Les Thibault. Le Cahier gris, 1922. Dans : CEuvres complètes, vol. 1, Paris (Gallimard) 1962.

Martin du Gard, Roger, Les Thibault. Le Pénitencier, 1922. Dans : Euvres complètes, vol. 1, Paris (Gallimard) 1962.

Martin du Gard, Roger, Notes sur André Gide, 1951. Dans : Euvres complètes, vol. 2, Paris (Gallimard) 1959.

Martin du Gard, Roger, Souvenirs autobiographiques et littéraires, 1955. Dans : EFuvres complètes, vol. 1, Paris (Gallimard)1962.

Martin du Gard, Roger, Un taciturne, 1932. Dans : Euvres complètes, vol. 2, Paris (Gallimard) 1959.

Martin du Gard, Roger, Vieille France, 1933. Dans : Euvres complètes, vol. 2, Paris (Gallimard) 1959.

Martin, Simon, Les Fleurs de la solitude, Paris (Alliot) 1652.

Martineau, Henri, Le Cœur de Stendhal. Histoire de sa vie et de ses sentiments, 2 vols., Paris (Albin Michel) 1952-1953.

Martineaud, Jean-Paul, L'Amour au temps de la vérole, Paris (Glyphe) 2010.

Maspero, François, Les Abeilles et la guêpe, 2002, Paris (Seuil) 2008. 
Massard-Vincent, Josiane et Simonne Pauwles (eds.), D'un nom à l'autre en Asie du Sud-Est, Paris (Karthala) 1999.

Massip, Renée, La Bête quaternaire, Paris (Gallimard) 1963.

Massis, Henri, Jugements, vol. 1, Paris (Plon) 1923.

Massoutre, Guylaine, Renaissances. Vivre avec Joyce, Aquin, Yourcenar, Québec (Fides) 2007.

Matthieu, Pierre , La Guisiade, 1589, Genève (Droz) 1990.

Matthieu, Pierre, Clytemnestre, 1589, Genève (Droz) 1984.

Matthieu, Pierre, Histoire de la mort deplorable de Henri IV, Paris (Guillemot / Thiboust) 1613.

Mauduit, Laurent, Sous le Tapie, Paris (Stock) 2008.

Maumont, Jean de, Les Histoires et chroniques du monde [trad.], Paris (Michel de Vascosan) 1561.

Maupassant, Guy de, Bel-Ami, 1885. Dans : Euvres complètes illustrées, vol. 11, Paris (Librairie de France) 1934.

Maupassant, Guy de, Contes et nouvelles, 1881-1887, Paris (Albin Michel) 1959-1960.

Maupassant, Guy de, La Maison Tellier, Une partie de campagne et autres nouvelles, 1891, Paris (Gallimard) 2010.

Maupassant, Guy de, Notre cœur, 1890. Dans : Euvres complètes illustrées, vol. 12, Paris (Librairie de France) 1938.

Maupassant, Guy de, Une vie, 1883. Dans : CEuvres complètes illustrées, vol. 10, Paris (Librairie de France) 1935.

Mauriac, Claude, La Marquise sortit à cinq heures, 1961, Paris (Gallimard) 1984.

Mauriac, Claude, La Terrasse de Malagar, Paris (Grasset) 1977.

Mauriac, François, Génitrix, 1923. Dans : Euuvres complètes, vol. 1, Paris (Fayard) 1950.

Mauriac, François, Journal 2, 1937. Dans : Euvres complètes, vol. 11, Paris (Fayard) 1952.

Mauriac, François, Journal 3, 1940. Dans : Euvres complètes, vol. 11, Paris (Fayard) 1952.

Mauriac, François, La Vie de Jean Racine, Paris (Plon) 1928.

Mauriac, François, Le Bâillon dénoué après quatre ans de silence, 1945. Dans : Euvres complètes, vol. 11, Paris (Fayard) 1952.

Mauriac, François, Le Baiser au lépreux, 1922. Dans : Euvres complètes, vol. 1, Paris (Fayard) 1950. Mauriac, François, Le Mystère Frontenac, Paris (Grasset) 1933.

Mauriac, François, Le Nœud de vipères, Paris (Grasset) 1932.

Maurois, André, Bernard Quesnay, 1926, Paris (Gallimard) 1973.

Maurois, André, Climats, Paris (Grasset) 1928.

Maurois, André, La Vie de Disraëli, Paris (Gallimard) 1927.

Maurras, Charles, Kiel et Tanger, 1895-1905 : la République française devant l'Europe, 1914, Paris (Nouvelle librairie nationale) 1916.

Maurras, Charles, L'Avenir de l'intelligence, Paris (Nouvelle librairie nationale) 1909.

Maurras, Charles, Le Chemin de Paradis, 1895, Paris (Flammarion) 1927.

Maximin, Daniel, Tu, c'est l'enfance, 2004, Paris (Gallimard) 2008.

Maximy, Hubert de, La Rebouteuse de Champvieille, Montréal (L’Archipel) 2009.

Maynard, François, Le Philandre : poème pastoral, 1623, Genève (J. Gay et fils) 1867.

Maynard, François, Poésies : recueil de 1646 et choix de divers autres recueils, 1646, Paris (Garnier) 1927.

McFarlane, Mhairi, Comme si c'était toi [trad. de l'anglais par Odile Carton], sans lieu, sans éditeur, 2015.

Méda, Dominique, Le Temps des femmes. Pour un nouveau partage des rôles, 2001, Paris

(Flammarion) 2008.

Meigret, Loys, Le Tiers et le Quatriesme Livres de Lucius Moderatus Columella touchant le labour des vignes [trad.], Paris (D. Janot) 1542.

Meilhac, Henri et Ludovic Halévy, La Boule, 1875, Paris (Calmann-Lévy) 1880. 
Meilhac, Henri et Ludovic Halévy, La Grande Duchesse de Géroldstein, 1867. Dans : Théâtre, vol. 2, Paris (Calmann-Lévy) 1899.

Mémoire historique sur la fonte des canons en fer, Paris (Grange) 1758.

Memoire pour le sieur Pierre-Paul Sirven [par Pierre-Firmin de Lacroix, auteur présumé], sans lieu ni éditeur, 1771.

Mémoires de l'Académie de Vaucluse, Avignon.

Mémoires de l'Institut national des sciences et arts : sciences morales et politiques, vol. 2, Paris (Baudouin) An VII, 1799.

Ménard, Louis, Rêveries d'un païen mystique, 1876, Paris (Crès) 1911.

Menestrier, Claude-François, L'Autel de Lyon, Lyon (Jean Molin) 1658.

Menon, Pierre-Louis et Roger Lecotté, Au village de France. Livre 1 : De la Chandeleur à la Saint-Jean, Paris (Bourrelier) 1954.

Menon, Pierre-Louis et Roger Lecotté, Au village de France. Livre 2 : Des moissons à la Noël, Paris (Bourrelier) 1954.

Mercier, Joseph, Le Football, Paris (Presses universitaires de France) 1966.

Mercier, Louis, Hélène Sorbiers, 1911, Lyon (Sud-est) 1952.

Mercier, Louis-Sébastien, Jenneval ou Le Barnevelt françois, 1769, Paris (Cailleau) 1770.

Mercier, Louis-Sébastien, Jezennemours : roman dramatique, 2 vols., Amsterdam (sans éditeur) 1776.

Mercier, Louis-Sébastien, L'An deux mille quatre cent quarante : rêve s'il en fut jamais, Londres (sans éditeur) 1776.

Mercier, Louis-Sébastien, La Brouette du vinaigrier, 1775. Dans : Théâtre du xvIII siècle, vol. 2, Paris (Gallimard) 1974.

Mercier, Louis-Sébastien, La Destruction de la Ligue ou La Réduction de Paris, Amsterdam (sans éditeur) 1782.

Mercier, Louis-Sébastien, Néologie ou Vocabulaire de mots nouveaux, Paris (Moussard / Maradan) 1801.

Mercier, Louis-Sébastien, Tableau de Paris, 8 vols., Amsterdam (Michaud, François et Louis Gabriel) 1782-1783.

Mercure de France, revue, Paris.

Mercure turc, hebdomadaire, Londres.

Méré, Antoine Gombaud, chevalier de, Les Conversations, 1668, Paris (F. Roches) 1930.

Mérijot, É[douard], Traité complet de fabrication et raffinage du sucre de betteraves [trad. de l'allemand ; original de Ludwig Walkhoff], Paris (Savy) 1870.

Mérimée, Prosper, Carmen, 1845, Paris (F. Roches) 1930.

Mérimée, Prosper, Colomba, 1840, Paris (Droz) 1947.

Mérimée, Prosper, La Vénus d'Ille, 1859. Dans : La Vénus d'Ille et autres nouvelles, Paris (GarnierFlammarion) 1982.

Mérimée, Prosper, Lokis, 1869. Dans : La Vénus d'lle et autres nouvelles, Paris (Garnier-Flammarion) 1982.

Merlet, Jean et Claude Saint Étienne, Traité de la connoissance des bons fruits, Paris (Lamy) ${ }^{4} 1782$.

Merlin [attribué à Robert de Boron], $1^{\text {er }}$ quart XIII ${ }^{\mathrm{e}}$, éd. Gaston Paris et Jacob Ulrich, manuscrit Huth, Paris (Didot). 1886. DEAF : MerlinP [nous n'avons pas réussi à retrouver les citations du manuscrit Huth dans l'édition Alexandre Micha, Genève (Droz) 2000]

Merrien, Jean, L'Homme de la mer, 1947, Paris (Hachette) 1962.

Merrien, Jean, Rien que la mer, Paris (Self) 1946.

Merrien, Jean, Votre première voile, Paris (Denoël) 1958.

Mersenne, le père Marin, Correspondance, vol. 1 : 1617-1627, 1627, Paris (Presses universitaires de France) 1945. 
Mersenne, le père Marin, Correspondance, vol. 3 : 1631-1633, 1633, Paris (Presses universitaires de France) 1946.

Mersenne, le père Marin, Correspondance, vol. $4: 1634$, Paris (Presses universitaires de France) 1955.

Mersenne, le père Marin, L'Impiété des déistes, athées et libertins de ce temps, Paris (P. Bilaine) 1624.

Metraux, Alfred, Manuel d'anthropologie culturelle [trad. ; original : Robert Harry Lowie, An Introduction to Cultural Anthropology], Paris (Payot) 1936.

Meynne, Charles, Liquidation de société commerciale, Bruges (de Moor) 1835.

Michaux, Henri, Un certain Plume, 1936, Paris (Gallimard) 1963.

Michel, André, Canova et le retour à l'Antique. Dans : Revue des deux mondes, 15 octobre 1922.

Michel, Claude, Psy... en liberté, vol. 2, Paris (Publibook) 2013.

Michel, Louise, Manifeste des anarchistes. Dans : Mémoires de Louise Michel écrits par elle-même, Paris (F. Roy) 1886.

Michelet, Jules, Écrits de Jeunesse : Journal (1820-1823), Paris (Gallimard) 1959.

Michelet, Jules, Histoire de France, vol. 17, Paris (Chamerot et Lauwereyns) 1867.

Michelet, Jules, Journal, vol. 1 : 1828-1848, Paris (Gallimard) 1959.

Michelet, Jules, Journal, vol. 2 : 1849-1860, Paris (Gallimard) 1962.

Michelet, Jules, L'Insecte, 1857, Paris (Hachette) 1858.

Michelet, Jules, L'Oiseau, 1856, Paris (Hachette) 1857.

Michelet, Jules, La Mer, 1861, Paris (Gallimard) 1983.

Michelet, Jules, Le Peuple, Paris (Hachette / Paulin) 1846.

Michelet, Jules, Mémorial, 1822. Dans : Écrits de jeunesse, Paris (Gallimard) 1959.

Michelet, Jules, Tableau de la France, 1833, Bruxelles (Complexe) 1995.

Milet-Mureau, Louis-Antoine Destouff, Voyage de La Pérouse autour du monde, 4 vols., Paris (Imprimerie de la République) An V, 1797.

Mille, Pierre, Barnavaux et quelques femmes, Paris (Calmann-Lévy) 1908.

Millet, Catherine, La Vie sexuelle de Catherine M. précédé de Pourquoi et comment, 2001, Paris (Seuil) 2002.

Millien, Achille, Légendes d'aujourd'hui, Paris (Garnier) 1870.

Milosz, Oscar, L'Amoureuse Initiation, 1910, Paris (Silvaire) 1958.

Miomandre, Francis de, Écrit sur de l'eau, 1908, Paris (Émile-Paul) 1919.

Mirabeau, comte Honoré de, Le Libertin de qualité ou Ma conversion, 1783, Paris (Bibliothèque des curieux) 1911.

Mirabeau, comte Honoré de, Lettres originales écrites du donjon de Vincennes pendant les années 1777-1780, 4 vols. Paris (Garnery) / Strasbourg (Treuttel) / Londres (de Boffe) 1792.

Mirabeau, marquis Victor de, L'Ami des hommes ou Traité de la population, vol. 1, 1755, Avignon (sans nom) 1756.

Miracle de Amis et Amille, prob. 1365. Dans : Miracles de Nostre Dame par personnages. DEAF : MirNDPers23S

Miracle de Clovis, prob. 1381. Dans : Miracles de Nostre Dame par personnages.

Miracle de l'abbeesse grosse, 1340. Dans : Miracles de Nostre Dame par personnages.

Miracle de l'enfant donné au diable, prob. 1339. Dans : Miracles de Nostre Dame par personnages. DEAF : MirNDPers1K

Miracle de l'evesque a qui Nostre Dame s'apparut, prob. 1348. Dans : Miracles de Nostre Dame par personnages.

Miracle de l'evesque que l'arcediacre murtrit, prob. 1341. Dans : Miracles de Nostre Dame par personnages. 
Miracle de la femme du roy de Portigal, prob. 1342. Dans : Miracles de Nostre Dame par personnages.

Miracle de la fille d'un roy, prob. 1379. Dans : Miracles de Nostre Dame par personnages.

Miracle de la fille du roy de Hongrie, prob. 1371. Dans : Miracles de Nostre Dame par personnages. DEAF : MirNDPers29M

Miracle de la marquise de la Gaudine, 1350. Dans : Miracles de Nostre Dame par personnages.

Miracle de notre dame Berthe, prob. 1373. Dans : Miracles de Nostre Dame par personnages.

Miracle de Robert le Dyable, prob. 1375. Dans : Miracles de Nostre Dame par personnages. DEAF : MirNDPers33S

Miracle de saint Alexis, 1382. Dans : Miracles de Nostre Dame par personnages. DEAF : MirNDPers40M Miracle de saint Jehan Crisothomes, prob. 1344. Dans : Miracles de Nostre Dame par personnages. Miracle de saint Jehan le Paulu, prob. 1372. Dans : Miracles de Nostre Dame par personnages. Miracle de saint Lorens, 1380. Dans : Miracles de Nostre Dame par personnages.

Miracle de saint Panthaleon, prob. 1364. Dans : Miracles de Nostre Dame par personnages.

Miracle de Theodore, 1357. Dans : Miracles de Nostre Dame par personnages.

Miracle de un Pape qui vendi le basme, 1346. Dans : Miracles de Nostre Dame par personnages.

Miracle de un paroissian esconmenié, 1356. Dans : Miracles de Nostre Dame par personnages.

Miracle de un prevost que Nostre Dame delivra, 1352. Dans : Miracles de Nostre Dame par personnages.

Miracle du roy Thierry, prob. 1374. Dans : Miracles de Nostre Dame par personnages.

Miracles de Nostre Dame par personnages, prob. 1339-1382, éd. Gaston Paris / Ulysse Robert, 8 vols., Paris (Firmin Didot) 1876-1893. DEAF : MirNDPers1-40P

Mirbeau, Octave, Le Journal d'une femme de chambre, 1900, Paris (Fasquelle) 1937.

Mocky, Jean-Pierre, Les Vacances du pouvoir, Paris (Michalon) 2007.

Modiano, Patrick, Les Boulevards de ceinture, 1972, Paris (Gallimard) 1987.

Modiano, Patrick, Un pedigree, Paris (Gallimard) 2005.

Modiano, Patrick, Villa Triste, 1975, Paris (Gallimard) 1993.

Mohrt, Michel, Vers l'ouest, 1988. Dans : La Maison du père suivi de Vers l'Ouest : souvenirs de jeunesse, Paris (Gallimard) 1990.

Moigno, abbé François, Les Splendeurs de la foi, vol. 4, Paris (Blériot) 1879.

Moinot, Pierre, Le Guetteur d'ombre, 1979, Paris (Gallimard) 1984.

Moinot, Pierre, Le Sable vif, Paris (Gallimard) 1963.

Moles, A., Cerveaux géants, machines qui pensent [trad. ; original de Edmund Callis Berkeley], Paris (Dunod) 1957.

Molfino, Miguel Ángel, Monstres à l'état pur [trad. de l'espagnol par Christilla Vasserot], Paris (Ombres noires) 2013.

Molière, Dépit amoureux, 1663. Dans : Euvres, vol. 1.

Molière, Dom Juan ou Le Festin de Pierre, 1673. Dans : Euvres, vol. 5.

Molière, George Dandin ou Le Mari confondu, 1669. Dans : Euvres, vol. 6.

Molière, L'Avare, 1669. Dans: EFuvres, vol. 7.

Molière, L'École des femmes, 1663. Dans : Euvres, vol. 3.

Molière, L'École des maris, 1661. Dans : EFuvres, vol. 2.

Molière, La Comtesse d'Escarbagnas, 1671. Dans : CEuvres complètes, Paris (Firmin Didot) 1838.

Molière, La Princesse d'Élide, 1664. Dans : Euvres, vol. 4.

Molière, Le Misanthrope, 1667. Dans : EFuvres, vol. 5.

Molière, Le Sicilien ou L'Amour peintre, 1668. Dans : Euvres, vol. 6.

Molière, Le Tartuffe ou L'Imposteur, 1669. Dans : Euvres, vol. 4.

Molière, Les Amants magnifiques, 1673. Dans : Euvres, vol. 7.

Molière, Les Fâcheux, 1662. Dans : Fuvres, vol. 3. 
Molière, Les Femmes savantes, 1673. Dans : Fuvres, vol. 9.

Molière, Les Fourberies de Scapin, 1671. Dans : Euvres, vol. 8.

Molière, Les Précieuses ridicules, 1660. Dans : CFuvres, vol. 2.

Molière, Monsieur de Pourceaugnac, 1670. Dans : Euvres, vol. 7.

Molière, Euvres de Molière, éd. Eugène Despois et Paul Mesnard, 9 vols., Paris (Hachette) 1873 et suiv.

Molière, Sganarelle ou Le Cocu imaginaire, 1660. Dans : CEuvres, vol. 2.

Molinié, Jean, La Jeune Femme indigne, vol. 2, Paris (Le Manuscrit) 2012.

Mondiot, Vincent, L'Ombre des arches, Saint-Laurent d'Oingt (Mnémos) 2019.

Monési, Irène, Nature morte devant la fenêtre, Paris (Mercure de France) 1966.

Monnier, Adrienne, Rue de l'Odéon, Paris (Albin Michel) 1960.

Monnier, Marc, Un détraqué : roman expérimental, Paris (Calmann-Lévy) 1883.

Monnier, Thyde, Je ne suis pas des vôtres, Paris (Fayard) 1958.

Monselet, Charles, La Lorgnette littéraire: dictionnaire des grands et des petits auteurs de mon temps, Paris (Poulet-Malassis et De Broise) 1859.

Montaigne, Michel de, Essais, 1592, 2 vols., Paris (Presses universitaires de France) 1965.

Montchrestien, Antoine de, 1615, Traicté de l'économie politique, Genève (Droz) 1999.

Montchrestien, Antoine de, Aman, 1604, éd. George Otto Seiver, Philadelphia (University of Philadelphia press) / London (Oxford university press) 1939.

Montchrestien, Antoine de, Épistre, 1604. Dans : idem, Two Tragedies. Hector and La Reine d'Escosse, éd. C.N. Smith, London (The Athlone press) $1972: 27-29$.

Montchrestien, Antoine de, Hector, 1604. Dans : Les Tragédies de Montchrestien, éd. Louis Petit de Juleville, Paris (Plon) 1891.

Montchrestien, Antoine de, L'Escossoise ou Le Désastre, 1601. Dans : La Reine d'Escosse, Paris / La Haye (Mouton) 1975.

Montchrestien, Antoine de, Les Lacènes, 1604, Philadelphia (University of Philadelphia) 1943.

Montcorbier, Flora, Le Communisme de marché. De l'utopie marxiste à l'utopie mondialiste, Lausanne (L'Âge d'homme) 2000.

Montépin, Xavier de, Les Chevaliers du lansquenet, Paris (Alexandre Cadot) 1857.

Montesquieu, Correspondance (1716-1755), 2 vols., Paris (Champion) 1914.

Montesquieu, De l'esprit des loix, vol. 3, 1755, Paris (Belles lettres) 1950.

Montesquieu, Lettres persanes, 1721, 3 vols., Paris (F. Roches) 1929.

Montesquiou-Fezensac, Raymond de, Souvenirs militaires de 1804 à 1814, 1858 (extrait publié dans La Correspondance littéraire), Paris (Librairie militaire) 1870.

Montherlant, Henry de, Encore un instant de bonheur, 1934. Dans : Romans, Paris (Gallimard) 1962.

Montherlant, Henry de, Fils de personne, 1943. Dans : Théâtre, Paris (Gallimard) 1961.

Montherlant, Henry de, L'Exil, 1929. Dans : Théâtre, Paris (Gallimard) 1961.

Montherlant, Henry de, La Petite Infante de Castille, 1929. Dans : Romans, Paris (Gallimard) 1962.

Montherlant, Henry de, La Reine morte, 1942. Dans : Théâtre, Paris (Gallimard) 1961.

Montherlant, Henry de, La Relève du matin, 1920, Paris (Gallimard) 1953.

Montherlant, Henry de, La Ville dont le prince est un enfant, 1951. Dans : Théâtre, Paris (Gallimard) 1961.

Montherlant, Henry de, Le Démon du bien, 1937. Dans : Romans, Paris (Gallimard) 1962.

Montherlant, Henry de, Le Songe, 1922. Dans : Romans, Paris (Gallimard) 1962.

Montherlant, Henry de, Les Bestiaires, 1926. Dans : Romans, Paris (Gallimard) 1962.

Montherlant, Henry de, Les Célibataires, 1934. Dans : Romans, Paris (Gallimard) 1962.

Montherlant, Henry de, Les Jeunes Filles, 1936. Dans : Romans, Paris (Gallimard) 1962.

Montherlant, Henry de, Les Lépreuses, 1939. Dans : Romans, Paris (Gallimard) 1962.

Montherlant, Henry de, Les Olympiques, 1924. Dans : Romans, Paris (Gallimard) 1962. 
Montherlant, Henry de, Pasiphaé, 1936. Dans : Théâtre, Paris (Gallimard) 1961.

Montherlant, Henry de, Pitié pour les femmes, 1936. Dans : Romans, Paris (Gallimard) 1962.

Montho, Gaston, Brin d'amour, Paris (Panama) 1950.

Montluc, Adrien de, La Comédie de proverbes, Paris (Fr. Targa) 1635.

Montluc, Adrien de, La Comédie des proverbes, 1633. Dans : Ancien Théâtre françois, vol. 9.

Montolieu, Isabelle de, Le Fils d'adoption ou Amour et coquetterie, [trad. libre de l'allemand; original : Auguste Lafontaine, Henriette Belman], vol. 2, Paris (Debray) An XII, 1803-1804.

Montreux, Nicolas de, La Sophonisbe, 1601, Genève (Droz) 1976.

Morand, Paul, Fermé la nuit, 1923, Paris (Gallimard) (1957).

Morand, Paul, Londres, Paris (Plon) 1933.

Morand, Paul, New-York, Paris (Flammarion) 1930.

Morard, Marius, Les Secrets de la cuisine dévoilés, Marseille (Archard) 1886.

Moréas, Jean et Paul Adam, Le Thé chez Miranda, Paris (Tresse et Stock) 1886.

Moréas, Jean, Iphigénie, 1904, Paris (Mercure de France) 1921.

Moréas, Jean, Les Syrtes, 1884. Dans : Premières poésies, Paris (Mercure de France), sans date.

Moréas, Jean, Poèmes et sylves : 1886-1896, Paris (Mercure de France), sans date.

Moreau, Hégésippe, Le Neveu de la fruitière. Dans : Les Ouvriers-poètes, éd. H. Bondilh et Amédée Lacrois, Paris (Imprimeurs-Unis) / Marseille (Deretz jeune) 1845.

Morel, François et Valentin, Dictionnaire amoureux de l'inutile, Paris (Plon) 2020.

Moreno, Blake, Si différent [trad. de l'anglais par S. Christelle; titre original : The Difference Between], Bessancourt (Juno) 2019.

Morgiève, Richard, Ma vie folle, Paris (Pauvert) 2000.

Morgiève, Richard, Ton corps, Paris (Pauvert) 2000.

Morice, Hyacinthe, Mémoires pour servir de preuves à l'histoire ecclésiastique et civile de Bretagne, vol. 3, Paris (Osmont) 1746.

Morot-Sir, Isabelle et Marie-Hélène, De lettres en lettres... Année 1912, Paris (Publibook) 2005.

Mort Artu [= La Mort le roi Artu], $1^{\text {er }}$ quart XIII ${ }^{\mathrm{e}}$ éd. Jean Frappier, Genève (Droz) ${ }^{31996 .}$ DEAF : MortArtuF 2(3?)

Moselly, Émile, Terres lorraines, Paris (Plon) 1907.

Mouhy, Charles Fieux de, La Paysanne parvenue ou Les Mémoires de Madame la Marquise de L. V., vol. 1, 1735, Amsterdam (Arkstee) / Leipzig (Merkus) 1740.

Moumen, Abderahmen, Les Français musulmans en Vaucluse (1962-1991), Paris (L'Harmattan) 2003.

Mounier, Emmanuel, L'Éveil de l'Afrique noire, 1948. Dans : EFuvres, vol. 3, Paris (Seuil) 1962.

Mounier, Emmanuel, Le Personnalisme, 1947, Paris (Presses universitaires de France) 1959.

Mounier, Emmanuel, Traité du caractère, 1946, Paris (Seuil) 1961.

Mourier, Samuel, Vers les rivages de l'Amer, Paris (manuscrit.com) 2001.

Mourier-Casile, Pascaline, La Fente d'eau, sans lieu (Nadeau) 2011.

Mréjen, Valérie, Eau sauvage, Paris (Allia) 2004.

Muhimpundu, Félicité, Éducation et citoyenneté au Rwanda, Paris (L’Harmattan) 2002.

Murger, Henri, Les Nuits d'hiver, 1861, Paris (Michel Lévy) 1868.

Murger, Henri, Scènes de la vie de bohème, 1848, Paris (Michel Lévy) 1869.

Murger, Henri, Scènes de la vie de jeunesse, 1851, Paris (Michel Lévy) 1861.

Murhega, Jean B., La Problématique de la mondialisation en Afrique noire, Saint-Denis (Mon petit éditeur) 2010.

Muselli, Vincent, Euvre poétique, 1941, Paris (Points et contrepoints) 1957.

Musset, Alfred de, André del Sarto, 1833. Dans : Comédies et proverbes, vol. 1, Paris (Belles lettres) 1934.

Musset, Alfred de, Articles publiés dans la Revue des deux mondes (1832-1833), Chroniques de la quinzaine. 
Musset, Alfred de, Confessions d'un enfant du siècle, 1836. Dans : Euvres complètes, vol. 7, Paris (Conard) 1937.

Musset, Alfred de, Croisilles, 1839. Dans : Nouvelles de Alfred de Musset, Paris (Charpentier) 1866. Musset, Alfred de, Emmeline, 1841. Dans : Nouvelles de Alfred de Musset, Paris (Charpentier) 1861. Musset, Alfred de, La Nuit de mai, 1835. Dans : CFuvres complètes, vol. 2, Paris (Conard) 1923.

Musset, Alfred de, Lettres de Dupuis et Cotonet (1836-1837). Dans : Revue des deux mondes, vol. 3, 1837.

Musset, Alfred de, Lorenzaccio, 1834. Dans : Comédies et proverbes, vol. 2, Paris (Belles lettres) 1952.

Musset, Alfred de, Margot, 1841. Dans : Nouvelles de Alfred de Musset, Paris (Charpentier) 1861. Musset, Alfred de, Mimi Pinson, 1845. Dans : CEuvres complètes, vol. 9, Paris (Conard) 1940. Musset, Alfred de, Namouna, 1832. Dans : Euvres complètes, vol. 1, Paris (Conard) 1923. Musset, Alfred de, Premières Poésies (1829-1835), Paris (Charpentier) 1878.

Musset, Alfred de, Rolla, 1833. Dans : Euvres complètes, vol. 2, Paris (Conard) 1923.

Nadal, abbé Augustin, Du luxe des dames romaines, 1712. Dans : Mémoires de littérature, tirez des registres de l'Académie royale des inscriptions et Belles lettres, vol. 4, Paris (Imprimerie royale) 1723.

Nail, Isabel, Bleu horizon, Coudray-Macouard (Cheminements) 2005.

Nannicini, Chiara, Heinrich Böll et Leonardo Sciasca « ennemis de l'État » (L'Honneur perdu de Katharina Blum, L’Affaire Moro). Dans : Vincent Ferré et Daniel Mortier (éds.), Littérature, histoire et politique au xxe siècle : hommage à Jean-Pierre Morel, Paris (Le Manuscrit / L'esprit des Lettres) 2010.

Narcissus, 1426. Dans : Alfons Hilka, Das mittelfranzösische Narcissusspiel, Zeitschrift für Romanische Philologie 56-3 (1936), pp. 275-321.

Naudé, Gabriel, Apologie pour tous les grands hommes qui ont esté accusez de magie, Paris (Eschart) 1669.

Navarre, Yves, Biographie, Paris (Flammarion) 1981.

Navarre, Yves, Lady Black, Paris (Flammarion) 1971.

Nel, Raoul, Boesinghe ou Les Combats de la $87^{7}$ division territoriale sur l'Yser (1914-1918), Rennes (Nouvelliste de Bretagne) 1918.

Nerval, Gérard de, Faust [trad. ; original de Goethe], 1828, Paris (Garnier) 1956.

Nerval, Gérard de, Le Second Faust [trad. ; original de Goethe], 1840, Paris (Garnier) 1956.

Nerval, Gérard de, Les Filles du feu, 1854. Dans : Euvres, vol. 1, Paris (Garnier) 1958.

Nerval, Gérard de, Voyage en Orient, 1851. Dans : Euvres complètes, vol. 2, Paris (Gallimard) 1984. Nesmy, Jean, L'Ivraie. Dans : La Revue hebdomadaire, vol. 1, 1905.

Nève, François-Xavier, Thèses, mémoires et TFE. Minidico d'écriture, de ponctuation et d'apparat critique, Liège (Céfal) 2008.

Nicolas de Baye, Journal (1400-1417), éd. Alexandre Tuetey, Paris (Renouard) 1885. [cité d'après Frantext]

Nicole Oresme, Le Livre de Ethiques d'Aristote [traduction commentée du latin], 1370, éd. Albert Douglas Menut, New York (Stechert) 1940. DEAF : OresmeEthM

Nicole Oresme, Le Livre du ciel et du monde, 1377, éd. Albert D. Menut et Alexander J. Denomy, Madison, Milwaukee, London (University of Wisconsin press) 1968. DEAF : OresmeCielM

Nicole, Pierre, Essais de morale contenus en divers traités, vol. 2, 1671, Paris (G. Desprez) 1701.

Nizan, Paul, La Conspiration, Paris (Gallimard) 1938.

Nizan, Paul, Les Chiens de garde, Paris (Rieder) 1932.

Nodier, Charles, Jean Sbogar, 1818. Dans : Romans, Paris (Charpentier) 1873.

Nodier, Charles, Smarra ou Les Démons de la nuit, 1821. Dans : Smarra suivi de Trilby, Paris (Quatre Vents) 1946. 
Nodier, Charles, Trilby ou Le Lutin d'Arguil, 1822. Dans : Smarra suivi de Trilby, Paris (Quatre Vents) 1946.

Noirez, Jérôme, Féerie pour les ténèbres, Saint-Mammès (Le Bélial) 2012.

Noirot-Bonnet, Louis, Traité de la culture des forêts, Paris (Huzard) 1832.

Nolot, Pascaline, Sur l'écorchure de tes mots, Chasseneuil sur Bonnieur (Chat noir) 2019.

Nora, Dominique, Les Pionniers de l'or vert, Paris (Grasset) 2009.

Nord, Pierre, Bonne chance, Fathima !, Paris (Fayard) 1958.

Nosban, Paul, Nouveau Manuel complet de l'ébéniste, du layetier, du marqueteur, du sculpteur, vol. 2, Paris (Librairie encyclopédique de Roret) 1857.

Nourissier, François, À défaut de génie, 2000, Paris (Gallimard) 2011.

Nourissier, François, Le Maître de maison, Paris (Grasset) 1968.

Nourissier, François, Lettre à mon chien, 1975, Paris (Gallimard) 1990.

Nourissier, François, Un petit bourgeois, 1963, Paris (Gallimard) 2002.

Nouveau dictionnaire françois, éd. Jean-Baptiste Delamollière, Paris / Lyon (Delamollière) 1793.

Nouveau Dictionnaire historique des sièges et batailles, vol. 5, Paris (Gilbert / Fantin) 1809.

Nouveau Recueil complet des fabliaux, éd. Willem Noomen et Nico van den Boogaard, 10 vols., Assen (Van Gorcum) 1983-1998. DEAF : NoomenFabl [sauf indication contraire, nous citons le « texte critique ", suivi du numéro du vers]

Nouvelle Biographie générale, vol. 13, Paris (Didot) 1855.

Nouvelles françaises du XVe siècle, éd. E. Langlois, Paris (Champion) 1908.

Nouvelles françoises en prose du xıve siècle, éd. L. Moland et C. d'Héricault, Paris (Jannet) 1858. DEAF : MolandHéricault ${ }^{2}$

Octovien de Saint Gelais et André de La Vigne, entre 1498 et 1502, Le Vergier d'honneur, Paris (Philippe Lenoir et Jean Jehannot) 1521-1522.

Octovien de Saint-Gelais, L'Ystoire de Eurialus et Lucresse, avant 1489. Dans : Eneas Silvius Piccolomini, Euvres érotiques, éd. et trad. Frédéric Duval, Turnhout (Brepols) 2003.

Oduaga-Zolarde, M., Les Courses de taureaux expliquées, Paris (Dentu) 1854.

Office national de la propriété industrielle, Brevet d'invention [périodique], Paris.

Ohnet, Georges, Le Curé de Favières, 1897, Paris (Albin Michel) 1948.

Ohnet, Georges, Le Maître de forges, Paris (Ollendorf) 1882.

Oldenbourg, Zoé, Les Cités charnelles ou L'Histoire de Roger de Montbrun, 1961, Paris (Gallimard) 1983.

Oldenbourg, Zoé, Visages d'un autoportrait, 1977, Paris (Gallimard) 1988.

Olivier de La Haye, Poëme sur la grande peste de 1348, 1426, Lyon (H. Georg) 1888.

Olivier de la Marche, Mémoires, $4^{\mathrm{e}}$ quart xve [commencé 1472 , écrit surtout après 1477 et jusqu'avant 1502], Paris (Renouard) 1883. DEAF : OIMarche [cité d'après Frantext]

Ollivier, Bernard, Marche et invente ta vie, Paris (Flammarion) 2015.

Ollivier, Éric, L'Orphelin de mer, 1982, Paris (Gallimard) 1984.

Orban, Christine, Fringues, Paris (Albin Michel) 2002.

Ormesson, Jean d', Au plaisir de dieu, 1974, Paris (Gallimard) 1995.

Ormesson, Jean d', La Douane de mer, 1993, Paris (Gallimard) 1995.

Ormesson, Jean d', Le Bonheur à San Miniato, 1987, Paris (Livre de poche) 1994.

Ormesson, Jean d', Le Vent du soir, 1985, Paris (Livre de poche) 1988.

Ormesson, Jean d', Tous les hommes sont fous, 1986, Paris (Livre de poche) 1989.

Orsenna, Erik, Grand Amour, 1993, Paris (Seuil) 1995.

Osmont, Stéphane, Éléments incontrôlés, Paris (Grasset) 2012.

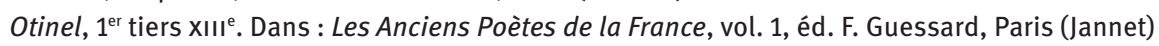
1858. DEAF : OtinG 
Otreppe de Bouvette, Albert d', Tout ce qu'on voudra: antiquités, sentiments, pensées diverses. Essai de tablettes liégeoises, Liége (J.-G. Carmanne) 1865.

Ott, Jacqueline et Bertrand, La Pédagogie du chant classique et les techniques européennes de la voix, Paris (L'Harmattan) 2006.

Otte, Jean-Pierre, Le Ravissement, Paris (Laffont) 1987.

Oudin, Antoine, Curiositez françoises, pour supplement aux dictionnaires, Paris (Antoine de Sommaville) 1640.

Ouville, Antoine d', L'Esprit folet, 1642, éd. critique établie par Elsa Jollès dans le cadre d'un mémoire de maîtrise sous la direction de Georges Forestier (2000) (http://dramacode.github. io/html/ouville_espritfolet.html, consulté le 16.3.2020).

Ovidio, Pierre d', Le Paradis pour demeure, Paris (Presses de la Cité) 2013.

Ozanam, Frédéric, Essai sur la philosophie de Dante, 1838. Dans : Deux Euvres de jeunesse, Paris / Lyon (E. Vitte) 1913.

Ozouf, Mona, Composition française : retour sur une enfance bretonne, 2009, Paris (Gallimard) 2010. Page, Alain, Tchao Pantin, Paris (Denoël) 1982.

Pagnol, Marcel, La Belle Meunière, 1948 [film], Dans : EFuvres complètes, vol. 6, Paris (Club de l'Honnête homme) 1970.

Paillot de Montabert, Jacques-Nicolas, Traité complet de la peinture, vol. 9, Paris (J. F. Delion) 1829.

Palissot de Montenoy, Charles, Le Cercle ou Les Originaux, 1755. Dans : Euvres complètes, vol. 4, Paris (L. Collin) 1809.

Palissot de Montenoy, Charles, Les Philosophes, Paris (Duchesne) 1760.

Palissot de Montenoy, Charles, Petites Lettres sur de grands philosophes, 1757. Dans : Euvres complètes, vol. 1, Paris (L. Collin) 1809.

Palissy, Bernard. Euvres complètes, 1580, Paris (Dubochet) 1844.

Pallissy, Bernard, Recepte veritable, 1563, Genève (Droz) 1988.

Papillon de Lasphrise, Marc, Diverses poésies, 1599, éd. par Nerina Clerici Balmas, Paris / Genève (Droz) 1988.

Papon, Loys, Pastorelle : sur la victoire obtenue contre les Alemands, Reytres, Lansquenets, Souysses et Françoys rebelles à Dieu et au Roy treschretien l'an 1587, 1588, St Étienne (Centre d'études foréziennes) 1976.

Paraz, Albert, L’Adorable Métisse, Givors (Martel) 1953.

Paraz, Albert, Remous, Paris (Bateau ivre) 1947.

Paraz, Albert, Valsez saucisses, Paris (Amiot-Dumont) 1950.

Parenteau, F., La Découverte du Jardin des Plantes de Nantes. Dans : Bulletin de la Société archéologique de Nantes et du Département de la Loire-Inférieure, Nantes (Vincent Forest) 1868.

Parfaict, François et Claude, Dictionnaire des théatres de Paris, Paris (Lambert) 1756.

Parnet, François, En suivant la flamme, Paris (Calmann-Lévy) 1918.

Pascal, Blaise, Les Provinciales ou Les Lettres écrites par Louis de Montalte à un provincial de ses amis et aux RR.PP. Jésuites, 1656-1657, Paris (Garnier) 1965.

Pascal, Blaise, Pensées, 1662, Paris (Gallimard) 1998.

Pasquier, Dominique, L'Internet des familles modestes : enquête dans la France rurale, Paris (Presses des mines) 2018.

Pasquier, Estienne, Lettres familières, 1613, Paris / Genève (Droz) 1974.

Pasteur, Louis, Correspondance, vol. 3 (1877-1884), 1884, éd. Pasteur Vallery-Radot, Paris (Flammarion) 1951.

Patin, Guy, Lettres, vol. 1 : Lettres (1630-1649), 1649, Paris (Champion) 1907.

Patin, Guy, Lettres, vol. 3 : Lettres de Gui Patin, 1672, , éd. J.-H. Réveillé-Parisi, Paris (Baillière) 1846. Patouillet, Jules, Les Idées de A. N. Ostrovskij sur l'art dramatique. Dans : Revue des études slaves, Paris, 1929. 
Paulet, Jean, L'Art du fabriquant d'étoffes de soie, vol. 5, [Paris] (Delatour) 1774.

Paulin, Rachel, 6 petits enfants disparus..., sans lieu ni éditeur, 2014.

Paulmier, Julien le, Traité du vin et du sidre [trad. du latin par Jacques de Cahaignes], Caen (Pierre le Chandelier) 1589 [reproduction : Rouen (H. Lestringant) 1896].

Pauls, Charmaine, En eaux troubles: Le Requin de la Pègre [trad. par Laure Valentin], vol. 1, sans lieu (Grey eagle) 2018.

Paysan, Catherine, Les Feux de la Chandeleur, Paris (Denoël) 1966.

Péguy, Charles, L’Argent, 1913. Dans : Euvres en prose, vol. 2, Paris (Gallimard) 1961.

Péguy, Charles, La Tapisserie de Notre-Dame, 1913. Dans : CEuvres poétiques complètes, Paris (Gallimard) 1941.

Péguy, Charles, Le Mystère de la charité de Jeanne d'Arc, 1910. Dans : CEuvres poétiques complètes, Paris (Gallimard) 1941.

Péguy, Charles, Le Porche du mystère de la deuxième vertu, 1911. Dans : Euvres poétiques complètes, Paris (Gallimard) 1941.

Péguy, Charles, Quatrains, 1914. Dans : Euvres poétiques complètes, Paris (Gallimard) 1941.

Péguy, Charles, Victor-Marie, comte Hugo, 1910. Dans : Euvres en prose, vol. 2, Paris (Gallimard) 1961.

Peiresc, Nicolas [Nicolas-Claude Fabri] de, Lettres, vol. 1 : Lettres aux frères Dupuy (1617-1627), 1627, Paris (Imprimerie nationale) 1888.

Peiresc, Nicolas [Nicolas-Claude Fabri] de, Lettres, vol. 3 : Lettres aux frères Dupuy (1634), 1634, Paris (Imprimerie nationale) 1892.

Peiresc, Nicolas [Nicolas-Claude Fabri] de, Lettres, vol. 5 : Lettres à Guillemin (1610-1637), Paris (Imprimerie nationale) 1894.

Peiresc, Nicolas [Nicolas-Claude Fabri] de, Lettres, vol. 6 : Lettres à sa famille, 1625, Paris (Imprimerie nationale) 1896.

Peissel, Philippe, Les Natures fondamentales, Paris (Interéditions) 1996.

Peisson, Édouard, La Mer est un pays secret, Paris (Grasset) 1948.

Peisson, Édouard, Parti de Liverpool, 1932, Paris (Grasset) 1933.

Péladan, Joséphin, Le Vice suprême, 1884, Paris (Laurens) 1886.

Pèlerinage ou Voyage de Charlemagne à Jérusalem et à Constantinople [= Karls des Großen Reise nach Jerusalem und Constantinopel], $2^{\mathrm{e}}$ moitié $\mathrm{xII}{ }^{\mathrm{e}}$, éd. Eduard Koschwitz, Leipzig (Reisland) 41900. DEAF : PelCharlK

Pellisson, Paul, Lettres historiques, vol. 2, Paris (François Barois) 1729.

Pelt, Jean-Marie, La Compétition, mère de toutes choses ?, [Paris] (L’Emmanuel) 2008.

Pennac, Daniel, Au bonheur des ogres, 1985, Paris (Gallimard) 2010.

Pennac, Daniel, La Fée Carabine, 1987, Paris (Gallimard) 2011.

Pennac, Daniel, La Petite Marchande de prose, 1989, Paris (Gallimard) 1995.

Perec, Georges, L'Infra-ordinaire, Paris (Seuil) 1989.

Perec, Georges, La Disparition, 1969, Paris (Gallimard) 1995.

Perec, Georges, La Vie mode d'emploi : romans, 1978, Paris (Livre de poche) 1995.

Pergaud, Louis, De Goupil à Margot : histoire de bêtes, 1910, Paris (Mercure de France) 1932.

Pergaud, Louis, La Guerre des boutons : le roman de ma douzième année, 1912, Paris (Mercure de France) sans date.

Perochon, Ernest, Nêne, 1920, Cinq-Mars-la-Pile (Neobook) 2015.

Perpillou, Aimé, L'Industrie des constructions navales, Paris (Centre de documentation universitaire) 1967.

Perret, Jacques, Bâtons dans les roues, Paris (Gallimard) 1953.

Perret, Jacques, Cheveux sur la soupe, Paris (Gallimard) 1954.

Perret, Jacques, Roucou, 1936, Paris (Gallimard) 1984. 
Perret, Pierre, Mon almanach, Paris (Le Cherche Midi) 2014.

Perroux, François, L'Économie du xx siècle, Paris (Presses universitaires de France) 1964.

Perrut, Dominique, Patria o muerte, 2009, Paris (Denoël) 2010.

Perry, Jacques, Vie d'un païen, 1965, Paris (Gallimard) 1984.

Pesquidoux, Joseph de, Chez nous : travaux et jeux rustiques, vol. 1, Paris (Plon) 1921.

Pesquidoux, Joseph de, Chez nous : travaux et jeux rustiques, vol. 2, Paris (Plon) 1923.

Pesquidoux, Joseph de, Le Livre de raison, vol. 1, 1925, Paris (Plon) 1928.

Pesquidoux, Joseph de, Le Livre de raison, vol. 2, Paris (Plon) 1928.

Petit Courrier des dames, Paris.

Petites Annales de Provence, hebdomadaire, Marseille.

Petitgand, E. et Antoine Ronna, Traité complet de métallurgie [trad. ; original : John Percy, A Treatise on Metallurgy], Paris / Liège (Noblet / Baudry) 1864.

Pétrone, Satyricon [trad. de Laurent Thailhade], Paris (Charpentier-Fasquelle) 1902.

Peyrade, Jean, Scouts et guides de France, Paris (Fayard) 1961.

Peyré, Joseph, Matterhorn, Paris (Grasset) 1939.

Pézard, André, Nous autres à Vauquois (1915-1916), 1918, Nancy (Presses universitaires de Nancy) 2001.

Philippe de Commynes, Mémoires, 1489-1498 [BFM : 1490-1505], éd. Joseph Calmette, Paris (Belles lettres) 1925. DEAF : CommC [cité d'après BFM]

Philippe de Remi, sire de Beaumanoir, La Manekine, 1235, Dans : Euvres poétiques, éd. Hermann Suchier, vol. 1, Paris (Didot) 1884. DEAF : BeaumS

Philippe de Thaon, Bestiaire [= Le Bestiaire de Philippe de Thaün], 1121-1135, éd. Emmanuel Walberg, Lund / Paris (Möller / Welter) 1900. DEAF : PhThBestWa

Philippe de Thaon, Comput [= Li Cumpoz Philipe de Thaün. Der Computus des Philipp von Thaun], 1119 ou 1113, éd. Eduard Mall, Strassburg (Trübner) 1873. DEAF : PhThCompM

Philippe, Charles-Louis, Le Père Perdrix, 1902. Dans : La Mère et l'enfant; Le Père Perdrix, Paris (Gallimard) 1983.

Philosophie, religion, éd. Gaston Berger, Paris (Société nouvelle de l'encyclopédie française) 1957.

Piaget, Jean, Réussir et comprendre, Paris (Presses universitaires de France) 1974.

Picard, Louis-Benoît, Manie de briller, 1806. Dans : Théâtre de L. B. Picard, Bruxelles (Hayez) 1822.

Pichou, L'Infidèle confidente, 1631, Genève (Droz) 1991.

Pichou, Les Folies de Cardenio, 1629. Dans : Les Folies de Cardenio, tragi-comédie suivie des autres œuvres poétiques (1630-1629), Genève (Droz) 1989.

Pierquin, Claude-Charles, Histoire littéraire, philologique et bibliographique des patois, et de l'utilité de leur étude, Paris (Techner) / Berlin (Brockhaus et Avenarius) 1841.

Pierre Antilogus, Jean-Louis Festjens, Ces petits riens qui font une vie, Paris (Fleuve) 2020.

Pierre Bersuire, Les Décades de Titus Livius [1 ${ }^{\text {re }}$ Décade, Livre I] [trad.] [probablement 1354-1358]). DEAF : Bersuire [cité d'après Frantext]

Pierre Crapillet, Le «Cur deus homo » d'Anselme de Canterbury et le "De arrha animae » d'Hugues de Saint-Victor [trad.], 1450, éd. Robert Bultot et Geneviève Hasenohr, Louvain-la-Neuve (Institut d'études médiévales) 1984. DEAF : PCrapCurB

Pieyre de Mandiargues, André, Le Lis de mer, 1956, Paris (Gallimard) 1991.

Piga, La Journée de sang voisin, Saint-Denis (Mon petit éditeur) 2016.

Pignant, Paul, Principes d'assainissement des habitations des villes et de la banlieue, Paris (Darantière) 1892.

Pilhes, René-Victor, La Rhubarbe, Paris (Seuil) 1965.

Piré, L., La Forêt. Dans : Bulletin de la Société royale linnéenne de Bruxelles, 1872.

Piron, Alexis, Arlequin-Deucalion, 1722. Dans : Euvres choisies, Paris (Garnier) 1883. 
Piron, Alexis, Épitres, odes, poëmes. Dans : CEuvres complettes, éd. Rigoley de Juvigny, vol. 6, Paris (Lambert) 1776.

Piron, Alexis, Gustave-Wasa, 1733. Dans : Répertoire général du théâtre français, vol. 25, Paris (Ménard / Raymond) 1813.

Piron, Alexis, L'École des pères, 1729. Dans : EFuvres complettes, vol. 1, Paris (M. Lambert) 1776.

Piron, Alexis, La Métromanie, 1738. Dans : Euurres choisies, Paris (Garnier) 1883.

Piron, Alexis, Les Chimères, 1726. Dans : Euvres complettes, éd. Rigoley de Juvigny, vol. 4, Paris (Lambert) 1776.

Pissarro, Camille, Correspondance (1895-1898), éd. Janine Bailly-Herzberg, Paris (Presses universitaires de France) 1980.

Pitrois, Yvonne, Jeunes Vies, Paris (Sack) 1905.

Plagnat, F[rançois], Le Gui du sapin, Annales de l'École nationale des eaux et forêts, Nancy (École nationale des eaux et forêts) 1950.

Plainte d'Amour [attribué à Nicole Bozon], 1312, éd. Johan Vising, Göteborg (Zachrissons) 1905. DEAF : PlainteAmV

Planque, François, Bibliothèque choisie de médecine, vol. 6, Paris (d'Houry) 1761.

Podalydès, Denis, Voix off, 2008, Paris (Gallimard) 2010.

Poirot-Delpech, Bertrand, L'Été 36, 1984, Paris (Gallimard) 1994.

Poissenot, Bénigne, L'Esté, 1583, Genève (Droz) 1987.

Poizat, Michel, L'Opéra ou Le Cri de l'ange : essai sur la jouissance de l'amateur d'opéra, Paris (Métailié)1986.

Polain, Mathieu Lambert, Henri de Dinant. Histoire de la révolution communale de Liège, au XIII ${ }^{e}$ siècle (1252-1257), Liège (Félix Oudárt) 1843.

Politique aujourd'hui, revue mensuelle, Paris.

Ponchon, Raoul, La Muse au cabaret, Paris (Fasquelle) 1920.

Pons de Verdun, Philippe-Laurent, Le Pourquoi. Dans : Les Loisirs ou Contes et poésies diverses, Paris (Brasseur ainé) 1807.

Pons, François-Marie et Sylvie, Le Fauteuil roulant malgré lui, sans lieu (Éditions du cœur) 2016.

Ponsard, François, L'Honneur et l'argent, 1853. Dans : Euvres complètes, Paris (Michel Lévy) 1865.

Ponson du Terrail, Pierre-Alexis, Rocambole, les drames de Paris, 1859, Monaco (Éditions du rocher) 1963.

Pont de Vesle, Antoine de Fériol, comte de, Le Somnambule, 1739, Paris (Delain) 1776.

Porte, Alain, Les Cinq Livres de la sagesse : Pañcatantra [trad. du sanscrit], Arles (Picquier) 2017.

Portevin, Gaston, Ce qu'il faut savoir pour manger les bons champignons : précis de mycophagie, Paris (Paul Lechevalier) 1939.

Potiron, Henri, La Musique d'église : esquisse d'un traité de composition, Paris (Laurens) 1945.

Potocki, Jean, Manuscrit trouvé à Saragosse, 1815, Paris (Librairie générale française) 2000.

Pouget, Jean, Bataillon R.A.S. Algérie 1956, Paris (Presses de la Cité) 1981.

Poulat, Émile, La Galaxie Jésus, Paris (Éditions de l'atelier / Éditons ouvrières) 1994.

Pouquet, Jeanne, Journal sous l'Occupation en Périgord (1942-1945), Monaco (Éditions du rocher) 2006.

Pourquery, Didier, Les Mots de l'époque. 100 tics, trouvailles et autres extravagances du langage quotidien, Paris (Flammarion) 2014.

Pourrat, Henri, L'Auberge de la Belle Bergère ou Quand Gaspard de guerre revint. Dans : Les Vaillances, farces et aventures de Gaspard des montagnes, vol. 2, Paris (Albin Michel) 1925.

Pourrat, Henri, La Tour du Levant ou Quand Gaspard mit fin à l'histoire. Dans : Les Vaillances, farces et aventures de Gaspard des montagnes, vol. 4, Paris (Albin Michel) 1931.

Pourrat, Henri, Le Château des sept portes ou Les Enfances de Gaspard. Dans : Les Vaillances, farces et aventures de Gaspard des montagnes, vol. 1, Paris (Albin Michel) 1922. 
Pourrat, Henri, Le Pavillon des amourettes ou Gaspard et les bourgeois d'Ambert. Dans : Les Vaillances, farces et aventures de Gaspard des montagnes, vol. 3, Paris (Albin Michel) 1930.

Pourriol, Ollivier, Vertiges du désir, Paris (NiL) 2011.

Pouy, Jean-Bernard, La Clef des mensonges, Paris (Gallimard) 1988.

Précis analytique des travaux de l'Académie royale des sciences, belles-lettres et arts de Rouen, Rouen (Alfred Péron) 1847.

Prévert, Jacques, Histoires, 1963, Paris (Gallimard) 1998.

Prévert, Jacques, La Pluie et le beau temps, 1955, Paris (Gallimard) 1998.

Prévert, Jacques, Le Quai des brumes, 1977. Dans : Jenny. Le Quai des brumes, Paris (Gallimard) 1988.

Prévert, Jacques, Spectacle, 1951, Paris (Gallimard) 1997.

Prévost, abbé [Antoine François], Histoire du Chevalier des Grieux et de Manon Lescaut, 1731, Paris (Garnier) 1957.

Prévost, abbé [Antoine François], Le Monde moral ou Mémoires pour servir à l'histoire du cœur humain, 1760, Amsterdam / Paris (sans éditeur) 1784.

Prévost, abbé [Antoine François], Le Philosophe anglois ou Histoire de Monsieur Cleveland, fils naturel de Cromwell, plusieurs vols., 1731, 1738, Londres (Vaillant) 1777.

Prévost, abbé [Antoine François], Lettres angloises ou Histoire de Miss Clarisse Harlove [trad.], 1751, Amsterdam / Paris (sans éditeur) 1784.

Prévost, abbé [Antoine François], Nouvelles Lettres angloises ou Histoire du chevalier Grandisson [trad.], vol. 2, 1755, Amsterdam / Paris (sans éditeur) 1784.

Prévost-Bouré, Jacques, Jean de Luxembourg et Jeanne d'Arc, Paris (Debresse) 1980.

Prin, Alice, Souvenirs retrouvés (de Kiki de Montparnasse), 2005, Paris (Corti) 2009.

Proudhon, Pierre-Joseph, Qu'est-ce que la propriété ?, 1840. Dans : Euvres complètes, vol. 4, Paris (Rivière) 1926.

Proudhon, Pierre-Joseph, Système des contradictions économiques ou Philosophie de la misère, vol. 1, 1846, Paris (Librairie internationale) 1872.

Proust, Marcel, À l'ombre des jeunes filles en fleurs, 1918. Dans : $A ̀$ la recherche du temps perdu, vol. 1, Paris (Gallimard) 1962.

Proust, Marcel, Du côté de chez Swann, 1913. Dans : À la recherche du temps perdu, vol. 1, Paris (Gallimard) 1962.

Proust, Marcel, Du côté de Guermantes 1, 1920. Dans : À la recherche du temps perdu, vol. 2, Paris (Gallimard) 1961.

Proust, Marcel, Du côté de Guermantes 2, 1921. Dans : À la recherche du temps perdu, vol. 2, Paris (Gallimard) 1961.

Proust, Marcel, La Fugitive, 1922. Dans : À la recherche du temps perdu, vol. 3, Paris (Gallimard) 1961.

Proust, Marcel, La Prisonnière, 1922. Dans : À la recherche du temps perdu, vol. 3, Paris (Gallimard) 1961.

Proust, Marcel, Sodome et Gomorrhe, 1922. Dans : À la recherche du temps perdu, vol. 2, Paris (Gallimard) 1961.

Przybylski, Eddy, Brel, la valse à mille rêves, Paris (L’Archipel) 2008.

Psautier lorrain [= Lothringischer Psalter], 1365, éd. Friedrich Apfelstedt, Heilbronn (Henninger) 1881. DEAF : PsLorrA

Psichari, Ernest, Le Voyage du centurion, 1914, Paris (Conard) 1916.

Puijalon, Bernadette, Un parfum de gentiane, Paris (De Borée) 2004.

Pure, abbé Michel de, La Prétieuse ou Le Mystère des ruelles : parties 1-2, 1656, Paris (Droz) 1938.

Pure, abbé Michel de, La Prétieuse ou Le Mystère des ruelles : parties 3-4, 1658, Paris (Droz) 1939. 
Puységur, Armand Marc Jacques Chastenet, marquis de, Appel aux savans observateurs du xix siècle, de la décision portée par leurs prédécesseurs contre le magnétisme animal et fin du traitement du jeune Hébert, vol. 2, Paris (Dentu) 1813.

Quadrum, Bruxelles.

Quatre Livres des rois [= Li Quatre Livre des reis], $2^{\mathrm{e}}$ moitié xII ${ }^{\mathrm{e}}$ [BFM : 1190], éd. Ernst Robert Curtius, Dresden (Gesellschaft für romanische Literatur) / Halle (Niemeyer) 1911. DEAF : RoisC Queffélec, Corentin, Jusqu'au fond du gouffre : record du monde à la Pierre Saint-Martin, Paris (Stock) 1968.

Queffélec, Henri, Celui qui cherchait le soleil, Paris (Seuil) 1953.

Queffélec, Henri, Un Breton bien tranquille, Paris (Stock) 1978.

Queffélec, Henri, Un recteur de l'île de Sein, Paris (Stock) 1944.

Queffélec, Yann, Les Noces barbares, 1985, Paris (Gallimard) 1989.

Quelle politique de sécurité et de défense pour l'Europe, Pierre Pascallon et André Dumoulin (éds.), Paris (L'Harmattan) 2009.

Queneau, Raymond, Le Dimanche de la vie, 1951, Paris (Gallimard) 2003.

Queneau, Raymond, Le Vol d'Icare, 1968, Paris (Gallimard) 1995.

Queneau, Raymond, Loin de Rueil, 1944, Paris (Gallimard) 1946.

Queneau, Raymond, Odile, 1937. Dans : E Fuvres complètes : Romans, vol. 1, Paris (Gallimard) 2002.

Queneau, Raymond, Pierrot mon ami, Paris (Gallimard) 1942.

Queneau, Raymond, Zazie dans le métro, 1959, Paris (Gallimard) 1967.

Queste del saint Graal, 1225, éd. Christiane Marchello-Nizia et Alexei Lavrentiev [manuscrit K (Lyon) : fin XIII'], Lyon (École Normale Supérieure de Lyon) 2019. DEAF : SGraalIVQuesteкM [pour les variantes v. l'édition (critiquée) d'Albert Pauphilet, La Queste del Saint Graal, Paris (Champion) 1923. DEAF : SGraallVQuesteP] [cité d'après BFM]

Quinault, Philippe, Roland, Paris (C. Ballard) 1685.

Quinet, Edgar, Ahasvérus. Dans : Euuvres complètes, vol. 7, 1833, Paris (Pagnerre) 1858.

Quinet, Edgar, Napoléon. Dans : CEuvres complètes, vol. 8, 1836, Paris (Pagnerre) 1857.

Quint, Michel, Fox-trot, Paris (Héloïse d'Ormesson) 2015.

Quinze Joies de mariage, 1400, éd. Naomi Kanaoka, Lyon (ENS de Lyon), 2018 sur la base de l'éd. Michèle Guéret-Laferté, Sylvain Louis et Camille Mira, Rouen (Presses universitaires de Rouen et du Havre) 2009. DEAF : QJoyesG [cité d'après BFM]

Rabelais, François, Cinquième Livre [deuxième partie probablement attribuée à tort]. Dans : Euvres de Rabelais.

Rabelais, François, Gargantua, 1534. Dans : Euvres de François Rabelais.

Rabelais, François, Le Quart Livre, 1552. Dans : Euvres de François Rabelais.

Rabelais, François, Euvres de François Rabelais, éd. Burgaud des Marets et Rathery, 2 vols., Paris (Firmin Didot) ${ }^{3} 1890$.

Rabelais, François, Pantagruel, 1532. Dans : Euvres de François Rabelais.

Rabelais, François, Tiers Livre, 1546. Dans : Euvres de François Rabelais.

Racan, Honorat de Bueil, chevalier de, Les Bergeries, 1632. Dans : Poésies, vol. 2, Paris (Droz) 1937.

Racan, Honorat de Bueil, chevalier de, Les Psaumes, 1660. Dans : Fuuvres complètes, vol. 2, Paris

(P. Jannet) 1857.

Racine, Jean, Abrégé de l'histoire de Port-Royal, 1699. Dans : Euuvres, vol. 4.

Racine, Jean, Andromaque, 1668, Genève (Droz) 1977.

Racine, Jean, Andromaque, 1697. Dans : EFuvres, vol. 2.

Racine, Jean, Esther : tragédie tirée de l'Écriture sainte, 1697. Dans : CEuvres, vol. 3.

Racine, Jean, Les Plaideurs, 1697. Dans : Euvres, vol. 1.

Racine, Jean, Mithridate, 1697. Dans : Euvres, vol. 3.

Racine, Jean, E Fuvres de J. Racine, éd. Paul Mesnard, vols. 2-4, Paris (Hachette) 1865. 
Racine, Louis, La Religion, Paris (Coignard) 1742.

Radiguet, Raymond, Le Bal du comte d'Orgel, 1923, Paris (Grasset) 1947.

Raguenet, François, Histoire d'Olivier Cromwel, Paris (Barbin) 1691.

Rambaud, Patrick, La Bataille, Paris (Grasset) 1997.

Ramond de Carbonnières, Louis, Lettres de M. William Coxe à M. W. Melmoth sur l'état politique, civil et naturel de la Suisse [trad. ; original de William Coxe], vol. 1, Paris (Belin) / Lausanne (Grasset) 1781.

Ramuz, Charles-Ferdinand, Aimé Pache, peintre vaudois, 1911, Paris (Grasset) 1942.

Ramuz, Charles-Ferdinand, Derborence, 1934, Paris (Grasset) 1949.

Ramuz, Charles-Ferdinand, La Grande Peur dans la montagne, 1926, Paris (Grasset) 1942.

Randau, Robert, Celui qui s'endurcit, Paris (E. Sansot) 1913.

Rank, Claude, L'autre no man's land, Paris (Fleuve noir) 1986.

Raoul de Houdenc, La Vengeance Raguidel, début XIII', éd. Gilles Roussineau, Genève (Droz) 2006. DEAF : VengRagR

Raoul de Houdenc, Meraugis de Portlesguez [= Meraugis von Portlesguez], début XIII', éd. Mathias Friedwanger, Halle (Niemeyer) 1897. DEAF : MeraugisF

Raoul Lefevre, L'Histoire de Jason, 1460, éd. Gert Pinkernell, Frankfurt (Athenäum Verlag) 1971. DEAF : RLefevreJasonP

Rattazzi, Maire Lètizia, Les Vieilles Amours. Dans : Les Matinées italiennes 2 [revue, Florence] 1868.

Raynal, abbé, Histoire philosophique et politique des établissements et du commerce des Européens dans les Deux Indes, vol. 1, 1770, La Haye (Gosse fils) 1776.

Recueil Dalloz Sirey, Paris (Jurisprudence générale Dalloz) 1987.

Recueil de médecine vétérinaire, publication périodique, Paris.

Recueil de plusieurs notables arrests de la Cour de parlement, aydes et finances de Dauphiné, compilés par Jean-Guy Basset, Grenoble (François Provensal) 1686.

Recueil de plusieurs pièces d'éloquence et de poësie [datation individuelle des pièces], Paris (Veuve Brunet) 1762.

Recueil de quelques pièces concernant les arts, Paris (Charles-Antoine Jombert) 1757.

Recueil de quelques sermons prononcez par monsieur l'abbé de Pezenne, Paris (Couterot) 1694.

Recueil des actes, titres et memoires concernant les affaires du clergé de France, Paris (Pierre Simon) 1740.

Recueil des textes authentiques des programmes et engagements électoraux des députés proclamés élus à la suite des élections générales, vol. 1, Paris (Assemblée nationale) 1959.

Recueil général et complet des fabliaux des XIII ${ }^{e}$ et XIVe siècles, éd. Anatole de Montaiglon et Gaston Raynaud, 6 vols., Paris (Librairie des bibliophiles) 1872-1890. DEAF : MontRayn [nous citons de préférence NoomenFabl, sauf quand la fable n'est pas incluse dans cette œuvre]

Registre criminel du Châtelet de Paris du 6 septembre 1389 au 18 mai 1392, vol. 1, Paris (Ch. Lahure) 1861. [cité d'après Frantext]

Regnard, Jean-François, La Provençale, 1709. Dans : CEuvres, vol. 1, Paris (Lequien) 1820.

Regnard, Jean-François, Le Distrait, 1698. Dans : CFuvres, vol. 2, Paris (Lequien) 1820.

Regnard, Jean-François, Le Divorce, 1694. Dans : Euvres, vol. 5, Paris (Lequien) 1820.

Regnard, Jean-François, Le Joueur, 1697. Dans : EFuvres, vol. 2, Paris (Lequien) 1820.

Regnard, Jean-François, Le Légataire universel, 1708. Dans : Le Légataire universel, suivi de La

Critique du Légataire, Genève (Droz) 1994.

Regnard, Jean-François, Les Folies amoureuses, 1704. Dans : Euvres, vol. 3, Paris (Lequien) 1820.

Regnard, Jean-François, Voyage de Laponie, 1709. Dans : EFuvres, vol. 1, Paris (Lequien) 1820.

Régnier de La Planche, Louis, Histoire de l'Estat de France, tant de la république que de la religion, sous le regne de François II, sans lieu ni éditeur, 1576. 
Régnier, Mathurin, Les Satires 1 à 13, 1609. Dans : Euvres complètes, Paris (F. Roches) 1930. Régnier, Mathurin, Poésies diverses, 1613. Dans : Fuvres complètes, Paris (F. Roches) 1930. Reider, Paul, Mademoiselle Vallantin, 1862, Bruxelles (Palais des Académies) 1959.

Reiner, Silvain, Le Tapis rouge, Paris (Vertiges) 1986.

Remarques sur un écrit dicté à Douay par le père Fr. Jacops, Paris (Pralart) 1678.

Renan, Ernest, Drames philosophiques, 1888, Paris (Calmann-Lévy) 1949.

Renan, Ernest, L’Avenir de la science, 1890, Paris (Calmann-Lévy) 1910.

Renan, Ernest, Marc Aurèle et la fin du monde antique : le règne de Marc Aurèle (161-180), 1881, Paris (Librairie générale française) 1984.

Renan, Ernest, Souvenirs d'enfance et de jeunesse, 1883, Paris (Calmann-Lévy) 1908.

Renan, Ernest, Vie de Jésus, 1867, Paris (Gallimard) 1993.

Renard, Georges, Aux femmes. Dans : Revue socialiste, vol. 20, Paris, 1894.

Renard, Jules, Bucoliques, Paris (Paul Ollendorff) 1898.

Renard, Jules, Journal (1887-1910), 1910, Paris (Gallimard) 1960.

Renard, Jules, L'Écornifleur, Paris (Ollendorff) 1892.

Renard, Jules, Poil de carotte, 1894, Paris (Flammarion) 1936.

Renou, Jean de, Le Grand Dispensaire medicinal, Paris (Pierre Rigaud) 1624.

Renouvier, Charles, Essais de critique générale, Paris (Ladrange) 1864.

Renouvier, Charles, Les Doctrines physico-religieuses de l'immoralité personnelle. Dans : La Critique philosophique, Paris (Critique philosophique) 1875.

Réponses cuisine, revue, printemps 2008.

Rességuier, Jules de, Les Prismes poétiques, Paris (Allardin) 1838.

Rétif de La Bretonne, Nicolas, Histoire de Sara, 1796. Dans : Monsieur Nicolas, vol. 12, Paris (Lisieux) 1883.

Rétif de La Bretonne, Nicolas, La Paysanne pervertie ou Les Dangers de la ville, vol. 1, La Haye (Duchesne) 1784.

Rétif de La Bretonne, Nicolas, La Vie de mon père, 1778, Paris (Garnier) 1983.

Rétif de La Bretonne, Nicolas, Le Nouvel Abeilard ou Lettres de deux amants qui ne se sont jamais vus, Suisse (Libraires associés) 1779.

Rétif de La Bretonne, Nicolas, Le Paysan perverti ou Les Dangers de la ville, vol. 1, Amsterdam (La Compagnie) 1776.

Rétif de La Bretonne, Nicolas, Les Contemporaines communes ou Avantures des belles marchandes, ouvrières, etc., de l'âge présent, 1785, Leipzig (Büchel) 1790.

Révay, Theresa, Tous les rêves du monde, Paris (Belfond) 2009.

Reverdy, Pierre, Cette émotion appelée poésie (1932-1960), 1956, Paris (Flammarion) 1974.

Reverdy, Pierre, Écrits sur l'art et la poésie (1912-1926), 1926. Dans : Nord-Sud, Self defence et autres écrits, Paris (Flammarion) 1975.

Reverdy, Pierre, Le Gant de crin, Paris (Plon) 1927.

Reverdy, Pierre, Le Livre de mon bord : notes (1930-1936), 1936, Paris (Mercure de France) 1948.

Reverdy, Pierre, Main-d'œuvre (1913-1949), 1949, Paris (Mercure de France) 1964.

Reverdy, Pierre, Nord-Sud (15 mars 1917 - octobre 1918), 1918. Dans : Nord-Sud, Self defence et autres écrits, Paris (Flammarion) 1975.

Reverdy, Pierre, Plupart du temps : poèmes (1915-1922), 1945, Paris (Flammarion) 1967.

Revue de Champagne et de Brie, Arcis-sur-Aube.

Revue de l'art ancien et moderne, Paris.

Revue de métallurgie, Paris.

Revue des études napoléoniennes, Paris.

Revue des jardins et des champs, journal d'horticulture et d'agriculture, Lyon.

Revue des Pyrénées, Lourdes. 
Revue des traditions populaires, revue mensuelle, Paris.

Revue du siècle, Lyon.

Revue forestière française, École nationale du génie rural, des eaux et des forêts.

Revue générale de chemins de fer, Paris.

Revue illustrée, Paris.

Revue politique et parlementaire, Paris.

Revue universelle des mines, de la metallurgie, des travaux publics, des sciences et des arts

appliqués à l'industrie, Paris et Liège.

Reybaud, Charles Mme, Mézélie, Bruxelles (Société belge de librairie) 1839.

Reybaud, Louis, Jérôme Paturot à la recherche d'une position sociale, 1842, Paris (Paulin) 1844.

Reynaud, Jean-Daniel, Les Syndicats en France, Paris (Armand Colin) 1963.

Rhaïs, Elissa [pseudonyme de Rosine Boumendi], La Fille des pachas. Dans : Revue des deux mondes, $1^{\text {er }}$ août 1922.

Rheims, Maurice, Les Greniers de Sienne, 1987, Paris (Gallimard) 1990.

Rhyxand, Adrien, Mouthernaz, Blainville-sur-Mer (L'Amitié par le livre) 1960.

Ribelle, Charles de, Les Fastes de la marine française, Paris (Amable Rigaud) 1860.

Ricard, Samuel, L'Art de bien tenir les livres de comptes en parties doubles à l'italienne, Amsterdam (sans éditeur) 1717.

Riccoboni, Marie-Jeanne, Histoire de Miss Jenny, écrite et envoyée par elle à Miladi, Comtesse de Roscomond, 1764. Dans : CEuvres complètes, vol. 1, Paris (Foucault) 1818.

Riccoboni, Marie-Jeanne, Histoire du marquis de Cressy, 1758, Paris (Didot Ainé) 1814.

Riccoboni, Marie-Jeanne, Lettres de Fanni Butler à Milord Charles Alfred de Caitombridge, 1757.

Dans : Collection complète des œuvres, vol. 1, Neuchâtel (Société typographique) 1773.

Richard, Jérôme, Histoire naturelle de l'air et des météores, vol. 5, Paris (Saillant et Nyon) 1770.

Richards, Emilie, L'Écho de la rivière [trad. de l'anglais par Florence Godebska], Paris (Harlequin) 2012.

Richars li Biaus, $3^{e}$ tiers XIII', éd. Anthony J. Holden, Paris (Honoré Champion) 1983. DEAF : RichH

Richepin, Jean, Le Pavé, Paris (Maurice Dreyfous) 1883.

Richerand, Anthelme, De la population dans ses rapports avec la nature des gouvernemens, Paris (Béchet Jeune / Delaunay) 1837.

Ricœur, Paul, Philosophie de la volonté : le volontaire et l'involontaire, Paris (Aubier) 1949.

Riel, Louis, Selected Poetry of Louis Riel, 1885 [date de la mort], éd. Glen Campbell, Toronto (Exile editions) 2000.

Rigaud, Lucien, Dictionnaire du jargon parisien, Paris (Ollendorff) 1878.

Rimbaud, Arthur, Illuminations, 1873. Dans : E Euvres, Paris (Garnier) 1964.

Rimbaud, Arthur, Poésies (1869-1871). Dans : E Fuvres, Paris (Garnier) 1964.

Rimbaud, Madame, Lettre de Madame Rimbaud à Isabelle (Roche, 6 juin 1907). Dans : Suzanne

Briet, Madame Rimbaud : essai de biographie, Paris (Minard) 1968.

Risser, Jacques, Le Bon Fade, Paris (Gallimard) 1969.

Ritter, Élie, Traité élémentaire d'arithmétique, Genève / Paris (Abraham Cherbuliez) 1837.

Rivarol, Antoine de, Petit Almanach des grands hommes, 1788. Dans : Euvres complètes, vol. 5 , Paris (Collin) 1808.

Rivaudeau, André de, Aman : tragédie sainte, 1566, Genève (Droz) / Paris (Minard) 1969.

Rivaudeau, André de, Les CEuvres poétiques d'André de Rivaudeau, gentilhomme du Bas Poitou, 1580, Genève (Slatkine) 1968.

Rivoyre, Christine de, Les Sultans, Paris (Grasset) 1964.

Robbe-Grillet, Alain, Le Voyeur, 1955, Paris (Minuit) 1988.

Robbe-Grillet, Alain, Les Gommes, 1952, Paris (Minuit) 1990.

Robello, G., Les Curiosités de Rome et de ses environs, Paris (L. Maison) 1854. 
Robert de Blois, Floris et Lyriopé, $2^{e}$ tiers XIII', éd. Wolfram v. Zingerle, Leipzig (Reisland) 1891. DEAF : RobBloisFlorZ

Robertet, Jean, Euuvres, 1451, éd. Margaret Zsuppán, Genève (Droz) 1970.

Robespierre, Maximilien de, Discours, 1793. Dans : EEuvres, vols. 6-9, Paris (Presses universitaires de France) 1950-1958.

Robinet, Jean-François, Le Mouvement religieux à Paris pendant la Révolution (1789-1801), Paris (L. Serf) 1896.

Rochant, Éric, Un monde sans pitié, Paris (Gallimard) 1990.

Rochefort, Christiane, Encore heureux qu'on va vers l'été, 1975, Paris (Grasset) 1981.

Rochefort, Christiane, Le Repos de guerrier, Paris (Grasset) 1958.

Rochefort, Christiane, Les Petits Enfants du siècle, 1961, Paris (Grasset) 1979.

Rochefort, Christiane, Les Stances à Sophie, Paris (Grasset) 1963.

Rod, Édouard, Le Silence, 1894, Paris (Perrin) 1901.

Rodenbach, Georges, Le Règne du silence, 1891, Paris (Fasquelle) 1914.

Roger-Marx, Claude, La Tragédie légère, Paris (Albin Michel) 1922.

Roguenant, Albert, Le Grand Soir, Paris (É. Dentu) 1800.

Rohmer, Éric, Ma nuit chez Maud, 1969. Dans : Six Contes moraux, Paris (Cahiers du cinéma) 1998.

Roisin, Ferdinand de, Un mystère de la Passion, représenté au xIXe siècle. Dans : Beiträge zur

Geschichte, Toponymie und Statistik des Erzbistums München und Freising, 1851.

Rolin, Jean, L'Organisation, Paris (Gallimard) 1996.

Rolin, Olivier, Tigre en papier, 2002, Paris (Seuil) 2010.

Rolland, Romain, Beethoven : Les Grandes Époques créatrices : le chant de la résurrection, Paris

(Éditions du sablier) 1937.

Rolland, Romain, Jean-Christophe, Le Matin, 1904, Paris (Albin Michel) 1961.

Rolland, Romain, Jean-Christophe. Antoinette, 1908, Paris (Albin Michel) 1961.

Rolland, Romain, Jean-Christophe. Dans la maison, 1909, Paris (Albin Michel) 1961.

Rolland, Romain, Jean-Christophe. L'Adolescent, 1905, Paris (Albin Michel) 1961.

Rolland, Romain, Jean-Christophe. L'Aube, 1904, Paris (Albin Michel) 1961.

Rolland, Romain, Jean-Christophe. La Foire sur la place, 1908, Paris (Albin Michel) 1961.

Rolland, Romain, Jean-Christophe. La Nouvelle Journée, 1912, Paris (Albin Michel) 1961.

Rolland, Romain, Jean-Christophe. La Révolte, 1907, Paris (Albin Michel) 1961.

Rolland, Romain, Jean-Christophe. Les Amies, 1910, Paris (Albin Michel) 1961.

Romains, Jules, Le Dieu des corps, 1928. Dans : Psyché, Paris (Gallimard) 1985.

Romains, Jules, Les Copains, 1913, Paris (Club du meilleur livre) 1953.

Romains, Jules, Les Hommes de bonne volonté, vol. 1 : Le 6 octobre, Paris (Flammarion) 1932.

Romains, Jules, Les Hommes de bonne volonté, vol. 7 : Recherche d'une Église, Paris (Flammarion) 1934.

Romains, Jules, Les Hommes de bonne volonté, vol. 13 : Mission à Rome, Paris (Flammarion) 1937.

Romains, Jules, Les Hommes de bonne volonté, vol. 15 : Prélude à Verdun, Paris (Flammarion) 1938.

Romains, Jules, Les Hommes de bonne volonté, vol. 16 : Montée des périls, Paris (Flammarion) 1936.

Romains, Jules, Les Hommes de bonne volonté, vol. 16 : Verdun, Paris (Flammarion) 1938.

Romains, Jules, Les Hommes de bonne volonté, vol. 17 : Vorge contre Quinette, Paris (Flammarion) 1939.

Romains, Jules, Les Hommes de bonne volonté, vol. 24 : Comparutions, Paris (Flammarion) 1946.

Romains, Jules, Lucienne, 1922. Dans : Psyché, Paris (Gallimard) 1985.

Romains, Jules, Mort de quelqu'un, 1911, Paris (Gallimard) 1923.

Roman d'Alexandre, 1185. Dans : Karl Bartsch, Chrestomathie de l'ancien français, pièce 36.

Roman de Berinus, $\sim 1370$, éd. Robert Bossuat, 2 vols., Paris (Société des anciens textes français) 1931/1933. DEAF : BerinB 
Roman de Jehan de Paris, 1495 [BFM : 1494], éd. Édith Wickersheimer, Paris (Champion) 1923.

DEAF : JParisW [cité d'après BFM]

Roman de la rose, v. sous Guillaume de Lorris et sous Jehan de Meun.

Roman de Thèbes, 1160, éd. Léopold Constans, publié d'après tous les manuscrits, 2 vols., Paris

(Didot) 1890. DEAF : ThebesC [cité uniquement pour les variantes]

Roman de Thèbes, $2^{\mathrm{e}}$ tiers XIII', éd. Guy Raynaud de Lage, 2 vols., Paris (Champion) 1966 / 1968.

DEAF : ThebesR [= édition citée ; BFM]

Roman de Troilus et Cressida [attribution à Jean, Pierre ou Louis de Beauveau discutée ; traduction du Filostrato de Boccaccio], 1450. Dans : Nouvelles françoises en prose du xIve siècle. DEAF : TroilusM

Roman de Wistasce le Moine [= Le Roman d'Eustache le Moine], $2^{\mathrm{e}}$ tiers XIII (après 1227), éd. A. J. Holden et J. Monfrin, Louvain / Paris / Dudley (Peeters) 2005. DEAF : EustMoineH

Roman du Chastellain de Coucy [= Le Livre des amours du chastellain de Coucy et de la dame de Fayel), $2^{\mathrm{e}}$ tiers XVe éd. Aimé Petit et François Suard, Lilles (Presses universitaires de Lille) 1994. DEAF : ChastCoucyP

Romances et pastourelles françaises des $\mathrm{XII}^{e}$ et XIII' siècles, éd. Karl Bartsch [= Altfranzösische Romanzen und Pastourellen], Leipzig (Vogel) 1870. DEAF : RomPast

Romilly, Jacqueline de, Les Eufs de Pâques, Paris (de Fallois) 1993.

Ronchard-Siauve, Traité de la fabrication des canons de fusils, Saint-Étienne (Théolier ainé) 1864.

Ronsard, Pierre de, Discours des misères de ce temps, 1562, Paris (Société des textes français modernes) 2009.

Ronsard, Pierre de, Élégies [datation individuelle des poèmes]. Dans : Euuvres complètes, vol. 4.

Ronsard, Pierre de, La Franciade, 1572. Dans : CEuvres complètes, vol. 3.

Ronsard, Pierre de, Le Bocage royal [datation individuelle des poèmes]. Dans : Euvres complètes, vol. 3.

Ronsard, Pierre de, Le Premier Livre des amours, 1552. Dans : EFuvres complètes, vol. 1.

Ronsard, Pierre de, Le Second Livre des amours, 1556/1578, Genève (Droz) 1951.

Ronsard, Pierre de, Les Amours, 1535, Les Amours et les folastries, éd. A. Gendre, Paris (Libraire générale française) 1993.

Ronsard, Pierre de, Les Éclogues, 1559. Dans : CEuvres complètes, vol. 4.

Ronsard, Pierre de, Les Odes [= Les Quatre Premiers Livres des Odes (1550)]. Dans : Euvres complètes, vol. 2.

Ronsard, Pierre de, Mascarades [datation individuelle des poèmes]. Dans : Euvres complètes, vol. 4.

Ronsard, Pierre de, Odes retranchées [datation individuelle des poèmes]. Dans : Euvres complètes, vol. 2.

Ronsard, Pierre de, Fuvres complètes, éd. Prosper Blanchemain, 4 vols., Paris (Jannet) 1857-1860.

Ronsard, Pierre de, Sonnets et madrigals pour Astrée, 1578. Dans : CEuvres complètes, vol. 1.

Ronsard, Pierre de, Sonnets pour Hélène, 1584, Paris (Droz) 1947.

Rosny aîné, J.-H., Vamireh, 1892, sans lieu (Ligaran) sans date.

Rostand, Edmond, Cyrano de Bergerac, Paris (Fasquelle) 1898.

Rostand, Jean, La Genèse de la vie, 1943, Paris (Hachette) 1951.

Rotrou, Jean de, Don Bernard de Cabrère, 1647, Paris (Laplace, Sanchez et Cie.) 1883.

Rotrou, Jean de, Hercule mourant, 1636, Exeter (University of Exeter) 1971.

Rotrou, Jean de, La Sœeur, 1645, Paris (Laplace, Sanchez et Cie.) 1883.

Rotrou, Jean de, Laure persécutée, 1639, Mont-de-Marsan (J. Feijoo) 1991.

Rotrou, Jean de, Les Sosies, 1638, Paris (Laplace, Sanchez et Cie.) 1883.

Rotrou, Jean de, Venceslas, 1648, Saarbrücken (West-Ost-Verlag) 1956.

Rouaix, Paul, Histoire des beaux-arts, Paris (H. Laurens) 1901. 
Rouaud, Jean, Les Champs d'honneur, 1990, Paris (Minuit) 1996.

Roubaud, Jacques, La Bibliothèque de Warburg : version mixte, Paris (Seuil) 2002.

Roubaud, Jacques, Poésie : récit, Paris (Seuil) 2000.

Roubaud, Pierre Joseph André, Nouveaux Synonymes françois, vol. 3, Paris (Moutard) 1785.

Roucarie, Philippe, Un passé pas si simple, Nonette (Créer) 2004.

Roucher, Jean-Antoine, Les Mois, poëmes en douze chants, vol. 2, Paris (Quillau) 1779.

Rouilly, Guérard de, Du système financier, Paris (Librairie française de ladvocat) 1822.

Roumain, Jacques, Gouverneurs de la rosée, 1944, Paris (Messidor) 1992.

Rousseau, Jean-Jacques, Discours sur l'origine et les fondements de l'inégalité parmi les hommes, 1755. Dans : E Euvres complètes, vol. 3, Paris (Gallimard) 1966.

Rousseau, Jean-Jacques, Émile ou De l'éducation, 1762. Dans : Euvres complètes, vol. 4, Paris (Gallimard) 1969.

Rousseau, Jean-Jacques, La Nouvelle Hélö̈se, vol. 2, 1761, Paris (Hachette) 1925.

Rousseau, Jean-Jacques, Les Confessions, 1778, Paris (Gallimard) 1997.

Rousseau, Jean-Jacques, Lettres écrites de la montagne, 1764. Dans : EFuvres complètes, vol. 3, Paris (Gallimard) 1964.

Rousseau, Jean-Jacques, Rousseau juge de Jean-Jacques, 1776, Paris (A. Colin) 1962.

Rousseau, Pierre, Histoire des techniques et des inventions, Paris (Hachette) 1967.

Roussel, Raymond, Locus solus, 1914, Paris (Pauvert) 1996.

Rousset de Missy, Jean, Recueil historique d'actes, négociations, mémoires et traitez, vol. 6, La Haye

(Pierre Gosse) 1732.

Rousset, H. J., Travail des petits matériaux, Paris (Béranger) 1928.

Roussot, Thomas, Le Lob du destin, Marseille (Salto) 2015.

Rouvière, Camille Arthur Augustin, Journal de guerre d'un combattant pacifiste, 1918, Biarritz (Atlantica) 2007.

Roy, Claude, À tort ou à raison, Paris (Gallimard) 1955.

Roy, Claude, La Traversée du Pont des Arts, 1979, Paris (Gallimard) 1983.

Roy, Claude, Le Commerce des classiques, Paris (Gallimard) 1953.

Roy, Claude, Le Journal des voyages, Paris (Gallimard) 1960.

Roy, Claude, Somme toute, 1976, 3 vols., Paris (Gallimard) 1982.

Roy, Gabrielle, Bonheur d'occasion, 1945, Paris (Flammarion) 1947.

Roze, Pascale, Le Chasseur zéro, Paris (Albin Michel) 1996.

Rozier, abbé, Cours complet d'agriculture, Paris (sans éditeur) 1786.

Ruggieri, Marion, Pas ce soir, je dîne avec mon père, Paris (Grasset) 2008.

Rutebeuf [= CFuvres complètes de Rutebeuf], textes datables de 1249 à 1272, éd. Edmond Faral et Julia Bastin, 2 vols., Paris (Picard) 1969. DEAF : RutebF

Ruyer, Raymond, La Cybernétique et l'origine de l'information, Paris (Flammarion) 1954.

Ryck, Francis, Requiem pour un navire, Paris (Ramsay) 1989.

S.I.M., revue musicale, Paris.

Sabatier, Robert, David et Olivier, Paris (Albin Michel) 1985.

Sabatier, Robert, Le Chinois d'Afrique, Paris (Albin Michel) 1966.

Sabatier, Robert, Les Allumettes suédoises, 1969, Paris (Albin Michel) 1986.

Sabatier, Robert, Les Fillettes chantantes, Paris (Albin Michel) 1980.

Sabatier, Robert, Les Noisettes sauvages, 1974, Paris (Albin Michel) 1983.

Sabatier, Robert, Trois Sucettes à la menthe, 1972, Paris (Albin Michel) 1983.

Sabbatini, Nicola, Pratique pour fabriquer scènes et machines de théâtre, Ravenne (Pietro de Paoli / Giovanni Battista Giovanelli) 1638.

Sade, Marquis de, Justine ou Les Malheurs de la vertu, 1791, Paris (Pauvert) 1966.

Sagan, Françoise, Bonjour tristesse, 1954, Paris (Julliard) 1956. 
Sagan, Françoise, Dans un mois, dans un an, 1957, Paris (Juillard) 1958. Sagan, Françoise, Un certain sourire, 1956, Paris (Presses pocket) 1992. Saïd, Mohamed, Jours de liesse, Bruxelles (Les Carnets de la lune) 2015.

Saint Georges, Georges Guillet de, Les Arts de l'homme d'epée ou Le Dictionnaire du gentilhomme, Paris (Gervais Clouzier) 1678.

Sainte-Beuve, Charles, Correspondance générale, vol. 1, Paris (Stock) 1935.

Sainte-Beuve, Charles, Mes poisons, 1869, Paris (Plon) 1926.

Sainte-Beuve, Charles, Pensées et maximes, 1869, Paris (Grasset) 1955.

Sainte-Beuve, Charles, Poésies, 1829, Paris (Nouvelles éditions latines) 1957.

Sainte-Beuve, Charles, Port-Royal, vol. 1, 1840, Paris (Hachette) 1860.

Sainte-Beuve, Charles, Port-Royal, vol. 2, 1842, Paris (Hachette) 1860.

Sainte-Beuve, Charles, Port-Royal, vol. 3, 1848, Paris (Hachette) 1860.

Sainte-Beuve, Charles, Port-Royal, vol. 4, 1859, Paris (Hachette) 1860.

Sainte-Beuve, Charles, Tableau historique et critique de la poésie française et du théâtre français au $x V I^{e}$ siècle, 1828, Paris (Charpentier) 1843.

Sainte-Beuve, Charles, Volupté, 1834, Paris (Belles lettres) 1927.

Sainte-Croix, François Noël Le Roy de, L'Alsace en fête, Strasbourg (Hagermann) 1880.

Saint-Exupéry, Antoine de, Citadelle, 1944. Dans : Fuvres, Paris (Gallimard) 1961.

Saint-Exupéry, Antoine de, Courrier Sud, 1928. Dans : Euvres, Paris (Gallimard) 1961.

Saint-Exupéry, Antoine de, Pilote de guerre, 1942. Dans : Euvres, Paris (Gallimard) 1961.

Saint-Exupéry, Antoine de, Terre des hommes, 1939. Dans : CFuvres, Paris (Gallimard) 1961.

Saint-Exupéry, Antoine de, Vol de nuit, 1931. Dans : Euvres, Paris (Gallimard) 1961.

Saint-John Perse, Amers, 1957. Dans : Euvres complètes, Paris (Gallimard) 1986.

Saint-John Perse, Exil, 1942. Dans : Euvres poétiques, Paris (Gallimard) 1953.

Saint-John Perse, Hommages, 1971. Dans : Euvres complètes, Paris (Gallimard) 1986.

Saint-John Perse, Vents, 1946. Dans : Euvres complètes, Paris (Gallimard) 1986.

Saint-Just, De la nature, de l'état-civil, de la cité ou Les Règles de l'indépendance du gouvernement, 1792. Dans : Euvres complètes, Paris (Lebovici) 1984.

Saint-Réal, César de, Conjuration des Espagnols contre la République de Venise en l'année 1618, 1674. Dans : Don Carlos. La Conjuration des Espagnols, Genève (Droz) 1977.

Saint-René Taillandier, De la crise actuelle de la philosophie hégélienne. Dans : Revue des deux mondes, 1847.

Saint-Simon, duc de, Mémoires complets et authentiques du Duc de Saint-Simon sur le siècle de Louis XIV et la Régence, 1739-1749, Paris (Hachette) 1865.

Saint-Simon, duc de, Euvres complettes, vol. 8, Strasbourg (Treuttel) 1791.

Saint-Simoniens, Poèmes, 1833. Dans : Le Livre nouveau des saint-simoniens, Tusson (Du Lérot) 1992.

Sáinz de la Maza, Aro, Le Bourreau de Gaudí [trad. de l'espagnol par Serge Mestre ; titre original : El Asesino de La Pedrera (2012), publié de nouveau sous le titre de El Verdugo de Gaudí (2020)], Arles (Actes Sud) 2014.

Salacrou, Armand, La Terre est ronde, Paris (Gallimard) 1938.

Salet, Francis, Cluny et Vézelay : l'œuvre des sculpteurs, Paris (Société française d'archéologie) 1995.

Salle, Adama, Un mariage oblique, Paris (Le Manuscrit) 2006.

Salnove, Robert de, La Venerie royale, Paris (Antoine de Sommaville) 1665.

Salvayre, Lydie, La Puissance des mouches, 1995, Paris (Seuil) 1997.

Samain, Albert, Carnets intimes, Paris (Mercure de France) 1939.

Samain, Albert, Le Chariot d'or, 1900, Paris (Mercure de France) 1912.

Samaké, Guédouma, Le Chemin de l'honneur, Bamako [Mali] (Jamana) 1998. 
San-Antonio, Appelez-moi chérie !, Paris (Fleuve) 2010.

San-Antonio, Buffalo Bide, Paris (Fleuve noir) 2011.

San-Antonio, Les Deux Oreilles et la queue, Paris (Fleuve) 1984.

San-Antonio, Ménage tes méninges, Paris (Fleuve) 1962.

San-Antonio, Si ma tante en avait, Paris (Fleuve) 1978.

Sand, George, Consuelo, vol. 2, 1843, Grenoble (L’Aurore) 1991.

Sand, George, Correspondance, vol. 1 : 1812-1831 Paris (Garnier) 1987.

Sand, George, Correspondance, vol. 2 : 1832-1833, Paris (Garnier) 1985.

Sand, George, Correspondance, vol. 3 : 1836-1837, Paris (Garnier) 1967.

Sand, George, Correspondance, vol. 4 : 1837-1839, Paris (Garnier) 1968.

Sand, George, Correspondance, vol. 5 : 1842, Paris (Garnier) 1969.

Sand, George, Correspondance, vol. 6 : 1843-1844, Paris (Garnier) 1969.

Sand, George, Correspondance, vol. 7 : 1845-1846, Paris (Garnier) 1970.

Sand, George, Correspondance, vol. 8 : 1847, Paris (Garnier) 1961.

Sand, George, Correspondance, vol. 9 : 1849-1850, Paris (Garnier) 1972.

Sand, George, Correspondance, vol. 10 : 1851-1852, Paris (Garnier) 1973.

Sand, George, François le Champi, 1850, Paris (Garnier) 1981.

Sand, George, Histoire de ma vie, 1855. Dans : CEuvres complètes, vols. 40-43, Paris (Calmann-Lévy) 1879.

Sand, George, Indiana, 1857, Paris (Garnier) 1985.

Sand, George, Jeanne, 1844, Grenoble (Glénat) 1993.

Sand, George, La Comtesse de Rudolstadt, 1843. Dans : Consuelo, vol. 3, Grenoble (L'Aurore) 1991.

Sand, George, La Mare au diable, 1846, Paris (Garnier) 1981.

Sand, George, La Petite Fadette, 1849, Paris (Gallimard) 1981.

Sand, George, Le Compagnon du Tour de France, 1851, Grenoble (Presses universitaires de Grenoble) 1994.

Sand, George, Le Marquis de Villemer, 1864, Meylan (L’Aurore) 1988.

Sand, George, Le Meunier d'Angibault, 1845, Grenoble (L'Aurore) 1990.

Sand, George, Le Péché de Monsieur Antoine, 1845, Meylan (L’Aurore) 1982.

Sand, George, Lélia, 1833, Paris (Garnier) 1960.

Sand, George, Lélia, 1839, Paris (Garnier) 1960.

Sand, George, Les Beaux Messieurs de Bois-Doré, 1858, 2 vols., Grenoble (L'Aurore) 1990.

Sand, George, Les Maîtres sonneurs, 1865, Paris (Garnier) 1980.

Sand, George, Mademoiselle La Quintinie, 1877, Genève (Slatkine) 1979.

Sand, George, Mauprat, 1852, Paris (Gallimard) 1992.

Sand, George, Monsieur Sylvestre, 1865, Genève (Slatkine) 1980.

Sand, George, Un hiver à Majorque, 1842, Paris (Glénat) 1993.

Sandeau, Jules, Mademoiselle de la Seiglière, 1848, Paris (Fasquelle) 1924.

Sandeau, Jules, Sacs et parchemins, 1851, Paris (Michel Lévy) 1855.

Santa María, Francisco de, Histoire generale des Carmes deschaussees et Carmelites deschaussees [trad. de P. Gabriel de la Croix], Paris (Huré) 1655.

Sardou, Victorien et Émile de Najac, Divorçons, Paris (Calmann-Lévy) 1883.

Sarraute, Nathalie, Enfance, 1983, Paris (Gallimard) 1995.

Sarraute, Nathalie, L'Ėre du soupçon, 1956, Paris (Gallimard) 1973.

Sarraute, Nathalie, Le Planétarium, 1959, Paris (Gallimard) 1993.

Sarrazin , Albertine, L'Astragale, 1965, Paris (Pauvert) 1986.

Sarrazin, Albertine, La Cavale, 1965, Paris (Livre de poche) 1969.

Sarrazin, Albertine, Lettres de la vie littéraire (1965-1967), Paris (Pauvert) 1974.

Sartre, Jean-Paul, Baudelaire, 1947, Paris (Gallimard) 1963. 
Sartre, Jean-Paul, Carnets de la Drôle de Guerre : septembre 1939 à mars 1940,1983. Dans : Les

Mots et autres écrits autobiographiques, Paris (Gallimard) 2010.

Sartre, Jean-Paul, L'Âge de raison, Paris (Gallimard) 1945.

Sartre, Jean-Paul, La Mort dans l'âme, Paris (Gallimard) 1949.

Sartre, Jean-Paul, La Nausée, Paris (Gallimard) 1938.

Sartre, Jean-Paul, Le Sursis, Paris (Gallimard) 1945.

Sartre, Jean-Paul, Les Mains sales, Paris (Gallimard) 1948.

Sartre, Jean-Paul, Les Mots, Paris (Gallimard) 1964.

Sartre, Jean-Paul, Les Séquestrés d'Altona, 1960, Paris (Gallimard) 1995.

Sartre, Jean-Paul, Lettres au Castor et à quelques autres, vol. 1 (1926-1939), Paris (Gallimard) 2010.

Sartre, Jean-Paul, Lettres au Castor et à quelques autres, vol. 2 (1940-1963), Paris (Gallimard) 2008

Satyre Ménippée ou La Vertu du catholicon, 1594, éd. Charles Read, Paris (Flammarion) 1892.

Saulcy, Louis Félicien Caignart de, Voyage autour de la Mer morte et dans les terres bibliques, vol. 1 , Paris (Gide et Baudry) 1853.

Saumont, Annie, Embrassons-nous, Paris (Julliard) 1998.

Sautter, Christian, Lettres à nos amis (2013-2014), sans lieu (Boostzone) 2015.

Sauzier, Théodore et Henri du Quesne, Un projet de république à l'île d'Éden (l'île Bourbon) en 1689, Amsterdam (Henri Desbordes) 1689.

Savary Des Bruslons, Jacques, Dictionnaire universel de commerce, d'histoire naturelle et des arts, 1723, Genève (Cramer / Philibert) 1742.

Savignac, Raymond, L'Affiche de A à Z, Paris (Seuil) 1992.

Savigneau, Josyane, Point de côté, Paris (Stock) 2008.

Say, Jean-Baptiste, Traité d'économie politique, 1832, Paris (Guillaumin) 1841.

Sazie, Léon, Zigomar. Livre premier : Le Maître invisible, 1909-1910, sans lieu (lulu.com) 2014.

Scalese, Laurent, La Cicatrice du diable, Paris (Belfond) 2009.

Scarron, Paul, Don Japhet d'Arménie, 1653, Paris (Didier) 1967.

Scarron, Paul, L'Héritier ridicule ou La Dame intéressée, 1650, Paris (S.T.F.M.) 1995.

Scarron, Paul, Le Jodelet ou Le Maistre valet, 1645, Exeter (University of Exeter) 1986.

Scarron, Paul, Le Roman comique, 1651, Paris (Gallimard) 1985.

Scève, Maurice, Délie, object de plus haulte vertu, 1544, Paris (Hachette) 1916.

Schefer, Jean-Louis, Goya, la dernière hypothèse, Paris (Maeght) 1998.

Schélandre, Jean de, Tyr et Sidon ou Les Funestes amours de Belcar et Méliane (1608) et Tyr et Sidon. Tragicomédie divisée en deux journées (1628), éd. Joseph W. Barker, Paris (Nizet) 1974.

Schmid, Christoph[e], L'Image de Marie [trad. de l'allemand per Blanche Écort]. Dans : Le Rossignol. La Chapelle au bois. L'Image de Maire, Stuttgart (J.-B. Müller) 1848.

Schmitt, Eric-Emmanuel, La Femme au miroir, Paris (Albin Michel) 2011.

Schneider, Louis, Les Maîtres de l'opérette française, Paris (Perrin) 1924.

Schneider, Michel, Prima donna, Paris (Odile Jacob) 2001

Schreiber, Boris, Un silence d'environ une demi-heure, Paris (Le Cherche Midi) 1996.

Schwartz, Laurent, Un mathématicien aux prises avec le siècle, 1997, Paris (Odile Jacob) 2006.

Schwob, Marcel, Le Livre de Monelle, 1894, Paris (Mercure de France) 1959.

Scott, Walter, Saint-Cloud [trad. par Albert de Montémont et L. Barré], 1815. Dans : E Euvres de Walter Scott. Euvres poétiques, vol. 1, Paris (Didot) 1836.

Scribe, Eugène, Bertrand et Raton, 1833. Dans : Théâtre, vol. 1, Paris (Michel Lévy) 1856.

Scribe, Eugène, Le Mariage de raison, 1826. Dans : Euvres complètes, vol. 5, Paris (Furne / André) 1845.

Scribe, Eugène, Le Verre d'eau, 1840. Dans : EFuvres complètes, vol. 5, Paris (Furne / André) 1845.

Scudéry, Georges de, Alaric ou Rome vaincue, Paris (A. Courbé) 1654.

Scudéry ,Georges de, Ligdamon et Lidias ou La Ressemblance, Paris (F. Targa) 1631. 
Scudéry, Madeleine de, Les Jeux servant de préface. Dans : Mathilde, Paris (Martin) 1667.

Scudéry, Madeleine de, Mathilde, Paris (Martin) 1667.

Sébillot, Paul, Littérature orale de la Haute-Bretagne, Paris (Maisonneuve) 1881.

Segalen, Victor, Stelae [Stèles], Santa Barbara (Unicorn press) 1969.

Segrais, Jean-Regnault de, Eneïde [trad. ; original de Virgile], Paris (Claude Barbin) 1668.

Seguin, Boris et Frédéric Teillard, Les Céfrans parlent aux français : chronique de la langue des cités, Paris (Calmann-Lévy) 2014.

Seguin, Fanny, L'Arme à gauche, Paris (Juillard) 1990.

Semur, Gratien de, Traité des erreurs et des préjugés, Paris (Alphonse Levasseur) 1843.

Sénac de Meilhan, Gabriel, L'Émigré, 1797. Dans : Romanciers du xvIII' siècle, vol. 2, Paris (Gallimard) 1965.

Senancour, Étienne de, Obermann, vol. 1, 1840, Paris (Société nouvelle de librairie et d'édition) 1912.

Senancour, Étienne de, Rêveries sur la nature primitive de l'homme, 1802, Paris (Droz) 1939.

Senghor, Léopold Sédar, Élégies majeures, 1979. Dans : Poèmes, Paris (Seuil) 1985.

Senghor, Léopold Sédar, Nocturnes, 1961. Dans : Poèmes, Paris (Seuil) 1985.

Senlis, R.P. Sébastien de, La Philosophie des contemplatifs, Cambray (Jean de la Rivière) 1620.

Serces, Jaques, Traité sur les miracles, Amsterdam (Pierre Humbert) 1729.

Sermon nouveau d'ung fol changant divers propos, 1480-1490. Dans : Le Recueil Trepperel, vol. 2 :

Les Farces, éd. Eugénie Droz et Halina Lewicka, Genève (Droz) 1961.

Sernoz, Michel, Il n'y a pas de mal, Paris (Corrêa) 1954.

Serres, Michel, Le Tiers-Instruit, 1991, Paris (Gallimard) 1997.

Serres, Olivier de, Le Théâtre d'agriculture et mesnage des champs, vol. 1, 1603, Grenoble (Dardelet) 1973.

Servais, Étienne, Les Sources de «Bug-Jargal », Bruxelles (Palais des Académies) 1923.

Sevelinges, Charles Louis de, La Contemporaine en miniature, Paris (Dentu) 1828.

Sévigné, Madame de, Correspondance, vol. 1 : 1646-1675, Paris (Gallimard) 1972.

Sévigné, Madame de, Correspondance, vol. 2 : 1675-1680, Paris (Gallimard) 1974.

Sévigné, Madame de, Correspondance, vol. 3 :1680-1696, Paris (Gallimard) 1978.

Siegfried, Robert, Sabine ou La Décision, scénario pour cinéma intérieur, Paris (Mercure de France) 1967.

Sieyès, Emmanuel, Euvres, vol. 2, 1791, Paris (Edhis) 1989.

Sieyès, Emmanuel, Euvres, vol. 3, 1799, Paris (Edhis) 1989.

Sieyès, Emmanuel, Qu'est-ce que le Tiers état ?, 1789, Paris (Société de l'histoire de la Révolution française) 1888.

Sigogne, Charles-Timoléon de, Satires, vol. 1, 1619. Dans : Le Cabinet satyrique, Paris (J. Fort) 1924.

Sigogne, Charles-Timoléon de, Songe. Dans : Le Cabinet satyrique, Paris (sans éditeur) 1634.

Simenon, Georges, Les Vacances de Maigret, Paris (Presses de la Cité) 1948.

Simon de Phares, Recueil des plus celebres astrologues, 1494-1498, éd. Jean-Patrice Boudet, vol. 1, Paris (Honoré Champion) 1997. DEAF : SimPharesB

Simon, Claude, L’Acacia, Paris (Minuit) 1989.

Simon, Claude, La Route des Flandres, Paris (Minuit) 1960.

Simon, Claude, Les Géorgiques, 1981, Paris (Minuit) 1992.

Simonet, Mathieu et Françoise Olivès, Marc Beltra : roman autour d'une disparition, MouansSartoux (Omniscience) 2013.

Simonin, Albert, Confessions d'un enfant de La Chapelle, 1977, Paris (Gallimard) 1984.

Simonin, Albert, Du mouron pour les petits oiseaux, Paris (Gallimard) 1960.

Simonin, Albert, Le Cave se rebiffe. Dans : Touchez pas au grisbi! Le Cave se rebiffe. Grisbi or not grisbi, Paris (Gallimard) 1955. 
Simonin, Albert, Touchez pas au grisbi !, 1953, Paris (Gallimard) 1989.

Sizun, Marie, Éclats d'enfance, Paris (Arléa) 2009.

Société de patronage pour les jeunes libérés du Département du Rhône, Assemblée générale, procès verbal des séances, Lyon (Pélagaud / Lesne) 1838.

Société économique de Zurich, Avis aux cultivateurs touchant l'économie du bois, 1769, Berne (Imprimerie de LL.EE.] 1779.

Socque, L'Origine du monde, 2016, http://www.oniris.be/nouvelle/socque-l-originedu-monde-4007.html (30.6.2020).

Solence, Nathalie, Mes années Serize. La vie de Jacques Serizier, Paris (L'Harmattan) 2013.

Sollers, Philippe, Le Cour absolu, 1987, Paris (Gallimard) 1991.

Sollers, Philippe, Le Secret, 1993, Paris (Gallimard) 1995.

Solleysel, Jacques de, Le Parfait Maréchal, Paris (Gervais Clousier) 1668.

Sonnet de Courval, Thomas, Les Satyres du sieur de Courval contre les abus et désordres de la France, Rouen (Guillaume de la Haye) 1627.

Sonnet, Martine, Atelier 62, Cognac (Le Temps qu'il fait) 2008.

Sorel, Charles, La Bibliothèque françoise de M. C. Sorel ou Le Choix et l'examen des livres françois qui traitent de l'éloquence, de la philosophie, de la dévotion et de la conduite des mœurs, Paris (Libraires du palais) 1664.

Sorel, Charles, Le Berger extravagant, 1627, Genève (Slatkine) 1972.

Sorel, Charles, Les Nouvelles françaises où se trouvent divers effets de l'amour et de la fortune, 1623, Genève (Slatkine) 1972.

Sorel, Georges, Réflexions sur la violence, 1912, Paris (M. Rivière) 1921.

Sottie de Maître Pierre Doribus, après 1480. Dans : Le Recueil Trepperel, vol. 1 : Les Sotties, éd. Eugénie Droz, Paris (Droz) 1935.

Sottie de Trote Menu et Mirre Loret, fin xve. Dans : Le Recueil Trepperel, vol. 1 : Les Sotties, éd. Eugénie Droz, Paris (Droz) 1935.

Sottie des sots qui corrigent le Magnificat, avant 1488. Dans : Le Recueil Trepperel, vol. 1 : Les Sotties, éd. Eugénie Droz, Paris (Droz) 1935.

Soulié, Frédéric, Les Mémoires du diable, vol. 1, Paris (A. Dupont) 1837.

Soupault, Philippe, Les Dernières Nuits de Paris, 1928, Paris (Gallimard) 1997.

Spadacine, Sinibal de, Le Miroir d'astrologie naturel, sans lieu ni éditeur, 1651.

St John de Crèvecœur, J. Hector, Voyage dans la Haute Pensylvanie et dans l'État de New-York, Paris (Maradan) 1801.

St Nicolas, hebdomadaire, Paris (Ch. Delagrave).

Staël, Germaine de, Considérations sur les principaux événements de la Révolution française, vol. 1 , 1817, Paris (Charpentier) 1862.

Staël, Germaine de, Corinne ou L'Italie, vol. 1, Paris (Librairie stéréotype) 1807.

Staël, Germaine de, Lettres de jeunesse. Deuxième partie : septembre 1788-décembre 1791. Dans : Correspondance générale, vol. 1, Paris (Pauvert) 1962.

Staël, Germaine de, Lettres de jeunesse. Première Partie : 1777-août 1788. Dans : Correspondance générale, vol. 1, Paris (Pauvert) 1962.

Staël, Germaine de, Lettres inédites à Louis de Narbonne, 1794. Dans : Correspondance générale, vol. 2, Paris (Pauvert) 1960.

Statistique des accidents du travail, vol. 2, Office du travail de Belgique, 1912.

Stendhal, Correspondance, éd. Adolphe Paupe et Paul Arthur Chéramy, Paris (C. Bosse) 1908.

Stendhal, De l'amour, 1822, Paris (Garnier) 1959.

Stendhal, Journal de Stendhal (1801-1814), éd. Casimir Stryienski et François de Nion, Paris (Charpentier) 1888.

Stendhal, La Chartreuse de Parme, 1839, Paris (Garnier) 1962. 
Stendhal, Lamiel, 1842, Lausanne (Rencontre) 1962.

Stendhal, Le Rouge et le noir, 1830, Paris (Garnier) 1963.

Stendhal, Lucien Leuwen, vol. 1, 1835, Paris (Le Divan) 1929.

Stendhal, Mélanges de littérature, vol. 2: Stendhal, éd. Henri Martineau, Paris (Le Divan) 1933.

Stendhal, Promenades dans Rome, 1829, Paris (Michel Lévy) 1858.

Stendhal, Souvenirs d'égotisme, 1832, Paris (Le Divan) 1950.

Stendhal, Suora Scolastica, 1839, www.bibebook.com (Bibebook) 2013.

Stendhal, Vie de Henri Brulard, 1836, Paris (Le Divan) 1949.

Stéphane, L'Art de la coiffure féminine, Paris (La Coiffure de Paris) 1932.

Stern, Marianne, Récits du monde mécanique : realm of broken faces, [Chasseneuil sur Bonnieure] (Chat noir) 2018.

Streel, André, Des sectes à l'avatar, Paris (Publibook) 2008.

Sue, Eugène, Atar-Gull, 1831. Dans : CFuvres illustrées, vol. 1, Paris (Schneider) sans date.

Sue, Eugène, Le Juif errant, 1845, Paris (Laffont) 1996.

Sue, Eugène, Les Mystères de Paris, 1843, Paris (Laffont) 1996.

Sullerot, Evelyne, L'Enveloppe, Paris (Fayard) 1987.

Sully Prudhomme, Armand, La Justice, 1878. Dans : Euvres : poésies, vol. 4, Paris (Lemerre) sans date.

Sully Prudhomme, Armand, Les Solitudes, 1869. Dans : Euuvres : poésies, vol. 2, Paris (Lemerre) sans date.

Supervielle, Jules, Gravitations, 1925, Paris (Gallimard) 1994.

Supervielle, Jules, La Fable du monde, 1938, Paris (Gallimard) 1993.

Supervielle, Jules, Le Forçat innocent, 1930, Paris (Gallimard) 1994.

Supervielle, Jules, Oublieuse Mémoire, 1949, Paris (Gallimard) 1993.

Szczupak-Thomas, Yvette, Un diamant brut. Vézelay-Paris 1938-1950, Paris (Métailié) 2008.

T'Serstevens, Albert, L'Itinéraire espagnol, Paris (Arthaud) 1963.

Tahureau, Jacques, Poésies, Paris (Jehan Borel) 1574.

Taine, Hippolyte, Notes sur Paris. Vie et opinions de M. Frédéric Thomas Graindorge, Docteur en philosophie de l'Université d'léna, recueillies et publiées par H. Taine, son exécuteur testamentaire, 1867, Paris (Hachette) 1921.

Talhian, Pierre Alain, Chemin de traverse, Paris (Ramsay) 1987.

Tanguy, Christophe, Carnets d'un expatrié au cœur de la Chine, Paris (Maxima) 2008.

Tardieu, Jean, Une voix sans personne (1948-1950), 1954. Dans : Le Fleuve caché. Poésies 1938-1961, Paris (Gallimard) 1996.

Tariffe de la Doanne de Lyon, Lyon (Jullieron) 1680.

Tauxier, Louis, La Religion Bambara, Paris (Geuthner) 1927.

Teboul, Jacques, Cours, Hölderlin!, Paris (Seuil) 1979.

Teilhard de Chardin, Pierre, Le Milieu divin, 1955, Paris (Seuil) 1962.

Teilhard de Chardin, Pierre, Le Phénomène humain, 1955, Paris (Seuil) 1962.

Tenenbaum, Gérald, L'Ordre des jours, Paris (Héloïse d'Ormesson) 2008.

Tenenbaum, Gérald, Le Geste, Paris (Héloïse d'Ormesson) 2005.

Ténint, Wilhelm, Salon de 1840. Dans : La France littéraire, vol. 38, 1840.

Terrasson, abbé Jean, Sethos, histoire ou Vie tirée des monumens. Anecdotes de l'ancienne Égypte, traduit d'un ancien manuscrit grec, vol. 1, Paris (Guérin) 1731.

Téry, Simone, Beaux Enfants qui n'hésitez pas, Paris (Éditeurs français réunis) 1957.

Tharaud, Jérôme et Jean, Dingley, l'illustre écrivain, Paris (Pelletan) 1906.

Thelen, Lionel, L'Exil de soi, Bruxelles (Presse de l'Université Saint-Louis) 2006.

Thérame, Victoria, Bastienne, Paris (Flammarion) 1985.

Theuriet, André, La Maison des deux barbeaux, 1879, Paris (Alphonse Lemerre) 1891. 
Theuriet, André, Le Mariage de Gérard, 1875, Paris (Charpentier / Fasquelle) sans date [1923]. Theuriet, André, Mon oncle Flo, Paris (Flammarion) 1906.

Theuriet, André, Tentation, Paris (Alphonse Lemerre) 1894.

Thibaudet, Albert, Réflexions sur la littérature, 1936, Paris (Gallimard) 1938.

Thierry, Augustin, Récits des temps mérovingiens, Paris (Tessier) 1840.

Thomas a Kempis, L'Imitation de Jésus-Christ [= Quatre Livres de l'imitation de N. seigneur

Jesus-Christ ; trad. du latin], Paris (Blageart) 1651.

Thomas, Adrienne, Catherine soldat, Paris (Stock) 1933.

Thomas, Antoine-Léonard, Essai sur les éloges, vol. 2, 1773. Dans : Euvres complètes, vol. 4, Paris

(Desessarts) 1802.

Thoorens, Léon, La Vie passionnée de Honoré de Balzac, Paris (Seghers / L'Inter) 1959.

Thorez, Paul, Les Enfants modèles, 1982, Paris (Gallimard) 1986.

Thoüin, André, Cours de culture et de naturalisation des végétaux, Paris (Huzard) 1827.

Tibaut, Le Roman de la poire, milieu XIII é éd. Christiane Marchello-Nizia, Paris (Société des anciens textes français) 1984. DEAF : PoireM

Tissot, Samuel Auguste, Avis au peuple, 1761, Paris (Didot) 1782.

Tissus et nouveautés, revue mensuelle, éd. française de Tissues and dry goods.

Tocqueville, Alexis de, Correspondance avec Henry Reeve, 1859. Dans : Euvres complètes, vol. 6, Paris (Gallimard) 1954.

Tocqueville, Alexis de, Correspondance d'Alexis de Tocqueville et d'Arthur de Gobineau, 1859. Dans :

Euvres complètes d' Alexis de Tocqueville, Paris (Gallimard) 1959.

Tocqueville, Alexis de, De la démocratie en Amérique, vol. 1, 1835, Paris (Gallimard) 1998.

Tocqueville, Alexis de, De la démocratie en Amérique, vol. 2, 1840, Paris (Gallimard) 1998.

Toepffer, Rodolphe, Nouvelles genevoises, 1839, Paris (Charpentier) 1846.

Toepffer, Rodolphe, Réflexions et menus propos d'un peintre genevois, Paris (Hachette) 1872.

Toulet, Paul-Jean, Les Contrerimes, 1920, Paris (Émile-Paul) 1949.

Tournier, Michel, Le Coq de bruyère, 1978, Paris (Gallimard) 1989.

Tournier, Michel, Le Roi des aulnes, 1970, Paris (Gallimard) 1995.

Tournier, Michel, Le Vent Paraclet, 1977, Paris (Gallimard) 1993.

Tournier, Michel, Les Météores, 1975, Paris (Gallimard) 1995.

Tournier, Michel, Vendredi ou Les Limbes du Pacifique, 1967, Paris (Gallimard) 1995.

Toutes les questions que vous vous posez sur votre cerveau, F.-Xavier Alario (éd.), Paris (Odile Jacob) 2011.

Traduction des œuvres médicales d'Hippocrates [trad. du grec par le Dr Gardeil ; éd. par Tournon], vol. 2, Toulouse (Fages / Meilhac) 1801.

Trenet, Charles, Chansons (1946-1959). Dans : Le Jardin extraordinaire, Paris (Le Livre de poche) 1993.

Trenet, Charles, Chansons (1960-1992). Dans : Le Jardin extraordinaire, Paris (Le Livre de poche) 1993.

Tresch, Mathias, La Fontaine, naturaliste, dans ses fables, Luxembourg (Beffort) 1907.

Triolet, Elsa, Le Premier Accroc coûte deux cents francs, Paris (Denoël) 1945.

Tristan l'Hermite, La Célimène. Comédie de Rotrou, accomodée au théatre sous le titre d'Amarillis : pastorale, 1653. Dans : Le Théâtre complet, Tuscaloosa (University of Alabama press) 1975.

Tristan l'Hermite, La Folie du sage, 1645, Paris (Droz) 1936.

Tristan l'Hermite, La Lyre, 1641, Genève (Droz) 1977.

Tristan l'Hermite, La Mariane, 1637, Paris (Hachette) 1917.

Tristan l'Hermite, La Mort de Sénèque, 1645, Paris (Hachette) 1919.

Tristan l'Hermite, Le Page disgracié, 1667, Paris (Plon) 1898.

Tristan l'Hermite, Les Vers héroïques, 1648, Genève (Droz) 1967. 
Tristan l'Hermite, Osman, 1655. Dans : Le Théâtre complet, Tuscaloosa (University of Alabama press) 1975.

Tristan l'Hermite, Panthée, 1639. Dans : Le Théâtre complet, Tuscaloosa (University of Alabama press) 1975.

Tristani, Philippe, Fleur d'espérance. Dans : Les Camps d'Allemagne, numéros 67-68, 1916.

Tristran, manuscrit d'Oxford, $4^{e}$ quart XII'. Dans : Karl Bartsch, Chrestomathie de l'ancien français, pièce 24.

Tscheuschner, Hubert, La Prévision du temps sans instrument, Paris (Henriot) 1919.

Tschudi, Frédéric de [Friedrich von Tschudi], Les Alpes: description pittoresque de la nature et de la faune alpestres [trad. de l'allemand par Vouga et Schimper], Berne / Strasbourg (Dalp, Treuttel et Wurtz) 1859.

Turian Cardozo, Jacqueline, On ne guérit pas de son enfance, Port au Prince (H. Descamps) 1987.

Turnèbe, Odet de, Les Contens, 1584. Dans : Le Théâtre français au XVI ${ }^{e}$ et au XVII ${ }^{e}$ siècle, éd. Édouard Fournier, vol. 1, Paris (Laplace / Sanchez) 1873.

Tyard, Pontus de, Solitaire premier, 1587, Genève (Droz) / Lille (Giard) 1950.

Tyssot de Patot, Simon, Voyages et avantures de Jaques Massé, vol. 1, 1710, Bordeaux (Jacques L’Aveugle) 1760.

Tzara, Tristan, L'Antitête, 1933. Dans : EFuvres complètes, vol. 2, Paris (Flammarion) 1977.

Tzara, Tristan, Manifestes, lampisteries, articles : 1912-1924. Dans : Euvres complètes, vol. 1, Paris (Flammarion) 1975.

U.O., Un coin du Jura. Dans : Bibliothèque universelle, Genève (Bibliothèque universelle) 1861.

Ulenspiegel, 1530, Antwerpen / Rotterdam (De Vries / Brouwers) 1988.

Un chivalier et sa dame et un clerk, $2^{\mathrm{e}}$ tiers XIII'. Dans : Nouveau Recueil complet des fabliaux, vol. 10. DEAF : ChevDameClercN

Un sermon en vers [= Hermann Suchier, Reimpredigt], $2^{\mathrm{e}}$ quart XII ${ }^{\mathrm{e}}$, Halle (Niemeyer) 1879.

Une icône historiée de Saint Georges du xIII' siècle. Dans : Efthalia Constantinides (éd.), Images from the Byzatine Periphery, sans lieu (Alexandros Press) 2007.

Urfé, Honoré d', L'Astrée, vol. 1, 1612, Genève (Slatkine) 1966.

Urfé, Honoré d', L'Astrée, vol. 2, 1610, Genève (Slatkine) 1966.

Urfé, Honoré d', L'Astrée, vol. 3, 1631, Genève (Slatkine) 1966.

Urfé, Honoré d', L'Astrée, vol. 4, 1627, Genève (Slatkine) 1966.

Urfé, Honoré d', La Sylvanire ou La Morte-Vive : fable bocagère, Paris (R. Fouet) 1627.

Vac, Bertrand, Louise Genest, Paris (Cercle du livre de France) 1950.

Vadier, Berthe, La Comtesse de Löwenstein, Paris (Payot) 1800.

Vailland, Roger, Drôle de jeu, Paris (Correa) 1945.

Vailland, Roger. La Loi, Paris (Gallimard) 1957.

Valentinian, Théodose [= prob. pseudonyme de Nicolas Denisot], L'Amant resuscité de la mort d'amour, 1558, éd. Véronique Duché-Gavet, Genève (Droz) 1998.

Valéry, Paul, Variété I, 1924, Paris (Gallimard) 1948.

Valéry, Paul, Variété II, 1929, Paris (Gallimard) 1948.

Valéry, Paul, Variété IV, 1938, Paris (Gallimard) 1947.

Valette, Cécile Éluard, Madame Robert, Les Grandes Heures de la cuisine française, Paris (Club des libraires de France) 1964.

Vallès, Jules, Jacques Vingtras : L'Enfant, 1879, Paris (Gallimard) 1997.

Vallès, Jules, Jacques Vingtras : L'Insurgé, 1886, Paris (Gallimard) 1998.

Vallès, Jules, Jacques Vingtras : Le Bachelier, 1881, Paris (Gallimard) 1999.

Vallotton, Benjamin, Jardiniers du paradis, Lausanne (Spes) 1957.

Van Cauwelaert, Didier, Un aller simple, Paris (Albin Michel) 1994.

Van der Meersch, Maxence, Invasion 14, Paris (Albin Michel) 1935. 
Van der Meersch, Maxence, L'Empreinte du dieu, Paris (Albin Michel) 1936.

Van Torre, Antonii, Dialogi familiares litterarum tironibus [trad. du latin en français], Liège (G.

Barnabé) 1747.

Vaneigem, Raoul, Nous qui désirons sans fin, Paris (Le Cherche Midi) 1996.

Varenne, Jacques de, Mémoires du chevalier de Ravanne, vol. 1, 1740, sans lieu (Aux dépens de la Compagnie) 1782.

Varenne-Fenille, Philibert Charles, Mémoires sur l'administration forestière, Paris (Marchant) 1792.

Vargas, Fred, Dans les bois éternels, 2006, Paris (J'ai lu) 2014.

Varillas, Antoine, Histoire des révolutions arrivées dans l'Europe en matière de religion, vol. 1, Paris (Barbin) 1686.

Vasse, Christophe, Celle qui ne pleurait jamais, Paris (Les nouveaux auteurs) 2018.

Vauban, Sébastien Le Prestre de, Projet d'une dixme royale, sans lieu ni éditeur, 1707.

Vauquelin des Yveteaux, Nicolas, EFuvres poétiques, 1648. Dans : Euvres complètes, Genève

(Slatkine) 1967.

Vautrin, Jean, Billy-Ze-Kick, 1974, Paris (Mazarine) 1980.

Vautrin, Jean, Bloody Mary, Paris (Mazarine) 1979.

Vauvenargues, Luc de Clapiers, marquis de, Réflexions et maximes, 1747. Dans : CEuvres, Paris (Furne) 1857.

Vauvenargues, Luc de Clapiers, marquis de, Traité sur le libre arbitre, 1744. Dans : Euvres, Paris (Furne) 1857.

Vaux, Charles-Maurice de, Notre ami le chien, Paris (Rothschild) 1897.

Veaux, Monique, À la découverte de Dax et de sa région, Pau (Marrimpouey jeune) 1978.

Vedel, Georges, Manuel élémentaire de droit constitutionnel, Paris (Sirey) 1949.

Védrines, Jean, Âge d'or, Paris (Fayard) 2019.

Veil, Simone, Une vie, 2007, Paris (Stock) 2008.

Vercel, Roger, Capitaine Conan, Paris (Albin Michel) 1934.

Vercel, Roger, Notre père Trajan, Paris (Albin Michel) 1930.

Verdure, Gaspard, Tu l'écris, je le crie, Kindle, 2019.

Vergne, Anne, L'Innocence du boucher, Paris (Lattès) 1984.

Verhaeren, Émile, La Multiple Splendeur, 1906, Paris (Mercure de France) 1913.

Verhaeren, Émile, Les Campagnes hallucinées, 1893. Dans : Les Villes tentaculaires, précédées des Campagnes hallucinées, Paris (Mercure de France) 1913.

Verhaeren, Émile, Les Villes tentaculaires, 1895, Paris (Mercure de France) 1913.

Verhaeren, Émile, Poèmes, Paris (Mercure de France) 1894.

Verlaine, Paul, Euvres poétiques complètes, 1896, Paris (Gallimard) 1962.

Verne, Jules, L'île mystérieuse, 1874, Paris (Hetzel) sans date.

Verne, Jules, Le Tour du monde en quatre-vingts jours, 1873, Paris (Hetzel) sans date.

Verne, Jules, Les Enfants du Capitaine Grant, 1868, Paris (Hachette) 1930.

Verne, Jules, Paris au Xxe siècle, 1860, Paris (Beta publisher) 2020.

Véron, Pierre, Galop Général !, Paris (Dentu) 1885.

Véron, Pierre, Le Roman de la femme à barbe, Paris (Michel Lévy) 1872.

Vertot, René de, Histoire des révolutions arrivées dans le gouvernement de la République romaine, Paris (Barois) 1719.

Vespini, Jean-Paul, Le Tour de France pour les nuls, Paris (First-Gründ) 2013.

Veuillot, Louis François, Les Odeurs de Paris, 1866, Paris (Palmé) 1867.

Vian, Boris, J'irai cracher sur vos tombes, 1946, Paris (10/18) 1993.

Vian, Boris, L'Arrache-Cœur, 1953, Paris (Hachette) 1994.

Vian, Boris, L'Écume des jours, 1947, Paris (10/18) 1995. 
Vian, Boris, L'Herbe rouge, 1950. Dans : L'Herbe rouge, Les Lurettes fourrées, Paris (Le Livre de poche) 1994.

Vian, Boris, Le Grand Sommeil [trad. ; original de Raymond Chandler], 1948, Paris (Gallimard) 1999.

Vian, Boris, Les Fourmis, 1949, Paris (Pauvert) 1997.

Vian, Boris, Les Lurettes fourrées, 1962. Dans : L'Herbe rouge, Les Lurettes fourrées, Paris (Le Livre de poche) 1994.

Vianin, Pierre, L’Aide stratégique aux élèves en difficulté scolaire, Bruxelles (de Boeck) 2009.

Viau, Théophile de, Euvres poétiques : $1^{\text {re }}$ partie, 1621, Genève (Droz) 1951.

Viborg, Erik, Mémoires sur l'éducation, les maladies, l'engrais et l'emploi du porc, Paris (Huzard) 1835.

Victoires, conquêtes, désastres, revers et guerres civiles des Français, vol. 6, Paris (Panckoucke) 1823.

Vidal de la Blache, Paul, Tableau de la géographie de la France, vol. 1, Paris (Hachette) 1908.

Vidron, François, La Chasse en plaine et au bois, Paris (Presses universitaires de France) 1945.

Vie de saint Alexis, fin $\mathrm{xl}^{\mathrm{e}}$, éd. Thomas Rainsford et Christiane Marchello-Nizia. [cité d'après BFM] ; [pour les citations datées au XIII ${ }^{\mathrm{e}}$ et XIV ${ }^{\mathrm{e}}$ siècles v. éd. Gaston Paris et Léopold Pannier]

Vie de saint Alexis, textes du XIII ou du xIV ${ }^{\mathrm{e}}$ siècle, éd. Gaston Paris et Léopold Pannier, Paris (Franck) 1872.

Vie de saint Léger, 1000 . Dans : Eduard Koschwitz, Les Plus Anciens Monuments de la langue française, Leipzig (Reisland) 71907. DEAF : SLégerK

Vieilleville, François de Scépeaux, sire de, Mémoires, 1553. Dans : Nouvelle Collection des mémoires relatifs à l'histoire de France, vol. 9, éd. MM. Michaud et Poujoulat, Paris (Didier) 1854.

Vigenère, Blaise de et Anthoine de La Faye, Les Decades [trad. ; original de Tite-Live], Paris (Jacques du Puy) 1583.

Vigenère, Blaise de, L'Histoire de la décadence de l'Empire grec, et establissement de celuy des turcs, comprise en dix livres par Nicolas Chalcondyle [trad.], Paris (Nicolas Chesneau) 1577.

Vigenère, Blaise de, La Vie d'Appolonius Thyaneen [trad.], Paris (Matthieu Guillemot) 1611.

Vigenère, Blaise de, Les Chroniques et annales de Poloigne, Paris (Jean Richer) 1573.

Vigenère, Blaise de, Les Illustrations sur l'histoire [trad. ; original de Chalcondyle] / Histoire generale des Turcs, vol. 2, Paris (Augustin Courbe) 1662.

Vigneau, H., La Bayadère. Dans : Revue contemporaine, Paris, 1861.

Vigneulles, Philippe de, Les Cent Nouvelles nouvelles, 1515, éd. Charles H. Livingston, Genève (Droz) 1972.

Vigny, Alfred de, Chatterton, 1835. Dans : CFuvres complètes, vol. 2, Paris (Conard) 1927.

Vigny, Alfred de, Cinq-Mars, 1826, Paris (Gallimard) 1999.

Vigny, Alfred de, La Maréchale d'Ancre, 1830. Dans : CEuvres complètes : Théâtre, vol. 2, Paris (Alphonse Lemerre) 1885.

Vigny, Alfred de, Le Journal d'un poète, 1863. Dans : Euvres complètes, vol. 2, Paris (Gallimard) 1948.

Vigny, Alfred de, Les Destinées, 1863, Genève (Droz) 1967.

Vigny, Alfred de, Mémoires inédits, 1863, Paris (Gallimard) 1959.

Vigny, Alfred de, Poèmes antiques et modernes, 1863, Paris (Hachette) 1914.

Vigny, Alfred de, Servitude et grandeur militaires, 1835 Paris (Garnier) 1965.

Vigny, Alfred, Poésies complètes, 1822-1863, Paris (Calmann-Lévy) 1892.

Vilallonga, José Luis de, Furia, Paris (Seuil) 1974.

Villeneuve, Ferdinand de, Le Hussard de Felsheim, Paris (Jules Dinot) 1827.

Villiers de L'Isle-Adam, Auguste de, Contes cruels, 1883. Dans : Euvres complètes, vol. 2, Paris

(Mercure de France) 1922. 
Villiers de L'Isle-Adam, Auguste de, Correspondance générale, vol. 1, 1889, Paris (Mercure de France) 1962.

Villon, François, Le Jargon ou Jobelin, 1455-1463. Dans : , Euvres complètes de François Villon, éd. Auguste Longnon, Paris (Lemerre) 1892. DEAF : Villon L ${ }^{1}$

Villon, François, Le Lais, 1456 [= Le Lais Villon et les poèmes variés, vol. 1], éd. Jean Rychner et Albert Henry, Genève (Droz) 1977. DEAF : VillonLaisR

Villon, François, Le Testament, 1461 [= Le Testament Villon], éd. Jean Rychner et Albert Henry, vol. 1, Genève (Droz) 1974. DEAF : VillonTestR

Vincenot, Henri, Le Pape des escargots, 1972, Paris (Gallimard) 1987.

Viollet-le-Duc, Eugène, Entretiens sur l'architecture, vol. 1, Paris (A. Morel) 1863.

Viollis, Jean, L'Auvergnate. Dans : CEuvres libres, septembre 1922.

Viret, Pierre, Exposition de la doctrine de la foy chrestienne, Genève (Jean Rivery) 1564.

Viret, Pierre, Instruction chrétienne, 1564, éd. Arthur-Louis Hofer, vol. 1, sans lieu (L’Âge d'homme) sans date.

Virey, Julien-Joseph, Traité de pharmacie théorique et pratique, Paris (Rémont / Ferra) 1811.

Vital, Laurent, Premier Voyage de Charles Quint en Espagne de 1517 à 1518, 1518. Dans : Louis Prosper Gachard, P. Piot (éds.), Collection des voyages de souverains des Pays-Bas, Bruxelles (F. Hayaz) 1881.

Vivien de Nogent, La Clef d'amour [= La Clef d'amors], 1280, éd. Auguste Doutrepont, Halle (Niemeyer) 1890. DEAF : ClefD

Vogüé, Eugène, Les Morts qui parlent, 1899, Paris (Nelson) 1910.

Voisenon, Claude-Henri de Fusée de, Le Sultan Misapouf et la princesse Grisemine, 1746. Dans : Contes, Paris (I. Liseux) 1879.

Voiture, Vincent, Lettres, 1648. Dans : Les Fuvres, vol. 1, Paris (A. Courbe) 1654.

Voiture, Vincent, Poésies. Dans : Les Euvres, vol. 2, Paris (A. Courbe) 1654.

Volney, Constantin-François de Chassebœuf, comte de, Les Ruines ou Méditations sur les révolutions des empires, 1791, Paris (Dugour / Durand) 1799.

Volney, Constantin-François de Chassebœuf, comte de, Voyage en Égypte et en Syrie, vol. 1, Paris (Volland) 1787.

Voltaire, Adélaïde du Guesclin, 1734, Paris (Didot) 1859.

Voltaire, Alzire ou Les Américains, Amsterdam (Desbordes) 1736.

Voltaire, Candide ou L'Optimisme, 1759, Paris (Hachette) 1913.

Voltaire, Charles XII. Roi de Suède, 1731. Münster (Theissing), 1874.

Voltaire, Charlot, 1767, Paris (Didot) 1859.

Voltaire, Correspondance. Dans : Euvres complètes, vol. 14, 1770, Paris (Didot) 1869.

Voltaire, Dictionnaire philosophique, 1764, Paris (Garnier) 1954.

Voltaire, Épîtres, 1778. Dans : Euuvres complètes, vol. 10, Paris (Garnier) 1877.

Voltaire, Essay sur l'histoire générale et sur les mœurs et sur l'esprit des nations, vol. 1, Genève

(Cramer) 1756.

Voltaire, Histoire de Jenni ou L'Athée et le sage, 1775. Dans : Romans et contes, Paris (Garnier) 1963.

Voltaire, L'Homme aux quarante écus, Paris (Libraires associés) 1768.

Voltaire, L'Ingénu : histoire véritable, 1767, Genève (Droz) / Paris (Minard) 1957.

Voltaire, La Bible enfin expliquée par plusieurs aumoniers de S.M. L.R.D.P., 1776, sans lieu / sans éditeur. [cité d'après Frantext]

Voltaire, La Pucelle d'Orléans, Louvain (sans éditeur) 1755. [cité d'après Frantext]

Voltaire, Le Dépositaire, 1769, Paris (Didot) 1859.

Voltaire, Le Dîner du comte de Boulainvilliers, 1767. Dans : Mélanges, Paris (Gallimard) 1961.

Voltaire, Le Philosophe ignorant, 1766. Dans : Mélanges, Paris (Gallimard) 1961.

Voltaire, Les Deux Tonneaux, 1773, Paris (Didot) 1859. 
Voltaire, Les Scythes, 1767, Paris (Didot) 1859.

Voltaire, lettre de Voltaire à Frédéric II datée 1740. Dans : Correspondance de Frédéric II, roi de Prusse, vol. 7, Berlin (Decker) 1853.

Voltaire, Lettres à son imprimeur, 1778, Genève (Droz) / Lille (Giard) 1952.

Voltaire, Lettres philosophiques, vol. 1, 1734, Paris (Hachette) 1915-1919.

Voltaire, Micromégas, 1752, Princeton (University press) 1950.

Voltaire, Édipe, 1730. Dans : EFuvres complètes : Théâtre 1, Paris (Garnier) 1877.

Voltaire, Pièces inédites, Paris (P. Didot) 1820.

Voltaire, Précis du siècle de Louis XV, vol. 1, 1769, sans lieu ni éditeur, 1770. [cité d'après Frantext]

Voltaire, Voyage à Berlin, 1750, Paris (Didot) 1859.

Voyage d'Italie, 1606, Genève (Slatkine) 1982.

Vuillemin, Roger, Mémento d'éducation physique et d'initiation sportive, Grenoble (Saint-Bruno) 1941.

Warembourg, Gilles, L'Ellipse, Douai (Atria) 2011.

Warusfel, André, Les Mathématiques modernes, Paris (Seuil) 1969.

Watelet, Claude-Henri, Encyclopédie méthodique : Beaux arts, vol. 2, Paris (Panckoucke) 1791.

Watriquet de Couvin, Dits [= Dits de Watriquet de Couvin], 1325, éd. August Scheler, Bruxelles

(Devaux) 1868. DEAF : WatrS

Weight Watchers, Cuisine saine et facile. Le livre de cuisine ultra-rapide de Weight Watchers, Tielt (Lannoo) 2012.

Weil, Simone, La Pesanteur et la grâce, 1943, Paris (Union générale d’éditions) 1963.

Weiss, Otto Georges, L'Économie française, vol. 2, Paris (Structures nouvelles) 1969.

Wey, Francis, L'Ami des artistes. Dans : Les Français peints par eux-mêmes, Paris (Curmer) 1840.

Weyergans, François, Macaire le copte, 1981, Paris (Gallimard) 1984.

Wheler, George, Voyage de Dalmatie, de Grèce et du Levant [trad. de l'anglais], vol. 1, Anvers / Paris (Daniel Hortemels) 1689.

Wieger, Léon, Moralisme. Dans : Chine moderne 9, 1920.

Wilbois, Joseph, Comment fonctionne une entreprise, Paris (Presses universitaires de France) 1941. Wilmotte, Maurice, La Renaissance du livre. Dans : Revue des nations latines, vol. 2, 1917.

Winock, Michel, Jeanne et les siens, 2003, Paris (Seuil) 2004.

Winthrop, Theodore, Don Fulano [trad. de E. St. G. ; titre original : John Brent] Dans : Revue britannique, 1864.

Witcomb, Henry et Edmond Tiret, Dictionnaire des termes de marine, vol. 1 : français-anglais, Paris (Challamel aîné) 1883.

Wurmser, André, Un homme vient au monde, Paris (Éditeurs français reunies) 1953.

Yon, Anna, Guide pratique pour un cours de langue française, Paris (Hachette) 1880.

Yourcenar, Marguerite, Anna, soror, 1935. Dans : CEuvres romanesques, Paris (Gallimard) 1991.

Yourcenar, Marguerite, Feux, 1936. Dans : E Fuvres romanesques, Paris (Gallimard) 1991.

Yourcenar, Marguerite, L'CFuvre au noir, 1968. Dans : F Fuvres romanesques, Paris (Gallimard) 1991.

Yourcenar, Marguerite, Le Coup de grâce, 1939. Dans : Euvres romanesques, Paris (Gallimard) 1991.

Yourcenar, Marguerite, Le Labyrinthe du monde 3 : Quoi ? L'Éternité, 1988. Dans : Essais et mémoires, Paris (Gallimard) 1991.

Yourcenar, Marguerite, Les Vagues [trad. ; original de Virginia Woolf], 1937, Paris (Le Livre de poche) 1993.

Yourcenar, Marguerite, Mémoires d'Hadrien, 1951. Dans : CEuvres romanesques, Paris (Gallimard) 1991.

Yourcenar, Marguerite, Nouvelles orientales, 1978. Dans : Euvres romanesques, Paris (Gallimard) 1991. 
Yourcenar, Marguerite, Un homme obscur, 1982. Dans : CEuvres romanesques, Paris (Gallimard) 1991.

Yourcenar, Marguerite, Une belle matinée, 1982. Dans : Euvres romanesques, Paris (Gallimard) 1991.

Ysaÿe le triste, fin XIVe, éd. André Giacchetti, Rouen (Université de Rouen) 1989. DEAF : YsayeTrG

Ysopet de Lyon [= Lyoner Yzopet], $2^{\mathrm{e}}$ moitié XIII' ${ }^{\mathrm{e}}$ éd. Wendelin Foerster, Heilbronn (Henninger) 1882. DEAF : YsLyonF

Yver, Jacques, Le Printemps (extraits), 1572. Dans : Conteurs français du XVI ${ }^{e}$ siècle, Paris (Gallimard) 1965.

Ziegesar, Cecily von, Gossip girl, Paris (Fleuve) 2015.

Zimmermann, Wilhelm, L'Angine couenneuse et le croup, Valenciennes (E. Prignet) 1860.

Zitrone, Léon, Léon Zitrone vous emmène aux courses, Paris (Del Duca) 1962.

Zobel, Joseph, La Rue Cases-Nègres, 1950, Paris (Présence africaine) 1999.

Zola, Émile, Au bonheur des dames, 1883. Dans : Les Rougon-Macquart, vol. 3, Paris (Gallimard) 1964.

Zola, Émile, Germinal, 1885. Dans : Les Rougon-Macquart, vol. 3, Paris (Gallimard) 1964.

Zola, Émile, L’Argent, 1891. Dans : Euvres complètes, vol. 19, Paris (Bernouard) 1928.

Zola, Émile, L'Assommoir, 1877. Dans : Les Rougon-Macquart, vol. 2, Paris (Gallimard) 1961.

Zola, Émile, L'CFuvre, 1886. Dans : CFuvres complètes, vol. 15, Paris (Bernouard) 1928.

Zola, Émile, La Bête humaine, 1890. Dans : Les Rougon-Macquart, Paris (Fasquelle) 1953.

Zola, Émile, La Conquête de Plassans, 1874. Dans : Les Rougon-Macquart, vol. 1, Paris (Gallimard) 1960.

Zola, Émile, La Curée, 1872. Dans : Les Rougon-Macquart, vol. 1, Paris (Gallimard) 1960.

Zola, Émile, La Débâcle, 1892. Dans : Les Rougon-Macquart, Paris (Fasquelle) 1897.

Zola, Émile, La Faute de l'abbé Mouret, 1875. Dans : Les Rougon-Macquart, vol. 1, Paris (Gallimard) 1960.

Zola, Émile, La Fortune des Rougon, 1871. Dans : Les Rougon-Macquart, vol. 1, Paris (Gallimard) 1960.

Zola, Émile, La Joie de vivre, 1884. Dans : Les Rougon-Macquart, vol. 3, Paris (Gallimard) 1964.

Zola, Émile, La Mort d’Olivier Bécaille, 1884. Dans : Naïs Micoulin et autres nouvelles, Paris

(Fasquelle) 1904.

Zola, Émile, La Terre, 1887, Paris (Charpentier) 1887.

Zola, Émile, Le Docteur Pascal, 1893. Dans : Euvres complètes, vol. 22, Paris (Bernouard) 1928.

Zola, Émile, Le Rêve, 1888. Dans : Euuvres complètes, vol. 17, Paris (Bernouard) 1928.

Zola, Émile, Le Ventre de Paris, 1873. Dans : Les Rougon-Macquart, vol. 1, Paris (Gallimard) 1960.

Zola, Émile, Madeleine Férat, 1868. Dans : Euuvres complètes, vol. 34, Paris (Bernouard) 1928.

Zola, Émile, Nana, 1880. Dans : Les Rougon-Macquart, vol. 2, Paris (Gallimard) 1961.

Zola, Émile, Pot-Bouille, 1882. Dans : Les Rougon-Macquart, vol. 3, Paris (Gallimard) 1964.

Zola, Émile, Son Excellence Eugène Rougon, 1876. Dans : Les Rougon-Macquart, vol. 2, Paris (Gallimard) 1961.

Zola, Émile, Thérèse Raquin, 1867. Dans : EFuvres complètes, vol. 34, Paris (Bernouard) 1928.

Zola, Émile, Une campagne (1880-1881), 1882, édition numérique, sans lieu (Arvensa éditions) sans date (consulté en janvier 2020).

Zola, Émile, Une page d'amour, 1878. Dans : Les Rougon-Macquart, vol. 2, Paris (Gallimard) 1961.

Zoo Anvers, Société royale de zoologie d'Anvers, revue. 


\section{Index alphabétique des adjectifs-adverbes}

\begin{tabular}{|c|c|}
\hline abominable & cogner \\
\hline abondant & couler, tomber \\
\hline abstrait & peindre \\
\hline acertes & parler \\
\hline âcre & sentir \\
\hline aérien & sonner \\
\hline affectueux & sonner \\
\hline affranchi & écrire \\
\hline aigu & aboyer, aller, chanter, gémir, regarder, siffler, sonner \\
\hline aimable & chanter, proposer \\
\hline aise & $\begin{array}{l}\text { aller, coucher, descendre, dormir, finir, mettre, passer, porter, reculer, tenir, } \\
\text { veiller, venir, vivre }\end{array}$ \\
\hline allongé & parler \\
\hline ambigu & jouer \\
\hline amer & juter, mâcher \\
\hline ample & dessiner \\
\hline amusant & sonner \\
\hline ancien & sonner \\
\hline anglais & boire, danser, manger \\
\hline anguleux & faire \\
\hline appétissant & acheter \\
\hline appuyé & écrire \\
\hline âpre & faire, souffler \\
\hline attractif & écrire \\
\hline austère & sonner \\
\hline automatique & faire \\
\hline avenant & vêtir \\
\hline baroque & décorer \\
\hline bas & $\begin{array}{l}\text { abaisser, accuser, affonder, agiter, aimer, ajouter, aller, appeler, applaudir, } \\
\text { asseoir, avaler, battre, boiter, buquer, caler, causer, chanter, chantonner, } \\
\text { chevaucher, choir, choisir, chuchoter, coloïer, commencer, condamner, } \\
\text { confier, conseiller, conter, continuer, couler, couver, déclarer, demander, } \\
\text { descendre, dévaler, deviser, dire, diriger, éclater, enrager, exciter, expliquer, } \\
\text { faire, férir, fredonner, gémir, gronder, hurler, incliner, jacasser, jaser, jeter, } \\
\text { juger, jurer, lire, manger, marmotter, maudire, menacer, mendier, mener, } \\
\text { mettre, meugler, moquer, mordre, mourir, murmurer, naître, nommer, } \\
\text { noter, opérer, parler, pendre, penser, placer, plaindre, pleurer, porter, } \\
\text { poser, précipiter, prendre, prier, prononcer, proposer, protester, raisonner, } \\
\text { ramper, ravaler, réciter, regarder, regretter, répéter, répondre, reprendre, } \\
\text { reprocher, résonner, retomber, retordre, ricaner, rire, ronfler, rouler, saluer, } \\
\text { sangloter, sonner, souffler, soupirer, sourire, supplier, tendre, tenir, tirer, } \\
\text { tomber, tourner, traîner, traiter, viser, vivre, voir, voler }\end{array}$ \\
\hline basique & construire \\
\hline beau (bel) & $\begin{array}{l}\text { accueillir, acesmer, acheter, acostumer, aller, appareiller, appeler, ardre, } \\
\text { armer, arraisonner, arroyer (areer), assaillir, atourner, chanter, chevaucher, } \\
\text { conforter, contenir, croître, déduire, défendre, demander, déporter, } \\
\text { dîner, dire, échapper, écrire, encager, esbanier, faire, garnir, gouverner, }\end{array}$ \\
\hline
\end{tabular}




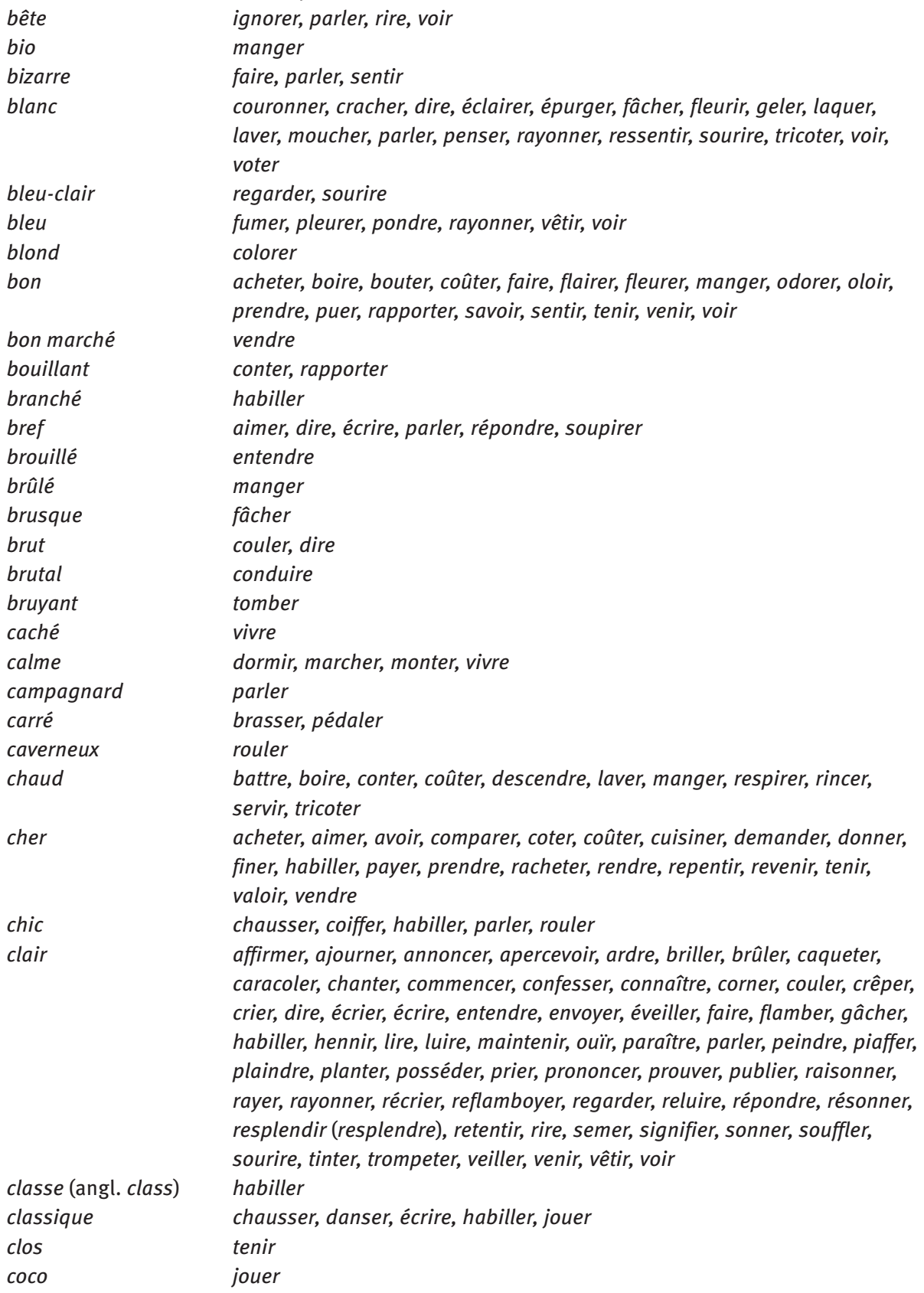
ignorer, parler, rire, voir anger couronner, cracher, dire, éclairer, épurger, fâcher, fleurir, geler, laquer, laver, moucher, parler, penser, rayonner, ressentir, sourire, tricoter, voir, voter

fumer, pleurer, pondre, rayonner, vêtir, voir colorer

acheter, boire, bouter, coûter, faire, flairer, fleurer, manger, odorer, oloir, prendre, puer, rapporter, savoir, sentir, tenir, venir, voir

habiller

aimer, dire, écrire, parler, répondre, soupirer

fâcher

couler, dire

conduire

tomber

dormir, marcher, monter, vivre

parler

brasser, pédaler

rouler

battre, boire, conter, coûter, descendre, laver, manger, respirer, rincer, servir, tricoter

finer, habiller, payer, prendre, racheter, rendre, repentir, revenir, tenir, ir, vendre

affirmer, ajourner, annoncer, apercevoir, ardre, briller, brûler, caqueter, caracoler, chanter, commencer, confesser, connaître, corner, couler, crêper, crier, dire, écrier, écrire, entendre, envoyer, éveiller, faire, flamber, gâcher, habiller, hennir, lire, luire, maintenir, ouïr, paraître, parler, peindre, piaffer, plaindre, planter, posséder, prier, prononcer, prouver, publier, raisonner rayer, rayonner, récrier, reflamboyer, regarder, reluire, répondre, résonner, resplendir (resplendre), retentir, rire, semer, signifier, sonner, souffler, sourire, tinter, trompeter, veiller, venir, vêtir, voir chausser, danser, écrire, habiller, jouer

jouer

guerroyer, guimpler, habiller, joster, lever, loger, losangier, luire, marcher, mener, mentir, naître, œuvrer, ouvrer, parer, parler, passer, paumoier, payer, penser, porter, pourvoir, prier, promettre, raisonner, recevoir, recueillir, regarder, remuer, rendre, répondre, résonner, retraire, rêver, rhétoriquer, rire, saillir, saluer, sonner, tenir, venir, vêtir, vivre, voir 
coi

cointe

coloré

colossal

compact

complet

compliqué

compréhensible

comptant

concentré

concis

concret

confortable

confus

contemporain

content

contenu

correct

cosmique

couché

coupé

courant

courbe

court

creux

critique

cru

cuit

décontracté

déhanché

demi-creux

démodé

dense

dépointé

désespérant

destroit

détendu

différent

difficile

digne

direct

double arrêter, choir, demeurer, rester, taire, tenir

chanter

habiller

voir

marcher

désarêter, tenir

écrire, parler

dire

payer, régler

jouer

écrire

écrire

dessiner, manger

voir

danser

vivre

jouer

dessiner, parler

penser

dormir

trottiner

envoyer, lire

raisonner

arrêter, attacher, atterrir, carguer, chevaucher, clouer, coiffer, couper, déclarer, décoller, demeurer, détourner, dire, écrire, étrangler, faire, friser, gérer, habiller, ignorer, mettre, mouiller, nommer, pardonner, parler, pendre, penser, perdre, planter, rebrousser, respirer, rester, retirer, retourner, revenir, souffler, soupirer, tailler, tirer, tondre, tourner, trancher, trotter, trouver, venir, vêtir, vibrer, virer

cheviller, enfoncer, penser, raisonner, résonner, rêver, songer, sonner

examiner

chanter, dire, manger, parler

manger

jouer

pédaler

sonner

écrire, habiller, sonner

écrire, parler

tirer

écrire

(v. étroit)

monter

louer, faire

faire

aller

aller, changer, décoincer, dire, écrire, gerber, partir, prendre, regarder, retrouver, user, voir

aimer, compter, entendre, manger, naître, parler, payer, travailler, vendre, vivre, voir, voter 
douloureux

doux

droit

$d r u$

dur

durable

dynamique

économique

efficace

égal

électrique

élégant

enclos

engagé

ennuyeux

énorme

enragé

enroué

entier

épais préparer, voir

aller, arriver, avaler, briller, chanter, chantonner, circuler, commencer, couler, courir, cracher, descendre, filer, flairer, fleurer, luire, marcher, monter, odorer, parler, poindre, raconter, redescendre, répondre, résonner, sonner, tomber

accourir, acheminer, adresser, alever, aller, allonger, amener, apporter, arrêter, arriver, assener, atourner, avaler, bifurquer, boire, bouler, bouter, boutonner, carapater, charrier, cheminer, chevaucher, choir, coiffer, compter, conduire, connaître, conter, continuer, couper, courir, déchaumer, décocher, descendre, dire, diriger, écarter, écrire, élancer, élever, emmener, entrer, envoyer, errer, esgarder, faire, férir, filer, frapper, fuir, garder, guier, issir, jaillir, jeter, juger, labourer, lancer, marcher, mener, mettre, monter, mourir, mouvoir, nommer, ouvrir, parler, partir, passer, penser, piquer, pisser, planter, porter, poser, prendre, préparer, prévenir, raisonner, recorder, redresser, regarder, rejoindre, rentrer, repairer, répondre, retourner, retravailler, revenir, revertir, rouler, sauter, semer, sortir, soutenir, suivre, tenir, tirer, tomber, tourner (atourner), traire, transporter, traverser, trépasser, tricoter, vendre, venir, viser, vivre, voir aller, armer, baisser, bruire, brûler, caqueter, couler, départir, descendre, deviser, écrire, élancer, émouver, entre-pousser, flamber, frapper, geler, germer, hacher, hausser, hurler, jaillir, jaser, lacer, lancer, monter, mourir, parler, perler, piller, piquer, pisser, pleuvoir, pousser, reverser, saillir, semer, souffler, taper, tomber, trancher, tuer apprendre, assaillir, asseoir, battre, besogner, boire, boulotter, bousculer, brûler, buter, casquer, chauffer, chier, claquer, cogner, conduire, cosser, coucher, cracher, crocher, croire, cuire, déchevaucher, défendre, désafeutrer, dire, dormir, écrire, encontrer, enformer, entendre, férir, fraîchir, frapper, frotter, gagner, geler, jaillir, jaser, jouer, manger, marcher, mener, monter, navrer, organiser, ouïr, parler, partir, peiner, penser, percer, perturber, peser, pilonner, pincer, piocher, piquer, pousser, rebouter, résonner, secouer, serrer, sonner, souffler, souquer, talocher, taper, temprer (tremper), tenir, tonner, tourner, traire, traiter, travailler, tricoter, trimer, trotter, venir, venter, vivre construire, produire

vivre

écrire, rouler

écrire, faire

chauffer, filer, peser

pédaler, raser, rouler

habiller

tenir

écrire

vivre

dessiner

taper

aboyer

absorber, répondre

accompagner, aller, boire, couler, couper, cracher, errer, fourmiller, lancer, moucher, parler, paver, rire, semer, tapisser, vêtir 


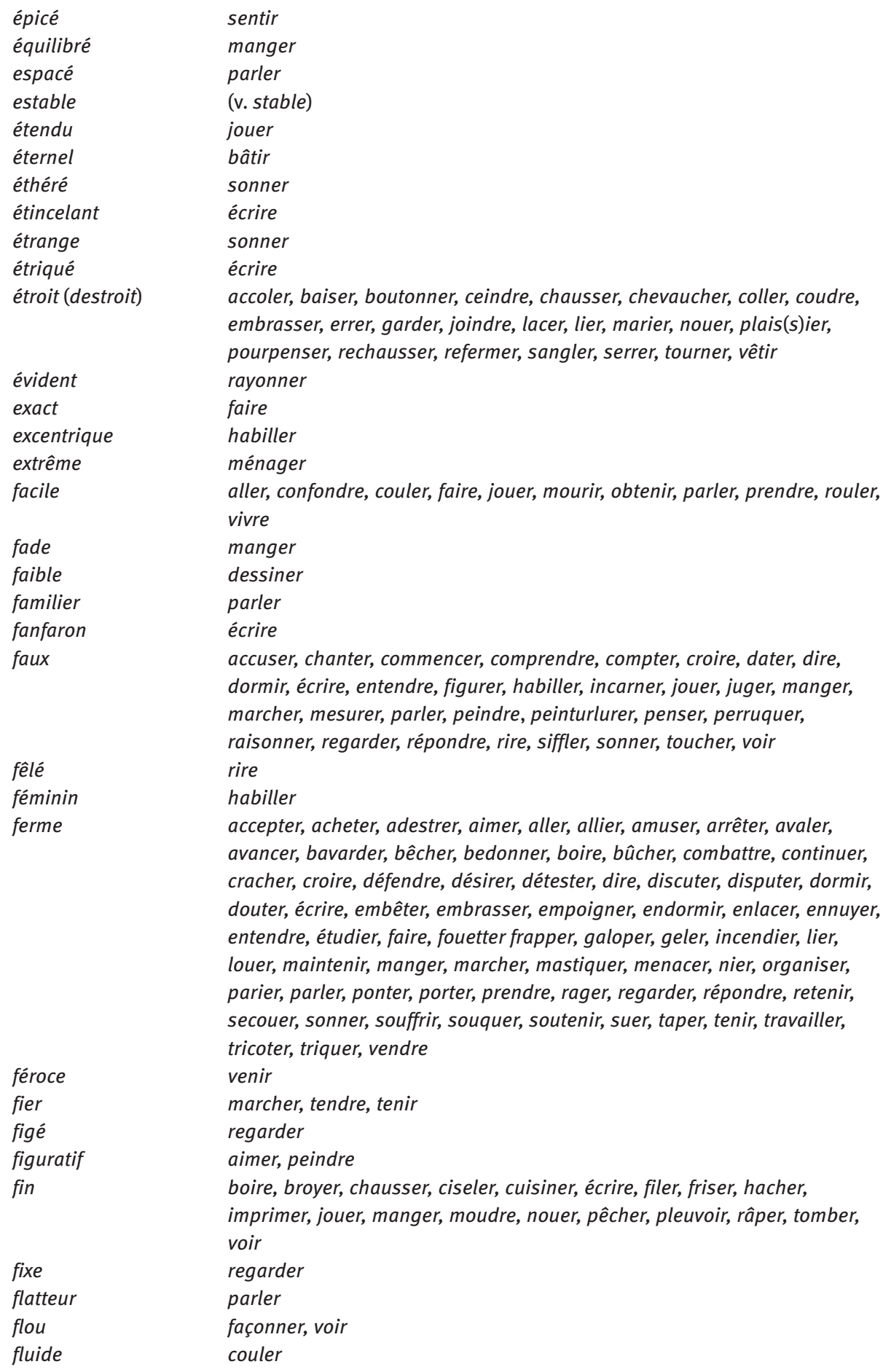


fonctionnel

forcé

fort

fou

frais

franc

frémissant

froid

furtif

gagnant

gagné

gai

gavé

génial

gent

glacé

global

gothique

gourmand

grand

gras

gratuit

grave (grief) jouer

rire, sonner

accélérer, acoudre (v. coudre), adorer, affirmer, aller, appeler, approcher, baiser, baisser, battre, blesser, boire, bouter, bruire, brûler, causer, chanter, chasser, cheminer, chevaucher, clamer, claquer, cogner, combattre, commenter, confesser, connaître, conter, continuer, corner, coudre (acoudre), courir, courroucer, crier, croître, défendre, demander, dénoncer, dessiner, détester, dire, disputer, dormir, douter, dresser, éclater, écouter, écrier, écrire, embrasser, émouvoir, empoigner, endormir, enfler, ennouer, enseigner, entendre, entreheurter, estimer, étreindre, étudier, fâcher, faire, férir, ferrer, fleurer, frapper, gémir, goder, grever, gronder, guerroyer, hâter, hausser, heurter, imaginer, interroger, joindre, joster (jouter), jouer, jurer, lacer, lâcher, lamenter, lancer, lier, louer (1), luire, maintenir, marcher, mêler, menacer, mentir, monter, moquer, murmurer, navrer, neiger, nier, nouer, nuire, ouvrer, parler, parvenir, penser, piquer, plaindre, plaire, player, pleurer, pleuvoir, porter, poursuivre, pratiquer, presser, prier, priser, proférer, promettre, prononcer, publier, puer, randonner, récriminer, redouter, regarder, regretter, réjouir, répondre, reprendre, reprocher, résonner, respirer, retentir, rêver, rire, rompre, saluer, sangloter, sentir, seoir, serrer, siffler, sonner, souffler, souhaiter, soulever, soupirer, soutenir, supplier, taper, tendre, tenir, tirer, tomber, tonner, toucher, tousser, traire, trancher, travailler, troubler, venter, vêtir, vibrer, vivre

monter, tourner

acheter, battre, boire, bruire, couler, éclore, parler, pleuvoir, rire, sentir, sonner, sortir, tricoter, venir

causer, claquer, dire, jouer, marcher, parler, regarder, répondre, rire, sonner, vivre

vivre

battre, boire, écrire, manger, respirer, rincer, servir

glisser

jouer

donner

aller, jouer, vivre

aimer, gagner

effacer

aller, atourner, chevaucher, conreer, mener, pleurer, recevoir, saluer, tenir, venir

boire, manger

agir, penser

sculpter

cuisiner

chanter, chausser, chercher, déplier, déployer, dresser, esgarder, faire, férir, ouvrir, prévoir, produire, rayonner, regarder, rêver, tailler, voir avoir, chanter, écrire, étamper, faire, manger, mourir, parler, payer, peindre, rire, servir, tousser, transpirer, vivre

faire, tuer

aboyer, chanter, craindre, halluciner, kiffer, péter, piquer, regretter, rire, rouler, secouer, songer, sonner, soupirer, venir 







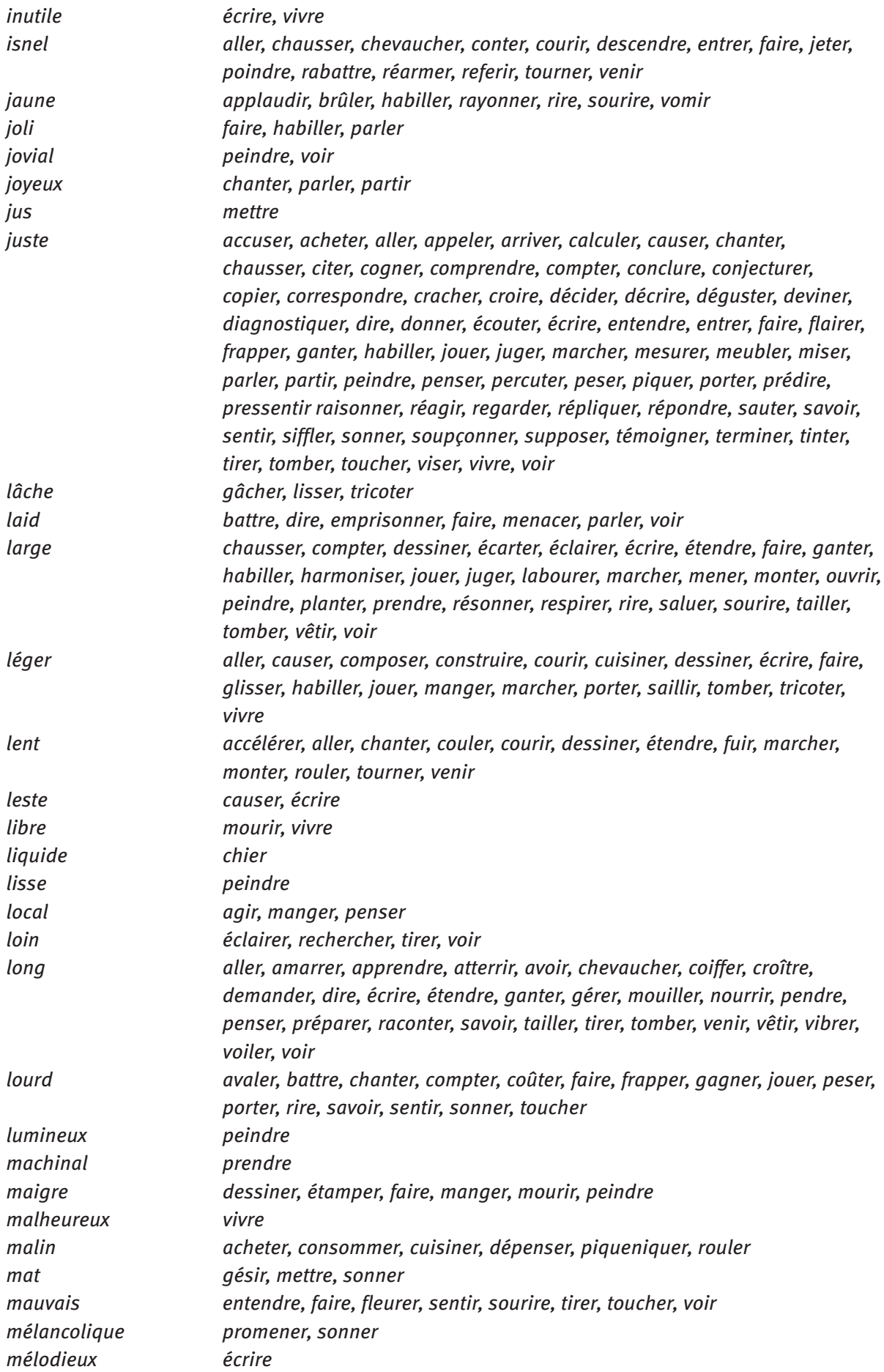


menu

mesquin

mi-long

mince

minuscule

misérable

moche

moderne

modeste

mollet

mollo

monotone

mordant

mort

mortel

mou (mol)

moyen

mu

musclé

musical

négatif

nerveux

net

neuf

neutre

niais

niquel

noble

noir

noir sur blanc

nonchalant

normal

nourrissant abattre, aller, baiser, barboter, battre, briser, broder, chanter, chiqueter, clamer, coudre, couper, cracher, déchirer, découper, deviser, écrire, entrelacer, étinceler, étoiler, férir, filer, frapper, friser, garcier, goter, griller, hacher, hausser, heurter, jeter, lancer, lier, mailler, penser, piler, pleurer, plier, poindre, randonner, remuer, répondre, rire, sangloter, serrer, siffler, sortir, soupirer, tailler, tomber, tornoyer, tourner, trancher, tresser, trotter, trottiner, varier, voir

écrire

coiffer

écrire

dessiner

vivre

aller, causer, écrire, faire, habiller, parler

équiper, meubler, voir

aller

cuire

aller

faire, jouer, vivre

rouler

abattre, gésir, trébucher

kiffer, sonner

aller, articuler, asseoir, chier, conduire, coucher, donner, emblaver, manger, marcher, parler, pédaler, travailler, voter (v. aussi mollet, mollo)

aimer, apprécier

tenir

écrire

sonner

penser, tester

écrire

abandonner, absorber, agir, aller, allonger, arrêter, assommer, avaler, boire, briser, cabrioler, calmer, casser, cesser, claquer, connaître, conter, couper, crever, décapiter, déclarer, défendre, demander, dire, éclairer, écraser, écrire, élancer, engager, entendre, envoyer, essouffler, éteindre, étouffer, étrangler, fâcher, faire, fêler, figer, frapper, habiller, interrompre, jouer, monter, oublier, parler, passer, payer, peigner, penser, percer, percevoir, planter, poser, posséder, prouver, quitter, raisonner, redraper, refuser, répondre, rester, retourner, rompre, saluer, signaler, signifier, sortir, stopper, tailler, tenir, tomber, trancher, tuer, vivre, voir habiller, penser, sonner

écrire

parler, rire

passer

chanter

chasser, cracher, croire, dire, écrire, entendre, faire, fumer, parler, regarder, répondre, rêver, rire, servir, vêtir, voir

mettre

jouer

chausser

gâcher 


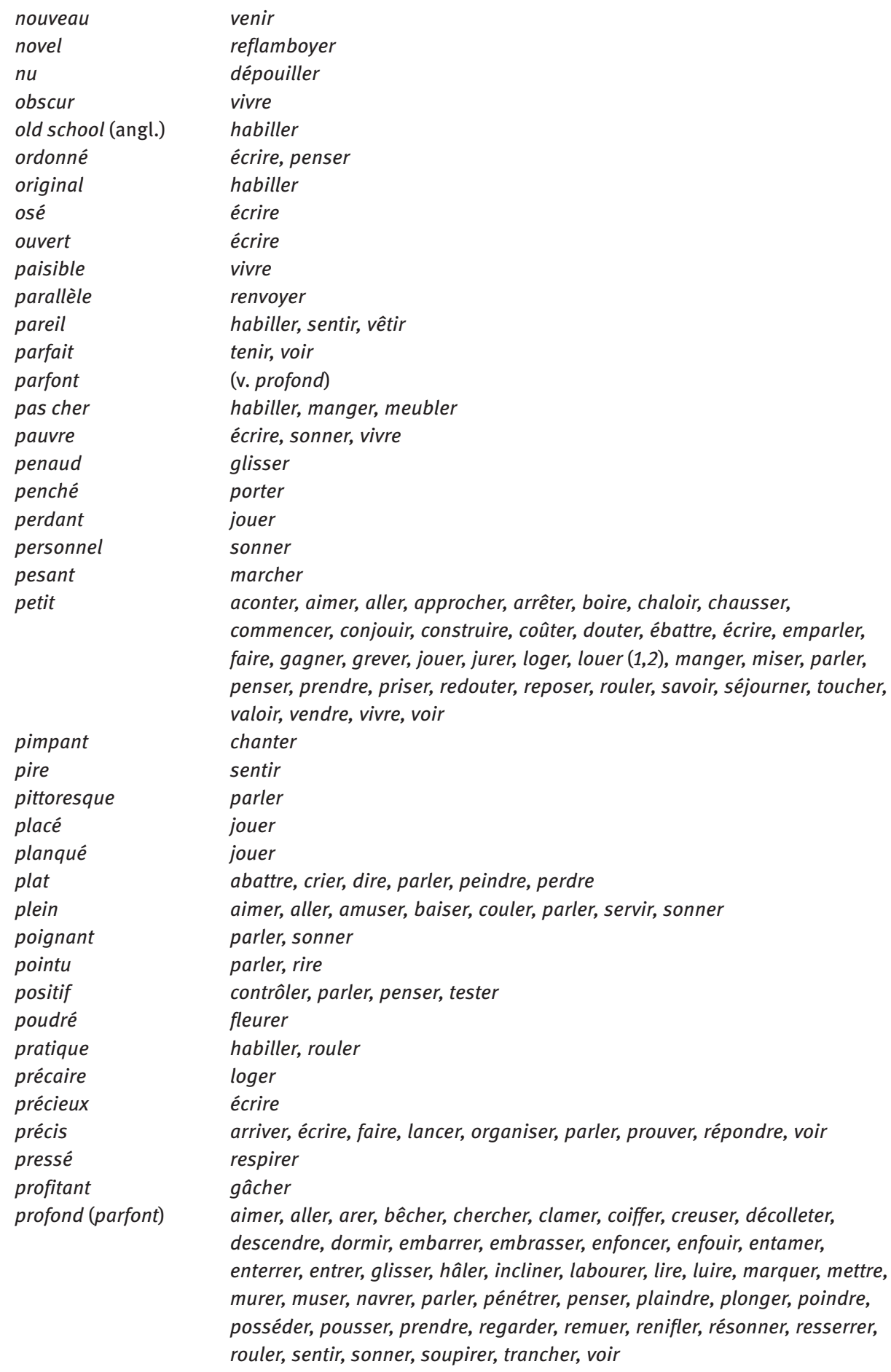




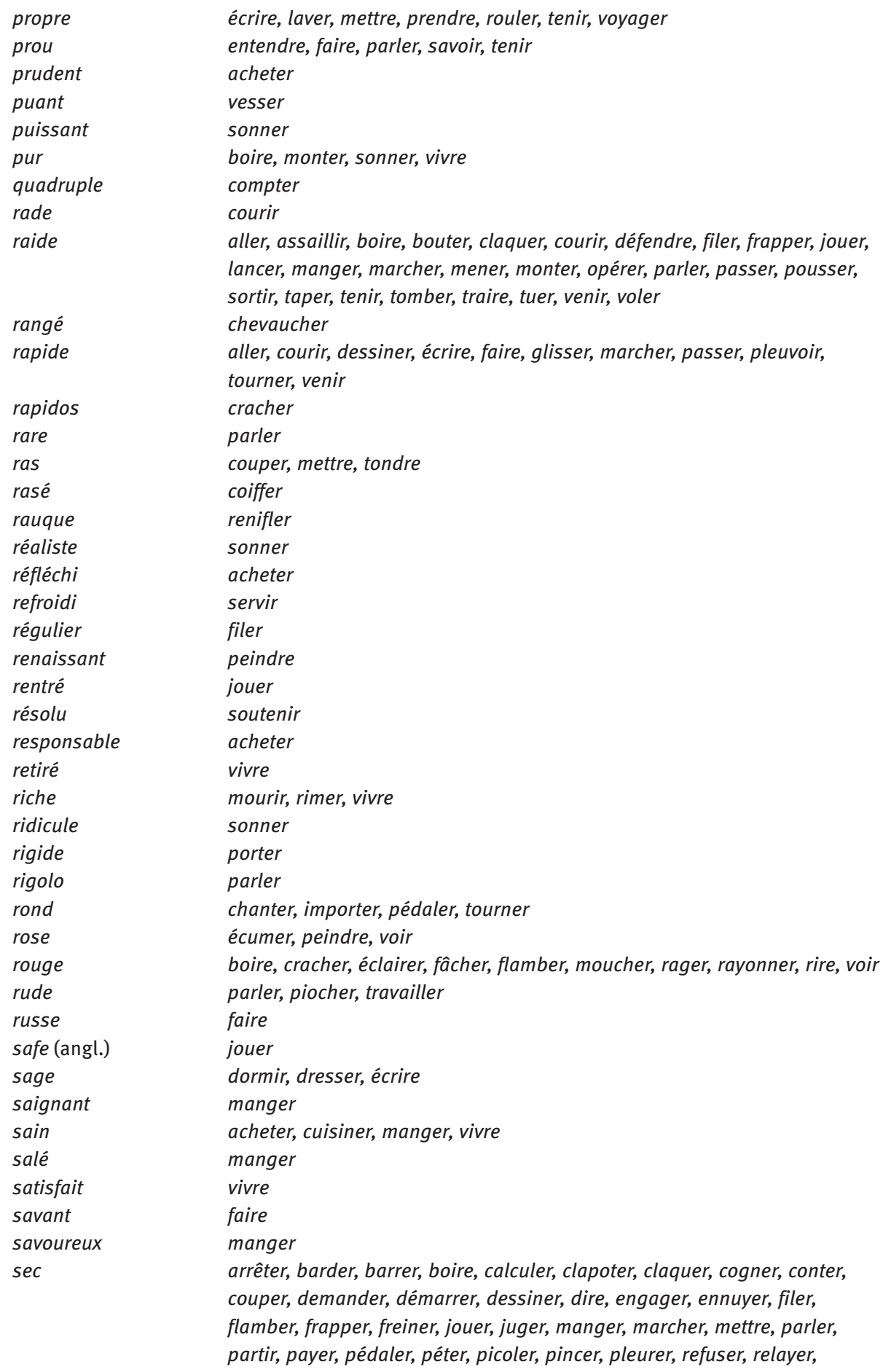


sensible

serein (seri)

sérieux

serré

seul

sévère

sexy

sibilant

simple

sobre

socialiste

soef (suave)

soigné

solennel

solidaire

solide

sombre

sonore

souple

sourd

souriant

soutenu

stable (estable)

stratégique

structuré

suave

subit

sublime

$\operatorname{succin}(c) t$

sucré

sûr

surgelé

symétrique

sympathique

tapageur

tapi

tenace remettre, remiser, renifler, répliquer, répondre, rire, sonner, suer, taper, tenir, tomber, tousser, trotter, vibrer, virer, virevolter

pêcher

abattre, chanter, commencer, dire, émouvoir, férir, marcher, monter, prier acheter, dresser, habiller, parler, travailler

aller, attacher, boxer, cacher, chevaucher, cogiter, corseter, coudre, crocher, croître, dormir, écrire, embrasser, errer, estimer, faucher, friser, gâcher, ganter, gaufrer, habiller, jouer, larder, lier, louvoyer, marcher, mordre, parler, pelotonner, pincer, planter, pleuvoir, prononcer, raisonner, rayer, surveiller, tenir, tomber, tordre, tricoter, venir, vivre

achever, aller, descendre, éteindre, litronner, loger, marcher, monter, vivre déshydrater, engueuler, gaffer

habiller

parler

commencer, écrire, faire, habiller, manger, meubler, naître, parler, penser, prendre, vivre, voir

jouer

voter

abattre, aller, ambler, appeler, baiser, chanter, chevaucher, conduire, conseiller, coucher, demander, désarmer, descendre, dire, dormir, emmener, émouvoir, endormir, entrer, estraindre, férir, flairer, guier, hucher, incliner, issir, jeter, jurer, mener, mettre, monter, nager, nouer, odorer, oloir, parler, porter, prendre, presser, ramener, réclamer, relever, résonner, rire, sauter, sigler, sonner, tailler, tenir, traire, trancher, tressauter, trotter, vivre écrire

dresser

acheter, vivre

attacher, construire, faire, pêcher, prendre, tenir

peindre

écrire, parler

écrire, tenir

gronder

vivre

parler

louer, tenir

penser

écrire

(v. soef)

allumer, courir, réallumer

jouer

écrire

boire, juter, manger, sentir

aller, marcher, vivre

manger

peindre

rouler

habiller

tenir

tomber 


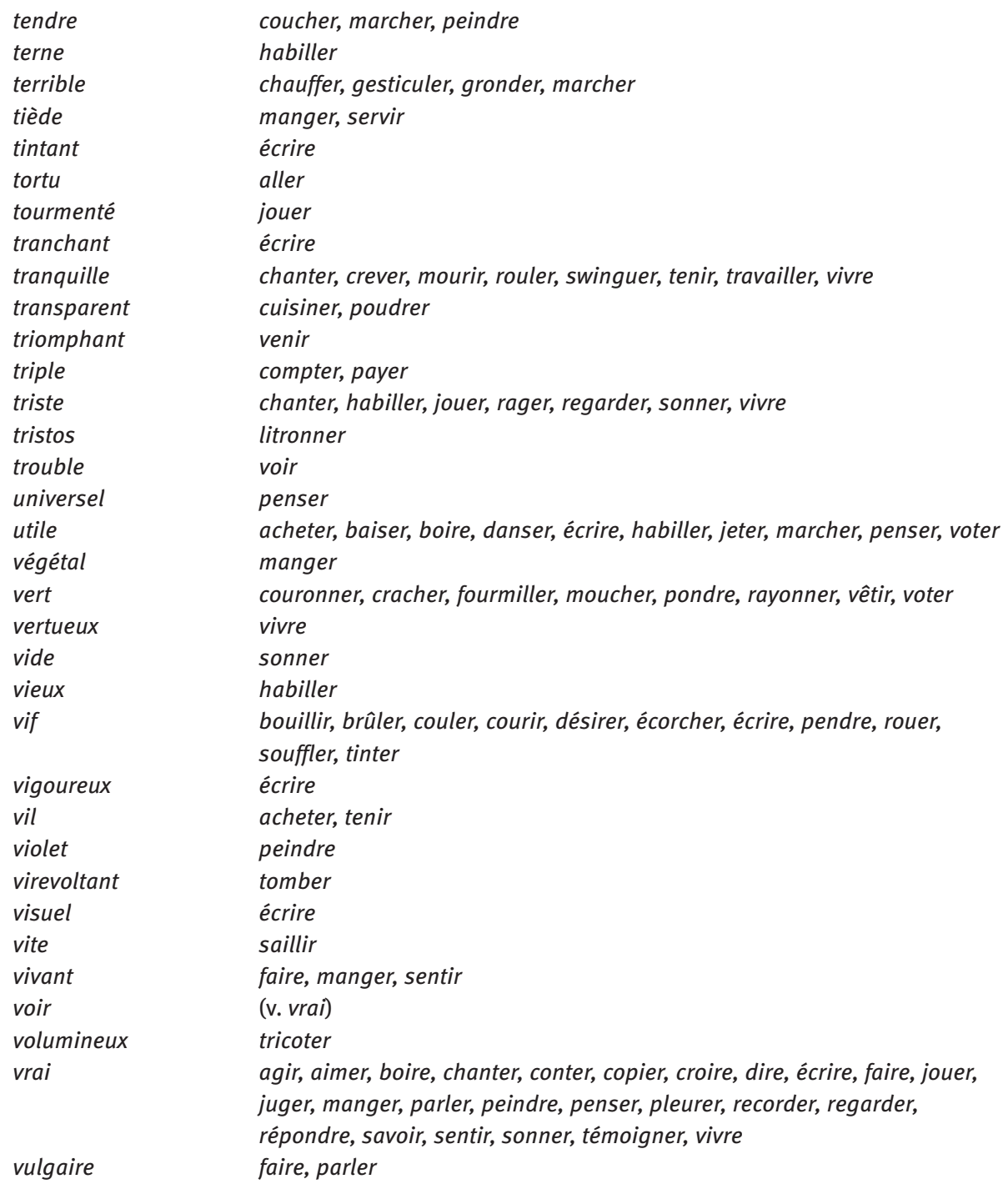





\section{Index des adjectifs-adverbes selon leur fréquence-type}

Exemple: l'adjectif-adverbe fort se trouve dans 169 groupes syntaxiques différents, c'est-à-dire, il se combine avec 169 verbes différents

\begin{tabular}{|c|c|c|c|c|c|c|}
\hline fort & 169 & direct & 12 & calme & 4 & aimable \\
\hline haut & 145 & double & 12 & cru & 4 & amer \\
\hline bas & 120 & grave & 12 & loin & 4 & âpre \\
\hline droit & 110 & simple & 12 & positif & 4 & bouillant \\
\hline dur & 81 & chaud & 11 & pur & 4 & brut \\
\hline net & 78 & facile & 11 & sain & 4 & carré \\
\hline beau (bel) & 75 & franc & 11 & sucré & 4 & complet \\
\hline ferme & 73 & rapide & 11 & terrible & 4 & compliqué \\
\hline juste & 72 & vif & 11 & rond & 4 & comptant \\
\hline clair & 66 & gent & 10 & profond (parfont) & 4 & confortable \\
\hline menu & 58 & rouge & 10 & anglais & 3 & correct \\
\hline soef (suave) & 53 & utile & 10 & bizarre & 3 & courant \\
\hline $\mathrm{sec}$ & 51 & précis & 9 & démodé & 3 & dense \\
\hline court & 48 & seul & 9 & égal & 3 & destroit \\
\hline gros & 47 & seri (serein) & 9 & électrique & 3 & différent \\
\hline profond & 45 & creux & 8 & fier & 3 & douloureux \\
\hline dru & 42 & mauvais & 8 & gai & 3 & durable \\
\hline serré & 42 & plein & 8 & grief & 3 & économique \\
\hline petit & 40 & tranquille & 8 & joli & 3 & efficace \\
\hline faux & 32 & vert & 8 & joyeux & 3 & entier \\
\hline large & 30 & impec(cable) & 8 & lâche & 3 & figuratif \\
\hline long & 29 & aigu & 7 & local & 3 & flou \\
\hline doux & 27 & froid & 7 & mat & 3 & forcé \\
\hline raide & 27 & laid & 7 & moderne & 3 & fou \\
\hline étroit & 22 & propre & 7 & monotone & 3 & gavé \\
\hline cher & 20 & triste & 7 & mort & 3 & glacé \\
\hline blanc & 19 & vrai (voir) & 7 & neuf & 3 & global \\
\hline fin & 19 & bleu & 6 & pareil & 3 & gratuit \\
\hline léger & 19 & bref & 6 & pas cher & 3 & grêle \\
\hline bon & 18 & coi & 6 & pauvre & 3 & groseille \\
\hline vrai & 18 & jaune & 6 & ras & 3 & humide \\
\hline grand & 17 & maigre & 6 & riche & 3 & immobile \\
\hline noir & 17 & malin & 6 & rose & 3 & intelligent \\
\hline épais & 16 & moche & 6 & rude & 3 & inutile \\
\hline lourd & 16 & solide & 6 & sage & 3 & jovial \\
\hline gras & 15 & plat & 6 & sévère & 3 & leste \\
\hline isnel & 15 & chic & 5 & subit & 3 & libre \\
\hline frais & 14 & classique & 5 & sûr & 3 & mélancolique \\
\hline aise & 13 & prou & 5 & tendre & 3 & mortel \\
\hline lent & 13 & sérieux & 5 & vivant & 3 & moyen \\
\hline mou & 13 & bête & 4 & abondant & 2 & négatif \\
\hline
\end{tabular}




\begin{tabular}{|c|c|c|c|c|c|c|}
\hline niais & 2 & classe (class) & 1 & exact & 1 & mesquin \\
\hline ordonné & 2 & clos & 1 & excentrique & 1 & mi-long \\
\hline parfait & 2 & coco & 1 & extrême & 1 & mince \\
\hline poignant & 2 & cointe & 1 & fade & 1 & minuscule \\
\hline pointu & 2 & coloré & 1 & faible & 1 & misérable \\
\hline pratique & 2 & colossal & 1 & familier & 1 & modeste \\
\hline solidaire & 2 & compact & 1 & fanfaron & 1 & mollet \\
\hline sonore & 2 & compréhensible & 1 & fêlé & 1 & mollo \\
\hline souple & 2 & concentré & 1 & féminin & 1 & mordant \\
\hline tiède & 2 & concis & 1 & féroce & 1 & mou (mol) \\
\hline transparent & 2 & concret & 1 & figé & 1 & $\mathrm{mu}$ \\
\hline triple & 2 & confus & 1 & fixe & 1 & musclé \\
\hline vil & 2 & contemporain & 1 & flatteur & 1 & musical \\
\hline vulgaire & 2 & content & 1 & fluide & 1 & nerveux \\
\hline bleu-clair & 2 & contenu & 1 & fonctionnel & 1 & neutre \\
\hline nouveau (novel) & 2 & cosmique & 1 & frémissant & 1 & niquel \\
\hline abominable & 1 & couché & 1 & furtif & 1 & noble \\
\hline abstrait & 1 & coupé & 1 & gagnant & 1 & nonchalant \\
\hline acertes & 1 & courbe & 1 & gagné & 1 & normal \\
\hline âcre & 1 & critique & 1 & génial & 1 & nourrissant \\
\hline aérien & 1 & cuit & 1 & gothique & 1 & nu \\
\hline affectueux & 1 & décontracté & 1 & gourmand & 1 & obscur \\
\hline affranchi & 1 & déhanché & 1 & groupé & 1 & old school \\
\hline allongé & 1 & demi-creux & 1 & habillé & 1 & original \\
\hline ambigu & 1 & dépointé & 1 & hardi & 1 & osé \\
\hline ample & 1 & désespérant & 1 & herbal & 1 & ouvert \\
\hline amusant & 1 & détendu & 1 & heureux & 1 & paisible \\
\hline ancien & 1 & détroit & 1 & heurté & 1 & parallèle \\
\hline anguleux & 1 & difficile & 1 & honnête & 1 & penaud \\
\hline appétissant & 1 & digne & 1 & horizontal & 1 & penché \\
\hline appuyé & 1 & dynamique & 1 & idiot & 1 & perdant \\
\hline attractif & 1 & élégant & 1 & ignorant & 1 & personnel \\
\hline austère & 1 & enclos & 1 & immense & 1 & pesant \\
\hline automatique & 1 & engagé & 1 & imprévu & 1 & pimpant \\
\hline avenant & 1 & ennuyeux & 1 & incontinent & 1 & pire \\
\hline baroque & 1 & énorme & 1 & indépendant & 1 & pittoresque \\
\hline basique & 1 & enragé & 1 & indiscipliné & 1 & placé \\
\hline bio & 1 & enroué & 1 & infini & 1 & planqué \\
\hline blond & 1 & épicé & 1 & intact & 1 & poudré \\
\hline bon marché & 1 & équilibré & 1 & intellectuel & 1 & précaire \\
\hline branché & 1 & espacé & 1 & intime & 1 & précieux \\
\hline brouillé & 1 & estable & 1 & jeune & 1 & pressé \\
\hline brûlé & 1 & étendu & 1 & jus & 1 & profitant \\
\hline brusque & 1 & éternel & 1 & liquide & 1 & prudent \\
\hline brutal & 1 & éthéré & 1 & lisse & 1 & puant \\
\hline bruyant & 1 & étincelant & 1 & lumineux & 1 & puissant \\
\hline caché & 1 & étrange & 1 & machinal & 1 & quadruple \\
\hline campagnard & 1 & étriqué & 1 & malheureux & 1 & rade \\
\hline caverneux & 1 & évident & 1 & mélodieux & 1 & rangé \\
\hline
\end{tabular}




\begin{tabular}{|c|c|c|c|c|c|c|}
\hline rapidos & 1 & russe & 1 & souriant & 1 & tourmenté \\
\hline rare & 1 & safe (anglais) & 1 & soutenu & 1 & tranchant \\
\hline rasé & 1 & saignant & 1 & stable & 1 & triomphant \\
\hline rauque & 1 & salé & 1 & stratégique & 1 & tristos \\
\hline réaliste & 1 & satisfait & 1 & structuré & 1 & trouble \\
\hline réfléchi & 1 & savant & 1 & sublime & 1 & universel \\
\hline refroidi & 1 & savoureux & 1 & $\operatorname{succin}(\mathrm{c}) \mathrm{t}$ & 1 & végétal \\
\hline régulier & 1 & sensible & 1 & surgelé & 1 & vertueux \\
\hline renaissant & 1 & sexy & 1 & symétrique & 1 & vide \\
\hline rentré & 1 & sibilant & 1 & sympathique & 1 & vieux \\
\hline résolu & 1 & sobre & 1 & tapageur & 1 & vigoureux \\
\hline responsable & 1 & socialiste & 1 & tapi & 1 & violet \\
\hline retiré & 1 & soigné & 1 & tenace & 1 & virevoltant \\
\hline ridicule & 1 & solennel & 1 & terne & 1 & visuel \\
\hline rigide & 1 & sombre & 1 & tintant & 1 & volumineux \\
\hline rigolo & 1 & sourd & 1 & tortu & 1 & \\
\hline
\end{tabular}





\section{Index des verbes selon leur fréquence-type}

Exemple: le verbe écrire se trouve dans 73 groupes syntaxiques différents, c'est-à-dire, il se combine avec 73 adjectifs-adverbes différents

\begin{tabular}{|c|c|c|c|c|c|c|}
\hline écrire & 73 & demander & 10 & croire & 6 & siffler \\
\hline parler & 68 & descendre & 10 & défendre & 6 & sortir \\
\hline vivre & 50 & mourir & 10 & dresser & 6 & soutenir \\
\hline sonner & 47 & raisonner & 10 & lier & 6 & traire \\
\hline faire & 45 & tricoter & 10 & partir & 6 & trotter \\
\hline voir & 40 & battre & 9 & pédaler & 6 & agir \\
\hline jouer & 39 & férir & 9 & piquer & 6 & asseoir \\
\hline manger & 39 & mener & 9 & planter & 6 & avoir \\
\hline aller & 38 & pleurer & 9 & pleuvoir & 6 & bouter \\
\hline habiller & 36 & souffler & 9 & prier & 6 & clamer \\
\hline tenir & 32 & tirer & 9 & rêver & 6 & crier \\
\hline chanter & 29 & causer & 8 & toucher & 6 & croître \\
\hline marcher & 29 & commencer & 8 & vendre & 6 & danser \\
\hline dire & 28 & compter & 8 & voter & 6 & déclarer \\
\hline penser & 28 & filer & 8 & abattre & 5 & envoyer \\
\hline rire & 25 & jeter & 8 & arriver & 5 & errer \\
\hline boire & 21 & lancer & 8 & cogner & 5 & flairer \\
\hline peindre & 20 & louer & 8 & conduire & 5 & friser \\
\hline regarder & 20 & passer & 8 & connaître & 5 & ganter \\
\hline répondre & 20 & payer & 8 & construire & 5 & geler \\
\hline venir & 20 & rayonner & 8 & continuer & 5 & gémir \\
\hline tomber & 19 & soupirer & 8 & donner & 5 & hausser \\
\hline monter & 18 & sourire & 8 & éclairer & 5 & jaillir \\
\hline acheter & 17 & tailler & 8 & embrasser & 5 & maintenir \\
\hline rouler & 17 & travailler & 8 & entrer & 5 & mentir \\
\hline sentir & 17 & appeler & 7 & étendre & 5 & meubler \\
\hline couler & 15 & arrêter & 7 & fâcher & 5 & moucher \\
\hline porter & 15 & avaler & 7 & flamber & 5 & naître \\
\hline prendre & 15 & brûler & 7 & fleurer & 5 & nommer \\
\hline dessiner & 14 & coiffer & 7 & gâcher & 5 & nouer \\
\hline entendre & 14 & couper & 7 & gagner & 5 & pêcher \\
\hline aimer & 13 & cuisiner & 7 & glisser & 5 & peser \\
\hline mettre & 13 & juger & 7 & gronder & 5 & poindre \\
\hline vêtir & 13 & respirer & 7 & jurer & 5 & promettre \\
\hline chevaucher & 12 & saluer & 7 & lire & 5 & regretter \\
\hline dormir & 12 & savoir & 7 & loger & 5 & saillir \\
\hline frapper & 12 & servir & 7 & luire & 5 & sangloter \\
\hline courir & 11 & taper & 7 & menacer & 5 & sauter \\
\hline cracher & 11 & trancher & 7 & pendre & 5 & semer \\
\hline résonner & 11 & baiser & 6 & plaindre & 5 & serrer \\
\hline tourner & 11 & claquer & 6 & pousser & 5 & tendre \\
\hline chausser & 10 & coucher & 6 & prononcer & 5 & tinter \\
\hline conter & 10 & coûter & 6 & retenir & 5 & tousser \\
\hline
\end{tabular}




\begin{tabular}{|c|c|c|c|c|c|c|}
\hline tuer & 4 & prouver & 3 & conseiller & 2 & lâcher \\
\hline vibrer & 4 & publier & 3 & contrôler & 2 & litronner \\
\hline viser & 4 & rager & 3 & copier & 2 & maudire \\
\hline aboyer & 3 & rapporter & 3 & couronner & 2 & mesurer \\
\hline accuser & 3 & remuer & 3 & crever & 2 & moquer \\
\hline affirmer & 3 & renifler & 3 & crocher & 2 & moudre \\
\hline assaillir & 3 & reprendre & 3 & cuire & 2 & mouiller \\
\hline atourner & 3 & reprocher & 3 & demeurer & 2 & nier \\
\hline attacher & 3 & rester & 3 & dénoncer & 2 & noter \\
\hline bruire & 3 & retourner & 3 & désirer & 2 & oloir \\
\hline chauffer & 3 & revenir & 3 & détester & 2 & opérer \\
\hline chercher & 3 & rompre & 3 & disputer & 2 & ouïr \\
\hline chier & 3 & secouer & 3 & écarter & 2 & ouvrer \\
\hline choir & 3 & songer & 3 & écouter & 2 & pardonner \\
\hline confesser & 3 & tondre & 3 & élever & 2 & parier \\
\hline corner & 3 & valoir & 3 & emmener & 2 & parvenir \\
\hline coudre & 3 & absorber & 2 & empoigner & 2 & percer \\
\hline deviser & 3 & accélérer & 2 & enfler & 2 & perdre \\
\hline diriger & 3 & adorer & 2 & enfoncer & 2 & piocher \\
\hline douter & 3 & agiter & 2 & engager & 2 & placer \\
\hline éclater & 3 & ajouter & 2 & ennuyer & 2 & pondre \\
\hline écrier & 3 & allonger & 2 & enrager & 2 & proférer \\
\hline élancer & 3 & allumer & 2 & enseigner & 2 & proposer \\
\hline émouvoir & 3 & amuser & 2 & esgarder & 2 & puer \\
\hline endormir & 3 & annoncer & 2 & étamper & 2 & raconter \\
\hline estimer & 3 & applaudir & 2 & éteindre & 2 & randonner \\
\hline hacher & 3 & apprendre & 2 & étrangler & 2 & raser \\
\hline ignorer & 3 & approcher & 2 & étreindre & 2 & rayer \\
\hline incliner & 3 & ardre & 2 & étudier & 2 & recevoir \\
\hline jaser & 3 & armer & 2 & finir & 2 & rechercher \\
\hline labourer & 3 & assener & 2 & fourmiller & 2 & réciter \\
\hline lacer & 3 & atterrir & 2 & fuir & 2 & réclamer \\
\hline laver & 3 & baisser & 2 & fumer & 2 & recorder \\
\hline miser & 3 & bâtir & 2 & garder & 2 & récriminer \\
\hline mordre & 3 & bêcher & 2 & gérer & 2 & redouter \\
\hline murmurer & 3 & boutonner & 2 & gésir & 2 & reflamboyer \\
\hline navrer & 3 & briller & 2 & grever & 2 & refuser \\
\hline odorer & 3 & briser & 2 & guerroyer & 2 & régler \\
\hline organiser & 3 & buquer & 2 & guier & 2 & rendre \\
\hline ouvrir & 3 & calculer & 2 & harmoniser & 2 & répéter \\
\hline péter & 3 & caqueter & 2 & heurter & 2 & répliquer \\
\hline pincer & 3 & changer & 2 & hucher & 2 & rincer \\
\hline pisser & 3 & chantonner & 2 & hurler & 2 & seoir \\
\hline poser & 3 & chasser & 2 & interroger & 2 & signifier \\
\hline posséder & 3 & cheminer & 2 & issir & 2 & soulever \\
\hline préparer & 3 & coloïer & 2 & joindre & 2 & souquer \\
\hline presser & 3 & combattre & 2 & joster & 2 & suer \\
\hline priser & 3 & commenter & 2 & juter & 2 & supplier \\
\hline produire & 3 & comprendre & 2 & kiffer & 2 & témoigner \\
\hline
\end{tabular}




\begin{tabular}{|c|c|c|}
\hline tester & 2 & bavarder \\
\hline tonner & 2 & bedonner \\
\hline traiter & 2 & besogner \\
\hline trottiner & 2 & bifurquer \\
\hline veiller & 2 & blesser \\
\hline venter & 2 & boiter \\
\hline virer & 2 & bouillir \\
\hline voler & 2 & bouler \\
\hline abaisser & 1 & boulotter \\
\hline abandonner & 1 & bousculer \\
\hline accepter & 1 & boxer \\
\hline accoler & 1 & braire \\
\hline accompagner & 1 & brasser \\
\hline accourir & 1 & broder \\
\hline accroître & 1 & bronzer \\
\hline accueillir & 1 & broyer \\
\hline acesmer & 1 & bûcher \\
\hline acheminer & 1 & buter \\
\hline achever & 1 & cabrioler \\
\hline aconter & 1 & cacher \\
\hline acostumer & 1 & caler \\
\hline acoudre & 1 & calmer \\
\hline adestrer & 1 & caracoler \\
\hline adresser & 1 & carapater \\
\hline affonder & 1 & carguer \\
\hline ajourner & 1 & casquer \\
\hline alever & 1 & casser \\
\hline allier & 1 & cataloguer \\
\hline amarrer & 1 & ceindre \\
\hline ambler & 1 & cesser \\
\hline amener & 1 & chaloir \\
\hline apercevoir & 1 & charrier \\
\hline appareiller & 1 & cheviller \\
\hline apporter & 1 & chiqueter \\
\hline apprécier & 1 & choisir \\
\hline areer & 1 & chuchoter \\
\hline arer & 1 & circuler \\
\hline arraisonner & 1 & ciseler \\
\hline arroyer (areer) & 1 & citer \\
\hline articuler & 1 & clapoter \\
\hline aspirer & 1 & clouer \\
\hline assommer & 1 & cogiter \\
\hline atteindre & 1 & coller \\
\hline avancer & 1 & colloquer \\
\hline avouer & 1 & colorer \\
\hline baer & 1 & comparer \\
\hline barboter & 1 & composer \\
\hline barder & 1 & conclure \\
\hline barrer & 1 & condamner \\
\hline
\end{tabular}

\begin{tabular}{|c|c|c|c|}
\hline 1 & confier & 1 & devoir \\
\hline 1 & confondre & 1 & diagnostiquer \\
\hline & conforter & 1 & dîner \\
\hline & conjecturer & 1 & discuter \\
\hline & conjouir & 1 & ébattre \\
\hline & conreer & 1 & échapper \\
\hline & consommer & 1 & éclore \\
\hline & contenir & 1 & écorcher \\
\hline & correspondre & 1 & écraser \\
\hline & corseter & 1 & écumer \\
\hline & cosser & 1 & effacer \\
\hline & coter & 1 & embarrer \\
\hline & coudre / acoudre & 1 & embêter \\
\hline & courroucer & 1 & emblaver \\
\hline & couver & 1 & émouver \\
\hline & craindre & 1 & emparler \\
\hline & crêper & 1 & emprisonner \\
\hline & creuser & 1 & encager \\
\hline & dater & 1 & encaisser \\
\hline & décapiter & 1 & encontrer \\
\hline & déchaumer & 1 & enformer \\
\hline & déchevaucher & 1 & enfouir \\
\hline & déchirer & 1 & engueuler \\
\hline & décider & 1 & enlacer \\
\hline & décocher & 1 & ennouer \\
\hline & décoincer & 1 & entamer \\
\hline & décoller & 1 & enterrer \\
\hline & décolleter & 1 & entreheurter \\
\hline & décorer & 1 & entrelacer \\
\hline & découper & 1 & entre-pousser \\
\hline & décrire & 1 & éplucher \\
\hline & déduire & 1 & épurger \\
\hline & déguster & 1 & équiper \\
\hline & démarrer & 1 & esbanier \\
\hline & départir & 1 & essouffler \\
\hline & dépenser & 1 & étinceler \\
\hline & déplier & 1 & étoiler \\
\hline & déployer & 1 & étouffer \\
\hline . & déporter & 1 & éveiller \\
\hline 1 & dépouiller & 1 & examiner \\
\hline 1 & dérouler & 1 & exciter \\
\hline 1 & désafeutrer & 1 & expliquer \\
\hline & désarêter & 1 & façonner \\
\hline & désarmer & 1 & faucher \\
\hline & déshydrater & 1 & fêler \\
\hline & destiner & 1 & ferrer \\
\hline & détourner & 1 & figer \\
\hline & dévaler & 1 & figurer \\
\hline & deviner & 1 & finer \\
\hline
\end{tabular}




\begin{tabular}{|c|c|c|c|c|c|c|}
\hline fleurir & 1 & mêler & 1 & prenez & 1 & retraire \\
\hline fonctionner & 1 & ménager & 1 & pressentir & 1 & retravailler \\
\hline fouetter & 1 & mendier & 1 & prévenir & 1 & retrouver \\
\hline fourrer & 1 & meugler & 1 & prévoir & 1 & rêvasser \\
\hline fraîchir & 1 & mouvoir & 1 & promener & 1 & reverser \\
\hline fredonner & 1 & murer & 1 & protester & 1 & revertir \\
\hline freiner & 1 & muser & 1 & quitter & 1 & rhétoriquer \\
\hline frotter & 1 & nager & 1 & rabattre & 1 & ricaner \\
\hline gaffer & 1 & neiger & 1 & racheter & 1 & rimer \\
\hline galoper & 1 & nourrir & 1 & ramener & 1 & risquer \\
\hline garnir & 1 & nuire & 1 & ramper & 1 & ronfler \\
\hline gaufrer & 1 & obtenir & 1 & râper & 1 & rouer \\
\hline gerber & 1 & œuvrer & 1 & ravaler & 1 & sangler \\
\hline germer & 1 & oublier & 1 & réagir & 1 & sculpter \\
\hline gesticuler & 1 & paraître & 1 & réallumer & 1 & séjourner \\
\hline goder & 1 & parer & 1 & réarmer & 1 & sigler \\
\hline goter & 1 & paumoier & 1 & rebondir & 1 & signaler \\
\hline gouverner & 1 & paver & 1 & rebouter & 1 & souffrir \\
\hline gracier & 1 & peigner & 1 & rebrousser & 1 & souhaiter \\
\hline griller & 1 & peiner & 1 & rechausser & 1 & soupçonner \\
\hline guimpler & 1 & peinturlurer & 1 & récrier & 1 & stopper \\
\hline habiter & 1 & pelotonner & 1 & recueillir & 1 & suivre \\
\hline hâler & 1 & pénétrer & 1 & reculer & 1 & supposer \\
\hline halluciner & 1 & percevoir & 1 & redescendre & 1 & surveiller \\
\hline hâter & 1 & percuter & 1 & redraper & 1 & swinguer \\
\hline hennir & 1 & perler & 1 & redresser & 1 & taire \\
\hline honnir & 1 & perruqué & 1 & referir & 1 & talocher \\
\hline imaginer & 1 & perturber & 1 & refermer & 1 & tapisser \\
\hline importer & 1 & piaffer & 1 & réfléchir & 1 & tartiner \\
\hline imprimer & 1 & picoler & 1 & rejoindre & 1 & temprer (tremper) \\
\hline incarner & 1 & piler & 1 & réjouir & 1 & terminer \\
\hline incendier & 1 & piller & 1 & relayer & 1 & tisser \\
\hline informer & 1 & pilonner & 1 & relever & 1 & tordre \\
\hline interrompre & 1 & piqueniquer & 1 & reluire & 1 & tornoyer \\
\hline jacasser & 1 & plaire & 1 & remettre & 1 & tourner (atourner) \\
\hline jucher & 1 & plais(s)ier & 1 & remiser & 1 & traîner \\
\hline lamenter & 1 & planer & 1 & remonter & 1 & transpirer \\
\hline laquer & 1 & player & 1 & rentrer & 1 & transporter \\
\hline larder & 1 & plier & 1 & renvoyer & 1 & traverser \\
\hline lever & 1 & plonger & 1 & repairer & 1 & trébucher \\
\hline losangier & 1 & ponter & 1 & repentir & 1 & trépasser \\
\hline louvoyer & 1 & poudrer & 1 & reposer & 1 & tressauter \\
\hline mâcher & 1 & pourpenser & 1 & resplendir & & tresser \\
\hline mailler & 1 & poursuivre & 1 & (resplendre) & 1 & trimer \\
\hline marier & 1 & pourvoir & 1 & ressentir & 1 & triquer \\
\hline marmotter & 1 & pratiquer & 1 & resserrer & 1 & tromper \\
\hline marquer & 1 & prêcher & 1 & retirer & 1 & trompeter (tromper) \\
\hline mastiquer & 1 & précipiter & 1 & retomber & 1 & trompeter \\
\hline médire & 1 & prédire & 1 & retordre & 1 & troubler \\
\hline
\end{tabular}




$\begin{array}{llllll}\text { trouver } & 1 & \text { varier } & 1 & \text { voiler } & 1 \\ \text { user } & 1 & \text { vesser } & 1 & \text { vomir } & 1 \\ \text { vanter } & 1 & \text { virevolter } & 1 & \text { voyager } & 1\end{array}$


